\section{Pacific Northwest}

National Laboratory

Operated by Battelle for the

U.S. Department of Energy

\title{
Groundwater Data Package for the 2004 Composite Analysis
}

\author{
P. D. Thorne
}

August 2004

Prepared for the U.S. Department of Energy

under Contract DE-AC06-76RL01830

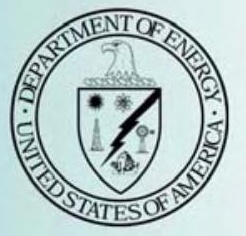




\title{
DISCLAIMER
}

This report was prepared as an account of work sponsored by an agency of the United States Government. Neither the United States Government nor any agency thereof, nor Battelle Memorial Institute, nor any of their employees, makes any warranty, express or implied, or assumes any legal liability or responsibility for the accuracy, completeness, or usefulness of any information, apparatus, product, or process disclosed, or represents that its use would not infringe privately owned rights. Reference herein to any specific commercial product, process, or service by trade name, trademark, manufacturer, or otherwise does not necessarily constitute or imply its endorsement, recommendation, or favoring by the United States Government or any agency thereof, or Battelle Memorial Institute. The views and opinions of authors expressed herein do not necessarily state or reflect those of the United States Government or any agency thereof.

\author{
PACIFIC NORTHWEST NATIONAL LABORATORY \\ operated by \\ BATTELLE \\ for the
UNITED STATES DEPARTMENT OF ENERGY under Contract DE-AC06-76RL01830

Printed in the United States of America
Available to DOE and DOE contractors from the Office of Scientific and Technical Information, P.O. Box 62, Oak Ridge, TN 37831-0062; ph: (865) 576-8401 fax: (865) 576-5728
email: reports@adonis.osti.gov

\author{
Available to the public from the National Technical Information Service, \\ U.S. Department of Commerce, 5285 Port Royal Rd., Springfield, VA 22161 \\ ph: (800) 553-6847 \\ fax: (703) 605-6900 \\ email: orders@ntis.fedworld.gov \\ online ordering: http://www.ntis.gov/ordering.htm
}




\title{
Groundwater Data Package for the 2004 Composite Analysis
}

\author{
P. D. Thorne
}

August 2004

Prepared for

the U.S. Department of Energy

under Contract DE-AC06-76RL01830

Pacific Northwest National Laboratory

Richland, Washington 99352 


\section{Summary}

A composite analysis is required by U.S. Department of Energy (DOE) Order 435.1 to ensure public safety through the management of active and planned low-level radioactive waste disposal facilities associated with the Hanford Site. The original composite analysis performed in 1998 must be revised because of updated waste site information, updated performance assessments and environmental impact statements, changes in inventory estimates for key sites and constituents, and a change in the definition of offsite receptors.

Beginning in fiscal year 2003, the DOE Richland Operations Office initiated activities, including the development of data packages, to support the composite analysis. This report presents data and inter-

preted information that supports the groundwater module for the composite analysis. The objective of the groundwater module is to predict movement of radioactive and chemical contaminants through the aquifer to the Columbia River or other potential discharge locations. Future contaminant concentrations in groundwater also need to be known for any location where groundwater may be acquired from watersupply wells. For the composite analysis, this includes all areas outside of the "Core Zone" surrounding the 200 Areas. The Core Zone is assumed to remain under institutional control for the foreseeable future and it is assumed that water supply wells in this zone will be prohibited.

The groundwater module will provide estimates of contaminant concentrations over the time period of the analysis within the unconfined aquifer underlying the Hanford Site outside of the Core Zone.

These concentrations will provide the basis for the estimated impact to human health and supplemental ecosystem risk. The groundwater module will also provide predictions of contaminant mass and volumetric flux to the Columbia River over time for the period of analysis. The groundwater prediction for the composite analysis will be for radionuclide contaminants. Chemical contaminants will be simulated as an additional effort to provide perspective to stakeholders, regulators, and Tribal Nations.

This report presents data and information that supports the groundwater module. The conceptual model of groundwater flow and transport at the Hanford Site is described and specific information applied in the numerical implementation module is provided. 


\section{Contents}

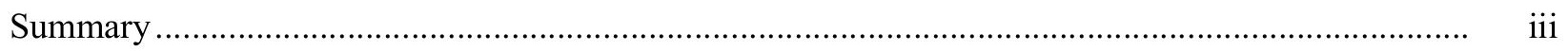

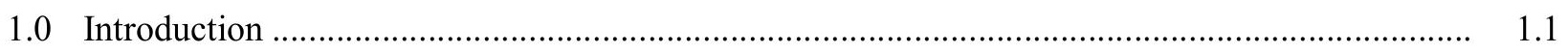

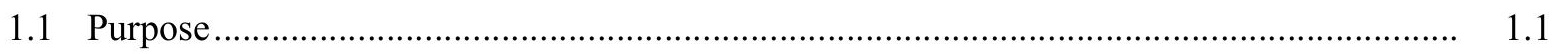

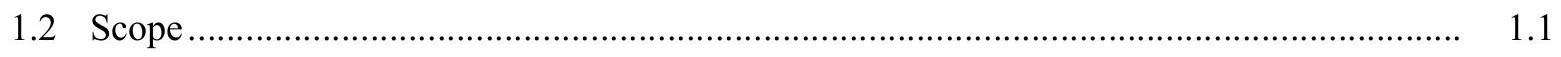

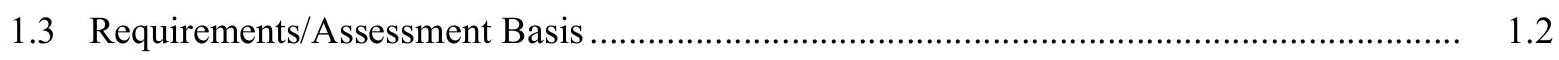

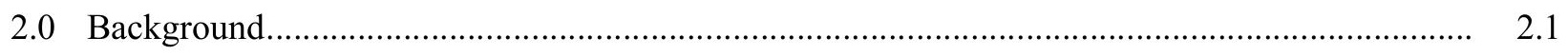

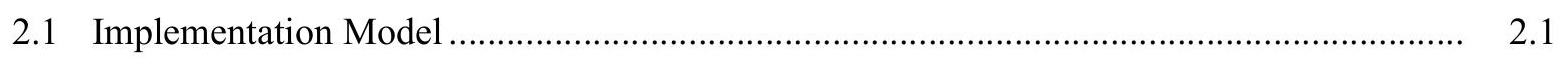

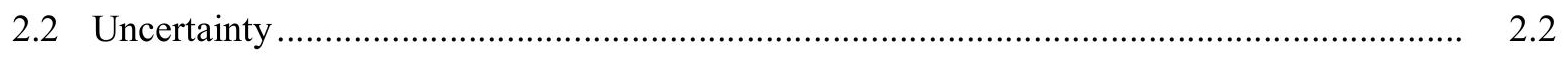

2.3 Continuing Model Improvements …................................................................... 2.2

2.4 Interaction with Other SAC Modules.................................................................... 2.2

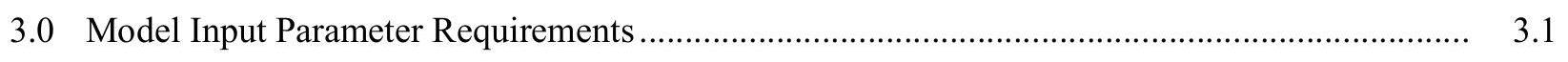

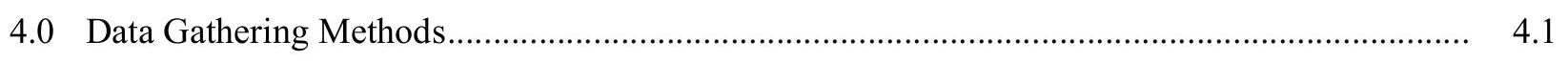

$5.0 \quad$ Data and Information for the Groundwater Module ....................................................... 5.1

5.1 Groundwater Flow System .............................................................................. 5.1

5.2 Hydrogeologic Units of the Unconfined Aquifer System ............................................. 5.3

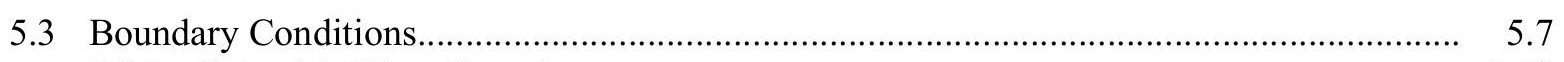

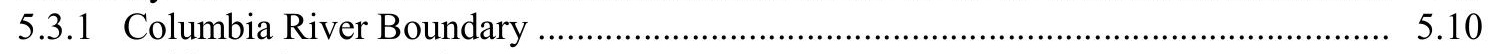

5.3.2 Yakima River Boundary......................................................................... 5.12

5.3.3 Natural Surface Recharge at Upper Boundary ................................................. 5.13

5.3.4 Recharge Along Western Model Boundary and Basalt Subcrops............................ 5.15

5.3.5 Artificial Recharge at Upper Boundary......................................................... 5.16

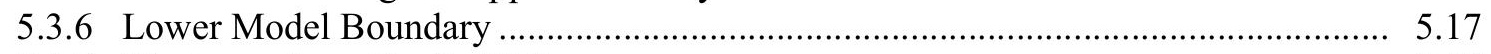

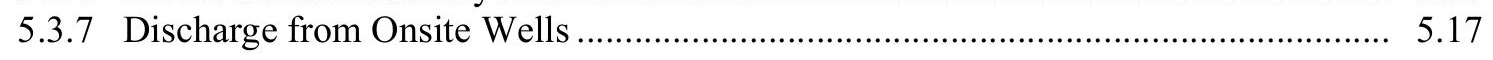

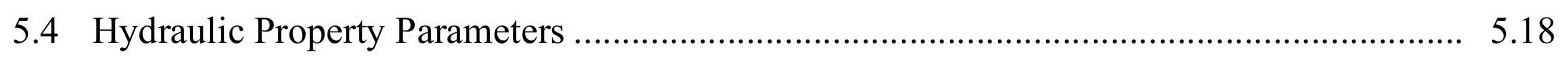


5.5 Contaminant Transport Parameters

5.6 Contaminant Data for Groundwater

6.0 References

\section{Figures}

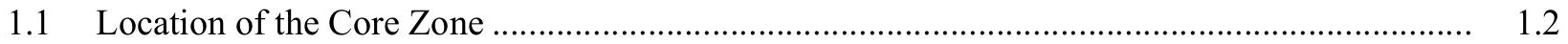

5.1 Extent of Regional and Local Groundwater Flow Systems Beneath the Hanford Site............... 5.2

5.2 Schematic Cross Section of the Pasco Basin .........................................................................

5.3 Cross-Sections Showing Distributions of Hydrogeologic Units Below the Maximum Water Table Elevation Along A-A' and B-B'

5.4 Distribution of Hydrogeologic Units at the Top of the Model............................................. 5.5

5.5 Distribution of Hydrogeologic Units Present at the Water Table for 1944 Conditions .............. 5.6

5.6 Distribution of Boreholes Used to Determine Hydrogeologic Structure for the Composite Analysis Groundwater Model ...........................................................................................

5.7 Groundwater Model Grid and Lateral Boundary Conditions............................................... 5.9

5.8 Hanford Site and Outlying Areas Water Table Map, March/April 2000 ................................. 5.11

5.9 Estimates of Natural Recharge Based on 1979 Vegetation and Land-Use Patterns Without Considering Anthropomorphic Alternation ............................................................................ 5.14

5.10 Artificial Discharges to the Unconfined Aquifer from 1943 to 1998 ...................................... 5.16

5.11 Hydraulic Conductivity Distribution for Units at Top of Model ............................................ 5.19

5.12 Cross Section of Model Along A-A' Showing Distribution of Hydrogeologic Units and Hydraulic Conductivity

5.13 Cross Section of Model Along B-B' Showing Distribution of Hydrogeologic Units and Hydraulic Conductivity 


\section{Tables}

4.1 Summary of Groundwater Data and Information Supporting the Composite Analysis Groundwater Model.

5.1 Fluxes from Four Recharge Sources Resulting from Transient Calibration ............................. 5.15

5.2 Ranges of Hydraulic Property Values Applied to Each Composite Analysis Model Unit .......... 5.18

5.3 Dispersivity Values Used in the Composite Analysis Groundwater Transport Model.............. 5.22

5.4 Half-Lives and Specific Activities for Radioactive Contaminants ......................................... 5.23

5.5 Distribution Coefficients and Effective Retardation Factors ................................................. 5.23 


\subsection{Introduction}

This report presents data and interpreted information that supports the groundwater module of the System Assessment Capability (SAC) as applied to the Hanford Site Composite Analysis.

The composite analysis is an assessment of the cumulative impact from all sources of radioactive contamination, including present and future low-level waste disposal facilities, on the radiation dose to future members of the public (Kincaid et al. 2004). At the Hanford Site, a composite analysis is required for continued disposal of radioactive waste at several existing and planned facilities that are critical for site cleanup.

The SAC is an integrated assessment tool that includes several linked computer models designed to simulate the movement of contaminants from waste sites through the vadose zone, groundwater, and Columbia River to receptors. It also incorporates modules that calculate the risks to human health and the environment. Background information on the development of the SAC is presented in Preliminary System Assessment Capability Concepts for Architecture, Platform and Data Management and Kincaid et al. (2000). A discussion of an initial assessment performed with the SAC is presented in Bryce et al. (2002).

\subsection{Purpose}

The objective of the groundwater module is to predict movement of radioactive and chemical contaminants through the aquifer to the Columbia River or other potential discharge locations. Future contaminant concentrations in groundwater also need to be known for any location where groundwater may be acquired from water-supply wells. For the composite analysis, this includes all areas outside of the "Core Zone" surrounding the 200 Areas (Figure 1.1). The Core Zone is assumed to remain under institutional control for the foreseeable future, and it is assumed that water supply wells in this zone will be prohibited (Kincaid et al. 2004).

The groundwater module will provide estimates of contaminant concentrations over the time period of the analysis within the unconfined aquifer underlying the Hanford Site outside of the Core Zone. These concentrations will provide the basis for the estimated impact to human health and supplemental ecosystem risk. The groundwater module will also provide predictions of contaminant mass and volumetric flux to the Columbia River over time for the period of analysis. The groundwater prediction for the composite analysis will be for radionuclide contaminants. Chemical contaminants will be simulated as an additional effort to provide perspective to stakeholders, regulators, and Tribal Nations.

\subsection{Scope}

The scope of the groundwater module is limited to the unconfined aquifer system within sediments overlying the Columbia River Basalts. The unconfined aquifer system includes some aquifer sediment that is locally confined beneath relatively extensive Ringold Formation mud units. However, the permeable Ringold sediment is interconnected on a site-wide scale. Confined aquifers within the 


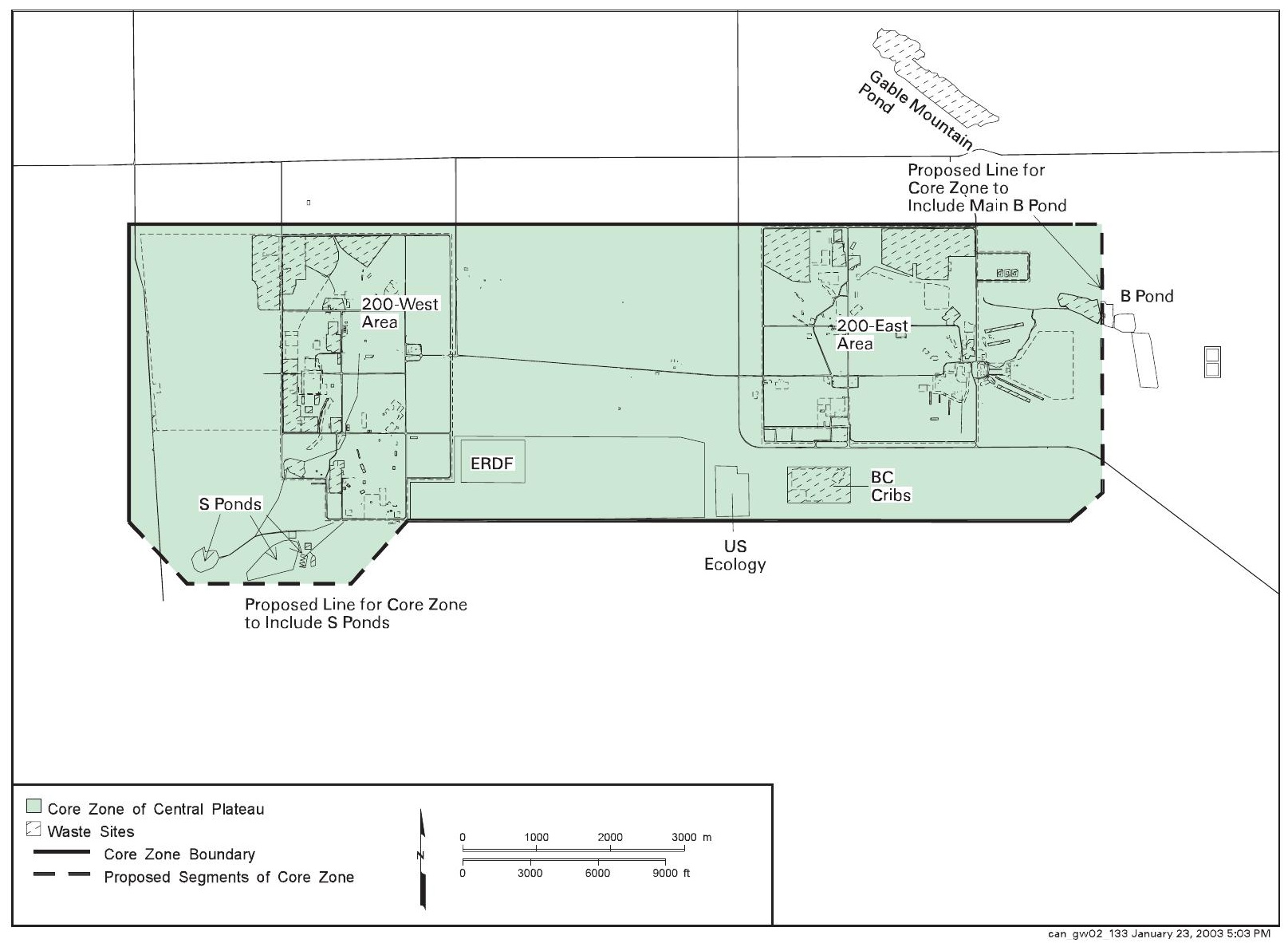

Figure 1.1. Location of the Core Zone

Columbia River Basalt are not included in the scope of composite analysis simulations. However, potential impacts from groundwater contaminants within the basalt-confined aquifers have been considered in other studies (Spane and Webber 1995; Thorne 1998; Newcomer et al. 2002). Although some Hanford Site contaminants have been found within the basalt-confined aquifers, the concentrations are much lower than those found in the overlying sedimentary aquifer. Therefore, the maximum impact is predicted without including the small mass of contaminants in the basalt-confined aquifer system. Groundwater simulations will extend through the year 3035, thereby including the 1,000 years following an assumed Hanford Site closure date of 2035 as required by U.S. Department of Energy (DOE) Order 435.1 (Kincaid et al. 2004).

\subsection{Requirements/Assessment Basis}

The objectives, requirements, assessment basis, and scope of the composite analysis are presented in Kincaid et al. (2004). They also describe the modified data quality objectives process applied to the composite analysis. 


\subsection{Background}

Data presented in this report supports a conceptual model of groundwater flow. The conceptual model is a working description of the characteristics and processes that describe the dynamics of the physical and chemical hydrogeologic system. The conceptual model must be consistent with available data and understanding. Assumptions are made to define the conceptual model where information is lacking. However, assumptions must also be consistent with available data and understanding of the groundwater flow system.

\subsection{Implementation Model}

An "implementation model" was developed based on the conceptual model and incorporated simplifications where needed and appropriate. For example, groundwater-river interactions have been implemented in the model using a specified-head boundary where head in the Columbia River does not change over time. The simplification of the boundary condition would be part of the description of the implementation model. However, the actual groundwater-river interactions, which are affected by both annual and daily fluctuations of river stage, are described in the conceptual model. This simplification is appropriate because only long-term transport to the river is being evaluated in the composite analysis and the effect of short-term river-stage fluctuations is expected to be small. Assumptions, parameters, and even processes in an implementation model may conflict with the available information regarding local details. This is part of the spatial and temporal aggregation process associated with choosing the appropriate simplifications needed to model complex systems (Cole et al. 2001a).

The groundwater flow model used to simulate contaminant transport for the composite analysis is based on the three-dimensional model presented in Cole et al. (2001b). This Hanford site-wide groundwater model has evolved over the past 30 years. A two-dimensional model was initially developed in the 1970s. In the 1980s, work began on building two- and three-dimensional models using the Coupled Fluid, Energy, and Solute Transport (CFEST) code (Gupta 1997). Historical development and earlier calibrations of the CFEST model are described in Chapter 5 of Evans et al. (1989) and in Wurstner et al. (1995). The CFEST code was also used to implement the groundwater flow and transport model used for the composite analysis.

For the composite analysis, the model grid used to simulate transport was refined to reduce errors caused by "numerical dispersion" and permit the use of lower values for hydrodynamic dispersion parameters. The model was calibrated to transient head conditions using an automated inverse modeling technique as described in Cole et al. (2001b). Calibration of the model matched model-predicted hydraulic heads to historical observations of hydraulic head from 1944 through 1996. The transient calibration process included the discharge of large volumes of wastewater to a variety of waste facilities during this period, which caused changes in hydraulic head over parts of the Hanford Site. This artificial recharge to the aquifer raised the water table and created groundwater mounds near discharge facilities. In 1988, the change in Hanford's mission from weapons production to environmental restoration resulted in a reduction in wastewater discharges and significant declines in hydraulic heads. 


\subsection{Uncertainty}

Uncertainties in the conceptual model arise from a lack of information concerning features and events, or a lack of understanding of the processes controlling groundwater flow and transport. It is important to understand these uncertainties and their potential impact on model results. Additional uncertainty arises from simplifications in developing the implementation model. Cole et al. (2001a) provides a detailed discussion of sources of uncertainty in the Hanford site-wide groundwater model. Specific sources of uncertainty pertaining to various components of the groundwater model are discussed in Chapter 5.

\subsection{Continuing Model Improvements}

Improvements continue to be made in the site-wide groundwater model. These improvements are aimed at quantifying uncertainty within the model and improving model accuracy as recommended by an outside review panel in 1998 (Cole et al. 2001a). The review panel recommended that the concept of uncertainty be acknowledged and that a new modeling framework be established that is stochastic rather than purely deterministic. The panel also requested an assessment of the relative importance of uncertainties due to alternative model structures and constructs of processes (e.g., different zonation, different boundary conditions, large-scale features, stresses, chemical reactions) and due to variations in parameter values. Based on the panel's recommendations, a strategy was devised for assessing model uncertainty through the development and calibration of alternative conceptual models, where the calibration is based on the transient changes in hydraulic heads since the start of Hanford operations. Cole et al. (2001a) presents the proposed strategy for assessing model uncertainty. The model used for the composite analysis is a revision of the "baseline" model resulting from transient calibration. Additional "alternative" conceptual models have been developed that consider hydraulic interactions with the underlying basaltconfined aquifers (Vermeul et al. 2001) and that also include a geologically based zonation of hydraulic properties within the Hanford formation (Unit 1) and the middle Ringold Formation (Unit 5) (Vermeul et al. 2003).

\subsection{Interaction with Other SAC Modules}

The vadose zone module of SAC provides contaminant flux out of the vadose zone as input to the groundwater module. Water fluxes from large volume waste sites to the water table are also calculated in the vadose zone module. This helps account for the time delay between disposal to the ground and recharge of the aquifer. The input volumes from this artificial recharge are added to natural recharge to define the specified flux boundary at the top of the groundwater model.

Contaminant flux out of the groundwater module is used as input to the Columbia River module and concentrations in groundwater at specified locations are used in the risk module. The groundwater module will provide predictions of contaminant mass and volumetric flux to the Columbia River over time for the period of analysis. The groundwater module will also provide estimates of contaminant concentrations over the time period of the analysis within the unconfined aquifer. These concentrations are used in the Human Health Risk Assessment and Supplemental Ecological Risk Assessment modules. 


\subsection{Model Input Parameter Requirements}

The groundwater flow and transport model required the following types of data and information:

- Model structure (geometry) - Three-dimensional model layers representing major hydrogeologic units.

- Hydraulic property distributions - Estimates of horizontal and vertical hydraulic conductivity, specific storage, and specific yield for each of the hydrogeologic units.

- Boundary conditions - Definitions of each model boundary as specified head, specified flux, headdependent flux, or no flow. This includes the top and bottom surfaces of the model domain as well as the lateral boundaries.

- Transport properties - Distributions of effective porosity, dispersivity, radioactive decay coefficients, and retardation factors for sorbed contaminants.

- Initial conditions - Distributions of hydraulic head and contaminant concentrations at the start of the simulation period.

- Inputs and withdrawals - Inputs and withdrawals of water volume and contaminant mass (or activity) at specific locations and times during the simulation period. This includes pumping from wells, natural and artificial recharge to the aquifer, and contaminant inputs. Some of the water volume inputs are included in boundary conditions. 


\subsection{Data Gathering Methods}

Data and information supporting the groundwater conceptual model are available in several different documents and electronic databases. Where possible, applicable documents and files containing the data and information are described and referenced rather than listing all information in this data package. Table 4.1 lists pertinent data files. The files are available on the CD distributed with this report. Documents supporting the conceptual model are cited throughout Chapter 5 and are listed in Chapter 9. All elevations in the data tables are based on the NAVD88 sea-level datum. All lateral locations are based on the NAD83 datum and expressed in state plane coordinates (m) for FIPSZONE 4602. Some older documents (pre-1995) may use a different reference datum.

A distinction is made between data and interpreted information as recommended by the Groundwater Modeling Project Peer Review Panel (DOE 1999). For example, measured contaminant concentrations in groundwater samples are data, but plume maps or grids of interpolated contaminant concentrations in the aquifer are interpreted information.

Table 4.1. Summary of Groundwater Data and Information Supporting the Composite Analysis Groundwater Model (files are on the CD distributed with this report)

\begin{tabular}{||l|c|c||}
\hline \multicolumn{1}{|c|}{ Description } & Value or File Name & File Type \\
\hline \hline Elevation of the bottom of the model domain & bndbot_CA.dat & ascii grid file \\
\hline $\begin{array}{l}\text { Interpreted elevation for the top of each hydrogeologic } \\
\text { unit at wells }\end{array}$ & geo_CA.xls & EXCEL file \\
\hline $\begin{array}{l}\text { Elevation grids for the top of each hydrogeologic unit } \\
\text { applied in the model }\end{array}$ & u$^{*}$ _top_elev.dat & ascii grid file \\
\hline Grid node and element locations & elem_nod_CA.xls & EXCEL file \\
\hline Fluxes at constant flux boundaries & Table 5-1 & table in text \\
\hline Specified-head condition for Columbia River & col_river_CA.dat & text file \\
\hline Specified-head condition for Yakima River & yak_river_CA.dat & text file \\
\hline Natural recharge from precipitation & n_rech79_CA.dat & ascii grid file \\
\hline Artificial recharge/discharge & a_rech_CA.xls & EXCEL file \\
\hline Hydraulic conductivity for each model node & nod_K_CA.dat & text file \\
\hline Specific storage applied to model units & Table 5.2 & table in text \\
\hline Specific yield applied to model units & Table 5.2 & table in text \\
\hline Anisotropy (Kz/Kx) applied to model units & Table 5.2 & table in text \\
\hline Porosity - Hanford Gravels (Unit 1$)^{(a)}$ & 0.25 & table in text \\
\hline Porosity - Ringold Gravels (Units 5, 7,9) & Table 5.3 & table in text \\
\hline Longitudinal dispersivity & Table 5.3 & table in text \\
\hline Transverse dispersivity & Table 5.4 & table in text \\
\hline Radionuclide half-life/specific activity & Table 5.5 & \\
\hline $\begin{array}{l}\text { Distribution coefficients for sorbed contaminants (linear } \\
\text { sorption isotherm) }\end{array}$ & & \\
\hline (a) Total and effective porosity assumed to be equal. & \multicolumn{2}{|c||}{} \\
\hline
\end{tabular}




\subsection{Data and Information for the Groundwater Module}

This section describes the conceptual model of groundwater flow and transport at the Hanford Site. Supporting data and interpreted information are presented or referenced. It also provides specific information that defines the implementation model. The three-dimensional Hanford site-wide groundwater flow model described in Cole et al. (2001b) was used as a basis for the SAC simulations. However, to support the required transport simulations, a refined model grid was used.

\subsection{Groundwater Flow System}

Both local and regional groundwater flow systems exist beneath the Hanford Site. The regional aquifer system is composed of saturated transmissive units within the Columbia River Basalt Group and extends from western Idaho through eastern Washington and northeastern Oregon (Figure 5.1). Basaltconfined aquifers within the regional groundwater flow system beneath the Hanford Site are grouped into three separate hydrogeologic units corresponding to three distinct basalt formations (DOE 1989; Cole 2001b). From lowest to highest in elevation, these are the Grande Ronde, the Wanapum, and the Saddle Mountains (Figure 5.1). The basalt-confined aquifers are composed of the brecciated tops of individual basalt flows and sedimentary interbeds between basalt flows. Sediments within the basalts are collectively referred to as the Ellensburg Formation. These aquifers are confined by the relatively impermeable interiors of basalt flows. The local flow system exists within fluvial, lacustrine, and glaciofluvial sediment that have been deposited on top of the Columbia River Basalts within the Pasco Basin. Figure 5.2 shows a cross section of the basalt formations and sediment accumulated within the Pasco Basin. The local aquifer system provides a pathway for transport of contaminants released from past, present, and future site activities. This uppermost saturated zone is termed the unconfined aquifer system, although locally confined conditions may exist in certain areas.

The regional basalt-confined aquifers were excluded from the implementation model because they are generally isolated from contaminants by low-permeability basalt confining layers. Although there is some hydraulic communication between the basalt-confined and unconfined sedimentary flow systems and Hanford Site contaminants have been found within the basalt-confined aquifers, the concentrations are much lower than those found in the overlying sedimentary aquifer (Hartman 2003). The potential for contaminant transport through the confined aquifer has been evaluated by Thorne (1998) and found to present a small risk compared to the potential for contaminant transport in the local unconfined aquifer system. Additional information on the basalt-confined regional aquifer system and communication between the aquifer systems is available in Spane and Vermeul (1994), Spane and Webber (1995), Graham et al. (1984), and Gephardt et al. (1979).

Only the local Pasco Basin unconfined aquifer system that lies west and south of the Columbia River and east and north of the Yakima River were included in the composite analysis groundwater model. The unconfined aquifer system also extends beneath these rivers and exists on both sides of the rivers. However, the model implementation assumes no communication under the rivers. For the Columbia River, 


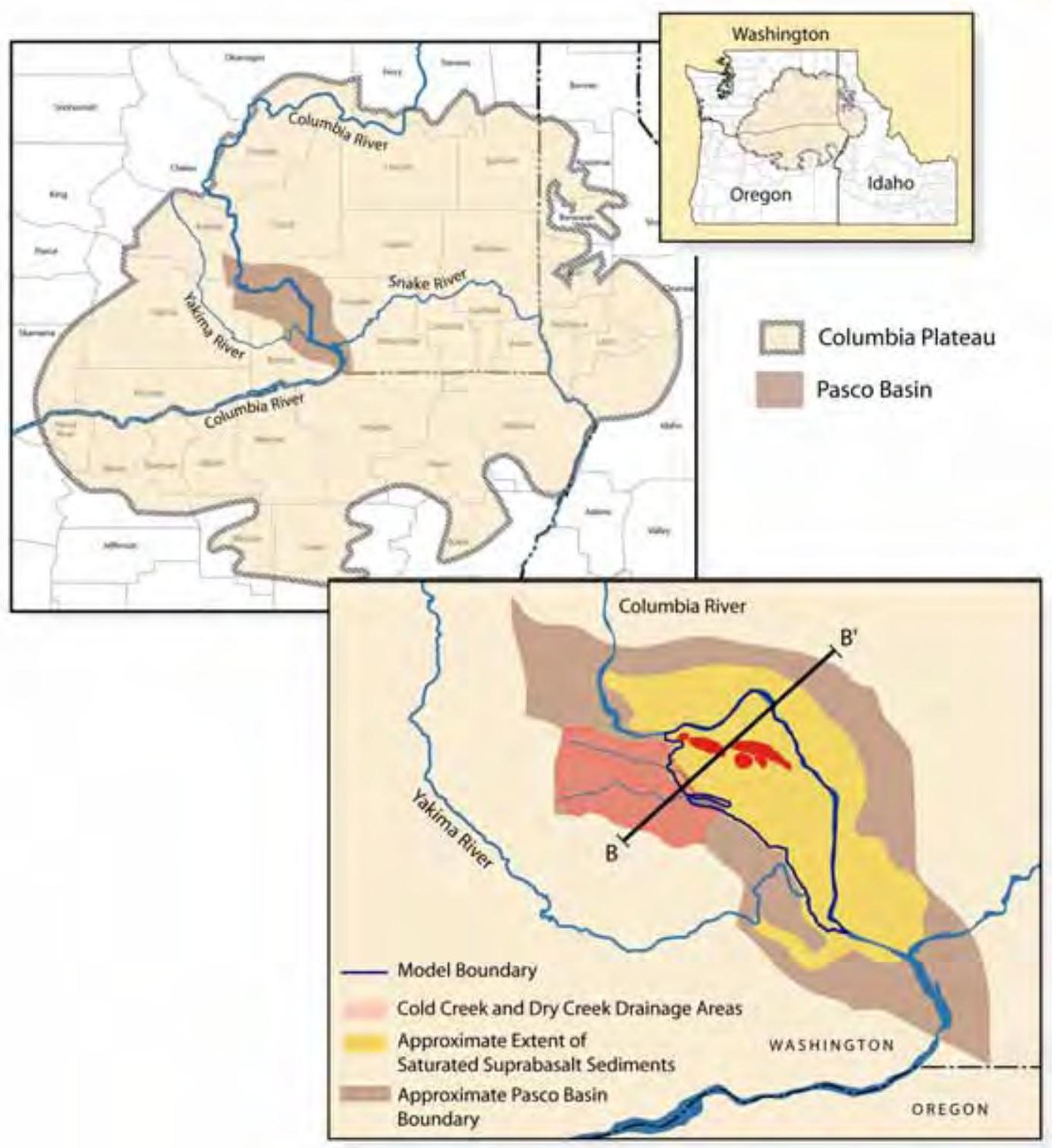

Figure 5.1. Extent of Regional and Local Groundwater Flow Systems Beneath the Hanford Site

this is consistent with the river being a regional discharge area for the aquifer system. For the Yakima River, it is consistent with the very limited extent of the unconfined aquifer system on the opposite side of the river. Additional information on these two rivers and their implementation as boundaries of the groundwater model domain is presented below.

Limiting the groundwater implementation model to the supra-basalt sediment introduces uncertainty because interaction with deeper basalt-confined aquifers is ignored. The nature and significance of this information is being evaluated through the development and calibration of alternative conceptual models as part of a separate groundwater model development task (Vermeul et al. 2001, 2003). 


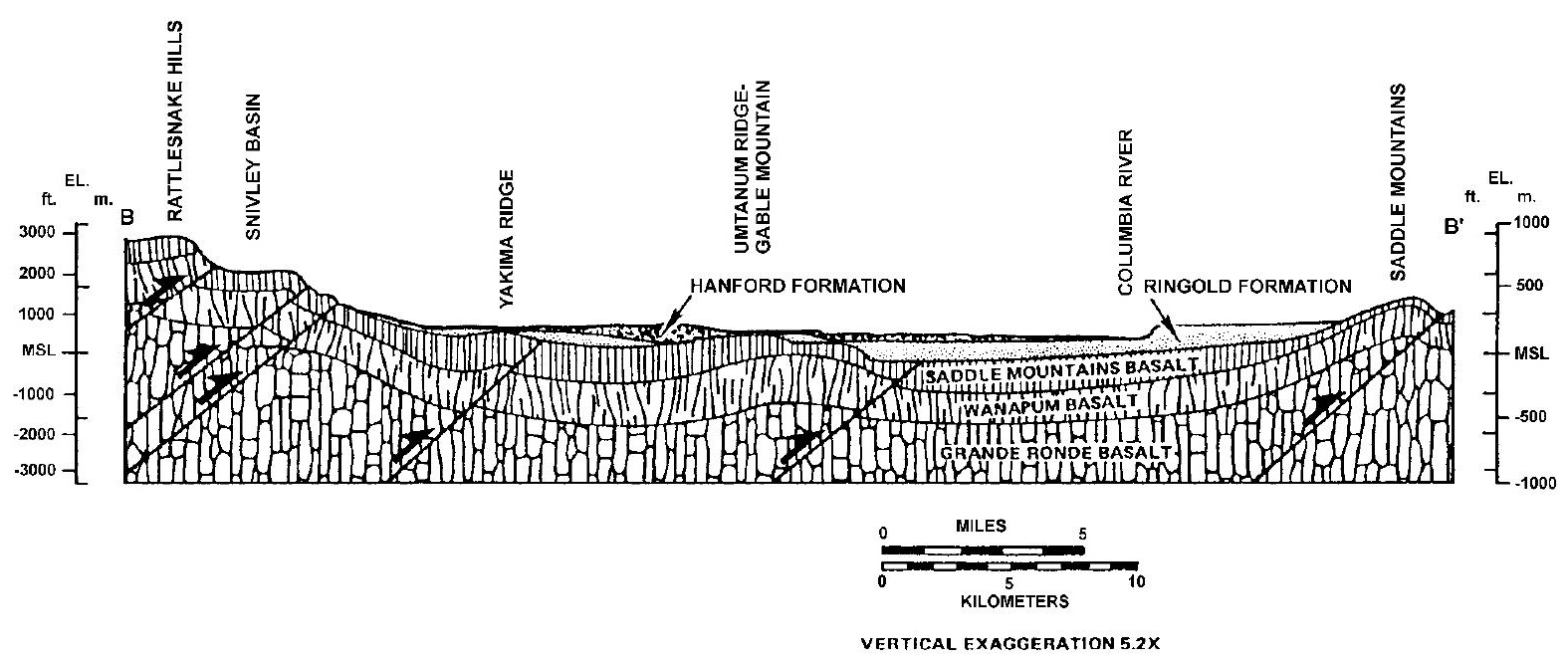

Figure 5.2. Schematic Cross Section of the Pasco Basin (see Figure 5.1 for location)

\subsection{Hydrogeologic Units of the Unconfined Aquifer System}

Distinct hydrogeologic units within the sediment overlying the basalt bedrock can be correlated between boreholes over distances of several kilometers. The hydrogeologic structure of the groundwater model was designed to reflect differences in hydraulic properties of sediment such as effective porosity and hydraulic conductivity. These properties are related to sediment texture, which is a function of grainsize distribution, sorting, and consolidation/cementation. In developing the three-dimensional model, an effort was made to identify major textural units that influence groundwater flow directions and contaminant transport on a site-wide scale. Delineation of textural units was based primarily on the stratigraphy and sediment facies described by Lindsey (1995).

For the implementation model, sediment overlying the basalt bedrock was grouped into nine major hydrogeologic units. Seven of these units are found below the water table and compose the modeled aquifer system. Units 2 and 3 are above the water table in this implementation of the model. The nine hydrogeologic model units are:

- Unit 1 - Hanford formation and the underlying, texturally similar, coarse-grained multilithic facies of the Cold Creek Unit (pre-Missoula gravels).

- Unit 2 - Fluvial/eolian facies of the Cold Creek Unit.

- Unit 3 - Calcic paleosol sequence of the Cold Creek Units.

- Unit 4 - Silt and clay facies of the Upper Ringold Unit.

- Unit 5 - Lindsey's (1995) Ringold gravel units E and C, also includes sand facies of the Upper Ringold Unit where it directly overlies the other $\mathrm{E}$ and $\mathrm{C}$ gravel units. 
- Unit 6 - Fine-grained overbank and paleosol deposits that vertically separate Lindsey's (1995) unit $\mathrm{B}$ from overlying unit $\mathrm{C}$ in the eastern part of the Hanford Site.

- Unit 7 - Lindsey's (1995) Ringold gravel units B and D.

- Unit 8 - Lower Ringold mud unit (Lindsey 1995).

- Unit 9 - Lindsey's (1995) Ringold unit A, a gravel and sand facies that is dominated by sand in the western part of the Pasco Basin.

Cross sections of the model units are shown in Figure 5.3. Cross section locations are shown on Figure 5.4. Figure 5.4 also shows the units present at the top of the groundwater model, which is slightly higher than the maximum historical water table at each location. Figure 5.5 shows the units present at the water table for 1944 (pre-Hanford) conditions.

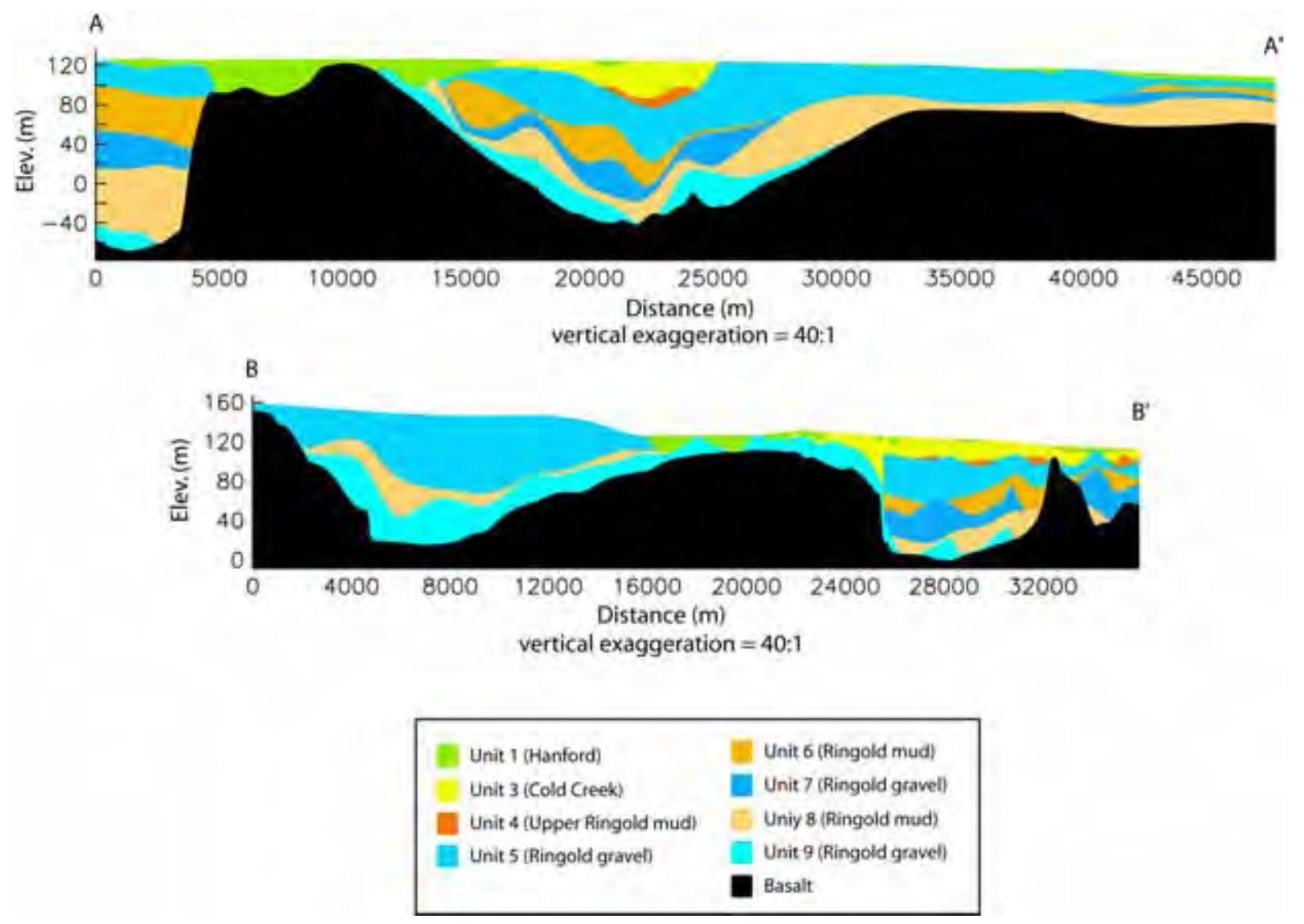

Figure 5.3. Cross-Sections Showing Distributions of Hydrogeologic Units Below the Maximum Water Table Elevation Along A-A' and B-B' (see Figure 5.4 for transect locations) 


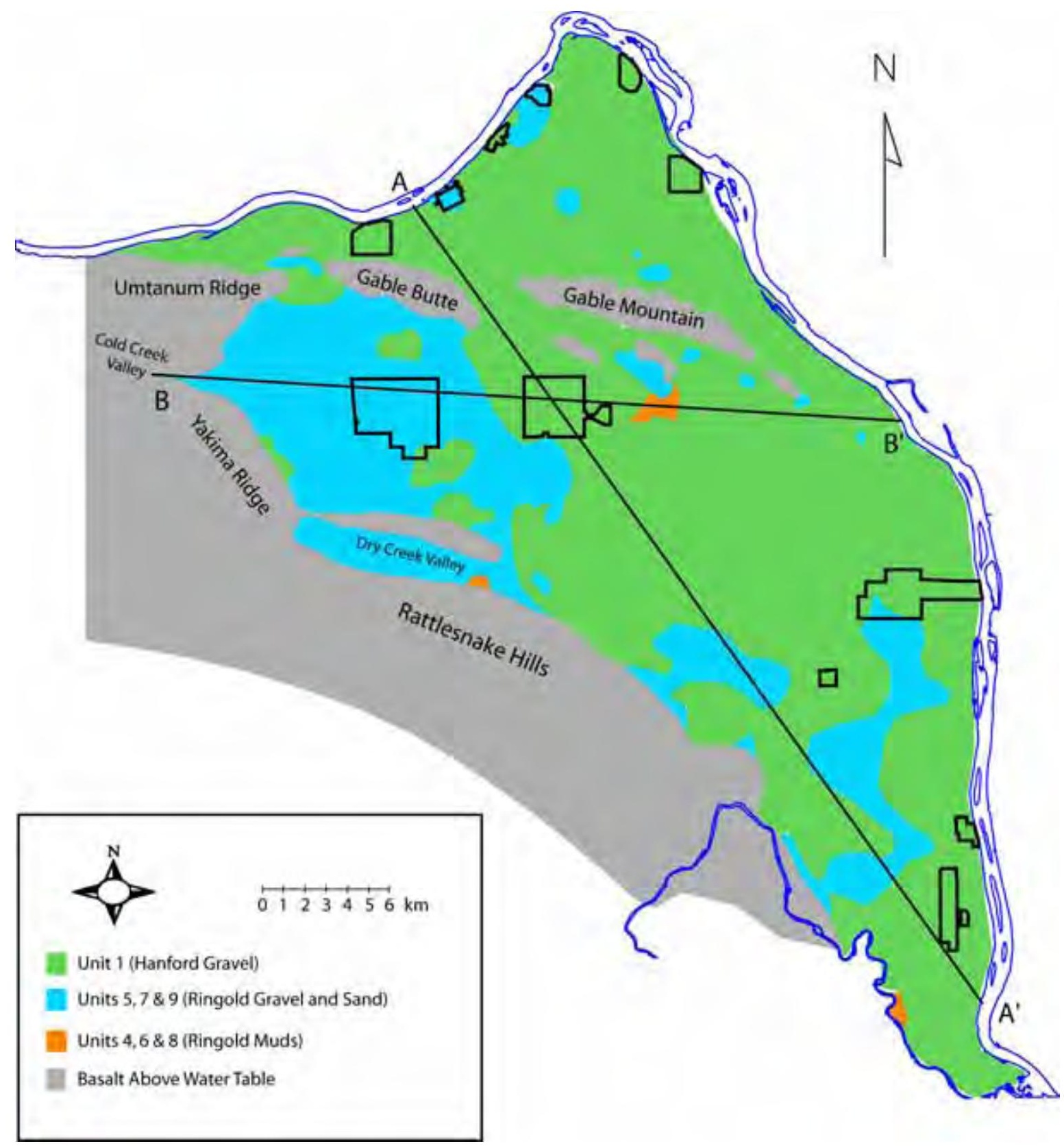

Figure 5.4. Distribution of Hydrogeologic Units at the Top of the Model (maximum water table) 


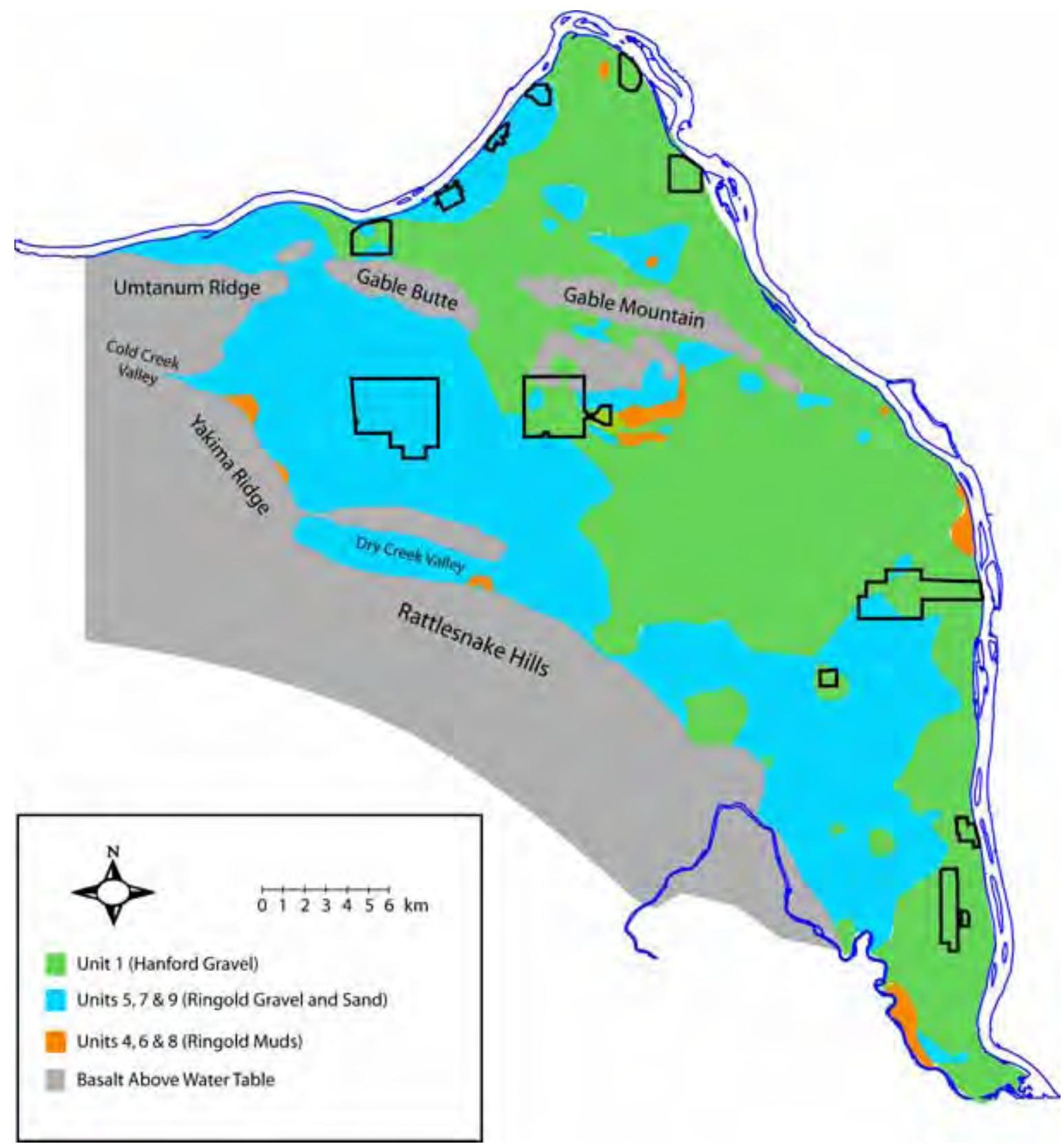

Figure 5.5. Distribution of Hydrogeologic Units Present at the Water Table for 1944 (pre-Hanford) Conditions 
In subsequent model implementations (Vermeul et al. 2003), the coarse-grained multilithic facies of the Cold Creek Unit (pre-Missoula gravels) were included in model unit 3 and are found below the water table. This later implementation was still undergoing calibration refinement at the time of the SAC simulations. Information on the geologic setting and additional details on the grouping of sediment for the model units is provided in Cole et al. (2001a). Classification of Ringold Formation sediment into different facies associations based on geologic characteristics and depositional environment is discussed in Lindsey (1995). The depositional environment, facies classifications, and depositional environments of post-Ringold sediment including the Cold Creek Unit and the Hanford formation are discussed in DOE (2002).

Unit top elevations and thicknesses, as well as the elevation for the top of basalt, which forms the base of the groundwater flow model, are primarily based on data from boreholes. The unit geometry information is in the form of unit elevation grids, which are based on "unit picks" for each well used in the interpretation. The unit picks are listed in the file geo_CA.xls, which is on the CD provided with this report. Files containing grids that define elevations for the top and bottom of each of the model units are also provided. Borehole data that are the basis for the unit picks include descriptions of borehole samples (cuttings), particle size analyses of samples, and geophysical logs. Figure 5.6 shows the distribution of wells used for defining model unit geometries.

Sources of uncertainty arising from the borehole data used for defining unit picks include the following:

- Differences in drilling techniques

- Differences in procedures for describing sediments

- Differences in knowledge or training of person making the descriptions

- Losses of coarse-grained particle fraction caused by drilling

- Vertical density of samples

- Quality of geophysical logs

In addition, there is uncertainty in the spatial geometry and continuity of model units that arises from the spatial distribution of borehole data and the lack of knowledge concerning unit configuration below the surface. Differences in hydraulic properties caused by differences in texture, sorting, cementation, and compaction also occur within major units defined for the model. These differences are another source of model uncertainty.

\subsection{Boundary Conditions}

The conceptual model of groundwater flow beneath the Hanford Site includes several important flowsystem boundaries. These include the top and bottom surfaces of the model domain as well as the lateral boundaries. The flow system is bounded by the Columbia River on the north and east and by the Yakima River and basalt ridges on the south and west, respectively. It is bounded below by the Columbia River Basalt formations. Groundwater recharge and discharge takes place at the river boundaries, at the top of the model, and at the bottom of the model. There are also boundaries within the model where basalt 


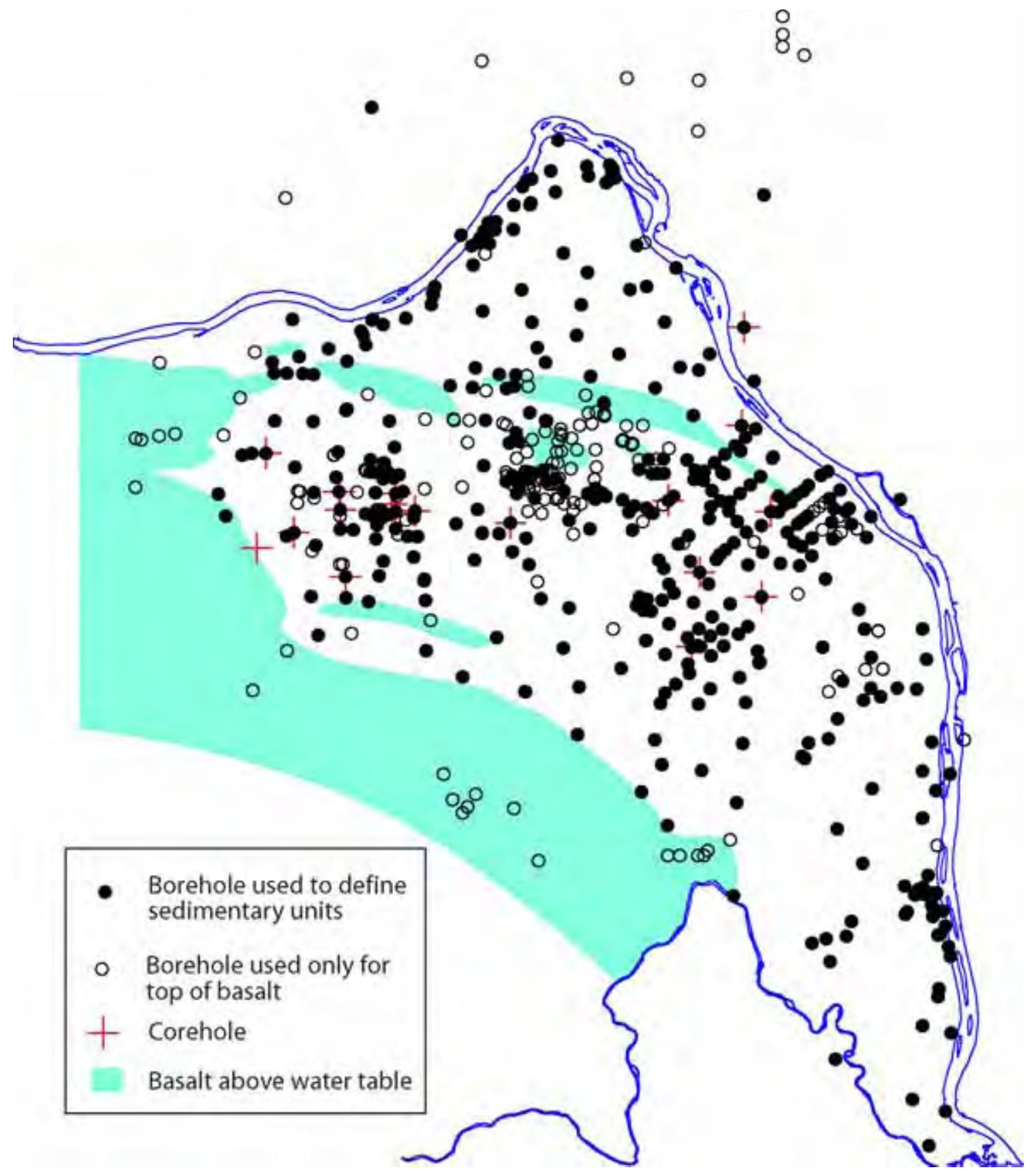

Figure 5.6. Distribution of Boreholes Used to Determine Hydrogeologic Structure for the Composite Analysis Groundwater Model 
subcrops above the water table. However, the implementation model assumes that no flow takes place at the bottom of the model or at the boundaries formed by basalt subcrops within the model domain.

For each boundary in the implementation model, a spatial geometry is needed as well as a definition as being a specified head, specified flux, head-dependent flux, or no flow boundary. Parameters defining the flux at boundaries are also needed. The lateral boundary conditions implemented in the groundwater model are illustrated in Figure 5.7 together with the model grid used for the SAC simulations.

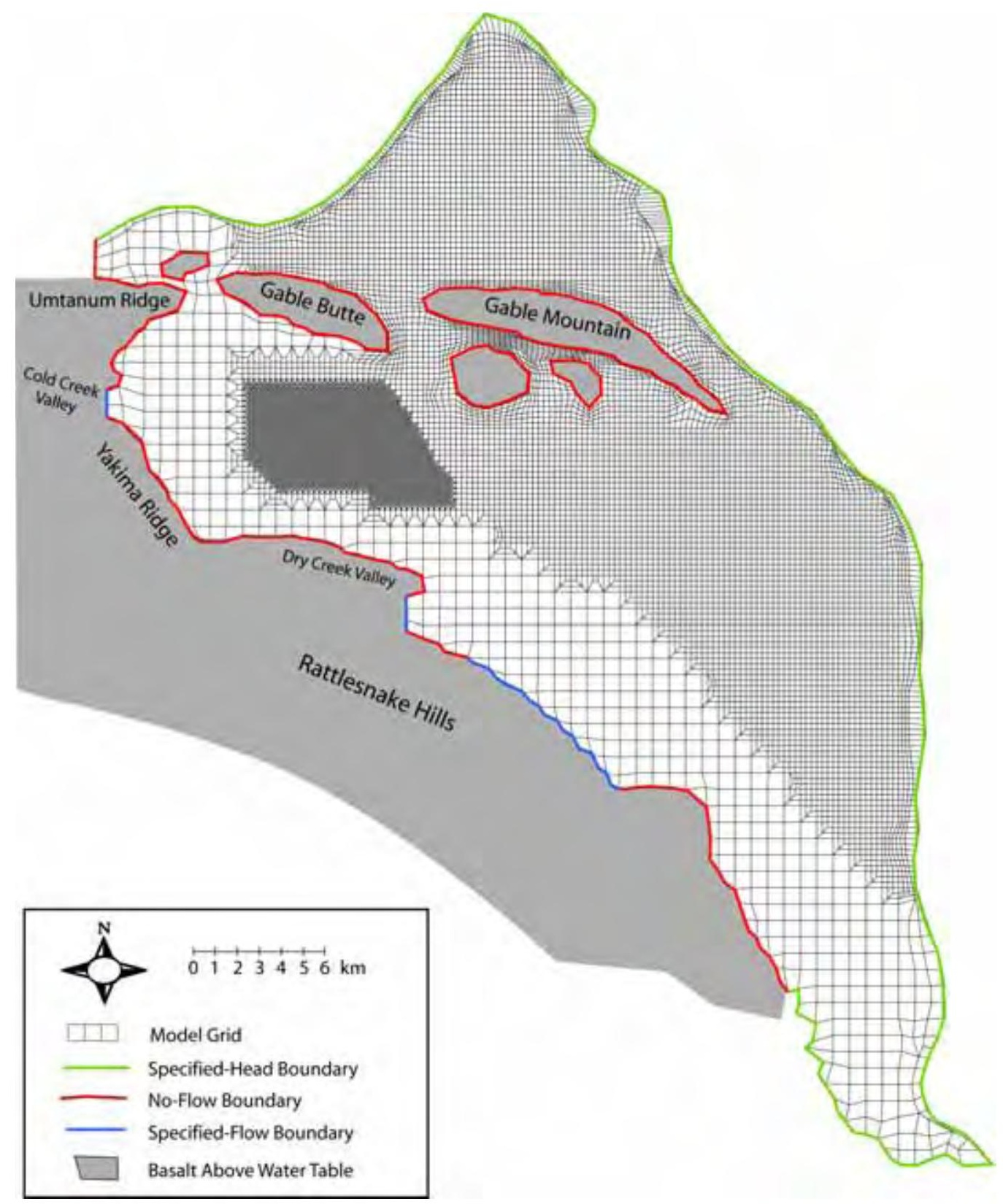

Figure 5.7. Groundwater Model Grid and Lateral Boundary Conditions 


\subsubsection{Columbia River Boundary}

The Columbia River is assumed to represent a point of regional discharge for the unconfined aquifer system. Interpreted water-table elevation contours (Figure 5.8) support this assumption. The amount of groundwater discharging to the river is a function of the local hydraulic gradient between the groundwater elevation adjacent to the river and the river-stage elevation. This hydraulic gradient is highly variable because the river stage is affected by releases from upstream dams. For the section of river below the 300 Area, it is also affected by releases from McNary Dam, below the Hanford Site, because the McNary pool backs up into this area. All available data indicate that groundwater from the shallow flow system discharges to the Columbia River from both banks. The width of the river varies from approximately 300 to 1,000 meters at the Hanford Site. Transects of the river bottom elevation have been measured about every kilometer. The maximum depth of the Columbia River in the area adjacent to the Hanford Site is about 11 meters.

The flow rate of the Columbia River in the Hanford Reach fluctuates significantly and is controlled primarily by releases from dams. There are both seasonal and daily fluctuations in flow, which also cause fluctuations in river stage. Seasonal flows typically peak from April through June, during spring runoff from snowmelt, and are lowest from September through October. The seasonal change in average water level is up to about 2 meters. Daily fluctuations in discharge are caused by releases from dams based on demand for power production. Because of these changes in flow, the river stage varies significantly over a short time period. Vertical fluctuations of more than 1.5 meters during a 24-hour period are common along the Hanford Reach (Dirkes and Hanf 1996).

For the composite analysis implementation model, short-term fluctuations of river stage are not considered. These fluctuations are not expected to have a significant effect on model predictions. Near the river, daily fluctuations may be important because of bank storage effects. River water moving into and out of the aquifer would dilute the concentration of contaminants in the groundwater and may cause contaminants to move some distance downstream parallel to the river before leaving the aquifer. Sampling tubes have recently been installed at multiple depths along the 100 Area shoreline to increase the understanding of the groundwater/river interface (Peterson et al. 1998; Hartman and Peterson 2003). These tubes monitor conditions within or very close to the interface between groundwater and river water. Effects of river stage changes on groundwater near the river have been simulated by using a crosssectional pathline model near the 100-N Area (Peterson and Connelly 2001). This work showed a delay in contaminants reaching the river because each particle takes a circuitous route rather than moving directly to the riverbank. Movement of water in and out of the aquifer can also increase the release of sorbed contaminants in sediment near the Columbia River as river water moves in and out of the contaminated material. However, these effects are only significant locally, close to the river, and are not expected to have an effect on the long-term predictions of contaminant transport from the Central Plateau to the Columbia River.

The implementation model represents the Columbia River as a prescribed-head boundary. Flow from the aquifer to the river is controlled by the relative heads between the river and aquifer and the hydraulic conductivity of the sediments in contact with the river. To approximate the river boundary conditions, water-surface elevations for the Hanford Reach of the Columbia River were generated using the Modular Aquatic Simulation System 1D (MASS1). The MASS1 simulations are described in detail in Appendix C 


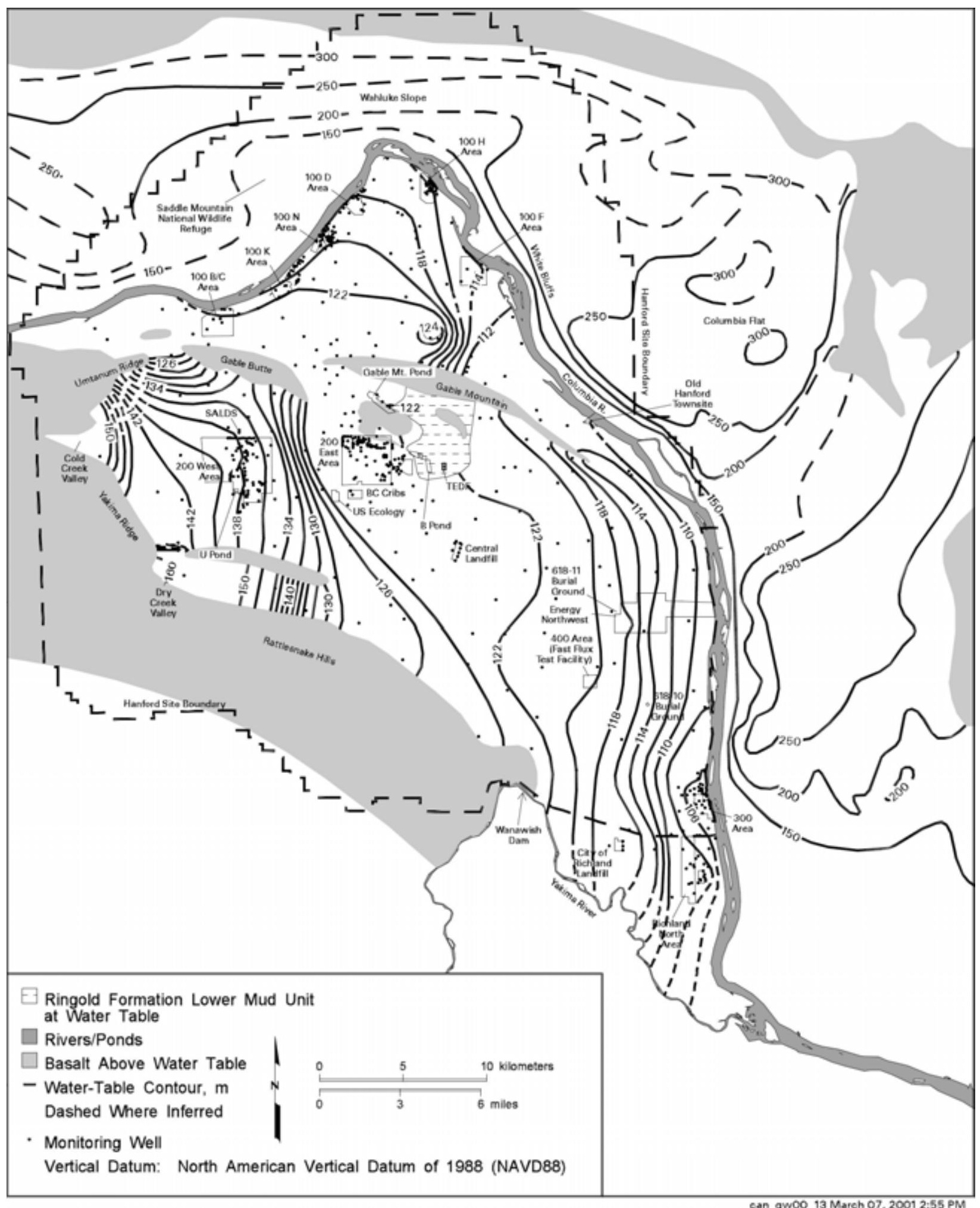

Figure 5.8. Hanford Site and Outlying Areas Water Table Map, March/April 2000 (Hartman et al. 2001) 
of Cole et al. (2001b). The geometry and prescribed-head boundary condition of the Columbia River boundary as applied in the composite analysis model is contained in the file col_river_CA.dat, which is on the $\mathrm{CD}$ provided with this report.

\subsubsection{Yakima River Boundary}

The Yakima River follows the southwestern boundary of the Hanford Site for about 2 kilometers (Figure 5.8), then flows southwest of Richland, partially defining the southern extent of the groundwater model domain. Surface runoff from approximately one-third of the Hanford Site is drained by the Yakima River system. The Yakima River carries much less flow than the Columbia River. The average flow, based on nearly 60 years of records, is about $104 \mathrm{~m}^{3} / \mathrm{s}$, compared to $3,360 \mathrm{~m}^{3} / \mathrm{s}$ for the Columbia River.

River stage of the Yakima is generally higher than the water table of the adjacent unconfined aquifer (Figure 5.8). Therefore, the Yakima River represents a potential source of recharge to the aquifer in the southwestern portion of the Hanford Site. As part of a study of groundwater chemistry of the Pasco Basin (Ebbert et al. 1991), the U.S. Geological Survey found evidence that the Yakima River recharges into the unconfined aquifer adjacent to the Hanford Site. This conclusion was based on a comparison between the chemical composition of river water, groundwater from a well completed in the Saddle Mountains Basalt, and groundwater from an offsite well completed in the unconfined aquifer (Ringold Formation) near the river. The recharge rate from the river is controlled by the hydraulic conductivity of sediment adjacent to the river and the head difference between the river and aquifer. The rate of recharge at this boundary is uncertain because of a lack of wells and a corresponding lack of information concerning hydraulic properties and water-level elevations near the river.

To help define aquifer interaction with the Yakima River, river-stage elevation and water levels in an adjacent well were monitored at a location just below Horn Rapids Dam. As reported in Thorne et al. (1993), water levels in the unconfined aquifer at this well showed very little response to changes in river stage. However, the water level of the unconfined aquifer does respond to the filling of a canal (the Horn Rapids Ditch) between the well and the river. The observed response indicates that at this location the Yakima River is isolated from the aquifer by relatively low-permeability sediment. The section of the Yakima River below Horn Rapids Dam flows through flood plain sediment that mainly consists of finegrained overbank and oxbow lake deposits. The adjacent canal is within the more permeable sediment lying above the water table.

The implementation model represents the Yakima River as a prescribed-head boundary. Flow to the aquifer is controlled by the relative heads between the river and aquifer and the hydraulic conductivity of the sediment in contact with the river. To approximate the river boundary conditions, water-surface elevations for the lower reach of the Yakima River were generated using the MASS1 (Cole et al. 2001b). Results of the MASS1 modeling provided the historical Yakima River stages that were averaged for the model boundary. Seasonal river-stage fluctuations are not expected to significantly affect model predictions. The geometry and prescribed-head boundary condition of the Yakima River boundary as applied in the composite analysis model is contained in the file yak_river_CA.dat, which is on the CD provided with this report. 
Flooding of the Yakima River also presents a potential for recharge events to the unconfined aquifer. There have been fewer than 20 major floods on the Yakima River since 1862 (DOE 1988). The development of irrigation reservoirs within the Yakima River Basin has considerably reduced the flood potential of the river. The southern border of the Hanford Site could be susceptible to a 100 -year flood on the Yakima River. However, because these events would be infrequent and not greatly influence average patterns of groundwater flow and transport, the potential impact of increased recharge from Yakima flood events has not been considered in the implementation model.

\subsubsection{Natural Surface Recharge at Upper Boundary}

Natural recharge from precipitation falling on the Hanford Site is highly variable both spatially and temporally, ranging from near zero to more than $100 \mathrm{~mm} / \mathrm{yr}$ depending on climate, vegetation, and soil texture (Gee et al. 1992; Fayer and Walters 1995). Areas with shrubs and fine-textured soil like silt loams tend to have low recharge rates, while areas with little vegetation and coarse-textured soil, such as dune sands, tend to have high recharge rates. Recharge is also generally higher near the basalt ridges because of greater precipitation and runoff.

Fayer and Walters (1995) developed estimates of natural recharge for 1992 conditions. Distributions of soil and vegetation types were mapped first. A recharge rate was then assigned to each combination on the basis of data from lysimeters, tracer studies, neutron probe measurements, and computer modeling. Estimated recharge rates for 1992 were found to range from 2.6 to $127 \mathrm{~mm} / \mathrm{yr}$, and the total volume of natural recharge from precipitation over the Hanford Site was estimated to be $2.35 \times 10^{4} \mathrm{~m}^{3} / \mathrm{d}$. This value is of the same order of magnitude as the artificial recharge to the 200-Area waste disposal facilities during 1992 and approximately six times less than peak discharges to these facilities during the 1960s. Uncertainty in the recharge estimates results from gaps in data and incomplete consideration and understanding of processes involved. These uncertainties are discussed in Fayer and Walters (1995) and Cole et al. 2001a.

To support the Hanford site-wide groundwater model, recharge was also calculated for 1979 vegetation/land-use patterns (Fayer et al. 1996). The 1992 estimates were affected by vegetation changes resulting from a fire in the southern part of the Hanford Site. Anthropomorphic alteration of soil and vegetation (e.g., gravel-covered tank farms; subsoil sand brought to the surface in many waste disposal areas) was not accounted for because it is not expected to remain over the time scale of the model simulations. A map of recharge based on 1979 conditions is shown in Figure 5.9. The recharge estimates applied in the model were scaled to $171 \%$ of the values shown in Figure 5.9 based on model calibration (Cole et al. 2001b). Natural recharge applied to the model was assumed to be constant over time. The recharge information is contained in the file called n_rech_CA.dat, which is on the CD provided with this report. This file represents a regular grid with a 50-meter by 50-meter spacing. The recharge values are in millimeters per year.

The estimated recharge rates applied in the composite analysis model do not reflect historical 1979 recharge rates. Rather, they reflect the distribution of recharge estimated using the current climate, the Hajek (1966) soil map, and the 1979 vegetation/land-use patterns. Exactly when these estimated rates apply to the water table depends on the propagation of the diffused pressure wave through the unsaturated zone, which varies as a function of precipitation intensity and duration, atmospheric conditions, initial 


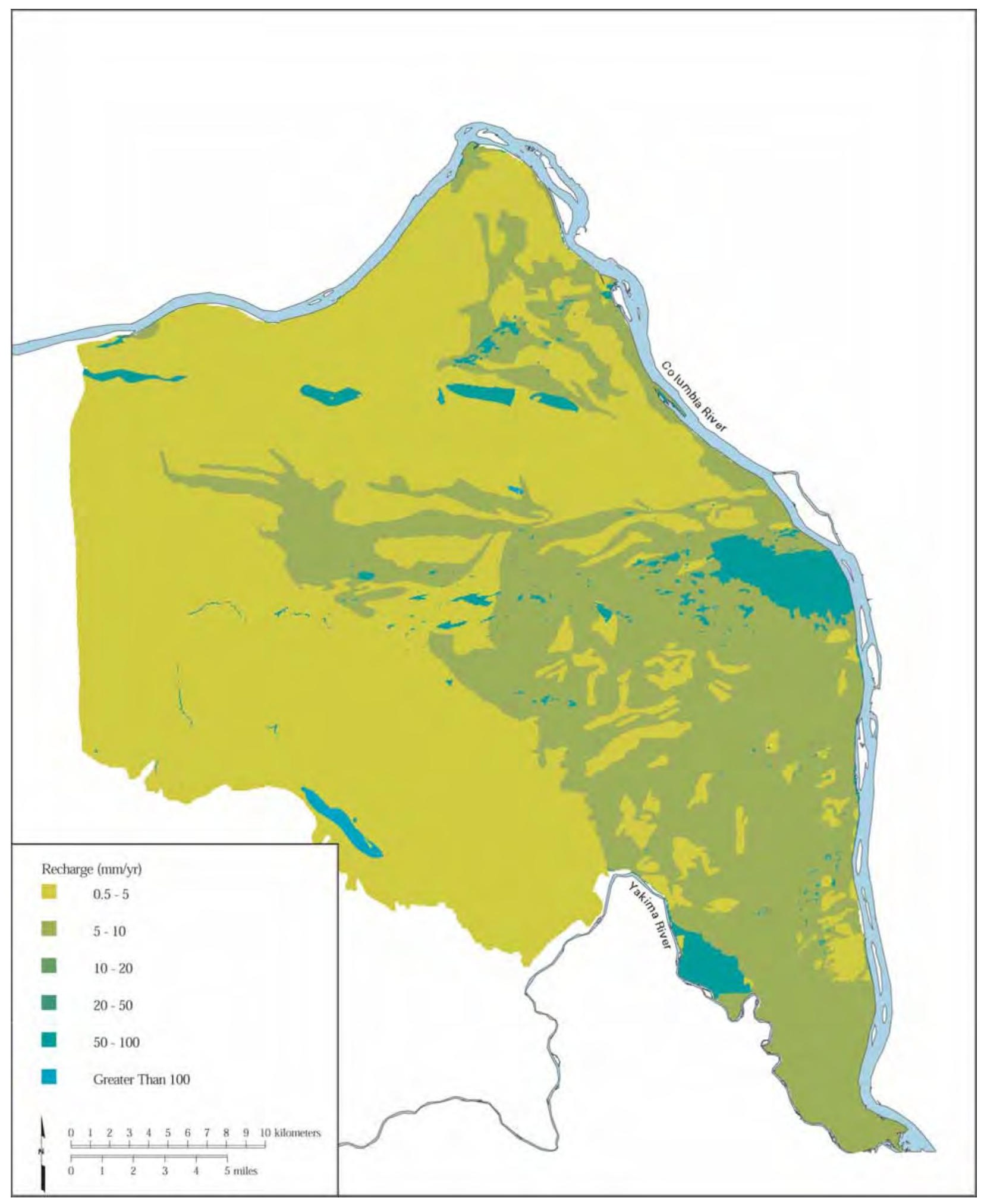

Figure 5.9. Estimates of Natural Recharge Based on 1979 Vegetation and Land-Use Patterns Without Considering Anthropomorphic Alternation 
water content, type of topsoil, geostratigraphy, and vadose zone thickness across the site. At this point, very little is known quantitatively about most of these characteristics and the complex relationships between them across the site.

\subsubsection{Recharge Along Western Model Boundary and Basalt Subcrops}

Two main sources of natural recharge occur along the western model boundary. These are infiltration from stream flow or runoff that originates outside the domain and flows into the model domain, and lateral subsurface flow from outside the model domain. Springs contribute to both these sources. Cushing and Vaughan (1988) indicated that there may be more than 100 springs and spring locations in the higher elevations to the west of Hanford, but only two (Snively and Rattlesnake) appeared to be significant. Flow from both of these springs is thought to originate from basalt-confined aquifers. Studies of Rattlesnake Springs indicate that baseflow is $864 \mathrm{~m}^{3} / \mathrm{d}$ and can range up to $1,340 \mathrm{~m}^{3} / \mathrm{d}$ in winter. Baseflow for Snively Springs was estimated to be $432 \mathrm{~m}^{3} / \mathrm{d}$.

To approximate the groundwater flux entering the model domain, both prescribed head and prescribed flux boundary conditions were defined in the implementation model. Prescribed-head boundary conditions were used in previous steady-state calibration of the model (Cole et al. 1997) to estimate boundary fluxes entering into the aquifer system from the Cold Creek and Dry Creek Valleys as well as along the Rattlesnake Hills. These calculated fluxes provided the initial estimates of boundary fluxes used in the transient inverse calibration. The boundary recharge fluxes are summarized in Table 5.1 and compared with the volume of natural recharge from the surface. The boundary fluxes and natural surface recharge were scaled as parameters in the inversing process together with the hydraulic properties of conductive hydrogeologic units to achieve the best match to observed hydraulic head data over the transient calibration period. The inverse calibration process and results are described in more detail in Cole et al. (2001b). The recharge from the Dry Creek Valley boundary was insensitive in the inversing and was, therefore, fixed at the initial value.

Table 5.1. Fluxes from Four Recharge Sources Resulting from Transient Calibration (Cole et al. 2001b)

\begin{tabular}{||l|c|c||}
\hline \multicolumn{1}{|c|}{ Recharge Area } & Initial Values & Transient Calibration ${ }^{(a)}$ \\
\hline \hline Cold Creek Valley & $2,881 \mathrm{~m}^{3} / \mathrm{d}$ & $6,021 \mathrm{~m}^{3} / \mathrm{d}$ \\
\hline Dry Creek Valley & $1,207 \mathrm{~m}^{3} / \mathrm{d}$ & $1,207 \mathrm{~m}^{3} / \mathrm{d}$ \\
\hline Rattlesnake Hills & $3,104 \mathrm{~m}^{3} / \mathrm{d}$ & $13,566 \mathrm{~m}^{3} / \mathrm{d}$ \\
\hline Surface natural recharge & $8.47 \times 10^{6} \mathrm{~m}^{3} / \mathrm{yr}$ & $1.45 \times 10^{7} \mathrm{~m}^{3} / \mathrm{yr}$ \\
\hline (a) Values applied in composite analysis groundwater model. \\
\hline
\end{tabular}

Lateral perimeter boundary segments not identified as constant-head boundaries in Figure 5.6 were defined as no-flow boundaries in the model. Except the short segment between Umtanum Ridge and the Columbia River, these boundaries represent basalt rising above the water table. For the segment between Umtanum Ridge and the Columbia River, flow is assumed to be predominantly toward the river and little flow is expected across the boundary. Inflow from precipitation on Rattlesnake Mountain is accounted 
for by the Rattlesnake Hills constant-flux boundary (Figure 5.7). No-flow boundaries also occur within the model domain where basalt subcrops above the water table.

There is uncertainty in the boundary fluxes because they were not measured independently. There is an ongoing effort to independently estimate the runoff and potential underflow for these boundaries (Waichler et al. 2004). Also, the applied recharge is constant over time, whereas actual recharge events are episodic. Potential runoff from elevated basalt areas along part of the western boundary and within the model domain, such as Gable Mountain, was not accounted for in the current model. However, it is known that some runoff does occur.

\subsubsection{Artificial Recharge at Upper Boundary}

Artificial recharge from wastewater disposal is important information for groundwater modeling at Hanford because the volumes of artificial recharge since 1944 have been significantly greater than the volume of recharge from natural sources. Over the past 50 years, the large volume of wastewater discharged to disposal facilities at the Hanford Site has significantly affected groundwater flow and contaminant transport in the unconfined aquifer. As shown in Figure 5.10, the annual volume of artificial recharge has decreased significantly since 1985.

Artificial recharge information for the groundwater flow model is contained in the EXCEL file a_rech_CA.xls, which is on the CD provided with this report. This file lists the estimated volume of artificial recharge over time for each wastewater discharge site. The values are based on data presented in quarterly discharge reports for Hanford facilities. The file also includes net recharge at the North Richland well field where water is pumped from the Columbia River into recharge basins and then a smaller volume is extracted from nearby wells.

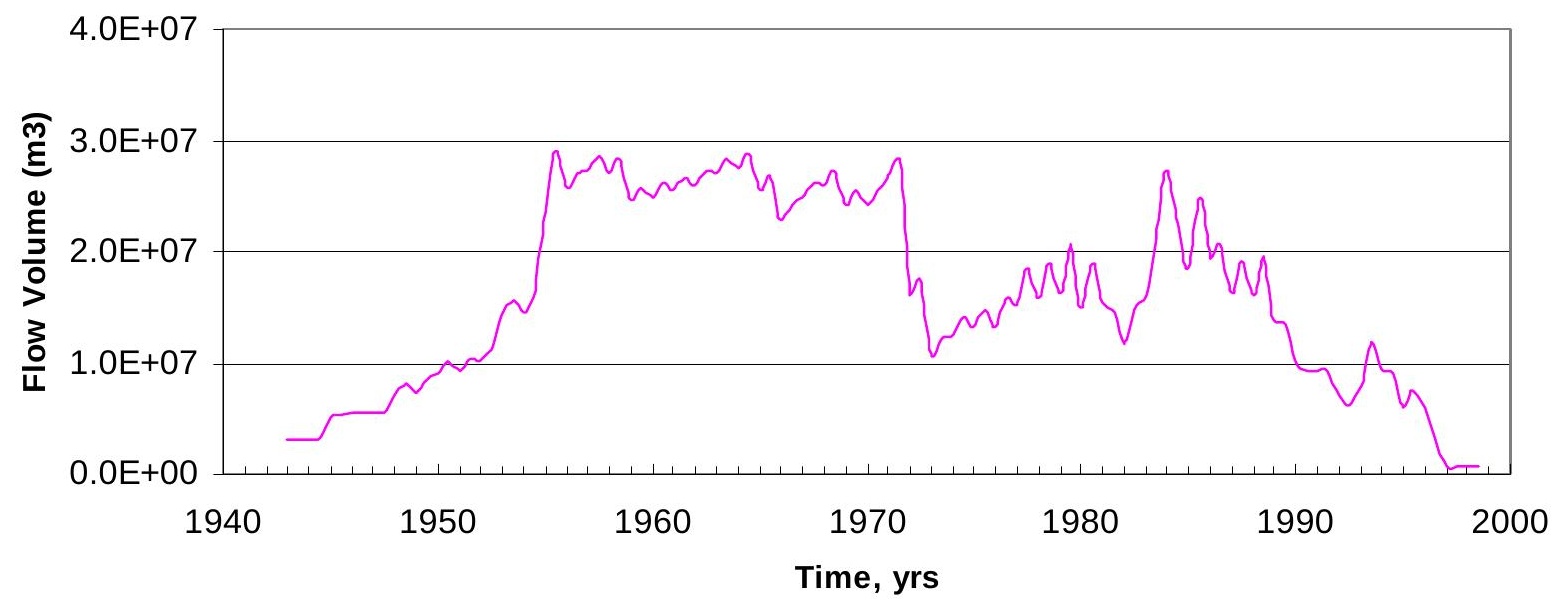

Figure 5.10. Artificial Discharges to the Unconfined Aquifer from 1943 to 1998

Uncertainties in the volume and timing of artificial recharge arise from uncertainty in the available discharge records and from simplification concerning delivery of water from the discharge point to the aquifer. The artificial recharge sources included in the current composite analysis model are based on information reported in a series of internal reports on effluent discharges and solid waste management 
issued by the Hanford Operations Contractor. Because of incomplete records, only about $80 \%$ of the sources are known with some accuracy. It is also possible that a significant volume of artificial recharge occurred through leaks in the water distribution system, but has not been accounted for in the model. The model also does not account for evaporation from surface ponds and ditches. Uncertainties also exist in the spatial location and timing of recharge arrival at the water table. The flux of artificial recharge to groundwater model nodes beneath each disposal facility is calculated in the composite analysis vadose zone module using a simple one-dimensional unsaturated flow model (Last et al. 2004).

Future land use on the Hanford Site is another source of uncertainty in predicted future artificial recharge. Previous analyses of post-Hanford Site unconfined aquifer conditions have considered land uses such as large-scale irrigation on the Hanford Site that could significantly alter the long-term behavior of the unconfined aquifer beneath the Hanford Site. The potential for large-scale agricultural irrigation on the Hanford Site in the future was examined for the composite analysis. Consultations with staff from the Agricultural Research Service at the Agricultural Experiment Station in Prosser, Washington, resulted in the conclusion that the prospect of large-scale irrigation occurring on the Hanford Site is unlikely because of limitations on regional water resources (Kincaid et al. 1998).

\subsubsection{Lower Model Boundary}

Interflow (recharge and discharge) between the basalt-confined aquifer system and the unconfined aquifer system is known to occur (Graham et al. 1984; DOE 1988; Jensen 1987). However, it is postulated to be small relative to the large volume of artificial recharge during the Hanford Site operational period. Lower artificial recharge volumes during the past decade and predicted for future Hanford Site conditions make interflow with the underlying basalt aquifers a more significant component of groundwater flow in the future.

The composite analysis groundwater model assumes that the lower boundary of the sedimentary aquifer system is the top of the underlying basalt bedrock and that the basalt is impermeable. Hydraulic interaction between the unconfined aquifer system and the underlying basalt-confined aquifers is being investigated as an alternative conceptual model (Vermeul et al. 2001). For additional information on mechanisms of potential interaction between the aquifers and volumes estimated through calibration of an alternative conceptual model, see Vermeul et al. (2001).

The geometry of the lower impermeable boundary applied in the composite analysis model is defined by the grid file "bnd_bot_CA.dat" and can be found on the CD provided with this report.

\subsubsection{Discharge from Onsite Wells}

Wells used for water supply on the Hanford Site and the adjacent Arid Lands Ecology Reserve are described in Poston et al. (2000). Within the Hanford Site boundary, only the Fast Flux Test Facility water supply wells are accounted for in the composite analysis groundwater model. The volume of withdrawal at the other Hanford Site wells is too low to affect model results. Other water-supply wells located south of the Hanford Site, but within the model domain were also accounted for in the flow model. Extraction volumes for wells are listed as negative values in the file "a_rech_CA.xls," which lists the artificial recharge applied in the model. 


\subsection{Hydraulic Property Parameters}

Hydraulic properties needed for the groundwater model include spatial distributions of hydraulic conductivity, specific storage, and specific yield for each of the hydrogeologic units. In addition, the distribution of vertical anisotropy of hydraulic conductivity was needed. Ranges and values for these parameters applied to each of the hydrogeologic units in the composite analysis groundwater model are listed in Table 5.2. Ranges given for hydraulic conductivity reflect the spatial variability resulting from calibration of the groundwater flow model (see Cole et al. 2001b for details) rather than probability distributions. Single values were applied for the other parameters.

Table 5.2. Ranges of Hydraulic Property Values Applied to Each Composite Analysis Model Unit

\begin{tabular}{||c|c|c|c|c|c||}
\hline Unit & $\begin{array}{c}\text { Minimum } \\
\mathrm{Kx}(\mathrm{m} / \mathrm{d})\end{array}$ & $\begin{array}{c}\text { Maximum } \\
\mathrm{Kx}(\mathrm{m} / \mathrm{d})\end{array}$ & $\begin{array}{c}\text { Specific } \\
\text { Yield }\end{array}$ & $\begin{array}{c}\text { Storage } \\
\text { Coefficient }\end{array}$ & $\begin{array}{c}\text { Anisotropy } \\
(\mathrm{Kz} / \mathrm{Kx})\end{array}$ \\
\hline \hline 1 & 1.6 & 29843 & 0.07 & $1 \mathrm{E}-06$ & 0.1 \\
\hline 2 & NA & NA & NA & NA & NA \\
\hline 3 & 14.2 & 190.5 & 0.1 & $1 \mathrm{E}-06$ & 0.1 \\
\hline 4 & 0.005 & 0.005 & 0.05 & $1 \mathrm{E}-06$ & 0.1 \\
\hline 5 & 0.09 & 3817 & 0.212 & $1 \mathrm{E}-06$ & 0.1 \\
\hline 6 & 0.01 & 0.10 & 0.05 & $1 \mathrm{E}-06$ & 0.1 \\
\hline 7 & 0.008 & 85.7 & 0.1 & $1 \mathrm{E}-06$ & 0.1 \\
\hline 8 & 0.00005 & 0.00005 & 0.05 & $1 \mathrm{E}-06$ & 0.1 \\
\hline 9 & 0.008 & 210.8 & 0.1 & $1 \mathrm{E}-06$ & 0.1 \\
\hline
\end{tabular}

Hydraulic conductivity and specific yield values applied in the implementation model resulted from a three-dimensional transient inverse calibration of the flow model described in Cole et al. (2001b). This calibration was recommended by an external peer review panel and was performed using UCODE, a universal inverse modeling code developed jointly by the U.S. Geological Survey and the International Groundwater Modeling Center of the Colorado School of Mines. See Cole et al. (2001b) for additional details on the calibration procedure and information on UCODE and its application to the inverse transient calibration.

The calibration period was 1943 through 1996. During this period of time, large volumes of wastewater were discharged to a variety of waste facilities resulting in large water-table changes over much of the Hanford Site. The discharges created significant groundwater mounds (in excess of 20 meters) under waste management facilities in the central part of the site. Since 1988, the mission of the Hanford Site has changed from producing weapons to restoring the environment, and wastewater discharges have declined significantly, which has caused significant water-table declines. The transient inverse calibration was implemented with the CFEST code, which is the forward model whose parameters are estimated by UCODE. The transient inverse calibration uses over 76,000 water-level measurements taken in about 1,200 wells at the Hanford Site since the mid-1940s. The initial baseline transient inverse calibration effort (Cole et al. 2001b) significantly improved the capability of the baseline model over the prior model to simulate historical trends in water-table changes over the entire site for the entire 1943-1996 period of 
calibration, most notably the historical trends of water-table changes and mound building observed near major discharge facilities in the 200 West Area.

Figure 5.11 shows the hydraulic conductivity distribution that resulted from the calibration process for sediment at the top of the model. The top of the model represents the maximum water table at each location over the calibration period. Figures 5.12 and 5.13 show cross sections through the model that compare unit definition with the calculated hydraulic conductivities. Cross section locations are shown on Figure 5.11. Files containing the hydraulic conductivity values for each model node (node_K_CA.dat) and the grid node and element locations (elem_nod_CA.dat.) are on the CD provided with this report.

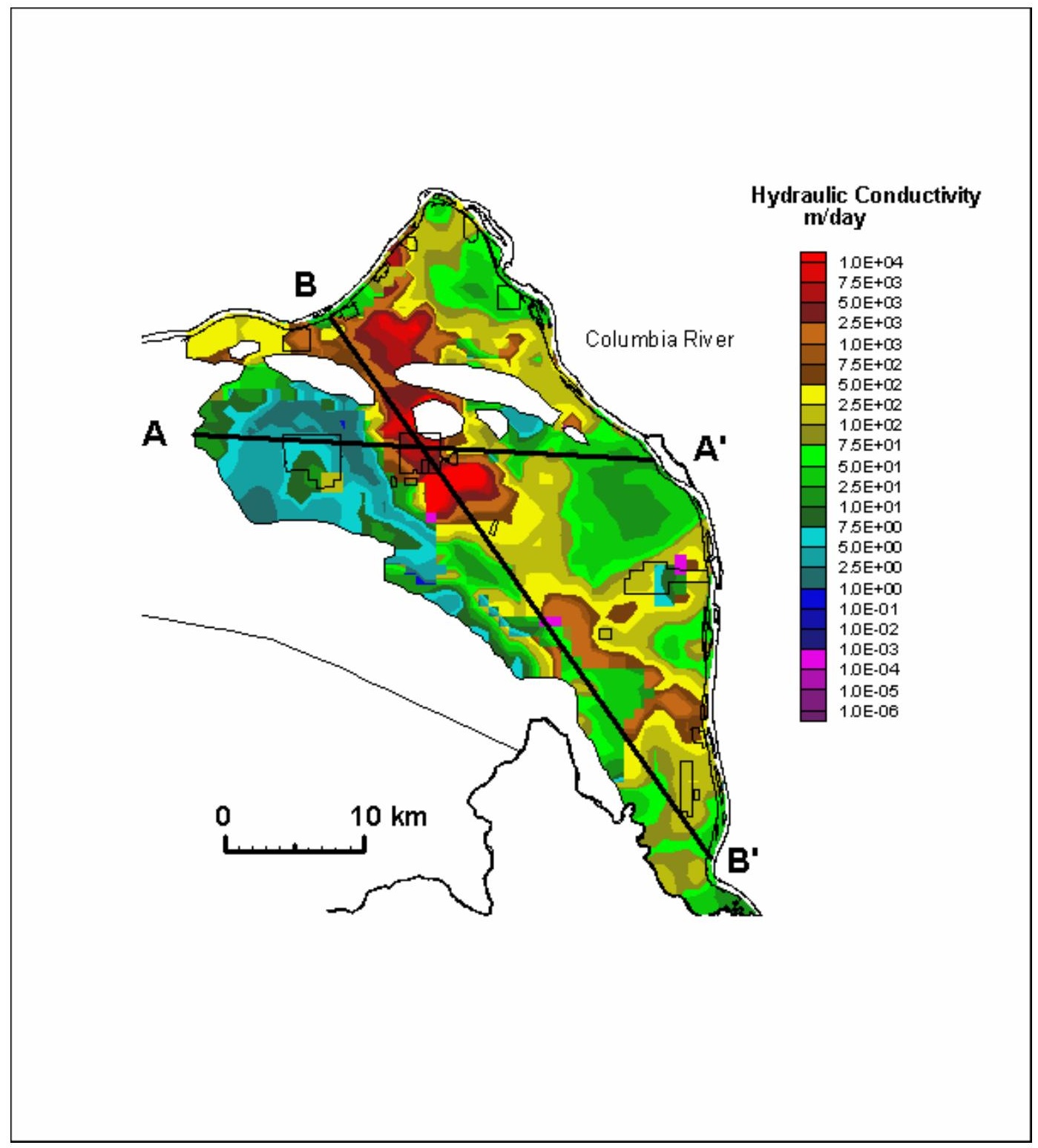

Figure 5.11. Hydraulic Conductivity Distribution for Units at Top of Model (maximum water table) 

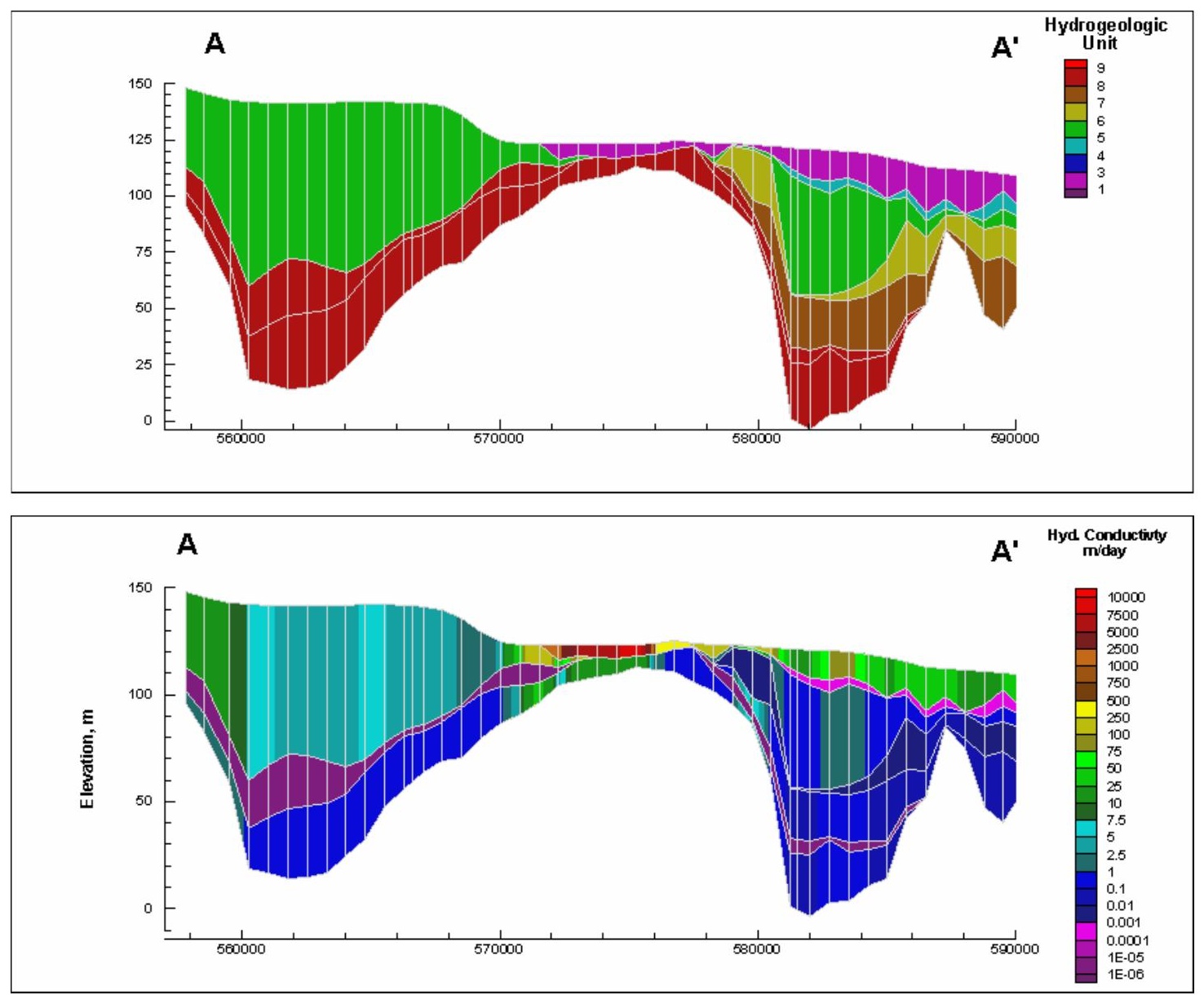

Figure 5.12. Cross Section of Model Along A-A' Showing Distribution of Hydrogeologic Units (top) and Hydraulic Conductivity (bottom)

Values for specific storage and anisotropy were set as constants for each of the model units as specified in Table 5.2. These values were based on data on aquifer tests and on knowledge of sediment characteristics. Because the aquifer is predominantly unconfined, errors in the specific storage values applied in the model are not expected to have a significant effect on predicted hydraulic head or contaminant transport. Errors in the estimated vertical anisotropy may affect the vertical flow of groundwater within the model.

Hydraulic property data from aquifer tests are available for wells within the model domain. These data are useful for qualitative comparison with hydraulic property values resulting from model calibration. The aquifer test data are described in Thorne and Newcomer (1992), Thorne et al. (1993, 1994), Wurstner et al. (1995), and Cole et al. (2001a). A database for aquifer hydraulic properties derived from aquifer tests is under development (Thorne and Newcomer 2002). 

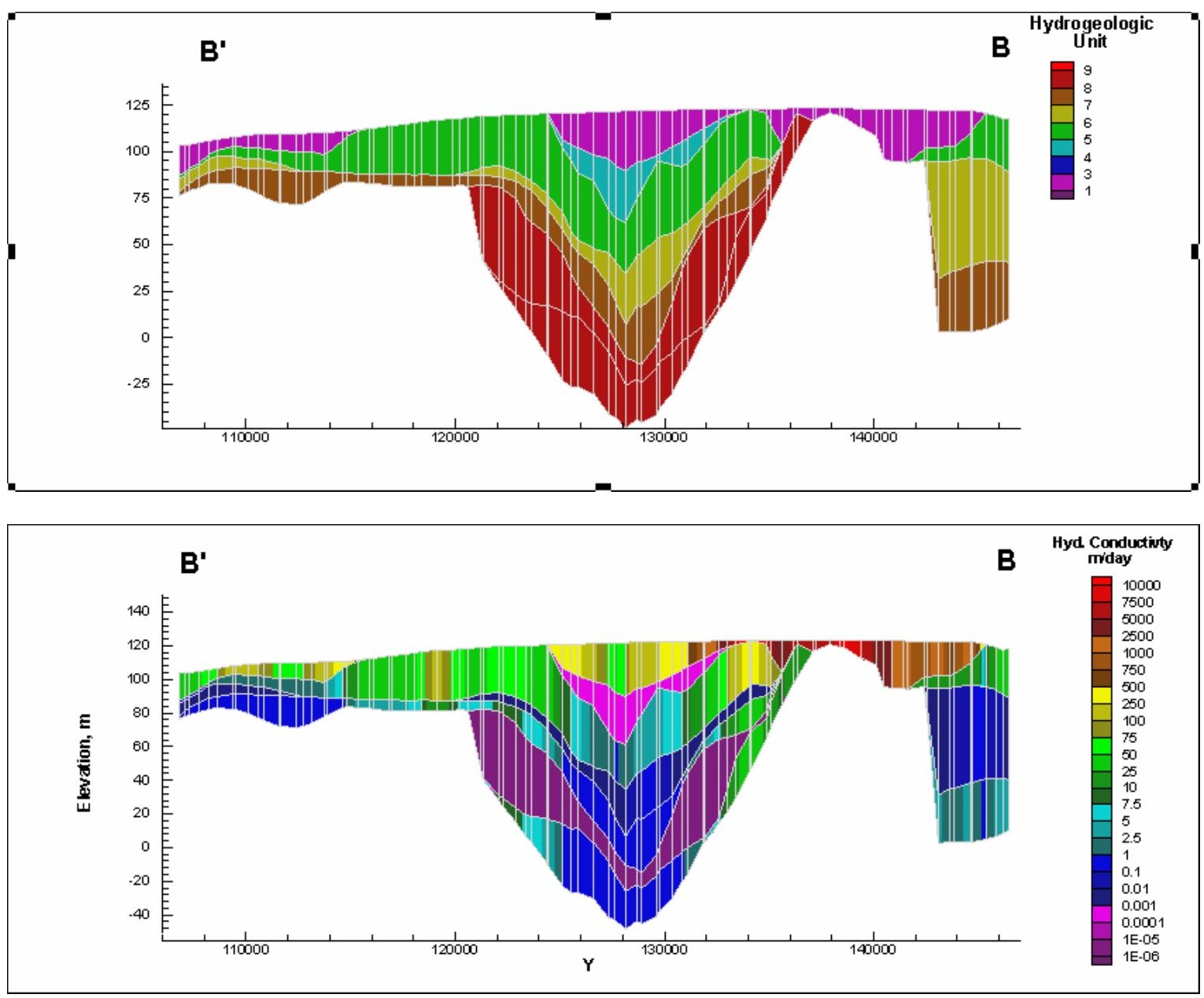

Figure 5.13. Cross Section of Model Along B-B' Showing Distribution of Hydrogeologic Units (top) and Hydraulic Conductivity (bottom)

\subsection{Contaminant Transport Parameters}

Contaminant transport through groundwater was modeled based on the discharge velocity field calculated by the groundwater flow model and specified transport properties. The initial conditions assumed that concentrations of modeled contaminants were negligible in 1944, prior to the start of Hanford Site operations. Transport properties used in the model include the following:

- Porosity

- Dispersivity

- Radioactive decay coefficients (or half-lives)

- Retardation factors for sorbed contaminants

Porosity (equivalent to effective porosity) was assumed to be 0.25 for the Hanford formation and Cold Creek gravel unit sediment. For the Ringold gravels, a porosity of 0.1 was assumed. These values 
are in the ranges from measurements for Ringold and Hanford formation gravel sediment (Wurstner et al. 1995) and are also reasonable based on values from the literature (Freeze and Cherry 1979).

Values for longitudinal dispersivity, $\mathrm{I}_{\mathrm{L}}$, and transverse dispersivity, $\mathrm{I}_{\mathrm{T}}$, used in the groundwater transport model are listed in Table 5.3. Dispersivity is a scale dependent parameter and can only be determined from inverse modeling of tracer tests on the scale of interest. Because very few such largescale tracer tests have been conducted and none have been conducted at the Hanford Site, the dispersivity values used in the groundwater transport model were not based on Hanford Site data. However, $\mathrm{I}_{\mathrm{L}}$ for the Hanford formation and Cold Creek gravel unit is in the range of 60 to 120 meters determined by Van der Kamp et al. (1994) for a plume that moved 7.7 kilometers at an average pore velocity of 380 meters per year. By comparison, the distance moved by the tritium plume from 200 East Area to the Columbia River was about 14 kilometers at a velocity of about 800 meters per year (Freshley and Graham 1988).

Table 5.3. Dispersivity Values Used in the Composite Analysis Groundwater Transport Model

\begin{tabular}{||l|c|c||}
\hline \multicolumn{1}{|c|}{ Sediment Type } & $\mathrm{I}_{\mathrm{L}}(\mathrm{m})$ & $\mathrm{I}_{\mathrm{T}}(\mathrm{m})$ \\
\hline \hline Hanford/Pre-Missoula Gravels (unit 1) & 62.5 & 12.5 \\
\hline Ringold Gravels (units 5, 7, and 9) & 30 & 6 \\
\hline \hline
\end{tabular}

Dispersivity values used in the Hanford site-wide groundwater model also satisfy the following constraints:

- The grid Peclet number, $\mathrm{P}_{\mathrm{e}}=$ (grid spacing) $/ \mathrm{I}_{\mathrm{L}}$ must be less than 4 for acceptable solutions in finite element simulations (Campbell et al. 1981). The 30-meter longitudinal dispersivity value meets this criterion for the 83-meter grid spacing, which is used where most contaminant transport from the 200 West Area occurs. The 62.5-meter longitudinal dispersivity value meets this criterion for the 250- by 250-meter grid spacing, which is used where most contaminant transport from the 200 East Area occurs. A larger value was not selected because large values of $\mathrm{I}_{\mathrm{L}}$ are not conservative in transport calculations.

- At the grid scale, the flow system is homogeneous. Heterogeneities at scales less than 150 meters are uncharacterized and the maximum selected $\mathrm{I}_{\mathrm{L}}$ of $62.5 \mathrm{~m}$ is less than this distance.

- The ratio of $I_{L} / I_{T}=5$ is within the suggested range of 1 to 24 cited by Walton (1985) and 5 to 20 indicated by Freeze and Cherry (1979).

The U.S. Environmental Protection Agency (Mills et al. 1995) indicates that "A rough estimate of longitudinal dispersivity in saturated porous media may be made by setting $\mathrm{I}_{\mathrm{L}}$ equal to $10 \%$ of the mean travel distance." The distance from the closest source in the 200 East Area to the Columbia River is about 17 kilometers. Using the $10 \%$ rule-of-thumb would suggest a value of 1,700 meters for $\mathrm{I}_{\mathrm{L}}$ for this simulation. However, this is much larger than the scale of uncharacterized heterogeneity within the model. Also, large values of dispersivity are not conservative in that they tend to reduce maximum contaminant concentrations too much at smaller distances. Using the 62.5 -meter value for $\mathrm{I}_{\mathrm{L}}$, estimates of concentration at 625 meters from the source should be accurate and for greater distances, they should be 
conservative. This is also the smallest value that could be used with the grid spacing selected and meet the condition for the Peclet number described above.

Decay of radioactive constituents is controlled by the specific activity, which is related to the half-life of the radioactive isotope. Consistent values are used in all of the SAC modules and are listed in Table 5.4.

Retardation of sorbed contaminants was calculated based on a linear isotherm model. The distribution coefficients $\left(\mathrm{K}_{\mathrm{d}}\right)$ assigned to each contaminant are listed in Table 5.5. These values were consistently used in all SAC modules. The $\mathrm{K}_{d}$ was treated as a stochastic parameter for the non-zero $\mathrm{K}_{\mathrm{d}}$ contaminants in the assessment. Therefore, the minimum, maximum, and type of population distribution for each parameter is also listed. The $\mathrm{K}_{\mathrm{d}}$ values used for groundwater transport assume low ionic strength and near neutral acidity with low organic content.

Table 5.4. Half-Lives and Specific Activities for Radioactive Contaminants

\begin{tabular}{||l|c|c||}
\hline \multicolumn{1}{|c|}{ Contaminant } & Half-Life (Y) & Specific Activity (Ci/g) \\
\hline \hline Tritium & 12.3 & $9.681 \mathrm{E}+3$ \\
\hline Tc-99 & $2.13 \mathrm{E}+5$ & $1.697 \mathrm{E}-2$ \\
\hline I-129 & $1.70 \mathrm{E}+7$ & $1.632 \mathrm{E}-4$ \\
\hline U-238 & $4.51 \mathrm{E}+09$ & $3.363 \mathrm{E}-7$ \\
\hline Sr-90 & 28.9 & $1.366 \mathrm{E}+2$ \\
\hline Cs-137 & 30.2 & $8.706 \mathrm{E}+1$ \\
\hline Pu-239/240 & $2.44 \mathrm{E}+04$ & $6.209 \mathrm{E}-2$ \\
\hline
\end{tabular}

Table 5.5. Distribution Coefficients and Effective Retardation Factors

\begin{tabular}{|c|c|c|c|c|}
\hline \multicolumn{5}{|c|}{ Waste Chemistry/Source Category 6: Low Organic/Low Salt/Near Neutral - Groundwater } \\
\hline \multirow[b]{2}{*}{ Element } & Best & Min & Max & \multirow[b]{2}{*}{ Probability Distribution } \\
\hline & $\mathrm{K}_{\mathrm{d}}(\mathrm{mL} / \mathrm{g})$ & $\mathrm{K}_{\mathrm{d}}(\mathrm{mL} / \mathrm{g})$ & $\mathrm{K}_{\mathrm{d}}(\mathrm{mL} / \mathrm{g})$ & \\
\hline Tritium & 0 & 0 & 0 & NA \\
\hline Technetium & 0 & 0 & 0.1 & Ln normal \\
\hline Iodine & 0.2 & 0 & 2 & Ln normal \\
\hline Uranium & 0.8 & 0.2 & 4 & Ln normal \\
\hline Strontium & 22 & 10 & 50 & Ln normal \\
\hline Cesium & 2,000 & 200 & 10,000 & Ln normal \\
\hline Plutonium & 600 & 200 & 2,000 & Ln normal \\
\hline Carbon Tetrachloride & 0.2 & 0.1 & 0.6 & Ln normal \\
\hline Chromium & 0 & 0 & 0.3 & Ln normal \\
\hline
\end{tabular}




\subsection{Contaminant Data for Groundwater}

A large amount of historical data is available on the concentration of contaminants in groundwater at the Hanford Site. These data are mostly contained in the Hanford Environmental Information System database. Data have been assessed and presented in annual reports for the past several years. The most recent annual report summarizing the groundwater data sampling conducted in 2002 is Hartman et al. (2003). Background information on the methods used in groundwater monitoring effort is given in Hartman (2000). Additional data have been collected on samples from sampling tubes installed at the bank of the Columbia River in recent years. These data and information on the sampling tubes are presented in Peterson et al. (1998) and Hartman and Peterson (2003).

Groundwater contaminant data were not used directly in the composite analysis groundwater model. However, they were used for a general understanding of the groundwater flow system. They are also used in "history matching" to evaluate groundwater transport model results.

For history matching of the composite analysis model results, the contaminant observations have been analyzed geostatistically. This analysis is presented by Murray et al. (2004). The purpose of that analysis was to generate maps and statistics that quantify the contamination in the groundwater, based on the historical groundwater concentration data for multiple points in time. The maps and statistics could then be used for verification of the composite analysis model results. The results generated from the study include several quantitative summaries of contaminant distribution, e.g., the location of the center of mass of contaminant plumes and the total mass of contaminants in the plume, and are collectively referred to as history matching data. A primary goal of the history matching study was to use geostatistical and Monte Carlo methods that allow one to provide an estimate of the uncertainty in the history matching data generated by the study. The scope of the analysis was restricted to four radioactive contaminants with a wide distribution at the site: tritium, technetium-99, iodine-129, and uranium. All four are current contaminants of concern at the site that will be examined in detail by the composite analysis (Kincaid et al. 2004, Table A.4). Results were generated for two time periods, fiscal years 2001 and 1992. In order to support the geographic scope of the composite analysis, the geostatistical analysis covered the entire Hanford Site, including the 200 West and 200 East Areas in the Central Plateau, and the 100 Areas and 300 Area in the Columbia River corridor. History matching data are currently being generated for several chemical contaminants of concern. Those contaminants are nitrate, carbon tetrachloride, and chromium. 


\subsection{References}

Bryce RW, CT Kincaid, PW Eslinger, and LF Morasch. 2002. An Initial Assessment of Hanford Impact Performed with the System Assessment Capability. PNNL-14027, Pacific Northwest National Laboratory, Richland, Washington.

Campbell JE, DE Longsine, and M Reeves. 1981. "Distributed velocity method of solving the convective-dispersion equation: 1. Introduction, mathematical theory, and numerical implementation." Adv. Water Resources 4:102.

Cole CR, SK Wurstner, MP Bergeron, MD Williams, and PD Thorne. 1997. Three-Dimensional Analysis of Future Groundwater Flow Conditions and Contaminant Plume Transport in the Hanford Site Unconfined Aquifer System: FY 1996 and 1997 Status Report. PNNL-11801, Pacific Northwest National Laboratory, Richland, Washington.

Cole CR, MP Bergeron, CJ Murray, PD Thorne, SK Wurstner, and P Rogers. 2001a. Uncertainty Analysis Framework Hanford Site-Wide Groundwater Flow and Transport Model. PNNL-13641, Pacific Northwest National Laboratory, Richland, Washington.

Cole CR, MP Bergeron, SK Wurstner, PD Thorne, S Orr, and MI McKinley. 2001b. Transient Inverse Calibration of Hanford Site-Wide Groundwater Model to Hanford Operational Impacts - 1943 to 1996. PNNL-13447, Pacific Northwest National Laboratory, Richland, Washington.

Cushing CE and BE Vaughan. 1988. "Springs and streams in shrub-steppe balance and change in a semiarid terrestrial ecosystem." Developments in Agricultural and Managed-Forest Ecology 20, WH Rickard et al. (eds.), Elsevier Science Publishers, New York.

Dirkes RL and RW Hanf (eds.). 1996. Hanford Site Environmental Report for Calendar Year 1995. PNNL-11139, Pacific Northwest National Laboratory, Richland, Washington.

DOE. 1988. Consultation Draft, Site Characterization Plan, Reference Repository Location, Hanford Site, Washington. DOE/RW-0164, Vols. 1 and 2, U.S. Department of Energy, Richland Operations Office, Richland, Washington.

DOE. 1999. Selection and Review of a Site-Wide Groundwater Model at the Hanford Site.

DOE/RL-2000-11, U.S. Department of Energy, Richland Operations Office, Richland, Washington.

DOE. 2002. Standardized Stratigraphic Nomenclature for Post-Ringold Formation Sediments Within the Central Pasco Basin. DOE/RL-2002-39, U.S. Department of Energy, Richland Operations Office, Richland, Washington.

DOE Order 435.1. 1999. Radioactive Waste Management. U.S. Department of Energy, Washington, D.C. Available on the Internet at http://www.hanford.gov/wastemgt/doe/psg/pdf/doeo435.1.pdf 
Ebbert JC, SE Cox, and BW Drost. 1991. "The Effects of Lining Irrigation Canals on Nitrate Concentrations in Ground Water." In Proceedings of the Conference on Nonpoint Source Pollution: The Unfinished Agenda for the Protection of Our Water Quality. Tacoma, Washington.

Evans JC, RW Bryce, and DR Sherwood. 1989. Hanford Site Ground-Water Monitoring for January Through June 1988. PNL-6886, Pacific Northwest Laboratory, Richland, Washington.

Fayer MJ and TB Walters. 1995. Estimated Recharge Rates at the Hanford Site. PNL-10285, Pacific Northwest Laboratory, Richland, Washington.

Fayer MJ, GW Gee, ML Rockhold, MD Freshley, and TB Walters. 1996. "Estimating recharge rates for a groundwater model using a GIS." J. Environ. Qual. 25:510-518.

Freeze RA and JA Cherry. 1979. Groundwater. Prentice-Hall, Inc., Englewood Cliffs, New Jersey.

Freshley MD and MJ Graham. 1988. Estimation of Ground-Water Travel Time at the Hanford Site: Description, Past Work and Future Needs. PNL-6328, Pacific Northwest Laboratory, Richland, Washington.

Gee GW, MJ Fayer, ML Rockhold, and MD Campbell. 1992. "Variations in Recharge at the Hanford Site." Northwest Science 66:237-250.

Gephart RE, RC Arnett, RG Baca, LS Leonhart, and FA Spane, Jr. 1979. Hydrologic Studies Within the Columbia Plateau, Washington: An Integration of Current Knowledge. RHO-BWI-ST-5, Rockwell Hanford Operations, Richland, Washington.

Graham MJ, GV Last, and KR Fecht. 1984. An Assessment of Aquifer Intercommunication in the B Pond, Gable Mountain Pond Area. RHO-RE-ST-12P, Rockwell Hanford Operations, Richland, Washington.

Gupta SK. 1997. Draft User's Manual, CFEST-96 Flow and Solute Transport, Constant/Variable Density, Computationally Efficient, and Low Disk PC/Unix Version. Consultant for Environmental System Technologies, Irvine, California.

Hajek BF. 1966. Soil Survey Hanford Project in Benton County, Washington. BNWL-243, Battelle Northwest Laboratory, Richland, Washington.

Hartman MJ (ed.). 2000. Hanford Site Groundwater Monitoring: Setting, Sources, and Methods. PNNL-13080. Pacific Northwest National Laboratories.

Hartman MJ, LF Morasch, and WD Webber (eds.). 2001. Hanford Site Groundwater Monitoring for Fiscal Year 2000. PNNL-13404, Pacific Northwest National Laboratory, Richland, Washington.

Hartman MJ, LF Morasch, and WD Webber. 2003. Hanford Site Groundwater Monitoring for Fiscal Year 2002. PNNL-14187, Pacific Northwest National Laboratory, Richland, Washington. 
Hartman MJ and RE Peterson. 2003. Aquifer Sampling Tube Results for Fiscal Year 2003.

PNNL-14444, Pacific Northwest National Laboratory, Richland, Washington.

Jensen EJ. 1987. An Evaluation of Aquifer Intercommunication Between the Unconfined and Rattlesnake Ridge Aquifers on the Hanford Site. PNL-6313, Pacific Northwest Laboratory, Richland, Washington.

Kincaid CT, MP Bergeron, CR Cole, MD Freshley, NL Hassig, VG Johnson, DI Kaplan, RJ Serne, GP Streile, DL Strenge, PD Thorne, LW Vail, GA Whyatt, and SK Wurstner. 1998. Composite Analysis for Low-Level Waste Disposal in the 200-Area Plateau of the Hanford Site. PNNL-11800, Pacific Northwest National Laboratory, Richland, Washington.

Kincaid CT, PW Eslinger, WE Nichols, AL Bunn, RW Bryce, TB Miley, MC Richmond, SF Snyder, and RL Aaberg. 2000. System Assessment Capability (Revision 0); Assessment Description, Requirements, Software Design, and Test Plan. BHI-01365, Draft A, Bechtel Hanford, Inc., Richland, Washington.

Kincaid CT, RW Bryce, and JW Buck. 2004. Technical Scope and Approach for the 2004 Composite Analysis of Low Level Waste Disposal at the Hanford Site. PNNL-14372, Pacific Northwest National Laboratory, Richland, Washington.

Kipp KL and RD Mudd. 1974. Selected Water Table Contour Maps and Well Hydrographs for the Hanford Reservation, 1944-1973. BNWL-B-360, Battelle Northwest Laboratory, Richland, Washington.

Last GV, GW Gee, EJ Freeman, WE Nichols, KJ Cantrell, BN Bjornstad, and MJ Fayer. 2004. Vadose Zone Hydrogeology Data Package for the 2004 Composite Analysis. PNNL-XXXXX, Pacific Northwest National Laboratory, Richland, Washington.

Lindsey KA. 1995. Miocene- to Pliocene-Aged Suprabasalt Sediments of the Hanford Site, SouthCentral Washington. BHI-00184, Rev. 0, Bechtel Hanford, Inc., Richland, Washington.

Mills DB, DB Porcella, MJ Ungs, SA Gherini, KV Summers, L. Mok, GL Rupp, GL Bowie, and DA Haith. 1985. Water Quality Assessment: A Screening Procedure for Toxic and Conventional Pollutants (Revised 1985) Part II. EPA/600/6-85/002b, Environmental Research Laboratory Office of Research and Development, U.S. Environmental Protection Agency, Athens, Georgia.

Murray CJ, Y-J Chein, and PD Thorne. 2004. A Geostatistical Analysis of Historical Field Data on Tritium, Technetium-99, Iodine-129, and Uranium. PNNL-14618, Rev. 0, Pacific Northwest National Laboratory, Richland, Washington.

NAD83. 1983. North American Datum of 1983.

NAVD88. 1988. North American Vertical Datum of 1988.

Newcomer DR, EC Thornton, and TL Liikala. 2002. Groundwater Chemistry and Hydrogeology of the Upper Saddle Mountains Basalt-Confined Aquifer South and Southeast of the Hanford Site. PNNL14107, Pacific Northwest National Laboratory, Richland, Washington. 
Peterson RE, JV Borghese, and DB Erb. 1998. Aquifer Sampling Tube Installation Completion Report: 100 Area and Hanford Townsite Shorelines. BHI-01153, Bechtel Hanford Inc., Richland, Washington.

Peterson RE and MP Connelly. 2001. Zone of Interaction Between Hanford Site Groundwater and Adjacent Columbia River. PNNL-13674, Pacific Northwest National Laboratory, Richland, Washington.

Poston TM, RW Hanf, and RL Dirkes. 2000. Hanford Site Environmental Report for Calendar Year 1999. PNNL-13230, Pacific Northwest National Laboratory, Richland, Washington.

Spane FA Jr. and VR Vermeul. 1994. Summary and Evaluation of Hydraulic Property Data Available for the Hanford Site Upper Basalt Confined Aquifer System. PNL-10158, Pacific Northwest Laboratory, Richland, Washington.

Spane FA Jr. and WD Webber. 1995. Hydrochemistry and Hydrogeologic Conditions Within the Hanford Upper Basalt Confined Aquifer System. PNL-10817, Pacific Northwest Laboratory, Richland, Washington.

Thorne PD. 1998. Upper Basalt-Confined Aquifer System in the Southern Hanford Site. PNNL-12067, Pacific Northwest National Laboratory, Richland, Washington.

Thorne PD and DR Newcomer. 2002. Prototype Database and User's Guide of Saturated Zone Hydraulic Properties for the Hanford Site. PNNL-14058, Pacific Northwest National Laboratory, Richland, Washington.

Thorne PD and DR Newcomer. 1992. Summary and Evaluation of Available Hydraulic Property Data for the Hanford Site Unconfined Aquifer System. PNL-8337, Pacific Northwest National Laboratory, Richland, Washington.

Thorne PD, MA Chamness, FA Spane, Jr., VR Vermeul, and WD Webber. 1993. Three-Dimensional Conceptual Model for the Hanford Site Unconfined Aquifer System, FY 93 Status Report. PNL-8971, Pacific Northwest Laboratory, Richland, Washington.

Thorne PD, MA Chamness, VR Vermeul, QC MacDonald, and SE Schubert. 1994. Three-Dimensional Conceptual Model for the Hanford Site Unconfined Aquifer System: FY 1994 Status Report. PNL-10195, Pacific Northwest Laboratory, Richland, Washington.

Van der Kamp G, LD Luba, JA Cherry, and H Maathuis. 1994. "Field Study of a Long and Very Narrow Contaminant Plume.” Ground Water 32(6):1008-1016.

Vermeul VR, CR Cole, MP Bergeron, PD Thorne, and SK Wurstner. 2001. Transient Inverse Calibration of Sitewide Groundwater Model to Hanford Operational Impacts from 1943 to 1996 - Alternative Conceptual Model Considering Interaction with Uppermost Basalt Confined Aquifer. PNNL-13623, Pacific Northwest National Laboratory, Richland, Washington. 
Vermeul VR, MP Bergeron, CR Cole, CJ Murray, WE Nichols, TD Scheibe, PD Thorne, SR Waichler, and Y Xie. 2003. Transient Inverse Calibration of the Site-Wide Groundwater Flow Model (ACM-2): Progress Report. PNNL-14398, Pacific Northwest National Laboratory, Richland, Washington.

Waichler SR, MS Wigmosta, and A Coleman. 2004. Natural Recharge to the Unconfined Aquifer System on the Hanford Site from the Greater Cold Creek Watershed. PNNL-14717, Pacific Northwest National Laboratory, Richland, Washington.

Walton WC. 1985. Practical Aspects of Groundwater Modeling. Second Edition, National Water Well Association, Worthington, Ohio.

Williams BA, BN Bjornstad, R Schalla, and WD Webber. 2000. Revised Hydrogeology for the Suprabasalt Aquifer System, 200-East Area and Vicinity, Hanford Site, Washington. PNNL-12261, Pacific Northwest National Laboratory, Richland, Washington.

Williams BA, BN Bjornstad, R Schalla, and WD Webber. 2002. Revised Hydrogeology for the Suprabasalt Aquifer System, 200-West Area and Vicinity, Hanford Site, Washington. PNNL-13858, Pacific Northwest National Laboratory, Richland, Washington.

Wurstner SK, PD Thorne, MA Chamness, MD Freshley, and MD Williams. 1995. Development of a Three-Dimensional Ground-Water Model of the Hanford Site Unconfined Aquifer System: FY 1995 Status Report. PNL-10886, Pacific Northwest Laboratory, Richland, Washington. 


\section{Distribution}

No. of

Copies

\section{ONSITE}

2 DOE Office of River Protection

R. M. Yasek

R. W. Lober

9 DOE Richland Operations Office

B. L. Charboneau A6-33

B. L. Foley A6-38

J. P. Hanson A5-13

R. D. Hildebrand A6-38

J. G. Morse A6-38

K. M. Thompson A6-38

S. H. Wisness A3-04

DOE Public Reading Room (2) H2-53

5 Bechtel Hanford Inc.

P. G. Doctor

H9-01

K. R. Fecht

K. A. Gano

J. K. Linville

S. G. Weiss

9 CH2M HILL Hanford Group, Inc.
F. J. Anderson
A. J. Knepp
M. N. Jarayssi
F. M. Mann
W. J. McMahon
C. W. Miller
D. A. Myers
C. D. Wittreich
M. I. Wood

E6-35

H6-03

H6-03

E6-35

E6-35

H6-62

E6-35

H6-62

H8-44

\section{Fluor Federal Services}

R. Khaleel

R. J. Puigh

E6-17

E6-17
No. of

Copies

8 Fluor Hanford, Inc.

J. V. Borghese E6-35

F. M. Coony E6-35

B. H. Ford E6-35

T. W. Fogwell E6-35

R. Jackson E6-35

V. J. Rohay E6-35

L. C. Swanson E6-35

M. E. Todd-Robertson E6-35

Stoller

R. G. McCain $\quad$ B2-62

51 Pacific Northwest National Laboratory

R. L. Aaberg K3-54

C. Arimescu K6-04

M. P. Bergeron K9-36

B. N. Bjornstad K6-81

R. W. Bryce E6-35

A. L. Bunn K6-85

K. J. Cantrell K6-81

Y. J. Chien K6-81

R. L. Dirkes K6-75

J. L. Downs K6-85

D. W. Engle K5-12

P. W. Eslinger K6-04

M. J. Fayer K9-33

E. J. Freeman K9-36

M. D. Freshley K9-33

G. W. Gee K9-33

T. J. Gilmore K6-81

D. G. Horton K6-81

C. T. Kincaid K9-33

G. V. Last (5) K6-81

C. A. LoPresti K5-12

W. J. Martin K6-81

T. B. Miley K6-04

C. J. Murray K6-81

B. A. Napier K3-54

W. E. Nichols K9-33

Distr.1 
PNNL-14753, Rev. 0

No. of

Copies

G. W. Patton

J. V. Ramsdell, Jr.

S. P. Reidel

M. C. Richmond

R. G. Riley

M. L. Rockhold

R. J. Serne

D. L. Strenge
No. of

Copies

M. B. Triplett

K6-04

P. D. Thorne (5)

K9-33

A. L. Ward

K9-33

M. D. White

K9-36

M. D. Williams

K9-36

S. K. Wurstner

K9-36

S. B. Yabusaki

K9-36

Hanford Technical Library (2)

$\mathrm{H} 2-53$ 


\section{Data Files from CD}


a_rechCA 


\begin{tabular}{|c|c|c|c|c|c|c|c|c|c|c|c|c|c|c|c|c|}
\hline & & & & & & & & & & & & & & & & \\
\hline Site & 1944 & 1945 & 1946 & 1947 & 1948 & 1949 & 1950 & 1951 & 1952 & 1953 & 1954 & 1955 & 1956 & 1957 & 1958 & 195 \\
\hline 216-U-1\%2-Fast & $3.68 \mathrm{E}-08$ & 67E-08 & 67E-08 & 67E-08 & $68 \mathrm{E}-08$ & $67 \mathrm{E}-08$ & $3.67 \mathrm{E}-08$ & $8.12 \mathrm{E}+00$ & $8.14 \mathrm{E}+00$ & $8.12 \mathrm{E}+00$ & $8.12 \mathrm{E}+00$ & $8.12 \mathrm{E}+00$ & $8.14 \mathrm{E}+00$ & $8.12 \mathrm{E}+00$ & $8.12 \mathrm{E}+00$ & $8.12 \mathrm{E}+00$ \\
\hline $100-B-5$ & 14E-07 & & & 12E-07 & 14E-07 & $12 \mathrm{E}-07$ & $6.12 \mathrm{E}-07$ & $6.12 \mathrm{E}-07$ & $6.14 \mathrm{E}-07$ & $6.12 \mathrm{E}-07$ & $2.37 \mathrm{E}+04$ & $2.41 \mathrm{E}+04$ & $2.42 \mathrm{E}+04$ & $4.32 \mathrm{E}+02$ & $4.13 \mathrm{E}+01$ & $2.20 \mathrm{E}+01$ \\
\hline 100-D-3 & 0E-08 & 90E-08 & & 90E-08 & 90E-08 & 90E-08 & $2.90 \mathrm{E}-08$ & $2.90 \mathrm{E}-08$ & $2.90 \mathrm{E}-08$ & $2.90 \mathrm{E}-08$ & $2.90 \mathrm{E}-08$ & 5.23E-07 & 1.22E-05 & 7.56E-05 & $3.35 \mathrm{E}-04$ & $1.19 \mathrm{E}-03$ \\
\hline -D-32 & E-09 & & & J9E-09 & 10E-09 & 09E-09 & 5.09E-09 & 5.09E-09 & 5.10E-09 & 5.09E-09 & 5.09E-09 & 5.09E-09 & 5.10E-09 & 5.09E-09 & $1.24 \mathrm{E}-07$ & 2.66E-06 \\
\hline -D-40 & E-09 & & & 56E-09 & 57E-09 & $3.56 \mathrm{E}-09$ & 3.56E-09 & $3.56 \mathrm{E}-09$ & $3.57 \mathrm{E}-09$ & 3.56E-09 & $3.56 \mathrm{E}-09$ & $6.40 \mathrm{E}-08$ & $1.44 \mathrm{E}-06$ & 8.85E-06 & 3.91E-05 & 1.40E-04 \\
\hline$-D-47$ & E-07 & $E-07$ & & 21E-07 & $1.21 \mathrm{E}-07$ & 1.21E-07 & 1.21E-07 & $1.21 \mathrm{E}-07$ & $1.21 \mathrm{E}-07$ & 1.21E-07 & 1.21E-07 & $2.17 \mathrm{E}-06$ & 4.86E-05 & 2.99E-04 & 1.32E-03 & $4.72 \mathrm{E}-03$ \\
\hline $0-F-25$ & & & & $26 \mathrm{E}-13$ & $26 \mathrm{E}-13$ & $2.26 \mathrm{E}-13$ & $2.26 \mathrm{E}-13$ & $2.26 \mathrm{E}-13$ & $2.26 \mathrm{E}-13$ & $2.26 \mathrm{E}-13$ & $2.26 \mathrm{E}-13$ & $2.26 \mathrm{E}-13$ & $2.27 \mathrm{E}+01$ & $2.60 \mathrm{E}+01$ & $2.60 \mathrm{E}+01$ & $2.59 \mathrm{E}+01$ \\
\hline$-\mathrm{H}-10$ & & & & $71 \mathrm{E}-13$ & $73 E-13$ & $2.38 \mathrm{E}+01$ & $2.51 \mathrm{E}+01$ & $2.50 \mathrm{E}+01$ & $2.51 \mathrm{E}+01$ & $2.51 \mathrm{E}+01$ & $2.51 \mathrm{E}+01$ & $2.50 \mathrm{E}+01$ & $2.51 \mathrm{E}+01$ & $E+01$ & $E+01$ & $\mathrm{E}+01$ \\
\hline & & & & $1 \mathrm{E}-14$ & $2.71 \mathrm{E}-14$ & $2.71 \mathrm{E}-14$ & $2.71 \mathrm{E}-14$ & $2.71 \mathrm{E}-14$ & $2.71 \mathrm{E}-14$ & E-02 & $39 \mathrm{E}+00$ & $27 \mathrm{E}+01$ & $3.68 \mathrm{E}+01$ & $3 E+01$ & $E+01$ & $.63 \mathrm{E}+01$ \\
\hline & & & & E-18 & $53 E-18$ & $2.46 \mathrm{E}+01$ & $2.50 \mathrm{E}+01$ & $2.50 \mathrm{E}+01$ & $E+01$ & $E+01$ & $E+01$ & $E+01$ & $2.51 \mathrm{E}+01$ & $E+01$ & $E+01$ & $.50 \mathrm{E}+01$ \\
\hline & & & & E-18 & $E-18$ & $44 \mathrm{E}+01$ & $E+01$ & $E+01$ & $E+01$ & $E+01$ & $E+01$ & $E+01$ & $1 \mathrm{E}+01$ & $E+01$ & $\mathrm{E}+01$ & $.50 \mathrm{E}+01$ \\
\hline & & & & $=-19$ & $=-19$ & $2.47 \mathrm{E}+01$ & $2.50 \mathrm{E}+01$ & $E+01$ & $E+01$ & $E+01$ & $2.50 \mathrm{E}+01$ & $E+01$ & $2.51 \mathrm{E}+01$ & $E+01$ & $\mathrm{E}+01$ & $2.49 \mathrm{E}+01$ \\
\hline & & & & $E-08$ & E-08 & 5.23E-08 & 5.23E-08 & 5.23E-08 & E-08 & 5.23E-08 & 5.23E-08 & 3E-08 & $5.24 \mathrm{E}-08$ & $5 \mathrm{E}-06$ & 0E-05 & $1.27 \mathrm{E}-04$ \\
\hline & & & & $70 \mathrm{E}-10$ & 70E-10 & 70E-10 & $1.70 \mathrm{E}-10$ & $1.70 \mathrm{E}-10$ & $1.70 \mathrm{E}-10$ & $1.70 \mathrm{E}-10$ & $1.70 \mathrm{E}-10$ & $1.70 \mathrm{E}-10$ & $1.26 \mathrm{E}+01$ & $1.82 \mathrm{E}+01$ & $1.82 \mathrm{E}+01$ & $1.82 \mathrm{E}+01$ \\
\hline-60 & & & & E-06 & $E-06$ & 01E-06 & $2.01 \mathrm{E}-06$ & $2.01 \mathrm{E}-06$ & $2.02 \mathrm{E}-06$ & 01E-06 & $2.01 \mathrm{E}-06$ & $2.01 \mathrm{E}-06$ & $2.02 \mathrm{E}-06$ & .01E-06 & $2.01 \mathrm{E}-06$ & 2.01E-06 \\
\hline J-66 & & -11 & -11 & 93E-11 & 9.96E-11 & 9.93E-11 & $9.93 \mathrm{E}-11$ & $9.93 \mathrm{E}-11$ & $9.96 \mathrm{E}-11$ & $3 \mathrm{E}-11$ & 9.93E-11 & 3E-11 & 9.96E-11 & $9.93 \mathrm{E}-11$ & $9.93 \mathrm{E}-11$ & $9.93 \mathrm{E}-11$ \\
\hline & & $1.8 \varepsilon$ & $1.88 \mathrm{E}-07$ & $1.88 \mathrm{E}-07$ & $36 \mathrm{E}+03$ & $3.32 \mathrm{E}+03$ & $8.45 \mathrm{E}+02$ & $2.33 \mathrm{E}+05$ & $4.49 \mathrm{E}+05$ & $9.34 \mathrm{E}+04$ & $6.28 \mathrm{E}+03$ & $E+02$ & $4.50 \mathrm{E}+02$ & $3.01 \mathrm{E}+02$ & $2.30 \mathrm{E}+02$ & $1.74 \mathrm{E}+02$ \\
\hline & & & $3.86 \mathrm{E}+03$ & $1.05 \mathrm{E}+02$ & 09E+01 & $64 \mathrm{E}+00$ & $98 \mathrm{E}+00$ & $2.52 \mathrm{E}+00$ & $2.51 \mathrm{E}+00$ & $E+00$ & $E+00$ & $E+00$ & $1.37 \mathrm{E}+00$ & $E+00$ & $E+00$ & \\
\hline & & & & 4.42E-09 & 4.43E-09 & $4.42 \mathrm{E}-09$ & 4.42E-09 & 4.42E-09 & E-06 & E-03 & E-02 & E-01 & $1.88 \mathrm{E}-01$ & & $\mathrm{E}-01$ & 6E-01 \\
\hline & & & & E-13 & E-13 & E-13 & 01E-13 & $2.01 \mathrm{E}-13$ & $1 \mathrm{E}-13$ & $E-13$ & $1 \mathrm{E}-13$ & $=-13$ & $E-13$ & +01 & -01 & $\mathrm{E}+01$ \\
\hline & & & & -09 & & E-09 & +02 & +02 & +02 & +02 & +02 & +02 & $E+02$ & & & $\mathrm{E}+02$ \\
\hline & & & & $E-11$ & -11 & E-11 & -09 & -04 & -01 & $E-01$ & $E-01$ & E-01 & $4.22 \mathrm{E}-01$ & E-01 & 3E-01 & 2.43E-01 \\
\hline & & & & -08 & -08 & $E-08$ & E-08 & $E-08$ & $E-08$ & $E+05$ & $E+06$ & $E+06$ & $6.87 \mathrm{E}+05$ & $E+06$ & $E+05$ & $2.31 \mathrm{E}+05$ \\
\hline$-2 A$ & & & & $=-10$ & $=-10$ & E-10 & 1.90E-10 & E-10 & $\mathrm{E}+02$ & $4.18 \mathrm{E}+02$ & $4.18 \mathrm{E}+02$ & $E+02$ & $4.19 \mathrm{E}+02$ & $3 E+02$ & $\mathrm{E}+02$ & $4.17 \mathrm{E}+02$ \\
\hline$-2 C$ & & & & E-11 & 2E-11 & $2.21 \mathrm{E}-11$ & $2.21 \mathrm{E}-11$ & $2.21 \mathrm{E}-11$ & $E+02$ & $4.18 \mathrm{E}+02$ & $4.18 \mathrm{E}+02$ & $E+02$ & $4.19 \mathrm{E}+02$ & $3 E+02$ & $3 \mathrm{E}+02$ & $4.16 E+02$ \\
\hline$-1 A$ & & & & $1.31 \mathrm{E}-06$ & 76E-01 & $1.56 \mathrm{E}+01$ & $3.23 E+01$ & $3.49 \mathrm{E}+01$ & $3.52 \mathrm{E}+01$ & $2.33 \mathrm{E}+01$ & $1.45 \mathrm{E}+01$ & $8.33 \mathrm{E}+00$ & $7.67 \mathrm{E}+00$ & $4.52 \mathrm{E}+00$ & $4.52 \mathrm{E}+00$ & $4.07 \mathrm{E}+00$ \\
\hline$-1 B$ & & & & $8 \mathrm{E}-10$ & 19E-10 & $5.18 \mathrm{E}-10$ & $5.18 \mathrm{E}-10$ & $5.18 \mathrm{E}-10$ & $5.19 \mathrm{E}-10$ & $3.76 \mathrm{E}+02$ & $5.34 \mathrm{E}+02$ & $5.33 \mathrm{E}+02$ & $5.36 \mathrm{E}+02$ & $5.34 \mathrm{E}+02$ & $5.34 \mathrm{E}+02$ & $5.33 \mathrm{E}+02$ \\
\hline 6-DR-1\%2 & $1 \mathrm{E}-06$ & 2.60 & $2.60 \mathrm{~B}$ & $2.60 \mathrm{E}-06$ & $2.61 \mathrm{E}-06$ & $2.60 \mathrm{E}-06$ & $2.59 E+04$ & $1.11 E+06$ & $7.42 \mathrm{E}+05$ & $6.87 \mathrm{E}+04$ & $1.01 \mathrm{E}+04$ & $3.41 \mathrm{E}+03$ & $1.43 \mathrm{E}+03$ & $1.25 \mathrm{E}+03$ & $6.26 \mathrm{E}+02$ & $6.26 \mathrm{E}+02$ \\
\hline 116-DR-3 & $9 \mathrm{E}-11$ & $2.28 \mathrm{E}-11$ & $28 \mathrm{E}-11$ & $2.28 \mathrm{E}-11$ & $2.29 \mathrm{E}-11$ & $2.28 \mathrm{E}-11$ & $2.28 \mathrm{E}-11$ & $2.28 \mathrm{E}-11$ & $2.29 \mathrm{E}-11$ & $2.28 \mathrm{E}-11$ & $2.28 \mathrm{E}-11$ & $3.52 \mathrm{E}+03$ & $3.11 \mathrm{E}+02$ & $5.27 \mathrm{E}+01$ & $2.39 \mathrm{E}+01$ & $1.62 \mathrm{E}+01$ \\
\hline $116-F-1$ & E-10 & $=-10$ & $4.31 \mathrm{E}-10$ & $4.31 \mathrm{E}-10$ & $4.32 \mathrm{E}-10$ & $4.31 \mathrm{E}-10$ & $4.31 \mathrm{E}-10$ & $4.31 \mathrm{E}-10$ & 4.32E-10 & $3.46 \mathrm{E}+02$ & $6.22 \mathrm{E}+03$ & $7.97 \mathrm{E}+03$ & $8.12 \mathrm{E}+03$ & $8.11 \mathrm{E}+03$ & $8.12 \mathrm{E}+03$ & $3.10 \mathrm{E}+03$ \\
\hline $6-F-10$ & E-16 & -16 & 3.86 & $3.86 \mathrm{E}-16$ & $04 \mathrm{E}+01$ & $22 \mathrm{E}+01$ & $2.22 \mathrm{E}+01$ & $2.22 \mathrm{E}+01$ & $2.23 \mathrm{E}+01$ & $2.22 \mathrm{E}+01$ & $22 \mathrm{E}+01$ & $2.22 \mathrm{E}+01$ & $2.23 \mathrm{E}+01$ & $E+01$ & +01 & $E+01$ \\
\hline$-F-11$ & & & & $1 \mathrm{E}-17$ & $\mathrm{E}-17$ & 4.31E-17 & $4.31 \mathrm{E}-17$ & $4.31 \mathrm{E}-17$ & $4.32 \mathrm{E}-17$ & $1.39 \mathrm{E}+01$ & $1.54 \mathrm{E}+01$ & $1.54 \mathrm{E}+01$ & $1.55 \mathrm{E}+01$ & $1.54 \mathrm{E}+01$ & $1.54 \mathrm{E}+01$ & $1.54 \mathrm{E}+01$ \\
\hline 116-F-2 & & & & $1.27 \mathrm{E}-12$ & $01 \mathrm{E}+03$ & $2.97 \mathrm{E}+03$ & $1.10 \mathrm{E}+03$ & $1.53 E+05$ & $4.72 \mathrm{E}+05$ & $1.61 \mathrm{E}+05$ & $6.95 \mathrm{E}+03$ & $1.30 \mathrm{E}+03$ & $7.06 \mathrm{E}+02$ & $E+02$ & $\mathrm{E}+02$ & $3.17 \mathrm{E}+02$ \\
\hline & & & & $1.16 \mathrm{E}+03$ & $1.62 \mathrm{E}+03$ & $1.61 \mathrm{E}+03$ & $1.61 \mathrm{E}+03$ & $1.61 E+03$ & $2.22 \mathrm{E}+02$ & $7.26 \mathrm{E}+01$ & $4.19 \mathrm{E}+01$ & $2.38 \mathrm{E}+01$ & $2.38 \mathrm{E}+01$ & $\mathrm{E}+01$ & $E+01$ & $1.60 \mathrm{E}+01$ \\
\hline & & & & $9.45 \mathrm{E}-14$ & $9.47 \mathrm{E}-14$ & $45 E-14$ & 05E-03 & E-02 & E-01 & 7.06E-01 & 6.57E-01 & $\mathrm{E}-01$ & $5.24 \mathrm{E}-01$ & 4.30E-01 & 4.30E-01 & $4.21 \mathrm{E}-01$ \\
\hline & & & & E-11 & 93E-11 & 91E-11 & 5.91E-11 & E-11 & $\mathrm{E}-03$ & 7.14E-02 & $2.79 \mathrm{E}-01$ & E-01 & $1.75 \mathrm{E}+00$ & $E+00$ & $1.22 \mathrm{E}+01$ & $2.88 \mathrm{E}+01$ \\
\hline & & & & 4.65E-14 & $66 \mathrm{E}-14$ & 65E-14 & $2.76 \mathrm{E}+04$ & $5.06 \mathrm{E}+05$ & $7.83 \mathrm{E}+05$ & $2.38 \mathrm{E}+05$ & $7.05 \mathrm{E}+03$ & $1.18 \mathrm{E}+03$ & $7.11 \mathrm{E}+02$ & $5.58 \mathrm{E}+02$ & $4.97 \mathrm{E}+02$ & $4.78 \mathrm{E}+02$ \\
\hline & & & & $8.13 \mathrm{E}-11$ & $15 \mathrm{E}-11$ & 8.13E-11 & $8.13 \mathrm{E}-11$ & $8.13 \mathrm{E}-11$ & $8.15 \mathrm{E}-11$ & $4.57 \mathrm{E}+04$ & $4.62 \mathrm{E}+04$ & $4.61 \mathrm{E}+04$ & $4.64 \mathrm{E}+04$ & $4.62 \mathrm{E}+04$ & $4.62 \mathrm{E}+04$ & $4.61 \mathrm{E}+04$ \\
\hline & & & & $4.58 \mathrm{E}-19$ & $.59 \mathrm{E}-19$ & $.58 \mathrm{E}-19$ & $2.44 \mathrm{E}+01$ & $2.50 \mathrm{E}+01$ & $2.51 \mathrm{E}+01$ & $.50 \mathrm{E}+01$ & $2.50 \mathrm{E}+01$ & $2.50 \mathrm{E}+01$ & $2.51 \mathrm{E}+01$ & $2.50 \mathrm{E}+01$ & $2.50 \mathrm{E}+01$ & $2.50 \mathrm{E}+01$ \\
\hline & & & & $3 \mathrm{E}-12$ & $2.29 \mathrm{E}-12$ & $1.68 \mathrm{E}+03$ & $7.61 \mathrm{E}+03$ & $8.00 E+03$ & $8.04 \mathrm{E}+03$ & $8.02 \mathrm{E}+03$ & $8.02 \mathrm{E}+03$ & $\mathrm{E}+03$ & $8.04 \mathrm{E}+03$ & $8.02 \mathrm{E}+03$ & $8.02 E+03$ & $8.01 \mathrm{E}+03$ \\
\hline $116-\mathrm{K}-2$ & 1.84E-08 & 1.84E-08 & 1.84E-08 & 1.84E-08 & 1.84E-08 & 1.84E-08 & $1.84 \mathrm{E}-08$ & 1.84E-08 & 1.84E-08 & 1.84E-08 & 1.84E-08 & 1.84E-08 & $1.88 E+07$ & $2.05 \mathrm{E}+07$ & $2.04 \mathrm{E}+07$ & $1.89 \mathrm{E}+07$ \\
\hline
\end{tabular}




\begin{tabular}{|c|c|c|c|c|c|c|c|c|c|c|c|c|c|c|c|c|}
\hline & & & & & & & & & & & & & & & & \\
\hline Site & 1944 & 1945 & 1946 & 1947 & 1948 & 1949 & 1950 & 1951 & 1952 & 1953 & 1954 & 1955 & 1956 & 1957 & 1958 & 1959 \\
\hline 116-KE-1 & $4.78 \mathrm{E}-09$ & $4.76 \mathrm{E}-09$ & 4.76E-09 & .76E-09 & 4.78E-09 & $4.76 \mathrm{E}-09$ & 4.76E-09 & 4.76E-09 & $4.78 \mathrm{E}-09$ & 4.76E-09 & $4.76 \mathrm{E}-09$ & 3.95E-07 & $4.78 \mathrm{E}+00$ & $3.57 \mathrm{E}+01$ & $4.76 \mathrm{E}+01$ & $4.87 \mathrm{E}+01$ \\
\hline 116-KE-2 & 51E-15 & $4.60 \mathrm{E}-15$ & $4.60 \mathrm{E}-15$ & $60 \mathrm{E}-15$ & $61 \mathrm{E}-15$ & $4.60 \mathrm{E}-15$ & $4.60 \mathrm{E}-15$ & $60 \mathrm{E}-15$ & $61 \mathrm{E}-15$ & $4.60 \mathrm{E}-15$ & $4.60 \mathrm{E}-15$ & $1.28 \mathrm{E}+02$ & $1.77 \mathrm{E}+02$ & $1.76 \mathrm{E}+02$ & L.76E+02 & $1.76 \mathrm{E}+02$ \\
\hline 116-KE-3 & $5 \mathrm{E}-11$ & $5.64 \mathrm{E}-11$ & 5.64E-11 & 64E-11 & $65 \mathrm{E}-11$ & $5.64 \mathrm{E}-11$ & 5.64E-11 & 5.64E-11 & $65 \mathrm{E}-11$ & $5.64 \mathrm{E}-11$ & 1.51E-02 & $1.63 \mathrm{E}+01$ & $1.67 \mathrm{E}+01$ & $1.67 \mathrm{E}+01$ & $1.69 \mathrm{E}+01$ & $1.74 \mathrm{E}+01$ \\
\hline $116-K W-2$ & $4 \mathrm{E}-11$ & $6.22 \mathrm{E}-11$ & $6.22 \mathrm{E}-11$ & $22 \mathrm{E}-11$ & 24E-11 & $6.22 \mathrm{E}-11$ & $6.22 \mathrm{E}-11$ & $6.22 \mathrm{E}-11$ & $24 \mathrm{E}-11$ & $6.22 \mathrm{E}-11$ & 1.51E-02 & $1.63 \mathrm{E}+01$ & $1.67 \mathrm{E}+01$ & $1.67 \mathrm{E}+01$ & $1.68 \mathrm{E}+01$ & $1.68 \mathrm{E}+01$ \\
\hline $116-\mathrm{N}-1$ & $6 \mathrm{E}-10$ & $3.75 \mathrm{E}-10$ & $3.75 \mathrm{E}-10$ & $3.75 \mathrm{E}-10$ & $3.76 \mathrm{E}-10$ & $3.75 \mathrm{E}-10$ & $3.75 \mathrm{E}-10$ & $3.75 \mathrm{E}-10$ & $3.76 \mathrm{E}-10$ & $3.75 \mathrm{E}-10$ & $3.75 \mathrm{E}-10$ & $3.75 \mathrm{E}-10$ & $3.76 \mathrm{E}-10$ & $3.75 \mathrm{E}-10$ & $3.75 \mathrm{E}-10$ & $3.75 \mathrm{E}-10$ \\
\hline $116-N-3$ & $2 \mathrm{E}-10$ & $4.71 \mathrm{E}-10$ & $4.71 \mathrm{E}-10$ & $4.71 \mathrm{E}-10$ & $4.72 \mathrm{E}-10$ & $4.71 \mathrm{E}-10$ & $4.71 \mathrm{E}-10$ & $4.71 \mathrm{E}-10$ & $4.72 \mathrm{E}-10$ & $4.71 \mathrm{E}-10$ & $4.71 \mathrm{E}-10$ & $4.71 \mathrm{E}-10$ & $4.72 \mathrm{E}-10$ & $4.71 \mathrm{E}-10$ & $4.71 \mathrm{E}-10$ & $4.71 \mathrm{E}-10$ \\
\hline & & 2.06E-07 & 2.06E-07 & 2.06E-07 & 2.06E-07 & 2.06E-07 & 2.06E-07 & 2.06E-07 & 2.06E-07 & 2.06E-07 & 2.06E-07 & 2.06E-07 & 2.06E-07 & 2.06E-07 & 06E-07 & E-07 \\
\hline & & & $8.34 \mathrm{E}-11$ & 8.34E-11 & .36E-11 & $8.34 \mathrm{E}-11$ & $8.34 \mathrm{E}-11$ & 7.04E-10 & $3.20 \mathrm{E}-07$ & 2.85E-06 & 1.49E-05 & 5.76E-05 & $.88 \mathrm{E}-04$ & 5.39E-04 & 42E-03 & E-03 \\
\hline & & 5.00 & & $5.00 \mathrm{E}-11$ & $5.02 \mathrm{E}-11$ & $5.00 \mathrm{E}-11$ & $5.00 \mathrm{E}-11$ & $5.00 \mathrm{E}-11$ & LE-10 & 29E-07 & 7E-06 & LE-06 & $2.43 \mathrm{E}-05$ & 7.89E-05 & .27E-04 & $6.02 \mathrm{E}-04$ \\
\hline & & 0.00 & 0.00 & $0.00 \mathrm{E}+00$ & $00 \mathrm{E}+00$ & $0.00 \mathrm{E}+00$ & $0.00 \mathrm{E}+00$ & $0.00 \mathrm{E}+00$ & $0.00 \mathrm{E}+00$ & $0.00 \mathrm{E}+00$ & $E+00$ & $0.00 \mathrm{E}+00$ & $0.00 \mathrm{E}+00$ & $0.00 \mathrm{E}+00$ & $0.00 \mathrm{E}+00$ & $.00 \mathrm{E}+00$ \\
\hline C-1 & & 8.35 & & 8.39E-08 & E-08 & $8.39 \mathrm{E}-08$ & 8.39E-08 & $8.39 \mathrm{E}-08$ & LE-08 & 8.39E-08 & $4 \mathrm{E}-06$ & OE-04 & 9E-03 & $8 \mathrm{E}-02$ & 73E-02 & 0E-01 \\
\hline & & 0.00 & 0.00 & $0.00 \mathrm{E}+00$ & $\mathrm{E}+00$ & $0.00 \mathrm{E}+00$ & $0.00 \mathrm{E}+00$ & $0.00 \mathrm{E}+00$ & $\mathrm{E}+00$ & $.00 \mathrm{E}+00$ & $0.00 \mathrm{E}+00$ & $0.00 \mathrm{E}+00$ & $0.00 \mathrm{E}+00$ & $0.00 \mathrm{E}+00$ & $0.00 \mathrm{E}+00$ & $.00 \mathrm{E}+00$ \\
\hline & & 8.86 & -15 & 8.86E-15 & 8.88E-15 & 8.86E-15 & 7.93E-13 & 1.11E-08 & LE-06 & 06E-05 & 5E-04 & 9.28E-04 & 74E-03 & 1.30E-02 & 07E-02 & $1.12 \mathrm{E}-01$ \\
\hline & & -06 & -06 & 1.46E-06 & 1.47E-06 & 1.46E-06 & 1.46E-06 & 1.74E-05 & $4.09 \mathrm{E}-04$ & $2.53 \mathrm{E}-03$ & 1.12E-02 & 3.99E-02 & $25 \mathrm{E}-01$ & $49 \mathrm{E}-01$ & $9.15 \mathrm{E}-01$ & $2.30 \mathrm{E}+00$ \\
\hline & & -07 & 5.2 & $5.27 \mathrm{E}-07$ & E-07 & $5.27 \mathrm{E}-07$ & $5.27 \mathrm{E}-07$ & $5.27 \mathrm{E}-07$ & $9 \mathrm{E}-07$ & $5.27 \mathrm{E}-07$ & $5.27 \mathrm{E}-07$ & $5.27 \mathrm{E}-07$ & $.29 \mathrm{E}-07$ & $5.27 \mathrm{E}-07$ & $1.28 \mathrm{E}-05$ & $2.68 \mathrm{E}-04$ \\
\hline D-4 & LE-07 & $3.40 \mathrm{E}-07$ & 3.40E-07 & $3.40 \mathrm{E}-07$ & 3.41E-07 & $3.40 \mathrm{E}-07$ & $3.40 \mathrm{E}-07$ & 3.40E-07 & $3.41 \mathrm{E}-07$ & $3.40 \mathrm{E}-07$ & $3.40 \mathrm{E}-07$ & $6.10 \mathrm{E}-06$ & 1.37E-04 & 8.44E-04 & $3.73 \mathrm{E}-03$ & $1.33 \mathrm{E}-02$ \\
\hline -DR-2 & & $2.01 \mathrm{E}-11$ & $2.01 \mathrm{E}-11$ & $2.01 \mathrm{E}-11$ & $2.01 \mathrm{E}-11$ & $2.00 \mathrm{E}-11$ & $1.98 \mathrm{E}-11$ & $8.87 \mathrm{E}-12$ & $0.00 \mathrm{E}+00$ & $0.00 \mathrm{E}+00$ & $0.00 \mathrm{E}+00$ & $0.00 \mathrm{E}+00$ & $0.00 \mathrm{E}+00$ & $0.00 \mathrm{E}+00$ & $0.00 \mathrm{E}+00$ & $\mathrm{E}+00$ \\
\hline & & & & $6.18 \mathrm{E}-11$ & $20 \mathrm{E}-11$ & $6.18 \mathrm{E}-11$ & $6.18 \mathrm{E}-11$ & $6.18 \mathrm{E}-11$ & $6.20 \mathrm{E}-11$ & $6.18 \mathrm{E}-11$ & $2.45 \mathrm{E}-07$ & $5.88 \mathrm{E}-04$ & $2.87 \mathrm{E}-02$ & 1.90E-01 & $8.08 \mathrm{E}-01$ & \\
\hline & & -13 & & 3.83E-13 & $3.84 \mathrm{E}-13$ & 8.09E-10 & 2.13E-06 & 9.09E-05 & 8E-04 & $2.63 \mathrm{E}-03$ & 1E-03 & $7 \mathrm{E}-02$ & $6 \mathrm{E}-02$ & .39E-01 & $0 \mathrm{E}-01$ & \\
\hline & & & & $00 \mathrm{E}+00$ & $.00 \mathrm{E}+00$ & $00 \mathrm{E}+00$ & $0.00 \mathrm{E}+00$ & $0.00 \mathrm{E}+00$ & $E+00$ & $0.00 \mathrm{E}+00$ & $0 \mathrm{E}+00$ & $0.00 \mathrm{E}+00$ & $0.00 \mathrm{E}+00$ & $0.00 \mathrm{E}+00$ & $.00 \mathrm{E}+00$ & $E+00$ \\
\hline & & & & $E-13$ & E-13 & -01 & +01 & & & $E+02$ & $E+03$ & & & $E+03$ & $E+03$ & $\mathrm{E}+03$ \\
\hline & & 0.0 & 0.0 & +00 & $=+00$ & $=+00$ & +00 & $=00$ & $E+00$ & $E+00$ & $E+00$ & 0.0 & $E+00$ & $E+00$ & $E+00$ & $E+00$ \\
\hline & & & & E-06 & E-06 & E-06 & E-06 & $\mathrm{E}-06$ & $\mathrm{E}-06$ & E-06 & E-06 & E-05 & E-03 & $5 \mathrm{E}-03$ & $4 \mathrm{E}-02$ & $5 \mathrm{E}-01$ \\
\hline E-1 & & & & E-11 & E-11 & $2.72 \mathrm{E}-11$ & $2.72 \mathrm{E}-11$ & $2.72 \mathrm{E}-11$ & $2 \mathrm{E}-11$ & $2.72 \mathrm{E}-11$ & $1 \mathrm{E}-11$ & $7 \mathrm{E}-11$ & $2 \mathrm{E}-11$ & $0.00 \mathrm{E}+00$ & $\mathrm{JE}+00$ & $\mathrm{E}+00$ \\
\hline W-1 & & & -11 & $2.32 \mathrm{E}-11$ & $3 E-11$ & $2.32 \mathrm{E}-11$ & 2.32E-11 & 2.32E-11 & 3E-11 & $32 \mathrm{E}-11$ & $2.32 \mathrm{E}-11$ & $2.28 \mathrm{E}-11$ & $.04 \mathrm{E}-11$ & $0.00 E+00$ & $0.00 \mathrm{E}+00$ & $0.00 E+00$ \\
\hline$W-2$ & $E-13$ & $1.61 \mathrm{E}-13$ & $61 \mathrm{E}-13$ & $1.61 \mathrm{E}-13$ & $1.62 \mathrm{E}-13$ & $1.61 \mathrm{E}-13$ & $1.61 \mathrm{E}-13$ & $1.61 \mathrm{E}-13$ & $1.62 \mathrm{E}-13$ & $1.61 \mathrm{E}-13$ & $1.61 \mathrm{E}-13$ & $1.61 \mathrm{E}-13$ & 1.10E-09 & $2.41 \mathrm{E}-07$ & $3.09 \mathrm{E}-06$ & $2.23 \mathrm{E}-05$ \\
\hline-100 & & $1.52 \mathrm{E}$ & 4.39 & $4.38 \mathrm{E}+00$ & $4.40 \mathrm{E}+00$ & $4.39 \mathrm{E}+00$ & $4.39 \mathrm{E}+00$ & $4.38 \mathrm{E}+00$ & $4.40 \mathrm{E}+00$ & $4.39 \mathrm{E}+00$ & $4.39 \mathrm{E}+00$ & $4.38 \mathrm{E}+00$ & $4.40 \mathrm{E}+00$ & $4.39 \mathrm{E}+00$ & $4.39 \mathrm{E}+00$ & $4.37 \mathrm{E}+00$ \\
\hline -E-102 & 57E-04 & 1.56E-04 & 1.56E-04 & 1.56E-04 & 1.57E-04 & 1.56E-04 & 1.56E-04 & 1.56E-04 & 1.57E-04 & 1.56E-04 & 1.56E-04 & 1.56E-04 & 1.57E-04 & 1.56E-04 & $7.76 \mathrm{E}+02$ & $4.24 \mathrm{E}+02$ \\
\hline $200-E-103$ & DOE+00 & $0.00 \mathrm{E}+00$ & $0.00 \mathrm{E}+00$ & $0.00 \mathrm{E}+00$ & $00 \mathrm{E}+00$ & $0.00 \mathrm{E}+00$ & $0.00 \mathrm{E}+00$ & $0.00 \mathrm{E}+00$ & $0.00 \mathrm{E}+00$ & $0.00 \mathrm{E}+00$ & $0.00 \mathrm{E}+00$ & $0.00 \mathrm{E}+00$ & $0.00 \mathrm{E}+00$ & $0.00 \mathrm{E}+00$ & $0.00 \mathrm{E}+00$ & $0.00 \mathrm{E}+00$ \\
\hline$=-107$ & $0.00 \mathrm{E}+00$ & $0.00 \mathrm{E}+00$ & $0.00 \mathrm{E}+00$ & $0.00 \mathrm{E}+00$ & $00 \mathrm{E}+00$ & $0.00 \mathrm{E}+00$ & $0.00 \mathrm{E}+00$ & $0.00 \mathrm{E}+00$ & $0.00 \mathrm{E}+00$ & $0.00 \mathrm{E}+00$ & $0.00 \mathrm{E}+00$ & $0.00 \mathrm{E}+00$ & $0.00 \mathrm{E}+00$ & $0.00 \mathrm{E}+00$ & $0.00 \mathrm{E}+00$ & $0.00 \mathrm{E}+00$ \\
\hline-25 & E-08 & 19E-08 & 1.19E-08 & 1.19E-08 & 1.19E-08 & 1.19E-08 & 1.19E-08 & 1.19E-08 & 9E-08 & 1.19E-08 & 1.19E-08 & 1.19E-08 & 9E-08 & 1.19E-08 & 1.19E-08 & E-08 \\
\hline-28 & & -10 & -10 & $2.69 \mathrm{E}-10$ & $2.70 \mathrm{E}-10$ & $2.69 \mathrm{E}-10$ & $2.69 \mathrm{E}-10$ & $2.69 \mathrm{E}-10$ & $2.70 \mathrm{E}-10$ & $2.69 \mathrm{E}-10$ & $2.69 \mathrm{E}-10$ & $2.69 \mathrm{E}-10$ & $2.70 \mathrm{E}-10$ & $2.69 \mathrm{E}-10$ & $2.69 \mathrm{E}-10$ & $2.69 \mathrm{E}-10$ \\
\hline-41 & $0 \mathrm{E}+00$ & $0.00 \mathrm{E}+00$ & $0.00 \mathrm{E}+00$ & $0.00 \mathrm{E}+00$ & $0.00 \mathrm{E}+00$ & $0.00 \mathrm{E}+00$ & $0.00 \mathrm{E}+00$ & $0.00 \mathrm{E}+00$ & $0.00 \mathrm{E}+00$ & $0.00 \mathrm{E}+00$ & $0.00 \mathrm{E}+00$ & $E+00$ & $0.00 \mathrm{E}+00$ & $0.00 \mathrm{E}+00$ & $0.00 \mathrm{E}+00$ & $E+00$ \\
\hline & & & & $4.56 \mathrm{E}-07$ & $4.57 \mathrm{E}-07$ & $4.56 \mathrm{E}-07$ & 4.56E-07 & $4.56 \mathrm{E}-07$ & E-07 & $4.56 \mathrm{E}-07$ & $4.56 \mathrm{E}-07$ & E-07 & E-07 & 4.56E-07 & $4.56 \mathrm{E}-07$ & E-07 \\
\hline & & & & $1.73 \mathrm{E}-06$ & 1.42E-01 & $4.33 \mathrm{E}+00$ & $4.38 \mathrm{E}+00$ & $4.38 \mathrm{E}+00$ & $4.39 \mathrm{E}+00$ & $4.38 \mathrm{E}+00$ & $4.38 \mathrm{E}+00$ & $4.38 \mathrm{E}+00$ & $4.38 \mathrm{E}+00$ & $4.37 \mathrm{E}+00$ & $4.37 \mathrm{E}+00$ & $=00$ \\
\hline & & & & 3.13E-07 & $.14 \mathrm{E}-07$ & 3.13E-07 & 3.13E-07 & 3.13E-07 & 4E-07 & 3.13E-07 & 3.13E-07 & 3.13E-07 & 3.14E-07 & $3 \mathrm{E}-07$ & $3.13 \mathrm{E}-07$ & E-07 \\
\hline & & & & 4.42E-06 & .44E-06 & 42E-06 & 4.42E-06 & 4.42E-06 & $4 \mathrm{E}-06$ & 42E-06 & E-06 & E-06 & $E-06$ & $\mathrm{E}+00$ & $4.92 \mathrm{E}+01$ & $E+01$ \\
\hline$E-60$ & & & $4.08 \mathrm{E}-13$ & $4.08 \mathrm{E}-13$ & $4.09 \mathrm{E}-13$ & $4.08 \mathrm{E}-13$ & $4.08 \mathrm{E}-13$ & $4.08 \mathrm{E}-13$ & 4.09E-13 & $4.08 \mathrm{E}-13$ & $4.08 \mathrm{E}-13$ & $4.08 \mathrm{E}-13$ & 4.09E-13 & $4.08 \mathrm{E}-13$ & $4.08 \mathrm{E}-13$ & $4.08 \mathrm{E}-13$ \\
\hline E-61 & & & & $.00 \mathrm{E}+00$ & $00 \mathrm{E}+00$ & $0.00 \mathrm{E}+00$ & $0.00 \mathrm{E}+00$ & $0.00 \mathrm{E}+00$ & $0.00 \mathrm{E}+00$ & $.00 \mathrm{E}+00$ & $0.00 \mathrm{E}+00$ & $0.00 \mathrm{E}+00$ & $0.00 \mathrm{E}+00$ & $0.00 \mathrm{E}+00$ & $0.00 \mathrm{E}+00$ & $\mathrm{E}+00$ \\
\hline$E-62$ & & $0.00 \mathrm{E}+00$ & $0.00 \mathrm{E}+00$ & $0.00 \mathrm{E}+00$ & $00 \mathrm{E}+00$ & $0.00 \mathrm{E}+00$ & $0.00 \mathrm{E}+00$ & $0.00 \mathrm{E}+00$ & $0.00 \mathrm{E}+00$ & $.00 \mathrm{E}+00$ & $0.00 \mathrm{E}+00$ & $0.00 \mathrm{E}+00$ & $0.00 \mathrm{E}+00$ & $0.00 \mathrm{E}+00$ & $.00 \mathrm{E}+00$ & $0.00 \mathrm{E}+00$ \\
\hline $200-E-63$ & $0.00 \mathrm{E}+00$ & $0.00 \mathrm{E}+00$ & $0.00 E+00$ & $0.00 \mathrm{E}+00$ & $0.00 \mathrm{E}+00$ & $0.00 \mathrm{E}+00$ & $0.00 \mathrm{E}+00$ & $0.00 \mathrm{E}+00$ & $0.00 \mathrm{E}+00$ & $0.00 \mathrm{E}+00$ & $0.00 \mathrm{E}+00$ & $0.00 E+00$ & $0.00 \mathrm{E}+00$ & $0.00 E+00$ & $0.00 \mathrm{E}+00$ & $0.00 \mathrm{E}+0$ \\
\hline
\end{tabular}




\begin{tabular}{|c|c|c|c|c|c|c|c|c|c|c|c|c|c|c|c|c|}
\hline & & & & & & & & & & & & & & & & \\
\hline Site & 1944 & 1945 & 1946 & 1947 & 1948 & 1949 & 1950 & 1951 & 1952 & 1953 & 1954 & 1955 & 1956 & 1957 & 1958 & 195 \\
\hline $200-E-64$ & $00 \mathrm{E}+00$ & $0.00 \mathrm{E}+00$ & $0.00 \mathrm{E}+00$ & $00 \mathrm{E}+00$ & $00 \mathrm{E}+00$ & $0.00 \mathrm{E}+00$ & $0.00 \mathrm{E}+00$ & $0.00 \mathrm{E}+00$ & $0.00 \mathrm{E}+00$ & $0.00 \mathrm{E}+00$ & $0.00 \mathrm{E}+00$ & $0.00 \mathrm{E}+00$ & $0.00 \mathrm{E}+00$ & $0.00 \mathrm{E}+00$ & $0.00 \mathrm{E}+00$ & $.00 \mathrm{E}+00$ \\
\hline $200-E-65$ & 16E-07 & 4.15E-07 & 4.15E-07 & 4.15E-07 & .16E-07 & $.15 \mathrm{E}-07$ & $4.15 \mathrm{E}-07$ & 4.15E-07 & $4.16 \mathrm{E}-07$ & $4.15 \mathrm{E}-07$ & $4.15 \mathrm{E}-07$ & 4.15E-07 & $4.16 \mathrm{E}-07$ & 4.15E-07 & $4.15 \mathrm{E}-07$ & 4.15E-07 \\
\hline 200-E-67 & $0 \mathrm{E}+00$ & $0.00 \mathrm{E}+00$ & $0.00 \mathrm{E}+00$ & $00 \mathrm{E}+00$ & $00 \mathrm{E}+00$ & $00 \mathrm{E}+00$ & $0.00 \mathrm{E}+00$ & $0.00 \mathrm{E}+00$ & $0.00 \mathrm{E}+00$ & $0.00 \mathrm{E}+00$ & $0.00 \mathrm{E}+00$ & $0.00 \mathrm{E}+00$ & $0.00 \mathrm{E}+00$ & $0.00 \mathrm{E}+00$ & $0.00 \mathrm{E}+00$ & $0 \mathrm{E}+00$ \\
\hline 200-E-68 & $6 \mathrm{E}-07$ & E-07 & $4.15 \mathrm{E}-07$ & 4.15E-07 & $16 \mathrm{E}-07$ & 15E-07 & 4.15E-07 & $4.15 \mathrm{E}-07$ & 4.16E-07 & $4.15 \mathrm{E}-07$ & $4.15 \mathrm{E}-07$ & 4.15E-07 & 4.16E-07 & $4.15 \mathrm{E}-07$ & $4.15 \mathrm{E}-07$ & $5 \mathrm{E}-07$ \\
\hline 200-E-69 & $00 \mathrm{E}+00$ & $0.00 \mathrm{E}+00$ & $0.00 \mathrm{E}+00$ & $0.00 \mathrm{E}+00$ & $.00 \mathrm{E}+00$ & $00 \mathrm{E}+00$ & $0.00 \mathrm{E}+00$ & $0.00 \mathrm{E}+00$ & $0.00 \mathrm{E}+00$ & $0.00 \mathrm{E}+00$ & $0.00 \mathrm{E}+00$ & $0.00 \mathrm{E}+00$ & $0.00 \mathrm{E}+00$ & $0.00 \mathrm{E}+00$ & $0.00 \mathrm{E}+00$ & $\mathrm{DE}+00$ \\
\hline 200-E-70 & 41E-05 & $3.40 \mathrm{E}-05$ & $3.40 \mathrm{E}-05$ & $3.40 \mathrm{E}-05$ & $3.41 \mathrm{E}-05$ & 3.40E-05 & $3.40 \mathrm{E}-05$ & $3.40 \mathrm{E}-05$ & $3.41 \mathrm{E}-05$ & 3.40E-05 & $3.40 \mathrm{E}-05$ & $3.40 \mathrm{E}-05$ & 3.41E-05 & 3.40E-05 & $3.40 \mathrm{E}-05$ & 0E-05 \\
\hline $0-E-71$ & & & 63E-05 & $63 \mathrm{E}-05$ & $2.64 \mathrm{E}-05$ & 2.63E-05 & $2.63 \mathrm{E}-05$ & $2.63 \mathrm{E}-05$ & 2.64E-05 & 2.63E-05 & 2.63E-05 & 2.63E-05 & 2.64E-05 & $63 \mathrm{E}-05$ & $3 \mathrm{E}-05$ & $3 \mathrm{E}-05$ \\
\hline E-72 & & & -05 & $3.40 \mathrm{E}-05$ & $3.41 \mathrm{E}-05$ & .40E-05 & $3.40 \mathrm{E}-05$ & $3.40 \mathrm{E}-05$ & 3.41E-05 & $3.40 \mathrm{E}-05$ & 3.40E-05 & 3.40E-05 & 3.41E-05 & 40E-05 & OE-05 & 10E-05 \\
\hline-73 & & & & 5.84E-07 & 5.86E-07 & 5.84E-07 & $4 \mathrm{E}-07$ & E-07 & $6 \mathrm{E}-07$ & $4 \mathrm{E}-07$ & $4 \mathrm{E}-07$ & 4E-07 & $6 \mathrm{E}-07$ & $4 \mathrm{E}-07$ & 4E-07 & $4 \mathrm{E}-07$ \\
\hline-74 & & & & $\mathrm{E}-05$ & E-05 & E-05 & $\mathrm{E}-05$ & $\mathrm{E}-05$ & LE-05 & E-05 & E-05 & $\mathrm{E}-05$ & E-05 & E-05 & DE-05 & OE-05 \\
\hline-75 & & & & E-05 & E-05 & E-05 & E-05 & E-05 & E-05 & E-05 & E-05 & E-05 & $1 \mathrm{E}-05$ & DE-05 & $0 \mathrm{E}-05$ & OE-05 \\
\hline & & 0.0 & 0.0 & $E+00$ & $E+00$ & $E+00$ & $0.00 \mathrm{E}+00$ & $E+00$ & $\mathrm{E}+00$ & $E+00$ & $0.00 \mathrm{E}+00$ & $E+00$ & $0 \mathrm{E}+00$ & $\mathrm{DE}+00$ & $0.00 \mathrm{E}+00$ & $\mathrm{E}+00$ \\
\hline & & 00 & 0.00 & $E+00$ & $E+00$ & $E+00$ & $0.00 E+00$ & $E+00$ & $E+00$ & $E+00$ & $0.00 E+00$ & $E+00$ & $\mathrm{E}+00$ & $E+00$ & $\mathrm{E}+00$ & $\mathrm{E}+00$ \\
\hline-78 & +00 & 00 & 100 & $0.00 \mathrm{E}+00$ & $00 \mathrm{E}+00$ & $00 \mathrm{E}+00$ & $0.00 \mathrm{E}+00$ & $0.00 \mathrm{E}+00$ & $0.00 \mathrm{E}+00$ & $0.00 \mathrm{E}+00$ & $0.00 \mathrm{E}+00$ & $0.00 \mathrm{E}+00$ & $0.00 \mathrm{E}+00$ & $0.00 \mathrm{E}+00$ & $\mathrm{DE}+00$ & $\mathrm{E}+00$ \\
\hline-79 & & & -00 & $E+00$ & $00 \mathrm{E}+00$ & $E+00$ & $00 \mathrm{E}+00$ & $0.00 \mathrm{E}+00$ & $.00 \mathrm{E}+00$ & $.00 \mathrm{E}+00$ & $.00 \mathrm{E}+00$ & $0.00 \mathrm{E}+00$ & $0.00 \mathrm{E}+00$ & $0.00 \mathrm{E}+00$ & $\mathrm{E}+00$ & $\mathrm{E}+00$ \\
\hline $200-E-80$ & $E+00$ & +00 & $0.00 \mathrm{E}+00$ & $0.00 \mathrm{E}+00$ & $00 \mathrm{E}+00$ & $00 \mathrm{E}+00$ & $0.00 \mathrm{E}+00$ & $0.00 \mathrm{E}+00$ & $.00 \mathrm{E}+00$ & $\mathrm{E}+00$ & $0 \mathrm{E}+00$ & $0.00 \mathrm{E}+00$ & $0.00 \mathrm{E}+00$ & $0.00 \mathrm{E}+00$ & $0.00 \mathrm{E}+00$ & $\mathrm{E}+00$ \\
\hline 200-E-81 & $E+00$ & 0.00 & $0.00 \mathrm{E}+00$ & $0.00 \mathrm{E}+00$ & $00 \mathrm{E}+00$ & $00 \mathrm{E}+00$ & $0.00 \mathrm{E}+00$ & $0.00 \mathrm{E}+00$ & $0.00 \mathrm{E}+00$ & $0 \mathrm{E}+00$ & $0.00 \mathrm{E}+00$ & $0.00 \mathrm{E}+00$ & $0.00 \mathrm{E}+00$ & $0.00 \mathrm{E}+00$ & $.00 \mathrm{E}+00$ & $\mathrm{E}+00$ \\
\hline $200-E-82$ & & +00 & 0.00 & $0.00 \mathrm{E}+00$ & $00 \mathrm{E}+00$ & $0.00 \mathrm{E}+00$ & $0.00 \mathrm{E}+00$ & $0.00 \mathrm{E}+00$ & $0.00 \mathrm{E}+00$ & $0 \mathrm{E}+00$ & $.00 \mathrm{E}+00$ & $0.00 \mathrm{E}+00$ & $0 \mathrm{E}+00$ & $0 \mathrm{E}+00$ & $0 \mathrm{E}+00$ & \\
\hline & $E-07$ & & -07 & 9.42E-07 & 9.44E-07 & $.42 \mathrm{E}-07$ & 9.42E-07 & 9.42E-07 & $4 \mathrm{E}-07$ & $2 \mathrm{E}-07$ & $2 \mathrm{E}-07$ & 2E-07 & & $2 \mathrm{E}-07$ & $2 \mathrm{E}-07$ & -07 \\
\hline E-85 & & & & $00 \mathrm{E}+00$ & $00 \mathrm{E}+00$ & $\mathrm{E}+00$ & $0.00 \mathrm{E}+00$ & $0.00 \mathrm{E}+00$ & $0.00 \mathrm{E}+00$ & $.00 \mathrm{E}+00$ & $0 \mathrm{E}+00$ & $E+00$ & $0.00 \mathrm{E}+00$ & $0.00 \mathrm{E}+00$ & $0 \mathrm{E}+00$ & $\mathrm{DE}+00$ \\
\hline E-88 & & & & E-04 & $E-04$ & E-04 & $E-04$ & -04 & $=-04$ & E-04 & $\mathrm{E}-04$ & & & E-04 & E-04 & E-04 \\
\hline & & & & $E-03$ & $E-03$ & $E-03$ & $E-03$ & -03 & $E-03$ & $E-03$ & E-03 & & -03 & E-03 & E-03 & E-03 \\
\hline & & & & $=-04$ & E-04 & $E-04$ & $\mathrm{E}-04$ & $E-04$ & $\mathrm{E}-04$ & E-04 & 3E-04 & $=-04$ & E-04 & 3E-04 & 3E-04 & E-04 \\
\hline-91 & & & & $E-05$ & $E-05$ & $E-05$ & $E-05$ & $E-05$ & E-05 & E-05 & E-05 & E-05 & E-05 & $9 \mathrm{E}-05$ & $9 \mathrm{E}-05$ & E-05 \\
\hline-92 & & & -03 & E-03 & E-03 & $\mathrm{E}-03$ & 1.84E-03 & $\mathrm{E}-03$ & $4 \mathrm{E}-03$ & $4 \mathrm{E}-03$ & 84E-03 & E-03 & $4 \mathrm{E}-03$ & .84E-03 & $.84 \mathrm{E}-03$ & $4 \mathrm{E}-03$ \\
\hline-93 & -03 & -03 & $E-03$ & 04E-03 & J4E-03 & 04E-03 & 1.04E-03 & 1.04E-03 & 04E-03 & 04E-03 & 1.04E-03 & 1.04E-03 & $.04 \mathrm{E}-03$ & 1.04E-03 & $1.04 \mathrm{E}-03$ & $1.04 \mathrm{E}-03$ \\
\hline-94 & $E-04$ & -04 & -04 & 53E-04 & $55 E-04$ & 53E-04 & $6.53 \mathrm{E}-04$ & .53E-04 & 55E-04 & 53E-04 & $6.53 \mathrm{E}-04$ & $6.53 \mathrm{E}-04$ & $.55 \mathrm{E}-04$ & $6.53 \mathrm{E}-04$ & $6.53 \mathrm{E}-04$ & $6.53 \mathrm{E}-04$ \\
\hline 200-E-95 & $35 \mathrm{E}-05$ & $2.65 \mathrm{E}+00$ & $4.38 \mathrm{E}+00$ & $4.37 \mathrm{E}+00$ & $40 \mathrm{E}+00$ & $4.38 \mathrm{E}+00$ & $4.38 \mathrm{E}+00$ & $4.37 \mathrm{E}+00$ & $4.40 \mathrm{E}+00$ & $4.39 \mathrm{E}+00$ & $4.39 \mathrm{E}+00$ & $4.37 \mathrm{E}+00$ & $4.40 \mathrm{E}+00$ & $4.39 \mathrm{E}+00$ & $4.39 \mathrm{E}+00$ & $4.37 \mathrm{E}+00$ \\
\hline 200-E-97 & LE-05 & $2.71 \mathrm{E}+00$ & $4.39 \mathrm{E}+00$ & $4.37 \mathrm{E}+00$ & $4.40 \mathrm{E}+00$ & $4.39 \mathrm{E}+00$ & $4.39 \mathrm{E}+00$ & $4.37 \mathrm{E}+00$ & $4.40 \mathrm{E}+00$ & $4.39 \mathrm{E}+00$ & $4.39 \mathrm{E}+00$ & $4.37 \mathrm{E}+00$ & $4.40 \mathrm{E}+00$ & $4.39 \mathrm{E}+00$ & $4.39 \mathrm{E}+00$ & $4.37 \mathrm{E}+00$ \\
\hline 200-E-98 & 3E-04 & 1.32E-04 & 1.32E-04 & $3.25 \mathrm{E}+00$ & $70 \mathrm{E}+00$ & $69 \mathrm{E}+00$ & $3.69 \mathrm{E}+00$ & $3.69 \mathrm{E}+00$ & $3.70 \mathrm{E}+00$ & $3.69 \mathrm{E}+00$ & $3.69 \mathrm{E}+00$ & $3.68 \mathrm{E}+00$ & $3.70 \mathrm{E}+00$ & $3.69 \mathrm{E}+00$ & $3.69 \mathrm{E}+00$ & $68 \mathrm{E}+00$ \\
\hline 200-E-99 & E-06 & $E-06$ & 6.74E-01 & $.42 \mathrm{E}+00$ & $4.42 \mathrm{E}+00$ & $4.42 \mathrm{E}+00$ & $4.42 \mathrm{E}+00$ & $4.41 \mathrm{E}+00$ & $4.43 \mathrm{E}+00$ & $4.42 \mathrm{E}+00$ & $4.42 \mathrm{E}+00$ & $4.41 \mathrm{E}+00$ & $4.43 \mathrm{E}+00$ & $4.42 \mathrm{E}+00$ & $4.42 \mathrm{E}+00$ & +00 \\
\hline W-22 & & & -06 & $4 \mathrm{E}-06$ & $2.24 \mathrm{E}-06$ & 2.24E-06 & $2.24 \mathrm{E}-06$ & $2.24 \mathrm{E}-06$ & $2.24 \mathrm{E}-06$ & $24 \mathrm{E}-06$ & 2.24E-06 & $2.24 \mathrm{E}-06$ & $2.24 \mathrm{E}-06$ & $2.24 \mathrm{E}-06$ & $2.24 \mathrm{E}-06$ & $2.24 \mathrm{E}-06$ \\
\hline$W-42$ & & & & 2.03E-05 & 2.03E-05 & 2.03E-05 & 2.03E-05 & 2.03E-05 & 2.03E-05 & 2.03E-05 & 2.03E-05 & $=-05$ & E-05 & 2.03E-05 & 2.03E-05 & 2.03E-05 \\
\hline W-52 & & & & E-08 & $2.66 \mathrm{E}+03$ & $1.19 \mathrm{E}+04$ & $1.19 \mathrm{E}+04$ & $1.19 E+04$ & $1.20 \mathrm{E}+04$ & $1.19 \mathrm{E}+04$ & $1.19 \mathrm{E}+04$ & $=04$ & $5+03$ & $1.35 E+03$ & $7.15 E+02$ & $4.87 \mathrm{E}+02$ \\
\hline$W-9$ & & & & 5E-11 & $1.66 \mathrm{E}-11$ & 1.65E-11 & 1.65E-11 & $5 E-11$ & $6 \mathrm{E}-11$ & 1.65E-11 & 1.65E-11 & $E-11$ & $1.66 \mathrm{E}-11$ & $5 \mathrm{E}-11$ & $1.65 \mathrm{E}-11$ & E-11 \\
\hline $\mathrm{M}-\mathrm{PO}$ & & & & $2.03 \mathrm{E}-02$ & 04E-02 & .03E-02 & 2.03E-02 & 2.03E-02 & $4 \mathrm{E}-02$ & $7.59 \mathrm{E}+02$ & $2.60 \mathrm{E}+04$ & $2.59 \mathrm{E}+04$ & $2.60 \mathrm{E}+04$ & $2.60 \mathrm{E}+04$ & $2.60 \mathrm{E}+04$ & $E+04$ \\
\hline-10 & & & & 1.74E-05 & 74E-05 & $.74 \mathrm{E}-05$ & 1.74E-05 & 1.74E-05 & $E-05$ & 1.74E-05 & 1.74E-05 & E-05 & $1.10 \mathrm{E}+05$ & $6.03 E+04$ & $1.47 \mathrm{E}+04$ & $7.61 \mathrm{E}+03$ \\
\hline$-A-11$ & & & & 4.17E-07 & 19E-07 & 4.17E-07 & $4.17 \mathrm{E}-07$ & 17E-07 & 4.19E-07 & E-07 & 4.17E-07 & E-07 & 4.19E-07 & $4.09 \mathrm{E}+00$ & $5.90 \mathrm{E}+00$ & $5.89 \mathrm{E}+00$ \\
\hline & & & & 7.12E-09 & 14E-09 & 12E-09 & $12 \mathrm{E}-09$ & $2 \mathrm{E}-09$ & & EE-09 & 7.12E-09 & E-09 & $3.66 \mathrm{E}+00$ & $5.57 \mathrm{E}+00$ & $5.57 \mathrm{E}+00$ & $5.56 \mathrm{E}+00$ \\
\hline & & & & 1.86E-06 & .87E-06 & .86E-06 & 86E-06 & & & $6 \mathrm{E}-06$ & $.86 \mathrm{E}-06$ & & & & 1.86E-06 & 6E-06 \\
\hline $216-A-14$ & $6.90 \mathrm{E}-07$ & $6.88 \mathrm{E}-07$ & $6.88 \mathrm{E}-07$ & $6.88 \mathrm{E}-07$ & $6.90 \mathrm{E}-07$ & $6.88 \mathrm{E}-07$ & $6.88 \mathrm{E}-07$ & $6.88 \mathrm{E}-07$ & $6.90 \mathrm{E}-07$ & 6.88E-07 & $6.88 \mathrm{E}-07$ & $6.88 \mathrm{E}-07$ & $6.90 \mathrm{E}-07$ & $6.88 \mathrm{E}-07$ & $6.88 \mathrm{E}-07$ & $6.88 \mathrm{E}-0$ \\
\hline
\end{tabular}




\begin{tabular}{|c|c|c|c|c|c|c|c|c|c|c|c|c|c|c|c|c|}
\hline \multirow[b]{2}{*}{ Site } & \multicolumn{4}{|c|}{ ANNUAL DISCHARGE VOLUMES IN M ${ }^{3}$} & \multirow[b]{2}{*}{1948} & \multirow[b]{2}{*}{1949} & \multirow[b]{2}{*}{1950} & \multirow[b]{2}{*}{1951} & \multirow[b]{2}{*}{1952} & \multirow[b]{2}{*}{1953} & \multirow[b]{2}{*}{1954} & \multirow[b]{2}{*}{1955} & \multirow[b]{2}{*}{1956} & \multirow[b]{2}{*}{1957} & \multirow[b]{2}{*}{1958} & \multirow[b]{2}{*}{1959} \\
\hline & 1944 & 1945 & 1946 & 1947 & & & & & & & & & & & & \\
\hline 216-A-15 & 2.51E-08 & 2.51E-08 & $2.51 \mathrm{E}-08$ & $.51 \mathrm{E}-08$ & 2.51E-08 & 2.51E-08 & 2.51E-08 & $2.51 \mathrm{E}-08$ & $2.51 \mathrm{E}-08$ & 2.51E-08 & 2.51E-08 & $3.88 \mathrm{E}+02$ & $5.58 \mathrm{E}+02$ & $5.56 \mathrm{E}+02$ & $5.56 \mathrm{E}+02$ & $5.55 \mathrm{E}+02$ \\
\hline $216-A-16$ & $19 \mathrm{E}-08$ & $5.18 \mathrm{E}-08$ & $5.18 \mathrm{E}-08$ & .18E-08 & 5.19E-08 & $5.18 \mathrm{E}-08$ & $5.18 \mathrm{E}-08$ & $5.18 \mathrm{E}-08$ & 5.19E-08 & $5.18 \mathrm{E}-08$ & $5.18 \mathrm{E}-08$ & $5.18 \mathrm{E}-08$ & 5.19E-08 & $1.90 \mathrm{E}+00$ & $8.75 \mathrm{E}+00$ & $.74 \mathrm{E}+00$ \\
\hline $216-A-17$ & $3 \mathrm{E}-06$ & $42 \mathrm{E}-06$ & $2.42 \mathrm{E}-06$ & $2.42 \mathrm{E}-06$ & $2.43 \mathrm{E}-06$ & $2.42 \mathrm{E}-06$ & $2.42 \mathrm{E}-06$ & $2.42 \mathrm{E}-06$ & $2.43 \mathrm{E}-06$ & $2.42 \mathrm{E}-06$ & $2.42 \mathrm{E}-06$ & $2.42 \mathrm{E}-06$ & $2.43 \mathrm{E}-06$ & 2.42E-06 & $2.42 \mathrm{E}-06$ & $.04 \mathrm{E}+00$ \\
\hline $216-A-2$ & & & & 84E-05 & 9.87E-05 & 9.84E-05 & 9.84E-05 & 9.84E-05 & $9.87 \mathrm{E}-05$ & & 9.84E-05 & 9.84E-05 & 9.87E-05 & & & \\
\hline & & & & $46 \mathrm{E}-05$ & & $1.46 \mathrm{E}-05$ & $1.46 \mathrm{E}-05$ & $1.46 \mathrm{E}-05$ & & & $1.46 \mathrm{E}-05$ & $1.46 \mathrm{E}-05$ & $3.62 E+02$ & $1.20 \mathrm{E}+02$ & $6.36 \mathrm{E}+01$ & \\
\hline & & & & 56E-04 & $2.57 E-04$ & $2.56 \mathrm{E}-04$ & $2.56 \mathrm{E}-04$ & & 2.57E-04 & & $2.56 \mathrm{E}-04$ & $2.56 \mathrm{E}-04$ & 2.57E-04 & 2.56E-04 & $2.56 \mathrm{E}-04$ & \\
\hline & & 2.06E-04 & & $2.06 \mathrm{E}-04$ & -04 & E-04 & E-04 & E-04 & $E-04$ & E-04 & $6 \mathrm{E}-04$ & E-04 & & & & \\
\hline & & & & $3.22 \mathrm{E}-05$ & & E-05 & & $=-05$ & & & & & & & & \\
\hline & & & & 54E-05 & & & & & & & & & & & & \\
\hline $216-A-24$ & & $6.96 \mathrm{E}-02$ & 6.96E-02 & $6.96 \mathrm{E}-02$ & $6.98 \mathrm{E}-02$ & $6.96 \mathrm{E}-02$ & 6.96E-02 & $6.96 \mathrm{E}-02$ & $6.98 \mathrm{E}-02$ & 6.96E-02 & 6.96E-02 & $6 \mathrm{E}-02$ & $6.98 \mathrm{E}-02$ & $6.96 \mathrm{E}-02$ & $1.90 \mathrm{E}+05$ & \\
\hline $216-A-25$ & 33E-11 & $1.98 \mathrm{E}-11$ & 1.98E-11 & 1.98E-11 & 1.98E-11 & $1.98 \mathrm{E}-11$ & 1.98E-11 & 1.98E-11 & 1.98E-11 & $1.98 \mathrm{E}-11$ & 1.98E-11 & 1.98E-11 & 1.98E-11 & $6.35 \mathrm{E}-09$ & $3.60 \mathrm{E}+06$ & $8.20 \mathrm{E}+06$ \\
\hline $216-A-26$ & & 2.13E-06 & 2.13E-06 & 2.13E-06 & $2.14 \mathrm{E}-06$ & $2.13 \mathrm{E}-06$ & 2.13E-06 & $2.13 \mathrm{E}-06$ & $2.14 \mathrm{E}-06$ & 2.13E-06 & 2.13E-06 & $2.13 \mathrm{E}-06$ & 2.14E-06 & $2.13 \mathrm{E}-06$ & 2.13E-06 & $2.13 \mathrm{E}-06$ \\
\hline 216-A-26A & & 2.17E-06 & 2.17E-06 & 2.17E-06 & $2.18 \mathrm{E}-06$ & 2.17E-06 & 2.17E-06 & 2.17E-06 & $2.18 \mathrm{E}-06$ & 2.17E-06 & 2.17E-06 & $2.17 E-06$ & $2.18 \mathrm{E}-06$ & $2.17 E-06$ & 2.17E-06 & 2.17E-06 \\
\hline $216-A-27$ & & & & $6.60 \mathrm{E}-04$ & $6.62 \mathrm{E}-04$ & $6.60 \mathrm{E}-04$ & $6.60 \mathrm{E}-04$ & $6.60 \mathrm{E}-04$ & $6.62 \mathrm{E}-04$ & $6.60 \mathrm{E}-04$ & $6.60 \mathrm{E}-04$ & $6.60 \mathrm{E}-04$ & $6.62 \mathrm{E}-04$ & $6.60 \mathrm{E}-04$ & $6.60 \mathrm{E}-04$ & 50E-04 \\
\hline & & & & $1.26 \mathrm{E}-03$ & $1.27 \mathrm{E}-03$ & $1.26 \mathrm{E}-03$ & E-03 & $1.26 \mathrm{E}-03$ & $\mathrm{E}-03$ & E-03 & $\mathrm{E}-03$ & E-03 & E-03 & E-03 & $6 \mathrm{E}-03$ & E-03 \\
\hline & & & & -06 & -06 & -06 & -06 & -06 & & & & -06 & -06 & & & $E+02$ \\
\hline & & & & -01 & -01 & $E-01$ & -01 & -01 & -01 & -01 & -01 & -01 & $E-01$ & -01 & E-01 & E-01 \\
\hline & & 0.0 & 00 & $E+00$ & +00 & $E+00$ & +00 & $E+00$ & +00 & $E+00$ & +00 & $E+00$ & $E+00$ & $E+00$ & $E+00$ & $E+00$ \\
\hline & & 00 & 100 & $E+00$ & $E+00$ & $E+00$ & +00 & $E+00$ & $E+00$ & $E+00$ & +00 & $E+00$ & $E+00$ & $E+00$ & $E+00$ & $E+00$ \\
\hline-35 & & 0.00 & +00 & $\mathrm{E}+00$ & $E+00$ & $E+00$ & +00 & $0.00 \mathrm{E}+00$ & $0.00 \mathrm{E}+00$ & $\mathrm{E}+00$ & $0.00 \mathrm{E}+00$ & $0.00 \mathrm{E}+00$ & $0 \mathrm{E}+00$ & $0.00 \mathrm{E}+00$ & $0.00 \mathrm{E}+00$ & $E+00$ \\
\hline $6-A-36 A$ & & & -02 & E-02 & -02 & -02 & -02 & -02 & -02 & -02 & -02 & $=-02$ & $E-02$ & $=-02$ & -02 & $E-02$ \\
\hline 216-A-36B & & -02 & -02 & 1.13E-02 & $1.14 \mathrm{E}-02$ & 1.13E-02 & $E-02$ & 1.13E-02 & $\mathrm{E}-02$ & $\mathrm{E}-02$ & E-02 & 1.13E-02 & $1.14 \mathrm{E}-02$ & 3E-02 & 1.13E-02 & $3 \mathrm{E}-02$ \\
\hline 216-A-37-1 & $=-05$ & $2.41 \mathrm{E}-05$ & $2.41 \mathrm{E}-05$ & $2.41 \mathrm{E}-05$ & $2.41 \mathrm{E}-05$ & $2.41 \mathrm{E}-05$ & $2.41 \mathrm{E}-05$ & $2.41 \mathrm{E}-05$ & $2.41 \mathrm{E}-05$ & $2.41 \mathrm{E}-05$ & $2.41 \mathrm{E}-05$ & $2.41 \mathrm{E}-05$ & $2.41 \mathrm{E}-05$ & $2.41 \mathrm{E}-05$ & $2.41 \mathrm{E}-05$ & 2.41E-05 \\
\hline 216-A-37-2 & 4.32E-03 & 4.31E-03 & 4.31E-03 & 4.31E-03 & 4.32E-03 & 4.31E-03 & 4.31E-03 & 4.31E-03 & 4.32E-03 & 4.31E-03 & 4.31E-03 & 4.31E-03 & 4.32E-03 & 4.31E-03 & 4.31E-03 & 4.31E-03 \\
\hline 216-A-39 & & $0.00 \mathrm{E}+00$ & $0.00 \mathrm{E}+00$ & $0.00 \mathrm{E}+00$ & $0.00 \mathrm{E}+00$ & $0.00 \mathrm{E}+00$ & $0.00 \mathrm{E}+00$ & $0.00 \mathrm{E}+00$ & $0.00 \mathrm{E}+00$ & $0.00 \mathrm{E}+00$ & $0.00 \mathrm{E}+00$ & $0.00 \mathrm{E}+00$ & $0.00 \mathrm{E}+00$ & $0.00 \mathrm{E}+00$ & $0.00 \mathrm{E}+00$ & $0.00 \mathrm{E}+00$ \\
\hline & & & & $4.76 \mathrm{E}-04$ & $4.77 \mathrm{E}-04$ & .76E-04 & E-04 & $4.76 \mathrm{E}-04$ & 7E-04 & E-04 & E-04 & $6 \mathrm{E}-04$ & $\mathrm{E}+03$ & $E+03$ & $5 \mathrm{E}+03$ & $5 \mathrm{E}+02$ \\
\hline & & & & $0.00 \mathrm{E}+00$ & $0.00 \mathrm{E}+00$ & $0.00 \mathrm{E}+00$ & $0.00 \mathrm{E}+00$ & $E+00$ & $0.00 \mathrm{E}+00$ & $E+00$ & $0.00 \mathrm{E}+00$ & $E+00$ & $0.00 \mathrm{E}+00$ & $E+00$ & $.00 \mathrm{E}+00$ & $\mathrm{E}+00$ \\
\hline & & & & +00 & 100 & 50 & & +00 & +00 & +00 & & +00 & & +00 & & \\
\hline & & & & $E-03$ & -03 & $=-03$ & -03 & E-03 & $E-03$ & $=-03$ & $E-03$ & E-03 & $E-03$ & E-03 & E-03 & E-03 \\
\hline & & & & E-03 & -03 & $=-03$ & -03 & $=-03$ & -03 & $=-03$ & $=-03$ & E-03 & $E+05$ & $E+05$ & $E+05$ & $\mathrm{E}+05$ \\
\hline & & & & 7.09E-03 & 10E-03 & 09E-03 & $.09 \mathrm{E}-03$ & 7.09E-03 & 7.10E-03 & E-03 & E-03 & E-03 & $1.30 \mathrm{E}+05$ & $\mathrm{E}+05$ & $7.68 \mathrm{E}+05$ & ETTS \\
\hline$-A-7$ & & $2.41 \mathrm{E}-05$ & $2.41 \mathrm{E}-05$ & $2.41 \mathrm{E}-05$ & $2.42 \mathrm{E}-05$ & $2.41 \mathrm{E}-05$ & $2.41 \mathrm{E}-05$ & $2.41 \mathrm{E}-05$ & $2.42 \mathrm{E}-05$ & $2.41 \mathrm{E}-05$ & LE-05 & $2.41 \mathrm{E}-05$ & $2.42 \mathrm{E}-05$ & $1 \mathrm{E}-05$ & $9.74 \mathrm{E}+00$ & $9.72 \mathrm{E}+00$ \\
\hline 216-A-8 & $\mathrm{E}-05$ & $6.77 \mathrm{E}-05$ & 6.77E-05 & 6.77E-05 & 6.79E-05 & 6.77E-05 & $6.77 \mathrm{E}-05$ & $6.77 \mathrm{E}-05$ & 6.79E-05 & $6.77 \mathrm{E}-05$ & 6.77E-05 & 6.77E-05 & $4.33 E+05$ & $2.44 \mathrm{E}+05$ & $1.29 \mathrm{E}+05$ & $4.70 \mathrm{E}+04$ \\
\hline 216-A-9 & 4E-03 & 5.63E-03 & 5.63E-03 & 5.63E-03 & $5.64 \mathrm{E}-03$ & 5.63E-03 & 5.63E-03 & 5.63E-03 & 5.64E-03 & 5.63E-03 & 5.63E-03 & 5.63E-03 & $4.91 \mathrm{E}+05$ & $2.72 \mathrm{E}+05$ & $8.74 \mathrm{E}+04$ & $3.17 \mathrm{E}+04$ \\
\hline 216-B-10A & 8.67E-03 & 8.65E-03 & 8.65E-03 & 8.65E-03 & 8.67E-03 & 8.65E-03 & 8.65E-03 & $2.72 \mathrm{E}+03$ & $2.76 \mathrm{E}+03$ & $1.04 \mathrm{E}+03$ & $5.63 \mathrm{E}+02$ & $3.42 \mathrm{E}+02$ & $2.67 \mathrm{E}+02$ & $2.00 \mathrm{E}+02$ & $1.74 \mathrm{E}+02$ & $1.19 \mathrm{E}+02$ \\
\hline 216-B-10B & 2.05E-05 & 2.05E-05 & 2.05E-05 & 2.05E-05 & 2.05E-05 & 2.05E-05 & 2.05E-05 & 2.05E-05 & 2.05E-05 & 2.05E-05 & 2.05E-05 & 2.05E-05 & 2.05E-05 & 2.05E-05 & 2.05E-05 & 2.05E-05 \\
\hline $216-B-11 A \% B$ & 1.51E-03 & 1.51E-03 & 1.51E-03 & 1.51E-03 & 1.51E-03 & 1.51E-03 & 1.51E-03 & 1.51E-03 & $1.18 \mathrm{E}+04$ & $8.27 \mathrm{E}+03$ & $7.34 \mathrm{E}+03$ & $1.33 \mathrm{E}+03$ & $2.20 \mathrm{E}+02$ & $1.13 \mathrm{E}+02$ & $7.37 \mathrm{E}+01$ & $4.62 \mathrm{E}+01$ \\
\hline 216-B-12 & 4.51E-04 & & $4.50 \mathrm{E}-04$ & $4.50 \mathrm{E}-04$ & 4.51E-04 & $4.50 \mathrm{E}-04$ & 4.50E-04 & $4.50 \mathrm{E}-04$ & $1.74 \mathrm{E}+03$ & $8.88 \mathrm{E}+04$ & $1.03 E+05$ & $7.96 \mathrm{E}+04$ & $7.89 E+04$ & $1.15 \mathrm{E}+04$ & $2.35 \mathrm{E}+03$ & $1.20 \mathrm{E}+03$ \\
\hline $216-\mathrm{B}-13$ & $2 E-05$ & & 1.32E-05 & 1.32E-05 & 1.32E-05 & 1.32E-05 & 1.32E-05 & 1.32E-05 & 9.19E-03 & 6.17E-01 & 6.89E-01 & 6.89E-01 & 6.91E-01 & 6.89E-01 & 6.89E-01 & 6.89E-01 \\
\hline 216-B-14 & & & 5.33E-04 & 5.33E-04 & 5.34E-04 & 5.33E-04 & 5.33E-04 & 5.33E-04 & 5.34E-04 & 5.33E-04 & 5.33E-04 & 5.33E-04 & 5.34E-04 & 5.33E-04 & 5.33E-04 & \\
\hline 216-B-15 & 8.07E-04 & 8.05E-04 & 8.05E-04 & 8.05E-04 & 8.07E-04 & 8.05E-04 & 8.05E-04 & 8.05E-04 & 8.07E-04 & 8.05E-04 & 8.05E-04 & 8.05E-04 & 8.07E-04 & 8.05E-04 & 8.05E-04 & T.6ר \\
\hline
\end{tabular}




\begin{tabular}{|c|c|c|c|c|c|c|c|c|c|c|c|c|c|c|c|c|}
\hline & ANNUAL D & ISCHARGE & E VOLUME & $S$ IN M ${ }^{3}$ & & & & & & & & & & & & \\
\hline Site & 1944 & \begin{tabular}{|l|}
1945 \\
\end{tabular} & 1946 & 1947 & 1948 & 1949 & 1950 & 1951 & 1952 & 1953 & 1954 & 1955 & 1956 & 1957 & 1958 & 1959 \\
\hline 216-B-16 & 4.95E-02 & 4.93E-02 & 4.93E-02 & 4.93E-02 & 4.95E-02 & 4.93E-02 & 4.93E-02 & 4.93E-02 & 4.95E-02 & 4.93E-02 & 4.93E-02 & 4.93E-02 & 4.95E-02 & 4.93E-02 & 4.93E-02 & 4.93E-02 \\
\hline 216-B-17 & 93E-03 & 92E-03 & 1.92E-03 & 1.92E-03 & $.93 \mathrm{E}-03$ & 1.92E-03 & 1.92E-03 & 1.92E-03 & 1.93E-03 & 1.92E-03 & 1.92E-03 & 1.92E-03 & 1.93E-03 & $.92 \mathrm{E}-03$ & 1.92E-03 & 1.92E-03 \\
\hline 216-B-18 & & & $3.58 \mathrm{E}-02$ & 58E-02 & $3.59 \mathrm{E}-02$ & $3.58 \mathrm{E}-02$ & $3.58 \mathrm{E}-02$ & $3.58 \mathrm{E}-02$ & 59E-02 & 58E-02 & & $3.58 \mathrm{E}-02$ & $3.59 \mathrm{E}-02$ & $58 \mathrm{E}-02$ & & $58 \mathrm{E}-02$ \\
\hline 216-B-19 & & & & 5E-02 & & & & $3.55 \mathrm{E}-02$ & $3.56 \mathrm{E}-02$ & & & $3.55 \mathrm{E}-02$ & $3.56 \mathrm{E}-02$ & & & $\mathrm{E}-02$ \\
\hline & & & & 52E-03 & & $7.52 \mathrm{E}-03$ & 7.52E-03 & $7.52 \mathrm{E}-03$ & 7.54E-03 & 7.52E-03 & 7.52E-03 & 7.52E-03 & 7.54E-03 & 7.52E-03 & 7.52E-03 & \\
\hline & & & & 64E-03 & $7.66 \mathrm{E}$ & 7.64E-03 & 7.64E-03 & 7.64E-03 & $7.66 \mathrm{E}-03$ & & 7.64E-03 & 7.64E-03 & 7.66E-03 & & 7.64E-03 & 7.64E-03 \\
\hline -B-22 & & & & E-03 & & LE-03 & 9.61E-03 & 1E-03 & 3E-03 & 1E-03 & 9.61E-03 & 9.61E-03 & 9.63E-03 & & 9.61E-03 & \\
\hline -B-23 & & & & 4E-04 & & & & & 6E-04 & & 6.84E-04 & E-04 & $6.86 \mathrm{E}-04$ & & & \\
\hline & & & & 04E-04 & & & & & -04 & & & $=-04$ & $5 \mathrm{E}-04$ & & & \\
\hline $216-B-25$ & E-03 & $2.37 \mathrm{E}-03$ & $2.37 \mathrm{E}-03$ & $2.37 \mathrm{E}-03$ & $2.38 \mathrm{E}-03$ & $2.37 \mathrm{E}-03$ & 2.37E-03 & 7E-03 & $2.38 \mathrm{E}-03$ & 7E-03 & $2.37 \mathrm{E}-03$ & $2.37 \mathrm{E}-03$ & $2.38 \mathrm{E}-03$ & $2.37 \mathrm{E}-03$ & $2.37 \mathrm{E}-03$ & $2.37 \mathrm{E}-03$ \\
\hline $216-B-26$ & $5 \mathrm{E}-04$ & 5.63E-04 & 5.63E-04 & 5.63E-04 & 5.65E-04 & 5.63E-04 & 5.63E-04 & 5.63E-04 & 5.65E-04 & 5.63E-04 & 5.63E-04 & 5.63E-04 & 5.65E-04 & 5.63E-04 & 5.63E-04 & 5.63E-04 \\
\hline 216-B-27 & 58E-05 & 8.56E-05 & 8.56E-05 & 8.56E-05 & 8.58E-05 & 8.56E-05 & 8.56E-05 & 8.56E-05 & 8.58E-05 & 8.56E-05 & 8.56E-05 & 8.56E-05 & 8.58E-05 & 8.56E-05 & 8.56E-05 & 8.56E-05 \\
\hline 216-B-28 & & & & 8.36E-05 & 8.38E-05 & 8.36E-05 & 8.36E-05 & 8.36E-05 & 8.38E-05 & 8.36E-05 & 8.36E-05 & 8.36E-05 & 8.38E-05 & 8.36E-05 & 8.36E-05 & 8.36E-05 \\
\hline B-29 & & & & $1.17 \mathrm{E}-03$ & $1.17 \mathrm{E}-03$ & $1.17 \mathrm{E}-03$ & 1.17E-03 & 1.17E-03 & $1.17 \mathrm{E}-03$ & 1.17E-03 & 1.17E-03 & E-03 & 1.17E-03 & 1.17E-03 & 1.17E-03 & $7 \mathrm{E}-03$ \\
\hline & & & & $3.38 \mathrm{E}-07$ & $3.35 \mathrm{E}+04$ & $1.09 E+06$ & $1.73 \mathrm{E}+06$ & $3.26 \mathrm{E}+06$ & $2.72 \mathrm{E}+06$ & $1.48 \mathrm{E}+06$ & $1.07 \mathrm{E}+06$ & $8.26 \mathrm{E}+05$ & $5.71 \mathrm{E}+06$ & $1.09 \mathrm{E}+07$ & $7.19 \mathrm{E}+06$ & $4.68 E+06$ \\
\hline-30 & & & & -03 & & -03 & -03 & -03 & -03 & -03 & -03 & -03 & $E-03$ & -03 & -03 & E-03 \\
\hline-31 & & & & -03 & -03 & -03 & -03 & -03 & -03 & -03 & $\mathrm{E}-03$ & -03 & E-03 & -03 & E-03 & E-03 \\
\hline-32 & & & & -05 & -05 & -05 & -05 & -05 & -05 & -05 & $=-05$ & -05 & E-05 & -05 & E-05 & E-05 \\
\hline-33 & & & & -04 & -04 & $=-04$ & -04 & -04 & E-04 & E-04 & E-04 & E-04 & $5 \mathrm{E}-04$ & E-04 & E-04 & E-04 \\
\hline B-34 & E-03 & -03 & 1. & E-03 & LE-03 & E-03 & $=-03$ & $=-03$ & 1E-03 & E-03 & $1.50 \mathrm{E}-03$ & E-03 & $1.51 \mathrm{E}-03$ & $1.50 \mathrm{E}-03$ & $1.50 \mathrm{E}-03$ & OE-03 \\
\hline-35 & & 03 & 3.96 & -03 & -03 & E-03 & -03 & -03 & E-03 & $E-03$ & -03 & +00 & $E+02$ & $E+02$ & $E+01$ & $E+01$ \\
\hline & & & & -08 & -08 & -08 & -08 & -08 & -08 & $=-08$ & 1.19E-08 & $E+02$ & $2.54 \mathrm{E}+02$ & $1.31 \mathrm{E}+02$ & $\mathrm{E}+01$ & $5.86 \mathrm{E}+01$ \\
\hline $216-B-37$ & E-03 & $1.08 \mathrm{E}-03$ & 1.08E-03 & $1.08 \mathrm{E}-03$ & 1.09E-03 & $1.08 \mathrm{E}-03$ & 1.08E-03 & 1.08E-03 & 1.09E-03 & $1.08 \mathrm{E}-03$ & $1.69 \mathrm{E}+03$ & $1.34 \mathrm{E}+03$ & $3.06 \mathrm{E}+02$ & $1.65 \mathrm{E}+02$ & $1.05 \mathrm{E}+02$ & $6.91 \mathrm{E}+01$ \\
\hline 216-B-38 & $7 \mathrm{E}-03$ & $2.26 \mathrm{E}-03$ & $2.26 \mathrm{E}-03$ & $2.26 \mathrm{E}-03$ & 2.27E-03 & $2.26 \mathrm{E}-03$ & $2.26 \mathrm{E}-03$ & $2.26 \mathrm{E}-03$ & $2.27 \mathrm{E}-03$ & 6E-03 & $2.26 \mathrm{E}-03$ & $3.25 E+02$ & $2.40 \mathrm{E}+02$ & $1.27 \mathrm{E}+02$ & $8.00 \mathrm{E}+01$ & $6.19 \mathrm{E}+01$ \\
\hline -B-39 & & & & 2.79E-04 & 2.80E-04 & 2.79E-04 & & $=-04$ & E-04 & E-04 & $2.79 \mathrm{E}-04$ & $=+02$ & $E+02$ & $1.27 \mathrm{E}+02$ & $E+01$ & $6.21 E+01$ \\
\hline & & & & $2.34 \mathrm{E}-05$ & -05 & E-05 & & -05 & -05 & -05 & E-05 & $E-05$ & E-05 & $2.34 \mathrm{E}-05$ & $4 \mathrm{E}-05$ & $2.34 \mathrm{E}-05$ \\
\hline & & & & $2.95 \mathrm{E}-06$ & & $2.95 \mathrm{E}-06$ & & $E-06$ & -06 & E-06 & $2.95 \mathrm{E}-06$ & $E+02$ & $E+02$ & $1.27 \mathrm{E}+02$ & $8.10 \mathrm{E}+01$ & $\mathrm{E}+01$ \\
\hline & & & & & & & & & & & -07 & 02 & +02 & +02 & +01 & $E+01$ \\
\hline-42 & & & & -06 & -06 & -06 & -06 & -06 & $E-06$ & -06 & E-06 & 02 & $E+02$ & +02 & $E+01$ & $6.09 E+01$ \\
\hline-43 & & & & E-03 & $E-03$ & $=-03$ & -03 & $E-03$ & $E-03$ & E-03 & E-03 & E-03 & $9 \mathrm{E}+02$ & $E+02$ & $1.76 \mathrm{E}+02$ & $1.27 E+02$ \\
\hline B-44 & & & & $2.77 \mathrm{E}-03$ & $2.78 \mathrm{E}-03$ & $.77 \mathrm{E}-03$ & $.77 \mathrm{E}-03$ & $=-03$ & 8E-03 & E-03 & $2.77 \mathrm{E}-03$ & $E+03$ & $1.55 \mathrm{E}+03$ & $E+02$ & $3.39 \mathrm{E}+02$ & $2.00 \mathrm{E}+02$ \\
\hline B-45 & E-09 & E-09 & 3.95E-09 & 3.95E-09 & 3.96E-09 & 3.95E-09 & 3.95E-09 & 3.95E-09 & 3.96E-09 & $5 E-09$ & 3.95E-09 & 3.95E-09 & $2.31 \mathrm{E}+03$ & $3 \mathrm{E}+02$ & $3.03 \mathrm{E}+02$ & $1.83 \mathrm{E}+02$ \\
\hline 216-B-46 & $5 \mathrm{E}-06$ & 1.24E-06 & 1.24E-06 & 1.24E-06 & $1.25 \mathrm{E}-06$ & $24 \mathrm{E}-06$ & $1.24 \mathrm{E}-06$ & $1.24 \mathrm{E}-06$ & 1.25E-06 & 1.24E-06 & $1.24 \mathrm{E}-06$ & $1.28 \mathrm{E}+03$ & $2.69 \mathrm{E}+03$ & $6.24 \mathrm{E}+02$ & $3.30 \mathrm{E}+02$ & $2.27 \mathrm{E}+02$ \\
\hline $216-B-47$ & 3E-07 & 6.01E-07 & 6.01E-07 & 6.01E-07 & $6.03 \mathrm{E}-07$ & $6.01 \mathrm{E}-07$ & 6.01E-07 & 6.01E-07 & 6.03E-07 & 01E-07 & 6.01E-07 & 6.01E-07 & $1.19 \mathrm{E}+03$ & $5.43 \mathrm{E}+02$ & $2.82 \mathrm{E}+02$ & $1.94 \mathrm{E}+02$ \\
\hline 216-B-48 & 3.75E-08 & $3.74 \mathrm{E}-08$ & 3.74E-08 & 3.74E-08 & $3.75 E-08$ & $3.74 \mathrm{E}-08$ & 3.74E-08 & 3.74E-08 & $3.75 \mathrm{E}-08$ & 3.74E-08 & $3.74 \mathrm{E}-08$ & 3.74E-08 & $1.57 \mathrm{E}+03$ & $5.51 \mathrm{E}+02$ & $2.92 \mathrm{E}+02$ & $1.84 \mathrm{E}+02$ \\
\hline 216-B-49 & $8.29 \mathrm{E}-07$ & 8.26E-07 & 8.26E-07 & $8.26 \mathrm{E}-07$ & $8.29 \mathrm{E}-07$ & $8.26 \mathrm{E}-07$ & $8.26 \mathrm{E}-07$ & $8.26 \mathrm{E}-07$ & 8.29E-07 & $8.26 \mathrm{E}-07$ & $8.26 \mathrm{E}-07$ & $1.27 \mathrm{E}+03$ & $2.70 \mathrm{E}+03$ & $6.49 \mathrm{E}+02$ & $3.25 \mathrm{E}+02$ & $1.93 \mathrm{E}+02$ \\
\hline 216-B-5 & 7.80E-06 & $9.13 E+03$ & $1.37 \mathrm{E}+04$ & $9.16 \mathrm{E}+03$ & $7.86 \mathrm{E}+01$ & $2.80 \mathrm{E}+00$ & $1.29 \mathrm{E}+00$ & 8.13E-01 & 4.84E-01 & 4.07E-01 & 2.42E-01 & 2.42E-01 & 1.84E-01 & 1.10E-01 & 1.10E-01 & 1.10E-01 \\
\hline $216-B-50$ & $3.12 \mathrm{E}-08$ & 3.11E-08 & 3.11E-08 & 3.11E-08 & $3.12 \mathrm{E}-08$ & 3.11E-08 & $3.11 \mathrm{E}-08$ & $3.11 \mathrm{E}-08$ & $3.12 \mathrm{E}-08$ & $3.11 \mathrm{E}-08$ & $3.11 \mathrm{E}-08$ & $3.11 \mathrm{E}-08$ & $3.12 \mathrm{E}-08$ & $3.11 \mathrm{E}-08$ & 3.11E-08 & 3.11E-08 \\
\hline $216-B-51$ & 1.57E-08 & 1.57E-08 & & 1.57E-08 & 1.57E-08 & 1.57E-08 & 1.57E-08 & 1.57E-08 & 1.57E-08 & 1.57E-08 & 1.57E-08 & 1.57E-08 & 1.57E-08 & 1.57E-08 & 1.57E-08 & 1.57E-08 \\
\hline 216-B-52 & 9.12E-05 & $9.10 \mathrm{E}-05$ & $9.10 \mathrm{E}-05$ & 9.10E-05 & 9.12E-05 & $9.10 \mathrm{E}-05$ & $9.10 \mathrm{E}-05$ & 9.10E-05 & 9.12E-05 & $9.10 \mathrm{E}-05$ & $9.10 \mathrm{E}-05$ & $9.10 \mathrm{E}-05$ & 9.12E-05 & $9.10 \mathrm{E}-05$ & $9.10 \mathrm{E}-05$ & 9.10E-05 \\
\hline 216-B-53A & 3.75E-05 & 3.74E-05 & 3.74E-05 & 3.74E-05 & 3.75E-05 & 3.74E-05 & 3.74E-05 & 3.74E-05 & 3.75E-05 & 3.74E-05 & 3.74E-05 & 3.74E-05 & 3.75E-05 & 3.74E-05 & 3.74E-05 & 3.74E-05 \\
\hline
\end{tabular}




\section{ANNUAL DISCHARGE VOLUMES IN $\mathrm{M}^{3}$}

\begin{tabular}{|l|r|r|r|r|r|r|r|r|r|r|r|r|r|r|r|r|}
\hline 1944 & 1945 & 1946 & 1947 & 1948 & 1949 & 1950 & 1951 & 1952 & 1953 & 1954 & 1955 & 1956 & 1957 & 1958 & 1959 \\
\hline
\end{tabular} \begin{tabular}{|l|r|r|r|r|r|r|r|r|r|r|r|r|r|r|r|r|r|r|r|}
\hline $3.31 \mathrm{E}-04$ & $3.30 \mathrm{E}-04$ & $3.30 \mathrm{E}-04$ & $3.30 \mathrm{E}-04$ & $3.31 \mathrm{E}-04$ & $3.30 \mathrm{E}-04$ & $3.30 \mathrm{E}-04$ & $3.30 \mathrm{E}-04$ & $3.31 \mathrm{E}-04$ & $3.30 \mathrm{E}-04$ & $3.30 \mathrm{E}-04$ & $3.30 \mathrm{E}-04$ & $3.31 \mathrm{E}-04$ & $3.30 \mathrm{E}-04$ & $3.30 \mathrm{E}-04$ & $3.30 \mathrm{E}-04$ \\
\hline $4.62 \mathrm{E}-04$ & $4.61 \mathrm{E}-04$ & $4.61 \mathrm{E}-04$ & $4.61 \mathrm{E}-04$ & $4.62 \mathrm{E}-04$ & $4.61 \mathrm{E}-04$ & $4.61 \mathrm{E}-04$ & $4.61 \mathrm{E}-04$ & $4.62 \mathrm{E}-04$ & $4.61 \mathrm{E}-04$ & $4.61 \mathrm{E}-04$ & $4.61 \mathrm{E}-04$ & $4.62 \mathrm{E}-04$ & $4.61 \mathrm{E}-04$ & $4.61 \mathrm{E}-04$ & $4.61 \mathrm{E}-04$ \\
\hline
\end{tabular} \begin{tabular}{|c|c|c|c|c|c|c|c|c|c|c|c|c|c|c|c|c|c|c|c|}
$4.62 \mathrm{E}-04$ & $4.61 \mathrm{E}-04$ & $4.61 \mathrm{E}-04$ & $4.61 \mathrm{E}-04$ & $4.62 \mathrm{E}-04$ & $4.61 \mathrm{E}-04$ & $4.61 \mathrm{E}-04$ & $4.61 \mathrm{E}-04$ & $4.62 \mathrm{E}-04$ & $4.61 \mathrm{E}-04$ & $4.61 \mathrm{E}-04$ & $4.61 \mathrm{E}-04$ & $4.62 \mathrm{E}-04$ & $4.61 \mathrm{E}-04$ & $4.61 \mathrm{E}-04$ & $4.61 \mathrm{E}-04$ \\
\hline $1.61 \mathrm{E}-07$ & $1.60 \mathrm{E}-07$ & $1.60 \mathrm{E}-07$ & $1.60 \mathrm{E}-07$ & $1.61 \mathrm{E}-07$ & $1.60 \mathrm{E}-07$ & $1.60 \mathrm{E}-07$ & $1.60 \mathrm{E}-07$ & $1.61 \mathrm{E}-07$ & $1.60 \mathrm{E}-07$ & $1.60 \mathrm{E}-07$ & $1.60 \mathrm{E}-07$ & $1.61 \mathrm{E}-07$ & $1.60 \mathrm{E}-07$ & $1.60 \mathrm{E}-07$ & $1.60 \mathrm{E}-07$ \\
\hline
\end{tabular} \begin{tabular}{|l|l|l|l|l|l|l|l|l|l|l|l|l|l|l|l|l|l|l|l|l|l|}
$1.61 \mathrm{E}-07$ & $1.60 \mathrm{E}-07$ & $1.60 \mathrm{E}-07$ & $1.60 \mathrm{E}-07$ & $1.61 \mathrm{E}-07$ & $1.60 \mathrm{E}-07$ & $1.60 \mathrm{E}-07$ & $1.60 \mathrm{E}-07$ & $1.61 \mathrm{E}-07$ & $1.60 \mathrm{E}-07$ & $1.60 \mathrm{E}-07$ & $1.60 \mathrm{E}-07$ & $1.61 \mathrm{E}-07$ & $1.60 \mathrm{E}-07$ & $1.60 \mathrm{E}-07$ & $1.60 \mathrm{E}-07$ \\
\hline $1.16 \mathrm{E}-05$ & $1.15 \mathrm{E}-05$ & $1.15 \mathrm{E}-05$ & $1.15 \mathrm{E}-05$ & $1.16 \mathrm{E}-05$ & $1.15 \mathrm{E}-05$ & $1.15 \mathrm{E}-05$ & $1.15 \mathrm{E}-05$ & $1.16 \mathrm{E}-05$ & $1.15 \mathrm{E}-05$ & $1.15 \mathrm{E}-05$ & $1.15 \mathrm{E}-05$ & $1.16 \mathrm{E}-05$ & $1.15 \mathrm{E}-05$ & $1.15 \mathrm{E}-05$ & $1.15 \mathrm{E}-05$ \\
\hline
\end{tabular}

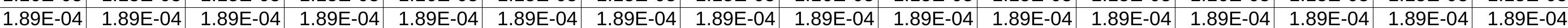

$216-B-58$

(16-B-59 \begin{tabular}{|l|l|l|l|l|l|l|l|l|l|l|l|l|l|l|l|}
$9.48 \mathrm{E}-07$ & $9.45 \mathrm{E}-07$ & $9.45 \mathrm{E}-07$ & $9.45 \mathrm{E}-07$ & $9.48 \mathrm{E}-07$ & $9.45 \mathrm{E}-07$ & $9.45 \mathrm{E}-07$ & $9.45 \mathrm{E}-07$ & $9.48 \mathrm{E}-07$ & $9.45 \mathrm{E}-07$ & $9.45 \mathrm{E}-07$ & $9.45 \mathrm{E}-07$ & $9.48 \mathrm{E}-07$ & $9.45 \mathrm{E}-07$ & $9.45 \mathrm{E}-07$ & $9.45 \mathrm{E}-07$ \\
\hline
\end{tabular} \begin{tabular}{|r|r|r|r|r|r|r|r|r|r|r|r|r|r|r|r|r|r|r|r|}
\hline $4.20 \mathrm{E}-03$ & $1.89 \mathrm{E}+02$ & $1.21 \mathrm{E}+03$ & $1.29 \mathrm{E}+03$ & $1.29 \mathrm{E}+03$ & $1.29 \mathrm{E}+03$ & $3.21 \mathrm{E}+02$ & $1.18 \mathrm{E}+02$ & $5.21 \mathrm{E}+01$ & $4.50 \mathrm{E}+01$ & $2.07 \mathrm{E}+01$ & $2.07 \mathrm{E}+01$ & $1.81 \mathrm{E}+01$ & $1.00 \mathrm{E}+01$ & $1.00 \mathrm{E}+01$ & $1.00 \mathrm{E}+01$ \\
\hline $1.12 \mathrm{E}-07$ & $1.11 \mathrm{E}-07$ & $1.11 \mathrm{E}-07$ & $1.11 \mathrm{E}-07$ & $1.12 \mathrm{E}-07$ & $1.11 \mathrm{E}-07$ & $1.11 \mathrm{E}-07$ & $1.11 \mathrm{E}-07$ & $1.12 \mathrm{E}-07$ & $1.11 \mathrm{E}-07$ & $1.11 \mathrm{E}-07$ & $1.11 \mathrm{E}-07$ & $1.12 \mathrm{E}-07$ & $1.11 \mathrm{E}-07$ & $1.11 \mathrm{E}-07$ & $1.11 \mathrm{E}-07$ \\
\hline
\end{tabular}

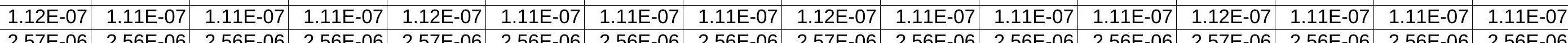

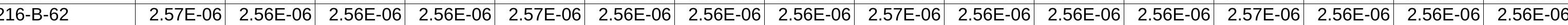
\begin{tabular}{l|l|l|l|l|l|l|l|l|l|l|l|l|l|l|l|l|l|l}
$1.89 \mathrm{E}-03$ & $1.89 \mathrm{E}-03$ & $1.89 \mathrm{E}-03$ & $1.89 \mathrm{E}-03$ & $1.89 \mathrm{E}-03$ & $1.89 \mathrm{E}-03$ & $1.89 \mathrm{E}-03$ & $1.89 \mathrm{E}-03$ & $1.89 \mathrm{E}-03$ & $1.89 \mathrm{E}-03$ & $1.89 \mathrm{E}-03$ & $1.89 \mathrm{E}-03$ & $1.89 \mathrm{E}-03$ & $1.89 \mathrm{E}-03$ & $1.89 \mathrm{E}-03$ & $1.89 \mathrm{E}-03$ \\
\hline
\end{tabular} $216-\mathrm{B}-7 \mathrm{~A} \% \mathrm{~B}$ 216-B-8

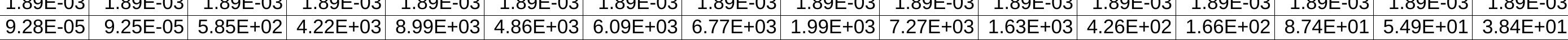

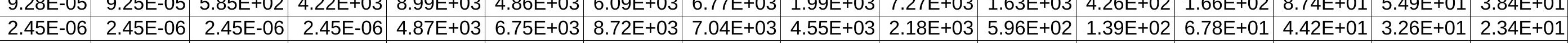
\begin{tabular}{|r|r|r|r|r|r|r|r|r|r|r|r|r|r|r|r|r|r|}
$2.47 \mathrm{E}-03$ & $2.47 \mathrm{E}-03$ & $2.47 \mathrm{E}-03$ & $2.47 \mathrm{E}-03$ & $2.47 \mathrm{E}-03$ & $2.31 \mathrm{E}+03$ & $1.20 \mathrm{E}+04$ & $8.71 \mathrm{E}+03$ & $3.87 \mathrm{E}+03$ & $1.99 \mathrm{E}+03$ & $1.02 \mathrm{E}+03$ & $7.94 \mathrm{E}+02$ & $5.09 \mathrm{E}+02$ & $5.07 \mathrm{E}+02$ & $2.83 \mathrm{E}+02$ & $2.63 \mathrm{E}+02$ \\
\hline
\end{tabular} 216-B-9 \begin{tabular}{|l|l|l|l|l|l|l|l|l|l|l|l|l|l|l|l|l}
$1.26 \mathrm{E}-09$ & $1.26 \mathrm{E}-09$ & $1.26 \mathrm{E}-09$ & $1.26 \mathrm{E}-09$ & $1.26 \mathrm{E}-09$ & $1.26 \mathrm{E}-09$ & $1.26 \mathrm{E}-09$ & $1.26 \mathrm{E}-09$ & $1.26 \mathrm{E}-09$ & $1.26 \mathrm{E}-09$ & $1.26 \mathrm{E}-09$ & $2.84 \mathrm{E}+01$ & $7.17 \mathrm{E}+00$ & $1.61 \mathrm{E}+00$ & $7.68 \mathrm{E}-01$ & $5.22 \mathrm{E}-01$ \\
\hline
\end{tabular} 216-BY-201

216-C-1 \begin{tabular}{|l|l|l|l|l|l|l|l|l|l|l|l|l|l|l|l|l|l|l|l}
$1.10 \mathrm{E}-04$ & $1.10 \mathrm{E}-04$ & $1.10 \mathrm{E}-04$ & $1.10 \mathrm{E}-04$ & $1.10 \mathrm{E}-04$ & $1.10 \mathrm{E}-04$ & $1.10 \mathrm{E}-04$ & $1.10 \mathrm{E}-04$ & $1.10 \mathrm{E}-04$ & $6.95 \mathrm{E}+03$ & $4.55 \mathrm{E}+03$ & $5.40 \mathrm{E}+03$ & $4.06 \mathrm{E}+03$ & $1.17 \mathrm{E}+03$ & $2.95 \mathrm{E}+02$ & $1.45 \mathrm{E}+02$ \\
\hline
\end{tabular} $216-\mathrm{C}-10$ $216-\mathrm{C}-2$ 216-C-3

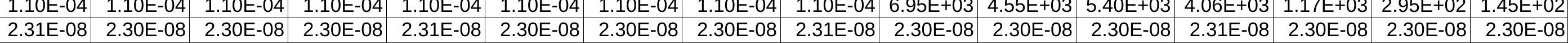
\begin{tabular}{|l|l|l|l|l|l|l|l|l|l|l|l|l|l|l|l|l|l|l|l|l|l|}
\hline $2.31 \mathrm{E}-08$ & $2.30 \mathrm{E}-08$ & $2.30 \mathrm{E}-08$ & $2.30 \mathrm{E}-08$ & $2.31 \mathrm{E}-08$ & $2.30 \mathrm{E}-08$ & $2.30 \mathrm{E}-08$ & $2.30 \mathrm{E}-08$ & $2.31 \mathrm{E}-08$ & $2.30 \mathrm{E}-08$ & $2.30 \mathrm{E}-08$ & $2.30 \mathrm{E}-08$ & $2.31 \mathrm{E}-08$ & $2.30 \mathrm{E}-08$ & $2.30 \mathrm{E}-08$ & $2.30 \mathrm{E}-08$ \\
\hline $8.49 \mathrm{E}-05$ & $8.46 \mathrm{E}-05$ & $8.46 \mathrm{E}-05$ & $8.46 \mathrm{E}-05$ & $8.49 \mathrm{E}-05$ & $8.46 \mathrm{E}-05$ & $8.46 \mathrm{E}-05$ & $8.46 \mathrm{E}-05$ & $8.49 \mathrm{E}-05$ & $8.46 \mathrm{E}-05$ & $8.46 \mathrm{E}-05$ & $8.46 \mathrm{E}-05$ & $8.49 \mathrm{E}-05$ & $8.46 \mathrm{E}-05$ & $8.46 \mathrm{E}-05$ & $8.46 \mathrm{E}-05$ \\
\hline
\end{tabular} (16-C-4

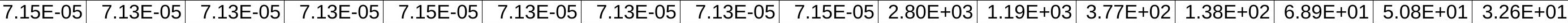

$216-\mathrm{C}-4$

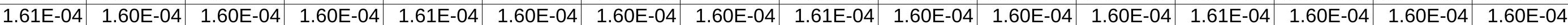
$216-\mathrm{C}-6$ \begin{tabular}{|l|l|l|l|l|l|l|l|l|l|l|l|l|l|l|l|}
$1.61 \mathrm{E}-04$ & $1.60 \mathrm{E}-04$ & $1.60 \mathrm{E}-04$ & $1.60 \mathrm{E}-04$ & $1.61 \mathrm{E}-04$ & $1.60 \mathrm{E}-04$ & $1.60 \mathrm{E}-04$ & $1.60 \mathrm{E}-04$ & $1.61 \mathrm{E}-04$ & $1.60 \mathrm{E}-04$ & $1.60 \mathrm{E}-04$ & $1.60 \mathrm{E}-04$ & $1.61 \mathrm{E}-04$ & $1.60 \mathrm{E}-04$ & $1.60 \mathrm{E}-04$ & $1.60 \mathrm{E}-04$ \\
\hline $6.59 \mathrm{E}-07$ & $6.57 \mathrm{E}-07$ & $6.57 \mathrm{E}-07$ & $6.57 \mathrm{E}-07$ & $6.59 \mathrm{E}-07$ & $6.57 \mathrm{E}-07$ & $6.57 \mathrm{E}-07$ & $6.57 \mathrm{E}-07$ & $6.59 \mathrm{E}-07$ & $6.57 \mathrm{E}-07$ & $6.57 \mathrm{E}-07$ & $6.57 \mathrm{E}-07$ & $6.59 \mathrm{E}-07$ & $6.57 \mathrm{E}-07$ & $6.57 \mathrm{E}-07$ & $6.57 \mathrm{E}-07$ \\
\hline
\end{tabular} 216-C-8 \begin{tabular}{|c|c|c|c|c|c|c|c|c|c|c|c|c|c|c|c|c|c|c|c|c|c|}
\hline $6.59 \mathrm{E}-07$ & $6.57 \mathrm{E}-07$ & $6.57 \mathrm{E}-07$ & $6.57 \mathrm{E}-07$ & $6.59 \mathrm{E}-07$ & $6.57 \mathrm{E}-07$ & $6.57 \mathrm{E}-07$ & $6.57 \mathrm{E}-07$ & $6.59 \mathrm{E}-07$ & $6.57 \mathrm{E}-07$ & $6.57 \mathrm{E}-07$ & $6.57 \mathrm{E}-07$ & $6.59 \mathrm{E}-07$ & $6.57 \mathrm{E}-07$ & $6.57 \mathrm{E}-07$ & $6.57 \mathrm{E}-07$ \\
\hline $1.87 \mathrm{E}-04$ & $1.87 \mathrm{E}-04$ & $1.87 \mathrm{E}-04$ & $1.87 \mathrm{E}-04$ & $1.87 \mathrm{E}-04$ & $1.87 \mathrm{E}-04$ & $1.87 \mathrm{E}-04$ & $1.87 \mathrm{E}-04$ & $1.87 \mathrm{E}-04$ & $1.87 \mathrm{E}-04$ & $1.87 \mathrm{E}-04$ & $1.87 \mathrm{E}-04$ & $1.87 \mathrm{E}-04$ & $1.87 \mathrm{E}-04$ & $1.87 \mathrm{E}-04$ & $1.87 \mathrm{E}-04$ \\
\hline
\end{tabular} $216-\mathrm{C}-9$

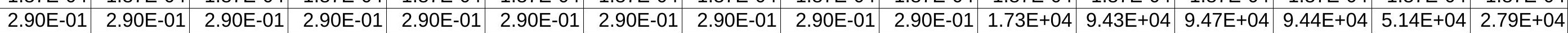
$216-\mathrm{N}-2$ \begin{tabular}{llll|l|l|l|l|l|l|l|l|l|l|l|l|l|l}
$1.37 \mathrm{E}-09$ & $1.36 \mathrm{E}-09$ & $1.36 \mathrm{E}-09$ & $5.78 \mathrm{E}+03$ & $1.16 \mathrm{E}+03$ & $2.57 \mathrm{E}+02$ & $1.16 \mathrm{E}+02$ & $7.71 \mathrm{E}+01$ & $6.23 \mathrm{E}+01$ & $4.02 \mathrm{E}+01$ & $3.52 \mathrm{E}+01$ & $3.52 \mathrm{E}+01$ & $2.11 \mathrm{E}+01$ & $2.06 \mathrm{E}+01$ & $2.06 \mathrm{E}+01$ & $2.06 \mathrm{E}+01$ \\
\hline
\end{tabular} \begin{tabular}{l|l|l|l|l|l|l|l|l|l|l|l|l|l|l|l|l|l}
$1.52 \mathrm{E}-05$ & $1.51 \mathrm{E}-05$ & $1.51 \mathrm{E}-05$ & $1.51 \mathrm{E}-05$ & $152 \mathrm{E}-05$ & $151 \mathrm{E}-05$ & $151 \mathrm{E}-05$ & $151 \mathrm{E}-05$ & $5.51 \mathrm{E}+03$ & $1.18 \mathrm{E}+03$ & $1.98 \mathrm{E}+02$ & $1.03 \mathrm{E}+02$ & $6.74 \mathrm{E}+01$ & $5.28 \mathrm{E}+01$ & $3.52 \mathrm{E}+01$ & $3.16 \mathrm{E}+01$ \\
\hline
\end{tabular} $216-\mathrm{N}-4$ $216-\mathrm{N}-5$

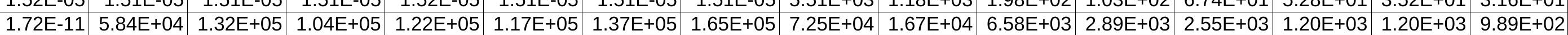
$216-\mathrm{N}-6$ \begin{tabular}{r|r|r|r|r|r|r|r|r|r|r|r|r|r|r|r|r|r|r|r|r|r|}
$1.72 \mathrm{E}-11$ & $5.84 \mathrm{E}+04$ & $1.32 \mathrm{E}+05$ & $1.04 \mathrm{E}+05$ & $1.22 \mathrm{E}+05$ & $1.17 \mathrm{E}+05$ & $1.37 \mathrm{E}+05$ & $1.65 \mathrm{E}+05$ & $7.25 \mathrm{E}+04$ & $1.67 \mathrm{E}+04$ & $6.58 \mathrm{E}+03$ & $2.89 \mathrm{E}+03$ & $2.55 \mathrm{E}+03$ & $1.20 \mathrm{E}+03$ & $1.20 \mathrm{E}+03$ & $9.89 \mathrm{E}+02$ \\
\hline $1.51 \mathrm{E}-05$ & $1.51 \mathrm{E}-05$ & $1.51 \mathrm{E}-05$ & $1.51 \mathrm{E}-05$ & $1.51 \mathrm{E}-05$ & $1.51 \mathrm{E}-05$ & $1.51 \mathrm{E}-05$ & $1.51 \mathrm{E}-05$ & $5.51 \mathrm{E}+03$ & $1.18 \mathrm{E}+03$ & $1.98 \mathrm{E}+02$ & $1.03 \mathrm{E}+02$ & $6.74 \mathrm{E}+01$ & $5.28 \mathrm{E}+01$ & $3.52 \mathrm{E}+01$ & $3.16 \mathrm{E}+01$ \\
\hline
\end{tabular} $216-\mathrm{N}-7$ \begin{tabular}{ll|l|l|l|l|l|l|l|l|l|l|l|l|l|l|l|l}
$1.46 \mathrm{E}-11$ & $6.33 \mathrm{E}+04$ & $1.33 \mathrm{E}+05$ & $1.04 \mathrm{E}+05$ & $1.22 \mathrm{E}+05$ & $1.17 \mathrm{E}+05$ & $1.37 \mathrm{E}+05$ & $1.65 \mathrm{E}+05$ & $7.12 \mathrm{E}+04$ & $1.51 \mathrm{E}+04$ & $5.77 \mathrm{E}+03$ & $2.50 \mathrm{E}+03$ & $2.20 \mathrm{E}+03$ & $1.03 \mathrm{E}+03$ & $1.03 \mathrm{E}+03$ & $8.49 \mathrm{E}+02$ \\
\hline
\end{tabular} $216-\mathrm{S}-1 \% 2$ \begin{tabular}{lllll|l|l|l|l|l|l|l|l|l|l|l|l|l|l}
$1.52 \mathrm{E}-05$ & $1.52 \mathrm{E}-05$ & $1.52 \mathrm{E}-05$ & $1.52 \mathrm{E}-05$ & $1.52 \mathrm{E}-05$ & $1.52 \mathrm{E}-05$ & $1.52 \mathrm{E}-05$ & $1.52 \mathrm{E}-05$ & $5.51 \mathrm{E}+03$ & $1.18 \mathrm{E}+03$ & $1.98 \mathrm{E}+02$ & $1.03 \mathrm{E}+02$ & $6.74 \mathrm{E}+01$ & $5.28 \mathrm{E}+01$ & $3.52 \mathrm{E}+01$ & $3.16 \mathrm{E}+01$ \\
\hline
\end{tabular} $216-\mathrm{S}-10 \mathrm{P}$ $216-\mathrm{S}-12$

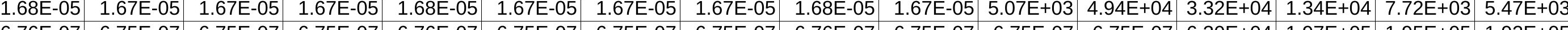
$216-\mathrm{S}-13$ \begin{tabular}{|r|r|r|r|r|r|r|r|r|r|r|r|r|r|r|r|r|}
\hline $6.76 \mathrm{E}-07$ & $6.75 \mathrm{E}-07$ & $6.75 \mathrm{E}-07$ & $6.75 \mathrm{E}-07$ & $6.76 \mathrm{E}-07$ & $6.75 \mathrm{E}-07$ & $6.75 \mathrm{E}-07$ & $6.75 \mathrm{E}-07$ & $6.76 \mathrm{E}-07$ & $6.75 \mathrm{E}-07$ & $6.75 \mathrm{E}-07$ & $6.75 \mathrm{E}-07$ & $6.30 \mathrm{E}+04$ & $1.97 \mathrm{E}+05$ & $1.95 \mathrm{E}+05$ & $1.92 \mathrm{E}+05$ \\
\hline $7.64 \mathrm{E}-07$ & $7.61 \mathrm{E}-07$ & $7.61 \mathrm{E}-07$ & $7.61 \mathrm{E}-07$ & $7.64 \mathrm{E}-07$ & $7.61 \mathrm{E}-07$ & $7.61 \mathrm{E}-07$ & $7.61 \mathrm{E}-07$ & $7.64 \mathrm{E}-07$ & $7.61 \mathrm{E}-07$ & $7.61 \mathrm{E}-07$ & $7.61 \mathrm{E}-07$ & $7.64 \mathrm{E}-07$ & $7.61 \mathrm{E}-07$ & $7.61 \mathrm{E}-07$ & $7.61 \mathrm{E}-07$ \\
\hline
\end{tabular} $216-\mathrm{S}-15$ \begin{tabular}{llllllll|l|l|l|l|l|l|l|l|l|l|l}
$5.38 \mathrm{E}-06$ & $5.37 \mathrm{E}-06$ & $5.37 \mathrm{E}-06$ & $5.37 \mathrm{E}-06$ & $5.38 \mathrm{E}-06$ & $5.37 \mathrm{E}-06$ & $5.37 \mathrm{E}-06$ & $5.37 \mathrm{E}-06$ & $5.38 \mathrm{E}-06$ & $9.37 \mathrm{E}+01$ & $7.08 \mathrm{E}+02$ & $6.23 \mathrm{E}+02$ & $4.09 \mathrm{E}+02$ & $2.82 \mathrm{E}+02$ & $1.69 \mathrm{E}+02$ & $1.19 \mathrm{E}+02$ \\
\hline
\end{tabular}

$216-\mathrm{S}-15$ $216-\mathrm{S}-16$ 216-S-17 \begin{tabular}{|l|l|l|l|l|l|l|l|l|l|l|l|l|l|l|l|l|l|l|}
$3.37 \mathrm{E}-07$ & $3.36 \mathrm{E}-07$ & $3.36 \mathrm{E}-07$ & $3.36 \mathrm{E}-07$ & $3.37 \mathrm{E}-07$ & $3.36 \mathrm{E}-07$ & $3.36 \mathrm{E}-07$ & $3.36 \mathrm{E}-07$ & $3.37 \mathrm{E}-07$ & $3.36 \mathrm{E}-07$ & $3.36 \mathrm{E}-07$ & $3.36 \mathrm{E}-07$ & $3.37 \mathrm{E}-07$ & $3.36 \mathrm{E}-07$ & $3.36 \mathrm{E}-07$ & $3.36 \mathrm{E}-07$ \\
\hline
\end{tabular} $216-\mathrm{S}-19$ \begin{tabular}{r|r|r|r|r|r|r|r|r|r|r|r|r|r|r|r|r|r|r|r|r|r|r|}
\hline $2.34 \mathrm{E}-01$ & $2.33 \mathrm{E}-01$ & $2.33 \mathrm{E}-01$ & $2.33 \mathrm{E}-01$ & $2.34 \mathrm{E}-01$ & $2.33 \mathrm{E}-01$ & $2.33 \mathrm{E}-01$ & $2.33 \mathrm{E}-01$ & $2.34 \mathrm{E}-01$ & $2.33 \mathrm{E}-01$ & $1.07 \mathrm{E}+06$ & $9.63 \mathrm{E}+05$ & $6.03 \mathrm{E}+05$ & $4.07 \mathrm{E}+05$ & $3.12 \mathrm{E}+05$ & $2.61 \mathrm{E}+05$ \\
\hline $1.73 \mathrm{E}-07$ & $1.72 \mathrm{E}-07$ & $1.72 \mathrm{E}-07$ & $1.72 \mathrm{E}-07$ & $1.73 \mathrm{E}-07$ & $1.72 \mathrm{E}-07$ & $1.72 \mathrm{E}-07$ & $1.72 \mathrm{E}-07$ & $1.73 \mathrm{E}-07$ & $1.72 \mathrm{E}-07$ & $1.72 \mathrm{E}-07$ & $1.72 \mathrm{E}-07$ & $1.73 \mathrm{E}-07$ & $1.72 \mathrm{E}-07$ & $1.72 \mathrm{E}-07$ & $1.72 \mathrm{E}-07$ \\
\hline $2.40 \mathrm{E}-03$ & $2.39 \mathrm{E}-03$ & $2.39 \mathrm{E}-03$ & $2.39 \mathrm{E}-03$ & $2.40 \mathrm{E}-03$ & $2.39 \mathrm{E}-03$ & $2.39 \mathrm{E}-03$ & $2.39 \mathrm{E}-03$ & $2.40 \mathrm{E}-03$ & $2.39 \mathrm{E}-03$ & $2.39 \mathrm{E}-03$ & $2.39 \mathrm{E}-03$ & $2.40 \mathrm{E}-03$ & $5.22 \mathrm{E}+03$ & $8.40 \mathrm{E}+03$ & $6.83 \mathrm{E}+03$ \\
\hline
\end{tabular}

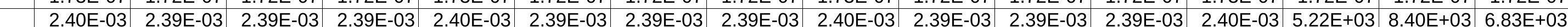




\section{ANNUAL DISCHARGE VOLUMES IN $\mathrm{M}^{3}$}

\begin{tabular}{|c|c|c|c|c|c|c|c|c|c|c|c|c|c|c|c|c|}
\hline & NNUA & SHAR & |ll & IN $\mathrm{M}^{3}$ & & & & & & & & & & & & \\
\hline Site & 1944 & 1945 & 1946 & 1947 & 1948 & 1949 & 1950 & 1951 & 1952 & 1953 & 1954 & 1955 & 1956 & 1957 & 1958 & 1959 \\
\hline j-S-26 & 08E-08 & 07E-08 & 07E-08 & .07E-08 & 4.08E-08 & 4.07E-08 & $4.07 \mathrm{E}-08$ & 4.07E-08 & 4.08E-08 & 4.07E-08 & 4.07E-08 & 4.07E-08 & $4.08 \mathrm{E}-08$ & 4.07E-08 & 4.07E-08 & 4.07E-08 \\
\hline $6-S-3$ & $34 \mathrm{E}-06$ & $33 \mathrm{E}-06$ & $6.33 \mathrm{E}-06$ & 6.33E-06 & 6.34E-06 & $33 \mathrm{E}-06$ & $33 \mathrm{E}-06$ & $33 \mathrm{E}-06$ & $34 \mathrm{E}-06$ & 6.33E-06 & $6.33 \mathrm{E}-06$ & $9.47 \mathrm{E}+01$ & $7.49 \mathrm{E}+02$ & $4.78 \mathrm{E}+02$ & $3.42 E+02$ & $2.53 \mathrm{E}+02$ \\
\hline 16-S-4 & $0 \mathrm{E}-10$ & $49 \mathrm{E}-10$ & 49E-10 & $1.49 \mathrm{E}-10$ & $50 \mathrm{E}-10$ & $49 \mathrm{E}-10$ & $49 \mathrm{E}-10$ & $49 E-10$ & $50 \mathrm{E}-10$ & $49 \mathrm{E}-10$ & $49 \mathrm{E}-10$ & $73 E+01$ & $2.64 \mathrm{E}+02$ & $1.56 \mathrm{E}+02$ & $8.20 E+01$ & $47 \mathrm{E}+01$ \\
\hline $6-S-5$ & $2 \mathrm{E}-02$ & $9.60 \mathrm{E}-02$ & $9.60 \mathrm{E}-02$ & $9.60 \mathrm{E}-02$ & $9.62 \mathrm{E}-02$ & $60 \mathrm{E}-02$ & $60 \mathrm{E}-02$ & $60 \mathrm{E}-02$ & $62 \mathrm{E}-02$ & $9.60 \mathrm{E}-02$ & $9.60 \mathrm{E}-02$ & $9.60 \mathrm{E}-02$ & $2.00 \mathrm{E}+04$ & $7.17 \mathrm{E}+05$ & $5.21 \mathrm{E}+05$ & $5 \mathrm{E}+05$ \\
\hline $6-S-6$ & 16E-04 & $3.15 \mathrm{E}-04$ & $3.15 \mathrm{E}-04$ & $3.15 \mathrm{E}-04$ & $3.16 \mathrm{E}-04$ & $3.15 \mathrm{E}-04$ & $5 \mathrm{E}-04$ & 15E-04 & 16E-04 & $5 \mathrm{E}-04$ & $5 \mathrm{E}-04$ & $5 \mathrm{E}-04$ & $1.37 \mathrm{E}+05$ & $5.98 \mathrm{E}+05$ & $2.97 \mathrm{E}+05$ & $9 \mathrm{E}+05$ \\
\hline b-S-7 & 01E-05 & 3.00E-05 & $3.00 \mathrm{E}-05$ & 3.00E-05 & $3.01 \mathrm{E}-05$ & $3.00 \mathrm{E}-05$ & 00E-05 & 3.00E-05 & E-05 & OE-05 & OE-05 & 3.00E-05 & 3.01E-05 & $3.00 \mathrm{E}-05$ & $3.70 \mathrm{E}+04$ & $4.39 E+04$ \\
\hline $16-S-9$ & 96E-05 & 2.96E-05 & $2.96 \mathrm{E}-05$ & 2.96E-05 & $2.96 \mathrm{E}-05$ & 2.96E-05 & 96E-05 & 2.96E-05 & 2.96E-05 & $6 \mathrm{E}-05$ & 2.96E-05 & 2.96E-05 & $2.96 \mathrm{E}-05$ & 2.96E-05 & $2.96 \mathrm{E}-05$ & $2.96 \mathrm{E}-05$ \\
\hline $16-S X-2$ & 1.67E-07 & 1.66E-07 & 1.66E-07 & 1.66E-07 & 1.67E-07 & 1.66E-07 & $1.66 \mathrm{E}-07$ & 1.66E-07 & 1.67E-07 & 5.24E-07 & $5.03 E+03$ & $5.91 \mathrm{E}+03$ & $5.93 \mathrm{E}+03$ & $5.92 \mathrm{E}+03$ & $5.92 \mathrm{E}+03$ & $91 \mathrm{E}+03$ \\
\hline $6-\mathrm{T}-1$ & 3.99E-12 & $3.98 \mathrm{E}-12$ & 7.61E-09 & 2.82E-06 & $6.45 \mathrm{E}-05$ & 7.37E-04 & 91E-03 & $3.72 \mathrm{E}-02$ & 2.07E-01 & $1.03 \mathrm{E}+00$ & $4.87 \mathrm{E}+00$ & $2.13 \mathrm{E}+01$ & $7.79 \mathrm{E}+01$ & $1.89 \mathrm{E}+02$ & $2.97 \mathrm{E}+02$ & $3.52 \mathrm{E}+02$ \\
\hline 216-T-12 & $27 E-08$ & $2.26 \mathrm{E}-08$ & 2.26E-08 & $2.26 \mathrm{E}-08$ & $2.27 \mathrm{E}-08$ & $2.26 \mathrm{E}-08$ & 6E-08 & 2.26E-08 & 2.27E-08 & 2.26E-08 & $1.12 \mathrm{E}+03$ & $1.74 \mathrm{E}+03$ & $39 \mathrm{E}+02$ & $2.40 E+02$ & $1.70 E+02$ & $9 \mathrm{E}+02$ \\
\hline-14 & 09E-05 & 6.07E-05 & 6.07E-05 & 6.07E-05 & E-05 & 6.07E-05 & E-05 & 6.07E-05 & E-05 & 6.07E-05 & E-05 & 6.07E-05 & E-05 & 7.02E-01 & $1.27 \mathrm{E}+01$ & $0 \mathrm{E}+01$ \\
\hline T-15 & $8.46 \mathrm{E}-05$ & 8.43E-05 & 8.43E-05 & 8.43E-05 & E-05 & E-05 & E-05 & E-05 & E-05 & E-05 & E-05 & E-05 & E-04 & $2.97 \mathrm{E}+00$ & $1.56 \mathrm{E}+01$ & $3 \mathrm{E}+01$ \\
\hline-16 & $2.74 \mathrm{E}-05$ & 2.74E-05 & $2.74 \mathrm{E}-05$ & 2.74E-05 & E-05 & 2.74E-05 & E-05 & E-05 & E-05 & $4 \mathrm{E}-05$ & E-05 & 2.74E-05 & E-04 & $2.09 E+00$ & $1.00 \mathrm{E}+01$ & $9 \mathrm{E}+01$ \\
\hline-17 & $6.28 \mathrm{E}-09$ & $6.26 \mathrm{E}-09$ & $6.26 \mathrm{E}-09$ & $6.26 \mathrm{E}-09$ & $6.28 \mathrm{E}-09$ & $6.26 \mathrm{E}-09$ & $6 \mathrm{E}-09$ & 6.26E-09 & $6.28 \mathrm{E}-09$ & $6.26 \mathrm{E}-09$ & $6.26 \mathrm{E}-09$ & $6.26 \mathrm{E}-09$ & $6.28 \mathrm{E}-09$ & $1.38 \mathrm{E}-06$ & $1.66 \mathrm{E}-02$ & $0 \mathrm{E}+00$ \\
\hline-18 & $1.33 \mathrm{E}-10$ & 1.32E-10 & $1.32 \mathrm{E}-10$ & $1.32 \mathrm{E}-10$ & $1.33 \mathrm{E}-10$ & $1.32 \mathrm{E}-10$ & $32 \mathrm{E}-10$ & 1.32E-10 & 1.33E-10 & 1.32E-10 & $3.65 E+02$ & $1.20 \mathrm{E}+02$ & $6.77 \mathrm{E}+01$ & $4.56 \mathrm{E}+01$ & $3.61 \mathrm{E}+01$ & $2.47 \mathrm{E}+01$ \\
\hline-19 & $3.25 \mathrm{E}-06$ & $3.25 \mathrm{E}-06$ & $3.25 \mathrm{E}-06$ & $3.25 \mathrm{E}-06$ & $3.25 \mathrm{E}-06$ & $3.25 \mathrm{E}-06$ & $3.25 \mathrm{E}-06$ & $3.25 \mathrm{E}-06$ & $3.25 \mathrm{E}-06$ & $3.25 \mathrm{E}-06$ & $3.97 \mathrm{E}+00$ & $4.08 \mathrm{E}+03$ & $8.09 E+03$ & $7.07 \mathrm{E}+03$ & $4.96 \mathrm{E}+03$ & $7 \mathrm{E}+03$ \\
\hline 216-T-2 & $2.35 \mathrm{E}-04$ & $1.98 \mathrm{E}+02$ & $1.11 \mathrm{E}+03$ & $1.11 \mathrm{E}+03$ & $1.11 \mathrm{E}+03$ & $1.11 \mathrm{E}+03$ & $6.06 \mathrm{E}+02$ & $2.33 \mathrm{E}+02$ & $1.14 \mathrm{E}+02$ & $6.67 \mathrm{E}+01$ & $4.15 \mathrm{E}+01$ & $3.45 \mathrm{E}+01$ & $2.67 \mathrm{E}+01$ & $1.85 \mathrm{E}+01$ & $1.85 \mathrm{E}+01$ & $1.80 \mathrm{E}+01$ \\
\hline 216-T-20 & $2.47 \mathrm{E}-10$ & $2.46 \mathrm{E}-10$ & $2.46 \mathrm{E}-10$ & $2.46 \mathrm{E}-10$ & $2.47 \mathrm{E}-10$ & $2.46 \mathrm{E}-10$ & $2.46 \mathrm{E}-10$ & $2.46 \mathrm{E}-10$ & $2.47 \mathrm{E}-10$ & $2.46 \mathrm{E}-10$ & $2.46 \mathrm{E}-10$ & $2.46 \mathrm{E}-10$ & $1.93 \mathrm{E}-08$ & 5.67E-08 & 1.42E-04 & $.25 \mathrm{E}-04$ \\
\hline $16-T-21$ & 7.06E-06 & 7.04E-06 & 7.04E-06 & 7.04E-06 & 7.06E-06 & 7.04E-06 & 7.04E-06 & 7.04E-06 & 7.06E-06 & 7.04E-06 & $.04 \mathrm{E}-06$ & 7.04E-06 & 7.06E-06 & 7.04E-06 & $4 \mathrm{E}-06$ & $26 \mathrm{E}-04$ \\
\hline$T-22$ & .06E-07 & 3.05E-07 & 3.05E-07 & 3.05E-07 & 3.06E-07 & 3.05E-07 & E-07 & E-07 & E-07 & E-07 & -07 & $4 \mathrm{E}+01$ & $2.57 \mathrm{E}+02$ & $1.72 \mathrm{E}+02$ & $\mathrm{E}+02$ & $9 \mathrm{E}+01$ \\
\hline$T-23$ & 02E-08 & $5.00 \mathrm{E}-08$ & E-08 & $5.00 \mathrm{E}-08$ & & $E-08$ & & & & $=-08$ & & $8 \mathrm{E}+01$ & $E+02$ & $.72 E+02$ & $1.13 E+02$ & $3 \mathrm{E}+01$ \\
\hline-24 & $4 \mathrm{E}-05$ & $E-05$ & $=-05$ & $2.33 \mathrm{E}-05$ & -05 & -05 & & -05 & -05 & -05 & -05 & $E+01$ & $E+02$ & $E+02$ & $E+02$ & $\mathrm{E}+01$ \\
\hline-25 & $1.36 \mathrm{E}-08$ & 1.36E-08 & E-08 & 1.36E-08 & E-08 & $E-08$ & $=-08$ & $=-08$ & E-08 & E-08 & $E+02$ & $E+03$ & $\mathrm{E}+02$ & $1.44 \mathrm{E}+02$ & $2 \mathrm{E}+02$ & $E+01$ \\
\hline-26 & $3.17 \mathrm{E}-08$ & 3.16E-08 & 3.16E-08 & 3.16E-08 & E-08 & $E-08$ & $E-08$ & $\mathrm{E}-08$ & $\mathrm{E}-08$ & E-08 & -08 & $1.70 \mathrm{E}+03$ & $E+03$ & $1.72 \mathrm{E}+03$ & $\mathrm{E}+02$ & $3 \mathrm{E}+02$ \\
\hline-27 & $1.62 \mathrm{E}-08$ & 1.62E-08 & $1.62 \mathrm{E}-08$ & 1.62E-08 & 1.62E-08 & E-08 & E-08 & 1.62E-08 & 1.62E-08 & E-08 & E-08 & 1.62E-08 & $2 \mathrm{E}-08$ & 1.62E-08 & 1.62E-08 & 2E-08 \\
\hline$\Gamma-28$ & $1.29 \mathrm{E}-07$ & 1.29E-07 & 1.29E-07 & 1.29E-07 & 1.29E-07 & 1.29E-07 & $29 \mathrm{E}-07$ & 1.29E-07 & 1.29E-07 & 1.29E-07 & 1.29E-07 & 1.29E-07 & $1.29 \mathrm{E}-07$ & 1.29E-07 & $1.29 \mathrm{E}-07$ & L.29E-07 \\
\hline$\Gamma-29$ & $9.91 \mathrm{E}-12$ & $9.88 \mathrm{E}-12$ & $88 \mathrm{E}-12$ & $9.88 \mathrm{E}-12$ & $9.91 \mathrm{E}-12$ & 3.60E-01 & $4.83 \mathrm{E}+00$ & $4.91 \mathrm{E}+00$ & $4.93 \mathrm{E}+00$ & $4.92 \mathrm{E}+00$ & $4.92 \mathrm{E}+00$ & $4.91 \mathrm{E}+00$ & $4.93 \mathrm{E}+00$ & $4.92 \mathrm{E}+00$ & $4.92 \mathrm{E}+00$ & $91 \mathrm{E}+00$ \\
\hline 216-T-3 & $4.38 \mathrm{E}-03$ & $1.62 \mathrm{E}+03$ & $6.31 \mathrm{E}+03$ & $1.45 \mathrm{E}+03$ & $4.58 \mathrm{E}+02$ & $2.26 \mathrm{E}+02$ & $1.66 \mathrm{E}+02$ & $1.06 \mathrm{E}+02$ & $1.02 \mathrm{E}+02$ & $5.80 \mathrm{E}+01$ & $5.80 \mathrm{E}+01$ & $5.80 \mathrm{E}+01$ & $4.02 \mathrm{E}+01$ & $3.22 \mathrm{E}+01$ & $3.22 \mathrm{E}+01$ & $3.22 \mathrm{E}+01$ \\
\hline 216-T-32 & $2.84 \mathrm{E}-06$ & $2.83 \mathrm{E}-06$ & $2.83 \mathrm{E}-06$ & $2.83 \mathrm{E}-06$ & $4.14 \mathrm{E}+03$ & $5.17 \mathrm{E}+03$ & $5.62 \mathrm{E}+03$ & $7.33 E+03$ & $3.46 \mathrm{E}+03$ & $1.44 \mathrm{E}+03$ & $6.46 \mathrm{E}+02$ & $3.86 \mathrm{E}+02$ & $2.83 \mathrm{E}+02$ & $1.73 \mathrm{E}+02$ & $1.65 E+02$ & $1.25 \mathrm{E}+02$ \\
\hline 216-T-33 & 4.77E-09 & 4.75E-09 & $4.75 \mathrm{E}-09$ & 4.75E-09 & 4.77E-09 & $4.75 \mathrm{E}-09$ & $4.75 \mathrm{E}-09$ & $4.75 \mathrm{E}-09$ & 4.77E-09 & $4.75 \mathrm{E}-09$ & $4.75 \mathrm{E}-09$ & 4.75E-09 & 4.77E-09 & $4.75 \mathrm{E}-09$ & $4.75 \mathrm{E}-09$ & 75E-09 \\
\hline 216-T-34 & $3.01 \mathrm{E}-08$ & 3.01E-08 & $3.01 \mathrm{E}-08$ & 3.01E-08 & 3.01E-08 & .01E-08 & 01E-08 & 01E-08 & .01E-08 & $.01 \mathrm{E}-08$ & $1 \mathrm{E}-08$ & .01E-08 & $1 \mathrm{E}-08$ & $3.01 \mathrm{E}-08$ & $.01 \mathrm{E}-08$ & 01E-08 \\
\hline $216-T-35$ & 55E-11 & 9.53E-11 & $9.53 \mathrm{E}-11$ & 9.53E-11 & 9.55E-11 & 9.53E-11 & 53E-11 & 53E-11 & 9.55E-11 & 9.53E-11 & 9.53E-11 & $.53 \mathrm{E}-11$ & $.55 \mathrm{E}-11$ & 9.53E-11 & 9.53E-11 & $.53 \mathrm{E}-11$ \\
\hline T-36 & 61E-09 & 1.60E-09 & 1.60E-09 & 1.60E-09 & E-09 & $E-09$ & E-09 & E-09 & E-09 & E-09 & $E-09$ & OE-09 & $1 \mathrm{E}-09$ & 1.60E-09 & E-09 & 1.60E-09 \\
\hline$T-4 A$ & $=-10$ & $=-10$ & E-10 & $2.07 \mathrm{E}-10$ & $=-10$ & -10 & -10 & $=-10$ & $=-10$ & $E-10$ & -10 & E-10 & $E+05$ & $7.53 \mathrm{E}+05$ & $E+05$ & $1.06 \mathrm{E}+05$ \\
\hline & 1.31E-08 & 1.30E-08 & 1.30E-08 & 1.30E-08 & 1.31E-08 & 1.30E-08 & 1.30E-08 & 1.30E-08 & 1.31E-08 & 1.30E-08 & 1.30E-08 & $7.02 \mathrm{E}+02$ & $\mathrm{E}+03$ & $2.75 E+02$ & $1.51 \mathrm{E}+02$ & $E+02$ \\
\hline & E-09 & 2.08E-09 & $2.08 \mathrm{E}-09$ & $2.33 E+04$ & $9.84 \mathrm{E}+03$ & $2.42 \mathrm{E}+03$ & $1.34 \mathrm{E}+03$ & $9.53 \mathrm{E}+02$ & $6.09 \mathrm{E}+02$ & +02 & $3.75 \mathrm{E}+02$ & $3.75 \mathrm{E}+02$ & $E+02$ & $2.33 E+02$ & $2.33 \mathrm{E}+02$ & $E+02$ \\
\hline & 7.39E-06 & 7.37E-06 & $7.37 \mathrm{E}-06$ & 7.37E-06 & 7.39E-06 & 7.37E-06 & 7.37E-06 & $3.07 \mathrm{E}+03$ & $7.96 \mathrm{E}+03$ & $1.21 \mathrm{E}+04$ & $2.27 \mathrm{E}+04$ & $3.08 \mathrm{E}+04$ & $1.12 \mathrm{E}+04$ & $4.25 \mathrm{E}+03$ & $2.25 \mathrm{E}+03$ & $1.69 E+03$ \\
\hline & $1.58 \mathrm{E}-06$ & $1.58 \mathrm{E}-06$ & $1.58 \mathrm{E}-06$ & $1.58 \mathrm{E}-06$ & $1.58 \mathrm{E}-06$ & 1.58E-06 & $1.58 \mathrm{E}-06$ & $1.58 \mathrm{E}-06$ & $1.58 \mathrm{E}-06$ & $1.58 \mathrm{E}-06$ & $1.58 \mathrm{E}-06$ & $1.58 \mathrm{E}-06$ & $1.58 \mathrm{E}-06$ & $1.58 \mathrm{E}-06$ & $2.34 \mathrm{E}-04$ & $2.46 \mathrm{E}-04$ \\
\hline 216-TY-2 & 10E-08 & $2.09 \mathrm{E}-08$ & $.09 E-08$ & 2.09E-08 & 2.10E-08 & & $9 \mathrm{E}-08$ & 09E-08 & $10 \mathrm{E}-08$ & $9 \mathrm{E}-08$ & $2.08 \mathrm{E}+00$ & $6.22 \mathrm{E}+00$ & $6.25 \mathrm{E}+00$ & $6.24 \mathrm{E}+00$ & $6.24 \mathrm{E}+00$ & $6.22 \mathrm{E}+00$ \\
\hline $216-U-1 \%$ & $3.56 \mathrm{E}-06$ & 3.55E-06 & $3.55 \mathrm{E}-06$ & $3.55 \mathrm{E}-06$ & 3.56E-06 & E-06 & $3.55 \mathrm{E}-06$ & 3.55E-06 & 3.56E-06 & 5E-06 & $3.55 \mathrm{E}-06$ & 3.55E-06 & 3.56E-06 & $3.55 \mathrm{E}-06$ & $3.55 \mathrm{E}-06$ & $5 \mathrm{E}-06$ \\
\hline 216-U-10 & $3.30 \mathrm{E}-09$ & 3.30E-09 & $3.30 \mathrm{E}-09$ & 3.30E-09 & 3.31E-09 & $3.30 \mathrm{E}-09$ & 3.30E-09 & 3.30E-09 & 3.31E-09 & $4.49 E+04$ & $1.07 \mathrm{E}+07$ & $1.11 E+07$ & $1.15 \mathrm{E}+07$ & $1.11 \mathrm{E}+07$ & $1.05 E+07$ & $7.97 \mathrm{E}+0$ \\
\hline
\end{tabular}




\begin{tabular}{|c|c|c|c|c|c|c|c|c|c|c|c|c|c|c|c|c|}
\hline & & & & & & & & & & & & & & & & \\
\hline Site & 1944 & 1945 & 1946 & 1947 & 1948 & 1949 & 1950 & 1951 & 1952 & 1953 & 1954 & 1955 & 1956 & 1957 & 1958 & 195 \\
\hline $216-U-12$ & 89E-05 & 88E-05 & 88E-05 & $2.88 \mathrm{E}-05$ & $89 \mathrm{E}-05$ & $2.88 \mathrm{E}-05$ & $2.88 \mathrm{E}-05$ & $2.88 \mathrm{E}-05$ & $2.89 \mathrm{E}-05$ & $2.88 \mathrm{E}-05$ & $2.88 \mathrm{E}-05$ & $2.88 \mathrm{E}-05$ & 2.89E-05 & $2.88 \mathrm{E}-05$ & $2.88 \mathrm{E}-05$ & $2.88 \mathrm{E}-$ \\
\hline 216-U-13 & 0E-06 & & & 99E-06 & 00E-06 & 99E-06 & $4.99 \mathrm{E}-06$ & $4.99 \mathrm{E}-06$ & $5.00 \mathrm{E}-06$ & 4.99E-06 & 4.99E-06 & 4.99E-06 & $5.00 \mathrm{E}-06$ & 4.99E-06 & $4.99 \mathrm{E}-06$ & 4.99E-06 \\
\hline & E-10 & & & $51 \mathrm{E}-10$ & $51 \mathrm{E}-10$ & 51E-10 & 51E-10 & $1.51 \mathrm{E}-10$ & $51 \mathrm{E}-10$ & $51 \mathrm{E}-10$ & $1.51 \mathrm{E}-10$ & $1.51 \mathrm{E}-10$ & $1.51 \mathrm{E}-10$ & $51 \mathrm{E}-10$ & $51 \mathrm{E}-10$ & 1E-10 \\
\hline & & & & 9E-06 & DOE-06 & 9E-06 & 99E-06 & $2.99 \mathrm{E}-06$ & 00E-06 & 99E-06 & $2.99 \mathrm{E}-06$ & $2.99 \mathrm{E}-06$ & $3.00 \mathrm{E}-06$ & $99 \mathrm{E}-06$ & $2.99 \mathrm{E}-06$ & 2.99E-06 \\
\hline & 8E-02 & & 16E-02 & 16E-02 & $7.18 \mathrm{E}-02$ & 7.16E-02 & $7.16 \mathrm{E}-02$ & $7.16 \mathrm{E}-02$ & $7.18 \mathrm{E}-02$ & 7.16E-02 & $7.16 \mathrm{E}-02$ & 7.16E-02 & $7.18 \mathrm{E}-02$ & $.16 \mathrm{E}-02$ & $7.16 \mathrm{E}-02$ & 7.16E-02 \\
\hline & & & & 93E-09 & $9.95 \mathrm{E}-09$ & 93E-09 & 9.93E-09 & 9.93E-09 & 9.95E-09 & 93E-09 & 9.93E-09 & 9.93E-09 & 9.95E-09 & 93E-09 & $9.93 \mathrm{E}-09$ & 9.93E-09 \\
\hline & & & & 33E-05 & 34E-05 & 3.33E-05 & $33 E-05$ & $3.33 \mathrm{E}-05$ & $34 \mathrm{E}-05$ & 3.33E-05 & $3.33 \mathrm{E}-05$ & 3.33E-05 & $5.77 \mathrm{E}+00$ & $6.50 \mathrm{E}+01$ & $7.74 \mathrm{E}+01$ & $6.46 \mathrm{E}+01$ \\
\hline & & & & 4E-08 & 97E-08 & 94E-08 & 94E-08 & 4E-08 & $6.92 \mathrm{E}-05$ & 7E-02 & $2.41 \mathrm{E}+00$ & $1.97 \mathrm{E}+01$ & $2.91 \mathrm{E}+01$ & $2.65 \mathrm{E}+01$ & $1.98 \mathrm{E}+01$ & $9 \mathrm{E}+01$ \\
\hline & & & & LE-08 & 1.31E-08 & 1.31E-08 & 31E-08 & LE-08 & 1.31E-08 & E-08 & $1 \mathrm{E}-08$ & $1 \mathrm{E}-08$ & 1.31E-08 & $1 E-08$ & 1.31E-08 & 31E-08 \\
\hline & & & & $E-11$ & $E-11$ & E-11 & $\mathrm{E}-11$ & $E-11$ & 3E-11 & $E-11$ & E-11 & $2 E-11$ & 3E-11 & E-11 & $2 \mathrm{E}-11$ & $2 \mathrm{E}-11$ \\
\hline & & & & $=-09$ & $=-09$ & E-09 & $E-09$ & E-09 & E-09 & $E-09$ & E-09 & $9 \mathrm{E}-07$ & 8.82E-01 & $E+00$ & $9.15 \mathrm{E}-01$ & $98 \mathrm{E}-01$ \\
\hline & & & & $=-05$ & E-05 & E-05 & E-05 & E-05 & E-05 & E-05 & $E+03$ & $E+04$ & $7.88 \mathrm{E}+04$ & $E+04$ & $2.88 E+04$ & $2 \mathrm{E}+04$ \\
\hline 21 & & & & $E-07$ & $E-07$ & E-07 & E-07 & E-07 & $\mathrm{E}-07$ & E-07 & $\mathrm{E}-07$ & E-07 & 4.17E-07 & E-07 & $4.16 \mathrm{E}-07$ & 6E-07 \\
\hline 216 & & & & E-08 & 08E-08 & 4.07E-08 & 4.07E-08 & $3.90 \mathrm{E}+03$ & $8.36 \mathrm{E}+03$ & $E+03$ & $2.76 \mathrm{E}+03$ & $87 \mathrm{E}+03$ & $1.36 \mathrm{E}+03$ & $4 \mathrm{E}+03$ & $8.26 \mathrm{E}+02$ & $.79 E+02$ \\
\hline & & & & $E+02$ & $68 \mathrm{E}+01$ & $E+01$ & $E+01$ & $E+01$ & $E+01$ & $E+01$ & $E+01$ & $E+01$ & $1.36 \mathrm{E}+01$ & $\mathrm{E}+01$ & $1.25 \mathrm{E}+01$ & $E+00$ \\
\hline-12 & & 5.55 & -06 & 55E-06 & 5.57E-06 & 55E-06 & $5.55 \mathrm{E}-06$ & $5.55 \mathrm{E}-06$ & $5.57 \mathrm{E}-06$ & 5E-06 & 55E-06 & $5.55 \mathrm{E}-06$ & 5.57E-06 & 5.55E-06 & 5.55E-06 & $5.55 \mathrm{E}-06$ \\
\hline & & & & 1.04E-06 & $1.04 \mathrm{E}-06$ & 04E-06 & $.04 \mathrm{E}-06$ & $.04 \mathrm{E}-06$ & $1.04 \mathrm{E}-06$ & 4E-06 & 1.04E-06 & $3.62 \mathrm{E}-04$ & $2.82 \mathrm{E}+04$ & $3.24 \mathrm{E}+04$ & $3.49 \mathrm{E}+04$ & $2.43 E+04$ \\
\hline & & & & 00E-08 & $2.01 \mathrm{E}-08$ & 00E-08 & $.00 \mathrm{E}-08$ & $2.00 \mathrm{E}-08$ & .01E-08 & E-08 & E-08 & $.76 \mathrm{E}-07$ & 1.54E-06 & $1.53 \mathrm{E}-06$ & 1.53E-06 & \\
\hline & & & & $2.52 \mathrm{E}+03$ & $10 \mathrm{E}+03$ & $07 \mathrm{E}+03$ & $20 \mathrm{E}+03$ & $1.78 \mathrm{E}+03$ & $\mathrm{E}+03$ & $E+03$ & $E+02$ & $E+02$ & $7.56 \mathrm{E}+02$ & $E+02$ & $4.72 \mathrm{E}+02$ & $E+02$ \\
\hline & & & & E-06 & E-06 & E-06 & 79E-06 & 7.79E-06 & 7.81E-06 & E-04 & E-04 & 4E-04 & E-04 & -01 & -01 & 4E-01 \\
\hline & & & & -08 & & & +04 & +04 & & & +03 & +03 & +03 & & & $E+02$ \\
\hline & & 0.0 & 0.0 & +00 & +00 & $E+00$ & +00 & +00 & +00 & +00 & +00 & $E+00$ & $E+00$ & & $E+00$ & $E+00$ \\
\hline 21 & & & & -03 & $E-03$ & $E-03$ & $E-03$ & $E-03$ & $E-03$ & $E-03$ & E-03 & $\mathrm{E}-03$ & $\mathrm{E}-03$ & E-03 & E-03 & LE-03 \\
\hline 21 & & & & $=-02$ & E-02 & $\mathrm{E}-02$ & E-02 & $\mathrm{E}-02$ & $\mathrm{E}-02$ & E-02 & $6 \mathrm{E}-02$ & 3E-02 & 1.51E-02 & E-02 & 6E-02 & $4 \mathrm{E}-02$ \\
\hline$-3 A$ & & 0.0 & 0.00 & $E+00$ & $.00 \mathrm{E}+00$ & $0.00 E+00$ & $0.00 \mathrm{E}+00$ & $0.00 E+00$ & $0.00 \mathrm{E}+00$ & $0.00 \mathrm{E}+00$ & $0.00 \mathrm{E}+00$ & $0.00 E+00$ & $0.00 E+00$ & $0.00 E+00$ & $0.00 E+00$ & $0.00 E+00$ \\
\hline V-3AE & 100 & -00 & & $0.00 \mathrm{E}+00$ & $00 \mathrm{E}+00$ & $00 \mathrm{E}+00$ & $00 \mathrm{E}+00$ & $0.00 \mathrm{E}+00$ & $0.00 \mathrm{E}+00$ & $0.00 \mathrm{E}+00$ & $0.00 \mathrm{E}+00$ & $0.00 \mathrm{E}+00$ & $0.00 \mathrm{E}+00$ & $0.00 \mathrm{E}+00$ & $0.00 \mathrm{E}+00$ & $0.00 \mathrm{E}+00$ \\
\hline V-4B & & & & $E+00$ & $00 \mathrm{E}+00$ & $E+00$ & $\mathrm{E}+00$ & $E+00$ & $0.00 \mathrm{E}+00$ & $E+00$ & $0 \mathrm{E}+00$ & $00 \mathrm{E}+00$ & $0.00 \mathrm{E}+00$ & $00 \mathrm{E}+00$ & $0.00 \mathrm{E}+00$ & $0.00 \mathrm{E}+00$ \\
\hline V-4C & $E+00$ & $00 \mathrm{E}+00$ & $0.00 \mathrm{E}+00$ & $0.00 \mathrm{E}+00$ & $00 \mathrm{E}+00$ & $00 \mathrm{E}+00$ & $00 \mathrm{E}+00$ & $0.00 \mathrm{E}+00$ & $0.00 \mathrm{E}+00$ & $0.00 E+00$ & $0.00 \mathrm{E}+00$ & $0.00 \mathrm{E}+00$ & $0.00 \mathrm{E}+00$ & $E+00$ & $0.00 \mathrm{E}+00$ & $0.00 \mathrm{E}+00$ \\
\hline $218-W-5$ & $E+00$ & $00 \mathrm{E}+00$ & $0.00 \mathrm{E}+00$ & $0.00 \mathrm{E}+00$ & $00 \mathrm{E}+00$ & $00 \mathrm{E}+00$ & $0.00 \mathrm{E}+00$ & $0.00 \mathrm{E}+00$ & $0.00 \mathrm{E}+00$ & $0.00 \mathrm{E}+00$ & $.00 \mathrm{E}+00$ & $.00 \mathrm{E}+00$ & $0.00 \mathrm{E}+00$ & $\mathrm{DE}+00$ & $0.00 \mathrm{E}+00$ & $.00 \mathrm{E}+00$ \\
\hline 241-A-101 & +00 & DOE +00 & $0.00 \mathrm{E}+00$ & $0.00 \mathrm{E}+00$ & $00 \mathrm{E}+00$ & $00 \mathrm{E}+00$ & $00 \mathrm{E}+00$ & $0.00 \mathrm{E}+00$ & $0.00 \mathrm{E}+00$ & $.00 \mathrm{E}+00$ & $.00 \mathrm{E}+00$ & $0.00 \mathrm{E}+00$ & $0.00 \mathrm{E}+00$ & $0.00 \mathrm{E}+00$ & $0.00 \mathrm{E}+00$ & $0.00 \mathrm{E}+00$ \\
\hline-102 & +00 & $00 \mathrm{E}+00$ & $0.00 \mathrm{E}+00$ & $0.00 \mathrm{E}+00$ & $00 \mathrm{E}+00$ & $00 \mathrm{E}+00$ & $0.00 \mathrm{E}+00$ & $0.00 \mathrm{E}+00$ & $0.00 \mathrm{E}+00$ & $0 \mathrm{E}+00$ & $00 \mathrm{E}+00$ & $.00 \mathrm{E}+00$ & $0.00 \mathrm{E}+00$ & $E+00$ & $E+00$ & $\mathrm{E}+00$ \\
\hline 103 & & 0.0 & & $E+00$ & $00 \mathrm{E}+00$ & DOE+00 & $E+00$ & $E+00$ & $E+00$ & $E+00$ & $E+00$ & $E+00$ & $0.00 \mathrm{E}+00$ & $0.00 \mathrm{E}+00$ & $0.00 \mathrm{E}+00$ & $0.00 \mathrm{E}+00$ \\
\hline 241-A-104 & & & & E-05 & 1.23E-05 & $23 E-05$ & $1.23 \mathrm{E}-05$ & 1.23E-05 & $\mathrm{E}-05$ & 3E-05 & 1.23E-05 & $1.23 \mathrm{E}-05$ & 1.23E-05 & 23E-05 & $1.23 \mathrm{E}-05$ & $1.23 \mathrm{E}-05$ \\
\hline & & & & $1.28 \mathrm{E}-05$ & $1.29 \mathrm{E}-05$ & $.28 \mathrm{E}-05$ & $1.28 \mathrm{E}-05$ & $1.28 \mathrm{E}-05$ & E-05 & BE-05 & $3 E-05$ & $1.28 \mathrm{E}-05$ & 1.29E-05 & .28E-05 & $1.28 \mathrm{E}-05$ & 1.28E-05 \\
\hline 241 & & & & $0.00 \mathrm{E}+00$ & $0.00 \mathrm{E}+00$ & $0.00 \mathrm{E}+00$ & $0.00 \mathrm{E}+00$ & $0.00 \mathrm{E}+00$ & $0.00 \mathrm{E}+00$ & $0.00 \mathrm{E}+00$ & $0.00 \mathrm{E}+00$ & $0.00 \mathrm{E}+00$ & $0.00 \mathrm{E}+00$ & $\mathrm{DE}+00$ & $E+00$ & $\mathrm{E}+00$ \\
\hline & & & & $0.00 \mathrm{E}+00$ & $00 \mathrm{E}+00$ & $00 \mathrm{E}+00$ & $0.00 \mathrm{E}+00$ & $0.00 \mathrm{E}+00$ & $0.00 \mathrm{E}+00$ & $0.00 \mathrm{E}+00$ & $\mathrm{E}+00$ & $E+00$ & $0.00 \mathrm{E}+00$ & $\mathrm{E}+00$ & $0.00 \mathrm{E}+00$ & $\mathrm{E}+00$ \\
\hline 241 & & & & $0.00 \mathrm{E}+00$ & $00 \mathrm{E}+00$ & $00 \mathrm{E}+00$ & $0.00 \mathrm{E}+00$ & $0.00 \mathrm{E}+00$ & $0.00 \mathrm{E}+00$ & $0.00 \mathrm{E}+00$ & $0.00 \mathrm{E}+00$ & $0.00 \mathrm{E}+00$ & $0.00 \mathrm{E}+00$ & $0.00 \mathrm{E}+00$ & $0.00 \mathrm{E}+00$ & $0.00 \mathrm{E}+00$ \\
\hline $\mathrm{V}-10$ & & & & $0.00 \mathrm{E}+00$ & $00 \mathrm{E}+00$ & $00 \mathrm{E}+00$ & $0.00 \mathrm{E}+00$ & $0.00 \mathrm{E}+00$ & $0.00 \mathrm{E}+00$ & $0.00 \mathrm{E}+00$ & $0.00 \mathrm{E}+00$ & $0.00 \mathrm{E}+00$ & $0.00 \mathrm{E}+00$ & $0.00 \mathrm{E}+00$ & $0.00 E+00$ & $0.00 \mathrm{E}+00$ \\
\hline & & & & $0.00 \mathrm{E}+00$ & $00 \mathrm{E}+00$ & $00 \mathrm{E}+00$ & $0.00 \mathrm{E}+00$ & $0.00 \mathrm{E}+00$ & $.00 \mathrm{E}+00$ & $0 \mathrm{E}+00$ & $0.00 \mathrm{E}+00$ & $0.00 \mathrm{E}+00$ & $0.00 \mathrm{E}+00$ & $0.00 \mathrm{E}+00$ & $0.00 E+00$ & $0.00 \mathrm{E}+00$ \\
\hline & & & & $00 \mathrm{E}+00$ & $00 \mathrm{E}+00$ & $00 \mathrm{E}+00$ & $0.00 \mathrm{E}+00$ & $0.00 \mathrm{E}+00$ & $0.00 \mathrm{E}+00$ & $0 \mathrm{E}+00$ & $0 \mathrm{E}+00$ & $0 \mathrm{E}+00$ & $0.00 \mathrm{E}+00$ & $0.00 \mathrm{E}+00$ & $0.00 \mathrm{E}+00$ & $0.00 \mathrm{E}+00$ \\
\hline 241-AN-106 & $0.00 \mathrm{E}+00$ & $0.00 \mathrm{E}+00$ & $0.00 \mathrm{E}+00$ & $0.00 \mathrm{E}+00$ & $0.00 E+00$ & $0.00 \mathrm{E}+00$ & $0.00 \mathrm{E}+00$ & $0.00 \mathrm{E}+00$ & $0.00 \mathrm{E}+00$ & $0.00 \mathrm{E}+00$ & $0.00 \mathrm{E}+00$ & $0.00 \mathrm{E}+00$ & $0.00 \mathrm{E}+00$ & $0.00 \mathrm{E}+00$ & $0.00 \mathrm{E}+00$ & $0.00 \mathrm{E}+0 \mathrm{C}$ \\
\hline
\end{tabular}




\begin{tabular}{|c|c|c|c|c|c|c|c|c|c|c|c|c|c|c|c|c|}
\hline & & & & & & & & & & & & & & & & \\
\hline Site & 1944 & 1945 & 1946 & 1947 & 1948 & 1949 & 1950 & 1951 & 1952 & 1953 & 1954 & 1955 & 1956 & 1957 & 1958 & 195 \\
\hline 241-AN-107 & $00 \mathrm{E}+00$ & $00 \mathrm{E}+00$ & $0.00 \mathrm{E}+00$ & $0.00 \mathrm{E}+00$ & $00 \mathrm{E}+00$ & $.00 \mathrm{E}+00$ & $0.00 \mathrm{E}+00$ & $0.00 \mathrm{E}+00$ & $0.00 \mathrm{E}+00$ & $0.00 \mathrm{E}+00$ & $0.00 \mathrm{E}+00$ & $0.00 \mathrm{E}+00$ & $0.00 \mathrm{E}+00$ & $0.00 \mathrm{E}+00$ & $0.00 \mathrm{E}+00$ & $0.00 \mathrm{E}+00$ \\
\hline 241-AP-101 & $0 \mathrm{E}+00$ & $00 \mathrm{E}+00$ & & $0.00 \mathrm{E}+00$ & $00 \mathrm{E}+00$ & $00 \mathrm{E}+00$ & $00 \mathrm{E}+00$ & $0.00 \mathrm{E}+00$ & $.00 \mathrm{E}+00$ & $00 \mathrm{E}+00$ & $.00 \mathrm{E}+00$ & $0.00 \mathrm{E}+00$ & $0.00 \mathrm{E}+00$ & $0.00 \mathrm{E}+00$ & $0.00 \mathrm{E}+00$ & \\
\hline 241-AP-102 & $E+00$ & $0 \mathrm{E}+00$ & $0.00 \mathrm{E}+00$ & $0.00 \mathrm{E}+00$ & DOE+00 & $00 \mathrm{E}+00$ & $00 \mathrm{E}+00$ & $00 \mathrm{E}+00$ & $00 \mathrm{E}+00$ & $00 \mathrm{E}+00$ & $.00 \mathrm{E}+00$ & $.00 \mathrm{E}+00$ & $0.00 \mathrm{E}+00$ & $0.00 \mathrm{E}+00$ & $0.00 E+00$ & $0 \mathrm{E}+00$ \\
\hline 241-AP-103 & $E+00$ & $0 \mathrm{E}+00$ & $0.00 \mathrm{E}+00$ & $00 \mathrm{E}+00$ & $00 \mathrm{E}+00$ & DOE+00 & $00 \mathrm{E}+00$ & $0.00 \mathrm{E}+00$ & $0.00 \mathrm{E}+00$ & $00 \mathrm{E}+00$ & $0.00 \mathrm{E}+00$ & $0.00 \mathrm{E}+00$ & $0.00 \mathrm{E}+00$ & $0.00 \mathrm{E}+00$ & $\mathrm{E}+00$ & DOE+00 \\
\hline 241-AP-104 & $0 \mathrm{E}+00$ & $0.00 \mathrm{E}+00$ & $0.00 \mathrm{E}+00$ & $0.00 \mathrm{E}+00$ & $00 \mathrm{E}+00$ & DOE+00 & DOE+00 & $0.00 \mathrm{E}+00$ & $0.00 \mathrm{E}+00$ & $0.00 \mathrm{E}+00$ & $0.00 \mathrm{E}+00$ & $0.00 \mathrm{E}+00$ & $0.00 \mathrm{E}+00$ & $0.00 \mathrm{E}+00$ & $0.00 \mathrm{E}+00$ & $.00 \mathrm{E}+00$ \\
\hline 241-AP-105 & $0 \mathrm{E}+00$ & $0.00 \mathrm{E}+00$ & $0.00 \mathrm{E}+00$ & $0.00 \mathrm{E}+00$ & $00 \mathrm{E}+00$ & $00 \mathrm{E}+00$ & $0.00 \mathrm{E}+00$ & $0.00 \mathrm{E}+00$ & $0.00 \mathrm{E}+00$ & $0.00 \mathrm{E}+00$ & $E+00$ & $0.00 \mathrm{E}+00$ & $0.00 \mathrm{E}+00$ & $0 \mathrm{E}+00$ & $0 \mathrm{E}+00$ & $\mathrm{DE}+00$ \\
\hline P-106 & $E+00$ & $00 \mathrm{E}+00$ & $0.00 \mathrm{E}+00$ & $0.00 \mathrm{E}+00$ & $00 \mathrm{E}+00$ & $00 \mathrm{E}+00$ & $0.00 \mathrm{E}+00$ & $0.00 \mathrm{E}+00$ & $0.00 \mathrm{E}+00$ & $.00 \mathrm{E}+00$ & $0.00 \mathrm{E}+00$ & $0.00 \mathrm{E}+00$ & $0.00 \mathrm{E}+00$ & $0 \mathrm{E}+00$ & $\mathrm{OE}+00$ & $\mathrm{DE}+00$ \\
\hline & +00 & $E+00$ & $0.00 \mathrm{E}+00$ & $0.00 \mathrm{E}+00$ & $00 \mathrm{E}+00$ & $00 \mathrm{E}+00$ & $0.00 \mathrm{E}+00$ & $0.00 \mathrm{E}+00$ & $0.00 \mathrm{E}+00$ & $\mathrm{E}+00$ & $\mathrm{E}+00$ & $0 \mathrm{E}+00$ & $E+00$ & $\mathrm{E}+00$ & $\mathrm{E}+00$ & $0 \mathrm{E}+00$ \\
\hline & & & & $0.00 \mathrm{E}+00$ & $00 \mathrm{E}+00$ & $00 \mathrm{E}+00$ & $0.00 \mathrm{E}+00$ & $0.00 \mathrm{E}+00$ & $\mathrm{E}+00$ & $E+00$ & $E+00$ & $00 \mathrm{E}+00$ & $E+00$ & $E+00$ & $E+00$ & $.00 \mathrm{E}+00$ \\
\hline & & & & $=00$ & $00 \mathrm{E}+00$ & $E+00$ & $E+00$ & $E+00$ & $\mathrm{E}+00$ & $E+00$ & $E+00$ & $E+00$ & $E+00$ & $\mathrm{E}+00$ & $E+00$ & $E+00$ \\
\hline & & & & $=00$ & DOE+00 & $E+00$ & $E+00$ & $E+00$ & $E+00$ & $E+00$ & $E+00$ & $E+00$ & $E+00$ & $\mathrm{E}+00$ & $E+00$ & $\mathrm{DE}+00$ \\
\hline & & & & +00 & $00 \mathrm{E}+00$ & $E+00$ & $E+00$ & $E+00$ & $\mathrm{E}+00$ & $E+00$ & $E+00$ & $E+00$ & $E+00$ & $E+00$ & $E+00$ & $E+00$ \\
\hline & & & & $=00$ & $00 \mathrm{E}+00$ & $\mathrm{E}+00$ & $\mathrm{E}+00$ & $E+00$ & $\mathrm{E}+00$ & $E+00$ & $\mathrm{E}+00$ & $E+00$ & $E+00$ & $E+00$ & $E+00$ & $\mathrm{DE}+00$ \\
\hline L05 & & & -00 & $E+00$ & $00 \mathrm{E}+00$ & $00 \mathrm{E}+00$ & $\mathrm{E}+00$ & $E+00$ & $0.00 \mathrm{E}+00$ & $\mathrm{DE}+00$ & $\mathrm{E}+00$ & $0.00 \mathrm{E}+00$ & $E+00$ & $E+00$ & $E+00$ & $0.00 \mathrm{E}+00$ \\
\hline 06 & & & 00 & $=+00$ & $E+00$ & $E+00$ & $E+00$ & +00 & $E+00$ & $E+00$ & $E+00$ & $E+00$ & +00 & $E+00$ & +00 & -00 \\
\hline 101 & +00 & $\mathrm{E}+00$ & $0.00 \mathrm{E}+00$ & $0.00 \mathrm{E}+00$ & $00 \mathrm{E}+00$ & $00 \mathrm{E}+00$ & $00 \mathrm{E}+00$ & $0.00 \mathrm{E}+00$ & $0.00 \mathrm{E}+00$ & $E+00$ & $\mathrm{E}+00$ & $\mathrm{DE}+00$ & $E+00$ & $\mathrm{E}+00$ & $E+00$ & $0 \mathrm{E}+00$ \\
\hline 241- & +00 & 0.00 & $0.00 \mathrm{E}+00$ & $0.00 \mathrm{E}+00$ & $00 \mathrm{E}+00$ & $00 \mathrm{E}+00$ & $00 \mathrm{E}+00$ & $0.00 \mathrm{E}+00$ & $0.00 \mathrm{E}+00$ & $E+00$ & $E+00$ & $\mathrm{DE}+00$ & $E+00$ & $E+00$ & $E+00$ & $0 \mathrm{E}+00$ \\
\hline & +00 & & & $0.00 \mathrm{E}+00$ & $00 \mathrm{E}+00$ & $00 \mathrm{E}+00$ & $00 \mathrm{E}+00$ & $0.00 \mathrm{E}+00$ & $0.00 \mathrm{E}+00$ & $\mathrm{E}+00$ & $E+00$ & & & & & \\
\hline & & & +00 & $E+00$ & $00 \mathrm{E}+00$ & $\mathrm{E}+00$ & $\mathrm{DE}+00$ & $E+00$ & $E+00$ & $E+00$ & $E+00$ & $E+00$ & & $E+00$ & $E+00$ & \\
\hline & & & & & & & $E+00$ & & & & $E+00$ & $E+00$ & $E+00$ & $E+00$ & $E+00$ & $0 \mathrm{E}+00$ \\
\hline & & & & & & & $E+00$ & & & & & & & $\mathrm{E}+00$ & $E+00$ & \\
\hline & & & & 0.0 & $E+00$ & $E+00$ & +00 & 00 & $E+00$ & +00 & +00 & & & & $E+00$ & -00 \\
\hline & & 0.0 & & 0.0 & $E+00$ & $E+00$ & $E+00$ & +00 & $E+00$ & $E+00$ & $E+00$ & $E+00$ & +00 & $E+00$ & $E+00$ & $\mathrm{E}+00$ \\
\hline & & & & -08 & $\mathrm{E}-08$ & E-08 & E-08 & $E-08$ & E-08 & E-08 & E-08 & E-08 & E-08 & E-08 & $E-08$ & $4 \mathrm{E}-08$ \\
\hline & & & & E-08 & E-08 & E-08 & E-08 & $E-08$ & $\mathrm{E}-08$ & E-08 & $4 \mathrm{E}-08$ & 4E-08 & E-08 & $4 \mathrm{E}-08$ & $4 \mathrm{E}-08$ & 4.44E-08 \\
\hline & & & -08 & E-08 & $4.46 \mathrm{E}-08$ & 4E-08 & 44E-08 & 4.44E-08 & 46E-08 & 44E-08 & 4.44E-08 & 4.44E-08 & 4.46E-08 & $44 \mathrm{E}-08$ & $44 \mathrm{E}-08$ & 4.44E-08 \\
\hline & & & & $E-08$ & E-08 & E-08 & E-08 & $E-08$ & 3E-08 & $2 \mathrm{E}-08$ & $92 \mathrm{E}-08$ & $2 \mathrm{E}-08$ & .93E-08 & 92E-08 & 92E-08 & 5.92E-08 \\
\hline & & 05 & -05 & $1 E-05$ & $4.22 \mathrm{E}-05$ & 21E-05 & 21E-05 & $1 \mathrm{E}-05$ & $22 \mathrm{E}-05$ & 21E-05 & $4.21 \mathrm{E}-05$ & $4.21 \mathrm{E}-05$ & $4.22 \mathrm{E}-05$ & 21E-05 & 21E-05 & 21E-05 \\
\hline & & & -08 & E-08 & 40E-08 & 9E-08 & 9E-08 & $=-08$ & OE-08 & E-08 & $9 \mathrm{E}-08$ & E-08 & DE-08 & $9 \mathrm{E}-08$ & E-08 & $9 \mathrm{E}-08$ \\
\hline & -08 & & -08 & E-08 & 9E-08 & $6 \mathrm{E}-08$ & $6 \mathrm{E}-08$ & E-08 & $9 \mathrm{E}-08$ & $6 \mathrm{E}-08$ & 6E-08 & E-08 & $9 \mathrm{E}-08$ & $6 \mathrm{E}-08$ & E-08 & 06E-08 \\
\hline & -08 & -08 & -08 & EE-08 & $6 \mathrm{E}-08$ & $5 E-08$ & 5E-08 & $=-08$ & E-08 & E-08 & E-08 & $E-08$ & $E-08$ & E-08 & $E-08$ & 15E-08 \\
\hline & & & & E-08 & 3E-08 & $2 \mathrm{E}-08$ & $2 \mathrm{E}-08$ & E-08 & 3E-08 & 2E-08 & 2E-08 & 2E-08 & $E-08$ & $2 \mathrm{E}-08$ & $2 \mathrm{E}-08$ & $5.92 \mathrm{E}-08$ \\
\hline & & & & & E-11 & $49 \mathrm{E}-11$ & $2.49 \mathrm{E}-11$ & & & $\mathrm{E}-11$ & E-11 & $E-11$ & $E-11$ & $\mathrm{E}-11$ & $\mathrm{E}-11$ & 2.49E-11 \\
\hline & & & & & & & & & & & E-08 & E-08 & & E-08 & $E-08$ & 4.44E-08 \\
\hline & & & & & $5.94 \mathrm{E}-08$ & 92E-08 & $5.92 \mathrm{E}-08$ & & EE-08 & E-08 & E-08 & E-08 & $=-08$ & $=-08$ & E-08 & 5.92E-08 \\
\hline & & & & & & E-09 & E-09 & & & E-09 & E-09 & $=-09$ & & E-09 & $E-09$ & 2.90E-09 \\
\hline & & & & & & & $.95 \mathrm{E}-09$ & & & 2.95E-09 & $2.95 \mathrm{E}-09$ & 2.95E-09 & 2.96E-09 & E-09 & $\mathrm{E}-09$ & $2.95 \mathrm{E}-09$ \\
\hline & & & & & $62 \mathrm{E}-08$ & $62 \mathrm{E}-08$ & $62 \mathrm{E}-08$ & & 1.62E-08 & $1.62 \mathrm{E}-08$ & 1.62E-08 & 1.62E-08 & 1.62E-08 & 1.62E-08 & $1.62 \mathrm{E}-08$ & 1.62E-08 \\
\hline & & & & & & & 0E-09 & & & & & & & & 7.70E-09 & 7.70E-09 \\
\hline & & & & & $3.85 \mathrm{E}-06$ & $4 \mathrm{E}-06$ & $84 \mathrm{E}-06$ & 4E-06 & & 4E-06 & $3.84 \mathrm{E}-06$ & 4E-06 & & & $3.84 \mathrm{E}-06$ & $3.84 \mathrm{E}-06$ \\
\hline 241-BX-102 & 3.03E-05 & 3.03E-05 & $3.03 \mathrm{E}-05$ & 3.03E-05 & 3.03E-05 & $3.03 \mathrm{E}-05$ & 3.03E-05 & $2.32 \mathrm{E}+02$ & $7.26 \mathrm{E}+01$ & $1.09 \mathrm{E}+01$ & $5.33 \mathrm{E}+00$ & $3.33 \mathrm{E}+00$ & $2.42 \mathrm{E}+00$ & $1.86 \mathrm{E}+00$ & $1.49 \mathrm{E}+00$ & $1225+00$ \\
\hline
\end{tabular}




\section{ANNUAL DISCHARGE VOLUMES IN $\mathrm{M}^{3}$}

\begin{tabular}{|r|r|r|r|r|r|r|r|r|r|r|r|r|r|r|r|r|}
\hline 1944 & 1945 & 1946 & 1947 & 1948 & 1949 & 1950 & 1951 & 1952 & 1953 & 1954 & 1955 & 1956 & 1957 & 1958 & 1959 \\
\hline
\end{tabular}

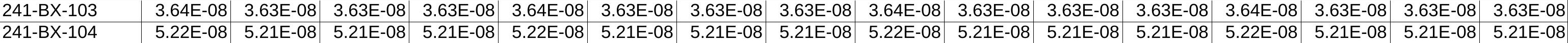

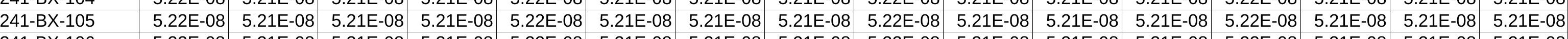

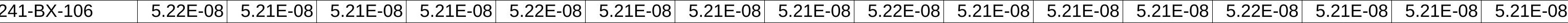

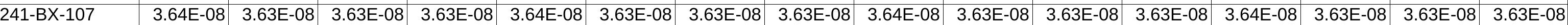

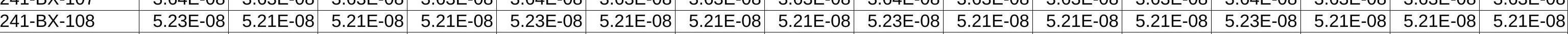

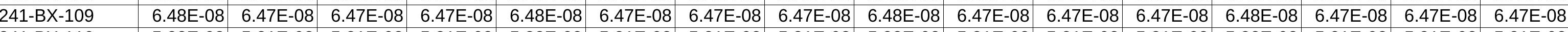

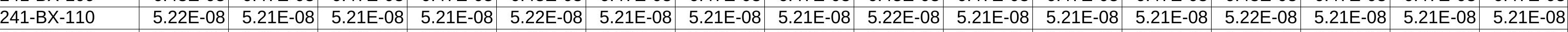

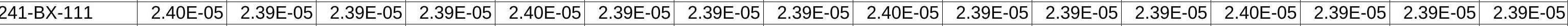

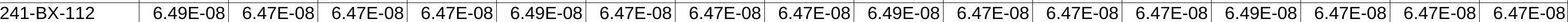

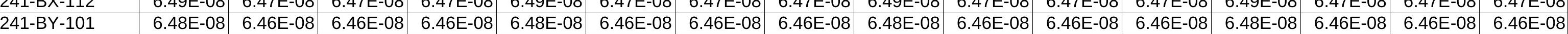

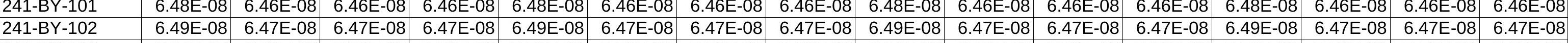

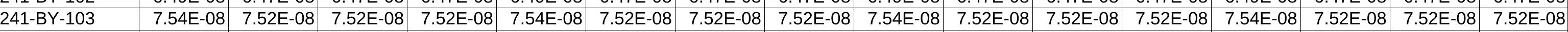

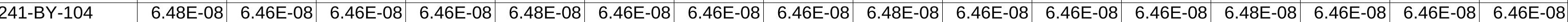

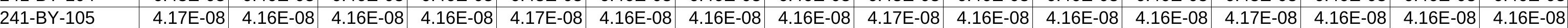

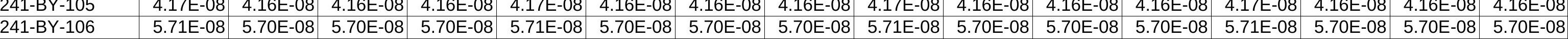

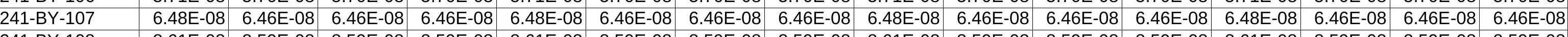

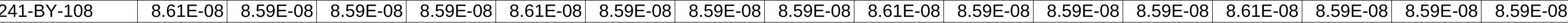

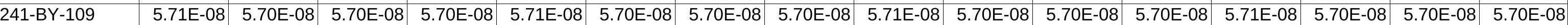

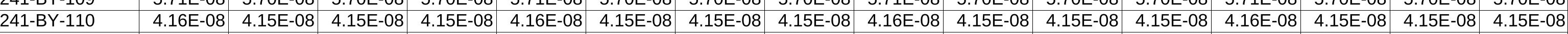

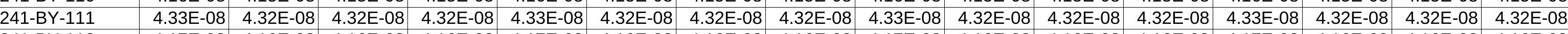

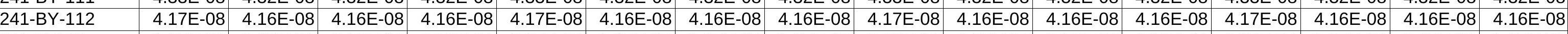

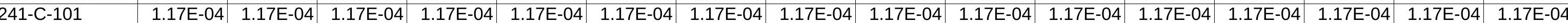

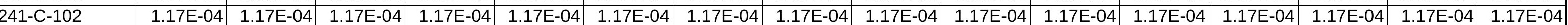

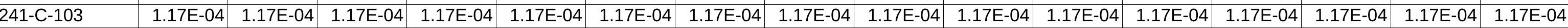

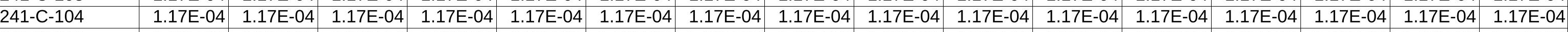

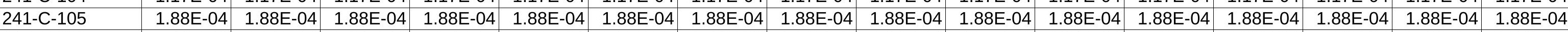

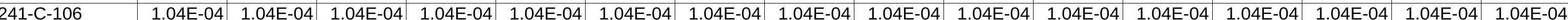

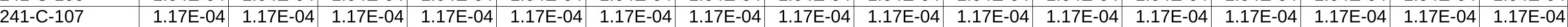

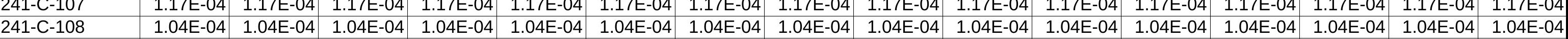

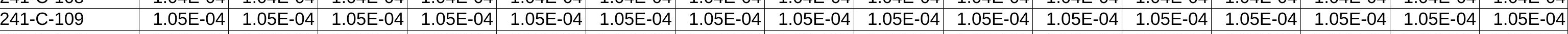

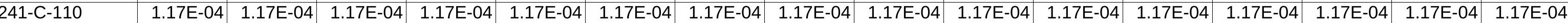

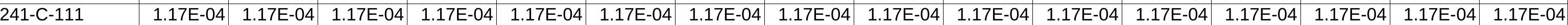

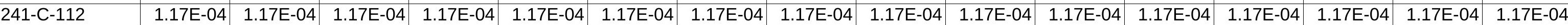

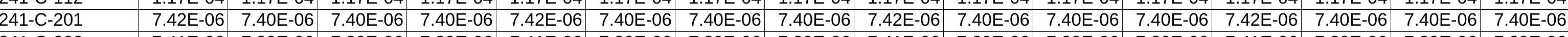

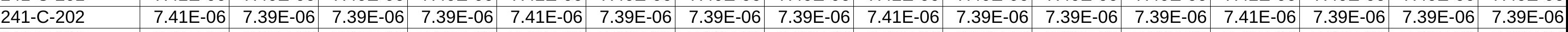

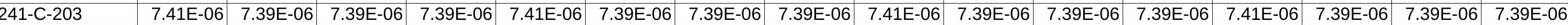

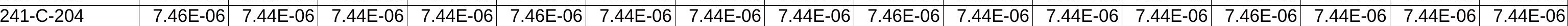

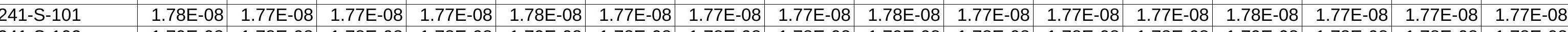

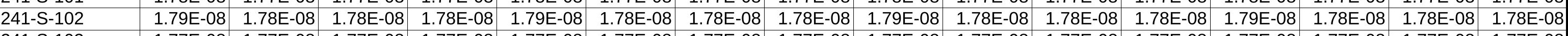

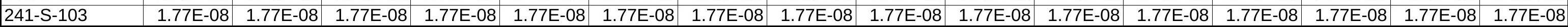




\section{ANNUAL DISCHARGE VOLUMES IN M ${ }^{3}$}

\begin{tabular}{|r|r|r|r|r|r|r|r|r|r|r|r|r|r|r|r|r|}
\hline 1944 & 1945 & 1946 & 1947 & 1948 & 1949 & 1950 & 1951 & 1952 & 1953 & 1954 & 1955 & 1956 & 1957 & 1958 & 1959 \\
\hline
\end{tabular}

241-S-104 \begin{tabular}{|l|r|r|r|r|r|r|r|r|r|r|r|r|r|r|r|r|r|r|r|}
\hline $4.46 \mathrm{E}-09$ & $4.44 \mathrm{E}-09$ & $4.44 \mathrm{E}-09$ & $4.44 \mathrm{E}-09$ & $4.46 \mathrm{E}-09$ & $4.44 \mathrm{E}-09$ & $4.44 \mathrm{E}-09$ & $4.44 \mathrm{E}-09$ & $4.46 \mathrm{E}-09$ & $4.44 \mathrm{E}-09$ & $4.44 \mathrm{E}-09$ & $4.44 \mathrm{E}-09$ & $4.46 \mathrm{E}-09$ & $4.44 \mathrm{E}-09$ & $4.44 \mathrm{E}-09$ & $4.44 \mathrm{E}-09$ \\
\hline $1.78 \mathrm{E}-08$ & $1.77 \mathrm{E}-08$ & $1.77 \mathrm{E}-08$ & $1.77 \mathrm{E}-08$ & $1.78 \mathrm{E}-08$ & $1.77 \mathrm{E}-08$ & $1.77 \mathrm{E}-08$ & $1.77 \mathrm{E}-08$ & $1.78 \mathrm{E}-08$ & $1.77 \mathrm{E}-08$ & $1.77 \mathrm{E}-08$ & $1.77 \mathrm{E}-08$ & $1.78 \mathrm{E}-08$ & $1.77 \mathrm{E}-08$ & $1.77 \mathrm{E}-08$ & $1.77 \mathrm{E}-08$ \\
\hline
\end{tabular} $241-\mathrm{S}-105$ 241-S-106 \begin{tabular}{|l|l|l|l|l|l|l|l|l|l|l|l|l|l|l|l|l|l|l|l|l|l|l|}
$1.78 \mathrm{E}-08$ & $1.77 \mathrm{E}-08$ & $1.77 \mathrm{E}-08$ & $1.77 \mathrm{E}-08$ & $1.78 \mathrm{E}-08$ & $1.77 \mathrm{E}-08$ & $1.77 \mathrm{E}-08$ & $1.77 \mathrm{E}-08$ & $1.78 \mathrm{E}-08$ & $1.77 \mathrm{E}-08$ & $1.77 \mathrm{E}-08$ & $1.77 \mathrm{E}-08$ & $1.78 \mathrm{E}-08$ & $1.77 \mathrm{E}-08$ & $1.77 \mathrm{E}-08$ & $1.77 \mathrm{E}-08$ \\
\hline $1.77 \mathrm{E}-08$ & $1.77 \mathrm{E}-08$ & $1.77 \mathrm{E}-08$ & $1.77 \mathrm{E}-08$ & $1.77 \mathrm{E}-08$ & $1.77 \mathrm{E}-08$ & $1.77 \mathrm{E}-08$ & $1.77 \mathrm{E}-08$ & $1.77 \mathrm{E}-08$ & $1.77 \mathrm{E}-08$ & $1.77 \mathrm{E}-08$ & $1.77 \mathrm{E}-08$ & $1.77 \mathrm{E}-08$ & $1.77 \mathrm{E}-08$ & $1.77 \mathrm{E}-08$ & $1.77 \mathrm{E}-08$ \\
\hline
\end{tabular}

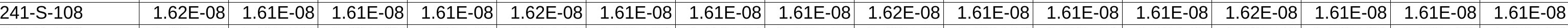
\begin{tabular}{|l|l|l|l|l|l|l|l|l|l|l|l|l|l|l|l|}
$1.62 \mathrm{E}-08$ & $1.62 \mathrm{E}-08$ & $1.62 \mathrm{E}-08$ & $1.62 \mathrm{E}-08$ & $1.62 \mathrm{E}-08$ & $1.62 \mathrm{E}-08$ & $1.62 \mathrm{E}-08$ & $1.62 \mathrm{E}-08$ & $1.62 \mathrm{E}-08$ & $1.62 \mathrm{E}-08$ & $1.62 \mathrm{E}-08$ & $1.62 \mathrm{E}-08$ & $1.62 \mathrm{E}-08$ & $1.62 \mathrm{E}-08$ & $1.62 \mathrm{E}-08$ & $1.62 \mathrm{E}-08$ \\
\hline
\end{tabular}

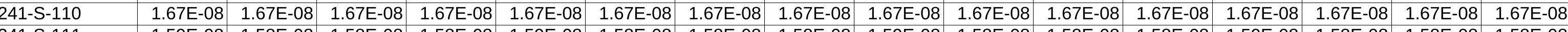

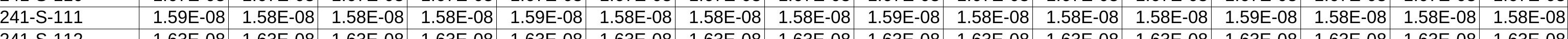

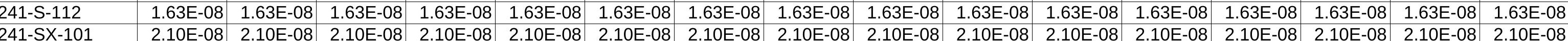

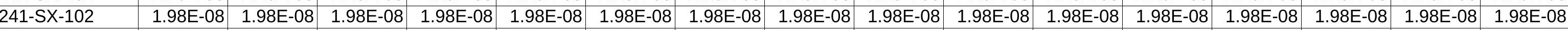

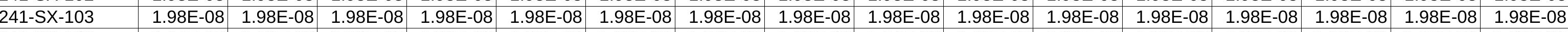

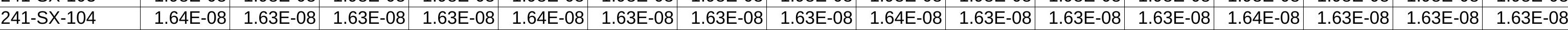

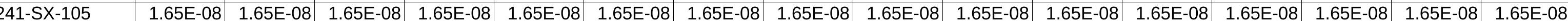
241-SX-106 \begin{tabular}{|l|l|l|l|l|l|l|l|l|l|l|l|l|l|l|l|l|l|l|l|l|}
\hline $2.08 \mathrm{E}-08$ & $2.07 \mathrm{E}-08$ & $2.07 \mathrm{E}-08$ & $2.07 \mathrm{E}-08$ & $2.08 \mathrm{E}-08$ & $2.07 \mathrm{E}-08$ & $2.07 \mathrm{E}-08$ & $2.07 \mathrm{E}-08$ & $2.08 \mathrm{E}-08$ & $2.07 \mathrm{E}-08$ & $2.07 \mathrm{E}-08$ & $2.07 \mathrm{E}-08$ & $2.08 \mathrm{E}-08$ & $2.07 \mathrm{E}-08$ & $2.07 \mathrm{E}-08$ & $2.07 \mathrm{E}-08$ \\
\hline
\end{tabular}

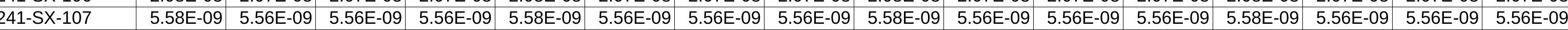

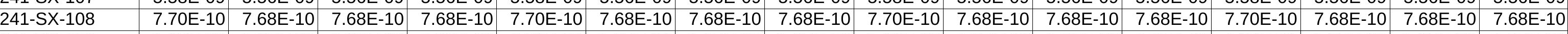

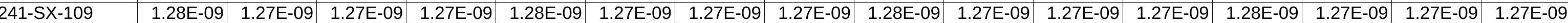

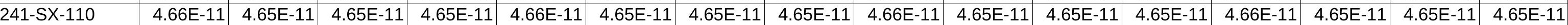

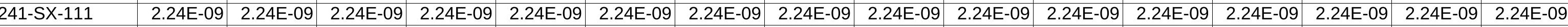

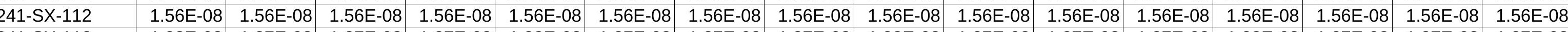

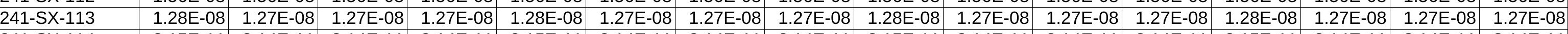

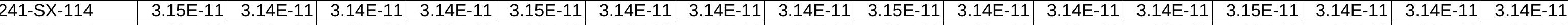

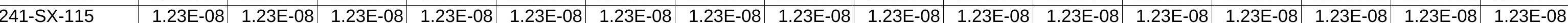

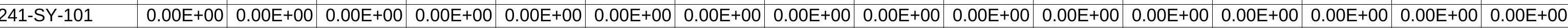

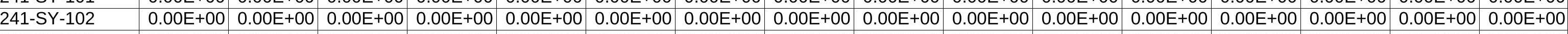

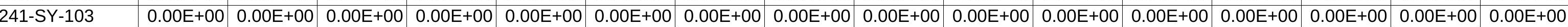
$241-\mathrm{T}-101$ \begin{tabular}{|l|l|l|l|l|l|l|l|l|l|l|l|l|l|l|l|l|l}
$5.36 \mathrm{E}-16$ & $5.35 \mathrm{E}-16$ & $5.35 \mathrm{E}-16$ & $5.35 \mathrm{E}-16$ & $5.36 \mathrm{E}-16$ & $5.35 \mathrm{E}-16$ & $5.35 \mathrm{E}-16$ & $5.35 \mathrm{E}-16$ & $5.36 \mathrm{E}-16$ & $5.35 \mathrm{E}-16$ & $5.35 \mathrm{E}-16$ & $5.35 \mathrm{E}-16$ & $5.36 \mathrm{E}-16$ & $5.35 \mathrm{E}-16$ & $5.35 \mathrm{E}-16$ & $5.35 \mathrm{E}-16$ \\
\hline
\end{tabular}

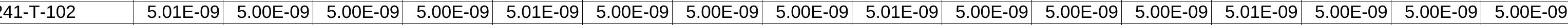

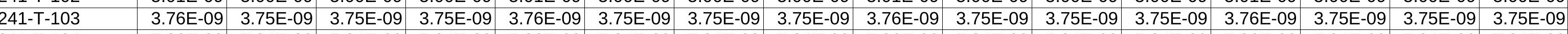

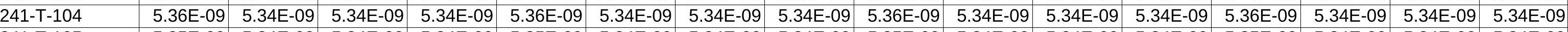

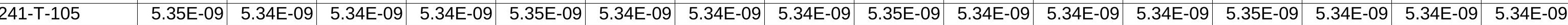

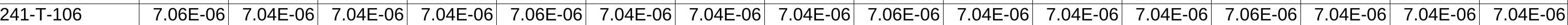

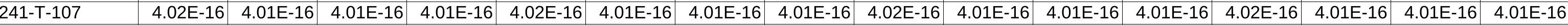

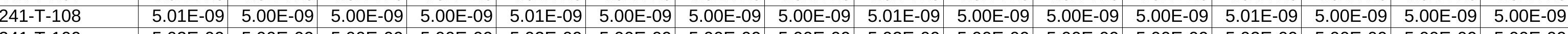

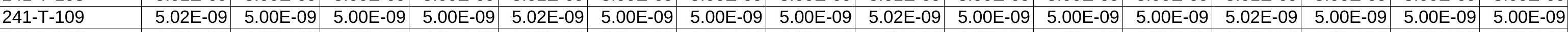

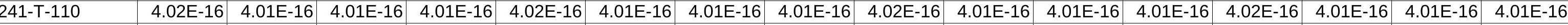

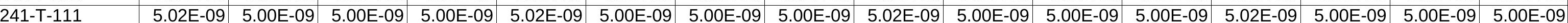

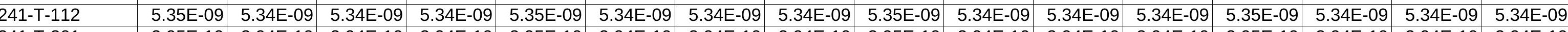

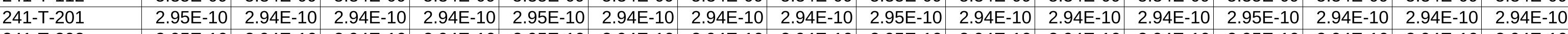

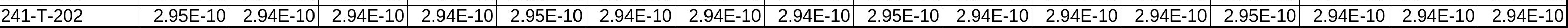




\begin{tabular}{|c|c|c|c|c|c|c|c|c|c|c|c|c|c|c|c|c|}
\hline & & & & & & & & & & & & & & & & \\
\hline Site & 1944 & 1945 & 1946 & 1947 & 1948 & 1949 & 1950 & 1951 & 1952 & 1953 & 1954 & 1955 & 1956 & 1957 & 1958 & 1959 \\
\hline 241-T-203 & $2.95 \mathrm{E}-10$ & $2.94 \mathrm{E}-10$ & $2.94 \mathrm{E}-10$ & $94 \mathrm{E}-10$ & $95 \mathrm{E}-10$ & $2.94 \mathrm{E}-10$ & $.94 \mathrm{E}-10$ & $94 \mathrm{E}-10$ & $2.95 \mathrm{E}-10$ & $2.94 \mathrm{E}-10$ & $2.94 \mathrm{E}-10$ & $2.94 \mathrm{E}-10$ & $2.95 \mathrm{E}-10$ & $2.94 \mathrm{E}-10$ & $2.94 \mathrm{E}-10$ & $2.94 \mathrm{E}-10$ \\
\hline 241-T-204 & $5 \mathrm{E}-10$ & 94E-10 & & 94E-10 & 95E-10 & $94 \mathrm{E}-10$ & 94E-10 & $94 \mathrm{E}-10$ & $2.95 \mathrm{E}-10$ & $2.94 \mathrm{E}-10$ & $2.94 \mathrm{E}-10$ & $2.94 \mathrm{E}-10$ & $2.95 \mathrm{E}-10$ & $2.94 \mathrm{E}-10$ & $94 \mathrm{E}-10$ & 94E-10 \\
\hline 241-TX-101 & 9E-09 & & & 8E-09 & 79E-09 & $78 \mathrm{E}-09$ & $78 \mathrm{E}-09$ & $78 \mathrm{E}-09$ & 79E-09 & $4.78 \mathrm{E}-09$ & $4.78 \mathrm{E}-09$ & $4.78 \mathrm{E}-09$ & $4.79 \mathrm{E}-09$ & $4.78 \mathrm{E}-09$ & $78 \mathrm{E}-09$ & 78E-09 \\
\hline 241-TX-102 & & & & $8 \mathrm{E}-09$ & J9E-09 & 08E-09 & 08E-09 & 08E-09 & 09E-09 & $5.08 \mathrm{E}-09$ & $5.08 \mathrm{E}-09$ & $5.08 \mathrm{E}-09$ & 5.09E-09 & $5.08 \mathrm{E}-09$ & $5.08 \mathrm{E}-09$ & $5.08 \mathrm{E}-09$ \\
\hline 241-TX-103 & E-09 & $5.08 \mathrm{E}-09$ & $5.08 \mathrm{E}-09$ & 08E-09 & 10E-09 & $5.08 \mathrm{E}-09$ & $5.08 \mathrm{E}-09$ & $5.08 \mathrm{E}-09$ & $10 \mathrm{E}-09$ & $5.08 \mathrm{E}-09$ & $5.08 \mathrm{E}-09$ & $5.08 \mathrm{E}-09$ & $5.10 \mathrm{E}-09$ & $5.08 \mathrm{E}-09$ & $5.08 \mathrm{E}-09$ & $5.08 \mathrm{E}-09$ \\
\hline 241-TX-104 & 0E-09 & $5.08 \mathrm{E}-09$ & $5.08 \mathrm{E}-09$ & 08E-09 & $10 \mathrm{E}-09$ & $5.08 \mathrm{E}-09$ & $5.08 \mathrm{E}-09$ & $5.08 \mathrm{E}-09$ & $10 \mathrm{E}-09$ & $5.08 \mathrm{E}-09$ & 5.08E-09 & $5.08 \mathrm{E}-09$ & 5.10E-09 & $5.08 \mathrm{E}-09$ & $.08 \mathrm{E}-09$ & $5.08 \mathrm{E}-09$ \\
\hline & & & & 16E-09 & 17E-09 & 4.16E-09 & 4.16E-09 & $16 \mathrm{E}-09$ & 17E-09 & $4.16 \mathrm{E}-09$ & 4.16E-09 & 4.16E-09 & 4.17E-09 & 4.16E-09 & $16 \mathrm{E}-09$ & $16 \mathrm{E}-09$ \\
\hline & & & & 24E-10 & $25 \mathrm{E}-10$ & $4.24 \mathrm{E}-10$ & $24 \mathrm{E}-10$ & $24 \mathrm{E}-10$ & $4.25 \mathrm{E}-10$ & $4.24 \mathrm{E}-10$ & $4.24 \mathrm{E}-10$ & $4.24 \mathrm{E}-10$ & $4.25 \mathrm{E}-10$ & $4.24 \mathrm{E}-10$ & $24 \mathrm{E}-10$ & $24 \mathrm{E}-10$ \\
\hline & & & & $75 \mathrm{E}-11$ & $2.76 \mathrm{E}-11$ & $2.75 \mathrm{E}-11$ & $2.75 \mathrm{E}-11$ & $2.75 \mathrm{E}-11$ & $2.76 \mathrm{E}-11$ & $2.75 \mathrm{E}-11$ & $2.75 \mathrm{E}-11$ & $2.75 \mathrm{E}-11$ & $2.76 \mathrm{E}-11$ & $2.75 \mathrm{E}-11$ & $2.75 \mathrm{E}-11$ & $75 E-11$ \\
\hline & & & & E-09 & E-09 & E-09 & $4.16 \mathrm{E}-09$ & E-09 & $4.17 \mathrm{E}-09$ & E-09 & 4.16E-09 & $4.16 \mathrm{E}-09$ & 4.17E-09 & $6 \mathrm{E}-09$ & $16 \mathrm{E}-09$ & 16E-09 \\
\hline & & & & $=-09$ & E-09 & E-09 & 77E-09 & $\mathrm{E}-09$ & E-09 & 7E-09 & 4.77E-09 & $4.77 \mathrm{E}-09$ & $4.79 \mathrm{E}-09$ & 4.77E-09 & $4.77 \mathrm{E}-09$ & 77E-09 \\
\hline 24 & & & & $=-09$ & E-09 & E-09 & 78E-09 & E-09 & E-09 & E-09 & $4.78 \mathrm{E}-09$ & 3E-09 & $9 \mathrm{E}-09$ & $8 \mathrm{E}-09$ & $4.78 \mathrm{E}-09$ & 78E-09 \\
\hline & & & & E-09 & E-09 & E-09 & 08E-09 & E-09 & E-09 & 3E-09 & $08 \mathrm{E}-09$ & $8 \mathrm{E}-09$ & 9E-09 & $8 \mathrm{E}-09$ & $.08 \mathrm{E}-09$ & $8 \mathrm{E}-09$ \\
\hline 241 & & & & E-09 & 09E-09 & 08E-09 & $.08 \mathrm{E}-09$ & $5.08 \mathrm{E}-09$ & $5.09 \mathrm{E}-09$ & $5.08 \mathrm{E}-09$ & $5.08 \mathrm{E}-09$ & $5.08 \mathrm{E}-09$ & 5.09E-09 & $5.08 \mathrm{E}-09$ & $5.08 \mathrm{E}-09$ & 08E-09 \\
\hline & & & & $E-09$ & $E-09$ & $E-09$ & 16E-09 & $E-09$ & 7E-09 & 5-09 & 4.16E-09 & 6E-09 & 4.17E-09 & $16 \mathrm{E}-09$ & $4.16 \mathrm{E}-09$ & 16E-09 \\
\hline 241-TX & & & & E-09 & E-09 & E-09 & $16 \mathrm{E}-09$ & $\mathrm{E}-09$ & 7E-09 & E-09 & $4.16 \mathrm{E}-09$ & $6 \mathrm{E}-09$ & 4.17E-09 & $16 \mathrm{E}-09$ & $4.16 \mathrm{E}-09$ & $16 \mathrm{E}-09$ \\
\hline 241-TX-115 & & & & 16E-09 & $4.17 \mathrm{E}-09$ & $4.16 \mathrm{E}-09$ & $4.16 \mathrm{E}-09$ & 16E-09 & $4.17 \mathrm{E}-09$ & $6 \mathrm{E}-09$ & $4.16 \mathrm{E}-09$ & $4.16 \mathrm{E}-09$ & $4.17 \mathrm{E}-09$ & 16E-09 & $4.16 \mathrm{E}-09$ & $16 \mathrm{E}-09$ \\
\hline & & & & 16E-09 & 17E-09 & 16E-09 & 16E-09 & 16E-09 & 17E-09 & 6E-09 & $16 \mathrm{E}-09$ & $16 \mathrm{E}-09$ & .17E-09 & 6E-09 & $16 \mathrm{E}-09$ & 6E-09 \\
\hline & & & & E-09 & E-09 & E-09 & 15E-09 & $E-09$ & EE-09 & & 5E-09 & E-09 & 7E-09 & & 5E-09 & 5E-09 \\
\hline & & & & E-09 & & & $6 \mathrm{E}-09$ & $E-09$ & 7E-09 & E-09 & $16 \mathrm{E}-09$ & E-09 & 7E-09 & 6E-09 & 16E-09 & $6 \mathrm{E}-09$ \\
\hline & & & & & & & E-12 & -12 & $=-12$ & & $E-12$ & $=-12$ & $E-12$ & -12 & -12 & E-12 \\
\hline & & & & $E-12$ & -12 & $=-12$ & $\mathrm{E}-12$ & $=-12$ & $\mathrm{E}-12$ & $\mathrm{E}-12$ & $\mathrm{E}-12$ & $\mathrm{E}-12$ & $\mathrm{E}-12$ & bE-12 & $6 \mathrm{E}-12$ & $6 \mathrm{E}-12$ \\
\hline & & & & $=-09$ & $E-09$ & E-09 & $2.53 \mathrm{E}-09$ & E-09 & E-09 & 3E-09 & $2.53 \mathrm{E}-09$ & 3E-09 & $4 \mathrm{E}-09$ & 3E-09 & $2.53 \mathrm{E}-09$ & $.53 \mathrm{E}-09$ \\
\hline & & & & $E-12$ & $\mathrm{E}-12$ & E-12 & $27 \mathrm{E}-12$ & $\mathrm{E}-12$ & E-12 & E-12 & $1.27 \mathrm{E}-12$ & E-12 & E-12 & $7 \mathrm{E}-12$ & $1.27 \mathrm{E}-12$ & $1.27 \mathrm{E}-12$ \\
\hline & & & & E-06 & E-06 & E-06 & 04E-06 & 5.04E-06 & 5E-06 & 4E-06 & 5.04E-06 & 5.04E-06 & $5 \mathrm{E}-06$ & $.04 \mathrm{E}-06$ & 3.33E-01 & $2.37 \mathrm{E}+01$ \\
\hline 106 & & 3.06 & $E-08$ & 06E-08 & 07E-08 & $3.06 \mathrm{E}-08$ & $3.06 \mathrm{E}-08$ & $3.06 \mathrm{E}-08$ & $3.07 \mathrm{E}-08$ & $3.06 \mathrm{E}-08$ & $3.06 \mathrm{E}-08$ & $3.06 \mathrm{E}-08$ & $3.07 \mathrm{E}-08$ & $3.06 \mathrm{E}-08$ & $3.06 \mathrm{E}-08$ & 2.23E-01 \\
\hline & & & & E-08 & $7 \mathrm{E}-08$ & $7 \mathrm{E}-08$ & $7 \mathrm{E}-08$ & 2.07E-08 & 07E-08 & 07E-08 & 07E-08 & 2.07E-08 & .07E-08 & $.07 \mathrm{E}-08$ & $2.07 \mathrm{E}-08$ & $2.07 \mathrm{E}-08$ \\
\hline$-U-102$ & E-08 & 2.13 & $2.13 \mathrm{E}-08$ & 13E-08 & 13E-08 & $2.13 \mathrm{E}-08$ & $2.13 \mathrm{E}-08$ & 2.13E-08 & $2.13 \mathrm{E}-08$ & $2.13 \mathrm{E}-08$ & $2.13 \mathrm{E}-08$ & $2.13 \mathrm{E}-08$ & $2.13 \mathrm{E}-08$ & .13E-08 & $2.13 \mathrm{E}-08$ & $2.13 \mathrm{E}-08$ \\
\hline 241-U-103 & $E-08$ & 1.79 & 79E-08 & 79E-08 & $1.79 \mathrm{E}-08$ & 1.79E-08 & 79E-08 & 1.79E-08 & 1.79E-08 & 79E-08 & $1.79 \mathrm{E}-08$ & 1.79E-08 & 1.79E-08 & 79E-08 & 1.79E-08 & 79E-08 \\
\hline J-104 & E-09 & 9.79E-09 & 79E-09 & 79E-09 & 82E-09 & 9.79E-09 & .79E-09 & 9.79E-09 & 9.82E-09 & 79E-09 & 9.79E-09 & 9.79E-09 & $9.82 \mathrm{E}-09$ & .79E-09 & 9.79E-09 & 9.79E-09 \\
\hline & & 1.77 & & $7 \mathrm{E}-08$ & 77E-08 & 77E-08 & 77E-08 & 77E-08 & 77E-08 & 77E-08 & 1.77E-08 & 1.77E-08 & 1.77E-08 & 77E-08 & 1.77E-08 & 1.77E-08 \\
\hline -U-106 & & & 1.77E-08 & 77E-08 & 77E-08 & 1.77E-08 & 1.77E-08 & 1.77E-08 & 1.77E-08 & 1.77E-08 & 1.77E-08 & 1.77E-08 & 1.77E-08 & 1.77E-08 & 1.77E-08 & 1.77E-08 \\
\hline & & & & 66E-08 & 1.67E-08 & $1.66 \mathrm{E}-08$ & $66 \mathrm{E}-08$ & $66 \mathrm{E}-08$ & $67 \mathrm{E}-08$ & 6E-08 & 1.66E-08 & 1.66E-08 & 1.67E-08 & 1.66E-08 & $1.66 \mathrm{E}-08$ & 1.66E-08 \\
\hline & & & & & E-08 & E-08 & $.88 \mathrm{E}-08$ & $E-08$ & $E-08$ & 3E-08 & $1.88 \mathrm{E}-08$ & $1.88 \mathrm{E}-08$ & E-08 & $.88 \mathrm{E}-08$ & $1.88 \mathrm{E}-08$ & 1.88E-08 \\
\hline & & & & LE-08 & E-08 & E-08 & 1.91E-08 & E-08 & E-08 & E-08 & LE-08 & E-08 & E-08 & $1 \mathrm{E}-08$ & 1.91E-08 & 1.91E-08 \\
\hline & & & & $4.52 \mathrm{E}-09$ & $4.53 \mathrm{E}-09$ & $.52 \mathrm{E}-09$ & $4.52 \mathrm{E}-09$ & $4.52 \mathrm{E}-09$ & E-09 & E-09 & $4.52 \mathrm{E}-09$ & E-09 & 4.53E-09 & $2 \mathrm{E}-09$ & $4.52 \mathrm{E}-09$ & 4.52E-09 \\
\hline & & & & 73E-08 & $1.74 \mathrm{E}-08$ & .73E-08 & $1.73 \mathrm{E}-08$ & 73E-08 & 1.74E-08 & $1.73 \mathrm{E}-08$ & $1.73 \mathrm{E}-08$ & 1.73E-08 & 1.74E-08 & $.73 \mathrm{E}-08$ & $1.73 \mathrm{E}-08$ & 1.73E-08 \\
\hline & & & & 16E-08 & $4.17 \mathrm{E}-08$ & $4.16 \mathrm{E}-08$ & $4.16 \mathrm{E}-08$ & $16 \mathrm{E}-08$ & $4.17 \mathrm{E}-08$ & $4.16 \mathrm{E}-08$ & $4.16 \mathrm{E}-08$ & $4.16 \mathrm{E}-08$ & 4.17E-08 & $4.16 \mathrm{E}-08$ & $4.16 \mathrm{E}-08$ & $4.16 \mathrm{E}-08$ \\
\hline & & & & $1.75 \mathrm{E}-09$ & $1.75 \mathrm{E}-09$ & $1.75 \mathrm{E}-09$ & $75 E-09$ & $5 \mathrm{E}-09$ & $5 \mathrm{E}-09$ & 1.75E-09 & 1.75E-09 & $.75 \mathrm{E}-09$ & $.75 \mathrm{E}-09$ & 1.75E-09 & 1.75E-09 & $1.75 \mathrm{E}-09$ \\
\hline & & & & 1.72E-09 & $1.73 \mathrm{E}-09$ & $1.72 \mathrm{E}-09$ & $.72 E-09$ & $2 \mathrm{E}-09$ & 3E-09 & 1.72E-09 & 1.72E-09 & $.72 \mathrm{E}-09$ & .73E-09 & 1.72E-09 & $1.72 \mathrm{E}-09$ & 1.72E-09 \\
\hline $241-U-203$ & 1.73E-09 & $1.72 \mathrm{E}-09$ & $1.72 \mathrm{E}-09$ & 1.72E-09 & $1.73 \mathrm{E}-09$ & 1.72E-09 & $1.72 \mathrm{E}-09$ & $1.72 \mathrm{E}-09$ & 1.73E-09 & $1.72 \mathrm{E}-09$ & $1.72 \mathrm{E}-09$ & 1.72E-09 & $1.73 \mathrm{E}-09$ & 1.72E-09 & $1.72 \mathrm{E}-09$ & $1.72 \mathrm{E}-09$ \\
\hline
\end{tabular}




\begin{tabular}{|c|c|c|c|c|c|c|c|c|c|c|c|c|c|c|c|c|}
\hline & & & & & & & & & & & & & & & & \\
\hline Site & 1944 & 1945 & 1946 & 1947 & 1948 & 1949 & 1950 & 1951 & 1952 & 1953 & 1954 & 1955 & 1956 & 1957 & 1958 & 1959 \\
\hline 241-U-204 & DOE-09 & 00E-09 & 00E-09 & 00E-09 & 00E-09 & 00E-09 & 00E-09 & $2.00 \mathrm{E}-09$ & $2.00 \mathrm{E}-09$ & 2.00E-09 & $2.00 \mathrm{E}-09$ & 2.00E-09 & 2.00E-09 & $.00 \mathrm{E}-09$ & 2.00E-09 & 2.00E-09 \\
\hline $300-224$ & & & & 38E-07 & 39E-07 & & $38 \mathrm{E}-07$ & $38 \mathrm{E}-07$ & 39E-07 & 3.38E-07 & $3.38 \mathrm{E}-07$ & 3.38E-07 & & & & \\
\hline 316-1 & E-12 & $1.55 E+06$ & $2.39 \mathrm{E}+06$ & $2.38 \mathrm{E}+06$ & $39 \mathrm{E}+06$ & $30 \mathrm{E}+06$ & $20 \mathrm{E}+06$ & $1.20 \mathrm{E}+06$ & $1.20 \mathrm{E}+06$ & $1.20 \mathrm{E}+06$ & $1.20 \mathrm{E}+06$ & $1.20 \mathrm{E}+06$ & $1.20 \mathrm{E}+06$ & $1.20 \mathrm{E}+06$ & $1.20 \mathrm{E}+06$ & $1.20 \mathrm{E}+06$ \\
\hline $316-2$ & & & & $2.19 \mathrm{E}-06$ & $2.19 \mathrm{E}-06$ & $15 \mathrm{E}+05$ & $20 \mathrm{E}+06$ & $1.20 \mathrm{E}+06$ & $1.21 \mathrm{E}+06$ & $20 \mathrm{E}+06$ & $1.20 \mathrm{E}+06$ & $1.20 \mathrm{E}+06$ & $1.21 \mathrm{E}+06$ & $1.20 \mathrm{E}+06$ & $1.20 \mathrm{E}+06$ & $.20 \mathrm{E}+06$ \\
\hline $316-3$ & $E-11$ & & 34E-11 & $34 \mathrm{E}-11$ & 34E-11 & $2.34 \mathrm{E}-11$ & $2.34 \mathrm{E}-11$ & $2.34 \mathrm{E}-11$ & $2.34 \mathrm{E}-11$ & $99 \mathrm{E}+04$ & $9.10 \mathrm{E}+04$ & $9.08 \mathrm{E}+04$ & $9.13 \mathrm{E}+04$ & $9.10 \mathrm{E}+04$ & $9.10 \mathrm{E}+04$ & $.08 \mathrm{E}+04$ \\
\hline $316-5$ & & $=-10$ & 07E-10 & 07E-10 & $3.08 \mathrm{E}-10$ & $3.07 \mathrm{E}-10$ & $3.07 \mathrm{E}-10$ & $3.07 \mathrm{E}-10$ & $3.08 \mathrm{E}-10$ & $3.07 \mathrm{E}-10$ & $3.07 \mathrm{E}-10$ & 3.07E-10 & $3.08 \mathrm{E}-10$ & $3.07 \mathrm{E}-10$ & 3.07E-10 & $7 \mathrm{E}-10$ \\
\hline & & $0.00 \mathrm{E}+00$ & $0.00 \mathrm{E}+00$ & $0.00 \mathrm{E}+00$ & $00 \mathrm{E}+00$ & $00 \mathrm{E}+00$ & $0.00 \mathrm{E}+00$ & $0.00 \mathrm{E}+00$ & $0.00 \mathrm{E}+00$ & $0.00 \mathrm{E}+00$ & $0.00 \mathrm{E}+00$ & $00 \mathrm{E}+00$ & $0.00 \mathrm{E}+00$ & $0.00 \mathrm{E}+00$ & $0.00 \mathrm{E}+00$ & $\mathrm{E}+00$ \\
\hline & & & & 23E-09 & 4.24E-09 & 23E-09 & $23 \mathrm{E}-09$ & 4.23E-09 & 4E-09 & 3E-09 & 3E-09 & 4.23E-09 & $4.24 \mathrm{E}-09$ & 3E-09 & E-09 & E-09 \\
\hline 3-11 & & & & $\mathrm{E}-11$ & $\mathrm{E}-10$ & E-10 & $E-10$ & $E-10$ & $E-10$ & E-10 & E-10 & E-10 & $\mathrm{E}-10$ & $E-10$ & $\mathrm{E}-10$ & $7 \mathrm{E}-10$ \\
\hline $\mathrm{F}$ & & & & +00 & $00 \mathrm{E}+00$ & $E+00$ & $E+00$ & +00 & +00 & $=+00$ & $E+00$ & $=00$ & $E+00$ & +00 & $E+00$ & $E+00$ \\
\hline GTFL & & & & +00 & $E+00$ & $E+00$ & +00 & +00 & $E+00$ & $E+00$ & $E+00$ & +00 & $E+00$ & & $E+00$ & $\mathrm{E}+00$ \\
\hline ILAW-I & & & & +00 & $E+00$ & $E+00$ & $E+00$ & +00 & +00 & $E+00$ & $E+00$ & +00 & $E+00$ & $E+00$ & $E+00$ & $E+00$ \\
\hline RMWSF & & & & +00 & $=+00$ & $E+00$ & $=+00$ & +00 & $E+00$ & $E+00$ & $E+00$ & $E+00$ & $E+00$ & $E+00$ & $E+00$ & $E+00$ \\
\hline UPR-10 & & & & E-12 & $E-12$ & $\mathrm{E}-12$ & $E-12$ & $E-12$ & $=-12$ & E-12 & E-12 & E-12 & E-12 & E-12 & E-12 & 45E-12 \\
\hline UPR-1 & & & & -15 & $E-15$ & $E-15$ & $=-15$ & -15 & $E-15$ & $E-15$ & $E-15$ & $=-15$ & $E-15$ & $E-15$ & $E-15$ & $8 \mathrm{E}-15$ \\
\hline UPR-10C & & & & BE-13 & $68 \mathrm{E}-13$ & $46 \mathrm{E}-13$ & $8 \mathrm{E}-12$ & $\mathrm{E}-12$ & E-12 & EE-12 & $3 \mathrm{E}-12$ & $\mathrm{E}-12$ & $.19 \mathrm{E}-12$ & $.18 \mathrm{E}-12$ & $18 \mathrm{E}-12$ & $18 \mathrm{E}-12$ \\
\hline UPR-10C & & & & $85 E-15$ & $86 \mathrm{E}-15$ & 87E-15 & 01E-14 & LE-14 & $2 E-14$ & LE-14 & LE-14 & $E-14$ & $.02 \mathrm{E}-14$ & $1 \mathrm{E}-14$ & $01 \mathrm{E}-14$ & 01E-14 \\
\hline UPR-20C & & & & $9 \mathrm{E}-09$ & & & 01E-07 & $=-03$ & & & E-02 & & & & & \\
\hline UPR-2C & & & & E-04 & & & E-04 & & & & $\mathrm{E}-04$ & & & & & \\
\hline UPR-2 & & & & & & & 2E-05 & & & E-05 & $2 \mathrm{E}-05$ & E-05 & 3E-05 & EE-05 & 4.32E-05 & 2E-05 \\
\hline UPR & & & & & & & & & & & & & & & & E-09 \\
\hline UPR-2 & & & & & & -07 & -07 & & & & $=-07$ & & & & E-07 & 2E-07 \\
\hline UPR-2C & & & & $E-11$ & $E-11$ & $E-11$ & $\mathrm{E}-11$ & $=-11$ & $=-11$ & $E-11$ & E-11 & $E+01$ & $E+00$ & $E+00$ & $E+00$ & DE-01 \\
\hline UPR-2C & & & & +00 & $E+00$ & $E+00$ & $E+00$ & $=00$ & $E+00$ & $E+00$ & $\mathrm{E}+00$ & $E+00$ & $E+00$ & +00 & $E+00$ & $\mathrm{E}+00$ \\
\hline UPR-2C & & & & +00 & $E+00$ & $E+00$ & $E+00$ & +00 & $=00$ & $E+00$ & $\mathrm{E}+00$ & $E+00$ & $E+00$ & $E+00$ & $E+00$ & $E+00$ \\
\hline UPR-20 & -08 & & -08 & 3E-08 & $1.39 \mathrm{E}-08$ & 1.38E-08 & $1.38 \mathrm{E}-08$ & 8E-08 & 1.39E-08 & $1.38 \mathrm{E}-08$ & $1.38 \mathrm{E}-08$ & 1.38E-08 & 1.39E-08 & 1.38E-08 & $1.38 \mathrm{E}-08$ & 1.38E-08 \\
\hline UPR-2C & & & & $E+00$ & $E+00$ & $E+00$ & $\mathrm{E}+00$ & $E+00$ & $\mathrm{E}+00$ & $0 \mathrm{E}+00$ & $00 \mathrm{E}+00$ & $E+00$ & $0.00 \mathrm{E}+00$ & $0.00 \mathrm{E}+00$ & $0.00 \mathrm{E}+00$ & $.00 \mathrm{E}+00$ \\
\hline UPR-200 & $E+00$ & $0.00 \mathrm{E}$ & 0.00 & $0.00 \mathrm{E}+00$ & $00 \mathrm{E}+00$ & $00 \mathrm{E}+00$ & DOE+00 & $E+00$ & $0.00 \mathrm{E}+00$ & $E+00$ & $E+00$ & $E+00$ & $E+00$ & $E+00$ & $0.00 \mathrm{E}+00$ & $0.00 \mathrm{E}+00$ \\
\hline UPR-200-E & E-08 & -08 & $=-08$ & $7.10 \mathrm{E}-08$ & $7.12 \mathrm{E}-08$ & 7.10E-08 & 7.10E-08 & 7.10E-08 & $7.12 \mathrm{E}-08$ & 7.10E-08 & $7.10 \mathrm{E}-08$ & 7.10E-08 & $7.12 \mathrm{E}-08$ & $7.10 \mathrm{E}-08$ & 7.10E-08 & 10E-08 \\
\hline UPR-200 & +00 & +00 & $0.00 \mathrm{E}+00$ & $.00 \mathrm{E}+00$ & $00 \mathrm{E}+00$ & DOE+00 & DOE+00 & $00 \mathrm{E}+00$ & $00 \mathrm{E}+00$ & $00 \mathrm{E}+00$ & $00 \mathrm{E}+00$ & $E+00$ & $E+00$ & $\mathrm{DE}+00$ & $\mathrm{DE}+00$ & $00 \mathrm{E}+00$ \\
\hline UPR-20 & +00 & +00 & 0.00 & $E+00$ & $00 \mathrm{E}+00$ & $E+00$ & $E+00$ & $=00$ & $E+00$ & $=+00$ & $E+00$ & +00 & $E+00$ & +00 & & +00 \\
\hline UPR-200 & & & -05 & $5.29 \mathrm{E}-05$ & 31E-05 & $99 \mathrm{E}-05$ & 29E-05 & $9 \mathrm{E}-05$ & $1 \mathrm{E}-05$ & $5.29 \mathrm{E}-05$ & $5.29 \mathrm{E}-05$ & $5.29 \mathrm{E}-05$ & 5.31E-05 & 5.29E-05 & 5.29E-05 & $5.29 \mathrm{E}-05$ \\
\hline UPR-200 & & 0.00 & +00 & 0.00 & $00 \mathrm{E}+00$ & $0.00 \mathrm{E}+00$ & $0.00 \mathrm{E}+00$ & $E+00$ & $E+00$ & $.00 \mathrm{E}+00$ & $0.00 \mathrm{E}+00$ & +00 & $E+00$ & $0.00 \mathrm{E}+00$ & $0.00 \mathrm{E}+00$ & $0.00 \mathrm{E}+00$ \\
\hline UPR-20C & & & & & & & E-07 & & & E-07 & E-07 & $E-07$ & E-07 & E-07 & E-07 & E-07 \\
\hline UPR-200 & & & & $2.14 \mathrm{E}-12$ & $2.14 \mathrm{E}-12$ & $2.14 \mathrm{E}-12$ & $2.14 \mathrm{E}-12$ & $E-12$ & $E-12$ & $E-12$ & E-12 & $E-12$ & $E-12$ & $E-12$ & $\mathrm{E}-12$ & E-12 \\
\hline UPR-200 & & & & $0.00 \mathrm{E}+00$ & $0.00 \mathrm{E}+00$ & $0.00 \mathrm{E}+00$ & $0.00 \mathrm{E}+00$ & $\mathrm{E}+00$ & $E+00$ & $E+00$ & $E+00$ & +00 & $E+00$ & $E+00$ & $0.00 \mathrm{E}+00$ & \\
\hline UPR-200 & & & & & & & $23 E-10$ & 3E-10 & & $E-10$ & $6.23 \mathrm{E}-10$ & $3 E-10$ & $6.25 \mathrm{E}-10$ & $6.23 \mathrm{E}-10$ & .23E-10 & $6.23 \mathrm{E}-10$ \\
\hline UPR-200 & & & & & & 39E-07 & $39 E-07$ & & & $\mathrm{E}-07$ & 8.39E-07 & $\mathrm{E}+00$ & $2.85 \mathrm{E}+00$ & $1.50 \mathrm{E}+00$ & .17E-01 & 7.13E-01 \\
\hline UPR-200 & & & & & & & & & & & & & & & & $9.39 \mathrm{E}-08$ \\
\hline DR-200-E-74 & & & & E-08 & EE-08 & E-08 & $6 \mathrm{E}-08$ & $\mathrm{E}-08$ & & & $6 \mathrm{E}-08$ & & & & $66 \mathrm{E}-08$ & $2.66 \mathrm{E}-08$ \\
\hline UPR-200-E-75 & 1.05E-04 & 1.05E-04 & 1.05E-04 & $1.05 \mathrm{E}-04$ & 1.05E-04 & 1.05E-04 & 1.05E-04 & 1.05E-04 & 1.05E-04 & 1.05E-04 & 1.05E-04 & 1.05E-04 & $1.05 \mathrm{E}-04$ & $1.05 \mathrm{E}-04$ & 1.05E-04 & $1.05 \mathrm{E}-0$ \\
\hline
\end{tabular}




\begin{tabular}{|c|c|c|c|c|c|c|c|c|c|c|c|c|c|c|c|c|}
\hline & & & & & & & & & & & & & & & & \\
\hline Site & 1944 & 1945 & 1946 & 1947 & 1948 & 1949 & 1950 & 1951 & 1952 & 1953 & 1954 & 1955 & 1956 & 1957 & 1958 & 19 \\
\hline JPR-200-E-77 & $3 \mathrm{E}-09$ & $1 \mathrm{E}-09$ & & $1 \mathrm{E}-\mathrm{C}$ & 43E-09 & 41E-09 & 41E-09 & 41E-09 & 43E-09 & 41E-09 & 41E-09 & 41E-09 & $43 \mathrm{E}-09$ & 41E-09 & 41E-09 & \\
\hline JPR-200-E-78 & & & & & & & & & & & & & & & & \\
\hline PR-200-E-79 & & & & & & & & & & & & & & & & \\
\hline PR-200-E-80 & & & & & & & & & & & & & & & & \\
\hline PR-200-E-81 & & & & & & & & & & & & & & & & \\
\hline JPR-20 & & & & & & & & & & & & & & & & \\
\hline PR-20 & & & E-08 & $9 \mathrm{E}-08$ & E-08 & 09E-08 & E-08 & & E-08 & $09 E-08$ & $75 \mathrm{E}+00$ & $1.03 \mathrm{E}+00$ & & & $68 \mathrm{E}-01$ & $\mathrm{E}-\mathrm{C}$ \\
\hline JPR-20 & & & & $8 \mathrm{E}-09$ & 90E-09 & 88E-09 & 8E-09 & & E-09 & $88 \mathrm{E}-09$ & $6.88 \mathrm{E}-09$ & & & & 6.88E-09 & $8 \mathrm{E}-0$ \\
\hline JPR-2C & & & & 3E-03 & $\mathrm{E}-03$ & 78E-03 & E-03 & & E-03 & $3 \mathrm{E}-03$ & & & & & & $\mathrm{E}-\mathrm{C}$ \\
\hline PR-2 & & & & E-06 & E-06 & $E-06$ & $E-06$ & & $\mathrm{E}-06$ & & & & & $=-06$ & $\mathrm{E}-06$ & $E-C$ \\
\hline PR-2C & & & & $E-05$ & & & & & & & & & & & & $\mathrm{E}-\mathrm{C}$ \\
\hline JPR-2 & & & & & & & & & & & & & & & & \\
\hline JPR-2 & & & & & & & & & & & & & & & & \\
\hline PPR-20 & & & & & & & & & & & & & & & & \\
\hline JPR-20 & & & & & & & & & & & & -07 & & & -07 & $=-4$ \\
\hline PR-2C & & & & & & & & & & & & -03 & -03 & -03 & -03 & $=-\mathrm{c}$ \\
\hline PR-20 & & & & -07 & & -07 & & & & 07 & -07 & -07 & 07 & -07 & E-07 & $E-C$ \\
\hline JPR-2 & & & & & & & & & & & & -09 & & & $=-09$ & $5-c$ \\
\hline UPR-2 & & & & & & & & & & & & & & & & $=-1$ \\
\hline UPR-2C & & & & $\mathrm{E}-06$ & & & & & & & & & & & $=-06$ & \\
\hline JPR-2 & & & & & & & & & & & & & & & & \\
\hline 13 & & & & & & & & & & & & & & & & \\
\hline PR-2 & & & & & & & & & & & & & & & & \\
\hline PR-2 & & & & & & & & & & & & & & & & \\
\hline PR-2 & & & & & & & & & & & & & & & & \\
\hline PR-2 & & & & -11 & -11 & -11 & -11 & & -11 & & & -11 & & & $=-11$ & \\
\hline PR-2C & & & & & & & & & & -07 & -07 & -07 & & -07 & E-07 & $E-C$ \\
\hline PR-2C & & & & & & & & & & & & -08 & -08 & -08 & E-08 & $E-($ \\
\hline PR-20 & & & -07 & $=-07$ & -07 & $=-07$ & -07 & -07 & E-07 & E-07 & E-07 & $E-07$ & $\mathrm{E}-07$ & $=-07$ & 3E-07 & $3 \mathrm{E}-\mathrm{C}$ \\
\hline JPR-20 & & & & $E-05$ & & & -05 & & & & $=-05$ & & & & 7E-05 & $\mathrm{E}-\mathrm{O}$ \\
\hline JPR-20 & & & & & & & $=-10$ & & & & & & & & $=-10$ & $E-1$ \\
\hline PR-20 & $E-11$ & & E-11 & E-11 & E-11 & $96 \mathrm{E}-11$ & jE-11 & E-11 & $\mathrm{E}-11$ & -11 & $E-11$ & $=-11$ & & E-09 & 5E-09 & $E-C$ \\
\hline PR-2C & E-09 & & & & & & & & & & & & & & & \\
\hline PR-2C & & & & & & & & & & & & & & & 6E-06 & \\
\hline JPR-20 & & & & & & & & & & & & & & & 4.65E-06 & \\
\hline JPR-20 & & & & & & & & & & & & & & & & \\
\hline JPR-20 & & & & & & & & & & & & & & & & \\
\hline JPR-20 & & & & & & & & & & & & & & & 1.18E-06 & \\
\hline JPR-20 & & & & & & & & & & & & & & & & \\
\hline & & & & & & & & & & & & & & & & \\
\hline $1 F R-200-v v-30$ & $2.09 \mathrm{E}-06$ & & & & & & & & & & & & & & & \\
\hline
\end{tabular}


ANNUAL DISCHARGE VOLUMES IN $\mathrm{M}^{3}$

\begin{tabular}{|c|c|c|c|c|c|c|c|c|c|c|c|c|c|c|c|c|}
\hline & & & & & & & & & & & & & & & & \\
\hline Site & 1944 & 1945 & 1946 & 1947 & 1948 & 1949 & 1950 & 1951 & 1952 & 1953 & 1954 & 1955 & 1956 & 1957 & 1958 & 1959 \\
\hline JPR-200-W-39 & $1.89 \mathrm{E}-07$ & 1.89E-07 & $.89 \mathrm{E}-07$ & 1.89E-07 & $1.89 \mathrm{E}-07$ & 1.89E-07 & 1.89E-07 & 1.89E-07 & 1.89E-07 & 1.89E-07 & 1.89E-07 & 1.89E-07 & 1.89E-07 & 1.89E-07 & 1.89E-07 & $1.89 \mathrm{E}-07$ \\
\hline JPR-200-W-49 & $5.16 \mathrm{E}-08$ & 5.14E-08 & $5.14 \mathrm{E}-08$ & $5.14 \mathrm{E}-08$ & $5.16 \mathrm{E}-08$ & $5.14 \mathrm{E}-08$ & $5.14 \mathrm{E}-08$ & & $5.16 \mathrm{E}-08$ & & 5.14E-08 & & $5.16 \mathrm{E}-08$ & & $5.14 \mathrm{E}-08$ & \\
\hline JPR-200-W-5 & $3.45 \mathrm{E}-10$ & $3.45 \mathrm{E}-10$ & $3.45 \mathrm{E}-10$ & $3.45 \mathrm{E}-10$ & $3.45 \mathrm{E}-10$ & $3.45 \mathrm{E}-10$ & $3.45 \mathrm{E}-10$ & & $3.45 \mathrm{E}-10$ & $3.45 \mathrm{E}-10$ & $3.45 \mathrm{E}-10$ & & 5.70E-08 & 5.69E-08 & & 5.87E- \\
\hline JPR-200-W-51 & $1.24 \mathrm{E}-08$ & 1.23E-08 & 1.23E-08 & 1.23E-08 & 1.24E-08 & 1.23E-08 & & $1.23 E-08$ & $1.24 \mathrm{E}-08$ & & & & 1.24E-08 & & & $1.23 \mathrm{E}-08$ \\
\hline JPR-200-W-59 & 24E-05 & 1.23E-05 & 1.23E-05 & 1.23E-05 & 1.24E-05 & 1.23 & & 1.2 & 1.24E-05 & & & & 1.24E-05 & & $=-05$ & E-05 \\
\hline JPR-200-W-6 & & 7.65E-09 & 7.65E-09 & 7.65E-09 & & & & & & & & & & & & \\
\hline JPR- & & & & 3.2 & & & & & & & & & & & & \\
\hline JPR- & -10 & 1.38 & $=-10$ & $1.38 \mathrm{E}-10$ & & & 1.3 & 1.38 & & & & & & & & \\
\hline UPR- & E-10 & $E-10$ & $E-10$ & 3.63E-10 & 3.62 & & -10 & 3.6 & 3.6 & & & & & & -10 & $3.6 ?$ \\
\hline JPR-2 & 61E-05 & 1.60E-05 & 1.60E-05 & $1.60 \mathrm{E}-05$ & 1.61E-05 & 1.60E-05 & 1.60E-05 & 1.60E-05 & 1.61E-05 & 1.60E-05 & 1.60E-05 & 1.60E-05 & 1.61E-05 & 1.60E-05 & 1.60E-05 & $1.60 \mathrm{E}-05$ \\
\hline JPR-200-W-96 & 4.74E-08 & $4.72 \mathrm{E}-08$ & 4.72E-08 & $4.72 \mathrm{E}-08$ & 4.74E-08 & 4.72 & -08 & 4.72 & 4.74 & 4.72 & $E-08$ & $4.72 \mathrm{E}-08$ & 4.74E-08 & $\mathrm{E}-08$ & $4.72 \mathrm{E}-08$ & $4.72 \mathrm{E}-08$ \\
\hline JPR-20C & $3.95 \mathrm{E}-10$ & 3.93E-10 & 3.93E-10 & $3.93 \mathrm{E}-10$ & 3.95 & 3.93E-10 & 3.93E-10 & $3.93 \mathrm{E}-10$ & 3.95 & 3.93 & 3.93 & 3.93 & 3.9 & 3.93 & $E-10$ & $E-1$ \\
\hline JPR-200-W-98 & $7.10 \mathrm{E}-10$ & $7.08 \mathrm{E}-10$ & $7.08 \mathrm{E}-10$ & $7.08 \mathrm{E}-10$ & $7.10 \mathrm{E}-10$ & $7.08 \mathrm{E}-10$ & $7.0 \varepsilon$ & $7.08 \mathrm{E}-10$ & 7.10 & 7.08 & 7.08 & $E-08$ & 5.4 & 5.4 & $E-08$ & 5.41E-08 \\
\hline JPR-300-4 & $7.22 \mathrm{E}-10$ & $7.20 \mathrm{E}-10$ & $7.20 \mathrm{E}-10$ & $7.20 \mathrm{E}-10$ & $7.22 \mathrm{E}-10$ & 8.35E-08 & 4.06E-06 & 7.14E-05 & 1.10E-03 & 1.38E-02 & 1.49E-01 & $1.29 \mathrm{E}+00$ & $1.35 \mathrm{E}+01$ & $3.99 \mathrm{E}+01$ & $8.22 \mathrm{E}+01$ & $8.63 \mathrm{E}+01$ \\
\hline US_Ecology & $0.00 \mathrm{E}+00$ & $0.00 \mathrm{E}+00$ & $0.00 \mathrm{E}+00$ & $0.00 \mathrm{E}+00$ & $0.00 \mathrm{E}+00$ & $0.00 \mathrm{E}+00$ & $0.00 \mathrm{E}+00$ & $0.00 \mathrm{E}+00$ & $0.00 E+00$ & $0.00 \mathrm{E}+00$ & $0.00 \mathrm{E}+00$ & $0.00 \mathrm{E}+00$ & $0.00 \mathrm{E}+00$ & $0.00 \mathrm{E}+00$ & $0.00 \mathrm{E}+00$ & $0.00 \mathrm{E}+00$ \\
\hline
\end{tabular}




\begin{tabular}{|c|c|c|c|c|c|c|c|c|c|c|c|c|c|c|c|c|}
\hline Site & 1960 & 1961 & 1962 & 1963 & 1964 & 1965 & 1966 & 1967 & 1968 & 1969 & 1970 & 1971 & 1972 & 1973 & 1974 & 1975 \\
\hline 216-U-1\%2-Fast & $14 \mathrm{E}+00$ & $12 \mathrm{E}+00$ & $12 \mathrm{E}+00$ & $8.12 \mathrm{E}+00$ & $14 \mathrm{E}+00$ & $12 \mathrm{E}+00$ & $12 \mathrm{E}+00$ & $.12 \mathrm{E}+00$ & $14 \mathrm{E}+00$ & $12 \mathrm{E}+00$ & $3.12 \mathrm{E}+00$ & $8.12 \mathrm{E}+00$ & $8.14 \mathrm{E}+00$ & $8.12 \mathrm{E}+00$ & $8.12 \mathrm{E}+00$ & $3.12 \mathrm{E}+00$ \\
\hline & & $18 \mathrm{E}+01$ & $8.37 \mathrm{E}+00$ & $7.83 \mathrm{E}+00$ & $29 \mathrm{E}+00$ & $73 \mathrm{E}+00$ & $73 E+00$ & $73 \mathrm{E}+00$ & $39 \mathrm{E}+00$ & $78 \mathrm{E}+00$ & $.78 \mathrm{E}+00$ & $.78 \mathrm{E}+00$ & $4.79 \mathrm{E}+00$ & $4.78 \mathrm{E}+00$ & & $4.45 \mathrm{E}+00$ \\
\hline -D-3 & $73 E-03$ & 04E-02 & $2.73 \mathrm{E}-02$ & $6.87 \mathrm{E}-02$ & $.71 \mathrm{E}-01$ & $15 \mathrm{E}-01$ & $9.83 \mathrm{E}-01$ & $2.17 \mathrm{E}+00$ & $22 \mathrm{E}+00$ & $86 \mathrm{E}+00$ & $49 \mathrm{E}+00$ & $1.16 \mathrm{E}+01$ & $1.31 \mathrm{E}+01$ & $1.40 \mathrm{E}+01$ & & \\
\hline D-D-32 & $9 \mathrm{E}-05$ & 49E-05 & 69E-04 & $35 E-04$ & $37 \mathrm{E}-03$ & $21 \mathrm{E}-03$ & 57E-02 & $3.87 \mathrm{E}-02$ & $9.52 \mathrm{E}-02$ & $2.26 \mathrm{E}-01$ & $5.00 \mathrm{E}-01$ & $9.70 \mathrm{E}-01$ & $1.59 \mathrm{E}+00$ & $2.20 \mathrm{E}+00$ & & \\
\hline $0-D-40$ & $7 \mathrm{E}-04$ & $1.22 \mathrm{E}-03$ & 20E-03 & 8.04E-03 & $2.00 \mathrm{E}-02$ & 85E-02 & $15 \mathrm{E}-01$ & $2.53 \mathrm{E}-01$ & 4.94E-01 & 8.03E-01 & $1.11 \mathrm{E}+00$ & $1.36 \mathrm{E}+00$ & $1.53 \mathrm{E}+00$ & $1.64 \mathrm{E}+00$ & & \\
\hline$-\mathrm{D}-47$ & $48 \mathrm{E}-02$ & 4.13E-02 & $1.08 \mathrm{E}-01$ & $2.72 \mathrm{E}-01$ & $6.76 \mathrm{E}-01$ & $64 \mathrm{E}+00$ & $89 \mathrm{E}+00$ & $8.57 \mathrm{E}+00$ & $1.67 \mathrm{E}+01$ & $2.72 \mathrm{E}+01$ & $76 \mathrm{E}+01$ & $4.59 \mathrm{E}+01$ & $5.18 \mathrm{E}+01$ & $5.53 \mathrm{E}+01$ & $5.76 \mathrm{E}+01$ & $\mathrm{DE}+01$ \\
\hline $0-F-25$ & $60 \mathrm{E}+01$ & $2.60 \mathrm{E}+01$ & $2.60 \mathrm{E}+01$ & $2.59 \mathrm{E}+01$ & $2.60 \mathrm{E}+01$ & $60 \mathrm{E}+01$ & $2.60 \mathrm{E}+01$ & $2.59 E+01$ & $2.60 \mathrm{E}+01$ & $2.60 \mathrm{E}+01$ & $2.60 \mathrm{E}+01$ & $2.59 \mathrm{E}+01$ & $2.60 \mathrm{E}+01$ & $2.60 \mathrm{E}+01$ & $2.60 \mathrm{E}+01$ & $2.59 \mathrm{E}+01$ \\
\hline $100-\mathrm{H}-10$ & $51 \mathrm{E}+01$ & $2.51 \mathrm{E}+01$ & $2.51 \mathrm{E}+01$ & $2.50 \mathrm{E}+01$ & $2.51 \mathrm{E}+01$ & $50 \mathrm{E}+01$ & $9.34 \mathrm{E}-01$ & 1.39E-01 & 8.54E-02 & 7.18E-02 & $6.58 \mathrm{E}-02$ & 6.34E-02 & 6.21E-02 & $6.19 \mathrm{E}-02$ & $6.13 \mathrm{E}-02$ & $11 \mathrm{E}-02$ \\
\hline )-H-5 & $33 E+01$ & $7.87 \mathrm{E}+01$ & $7.89 \mathrm{E}+01$ & $7.90 \mathrm{E}+01$ & $7.93 \mathrm{E}+01$ & $91 \mathrm{E}+01$ & $7.91 \mathrm{E}+01$ & $7.91 \mathrm{E}+01$ & $7.93 \mathrm{E}+01$ & $7.91 \mathrm{E}+01$ & $7.91 \mathrm{E}+01$ & $7.91 \mathrm{E}+01$ & $7.93 \mathrm{E}+01$ & $7.91 \mathrm{E}+01$ & $7.91 \mathrm{E}+01$ & $.91 \mathrm{E}+01$ \\
\hline & $51 \mathrm{E}+01$ & $2.50 \mathrm{E}+01$ & $2.50 \mathrm{E}+01$ & $2.50 \mathrm{E}+01$ & $2.51 \mathrm{E}+01$ & $50 \mathrm{E}+01$ & $3.79 \mathrm{E}-01$ & 4.94E-02 & 2.99E-02 & $2.50 \mathrm{E}-02$ & $2.28 \mathrm{E}-02$ & $2.20 \mathrm{E}-02$ & $2.15 \mathrm{E}-02$ & $2.14 \mathrm{E}-02$ & $2.12 \mathrm{E}-02$ & $11 \mathrm{E}-02$ \\
\hline & $E+01$ & $2.50 E+01$ & $2.50 \mathrm{E}+01$ & $2.50 \mathrm{E}+01$ & $2.51 \mathrm{E}+01$ & $50 \mathrm{E}+01$ & 5.31E-01 & 7.17E-02 & 4.36E-02 & $65 \mathrm{E}-02$ & 3.34E-02 & $3.21 E-02$ & $3.14 \mathrm{E}-02$ & 14E-02 & OE-02 & 09E-02 \\
\hline & $E+01$ & $2.50 \mathrm{E}+01$ & $2.50 \mathrm{E}+01$ & $2.49 \mathrm{E}+01$ & $E+01$ & $\mathrm{DE}+01$ & $4 \mathrm{E}-01$ & $2.69 \mathrm{E}-02$ & 1.84E-02 & 1.62E-02 & $1.50 \mathrm{E}$ & 1.49E-02 & 1.46E-02 & $6 \mathrm{E}-02$ & -02 & $5 \mathrm{E}-02$ \\
\hline & $E-04$ & $2.06 \mathrm{E}-03$ & 6.48E-03 & 1.85E-02 & E-02 & $32 \mathrm{E}-01$ & 3.37E-01 & 8.15E-01 & $1.80 \mathrm{E}+00$ & $3.41 E+00$ & $5.57 \mathrm{E}+00$ & $7.90 \mathrm{E}+00$ & $1.01 E+01$ & $E+01$ & $E+01$ & $7 \mathrm{E}+01$ \\
\hline & $83 \mathrm{E}+01$ & $1.82 \mathrm{E}+01$ & $1.82 \mathrm{E}+01$ & $1.82 \mathrm{E}+01$ & $.83 E+01$ & $82 \mathrm{E}+01$ & $1.82 \mathrm{E}+01$ & $1.82 \mathrm{E}+01$ & $1.83 E+01$ & $1.82 \mathrm{E}+01$ & $1.82 \mathrm{E}+01$ & $1.82 \mathrm{E}+01$ & $1.83 \mathrm{E}+01$ & $2 \mathrm{E}+01$ & $E+00$ & $8 \mathrm{E}-01$ \\
\hline J-60 & E-06 & $2.01 \mathrm{E}-06$ & $2.01 \mathrm{E}-06$ & 1.24E-05 & 98E-02 & 39E-01 & $2.96 \mathrm{E}-01$ & $2.99 \mathrm{E}-01$ & $3.00 \mathrm{E}-01$ & $2.99 \mathrm{E}-01$ & $2.99 \mathrm{E}-01$ & $2.99 \mathrm{E}-01$ & 3.00E-01 & $.99 \mathrm{E}-01$ & 9E-01 & $2.99 \mathrm{E}-01$ \\
\hline-66 & 36E-11 & 9.93E-11 & $9.90 \mathrm{E}-11$ & $9.81 \mathrm{E}-11$ & $00 \mathrm{E}+00$ & $.00 \mathrm{E}+00$ & $00 \mathrm{E}+00$ & $0.00 E+00$ & $0.00 E+00$ & $0.00 \mathrm{E}+00$ & $0.00 \mathrm{E}+00$ & $0.00 \mathrm{E}+00$ & $0.00 \mathrm{E}+00$ & $0.00 \mathrm{E}+00$ & $0.00 \mathrm{E}+00$ & $.00 \mathrm{E}+00$ \\
\hline 6-B-1 & $47 \mathrm{E}+02$ & $1.47 \mathrm{E}+02$ & $1.12 \mathrm{E}+02$ & $1.06 \mathrm{E}+02$ & $1.06 \mathrm{E}+02$ & $06 \mathrm{E}+02$ & $49 \mathrm{E}+01$ & $8.81 \mathrm{E}+01$ & $8.83 \mathrm{E}+01$ & $8.81 \mathrm{E}+01$ & $8.81 \mathrm{E}+01$ & $8.81 \mathrm{E}+01$ & $8.68 \mathrm{E}+01$ & $8.22 \mathrm{E}+01$ & $8.22 \mathrm{E}+01$ & $3.22 \mathrm{E}+01$ \\
\hline 6-B-2 & $28 \mathrm{E}+00$ & $14 \mathrm{E}+00$ & $1.14 \mathrm{E}+00$ & $1.14 \mathrm{E}+00$ & $15 \mathrm{E}+00$ & $14 \mathrm{E}+00$ & $1.14 \mathrm{E}+00$ & $1.13 \mathrm{E}+00$ & $1.10 \mathrm{E}+00$ & $1.09 \mathrm{E}+00$ & $1.09 \mathrm{E}+00$ & $1.09 \mathrm{E}+00$ & $1.10 \mathrm{E}+00$ & $1.09 \mathrm{E}+00$ & $1.09 \mathrm{E}+00$ & $.09 \mathrm{E}+00$ \\
\hline & $7 \mathrm{E}-01$ & 4.06E-01 & 4.06E-01 & 4.04E-01 & 3.85E-01 & $84 \mathrm{E}-01$ & 3.84E-01 & 3.84E-01 & $3.85 \mathrm{E}-01$ & E-01 & $3.72 \mathrm{E}-01$ & 3.69E-01 & E-01 & E-01 & & \\
\hline B-4 & $52 E+01$ & $2.51 \mathrm{E}+01$ & $2.51 \mathrm{E}+01$ & $2.50 \mathrm{E}+01$ & $52 \mathrm{E}+01$ & $51 \mathrm{E}+01$ & $51 \mathrm{E}+01$ & $2.50 \mathrm{E}+01$ & $2.51 \mathrm{E}+01$ & $4.02 \mathrm{E}+00$ & $34 \mathrm{E}+00$ & $6.05 \mathrm{E}-01$ & 5.27E-01 & $1 \mathrm{E}-01$ & E-01 & E-01 \\
\hline & $8 \mathrm{E}+02$ & $27 \mathrm{E}+02$ & $5.27 \mathrm{E}+02$ & $5.26 \mathrm{E}+02$ & $28 \mathrm{E}+02$ & $27 \mathrm{E}+02$ & $27 \mathrm{E}+02$ & $5.26 \mathrm{E}+02$ & $5.27 \mathrm{E}+02$ & $E+01$ & $E+01$ & $7.34 \mathrm{E}+00$ & $4.65 E+00$ & $E+00$ & $E+00$ & $E+00$ \\
\hline$-6 \mathrm{~B}$ & & 1.67E-01 & 1.67E-01 & 1.67E-01 & 1.67E-01 & 35E-01 & .34E-01 & 1.34E-01 & 1.34E-01 & $\mathrm{E}-01$ & 4 E-01 & 1.27E-01 & 1.23E-01 & 1.23E-01 & -01 & $3 \mathrm{E}-01$ \\
\hline & & $1.57 \mathrm{E}+05$ & $4.14 \mathrm{E}+05$ & $1.56 \mathrm{E}+05$ & $.02 \mathrm{E}+05$ & $6 \mathrm{E}+05$ & $2 E+04$ & $7.33 \mathrm{E}+04$ & $7.64 \mathrm{E}+04$ & $7.60 \mathrm{E}+04$ & $1.02 \mathrm{E}+04$ & $3.27 \mathrm{E}+03$ & $1.38 \mathrm{E}+03$ & $E+03$ & $E+02$ & $\mathrm{E}+02$ \\
\hline$-2 \mathrm{~A}$ & +02 & $8 \mathrm{E}+02$ & $4.18 \mathrm{E}+02$ & +02 & $9 \mathrm{E}+02$ & $E+02$ & $E+02$ & $4.17 \mathrm{E}+02$ & $4.19 \mathrm{E}+02$ & $E+02$ & 01 & $E+01$ & $9.62 \mathrm{E}+$ & $\mathrm{E}+00$ & $E+00$ & $E+00$ \\
\hline$-2 C$ & $E+02$ & $18 \mathrm{E}+02$ & $4.18 \mathrm{E}+02$ & $4.16 \mathrm{E}+02$ & $19 \mathrm{E}+02$ & $3 E+02$ & $\mathrm{E}+02$ & $4.16 \mathrm{E}+02$ & $4.19 \mathrm{E}+02$ & $E+02$ & $3.22 \mathrm{E}+01$ & $8.76 \mathrm{E}+00$ & $4.01 \mathrm{E}+00$ & $E+00$ & $E+00$ & $E+00$ \\
\hline$-1 A$ & $2 E+00$ & $91 \mathrm{E}+00$ & $2.91 \mathrm{E}+00$ & $2.85 \mathrm{E}+00$ & $.21 \mathrm{E}+00$ & $1 \mathrm{E}+00$ & $21 \mathrm{E}+00$ & $2.21 E+00$ & $2.21 \mathrm{E}+00$ & $2.21 \mathrm{E}+00$ & $2.00 \mathrm{E}+00$ & $1.95 \mathrm{E}+00$ & $1.96 \mathrm{E}+00$ & $95 \mathrm{E}+00$ & $E+00$ & $1.95 \mathrm{E}+00$ \\
\hline$-1 B$ & $36 \mathrm{E}+02$ & $34 \mathrm{E}+02$ & $5.34 \mathrm{E}+02$ & $5.33 \mathrm{E}+02$ & $.36 \mathrm{E}+02$ & $4 \mathrm{E}+02$ & $34 \mathrm{E}+02$ & $5.33 \mathrm{E}+02$ & $8.07 \mathrm{E}+01$ & $2.51 \mathrm{E}+01$ & $1.17 \mathrm{E}+01$ & $7.10 \mathrm{E}+00$ & $5.48 \mathrm{E}+00$ & $4.42 \mathrm{E}+00$ & $3.00 \mathrm{E}+00$ & $3.00 \mathrm{E}+00$ \\
\hline DR-1\% & $8 \mathrm{E}+02$ & $57 \mathrm{E}+02$ & $3.57 \mathrm{E}+02$ & $3.57 \mathrm{E}+02$ & $39 \mathrm{E}+02$ & $50 \mathrm{E}+02$ & $50 \mathrm{E}+02$ & $2.50 \mathrm{E}+02$ & $2.51 \mathrm{E}+02$ & $2.50 \mathrm{E}+02$ & $2.50 \mathrm{E}+02$ & $2.15 E+02$ & $2.13 \mathrm{E}+02$ & $2.13 \mathrm{E}+02$ & $2.13 \mathrm{E}+02$ & $2.13 \mathrm{E}+02$ \\
\hline 6-DR-3 & $10 \mathrm{E}+01$ & $9.43 E+00$ & $6.71 \mathrm{E}+00$ & $6.71 \mathrm{E}+00$ & $6.15 \mathrm{E}+00$ & $67 \mathrm{E}+00$ & $4.67 \mathrm{E}+00$ & $4.67 \mathrm{E}+00$ & $4.68 \mathrm{E}+00$ & $4.11 \mathrm{E}+00$ & $3.80 \mathrm{E}+00$ & $3.80 \mathrm{E}+00$ & $3.81 E+00$ & $3.80 \mathrm{E}+00$ & $3.80 \mathrm{E}+00$ & $3.80 \mathrm{E}+00$ \\
\hline 116-F-1 & $13 \mathrm{E}+03$ & $8.11 E+03$ & $8.12 \mathrm{E}+03$ & $8.10 \mathrm{E}+03$ & $13 E+03$ & $10 \mathrm{E}+03$ & $3.29 \mathrm{E}+03$ & $1.68 \mathrm{E}+03$ & $9.81 \mathrm{E}+02$ & $9.01 \mathrm{E}+02$ & $5.96 \mathrm{E}+02$ & $5.96 \mathrm{E}+02$ & $5.69 \mathrm{E}+02$ & $4.73 E+02$ & $4.73 \mathrm{E}+02$ & $4.73 \mathrm{E}+02$ \\
\hline $116-F-10$ & $23 \mathrm{E}+01$ & $2.22 \mathrm{E}+01$ & $2.22 \mathrm{E}+01$ & $2.22 \mathrm{E}+01$ & $2.23 \mathrm{E}+01$ & $22 \mathrm{E}+01$ & $1.06 \mathrm{E}+00$ & $2.95 \mathrm{E}-01$ & 1.43E-01 & 1.19E-01 & 6.81E-02 & $6.53 \mathrm{E}-02$ & 6.42E-02 & 4.69E-02 & $4.69 \mathrm{E}-02$ & $4.69 \mathrm{E}-02$ \\
\hline 116-F-11 & $55 \mathrm{E}+01$ & $1.54 \mathrm{E}+01$ & $1.54 \mathrm{E}+01$ & $1.54 \mathrm{E}+01$ & $.55 \mathrm{E}+01$ & $1.54 \mathrm{E}+01$ & $8.23 \mathrm{E}-01$ & $2.35 \mathrm{E}-01$ & 1.11E-01 & $9.57 \mathrm{E}-02$ & $5.28 \mathrm{E}-02$ & $5.25 \mathrm{E}-02$ & $5.05 \mathrm{E}-02$ & $.77 \mathrm{E}-02$ & $.77 \mathrm{E}-02$ & $3.77 \mathrm{E}-02$ \\
\hline $6-\mathrm{F}-2$ & $96 \mathrm{E}+02$ & $2.49 E+02$ & $2.49 \mathrm{E}+02$ & $2.49 \mathrm{E}+02$ & $2.34 \mathrm{E}+02$ & $2.25 \mathrm{E}+02$ & $25 \mathrm{E}+02$ & $2.25 \mathrm{E}+02$ & $2.26 \mathrm{E}+02$ & $2.25 \mathrm{E}+02$ & $2.20 \mathrm{E}+02$ & $2.20 \mathrm{E}+02$ & $2.20 \mathrm{E}+02$ & $2.20 \mathrm{E}+02$ & $2.20 \mathrm{E}+02$ & $2.20 \mathrm{E}+02$ \\
\hline $6-\mathrm{F}-3$ & $34 \mathrm{E}+01$ & $1.31 \mathrm{E}+01$ & $1.31 \mathrm{E}+01$ & $1.31 \mathrm{E}+01$ & $1.29 \mathrm{E}+01$ & $1.23 \mathrm{E}+01$ & $1.23 \mathrm{E}+01$ & $1.23 \mathrm{E}+01$ & $1.23 \mathrm{E}+01$ & $1.23 \mathrm{E}+01$ & $1.23 \mathrm{E}+01$ & $1.22 \mathrm{E}+01$ & $1.22 \mathrm{E}+01$ & $1.21 \mathrm{E}+01$ & $1.21 \mathrm{E}+01$ & $1.21 \mathrm{E}+01$ \\
\hline $116-F-4$ & $86 \mathrm{E}-01$ & $3.85 \mathrm{E}-01$ & $3.85 \mathrm{E}-01$ & $3.85 \mathrm{E}-01$ & 3.72E-01 & 3.71E-01 & $3.71 \mathrm{E}-01$ & $3.71 \mathrm{E}-01$ & $3.72 \mathrm{E}-01$ & $3.71 \mathrm{E}-01$ & $3.69 \mathrm{E}-01$ & $3.68 \mathrm{E}-01$ & $3.69 \mathrm{E}-01$ & $3.68 \mathrm{E}-01$ & $3.68 \mathrm{E}-01$ & $3.68 \mathrm{E}-01$ \\
\hline 116-F-6 & $44 \mathrm{E}+01$ & $7.97 \mathrm{E}+01$ & $9.75 \mathrm{E}+01$ & $1.08 \mathrm{E}+02$ & $1.13 \mathrm{E}+02$ & $1.16 \mathrm{E}+02$ & $1.16 \mathrm{E}+02$ & $1.15 \mathrm{E}+02$ & $1.14 \mathrm{E}+02$ & $1.13 \mathrm{E}+02$ & $1.12 \mathrm{E}+02$ & $1.12 \mathrm{E}+02$ & $1.12 \mathrm{E}+02$ & $1.12 \mathrm{E}+02$ & $1.12 \mathrm{E}+02$ & $1.12 \mathrm{E}+02$ \\
\hline $\mathrm{H}-1$ & $72 E+02$ & $4.57 \mathrm{E}+02$ & $4.57 \mathrm{E}+02$ & $4.57 \mathrm{E}+02$ & $56 \mathrm{E}+02$ & $54 \mathrm{E}+02$ & $4.54 \mathrm{E}+02$ & $4.54 \mathrm{E}+02$ & $4.55 E+02$ & $4.54 \mathrm{E}+02$ & $4.53 \mathrm{E}+02$ & $4.53 \mathrm{E}+02$ & $4.54 \mathrm{E}+02$ & $4.53 \mathrm{E}+02$ & $4.53 \mathrm{E}+02$ & $.53 \mathrm{E}+02$ \\
\hline $5-\mathrm{H}-2$ & $4 \mathrm{E}+04$ & $4.62 \mathrm{E}+04$ & $4.62 \mathrm{E}+04$ & $4.61 \mathrm{E}+04$ & $64 \mathrm{E}+04$ & $62 \mathrm{E}+04$ & $4.50 \mathrm{E}+02$ & $5.00 \mathrm{E}+01$ & $3.39 \mathrm{E}+01$ & $2.94 \mathrm{E}+01$ & $2.80 \mathrm{E}+01$ & $2.74 \mathrm{E}+01$ & $2.72 \mathrm{E}+01$ & $2.69 \mathrm{E}+01$ & $2.69 \mathrm{E}+01$ & $2.69 \mathrm{E}+01$ \\
\hline & $51 \mathrm{E}+01$ & $2.50 E+01$ & $2.50 \mathrm{E}+01$ & $2.50 \mathrm{E}+01$ & $51 \mathrm{E}+01$ & $2.50 \mathrm{E}+01$ & 5.24E-01 & $6.52 \mathrm{E}-02$ & $4.22 \mathrm{E}-02$ & 3.49E-02 & $3.20 \mathrm{E}-02$ & 3.13E-02 & 3.08E-02 & 3.03E-02 & $3.03 \mathrm{E}-02$ & $3.02 \mathrm{E}-02$ \\
\hline & $4 \mathrm{E}+03$ & $8.02 \mathrm{E}+03$ & $8.02 \mathrm{E}+03$ & $8.01 \mathrm{E}+03$ & $.04 \mathrm{E}+03$ & $8.01 E+03$ & $3.07 \mathrm{E}+03$ & $1.62 \mathrm{E}+03$ & $1.10 \mathrm{E}+03$ & $1.04 \mathrm{E}+03$ & $8.80 \mathrm{E}+02$ & $8.80 \mathrm{E}+02$ & $8.74 \mathrm{E}+02$ & $8.42 \mathrm{E}+02$ & $8.42 \mathrm{E}+02$ & $8.42 \mathrm{E}+02$ \\
\hline $116-\mathrm{K}-2$ & $2.01 E+07$ & $1.85 E+07$ & $1.82 \mathrm{E}+07$ & $1.82 \mathrm{E}+07$ & $1.79 \mathrm{E}+07$ & $1.85 E+07$ & $1.81 \mathrm{E}+07$ & $1.84 \mathrm{E}+07$ & $1.84 \mathrm{E}+07$ & $1.80 \mathrm{E}+07$ & $5.05 E+05$ & $4.77 \mathrm{E}+04$ & $2.47 E+04$ & $1.66 \mathrm{E}+04$ & $1.13 E+04$ & \\
\hline
\end{tabular}




\begin{tabular}{|c|c|c|c|c|c|c|c|c|c|c|c|c|c|c|c|c|}
\hline Site & 1960 & 1961 & 1962 & 1963 & 1964 & 1965 & 1966 & 1967 & 1968 & 1969 & 1970 & 1971 & 1972 & 1973 & 1974 & 1975 \\
\hline 116-KE-1 & $89 \mathrm{E}+01$ & $88 \mathrm{E}+01$ & $4.88 \mathrm{E}+01$ & $87 \mathrm{E}+01$ & $89 \mathrm{E}+01$ & $4.88 \mathrm{E}+01$ & $4.88 \mathrm{E}+01$ & $4.87 \mathrm{E}+01$ & $4.89 \mathrm{E}+01$ & $4.88 \mathrm{E}+01$ & $4.88 \mathrm{E}+01$ & $4.87 \mathrm{E}+01$ & $3.04 \mathrm{E}+01$ & $1.78 \mathrm{E}+01$ & $9.83 \mathrm{E}+00$ & $8.96 \mathrm{E}+00$ \\
\hline 116-KE-2 & $77 \mathrm{E}+02$ & 76E+02 & $1.76 \mathrm{E}+02$ & 76E+02 & $77 \mathrm{E}+02$ & $76 \mathrm{E}+02$ & $76 \mathrm{E}+02$ & $1.76 \mathrm{E}+02$ & $77 \mathrm{E}+02$ & $76 \mathrm{E}+02$ & $1.76 \mathrm{E}+02$ & $1.76 \mathrm{E}+02$ & $2.50 \mathrm{E}+01$ & $7.74 \mathrm{E}+00$ & & $.22 \mathrm{E}+00$ \\
\hline 116-KE-3 & $3 \mathrm{E}+01$ & $2.41 \mathrm{E}+01$ & $3.58 \mathrm{E}+01$ & $22 \mathrm{E}+01$ & $21 E+02$ & $42 \mathrm{E}+02$ & $74 \mathrm{E}+02$ & $8.53 E+02$ & $37 \mathrm{E}+03$ & $.92 \mathrm{E}+03$ & $2.42 \mathrm{E}+03$ & $2.82 \mathrm{E}+03$ & $3.14 \mathrm{E}+03$ & $3.32 \mathrm{E}+03$ & $3.49 E+03$ & $.52 \mathrm{E}+03$ \\
\hline KW-2 & $73 \mathrm{E}+01$ & $1.84 \mathrm{E}+01$ & $2.11 \mathrm{E}+01$ & $.71 \mathrm{E}+01$ & $06 \mathrm{E}+01$ & $82 \mathrm{E}+01$ & $21 \mathrm{E}+02$ & $2.08 \mathrm{E}+02$ & $3.25 \mathrm{E}+02$ & $51 \mathrm{E}+02$ & $5.66 \mathrm{E}+02$ & $6.52 \mathrm{E}+02$ & $7.16 \mathrm{E}+02$ & $7.72 \mathrm{E}+02$ & $7.80 \mathrm{E}+02$ & $8.18 \mathrm{E}+02$ \\
\hline $116-\mathrm{N}-1$ & $3.76 \mathrm{E}-10$ & $3.75 \mathrm{E}-10$ & $3.75 \mathrm{E}-10$ & $3.43 \mathrm{E}+06$ & $65 \mathrm{E}+06$ & $3.64 \mathrm{E}+06$ & $3.64 \mathrm{E}+06$ & $3.63 E+06$ & $3.65 E+06$ & $3.64 \mathrm{E}+06$ & $3.64 \mathrm{E}+06$ & $3.63 E+06$ & $3.65 E+06$ & $3.64 \mathrm{E}+06$ & $3.64 E+06$ & $3.63 E+06$ \\
\hline $116-N-3$ & $4.72 \mathrm{E}-10$ & $4.71 \mathrm{E}-10$ & $4.71 \mathrm{E}-10$ & $4.71 \mathrm{E}-10$ & $4.72 \mathrm{E}-10$ & $4.71 \mathrm{E}-10$ & $4.71 \mathrm{E}-10$ & $4.71 \mathrm{E}-10$ & $4.72 \mathrm{E}-10$ & $4.71 \mathrm{E}-10$ & $4.71 \mathrm{E}-10$ & $4.71 \mathrm{E}-10$ & $4.72 \mathrm{E}-10$ & $4.71 \mathrm{E}-10$ & $4.71 \mathrm{E}-10$ & $4.71 \mathrm{E}-10$ \\
\hline & 06E-07 & 2.06E-07 & 2.06E-07 & $8.23 \mathrm{E}+05$ & $1.68 \mathrm{E}+04$ & $1.39 \mathrm{E}+03$ & $6.93 \mathrm{E}+02$ & $4.43 \mathrm{E}+02$ & $3.47 \mathrm{E}+02$ & $2.89 \mathrm{E}+02$ & $2.53 \mathrm{E}+02$ & $2.07 \mathrm{E}+02$ & $2.08 \mathrm{E}+02$ & $2.02 \mathrm{E}+02$ & $1.70 \mathrm{E}+02$ & $.70 \mathrm{E}+02$ \\
\hline & 44E-03 & 1.87E-02 & $3.76 \mathrm{E}-02$ & 6.63E-02 & $1.02 \mathrm{E}-01$ & 1.35E-01 & 1.63E-01 & 1.82E-01 & 1.95E-01 & 2.03E-01 & 2.07E-01 & $2.10 \mathrm{E}-01$ & 2.13E-01 & 2.13E-01 & $2.14 \mathrm{E}-01$ & $15 \mathrm{E}-01$ \\
\hline & $52 \mathrm{E}-03$ & 3.61E-03 & 8.05E-03 & 1.63E-02 & 2.90E-02 & 4.43E-02 & $2 \mathrm{E}-02$ & 7.12E-02 & 7.99E-02 & 52E-02 & 8.86E-02 & 9.07E-02 & 3E-02 & $28 \mathrm{E}-02$ & 34E-02 & $9.37 \mathrm{E}-02$ \\
\hline & $00 \mathrm{E}+00$ & $0.00 \mathrm{E}+00$ & $0.00 \mathrm{E}+00$ & $0.00 \mathrm{E}+00$ & $0.00 \mathrm{E}+00$ & $E+00$ & $0.00 \mathrm{E}+00$ & $0.00 \mathrm{E}+00$ & $0.00 \mathrm{E}+00$ & $0.00 \mathrm{E}+00$ & $0.00 \mathrm{E}+00$ & $0.00 \mathrm{E}+00$ & $0.00 \mathrm{E}+00$ & $0.00 \mathrm{E}+00$ & $0.00 \mathrm{E}+00$ & $.00 \mathrm{E}+00$ \\
\hline & E-01 & $E+00$ & $4.78 \mathrm{E}+00$ & $1.13 \mathrm{E}+01$ & $3 \mathrm{E}+01$ & $E+01$ & $9.02 \mathrm{E}+01$ & $1.38 \mathrm{E}+02$ & $E+02$ & $2.22 \mathrm{E}+02$ & $8 \mathrm{E}+02$ & $5 \mathrm{E}+02$ & $6 \mathrm{E}+02$ & $2 \mathrm{E}+02$ & $36 \mathrm{E}+02$ & $2.89 \mathrm{E}+02$ \\
\hline & $00 \mathrm{E}+00$ & $0.00 \mathrm{E}+00$ & $0.00 \mathrm{E}+00$ & $0.00 \mathrm{E}+00$ & $\mathrm{OE}+00$ & $\mathrm{DE}+00$ & $00 \mathrm{E}+00$ & $0.00 \mathrm{E}+00$ & $0.00 \mathrm{E}+00$ & $0.00 \mathrm{E}+00$ & $0.00 \mathrm{E}+00$ & $0.00 \mathrm{E}+00$ & $0.00 \mathrm{E}+00$ & $0.00 \mathrm{E}+00$ & $\mathrm{JE}+00$ & $0.00 \mathrm{E}+00$ \\
\hline & $62 \mathrm{E}-01$ & 00E-01 & 7.79E-01 & $1.03 E+00$ & $20 \mathrm{E}+00$ & $31 \mathrm{E}+00$ & $1.37 \mathrm{E}+00$ & $1.40 E+00$ & $1.42 \mathrm{E}+00$ & $1.42 \mathrm{E}+00$ & $1.43 \mathrm{E}+00$ & $1.43 E+00$ & $4 \mathrm{E}+00$ & $1.43 E+00$ & $1.43 E+00$ & $1.43 \mathrm{E}+00$ \\
\hline & $72 \mathrm{E}+00$ & $1.39 \mathrm{E}+01$ & $3.29 \mathrm{E}+01$ & $7.25 \mathrm{E}+01$ & $41 \mathrm{E}+02$ & $29 \mathrm{E}+02$ & $17 \mathrm{E}+02$ & $3.88 \mathrm{E}+02$ & $1.38 \mathrm{E}+02$ & $4.68 \mathrm{E}+02$ & $4.87 \mathrm{E}+02$ & $4.98 \mathrm{E}+02$ & $5.07 \mathrm{E}+02$ & $5.10 \mathrm{E}+02$ & $5.13 \mathrm{E}+02$ & $5.15 \mathrm{E}+02$ \\
\hline & 9E-03 & 52E-03 & $2.70 \mathrm{E}-02$ & $8.38 \mathrm{E}-02$ & $2.38 \mathrm{E}-01$ & 6.23E-01 & $1.57 \mathrm{E}+00$ & $3.88 \mathrm{E}+00$ & $.55 \mathrm{E}+00$ & $26 \mathrm{E}+01$ & $5.02 \mathrm{E}+01$ & $9.74 \mathrm{E}+01$ & $1.60 \mathrm{E}+02$ & $2.21 \mathrm{E}+02$ & $2.70 \mathrm{E}+02$ & $.03 \mathrm{E}+02$ \\
\hline D-4 & 4.16E-02 & $1.16 \mathrm{E}-01$ & $3.05 \mathrm{E}-01$ & 7.66E-01 & $.91 \mathrm{E}+00$ & $4.63 \mathrm{E}+00$ & $1.10 \mathrm{E}+01$ & $2.42 \mathrm{E}+01$ & $4.71 \mathrm{E}+01$ & $7.65 E+01$ & $1.06 \mathrm{E}+02$ & $1.29 \mathrm{E}+02$ & $1.46 \mathrm{E}+02$ & $1.56 \mathrm{E}+02$ & $1.62 \mathrm{E}+02$ & $.66 \mathrm{E}+02$ \\
\hline -DR-2 & $0.00 \mathrm{E}+00$ & $0.00 \mathrm{E}+00$ & $0.00 \mathrm{E}+00$ & $0.00 \mathrm{E}+00$ & $00 \mathrm{E}+00$ & $0.00 \mathrm{E}+00$ & $0.00 \mathrm{E}+00$ & $0.00 \mathrm{E}+00$ & $0.00 \mathrm{E}+00$ & $0.00 \mathrm{E}+00$ & $0.00 \mathrm{E}+00$ & $0.00 \mathrm{E}+00$ & $0.00 \mathrm{E}+00$ & $0.00 \mathrm{E}+00$ & $0.00 \mathrm{E}+00$ & $.00 \mathrm{E}+00$ \\
\hline & $20 \mathrm{E}+00$ & $2.08 \mathrm{E}+01$ & $4.22 \mathrm{E}+01$ & $6.66 \mathrm{E}+01$ & $62 \mathrm{E}+01$ & $9.79 \mathrm{E}+01$ & $1.04 \mathrm{E}+02$ & $1.08 \mathrm{E}+02$ & $.10 \mathrm{E}+02$ & $10 \mathrm{E}+02$ & $.11 \mathrm{E}+02$ & $1.11 \mathrm{E}+02$ & $1 \mathrm{E}+02$ & $.11 \mathrm{E}+02$ & $1 \mathrm{E}+02$ & \\
\hline & $25 \mathrm{E}-01$ & $3.45 \mathrm{E}-01$ & $3.56 \mathrm{E}-01$ & $3.62 \mathrm{E}-01$ & $66 \mathrm{E}-01$ & 66E-01 & 3.67E-01 & 3.67E-01 & 69E-01 & 8E-01 & 8E-01 & $3.68 \mathrm{E}-01$ & 9E-01 & $8 \mathrm{E}-01$ & $8 \mathrm{E}-01$ & $8 \mathrm{E}-01$ \\
\hline & $E+00$ & $0.00 \mathrm{E}+00$ & $0.00 \mathrm{E}+00$ & $.00 \mathrm{E}+00$ & $00 \mathrm{E}+00$ & $00 \mathrm{E}+00$ & $0.00 \mathrm{E}+00$ & $0.00 \mathrm{E}+00$ & $.00 \mathrm{E}+00$ & $0 \mathrm{E}+00$ & $0 \mathrm{E}+00$ & $0.00 \mathrm{E}+00$ & $\mathrm{EE}+00$ & $0.00 \mathrm{E}+00$ & $0 \mathrm{E}+00$ & \\
\hline & $E+03$ & $22 \mathrm{E}+03$ & $E+03$ & & $22 \mathrm{E}+03$ & $E+03$ & $E+03$ & & $E+03$ & $E+03$ & $\mathrm{E}+03$ & & 03 & & $E+03$ & $E+03$ \\
\hline & +00 & +00 & $E+00$ & $E+00$ & $E+00$ & $E+00$ & $E+00$ & 0.0 & $E+00$ & $E+00$ & $E+00$ & 0.0 & $\mathrm{E}+00$ & $E+00$ & $E+00$ & $0 \mathrm{E}+00$ \\
\hline & E-01 & $E+00$ & $E+00$ & $9.19 \mathrm{E}+00$ & $\mathrm{E}+01$ & $E+01$ & $E+02$ & +02 & $\mathrm{E}+02$ & $\mathrm{E}+02$ & $\mathrm{E}+02$ & $E+02$ & $\mathrm{E}+02$ & $E+02$ & $\mathrm{E}+02$ & $8 \mathrm{E}+02$ \\
\hline E-1 & $E+00$ & $\mathrm{E}+00$ & $0.00 \mathrm{E}+00$ & $0.00 \mathrm{E}+00$ & $00 \mathrm{E}+00$ & $E+00$ & $00 \mathrm{E}+00$ & $0.00 \mathrm{E}+00$ & $E+00$ & $E+00$ & $E+00$ & $0.00 \mathrm{E}+00$ & $E+00$ & $\mathrm{DE}+00$ & $\mathrm{E}+00$ & $0.00 \mathrm{E}+00$ \\
\hline W-1 & $\mathrm{E}+00$ & $0.00 \mathrm{E}+00$ & $0.00 \mathrm{E}+00$ & $0.00 \mathrm{E}+00$ & $00 \mathrm{E}+00$ & $0.00 \mathrm{E}+00$ & $0.00 \mathrm{E}+00$ & $0.00 \mathrm{E}+00$ & $0.00 \mathrm{E}+00$ & $0.00 \mathrm{E}+00$ & $0.00 \mathrm{E}+00$ & $0.00 \mathrm{E}+00$ & $0.00 \mathrm{E}+00$ & $0.00 \mathrm{E}+00$ & $0.00 \mathrm{E}+00$ & $0.00 \mathrm{E}+00$ \\
\hline$W-2$ & $1 \mathrm{E}-04$ & $5.34 \mathrm{E}-04$ & 2.07E-03 & 7.34E-03 & $2.45 \mathrm{E}-02$ & 7.27E-02 & $1.82 \mathrm{E}-01$ & $3.68 \mathrm{E}-01$ & $6.14 \mathrm{E}-01$ & 8.59E-01 & $1.06 \mathrm{E}+00$ & $1.21 \mathrm{E}+00$ & $1.31 \mathrm{E}+00$ & $1.36 \mathrm{E}+00$ & $1.39 \mathrm{E}+00$ & $1.41 \mathrm{E}+00$ \\
\hline-100 & $E+00$ & $4.39 \mathrm{E}+00$ & $4.38 \mathrm{E}+00$ & $4.37 \mathrm{E}+00$ & $40 \mathrm{E}+00$ & $39 \mathrm{E}+00$ & $39 \mathrm{E}+00$ & $4.37 \mathrm{E}+00$ & $4.40 \mathrm{E}+00$ & $38 \mathrm{E}+00$ & $4.38 \mathrm{E}+00$ & $4.38 \mathrm{E}+00$ & $4.39 \mathrm{E}+00$ & $4.39 \mathrm{E}+00$ & $4.39 \mathrm{E}+00$ & $4.38 \mathrm{E}+00$ \\
\hline -E-102 & $2 E+02$ & $5.30 \mathrm{E}+01$ & $3.14 \mathrm{E}+01$ & $2.49 \mathrm{E}+01$ & $81 \mathrm{E}+01$ & $74 \mathrm{E}+01$ & $1.05 E+01$ & $1.05 E+01$ & $1.05 \mathrm{E}+01$ & $8.39 E+00$ & $6.22 \mathrm{E}+00$ & $6.22 \mathrm{E}+00$ & $6.24 \mathrm{E}+00$ & $6.22 \mathrm{E}+00$ & $5.99 \mathrm{E}+00$ & $3.82 \mathrm{E}+00$ \\
\hline E-103 & DOE+00 & $0.00 \mathrm{E}+00$ & $0.00 \mathrm{E}+00$ & $0.00 \mathrm{E}+00$ & $00 \mathrm{E}+00$ & $00 \mathrm{E}+00$ & $0.00 \mathrm{E}+00$ & $0.00 \mathrm{E}+00$ & $0.00 \mathrm{E}+00$ & $0.00 \mathrm{E}+00$ & $0.00 \mathrm{E}+00$ & $0.00 \mathrm{E}+00$ & $0.00 \mathrm{E}+00$ & $0.00 \mathrm{E}+00$ & $0.00 \mathrm{E}+00$ & $0.00 \mathrm{E}+00$ \\
\hline E-107 & $0.00 \mathrm{E}+00$ & $0.00 \mathrm{E}+00$ & $0.00 \mathrm{E}+00$ & $0.00 \mathrm{E}+00$ & $00 \mathrm{E}+00$ & $0.00 \mathrm{E}+00$ & $0.00 \mathrm{E}+00$ & $0.00 \mathrm{E}+00$ & $0.00 \mathrm{E}+00$ & $0.00 \mathrm{E}+00$ & $0.00 \mathrm{E}+00$ & $0.00 \mathrm{E}+00$ & $0.00 \mathrm{E}+00$ & $0.00 \mathrm{E}+00$ & $0.00 \mathrm{E}+00$ & $0.00 \mathrm{E}+00$ \\
\hline$=-25$ & 9E-08 & 1.19E-08 & 1.19E-08 & 1.19E-08 & 1.19E-08 & 1.19E-08 & 1.19E-08 & 1.19E-08 & 19E-08 & 9E-08 & 1.19E-08 & 1.19E-08 & $2.47 \mathrm{E}+00$ & $3.66 \mathrm{E}+00$ & $3.66 \mathrm{E}+00$ & $.65 \mathrm{E}+00$ \\
\hline & 0E-10 & 59E-10 & 2.69E-10 & 69E-10 & $2.70 \mathrm{E}-10$ & $9 \mathrm{E}-10$ & 2.69E-10 & 2.69E-10 & $2.70 \mathrm{E}-10$ & $2.69 \mathrm{E}-10$ & 2.69E-10 & 2.69E-10 & $2.70 \mathrm{E}-10$ & 2.69E-10 & 2.69E-10 & 2.69E-10 \\
\hline$E-41$ & DOE+00 & $0.00 \mathrm{E}+00$ & $0.00 \mathrm{E}+00$ & $0.00 \mathrm{E}+00$ & $0.00 \mathrm{E}+00$ & $0.00 \mathrm{E}+00$ & $0.00 \mathrm{E}+00$ & $0.00 \mathrm{E}+00$ & $0.00 \mathrm{E}+00$ & $0.00 \mathrm{E}+00$ & $0.00 \mathrm{E}+00$ & $0.00 \mathrm{E}+00$ & $0.00 \mathrm{E}+00$ & $0.00 \mathrm{E}+00$ & $0.00 \mathrm{E}+00$ & $.00 \mathrm{E}+00$ \\
\hline & 57E-07 & $4.56 \mathrm{E}-07$ & $4.56 \mathrm{E}-07$ & $4.56 \mathrm{E}-07$ & 4.57E-07 & 4.56E-07 & $4.56 \mathrm{E}-07$ & $4.56 \mathrm{E}-07$ & $4.57 \mathrm{E}-07$ & $4.56 \mathrm{E}-07$ & $4.56 \mathrm{E}-07$ & $4.56 \mathrm{E}-07$ & $4.57 \mathrm{E}-07$ & $4.56 \mathrm{E}-07$ & $4.56 \mathrm{E}-07$ & $4.56 \mathrm{E}-07$ \\
\hline & $E+00$ & $4.38 \mathrm{E}+00$ & $4.38 \mathrm{E}+00$ & $4.37 \mathrm{E}+00$ & $4.38 \mathrm{E}+00$ & $4.37 \mathrm{E}+00$ & $4.37 \mathrm{E}+00$ & $4.37 \mathrm{E}+00$ & $4.39 \mathrm{E}+00$ & $4.40 \mathrm{E}+00$ & $4.47 \mathrm{E}+00$ & $4.48 \mathrm{E}+00$ & $4.49 \mathrm{E}+00$ & $4.48 \mathrm{E}+00$ & $4.49 \mathrm{E}+00$ & $4.49 \mathrm{E}+00$ \\
\hline & $E+00$ & $7.11 \mathrm{E}+00$ & $5.08 \mathrm{E}+00$ & $3.89 \mathrm{E}+00$ & $12 \mathrm{E}+00$ & $2.78 \mathrm{E}+00$ & $2.28 \mathrm{E}+00$ & $1.91 E+00$ & $1.92 \mathrm{E}+00$ & $1.66 \mathrm{E}+00$ & $1.29 \mathrm{E}+00$ & $1.29 \mathrm{E}+00$ & $1.29 \mathrm{E}+00$ & $1.29 \mathrm{E}+00$ & $1.02 \mathrm{E}+00$ & 8.69E-01 \\
\hline & $9 \mathrm{E}+00$ & $4.45 \mathrm{E}+00$ & $2.84 \mathrm{E}+00$ & $2.70 \mathrm{E}+00$ & $1.78 \mathrm{E}+00$ & $1.63 \mathrm{E}+00$ & $1.63 \mathrm{E}+00$ & $1.12 \mathrm{E}+00$ & 9.91E-01 & 38E-01 & 9.88E-01 & 9.23E-01 & $6.12 \mathrm{E}-01$ & $6.10 \mathrm{E}-01$ & 0E-01 & $6.10 \mathrm{E}-01$ \\
\hline$E-60$ & 09E-13 & $4.08 \mathrm{E}-13$ & $4.08 \mathrm{E}-13$ & $4.08 \mathrm{E}-13$ & 4.09E-13 & $4.08 \mathrm{E}-13$ & $4.08 \mathrm{E}-13$ & $4.08 \mathrm{E}-13$ & $4.09 \mathrm{E}-13$ & $4.08 \mathrm{E}-13$ & $4.08 \mathrm{E}-13$ & $4.08 \mathrm{E}-13$ & 4.09E-13 & $4.08 \mathrm{E}-13$ & $4.08 \mathrm{E}-13$ & $4.08 \mathrm{E}-13$ \\
\hline E-61 & $0 \mathrm{E}+00$ & $0.00 \mathrm{E}+00$ & $0.00 \mathrm{E}+00$ & $0.00 \mathrm{E}+00$ & $00 \mathrm{E}+00$ & $0.00 \mathrm{E}+00$ & $0.00 \mathrm{E}+00$ & $0.00 \mathrm{E}+00$ & $0.00 \mathrm{E}+00$ & $0.00 \mathrm{E}+00$ & $0.00 \mathrm{E}+00$ & $0.00 \mathrm{E}+00$ & $0.00 \mathrm{E}+00$ & $0.00 \mathrm{E}+00$ & $0.00 \mathrm{E}+00$ & $.00 \mathrm{E}+00$ \\
\hline E-62 & $0 \mathrm{E}+00$ & $0.00 \mathrm{E}+00$ & $0.00 \mathrm{E}+00$ & $0.00 \mathrm{E}+00$ & $00 \mathrm{E}+00$ & $0.00 \mathrm{E}+00$ & $0.00 \mathrm{E}+00$ & $0.00 \mathrm{E}+00$ & $0.00 \mathrm{E}+00$ & $00 \mathrm{E}+00$ & $0.00 \mathrm{E}+00$ & $0.00 \mathrm{E}+00$ & $0.00 \mathrm{E}+00$ & $0.00 \mathrm{E}+00$ & $0.00 \mathrm{E}+00$ & $0.00 \mathrm{E}+00$ \\
\hline $200-E-63$ & $0.00 \mathrm{E}+00$ & $0.00 \mathrm{E}+00$ & $0.00 \mathrm{E}+00$ & $0.00 \mathrm{E}+00$ & $0.00 \mathrm{E}+00$ & $0.00 \mathrm{E}+00$ & $0.00 \mathrm{E}+00$ & $0.00 \mathrm{E}+00$ & $0.00 \mathrm{E}+00$ & $0.00 \mathrm{E}+00$ & $0.00 \mathrm{E}+00$ & $0.00 \mathrm{E}+00$ & $0.00 \mathrm{E}+00$ & $0.00 \mathrm{E}+00$ & $0.00 \mathrm{E}+00$ & \\
\hline
\end{tabular}




\begin{tabular}{|c|c|c|c|c|c|c|c|c|c|c|c|c|c|c|c|c|}
\hline Site & 1960 & 1961 & 1962 & 1963 & 1964 & 1965 & 1966 & 1967 & 1968 & 1969 & 1970 & 1971 & 1972 & 1973 & 1974 & 1975 \\
\hline $200-E-64$ & $00 \mathrm{E}+00$ & $0.00 \mathrm{E}+00$ & $.00 \mathrm{E}+00$ & $00 \mathrm{E}+00$ & $00 \mathrm{E}+00$ & $0.00 \mathrm{E}+00$ & $0.00 \mathrm{E}+00$ & $0.00 \mathrm{E}+00$ & $0.00 \mathrm{E}+00$ & $0.00 \mathrm{E}+00$ & $0.00 \mathrm{E}+00$ & $0.00 \mathrm{E}+00$ & $0.00 \mathrm{E}+00$ & $0.00 \mathrm{E}+00$ & $0.00 \mathrm{E}+00$ & $0.00 \mathrm{E}+00$ \\
\hline $200-E-65$ & 16E-07 & 4.15E-07 & 4.15E-07 & .15E-07 & .16E-07 & $.15 \mathrm{E}-07$ & 4.15E-07 & 4.15E-07 & $4.16 \mathrm{E}-07$ & $4.15 \mathrm{E}-07$ & 4.15E-07 & 4.15E-07 & 4.16E-07 & $4.15 \mathrm{E}-07$ & $4.15 \mathrm{E}-07$ & $4.15 \mathrm{E}-07$ \\
\hline 200-E-67 & $0 \mathrm{E}+00$ & $0.00 \mathrm{E}+00$ & $0.00 \mathrm{E}+00$ & $00 \mathrm{E}+00$ & $00 \mathrm{E}+00$ & $00 \mathrm{E}+00$ & $0.00 \mathrm{E}+00$ & $0.00 \mathrm{E}+00$ & $0.00 \mathrm{E}+00$ & $0.00 \mathrm{E}+00$ & $0.00 \mathrm{E}+00$ & $0.00 \mathrm{E}+00$ & $0.00 \mathrm{E}+00$ & $00 \mathrm{E}+00$ & $00 \mathrm{E}+00$ & $\mathrm{DE}+00$ \\
\hline $200-E-68$ & $16 \mathrm{E}-07$ & $4.15 \mathrm{E}-07$ & 4.15E-07 & $4.15 \mathrm{E}-07$ & 4.16E-07 & 15E-07 & $4.15 \mathrm{E}-07$ & 4.15E-07 & 4.16E-07 & $4.15 \mathrm{E}-07$ & 4.15E-07 & 4.15E-07 & 4.16E-07 & 4.15E-07 & $4.15 \mathrm{E}-07$ & $4.15 \mathrm{E}-07$ \\
\hline $0-E-69$ & $00 \mathrm{E}+00$ & $0.00 \mathrm{E}+00$ & $0.00 \mathrm{E}+00$ & $0.00 \mathrm{E}+00$ & $0.00 \mathrm{E}+00$ & $00 \mathrm{E}+00$ & $0.00 \mathrm{E}+00$ & $0.00 \mathrm{E}+00$ & $0.00 \mathrm{E}+00$ & $0.00 \mathrm{E}+00$ & $0.00 \mathrm{E}+00$ & $0.00 \mathrm{E}+00$ & $0.00 \mathrm{E}+00$ & $0.00 \mathrm{E}+00$ & $0.00 \mathrm{E}+00$ & $0 E+00$ \\
\hline 200-E-70 & 41E-05 & $3.40 \mathrm{E}-05$ & $3.40 \mathrm{E}-05$ & $3.40 \mathrm{E}-05$ & $3.41 \mathrm{E}-05$ & 3.40E-05 & $3.40 \mathrm{E}-05$ & $3.40 \mathrm{E}-05$ & $3.41 \mathrm{E}-05$ & $3.40 \mathrm{E}-05$ & $3.40 \mathrm{E}-05$ & $3.40 \mathrm{E}-05$ & $3.41 \mathrm{E}-05$ & 3.40E-05 & $3.40 \mathrm{E}-05$ & OE-05 \\
\hline 200-E-71 & 64E-05 & $63 \mathrm{E}-05$ & $2.63 \mathrm{E}-05$ & $2.63 \mathrm{E}-05$ & $2.64 \mathrm{E}-05$ & 2.63E-05 & $2.63 \mathrm{E}-05$ & $2.63 \mathrm{E}-05$ & $2.64 \mathrm{E}-05$ & 2.63E-05 & 2.63E-05 & 2.63E-05 & $64 \mathrm{E}-05$ & 63E-05 & 33E-05 & $3 E-05$ \\
\hline$E-72$ & 41E-05 & $3.40 \mathrm{E}-05$ & $3.40 \mathrm{E}-05$ & $3.40 \mathrm{E}-05$ & $3.41 \mathrm{E}-05$ & 40E-05 & $3.40 \mathrm{E}-05$ & $3.40 \mathrm{E}-05$ & 3.41E-05 & $3.40 \mathrm{E}-05$ & $3.40 \mathrm{E}-05$ & OE-05 & 41E-05 & 40E-05 & $0 \mathrm{E}-05$ & E-05 \\
\hline & $6 \mathrm{E}-07$ & 4E-07 & 4E-07 & 5.84E-07 & 5.86E-07 & HE-07 & 4E-07 & E-07 & E-07 & 4E-07 & 4E-07 & 4E-07 & $6 \mathrm{E}-07$ & 4E-07 & 4E-07 & 4E-07 \\
\hline & E-05 & E-05 & $3.40 \mathrm{E}-05$ & $3.40 \mathrm{E}-05$ & E-05 & E-05 & $3.40 \mathrm{E}-05$ & E-05 & $1 \mathrm{E}-05$ & DE-05 & DE-05 & E-05 & $1 \mathrm{E}-05$ & DE-05 & DE-05 & DE-05 \\
\hline-75 & $E-05$ & E-05 & E-05 & E-05 & E-05 & E-05 & E-05 & $\mathrm{E}-05$ & E-05 & E-05 & E-05 & E-05 & $1 \mathrm{E}-05$ & E-05 & $0 \mathrm{E}-05$ & DE-05 \\
\hline & +00 & $0.00 \mathrm{E}+00$ & $0.00 \mathrm{E}+00$ & $0.00 \mathrm{E}+00$ & $0.00 \mathrm{E}+00$ & $0.00 \mathrm{E}+00$ & $0.00 \mathrm{E}+00$ & $E+00$ & $\mathrm{E}+00$ & $E+00$ & $0.00 \mathrm{E}+00$ & $E+00$ & $\mathrm{EE}+00$ & $E+00$ & $\mathrm{JE}+00$ & $E+00$ \\
\hline & $E+00$ & $\mathrm{E}+00$ & $0.00 E+00$ & $0.00 E+00$ & $.00 \mathrm{E}+00$ & $E+00$ & $0.00 E+00$ & $E+00$ & $E+00$ & $E+00$ & $0.00 \mathrm{E}+00$ & $E+00$ & $\mathrm{DE}+00$ & $E+00$ & $E+00$ & $\mathrm{E}+00$ \\
\hline-78 & DOE+00 & DOE+00 & $0.00 E+00$ & $.00 \mathrm{E}+00$ & $00 \mathrm{E}+00$ & $00 \mathrm{E}+00$ & $0.00 E+00$ & $0.00 \mathrm{E}+00$ & $0.00 \mathrm{E}+00$ & $0.00 \mathrm{E}+00$ & $0.00 \mathrm{E}+00$ & $0.00 E+00$ & $0.00 \mathrm{E}+00$ & $0.00 E+00$ & $0.00 \mathrm{E}+00$ & $E+00$ \\
\hline-79 & $=00$ & $E+00$ & $0.00 \mathrm{E}+00$ & $E+00$ & $00 \mathrm{E}+00$ & $E+00$ & $00 \mathrm{E}+00$ & $0.00 \mathrm{E}+00$ & $.00 \mathrm{E}+00$ & $.00 \mathrm{E}+00$ & $00 \mathrm{E}+00$ & $0.00 \mathrm{E}+00$ & $0.00 \mathrm{E}+00$ & $0.00 \mathrm{E}+00$ & $\mathrm{E}+00$ & $\mathrm{E}+00$ \\
\hline 200-E-80 & $0 E+00$ & $00 \mathrm{E}+00$ & $0.00 \mathrm{E}+00$ & $.00 \mathrm{E}+00$ & $00 \mathrm{E}+00$ & $00 \mathrm{E}+00$ & $0.00 \mathrm{E}+00$ & $0.00 \mathrm{E}+00$ & $.00 \mathrm{E}+00$ & $E+00$ & $0 \mathrm{E}+00$ & $0.00 \mathrm{E}+00$ & $0.00 \mathrm{E}+00$ & $0.00 \mathrm{E}+00$ & $0.00 \mathrm{E}+00$ & $\mathrm{E}+00$ \\
\hline 200-E-81 & $0 \mathrm{E}+00$ & $0.00 \mathrm{E}+00$ & $0.00 \mathrm{E}+00$ & $0.00 \mathrm{E}+00$ & $00 \mathrm{E}+00$ & $00 \mathrm{E}+00$ & $0.00 \mathrm{E}+00$ & $0.00 \mathrm{E}+00$ & $0.00 \mathrm{E}+00$ & $0.00 \mathrm{E}+00$ & $.00 \mathrm{E}+00$ & $0.00 \mathrm{E}+00$ & $0.00 \mathrm{E}+00$ & $0.00 \mathrm{E}+00$ & $.00 \mathrm{E}+00$ & $\mathrm{E}+00$ \\
\hline $200-E-82$ & $0 \mathrm{E}+00$ & $0.00 \mathrm{E}+00$ & $0.00 \mathrm{E}+00$ & $.00 \mathrm{E}+00$ & $00 \mathrm{E}+00$ & $00 \mathrm{E}+00$ & $0.00 \mathrm{E}+00$ & $0.00 \mathrm{E}+00$ & $0.00 \mathrm{E}+00$ & $.00 \mathrm{E}+00$ & $.00 \mathrm{E}+00$ & $0.00 \mathrm{E}+00$ & $\mathrm{OE}+00$ & $0 \mathrm{E}+00$ & $0 \mathrm{E}+00$ & \\
\hline$E-84$ & 44E-07 & 9.42E-07 & 9.42E-07 & 9.42E-07 & 9.44E-07 & $.42 \mathrm{E}-07$ & 9.42E-07 & .42E-07 & 9.44E-07 & $9.42 \mathrm{E}-07$ & $2 \mathrm{E}-07$ & $2 \mathrm{E}-07$ & $4 \mathrm{E}-07$ & $2 \mathrm{E}-07$ & $42 \mathrm{E}-07$ & \\
\hline & $\mathrm{E}+00$ & $0.00 \mathrm{E}+00$ & $0.00 \mathrm{E}+00$ & $00 \mathrm{E}+00$ & $00 \mathrm{E}+00$ & $\mathrm{E}+00$ & $0.00 \mathrm{E}+00$ & $E+00$ & $.00 \mathrm{E}+00$ & $00 \mathrm{E}+00$ & $0 \mathrm{E}+00$ & $E+00$ & $\mathrm{EE}+00$ & $0.00 \mathrm{E}+00$ & $.00 \mathrm{E}+00$ & $\mathrm{DE}+00$ \\
\hline & E-04 & E-04 & E-04 & E-04 & E-04 & E-04 & E-04 & $=-04$ & & E-04 & E-04 & $=-04$ & E-04 & & E-04 & E-04 \\
\hline & -03 & $E-03$ & -03 & $=-03$ & $E-03$ & $E-03$ & $E-03$ & $=-03$ & $E-03$ & $E-03$ & $\mathrm{E}-03$ & $E-03$ & $E-03$ & E-03 & E-03 & E-03 \\
\hline & $E-04$ & E-04 & $E-04$ & E-04 & E-04 & $E-04$ & $\mathrm{E}-04$ & $E-04$ & $\mathrm{E}-04$ & E-04 & 3E-04 & E-04 & E-04 & E-04 & 3E-04 & E-04 \\
\hline-91 & $E-05$ & $E-05$ & $E-05$ & $E-05$ & $E-05$ & $E-05$ & $E-05$ & E-05 & E-05 & E-05 & E-05 & E-05 & E-05 & E-05 & $9 \mathrm{E}-05$ & E-05 \\
\hline-92 & $E-03$ & $4 \mathrm{E}-03$ & $E-03$ & 4E-03 & E-03 & EE-03 & $4 \mathrm{E}-03$ & 4E-03 & $4 \mathrm{E}-03$ & 84E-03 & 1.84E-03 & E-03 & $4 \mathrm{E}-03$ & $4 \mathrm{E}-03$ & $4 \mathrm{E}-03$ & $4 \mathrm{E}-03$ \\
\hline-93 & E-03 & 04E-03 & 04E-03 & 04E-03 & J4E-03 & 04E-03 & 1.04E-03 & 1.04E-03 & 04E-03 & 1.04E-03 & 1.04E-03 & 1.04E-03 & $.04 \mathrm{E}-03$ & 1.04E-03 & $1.04 \mathrm{E}-03$ & $1.04 \mathrm{E}-03$ \\
\hline-94 & E-04 & $3 \mathrm{E}-04$ & 53E-04 & 53E-04 & 55E-04 & 53E-04 & $6.53 \mathrm{E}-04$ & .53E-04 & 55E-04 & 53E-04 & $6.53 \mathrm{E}-04$ & $6.53 \mathrm{E}-04$ & $.55 \mathrm{E}-04$ & 53E-04 & $6.53 \mathrm{E}-04$ & $6.53 \mathrm{E}-04$ \\
\hline 200-E-95 & $40 \mathrm{E}+00$ & $4.39 \mathrm{E}+00$ & $4.39 \mathrm{E}+00$ & $4.37 \mathrm{E}+00$ & $39 \mathrm{E}+00$ & $38 \mathrm{E}+00$ & $4.39 \mathrm{E}+00$ & $4.37 \mathrm{E}+00$ & $4.40 \mathrm{E}+00$ & $4.39 \mathrm{E}+00$ & $4.39 \mathrm{E}+00$ & $4.37 \mathrm{E}+00$ & $4.40 \mathrm{E}+00$ & $4.38 \mathrm{E}+00$ & $4.38 \mathrm{E}+00$ & $4.37 \mathrm{E}+00$ \\
\hline 200-E-97 & $39 \mathrm{E}+00$ & $4.38 \mathrm{E}+00$ & $4.39 \mathrm{E}+00$ & $.37 \mathrm{E}+00$ & $4.40 \mathrm{E}+00$ & $4.39 \mathrm{E}+00$ & $4.39 \mathrm{E}+00$ & $4.37 \mathrm{E}+00$ & $4.40 \mathrm{E}+00$ & $4.39 \mathrm{E}+00$ & $4.38 \mathrm{E}+00$ & $4.37 \mathrm{E}+00$ & $4.40 \mathrm{E}+00$ & $4.39 \mathrm{E}+00$ & $4.39 \mathrm{E}+00$ & $1.37 \mathrm{E}+00$ \\
\hline 200-E-98 & $70 \mathrm{E}+00$ & $3.69 \mathrm{E}+00$ & $3.69 \mathrm{E}+00$ & $69 \mathrm{E}+00$ & $70 \mathrm{E}+00$ & $69 \mathrm{E}+00$ & $69 \mathrm{E}+00$ & $3.69 \mathrm{E}+00$ & $3.70 \mathrm{E}+00$ & $3.69 \mathrm{E}+00$ & $3.69 \mathrm{E}+00$ & $3.69 \mathrm{E}+00$ & $3.70 \mathrm{E}+00$ & $3.69 \mathrm{E}+00$ & $3.69 \mathrm{E}+00$ & $69 \mathrm{E}+00$ \\
\hline 200-E-99 & $4.43 \mathrm{E}+00$ & $4.42 \mathrm{E}+00$ & $4.42 \mathrm{E}+00$ & $42 \mathrm{E}+00$ & $4.43 \mathrm{E}+00$ & $4.42 \mathrm{E}+00$ & $4.42 \mathrm{E}+00$ & $4.42 \mathrm{E}+00$ & $4.43 \mathrm{E}+00$ & $4.42 \mathrm{E}+00$ & $4.42 \mathrm{E}+00$ & $4.42 \mathrm{E}+00$ & $4.42 \mathrm{E}+00$ & $4.42 \mathrm{E}+00$ & $4.42 \mathrm{E}+00$ & $42 \mathrm{E}+00$ \\
\hline $\mathrm{W}-22$ & E-06 & 24E-06 & $2.24 \mathrm{E}-06$ & $2.24 \mathrm{E}-06$ & 4E-06 & 4E-06 & $2.24 \mathrm{E}-06$ & 4E-06 & 24E-06 & 24E-06 & $2.24 \mathrm{E}-06$ & $2.24 \mathrm{E}-06$ & 24E-06 & 24E-06 & $2.24 \mathrm{E}-06$ & $2.24 \mathrm{E}-06$ \\
\hline$W-42$ & $2.03 \mathrm{E}-05$ & $2.03 \mathrm{E}-05$ & 2.03E-05 & 2.03E-05 & 2.03E-05 & 2.03E-05 & 2.03E-05 & 2.03E-05 & 2.03E-05 & 2.03E-05 & 2.03E-05 & $E-05$ & 3E-05 & 2.03E-05 & 2.03E-05 & 2.03E-05 \\
\hline$W-52$ & $3.60 \mathrm{E}+02$ & $3.17 \mathrm{E}+02$ & $1.91 \mathrm{E}+02$ & $1.91 \mathrm{E}+02$ & $1.92 \mathrm{E}+02$ & $1.34 \mathrm{E}+02$ & $1.07 \mathrm{E}+02$ & $1.07 \mathrm{E}+02$ & $E+02$ & $1.07 \mathrm{E}+02$ & $9.37 \mathrm{E}+01$ & $E+01$ & $\mathrm{E}+01$ & $\mathrm{DE}+01$ & $6.30 \mathrm{E}+01$ & $E+01$ \\
\hline & $66 \mathrm{E}-11$ & 1.65E-11 & $1.65 \mathrm{E}-11$ & $1.65 \mathrm{E}-11$ & $1.66 \mathrm{E}-11$ & 1.65E-11 & $1.65 \mathrm{E}-11$ & 1.65E-11 & $1.66 \mathrm{E}-11$ & 1.65E-11 & $1.65 \mathrm{E}-11$ & $E-11$ & 66E-11 & $55 E-11$ & $1.65 \mathrm{E}-11$ & E-11 \\
\hline$-M-P O N$ & $30 \mathrm{E}+04$ & $2.60 \mathrm{E}+04$ & $2.60 \mathrm{E}+04$ & $2.59 \mathrm{E}+04$ & $2.60 \mathrm{E}+04$ & $2.60 \mathrm{E}+04$ & $2.60 \mathrm{E}+04$ & $2.59 E+04$ & $2.60 \mathrm{E}+04$ & $2.60 \mathrm{E}+04$ & $2.60 \mathrm{E}+04$ & $2.59 \mathrm{E}+04$ & $2.60 \mathrm{E}+04$ & $0 \mathrm{E}+04$ & $2.60 \mathrm{E}+04$ & $E+04$ \\
\hline 216-A-10 & $39 \mathrm{E}+03$ & $3.70 \mathrm{E}+03$ & $3.12 \mathrm{E}+05$ & $08 \mathrm{E}+05$ & $3.76 \mathrm{E}+05$ & $23 \mathrm{E}+05$ & $2.90 \mathrm{E}+05$ & $3.10 \mathrm{E}+05$ & $2.61 \mathrm{E}+05$ & $1.32 \mathrm{E}+05$ & $6.61 \mathrm{E}+04$ & $6.22 \mathrm{E}+04$ & $4.42 \mathrm{E}+04$ & $2.19 \mathrm{E}+04$ & $1.21 \mathrm{E}+04$ & $7.48 \mathrm{E}+03$ \\
\hline $216-A-11$ & $1 \mathrm{E}+00$ & $5.90 \mathrm{E}+00$ & $5.90 \mathrm{E}+00$ & $89 \mathrm{E}+00$ & $91 \mathrm{E}+00$ & $90 \mathrm{E}+00$ & $5.90 \mathrm{E}+00$ & $5.89 \mathrm{E}+00$ & $5.91 \mathrm{E}+00$ & $.90 \mathrm{E}+00$ & $5.90 \mathrm{E}+00$ & $5.89 \mathrm{E}+00$ & $5.90 \mathrm{E}+00$ & $2.46 \mathrm{E}+00$ & $1.10 \mathrm{E}+00$ & $6.65 \mathrm{E}-01$ \\
\hline $6-A-12$ & $8 \mathrm{E}+00$ & $5.57 \mathrm{E}+00$ & $5.57 \mathrm{E}+00$ & $56 \mathrm{E}+00$ & $5.58 \mathrm{E}+00$ & $5.57 \mathrm{E}+00$ & $5.57 \mathrm{E}+00$ & $5.56 \mathrm{E}+00$ & $5.58 \mathrm{E}+00$ & $5.57 \mathrm{E}+00$ & $5.57 \mathrm{E}+00$ & $5.56 \mathrm{E}+00$ & $5.57 \mathrm{E}+00$ & $2.30 \mathrm{E}+00$ & $1.11 \mathrm{E}+00$ & $5.29 \mathrm{E}-01$ \\
\hline $6-A-13$ & 08E-02 & $1.44 \mathrm{E}+00$ & $1.46 \mathrm{E}+00$ & $29 \mathrm{E}+00$ & 8.89E-01 & $2 \mathrm{E}-01$ & 4.39E-01 & $3.29 \mathrm{E}-01$ & $2.86 \mathrm{E}-01$ & 3E-01 & 1.93E-01 & 9E-01 & $3 \mathrm{E}-01$ & $3 \mathrm{E}-01$ & 1.13E-01 & 3E-01 \\
\hline $216-A-14$ & $6.90 \mathrm{E}-07$ & $6.88 \mathrm{E}-07$ & $6.88 \mathrm{E}-07$ & $6.88 \mathrm{E}-07$ & $6.90 \mathrm{E}-07$ & $6.88 \mathrm{E}-07$ & $6.88 \mathrm{E}-07$ & $6.88 \mathrm{E}-07$ & $6.90 \mathrm{E}-07$ & $6.88 \mathrm{E}-07$ & $6.88 \mathrm{E}-07$ & $6.88 \mathrm{E}-07$ & $6.90 \mathrm{E}-07$ & $6.88 \mathrm{E}-07$ & $6.88 \mathrm{E}-07$ & $6.88 \mathrm{E}-07$ \\
\hline
\end{tabular}




\begin{tabular}{|c|c|c|c|c|c|c|c|c|c|c|c|c|c|c|c|c|}
\hline Site & 1960 & 1961 & 1962 & 1963 & 1964 & 1965 & 1966 & 1967 & 1968 & 1969 & 1970 & 1971 & 1972 & 1973 & 1974 & 1975 \\
\hline 216-A-15 & $58 \mathrm{E}+02$ & $.56 \mathrm{E}+02$ & $5.56 \mathrm{E}+02$ & $55 \mathrm{E}+02$ & $58 \mathrm{E}+02$ & $5.56 \mathrm{E}+02$ & $5.56 \mathrm{E}+02$ & $5.55 \mathrm{E}+02$ & $5.58 \mathrm{E}+02$ & $5.56 \mathrm{E}+02$ & $5.56 \mathrm{E}+02$ & $5.55 \mathrm{E}+02$ & $5.58 \mathrm{E}+02$ & $9.02 \mathrm{E}+01$ & $1.61 \mathrm{E}+01$ & $8.27 \mathrm{E}+00$ \\
\hline $216-A-16$ & $77 \mathrm{E}+00$ & $8.75 \mathrm{E}+00$ & $8.75 \mathrm{E}+00$ & $74 \mathrm{E}+00$ & $77 \mathrm{E}+00$ & $75 \mathrm{E}+00$ & $8.75 \mathrm{E}+00$ & $8.74 \mathrm{E}+00$ & $.77 \mathrm{E}+00$ & $8.74 \mathrm{E}+00$ & $4.40 \mathrm{E}+00$ & $2.22 \mathrm{E}+00$ & $1.28 \mathrm{E}+00$ & 8.07E-01 & $6.50 \mathrm{E}-01$ & 5.15E-01 \\
\hline 216-A-17 & $33 \mathrm{E}+00$ & $4.32 \mathrm{E}+00$ & $4.32 \mathrm{E}+00$ & $32 \mathrm{E}+00$ & $33 \mathrm{E}+00$ & $4.32 \mathrm{E}+00$ & $4.32 \mathrm{E}+00$ & $4.32 \mathrm{E}+00$ & $4.33 \mathrm{E}+00$ & $4.32 \mathrm{E}+00$ & $2.87 \mathrm{E}+00$ & $1.73 \mathrm{E}+00$ & $1.01 \mathrm{E}+00$ & 07E-01 & 90E-01 & $\mathrm{E}-01$ \\
\hline s-A-2 & 87E-05 & 9.84E-05 & $9.84 \mathrm{E}-05$ & $3.49 \mathrm{E}-03$ & $34 \mathrm{E}+01$ & $83 \mathrm{E}+01$ & $38 \mathrm{E}+01$ & $1.12 \mathrm{E}+01$ & $.01 \mathrm{E}+01$ & $7.79 \mathrm{E}+00$ & $7.05 \mathrm{E}+00$ & $7.05 E+00$ & $5.18 E+00$ & $2 E+00$ & $4.82 \mathrm{E}+00$ & $4.82 \mathrm{E}+00$ \\
\hline $216-A-20$ & $3.10 \mathrm{E}+01$ & $2.40 \mathrm{E}+01$ & $1.90 \mathrm{E}+01$ & $1.90 \mathrm{E}+01$ & $22 \mathrm{E}+01$ & $16 \mathrm{E}+01$ & $1.16 \mathrm{E}+01$ & $1.16 \mathrm{E}+01$ & $7.46 \mathrm{E}+00$ & $7.20 \mathrm{E}+00$ & $7.20 \mathrm{E}+00$ & $7.20 \mathrm{E}+00$ & $7.22 \mathrm{E}+00$ & $7.20 \mathrm{E}+00$ & $4.68 \mathrm{E}+00$ & $4 \mathrm{E}+00$ \\
\hline $6-A-21$ & $.01 \mathrm{E}+03$ & $7.41 \mathrm{E}+03$ & $1.92 \mathrm{E}+04$ & $1.29 \mathrm{E}+04$ & $52 E+04$ & $9.00 \mathrm{E}+03$ & $2.51 \mathrm{E}+03$ & $6.51 \mathrm{E}+02$ & $3.27 \mathrm{E}+02$ & $2.16 \mathrm{E}+02$ & $1.63 E+02$ & $1.16 \mathrm{E}+02$ & $9.36 \mathrm{E}+01$ & $4 \mathrm{E}+01$ & $.01 \mathrm{E}+01$ & $4 \mathrm{E}+01$ \\
\hline $16-A-22$ & 07E-04 & 2.06E-04 & 2.06E-04 & 2.06E-04 & 2.07E-04 & 2.06E-04 & $2.06 \mathrm{E}-04$ & 2.06E-04 & 2.07E-04 & $2.06 \mathrm{E}-04$ & $2.06 \mathrm{E}-04$ & $2.06 \mathrm{E}-04$ & 2.07E-04 & 2.06E-04 & 2.06E-04 & 6E-04 \\
\hline $6-A-23 A$ & 3.23E-05 & $3.22 \mathrm{E}-05$ & $3.22 \mathrm{E}-05$ & $3.22 \mathrm{E}-05$ & 3.23E-05 & 3.22E-05 & $3.22 \mathrm{E}-05$ & $3.22 \mathrm{E}-05$ & 3.23E-05 & $3.22 \mathrm{E}-05$ & $3.22 \mathrm{E}-05$ & $3.22 \mathrm{E}-05$ & 23E-05 & $2 \mathrm{E}-05$ & $22 \mathrm{E}-05$ & $2 \mathrm{E}-05$ \\
\hline & 3.55E-05 & 3.54E-05 & 3.54E-05 & 3.54E-05 & 3.55E-05 & 3.54E-05 & 3.54E-05 & 3.54E-05 & 3.55E-05 & $54 \mathrm{E}-05$ & 4E-05 & 3.54E-05 & $5 \mathrm{E}-05$ & 4E-05 & 54E-05 & 54E-05 \\
\hline & $6.72 \mathrm{E}+04$ & $2.11 \mathrm{E}+04$ & $1.85 \mathrm{E}+04$ & $1.93 \mathrm{E}+04$ & $1.78 \mathrm{E}+04$ & $1.45 \mathrm{E}+04$ & $1.26 \mathrm{E}+04$ & $1.22 \mathrm{E}+04$ & $1.63 \mathrm{E}+04$ & $9.83 E+03$ & $6.24 \mathrm{E}+03$ & $4.64 \mathrm{E}+03$ & $3.16 \mathrm{E}+03$ & $2.37 \mathrm{E}+03$ & $1.91 \mathrm{E}+03$ & $3 \mathrm{E}+03$ \\
\hline $6-A-25$ & $7.85 E+06$ & $9.85 \mathrm{E}+06$ & $1.24 \mathrm{E}+07$ & $.25 E+07$ & $09 \mathrm{E}+07$ & $1.08 \mathrm{E}+07$ & $8.92 \mathrm{E}+06$ & $9.94 \mathrm{E}+06$ & $1.33 \mathrm{E}+07$ & $8.72 \mathrm{E}+06$ & $1.03 \mathrm{E}+07$ & $1.60 \mathrm{E}+07$ & $1.27 \mathrm{E}+07$ & $3 \mathrm{E}+06$ & $E+06$ & $2 E+06$ \\
\hline 26 & $2.14 \mathrm{E}-06$ & $2.13 \mathrm{E}-06$ & $2.13 \mathrm{E}-06$ & $2.13 \mathrm{E}-06$ & $2.14 \mathrm{E}-06$ & 2.13E-06 & 2.13E-06 & $2.13 \mathrm{E}-06$ & $2.14 \mathrm{E}-06$ & 2.13E-06 & 2.13E-06 & $2.13 \mathrm{E}-06$ & $2.14 \mathrm{E}-06$ & $3 \mathrm{E}-06$ & $3 \mathrm{E}-06$ & $3 \mathrm{E}-06$ \\
\hline $6 \mathrm{~A}$ & 18E-06 & $2.17 \mathrm{E}-06$ & 17E-06 & 17E-06 & 2.18E-06 & $2.17 \mathrm{E}-06$ & 2.17E-06 & $2.17 \mathrm{E}-06$ & $2.18 \mathrm{E}-06$ & 2.17E-06 & 2.17E-06 & 2.17E-06 & 2.18E-06 & $2.17 \mathrm{E}-06$ & 7E-06 & F-06 \\
\hline $216-A-27$ & $62 \mathrm{E}-04$ & $6.60 \mathrm{E}-04$ & $6.60 \mathrm{E}-04$ & $6.60 \mathrm{E}-04$ & $6.62 \mathrm{E}-04$ & $2.61 \mathrm{E}+03$ & $8.00 \mathrm{E}+03$ & $4.61 E+03$ & $2.41 \mathrm{E}+03$ & $1.56 \mathrm{E}+03$ & $1.20 \mathrm{E}+03$ & $6.70 \mathrm{E}+02$ & $3.82 \mathrm{E}+02$ & $2.07 \mathrm{E}+02$ & $1.88 \mathrm{E}+02$ & $9.93 \mathrm{E}+01$ \\
\hline $6-A-28$ & $27 \mathrm{E}-03$ & $1.26 \mathrm{E}-03$ & $1.26 \mathrm{E}-03$ & $1.26 \mathrm{E}-03$ & 1.27E-03 & $1.26 \mathrm{E}-03$ & $1.26 \mathrm{E}-03$ & $1.26 \mathrm{E}-03$ & $1.27 \mathrm{E}-03$ & $1.26 \mathrm{E}-03$ & $1.26 \mathrm{E}-03$ & $1.26 \mathrm{E}-03$ & $1.27 \mathrm{E}-03$ & $1.26 \mathrm{E}-03$ & $1.26 \mathrm{E}-03$ & 6E-03 \\
\hline 216-A-3 & $46 \mathrm{E}+02$ & $3.71 \mathrm{E}+02$ & $2.52 \mathrm{E}+02$ & $26 \mathrm{E}+02$ & $74 \mathrm{E}+02$ & $2.68 \mathrm{E}+02$ & $1.05 \mathrm{E}+02$ & $6.08 \mathrm{E}+01$ & $4.04 \mathrm{E}+01$ & $.90 \mathrm{E}+01$ & $2.22 \mathrm{E}+01$ & $1.76 \mathrm{E}+01$ & $1.45 \mathrm{E}+01$ & $1.21 \mathrm{E}+01$ & $1.03 \mathrm{E}+01$ & $\mathrm{E}+00$ \\
\hline $216-A-30$ & 78E-01 & $1.77 \mathrm{E}-01$ & 1.77E-01 & $99 \mathrm{E}+05$ & $31 \mathrm{E}+05$ & $4.73 E+05$ & $3.57 \mathrm{E}+05$ & $2.43 \mathrm{E}+05$ & $1.89 \mathrm{E}+05$ & $.55 \mathrm{E}+05$ & $1.45 \mathrm{E}+05$ & $1.96 \mathrm{E}+05$ & $2.28 \mathrm{E}+05$ & $6 \mathrm{E}+05$ & $.13 \mathrm{E}+05$ & $E+04$ \\
\hline $216-A-31$ & $0 \mathrm{E}+00$ & $0.00 \mathrm{E}+00$ & $0.00 \mathrm{E}+00$ & $00 \mathrm{E}+00$ & $00 \mathrm{E}+00$ & $00 \mathrm{E}+00$ & $0.00 \mathrm{E}+00$ & $0.00 \mathrm{E}+00$ & $.00 \mathrm{E}+00$ & $.00 \mathrm{E}+00$ & $00 \mathrm{E}+00$ & $0.00 \mathrm{E}+00$ & $0 \mathrm{E}+00$ & $0 \mathrm{E}+00$ & $0 \mathrm{E}+00$ & \\
\hline 32 & $0 \mathrm{E}+00$ & $0.00 \mathrm{E}+00$ & $0.00 \mathrm{E}+00$ & $00 \mathrm{E}+00$ & $00 \mathrm{E}+00$ & $00 \mathrm{E}+00$ & $0.00 \mathrm{E}+00$ & $0.00 \mathrm{E}+00$ & $E+00$ & $0 \mathrm{E}+00$ & $0 \mathrm{E}+00$ & $0.00 \mathrm{E}+00$ & $E+00$ & $\mathrm{E}+00$ & $\mathrm{E}+00$ & $\mathrm{E}+00$ \\
\hline & $0 \mathrm{E}+00$ & $00 \mathrm{E}+00$ & $0.00 \mathrm{E}+00$ & $0.00 \mathrm{E}+00$ & $00 \mathrm{E}+00$ & $00 \mathrm{E}+00$ & $\mathrm{E}+00$ & & & $0.00 \mathrm{E}+00$ & $\mathrm{E}+00$ & $0.00 \mathrm{E}+00$ & $E+00$ & $E+00$ & $\mathrm{EE}+00$ & $\mathrm{E}+00$ \\
\hline & $\mathrm{E}-02$ & 27E-02 & 1.27E-02 & 1.27E-02 & BE-02 & 27E-02 & 7E-02 & & & 1.27E-02 & 7E-02 & & & & 7E-02 & $E-02$ \\
\hline & -02 & $E-02$ & $E-02$ & $E-02$ & $E-02$ & E-02 & $\mathrm{E}-02$ & E-02 & & E-02 & $\mathrm{E}-02$ & $3.48 \mathrm{E}+03$ & $E+04$ & $E+04$ & & $E+03$ \\
\hline 77-1 & E-05 & E-05 & E-05 & E-05 & E-05 & E-05 & LE-05 & E-05 & E-05 & $1 \mathrm{E}-05$ & E-05 & $2.41 \mathrm{E}$ & $E-05$ & E-05 & E-05 & E-05 \\
\hline$-A-37-2$ & $32 \mathrm{E}-03$ & $4.31 \mathrm{E}-03$ & 4.31E-03 & $4.31 \mathrm{E}-03$ & 4.32E-03 & $31 \mathrm{E}-03$ & 4.31E-03 & $4.31 \mathrm{E}-03$ & E-03 & $4.31 \mathrm{E}-03$ & LE-03 & $4.31 \mathrm{E}-03$ & $\mathrm{E}-03$ & E-03 & $1 \mathrm{E}-03$ & LE-03 \\
\hline -A-39 & $00 \mathrm{E}+00$ & $0.00 \mathrm{E}+00$ & $0.00 E+00$ & $.00 \mathrm{E}+00$ & $0.00 \mathrm{E}+00$ & $0.00 E+00$ & $0.00 E+00$ & $0.00 \mathrm{E}+00$ & $0.00 E+00$ & $0.00 E+00$ & $0.00 E+00$ & $0.00 E+00$ & $0.00 E+00$ & $0.00 E+00$ & $0.00 E+00$ & $0.00 E+00$ \\
\hline $216-A-4$ & $30 \mathrm{E}+01$ & $4.75 \mathrm{E}+01$ & $2.91 \mathrm{E}+01$ & $.20 \mathrm{E}+01$ & $70 \mathrm{E}+01$ & $49 \mathrm{E}+01$ & $1.00 \mathrm{E}+01$ & $1.00 \mathrm{E}+01$ & $1.00 \mathrm{E}+01$ & $6.55 \mathrm{E}+00$ & $5.96 \mathrm{E}+00$ & $5.96 \mathrm{E}+00$ & $5.98 \mathrm{E}+00$ & $5.96 \mathrm{E}+00$ & $4.39 \mathrm{E}+00$ & $3.67 \mathrm{E}+00$ \\
\hline$-A-40$ & $\mathrm{DE}+00$ & DOE+00 & $0.00 \mathrm{E}+00$ & $.00 \mathrm{E}+00$ & DOE+00 & $00 \mathrm{E}+00$ & $00 \mathrm{E}+00$ & $0.00 \mathrm{E}+00$ & $0.00 \mathrm{E}+00$ & $00 \mathrm{E}+00$ & $0.00 \mathrm{E}+00$ & $0.00 \mathrm{E}+00$ & $0.00 \mathrm{E}+00$ & $0.00 \mathrm{E}+00$ & $0.00 \mathrm{E}+00$ & $0.00 \mathrm{E}+00$ \\
\hline $16-A-41$ & $00 \mathrm{E}+00$ & $0.00 \mathrm{E}+00$ & $0.00 \mathrm{E}+00$ & $0.00 \mathrm{E}+00$ & $.00 \mathrm{E}+00$ & $0.00 \mathrm{E}+00$ & $0.00 \mathrm{E}+00$ & $0.00 \mathrm{E}+00$ & $0.00 \mathrm{E}+00$ & $0.00 \mathrm{E}+00$ & $0.00 \mathrm{E}+00$ & $0.00 \mathrm{E}+00$ & $0.00 \mathrm{E}+00$ & $0.00 \mathrm{E}+00$ & $0.00 \mathrm{E}+00$ & $0.00 \mathrm{E}+00$ \\
\hline $216-A-45$ & $4.36 \mathrm{E}-03$ & $4.35 \mathrm{E}-03$ & $4.35 \mathrm{E}-03$ & 4.35E-03 & 4.36E-03 & 4.35E-03 & $4.35 \mathrm{E}-03$ & 4.35E-03 & 4.36E-03 & 4.35E-03 & 4.35E-03 & 4.35E-03 & 4.36E-03 & 4.35E-03 & 4.35E-03 & $5 E-03$ \\
\hline $6-A-5$ & $07 \mathrm{E}+05$ & $2.44 \mathrm{E}+05$ & $5.94 \mathrm{E}+04$ & $1.29 \mathrm{E}+04$ & $66 \mathrm{E}+03$ & $45 \mathrm{E}+03$ & $3.50 \mathrm{E}+03$ & $2.49 \mathrm{E}+03$ & $1.94 \mathrm{E}+03$ & $.55 \mathrm{E}+03$ & $1.39 \mathrm{E}+03$ & $1.20 \mathrm{E}+03$ & $1.18 \mathrm{E}+03$ & $9.57 \mathrm{E}+02$ & $.57 \mathrm{E}+02$ & $57 \mathrm{E}+02$ \\
\hline $6-A-6$ & $80 \mathrm{E}+05$ & $1.17 \mathrm{E}+05$ & $2.81 \mathrm{E}+04$ & $.49 \mathrm{E}+04$ & $75 E+03$ & $02 \mathrm{E}+03$ & $3.18 \mathrm{E}+04$ & $1.74 \mathrm{E}+05$ & $1.57 \mathrm{E}+05$ & $1.29 \mathrm{E}+05$ & $5.88 \mathrm{E}+04$ & $2.58 \mathrm{E}+04$ & $1.52 \mathrm{E}+04$ & $.56 \mathrm{E}+03$ & $7.85 \mathrm{E}+03$ & $3 \mathrm{E}+03$ \\
\hline$-A-7$ & $3 \mathrm{E}+00$ & $70 \mathrm{E}+00$ & $3.72 \mathrm{E}+00$ & $.04 E+00$ & $2.56 \mathrm{E}+00$ & $19 \mathrm{E}+00$ & $9.99 \mathrm{E}+01$ & $8.59 \mathrm{E}+01$ & $2.16 \mathrm{E}+01$ & $.18 \mathrm{E}+01$ & $7.92 \mathrm{E}+00$ & $4.99 \mathrm{E}+00$ & $4.60 \mathrm{E}+00$ & $3.27 \mathrm{E}+00$ & $2.68 \mathrm{E}+00$ & $2.68 \mathrm{E}+00$ \\
\hline$-A-8$ & $73 E+04$ & $9.66 \mathrm{E}+03$ & $6.29 \mathrm{E}+03$ & $50 \mathrm{E}+03$ & $43 \mathrm{E}+03$ & $2.72 \mathrm{E}+03$ & $2.33 \mathrm{E}+03$ & $1.30 \mathrm{E}+04$ & $5.54 \mathrm{E}+04$ & $2.81 \mathrm{E}+04$ & $2.17 \mathrm{E}+04$ & $1.69 \mathrm{E}+04$ & $1.58 \mathrm{E}+04$ & $1.33 \mathrm{E}+04$ & $1.13 \mathrm{E}+04$ & $E+04$ \\
\hline$-A-9$ & $7 \mathrm{E}+04$ & $1.12 \mathrm{E}+04$ & $7.83 \mathrm{E}+03$ & $5.82 \mathrm{E}+03$ & $4.54 \mathrm{E}+03$ & $3.65 \mathrm{E}+03$ & $3.02 \mathrm{E}+03$ & $2.67 \mathrm{E}+03$ & $2.21 \mathrm{E}+03$ & $1.88 \mathrm{E}+03$ & $E+03$ & $1.46 \mathrm{E}+03$ & $1.26 \mathrm{E}+03$ & $E+03$ & $E+02$ & +02 \\
\hline 216-B-10A & $19 \mathrm{E}+02$ & $1.16 \mathrm{E}+02$ & $7.00 \mathrm{E}+01$ & $7.00 \mathrm{E}+01$ & $7.02 \mathrm{E}+01$ & $7.00 \mathrm{E}+01$ & $6.61 \mathrm{E}+01$ & $4.17 \mathrm{E}+01$ & $4.18 \mathrm{E}+01$ & $4.17 \mathrm{E}+01$ & $E+01$ & $4.17 \mathrm{E}+01$ & $E+01$ & $E+01$ & $E+01$ & $E+01$ \\
\hline $\mathrm{OB}$ & 05E-05 & 2.05E-05 & $2.05 E-05$ & 2.05E-05 & $2.05 \mathrm{E}-05$ & 2.05E-05 & 2.05E-05 & $2.05 \mathrm{E}-05$ & 5E-05 & 2.05E-05 & 5E-05 & 2.05E-05 & $\mathrm{E}-05$ & E-05 & E-05 & E-05 \\
\hline 216-B-11A\%B & 19E+01 & $3.00 \mathrm{E}+01$ & $2.40 \mathrm{E}+01$ & $2.40 \mathrm{E}+01$ & $04 \mathrm{E}+01$ & $1.40 \mathrm{E}+01$ & $1.40 \mathrm{E}+01$ & $1.40 \mathrm{E}+01$ & $1.40 \mathrm{E}+01$ & $1.16 \mathrm{E}+01$ & $8.29 \mathrm{E}+00$ & $8.29 \mathrm{E}+00$ & $8.31 \mathrm{E}+00$ & $8.29 \mathrm{E}+00$ & $.29 \mathrm{E}+00$ & $3.29 \mathrm{E}+00$ \\
\hline 216-B-12 & $6 \mathrm{E}+02$ & $4.93 \mathrm{E}+02$ & $3.62 \mathrm{E}+02$ & $2.79 \mathrm{E}+02$ & $2.25 \mathrm{E}+02$ & $1.85 \mathrm{E}+02$ & $1.56 \mathrm{E}+02$ & $1.39 \mathrm{E}+02$ & $1.03 \mathrm{E}+04$ & $2.00 \mathrm{E}+04$ & $2.23 \mathrm{E}+04$ & $3.17 \mathrm{E}+04$ & $3.02 E+04$ & $2.34 \mathrm{E}+04$ & $6.90 \mathrm{E}+03$ & $.63 \mathrm{E}+03$ \\
\hline -B-13 & 91E-01 & 89E-01 & $6.89 \mathrm{E}-01$ & 6.89E-01 & 6.91E-01 & 6.89E-01 & 6.89E-01 & & 6.91E-01 & 6.89E-01 & 6.89E-01 & $6.89 \mathrm{E}-01$ & 6.91E-01 & $6.89 \mathrm{E}-01$ & $6.89 \mathrm{E}-01$ & $6.89 \mathrm{E}-01$ \\
\hline & $34 \mathrm{E}-04$ & $5.33 \mathrm{E}-04$ & $5.33 \mathrm{E}-04$ & 5.33E-04 & 5.34E-04 & 5.33E-04 & $.39 \mathrm{E}-02$ & 8.12E-02 & $1.23 \mathrm{E}+01$ & $1.54 \mathrm{E}+01$ & $5.16 \mathrm{E}+01$ & $1.23 \mathrm{E}+02$ & $1.23 \mathrm{E}+02$ & $3 \mathrm{E}+02$ & $1.97 \mathrm{E}+02$ & $=+02$ \\
\hline $216-B-15$ & 8.07E-04 & 8.05E-04 & 8.05E-04 & 8.05E-04 & 8.07E-04 & 8.05E-04 & $8.05 \mathrm{E}-04$ & $8.05 \mathrm{E}-04$ & 8.07E-04 & 8.05 & & & & & $1.18 \mathrm{E}+01$ & $1.32 \mathrm{E}+01$ \\
\hline
\end{tabular}




\begin{tabular}{|c|c|c|c|c|c|c|c|c|c|c|c|c|c|c|c|c|}
\hline Site & 1960 & 1961 & 1962 & 1963 & 1964 & 1965 & 1966 & 1967 & 1968 & 1969 & 1970 & 1971 & 1972 & 1973 & 1974 & 1975 \\
\hline $216-B-16$ & 95E-02 & $.93 \mathrm{E}-02$ & 4.93E-02 & 93E-02 & 95E-02 & 4.93E-02 & 4.93E-02 & $4.93 \mathrm{E}-02$ & $4.95 \mathrm{E}-02$ & 4.93E-02 & $4.93 \mathrm{E}-02$ & 4.93E-02 & 4.95E-02 & 4.93E-02 & 4.93E-02 & $1.79 \mathrm{E}+00$ \\
\hline 216-B-17 & 93E-03 & 92E-03 & 92E-03 & 92E-03 & $.93 \mathrm{E}-03$ & 92E-03 & 1.92E-03 & $92 \mathrm{E}-03$ & $1.93 \mathrm{E}-03$ & 1.92E-03 & 1.92E-03 & 1.92E-03 & $.93 \mathrm{E}-03$ & $.92 \mathrm{E}-03$ & 1.92E-03 & 1.92E-03 \\
\hline 216-B-18 & 59E-02 & 58E-02 & $3.58 \mathrm{E}-02$ & $58 \mathrm{E}-02$ & 59E-02 & $3.58 \mathrm{E}-02$ & $3.58 \mathrm{E}-02$ & $3.58 \mathrm{E}-02$ & $5.43 \mathrm{E}+00$ & $6.27 \mathrm{E}+00$ & $5.74 \mathrm{E}+01$ & $8.36 \mathrm{E}+01$ & $8.38 E+01$ & $1.03 E+02$ & $2.14 \mathrm{E}+02$ & $2.14 \mathrm{E}+02$ \\
\hline B-19 & $56 \mathrm{E}-02$ & 55E-02 & $3.55 \mathrm{E}-02$ & $3.55 \mathrm{E}-02$ & $.56 \mathrm{E}-02$ & 55E-02 & $3.55 \mathrm{E}-02$ & 3.55E-02 & $3.56 \mathrm{E}-02$ & $3.55 \mathrm{E}-02$ & $3.55 \mathrm{E}-02$ & $3.55 \mathrm{E}-02$ & 3.56E-02 & $3.55 \mathrm{E}-02$ & $4.58 \mathrm{E}+00$ & $5.67 \mathrm{E}+00$ \\
\hline 216-B-20 & 7.54E-03 & 7.52E-03 & $7.52 \mathrm{E}-03$ & $7.52 \mathrm{E}-03$ & 7.54E-03 & 7.52E-03 & 7.52E-03 & 7.52E-03 & $7.54 \mathrm{E}-03$ & 7.52E-03 & 7.52E-03 & 7.52E-03 & 7.54E-03 & 7.52E-03 & $1.23 \mathrm{E}+00$ & $2.15 \mathrm{E}+00$ \\
\hline $216-B-21$ & 7.66E-03 & 7.64E-03 & 7.64E-03 & 7.64E-03 & 7.66E-03 & 7.64E-03 & 7.64E-03 & 7.64E-03 & 7.66E-03 & 7.64E-03 & 7.64E-03 & 7.64E-03 & 7.66E-03 & 7.64E-03 & $1.25 \mathrm{E}+00$ & $2.19 \mathrm{E}+00$ \\
\hline B-22 & 63E-03 & $9.61 \mathrm{E}-03$ & $9.61 \mathrm{E}-03$ & $9.61 \mathrm{E}-03$ & 9.63E-03 & $9.61 \mathrm{E}-03$ & 9.61E-03 & $9.61 \mathrm{E}-03$ & 9.63E-03 & $9.61 \mathrm{E}-03$ & $9.61 \mathrm{E}-03$ & $9.61 \mathrm{E}-03$ & $.63 \mathrm{E}-03$ & $1 \mathrm{E}-03$ & $.57 \mathrm{E}+00$ & $.75 \mathrm{E}+00$ \\
\hline B-23 & 86E-04 & $6.84 \mathrm{E}-04$ & $6.84 \mathrm{E}-04$ & $6.84 \mathrm{E}-04$ & $6.86 \mathrm{E}-04$ & $6.84 \mathrm{E}-04$ & $6.84 \mathrm{E}-04$ & $6.84 \mathrm{E}-04$ & 6.86E-04 & 6.84E-04 & $6.84 \mathrm{E}-04$ & 4 E-04 & 86E-04 & $4 \mathrm{E}-04$ & $6.84 \mathrm{E}-04$ & $4 \mathrm{E}-04$ \\
\hline & $5 \mathrm{E}-04$ & 3.04E-04 & $3.04 \mathrm{E}-04$ & 3.04E-04 & 3.05E-04 & 3.04E-04 & 3.04E-04 & 4E-04 & 5E-04 & 3.04E-04 & 3.04E-04 & 4E-04 & 5E-04 & 4E-04 & 04E-04 & $5.52 \mathrm{E}-01$ \\
\hline & E-03 & E-03 & $2.37 \mathrm{E}-03$ & $2.37 \mathrm{E}-03$ & $2.38 \mathrm{E}-03$ & $2.37 \mathrm{E}-03$ & 2.37E-03 & $2.37 \mathrm{E}-03$ & $2.38 \mathrm{E}-03$ & $2.37 \mathrm{E}-03$ & $2.37 \mathrm{E}-03$ & $2.37 \mathrm{E}-03$ & $8 \mathrm{E}-03$ & $2.37 \mathrm{E}-03$ & $2.37 \mathrm{E}-03$ & $2.84 \mathrm{E}+00$ \\
\hline & $5.65 \mathrm{E}-04$ & 5.63E-04 & BE-04 & $\mathrm{E}-04$ & $5.65 \mathrm{E}-04$ & $5.63 \mathrm{E}-04$ & 5.63E-04 & $\mathrm{E}-04$ & $5.65 \mathrm{E}-04$ & $5.63 \mathrm{E}-04$ & 5.63E-04 & E-04 & 5E-04 & $7 \mathrm{E}+00$ & $E+01$ & $1.71 \mathrm{E}+02$ \\
\hline & $8.58 \mathrm{E}-05$ & 8.56E-05 & $8.56 \mathrm{E}-05$ & $8.56 \mathrm{E}-05$ & $8.58 \mathrm{E}-05$ & 8.56E-05 & 8.56E-05 & $8.56 \mathrm{E}-05$ & 8.58E-05 & 8.56E-05 & 8.56E-05 & 8.56E-05 & $8.58 \mathrm{E}-05$ & $6 \mathrm{E}-05$ & $6 \mathrm{E}-05$ & $8.56 \mathrm{E}-05$ \\
\hline-28 & 38E-05 & 8.36E-05 & 36E-05 & $36 \mathrm{E}-05$ & 8.38E-05 & 8.36E-05 & 8.36E-05 & 8.36E-05 & 8.38E-05 & 8.36E-05 & 8.36E-05 & 8.36E-05 & 8.38E-05 & 8.36E-05 & 6E-05 & $3.71 \mathrm{E}-01$ \\
\hline-29 & 17E-03 & 1.17E-03 & $1.17 \mathrm{E}-03$ & 1.17E-03 & 1.17E-03 & 1.17E-03 & 1.17E-03 & $1.17 \mathrm{E}-03$ & 1.17E-03 & 1.17E-03 & 1.17E-03 & 1.17E-03 & 1.17E-03 & 1.17E-03 & $1.17 \mathrm{E}-03$ & $1.17 \mathrm{E}-03$ \\
\hline & $2 \mathrm{E}+06$ & $3.92 \mathrm{E}+06$ & $2.54 \mathrm{E}+06$ & $65 \mathrm{E}+06$ & $31 \mathrm{E}+06$ & $1.96 \mathrm{E}+06$ & $1.02 \mathrm{E}+06$ & $1.22 \mathrm{E}+06$ & $4.62 \mathrm{E}+06$ & $4.19 \mathrm{E}+06$ & $3.37 \mathrm{E}+06$ & $3.50 \mathrm{E}+06$ & $3.90 \mathrm{E}+06$ & $3.91 \mathrm{E}+06$ & $3.66 \mathrm{E}+06$ & $3.51 \mathrm{E}+06$ \\
\hline 216-B-30 & $27 \mathrm{E}-03$ & $2.26 \mathrm{E}-03$ & $2.26 \mathrm{E}-03$ & $2.26 \mathrm{E}-03$ & $2.27 \mathrm{E}-03$ & $2.26 \mathrm{E}-03$ & $2.26 \mathrm{E}-03$ & $2.26 \mathrm{E}-03$ & $2.27 \mathrm{E}-03$ & $2.26 \mathrm{E}-03$ & $2.26 \mathrm{E}-03$ & $2.26 \mathrm{E}-03$ & $2.27 \mathrm{E}-03$ & $2.26 \mathrm{E}-03$ & $2.26 \mathrm{E}-03$ & $2.26 \mathrm{E}-03$ \\
\hline 216-B-31 & $43 E-03$ & 1.42E-03 & 1.42E-03 & $1.42 \mathrm{E}-03$ & 1.43E-03 & $1.42 \mathrm{E}-03$ & 1.42E-03 & $1.42 \mathrm{E}-03$ & 1.43E-03 & 1.42E-03 & 1.42E-03 & $1.42 \mathrm{E}-03$ & 1.43E-03 & 1.42E-03 & $42 \mathrm{E}-03$ & $1.42 \mathrm{E}-03$ \\
\hline & 88E-05 & $3.37 \mathrm{E}-05$ & 3.37E-05 & $3.37 \mathrm{E}-05$ & $3.38 \mathrm{E}-05$ & 3.37E-05 & 3.37E-05 & $3.37 \mathrm{E}-05$ & $3.38 \mathrm{E}-05$ & 3.37E-05 & $3.37 \mathrm{E}-05$ & $37 \mathrm{E}-05$ & $38 \mathrm{E}-05$ & 7E-05 & 7E-05 & \\
\hline & $5 \mathrm{E}-04$ & $4.54 \mathrm{E}-04$ & 4.54E-04 & $4.54 \mathrm{E}-04$ & 4.55E-04 & $4.54 \mathrm{E}-04$ & 4.54E-04 & $54 \mathrm{E}-04$ & 4.55E-04 & $4.54 \mathrm{E}-04$ & 4.54E-04 & E-04 & E-04 & E-04 & & \\
\hline & 51E-03 & 1.50E-03 & $1.50 \mathrm{E}-03$ & 1.50E-03 & 1.51E-03 & 1.50E-03 & $1.50 \mathrm{E}-03$ & $0 \mathrm{E}-03$ & E-03 & $1.50 \mathrm{E}-03$ & $1.50 \mathrm{E}-03$ & E-03 & E-03 & E-03 & 0E-03 & $1.50 \mathrm{E}-03$ \\
\hline & $8 \mathrm{E}+01$ & $3.63 \mathrm{E}+01$ & $3.01 \mathrm{E}+01$ & $E+01$ & +01 & +01 & $E+01$ & +01 & $E+01$ & $E+01$ & $E+01$ & +01 & & +01 & & $\mathrm{E}+00$ \\
\hline & $E+01$ & $=+01$ & +01 & $E+01$ & $E+01$ & +01 & $E+01$ & +01 & $E+01$ & +01 & $E+01$ & $E+01$ & $E+01$ & $E+01$ & $\mathrm{E}+00$ & $4 \mathrm{E}+00$ \\
\hline & $3 \mathrm{E}+01$ & $4.70 \mathrm{E}+01$ & $E+01$ & $E+01$ & $3.30 \mathrm{E}+01$ & $96 \mathrm{E}+01$ & $90 \mathrm{E}+01$ & $E+01$ & $1.90 \mathrm{E}+01$ & $1.90 \mathrm{E}+01$ & $E+01$ & $E+01$ & $2 \mathrm{E}+01$ & $E+01$ & $E+01$ & $1.12 \mathrm{E}+01$ \\
\hline & $63 \mathrm{E}+01$ & $4.09 \mathrm{E}+01$ & $2.87 \mathrm{E}+01$ & $2.87 \mathrm{E}+01$ & $2.74 \mathrm{E}+01$ & $1.77 \mathrm{E}+01$ & $1.77 \mathrm{E}+01$ & $\mathrm{E}+01$ & $1.77 \mathrm{E}+01$ & $1.53 \mathrm{E}+01$ & $1.09 \mathrm{E}+01$ & $E+01$ & $1.10 \mathrm{E}+01$ & $E+01$ & $\mathrm{E}+01$ & $\mathrm{E}+01$ \\
\hline-39 & $68 \mathrm{E}+01$ & $3.83 E+01$ & $3.73 E+01$ & $2.34 \mathrm{E}+01$ & $2.35 E+01$ & $2.34 \mathrm{E}+01$ & $2.16 \mathrm{E}+01$ & $1.43 E+01$ & $1.44 \mathrm{E}+01$ & $1.43 E+01$ & $1.43 E+01$ & $1.43 E+01$ & $1.22 \mathrm{E}+01$ & $8.90 E+00$ & $\mathrm{DE}+00$ & $8.90 E+00$ \\
\hline & $35 E-05$ & $2.34 \mathrm{E}-05$ & $2.34 \mathrm{E}-05$ & $2.34 \mathrm{E}-05$ & 1.30E-04 & 1.49E-04 & 1.49E-04 & $2.60 \mathrm{E}-03$ & $3.75 \mathrm{E}-03$ & $3.74 \mathrm{E}-03$ & $3.74 \mathrm{E}-03$ & $3.74 \mathrm{E}-03$ & $3.75 \mathrm{E}-03$ & $3.74 \mathrm{E}-03$ & $3.74 \mathrm{E}-03$ & 3.74E-03 \\
\hline-40 & $6 \mathrm{E}+01$ & $3.72 \mathrm{E}+01$ & $3.11 \mathrm{E}+01$ & $.11 \mathrm{E}+01$ & $33 \mathrm{E}+01$ & $1.90 \mathrm{E}+01$ & $1.90 \mathrm{E}+01$ & $1.90 \mathrm{E}+01$ & $1.84 \mathrm{E}+01$ & $.17 \mathrm{E}+01$ & $1.17 \mathrm{E}+01$ & $1.17 \mathrm{E}+01$ & $1.17 \mathrm{E}+01$ & $1.17 \mathrm{E}+01$ & $1.17 \mathrm{E}+01$ & $1.06 \mathrm{E}+01$ \\
\hline $3-41$ & $28 \mathrm{E}+01$ & $4.01 E+01$ & $3.19 E+01$ & $2.50 \mathrm{E}+01$ & $51 \mathrm{E}+01$ & $2.48 \mathrm{E}+01$ & $1.54 \mathrm{E}+01$ & $1.54 \mathrm{E}+01$ & $1.55 \mathrm{E}+01$ & $1.54 \mathrm{E}+01$ & $1.54 \mathrm{E}+01$ & $1.12 \mathrm{E}+01$ & $9.66 \mathrm{E}+00$ & $9.64 \mathrm{E}+00$ & $9.64 \mathrm{E}+00$ & $9.64 \mathrm{E}+00$ \\
\hline $3-42$ & $72 \mathrm{E}+01$ & $3.96 \mathrm{E}+01$ & $2.92 \mathrm{E}+01$ & $2.92 \mathrm{E}+01$ & $60 \mathrm{E}+01$ & $1.80 \mathrm{E}+01$ & $80 \mathrm{E}+01$ & $1.80 \mathrm{E}+01$ & $1.80 \mathrm{E}+01$ & $1.39 \mathrm{E}+01$ & $1.11 \mathrm{E}+01$ & $1.11 \mathrm{E}+01$ & $1.12 \mathrm{E}+01$ & $1.11 \mathrm{E}+01$ & $1.11 \mathrm{E}+01$ & $1.11 \mathrm{E}+01$ \\
\hline-43 & $09 E+02$ & $7.26 \mathrm{E}+01$ & $7.26 \mathrm{E}+01$ & $5.77 \mathrm{E}+01$ & $4.73 \mathrm{E}+01$ & $4.72 \mathrm{E}+01$ & $4.72 \mathrm{E}+01$ & $3.12 \mathrm{E}+01$ & $3.02 \mathrm{E}+01$ & $3.02 \mathrm{E}+01$ & $3.02 \mathrm{E}+01$ & $3.02 \mathrm{E}+01$ & $2.51 \mathrm{E}+01$ & $1.94 \mathrm{E}+01$ & $1.94 \mathrm{E}+01$ & $.94 \mathrm{E}+01$ \\
\hline $3-44$ & $64 \mathrm{E}+02$ & $1.14 \mathrm{E}+02$ & $1.14 \mathrm{E}+02$ & $6.92 \mathrm{E}+01$ & $6.54 \mathrm{E}+01$ & $6.52 \mathrm{E}+01$ & $6.10 \mathrm{E}+01$ & $3.79 \mathrm{E}+01$ & $3.80 \mathrm{E}+01$ & $3.79 \mathrm{E}+01$ & $3.79 \mathrm{E}+01$ & $3.79 \mathrm{E}+01$ & $3.02 \mathrm{E}+01$ & $2.26 \mathrm{E}+01$ & $2.26 \mathrm{E}+01$ & $26 \mathrm{E}+01$ \\
\hline B-45 & 1.47E+02 & $1.10 \mathrm{E}+02$ & $9.91 \mathrm{E}+01$ & $6.56 \mathrm{E}+01$ & $6.58 \mathrm{E}+01$ & $56 \mathrm{E}+01$ & $4.32 \mathrm{E}+01$ & $E+01$ & $3.95 \mathrm{E}+01$ & $E+01$ & $3.94 \mathrm{E}+01$ & $E+01$ & $2.40 \mathrm{E}+01$ & $2.39 \mathrm{E}+01$ & $2.39 \mathrm{E}+01$ & $2.39 \mathrm{E}+01$ \\
\hline & $5 \mathrm{E}+02$ & $1.35 \mathrm{E}+02$ & $7.90 \mathrm{E}+01$ & $7.90 \mathrm{E}+01$ & $7.92 \mathrm{E}+01$ & $4.91 \mathrm{E}+01$ & $4.65 \mathrm{E}+01$ & $4.65 \mathrm{E}+01$ & $4.66 \mathrm{E}+01$ & $4.09 \mathrm{E}+01$ & $2.78 \mathrm{E}+01$ & $2.78 \mathrm{E}+01$ & $2.78 \mathrm{E}+01$ & $2.78 \mathrm{E}+01$ & $2.78 \mathrm{E}+01$ & $2.78 \mathrm{E}+01$ \\
\hline & 30E+02 & $1.11 \mathrm{E}+02$ & $8.04 \mathrm{E}+01$ & $8.04 \mathrm{E}+01$ & $93 \mathrm{E}+01$ & $4.92 \mathrm{E}+01$ & $4.92 \mathrm{E}+01$ & $4.92 \mathrm{E}+01$ & $3.71 \mathrm{E}+01$ & $3.02 \mathrm{E}+01$ & $3.02 \mathrm{E}+01$ & $3.02 \mathrm{E}+01$ & $3.02 \mathrm{E}+01$ & $3.02 \mathrm{E}+01$ & $2.36 \mathrm{E}+01$ & $1.88 \mathrm{E}+01$ \\
\hline & $47 \mathrm{E}+02$ & $1.01 \mathrm{E}+02$ & $1.01 \mathrm{E}+02$ & $6.16 \mathrm{E}+01$ & $18 \mathrm{E}+01$ & $6.16 \mathrm{E}+01$ & $4.77 \mathrm{E}+01$ & $3.74 \mathrm{E}+01$ & $3.75 \mathrm{E}+01$ & $3.74 \mathrm{E}+01$ & $3.74 \mathrm{E}+01$ & $3.12 \mathrm{E}+01$ & $2.31 \mathrm{E}+01$ & $2.30 \mathrm{E}+01$ & $\mathrm{E}+01$ & $E+01$ \\
\hline & $54 \mathrm{E}+02$ & $1.13 \mathrm{E}+02$ & $1.05 \mathrm{E}+02$ & $6.66 \mathrm{E}+01$ & $6.68 \mathrm{E}+01$ & $6.66 \mathrm{E}+01$ & $4.72 \mathrm{E}+01$ & $3.95 \mathrm{E}+01$ & $3.96 \mathrm{E}+01$ & $3.95 \mathrm{E}+01$ & $3.95 \mathrm{E}+01$ & $3.15 \mathrm{E}+01$ & $2.39 \mathrm{E}+01$ & $2.38 \mathrm{E}+01$ & $2.38 \mathrm{E}+01$ & $2.38 \mathrm{E}+01$ \\
\hline & 02E-01 & 4.27E-02 & $4.27 \mathrm{E}-02$ & 4.27E-02 & $4.28 \mathrm{E}-02$ & $4.27 \mathrm{E}-02$ & 4.27E-02 & 2.37E-02 & 1.35E-02 & 1.35E-02 & 1.35E-02 & 1.35E-02 & 1.35E-02 & 1.35E-02 & 1.35E-02 & 1.35E-02 \\
\hline & $2 \mathrm{E}-08$ & 3.11E-08 & $3.11 \mathrm{E}-08$ & 3.11E-08 & $3.12 \mathrm{E}-08$ & $3.78 \mathrm{E}+02$ & $5.37 \mathrm{E}+03$ & $8.32 \mathrm{E}+03$ & $7.51 \mathrm{E}+03$ & $8.73 \mathrm{E}+03$ & $8.58 \mathrm{E}+03$ & $6.50 \mathrm{E}+03$ & $3.79 \mathrm{E}+03$ & $1.98 \mathrm{E}+03$ & $1.00 \mathrm{E}+03$ & $5.22 \mathrm{E}+02$ \\
\hline & 77E-08 & 1.57E-08 & 57E-08 & $.57 \mathrm{E}-08$ & 1.57E-08 & 1.57E-08 & 1.57E-08 & $1.57 \mathrm{E}-08$ & $1.57 \mathrm{E}-08$ & 1.57E-08 & $1.57 \mathrm{E}-08$ & 1.57E-08 & $4.98 \mathrm{E}-07$ & 9.84E-07 & 9.84E-07 & 9.84E-07 \\
\hline & 12E-05 & $9.10 \mathrm{E}-05$ & $9.10 \mathrm{E}-05$ & $9.10 \mathrm{E}-05$ & $9.12 \mathrm{E}-05$ & $9.10 \mathrm{E}-05$ & $9.10 \mathrm{E}-05$ & $9.10 \mathrm{E}-05$ & $9.12 \mathrm{E}-05$ & $2.84 \mathrm{E}+00$ & $9.24 \mathrm{E}+01$ & $2.34 \mathrm{E}+02$ & $2.97 \mathrm{E}+02$ & $3.19 E+02$ & $3.08 \mathrm{E}+02$ & $3.02 \mathrm{E}+02$ \\
\hline $216-B-53 A$ & $3.75 \mathrm{E}-05$ & $3.74 \mathrm{E}-05$ & $3.74 \mathrm{E}-05$ & $3.74 \mathrm{E}-05$ & $3.75 \mathrm{E}-05$ & 3.74E-05 & 3.74E-05 & $3.74 \mathrm{E}-05$ & $3.75 \mathrm{E}-05$ & 3.74E-05 & 3.74E-05 & 3.74E-05 & $3.75 \mathrm{E}-05$ & 3.74E-05 & $3.74 \mathrm{E}-05$ & $3.74 \mathrm{E}-0$ \\
\hline
\end{tabular}




\begin{tabular}{|c|c|c|c|c|c|c|c|c|c|c|c|c|c|c|c|c|}
\hline Site & 1960 & 1961 & 1962 & 1963 & 1964 & 1965 & 1966 & 1967 & 1968 & 1969 & 1970 & 1971 & 1972 & 1973 & 1974 & 1975 \\
\hline 216-B-53B & 31E-04 & $3.30 \mathrm{E}-04$ & 3.30E-04 & $3.30 \mathrm{E}-04$ & 31E-04 & 30E-04 & 3.30E-04 & 3.30E-04 & $3.31 \mathrm{E}-04$ & 3.30E-04 & 3.30E-04 & 3.30E-04 & 3.31E-04 & 3.30E-04 & 3.30E-04 & 3.30E-04 \\
\hline & $62 \mathrm{E}-04$ & 61E-04 & $61 \mathrm{E}-04$ & 61E-04 & $62 \mathrm{E}-04$ & $61 \mathrm{E}-04$ & $.61 \mathrm{E}-04$ & $61 \mathrm{E}-04$ & $4.62 \mathrm{E}-04$ & 4.61E-04 & 4.61E-04 & $4.61 \mathrm{E}-04$ & $4.62 \mathrm{E}-04$ & $61 \mathrm{E}-04$ & 4.61E-04 & 4.61E-04 \\
\hline & $1 \mathrm{E}-07$ & 60E-07 & $60 \mathrm{E}-07$ & 60E-07 & 61E-07 & 60E-07 & 1.60E-07 & 60E-07 & $2.04 E+04$ & $8.20 E+04$ & $8.83 E+04$ & $1.50 \mathrm{E}+05$ & $1.48 \mathrm{E}+05$ & $8.89 E+04$ & $8.11 E+04$ & $6.76 \mathrm{E}+04$ \\
\hline & $6 \mathrm{E}-05$ & $1.15 \mathrm{E}-05$ & $15 \mathrm{E}-05$ & 15E-05 & 16E-05 & 15E-05 & 1.15E-05 & 1.15E-05 & 1.16E-05 & 1.15E-05 & $3.98 \mathrm{E}+03$ & $1.73 E+04$ & $1.41 \mathrm{E}+04$ & $1.19 E+04$ & $7.15 \mathrm{E}+03$ & $4.74 \mathrm{E}+03$ \\
\hline & 39E-04 & $1.89 \mathrm{E}-04$ & $1.89 \mathrm{E}-04$ & $1.89 \mathrm{E}-04$ & 1.89E-04 & 1.89E-04 & 1.89E-04 & 1.89E-04 & $.89 \mathrm{E}-04$ & 89E-04 & 1.89E-04 & 1.89E-04 & 1.89E-04 & 1.89E-04 & 1.89E-04 & 1.89E-04 \\
\hline & 48E-07 & $9.45 \mathrm{E}-07$ & $9.45 \mathrm{E}-07$ & $9.45 \mathrm{E}-07$ & 9.48E-07 & $9.45 \mathrm{E}-07$ & 9.45E-07 & $9.45 \mathrm{E}-07$ & $9.48 \mathrm{E}-07$ & $9.45 \mathrm{E}-07$ & 9.45E-07 & $9.45 \mathrm{E}-07$ & $9.48 \mathrm{E}-07$ & $9.45 \mathrm{E}-07$ & $9.45 \mathrm{E}-07$ & E-07 \\
\hline & $83 \mathrm{E}+00$ & $5.07 \mathrm{E}+00$ & $5.07 \mathrm{E}+00$ & $5.07 \mathrm{E}+00$ & $08 \mathrm{E}+00$ & $5.07 \mathrm{E}+00$ & $5.07 \mathrm{E}+00$ & $3.30 \mathrm{E}+00$ & $2.63 \mathrm{E}+00$ & $2.63 \mathrm{E}+00$ & $2.63 \mathrm{E}+00$ & $2.63 \mathrm{E}+00$ & $2.63 E+00$ & $2.63 \mathrm{E}+00$ & $2.63 \mathrm{E}+00$ & $.63 \mathrm{E}+00$ \\
\hline & $12 \mathrm{E}-07$ & 1.11E-07 & 1.11E-07 & $1.11 \mathrm{E}-07$ & $1.12 \mathrm{E}-07$ & 1.11E-07 & $1.11 \mathrm{E}-07$ & 1.11E-07 & $1.12 \mathrm{E}-07$ & 1.11E-07 & $2.59 \mathrm{E}+00$ & $2.35 \mathrm{E}+00$ & $1.55 \mathrm{E}+00$ & $1.14 \mathrm{E}+00$ & $9.21 \mathrm{E}-01$ & $0 \mathrm{E}-01$ \\
\hline & 57E-06 & $2.56 \mathrm{E}-06$ & $2.56 \mathrm{E}-06$ & 2.56E-06 & 2.57E-06 & $.56 \mathrm{E}-06$ & 6E-06 & $.56 \mathrm{E}-06$ & E-06 & 6E-06 & E-06 & 5E-06 & 7E-06 & $1.30 \mathrm{E}+04$ & $2.68 \mathrm{E}+04$ & $3.69 \mathrm{E}+04$ \\
\hline & 1.89E-03 & $1.89 \mathrm{E}-03$ & $1.89 \mathrm{E}-03$ & 1.89E-03 & $\mathrm{E}-03$ & 1.89E-03 & 1.89E-03 & 1.89E-03 & 9E-03 & 1.89E-03 & 1.89E-03 & 1.89E-03 & 1.89E-03 & $3.33 \mathrm{E}+05$ & $\mathrm{LE}+05$ & $3.13 E+05$ \\
\hline 216 & $88 \mathrm{E}+01$ & $2.26 \mathrm{E}+01$ & $1.84 \mathrm{E}+01$ & $1.54 \mathrm{E}+01$ & $31 \mathrm{E}+01$ & $13 \mathrm{E}+01$ & $27 \mathrm{E}+02$ & $4.98 \mathrm{E}+02$ & $1.98 \mathrm{E}+02$ & $9.78 \mathrm{E}+01$ & $6.12 \mathrm{E}+01$ & $3.86 \mathrm{E}+01$ & $3.49 \mathrm{E}+01$ & $2.13 E+01$ & $7 \mathrm{E}+01$ & $1.97 \mathrm{E}+01$ \\
\hline & $E+01$ & $1.85 \mathrm{E}+01$ & $E+01$ & $1.06 \mathrm{E}+01$ & $E+01$ & $06 \mathrm{E}+01$ & $1 E+00$ & $6.23 E+00$ & $E+00$ & $6.23 E+00$ & $E+00$ & $6.23 E+00$ & $6 \mathrm{E}+00$ & $7 \mathrm{E}+00$ & $7 E+00$ & $\mathrm{E}+00$ \\
\hline & $E+02$ & $2.48 \mathrm{E}+02$ & $1.42 \mathrm{E}+02$ & $.42 \mathrm{E}+02$ & $42 \mathrm{E}+02$ & $42 \mathrm{E}+02$ & $1.42 E+02$ & $E+02$ & 8.01E+01 & $7.99 E+01$ & $7.99 E+01$ & $7.99 \mathrm{E}+01$ & $8.01 E+01$ & $7.99 E+01$ & $9 \mathrm{E}+01$ & $7.99 \mathrm{E}+01$ \\
\hline -BY-201 & $1 \mathrm{E}-01$ & 3.02E-01 & 1.70E-01 & $1.70 \mathrm{E}-01$ & 71E-01 & 1.11E-01 & 9.59E-02 & $9.59 \mathrm{E}-02$ & $9.62 \mathrm{E}-02$ & 9.59E-02 & $5.90 \mathrm{E}-02$ & $5.56 \mathrm{E}-02$ & $5.57 \mathrm{E}-02$ & $5.56 \mathrm{E}-02$ & $5.56 \mathrm{E}-02$ & $5.56 \mathrm{E}-02$ \\
\hline & $0 \mathrm{E}+02$ & $6.12 \mathrm{E}+01$ & $5.81 \mathrm{E}+01$ & $73 \mathrm{E}+01$ & $74 \mathrm{E}+01$ & $25 \mathrm{E}+01$ & $2.26 \mathrm{E}+01$ & $2.26 \mathrm{E}+01$ & $2.27 \mathrm{E}+01$ & $.16 \mathrm{E}+01$ & $1.39 \mathrm{E}+01$ & $1.39 \mathrm{E}+01$ & $1.40 \mathrm{E}+01$ & $1.39 \mathrm{E}+01$ & $.39 \mathrm{E}+01$ & $.39 \mathrm{E}+01$ \\
\hline 216-C-10 & $31 \mathrm{E}-08$ & $2.30 \mathrm{E}-08$ & $2.30 \mathrm{E}-08$ & $2.30 \mathrm{E}-08$ & 2.31E-08 & $1.09 \mathrm{E}+01$ & $4.71 E+02$ & $1.80 \mathrm{E}+02$ & $6.31 \mathrm{E}+01$ & $3.29 E+01$ & $1.73 E+01$ & $1.56 \mathrm{E}+01$ & $8.13 E+00$ & $8.11 E+00$ & $7.16 \mathrm{E}+00$ & $28 \mathrm{E}+00$ \\
\hline $216-C-2$ & 49E-05 & $8.46 \mathrm{E}-05$ & 8.46E-05 & $8.46 \mathrm{E}-05$ & 8.49E-05 & $8.46 \mathrm{E}-05$ & 8.46E-05 & $8.46 \mathrm{E}-05$ & 8.49E-05 & 8.46E-05 & 8.46E-05 & $8.46 \mathrm{E}-05$ & $8.49 \mathrm{E}-05$ & 8.46E-05 & $8.46 \mathrm{E}-05$ & 8.46E-05 \\
\hline & $8 \mathrm{E}+01$ & $1.77 \mathrm{E}+01$ & $1.77 \mathrm{E}+01$ & $1.77 \mathrm{E}+01$ & $.20 \mathrm{E}+01$ & $9.96 \mathrm{E}+00$ & $9.96 \mathrm{E}+00$ & $9.96 \mathrm{E}+00$ & $9.99 \mathrm{E}+00$ & $7.18 \mathrm{E}+00$ & $5.84 \mathrm{E}+00$ & $5.84 \mathrm{E}+00$ & $5.85 \mathrm{E}+00$ & $5.84 \mathrm{E}+00$ & $4 \mathrm{E}+00$ & \\
\hline & $1 \mathrm{E}-04$ & $1.60 \mathrm{E}-04$ & 1.60E-04 & $1.60 \mathrm{E}-04$ & 1.61E-04 & $96 \mathrm{E}+00$ & $2.70 \mathrm{E}+01$ & $1.74 \mathrm{E}+01$ & $1.23 \mathrm{E}+01$ & $96 \mathrm{E}+00$ & $3 \mathrm{E}+00$ & $5.91 \mathrm{E}+00$ & $5.17 \mathrm{E}+00$ & $0 \mathrm{E}+00$ & $0 \mathrm{E}+00$ & $E+00$ \\
\hline & $E-07$ & 57E-07 & $57 \mathrm{E}-07$ & $26 \mathrm{E}+01$ & $92 \mathrm{E}+02$ & $13 \mathrm{E}+01$ & $E+01$ & $2.31 \mathrm{E}+01$ & $\mathrm{E}+01$ & $E+01$ & $E+00$ & $E+00$ & $E+00$ & $4.73 \mathrm{E}+00$ & $3 \mathrm{E}+00$ & $E+00$ \\
\hline & E-04 & E-04 & E-04 & E-04 & $E-04$ & E-04 & $E-04$ & $=-04$ & & E-04 & $E-04$ & -04 & -04 & -04 & E-04 & 7E-04 \\
\hline & +04 & $2.06 \mathrm{E}+04$ & $=04$ & $E+04$ & $49 \mathrm{E}+04$ & $E+04$ & $E+04$ & $E+04$ & $E+04$ & $E+04$ & $E+04$ & +03 & $6 \mathrm{E}+03$ & $3 E+03$ & $\mathrm{E}+03$ & $E+03$ \\
\hline & $E+01$ & $1.26 \mathrm{E}+01$ & $E+01$ & $E+01$ & $E+01$ & $26 \mathrm{E}+01$ & $E+01$ & $E+00$ & $2 E+00$ & $E+00$ & $\mathrm{E}+00$ & $E+00$ & $2 \mathrm{E}+00$ & $E+00$ & $\mathrm{E}+00$ & $\mathrm{E}+00$ \\
\hline & $E+01$ & 1.92E+01 & $E+01$ & $E+01$ & $79 \mathrm{E}+01$ & $21 E+01$ & $E+01$ & $\mathrm{E}+01$ & $1.21 E+01$ & $1.21 E+01$ & $2 \mathrm{E}+01$ & $8.22 E+00$ & $8.24 \mathrm{E}+00$ & $2 \mathrm{E}+00$ & $2 E+00$ & $E+00$ \\
\hline & $\mathrm{E}+02$ & $5.53 \mathrm{E}+02$ & $5.53 \mathrm{E}+02$ & $5.00 \mathrm{E}+02$ & $46 E+02$ & $2.45 E+02$ & $2.45 \mathrm{E}+02$ & $2.45 E+02$ & $2.46 \mathrm{E}+02$ & $2.45 E+02$ & $1.06 E+02$ & $9.69 \mathrm{E}+01$ & $9.72 \mathrm{E}+01$ & $9.69 E+01$ & $9.69 \mathrm{E}+01$ & $9.69 \mathrm{E}+01$ \\
\hline & $5 \mathrm{E}+01$ & $1.92 \mathrm{E}+01$ & $1.92 \mathrm{E}+01$ & $1.92 \mathrm{E}+01$ & $79 \mathrm{E}+01$ & $1.21 \mathrm{E}+01$ & $1.21 \mathrm{E}+01$ & $1.21 \mathrm{E}+01$ & $1.21 \mathrm{E}+01$ & $1.21 \mathrm{E}+01$ & $1.12 \mathrm{E}+01$ & $8.22 \mathrm{E}+00$ & $8.24 \mathrm{E}+00$ & $8.22 \mathrm{E}+00$ & $8.22 \mathrm{E}+00$ & $8.22 \mathrm{E}+00$ \\
\hline & $E+02$ & $4.74 \mathrm{E}+02$ & $4.74 \mathrm{E}+02$ & $28 \mathrm{E}+02$ & $10 \mathrm{E}+02$ & $10 \mathrm{E}+02$ & $2.10 \mathrm{E}+02$ & $2.10 \mathrm{E}+02$ & $2.10 \mathrm{E}+02$ & $2.10 \mathrm{E}+02$ & $9.06 \mathrm{E}+01$ & $8.28 \mathrm{E}+01$ & $8.30 \mathrm{E}+01$ & $8.28 \mathrm{E}+01$ & $8.28 \mathrm{E}+01$ & $8.28 \mathrm{E}+01$ \\
\hline $216-\mathrm{N}-7$ & $35 E+01$ & $1.92 \mathrm{E}+01$ & $1.92 \mathrm{E}+01$ & $1.92 \mathrm{E}+01$ & $79 E+01$ & $1.21 \mathrm{E}+01$ & $1.21 \mathrm{E}+01$ & $1.21 \mathrm{E}+01$ & $1.21 \mathrm{E}+01$ & $1.21 \mathrm{E}+01$ & $1.12 \mathrm{E}+01$ & $8.22 \mathrm{E}+00$ & $8.24 \mathrm{E}+00$ & $8.22 \mathrm{E}+00$ & $8.22 \mathrm{E}+00$ & $8.22 \mathrm{E}+00$ \\
\hline $216-S-1 \% 2$ & $04 \mathrm{E}+03$ & $3.16 \mathrm{E}+03$ & $2.61 \mathrm{E}+03$ & $2.53 \mathrm{E}+03$ & $66 \mathrm{E}+03$ & $66 \mathrm{E}+03$ & $66 \mathrm{E}+03$ & $1.48 \mathrm{E}+03$ & $1.05 E+03$ & $1.05 E+03$ & $1.05 \mathrm{E}+03$ & $1.05 \mathrm{E}+03$ & $1.05 \mathrm{E}+03$ & $8.19 E+02$ & $6.75 \mathrm{E}+02$ & $6.75 \mathrm{E}+02$ \\
\hline$-10 P$ & $93 \mathrm{E}+05$ & $1.93 \mathrm{E}+05$ & $1.92 \mathrm{E}+05$ & $1.93 \mathrm{E}+05$ & $1.93 \mathrm{E}+05$ & $1.92 \mathrm{E}+05$ & $1.93 \mathrm{E}+05$ & $1.23 \mathrm{E}+05$ & $8.78 \mathrm{E}+04$ & $8.94 \mathrm{E}+04$ & $8.14 \mathrm{E}+04$ & $7.49 \mathrm{E}+04$ & $1.47 \mathrm{E}+05$ & $2.00 \mathrm{E}+05$ & $2.00 \mathrm{E}+05$ & $2.00 \mathrm{E}+05$ \\
\hline-12 & $64 \mathrm{E}-07$ & 7.61E-07 & 7.61E-07 & 7.61E-07 & 7.64E-07 & 7.61E-07 & 7.61E-07 & 7.61E-07 & 7.64E-07 & $7.40 \mathrm{E}-05$ & $1.28 \mathrm{E}-04$ & $1.28 \mathrm{E}-04$ & $1.28 \mathrm{E}-04$ & $28 \mathrm{E}-04$ & $1.28 \mathrm{E}-04$ & 8E-04 \\
\hline & $3 \mathrm{E}+01$ & $7.48 \mathrm{E}+01$ & $6.40 \mathrm{E}+01$ & $5.33 \mathrm{E}+01$ & $4.79 \mathrm{E}+01$ & $3.63 \mathrm{E}+02$ & $3.88 \mathrm{E}+02$ & $2.36 \mathrm{E}+02$ & $1.63 E+02$ & $1.17 \mathrm{E}+02$ & $8.45 \mathrm{E}+01$ & $7.31 \mathrm{E}+01$ & $6.11 \mathrm{E}+01$ & $4.45 \mathrm{E}+01$ & $4.45 \mathrm{E}+01$ & $4.45 \mathrm{E}+01$ \\
\hline $5-15$ & E-07 & 3.36E-07 & 3.36E-07 & 3.36E-07 & 3.37E-07 & 3.36E-07 & 3.36E-07 & $2.36 \mathrm{E}-05$ & 5.30E-05 & $5.28 \mathrm{E}-05$ & $5.28 \mathrm{E}-05$ & $E-05$ & $5.30 \mathrm{E}-05$ & $5.28 \mathrm{E}-05$ & $5.28 \mathrm{E}-05$ & $6.79 \mathrm{E}-03$ \\
\hline$-16 P$ & 6E-01 & $2.67 \mathrm{E}+06$ & $4.07 \mathrm{E}+06$ & $4.54 \mathrm{E}+06$ & $86 \mathrm{E}+06$ & $5.02 \mathrm{E}+06$ & $3.23 \mathrm{E}+06$ & $2.00 \mathrm{E}+06$ & $1.53 E+06$ & $1.06 \mathrm{E}+06$ & $8.21 E+05$ & $8.55 E+05$ & $9.80 \mathrm{E}+05$ & $8.94 \mathrm{E}+05$ & $7.70 \mathrm{E}+05$ & $5.75 \mathrm{E}+05$ \\
\hline & $06 \mathrm{E}+05$ & $1.63 \mathrm{E}+05$ & $1.63 \mathrm{E}+05$ & $1.35 \mathrm{E}+05$ & $9.98 \mathrm{E}+04$ & $9.95 \mathrm{E}+04$ & $9.95 \mathrm{E}+04$ & $9.95 E+04$ & $7.15 E+04$ & $6.11 \mathrm{E}+04$ & $6.11 \mathrm{E}+04$ & $6.11 \mathrm{E}+04$ & $6.13 \mathrm{E}+04$ & $1 \mathrm{E}+04$ & $E+04$ & $E+04$ \\
\hline & 73E-07 & 1.72E-07 & 1.72E-07 & $1.72 \mathrm{E}-07$ & 1.73E-07 & $1.72 \mathrm{E}-07$ & $1.72 \mathrm{E}-07$ & $1.72 \mathrm{E}-07$ & 1.73E-07 & 1.72E-07 & 3.83E-04 & $1.99 \mathrm{E}+02$ & $5.77 \mathrm{E}+03$ & $E+03$ & $\mathrm{E}+03$ & $E+03$ \\
\hline & $0 \mathrm{E}+03$ & $6.48 \mathrm{E}+03$ & $8.25 E+03$ & $14 \mathrm{E}+04$ & $11 \mathrm{E}+04$ & $8.95 \mathrm{E}+03$ & $6.94 \mathrm{E}+03$ & $5.41 \mathrm{E}+03$ & $4.33 E+03$ & $3.52 \mathrm{E}+03$ & $2.94 \mathrm{E}+03$ & $2.51 \mathrm{E}+03$ & $2.25 \mathrm{E}+03$ & $1.95 E+03$ & $1.68 \mathrm{E}+03$ & $1.47 \mathrm{E}+03$ \\
\hline & $4 \mathrm{E}+03$ & $5.21 \mathrm{E}+03$ & $4.79 \mathrm{E}+03$ & $4.60 \mathrm{E}+03$ & $5.24 \mathrm{E}+03$ & $8.81 \mathrm{E}+03$ & $1.31 \mathrm{E}+04$ & $1.00 \mathrm{E}+04$ & $5.67 \mathrm{E}+03$ & $3.64 \mathrm{E}+03$ & $2.16 \mathrm{E}+03$ & $1.51 \mathrm{E}+03$ & $1.10 \mathrm{E}+03$ & $9.32 \mathrm{E}+02$ & $7.31 \mathrm{E}+02$ & $7.08 \mathrm{E}+02$ \\
\hline & 79E-06 & $1.78 \mathrm{E}-06$ & $1.78 \mathrm{E}-06$ & $1.78 \mathrm{E}-06$ & 1.79E-06 & $4.97 \mathrm{E}-04$ & $6.53 \mathrm{E}-04$ & $6.53 \mathrm{E}-04$ & $2.53 \mathrm{E}-01$ & $2.59 \mathrm{E}-01$ & $2.59 \mathrm{E}-01$ & $2.59 \mathrm{E}-01$ & $1.44 \mathrm{E}+00$ & $1.91 \mathrm{E}+00$ & $1.91 \mathrm{E}+00$ & $1.91 \mathrm{E}+00$ \\
\hline & $1 \mathrm{E}-04$ & $7.58 \mathrm{E}-04$ & $7.58 \mathrm{E}-04$ & $7.58 \mathrm{E}-04$ & 7.61E-04 & $7.58 \mathrm{E}-04$ & 7.58E-04 & $7.58 \mathrm{E}-04$ & 7.61E-04 & 7.58E-04 & 7.58E-04 & $4.06 \mathrm{E}+03$ & $6.69 E+03$ & $4.51 \mathrm{E}+03$ & $2.84 \mathrm{E}+03$ & $1.98 \mathrm{E}+03$ \\
\hline $216-S-25$ & $6.27 \mathrm{E}-05$ & $6.25 \mathrm{E}-05$ & $6.25 \mathrm{E}-05$ & $6.25 \mathrm{E}-05$ & $6.27 \mathrm{E}-05$ & $6.25 \mathrm{E}-05$ & $6.25 \mathrm{E}-05$ & $6.25 \mathrm{E}-05$ & $6.27 \mathrm{E}-05$ & $6.25 \mathrm{E}-05$ & $6.25 \mathrm{E}-05$ & $6.25 \mathrm{E}-05$ & $6.27 \mathrm{E}-05$ & $6.25 \mathrm{E}-05$ & $6.25 \mathrm{E}-05$ & $6.25 \mathrm{E}-0$ \\
\hline
\end{tabular}




\begin{tabular}{|c|c|c|c|c|c|c|c|c|c|c|c|c|c|c|c|c|}
\hline Site & 1960 & 1961 & 1962 & 1963 & 1964 & 1965 & 1966 & 1967 & 1968 & 1969 & 1970 & 1971 & 1972 & 1973 & 1974 & 1975 \\
\hline & 08E-08 & $.07 \mathrm{E}-08$ & $4.07 \mathrm{E}-08$ & 07E-08 & $4.08 \mathrm{E}-08$ & 4.07E-08 & $4.07 \mathrm{E}-08$ & 4.07E-08 & $4.08 \mathrm{E}-08$ & 4.07E-08 & 4.07E-08 & 4.07E-08 & $4.08 \mathrm{E}-08$ & $4.07 \mathrm{E}-08$ & $4.07 \mathrm{E}-08$ & 4.07E-08 \\
\hline & $8 \mathrm{E}+02$ & $57 \mathrm{E}+02$ & $1.57 \mathrm{E}+02$ & $\mathrm{~L} 1 \mathrm{E}+02$ & $03 E+02$ & $02 E+02$ & $18 \mathrm{E}+01$ & $51 \mathrm{E}+01$ & $6.52 \mathrm{E}+01$ & $6.51 \mathrm{E}+01$ & $51 \mathrm{E}+01$ & $6.51 \mathrm{E}+01$ & $4.25 \mathrm{E}+01$ & $4.14 \mathrm{E}+01$ & $4.14 \mathrm{E}+01$ & $4.14 \mathrm{E}+01$ \\
\hline b-S-4 & $1 \mathrm{E}+01$ & $98 \mathrm{E}+01$ & $2.09 E+01$ & $2.09 E+01$ & $50 \mathrm{E}+01$ & $25 E+01$ & $25 E+01$ & $1.25 E+01$ & $8.98 E+00$ & $7.52 E+00$ & $52 \mathrm{E}+00$ & $7.52 \mathrm{E}+00$ & $7.54 \mathrm{E}+00$ & $7.52 E+00$ & $5.46 \mathrm{E}+00$ & $65 \mathrm{E}+00$ \\
\hline & $43 \mathrm{E}+05$ & $05 \mathrm{E}+05$ & $1.38 \mathrm{E}+05$ & $1.38 \mathrm{E}+05$ & $03 \mathrm{E}+05$ & $8.70 \mathrm{E}+04$ & $8.70 \mathrm{E}+04$ & $8.48 \mathrm{E}+04$ & $5.46 \mathrm{E}+04$ & $5.44 \mathrm{E}+04$ & $5.44 \mathrm{E}+04$ & $5.44 \mathrm{E}+04$ & $5.46 \mathrm{E}+04$ & $4.20 \mathrm{E}+04$ & $5 E+04$ & $45 \mathrm{E}+04$ \\
\hline & $E+05$ & $2.03 E+05$ & $37 \mathrm{E}+05$ & $1 \mathrm{E}+05$ & $2.06 \mathrm{E}+05$ & $2.26 \mathrm{E}+05$ & $2.31 \mathrm{E}+05$ & $2.18 \mathrm{E}+05$ & $1.72 \mathrm{E}+05$ & $1.31 \mathrm{E}+05$ & $1.09 \mathrm{E}+05$ & $8.32 \mathrm{E}+04$ & $7.36 \mathrm{E}+04$ & $7.52 \mathrm{E}+04$ & $7.60 \mathrm{E}+04$ & $.54 \mathrm{E}+04$ \\
\hline S-7 & $65 E+04$ & $3.28 E+04$ & $3.27 \mathrm{E}+04$ & $3.58 E+04$ & $18 \mathrm{E}+04$ & $22 E+04$ & $1.81 \mathrm{E}+04$ & $1.19 \mathrm{E}+04$ & $7.36 \mathrm{E}+03$ & $6.79 \mathrm{E}+03$ & $4.04 \mathrm{E}+03$ & $4.04 \mathrm{E}+03$ & $3.57 \mathrm{E}+03$ & $2.33 E+03$ & $2.33 \mathrm{E}+03$ & $2.33 \mathrm{E}+03$ \\
\hline & 96E-05 & $2.96 \mathrm{E}-05$ & 2.96E-05 & $2.96 \mathrm{E}-05$ & 96E-05 & 96E-05 & $96 \mathrm{E}-05$ & $2.67 \mathrm{E}+03$ & $1.02 \mathrm{E}+04$ & $8.59 \mathrm{E}+03$ & $4.63 \mathrm{E}+03$ & $3.09 E+03$ & $1.96 \mathrm{E}+03$ & $1.82 \mathrm{E}+03$ & & $1.12 \mathrm{E}+03$ \\
\hline $5 X-2$ & $3 E+03$ & $5.92 \mathrm{E}+03$ & $5.92 \mathrm{E}+03$ & $5.91 \mathrm{E}+03$ & $93 \mathrm{E}+03$ & $92 \mathrm{E}+03$ & $38 \mathrm{E}+03$ & $1.56 \mathrm{E}+03$ & $9.34 \mathrm{E}+02$ & $6.79 \mathrm{E}+02$ & $52 \mathrm{E}+02$ & $4.25 \mathrm{E}+02$ & $2.83 \mathrm{E}+02$ & $2.82 \mathrm{E}+02$ & $2.60 \mathrm{E}+02$ & $5 E+02$ \\
\hline$\Gamma-1$ & $E+02$ & $53 E+02$ & +02 & $E+02$ & $12 \mathrm{E}+03$ & $49 E+04$ & $E+04$ & $E+04$ & $2.50 \mathrm{E}+04$ & $49 \mathrm{E}+04$ & $3 \mathrm{E}+04$ & $E+04$ & $4.32 \mathrm{E}+03$ & $3.31 \mathrm{E}+03$ & $\mathrm{E}+03$ & \\
\hline-12 & $6 \mathrm{E}+02$ & $37 \mathrm{E}+01$ & $E+01$ & $E+01$ & $43 \mathrm{E}+01$ & 03E+01 & $E+01$ & $E+01$ & $3.68 \mathrm{E}+01$ & $2.56 \mathrm{E}+01$ & & $E+01$ & $2.57 \mathrm{E}+01$ & $2.56 \mathrm{E}+01$ & $E+01$ & \\
\hline 6-T-14 & $20 \mathrm{E}+01$ & $4.99 \mathrm{E}+01$ & $4.89 \mathrm{E}+01$ & $4.89 \mathrm{E}+01$ & $94 \mathrm{E}+01$ & $31 \mathrm{E}+01$ & $1 E+01$ & $31 \mathrm{E}+01$ & $3.28 \mathrm{E}+01$ & $2.16 \mathrm{E}+01$ & $16 \mathrm{E}+01$ & $2.16 \mathrm{E}+01$ & $2.17 \mathrm{E}+01$ & $2.16 \mathrm{E}+01$ & $2.16 \mathrm{E}+01$ & $2.05 E+01$ \\
\hline 216-T-15 & $72 \mathrm{E}+01$ & $5.23 \mathrm{E}+01$ & $5.22 \mathrm{E}+01$ & $5.10 \mathrm{E}+01$ & $52 \mathrm{E}+01$ & $51 \mathrm{E}+01$ & $51 \mathrm{E}+01$ & $3.51 \mathrm{E}+01$ & $2.63 E+01$ & $2.28 \mathrm{E}+01$ & $28 \mathrm{E}+01$ & $2.28 \mathrm{E}+01$ & $2.29 \mathrm{E}+01$ & $2.28 \mathrm{E}+01$ & $2.14 \mathrm{E}+01$ & $.56 \mathrm{E}+01$ \\
\hline 216-T-16 & $17 \mathrm{E}+01$ & $17 \mathrm{E}+01$ & $5.17 \mathrm{E}+01$ & $4.89 \mathrm{E}+01$ & $55 \mathrm{E}+01$ & $54 \mathrm{E}+01$ & $3.54 \mathrm{E}+01$ & $3.54 \mathrm{E}+01$ & $2.46 \mathrm{E}+01$ & $2.30 \mathrm{E}+01$ & $30 \mathrm{E}+01$ & $2.30 \mathrm{E}+01$ & $2.31 \mathrm{E}+01$ & $2.30 \mathrm{E}+01$ & $.98 \mathrm{E}+01$ & $.57 \mathrm{E}+01$ \\
\hline 216-T-17 & $34 \mathrm{E}+00$ & $6.22 \mathrm{E}+00$ & $2.65 \mathrm{E}+01$ & $2.65 \mathrm{E}+01$ & $66 \mathrm{E}+01$ & $2.72 \mathrm{E}+01$ & $2.73 \mathrm{E}+01$ & $2.73 E+01$ & $2.74 \mathrm{E}+01$ & $2.73 \mathrm{E}+01$ & $5 \mathrm{E}+01$ & $1.96 \mathrm{E}+01$ & $1.97 \mathrm{E}+01$ & $1.96 \mathrm{E}+01$ & $.96 \mathrm{E}+01$ & $.96 \mathrm{E}+01$ \\
\hline $6-T-18$ & $26 \mathrm{E}+01$ & $02 \mathrm{E}+01$ & $1.40 \mathrm{E}+01$ & $1.40 \mathrm{E}+01$ & $40 \mathrm{E}+01$ & $18 \mathrm{E}+01$ & $79 E+00$ & $8.79 \mathrm{E}+00$ & $8.82 \mathrm{E}+00$ & $.79 \mathrm{E}+00$ & $9 \mathrm{E}+00$ & $89 \mathrm{E}+00$ & $5.80 \mathrm{E}+00$ & $5.79 \mathrm{E}+00$ & $.79 E+00$ & $9 \mathrm{E}+00$ \\
\hline -T-19 & $53 E+03$ & $93 \mathrm{E}+03$ & $E+03$ & $1.26 \mathrm{E}+03$ & $.05 \mathrm{E}+03$ & $E+02$ & $\mathrm{E}+03$ & $E+04$ & $6.59 \mathrm{E}+04$ & $E+04$ & $E+04$ & $E+04$ & $3.89 \mathrm{E}+$ & $2.42 \mathrm{E}+04$ & $3 E+04$ & $7 \mathrm{E}+04$ \\
\hline T-2 & $01 \mathrm{E}+01$ & $01 \mathrm{E}+01$ & $=01$ & $1.01 \mathrm{E}+01$ & $01 \mathrm{E}+01$ & $6.15 \mathrm{E}+00$ & $E+00$ & $E+00$ & $5.77 \mathrm{E}+00$ & $5.76 \mathrm{E}+00$ & $E+00$ & $E+00$ & $5.48 \mathrm{E}+00$ & $4.14 \mathrm{E}+00$ & $4 E+00$ & $4.14 \mathrm{E}+00$ \\
\hline T-20 & $6 \mathrm{E}-04$ & $94 \mathrm{E}-02$ & E-02 & $\mathrm{E}-02$ & 06E-02 & $45 \mathrm{E}-01$ & $5 \mathrm{E}-01$ & $5 \mathrm{E}-01$ & $3.46 \mathrm{E}-01$ & $3.45 \mathrm{E}-01$ & E-01 & E-01 & $5.04 \mathrm{E}$ & 5.03E-01 & 3E-01 & 3E-01 \\
\hline -T-21 & 1.61E-03 & $1.60 \mathrm{E}-03$ & $3.90 \mathrm{E}-01$ & 5.04E-01 & $5.05 \mathrm{E}-01$ & 5.04E-01 & $4 \mathrm{E}+00$ & $7.18 \mathrm{E}+00$ & $7.20 \mathrm{E}+00$ & $7.18 \mathrm{E}+00$ & $E+00$ & $7 \mathrm{E}+00$ & $1.23 \mathrm{E}+01$ & $1.23 \mathrm{E}+01$ & $3 \mathrm{E}+01$ & $3 \mathrm{E}+01$ \\
\hline $216-\mathrm{T}-22$ & $11 \mathrm{E}+01$ & $6.08 \mathrm{E}+01$ & $4.66 \mathrm{E}+01$ & $3.86 \mathrm{E}+01$ & $87 \mathrm{E}+01$ & $3.72 \mathrm{E}+01$ & $46 \mathrm{E}+01$ & $2.46 \mathrm{E}+01$ & $2.47 \mathrm{E}+01$ & $2.46 \mathrm{E}+01$ & $2.46 \mathrm{E}+01$ & $1.80 \mathrm{E}+01$ & $1.62 \mathrm{E}+01$ & $1.62 \mathrm{E}+01$ & $1.62 \mathrm{E}+01$ & $1.62 \mathrm{E}+01$ \\
\hline 216-T-23 & $70 \mathrm{E}+01$ & $97 \mathrm{E}+01$ & $4.28 \mathrm{E}+01$ & $4.28 \mathrm{E}+01$ & $.08 \mathrm{E}+01$ & $.74 \mathrm{E}+01$ & $74 \mathrm{E}+01$ & $2.74 \mathrm{E}+01$ & $2.74 \mathrm{E}+01$ & $2.36 \mathrm{E}+01$ & $1.79 \mathrm{E}+01$ & $1.79 E+01$ & $1.79 \mathrm{E}+01$ & $1.79 \mathrm{E}+01$ & $1.79 E+01$ & $1.79 \mathrm{E}+01$ \\
\hline 6-T-24 & $28 \mathrm{E}+01$ & $93 \mathrm{E}+01$ & $4.81 \mathrm{E}+01$ & $3.78 \mathrm{E}+01$ & $79 \mathrm{E}+01$ & $78 \mathrm{E}+01$ & $48 \mathrm{E}+01$ & $2.42 \mathrm{E}+01$ & $2.42 \mathrm{E}+01$ & $2.42 \mathrm{E}+01$ & $42 \mathrm{E}+01$ & $1.93 \mathrm{E}+01$ & $1.60 \mathrm{E}+01$ & $1.60 \mathrm{E}+01$ & $1.60 \mathrm{E}+01$ & $1.60 \mathrm{E}+01$ \\
\hline 216-T-25 & $32 \mathrm{E}+01$ & $4.11 \mathrm{E}+01$ & $3.89 \mathrm{E}+01$ & $3.89 \mathrm{E}+01$ & $.65 \mathrm{E}+01$ & $2.41 \mathrm{E}+01$ & $41 \mathrm{E}+01$ & $2.41 \mathrm{E}+01$ & $2.20 \mathrm{E}+01$ & $1.53 \mathrm{E}+01$ & $1.53 \mathrm{E}+01$ & $1.53 \mathrm{E}+01$ & $1.53 \mathrm{E}+01$ & $1.53 \mathrm{E}+01$ & $1.53 \mathrm{E}+01$ & $.36 \mathrm{E}+01$ \\
\hline 216-T-26 & $69 \mathrm{E}+02$ & $2.03 E+02$ & $1.54 \mathrm{E}+02$ & $1.53 \mathrm{E}+02$ & $03 \mathrm{E}+01$ & $01 \mathrm{E}+01$ & $01 \mathrm{E}+01$ & $8.28 \mathrm{E}+01$ & $5.40 \mathrm{E}+01$ & $5.39 \mathrm{E}+01$ & $E+01$ & $9 \mathrm{E}+01$ & $5.40 \mathrm{E}+01$ & $4.46 \mathrm{E}+01$ & $3.39 \mathrm{E}+01$ & $39 \mathrm{E}+01$ \\
\hline 6-T-27 & 62E-08 & 1.62E-08 & 1.62E-08 & 1.62E-08 & 1.62E-08 & $61 \mathrm{E}+03$ & $50 \mathrm{E}+03$ & $6.30 \mathrm{E}+02$ & $3.47 \mathrm{E}+02$ & $2.44 \mathrm{E}+02$ & $6 \mathrm{E}+02$ & $1 \mathrm{E}+02$ & $9.92 \mathrm{E}+01$ & $9.35 \mathrm{E}+01$ & $.35 E+01$ & $36 \mathrm{E}+01$ \\
\hline $216-T-28$ & $29 \mathrm{E}-07$ & 1.29E-07 & 1.29E-07 & $1.15 \mathrm{E}+03$ & $46 \mathrm{E}+04$ & $E+04$ & $79 E+03$ & $1.72 \mathrm{E}+03$ & $9.85 \mathrm{E}+02$ & $\mathrm{E}+02$ & $E+02$ & $E+02$ & $3.06 \mathrm{E}+02$ & $3.05 \mathrm{E}+02$ & $2.02 \mathrm{E}+02$ & $5 E+02$ \\
\hline$-\mathrm{T}-29$ & $3 \mathrm{E}+00$ & $91 \mathrm{E}+00$ & $4.92 \mathrm{E}+00$ & $4.91 \mathrm{E}+00$ & $97 \mathrm{E}+00$ & $6 \mathrm{E}-01$ & 7E-01 & 2.32E-01 & $2.11 \mathrm{E}-01$ & 4EE-01 & 4E-01 & E-01 & $6.24 \mathrm{E}-02$ & $6.23 \mathrm{E}-02$ & $6.23 \mathrm{E}-02$ & $6.13 \mathrm{E}-02$ \\
\hline T-3 & $3 E+01$ & $39 \mathrm{E}+01$ & $E+01$ & +01 & $83 E+01$ & $E+01$ & $E+01$ & $E+01$ & $1.83 \mathrm{E}+01$ & $E+01$ & $E+01$ & $E+01$ & $1.20 \mathrm{E}+01$ & $1.20 \mathrm{E}+01$ & $E+01$ & $E+01$ \\
\hline T-32 & $1 E+01$ & $68 \mathrm{E}+01$ & +01 & 5.8 & $E+01$ & $E+01$ & $E+01$ & +01 & $4.09 \mathrm{E}+01$ & $E+01$ & $E+01$ & +01 & $3.63 \mathrm{E}+$ & $3.62 \mathrm{E}+01$ & $E+01$ & +01 \\
\hline T-33 & & & -09 & 4.30 & $6.75 \mathrm{E}+02$ & +02 & $=01$ & +01 & $4.20 \mathrm{E}+01$ & +01 & +01 & +01 & 2.5 & & +01 & +01 \\
\hline T-34 & & 08 & -08 & -08 & -08 & -08 & $E+03$ & +03 & $2.30 \mathrm{E}+03$ & $E+03$ & +02 & 102 & $3.64 \mathrm{E}$ & -02 & $E+02$ & +02 \\
\hline 5-T-35 & $5 \mathrm{E}-11$ & $3 \mathrm{E}-11$ & $3 \mathrm{E}-11$ & $53 \mathrm{E}-11$ & $55 \mathrm{E}-11$ & $53 E-11$ & $53 \mathrm{E}-11$ & $1.80 \mathrm{E}+02$ & $2.35 \mathrm{E}+03$ & $6.51 \mathrm{E}+02$ & $E+02$ & $2.51 \mathrm{E}+02$ & $1.70 \mathrm{E}+02$ & $1.50 \mathrm{E}+02$ & $1.08 \mathrm{E}+02$ & $1.08 \mathrm{E}+02$ \\
\hline 6-T-36 & $1 \mathrm{E}-09$ & 1.60E-09 & OE-09 & 60E-09 & 61E-09 & 1.60E-09 & 60E-09 & 1.60E-09 & 1.61E-09 & 1.60E-09 & 24E-08 & $5.45 \mathrm{E}-03$ & 1.34E-01 & $5.21 \mathrm{E}+00$ & $7.73 \mathrm{E}+00$ & $2.07 \mathrm{E}+01$ \\
\hline 216-T-4A & $37 \mathrm{E}+05$ & $9.28 \mathrm{E}+05$ & $9.66 \mathrm{E}+05$ & $9.64 \mathrm{E}+05$ & $9.68 \mathrm{E}+05$ & $9.66 \mathrm{E}+05$ & $66 \mathrm{E}+05$ & $8.32 \mathrm{E}+05$ & $7.77 \mathrm{E}+05$ & $7.35 \mathrm{E}+05$ & $5.95 \mathrm{E}+05$ & $5.04 \mathrm{E}+05$ & $4.79 \mathrm{E}+05$ & $3.99 \mathrm{E}+05$ & $3.17 \mathrm{E}+05$ & $2.73 \mathrm{E}+05$ \\
\hline 216-T-5 & $85 \mathrm{E}+01$ & $6.62 \mathrm{E}+01$ & $4.32 \mathrm{E}+01$ & $4.08 \mathrm{E}+01$ & $4.09 \mathrm{E}+01$ & $2.78 \mathrm{E}+01$ & $53 \mathrm{E}+01$ & $2.53 \mathrm{E}+01$ & $2.54 \mathrm{E}+01$ & $2.30 E+01$ & $1.61 \mathrm{E}+01$ & $1.61 \mathrm{E}+01$ & $1.61 \mathrm{E}+01$ & $1.61 \mathrm{E}+01$ & $1.61 \mathrm{E}+01$ & $1.61 \mathrm{E}+01$ \\
\hline 216-T-6 & $33 \mathrm{E}+02$ & $1.75 \mathrm{E}+02$ & $1.48 \mathrm{E}+02$ & $1.48 \mathrm{E}+02$ & $1.48 \mathrm{E}+02$ & $1.48 \mathrm{E}+02$ & $48 \mathrm{E}+02$ & $1.48 \mathrm{E}+02$ & $9.99 \mathrm{E}+01$ & $9.96 \mathrm{E}+01$ & $9.96 \mathrm{E}+01$ & $9.96 \mathrm{E}+01$ & $9.99 \mathrm{E}+01$ & $9.96 \mathrm{E}+01$ & $9.96 \mathrm{E}+01$ & $9.96 \mathrm{E}+01$ \\
\hline 216-T-7 & $1.09 \mathrm{E}+03$ & $1.07 \mathrm{E}+03$ & $6.13 \mathrm{E}+02$ & $6.13 \mathrm{E}+02$ & $6.14 \mathrm{E}+02$ & $4.55 \mathrm{E}+02$ & $55 \mathrm{E}+02$ & $3.55 \mathrm{E}+02$ & $3.56 \mathrm{E}+02$ & $3.55 \mathrm{E}+02$ & $2.91 \mathrm{E}+02$ & $2.16 \mathrm{E}+02$ & $2.16 \mathrm{E}+02$ & $2.16 \mathrm{E}+02$ & $2.16 \mathrm{E}+02$ & $2.16 \mathrm{E}+02$ \\
\hline 216-T-8 & $2.46 \mathrm{E}-04$ & $4.29 \mathrm{E}-02$ & 7.02E-02 & $7.02 \mathrm{E}-02$ & 7.04E-02 & 7.02E-02 & $39 \mathrm{E}+00$ & $2.94 \mathrm{E}+00$ & $2.94 \mathrm{E}+00$ & $2.94 \mathrm{E}+00$ & $2.94 \mathrm{E}+00$ & $2.94 \mathrm{E}+00$ & $2.94 \mathrm{E}+00$ & $2.94 \mathrm{E}+00$ & $9.73 \mathrm{E}+00$ & $1.21 \mathrm{E}+01$ \\
\hline 216-TY-201 & $6.25 \mathrm{E}+00$ & $6.24 \mathrm{E}+00$ & $6.24 \mathrm{E}+00$ & $6.22 \mathrm{E}+00$ & $6.25 \mathrm{E}+00$ & $6.24 \mathrm{E}+00$ & $6.23 \mathrm{E}+00$ & $2.96 \mathrm{E}+00$ & $1.46 \mathrm{E}+00$ & $9.40 \mathrm{E}-01$ & 4.97E-01 & 4.97E-01 & 3.03E-01 & $2.72 \mathrm{E}-01$ & $2.72 \mathrm{E}-01$ & 1.94E-01 \\
\hline $216-U-1 \% 2$ & $3.56 \mathrm{E}-06$ & $3.55 \mathrm{E}-06$ & $3.55 \mathrm{E}-06$ & $3.55 \mathrm{E}-06$ & 3.56E-06 & $3.55 \mathrm{E}-06$ & $3.55 \mathrm{E}-06$ & $3.55 \mathrm{E}-06$ & $3.56 \mathrm{E}-06$ & $3.55 \mathrm{E}-06$ & $3.55 \mathrm{E}-06$ & $3.55 \mathrm{E}-06$ & $3.56 \mathrm{E}-06$ & $3.55 \mathrm{E}-06$ & $3.55 \mathrm{E}-06$ & $3.55 \mathrm{E}-06$ \\
\hline 216-U-10 & $3.48 \mathrm{E}+06$ & $2.15 E+06$ & $2.79 \mathrm{E}+06$ & $2.27 \mathrm{E}+06$ & $2.06 \mathrm{E}+06$ & $2.22 \mathrm{E}+06$ & $2.23 \mathrm{E}+06$ & $2.27 \mathrm{E}+06$ & $2.51 \mathrm{E}+06$ & $3.25 E+06$ & $2.84 \mathrm{E}+06$ & $2.54 \mathrm{E}+06$ & $2.22 \mathrm{E}+06$ & $2.24 \mathrm{E}+06$ & $2.04 \mathrm{E}+06$ & $3.60 \mathrm{E}+06$ \\
\hline
\end{tabular}




\begin{tabular}{|c|c|c|c|c|c|c|c|c|c|c|c|c|c|c|c|c|}
\hline Site & 1960 & 1961 & 1962 & 1963 & 1964 & 1965 & 1966 & 1967 & 1968 & 1969 & 1970 & 1971 & 1972 & 1973 & 1974 & 1975 \\
\hline $216-U-12$ & 89E-05 & $2.88 \mathrm{E}-05$ & $34 \mathrm{E}+03$ & $42 \mathrm{E}+04$ & $63 E+04$ & $1.42 \mathrm{E}+04$ & $1.14 \mathrm{E}+04$ & $1.05 E+04$ & $9.68 \mathrm{E}+03$ & $8.50 \mathrm{E}+03$ & $6.56 \mathrm{E}+03$ & $5.41 \mathrm{E}+03$ & $5.02 \mathrm{E}+03$ & $4.32 \mathrm{E}+03$ & $3.30 \mathrm{E}+03$ & $2.48 \mathrm{E}+03$ \\
\hline & 00E-06 & 99E-06 & $4.99 \mathrm{E}-06$ & 4.99E-06 & $.00 \mathrm{E}-06$ & 4.99E-06 & $4.99 \mathrm{E}-06$ & $4.99 \mathrm{E}-06$ & $5.00 \mathrm{E}-06$ & 4.99E-06 & $4.99 \mathrm{E}-06$ & $4.99 \mathrm{E}-06$ & $5.00 \mathrm{E}-06$ & 4.99E-06 & & $9.96 \mathrm{E}-\mathrm{C}$ \\
\hline & 51E-10 & $1.51 \mathrm{E}-10$ & 51E-10 & 51E-10 & 51E-10 & 51E-10 & $1.51 \mathrm{E}-10$ & $.51 \mathrm{E}-10$ & 51E-10 & $51 \mathrm{E}-10$ & $1.51 \mathrm{E}-10$ & $1.51 \mathrm{E}-10$ & $51 \mathrm{E}-10$ & 51E-10 & $51 \mathrm{E}-10$ & E-10 \\
\hline-15 & OE-06 & $2.99 \mathrm{E}-06$ & 99E-06 & 99E-06 & 00E-06 & 99E-06 & $2.99 \mathrm{E}-06$ & $3.84 \mathrm{E}-04$ & $82 \mathrm{E}-04$ & 30E-04 & 5.80E-04 & DE-04 & 52E-02 & $2 \mathrm{E}-02$ & 92E-02 & $\mathrm{E}-02$ \\
\hline $5-U-16$ & 8E-02 & 7.16E-02 & $7.16 \mathrm{E}-02$ & 7.16E-02 & $7.18 \mathrm{E}-02$ & 7.16E-02 & $7.16 \mathrm{E}-02$ & 7.16E-02 & $7.18 \mathrm{E}-02$ & 16E-02 & 7.16E-02 & 7.16E-02 & 7.18E-02 & $6 \mathrm{E}-02$ & 7.16E-02 & $6 \mathrm{E}-02$ \\
\hline $5-U-17$ & 95E-09 & 9.93E-09 & $9.93 \mathrm{E}-09$ & 9.93E-09 & 9.95E-09 & 9.93E-09 & 9.93E-09 & 9.93E-09 & 9.95E-09 & 9.93E-09 & 9.93E-09 & $3 \mathrm{E}-09$ & 9.95E-09 & $3 \mathrm{E}-09$ & 9.93E-09 & 3E-09 \\
\hline & $85 \mathrm{E}+01$ & $4.30 \mathrm{E}+01$ & $3.08 \mathrm{E}+01$ & $3.08 \mathrm{E}+01$ & $76 \mathrm{E}+01$ & $1.92 \mathrm{E}+01$ & $1.92 \mathrm{E}+01$ & $1.92 \mathrm{E}+01$ & $1.92 \mathrm{E}+01$ & $1.39 E+01$ & $1.20 \mathrm{E}+01$ & $1.20 \mathrm{E}+01$ & $1.20 \mathrm{E}+01$ & $1.20 E+01$ & $1.20 \mathrm{E}+01$ & $0 \mathrm{E}+01$ \\
\hline & $26 \mathrm{E}+01$ & $1.25 \mathrm{E}+01$ & $1.12 \mathrm{E}+01$ & $7.62 \mathrm{E}+00$ & $7.64 \mathrm{E}+00$ & $7.62 \mathrm{E}+00$ & $7.33 \mathrm{E}+00$ & $4.50 \mathrm{E}+00$ & $4.51 \mathrm{E}+00$ & $.50 \mathrm{E}+00$ & $4.50 \mathrm{E}+00$ & $4.50 \mathrm{E}+00$ & $4.51 \mathrm{E}+00$ & $1 \mathrm{E}+00$ & $66 \mathrm{E}+00$ & $E+00$ \\
\hline & 31E-08 & $1.31 \mathrm{E}-08$ & 1.31E-08 & 1.31E-08 & 1.31E-08 & 1.31E-08 & 1.31E-08 & E-08 & $E+01$ & $E+02$ & $9.78 \mathrm{E}+01$ & $E+01$ & $3.13 \mathrm{E}+01$ & $2 \mathrm{E}+01$ & $6 \mathrm{E}+01$ & $3 E+00$ \\
\hline & E-11 & E-11 & E-11 & E-11 & E-11 & $62 \mathrm{E}-11$ & $2.90 \mathrm{E}+00$ & $7.12 \mathrm{E}+00$ & $\mathrm{E}+00$ & $.52 \mathrm{E}+00$ & $2.07 \mathrm{E}+00$ & $E+00$ & $6 \mathrm{E}+00$ & EE-01 & 48E-01 & $9 \mathrm{E}-01$ \\
\hline & 29E-01 & $2.87 \mathrm{E}-01$ & E-01 & E-01 & $\mathrm{E}-01$ & 1.42E-01 & 9.94E-02 & E-02 & E-02 & $.94 \mathrm{E}-02$ & $4 \mathrm{E}-02$ & E-02 & $3 \mathrm{E}-02$ & 2E-02 & 92E-02 & E-02 \\
\hline & $E+04$ & $E+04$ & $9.00 \mathrm{E}+03$ & $E+03$ & $35 \mathrm{E}+03$ & $44 \mathrm{E}+03$ & $4.44 \mathrm{E}+03$ & $3.91 \mathrm{E}+03$ & $2.86 \mathrm{E}+03$ & $2.85 E+03$ & $2.85 \mathrm{E}+03$ & $E+03$ & $1.80 \mathrm{E}+03$ & $E+03$ & $1.80 \mathrm{E}+03$ & $E+03$ \\
\hline & 7E-07 & 16E-07 & E-07 & 16E-07 & 4.17E-07 & E-07 & 4.16E-07 & E-07 & 4.17E-07 & $4.16 \mathrm{E}-07$ & 4.16E-07 & E-07 & 4.17E-07 & $6 \mathrm{E}-07$ & $16 \mathrm{E}-07$ & $6 \mathrm{E}-07$ \\
\hline 216 & $72 E+02$ & $4.89 \mathrm{E}+02$ & $4.26 \mathrm{E}+02$ & $.75 E+02$ & $35 \mathrm{E}+02$ & $00 \mathrm{E}+02$ & $2.79 \mathrm{E}+02$ & $2.50 \mathrm{E}+02$ & $2.33 \mathrm{E}+02$ & $2.14 \mathrm{E}+02$ & $1.94 \mathrm{E}+02$ & $1.79 \mathrm{E}+02$ & $1.64 E+02$ & $1.54 \mathrm{E}+02$ & $.42 \mathrm{E}+02$ & $1.40 \mathrm{E}+02$ \\
\hline & $E+00$ & $11 \mathrm{E}+00$ & $E+00$ & $8.11 \mathrm{E}+00$ & $13 \mathrm{E}+00$ & $59 \mathrm{E}+00$ & $78 \mathrm{E}+00$ & $4.78 \mathrm{E}+00$ & $4.80 \mathrm{E}+00$ & $.78 \mathrm{E}+00$ & $.78 \mathrm{E}+00$ & $4.78 \mathrm{E}+00$ & $4.80 \mathrm{E}+00$ & $4.78 \mathrm{E}+00$ & 1.65E+00 & $9 \mathrm{E}+00$ \\
\hline-12 & $57 \mathrm{E}-06$ & $3.34 \mathrm{E}+04$ & $3.19 \mathrm{E}+04$ & $2.45 \mathrm{E}+04$ & $14 \mathrm{E}+04$ & $90 \mathrm{E}+04$ & $1.70 \mathrm{E}+04$ & $1.50 \mathrm{E}+04$ & $1.24 \mathrm{E}+04$ & $1.05 E+04$ & $8.01 E+03$ & $6.85 E+03$ & $6.01 \mathrm{E}+03$ & $7.50 \mathrm{E}+03$ & $7.57 \mathrm{E}+03$ & $E+03$ \\
\hline & $11 \mathrm{E}+04$ & $6.86 \mathrm{E}+03$ & $4.76 \mathrm{E}+03$ & $81 \mathrm{E}+03$ & $47 \mathrm{E}+03$ & $42 \mathrm{E}+03$ & $1.83 E+03$ & $1.50 \mathrm{E}+03$ & $1.50 \mathrm{E}+03$ & $1.41 \mathrm{E}+03$ & $9.17 \mathrm{E}+02$ & $9.17 \mathrm{E}+02$ & $9.20 \mathrm{E}+02$ & $9.17 \mathrm{E}+02$ & $9.17 \mathrm{E}+02$ & $6 \mathrm{E}+02$ \\
\hline & 73E-04 & $6.48 \mathrm{E}-04$ & $6.48 \mathrm{E}-04$ & $6.48 \mathrm{E}-04$ & $6.50 \mathrm{E}-04$ & $.48 \mathrm{E}-04$ & $6.48 \mathrm{E}-04$ & $6.26 \mathrm{E}-03$ & $3.94 \mathrm{E}-02$ & $3.93 \mathrm{E}-02$ & 3.93E-02 & $3 \mathrm{E}-02$ & $3.94 \mathrm{E}-02$ & 3.93E-02 & $3 E-02$ & \\
\hline & $73 \mathrm{E}+02$ & $4.72 \mathrm{E}+02$ & $3.67 \mathrm{E}+02$ & $97 \mathrm{E}+02$ & $97 \mathrm{E}+02$ & $97 \mathrm{E}+02$ & $2.97 \mathrm{E}+02$ & $2.97 \mathrm{E}+02$ & $2.97 \mathrm{E}+02$ & $76 \mathrm{E}+02$ & $1.94 \mathrm{E}+02$ & $E+02$ & $\mathrm{E}+02$ & $E+02$ & $4 \mathrm{E}+02$ & +02 \\
\hline & 4E-01 & $1.74 \mathrm{E}-01$ & 4.01E-01 & $48 \mathrm{E}+00$ & $49 \mathrm{E}+00$ & $48 \mathrm{E}+00$ & $1.48 \mathrm{E}+00$ & $1.48 \mathrm{E}+00$ & $49 \mathrm{E}+00$ & $.48 \mathrm{E}+00$ & $48 \mathrm{E}+00$ & $E+00$ & $2.09 \mathrm{E}+00$ & $9 \mathrm{E}+00$ & $9 \mathrm{E}+00$ & $\mathrm{E}+00$ \\
\hline & $7 \mathrm{E}+02$ & $54 \mathrm{E}+02$ & E+02 & $E+02$ & $E+02$ & $E+02$ & $11 \mathrm{E}+02$ & & $E+02$ & $E+02$ & $E+02$ & $E+02$ & $\mathrm{E}+02$ & $E+02$ & $E+02$ & $E+02$ \\
\hline & +00 & +00 & +00 & $=+00$ & $E+00$ & +00 & $E+00$ & $E+00$ & $E+00$ & $E+00$ & $E+00$ & $E+00$ & $E+00$ & +00 & +00 & $E+00$ \\
\hline & & E-03 & E-03 & $=-03$ & $E-03$ & $E-03$ & $6 \mathrm{E}-03$ & E-03 & $\mathrm{E}-03$ & E-03 & 3E-03 & $\mathrm{E}-03$ & E-03 & E-03 & DE-03 & E-03 \\
\hline & $E-02$ & 1.39E-02 & $37 \mathrm{E}-02$ & $5-02$ & 3E-02 & 30E-02 & $1.28 \mathrm{E}-02$ & E-02 & 4E-02 & 22E-02 & E-02 & E-02 & $6 \mathrm{E}-02$ & 4E-02 & $2 \mathrm{E}-02$ & DE-02 \\
\hline$-3 A$ & $00 \mathrm{E}+00$ & $0.00 \mathrm{E}+00$ & $0.00 \mathrm{E}+00$ & $0.00 \mathrm{E}+00$ & $0.00 \mathrm{E}+00$ & $0.00 \mathrm{E}+00$ & $0.00 \mathrm{E}+00$ & $0.00 \mathrm{E}+00$ & $0.00 \mathrm{E}+00$ & $0.00 \mathrm{E}+00$ & $0.00 \mathrm{E}+00$ & $E+00$ & $0.00 \mathrm{E}+00$ & $\mathrm{DE}+00$ & $0.00 \mathrm{E}+00$ & $\mathrm{E}+00$ \\
\hline$N-3 A E$ & $0 \mathrm{E}+00$ & $0.00 \mathrm{E}+00$ & $0.00 \mathrm{E}+00$ & $0.00 \mathrm{E}+00$ & $.00 \mathrm{E}+00$ & $0.00 \mathrm{E}+00$ & $0.00 \mathrm{E}+00$ & $0.00 \mathrm{E}+00$ & $0.00 \mathrm{E}+00$ & $0.00 \mathrm{E}+00$ & $0.00 \mathrm{E}+00$ & $0.00 \mathrm{E}+00$ & $0.00 \mathrm{E}+00$ & $0.00 \mathrm{E}+00$ & $0.00 \mathrm{E}+00$ & $0.00 \mathrm{E}+00$ \\
\hline $\mathrm{N}-4 \mathrm{~B}$ & $E+00$ & $0 \mathrm{E}+00$ & $00 \mathrm{E}+00$ & $00 \mathrm{E}+00$ & DOE+00 & $00 \mathrm{E}+00$ & $00 \mathrm{E}+00$ & $0.00 \mathrm{E}+00$ & $0.00 \mathrm{E}+00$ & $00 \mathrm{E}+00$ & $00 \mathrm{E}+00$ & $0.00 \mathrm{E}+00$ & $0.00 \mathrm{E}+00$ & DOE+00 & $0.00 \mathrm{E}+00$ & $0.00 \mathrm{E}+00$ \\
\hline $218-W-4 C$ & $0 \mathrm{E}+00$ & $0.00 \mathrm{E}+00$ & $0.00 \mathrm{E}+00$ & $0.00 \mathrm{E}+00$ & $00 \mathrm{E}+00$ & $00 \mathrm{E}+00$ & $0.00 \mathrm{E}+00$ & $0.00 \mathrm{E}+00$ & $0.00 \mathrm{E}+00$ & $.00 \mathrm{E}+00$ & $0.00 \mathrm{E}+00$ & $0.00 \mathrm{E}+00$ & $0.00 \mathrm{E}+00$ & $0.00 \mathrm{E}+00$ & $0.00 \mathrm{E}+00$ & $0.00 \mathrm{E}+00$ \\
\hline $218-W-5$ & DOE+00 & $0.00 \mathrm{E}+00$ & $0.00 \mathrm{E}+00$ & $0.00 \mathrm{E}+00$ & $00 \mathrm{E}+00$ & $0.00 \mathrm{E}+00$ & $0.00 \mathrm{E}+00$ & $0.00 \mathrm{E}+00$ & $0.00 \mathrm{E}+00$ & $0.00 \mathrm{E}+00$ & $0.00 \mathrm{E}+00$ & $0.00 \mathrm{E}+00$ & $0.00 \mathrm{E}+00$ & $0.00 \mathrm{E}+00$ & $0.00 \mathrm{E}+00$ & $0 \mathrm{E}+00$ \\
\hline-101 & $0 \mathrm{E}+00$ & $0.00 \mathrm{E}+00$ & $0.00 \mathrm{E}+00$ & $0.00 \mathrm{E}+00$ & $00 \mathrm{E}+00$ & $00 \mathrm{E}+00$ & $0.00 \mathrm{E}+00$ & $0.00 \mathrm{E}+00$ & $0.00 \mathrm{E}+00$ & $0.00 \mathrm{E}+00$ & $0.00 \mathrm{E}+00$ & $0.00 \mathrm{E}+00$ & $0.00 \mathrm{E}+00$ & $0 \mathrm{E}+00$ & $0.00 \mathrm{E}+00$ & $.00 \mathrm{E}+00$ \\
\hline 102 & $0 \mathrm{E}+00$ & $0.00 \mathrm{E}+00$ & $0.00 \mathrm{E}+00$ & $.00 \mathrm{E}+00$ & $00 \mathrm{E}+00$ & $0.00 \mathrm{E}+00$ & $0.00 \mathrm{E}+00$ & $0.00 \mathrm{E}+00$ & $0.00 \mathrm{E}+00$ & $0.00 \mathrm{E}+00$ & $0.00 \mathrm{E}+00$ & $0.00 \mathrm{E}+00$ & $0.00 \mathrm{E}+00$ & $0 \mathrm{E}+00$ & $0 \mathrm{E}+00$ & $0.00 \mathrm{E}+00$ \\
\hline 03 & $00 \mathrm{E}+00$ & $0.00 \mathrm{E}+00$ & $0.00 \mathrm{E}+00$ & $0.00 \mathrm{E}+00$ & $0.00 \mathrm{E}+00$ & $00 \mathrm{E}+00$ & $0.00 \mathrm{E}+00$ & $0.00 \mathrm{E}+00$ & $0.00 \mathrm{E}+00$ & $0.00 \mathrm{E}+00$ & $0.00 \mathrm{E}+00$ & $E+00$ & $0.00 \mathrm{E}+00$ & $\mathrm{DE}+00$ & $0.00 \mathrm{E}+00$ & $.00 \mathrm{E}+00$ \\
\hline-104 & $3 \mathrm{E}-05$ & $23 \mathrm{E}-05$ & 23E-05 & 1.23E-05 & $1.23 \mathrm{E}-05$ & 23E-05 & $1.23 \mathrm{E}-05$ & $1.23 \mathrm{E}-05$ & $1.23 \mathrm{E}-05$ & $1.23 \mathrm{E}-05$ & 1.23E-05 & E-05 & $1.23 \mathrm{E}-05$ & 23E-05 & $1.23 \mathrm{E}-05$ & 1.23E-05 \\
\hline & 99E-05 & $1.28 \mathrm{E}-05$ & $1.28 \mathrm{E}-05$ & $28 \mathrm{E}-05$ & 29E-05 & $23 E+02$ & $3.08 \mathrm{E}+02$ & $7.29 \mathrm{E}+01$ & $3.85 E+01$ & $2.47 \mathrm{E}+01$ & $E+01$ & $=01$ & $1.08 \mathrm{E}+01$ & $E+00$ & $16 \mathrm{E}+00$ & +00 \\
\hline 106 & $0 \mathrm{E}+00$ & $0.00 \mathrm{E}+00$ & $0.00 \mathrm{E}+00$ & $0.00 \mathrm{E}+00$ & $00 \mathrm{E}+00$ & $00 \mathrm{E}+00$ & $0.00 \mathrm{E}+00$ & $0.00 \mathrm{E}+00$ & $0.00 \mathrm{E}+00$ & $0.00 \mathrm{E}+00$ & $\mathrm{E}+00$ & $0.00 \mathrm{E}+00$ & $0.00 \mathrm{E}+00$ & $\mathrm{E}+00$ & $E+00$ & $E+00$ \\
\hline & $0 \mathrm{E}+00$ & $0.00 \mathrm{E}+00$ & $0.00 \mathrm{E}+00$ & $0.00 \mathrm{E}+00$ & $00 \mathrm{E}+00$ & $0.00 \mathrm{E}+00$ & $0.00 \mathrm{E}+00$ & $0.00 \mathrm{E}+00$ & $0.00 \mathrm{E}+00$ & $0.00 \mathrm{E}+00$ & $\mathrm{E}+00$ & $0.00 \mathrm{E}+00$ & $0.00 \mathrm{E}+00$ & $E+00$ & $E+00$ & $E+00$ \\
\hline & $0 \mathrm{E}+00$ & $0.00 \mathrm{E}+00$ & $0.00 \mathrm{E}+00$ & $0.00 \mathrm{E}+00$ & $0.00 \mathrm{E}+00$ & $0.00 \mathrm{E}+00$ & $0.00 \mathrm{E}+00$ & $0.00 \mathrm{E}+00$ & $0.00 \mathrm{E}+00$ & $0.00 \mathrm{E}+00$ & $0.00 \mathrm{E}+00$ & $0.00 \mathrm{E}+00$ & $0.00 \mathrm{E}+00$ & $0.00 \mathrm{E}+00$ & $0.00 \mathrm{E}+00$ & $.00 \mathrm{E}+00$ \\
\hline $\mathrm{V}-103$ & $0 \mathrm{E}+00$ & $0.00 \mathrm{E}+00$ & $0.00 \mathrm{E}+00$ & $0.00 \mathrm{E}+00$ & $0.00 \mathrm{E}+00$ & $0.00 \mathrm{E}+00$ & $0.00 \mathrm{E}+00$ & $0.00 \mathrm{E}+00$ & $0.00 \mathrm{E}+00$ & $0.00 \mathrm{E}+00$ & $0.00 \mathrm{E}+00$ & $0.00 \mathrm{E}+00$ & $0.00 \mathrm{E}+00$ & $0.00 \mathrm{E}+00$ & $0.00 \mathrm{E}+00$ & $.00 \mathrm{E}+00$ \\
\hline & $0 \mathrm{E}+00$ & $00 \mathrm{E}+00$ & $0.00 \mathrm{E}+00$ & $00 \mathrm{E}+00$ & $00 \mathrm{E}+00$ & $0.00 \mathrm{E}+00$ & $0.00 \mathrm{E}+00$ & $0.00 \mathrm{E}+00$ & $0.00 \mathrm{E}+00$ & $00 \mathrm{E}+00$ & $0.00 \mathrm{E}+00$ & $0.00 \mathrm{E}+00$ & $0.00 \mathrm{E}+00$ & $.00 \mathrm{E}+00$ & $.00 \mathrm{E}+00$ & IT+U \\
\hline & $0 \mathrm{E}+00$ & $0.00 \mathrm{E}+00$ & $0.00 \mathrm{E}+00$ & $0.00 \mathrm{E}+00$ & $00 \mathrm{E}+00$ & $0.00 \mathrm{E}+00$ & $0.00 \mathrm{E}+00$ & $0.00 \mathrm{E}+00$ & $0.00 \mathrm{E}+00$ & $0.00 \mathrm{E}+00$ & $0.00 \mathrm{E}+00$ & $0.00 \mathrm{E}+00$ & $0.00 \mathrm{E}+00$ & $0.00 \mathrm{E}+00$ & $0.00 \mathrm{E}+00$ & $= \pm+00$ \\
\hline 241-AN-106 & $0.00 \mathrm{E}+00$ & $0.00 \mathrm{E}+00$ & $0.00 \mathrm{E}+00$ & $0.00 \mathrm{E}+00$ & $0.00 \mathrm{E}+00$ & $0.00 \mathrm{E}+00$ & $0.00 \mathrm{E}+00$ & $0.00 \mathrm{E}+00$ & $0.00 \mathrm{E}+00$ & $0.00 \mathrm{E}+00$ & $0.00 \mathrm{E}+00$ & $0.00 \mathrm{E}+00$ & $0.00 \mathrm{E}+00$ & $0.00 \mathrm{E}+00$ & $0.00 \mathrm{E}+00$ & \\
\hline
\end{tabular}




\begin{tabular}{|c|c|c|c|c|c|c|c|c|c|c|c|c|c|c|c|c|}
\hline Site & 1960 & 1961 & 1962 & 1963 & 1964 & 1965 & 1966 & 1967 & 1968 & 1969 & 1970 & 1971 & 1972 & 1973 & 1974 & 1975 \\
\hline $1-A N-107$ & $00 \mathrm{E}+00$ & $0.00 \mathrm{E}+00$ & $0.00 \mathrm{E}+00$ & $.00 \mathrm{E}+00$ & $.00 \mathrm{E}+00$ & $0.00 \mathrm{E}+00$ & $0.00 \mathrm{E}+00$ & $0.00 \mathrm{E}+00$ & $0.00 \mathrm{E}+00$ & $0.00 \mathrm{E}+00$ & $0.00 \mathrm{E}+00$ & $0.00 \mathrm{E}+00$ & $0.00 E+00$ & $0.00 \mathrm{E}+00$ & $0.00 \mathrm{E}+00$ & $0.00 \mathrm{E}+00$ \\
\hline & $0 \mathrm{E}+00$ & $00 \mathrm{E}+00$ & $0.00 \mathrm{E}+00$ & $00 \mathrm{E}+00$ & $00 \mathrm{E}+00$ & $00 \mathrm{E}+00$ & $0.00 \mathrm{E}+00$ & $.00 \mathrm{E}+00$ & $.00 \mathrm{E}+00$ & $00 \mathrm{E}+00$ & $0.00 \mathrm{E}+00$ & $0.00 \mathrm{E}+00$ & $0.00 \mathrm{E}+00$ & $.00 \mathrm{E}+00$ & $.00 \mathrm{E}+00$ & $.00 \mathrm{E}+00$ \\
\hline AP-102 & $0 \mathrm{E}+00$ & $0.00 \mathrm{E}+00$ & $0.00 E+00$ & $00 \mathrm{E}+00$ & $00 E+00$ & $00 \mathrm{E}+00$ & $0.00 \mathrm{E}+00$ & $0.00 \mathrm{E}+00$ & $.00 \mathrm{E}+00$ & $00 \mathrm{E}+00$ & $0.00 E+00$ & $0.00 E+00$ & $0.00 E+00$ & $.00 \mathrm{E}+00$ & $.00 \mathrm{E}+00$ & $0 \mathrm{E}+00$ \\
\hline -AP-103 & $00 \mathrm{E}+00$ & $0.00 \mathrm{E}+00$ & $0.00 \mathrm{E}+00$ & $00 \mathrm{E}+00$ & $00 \mathrm{E}+00$ & $0.00 \mathrm{E}+00$ & $0.00 \mathrm{E}+00$ & $0.00 \mathrm{E}+00$ & $.00 \mathrm{E}+00$ & $0.00 \mathrm{E}+00$ & $0.00 \mathrm{E}+00$ & $0.00 \mathrm{E}+00$ & $0.00 \mathrm{E}+00$ & $\mathrm{DE}+00$ & $0 \mathrm{E}+00$ & $.00 \mathrm{E}+00$ \\
\hline & $\mathrm{E}+00$ & $0.00 \mathrm{E}+00$ & $0.00 \mathrm{E}+00$ & $0.00 \mathrm{E}+00$ & $00 \mathrm{E}+00$ & $00 \mathrm{E}+00$ & $0.00 \mathrm{E}+00$ & $0.00 \mathrm{E}+00$ & $0.00 \mathrm{E}+00$ & $0.00 \mathrm{E}+00$ & $0.00 \mathrm{E}+00$ & $0.00 \mathrm{E}+00$ & $0.00 \mathrm{E}+00$ & $0.00 \mathrm{E}+00$ & $.00 \mathrm{E}+00$ & $.00 \mathrm{E}+00$ \\
\hline & $=00$ & $0.00 \mathrm{E}+00$ & $0.00 E+00$ & $.00 \mathrm{E}+00$ & $00 \mathrm{E}+00$ & $0.00 \mathrm{E}+00$ & $0.00 \mathrm{E}+00$ & $0.00 \mathrm{E}+00$ & $0.00 \mathrm{E}+00$ & $0.00 \mathrm{E}+00$ & $0.00 \mathrm{E}+00$ & $0.00 \mathrm{E}+00$ & $0.00 \mathrm{E}+00$ & $0.00 \mathrm{E}+00$ & $0.00 \mathrm{E}+00$ & $.00 \mathrm{E}+00$ \\
\hline & $E+00$ & $00 \mathrm{E}+00$ & $0.00 E+00$ & $.00 \mathrm{E}+00$ & $00 \mathrm{E}+00$ & $00 \mathrm{E}+00$ & $00 \mathrm{E}+00$ & $0.00 E+00$ & $00 \mathrm{E}+00$ & $.00 \mathrm{E}+00$ & $0 \mathrm{E}+00$ & $0.00 \mathrm{E}+00$ & $0.00 E+00$ & $.00 \mathrm{E}+00$ & $.00 \mathrm{E}+00$ & $00 \mathrm{E}+00$ \\
\hline & $=00$ & $E+00$ & $E+00$ & $.00 \mathrm{E}+00$ & $\mathrm{E}+00$ & $E+00$ & $00 \mathrm{E}+00$ & $0.00 \mathrm{E}+00$ & $0.00 \mathrm{E}+00$ & $0 \mathrm{E}+00$ & $.00 \mathrm{E}+00$ & $0.00 \mathrm{E}+00$ & $0.00 \mathrm{E}+00$ & $0 \mathrm{E}+00$ & $0.00 \mathrm{E}+00$ & $\mathrm{DE}+00$ \\
\hline & +00 & $E+00$ & $E+00$ & $E+00$ & $E+00$ & $E+00$ & $E+00$ & $E+00$ & $E+00$ & $E+00$ & $\mathrm{DE}+00$ & $0.00 \mathrm{E}+00$ & $0.00 \mathrm{E}+00$ & $\mathrm{DE}+00$ & $\mathrm{DE}+00$ & $\mathrm{E}+00$ \\
\hline & $E+00$ & $E+00$ & $E+00$ & $=00$ & $E+00$ & $E+00$ & $E+00$ & $E+00$ & $E+00$ & $E+00$ & $E+00$ & $0.00 \mathrm{E}+$ & $\mathrm{DE}+00$ & $E+00$ & & \\
\hline-102 & $E+00$ & $00 \mathrm{E}+00$ & $0.00 \mathrm{E}+00$ & $.00 \mathrm{E}+00$ & $00 \mathrm{E}+00$ & $0 \mathrm{E}+00$ & $0.00 \mathrm{E}+00$ & $0.00 \mathrm{E}+00$ & $.00 \mathrm{E}+00$ & $00 \mathrm{E}+00$ & $0 \mathrm{E}+00$ & $0.00 \mathrm{E}+00$ & $0.00 \mathrm{E}+00$ & $0.00 \mathrm{E}+00$ & $0.00 \mathrm{E}+00$ & \\
\hline 241-AW-103 & $00 \mathrm{E}+00$ & $0.00 \mathrm{E}+00$ & $0.00 E+00$ & $0.00 \mathrm{E}+00$ & $00 \mathrm{E}+00$ & $00 \mathrm{E}+00$ & $0.00 E+00$ & $0.00 \mathrm{E}+00$ & $0.00 \mathrm{E}+00$ & $0.00 \mathrm{E}+00$ & $0.00 \mathrm{E}+00$ & $0.00 \mathrm{E}+00$ & $0.00 \mathrm{E}+00$ & $0.00 E+00$ & $0.00 \mathrm{E}+00$ & $.00 \mathrm{E}+00$ \\
\hline W-104 & $0 \mathrm{E}+00$ & $0.00 \mathrm{E}+00$ & $0.00 \mathrm{E}+00$ & $0.00 \mathrm{E}+00$ & $00 \mathrm{E}+00$ & $00 \mathrm{E}+00$ & $0.00 \mathrm{E}+00$ & $0.00 \mathrm{E}+00$ & $0.00 \mathrm{E}+00$ & $0.00 \mathrm{E}+00$ & $0.00 \mathrm{E}+00$ & $0.00 \mathrm{E}+00$ & $0.00 \mathrm{E}+00$ & $0.00 \mathrm{E}+00$ & $.00 \mathrm{E}+00$ & $0 \mathrm{E}+00$ \\
\hline & $0 \mathrm{E}+00$ & $0.00 \mathrm{E}+00$ & $0.00 \mathrm{E}+00$ & $.00 \mathrm{E}+00$ & $00 \mathrm{E}+00$ & $00 \mathrm{E}+00$ & $0.00 \mathrm{E}+00$ & $0.00 \mathrm{E}+00$ & $.00 \mathrm{E}+00$ & $.00 \mathrm{E}+00$ & $0 \mathrm{E}+00$ & $0.00 \mathrm{E}+00$ & $0.00 E+00$ & $0 \mathrm{E}+00$ & $0 \mathrm{E}+00$ & $0 \mathrm{E}+00$ \\
\hline & $\mathrm{E}+00$ & DOE+00 & $0.00 \mathrm{E}+00$ & $00 \mathrm{E}+00$ & DOE+00 & $00 \mathrm{E}+00$ & $0.00 \mathrm{E}+00$ & $0.00 \mathrm{E}+00$ & $00 \mathrm{E}+00$ & $0 \mathrm{E}+00$ & $00 \mathrm{E}+00$ & $0.00 \mathrm{E}+00$ & $0.00 \mathrm{E}+00$ & $0 \mathrm{E}+00$ & $0 \mathrm{E}+00$ & $0 \mathrm{E}+00$ \\
\hline & $E+00$ & $E+00$ & $\mathrm{E}+00$ & $00 \mathrm{E}+00$ & $E+00$ & $E+00$ & $\mathrm{E}+00$ & & $E+00$ & $E+00$ & $\mathrm{DE}+00$ & $0.00 \mathrm{E}+$ & $\mathrm{DE}+00$ & $\mathrm{E}+00$ & $0 \mathrm{E}+00$ & $\mathrm{E}+00$ \\
\hline & $E+00$ & $E+00$ & $E+00$ & $E+00$ & $E+00$ & $E+00$ & $E+00$ & $0.00 \mathrm{E}+00$ & $0 \mathrm{E}+00$ & $\mathrm{DE}+00$ & $\mathrm{E}+00$ & $0.00 \mathrm{E}+00$ & $0 \mathrm{E}+00$ & $\mathrm{E}+00$ & $\mathrm{DE}+00$ & $.00 \mathrm{E}+00$ \\
\hline & $E+00$ & $E+00$ & $E+00$ & $E+00$ & $E+00$ & $E+00$ & $\mathrm{E}+00$ & $0.00 \mathrm{E}+00$ & $E+00$ & $E+00$ & $E+00$ & $0.00 \mathrm{E}+00$ & $0 \mathrm{E}+00$ & $\mathrm{DE}+00$ & $E+00$ & $0 \mathrm{E}+00$ \\
\hline & $E+00$ & $E+00$ & $0.00 \mathrm{E}+00$ & $.00 \mathrm{E}+00$ & $E+00$ & $E+00$ & $0.00 \mathrm{E}+00$ & $0.00 \mathrm{E}+00$ & $0.00 \mathrm{E}+00$ & $E+00$ & $0 \mathrm{E}+00$ & $0.00 \mathrm{E}+00$ & $0.00 \mathrm{E}+00$ & $\mathrm{DE}+00$ & $\mathrm{DE}+00$ & $0.00 \mathrm{E}+00$ \\
\hline & $0 \mathrm{E}+00$ & $00 \mathrm{E}+00$ & $0.00 \mathrm{E}+00$ & $0.00 \mathrm{E}+00$ & $00 \mathrm{E}+00$ & $\mathrm{E}+00$ & $0.00 \mathrm{E}+00$ & $0.00 \mathrm{E}+00$ & $0.00 \mathrm{E}+00$ & $0.00 \mathrm{E}+00$ & $0.00 \mathrm{E}+00$ & $0.00 \mathrm{E}+00$ & $0.00 \mathrm{E}+00$ & $0.00 \mathrm{E}+00$ & $0.00 \mathrm{E}+00$ & $0.00 \mathrm{E}+00$ \\
\hline 102 & $0 E+00$ & $00 \mathrm{E}+00$ & $0.00 E+00$ & $.00 \mathrm{E}+00$ & $00 \mathrm{E}+00$ & $00 \mathrm{E}+00$ & $0.00 \mathrm{E}+00$ & $0.00 \mathrm{E}+00$ & $0.00 \mathrm{E}+00$ & $0.00 \mathrm{E}+00$ & $0.00 \mathrm{E}+00$ & $0.00 \mathrm{E}+00$ & $0.00 \mathrm{E}+00$ & $0.00 \mathrm{E}+00$ & $0.00 \mathrm{E}+00$ & $0.00 \mathrm{E}+00$ \\
\hline L01 & $E+00$ & $0 \mathrm{E}+00$ & $0.00 \mathrm{E}+00$ & $.00 \mathrm{E}+00$ & $00 \mathrm{E}+00$ & $00 \mathrm{E}+00$ & $0.00 \mathrm{E}+00$ & $0.00 \mathrm{E}+00$ & $0.00 \mathrm{E}+00$ & $00 \mathrm{E}+00$ & $0.00 \mathrm{E}+00$ & $0.00 \mathrm{E}+00$ & $0.00 \mathrm{E}+00$ & $0.00 \mathrm{E}+00$ & $0.00 \mathrm{E}+00$ & $0.00 \mathrm{E}+00$ \\
\hline 241-AZ-102 & OOE+00 & $0.00 \mathrm{E}+00$ & $0.00 E+00$ & $0.00 \mathrm{E}+00$ & $.00 \mathrm{E}+00$ & $0.00 \mathrm{E}+00$ & $0.00 \mathrm{E}+00$ & $0.00 E+00$ & $0.00 \mathrm{E}+00$ & $0.00 E+00$ & $0.00 \mathrm{E}+00$ & $0.00 \mathrm{E}+00$ & $0.00 E+00$ & $0.00 E+00$ & $0.00 \mathrm{E}+00$ & $0.00 \mathrm{E}+00$ \\
\hline & 16E-08 & 4.44E-08 & 4.44E-08 & 4.44E-08 & $46 \mathrm{E}-08$ & .44E-08 & 4.44E-08 & 4.44E-08 & $4.46 \mathrm{E}-08$ & 44E-08 & 4.44E-08 & 4.44E-08 & 4.46E-08 & $.44 \mathrm{E}-08$ & $3.29 \mathrm{E}-06$ & 03E-03 \\
\hline & $5 \mathrm{E}-08$ & 44E-08 & 4.44E-08 & 4.44E-08 & $4.45 \mathrm{E}-08$ & 44E-08 & 4.44E-08 & $4.44 \mathrm{E}-08$ & $4.45 \mathrm{E}-08$ & 4.44E-08 & 4.44E-08 & 4.44E-08 & $4.45 \mathrm{E}-08$ & $.44 \mathrm{E}-08$ & $3.29 \mathrm{E}-06$ & $1.03 \mathrm{E}-03$ \\
\hline & E-08 & EE-08 & 44E-08 & $4 \mathrm{E}-08$ & $4.46 \mathrm{E}-08$ & $4 \mathrm{E}-08$ & 4.44E-08 & 4.44E-08 & 4.46E-08 & 4E-08 & $4 \mathrm{E}-08$ & 4.44E-08 & 4.46E-08 & $4 \mathrm{E}-08$ & $9 \mathrm{E}-06$ & $3 \mathrm{E}-03$ \\
\hline & & E-08 & E-08 & -08 & $E-08$ & E-08 & E-08 & 5.92E-08 & 93E-08 & 92E-08 & 5.92E-08 & 5.92E-08 & 5.93E-08 & 5.92E-08 & $5.92 \mathrm{E}-08$ & E-07 \\
\hline & $E-05$ & -05 & -05 & & E-05 & E-05 & E-05 & & -05 & E-05 & LE-05 & $7.60 \mathrm{E}$ & $E+00$ & $2.21 \mathrm{E}+00$ & $E+00$ & +00 \\
\hline & -08 & -08 & $=-08$ & & E-08 & -08 & E-08 & & E-08 & E-08 & E-08 & $3.39 \mathrm{E}$ & E-08 & E-08 & $9 \mathrm{E}-08$ & E-08 \\
\hline & & $E-08$ & $E-08$ & & & $E-08$ & $E+01$ & 9.3 & 4.8 & $E+00$ & $\mathrm{E}+00$ & 1.8 & 1.5 & $E+00$ & $=+00$ & \\
\hline & $E-08$ & E-08 & $E-08$ & $\mathrm{E}-08$ & E-08 & $5 \mathrm{E}-08$ & $5 \mathrm{E}-08$ & $4.45 \mathrm{E}-08$ & E-08 & 4.45E-08 & $45 \mathrm{E}-08$ & 4.45E-08 & $6 \mathrm{E}-08$ & 5E-08 & 0E-06 & 1.03E-03 \\
\hline & EE-08 & 92E-08 & 92E-08 & 5.92E-08 & $3 \mathrm{E}-08$ & 5.92E-08 & 5.92E-08 & 5.92E-08 & 93E-08 & 5.92E-08 & $5.92 \mathrm{E}-08$ & 5.92E-08 & $5.93 \mathrm{E}-$ & 5.92E-08 & $5.92 \mathrm{E}-08$ & $7.16 \mathrm{E}-07$ \\
\hline & $0 \mathrm{E}-11$ & 49E-11 & $49 \mathrm{E}-11$ & $2.49 \mathrm{E}-11$ & 50E-11 & $2.49 \mathrm{E}-11$ & 2.49E-11 & $2.49 \mathrm{E}-11$ & $.50 \mathrm{E}-11$ & $2.49 \mathrm{E}-11$ & $2.55 \mathrm{E}+01$ & $4.20 \mathrm{E}+01$ & $1.06 \mathrm{E}+01$ & $5.50 \mathrm{E}+00$ & $3.61 \mathrm{E}+00$ & $2.62 \mathrm{E}+00$ \\
\hline & $46 \mathrm{E}-08$ & 4.44E-08 & 4.44E-08 & 4.44E-08 & $4.46 \mathrm{E}-08$ & 4.44E-08 & 4.44E-08 & 4.44E-08 & 4.46E-08 & 4.44E-08 & 4.44E-08 & 4.44E-08 & 4.46E-08 & 4.44E-08 & $3.29 \mathrm{E}-06$ & $1.03 \mathrm{E}-03$ \\
\hline -B-112 & $.94 \mathrm{E}-08$ & 5.92E-08 & $5.92 \mathrm{E}-08$ & 5.92E-08 & 5.94E-08 & 5.92E-08 & 5.92E-08 & 5.92E-08 & 5.94E-08 & 5.92E-08 & $5.92 \mathrm{E}-08$ & 5.92E-08 & 5.94E-08 & 5.92E-08 & $5.92 \mathrm{E}-08$ & 7.17E-07 \\
\hline$-\mathrm{B}-201$ & 2.91E-09 & $2.90 \mathrm{E}-09$ & $2.90 \mathrm{E}-09$ & $2.90 \mathrm{E}-09$ & 2.91E-09 & $2.90 \mathrm{E}-09$ & $2.10 \mathrm{E}+00$ & $6.66 \mathrm{E}-01$ & $3.56 \mathrm{E}-01$ & $2.33 \mathrm{E}-01$ & 1.71E-01 & 1.34E-01 & 1.10E-01 & $9.35 \mathrm{E}-02$ & $8.20 \mathrm{E}-02$ & 7.39E-02 \\
\hline -B-202 & 2.96E-09 & 95E-09 & $2.95 \mathrm{E}-09$ & $2.95 \mathrm{E}-09$ & 2.96E-09 & 2.95E-09 & $2.95 \mathrm{E}-09$ & $2.95 \mathrm{E}-09$ & 2.96E-09 & 2.95E-09 & $2.95 \mathrm{E}-09$ & 2.95E-09 & 2.96E-09 & $2.95 \mathrm{E}-09$ & $2.95 \mathrm{E}-09$ & $2.95 \mathrm{E}-09$ \\
\hline -B-203 & 1.62E-08 & 62E-08 & $1.62 \mathrm{E}-08$ & 1.62E-08 & 1.62E-08 & 1.62E-08 & 1.62E-08 & $1.62 \mathrm{E}-08$ & $6.68 \mathrm{E}-05$ & 6.41E-02 & 1.43E-01 & 1.24E-01 & 1.04E-01 & 8.87E-02 & $7.86 \mathrm{E}-02$ & $7.15 \mathrm{E}-02$ \\
\hline-204 & 72E-09 & 7.70E-09 & 7.70E-09 & $7.70 \mathrm{E}-09$ & 7.72E-09 & 7.70E-09 & 7.70E-09 & 1.86E-04 & $2.30 \mathrm{E}-01$ & $2.09 \mathrm{E}-01$ & $1.53 \mathrm{E}-01$ & $1.22 \mathrm{E}-01$ & 1.02E-01 & 8.78E-02 & 7.80E-02 & 7.12E-02 \\
\hline 241-BX-101 & $3.85 \mathrm{E}-06$ & $3.84 \mathrm{E}-06$ & $3.84 \mathrm{E}-06$ & $3.84 \mathrm{E}-06$ & $3.85 \mathrm{E}-06$ & 3.84E-06 & $3.84 \mathrm{E}-06$ & $3.84 \mathrm{E}-06$ & $3.85 \mathrm{E}-06$ & $3.84 \mathrm{E}-06$ & 3.84E-06 & $3.84 \mathrm{E}-06$ & 3.85E-06 & 3.84E-06 & 3.84E-06 & 3.84E-06 \\
\hline 241-BX-102 & $1.05 E+00$ & $9.00 \mathrm{E}-01$ & 7.91E-01 & 7.07E-01 & $6.47 \mathrm{E}-01$ & 6.06E-01 & $5.93 \mathrm{E}-01$ & $6.10 \mathrm{E}-01$ & $6.56 \mathrm{E}-01$ & 7.10E-01 & $7.62 \mathrm{E}-01$ & 7.97E-01 & $8.20 \mathrm{E}-01$ & $8.28 \mathrm{E}-01$ & 8.32E-01 & 8.34E-01 \\
\hline
\end{tabular}




\begin{tabular}{|c|c|c|c|c|c|c|c|c|c|c|c|c|c|c|c|c|}
\hline Site & 1960 & 1961 & 1962 & 1963 & 1964 & 1965 & 1966 & 1967 & 1968 & 1969 & 1970 & 1971 & 1972 & 1973 & 1974 & 1975 \\
\hline 241-BX-103 & $64 \mathrm{E}-08$ & 3.63E-08 & $63 \mathrm{E}-08$ & $3.63 \mathrm{E}-08$ & $3.64 \mathrm{E}-08$ & $3.63 \mathrm{E}-08$ & $3.63 \mathrm{E}-08$ & $3.63 \mathrm{E}-08$ & $3.64 \mathrm{E}-08$ & 3.63E-08 & $3.63 \mathrm{E}-08$ & 3.63E-08 & 3.64E-08 & $3.63 \mathrm{E}-08$ & $3.63 \mathrm{E}-08$ & 3.63E-08 \\
\hline 1-BX-104 & 22E-08 & 21E-08 & 21E-08 & 21E-08 & $5.22 \mathrm{E}-08$ & 5.21E-08 & $5.21 \mathrm{E}-08$ & $5.21 \mathrm{E}-08$ & $5.22 \mathrm{E}-08$ & 5.21E-08 & $5.21 \mathrm{E}-08$ & 5.21E-08 & $5.22 \mathrm{E}-08$ & $5.21 \mathrm{E}-08$ & $5.21 \mathrm{E}-08$ & 5.21E-08 \\
\hline 241-BX-105 & $22 \mathrm{E}-08$ & 21E-08 & 21E-08 & 21E-08 & $5.22 \mathrm{E}-08$ & $5.21 \mathrm{E}-08$ & $5.21 \mathrm{E}-08$ & $5.21 \mathrm{E}-08$ & $5.22 \mathrm{E}-08$ & $5.21 \mathrm{E}-08$ & $5.21 \mathrm{E}-08$ & $5.21 \mathrm{E}-08$ & $5.22 \mathrm{E}-08$ & $21 \mathrm{E}-08$ & $5.21 \mathrm{E}-08$ & $5.21 \mathrm{E}-08$ \\
\hline 1-BX-106 & $22 \mathrm{E}-08$ & 5.21E-08 & $5.21 \mathrm{E}-08$ & $5.21 \mathrm{E}-08$ & $5.22 \mathrm{E}-08$ & 5.21E-08 & $5.21 \mathrm{E}-08$ & 5.21E-08 & $5.22 \mathrm{E}-08$ & 5.21E-08 & $5.21 \mathrm{E}-08$ & 5.21E-08 & $5.22 \mathrm{E}-08$ & $21 \mathrm{E}-08$ & $5.21 \mathrm{E}-08$ & $5.21 \mathrm{E}-08$ \\
\hline & 54E-08 & 3.63E-08 & 63E-08 & $3.63 \mathrm{E}-08$ & $3.64 \mathrm{E}-08$ & 3.63E-08 & $3.63 \mathrm{E}-08$ & $3.63 \mathrm{E}-08$ & 3.64E-08 & 3.63E-08 & $3.63 \mathrm{E}-08$ & 3.63E-08 & $3.64 \mathrm{E}-08$ & $3.63 \mathrm{E}-08$ & $3.63 \mathrm{E}-08$ & 63E-08 \\
\hline & & 21E-08 & 21E-08 & & $5.23 \mathrm{E}-08$ & & 21E-08 & 21E-08 & 5.23E-08 & 21E-08 & $5.21 \mathrm{E}-08$ & 5.21E-08 & $5.23 \mathrm{E}-08$ & $5.21 \mathrm{E}-08$ & $5.21 \mathrm{E}-08$ & 5.21E-08 \\
\hline & $E-08$ & $E-08$ & 47E-08 & $7 \mathrm{E}-08$ & E-08 & $6.47 \mathrm{E}-08$ & $6.47 \mathrm{E}-08$ & 47E-08 & 6.48E-08 & 6.47E-08 & 6.47E-08 & $6.47 \mathrm{E}-08$ & $6.48 \mathrm{E}-08$ & $6.47 \mathrm{E}-08$ & $6.47 \mathrm{E}-08$ & $6.47 \mathrm{E}-08$ \\
\hline & $E-08$ & E-08 & 21E-08 & LE-08 & E-08 & 5.21E-08 & 21E-08 & 21E-08 & $2 \mathrm{E}-08$ & 5.21E-08 & 5.21E-08 & $5.21 \mathrm{E}-08$ & $5.22 \mathrm{E}-08$ & $5.21 \mathrm{E}-08$ & $5.21 \mathrm{E}-08$ & $21 \mathrm{E}-08$ \\
\hline & $E-05$ & 39E-05 & 39E-05 & 39E-05 & E-05 & 2.39E-05 & $39 E-05$ & 39E-05 & E-03 & $1.10 \mathrm{E}+00$ & $1.97 \mathrm{E}+00$ & $1.77 \mathrm{E}+00$ & $1.50 \mathrm{E}+00$ & $1.29 \mathrm{E}+00$ & $1.14 \mathrm{E}+00$ & $4 \mathrm{E}+00$ \\
\hline & E-08 & $47 \mathrm{E}-08$ & 47E-08 & 47E-08 & E-08 & $6.47 \mathrm{E}-08$ & $47 \mathrm{E}-08$ & $47 \mathrm{E}-08$ & E-08 & 7E-08 & $6.47 \mathrm{E}-08$ & $6.47 \mathrm{E}-08$ & 6.49E-08 & $6.47 \mathrm{E}-08$ & & \\
\hline 241-BY-101 & 6.48E-08 & $6.46 \mathrm{E}-08$ & $6.46 \mathrm{E}-08$ & $6.46 \mathrm{E}-08$ & $6.48 \mathrm{E}-08$ & $6.46 \mathrm{E}-08$ & $6.46 \mathrm{E}-08$ & $6.46 \mathrm{E}-08$ & $6.48 \mathrm{E}-08$ & $6.46 \mathrm{E}-08$ & $6.46 \mathrm{E}-08$ & $6 \mathrm{E}-08$ & & $6 \mathrm{E}-08$ & $.46 \mathrm{E}-08$ & \\
\hline 241-BY-102 & 6.49E-08 & $6.47 \mathrm{E}-08$ & $6.47 \mathrm{E}-08$ & $6.47 \mathrm{E}-08$ & $6.49 \mathrm{E}-08$ & $6.47 \mathrm{E}-08$ & $6.47 \mathrm{E}-08$ & $6.47 \mathrm{E}-08$ & 6.49E-08 & 6.47E-08 & $6.47 \mathrm{E}-08$ & 6.47E-08 & $9 \mathrm{E}-08$ & & $6.47 \mathrm{E}-08$ & \\
\hline & 7.54E-08 & $7.52 \mathrm{E}-08$ & $7.52 \mathrm{E}-08$ & $7.52 \mathrm{E}-08$ & 7.54E-08 & $7.52 \mathrm{E}-08$ & $7.52 \mathrm{E}-08$ & $7.52 \mathrm{E}-08$ & 7.54E-08 & $7.52 \mathrm{E}-08$ & $7.52 \mathrm{E}-08$ & 7.52E-08 & 7.54E-08 & $7.52 \mathrm{E}-08$ & $7.52 \mathrm{E}-08$ & $3.30 \mathrm{E}+00$ \\
\hline & $48 \mathrm{E}-08$ & $6.46 \mathrm{E}-08$ & $6.46 \mathrm{E}-08$ & $6.46 \mathrm{E}-08$ & $6.48 \mathrm{E}-08$ & $6.46 \mathrm{E}-08$ & $6.46 \mathrm{E}-08$ & $6.46 \mathrm{E}-08$ & $6.48 \mathrm{E}-08$ & $6.46 \mathrm{E}-08$ & $6.46 \mathrm{E}-08$ & $6.46 \mathrm{E}-08$ & $48 \mathrm{E}-08$ & $6.46 \mathrm{E}-08$ & $6.46 \mathrm{E}-08$ & $6.46 \mathrm{E}-08$ \\
\hline & 17E-08 & $4.16 \mathrm{E}-08$ & $4.16 \mathrm{E}-08$ & $4.16 \mathrm{E}-08$ & 4.17E-08 & 4.16E-08 & $4.16 \mathrm{E}-08$ & $4.16 \mathrm{E}-08$ & 4.17E-08 & $4.16 \mathrm{E}-08$ & $4.16 \mathrm{E}-08$ & $4.16 \mathrm{E}-08$ & .17E-08 & 16E-08 & $4.16 \mathrm{E}-08$ & $4.16 \mathrm{E}-08$ \\
\hline & $71 \mathrm{E}-08$ & $70 \mathrm{E}-08$ & 70E-08 & $5.70 \mathrm{E}-08$ & $5.71 \mathrm{E}-08$ & $5.70 \mathrm{E}-08$ & $5.70 \mathrm{E}-08$ & $5.70 \mathrm{E}-08$ & $E-08$ & $70 \mathrm{E}-08$ & $5.70 \mathrm{E}-08$ & DE-08 & $1 \mathrm{E}-08$ & $70 \mathrm{E}-08$ & $70 \mathrm{E}-08$ & $70 \mathrm{E}-08$ \\
\hline & E-08 & 6.46E-08 & $6.46 \mathrm{E}-08$ & $6.46 \mathrm{E}-08$ & BE-08 & 6.46E-08 & $6.46 \mathrm{E}-08$ & $6.46 \mathrm{E}-08$ & E-08 & 6.46E-08 & $6.46 \mathrm{E}-08$ & 6.46E-08 & $6.48 \mathrm{E}-08$ & 6.46E-08 & $6.46 \mathrm{E}-08$ & $6 \mathrm{E}-08$ \\
\hline & 51E-08 & 8.59E-08 & $8.59 \mathrm{E}-08$ & $8.59 \mathrm{E}-08$ & 8.61E-08 & 8.59E-08 & $8.59 \mathrm{E}-08$ & $8.59 \mathrm{E}-08$ & 8.61E-08 & 59E-08 & $8.59 \mathrm{E}-08$ & 8.59E-08 & 8.61E-08 & $8.59 \mathrm{E}-08$ & $1.84 \mathrm{E}+00$ & $4.60 \mathrm{E}+00$ \\
\hline & E-08 & 5.70E-08 & $5.70 \mathrm{E}-08$ & $5.70 \mathrm{E}-08$ & E-08 & $5.70 \mathrm{E}-08$ & $5.70 \mathrm{E}-08$ & $5.70 \mathrm{E}-08$ & 5.71E-08 & $5.70 \mathrm{E}-08$ & $5.70 \mathrm{E}-08$ & 5.70E-08 & 5.71E-08 & 5.70E-08 & 5.70E-08 & 5.70E-08 \\
\hline & 16E-08 & 4.15E-08 & 4.15E-08 & 15E-08 & $4.16 \mathrm{E}-08$ & 4.15E-08 & $4.15 E-08$ & $4.15 \mathrm{E}-08$ & 4.16E-08 & 4.15E-08 & $4.15 E-08$ & $4.15 \mathrm{E}-08$ & $4.16 \mathrm{E}-08$ & $4.15 E-08$ & $4.15 E-08$ & 4.15E-08 \\
\hline & 33E-08 & 4.32E-08 & $32 \mathrm{E}-08$ & $32 \mathrm{E}-08$ & 4.33E-08 & 4.32E-08 & $4.32 \mathrm{E}-08$ & 4.32E-08 & 4.33E-08 & 4.32E-08 & 4.32E-08 & 4.32E-08 & 4.33E-08 & $4.32 \mathrm{E}-08$ & $4.32 \mathrm{E}-08$ & 4.32E-08 \\
\hline & 27E-08 & 4.16E-08 & 16E-08 & 16E-08 & 17E-08 & 4.16E-08 & 4.16E-08 & .16E-08 & E-08 & $16 \mathrm{E}-08$ & 4.16E-08 & 4.16E-08 & $17 \mathrm{E}-08$ & $16 \mathrm{E}-08$ & $4.16 \mathrm{E}-08$ & $1.16 \mathrm{E}-08$ \\
\hline-101 & 1.17E-04 & 1.17E-04 & 1.17E-04 & 1.17E-04 & 1.17E-04 & 1.17E-04 & 1.17E-04 & 1.17E-04 & 1.17E-04 & 1.17E-04 & 1.17E-04 & 1.17E-04 & 1.17E-04 & 1.17E-04 & 1.17E-04 & 1.17E-04 \\
\hline & 7E-04 & 1.17E-04 & 17E-04 & 1.17E-04 & E-04 & 1.17E-04 & 1.17E-04 & 1.17E-04 & 7E-04 & 1.17E-04 & 1.17E-04 & 1.17E-04 & $.17 \mathrm{E}-04$ & $.17 \mathrm{E}-04$ & $.17 \mathrm{E}-04$ & 17E-04 \\
\hline & $17 \mathrm{E}-04$ & 1.17E-04 & 17E-04 & 1.17E-04 & 1.17E-04 & 1.17E-04 & 1.17E-04 & 1.17E-04 & E-04 & 1.17E-04 & 1.17E-04 & 1.17E-04 & 1.17E-04 & $.17 \mathrm{E}-04$ & $.17 \mathrm{E}-04$ & $.17 \mathrm{E}-04$ \\
\hline & E-04 & 17E-04 & 17E-04 & 1.17E-04 & E-04 & 1.17E-04 & 1.17E-04 & 1.17E-04 & 1.17E-04 & 1.17E-04 & 1.17E-04 & 1.17E-04 & 1.17E-04 & 1.17E-04 & 1.17E-04 & $1.17 \mathrm{E}-04$ \\
\hline & 38E-04 & 88E-04 & 88E-04 & 88E-04 & E-04 & EE-04 & 1.88E-04 & E-04 & $E-04$ & EE-04 & 1.88E-04 & $.88 \mathrm{E}-04$ & $3 \mathrm{E}-04$ & $8 \mathrm{E}-04$ & $1.88 \mathrm{E}-04$ & $1.88 \mathrm{E}-04$ \\
\hline & & 04E-04 & 04E-04 & E-04 & -04 & E-04 & 1.04E-04 & E-04 & $E-04$ & E-04 & 1.04E-04 & $4 \mathrm{E}-04$ & $4 \mathrm{E}-04$ & $4 \mathrm{E}-04$ & $1.04 \mathrm{E}-04$ & $4 \mathrm{E}-04$ \\
\hline & & -04 & $=-04$ & $E-04$ & -04 & $E-04$ & E-04 & E-04 & -04 & E-04 & E-04 & 7E-04 & 7E-04 & 7E-04 & E-04 & 7E-04 \\
\hline & & & -04 & & -04 & -04 & $E-04$ & -04 & & & -04 & $E-04$ & & -04 & & $E-04$ \\
\hline & & $E-04$ & $=-04$ & E-04 & $=-04$ & E-04 & E-04 & E-04 & -04 & E-04 & E-04 & E-04 & $\mathrm{E}-04$ & $5 E-04$ & E-04 & E-04 \\
\hline & E-04 & 17E-04 & 17E-04 & 17E-04 & E-04 & 1.17E-04 & 1.17E-04 & 1.17E-04 & 17E-04 & 17E-04 & 1.17E-04 & E-04 & 1.17E-04 & 1.17E-04 & 1.17E-04 & 1.17E-04 \\
\hline & E-04 & 17E-04 & 7E-04 & 17E-04 & E-04 & 17E-04 & 17E-04 & .17E-04 & 7E-04 & 17E-04 & 1.17E-04 & 1.17E-04 & 1.17E-04 & 1.17E-04 & 1.17E-04 & 1.17E-04 \\
\hline 2 & 17E-04 & 1.17E-04 & $1.17 \mathrm{E}-04$ & $1.17 \mathrm{E}-04$ & 1.17E-04 & 1.17E-04 & 1.17E-04 & 1.17E-04 & .17E-04 & 17E-04 & $1.17 \mathrm{E}-04$ & 1.17E-04 & 1.17E-04 & $.17 \mathrm{E}-04$ & $1.17 \mathrm{E}-04$ & $1.17 \mathrm{E}-04$ \\
\hline$-C-201$ & 7.42E-06 & 7.40E-06 & 7.40E-06 & $7.40 \mathrm{E}-06$ & 7.42E-06 & 7.40E-06 & 7.40E-06 & 7.40E-06 & 7.42E-06 & 7.40E-06 & 7.40E-06 & 7.40E-06 & 7.42E-06 & $7.40 \mathrm{E}-06$ & $7.40 \mathrm{E}-06$ & 7.40E-06 \\
\hline$-C-202$ & 7.41E-06 & 7.39E-06 & 7.39E-06 & 7.39E-06 & 7.41E-06 & 7.39E-06 & 7.39E-06 & 7.39E-06 & 7.41E-06 & 7.39E-06 & 7.39E-06 & 7.39E-06 & 7.41E-06 & $7.39 \mathrm{E}-06$ & $7.39 \mathrm{E}-06$ & $7.39 \mathrm{E}-06$ \\
\hline$-C-203$ & 7.41E-06 & 7.39E-06 & 7.39E-06 & 7.39E-06 & 7.41E-06 & 7.39E-06 & 7.39E-06 & 7.39E-06 & 7.41E-06 & 7.39E-06 & 7.39E-06 & 7.39E-06 & 7.41E-06 & 7.39E-06 & 7.39E-06 & 7.39E-06 \\
\hline$-\mathrm{C}-204$ & 7.46E-06 & 7.44E-06 & 7.44E-06 & 7.44E-06 & 7.46E-06 & 7.44E-06 & $7.44 \mathrm{E}-06$ & $7.44 \mathrm{E}-06$ & 7.46E-06 & 7.44E-06 & $7.44 \mathrm{E}-06$ & 7.44E-06 & 7.46E-06 & 7.44E-06 & 7.44E-06 & 7.44E-06 \\
\hline 241-S-101 & 1.78E-08 & 1.77E-08 & 1.77E-08 & $1.77 \mathrm{E}-08$ & $1.78 \mathrm{E}-08$ & 1.77E-08 & 1.77E-08 & $1.77 \mathrm{E}-08$ & $1.78 \mathrm{E}-08$ & 1.77E-08 & 1.77E-08 & 1.77E-08 & 1.78E-08 & 1.77E-08 & 1.77E-08 & 1.77E-08 \\
\hline 241-S-102 & 1.79E-08 & 1.78E-08 & 1.78E-08 & 1.78E-08 & 1.79E-08 & 1.78E-08 & 1.78E-08 & 1.78E-08 & 1.79E-08 & 1.78E-08 & 1.78E-08 & 1.78E-08 & 1.79E-08 & $1.78 \mathrm{E}-08$ & 1.78E-08 & 1.78E-08 \\
\hline 241-S-103 & 1.77E-08 & 1.77E-08 & $1.77 \mathrm{E}-08$ & $1.77 \mathrm{E}-08$ & 1.77E-08 & $1.77 \mathrm{E}-08$ & $1.77 \mathrm{E}-08$ & 1.77E-08 & 1.77E-08 & $1.77 \mathrm{E}-08$ & 1.77E-08 & 1.77E-08 & $1.77 \mathrm{E}-08$ & $1.77 \mathrm{E}-08$ & $1.77 \mathrm{E}-08$ & 1.77E-08 \\
\hline
\end{tabular}




\begin{tabular}{|c|c|c|c|c|c|c|c|c|c|c|c|c|c|c|c|c|}
\hline Site & 1960 & 1961 & 1962 & 1963 & 1964 & 1965 & 1966 & 1967 & 1968 & 1969 & 1970 & 1971 & 1972 & 1973 & 1974 & 1975 \\
\hline & $46 \mathrm{E}-09$ & 4.44E-09 & $4.44 \mathrm{E}-09$ & 44E-09 & $46 \mathrm{E}-09$ & 4.44E-09 & $4.44 \mathrm{E}-09$ & $.44 \mathrm{E}-09$ & 4.46E-09 & 4.44E-09 & 4.44E-09 & 4.44E-09 & $4.46 \mathrm{E}-09$ & 4.44E-09 & $3.99 \mathrm{E}-06$ & 3.51E-04 \\
\hline 241-S-105 & $78 \mathrm{E}-08$ & $77 \mathrm{E}-08$ & 77E-08 & 77E-08 & $78 \mathrm{E}-08$ & $1.77 \mathrm{E}-08$ & $1.77 \mathrm{E}-08$ & $1.77 \mathrm{E}-08$ & $1.78 \mathrm{E}-08$ & $1.77 \mathrm{E}-08$ & $1.77 \mathrm{E}-08$ & $1.77 \mathrm{E}-08$ & $1.78 \mathrm{E}-08$ & $1.77 \mathrm{E}-08$ & $1.77 \mathrm{E}-08$ & $1.77 \mathrm{E}-08$ \\
\hline 241-S-106 & 77E-08 & 1.77E-08 & 77E-08 & 77E-08 & $1.77 \mathrm{E}-08$ & $1.77 \mathrm{E}-08$ & $1.77 \mathrm{E}-08$ & .77E-08 & $1.77 \mathrm{E}-08$ & $1.77 \mathrm{E}-08$ & 1.77E-08 & $1.77 \mathrm{E}-08$ & $1.77 \mathrm{E}-08$ & $.77 \mathrm{E}-08$ & $77 \mathrm{E}-08$ & $.77 \mathrm{E}-08$ \\
\hline & 62E-08 & 1.61E-08 & $1.61 \mathrm{E}-08$ & 61E-08 & $1.62 \mathrm{E}-08$ & $1.61 \mathrm{E}-08$ & 1.61E-08 & $1.61 \mathrm{E}-08$ & 1.62E-08 & 1.61E-08 & 1.61E-08 & 1.61E-08 & 1.62E-08 & $61 \mathrm{E}-08$ & $61 \mathrm{E}-08$ & 61E-08 \\
\hline & $2 E-08$ & 1.61E-08 & 1.61E-08 & 61E-08 & 1.62E-08 & $1.61 \mathrm{E}-08$ & 61E-08 & 61E-08 & $1.62 \mathrm{E}-08$ & 61E-08 & & & 1.62E-08 & & & \\
\hline & & & & & & & & & $62 \mathrm{E}-08$ & $2 \mathrm{E}-08$ & & $2 \mathrm{E}-08$ & $1.62 \mathrm{E}-08$ & $2 \mathrm{E}-08$ & $1.62 \mathrm{E}-08$ & \\
\hline & & $E-08$ & $E-08$ & 67E-08 & $1.67 \mathrm{E}-08$ & $1.67 \mathrm{E}-08$ & $1.67 \mathrm{E}-08$ & $67 \mathrm{E}-08$ & $1.67 \mathrm{E}-08$ & 7E-08 & $1.67 \mathrm{E}-08$ & $7 \mathrm{E}-08$ & 7E-08 & & $67 \mathrm{E}-08$ & 1.67E-08 \\
\hline & E-08 & E-08 & $1.58 \mathrm{E}-08$ & 58E-08 & 59E-08 & $.58 \mathrm{E}-08$ & $1.58 \mathrm{E}-08$ & 58E-08 & 1.59E-08 & 58E-08 & $1.58 \mathrm{E}-08$ & $1.58 \mathrm{E}-08$ & $1.59 \mathrm{E}-08$ & $8 \mathrm{E}-08$ & $58 \mathrm{E}-08$ & $1.58 \mathrm{E}-08$ \\
\hline & $E-08$ & $E-08$ & $E-08$ & $E-08$ & E-08 & E-08 & E-08 & E-08 & $3 \mathrm{E}-08$ & E-08 & 3E-08 & $\mathrm{E}-08$ & $63 \mathrm{E}-08$ & & 3E-08 & \\
\hline & & $E-08$ & E-08 & & E-08 & $\mathrm{E}-08$ & 10E-08 & & 0E-08 & E-08 & 10E-08 & & & & $10 \mathrm{E}-08$ & \\
\hline$X-102$ & $98 \mathrm{E}-08$ & $1.98 \mathrm{E}-08$ & $1.98 \mathrm{E}-08$ & 98E-08 & $98 \mathrm{E}-08$ & $1.98 \mathrm{E}-08$ & 98E-08 & 98E-08 & 98E-08 & 98E-08 & $1.98 \mathrm{E}-08$ & $1.98 \mathrm{E}-08$ & $.98 \mathrm{E}-08$ & $.98 \mathrm{E}-08$ & $.98 \mathrm{E}-08$ & \\
\hline $\mathrm{X}-103$ & 98E-08 & $1.98 \mathrm{E}-08$ & 1.98E-08 & 98E-08 & $.98 \mathrm{E}-08$ & $1.98 \mathrm{E}-08$ & 1.98E-08 & $98 \mathrm{E}-08$ & 98E-08 & $1.98 \mathrm{E}-08$ & $1.98 \mathrm{E}-08$ & $1.98 \mathrm{E}-08$ & 1.98E-08 & $.98 \mathrm{E}-08$ & $1.98 \mathrm{E}-08$ & 1.98E-08 \\
\hline & $64 \mathrm{E}-08$ & 1.63E-08 & $1.63 \mathrm{E}-08$ & $63 \mathrm{E}-08$ & $1.64 \mathrm{E}-08$ & $1.63 \mathrm{E}-08$ & $1.63 \mathrm{E}-08$ & $1.63 \mathrm{E}-08$ & $64 \mathrm{E}-08$ & $63 \mathrm{E}-08$ & $1.63 \mathrm{E}-08$ & $1.63 \mathrm{E}-08$ & $.64 \mathrm{E}-08$ & $63 \mathrm{E}-08$ & $1.63 \mathrm{E}-08$ & 1.63E-08 \\
\hline & $65 E-08$ & $1.65 \mathrm{E}-08$ & $1.65 \mathrm{E}-08$ & $65 \mathrm{E}-08$ & $1.65 \mathrm{E}-08$ & $1.65 \mathrm{E}-08$ & $1.65 \mathrm{E}-08$ & $65 \mathrm{E}-08$ & $1.65 \mathrm{E}-08$ & $1.65 \mathrm{E}-08$ & $1.65 \mathrm{E}-08$ & $65 \mathrm{E}-08$ & $65 \mathrm{E}-08$ & $65 \mathrm{E}-08$ & $1.65 \mathrm{E}-08$ & $1.65 \mathrm{E}-08$ \\
\hline & 08E-08 & 2.07E-08 & $2.07 \mathrm{E}-08$ & 07E-08 & $2.08 \mathrm{E}-08$ & $2.07 \mathrm{E}-08$ & $2.07 E-08$ & 07E-08 & $.08 \mathrm{E}-08$ & 07E-08 & $2.07 E-08$ & $.07 \mathrm{E}-08$ & $.08 \mathrm{E}-08$ & & .07E-08 & $2.07 \mathrm{E}-08$ \\
\hline & 58E-09 & 5.56E-09 & 56E-09 & 56E-09 & $5.58 \mathrm{E}-09$ & $5.56 \mathrm{E}-09$ & 5.56E-09 & E-09 & $58 \mathrm{E}-09$ & E-09 & 5.56E-09 & E-09 & $.58 \mathrm{E}-09$ & $6 \mathrm{E}-09$ & $33 \mathrm{E}-06$ & $1.54 \mathrm{E}-04$ \\
\hline & $E-10$ & E-10 & $7.68 \mathrm{E}-10$ & E-10 & E-10 & $7.68 \mathrm{E}-10$ & $7.68 \mathrm{E}-10$ & E-10 & $7.70 \mathrm{E}-10$ & $68 \mathrm{E}-10$ & $68 \mathrm{E}-10$ & $3 \mathrm{E}-10$ & $7.70 \mathrm{E}-10$ & E-10 & $68 \mathrm{E}-10$ & $9.82 \mathrm{E}-08$ \\
\hline & E-09 & E-09 & 1.27E-09 & E-09 & 28E-09 & E-09 & 27E-09 & E-09 & $1.28 \mathrm{E}-09$ & E-09 & 27E-09 & E-09 & $1.28 \mathrm{E}-09$ & 7E-09 & 1.27E-09 & 1.27E-09 \\
\hline & 66E-11 & 4.65E-11 & $4.65 \mathrm{E}-11$ & E-11 & 66E-11 & $4.65 \mathrm{E}-11$ & $4.65 E-11$ & $\mathrm{E}-11$ & $4.66 \mathrm{E}-11$ & 5E-11 & $4.65 E-11$ & E-11 & $4.66 \mathrm{E}-11$ & E-11 & $4.65 \mathrm{E}-11$ & $4.65 \mathrm{E}-11$ \\
\hline 24 & 24E-09 & 2.24E-09 & $2.24 \mathrm{E}-09$ & 24E-09 & 24E-09 & 2.24E-09 & 2.24E-09 & 2.24E-09 & 2.24E-09 & 2.24E-09 & 2.24E-09 & $4 \mathrm{E}-09$ & $2.24 \mathrm{E}-09$ & $4 \mathrm{E}-09$ & $2.24 \mathrm{E}-09$ & 2.24E-09 \\
\hline 112 & 6E-08 & 56E-08 & $1.56 \mathrm{E}-08$ & 56E-08 & 56E-08 & 56E-08 & 1.56E-08 & 1.56E-08 & 56E-08 & 56E-08 & $1.56 \mathrm{E}-08$ & 1.56E-08 & 1.56E-08 & $.56 \mathrm{E}-08$ & $1.56 \mathrm{E}-08$ & 1.56E-08 \\
\hline 24 & $8 \mathrm{E}-08$ & $27 \mathrm{E}-08$ & 27E-08 & 27E-08 & 28E-08 & 27E-08 & $27 \mathrm{E}-08$ & $27 \mathrm{E}-08$ & $28 \mathrm{E}-08$ & 27E-08 & 27E-08 & $1.27 \mathrm{E}-08$ & L.28E-08 & $5.93 \mathrm{E}-06$ & $1.36 \mathrm{E}-04$ & $2.19 \mathrm{E}-03$ \\
\hline-114 & 15E-11 & 3.14E-11 & $3.14 \mathrm{E}-11$ & $3.14 \mathrm{E}-11$ & 15E-11 & 14E-11 & 3.14E-11 & $3.14 \mathrm{E}-11$ & $3.15 \mathrm{E}-11$ & $14 \mathrm{E}-11$ & $3.14 \mathrm{E}-11$ & $3.14 \mathrm{E}-11$ & $3.15 \mathrm{E}-11$ & $3.14 \mathrm{E}-11$ & $3.14 \mathrm{E}-11$ & $3.14 \mathrm{E}-11$ \\
\hline 241 & $23 \mathrm{E}-08$ & $1.23 \mathrm{E}-08$ & $1.23 \mathrm{E}-08$ & $1.23 \mathrm{E}-08$ & $1.23 \mathrm{E}-08$ & $1.23 \mathrm{E}-08$ & $1.23 \mathrm{E}-08$ & $1.23 \mathrm{E}-08$ & $23 \mathrm{E}-08$ & $23 E-08$ & $1.23 \mathrm{E}-08$ & EE-08 & $23 \mathrm{E}-08$ & 3E-08 & $1.23 \mathrm{E}-08$ & $1.23 \mathrm{E}-08$ \\
\hline 101 & $0 \mathrm{E}+00$ & $00 \mathrm{E}+00$ & $0.00 \mathrm{E}+00$ & $00 \mathrm{E}+00$ & $00 \mathrm{E}+00$ & $00 \mathrm{E}+00$ & $0.00 \mathrm{E}+00$ & $0.00 \mathrm{E}+00$ & $0.00 \mathrm{E}+00$ & $00 \mathrm{E}+00$ & $0.00 \mathrm{E}+00$ & $0.00 \mathrm{E}+00$ & $0.00 \mathrm{E}+00$ & $E+00$ & $00 \mathrm{E}+00$ & $0.00 E+00$ \\
\hline 102 & DOE+00 & $00 \mathrm{E}+00$ & $0.00 \mathrm{E}+00$ & $0.00 \mathrm{E}+00$ & $00 \mathrm{E}+00$ & DOE+00 & $00 \mathrm{E}+00$ & +00 & $.00 \mathrm{E}+00$ & $00 \mathrm{E}+00$ & $0.00 \mathrm{E}+00$ & $E+00$ & $0.00 \mathrm{E}+00$ & $0.00 \mathrm{E}+00$ & $0.00 \mathrm{E}+00$ & $0.00 \mathrm{E}+00$ \\
\hline 103 & DOE+00 & $00 \mathrm{E}+00$ & $0.00 \mathrm{E}+00$ & $E+00$ & $\mathrm{E}+00$ & $E+00$ & $E+00$ & $E+00$ & $\mathrm{E}+00$ & $\mathrm{E}+00$ & $E+00$ & $E+00$ & $0.00 \mathrm{E}+00$ & $\mathrm{E}+00$ & $.00 \mathrm{E}+00$ & $.00 \mathrm{E}+00$ \\
\hline & E-16 & $35 \mathrm{E}-16$ & E-16 & $E-16$ & $E-16$ & $E-16$ & $E-16$ & $E-16$ & E-16 & $\mathrm{E}-11$ & E-01 & $E+00$ & $E+00$ & $E+00$ & $3.84 \mathrm{E}+00$ & $2.85 E+00$ \\
\hline & & -09 & -09 & & & -09 & -09 & -09 & -09 & $=-09$ & $E-09$ & E-09 & E-09 & E-09 & $5.00 \mathrm{E}-09$ & 5.00E-09 \\
\hline & & -09 & & -09 & & -09 & $E-09$ & $=-09$ & & & $E-09$ & E-09 & E-09 & & -09 & .75E-09 \\
\hline & $E-09$ & $E-09$ & $=-09$ & $E-09$ & E-09 & E-09 & E-09 & $E-09$ & E-09 & E-09 & E-09 & E-09 & E-09 & & $4 \mathrm{E}-09$ & E-09 \\
\hline & $\mathrm{E}-09$ & E-09 & $34 \mathrm{E}-09$ & $=-09$ & $35 \mathrm{E}-09$ & $34 \mathrm{E}-09$ & $34 \mathrm{E}-09$ & E-09 & $35 \mathrm{E}-09$ & $34 \mathrm{E}-09$ & $5.34 \mathrm{E}-09$ & $5.34 \mathrm{E}-09$ & $5.35 \mathrm{E}-09$ & $5.34 \mathrm{E}-09$ & 5.34E-09 & 5.34E-09 \\
\hline & 6E-06 & $4 \mathrm{E}-06$ & $4 \mathrm{E}-06$ & 4E-06 & j6E-06 & 54E-06 & 54E-06 & $4 \mathrm{E}-06$ & $7.06 \mathrm{E}-06$ & $04 \mathrm{E}-06$ & $04 \mathrm{E}-06$ & 7.04E-06 & 7.06E-06 & 7.04E-06 & $8.72 \mathrm{E}+01$ & $9.48 \mathrm{E}+01$ \\
\hline 241-T-107 & $02 \mathrm{E}-16$ & $01 \mathrm{E}-16$ & $4.01 \mathrm{E}-16$ & $4.01 \mathrm{E}-16$ & $4.02 \mathrm{E}-16$ & $01 \mathrm{E}-16$ & $4.01 \mathrm{E}-16$ & $4.01 \mathrm{E}-16$ & $4.02 \mathrm{E}-16$ & $4.01 \mathrm{E}-16$ & $4.01 \mathrm{E}-16$ & $4.01 \mathrm{E}-16$ & $4.02 \mathrm{E}-16$ & $4.01 \mathrm{E}-16$ & $4.01 \mathrm{E}-16$ & $4.01 \mathrm{E}-16$ \\
\hline 241-T-108 & 5.01E-09 & $5.00 \mathrm{E}-09$ & $5.00 \mathrm{E}-09$ & $5.00 \mathrm{E}-09$ & 5.01E-09 & $5.00 \mathrm{E}-09$ & $5.00 \mathrm{E}-09$ & $5.00 \mathrm{E}-09$ & 5.01E-09 & $5.00 \mathrm{E}-09$ & $5.00 \mathrm{E}-09$ & $5.00 \mathrm{E}-09$ & 5.01E-09 & $5.00 \mathrm{E}-09$ & $5.00 \mathrm{E}-09$ & 5.00E-09 \\
\hline 241-T-109 & $5.02 \mathrm{E}-09$ & 5.00E-09 & $5.00 \mathrm{E}-09$ & $5.00 \mathrm{E}-09$ & 5.02E-09 & $5.00 \mathrm{E}-09$ & $5.00 \mathrm{E}-09$ & $5.00 \mathrm{E}-09$ & 5.02E-09 & $5.00 \mathrm{E}-09$ & $5.00 \mathrm{E}-09$ & $5.00 \mathrm{E}-09$ & 5.02E-09 & $5.00 \mathrm{E}-09$ & $5.00 \mathrm{E}-09$ & 5.00E-09 \\
\hline 241-T & $4.02 \mathrm{E}-16$ & $4.01 \mathrm{E}-16$ & $4.01 \mathrm{E}-16$ & $4.01 \mathrm{E}-16$ & $4.02 \mathrm{E}-16$ & $4.01 \mathrm{E}-16$ & $4.01 \mathrm{E}-16$ & $4.01 \mathrm{E}-16$ & $4.02 \mathrm{E}-16$ & $4.01 \mathrm{E}-16$ & $4.01 \mathrm{E}-16$ & $4.01 \mathrm{E}-16$ & $4.02 \mathrm{E}-16$ & $1 \mathrm{E}-16$ & $4.01 \mathrm{E}-16$ & $4.01 \mathrm{E}-16$ \\
\hline-111 & 5.02E-09 & 5.00E-09 & $5.00 \mathrm{E}-09$ & $5.00 \mathrm{E}-09$ & 5.02E-09 & 5.00E-09 & 5.00E-09 & $5.00 \mathrm{E}-09$ & 5.02E-09 & 5.00E-09 & 5.00E-09 & $5.00 \mathrm{E}-09$ & 5.02E-09 & 5.00E-09 & $5.00 \mathrm{E}-09$ & 5.00E-09 \\
\hline 241-T-112 & 5.35E-09 & 5.34E-09 & 5.34E-09 & 5.34E-09 & $5.35 \mathrm{E}-09$ & $5.34 \mathrm{E}-09$ & 5.34E-09 & $5.34 \mathrm{E}-09$ & 5.35E-09 & 5.34E-09 & 5.34E-09 & 5.34E-09 & 5.35E-09 & 5.34E-09 & 5.34E-09 & 5.34E-09 \\
\hline 241-T-201 & $2.95 \mathrm{E}-10$ & 2.94E-10 & 2.94E-10 & $2.94 \mathrm{E}-10$ & $2.95 \mathrm{E}-10$ & $2.94 \mathrm{E}-10$ & $2.94 \mathrm{E}-10$ & 2.94E-10 & 2.95E-10 & $2.94 \mathrm{E}-10$ & $2.94 \mathrm{E}-10$ & 2.94E-10 & 2.95E-10 & 2.94E-10 & 2.94E-10 & $2.94 \mathrm{E}-10$ \\
\hline 241-T-202 & $2.95 \mathrm{E}-10$ & $2.94 \mathrm{E}-10$ & $2.94 \mathrm{E}-10$ & $2.94 \mathrm{E}-10$ & $2.95 \mathrm{E}-10$ & $2.94 \mathrm{E}-10$ & $2.94 \mathrm{E}-10$ & $2.94 \mathrm{E}-10$ & $2.95 \mathrm{E}-10$ & $2.94 \mathrm{E}-10$ & $2.94 \mathrm{E}-10$ & $2.94 \mathrm{E}-10$ & $2.95 \mathrm{E}-10$ & $2.94 \mathrm{E}-10$ & 2.94E-10 & $2.94 \mathrm{E}-10$ \\
\hline
\end{tabular}




\begin{tabular}{|c|c|c|c|c|c|c|c|c|c|c|c|c|c|c|c|c|}
\hline Site & 1960 & 1961 & 1962 & 1963 & 1964 & 1965 & 1966 & 1967 & 1968 & 1969 & 1970 & 1971 & 1972 & 1973 & 1974 & 1975 \\
\hline 241-T-203 & 95E-10 & $2.94 \mathrm{E}-10$ & $2.94 \mathrm{E}-10$ & 94E-10 & $.95 \mathrm{E}-10$ & $2.94 \mathrm{E}-10$ & $2.94 \mathrm{E}-10$ & $2.94 \mathrm{E}-10$ & $2.95 \mathrm{E}-10$ & $2.94 \mathrm{E}-10$ & $2.94 \mathrm{E}-10$ & $2.94 \mathrm{E}-10$ & $2.95 \mathrm{E}-10$ & $2.94 \mathrm{E}-10$ & $2.94 \mathrm{E}-10$ & $2.94 \mathrm{E}-10$ \\
\hline 241-T-204 & 95E-10 & $2.94 \mathrm{E}-10$ & $2.94 \mathrm{E}-10$ & $94 \mathrm{E}-10$ & $2.95 \mathrm{E}-10$ & $2.94 \mathrm{E}-10$ & $2.94 \mathrm{E}-10$ & $2.94 \mathrm{E}-10$ & $2.95 \mathrm{E}-10$ & $2.94 \mathrm{E}-10$ & $2.94 \mathrm{E}-10$ & $2.94 \mathrm{E}-10$ & $2.95 \mathrm{E}-10$ & $2.94 \mathrm{E}-10$ & $2.94 \mathrm{E}-10$ & $2.94 \mathrm{E}-10$ \\
\hline 241-TX-101 & 79E-09 & 4.78E-09 & 4.78E-09 & 4.78E-09 & $4.79 \mathrm{E}-09$ & $4.78 \mathrm{E}-09$ & 4.78E-09 & 4.78E-09 & $4.79 \mathrm{E}-09$ & $4.78 \mathrm{E}-09$ & 4.78E-09 & $4.78 \mathrm{E}-09$ & 4.79E-09 & $.78 \mathrm{E}-09$ & $78 \mathrm{E}-09$ & 4.78E-09 \\
\hline L-TX-102 & 5.09E-09 & 5.08E-09 & $5.08 \mathrm{E}-09$ & 5.08E-09 & 5.09E-09 & $5.08 \mathrm{E}-09$ & 5.08E-09 & $5.08 \mathrm{E}-09$ & 5.09E-09 & $5.08 \mathrm{E}-09$ & 5.08E-09 & $5.08 \mathrm{E}-09$ & 5.09E-09 & $.08 \mathrm{E}-09$ & $08 \mathrm{E}-09$ & $5.08 \mathrm{E}-09$ \\
\hline & LE-09 & $5.08 \mathrm{E}-09$ & 5.08E-09 & 08E-09 & $5.10 \mathrm{E}-09$ & $5.08 \mathrm{E}-09$ & $5.08 \mathrm{E}-09$ & 08E-09 & $5.10 \mathrm{E}-09$ & $5.08 \mathrm{E}-09$ & 08E-09 & $5.08 \mathrm{E}-09$ & $10 \mathrm{E}-09$ & & & \\
\hline & & $5.0 \varepsilon$ & J8E-09 & 99 & 10E-09 & 08E-09 & 5.08E-09 & 08E-09 & $10 \mathrm{E}-09$ & 5.08E-09 & 5.08E-09 & $5.08 \mathrm{E}-09$ & $10 \mathrm{E}-09$ & $5.08 \mathrm{E}-09$ & 08E-09 & \\
\hline & & 4.16 & 4.16E-09 & E-09 & $4.17 \mathrm{E}-09$ & 4.16E-09 & 4.16E-09 & 4.16E-09 & 7E-09 & $6 \mathrm{E}-09$ & 4.16E-09 & 4.16E-09 & 7E-09 & & & 4.16E-09 \\
\hline & $E-10$ & $E-10$ & $4.24 \mathrm{E}-10$ & 24E-10 & $25 \mathrm{E}-10$ & $4.24 \mathrm{E}-10$ & $4.24 \mathrm{E}-10$ & $24 \mathrm{E}-10$ & $25 E-10$ & $4.24 \mathrm{E}-10$ & $4.24 \mathrm{E}-10$ & $4.24 \mathrm{E}-10$ & $4.25 \mathrm{E}-10$ & $4 \mathrm{E}-10$ & $24 \mathrm{E}-10$ & \\
\hline & -11 & $E-11$ & $75 \mathrm{E}-11$ & $75 E-11$ & 5E-11 & E-11 & $75 E-11$ & $75 E-11$ & 76E-11 & E-11 & $75 E-11$ & $2.75 \mathrm{E}-11$ & $6 \mathrm{E}-11$ & & $75 E-11$ & \\
\hline & & $E-09$ & $=-09$ & & & E-09 & 16E-09 & & E-09 & E-09 & 6E-09 & $\mathrm{E}-09$ & & & & \\
\hline & 79E-09 & .77E-09 & 4.77E-09 & 77E-09 & 4.79E-09 & 4.77E-09 & 4.77E-09 & $.77 \mathrm{E}-09$ & .79E-09 & 7E-09 & 4.77E-09 & 4.77E-09 & 4.79E-09 & & $.77 \mathrm{E}-09$ & \\
\hline 241-TX-110 & 79E-09 & $4.78 \mathrm{E}-09$ & $4.78 \mathrm{E}-09$ & $4.78 \mathrm{E}-09$ & 4.79E-09 & $4.78 \mathrm{E}-09$ & $4.78 \mathrm{E}-09$ & 4.78E-09 & 4.79E-09 & $4.78 \mathrm{E}-09$ & $4.78 \mathrm{E}-09$ & $4.78 \mathrm{E}-09$ & 4.79E-09 & & $4.78 \mathrm{E}-09$ & 4.78E-09 \\
\hline & 09E-09 & $5.08 \mathrm{E}-09$ & $5.08 \mathrm{E}-09$ & $5.08 \mathrm{E}-09$ & 5.09E-09 & $5.08 \mathrm{E}-09$ & $5.08 \mathrm{E}-09$ & $5.08 \mathrm{E}-09$ & 5.09E-09 & $5.08 \mathrm{E}-09$ & 5.08E-09 & $5.08 \mathrm{E}-09$ & $.09 \mathrm{E}-09$ & $.08 \mathrm{E}-09$ & $5.08 \mathrm{E}-09$ & 5.08E-09 \\
\hline & $5.09 E-09$ & 5.08E-09 & $5.08 \mathrm{E}-09$ & $08 \mathrm{E}-09$ & $5.09 E-09$ & $5.08 \mathrm{E}-09$ & $5.08 E-09$ & 5.08E-09 & $.09 \mathrm{E}-09$ & $5.08 E-09$ & $5.08 E-09$ & $5.08 \mathrm{E}-09$ & $.09 \mathrm{E}-09$ & & $5.08 \mathrm{E}-09$ & 5.08E-09 \\
\hline & 17E-09 & 4.16E-09 & $4.16 \mathrm{E}-09$ & 16E-09 & $4.17 \mathrm{E}-09$ & $4.16 \mathrm{E}-09$ & $4.16 \mathrm{E}-09$ & $16 E-09$ & 17E-09 & $4.16 \mathrm{E}-09$ & $4.16 \mathrm{E}-09$ & 16E-09 & 17E-09 & & $16 \mathrm{E}-09$ & 4.16E-09 \\
\hline & 17E-09 & $4.16 \mathrm{E}-09$ & 16E-09 & 16E-09 & $4.17 \mathrm{E}-09$ & 4.16E-09 & 4.16E-09 & $16 \mathrm{E}-09$ & 17E-09 & E-09 & 4.16E-09 & $4.16 \mathrm{E}-09$ & .17E-09 & E-09 & 16E-09 & $4.16 \mathrm{E}-09$ \\
\hline & E-09 & E-09 & $4.16 \mathrm{E}-09$ & E-09 & E-09 & E-09 & 4.16E-09 & E-09 & $E-09$ & $\mathrm{E}-09$ & 16E-09 & 5E-09 & E-09 & E-09 & E-09 & $6 \mathrm{E}-09$ \\
\hline & $E-09$ & E-09 & 4.16E-09 & E-09 & E-09 & 16E-09 & 4.16E-09 & E-09 & E-09 & E-09 & 16E-09 & 5E-09 & 7E-09 & E-09 & 16E-09 & $4.16 \mathrm{E}-09$ \\
\hline & E-09 & E-09 & 4.15E-09 & 15E-09 & 17E-09 & $4.15 \mathrm{E}-09$ & 4.15E-09 & 4.15E-09 & $4.17 \mathrm{E}-09$ & $4.15 \mathrm{E}-09$ & $4.15 E-09$ & 4.15E-09 & $4.17 \mathrm{E}-09$ & $5 \mathrm{E}-09$ & $4.15 \mathrm{E}-09$ & $4.15 \mathrm{E}-09$ \\
\hline & 17E-09 & 16E-09 & 4.16E-09 & 16E-09 & 17E-09 & 16E-09 & 4.16E-09 & 4.16E-09 & 17E-09 & 16E-09 & 4.16E-09 & $4.16 \mathrm{E}-09$ & 4.17E-09 & $6 \mathrm{E}-09$ & $4.16 \mathrm{E}-09$ & 4.16E-09 \\
\hline 101 & $8 \mathrm{E}-12$ & $8.36 \mathrm{E}-12$ & $8.36 \mathrm{E}-12$ & 36E-12 & $38 \mathrm{E}-12$ & $36 \mathrm{E}-12$ & $8.36 \mathrm{E}-12$ & $8.36 \mathrm{E}-12$ & $38 \mathrm{E}-12$ & $36 \mathrm{E}-12$ & $8.36 \mathrm{E}-12$ & $8.36 \mathrm{E}-12$ & $38 \mathrm{E}-12$ & $36 \mathrm{E}-12$ & $36 \mathrm{E}-12$ & $8.36 \mathrm{E}-12$ \\
\hline & $8 \mathrm{E}-12$ & $36 \mathrm{E}-12$ & $8.36 \mathrm{E}-12$ & $36 \mathrm{E}-12$ & $38 \mathrm{E}-12$ & $36 \mathrm{E}-12$ & $8.36 \mathrm{E}-12$ & 8.36E-12 & $38 \mathrm{E}-12$ & $36 \mathrm{E}-12$ & $36 \mathrm{E}-12$ & b-12 & $8 \mathrm{E}-12$ & .36E-12 & $36 \mathrm{E}-12$ & $36 \mathrm{E}-12$ \\
\hline 241-TY-103 & $2.54 \mathrm{E}-09$ & 2.53E-09 & 2.53E-09 & 2.53E-09 & 54E-09 & $2.53 \mathrm{E}-09$ & 2.53E-09 & 2.53E-09 & $.54 \mathrm{E}-09$ & $2.53 \mathrm{E}-09$ & 2.53E-09 & $2.53 \mathrm{E}-09$ & 2.54E-09 & $.53 \mathrm{E}-09$ & $2.53 \mathrm{E}-09$ & $2.53 \mathrm{E}-09$ \\
\hline $241-7$ & $1.27 \mathrm{E}-12$ & $1.27 \mathrm{E}-12$ & $1.27 \mathrm{E}-12$ & $1.27 \mathrm{E}-12$ & $1.27 \mathrm{E}-12$ & $1.27 \mathrm{E}-12$ & $1.27 \mathrm{E}-12$ & $1.27 \mathrm{E}-12$ & $27 \mathrm{E}-12$ & $27 \mathrm{E}-12$ & $1.27 \mathrm{E}-12$ & $1.27 \mathrm{E}-12$ & L.27E-12 & $27 \mathrm{E}-12$ & $1.27 \mathrm{E}-12$ & 1.27E-12 \\
\hline & $59 \mathrm{E}+01$ & LE +01 & $8.26 \mathrm{E}+00$ & $6.52 \mathrm{E}+00$ & $35 E+00$ & $48 \mathrm{E}+00$ & $3.84 \mathrm{E}+00$ & $3.35 \mathrm{E}+00$ & $2.98 \mathrm{E}+00$ & $E+00$ & $2.41 \mathrm{E}+00$ & $2.21 \mathrm{E}+00$ & $E+00$ & $E+00$ & $.80 \mathrm{E}+00$ & $1.72 \mathrm{E}+00$ \\
\hline 241-TY-106 & $35 \mathrm{E}+01$ & $9.01 \mathrm{E}+00$ & $6.06 \mathrm{E}+00$ & $4.59 \mathrm{E}+00$ & $3.65 \mathrm{E}+00$ & $2.99 \mathrm{E}+00$ & $2.53 \mathrm{E}+00$ & $2.18 \mathrm{E}+00$ & $1.92 \mathrm{E}+00$ & $1.70 \mathrm{E}+00$ & $1.53 \mathrm{E}+00$ & $1.40 \mathrm{E}+00$ & $1.29 \mathrm{E}+00$ & $1.20 \mathrm{E}+00$ & $1.12 \mathrm{E}+00$ & $1.07 \mathrm{E}+00$ \\
\hline & 07E-08 & 2.07E-08 & 2.07E-08 & 2.07E-08 & 2.07E-08 & 2.07E-08 & 2.07E-08 & 2.07E-08 & E-08 & E-08 & 2.07E-08 & 7E-08 & 2.07E-08 & 2.07E-08 & 2.07E-08 & 2.07E-08 \\
\hline & $E-08$ & E-08 & 13E-08 & 13E-08 & -08 & $E-08$ & $E-08$ & $E-08$ & $\mathrm{E}-08$ & E-08 & $2.13 \mathrm{E}-08$ & E-08 & 3E-08 & $.13 \mathrm{E}-08$ & $2.13 \mathrm{E}-08$ & 2.13E-08 \\
\hline & & & 79E-08 & -08 & -08 & -08 & $E-08$ & $E-08$ & $=-08$ & $=-08$ & 9E-08 & E-08 & E-08 & $=-08$ & E-08 & 1.79E-08 \\
\hline & & & & & & & -06 & -04 & -02 & $=-01$ & $2.94 \mathrm{E}+00$ & $E+00$ & $9.26 \mathrm{E}+00$ & $E+00$ & $8.79 \mathrm{E}+00$ & $E+00$ \\
\hline & -08 & $E-08$ & $=-08$ & -08 & $E-08$ & $E-08$ & $1.77 \mathrm{E}-08$ & $E-08$ & E-08 & $E-08$ & $1.77 \mathrm{E}-08$ & $E-08$ & E-08 & -08 & 7E-08 & E-08 \\
\hline & $E-08$ & $7 \mathrm{E}-08$ & $77 \mathrm{E}-08$ & 77E-08 & $\mathrm{E}-08$ & E-08 & 77E-08 & E-08 & 77E-08 & 7E-08 & 77E-08 & 7E-08 & $.77 \mathrm{E}-08$ & 7E-08 & 1.77E-08 & $1.77 \mathrm{E}-08$ \\
\hline & E-08 & 66E-08 & $1.66 \mathrm{E}-08$ & 66E-08 & 67E-08 & 66E-08 & 1.66E-08 & 1.66E-08 & 67E-08 & 66E-08 & 1.66E-08 & 1.66E-08 & 1.67E-08 & $.66 \mathrm{E}-08$ & $1.66 \mathrm{E}-08$ & 1.66E-08 \\
\hline & $39 \mathrm{E}-08$ & $88 \mathrm{E}-08$ & $1.88 \mathrm{E}-08$ & 1.88E-08 & 1.89E-08 & 88E-08 & $1.88 \mathrm{E}-08$ & $1.88 \mathrm{E}-08$ & $89 \mathrm{E}-08$ & $88 \mathrm{E}-08$ & $1.88 \mathrm{E}-08$ & $1.88 \mathrm{E}-08$ & $1.89 \mathrm{E}-08$ & $1.88 \mathrm{E}-08$ & $1.88 \mathrm{E}-08$ & $1.88 \mathrm{E}-08$ \\
\hline 241-U-109 & 91E-08 & 1.91E-08 & 1.91E-08 & $1.91 \mathrm{E}-08$ & 1.91E-08 & 1.91E-08 & 1.91E-08 & 1.91E-08 & 1.91E-08 & 1.91E-08 & 1.91E-08 & 1.91E-08 & 1.91E-08 & 1.91E-08 & 1.91E-08 & 1.91E-08 \\
\hline-110 & $53 \mathrm{E}-09$ & $4.52 \mathrm{E}-09$ & 4.52E-09 & $4.52 \mathrm{E}-09$ & 4.53E-09 & $4.52 \mathrm{E}-09$ & $4.52 \mathrm{E}-09$ & 4.52E-09 & 4.53E-09 & 4.52E-09 & 4.52E-09 & 4.52E-09 & 4.53E-09 & 4.52E-09 & 4.52E-09 & $4.52 \mathrm{E}-09$ \\
\hline ל- & 1.74E-08 & 1.73E-08 & $1.73 \mathrm{E}-08$ & 1.73E-08 & $1.74 \mathrm{E}-08$ & 1.73E-08 & 1.73E-08 & 1.73E-08 & $1.74 \mathrm{E}-08$ & $1.73 \mathrm{E}-08$ & 1.73E-08 & 1.73E-08 & $1.74 \mathrm{E}-08$ & 1.73E-08 & $.73 \mathrm{E}-08$ & 1.73E-08 \\
\hline 241-U-112 & 17E-08 & $4.16 \mathrm{E}-08$ & $4.16 \mathrm{E}-08$ & $4.16 \mathrm{E}-08$ & $4.17 \mathrm{E}-08$ & $4.16 \mathrm{E}-08$ & $4.16 \mathrm{E}-08$ & $4.16 \mathrm{E}-08$ & $4.17 \mathrm{E}-08$ & $4.16 \mathrm{E}-08$ & $4.16 \mathrm{E}-08$ & $4.16 \mathrm{E}-08$ & $4.17 \mathrm{E}-08$ & $4.16 \mathrm{E}-08$ & $3.70 \mathrm{E}-05$ & $3.01 \mathrm{E}-03$ \\
\hline 241-U-201 & 1.75E-09 & 1.75E-09 & 1.75E-09 & 1.75E-09 & 1.75E-09 & $1.75 \mathrm{E}-09$ & 1.75E-09 & 1.75E-09 & 1.75E-09 & 1.75E-09 & 1.75E-09 & 1.75E-09 & 1.75E-09 & 1.75E-09 & 1.75E-09 & 1.75E-09 \\
\hline J-202 & 1.73E-09 & 1.72E-09 & 1.72E-09 & 1.72E-09 & 1.73E-09 & 1.72E-09 & 1.72E-09 & 1.72E-09 & 1.73E-09 & 1.72E-09 & 1.72E-09 & 1.72E-09 & 1.73E-09 & 1.72E-09 & 1.72E-09 & 1.72E-09 \\
\hline $241-U-203$ & 1.73E-09 & 1.72E-09 & 1.72E-09 & 1.72E-09 & 1.73E-09 & $1.72 \mathrm{E}-09$ & 1.72E-09 & 1.72E-09 & $1.73 \mathrm{E}-09$ & $1.72 \mathrm{E}-09$ & $1.72 \mathrm{E}-09$ & 1.72E-09 & 1.73E-09 & 1.72E-09 & 1.72E-09 & 1.72E-09 \\
\hline
\end{tabular}




\begin{tabular}{|c|c|c|c|c|c|c|c|c|c|c|c|c|c|c|c|c|}
\hline Site & 1960 & 1961 & 1962 & 1963 & 1964 & 1965 & 1966 & 1967 & 1968 & 1969 & 1970 & 1971 & 1972 & 1973 & 1974 & \\
\hline $241-U-204$ & 00E-09 & $2.00 \mathrm{E}-09$ & 2.00E-09 & $.00 \mathrm{E}-09$ & $.00 \mathrm{E}-09$ & $.00 \mathrm{E}-09$ & $2.00 \mathrm{E}-09$ & $2.00 \mathrm{E}-09$ & $2.00 \mathrm{E}-09$ & $2.00 \mathrm{E}-09$ & 2.00E-09 & 2.00E-09 & 2.00E-09 & $2.00 \mathrm{E}-09$ & $2.00 \mathrm{E}-09$ & \\
\hline $300-224$ & $69 \mathrm{E}+02$ & $20 \mathrm{E}+03$ & $20 \mathrm{E}+03$ & $20 \mathrm{E}+03$ & $21 \mathrm{E}+03$ & $20 \mathrm{E}+03$ & $20 \mathrm{E}+03$ & $1.20 \mathrm{E}+03$ & $1.21 \mathrm{E}+03$ & $1.20 \mathrm{E}+03$ & $1.20 \mathrm{E}+03$ & $1.20 \mathrm{E}+03$ & $1.21 \mathrm{E}+03$ & $1.20 \mathrm{E}+03$ & & $0 \mathrm{E}+\mathrm{C}$ \\
\hline $316-1$ & $0 \mathrm{E}+06$ & $20 \mathrm{E}+06$ & $1.20 \mathrm{E}+06$ & $20 \mathrm{E}+06$ & $20 \mathrm{E}+06$ & $20 \mathrm{E}+06$ & $20 E+06$ & $1.20 \mathrm{E}+06$ & $20 \mathrm{E}+06$ & $20 \mathrm{E}+06$ & $20 \mathrm{E}+06$ & $1.20 \mathrm{E}+06$ & $1.20 \mathrm{E}+06$ & $1.20 \mathrm{E}+06$ & & $\mathrm{E}+06$ \\
\hline & $21 \mathrm{E}+06$ & $1.20 \mathrm{E}+06$ & $1.20 \mathrm{E}+06$ & $20 \mathrm{E}+06$ & $21 \mathrm{E}+06$ & $20 \mathrm{E}+06$ & $20 \mathrm{E}+06$ & $1.20 \mathrm{E}+06$ & $.21 \mathrm{E}+06$ & $20 \mathrm{E}+06$ & $1.20 \mathrm{E}+06$ & $1.20 \mathrm{E}+06$ & $1.21 \mathrm{E}+06$ & $1.20 \mathrm{E}+06$ & $20 \mathrm{E}+06$ & $\mathrm{DE}+\mathrm{C}$ \\
\hline $316-3$ & $13 E+04$ & $9.10 \mathrm{E}+04$ & $9.10 \mathrm{E}+04$ & $9.08 \mathrm{E}+04$ & $70 \mathrm{E}+04$ & $58 \mathrm{E}+03$ & $1.96 \mathrm{E}+03$ & $1.35 E+03$ & $8.14 \mathrm{E}+02$ & $8.07 \mathrm{E}+02$ & $4.78 \mathrm{E}+02$ & $4.78 \mathrm{E}+02$ & $4.80 \mathrm{E}+02$ & $3.13 \mathrm{E}+02$ & $.95 \mathrm{E}+02$ & $E+02$ \\
\hline $316-5$ & $3.08 \mathrm{E}-10$ & $3.07 \mathrm{E}-10$ & $3.07 \mathrm{E}-10$ & $3.07 \mathrm{E}-10$ & $3.08 \mathrm{E}-10$ & 3.07E-10 & $3.07 \mathrm{E}-10$ & $3.07 \mathrm{E}-10$ & $3.08 \mathrm{E}-10$ & $3.07 \mathrm{E}-10$ & $3.07 \mathrm{E}-10$ & $3.07 \mathrm{E}-10$ & $3.08 \mathrm{E}-10$ & $3.07 \mathrm{E}-10$ & 3.07E-10 & +05 \\
\hline $600-148$ & $00 \mathrm{E}+00$ & $0.00 \mathrm{E}+00$ & $0.00 \mathrm{E}+00$ & $0.00 \mathrm{E}+00$ & $00 \mathrm{E}+00$ & $00 \mathrm{E}+00$ & $0.00 \mathrm{E}+00$ & $0.00 \mathrm{E}+00$ & $0.00 \mathrm{E}+00$ & $0.00 \mathrm{E}+00$ & $0.00 \mathrm{E}+00$ & $0.00 \mathrm{E}+00$ & $0.00 \mathrm{E}+00$ & $0.00 \mathrm{E}+00$ & $0.00 \mathrm{E}+00$ & $0 \mathrm{E}+00$ \\
\hline & 24E-09 & 4.23E-09 & 4.23E-09 & 4.23E-09 & $4.24 \mathrm{E}-09$ & $23 \mathrm{E}-09$ & $4.23 \mathrm{E}-09$ & 4.23E-09 & $4.24 \mathrm{E}-09$ & 4.23E-09 & 4.23E-09 & 4.23E-09 & 4.24E-09 & 4.23E-09 & 4.23E-09 & $3 \mathrm{E}-09$ \\
\hline $3-11$ & 27E-10 & 3.27E-10 & 3.05E-09 & 4.28E-05 & 1.38E-02 & $.81 \mathrm{E}-01$ & $1.53 \mathrm{E}+00$ & $1.05 \mathrm{E}+01$ & $6.45 \mathrm{E}+01$ & $2.78 \mathrm{E}+02$ & $9 \mathrm{E}+02$ & $1.08 \mathrm{E}+03$ & $1.28 \mathrm{E}+03$ & $5 E+03$ & $\mathrm{E}+03$ & $E+03$ \\
\hline & $E+00$ & $E+00$ & $E+00$ & $0.00 \mathrm{E}+00$ & $00 \mathrm{E}+00$ & $E+00$ & $00 \mathrm{E}+00$ & $E+00$ & $E+00$ & $0.00 \mathrm{E}+00$ & $00 \mathrm{E}+00$ & $E+00$ & $0.00 \mathrm{E}+00$ & $\mathrm{DE}+00$ & $E+00$ & $\mathrm{E}+00$ \\
\hline GTFL & $E+00$ & $E+00$ & +00 & $E+00$ & $E+00$ & $E+00$ & $E+00$ & $E+00$ & $E+00$ & $E+00$ & $\mathrm{E}+00$ & $E+00$ & $\mathrm{E}+00$ & $E+00$ & $\mathrm{E}+00$ & $E+00$ \\
\hline ILAW- & $E+00$ & $E+00$ & $0.00 \mathrm{E}+00$ & $E+00$ & $E+00$ & $E+00$ & $00 \mathrm{E}+00$ & $E+00$ & $E+00$ & $0.00 \mathrm{E}+00$ & $\mathrm{DE}+00$ & $E+00$ & $E+00$ & $\mathrm{DE}+00$ & $E+00$ & $\mathrm{E}+00$ \\
\hline RMWS & $E+00$ & $E+00$ & $0.00 E+00$ & $.00 \mathrm{E}+00$ & $00 \mathrm{E}+00$ & $E+00$ & $0.00 \mathrm{E}+00$ & $0.00 E+00$ & $0.00 E+00$ & $0.00 \mathrm{E}+00$ & $0.00 \mathrm{E}+00$ & $0.00 E+00$ & $0 \mathrm{E}+00$ & $0.00 \mathrm{E}+00$ & $\mathrm{E}+00$ & $\mathrm{E}+00$ \\
\hline UPR-1 & 47E-12 & $9.45 \mathrm{E}-12$ & $9.45 \mathrm{E}-12$ & $45 \mathrm{E}-12$ & $9.47 \mathrm{E}-12$ & $45 E-12$ & $9.45 \mathrm{E}-12$ & $9.45 \mathrm{E}-12$ & $9.47 \mathrm{E}-12$ & $45 \mathrm{E}-12$ & $9.45 \mathrm{E}-12$ & $9.45 \mathrm{E}-12$ & 9.47E-12 & $.43 \mathrm{E}-12$ & $35 \mathrm{E}-08$ & $5 \mathrm{E}-04$ \\
\hline UPR-1 & $E-15$ & $5.08 \mathrm{E}-15$ & 08E-15 & 08E-15 & E-15 & J8E-15 & $5.08 \mathrm{E}-15$ & $5.08 \mathrm{E}-15$ & E-15 & 08E-15 & $E-15$ & $=-14$ & E-09 & .47E-07 & 3E-06 & \\
\hline UPR-1 & $9 \mathrm{E}-12$ & $1.18 \mathrm{E}-12$ & $1.18 \mathrm{E}-12$ & $1.18 \mathrm{E}-12$ & $1.19 \mathrm{E}-12$ & 1.18E-12 & $1.18 \mathrm{E}-12$ & $.18 \mathrm{E}-12$ & $9 \mathrm{E}-12$ & $18 \mathrm{E}-12$ & $1.18 \mathrm{E}-12$ & $4.94 \mathrm{E}-12$ & $3.08 \mathrm{E}-07$ & 3.34E-05 & $6 \mathrm{E}-05$ & E-03 \\
\hline UPR-1 & $2 \mathrm{E}-14$ & $2.01 \mathrm{E}-14$ & $2.01 \mathrm{E}-14$ & $2.01 \mathrm{E}-14$ & $.02 \mathrm{E}-14$ & 01E-14 & $.01 \mathrm{E}-14$ & $2.01 \mathrm{E}-14$ & $2 E-14$ & $.01 \mathrm{E}-14$ & $1 \mathrm{E}-14$ & $.01 \mathrm{E}-14$ & $3.34 \mathrm{E}+02$ & $6.10 \mathrm{E}+00$ & 71E-01 & E-01 \\
\hline UPR-2 & $32 \mathrm{E}-02$ & 4.83E-02 & $4.83 \mathrm{E}-02$ & 4.83E-02 & $4.85 \mathrm{E}-02$ & 4.83E-02 & $83 \mathrm{E}-02$ & 4E-02 & & 14E-02 & $E-02$ & & & & $4 \mathrm{E}-02$ & \\
\hline UPR-2 & $26 \mathrm{E}+00$ & $3.09 \mathrm{E}+00$ & $2.90 \mathrm{E}+00$ & $.04 \mathrm{E}+00$ & $05 \mathrm{E}+00$ & $04 \mathrm{E}+00$ & $1.95 \mathrm{E}+00$ & & & $1.33 \mathrm{E}+00$ & $E+00$ & & & & & \\
\hline & & 32E-05 & $4.32 \mathrm{E}-05$ & $4.32 \mathrm{E}-05$ & 33E-05 & .32E-05 & 4.32E-05 & $4.32 \mathrm{E}-05$ & 4.33E-05 & $4.32 \mathrm{E}-05$ & $4.32 \mathrm{E}-05$ & & BE-05 & $32 \mathrm{E}-05$ & 32E-05 & E-05 \\
\hline & & & & & & & 33E-09 & & & & & & & & & E-09 \\
\hline UP & -07 & -07 & -07 & & -07 & -07 & $E-07$ & & & E-07 & $\mathrm{E}-07$ & & & E-07 & E-07 & $E-07$ \\
\hline UP & $\mathrm{E}-01$ & E-01 & $E-01$ & $E-01$ & E-01 & 70E-01 & E-01 & -01 & E-02 & E-02 & $\mathrm{E}-02$ & & $\mathrm{E}-02$ & 5E-02 & DE-02 & E-02 \\
\hline UP & $00 \mathrm{E}+00$ & $0.00 \mathrm{E}+00$ & $0.00 \mathrm{E}+00$ & $.00 \mathrm{E}+00$ & $00 \mathrm{E}+00$ & $0.00 \mathrm{E}+00$ & $0.00 \mathrm{E}+00$ & $E+00$ & $0.00 \mathrm{E}+00$ & $0.00 \mathrm{E}+00$ & $E+00$ & +00 & $\mathrm{E}+00$ & $0.00 \mathrm{E}+00$ & $\mathrm{E}+00$ & $\mathrm{E}+00$ \\
\hline UPR-2 & $00 \mathrm{E}+00$ & $0.00 \mathrm{E}+00$ & $E+00$ & $E+00$ & $00 \mathrm{E}+00$ & $0.00 E+00$ & $0.00 E+00$ & $0.00 E+00$ & $0.00 \mathrm{E}+00$ & $0.00 \mathrm{E}+00$ & $E+00$ & $=00$ & $E+00$ & $0.00 \mathrm{E}+00$ & $\mathrm{E}+00$ & $E+00$ \\
\hline UPR-2 & 39E-08 & $1.38 \mathrm{E}-08$ & 1.38E-08 & $1.38 \mathrm{E}-08$ & 1.39E-08 & 1.38E-08 & $1.38 \mathrm{E}-08$ & $1.38 \mathrm{E}-08$ & 1.39E-08 & 1.38E-08 & $1.38 \mathrm{E}-08$ & 1.38E-08 & 1.39E-08 & $1.38 \mathrm{E}-08$ & $1.38 \mathrm{E}-08$ & $1.38 \mathrm{E}-08$ \\
\hline UPR-2 & DOE+00 & DOE+00 & $0.00 \mathrm{E}+00$ & $00 \mathrm{E}+00$ & $00 \mathrm{E}+00$ & $00 \mathrm{E}+00$ & $00 \mathrm{E}+00$ & $0.00 \mathrm{E}+00$ & $0.00 \mathrm{E}+00$ & $00 \mathrm{E}+00$ & $.00 \mathrm{E}+00$ & $0.00 \mathrm{E}+00$ & $0.00 \mathrm{E}+00$ & $0.00 \mathrm{E}+00$ & $0.00 \mathrm{E}+00$ & $\mathrm{DE}+00$ \\
\hline UPR-2C & $00 \mathrm{E}+00$ & $0.00 \mathrm{E}+00$ & $0.00 \mathrm{E}+00$ & $0.00 \mathrm{E}+00$ & $00 \mathrm{E}+00$ & $0.00 \mathrm{E}+00$ & $0.00 \mathrm{E}+00$ & $0.00 \mathrm{E}+00$ & $0.00 \mathrm{E}+00$ & $0.00 \mathrm{E}+00$ & $0.00 \mathrm{E}+00$ & $0.00 \mathrm{E}+00$ & $0.00 \mathrm{E}+00$ & $0.00 \mathrm{E}+00$ & $0.00 \mathrm{E}+00$ & $.00 \mathrm{E}+00$ \\
\hline UPR-200 & 7.12E-08 & 7.10E-08 & 7.10E-08 & $7.10 \mathrm{E}-08$ & $7.12 \mathrm{E}-08$ & 7.10E-08 & $7.10 \mathrm{E}-08$ & $7.10 \mathrm{E}-08$ & 7.12E-08 & $7.10 \mathrm{E}-08$ & 7.10E-08 & 7.10E-08 & $7.12 \mathrm{E}-08$ & $7.10 \mathrm{E}-08$ & $1.37 \mathrm{E}-01$ & $.58 \mathrm{E}+00$ \\
\hline UPR-2 & $00 \mathrm{E}+00$ & $00 \mathrm{E}+00$ & $0.00 \mathrm{E}+00$ & $00 \mathrm{E}+00$ & $00 \mathrm{E}+00$ & $00 \mathrm{E}+00$ & $00 \mathrm{E}+00$ & $0.00 \mathrm{E}+00$ & $.00 \mathrm{E}+00$ & $.00 \mathrm{E}+00$ & $00 \mathrm{E}+00$ & $0.00 \mathrm{E}+00$ & $0.00 \mathrm{E}+00$ & $0.00 \mathrm{E}+00$ & $.00 \mathrm{E}+00$ & $0 \mathrm{E}+00$ \\
\hline UPR-2 & $00 \mathrm{E}+00$ & $0.00 \mathrm{E}+00$ & $0.00 \mathrm{E}+00$ & $00 \mathrm{E}+00$ & $00 \mathrm{E}+00$ & $00 \mathrm{E}+00$ & $0.00 \mathrm{E}+00$ & $E+00$ & $E+00$ & $E+00$ & $E+00$ & +00 & $E+00$ & $\mathrm{E}+00$ & $\mathrm{EE}+00$ & \\
\hline UPR-2 & $=-05$ & $29 \mathrm{E}-05$ & $5.29 \mathrm{E}-05$ & $5.29 \mathrm{E}-05$ & 5.31E-05 & 5.29E-05 & $5.29 \mathrm{E}-05$ & $5.29 \mathrm{E}-05$ & $5.31 \mathrm{E}-05$ & $5.29 \mathrm{E}-05$ & $5.29 \mathrm{E}-05$ & $5.29 \mathrm{E}-05$ & 5.31E-05 & $5.29 \mathrm{E}-05$ & $6.76 \mathrm{E}-04$ & $7.08 \mathrm{E}-03$ \\
\hline UPR-2 & $00 \mathrm{E}+00$ & $0.00 \mathrm{E}+00$ & $0.00 \mathrm{E}+00$ & $0.00 \mathrm{E}+00$ & $00 \mathrm{E}+00$ & $0.00 \mathrm{E}+00$ & $0.00 \mathrm{E}+00$ & $0.00 \mathrm{E}+00$ & $0.00 \mathrm{E}+00$ & $0.00 \mathrm{E}+00$ & $0.00 \mathrm{E}+00$ & $0.00 \mathrm{E}+00$ & $0.00 \mathrm{E}+00$ & $0.00 \mathrm{E}+00$ & $0.00 \mathrm{E}+00$ & +00 \\
\hline UPR-2 & 73E-07 & 3.72E-07 & E-07 & E-07 & 3E-07 & EE-07 & E-07 & E-07 & $3.73 \mathrm{E}-07$ & 3.72E-07 & E-07 & & E-07 & $2 \mathrm{E}-07$ & 9E-06 & $=-05$ \\
\hline & $2.14 \mathrm{E}-12$ & $2.14 \mathrm{E}-12$ & $2.14 \mathrm{E}-12$ & $2.14 \mathrm{E}-12$ & $2.14 \mathrm{E}-12$ & $2.14 \mathrm{E}-12$ & $2.14 \mathrm{E}-12$ & $2.14 \mathrm{E}-12$ & $8.90 \mathrm{E}+00$ & $5.95 \mathrm{E}+00$ & $E+00$ & $=-01$ & $=-01$ & $1 \mathrm{E}-01$ & 3E-01 & $E-01$ \\
\hline & $00 \mathrm{E}+00$ & $0.00 \mathrm{E}+00$ & $0.00 \mathrm{E}+00$ & $0.00 \mathrm{E}+00$ & $0.00 \mathrm{E}+00$ & $0.00 \mathrm{E}+00$ & $0.00 \mathrm{E}+00$ & $0.00 \mathrm{E}+00$ & $0.00 \mathrm{E}+00$ & $0.00 \mathrm{E}+00$ & $E+00$ & +00 & $E+00$ & $0.00 \mathrm{E}+00$ & $E+00$ & +00 \\
\hline & $5 \mathrm{E}-10$ & $6.23 \mathrm{E}-10$ & 6.23E-10 & & $6.25 \mathrm{E}-10$ & $6.23 \mathrm{E}-10$ & $6.23 \mathrm{E}-10$ & & & $6.23 \mathrm{E}-10$ & E-10 & $=-10$ & E-10 & 6.23E-10 & $6.23 \mathrm{E}-10$ & E-10 \\
\hline PR-2 & 49E-01 & $4.69 \mathrm{E}-01$ & 3.34E-01 & 3.34E-01 & 16E-01 & 04E-01 & $.04 \mathrm{E}-01$ & 4E-01 & 2.04E-01 & 79E-01 & $5 \mathrm{E}-01$ & $=-01$ & $25 \mathrm{E}-01$ & $25 \mathrm{E}-01$ & $1.25 \mathrm{E}-01$ & $1.25 \mathrm{E}-01$ \\
\hline & 41E-08 & 39E-08 & 39E-08 & & $9.41 \mathrm{E}-08$ & 39E-08 & $39 \mathrm{E}-08$ & & & $9 \mathrm{E}-08$ & & & & 9E-08 & 39E-08 & JE-U \\
\hline & 67E-08 & 66E-08 & $66 \mathrm{E}-08$ & & & $2.66 \mathrm{E}-08$ & 66E-08 & 66E-08 & & 2.66E-08 & $6 \mathrm{E}-08$ & & & $6 \mathrm{E}-08$ & 66E-08 & E-08 \\
\hline UPR-200-E-75 & 1.05E-04 & 1.05E-04 & 1.05E-04 & 1.05E-04 & 1.05E-04 & 1.05E-04 & 1.05E-04 & 1.05E-04 & 1.05E-04 & 1.05E-04 & 1.05E-04 & 1.05E-04 & $1.05 \mathrm{E}-04$ & 1.05E-04 & 1.05E-04 & $1.0 J 5-0$ \\
\hline
\end{tabular}




\begin{tabular}{|c|c|c|c|c|c|c|c|c|c|c|c|c|c|c|c|c|}
\hline Site & 1960 & 1961 & 1962 & 1963 & 1964 & 1965 & 1966 & 1967 & 1968 & 1969 & 1970 & 1971 & 1972 & 1973 & 1974 & 1975 \\
\hline UPR-200-E-77 & 43E-09 & 41E-09 & 41E-09 & 41E-09 & 43E-09 & 41E-09 & 41E-09 & 41E-09 & 7.43E-09 & $2.14 \mathrm{E}-07$ & $3.48 \mathrm{E}-07$ & $48 \mathrm{E}-07$ & 3.49E-07 & $48 \mathrm{E}-07$ & $3.48 \mathrm{E}-07$ & 3.48E-07 \\
\hline UPR-200-E-78 & $5 \mathrm{E}-07$ & & & $65 E-07$ & 65E-07 & $65 \mathrm{E}-07$ & $65 E-07$ & $65 \mathrm{E}-07$ & $65 E-07$ & $65 E-07$ & 65E-07 & $1.65 \mathrm{E}-07$ & & & & \\
\hline UPR-200-E-79 & $8 \mathrm{E}-07$ & $95 \mathrm{E}-07$ & $5 \mathrm{E}-07$ & $95 \mathrm{E}-07$ & $98 \mathrm{E}-07$ & 95E-07 & 5E-07 & 95E-07 & 17E-05 & $88 \mathrm{E}-05$ & $4.88 \mathrm{E}-05$ & $4.88 \mathrm{E}-05$ & 4.89E-05 & 88E-05 & & $6.57 \mathrm{E}-03$ \\
\hline UPR-200 & 7E-05 & $66 \mathrm{E}-05$ & 66E-05 & 66E-05 & 67E-05 & $6 \mathrm{E}-05$ & 6E-05 & 66E-05 & 67E-05 & 06E-03 & 72E-03 & $1.72 \mathrm{E}-03$ & $.72 \mathrm{E}-03$ & $72 \mathrm{E}-03$ & & 1.72E-03 \\
\hline UPR-200-E-81 & $4 \mathrm{E}-03$ & 64E-03 & 64E-03 & 54E-03 & 54E-03 & $4 \mathrm{E}-03$ & 64E-03 & 64E-03 & 64E-03 & 64E-03 & 1.64E-03 & $1.64 \mathrm{E}-03$ & $1.64 \mathrm{E}-03$ & $64 \mathrm{E}-03$ & $5.10 \mathrm{E}+00$ & $8.98 \mathrm{E}+00$ \\
\hline UPR-200-E-82 & 17E-07 & 5.16E-07 & $5.16 \mathrm{E}-07$ & 16E-07 & 17E-07 & 16E-07 & 5.16E-07 & $5.16 \mathrm{E}-07$ & 17E-07 & 16E-07 & $5.16 \mathrm{E}-07$ & $5.16 \mathrm{E}-07$ & $17 \mathrm{E}-07$ & $16 \mathrm{E}-07$ & & 5.16E-07 \\
\hline UPR-200-E-84 & 81E-01 & 18E-01 & 18E-01 & 18E-01 & $7.80 \mathrm{E}-02$ & $7.28 \mathrm{E}-02$ & $7.28 \mathrm{E}-02$ & $7.28 \mathrm{E}-02$ & 7.29E-02 & $4.50 \mathrm{E}-02$ & $4.50 \mathrm{E}-02$ & $4.50 \mathrm{E}-02$ & $.51 \mathrm{E}-02$ & $50 \mathrm{E}-02$ & $50 \mathrm{E}-02$ & 50E-02 \\
\hline UPR-20 & OE-09 & 88E-09 & 88E-09 & 88E-09 & $90 \mathrm{E}-09$ & $88 \mathrm{E}-09$ & $88 \mathrm{E}-09$ & $88 \mathrm{E}-09$ & 90E-09 & $6.88 \mathrm{E}-09$ & $6.88 \mathrm{E}-09$ & $6.88 \mathrm{E}-09$ & $0 \mathrm{E}-09$ & $88 \mathrm{E}-09$ & $88 \mathrm{E}-09$ & $6.88 \mathrm{E}-09$ \\
\hline-86 & E-03 & E-03 & 78E-03 & E-03 & E-03 & 78E-03 & 78E-03 & BE-03 & E-03 & 8E-03 & 78E-03 & 8E-03 & E-03 & E-03 & 78E-03 & .78E-03 \\
\hline UPR-2C & -06 & -06 & -06 & $E-06$ & -06 & $\mathrm{E}-06$ & 14E-06 & E-06 & $E-06$ & E-06 & 14E-06 & E-06 & 7E-04 & 0E-04 & 00E-04 & $00 \mathrm{E}-04$ \\
\hline UPR-20 & -05 & $E-05$ & $E-05$ & $=-05$ & -05 & E-05 & E-05 & E-05 & $E-05$ & E-05 & 26E-05 & E-05 & E-05 & $6 \mathrm{E}-05$ & 26E-05 & .26E-05 \\
\hline UPR-20 & -09 & $E-09$ & $E-09$ & $E-09$ & -09 & E-09 & E-09 & E-07 & $=-07$ & E-07 & E-07 & $\mathrm{E}-07$ & E-07 & & 3E-07 & $1 \mathrm{E}-04$ \\
\hline UPR-20 & -06 & $E-06$ & $E-06$ & $E-06$ & $E-06$ & $\mathrm{E}-06$ & 97E-06 & E-06 & $\mathrm{E}-06$ & E-04 & 66E-04 & $\mathrm{E}-04$ & $\mathrm{E}-04$ & E-04 & $6 \mathrm{E}-04$ & .66E-04 \\
\hline UPR-20C & E-08 & 6.96E-08 & 96E-08 & E-08 & E-08 & E-08 & $6.96 \mathrm{E}-08$ & $6 \mathrm{E}-08$ & $8 \mathrm{E}-08$ & 96E-08 & $96 \mathrm{E}-08$ & 6.96E-08 & 5E-06 & E-05 & $30 \mathrm{E}-05$ & $1.30 \mathrm{E}-05$ \\
\hline UPR-20 & $E-07$ & 1.34E-07 & 34E-07 & $E-07$ & $E-07$ & E-07 & 34E-07 & $\mathrm{E}-07$ & $34 \mathrm{E}-07$ & 34E-07 & 1.34E-07 & 1.34E-07 & $4 \mathrm{E}-07$ & $4 \mathrm{E}-07$ & 1.34E-07 & $1.34 \mathrm{E}-07$ \\
\hline UPR-200-W-107 & $8.71 \mathrm{E}+03$ & $2.18 \mathrm{E}+04$ & $2.01 E+04$ & $1.83 \mathrm{E}+04$ & $.37 \mathrm{E}+04$ & $37 \mathrm{E}+04$ & $05 E+04$ & $8.80 \mathrm{E}+03$ & $\mathrm{E}+03$ & $E+03$ & $6.57 \mathrm{E}+03$ & $5.61 \mathrm{E}+03$ & $5.62 \mathrm{E}+03$ & $1 E+03$ & $5.61 \mathrm{E}+03$ & $5.61 \mathrm{E}+03$ \\
\hline UPR-200-W-115 & 3.11E-07 & 3.10E-07 & $3.10 \mathrm{E}-07$ & $3.10 \mathrm{E}-07$ & $3.11 \mathrm{E}-07$ & $3.10 \mathrm{E}-07$ & $3.10 \mathrm{E}-07$ & $3.10 \mathrm{E}-07$ & 3.11E-07 & E-07 & $3.10 \mathrm{E}-07$ & $3.10 \mathrm{E}-07$ & 3.11E-07 & DE-07 & $10 \mathrm{E}-07$ & $3.10 \mathrm{E}-07$ \\
\hline UPR-20C & $5.28 \mathrm{E}-09$ & 27E-09 & 5.27E-09 & 27E-09 & 28E-09 & E-09 & 55E-07 & 7.92E-07 & $5 \mathrm{E}-07$ & E-07 & 92E-07 & $.92 \mathrm{E}-07$ & & & & \\
\hline UPR-20 & $73 \mathrm{E}-10$ & $72 \mathrm{E}-10$ & $72 \mathrm{E}-10$ & $72 \mathrm{E}-10$ & $73 \mathrm{E}-10$ & $72 \mathrm{E}-10$ & $72 \mathrm{E}-10$ & E-10 & & & $72 \mathrm{E}-10$ & $E-10$ & & & & -10 \\
\hline UPR-2 & & $E-06$ & 59E-06 & $\mathrm{E}-06$ & & E-06 & 59E-06 & E-06 & DE-06 & E-06 & 2.59E-06 & 9E-06 & E-06 & & & EE-01 \\
\hline-129 & & & & & & & & & & & & & & & & E-09 \\
\hline UPR-20 & & -07 & -07 & & & -07 & -07 & -05 & & -05 & $E-05$ & -05 & & & -05 & $4 \mathrm{E}-02$ \\
\hline UPR-20 & -09 & $E-09$ & $=-09$ & -09 & & $E-09$ & $E-09$ & $=-09$ & -07 & $=-07$ & E-07 & E-07 & E-07 & & E-07 & $53 \mathrm{E}-05$ \\
\hline UPR-20 & -08 & $E-08$ & $E-08$ & E-08 & $E-08$ & E-08 & $\mathrm{E}-08$ & E-08 & $E-08$ & $\mathrm{E}-08$ & DE-08 & $\mathrm{E}-07$ & $\mathrm{E}-06$ & $E-06$ & E-06 & $3 E-06$ \\
\hline UPR-20 & -02 & $\mathrm{E}-02$ & E-01 & $E-01$ & $E-01$ & E-01 & $26 \mathrm{E}-01$ & $\mathrm{E}-01$ & $E-01$ & E-01 & 17E-02 & E-02 & $\mathrm{E}-02$ & E-02 & $45 \mathrm{E}-02$ & $.45 \mathrm{E}-02$ \\
\hline UPR-20C & E-11 & 61E-11 & $8.61 \mathrm{E}-11$ & LE-11 & $3 \mathrm{E}-11$ & 1E-11 & $8.61 \mathrm{E}-11$ & 51E-11 & 4E-09 & 39E-08 & 1.39E-08 & $1.39 \mathrm{E}-08$ & 1.39E-08 & $39 \mathrm{E}-08$ & $1.39 \mathrm{E}-08$ & $1.18 \mathrm{E}-06$ \\
\hline UPR-20 & $=-07$ & $3 \mathrm{E}-07$ & 3E-07 & E-07 & E-07 & $3 \mathrm{E}-07$ & J3E-07 & 3E-07 & E-05 & $8 \mathrm{E}-05$ & $28 \mathrm{E}-05$ & $3 \mathrm{E}-05$ & $9 \mathrm{E}-05$ & $28 \mathrm{E}-05$ & $28 \mathrm{E}-05$ & .21E-03 \\
\hline UPR-200 & 34E-08 & $33 E-08$ & 33E-08 & $3 \mathrm{E}-08$ & 34E-08 & 3E-08 & $33 \mathrm{E}-08$ & $6 \mathrm{E}-07$ & $0 \mathrm{E}-06$ & J9E-06 & 09E-06 & 09E-06 & 10E-06 & $9 \mathrm{E}-06$ & $.09 E-06$ & $67 \mathrm{E}-04$ \\
\hline UPR-200-W-15 & 23E-07 & 2.23E-07 & 23E-07 & 2.23E-07 & 3E-07 & 23E-07 & 2.23E-07 & 56E-05 & $1 \mathrm{E}-05$ & 50E-05 & 50E-05 & 50E-05 & $1 \mathrm{E}-05$ & $0 \mathrm{E}-05$ & $50 \mathrm{E}-05$ & 44E-02 \\
\hline UPR-20C & $7 \mathrm{E}-05$ & 37E-05 & 37E-05 & 37E-05 & $37 \mathrm{E}-05$ & $37 E-05$ & 37E-05 & 37E-05 & $37 E-05$ & 37E-05 & 1.37E-05 & 37E-05 & $37 \mathrm{E}-05$ & 7E-05 & $37 \mathrm{E}-05$ & $37 E-05$ \\
\hline UPR-20 & $E-10$ & J3E-10 & $3 E-10$ & 7.03E-10 & E-10 & $3 E-10$ & J3E-10 & $3 \mathrm{E}-10$ & $E-08$ & $\mathrm{E}-07$ & $E-07$ & -07 & $E-07$ & -07 & & $=-05$ \\
\hline UPR-2 & -09 & $E-09$ & E-06 & -06 & $=-06$ & $E-06$ & 4.67E-06 & $E-06$ & $E-06$ & E-06 & 4.95E-04 & $4 \mathrm{E}-04$ & $\mathrm{E}-04$ & $24 \mathrm{E}-04$ & $5.24 \mathrm{E}-04$ & $5.24 \mathrm{E}-04$ \\
\hline UPR-200 & & -09 & $E-09$ & -09 & -09 & -09 & $E-09$ & -09 & & $E-06$ & $\mathrm{E}-06$ & -06 & & 2E-06 & $E-06$ & $8 \mathrm{E}-04$ \\
\hline UPR-200 & & & & & & & & & & & E-04 & E-04 & & $2 \mathrm{E}-04$ & E-04 & $1 \mathrm{E}-02$ \\
\hline UPR-200 & $E-06$ & $E-06$ & E-06 & $=-06$ & $E-06$ & E-06 & $\mathrm{E}-06$ & $=-06$ & $E-04$ & E-04 & 3E-04 & E-04 & $E-04$ & $8 \mathrm{E}-04$ & $48 \mathrm{E}-04$ & 9E-02 \\
\hline UPR-20C & & $E-07$ & $E-07$ & -07 & $=-07$ & $E-07$ & $\mathrm{E}-07$ & -07 & $=-0 /$ & $\mathrm{E}-05$ & 46E-04 & -04 & $E-04$ & $\mathrm{E}-04$ & $46 \mathrm{E}-04$ & \\
\hline UPR-200 & & 29E-08 & $4.29 \mathrm{E}-08$ & & & & & E-06 & & & 41E-02 & LE-02 & E-02 & 1E-02 & $41 \mathrm{E}-02$ & 1.41E-02 \\
\hline UPR-200 & & 76E-03 & $76 \mathrm{E}-03$ & $30 \mathrm{E}-02$ & 31E-02 & E-02 & 29E-02 & E-02 & E-01 & $6 \mathrm{E}-01$ & 1.06E-01 & 1.06E-01 & E-01 & $6 \mathrm{E}-01$ & $85 \mathrm{E}-02$ & 7.83E-02 \\
\hline UPR-200 & & 84E-09 & 84E-09 & E-09 & & $4 \mathrm{E}-09$ & & E-09 & & $4 \mathrm{E}-09$ & $1.46 \mathrm{E}-07$ & $3.26 \mathrm{E}-07$ & E-07 & $6 \mathrm{E}-07$ & $26 \mathrm{E}-07$ & $3.26 \mathrm{E}-07$ \\
\hline R-200 & & 17E-08 & 09E-05 & E-04 & $5 E-04$ & $\mathrm{E}-04$ & $1 \mathrm{E}-02$ & $\mathrm{E}-02$ & E-02 & $\mathrm{E}-02$ & & E-02 & E-02 & $5 \mathrm{E}-02$ & $25 \mathrm{E}-02$ & $6.25 \mathrm{E}-02$ \\
\hline UPR-200-W-38 & 2.09E-06 & $2.08 \mathrm{E}-06$ & $2.08 \mathrm{E}-06$ & $2.08 \mathrm{E}-06$ & 2.09E-06 & $2.08 \mathrm{E}-06$ & $2.08 \mathrm{E}-06$ & $2.08 \mathrm{E}-06$ & 2.09E-06 & $2.08 \mathrm{E}-06$ & $1.65 \mathrm{E}-04$ & 3.69E-04 & $3.70 \mathrm{E}-04$ & 3.69E-04 & 3.69E-04 & $3.69 \mathrm{E}-04$ \\
\hline
\end{tabular}




\begin{tabular}{|c|c|c|c|c|c|c|c|c|c|c|c|c|c|c|c|c|}
\hline Site & 1960 & 1961 & 1962 & 1963 & 1964 & 1965 & 1966 & 1967 & 1968 & 1969 & 1970 & 1971 & 1972 & 1973 & 1974 & 1975 \\
\hline UPR-200-W-39 & 89E-07 & 89E-07 & $1.89 \mathrm{E}-07$ & $1.89 \mathrm{E}-07$ & $.89 \mathrm{E}-07$ & 1.89E-07 & 1.89E-07 & 1.89E-07 & 1.89E-07 & 1.84E-05 & $3.17 \mathrm{E}-05$ & 3.17E-05 & 3.17E-05 & 3.17E-05 & 3.17E-05 & 3.17E-05 \\
\hline UPR-200-W-49 & $16 \mathrm{E}-08$ & 5.14E-08 & 5.14E-08 & 14E-08 & $5.16 \mathrm{E}-08$ & $5.14 \mathrm{E}-08$ & $5.14 \mathrm{E}-08$ & $5.14 \mathrm{E}-08$ & .16E-08 & $5.14 \mathrm{E}-08$ & $5.14 \mathrm{E}-08$ & $5.14 \mathrm{E}-08$ & $5.16 \mathrm{E}-08$ & $5.78 \mathrm{E}-06$ & $98 \mathrm{E}-06$ & 9.98E-06 \\
\hline UPR-200-W-5 & $5.88 \mathrm{E}-05$ & 5.87E-05 & $5.55 \mathrm{E}-03$ & $5.94 \mathrm{E}-03$ & 5.95E-03 & 5.94E-03 & 5.94E-03 & $1.10 \mathrm{E}-02$ & 3.53E-02 & $3.52 \mathrm{E}-02$ & $3.52 \mathrm{E}-02$ & $3.52 \mathrm{E}-02$ & 3.53E-02 & $52 \mathrm{E}-02$ & $3.52 \mathrm{E}-02$ & $3.52 \mathrm{E}-02$ \\
\hline UPR-200-W-51 & $1.24 \mathrm{E}-08$ & $1.23 \mathrm{E}-08$ & $1.23 \mathrm{E}-08$ & $1.23 \mathrm{E}-08$ & $1.24 \mathrm{E}-08$ & $1.23 \mathrm{E}-08$ & $1.23 \mathrm{E}-08$ & $1.23 \mathrm{E}-08$ & $1.24 \mathrm{E}-08$ & $1.23 \mathrm{E}-08$ & $1.23 \mathrm{E}-08$ & $1.23 \mathrm{E}-08$ & $1.24 \mathrm{E}-08$ & 1.39E-06 & $2.39 \mathrm{E}-06$ & 2.39E-06 \\
\hline UPR-200-W-59 & 1.24E-05 & 1.23E-05 & $1.23 \mathrm{E}-05$ & $1.23 \mathrm{E}-05$ & $1.24 \mathrm{E}-05$ & $1.23 \mathrm{E}-05$ & 1.23E-05 & $1.23 \mathrm{E}-05$ & 1.24E-05 & E-05 & $1.23 \mathrm{E}-05$ & E-05 & E-05 & $3 \mathrm{E}-05$ & $1.23 \mathrm{E}-05$ & $1.23 \mathrm{E}-05$ \\
\hline UPR-2C & 7.67E-09 & 7.65E-09 & $7.65 \mathrm{E}-09$ & $7.65 \mathrm{E}-09$ & 7.67E-09 & $6.27 \mathrm{E}-07$ & $1.08 \mathrm{E}-06$ & 1.08E-06 & $8 \mathrm{E}-06$ & -06 & $\mathrm{E}-06$ & $=-06$ & 2.84E-05 & -04 & -04 & -04 \\
\hline UPR-2 & E-09 & 3.20E-09 & $3.20 \mathrm{E}-09$ & $3.20 \mathrm{E}-09$ & 3.21E-09 & $3.20 \mathrm{E}-09$ & $3.20 \mathrm{E}-09$ & $0 \mathrm{E}-09$ & -09 & -09 & $\mathrm{E}-09$ & E-09 & $E-09$ & $=-09$ & E-09 & \\
\hline UPR-2 & -10 & 1.38E-10 & $1.38 \mathrm{E}-10$ & $1.38 \mathrm{E}-10$ & $=-10$ & $1.38 \mathrm{E}-10$ & $1.38 \mathrm{E}-10$ & $1.38 \mathrm{E}-10$ & $9 \mathrm{E}-10$ & -10 & $1.38 \mathrm{E}-10$ & $1.38 \mathrm{E}-10$ & 1.39E-10 & $1.38 \mathrm{E}-10$ & $1.38 \mathrm{E}-10$ & 1.38E-10 \\
\hline UPR-20 & -10 & $3.63 E-10$ & $63 \mathrm{E}-10$ & $3.63 \mathrm{E}-10$ & -10 & $E-10$ & -10 & $3 \mathrm{E}-10$ & $=-10$ & $=-10$ & $\mathrm{E}-10$ & $3 \mathrm{E}-10$ & $E-10$ & $3.63 \mathrm{E}-10$ & $=-10$ & $3.63 \mathrm{E}-10$ \\
\hline UPR-2C & & $E-05$ & -05 & -05 & & -05 & & -05 & & -05 & -05 & $E-05$ & -03 & $=-03$ & -03 & $E-03$ \\
\hline UPR-2C & 08 & 4.72 & $4.72 \mathrm{E}-08$ & E-08 & -08 & E-08 & $\mathrm{E}-08$ & E-08 & $E-08$ & -08 & E-08 & $E-08$ & E-08 & $=-08$ & $2 \mathrm{E}-08$ & $2 \mathrm{E}-08$ \\
\hline UPR-2C & & -10 & $=-10$ & -10 & -10 & -10 & $E-10$ & -10 & -10 & -10 & $E-10$ & $E-10$ & $=-10$ & -10 & $E-10$ & E-10 \\
\hline UPR-200-W-98 & 1.13E-05 & 1.55E-05 & 1.55E-05 & $1.55 \mathrm{E}-05$ & $1.55 \mathrm{E}-05$ & 1.55E-05 & 1.55E-05 & 2.01E-04 & 1.29E-03 & 1.29E-03 & 1.29E-03 & 1.29E-03 & E-03 & 1.29E-03 & 1.29E-03 & 1.29E-03 \\
\hline UPR-300-4 & $54 \mathrm{E}+01$ & $9.51 \mathrm{E}+01$ & $9.07 \mathrm{E}+01$ & $7.60 \mathrm{E}+01$ & $7.62 \mathrm{E}+01$ & $7.60 \mathrm{E}+01$ & $7.58 \mathrm{E}+01$ & $5.56 \mathrm{E}+01$ & $5.58 \mathrm{E}+01$ & $5.56 \mathrm{E}+01$ & $5.56 \mathrm{E}+01$ & $5.56 \mathrm{E}+01$ & $5.58 \mathrm{E}+01$ & $4.74 \mathrm{E}+01$ & $4.36 \mathrm{E}+01$ & $4.36 \mathrm{E}+01$ \\
\hline US_Ecology & $0.00 \mathrm{E}+00$ & $0.00 \mathrm{E}+00$ & $0.00 \mathrm{E}+00$ & $0.00 \mathrm{E}+00$ & $0.00 \mathrm{E}+00$ & $0.00 \mathrm{E}+00$ & $0.00 \mathrm{E}+00$ & $0.00 \mathrm{E}+00$ & $0.00 \mathrm{E}+00$ & $0.00 \mathrm{E}+00$ & $0.00 \mathrm{E}+00$ & $0.00 \mathrm{E}+00$ & $0.00 \mathrm{E}+00$ & $0.00 \mathrm{E}+00$ & $0.00 \mathrm{E}+00$ & $0.00 \mathrm{E}+00$ \\
\hline
\end{tabular}




\begin{tabular}{|c|c|c|c|c|c|c|c|c|c|c|c|c|c|c|c|c|}
\hline Site & 1976 & 1977 & 1978 & 1979 & 1980 & 1981 & 1982 & 1983 & 1984 & 1985 & 1986 & 1987 & 1988 & 1989 & 1990 & 19 \\
\hline 216-U-1\%2-Fast & $14 \mathrm{E}+00$ & $8.12 \mathrm{E}+00$ & $8.12 \mathrm{E}+00$ & $12 \mathrm{E}+00$ & $8.14 \mathrm{E}+00$ & $8.12 \mathrm{E}+00$ & $8.12 \mathrm{E}+00$ & $8.12 \mathrm{E}+00$ & $8.14 \mathrm{E}+00$ & $8.12 \mathrm{E}+00$ & $8.12 \mathrm{E}+00$ & $8.12 \mathrm{E}+00$ & $8.14 \mathrm{E}+00$ & $8.12 \mathrm{E}+00$ & $8.12 \mathrm{E}+00$ & $8.12 \mathrm{E}+00$ \\
\hline $100-B-5$ & $46 \mathrm{E}+00$ & $4.45 \mathrm{E}+00$ & $4.45 \mathrm{E}+00$ & $.45 \mathrm{E}+00$ & $46 \mathrm{E}+00$ & $4.45 \mathrm{E}+00$ & $4.45 \mathrm{E}+00$ & $4.38 \mathrm{E}+00$ & $4.37 \mathrm{E}+00$ & $4.36 \mathrm{E}+00$ & $4.36 \mathrm{E}+00$ & $4.36 \mathrm{E}+00$ & $4.37 \mathrm{E}+00$ & $4.36 \mathrm{E}+00$ & $4.36 \mathrm{E}+00$ & $4.36 \mathrm{E}+00$ \\
\hline$D-3$ & $52 \mathrm{E}+01$ & $1.52 \mathrm{E}+01$ & 1.53E+01 & $54 \mathrm{E}+01$ & $55 \mathrm{E}+01$ & $54 \mathrm{E}+01$ & $55 \mathrm{E}+01$ & $1.55 \mathrm{E}+01$ & $1.55 \mathrm{E}+01$ & $1.55 \mathrm{E}+01$ & $1.55 \mathrm{E}+01$ & $1.55 \mathrm{E}+01$ & $1.55 \mathrm{E}+01$ & $1.55 \mathrm{E}+01$ & $1.55 \mathrm{E}+01$ & $1.55 \mathrm{E}+01$ \\
\hline 100-D-32 & $3.25 E+00$ & $3.37 \mathrm{E}+00$ & $3.45 \mathrm{E}+00$ & $3.50 \mathrm{E}+00$ & $54 \mathrm{E}+00$ & $55 \mathrm{E}+00$ & $56 \mathrm{E}+00$ & $3.57 \mathrm{E}+00$ & $3.58 \mathrm{E}+00$ & $3.58 \mathrm{E}+00$ & $3.58 \mathrm{E}+00$ & $3.58 \mathrm{E}+00$ & $3.59 \mathrm{E}+00$ & $3.58 \mathrm{E}+00$ & $3.58 \mathrm{E}+00$ & $3.58 \mathrm{E}+00$ \\
\hline $100-D-40$ & $77 \mathrm{E}+00$ & $1.78 \mathrm{E}+00$ & $1.79 \mathrm{E}+00$ & $1.80 \mathrm{E}+00$ & $81 \mathrm{E}+00$ & $1.81 \mathrm{E}+00$ & $1.81 \mathrm{E}+00$ & $1.81 \mathrm{E}+00$ & $1.82 \mathrm{E}+00$ & $1.81 \mathrm{E}+00$ & $1.81 \mathrm{E}+00$ & $1.81 \mathrm{E}+00$ & $1.82 \mathrm{E}+00$ & $1.81 \mathrm{E}+00$ & $1.81 \mathrm{E}+00$ & $1 \mathrm{E}+00$ \\
\hline -D-47 & O0E+01 & $6.03 \mathrm{E}+01$ & $6.07 \mathrm{E}+01$ & $6.09 \mathrm{E}+01$ & $12 \mathrm{E}+01$ & $11 \mathrm{E}+01$ & $6.12 \mathrm{E}+01$ & $6.12 \mathrm{E}+01$ & $6.14 \mathrm{E}+01$ & $6.13 \mathrm{E}+01$ & $6.13 \mathrm{E}+01$ & $6.13 \mathrm{E}+01$ & $6.15 \mathrm{E}+01$ & $6.13 \mathrm{E}+01$ & $.13 \mathrm{E}+01$ & $.13 E+01$ \\
\hline $100-F-25$ & $77 \mathrm{E}+00$ & 5.31E-01 & 2.48E-01 & 1.83E-01 & 1.34E-01 & 1.28E-01 & 9.16E-02 & $9.16 \mathrm{E}-02$ & $9.18 \mathrm{E}-02$ & 8.52E-02 & 7.77E-02 & 7.77E-02 & 7.80E-02 & 7.77E-02 & $7 \mathrm{E}-02$ & 4E-02 \\
\hline-10 & E-02 & E-02 & $6.10 \mathrm{E}-02$ & $6.10 \mathrm{E}-02$ & $E-02$ & DE-02 & OE-02 & $6.10 \mathrm{E}-02$ & E-02 & $6.10 \mathrm{E}-02$ & $6.10 \mathrm{E}-02$ & 6.10E-02 & 6.11E-02 & $6.10 \mathrm{E}-02$ & $6.10 \mathrm{E}-02$ & $6.10 \mathrm{E}-02$ \\
\hline-5 & 7.93E+01 & $E+01$ & 7.91E+01 & 7.91E+01 & $93 E+01$ & $E+01$ & $\mathrm{E}+01$ & $7.91 \mathrm{E}+01$ & $7.93 \mathrm{E}+01$ & $7.91 E+01$ & $7.91 E+01$ & $7.91 \mathrm{E}+01$ & $7.93 E+01$ & $7.91 E+01$ & $7.91 \mathrm{E}+01$ & $7.91 \mathrm{E}+01$ \\
\hline & E-02 & $=-02$ & $1 \mathrm{E}-02$ & $2.11 \mathrm{E}-02$ & E-02 & $\mathrm{E}-02$ & $1 \mathrm{E}-02$ & $2.11 \mathrm{E}-02$ & $2.11 \mathrm{E}-02$ & $2.11 \mathrm{E}-02$ & $2.11 \mathrm{E}-02$ & $2.11 \mathrm{E}-02$ & $1 \mathrm{E}-02$ & $2.11 \mathrm{E}-02$ & 11E-02 & $2.11 \mathrm{E}-02$ \\
\hline & E-02 & $=-02$ & 09E-02 & 3.08E-02 & $\mathrm{E}-02$ & $\mathrm{E}-02$ & 3.08E-02 & $3.08 \mathrm{E}-02$ & $9 \mathrm{E}-02$ & 3.08E-02 & 3.08E-02 & 3.08E-02 & 3.09E-02 & 3.08E-02 & 3.08E-02 & $3.08 \mathrm{E}-02$ \\
\hline & E-02 & 45E-02 & 1.45E-02 & $1.45 E-02$ & E-02 & $.45 \mathrm{E}-02$ & 1.45E-02 & 1.45E-02 & 1.45E-02 & 1.45E-02 & $1.45 \mathrm{E}-02$ & $1.45 \mathrm{E}-02$ & 1.45E-02 & 1.45E-02 & 1.45E-02 & 1.45E-02 \\
\hline & +01 & $1.46 \mathrm{E}+01$ & $1.48 \mathrm{E}+01$ & $1.49 \mathrm{E}+01$ & $0 \mathrm{E}+01$ & $50 \mathrm{E}+01$ & $1.51 \mathrm{E}+01$ & $1.51 \mathrm{E}+01$ & $1.51 \mathrm{E}+01$ & $.51 \mathrm{E}+01$ & $1.51 \mathrm{E}+01$ & $1.51 \mathrm{E}+01$ & $1.52 \mathrm{E}+01$ & $1.51 \mathrm{E}+01$ & $1.51 \mathrm{E}+01$ & $1.51 \mathrm{E}+01$ \\
\hline & $2 \mathrm{E}-01$ & $3.26 \mathrm{E}-01$ & 1.70E-01 & 1.70E-01 & $1.28 \mathrm{E}-01$ & $9.18 \mathrm{E}-02$ & $9.18 \mathrm{E}-02$ & $9.18 \mathrm{E}-02$ & $7.62 \mathrm{E}-02$ & $6.08 \mathrm{E}-02$ & $6.08 \mathrm{E}-02$ & $6.08 \mathrm{E}-02$ & $6.09 \mathrm{E}-02$ & $6.08 \mathrm{E}-02$ & $5.57 \mathrm{E}-02$ & 4.99E-02 \\
\hline $100-N-60$ & 00E-01 & 2.99E-01 & $2.99 \mathrm{E}-01$ & 2.99E-01 & $3.00 \mathrm{E}-01$ & 2.99E-01 & 2.99E-01 & $2.99 \mathrm{E}-01$ & 3.00E-01 & 2.99E-01 & $2.99 \mathrm{E}-01$ & 2.99E-01 & 1.81E-01 & 1.05E-01 & 5.87E-02 & $5.37 \mathrm{E}-02$ \\
\hline $\mathrm{N}-66$ & $0 \mathrm{E}+00$ & $0.00 \mathrm{E}+00$ & $0.00 \mathrm{E}+00$ & $0.00 \mathrm{E}+00$ & $00 \mathrm{E}+00$ & $00 \mathrm{E}+00$ & $0.00 \mathrm{E}+00$ & $0.00 \mathrm{E}+00$ & $0.00 \mathrm{E}+00$ & $0.00 \mathrm{E}+00$ & $0.00 \mathrm{E}+00$ & $0.00 \mathrm{E}+00$ & $0.00 \mathrm{E}+00$ & $0.00 \mathrm{E}+00$ & $0.00 \mathrm{E}+00$ & \\
\hline & $5 E+01$ & $22 \mathrm{E}+01$ & $8.22 \mathrm{E}+01$ & $8.22 \mathrm{E}+01$ & $25 \mathrm{E}+01$ & $22 \mathrm{E}+01$ & $8.13 E+01$ & $8.09 E+01$ & $.11 \mathrm{E}+01$ & $.09 \mathrm{E}+01$ & $8.09 \mathrm{E}+01$ & $8.09 \mathrm{E}+01$ & $E+01$ & $8.09 E+01$ & $.09 \mathrm{E}+01$ & $.09 \mathrm{E}+01$ \\
\hline & $\mathrm{E}+00$ & $09 \mathrm{E}+00$ & $1.09 \mathrm{E}+00$ & $.08 \mathrm{E}+00$ & $\mathrm{E}+00$ & $3 \mathrm{E}+00$ & $1.08 \mathrm{E}+00$ & $1.08 \mathrm{E}+$ & $E+00$ & $08 \mathrm{E}+00$ & $.08 \mathrm{E}+00$ & $1.08 \mathrm{E}+$ & 00 & $.08 \mathrm{E}+00$ & $.08 \mathrm{E}+00$ & $.08 \mathrm{E}+00$ \\
\hline & E-01 & 9E-01 & 3.69E-01 & 3.67E-01 & & 5E-01 & 5E-01 & & E-01 & 3.65E-01 & 3.65E-01 & & & & 5E-01 & -01 \\
\hline & & E-01 & E-01 & 1.55E-01 & -01 & $E-01$ & $3 \mathrm{E}-01$ & 1.13E-01 & & 1.13E-01 & 1.05E-01 & 9.96E-02 & 9.99E-02 & 9.96E-02 & 9.96E-02 & $9.96 \mathrm{E}-02$ \\
\hline & $E+00$ & $E+00$ & $1.44 \mathrm{E}+00$ & $1.33 \mathrm{E}+00$ & $E+00$ & $E+00$ & $E+00$ & $1.21 \mathrm{E}+00$ & $E+00$ & $1.10 \mathrm{E}+00$ & $1.10 \mathrm{E}+00$ & $1.10 \mathrm{E}+00$ & $E+00$ & $1.10 \mathrm{E}+00$ & $1.10 \mathrm{E}+00$ & $1.07 \mathrm{E}+00$ \\
\hline$-6 B$ & E-01 & E-01 & 23E-01 & 1.23E-01 & E-01 & $E-01$ & E-01 & $1.20 \mathrm{E}-01$ & $E-01$ & 1.20E-01 & 1.20E-01 & $1.20 \mathrm{E}-$ & $E-01$ & 1.20E-01 & $1.20 \mathrm{E}-01$ & $1.20 \mathrm{E}-01$ \\
\hline & $33 \mathrm{E}+02$ & $E+02$ & $3.61 E+02$ & $3.61 \mathrm{E}+02$ & $44 \mathrm{E}+02$ & $61 \mathrm{E}+02$ & $2.61 E+02$ & $2.61 \mathrm{E}+02$ & $2.62 E+02$ & $2.61 E+02$ & $2.61 E+02$ & $2.30 \mathrm{E}+02$ & $2.29 E+02$ & $2.28 \mathrm{E}+02$ & $2.28 \mathrm{E}+02$ & $2.28 \mathrm{E}+02$ \\
\hline$-2 A$ & $9 \mathrm{E}+00$ & $59 \mathrm{E}+00$ & $2.21 \mathrm{E}+00$ & $1.74 \mathrm{E}+00$ & $74 \mathrm{E}+00$ & $74 \mathrm{E}+00$ & $1.74 \mathrm{E}+00$ & $1.57 \mathrm{E}+00$ & $1.42 \mathrm{E}+00$ & $1.41 \mathrm{E}+00$ & $1.41 \mathrm{E}+00$ & $1.41 \mathrm{E}+00$ & $1.42 \mathrm{E}+00$ & $1.41 \mathrm{E}+00$ & $1.40 \mathrm{E}+00$ & $1.33 \mathrm{E}+00$ \\
\hline$-2 C$ & $4 \mathrm{E}+00$ & $4 \mathrm{E}+00$ & $1.04 \mathrm{E}+00$ & 7.05E-01 & 7.01E-01 & 6.99E-01 & 6.99E-01 & 6.99E-01 & 6.03E-01 & 5.75E-01 & 5.75E-01 & 5.75E-01 & 5.76E-01 & 5.75E-01 & $5.75 \mathrm{E}-01$ & 5.75E-01 \\
\hline $6-D-1 A$ & $96 \mathrm{E}+00$ & $1.95 \mathrm{E}+00$ & $1.95 \mathrm{E}+00$ & $1.93 \mathrm{E}+00$ & $89 \mathrm{E}+00$ & $1.89 \mathrm{E}+00$ & $1.89 \mathrm{E}+00$ & $1.89 \mathrm{E}+00$ & $1.89 \mathrm{E}+00$ & $1.89 \mathrm{E}+00$ & $1.89 \mathrm{E}+00$ & $1.89 \mathrm{E}+00$ & $1.89 \mathrm{E}+00$ & $1.89 \mathrm{E}+00$ & $1.89 \mathrm{E}+00$ & $1.89 \mathrm{E}+00$ \\
\hline 16-D-1B & $01 \mathrm{E}+00$ & $2.03 \mathrm{E}+00$ & $1.98 \mathrm{E}+00$ & $.98 \mathrm{E}+00$ & $98 \mathrm{E}+00$ & $98 \mathrm{E}+00$ & $69 \mathrm{E}+00$ & $1.58 \mathrm{E}+00$ & $1.59 \mathrm{E}+00$ & $1.58 \mathrm{E}+00$ & $1.58 \mathrm{E}+00$ & $1.58 \mathrm{E}+00$ & $1.59 \mathrm{E}+00$ & $1.58 \mathrm{E}+00$ & $1.48 \mathrm{E}+00$ & $1.47 \mathrm{E}+00$ \\
\hline R-1\%2 & $13 \mathrm{E}+02$ & $2.13 \mathrm{E}+02$ & $2.13 \mathrm{E}+02$ & $2.13 \mathrm{E}+02$ & $07 \mathrm{E}+02$ & $03 \mathrm{E}+02$ & $2.03 \mathrm{E}+02$ & $2.03 \mathrm{E}+02$ & $2.03 \mathrm{E}+02$ & $2.03 \mathrm{E}+02$ & $2.03 \mathrm{E}+02$ & $2.03 \mathrm{E}+02$ & $2.03 \mathrm{E}+02$ & $2.03 \mathrm{E}+02$ & $2.03 E+02$ & $.03 \mathrm{E}+02$ \\
\hline 6-DR-3 & $61 \mathrm{E}+00$ & $3.52 \mathrm{E}+00$ & $3.52 \mathrm{E}+00$ & $3.52 \mathrm{E}+00$ & $3.53 \mathrm{E}+00$ & $52 \mathrm{E}+00$ & $3.52 \mathrm{E}+00$ & $3.52 \mathrm{E}+00$ & $3.53 \mathrm{E}+00$ & $3.52 \mathrm{E}+00$ & $3.50 \mathrm{E}+00$ & $3.45 \mathrm{E}+00$ & $3.46 \mathrm{E}+00$ & $3.45 E+00$ & $3.45 E+00$ & $3.45 \mathrm{E}+00$ \\
\hline -F-1 & $4.74 \mathrm{E}+02$ & $4.35 \mathrm{E}+02$ & 4.35E+02 & $4.35 \mathrm{E}+02$ & $4.36 \mathrm{E}+02$ & $4.35 \mathrm{E}+02$ & $4.35 \mathrm{E}+02$ & $4.29 \mathrm{E}+02$ & $4.28 \mathrm{E}+02$ & $4.27 E+02$ & $4.27 \mathrm{E}+02$ & $4.27 E+02$ & $4.28 \mathrm{E}+02$ & $4.27 E+02$ & $4.27 \mathrm{E}+02$ & +02 \\
\hline & E-02 & $8 \mathrm{E}-02$ & E-02 & 4.14E-02 & 5E-02 & 4E-02 & HE-02 & $4.10 \mathrm{E}-02$ & $E-02$ & 02E-02 & $4.02 \mathrm{E}-02$ & $4.02 \mathrm{E}-02$ & E-02 & $4.02 \mathrm{E}-02$ & 4.02E-02 & $4.02 \mathrm{E}-02$ \\
\hline F-11 & BE-02 & E-02 & $3.32 \mathrm{E}-02$ & 3.32E-02 & BE-02 & E-02 & EE-02 & 3.27E-02 & E-02 & 3.22E-02 & $3.22 \mathrm{E}-02$ & 3.22E-02 & $\mathrm{E}-02$ & 3.22E-02 & 3.22E-02 & 3.22E-02 \\
\hline & $E+02$ & +02 & $E+02$ & $2.19 \mathrm{E}+02$ & $2.19 \mathrm{E}+02$ & +02 & +02 & $2.19 \mathrm{E}+02$ & +02 & $2.19 \mathrm{E}+02$ & $2.19 \mathrm{E}+02$ & $2.19 \mathrm{E}+02$ & $E+02$ & $2.19 \mathrm{E}+02$ & $2.19 \mathrm{E}+02$ & $\mathrm{E}+02$ \\
\hline & $22 \mathrm{E}+01$ & $1.21 \mathrm{E}+01$ & $1.21 \mathrm{E}+01$ & $1.21 \mathrm{E}+01$ & $1.22 \mathrm{E}+01$ & $1.21 \mathrm{E}+01$ & $E+01$ & $1.21 \mathrm{E}+01$ & $E+01$ & $1.21 \mathrm{E}+01$ & $1.21 \mathrm{E}+01$ & $1.21 \mathrm{E}+01$ & $E+01$ & $1.21 \mathrm{E}+01$ & $1.21 \mathrm{E}+01$ & $1.21 \mathrm{E}+01$ \\
\hline & 69E-01 & 3.68E-01 & 3.68E-01 & 3.68E-01 & 3.68E-01 & 3.67E-01 & 3.67E-01 & 3.67E-01 & E-01 & 3.67E-01 & 3.67E-01 & 3.67E-01 & E-01 & 7E-01 & 3.67E-01 & 3.67E-01 \\
\hline & $2 \mathrm{E}+02$ & $1.11 \mathrm{E}+02$ & 1.11E+02 & $1.11 \mathrm{E}+02$ & $12 \mathrm{E}+02$ & $1.11 \mathrm{E}+02$ & $1.11 \mathrm{E}+02$ & $1.11 \mathrm{E}+02$ & $1.12 \mathrm{E}+02$ & $1.11 E+02$ & $1.11 E+02$ & $1.11 \mathrm{E}+02$ & $1.12 \mathrm{E}+02$ & $1.11 E+02$ & $1.11 \mathrm{E}+02$ & $1.11 \mathrm{E}+02$ \\
\hline & $4 \mathrm{E}+02$ & $4.53 \mathrm{E}+02$ & $4.53 E+02$ & $4.53 \mathrm{E}+02$ & $54 \mathrm{E}+02$ & $4.53 \mathrm{E}+02$ & $4.53 \mathrm{E}+02$ & $4.53 \mathrm{E}+02$ & $4.54 \mathrm{E}+02$ & $4.53 E+02$ & $4.53 E+02$ & $4.53 \mathrm{E}+02$ & $4.54 \mathrm{E}+02$ & $4.53 E+02$ & $4.53 \mathrm{E}+02$ & $4.53 \mathrm{E}+02$ \\
\hline $\mathrm{H}-2$ & $69 \mathrm{E}+01$ & $2.68 \mathrm{E}+01$ & $2.68 \mathrm{E}+01$ & $2.68 \mathrm{E}+01$ & $2.69 \mathrm{E}+01$ & $2.68 \mathrm{E}+01$ & $2.68 \mathrm{E}+01$ & $2.68 \mathrm{E}+01$ & $2.68 \mathrm{E}+01$ & $2.68 \mathrm{E}+01$ & $2.68 \mathrm{E}+01$ & $2.68 \mathrm{E}+01$ & $2.68 \mathrm{E}+01$ & $2.68 \mathrm{E}+01$ & $2.68 \mathrm{E}+01$ & $2.68 \mathrm{E}+01$ \\
\hline & $2 \mathrm{E}-02$ & $3.01 E-02$ & 3.01E-02 & 3.01E-02 & 3.02E-02 & 3.01E-02 & 3.01E-02 & 3.01E-02 & 3.01E-02 & 3.01E-02 & $3.01 \mathrm{E}-02$ & 3.01E-02 & 3.01E-02 & 3.01E-02 & 3.01E-02 & $3.01 \mathrm{E}-02$ \\
\hline & $44 \mathrm{E}+02$ & $8.36 \mathrm{E}+02$ & $8.36 \mathrm{E}+02$ & $8.36 \mathrm{E}+02$ & $8.38 \mathrm{E}+02$ & $8.36 \mathrm{E}+02$ & $8.36 \mathrm{E}+02$ & $8.35 E+02$ & $8.37 \mathrm{E}+02$ & $8.35 E+02$ & $8.35 \mathrm{E}+02$ & $8.35 \mathrm{E}+02$ & $8.37 \mathrm{E}+02$ & $8.35 \mathrm{E}+02$ & $8.35 \mathrm{E}+02$ & $8.35 \mathrm{E}+02$ \\
\hline $16-K-2$ & $7.19 \mathrm{E}+03$ & $7.17 \mathrm{E}+03$ & $6.01 \mathrm{E}+03$ & $5.04 \mathrm{E}+03$ & $5.06 \mathrm{E}+03$ & $5.04 \mathrm{E}+03$ & $4.78 E+03$ & $1.10 \mathrm{E}+03$ & $4.11 E+03$ & $.10 \mathrm{E}+03$ & $.10 \mathrm{E}+03$ & $4.10 \mathrm{E}+03$ & & $E+03$ & $.77 \mathrm{E}+03$ & $0.11 \mathrm{~L}, 10 \mathrm{~S}$ \\
\hline
\end{tabular}




\begin{tabular}{|c|c|c|c|c|c|c|c|c|c|c|c|c|c|c|c|c|}
\hline Site & 1976 & 1977 & 1978 & 1979 & 1980 & 1981 & 1982 & 1983 & 1984 & 1985 & 1986 & 1987 & 1988 & 1989 & 1990 & 1991 \\
\hline 116-KE-1 & $03 E+00$ & $.02 \mathrm{E}+00$ & $4.47 \mathrm{E}+00$ & $.04 \mathrm{E}+00$ & $.05 E+00$ & $3.04 \mathrm{E}+00$ & $2.96 \mathrm{E}+00$ & $2.19 \mathrm{E}+00$ & $2.20 \mathrm{E}+00$ & $2.19 \mathrm{E}+00$ & $2.19 \mathrm{E}+00$ & $2.19 \mathrm{E}+00$ & $2.20 \mathrm{E}+00$ & $1.95 \mathrm{E}+00$ & $1.89 \mathrm{E}+00$ & $1.89 \mathrm{E}+00$ \\
\hline 116-KE-2 & $58 \mathrm{E}+00$ & $1.36 \mathrm{E}+00$ & 8.30E-01 & 8.30E-01 & $32 \mathrm{E}-01$ & $6.13 \mathrm{E}-01$ & $5.26 \mathrm{E}-01$ & $5.26 \mathrm{E}-01$ & $5.28 \mathrm{E}-01$ & $5.26 \mathrm{E}-01$ & $4.85 \mathrm{E}-01$ & $4.13 \mathrm{E}-01$ & 4.14E-01 & 4.13E-01 & $4.13 \mathrm{E}-01$ & 4.13E-01 \\
\hline 116-KE-3 & $64 \mathrm{E}+03$ & $3.63 \mathrm{E}+03$ & $3.65 \mathrm{E}+03$ & $3.70 \mathrm{E}+03$ & $71 \mathrm{E}+03$ & $70 \mathrm{E}+03$ & $3.70 \mathrm{E}+03$ & $3.72 \mathrm{E}+03$ & $3.73 \mathrm{E}+03$ & $3.72 \mathrm{E}+03$ & $3.72 \mathrm{E}+03$ & $3.72 \mathrm{E}+03$ & $3.73 \mathrm{E}+03$ & $3.73 \mathrm{E}+03$ & $3.73 E+03$ & $3 \mathrm{E}+03$ \\
\hline $116-K W-2$ & $21 \mathrm{E}+02$ & $8.25 \mathrm{E}+02$ & $8.40 \mathrm{E}+02$ & $8.40 \mathrm{E}+02$ & $43 \mathrm{E}+02$ & $8.41 \mathrm{E}+02$ & $8.49 \mathrm{E}+02$ & $8.49 \mathrm{E}+02$ & $8.51 \mathrm{E}+02$ & $8.49 E+02$ & $8.49 \mathrm{E}+02$ & $8.49 \mathrm{E}+02$ & $8.54 \mathrm{E}+02$ & $8.52 \mathrm{E}+02$ & $8.52 \mathrm{E}+02$ & $8.52 \mathrm{E}+02$ \\
\hline $116-\mathrm{N}-1$ & $3.65 E+06$ & $3.64 \mathrm{E}+06$ & $3.64 \mathrm{E}+06$ & $3.63 E+06$ & $65 \mathrm{E}+06$ & $3.64 \mathrm{E}+06$ & $3.64 \mathrm{E}+06$ & $3.63 E+06$ & $3.65 \mathrm{E}+06$ & $3.63 E+06$ & $1.56 \mathrm{E}+05$ & $1.91 \mathrm{E}+04$ & $8.75 E+03$ & $5.22 \mathrm{E}+03$ & $4.51 \mathrm{E}+03$ & $3.11 \mathrm{E}+03$ \\
\hline $116-N-3$ & $4.72 \mathrm{E}-10$ & $4.71 \mathrm{E}-10$ & $4.71 \mathrm{E}-10$ & $4.71 \mathrm{E}-10$ & $4.72 \mathrm{E}-10$ & $4.71 \mathrm{E}-10$ & $4.71 \mathrm{E}-10$ & $8.05 E+05$ & $8.47 \mathrm{E}+05$ & $8.44 \mathrm{E}+05$ & $8.44 \mathrm{E}+05$ & $8.42 E+05$ & $8.47 \mathrm{E}+05$ & $4 \mathrm{E}+05$ & $8.44 \mathrm{E}+05$ & $8.42 \mathrm{E}+05$ \\
\hline & $70 \mathrm{E}+02$ & $1.70 \mathrm{E}+02$ & $1.67 \mathrm{E}+02$ & $1.56 \mathrm{E}+02$ & $1.56 \mathrm{E}+02$ & $1.56 \mathrm{E}+02$ & $1.56 \mathrm{E}+02$ & $1.56 \mathrm{E}+02$ & $1.56 \mathrm{E}+02$ & $1.56 \mathrm{E}+02$ & $1.53 \mathrm{E}+02$ & $1.52 \mathrm{E}+02$ & $1.52 \mathrm{E}+02$ & $1.52 \mathrm{E}+02$ & $1.52 \mathrm{E}+02$ & $52 \mathrm{E}+02$ \\
\hline & $16 \mathrm{E}-01$ & $2.15 \mathrm{E}-01$ & $2.15 \mathrm{E}-01$ & $2.15 \mathrm{E}-01$ & $2.16 \mathrm{E}-01$ & 2.16E-01 & $2.16 \mathrm{E}-01$ & 2.16E-01 & $2.16 \mathrm{E}-01$ & $2.16 \mathrm{E}-01$ & $2.16 \mathrm{E}-01$ & $2.16 \mathrm{E}-01$ & $2.16 \mathrm{E}-01$ & 16E-01 & $2.16 \mathrm{E}-01$ & $6 \mathrm{E}-01$ \\
\hline & $1 \mathrm{E}-02$ & $9.40 \mathrm{E}-02$ & $9.41 \mathrm{E}-02$ & $9.42 \mathrm{E}-02$ & 9.45E-02 & $9.42 \mathrm{E}-02$ & $9.42 \mathrm{E}-02$ & 9.43E-02 & 9.45E-02 & 43E-02 & 3E-02 & 3E-02 & 5E-02 & 43E-02 & 3E-02 & 3E-02 \\
\hline & $00 \mathrm{E}+00$ & $0.00 \mathrm{E}+00$ & $0.00 \mathrm{E}+00$ & $0.00 \mathrm{E}+00$ & $0.00 \mathrm{E}+00$ & $0.00 \mathrm{E}+00$ & $0.00 \mathrm{E}+00$ & $0.00 \mathrm{E}+00$ & $0.00 \mathrm{E}+00$ & $0.00 \mathrm{E}+00$ & $0.00 \mathrm{E}+00$ & $0.00 \mathrm{E}+00$ & $0.00 \mathrm{E}+00$ & $0.00 \mathrm{E}+00$ & $0.00 \mathrm{E}+00$ & $0.00 \mathrm{E}+00$ \\
\hline & $E+02$ & $2.92 \mathrm{E}+02$ & $2.92 \mathrm{E}+02$ & $2.93 \mathrm{E}+02$ & $94 \mathrm{E}+02$ & $93 \mathrm{E}+02$ & $2.93 E+02$ & $2.93 E+02$ & $2.94 \mathrm{E}+02$ & $2.93 E+02$ & $2.93 \mathrm{E}+02$ & $2.93 E+02$ & $4 \mathrm{E}+02$ & $3 \mathrm{E}+02$ & $2.93 \mathrm{E}+02$ & $2.94 \mathrm{E}+02$ \\
\hline & +00 & $0.00 \mathrm{E}+00$ & $0.00 \mathrm{E}+00$ & $0.00 \mathrm{E}+00$ & $00 \mathrm{E}+00$ & $00 \mathrm{E}+00$ & $0.00 \mathrm{E}+00$ & $0.00 \mathrm{E}+00$ & $0.00 \mathrm{E}+00$ & $0.00 \mathrm{E}+00$ & $0.00 \mathrm{E}+00$ & $0.00 \mathrm{E}+00$ & $0 \mathrm{E}+00$ & $0.00 \mathrm{E}+00$ & $0.00 \mathrm{E}+00$ & $0.00 \mathrm{E}+00$ \\
\hline & $E+00$ & $1.43 \mathrm{E}+00$ & $1.43 E+00$ & $1.43 E+00$ & $44 \mathrm{E}+00$ & $43 E+00$ & $1.43 E+00$ & $1.43 E+00$ & $1.44 \mathrm{E}+00$ & $1.43 E+00$ & $1.43 E+00$ & $1.43 E+00$ & $4 \mathrm{E}+00$ & $1.43 E+00$ & $1.43 E+00$ & $1.43 E+00$ \\
\hline & $E+02$ & $5.17 \mathrm{E}+02$ & $5.17 \mathrm{E}+02$ & $5.17 \mathrm{E}+02$ & $19 \mathrm{E}+02$ & $18 \mathrm{E}+02$ & $5.18 \mathrm{E}+02$ & $5.18 \mathrm{E}+02$ & $5.19 \mathrm{E}+02$ & $5.18 \mathrm{E}+02$ & $5.18 \mathrm{E}+02$ & $5.18 \mathrm{E}+02$ & $5.19 \mathrm{E}+02$ & $5.18 \mathrm{E}+02$ & $5.18 \mathrm{E}+02$ & $5.18 \mathrm{E}+02$ \\
\hline & $\mathrm{E}+02$ & $38 \mathrm{E}+02$ & $3.46 \mathrm{E}+02$ & $3.51 \mathrm{E}+02$ & $55 \mathrm{E}+02$ & $56 \mathrm{E}+02$ & $3.57 \mathrm{E}+02$ & $3.58 \mathrm{E}+02$ & $3.60 \mathrm{E}+02$ & $3.59 \mathrm{E}+02$ & $3.59 \mathrm{E}+02$ & $3.59 \mathrm{E}+02$ & $3.61 \mathrm{E}+02$ & $3.60 \mathrm{E}+02$ & $3.60 \mathrm{E}+02$ & $60 \mathrm{E}+02$ \\
\hline $\mathrm{D}-4$ & $59 \mathrm{E}+02$ & $1.70 \mathrm{E}+02$ & $1.71 \mathrm{E}+02$ & $1.72 \mathrm{E}+02$ & $72 \mathrm{E}+02$ & $72 \mathrm{E}+02$ & $1.72 \mathrm{E}+02$ & $1.73 \mathrm{E}+02$ & $1.73 \mathrm{E}+02$ & $1.73 E+02$ & $1.73 \mathrm{E}+02$ & $1.73 \mathrm{E}+02$ & $3 \mathrm{E}+02$ & $1.73 E+02$ & $1.73 \mathrm{E}+02$ & $1.73 \mathrm{E}+02$ \\
\hline DR-2 & $00 \mathrm{E}+00$ & $0.00 \mathrm{E}+00$ & $0.00 \mathrm{E}+00$ & $0.00 \mathrm{E}+00$ & $00 \mathrm{E}+00$ & $0.00 \mathrm{E}+00$ & $0.00 \mathrm{E}+00$ & $0.00 \mathrm{E}+00$ & $0.00 \mathrm{E}+00$ & $0.00 \mathrm{E}+00$ & $0.00 \mathrm{E}+00$ & $0.00 \mathrm{E}+00$ & $0.00 \mathrm{E}+00$ & $0.00 \mathrm{E}+00$ & $0.00 \mathrm{E}+00$ & $0 \mathrm{E}+00$ \\
\hline & $2 \mathrm{E}+02$ & $1.11 \mathrm{E}+02$ & $1.11 \mathrm{E}+02$ & $1.11 \mathrm{E}+02$ & $12 \mathrm{E}+02$ & $11 \mathrm{E}+02$ & $1.11 \mathrm{E}+02$ & $1.11 \mathrm{E}+02$ & $1.12 \mathrm{E}+02$ & $11 \mathrm{E}+02$ & $1.11 \mathrm{E}+02$ & $1.11 \mathrm{E}+02$ & $2 \mathrm{E}+02$ & $1 \mathrm{E}+02$ & $1 \mathrm{E}+02$ & $1 E+02$ \\
\hline & $9 \mathrm{E}-01$ & 3.68E-01 & 3.68E-01 & $3.68 \mathrm{E}-01$ & 69E-01 & 68E-01 & 3.68E-01 & $3.68 \mathrm{E}-01$ & 3.69E-01 & 68E-01 & 8E-01 & $3.68 \mathrm{E}-01$ & E-01 & $8 \mathrm{E}-01$ & 88E-01 & E-01 \\
\hline & $E+00$ & $0.00 \mathrm{E}+00$ & $0.00 \mathrm{E}+00$ & $.00 \mathrm{E}+00$ & $00 \mathrm{E}+00$ & $00 \mathrm{E}+00$ & $0.00 \mathrm{E}+00$ & $0.00 \mathrm{E}+00$ & $0.00 \mathrm{E}+00$ & $.00 \mathrm{E}+00$ & $0 \mathrm{E}+00$ & $0.00 \mathrm{E}+00$ & $E+00$ & $0 \mathrm{E}+00$ & $.00 \mathrm{E}+00$ & \\
\hline & $=03$ & $E+03$ & E+03 & 03 & $E+03$ & $E+03$ & $E+03$ & $1.22 \mathrm{E}+$ & $E+03$ & $E+03$ & $E+03$ & 03 & $E+03$ & & $E+03$ & $E+03$ \\
\hline & +00 & $=00$ & +00 & +00 & $E+00$ & $E+00$ & $E+00$ & $0.00 \mathrm{E}+00$ & $E+00$ & $E+00$ & $E+00$ & 0.0 & $E+00$ & $E+00$ & $E+00$ & +00 \\
\hline & +03 & $E+03$ & $E+03$ & $1.03 \mathrm{E}+03$ & $\mathrm{E}+03$ & $E+03$ & $E+03$ & $1.03 E+03$ & $E+03$ & $E+03$ & $\mathrm{E}+03$ & $\mathrm{E}+03$ & $E+03$ & $E+03$ & $\mathrm{E}+03$ & $E+03$ \\
\hline & $E+00$ & $00 \mathrm{E}+00$ & $0.00 \mathrm{E}+00$ & $0.00 \mathrm{E}+00$ & $00 \mathrm{E}+00$ & $\mathrm{E}+00$ & $0.00 \mathrm{E}+00$ & $0.00 E+00$ & $0.00 \mathrm{E}+00$ & $0.00 \mathrm{E}+00$ & $\mathrm{E}+00$ & $0.00 \mathrm{E}+00$ & $E+00$ & $E+00$ & $\mathrm{E}+00$ & $E+00$ \\
\hline W-1 & $E+00$ & $0.00 \mathrm{E}+00$ & $0.00 \mathrm{E}+00$ & $0.00 \mathrm{E}+00$ & $00 \mathrm{E}+00$ & $00 \mathrm{E}+00$ & $0.00 \mathrm{E}+00$ & $0.00 \mathrm{E}+00$ & $0.00 \mathrm{E}+00$ & $0.00 \mathrm{E}+00$ & $0.00 \mathrm{E}+00$ & $0.00 \mathrm{E}+00$ & $\mathrm{DE}+00$ & $0 \mathrm{E}+00$ & $0 \mathrm{E}+00$ & $0.00 \mathrm{E}+00$ \\
\hline$W-2$ & $43 \mathrm{E}+00$ & $1.43 \mathrm{E}+00$ & $1.43 \mathrm{E}+00$ & $1.43 \mathrm{E}+00$ & $44 \mathrm{E}+00$ & $1.44 \mathrm{E}+00$ & $1.44 \mathrm{E}+00$ & $1.44 \mathrm{E}+00$ & $1.44 \mathrm{E}+00$ & $1.44 \mathrm{E}+00$ & $1.44 \mathrm{E}+00$ & $1.44 \mathrm{E}+00$ & $1.44 \mathrm{E}+00$ & $1.44 \mathrm{E}+00$ & $1.44 \mathrm{E}+00$ & $1.44 \mathrm{E}+00$ \\
\hline-100 & $\mathrm{E}+00$ & $4.39 \mathrm{E}+00$ & $4.39 \mathrm{E}+00$ & $4.38 \mathrm{E}+00$ & $40 \mathrm{E}+00$ & $38 \mathrm{E}+00$ & $4.39 \mathrm{E}+00$ & $4.38 \mathrm{E}+00$ & $4.40 \mathrm{E}+00$ & $4.39 \mathrm{E}+00$ & $4.39 \mathrm{E}+00$ & $4.38 \mathrm{E}+00$ & $4.39 E+00$ & $4.39 \mathrm{E}+00$ & $4.39 \mathrm{E}+00$ & $4.38 \mathrm{E}+00$ \\
\hline -E-102 & $84 \mathrm{E}+00$ & $3.82 \mathrm{E}+00$ & $3.82 \mathrm{E}+00$ & $3.82 \mathrm{E}+00$ & $84 \mathrm{E}+00$ & $3.82 \mathrm{E}+00$ & $3.82 \mathrm{E}+00$ & $2.56 \mathrm{E}+00$ & $2.56 \mathrm{E}+00$ & $2.56 \mathrm{E}+00$ & $2.56 \mathrm{E}+00$ & $2.56 \mathrm{E}+00$ & $2.56 \mathrm{E}+00$ & $2.56 \mathrm{E}+00$ & $2.56 \mathrm{E}+00$ & $2.56 \mathrm{E}+00$ \\
\hline E-103 & $00 \mathrm{E}+00$ & $0.00 \mathrm{E}+00$ & $0.00 \mathrm{E}+00$ & $0.00 \mathrm{E}+00$ & $00 \mathrm{E}+00$ & $0.00 \mathrm{E}+00$ & $0.00 \mathrm{E}+00$ & $0.00 \mathrm{E}+00$ & $0.00 \mathrm{E}+00$ & $0.00 \mathrm{E}+00$ & $0.00 \mathrm{E}+00$ & $0.00 \mathrm{E}+00$ & $0.00 \mathrm{E}+00$ & $0.00 \mathrm{E}+00$ & $0.00 \mathrm{E}+00$ & $0.00 \mathrm{E}+00$ \\
\hline E-107 & $00 \mathrm{E}+00$ & $0.00 \mathrm{E}+00$ & $0.00 \mathrm{E}+00$ & $0.00 \mathrm{E}+00$ & $00 \mathrm{E}+00$ & $0.00 \mathrm{E}+00$ & $0.00 \mathrm{E}+00$ & $0.00 \mathrm{E}+00$ & $0.00 \mathrm{E}+00$ & $0.00 \mathrm{E}+00$ & $0.00 \mathrm{E}+00$ & $0.00 \mathrm{E}+00$ & $0.00 \mathrm{E}+00$ & $0.00 \mathrm{E}+00$ & $0.00 \mathrm{E}+00$ & $.00 \mathrm{E}+00$ \\
\hline E-25 & $3.67 \mathrm{E}+00$ & $3.66 \mathrm{E}+00$ & $3.66 \mathrm{E}+00$ & $3.65 \mathrm{E}+00$ & $3.67 \mathrm{E}+00$ & $3.66 \mathrm{E}+00$ & $3.66 \mathrm{E}+00$ & $3.65 E+00$ & $3.67 \mathrm{E}+00$ & $3.66 \mathrm{E}+00$ & $3.66 \mathrm{E}+00$ & $3.65 E+00$ & $3.67 \mathrm{E}+00$ & $3.66 \mathrm{E}+00$ & $3.66 \mathrm{E}+00$ & $.92 \mathrm{E}+00$ \\
\hline-28 & 0E-10 & 69E-10 & 2.69E-10 & $2.69 \mathrm{E}-10$ & $2.70 \mathrm{E}-10$ & 2.69E-10 & 2.69E-10 & 2.69E-10 & $2.70 \mathrm{E}-10$ & $2.69 \mathrm{E}-10$ & 2.69E-10 & $2.69 \mathrm{E}-10$ & 2.70E-10 & 2.69E-10 & $2.64 \mathrm{E}+02$ & $1.65 \mathrm{E}+02$ \\
\hline-41 & $00 \mathrm{E}+00$ & $0.00 \mathrm{E}+00$ & $0.00 \mathrm{E}+00$ & $0.00 \mathrm{E}+00$ & $0.00 \mathrm{E}+00$ & $0.00 \mathrm{E}+00$ & $0.00 \mathrm{E}+00$ & $0.00 \mathrm{E}+00$ & $0.00 \mathrm{E}+00$ & $0.00 \mathrm{E}+00$ & $0.00 \mathrm{E}+00$ & $0.00 \mathrm{E}+00$ & $0.00 \mathrm{E}+00$ & $0.00 \mathrm{E}+00$ & $0.00 \mathrm{E}+00$ & $0.00 \mathrm{E}+00$ \\
\hline & 57E-07 & $4.56 \mathrm{E}-07$ & 4.56E-07 & $4.56 \mathrm{E}-07$ & 4.57E-07 & $4.56 \mathrm{E}-07$ & $4.56 \mathrm{E}-07$ & $4.56 \mathrm{E}-07$ & E-07 & $4.56 \mathrm{E}-07$ & $4.56 \mathrm{E}-07$ & $4.56 \mathrm{E}-07$ & E-07 & $4.56 \mathrm{E}-07$ & $4.56 \mathrm{E}-07$ & E-01 \\
\hline & & $4.49 \mathrm{E}+00$ & $4.49 \mathrm{E}+00$ & $4.49 \mathrm{E}+00$ & $4.50 \mathrm{E}+00$ & $4.49 \mathrm{E}+00$ & $4.49 \mathrm{E}+00$ & $4.49 \mathrm{E}+00$ & $4.50 \mathrm{E}+00$ & $4.49 \mathrm{E}+00$ & $4.49 \mathrm{E}+00$ & $4.49 \mathrm{E}+00$ & $E+00$ & $4.49 \mathrm{E}+00$ & $4.49 \mathrm{E}+00$ & $E+00$ \\
\hline & E-01 & 8.69E-01 & $8.69 \mathrm{E}-01$ & $8.69 \mathrm{E}-01$ & $8.72 \mathrm{E}-01$ & 7.49E-01 & $6.16 \mathrm{E}-01$ & 6.16E-01 & 6.17E-01 & $6.16 \mathrm{E}-01$ & $6.16 \mathrm{E}-01$ & $6.16 \mathrm{E}-01$ & E-01 & $6.16 \mathrm{E}-01$ & $6 \mathrm{E}-01$ & $E-01$ \\
\hline$=-57$ & $2 \mathrm{E}-01$ & $6.10 \mathrm{E}-01$ & 5.57E-01 & 3.97E-01 & 98E-01 & 97E-01 & 3.97E-01 & 3.97E-01 & $.98 \mathrm{E}-01$ & 97E-01 & 3.97E-01 & 3.97E-01 & 98E-01 & 17E-01 & 3.04E-01 & E-01 \\
\hline$E-60$ & $9 \mathrm{E}-13$ & $4.08 \mathrm{E}-13$ & $2.25 \mathrm{E}+00$ & $6.76 \mathrm{E}-01$ & $3.54 \mathrm{E}-01$ & 2.19E-01 & $1.76 \mathrm{E}-01$ & 1.31E-01 & $1.24 \mathrm{E}-01$ & $8.58 \mathrm{E}-02$ & $8.58 \mathrm{E}-02$ & $8.58 \mathrm{E}-02$ & 6.79E-02 & $6.27 \mathrm{E}-02$ & $6.27 \mathrm{E}-02$ & $6.27 \mathrm{E}-02$ \\
\hline E-61 & $0 \mathrm{E}+00$ & $0.00 \mathrm{E}+00$ & $0.00 \mathrm{E}+00$ & $.00 \mathrm{E}+00$ & $00 \mathrm{E}+00$ & $0.00 \mathrm{E}+00$ & $0.00 \mathrm{E}+00$ & $0.00 \mathrm{E}+00$ & $0.00 \mathrm{E}+00$ & $0.00 \mathrm{E}+00$ & $0.00 \mathrm{E}+00$ & $0.00 \mathrm{E}+00$ & $0.00 \mathrm{E}+00$ & $0.00 \mathrm{E}+00$ & $0.00 \mathrm{E}+00$ & $0.00 \mathrm{E}+00$ \\
\hline$E-62$ & $0 \mathrm{E}+00$ & $0.00 \mathrm{E}+00$ & $0.00 \mathrm{E}+00$ & $0.00 \mathrm{E}+00$ & $00 \mathrm{E}+00$ & $0.00 \mathrm{E}+00$ & $0.00 \mathrm{E}+00$ & $0.00 \mathrm{E}+00$ & $0.00 \mathrm{E}+00$ & $0.00 \mathrm{E}+00$ & $0.00 \mathrm{E}+00$ & $0.00 \mathrm{E}+00$ & $0.00 \mathrm{E}+00$ & $0.00 \mathrm{E}+00$ & $0.00 \mathrm{E}+00$ & $0.00 \mathrm{E}+00$ \\
\hline $200-E-63$ & $0.00 \mathrm{E}+00$ & $0.00 \mathrm{E}+00$ & $0.00 \mathrm{E}+00$ & $0.00 \mathrm{E}+00$ & $0.00 \mathrm{E}+00$ & $0.00 \mathrm{E}+00$ & $0.00 \mathrm{E}+00$ & $0.00 \mathrm{E}+00$ & $0.00 \mathrm{E}+00$ & $0.00 \mathrm{E}+00$ & $0.00 \mathrm{E}+00$ & $0.00 \mathrm{E}+00$ & $0.00 \mathrm{E}+00$ & $0.00 \mathrm{E}+00$ & $0.00 \mathrm{E}+00$ & \\
\hline
\end{tabular}




\begin{tabular}{|c|c|c|c|c|c|c|c|c|c|c|c|c|c|c|c|c|}
\hline Site & 1976 & 1977 & 1978 & 1979 & 1980 & 1981 & 1982 & 1983 & 1984 & 1985 & 1986 & 1987 & 1988 & 1989 & 1990 & 1991 \\
\hline & $00 \mathrm{E}+00$ & $0.00 \mathrm{E}+00$ & $0.00 \mathrm{E}+00$ & $.00 \mathrm{E}+00$ & $00 \mathrm{E}+00$ & $0.00 \mathrm{E}+00$ & $0.00 \mathrm{E}+00$ & $0.00 \mathrm{E}+00$ & $0.00 \mathrm{E}+00$ & $0.00 \mathrm{E}+00$ & $0.00 \mathrm{E}+00$ & $0.00 \mathrm{E}+00$ & $0.00 E+00$ & $0.00 \mathrm{E}+00$ & $0.00 \mathrm{E}+00$ & $0.00 E+00$ \\
\hline $0-E-65$ & 16E-07 & 4.15E-07 & 4.15E-07 & .15E-07 & 16E-07 & 15E-07 & 4.15E-07 & $4.15 \mathrm{E}-07$ & 4.16E-07 & $.15 \mathrm{E}-07$ & $4.15 \mathrm{E}-07$ & 4.15E-07 & 4.16E-07 & $4.15 \mathrm{E}-07$ & 4.15E-07 & 15E-07 \\
\hline -E-67 & DOE+00 & $0.00 \mathrm{E}+00$ & $0.00 \mathrm{E}+00$ & $00 \mathrm{E}+00$ & $00 \mathrm{E}+00$ & $00 \mathrm{E}+00$ & $00 \mathrm{E}+00$ & $0.00 \mathrm{E}+00$ & $0.00 \mathrm{E}+00$ & $.00 \mathrm{E}+00$ & $0.00 \mathrm{E}+00$ & $0.00 E+00$ & $0.00 E+00$ & $0.00 E+00$ & $00 \mathrm{E}+00$ & $.00 \mathrm{E}+00$ \\
\hline $0-E-68$ & $16 \mathrm{E}-07$ & $4.15 \mathrm{E}-07$ & 4.15E-07 & 4.15E-07 & .16E-07 & 15E-07 & $4.15 \mathrm{E}-07$ & $4.15 \mathrm{E}-07$ & 4.16E-07 & 4.15E-07 & $4.15 \mathrm{E}-07$ & 4.15E-07 & 4.16E-07 & 4.15E-07 & 4.15E-07 & 4.15E-07 \\
\hline 200-E-69 & $00 \mathrm{E}+00$ & $0.00 \mathrm{E}+00$ & $0.00 \mathrm{E}+00$ & $0.00 \mathrm{E}+00$ & $00 \mathrm{E}+00$ & $0.00 \mathrm{E}+00$ & $0.00 \mathrm{E}+00$ & $0.00 \mathrm{E}+00$ & $0.00 \mathrm{E}+00$ & $0.00 \mathrm{E}+00$ & $0.00 \mathrm{E}+00$ & $0.00 \mathrm{E}+00$ & $0.00 \mathrm{E}+00$ & $0.00 \mathrm{E}+00$ & $0.00 \mathrm{E}+00$ & $0.00 \mathrm{E}+00$ \\
\hline 200 & & 3.40E-05 & 3.40E-05 & $3.40 \mathrm{E}-\mathrm{C}$ & & 3.40E-05 & 3.40E-05 & $3.40 \mathrm{E}-05$ & $3.41 \mathrm{E}-05$ & $3.40 \mathrm{E}-05$ & $3.40 \mathrm{E}-05$ & $3.40 \mathrm{E}-05$ & $3.41 \mathrm{E}-05$ & 3.40E-05 & 3.40E-05 & $3.40 \mathrm{E}-05$ \\
\hline & & $63 \mathrm{E}-05$ & 63E-05 & $63 \mathrm{E}-05$ & E-05 & 63E-05 & 63E-05 & $2.63 \mathrm{E}-05$ & $4 \mathrm{E}-05$ & 63E-05 & 2.63E-05 & 2.63E-05 & $64 \mathrm{E}-05$ & 2.63E-05 & $63 \mathrm{E}-05$ & \\
\hline & & E-05 & E-05 & E-05 & E-05 & E-05 & 40E-05 & $0 \mathrm{E}-05$ & LE-05 & 40E-05 & 3.40E-05 & $3.40 \mathrm{E}-05$ & $1 \mathrm{E}-05$ & $40 \mathrm{E}-05$ & 3.40E-05 & 40E-05 \\
\hline-73 & E-07 & 84E-07 & E-07 & 4E-07 & E-07 & E-07 & .84E-07 & E-07 & E-07 & E-07 & 5.84E-07 & $4 \mathrm{E}-07$ & $6 \mathrm{E}-07$ & E-07 & 84E-07 & \\
\hline & $E-05$ & $3.40 \mathrm{E}-05$ & 3.40E-05 & DE-05 & E-05 & 40E-05 & 3.40E-05 & 0E-05 & $E-05$ & E-05 & 3.40E-05 & DE-05 & $1 \mathrm{E}-05$ & DE-05 & & \\
\hline 200-E-75 & 41E-05 & $3.40 \mathrm{E}-05$ & 3.40E-05 & $3.40 \mathrm{E}-05$ & 3.41E-05 & $3.40 \mathrm{E}-05$ & 3.40E-05 & $3.40 \mathrm{E}-05$ & $1 \mathrm{E}-05$ & $3.40 \mathrm{E}-05$ & $3.40 \mathrm{E}-05$ & $3.40 \mathrm{E}-05$ & $3.41 \mathrm{E}-05$ & $3.40 \mathrm{E}-05$ & 3.40E-05 & 3.40E-05 \\
\hline 200-E-76 & $0.00 E+00$ & $0.00 \mathrm{E}+00$ & $0.00 \mathrm{E}+00$ & $0.00 \mathrm{E}+00$ & $0.00 \mathrm{E}+00$ & $0.00 \mathrm{E}+00$ & $0.00 \mathrm{E}+00$ & $0.00 \mathrm{E}+00$ & $0.00 \mathrm{E}+00$ & $0.00 \mathrm{E}+00$ & $0.00 E+00$ & $0.00 \mathrm{E}+00$ & $0.00 \mathrm{E}+00$ & $0.00 \mathrm{E}+00$ & $0.00 \mathrm{E}+00$ & $0.00 \mathrm{E}+00$ \\
\hline 200-E-77 & $0 \mathrm{E}+00$ & $0.00 \mathrm{E}+00$ & $0.00 \mathrm{E}+00$ & $0.00 \mathrm{E}+00$ & $00 \mathrm{E}+00$ & $0.00 \mathrm{E}+00$ & $0.00 \mathrm{E}+00$ & $0.00 \mathrm{E}+00$ & $0.00 \mathrm{E}+00$ & $0.00 \mathrm{E}+00$ & $0.00 \mathrm{E}+00$ & $0.00 \mathrm{E}+00$ & $0.00 \mathrm{E}+00$ & $0.00 \mathrm{E}+00$ & $.00 \mathrm{E}+00$ & $0 \mathrm{E}+00$ \\
\hline E-78 & $0 \mathrm{E}+00$ & $0.00 \mathrm{E}+00$ & $0.00 \mathrm{E}+00$ & $0.00 \mathrm{E}+00$ & $00 \mathrm{E}+00$ & $00 \mathrm{E}+00$ & $0.00 \mathrm{E}+00$ & $0.00 \mathrm{E}+00$ & $.00 \mathrm{E}+00$ & $.00 \mathrm{E}+00$ & $0.00 \mathrm{E}+00$ & $0.00 \mathrm{E}+00$ & $0.00 E+00$ & $0.00 \mathrm{E}+00$ & $.00 \mathrm{E}+00$ & $0 \mathrm{E}+00$ \\
\hline E-79 & $0 E+00$ & $0.00 E+00$ & $0.00 E+00$ & $.00 \mathrm{E}+00$ & $00 E+00$ & $00 \mathrm{E}+00$ & $00 \mathrm{E}+00$ & $0.00 \mathrm{E}+00$ & $\mathrm{E}+00$ & $E+00$ & $\mathrm{E}+00$ & $E+00$ & $E+00$ & $E+00$ & $\mathrm{DE}+00$ & $0 \mathrm{E}+00$ \\
\hline-80 & $0 \mathrm{E}+00$ & $00 \mathrm{E}+00$ & $0.00 \mathrm{E}+00$ & $E+00$ & +00 & $E+00$ & $E+00$ & $E+00$ & $E+00$ & $E+00$ & $.00 \mathrm{E}+00$ & $0.00 \mathrm{E}+00$ & $\mathrm{DE}+00$ & $E+00$ & $0.00 \mathrm{E}+00$ & $E+00$ \\
\hline-81 & +00 & $E+00$ & $E+00$ & $.00 \mathrm{E}+00$ & $E+00$ & $E+00$ & $00 \mathrm{E}+00$ & $0.00 \mathrm{E}+00$ & $E+00$ & $\mathrm{E}+00$ & $0.00 \mathrm{E}+00$ & $0.00 \mathrm{E}+00$ & $\mathrm{E}+00$ & $0.00 \mathrm{E}+00$ & $0.00 \mathrm{E}+00$ & $0.00 \mathrm{E}+00$ \\
\hline-82 & $E+00$ & $0.00 \mathrm{E}+00$ & $0.00 E+00$ & $0.00 \mathrm{E}+00$ & $.00 \mathrm{E}+00$ & $.00 \mathrm{E}+00$ & $0.00 \mathrm{E}+00$ & $0.00 \mathrm{E}+00$ & $E+00$ & $0.00 E+00$ & $0.00 \mathrm{E}+00$ & $0.00 \mathrm{E}+00$ & $0.00 E+00$ & $0.00 E+00$ & $0.00 \mathrm{E}+00$ & $0.00 E+00$ \\
\hline-84 & E-07 & 9.42E-07 & $9.42 \mathrm{E}-07$ & $9.42 \mathrm{E}-07$ & 4E-07 & $42 E-07$ & 9.42E-07 & $9.42 \mathrm{E}-07$ & E-07 & $42 \mathrm{E}-07$ & 9.42E-07 & 9.42E-07 & 9.44E-07 & 9.42E-07 & 9.42E-07 & 9.42E-07 \\
\hline$=-85$ & $0.00 \mathrm{E}+00$ & $0.00 \mathrm{E}+00$ & $0.00 \mathrm{E}+00$ & $0.00 \mathrm{E}+00$ & $00 \mathrm{E}+00$ & $0.00 \mathrm{E}+00$ & $0.00 \mathrm{E}+00$ & $0.00 \mathrm{E}+00$ & $0.00 \mathrm{E}+00$ & $0.00 \mathrm{E}+00$ & $0.00 \mathrm{E}+00$ & $0.00 \mathrm{E}+00$ & $0.00 \mathrm{E}+00$ & $0.00 \mathrm{E}+00$ & $0.00 \mathrm{E}+00$ & $0.00 \mathrm{E}+00$ \\
\hline $200-E-88$ & 5 E-04 & $6.53 \mathrm{E}-04$ & $6.53 \mathrm{E}-04$ & $6.53 \mathrm{E}-04$ & $6.55 \mathrm{E}-04$ & $6.53 \mathrm{E}-04$ & $6.53 \mathrm{E}-04$ & $6.53 \mathrm{E}-04$ & $6.55 \mathrm{E}-04$ & $53 \mathrm{E}-04$ & $6.53 \mathrm{E}-04$ & $6.53 \mathrm{E}-04$ & $6.55 \mathrm{E}-04$ & 1.47E-01 & $1.00 \mathrm{E}+01$ & $1.17 \mathrm{E}+02$ \\
\hline$=-89$ & $1 \mathrm{E}-03$ & 1.01E-03 & 01E-03 & 01E-03 & 01E-03 & J1E-03 & $.01 \mathrm{E}-03$ & .01E-03 & 01E-03 & 01E-03 & 1.01E-03 & $1.01 \mathrm{E}-03$ & $1.01 \mathrm{E}-03$ & $13 \mathrm{E}-01$ & $1.12 \mathrm{E}+01$ & $.51 \mathrm{E}+01$ \\
\hline 200-E-90 & 8.26E-04 & $8.23 \mathrm{E}-04$ & 8.23E-04 & $8.23 \mathrm{E}-04$ & 8.26E-04 & 8.23E-04 & 8.23E-04 & 8.23E-04 & 8.26E-04 & 8.23E-04 & 8.23E-04 & $8.23 \mathrm{E}-04$ & $8.26 \mathrm{E}-04$ & 1.78E-01 & $1.04 \mathrm{E}+01$ & $1.03 \mathrm{E}+02$ \\
\hline$E-91$ & $29 \mathrm{E}-05$ & $2.29 \mathrm{E}-05$ & 29E-05 & $2.29 \mathrm{E}-05$ & 29E-05 & $2.29 \mathrm{E}-05$ & 2.29E-05 & $2.29 \mathrm{E}-05$ & $2.29 \mathrm{E}-05$ & $2.29 \mathrm{E}-05$ & $2.29 \mathrm{E}-05$ & $2.29 \mathrm{E}-05$ & $8.17 \mathrm{E}-03$ & $1.33 E+00$ & $2.30 \mathrm{E}+01$ & $.51 \mathrm{E}+01$ \\
\hline$E-92$ & 34E-03 & 84E-03 & 84E-03 & 84E-03 & 1.84E-03 & 1.84E-03 & $.84 \mathrm{E}-03$ & $1.84 \mathrm{E}-03$ & 1.84E-03 & 84E-03 & 1.84E-03 & 1.84E-03 & $1.84 \mathrm{E}-03$ & $72 \mathrm{E}-01$ & $.47 \mathrm{E}+01$ & $.41 \mathrm{E}+01$ \\
\hline$E-93$ & E-03 & 04E-03 & 04E-03 & 04E-03 & E-03 & E-03 & $4 \mathrm{E}-03$ & $E-03$ & -03 & -03 & $4 \mathrm{E}-03$ & 1.04E-03 & -03 & & +01 & +01 \\
\hline & $E-04$ & E-04 & $3 \mathrm{E}-04$ & E-04 & $55 \mathrm{E}-04$ & 3E-04 & 53E-04 & 3E-04 & 55E-04 & BE-04 & $6.53 \mathrm{E}-04$ & $6.53 \mathrm{E}-04$ & E-04 & 7E-01 & $\mathrm{DE}+01$ & $1.17 \mathrm{E}+02$ \\
\hline & +00 & $E+00$ & $E+00$ & $E+00$ & +00 & $E+00$ & $4.39 \mathrm{E}+00$ & $E+00$ & $=+00$ & $E+00$ & $4.39 \mathrm{E}+00$ & $4.37 \mathrm{E}+00$ & $E+00$ & +00 & $\mathrm{E}+00$ & $E+00$ \\
\hline & +00 & +00 & +00 & +00 & $=+00$ & +00 & $E+00$ & +00 & $E+00$ & $E+00$ & $4.39 \mathrm{E}+00$ & $E+00$ & $E+00$ & $E+00$ & $\mathrm{E}+00$ & +00 \\
\hline & & +00 & & +00 & 100 & +00 & +00 & +00 & +00 & +00 & +00 & +00 & +00 & +00 & +00 & +00 \\
\hline & $E+00$ & 4.42 & 4.42 & $E+00$ & $4.42 E+00$ & $E+00$ & $4.42 E+00$ & $E+00$ & $E+00$ & $E+00$ & $4.42 E+00$ & $4.41 E+00$ & $E+00$ & $E+00$ & $4.42 E+00$ & $4.41 E+00$ \\
\hline$N-22$ & $4 \mathrm{E}-06$ & $2.24 \mathrm{E}-06$ & $2.24 \mathrm{E}-06$ & $2.24 \mathrm{E}-06$ & $2.24 \mathrm{E}-06$ & $2.24 \mathrm{E}-06$ & $2.24 \mathrm{E}-06$ & $2.24 \mathrm{E}-06$ & 2.24E-06 & $2.24 \mathrm{E}-06$ & $2.24 \mathrm{E}-06$ & $2.24 \mathrm{E}-06$ & $2.24 \mathrm{E}-06$ & 2.24E-06 & $9.29 \mathrm{E}-05$ & 7.01E-04 \\
\hline W-42 & 03E-05 & 2.03E-05 & 2.03E-05 & 03E-05 & 2.03E-05 & 03E-05 & 2.03E-05 & $2.03 \mathrm{E}-05$ & $.03 \mathrm{E}-05$ & $.03 E-05$ & 2.03E-05 & 2.03E-05 & 2.03E-05 & 2.03E-05 & 2.03E-05 & 2.03E-05 \\
\hline W-52 & $32 \mathrm{E}+01$ & $6.30 \mathrm{E}+01$ & $5.79 \mathrm{E}+01$ & $4.12 \mathrm{E}+01$ & $13 \mathrm{E}+01$ & $4.12 \mathrm{E}+01$ & $4.12 \mathrm{E}+01$ & $4.12 \mathrm{E}+01$ & $4.13 \mathrm{E}+01$ & $4.12 \mathrm{E}+01$ & $4.12 \mathrm{E}+01$ & $4.12 \mathrm{E}+01$ & $4.13 \mathrm{E}+01$ & $4.12 \mathrm{E}+01$ & $4.01 \mathrm{E}+01$ & $3.39 \mathrm{E}+01$ \\
\hline $200-W-9$ & $1.66 \mathrm{E}-11$ & $1.65 \mathrm{E}-11$ & 1.65E-11 & $1.65 \mathrm{E}-11$ & $1.66 \mathrm{E}-11$ & 1.65E-11 & $1.65 \mathrm{E}-11$ & 1.65E-11 & $1.66 \mathrm{E}-11$ & $1.65 \mathrm{E}-11$ & 1.65E-11 & $1.65 \mathrm{E}-11$ & 1.66E-11 & $1.65 \mathrm{E}-11$ & $1.65 \mathrm{E}-11$ & $1.65 \mathrm{E}-11$ \\
\hline 2101-M-PON & $2.60 E+04$ & $2.60 \mathrm{E}+04$ & $2.60 E+04$ & $2.59 \mathrm{E}+04$ & $2.60 \mathrm{E}+04$ & $2.60 \mathrm{E}+04$ & $2.60 \mathrm{E}+04$ & $2.59 \mathrm{E}+04$ & $2.60 E+04$ & $2.60 \mathrm{E}+04$ & $2.60 \mathrm{E}+04$ & $2.59 \mathrm{E}+04$ & $2.60 \mathrm{E}+04$ & $2.60 \mathrm{E}+04$ & $2.60 \mathrm{E}+04$ & $2.59 \mathrm{E}+04$ \\
\hline $216-A-10$ & $5.11 \mathrm{E}+03$ & $3.98 \mathrm{E}+03$ & $2.88 \mathrm{E}+03$ & $2.25 \mathrm{E}+03$ & $1.86 \mathrm{E}+03$ & $1.63 \mathrm{E}+03$ & $1.39 E+03$ & $1.20 \mathrm{E}+03$ & $6.52 \mathrm{E}+04$ & $1.03 E+05$ & $8.04 \mathrm{E}+04$ & $3.69 \mathrm{E}+04$ & $1.51 \mathrm{E}+04$ & $8.53 E+03$ & $5.92 \mathrm{E}+03$ & $3.53 \mathrm{E}+03$ \\
\hline $216-A-11$ & $42 \mathrm{E}-01$ & $3.41 \mathrm{E}-01$ & 1.85E-01 & $1.78 \mathrm{E}-01$ & $1.78 \mathrm{E}-01$ & 11E-01 & $9.66 \mathrm{E}-02$ & $9.66 \mathrm{E}-02$ & $9.69 \mathrm{E}-02$ & $9.23 \mathrm{E}-02$ & 5.49E-02 & $5.49 \mathrm{E}-02$ & 5.51E-02 & $5.49 \mathrm{E}-02$ & 5.49E-02 & $5.49 \mathrm{E}-02$ \\
\hline & 43E-01 & $2.59 \mathrm{E}-01$ & $2.59 \mathrm{E}-01$ & 1.71E-01 & 1.34E-01 & 1.34E-01 & 1.34E-01 & $8.59 \mathrm{E}-02$ & 7.30E-02 & $7.28 \mathrm{E}-02$ & $7.28 \mathrm{E}-02$ & 7.28E-02 & 7.30E-02 & $4.50 \mathrm{E}-02$ & 4.21E-02 & $4.21 \mathrm{E}-02$ \\
\hline $216-A-13$ & 07E-01 & $6.77 \mathrm{E}-02$ & $6.77 \mathrm{E}-02$ & $6.77 \mathrm{E}-02$ & $6.79 \mathrm{E}-02$ & $6.77 \mathrm{E}-02$ & $6.77 \mathrm{E}-02$ & $6.77 \mathrm{E}-02$ & 4.89E-02 & 4.34E-02 & 4.34E-02 & 4.34E-02 & 4.35E-02 & 4.34E-02 & 4.34E-02 & 4.34E-02 \\
\hline $216-A-14$ & $6.90 \mathrm{E}-07$ & $6.88 \mathrm{E}-07$ & $6.88 \mathrm{E}-07$ & $6.88 \mathrm{E}-07$ & $6.90 \mathrm{E}-07$ & 6.88E-07 & $6.88 \mathrm{E}-07$ & $6.88 \mathrm{E}-07$ & 1.02E-04 & 1.19E-04 & 1.19E-04 & 1.19E-04 & 1.19E-04 & 1.19E-04 & 9.82E-03 & $1.21 \mathrm{E}-02$ \\
\hline
\end{tabular}




\begin{tabular}{|c|c|c|c|c|c|c|c|c|c|c|c|c|c|c|c|c|}
\hline Site & 1976 & 1977 & 1978 & 1979 & 1980 & 1981 & 1982 & 1983 & 1984 & 1985 & 1986 & 1987 & 1988 & 1989 & 1990 & 1991 \\
\hline 216-A-15 & $16 \mathrm{E}+00$ & $96 \mathrm{E}+00$ & $3.11 \mathrm{E}+00$ & $2.66 \mathrm{E}+00$ & $89 \mathrm{E}+00$ & $88 \mathrm{E}+00$ & $1.84 \mathrm{E}+00$ & $1.14 \mathrm{E}+00$ & $1.15 \mathrm{E}+00$ & $1.14 \mathrm{E}+00$ & $1.14 \mathrm{E}+00$ & $1.11 \mathrm{E}+00$ & $7.14 \mathrm{E}-01$ & $7.12 \mathrm{E}-01$ & $7.12 \mathrm{E}-01$ & 7.12E-01 \\
\hline $216-A-16$ & 43E-01 & $3.42 \mathrm{E}-01$ & $3.42 \mathrm{E}-01$ & $1.92 \mathrm{E}-01$ & 1.88E-01 & 1.87E-01 & 1.87E-01 & 1.87E-01 & 1.26E-01 & $1.08 \mathrm{E}-01$ & $1.08 \mathrm{E}-01$ & $1.08 \mathrm{E}-01$ & 1.08E-01 & $.08 \mathrm{E}-01$ & $08 \mathrm{E}-01$ & $1.08 \mathrm{E}-01$ \\
\hline 216-A-17 & 55E-01 & 2.55E-01 & $2.55 \mathrm{E}-01$ & $2.55 \mathrm{E}-01$ & 2.56E-01 & $65 \mathrm{E}-01$ & 42E-01 & 1.42E-01 & 1.43E-01 & $1.42 \mathrm{E}-01$ & $1.42 \mathrm{E}-01$ & 1.22E-01 & 8.47E-02 & 8.45E-02 & & $8.45 \mathrm{E}-02$ \\
\hline $216-A-2$ & $08 \mathrm{E}+00$ & $3.28 \mathrm{E}+00$ & $3.28 \mathrm{E}+00$ & $3.28 \mathrm{E}+00$ & $3.29 \mathrm{E}+00$ & $3.28 \mathrm{E}+00$ & $3.28 \mathrm{E}+00$ & $2.38 \mathrm{E}+00$ & $2.34 \mathrm{E}+00$ & $2.33 \mathrm{E}+00$ & $2.33 \mathrm{E}+00$ & $2.33 \mathrm{E}+00$ & $2.34 \mathrm{E}+00$ & $2.33 \mathrm{E}+00$ & $2.33 \mathrm{E}+00$ & $2.33 E+00$ \\
\hline $16-A-20$ & $65 E+00$ & $4.64 \mathrm{E}+00$ & $4.64 \mathrm{E}+00$ & $4.64 \mathrm{E}+00$ & $4.65 E+00$ & $4.64 \mathrm{E}+00$ & $59 \mathrm{E}+00$ & $3.29 \mathrm{E}+00$ & $3.30 \mathrm{E}+00$ & $3.29 \mathrm{E}+00$ & $3.29 \mathrm{E}+00$ & $3.29 \mathrm{E}+00$ & $3.30 \mathrm{E}+00$ & $3.29 \mathrm{E}+00$ & $3.29 \mathrm{E}+00$ & $29 \mathrm{E}+00$ \\
\hline & $46 \mathrm{E}+01$ & $5.44 \mathrm{E}+01$ & $4.10 \mathrm{E}+01$ & $3.25 \mathrm{E}+01$ & $3.26 \mathrm{E}+01$ & $25 E+01$ & $3.25 \mathrm{E}+01$ & $3.25 \mathrm{E}+01$ & $2.95 \mathrm{E}+01$ & $2.04 \mathrm{E}+01$ & $2.04 \mathrm{E}+01$ & $2.04 \mathrm{E}+01$ & $2.05 \mathrm{E}+01$ & $2.04 \mathrm{E}+01$ & $2.04 \mathrm{E}+01$ & $.04 \mathrm{E}+01$ \\
\hline & 07E-04 & 2.06E-04 & 2.06E-04 & 2.06E-04 & 2.07E-04 & 2.06E-04 & 2.06E-04 & 2.06E-04 & 2.07E-04 & 2.06E-04 & 2.06E-04 & 2.06E-04 & E-04 & & & EE-04 \\
\hline & E-05 & $3.22 \mathrm{E}-05$ & $3.22 \mathrm{E}-05$ & $3.63 \mathrm{E}-03$ & 7.07E-03 & 5.79E-02 & -02 & E-02 & $\mathrm{E}-02$ & $2 \mathrm{E}-02$ & EE-02 & $8.82 \mathrm{E}-02$ & 8.01E-02 & $6.87 \mathrm{E}-02$ & $6.87 \mathrm{E}-02$ & $6.87 \mathrm{E}-02$ \\
\hline $3 B$ & $3.55 E-05$ & 3.54E-05 & 3.54E-05 & $3.99 \mathrm{E}-03$ & $7.77 \mathrm{E}-03$ & 5.89E-02 & $7.78 \mathrm{E}-02$ & 7.78E-02 & $8.65 \mathrm{E}-02$ & 8.83E-02 & 8.83E-02 & 8.83E-02 & $E-02$ & $E-02$ & $6.86 \mathrm{E}-02$ & $6.86 \mathrm{E}-02$ \\
\hline & $E+03$ & $16 \mathrm{E}+03$ & $1.01 \mathrm{E}+03$ & $8.79 E+02$ & $7.89 \mathrm{E}+02$ & $6.68 E+02$ & $6.49 \mathrm{E}+02$ & $5.35 E+02$ & $5.36 E+02$ & $4.96 E+02$ & $4.18 \mathrm{E}+02$ & $4.18 E+02$ & $E+02$ & +02 & $3.23 E+02$ & $3.23 E+02$ \\
\hline & $E+06$ & $85 E+06$ & $1.10 \mathrm{E}+07$ & $1.13 \mathrm{E}+07$ & $91 \mathrm{E}+06$ & 15E+06 & $E+06$ & $1.35 E+07$ & $2.24 \mathrm{E}+07$ & $1.79 E+07$ & $8.82 E+05$ & $7.48 E+04$ & $3.61 E+04$ & $2.44 \mathrm{E}+04$ & 1.99E+04 & $1.76 \mathrm{E}+04$ \\
\hline & E-06 & 13E-06 & 13E-06 & 2.13E-06 & 14E-06 & 2.13E-06 & E-06 & 2.13E-06 & $2.14 \mathrm{E}-06$ & 2.13E-06 & 2.13E-06 & 2.13E-06 & E-06 & 2.13E-06 & 2.13E-06 & 2.13E-06 \\
\hline $26 \mathrm{~A}$ & LEE-06 & 2.17E-06 & 17E-06 & $2.17 \mathrm{E}-06$ & $2.18 \mathrm{E}-06$ & 2.17E-06 & $2.17 \mathrm{E}-06$ & $2.17 \mathrm{E}-06$ & $2.18 \mathrm{E}-06$ & $2.17 \mathrm{E}-06$ & $2.17 \mathrm{E}-06$ & $2.17 \mathrm{E}-06$ & $2.18 \mathrm{E}-06$ & $2.17 \mathrm{E}-06$ & $2.17 \mathrm{E}-06$ & $2.17 \mathrm{E}-06$ \\
\hline-27 & $96 \mathrm{E}+01$ & $8.77 \mathrm{E}+01$ & $5.28 \mathrm{E}+01$ & $5.28 \mathrm{E}+01$ & $.30 \mathrm{E}+01$ & $19 \mathrm{E}+01$ & $2.93 \mathrm{E}+01$ & $2.93 \mathrm{E}+01$ & $2.93 \mathrm{E}+01$ & $2.93 \mathrm{E}+01$ & $2.93 \mathrm{E}+01$ & $2.93 \mathrm{E}+01$ & $2.06 \mathrm{E}+01$ & $1.72 \mathrm{E}+01$ & $1.72 \mathrm{E}+01$ & $1.72 \mathrm{E}+01$ \\
\hline $216-A-28$ & $27 \mathrm{E}-03$ & 26E-03 & 1.26E-03 & $1.26 \mathrm{E}-03$ & 1.27E-03 & $1.26 \mathrm{E}-03$ & $1.26 \mathrm{E}-03$ & $1.26 \mathrm{E}-03$ & 1.27E-03 & $1.26 \mathrm{E}-03$ & $1.26 \mathrm{E}-03$ & $1.26 \mathrm{E}-03$ & 1.27E-03 & $1.26 \mathrm{E}-03$ & $1.26 \mathrm{E}-03$ & 1.26E-03 \\
\hline & $2 \mathrm{E}+00$ & $7.14 \mathrm{E}+00$ & $6.27 \mathrm{E}+00$ & $6.99 \mathrm{E}+00$ & $39 \mathrm{E}+01$ & $15 \mathrm{E}+01$ & $3.73 \mathrm{E}+01$ & $3.02 \mathrm{E}+01$ & $2.17 \mathrm{E}+01$ & $E+01$ & $1.35 \mathrm{E}+01$ & $1.35 \mathrm{E}+01$ & & & $8.32 \mathrm{E}+00$ & \\
\hline & $2 E+04$ & $07 E+04$ & $6.31 \mathrm{E}+04$ & $1.26 \mathrm{E}+05$ & 36E+05 & 19E+05 & 39E+05 & $1.84 \mathrm{E}+05$ & $3.16 \mathrm{E}+05$ & $.71 \mathrm{E}+05$ & $52 \mathrm{E}+05$ & & & & $2.80 \mathrm{E}+05$ & \\
\hline & $0 \mathrm{E}+00$ & $00 \mathrm{E}+00$ & $.00 \mathrm{E}+00$ & $0.00 \mathrm{E}+00$ & $00 \mathrm{E}+00$ & $00 \mathrm{E}+00$ & $00 \mathrm{E}+00$ & $0.00 \mathrm{E}+00$ & $0.00 \mathrm{E}+00$ & $E+00$ & $00 \mathrm{E}+00$ & & & & $.00 \mathrm{E}+00$ & $0 \mathrm{E}+00$ \\
\hline & $0 \mathrm{E}+00$ & $0 \mathrm{E}+00$ & $00 \mathrm{E}+00$ & $0.00 \mathrm{E}+00$ & $00 \mathrm{E}+00$ & DOE+00 & $E+00$ & $00 \mathrm{E}+00$ & $E+00$ & +00 & +00 & & & & & $E+00$ \\
\hline & $=00$ & $00 \mathrm{E}+00$ & $0.00 \mathrm{E}+00$ & $0.00 \mathrm{E}+00$ & $00 \mathrm{E}+00$ & $00 \mathrm{E}+00$ & $E+00$ & $0.00 \mathrm{E}+00$ & $0.00 \mathrm{E}+00$ & $E+00$ & $E+00$ & $0.00 \mathrm{E}+00$ & +00 & +00 & +00 & $\mathrm{E}+00$ \\
\hline & -02 & $7 \mathrm{E}-02$ & 27E-02 & 1.27E-02 & $1.28 \mathrm{E}-02$ & 27E-02 & E-02 & 1.27E-02 & $1.28 \mathrm{E}-02$ & E-02 & E-02 & $1.27 \mathrm{E}-02$ & -02 & -02 & 1.27E-02 & $7 \mathrm{E}-02$ \\
\hline & $E+03$ & $E+03$ & $2.38 E+03$ & $1.91 E+03$ & $59 \mathrm{E}+03$ & $34 \mathrm{E}+03$ & $E+03$ & $1.00 E+03$ & $8.73 E+02$ & $E+02$ & $6.91 E+02$ & $6.12 E+02$ & +02 & $E+02$ & $5.11 \mathrm{E}+02$ & $L+02$ \\
\hline $7-1$ & $1 \mathrm{E}-05$ & $3.15 E+03$ & $2.00 \mathrm{E}+04$ & $1.96 \mathrm{E}+04$ & $.86 \mathrm{E}+04$ & $.37 \mathrm{E}+04$ & $1.34 \mathrm{E}+04$ & $1.45 E+04$ & 4.91E+04 & $4.94 \mathrm{E}+04$ & $5.03 E+04$ & $2.43 E+04$ & $E+04$ & $E+04$ & $5.69 \mathrm{E}+03$ & $2.66 \mathrm{E}+03$ \\
\hline $37-2$ & $32 \mathrm{E}-03$ & 31E-03 & 4.31E-03 & 4.31E-03 & 4.32E-03 & 4.31E-03 & 31E-03 & 4.31E-03 & $3.87 E+04$ & $2.31 \mathrm{E}+05$ & $2.55 \mathrm{E}+05$ & $1.97 \mathrm{E}+05$ & $1.28 \mathrm{E}+05$ & $1.69 \mathrm{E}+05$ & $1.15 \mathrm{E}+05$ & $9.23 \mathrm{E}+04$ \\
\hline & $0 \mathrm{E}+00$ & $0 \mathrm{E}+00$ & $0.00 \mathrm{E}+00$ & $.00 \mathrm{E}+00$ & $00 \mathrm{E}+00$ & $00 \mathrm{E}+00$ & $00 \mathrm{E}+00$ & $0.00 \mathrm{E}+00$ & $0.00 \mathrm{E}+00$ & $0.00 \mathrm{E}+00$ & $0.00 \mathrm{E}+00$ & $0.00 \mathrm{E}+00$ & $0.00 \mathrm{E}+00$ & $0.00 \mathrm{E}+00$ & $0.00 \mathrm{E}+00$ & $0.00 \mathrm{E}+00$ \\
\hline 16-A-4 & $8 \mathrm{E}+00$ & $67 \mathrm{E}+00$ & $3.67 \mathrm{E}+00$ & $3.67 \mathrm{E}+00$ & $68 \mathrm{E}+00$ & $3.67 \mathrm{E}+00$ & $51 \mathrm{E}+00$ & $2.44 \mathrm{E}+00$ & $2.45 \mathrm{E}+00$ & $2.44 \mathrm{E}+00$ & $2.44 \mathrm{E}+00$ & $2.44 \mathrm{E}+00$ & $2.45 \mathrm{E}+00$ & $2.44 \mathrm{E}+00$ & $2.44 \mathrm{E}+00$ & $2.44 \mathrm{E}+00$ \\
\hline$-A-40$ & DOE+00 & $00 \mathrm{E}+00$ & $0.00 \mathrm{E}+00$ & $0.00 \mathrm{E}+00$ & $00 \mathrm{E}+00$ & $00 \mathrm{E}+00$ & $00 \mathrm{E}+00$ & $0.00 \mathrm{E}+00$ & $0.00 \mathrm{E}+00$ & $0.00 \mathrm{E}+00$ & $0.00 \mathrm{E}+00$ & $0.00 \mathrm{E}+00$ & $0.00 \mathrm{E}+00$ & $0.00 \mathrm{E}+00$ & $0.00 \mathrm{E}+00$ & $.00 \mathrm{E}+00$ \\
\hline & $00 \mathrm{E}+00$ & $0.00 \mathrm{E}+00$ & $0.00 \mathrm{E}+00$ & $0.00 \mathrm{E}+00$ & $00 \mathrm{E}+00$ & $0.00 \mathrm{E}+00$ & $0.00 \mathrm{E}+00$ & $0.00 \mathrm{E}+00$ & $0.00 \mathrm{E}+00$ & $0.00 \mathrm{E}+00$ & $0.00 \mathrm{E}+00$ & $0.00 \mathrm{E}+00$ & $0.00 \mathrm{E}+00$ & $0.00 \mathrm{E}+00$ & $0.00 \mathrm{E}+00$ & $.00 \mathrm{E}+00$ \\
\hline$A-45$ & 36E-03 & 4.35E-03 & 4.35E-03 & 4.35E-03 & 4.36E-03 & 4.35E-03 & 4.35E-03 & 4.35E-03 & 4.36E-03 & 4.35E-03 & 4.35E-03 & $9.35 \mathrm{E}+03$ & $4.92 \mathrm{E}+04$ & $1.86 \mathrm{E}+04$ & $6.64 \mathrm{E}+03$ & $.61 \mathrm{E}+03$ \\
\hline & 90E+02 & $7.14 \mathrm{E}+02$ & $7.14 \mathrm{E}+02$ & $7.14 \mathrm{E}+02$ & 7.16E+02 & $5.84 \mathrm{E}+02$ & 4.97E+02 & 4.97E+02 & $4.98 \mathrm{E}+02$ & $4.97 \mathrm{E}+02$ & $4.97 \mathrm{E}+02$ & $4.97 \mathrm{E}+02$ & +02 & $\mathrm{E}+02$ & $.50 \mathrm{E}+02$ & +02 \\
\hline & +03 & $=+03$ & $4 \mathrm{E}+03$ & $2.54 \mathrm{E}+03$ & $55 \mathrm{E}+03$ & $36 \mathrm{E}+03$ & $E+03$ & $1.47 \mathrm{E}+03$ & 1.47 & $E+03$ & $E+03$ & $E+03$ & 9.3 & $E+02$ & $E+02$ & $E+02$ \\
\hline & $4 \mathrm{E}+00$ & $58 \mathrm{E}+00$ & $1.58 \mathrm{E}+00$ & $1.58 \mathrm{E}+00$ & $59 \mathrm{E}+00$ & $29 \mathrm{E}+00$ & E-01 & E-01 & E-01 & 5E-01 & E-01 & 9.65E-01 & -01 & -01 & E-01 & $1 \mathrm{E}-01$ \\
\hline & $6 \mathrm{E}+03$ & $64 \mathrm{E}+03$ & $5.84 \mathrm{E}+03$ & $4.51 \mathrm{E}+03$ & $57 \mathrm{E}+03$ & $2.89 \mathrm{E}+03$ & +03 & $2.10 \mathrm{E}+03$ & $E+03$ & $E+03$ & $E+03$ & $=+03$ & & +02 & +02 & $E+02$ \\
\hline & $E+02$ & $8.27 \mathrm{E}+02$ & $7.34 \mathrm{E}+02$ & $7.34 \mathrm{E}+02$ & $36 \mathrm{E}+02$ & $7.34 \mathrm{E}+02$ & +02 & $5.62 \mathrm{E}+02$ & $E+02$ & $E+02$ & $E+02$ & +02 & 5.6 & & +02 & $E+02$ \\
\hline & $9 \mathrm{E}+01$ & $2.58 \mathrm{E}+01$ & $2.58 \mathrm{E}+01$ & $2.58 \mathrm{E}+01$ & $2.59 \mathrm{E}+01$ & $2.58 \mathrm{E}+01$ & $2.58 \mathrm{E}+01$ & $2.58 \mathrm{E}+01$ & $E+01$ & $E+01$ & $E+01$ & $1.79 \mathrm{E}+01$ & +01 & $E+01$ & $1.79 \mathrm{E}+01$ & $\mathrm{E}+01$ \\
\hline & J5E-05 & 2.05E-05 & $3.46 \mathrm{E}-03$ & 5.56E-03 & 5.84E-01 & 6.86E-01 & 6.87E-01 & $1.21 \mathrm{E}+00$ & $1.21 \mathrm{E}+00$ & $1.21 \mathrm{E}+00$ & $1.21 \mathrm{E}+00$ & 9.89E-01 & E-01 & 9.09E-01 & 9.09E-01 & 9.09E-01 \\
\hline$-11 \mathrm{~A} \% \mathrm{E}$ & $1 \mathrm{E}+00$ & $18 \mathrm{E}+00$ & $5.14 \mathrm{E}+00$ & $5.14 \mathrm{E}+00$ & $15 \mathrm{E}+00$ & $14 \mathrm{E}+00$ & $5.14 \mathrm{E}+00$ & $5.14 \mathrm{E}+00$ & $5.15 E+00$ & $5.14 \mathrm{E}+00$ & $5.14 \mathrm{E}+00$ & $5.14 \mathrm{E}+00$ & $E+00$ & $3.74 \mathrm{E}+00$ & $3.74 \mathrm{E}+00$ & $3.74 \mathrm{E}+00$ \\
\hline & $90 \mathrm{E}+02$ & $5.13 \mathrm{E}+02$ & $3.87 \mathrm{E}+02$ & $2.67 \mathrm{E}+02$ & $20 \mathrm{E}+02$ & $2.20 \mathrm{E}+02$ & $1.35 \mathrm{E}+02$ & $1.27 \mathrm{E}+02$ & $1.27 \mathrm{E}+02$ & $1.27 \mathrm{E}+02$ & $8.96 \mathrm{E}+01$ & $7.41 \mathrm{E}+01$ & $7.43 \mathrm{E}+01$ & $7.41 \mathrm{E}+01$ & $7.41 \mathrm{E}+01$ & $7.41 \mathrm{E}+01$ \\
\hline & 6.91E-01 & $6.56 \mathrm{E}-01$ & 5.54E-01 & 4.66E-01 & $3.28 \mathrm{E}-01$ & $3.20 \mathrm{E}-01$ & 2.03E-01 & 2.03E-01 & $2.04 \mathrm{E}-01$ & $1.22 \mathrm{E}-01$ & 1.21E-01 & $1.21 \mathrm{E}-01$ & 1.21E-01 & 1.03E-01 & 7.16E-02 & 7.16E-02 \\
\hline & $39 \mathrm{E}+02$ & $2.38 \mathrm{E}+02$ & $2.38 \mathrm{E}+02$ & $2.40 \mathrm{E}+02$ & $2.56 \mathrm{E}+02$ & $2.63 \mathrm{E}+02$ & $2.70 \mathrm{E}+02$ & $2.70 \mathrm{E}+02$ & $2.69 \mathrm{E}+02$ & $2.66 \mathrm{E}+02$ & $2.62 \mathrm{E}+02$ & $2.61 \mathrm{E}+02$ & $2.61 \mathrm{E}+02$ & $2.49 \mathrm{E}+02$ & $2.49 \mathrm{E}+02$ & $2.49 \mathrm{E}+02$ \\
\hline 216-B-15 & $1.33 \mathrm{E}+01$ & $5.21 \mathrm{E}+01$ & $7.76 \mathrm{E}+01$ & $7.76 \mathrm{E}+01$ & $7.78 \mathrm{E}+01$ & $9.24 \mathrm{E}+01$ & $1.37 \mathrm{E}+02$ & $1.80 \mathrm{E}+02$ & $2.09 \mathrm{E}+02$ & $E+02$ & & $5 \mathrm{E}+02$ & & & $44 \mathrm{E}+02$ & $2.44 \mathrm{C}+02$ \\
\hline
\end{tabular}




\begin{tabular}{|c|c|c|c|c|c|c|c|c|c|c|c|c|c|c|c|c|}
\hline Site & 1976 & 1977 & 1978 & 1979 & 1980 & 1981 & 1982 & 1983 & 1984 & 1985 & 1986 & 1987 & 1988 & 1989 & 1990 & 1991 \\
\hline & $46 \mathrm{E}+00$ & $44 \mathrm{E}+00$ & $8.44 \mathrm{E}+00$ & $04 \mathrm{E}+01$ & $2.23 \mathrm{E}+01$ & $83 \mathrm{E}+01$ & $5.29 \mathrm{E}+01$ & $9.54 \mathrm{E}+01$ & $1.40 \mathrm{E}+02$ & $1.73 E+02$ & $2.07 \mathrm{E}+02$ & $2.22 \mathrm{E}+02$ & $2.23 E+02$ & $2.38 \mathrm{E}+02$ & $2.38 \mathrm{E}+02$ & $2.38 \mathrm{E}+02$ \\
\hline & 93E-03 & 1.92E-03 & $1.92 \mathrm{E}-03$ & $1.92 \mathrm{E}-03$ & L.93E-03 & $.92 \mathrm{E}-03$ & 1.92E-03 & 1.92E-03 & 8.30E-02 & $3.53 \mathrm{E}-01$ & $8.12 \mathrm{E}+00$ & $1.18 \mathrm{E}+01$ & $1.31 \mathrm{E}+01$ & $8.13 E+01$ & $8.13 \mathrm{E}+01$ & $8.13 \mathrm{E}+01$ \\
\hline & $15 E+02$ & $2.14 \mathrm{E}+02$ & $2.14 \mathrm{E}+02$ & $44 \mathrm{E}+02$ & $48 E+02$ & $57 \mathrm{E}+02$ & $2.66 \mathrm{E}+02$ & $2.68 \mathrm{E}+02$ & $2.67 \mathrm{E}+02$ & $65 \mathrm{E}+02$ & $62 \mathrm{E}+02$ & $60 \mathrm{E}+02$ & $2.61 \mathrm{E}+02$ & $2.49 E+02$ & $.49 \mathrm{E}+02$ & $49 \mathrm{E}+02$ \\
\hline 216-B-19 & $68 \mathrm{E}+00$ & $4.28 \mathrm{E}+01$ & $5.31 E+01$ & $5.31 \mathrm{E}+01$ & $5.32 E+01$ & $6.35 E+01$ & $1.00 \mathrm{E}+02$ & $1.45 E+02$ & $1.83 E+02$ & $2.08 E+02$ & $2.28 E+02$ & $2.38 \mathrm{E}+02$ & $2.38 \mathrm{E}+02$ & $2.42 E+02$ & $.42 \mathrm{E}+02$ & $.42 \mathrm{E}+02$ \\
\hline & $E+00$ & $17 \mathrm{E}+01$ & $5.17 \mathrm{E}+01$ & $5.17 \mathrm{E}+01$ & $25 E+01$ & $68 \mathrm{E}+01$ & $76 \mathrm{E}+01$ & $1.60 \mathrm{E}+02$ & $2.22 \mathrm{E}+02$ & $2.66 \mathrm{E}+02$ & $2.96 \mathrm{E}+02$ & $3.16 \mathrm{E}+02$ & $3.27 \mathrm{E}+02$ & $3.26 \mathrm{E}+02$ & $.03 \mathrm{E}+02$ & $3.03 E+02$ \\
\hline & & $9 \mathrm{E}+01$ & 5.19 & 5.19 & $28 \mathrm{E}+01$ & $71 \mathrm{E}+01$ & $79 \mathrm{E}+01$ & $1.60 \mathrm{E}$ & $2.22 \mathrm{E}+02$ & $2.66 \mathrm{E}+02$ & $2.96 \mathrm{E}+02$ & $3.16 \mathrm{E}+02$ & $3.26 \mathrm{E}+02$ & $3.25 E+02$ & $.02 \mathrm{E}+02$ & $3.02 \mathrm{E}+02$ \\
\hline 216 & +00 & $\mathrm{E}+01$ & $5.70 \mathrm{E}+01$ & $.70 \mathrm{E}+01$ & $78 \mathrm{E}+01$ & $8.39 \mathrm{E}+01$ & $1.06 \mathrm{E}+02$ & $1.69 \mathrm{E}+02$ & $2.28 \mathrm{E}+02$ & $2.70 \mathrm{E}+02$ & $2.98 \mathrm{E}+02$ & $3.17 E+02$ & $3.27 E+02$ & $3.26 E+02$ & $3.03 E+02$ & $3.03 E+02$ \\
\hline-23 & E-04 & $E+00$ & $1.63 \mathrm{E}+01$ & $4.73 \mathrm{E}+01$ & $14 \mathrm{E}+02$ & $18 \mathrm{E}+02$ & $1.67 \mathrm{E}+02$ & $2.39 E+02$ & $2.92 \mathrm{E}+02$ & $3.24 \mathrm{E}+02$ & $3.45 E+02$ & $3.49 \mathrm{E}+02$ & $3.51 \mathrm{E}+02$ & $3.50 \mathrm{E}+02$ & $8 \mathrm{E}+02$ & $.08 \mathrm{E}+02$ \\
\hline-24 & $=01$ & $E+01$ & $E+01$ & $1.17 \mathrm{E}+02$ & $84 \mathrm{E}+02$ & $84 \mathrm{E}+02$ & $2.09 E+02$ & $2.55 E+02$ & $2.93 \mathrm{E}+02$ & $3.20 \mathrm{E}+02$ & $3.38 \mathrm{E}+02$ & $3.44 \mathrm{E}+02$ & $3.47 \mathrm{E}+02$ & $3.46 \mathrm{E}+02$ & $6 \mathrm{E}+02$ & $6 \mathrm{E}+02$ \\
\hline & +01 & $E+01$ & $E+01$ & $72 \mathrm{E}+02$ & $72 \mathrm{E}+02$ & $76 \mathrm{E}+02$ & $11 \mathrm{E}+02$ & $2.55 E+02$ & $2.91 \mathrm{E}+02$ & $17 \mathrm{E}+02$ & $35 \mathrm{E}+02$ & $3.42 \mathrm{E}+02$ & $3.46 \mathrm{E}+02$ & $44 \mathrm{E}+02$ & & \\
\hline $216-B-26$ & $85 \mathrm{E}+02$ & $3.10 \mathrm{E}+02$ & $3.62 \mathrm{E}+02$ & $3.68 \mathrm{E}+02$ & $69 \mathrm{E}+02$ & $76 \mathrm{E}+02$ & $3.79 \mathrm{E}+02$ & $3.81 \mathrm{E}+02$ & $3.82 \mathrm{E}+02$ & $3.80 \mathrm{E}+02$ & $3.79 E+02$ & $3.67 \mathrm{E}+02$ & $3.62 \mathrm{E}+02$ & $3.60 \mathrm{E}+02$ & $3.10 \mathrm{E}+02$ & \\
\hline 216-B-27 & $8.58 \mathrm{E}-05$ & 8.56E-05 & 7.47E-02 & $4.22 \mathrm{E}+00$ & $45 E+01$ & $5.42 \mathrm{E}+01$ & $1.05 E+02$ & $2.06 \mathrm{E}+02$ & $2.82 \mathrm{E}+02$ & $3.24 \mathrm{E}+02$ & $3.47 \mathrm{E}+02$ & $3.51 E+02$ & $3.53 E+02$ & $3.51 E+02$ & $3.08 \mathrm{E}+02$ & $.08 \mathrm{E}+02$ \\
\hline & $53 \mathrm{E}+00$ & $2.86 \mathrm{E}+01$ & $8.78 \mathrm{E}+01$ & $1.12 \mathrm{E}+02$ & $82 \mathrm{E}+02$ & $81 \mathrm{E}+02$ & $2.08 \mathrm{E}+02$ & $2.55 \mathrm{E}+02$ & $2.93 \mathrm{E}+02$ & $3.20 \mathrm{E}+02$ & $.39 \mathrm{E}+02$ & $3.44 \mathrm{E}+02$ & $3.47 \mathrm{E}+02$ & $3.46 \mathrm{E}+02$ & $.06 \mathrm{E}+02$ & $.06 \mathrm{E}+02$ \\
\hline $216-B-29$ & 17E-03 & 8.71E-02 & $3.93 E+00$ & $1.85 \mathrm{E}+01$ & $89 \mathrm{E}+01$ & $6.19 \mathrm{E}+01$ & $1.01 \mathrm{E}+02$ & $1.83 \mathrm{E}+02$ & $2.53 \mathrm{E}+02$ & $2.99 \mathrm{E}+02$ & $3.28 \mathrm{E}+02$ & $3.41 \mathrm{E}+02$ & $3.48 \mathrm{E}+02$ & $.46 \mathrm{E}+02$ & $2 E+02$ & $12 \mathrm{E}+02$ \\
\hline & $3.29 E+06$ & $3.10 \mathrm{E}+06$ & $3.60 \mathrm{E}+06$ & $3.48 \mathrm{E}+06$ & $3.46 \mathrm{E}+06$ & $99 \mathrm{E}+06$ & $5.05 \mathrm{E}+06$ & $5.95 \mathrm{E}+06$ & $5.44 \mathrm{E}+06$ & $4.87 \mathrm{E}+06$ & $1.96 \mathrm{E}+07$ & $2.16 \mathrm{E}+07$ & $2.60 \mathrm{E}+07$ & $.53 \mathrm{E}+07$ & $3 \mathrm{E}+06$ & $.71 E+06$ \\
\hline & $27 \mathrm{E}-03$ & $2.26 \mathrm{E}-03$ & $E-01$ & $1.06 \mathrm{E}+01$ & $4.51 \mathrm{E}+01$ & $10 \mathrm{E}+01$ & $8.91 \mathrm{E}+01$ & $1.73 \mathrm{E}+02$ & $2.48 \mathrm{E}+02$ & $97 \mathrm{E}+02$ & $28 \mathrm{E}+02$ & $3.41 \mathrm{E}+02$ & $3.48 \mathrm{E}+02$ & $.47 \mathrm{E}+02$ & $3 \mathrm{E}+02$ & $3 \mathrm{E}+02$ \\
\hline & E-03 & 13E-01 & +00 & $2.05 E+01$ & $6.13 E+01$ & $49 \mathrm{E}+01$ & $1.05 E+02$ & $1.87 \mathrm{E}+02$ & $2.55 \mathrm{E}+02$ & $3.00 \mathrm{E}+02$ & $3.29 \mathrm{E}+02$ & $3.41 \mathrm{E}+02$ & $3.48 \mathrm{E}+02$ & $3.46 \mathrm{E}+02$ & $E+02$ & $3.12 \mathrm{E}+02$ \\
\hline $216-$ & E-05 & $5.48 \mathrm{E}-03$ & $E+00$ & $2.08 \mathrm{E}+01$ & $3.75 E+01$ & $98 \mathrm{E}+01$ & $8.60 \mathrm{E}+01$ & $1.71 \mathrm{E}+02$ & $2.46 \mathrm{E}+02$ & $2.95 E+02$ & $3.26 \mathrm{E}+02$ & $3.40 \mathrm{E}+02$ & $3.47 \mathrm{E}+02$ & $3.46 E+02$ & $2 \mathrm{E}+02$ & $3.12 \mathrm{E}+02$ \\
\hline-33 & $55 E-04$ & 1.79E-02 & $\mathrm{E}+00$ & $1.07 \mathrm{E}+01$ & $.92 \mathrm{E}+01$ & $5.07 \mathrm{E}+01$ & $8.39 E+01$ & $1.68 \mathrm{E}+02$ & $2.45 E+02$ & $2.95 E+02$ & $3.26 \mathrm{E}+02$ & $3.40 \mathrm{E}+02$ & $3.47 E+02$ & $3.46 \mathrm{E}+02$ & $3.12 E+02$ & $3.12 E+02$ \\
\hline-34 & $5 \mathrm{E}-01$ & $4.86 \mathrm{E}+00$ & $3.66 \mathrm{E}+01$ & $9.48 \mathrm{E}+01$ & $.24 \mathrm{E}+02$ & $1.53 \mathrm{E}+02$ & $1.94 \mathrm{E}+02$ & $2.51 E+02$ & $2.97 \mathrm{E}+02$ & $3.26 \mathrm{E}+02$ & $3.45 E+02$ & $3.48 \mathrm{E}+02$ & $3.51 \mathrm{E}+02$ & $3.49 \mathrm{E}+02$ & $7 \mathrm{E}+02$ & $3.07 \mathrm{E}+02$ \\
\hline 216-E & $70 \mathrm{E}+00$ & $7.68 \mathrm{E}+00$ & $7.68 \mathrm{E}+00$ & $7.68 \mathrm{E}+00$ & $7.70 \mathrm{E}+00$ & $7.68 \mathrm{E}+00$ & $7.68 \mathrm{E}+00$ & $7.68 \mathrm{E}+00$ & $5.76 \mathrm{E}+00$ & $5.26 \mathrm{E}+00$ & $5.26 \mathrm{E}+00$ & $5.26 \mathrm{E}+00$ & $5.28 E+00$ & $5.26 \mathrm{E}+00$ & $5.26 E+00$ & $5.26 E+00$ \\
\hline $216-\mathrm{E}$ & $17 \mathrm{E}+00$ & $8.14 \mathrm{E}+00$ & $8.14 E+00$ & $8.14 \mathrm{E}+00$ & $8.17 E+00$ & $8.14 \mathrm{E}+00$ & $8.14 \mathrm{E}+00$ & $7.42 \mathrm{E}+00$ & $5.46 \mathrm{E}+00$ & $5.45 E+00$ & $5.45 E+00$ & $5.45 \mathrm{E}+00$ & $5.46 \mathrm{E}+00$ & $5.45 \mathrm{E}+00$ & $5.45 \mathrm{E}+00$ & $5.45 \mathrm{E}+00$ \\
\hline $216-B-37$ & $12 \mathrm{E}+01$ & $1.12 \mathrm{E}+01$ & $7.46 \mathrm{E}+00$ & $6.95 \mathrm{E}+00$ & $6.97 \mathrm{E}+00$ & $6.95 \mathrm{E}+00$ & $6.95 \mathrm{E}+00$ & $6.95 \mathrm{E}+00$ & $6.97 \mathrm{E}+00$ & $6.95 \mathrm{E}+00$ & $6.95 \mathrm{E}+00$ & $6.95 \mathrm{E}+00$ & $6.97 \mathrm{E}+00$ & $6.76 \mathrm{E}+00$ & $5.29 \mathrm{E}+00$ & $5.29 \mathrm{E}+00$ \\
\hline $216-E$ & $02 E+01$ & $7.00 \mathrm{E}+00$ & $7.00 \mathrm{E}+00$ & $7.00 \mathrm{E}+00$ & $7.02 \mathrm{E}+00$ & $7.00 \mathrm{E}+00$ & $7.00 \mathrm{E}+00$ & $7.00 \mathrm{E}+00$ & $7.02 \mathrm{E}+00$ & $7.00 \mathrm{E}+00$ & $7.00 \mathrm{E}+00$ & $6.13 E+00$ & $5.12 \mathrm{E}+00$ & $5.11 \mathrm{E}+00$ & $1 \mathrm{E}+00$ & $.11 \mathrm{E}+00$ \\
\hline-39 & $8.92 \mathrm{E}+00$ & $8.90 \mathrm{E}+00$ & $8.90 \mathrm{E}+00$ & $8.90 \mathrm{E}+00$ & $8.92 \mathrm{E}+00$ & $6.80 \mathrm{E}+00$ & $5.86 \mathrm{E}+00$ & $5.86 \mathrm{E}+00$ & $5.87 \mathrm{E}+00$ & $5.86 \mathrm{E}+00$ & $5.86 \mathrm{E}+00$ & $5.86 \mathrm{E}+00$ & $5.87 \mathrm{E}+00$ & $5.86 \mathrm{E}+00$ & $.86 \mathrm{E}+00$ & $.86 \mathrm{E}+00$ \\
\hline 216-B-4 & 4E-02 & 4.37E-02 & 4.37E-02 & 4.37E-02 & $4.38 \mathrm{E}-02$ & 4.37E-02 & $4.37 \mathrm{E}-02$ & 4.37E-02 & $4.38 \mathrm{E}-02$ & 4.37E-02 & 4.37E-02 & 4.37E-02 & $8 \mathrm{E}-02$ & $37 \mathrm{E}-02$ & 78E-02 & $1.10 \mathrm{E}-01$ \\
\hline & $=00$ & $7.40 \mathrm{E}+00$ & $E+00$ & $7.40 \mathrm{E}+00$ & $7.42 \mathrm{E}+00$ & $40 \mathrm{E}+00$ & $7.40 \mathrm{E}+00$ & $7.40 \mathrm{E}+00$ & $7.42 \mathrm{E}+00$ & $39 \mathrm{E}+00$ & $5.17 \mathrm{E}+00$ & $5.17 \mathrm{E}+00$ & $5.19 \mathrm{E}+00$ & $5.17 \mathrm{E}+00$ & $5.17 \mathrm{E}+00$ & $5.17 \mathrm{E}+00$ \\
\hline-41 & $6 \mathrm{E}+00$ & $E+00$ & $E+00$ & $E+00$ & $30 \mathrm{E}+00$ & $28 \mathrm{E}+00$ & $6.28 \mathrm{E}+00$ & $6.28 \mathrm{E}+00$ & $6.30 \mathrm{E}+00$ & $28 \mathrm{E}+00$ & $6.28 \mathrm{E}+00$ & $6.28 \mathrm{E}+00$ & $E+00$ & $3 E+00$ & $E+00$ & +00 \\
\hline & $39 \mathrm{E}+00$ & $E+00$ & +00 & 7.10 & $7.12 \mathrm{E}+00$ & $E+00$ & $\mathrm{DE}+00$ & $7.10 \mathrm{E}+00$ & $E+00$ & $E+00$ & $7.08 \mathrm{E}+00$ & $5.11 \mathrm{E}+00$ & $E+00$ & $\mathrm{E}+00$ & $E+00$ & +00 \\
\hline & $=01$ & +01 & +01 & $E+01$ & $77 \mathrm{E}+01$ & $E+01$ & +01 & $1.30 \mathrm{E}+01$ & $E+01$ & $E+01$ & $E+01$ & $1.30 \mathrm{E}$ & $E+01$ & $E+01$ & $E+01$ & +01 \\
\hline & +01 & $=01$ & +01 & $E+01$ & $23 E+01$ & $43 \mathrm{E}+01$ & $43 E+01$ & $1.43 \mathrm{E}+01$ & $1.43 \mathrm{E}+01$ & $E+01$ & $1.43 E+01$ & $1.43 \mathrm{E}$ & $3 \mathrm{E}+01$ & $3 E+01$ & $E+01$ & $1.43 \mathrm{E}+01$ \\
\hline $216-E$ & $40 \mathrm{E}+01$ & $2.39 \mathrm{E}+01$ & $2.25 E+01$ & $1.52 \mathrm{E}+01$ & $1.52 \mathrm{E}+01$ & $1.52 \mathrm{E}+01$ & $1.52 \mathrm{E}+01$ & $1.52 \mathrm{E}+01$ & $1.52 \mathrm{E}+01$ & $1.52 \mathrm{E}+01$ & $1.52 \mathrm{E}+01$ & $1.52 \mathrm{E}+01$ & $1.52 \mathrm{E}+01$ & $1.52 \mathrm{E}+01$ & $1.26 \mathrm{E}+01$ & $1.17 \mathrm{E}+01$ \\
\hline $216-\mathrm{E}$ & $39 \mathrm{E}+01$ & $72 \mathrm{E}+01$ & $1.72 \mathrm{E}+01$ & $1.72 \mathrm{E}+01$ & $72 \mathrm{E}+01$ & $1.72 \mathrm{E}+01$ & $1.72 \mathrm{E}+01$ & $1.72 \mathrm{E}+01$ & $1.72 \mathrm{E}+01$ & $1.72 \mathrm{E}+01$ & $1.72 \mathrm{E}+01$ & $1.22 \mathrm{E}+01$ & $1.20 \mathrm{E}+01$ & $1.20 \mathrm{E}+01$ & $1.20 \mathrm{E}+01$ & $1.20 \mathrm{E}+01$ \\
\hline $216-B-47$ & $89 \mathrm{E}+01$ & $1.88 \mathrm{E}+01$ & $1.88 \mathrm{E}+01$ & $1.88 \mathrm{E}+01$ & $1.89 \mathrm{E}+01$ & $1.88 \mathrm{E}+01$ & $1.88 \mathrm{E}+01$ & $1.58 \mathrm{E}+01$ & $1.26 \mathrm{E}+01$ & $1.25 \mathrm{E}+01$ & $1.25 E+01$ & $1.25 \mathrm{E}+01$ & $1.26 \mathrm{E}+01$ & $1.25 E+01$ & $1.25 \mathrm{E}+01$ & $1.25 \mathrm{E}+01$ \\
\hline $216-B-48$ & $2.31 E+01$ & $2.30 \mathrm{E}+01$ & $2.30 \mathrm{E}+01$ & $1.70 \mathrm{E}+01$ & $1.48 \mathrm{E}+01$ & $1.48 \mathrm{E}+01$ & $1.48 \mathrm{E}+01$ & $1.48 \mathrm{E}+01$ & $1.48 \mathrm{E}+01$ & $1.48 \mathrm{E}+01$ & $1.48 \mathrm{E}+01$ & $1.48 \mathrm{E}+01$ & $1.48 \mathrm{E}+01$ & $1.48 \mathrm{E}+01$ & $1.42 \mathrm{E}+01$ & $1.16 \mathrm{E}+01$ \\
\hline $216-B-49$ & $2.39 \mathrm{E}+01$ & $2.38 \mathrm{E}+01$ & $2.38 \mathrm{E}+01$ & $1.76 \mathrm{E}+01$ & $1.51 \mathrm{E}+01$ & $1.51 \mathrm{E}+01$ & $1.51 \mathrm{E}+01$ & $1.51 \mathrm{E}+01$ & $1.51 \mathrm{E}+01$ & $1.51 \mathrm{E}+01$ & $1.51 \mathrm{E}+01$ & $1.51 \mathrm{E}+01$ & $1.51 \mathrm{E}+01$ & $1.51 \mathrm{E}+01$ & $1.51 \mathrm{E}+01$ & $1.18 \mathrm{E}+01$ \\
\hline 216-B-5 & 1.35E-02 & 1.08E-02 & 1.07E-02 & 1.07E-02 & 1.07E-02 & 1.07E-02 & 1.07E-02 & 1.07E-02 & 1.07E-02 & 1.07E-02 & 1.07E-02 & 1.07E-02 & 1.07E-02 & 1.07E-02 & 1.07E-02 & $1.55 \mathrm{E}-02$ \\
\hline $216-B-50$ & $3.30 \mathrm{E}+02$ & $1.96 \mathrm{E}+02$ & $1.81 \mathrm{E}+02$ & $1.06 \mathrm{E}+02$ & $1.06 \mathrm{E}+02$ & $9.30 \mathrm{E}+01$ & $6.02 \mathrm{E}+01$ & $6.02 \mathrm{E}+01$ & $6.04 \mathrm{E}+01$ & $5.78 \mathrm{E}+01$ & $3.48 \mathrm{E}+01$ & $3.48 \mathrm{E}+01$ & $3.49 \mathrm{E}+01$ & $3.48 \mathrm{E}+01$ & $3.48 \mathrm{E}+01$ & $3.48 \mathrm{E}+01$ \\
\hline 216-B-51 & 9.87E-07 & 9.84E-07 & $3.61 \mathrm{E}-04$ & $6.10 \mathrm{E}-04$ & $6.11 \mathrm{E}-04$ & $6.10 \mathrm{E}-04$ & $6.10 \mathrm{E}-04$ & $6.10 \mathrm{E}-04$ & $6.11 \mathrm{E}-04$ & $6.10 \mathrm{E}-04$ & $6.10 \mathrm{E}-04$ & 1.07E-03 & 1.01E-02 & 1.01E-02 & 1.01E-02 & 1.01E-02 \\
\hline $216-B-52$ & $3.03 E+02$ & $3.02 \mathrm{E}+02$ & $3.02 \mathrm{E}+02$ & $3.02 \mathrm{E}+02$ & $3.03 E+02$ & $3.05 E+02$ & $3.08 \mathrm{E}+02$ & $3.21 E+02$ & $3.41 \mathrm{E}+02$ & $3.61 \mathrm{E}+02$ & $3.77 \mathrm{E}+02$ & $3.85 \mathrm{E}+02$ & $3.90 \mathrm{E}+02$ & $3.89 \mathrm{E}+02$ & $3.50 \mathrm{E}+02$ & $3.50 \mathrm{E}+02$ \\
\hline 216-B-53A & 3.75E-05 & $3.74 \mathrm{E}-05$ & 3.74E-05 & 3.74E-05 & $3.75 \mathrm{E}-05$ & 3.74E-05 & 3.74E-05 & 3.74E-05 & $3.75 \mathrm{E}-05$ & $2.73 \mathrm{E}-01$ & $4.56 E+00$ & $1.36 \mathrm{E}+01$ & $2.57 \mathrm{E}+01$ & $3.10 \mathrm{E}+01$ & $3.66 \mathrm{E}+01$ & $3.66 \mathrm{E}+01$ \\
\hline
\end{tabular}




\begin{tabular}{|c|c|c|c|c|c|c|c|c|c|c|c|c|c|c|c|c|}
\hline Site & 1976 & 1977 & 1978 & 1979 & 1980 & 1981 & 1982 & 1983 & 1984 & 1985 & 1986 & 1987 & 1988 & 1989 & 1990 & 19 \\
\hline 216-B-53B & 3.31E-04 & $3.30 \mathrm{E}-04$ & 3.30E-04 & 3.30E-04 & 3.31E-04 & 3.30E-04 & 3.30E-04 & 3.30E-04 & $3.31 \mathrm{E}-04$ & 3.30E-04 & 3.30E-04 & 3.30E-04 & 3.31E-04 & 3.30E-04 & $3.30 \mathrm{E}-04$ & $3.30 \mathrm{E}-($ \\
\hline-54 & $62 \mathrm{E}-04$ & $4.61 \mathrm{E}-04$ & 4.61E-04 & $4.61 \mathrm{E}-04$ & 4.62E-04 & 61E-04 & 4.61E-04 & $4.61 \mathrm{E}-04$ & $4.62 \mathrm{E}-04$ & $4.61 \mathrm{E}-04$ & 4.61E-04 & $4.61 \mathrm{E}-04$ & $4.62 \mathrm{E}-04$ & 3.97E-02 & $3.35 \mathrm{E}+00$ & $3.01 \mathrm{E}+01$ \\
\hline B-55 & $76 \mathrm{E}+04$ & $6.25 E+04$ & $6.65 E+04$ & $6.93 E+04$ & $31 \mathrm{E}+04$ & $4.09 \mathrm{E}+04$ & $2.35 \mathrm{E}+04$ & $3.58 \mathrm{E}+04$ & $3.47 \mathrm{E}+04$ & $1.40 \mathrm{E}+04$ & $6.76 \mathrm{E}+03$ & $3.48 \mathrm{E}+03$ & $2.19 \mathrm{E}+03$ & $1.62 \mathrm{E}+03$ & $1.41 \mathrm{E}+03$ & $.01 \mathrm{E}+03$ \\
\hline & $2.87 \mathrm{E}+03$ & $2.64 \mathrm{E}+03$ & $1.53 E+03$ & $1.53 \mathrm{E}+03$ & $34 \mathrm{E}+03$ & $8.54 \mathrm{E}+02$ & $8.54 \mathrm{E}+02$ & $8.54 \mathrm{E}+02$ & $8.21 \mathrm{E}+02$ & $4.83 \mathrm{E}+02$ & $4.83 E+02$ & $4.83 E+02$ & $4.84 \mathrm{E}+02$ & $4.83 E+02$ & $4.83 \mathrm{E}+02$ & $4.04 \mathrm{E}+02$ \\
\hline & $1.89 \mathrm{E}-04$ & $1.89 \mathrm{E}-04$ & 1.89E-04 & 1.89E-04 & $1.89 \mathrm{E}-04$ & $1.89 \mathrm{E}-04$ & $1.89 \mathrm{E}-04$ & $1.89 \mathrm{E}-04$ & 1.89E-04 & $1.89 \mathrm{E}-04$ & $1.89 \mathrm{E}-04$ & $1.89 \mathrm{E}-04$ & 1.89E-04 & 1.89E-04 & 1.89E-04 & 39E-04 \\
\hline 216-B-59 & $9.48 \mathrm{E}-07$ & 9.45E-07 & $9.45 \mathrm{E}-07$ & 9.45E-07 & 9.48E-07 & 2.82E-05 & 7.39E-05 & 7.39E-05 & 7.41E-05 & 7.39E-05 & 8.53E-02 & 1.52E-01 & 1.53E-01 & $1.52 \mathrm{E}-01$ & $.52 \mathrm{E}-01$ & $1.52 \mathrm{E}-01$ \\
\hline & $.33 \mathrm{E}+00$ & $1.45 \mathrm{E}+00$ & 1.45E+00 & $1.45 \mathrm{E}+00$ & $1.45 \mathrm{E}+00$ & $1.45 \mathrm{E}+00$ & $1.45 \mathrm{E}+00$ & $1.45 \mathrm{E}+00$ & 1.45E+00 & 1.45E+00 & $1.45 \mathrm{E}+00$ & $1.45 \mathrm{E}+00$ & 1.45E+00 & 1.45E+00 & $1.43 \mathrm{E}+00$ & 1.15E+00 \\
\hline & 6.07E-01 & 5.74E-01 & 3.89E-01 & 3.89E-01 & 3.90E-01 & 3.58E-01 & $2.47 \mathrm{E}-01$ & $2.47 \mathrm{E}-01$ & $2.48 \mathrm{E}-01$ & 2.47E-01 & $2.47 \mathrm{E}-01$ & 2.19E-01 & 1.59E-01 & 1.59E-01 & 1.59E-01 & 1.59E-01 \\
\hline-62 & $2.57 E+04$ & $3.07 E+04$ & $2.90 E+04$ & $2.66 \mathrm{E}+04$ & $66 \mathrm{E}+04$ & $1.78 \mathrm{E}+04$ & $1.27 \mathrm{E}+04$ & $2.29 E+04$ & $8.49 \mathrm{E}+03$ & $4.54 \mathrm{E}+03$ & $3.93 E+03$ & $1.51 \mathrm{E}+03$ & $6.79 E+02$ & $3.12 E+02$ & $2.78 \mathrm{E}+02$ & $.39 \mathrm{E}+02$ \\
\hline & $65 E+05$ & $3.58 E+05$ & $3.16 E+05$ & $3.80 E+05$ & $E+05$ & $E+05$ & $3.41 E+05$ & $3.20 E+05$ & $E+05$ & $3.08 E+05$ & $3.90 E+05$ & $4.32 E+05$ & $3.42 E+05$ & $3.34 E+05$ & $3.23 E+05$ & $2.68 \mathrm{E}+05$ \\
\hline $7 A \%$ & $16 \mathrm{E}+01$ & $1.13 \mathrm{E}+01$ & $1.13 E+01$ & $1.13 E+01$ & $68 \mathrm{E}+00$ & $E+00$ & $6.53 E+00$ & $6.53 E+00$ & $\mathrm{E}+00$ & $6.53 E+00$ & $6.53 E+00$ & $4.08 \mathrm{E}+00$ & $3.93 E+00$ & $3.92 E+00$ & $3.92 \mathrm{E}+00$ & $3.92 \mathrm{E}+00$ \\
\hline & $78 \mathrm{E}+00$ & $3.77 \mathrm{E}+00$ & $3.77 E+00$ & $3.77 \mathrm{E}+00$ & $78 E+00$ & $77 \mathrm{E}+00$ & $3.02 E+00$ & $2.46 \mathrm{E}+00$ & $2.47 \mathrm{E}+00$ & $2.46 \mathrm{E}+00$ & $2.46 \mathrm{E}+00$ & $2.46 \mathrm{E}+00$ & $2.47 E+00$ & $2.46 \mathrm{E}+00$ & $2.46 \mathrm{E}+00$ & $2.46 \mathrm{E}+00$ \\
\hline & $E+01$ & $4.82 \mathrm{E}+01$ & $4.82 \mathrm{E}+01$ & $82 \mathrm{E}+01$ & $E+01$ & $E+01$ & $4.82 \mathrm{E}+01$ & $4.82 \mathrm{E}+01$ & $4.83 \mathrm{E}+01$ & $4.82 \mathrm{E}+01$ & $4.82 E+01$ & $4.82 \mathrm{E}+01$ & $4.70 \mathrm{E}+01$ & $3.62 E+01$ & $3.62 E+01$ & $62 \mathrm{E}+01$ \\
\hline 216-BY-201 & 5.57E-02 & $4.28 \mathrm{E}-02$ & $3.38 \mathrm{E}-02$ & 3.38E-02 & $3.38 \mathrm{E}-02$ & $3.38 \mathrm{E}-02$ & $3.38 \mathrm{E}-02$ & $3.38 \mathrm{E}-02$ & $3.38 \mathrm{E}-02$ & $3.38 \mathrm{E}-02$ & $3.38 \mathrm{E}-02$ & $3.38 \mathrm{E}-02$ & $2.82 \mathrm{E}-02$ & $2.42 \mathrm{E}-02$ & $2.42 \mathrm{E}-02$ & $2.42 \mathrm{E}-02$ \\
\hline 216-C-1 & $98 \mathrm{E}+00$ & $8.97 \mathrm{E}+00$ & $8.97 \mathrm{E}+00$ & $8.97 \mathrm{E}+00$ & $9.00 \mathrm{E}+00$ & $8.97 \mathrm{E}+00$ & $8.97 \mathrm{E}+00$ & $8.97 \mathrm{E}+00$ & $9.00 \mathrm{E}+00$ & $8.12 \mathrm{E}+00$ & $6.41 \mathrm{E}+00$ & $6.41 \mathrm{E}+00$ & $6.42 \mathrm{E}+00$ & $6.41 \mathrm{E}+00$ & $6.41 \mathrm{E}+00$ & $.41 \mathrm{E}+00$ \\
\hline & $29 \mathrm{E}+00$ & $4.28 \mathrm{E}+00$ & $4.20 \mathrm{E}+00$ & $2.36 \mathrm{E}+00$ & $36 \mathrm{E}+00$ & $2.36 \mathrm{E}+00$ & $2.36 \mathrm{E}+00$ & $2.36 \mathrm{E}+00$ & $2.36 \mathrm{E}+00$ & $1.65 \mathrm{E}+00$ & $.39 \mathrm{E}+00$ & $1.39 \mathrm{E}+00$ & $1.39 \mathrm{E}+00$ & $1.39 \mathrm{E}+00$ & $1.39 \mathrm{E}+00$ & \\
\hline & 49E-05 & $8.46 \mathrm{E}-05$ & 8.46E-05 & 8.46E-05 & 8.49E-05 & 7.90E-02 & $1.58 \mathrm{E}+01$ & $9.28 \mathrm{E}+01$ & $E+02$ & $\mathrm{E}+02$ & $4 \mathrm{E}+02$ & $4 \mathrm{E}+02$ & $1.25 \mathrm{E}+02$ & $24 \mathrm{E}+02$ & $24 \mathrm{E}+02$ & $2 \mathrm{E}+02$ \\
\hline & $72 \mathrm{E}+00$ & $3.70 \mathrm{E}+00$ & $3.70 \mathrm{E}+00$ & $.70 \mathrm{E}+00$ & $71 \mathrm{E}+00$ & $3.70 \mathrm{E}+00$ & $3.70 \mathrm{E}+00$ & $3.70 \mathrm{E}+00$ & & 70E+00 & $.70 \mathrm{E}+00$ & 00 & $E+00$ & $4 \mathrm{E}+00$ & $4 \mathrm{E}+00$ & $4 \mathrm{E}+00$ \\
\hline & $59 \mathrm{E}+00$ & $2.43 \mathrm{E}+00$ & $2.43 \mathrm{E}+00$ & $.43 E+00$ & $44 \mathrm{E}+00$ & $E+00$ & $1.58 \mathrm{E}+00$ & & 0 & +00 & $\mathrm{E}+00$ & $E+00$ & & +00 & $2 \mathrm{E}+00$ & $E+00$ \\
\hline & $77 \mathrm{E}+00$ & 2.76 & $2.76 \mathrm{E}+00$ & $2.76 \mathrm{E}+00$ & $2.77 \mathrm{E}+00$ & 2.39 & $E+00$ & +00 & $E+00$ & $E+00$ & $1.69 \mathrm{E}+00$ & $9 \mathrm{E}+00$ & $E+00$ & $1.69 \mathrm{E}+00$ & $5 \mathrm{E}+00$ & $1.20 \mathrm{E}+00$ \\
\hline & E-04 & 1.87E-04 & 1.87E-04 & E-04 & E-04 & $E-04$ & E-04 & $E-04$ & E-02 & $\mathrm{E}-02$ & $3.23 \mathrm{E}-02$ & $3.23 \mathrm{E}-02$ & 4E-02 & $3.23 \mathrm{E}-02$ & 3.23E-02 & 3.23E-02 \\
\hline & $85 E+03$ & $E+03$ & $2.07 \mathrm{E}+03$ & $1.82 E+03$ & $1.62 E+03$ & $E+03$ & $E+03$ & +03 & $E+03$ & $E+03$ & $1.04 \mathrm{E}+03$ & $1.00 \mathrm{E}+03$ & $3 E+02$ & $9.65 E+02$ & $9.23 E+02$ & $9.23 E+02$ \\
\hline & $7.19 E+00$ & $6.61 \mathrm{E}+00$ & $6.61 E+00$ & $6.61 E+00$ & $6.63 E+00$ & $6.61 E+00$ & $6.61 E+00$ & $6.61 E+00$ & $6.63 \mathrm{E}+00$ & $6.61 E+00$ & $6.61 E+00$ & $6.61 E+00$ & $6.63 E+00$ & $6.61 E+00$ & $6.46 \mathrm{E}+00$ & $6.12 E+00$ \\
\hline & $24 \mathrm{E}+00$ & $8.22 \mathrm{E}+00$ & $8.22 \mathrm{E}+00$ & $7.74 \mathrm{E}+00$ & $6.40 \mathrm{E}+00$ & $6.38 \mathrm{E}+00$ & $6.38 \mathrm{E}+00$ & $6.38 \mathrm{E}+00$ & $6.40 \mathrm{E}+00$ & $6.38 \mathrm{E}+00$ & $6.38 \mathrm{E}+00$ & $6.38 \mathrm{E}+00$ & $6.40 \mathrm{E}+00$ & $6.38 \mathrm{E}+00$ & $6.38 \mathrm{E}+00$ & $6.38 \mathrm{E}+00$ \\
\hline & $2 \mathrm{E}+01$ & $9.69 \mathrm{E}+01$ & $9.69 \mathrm{E}+01$ & $5.80 \mathrm{E}+01$ & $3.05 E+01$ & $3.04 \mathrm{E}+01$ & $3.04 \mathrm{E}+01$ & $3.04 \mathrm{E}+01$ & $3.05 \mathrm{E}+01$ & $3.04 \mathrm{E}+01$ & $3.04 \mathrm{E}+01$ & $3.04 \mathrm{E}+01$ & $3.05 \mathrm{E}+01$ & $3.04 \mathrm{E}+01$ & $3.04 \mathrm{E}+01$ & $3.04 \mathrm{E}+01$ \\
\hline$-N-5$ & $8.24 \mathrm{E}+00$ & $8.22 \mathrm{E}+00$ & $8.22 \mathrm{E}+00$ & $7.74 \mathrm{E}+00$ & $6.40 \mathrm{E}+00$ & $6.38 \mathrm{E}+00$ & $6.38 \mathrm{E}+00$ & $6.38 \mathrm{E}+00$ & $6.40 \mathrm{E}+00$ & $6.38 \mathrm{E}+00$ & $6.38 \mathrm{E}+00$ & $6.38 \mathrm{E}+00$ & $6.40 \mathrm{E}+00$ & $6.38 \mathrm{E}+00$ & $6.38 \mathrm{E}+00$ & $6.38 \mathrm{E}+00$ \\
\hline $216-\mathrm{N}-6$ & $30 \mathrm{E}+01$ & $8.28 \mathrm{E}+01$ & $8.28 \mathrm{E}+01$ & $4.96 \mathrm{E}+01$ & $61 \mathrm{E}+01$ & $2.60 \mathrm{E}+01$ & $2.60 \mathrm{E}+01$ & $2.60 \mathrm{E}+01$ & $2.61 \mathrm{E}+01$ & $2.60 \mathrm{E}+01$ & $2.60 \mathrm{E}+01$ & $2.60 \mathrm{E}+01$ & $2.61 \mathrm{E}+01$ & $2.60 \mathrm{E}+01$ & $2.60 \mathrm{E}+01$ & $2.60 \mathrm{E}+01$ \\
\hline N-7 & $8.24 \mathrm{E}+00$ & $8.22 \mathrm{E}+00$ & $8.22 \mathrm{E}+00$ & $7.74 \mathrm{E}+00$ & $6.40 \mathrm{E}+00$ & $6.38 \mathrm{E}+00$ & $6.38 \mathrm{E}+00$ & $6.38 \mathrm{E}+00$ & $6.40 \mathrm{E}+00$ & $6.38 \mathrm{E}+00$ & $6.38 \mathrm{E}+00$ & $6.38 \mathrm{E}+00$ & $6.40 \mathrm{E}+00$ & $6.38 \mathrm{E}+00$ & $6.38 \mathrm{E}+00$ & $6.38 \mathrm{E}+00$ \\
\hline -S-1\%2 & $6.77 \mathrm{E}+02$ & $6.75 \mathrm{E}+02$ & $6.75 \mathrm{E}+02$ & $6.75 \mathrm{E}+02$ & $6.77 \mathrm{E}+02$ & $6.56 \mathrm{E}+02$ & $4.62 \mathrm{E}+02$ & $4.62 \mathrm{E}+02$ & $4.63 \mathrm{E}+02$ & $4.62 \mathrm{E}+02$ & $4.62 \mathrm{E}+02$ & $4.62 \mathrm{E}+02$ & $4.63 \mathrm{E}+02$ & $4.62 \mathrm{E}+02$ & $4.62 \mathrm{E}+02$ & $4.62 \mathrm{E}+02$ \\
\hline$-10 P$ & $2.01 E+05$ & $2.00 \mathrm{E}+05$ & $2.00 E+05$ & $2.00 \mathrm{E}+05$ & $1.91 \mathrm{E}+05$ & $1.95 \mathrm{E}+05$ & $2.00 \mathrm{E}+05$ & $2.00 \mathrm{E}+05$ & $2.01 \mathrm{E}+05$ & $2.03 E+05$ & $2.01 \mathrm{E}+05$ & $1.99 \mathrm{E}+05$ & $2.08 \mathrm{E}+05$ & $2.04 \mathrm{E}+05$ & $2.01 \mathrm{E}+05$ & $1.54 \mathrm{E}+05$ \\
\hline-12 & 3.59E-03 & $2.35 \mathrm{E}-02$ & 2.35E-02 & $E-02$ & 2.36E-02 & E-02 & E-02 & $=-02$ & 5E-02 & 2.35E-02 & 2.35E-02 & $2.35 \mathrm{E}-02$ & 5E-01 & $3.62 \mathrm{E}-01$ & 3.62E-01 & $3.62 \mathrm{E}-01$ \\
\hline & $78 \mathrm{E}+01$ & $2.69 \mathrm{E}+01$ & $2.69 \mathrm{E}+01$ & $2.69 \mathrm{E}+01$ & $2.70 \mathrm{E}+01$ & $E+01$ & $E+01$ & 1.64 & $\mathrm{E}+01$ & $1.64 \mathrm{E}+01$ & $1.64 \mathrm{E}+01$ & $1.64 \mathrm{E}+01$ & $1.65 \mathrm{E}+01$ & $1.12 \mathrm{E}+01$ & $1.07 \mathrm{E}+01$ & $1.07 \mathrm{E}+01$ \\
\hline & $22 \mathrm{E}-03$ & E-03 & $7.20 \mathrm{E}-03$ & 7.20 & $7.22 \mathrm{E}-03$ & E-03 & $E-03$ & 7.2 & $=-03$ & E-03 & $\mathrm{E}-02$ & 2E-01 & E-01 & EE-01 & 2E-01 & EE-01 \\
\hline $6 \mathrm{P}$ & $E+05$ & $E+05$ & $3.76 \mathrm{E}+05$ & $3.29 \mathrm{E}+05$ & $2.36 \mathrm{E}+05$ & $E+05$ & $=+05$ & 2.20 & +05 & $=05$ & $E+05$ & $1.45 \mathrm{E}+05$ & +05 & $1.45 \mathrm{E}+05$ & $.36 \mathrm{E}+04$ & $E+04$ \\
\hline-17 & 90E+04 & $3.89 \mathrm{E}+04$ & $3.89 E+04$ & $3.89 \mathrm{E}+04$ & $3.90 \mathrm{E}+04$ & $3.89 \mathrm{E}+04$ & $E+04$ & $3.89 \mathrm{E}+04$ & $3.90 \mathrm{E}+04$ & $E+04$ & $2.78 \mathrm{E}+04$ & $2.78 \mathrm{E}+04$ & $2.79 \mathrm{E}+04$ & $2.78 \mathrm{E}+04$ & $2.78 \mathrm{E}+04$ & $.78 \mathrm{E}+04$ \\
\hline & $8 \mathrm{E}+03$ & $.95 E+03$ & $6.97 \mathrm{E}+03$ & $7.02 \mathrm{E}+03$ & $7.06 \mathrm{E}+03$ & $8.71 \mathrm{E}+03$ & $1.62 \mathrm{E}+04$ & $2.71 \mathrm{E}+04$ & $2.58 \mathrm{E}+04$ & $2.49 \mathrm{E}+04$ & $2.20 \mathrm{E}+04$ & $1.59 \mathrm{E}+04$ & $1.22 \mathrm{E}+04$ & $1.01 E+04$ & $7.77 \mathrm{E}+03$ & $.87 \mathrm{E}+03$ \\
\hline & $9 E+03$ & $20 \mathrm{E}+03$ & $1.09 E+03$ & $1.08 \mathrm{E}+03$ & $9.68 \mathrm{E}+02$ & $9.65 \mathrm{E}+02$ & $9.65 \mathrm{E}+02$ & $8.79 \mathrm{E}+02$ & $8.43 \mathrm{E}+02$ & $8.41 \mathrm{E}+02$ & $8.41 \mathrm{E}+02$ & $8.41 \mathrm{E}+02$ & $7.39 \mathrm{E}+02$ & $6.66 \mathrm{E}+02$ & $6.66 \mathrm{E}+02$ & $6.66 \mathrm{E}+02$ \\
\hline$S-21$ & $96 \mathrm{E}+02$ & $4.95 \mathrm{E}+02$ & $4.95 \mathrm{E}+02$ & $3.77 \mathrm{E}+02$ & $3.26 \mathrm{E}+02$ & $3.26 \mathrm{E}+02$ & $3.26 \mathrm{E}+02$ & $3.26 \mathrm{E}+02$ & $2.59 \mathrm{E}+02$ & $2.12 \mathrm{E}+02$ & $2.12 \mathrm{E}+02$ & $2.12 \mathrm{E}+02$ & $2.13 \mathrm{E}+02$ & $2.12 \mathrm{E}+02$ & $2.12 \mathrm{E}+02$ & $2.12 \mathrm{E}+02$ \\
\hline S-22 & $92 \mathrm{E}+00$ & $1.91 \mathrm{E}+00$ & $2.04 \mathrm{E}+00$ & $2.30 \mathrm{E}+00$ & $2.31 \mathrm{E}+00$ & $2.30 \mathrm{E}+00$ & $2.30 \mathrm{E}+00$ & $2.30 \mathrm{E}+00$ & $2.31 \mathrm{E}+00$ & $2.30 \mathrm{E}+00$ & $2.30 \mathrm{E}+00$ & $2.30 \mathrm{E}+00$ & $1.99 \mathrm{E}+00$ & $1.87 \mathrm{E}+00$ & $1.87 \mathrm{E}+00$ & $1.87 \mathrm{E}+00$ \\
\hline & 41E+03 & $1.10 \mathrm{E}+03$ & $8.33 \mathrm{E}+02$ & $8.33 \mathrm{E}+02$ & $5.78 \mathrm{E}+02$ & $4.91 \mathrm{E}+02$ & $4.91 \mathrm{E}+02$ & $4.91 \mathrm{E}+02$ & $3.78 \mathrm{E}+02$ & $2.92 \mathrm{E}+02$ & $2.92 \mathrm{E}+02$ & $2.92 \mathrm{E}+$ & $2.93 \mathrm{E}+02$ & $2.92 \mathrm{E}+02$ & $2.57 \mathrm{E}+02$ & $1.80 \mathrm{E}+02$ \\
\hline $16-S-25$ & $2.99 \mathrm{E}+04$ & $E+04$ & $2.71 E+04$ & $2.14 \mathrm{E}+04$ & $2.08 E+04$ & $2.18 \mathrm{E}+04$ & $1.58 \mathrm{E}+04$ & $1.15 E+04$ & $E+03$ & +03 & & & Tus & +0 & $\mathrm{E}+03$ & 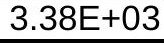 \\
\hline
\end{tabular}




\begin{tabular}{|c|c|c|c|c|c|c|c|c|c|c|c|c|c|c|c|c|}
\hline Site & 1976 & 1977 & 1978 & 1979 & 1980 & 1981 & 1982 & 1983 & 1984 & 1985 & 1986 & 1987 & 1988 & 1989 & 1990 & 1991 \\
\hline & 08E-08 & $.07 \mathrm{E}-08$ & $4.07 \mathrm{E}-08$ & 4.07E-08 & 08E-08 & 07E-08 & $4.07 \mathrm{E}-08$ & 4.07E-08 & $4.08 \mathrm{E}-08$ & 4.07E-08 & $3.06 \mathrm{E}+03$ & $3.87 E+04$ & $2.88 \mathrm{E}+04$ & $2.07 \mathrm{E}+04$ & $1.50 \mathrm{E}+04$ & $1.15 E+04$ \\
\hline $216-S-3$ & $15 E+01$ & $14 \mathrm{E}+01$ & $4.14 \mathrm{E}+01$ & $4.14 \mathrm{E}+01$ & $81 \mathrm{E}+01$ & $76 \mathrm{E}+01$ & $76 \mathrm{E}+01$ & $2.76 \mathrm{E}+01$ & $2.77 \mathrm{E}+01$ & $2.76 \mathrm{E}+01$ & $2.76 \mathrm{E}+01$ & $2.76 \mathrm{E}+01$ & $2.77 \mathrm{E}+01$ & $2.76 \mathrm{E}+01$ & $2.76 \mathrm{E}+01$ & $2.76 \mathrm{E}+01$ \\
\hline $6-S-4$ & $57 \mathrm{E}+00$ & $65 \mathrm{E}+00$ & $4.65 \mathrm{E}+00$ & $4.65 \mathrm{E}+00$ & $67 \mathrm{E}+00$ & $65 \mathrm{E}+00$ & $65 E+00$ & $3.53 \mathrm{E}+00$ & $3.11 \mathrm{E}+00$ & $3.10 \mathrm{E}+00$ & $10 \mathrm{E}+00$ & $10 \mathrm{E}+00$ & $3.11 \mathrm{E}+00$ & $3.10 \mathrm{E}+00$ & $3.10 \mathrm{E}+00$ & $3.10 \mathrm{E}+00$ \\
\hline $6-S-5$ & $46 \mathrm{E}+04$ & $45 E+04$ & $3.45 E+04$ & $3.45 E+04$ & $.46 \mathrm{E}+04$ & $2.92 \mathrm{E}+04$ & $31 \mathrm{E}+04$ & $2.31 \mathrm{E}+04$ & $2.31 E+04$ & $2.31 E+04$ & $2.31 E+04$ & $31 \mathrm{E}+04$ & $2.31 \mathrm{E}+04$ & $2.31 \mathrm{E}+04$ & $2.31 \mathrm{E}+04$ & $31 \mathrm{E}+04$ \\
\hline & $7 \mathrm{E}+04$ & $62 \mathrm{E}+04$ & $4.62 \mathrm{E}+04$ & $4.22 \mathrm{E}+04$ & $3.01 \mathrm{E}+04$ & $3.00 \mathrm{E}+04$ & D0E+04 & $2.96 \mathrm{E}+04$ & $1.88 \mathrm{E}+04$ & $1.88 \mathrm{E}+04$ & $1.88 \mathrm{E}+04$ & $1.88 \mathrm{E}+04$ & $1.88 \mathrm{E}+04$ & $1.88 \mathrm{E}+04$ & $1.38 \mathrm{E}+04$ & $19 \mathrm{E}+04$ \\
\hline & +03 & $36 \mathrm{E}+03$ & $\mathrm{E}+03$ & $1.36 \mathrm{E}+03$ & $36 \mathrm{E}+03$ & $36 \mathrm{E}+03$ & $E+03$ & $25 \mathrm{E}+02$ & $8.25 \mathrm{E}+02$ & $8.23 E+02$ & $8.23 \mathrm{E}+02$ & $23 \mathrm{E}+02$ & $8.25 E+02$ & $8.23 \mathrm{E}+02$ & $8.23 \mathrm{E}+02$ & $8.23 E+02$ \\
\hline & & $72 \mathrm{E}+02$ & $72 \mathrm{E}+02$ & $6.72 \mathrm{E}+02$ & $49 \mathrm{E}+02$ & $E+02$ & $\hat{b}+02$ & $4.06 \mathrm{E}+02$ & $4.07 \mathrm{E}+02$ & $4.06 \mathrm{E}+02$ & $4.06 \mathrm{E}+02$ & $2.82 \mathrm{E}+02$ & & $2.53 \mathrm{E}+02$ & & $2.53 \mathrm{E}+02$ \\
\hline$x-2$ & $E+02$ & $5 \mathrm{E}+02$ & $75 E+02$ & $1.24 \mathrm{E}+02$ & $09 E+02$ & $9 \mathrm{E}+02$ & $9 \mathrm{E}+02$ & $1.09 E+02$ & $1.09 \mathrm{E}+02$ & $1.04 \mathrm{E}+02$ & $7.05 \mathrm{E}+01$ & $7.05 E+01$ & $7.07 \mathrm{E}+01$ & $7.05 \mathrm{E}+01$ & $7.05 \mathrm{E}+01$ & $5 \mathrm{E}+01$ \\
\hline & +03 & $E+03$ & $E+03$ & $E+03$ & $20 \mathrm{E}+03$ & $E+03$ & $E+03$ & $E+03$ & $21 \mathrm{E}+03$ & $20 \mathrm{E}+03$ & $\mathrm{DE}+03$ & $E+03$ & $3.19 \mathrm{E}+03$ & $3.43 \mathrm{E}+03$ & $5.25 E+03$ & \\
\hline-12 & $4 \mathrm{E}+01$ & $E+01$ & $E+01$ & $E+01$ & $74 \mathrm{E}+01$ & $E+01$ & $E+01$ & $E+01$ & $74 \mathrm{E}+01$ & $3 \mathrm{E}+01$ & & $E+01$ & & & & \\
\hline 216-T-14 & $50 \mathrm{E}+01$ & $49 \mathrm{E}+01$ & $.49 \mathrm{E}+01$ & $1.49 \mathrm{E}+01$ & $50 \mathrm{E}+01$ & $49 \mathrm{E}+01$ & $49 \mathrm{E}+01$ & $1.49 \mathrm{E}+01$ & $1.50 \mathrm{E}+01$ & $49 \mathrm{E}+01$ & $22 \mathrm{E}+01$ & $18 \mathrm{E}+01$ & $1.19 \mathrm{E}+01$ & $1.18 \mathrm{E}+01$ & $1.18 \mathrm{E}+01$ & \\
\hline 216-T-15 & $56 \mathrm{E}+01$ & $56 \mathrm{E}+01$ & $1.56 \mathrm{E}+01$ & $1.56 \mathrm{E}+01$ & $56 \mathrm{E}+01$ & $56 \mathrm{E}+01$ & $56 \mathrm{E}+01$ & $1.56 \mathrm{E}+01$ & $1.41 \mathrm{E}+01$ & $20 \mathrm{E}+01$ & $20 \mathrm{E}+01$ & $20 \mathrm{E}+01$ & & $1.20 \mathrm{E}+01$ & $1.20 \mathrm{E}+01$ & $.20 \mathrm{E}+01$ \\
\hline 216-T-16 & $58 \mathrm{E}+01$ & $57 \mathrm{E}+01$ & $1.57 \mathrm{E}+01$ & $1.57 \mathrm{E}+01$ & $58 \mathrm{E}+01$ & $57 \mathrm{E}+01$ & $57 \mathrm{E}+01$ & $1.57 \mathrm{E}+01$ & $1.29 \mathrm{E}+01$ & $20 \mathrm{E}+01$ & $20 \mathrm{E}+01$ & $20 \mathrm{E}+01$ & & & $1.20 \mathrm{E}+01$ & $20 \mathrm{E}+01$ \\
\hline $216-\mathrm{T}-17$ & $97 \mathrm{E}+01$ & $64 \mathrm{E}+01$ & $1.41 \mathrm{E}+01$ & $1.41 \mathrm{E}+01$ & $41 \mathrm{E}+01$ & $41 E+01$ & $1.41 \mathrm{E}+01$ & $1.41 \mathrm{E}+01$ & $1.41 \mathrm{E}+01$ & $41 \mathrm{E}+01$ & $41 \mathrm{E}+01$ & $41 \mathrm{E}+01$ & $1.27 \mathrm{E}+01$ & $1.17 \mathrm{E}+01$ & $1.17 \mathrm{E}+01$ & $.17 \mathrm{E}+01$ \\
\hline 216-T-18 & $80 \mathrm{E}+00$ & $5.79 \mathrm{E}+00$ & $5.79 \mathrm{E}+00$ & $5.79 \mathrm{E}+00$ & $30 \mathrm{E}+00$ & $22 \mathrm{E}+00$ & $22 \mathrm{E}+00$ & $4.22 \mathrm{E}+00$ & $4.23 \mathrm{E}+00$ & $4.22 \mathrm{E}+00$ & $22 \mathrm{E}+00$ & $22 \mathrm{E}+00$ & $4.23 \mathrm{E}+00$ & $4.22 \mathrm{E}+00$ & $22 \mathrm{E}+00$ & $22 \mathrm{E}+00$ \\
\hline 6-T-19 & $96 \mathrm{E}+03$ & $04 \mathrm{E}+03$ & $4.05 E+03$ & $2.54 \mathrm{E}+03$ & $2.37 \mathrm{E}+03$ & $41 \mathrm{E}+03$ & $41 \mathrm{E}+03$ & $1.27 \mathrm{E}+03$ & $8.26 \mathrm{E}+02$ & $8.23 E+02$ & $23 \mathrm{E}+02$ & $11 \mathrm{E}+02$ & $4.92 \mathrm{E}+02$ & $4.91 \mathrm{E}+02$ & $.91 \mathrm{E}+02$ & $91 \mathrm{E}+02$ \\
\hline T-2 & $15 \mathrm{E}+00$ & $4.14 \mathrm{E}+00$ & $E+00$ & $4.14 \mathrm{E}+00$ & $.15 \mathrm{E}+00$ & $14 \mathrm{E}+00$ & $E+00$ & $14 \mathrm{E}+00$ & $4.49 \mathrm{E}+00$ & $4.71 \mathrm{E}+00$ & $E+00$ & $71 \mathrm{E}+00$ & $4.72 \mathrm{E}+00$ & $4.71 \mathrm{E}+00$ & $4.71 \mathrm{E}+00$ & $4.71 \mathrm{E}+00$ \\
\hline T-20 & $4 \mathrm{E}-01$ & 5.03E-01 & 03E-01 & 4.92E-01 & 4.44E-01 & $43 E-01$ & 3E-01 & 43E-01 & 4.44E-01 & 4.43E-01 & $3 \mathrm{E}-01$ & 4.43E-01 & 4.44E-01 & 4.43E-01 & 4.43E-01 & 43E-01 \\
\hline 216-T-21 & $23 E+01$ & $23 \mathrm{E}+01$ & $1.23 \mathrm{E}+01$ & $1.23 \mathrm{E}+01$ & $.16 \mathrm{E}+01$ & $10 \mathrm{E}+01$ & $10 \mathrm{E}+01$ & $1.10 \mathrm{E}+01$ & $1.11 \mathrm{E}+01$ & $1.10 \mathrm{E}+01$ & $1.10 \mathrm{E}+01$ & $1.10 \mathrm{E}+01$ & $1.11 \mathrm{E}+01$ & $1.10 \mathrm{E}+01$ & $1.10 \mathrm{E}+01$ & $0 \mathrm{E}+01$ \\
\hline 216-T-22 & $2 \mathrm{E}+01$ & $62 \mathrm{E}+01$ & $62 \mathrm{E}+01$ & $1.25 \mathrm{E}+01$ & $17 \mathrm{E}+01$ & $16 \mathrm{E}+01$ & $\mathrm{E}+01$ & $E+01$ & $1.17 \mathrm{E}+01$ & $.16 \mathrm{E}+01$ & $.16 \mathrm{E}+01$ & $.16 \mathrm{E}+01$ & $1.17 \mathrm{E}+01$ & $1.16 \mathrm{E}+01$ & $1.16 \mathrm{E}+01$ & $1.03 \mathrm{E}+01$ \\
\hline 6-T-23 & $3 E+01$ & $25 \mathrm{E}+01$ & $25 \mathrm{E}+01$ & $1.25 \mathrm{E}+01$ & $26 \mathrm{E}+01$ & $25 \mathrm{E}+01$ & $\mathrm{E}+01$ & $\mathrm{E}+01$ & $1.26 \mathrm{E}+01$ & $.25 \mathrm{E}+01$ & $1.25 \mathrm{E}+01$ & $10 \mathrm{E}+01$ & $1.02 \mathrm{E}+01$ & $1.02 \mathrm{E}+01$ & $1.02 \mathrm{E}+01$ & $.02 \mathrm{E}+01$ \\
\hline b-T-24 & $0 \mathrm{E}+01$ & $60 \mathrm{E}+01$ & $50 \mathrm{E}+01$ & $.35 \mathrm{E}+01$ & $16 \mathrm{E}+01$ & $16 \mathrm{E}+01$ & $6 \mathrm{E}+01$ & $16 \mathrm{E}+01$ & $1.16 \mathrm{E}+01$ & $16 \mathrm{E}+01$ & $6 \mathrm{E}+01$ & $16 \mathrm{E}+01$ & $1.16 \mathrm{E}+01$ & $1.16 \mathrm{E}+01$ & $1.16 \mathrm{E}+01$ & $.08 \mathrm{E}+01$ \\
\hline 216-T-25 & $04 \mathrm{E}+01$ & $1.04 \mathrm{E}+01$ & $1.04 \mathrm{E}+01$ & $1.04 \mathrm{E}+01$ & $.04 \mathrm{E}+01$ & $04 \mathrm{E}+01$ & $04 \mathrm{E}+01$ & $1.04 \mathrm{E}+01$ & $1.04 \mathrm{E}+01$ & $1.04 E+01$ & $3.13 \mathrm{E}+00$ & $13 \mathrm{E}+00$ & $8.15 E+00$ & $8.13 \mathrm{E}+00$ & $3.13 \mathrm{E}+00$ & $13 \mathrm{E}+00$ \\
\hline 216-T-26 & $40 \mathrm{E}+01$ & $39 \mathrm{E}+01$ & $39 \mathrm{E}+01$ & $3.39 \mathrm{E}+01$ & $40 \mathrm{E}+01$ & $39 \mathrm{E}+01$ & $51 \mathrm{E}+01$ & $36 \mathrm{E}+01$ & $2.37 \mathrm{E}+01$ & $.36 \mathrm{E}+01$ & $6 \mathrm{E}+01$ & $E+01$ & $2.37 \mathrm{E}+01$ & $2.36 \mathrm{E}+01$ & $.36 \mathrm{E}+01$ & $6 \mathrm{E}+01$ \\
\hline 216-T-27 & $31 \mathrm{E}+01$ & $79 \mathrm{E}+01$ & $5.79 \mathrm{E}+01$ & $5.28 \mathrm{E}+01$ & $69 \mathrm{E}+01$ & $68 \mathrm{E}+01$ & $68 \mathrm{E}+01$ & $3.68 \mathrm{E}+01$ & $3.69 \mathrm{E}+01$ & $3.68 \mathrm{E}+01$ & $E+01$ & $0 \mathrm{E}+01$ & $2.51 \mathrm{E}+01$ & $2.50 \mathrm{E}+01$ & $2.50 \mathrm{E}+01$ & $.50 \mathrm{E}+01$ \\
\hline 6-T-28 & $76 \mathrm{E}+02$ & $1.75 \mathrm{E}+02$ & $E+02$ & $1.04 \mathrm{E}+02$ & $1.04 \mathrm{E}+02$ & $1.04 \mathrm{E}+02$ & $E+02$ & +02 & $1.04 \mathrm{E}+02$ & $8.29 \mathrm{E}+01$ & $6.59 \mathrm{E}+01$ & $6.59 \mathrm{E}+01$ & $6.61 \mathrm{E}+01$ & $6.59 \mathrm{E}+01$ & $6.59 \mathrm{E}+01$ & $6.59 \mathrm{E}+01$ \\
\hline 216-T-29 & 56E-02 & 3.56E-02 & $3.56 \mathrm{E}-02$ & 3.56E-02 & $3.56 \mathrm{E}-02$ & 3.56E-02 & $2.55 E-02$ & 2.17E-02 & $2.18 \mathrm{E}-02$ & $2.17 \mathrm{E}-02$ & $2.17 \mathrm{E}-02$ & 7E-02 & $2.18 \mathrm{E}-02$ & $2.17 \mathrm{E}-02$ & 2.17E-02 & 2.04E-02 \\
\hline T-3 & $\mathrm{OE}+01$ & $1.20 \mathrm{E}+01$ & $E+01$ & $1.20 \mathrm{E}+01$ & $29 \mathrm{E}+01$ & $38 \mathrm{E}+01$ & $E+01$ & $3 \mathrm{E}+01$ & $1.38 \mathrm{E}+01$ & $1.38 \mathrm{E}+01$ & $8 \mathrm{E}+01$ & $38 \mathrm{E}+01$ & $1.38 \mathrm{E}+01$ & $1.38 \mathrm{E}+01$ & $1.38 \mathrm{E}+01$ & $.38 \mathrm{E}+01$ \\
\hline T-32 & +01 & $E+01$ & $E+01$ & 2.47 & 48E+01 & $E+01$ & $E+01$ & +01 & $2.48 \mathrm{E}+01$ & $2.47 \mathrm{E}+01$ & $E+01$ & $7 \mathrm{E}+01$ & $2.03 \mathrm{E}+01$ & $2.02 \mathrm{E}+01$ & $.02 \mathrm{E}+01$ & $.02 \mathrm{E}+01$ \\
\hline$\Gamma-33$ & $E+01$ & $=01$ & 00 & & 00 & 100 & 100 & +00 & $8.77 \mathrm{E}-$ & $E+00$ & $E+00$ & $E+00$ & 00 & $E+00$ & +00 & +00 \\
\hline T-34 & $E+02$ & $0 \mathrm{E}+02$ & $\mathrm{E}+02$ & $9.64 \mathrm{E}+01$ & $67 \mathrm{E}+01$ & $E+01$ & $E+01$ & +01 & $8.74 \mathrm{E}+01$ & $E+01$ & $E+01$ & $E+01$ & 6.1 & $E+01$ & $6.10 \mathrm{E}+01$ & +01 \\
\hline 216-T-35 & $9 \mathrm{E}+01$ & $77 \mathrm{E}+01$ & $7 \mathrm{E}+01$ & $6.77 \mathrm{E}+01$ & $34 \mathrm{E}+01$ & $9 \mathrm{E}+01$ & $E+01$ & $\mathrm{E}+01$ & $4.30 \mathrm{E}+01$ & $4.29 \mathrm{E}+01$ & $54 \mathrm{E}+01$ & $4 \mathrm{E}+01$ & $2.85 \mathrm{E}+01$ & $2.84 \mathrm{E}+01$ & $2.84 \mathrm{E}+01$ & $2.84 \mathrm{E}+01$ \\
\hline 6-T-36 & $7 E+01$ & $04 \mathrm{E}+01$ & $2.00 \mathrm{E}+01$ & $2.00 \mathrm{E}+01$ & $.00 \mathrm{E}+01$ & $88 \mathrm{E}+01$ & $39 \mathrm{E}+01$ & $1.39 \mathrm{E}+01$ & $1.39 \mathrm{E}+01$ & $.39 \mathrm{E}+01$ & $1.39 \mathrm{E}+01$ & $1.39 E+01$ & $9.86 \mathrm{E}+00$ & $9.51 \mathrm{E}+00$ & $9.51 \mathrm{E}+00$ & $9.51 \mathrm{E}+00$ \\
\hline $6-T-4 A$ & $22 \mathrm{E}+05$ & 61E+05 & $1.15 \mathrm{E}+05$ & $8.39 \mathrm{E}+04$ & $.37 E+04$ & 99E+04 & $04 \mathrm{E}+04$ & $3.38 \mathrm{E}+04$ & $2.91 \mathrm{E}+04$ & $2.56 \mathrm{E}+04$ & $2.31 \mathrm{E}+04$ & $2.15 \mathrm{E}+04$ & $2.05 \mathrm{E}+04$ & $1.97 \mathrm{E}+04$ & $1.94 \mathrm{E}+04$ & $1.92 \mathrm{E}+04$ \\
\hline 216-T-5 & $43 \mathrm{E}+01$ & $1.09 \mathrm{E}+01$ & $1.09 \mathrm{E}+01$ & $1.09 \mathrm{E}+01$ & $1.10 \mathrm{E}+01$ & $1.09 \mathrm{E}+01$ & $1.09 \mathrm{E}+01$ & $1.09 \mathrm{E}+01$ & $1.10 \mathrm{E}+01$ & $1.09 \mathrm{E}+01$ & $1.09 \mathrm{E}+01$ & $8.60 \mathrm{E}+00$ & $8.63 \mathrm{E}+00$ & $8.60 \mathrm{E}+00$ & $8.60 \mathrm{E}+00$ & $3.60 \mathrm{E}+00$ \\
\hline 216-T-6 & $99 \mathrm{E}+01$ & $9.96 \mathrm{E}+01$ & $7.64 \mathrm{E}+01$ & $7.62 \mathrm{E}+01$ & $7.64 \mathrm{E}+01$ & $7.62 \mathrm{E}+01$ & $7.62 \mathrm{E}+01$ & $7.62 \mathrm{E}+01$ & $7.64 \mathrm{E}+01$ & $7.62 \mathrm{E}+01$ & $7.62 \mathrm{E}+01$ & $7.62 \mathrm{E}+01$ & $7.64 \mathrm{E}+01$ & $7.62 \mathrm{E}+01$ & $7.62 \mathrm{E}+01$ & $7.62 \mathrm{E}+01$ \\
\hline 216-T-7 & $16 \mathrm{E}+02$ & $2.16 \mathrm{E}+02$ & $1.62 \mathrm{E}+02$ & $1.43 \mathrm{E}+02$ & $1.44 \mathrm{E}+02$ & $1.43 \mathrm{E}+02$ & $1.43 \mathrm{E}+02$ & $1.43 \mathrm{E}+02$ & $1.44 \mathrm{E}+02$ & $1.43 \mathrm{E}+02$ & $1.43 \mathrm{E}+02$ & $1.43 \mathrm{E}+02$ & $1.44 \mathrm{E}+02$ & $1.39 \mathrm{E}+02$ & $1.16 \mathrm{E}+02$ & $1.16 \mathrm{E}+02$ \\
\hline 216-T-8 & $1.22 \mathrm{E}+01$ & $1.21 \mathrm{E}+01$ & $1.21 \mathrm{E}+01$ & $1.21 \mathrm{E}+01$ & $1.22 \mathrm{E}+01$ & $1.21 \mathrm{E}+01$ & $1.21 \mathrm{E}+01$ & $1.21 \mathrm{E}+01$ & $1.22 \mathrm{E}+01$ & $1.27 \mathrm{E}+01$ & $1.58 \mathrm{E}+01$ & $1.58 \mathrm{E}+01$ & $1.58 \mathrm{E}+01$ & $1.58 \mathrm{E}+01$ & $1.58 \mathrm{E}+01$ & $1.58 \mathrm{E}+01$ \\
\hline 216-TY-201 & 1.54E-01 & $1.54 \mathrm{E}-01$ & 1.54E-01 & $1.54 \mathrm{E}-01$ & 1.00E-01 & $9.08 \mathrm{E}-02$ & $9.08 \mathrm{E}-02$ & 9.08E-02 & $9.10 \mathrm{E}-02$ & $9.08 \mathrm{E}-02$ & $9.08 \mathrm{E}-02$ & 6.96E-02 & 5.84E-02 & 5.82E-02 & 5.82E-02 & $5.82 \mathrm{E}-02$ \\
\hline 216-U-1\%2 & 3.56E-06 & 3.55E-06 & $3.55 \mathrm{E}-06$ & 3.55E-06 & 3.56E-06 & 3.55E-06 & 7.66E-04 & 7.04E-03 & 3.53E-02 & 7.74E-02 & 4.06E-01 & $4.30 \mathrm{E}+00$ & $1.20 \mathrm{E}+02$ & $7.14 \mathrm{E}+02$ & $1.67 \mathrm{E}+03$ & $1.76 \mathrm{E}+03$ \\
\hline $216-U-10$ & $5.12 \mathrm{E}+06$ & $5.84 \mathrm{E}+06$ & $5.35 \mathrm{E}+06$ & $5.24 \mathrm{E}+06$ & $4.26 \mathrm{E}+06$ & $3.52 \mathrm{E}+06$ & $2.79 \mathrm{E}+06$ & $1.95 \mathrm{E}+06$ & $1.46 \mathrm{E}+06$ & $1.13 \mathrm{E}+06$ & $8.54 \mathrm{E}+05$ & $6.52 \mathrm{E}+05$ & $5.23 \mathrm{E}+05$ & $4.55 \mathrm{E}+05$ & $3.73 \mathrm{E}+05$ & $3.26 \mathrm{E}+05$ \\
\hline
\end{tabular}




\begin{tabular}{|c|c|c|c|c|c|c|c|c|c|c|c|c|c|c|c|c|}
\hline Site & 1976 & 1977 & 1978 & 1979 & 1980 & 1981 & 1982 & 1983 & 1984 & & 1986 & 1987 & 1988 & 1989 & 1990 & 1991 \\
\hline & $90 \mathrm{E}+03$ & $50 \mathrm{E}+03$ & $1.22 \mathrm{E}+03$ & $01 \mathrm{E}+03$ & $63 \mathrm{E}+02$ & $7.68 \mathrm{E}+02$ & $6.67 \mathrm{E}+02$ & $5.86 \mathrm{E}+02$ & $5.22 \mathrm{E}+02$ & $4.60 \mathrm{E}+02$ & $5.61 \mathrm{E}+02$ & $1.91 \mathrm{E}+03$ & $2.87 \mathrm{E}+03$ & $2.38 E+03$ & $1.88 \mathrm{E}+03$ & $1.35 E+03$ \\
\hline & 99E-04 & $96 \mathrm{E}-04$ & 9.96E-04 & $9.96 \mathrm{E}-04$ & $.99 \mathrm{E}-04$ & 96E-04 & 9.96E-04 & $5.75 \mathrm{E}-02$ & 1.48E-01 & 1.47E-01 & 1.47E-01 & 1.47E-01 & 1.48E-01 & 1.47E-01 & 1.47E-01 & 1.47E-01 \\
\hline & 51E-10 & 51E-10 & 51E-10 & 51E-10 & $.51 \mathrm{E}-10$ & $.51 \mathrm{E}-10$ & 51E-10 & 51E-10 & $1.51 \mathrm{E}-10$ & $.60 \mathrm{E}-10$ & $2.86 \mathrm{E}+04$ & $4.27 \mathrm{E}+05$ & $3.29 E+05$ & $3.31 E+05$ & $3.13 E+05$ & $2.75 E+05$ \\
\hline 216-U-15 & 95E-02 & 8.92E-02 & $8.92 \mathrm{E}-02$ & $2.09 \mathrm{E}-01$ & 9.17E-01 & $9.14 \mathrm{E}-01$ & $9.14 \mathrm{E}-01$ & $9.14 \mathrm{E}-01$ & $9.17 \mathrm{E}-01$ & $14 \mathrm{E}-01$ & $9.14 \mathrm{E}-01$ & $9.14 \mathrm{E}-01$ & 9.17E-01 & $9.14 \mathrm{E}-01$ & $9.14 \mathrm{E}-01$ & $36 \mathrm{E}+00$ \\
\hline & & 16E-02 & 16E-02 & 7.16E-02 & 7.18 & 7.16E-02 & $6 \mathrm{E}-02$ & 7.16E-02 & & & 16E-02 & 7.16E-02 & & & 7.16E-02 & 7.16E-02 \\
\hline & & 9.93E-( & & & & & & & & & $9.93 \mathrm{E}$ & 9.93E-09 & 95E-09 & 9.93E-09 & 9.93E-09 & 9.93E-09 \\
\hline & +00 & $7.72 \mathrm{E}+00$ & $7.72 \mathrm{E}+00$ & $7.72 \mathrm{E}+00$ & $74 \mathrm{E}+00$ & $7.72 \mathrm{E}+00$ & $7.72 \mathrm{E}+00$ & $7.72 \mathrm{E}+00$ & $7.74 \mathrm{E}+00$ & $7.72 \mathrm{E}+00$ & $6.18 \mathrm{E}+00$ & $5.55 E+00$ & $5.56 \mathrm{E}+00$ & $5.55 E+00$ & $5.55 E+00$ & \\
\hline & +00 & $66 \mathrm{E}+00$ & $2.66 \mathrm{E}+00$ & $.66 \mathrm{E}+00$ & $67 \mathrm{E}+00$ & $66 \mathrm{E}+00$ & $37 \mathrm{E}+00$ & $1.92 \mathrm{E}+00$ & $1.93 \mathrm{E}+00$ & $.92 \mathrm{E}+00$ & $92 \mathrm{E}+00$ & $1.92 \mathrm{E}+00$ & $1.93 \mathrm{E}+00$ & $1.92 \mathrm{E}+00$ & $1.92 \mathrm{E}+00$ & $.92 \mathrm{E}+00$ \\
\hline & +00 & $7.09 \mathrm{E}+00$ & $5.75 E+00$ & $75 E+00$ & $40 \mathrm{E}+00$ & $47 \mathrm{E}+00$ & $3.47 \mathrm{E}+00$ & $3.47 \mathrm{E}+00$ & $3.48 \mathrm{E}+00$ & $47 \mathrm{E}+00$ & $2.23 E+00$ & $3 E+00$ & $\mathrm{HE}+00$ & $2.13 E+00$ & $2.13 \mathrm{E}+00$ & $3 \mathrm{E}+00$ \\
\hline & E-01 & 3.92E-01 & 3.82E-01 & $2.38 \mathrm{E}-01$ & 3E-01 & 2.38E-01 & $2.38 \mathrm{E}-01$ & 2.38E-01 & $6 \mathrm{E}-01$ & $.46 \mathrm{E}-01$ & 1.46E-01 & & 7E-01 & 1.46E-01 & 1.46E-01 & \\
\hline & $.00 \mathrm{E}-02$ & $3.65 \mathrm{E}-02$ & $3.65 \mathrm{E}-02$ & $3.65 \mathrm{E}-02$ & $3.66 \mathrm{E}-02$ & $3.65 \mathrm{E}-02$ & $3.65 \mathrm{E}-02$ & $3.65 \mathrm{E}-02$ & $3.66 \mathrm{E}-02$ & 3.65E-02 & 3.04E-02 & $2.50 \mathrm{E}-02$ & $2.51 \mathrm{E}-02$ & $2.50 \mathrm{E}-02$ & $2.50 \mathrm{E}-02$ & \\
\hline $216-$ & $80 \mathrm{E}+03$ & $1.80 \mathrm{E}+03$ & $1.18 \mathrm{E}+03$ & $1.14 \mathrm{E}+03$ & $1.14 \mathrm{E}+03$ & $1.14 \mathrm{E}+03$ & $1.14 \mathrm{E}+03$ & $1.14 \mathrm{E}+03$ & $1.14 \mathrm{E}+03$ & $1.14 \mathrm{E}+03$ & $1.14 \mathrm{E}+03$ & $9.38 \mathrm{E}+02$ & $7.95 E+02$ & $7.93 \mathrm{E}+02$ & $7.93 \mathrm{E}+02$ & $7.93 \mathrm{E}+02$ \\
\hline 216 & 17E-07 & $4.16 \mathrm{E}-07$ & $4.16 \mathrm{E}-07$ & 4.16E-07 & $4.17 \mathrm{E}-07$ & 4.16E-07 & $4.16 \mathrm{E}-07$ & $3.13 \mathrm{E}+05$ & $1.60 \mathrm{E}+05$ & $18 \mathrm{E}+04$ & $32 \mathrm{E}+04$ & $5.57 \mathrm{E}+04$ & $4.88 \mathrm{E}+04$ & $3.51 \mathrm{E}+04$ & $.49 \mathrm{E}+04$ & $44 \mathrm{E}+04$ \\
\hline & $22 \mathrm{E}+02$ & $1.22 \mathrm{E}+02$ & $1.22 \mathrm{E}+02$ & $1.09 \mathrm{E}+02$ & $04 \mathrm{E}+02$ & $04 \mathrm{E}+02$ & $04 \mathrm{E}+02$ & $1.04 \mathrm{E}+02$ & $65 \mathrm{E}+01$ & $09 \mathrm{E}+01$ & $.09 \mathrm{E}+01$ & $9.09 \mathrm{E}+01$ & $9.11 \mathrm{E}+01$ & $.09 \mathrm{E}+01$ & $.09 \mathrm{E}+01$ & $09 \mathrm{E}+01$ \\
\hline & $20 \mathrm{E}+00$ & $3.19 \mathrm{E}+00$ & $3.19 \mathrm{E}+00$ & $19 \mathrm{E}+00$ & $20 \mathrm{E}+00$ & $19 \mathrm{E}+00$ & $19 \mathrm{E}+00$ & $3.19 \mathrm{E}+00$ & $3.20 \mathrm{E}+00$ & $3.19 \mathrm{E}+00$ & $3.19 \mathrm{E}+00$ & $3.19 \mathrm{E}+00$ & $3.20 \mathrm{E}+00$ & $3.13 \mathrm{E}+00$ & $.09 \mathrm{E}+00$ & $.09 \mathrm{E}+00$ \\
\hline & $27 \mathrm{E}+03$ & $4.02 \mathrm{E}+03$ & $2.60 \mathrm{E}+03$ & $2.60 \mathrm{E}+03$ & $32 \mathrm{E}+03$ & $59 \mathrm{E}+03$ & $59 \mathrm{E}+03$ & $1.59 \mathrm{E}+03$ & $1.53 E+03$ & $9.64 \mathrm{E}+02$ & $9.64 \mathrm{E}+02$ & $E+02$ & $6 \mathrm{E}+02$ & $E+02$ & $9.64 \mathrm{E}+02$ & $.77 \mathrm{E}+02$ \\
\hline & $71 \mathrm{E}+02$ & $5.69 \mathrm{E}+02$ & $5.69 \mathrm{E}+02$ & $5.69 \mathrm{E}+02$ & $71 E+02$ & $5.69 \mathrm{E}+02$ & $5.53 \mathrm{E}+02$ & $3.72 \mathrm{E}+02$ & $3.73 E+02$ & $3.72 \mathrm{E}+02$ & $3.72 \mathrm{E}+02$ & $3.72 \mathrm{E}+02$ & $3.73 E+02$ & $3.72 \mathrm{E}+02$ & $3.72 \mathrm{E}+02$ & $3.72 \mathrm{E}+02$ \\
\hline & $4 \mathrm{E}-02$ & 3.93E-02 & 3.93E-02 & 1.88E-01 & 2.32E-01 & 2.32E-01 & 2.32E-01 & 2.32E-01 & $2 \mathrm{E}-01$ & 2.32E-01 & 2.32E-01 & $2.32 \mathrm{E}-01$ & 2E-01 & $2 \mathrm{E}-01$ & 2.32E-01 & 2.32E-01 \\
\hline & $95 \mathrm{E}+02$ & $1.94 \mathrm{E}+02$ & $1.94 \mathrm{E}+02$ & $.94 \mathrm{E}+02$ & $89 \mathrm{E}+02$ & $41 \mathrm{E}+02$ & $1.41 \mathrm{E}+02$ & $1.41 E+02$ & $1.41 \mathrm{E}+02$ & $1.41 \mathrm{E}+02$ & $1.41 \mathrm{E}+02$ & $1.41 \mathrm{E}+02$ & $1.41 \mathrm{E}+02$ & $1.41 \mathrm{E}+02$ & $1.41 \mathrm{E}+02$ & $1.41 \mathrm{E}+02$ \\
\hline & $09 \mathrm{E}+00$ & $2.09 \mathrm{E}+00$ & $2.09 \mathrm{E}+00$ & $.09 \mathrm{E}+00$ & $.09 \mathrm{E}+00$ & $2.09 \mathrm{E}+00$ & $2.09 \mathrm{E}+00$ & $2.09 \mathrm{E}+00$ & $1.98 \mathrm{E}+00$ & $1.90 \mathrm{E}+00$ & $1.90 \mathrm{E}+00$ & $1.90 \mathrm{E}+00$ & $1.90 \mathrm{E}+00$ & $1.90 \mathrm{E}+00$ & $1.90 \mathrm{E}+00$ & $1.90 \mathrm{E}+00$ \\
\hline & $3 \mathrm{E}+02$ & $3.66 \mathrm{E}+02$ & $3.66 \mathrm{E}+02$ & $66 \mathrm{E}+02$ & $67 \mathrm{E}+02$ & $82 \mathrm{E}+02$ & $2.26 \mathrm{E}+02$ & $2.26 \mathrm{E}+02$ & $2.27 \mathrm{E}+02$ & $2.26 \mathrm{E}+02$ & $2.26 \mathrm{E}+02$ & $2.26 \mathrm{E}+02$ & $2.27 \mathrm{E}+02$ & $1.51 \mathrm{E}+02$ & $1.47 \mathrm{E}+02$ & $1.47 \mathrm{E}+02$ \\
\hline-10 & $0 \mathrm{E}+00$ & $0.00 \mathrm{E}+00$ & $0.00 \mathrm{E}+00$ & $0.00 \mathrm{E}+00$ & $.00 \mathrm{E}+00$ & $0.00 \mathrm{E}+00$ & $0.00 \mathrm{E}+00$ & $0.00 \mathrm{E}+00$ & $0.00 \mathrm{E}+00$ & $0.00 \mathrm{E}+00$ & $0.00 \mathrm{E}+00$ & $0.00 \mathrm{E}+00$ & $0.00 \mathrm{E}+00$ & $0.00 \mathrm{E}+00$ & $0.00 \mathrm{E}+00$ & $0.00 \mathrm{E}+00$ \\
\hline 218-E-Cores & 42E-03 & $2.37 \mathrm{E}-03$ & 2.33E-03 & $2.29 \mathrm{E}-03$ & $2.26 \mathrm{E}-03$ & 2.21E-03 & 2.18E-03 & $2.14 \mathrm{E}-03$ & 2.11E-03 & 2.06E-03 & 2.03E-03 & 1.99E-03 & $1.96 \mathrm{E}-03$ & 1.92E-03 & 1.89E-03 & $1.85 \mathrm{E}-03$ \\
\hline$-L L W$ & 08E-02 & 1.06E-02 & $1.05 \mathrm{E}-02$ & 1.03E-02 & 01E-02 & 9.92E-03 & 9.75E-03 & $9.58 \mathrm{E}-03$ & 9.44E-03 & $9.25 \mathrm{E}-03$ & $9.08 \mathrm{E}-03$ & 8.92E-03 & $3.79 \mathrm{E}-03$ & 61E-03 & 8.46E-03 & $31 \mathrm{E}-03$ \\
\hline V-3A & DOE+00 & $0.00 \mathrm{E}+00$ & $0.00 \mathrm{E}+00$ & $0.00 \mathrm{E}+00$ & $00 \mathrm{E}+00$ & $00 \mathrm{E}+00$ & $0.00 \mathrm{E}+00$ & $0.00 \mathrm{E}+00$ & $.00 \mathrm{E}+00$ & $.00 \mathrm{E}+00$ & $0.00 \mathrm{E}+00$ & $0.00 \mathrm{E}+00$ & $0.00 \mathrm{E}+00$ & $0.00 \mathrm{E}+00$ & $0.00 \mathrm{E}+00$ & $.00 \mathrm{E}+00$ \\
\hline V-3AE & DOE+00 & $.00 \mathrm{E}+00$ & $0.00 \mathrm{E}+00$ & $.00 \mathrm{E}+00$ & $00 \mathrm{E}+00$ & $00 \mathrm{E}+00$ & $0.00 \mathrm{E}+00$ & $0.00 \mathrm{E}+00$ & $E+00$ & $\mathrm{DE}+00$ & $0 \mathrm{E}+00$ & $E+00$ & $E+00$ & $E+00$ & $0 \mathrm{E}+00$ & $.00 \mathrm{E}+00$ \\
\hline$-4 B$ & $=00$ & $=00$ & $00 \mathrm{E}+00$ & $E+00$ & $=00$ & +00 & $=+00$ & +00 & DOE+00 & $00 \mathrm{E}+00$ & $00 \mathrm{E}+00$ & $00 \mathrm{E}+00$ & $0.00 \mathrm{E}+00$ & $\mathrm{DE}+00$ & $.00 \mathrm{E}+00$ & $.00 \mathrm{E}+00$ \\
\hline$-4 C$ & +00 & $E+00$ & $E+00$ & $E+00$ & +00 & $E+00$ & $E+00$ & $E+00$ & $E+00$ & $E+00$ & $\mathrm{E}+00$ & $E+00$ & $E+00$ & $E+00$ & $E+00$ & +00 \\
\hline & +00 & +00 & +00 & +00 & $E+00$ & $=00$ & $=+00$ & $=00$ & $E+00$ & $E+00$ & $\mathrm{E}+00$ & +00 & $E+00$ & $E+00$ & $\mathrm{E}+00$ & \\
\hline & +00 & $E+00$ & 0.00 & +00 & +00 & $E+00$ & +00 & $E+00$ & $=+00$ & $E+00$ & $=+00$ & +00 & +00 & +00 & +00 & +00 \\
\hline & $=00$ & +00 & $0.00 \mathrm{E}+00$ & $E+00$ & $E+00$ & $E+00$ & $E+00$ & $E+00$ & $E+00$ & $E+00$ & $.00 \mathrm{E}+00$ & $E+00$ & $E+00$ & $=00$ & +00 & +00 \\
\hline 103 & $0 \mathrm{E}+00$ & $00 \mathrm{E}+00$ & $0.00 \mathrm{E}+00$ & $0.00 \mathrm{E}+00$ & $00 \mathrm{E}+00$ & $0.00 \mathrm{E}+00$ & $0.00 \mathrm{E}+00$ & $0.00 \mathrm{E}+00$ & $0.00 \mathrm{E}+00$ & $0.00 \mathrm{E}+00$ & $0.00 \mathrm{E}+00$ & $0.00 \mathrm{E}+00$ & $0.00 \mathrm{E}+00$ & $0.00 \mathrm{E}+00$ & $0.00 \mathrm{E}+00$ & $0.00 \mathrm{E}+00$ \\
\hline & $3 \mathrm{E}-05$ & 23E-05 & 1.23E-05 & 1.23E-05 & 23E-05 & 23E-05 & 1.23E-05 & 1.23E-05 & 1.23E-05 & 1.23E-05 & 1.23E-05 & $1.23 \mathrm{E}-05$ & 1.23E-05 & 1.23E-05 & 1.23E-05 & 1.23E-05 \\
\hline-105 & $50 \mathrm{E}+00$ & $4.93 \mathrm{E}+00$ & $4.40 \mathrm{E}+00$ & $.97 \mathrm{E}+00$ & $61 \mathrm{E}+00$ & $3.29 \mathrm{E}+00$ & $3.03 E+00$ & $2.81 \mathrm{E}+00$ & $2.63 E+00$ & $2.47 \mathrm{E}+00$ & $2.35 \mathrm{E}+00$ & $2.27 \mathrm{E}+00$ & $2.24 \mathrm{E}+00$ & $2.26 \mathrm{E}+00$ & $2.34 \mathrm{E}+00$ & $2.45 E+00$ \\
\hline 241-A-106 & $00 \mathrm{E}+00$ & $0.00 \mathrm{E}+00$ & $0.00 \mathrm{E}+00$ & $.00 \mathrm{E}+00$ & $.00 \mathrm{E}+00$ & $0.00 \mathrm{E}+00$ & $0.00 \mathrm{E}+00$ & $0.00 \mathrm{E}+00$ & $0.00 \mathrm{E}+00$ & $0.00 E+00$ & $0.00 \mathrm{E}+00$ & $0.00 \mathrm{E}+00$ & $0.00 \mathrm{E}+00$ & $0.00 \mathrm{E}+00$ & $0.00 \mathrm{E}+00$ & $0.00 \mathrm{E}+00$ \\
\hline 241-AN-101 & $00 \mathrm{E}+00$ & $0.00 \mathrm{E}+00$ & $0.00 \mathrm{E}+00$ & $.00 \mathrm{E}+00$ & $00 \mathrm{E}+00$ & $0.00 \mathrm{E}+00$ & $0.00 \mathrm{E}+00$ & $0.00 \mathrm{E}+00$ & $0.00 \mathrm{E}+00$ & $0.00 \mathrm{E}+00$ & $0.00 \mathrm{E}+00$ & $0.00 \mathrm{E}+00$ & $0.00 \mathrm{E}+00$ & $0.00 \mathrm{E}+00$ & $0.00 \mathrm{E}+00$ & $0.00 \mathrm{E}+00$ \\
\hline $\mathrm{N}-102$ & $00 \mathrm{E}+00$ & $0.00 \mathrm{E}+00$ & $0.00 \mathrm{E}+00$ & $.00 \mathrm{E}+00$ & $.00 \mathrm{E}+00$ & $0.00 \mathrm{E}+00$ & $0.00 \mathrm{E}+00$ & $0.00 \mathrm{E}+00$ & $0.00 \mathrm{E}+00$ & $0.00 E+00$ & $0.00 \mathrm{E}+00$ & $0.00 \mathrm{E}+00$ & $0.00 E+00$ & $0.00 E+00$ & $0.00 \mathrm{E}+00$ & $0.00 \mathrm{E}+00$ \\
\hline $\mathrm{N}-103$ & $00 \mathrm{E}+00$ & $0.00 \mathrm{E}+00$ & $0.00 \mathrm{E}+00$ & $.00 \mathrm{E}+00$ & $00 \mathrm{E}+00$ & $0.00 \mathrm{E}+00$ & $0.00 \mathrm{E}+00$ & $0.00 \mathrm{E}+00$ & $0.00 \mathrm{E}+00$ & $0.00 \mathrm{E}+00$ & $0.00 \mathrm{E}+00$ & $0.00 \mathrm{E}+00$ & $0.00 \mathrm{E}+00$ & $0.00 \mathrm{E}+00$ & $0.00 \mathrm{E}+00$ & $0.00 \mathrm{E}+00$ \\
\hline & $0 \mathrm{E}+00$ & $0.00 \mathrm{E}+00$ & $0.00 \mathrm{E}+00$ & $0.00 \mathrm{E}+00$ & $0.00 \mathrm{E}+00$ & $0.00 \mathrm{E}+00$ & $0.00 \mathrm{E}+00$ & $0.00 \mathrm{E}+00$ & $0.00 \mathrm{E}+00$ & $0.00 \mathrm{E}+00$ & $0.00 \mathrm{E}+00$ & $0.00 \mathrm{E}+00$ & $0.00 \mathrm{E}+00$ & $0.00 \mathrm{E}+00$ & $0.00 \mathrm{E}+00$ & $0.00 \mathrm{E}+00$ \\
\hline $241-$ & $00 \mathrm{E}+00$ & $0.00 \mathrm{E}+00$ & $0.00 \mathrm{E}+00$ & $0.00 \mathrm{E}+00$ & $0.00 \mathrm{E}+00$ & $0.00 \mathrm{E}+00$ & $0.00 \mathrm{E}+00$ & $0.00 \mathrm{E}+00$ & $0.00 \mathrm{E}+00$ & $0.00 \mathrm{E}+00$ & $0.00 \mathrm{E}+00$ & $0.00 \mathrm{E}+00$ & $0.00 \mathrm{E}+00$ & $0.00 \mathrm{E}+00$ & $0.00 \mathrm{E}+00$ & $0.00 \mathrm{E}+00$ \\
\hline 241-AN-106 & $0.00 \mathrm{E}+00$ & $0.00 \mathrm{E}+00$ & $0.00 \mathrm{E}+00$ & $0.00 \mathrm{E}+00$ & $0.00 \mathrm{E}+00$ & $0.00 \mathrm{E}+00$ & $0.00 \mathrm{E}+00$ & $0.00 \mathrm{E}+00$ & $0.00 \mathrm{E}+00$ & $0.00 \mathrm{E}+00$ & $0.00 \mathrm{E}+00$ & $0.00 \mathrm{E}+00$ & $0.00 \mathrm{E}+00$ & $0.00 \mathrm{E}+00$ & $0.00 E+00$ & U.UUE +00 \\
\hline
\end{tabular}




\begin{tabular}{|c|c|c|c|c|c|c|c|c|c|c|c|c|c|c|c|c|}
\hline Site & 1976 & 1977 & 1978 & 1979 & 1980 & 1981 & 1982 & 1983 & 1984 & 1985 & 1986 & 1987 & 1988 & 1989 & 1990 & 1991 \\
\hline 41-AN-107 & $00 \mathrm{E}+00$ & $0.00 \mathrm{E}+00$ & $0.00 \mathrm{E}+00$ & $.00 \mathrm{E}+00$ & $.00 \mathrm{E}+00$ & $0.00 \mathrm{E}+00$ & $0.00 \mathrm{E}+00$ & $0.00 \mathrm{E}+00$ & $0.00 \mathrm{E}+00$ & $0.00 \mathrm{E}+00$ & $0.00 \mathrm{E}+00$ & $0.00 \mathrm{E}+00$ & $0.00 E+00$ & $0.00 \mathrm{E}+00$ & $0.00 \mathrm{E}+00$ & $0.00 E+00$ \\
\hline & $0 \mathrm{E}+00$ & $00 \mathrm{E}+00$ & $0.00 \mathrm{E}+00$ & $00 \mathrm{E}+00$ & $00 \mathrm{E}+00$ & $00 \mathrm{E}+00$ & $0.00 \mathrm{E}+00$ & $0.00 \mathrm{E}+00$ & $.00 \mathrm{E}+00$ & $.00 \mathrm{E}+00$ & $0.00 \mathrm{E}+00$ & $0.00 \mathrm{E}+00$ & $0.00 \mathrm{E}+00$ & $.00 \mathrm{E}+00$ & $0.00 \mathrm{E}+00$ & $00 \mathrm{E}+00$ \\
\hline -AP-102 & DOE+00 & $0.00 \mathrm{E}+00$ & $0.00 \mathrm{E}+00$ & $00 \mathrm{E}+00$ & $00 \mathrm{E}+00$ & $00 \mathrm{E}+00$ & $0.00 \mathrm{E}+00$ & $0.00 \mathrm{E}+00$ & $0.00 \mathrm{E}+00$ & $00 \mathrm{E}+00$ & $0.00 \mathrm{E}+00$ & $0.00 \mathrm{E}+00$ & $0.00 E+00$ & $0.00 E+00$ & $00 \mathrm{E}+00$ & $00 \mathrm{E}+00$ \\
\hline -AP-103 & $00 \mathrm{E}+00$ & $.00 \mathrm{E}+00$ & $0.00 \mathrm{E}+00$ & $00 \mathrm{E}+00$ & $00 \mathrm{E}+00$ & $0.00 \mathrm{E}+00$ & $0.00 \mathrm{E}+00$ & $0.00 \mathrm{E}+00$ & $0.00 \mathrm{E}+00$ & $0.00 \mathrm{E}+00$ & $0.00 \mathrm{E}+00$ & $0.00 \mathrm{E}+00$ & $0.00 \mathrm{E}+00$ & $.00 \mathrm{E}+00$ & $0.00 \mathrm{E}+00$ & $0.00 \mathrm{E}+00$ \\
\hline & $E+00$ & $0.00 \mathrm{E}+00$ & $0.00 \mathrm{E}+00$ & $0.00 \mathrm{E}+00$ & $00 \mathrm{E}+00$ & $00 \mathrm{E}+00$ & $0.00 \mathrm{E}+00$ & $0.00 \mathrm{E}+00$ & $0.00 \mathrm{E}+00$ & $0.00 \mathrm{E}+00$ & $0.00 \mathrm{E}+00$ & $0.00 \mathrm{E}+00$ & $0.00 \mathrm{E}+00$ & $0.00 \mathrm{E}+00$ & $0.00 \mathrm{E}+00$ & $.00 \mathrm{E}+00$ \\
\hline & $=00$ & $0.00 \mathrm{E}+00$ & $0.00 E+00$ & $0.00 \mathrm{E}+\mathrm{C}$ & $00 \mathrm{E}+00$ & $0.00 \mathrm{E}+00$ & $00 \mathrm{E}+00$ & $0.00 \mathrm{E}+00$ & $0.00 \mathrm{E}+00$ & $0.00 \mathrm{E}+00$ & $0.00 \mathrm{E}+00$ & $0.00 \mathrm{E}+00$ & $0.00 \mathrm{E}+00$ & $0.00 E+00$ & $0.00 \mathrm{E}+00$ & $0.00 E+00$ \\
\hline & $E+00$ & $00 \mathrm{E}+00$ & $0.00 E+00$ & $0.00 \mathrm{E}+00$ & $00 \mathrm{E}+00$ & $00 \mathrm{E}+00$ & $00 \mathrm{E}+00$ & $0.00 \mathrm{E}+00$ & $00 \mathrm{E}+00$ & $.00 \mathrm{E}+00$ & $0 \mathrm{E}+00$ & $0.00 \mathrm{E}+00$ & $0.00 E+00$ & $.00 \mathrm{E}+00$ & $.00 \mathrm{E}+00$ & $00 \mathrm{E}+00$ \\
\hline & $=00$ & $E+00$ & $\mathrm{E}+00$ & $.00 \mathrm{E}+00$ & $0 \mathrm{E}+00$ & $E+00$ & $0.00 \mathrm{E}+00$ & $0.00 \mathrm{E}+00$ & $0.00 \mathrm{E}+00$ & $0 \mathrm{E}+00$ & $.00 \mathrm{E}+00$ & $0.00 \mathrm{E}+00$ & $0.00 \mathrm{E}+00$ & $0.00 \mathrm{E}+00$ & $0.00 \mathrm{E}+00$ & $\mathrm{DE}+00$ \\
\hline & +00 & $E+00$ & $E+00$ & $E+00$ & $\mathrm{E}+00$ & $E+00$ & $E+00$ & $E+00$ & $E+00$ & $E+00$ & $\mathrm{DE}+00$ & $0.00 \mathrm{E}+00$ & $0.00 \mathrm{E}+00$ & $\mathrm{DE}+00$ & $\mathrm{DE}+00$ & $\mathrm{E}+00$ \\
\hline & $E+00$ & $E+00$ & $E+00$ & $=00$ & $\mathrm{E}+00$ & $E+00$ & $E+00$ & $E+00$ & $E+00$ & $E+00$ & $E+00$ & $0 \mathrm{E}+00$ & $\mathrm{DE}+00$ & $E+00$ & & \\
\hline-102 & $E+00$ & $0.00 \mathrm{E}+00$ & $0.00 \mathrm{E}+00$ & $0.00 \mathrm{E}+00$ & $00 \mathrm{E}+00$ & $0 \mathrm{E}+00$ & $0.00 \mathrm{E}+00$ & $0.00 \mathrm{E}+00$ & $.00 \mathrm{E}+00$ & $00 \mathrm{E}+00$ & $0.00 \mathrm{E}+00$ & $0.00 \mathrm{E}+00$ & $0.00 \mathrm{E}+00$ & $0.00 \mathrm{E}+00$ & $0.00 \mathrm{E}+00$ & \\
\hline 241-AW-103 & $00 \mathrm{E}+00$ & $0.00 \mathrm{E}+00$ & $0.00 \mathrm{E}+00$ & $0.00 \mathrm{E}+00$ & $00 \mathrm{E}+00$ & $00 \mathrm{E}+00$ & $0.00 E+00$ & $0.00 \mathrm{E}+00$ & $0.00 \mathrm{E}+00$ & $0.00 E+00$ & $0.00 \mathrm{E}+00$ & $0.00 \mathrm{E}+00$ & $0.00 \mathrm{E}+00$ & $0.00 E+00$ & $0.00 \mathrm{E}+00$ & $.00 \mathrm{E}+00$ \\
\hline W-104 & $0 \mathrm{E}+00$ & $0.00 \mathrm{E}+00$ & $0.00 \mathrm{E}+00$ & $0.00 \mathrm{E}+00$ & $00 \mathrm{E}+00$ & $00 \mathrm{E}+00$ & $0.00 \mathrm{E}+00$ & $0.00 \mathrm{E}+00$ & $0.00 \mathrm{E}+00$ & $0.00 \mathrm{E}+00$ & $0.00 \mathrm{E}+00$ & $0.00 \mathrm{E}+00$ & $0.00 \mathrm{E}+00$ & $0.00 \mathrm{E}+00$ & $.00 \mathrm{E}+00$ & $0 \mathrm{E}+00$ \\
\hline & $0 \mathrm{E}+00$ & $0.00 \mathrm{E}+00$ & $0.00 \mathrm{E}+00$ & $.00 \mathrm{E}+00$ & $00 \mathrm{E}+00$ & $00 \mathrm{E}+00$ & $0.00 \mathrm{E}+00$ & $0.00 \mathrm{E}+00$ & $.00 \mathrm{E}+00$ & $.00 \mathrm{E}+00$ & $0.00 \mathrm{E}+00$ & $0.00 \mathrm{E}+00$ & $0.00 \mathrm{E}+00$ & $.00 \mathrm{E}+00$ & $0 \mathrm{E}+00$ & $0 \mathrm{E}+00$ \\
\hline & $\mathrm{E}+00$ & $00 \mathrm{E}+00$ & $0.00 \mathrm{E}+00$ & $00 \mathrm{E}+00$ & $00 \mathrm{E}+00$ & $00 \mathrm{E}+00$ & $0.00 \mathrm{E}+00$ & $0.00 \mathrm{E}+00$ & $.00 \mathrm{E}+00$ & $0 \mathrm{E}+00$ & $.00 \mathrm{E}+00$ & $0.00 \mathrm{E}+00$ & $0.00 \mathrm{E}+00$ & $.00 \mathrm{E}+00$ & $0 \mathrm{E}+00$ & $.00 \mathrm{E}+00$ \\
\hline & $E+00$ & $E+00$ & $0.00 \mathrm{E}+00$ & & $\mathrm{E}+00$ & $E+00$ & $\mathrm{E}+00$ & & $0 \mathrm{E}+00$ & $E+00$ & $\mathrm{DE}+00$ & $0.00 \mathrm{E}+$ & $0 \mathrm{E}+00$ & $\mathrm{DE}+00$ & $0 \mathrm{E}+00$ & $\mathrm{E}+00$ \\
\hline & $E+00$ & $E+00$ & $E+00$ & $E+00$ & $E+00$ & $E+00$ & $E+00$ & $E+00$ & $E+00$ & $\mathrm{DE}+00$ & $\mathrm{E}+00$ & $0.00 \mathrm{E}+00$ & $0.00 \mathrm{E}+00$ & $0 \mathrm{E}+00$ & $0 \mathrm{E}+00$ & $0.00 \mathrm{E}+00$ \\
\hline & $E+00$ & $E+00$ & $E+00$ & $E+00$ & $E+00$ & $E+00$ & $\mathrm{E}+00$ & $0.00 \mathrm{E}+00$ & $0.00 \mathrm{E}+00$ & $E+00$ & $E+00$ & $0.00 \mathrm{E}+00$ & $0.00 E+00$ & $0 \mathrm{E}+00$ & $E+00$ & $0 \mathrm{E}+00$ \\
\hline & $E+00$ & $E+00$ & $0.00 \mathrm{E}+00$ & $0.00 \mathrm{E}+00$ & $E+00$ & $E+00$ & $0.00 \mathrm{E}+00$ & $0.00 \mathrm{E}+00$ & $0.00 \mathrm{E}+00$ & $\mathrm{DE}+00$ & $0 \mathrm{E}+00$ & $0.00 \mathrm{E}+00$ & $0.00 \mathrm{E}+00$ & $0.00 \mathrm{E}+00$ & $\mathrm{DE}+00$ & $0.00 \mathrm{E}+00$ \\
\hline & $0 \mathrm{E}+00$ & $0.00 \mathrm{E}+00$ & $0.00 \mathrm{E}+00$ & $0.00 \mathrm{E}+00$ & $00 \mathrm{E}+00$ & $00 \mathrm{E}+00$ & $0.00 \mathrm{E}+00$ & $0.00 \mathrm{E}+00$ & $0.00 \mathrm{E}+00$ & $0.00 \mathrm{E}+00$ & $0.00 \mathrm{E}+00$ & $0.00 \mathrm{E}+00$ & $0.00 \mathrm{E}+00$ & $0.00 \mathrm{E}+00$ & $0.00 \mathrm{E}+00$ & $0.00 \mathrm{E}+00$ \\
\hline 102 & $0 E+00$ & $00 \mathrm{E}+00$ & $0.00 E+00$ & $0.00 \mathrm{E}+00$ & $00 \mathrm{E}+00$ & $00 \mathrm{E}+00$ & $0.00 \mathrm{E}+00$ & $0.00 \mathrm{E}+00$ & $0.00 \mathrm{E}+00$ & $0.00 \mathrm{E}+00$ & $0.00 \mathrm{E}+00$ & $0.00 \mathrm{E}+00$ & $0.00 E+00$ & $0.00 \mathrm{E}+00$ & $0.00 \mathrm{E}+00$ & $0.00 E+00$ \\
\hline L01 & $E+00$ & $00 E+00$ & $0.00 \mathrm{E}+00$ & $.00 \mathrm{E}+00$ & $00 \mathrm{E}+00$ & $00 \mathrm{E}+00$ & $0.00 \mathrm{E}+00$ & $0.00 \mathrm{E}+00$ & $0.00 \mathrm{E}+00$ & $00 \mathrm{E}+00$ & $0.00 \mathrm{E}+00$ & $0.00 \mathrm{E}+00$ & $0.00 \mathrm{E}+00$ & $0.00 \mathrm{E}+00$ & $0.00 \mathrm{E}+00$ & $0.00 \mathrm{E}+00$ \\
\hline 241-AZ-102 & $00 \mathrm{E}+00$ & $0.00 \mathrm{E}+00$ & $0.00 E+00$ & $0.00 \mathrm{E}+00$ & $00 \mathrm{E}+00$ & $0.00 \mathrm{E}+00$ & $0.00 \mathrm{E}+00$ & $0.00 E+00$ & $0.00 \mathrm{E}+00$ & $0.00 E+00$ & $0.00 \mathrm{E}+00$ & $0.00 \mathrm{E}+00$ & $0.00 E+00$ & $0.00 E+00$ & $0.00 \mathrm{E}+00$ & $0.00 \mathrm{E}+00$ \\
\hline & $80 \mathrm{E}-02$ & $4.74 \mathrm{E}-01$ & 7.59E-01 & $8.24 \mathrm{E}-01$ & $36 \mathrm{E}-01$ & $35 \mathrm{E}-01$ & 8.35E-01 & 8.35E-01 & 8.37E-01 & 35E-01 & 8.35E-01 & 8.35E-01 & 8.37E-01 & $35 \mathrm{E}-01$ & $35 \mathrm{E}-01$ & $5 \mathrm{E}-01$ \\
\hline & $0 \mathrm{E}-02$ & 73E-01 & $7.59 \mathrm{E}-01$ & 24E-01 & 36E-01 & 34E-01 & 35E-01 & .35E-01 & 8.37E-01 & 8.35E-01 & $35 \mathrm{E}-01$ & 8.35E-01 & $37 \mathrm{E}-01$ & 35E-01 & 35E-01 & $5 \mathrm{E}-01$ \\
\hline & 0E-02 & $3 \mathrm{E}-01$ & 7.59E-01 & 4E-01 & $36 \mathrm{E}-01$ & EE-01 & $5 \mathrm{E}-01$ & 5E-01 & EE-01 & E-01 & $5 \mathrm{E}-01$ & 8.35E-01 & -01 & $35 \mathrm{E}-01$ & 35E-01 & $5 \mathrm{E}-01$ \\
\hline & $E-03$ & 0E-02 & $3 \mathrm{E}-01$ & $E-01$ & $\mathrm{E}-01$ & E-01 & E-01 & -01 & 01 & E-01 & $5 \mathrm{E}-01$ & & -01 & & E-01 & -01 \\
\hline & +00 & $=00$ & $\mathrm{E}+00$ & & $E-01$ & E-01 & E-01 & & -01 & $\mathrm{E}-01$ & E-01 & & & & EE-01 & $E-01$ \\
\hline & & -04 & $E-02$ & & $\mathrm{E}-01$ & -01 & $\mathrm{E}-01$ & & & $E-01$ & 4E-01 & & & & E-01 & \\
\hline & $E-01$ & $=-01$ & & & & $\mathrm{E}-01$ & -01 & & & E-01 & E-01 & & & & $5 \mathrm{E}-01$ & \\
\hline & $E-02$ & $E-01$ & $\mathrm{E}-01$ & 1 & $E-01$ & E-01 & $6 \mathrm{E}-01$ & $8.36 \mathrm{E}$. & BE-01 & E-01 & $6 \mathrm{E}-01$ & $8.36 \mathrm{E}$ & & $6 \mathrm{E}-01$ & $6 \mathrm{E}-01$ & 6E-01 \\
\hline & E-03 & 90E-02 & 73E-01 & $7.58 \mathrm{E}-01$ & 26E-01 & E-01 & $.35 \mathrm{E}-01$ & 35E-01 & 7E-01 & 5E-01 & 8.35E-01 & 8.35E-01 & 8.37E-01 & 8.35E-01 & $8.35 \mathrm{E}-01$ & 8.35E-01 \\
\hline & $\mathrm{HE}+00$ & $1.65 \mathrm{E}+00$ & $1.39 \mathrm{E}+00$ & $21 \mathrm{E}+00$ & $09 \mathrm{E}+00$ & $5 \mathrm{E}-01$ & 33E-01 & 8.92E-01 & $68 \mathrm{E}-01$ & 51E-01 & $8.42 \mathrm{E}-01$ & 8.38E-01 & 8.38E-01 & 8.35E-01 & $8.35 \mathrm{E}-01$ & $8.35 \mathrm{E}-01$ \\
\hline & 30E-02 & 4.74E-01 & 7.59E-01 & 8.24E-01 & 8.36E-01 & 35E-01 & 8.35E-01 & 8.35E-01 & $8.37 \mathrm{E}-01$ & 8.35E-01 & 8.35E-01 & 8.35E-01 & 8.37E-01 & 8.35E-01 & $8.35 \mathrm{E}-01$ & $8.35 \mathrm{E}-01$ \\
\hline 241-B-112 & 29E-03 & 7.91E-02 & 4.74E-01 & $7.59 \mathrm{E}-01$ & 8.27E-01 & 8.34E-01 & 8.35E-01 & 8.36E-01 & $8.38 \mathrm{E}-01$ & 8.36E-01 & 8.36E-01 & 8.36E-01 & 8.38E-01 & 8.36E-01 & $8.36 \mathrm{E}-01$ & 8.36E-01 \\
\hline$-B-201$ & $85 \mathrm{E}-02$ & $6.45 \mathrm{E}-02$ & $6.21 \mathrm{E}-02$ & $6.07 \mathrm{E}-02$ & $6.00 \mathrm{E}-02$ & 5.95E-02 & 5.93E-02 & 5.92E-02 & 5.93E-02 & 5.92E-02 & $5.92 \mathrm{E}-02$ & 5.92E-02 & 5.93E-02 & 5.92E-02 & $5.92 \mathrm{E}-02$ & $5.92 \mathrm{E}-02$ \\
\hline$-B-202$ & 2.96E-09 & $2.95 \mathrm{E}-09$ & $2.95 \mathrm{E}-09$ & $2.95 \mathrm{E}-09$ & 2.26E-07 & $6.90 \mathrm{E}-05$ & 1.78E-03 & 3.43E-02 & $5.65 \mathrm{E}-02$ & $5.90 \mathrm{E}-02$ & $5.93 \mathrm{E}-02$ & 5.93E-02 & $5.94 \mathrm{E}-02$ & 5.93E-02 & $5.93 \mathrm{E}-02$ & $5.93 \mathrm{E}-02$ \\
\hline 241-B-203 & 68E-02 & 34E-02 & 14E-02 & 6.03E-02 & 5.98E-02 & 5.94E-02 & 5.92E-02 & $5.92 \mathrm{E}-02$ & 5.93E-02 & 5.91E-02 & 5.91E-02 & 5.91E-02 & 5.93E-02 & 5.91E-02 & $5.91 \mathrm{E}-02$ & $5.91 \mathrm{E}-02$ \\
\hline $1-B-204$ & $6.67 \mathrm{E}-02$ & $6.34 \mathrm{E}-02$ & $6.15 \mathrm{E}-02$ & $6.04 \mathrm{E}-02$ & $5.99 \mathrm{E}-02$ & 5.94E-02 & 5.93E-02 & 5.92E-02 & 5.93E-02 & 5.92E-02 & $5.92 \mathrm{E}-02$ & 5.92E-02 & 5.93E-02 & 5.92E-02 & 5.92E-02 & $5.92 \mathrm{E}-02$ \\
\hline 241-BX-101 & $4.55 \mathrm{E}-01$ & $2.14 \mathrm{E}+00$ & $1.86 \mathrm{E}+00$ & $1.53 \mathrm{E}+00$ & $1.31 \mathrm{E}+00$ & $1.15 \mathrm{E}+00$ & $1.03 \mathrm{E}+00$ & $9.55 \mathrm{E}-01$ & $9.06 \mathrm{E}-01$ & 8.71E-01 & 8.53E-01 & 8.43E-01 & 8.41E-01 & 8.36E-01 & 8.36E-01 & 8.35E-01 \\
\hline 241-BX-102 & 8.37E-01 & $8.35 \mathrm{E}-01$ & 8.36E-01 & 8.36E-01 & $8.38 \mathrm{E}-01$ & 8.36E-01 & 8.36E-01 & 8.36E-01 & 8.38E-01 & 8.36E-01 & 8.36E-01 & 8.36E-01 & 8.38E-01 & 8.36E-01 & 8.36E-01 & 8.36E-01 \\
\hline
\end{tabular}




\begin{tabular}{|c|c|c|c|c|c|c|c|c|c|c|c|c|c|c|c|c|}
\hline Site & 1976 & 1977 & 1978 & 1979 & 1980 & 1981 & 1982 & 1983 & 1984 & 1985 & 1986 & 1987 & 1988 & 1989 & 1990 & 1991 \\
\hline & 64E-08 & .11E-06 & $9.72 \mathrm{E}-04$ & $2.47 \mathrm{E}-02$ & $4.86 \mathrm{E}-01$ & $7.93 \mathrm{E}-01$ & 8.31E-01 & 8.35E-01 & 8.37E-01 & 8.35E-01 & 8.35E-01 & $8.35 \mathrm{E}-01$ & 8.37E-01 & $8.35 \mathrm{E}-01$ & 8.35E-01 & 8.35E-01 \\
\hline 241-BX-104 & $22 \mathrm{E}-08$ & $5.21 \mathrm{E}-08$ & 39E-06 & $1.03 \mathrm{E}-03$ & $7.80 \mathrm{E}-02$ & $4.73 \mathrm{E}-01$ & $7.59 \mathrm{E}-01$ & $8.24 \mathrm{E}-01$ & $8.36 \mathrm{E}-01$ & 8.34E-01 & $8.35 \mathrm{E}-01$ & $35 \mathrm{E}-01$ & $37 \mathrm{E}-01$ & 8.35E-01 & $8.35 \mathrm{E}-01$ & $8.35 \mathrm{E}-01$ \\
\hline 241-BX-105 & $5.22 \mathrm{E}-08$ & $5.21 \mathrm{E}-08$ & 39E-06 & 1.03E-03 & $7.80 \mathrm{E}-02$ & $4.74 \mathrm{E}-01$ & 7.59E-01 & $8.24 \mathrm{E}-01$ & $36 \mathrm{E}-01$ & 8.35E-01 & 8.35E-01 & $35 \mathrm{E}-01$ & $37 \mathrm{E}-01$ & $35 \mathrm{E}-01$ & $35 \mathrm{E}-01$ & $35 \mathrm{E}-01$ \\
\hline & $5.22 \mathrm{E}-08$ & $5.21 \mathrm{E}-08$ & $3.39 \mathrm{E}-06$ & $1.03 \mathrm{E}-03$ & 7.81E-02 & $4.74 \mathrm{E}-01$ & $7.60 \mathrm{E}-01$ & $8.25 \mathrm{E}-01$ & $36 \mathrm{E}-01$ & 8.35E-01 & $8.35 \mathrm{E}-01$ & $8.35 \mathrm{E}-01$ & $8.38 \mathrm{E}-01$ & $8.35 \mathrm{E}-01$ & $35 \mathrm{E}-01$ & 35E-01 \\
\hline & $3.64 \mathrm{E}-08$ & $3.11 E-06$ & $9.72 \mathrm{E}-04$ & 47E-02 & 4.86E-01 & $7.94 \mathrm{E}-01$ & 8.31E-01 & $8.35 \mathrm{E}-01$ & 8.37E-01 & $8.35 \mathrm{E}-01$ & $35 \mathrm{E}-01$ & $35 \mathrm{E}-01$ & 8.37E-01 & & & $35 \mathrm{E}-01$ \\
\hline & & & 39E-06 & & 81E-02 & $4.74 \mathrm{E}-01$ & $7.60 \mathrm{E}$ & $8.25 \mathrm{E}-01$ & $36 \mathrm{E}-01$ & 8.35E-01 & $36 \mathrm{E}-01$ & 8.36E-01 & $38 \mathrm{E}-01$ & -01 & 8.36E-01 & 36E-01 \\
\hline & $E-08$ & & $6.47 \mathrm{E}-08$ & & $1.29 \mathrm{E}-03$ & $7.90 \mathrm{E}-02$ & $4.73 \mathrm{E}-01$ & $7.58 \mathrm{E}-01$ & $8.26 \mathrm{E}-01$ & $8.33 \mathrm{E}-01$ & $8.35 \mathrm{E}-01$ & 8.35E-01 & $8.37 \mathrm{E}-01$ & & & $35 \mathrm{E}-01$ \\
\hline & $E-08$ & E-08 & 3.39E-06 & E-03 & $7.80 \mathrm{E}-02$ & 4.73E-01 & 7.59E-01 & 8.24E-01 & 8.36E-01 & 8.34E-01 & 8.35E-01 & 8.35E-01 & 8.37E-01 & 8.35E-01 & $35 \mathrm{E}-01$ & $35 \mathrm{E}-01$ \\
\hline & $E-01$ & $E-01$ & 8.81E-01 & $=-01$ & E-01 & E-01 & $38 \mathrm{E}-01$ & $8.36 \mathrm{E}-01$ & $38 \mathrm{E}-01$ & 5E-01 & $35 \mathrm{E}-01$ & $35 \mathrm{E}-01$ & 37E-01 & 5E-01 & $35 \mathrm{E}-01$ & \\
\hline & $E-08$ & $E-08$ & $6.47 \mathrm{E}-08$ & $=-07$ & & & $4.74 \mathrm{E}-01$ & $7.59 \mathrm{E}-01$ & & & $35 \mathrm{E}-01$ & $35 \mathrm{E}-01$ & & & & \\
\hline & 48E-08 & $6.46 \mathrm{E}-08$ & $6.46 \mathrm{E}-08$ & E-07 & 29E-03 & $7.89 \mathrm{E}-02$ & $4.73 \mathrm{E}-01$ & $7.58 \mathrm{E}-01$ & $25 \mathrm{E}-01$ & 3E-01 & $8.34 \mathrm{E}-01$ & $34 \mathrm{E}-01$ & 8.36E-01 & $34 \mathrm{E}-01$ & & 34E-01 \\
\hline Y-102 & $6.49 \mathrm{E}-08$ & $6.47 \mathrm{E}-08$ & $6.47 \mathrm{E}-08$ & 8.06E-07 & 1.29E-03 & 7.91E-02 & $4.74 \mathrm{E}-01$ & $7.59 \mathrm{E}-01$ & $8.27 \mathrm{E}-01$ & 8.34E-01 & 8.35E-01 & $8.35 \mathrm{E}-01$ & 8.38E-01 & & 8.35E-01 & $.35 \mathrm{E}-01$ \\
\hline & $57 \mathrm{E}+00$ & $3.01 \mathrm{E}+00$ & $2.27 \mathrm{E}+00$ & $1.80 \mathrm{E}+00$ & $.50 \mathrm{E}+00$ & $1.29 \mathrm{E}+00$ & $1.14 \mathrm{E}+00$ & $1.03 \mathrm{E}+00$ & $9.62 \mathrm{E}-01$ & $9.10 \mathrm{E}-01$ & $8.78 \mathrm{E}-01$ & $8.58 \mathrm{E}-01$ & $8.49 \mathrm{E}-01$ & $40 \mathrm{E}-01$ & $8.37 \mathrm{E}-01$ & $8.36 \mathrm{E}-01$ \\
\hline & $6.48 E-08$ & 6.46E-08 & $6.46 \mathrm{E}-08$ & 8.05E-07 & $1.29 \mathrm{E}-03$ & $7.89 \mathrm{E}-02$ & $4.73 \mathrm{E}-01$ & $7.58 \mathrm{E}-01$ & $8.25 \mathrm{E}-01$ & 8.33E-01 & 8.34E-01 & 8.34E-01 & $8.36 \mathrm{E}-01$ & & 8.34E-01 & $8.34 \mathrm{E}-01$ \\
\hline & 4.17E-08 & $4.16 \mathrm{E}-08$ & $4.16 \mathrm{E}-08$ & $4.16 \mathrm{E}-08$ & $3.18 \mathrm{E}-06$ & $9.73 \mathrm{E}-04$ & $2.51 \mathrm{E}-02$ & $4.84 \mathrm{E}-01$ & $7.96 \mathrm{E}-01$ & $8.32 \mathrm{E}-01$ & 8.35E-01 & 8.35E-01 & $8.38 \mathrm{E}-01$ & & $35 \mathrm{E}-01$ & 8.35E-01 \\
\hline & $71 \mathrm{E}-08$ & $5.70 \mathrm{E}-08$ & $5.70 \mathrm{E}-08$ & $5.70 \mathrm{E}-08$ & $5.71 \mathrm{E}-08$ & $5.70 \mathrm{E}-08$ & $3.47 \mathrm{E}-06$ & 1.03E-03 & $7.80 \mathrm{E}-02$ & $4.73 \mathrm{E}-01$ & $7.59 \mathrm{E}-01$ & $8.24 \mathrm{E}-01$ & $8.36 \mathrm{E}-01$ & 5E-01 & $35 \mathrm{E}-01$ & $35 \mathrm{E}-01$ \\
\hline & $E-08$ & $6.46 \mathrm{E}-08$ & $6.46 \mathrm{E}-08$ & $=-07$ & E-03 & $7.89 \mathrm{E}-02$ & $4.73 \mathrm{E}-01$ & 58E-01 & $8.25 \mathrm{E}-01$ & 33E-01 & $34 \mathrm{E}-01$ & 8.34E-01 & 8.36E-01 & 34E-01 & 34E-01 & $34 \mathrm{E}-01$ \\
\hline & $3.01 E+00$ & $2.24 \mathrm{E}+00$ & $1.77 \mathrm{E}+00$ & $E+00$ & $1.26 \mathrm{E}+00$ & $1.11 \mathrm{E}+00$ & $1.01 \mathrm{E}+00$ & $9.38 \mathrm{E}-01$ & 8.96E-01 & $8.66 \mathrm{E}-01$ & $8.50 \mathrm{E}-01$ & $8.42 \mathrm{E}-01$ & 8.41E-01 & 8.37E- & $8.36 \mathrm{E}-01$ & 8.36E-01 \\
\hline & E-08 & $E-08$ & $5.70 \mathrm{E}-08$ & $E-08$ & $5.71 \mathrm{E}-08$ & E-08 & 47E-06 & 1.03E-03 & 7.80E-02 & 4.74E-01 & 7.59E-01 & 8.24E-01 & 8.36E-01 & 5E-01 & 8.35E-01 & 8.35E-01 \\
\hline & $6 \mathrm{E}-08$ & 4.15E-08 & $4.15 \mathrm{E}-08$ & E-08 & 18E-06 & 9.72E-04 & $2.50 \mathrm{E}-02$ & 4.83E-01 & 7.95E-01 & 8.31E-01 & 8.34E-01 & 8.34E-01 & 8.37E-01 & 8.34E-01 & $8.34 \mathrm{E}-01$ & $8.34 \mathrm{E}-01$ \\
\hline & $33 \mathrm{E}-08$ & $4.32 \mathrm{E}-08$ & $4.32 \mathrm{E}-08$ & $32 \mathrm{E}-08$ & $33 E-08$ & $3.21 \mathrm{E}-06$ & $9.73 \mathrm{E}-04$ & $2.47 \mathrm{E}-02$ & $4.86 \mathrm{E}-01$ & 7.93E-01 & $8.31 \mathrm{E}-01$ & 8.34E-01 & 8.37E-01 & $8.35 \mathrm{E}-01$ & $8.35 \mathrm{E}-01$ & 8.35E-01 \\
\hline & $7 \mathrm{E}-08$ & $16 \mathrm{E}-08$ & $4.16 \mathrm{E}-08$ & E-08 & 8E-06 & 72E-04 & $2.50 \mathrm{E}-02$ & $4.84 \mathrm{E}-01$ & $7.96 \mathrm{E}-01$ & 31E-01 & 8.35E-01 & $8.35 \mathrm{E}-01$ & $8.37 \mathrm{E}-01$ & $8.35 \mathrm{E}-01$ & $8.35 \mathrm{E}-01$ & $8.35 \mathrm{E}-01$ \\
\hline 241- & 17E-04 & 1.17E-04 & 1.17E-04 & 1.17E-04 & 17E-04 & 1.17E-04 & 1.17E-04 & 1.17E-04 & 1.17E-04 & 1.17E-04 & 1.17E-04 & 1.17E-04 & 1.17E-04 & 1.17E-04 & 1.17E-04 & 1.17E-04 \\
\hline & $7 \mathrm{E}-04$ & 17E-04 & 1.17E-04 & 17E-04 & 17E-04 & 17E-04 & 1.17E-04 & 1.17E-04 & 1.17E-04 & 17E-04 & 1.17E-04 & L.17E-04 & 1.17E-04 & .17E-04 & 1.17E-04 & $.17 \mathrm{E}-04$ \\
\hline & $7 \mathrm{E}-04$ & 17E-04 & 1.17E-04 & 17E-04 & 17E-04 & $1.17 \mathrm{E}-04$ & $1.17 \mathrm{E}-04$ & 1.17E-04 & 1.17E-04 & 17E-04 & 1.17E-04 & $.17 \mathrm{E}-04$ & 1.17E-04 & .17E-04 & .17E-04 & 1.17E-04 \\
\hline & $=-04$ & E-04 & 1.17E-04 & E-04 & E-04 & E-04 & 1.17E-04 & 1.17E-04 & 1.17E-04 & 1.17E-04 & 1.17E-04 & 1.17E-04 & 1.17E-04 & $.17 \mathrm{E}-04$ & 1.17E-04 & 1.17E-04 \\
\hline & E-04 & E-04 & $1.88 \mathrm{E}-04$ & -04 & E-04 & E-04 & 1.88E-04 & $1.88 \mathrm{E}-04$ & $=-04$ & 8E-04 & $1.88 \mathrm{E}-04$ & $1.88 \mathrm{E}-04$ & $1.88 \mathrm{E}-04$ & $.88 \mathrm{E}-04$ & $1.88 \mathrm{E}-04$ & 1.88E-04 \\
\hline & $E-04$ & $E-04$ & 04E-04 & -04 & & -04 & 04E-04 & $4 \mathrm{E}-04$ & & -04 & 1.04E-04 & 1.04E-04 & 1.04E-04 & -04 & $1.04 \mathrm{E}-04$ & $1.04 \mathrm{E}-04$ \\
\hline & & $E-04$ & & -04 & & & & $=-04$ & & -04 & 1.17E-04 & 1.17E-04 & E-04 & -04 & 1.17E-04 & $1.17 \mathrm{E}-04$ \\
\hline & & & & & & & & -04 & & & & -04 & & & & E-04 \\
\hline & -04 & $E-04$ & -04 & -04 & $E-04$ & $E-04$ & E-04 & E-04 & E-04 & -04 & 5E-04 & E-04 & E-04 & & $.05 \mathrm{E}-04$ & 1.05E-04 \\
\hline & $E-04$ & $E-04$ & 7E-04 & $=-04$ & E-04 & E-04 & 1.17E-04 & 1.17E-04 & .17E-04 & 17E-04 & 1.17E-04 & 1.17E-04 & 1.17E-04 & 1.17E-04 & 1.17E-04 & 1.17E-04 \\
\hline & E-04 & E-04 & 7E-04 & $=-04$ & F-04 & E-04 & 17E-04 & 17E-04 & 17E-04 & 7E-04 & 1.17E-04 & 1.17E-04 & 1.17E-04 & 1.17E-04 & 1.17E-04 & $1.17 \mathrm{E}-04$ \\
\hline & 17E-04 & 17E-04 & 1.17E-04 & $1.17 \mathrm{E}-04$ & $.17 \mathrm{E}-04$ & $.17 \mathrm{E}-04$ & 1.17E-04 & 1.17E-04 & 1.17E-04 & 17E-04 & 1.17E-04 & 1.17E-04 & 1.17E-04 & 1.17E-04 & 1.17E-04 & $1.17 \mathrm{E}-04$ \\
\hline 241-C-201 & $7.42 \mathrm{E}-06$ & 7.40E-06 & $7.40 \mathrm{E}-06$ & 7.40E-06 & 7.42E-06 & $7.40 \mathrm{E}-06$ & $7.40 \mathrm{E}-06$ & 7.40E-06 & $7.42 \mathrm{E}-06$ & $7.40 \mathrm{E}-06$ & $7.40 \mathrm{E}-06$ & 7.40E-06 & 7.42E-06 & 7.40E-06 & $7.40 \mathrm{E}-06$ & 7.40E-06 \\
\hline 241-C & 7.41E-06 & 7.39E-06 & 7.39E-06 & 7.39E-06 & 7.41E-06 & 7.39E-06 & 7.39E-06 & 7.39E-06 & 7.41E-06 & $7.39 \mathrm{E}-06$ & $7.39 \mathrm{E}-06$ & $7.39 \mathrm{E}-06$ & 7.41E-06 & $7.39 \mathrm{E}-06$ & $7.39 \mathrm{E}-06$ & 7.39E-06 \\
\hline $241-C$ & $7.41 \mathrm{E}-06$ & 7.39E-06 & 7.39E-06 & $7.39 \mathrm{E}-06$ & 7.41E-06 & $7.39 \mathrm{E}-06$ & $7.39 \mathrm{E}-06$ & $7.39 \mathrm{E}-06$ & 7.41E-06 & $7.39 \mathrm{E}-06$ & 7.39E-06 & 7.39E-06 & 7.41E-06 & $7.39 \mathrm{E}-06$ & $39 E-06$ & 7.39E-06 \\
\hline $241-C$ & $7.46 \mathrm{E}-06$ & 7.44E-06 & 7.44E-06 & 7.44E-06 & 7.46E-06 & 7.44E-06 & $7.44 \mathrm{E}-06$ & 7.44E-06 & 7.46E-06 & 7.44E-06 & 7.44E-06 & 7.44E-06 & $7.46 \mathrm{E}-06$ & 7.44E-06 & 7.44E-06 & 7.44E-06 \\
\hline 241-S-101 & $1.78 \mathrm{E}-08$ & 1.77E-08 & $1.77 \mathrm{E}-08$ & $1.77 \mathrm{E}-08$ & $1.78 \mathrm{E}-08$ & $1.77 \mathrm{E}-08$ & $1.77 \mathrm{E}-08$ & $1.77 \mathrm{E}-08$ & $1.78 \mathrm{E}-08$ & $1.77 \mathrm{E}-08$ & $1.77 \mathrm{E}-08$ & $1.77 \mathrm{E}-08$ & $1.78 \mathrm{E}-08$ & $1.77 \mathrm{E}-08$ & $1.77 \mathrm{E}-08$ & 1.77E-08 \\
\hline 241-S-102 & 1.79E-08 & 1.78E-08 & $1.78 \mathrm{E}-08$ & $1.78 \mathrm{E}-08$ & $1.79 \mathrm{E}-08$ & $1.78 \mathrm{E}-08$ & 1.78E-08 & $1.78 \mathrm{E}-08$ & $1.79 \mathrm{E}-08$ & $1.78 \mathrm{E}-08$ & 1.78E-08 & $1.78 \mathrm{E}-08$ & $1.79 \mathrm{E}-08$ & $1.78 \mathrm{E}-08$ & $1.78 \mathrm{E}-08$ & 1.78E-08 \\
\hline 241-S-103 & $1.77 \mathrm{E}-08$ & $1.77 \mathrm{E}-08$ & $1.77 \mathrm{E}-08$ & 1.77E-08 & $1.77 \mathrm{E}-08$ & $1.77 \mathrm{E}-08$ & $1.77 \mathrm{E}-08$ & $1.77 \mathrm{E}-08$ & $1.77 \mathrm{E}-08$ & $1.77 \mathrm{E}-08$ & $1.77 \mathrm{E}-08$ & $1.77 \mathrm{E}-08$ & $1.77 \mathrm{E}-08$ & 1.77E-08 & $1.77 \mathrm{E}-08$ & 1.17 E-08 \\
\hline
\end{tabular}




\begin{tabular}{|c|c|c|c|c|c|c|c|c|c|c|c|c|c|c|c|c|}
\hline Site & 1976 & 1977 & 1978 & 1979 & 1980 & 1981 & 1982 & 1983 & 1984 & 1985 & 1986 & 1987 & 1988 & 1989 & 1990 & 1991 \\
\hline & 90E-02 & 4.84E-01 & $2.79 \mathrm{E}+00$ & $73 E+00$ & $05 E+00$ & $4.81 \mathrm{E}+00$ & $4.52 \mathrm{E}+00$ & $4.24 \mathrm{E}+00$ & $4.02 \mathrm{E}+00$ & $3.80 \mathrm{E}+00$ & $3.62 \mathrm{E}+00$ & $3.47 \mathrm{E}+00$ & $3.35 E+00$ & $3.24 \mathrm{E}+00$ & $3.14 \mathrm{E}+00$ & $3.07 E+00$ \\
\hline & $78 \mathrm{E}-08$ & 77E-08 & 1.77E-08 & $1.77 \mathrm{E}-08$ & 1.78E-08 & 1.77E-08 & 1.77E-08 & 1.77E-08 & $1.78 \mathrm{E}-08$ & 1.77E-08 & 1.77E-08 & 1.77E-08 & 1.78E-08 & 1.77E-08 & 1.77E-08 & 1.77E-08 \\
\hline 1-S-106 & 77E-08 & 1.77E-08 & 1.77E-08 & $1.77 \mathrm{E}-08$ & $1.77 \mathrm{E}-08$ & $1.77 \mathrm{E}-08$ & $1.77 \mathrm{E}-08$ & $1.77 \mathrm{E}-08$ & 1.77E-08 & 1.77E-08 & $.77 \mathrm{E}-08$ & 1.77E-08 & 1.77E-08 & $.77 \mathrm{E}-08$ & $.77 \mathrm{E}-08$ & $1.77 \mathrm{E}-08$ \\
\hline 241-S-107 & 1.62E-08 & 1.61E-08 & $1.61 \mathrm{E}-08$ & 1.61E-08 & $1.62 \mathrm{E}-08$ & 1.61E-08 & 1.61E-08 & 1.61E-08 & $1.62 \mathrm{E}-08$ & 1.61E-08 & 1.61E-08 & 1.61E-08 & $1.62 \mathrm{E}-08$ & 1.61E-08 & $1.61 \mathrm{E}-08$ & $1.61 \mathrm{E}-08$ \\
\hline & & & & 61E-08 & $1.62 \mathrm{E}-08$ & 61E-08 & 61E-08 & 1.61E-08 & $62 \mathrm{E}-08$ & 1.61E-08 & 1.61E-08 & 61E-08 & $62 \mathrm{E}-08$ & & 61E-08 & $1.61 \mathrm{E}-08$ \\
\hline & & & & & & & & & $62 E-08$ & $62 \mathrm{E}-08$ & 1.62E-08 & $62 \mathrm{E}-08$ & 1.62E-08 & 1.62E-08 & $1.62 \mathrm{E}-08$ & $1.62 \mathrm{E}-08$ \\
\hline & & $E-08$ & 67E-08 & 1.67E-08 & E-08 & 1.67E-08 & 1.67E-08 & $1.67 \mathrm{E}-08$ & 7E-08 & 1.67E-08 & 1.67E-08 & 1.67E-08 & 1.67E-08 & & $1.67 \mathrm{E}-08$ & \\
\hline & $E-08$ & 58E-08 & $58 \mathrm{E}-08$ & 58E-08 & 59E-08 & 58E-08 & $1.58 \mathrm{E}-08$ & 58E-08 & $.59 \mathrm{E}-08$ & $.58 \mathrm{E}-08$ & $1.58 \mathrm{E}-08$ & $1.58 \mathrm{E}-08$ & $.59 \mathrm{E}-08$ & $.58 \mathrm{E}-08$ & $1.58 \mathrm{E}-08$ & $58 \mathrm{E}-08$ \\
\hline & $E-08$ & E-08 & 63E-08 & 63E-08 & 63E-08 & E-08 & 1.63E-08 & $63 \mathrm{E}-08$ & $3 \mathrm{E}-08$ & 63E-08 & 1.63E-08 & 1.63E-08 & 63E-08 & $63 \mathrm{E}-08$ & 63E-08 & $3 \mathrm{E}-08$ \\
\hline & & $2.10 \mathrm{E}-08$ & $10 \mathrm{E}-08$ & $10 \mathrm{E}-08$ & 10E-08 & 10E-08 & $2.10 \mathrm{E}-08$ & & DE-08 & E-08 & $2.10 \mathrm{E}-08$ & & & DE-08 & & \\
\hline$X-102$ & 98E-08 & 1.98E-08 & $1.98 \mathrm{E}-08$ & $1.98 \mathrm{E}-08$ & $1.98 \mathrm{E}-08$ & 1.98E-08 & 1.98E-08 & $98 \mathrm{E}-08$ & 98E-08 & 98E-08 & 1.98E-08 & $.98 \mathrm{E}-08$ & 98E-08 & & & \\
\hline 241-SX-103 & 98E-08 & 1.98E-08 & $1.98 \mathrm{E}-08$ & $1.98 \mathrm{E}-08$ & $1.98 \mathrm{E}-08$ & 1.98E-08 & 1.98E-08 & 1.98E-08 & 1.98E-08 & 1.98E-08 & 1.98E-08 & 1.98E-08 & $.98 \mathrm{E}-08$ & & $1.98 \mathrm{E}-08$ & $1.98 \mathrm{E}-08$ \\
\hline & 64E-08 & 1.63E-08 & $1.63 \mathrm{E}-08$ & 1.63E-08 & 1.64E-08 & $1.63 \mathrm{E}-08$ & $1.63 \mathrm{E}-08$ & 1.63E-08 & 1.64E-08 & 1.63E-08 & 1.63E-08 & $.63 \mathrm{E}-08$ & 64E-08 & & $.63 \mathrm{E}-08$ & $1.63 \mathrm{E}-08$ \\
\hline & 65E-08 & 1.65E-08 & $1.65 \mathrm{E}-08$ & 1.65E-08 & 1.65E-08 & 1.65E-08 & 1.65E-08 & 1.65E-08 & 1.65E-08 & 1.65E-08 & 1.65E-08 & 1.65E-08 & $.65 \mathrm{E}-08$ & $65 \mathrm{E}-08$ & $.65 \mathrm{E}-08$ & $1.65 \mathrm{E}-08$ \\
\hline & 08E-08 & $2.07 \mathrm{E}-08$ & $2.07 \mathrm{E}-08$ & $2.07 \mathrm{E}-08$ & $2.08 \mathrm{E}-08$ & $2.07 \mathrm{E}-08$ & $2.07 \mathrm{E}-08$ & $2.07 \mathrm{E}-08$ & $2.08 \mathrm{E}-08$ & $2.07 \mathrm{E}-08$ & $2.07 \mathrm{E}-08$ & $.07 \mathrm{E}-08$ & $.08 \mathrm{E}-08$ & $.07 \mathrm{E}-08$ & 2.07E-08 & 2.07E-08 \\
\hline & 80E-03 & $9.71 \mathrm{E}-02$ & $7.95 \mathrm{E}-01$ & $2.00 \mathrm{E}+00$ & $2.55 \mathrm{E}+00$ & $2.58 \mathrm{E}+00$ & $2.48 \mathrm{E}+00$ & $2.37 \mathrm{E}+00$ & $2.27 \mathrm{E}+00$ & $2.17 \mathrm{E}+00$ & $2.09 \mathrm{E}+00$ & $.02 \mathrm{E}+00$ & $1.97 \mathrm{E}+00$ & $1.92 \mathrm{E}+00$ & $1.88 \mathrm{E}+00$ & $.85 E+00$ \\
\hline & E-04 & E-03 & $2.20 \mathrm{E}-01$ & $2.27 \mathrm{E}+00$ & $5.77 \mathrm{E}+00$ & $6.99 \mathrm{E}+00$ & $6.90 \mathrm{E}+00$ & $6.52 \mathrm{E}+00$ & $6.16 \mathrm{E}+00$ & $5.80 \mathrm{E}+00$ & $5.50 \mathrm{E}+00$ & $5.25 \mathrm{E}+00$ & $5.04 \mathrm{E}+00$ & $4.85 \mathrm{E}+00$ & $4.69 \mathrm{E}+00$ & $1.56 \mathrm{E}+00$ \\
\hline & $8 \mathrm{E}-09$ & 1.27E-09 & 7E-09 & 1.27E-09 & 1.28E-09 & E-09 & 1.27E-09 & 1.27E-09 & $1.28 \mathrm{E}-09$ & 27E-09 & 1.27E-09 & 7E-09 & $8 \mathrm{E}-09$ & $7 \mathrm{E}-09$ & $2 \mathrm{E}-07$ & $6.92 \mathrm{E}-06$ \\
\hline & 66E-11 & $4.65 \mathrm{E}-11$ & $4.65 \mathrm{E}-11$ & $4.65 E-11$ & $4.66 \mathrm{E}-11$ & E-11 & $4.65 E-11$ & $4.65 E-11$ & $4.66 \mathrm{E}-11$ & $4.65 \mathrm{E}-11$ & $4.65 E-11$ & $5-11$ & $4.66 \mathrm{E}-11$ & $4.65 \mathrm{E}-11$ & $4.65 \mathrm{E}-11$ & $4.65 \mathrm{E}-11$ \\
\hline 2 & 24E-09 & 2.24E-09 & $2.24 \mathrm{E}-09$ & $2.24 \mathrm{E}-09$ & $24 \mathrm{E}-09$ & $24 \mathrm{E}-09$ & $2.24 \mathrm{E}-09$ & 2.24E-09 & $2.24 \mathrm{E}-09$ & $2.24 \mathrm{E}-09$ & $2.24 \mathrm{E}-09$ & $2.24 \mathrm{E}-09$ & 2.24E-09 & 2.24E-09 & $2.24 \mathrm{E}-09$ & $1.22 \mathrm{E}-06$ \\
\hline 2 & $56 \mathrm{E}-08$ & 1.56E-08 & 56E-08 & 1.56E-08 & 1.56E-08 & 1.56E-08 & 1.56E-08 & 1.56E-08 & $1.56 \mathrm{E}-08$ & 1.56E-08 & 1.56E-08 & 1.56E-08 & 1.56E-08 & 1.56E-08 & $1.56 \mathrm{E}-08$ & 1.56E-08 \\
\hline 2 & $7 \mathrm{E}-02$ & 2.64E-01 & 86E-01 & $1.70 \mathrm{E}+00$ & $00 \mathrm{E}+00$ & $2.04 \mathrm{E}+00$ & $2.01 \mathrm{E}+00$ & $1.96 \mathrm{E}+00$ & $1.92 \mathrm{E}+00$ & $1.88 \mathrm{E}+00$ & $1.85 \mathrm{E}+00$ & $1.83 \mathrm{E}+00$ & $1.81 \mathrm{E}+00$ & $1.79 \mathrm{E}+00$ & $1.78 \mathrm{E}+00$ & $1.78 \mathrm{E}+00$ \\
\hline-114 & $15 \mathrm{E}-11$ & 3.14E-11 & $3.14 \mathrm{E}-11$ & $3.14 \mathrm{E}-11$ & $3.15 \mathrm{E}-11$ & $3.14 \mathrm{E}-11$ & $3.14 \mathrm{E}-11$ & $3.14 \mathrm{E}-11$ & $3.15 \mathrm{E}-11$ & 3.14E-11 & 3.14E-11 & $3.14 \mathrm{E}-11$ & 3.15E-11 & $3.14 \mathrm{E}-11$ & $3.14 \mathrm{E}-11$ & $3.14 \mathrm{E}-11$ \\
\hline 115 & 56E-06 & 4.64E-04 & $1.39 \mathrm{E}-02$ & 2.92E-01 & $62 \mathrm{E}+00$ & $6.88 \mathrm{E}+00$ & $8.92 \mathrm{E}+00$ & $9.10 \mathrm{E}+00$ & $3.78 \mathrm{E}+00$ & $.35 \mathrm{E}+00$ & $7.97 \mathrm{E}+00$ & $7.65 \mathrm{E}+00$ & $7.38 \mathrm{E}+00$ & $7.13 \mathrm{E}+00$ & $6.93 \mathrm{E}+00$ & $0.76 \mathrm{E}+00$ \\
\hline 101 & $00 \mathrm{E}+00$ & $0.00 \mathrm{E}+00$ & $0.00 \mathrm{E}+00$ & $.00 \mathrm{E}+00$ & $00 \mathrm{E}+00$ & $00 \mathrm{E}+00$ & $0.00 \mathrm{E}+00$ & $0.00 \mathrm{E}+00$ & $.00 \mathrm{E}+00$ & $.00 \mathrm{E}+00$ & $0.00 \mathrm{E}+00$ & $0.00 \mathrm{E}+00$ & $0.00 \mathrm{E}+00$ & $0.00 \mathrm{E}+00$ & $0.00 \mathrm{E}+00$ & $.00 \mathrm{E}+00$ \\
\hline 102 & DOE+00 & $00 \mathrm{E}+00$ & $0.00 \mathrm{E}+00$ & $00 \mathrm{E}+00$ & $00 \mathrm{E}+00$ & $00 \mathrm{E}+00$ & $00 \mathrm{E}+00$ & $0.00 \mathrm{E}+00$ & $E+00$ & $.00 \mathrm{E}+00$ & $00 \mathrm{E}+00$ & $E+00$ & $E+00$ & $\mathrm{E}+00$ & $\mathrm{E}+00$ & $.00 \mathrm{E}+00$ \\
\hline & +00 & +00 & $E+00$ & $00 \mathrm{E}+00$ & $00 \mathrm{E}+00$ & $=00$ & $0.00 \mathrm{E}+00$ & $E+00$ & $0.00 \mathrm{E}+00$ & $0.00 \mathrm{E}+00$ & $0.00 \mathrm{E}+00$ & $E+00$ & $0.00 \mathrm{E}+00$ & $0.00 \mathrm{E}+00$ & $0.00 \mathrm{E}+00$ & $0.00 \mathrm{E}+00$ \\
\hline & $=00$ & $1.70 \mathrm{E}+00$ & $\mathrm{E}+00$ & $1.07 \mathrm{E}+00$ & $E-01$ & E-01 & E-01 & $E-01$ & $E-01$ & $E-01$ & E-01 & -01 & E-01 & .44E-02 & $3 \mathrm{E}-02$ & $4.98 \mathrm{E}-02$ \\
\hline & $E-09$ & $5.00 \mathrm{E}-09$ & DE-09 & $5.00 \mathrm{E}-09$ & -09 & $E-08$ & E-06 & $E-06$ & E-05 & $\mathrm{E}-04$ & 1.83E-03 & $E-02$ & $\mathrm{E}-02$ & $E-01$ & $6 \mathrm{E}-01$ & $E-01$ \\
\hline & & & E-09 & -06 & -04 & -03 & -01 & -01 & $E+00$ & $=00$ & $E+00$ & +00 & $E+00$ & $E+00$ & $=+00$ & +00 \\
\hline & E-09 & E-09 & $4 \mathrm{E}-09$ & 5.34E-09 & E-09 & E-09 & 87E-08 & E-06 & E-06 & 5.53E-05 & 3.22E-04 & E-03 & $\mathrm{E}-02$ & E-02 & 7E-01 & 3.96E-01 \\
\hline & 35E-09 & 5.34E-09 & 5.34E-09 & 5.34E-09 & 5.35E-09 & $.34 \mathrm{E}-09$ & $5.86 \mathrm{E}-08$ & 1.70E-06 & $.73 \mathrm{E}-06$ & 5.53E-05 & $3.22 \mathrm{E}-04$ & $1.85 \mathrm{E}-03$ & $1.05 E-02$ & $5.06 \mathrm{E}-02$ & $1.77 \mathrm{E}-01$ & 3.96E-01 \\
\hline & $2 \mathrm{E}+01$ & $3.57 \mathrm{E}+01$ & $2.70 \mathrm{E}+01$ & $2.15 \mathrm{E}+01$ & $1.77 \mathrm{E}+01$ & $1.50 \mathrm{E}+01$ & $1.29 \mathrm{E}+01$ & $1.14 \mathrm{E}+01$ & $1.01 \mathrm{E}+01$ & $9.13 \mathrm{E}+00$ & $8.34 \mathrm{E}+00$ & $7.69 \mathrm{E}+00$ & $7.18 \mathrm{E}+00$ & $6.72 \mathrm{E}+00$ & $6.37 \mathrm{E}+00$ & $6.08 \mathrm{E}+00$ \\
\hline & $02 E-16$ & $4.01 \mathrm{E}-16$ & $4.01 \mathrm{E}-16$ & $4.01 \mathrm{E}-16$ & $4.02 \mathrm{E}-16$ & $4.01 \mathrm{E}-16$ & $4.01 \mathrm{E}-16$ & $4.01 \mathrm{E}-16$ & $4.02 \mathrm{E}-16$ & $4.01 \mathrm{E}-16$ & $4.01 \mathrm{E}-16$ & $4.01 \mathrm{E}-16$ & $4.02 \mathrm{E}-16$ & $4.01 \mathrm{E}-16$ & $4.01 \mathrm{E}-16$ & $4.01 \mathrm{E}-16$ \\
\hline -T-108 & 5.01E-09 & $5.00 \mathrm{E}-09$ & $5.00 \mathrm{E}-09$ & $5.00 \mathrm{E}-09$ & 5.01E-09 & $5.58 \mathrm{E}-08$ & 1.63E-06 & $9.17 \mathrm{E}-06$ & 5.34E-05 & $3.12 \mathrm{E}-04$ & 1.83E-03 & 1.02E-02 & 5.01E-02 & L.76E-01 & 3.96E-01 & $6.01 \mathrm{E}-01$ \\
\hline -T-109 & $5.02 \mathrm{E}-09$ & $5.00 \mathrm{E}-09$ & $5.00 \mathrm{E}-09$ & $5.00 \mathrm{E}-09$ & $5.02 \mathrm{E}-09$ & $5.58 \mathrm{E}-08$ & $1.63 \mathrm{E}-06$ & $9.18 \mathrm{E}-06$ & 5.35E-05 & $3.12 \mathrm{E}-04$ & 1.83E-03 & 1.02E-02 & 5.01E-02 & $1.76 \mathrm{E}-01$ & $3.96 \mathrm{E}-01$ & $6.02 \mathrm{E}-01$ \\
\hline-110 & $4.02 \mathrm{E}-16$ & $4.01 \mathrm{E}-16$ & 4.01E-16 & $4.01 \mathrm{E}-16$ & $4.02 \mathrm{E}-16$ & $4.01 \mathrm{E}-16$ & $4.01 \mathrm{E}-16$ & $4.01 \mathrm{E}-16$ & $4.02 \mathrm{E}-16$ & $4.01 \mathrm{E}-16$ & $4.01 \mathrm{E}-16$ & $4.01 \mathrm{E}-16$ & $4.02 \mathrm{E}-16$ & $.01 E-16$ & $4.01 \mathrm{E}-16$ & 4.01E-16 \\
\hline T-111 & 5.02E-09 & 5.00E-09 & 5.00E-09 & 5.00E-09 & 5.02E-09 & 5.58E-08 & 1.63E-06 & $9.18 \mathrm{E}-06$ & $5.35 E-05$ & $3.12 \mathrm{E}-04$ & $1.83 \mathrm{E}-03$ & 1.02E-02 & 5.01E-02 & 1.76E-01 & 3.96E-01 & $6.02 \mathrm{E}-01$ \\
\hline 41-T-112 & $5.35 \mathrm{E}-09$ & 5.34E-09 & $5.34 \mathrm{E}-09$ & 5.34E-09 & 5.35E-09 & 5.34E-09 & $5.86 \mathrm{E}-08$ & $1.70 \mathrm{E}-06$ & $9.73 \mathrm{E}-06$ & 5.53E-05 & $3.22 \mathrm{E}-04$ & $1.85 \mathrm{E}-03$ & 1.05E-02 & 5.05E-02 & 1.77E-01 & 3.96E-01 \\
\hline 241-T-201 & $2.95 \mathrm{E}-10$ & $2.94 \mathrm{E}-10$ & $2.94 \mathrm{E}-10$ & $2.94 \mathrm{E}-10$ & $2.95 \mathrm{E}-10$ & $2.94 \mathrm{E}-10$ & $2.94 \mathrm{E}-10$ & $2.94 \mathrm{E}-10$ & $2.95 \mathrm{E}-10$ & $2.94 \mathrm{E}-10$ & $2.94 \mathrm{E}-10$ & $2.94 \mathrm{E}-10$ & 3.97E-09 & 1.10E-07 & $6.22 \mathrm{E}-07$ & $3.54 \mathrm{E}-06$ \\
\hline 241-T-202 & $2.95 \mathrm{E}-10$ & $2.94 \mathrm{E}-10$ & $2.94 \mathrm{E}-10$ & $2.94 \mathrm{E}-10$ & $2.95 \mathrm{E}-10$ & $2.94 \mathrm{E}-10$ & $2.94 \mathrm{E}-10$ & $2.94 \mathrm{E}-10$ & 2.95E-10 & 2.94E-10 & 2.94E-10 & $2.94 \mathrm{E}-10$ & 3.97E-09 & 1.10E-07 & 6.22E-07 & $3.54 \mathrm{E}-06$ \\
\hline
\end{tabular}




\begin{tabular}{|c|c|c|c|c|c|c|c|c|c|c|c|c|c|c|c|c|}
\hline Site & 1976 & 1977 & 1978 & 1979 & 1980 & 1981 & 1982 & 1983 & 1984 & 1985 & 1986 & 1987 & 1988 & 1989 & 1990 & 1991 \\
\hline 241-T-203 & 95E-10 & $94 \mathrm{E}-10$ & $2.94 \mathrm{E}-10$ & 94E-10 & $95 \mathrm{E}-10$ & $2.94 \mathrm{E}-10$ & $2.94 \mathrm{E}-10$ & $2.94 \mathrm{E}-10$ & $2.95 \mathrm{E}-10$ & $2.94 \mathrm{E}-10$ & $2.94 \mathrm{E}-10$ & $2.94 \mathrm{E}-10$ & $3.97 \mathrm{E}-09$ & 1.09E-07 & $6.21 \mathrm{E}-07$ & 3.54E-06 \\
\hline 241-T-204 & 95E-10 & $94 \mathrm{E}-10$ & 94E-10 & $94 \mathrm{E}-10$ & $2.95 \mathrm{E}-10$ & $2.94 \mathrm{E}-10$ & $2.94 \mathrm{E}-10$ & $2.94 \mathrm{E}-10$ & $2.95 \mathrm{E}-10$ & $2.94 \mathrm{E}-10$ & $2.94 \mathrm{E}-10$ & $2.94 \mathrm{E}-10$ & $3.97 \mathrm{E}-09$ & $1.09 \mathrm{E}-07$ & $6.21 \mathrm{E}-07$ & $3.54 \mathrm{E}-06$ \\
\hline 241-TX-101 & 79E-09 & $4.78 \mathrm{E}-09$ & $78 \mathrm{E}-09$ & 4.78E-09 & 4.79E-09 & 4.78E-09 & $4.78 \mathrm{E}-09$ & 4.78E-09 & $4.79 \mathrm{E}-09$ & $5.78 \mathrm{E}-08$ & $1.65 \mathrm{E}-06$ & $9.18 \mathrm{E}-06$ & $35 \mathrm{E}-05$ & $.12 \mathrm{E}-04$ & $83 \mathrm{E}-03$ & $.02 \mathrm{E}-02$ \\
\hline -TX-102 & $5.09 \mathrm{E}-09$ & $5.08 \mathrm{E}-09$ & 5.08E-09 & $5.08 \mathrm{E}-09$ & 5.09E-09 & 5.08E-09 & $5.08 \mathrm{E}-09$ & 5.08E-09 & 5.09E-09 & 5.08E-09 & $6.04 \mathrm{E}-08$ & $1.71 \mathrm{E}-06$ & $9.74 \mathrm{E}-06$ & $.53 \mathrm{E}-05$ & $22 \mathrm{E}-04$ & 85E-03 \\
\hline & LE-09 & $5.08 \mathrm{E}-09$ & 5.08E-09 & 08E-09 & $5.10 \mathrm{E}-09$ & 5.08E-09 & $5.08 \mathrm{E}-09$ & 5.08E-09 & $5.10 \mathrm{E}-09$ & 5.08E-09 & $6.05 \mathrm{E}-08$ & $1.71 \mathrm{E}-06$ & $9.75 \mathrm{E}-06$ & & & $6 \mathrm{E}-03$ \\
\hline & & $5.0 \varepsilon$ & J8E-09 & 99 & 10E-09 & & $5.08 \mathrm{E}-09$ & 5.08E-09 & 10E-09 & 5.08E-09 & $05 E-08$ & $1.71 \mathrm{E}-06$ & $9.75 \mathrm{E}-06$ & $53 E-05$ & $3.22 \mathrm{E}-04$ & 86E-03 \\
\hline & & 4.16 & $16 \mathrm{E}-09$ & E-09 & 17E-09 & 4.16E-09 & $4.16 \mathrm{E}-09$ & 4.16E-09 & $4.17 \mathrm{E}-09$ & $6 \mathrm{E}-09$ & 4.16E-09 & 4.16E-09 & $1 \mathrm{E}-08$ & & & $5.00 \mathrm{E}-05$ \\
\hline & $E-10$ & $E-10$ & $4.24 \mathrm{E}-10$ & 24E-10 & $25 \mathrm{E}-10$ & $4.24 \mathrm{E}-10$ & $4.24 \mathrm{E}-10$ & $4.24 \mathrm{E}-10$ & $4.25 E-10$ & 4.24E-10 & $4.24 \mathrm{E}-10$ & $4.24 \mathrm{E}-10$ & $2.21 \mathrm{E}-07$ & $1.55 \mathrm{E}-06$ & $8.79 \mathrm{E}-06$ & \\
\hline & -11 & $E-11$ & $75 \mathrm{E}-11$ & E-08 & $\mathrm{E}-03$ & $54 \mathrm{E}+00$ & $3.90 \mathrm{E}+00$ & $3.57 \mathrm{E}+00$ & $2.97 \mathrm{E}+00$ & $E+00$ & $2.14 \mathrm{E}+00$ & $1.88 \mathrm{E}+00$ & $7 \mathrm{E}+00$ & $1.50 \mathrm{E}+00$ & $1.36 \mathrm{E}+00$ & \\
\hline & & $=-09$ & & & & E-09 & E-09 & & 4.17E-09 & E-09 & E-09 & & & & $8.78 \mathrm{E}-06$ & \\
\hline & 9E-09 & 77E-09 & $4.77 \mathrm{E}-09$ & 77E-09 & 79E-09 & 77E-09 & 4.77E-09 & $4.77 \mathrm{E}-09$ & .79E-09 & E-08 & $1.64 \mathrm{E}-06$ & $.18 \mathrm{E}-06$ & 5E-05 & $.12 \mathrm{E}-04$ & & 1.02E-02 \\
\hline 241-TX-110 & 79E-09 & $4.78 \mathrm{E}-09$ & $4.78 \mathrm{E}-09$ & 78E-09 & 4.79E-09 & $4.78 \mathrm{E}-09$ & $4.78 \mathrm{E}-09$ & 4.78E-09 & 4.79E-09 & $5.78 \mathrm{E}-08$ & $1.65 \mathrm{E}-06$ & $9.19 \mathrm{E}-06$ & $35 \mathrm{E}-05$ & & $1.83 \mathrm{E}-03$ & $1.02 \mathrm{E}-02$ \\
\hline & 5.09E-09 & $5.08 \mathrm{E}-09$ & $5.08 \mathrm{E}-09$ & $5.08 \mathrm{E}-09$ & 5.09E-09 & 5.08E-09 & $5.08 \mathrm{E}-09$ & $5.08 \mathrm{E}-09$ & 5.09E-09 & 5.08E-09 & $6.04 \mathrm{E}-08$ & 1.71E-06 & $9.74 \mathrm{E}-06$ & 5.53E-05 & $3.22 \mathrm{E}-04$ & 1.85E-03 \\
\hline & $5.09 E-09$ & $5.08 E-09$ & $5.08 \mathrm{E}-09$ & $08 \mathrm{E}-09$ & $5.09 E-09$ & 5.08E-09 & $5.08 \mathrm{E}-09$ & 5.08E-09 & $5.09 E-09$ & 5.08E-09 & $6.04 \mathrm{E}-08$ & $1.71 \mathrm{E}-06$ & $9.73 \mathrm{E}-06$ & & $3.21 \mathrm{E}-04$ & $1.85 \mathrm{E}-03$ \\
\hline & 17E-09 & $4.16 \mathrm{E}-09$ & $4.16 \mathrm{E}-09$ & 16E-09 & $4.17 \mathrm{E}-09$ & 4.16E-09 & $4.16 \mathrm{E}-09$ & 4.16E-09 & 17E-09 & & $4.16 \mathrm{E}-09$ & $16 \mathrm{E}-09$ & $61 E-08$ & & $8.78 \mathrm{E}-06$ & 5.00E-05 \\
\hline & & $4.16 \mathrm{E}-09$ & 16E-09 & 16E-09 & $4.17 \mathrm{E}-09$ & 4.16E-09 & $4.16 \mathrm{E}-09$ & 4.16E-09 & .17E-09 & E-09 & 4.16E-09 & b-09 & $1 \mathrm{E}-08$ & $5 \mathrm{E}-06$ & .78E-06 & $5.00 \mathrm{E}-05$ \\
\hline & $E-09$ & E-09 & $16 \mathrm{E}-09$ & E-09 & E-09 & E-09 & 4.16E-09 & E-09 & E-09 & E-09 & E-09 & E-09 & $=-08$ & E-06 & $79 \mathrm{E}-06$ & 0E-05 \\
\hline & $E-09$ & $E-09$ & 16E-09 & E-09 & E-09 & E-09 & 16E-09 & E-09 & E-09 & $E-09$ & E-09 & E-09 & E-08 & E-06 & $8.79 \mathrm{E}-06$ & OE-05 \\
\hline & E-09 & $E-09$ & 4.15E-09 & E-09 & 17E-09 & E-09 & 4.15E-09 & 4.15E-09 & $4.17 \mathrm{E}-09$ & E-09 & $\mathrm{E}-09$ & E-09 & $\mathrm{E}-08$ & $5 \mathrm{E}-06$ & $8.77 \mathrm{E}-06$ & $5.00 \mathrm{E}-05$ \\
\hline & 7E-09 & 16E-09 & 4.16E-09 & 16E-09 & 17E-09 & 16E-09 & 4.16E-09 & 4.16E-09 & 17E-09 & E-09 & 4.16E-09 & jE-09 & LE-08 & $1.55 \mathrm{E}-06$ & $8.78 \mathrm{E}-06$ & $5.00 \mathrm{E}-05$ \\
\hline L01 & $8 \mathrm{E}-12$ & $8.36 \mathrm{E}-12$ & $8.36 \mathrm{E}-12$ & 36E-12 & $38 \mathrm{E}-12$ & $36 \mathrm{E}-12$ & $8.36 \mathrm{E}-12$ & $8.36 \mathrm{E}-12$ & $38 \mathrm{E}-12$ & $6 \mathrm{E}-12$ & $36 \mathrm{E}-12$ & $8.36 \mathrm{E}-12$ & $5 E-10$ & $2.64 \mathrm{E}-07$ & $1.65 \mathrm{E}-06$ & $9.19 \mathrm{E}-06$ \\
\hline & $8 \mathrm{E}-12$ & $36 \mathrm{E}-12$ & $8.36 \mathrm{E}-12$ & $36 \mathrm{E}-12$ & $38 \mathrm{E}-12$ & $36 \mathrm{E}-12$ & $8.36 \mathrm{E}-12$ & 8.36E-12 & $38 \mathrm{E}-12$ & E-12 & $36 \mathrm{E}-12$ & E-12 & E-10 & $64 \mathrm{E}-07$ & $1.65 \mathrm{E}-06$ & $19 \mathrm{E}-06$ \\
\hline 241-TY-103 & $2.54 \mathrm{E}-09$ & $2.53 \mathrm{E}-09$ & 2.53E-09 & 2.53E-09 & 14E-06 & 2.49E-05 & $4.05 \mathrm{E}-04$ & 5.36E-03 & $39 \mathrm{E}-02$ & 2.80E-01 & 6.66E-01 & 9.14E-01 & 9.84E-01 & $9.73 \mathrm{E}-01$ & 9.44E-01 & $9.15 \mathrm{E}-01$ \\
\hline 104 & $1.27 \mathrm{E}-12$ & $1.27 \mathrm{E}-12$ & $1.27 \mathrm{E}-12$ & $1.27 \mathrm{E}-12$ & 27E-12 & $5.46 \mathrm{E}-10$ & $1.90 \mathrm{E}-07$ & $9.76 \mathrm{E}-07$ & $4.78 \mathrm{E}-06$ & $48 \mathrm{E}-05$ & $1.38 \mathrm{E}-04$ & $\mathrm{E}-04$ & $5 E-03$ & $2.39 \mathrm{E}-02$ & 1.00E-01 & $1 \mathrm{E}-01$ \\
\hline & $6 \mathrm{E}+00$ & $1.61 \mathrm{E}+00$ & $1.58 \mathrm{E}+00$ & $1.56 \mathrm{E}+00$ & $56 \mathrm{E}+00$ & $55 \mathrm{E}+00$ & $1.55 \mathrm{E}+00$ & $1.55 E+00$ & $55 E+00$ & $1.55 E+00$ & $1.56 \mathrm{E}+00$ & $E+00$ & $E+00$ & $6 \mathrm{E}+00$ & $1.56 \mathrm{E}+00$ & $1.56 \mathrm{E}+00$ \\
\hline 241-TY-106 & $2 \mathrm{E}+00$ & $9.80 \mathrm{E}-01$ & 9.51E-01 & $9.29 \mathrm{E}-01$ & $9.15 \mathrm{E}-01$ & 9.00E-01 & 8.92E-01 & 8.86E-01 & 8.84E-01 & $8.80 \mathrm{E}-01$ & $8.78 \mathrm{E}-01$ & 8.77E-01 & $8.79 \mathrm{E}-01$ & $8.76 \mathrm{E}-01$ & 8.76E-01 & 8.76E-01 \\
\hline & 07E-08 & $2.07 E-08$ & 07E-08 & 2.07E-08 & $2.07 \mathrm{E}-08$ & 2.07E-08 & $.07 \mathrm{E}-08$ & 2.07E-08 & $2.07 \mathrm{E}-08$ & E-08 & 2.07E-08 & $2.07 E-08$ & 2.07E-08 & 2.69E-07 & 8.86E-06 & 5.37E-05 \\
\hline & $E-08$ & $E-08$ & 13E-08 & E-08 & -08 & $E-08$ & E-08 & $E-08$ & E-08 & -08 & E-08 & E-08 & E-08 & E-07 & .12E-06 & 5.53E-05 \\
\hline & & & 79E-08 & $E-08$ & -08 & -08 & 79E-08 & $E-08$ & $E-08$ & -08 & -08 & E-08 & -08 & $=-08$ & E-07 & $8.22 \mathrm{E}-06$ \\
\hline & +00 & 7.54 & $7.22 \mathrm{E}+00$ & $6.96 \mathrm{E}+00$ & $E+00$ & $=00$ & $6.39 \mathrm{E}+00$ & 6.26 & $E+00$ & $6.0 \varepsilon$ & $6.02 \mathrm{E}+00$ & $E+00$ & $E+00$ & +00 & $5.89 \mathrm{E}+00$ & -00 \\
\hline & -08 & $=-08$ & 1.77E-08 & $E-08$ & $E-08$ & $E-08$ & $1.77 \mathrm{E}-08$ & -08 & $7 \mathrm{E}-08$ & -08 & E-08 & $E-08$ & $E-08$ & -08 & E-07 & \\
\hline & $E-08$ & $7 \mathrm{E}-08$ & 77E-08 & 77E-08 & $77 \mathrm{E}-08$ & E-08 & 77E-08 & E-08 & 77E-08 & E-08 & 77E-08 & E-08 & E-08 & $7 \mathrm{E}-08$ & 1.77E-08 & $2.44 \mathrm{E}-07$ \\
\hline & E-08 & 66E-08 & $1.66 \mathrm{E}-08$ & 66E-08 & 67E-08 & 66E-08 & 1.66E-08 & 1.66E-08 & $67 \mathrm{E}-08$ & 66E-08 & 1.66E-08 & 1.66E-08 & 1.67E-08 & $1.66 \mathrm{E}-08$ & $1.66 \mathrm{E}-08$ & 2.29E-07 \\
\hline & $39 \mathrm{E}-08$ & 88E-08 & $1.88 \mathrm{E}-08$ & $1.88 \mathrm{E}-08$ & $.89 \mathrm{E}-08$ & $88 \mathrm{E}-08$ & $1.88 \mathrm{E}-08$ & $1.88 \mathrm{E}-08$ & $1.89 \mathrm{E}-08$ & $88 \mathrm{E}-08$ & $88 \mathrm{E}-08$ & $1.88 \mathrm{E}-08$ & $1.89 \mathrm{E}-08$ & $1.88 \mathrm{E}-08$ & $1.88 \mathrm{E}-08$ & $1.88 \mathrm{E}-08$ \\
\hline 241-U-109 & 91E-08 & 1.91E-08 & 1.91E-08 & 1.91E-08 & 1.91E-08 & 1.91E-08 & 1.91E-08 & 1.91E-08 & 1.91E-08 & 1.91E-08 & 1.91E-08 & 1.91E-08 & 1.91E-08 & 1.91E-08 & 1.91E-08 & 1.91E-08 \\
\hline 110 & $53 \mathrm{E}-09$ & 4.52E-09 & 4.52E-09 & 4.52E-09 & $6.22 \mathrm{E}-06$ & $8.47 \mathrm{E}-04$ & $5.53 \mathrm{E}-02$ & 8.06E-01 & $2.10 \mathrm{E}+00$ & $2.42 \mathrm{E}+00$ & $2.29 \mathrm{E}+00$ & $2.10 \mathrm{E}+00$ & $1.92 \mathrm{E}+00$ & $1.77 \mathrm{E}+00$ & $1.64 \mathrm{E}+00$ & $1.53 \mathrm{E}+00$ \\
\hline-111 & $1.74 \mathrm{E}-08$ & $1.73 \mathrm{E}-08$ & 1.73E-08 & 1.73E-08 & $1.74 \mathrm{E}-08$ & 1.73E-08 & $1.73 \mathrm{E}-08$ & 1.73E-08 & $1.74 \mathrm{E}-08$ & 1.73E-08 & 1.73E-08 & 1.73E-08 & $1.74 \mathrm{E}-08$ & 1.73E-08 & $2.52 \mathrm{E}-07$ & 7.98E-06 \\
\hline 241-U-112 & $1.41 \mathrm{E}-01$ & $1.16 \mathrm{E}+00$ & $2.22 \mathrm{E}+00$ & $2.38 \mathrm{E}+00$ & $2.24 \mathrm{E}+00$ & $2.05 \mathrm{E}+00$ & $1.89 \mathrm{E}+00$ & $1.75 \mathrm{E}+00$ & $1.64 \mathrm{E}+00$ & $1.53 \mathrm{E}+00$ & $1.44 \mathrm{E}+00$ & $1.37 \mathrm{E}+00$ & $1.30 \mathrm{E}+00$ & $1.25 \mathrm{E}+00$ & $1.20 \mathrm{E}+00$ & $1.16 \mathrm{E}+00$ \\
\hline 241-U-201 & 1.75E-09 & 1.75E-09 & 1.75E-09 & 1.75E-09 & 1.75E-09 & 1.75E-09 & 1.75E-09 & 1.75E-09 & 1.75E-09 & 1.75E-09 & 1.75E-09 & 1.75E-09 & 1.75E-09 & 1.75E-09 & 1.75E-09 & 1.75E-09 \\
\hline 241- & 1.73E-09 & 1.72E-09 & 1.72E-09 & 1.72E-09 & 1.73E-09 & 1.72E-09 & 1.72E-09 & 1.72E-09 & 1.73E-09 & 1.72E-09 & 1.72E-09 & 1.72E-09 & 1.73E-09 & 1.72E-09 & 1.72E-09 & 1.72E-09 \\
\hline $241-U-203$ & 1.73E-09 & $1.72 \mathrm{E}-09$ & 1.72E-09 & 1.72E-09 & $1.73 \mathrm{E}-09$ & 1.72E-09 & $1.72 \mathrm{E}-09$ & 1.72E-09 & 1.73E-09 & $1.72 \mathrm{E}-09$ & 1.72E-09 & 1.72E-09 & 1.73E-09 & 1.72E-09 & 1.72E-09 & 1.72E-09 \\
\hline
\end{tabular}




\begin{tabular}{|c|c|c|c|c|c|c|c|c|c|c|c|c|c|c|c|c|}
\hline Site & 1976 & 1977 & 1978 & 1979 & 1980 & 1981 & 1982 & & 1984 & 1985 & 1986 & 1987 & 1988 & 1989 & 1990 & 1991 \\
\hline & 00E-09 & $2.00 \mathrm{E}-09$ & $2.00 \mathrm{E}-09$ & $2.00 \mathrm{E}-09$ & $2.00 \mathrm{E}-09$ & 2.00E-09 & 2.00E-09 & $2.00 \mathrm{E}-09$ & 2.00E-09 & 2.00E-09 & 2.00E-09 & $2.00 \mathrm{E}-09$ & 2.00E-09 & 2.00E-09 & 2.00E-09 & 2.00E-09 \\
\hline & $21 \mathrm{E}+03$ & $1.20 \mathrm{E}+03$ & $1.20 \mathrm{E}+03$ & $.20 \mathrm{E}+03$ & $21 E+03$ & $20 \mathrm{E}+03$ & $20 \mathrm{E}+03$ & $1.20 \mathrm{E}+03$ & $1.21 \mathrm{E}+03$ & $1.20 \mathrm{E}+03$ & $20 \mathrm{E}+03$ & $1.20 \mathrm{E}+03$ & $1.21 \mathrm{E}+03$ & $3.55 E+02$ & $1.56 \mathrm{E}+02$ & $0.83 \mathrm{E}+01$ \\
\hline & $29 E+05$ & $08 \mathrm{E}+05$ & $5.72 E+04$ & $64 \mathrm{E}+04$ & $21 \mathrm{E}+04$ & $92 \mathrm{E}+04$ & 31E+04 & $9.52 \mathrm{E}+03$ & $.55 E+03$ & $87 \mathrm{E}+03$ & $22 \mathrm{E}+03$ & $4.22 E+03$ & $4.23 \mathrm{E}+03$ & $4.22 \mathrm{E}+03$ & $32 \mathrm{E}+03$ & $5 E+03$ \\
\hline & $11 \mathrm{E}+05$ & $6.97 \mathrm{E}+04$ & $3.83 \mathrm{E}+04$ & $2.66 \mathrm{E}+04$ & $55 \mathrm{E}+04$ & $54 \mathrm{E}+04$ & $92 \mathrm{E}+03$ & $9.05 \mathrm{E}+03$ & $9.08 \mathrm{E}+03$ & $6.74 \mathrm{E}+03$ & $5.59 \mathrm{E}+03$ & $5.59 \mathrm{E}+03$ & $61 \mathrm{E}+03$ & $.59 \mathrm{E}+03$ & $.06 \mathrm{E}+03$ & $\mathrm{E}+03$ \\
\hline & $2.95 \mathrm{E}+02$ & $2.73 \mathrm{E}+02$ & $2.00 \mathrm{E}+02$ & $2.00 \mathrm{E}+\mathrm{C}$ & $.01 E+02$ & $00 \mathrm{E}+02$ & $2.00 \mathrm{E}+02$ & $2.00 \mathrm{E}+02$ & $1.91 \mathrm{E}+02$ & $1.59 \mathrm{E}+02$ & $1.59 \mathrm{E}+02$ & $1.59 \mathrm{E}+02$ & $1.59 \mathrm{E}+02$ & $1.59 \mathrm{E}+02$ & $.59 \mathrm{E}+02$ & $59 \mathrm{E}+02$ \\
\hline & $36 \mathrm{E}+06$ & $46 \mathrm{E}+06$ & $3.46 \mathrm{E}+06$ & $.45 \mathrm{E}+06$ & $46 \mathrm{E}+06$ & $46 \mathrm{E}+06$ & $46 \mathrm{E}+06$ & $3.45 E+06$ & $3.46 \mathrm{E}+06$ & $3.46 \mathrm{E}+06$ & $.70 \mathrm{E}+05$ & $1.26 \mathrm{E}+05$ & $6.65 E+04$ & $4.58 \mathrm{E}+04$ & $.95 \mathrm{E}+04$ & $0 \mathrm{E}+04$ \\
\hline & $0 \mathrm{E}+00$ & $0.00 \mathrm{E}+00$ & $0.00 E+00$ & $.00 \mathrm{E}+00$ & $00 \mathrm{E}+00$ & $00 \mathrm{E}+00$ & $0.00 \mathrm{E}+00$ & $0.00 E+00$ & $.00 \mathrm{E}+00$ & $.00 \mathrm{E}+00$ & $0.00 E+00$ & $0.00 \mathrm{E}+00$ & $0.00 E+00$ & $0.00 E+00$ & $0.00 \mathrm{E}+00$ & $.00 \mathrm{E}+00$ \\
\hline 600 & E-09 & $4.23 \mathrm{E}-09$ & $4.23 \mathrm{E}-09$ & $4.23 \mathrm{E}-09$ & $4.24 \mathrm{E}-09$ & 4.23E-09 & $4.23 \mathrm{E}-09$ & $4.23 \mathrm{E}-09$ & $4 \mathrm{E}-09$ & 23E-09 & $4.23 \mathrm{E}-09$ & $4.23 \mathrm{E}-09$ & $4.24 \mathrm{E}-09$ & $23 \mathrm{E}-09$ & 4.23E-09 & $3 \mathrm{E}-09$ \\
\hline 618-11 & $9 \mathrm{E}+03$ & $39 E+03$ & $E+03$ & $39 \mathrm{E}+03$ & $40 \mathrm{E}+03$ & $E+03$ & $\mathrm{E}+03$ & $E+03$ & $\mathrm{E}+03$ & $E+03$ & $9 \mathrm{E}+03$ & $9 \mathrm{E}+03$ & $1.40 \mathrm{E}+03$ & $39 \mathrm{E}+03$ & $39 \mathrm{E}+03$ & $\mathrm{E}+03$ \\
\hline GTF & $0 E+00$ & $0 \mathrm{E}+00$ & 0.00 & $.00 \mathrm{E}+\mathrm{C}$ & OOE+00 & $E+00$ & 00 & $E+00$ & $\mathrm{E}+00$ & $E+00$ & 00 & $0 \mathrm{E}+00$ & $0.00 \mathrm{E}+00$ & $.00 \mathrm{E}+00$ & & \\
\hline GTFL & DOE+00 & $0.00 \mathrm{E}+00$ & $0.00 \mathrm{E}+00$ & $.00 \mathrm{E}+00$ & $00 \mathrm{E}+00$ & $E+00$ & $00 \mathrm{E}+00$ & $0.00 \mathrm{E}+00$ & $.00 \mathrm{E}+00$ & $E+00$ & $00 \mathrm{E}+00$ & $.00 \mathrm{E}+00$ & $0.00 \mathrm{E}+00$ & $0.00 \mathrm{E}+00$ & & \\
\hline ILAW-liquid & $.00 \mathrm{E}+00$ & $0.00 \mathrm{E}+00$ & $0.00 \mathrm{E}+00$ & $0.00 \mathrm{E}+00$ & $00 \mathrm{E}+00$ & $00 \mathrm{E}+00$ & $0.00 \mathrm{E}+00$ & $0.00 \mathrm{E}+00$ & $.00 \mathrm{E}+00$ & $0.00 \mathrm{E}+00$ & $.00 \mathrm{E}+00$ & $0.00 \mathrm{E}+00$ & $0.00 \mathrm{E}+00$ & $0.00 \mathrm{E}+00$ & $.00 \mathrm{E}+00$ & $.00 \mathrm{E}+00$ \\
\hline RMWSF & $00 \mathrm{E}+00$ & $0.00 \mathrm{E}+00$ & $0.00 \mathrm{E}+00$ & $.00 \mathrm{E}+00$ & $00 \mathrm{E}+00$ & $00 \mathrm{E}+00$ & $0.00 \mathrm{E}+00$ & $0.00 \mathrm{E}+00$ & $0.00 \mathrm{E}+00$ & $.00 \mathrm{E}+00$ & $0.00 \mathrm{E}+00$ & $0.00 \mathrm{E}+00$ & $0.00 \mathrm{E}+00$ & $0.00 \mathrm{E}+00$ & $.00 \mathrm{E}+00$ & $\mathrm{DE}+00$ \\
\hline UPR-1 & 64E-02 & $1.32 \mathrm{E}+00$ & $4.81 \mathrm{E}+00$ & $87 \mathrm{E}+00$ & $18 \mathrm{E}+01$ & $20 \mathrm{E}+01$ & $2.20 \mathrm{E}+01$ & $2.20 \mathrm{E}+01$ & $2.64 \mathrm{E}+01$ & $76 \mathrm{E}+01$ & $2.76 \mathrm{E}+01$ & $2.76 \mathrm{E}+01$ & $2.77 \mathrm{E}+01$ & $2.84 \mathrm{E}+01$ & $.87 \mathrm{E}+01$ & $87 \mathrm{E}+01$ \\
\hline UPR-1 & 92E-01 & 1.34E-01 & 6.77E-02 & 4.63E-02 & 07E-02 & 87E-02 & 2.09E-02 & 2.09E-02 & $5 \mathrm{E}-02$ & $.70 \mathrm{E}-02$ & 1.70E-02 & $1.70 \mathrm{E}-02$ & 1.70E-02 & 64E-02 & $.58 \mathrm{E}-02$ & $3 \mathrm{E}-02$ \\
\hline & $58 \mathrm{E}-02$ & 6.03E-01 & $1.26 \mathrm{E}+00$ & $27 \mathrm{E}+00$ & $39 \mathrm{E}+00$ & $3.37 \mathrm{E}+00$ & $E+00$ & $3.37 \mathrm{E}+00$ & $3.55 E+00$ & $3.61 \mathrm{E}+00$ & $3.61 \mathrm{E}+00$ & $3.61 \mathrm{E}+00$ & $3.62 \mathrm{E}+$ & $3.61 E$ & $3.62 E$ & $E+00$ \\
\hline UPR-1 & 44E-01 & 1.17E-01 & $9.60 \mathrm{E}-02$ & 8.80E-02 & 7.33E-02 & E-02 & $\mathrm{E}-02$ & $6.43 \mathrm{E}-02$ & 6.45E-02 & 43E-02 & 6.43E-02 & $6.42 \mathrm{E}-02$ & $6.20 \mathrm{E}-02$ & $18 \mathrm{E}-02$ & $18 \mathrm{E}-02$ & $8 \mathrm{E}-02$ \\
\hline R-2 & $4 \mathrm{E}-02$ & 28E-02 & E-02 & $2.17 \mathrm{E}-02$ & 18E-02 & 7E-02 & 7E-02 & 02 & 2.18E-02 & E-02 & 2.17E-02 & 02 & $8 \mathrm{E}-02$ & .17E-02 & 17E-02 & OE-02 \\
\hline UPR- & 74E-01 & 72E-01 & $E-01$ & $72 \mathrm{E}-01$ & 8.74E-01 & 72E-01 & $6 \mathrm{E}-01$ & & E-01 & DE-01 & $6.10 \mathrm{E}-01$ & $6.10 \mathrm{E}-01$ & $6.11 \mathrm{E}-01$ & .10E-01 & $6.10 \mathrm{E}-01$ & $6.10 \mathrm{E}-01$ \\
\hline UPR-2 & 4.33E-05 & 4.32E-05 & 32E-05 & $4.32 \mathrm{E}-05$ & 4.33E-05 & 32E-05 & 4.32E-05 & 4.32E-05 & 33E-05 & 32E-05 & 4.32E-05 & 4.32E-05 & 4.33E-05 & 4.32E-05 & 4.32E-05 & 4.32E-05 \\
\hline UPR-2 & 2.32E-07 & 3.79E-07 & 79E-07 & 79E-07 & 3.80E-07 & 79E-07 & 3.79E-07 & 3.79E-07 & 80E-07 & 79E-07 & 3.79E-07 & 2.02E-05 & $2.61 \mathrm{E}-05$ & $2.60 \mathrm{E}-05$ & $2.60 \mathrm{E}-05$ & 2.60E-05 \\
\hline UPR-2 & 12E-07 & 1.12E-07 & $12 \mathrm{E}-07$ & 12E-07 & 12E-07 & 12E-07 & 12E-07 & $12 \mathrm{E}-07$ & 12E-07 & $12 \mathrm{E}-07$ & 1.12E-07 & 1.12E-07 & 12E-07 & $.12 \mathrm{E}-07$ & $.12 \mathrm{E}-07$ & $1.12 \mathrm{E}-07$ \\
\hline UPR-2 & 5.82E-02 & $5.80 \mathrm{E}-02$ & 5.80E-02 & $5.80 \mathrm{E}-02$ & 5.82E-02 & $5.80 \mathrm{E}-02$ & 4.20E-02 & $3.69 \mathrm{E}-02$ & 3.70E-02 & 3.69E-02 & 3.69E-02 & $3.69 \mathrm{E}-02$ & 3.70E-02 & $69 \mathrm{E}-02$ & $3.69 \mathrm{E}-02$ & $69 \mathrm{E}-02$ \\
\hline UPR-2 & $0.00 \mathrm{E}+00$ & $0.00 \mathrm{E}+00$ & $0.00 \mathrm{E}+00$ & $0.00 \mathrm{E}+00$ & $00 \mathrm{E}+00$ & $0.00 \mathrm{E}+00$ & $00 \mathrm{E}+00$ & $0.00 \mathrm{E}+00$ & $.00 \mathrm{E}+00$ & $0.00 \mathrm{E}+00$ & $0.00 \mathrm{E}+00$ & $0.00 \mathrm{E}+00$ & $0.00 E+00$ & $0.00 \mathrm{E}+00$ & $.00 \mathrm{E}+00$ & $0 \mathrm{E}+00$ \\
\hline UPR-2 & $0.00 \mathrm{E}+00$ & $0.00 \mathrm{E}+00$ & $0.00 \mathrm{E}+00$ & $00 \mathrm{E}+00$ & $00 \mathrm{E}+00$ & $00 \mathrm{E}+00$ & $0.00 \mathrm{E}+00$ & $0.00 \mathrm{E}+00$ & $.00 \mathrm{E}+00$ & $0.00 \mathrm{E}+00$ & $0.00 \mathrm{E}+00$ & $0.00 \mathrm{E}+00$ & $0.00 \mathrm{E}+00$ & $0.00 \mathrm{E}+00$ & $.00 \mathrm{E}+00$ & $.00 \mathrm{E}+00$ \\
\hline UPR-2 & 39E-08 & $1.38 \mathrm{E}-08$ & 1.38E-08 & 1.38E-08 & 1.39E-08 & $38 \mathrm{E}-08$ & .38E-08 & $=-08$ & E-08 & $\mathrm{E}-08$ & 1.38E-08 & $1.38 \mathrm{E}-08$ & $9 \mathrm{E}-08$ & $.38 \mathrm{E}-08$ & 3.63E-07 & \\
\hline & $E+00$ & $=+00$ & OOE+00 & $E+00$ & $00 \mathrm{E}+00$ & $E+00$ & $00 E+00$ & $E+00$ & $E+00$ & $E+00$ & $0.00 \mathrm{E}+00$ & $E+00$ & $E+00$ & $E+00$ & $0.00 \mathrm{E}+00$ & +00 \\
\hline UPR & +00 & +00 & +00 & & +00 & +00 & +00 & & & +00 & $E+00$ & +00 & +00 & +00 & +00 & \\
\hline UPR & +00 & & -01 & & -01 & -01 & $E-01$ & & & -02 & $\mathrm{E}-02$ & -02 & & $E-02$ & E-02 & \\
\hline & & $=+00$ & 00 & 0 & & +00 & & & & +00 & +00 & 100 & & +00 & +00 & \\
\hline & $0 \mathrm{E}+00$ & $0.00 \mathrm{E}+00$ & $E+00$ & $.00 \mathrm{E}+\mathrm{C}$ & +00 & $E+00$ & $E+00$ & +00 & +00 & $E+00$ & $0.00 E+00$ & $=00$ & +00 & $E+00$ & $0.00 \mathrm{E}+00$ & $E+00$ \\
\hline $\mathrm{U}$ & $9 \mathrm{E}-03$ & 7.08E-03 & 08E-03 & $7.08 \mathrm{E}-\mathrm{C}$ & 1.00E-02 & $4.56 \mathrm{E}-02$ & $4.56 \mathrm{E}-02$ & $4.56 \mathrm{E}-02$ & $4.58 \mathrm{E}-02$ & $4.56 \mathrm{E}-02$ & $4.56 \mathrm{E}-02$ & 4.56E-02 & $4.58 \mathrm{E}-02$ & $4.56 \mathrm{E}-02$ & 4.99E-02 & $5.16 \mathrm{E}-02$ \\
\hline UPR-2 & $0 \mathrm{E}+00$ & $0.00 \mathrm{E}+00$ & $0.00 \mathrm{E}+00$ & $.00 \mathrm{E}+00$ & $00 \mathrm{E}+00$ & $0.00 \mathrm{E}+00$ & $0.00 \mathrm{E}+00$ & $0.00 \mathrm{E}+00$ & $0.00 \mathrm{E}+00$ & $0.00 \mathrm{E}+00$ & $0.00 \mathrm{E}+00$ & $0.00 \mathrm{E}+00$ & $0.00 \mathrm{E}+00$ & $0.00 \mathrm{E}+00$ & $0.00 \mathrm{E}+00$ & $0.00 \mathrm{E}+00$ \\
\hline UPR-2 & 19E-05 & $2.18 \mathrm{E}-05$ & 2.18E-05 & 2.18E-05 & 2.19E-05 & 2.18E-05 & $2.18 \mathrm{E}-05$ & 2.18E-05 & 2.19E-05 & 5.51E-04 & 1.16E-03 & 1.16E-03 & 1.16E-03 & 1.16E-03 & 1.16E-03 & 1.16E-03 \\
\hline UPR-200-E-38 & 1.59E-01 & 1.59E-01 & $9.73 \mathrm{E}-02$ & $9.11 \mathrm{E}-02$ & $9.14 \mathrm{E}-02$ & 9.11E-02 & 8.44E-02 & 5.34E-02 & 5.36E-02 & 5.34E-02 & 5.34E-02 & 5.34E-02 & 5.36E-02 & $.18 \mathrm{E}-02$ & $3.32 \mathrm{E}-02$ & $3.32 \mathrm{E}-02$ \\
\hline UPR-20C & $0.00 \mathrm{E}+00$ & $0.00 \mathrm{E}+00$ & $0.00 \mathrm{E}+00$ & $0.00 \mathrm{E}+00$ & $0.00 \mathrm{E}+00$ & $0.00 \mathrm{E}+00$ & $0.00 \mathrm{E}+00$ & $0.00 \mathrm{E}+00$ & $0.00 \mathrm{E}+00$ & $0.00 \mathrm{E}+00$ & $0.00 \mathrm{E}+00$ & $0.00 \mathrm{E}+00$ & $0.00 \mathrm{E}+00$ & $0.00 \mathrm{E}+00$ & $0.00 \mathrm{E}+00$ & $0.00 \mathrm{E}+00$ \\
\hline UPR-2C & $6.25 \mathrm{E}-10$ & $6.23 \mathrm{E}-10$ & $6.23 \mathrm{E}-10$ & $6.23 \mathrm{E}-10$ & $3.65 \mathrm{E}-05$ & 7.72E-03 & $2.98 \mathrm{E}-02$ & $6.25 \mathrm{E}-02$ & 7.15E-02 & 7.91E-02 & 7.91E-02 & 8.11E-02 & $8.15 \mathrm{E}-02$ & 8.13E-02 & 8.13E-02 & \\
\hline UPR-2 & 1.22E-01 & 7.94E-02 & 94E-02 & 7.94E-02 & 7.97E-02 & 7.94E-02 & $94 \mathrm{E}-02$ & 94E-02 & 7.97E-02 & $94 \mathrm{E}-02$ & 7.94E-02 & 7.52E-02 & 5.85E-02 & $.83 \mathrm{E}-02$ & $5.83 \mathrm{E}-02$ & $5.83 \mathrm{E}-02$ \\
\hline & LE-08 & $9.39 \mathrm{E}-08$ & 39E-08 & $9.39 \mathrm{E}-08$ & $9.41 \mathrm{E}-08$ & $3.45 \mathrm{E}-06$ & $6.53 \mathrm{E}-06$ & $6.53 \mathrm{E}-06$ & $6.55 \mathrm{E}-06$ & $6.53 \mathrm{E}-06$ & $6.53 \mathrm{E}-06$ & $6.53 \mathrm{E}-06$ & 6.55E-06 & $.53 E-06$ & $6.53 \mathrm{E}-06$ & $6.53 \mathrm{E}-06$ \\
\hline UPR-2C & $67 \mathrm{E}-08$ & 1.01E-06 & $1.64 \mathrm{E}-06$ & 1.64E-06 & 1.65E-06 & 1.64E-06 & 1.64E-06 & 1.64E-06 & $1.65 \mathrm{E}-06$ & 1.64E-06 & 1.64E-06 & 1.64E-06 & 4.95E-05 & 6.32E-05 & 6.32E-05 & 6.32E-05 \\
\hline UPR-200-E-75 & 1.05E-04 & 1.05E-04 & $1.05 \mathrm{E}-04$ & $1.05 E-04$ & 1.05E-04 & 1.05E-04 & 1.05E-04 & $4.17 \mathrm{E}-03$ & $7.85 \mathrm{E}-03$ & 7.83E-03 & 7.83E-03 & 7.83E-03 & 7.85E-03 & 7.83E-03 & 7.83E-03 & 7.83E-03 \\
\hline
\end{tabular}




\begin{tabular}{|c|c|c|c|c|c|c|c|c|c|c|c|c|c|c|c|c|}
\hline & & & & & & & & & & & & & & & & \\
\hline & & & & & & & & & & & & & & & & \\
\hline PR-2C & & 55E-07 & 70E-06 & J9E-05 & LOE-05 & & & & 10E-05 & & & & & & & 75 \\
\hline PR-200-E-79 & 0E-02 & 19E-02 & 49E-02 & 49E-02 & 50E-02 & & 49E-02 & & 50E-02 & & 49E-02 & .09E-01 & & $.03 E+00$ & $1.03 E+00$ & $1.03 E+$ \\
\hline PR-20 & 72E-03 & 72E-03 & $1.72 \mathrm{E}-03$ & $.72 \mathrm{E}-03$ & 48E-01 & $34 \mathrm{E}-01$ & 34E-01 & $34 \mathrm{E}-01$ & $37 \mathrm{E}-01$ & 34E-01 & 34E-01 & & & & $3.34 \mathrm{E}-01$ & 150 \\
\hline PR-2 & $32 \mathrm{E}+00$ & $6.28 \mathrm{E}+00$ & $97 \mathrm{E}+00$ & & $53 \mathrm{E}+00$ & $62 \mathrm{E}+00$ & $62 \mathrm{E}+00$ & & $E+00$ & $56 \mathrm{E}+00$ & $2.56 \mathrm{E}+00$ & $2.33 \mathrm{E}+00$ & & & & \\
\hline PR-2C & & & & & & & & & & & & & & & & \\
\hline PR-2 & & & & & & & & & & & & & & & & \\
\hline PR-2 & & & & & $=-09$ & & & & & & & & & & & \\
\hline 86 & & & & & & & & & & & & & & & & \\
\hline 87 & & & & & & & & & & & & & & & & \\
\hline $\mathrm{R}-2$ & & & & & & & & & & & & & & & & \\
\hline PR-2 & $E-04$ & 07E-04 & & & & & & & & & & & & & & $T L-C$ \\
\hline PR-20 & & $1.24 \mathrm{E}-01$ & & & & & & & & & & & & & & \\
\hline V-101 & & $1.30 \mathrm{E}-05$ & & & & & & & & & & & & & $8.32 \mathrm{E}-03$ & $1 \mathrm{E}-\mathrm{C}$ \\
\hline PR-2C & & 34E-07 & EE-07 & & & & & & & & & & & & & \\
\hline PR-2 & $11 \mathrm{E}+03$ & $3.64 \mathrm{E}+03$ & $64 \mathrm{E}+03$ & & & $64 \mathrm{E}+03$ & & & & & & & & & & \\
\hline PR-2 & & -07 & & & & & & & & & -07 & & & & & $E$ \\
\hline PR-2 & & & & & & & & & & & & & & & & \\
\hline PR-2 & & & & & & & & & & & & & & -10 & $E-10$ & $\mathrm{~F}=$ \\
\hline PR-2 & 100 & & & & & & & & & & & & & $E-01$ & $\mathrm{E}-01$ & F- \\
\hline PR-2 & & & & & & & & & & & & & & & & \\
\hline PR-2 & & & & & & & & & & & & & & & & \\
\hline PR-2 & & -04 & & & & & & & & & & & & & $E-03$ & $3 \mathrm{E}-\mathrm{O}$ \\
\hline UPR-2 & & & & & & & & & & & & & & & & E-C \\
\hline UPR-2C & 47E-02 & 7.49E-02 & E-02 & E-02 & E-02 & 85E-02 & -02 & & -02 & -02 & -02 & -02 & & $=-02$ & $\mathrm{E}-02$ & $6 \mathrm{E}-\mathrm{C}$ \\
\hline-138 & D7E-06 & 8.05E-06 & $\mathrm{E}-06$ & E-06 & & 05E-06 & & & & & $E-06$ & & & E-04 & $\mathrm{E}-04$ & $6 \mathrm{E}-0$ \\
\hline-139 & & & & & & & & & & & & & & & & \\
\hline JPR-2 & & & & & & & & & & & & & & & & \\
\hline JPR-2 & & & & & & & & & & & & & & & -01 & \\
\hline PR-2 & & & & & & & & & & & & & & & & \\
\hline PR-2 & & & & & & & & & & & & & & & & \\
\hline PR-2 & & & & & & & & & & & $E-02$ & & & $\mathrm{E}-02$ & LE-02 & $\mathrm{E}-\mathrm{C}$ \\
\hline PR-2 & & & & & & & & & & & & & & 3E-02 & $3.73 \mathrm{E}-02$ & C...6L \\
\hline PR-2C & & $4 \mathrm{E}-01$ & E-01 & 1 & E-01 & & $F_{-} 0$ & 5 & E-01 & E-01 & E-01 & $2.21 \mathrm{E}+00$ & $E+00$ & $E+00$ & $81 \mathrm{E}+00$ & \\
\hline PR-20 & E-01 & 70E-01 & E-01 & 70E-01 & $\mathrm{E}-01$ & $\mathrm{E}-01$ & $E_{0} 01$ & $\mathrm{I}_{-} 01$ & $\mathrm{E}-01$ & E-01 & E-01 & $4 \mathrm{E}+01$ & +01 & $E+01$ & $4 \mathrm{E}+01$ & $1.84 \mathrm{E}+0$ \\
\hline JPR-2C & $\mathrm{E}-03$ & $2.80 \mathrm{E}-02$ & 30E-02 & 30E-02 & 30E-02 & 80E-02 & E-02 & 02 & E-02 & $\mathrm{E}-02$ & E-02 & 02 & & 46E-01 & $46 \mathrm{E}-01$ & $4.46 \mathrm{E}-0$ \\
\hline JPR-20 & $1 \mathrm{E}-01$ & $3.64 \mathrm{E}+00$ & $3.64 \mathrm{E}+00$ & $64 \mathrm{E}+00$ & $65 \mathrm{E}+00$ & $3.64 \mathrm{E}+00$ & $3.64 \mathrm{E}+00$ & $.64 \mathrm{E}+00$ & $3.65 \mathrm{E}+00$ & $3.64 \mathrm{E}+00$ & $3.64 \mathrm{E}+00$ & $3.64 \mathrm{E}+00$ & $3 \mathrm{E}+01$ & $2.64 \mathrm{E}+01$ & $2.64 \mathrm{E}+01$ & $2.64 \mathrm{E}+0$ \\
\hline PR-20 & 35E-02 & 7.83E-02 & 7.83E-02 & 7.83E-02 & 7.85E-02 & 7.83E-02 & 7.83E-02 & 6.84E-02 & 5.58E-02 & 5.56E-02 & 5.56E-02 & 5.56E-02 & 5.58E-02 & 5.56E-02 & 5.56E-02 & $5.56 \mathrm{E}-0$ \\
\hline PR-20 & $27 \mathrm{E}-07$ & $3.26 \mathrm{E}-07$ & 2.08E-04 & $20 \mathrm{E}-04$ & 21E-04 & 20E-04 & $2.20 \mathrm{E}-04$ & 0E-04 & 21E-04 & 2.20E-04 & $2.20 \mathrm{E}-04$ & $2.20 \mathrm{E}-04$ & 21E-04 & 19E-03 & $2.30 \mathrm{E}-03$ & $2.30 \mathrm{E}-0$ \\
\hline PR-20 & 27E-02 & $6.25 \mathrm{E}-02$ & EE-02 & $6.18 \mathrm{E}-02$ & 19E-02 & 18E-02 & $.18 \mathrm{E}-02$ & OL & 19E-02 & 18E-02 & BE-02 & $6.18 \mathrm{E}-02$ & 9E-02 & $18 \mathrm{E}-02$ & $5.96 \mathrm{E}-02$ & 5.30E-C \\
\hline PR-200-W-38 & 3.70E-04 & 3.69E-04 & 5.65E-UL & $0.995-02$ & 6.01E-02 & 5.99E-02 & 5.99E-02 & $0.99 \mathrm{~L}-\mathrm{UL}$ & $6.01 \mathrm{E}-02$ & 5.99E-02 & $5.99 \mathrm{E}-02$ & S.99E-UL & $6.01 \mathrm{E}-02$ & $3.14 \mathrm{E}-01$ & 6.04E-01 & $0.04 \mathrm{~L}-\mathrm{U}$ \\
\hline
\end{tabular}




\begin{tabular}{|c|c|c|c|c|c|c|c|c|c|c|c|c|c|c|c|c|}
\hline Site & 1976 & 1977 & 1978 & 1979 & 1980 & 1981 & 1982 & 1983 & 1984 & 1985 & 1986 & 1987 & 1988 & 1989 & 1990 & 1991 \\
\hline UPR-200-W-39 & 14E-04 & 99E-03 & 5.99E-03 & 99E-03 & $6.01 \mathrm{E}-03$ & $.99 \mathrm{E}-03$ & $.99 \mathrm{E}-03$ & 5.99E-03 & $6.01 \mathrm{E}-03$ & 5.99E-03 & 5.99E-03 & 5.99E-03 & $7.42 \mathrm{E}-02$ & $9.38 \mathrm{E}-02$ & $9.38 \mathrm{E}-02$ & $9.38 \mathrm{E}-02$ \\
\hline UPR-200-W-49 & 00E-05 & $9.98 \mathrm{E}-06$ & 9.98E-06 & 98E-06 & 05E-03 & 7.01E-03 & 7.01E-03 & 7.01E-03 & 7.03E-03 & 7.01E-03 & 7.01E-03 & 7.01E-03 & 7.03E-03 & 7.01E-03 & $01 \mathrm{E}-03$ & \\
\hline UPR-200-W-5 & 16E-02 & 4.68E-02 & 4.68E-02 & 68E-02 & 4.70E-02 & 4.68E-02 & 4.68E-02 & 4.68E-02 & 4.70E-02 & 4.68E-02 & 4.68E-02 & 4.68E-02 & 4.70E-02 & 4.56E-02 & 4.47E-02 & 4.47E-02 \\
\hline UPR-200-W-51 & $2.40 \mathrm{E}-06$ & $2.39 \mathrm{E}-06$ & $2.39 \mathrm{E}-06$ & $2.39 \mathrm{E}-06$ & $2.66 \mathrm{E}-04$ & $1.78 \mathrm{E}-03$ & $1.78 \mathrm{E}-03$ & $1.78 \mathrm{E}-03$ & $1.78 \mathrm{E}-03$ & $1.78 \mathrm{E}-03$ & $1.78 \mathrm{E}-03$ & $1.78 \mathrm{E}-03$ & $1.78 \mathrm{E}-03$ & $1.78 \mathrm{E}-03$ & $1.78 \mathrm{E}-03$ & 1.78E-03 \\
\hline UPR-200-W-59 & $1.24 \mathrm{E}-05$ & 1.23E-05 & 1.23E-05 & 1.23E-05 & $1.72 \mathrm{E}-03$ & 2.97E-03 & 2.97E-03 & 2.97E-03 & 2.97E-03 & 2.97E-03 & 2.97E-03 & 2.69E-01 & $1.84 \mathrm{E}+00$ & $1.84 \mathrm{E}+00$ & $1.84 \mathrm{E}+00$ & $1.84 \mathrm{E}+00$ \\
\hline UPR-2C & 86E-04 & 1.85E-04 & 1.85E-04 & 1.85E-04 & 1.86E-04 & 1.85E-04 & E-04 & 1.85E-04 & -03 & -03 & $\mathrm{E}-03$ & 5.81E-03 & 5.83E-03 & 5.81E-03 & 5.81E-03 & -03 \\
\hline UPR-2 & $E-09$ & 3.20E-09 & 3.20E-09 & 3.20E-09 & 3.21E-09 & F-07 & E-07 & E-07 & & $=-07$ & E-07 & E-07 & E-05 & $=-04$ & E-04 & \\
\hline UPR-2C & -10 & $1.38 \mathrm{E}-10$ & $1.38 \mathrm{E}-10$ & $1.38 \mathrm{E}-10$ & -10 & 1.38E-10 & $1.38 \mathrm{E}-10$ & $1.38 \mathrm{E}-10$ & -10 & $1.38 \mathrm{E}-10$ & $1.38 \mathrm{E}-10$ & 1.38E-10 & 1.39E-10 & $1.38 \mathrm{E}-10$ & $\mathrm{E}-10$ & 1.38E-10 \\
\hline UPR-20 & $=-10$ & 3.63E-10 & 3.63E-10 & 3.63E-10 & -10 & $E-10$ & -10 & 3.63E-10 & & 3.63E-10 & E-10 & 3.63E-10 & $4 \mathrm{E}-10$ & $3 \mathrm{E}-10$ & -10 & 3.63E-10 \\
\hline UPR-20 & & 2.95 & -03 & -03 & & -01 & & $E-01$ & & & -01 & -01 & -01 & -01 & -01 & $4.80 \mathrm{E}-01$ \\
\hline UPR-2C & -08 & 4.72 & $4.72 \mathrm{E}-08$ & $4.72 \mathrm{E}-08$ & -08 & E-08 & E-08 & $4.72 \mathrm{E}-08$ & 7.2 & E-05 & E-05 & $1.26 \mathrm{E}-05$ & $\mathrm{E}-05$ & 5E-05 & $6 \mathrm{E}-05$ & $6.34 \mathrm{E}-05$ \\
\hline UPR-20 & -08 & -07 & -07 & -07 & -07 & -05 & -05 & -05 & & & -05 & -05 & E-03 & -02 & E-02 & 13E-02 \\
\hline UPR-20 & E-03 & 1.29E-03 & 1.29E-03 & $1.26 \mathrm{E}-02$ & 1.60E-02 & 1.60E-02 & $1.60 \mathrm{E}-02$ & 1.60E-02 & $\mathrm{E}-02$ & $1.60 \mathrm{E}-02$ & $1.60 \mathrm{E}-02$ & $1.60 \mathrm{E}-02$ & 0E-02 & E-02 & $1.60 \mathrm{E}-02$ & 1.60E-02 \\
\hline UPR-300-4 & $37 E+01$ & $4.36 \mathrm{E}+01$ & $4.36 \mathrm{E}+01$ & $4.36 \mathrm{E}+01$ & $4.37 \mathrm{E}+01$ & $4.36 \mathrm{E}+01$ & $4.26 \mathrm{E}+01$ & $3.87 \mathrm{E}+01$ & $3.88 \mathrm{E}+01$ & $3.87 \mathrm{E}+01$ & $3.87 \mathrm{E}+01$ & $3.87 \mathrm{E}+01$ & $3.88 \mathrm{E}+01$ & $3.87 \mathrm{E}+01$ & $3.87 \mathrm{E}+01$ & $3.87 \mathrm{E}+01$ \\
\hline US_Ecology & $0.00 \mathrm{E}+00$ & $0.00 \mathrm{E}+00$ & $0.00 \mathrm{E}+00$ & $0.00 \mathrm{E}+00$ & $0.00 \mathrm{E}+00$ & $0.00 \mathrm{E}+00$ & $0.00 \mathrm{E}+00$ & $0.00 \mathrm{E}+00$ & $0.00 \mathrm{E}+00$ & $0.00 \mathrm{E}+00$ & $0.00 \mathrm{E}+00$ & $0.00 \mathrm{E}+00$ & $0.00 \mathrm{E}+00$ & $0.00 \mathrm{E}+00$ & $0.00 \mathrm{E}+00$ & $0.00 \mathrm{E}+00$ \\
\hline
\end{tabular}




\begin{tabular}{|c|c|c|c|c|c|c|c|c|c|c|c|}
\hline Site & 1992 & 1993 & 1994 & 1995 & 1996 & 1997 & 1998 & 1999 & 2000 & 2001 & 2002 \\
\hline 216-U-1\%2-Fast & $14 \mathrm{E}+00$ & $12 \mathrm{E}+00$ & $8.12 \mathrm{E}+00$ & $8.12 \mathrm{E}+00$ & $14 \mathrm{E}+00$ & $8.12 \mathrm{E}+00$ & $8.12 \mathrm{E}+00$ & $8.12 \mathrm{E}+00$ & $0.00 \mathrm{E}+00$ & $0.00 \mathrm{E}+00$ & $0.00 \mathrm{E}+00$ \\
\hline & $37 \mathrm{E}+00$ & $36 \mathrm{E}+00$ & $4.36 \mathrm{E}+00$ & $4.36 \mathrm{E}+00$ & $37 \mathrm{E}+00$ & $35 E+00$ & $35 \mathrm{E}+00$ & $4.35 \mathrm{E}+00$ & $4.36 \mathrm{E}+00$ & $4.35 \mathrm{E}+00$ & $4.35 \mathrm{E}+00$ \\
\hline & $55 \mathrm{E}+01$ & $55 E+01$ & $1.55 \mathrm{E}+01$ & $1.55 E+01$ & $55 \mathrm{E}+01$ & $55 \mathrm{E}+01$ & $55 \mathrm{E}+01$ & $55 \mathrm{E}+01$ & $1.55 \mathrm{E}+01$ & $5 E+01$ & $54 \mathrm{E}+01$ \\
\hline D-32 & $59 \mathrm{E}+00$ & $59 \mathrm{E}+00$ & $3.59 \mathrm{E}+00$ & $3.59 \mathrm{E}+00$ & $60 \mathrm{E}+00$ & $59 \mathrm{E}+00$ & $59 \mathrm{E}+00$ & $3.59 \mathrm{E}+00$ & $3.60 \mathrm{E}+00$ & $59 \mathrm{E}+00$ & $58 \mathrm{E}+00$ \\
\hline $0-D-40$ & $82 \mathrm{E}+00$ & $81 \mathrm{E}+00$ & $1.81 \mathrm{E}+00$ & $1.81 \mathrm{E}+00$ & $.82 \mathrm{E}+00$ & $81 \mathrm{E}+00$ & $81 \mathrm{E}+00$ & $1.81 \mathrm{E}+00$ & $1.82 \mathrm{E}+00$ & $E+00$ & $31 \mathrm{E}+00$ \\
\hline & $15 E+01$ & $13 \mathrm{E}+01$ & $6.13 \mathrm{E}+01$ & $6.13 E+01$ & $15 \mathrm{E}+01$ & $3 \mathrm{E}+01$ & $13 \mathrm{E}+01$ & $13 \mathrm{E}+01$ & & $3 \mathrm{E}+01$ & $1 \mathrm{E}+01$ \\
\hline & $\mathrm{E}-02$ & 3E-02 & 13E-02 & 7.43E-02 & 7.45E-( & $3 \mathrm{E}-02$ & 02 & 41E-02 & E-02 & $7 \mathrm{E}-02$ & \\
\hline & $\mathrm{E}-02$ & 10E-02 & LE-02 & 10E-02 & $6.11 \mathrm{E}-02$ & E-02 & LEE-02 & 10E-02 & & $9 \mathrm{E}-02$ & $7 \mathrm{E}-02$ \\
\hline 100 & $E+01$ & $E+01$ & $E+01$ & $\mathrm{E}+01$ & $7.93 \mathrm{E}+01$ & $E+01$ & $\mathrm{LE}+01$ & $1 E+01$ & $3 \mathrm{E}+01$ & $E+01$ & $\mathrm{E}+01$ \\
\hline & -02 & E-02 & $E-02$ & E-02 & $2.11 \mathrm{E}-02$ & E-02 & LE-02 & LE-02 & $\mathrm{E}-02$ & E-02 & LE-02 \\
\hline 100 & $E-02$ & E-02 & 3E-02 & 3.08E-02 & 3.09E-02 & E-02 & 58E-02 & $3.08 \mathrm{E}-02$ & 3.09E-02 & EE-02 & $8 \mathrm{E}-02$ \\
\hline & $E-02$ & $\mathrm{E}-02$ & 45E-02 & 1.45E-02 & $1.45 \mathrm{E}-02$ & $5 E-02$ & $1.45 \mathrm{E}-02$ & E-02 & $1.45 \mathrm{E}-02$ & $.45 \mathrm{E}-02$ & $5 \mathrm{E}-02$ \\
\hline & $52 \mathrm{E}+01$ & $51 \mathrm{E}+01$ & $1.51 \mathrm{E}+01$ & $1.51 \mathrm{E}+01$ & $1.52 \mathrm{E}+01$ & $51 \mathrm{E}+01$ & $.51 \mathrm{E}+01$ & $1.51 \mathrm{E}+01$ & $1.52 \mathrm{E}+01$ & $1.51 \mathrm{E}+01$ & $1.51 \mathrm{E}+01$ \\
\hline 100 & 01E-02 & 4.99E-02 & 4.99E-02 & 4.99E-02 & 5.01E-02 & 4.99E-02 & 4.99E-02 & 4.97E-02 & 4.73E-02 & 4.72E-02 & $49 \mathrm{E}-02$ \\
\hline 60 & 18E-02 & $3.17 \mathrm{E}-02$ & $88 \mathrm{E}-02$ & $2.13 \mathrm{E}-02$ & 13E-02 & E-02 & 11E-02 & $5 E-02$ & 1.70E-02 & $0 \mathrm{E}-02$ & $3 \mathrm{E}-02$ \\
\hline & $00 \mathrm{E}+00$ & $00 \mathrm{E}+00$ & $0.00 \mathrm{E}+00$ & $0.00 \mathrm{E}+00$ & $.00 \mathrm{E}+00$ & $E+00$ & $.00 \mathrm{E}+00$ & $.00 \mathrm{E}+00$ & $0.00 \mathrm{E}+00$ & $\mathrm{E}+00$ & $\mathrm{DE}+00$ \\
\hline & L1E+01 & 09E+01 & $09 \mathrm{E}+01$ & $8.09 \mathrm{E}+01$ & $11 \mathrm{E}+01$ & $3 \mathrm{E}+01$ & $8 \mathrm{E}+01$ & $E+01$ & & $E+01$ & $E+01$ \\
\hline & $9 \mathrm{E}+00$ & $08 \mathrm{E}+00$ & $08 \mathrm{E}+00$ & $1.08 \mathrm{E}+00$ & $09 \mathrm{E}+00$ & $E+00$ & $\mathrm{E}+00$ & $E+00$ & 00 & & E-01 \\
\hline & E-01 & $E-01$ & E-01 & $E-01$ & $3.65 \mathrm{E}$ & & $\mathrm{E}-01$ & E-01 & & $\mathrm{E}-01$ & E-01 \\
\hline & E-02 & $E-02$ & E-02 & $E-02$ & 9.8 & $E-02$ & 6E-02 & E-02 & & E-02 & $2 \mathrm{E}-02$ \\
\hline & $E+00$ & $E+00$ & $\mathrm{E}+00$ & $1.05 E+00$ & $1.05 \mathrm{E}+00$ & $E+00$ & $3 \mathrm{E}+00$ & $E+00$ & 01 & 8E-01 & $3 \mathrm{E}-01$ \\
\hline$-6 B$ & E-01 & $\mathrm{E}-01$ & 0E-01 & $1.20 \mathrm{E}-01$ & 1.20E-01 & E-01 & $20 \mathrm{E}-01$ & 0E-01 & 0E-01 & E-01 & OE-02 \\
\hline & $29 \mathrm{E}+02$ & $28 \mathrm{E}+02$ & $2.28 \mathrm{E}+02$ & $2.28 \mathrm{E}+02$ & $2.28 \mathrm{E}+02$ & $.25 \mathrm{E}+02$ & $21 \mathrm{E}+02$ & $2.17 \mathrm{E}+02$ & $2.05 \mathrm{E}+02$ & $1.85 \mathrm{E}+02$ & $6.90 \mathrm{E}+01$ \\
\hline & $E+00$ & $33 E+00$ & $1.33 \mathrm{E}+00$ & $1.33 E+00$ & $1.33 \mathrm{E}+00$ & $33 \mathrm{E}+00$ & $33 E+00$ & $1.32 \mathrm{E}+00$ & $1.31 \mathrm{E}+00$ & $1.27 \mathrm{E}+00$ & 41E-01 \\
\hline $2 \mathrm{C}$ & 45E-01 & 43E-01 & $5.43 \mathrm{E}-01$ & 5.43E-01 & $5.45 \mathrm{E}-01$ & 43E-01 & 5.43E-01 & 5.41E-01 & 5.37E-01 & 20E-01 & $3.04 \mathrm{E}-01$ \\
\hline$-1 \mathrm{~A}$ & $89 \mathrm{E}+00$ & $89 \mathrm{E}+00$ & $1.88 \mathrm{E}+00$ & $1.88 \mathrm{E}+00$ & $1.89 \mathrm{E}+00$ & $.88 \mathrm{E}+00$ & $88 \mathrm{E}+00$ & $1.88 \mathrm{E}+00$ & $1.88 \mathrm{E}+00$ & $1.88 \mathrm{E}+00$ & $1.82 \mathrm{E}+00$ \\
\hline$-1 B$ & 47E+00 & 47E+00 & $47 \mathrm{E}+00$ & $1.47 \mathrm{E}+00$ & $47 \mathrm{E}+00$ & $47 \mathrm{E}+00$ & $47 \mathrm{E}+00$ & $47 \mathrm{E}+00$ & $1.46 \mathrm{E}+00$ & $5 \mathrm{E}+00$ & $0 \mathrm{E}+00$ \\
\hline R-1\%2 & $3 \mathrm{E}+02$ & $03 E+02$ & $2.02 \mathrm{E}+02$ & $2.01 \mathrm{E}+02$ & $.02 \mathrm{E}+02$ & $E+02$ & $E+02$ & $E+02$ & $2.02 \mathrm{E}+02$ & $\mathrm{E}+02$ & +02 \\
\hline R-3 & $6 \mathrm{E}+00$ & $45 \mathrm{E}+00$ & $E+00$ & +00 & $.46 \mathrm{E}+00$ & +00 & $5 \mathrm{E}+00$ & $\mathrm{E}+00$ & $3.45 \mathrm{E}+00$ & $3.44 \mathrm{E}+00$ & $3.15 \mathrm{E}+00$ \\
\hline & & 102 & +02 & 4.2 & $E+02$ & +02 & $E+02$ & $E+02$ & $E+02$ & $5 \mathrm{E}+02$ & $\mathrm{E}+02$ \\
\hline & & & -02 & & & -02 & $E-02$ & $E-02$ & & $\mathrm{E}-02$ & 7E-02 \\
\hline & -02 & & -02 & & 02 & & $E-02$ & $E-02$ & & E-02 & $E-02$ \\
\hline & +02 & +02 & +02 & +02 & $2.19 \mathrm{E}+02$ & $E+02$ & +02 & +02 & +02 & $E+02$ & $E+02$ \\
\hline & $E+01$ & +01 & $E+01$ & $E+01$ & & & $E+01$ & $E+01$ & & $E+01$ & $E+00$ \\
\hline & 8E-01 & E-01 & 7E-01 & 3.67E-01 & $3.68 \mathrm{E}-01$ & 7E-01 & 67E-01 & 3.67E-01 & $3.68 E-01$ & 3.67E-01 & 3.41E-01 \\
\hline & $2 \mathrm{E}+02$ & $E+02$ & $\mathrm{~L} 1 \mathrm{E}+02$ & $1.11 \mathrm{E}+02$ & $1.12 \mathrm{E}+02$ & $11 \mathrm{E}+02$ & $11 \mathrm{E}+02$ & $1.11 \mathrm{E}+02$ & $1.12 \mathrm{E}+02$ & $1.11 \mathrm{E}+02$ & $8.56 \mathrm{E}+01$ \\
\hline & $54 \mathrm{E}+02$ & $53 \mathrm{E}+02$ & $4.53 \mathrm{E}+02$ & $4.53 E+02$ & $4.54 \mathrm{E}+02$ & $4.53 \mathrm{E}+02$ & $4.53 \mathrm{E}+02$ & $4.53 \mathrm{E}+02$ & $4.54 \mathrm{E}+02$ & $4.29 \mathrm{E}+02$ & $1.89 \mathrm{E}+02$ \\
\hline & 58E+01 & $2.68 \mathrm{E}+01$ & $2.68 \mathrm{E}+01$ & $2.68 E+01$ & $2.68 \mathrm{E}+01$ & $2.68 \mathrm{E}+01$ & $2.68 \mathrm{E}+01$ & $2.68 \mathrm{E}+01$ & $2.68 \mathrm{E}+01$ & $2.53 \mathrm{E}+01$ & $1.49 \mathrm{E}+01$ \\
\hline & $1 E-02$ & D1E-02 & D1E-02 & $3.01 E-02$ & $3.01 E-02$ & 3.01E-02 & $3.01 E-02$ & 3.01E-02 & 3.01E-02 & 2.84E-02 & $67 \mathrm{E}-02$ \\
\hline & & $\mathrm{E}+02$ & $E+02$ & $E+02$ & $37 \mathrm{E}+02$ & +02 & +02 & +02 & & $E+02$ & $65 \mathrm{E}+02$ \\
\hline & & $=+03$ & +03 & $3.77 \mathrm{E}+03$ & $3.78 \mathrm{E}+03$ & $3.77 \mathrm{E}+03$ & $3.77 \mathrm{E}+03$ & $3.74 \mathrm{E}+03$ & $3.72 \mathrm{E}+03$ & $3.71 \mathrm{E}+03$ & $2.96 \mathrm{E}+03$ \\
\hline
\end{tabular}




\begin{tabular}{|c|c|c|c|c|c|c|c|c|c|c|c|}
\hline Site & 1992 & 1993 & 1994 & 1995 & 1996 & 1997 & 1998 & 1999 & 2000 & 2001 & 20 \\
\hline 116-KE-1 & $90 \mathrm{E}+00$ & $1.89 \mathrm{E}+00$ & $1.89 \mathrm{E}+00$ & $89 \mathrm{E}+00$ & $90 \mathrm{E}+00$ & $1.89 \mathrm{E}+00$ & $1.88 \mathrm{E}+00$ & $1.86 \mathrm{E}+00$ & $1.82 \mathrm{E}+00$ & $1.82 \mathrm{E}+00$ & $1.36 \mathrm{E}+00$ \\
\hline 16-KE-2 & $14 \mathrm{E}-01$ & 4.13E-01 & 4.04E-01 & $.87 \mathrm{E}-01$ & .88E-01 & 3.87E-01 & $3.87 \mathrm{E}-01$ & 3.87E-01 & 3.77E-01 & 3.76E-01 & $3.03 \mathrm{E}-01$ \\
\hline 116-KE-3 & $\mathrm{E}+03$ & $3.73 E+03$ & $3.73 \mathrm{E}+03$ & $73 \mathrm{E}+03$ & $74 \mathrm{E}+03$ & $.73 E+03$ & $3.73 \mathrm{E}+03$ & $3.73 \mathrm{E}+03$ & $3.74 \mathrm{E}+03$ & $3.73 \mathrm{E}+03$ & $2.12 \mathrm{E}+03$ \\
\hline $116-K W-2$ & $54 \mathrm{E}+02$ & $8.52 \mathrm{E}+02$ & $8.52 \mathrm{E}+02$ & $52 \mathrm{E}+02$ & $54 \mathrm{E}+02$ & $.52 \mathrm{E}+02$ & $8.52 \mathrm{E}+02$ & $8.52 \mathrm{E}+02$ & $8.55 \mathrm{E}+02$ & & $4.85 \mathrm{E}+02$ \\
\hline $16-\mathrm{N}-1$ & $12 \mathrm{E}+03$ & $2.45 \mathrm{E}+03$ & $2.21 \mathrm{E}+03$ & $2.21 \mathrm{E}+03$ & $2.21 \mathrm{E}+03$ & $93 \mathrm{E}+03$ & $1.91 \mathrm{E}+03$ & $1.91 \mathrm{E}+03$ & $1.75 \mathrm{E}+03$ & & $1.42 \mathrm{E}+03$ \\
\hline $16-N-3$ & $37 \mathrm{E}+04$ & $3.34 \mathrm{E}+03$ & $1.52 \mathrm{E}+03$ & $9.11 \mathrm{E}+02$ & $87 \mathrm{E}+02$ & $40 \mathrm{E}+02$ & $5.40 \mathrm{E}+02$ & $4.95 \mathrm{E}+02$ & $3.92 \mathrm{E}+02$ & $3.91 \mathrm{E}+02$ & $2.64 \mathrm{E}+02$ \\
\hline $6-\mathrm{N}-4$ & $52 \mathrm{E}+02$ & $1.52 \mathrm{E}+02$ & $1.52 \mathrm{E}+02$ & $1.52 \mathrm{E}+02$ & $1.52 \mathrm{E}+02$ & $1.52 \mathrm{E}+02$ & $1.52 \mathrm{E}+02$ & $1.52 \mathrm{E}+02$ & $1.52 \mathrm{E}+02$ & $1.51 \mathrm{E}+02$ & $1.39 \mathrm{E}+02$ \\
\hline 18-B-6 & 16E-01 & 2.16E-01 & $2.16 \mathrm{E}-01$ & $2.16 \mathrm{E}-01$ & $2.16 \mathrm{E}-01$ & $2.16 \mathrm{E}-01$ & $2.16 \mathrm{E}-01$ & $2.16 \mathrm{E}-01$ & $2.16 \mathrm{E}-01$ & $2.16 \mathrm{E}-01$ & $2.15 \mathrm{E}-01$ \\
\hline & 45E-02 & 9.43E-02 & 9.43E-02 & 9.43E-02 & 9.45E-02 & 9.43E-02 & 9.43E-02 & 9.43E-02 & $9.45 \mathrm{E}-02$ & $9.43 \mathrm{E}-02$ & $9.40 \mathrm{E}-02$ \\
\hline & $00 \mathrm{E}+00$ & $0.00 \mathrm{E}+00$ & $0.00 \mathrm{E}+00$ & $0.00 \mathrm{E}+00$ & $0.00 \mathrm{E}+00$ & $0.00 \mathrm{E}+00$ & $0.00 E+00$ & $0.00 E+00$ & $0.00 E+00$ & $0.00 \mathrm{E}+00$ & $0.00 \mathrm{E}+00$ \\
\hline & $E+02$ & $2.94 \mathrm{E}+02$ & $2.94 \mathrm{E}+02$ & $2.94 \mathrm{E}+02$ & $2.94 \mathrm{E}+02$ & $2.94 \mathrm{E}+02$ & $2.94 \mathrm{E}+02$ & $2.94 \mathrm{E}+02$ & $2.94 \mathrm{E}+02$ & $2.94 \mathrm{E}+02$ & $2.93 E+02$ \\
\hline & $E+00$ & $0.00 \mathrm{E}+00$ & $0.00 \mathrm{E}+00$ & $0.00 \mathrm{E}+00$ & $0.00 \mathrm{E}+00$ & $0.00 \mathrm{E}+00$ & $0.00 \mathrm{E}+00$ & $0.00 \mathrm{E}+00$ & $0.00 \mathrm{E}+00$ & $0.00 \mathrm{E}+00$ & $0.00 \mathrm{E}+00$ \\
\hline & $E+00$ & $E+00$ & $E+00$ & $1.43 \mathrm{E}+00$ & $E+00$ & $E+00$ & $1.43 \mathrm{E}+00$ & $1.43 \mathrm{E}+00$ & $4 \mathrm{E}+00$ & $3 \mathrm{E}+00$ & $1.43 \mathrm{E}+00$ \\
\hline & $E+02$ & $5.18 \mathrm{E}+02$ & $5.18 \mathrm{E}+02$ & $18 \mathrm{E}+02$ & $5.19 \mathrm{E}+02$ & $8 \mathrm{E}+02$ & $5.18 \mathrm{E}+02$ & $5.18 \mathrm{E}+02$ & $5.19 \mathrm{E}+02$ & $5.18 \mathrm{E}+02$ & $5.17 \mathrm{E}+02$ \\
\hline & $E+02$ & $3.60 \mathrm{E}+02$ & $3.60 \mathrm{E}+02$ & $3.60 \mathrm{E}+02$ & $3.61 \mathrm{E}+02$ & $3.60 \mathrm{E}+02$ & $3.60 \mathrm{E}+02$ & $3.60 \mathrm{E}+02$ & $3.61 \mathrm{E}+02$ & $3.60 \mathrm{E}+02$ & $3.59 \mathrm{E}+02$ \\
\hline & $E+02$ & $1.73 \mathrm{E}+02$ & $1.73 E+02$ & $.73 \mathrm{E}+02$ & $1.73 \mathrm{E}+02$ & $1.73 \mathrm{E}+02$ & $1.73 \mathrm{E}+02$ & $1.73 \mathrm{E}+02$ & $1.73 \mathrm{E}+02$ & $1.73 E+02$ & $1.72 \mathrm{E}+02$ \\
\hline R-2 & $00 \mathrm{E}+00$ & $0.00 \mathrm{E}+00$ & $0.00 \mathrm{E}+00$ & $.00 \mathrm{E}+00$ & $0.00 \mathrm{E}+00$ & $.00 \mathrm{E}+00$ & $0.00 \mathrm{E}+00$ & $0.00 \mathrm{E}+00$ & $0.00 \mathrm{E}+00$ & $0.00 \mathrm{E}+00$ & $0.00 \mathrm{E}+00$ \\
\hline $8-F-1$ & $12 \mathrm{E}+02$ & $1.11 \mathrm{E}+02$ & $1.11 \mathrm{E}+02$ & $.11 \mathrm{E}+02$ & $.12 \mathrm{E}+02$ & $1.11 \mathrm{E}+02$ & $1.11 \mathrm{E}+02$ & $1.11 \mathrm{E}+02$ & $1.12 \mathrm{E}+02$ & $1.11 \mathrm{E}+02$ & $1.11 \mathrm{E}+02$ \\
\hline & 59E-01 & $3.68 \mathrm{E}-01$ & $3.68 \mathrm{E}-01$ & $3.68 \mathrm{E}-01$ & 3.69E-01 & $3.68 \mathrm{E}-01$ & 3.68E-01 & 3.68E-01 & 3.69E-01 & 3.68E-01 & 3.67E-01 \\
\hline & $0 \mathrm{E}+00$ & $0.00 \mathrm{E}+00$ & $0.00 \mathrm{E}+00$ & $.00 \mathrm{E}+00$ & $0.00 \mathrm{E}+00$ & $0.00 \mathrm{E}+00$ & $0.00 \mathrm{E}+00$ & $0.00 \mathrm{E}+00$ & $0.00 \mathrm{E}+00$ & $.00 \mathrm{E}+00$ & $.00 \mathrm{E}+00$ \\
\hline & $E+03$ & $1.22 \mathrm{E}+03$ & $1.22 \mathrm{E}+03$ & $22 \mathrm{E}+03$ & $22 \mathrm{E}+03$ & $2 \mathrm{E}+03$ & $1.22 \mathrm{E}+03$ & $1.22 \mathrm{E}+03$ & $2 \mathrm{E}+03$ & $E+03$ & $.22 \mathrm{E}+03$ \\
\hline & $=+00$ & $E+00$ & $\mathrm{E}+00$ & $E+00$ & $\mathrm{E}+00$ & $E+00$ & & $E+00$ & $E+00$ & & +00 \\
\hline & +03 & +03 & +03 & $E+03$ & $E+03$ & $E+03$ & $E+03$ & $4 \mathrm{E}+03$ & $4 \mathrm{E}+03$ & +03 & $\mathrm{E}+03$ \\
\hline & +00 & +00 & 0.0 & $E+00$ & $E+00$ & $E+00$ & 0.0 & $E+00$ & $\mathrm{E}+00$ & & $E+00$ \\
\hline$N-1$ & +00 & $=00$ & 0.0 & $E+00$ & $E+00$ & $E+00$ & 0.0 & $\mathrm{DE}+00$ & $\mathrm{E}+00$ & 100 & $\mathrm{E}+00$ \\
\hline W-2 & $E+00$ & $\mathrm{E}+00$ & $1.44 \mathrm{E}+00$ & $1.44 \mathrm{E}+00$ & $1.44 \mathrm{E}+00$ & $1.44 \mathrm{E}+00$ & $1.44 \mathrm{E}+00$ & $1.44 \mathrm{E}+00$ & $1.44 \mathrm{E}+00$ & $1.44 \mathrm{E}+00$ & $1.43 \mathrm{E}+00$ \\
\hline-100 & $E+00$ & $E+00$ & 4.3. & $1.38 \mathrm{E}+00$ & $4.40 \mathrm{E}+00$ & $9 \mathrm{E}+00$ & $4.39 \mathrm{E}+00$ & $1.46 \mathrm{E}+00$ & 3.14E-01 & $1.68 \mathrm{E}-01$ & $1.12 \mathrm{E}-01$ \\
\hline 102 & $E+00$ & $2.56 \mathrm{E}+00$ & $2.56 \mathrm{E}+00$ & $2.29 \mathrm{E}+00$ & $2.26 \mathrm{E}+00$ & $2.25 \mathrm{E}+00$ & $2.25 \mathrm{E}+00$ & $2.25 \mathrm{E}+00$ & $1.93 \mathrm{E}+00$ & $1.93 \mathrm{E}+00$ & $1.90 \mathrm{E}+00$ \\
\hline-103 & $0 \mathrm{E}+00$ & $0.00 \mathrm{E}+00$ & $0.00 \mathrm{E}+00$ & $0.00 \mathrm{E}+00$ & $0.00 \mathrm{E}+00$ & $0.00 \mathrm{E}+00$ & $0.00 \mathrm{E}+00$ & $0.00 \mathrm{E}+00$ & $0.00 \mathrm{E}+00$ & $0.00 \mathrm{E}+00$ & $0.00 \mathrm{E}+00$ \\
\hline 200-E-107 & $00 \mathrm{E}+00$ & $0.00 \mathrm{E}+00$ & $0.00 \mathrm{E}+00$ & $0.00 \mathrm{E}+00$ & $0.00 \mathrm{E}+00$ & $0.00 \mathrm{E}+00$ & $0.00 \mathrm{E}+00$ & $0.00 \mathrm{E}+00$ & $0.00 \mathrm{E}+00$ & $0.00 \mathrm{E}+00$ & $0.00 \mathrm{E}+00$ \\
\hline $200-E-25$ & $01 \mathrm{E}+00$ & 4.34E-01 & $2.02 \mathrm{E}-01$ & $1.79 \mathrm{E}-01$ & 8.82E-02 & 8.79E-02 & $8.16 \mathrm{E}-02$ & 6.57E-02 & $4.26 \mathrm{E}-02$ & $4.25 \mathrm{E}-02$ & 3.69E-02 \\
\hline $200-E-28$ & $92 \mathrm{E}+01$ & $2.02 \mathrm{E}+01$ & $1.09 \mathrm{E}+01$ & $9.57 \mathrm{E}+00$ & $6.05 E+00$ & $6.03 \mathrm{E}+00$ & $4.92 \mathrm{E}+00$ & $4.40 \mathrm{E}+00$ & $3.07 \mathrm{E}+00$ & $3.06 \mathrm{E}+00$ & $2.43 \mathrm{E}+00$ \\
\hline D0-E-41 & $00 \mathrm{E}+00$ & $0.00 \mathrm{E}+00$ & $0.00 \mathrm{E}+00$ & $0.00 \mathrm{E}+00$ & $0.00 \mathrm{E}+00$ & $0.00 \mathrm{E}+00$ & $0.00 \mathrm{E}+00$ & $0.00 \mathrm{E}+00$ & $0.00 \mathrm{E}+00$ & $0.00 \mathrm{E}+00$ & $0.00 \mathrm{E}+00$ \\
\hline & $0 \mathrm{E}+01$ & $2.23 \mathrm{E}+01$ & 1.19E+01 & $8.27 \mathrm{E}+00$ & $5.26 \mathrm{E}+00$ & $4.97 \mathrm{E}+00$ & $3.50 \mathrm{E}+00$ & $3.50 \mathrm{E}+00$ & $2.29 \mathrm{E}+00$ & $2.28 \mathrm{E}+00$ & $2.19 \mathrm{E}+00$ \\
\hline 200-E-55 & $4.50 \mathrm{E}+00$ & $4.49 \mathrm{E}+00$ & $4.49 \mathrm{E}+00$ & $4.49 \mathrm{E}+00$ & $4.50 \mathrm{E}+00$ & $4.37 \mathrm{E}+00$ & $3.25 \mathrm{E}+00$ & $2.23 \mathrm{E}+00$ & $1.28 \mathrm{E}+00$ & $1.13 \mathrm{E}+00$ & $6.99 \mathrm{E}-01$ \\
\hline & $48 \mathrm{E}-01$ & $5.22 \mathrm{E}-01$ & $5.22 \mathrm{E}-01$ & $5.22 \mathrm{E}-01$ & 5.24E-01 & $5.22 \mathrm{E}-01$ & 5.22E-01 & 5.22E-01 & 4.63E-01 & 4.62E-01 & 3.94E-01 \\
\hline & 4E-01 & 3.04E-01 & & 3.04E-01 & 3.04E-01 & 3.04E-01 & & 3.04E-01 & $.55 \mathrm{E}-01$ & 2.55E-01 & $2.09 \mathrm{E}-01$ \\
\hline E-60 & 6.28E-02 & 5.63E-02 & 5.36E-02 & 5.36E-02 & 5.37E-02 & 5.36E-02 & 5.36E-02 & 5.36E-02 & $5.09 \mathrm{E}-02$ & $5.08 \mathrm{E}-02$ & $4.82 \mathrm{E}-02$ \\
\hline E-61 & $.00 E+00$ & $0.00 \mathrm{E}+00$ & $0.00 \mathrm{E}+00$ & $0.00 \mathrm{E}+00$ & $0.00 \mathrm{E}+00$ & $0.00 \mathrm{E}+00$ & $0.00 \mathrm{E}+00$ & $0.00 \mathrm{E}+00$ & $0.00 \mathrm{E}+00$ & $0.00 \mathrm{E}+00$ & $0.00 \mathrm{E}+00$ \\
\hline & & & & & $0.00 \mathrm{E}+00$ & & & $0.00 \mathrm{E}+00$ & $0.00 \mathrm{E}+00$ & & $0.00 \mathrm{E}+00$ \\
\hline $200-E-63$ & $0.00 \mathrm{E}+00$ & $0.00 \mathrm{E}+00$ & $0.00 \mathrm{E}+00$ & $0.00 \mathrm{E}+00$ & $0.00 \mathrm{E}+00$ & $0.00 \mathrm{E}+00$ & $0.00 \mathrm{E}+00$ & $0.00 \mathrm{E}+00$ & $0.00 \mathrm{E}+00$ & $0.00 \mathrm{E}+00$ & $0.00 \mathrm{E}+00$ \\
\hline
\end{tabular}




\begin{tabular}{|c|c|c|c|c|c|c|c|c|c|c|c|}
\hline Site & 1992 & 1993 & 1994 & 1995 & 1996 & 1997 & 1998 & 1999 & 2000 & 2001 & 2002 \\
\hline D0-E-64 & $00 \mathrm{E}+00$ & $0.00 \mathrm{E}+00$ & $0.00 \mathrm{E}+00$ & $.00 \mathrm{E}+00$ & $00 \mathrm{E}+00$ & $0.00 \mathrm{E}+00$ & $0.00 \mathrm{E}+00$ & $0.00 \mathrm{E}+00$ & $0.00 \mathrm{E}+00$ & $0.00 \mathrm{E}+00$ & $.00 \mathrm{E}+00$ \\
\hline & 16E-07 & $4.15 \mathrm{E}-07$ & 4.15E-07 & $4.15 \mathrm{E}-07$ & $.16 \mathrm{E}-07$ & 4.15E-07 & 4.15E-07 & 4.15E-07 & 4.16E-07 & & $1.16 \mathrm{E}-04$ \\
\hline & DOE+00 & $0.00 \mathrm{E}+00$ & $0.00 \mathrm{E}+00$ & $00 \mathrm{E}+00$ & $00 \mathrm{E}+00$ & $00 \mathrm{E}+00$ & $0.00 \mathrm{E}+00$ & $0.00 \mathrm{E}+00$ & $0.00 \mathrm{E}+00$ & $.00 \mathrm{E}+00$ & $.00 \mathrm{E}+00$ \\
\hline $0-E-68$ & 16E-07 & 4.15E-07 & 4.15E-07 & 4.15E-07 & 4.16E-07 & 4.15E-07 & 4.15E-07 & 4.15E-07 & 6E-07 & .19E-05 & $1.16 \mathrm{E}-04$ \\
\hline 0-E-69 & $00 \mathrm{E}+00$ & $0.00 \mathrm{E}+00$ & $0.00 \mathrm{E}+00$ & $00 \mathrm{E}+00$ & $00 \mathrm{E}+00$ & $0.00 \mathrm{E}+00$ & $0.00 \mathrm{E}+00$ & $0.00 \mathrm{E}+00$ & $0.00 \mathrm{E}+00$ & $.00 \mathrm{E}+00$ & $0 \mathrm{E}+00$ \\
\hline $0-E-70$ & 41E-05 & 3.40E-05 & 3.40E-05 & 3.40E-05 & 3.41E-05 & 3.40E-05 & 3.40E-05 & 0E-05 & 3.41E-05 & E-04 & $2 \mathrm{E}-03$ \\
\hline & E-05 & 2.63E-05 & 2.63E-05 & 2.63E-05 & E-05 & 2.63E-05 & 2.63E-05 & $3 \mathrm{E}-05$ & & & $2 \mathrm{E}-03$ \\
\hline-72 & & E-05 & E-05 & $E-05$ & E-05 & E-05 & E-05 & 0E-05 & & $0 \mathrm{E}-04$ & $2 \mathrm{E}-03$ \\
\hline 73 & E-07 & 5.84E-07 & $E-07$ & -07 & $E-07$ & E-07 & E-07 & E-07 & & E-05 & $3 \mathrm{E}-04$ \\
\hline 74 & $E-05$ & $.40 \mathrm{E}-05$ & E-05 & E-05 & E-05 & E-05 & DE-05 & DE-05 & $E-05$ & $0 \mathrm{E}-04$ & $2 \mathrm{E}-03$ \\
\hline-75 & $E-05$ & 3.40E-05 & 3.40E-05 & E-05 & LE-05 & 3.40E-05 & $3.40 \mathrm{E}-05$ & $3.40 \mathrm{E}-05$ & EE-05 & $.70 \mathrm{E}-04$ & $2 \mathrm{E}-03$ \\
\hline-76 & $E+00$ & $0.00 \mathrm{E}+00$ & $E+00$ & $E+00$ & $\mathrm{E}+00$ & $00 \mathrm{E}+00$ & $0.00 \mathrm{E}+00$ & $\mathrm{E}+00$ & $E+00$ & $\mathrm{E}+00$ & $E+00$ \\
\hline $0-E-77$ & $E+00$ & $0.00 \mathrm{E}+00$ & $0.00 \mathrm{E}+00$ & $00 \mathrm{E}+00$ & $00 \mathrm{E}+00$ & $00 \mathrm{E}+00$ & $0.00 \mathrm{E}+00$ & $0.00 \mathrm{E}+00$ & $E+00$ & $\mathrm{DE}+00$ & $\mathrm{E}+00$ \\
\hline D0-E-78 & $00 \mathrm{E}+00$ & $0.00 \mathrm{E}+00$ & $0.00 \mathrm{E}+00$ & $00 \mathrm{E}+00$ & $0.00 \mathrm{E}+00$ & $.00 \mathrm{E}+00$ & $0.00 \mathrm{E}+00$ & $0.00 \mathrm{E}+00$ & $0.00 \mathrm{E}+00$ & $0.00 \mathrm{E}+00$ & $\mathrm{DE}+00$ \\
\hline D0-E-79 & $00 \mathrm{E}+00$ & $0.00 \mathrm{E}+00$ & $0.00 \mathrm{E}+00$ & $.00 \mathrm{E}+00$ & $00 \mathrm{E}+00$ & $00 \mathrm{E}+00$ & $0.00 \mathrm{E}+00$ & $0.00 \mathrm{E}+00$ & $\mathrm{DE}+00$ & $0 \mathrm{E}+00$ & $\mathrm{DE}+00$ \\
\hline$=-80$ & $0 \mathrm{E}+00$ & $0.00 \mathrm{E}+00$ & $0.00 E+00$ & $00 \mathrm{E}+00$ & $00 \mathrm{E}+00$ & $.00 \mathrm{E}+00$ & $0.00 \mathrm{E}+00$ & $0.00 \mathrm{E}+00$ & $E+00$ & $0 \mathrm{E}+00$ & $\mathrm{OE}+00$ \\
\hline & $0 \mathrm{E}+00$ & $0.00 \mathrm{E}+00$ & $0.00 \mathrm{E}+00$ & $00 \mathrm{E}+00$ & $00 \mathrm{E}+00$ & $0 \mathrm{E}+00$ & $\mathrm{E}+00$ & $0.00 \mathrm{E}+00$ & & $\mathrm{E}+00$ & +00 \\
\hline & $0 \mathrm{E}+00$ & $0.00 \mathrm{E}+00$ & $0.00 \mathrm{E}+00$ & $E+00$ & $00 \mathrm{E}+00$ & $\mathrm{E}+00$ & $E+00$ & $\mathrm{DE}+00$ & +00 & $\mathrm{E}+00$ & $\mathrm{E}+00$ \\
\hline-84 & E-07 & $2 \mathrm{E}-07$ & E-07 & E-07 & E-07 & E-07 & $\mathrm{E}-07$ & $2 \mathrm{E}-07$ & -07 & $8 \mathrm{E}-04$ & $3 E-04$ \\
\hline & $E+00$ & $\mathrm{E}+00$ & $E+00$ & $E+00$ & $0.00 \mathrm{E}+00$ & $\mathrm{E}+00$ & $E+00$ & $0.00 \mathrm{E}+00$ & $E+00$ & $\mathrm{E}+00$ & $\mathrm{E}+00$ \\
\hline & +02 & $E+02$ & $E+02$ & $E+02$ & $4.36 \mathrm{E}+02$ & $\mathrm{E}+02$ & $E+02$ & $5 \mathrm{E}+02$ & $\mathrm{E}+02$ & $5 \mathrm{E}+02$ & $\mathrm{E}+02$ \\
\hline$=-89$ & $\mathrm{E}+02$ & $E+02$ & $E+02$ & $.71 \mathrm{E}+02$ & $2.73 \mathrm{E}+02$ & $2 \mathrm{E}+02$ & $2 \mathrm{E}+02$ & $2.72 \mathrm{E}+02$ & $3 \mathrm{E}+02$ & $2 \mathrm{E}+02$ & $\mathrm{E}+02$ \\
\hline$E-90$ & 44E+02 & $3.09 \mathrm{E}+02$ & $3.25 E+02$ & $.28 \mathrm{E}+02$ & $.30 \mathrm{E}+02$ & $3.29 \mathrm{E}+02$ & $3.29 \mathrm{E}+02$ & $3.29 \mathrm{E}+02$ & $3.30 \mathrm{E}+02$ & $3.29 \mathrm{E}+02$ & $8 \mathrm{E}+02$ \\
\hline-91 & $\mathrm{E}+02$ & $1.16 \mathrm{E}+02$ & $1.18 \mathrm{E}+02$ & $18 \mathrm{E}+02$ & $18 \mathrm{E}+02$ & $18 \mathrm{E}+02$ & $18 \mathrm{E}+02$ & $1.18 \mathrm{E}+02$ & $3 \mathrm{E}+02$ & $.18 \mathrm{E}+02$ & $7 \mathrm{E}+01$ \\
\hline 200-E-92 & $53 \mathrm{E}+02$ & $1.77 \mathrm{E}+02$ & $1.82 \mathrm{E}+02$ & $.83 \mathrm{E}+02$ & $1.84 \mathrm{E}+02$ & $84 \mathrm{E}+02$ & $1.84 \mathrm{E}+02$ & $1.84 \mathrm{E}+02$ & $1.84 \mathrm{E}+02$ & $1.84 \mathrm{E}+02$ & $.55 E+02$ \\
\hline E-93 & $05 E+02$ & $2.51 \mathrm{E}+02$ & $2.62 \mathrm{E}+02$ & $65 \mathrm{E}+02$ & $2.66 \mathrm{E}+02$ & $65 \mathrm{E}+02$ & $2.65 \mathrm{E}+02$ & $2.65 \mathrm{E}+02$ & $2.66 \mathrm{E}+02$ & $.65 \mathrm{E}+02$ & $4 \mathrm{E}+02$ \\
\hline$E-94$ & $8 \mathrm{E}+02$ & $4.04 \mathrm{E}+02$ & $4.29 \mathrm{E}+02$ & $34 \mathrm{E}+02$ & $4.36 \mathrm{E}+02$ & $35 \mathrm{E}+02$ & $4.35 \mathrm{E}+02$ & $4.35 \mathrm{E}+02$ & $4.36 \mathrm{E}+02$ & $4.35 \mathrm{E}+02$ & $8 \mathrm{E}+02$ \\
\hline $0-E-95$ & $40 \mathrm{E}+00$ & $4.39 \mathrm{E}+00$ & $4.38 \mathrm{E}+00$ & 9.51E-01 & $1.90 \mathrm{E}-01$ & 9.13E-02 & 9E-02 & 4.70E-02 & E-02 & 6E-02 & $2 \mathrm{E}-02$ \\
\hline & $E+00$ & $4.39 \mathrm{E}+00$ & $E+00$ & $37 \mathrm{E}+00$ & $40 \mathrm{E}+00$ & $8 \mathrm{E}+00$ & EE-01 & 1.79E-01 & E-02 & 6E-02 & 9E-02 \\
\hline & +00 & $E+00$ & $=00$ & $E+00$ & $E+00$ & $E+00$ & $E+00$ & $E+00$ & -01 & E-01 & E-01 \\
\hline & +00 & 4.4 & +00 & +00 & $=+00$ & +00 & +00 & +00 & +00 & E-01 & E-01 \\
\hline-22 & -04 & $=-04$ & 3.6 & -02 & & $=-02$ & & -02 & +00 & $=+00$ & $E+00$ \\
\hline-42 & & & & & -03 & -03 & $E-03$ & & & $\mathrm{E}-02$ & $\mathrm{E}-02$ \\
\hline-52 & $E+01$ & $3.39 \mathrm{E}+01$ & & $39 \mathrm{E}+01$ & $E+01$ & & $E+01$ & $3.39 \mathrm{E}+01$ & $E+01$ & $2.98 \mathrm{E}+01$ & $3 E+01$ \\
\hline & $6 \mathrm{E}-11$ & 1.65E-11 & $1.65 \mathrm{E}-11$ & $1.65 \mathrm{E}-11$ & $1.66 \mathrm{E}-11$ & $1.65 \mathrm{E}-11$ & $1.62 \mathrm{E}-08$ & $3.15 \mathrm{E}-08$ & 7E-05 & 3.52E-03 & $4.71 \mathrm{E}-03$ \\
\hline$M-P C$ & $0 E+04$ & $2.60 \mathrm{E}+04$ & $2.59 \mathrm{E}+04$ & $24 \mathrm{E}+04$ & $.00 \mathrm{E}+04$ & $2.85 \mathrm{E}+03$ & $1.60 \mathrm{E}+03$ & $1.17 \mathrm{E}+03$ & $7.59 \mathrm{E}+02$ & $5.93 \mathrm{E}+02$ & $4.86 \mathrm{E}+02$ \\
\hline $6-A-10$ & $50 \mathrm{E}+03$ & $2.02 \mathrm{E}+03$ & $2.02 \mathrm{E}+03$ & $2.02 \mathrm{E}+03$ & $1.30 \mathrm{E}+03$ & $1.24 \mathrm{E}+03$ & $1.24 \mathrm{E}+03$ & $1.24 \mathrm{E}+03$ & $7.60 \mathrm{E}+02$ & $7.58 \mathrm{E}+02$ & $7.16 \mathrm{E}+02$ \\
\hline-11 & 45E-02 & 3.74E-02 & $3.74 \mathrm{E}-02$ & $3.74 \mathrm{E}-02$ & $3.75 \mathrm{E}-02$ & 3.74E-02 & $3.74 \mathrm{E}-02$ & $3.74 \mathrm{E}-02$ & $2.66 \mathrm{E}-02$ & $2.66 \mathrm{E}-02$ & $2.47 \mathrm{E}-02$ \\
\hline & $22 \mathrm{E}-02$ & 21E-02 & 4.21E-02 & 4.21E-02 & $4.22 \mathrm{E}-02$ & 4.17E-02 & 3.73E-02 & 3.73E-02 & 2.73E-02 & $.72 \mathrm{E}-02$ & $2.56 \mathrm{E}-02$ \\
\hline & 4.35E-02 & 4E-02 & 4E-02 & 9E-02 & $3.73 \mathrm{E}-02$ & 2E-02 & $3.72 \mathrm{E}-02$ & $3.72 \mathrm{E}-02$ & $7 \mathrm{E}-02$ & $.07 \mathrm{E}-02$ & $2.60 \mathrm{E}-02$ \\
\hline 216-A-14 & 1.21E-02 & 1.21E-02 & 1.21E-02 & 1.21E-02 & 1.21E-02 & $1.21 \mathrm{E}-02$ & 1.21E-02 & $1.25 \mathrm{E}-02$ & $2.13 \mathrm{E}-02$ & $2.13 \mathrm{E}-02$ & $1.76 \mathrm{E}-02$ \\
\hline
\end{tabular}




\begin{tabular}{|c|c|c|c|c|c|c|c|c|c|c|c|}
\hline Site & 1992 & 1993 & 1994 & 1995 & 1996 & 1997 & 1998 & 1999 & 2000 & 2001 & 2002 \\
\hline $6-A-15$ & 7.14E-01 & $7.12 \mathrm{E}-01$ & 7.12E-01 & $6.21 \mathrm{E}-01$ & $5.67 \mathrm{E}-01$ & 5.65E-01 & $5.65 \mathrm{E}-01$ & $5.65 \mathrm{E}-01$ & $4.43 \mathrm{E}-01$ & 4.42E-01 & $4.34 \mathrm{E}-01$ \\
\hline$-A-16$ & 50E-02 & $7.38 \mathrm{E}-02$ & 7.38E-02 & $7.38 \mathrm{E}-02$ & $40 \mathrm{E}-02$ & 7.38E-02 & 7.38E-02 & 7.38E-02 & & & $5.11 \mathrm{E}-02$ \\
\hline$-A-17$ & 47E-02 & $8.45 \mathrm{E}-02$ & $8.45 \mathrm{E}-02$ & $8.45 \mathrm{E}-02$ & 8.47E-02 & 7.76E-02 & 7.42E-02 & 7.42E-02 & & & $5.12 \mathrm{E}-02$ \\
\hline$-A-2$ & $29 \mathrm{E}+00$ & $1.98 \mathrm{E}+00$ & $1.98 \mathrm{E}+00$ & $1.98 \mathrm{E}+00$ & $98 \mathrm{E}+00$ & $1.98 \mathrm{E}+00$ & $1.98 \mathrm{E}+00$ & $1.98 \mathrm{E}+00$ & $1.75 \mathrm{E}+00$ & $1.75 \mathrm{E}+00$ & $1.52 \mathrm{E}+00$ \\
\hline $6-A-20$ & $30 \mathrm{E}+00$ & $3.29 \mathrm{E}+00$ & $3.29 \mathrm{E}+00$ & $.29 \mathrm{E}+00$ & $15 \mathrm{E}+00$ & $3.05 \mathrm{E}+00$ & $3.05 \mathrm{E}+00$ & $3.05 E+00$ & $2.69 \mathrm{E}+00$ & $69 \mathrm{E}+00$ & $.46 \mathrm{E}+00$ \\
\hline$-A-21$ & 05E+01 & $2.04 \mathrm{E}+01$ & $1.77 \mathrm{E}+01$ & $66 \mathrm{E}+01$ & $66 \mathrm{E}+01$ & $1.66 \mathrm{E}+01$ & $1.66 \mathrm{E}+01$ & $1.66 \mathrm{E}+01$ & $1.35 \mathrm{E}+01$ & $.35 \mathrm{E}+01$ & $1.21 \mathrm{E}+01$ \\
\hline 22 & $2.07 \mathrm{E}-04$ & 2.06E-04 & $2.06 \mathrm{E}-04$ & $2.06 \mathrm{E}-04$ & 2.07E-04 & $2.06 \mathrm{E}-04$ & $2.06 \mathrm{E}-04$ & 2.06E-04 & $\mathrm{E}-02$ & 4.93E-02 & 4.06E-02 \\
\hline $23 \mathrm{~A}$ & $9 \mathrm{E}-02$ & 87E-02 & $\mathrm{E}-02$ & $.96 \mathrm{E}-02$ & E-02 & $5.81 \mathrm{E}-02$ & 81E-02 & $1 \mathrm{E}-02$ & & $4.92 \mathrm{E}-02$ & $8 \mathrm{E}-02$ \\
\hline $23 B$ & $\mathrm{E}-02$ & $6.86 \mathrm{E}-02$ & E-02 & $5.95 \mathrm{E}-02$ & $.81 \mathrm{E}-02$ & $5.80 \mathrm{E}-02$ & 0E-02 & $5.80 \mathrm{E}-02$ & $\mathrm{E}-02$ & 4.91E-02 & $7 \mathrm{E}-02$ \\
\hline & $E+02$ & $3.23 \mathrm{E}+02$ & $E+02$ & $23 \mathrm{E}+02$ & $88 \mathrm{E}+02$ & $84 \mathrm{E}+02$ & $2.84 \mathrm{E}+02$ & $2.84 \mathrm{E}+02$ & $\mathrm{E}+02$ & $2.50 \mathrm{E}+02$ & $2 \mathrm{E}+02$ \\
\hline $6-A-25$ & $E+04$ & $1.62 \mathrm{E}+04$ & $E+04$ & $55 \mathrm{E}+04$ & $56 \mathrm{E}+04$ & $55 \mathrm{E}+04$ & $1.54 \mathrm{E}+04$ & $1.54 \mathrm{E}+04$ & $1.54 \mathrm{E}+04$ & $1.53 \mathrm{E}+04$ & $1.27 \mathrm{E}+04$ \\
\hline$A-26$ & E-06 & 2.13E-06 & E-06 & 2.13E-06 & E-06 & $3.46 \mathrm{E}-04$ & 1.79E-02 & 4.71E-02 & E-01 & -01 & $4 \mathrm{E}-01$ \\
\hline $6-A-26 A$ & $18 \mathrm{E}-06$ & $2.17 \mathrm{E}-06$ & $2.17 \mathrm{E}-06$ & $2.17 \mathrm{E}-06$ & $2.18 \mathrm{E}-06$ & $2.17 \mathrm{E}-06$ & $2.17 \mathrm{E}-06$ & $2.17 \mathrm{E}-06$ & $8 \mathrm{E}-04$ & $5.19 \mathrm{E}-04$ & $4.30 \mathrm{E}-04$ \\
\hline $6-A-27$ & $73 \mathrm{E}+01$ & $1.72 \mathrm{E}+01$ & $1.72 \mathrm{E}+01$ & $1.72 \mathrm{E}+01$ & $1.73 \mathrm{E}+01$ & $1.68 \mathrm{E}+01$ & $1.54 \mathrm{E}+01$ & $1.54 \mathrm{E}+01$ & $\mathrm{HE}+01$ & $1.14 \mathrm{E}+01$ & $1.09 \mathrm{E}+01$ \\
\hline $6-A-28$ & 27E-03 & $1.26 \mathrm{E}-03$ & 1.26E-03 & 1.26E-03 & $1.27 \mathrm{E}-03$ & $1.26 \mathrm{E}-03$ & $1.26 \mathrm{E}-03$ & & $4 \mathrm{E}-01$ & & $2.43 \mathrm{E}-01$ \\
\hline $6-A-3$ & $4 \mathrm{E}+00$ & $5.06 E+00$ & $5.06 \mathrm{E}+00$ & $.06 \mathrm{E}+00$ & $08 \mathrm{E}+00$ & $5.06 E+00$ & $5.06 \mathrm{E}+00$ & $4.81 E+00$ & $\mathrm{E}+00$ & $3.36 \mathrm{E}+00$ & $3 \mathrm{E}+00$ \\
\hline i-A-30 & $39 \mathrm{E}+05$ & $8.76 \mathrm{E}+04$ & $5.02 \mathrm{E}+04$ & $59 \mathrm{E}+04$ & $55 \mathrm{E}+04$ & $2.54 \mathrm{E}+04$ & $2.39 \mathrm{E}+04$ & $1.98 \mathrm{E}+04$ & & $E+04$ & $E+04$ \\
\hline & $0 \mathrm{E}+00$ & $0.00 \mathrm{E}+00$ & $00 \mathrm{E}+00$ & $00 \mathrm{E}+00$ & $\mathrm{E}+00$ & $00 \mathrm{E}+00$ & $.00 \mathrm{E}+00$ & $0.00 \mathrm{E}+00$ & +00 & $\mathrm{E}+00$ & $\mathrm{E}+00$ \\
\hline & +00 & $E+00$ & +00 & $E+00$ & $=+00$ & $.00 \mathrm{E}+00$ & $E+00$ & $0 \mathrm{E}+00$ & $E+00$ & $0.00 \mathrm{E}+00$ & $E+00$ \\
\hline-35 & $E+00$ & $0.00 \mathrm{E}+00$ & $E+00$ & $0.00 \mathrm{E}+00$ & $\mathrm{E}+00$ & $0.00 \mathrm{E}+00$ & $0.00 \mathrm{E}+00$ & $0.00 \mathrm{E}+00$ & $E+00$ & $0.00 \mathrm{E}+00$ & $\mathrm{E}+00$ \\
\hline$A-36 A$ & $\mathrm{E}-02$ & 1.27E-02 & E-02 & 1.27E-02 & 3E-02 & 1.27E-02 & 1.27E-02 & 1.27E-02 & $3 \mathrm{E}+00$ & $3.04 \mathrm{E}+00$ & $\mathrm{E}+00$ \\
\hline$A-36 B$ & $5 \mathrm{E}+02$ & $4.43 \mathrm{E}+02$ & $4.43 \mathrm{E}+02$ & $43 \mathrm{E}+02$ & $.44 \mathrm{E}+02$ & $4.28 \mathrm{E}+02$ & $4.18 \mathrm{E}+02$ & $4.18 \mathrm{E}+02$ & $3.73 \mathrm{E}+02$ & $3.72 \mathrm{E}+02$ & $6 \mathrm{E}+02$ \\
\hline $6-A-37-1$ & $1 \mathrm{E}+03$ & $1.16 \mathrm{E}+03$ & $5.87 \mathrm{E}+02$ & $.87 \mathrm{E}+02$ & $17 \mathrm{E}+02$ & $3.33 \mathrm{E}+02$ & $3.33 \mathrm{E}+02$ & $3.33 \mathrm{E}+02$ & $1.93 \mathrm{E}+02$ & $1.92 \mathrm{E}+02$ & $1.85 \mathrm{E}+02$ \\
\hline$-A-37-2$ & $E+04$ & $8.34 \mathrm{E}+03$ & $E+03$ & $.80 \mathrm{E}+03$ & $1 \mathrm{E}+03$ & $51 \mathrm{E}+03$ & $24 \mathrm{E}+03$ & $1.24 \mathrm{E}+03$ & $7.32 \mathrm{E}+02$ & $7.30 \mathrm{E}+02$ & $.30 \mathrm{E}+02$ \\
\hline $6-A-39$ & $0 \mathrm{E}+00$ & $0.00 \mathrm{E}+00$ & $0.00 \mathrm{E}+00$ & $.00 \mathrm{E}+00$ & $.00 \mathrm{E}+00$ & $0.00 \mathrm{E}+00$ & $0.00 \mathrm{E}+00$ & $0.00 \mathrm{E}+00$ & $0.00 \mathrm{E}+00$ & $0.00 \mathrm{E}+00$ & $.00 \mathrm{E}+00$ \\
\hline $6-A-4$ & $45 \mathrm{E}+00$ & $2.32 \mathrm{E}+00$ & $2.08 \mathrm{E}+00$ & $.08 \mathrm{E}+00$ & $.08 \mathrm{E}+00$ & $2.08 \mathrm{E}+00$ & $2.08 \mathrm{E}+00$ & $2.08 \mathrm{E}+00$ & $1.79 \mathrm{E}+00$ & $1.79 \mathrm{E}+00$ & $1.79 \mathrm{E}+00$ \\
\hline$-A-40$ & $0 \mathrm{E}+00$ & $0.00 \mathrm{E}+00$ & $0.00 \mathrm{E}+00$ & $00 \mathrm{E}+00$ & $00 \mathrm{E}+00$ & $00 \mathrm{E}+00$ & $0.00 \mathrm{E}+00$ & $0.00 \mathrm{E}+00$ & $0.00 \mathrm{E}+00$ & $.00 \mathrm{E}+00$ & $.00 \mathrm{E}+00$ \\
\hline A-41 & $0 \mathrm{E}+00$ & $0.00 \mathrm{E}+00$ & $0.00 \mathrm{E}+00$ & $.00 \mathrm{E}+00$ & $00 \mathrm{E}+00$ & $0 \mathrm{E}+00$ & $0 \mathrm{E}+00$ & $0.00 \mathrm{E}+00$ & $\mathrm{E}+00$ & $.00 \mathrm{E}+00$ & $\mathrm{DE}+00$ \\
\hline A-45 & $E+03$ & $1.74 \mathrm{E}+03$ & $E+02$ & $26 \mathrm{E}+02$ & $E+02$ & $41 \mathrm{E}+02$ & $5.41 \mathrm{E}+02$ & $5.41 \mathrm{E}+02$ & $3.19 \mathrm{E}+02$ & $3.18 \mathrm{E}+02$ & $\mathrm{E}+02$ \\
\hline & $E+02$ & $3.50 \mathrm{E}+02$ & $E+02$ & $\mathrm{E}+02$ & +02 & $3.50 \mathrm{E}+02$ & $E+02$ & $3.50 \mathrm{E}+02$ & +02 & $\mathrm{E}+02$ & $E+02$ \\
\hline & +02 & 8.93 & 8.9 & $E+02$ & +02 & $E+02$ & $E+02$ & $E+02$ & +02 & $E+02$ & $E+02$ \\
\hline & -01 & $=-01$ & -01 & $=-01$ & $=-01$ & E-01 & $E-01$ & $E-01$ & -01 & $5 \mathrm{E}-01$ & $E-01$ \\
\hline & +02 & +02 & +02 & $E+02$ & +02 & $\mathrm{E}+02$ & $E+02$ & $5 \mathrm{E}+02$ & $=02$ & $E+02$ & $E+02$ \\
\hline & $E+02$ & $4.65 \mathrm{E}+02$ & $\mathrm{E}+02$ & $E+02$ & $E+02$ & $5 \mathrm{E}+02$ & $4.65 E+02$ & $4.65 \mathrm{E}+02$ & $4.20 \mathrm{E}+02$ & $4.19 \mathrm{E}+02$ & $3 E+02$ \\
\hline B-10 & $9 \mathrm{E}+01$ & $1.79 \mathrm{E}+01$ & $E+01$ & $79 \mathrm{E}+01$ & $79 \mathrm{E}+01$ & $1.79 \mathrm{E}+01$ & $1.79 \mathrm{E}+01$ & $1.79 \mathrm{E}+01$ & $1.45 \mathrm{E}+01$ & $1.45 \mathrm{E}+01$ & $1.45 \mathrm{E}+01$ \\
\hline & $2 \mathrm{E}-01$ & $8.29 \mathrm{E}-01$ & $6.65 \mathrm{E}-01$ & $6.65 \mathrm{E}-01$ & 66E-01 & $6.65 \mathrm{E}-01$ & $6.65 \mathrm{E}-01$ & $6.65 \mathrm{E}-01$ & $4.78 \mathrm{E}-01$ & 4.77E-01 & $3.38 \mathrm{E}-01$ \\
\hline$-\mathrm{B}-11 \mathrm{~A} \%$ & $75 E+00$ & $3.74 \mathrm{E}+00$ & $3.74 \mathrm{E}+00$ & $3.74 \mathrm{E}+00$ & $3.75 E+00$ & $3.74 \mathrm{E}+00$ & $3.74 \mathrm{E}+00$ & $3.74 \mathrm{E}+00$ & $3.07 \mathrm{E}+00$ & $3.07 \mathrm{E}+00$ & $2.72 \mathrm{E}+00$ \\
\hline 6-B-12 & $6.42 \mathrm{E}+01$ & $4.82 \mathrm{E}+01$ & $4.82 \mathrm{E}+01$ & $4.82 \mathrm{E}+01$ & $4.83 \mathrm{E}+01$ & $4.82 E+01$ & $4.82 E+01$ & $4.82 E+01$ & $3.23 E+01$ & $3.22 \mathrm{E}+01$ & $2.49 \mathrm{E}+01$ \\
\hline & 17E-02 & 7.16E-02 & 7.16E-02 & 7.16E-02 & 6.54E-02 & $5.71 \mathrm{E}-02$ & 5.71E-02 & 5.71E-02 & $4.12 \mathrm{E}-02$ & 4.11E-02 & $3.64 \mathrm{E}-02$ \\
\hline & 49E+02 & $2.18 \mathrm{E}+02$ & $2.18 \mathrm{E}+02$ & $2.18 \mathrm{E}+02$ & $E+02$ & $2.18 \mathrm{E}+02$ & $2.18 \mathrm{E}+02$ & $3 \mathrm{E}+02$ & $E+02$ & $9 \mathrm{E}+02$ & $19 \mathrm{E}+02$ \\
\hline & +02 & $2.17 \mathrm{E}+02$ & $E+02$ & $17 \mathrm{E}+02$ & $2.18 \mathrm{E}+02$ & $2.17 \mathrm{E}+02$ & $2.17 \mathrm{E}+02$ & $2.12 \mathrm{E}+02$ & $1.79 \mathrm{E}+02$ & $1.79 \mathrm{E}+02$ & $1.49 \mathrm{E}+0$ \\
\hline
\end{tabular}




\begin{tabular}{|c|c|c|c|c|c|c|c|c|c|c|c|}
\hline Site & 1992 & 1993 & 1994 & 1995 & 1996 & 1997 & 1998 & 1999 & 2000 & 2001 & 2002 \\
\hline 216-B-16 & $38 \mathrm{E}+02$ & $2.16 \mathrm{E}+02$ & $2.16 \mathrm{E}+02$ & $.16 \mathrm{E}+02$ & $2.17 \mathrm{E}+02$ & $2.16 \mathrm{E}+02$ & $2.16 \mathrm{E}+02$ & $2.12 \mathrm{E}+02$ & $1.79 \mathrm{E}+02$ & $1.79 \mathrm{E}+02$ & $1.49 \mathrm{E}+02$ \\
\hline 16-B-17 & $37 \mathrm{E}+01$ & $1.61 \mathrm{E}+02$ & $.61 \mathrm{E}+02$ & $61 \mathrm{E}+02$ & $62 \mathrm{E}+02$ & $1.61 \mathrm{E}+02$ & $1.62 \mathrm{E}+02$ & $1.73 E+02$ & $1.70 \mathrm{E}+02$ & $1.69 E+02$ & $.68 \mathrm{E}+02$ \\
\hline & $48 \mathrm{E}+02$ & $2.18 \mathrm{E}+02$ & $2.18 \mathrm{E}+02$ & $18 \mathrm{E}+02$ & $19 \mathrm{E}+02$ & $.18 \mathrm{E}+02$ & $2.18 \mathrm{E}+02$ & $2.13 E+02$ & $1.80 \mathrm{E}+02$ & $.79 \mathrm{E}+02$ & $1.78 \mathrm{E}+02$ \\
\hline & $42 \mathrm{E}+02$ & $2.17 \mathrm{E}+02$ & $2.17 \mathrm{E}+02$ & $2.17 \mathrm{E}+02$ & $.18 \mathrm{E}+02$ & $2.17 \mathrm{E}+02$ & $2.17 \mathrm{E}+02$ & $2.12 \mathrm{E}+02$ & $1.79 \mathrm{E}+02$ & $1.79 \mathrm{E}+02$ & $1.78 \mathrm{E}+02$ \\
\hline $6-\mathrm{B}-20$ & $.04 \mathrm{E}+02$ & $3.01 \mathrm{E}+02$ & $2.37 \mathrm{E}+02$ & $.37 \mathrm{E}+02$ & $2.38 \mathrm{E}+02$ & $2.37 \mathrm{E}+02$ & $2.37 \mathrm{E}+02$ & $2.37 E+02$ & $1.82 \mathrm{E}+02$ & $1.81 \mathrm{E}+02$ & $1.54 \mathrm{E}+02$ \\
\hline $6-B-21$ & $03 E+02$ & $3.01 \mathrm{E}+02$ & $2.36 \mathrm{E}+02$ & $2.36 \mathrm{E}+02$ & $2.37 \mathrm{E}+02$ & $2.36 \mathrm{E}+02$ & $2.36 \mathrm{E}+02$ & $2.36 \mathrm{E}+02$ & $1.81 \mathrm{E}+02$ & $1.81 \mathrm{E}+02$ & $1.54 \mathrm{E}+02$ \\
\hline B-22 & $04 \mathrm{E}+02$ & $3.01 \mathrm{E}+02$ & $2.37 \mathrm{E}+02$ & $2.37 \mathrm{E}+02$ & $2.38 \mathrm{E}+02$ & $2.37 \mathrm{E}+02$ & $2.37 \mathrm{E}+02$ & $2.37 \mathrm{E}+02$ & $1.82 \mathrm{E}+02$ & $1.81 \mathrm{E}+02$ & $1.54 \mathrm{E}+02$ \\
\hline B-23 & $09 \mathrm{E}+02$ & $3.06 \mathrm{E}+02$ & $2.33 \mathrm{E}+02$ & $33 \mathrm{E}+02$ & $2.33 \mathrm{E}+02$ & $2.33 \mathrm{E}+02$ & $2.33 E+02$ & $2.33 E+02$ & $1.76 \mathrm{E}+02$ & $1.75 E+02$ & $4 \mathrm{E}+02$ \\
\hline & $07 \mathrm{E}+02$ & $3.04 \mathrm{E}+02$ & $2.32 \mathrm{E}+02$ & $2.32 \mathrm{E}+02$ & $3 \mathrm{E}+02$ & $2 \mathrm{E}+02$ & $2.32 \mathrm{E}+02$ & $32 \mathrm{E}+02$ & $1.75 \mathrm{E}+02$ & $1.75 \mathrm{E}+02$ & $1.74 \mathrm{E}+02$ \\
\hline & $\mathrm{E}+02$ & $3.04 \mathrm{E}+02$ & $2.32 \mathrm{E}+02$ & $2.32 \mathrm{E}+02$ & $2.33 \mathrm{E}+02$ & $2.32 \mathrm{E}+02$ & $2.32 \mathrm{E}+02$ & $2.32 \mathrm{E}+02$ & $1.75 \mathrm{E}+02$ & $1.75 \mathrm{E}+02$ & $1.74 \mathrm{E}+02$ \\
\hline-26 & $E+02$ & $3.08 \mathrm{E}+02$ & $2.33 E+02$ & $2.33 E+02$ & $4 \mathrm{E}+02$ & $2.33 \mathrm{E}+02$ & $2.33 E+02$ & $2.33 E+02$ & $1.76 \mathrm{E}+02$ & $5 \mathrm{E}+02$ & $1.74 \mathrm{E}+02$ \\
\hline & $E+02$ & $E+02$ & $2.32 \mathrm{E}+02$ & $32 \mathrm{E}+02$ & $3 \mathrm{E}+02$ & $2 \mathrm{E}+02$ & $2.32 \mathrm{E}+02$ & $2.32 \mathrm{E}+02$ & $1.75 \mathrm{E}+02$ & $5 E+02$ & $1.74 \mathrm{E}+02$ \\
\hline-28 & $\mathrm{E}+02$ & $\mathrm{E}+02$ & $2.32 \mathrm{E}+02$ & $2 \mathrm{E}+02$ & $3 \mathrm{E}+02$ & $2.32 \mathrm{E}+02$ & $2.32 \mathrm{E}+02$ & $2.32 \mathrm{E}+02$ & $1.75 \mathrm{E}+02$ & $1.75 \mathrm{E}+02$ & $1.74 \mathrm{E}+02$ \\
\hline-29 & $\mathrm{E}+02$ & $3.10 \mathrm{E}+02$ & $2.40 \mathrm{E}+02$ & $40 \mathrm{E}+02$ & $2.41 \mathrm{E}+02$ & $2.40 \mathrm{E}+02$ & $2.40 \mathrm{E}+02$ & $2.40 \mathrm{E}+02$ & $1.83 \mathrm{E}+02$ & $1.82 \mathrm{E}+02$ & $1.61 \mathrm{E}+02$ \\
\hline & $E+06$ & $4.77 \mathrm{E}+06$ & $5.86 \mathrm{E}+06$ & $.46 \mathrm{E}+06$ & $34 \mathrm{E}+06$ & $21 \mathrm{E}+06$ & $1.40 \mathrm{E}+06$ & $8.33 E+05$ & $4.44 \mathrm{E}+05$ & $3.93 E+05$ & $2.35 \mathrm{E}+05$ \\
\hline $3-30$ & $14 \mathrm{E}+02$ & $3.11 \mathrm{E}+02$ & $2.40 \mathrm{E}+02$ & $2.40 \mathrm{E}+02$ & $2.41 \mathrm{E}+02$ & $2.40 \mathrm{E}+02$ & $2.40 \mathrm{E}+02$ & $2.40 \mathrm{E}+02$ & $1.83 \mathrm{E}+02$ & $1.82 \mathrm{E}+02$ & $1.61 \mathrm{E}+02$ \\
\hline $3-31$ & $13 \mathrm{E}+02$ & $3.10 \mathrm{E}+02$ & $2.40 \mathrm{E}+02$ & $2.40 \mathrm{E}+02$ & $2.41 \mathrm{E}+02$ & $2.40 \mathrm{E}+02$ & $2.40 \mathrm{E}+02$ & $2.40 \mathrm{E}+02$ & $1.83 \mathrm{E}+02$ & $1.82 \mathrm{E}+02$ & $1 \mathrm{E}+02$ \\
\hline-32 & $13 \mathrm{E}+02$ & $3.10 \mathrm{E}+02$ & $2.40 \mathrm{E}+02$ & $40 \mathrm{E}+02$ & $41 \mathrm{E}+02$ & $2.40 \mathrm{E}+02$ & $2.40 \mathrm{E}+02$ & $2.40 \mathrm{E}+02$ & $1.83 E+02$ & $32 \mathrm{E}+02$ & $1 \mathrm{E}+02$ \\
\hline-33 & $3 \mathrm{E}+02$ & $3.10 \mathrm{E}+02$ & $2.40 \mathrm{E}+02$ & $40 \mathrm{E}+02$ & $41 \mathrm{E}+02$ & $2.40 \mathrm{E}+02$ & $2.40 \mathrm{E}+02$ & $2.40 \mathrm{E}+02$ & $1.83 \mathrm{E}+02$ & $.82 \mathrm{E}+02$ & $1 \mathrm{E}+02$ \\
\hline & $3 \mathrm{E}+02$ & $\mathrm{E}+02$ & & $32 \mathrm{E}+02$ & $3 \mathrm{E}+02$ & $2 \mathrm{E}+02$ & & $2 \mathrm{E}+02$ & $.75 \mathrm{E}+02$ & $.75 \mathrm{E}+02$ & $.74 \mathrm{E}+02$ \\
\hline & $E+00$ & $E+00$ & 5.26 & 00 & $E+00$ & $E+00$ & & 00 & $4.29 \mathrm{E}+00$ & $8 \mathrm{E}+00$ & $2 \mathrm{E}+00$ \\
\hline & $E+00$ & $E+00$ & $5.4 !$ & $E+00$ & $\mathrm{E}+00$ & $E+00$ & $E+00$ & $7 \mathrm{E}+00$ & $4.35 \mathrm{E}+00$ & $4 \mathrm{E}+00$ & $E+00$ \\
\hline & $E+00$ & $E+00$ & $E+00$ & $E+00$ & $\mathrm{DE}+00$ & $\mathrm{E}+00$ & $\mathrm{E}+00$ & $9 \mathrm{E}+00$ & $4.41 \mathrm{E}+00$ & $4.40 \mathrm{E}+00$ & $\mathrm{E}+00$ \\
\hline & $\mathrm{E}+00$ & $\mathrm{E}+00$ & $E+00$ & $E+00$ & $2 \mathrm{E}+00$ & $E+00$ & $1 \mathrm{E}+00$ & $5.11 \mathrm{E}+00$ & $4.32 \mathrm{E}+00$ & $4.31 \mathrm{E}+00$ & $\mathrm{E}+00$ \\
\hline-39 & $E+00$ & $\mathrm{E}+00$ & $5.36 \mathrm{E}+00$ & $5.06 \mathrm{E}+00$ & $5.08 \mathrm{E}+00$ & $6 \mathrm{E}+00$ & $5.06 \mathrm{E}+00$ & $5.06 \mathrm{E}+00$ & $4.30 \mathrm{E}+00$ & $4.28 \mathrm{E}+00$ & $3.72 \mathrm{E}+00$ \\
\hline & $4 \mathrm{E}-01$ & 1.14E-01 & 1.14E-01 & 1.14E-01 & 1.14E-01 & 1.14E-01 & 1.14E-01 & 1.14E-01 & 8.46E-01 & 8.44E-01 & 4.01E-01 \\
\hline-40 & $E+00$ & $5.17 \mathrm{E}+00$ & $5.17 \mathrm{E}+00$ & $17 \mathrm{E}+00$ & $19 \mathrm{E}+00$ & $5.17 \mathrm{E}+00$ & $5.17 \mathrm{E}+00$ & $5.17 \mathrm{E}+00$ & $4.36 \mathrm{E}+00$ & $4.34 \mathrm{E}+00$ & $3.78 \mathrm{E}+00$ \\
\hline-41 & $04 E+00$ & $5.02 \mathrm{E}+00$ & $5.02 \mathrm{E}+00$ & $.02 \mathrm{E}+00$ & $5.04 \mathrm{E}+00$ & $5.02 \mathrm{E}+00$ & $5.02 \mathrm{E}+00$ & $5.02 E+00$ & $4.27 \mathrm{E}+00$ & $4.26 \mathrm{E}+00$ & $3.70 \mathrm{E}+00$ \\
\hline $3-42$ & $12 \mathrm{E}+00$ & $5.11 \mathrm{E}+00$ & $5.11 \mathrm{E}+00$ & $5.11 \mathrm{E}+00$ & $5.12 \mathrm{E}+00$ & $5.11 \mathrm{E}+00$ & $5.11 \mathrm{E}+00$ & $5.11 \mathrm{E}+00$ & $4.22 \mathrm{E}+00$ & $4.21 \mathrm{E}+00$ & $3.77 \mathrm{E}+00$ \\
\hline-43 & $30 \mathrm{E}+01$ & $1.10 \mathrm{E}+01$ & $1.10 \mathrm{E}+01$ & $.10 \mathrm{E}+01$ & $1.10 \mathrm{E}+01$ & $1.10 \mathrm{E}+01$ & $1.10 \mathrm{E}+01$ & $1.10 \mathrm{E}+01$ & $9.34 \mathrm{E}+00$ & $9.31 \mathrm{E}+00$ & $8.86 \mathrm{E}+00$ \\
\hline $3-44$ & 43E+01 & $1.35 \mathrm{E}+01$ & $1.19 \mathrm{E}+01$ & $1.19 \mathrm{E}+01$ & $1.20 \mathrm{E}+01$ & $1.19 \mathrm{E}+01$ & $1.19 \mathrm{E}+01$ & $1.19 \mathrm{E}+01$ & $9.77 \mathrm{E}+00$ & $9.75 \mathrm{E}+00$ & $8.00 \mathrm{E}+00$ \\
\hline & $E+01$ & $17 \mathrm{E}+01$ & $1.17 \mathrm{E}+01$ & $17 \mathrm{E}+01$ & $1.17 \mathrm{E}+01$ & $1.17 \mathrm{E}+01$ & $1.17 \mathrm{E}+01$ & $1.17 \mathrm{E}+01$ & $9.57 \mathrm{E}+00$ & $9.54 \mathrm{E}+00$ & $8.55 \mathrm{E}+00$ \\
\hline $3-46$ & $0 \mathrm{E}+01$ & $1.20 \mathrm{E}+01$ & $1.20 \mathrm{E}+01$ & $1.20 \mathrm{E}+01$ & $1.20 \mathrm{E}+01$ & $1.20 \mathrm{E}+01$ & $1.20 \mathrm{E}+01$ & $1.20 \mathrm{E}+01$ & $9.71 \mathrm{E}+00$ & $9.69 \mathrm{E}+00$ & $8.68 \mathrm{E}+00$ \\
\hline & $E+01$ & $1.25 \mathrm{E}+01$ & $1.25 \mathrm{E}+01$ & $1.25 \mathrm{E}+01$ & $1.26 \mathrm{E}+01$ & $E+01$ & $E+01$ & $1.16 \mathrm{E}+01$ & $9.54 \mathrm{E}+00$ & $9.51 \mathrm{E}+00$ & $8.77 \mathrm{E}+00$ \\
\hline & $\mathrm{E}+01$ & $1.16 \mathrm{E}+01$ & $1.16 \mathrm{E}+01$ & $1.16 \mathrm{E}+01$ & $1.16 \mathrm{E}+01$ & $1.16 \mathrm{E}+01$ & $1.16 \mathrm{E}+01$ & $1.16 \mathrm{E}+01$ & $9.53 \mathrm{E}+00$ & $9.50 \mathrm{E}+00$ & $E+00$ \\
\hline & $1.18 \mathrm{E}+01$ & $1.18 \mathrm{E}+01$ & $1.18 \mathrm{E}+01$ & $1.18 \mathrm{E}+01$ & $1.18 \mathrm{E}+01$ & $1.18 \mathrm{E}+01$ & $1.18 \mathrm{E}+01$ & $1.18 \mathrm{E}+01$ & $9.64 \mathrm{E}+00$ & $9.61 \mathrm{E}+00$ & $8.57 \mathrm{E}+00$ \\
\hline & 2.33E-02 & $2.32 \mathrm{E}-02$ & $2.32 \mathrm{E}-02$ & $2.32 \mathrm{E}-02$ & 2.33E-02 & $2.32 \mathrm{E}-02$ & $2.32 \mathrm{E}-02$ & $2.32 \mathrm{E}-02$ & 5.33E-01 & 4.35E-01 & $0.00 \mathrm{E}+00$ \\
\hline & $2.44 \mathrm{E}+01$ & $2.19 \mathrm{E}+01$ & $2.19 \mathrm{E}+01$ & $2.19 \mathrm{E}+01$ & $2.20 \mathrm{E}+01$ & $2.19 \mathrm{E}+01$ & $2.19 \mathrm{E}+01$ & $2.19 \mathrm{E}+01$ & $1.44 \mathrm{E}+01$ & $1.43 E+01$ & $1.08 \mathrm{E}+01$ \\
\hline & $1 \mathrm{E}-02$ & 1.01E-02 & 1.01E-02 & 1.01E-02 & 1.01E-02 & 1.01E-02 & 1.01E-02 & 1.01E-02 & $2.40 \mathrm{E}-02$ & $2.39 \mathrm{E}-02$ & 1.66E-02 \\
\hline & $51 \mathrm{E}+02$ & $3.48 \mathrm{E}+02$ & $2.68 \mathrm{E}+02$ & $2.68 \mathrm{E}+02$ & $2.68 \mathrm{E}+02$ & $8 \mathrm{E}+02$ & $2.68 \mathrm{E}+02$ & $2.68 \mathrm{E}+02$ & $2.03 E+02$ & $2.02 \mathrm{E}+02$ & $2.01 \mathrm{E}+02$ \\
\hline 216-B-53A & $3.47 \mathrm{E}+01$ & $3.38 \mathrm{E}+01$ & $3.38 \mathrm{E}+01$ & $3.38 \mathrm{E}+01$ & $3.09 \mathrm{E}+01$ & $2.87 \mathrm{E}+01$ & $2.87 \mathrm{E}+01$ & $2.87 \mathrm{E}+01$ & $2.21 \mathrm{E}+01$ & $2.20 \mathrm{E}+01$ & $1.83 \mathrm{E}+01$ \\
\hline
\end{tabular}




\begin{tabular}{|c|c|c|c|c|c|c|c|c|c|c|c|}
\hline Site & 1992 & 1993 & 1994 & 1995 & 1996 & 1997 & 1998 & 1999 & 2000 & 2001 & 20 \\
\hline 216-B-53B & $.31 \mathrm{E}-04$ & $3.30 \mathrm{E}-04$ & 3.30E-04 & $30 \mathrm{E}-04$ & 11E-01 & $24 \mathrm{E}+00$ & $9.84 \mathrm{E}+00$ & $1.41 \mathrm{E}+01$ & $18 \mathrm{E}+01$ & $3.82 \mathrm{E}+01$ & $3.21 \mathrm{E}+01$ \\
\hline & $11 \mathrm{E}+01$ & $8.26 \mathrm{E}+01$ & $9.16 \mathrm{E}+01$ & 94E+01 & $9.97 \mathrm{E}+01$ & $63 \mathrm{E}+01$ & $30 \mathrm{E}+01$ & $9.30 \mathrm{E}+01$ & $7.74 \mathrm{E}+01$ & & \\
\hline & $1 \mathrm{E}+02$ & $5.02 \mathrm{E}+02$ & $4.71 \mathrm{E}+02$ & $00 \mathrm{E}+02$ & $00 \mathrm{E}+02$ & $76 \mathrm{E}+02$ & $17 \mathrm{E}+02$ & $2.17 \mathrm{E}+02$ & $1.51 \mathrm{E}+02$ & & $.34 \mathrm{E}+02$ \\
\hline & $86 \mathrm{E}+02$ & $3.85 E+02$ & $3.67 \mathrm{E}+02$ & $34 \mathrm{E}+02$ & $08 \mathrm{E}+02$ & $2.85 E+02$ & $2.68 \mathrm{E}+02$ & $2.61 \mathrm{E}+02$ & $2.35 \mathrm{E}+02$ & & $.98 \mathrm{E}+02$ \\
\hline & 89E-04 & 1.89E-04 & 1.89E-04 & 9.48E-01 & $41 \mathrm{E}+00$ & $2.06 \mathrm{E}+01$ & $4.34 \mathrm{E}+01$ & $4.36 \mathrm{E}+01$ & $6.29 \mathrm{E}+01$ & & $3.58 \mathrm{E}+01$ \\
\hline & 53E-01 & 1.52E-01 & 7.10E-01 & $1.06 \mathrm{E}+00$ & $06 \mathrm{E}+00$ & $1.06 \mathrm{E}+00$ & $1.06 \mathrm{E}+00$ & $1.06 \mathrm{E}+00$ & $6.71 \mathrm{E}+00$ & & $4.23 E+00$ \\
\hline & $.15 \mathrm{E}+00$ & $1.15 \mathrm{E}+00$ & $1.15 \mathrm{E}+00$ & $1.15 \mathrm{E}+00$ & $.15 \mathrm{E}+00$ & $1.15 \mathrm{E}+00$ & $1.15 \mathrm{E}+00$ & $1.15 \mathrm{E}+00$ & $1.34 \mathrm{E}+00$ & $1.34 \mathrm{E}+00$ & $6.29 \mathrm{E}-01$ \\
\hline$-B-60$ & 1.59E-01 & $1.59 \mathrm{E}-01$ & 1.59E-01 & $1.59 \mathrm{E}-01$ & $1.48 \mathrm{E}-01$ & $1.36 \mathrm{E}-01$ & 1.36E-01 & $1.36 \mathrm{E}-01$ & 1.05E-01 & 1.05E-01 & $8.52 \mathrm{E}-02$ \\
\hline & $39 \mathrm{E}+02$ & $1.16 \mathrm{E}+02$ & $6.99 \mathrm{E}+01$ & $6.99 \mathrm{E}+01$ & $.01 \mathrm{E}+01$ & $6.67 \mathrm{E}+01$ & $5.18 \mathrm{E}+01$ & $5.18 \mathrm{E}+01$ & $3.45 \mathrm{E}+01$ & $3.44 \mathrm{E}+01$ & $3.33 \mathrm{E}+01$ \\
\hline & 48E+05 & $3.10 \mathrm{E}+05$ & $1.50 \mathrm{E}+05$ & $.19 E+04$ & $.17 \mathrm{E}+04$ & 4.00E+04 & $3.91 E+04$ & $3.09 E+04$ & $2.09 E+04$ & $2.08 \mathrm{E}+04$ & 1.48E+04 \\
\hline$-7 \mathrm{~A} 0$ & $93 \mathrm{E}+00$ & $3.92 \mathrm{E}+00$ & $3.92 \mathrm{E}+00$ & $3.92 \mathrm{E}+00$ & $3.92 E+00$ & $3.40 \mathrm{E}+00$ & $3.40 \mathrm{E}+00$ & $0 \mathrm{E}+00$ & $3 \mathrm{E}+00$ & $2.52 \mathrm{E}+00$ & $6 \mathrm{E}+00$ \\
\hline & $E+00$ & $2.46 \mathrm{E}+00$ & $2.46 \mathrm{E}+00$ & $2.46 \mathrm{E}+00$ & +00 & $\mathrm{E}+00$ & $2.26 \mathrm{E}+00$ & $\mathrm{E}+00$ & +00 & +00 & $1.65 \mathrm{E}+00$ \\
\hline & $=01$ & $3.62 \mathrm{E}+01$ & $3.62 \mathrm{E}$ & +01 & $E+01$ & $\mathrm{E}+01$ & $3.62 \mathrm{E}+$ & & $E+01$ & -01 & $2.63 \mathrm{E}+01$ \\
\hline Y-201 & E-02 & $2.42 \mathrm{E}-02$ & $2.42 \mathrm{E}-02$ & $2.42 \mathrm{E}-02$ & E-02 & $2.42 \mathrm{E}-02$ & 2.42 & 2E-02 & $3 E-02$ & 1.92E-02 & 3E-02 \\
\hline & $42 \mathrm{E}+00$ & $6.41 \mathrm{E}+00$ & $6.41 \mathrm{E}+00$ & $.41 \mathrm{E}+00$ & $6.42 \mathrm{E}+00$ & $6.41 \mathrm{E}+00$ & $6.41 \mathrm{E}+00$ & $6.40 \mathrm{E}+00$ & $7 E+00$ & $5.46 \mathrm{E}+00$ & $4.58 \mathrm{E}+00$ \\
\hline-10 & $39 \mathrm{E}+00$ & $1.39 \mathrm{E}+00$ & $1.31 \mathrm{E}+00$ & $.10 \mathrm{E}+00$ & $10 \mathrm{E}+00$ & $10 \mathrm{E}+00$ & $1.10 \mathrm{E}+00$ & $1.10 \mathrm{E}+00$ & E-01 & $.73 \mathrm{E}-01$ & 8.06E-01 \\
\hline & $22 \mathrm{E}+02$ & $1.12 \mathrm{E}+02$ & $1.12 \mathrm{E}+02$ & $.07 \mathrm{E}+02$ & $17 \mathrm{E}+01$ & $15 \mathrm{E}+01$ & $9.15 \mathrm{E}+01$ & $9.15 \mathrm{E}+01$ & $7 \mathrm{E}+01$ & 7.35E+01 & $5.97 \mathrm{E}+01$ \\
\hline & $35 \mathrm{E}+00$ & $2.84 \mathrm{E}+00$ & $2.84 \mathrm{E}+00$ & $.84 \mathrm{E}+00$ & $85 \mathrm{E}+00$ & $84 \mathrm{E}+00$ & $2.84 \mathrm{E}+00$ & $2.84 \mathrm{E}+00$ & $2.54 \mathrm{E}+00$ & $2.53 \mathrm{E}+00$ & $2.30 \mathrm{E}+00$ \\
\hline & $13 \mathrm{E}+00$ & $1.12 \mathrm{E}+00$ & $1.12 \mathrm{E}+00$ & $12 \mathrm{E}+00$ & $13 \mathrm{E}+00$ & $12 \mathrm{E}+00$ & $1.12 \mathrm{E}+00$ & $1.12 \mathrm{E}+00$ & E-01 & 9.08E-01 & 8.25E-01 \\
\hline & $20 \mathrm{E}+00$ & $1.20 \mathrm{E}+00$ & $1.20 \mathrm{E}+00$ & $20 \mathrm{E}+00$ & $20 \mathrm{E}+00$ & $20 \mathrm{E}+00$ & $1.20 \mathrm{E}+00$ & $1.20 \mathrm{E}+00$ & $E-01$ & 42E-01 & $9.29 \mathrm{E}-01$ \\
\hline & 28E-02 & 1.51E-01 & 1.51E-01 & 1.51E-01 & 1.52E-01 & 51E-01 & $E-01$ & 1E-01 & E-01 & -01 & $1.39 \mathrm{E}-01$ \\
\hline & $2 \mathrm{E}+02$ & $8.29 \mathrm{E}+02$ & $8.29 \mathrm{E}+02$ & $\mathrm{E}+02$ & $=+02$ & $E+02$ & & $E+02$ & $E+02$ & $6.38 \mathrm{E}$ & $E+02$ \\
\hline & +00 & 6.12 & 6.12 & $E+00$ & $=+00$ & $2 \mathrm{E}+00$ & $6.12 \mathrm{E}+00$ & $2 \mathrm{E}+00$ & $3 \mathrm{E}+00$ & 5.91 & $E+00$ \\
\hline & +00 & +00 & 5.93 & +00 & +00 & & 5.9 & 5.9 & +00 & & $E+00$ \\
\hline & $=01$ & $E+01$ & $1.48 \mathrm{E}$ & $E+01$ & $E+01$ & $E+01$ & 1.4 & 1.4 & $E+00$ & -00 & $E+00$ \\
\hline & $E+00$ & $6.01 \mathrm{E}+00$ & $5.93 \mathrm{E}+00$ & $5.93 \mathrm{E}+00$ & $5.95 \mathrm{E}+00$ & $5.93 \mathrm{E}+00$ & $5.93 \mathrm{E}+00$ & $5.93 \mathrm{E}+00$ & $5.69 \mathrm{E}+00$ & $5.68 \mathrm{E}+00$ & $3.58 \mathrm{E}+00$ \\
\hline & $E+01$ & $1.86 \mathrm{E}+01$ & 1.27E+01 & $.27 \mathrm{E}+01$ & $27 \mathrm{E}+01$ & $1.27 \mathrm{E}+01$ & $1.27 \mathrm{E}+01$ & $1.27 \mathrm{E}+01$ & $4.48 \mathrm{E}+00$ & $4.46 \mathrm{E}+00$ & $2.82 \mathrm{E}+00$ \\
\hline & $\mathrm{E}+00$ & $6.01 \mathrm{E}+00$ & $5.93 \mathrm{E}+00$ & $5.93 \mathrm{E}+00$ & $5.95 \mathrm{E}+00$ & $93 \mathrm{E}+00$ & $5.93 \mathrm{E}+00$ & $5.93 \mathrm{E}+00$ & $5.69 \mathrm{E}+00$ & $5.68 \mathrm{E}+00$ & $3.58 \mathrm{E}+00$ \\
\hline$-1 \%$ & $33 \mathrm{E}+02$ & $4.62 \mathrm{E}+02$ & $4.46 \mathrm{E}+02$ & $4.08 \mathrm{E}+02$ & $4.09 E+02$ & $4.08 \mathrm{E}+02$ & $4.08 \mathrm{E}+02$ & $4.08 \mathrm{E}+02$ & $3.50 \mathrm{E}+02$ & $3.49 \mathrm{E}+02$ & $2.99 \mathrm{E}+02$ \\
\hline$-10 P$ & $.76 \mathrm{E}+04$ & $5.37 \mathrm{E}+04$ & $3.13 E+04$ & $2.87 \mathrm{E}+04$ & $1.65 E+04$ & $1.65 \mathrm{E}+04$ & $1.55 \mathrm{E}+04$ & $1.30 \mathrm{E}+04$ & $8.91 \mathrm{E}+03$ & $8.89 \mathrm{E}+03$ & $8.08 \mathrm{E}+03$ \\
\hline-12 & 63E-01 & $3.62 \mathrm{E}-01$ & $3.62 \mathrm{E}-01$ & $3.62 \mathrm{E}-01$ & 3.63E-01 & $3.62 \mathrm{E}-01$ & $3.62 \mathrm{E}-01$ & $3.62 \mathrm{E}-01$ & $2.91 \mathrm{E}+00$ & $2.90 \mathrm{E}+00$ & $2.56 \mathrm{E}+00$ \\
\hline $5-13$ & $1.08 \mathrm{E}+01$ & $1.07 \mathrm{E}+01$ & $1.07 \mathrm{E}+01$ & $1.07 \mathrm{E}+01$ & $1.08 \mathrm{E}+01$ & $1.07 \mathrm{E}+01$ & $1.07 \mathrm{E}+01$ & $1.07 \mathrm{E}+01$ & $7.93 \mathrm{E}+00$ & $7.91 \mathrm{E}+00$ & $6.80 \mathrm{E}+00$ \\
\hline $6-S-15$ & 12E-01 & $1.12 \mathrm{E}-01$ & 1.12E-01 & $1.12 \mathrm{E}-01$ & 1.12E-01 & 1.12E-01 & 1.12E-01 & 1.12E-01 & 3.79E-01 & 3.78E-01 & 3.25E-01 \\
\hline S-16P & $5 \mathrm{E}+04$ & $9.03 E+04$ & $9.03 E+04$ & $9.03 \mathrm{E}+04$ & $.05 E+04$ & $9.03 E+04$ & $9.03 E+04$ & $8.87 \mathrm{E}+04$ & $6.42 E+04$ & $6.41 \mathrm{E}+04$ & $5.54 \mathrm{E}+04$ \\
\hline-17 & 79E+04 & $2.78 \mathrm{E}+04$ & $2.78 \mathrm{E}+04$ & $2.78 \mathrm{E}+04$ & $2.79 \mathrm{E}+04$ & $2.78 \mathrm{E}+04$ & $2.78 \mathrm{E}+04$ & $2.78 \mathrm{E}+04$ & $2.27 \mathrm{E}+04$ & $2.27 \mathrm{E}+04$ & $2.01 E+04$ \\
\hline & $75 \mathrm{E}+03$ & $4.55 \mathrm{E}+03$ & $4.55 \mathrm{E}+03$ & $4.55 \mathrm{E}+03$ & $4.50 \mathrm{E}+03$ & $3.51 \mathrm{E}+03$ & $3.51 \mathrm{E}+03$ & $3.51 \mathrm{E}+03$ & $2.62 \mathrm{E}+03$ & $2.61 \mathrm{E}+03$ & $2.32 \mathrm{E}+03$ \\
\hline & $68 \mathrm{E}+02$ & $6.66 \mathrm{E}+02$ & $6.66 \mathrm{E}+02$ & $6.66 \mathrm{E}+02$ & $5.94 \mathrm{E}+02$ & $5.88 \mathrm{E}+02$ & $5.88 \mathrm{E}+02$ & $5.88 \mathrm{E}+02$ & $4.80 \mathrm{E}+02$ & $4.79 \mathrm{E}+02$ & $4.79 \mathrm{E}+02$ \\
\hline S-21 & $58 \mathrm{E}+02$ & $1.55 \mathrm{E}+02$ & $1.55 E+02$ & $1.55 \mathrm{E}+02$ & $1.55 E+02$ & $1.55 E+02$ & $1.55 E+02$ & $1.55 \mathrm{E}+02$ & $1.17 \mathrm{E}+02$ & 1.16E+02 & $1.01 \mathrm{E}+02$ \\
\hline & $87 \mathrm{E}+00$ & $1.87 \mathrm{E}+00$ & $1.87 \mathrm{E}+00$ & $1.87 \mathrm{E}+00$ & $1.87 \mathrm{E}+00$ & $1.87 \mathrm{E}+00$ & $1.87 \mathrm{E}+00$ & $1.87 \mathrm{E}+00$ & $1.61 \mathrm{E}+00$ & $1.61 \mathrm{E}+00$ & $1.37 \mathrm{E}+00$ \\
\hline & $81 \mathrm{E}+02$ & $1.80 \mathrm{E}+02$ & & $1.80 \mathrm{E}+02$ & $1.81 \mathrm{E}+02$ & $1.80 \mathrm{E}+02$ & $1.80 \mathrm{E}+02$ & $1.80 \mathrm{E}+02$ & $1.32 \mathrm{E}+02$ & $1.31 \mathrm{E}+02$ & $1.12 \mathrm{E}+02$ \\
\hline $216-S-25$ & $3.27 \mathrm{E}+03$ & $3.18 \mathrm{E}+03$ & $3.14 \mathrm{E}+03$ & $2.99 \mathrm{E}+03$ & $2.96 \mathrm{E}+03$ & $2.57 E+03$ & $2.57 \mathrm{E}+03$ & $2.56 \mathrm{E}+03$ & $2.11 \mathrm{E}+03$ & $2.10 \mathrm{E}+03$ & $1.98 \mathrm{E}+03$ \\
\hline
\end{tabular}




\begin{tabular}{|c|c|c|c|c|c|c|c|c|c|c|c|}
\hline Site & 1992 & 1993 & 1994 & 1995 & 1996 & 1997 & 1998 & 1999 & 2000 & 2001 & 20 \\
\hline $216-S-26$ & $80 \mathrm{E}+03$ & $1.24 \mathrm{E}+04$ & $1.19 \mathrm{E}+04$ & $69 \mathrm{E}+03$ & $57 \mathrm{E}+03$ & $6.03 E+03$ & $4.32 \mathrm{E}+03$ & $4.20 \mathrm{E}+03$ & $3.04 \mathrm{E}+03$ & $2.90 \mathrm{E}+03$ & $1.97 \mathrm{E}+03$ \\
\hline & $29 \mathrm{E}+01$ & $2.28 \mathrm{E}+01$ & $2.28 \mathrm{E}+01$ & $28 \mathrm{E}+01$ & $28 \mathrm{E}+01$ & $28 \mathrm{E}+01$ & $28 \mathrm{E}+01$ & $28 \mathrm{E}+01$ & $1.97 \mathrm{E}+01$ & & $.73 \mathrm{E}+01$ \\
\hline & $1 \mathrm{E}+00$ & $3.10 \mathrm{E}+00$ & $3.10 \mathrm{E}+00$ & $10 \mathrm{E}+00$ & $05 \mathrm{E}+00$ & $2.84 \mathrm{E}+00$ & $2.84 \mathrm{E}+00$ & $2.84 \mathrm{E}+00$ & $2.45 \mathrm{E}+00$ & $2.44 \mathrm{E}+00$ & $.07 \mathrm{E}+00$ \\
\hline & $\mathrm{LE}+04$ & $2.24 \mathrm{E}+04$ & $1.97 \mathrm{E}+04$ & $97 E+04$ & $98 \mathrm{E}+04$ & $1.97 \mathrm{E}+04$ & $1.97 \mathrm{E}+04$ & $1.97 \mathrm{E}+04$ & $1.67 \mathrm{E}+04$ & & $1.46 \mathrm{E}+04$ \\
\hline & $19 \mathrm{E}+04$ & $1.19 \mathrm{E}+04$ & $1.19 \mathrm{E}+04$ & $19 \mathrm{E}+04$ & $19 \mathrm{E}+04$ & $1.19 \mathrm{E}+04$ & $1.19 \mathrm{E}+04$ & $1.18 \mathrm{E}+04$ & $8.63 \mathrm{E}+03$ & & \\
\hline S-7 & $45 \mathrm{E}+02$ & $6.17 \mathrm{E}+02$ & $6.17 \mathrm{E}+02$ & $17 \mathrm{E}+02$ & $19 \mathrm{E}+02$ & $6.17 \mathrm{E}+02$ & $6.17 \mathrm{E}+02$ & $6.17 \mathrm{E}+02$ & $4.75 \mathrm{E}+02$ & $4.74 \mathrm{E}+02$ & $4.18 \mathrm{E}+02$ \\
\hline b-S-9 & $54 \mathrm{E}+02$ & $2.53 \mathrm{E}+02$ & $2.53 \mathrm{E}+02$ & $2.53 E+02$ & $2.40 \mathrm{E}+02$ & $2.18 \mathrm{E}+02$ & $2.18 \mathrm{E}+02$ & $2.18 \mathrm{E}+02$ & 1.67E+02 & $1.67 \mathrm{E}+02$ & $1.48 \mathrm{E}+02$ \\
\hline $6-S X-2$ & $7.07 \mathrm{E}+01$ & $7.05 \mathrm{E}+01$ & $7.05 \mathrm{E}+01$ & $.90 \mathrm{E}+01$ & $6.06 \mathrm{E}+01$ & $6.04 \mathrm{E}+01$ & $6.04 \mathrm{E}+01$ & $6.04 \mathrm{E}+01$ & $4.83 \mathrm{E}+01$ & $4.81 \mathrm{E}+01$ & $4.19 \mathrm{E}+01$ \\
\hline 6-T-1 & $95 \mathrm{E}+03$ & $3.41 \mathrm{E}+03$ & $3.21 \mathrm{E}+03$ & $.87 \mathrm{E}+03$ & $2.18 \mathrm{E}+03$ & $1.62 \mathrm{E}+03$ & $1.07 \mathrm{E}+03$ & $1.02 \mathrm{E}+03$ & $6.82 \mathrm{E}+02$ & $6.44 \mathrm{E}+02$ & $3.94 \mathrm{E}+02$ \\
\hline -T-12 & $36 \mathrm{E}+01$ & $1.36 \mathrm{E}+01$ & $1.36 \mathrm{E}+01$ & $1.36 \mathrm{E}+01$ & $1.36 \mathrm{E}+01$ & $1.36 \mathrm{E}+01$ & $1.36 \mathrm{E}+01$ & $1.36 \mathrm{E}+01$ & 1.23E+01 & $1.22 \mathrm{E}+01$ & $1.22 \mathrm{E}+01$ \\
\hline -T-14 & $19 \mathrm{E}+01$ & $1.18 \mathrm{E}+01$ & $1.18 \mathrm{E}+01$ & $.18 \mathrm{E}+01$ & $19 \mathrm{E}+01$ & $1.18 \mathrm{E}+01$ & $1.18 \mathrm{E}+01$ & $1.18 \mathrm{E}+01$ & $8 \mathrm{E}+01$ & $8 E+01$ & $8 \mathrm{E}+01$ \\
\hline T-15 & $E+01$ & $E+01$ & $1.20 \mathrm{E}+01$ & $.20 \mathrm{E}+01$ & $1.20 \mathrm{E}+01$ & $\mathrm{E}+01$ & $1.20 \mathrm{E}+01$ & $1.19 \mathrm{E}+01$ & $E+01$ & +01 & $E+01$ \\
\hline$\Gamma-16$ & +01 & $E+01$ & $1.20 \mathrm{E}+01$ & $.20 \mathrm{E}+01$ & $1.21 \mathrm{E}+01$ & $E+01$ & $1.20 \mathrm{E}+01$ & $1.18 \mathrm{E}+01$ & $E+01$ & 01 & $E+01$ \\
\hline$\Gamma-17$ & $E+01$ & $E+01$ & $1.17 \mathrm{E}+01$ & $.17 \mathrm{E}+01$ & $1.17 \mathrm{E}+01$ & $1.17 \mathrm{E}+01$ & $1.17 \mathrm{E}+01$ & $1.17 \mathrm{E}+01$ & $3 \mathrm{E}+01$ & $E+01$ & $E+01$ \\
\hline-18 & $E+00$ & $E+00$ & $3.79 \mathrm{E}+00$ & $.79 \mathrm{E}+00$ & $3.80 \mathrm{E}+00$ & $3.79 \mathrm{E}+00$ & $3.79 \mathrm{E}+00$ & $3.79 \mathrm{E}+00$ & $9 \mathrm{E}+00$ & $\mathrm{E}+00$ & $9 \mathrm{E}+00$ \\
\hline$\Gamma-19$ & $92 \mathrm{E}+02$ & $E+02$ & $3.88 \mathrm{E}+02$ & $.49 \mathrm{E}+02$ & $3.50 \mathrm{E}+02$ & $3.49 \mathrm{E}+02$ & $3.49 \mathrm{E}+02$ & $3.49 \mathrm{E}+02$ & $2.55 \mathrm{E}+02$ & $2.54 \mathrm{E}+02$ & $3 \mathrm{E}+02$ \\
\hline T-2 & $4.72 \mathrm{E}+00$ & $4.71 \mathrm{E}+00$ & $4.71 \mathrm{E}+00$ & $.71 \mathrm{E}+00$ & $4.72 \mathrm{E}+00$ & $4.71 \mathrm{E}+00$ & $4.71 \mathrm{E}+00$ & $4.71 \mathrm{E}+00$ & $5.79 \mathrm{E}+00$ & $5.77 \mathrm{E}+00$ & $4.59 \mathrm{E}+00$ \\
\hline$-T-20$ & $4 \mathrm{E}-01$ & 4.16E-01 & 4.11E-01 & 4.11E-01 & $4.12 \mathrm{E}-01$ & 4.11E-01 & 4.11E-01 & 4.11E-01 & 3.88E-01 & 3.87E-01 & $3.32 \mathrm{E}-01$ \\
\hline$-\mathrm{T}-21$ & $11 \mathrm{E}+01$ & $1.05 \mathrm{E}+01$ & $1.02 \mathrm{E}+01$ & $.02 \mathrm{E}+01$ & $.02 \mathrm{E}+01$ & $1.02 \mathrm{E}+01$ & $1.02 \mathrm{E}+01$ & $1.02 \mathrm{E}+01$ & $9.38 \mathrm{E}+00$ & $E+00$ & $5 \mathrm{E}+00$ \\
\hline$-\mathrm{T}-22$ & $1 \mathrm{E}+01$ & $1.01 \mathrm{E}+01$ & $1.01 \mathrm{E}+01$ & $01 \mathrm{E}+01$ & $01 \mathrm{E}+01$ & $1.01 \mathrm{E}+01$ & $1.01 \mathrm{E}+01$ & $1.01 \mathrm{E}+01$ & $3 E+00$ & $E+00$ & $9 \mathrm{E}+00$ \\
\hline$\cdot T-23$ & $E+01$ & $E+01$ & $1.02 \mathrm{E}+01$ & $2 \mathrm{E}+01$ & $02 \mathrm{E}+01$ & $E+01$ & $1.02 \mathrm{E}+01$ & $1.02 \mathrm{E}+01$ & $E+00$ & $E+00$ & $E+00$ \\
\hline$\Gamma-24$ & $=01$ & $E+01$ & $1.01 \mathrm{E}+$ & $\mathrm{LE}+01$ & $E+01$ & & & 01 & $E+00$ & & \\
\hline$\Gamma-25$ & +00 & $=00$ & +00 & $3 \mathrm{E}+00$ & $15 \mathrm{E}+00$ & $3 \mathrm{E}+00$ & 8.1 & $3 E+00$ & $\mathrm{E}+00$ & & $E+00$ \\
\hline-26 & +01 & +01 & 2.36 & $E+01$ & $E+01$ & $E+01$ & $2.13 \mathrm{E}$ & $3 \mathrm{E}+01$ & $E+01$ & 01 & $E+01$ \\
\hline$\lceil-27$ & $E+01$ & $E+01$ & $2.50 \mathrm{E}$ & $0 \mathrm{E}+01$ & $1 \mathrm{E}+01$ & $E+01$ & 2.27 & $2.27 \mathrm{E}+01$ & $E+01$ & r01 & $E+01$ \\
\hline$\Gamma-28$ & $E+01$ & $6.59 \mathrm{E}+01$ & $6.59 \mathrm{E}+01$ & $6.16 \mathrm{E}+01$ & $5.63 \mathrm{E}+01$ & $5.61 \mathrm{E}+01$ & $5.61 \mathrm{E}+01$ & $5.61 \mathrm{E}+01$ & $4.60 \mathrm{E}+01$ & $\mathrm{E}+01$ & $E+01$ \\
\hline$\Gamma-29$ & EE-02 & 1.64E-02 & 1.64E-02 & 1.64E-02 & 1.65E-02 & 1.64E-02 & 1.64E-02 & 1.64E-02 & 1.33E-02 & 3E-02 & 1E-02 \\
\hline & $E+01$ & $1.38 \mathrm{E}+01$ & $1.38 \mathrm{E}+01$ & $38 \mathrm{E}+01$ & $1.38 \mathrm{E}+01$ & $1.39 \mathrm{E}+01$ & $1.42 \mathrm{E}+01$ & $1.42 \mathrm{E}+01$ & $1.83 \mathrm{E}+01$ & $1.83 \mathrm{E}+01$ & $1.70 \mathrm{E}+01$ \\
\hline$T-32$ & $3 \mathrm{E}+01$ & $2.02 \mathrm{E}+01$ & $2.02 \mathrm{E}+01$ & $.02 \mathrm{E}+01$ & $2.03 \mathrm{E}+01$ & $2.02 \mathrm{E}+01$ & $2.02 \mathrm{E}+01$ & $2.02 \mathrm{E}+01$ & $1.85 \mathrm{E}+01$ & $1.85 \mathrm{E}+01$ & $1.85 \mathrm{E}+01$ \\
\hline$-T-33$ & $71 \mathrm{E}+00$ & $6.70 \mathrm{E}+00$ & $6.69 E+00$ & $81 \mathrm{E}+00$ & $5.83 E+00$ & $5.81 \mathrm{E}+00$ & $5.81 \mathrm{E}+00$ & $5.81 \mathrm{E}+00$ & $5.02 \mathrm{E}+00$ & $5.01 \mathrm{E}+00$ & $4.88 \mathrm{E}+00$ \\
\hline$-T-34$ & $12 \mathrm{E}+01$ & $5.38 \mathrm{E}+01$ & $4.79 \mathrm{E}+01$ & $4.79 \mathrm{E}+01$ & $4.81 \mathrm{E}+01$ & $4.79 \mathrm{E}+01$ & $4.79 \mathrm{E}+01$ & $4.79 \mathrm{E}+01$ & $3.92 \mathrm{E}+01$ & $3.91 \mathrm{E}+01$ & $3.87 \mathrm{E}+01$ \\
\hline -6-T-35 & 85E+01 & $2.84 \mathrm{E}+01$ & $2.84 \mathrm{E}+01$ & $2.66 \mathrm{E}+01$ & $2.43 \mathrm{E}+01$ & $2.42 \mathrm{E}+01$ & $2.42 \mathrm{E}+01$ & $2.42 \mathrm{E}+01$ & $2.01 \mathrm{E}+01$ & $2.01 E+01$ & $1.97 \mathrm{E}+01$ \\
\hline 6-T-36 & $9.54 \mathrm{E}+00$ & $9.51 \mathrm{E}+00$ & $9.51 E+00$ & $9.51 \mathrm{E}+00$ & $9.54 \mathrm{E}+00$ & $9.07 \mathrm{E}+00$ & $8.67 \mathrm{E}+00$ & $8.67 \mathrm{E}+00$ & $7.16 \mathrm{E}+00$ & $7.14 \mathrm{E}+00$ & $7.09 \mathrm{E}+00$ \\
\hline 6-T-4A & $E+04$ & $1.90 \mathrm{E}+04$ & $1.90 E+04$ & $1.90 \mathrm{E}+04$ & $1.90 \mathrm{E}+04$ & $1.89 \mathrm{E}+04$ & $1.88 \mathrm{E}+04$ & $1.85 \mathrm{E}+04$ & $1.73 E+04$ & $1.64 E+04$ & $1.37 E+04$ \\
\hline 16-T-5 & $63 \mathrm{E}+00$ & $8.60 \mathrm{E}+00$ & $8.60 \mathrm{E}+00$ & $8.60 \mathrm{E}+00$ & $8.63 E+00$ & $8.60 \mathrm{E}+00$ & $8.60 \mathrm{E}+00$ & $8.60 \mathrm{E}+00$ & $7.79 \mathrm{E}+00$ & 7.77E+00 & $7.76 \mathrm{E}+00$ \\
\hline & $64 \mathrm{E}+01$ & $7.07 \mathrm{E}+01$ & $7.05 \mathrm{E}+01$ & $7.05 \mathrm{E}+01$ & $7.07 \mathrm{E}+01$ & $7.05 \mathrm{E}+01$ & $7.05 \mathrm{E}+01$ & $7.05 \mathrm{E}+01$ & $6.70 \mathrm{E}+01$ & $6.68 \mathrm{E}+01$ & $6.67 \mathrm{E}+01$ \\
\hline & $17 \mathrm{E}+02$ & $1.16 \mathrm{E}+02$ & $1.16 \mathrm{E}+02$ & $1.16 \mathrm{E}+02$ & $1.17 \mathrm{E}+02$ & $1.16 \mathrm{E}+02$ & $1.16 \mathrm{E}+02$ & $1.16 \mathrm{E}+02$ & $1.04 \mathrm{E}+02$ & $1.03 E+02$ & $E+02$ \\
\hline & $1.58 \mathrm{E}+01$ & $1.58 \mathrm{E}+01$ & $1.58 \mathrm{E}+01$ & $1.58 \mathrm{E}+01$ & $1.58 \mathrm{E}+01$ & $1.58 \mathrm{E}+01$ & $1.58 \mathrm{E}+01$ & $1.58 \mathrm{E}+01$ & $1.59 \mathrm{E}+01$ & $1.59 \mathrm{E}+01$ & $1.59 \mathrm{E}+01$ \\
\hline -TY-201 & $5.84 \mathrm{E}-02$ & 5.82E-02 & 5.82E-02 & $5.82 \mathrm{E}-02$ & 5.84E-02 & $5.82 \mathrm{E}-02$ & $5.48 \mathrm{E}-02$ & 5.42E-02 & 4.36E-02 & 4.34E-02 & $4.28 \mathrm{E}-02$ \\
\hline $216-U-1 \% 2$ & $51 \mathrm{E}+03$ & & & $2.08 \mathrm{E}+03$ & $1.92 \mathrm{E}+03$ & & & $1.92 \mathrm{E}+03$ & $1.25 E+03$ & $1.25 E+03$ & \\
\hline 216-U-10 & $2.77 \mathrm{E}+05$ & $2.44 \mathrm{E}+05$ & $2.30 \mathrm{E}+05$ & $2.54 \mathrm{E}+05$ & $3.06 \mathrm{E}+05$ & $3.65 E+05$ & $3.69 E+05$ & $3.77 \mathrm{E}+05$ & $3.41 \mathrm{E}+05$ & $3.28 \mathrm{E}+05$ & \\
\hline
\end{tabular}




\begin{tabular}{|c|c|c|c|c|c|c|c|c|c|c|c|}
\hline Site & 1992 & 1993 & 1994 & 1995 & 1996 & 1997 & 1998 & 1999 & 2000 & 20 & 20 \\
\hline $216-U-12$ & $28 \mathrm{E}+03$ & $8.66 \mathrm{E}+02$ & $66 \mathrm{E}+02$ & $79 \mathrm{E}+02$ & $56 \mathrm{E}+02$ & $5.54 \mathrm{E}+02$ & $5.54 \mathrm{E}+02$ & $5.54 \mathrm{E}+02$ & $3.91 \mathrm{E}+02$ & $3.90 \mathrm{E}+02$ & $3.63 E+02$ \\
\hline & 48E-01 & 1.47E-01 & 1.47E-01 & $.47 \mathrm{E}-01$ & $.48 \mathrm{E}-01$ & 1.54E-01 & $1.76 \mathrm{E}-01$ & 1.76E-01 & $2.25 \mathrm{E}+00$ & & \\
\hline & $9 \mathrm{E}+05$ & $2.80 \mathrm{E}+05$ & $2.23 \mathrm{E}+05$ & 47E+05 & $02 \mathrm{E}+05$ & $6.31 \mathrm{E}+04$ & $5.96 \mathrm{E}+04$ & $65 \mathrm{E}+04$ & $3.22 \mathrm{E}+04$ & & \\
\hline & $50 \mathrm{E}+00$ & $1.49 \mathrm{E}+00$ & $1.49 \mathrm{E}+00$ & $49 \mathrm{E}+00$ & $50 \mathrm{E}+00$ & $.49 \mathrm{E}+00$ & $1.49 \mathrm{E}+00$ & $1.49 \mathrm{E}+00$ & $1.61 \mathrm{E}+00$ & & $.41 \mathrm{E}+00$ \\
\hline & $21 \mathrm{E}+01$ & $6.55 \mathrm{E}+01$ & $6.55 \mathrm{E}+01$ & $84 \mathrm{E}+03$ & $84 \mathrm{E}+03$ & $83 \mathrm{E}+03$ & $3.83 \mathrm{E}+03$ & $3.83 E+03$ & $9.37 \mathrm{E}+03$ & & \\
\hline & 98E-05 & $4.50 \mathrm{E}+02$ & $1.60 \mathrm{E}+03$ & $12 \mathrm{E}+02$ & $38 \mathrm{E}+02$ & $.07 \mathrm{E}+02$ & $2.48 \mathrm{E}+02$ & $2.01 \mathrm{E}+02$ & $1.50 \mathrm{E}+02$ & $1.31 \mathrm{E}+02$ & $1.05 \mathrm{E}+02$ \\
\hline & $56 \mathrm{E}+00$ & $5.55 \mathrm{E}+00$ & $5.55 \mathrm{E}+00$ & $55 \mathrm{E}+00$ & $5.56 \mathrm{E}+00$ & $5.55 \mathrm{E}+00$ & $5.55 \mathrm{E}+00$ & $5.55 \mathrm{E}+00$ & $4.57 \mathrm{E}+00$ & $4.55 \mathrm{E}+00$ & $3.98 \mathrm{E}+00$ \\
\hline & $93 \mathrm{E}+00$ & $1.92 \mathrm{E}+00$ & $1.92 \mathrm{E}+00$ & $92 \mathrm{E}+00$ & $1.90 \mathrm{E}+00$ & $1.83 \mathrm{E}+00$ & $1.83 \mathrm{E}+00$ & $1.83 \mathrm{E}+00$ & $2.19 \mathrm{E}+00$ & $2.19 \mathrm{E}+00$ & $1.99 \mathrm{E}+00$ \\
\hline $\mathrm{J}-4 \mathrm{~A}$ & $14 \mathrm{E}+00$ & $2.09 \mathrm{E}+00$ & $1.60 \mathrm{E}+00$ & $60 \mathrm{E}+00$ & $61 \mathrm{E}+00$ & $60 \mathrm{E}+00$ & $1.60 \mathrm{E}+00$ & $1.60 \mathrm{E}+00$ & $1.22 \mathrm{E}+00$ & $.21 \mathrm{E}+00$ & $1.20 \mathrm{E}+00$ \\
\hline & 10E-01 & 1.05E-01 & 1.05E-01 & 1.05E-01 & 1.05E-01 & 1.05E-01 & 1.05E-01 & 1.05E-01 & 7.78E-02 & 7.76E-02 & 79E-02 \\
\hline & 51E-02 & 0E-02 & E-02 & E-02 & 2.51E-02 & DE-02 & 2.50E-02 & $.50 \mathrm{E}-02$ & 8E-02 & 7E-02 & 7E-02 \\
\hline & $E+02$ & $E+02$ & $E+02$ & $E+02$ & $7.95 \mathrm{E}+02$ & $7.93 \mathrm{E}+02$ & $7.93 \mathrm{E}+02$ & $7.93 \mathrm{E}+02$ & $6.27 \mathrm{E}+02$ & $\mathrm{E}+02$ & $E+02$ \\
\hline & $E+04$ & $E+04$ & +04 & & $E+04$ & $E+04$ & $8.22 \mathrm{E}$ & $8.22 \mathrm{E}+03$ & $0 \mathrm{E}+03$ & & $\mathrm{E}+03$ \\
\hline$\% 2$ & $40 \mathrm{E}+01$ & $E+01$ & 8.33 & $E+01$ & $35 \mathrm{E}+01$ & $33 \mathrm{E}+01$ & $8.33 \mathrm{E}+01$ & $8.33 \mathrm{E}+01$ & $7.82 \mathrm{E}+01$ & $E+01$ & $E+01$ \\
\hline & $0 \mathrm{E}+00$ & $\mathrm{E}+00$ & +00 & $E+00$ & $10 \mathrm{E}+00$ & $.09 \mathrm{E}+00$ & $3.09 \mathrm{E}+00$ & $3.09 \mathrm{E}+00$ & $5 \mathrm{E}+00$ & $E+00$ & $\mathrm{E}+00$ \\
\hline & $\mathrm{L} 2 \mathrm{E}+02$ & $6.10 \mathrm{E}+02$ & +02 & $.10 \mathrm{E}+02$ & $.12 \mathrm{E}+02$ & $10 \mathrm{E}+02$ & $6.10 \mathrm{E}+02$ & $6.10 \mathrm{E}+02$ & $4.36 \mathrm{E}+02$ & $\mathrm{E}+02$ & $2 \mathrm{E}+02$ \\
\hline & $73 \mathrm{E}+02$ & $3.72 \mathrm{E}+02$ & $3.55 \mathrm{E}+02$ & $19 \mathrm{E}+02$ & $20 \mathrm{E}+02$ & $3.19 \mathrm{E}+02$ & $3.19 \mathrm{E}+02$ & $3.19 \mathrm{E}+02$ & $2.68 \mathrm{E}+02$ & $E+02$ & $4 \mathrm{E}+02$ \\
\hline & 32E-01 & $2.32 \mathrm{E}-01$ & 2.32E-01 & $2.32 \mathrm{E}-01$ & $2.72 \mathrm{E}-01$ & 2.87E-01 & 2.87E-01 & 2.87E-01 & 3.56E-01 & 3.55E-01 & $3.15 \mathrm{E}-01$ \\
\hline & $41 \mathrm{E}+02$ & $1.41 \mathrm{E}+02$ & $1.41 \mathrm{E}+02$ & $.41 \mathrm{E}+02$ & $41 \mathrm{E}+02$ & $1.38 \mathrm{E}+02$ & $1.35 \mathrm{E}+02$ & $1.35 \mathrm{E}+02$ & $1.21 \mathrm{E}+02$ & $\mathrm{DE}+02$ & $9 \mathrm{E}+02$ \\
\hline & $90 \mathrm{E}+00$ & $1.90 \mathrm{E}+00$ & $1.90 \mathrm{E}+00$ & $90 \mathrm{E}+00$ & $90 \mathrm{E}+00$ & $90 \mathrm{E}+00$ & $1.90 \mathrm{E}+00$ & $1.90 \mathrm{E}+00$ & $E+00$ & $E+00$ & $1 \mathrm{E}+00$ \\
\hline & $7 \mathrm{E}+02$ & $1.47 \mathrm{E}+02$ & $1.47 \mathrm{E}+02$ & $E+02$ & $47 \mathrm{E}+02$ & $47 \mathrm{E}+02$ & $1.47 \mathrm{E}+02$ & $1.47 \mathrm{E}+02$ & +02 & +02 & $E+01$ \\
\hline & $0 \mathrm{E}+00$ & $E+00$ & & $=+00$ & $E+00$ & & & & & & \\
\hline & 33E-03 & E-03 & & & E-03 & $E-03$ & & -03 & E-03 & & -03 \\
\hline & & & & & -03 & & & & -03 & & $E-03$ \\
\hline & +00 & +00 & 0.0 & $E+00$ & $\mathrm{E}+00$ & $E+00$ & 0.0 & $0.00 \mathrm{E}+00$ & $\mathrm{E}+00$ & -00 & $E+00$ \\
\hline$-3 A E$ & $E+00$ & $E+00$ & $0.00 \mathrm{E}$ & $E+00$ & $.00 \mathrm{E}+00$ & $0.00 \mathrm{E}+00$ & $0.00 \mathrm{E}+00$ & $0.00 \mathrm{E}+00$ & $0.00 \mathrm{E}+00$ & $E+00$ & $E+00$ \\
\hline$-4 B$ & $E+00$ & $E+00$ & 0.0 & $E+00$ & $00 \mathrm{E}+00$ & $.00 \mathrm{E}+00$ & $0.00 \mathrm{E}+00$ & $0.00 \mathrm{E}+00$ & $0.00 \mathrm{E}+00$ & $\mathrm{E}+00$ & $E+00$ \\
\hline$-4 C$ & $\mathrm{E}+00$ & $E+00$ & $0.00 \mathrm{E}+00$ & $.00 \mathrm{E}+00$ & $00 \mathrm{E}+00$ & $00 \mathrm{E}+00$ & $0.00 \mathrm{E}+00$ & $0.00 \mathrm{E}+00$ & $0.00 \mathrm{E}+00$ & $\mathrm{DE}+00$ & $\mathrm{E}+00$ \\
\hline & $0 \mathrm{E}+00$ & $0.00 \mathrm{E}+00$ & $0.00 \mathrm{E}+00$ & $.00 \mathrm{E}+00$ & $.00 E+00$ & $.00 \mathrm{E}+00$ & $0.00 \mathrm{E}+00$ & $0.00 \mathrm{E}+00$ & $0.00 \mathrm{E}+00$ & $0.00 \mathrm{E}+00$ & $0.00 \mathrm{E}+00$ \\
\hline-101 & $00 \mathrm{E}+00$ & $0.00 \mathrm{E}+00$ & $0.00 \mathrm{E}+00$ & $00 \mathrm{E}+00$ & $00 \mathrm{E}+00$ & $0.00 \mathrm{E}+00$ & $0.00 \mathrm{E}+00$ & $0.00 \mathrm{E}+00$ & $0.00 \mathrm{E}+00$ & $0.00 \mathrm{E}+00$ & $0.00 \mathrm{E}+00$ \\
\hline-102 & $00 \mathrm{E}+00$ & $0.00 \mathrm{E}+00$ & $0.00 \mathrm{E}+00$ & $.00 \mathrm{E}+00$ & $.00 \mathrm{E}+00$ & $0.00 \mathrm{E}+00$ & $0.00 \mathrm{E}+00$ & $0.00 \mathrm{E}+00$ & $0.00 \mathrm{E}+00$ & $0.00 \mathrm{E}+00$ & $0 \mathrm{E}+00$ \\
\hline-103 & $.00 \mathrm{E}+00$ & $0.00 \mathrm{E}+00$ & $0.00 \mathrm{E}+00$ & $0.00 \mathrm{E}+00$ & $0.00 \mathrm{E}+00$ & $0.00 \mathrm{E}+00$ & $0.00 \mathrm{E}+00$ & $0.00 \mathrm{E}+00$ & $0.00 \mathrm{E}+00$ & $0.00 \mathrm{E}+00$ & $0.00 \mathrm{E}+00$ \\
\hline-104 & 23E-05 & 1.23E-05 & 1.23E-05 & 1.23E-05 & 1.23E-05 & 1.23E-05 & 1.23E-05 & 1.23E-05 & 1.23E-05 & $1 \mathrm{E}-04$ & $1.66 \mathrm{E}-01$ \\
\hline & $7 \mathrm{E}+00$ & $2.65 \mathrm{E}+00$ & $2.72 \mathrm{E}+00$ & $.76 \mathrm{E}+00$ & $.79 E+00$ & $9 \mathrm{E}+00$ & $2.79 \mathrm{E}+00$ & $2.80 \mathrm{E}+00$ & $2.81 \mathrm{E}+00$ & $2.80 \mathrm{E}+00$ & $2.79 \mathrm{E}+00$ \\
\hline & DOE+00 & $0.00 \mathrm{E}+00$ & $0.00 \mathrm{E}+00$ & $.00 \mathrm{E}+00$ & $.00 \mathrm{E}+00$ & $0.00 \mathrm{E}+00$ & $0.00 \mathrm{E}+00$ & $0.00 \mathrm{E}+00$ & $0.00 \mathrm{E}+00$ & $0.00 \mathrm{E}+00$ & $0.00 \mathrm{E}+00$ \\
\hline & $00 \mathrm{E}+00$ & $0.00 \mathrm{E}+00$ & $0.00 \mathrm{E}+00$ & $0.00 \mathrm{E}+00$ & $0.00 E+00$ & $0.00 \mathrm{E}+00$ & $0.00 \mathrm{E}+00$ & $0.00 \mathrm{E}+00$ & $0.00 \mathrm{E}+00$ & $0.00 \mathrm{E}+00$ & $.00 \mathrm{E}+00$ \\
\hline & $00 \mathrm{E}+00$ & $0.00 \mathrm{E}+00$ & $0.00 \mathrm{E}+00$ & $0.00 \mathrm{E}+00$ & $.00 \mathrm{E}+00$ & $0.00 \mathrm{E}+00$ & $0.00 \mathrm{E}+00$ & $0.00 \mathrm{E}+00$ & $0.00 \mathrm{E}+00$ & $0.00 \mathrm{E}+00$ & $E+00$ \\
\hline 2 & $.00 \mathrm{E}+00$ & $0.00 \mathrm{E}+00$ & $0.00 \mathrm{E}+00$ & $0.00 \mathrm{E}+00$ & $0.00 \mathrm{E}+00$ & $0.00 \mathrm{E}+00$ & $0.00 \mathrm{E}+00$ & $0.00 \mathrm{E}+00$ & $0.00 \mathrm{E}+00$ & $0.00 \mathrm{E}+00$ & $0.00 \mathrm{E}+00$ \\
\hline & $.00 E+00$ & $0.00 \mathrm{E}+00$ & $0.00 \mathrm{E}+00$ & $0.00 \mathrm{E}+00$ & $0.00 \mathrm{E}+00$ & $0.00 \mathrm{E}+00$ & $0.00 \mathrm{E}+00$ & $0.00 \mathrm{E}+00$ & $0.00 \mathrm{E}+00$ & $0.00 \mathrm{E}+00$ & $0.00 \mathrm{E}+00$ \\
\hline & $0 \mathrm{E}+00$ & & & & & & & & $0.00 \mathrm{E}+00$ & & \\
\hline 241-AN-106 & $0.00 \mathrm{E}+00$ & $0.00 \mathrm{E}+00$ & $0.00 \mathrm{E}+00$ & $0.00 \mathrm{E}+00$ & $0.00 E+00$ & $0.00 \mathrm{E}+00$ & $0.00 \mathrm{E}+00$ & $0.00 \mathrm{E}+00$ & $0.00 \mathrm{E}+00$ & $0.00 \mathrm{E}+00$ & \\
\hline
\end{tabular}




\begin{tabular}{|c|c|c|c|c|c|c|c|c|c|c|c|}
\hline Site & 1992 & 1993 & 1994 & 1995 & 1996 & 1997 & 1998 & 1999 & 2000 & 2001 & 2002 \\
\hline 41-AN-107 & $00 \mathrm{E}+00$ & $0.00 \mathrm{E}+00$ & $0.00 \mathrm{E}+00$ & $.00 \mathrm{E}+00$ & $0.00 \mathrm{E}+00$ & $0.00 \mathrm{E}+00$ & $0.00 \mathrm{E}+00$ & $0.00 \mathrm{E}+00$ & $0.00 \mathrm{E}+00$ & $0.00 \mathrm{E}+00$ & $.00 \mathrm{E}+00$ \\
\hline 1-AP-101 & $00 \mathrm{E}+00$ & $0.00 \mathrm{E}+00$ & $0.00 \mathrm{E}+00$ & $00 \mathrm{E}+00$ & $00 \mathrm{E}+00$ & $0.00 \mathrm{E}+00$ & $0.00 \mathrm{E}+00$ & $0.00 \mathrm{E}+00$ & $0.00 \mathrm{E}+00$ & $0.00 \mathrm{E}+00$ & $.00 \mathrm{E}+00$ \\
\hline -AP-102 & $00 \mathrm{E}+00$ & $0.00 \mathrm{E}+00$ & $0.00 \mathrm{E}+00$ & $00 \mathrm{E}+00$ & $00 \mathrm{E}+00$ & $.00 \mathrm{E}+00$ & $0.00 \mathrm{E}+00$ & $0.00 \mathrm{E}+00$ & $0.00 \mathrm{E}+00$ & $.00 \mathrm{E}+00$ & $.00 \mathrm{E}+00$ \\
\hline -AP-103 & $00 \mathrm{E}+00$ & $0.00 \mathrm{E}+00$ & $0.00 \mathrm{E}+00$ & $00 \mathrm{E}+00$ & $00 \mathrm{E}+00$ & $0.00 \mathrm{E}+00$ & $0.00 \mathrm{E}+00$ & $0.00 \mathrm{E}+00$ & $0.00 \mathrm{E}+00$ & $0.00 \mathrm{E}+00$ & $.00 \mathrm{E}+00$ \\
\hline & $00 \mathrm{E}+00$ & $0.00 \mathrm{E}+00$ & $0.00 \mathrm{E}+00$ & $00 \mathrm{E}+00$ & $.00 \mathrm{E}+00$ & $0.00 \mathrm{E}+00$ & $0.00 \mathrm{E}+00$ & $0.00 \mathrm{E}+00$ & $0.00 \mathrm{E}+00$ & $.00 \mathrm{E}+00$ & $.00 \mathrm{E}+00$ \\
\hline & $00 \mathrm{E}+00$ & $0.00 \mathrm{E}+00$ & $0.00 \mathrm{E}+00$ & $.00 \mathrm{E}+00$ & $0.00 \mathrm{E}+00$ & $0.00 \mathrm{E}+00$ & $0.00 \mathrm{E}+00$ & $0.00 \mathrm{E}+00$ & $0 \mathrm{E}+00$ & $.00 \mathrm{E}+00$ & \\
\hline & $E+00$ & $0.00 \mathrm{E}+00$ & $0.00 \mathrm{E}+00$ & $00 \mathrm{E}+00$ & $00 \mathrm{E}+00$ & $0.00 \mathrm{E}+00$ & $0.00 \mathrm{E}+00$ & $0.00 \mathrm{E}+00$ & & $\mathrm{DE}+00$ & $\mathrm{E}+00$ \\
\hline 07 & $E+00$ & $E+00$ & $=+00$ & $00 \mathrm{E}+00$ & $00 \mathrm{E}+00$ & $.00 \mathrm{E}+00$ & $0.00 \mathrm{E}+00$ & $.00 \mathrm{E}+00$ & & & $\mathrm{E}+00$ \\
\hline & $=00$ & $\mathrm{E}+00$ & +00 & $E+00$ & $\mathrm{E}+00$ & $\mathrm{E}+00$ & $E+00$ & $0 \mathrm{E}+00$ & $E+00$ & & $\mathrm{E}+00$ \\
\hline & $E+00$ & $E+00$ & +00 & $E+00$ & $\mathrm{E}+00$ & $\mathrm{E}+00$ & $\mathrm{E}+00$ & $0 \mathrm{E}+00$ & $\mathrm{E}+00$ & $\mathrm{E}+00$ & $E+00$ \\
\hline 102 & $E+00$ & 0.0 & $E+00$ & $00 \mathrm{E}+00$ & $00 \mathrm{E}+00$ & $0 \mathrm{E}+00$ & $0.00 \mathrm{E}+00$ & $0.00 \mathrm{E}+00$ & $\mathrm{E}+00$ & -00 & +00 \\
\hline 03 & $=00$ & 0.0 & 0.00 & $E+00$ & $\mathrm{E}+00$ & $E+00$ & $E+00$ & $\mathrm{DE}+00$ & $E+00$ & & \\
\hline-104 & $E+00$ & $0.00 \mathrm{E}+00$ & $0.00 \mathrm{E}+00$ & $00 \mathrm{E}+00$ & $00 \mathrm{E}+00$ & $0 \mathrm{E}+00$ & $0.00 \mathrm{E}+00$ & $0.00 \mathrm{E}+00$ & $E+00$ & $0 \mathrm{E}+00$ & \\
\hline -AW-105 & $00 \mathrm{E}+00$ & $0.00 \mathrm{E}+00$ & $0.00 \mathrm{E}+00$ & $00 \mathrm{E}+00$ & $.00 \mathrm{E}+00$ & $0.00 \mathrm{E}+00$ & $0.00 \mathrm{E}+00$ & $0.00 \mathrm{E}+00$ & $0 \mathrm{E}+00$ & $0 \mathrm{E}+00$ & $0 \mathrm{E}+00$ \\
\hline V-106 & $00 \mathrm{E}+00$ & $0.00 \mathrm{E}+00$ & $0.00 \mathrm{E}+00$ & $.00 \mathrm{E}+00$ & $00 \mathrm{E}+00$ & $0.00 \mathrm{E}+00$ & $0.00 \mathrm{E}+00$ & $0.00 \mathrm{E}+00$ & $0 \mathrm{E}+00$ & $0 \mathrm{E}+00$ & $\mathrm{DE}+00$ \\
\hline & $00 \mathrm{E}+00$ & $0.00 \mathrm{E}+00$ & $0.00 E+00$ & $.00 \mathrm{E}+00$ & $00 \mathrm{E}+00$ & $0.00 \mathrm{E}+00$ & $0.00 E+00$ & $0.00 E+00$ & $\mathrm{E}+00$ & $0 \mathrm{E}+00$ & $\mathrm{OE}+00$ \\
\hline & $0 \mathrm{E}+00$ & $0.00 \mathrm{E}+00$ & $0.00 \mathrm{E}+00$ & $00 \mathrm{E}+00$ & $00 \mathrm{E}+00$ & $0 \mathrm{E}+00$ & $0.00 \mathrm{E}+00$ & $0.00 \mathrm{E}+00$ & $\mathrm{E}+00$ & $0 \mathrm{E}+00$ & \\
\hline & $\mathrm{E}+00$ & $.00 \mathrm{E}+00$ & $0.00 \mathrm{E}+00$ & $00 \mathrm{E}+00$ & $00 \mathrm{E}+00$ & $.00 \mathrm{E}+00$ & $0.00 \mathrm{E}+00$ & $0.00 \mathrm{E}+00$ & $0 \mathrm{E}+00$ & $\mathrm{DE}+00$ & \\
\hline & $E+00$ & $E+00$ & 0.0 & $E+00$ & 00 & $E+00$ & 00 & $\mathrm{E}+00$ & $\mathrm{E}+00$ & -00 & $E+00$ \\
\hline & $E+00$ & $E+00$ & 0.0 & $E+00$ & $\mathrm{E}+00$ & $\mathrm{E}+00$ & $E+00$ & $\mathrm{E}+00$ & $E+00$ & 100 & $E+00$ \\
\hline & $E+00$ & $\mathrm{E}+00$ & $E+00$ & $E+00$ & $E+00$ & $\mathrm{E}+00$ & $E+00$ & $0 \mathrm{E}+00$ & $\mathrm{DE}+00$ & $\mathrm{E}+00$ & $=+00$ \\
\hline & $E+00$ & $\mathrm{E}+00$ & $0.00 \mathrm{E}+00$ & $.00 \mathrm{E}+00$ & $0 \mathrm{E}+00$ & $\mathrm{E}+00$ & $E+00$ & $0.00 \mathrm{E}+00$ & $0 \mathrm{E}+00$ & $\mathrm{E}+00$ & $E+00$ \\
\hline 102 & $00 \mathrm{E}+00$ & $0.00 \mathrm{E}+00$ & $0.00 \mathrm{E}+00$ & $0.00 \mathrm{E}+00$ & $0.00 \mathrm{E}+00$ & $0.00 \mathrm{E}+00$ & $0.00 \mathrm{E}+00$ & $0.00 \mathrm{E}+00$ & $0.00 \mathrm{E}+00$ & $\mathrm{DE}+00$ & $\mathrm{DE}+00$ \\
\hline & E-01 & $5 \mathrm{E}-01$ & E-01 & 5E-01 & 37E-01 & $35 \mathrm{E}-01$ & 8.35E-01 & 8.35E-01 & 37E-01 & $5 \mathrm{E}-01$ & 3E-01 \\
\hline & $7 \mathrm{E}-01$ & $35 \mathrm{E}-01$ & .35E-01 & $35 \mathrm{E}-01$ & 37E-01 & 8.35E-01 & $3.35 \mathrm{E}-01$ & $.35 \mathrm{E}-01$ & $37 \mathrm{E}-01$ & $35 \mathrm{E}-01$ & $2 \mathrm{E}-01$ \\
\hline & 37E-01 & $8.35 \mathrm{E}-01$ & 8.35E-01 & 8.35E-01 & 8.37E-01 & 8.35E-01 & $5 \mathrm{E}-01$ & $35 \mathrm{E}-01$ & 37E-01 & $5 \mathrm{E}-01$ & $3 \mathrm{E}-01$ \\
\hline & 7E-01 & $35 \mathrm{E}-01$ & 35E-01 & 8.35E-01 & 37E-01 & 8.35E-01 & $5 \mathrm{E}-01$ & .35E-01 & 37E-01 & $5 \mathrm{E}-01$ & 2E-01 \\
\hline & 7E-01 & $.35 \mathrm{E}-01$ & 8.35E-01 & 8.35E-01 & 37E-01 & $.35 \mathrm{E}-01$ & 5E-01 & .35E-01 & 7E-01 & -01 & $3 \mathrm{E}-01$ \\
\hline & E-01 & E-01 & E-01 & E-01 & E-01 & 4E-01 & E-01 & 4E-01 & 7E-01 & 34E-01 & 2E-01 \\
\hline & $E-01$ & E-01 & & & & $\mathrm{E}-01$ & & & E-01 & -01 & -01 \\
\hline & & -01 & & & & & & & & & -01 \\
\hline & & $=-01$ & & & & & & & & & \\
\hline & & & & & & & & & & & \\
\hline & $E-01$ & E-01 & & & & & & & & -01 & E-01 \\
\hline & $E-01$ & $8.36 \mathrm{E}-01$ & 6E-01 & 8.36E-01 & $\mathrm{E}-01$ & $36 \mathrm{E}-01$ & 6E-01 & 8.36E-01 & $8 \mathrm{E}-01$ & .36E-01 & $8.33 \mathrm{E}-01$ \\
\hline & $\mathrm{E}-02$ & $92 \mathrm{E}-02$ & 92E-02 & $.92 \mathrm{E}-02$ & $3 \mathrm{E}-02$ & 5.92E-02 & 5.92E-02 & $.92 \mathrm{E}-02$ & 93E-02 & $.92 \mathrm{E}-02$ & $5.90 \mathrm{E}-02$ \\
\hline & 4E-02 & $5.93 \mathrm{E}-02$ & 93E-02 & 5.93E-02 & 5.94E-02 & $5.93 \mathrm{E}-02$ & $5.93 \mathrm{E}-02$ & 5.93E-02 & 94E-02 & $93 \mathrm{E}-02$ & $5.91 \mathrm{E}-02$ \\
\hline & 93E-02 & $91 \mathrm{E}-02$ & 5.91E-02 & 5.91E-02 & $5.93 \mathrm{E}-02$ & 5.91E-02 & 5.91E-02 & 5.91E-02 & .93E-02 & 5.91E-02 & $5.90 \mathrm{E}-02$ \\
\hline & 3E-02 & 92E-02 & 5.92E-02 & 5.92E-02 & $.93 \mathrm{E}-02$ & 92E-02 & $5.92 \mathrm{E}-02$ & $5.92 \mathrm{E}-02$ & $93 \mathrm{E}-02$ & $.92 \mathrm{E}-02$ & $5.90 \mathrm{E}-02$ \\
\hline & 8.37E-01 & 8.35E-01 & 8.35E-01 & 8.35E-01 & $.37 \mathrm{E}-01$ & $.35 \mathrm{E}-01$ & 5E-01 & 8.35E-01 & 8.37E-01 & 8.35E-01 & 8.33E-01 \\
\hline 241-BX-102 & 8.38E-01 & 8.36E-01 & 8.36E-01 & 8.36E-01 & 8.38E-01 & 8.36E-01 & 8.36E-01 & 8.36E-01 & 8.38E-01 & 8.36E-01 & 8.33E-0 \\
\hline
\end{tabular}




\begin{tabular}{|c|c|c|c|c|c|c|c|c|c|c|c|}
\hline Site & 1992 & 1993 & 1994 & 1995 & 1996 & 1997 & 1998 & 1999 & 2000 & 2001 & 2002 \\
\hline $241-B X-103$ & $8.37 \mathrm{E}-01$ & 8.35E-01 & $8.35 \mathrm{E}-01$ & 3.35E-01 & 8.37E-01 & $8.35 \mathrm{E}-01$ & $3.35 \mathrm{E}-01$ & $8.35 \mathrm{E}-01$ & 8.37E-01 & 8.35E-01 & 8.33E-01 \\
\hline & 37E-01 & 35E-01 & 35E-01 & $.35 \mathrm{E}-01$ & $8.37 \mathrm{E}-01$ & $.35 \mathrm{E}-01$ & .35E-01 & .35E-01 & 8.37E-01 & 8.35E-01 & $8.32 \mathrm{E}-01$ \\
\hline BX-105 & 37E-01 & 35E-01 & $35 E-01$ & 8.35E-01 & $8.37 \mathrm{E}-01$ & 8.35E-01 & 35E-01 & 8.35E-01 & 8.37E-01 & $8.35 \mathrm{E}-01$ & 8.33E-01 \\
\hline$B X-106$ & 38E-01 & $35 \mathrm{E}-01$ & 35E-01 & 8.35E-01 & 8.38E-01 & 8.35E-01 & $35 \mathrm{E}-01$ & 8.35E-01 & 8.38E-01 & 8.35E-01 & 8.33E-01 \\
\hline & 37E-01 & 35E-01 & 35E-01 & 8.35E-01 & 8.37E-01 & 8.35E-01 & $.35 \mathrm{E}-01$ & 35E-01 & 8.37E-01 & $8.35 \mathrm{E}-01$ & $8.33 \mathrm{E}-01$ \\
\hline & 38E-01 & 8.36E-01 & 8.36E-01 & 8.36E-01 & 8.38E-01 & 8.36E-01 & 8.36E-01 & 8.36E-01 & 8.38E-01 & $3.36 \mathrm{E}-01$ & 33E-01 \\
\hline & 37E-01 & 8.35E-01 & 8.35E-01 & 8.35E-01 & $8.37 \mathrm{E}-01$ & 8.35E-01 & 8.35E-01 & 8.35E-01 & & $.35 \mathrm{E}-01$ & $33 \mathrm{E}-01$ \\
\hline & E-01 & 8.35E-01 & 35E-01 & 8.35E-01 & 8.37E-01 & 8.35E-01 & 8.35E-01 & 8.35E-01 & & $8.35 \mathrm{E}-01$ & $32 \mathrm{E}-01$ \\
\hline & $E-01$ & 8.35E-01 & 35E-01 & 8.35E-01 & E-01 & 8.35E-01 & 8.35E-01 & 8.35E-01 & & 8.35E-01 & 33E-01 \\
\hline & E-01 & 35E-01 & 35E-01 & 8.35E-01 & 3E-01 & 8.35E-01 & 8.35E-01 & 8.35E-01 & 8E-01 & 8.35E-01 & 33E-01 \\
\hline 101 & E-01 & 8.34E-01 & $34 \mathrm{E}-01$ & $8.34 \mathrm{E}-01$ & 8.36E-01 & 8.34E-01 & 8.34E-01 & 8.34E-01 & $36 \mathrm{E}-01$ & $.34 \mathrm{E}-01$ & $8.32 \mathrm{E}-01$ \\
\hline & E-01 & 35E-01 & $E-01$ & 35E-01 & E-01 & $8.35 \mathrm{E}-01$ & $35 \mathrm{E}-01$ & $35 \mathrm{E}-01$ & BE-01 & .35E-01 & $.33 \mathrm{E}-01$ \\
\hline Y-103 & E-01 & 8.35E-01 & 35E-01 & 8.35E-01 & 8.37E-01 & 8.35E-01 & $35 \mathrm{E}-01$ & 8.35E-01 & 7E-01 & 8.35E-01 & $8.32 \mathrm{E}-01$ \\
\hline BY-104 & 36E-01 & 8.34E-01 & 8.34E-01 & 8.34E-01 & 8.36E-01 & 8.34E-01 & 8.34E-01 & 8.34E-01 & $6 \mathrm{E}-01$ & 8.34E-01 & $8.32 \mathrm{E}-01$ \\
\hline Y-105 & 38E-01 & 8.35E-01 & 35E-01 & $8.35 \mathrm{E}-01$ & $8.38 \mathrm{E}-01$ & $8.35 \mathrm{E}-01$ & $35 \mathrm{E}-01$ & 8.35E-01 & $8 \mathrm{E}-01$ & $.35 \mathrm{E}-01$ & 8.33E-01 \\
\hline & 37E-01 & 8.35E-01 & .35E-01 & 8.35E-01 & 8.37E-01 & 8.35E-01 & $35 \mathrm{E}-01$ & $35 \mathrm{E}-01$ & 7E-01 & .35E-01 & $8.32 \mathrm{E}-01$ \\
\hline & 36E-01 & 8.34E-01 & $.34 \mathrm{E}-01$ & 8.34E-01 & 6E-01 & 8.34E-01 & 4E-01 & $4 \mathrm{E}-01$ & 6E-01 & $34 \mathrm{E}-01$ & $2 \mathrm{E}-01$ \\
\hline & E-01 & 8.36E-01 & 8.36E-01 & 8.36E-01 & E-01 & 8.36E-01 & 6E-01 & $6 \mathrm{E}-01$ & & $36 \mathrm{E}$ & 3E-01 \\
\hline & E-01 & 8.35E-01 & $E-01$ & 8.3 & -01 & 8.35E-01 & E-01 & & & 8.35E-01 & 3E-01 \\
\hline & E-01 & 8.34E-01 & E-01 & 4E-01 & E-01 & 8.34E-01 & E-01 & 01 & -01 & 8.34E-01 & $2 \mathrm{E}-01$ \\
\hline & E-01 & 8.35E-01 & 35E-01 & 8.35E-01 & E-01 & 8.35E-01 & EE-01 & $5 \mathrm{E}-01$ & E-01 & 8.35E-01 & 32E-01 \\
\hline 12 & E-01 & 8.35E-01 & .35E-01 & 8.35E-01 & 7E-01 & 8.35E-01 & 8.35E-01 & 8.35E-01 & 7E-01 & 8.35E-01 & 8.33E-01 \\
\hline 01 & 17E-04 & 1.17E-04 & 17E-04 & .17E-04 & 1.17E-04 & 1.17E-04 & 2.28E-03 & 1.98E-01 & 5.22E-01 & 8.00E-01 & $8.32 \mathrm{E}-01$ \\
\hline & $7 \mathrm{E}-04$ & 17E-04 & 17E-04 & 17E-04 & 17E-04 & $1.17 \mathrm{E}-04$ & $2.28 \mathrm{E}-03$ & $.98 \mathrm{E}-01$ & $23 \mathrm{E}-01$ & $8.00 \mathrm{E}-01$ & 8.33E-01 \\
\hline & 7.E-04 & .17E-04 & 17E-04 & 17E-04 & $.17 \mathrm{E}-04$ & 1.17E-04 & $2.28 \mathrm{E}-03$ & 1.98E-01 & 23E-01 & 8.00E-01 & 8.32E-01 \\
\hline 104 & 17E-04 & 1.17E-04 & $.17 \mathrm{E}-04$ & 1.17E-04 & 1.17E-04 & 1.17E-04 & 2.27E-03 & 1.98E-01 & $2 \mathrm{E}-01$ & 8.00E-01 & $8.32 \mathrm{E}-01$ \\
\hline & $38 \mathrm{E}-04$ & 88E-04 & $4.12 \mathrm{E}-02$ & 4.11E-01 & 7.43E-01 & $8.25 \mathrm{E}-01$ & $8.38 \mathrm{E}-01$ & $8.40 \mathrm{E}-01$ & $43 \mathrm{E}-01$ & $8.40 \mathrm{E}-01$ & $8.38 \mathrm{E}-01$ \\
\hline & 34E-04 & 1.04E-04 & 1.04E-04 & 1.04E-04 & 1.04E-04 & $1.04 \mathrm{E}-04$ & 1.04E-04 & 1E-03 & BE-01 & $6.23 \mathrm{E}-01$ & 7.99E-01 \\
\hline & E-04 & 17E-04 & 7E-04 & 1.17E-04 & E-04 & 1.17E-04 & E-03 & 1.98E-01 & $.22 \mathrm{E}-01$ & 7.99E-01 & 8.32E-01 \\
\hline & -04 & 04E-04 & -04 & -04 & $E-04$ & 1.04E-04 & E-04 & & -01 & $6.23 \mathrm{E}-01$ & $7.98 \mathrm{E}-01$ \\
\hline & & 05E-04 & & & -04 & $E-04$ & $E-04$ & & -03 & $1.99 \mathrm{E}-01$ & $2 \mathrm{E}-01$ \\
\hline & & -04 & & & -04 & 1.1 & -03 & & & $\mathrm{E}-01$ & E-01 \\
\hline & & -04 & -04 & & -04 & 1.1 & $E-03$ & & & E-01 & E-01 \\
\hline & & 17E-04 & & & & & $2.28 \mathrm{E}-03$ & & & $.00 \mathrm{E}-01$ & 8.33E-01 \\
\hline & 12E-06 & 7.40E-06 & 7.40E-06 & $7.40 \mathrm{E}-06$ & $7.42 \mathrm{E}-06$ & 7.40E-06 & $7.40 \mathrm{E}-06$ & $1.28 \mathrm{E}-04$ & 1.41E-02 & $4.42 \mathrm{E}-02$ & $5.67 \mathrm{E}-02$ \\
\hline & 11E-06 & $39 \mathrm{E}-06$ & $39 \mathrm{E}-06$ & 7.39E-06 & 41E-06 & 7.39E-06 & 7.39E-06 & $1.28 \mathrm{E}-04$ & .41E-02 & 4.42E-02 & $5.67 \mathrm{E}-02$ \\
\hline & 41E-06 & 7.39E-06 & 7.39E-06 & 7.39E-06 & 7.41E-06 & 7.39E-06 & 7.39E-06 & 1.28E-04 & $.41 \mathrm{E}-02$ & $4.42 \mathrm{E}-02$ & $5.66 \mathrm{E}-02$ \\
\hline -C-204 & 46E-06 & 7.44E-06 & 7.44E-06 & 7.44E-06 & 7.46E-06 & 7.44E-06 & 7.44E-06 & $7.44 \mathrm{E}-06$ & $.64 \mathrm{E}-04$ & 1.41E-02 & 4.40E-02 \\
\hline & 78E-08 & 1.77E-08 & 1.77E-08 & 1.77E-08 & 2.69E-07 & 8.47E-06 & 5.19E-05 & $3.10 E-04$ & .89E-03 & 1.08E-02 & $5.29 \mathrm{E}-02$ \\
\hline 2 & 79E-08 & 1.78E-08 & 1.78E-08 & 1.78E-08 & 2.70E-07 & 8.50E-06 & 5.21E-05 & E-04 & $E-03$ & 1.08E-02 & $.32 \mathrm{E}-02$ \\
\hline 241-S & $.77 \mathrm{E}-08$ & 1.77E-08 & 1.77E-08 & 1.77E-08 & $2.68 \mathrm{E}-07$ & 8.44E-06 & 5.17E-05 & 3.09E-04 & 1.89E-03 & $1.08 \mathrm{E}-02$ & $5.27 \mathrm{E}-02$ \\
\hline
\end{tabular}




\begin{tabular}{|c|c|c|c|c|c|c|c|c|c|c|c|}
\hline Site & 992 & 93 & 1994 & 95 & 1996 & 7 & 1998 & 1999 & 2000 & 01 & 2002 \\
\hline S-104 & $02 \mathrm{E}+00$ & $96 \mathrm{E}+00$ & $2.92 \mathrm{E}+00$ & $2.89 \mathrm{E}+00$ & $88 \mathrm{E}+00$ & $85 \mathrm{E}+00$ & $84 \mathrm{E}+00$ & $2.83 \mathrm{E}+00$ & $2.83 \mathrm{E}+00$ & $2.82 \mathrm{E}+00$ & $.81 \mathrm{E}+00$ \\
\hline & 78E-08 & 77E-08 & 1.77E-08 & 1.77E-08 & $69 \mathrm{E}-07$ & & & $3.10 \mathrm{E}-04$ & 1.89E-03 & 1.08E-02 & \\
\hline & & & & 77E-08 & 68E-07 & & & & & & \\
\hline & $2 E-08$ & 61E-08 & 61E-08 & 2.37E-07 & 96E-06 & 4.92E-05 & & & & & \\
\hline 241-S-108 & $2 \mathrm{E}-08$ & & & 2.37E-07 & 7.96E-06 & & & $1.79 \mathrm{E}-03$ & 1.05E-02 & & 90E-01 \\
\hline & $2 E-08$ & 1.62E-08 & 1.62E-08 & 2.38E-07 & 98E-06 & & & $1.80 \mathrm{E}-03$ & 1.06E-02 & & 91E-01 \\
\hline $241-S-110$ & $37 \mathrm{E}-08$ & $1.67 \mathrm{E}-08$ & 1.67E-08 & 2.45E-07 & $8.22 \mathrm{E}-06$ & $5.08 \mathrm{E}-05$ & $3.10 \mathrm{E}-04$ & $1.85 \mathrm{E}-03$ & 1.09E-02 & 5.42E-02 & 96E-01 \\
\hline 241-S-111 & 59E-08 & 1.58E-08 & $1.58 \mathrm{E}-08$ & 2.33E-07 & $7.80 \mathrm{E}-06$ & 4.82E-05 & $2.94 \mathrm{E}-04$ & $1.76 \mathrm{E}-03$ & 1.03E-02 & $5 \mathrm{E}-02$ & 86E-01 \\
\hline & 53E-08 & 1.63E-08 & 1.63E-08 & 2.40E-07 & 8.04E-06 & 4.97E-05 & 3.03E-04 & $1 \mathrm{E}-03$ & 1.06E-02 & E-02 & $93 \mathrm{E}-01$ \\
\hline & LEE-08 & 2.10E-08 & 10E-08 & $2.10 \mathrm{E}-08$ & 2.10E-08 & EE-07 & $9.88 \mathrm{E}-06$ & 4E-05 & .63E-04 & 6E-03 & $21 \mathrm{E}-02$ \\
\hline & E-08 & E-08 & E-08 & E-08 & E-08 & E-07 & E-06 & E-05 & 3E-04 & E-03 & 14E-02 \\
\hline & & & & & & & & & & & 14E-02 \\
\hline & & & & & & & & & & & $86 \mathrm{E}-03$ \\
\hline & -08 & 08 & & & -08 & & 07 & $=-06$ & -05 & E-04 & E-03 \\
\hline & -08 & $E-08$ & -08 & $E-08$ & $E-08$ & E-07 & $=-06$ & E-05 & E-04 & E-03 & OE-02 \\
\hline & $33 \mathrm{E}+00$ & $80 \mathrm{E}+00$ & $E+00$ & $1.78 \mathrm{E}+00$ & $1.78 \mathrm{E}+00$ & $E+00$ & $1.76 \mathrm{E}+00$ & $\mathrm{E}+00$ & $1.76 \mathrm{E}+00$ & $E+00$ & $1.75 \mathrm{E}+00$ \\
\hline 108 & $=00$ & $37 \mathrm{E}+00$ & $4.30 \mathrm{E}+00$ & $4.24 \mathrm{E}+00$ & $21 \mathrm{E}+00$ & $E+00$ & $4.14 \mathrm{E}+00$ & $4.13 \mathrm{E}+00$ & $4.13 \mathrm{E}+00$ & $4.11 \mathrm{E}+00$ & $4.09 \mathrm{E}+00$ \\
\hline$X-109$ & $4 \mathrm{E}-05$ & E-04 & E-03 & $1.12 \mathrm{E}-02$ & $71 \mathrm{E}-02$ & EE-01 & $4.65 \mathrm{E}-01$ & 7.06E-01 & $8.45 \mathrm{E}-01$ & 9.02E-01 & $22 \mathrm{E}-01$ \\
\hline$X-110$ & $6 \mathrm{E}-11$ & E-11 & $65 E-11$ & $65 \mathrm{E}-11$ & $4.66 \mathrm{E}-11$ & E-11 & E-11 & E-11 & $4.66 \mathrm{E}-11$ & E-11 & $.63 \mathrm{E}-11$ \\
\hline & $5 \mathrm{E}-06$ & $6.00 \mathrm{E}-05$ & $65 \mathrm{E}-04$ & 16E-03 & $1.25 \mathrm{E}-02$ & E-02 & E-01 & E-01 & $.08 \mathrm{E}-01$ & E-01 & \\
\hline & $6 \mathrm{E}-08$ & E-08 & $E-08$ & $1.56 \mathrm{E}-08$ & E-08 & -08 & $1.56 \mathrm{E}-08$ & E-07 & & 4E-05 & \\
\hline & & +00 & & +00 & +00 & +00 & $1.76 \mathrm{E}+00$ & $E+00$ & $\hat{E}+00$ & $E+00$ & $E+00$ \\
\hline & -11 & $E-11$ & $E-11$ & -11 & $=-11$ & & & E-11 & -06 & -06 & E-05 \\
\hline & r00 & 00 & r00 & 00 & +00 & & 00 & +00 & +00 & +00 & +00 \\
\hline & +00 & +00 & +00 & +00 & +00 & +00 & -00 & +00 & +00 & +00 & $E+00$ \\
\hline & $E+00$ & $E+00$ & $E+00$ & $E+00$ & $0.00 \mathrm{E}+00$ & $E+00$ & $0.00 \mathrm{E}+00$ & $E+00$ & $\mathrm{E}+00$ & $E+00$ & $E+00$ \\
\hline & +00 & $E+00$ & +00 & $E+00$ & $E+00$ & $E+00$ & $E+00$ & $E+00$ & $E+00$ & $E+00$ & $E+00$ \\
\hline & E-02 & $\mathrm{E}-02$ & E-02 & E-02 & 7.09E-03 & $1 \mathrm{E}-03$ & 3E-03 & 1.75E-03 & 1.07E-03 & $6.41 \mathrm{E}-04$ & $3.80 \mathrm{E}-04$ \\
\hline & 3E-01 & 74E-01 & 7.95E-01 & 04E-01 & 09E-01 & 08E-01 & 8.08E-01 & 8.08E-01 & $8.11 \mathrm{E}-01$ & .09E-01 & $.06 \mathrm{E}-01$ \\
\hline 103 & $7 \mathrm{E}-01$ & 9.52E-01 & $9.18 \mathrm{E}-01$ & 91E-01 & $8.72 \mathrm{E}-01$ & 3E-01 & 8.40E-01 & $31 \mathrm{E}-01$ & $26 \mathrm{E}-01$ & 19E-01 & .14E-01 \\
\hline & $4 \mathrm{E}-01$ & $7.22 \mathrm{E}-01$ & 7.75E-01 & 7.97E-01 & 8.07E-01 & 08E-01 & 09E-01 & 10E-01 & $12 \mathrm{E}-01$ & $10 \mathrm{E}-01$ & 08E-01 \\
\hline -T-105 & J3E-01 & 7.21E-01 & .75E-01 & 7.96E-01 & 8.06E-01 & 07E-01 & 8.09E-01 & 8.09E-01 & .11E-01 & $.09 \mathrm{E}-01$ & 8.07E-01 \\
\hline -T-106 & $86 \mathrm{E}+00$ & $5.65 E+00$ & $5.51 \mathrm{E}+00$ & $5.39 \mathrm{E}+00$ & $5.32 \mathrm{E}+00$ & $5.24 \mathrm{E}+00$ & $5.20 \mathrm{E}+00$ & $5.16 \mathrm{E}+00$ & $5.15 \mathrm{E}+00$ & $5.13 E+00$ & $5.10 \mathrm{E}+00$ \\
\hline & 2E-16 & E-16 & E-16 & $=-16$ & E-16 & E-16 & E-16 & $1 \mathrm{E}-16$ & 4.02E-16 & 1E-16 & 4.00E-16 \\
\hline & 24E-01 & E-01 & 7.96E-01 & -01 & 8.09E-01 & E-01 & $\mathrm{E}-01$ & 8.09E-01 & 8.11E-01 & $.09 \mathrm{E}-01$ & 8.07E-01 \\
\hline & 24E-01 & & & E-01 & & E-01 & & DE-01 & $8.12 \mathrm{E}-01$ & $10 \mathrm{E}-01$ & $.07 \mathrm{E}-01$ \\
\hline & $2 E-16$ & & E-16 & -16 & & & & E-16 & $2 \mathrm{E}-16$ & $.01 \mathrm{E}-16$ & $.00 \mathrm{E}-16$ \\
\hline & 24E-01 & 75E-01 & 7.97E-01 & E-01 & 8.10E-01 & 9E-01 & 8.09E-01 & 8.10E-01 & 8.12E-01 & 8.10E-01 & $.08 \mathrm{E}-01$ \\
\hline & 3E-01 & 7.21E-01 & 7.75E-01 & 7.96E-01 & 8.06E-01 & $3.07 \mathrm{E}-01$ & 8.08E-01 & 8.09E-01 & 8.11E-01 & 8.09E-01 & 8.07E-01 \\
\hline & & & & & & & & & $5.51 \mathrm{E}-02$ & & \\
\hline 241-T-202 & 2.13E-05 & $1.25 \mathrm{E}-04$ & $7.11 \mathrm{E}-04$ & $3.46 \mathrm{E}-03$ & 1.24E-02 & $2.81 \mathrm{E}-02$ & $4.27 \mathrm{E}-02$ & $5.12 \mathrm{E}-02$ & 5.51E-02 & 5.64E-02 & \\
\hline
\end{tabular}




\begin{tabular}{|c|c|c|c|c|c|c|c|c|c|c|c|}
\hline Site & 1992 & 1993 & 1994 & 1995 & 1996 & 1997 & 1998 & 1999 & 2000 & 2001 & 2002 \\
\hline $41-\mathrm{T}-203$ & $2.12 \mathrm{E}-05$ & $1.25 \mathrm{E}-04$ & 7.10E-04 & $3.46 \mathrm{E}-03$ & 1.24E-02 & $2.80 \mathrm{E}-02$ & $4.26 \mathrm{E}-02$ & 5.11E-02 & $5.50 \mathrm{E}-02$ & $5.63 \mathrm{E}-02$ & $5.67 \mathrm{E}-02$ \\
\hline & $12 \mathrm{E}-05$ & $.25 \mathrm{E}-04$ & $7.10 \mathrm{E}-04$ & $.46 \mathrm{E}-03$ & 1.24E-02 & $2.80 \mathrm{E}-02$ & 4.26E-02 & $.11 \mathrm{E}-02$ & $.50 \mathrm{E}-02$ & & $5.67 \mathrm{E}-02$ \\
\hline TX-101 & 01E-02 & $76 \mathrm{E}-01$ & 3.96E-01 & $6.02 \mathrm{E}-01$ & 7.24E-01 & 7.75E-01 & 7.96E-01 & 8.04E-01 & & & 8.07E-01 \\
\hline 02 & 05E-02 & 5.06E-02 & 1.77E-01 & $3.96 \mathrm{E}-01$ & $6.03 \mathrm{E}-01$ & 7.21E-01 & 7.75E-01 & 7.96E-01 & 8.06E-01 & 8.07E-01 & 8.06E-01 \\
\hline $1-T X-103$ & 05E-02 & $5.06 \mathrm{E}-02$ & 1.77E-01 & 3.96E-01 & $6.04 \mathrm{E}-01$ & $7.22 \mathrm{E}-01$ & 7.75E-01 & 7.96E-01 & $.07 \mathrm{E}-01$ & $.08 \mathrm{E}-01$ & $8.07 \mathrm{E}-01$ \\
\hline & $.05 E-02$ & 5.06E-02 & 1.77E-01 & 3.96E-01 & 6.04E-01 & 7.22E-01 & 7.75E-01 & 7.96E-01 & 8.07E-01 & $.08 \mathrm{E}-01$ & 8.07E-01 \\
\hline 05 & $.00 \mathrm{E}-04$ & 1.77E-03 & 1.00E-02 & 4.89E-02 & 1.76E-01 & 3.97E-01 & 6.03E-01 & 7.23E-01 & & -01 & 8.03E-01 \\
\hline 6 & $E-04$ & 77E-03 & E-02 & $9 \mathrm{E}-02$ & E-01 & 3.96E-01 & $6.03 \mathrm{E}-01$ & 7.22E-01 & & 96E-01 & $1 \mathrm{E}-01$ \\
\hline & $=+00$ & $1.08 \mathrm{E}+00$ & $E+00$ & E-01 & $=-01$ & 9.03E-01 & 8.78E-01 & $8 \mathrm{E}-01$ & & $8.33 \mathrm{E}-01$ & $3 \mathrm{E}-01$ \\
\hline & E-04 & $.77 \mathrm{E}-03$ & $\mathrm{E}-02$ & $9 \mathrm{E}-02$ & E-01 & 3.96E-01 & 6.03E-01 & $7.22 \mathrm{E}-01$ & E-01 & 7.96E-01 & $2 \mathrm{E}-01$ \\
\hline & $E-02$ & 76E-01 & $\mathrm{E}-01$ & E-01 & $7.24 \mathrm{E}-01$ & 7.75E-01 & 7.96E-01 & 8.04E-01 & $9 \mathrm{E}-01$ & $.08 \mathrm{E}-01$ & 7E-01 \\
\hline & -02 & 76E-01 & $E-01$ & -01 & $E-01$ & 7.76E-01 & 7.97E-01 & 5E-01 & $E-01$ & 8.09E-01 & E-01 \\
\hline-111 & $\mathrm{E}-02$ & $5.06 \mathrm{E}-02$ & 77E-01 & 3.96E-01 & 3E-01 & 7.21E-01 & 7.75E-01 & 7.96E-01 & $6 \mathrm{E}-01$ & 8.07E-01 & $6 \mathrm{E}-01$ \\
\hline 41-TX-112 & 05E-02 & $5.05 \mathrm{E}-02$ & $.76 \mathrm{E}-01$ & 3.95E-01 & $3 \mathrm{E}-01$ & $7.21 \mathrm{E}-01$ & 7.74E-01 & 7.95E-01 & $6 \mathrm{E}-01$ & 8.07E-01 & $6 \mathrm{E}-01$ \\
\hline & 00E-04 & $1.77 \mathrm{E}-03$ & $.00 \mathrm{E}-02$ & 4.89E-02 & $6 \mathrm{E}-01$ & $3.96 \mathrm{E}-01$ & $6.03 \mathrm{E}-01$ & 7.23E-01 & $8 \mathrm{E}-01$ & $.97 \mathrm{E}-01$ & $2 \mathrm{E}-01$ \\
\hline & 00E-04 & $1.77 \mathrm{E}-03$ & 1.00E-02 & 4.89E-02 & 1.76E-01 & 3.96E-01 & $6.03 \mathrm{E}-01$ & 7.22E-01 & $8 \mathrm{E}-01$ & 96E-01 & 02E-01 \\
\hline & $0 \mathrm{E}-04$ & $1.77 \mathrm{E}-03$ & $0 \mathrm{E}-02$ & $4.89 \mathrm{E}-02$ & $6 \mathrm{E}-01$ & 3.97E-01 & 6.03E-01 & 7.23E-01 & 8E-01 & 7.97E-01 & E-01 \\
\hline & & $1.77 \mathrm{E}-03$ & $E-02$ & & & E-01 & & & & & E-01 \\
\hline & -04 & $1.77 \mathrm{E}-03$ & E-02 & E-02 & $E-01$ & 3.96E-01 & E-01 & & & E-01 & 2E-01 \\
\hline & $E-04$ & $1.77 \mathrm{E}-03$ & $E-02$ & $\mathrm{E}-02$ & $E-01$ & 3.96E-01 & $\mathrm{E}-01$ & 7.2. & & $6 \mathrm{E}-01$ & $2 \mathrm{E}-01$ \\
\hline & $E-05$ & $3.12 \mathrm{E}-04$ & E-03 & $\mathrm{E}-02$ & E-02 & 1.76E-01 & 3.96E-01 & LE-01 & -01 & 7.74E-01 & $3 \mathrm{E}-01$ \\
\hline & E-05 & $3.12 \mathrm{E}-04$ & E-03 & 2E-02 & 5.01E-02 & 1.76E-01 & 3.96E-01 & $1 \mathrm{E}-01$ & E-01 & 7.74E-01 & $3 \mathrm{E}-01$ \\
\hline 103 & $2 \mathrm{E}-01$ & $8.68 \mathrm{E}-01$ & $.52 \mathrm{E}-01$ & 40E-01 & 8.33E-01 & $8.24 \mathrm{E}-01$ & 8.19E-01 & 8.16E-01 & 8.16E-01 & $8.12 \mathrm{E}-01$ & 8.09E-01 \\
\hline & $E-01$ & $6.73 \mathrm{E}-01$ & $\mathrm{E}-01$ & $7.88 \mathrm{E}-01$ & 8.03E-01 & 8.06E-01 & 8.08E-01 & 8.09E-01 & 8.11E-01 & $8.09 \mathrm{E}-01$ & $7 \mathrm{E}-01$ \\
\hline 105 & $56 \mathrm{E}+00$ & $1.56 \mathrm{E}+00$ & $1.56 \mathrm{E}+00$ & $1.56 \mathrm{E}+00$ & $1.57 \mathrm{E}+00$ & $1.56 \mathrm{E}+00$ & $1.56 \mathrm{E}+00$ & $1.56 \mathrm{E}+00$ & $1.57 \mathrm{E}+00$ & $1.56 \mathrm{E}+00$ & $1.56 \mathrm{E}+00$ \\
\hline-106 & 78E-01 & 8.76E-01 & 8.76E-01 & $8.76 \mathrm{E}-01$ & $8.78 \mathrm{E}-01$ & 8.76E-01 & 8.76E-01 & 8.76E-01 & $8.78 \mathrm{E}-01$ & 8.76E-01 & 8.73E-01 \\
\hline & $29 E-04$ & $1.96 \mathrm{E}-03$ & 1.11E-02 & $5.43 \mathrm{E}-02$ & 1.97E-01 & $4.50 \mathrm{E}-01$ & 6.94E-01 & 8.39E-01 & 9.06E-01 & $9.29 \mathrm{E}-01$ & $36 \mathrm{E}-01$ \\
\hline & 39E-04 & $2.01 \mathrm{E}-03$ & $\mathrm{E}-02$ & 5.59E-02 & EE-01 & 4.64E-01 & E-01 & 3E-01 & $E-01$ & $56 \mathrm{E}-01$ & $4 \mathrm{E}-01$ \\
\hline & 2 E-05 & $3.18 \mathrm{E}-04$ & 1.92E-03 & 1.10E-02 & 3E-02 & 2.03E-01 & 4.71E-01 & 7.27E-01 & 8.81E-01 & $9.46 \mathrm{E}-01$ & $9 \mathrm{E}-01$ \\
\hline & +00 & $5.86 \mathrm{E}+00$ & $5.86 \mathrm{E}+00$ & $\mathrm{E}+00$ & +00 & $E+00$ & $\mathrm{E}+00$ & $E+00$ & +00 & $5.85 \mathrm{E}+00$ & $E+00$ \\
\hline & & 3.15E-04 & $E-03$ & -02 & & & E-01 & & & 9.37E-01 & E-01 \\
\hline & & 5.21 & & -03 & & -02 & 2.0 & & & $=-01$ & $E-01$ \\
\hline & & & -04 & & -02 & $E-02$ & -01 & & & -01 & $E-01$ \\
\hline & & & & & & & & & & EE-01 & E-01 \\
\hline & E-07 & 8.71E-06 & 5.36E-05 & DE-04 & $1.95 \mathrm{E}-03$ & 1.11E-02 & $5.52 \mathrm{E}-02$ & 1.99E-01 & 4.62E-01 & 7.10E-01 & $8.56 \mathrm{E}-01$ \\
\hline & $43 \mathrm{E}+00$ & $1.35 \mathrm{E}+00$ & $1.28 \mathrm{E}+00$ & $1.22 \mathrm{E}+00$ & $1.17 \mathrm{E}+00$ & $1.12 \mathrm{E}+00$ & $1.08 \mathrm{E}+00$ & $1.05 \mathrm{E}+00$ & $1.03 E+00$ & $1.00 \mathrm{E}+00$ & $9.81 \mathrm{E}-01$ \\
\hline & 77E-05 & 3.09E-04 & $1.87 \mathrm{E}-03$ & $1.07 \mathrm{E}-02$ & $5.42 \mathrm{E}-02$ & 1.97E-01 & 4.57E-01 & 7.07E-01 & 8.56E-01 & 9.19E-01 & $9.42 \mathrm{E}-01$ \\
\hline & $.13 \mathrm{E}+00$ & $1.09 E+00$ & $1.07 E+00$ & $1.05 E+00$ & $1.04 \mathrm{E}+00$ & $1.02 \mathrm{E}+00$ & $1.01 \mathrm{E}+00$ & $1.00 \mathrm{E}+00$ & $1.00 \mathrm{E}+00$ & 9.95E-01 & $9.89 \mathrm{E}-01$ \\
\hline & 75E-09 & 1.75E-09 & 1.75E-09 & 1.75E-09 & 1.75E-09 & 75E-09 & 1.75E-09 & 2.74E-08 & 8.98E-07 & 5.53E-06 & 3.32E-05 \\
\hline & 1.73E-09 & $1.72 \mathrm{E}-09$ & 1.72E-09 & 72E-09 & 1.73E-09 & 1.72E-09 & 1.72E-09 & 2.70E-08 & 4E-07 & $5.44 \mathrm{E}-06$ & 3.27E-05 \\
\hline $41-U-$ & 1.73E-09 & 1.72E-09 & 1.72E-09 & 1.72E-09 & $1.73 \mathrm{E}-09$ & 1.72E-09 & 1.72E-09 & $2.70 \mathrm{E}-08$ & 8.84E-07 & 5.44E-06 & $3.27 \mathrm{E}-0$ \\
\hline
\end{tabular}




\begin{tabular}{|c|c|c|c|c|c|c|c|c|c|c|c|}
\hline Site & 1992 & 1993 & 1994 & 1995 & 1996 & 1997 & 1998 & 1999 & 2000 & 2001 & 200 \\
\hline 241-U-204 & 00E-09 & $.00 \mathrm{E}-09$ & $2.00 \mathrm{E}-09$ & $2.00 \mathrm{E}-09$ & $.00 \mathrm{E}-09$ & $2.97 \mathrm{E}-08$ & 9.41E-07 & $5.66 \mathrm{E}-06$ & $3.46 \mathrm{E}-05$ & $2.06 \mathrm{E}-04$ & \\
\hline & $3 E+01$ & $25 E+01$ & $3.25 E+01$ & $49 \mathrm{E}+01$ & $69 \mathrm{E}+01$ & $1.68 \mathrm{E}+01$ & $1.68 \mathrm{E}+01$ & & & & \\
\hline $316-1$ & $5 E+03$ & $55 E+03$ & $55 E+03$ & $1.55 E+03$ & $55 \mathrm{E}+03$ & $55 E+03$ & $15 E+03$ & $0 \mathrm{E}+03$ & & & \\
\hline & $5 E+03$ & $34 \mathrm{E}+03$ & $3.84 \mathrm{E}+03$ & $3.84 E+03$ & $85 E+03$ & $64 \mathrm{E}+03$ & $55 \mathrm{E}+03$ & $.46 \mathrm{E}+03$ & $3.31 \mathrm{E}+03$ & $9 \mathrm{E}+03$ & \\
\hline & $59 \mathrm{E}+02$ & $59 \mathrm{E}+02$ & $1.59 \mathrm{E}+02$ & $1.52 \mathrm{E}+02$ & $50 \mathrm{E}+02$ & $49 \mathrm{E}+02$ & $49 \mathrm{E}+02$ & $1.49 \mathrm{E}+02$ & $1.44 \mathrm{E}+02$ & & $.33 \mathrm{E}+02$ \\
\hline & $30 E+04$ & $80 \mathrm{E}+04$ & $1.61 \mathrm{E}+04$ & $1.21 \mathrm{E}+04$ & $22 \mathrm{E}+04$ & $21 E+04$ & $13 E+04$ & $1.00 E+04$ & $8.98 \mathrm{E}+03$ & & $5 \mathrm{E}+03$ \\
\hline & $0 \mathrm{E}+00$ & $00 \mathrm{E}+00$ & $0.00 \mathrm{E}+00$ & $0.00 E+00$ & $00 \mathrm{E}+00$ & $00 \mathrm{E}+00$ & $00 \mathrm{E}+00$ & $0.00 E+00$ & $0.00 \mathrm{E}+00$ & & $0 \mathrm{E}+00$ \\
\hline & 24E-09 & .23E-09 & 4.23E-09 & $4.23 \mathrm{E}-09$ & 4.24E-09 & $82 \mathrm{E}+03$ & $02 \mathrm{E}+05$ & $9 \mathrm{E}+04$ & $\mathrm{E}+04$ & $E+03$ & $8 \mathrm{E}+03$ \\
\hline & $E+03$ & $39 \mathrm{E}+03$ & $E+03$ & $E+03$ & $E+03$ & $\mathrm{E}+03$ & $E+03$ & $E+03$ & & & $\mathrm{E}+03$ \\
\hline & +00 & $E+00$ & $=+00$ & & $E+00$ & $E+00$ & $E+00$ & & & & +00 \\
\hline L & +00 & $=00$ & $=00$ & & & $E+00$ & $E+00$ & & & & +00 \\
\hline$|L A|$ & +00 & $=00$ & +00 & 00 & +00 & $E+00$ & $=00$ & & & & $E+00$ \\
\hline RMWS & $=00$ & $E+00$ & $=00$ & +00 & $E+00$ & $E+00$ & $E+00$ & +00 & & & $E+00$ \\
\hline UPR-1 & +01 & $=01$ & +01 & +01 & +01 & $E+01$ & $=01$ & & & & +01 \\
\hline UPR-1 & $E-02$ & $E-02$ & -02 & & $E-02$ & E-02 & $E-02$ & -02 & & & -02 \\
\hline UPR-10 & $63 E+00$ & $3.62 \mathrm{E}+00$ & $3.62 \mathrm{E}+00$ & $E+00$ & $63 E+00$ & $61 E+00$ & $1 E+00$ & $\mathrm{E}+00$ & $=00$ & $E+00$ & +00 \\
\hline UPR-10C & $20 \mathrm{E}-02$ & $6.18 \mathrm{E}-02$ & $6.18 \mathrm{E}-02$ & 6.16E-02 & $6.15 \mathrm{E}-02$ & 6.14E-02 & $6.14 \mathrm{E}-02$ & $6.14 \mathrm{E}-02$ & & & \\
\hline UPR-2 & & $88 \mathrm{E}-02$ & & & & & & & & & \\
\hline UPR-2 & & & & & & & & & & & \\
\hline & & & & & & & & & & & \\
\hline UPF & & & & & & & & & & & \\
\hline UPR & & & & & & & & & & & \\
\hline UPR-2 & $E-02$ & $E-02$ & $\mathrm{E}-02$ & & $E-02$ & $E-02$ & E-02 & & & & -02 \\
\hline UPR-2 & $=00$ & +00 & $E+00$ & & $E+00$ & $\mathrm{E}+00$ & $E+00$ & +00 & $E+00$ & $E+00$ & $\mathrm{E}+00$ \\
\hline UPR-2 & +00 & $E+00$ & +00 & & +00 & $\mathrm{E}+00$ & $E+00$ & & $E+00$ & $\mathrm{E}+00$ & +00 \\
\hline UPR-2 & $=-06$ & $3 \mathrm{E}-06$ & E-06 & $E-06$ & $1.24 \mathrm{E}-06$ & 1.23E-06 & $23 \mathrm{E}-06$ & E-06 & $3.38 \mathrm{E}-05$ & 3.37E-05 & 08E-05 \\
\hline UPR-2 & $E+00$ & $E+00$ & $E+00$ & +00 & $E+00$ & $\mathrm{E}+00$ & $\mathrm{E}+00$ & $=+00$ & $0 \mathrm{E}+00$ & $\mathrm{E}+00$ & $0 \mathrm{E}+00$ \\
\hline UPR-20 & DOE+00 & $00 \mathrm{E}+00$ & $E+00$ & +00 & $E+00$ & $.00 E+00$ & $E+00$ & +00 & $E+00$ & $\mathrm{E}+00$ & $E+00$ \\
\hline UPR-20 & $7 \mathrm{E}-02$ & $\mathrm{E}-02$ & $\mathrm{E}-02$ & $E-02$ & E-02 & $7 \mathrm{E}-02$ & $\mathrm{E}-02$ & $E-02$ & E-02 & E-02 & $1 \mathrm{E}-02$ \\
\hline UPR-2C & $0 \mathrm{E}+00$ & DOE+00 & $00 \mathrm{E}+00$ & +00 & DOE +00 & $0 E+00$ & $\mathrm{E}+00$ & $E+00$ & $\mathrm{E}+00$ & $\mathrm{E}+00$ & $00 \mathrm{E}+00$ \\
\hline UPR-2 & & $E+00$ & $E+00$ & & & & & & & & \\
\hline UPR-20C & & $.16 \mathrm{E}-02$ & $5.16 \mathrm{E}-02$ & -02 & E-02 & E-02 & $\mathrm{E}-02$ & & $E-02$ & E-02 & $6 \mathrm{E}-02$ \\
\hline UPR-20 & +00 & $\mathrm{E}+00$ & $E+00$ & & +00 & $=00$ & $=+00$ & & +00 & +00 & \\
\hline UPR-2C & & & & & & & & & & & \\
\hline UPR-20 & & & $E-02$ & & & & & & & $E-02$ & \\
\hline UPR-20 & +00 & $\mathrm{E}+00$ & & & & $0.00 \mathrm{E}+00$ & & & & $\mathrm{DE}+00$ & \\
\hline & & & & & & & & & & & \\
\hline UPR-20 & $E-02$ & BE-02 & $3 \mathrm{E}-02$ & & $5 \mathrm{E}-02$ & $.83 \mathrm{E}-02$ & 5.83E-02 & $E-02$ & & $.71 \mathrm{E}-02$ & $.55 \mathrm{E}-02$ \\
\hline $\mathrm{SR}-200$ & & BE-06 & $4 \mathrm{E}-06$ & & & $.13 \mathrm{E}-05$ & & & & $5 \mathrm{E}-04$ & $.95 \mathrm{E}-04$ \\
\hline תח חר & & & & & & & & & & 03 & $97 \mathrm{E}-03$ \\
\hline UPR-200-E-75 & 7.85E-03 & 7.83E-03 & 7.83E-03 & & $7.85 \mathrm{E}-03$ & & & & $2.71 \mathrm{E}-01$ & $2.70 \mathrm{E}-01$ & $1.76 \mathrm{E}-01$ \\
\hline
\end{tabular}




\begin{tabular}{|c|c|c|c|c|c|c|c|c|c|c|c|}
\hline Site & 1992 & 1993 & 1994 & 1995 & 1996 & & & & 2000 & & \\
\hline JPR-200-E-77 & 74E-04 & $1.73 \mathrm{E}-04$ & 73E-04 & .73E-04 & 1.74E-04 & 1.98E-04 & $2.08 \mathrm{E}-04$ & $.08 \mathrm{E}-04$ & & & \\
\hline & 67E-04 & $67 \mathrm{E}-04$ & $67 \mathrm{E}-04$ & $67 \mathrm{E}-04$ & & & & & & & $1.08 \mathrm{E}-02$ \\
\hline PR-200-E-79 & $4 \mathrm{E}+00$ & $03 \mathrm{E}+00$ & $03 E+00$ & $03 \mathrm{E}+00$ & $04 \mathrm{E}+00$ & & $.03 E+00$ & $1.03 E+00$ & & & $0 \mathrm{E}+00$ \\
\hline PR-200-E-80 & 37E-01 & $34 \mathrm{E}-01$ & 8.34E-01 & 8.34E-01 & $.37 \mathrm{E}-01$ & $.55 \mathrm{E}-01$ & $1.00 \mathrm{E}+00$ & $1.00 \mathrm{E}+00$ & & & $0 \mathrm{E}+01$ \\
\hline PR-20 & $80 \mathrm{E}+00$ & $1.80 \mathrm{E}+00$ & $.71 \mathrm{E}+00$ & $47 \mathrm{E}+00$ & $48 \mathrm{E}+00$ & $47 \mathrm{E}+00$ & $1.47 \mathrm{E}+00$ & $1.47 \mathrm{E}+00$ & & & $\mathrm{E}+00$ \\
\hline PR-20 & 07E-01 & 2.07E-01 & 1.72E-01 & 1.34E-01 & L.34E-01 & & 4E-01 & $3 \mathrm{E}-01$ & & & $\mathrm{E}-02$ \\
\hline PR-2 & & & & & & & & & & & \\
\hline UPR-2C & & & & & & & & & & & \\
\hline UPR-2C & & & & & & & & & & & \\
\hline UPR-2C & $E-02$ & $=-02$ & $E-02$ & & E-02 & 02 & E-02 & & & & \\
\hline UPR-20 & -02 & 26E-02 & $\mathrm{E}-02$ & $\mathrm{E}-02$ & E-02 & 02 & E-02 & 02 & +00 & 01 & EE-01 \\
\hline UPR-20 & & 03 & -03 & & E-03 & 03 & $E-03$ & & E-02 & & \\
\hline UPR-20C & $E+00$ & 1.97 & $97 \mathrm{E}+00$ & $E+00$ & $E+00$ & $E+00$ & $E+00$ & $E+00$ & & & \\
\hline UPR-200-W-101 & $4.43 \mathrm{E}-02$ & 4.42E-02 & $4.42 \mathrm{E}-02$ & EE-02 & $3 \mathrm{E}-02$ & 4.42E-02 & $4.42 \mathrm{E}-02$ & & $E+00$ & $.21 \mathrm{E}+00$ & $E+00$ \\
\hline UPR-20 & E-05 & $3.89 \mathrm{E}-05$ & E-05 & & E-04 & $\mathrm{E}-04$ & E-04 & & & & LE-03 \\
\hline PR-20 & $55 \mathrm{E}+03$ & $2.54 \mathrm{E}+03$ & $2.54 \mathrm{E}+03$ & $E+03$ & $E+03$ & $54 \mathrm{E}+03$ & $E+03$ & & & & $\mathrm{E}+03$ \\
\hline $\mathrm{V}-115$ & E-07 & 3.10E-07 & DE-07 & & & & & & & & $\mathrm{E}-04$ \\
\hline PR-2 & & & & & & & & & & & $E-02$ \\
\hline $\mathrm{R}-2 \mathrm{C}$ & & -10 & & & & & & & & & $E-07$ \\
\hline UPR-20 & -01 & $\mathrm{E}-01$ & & & & & & & & & $\mathrm{E}-01$ \\
\hline UPR-2C & -07 & $=-07$ & & & & & & & -04 & LE-04 & E-05 \\
\hline PR-20 & $E-01$ & $E-01$ & E-01 & & E-01 & E-01 & E-01 & & $E+01$ & $E+01$ & $E+01$ \\
\hline UPR-20 & $E-03$ & 2.13 & E-03 & & E-03 & 13E-03 & E-03 & E-03 & E-02 & 83E-02 & 7E-02 \\
\hline UPR-20 & -03 & -03 & & & $E-03$ & & & & & E-01 & EE-01 \\
\hline PR-20 & $E-02$ & $=-02$ & $E-02$ & -02 & -02 & -02 & -02 & & -02 & $E-02$ & $5 \mathrm{E}-02$ \\
\hline UPR-20 & $E-04$ & $6 \mathrm{E}-04$ & $E-04$ & -04 & $E-04$ & E-04 & $E-04$ & -04 & $E-03$ & E-03 & E-03 \\
\hline UPR-2C & $E-01$ & $E-01$ & -01 & -01 & $E-01$ & $E-01$ & -01 & -01 & +01 & $2 \mathrm{E}+01$ & $E+01$ \\
\hline UPR-2C & -03 & -03 & -03 & -03 & & & -03 & & & & \\
\hline UPR-2 & & -01 & & & & E-01 & & & +01 & $E+01$ & $E+01$ \\
\hline UPR-20 & & & & & & & & & & & -02 \\
\hline UPR-20 & & & & & & & & & & & \\
\hline UPR-20 & & & & & & & & & & & \\
\hline UPR-20 & & & & & & & & & & & \\
\hline PR-20 & & & & & & & & & $E+01$ & $.44 \mathrm{E}+01$ & $E+01$ \\
\hline R-20 & $4 \mathrm{E}+01$ & $1.84 \mathrm{E}+01$ & +01 & & $\mathrm{E}+01$ & $84 \mathrm{E}+01$ & $E+01$ & $E+01$ & $E+02$ & $4.25 \mathrm{E}+02$ & $.96 \mathrm{E}+02$ \\
\hline DR-20 & E-01 & $6 \mathrm{E}-01$ & & & 3E-01 & .46E-01 & E-01 & $4.46 \mathrm{E}-01$ & $E+00$ & $4.46 \mathrm{E}+00$ & $.88 \mathrm{E}+00$ \\
\hline DR-20C & $44 E+01$ & $2.64 \mathrm{E}+01$ & $64 \mathrm{E}+01$ & $64 \mathrm{E}+01$ & $64 E+01$ & $2.64 \mathrm{E}+01$ & $4 \mathrm{E}+01$ & $2.64 \mathrm{E}+01$ & $3 E+01$ & $4.92 \mathrm{E}+01$ & $1.78 \mathrm{E}+01$ \\
\hline PR-20C & 58E-02 & $5.56 \mathrm{E}-02$ & $5.56 \mathrm{E}-02$ & 5.56E-02 & $5.58 \mathrm{E}-02$ & $5.54 \mathrm{E}-02$ & 5.30E-02 & $5.30 \mathrm{E}-02$ & $4.51 \mathrm{E}-02$ & $4.49 \mathrm{E}-02$ & $9 \mathrm{E}-02$ \\
\hline R-20 & 30E-03 & 30E-03 & 0E-03 & E-03 & 30E-03 & 30E-03 & OE-03 & 0E-03 & OE-02 & 58E-02 & $5.70 \mathrm{E}-02$ \\
\hline R-20 & & 30E-02 & $E-02$ & & & & & & & $E-02$ & $=-02$ \\
\hline & & $\mathrm{E}-01$ & $6.04 \mathrm{E}-01$ & $6.04 \mathrm{E}-01$ & $6.06 \mathrm{E}-01$ & $6.04 \mathrm{E}-01$ & 6.04E-01 & $6.04 \mathrm{E}-01$ & $5.62 E+00$ & $5.60 \mathrm{E}+00$ & $3.50 \mathrm{C}+\mathrm{U}$ \\
\hline
\end{tabular}




\begin{tabular}{|c|c|c|c|c|c|c|c|c|c|c|c|}
\hline Site & 1992 & 1993 & 1994 & 1995 & 1996 & 1997 & 1998 & 1999 & 2000 & 2001 & 2002 \\
\hline UPR-200-W-39 & 40E-02 & $38 \mathrm{E}-02$ & $9.38 \mathrm{E}-02$ & $9.38 \mathrm{E}-02$ & $9.40 \mathrm{E}-02$ & $9.38 \mathrm{E}-02$ & $9.38 \mathrm{E}-02$ & $9.38 \mathrm{E}-02$ & $8.19 \mathrm{E}-01$ & 8.17E-01 & 7.09E-01 \\
\hline UPR-200-W-49 & 14E-02 & $55 \mathrm{E}-02$ & $2.55 \mathrm{E}-02$ & $2.55 \mathrm{E}-02$ & $2.55 \mathrm{E}-02$ & $2.55 \mathrm{E}-02$ & $2.55 \mathrm{E}-02$ & $2.55 \mathrm{E}-02$ & $5.44 \mathrm{E}-01$ & & $76 \mathrm{E}-01$ \\
\hline UPR-2 & 49E-02 & 4.47E-02 & $4.47 \mathrm{E}-02$ & $4.47 \mathrm{E}-02$ & 4.49E-02 & 4.4 & $4.47 \mathrm{E}$ & $4.47 \mathrm{E}-02$ & $4.18 \mathrm{E}-02$ & & $=-02$ \\
\hline UPR- & 42E-03 & $6.46 \mathrm{E}-03$ & 6.46E-03 & $6.46 \mathrm{E}-03$ & $6.47 \mathrm{E}-03$ & E-03 & $6.46 \mathrm{E}-03$ & 6.46E-03 & $E-01$ & & $E-01$ \\
\hline UPR- & $84 \mathrm{E}+00$ & $1.84 \mathrm{E}+00$ & $1.84 \mathrm{E}+00$ & $1.84 \mathrm{E}+00$ & $1.84 \mathrm{E}+00$ & $1.84 \mathrm{E}+00$ & $1.84 \mathrm{E}+00$ & $1.94 \mathrm{E}+00$ & $3.28 \mathrm{E}+01$ & $3.27 \mathrm{E}+01$ & 01 \\
\hline UPR & $=-03$ & E-03 & E-03 & E-03 & & & & & & & $\mathrm{E}-02$ \\
\hline & & & & E-04 & & & & 04 & & & $58 \mathrm{E}-02$ \\
\hline UPR-2 & -10 & -10 & & & & & & $\mathrm{E}-10$ & & & $5.16 \mathrm{E}-08$ \\
\hline UPR-2 & -10 & $=-10$ & E-07 & $E-07$ & & & & E-07 & 05 & 05 & $3.36 \mathrm{E}-05$ \\
\hline UPR-2 & E-01 & $E-01$ & $4.80 \mathrm{E}-01$ & $E-01$ & $E-01$ & $\mathrm{E}-01$ & 7.05E-01 & E-01 & $E+01$ & $1.00 \mathrm{E}+01$ & $8.87 \mathrm{E}+00$ \\
\hline UPR-2 & $E-04$ & 3.62E-04 & $3.62 \mathrm{E}-04$ & 3.62E-04 & 3E-04 & $3.62 \mathrm{E}-04$ & $3.62 \mathrm{E}-04$ & 3.62E-04 & E-02 & 3.62E-02 & $3.13 \mathrm{E}-02$ \\
\hline UPR-20 & |3E-02 & 13E-02 & 1.13E-02 & E-02 & 13E-02 & 1.13E-02 & 1.13E-02 & 1.13E-02 & 5.68E-02 & 5.67E-02 & $5.44 \mathrm{E}-02$ \\
\hline R-20 & 50E-02 & 50E-02 & 1.60E-02 & 60E-02 & 01E-02 & $2.16 \mathrm{E}-02$ & $2.16 \mathrm{E}-02$ & $2.16 \mathrm{E}-02$ & $3.53 \mathrm{E}-02$ & $3.52 \mathrm{E}-02$ & $3.05 \mathrm{E}-02$ \\
\hline UPR-300-4 & $88 \mathrm{E}+01$ & $3.87 \mathrm{E}+01$ & $3.87 \mathrm{E}+01$ & $3.87 \mathrm{E}+01$ & $3.88 \mathrm{E}+01$ & $3.81 \mathrm{E}+01$ & $3.81 \mathrm{E}+01$ & $3.81 \mathrm{E}+01$ & $3.75 \mathrm{E}+01$ & $3.74 \mathrm{E}+01$ & $3.16 \mathrm{E}+01$ \\
\hline US_Ecology & $0.00 \mathrm{E}+00$ & $0.00 \mathrm{E}+00$ & $0.00 \mathrm{E}+00$ & $0.00 \mathrm{E}+00$ & $0.00 \mathrm{E}+00$ & $0.00 \mathrm{E}+00$ & $0.00 \mathrm{E}+00$ & $0.00 \mathrm{E}+00$ & $0.00 \mathrm{E}+00$ & $0.00 \mathrm{E}+00$ & $0.00 \mathrm{E}+00$ \\
\hline
\end{tabular}


bndbot_CA 
ncols $\quad 389$

nrows $\quad 437$

xllcorner 545925

yllcorner 100925

cellsize $\quad 150$

NODATA_value -9999

99.99122619629103 .0477981567106 .1659011841109 .3452987671112 .5878982544

115.8335037231119 .1158981323122 .4050979614125 .7238006592129 .0509033203

132.403793335135 .7653961182139 .1497955322142 .5428924561145 .9564971924

149.378692627152 .8197937012156 .2696990967159 .7368927002163 .213104248

166.7055969238170 .2071075439173 .7241973877177 .25050354180 .7919006348

184.3426971436187 .9084014893191 .483795166195 .0744018555198 .6748962402

202.2911987305 205.9178009033209.5612030029 213.2151031494216.887298584

220.5704040527224 .2734069824227 .9877929688231 .7241973877235 .4723052979

239.2449035645 243.0299072266246 .8421020508250 .6672973633254 .5227966309

258.3919067383262 .2951049805266 .2124023438270 .1677856445274 .138092041

278.1506958008282 .179107666286 .254486084290 .3465881348294 .4906005859

298.6523132324302 .8711853027307 .1088867188311 .4093017578315 .7297058105

320.1184082031324 .5284118652329 .012512207333 .5191955566338 .1059875488

342.717010498347 .4140014648352 .1365966797356 .9512023926361 .7932128906

366.7330932617371 .7020874023376 .7749938965381 .878692627387 .092010498 392.3382873535397 .6994018555403 .095703125408 .6122131348414 .1659851074

419.8445129395425 .5628967285431 .4100036621437 .2992858887443 .3204956055 449.3858032227455 .5864868164461 .8327026367468 .2197875977474 .6538085938 481.2388000488487 .8729858398494 .6738891602501 .5285949707508 .5690002441 515.6702270508522 .9744873047530 .3477172852537 .9354858398545 .5994262695 553.4829711914561 .448425293569 .6345825195577 .9083862305586 .4041748047 594.9937133789603 .8079223633612 .7235717773621 .8676147461631 .1220092773 640.6071166992650 .2130126953660 .0476074219670 .0142211914680 .2009887695 690.5311889648701 .0654296875711 .7545776367722 .621887207733 .6561279297 744.8311157227756 .1848754883767 .6287841797779 .2620849609790 .9196777344 802.7755737305814 .5739135742826 .5762939453838 .4221801758850 .4749145508 862.2556152344874 .2434082031885 .8239746094897 .6301879883908 .8311157227 920.2036132812930 .7899780273941 .5454101562951 .3438110352961 .2739257812 970.0784301758978 .9683227539986 .5941162109994 .25347900391000 .554016113 1006.8400268551011 .7109985351016 .5310058591019 .8939819341023 .192993164 1024.9689941411026 .6870117191026 .7679443361026 .8120117191025 .052978516 1023.283020021019 .5130004881015 .7440185551009 .7819824221003 .793029785 995.4575195312987 .0294799805976 .1588134766965 .0908813477951 .5662841797 937.7318725586921 .5377197266904 .9271850586886 .2033081055866 .9705810547 846.0480957031824 .5424804688801 .9398193359778 .6984863281755 .05078125 730.7340698242706 .6759033203681 .9423828125657 .9887695312633 .3804931641 609.8541259766585 .7114868164562 .733215332539 .1870117188516 .7294921875 493.7590942383471 .7301025391449 .2367858887427 .571105957405 .495300293 384.2474975586362 .6448059082342 .0202026367321 .1015930176301 .4458007812 281.5546875263 .2901000977244 .846206665228 .3874969482211 .8045043945 
197.4797973633183 .0841064453171 .0814971924159 .0621032715149 .4151000977 139.7938995361132 .3903045654125 .0428009033119 .6493988037114 .3244018555 110.592300415106 .9233016968104 .3923034668101 .9066009521100 .0260009766 98.1701736450296 .3606872558694 .5673065185592 .3201904296990 .09049987793 87.0585632324284 .049667358480 .0961608886776 .1537780761771 .32495117188 66.4790573120160 .9361495971755 .3337287902849 .2678718566943 .1102104187 36.6814193725630 .1549491882323 .4774703979516 .687559127819 .835877418518 $2.873790025711-4.05509281158-11.0827598572-17.9501094818-24.9365196228$ $-31.5464801788-38.2313804626-44.2858390808-50.3932609558-55.6049880981$ $-60.8479614258-64.9250488281-69.0006713867-71.6436080933-74.2450332642$ $-75.1661529541-76.0116424561-74.9846115112-73.8533630371-70.736000061$ $-67.4945373535-62.243019104-56.8489494324-49.5145492554-42.0171318054$ -32.7371406555 -23.2688903809-12.2487001419-1.01153600216 11.49594020844 24.2491092681937 .9647483825751 .9512405395566 .5892181396581 .51734924316 96.80020904541112 .3861999512128 .0558929443144 .0372924805159 .8601989746 175.99659729191 .7373046875207 .7516021729223 .1869049072238 .8903961182 253.8867950439269 .1359863281283 .5852966309298 .2691040039312 .0905151367 326.1267089844339 .2619018555352 .5921020508365 .0026855469377 .5881958008 389.2517089844401 .0710144043411 .979095459423 .0242919922433 .1796875 443.4549865723452 .8700866699462 .3890991211471 .0841064453479 .8684997559 487.8700866699495 .9478149414503 .2874145508510 .6917114258517 .405090332 524.1726074219530 .2977905273536 .4683227539542 .0452270508547 .6597290039 552.7290039062557 .829284668562 .4312744141567 .0590209961571 .232421875 575.4268798828579 .208190918583 .0067138672586 .4291992188589 .8651733398 592.9595947266596 .0637817383598 .8588256836601 .6599731445604 .1832885742 606.7105102539608 .9907836914611 .2730712891613 .3383789062615 .4047851562 617.2816162109619 .1588134766620 .870300293622 .5817260742624 .1477050781 625.7127075195627 .1500244141628 .5856933594629 .9091186523631 .2301025391 632.453125633 .6732788086634 .8087158203635 .9409179688637 .0006713867 638.0568847656639 .0524291992640 .0438842773640 .9852294922641 .9227294922 642.8193969727643 .7122192383644 .5728149414645 .4293823242646 .2617797852 647.0900878906647 .901184082648 .7083129883649 .5043945312650 .2965698242 651.0833129883651 .866027832652 .6480712891653 .4265136719654 .2083129883 654.9865722656655 .7716064453656 .5532836914657 .3447265625658 .1329956055 658.9332275391659 .7302246094660 .5411987305661 .3491210938662 .1721801758 662.9923095703663 .8292236328664 .6630249023665 .5150146484666 .3635253906 667.2322998047668 .0966796875668 .9846191406669 .8643798828670 .7763061523 671.6715698242672 .6245727539673 .6121826172674 .6171264648 97.9592666626101 .0150985718104 .1195983887107 .2656021118110 .4726028442 113.693397522116 .9498977661120 .2162017822123 .5131988525126 .8180007935 130.1502075195133 .4891052246136 .853302002140 .2230987549143 .6165924072 147.0149993896150 .4360046387153 .8612976074157 .3083953857160 .7592926025 164.2315063477167 .7070007324171 .2035064697174 .7030029297178 .2232971191 181.74659729185 .290802002188 .8377990723192 .4062957764195 .9774932861 199.571105957203 .1674957275206 .7872009277210 .4100036621214 .0574951172 217.7084960938221 .3858032227225 .0670013428228 .7763061523232 .4900970459 
236.2344055176239 .983795166243 .7660980225247 .5543060303251 .3782958984 255.2089996338259 .078704834262 .9560852051266 .8760070801270 .8046875 274.7796936035278 .7647094727282 .799987793286 .8467102051290 .9480895996 295.0621948242299 .2358093262303 .4234924316307 .6755981445311 .9433898926 316.2807006836320 .6351928711325 .0646057129329 .5126953125334 .0414123535 338.5903015137343 .225402832347 .8822937012352 .6311950684357 .4034118652 362.2735900879367 .1684875488372 .1672973633377 .1924133301382 .3270874023 387.4895935059392 .7676086426398 .0747070312403 .503112793408 .9619140625 414.5476074219420 .1646118164425 .9136962891431 .6948852539437 .6129150391 443.5635070801449 .6557922363455 .7809143066462 .0538024902468 .3605041504 474.8244934082481 .3244018555487 .9956970215494 .7070007324501 .6070861816 508.5521850586515 .703918457522 .9050292969530 .3272094727537 .80078125 545.5056762695553 .2615966797561 .2564086914569 .3007202148577 .5916748047 585.9307861328594 .5258789062603 .1682739258612 .0773925781621 .0330810547 630.266418457639 .5452270508649 .1104125977658 .7183227539668 .6177978516 678.5551757812688 .7844238281699 .0443725586709 .5900268555720 .1561889648 730.9948120117741 .8405761719752 .9359130859764 .021484375775 .3222045898 786.5924072266798 .0308837891809 .4135131836820 .9038085938832 .3087158203 843.7462158203855 .0651855469866 .3270263672877 .4390258789888 .3538208008 899.0408935547909.391784668919.4807739258929.102722168938.4124145508 947.1119995117955 .455871582963 .059387207970 .276184082976 .6445922852 982.6088867188987 .6395874023992 .2564697266995 .8654174805999 .044921875 1001.1359863281002 .7620239261003 .200988771003 .1110229491001 .721984863 999.7277832031996 .3198242188992 .2418212891986 .6381835938980 .329284668 972.3864746094963 .7335205078953 .3419189453942 .2484130859929 .3331298828 915.7271728516900 .2791137695884 .1721801758866 .3057250977847 .8646240234 827.8740844727807 .4641113281785 .8383178711764 .0272827148741 .4016723633 718.8500976562695 .8673095703673 .1879272461650 .3693237305628 .0040283203 605.6585083008583 .8167114258562 .0297241211540 .7166748047519 .4174194336 498.5127868652477 .5595092773456 .904510498436 .1850891113415 .695098877 395.2240905762374 .9692993164354 .9296875335 .1604919434315 .8944091797 297.0143127441278 .9661865234261 .4501037598245 .0731964111229 .3612976074 215.0218048096201 .4355926514189 .3527069092178 .0525054932168 .2774963379 159.2651062012151 .7050018311144 .8578948975139 .308807373134 .3999938965 130.5527954102127 .2442016602124 .6774978638122 .5029983521120 .6843032837 119.0586013794117 .3900985718115 .6871032715113 .6066970825111 .2895965576 108.3908996582105 .1380996704101 .250701904397 .0038299560592 .19013977051 87.0980072021581 .5652999877975 .8654098510769 .85434722963 .77322006226 57.4681587219251 .1278610229544 .6123886108438 .0823783874531 .41426086426 24.7335491180417 .9714908599911 .219400405884 .476408004761 -2.22882509232 $-8.7675743103-15.1909999847-21.2488498688-27.1188907623-32.4157600403$ $-37.4355697632-41.6734199524-45.5617408752-48.4566001892-50.9085617065$ $-52.1632118225-52.8883094788-52.2572097778-51.0274887085-48.3450317383$ $-45.0232200623-40.2215805054-34.7758903503-27.8907394409-20.3959007263$ $-11.5603504181-2.183614969258 .39188575744619 .4150905609131 .46843910217$ 43.862579345757 .1068305969270 .5824279785284 .7286682128999 .0020904541 
113.7749023438128 .5798034668143 .7265014648158 .8233947754174 .12159729 189.3114013672204 .5480957031219 .5908966064234 .5494995117249 .2704925537 263.8168029785278 .0900878906292 .116394043305 .8486938477319 .2792053223 332.4021911621345 .1809997559357 .6458129883369 .7355957031381 .5104980469 392.888885498403 .9559936523414 .6135864258424 .966796875434 .9047851562 444.5481872559453 .7767944336462 .7225952148471 .2593994141479 .5271911621 487.3960876465 495.0107116699502.2403869629509.2316894531515.8551025391 522.2561035156528 .3087158203534 .1552734375539 .6744995117545 .0037841797 550.0280151367554 .8782958984559 .4456176758563 .8543701172568 .0020751953 572.0056152344575 .7686157227579 .4008178711582 .8114013672586 .1032104492 589.1912231445592 .1713867188594 .9644775391597 .6600952148600 .1854248047 602.6234741211604 .9083862305607 .1160888672609 .1879882812611 .1923217773 613.0767211914614 .9022827148616 .6223144531618 .2907714844619 .8657836914 621.395690918622 .8424072266624 .2495117188625 .5825805664626 .8811035156 628.114074707629 .3168945312630 .4622802734631 .5819091797632 .6516723633 633.6995849609634 .7047729492635 .6917114258636 .6425170898637 .5784301758 638.4843139648639 .3782958984640 .2476806641641 .1079101562641 .9484863281 642.7825927734643 .6015014648644 .4158935547645 .2194213867646 .020324707 646.8137817383647 .6063842773648 .3948974609649 .1840209961649 .9716186523 650.7612304688651 .5518188477652 .3452148438653 .1417236328653 .9417724609 654.7467041016655 .5560913086656 .3713989258657 .1917724609658 .0192260742 658.8521118164659 .6929931641660 .5399780273661 .3958129883662 .2584228516 663.1311035156664 .0112304688664 .9031982422665 .803527832666 .7194824219 667.6444091797668 .604309082669 .5941162109670 .6010131836 95.9027481079198 .9578704834102 .0445022583105 .1778030396108 .346496582 111.5476989746114 .7743988037118 .0249023438121 .2948989868124 .5842971802 127.8901977539131 .2133026123134 .5511016846137 .9044952393141 .2714996338 144.6531066895148 .0473022461151 .4553070068154 .8753967285158 .3083953857 161.7530059814165 .2102050781168 .6784973145172 .1591033936175 .6506958008 179.154296875182 .6690063477186 .1958007812189 .7339019775193 .2843933105 196.846496582200 .4214019775204 .008605957207 .6092987061211 .2229003906 214.8509979248218 .4929046631222 .1504058838225 .8227996826229 .5121002197 233.2176971436236.9416046143240.6831970215 244.445098877 248.2261962891 252.0296020508255 .854095459259 .7030029297263 .5752868652267 .4742126465 271.3988037109275 .3526916504279 .3346862793283 .3489074707287 .3937072754 291.4737854004295 .5874023438299 .7394104004303 .9277954102308 .157989502 312.4277038574316 .7426147461321 .1000976562325 .5065917969329 .9588928223 334.4637145996339 .0177001953343 .6279907227348 .290802002353 .0136108398 357.7922973633362 .6348876953367 .5367126465372 .5060119629377 .5379943848 382.641204834387 .8103942871393 .0544128418398 .3676147461403 .759185791 409.2229919434414 .7683105469420 .3887023926426 .0935058594431 .8760070801 437.745300293443 .6948852539449 .7340087891455 .8565063477462 .0726013184 468.3771057129474 .7814025879481 .2817993164487 .8912963867494 .6062011719 501.4413146973508 .3913879395515 .4716796875522 .674987793530 .0153808594 537.4838256836545 .0927734375552 .8331298828560 .7161865234568 .7337036133 576.8966064453585 .1975097656593 .6475830078602 .2401123047610 .9860229492 
619.8782958984628 .9276123047638 .1259765625647 .4824829102656 .9887084961 666.651184082676 .4603271484686 .4196777344696 .5189208984706 .7578125 717.1248168945727 .6151733398738 .2166137695748 .9188232422759 .7078857422 770.5676269531781 .4827880859792 .430480957803 .3942260742814 .3436889648 825.26171875836 .1104736328846 .8707885742857 .5015869141867 .9588012695 878.1558837891888 .0936279297897 .7105712891906 .9906005859915 .8541870117 924.2979736328932 .242980957939 .6943969727946 .583190918952 .9190063477 958.6458740234963 .7728881836968 .2473754883972 .0770263672975 .1915283203 977.6041259766979 .1995239258980 .0151977539979 .8688964844978 .8513793945 976.7155761719973 .6245727539969 .3087768555963 .9722290039957 .3906860352 949.7349853516940 .8698120117930 .8928833008919 .7437744141907 .459777832 893.9876098633879 .3916015625863 .5966186523846 .7573852539828 .8101196289 809.9627075195790 .2380981445769 .8466796875748 .9616088867727 .7026977539 706.346496582684 .8950805664663 .6632080078642 .5527954102621 .8167114258 601.307800293581 .1627807617561 .2542724609541 .5972900391522 .1265258789 502.7532958984483 .4858093262464 .1861877441444 .9356079102425 .5950012207 406.3244018555387 .020111084367 .8905944824348 .9054870605330 .2690124512 312.0646057129294 .424407959277 .5392150879261 .4245910645246 .3282928467 232.167098999219 .1777038574207 .2180938721196 .4611968994186 .7483062744 178.1977996826170 .6450958252164 .1770019531158 .6119995117154 .0229034424 150.1923065186147 .1782073975144 .7207946777142 .8329925537141 .2431030273 139.8688049316138 .5063934326136 .9443969727135 .1425018311132 .7929992676 130.0384063721126 .5774002075122 .6611022949118 .1235961914113 .1781997681 107.8392028809102 .194198608496 .3845367431690 .3858032226684 .36116027832 78.2221984863372 .0253982543965 .7500534057659 .4141082763753 .01890945435 46.5396614074740 .0210990905833 .456050872826 .9045505523720 .38364028931 $13.970009803777 .7227039337161 .702687978745-4.01447582245-9.36981964111$ -14.2424201965 -18.6196994781 -22.3927097321 -25.5348701477 -27.8979301453 -29.4942302704 -30.1476192474 -29.9239902496 -28.6289596558 -26.3869800568 -22.9981899261 -18.6377506256-13.1288003922 -6.67312002182 .8597750067711 9.2696218490618 .6282501220728 .7598495483439 .6778907775951 .24380874634 63.4239883422976 .1186065673889 .26383209229102 .7919006348116 .62449646 130.7162017822144 .9833984375159 .3975067139173 .8744049072188 .404006958 202.9297943115217 .4125976562231 .7621002197245 .9815063477260 .0022888184 273.8312072754287 .4035949707300 .7392883301313 .7865905762326 .565612793 339.0293884277351 .2018127441363 .0409851074374 .5732116699385 .7607116699 396.6321105957407 .1534118652417 .3546142578427 .2048034668436 .7358093262 445.9191894531454 .7878112793463 .3157043457471 .5368041992479 .4270019531 487.020904541494 .2965087891501 .2883911133507 .9767150879514 .3958129883 520.5272827148526 .4052734375532 .0134277344537 .3842163086542 .5032958984 547.4022216797552 .0676269531556 .5297241211560 .7764282227564 .8361816406 568.6981811523572 .3884277344575 .8970947266579 .2484130859582 .4329223633 585.4732055664588 .3607177734591 .116394043593 .7327270508596 .2293701172 598.6000976562600 .8635864258603 .0147705078605 .0709228516607 .0280151367 608.9013061523610 .6876220703612 .4003295898614 .0361938477615 .6071166992 617.1099853516618 .5554199219619 .9404296875621 .2744750977622 .5551757812 
623.791015625624 .9799804688626 .1298828125627 .239074707628 .3145751953 629.3552856445630 .3671875631 .3496704102632 .3079833984633 .2418823242 634.1558837891635 .049987793635 .9279174805636 .7899780273637 .6395263672 638.4768066406639 .3046875640 .1239013672640 .9362792969641 .742980957 642.5454101562643 .3447265625644 .1420288086644 .9384155273645 .7346191406 646.5319213867647 .3308105469648 .1325073242648 .9370117188649 .7457275391 650.5584106445651 .3764038086652 .1994018555653 .0286254883653 .8634033203 654.7053222656655 .5537109375656 .4099731445657 .2733154297658 .1453857422 659.0256958008659 .916015625660 .8162841797661 .7296142578662 .6564941406 663.6011962891664 .5667724609665 .5590820312666 .569519043 93.7828674316496 .8400497436599 .92608642578103 .0507965088106 .2030029297 109.3841018677112 .5916976929115 .8211975098119 .0714035034122 .3396987915 125.62550354128 .9272003174132 .2445068359135 .5764007568138 .9225006104 142.2821044922145 .6549987793149 .0406036377152 .4387969971155 .8489990234 159.271194458162 .7050018311166 .1502990723169 .6069030762173 .0747070312 176.5536956787180 .0438995361183 .5453948975187 .0581970215190 .5823974609 194.1183929443197 .6661987305201 .2263031006204 .7987976074208 .3842926025 211.9832000732215 .5957946777219 .2227935791222 .8648071289226 .5222015381 230.1959075928233 .8865966797237 .5950012207241 .3218994141245 .0682983398 248.8350067139252 .6230010986256 .4334106445260 .2673034668264 .125793457 268.0100097656271 .9212036133275 .8606872559279 .8298950195283 .8298950195 287.8623962402291 .9287109375296 .0303955078300 .1689147949304 .3457946777 308.5625915527312 .8210144043317 .1227111816321 .4693908691325 .862487793 330.303894043334 .7951049805339 .338104248343 .9345092773348 .5859985352 353.2943115234358 .0610961914362 .8882141113367 .7774047852372 .7301025391 377.7482910156382 .8334960938387 .9873962402393 .2114868164398 .5075073242 403.8768920898409 .3211975098414 .8416137695420 .4395141602426 .1159973145 431.8724975586437 .7099914551443 .6299133301449 .6339111328455 .7237854004 461.9024963379468 .1726989746474 .5385131836481 .00390625487 .5737915039 494.2529907227501 .045501709507 .9565124512514 .9880981445522 .1442260742 529.4259033203536 .8350830078544 .3726806641552 .0397949219559 .8375244141 567.7670288086575 .8300170898584 .0280761719592 .3629760742600 .8364868164 609.450012207618 .2050170898627 .1016845703636 .1406860352645 .3209228516 654.6414794922664 .0993041992673 .6918945312683 .4141235352693 .2612304688 703.2258300781713 .3004150391723 .4749145508733 .7388916016744 .0792236328 754.4818725586764 .930480957775 .4074707031785 .892578125796 .3646240234 806.799621582817 .1724243164827 .4548950195837 .6226196289847 .6170043945 857.378112793866 .8837280273876 .1016235352884 .991394043893 .5067749023 901.6177978516909 .2841796875916 .4829711914923 .1832275391929 .3660888672 935.0139770508940 .1013793945944 .6149902344948 .5134887695951 .7755737305 954.3366088867956.1522827148957.140625 957.2244873047956.332824707954.362121582 951.2973022461947 .0452270508941 .6544189453935 .0930175781927 .4022216797 918.6049194336908 .7210083008897 .8162231445885 .8447265625872 .8242797852 858.7366943359843 .5706176758827 .4019165039810 .2294921875792 .1868286133 773.3416748047753 .8958740234734 .0427856445713 .9478759766693 .832824707 673.7929077148654 .0396118164634 .5797729492615 .5261230469596 .8140258789 
578.4536132812560 .3640136719542 .4927978516524 .7645263672507 .0752868652 489.3790893555471 .5859985352453 .6781005859435 .5960998535417 .4024047852 399.0942993164380 .7915039062362 .5444946289344 .5195922852326 .8474121094 309.6860961914293 .2119140625277 .5184020996262 .7737121582249 .0137023926 236.354598999224 .779006958214 .30909729204 .9199981689196 .5939941406 189.2994995117182 .9985961914177 .649307251173 .2075958252169 .5993041992 166.7707061768164 .5895996094162 .9709014893161 .7169952393160 .6822967529 159.6470947266158 .3941040039156 .7906951904154 .6060943604151 .841003418 148.3287963867144 .2055053711139 .4640960693134 .2510070801128 .6840057373 122.8527984619116 .9341964722110 .931098938104 .958999633898 .96631622314 92.957733154386 .9129562377980 .8007736206174 .6321868896568 .38778686523 62.0791091918955 .6986808776949 .3063011169442 .9486694335936 .6752204895 30.5316905975324 .589839935318 .9199905395513 .592969894418 .686327934265 $4.265234947205 .4021970033646-2.82746291161-5.34869194031-7.08364200592$ -7.94587087631 -7.88495111465-6.82526683807 -4.74839687347 -1.59089303017 2.622920989997 .91875076293914 .239740371721 .569540023829 .83167076111 38.9716415405348 .9079818725659 .5595512390170 .8509521484482 .68926239014 95.01069641113107 .7240982056120 .7770004272134 .0883026123147 .6136932373 161.283493042175 .0603027344188 .8849029541202 .7292938232216 .5523986816 230.3137969971243 .9608001709257 .4667053223270 .7885131836283 .9070129395 296.7914123535309 .4332885742321 .8158874512333 .929901123345 .7618103027 357.3055114746368 .5516967773379 .4966125488390 .1343994141400 .4630126953 410.4796142578420 .183807373429 .575012207438 .6543884277447 .423614502 455.8851013184464 .0419921875471 .8981018066479 .4580993652486 .7268066406 493.7102050781500 .4140014648506 .8450927734513 .0098876953518 .9163818359 524.5712890625529 .9830932617535 .1588745117540 .1077270508544 .8366699219 549.3549194336553 .6696166992557 .7896118164561 .7219238281565 .4752197266 569.0557250977572 .4716796875575 .7288208008578 .834777832581 .7949829102 584.616394043587 .3043823242589 .8657226562592 .3057861328594 .6312866211 596.8477783203598 .9622192383600 .979675293602 .9071044922604 .7490234375 606.5115966797608 .1987915039609 .8161010742611 .3665771484612 .8552246094 614.2844848633615 .6586914062616 .9805297852618 .2534790039619 .4804077148 620.6644287109621 .8082275391622 .9149169922623 .9868164062625 .0269165039 626.0374755859627 .0211791992627 .9801025391628 .9166870117629 .8328857422 630.7307739258631 .6124267578632 .4794921875633 .3336181641634 .1768798828 635.0104980469635 .8359985352636 .6547851562637 .4685058594638 .2780151367 639.0847167969639 .8892822266640 .6932983398641 .4973754883642 .3024291992 643.1093139648643 .9187011719644 .7313232422645 .5479125977646 .3687133789 647.1945800781648 .0255737305648 .8626708984649 .7056884766650 .555480957 651.4122924805652 .2763061523653 .1483154297654 .0283203125654 .9174194336 655.8159179688656 .7255249023657 .6469116211658 .5830078125659 .5349731445 660.5031738281661 .4951782227662 .5015258789

91.5766677856494 .674102783297 .77616119385100 .8992996216104 .0419006348 107.209197998110 .3993988037113 .6100006104116 .8407974243120 .0891036987 123.3547973633126 .6361999512129 .9329071045133 .2438964844136 .5690002441 139.9073028564143 .258605957146 .6224060059149 .9983978271153 .3863067627 
156.7857971191160 .1965942383163 .6186065674167 .0514984131170 .4954071045 173.9501037598177 .4156036377180 .8917999268184 .3791046143187 .8773040771 191.3867950439194 .907699585198 .4403076172201 .9848937988205 .5419006348 209.1116027832212 .6945953369216 .2911987305219 .9022064209223 .5279998779 227.1692962646230 .8267974854234 .5012969971238 .1936035156241 .9044036865 245.6347045898249 .3854064941253 .1575012207256 .9522094727260 .7702941895 264.6133117676268 .4820861816272 .3779907227276 .3023986816280 .2565917969 284.2417907715 288.2596130371292.3113098145296.3984985352 300.5226135254 304.6852111816308 .8877868652313 .1318969727317 .4194030762321 .7515869141 326.1304016113330 .5571899414335 .0338134766339 .561706543344 .1429138184 348.7786865234353 .4710083008358 .2213134766363 .0314025879367 .9028015137 372.8371887207377 .8362121582382 .9012145996388 .033996582393 .236114502 398.5086975098403 .8534851074409 .2715148926414 .7640991211420 .3324890137 425.9776000977431 .7008056641437 .5029907227443 .3859863281449 .3512878418 455.4013061523461 .5386047363467 .7669067383474 .0898132324480 .5114135742 487.0364990234493 .6683959961500 .411895752507 .2690124512514 .2432861328 521.3353881836528 .5474243164535 .8795776367543 .333190918550 .9088134766 558.607421875566 .4301147461574 .3787231445582 .4539794922590 .6580200195 598.991027832607 .4547119141616 .0484008789624 .7731933594633 .6267089844 642.6088867188651 .7156982422660 .9450073242670 .2911987305679 .7504272461 689.3145141602 698.9769897461 708.727722168 718.5574951172 728.4531860352 738.4027709961748 .3903198242758 .4003295898768 .4138183594778 .4113769531 788.3717041016798 .2719116211808 .0858154297817 .7935791016827 .3394775391 836.6697998047845 .7623901367854 .5850219727863 .1024169922871 .270324707 879.0645751953886 .4506835938893 .4110717773899 .921875905 .9680786133 911.5424194336916 .6135253906921 .1804199219925 .1851196289928 .6173706055 931.3850097656933 .4498291016934 .6928710938935 .0319824219934 .362487793 932.5518188477929 .5927124023925 .3383178711919 .9196777344913 .2769165039 905.5264282227896 .7293701172886 .9124755859876 .2418823242864 .5966796875 852.0623779297838 .5532226562824 .0197143555808 .573425293792 .1010742188 774.8386230469756 .7924194336738 .2189941406719 .3220214844700 .2852172852 681.3712768555662 .6707763672644 .4124755859626 .5629272461609 .2374267578 592.309387207575 .792175293559 .5546264648543 .5073852539527 .5648803711 511.5629882812495 .4679870605479 .1796875462 .646697998445 .8207092285 428.7373962402411 .382598877393 .9096984863376 .3297119141358 .8750915527 341.6664123535324 .9010009766308 .7979125977293 .441192627279 .058807373 265.6543884277253 .3601989746242 .1369018555231 .9859008789222 .887298584 214.8052978516207 .7281036377201 .6022033691196 .4156951904192 .1293945312 188.6887969971186 .0733032227184 .1378936768182 .854095459181 .9615936279 181.3717041016180 .7597961426179 .9149017334178 .641204834176 .6361999512 173.9501953125170 .3011932373165 .9682006836160 .8887023926155 .3190002441 149.4396057129143 .3356933594137 .3119049072131 .2767028809125 .4056015015 119.5867004395113 .8098983765108 .0371017456102 .165298461996 .23802947998 90.2201309204184 .1183166503977 .9147872924871 .679542541565 .47039031982 59.3267593383853 .2745094299347 .3974990844741 .7648391723636 .43867111206 31.4908294677726 .995960235623 .0273094177219 .6699199676516 .97314071655 
15.04271984113 .954799652113 .7787199020414 .6028203964216 .44457054138 19.3977298736623 .4146709442128 .5494098663334 .7123603820841 .90687942505 50.0248107910259 .0168113708568 .7809524536179 .2278594970790 .27671051025 101.8195037842113 .7991027832126 .1106033325138 .7142944336151 .5209960938 164.5001068115177 .5805969238190 .7362976074203 .9134063721217 .0865936279 230.2109069824243 .2622070312256 .2033081055269 .0032043457281 .6189880371 294.0361022949306 .2267150879318 .184387207329 .8963928223341 .3544921875 352.5480957031363 .4719848633374 .1188964844384 .4854125977394 .5667114258 404.3612976074413 .8663024902423 .0817871094432 .0068969727440 .6430053711 448.9906005859457 .0526123047464 .8306884766472 .3293151855479 .5512084961 486.5015869141493 .1848144531499 .6066894531505 .7727050781511 .6892089844 517.362487793522 .799621582528 .0073242188532 .9927978516537 .763671875 542.3270263672546 .6906738281550 .8618774414554 .8483276367558 .6566162109 562.2946777344565 .7686157227569 .0856933594572 .2515869141575 .2731933594 578.1558227539580 .9055786133583 .5280761719586 .0294189453588 .4146728516 590.6904296875592 .8615722656594 .9348144531596 .9151000977598 .8087768555 600.6204833984602 .3557739258604 .0186767578605 .614074707607 .145324707 608.6165161133610 .0305786133611 .391418457612 .7015991211613 .9645996094 615.1829223633616 .3599243164617 .4979248047618 .6002197266619 .6688232422 620.7067260742621 .7161254883622 .6995239258623 .6591186523624 .5971069336 625.5153808594626 .4163208008627 .3012695312628 .1724853516629 .0311889648 629.8795166016630 .7186279297631 .549987793632 .375633 .1951904297634 .0114746094 634.825012207635 .6369018555636 .4481201172637 .2595825195638 .0723266602 638.8867797852639 .7039794922640 .5244140625641 .3486938477642 .1773071289 643.010925293643 .8497924805644 .6945800781645 .545715332646 .4033203125 647.2678833008648 .1397705078649 .0195922852649 .9075927734650 .8046875 651.7111816406652 .6286010742653 .5571289062654 .4984741211655 .4534301758 656.4199829102657 .3972167969658 .3801879883 89.3979263305792.4922027587995.6017532348698.7257232666 101.8616027832 105.0179977417108 .1937026978111 .3884963989114 .6015014648117 .8315963745 121.0781021118124 .3399963379127 .6166000366130 .9073028564134 .2115936279 137.5289001465140 .858795166144 .2010040283147 .5550994873150 .9207000732 154.2976074219157 .6855010986161 .0843048096164 .4936065674167 .9134979248 171.3439025879174 .7846069336178 .2357940674181 .6974945068185 .1696929932 188.6526947021192 .1466064453195 .6517028809199 .1683044434202 .6967010498 206.237197876209 .7904052734213 .3565979004216 .9364013672220 .5303955078 224.1392059326227 .7633972168231 .403793335235 .0610961914238 .7362060547 242.429901123246 .1430053711249 .8766937256253 .6318054199257 .4093933105 261.2106933594265 .0368041992268 .888885498272 .7683105469276 .6760864258 280.6138916016284 .5827941895288 .5842895508292 .6198120117296 .6907958984 300.798614502304 .9450073242309 .1312866211313 .3593139648317 .6303100586 321.9460144043326 .3078918457330 .7178039551335 .1770935059339 .6874084473 344.2503967285348 .8677978516353 .5409851074358 .271697998363 .0613098145 367.9115905762372 .8239135742377 .799987793382 .8410949707387 .9489135742 393.1243896484398 .3693847656403 .6848144531409 .0719909668414 .5317993164 420.0653991699425 .6738891602431 .3581848145437 .1199035645442 .9602050781 
448.8815002441454 .8858032227460 .9764099121467 .1567077637473 .4301147461 479.800994873486 .2723083496492 .8486022949499 .5311889648506 .3236999512 513.2263793945520 .2412719727527 .3685302734534 .6088256836541 .9627075195 549.4310302734557 .0144042969564 .7141723633572 .5311279297580 .4666137695 588.5203857422596 .6942138672604 .9868774414613 .3989257812621 .9279785156 630.5734863281639 .3314819336648 .1998291016657 .1727294922666 .24609375 675.4124755859684 .6654052734693 .9954223633703 .3934936523712 .8479003906 722.3468017578731 .8762817383741 .4218139648750 .9664916992760 .4923095703 769.9807739258779 .4113769531788 .76171875798 .010925293807 .1118164062 816.0172729492824 .7041015625833 .1373291016841 .2880249023849 .1151123047 856.5985107422863 .7064208984870 .4326782227876 .7606811523882 .6848144531 888.2000732422893 .2838745117897 .9310302734902 .0885009766905 .7326049805 908.7697753906911 .140625912 .7100830078913 .3690795898912 .9760742188 911.3740844727908 .5197143555904 .2598876953898 .750793457891 .9694213867 884.0838012695875 .2294921875865 .4644165039854 .9758300781843 .6726074219 831.6422729492818 .7462158203804 .9005737305790 .1712036133774 .3870239258 757.8190917969740 .5634155273722 .8148803711704 .7708740234686 .6975708008 668.9193115234651 .5336914062634 .7631835938618 .5604858398602 .963684082 587.8557739258573 .2177734375558 .8845214844544 .7119140625530 .5932006836 516.3137207031501 .8442993164487 .0845031738471 .9536132812456 .4035949707 440.436706543424 .0209960938407 .3252868652390 .3911132812373 .4461975098 356.6494140625340 .2207946777324 .4081115723309 .3380126953295 .282989502 282.2343139648270 .2941894531259 .4216918945249 .5852966309240 .7608032227 232.9066925049226 .0140991211220 .0310974121214 .9656982422210 .7919006348 207.4907989502205 .0547027588203 .3800964355202 .4358062744201 .9826049805 201.900100708201 .8273925781201 .4974060059200 .6394958496198 .8861999512 196.2557067871192 .4871063232187 .8547973633182 .3576965332176 .3186950684 170.0267944336163 .6060028076157 .4105072021151 .3603973389145 .6015930176 140.0075073242134 .5072937012129 .041595459123 .4709014893117 .8162002563 112.0274963379106 .1192016602100 .105697631894 .0340194702187 .95099639893 81.9087066650475 .9517135620170 .1375732421964 .5190963745159 .16915130615 54.1845207214449 .6108703613345 .5126113891641 .9846000671439 .09035110474 36.923961639435 .5644607543935 .103511810335 .6475410461437 .22954177856 39.9478416442943 .771350860648 .7402496337954 .7747306823761 .85581970215 69.8762664794978 .761863708588 .4050064086998 .69725799561109 .5487976074 120.8426971436132 .5137023926144 .459197998156 .6343994141168 .9597930908 181.4029998779193 .9051055908206 .44090271218 .9656066895231 .4613037109 243.9033050537256 .258392334268 .4891052246280 .5744934082292 .4815063477 304.1948852539315 .6897888184326 .962310791338 .0022888184348 .8039855957 359.3588867188369 .6630859375379 .7107849121389 .4993896484399 .024810791 408.2861022949417 .2806091309426 .008392334434 .4685058594442 .6619873047 450.5892028809458 .2522888184465 .6530151367472 .7944030762479 .679107666 486.3114929199492 .695098877498 .8352050781504 .7365112305510 .4043884277 515.8447875977521 .0635986328526 .0670776367530 .8618774414535 .4545288086 539.8516235352544 .0604248047548 .0872192383551 .9392700195555 .6228027344 559.1450195312562 .5112915039565 .7286987305568 .8024291992571 .7387084961 
574.5427246094577 .2200927734579 .7761230469582 .2163696289584 .5460205078 586.7708740234588 .8958740234590 .9271240234592 .8693847656594 .7288208008 596.5095214844598 .2169189453599 .8544921875601 .4273071289602 .938293457 604.3914794922605 .7896118164607 .1362304688608 .4340209961609 .6862792969 610.8953857422612 .0646972656613 .1964111328614 .2935180664615 .358215332 616.3933105469617 .4008789062618 .383605957619 .3433227539620 .2822265625 621.2022094727622 .1055297852622 .9935913086623 .8684082031624 .7313842773 625.5842895508626 .428527832627 .2653808594628 .0963745117628 .9227294922 629.7454223633630 .5656738281631 .3845214844632 .2028198242633 .021484375 633.8416137695634 .6635742188635 .4882202148636 .3159790039637 .1480102539 637.9843139648638 .825378418639 .6719970703640 .5244750977641 .3831176758 642.2482910156643 .1204223633643 .9998168945644 .8870239258645 .7822875977 646.6862792969647 .599609375648 .5228881836649 .4567871094650 .4016113281 651.3576049805652 .3209838867653 .2929077148654 .2753295898 87.18527984619 90.2952880859493.4106216430796.5327301025499.6643371582 102.8127975464105 .976600647109 .1574020386112 .3544998169115 .5673980713 118.7957992554122 .0386962891125 .2958984375128 .5666046143131 .8504943848 135.1470947266138 .4559936523141 .7767028809145 .1089935303148 .4524993896 151.8070068359155 .1721038818158 .5476074219161 .9335021973165 .329498291 168.7355041504172 .1515960693175 .5776977539179 .0137939453182 .4600067139 185.9165039062189 .3834075928192 .8609008789196 .349395752199 .849105835 203.3603973389 206.8836975098 210.4192962646 213.9678955078 217.5299072266 221.1060028076224 .6967926025228 .3029022217231 .925201416235 .5643005371 239.2210998535242 .8964996338246 .5914001465250 .3067016602254 .0435943604 257.8030090332261 .5862121582265 .3941955566269 .2282104492273 .0895080566 276.9794006348280 .8991088867284 .8500061035288 .8334960938292 .8510131836 296.9039001465300 .9937133789305 .121887207309 .2900085449313 .4993896484 317.7517089844322 .0484008789326 .391204834330 .7813110352335 .2206115723 339.7105102539344 .2525939941348 .8482971191353 .499206543358 .2067871094 362.9726867676367 .7981872559372 .6849060059377 .6340942383382 .6473083496 387.7255859375392 .8706054688398 .0830993652403 .3645019531408 .7156066895 414.137512207419 .6311035156425 .1973876953430 .8374938965436 .5527954102 442.3450927734448 .2164001465454 .1693115234460 .2069091797466 .3322143555 472.5491943359478 .8602905273485 .2695007324491 .7780151367498 .3891906738 505.1030883789511 .9213867188518 .8441162109525 .8720703125533 .0051879883 540.2442016602547 .5894165039555 .0418701172562 .6016845703570 .2700805664 578.0468139648585 .9326782227593 .9263916016602 .0280151367610 .2351074219 618.5465698242626 .9586791992635 .4688110352644 .0714111328652 .7620849609 661.5338745117670 .3803710938679 .2927856445688 .262512207697 .2786865234 706.330078125715 .4044799805724 .4879760742733 .5662841797742 .6226196289 751.6411743164760 .6040039062769 .4907226562778 .2817993164786 .9409179688 795.4290161133803 .7150268555811 .7623291016819 .5452270508827 .0317993164 834.2064819336 841.0391845703 847.5338745117853.6834716797 859.4885253906 864.9583129883870 .0667724609874 .8261108398879 .162902832883 .0720825195 886.4260253906889 .1801757812891 .1483154297892 .2310180664892 .2119750977 890.9237060547888 .2672729492884 .018371582878 .4180297852871 .36328125 
863.2518920898854 .2841796875844 .4896240234834 .2490234375823 .3112792969 811.9583129883799 .8939819336786 .8834838867772 .9876708984757 .778503418 741.8599853516725 .2769775391708 .2407836914690 .9893188477673 .7564086914 657.0208740234640 .9370727539625 .617980957611 .0015869141597 .1456298828 583.8289794922571 .1328125558 .7797241211546 .5092163086534 .2354125977 521.6326904297508 .7420043945495 .4844970703481 .7396850586467 .5581970215 452.7579956055437 .3046875421 .412109375405 .0273132324388 .5557861328 372.0732116699355 .849609375340 .2525939941325 .3995056152311 .6708984375 298.9981079102287 .4197998047276 .8847961426267 .3446044922258 .7773132324 251.1078948975244 .3567962646238 .4405059814233 .4192047119229 .2662963867 226.0090942383223 .6806945801222 .18800354221 .5783996582221 .5489044189 222.0814971924222 .6495056152223 .0482025146222 .7837982178221 .3901977539 218.9393005371214 .9611053467209 .9779052734203 .8318023682197 .0995941162 190.2472991943183 .3614959717177 .021697998170 .9696044922165 .4358062744 160.178894043155 .0222930908149 .9340057373144 .671005249139 .2884063721 133.7176971436127 .9908981323122 .1958999634116 .304901123110 .3436965942 104.415496826298 .5472412109492 .7980499267687 .1818771362381 .79371643066 76.790313720772 .1603164672967 .9179534912164 .2080764770561 .0584602356 58.6163406372156 .9093818664656 .0804100036656 .2789497375557 .53911972046 59.9983596801863 .5946388244668 .4149398803774 .3279266357481 .34706878662 89.3141784668 98.16011047363107.7470016479 117.9466018677 128.6649932861 139.7552947998151 .1674957275162 .7736968994174 .5516967773186 .407699585 198.3303985596210 .2563934326222 .1759033203234 .0442047119245 .8619995117 257.6198120117269.2784118652 280.7958068848 292.1614074707 303.354888916 314.3599853516 325.1565856934 335.7414855957 346.1088867188 356.2528076172 366.1693115234375 .8536071777385 .3031921387394 .5147094727403 .4859924316 412.2153015137420 .7012939453428 .9431152344436 .9401855469444 .6931152344 452.2016906738459 .4678955078466 .4926147461473 .278503418479 .8275146484 486.1431884766492 .2284851074498 .087890625503 .7250976562509 .1453857422 514.3532104492519 .3541870117524 .1538085938528 .7578735352533 .1723022461 537.4030761719541 .4567260742545 .3391113281549 .0565795898552 .6149902344 556.0208129883559 .2791748047562 .3964233398565 .3773193359568 .227722168 570.9522705078573 .5567016602576 .0454711914578 .4240722656580 .6973876953 582.8707275391584 .9487915039586 .9373779297588 .8411865234590 .6655273438 592.4144897461594 .0932006836595 .705078125597 .2545776367598 .7446289062 600.1790161133601 .5604248047602 .8922729492604 .1771240234605 .4179077148 606.6171875607 .7780761719608 .9027709961609 .9942016602611 .0545043945 612.0863037109613 .0916137695614 .0729980469615 .0322875977615 .9716796875 616.8930053711617 .7982788086618 .6889038086619 .5670166016620 .4337768555 621.2910766602622 .1400146484622 .9821777344623 .8187255859624 .6508789062 625.479675293626 .3065185547627 .132019043627 .9572143555628 .7828979492 629.6101074219630.4392700195 631.2711791992632.1065063477632.9459228516 633.7894897461634 .6381225586635 .4921264648636 .3519287109637 .2180175781 638.0903930664638 .9697265625639 .8560791016640 .7501831055641 .6522216797 642.5623779297643 .4813842773644 .4094848633645 .3469238281646 .2932128906 647.2487792969648 .2105102539649 .17578125650 .1458740234 
84.9831466674888 .090408325291 .2055969238394 .3267517089897 .45449829102 100.5951004028103 .7484970093106 .9166030884110 .0989990234113 .2959976196 116.5071029663119 .7321014404122 .9704971313126 .2219009399129 .4859008789 132.7621002197136 .050201416139 .3497009277142 .6605072021145 .9819946289 149.3141021729152 .6566009521156 .0090942383159 .3715057373162 .7436065674 166.1253967285169 .5167999268172 .9178009033176 .3283996582179 .7485961914 183.1784973145186 .6183929443190 .0684051514193 .5287017822196 .9996948242 200.4817047119203 .9750061035207 .4799957275210 .9971923828214 .5272064209 218.0704956055221 .6277008057225 .1994018555228 .7864074707232 .3894042969 236.0092010498239 .6466064453243 .3025054932246 .9779968262250 .6737976074 254.391204834258 .1311035156261 .8947143555265 .6831970215269 .4975891113 273.3393859863277 .2096862793281 .1097106934285 .0409851074289 .004699707 293.0022888184297 .0354003906301 .1050109863305 .2130126953309 .3604125977 313.5491027832317 .7803039551322 .0556945801326 .3764038086330 .7443847656 335.1607971191339 .6272888184344 .1452941895348 .7163085938353 .3416137695 358.0228881836362 .7611999512367 .5582885742372 .4154052734377 .3338012695 382.3146972656 387.3594055176 392.4689025879 397.6444091797402 .8866882324 408.196685791413 .5752868652419 .0234985352424 .5421142578430 .1323852539 435.7958068848441 .5342102051447 .3497009277453 .2449951172459 .2226867676 465.2861022949471 .4375477 .6802062988484 .015411377490 .4460144043496 .9718933105 503.5946044922510 .3139953613517 .1306152344524 .0441894531531 .0554199219 538.1641235352545 .3709106445552 .67578125560 .0795288086567 .5811767578 575.1815795898582 .8790283203590 .6729736328598 .5609741211606 .5416259766 614.6107788086622 .7659301758631 .0012817383639 .3128051758647 .6931762695 656.1365966797664 .6345214844673 .178527832681 .7590942383690 .3654785156 698.9866943359707 .6102294922716 .2232055664724 .8109741211733 .3599853516 741.853515625750 .2750244141758 .6060180664766 .8237304688774 .9047241211 782.8002929688790 .4542236328797 .8612060547805 .0021972656811 .8665161133 818.4296875824 .7009887695830 .6743774414836 .3693237305841 .8035888672 846.9639282227851 .8596801758856 .4268188477860 .6439208984864 .391784668 867.5997924805870 .0767822266871 .6843261719872 .1646728516871 .309387207 868.9257202148864 .7501220703859 .0023803711851 .5662231445843 .0872802734 834.0081787109824 .2728881836814 .1812744141803 .6660766602793 .1547241211 782.1486206055770 .2122192383757 .2094726562742 .5336303711727 .0770874023 711.2000732422694 .8718261719678 .2291259766661 .6641845703645 .8695068359 631.0355834961617 .1837768555604 .1859130859591 .9852294922580 .4412841797 569.7202758789559 .4185180664549 .0875854492538 .6420288086527 .6964111328 516.3458862305504 .5346069336492 .2002868652479 .4625854492465 .9363098145 451.4143066406436 .2290039062420 .404296875404 .3367004395388 .1130981445 372.0086975098356 .4682922363341 .7384033203328 .3500061035316 .1097106934 304.8829040527294 .6571044922285 .3994140625277 .0510864258269 .5215148926 262.8312988281256 .903503418251 .8177947998247 .5738983154244 .2516937256 241.9181060791240 .5520935059240 .2104949951240 .6578979492241 .8403930664 243.2250976562244 .5372009277245 .066192627244 .1437072754241 .8385925293 237.7207946777232 .2485046387225 .2667999268217 .587097168209 .9886932373 202.5814971924196 .0086975098190 .0227050781184 .8023071289180 .012802124 
175.3052978516170 .6434020996165 .737197876160 .6295013428155 .2601013184 149.7117004395144 .1587982178138 .4786987305132 .617401123126 .7733001709 121.0546035767115 .4119033813109 .7642974854104 .307899475199 .32736968994 94.6751708984490 .2612533569386 .297851562582 .8901596069380 .12242126465 77.9905471801876 .6967773437576 .4726028442477 .3648681640679 .50888824463 82.8721771240287 .5260162353593 .35418701172100 .3355026245108 .3128967285 117.1770019531126 .7782974243136 .9562072754147 .6011047363158 .5518951416 169.7449035645181 .0574951172192 .458694458203 .87109375215 .2796020508 226.6403045654237 .9429016113249 .1605072021260 .298614502271 .3588867188 282.3062133789 293.1076965332303.7525939941314.2250061035324.5155029297 334.6086120605344 .503112793354 .1944885254363 .6796875372 .9559020996 382.0208129883390 .8721008301399 .5079956055407 .9262084961416 .125793457 424.104888916431 .8633117676439 .399597168446 .7143859863453 .8070068359 460.6788024902467 .3299865723473 .7627868652479 .9782104492485 .979309082 491.7681884766497 .3485107422502 .7235107422507 .8973999023512 .8740234375 517.6583251953522 .2548828125526 .669128418530 .9061279297534 .9711303711 538.8701171875542 .608215332546 .19140625549 .6248168945552 .9144287109 556.0648193359559 .0817260742561 .9697265625564 .7340087891567 .3792114258 569.9102172852572 .3314819336574 .6480712891576 .8646240234578 .9860839844 581.0170288086582 .9625854492584 .8272705078586 .6162109375588 .3331298828 589.9827270508591 .5681762695593 .0938720703594 .5625595 .9776000977597 .3416748047 598.6580810547599 .9293212891601 .1580810547602 .3472290039603 .4990844727 604.6162719727605 .7014770508606 .7567749023607 .7847900391608 .7874145508 609.7670898438610 .7255249023611 .6651000977612 .5872802734613 .4940795898 614.3870849609615 .2681274414616 .1383056641616 .9995727539617 .8530273438 618.700012207619 .541809082620 .3795776367621 .2144165039622 .0474243164 622.8792724609623 .7111206055624 .5437011719625 .3778076172626 .2141113281 627.0531005859627 .8955078125628 .7421264648629 .5928955078630 .4487304688 631.3098754883632 .1768798828633 .0499267578633 .9293212891634 .8154296875 635.7084960938636 .6087036133637 .5166015625638 .4323120117639 .3560791016 640.2880249023641 .2282104492642 .1757202148643 .1306152344644 .0897216797 645.0532226562646 .0230712891 82.7663192749 85.87734985352 88.9919509887792.109649658295.23307037354 98.36681365967101 .5106964111104 .6672973633107 .8361968994111 .0183029175 114.2132034302117 .4207992554120 .6410980225123 .8735961914127 .1182022095 130.3744049072133 .641998291136 .9205932617140 .2100067139143 .5097045898 146.8197021484150 .1394958496153 .4691009521156 .8081054688160 .1564941406 163.5140991211166 .8809051514170 .2568054199173 .6417999268177 .0359954834 180.4394989014183 .8522949219187 .2747039795190 .7068939209194 .1492004395 197.6016998291201 .0650024414204 .5393066406208 .025100708211 .5229949951 215.0334014893218 .5567932129222 .0941009521225 .6455993652229 .2124023438 232.7949981689236 .3941955566240 .0110931396243 .6463928223247 .3011016846 250.9761962891254 .6726989746258 .3916931152262 .1343994141265 .9017944336 269.6951904297273 .5156860352277 .3646850586281 .2434082031285 .1531982422 289.0953063965293 .0712890625297 .0822143555301 .129699707305 .2150878906 309.3398132324313 .5051879883317 .712890625321 .9641113281326 .2604980469 
330.6032104492334 .9939880371339 .4339904785343 .9248046875348 .467590332 353.0639953613357 .7152099609362 .4224853516367 .187286377372 .0108032227 376.8941040039381 .8385009766386 .8447875977391 .9143066406397 .0476989746 402.2457885742407 .5094909668412 .8393859863418 .2366027832423 .7019042969 429.2366027832434 .8422851562440 .520690918446 .2741088867452 .1046142578 458.0151977539464 .007598877470 .0848999023476 .2478027344482 .4988098145 488.837890625495 .2665100098501 .7839050293508 .3908081055515 .0867919922 521.8720703125528 .7462768555535 .709777832542 .7622070312549 .9036865234 557.1334228516564 .4514160156571 .8557128906579 .3455200195586 .9179077148 594.5714111328602 .3015136719610 .1054077148617 .977722168625 .9135742188 633.9069213867641 .9509277344650 .0380249023658 .1599731445666 .3082885742 674.4724121094682 .6431884766690 .8082885742698 .957824707707 .0775146484 715.1569824219723 .1801147461731 .1353759766739 .0042724609746 .7750854492 754.4412231445761 .9395751953769 .1978759766776 .2293701172783 .0258178711 789.5770263672795 .8668823242801 .9108886719807 .7014770508813 .2808227539 818.673828125823 .8801879883828 .9244995117833 .7291870117838 .2935791016 842.4652709961846 .1890258789849 .233215332851 .4788818359852 .5806884766 852.3804931641850 .4658203125846 .5842285156840 .8189086914832 .8706054688 823.9443969727814 .5770263672804 .7097167969795 .0294189453785 .1939697266 775.9326782227766 .4957275391755 .9537963867744 .0941772461729 .9146728516 714.8557739258699 .2391967773683 .2490234375667 .3303222656651 .5571289062 636.7150878906623 .1347045898610 .4152832031598 .7064208984588 .1198730469 578.3162841797569 .6876220703561 .5374755859553 .1212768555544 .4191894531 534.9475097656524 .9357299805514 .3765869141503 .3247070312492 .1901855469 480.0484008789466 .7629089355452 .5006103516437 .0719909668421 .2981872559 405.0887145996388 .8634033203373 .3877868652358 .8435058594345 .7934875488 334.0036010742323 .1028137207313 .116394043304 .1034851074295 .9363098145 288.4726867676281 .7644042969275 .6933898926270 .4083862305265 .9085083008 262.3486938477259 .8432006836258 .4288024902258 .2301940918259 .0297851562 260.8778076172263 .111907959265 .6343994141267 .220489502267 .1279907227 265.283996582260 .9324951172254 .833694458246 .6166992188237 .6179046631 228.9918060303220 .8876037598214 .1837005615208 .3903961182203 .7019958496 199.5722961426195 .3883056641191 .1737976074186 .5467071533181 .6125946045 176.4219055176171 .0446014404165 .8179016113160 .4355010986154 .7680053711 149.1089935303143 .4812011719137 .8917999268132 .2263946533126 .7204971313 121.8125991821117 .2057037354112 .6865005493108 .5286026001104 .7611999512 101.579803466898 .8999328613397 .0292587280396 .2840728759896 .71349334717 98.4884185791101 .5539016724106 .054901123111 .7947006226118 .8050003052 126.8489990234135 .8182067871145 .5202941895155 .7512054443166 .4008026123 177.2593994141188 .2870025635199 .3278961182210 .3804931641221 .3531951904 232.2563934326 243.0460968018253.7308044434264.2907104492 274.740814209 285.091003418295 .3140869141305 .3909912109315 .308013916325 .0552978516 334.6246948242344 .0100097656353 .2095031738362 .2232055664371 .0476074219 379.6846008301388 .1303100586396 .3857116699404 .4475097656412 .3160095215 419.9885864258427 .4646911621434 .7430114746441 .8225097656448 .702911377 455.3833007812461 .8642883301468 .1455078125474 .2284851074480 .1135864258 
485.8031921387491 .2984008789496 .6025085449501 .7174987793506 .6471862793 511.3945922852515 .9641113281520 .3593139648524 .5850830078528 .6458129883 532.5463256836536 .2913818359539 .8862915039543 .3358764648546 .6450195312 549.8187866211552 .8618164062555 .7786865234558 .57421875561 .2526855469 563.8184814453566 .276184082568 .6301269531570 .8848266602573 .0443725586 575.1138916016577 .0974731445578 .9998779297580 .825378418582 .5786132812 584.2630004883585 .8831176758587 .4420166016588 .9434204102590 .3900756836 591.7854003906593 .1317749023594 .4323120117595 .6892700195596 .9058227539 598.0839233398599 .2265014648600 .3358154297601 .4144287109602 .4644165039 603.4880981445604 .487487793605 .4650878906606 .4224243164607 .3618164062 608.2844238281609 .1926269531610 .0875244141610 .9710083008611 .8444213867 612.7094116211613 .5670166016614 .4187011719615 .2655029297616 .1087036133 616.94921875617 .7880859375618 .6262207031619 .4644775391620 .3037109375 621.1444702148621 .9876098633622 .8336181641623 .6831054688624 .5366210938 625.3944702148626 .2573242188627 .1254272461627 .9993286133628 .8790283203 629.7650146484630 .6574707031631 .5567016602632 .4628295898633 .3759765625 634.2963867188635 .2241821289636 .1591186523637 .1013183594638 .0493774414 639.0034790039639 .9616699219640 .9221191406641 .8856811523

80.552459716883 .6597671508886 .7709579467889 .8852920532293 .00388336182 96.1303176879999 .26519012451102 .410697937105 .5668029785108 .7345962524 111.9140014648115 .1051025391118 .307800293121 .5220031738124 .7475967407 127.9841995239131 .2315979004134 .4895019531137 .7577972412141 .0359954834 144.3238983154147 .621307373150 .9279937744154 .2438049316157 .5684967041 160.9019927979164 .2442016602167 .5950927734170 .9546966553174 .3229064941 177.6999053955181 .0856933594184 .4804992676187 .8845062256191 .2980041504 194.7210998535198 .154296875201 .5979003906205 .0523071289208 .5178985596 211.995300293215 .4850006104218 .9875030518222 .5036010742226 .033996582 229.5792999268233 .1403045654236 .7178955078240 .3128967285243 .9263000488 247.5588989258251 .211807251254 .8860931396258 .5827941895262 .3028869629 266.0477905273269 .8183898926273 .6162109375277 .442199707281 .2977905273 285.1842041016289 .1028137207293 .0548095703297 .0416870117301 .0646972656 305.1253967285309 .2247924805313 .3646850586317 .5461120605321 .7705993652 326.0396118164330 .3544006348334 .7163085938339 .1267089844343 .5869140625 348.0983886719352 .662109375357 .2796020508361 .9519042969366 .6805114746 371.4660949707376 .3100891113381 .2132873535386 .1767883301391 .2012023926 396.2875061035401 .4361877441406 .6480102539411 .9238891602417 .2644042969 422.6706848145428 .1441040039433 .6859130859439 .2980957031444 .982208252 450.7409057617456 .5752868652462 .4881896973468 .4800109863474 .5531005859 480.7070007324486 .9429931641493 .2604064941499 .6597900391506 .1402893066 512.7020874023519 .3444213867526 .0673828125532 .8701782227539 .7529296875 546.7138061523553 .7529296875560 .8676147461568 .0571289062575 .3178710938 582.6483154297590 .0435791016597 .5006713867605 .0139770508612 .578918457 620.1889038086627 .8377075195635 .5178222656643 .2213745117650 .9404296875 658.665222168666 .3873291016674 .0958251953681 .7819824219689 .4337158203 697.0421142578704 .5936279297712 .079284668719 .4846191406726 .8018798828 734.0223999023741 .0963745117747 .9672851562754 .637512207761 .0927734375 
767.3308105469773 .334777832779 .1345214844784 .7360229492790 .1906738281 795.5302124023800 .7786865234805 .9686889648811 .033203125815 .9630737305 820.6129760742824 .8923950195828 .6060791016831 .5963745117833 .536315918 834.2194824219833 .0728149414829 .7114868164823 .9918823242815 .515625 806.0092163086796 .1516723633786 .1074829102776 .9445800781768 .1754150391 760.6533203125753 .3555908203744 .6591186523734 .0324707031720 .6597900391 705.9691772461689 .9376220703673 .6801757812658 .7302246094644 .0737304688 630.170715332617 .7066040039605 .7855834961594 .9586181641585 .9127197266 577.959777832571 .4544067383565 .5559082031559 .0236206055551 .8980712891 543.7014770508534 .7830810547525 .2178955078515 .4163208008505 .9395141602 495.4638977051483 .6810913086470 .5042114258455 .3830871582439 .6221008301 423.1885070801406 .5765075684391 .1748046875376 .9312133789364 .2294921875 352.8846130371342 .3198852539332 .5249938965323 .6889038086315 .6408996582 308.1593933105301 .3035888672294 .9574890137289 .2915039062284 .345703125 280.3351135254277 .4410095215275 .7861938477275 .5310058594276 .5981140137 279.0517883301282 .3333129883286 .2354125977289 .2273864746290 .4143981934 289.3280029297 284.7210998535277.6236877441 267.8181152344 257.0210876465 247.0113983154238 .0735931396231 .3265075684226 .0010986328222 .0639038086 218.8054962158215 .2891998291211 .5444946289207 .0818939209202 .1889038086 197.1248931885191 .9745025635187 .0776977539182 .0505065918176 .7783966064 171.4382019043165 .8222045898160 .1582946777154 .5532073975149 .1040039062 144.2445983887139 .6925048828135 .2449951172130 .966003418126 .7356033325 122.9428024292119 .6533966064117 .1051025391115 .7110977173115 .5895996094 116.9102020264119 .6552963257123 .964302063129 .6575927734136 .7160949707 144.904296875154 .0520935059163 .9425048828174 .3139038086185 .0335998535 195.871307373206 .7698059082217 .582901001228 .2998962402238 .8520965576 249.2485046387259 .4693908691269 .5264892578279 .4216003418289 .172088623 298.8012084961308 .2896118164317 .6285095215326 .8082885742335 .8232116699 344.6684875488353 .338104248361 .8374023438370 .169708252378 .3330078125 386.329498291394 .1578063965401 .8183898926409 .3095092773416 .6307983398 423.7804870605430 .7573852539437 .5600891113444 .1871032715450 .6376037598 456.9101867676463 .0049133301468 .9205932617474 .657989502480 .216796875 485.5986022949490 .803894043495 .8348999023500 .6931152344505 .3815917969 509.9024963379514 .2595214844518 .4556274414522 .4948730469526 .3812255859 530.1187744141533 .7117919922537 .1646728516540 .4819946289543 .6679077148 546.7271118164549 .6633300781552 .4813232422555 .1848754883557 .7783203125 560.2653198242562 .6503295898564 .9370727539567 .1301879883569 .2332763672 571.2509765625573 .1873168945575 .0465698242576 .832824707578 .5501708984 580.2020263672581 .7924804688583 .3242797852584 .8012695312586 .2257080078 587.6008911133588 .9290771484590 .2133789062591 .455871582592 .6596069336 593.8264770508594 .9594116211596 .0603027344597 .1318969727598 .1760864258 599.1953735352600 .1915283203601 .1666259766602 .1223754883603 .0610961914 603.9840087891604 .8931274414605 .7896728516606 .6755981445607 .5520019531 608.4204101562609 .2819824219610 .1381225586610 .9896240234611 .8380126953 612.6840820312613 .5286865234614 .3729248047615 .2174072266616 .0629272461 616.9102783203617 .7600708008618 .6129150391619 .4691162109620 .3294067383 
621.1939697266622 .0637207031622 .9384765625623 .8187866211624 .705078125 625.5972900391626 .4957275391627 .4005737305628 .3120117188629 .2299804688 630.1547241211631 .0861206055632 .0236206055632 .9672851562633 .9163208008 634.8698730469635 .8267822266636 .7868041992637 .7509155273

78.3327636718881 .4382400512784 .545898437587 .6551132202190 .76796722412 93.887130737397 .01306152344100 .1480026245103 .2919006348106 .4461975098 109.6106033325112 .785697937115 .9713973999119 .1678009033122 .3747024536 125.5921020508128 .8197021484132 .0572052002135 .3045043945138 .5612945557 141.8273925781145 .1026000977148 .386505127151 .6790924072154 .9801940918 158.2897033691161 .6074066162164 .933303833168 .2675018311171 .6098022461 174.9602966309178 .3191070557181 .6864013672185 .0621948242188 .4468994141 191.8406066895195 .2436981201198 .6564941406202 .0794067383205 .5126953125 208.9571075439 212.412902832 215.8807983398 219.3612976074222.8551940918 226.3630065918229 .8856964111233 .4239044189236 .9785003662240 .5503997803 244.1403961182247 .7496948242251 .3789978027255 .0294952393258 .7023010254 262.3984985352266 .1191101074269 .8653869629273 .6384887695277 .4397888184 281.2702941895285 .1314086914289 .0244140625292 .9505004883296 .9110107422 300.907409668304 .9407958984309 .0126037598313 .1241149902317 .2767028809 321.4717102051325 .7103881836329 .9941101074334 .3240966797338 .7015991211 343.1279907227347 .604309082352 .1318054199356 .7117004395361 .3452148438 366.033203125370 .7768859863375 .5768127441380 .434387207385 .3497924805 390.3243103027395 .3581848145400 .4522094727405 .6068115234410 .8229064941 416.1011962891421 .4426879883426 .8483886719432 .3198852539437 .8584899902 443.4661865234449 .1437988281454 .8937988281460 .7160949707466 .6129150391 472.5834960938478 .6290893555484 .7488098145490 .9431152344497 .2107849121 503.5520019531509 .9653930664516 .451171875523 .0078125529 .6351928711 536.3311767578543 .0955200195549 .924987793556 .8186035156563 .7725830078 570.7847290039577 .8500976562584 .9655151367592 .1251220703599 .3240966797 606.5560913086613 .8146972656621 .0928955078628 .3826293945635 .6766967773 642.9655761719650 .2426147461657 .4965209961664 .7213134766671 .9047241211 679.041809082686 .1193847656693 .1337280273700 .0706787109706 .9260864258 713.6878051758720 .3239135742726 .7965698242733 .0969848633739 .2039794922 745.1218261719750 .8302001953756 .3759765625761 .7659301758767 .0731201172 772.3115234375777 .5581054688782 .8436279297788 .1264038086793 .4235839844 798.5311279297803 .3671875807 .7387695312811 .4611206055814 .2719116211 816.0112304688815 .8734741211813 .6563110352808 .5883789062800 .2476806641 789.9567871094778 .8020019531768 .1893920898760 .1359863281753 .8386230469 748.8754272461744 .0966186523737 .2744750977728 .3709716797716 .8063964844 702.0994262695684 .3270263672667 .0308227539652 .9791259766640 .9442749023 629.1196289062617 .045715332604 .7083740234593 .8588867188585 .8466796875 580.2457885742576 .1909790039572 .2946166992567 .5927734375561 .6419067383 554.4252929688546 .295715332537 .25528 .3060302734520 .0706176758511 .4930114746 502.4736022949491 .0846862793476 .5476989746460 .0598144531442 .3681945801 425.486114502410 .4957885742397 .1575927734384 .8232116699373 .4083862305 362.9059143066353 .2012939453344 .5252990723336 .5311889648328 .9508972168 321.8280029297315 .0354919434308 .8031921387303 .2037963867298 .5380859375 
295.029510498292 .8947143555292 .3259887695293 .3662109375296 .1346130371 300.1734008789305 .2976074219310 .1235961914313 .5942077637313 .7803955078 309.1953125300 .558807373288 .7912902832276 .1098022461264 .1364135742 254.4156036377247 .5699005127243 .0417938232240 .1602020264237 .7241973877 234.9794006348231 .3896026611226 .8820953369221 .8347015381216 .9015960693 212.1143035889207 .5850067139203 .2339935303198 .8569030762193 .9956054688 188.1511993408182 .1058959961176 .5767059326171 .4692993164166 .6918029785 162.2673034668158 .1840057373153 .9806060791149 .188293457144 .5054931641 140.3397064209137 .1315002441134 .9994049072134 .1632995605134 .9221038818 137.216506958141 .3302001953146 .9561004639154 .1510009766162 .5605010986 171.9904022217182 .1721954346192 .7550048828203 .6181945801214 .466293335 225.2731933594235 .862197876246 .2537994385256 .3741149902266 .2567138672 275.8911132812285 .3060913086294 .5185852051303 .5520935059312 .4432983398 321.1781921387329 .7662963867338 .1969909668346 .4775085449354 .5934143066 362.5459899902370 .3403015137377 .9901123047385 .4924926758392 .8512878418 400.0640869141407 .1343994141414 .0591125488420 .8388977051427 .4710083008 433.9548034668440 .287902832446 .4685974121452 .4953918457458 .3662109375 464.0804138184469 .6359863281475 .0332946777480 .2708129883485 .3499145508 490.2695922852495 .0320129395499 .637298584504 .0881958008508 .3858947754 512.5336303711516 .5333862305520 .3889770508524 .1032714844527 .6801757812 531.1231079102534 .4359741211537 .6226806641540 .6870727539543 .6328735352 546.4641113281549 .1842041016551 .7971191406554 .3062744141556 .7155761719 559.0286254883561 .2493286133563 .3812255859565 .4282836914567 .3947143555 569.283996582571 .100402832572 .8474121094574 .5288696289576 .1481933594 577.7088012695579 .2136230469580 .6655883789582 .0676269531583 .4224243164 584.7321777344585 .9998779297587 .227722168588 .4182739258589 .5737304688 590.696472168591 .7888183594592 .8532104492593 .891418457594 .9058837891 595.8983154297596 .8707275391597 .8248291016598 .7625732422599 .6854248047 600.5952758789601 .4932861328602 .3814086914603 .2604980469604 .1322021484 604.9974975586605 .8577880859606 .7139892578607 .5673828125608 .4187011719 609.2689819336610 .1190185547610 .9696044922611 .8214111328612 .6751098633 613.5313110352614 .3906860352615 .2534790039616 .1204223633616 .9916992188 617.8679199219618 .7490844727619 .6358032227620 .5280761719621 .4262084961 622.3303222656623 .2404174805624 .1566772461625 .0792236328626 .0076293945 626.9420776367627 .8818969727628 .8270874023629 .7766113281630 .7302246094 631.6868286133632 .6448974609633 .6055297852

76.1137237548879 .214988708582 .3175430297985 .421463012788 .5280380249 91.6394195556694 .7564086914197 .88072967529101 .012802124104 .1537017822 107.3035964966110 .4632034302113 .6323013306116 .8113021851120123 .1985015869 126.40650177129 .6239013672132 .8506011963136 .0861968994139 .3305969238 142.5836029053145 .8450012207149 .1145935059152 .3921966553155 .6777038574 158.9710998535162 .2720947266165 .5807952881168 .8972015381172 .2214050293 175.5532073975178 .8928985596182 .2406005859185 .596496582188 .9608001709 192.3338012695195 .7158050537199 .1071014404202 .5081939697205 .9194030762 209.341293335212 .7745056152216 .2194061279219 .6766967773223 .1470947266 226.6313018799230 .1300048828233 .6441040039237 .1743927002240 .7218017578 
244.2872009277247 .8715057373251 .4757995605255 .1009979248258 .7484130859 262.4187927246266 .1135864258269 .8337097168273 .5805053711277 .3550109863 281.1585998535284 .9923095703288 .8575134277292 .7554931641296 .6874084473 300.6546020508304 .6582946777308 .699798584312 .7804870605316 .9013977051 321.0639953613325 .2694091797329 .5188903809333 .8135986328338 .1549072266 342.5437011719346 .9814147949351 .4688110352356 .0072937012360 .5975952148 365.2409973145369 .9378967285374 .6895141602379 .496307373384 .3591003418 389.2782897949394 .2546081543399 .2883911133404 .3804016113409 .5310058594 414.7410888672420 .0114135742425 .3431091309430 .7370910645436 .1950073242 441.7172851562447 .3057861328452 .9606018066458 .6831054688464 .4728088379 470.3305053711476 .2553100586482 .2473144531488 .3052978516494 .4289855957 500.6171875506 .8693847656513 .1838989258519 .5601196289525 .9956054688 532.4895019531539 .0385742188545 .641418457552 .2935180664558 .9926757812 565.7337036133572 .512878418579 .3245239258586 .1633911133593 .0228881836 599.8969726562606 .7781982422613 .6591796875620 .5327148438627 .3900146484 634.2244262695641 .0264892578647 .7902832031654 .5059814453661 .1694946289 667.7708129883674 .3073120117680 .7694702148687 .1555175781693 .4625854492 699.6594238281705 .7062988281711 .6060791016717 .3430175781722 .9204101562 728.3272094727733 .6008911133738 .7512817383743 .8552856445748 .9423217773 754.1171875759 .4326782227764 .8850097656770 .5244140625776 .0827026367 781.4118041992786 .3920288086790 .8323974609794 .6359863281797 .5894165039 798.9843139648798 .6478271484795 .2122802734787 .9608764648777 .3900146484 762.4083251953749 .0261230469744 .2553100586742 .8413696289741 .3311767578 739.4500732422734 .8046264648728 .0869140625720 .1699829102706 .5598144531 682.8790283203660 .6118164062650 .1248779297643 .8555297852635 .3773803711 623.8635864258608 .0131835938594 .1420898438587 .9506225586585 .8596191406 584.7022705078583 .1118774414579 .7457275391574 .5468139648567 .5833129883 559.5250244141550 .5350952148541 .9848022461534 .3270874023527 .7415161133 523.9116821289516 .830078125501 .6856079102482 .7745056152462 .3237915039 443.9096069336431 .3522949219420 .6994018555408 .2095947266395 .8630981445 385.2261962891375 .5956115723366 .9327087402358 .9327087402351 .1524047852 343.6278076172336 .1729125977329 .1192932129322 .6430053711317 .0642089844 312.6794128418309 .7543945312308 .5367126465309 .1614074707311 .770690918 316.1752929688322 .2481994629329 .2486877441337 .066192627340 .6838989258 335.0690917969323 .673614502309 .4078979492294 .1762084961279 .6405944824 268.3605957031262 .403503418259 .5372009277258 .2012939453257 .0292053223 254.8524017334251 .2951049805245 .908203125240 .1190032959235 .433807373 231.242401123227 .029006958223 .4351959229221 .2019042969217 .7993927002 210.5256958008202 .878692627198 .1217956543194 .1206970215189 .112701416 184.5359039307181 .7292022705178 .3856964111172 .3578033447165 .9447021484 160.9371948242157 .1112976074154 .1959991455152 .5388946533152 .5755004883 154.3441009521158 .1647033691163 .7554016113171 .1094970703179 .8419952393 189.6439056396200 .2097930908211 .0950927734222 .1517028809233 .0646057129 243.7931060791254 .1772003174264 .2344055176273 .9184875488283 .2679138184 292.299407959301 .0505065918309 .5609130859317 .8586120605325 .9894104004 333.9538879395341 .7731933594349 .446685791356 .9885864258364 .3782958984 
371.6047058105378 .6896057129385 .6549072266392 .4979858398399 .2203979492 405.8215026855412 .3055114746418 .6697998047424 .9139099121431 .0354003906 437.0327148438442 .9034118652448 .6447143555454 .2549133301459 .7308959961 465.0712890625470 .2735900879475 .3369140625480 .2593994141485 .0409851074 489.6807861328494 .1794128418498 .5367126465502 .7543029785506 .8328857422 510.7749938965514 .5819702148518 .2570800781521 .8024291992525 .2213745117 528.516784668531 .6920776367534 .7504882812537 .6953735352540 .5300292969 543.2576293945545 .8817138672548 .4052734375550 .8319091797553 .1646118164 555.4069824219557 .5623779297559 .6342773438561 .6262207031563 .541809082 565.3847045898567 .1586303711568 .8665771484570 .5125732422572 .0991821289 573.6301269531575 .1074829102576 .5347900391577 .9141235352579 .2484130859 580.5396118164581 .7905273438583 .0034179688584 .1806030273585 .3242797852 586.4368896484587 .5203857422588 .5772705078589 .6093139648590 .6187133789 591.6071777344592 .5767822266593 .5288696289594 .4656982422595 .3883056641 596.2987060547597 .1981201172598 .0880126953598 .9697265625599 .8444213867 600.7133178711601 .5776977539602 .4384155273603 .2965698242604 .1530761719 605.0087890625605 .8645019531606 .7208862305607 .5786743164608 .4387207031 609.3012084961 610.1668701172611.036315918611.9094848633612.7871704102 613.6696777344614 .5571899414615 .4498901367616 .3480224609617 .2517700195 618.1610717773619 .076171875619 .9970703125620 .9235839844621 .8555297852 622.7927856445623 .7349243164624 .6815185547625 .6317749023626 .5855102539 627.5416259766628 .5001220703629 .4614257812

73.8951416015676 .9910507202180 .088172912683 .1856079101686 .28513336182 89.3884735107492 .4962234497195 .6100921630998 .73037719727101 .8582992554 104.994102478108 .1384963989111 .2913970947114 .4533004761117 .6241989136 120.8041000366123 .9927978516127 .1903991699130 .3966064453133 .6112060547 136.834197998140 .0652008057143 .3041992188146 .5507965088149 .8050994873 153.066696167156 .3358001709159 .6119995117162 .895401001166 .1860046387 169.483795166172 .7886962891176 .1009063721179 .4203948975182 .7476043701 186.0825042725189 .4253997803192 .7765960693196 .1363983154199 .5050964355 202.8831939697206 .271194458209 .6694946289213 .078704834216 .49949646 219.9322967529223 .3780059814226 .8372039795230 .3106994629233 .7993927002 237.3040008545 240.8255004883244.3647003174 247.9226989746 251.5003051758 255.0986938477258 .7189025879262 .3619995117266 .0291137695269 .7213134766 273.4396972656277 .1856079102280 .9601135254284 .7643127441288 .599609375 292.4671020508296 .3680114746300 .3035888672304 .2750854492308 .2836914062 312.3305053711316 .4169921875320 .5440063477324 .7130126953328 .924987793 333.1812133789337 .4826049805341 .8304138184346 .2254943848350 .6690063477 355.1618041992359 .7048950195364 .2988891602368 .9447937012373 .6430969238 378.3944091797383 .1991882324388 .0581054688392 .9713134766397 .9395141602 402.962890625408 .0421142578413 .1777038574418 .370513916423 .6207885742 428.9302062988434 .298614502439 .7276000977445 .216796875450 .7674865723 456.378692627462 .0513916016467 .7840881348473 .5770874023479 .4288024902 485.3388977051491 .3056030273497 .3283996582503 .4049987793509 .5346984863 515.7144165039521 .9431762695528 .2172241211534 .5346069336540 .8909301758 547.2830810547553 .7061157227560 .1555786133566 .625793457573 .111328125 
579.6052246094586 .1013793945592 .592590332599 .071105957605 .5302734375 611.9614257812618 .3588256836624 .7125244141631 .0192260742637 .2681274414 643.4589233398649 .5808105469655 .6369018555661 .6166992188667 .5266723633 673.367980957679 .1129150391684 .7166748047690 .1967773438695 .545715332 700.7673950195705 .8594970703710 .8482055664715 .732421875720 .6022949219 725.4467773438730 .4603271484735 .6226806641741 .1041870117746 .9805297852 752.8939208984758 .7255859375764 .2536010742769 .2102050781773 .6967773438 777.3743286133780 .137878418781 .9158935547780 .954284668776 .2337036133 766.5593261719748 .7459106445733 .9694213867733 .792175293738 .3493041992 740.4987792969740 .6583862305737 .4536132812731 .8300170898726 .8577270508 715.9061889648689 .9384765625664 .5942993164656 .9426269531653 .5189819336 646.1290283203636 .0228881836618 .1343994141602 .2493896484597 .390625 596.9891967773596 .6401977539596 .0344848633593 .8850097656589 .4381713867 583.4146118164575 .7288208008566 .919128418558 .2255249023549 .2177734375 543.7138061523544 .2114257812542 .3154907227528 .7360229492508 .8984985352 487.4873046875467 .8829040527457 .199005127448 .1188049316434 .2253112793 420.5158996582409 .424987793399 .8568115234391 .1895141602382 .9753112793 374.8999938965366 .8400878906358 .6044921875350 .5730895996343 .0686035156 336.4714050293331 .0304870605327 .1228027344324 .9794921875324 .9143066406 326.9587097168331 .2539978027337 .7106018066345 .7164916992356 .6864929199 363.1590881348357 .128112793344 .9111938477330 .6614074707314 .7518005371 298.7615966797285 .5246887207279 .0181884766276 .2775878906274 .8890075684 274.0621032715271 .8655090332268 .4914855957262 .815612793256 .9884033203 253.1504058838249 .8289031982246 .1981964111243 .220703125242 .7893066406 240.7966003418232 .6448059082223 .945602417220 .2357940674217 .2583007812 212.0328063965207 .2312011719205 .3388061523202 .8571929932195 .9954986572 188.3690948486182 .5648956299177 .8733978271173 .7129058838171 .0057067871 170.1533050537171 .1876983643174 .7140045166180 .2297058105187 .8596038818 197.0399932861207 .3168945312218 .3511962891229 .5646972656240 .8392028809 251.8020935059262 .4401855469272 .5874023438282 .282409668291 .4937133789 300.2764892578308 .6698913574316 .7225952148324 .500213623332 .0307922363 339.3785095215 346.5479125977353.5840148926 360.4815979004 367.2770080566 373.9352111816380 .4447021484386 .8259887695393 .1146850586399 .3006896973 405.3915100098411 .3879089355417 .2939147949423 .1055908203428 .8229064941 434.4426879883439 .9630126953445 .3803100586450 .69140625455 .8938903809 460.9836120605465 .9588012695470 .8153991699475 .5526123047480 .166809082 484.6581115723489 .0238952637493 .2650146484497 .379486084501 .3691101074 505.2333068848508 .9743041992512 .592590332516 .0908813477519 .4708251953 522.7352294922525 .8862304688528 .9268188477531 .8594970703534 .6873779297 537.4130859375540 .0396118164542 .569519043545 .0059204102547 .3515014648 549.609375551 .782409668553 .8739013672555 .88671875557 .8245239258559 .6901245117 561.4871826172563 .2188720703564 .8884887695566 .4990234375568 .0532836914 569.5543212891571 .0045776367572 .4069824219573 .7634887695575 .0770874023 576.349609375577 .5836791992578 .7814941406579 .9453125581 .0770874023 582.1793823242583 .2540893555584 .3032836914585 .3289794922586 .3333129883 587.3176879883588 .2841796875589 .2343139648590 .1697998047591 .0919799805 
592.0029296875592 .9033813477593 .7951049805594 .6790771484595 .5568237305 596.4291992188597 .2974853516598 .1624755859599 .0255126953599 .8869018555 600.7479858398601 .6091918945602 .4713745117603 .3350830078604 .201171875 605.0698242188605 .9417114258606 .8173217773607 .6967773438608 .5806884766 609.4692993164610 .3626708984611 .2612915039612 .1649780273613 .07421875 613.9885253906614 .9083251953615 .8333740234616 .763671875617 .6989135742 618.6387939453619 .5828857422620 .5310058594621 .4822998047622 .4365234375 623.3928222656624 .3502807617625 .3096923828

71.6762695312574 .7677536010777 .8585662841880 .9492111206184 .04119873047 87.1359863281290 .2343063354593 .3375091552796 .4460830688599 .56114959717 102.6829986572105 .8124008179108 .9494018555112 .0945968628115 .2478027344 118.4094009399121 .5791015625124 .7571029663127 .9430007935131 .1369018555 134.3385925293137 .5478057861140 .7644958496143 .9884033203147 .2194061279 150.4573059082153 .7021026611156 .9535980225160 .211807251163 .4765930176 166.7480010986170 .0260925293173 .3108062744176 .6022949219179 .9008026123 183.2062988281 186.5191040039189.8394927979 193.1676940918 196.504196167 199.8491973877203 .2032012939206 .566696167209 .9402008057213 .3242950439 216.7196960449220 .1268005371223 .5464019775226 .9792938232230 .4263000488 233.8880004883237 .3656005859240 .8596038818244 .3712005615247 .9011993408 251.4506988525255 .0205993652258 .6119995117262 .2258911133265 .863494873 269.5257873535273 .2139892578276 .929107666280 .6723937988284 .4448852539 288.2479858398 292.082611084295.9501037598299.8514099121303.7879943848 307.7608032227311 .7710876465315 .8198852539319 .9083862305324 .037689209 328.2088928223332 .4229125977336 .6809997559340 .983795166345 .332611084 349.7279968262354 .1711120605358 .6622924805363 .2026977539367 .7926940918 372.432800293377 .1235046387381 .8652954102386 .6583862305391 .5032043457 396.3999023438401 .3489990234406 .3505859375411 .4053039551416 .5133972168 421.6755981445426 .8918151855432 .1632080078437 .4891052246442 .8703918457 448.3062133789453 .7968139648459 .341003418464 .9385070801470 .5877990723 476.2882080078482 .0378112793487 .8356018066493 .6791992188499 .5672912598 505.4967041016511 .4659118652517 .4705810547523 .5089111328529 .5756225586 535.6677246094541 .779296875547 .9063720703554 .0422973633560 .1818237305 566.3176269531572 .4434204102578 .551574707584 .6350097656590 .6865234375 596.6978149414602 .6630249023608 .5737304688614 .4254760742620 .2103881836 625.9271850586 631.5687255859637.1381225586 642.6301269531648.0518188477 653.4063110352658 .6749267578663 .8295288086668 .8826904297673 .8289794922 678.6770019531683 .4262084961688 .0900268555692 .6741943359697 .2241210938 701.7396240234706 .4094848633711 .2421875716 .5573120117722 .5380859375 728.7197265625735 .0255126953740 .9937133789746 .1389770508750 .7681884766 754.4033203125758 .016418457762 .5062866211765 .5574951172765 .746887207 760.0360717773744 .0114135742732 .2794799805739 .2407226562750 .9857788086 755.8441162109756 .4362792969753 .1624755859747 .5615234375741 .4901123047 731.9774169922716 .8560180664700 .2689819336686 .1994018555674 .1638183594 664.4251098633654 .4293823242640 .9110717773628 .7855834961621 .989074707 618.1356201172614 .4586181641611 .575378418610 .3204956055607 .6533203125 602.5659790039595 .5385131836586 .8977050781576 .7293701172563 .361328125 
555.3408813477559 .3486938477563 .4069824219556 .8942871094542 .7355957031 524.3192138672506 .3503112793493 .612487793481 .0577087402464 .1543884277 447.9241943359436 .271697998426 .8366088867417 .8664855957409 .1465148926 400.5772094727391 .9028015137382 .6241149902373 .3749084473364 .7244873047 356.9679870605350 .3013000488345 .1152954102341 .8049926758340 .6249084473 341.7431945801345 .2314147949351 .0209960938358 .4577026367367 .548614502 373.1933898926370 .1057128906362 .4794921875353 .9143066406342 .5618896484 327.1411132812311 .8991088867300 .6928100586292 .8682861328288 .1507873535 284.9034118652281 .6546020508278 .5144958496275 .0780029297272 .053894043 269.9973144531268 .1617126465266 .0624084473264 .2601928711263 .4151916504 261.1299133301255 .0099029541248 .3923034668244 .6157989502241 .2200927734 236.3652954102231 .7135009766228 .6802978516225 .3143005371219 .7364044189 213.0299072266205 .9727020264199 .4465026855193 .758605957189 .6470031738 187.7611999512188 .0386962891191 .0736999512196 .5124969482204 .4891052246 214.2756958008225 .1240997314236 .6804962158248 .2707061768259 .7536010742 270.7557067871281 .2634887695291 .1346130371300 .4191894531309 .1109924316 317.2811889648324 .9906921387332 .3048095703339 .3056030273346 .0353088379 352.5682067871358 .9234008789365 .1530151367371 .2626953125377 .2844848633 383.2012939453389 .0143127441394 .7224121094400 .3335876465405 .8634033203 411.3309936523416 .7326965332422 .0689086914427 .3369140625432 .537689209 437.6666870117442 .7203979492447 .6948852539452 .5862121582457 .3909912109 462.104309082466 .7232971191471 .2434997559475 .6628112793479 .9772949219 484.1856994629488 .2850036621492 .274810791496 .1531982422499 .920501709 503.5758972168507 .1207885742510 .5551147461513 .8811035156517 .0996704102 520.2133178711523 .2235107422526 .1326904297528 .9431152344531 .6569213867 534.2766113281536 .8043823242539 .2426757812541 .5941162109543 .8607788086 546.045715332548 .151184082550 .1801147461552 .1353759766554 .0198974609 555.8366699219557 .588684082559 .2789916992560 .9105224609562 .4860229492 564.0081176758565 .4796142578566 .9027709961568 .2802734375569 .6143188477 570.9072265625572 .1610107422573 .3782958984574 .5609741211575 .7113037109 576.8311767578577 .9232177734578 .9888916016580 .0305175781581 .0498046875 582.048828125583 .0288696289583 .9923095703584 .9401855469585 .8745117188 586.7963256836587 .7073974609588 .6088867188589 .5023193359590 .3884887695 591.2691040039592 .1447753906593 .0170288086593 .8862304688594 .7537231445 595.6201171875596 .486328125597 .3530273438598 .2208862305599 .0905151367 599.9624023438600 .837097168601 .7150878906602 .5966796875603 .482421875 604.3723144531605 .2667236328606 .1658935547607 .0700073242607 .9791259766 608.8933105469609 .8125610 .7368164062611 .6657714844612 .5996704102613 .5380249023 614.4805297852615 .4268188477616 .3762817383617 .328918457618 .2836303711 619.2401123047620 .1984863281621 .1586914062 69.4632415771572 .5465698242275 .6303710937578 .7134170532281 .79725646973 84.88316345215 87.971679687591.0641326904394.1609268188597.26320648193 100.3712005615103 .4858016968106 .6072006226109 .7358016968112 .8718032837 116.015296936119 .1662979126122 .324798584125 .4907989502128 .6640930176 131.8446044922135 .0321960449138 .2266998291141 .4279022217144 .6358032227 147.8500976562151 .0708007812154 .2976989746157 .5307006836160 .7698059082 
164.0149993896167 .266204834170 .5236053467173 .7870941162177 .0567932129 180.3329925537183 .6157989502186 .9053955078190 .2021026611193 .5063018799 196.8182067871200 .1383056641203 .4669952393206 .8047943115210 .1522979736 213.5099945068216 .8786010742220 .2586975098223 .6510009766227 .0561981201 230.4750976562233 .908706665237 .3574981689240 .8226928711244 .3050994873 247.8054962158251 .3251037598254 .8648071289258 .4255981445262 .0085144043 265.6146850586269 .2450866699272 .9009094238276 .583190918280 .2930908203 284.0315856934287 .799987793291 .599395752295 .4306945801299 .2952880859 303.1940917969307 .1282958984311 .0989074707315 .1070861816319 .1538085938 323.2401123047327 .3669128418331 .5353088379335 .74609375340 .0003051758 344.2984924316348 .6418151855353 .0304870605357 .4656982422361 .9476013184 366.4768981934371 .053894043375 .6789855957380 .3522949219385 .0741882324 389.8447875977394 .6643066406399 .5327148438404 .4504089355409 .4172058105 414.433807373419 .4996032715424 .6153869629429 .7803039551434 .9949951172 440.2579956055445 .5700073242450 .9289855957456 .3351135254461 .7858886719 467.2811889648472 .8181152344478 .3959960938484 .011505127489 .6636047363 495.3482971191501 .0639038086506 .8057861328512 .571472168518 .3557128906 524.1549072266529 .9630126953535 .7755126953541 .5853881836547 .387512207 553.1738891602558 .9381103516564 .6724853516570 .3696289062576 .022277832 581.6221923828587 .1638183594592 .637878418598 .0421142578603 .3668212891 608.6140136719613 .7747192383618 .8574829102623 .8555908203628 .7821044922 633.6353759766638 .4138793945643 .0977172852647 .7039794922652 .2219848633 656.6723022461661 .0609130859665 .3859863281669 .6781005859673 .9102783203 678.0745239258682 .3137817383686 .49609375691 .3115234375696 .7766723633 703.0341186523709 .8914794922716 .3170776367721 .7681274414725 .9732055664 728.9340209961732 .3068847656738 .0576171875743 .5635986328747 .6071777344 747.1782226562735 .7451171875728 .1270141602740 .4672241211756 .3724975586 762.0872802734762 .7310791016759 .3950805664753 .236328125745 .9628295898 738.9066772461736 .6602783203731 .3068847656712 .9749755859693 .3947143555 682.0797729492673 .2233276367665 .7307128906658 .4318237305649 .7418823242 640.9047241211632 .0828857422625 .6182250977624 .1442871094624 .5003051758 622.7014160156618 .9406738281612 .9395751953603 .3629760742588 .147277832 575.8176269531577 .4509887695581 .7949829102579 .8847045898573 .5457763672 560.9697875977545 .5399780273531 .0017700195515 .2880859375496 .3489990234 478.3182067871465 .7499084473455 .6358947754445 .7974853516436 .6268920898 427.5400085449418 .1564025879408 .0155029297397 .8460083008388 .2943115234 379.416809082371 .5168151855365 .1090087891360 .5676879883358 .2125854492 358.0599975586360 .2302856445364 .5013122559370 .2143859863375 .9401855469 379.9630126953380 .0700073242377 .4939880371375 .3713989258369 .4541931152 356.1991882324340 .3883056641325 .0611877441311 .8953857422302 .924987793 296.899810791292 .2658081055289 .1307067871287 .6560058594286 .7679138184 285.9690856934285 .3008117676284 .5274047852283 .3366088867281 .3966064453 278.6599121094275 .1140136719271 .3102111816267 .9472045898264 .3688964844 260.6592102051256 .6513061523252 .4324951172248 .1775054932244 .2061004639 239.2169036865231 .3692932129223 .1248016357215 .3589935303209 .3665924072 205.9859924316205 .1448974609207 .7772979736213 .1629943848221 .6188049316 
232.1620025635243 .6063995361255 .6381072998267 .5220947266279 .1120910645 290.0598144531300 .3445129395309 .8609008789318 .6577148438326 .7648010254 334.2565002441341 .2273864746347 .7456970215353 .9252929688359 .8078918457 365.4971008301371 .0065002441376 .4146118164381 .7150878906386 .9559936523 392.1214904785397 .2434082031402 .2878112793407 .2426147461412 .1326904297 416.9930114746421 .8117980957426 .5905151367431 .3291015625436 .0264892578 440.6777038574445 .2777099609449 .8226928711454 .3064880371458 .7257995605 463.0739135742467 .3482055664471 .5421142578475 .6536865234479 .6771850586 483.6117858887487 .4523925781491 .199005127494 .8479003906498 .399810791 501.8522033691505 .2067871094508 .4624023438511 .62109375514 .682800293 517.6499023438520 .5233154297523 .3049926758525 .9963989258528 .5996704102 531.116394043533 .5487060547535 .8980712891538 .1671142578540 .3571166992 542.4710083008544 .5106201172546 .4788208008548 .3776855469550 .2103881836 551.9791870117553 .6870727539555 .3366699219556 .9307250977558 .4716186523 559.9619140625561 .4041137695562 .8004150391564 .1531982422565 .4647216797 566.7369995117567 .9724121094569 .1727905273570 .3405151367571 .4774169922 572.5855102539573 .6671142578574 .7238769531575 .7578735352576 .770690918 577.7642822266578 .7404174805579 .7006225586580 .6461791992581 .5792236328 582.5004882812583 .4118041992584 .3142700195585 .2092895508586 .0977783203 586.9810180664587 .8599853516588 .7357788086589 .6091918945590 .4812011719 591.3524169922592 .223815918593 .0958251953593 .9692993164594 .8446044922 595.7224121094596 .6030273438597 .4868774414598 .3745117188599 .2659912109 600.1616821289601 .0620117188601 .9666748047602 .8762207031603 .7905273438 604.7095947266605 .6334228516606 .5618896484607 .4948120117608 .4321289062 609.3734741211 610.3184814453 611.266784668 612.2180786133613.1718139648 614.1275024414615 .084777832616 .0429077148617 .0023193359

67.2491989135770 .3280410766673 .4045562744176 .4795532226679 .55484008789 82.6313781738385 .7098388671988 .7912826538191 .8762283325294 .96563720703 98.05992889404101 .1598968506104 .2657012939107 .3779983521110 .4968032837 113.6223983765116 .7547988892119 .8940963745123 .0402984619126 .1931991577 129.3527984619132 .5189056396135 .69140625138 .8701934814142 .0549926758 145.245803833148 .4423980713151 .6448059082154 .8527984619158 .0662994385 161.2852935791164 .5097961426167 .7398071289170 .9752960205174 .2164001465 177.4633026123180 .7160949707183 .9750061035187 .2402954102190 .5122070312 193.7910003662197 .0771942139200 .3712005615203 .6732940674206 .9842071533 210.304397583213 .6343994141216 .974899292220 .3265991211223 .6900939941 227.0662994385230 .4557952881233 .8594970703237 .2783050537240 .7129058838 244.1645050049247 .6336975098251 .1217041016254 .6293029785258 .1577148438 261.7077026367265 .2804870605268 .8770141602272 .4982910156276 .1455078125 279.8197021484283 .5217895508287 .253112793291 .0144958496294 .8071899414 298.6321105957302 .4903869629306 .3829040527310 .3109130859314 .2750854492 318.2767944336322 .3164978027326 .3955078125330 .5144042969334 .6742858887 338.8756103516343 .1192932129347 .4059143066351 .7362060547356 .1104125977 360.5292053223364 .9927978516369 .5017089844374 .0557861328378 .6553955078 383.3004150391387 .9910888672392 .7272033691397 .5090026855402 .3359069824 407.2083129883412 .1254882812417 .087890625422 .0943908691427 .1452026367 
432.2388916016 437.3756103516442.5534057617447.7719116211453.0289001465 458.3233947754463 .6528015137469 .0158081055474 .408996582479 .8306884766 485.2768859863490 .7453918457496 .2312927246501 .7316894531507 .2409973145 512.7551879883518 .2681274414523 .7747802734529 .2678833008534 .7416992188 540.1881713867545 .6008300781550 .9711914062556 .2921142578561 .555480957 566.7537841797571 .8803100586576 .9270019531581 .8897705078586 .7609863281 591.5410766602596 .2241210938600 .8167724609605 .3173217773609 .7382202148 614.0872802734618 .3615112305622 .5462036133626 .6688232422630 .7313842773 634.7626953125638 .7797241211642 .7744140625646 .7758789062650 .6781005859 654.4575805664658 .0330200195661 .1994018555664 .850402832669 .1505126953 674.9525146484683 .0772094727690 .8134155273696 .1621704102699 .2583007812 700.2697143555701 .4331054688704 .3604125977707 .8322753906710 .9912719727 711.7633056641706 .7780761719704 .0670776367712 .200012207722 .5916748047 729.5247192383732 .0634155273728 .4708862305722 .5014038086718 .6657104492 717.3740234375719 .6326293945719 .3411865234711 .549621582700 .9849243164 693.957824707689 .1527099609685 .5405273438680 .3826293945671 .5994262695 659.8801269531646 .6212158203636 .7064819336634 .3759155273638 .133972168 646.9315185547654 .5526123047654 .8358764648649 .584777832641 .0723876953 629.0241699219611 .8928833008598 .1984863281595 .135925293593 .4680786133 585.3004150391573 .2412719727560 .4072875977546 .0084838867530 .1787719727 514.1331787109498 .4888916016484 .6726074219474 .437713623465 .3872070312 455.2897949219444 .8405151367434 .5953063965424 .4349975586414 .2182922363 404.3273925781395 .2177124023387 .500213623381 .8783874512378 .225189209 376.3116149902376 .3434143066378 .5040893555382 .2470092773387 .0918884277 391.4353942871392 .2883911133391 .5317077637390 .2533874512385 .6081848145 376.0953063965363 .1209106445348 .6672058105334 .8642883301324 .1723937988 316.7037963867312 .0321044922308 .8978881836305 .2734985352302 .0668945312 300.2380981445299 .0505981445297 .9007873535296 .2107849121293 .634185791 291.0161132812288 .9042053223287 .1650085449285 .570892334283 .6932983398 282.4585876465280 .4652099609276 .5320129395272 .4519958496269 .4216003418 265.2579040527257 .9555053711249 .0158996582238 .845993042230 .2364044189 225.0576934814222 .9263000488225 .0350952148230 .5144958496239 .524307251 250.957901001263 .0606079102275 .5054016113287 .5573120117299 .1137084961 309.8566894531319 .7974853516328 .8363952637337 .0523071289344 .478302002 351.217590332357 .3727111816363 .0372924805368 .3345031738373 .3283996582 378.1283874512382 .7672119141387 .324005127391 .8052978516396 .2560119629 400.673614502405 .079498291409 .4519042969413 .7828979492418 .0755004883 422.3395080566426 .5852050781430 .8251953125435 .0521850586439 .2612915039 443.4482116699447 .6098937988451 .7395019531455 .830291748459 .8771972656 463.8735046387467 .8147888184471 .6943054199475 .5086975098479 .2521972656 482.9219970703486 .5134887695490 .024810791493 .4525146484496 .7958068848 500.0524902344503 .2228088379506 .3056945801509 .3023071289512 .2125244141 515.0377807617517 .7789916992520 .4373168945523 .0139770508525 .5104980469 527.9279785156530 .2678833008532 .5314941406534 .7205810547536 .8366699219 538.8818969727540 .8577880859542 .766784668544 .6112060547546 .3931884766 548.1154174805549 .7800292969551 .3895874023552 .9467163086554 .4536132812 
555.9124755859557 .3259277344558 .6956176758560 .0241088867561 .3131713867 562.5653076172563 .7822265625564 .9661254883566 .1187744141567 .2424926758 568.3389282227569 .4102783203570 .458190918571 .4846191406572 .4910888672 573.4796142578574 .4514160156575 .4083251953576 .3518066406577 .2833251953 578.2042236328579 .1157226562580 .0189819336580 .9155883789581 .8062744141 582.6923828125583 .5745239258584 .4539794922585 .3314819336586 .2078857422 587.083984375587 .9603881836588 .8377075195589 .7166137695590 .5974731445 591.4810180664592 .3673706055593 .2572021484594 .1505737305595 .0479125977 595.9494018555596 .8552246094597 .7653198242598 .6801147461599 .5993041992 600.5230712891601 .4514160156602 .383972168603 .3206787109604 .2614135742 605.2056884766606 .1533203125607 .1038208008608 .0568237305609 .0117797852 609.9686279297610 .9266967773611 .8859863281612 .8463745117

65.0457382202168 .1140899658271 .1822814941474 .2487564086977 .31494903564 80.3817901611383 .4498291015686 .5200805664189 .5929870605592 .66954040527 95.7500915527398 .83545684814101 .9259033203105 .0218963623108 .1238021851 111.2316970825114 .345703125117 .4661026001120 .5925979614123 .7251968384 126.8639984131130 .0088043213133 .1593933105136 .3157958984139 .4777069092 142.6450958252145 .8179016113148 .995803833152 .1788024902155 .3666992188 158.5596923828161 .7575073242164 .9602966309168 .1678924561171 .3804931641 174.5980987549177 .8209991455181 .0491943359184 .2830963135187 .5227966309 190.7686004639194 .0209960938197 .2801971436200 .5467987061203 .821105957 207.1036987305210 .3952941895213 .6963043213217 .0072937012220 .3291931152 223.6625061035227 .008102417230 .3666992188233 .7391052246237 .1260986328 240.5287017822243 .9476928711247 .3840026855250 .8385009766254 .3123016357 257.8063049316261 .3214111328264 .8587036133268 .4191894531272 .0038146973 275.6137084961279 .2496948242282 .9130859375286 .6046142578290 .325592041 294.0766906738297 .8591918945301 .6737976074305 .5217895508309 .4036865234 313.320892334317 .2738952637321 .2637023926325 .2911071777329 .3568115234 333.4614868164337 .6061096191341 .7908935547346 .0166015625350 .2836914062 354.5924987793358 .9431152344363 .3362121582367 .7716064453372 .2495117188 376.7697143555381 .3323974609385 .9370117188390 .5838928223395 .2720947266 400.0018920898404 .7721862793409 .583404541414 .4336853027419 .3236083984 424.2510986328429 .2160949707434 .2164001465439 .2517089844444 .3190917969 449.4179077148454 .544708252459 .6983032227464 .874786377470 .0723876953 475.2864990234480 .5148010254485 .7518005371490 .9946899414496 .236907959 501.4750061035506 .7015075684511 .9119873047517 .0980834961522 .2542724609 527.3717041016532 .4439086914537 .4619750977542 .4185180664547 .3051147461 552.1137695312556 .8375854492561 .4680175781566 .0009765625570 .4279785156 574.7504882812578 .9608154297583 .0690917969587 .0708007812590 .986328125 594.8239135742598 .5864257812602 .2523803711605 .8679199219609 .4310302734 613.0009155273616 .5908203125620 .2147827148623 .9273071289627 .5413818359 631.1151733398634 .2255249023636 .6080932617638 .9038696289641 .3137817383 645.3297729492653 .0383911133661 .1077880859665 .9180297852668 .6804199219 669.1633911133668 .4000244141667 .8256835938667 .974609375668 .9338989258 670.4774780273671 .2351074219672 .1947021484674 .283203125677 .0806274414 682.9771728516687 .0001220703683 .4827270508679 .3502807617679 .826171875 
682.6541137695685 .6967163086688 .3720703125691 .3950805664692 .8668212891 692.3994140625691 .434387207690 .2822265625686 .6109008789678 .6525268555 667.5026855469653 .3792724609642 .3076171875639 .7518920898645 .2067871094 661.7222900391678 .6525268555684 .3021240234685 .1854858398686 .7294921875 677.9653930664645 .1124267578612 .7636108398606 .2169799805606 .6561889648 600.9611816406593 .1190795898583 .766418457572 .8126220703561 .8073730469 549.0603027344531 .5686035156514 .7412109375504 .0823974609494 .9684143066 483.7929077148472 .808807373462 .895690918453 .1234130859442 .6689147949 432.3089904785422 .7526855469414 .3440856934408 .0678100586403 .3297119141 399.7528076172397 .883392334397 .8319091797399 .7325134277403 .5307922363 407.0950927734 407.4092102051 406.0026855469 403.2771911621 399.2030029297 393.5851135254385 .3825073242374 .3323059082361 .8976135254351 .0616149902 342.199798584336 .4179992676332 .062713623325 .1213989258319 .0846862793 315.9041137695313 .4841918945311 .4018859863309 .1506958008306 .4956970215 304.1758117676303 .0616149902302 .3728942871302 .0057983398302 .2958068848 304.411895752305 .6480102539303 .1422119141299 .8644104004297 .7255859375 294.4408874512288 .4635009766279 .1560974121266 .3539123535254 .4304046631 245.6936035156241 .9532012939243 .8439025879249 .8394012451259 .729888916 271.5979003906283 .9849853516296 .4941101074308 .4686889648319 .7585144043 330.1441040039339 .5793151855348 .0299987793355 .547088623362 .2037963867 368.0982055664373 .3656921387378 .1010131836382 .4614868164386 .5078125 390.3843994141394 .112701416397 .8031921387401 .446685791405 .1102905273 408.7742004395412 .4696960449416 .1734924316419 .8989868164423 .6182861328 427.3150024414431 .0133056641434 .7365112305438 .4715881348442 .2098083496 445.9512939453449 .6915893555453 .4237976074457 .1370849609460 .8277893066 464.4862060547468 .108795166471 .6864013672475 .2163085938478 .6903076172 482.1066894531485 .458190918488 .7439880371491 .9584960938495 .1017150879 498.1694946289501 .162902832504 .0791931152506 .9198913574509 .6838989258 512.3728027344514 .9863891602517 .526184082519 .9923706055522 .3862304688 524.7080078125526 .9592285156529 .1400756836531 .2526245117533 .2971801758 535.276184082537 .1903076172539 .042175293540 .8333740234542 .5662841797 544.2426757812545 .8651733398547 .4357299805548 .9567260742550 .4301147461 551.858215332553 .2431030273554 .5866699219555 .8911743164557 .1583862305 558.3905029297559 .5891723633560 .7567138672561 .8947753906563 .0054931641 564.0905151367565 .1516723633566 .1909179688567 .2098999023568 .2100830078 569.1934814453570 .1611938477571 .1151123047572 .0565185547572 .9865722656 573.9069824219574 .8187255859575 .7230834961576 .6212158203577 .5140991211 578.4027709961579 .2883300781580 .1713867188581 .0529785156581 .9337768555 582.8145751953583 .6959838867584 .5784912109585 .4628295898586 .3491821289 587.2384033203588 .1306152344589 .0261230469589 .9251708984590 .8281860352 591.7352294922592 .646484375593 .5620117188594 .4818115234595 .4058837891 596.3344116211597 .2669067383598 .2036132812599 .1439208984600 .087890625 601.0350952148601 .9852905273602 .9379882812603 .8928833008604 .8494873047 605.8076171875606 .766784668607 .7265014648608 .6870727539 62.8407096862865 .9046325683668 .9647827148472 .0221481323275 .07888031006 78.1356124877981 .1929626464884 .2517395019587 .3124771118290 .37603759766 
93.4428329467896 .5136184692499 .58869171143102 .6686019897105 .7536010742 108.84400177111 .9397964478115 .0411987305118 .1482009888121 .2608032227 124.3788986206127 .5025024414130 .6313934326133 .7655029297136 .9046936035 140.0487976074143 .1976928711146 .3511962891149 .5093994141152 .6719055176 155.8388977051159 .0101013184162 .1856994629165 .3654937744168 .5496063232 171.7380981445174 .9311065674178 .1287994385181 .3312988281184 .5388946533 187.7518005371190 .9703979492194 .1949005127197 .4259033203200 .6638031006 203.908996582207 .1620941162210 .4235992432213 .6941070557216 .974395752 220.2649993896223 .566696167226 .8802032471230 .2062988281233 .5458068848 236.8995056152240 .2682952881243 .6529998779247 .0545959473250 .4739074707 253.9118041992257 .3693847656260 .8475952148264 .3472900391267 .8695068359 271.4151916504274 .9852905273278 .5808105469282 .2026977539285 .8521118164 289.5296020508 293.2365112305 296.9735107422 300.741607666304 .541595459 308.3745117188312 .2409973145316 .141998291320 .0780944824324 .0501098633 328.05859375332 .1044006348336 .1878051758340 .3095092773344 .4696960449 348.6690063477352 .9072875977357 .1852111816361 .5025024414365 .8593139648 370.2554016113374 .6907958984379 .1651000977383 .6781005859388 .229095459 392.8178100586397 .4432983398402 .1052856445406 .8023071289411 .533996582 416.2984924316421 .0953979492425 .9223937988430 .7785949707435 .6612854004 440.5692138672445 .4989013672450 .4487915039455 .4147033691460 .3944091797 465.383392334470 .3786010742475 .3746948242480 .3680114746485 .3522033691 490.3230895996495 .2731933594500 .1973876953505 .0874938965509 .9371948242 514.7376098633519 .4818115234524 .1604003906528 .7658081055533 .2888793945 537.7219238281542 .0562744141546 .2841796875550 .3994750977554 .3947753906 558.2689208984562 .016418457565 .6442260742569 .1519165039572 .5582885742 575.8771972656579 .1096191406582 .2495117188585 .3292236328588 .3510742188 591.3986206055594 .5015258789597 .7318115234601 .1704711914604 .6624755859 608.2659301758611 .245300293613 .328918457614 .2531738281613 .2150268555 612.9743041992616 .0355224609620 .6552124023625 .2770996094629 .5659790039 633.5358276367634 .9906005859632 .188293457629 .8732910156632 .2830810547636 .8125 638.9727783203639 .9136962891641 .5681152344642 .3276977539642 .1818237305 642.321472168641 .0045776367640 .3469238281641 .3690795898643 .9490966797 647.6118164062651 .6392822266654 .2637939453656 .6997070312659 .9848022461 662.083190918662 .3123168945660 .3323974609656 .5374755859650 .5693969727 642.4791259766635 .9453735352634 .6397705078639 .0833740234650 .1254272461 662.3922119141670 .1353149414676 .9317016602687 .1334838867685 .0175170898 657.704284668627 .3563842773617 .0164794922615 .3947143555611 .9349975586 607.7332763672602 .4801025391595 .6765136719587 .0059204102576 .0571289062 562.3856811523548 .0797729492536 .0452270508525 .132019043514 .3754272461 504.2849121094494 .870513916485 .5820007324475 .6507873535465 .912109375 457.5267944336450 .0646972656443 .532409668437 .9999084473433 .548614502 430.3630981445428 .8698120117428 .7626953125428 .6969909668428 .1307983398 425.7611083984422 .169708252418 .6979064941416 .4159851074415 .1229858398 412.3070068359404 .5775146484393 .6405029297382 .6968078613371 .8091125488 361.1525878906351 .9791870117344 .7943115234339 .5441894531336 .4278869629 333.9169006348330 .8922119141328 .2410888672326 .6590881348325 .6315002441 
324.1907958984322 .859588623321 .7580871582322 .8800048828328 .8835144043 334.3211975098334 .190612793332 .5952148438332 .0704040527330 .4233093262 325.986907959316 .0401000977299 .0185852051281 .6037902832267 .4295043945 260.3851928711264 .266998291272 .9767150879283 .2609863281294 .9815979004 306.9981994629319 .0567932129330 .5289916992341 .2951965332351 .0568847656 359.8243103027367 .5072937012374 .2038879395379 .9624023438384 .9172058105 389.1986999512392 .9327087402396 .2799987793399 .3288879395402 .2264099121 405.0163879395407 .8063964844410 .6036987305413 .4677124023416 .3861999512 419.3797912598422 .4341125488425 .5483093262428 .699005127431 .8667907715 435.0609130859438 .2892150879441 .550201416444 .8416137695448 .1585083008 451.4985961914454 .8512878418458 .2060852051461 .5566101074464 .8941040039 468.2124023438471 .5029907227474 .7608947754477 .9786987305481 .1524047852 484.2755126953487 .3452148438490 .3565063477493 .3077087402496 .1951904297 499.0185852051501 .775604248504 .4666137695507 .0907897949509 .6487121582 512.1403808594514 .5662841797516 .9268188477519 .2222290039521 .4525756836 523.6187744141525 .7205810547527 .7593994141529 .7354736328531 .6505126953 533.5053710938535 .3018798828537 .041809082538 .7268066406540 .3590087891 541.9403076172543 .4727783203544 .9583740234546 .3991088867547 .796875 549.1539916992550 .4719848633551 .7529296875552 .9985961914554 .2111816406 555.3922119141556 .5435791016557 .6674194336558 .7653808594559 .8391113281 560.890625561 .9213256836562 .9329833984563 .9271850586564 .9055786133 565.8693847656566 .8203125567 .7595825195568 .6885986328569 .6085205078 570.5206298828571 .4259033203572 .3256835938573 .2208251953574 .1121826172 575.0009155273575 .8878173828576 .7733764648577 .6586303711578 .544128418 579.430480957580 .3181762695581 .207824707582 .0997924805582 .9946289062 583.8922729492584 .7935791016585 .6983032227586 .6068725586587 .5194091797 588.4359741211589 .3566894531590 .2816162109591 .2103881836592 .143371582 593.0802001953594 .0208129883594 .9647216797595 .9119873047596 .8621826172 597.8150024414598 .7700195312599 .7269287109600 .6853027344601 .6447753906 602.6052246094603 .5662841797604 .5278930664 60.6506500244163 .7020912170466 .7527999877969 .8008804321372 .84770965576 75.8940200805778 .9403228759881 .9874267578185 .0357894897588 .08625030518 91.1392135620194 .1954269409297 .25518798828100 .3190994263103 .387298584 106.4601974487109 .537902832112 .6205978394115 .7081985474118 .8007965088 121.898399353125 .0009002686128 .1082000732131 .220199585134 .3367004395 137.4575958252140 .5827941895143 .712097168146 .8453979492149 .9826965332 153.1237030029156 .2684020996159 .4169006348162 .5690002441165 .7247009277 168.8842010498172 .0475006104175 .2145996094178 .3858947754181 .5614013672 184.7415008545187 .9264068604191 .116394043194 .3119049072197 .5133972168 200.721206665203 .9358978271207 .1580963135210 .3881988525213 .6269073486 216.8748931885220 .1327972412223 .4013061523226 .6813049316229 .9732971191 233.2781982422236 .5968933105239 .9300994873243 .278793335246 .6437072754 250.0258026123253 .4261016846256 .8452148438260 .2843933105263 .7442016602 267.2258911133270.7301940918274.2582092285277.8106079102 281.3886108398 284.9927978516288 .6242980957292 .2839050293295 .9725036621299 .6907958984 303.4397888184 307.2200927734311.0325927734 314.8778076172 318.7565002441 
322.6691894531326 .6166992188330 .5992126465334 .6173095703338 .671295166 342.7615966797346 .8882141113351 .0515136719355 .2513122559359 .4877929688 363.7605895996368 .0697021484372 .4143981934376 .794708252381 .2095947266 385.6589050293390 .141204834394 .6561889648399 .2020874023403 .7785949707 408.3832092285413 .0155944824417 .6730041504422 .3544921875427 .0570068359 431.7791137695436 .516998291441 .2688903809446 .0303039551450 .7990112305 455.5694885254460 .3393859863465 .1021118164469 .8546142578474 .5895996094 479.3031005859483 .9867858887488 .6359863281493 .2413024902497 .797088623 502.2933044434506 .7232971191511 .0766906738515 .3463134766519 .521484375 523.5947875977527 .5565795898531 .3984985352535 .1132202148538 .6923828125 542.1343994141545 .4323730469548 .5944213867551 .6182250977554 .5241699219 557.3267211914560 .0333251953562 .6458740234565 .1907958984567 .6450805664 570.1301269531572 .6442871094575 .3676147461578 .3900146484581 .6226806641 585.2186889648588 .3779907227590 .8350830078591 .2335205078587 .4962768555 583.4050292969581 .7631835938582 .2105102539585 .325378418590 .3148803711 597.5137939453602 .5958251953599 .6574707031596 .6666870117601 .3577880859 606.8681030273607 .4437866211606 .8685302734609 .6663818359611 .1090698242 606.9290771484602 .9182739258603 .5581054688605 .7255249023606 .0537719727 606.900390625609 .9719848633613 .2252807617612 .9569702148613 .4434204102 617.9655761719622 .0302124023622 .8704223633622 .387878418623 .0159912109 623.2042236328622 .5567016602622 .3145141602623 .0637817383625 .5095214844 628.3677978516633 .0062866211640 .2484741211648 .5899047852661 .7144165039 667.076171875652 .1196899414633 .4403076172624 .4094848633620 .0900268555 617.5858154297616 .2196044922614 .9763793945612 .0739135742605 .4506835938 596.5687866211587 .7874755859577 .862487793565 .8715820312554 .1198120117 544.3399047852535 .4771728516526 .4241943359517 .5753173828508 .202911377 499.4465942383492 .974395752487 .2116088867481 .1575012207475 .7579956055 471.5639953613468 .4229125977466 .8114013672464 .491394043459 .5358886719 453.9366149902448 .462890625444 .3164978027441 .9649963379440 .8406066895 441.7762145996441 .1026000977435 .1358032227426 .4287109375416 .8815002441 405.1088867188390 .1794128418376 .0758972168367 .93258666999363 .2226867676 359.2182922363356 .4415893555352 .9352111816350 .2307128906349 .9753112793 349.8481140137348 .2043151855346 .4067077637344 .8583984375346 .8109130859 356.262298584366 .0802001953369 .3308105469369 .625793457370 .1784973145 368.6151123047364 .9071960449356 .6937866211339 .5358886719319 .007598877 299.1536865234286 .0385131836289 .0730895996299 .5718078613309 .3736877441 320.2948913574331 .5607910156342 .7139892578353 .4389038086363 .4014892578 372.3811035156380 .3062133789387 .107208252392 .861114502397 .6258850098 401.5419006348404 .7564086914407 .4047851562409 .6781921387411 .6632080078 413.5463867188415 .3565063477417 .236114502419 .1716918945421 .2452087402 423.4248046875425 .7396850586428 .1604919434430 .6850891113433 .2894897461 435.9592895508438 .683807373441 .4471130371444 .2612915039447 .129486084 450.0473937988453 .0085144043456 .0042114258459 .0192871094462 .0498962402 465.0828857422468 .1142883301471 .1322937012474 .1335144043477 .1075134277 480.0516052246482 .9570922852485 .8221130371488 .6394042969491 .4083862305 494.1236877441496 .7856140137499 .3901977539501 .9388122559504 .4291992188 
506.862487793509 .237487793511 .5551147461513 .8143920898516 .0161132812 518.1591186523520 .2440795898522 .270324707524 .2387695312526 .1491088867 528.0029296875529 .8004760742531 .5438842773533 .2338867188534 .8728027344 536.4619140625538 .0032958984539 .4984741211540 .9497070312542 .358581543 543.7269897461545 .0568237305546 .3496704102547 .6077270508548 .8325195312 550.0258789062551 .1896972656552 .3256835938553 .4354858398554 .5211181641 555.583984375556 .6259765625557 .6486206055558 .6533203125559 .6416015625 560.6151733398561 .5753173828562 .5234985352563 .4608154297564 .3887939453 565.3082885742566 .2208862305567 .1273193359568 .0288085938568 .9260864258 569.8203735352570 .7124023438571 .6030273438572 .4926757812573 .3823852539 574.2725830078575 .1638793945576 .0568237305576 .9517822266577 .8491821289 578.7495727539579 .6530151367580 .5598144531581 .4702148438582 .3842773438 583.3021850586584 .2241210938585 .1499023438586 .0797119141587 .0133056641 587.9506835938588 .8917236328589 .8361206055590 .7838134766591 .7343139648 592.6873779297593 .6428833008594 .6002807617595 .559387207596 .5197143555 597.4807739258598 .4426879883599 .4047241211600 .3671875

58.4586486816461 .5058517456164 .5479278564567 .5859909057670 .62259674072 73.6581268310576 .6931304931679 .7282867431682 .7640991210985 .80132293701 88.8403701782291 .8819580078194 .9263992309697 .97425842285101 .0258026123 104.0812988281107 .1409988403110 .2050018311113 .2733001709116 .3460998535 119.4233016968122 .5047988892125 .5905990601128 .6804962158131 .7743988037 134.8722991943137 .9738006592141 .078994751144 .1876983643147 .299697876 150.4149017334153 .5332946777156 .6546936035159 .7792053223162 .9066009521 166.0370941162169 .1707000732172 .3074951172175 .4476013184178 .591293335 181.7386016846184 .8898925781188 .045501709191 .2055969238194 .370803833 197.5413970947200 .7178039551203 .9006958008207 .0904998779210 .287902832 213.4933013916216 .7075958252219 .9311981201223 .1651000977226 .4096984863 229.6661071777232 .9347991943236 .2167053223239 .5126037598242 .8233032227 246.1497039795249 .4927978516252 .8531036377256 .2318115234259 .6296081543 263.0474853516266 .4862060547269 .9468078613273 .4299926758276 .9368896484 280.4679870605284 .0245056152287 .6069030762291 .2163085938294 .853302002 298.5187072754302 .2131958008305 .9375915527309 .6924133301313 .478302002 317.2956848145321 .1452941895325 .0274047852328 .9425964355332 .8908996582 336.8728942871340 .8883972168344 .9378051758349 .020904541353 .1377868652 357.2880859375361 .4718017578365 .6881103516369 .9370117188374 .2171936035 378.528503418382 .8695068359387 .2395935059391 .6369018555396 .0607910156 400.5089111328404 .9801025391409 .4718933105413 .9829101562418 .5100097656 423.0513000488427 .6029968262432 .162689209436 .7261047363441 .2903137207 445.8500061035450 .4020080566454 .9401855469459 .4605102539463 .9559936523 468.422088623472 .8505859375477 .236114502481 .5694885254485 .8442993164 490.0506896973494 .1812133789498 .2253112793502 .1752929688506 .0202026367 509.7518005371513 .359375516 .8342895508520 .167175293523 .3494873047 526.3773803711529 .2443847656531 .9561157227534 .5131835938536 .9315185547 539.2255859375541 .4080200195543 .4976196289545 .4899902344547 .3715209961 549.2277832031551 .0535888672553 .1105957031555 .5197753906558 .3626708984 561.80078125565 .4901733398569 .6655273438571 .5266113281568 .1256103516 
563.6044921875561 .8217163086561 .1577148438559 .7186279297561 .2971191406 568.4865112305575 .1934204102575 .7280883789575 .7335205078580 .3403930664 583.7703857422579 .8499145508575 .9439086914580 .3347167969584 .7059936523 582.3815917969579 .2711791992579 .3029174805580 .6696166992580 .9122924805 580.4744262695580 .2009277344580 .4581298828581 .2630004883583 .573425293 586.9934082031590 .2938842773591 .5192260742592 .4232177734593 .9722290039 596.4600830078599 .1528930664601 .819519043604 .4202880859606 .3189697266 608.2003173828611 .3269042969616 .4948730469622 .0299072266625 .0344238281 626.1964111328624 .1992797852621 .1054077148619 .3065795898617 .7965698242 617.3626708984618 .2415771484620 .3547973633620 .9072265625617 .2449951172 611.3093261719604 .6821899414597 .1317138672588 .9876708984580 .2816772461 571.5675048828563 .0913696289554 .5905761719546 .1021118164537 .0446777344 529.1149902344524 .6903076172521 .1848144531516 .848815918513 .2280273438 511.7103881836511 .117401123511 .1332092285507 .9247131348497 .7065124512 487.0708007812481 .937286377480 .8445129395483 .1452941895484 .3649902344 479.1221923828471 .7585144043465 .3933105469458 .9483947754452 .7056884766 443.2315979004427 .8551940918411 .3179931641398 .2681884766388 .8593139648 381.7052001953376 .9151916504374 .6452026367373 .7536010742373 .4171142578 373.2518920898372 .9016113281372 .6882019043373 .483001709378 .4970092773 390.1282043457402 .8164978027411 .4782104492415 .4652099609413 .1965026855 408.2395935059 404.6541137695 400.4234924316 394.9284057617381 .9093933105 353.166809082327 .8348999023324 .283996582330 .8131103516338 .6481933594 348.0043029785357 .7925109863367 .7680053711377 .3060913086386 .229095459 394.1593017578401 .0794067383406 .8330993652411 .5268859863415 .1784057617 417.9588928223420 .0098876953421 .4964904785422 .6155090332423 .4841003418 424.2948913574425 .100402832426 .0389099121427 .1126098633428 .3898010254 429.8468017578431 .4973144531433 .312286377435 .2770996094437 .3688049316 439.5639038086441 .8421020508444 .1731872559446 .5718078613449 .0461120605 451.5892944336454 .1982116699456 .8588867188459 .5578918457462 .2874145508 465.0364074707467 .7976989746470 .5607910156473 .3196105957476 .0650939941 478.7922058105481 .4931030273484 .1642150879486 .7990112305489 .395111084 491.9479064941494 .4562988281496 .9171142578499 .330291748501 .6940917969 504.008605957506 .2732849121508 .487701416510 .6512145996512 .7636108398 514.8237304688516 .8314819336518 .7858886719520 .6871948242522 .5349121094 524.330078125526 .0729980469527 .7650756836529 .4072875977531 .0015258789 532.5490112305534 .0515136719535 .5108032227536 .928527832538 .3065185547 539.6461791992540 .9495849609542 .2183227539543 .4539794922544 .6586303711 545.8336181641546 .9805908203548 .1016235352549 .1981201172550 .2717895508 551.32421875552 .3571166992553 .3717041016554 .3698120117555 .352722168 556.3217773438557 .2783813477558 .2239990234559 .1597290039560 .0866699219 561.0062255859561 .9193115234562 .8270263672563 .7302856445564 .6301269531 565.5272827148566 .4226074219567 .3168945312568 .2108154297569 .1049194336 569.9998779297570 .8961791992571 .7943725586572 .6948242188573 .5977172852 574.5034790039575 .4124755859576 .3248901367577 .2407836914578 .1604003906 579.0836791992580 .010925293580 .9417724609581 .8765258789582 .8148193359 583.7565917969584 .7017822266585 .6500854492586 .6013183594587 .5551757812 
588.5114135742589 .4697265625590 .4296264648591 .3908081055592 .3530883789 593.3161010742594 .2794799805595 .2432861328596 .2067260742

56.2859497070359 .3188781738362 .3505516052265 .3786773681668 .40469360352 71.4291534423874 .4525375366277 .4755172729580 .4985733032283 .52240753174 86.547431945889 .5743408203192 .6034164428795 .6352767944398 .67008972168 101.7082977295104 .75107 .795501709110 .8445968628113 .8976974487116 .954498291 120.0151977539123 .079498291126 .1474990845129 .2189941406132 .2937927246 135.3719024658138 .4530029297141 .5370941162144 .6239013672147 .713394165 150.8054962158153 .8999938965156 .9969024658160 .0962982178163 .1979064941 166.3020019531169 .408493042172 .5175933838175 .6293945312178 .7440948486 181.8618927002184 .9832000732188 .1080932617191 .2371063232194 .3706054688 197.5090026855200 .6526947021203 .8023986816206 .9584960938210 .1215057373 213.2922973633216 .471206665219 .6591033936222 .8565979004226 .0644989014 229.2832946777232 .5140991211235 .7574005127239 .0142059326242 .2850952148 245.571105957248 .8728942871252 .1912994385255 .5272979736258 .8815917969 262.2550048828265 .6485900879269 .0628051758272 .4988098145275 .9572143555 279.4389038086282 .9446105957286 .475189209290 .0311889648293 .613494873 297.2226867676300 .8594055176304 .5242004395308 .2177124023311 .9403991699 315.6926879883319 .4750061035323 .287902832327 .1311950684331 .0056152344 334.9107055664338 .8469848633342 .8142089844346 .8124084473350 .8411865234 354.9005126953358 .9894104004363 .1079101562367 .2547912598371 .4296875 375.6310119629379 .8581848145384 .1091003418388 .3829956055392 .6773071289 396.9909057617401 .3207092285405 .6654968262410 .0215148926414 .3869934082 418.7575073242423 .1310119629427 .5024108887431 .8689880371436 .2249145508 440.5671081543444 .8887023926449 .1860961914453 .4515991211457 .6809082031 461.8651123047465 .9992980957470 .0733032227474 .0813903809478 .012298584 481.859588623485 .6109924316489 .2597961426492 .7929992676496 .2031860352 499.4772033691502.6069946289505.5804138184508.3890075684511.0259094238 513.4846191406515 .7692871094517 .8806762695519 .8345947266521 .6442260742 523.3270263672524 .9276123047526 .3986816406527 .7471923828528 .9962768555 530.0745849609531 .3792114258532 .9354858398535 .1469726562538 .2363891602 541.9362792969547 .440612793551 .0391235352548 .9713745117545 .599609375 545.132019043544 .1702270508538 .9265136719535 .6021118164540 .1812744141 546.9061279297551 .1517944336554 .2473144531557 .4119262695557 .5939941406 549.6038208008543 .5576171875549 .8939819336558 .0856933594559 .9442749023 559.9160766602559 .8568115234559 .3732299805558 .8701782227557 .883972168 555.2484741211553 .7147827148556 .6635742188560 .2827148438561 .7396240234 562.8176879883564 .0120239258565 .7271118164567 .4724121094570 .0955810547 573.7982177734577 .463684082580 .7697753906583 .2808227539586 .303527832 589.5115966797593 .205078125595 .0305786133587 .6959228516582 .5009155273 590.973815918601 .3120117188605 .8234863281608 .1450805664610 .1970825195 612.7794799805617 .3472900391621 .0673217773620 .7689208984618 .2573242188 614.1533813477609 .1633911133605 .720703125600 .9788208008594 .1112060547 586.276184082577 .6715087891569 .2725219727560 .1165771484552 .4807739258 549.6879882812548 .3073120117545 .7904052734544 .3635864258545 .4608154297 546.8109130859548544 .8997192383531 .6934204102518 .6469116211515 .4912719727 
517.2930297852523.3065185547526.2097167969514.6682739258500.6608886719 493.812286377488 .9165039062485 .6216125488479 .6592102051466 .449798584 450.8562011719435 .6044006348421 .3768920898408 .9744873047400 .4872131348 398.6624145508399 .0087890625396 .7947998047395 .3830871582396 .8340148926 400.2860107422404 .7514953613411 .9401855469424 .0093078613437 .2171020508 449.3581848145456 .387298584451 .8406982422444 .469909668441 .807800293 440.9119873047446 .4556884766442 .6127929688408 .9031982422374 .4616088867 364.6947937012365 .3966064453369 .4176940918376 .6796875384 .6315002441 393.167388916401 .3905944824409 .1141967773415 .9100036621421 .7284851074 426.3594970703429 .9189147949432 .3768005371433 .9450073242434 .754486084 435.0006103516434 .908203125434 .5976867676434 .3118896484434 .0833129883 434.0869140625434 .3002929688434 .8063049316435 .5628051758436 .583190918 437.8269958496439 .2705993652440 .8855895996442 .6391906738444 .5051879883 446.4371032715448 .4569091797450 .5679931641452 .7676086426455 .0495910645 457.4024963379459 .8071899414462 .259185791464 .7431945801467 .2543945312 469.7788085938472 .312713623474 .8435974121477 .3685913086479 .8770141602 482.3669128418484 .829498291487 .2637939453489 .6630859375492 .0274047852 494.3521118164496 .6380004883498 .8819885254501 .0848999023503 .2448120117 505.3619995117507 .4346923828509 .4627990723511 .4442138672513 .3787841797 515.2647094727517 .1024169922518 .8903198242520 .6295776367522 .3200073242 523.9630737305525 .5593261719527 .1104736328528 .6177978516530 .0828857422 531.5073852539532 .8928222656534 .2407226562535 .5529174805536 .8306884766 538.0759887695539 .2902832031540 .4752807617541 .6326293945542 .763671875 543.870300293544 .953918457546 .0162963867547 .0587158203548 .0828857422 549.0900878906550 .0819702148551 .0596923828552 .0247192383552 .9780883789 553.9213867188554 .8557128906555 .7822265625556 .7017211914557 .6154785156 558.5247192383559 .4299926758560 .3322753906561 .2324829102562 .1314086914 563.0296020508563 .9276733398564 .8264160156565 .7261962891566 .6276245117 567.5308837891568 .436706543569 .3452148438570 .2565917969571 .171081543 572.0891113281573 .0104980469573 .9354858398574 .8643188477575 .7966918945 576.7327270508577 .6721801758578 .6151123047579 .5614013672580 .5106811523 581.4630126953582 .4179077148583 .3751220703584 .3344726562585 .2955932617 586.2581787109587 .2218017578588 .1862792969589 .1513061523590 .1165161133 591.0816040039592 .0468139648

54.1110687255957 .1400909423860 .1626510620163 .1799888610866 .19508361816 69.2081604003972 .2196884155375 .2302627563578 .240379333581 .25064849854 84.2615432739387 .2736511230590 .2873382568493 .3031311035296 .32128143311 99.34219360352102 .3659973145105 .3928985596108 .422996521111 .4562988281 114.4928970337117 .5327987671120 .5757980347123 .6219024658126 .6709976196 129.7229003906132 .7776031494135 .8347015381138 .8943023682141 .9561004639 145.0200042725148 .0859069824151 .1535949707154 .2232055664157 .2944030762 160.3672943115163 .4420013428166 .5184020996169 .596496582172 .6766967773 175.758895874178 .8433990479181 .9304962158185 .0202941895188 .1134033203 191.2098999023194 .3103027344197 .4151000977200 .5247039795203 .6398010254 206.7606048584209 .8880004883213 .0223999023216 .1645965576219 .3150939941 222.4747009277225 .6439971924228 .8238067627232 .0146942139235 .2176971436 
238.4333953857241 .6625976562244 .9060058594248 .1645050049251 .4387969971 254.7299041748258 .0382995605261 .3651123047264 .7107849121268 .0762939453 271.4621887207274 .8695983887278 .2990112305281 .7510986328285 .2265930176 288.7261962891292 .2504882812295 .8001098633299 .3753967285302 .9772033691 306.6057128906310 .2614135742313 .9446105957317 .6557006836321 .3948974609 325.1622924805328 .9578857422332 .7818908691336 .6340942383340 .5145874023 344.4227905273348 .3586120605352 .3214111328356 .3107910156360 .3257141113 364.3656921387368 .429107666372 .5152893066376 .6221008301380 .7485046387 384.891998291389 .050994873393 .2225952148397 .4049987793401 .5945129395 405.7887878418409 .983795166414 .1766967773418 .3626098633422 .5382080078 426.6979064941430 .838104248434 .9520874023439 .0357055664443 .0816040039 447.0846862793451 .0368041992454 .9320068359458 .7607116699462 .5162963867 466.1879882812469 .7684936523473 .2460021973476 .612487793479 .8551940918 482.9653015137485 .9294128418488 .7377929688491 .3771972656493 .8375854492 496.1104125977498 .187713623500 .0729980469501 .7666931152503 .287902832 504.654296875505 .8901977539507 .0412902832508 .0382080078508 .8817138672 509.4934082031509 .798614502510 .1748046875510 .6617126465511 .8982849121 514.3281860352517 .4932861328521 .7680053711524 .7545166016523 .8225708008 521.6845703125520 .3489990234517 .5612792969512 .526184082507 .5768127441 505.4856872559507 .1965942383513 .6019897461518 .4813842773516 .374206543 511.1809997559506 .2976074219505 .2726135254511 .9931030273521 .4625854492 529.1948852539534 .4652709961536 .2222290039535 .7811889648534 .794921875 534.1896972656535 .2407836914537 .4984130859540 .9539794922543 .3197021484 542.2476806641540 .606628418540 .9442138672542 .6071777344544 .6909790039 547.3654785156550 .4334716797553 .6218261719556 .4055175781558 .825378418 561.2543945312563 .8973999023567 .73828125569 .3875732422565 .0278930664 563.8198242188572 .8958129883584 .1245117188588 .4415283203590 .0546875 593.3707885742597 .7711181641603 .8917236328610 .1489257812614 .2000732422 616.6533813477617 .750793457617 .7678833008617 .0106811523614 .1970214844 609.7807006836603 .1260986328593 .3991088867583 .5894165039574 .2382202148 566.4559936523563 .3739013672562 .1030273438560 .7930297852560 .6201171875 561.450012207561 .921875561 .7396240234557 .9810180664548 .3073730469 539.1608886719536 .7667236328538 .3228759766542 .8419189453543 .9453125 535.7625732422525 .4323730469519 .4188842773515 .6663208008512 .9329223633 508.6279907227500 .2395019531490 .1359863281481 .6376953125469 .7735900879 448.7742919922431 .366394043429 .3467102051429 .7344055176420 .5322875977 413.525390625419 .2893981934429 .0932922363435 .0891113281441 .3330993652 451.234588623461 .9271850586471 .4761047363477 .1954040527475 .8413085938 472.4533081055472 .1878967285473 .4844055176476 .1187133789470 .1965026855 445.0968933105417 .5414123535405 .1149902344400 .9671020508401 .6424865723 406.0210876465411 .8559875488418 .6509094238425 .4096984863431 .8591003418 437.445892334442 .1076049805445 .5629882812447 .920501709449 .1271972656 449.4078063965448 .9090881348447 .8500061035446 .4782104492444 .9468078613 443.5198974609442 .2503051758441 .3075866699440 .6796875440 .4310913086 440.5212097168440 .9442138672441 .6560058594442 .6188049316443 .7966918945 445.1477050781446 .6361999512448 .2083129883449 .8840942383451 .6683959961 
453.5551147461455 .5419006348457 .6123962402459 .7500915527461 .946685791 464.1889038086466 .4688110352468 .7746887207471 .099609375473 .4331054688 475.7697143555478 .1003112793480 .4208068848482 .7239074707485 .0064086914 487.263092041489 .4921875491 .6901855469493 .8564147949495 .988494873 498.0862121582500 .1481933594502 .1737060547504 .1611938477506 .109588623 508.0170898438509 .8825073242511 .7038879395513 .4810180664515 .2122192383 516.8983154297518 .5388183594520 .1348266602521 .6870727539523 .1970214844 524.6657714844526 .0949707031527 .4860229492528 .8402709961530 .1594848633 531.4450073242532 .698425293533 .9212036133535 .1151123047536 .2813720703 537.4218139648538 .5375976562539 .6306152344540 .7020263672541 .7537231445 542.7866821289543 .8026733398544 .8029785156545 .7891235352546 .7620239258 547.7233276367548 .6740112305549 .6154174805550 .5485229492551 .474609375 552.3944702148553 .3095092773554 .2202148438555 .1276855469556 .0327758789 556.9362182617557 .838684082558 .7409057617559 .643371582560 .5468139648 561.4514160156562 .3579101562563 .2666015625564 .1777954102565 .0916748047 566.0087890625566 .9290161133567 .8524780273568 .7794799805569 .7100219727 570.6441040039571 .5817260742572 .5228271484573 .4672241211574 .4146728516 575.3654785156576 .3190917969577 .2753295898578 .2338867188579 .1947021484 580.1572875977581 .1212768555582 .0866699219583 .0529174805584 .0197143555 584.9868164062585 .953918457586 .9207763672587 .88671875

51.9599685668954 .9730300903357 .9842987060560 .9911308288663 .99499893188 66.9964065551869 .9957962036172 .9937362670975 .9906768798878 .98725128174 81.9838409423884 .9810791015687 .9792785644590 .9789962768693 .98046112061 96.9840698242299 .98993682861102 .9983978271106 .0093994141109 .0231018066 112.0395965576115 .0587005615118 .0804977417121 .1047973633124 .1315994263 127.160697937130 .1920013428133 .2252960205136 .2604980469139 .2973022461 142.3356933594145 .37550354148 .416595459151 .4588012695154 .5021057129 157.5464019775160 .591796875163 .6381072998166 .6855926514169 .7342071533 172.7841033936175 .8354034424178 .8885040283181 .9434051514185 .0005950928 188.0603942871191 .1230010986194 .1891021729197 .258895874200 .3329925537 203.411895752206 .49609375209 .5863037109212 .6829071045215 .786605835 218.8981933594222 .0180969238225 .1472015381228 .2861022949231 .4355010986 234.596206665237 .7689056396240 .9541931152244 .1531066895247 .366104126 250.5941925049253 .8379974365257 .0982971191260 .3757019043263 .6711120605 266.9851989746270 .3186035156273 .6719970703277 .0462036133280 .4417114258 283.8591003418287 .2990112305290 .7619934082294 .2485046387297 .759185791 301.2940979004304 .8539123535308 .4386901855312 .0488891602315 .6845092773 319.3458862305 323.0328979492 326.745513916 330.4837036133 334.2473144531 338.0360107422341 .849609375345 .687286377349 .5488891602353 .4331970215 357.3398132324361 .266998291365 .2139892578369 .1787109375373 .1600952148 377.1552124023381 .1628112793385 .1792907715389 .2030029297393 .229888916 397.2579040527401 .2821044922405 .299987793409 .3062133789413 .2976074219 417.2680053711421 .2141113281425 .1286010742429 .0079040527432 .8436889648 436.6319885254440 .3630981445444 .0322875977447 .62890625451 .1473083496 454.5752868652457 .9068908691461 .1283874512464 .2330932617467 .2059936523 470.0397033691472 .7174072266475 .2309875488477 .563293457479 .7056884766 
481.6447143555483 .3736877441484 .8922119141486 .2008056641487 .3222961426 488.2750854492489 .0928039551489 .8304138184490 .4187011719490 .912689209 491.0635986328490 .8804016113490 .3728942871489 .6162109375489 .5570983887 490.7874145508493 .0874938965495 .9448852539498 .1318969727498 .3171081543 496.5314941406493 .1604003906488 .9551086426485 .4508056641481 .5285949707 474.4732971191470 .3208007812476 .712310791482 .4273986816475 .5804138184 467.6647949219468 .1307983398472 .4926147461478 .6221923828487 .1376037598 498.2456054688507 .7578125511 .186706543511 .6827087402510 .9610900879 511.100189209516 .2166748047522 .0700073242525 .3052978516526 .4096069336 523.662902832520 .5457763672520 .6021118164522 .0659179688524 .0620727539 526.4152832031528 .4177856445530 .1619262695531 .9033203125533 .5316162109 535.1762695312537 .219909668541 .0303955078544 .5081176758546 .1256103516 549.7642822266557 .1658935547564 .4885253906565 .4334716797565 .5330810547 570.1627197266576 .7838745117584 .3618774414592 .0726928711599 .4177856445 605.9468994141611 .8015136719615 .9332275391616 .5709838867615 .9771118164 616.1660766602612 .6356201172602 .9877929688590 .5322875977579 .4224853516 571.6430053711568 .4055175781567 .9766845703568 .1132202148568 .0725708008 567.0266723633565 .2089233398562 .6536254883559 .2913818359555 .0277099609 551.4088745117549 .9830932617549 .9782714844550 .8699951172550 .7122802734 547.9990844727544 .198425293540 .5579833984537 .4016113281534 .4583129883 531.4033813477528 .1580200195524 .2506713867523 .4227294922516 .3685302734 489.4854125977463 .9819030762460 .4198913574459 .4366149902443 .5046081543 431.6393127441440 .8566894531455 .0625460 .954498291465 .7569885254472 .9482116699 479.9991149902485 .4317016602489 .3569030762492 .0344848633493 .9489135742 496.599609375497 .5885925293493 .5461120605484 .4093933105470 .0740966797 454.2005004883442 .5527038574435 .0639953613432 .841003418434 .4346008301 438.0202026367443 .111114502448 .4104919434453 .6546020508458 .0828857422 461.6520080566463 .9374084473465 .1213989258465 .0372924805464 .0076904297 462.1390991211459 .7132873535457 .0288085938454 .2424926758451 .6871032715 449.3883972168447 .5412902832446 .1130065918445 .162109375444 .6383056641 444.5163879395444 .75445 .2799072266446 .0703125447 .0602111816448 .216003418 449.466796875450 .8399963379452 .3319091797453 .941986084455 .6624145508 457.4812927246459 .3765869141461 .3439025879463 .3652954102465 .4363098145 467.5414123535469 .6763000488471 .8276062012473 .9920043945476 .1578979492 478.3229064941480 .4775085449482 .6203918457484 .7441101074486 .8482971191 488.9277954102490 .9830932617493 .0104980469495 .0107116699496 .9807128906 498.9208068848500 .8281860352502 .7020874023504 .5397033691506 .3402099609 508.100402832509 .8204956055511 .4978942871513 .1334838867514 .7263793945 516.2777709961517 .7880859375519 .2587890625520 .6906738281522 .0855102539 523.444519043524 .7691040039526 .0607910156527 .3209838867528 .5510864258 529.7526245117530 .9268188477532 .075378418533 .1998291016534 .3012695312 535.3814086914536 .4415283203537 .4829711914538 .5073242188539 .5159301758 540.5098266602541 .4904785156542 .4592285156543 .417175293544 .3654785156 545.3054199219546 .2377929688547 .1638183594548 .0844726562549 .0006713867 549.9133911133550 .823425293551 .7313232422552 .6381835938553 .5443725586 554.4508056641555 .3577880859556 .2659301758557 .1757202148558 .0874023438 
559.0015258789559 .9182128906560 .8377075195561 .7603759766562 .6862182617 563.6154174805564 .5479736328565 .4840698242566 .4235839844567 .3665161133 568.3126220703569 .2619018555570 .2141723633571 .1693725586572 .1273193359 573.0875854492574 .0501098633575 .0144042969575 .9802856445576 .9475097656 577.9157104492578 .8845825195579 .8538208008580 .8231811523581 .7924804688 582.7612915039583 .7296142578

49.8065490722752 .8161010742255 .8178710937558 .8131904602161 .80554962158 64.7950134277367 .7820129394570 .7670822143673 .7506637573276 .73332214355 79.7154769897582 .6977233886785 .6803665161188 .6639480590891 .64866638184 94.6349487304797 .62291717529100 .6128997803103 .6048965454106 .5989990234 109.5952987671112 .5938034058115 .5942993164118 .5970001221121 .6015014648 124.6079025269127 .6158981323130 .6253967285133 .6363067627136 .6483001709 139.6613006592142 .6750946045145 .6896057129148 .7046966553151 .7200927734 154.7359924316157 .7521972656160 .7687072754163 .7855987549166 .8027954102 169.820602417172 .8388977051175 .8580932617178 .87840271181 .8999938965 184.9232025146187 .9483032227190 .9757995605194 .0059967041197 .0395050049 200.0765991211203 .1179046631206 .1638946533209 .2153015137212 .2725067139 215.3363037109218 .4071044922221 .4857940674224 .5727996826227 .6690979004 230.7749938965233 .891494751237 .0191040039240 .1585998535243 .3106994629 246.4761962891249 .6557006836252 .8500061035256 .0595092773259 .2853088379 262.5278015137265 .7878112793269 .0657043457272 .362487793275 .6784057617 279.0143127441282 .3703918457285 .7474975586289 .1458129883292 .5658874512 296.0079956055299 .4726867676302 .9598083496306 .469909668310 .0029907227 313.5592041016317 .1383972168320 .7406921387324 .365814209328 .0137939453 331.6841125488335 .3764953613339 .0905151367342 .825592041346 .5806884766 350.3552856445354 .1480102539357 .9577941895361 .7825012207365 .6209106445 369.4703979492373.3291015625 377.1939086914381.0624084473 384.9309082031 388.7966003418392 .655090332396 .5032043457400 .3359069824404 .1492919922 407.9378051758411 .6972961426415 .4212036133419 .1051940918422 .741607666 426.3254089355429 .8481140137433 .3039855957436 .6832885742439 .979309082 443.1809997559446 .2810058594449 .2669067383452 .1303100586454 .8569946289 457.437713623459 .8564147949462 .1026000977464 .1593017578466 .0151977539 467.6561889648469 .0725097656470 .2619934082471 .2226867676471 .9796142578 472.5495910645472 .9938964844473 .3688964844473 .6940002441474 .0768127441 474.1319885254473 .7850036621472 .554107666470 .0321960449467 .9111938477 467.2601013184468 .362487793472 .1523132324475 .7489013672476 .2568054199 473.7460021973467 .3840942383461 .4555053711460 .499786377459 .8186950684 455.0309143066451 .3364868164454 .3655090332457 .8098144531454 .7503051758 451.9071960449453 .5609130859457 .5427856445461 .9544067383467 .6138000488 475.120300293482 .311706543486 .2600097656487 .8877868652487 .7788085938 488.3602905273492 .1039123535496 .3164978027499 .2012023926500 .471496582 500.0338134766499 .5090026855500 .5874023438502 .3883056641504 .2987060547 506.1867980957507 .962890625508 .9858093262508 .7226867676508 .6932983398 510.2496032715512 .3449707031514 .1641845703516 .3120727539518 .4019165039 522.0980834961529 .8839111328536 .1049804688535 .5036010742535 .5466918945 542.444519043552 .1693725586561 .3767700195569 .8245849609576 .7122802734 
583.2272949219590 .4243164062595 .8552246094596 .5548706055598 .887512207 609.9354248047616 .1370849609606 .1290893555589 .4498291016574 .0709228516 564.3355102539565 .0274047852569 .1541137695570 .8762207031570 .2537231445 566.3186035156561 .5407714844558 .128112793556 .2111816406554 .8695068359 554.1853027344554 .2421264648554 .0181274414553 .9514770508554 .4909057617 554.6936035156554 .5701904297553 .4229125977551 .5300292969550 .0770874023 549.3856811523549 .3201293945548 .7780151367548 .2448730469540 .9102172852 518.9887695312496 .3949890137486 .8203125479 .3457946777465 .6216125488 456.5853881836461 .9010009766471 .9231872559477 .94140625482 .7784118652 488.5364074707493 .8418884277497 .9218139648501 .8940124512505 .5812072754 509.0571899414512 .2706298828512 .2431030273507 .3937072754500 .1310119629 490.3753967285480 .0310974121470 .8617858887463 .0049133301459 .6553955078 459.6397094727461 .8505859375465 .5687866211469 .7578125473 .9472961426 477.4078063965479 .9703063965481 .1903991699481 .2085876465479 .8953857422 477.5397949219474 .2780151367470 .4404907227466 .4111022949462 .3677062988 458.6834106445455 .3938903809452 .6821899414450 .5116882324448 .9190063477 447.8422851562447 .2399902344447 .0516967773447 .2085876465447 .6614990234 448.3446960449449 .2119140625450 .1888122559451 .2976989746452 .5378112793 453.9039001465455 .3937072754456 .9891052246458 .6723937988460 .4342041016 462.2605895996464 .1429138184466 .0689086914468 .0310974121470 .0187072754 472.0256958008474 .0425109863476 .0646972656478 .0844116211480 .0982971191 482.1005859375484 .0892944336486 .0603027344488 .0127868652489 .9440002441 491.8532104492493 .7387084961495 .5989990234497 .4320983887499 .2362976074 501.0089111328502 .7481079102504 .4512939453506 .1173095703507 .7441101074 509.3320007324510.8800048828512.3889770508513.8596191406 515.2927856445 516.6898193359518 .0520019531519 .3806152344520 .6771240234521 .9426879883 523.1787719727524 .3870239258525 .5682983398526 .7241821289527 .8560791016 528.9655151367530 .053527832531 .1215820312532 .171081543533 .2034301758 534.2197265625535 .2213745117536 .2095947266537 .1857299805538 .1506958008 539.1058959961540 .0523071289540 .991027832541 .9230957031542 .8494873047 543.7711791992544 .6890869141545 .6038818359546 .5167236328547 .4279174805 548.3383178711549 .2485961914550 .1594238281551 .0709838867551 .9841918945 552.8989868164553 .8161010742554 .7357177734555 .6580200195556 .583190918 557.5115966797558 .4431762695559 .378112793560 .31640625561 .2579956055 562.2028808594563 .1511230469564 .1024169922565 .0568237305566 .0139160156 566.9736938477567 .9359130859568 .900390625569 .8668212891570 .834777832 571.8040771484572 .774597168573 .7457885742574 .7175292969575 .6892700195 576.6611938477577 .6326904297578 .6032714844579 .5723876953 47.6815414428750 .6734580993753 .663089752256 .6473999023459 .62794113159 62.6051788330165 .579521179268 .5514907836971 .5214767456174 .49008178711 77.4576492309680 .4247665405383 .39174652186 .359100341889 .32702636719 92.2959671020595 .2660293579198 .23751831055101 .2105026245104 .1850967407 107.1612014771110 .1390991211113 .1184997559116 .0995025635119 .0819015503 122.0655975342125 .0503997803128 .0361938477131 .0229034424134 .0101013184 136.9978027344139 .9857025146142 .9738006592145 .961807251148 .9496002197 151.9371032715154 .9243011475157 .9111938477160 .8975982666163 .883605957 
166.8694000244169 .8549957275172 .8406066895175 .8262939453178 .8125181 .7993927002 184.7872009277187 .7763977051190 .7673034668193 .7602996826196 .7559051514 199.7545928955202 .7568969727205 .7631988525208 .7742004395211 .7904968262214 .8125 217.841003418220 .8766021729223 .9199066162226 .971496582230 .0321044922 233.1022949219236 .1829071045239 .2745056152242 .3778076172245 .4933013916 248.6219940186251 .7642059326254 .9207000732258 .0921936035261 .2791137695 264.482208252267 .7020874023270 .9390869141274 .1940002441277 .467010498 280.7587890625284 .0696105957287 .3999938965290 .75294 .1202087402297 .5105895996 300.9215087891304 .3528137207307 .8048095703311 .2773132324314 .7702941895 318.2835083008321 .8168945312325 .3699951172328 .9426879883332 .5340881348 336.1441040039339 .7715148926343 .415802002347 .0755004883350 .749786377 354.4364013672358 .1340942383361 .8400878906365 .5527954102369 .2684936523 372.9851989746376 .6986083984380 .4063110352384 .1032104492387 .7867126465 391.4508972168395 .0927124023398 .7055969238402 .2861938477405 .8272094727 409.325012207412 .7712097168416 .1617126465419 .4869995117422 .7426147461 425.9175109863429 .0065917969431 .9974975586434 .8843078613437 .6525878906 440.2961120605442 .7980041504445 .1509094238447 .3355102539449 .3435974121 451.1541137695452 .7587890625454 .1373901367455 .2846984863456 .1896972656 456.8541870117457 .2947998047457 .525604248457 .6246032715457 .6326904297 457.6758117676457 .9335021973458 .0151977539457 .8312072754456 .6918029785 453.4339904785449 .8810119629447 .4350891113447 .1871032715451 .7939147949 456.4417114258456 .7022094727453 .7160949707445 .8948974609438 .925201416 440.0177001953442 .2731933594440 .8288879395439 .4595031738439 .9038085938 441.2381896973443 .1572875977445 .4605102539447 .2951965332449 .4135131836 451.4248962402453 .7471008301456 .5134887695459 .5401000977462 .9407043457 465.4899902344466 .3153076172466 .8403930664467 .9082946777469 .2857055664 471.2708129883473 .2717895508475 .7166137695478 .2875061035480 .683013916 482.891998291484 .4424133301485 .6964111328487 .344909668488 .2164001465 486.6922912598485 .3938903809487 .2276000977489 .4410095215489 .4425964355 489.775604248490 .9393005371493 .7886047363500 .9645080566507 .0570983887 506.3695068359506 .7752990723515 .5076904297526 .5778198242535 .491027832 543.7111206055549 .5216064453555 .0748901367562 .3297119141568 .1091918945 569.0311279297572 .3466796875590 .8286132812605 .4998779297597 .2274780273 581.5354003906565 .9124145508555 .0485839844559 .0004272461566 .3471069336 568.7293701172567 .7968139648562 .0579833984555 .6967773438552 .4069824219 551.1900024414551 .0203857422551 .5194702148552 .4025878906552 .8673706055 553.1395874023554 .262512207555 .9431152344557 .6868896484558 .1333007812 557.8806762695558 .2443847656559 .3814697266561 .2039794922562 .5635986328 561.5551147461554 .3651123047539 .3978881836521 .0432739258505 .7080078125 493.2579956055483 .9349060059479 .3024902344479 .7486877441483 .6229858398 488.3576049805493 .422088623498 .3009033203502 .8009033203506 .7229919434 510.6791992188514 .4868774414517 .7741699219520 .1741943359520 .1354980469 516.7360229492511 .6494140625505 .0621948242497 .8770141602490 .8815917969 484.5436096191481 .5799865723480 .8865966797482 .2161865234485 .0021972656 488.3554077148491 .779510498494 .5321960449496 .3428039551496 .6245117188 495.6617126465493 .1304931641489 .4887084961484 .8086853027479 .520904541 
474.1770019531468 .9324951172464 .2156066895460 .0390930176456 .5657958984 453.7619934082451 .6167907715450 .0820922852449 .0721130371448 .5396118164 448.3819885254448 .5603942871448 .9848022461449 .6164855957450 .3615112305 451.2521972656452 .2773132324453 .4392089844454 .729309082456 .1346130371 457.6318969727459 .2164916992460 .8699035645462 .5874938965464 .3530883789 466.1628112793468 .0026855469469 .8692016602471 .7507019043473 .6445922852 475.5411071777477 .4386901855479 .3297119141481 .2135925293483 .0848999023 484.9436950684486 .7861022949488 .6123962402490 .4193115234492 .2063903809 493.9703979492495 .7101135254497 .4218139648499 .1041870117500 .7535095215 502.3692016602503 .9483032227505 .491394043506 .996887207508 .4661865234 509.8989868164511 .297088623512 .6610717773513 .9926147461515 .2924804688 516.5623779297517 .803527832519 .0172729492520 .2047119141521 .3671875 522.5059814453523 .6223754883524 .7177734375525 .7933959961526 .8505249023 527.8903198242528 .9141235352529 .9232177734530 .9188232422531 .9019165039 532.8740234375533 .8358764648534 .7888793945535 .7338867188536 .6721191406 537.6041870117538 .5314941406539 .4545898438540 .3745117188541 .2918701172 542.2077026367543 .1223754883544 .0366821289544 .9512939453545 .8665771484 546.783203125547 .7014770508548 .6217041016549 .5443115234550 .4694213867 551.3975219727552 .3286132812553 .2628173828554 .2001953125555 .1409912109 556.0850219727557 .0322265625557 .9827270508558 .9362792969559 .8928222656 560.8521728516561 .8142089844562 .7786865234563 .7454223633564 .7141113281 565.6845092773566 .6563720703567 .6292724609568 .6030883789569 .5775146484 570.5521240234571 .5267944336572 .5012207031573 .4750976562574 .4481811523 575.4204101562

45.5540885925348 .5429382324251 .5227203369154 .4948310852157 .46327972412 60.4280204772963 .3894691467366 .3480911254969 .3043136596772 .25863647461 75.2114715576278 .1633224487381 .1145172119184 .0655364990287 .01661682129 89.9681472778392 .9202728271595 .8732604980598 .82718658447101 .7822036743 104.7382965088107 .695602417110 .6539001465113 .6132965088116 .573600769 119.5346984863122 .4963989258125 .4586029053128 .4210968018131 .383605957 134.3460998535137 .308303833140 .2700042725143 .2310943604146 .19140625 149.1508026123152 .1091003418155 .06640625158 .0225982666160 .9776000977 163.9317016602166 .8847045898169 .8368988037172 .7884063721175 .7393035889 178.6900939941181 .6408996582184 .5919952393187 .5437927246190 .4967041016 193.4510955811196 .4075012207199 .3661956787202 .3278961182205 .2929992676 208.2621002197 211.2357025146 214.2144012451 217.1988067627 220.1894989014 223.1871032715226 .192199707229 .2055053711232 .2276000977235 .2590026855 238.3005065918241 .3527069092244 .4161071777247 .491394043250 .5792999268 253.6802062988256 .7947998047259 .923614502263 .0671081543266 .2257995605 269.400390625272 .5909118652275 .7981872559279 .0221862793282 .2636108398 285.5223999023288 .7991027832292 .0935974121295 .4061889648298 .7367858887 302.0856933594305 .4525146484308 .8371887207312 .2396850586315 .6597900391 319.0969848633322 .5510864258326 .0213928223329 .5078125333 .0089111328 336.5245056152340 .0528869629343 .5934143066347 .1438903809350 .702911377 354.267791748357 .8366088867361 .4061889648364 .9739074707368 .5358886719 372.0891113281375 .6290893555379 .1523132324382 .6536865234386 .1293945312 
389.5734863281392 .9820861816396 .3486022949399 .6684875488402 .9345092773 406.1416931152409 .2817077637412 .3489990234415 .3341064453418 .2305908203 421.0278015137423 .7184143066426 .2897033691428 .7334899902431 .0347900391 433.183807373435 .1630859375436 .9617004395438 .5609130859439 .9491882324 441.1091918945442 .0320129395442 .7059936523443 .1292114258443 .3059997559 443.2430114746443 .009185791442 .6387023926442 .3799133301442 .3692932129 442.5769042969443 .2412109375443 .4895935059442 .5852050781440 .4808959961 436.6272888184434 .6093139648438 .3471984863442 .3323059082441 .3818054199 438.1344909668434 .2072143555430 .8576965332429 .3911132812428 .9559936523 428.4242858887428 .4216003418430 .2352905273432 .5425109863433 .7874145508 435.0362854004436 .7662963867437 .9032897949438 .7868041992439 .5950012207 440.9317932129442 .6578063965444 .4299926758446 .2376098633447 .4794921875 448.0260925293447 .9648132324448 .1487121582449 .5822143555451 .7969970703 453.6130981445455 .816986084459 .0505981445461 .6760864258462 .4043884277 462.7889099121464 .4129943848465 .7856140137465 .6130981445465 .5273132324 467.1665039062468 .8360900879469 .0463867188469 .7278137207472 .0906066895 475.7135925293480 .6330871582484 .916595459485 .9324951172487 .9508972168 494.6052856445502 .1541137695507 .154510498512 .5894165039520 .4691162109 528.7036743164535 .4591064453540 .7567138672543 .7786865234547 .7465820312 556.5709838867565 .2255249023569 .1326293945568 .3773193359561 .2141723633 555.186706543557 .6394042969562 .135925293564 .276184082563 .7152709961 559.9213256836555 .6270751953552 .3259887695550 .4465942383549 .4481811523 549.1904907227549 .9926757812550 .5618286133550 .7640991211551 .7573242188 552.6791992188553 .9063110352555 .3165283203556 .1444702148556 .6729736328 558.046875560 .8264770508564 .6868896484570 .0654907227568 .853515625 552.2581176758530 .3950195312513 .643371582501 .1813964844494 .0008850098 490.9122009277490 .5953979492492 .1434936523495 .1376953125499 .2423095703 502.9831848145506 .4808044434509 .8919067383513 .4580078125517 .2274169922 520.4476928711522 .7252807617523 .3204956055521 .4473266602518 .3787841797 514.0979003906509 .2484130859504 .3322143555499 .7948913574497 .371887207 496.5867919922497 .7168884277500 .1438903809503 .2529907227506 .3601074219 508.8317871094510 .1765136719509 .7814025879507 .9359130859504 .3971862793 499.5361938477493 .4447021484486 .684387207480 .0645141602473 .7149963379 468.075592041463 .1406860352459 .0458068848455 .7275085449453 .1601867676 451.2640991211449 .9519042969449 .1505126953448 .7604064941448 .7233886719 448.9530029297449 .3960876465449 .9631958008450 .6776123047451 .5338134766 452.5278015137453 .6563110352454 .9012145996456 .2445068359457 .6769104004 459.1842956543460 .7583007812462 .3862915039464 .0614013672465 .7727050781 467.5141906738469 .2767028809471 .0553894043472 .8427124023474 .6351013184 476.4266967773478 .2155151367479 .9971923828481 .770690918483 .5331115723 485.2832946777487 .0190124512488 .7385864258490 .4396057129492 .1195068359 493.7752990723495 .4046936035497 .0042114258498 .5726928711500 .1075134277 501.6083984375503 .0743103027504 .5061035156505 .9039001465507 .2688903809 508.6021118164509 .9046936035511 .1781005859512 .4232177734513 .6416015625 514.8344116211516 .0026245117517 .1475830078518 .270690918519 .3729248047 520.4556274414521 .5197753906522 .5668945312523 .5980224609524 .6143188477 
525.6170043945526 .6071777344527 .5861206055528 .5548706055529 .5144042969 530.4658203125531 .4099731445532 .3480834961533 .2808837891534 .2094116211 535.1343994141536 .0568237305536 .9771118164537 .8963012695538 .8148193359 539.7333984375540 .6525268555541 .5726928711542 .4943847656543 .4179077148 544.3436889648545 .2719726562546 .2028808594547 .1369018555548 .0739135742 549.0140991211549 .9575195312550 .9041137695551 .8540039062552 .8070068359 553.7631225586554 .7222290039555 .6840820312556 .6486206055557 .6157226562 558.5848999023559 .5562133789560 .5291748047561 .5037841797562 .4796142578 563.4562988281564 .4337158203565 .411315918566 .3890991211567 .3668212891 568.3438720703569 .3204956055570 .2954711914571 .2683105469 43.4597396850646 .4292984008849 .3960990905852 .3566818237355 .31274032593 58.2647285461461 .2130088806264 .1580810546967 .100303649970 .0401763916 72.9780807495175 .9145278930778 .8498077392681 .7844161987384 .71855926514 87.6526336669990 .5867462158293 .5212326049896 .4561233520599 .39160919189 102.3276977539105 .2643966675108 .2015991211111 .1393966675114 .0775985718 117.0161972046119 .9548034668122 .8935012817125 .8319015503128 .7698974609 131.7073059082134 .6437988281137 .5794067383140 .5135955811143 .4465026855 146.3778991699149 .3076019287152 .2355041504155 .161605835158 .0859069824 161.0084075928163 .9290924072166 .8480987549169 .7655029297172 .6815948486 175.596496582178 .5104980469181 .4239044189184 .3368988037187 .25190 .1634979248 193.0778961182195 .9934997559198 .9107971191201 .8303070068204 .7525939941 207.6781005859210 .6074066162213 .5410003662216 .4795074463219 .4234924316 222.3735961914225 .3303070068228 .2942962646231 .2660064697234 .2462005615 237.2353973389240 .2342987061243 .2431945801246 .2628936768249 .2937927246 252.3367004395255 .3916931152258 .4596862793261 .5407104492264 .6355895996 267.7445068359270 .8678894043274 .0060119629277 .1592102051280 .3276977539 283.5116882324286 .7113037109289 .9266052246293 .1575927734296 .404296875 299.666595459302 .9443969727306 .2373046875309 .5452880859312 .8678894043 316.2048950195319 .5556030273322 .919708252326 .296295166329 .6846923828 333.0834960938336 .4920043945339 .9081115723343 .330291748346 .7561035156 350.18359375353 .6094055176357 .0310058594360 .4444885254363 .8468017578 367.2333068848370 .6007995605373 .9437866211377 .2589111328380 .5398864746 383.7832946777386 .9820861816390 .1325073242393 .2268066406396 .2608032227 399.2257080078402 .1167907715404 .9241027832407 .6424865723410 .2603149414 412.7719116211415 .1630859375417 .4278869629419 .5487060547421 .5184020996 423.3167114258424 .9353027344426 .3523864746427 .5606079102428 .5383911133 429.2836914062429 .7756958008430 .0224914551430 .0089111328429 .7473144531 429.2774047852428 .6235046387428 .0089111328427 .5620117188427 .7453918457 429.1901855469430 .7988891602432 .3357849121432 .2991943359428 .1310119629 424.6635131836426 .9231872559429 .5143127441427 .3081970215424 .6279907227 425.5335083008426 .0891113281422 .0620117188418 .1687927246417 .6654968262 418.8601989746422 .4448852539425 .8041992188425 .245513916424 .1694030762 425.0069885254425 .7423095703426 .1593017578426 .4371032715427 .3891906738 428.5137023926428 .8228149414429 .3453063965430 .4428100586431 .1636962891 430.6737976074430 .3924865723431 .7582092285433 .6210021973434 .0523071289 434.9436950684438 .1982116699440 .9966125488440 .9847106934440 .6516113281 
442.2796936035444 .2503051758445 .7358093262447 .1993103027448 .7539978027 450.2030944824451 .1492919922452 .6848144531456 .3225097656460 .404296875 463.1041870117465 .6380004883468 .5723876953472 .0663146973476 .2156982422 479.7921142578480 .5535888672482 .6556091309491 .7752990723501 .7405090332 507.1915893555511 .7585144043516 .951171875521 .7526245117520 .4990844727 521.9744873047537 .3154296875551 .416809082554 .082824707552 .7354125977 552.0330810547551 .8361206055553 .3635253906554 .8555297852554 .6361083984 553.2691040039550 .5720214844546 .992980957543 .4904174805541 .1884765625 541.7421264648543 .5067138672544 .6707763672545 .017578125543 .6566772461 542.4437866211543 .5491943359545 .3522949219546 .1837158203547 .6195068359 550.4022216797554 .5537719727564 .1293945312567 .4472045898549 .5308227539 526.8300170898512 .5623779297502 .5187988281497 .4755859375495 .6465148926 495.0733947754495 .746307373497 .5090942383500 .0215148926502 .2944030762 504.8120117188507 .5986022949510 .6846923828514 .0557861328517 .2266235352 519.8084716797521 .3947753906521 .2387695312519 .930480957517 .1838989258 513.8651733398510 .7329101562507 .8591918945506 .479309082506 .2344055176 507.5739135742510 .0603027344513 .2219848633516 .3231811523519 .0435791016 520.4163208008519 .7791137695517 .4564819336512 .8958129883506 .8017883301 499.349395752491 .2127990723483 .524597168476 .3406066895470 .0065917969 464.5707092285460 .0328063965456 .388885498453 .5238952637451 .4010925293 449.8753967285448 .9034118652448 .3469848633448 .1676025391448 .2528991699 448.5653991699448 .9981079102449 .5851135254450 .3099975586451 .1763000488 452.1748046875453 .2936096191454 .5096130371455 .8186950684457 .2026977539 458.6572875977460 .1671142578461 .7282104492463 .3272094727464 .9612121582 466.6185913086468 .2969970703469 .986907959471 .6870117188473 .3895874023 475.0942077637476 .7951965332478 .4926147461480 .1824951172481 .8645935059 483.5354919434485 .1943054199486 .837310791488 .462890625490 .0668945312 491.6476135254493 .2008972168494 .7257995605496 .2190856934497 .6810913086 499.1099853516500.5071105957501.8721008301503.2066040039504.5111083984 505.787109375507 .0356140137508 .2580871582509 .4554138184510 .62890625 511.7796020508512 .9088134766514 .0173950195515 .1066894531516 .1779174805 517.2319946289518 .2700805664519 .2935791016520 .3034057617521 .3007202148 522.2863769531523 .2617797852524 .2280273438525 .1857910156526 .1362304688 527.0803222656528 .0189208984528 .9530029297529 .8831787109530 .8107299805 531.7357788086532 .6594848633533 .5825195312534 .5051879883535 .4282836914 536.3522949219537 .2775878906538 .2047119141539 .1339111328540 .0654296875 540.9995117188541 .9365234375542 .8765258789543 .8195800781544 .7659301758 545.7153930664546 .6680908203547 .6239013672548 .582824707549 .5446166992 550.5092773438551 .4766845703552 .446472168553 .4185791016554 .3928222656 555.3687744141556 .3463745117557 .3253173828558 .3051757812559 .2858276367 560.266784668561 .2479858398562 .2291259766563 .209777832564 .1898803711 565.169128418566 .147277832567 .1240234375 41.3628501892144 .3297500610447 .2863197326750 .2340393066453 .17744064331 56.1164016723659 .0512886047461 .9825401306264 .9105529785267 .83577728271 70.7585906982473 .6794662475676 .5987167358479 .5167922973682 .43390655518 85.3504333496188 .2665100097791 .1824417114394 .0982818603597 .01421356201 
99.93020629883102 .8463973999105 .7626037598108 .6789016724111 .5951004028 114.511100769117 .4268035889120 .3419036865123 .256401062126 .1698989868 129.0823059082131 .9933013916134 .9026947021137 .8103942871140 .716003418 143.6195068359146 .5207061768149 .4194946289152 .3157958984155 .2093963623 158.1006011963160 .9891967773163 .8753051758166 .7590026855169 .6403961182 172.5198059082175 .3972930908178 .2731933594181 .1477966309184 .0213928223 186.8943023682189 .766998291192 .6398010254195 .5131072998198 .3874053955 201.2633056641204 .1410980225207 .0213012695209 .9046020508212 .7913970947 215.6822052002218 .5776977539221 .478302002224 .3845977783227 .2971954346 230.2165985107233 .1434020996236 .0782012939239 .0213012695241 .9734039307 244.9349975586247 .9066925049250 .8887023926253 .8816986084256 .8858032227 259.9017944336262 .9298095703265 .9702148438269 .0231933594272 .0892028809 275.1682128906278 .2605895996281 .3662109375284 .4854125977287 .6177062988 290.7634887695293 .9223937988297 .0945129395300 .2791137695303 .4765014648 306.6859130859309 .9071960449313 .1398010254316 .3833007812319 .6366882324 322.8995056152326 .170501709329 .4487915039332 .7322998047336 .0197143555 339.30859375342 .5968017578345 .8811950684349 .1592102051352 .4270935059 355.6816101074 358.9184875488362.1339111328 365.3233032227368.4826965332 371.6065063477374 .690612793377 .7290039062380 .7172851562383 .6487121582 386.5184020996389 .3187866211392 .0445861816394 .6870117188397 .2401123047 399.6939086914402 .041809082404 .2715148926406 .3754882812408 .3385925293 410.1512145996411 .7961120605413 .2619018555414 .5314941406415 .5935058594 416.433807373417 .0461120605417 .4182128906417 .5539855957417 .4403991699 417.0927124023416 .5003051758415 .6807861328414 .6785888672413 .4108886719 412.9836120605414 .5454101562416 .4573059082417 .1449890137416 .4937133789 414.1686096191411 .8428955078412 .0443115234412 .5845031738411 .5690917969 411.1055908203412 .4442138672413 .0072937012410 .8305969238408 .2708129883 407.8179016113409 .0426940918411 .7799987793413 .9436950684413 .6422119141 412.8247070312413 .3168029785413 .9731140137414 .065612793413 .8741149902 413.7395935059413 .6825866699413 .8507995605414 .3077087402415 .008392334 415.5155029297415 .2727050781415 .1639099121416 .1481933594417 .3999023438 418.0849914551419 .0786132812421 .2059936523423 .0221862793423 .0145874023 422.874206543424 .0385131836425 .7680053711427 .2016906738428 .7759094238 430.8786010742432 .9223937988434 .4876098633436 .3551940918439 .0584106445 441.8021850586444 .337310791447 .0238037109449 .8960876465453 .3754882812 458.2651062012461 .716796875461 .4378967285461 .9429016113466 .8989868164 472.7565917969476 .195098877479 .9822998047486 .0104064941492 .9978942871 499.5714111328508 .8862915039522 .6724853516535 .6359863281541 .5266723633 541.0142822266535 .5164794922530 .9520874023534 .9876708984541 .2830810547 543.2163085938543 .0966796875541 .9445800781537 .5161743164528 .9307250977 522.416015625524 .661315918529 .9086914062533 .3912963867533 .6478881836 527.92578125521 .9052124023521 .1937866211522 .9221801758525 .479675293 527.9625854492528 .8524780273529 .4647827148531 .2039794922529 .7017822266 520.2321777344508 .8193054199501 .1701049805496 .1706848145494 .037902832493 .5 493.5119018555493 .845489502494 .4679870605495 .3363037109496 .12890625 497.4425964355499 .5721130371502 .1766052246505 .0726928711508 .1917114258 
511.5274963379514 .3621826172515 .6381225586515 .6890869141514 .3521728516 512.4340820312510 .4331970215508 .7663879395508 .5707092285509 .2818908691 510.9942932129513 .7827148438517 .3278198242520 .8884887695524 .3657836914 526.3524780273526 .1030883789523 .734375518 .173828125510 .6861877441 502.0212097168492 .6943969727484 .1423950195476 .3980102539469 .7193908691 464.0498046875459 .361907959455 .5806884766452 .6199951172450 .395111084 448.7941894531447 .7387084961447 .1138916016446 .8566894531446 .8695983887 447.1010131836447 .4577026367447 .9605102539448 .5983886719449 .3706970215 450.2773132324451 .2998962402452 .4208068848453 .6317138672454 .9193115234 456.2759094238457 .6900939941459 .1553039551460 .6615905762462 .2033081055 463.7720947266465 .3633117676466 .9700012207468 .5888977051470 .2143859863 471.8445129395473 .4750976562475 .104888916476 .7309875488478 .3518981934 479.9653015137481 .5690002441483 .1600952148484 .736114502486 .2933959961 487.8293151855489 .3405151367490 .8251037598492 .2804870605493 .7063903809 495.1015014648496 .4664916992497 .8015136719499 .1076965332500 .3859863281 501.637512207502 .8635864258504 .0650939941505 .2434082031506 .3994140625 507.5343017578508 .6489868164509 .7448120117510 .8226928711511 .8836975098 512.928894043513 .9594726562514 .9763183594515 .9807128906516 .9733276367 517.9556884766518 .928527832519 .8928833008520 .8496704102521 .799987793 522.7446289062523 .684387207524 .6201782227525 .5529174805526 .4830932617 527.4116821289528 .3391723633529 .2662963867530 .1936035156531 .1215820312 532.05078125532 .981628418533 .9144287109534 .8493041992535 .7868041992 536.7271118164537 .6702270508538 .6165161133539 .5659179688540 .518371582 541.4741821289542 .4331054688543 .3950195312544 .3599243164545 .3275756836 546.2979736328547 .2709960938548 .2462158203549 .2235717773550 .2028198242 551.1837158203552 .166015625553 .1494140625554 .1334838867555 .1182250977 556.1030883789557 .0880126953558 .0725708008559 .0565795898560 .0399169922 561.0220947266562 .0021972656562 .9793701172

39.3036499023442 .2495918273945 .1923217773448 .1280212402351 .05847167969 53.9841499328656 .9053688049359 .8225898742762 .7361602783265 .64655303955 68.5540924072371 .459259033274 .3623275756877 .2637634277380 .16374206543 83.0626602172985 .9606323242288 .857978820891 .75473785494 .65110015869 97.54704284668100 .4425964355103 .3377990723106 .2325973511109 .1268997192 112.020401001114 .9132003784117 .8050003052120 .6955032349123 .5847015381 126.4721984863129 .3576965332132 .2411956787135 .1222991943138 .0009002686 140.8766937256143 .74949646146 .6194000244149 .4859924316152 .3493041992 155.2093963623158 .0661010742160 .9194946289163 .7696990967166 .6168060303 169.4609985352172 .3023071289175 .1410980225177 .9774932861180 .81199646 183.6448059082186 .4761047363189 .3065032959192 .1361999512194 .9656982422 197.7955932617200 .6260986328203 .4577941895206 .2911071777209 .1266021729 211.9647064209214 .8061065674217 .6510009766220 .5003051758223 .3542022705 226.213394165229 .0782928467231 .9496002197234 .8274993896237 .7127075195 240.6056060791243 .5068054199246 .4163970947249 .3352050781252 .2631988525 255.2010955811258 .1489868164261 .1072998047264 .0761108398267 .0557861328 270.0463867188273 .0480957031276 .0607910156279 .0848083496282 .1198120117 285.165802002 288.2226867676291.2901916504 294.3680114746297.4560852051 
300.5538024902303 .6608886719306 .7768859863309 .9013061523313 .0332946777 316.1723022461319 .3171081543322 .466796875325 .6195983887328 .7739868164 331.9277954102335 .0787963867338 .2239990234341 .3609008789344 .4856872559 347.5953979492350 .6854858398353 .7528076172356 .7922973633359 .8005065918 362.7717895508365 .7025146484368 .5863952637371 .4195861816374 .1953125 376.9094848633379 .5539855957382 .1246948242384 .612487793387 .012512207 389.3146057129 391.5133056641 393.5960083008 395.5567932129 397.379486084 399.0573120117400 .5704956055401 .9107055664403 .059387207404 .0078125 404.7431945801405 .2630004883405 .5570068359405 .6395874023405 .486907959 405.1430053711404 .5396118164403 .7080993652402 .6106872559400 .8352050781 399.8132019043401 .1453857422402 .5952148438401 .6236877441400 .0745849609 399.7390136719399 .2517089844397 .9201965332397 .0123901367397 .5892944336 398.753692627399 .0784912109399 .036895752399 .1028137207399 .0534057617 399.1597900391399 .7168884277400 .6983032227401 .4898071289401 .6693115234 401.6810913086402 .2242126465402 .6839904785402 .645690918402 .1960144043 401.2218017578400 .4410095215400 .7782897949401 .4731140137401 .7892150879 402.0422973633402 .1789855957402 .4106140137402 .9197998047403 .6762084961 404.7626953125405 .9039001465406 .80859375407 .4677124023407 .687286377 407.9379882812408 .7166137695409 .7939147949410 .6279907227411 .8677062988 414.2507019043416 .8651123047418 .9672851562420 .8027038574422 .0351867676 423.3399047852425 .9765014648428 .9403991699431 .1693115234433 .9296875 439.2792053223443 .6271057129443 .9060058594443 .4159851074443 .8062133789 444.9450073242446 .3200073242449 .3851928711455 .4494018555464 .3828125 479.5578918457495 .1228942871503 .2197875977509 .3510131836514 .7515258789 515.4304199219507 .3020935059500 .6913146973508 .6332092285518 .5662231445 520.8060302734519 .8585205078518 .8676147461515 .021484375503 .7106933594 494.9786987305499 .412902832507 .0705871582511 .9211120605512 .4517822266 503.3489990234493 .8576965332492 .0867004395494 .0397033691498 .3198852539 501.904510498501 .1940917969497 .7019958496490 .3356933594483 .6648864746 483.1643981934484 .2836914062484 .1034851074483 .8056030273484 .2231140137 484.6777954102485 .1863098145485 .3685913086485 .2549133301485 .0942993164 484.6030883789484 .8417053223486 .3055114746488 .3948974609490 .8406982422 493.9515991211497 .9107055664501 .7261962891503 .9034118652505 .1076965332 505.0011901855504 .0701904297502 .707611084501 .9397888184503 .2652893066 505.3664855957507 .7114868164510 .4431152344513 .8474731445517 .8543701172 522.4812011719526 .0637817383527 .6602783203525 .559387207519 .0142822266 509.8475036621500 .0025939941490 .4229125977481 .6596069336473 .9664001465 467.3133850098461 .7600097656457 .1234130859453 .4281921387450 .5043029785 448.330291748446 .7479858398445 .7166137695445 .0913085938444 .8340148926 444.8261108398445 .0350952148445 .3569030762445 .8214111328446 .4072875977 447.124786377447 .9703063965448 .9301147461449 .9820861816451 .1229858398 452.3364868164453 .6191101074454 .9567871094456 .3465881348457 .7763061523 459.2431945801460 .7370910645462 .2558898926463 .7911071777465 .3414916992 466.9002075195468 .4667053223470 .0356140137471 .6070861816473 .1767883301 474.7445068359476 .3064880371477 .8616943359479 .4061889648480 .9379882812 482.4527893066483 .9486083984485 .4211120605486 .8693847656488 .2898864746 
489.683013916491 .0469970703492 .3829040527493 .6903991699494 .9710998535 496.2254943848497 .4549865723498 .6606140137499 .8435058594501 .004486084 502.1449890137503 .2658081055504 .3678894043505 .4523925781506 .5202941895 507.5725097656508 .6101074219509 .634185791510 .645690918511 .6455993652 512.6348876953513 .6146850586514 .5858764648515 .5493164062516 .5059814453 517.4569091797518 .4027709961519 .3444213867520 .2827148438521 .2183227539 522.1519775391523 .0844116211524 .0161743164524 .9479980469525 .8801879883 526.8135986328527 .7484130859528 .6848754883529 .6235961914530 .5646972656 531.5084838867532 .455078125533 .4047241211534 .357421875535 .3131713867 536.2722167969537 .234375538 .1995849609539 .1677856445540 .1389160156 541.112487793542 .0889282227543 .0676269531544 .0484008789545 .0311889648 546.015625547 .0015258789547 .9885864258548 .9766235352549 .9652709961 550.9542236328551 .9431762695552 .9318847656553 .9202270508554 .9077148438 555.8942260742556 .8793945312557 .8632202148558 .8450927734 37.2417411804240 .1853790283243 .1174888610846 .0396499633848 .9568901062 51.868999481254 .7763290405357 .6792793273960 .5782089233463 .47354888916 66.365646362369 .2549362182672 .1417007446375 .0263519287177 .90911102295 80.790321350183 .6701507568486 .5488510131889 .426483154392 .30325317383 95.179122924898 .05419921875100 .9283981323103 .8016967773106 .6740036011 109.5451965332112 .4151000977115 .2835006714118 .1502990723121 .0150985718 123.8777999878126 .7380981445129 .595703125132 .4505004883135 .3020935059 138.1504058838140 .9951019287143 .8361053467146 .6732940674149 .5065002441 152.3356933594155 .1609039307157 .9819030762160 .7989044189163 .6119995117 166.4212036133169 .2266998291172 .0287017822174 .8273925781177 .6230926514 180.4160003662183 .2064971924185 .9947967529188 .7814025879191 .5664978027 194.3507995605 197.1345062256199.9179992676202.7019042969 205.4866027832 208.2725067139211.0603027344213.8502044678216.6428985596219.4387054443 222.2382049561225 .0419006348227 .8502044678230 .6636047363233 .4826049805 236.3074035645239 .1387939453241 .9768066406244 .8222045898247 .6748962402 250.5355072021253 .4042053223256 .2811889648259 .166809082262 .0611877441 264.9642944336267 .8764953613270 .7974853516273 .7275085449276 .6662902832 279.6138916016282 .5698852539285 .5343017578288 .5067138672291 .4869995117 294.474395752297 .4689941406300 .4700012207303 .4768981934306 .4891052246 309.5060119629312 .5263061523315 .5491943359318 .5729980469321 .5964050293 324.6170043945327 .6328125330 .6409912109333 .638885498336 .6231079102 339.5905151367342 .5369873047345 .4592895508348 .3526916504351 .2137145996 354.0372924805356 .8193969727359 .5546875362 .2390136719364 .866394043 367.4320983887369 .9296875372 .3539123535374 .6975097656376 .9548034668 379.117401123381 .1791992188383 .1299133301384 .9624938965386 .6637878418 388.225189209389 .6304931641390 .8688964844391 .9259033203392 .7896118164 393.4563903809 393.9216003418394.1899108887 394.2717895508 394.1636962891 393.8923950195393 .4193115234392 .7720031738391 .8883056641390 .667388916 389.9273071289390 .6059875488391 .2260131836390 .3269042969389 .3940124512 389.3432006836 389.1541137695388.0538024902 387.2651062012 387.8098144531 388.8038024902389 .0762023926389 .2338867188389 .7141113281390 .3348083496 390.8411865234391 .0960083008391 .4356994629391 .8008117676391 .9092102051 
392.0758972168392 .3559875488392 .4556884766392 .3116149902391 .8656005859 391.0817871094390 .5260009766390 .7645874023391 .2883911133391 .5606079102 391.7815856934391 .9692077637392 .1632995605392 .362487793392 .7301940918 393.4508056641394 .1148986816394 .5010070801394 .757598877394 .9624023438 395.2569885254395 .7106933594396 .2320861816396 .8125915527397 .7911071777 399.3532104492401 .3460083008403 .5935058594405 .3815917969406 .0109863281 406.579498291408 .2532043457410 .3254089355412 .0382995605414 .0025939941 416.9585876465419 .5498046875420 .5559082031420 .3627929688419 .6441955566 419.4621887207420 .9993896484424 .2445068359428 .6397094727434 .5197143555 441.8558044434447 .9193115234450 .6347045898453 .1780090332459 .4018859863 463.5252990723459 .1672058105456 .4110107422466 .0927124023475 .9653930664 475.1864013672470 .258392334466 .6228942871462 .7950134277458 .0299072266 455.7908935547459 .9599914551465 .9305114746470 .3136901855470 .5628051758 463.1806030273456 .013092041456 .675994873461 .1679077148466 .525604248 470.587097168470 .954498291467 .6445007324460 .8450927734456 .4183044434 457.8507995605462 .3872070312465 .6346130371467 .162902832468 .3877868652 469.0411071777468 .9020996094468 .3277893066468 .0213012695467 .5928039551 466.6737976074466 .4794006348467 .3562927246468 .7579040527471 .0397949219 474.2117004395477 .9768066406481 .6885070801484 .3360900879486 .407989502 487.8872070312488 .2327880859486 .7553100586486 .399597168490 .316986084 494.9176940918497 .4169006348499 .320098877501 .4815063477505 .2367858887 512.0678100586519 .0181274414524 .4052734375524 .356628418515 .0277099609 502.4486999512492 .1405944824483 .266204834475 .4338989258468 .561706543 462.574798584457 .4719848633453 .2322998047449 .8056945801447 .1333007812 445.1361083984443 .7160949707442 .7973937988442 .2713928223442 .0781860352 442.1239929199442 .3599853516442 .6968078613443 .1575012207443 .7351074219 444.4320068359445 .2524108887446 .1777954102447 .19140625448 .2864990234 449.4519958496450 .6812133789451 .9648132324453 .2966003418454 .6684875488 456.075592041457 .5107116699458 .9700927734460 .4475097656461 .9403991699 463.4440002441464 .9562072754466 .4737854004467 .9948120117469 .5169067383 471.0382080078472 .5563049316474 .0686950684475 .5726013184477 .0650024414 478.5422973633480 .0020141602481 .4401855469482 .8554077148484 .2449035645 485.6083068848486 .9444885254488 .2539978027489 .537109375490 .794708252 492.0280151367493 .237701416494 .4252929688495 .5916137695496 .737701416 497.8645019531498 .9731140137500 .0642089844501 .1390991211502 .1984863281 503.2434082031504 .274810791505 .2937927246506 .3010864258507 .2977905273 508.2847900391509 .263092041510 .2334899902511 .1971130371512 .1544799805 513.1068115234514 .0546264648514 .9987792969515 .9401245117516 .8793945312 517.8170776367518 .7540283203519 .690612793520 .6275024414521 .5651855469 522.5042114258523 .4448852539524 .3875732422525 .3325805664526 .2802124023 527.2305297852528 .1837158203529 .1398925781530 .0993041992531 .0618896484 532.0275268555532 .9962768555533 .9680175781534 .9426269531535 .9199829102 536.8999023438537 .8823242188538 .8668823242539 .853515625540 .841796875 541.8316040039542 .8228149414543 .8148193359544 .8076171875545 .8009033203 546.7943115234547 .7874755859548 .7802734375549 .7723999023550 .7636108398 551.7537231445552 .7421875553 .7282104492554 .7105712891 
35.2218399047938 .1428794860841 .0603103637743 .9699401855546 .87366867065 49.7719802856452 .6651382446355 .5536003112858 .4376716613861 .31779098511 64.1942520141667 .0675125122169 .9378204345772 .8056030273475 .67102050781 78.5344696044981 .3960571289184 .2560882568487 .1145629882889 .97171020508 92.8275070190495 .6820678710998 .53527832031101 .3871994019104 .2376022339 107.0864028931109 .9335021973112 .7787017822115 .6216964722118 .4623031616 121.3003005981124 .1354980469126 .9673995972129 .7958984375132 .6206970215 135.4416046143138 .2584075928141 .0709075928143 .87890625146 .6822052002 149.4808044434152 .274597168155 .0635986328157 .8477020264160 .6269989014 163.4017028809166 .1717071533168 .9373016357171 .6985931396174 .4559020996 177.2093963623179 .9593048096182 .7059936523185 .4499053955188 .1911010742 190.9302978516193 .6676025391196 .403503418199 .1383972168201 .8728027344 204.6071014404207 .341796875210 .0771026611212 .8137969971215 .5520935059 218.2926025391221 .0355987549223 .7816925049226 .5312042236229 .2846069336 232.0422058105234 .8045043945237 .5717010498240 .3444061279243 .1226959229 245.9069061279248 .6972961426251 .4940948486254 .2973022461257 .1073913574 259.9241943359262 .7478942871265 .5783081055268 .4155883789271 .2594909668 274.1098937988276 .9664916992279 .8293151855282 .6976928711285 .571685791 288.4505004883 291.3340148926294.2215881348297.1129150391300.0069885254 302.9034118652305 .800994873308 .699005127311 .5956115723314 .4896850586 317.37890625320 .2614135742323 .1344909668325 .9956054688328 .8413085938 331.6689147949334 .4743041992337 .2543945312340 .0049133301342 .7222900391 345.4017944336348 .0400085449350 .6312866211353 .1722106934355 .6567077637 358.0809936523360 .4382019043362 .7242126465364 .9314880371367 .0553894043 369.0877990723371 .0234985352372 .8529968262374 .5704956055376 .1635131836 377.6258850098378 .9407043457380 .1005859375381 .0887145996381 .8938903809 382.5180053711382 .9523925781383 .2202148438383 .3288879395383 .2937011719 383.1390991211382 .8659973145382 .5118103027382 .1003112793381 .7496948242 381.5061950684381 .5309143066381 .5071105957381 .1112060547380 .8044128418 380.7475891113380 .6524047852380 .2673950195379 .9612121582380 .117401123 380.4852905273380 .654296875380 .9356994629381 .4688110352382 .0609130859 382.6214904785382 .9206848145383 .1568908691383 .3179016113383 .3637084961 383.3619995117 383.1748962402 382.904510498 382.724609375 382.5282897949 382.3434143066382 .3010864258382 .5307922363382 .8837890625383 .1373901367 383.3731994629383 .5718994141383 .6541137695383 .5538024902383 .4472961426 383.5945129395383 .7637023926383 .8469848633383 .9565124512384 .1759033203 384.4559936523384 .6062927246384 .8393859863385 .3687133789386 .0928955078 386.7225036621387 .6789855957389 .5762939453391 .1901855469391 .4931945801 391.5898132324392 .337890625393 .3745117188394 .5219116211395 .5393066406 395.8500976562396 .1560974121397 .4672851562398 .2929077148397 .7112121582 397.5494995117399 .8884887695403 .1126098633405 .5477905273406 .767791748 403.5875854492399 .4234008789397 .1864013672397 .3598937988403 .8905029297 410.7119140625411 .0273132324412 .3021850586421 .9841003418429 .9153137207 425.5730895996417 .7987976074412 .5069885254409 .4682922363412 .1062011719 416.691986084419 .812713623422 .7734985352425 .487701416426 .0892944336 422.1901855469419 .115814209422 .8565979004428 .7290039062433 .4923095703 
437.0346984863438 .5690917969438 .2027893066435 .9718933105434 .7690124512 436.1344909668439 .1192016602441 .6834106445444 .1120910645446 .7387084961 447.9674072266447 .0332946777445 .7196960449446 .5242919922447 .0752868652 445.7767028809444 .3857116699444 .3982849121445 .7235107422448 .0353088379 451.1539001465454 .4024047852457 .7106018066460 .3579101562462 .3212890625 464.6155090332465 .7921142578464 .1209106445463 .8265075684469 .387512207 475.6834106445478 .3257141113479 .6521911621480 .6109008789483 .4483032227 491.417388916500 .6683044434508 .9941101074511 .8706970215502 .2572937012 489.0675964355480 .4431152344473 .1015014648466 .6019897461461 .0227966309 455.9194946289451 .5651855469447 .887512207444 .9269104004442 .628692627 440.9476928711439 .7784118652439 .0722961426438 .7080993652438 .6502075195 438.7955932617439 .1109008789439 .4991149902439 .9975891113440 .599609375 441.3121948242442 .1361083984443 .0575866699444 .0571899414445 .1329040527 446.2715148926447 .4703063965448 .7177124023450 .0114135742451 .3410949707 452.7051086426454 .0947875977455 .5089111328456 .9400939941458 .3876037598 459.8458862305461 .3146057129462 .7890014648464 .2688903809465 .7506103516 467.2331848145468 .7135009766470 .1896972656471 .6581115723473 .116607666 474.5609130859475 .9888000488477 .3963928223478 .7825927734480 .1441955566 481.4815063477482 .7927856445484 .0791931152485 .3405151367486 .5780944824 487.7925109863488 .9851989746490 .1570129395491 .3091125488492 .442199707 493.5574035645494 .6556091309495 .737701416496 .8045043945497 .8570861816 498.8962097168499 .9229125977500 .9379882812501 .9424133301502 .9371032715 503.9229125977504 .9007873535505 .8716125488506 .8360900879507 .7951965332 508.7496948242509 .7002868652510 .6477966309511 .5929870605512 .5363769531 513.4788208008514 .420715332515 .3626098633516 .3051757812517 .2487792969 518.1939086914519 .1409912109520 .0900878906521 .041809082521 .99609375 522.9531860352523 .9133300781524 .8765258789525 .8427734375526 .8123168945 527.7849121094528 .7603759766529 .7387695312530 .7199707031531 .703918457 532.6901855469533 .6787719727534 .6694946289535 .6619873047536 .6560058594 537.6514282227538 .6478881836539 .6450805664540 .6428833008541 .6409301758 542.6389770508543 .6365966797544 .6337280273545 .6298217773546 .6248779297 547.6187133789548 .6105957031549 .6008300781550 .588684082

33.1990318298336 .118030548139 .0243988037141 .9198493957544 .80981826782 47.6940307617250 .5728111267153 .4465408325256 .3155517578159 .1802406311 62.0409088134864 .8979721069367 .7516937255970 .6024627685573 .45046234131 76.2960510253979 .1393585205181 .9806213378984 .8199310302787 .65743255615 90.4931564331193 .3271865844796 .1594467163198 .98992919922101 .8184967041 104.6449966431107 .4693984985110 .2913970947113 .1107025146115 .9272994995 118.7406997681121 .5507965088124 .3571014404127 .1595001221129 .9577026367 132.7514953613135 .5404968262138 .3246002197141 .1036071777143 .8773040771 146.6455993652149 .4082946777152 .1654968262154 .917098999157 .6629943848 160.4033966064163 .1383056641165 .8677978516168 .5921936035171 .3114929199 174.025894165176 .7357940674179 .44140625182 .1428985596184 .8408050537 187.5352020264190 .2266998291192 .9154968262195 .6020050049198 .2866973877 200.9698028564203 .6519927979206 .3334960938209 .0146942139211 .6961975098 214.3782958984217 .0612945557219 .745803833222 .4320983887225 .1206970215 
227.811706543230 .5057983398233 .2030029297235 .9039001465238 .608505249 241.3173065186244 .0303039551246 .7478027344249 .4698944092252 .1967926025 254.9282989502257 .6647033691260 .4057922363263 .1516113281265 .9017944336 268.6564025879271 .4150085449274 .1776123047276 .9436035156279 .7127075195 282.484588623285 .2587890625288 .0346984863290 .8120117188293 .5896911621 296.3674926758299 .1441955566301 .9189147949304 .6901855469307 .4566955566 310.2164916992312 .9674987793315 .7073974609318 .4335021973321 .1429138184 323.8327941895326 .4996032715329 .1401062012331 .7504882812334 .3273010254 336.8664855957339 .3641967773341 .8161010742344 .2181091309346 .5653076172 348.853302002351 .0766906738353 .2307128906355 .3092041016357 .3070068359 359.2178039551361 .0357971191362 .7540893555364 .3667907715365 .8648071289 367.2419128418368 .4844055176369 .5841064453370 .524597168371 .2927856445 371.8926086426372 .3142089844372 .596496582372 .7520141602372 .8194885254 372.8324890137372 .8340148926372 .8778991699373 .0085144043373 .2503967285 373.3525085449373 .2659912109373 .0682983398372 .8063964844372 .7392883301 373.0094909668373 .3039855957373 .4189147949373 .3518981934373 .1264038086 372.9143066406372 .9556884766373 .2672119141373 .8342895508374 .4520874023 374.9728088379375 .3004150391375 .462890625375 .4966125488375 .4112854004 375.1628112793374 .6176147461374 .1055908203373 .9826049805374 .108795166 374.349395752374 .6763916016375 .1283874512375 .5349121094375 .7721862793 375.9896850586376 .3099060059376 .3640136719375 .8355102539375 .1647033691 374.8517150879374 .6773986816374 .5513000488374 .5658874512374 .7481079102 375.0148925781375 .2932128906375 .6628112793376 .2508850098376 .8613891602 377.3461914062 377.9052124023 378.7777099609 379.4888000488 379.4413146973 379.274597168379 .6489868164380 .2401123047380 .8467102051381 .129486084 380.7262878418380 .5028076172381 .053314209381 .6499023438381 .2760925293 381.0765075684382 .2471008301383 .8197021484385 .4002990723385 .1458129883 381.8268127441377 .9869995117375 .4132080078375 .333404541377 .7731933594 381.4166870117382 .9289855957385 .0512084961390 .4778137207394 .1954040527 391.6864929199387 .5633850098384 .4017028809383 .7258911133386 .1213989258 389.628112793392 .2077941895394 .0551147461395 .5479125977396 .7030029297 395.4859924316395 .1028137207398 .1763000488401 .6507873535403 .4469909668404 .75 406.0963134766407 .5327148438408 .6802978516409 .2796020508409 .1383972168 408.7265930176408 .291809082410 .3109130859417 .9804992676423 .8388977051 420.4325866699417 .2304992676423 .4213867188428 .825012207423 .9585876465 417.8309020996418 .1611938477420 .8410949707422 .8203125425 .249206543 428.7609863281432 .2838134766434 .1694030762434 .8976135254435 .2090148926 434.7763061523433 .5798034668433 .7356872559436 .797088623440 .8638916016 444.6767883301446 .9320068359446 .4429016113447 .345489502453 .4378967285 461.7141113281469 .6849975586474 .4570922852473 .2088928223468 .9732971191 464.5642089844459 .9254150391455 .4706115723451 .2677001953447 .4154968262 443.9851074219441 .1130981445438 .7755126953437 .0148925781435 .7589111328 434.9554138184434 .536895752434 .4176940918434 .548614502434 .8514099121 435.2842102051435 .7716064453436 .3440856934437 .008392334437 .7665100098 438.625793457439 .5687866211440 .5817871094441 .6603088379442 .7961120605 443.9837036133445 .2159118652446 .4879150391447 .7934875488449 .1288146973 
450.4883117676451 .8692932129453 .2673034668454 .6801147461456 .1044006348 457.5383911133458 .9794921875460 .425994873461 .8754882812463 .3262939453 464.7757873535466 .221496582467 .6604919434469 .0898132324470 .5060119629 471.9064941406473 .287902832474 .6487121582475 .9862976074477 .3005981445 478.5905151367479 .8566894531481 .0993041992482 .3194885254483 .5180969238 484.696105957485 .8547058105486 .9946899414488 .1171875489 .2228088379 490.3125915527491 .3873901367492 .4479980469493 .4953918457494 .5303039551 495.5537109375496 .56640625497 .5692138672498 .5632019043499 .5490112305 500.5275878906501 .4996948242502 .4661865234503 .4278869629504 .3854980469 505.3396911621506 .2914123535507 .2409973145508 .1893920898509 .1369934082 510.0845031738511 .0322875977511 .9811096191512 .9312133789513 .8828735352 514.8366088867515 .7927246094516 .7514038086517 .7128295898518 .6771240234 519.6442871094520 .6146850586521 .5883178711522 .5648803711523 .5443725586 524.5269775391525 .5123291016526 .5004272461527 .4909057617528 .4838256836 529.4788208008530 .4757080078531 .4743041992532 .4741821289533 .475402832 534.4774169922535 .4799804688536 .4829711914537 .4860229492538 .4887695312 539.491027832540 .4926147461541 .492980957542 .4921264648543 .4896850586 544.4855957031545 .4780883789546 .4663696289 31.2221508026134 .1169815063537 .0078392028839 .8902397155842 .76615905762 45.6360511779848 .5001792907751 .3589782714854 .2127189636257 .06179046631 59.9065017700262 .7472305297965 .5842285156268 .4178771972771 .24835968018 74.0760116577176 .900947570879 .7234420776482 .5435180664185 .36139678955 88.177040100190 .9905700683693 .8018722534296 .6109771728599 .41773986816 102.2220993042105 .0236968994107 .8226013184110 .6184005737113 .4110031128 116.1998977661118 .9850006104121 .7658996582124 .5423965454127 .314201355 130.0809020996132 .8424072266135 .5984039307138 .3486022949141 .0928955078 143.8312072754146 .5630950928149 .2888031006152 .008102417154 .720993042 157.4275054932160 .1275939941162 .8215026855165 .5092010498168 .1909942627 170.866897583173 .5370941162176 .2019958496178 .8618011475181 .5166015625 184.1670074463186 .8130950928189 .4553070068192 .0939941406194 .7294006348 197.3621063232199 .9922943115202 .6204986572205 .2469940186207 .8721008301 210.4965057373213 .1201934814215 .7438964844218 .3677062988220 .9922027588 223.6174926758226 .2440948486228 .8721923828231 .5021972656234 .1340942383 236.7684020996239 .4049987793242 .0442962646244 .6860961914247 .3309020996 249.9783935547252 .628692627255 .2816009521257 .937286377260 .5952148438 263.2554931641 265.9176025391268.5815124512 271.2464904785 273.9125976562 276.5790100098279 .2456054688281 .9115905762284 .5766906738287 .2398986816 289.9009094238292 .5585021973295 .2119140625297 .859588623300 .5003967285 303.1323852539305 .7538146973308 .3622131348310 .955291748313 .5302124023 316.0844116211318 .6145019531321 .1176147461323 .5902099609326 .0289916992 328.4303894043 330.7908935547333.1062927246 335.3732910156 337.5869140625 339.7435913086341 .8377075195343 .8656005859345 .820892334347 .6990966797 349.4945068359351 .2018127441352 .8158874512354 .3310852051355 .7419128418 357.0429077148358 .2235107422359 .2789916992360 .1899108887360 .9443969727 361.540802002361 .9578857422362 .2598876953362 .4431152344362 .6098022461 362.7803039551363 .0455932617363 .4672851562363 .9902038574364 .6401977539 
365.0772094727365 .0939941406364 .9578857422364 .837310791364 .9324035645 365.4468994141366 .0425109863366 .4926147461366 .6293945312366 .1166992188 365.5491027832365 .5354919434365 .8232116699366 .3244018555366 .9054870605 367.4135131836367 .7715148926367 .9867858887367 .9979858398367 .7831115723 367.3738098145366 .5701904297365 .9023132324365 .8843078613366 .203704834 366.7041931152367 .3192138672367 .9473876953368 .4731140137368 .7098999023 368.8565063477369 .2152099609369 .2413024902368 .3776855469367 .324005127 366.7414855957366 .362701416366 .1418151855366 .1210021973366 .228302002 366.5068969727366 .9620056152367 .5159912109368 .1534118652368 .7499084473 369.2922973633369 .6359863281369 .5981140137369 .3843078613369 .0918884277 368.8620910645369 .1046142578369 .4053039551369 .5509033203369 .4747009277 369.041809082368 .6552124023368 .509185791368 .4578857422368 .2612915039 368.0020141602367 .7315063477367 .5096130371368 .1664123535368 .2394104004 367.8165893555367 .1648864746366 .7401123047366 .6386108398364 .8876953125 363.9995117188365 .184387207366 .6723937988367 .1603088379367 .1571044922 367.834197998368 .5347900391368 .8815917969369 .6329040527369 .9262084961 370.4645996094372 .0685119629373 .5321044922374 .5799865723375 .6859130859 376.4473876953377 .2471008301378 .370300293378 .8410949707377 .6982116699 376.7817077637377 .946105957380 .1820983887383 .375213623385 .3399963379 383.3482055664380 .3194885254377 .2338867188377 .8839111328389 .2101135254 399.108001709394 .0924072266389 .3110961914400 .2096862793409 .6755065918 401.770111084392 .0349121094393 .1395874023396 .8348999023398 .129699707 399.6495056152403 .0942993164405 .8591918945405 .8877868652404 .9964904785 403.6619873047402 .7616882324402 .8696899414403 .3245849609403 .2835083008 404.1383056641408 .3996887207412 .3579101562411 .9375411 .799987793415 .5372009277 420.9749145508426 .7037963867432 .8128051758440 .2586975098445 .8434143066 446.4375915527444 .9068908691442 .7276916504440 .0544128418437 .5463867188 435.1423950195433 .1774902344431 .5687866211430 .4385986328429 .7077941895 429.3431091309429 .2916870117429 .4682006836429 .8422851562430 .3374023438 430.928314209431 .5472106934432 .2301025391432 .9852905273433 .8193969727 434.7381896973435 .729309082436 .7777099609437 .882598877439 .0347900391 440.232208252441 .466003418442 .7348022461444 .0307006836445 .3529052734 446.6947937012448 .0560913086449 .4316101074450 .8211975098452 .2207946777 453.6301879883455 .0459899902456 .4678039551457 .8923034668459 .3186035156 460.7432861328462 .1648864746463 .579498291464 .9851074219466 .3775939941 467.7553100586469 .1142883301470 .453704834471 .770690918473 .0657043457 474.3371887207475 .5864868164476 .8133850098478 .0191040039479 .2044067383 480.370513916481 .5181884766482 .6485900879483 .762512207484 .8606872559 485.9440917969487 .0134887695488 .0697021484489 .1135864258490 .1458129883 491.167388916492 .179107666493 .1817932129494 .1762084961495 .1632080078 496.1435852051497 .1181945801498 .0877075195499 .0528869629500 .0144958496 500.9732055664501 .9296875502 .8847045898503 .8387145996504 .7922058105 505.7459106445506 .7002868652507 .6557922363508 .6127929688509 .5715026855 510.532409668511 .4957885742512 .4619140625513 .4307250977514 .4025268555 515.3773193359516.3551025391517.3361206055 518.3200073242519.3068847656 520.2968139648521 .2891845703522 .2841796875523 .2816772461524 .2813110352 
525.2828979492526 .2861938477527 .291015625528 .2971191406529 .3041992188 530.3120117188531 .3201293945532 .3284301758533 .3366088867534 .3444213867 535.3515014648536 .3576049805537 .3624267578538 .3657836914539 .3676147461 540.3671264648541 .3646240234542 .3593139648

29.2420902252232 .1350517272935 .0144004821837 .88198089640 .74359130859 43.5988883972246 .4481697082549 .2918014526452 .1300697326754 .96334838867 57.7919311523460 .6161689758363 .4363288879466 .2527465820369 .06562042236 71.8752517700274 .681777954177 .4854431152380 .28627777183 .08450317383 85.88007354736 88.6730880737391.4634933471794.251251220797.03624725342 99.81839752197102 .5975036621105 .373298645108 .1456985474110 .9142990112 113.6789016724116 .439201355119 .1948013306121 .945602417124 .6911010742 127.4309997559130 .1651000977132 .8932037354135 .6148986816138 .3300933838 141.0384979248143 .7400054932146 .4344940186149 .1217956543151 .8020019531 154.4750061035157 .1407928467159 .7993927002162 .4508972168165 .0955047607 167.7333068848170 .3643951416172 .9891052246175 .6074981689178 .2200012207 180.8267974854183 .4279937744186 .024307251188 .6156005859191 .2024993896 193.7852020264196 .3641052246198 .9396057129201 .5119934082204 .0816040039 206.6488037109209 .2140045166211 .7776031494214 .3397064209216 .900894165 219.4613037109222 .0213012695224 .5811004639227 .1410064697229 .7012023926 232.2619018555234 .8231964111237 .3852996826239 .9481048584242 .5119018555 245.0765075684247 .641998291250 .2080993652252 .7749023438255 .3419952393 257.9093017578260 .4764099121263 .0432128906265 .6088867188268 .173614502 270.7363891602273 .297088623275 .854888916278 .4096069336280 .9602050781 283.5061950684286 .0465087891288 .5804138184291 .1062927246293 .6231994629 296.1293029785298 .6228027344301 .1015014648303 .563293457306 .0056152344 308.4256896973310 .8210144043313 .1883850098315 .5252075195317 .8280029297 320.0939025879322 .3194885254324 .5011901855326 .6358032227328 .7192993164 330.7478942871332 .717010498334 .6225891113336 .4594116211338 .2226867676 339.9075927734341 .5090026855343 .0237121582344 .4465026855345 .7755126953 347.0068054199348 .1348876953349 .1564941406350 .0523071289350 .8138122559 351.4172973633351 .829498291352 .1202087402352 .2950134277352 .4840087891 352.763092041353 .1841125488353 .7969970703354 .5226135254355 .3341064453 355.9316101074356 .1084899902356 .1398010254356 .2647094727356 .5528869629 357.1176147461357 .7267150879358 .2095947266358 .3911132812358 .1000976562 357.7320861816357 .7435913086358 .0046081543358 .4937133789359 .0822143555 359.6640930176360 .1445922852360 .4671020508360 .5346984863360 .3038024902 359.8534851074359 .0775146484358 .4258117676358 .3201904297358 .5331115723 359.0244140625359 .6525878906360 .2603149414360 .7481079102360 .974609375 361.0556945801361 .1900024414361 .0309143066360 .2811889648359 .3756103516 358.7651062012358 .3460083008358 .1554870605358 .1413879395358 .2213134766 358.4656982422358 .8918151855359 .3922119141359 .9155883789360 .3970947266 360.8609924316361 .0531921387360 .9002075195360 .6052856445360 .3435058594 360.2080993652360 .325012207360 .3757019043360 .2340087891359 .9403076172 359.3909912109358 .7781066895358 .3059997559357 .93359375357 .7302856445 357.4825134277357 .1397094727356 .770111084356 .7087097168356 .8836975098 356.8627929688356 .8316955566357 .0078125356 .2814025879354 .4905090332 
353.1384887695353 .7202148438354 .387298584353 .7893981934353 .4067077637 354.1235961914355 .7236938477357 .2406921387358 .0618896484358 .4585876465 358.6812133789359 .4486083984360 .2919006348360 .5451049805360 .9475097656 361.4984130859361 .7112121582361 .7366027832360 .9688110352359 .3977050781 358.5289001465359 .3099060059361 .419708252364 .3616943359366 .1513061523 365.0372009277362 .815612793360 .5053100586361 .5018005371369 .0249938965 375.7156982422373 .7218933105372 .0252075195379 .2037963867385 .1267089844 380.4478149414374 .1669921875374 .0957946777376 .0535888672376 .9324035645 377.6611022949378 .9851989746378 .854095459374 .8864135742371 .5263061523 373.4124145508377 .1106872559379 .1416931152380 .1763916016379 .9530029297 380.1420898438382 .7077941895386 .6842956543390 .6206970215393 .9418945312 395.6513061523397 .8074035645401 .8233947754408 .2434082031416 .1760864258 423.4884033203427 .30859375428 .650604248428 .6405944824427 .7793884277 426.6387023926425 .333404541424 .2833862305423 .4538879395422 .999786377 422.854309082422 .9982910156423 .3706054688423 .899810791424 .5562133789 425.2858886719426 .0650024414426 .850402832427 .6715087891428 .5458984375 429.479095459430 .483795166431 .5444946289432 .6516113281433 .8023986816 434.9920959473436 .2167053223437 .4710083008438 .7517089844440 .0544128418 441.3765869141442 .7149963379444 .0679016113445 .4331970215446 .8092956543 448.1947021484449 .588104248450 .9877929688452 .3922119141453 .7994995117 455.2077941895456 .6146850586458 .0176086426459 .4137878418460 .8005065918 462.174407959463 .5333862305464 .8742980957466 .1960144043467 .4963989258 468.7752990723470 .0321044922471 .2674865723472 .4818115234473 .6759033203 474.8507995605476 .0073852539477 .1469116211478 .2699890137479 .3775939941 480.470489502481 .5494995117482 .6153869629483 .6690063477484 .7109985352 485.7423095703486 .7637023926487 .7759094238488 .7796936035489 .7759094238 490.7652893066491 .7488098145492 .7268066406493 .7004089355494 .6700134277 495.6366882324496 .6007080078497 .5629882812498 .5239868164499 .4843139648 500.4444885254501 .4052124023502 .366607666503 .3293151855504 .2937011719 505.2600097656506 .2284851074507 .1997070312508 .1734924316509 .1500854492 510.129699707511 .1123046875512 .0980224609513 .0866088867514 .0781860352 515.0728149414516 .0698852539517 .0698242188518 .0720825195519 .0765991211 520.0831298828521 .0914916992522 .1013793945523 .1126708984524 .1251220703 525.1381835938526 .1519165039527 .1657714844528 .1796875529 .1932983398 530.2061767578531 .2183227539532 .229309082533 .2387695312534 .2465820312 535.2526245117536 .2564697266537 .2564697266538 .2515869141

27.3113708496130 .1786994934133 .0417518615735 .8957710266138 .74280166626 41.583290100144 .4174690246647 .2457389831550 .0683403015152 .88566970825 55.6979484558158 .5055885314961 .3087692260764 .1078720092866 .90305328369 69.6946029663172 .4826583862375 .2674636840878 .0490493774480 .82760620117 83.6031188964886 .3756637573289 .1451721191491 .9116516113394 .674949646 97.4349899292100 .1915969849102 .9445037842105 .6934967041108 .4383010864 111.1787033081113 .9142990112116 .6447982788119 .3699035645122 .089302063 124.802696228127 .5096969604130 .2100067139132 .903503418135 .5897064209 138.2686004639140 .9400024414143 .6036071777146 .2593994141148 .9071960449 151.5469970703154 .1788024902156 .8025054932159 .4183044434162 .0261993408 
164.6262969971167 .2187957764169 .8038024902172 .3813934326174 .9519958496 177.5157012939180 .0726928711182 .6233978271185 .1681060791187 .7070007324 190.2404022217192 .7686004639195 .2920074463197 .8110046387200 .3256988525 202.8365936279205 .3439941406207 .8482055664210 .349395752212 .8480987549 215.3444061279217 .8386993408220 .3311004639222 .8218994141225 .3112945557 227.7994995117230 .2864990234232 .7723999023235 .2574005127237 .741394043 240.2243041992242 .7062988281245 .1869049072247 .666305542250 .1439971924 252.6197967529255 .0935058594257 .5646057129260 .0328063965262 .4977111816 264.9585876465267 .4153137207269 .8669128418272 .3129882812274 .7528991699 277.1857910156279 .6108093262282 .0270080566284 .4331970215286 .8280944824 289.2099914551291 .5773925781293 .9281921387296 .2603149414298 .5715026855 300.8591918945303 .1211853027305 .3544921875307 .5567932129309 .7250976562 311.8568115234313 .949005127315 .9985961914318 .0028991699319 .9580078125 321.8615112305323 .708190918325 .495513916327 .2174072266328 .870300293 330.4494934082331 .9493103027333 .3688964844334 .7011108398335 .9507141113 337.109588623338 .1852111816339 .1719970703340 .0574035645340 .8443908691 341.4719848633341 .8902893066342 .187286377342 .3175964355342 .4814147949 342.7746887207343 .2163085938343 .8406982422344 .5739135742345 .3753967285 346.0603027344346 .4484863281346 .7337036133347 .1250915527347 .5768127441 348.1075134277348 .6181030273348 .9692077637349 .1679992676349 .2020874023 349.1708984375349 .2810974121349 .5398864746350 .0278015137350 .6528015137 351.2936096191351 .8876953125352 .4006958008352 .6643066406352 .5668945312 352.1463012695351 .4226074219350 .7550048828350 .4818115234350 .5776977539 351.0304870605351 .6246948242352 .1185913086352 .4768066406352 .6546020508 352.662109375352 .5303039551352 .2228088379351 .6982116699351 .1073913574 350.592590332350 .254699707350 .2012023926350 .2652893066350 .3306884766 350.4890136719350 .7921142578351 .172088623351 .5017089844351 .8116149902 352.141204834352 .3468933105352 .3768005371352 .2969055176352 .2580871582 352.2420959473352 .2976989746352 .2797851562352 .0885925293351 .6935119629 351.0126037598350 .2233886719349 .5141906738348 .979888916348 .737701416 348.6849060059348 .7495117188348 .7972106934348 .7240905762348 .6734924316 348.4177856445348 .2178039551348 .1234130859347 .6271972656346 .8819885254 346.2377929688346 .4306945801346 .746307373346 .4916992188346 .425994873 346.5882873535347 .4177856445348 .5281066895349 .4736938477350 .37890625 350.9870910645351 .665802002351 .9349975586351 .236907959350 .3147888184 349.5860900879348 .7723083496347 .8855895996346 .8497009277345 .9768981934 345.7267150879346 .1679992676347 .4159851074349 .1064147949350 .5729064941 351.228302002351 .2290039062351 .0080871582351 .5309143066353 .3916015625 355.5280151367356 .6955871582357 .8887023926359 .9447021484361 .2726135254 360.5621032715359 .0603027344358 .3124084473357 .9583129883358 .1554870605 358.0216064453357 .0815124512354 .5219116211347 .5266113281343 .0425109863 348.9971923828356 .9190063477360 .0409851074361 .2124938965361 .5456848145 361.9177856445363 .178314209366 .5534973145374 .3275146484381 .4053039551 382.0909118652382 .0452880859385 .4663085938390 .5797119141396 .5014038086 402.8648986816408 .1148071289412 .1365966797414 .2449035645414 .8204040527 414.9780883789414 .6358032227414 .5386047363414 .5244140625414 .816986084 
415.3186950684416 .0203857422416 .8663024902417 .7814941406418 .7475891113 419.7341918945420 .7275085449421 .7056884766422 .6960144043423 .7142944336 424.771697998425 .8823852539427 .0350036621428 .2196960449429 .4368896484 430.6812133789431 .9515991211433 .2412109375434 .5501098633435 .8723144531 437.208404541438 .5545043945439 .9112854004441 .2760925293442 .649597168 444.029510498445 .4161987305446 .8073120117448 .2025146484449 .5992126465 450.9964904785452 .391204834453 .7817077637455 .1643981934456 .5374145508 457.8970031738459 .2419128418460 .5686035156461 .8767089844463 .1637878418 464.4305114746465 .6756896973466 .900390625468 .1050109863469 .2904968262 470.4577026367471 .6076965332472 .7413024902473 .8594970703474 .9630126953 476.0527038574477 .1293945312478 .1936950684479 .2463989258480 .2883911133 481.3203125482 .3429870605483 .3570861816484 .363494873485 .3627929688 486.3559875488487 .3435058594488 .3262939453489 .304901123490 .280090332 491.2525024414492 .2229003906493 .1917114258494 .1594848633495 .1270141602 496.0945129395497 .062713623498 .0317993164499 .0022888184499 .974609375 500.949005127501 .9256896973502 .9049072266503 .8869018555504 .8717041016 505.8594055176506 .850189209507 .8439025879508 .8406066895509 .8400878906 510.8424072266511 .8472900391512 .854675293513 .8643798828514 .8762207031 515.8898925781516 .9052124023517 .921875518 .9398803711519 .9586791992 520.9780883789521 .9979858398523 .0178222656524 .0374755859525 .0565795898 526.075012207527 .0922241211528 .108215332529 .1224975586530 .1350097656 531.1453857422532 .1533813477533 .1588745117534 .161315918 25.3771800994928 .2427005767831 .0937690734933 .9323692321836 .76456832886 39.589981079142 .4088706970245 .2215614318848 .0283317565950 .8295211792 53.6253890991256 .4162712097259 .2023811340361 .9840583801364 .76146697998 67.5348892211970 .3044433593873 .0703506469775 .8326797485478 .59158325195 81.3470382690484 .0991363525486 .8478164672989 .5930633544992 .33471679688 95.0727233886797 .80684661865100 .5369033813103 .2627029419105 .9838027954 108.7001037598111 .4112014771114 .1166992188116 .8163986206119 .5099029541 122.1968002319124 .8768997192127 .5497970581130 .2153015137132 .8728942871 135.5225982666138 .1640930176140 .7971038818143 .4216003418146 .037399292 148.6445007324151 .2427062988153 .8320007324156 .4125061035158 .9842071533 161.5471038818164 .1013946533166 .6470947266169 .1844940186171 .7136993408 174.2348937988176 .7481994629179 .2541046143181 .7525939941184 .2442016602 186.7288970947189 .2071990967191 .6791992188194 .145401001196 .6060028076 199.0612945557201 .511505127203 .9571990967206 .3983001709208 .8352966309 211.2684020996213 .6977996826216 .1237030029218 .5464935303220 .9660949707 223.3827972412225 .7964935303228 .2075042725230 .6157073975233 .021194458 235.4237976074237 .8235015869240 .2200012207242 .6132965088245 .0030059814 247.3890075684249 .7707061768252 .1479949951254 .5202941895256 .8870849609 259.2479858398261 .6023864746263 .9497070312266 .2893066406268 .620300293 270.942199707273 .2538146973275 .5544128418277 .8427124023280 .117401123 282.3770141602284 .6200866699286 .8445129395289 .048614502291 .2301025391 293.3868103027295 .5166931152297 .6170959473299 .6860046387301 .7206115723 303.7190856934305 .6785888672307 .5969848633309 .4718017578311 .300201416 313.0797119141314 .8064880371316 .4775085449318 .0874938965319 .632598877 
321.1084899902322 .5098876953323 .8346862793325 .0765991211326 .2414855957 327.3251037598328 .3414916992329 .2904968262330 .1709899902330 .9910888672 331.6485900879332 .0935058594332 .3866882324332 .474609375332 .5469055176 332.7063903809332 .9708862305333 .4324035645334 .0252990723334 .7182922363 335.4375915527336 .0936889648336 .6932067871337 .1928100586337 .6730041504 338.3062133789338 .8569030762339 .1032104492339 .291595459339 .4747924805 339.6104125977339 .7372131348339 .975189209340 .6180114746341 .4060974121 341.9869995117342 .591796875343 .4873046875344 .1917114258344 .3615112305 344.0166015625342 .9977111816341 .9588928223341 .5871887207341 .7083129883 342.4368896484343 .2450866699343 .5495910645343 .6520080566343 .7445983887 343.6932983398343 .4570922852343 .1348876953342 .7138061523342 .270904541 341.824005127341 .5866088867341 .8676147461342 .1733093262342 .1357116699 342.0863037109342 .3259887695342 .636505127342 .7965087891342 .9522094727 343.2215881348343 .5234985352343 .750213623343 .8929138184343 .988494873 344.05859375344 .2590942383344 .4169006348344 .4953918457344 .2283935547 343.2120056152342 .0202941895341 .2496948242340 .7652893066340 .6608886719 340.9230041504341 .384185791341 .7821960449341 .979095459341 .8351135254 341.2560119629340 .8255004883340 .9556884766341 .1330871582340 .9946899414 340.7757873535340 .9740905762341 .2827148438341 .6462097168341 .7232971191 340.9526977539340 .6263122559342 .0660095215343 .7661132812344 .5018005371 344.9902038574346 .192199707346 .463104248344 .3609924316341 .6383972168 339.9182128906338 .5280151367337 .2030029297336 .149597168335 .3445129395 335.0062866211335 .287902832335 .996307373337 .2616882324339 .1571960449 341.5545959473343 .3422851562343 .1080932617341 .6828918457340 .7344970703 340.6925964355341 .6856994629342 .7849121094343 .2840881348343 .559387207 343.812286377343 .9472045898343 .3370056152342 .1282958984341 .6347961426 340.9866943359339 .4309082031336 .7820129395332 .0692138672330 .5770874023 337.2142028809344 .7814941406346 .2409057617345 .5072021484345 .7474975586 346.4819946289348 .158996582351 .8652954102358 .3613891602364 .3912963867 366.4877929688367 .5545043945370 .594909668374 .3581848145379 .1925048828 385.1333007812391 .5686035156397 .7174987793401 .0213012695402 .3452148438 403.0999145508403 .470703125404 .1466064453404 .9773864746406 .0093994141 407.1958007812 408.4938049316 409.8489074707 411.1760864258 412.4703063965 413.7229003906414 .9422912598416 .1386108398417 .3244934082418 .5104064941 419.7119140625420 .949798584422 .2113037109423 .4930114746424 .7932128906 426.1101074219427 .4410095215428 .782409668430 .132598877431 .4885864258 432.8500061035434 .2161865234435 .5869140625436 .962310791438 .3421020508 439.7261962891441 .1140136719442 .5050048828443 .8978881836445 .291595459 446.683807373448 .0728149414449 .4560852051450 .8309020996452 .1948852539 453.5451965332454 .8800048828456 .1968078613457 .4949035645458 .7727050781 460.0303955078461 .2674865723462 .4848022461463 .682800293464 .862487793 466.0249023438467 .1706848145468 .3010864258469 .4166870117470 .5184936523 471.6070861816472 .6834106445473 .7481079102474 .8019104004475 .845489502 476.879699707477 .9052124023478 .9227905273479 .9331054688480 .9370117188 481.9349975586482 .9278869629483 .9165039062484 .9013061523485 .8829956055 486.8623046875487 .8396911621488 .8160095215489 .7914123535490 .7668151855 
491.7423095703492 .7186889648493 .6960144043494 .674987793495 .6557922363 496.6387023926497 .6239929199498 .611907959499 .6023864746500 .5957946777 501.592010498502 .5911865234503 .5932922363504 .5982055664505 .6058959961 506.6163024902507 .6292114258508 .6442871094509 .6617126465510 .6809997559 511.7019958496512 .7244873047513 .7482910156514 .7730712891515 .7985839844 516.8245239258517 .8505859375518 .8765869141519 .9022216797520 .9271240234 521.9509887695522 .9735717773523 .9948120117525 .0142211914526 .0314941406 527.0465698242528 .0593261719529 .0676269531530 .0703125

23.4951705932626 .3337402343829 .1677703857431 .9923191070634 .80944061279 37.6195793151940 .4229316711443 .2198791503946 .0106315612848 .79555130005 51.5748481750554 .3488693237357 .1178092956559 .8819885253962 .64155960083 65.3968124389668 .1478271484470 .8948516845773 .6379013061576 .37715911865 79.112586975181 .844306945884 .5721969604587 .2962722778390 .01638793945 92.7324523925895 .4442367553798 .15158843994100 .8542022705103 .5518035889 106.2442016602108 .9309005737111 .6116027832114 .2860031128116 .9537963867 119.6145019531122 .2678985596124 .9135971069127 .5512008667130 .1806030273 132.8013000488135 .413192749138 .0160980225140 .6096038818143 .1938018799 145.7684936523148 .3334960938150 .8887939453153 .4344024658155 .9703063965 158.4965057373161 .0131072998163 .5202026367166 .0178985596168 .5061950684 170.9853973389173 .4557037354175 .9172973633178 .370300293180 .8150939941 183.2518005371185 .6808013916188 .1022033691190 .5162963867192 .9234008789 195.3238983154197 .7178039551200 .1056976318202 .4875030518204 .8638000488 207.2344970703209 .6000061035211 .9604034424214 .3159942627216 .6667938232 219.0130004883221 .3547058105223 .6918945312226 .0245056152228 .3527069092 230.6761016846232 .9949035645235 .3087005615237 .6174926758239 .9207000732 242.2183990479244 .5097961426246 .7949066162249 .0729980469251 .3437042236 253.6062927246255 .8605041504258 .1052856445260 .3403015137262 .5646057129 264.7774047852266 .9778137207269 .1648864746271 .337310791273 .4938964844 275.6332092285277 .753692627279 .8536987305281 .9312133789283 .9847106934 286.0116882324288 .0107116699289 .9789123535291 .9151000977293 .81640625 295.6817932129297 .5086975098299 .2958068848301 .041595459302 .7431030273 304.4002075195306 .0076904297307 .5651855469309 .0668029785310 .5093994141 311.887298584313 .1940917969314 .4291992188315 .5823974609316 .6640930176 317.6624145508318 .604309082319 .479309082320 .3229980469321 .1400146484 321.8569946289322 .4100952148322 .7135009766322 .6964111328322 .5621948242 322.4736022949322 .5008850098322 .7041015625323 .0726013184323 .5885009766 324.2532043457325 .0686035156325 .8736877441326 .4193115234326 .8877868652 327.6347961426328 .2522888184328 .4135131836328 .4648132324328 .5834960938 328.7372131348328 .8739013672329 .2114868164330 .0551147461330 .9309997559 331.3503112793331 .8806152344333 .1030883789334 .2231140137334 .6719970703 334.4778137207333 .2680969238332 .0238952637331 .6836853027331 .9285888672 332.9724121094333 .9978027344334 .1057128906333 .9859924316334 .0610046387 334.0517883301333 .8533935547333 .5296936035333 .1546936035332 .792388916 332.3562927246332 .1640930176332 .6225891113333 .166595459333 .1359863281 333.0241088867333 .2533874512333 .4726867676333 .5021057129333 .5364074707 333.7127075195333 .9642028809334 .2511901855334 .5609130859334 .753112793 
334.9760131836335 .4183044434335 .8511962891336 .2851867676336 .1754150391 334.8929138184333 .4595031738332 .7561950684332 .6177978516332 .8445129395 333.2629089355333 .8147888184334 .3236083984334 .6925964355334 .7802124023 334.0840148926333 .3544921875333 .6145935059334 .087310791334 .2684936523 334.5075073242334 .8680114746335 .3200073242336 .1803894043336 .549407959 334.9194030762333 .7182006836335 .4150085449337 .5038146973337 .9635009766 338.1994018555339 .8406066895340 .3626098633337 .287689209333 .5126953125 331.386505127329 .8616943359328 .5849914551327 .608001709326 .690612793 326.1510009766326 .1146850586326 .672088623327 .8396911621329 .8366088867 333.2503967285335 .8243103027334 .9147033691332 .4548034668330 .1755981445 328.5584106445328 .6224060059329 .1532897949328 .9418029785328 .8143920898 329.3487854004329 .7980957031329 .100402832327 .9093017578327 .342590332 326.5981140137325 .1908874512323 .8738098145322 .9921875324 .304107666 330.0238037109335 .1995849609333 .8898010254331 .3974914551331 .9678039551 333.8890075684336 .8865966797340 .6177978516344 .383392334347 .8335876465 350.7932128906353 .3517150879355 .8190002441359 .5407104492365 .2347106934 371.9039916992379 .0043029785384 .9805908203387 .8713989258389 .3958129883 390.6481018066391 .6564025879393 .1929931641394 .8906860352396 .7195129395 398.6195983887400 .5120849609402 .3622131348404 .1034851074405 .721496582 407.2597045898408 .7304992676410 .1701965332411 .5809936523412 .9570007324 414.3225097656415 .7056884766417 .0952148438418 .4905090332419 .8929138184 421.2968139648422 .7049865723424 .1098022461425 .5141906738426 .9140014648 428.3117980957429 .7078857422431 .1029052734432 .4978942871433 .8934936523 435.2898864746436 .6874084473438 .0853881836439 .4834899902440 .8800048828 442.2738037109443 .6622924805445 .0439147949446 .4154968262447 .7755126953 449.120513916450 .4497070312451 .7604980469453 .0526123047454 .3244934082 455.5766906738456 .808807373458 .0220031738459 .2164001465460 .3931884766 461.553314209462 .6978149414463 .8272094727464 .9426879883466 .0448913574 467.1346130371468 .2125854492469 .2796020508470 .3362121582471 .3832092285 472.4212036133473 .4512023926474 .4736938477475 .4894104004476 .4989929199 477.5032043457478 .5026855469479 .4981994629480 .4902038574481 .4794921875 482.4666137695483 .4520874023484 .4364929199485 .4204101562486 .404296875 487.3886108398488 .3736877441489 .3601074219490 .3481140137491 .337890625 492.3298950195493 .3241882324494 .321105957495 .3205871582496 .3229064941 497.3280029297498.3359069824 499.3467102051500.3601989746501.3764038086 502.395111084503 .4161071777504 .4393920898505 .4645080566506 .4914855957 507.520111084508 .549987793509 .5810852051510 .6129150391511 .6452026367 512.6777954102513 .7103881836514 .7426757812515 .7744140625516 .8051757812 517.8348999023518 .8630981445519 .8897094727520 .9141845703521 .9365844727 522.9566040039523 .9736938477524 .9879760742525 .9989013672

21.60936927795 24.4461002349927.26769065857 30.07624053955 32.87805938721 35.6726799011238 .4603309631341 .2413291931244 .0159187316946 .78440856934 49.5470314025952 .3040809631355 .0557594299357 .8023796081560 .54407119751 63.2811012268166 .0135726928768 .7416763305771 .4654769897574 .18511199951 76.9005737304779 .6119384765682 .3191223144585 .0221023559687 .72074890137 90.4149627685593 .1045379638795 .7892684936598 .46887207031101 .1430969238 
103.8115997314106 .4740982056109 .1302032471111 .7796020508114 .4217987061 117.056602478119 .6835021973122 .3022003174124 .912399292127 .5136032104 130.1056976318132 .6884002686135 .2613067627137 .8244018555140 .3773040771 142.9199066162145 .4521026611147 .9739074707150 .4851074219152 .9857025146 155.475692749157 .9550933838160 .4239959717162 .8825073242165 .3305969238 167.7684936523170 .1963043213172 .6141967773175 .0223999023177 .421005249 179.8103942871182 .1907043457184 .5621032715186 .9250030518189 .2794036865 191.625793457193 .9642028809196 .2951049805198 .6184997559200 .9347991943 203.2440948486205.5466003418207.8424987793210.1318969727 212.4149932861 214.6918945312216 .9624938965219 .2270965576221 .4853057861223 .7375030518 225.9830932617228 .2223968506230 .4548950195232 .6804962158234 .8988037109 237.1096954346239 .3126068115241 .5072021484243 .6927947998245 .8692016602 248.0355072021250 .1912994385252 .3356933594254 .4682006836256 .5877990723 258.6937866211260 .7850036621262 .8606872559264 .9193115234266 .9598083496 268.9808044434270 .9807128906272 .9578857422274 .9106140137276 .837310791 278.7356872559280 .6046142578282 .4413146973284 .2449035645286 .0130004883 287.7448120117289 .4385986328291 .0939025879292 .7096862793294 .2844848633 295.8183898926297 .3078918457298 .7522888184300 .1484069824301 .4956970215 302.7825927734303 .9974975586305 .1422119141306 .2134094238307 .2070007324 308.1070861816308 .9374084473309 .6926879883310 .4432067871311 .2137145996 311.9910888672312 .8447875977313 .3084106445312 .9012145996312 .263092041 311.941986084311 .770690918311 .6853942871311 .7697143555312 .1010131836 312.6297912598313 .2633056641313 .9656982422314 .5969848633315 .150604248 315.8207092285316 .3230895996316 .4002990723316 .254699707315 .8435974121 315.5885925293316 .0174865723316 .7608032227317 .5903930664318 .2702941895 318.4556884766318 .828704834320 .0922851562321 .3670959473321 .9762878418 321.9848937988321 .249786377320 .5072021484320 .4838867188320 .9964904785 322.1975097656323 .2485046387323 .2979125977323 .1633911133323 .4685058594 323.7312011719323 .6300048828323 .2850036621322 .8055114746322 .3322143555 321.907409668321 .6572875977321 .7231140137322 .0531921387322 .6488952637 323.1460876465323 .224609375323 .1661071777323 .2811889648323 .3422851562 323.0986022949322 .8648986816322 .895111084323 .1141052246323 .4721984863 323.9674072266324 .7106018066325 .470703125326 .0766906738326 .0199890137 324.7943115234323 .4719848633323 .1611938477323 .6033935547324 .4967956543 325.0887145996324 .6907958984324 .2770996094324 .8693847656325 .5018920898 325.3017883301324 .6535949707323 .9885864258323 .5188903809323 .558013916 323.9263000488324 .5194091797325 .0986938477325 .6225891113325 .6614990234 324.7825927734324 .1892089844325 .1839904785326 .4682922363327 .0899963379 327.5557861328328 .5856018066328 .7045898438326 .6465148926324 .095489502 322.6278991699321 .6653137207320 .9616088867320 .2261047363319 .0573120117 318.0629882812317 .8280944824318 .2059020996319 .2125854492320 .7578125 322.7721862793324 .1366882324323 .8064880371322 .1416015625319 .6812133789 317.5487060547317 .0014953613316 .9831848145316 .609588623316 .2540893555 316.0299987793315 .9295959473315 .8439025879315 .6416931152315 .5238952637 315.2854919434314 .6268920898314 .4187927246314 .7741088867316 .0546875 319.4995117188321 .6272888184319 .4840087891317 .4826049805319 .1597900391 
322.7734069824327 .3681945801331 .3092956543333 .2001037598334 .425201416 335.8544921875337 .4043884277338 .2842102051342 .4077148438355 .0820007324 367.7395019531372 .2893981934373 .7551879883375 .0094909668376 .0982055664 377.6789855957379 .50390625381 .8320007324384 .4285888672387 .0899963379 389.733001709392 .1813049316394 .486907959396 .6159057617398 .5520019531 400.3731994629402 .1174926758403 .825592041405 .4863891602407 .0758056641 408.6232910156410 .1690063477411 .7016906738413 .2268066406414 .7445983887 416.2532043457417 .7513122559419 .2327880859420 .7004089355422 .1553039551 423.5989990234425 .0346984863426 .4627075195427 .8864135742429 .3062133789 430.7233886719432 .1380004883433 .5505065918434 .9601135254436 .3660888672 437.766998291439 .1608886719440 .5456848145441 .9191894531443 .2793884277 444.6236877441445 .9512939453447 .2600097656448 .5497131348449 .8194885254 451.0696105957452 .300201416453 .5120849609454 .7059020996455 .8826904297 457.0433959961458 .1888122559459 .3200073242460 .4375915527461 .5425109863 462.6353149414463 .7171020508464 .7882080078465 .8494873047466 .9016113281 467.9453125468 .9811096191470 .0100097656471 .0325012207472 .0492858887 473.0609130859474 .0682067871475 .071685791476 .0721130371477 .0698852539 478.0657043457479 .0600891113480 .0537109375481 .0468139648482 .0400085449 483.0336914062484 .0284118652485 .0244140625486 .0219116211487 .0213012695 488.0228881836489 .0267028809490 .032989502491 .0419006348492 .0534973145 493.0678100586494 .0848999023495 .1047058105496 .1271057129497 .1520080566 498.1792907715499 .2087097168500 .2402038574501 .2734985352502 .3084106445 503.3447875977504 .3822937012505 .4206848145506 .4596862793507 .4991149902 508.5385131836509 .5777893066510 .616607666511 .6546020508512 .6915893555 513.7271728516514 .7612304688515 .7932739258516 .8233032227517 .8508911133 518.8759155273519 .8981933594520 .9155273438521 .926574707

19.7779903411922 .5866203308125 .3904991149928 .1845397949230 .97080993652 33.7497291564936 .521480560339 .2863883972242 .0446510314944 .79658889771 47.5424003601150 .2823905944853 .0167503356955 .7457504272558 .46952056885 61.1883087158263 .902210235666 .6114425659269 .3160171508872 .01609039307 74.7116165161177 .4027099609480 .0892486572382 .7712326049885 .4485168457 88.1210098266690 .7884826660293 .4507293701296 .1074829101698 .75846862793 101.4033966064104 .0418014526106 .673500061109 .297996521111 .9149017334 114.5239028931117 .1246032715119 .7165985107122 .2994995117124 .8730010986 127.4366989136129 .9904937744132 .5339050293135 .066696167137 .5886993408 140.0997924805142 .5997009277145 .0883026123147 .5655059814150 .0312957764 152.4855041504154 .9282989502157 .3596038818159 .7794036865162 .1878051758 164.5848999023166 .9707946777169 .345703125171 .7097015381174 .0628967285 176.4055938721178 .7378997803181 .0601043701183 .3724060059185 .6748962402 187.9680023193190 .2518005371192 .5265045166194 .7922973633197 .0494995117 199.2982025146 201.5386962891203.7709960938205.9954071045 208.211807251 210.4203948975212 .6212005615214 .8141937256216 .9992980957219 .1766967773 221.3459014893223 .5070037842225 .6596069336227 .8036956787229 .9387054443 232.0644073486234 .1802978516236 .2861938477238 .3811950684240 .4651031494 242.5370025635244 .596496582246 .6425933838248 .674697876250 .6918029785 252.6930999756254 .6775054932256 .6440124512258 .5910949707260 .5179138184 
262.4226989746264 .3039855957266 .1606140137267 .9902038574269 .791809082 271.5628967285273 .3027038574275 .008392334276 .6798095703278 .3140869141 279.911895752281 .4714050293282 .9934082031284 .4782104492285 .9254150391 287.3375854492288 .7109985352290 .0469970703291 .3416137695292 .5981140137 293.7995910645294 .9281921387295 .9885864258296 .9787902832297 .8869934082 298.6849060059299 .3992919922300 .0141906738300 .6109924316301 .229888916 301.9395141602302 .974609375303 .5848999023302 .8580932617301 .8028869629 301.3046875300 .9531860352300 .5924987793300 .4086914062300 .5444030762 300.854888916301 .1770019531301 .5604858398302 .0631103516302 .6718139648 303.3707885742303 .8703918457303 .8916015625303 .504699707302 .5674133301 301.9453125302 .6238098145303 .6405944824304 .3320007324304 .7853088379 304.7633056641304 .9436950684306 .0851135254307 .3530883789308 .0310058594 308.2977905273308 .1311035156307 .9742126465308 .2925109863309 .0237121582 310.2655944824311 .3479919434311 .474609375311 .3916931152311 .8823852539 312.3599853516312 .4049072266312 .2210083008311 .7636108398311 .2275085449 310.8312072754310 .5068969727310 .1101989746310 .0780029297311 .1138000488 312.1336975098312 .0733947754311 .8203125312 .0776062012312 .1770935059 311.5212097168310 .8045959473310 .5224914551310 .5557861328310 .9482116699 311.6321105957312 .6231079102313 .5202941895314 .020111084314 .0487060547 313.2119140625312 .4655151367312 .7486877441313 .408996582314 .4030151367 314.9711914062313 .7351989746312 .5286865234313 .1795043945314 .0523986816 314.2287902832313 .8890075684312 .4580993652311 .1740112305311 .1094970703 311.4937133789312 .0776977539312 .6022949219312 .6505126953312 .5120849609 312.536895752312 .6359863281312 .7731018066313 .1517028809313 .8572998047 314.576385498314 .9772949219314 .9580078125314 .4559936523313 .7373962402 313.3490905762313 .1130065918313 .0127868652312 .6625061035311 .3948974609 310.1925048828309 .9271850586310 .2355957031311 .0440063477311 .9237976074 312.0584106445311 .9316101074312 .2980041504311 .9526062012310 .0325012207 307.9913024902307 .0784912109306 .6000976562306 .1559143066305 .6987915039 304.5899047852303 .8416137695304 .3806152344305 .2070922852305 .7618103027 306.2710876465306 .5238037109306 .9453125307 .4444885254307 .863494873 308.520904541308 .3916015625306 .4989929199305 .624206543308 .4439086914 312.9836120605318 .2679138184322 .4390869141323 .1185913086322 .6047973633 322.5456848145322 .8330993652322 .2182006836326 .6643981934345 .3811950684 363.3677978516365 .2784118652362 .4948120117362 .1879882812362 .5953063965 364.423614502367 .141204834370 .2950134277373 .7236938477377 .258392334 380.5969848633383 .5340881348386 .1470947266388 .6109924316390 .8992919922 393.0653991699395 .1376037598397 .1376953125399 .062286377400 .8778991699 402.620513916404 .3499145508406 .0497131348407 .7255859375409 .3815002441 411.0054931641412 .6069030762414 .1718139648415 .7112121582417 .2269897461 418.7229003906420 .2054138184421 .6754150391423 .1361999512424 .5882873535 426.0338134766427 .4729919434428 .9064025879430 .3340148926431 .7550048828 433.1684875488434 .5723876953435 .9655151367437 .3450927734438 .7098999023 440.0574951172441 .3873901367442 .6978149414443 .9888916016445 .2597045898 446.5111999512447 .7431945801448 .9570922852450 .1531982422451 .3327941895 452.4966125488453 .6455993652454 .7807006836455 .9028015137457 .012512207 
458.1106872559459 .1980895996460 .2752990723461 .3429870605462 .4018859863 463.4526977539464 .4961853027465 .5328063965466 .5633850098467 .5885925293 468.6090087891469 .625213623470 .6379089355471 .6477050781472 .6549987793 473.6606140137474 .6647949219475 .6683044434476 .6713867188477 .6747131348 478.6785888672479 .6834106445480 .6895141602481 .6972045898482 .7066955566 483.7182922363484 .7320861816485 .7482910156486 .766998291487 .7883911133 488.812286377489 .8388061523490 .8678894043491 .8995056152492 .9334106445 493.9695129395495 .0076904297496 .0476074219497 .0892028809498 .1322937012 499.1766052246500 .2218933105501 .2679138184502 .3143005371503 .3609008789 504.407409668505 .4534912109506 .4989929199507 .5434875488508 .5867004395 509.6285095215510 .6683959961511 .7062988281512 .7418823242513 .7747802734 514.8051147461515 .8319702148516 .8560180664517 .8759765625 17.942520141620 .7491893768323 .5401706695626 .3176994323729 .08823013306 31.8512401580834 .6069107055737 .3555603027340 .0973701477142 .83264160156 45.5615501403848 .2844009399451 .0013694763253 .7126884460456 .4185218811 59.1190681457561 .8144302368264 .5047912597767 .1901931762769 .87074279785 72.5464172363375 .2173080444377 .8833084106480 .5444030761783 .20043182373 85.85131835938 88.4968109130991.1367263793993.770782470796.39868164062 99.02011108398101 .6346969604104 .2421035767106 .8420028687109 .4337997437 112.0173034668114 .5920028687117 .1575012207119 .7135009766122 .2594985962 124.7951965332127 .3203964233129 .8345947266132 .337600708134 .8291015625 137.3088989258139 .7769012451142 .2328033447144 .6764984131147 .108001709 149.5269927979151 .9337005615154 .3278045654156 .7095031738159 .0787963867 161.4358062744163 .7805023193166 .1128997803168 .433303833170 .7418060303 173.0384979248175 .3236999512177 .5973052979179 .8598022461182 .1110992432 184.3516998291186 .5816040039188 .800994873191 .0101013184193 .209197998 195.3983001709 197.5776977539199.7474060059201.907699585204.0583953857 206.1999053955208 .3320007324210 .4546966553212 .5679931641214 .6719055176 216.7660064697218 .850402832220 .9246063232222 .988494873225 .0417022705 227.0839996338229 .1147003174231 .1334991455233 .1398010254235 .133102417 237.1125946045239 .0778045654241 .0276031494242 .9615936279244 .87840271 246.7774047852248 .6571960449250 .5169067383252 .3549041748254 .1701965332 255.9611053467257 .7261962891259 .4638977051261 .1723937988262 .850189209 264.4953918457266 .1068115234267 .6820983887269 .2208862305270 .7210998535 272.1836853027273 .6076965332274 .9952087402276 .3471069336277 .666809082 278.9595947266280 .2224121094281 .4567871094282 .6575012207283 .8233032227 284.9400024414285 .9930114746286 .9768981934287 .8821105957288 .6953125 289.3959960938289.9841918945290.4479064941290.8174133301291.0758056641 291.4631958008292 .2727966309292 .7651977539292 .2190856934291 .3251953125 290.6852111816290 .1347961426289 .615814209289 .240814209289 .1395874023 289.1651000977289 .1914978027289 .1860961914289 .0238952637289 .2892150879 290.6299133301291 .7915039062291 .558807373290 .7576904297289 .9635009766 289.5635070801290290 .7077941895291 .2236938477291 .5040893555291 .3858032227 291.4736022949292 .3261108398293 .4082946777294 .2518920898294 .7815856934 294.6086120605294 .4313964844294 .837097168295 .6337890625296 .8963012695 298.063293457298 .5462036133298 .7160949707298 .796295166298 .9483947754 
299.4562072754299 .8811035156299 .8185119629299 .5433044434299 .2557983398 298.9093933105298 .4890136719298 .3138122559298 .6964111328299 .1615905762 299.2409973145299 .2159118652299 .3833007812299 .3301086426298 .653503418 297.8734130859297 .4739990234297 .3523864746297 .4072875977297 .8395080566 298.9067993164299 .7614135742299 .571685791299 .279296875299 .633392334 300.2160949707300 .729309082300 .8742980957300 .3721923828299 .7101135254 299.4569091797299.2702026367 298.9306030273298.7012023926298.8138122559 298.7278137207297 .946105957297 .3546142578297 .8659057617298 .5390014648 298.4364929199298 .2673034668298 .7051086426299 .0914001465298 .6300048828 298.062286377298 .0729980469298 .3900146484298 .916809082299 .6982116699 300.666809082301 .5786132812301 .9807128906302 .2279968262302 .5025939941 302.6781921387302 .9366149902302 .9072875977302 .2941894531301 .6506958008 301.5625915527301 .8617858887302 .537109375303 .037902832303 .003692627 302.9411010742303 .233795166303 .217590332301 .9158935547300 .2385864258 299.129699707298 .2721862793297 .6211853027296 .9754943848296 .0122070312 295.5042114258296 .045501709296 .9879150391297 .7937011719298 .5385131836 299.0773010254299 .5751953125300 .0646972656300 .0101928711299 .6495056152 299.0296020508297 .8266906738297 .8692016602300 .359588623304 .0025024414 308.2095031738311 .4585876465312 .3190002441312 .0458984375311 .7124938965 311.5982971191311 .2872009277316 .0476989746331 .849395752347 .029510498 350.8139038086349 .6947021484348 .3884887695348 .1577148438350 .8052978516 354.7127990723358 .6853027344362 .8909912109367 .4403991699371 .6249084473 374.7168884277377 .3518066406380 .0907897949382 .7659912109385 .3510131836 387.8276977539390 .1387023926392 .3280944824394 .3862915039396 .3385009766 398.2661132812400 .1534118652402 .0072021484403 .8205871582405 .5736999512 407.2814025879408 .9431152344410 .5616149902412 .1408996582413 .6907958984 415.2272949219416 .7473144531418 .2525939941419 .7443847656421 .2253112793 422.6955871582424 .1565856934425 .6079101562427 .0495910645428 .4804077148 429.8995056152431 .304901123432 .6950073242434 .0683898926435 .4234008789 436.7593078613438 .0751037598439 .3707885742440 .6463012695441 .9023132324 443.1390991211444 .3576965332445 .5589904785446 .7439880371447 .9136047363 449.0686950684450 .2102966309451 .3389892578452 .4558105469453 .5611877441 454.6561889648455 .7413024902456 .817199707457 .8846130371458 .9442138672 459.9967041016461 .0426025391462 .0827941895463 .1177062988464 .1480102539 465.174407959466 .1972961426467 .2174987793468 .2352905273469 .2514953613 470.2663879395471 .2807006836472 .2945861816473 .308807373474 .3234863281 475.3391113281476 .3559875488477 .3743896484478 .3945007324479 .4166870117 480.4408874512481 .4674987793482 .4964904785483 .5278930664484 .5617980957 485.5981140137486 .6368103027487 .6777954102488 .7210083008489 .766204834 490.813293457491 .8619995117492 .9122009277493 .9635925293495 .0161132812 496.0693969727497 .1231079102498 .1771850586499 .2311096191500 .2849121094 501.3380126953502 .3902893066503 .4414978027504 .4912109375505 .5393066406 506.5852966309507 .6292114258508 .6704101562509 .7090148926510 .7445983887 511.7770996094512 .8043212891513 .8245239258 16.1631393432618 .9407196044921 .7133903503424 .4759807586727 .23055076599 29.9774799346932 .7169113159235 .4491615295438 .174388885540 .89289093018 
43.6048202514646 .3104705810549 .0099792480551 .7036209106454 .39147949219 57.073799133359 .7506408691462 .4221801757865 .0884399414167 .74954986572 70.4054565429773 .0562515258875 .7018127441478 .3421325683680 .97705078125 83.60646820068 86.23014068604 88.8479003906291.4594116210994.06442260742 96.6625823974699 .25354766846101 .8368988037104 .4123001099106 .9793014526 109.5374984741112 .0865020752114 .6258010864117 .1550979614119 .6740036011 122.1819992065124 .6789016724127 .1641998291129 .637802124132 .0991973877 134.5482940674136 .9848022461139 .4084014893141 .8191070557144 .2167053223 146.6009979248148 .9720001221151 .3296051025153 .6737976074156 .0045928955 158.3220062256160 .6260070801162 .9167022705165 .1943054199167 .458694458 169.7100982666171 .9486999512174 .1746063232176 .3880004883178 .5888977051 180.7778015137182 .9546051025185 .1195983887187 .2729034424189 .4147033691 191.5451965332193 .6645050049195 .7725982666197 .8697967529199 .9559936523 202.0314025879204 .0959014893206 .149597168208 .192199707210 .2239074707 212.2442932129214 .2532958984216 .2505950928218 .2359924316220 .2088928223 222.1694030762224 .1165924072226 .0502929688227 .9696044922229 .8742980957 231.7633972168233 .6363067627235 .4920959473237 .3300933838239 .1490020752 240.9481048584242 .7257995605244 .4812011719246 .2127990723247 .9192047119 249.5988006592251 .25252 .8713989258254 .4609069824256 .0173034668257 .5380859375 259.0227050781260 .4682006836261 .8750915527263 .2406005859264 .5675048828 265.8541870117267 .1057128906268 .3233947754269 .5150146484270 .6893920898 271.8431091309272 .9800109863274 .0895996094275 .1682128906276 .2036132812 277.1836853027278 .0936889648278 .9124145508279 .629699707280 .2304077148 280.6957092285281 .012512207281 .1816101074281 .0877990723281 .0564880371 281.4613037109281 .7240905762281 .3922119141280 .774597168280 .0700073242 279.3398132324278 .7020874023278 .1702880859277 .8255004883277 .5726013184 277.3283081055 277.0469970703 276.3605957031276.2265014648 278.0278015137 279.682800293279 .2167053223278 .224609375277 .837890625277 .6969909668 277.7684936523278 .0104980469278 .3120117188278 .5444030762278 .513885498 278.6080932617279 .2044067383280 .0404052734280 .9865112305281 .6809082031 281.4309997559281 .1376953125281 .509185791282 .2420959473283 .3817138672 284.5213012695285 .3129882812285 .7286071777285 .4360961914285 .2499084473 286.1482849121287 .1423034668287 .4690856934287 .4898071289287 .3389892578 287.044708252286 .7427062988286 .4433898926286 .0574035645285 .8039855957 285.9772033691286 .1883850098286 .2105102539286 .0082092285285 .4164123535 284.7491149902284 .3554077148284 .1152038574283 .8203125283 .8818969727 284.8594055176285 .6481933594284 .8999023438284 .384185791285 .857208252 287.5158081055288 .0250854492287 .6036987305285 .6433105469283 .9094848633 284.803314209285 .7914123535284 .5708007812283 .200592041283 .1199035645 283.3676147461283 .4408874512283 .7778930664284 .8855895996285 .7356872559 284.9645080566284 .183807373285 .1112976074285 .9193115234284 .8113098145 283.5534973145283 .5745849609284 .0020141602284 .3529052734285 .092010498 286.587890625288 .2528991699289 .2539978027290 .0277099609290 .6799926758 291.1546020508291 .6751098633292 .053314209292 .2944030762292 .4567871094 292.708190918293 .0046081543293 .4666137695293 .9180908203294 .2633056641 294.6639099121295 .0018920898294 .9655151367294 .2482910156293 .0344848633 
291.8613891602290 .8175964355290 .0598144531289 .5035095215288 .963104248 288.8139038086289 .2282104492290 .0711975098291 .0090942383291 .8417053223 292.2802124023292 .4461975098292 .6279907227292 .4736022949292 .0600891113 291.6812133789291 .4937133789292 .0722961426293 .5860900879295 .7025146484 298.2431030273300 .4132080078301 .7860107422302 .4963989258302 .6496887207 303.1937866211304 .2510070801308 .3996887207318 .6477050781329 .050994873 334.486114502336 .696685791335 .7532043457335 .0751037598338 .2575073242 342.8517150879347 .2059020996351 .8583984375357 .1238098145361 .9598999023 365.219909668367 .959197998371 .0848999023374 .2015075684377 .3017883301 380.2265930176382 .8505859375385 .2633972168387 .5497131348389 .7471923828 391.9154052734394 .0306091309396 .0932922363398 .0940856934399 .9848022461 401.8078918457403 .5653076172405 .2627868652406 .907989502408 .5174865723 410.1135864258411 .6895141602413 .245300293414 .7835083008416 .3063049316 417.8143920898419 .3082885742420 .7887878418422 .2557983398423 .7088012695 425.1467895508426 .5687866211427 .9731140137429 .3590087891430 .7247924805 432.0704040527433 .3948059082434 .6987915039435 .9819946289437 .2456054688 438.4899902344439 .7164916992440 .9256896973442 .1188049316443 .2966003418 444.4602050781445 .6104125977446 .7479858398447 .8736877441448 .9885864258 450.0929870605451 .1878051758452 .2735900879453 .3511047363454 .4209899902 455.4840087891456 .5407104492457 .5917053223458 .6376037598459 .679107666 460.7166137695461 .7508850098462 .7825012207463 .8118896484464 .8395996094 465.8660888672466 .8919067383467 .917388916468 .9432067871469 .9693908691 470.9963989258472 .0246887207473 .0542907715474 .0856018066475 .1188049316 476.1539916992477 .19140625478 .2309875488479 .2728881836480 .3171081543 481.3635864258482 .412109375483 .462890625484 .5156860352485 .5701904297 486.6264038086487 .6841125488488 .7430114746489 .8031005859490 .8638916016 491.9252929688492 .9870910645494 .0488891602495 .1105041504496 .1715087891 497.2319030762 498.2911987305 499.3492126465 500.4056091309 501.4601135254 502.5123901367503 .562286377504 .6094970703505 .6536865234506 .6948852539 507.7323913574508 .7666931152509 .7966003418 14.3793497085617 .154779434219 .9141101837222 .65974044825 .39818000793 28.128839492830 .8518905639633 .5676002502436 .2761383056638 .97777175903 41.6726493835444 .3610382080147 .0430793762249 .7190017700252 .38890838623 55.0530204772957 .711360931460 .3641395568863 .0113410949765 .65308380127 68.2893218994170 .9201202392673 .5453796386776 .1650619506878 .77900695801 81.3871231079183 .9891433715886 .5848999023489 .1740722656291 .75637817383 94.3314819335996 .8990173339899 .45858001709102 .009803772104 .5522003174 107.0852966309 109.6089019775112.1222991943 114.6251983643 117.1172027588 119.5979003906122 .0669021606124 .5238037109126 .9682006836129 .3999938965 131.8186950684134 .224105835136 .6159973145138 .9940948486141 .3583068848 143.708404541146 .0444030762148 .3659973145150 .6732025146152 .9660949707 155.2445068359157 .5084991455159 .758102417161 .9933929443164 .2144927979 166.421295166168 .6141967773170 .7929992676172 .9580993652175 .1094970703 177.2474060059179 .3719940186181 .4833984375183 .5816955566185 .6672973633 187.7400054932189 .8000946045191 .8475952148193 .8827972412195 .9055938721 197.9161071777199 .9141998291201 .8999938965203 .8733062744205 .8341064453 
207.7819976807209.7171020508 211.6389007568 213.5473022461 215.4418029785 217.3220062256219 .1875221 .0377960205222 .8721008301224 .6900939941226 .4907989502 228.2736968994230 .0377044678231 .7819976807233 .5054016113235 .2070007324 236.8851928711238 .5390930176240 .1667022705241 .766998291243 .3379058838 244.8780975342246 .3856048584247 .8585968018249 .2953948975250 .6938934326 252.0527954102253 .3697052002254 .6446990967255 .8760070801257 .0660095215 258.2142028809259 .3281860352260 .412109375261 .4765930176262 .5322875977 263.577911377264 .6166992188265 .6364135742266 .6328125267 .5910949707 268.4956054688269 .3281860352270 .0674133301270 .6973876953271 .1935119629 271.540802002271 .7370910645271 .7607116699271 .5639038086271 .3446044922 271.3275146484271 .2486877441270 .8186035156270 .1944885254269 .4030151367 268.5404968262267 .791809082267 .1257019043266 .5791931152266 .1311035156 265.7554931641265 .43359375265 .1008911133265 .2094116211266 .2655944824 267.2070007324266 .9656982422266 .3847961426266 .1014099121265 .9064941406 265.7421875265 .7164001465265 .9888916016266 .3700866699266 .6068115234 266.8953857422267 .4390869141268 .154510498268 .9726867676269 .6116027832 269.6346130371269 .5863037109269 .8818969727270 .4148864746271 .1657104492 271.9841918945272 .6373901367273 .0362854004273 .004486084273 .083404541 273.8481140137274 .7630004883275 .2059936523275 .344909668275 .2587890625 275.0163879395 274.7442932129 274.3765869141 273.9255065918273.5976867676 273.6206054688273 .734588623273 .6235961914273 .3357849121272 .7955932617 272.2239990234271 .8138122559271 .4988098145271 .254699707271 .3287963867 272.0173950195272 .6164855957272 .3591003418272 .4335021973273 .7327880859 275.1315002441275 .6460876465275 .1907043457273 .6329956055272 .4455871582 272.9194946289273 .5169067383272 .7756958008271 .8313903809271 .7150878906 272.0947875977272 .3768005371272 .8734130859273 .7080078125274 .179901123 273.6944885254273 .2676086426273 .8446960449274 .3068847656273 .5192871094 272.6019897461272 .4224853516272 .5958862305272 .7846984863273 .2590026855 274.0816040039275 .2260131836276 .4108886719277 .4973144531278 .3999938965 279.1892089844279 .9927978516280 .8499145508281 .7286071777282 .5296020508 283.1842956543283 .6086120605283 .8344116211284 .1731872559284 .8942871094 285.8143920898286 .6712036133287 .0609130859286 .7056884766285 .725402832 284.3980102539283.2482910156282.8779907227 282.7572937012 282.3212890625 282.0982971191282 .5575866699283 .5068054199284 .9685058594286 .1625061035 286.2189941406285 .8565979004285 .7149963379285 .58660888667285 .4950866699 285.5257873535285 .5364990234285 .8519897461286 .8995056152288 .2037963867 289.8071899414291 .5116882324292 .825012207293 .9867858887294 .8807983398 296.3479003906299 .0436096191303 .1420898438310 .300201416317 .7767944336 322.5038146973325 .5152893066325 .7045898438325 .5643920898328 .0780944824 331.8623962402336 .0658874512340 .6836853027345 .7078857422350 .5288085938 354.4070129395357 .9111938477361 .5333862305365 .2001953125368 .9902038574 372.4989013672375 .3233032227377 .837890625380 .3554992676382 .8338012695 385.2972106934387 .6918945312389 .9988098145392 .2054138184394 .2626953125 396.2121887207398 .0604858398399 .8251037598401 .5427856445403 .2213134766 404.8785095215406 .511505127408 .1227111816409 .7124938965411 .2831115723 412.8344116211414 .3666992188415 .8807983398417 .37768555469418 .8568115234 
420.3179016113421 .7600097656423 .1823120117424 .5838928223425 .9639892578 427.3223876953428 .6590881348429 .9742126465431 .2684936523432 .5426940918 433.7976989746435 .0346069336436 .254486084437 .4580993652438 .646697998 439.8210144043440 .9820861816442 .1307067871443 .2676086426444 .3935852051 445.5093994141446 .6156005859447 .7130126953448 .8021850586449 .8840026855 450.9588928223452 .0277099609453 .0907897949454 .1489868164455 .2027893066 456.2526855469457 .2994995117458 .3434143066459 .3853149414460 .4254150391 461.4642944336462 .5025024414463 .5404052734464 .5783996582465 .6167907715 466.6559143066467 .696105957468 .737487793469 .7804870605470 .8252868652 471.871887207472 .920501709473 .9711914062475 .0239868164476 .0787963867 477.1357116699478 .1943969727479 .2551879883480 .3178100586481 .3819885254 482.4476013184483 .5144042969484 .5823974609485 .6510925293486 .7206115723 487.7903137207488 .8601989746489 .9299926758490 .9993896484492 .0679931641 493.1357116699494 .2022094727495 .2672119141496 .3304138184497 .3915100098 498.4501953125499 .5064086914500 .5595092773501 .6097106934502 .6565856934 503.700012207504 .737487793505 .7676086426

12.652729988115 .3982801437418 .1387996673620 .8691005706823 .59120941162 26.305459976229 .0119800567631 .7110404968334 .4027786254937 .0874786377 39.7652397155842 .4363403320345 .1008796691947 .7590904235850 .41106033325 53.0569801330655 .6968917846758 .3309707641660 .9591903686563 .58166885376 66.1983489990268 .8093032836971 .4143829345774 .0135879516676 .6067276001 79.1937026977581 .7742614746184 .3482284545986 .9152526855589 .47506713867 92.0273284912194 .5716781616297 .1076736450299 .63493347168102 .1529998779 104.6613998413107 .1597976685109 .6475982666112 .12449646114 .5899963379 117.0436019897119 .4850997925121 .9139022827124 .3296966553126 .7321014404 129.120803833131 .4956970215133 .8562011719136 .2021942139138 .5335998535 140.8500061035143 .1513977051145 .4376068115147 .7084960938149 .9640045166 152.2041015625154 .4286956787156 .6378936768158 .8316040039161 .0099945068 163.1730041504165 .3208007812167 .4532928467169 .5709075928171 .6734924316 173.7613983154175 .8345031738177 .8932037354179 .9375181 .9676055908183 .983505249 185.9853973389187 .9734039307189 .9476928711191 .9080963135193 .8547973633 195.7875976562197 .7068023682199 .6118927002201 .5032043457203 .3800964355 205.2427062988 207.0904998779208.9234008789210.7407989502 212.5426025391 214.3280029297216 .0966949463217 .8479003906219 .5812072754221 .2955932617 222.9907073975224 .6651000977226 .3182067871227 .9485015869229 .5552978516 231.1367034912232 .6918029785234 .2185058594235 .7156066895237 .1808929443 238.6130065918240 .0097961426241 .3692016602242 .6894073486243 .9680023193 245.2037963867246 .3939971924247 .5390014648248 .6363067627249 .6903076172 250.6986999512251 .674697876252 .6226959229253 .5581970215254 .4916992188 255.4250030518256 .3637084961257 .2932128906258 .2119140625259 .0935058594 259.9171142578 260.6701965332 261.3259887695 261.8604125977 262.2359008789 262.4678039551262 .5653991699262 .4917907715262 .2489929199261 .8890991211 261.5013122559261 .0452880859260 .4715881348259 .7284851074258 .7789916992 257.8091125488256 .9753112793256 .2424926758255 .5361938477254 .908706665 254.4347991943254 .1782989502254 .3569030762254 .6920013428254 .8433990479 254.9248962402254 .9553985596254 .8845977783254 .7236938477254 .4933929443 
254.1927032471254 .0411987305254 .3249053955254 .8489074707255 .3876037598 255.9553985596256 .5440063477257 .1517944336257 .7697143555258 .337890625 258.6878051758258 .9251098633259 .1611022949259 .3976135254259 .7113037109 260.0535888672260 .3640136719260 .7041015625261 .0686035156261 .5429077148 262.1415100098262 .7110900879263 .0599060059263 .1890869141263 .1206054688 262.8966064453262 .6312866211262 .291809082261 .9768981934261 .7388000488 261.6903991699261 .6394042969261 .3840026855261 .0025024414260 .5147094727 260.0259094238259 .6022949219259 .2973022461259 .2070007324259 .3458862305 259.734588623260 .2788085938260 .8113098145261 .4656982422262 .2344055176 262.8905029297263 .2539978027263 .1754150391262 .7137145996262 .2225036621 262.033996582261 .9773864746261 .8396911621261 .8265991211262 .077911377 262.4368896484262 .7157897949262 .9111938477263 .0805969238263 .1935119629 263.2460021973263 .3281860352263 .4949035645263 .5313110352263 .2934875488 262.9183959961262 .5707092285262 .4130859375262 .5202941895262 .6943969727 262.6014099121262 .745513916263 .6419067383264 .8276977539265 .8601074219 266.9111938477268 .0033874512269 .1770935059270 .4949035645271 .7058105469 272.6883850098273 .3393859863273 .5350036621273 .8099975586274 .8020935059 275.9107055664276 .8518066406277 .5347900391277 .6207885742277 .2471923828 276.2430114746275 .2988891602275 .499206543275 .8782043457275 .5274047852 275.3276977539275 .8605957031276 .9147949219278 .7493896484280 .2214050293 279.9560852051279 .2171020508278 .9935913086278 .9829101562279 .3357849121 279.7520141602279 .6940917969279 .7179870605280 .4016113281281 .3204040527 282.4909973145283 .8670043945285 .0946960449286 .5477905273288 .0979003906 290.417388916294 .425201416299 .158203125304 .5918884277309 .7858886719 313.4937133789316 .1217956543316 .9780883789317 .5069885254319 .0961914062 321.6445922852325 .3598022461329 .7385864258334 .2611999512338 .8175964355 343.2484130859347 .5220947266351 .6860046387355 .8179016113360 .2106018066 364.2611999512367 .3328857422370 .0315856934372 .8562927246375 .6463928223 378.4321899414381 .1546020508383 .754486084386 .1951904297388 .4222106934 390.4844055176392 .412109375394 .2532043457396 .0505065918397 .8059997559 399.5296020508401 .2244873047402 .8955078125404 .5421142578406 .1651916504 407.7644958496409 .3392944336410 .8912963867412 .4216918945413 .9305114746 415.4179992676416 .883605957418 .3269042969419 .7474975586421 .1449890137 422.5195007324423 .8711853027425 .2008056641426 .5089111328427 .7966918945 429.0650024414430 .3150939941431 .5480041504432 .7648010254433 .9663085938 435.1536865234436 .3276977539437 .4892883301438 .6393127441439 .7782897949 440.9071960449442 .0264892578443 .1370849609444 .2395935059445 .3346862793 446.4230041504447 .5050964355448 .5816955566449 .6532897949450 .720489502 451.783996582452 .8440856934453 .9014892578454 .9566955566456 .0101013184 457.062286377458 .1135864258459 .1646118164460 .2155151367461 .2666931152 462.3185119629463 .3711853027464 .424987793465 .4801940918466 .5369873047 467.5953979492468 .6557006836469 .7178039551470 .7817077637471 .8475036621 472.9151000977473 .9844970703475 .0556030273476 .1282043457477 .2022094727 478.2774963379479 .3537902832480 .4309082031481 .508605957482 .5867004395 483.6650085449484 .7432861328485 .821105957486 .8984069824487 .9747924805 489.0501098633490 .1239013672491 .196105957492 .266204834493 .3340148926 
494.3992919922495 .4617919922496 .5212097168497 .5773925781498 .6300964355 499.6788024902 500.7239990234501 .7643127441

10.9214401245113 .6645698547416 .3913497924819 .104280471821 .8099193573 24.507600784327 .197469711329 .8797702789332 .5546493530335 .22232055664 37.8829307556240 .5367012023943 .183731079145 .8242492675848 .45830917358 51.0860900878953 .7076416015656 .3230781555258 .9324302673361 .53575897217 64.1330108642666 .7242431640669 .3093109130971 .8881988525474 .46071624756 77.0267486572379 .5860519409282 .1384201049884 .6835327148487 .22110748291 89.7507629394592 .2721328735494 .7848281860497 .2884063720799 .78241729736 102.2664031982104 .7398986816107 .2024993896109 .6537017822112 .0930023193 114.5198974609116 .9341964722119 .3352966309121 .7228012085124 .0962982178 126.4555969238128 .800201416131 .1298980713133 .4443969727135 .7433929443 138.0267028809140 .2940979004142 .5453948975144 .7805023193146 .9992980957 149.2017059326151 .3874969482153 .5569000244155 .7097930908157 .846206665 159.966003418162 .0695037842164 .1564941406166 .2274017334168 .2819976807 170.320602417172 .3432006836174 .3500061035176 .3410949707178 .316696167 180.2767028809182 .221496582184 .1510009766186 .0653076172187 .9644012451 189.8484039307191 .7171936035193 .5709075928195 .4091949463197 .2321929932 199.0393981934200 .8309020996202 .6062011719204 .3650970459206 .1071929932 207.8321075439209 .5393066406211 .228302002212 .8983001709214 .5489044189 216.1791992188217 .7884979248219 .3757019043220 .9400024414222 .4799041748 223.9945068359225 .4819946289226 .941192627228 .3699951172229 .7671051025 231.1300964355232 .4573974609233 .7467041016234 .995803833236 .2024993896 237.3645019531238 .4797058105239 .5457000732240 .5623016357241 .5274963379 242.445098877243 .3141021729244 .1497039795244 .9604949951245 .7630004883 246.570098877247 .3871002197248 .2225036621249 .0621032715249 .9060974121 250.713104248251 .4461975098252 .1091003418252 .686706543253 .1259002686 253.3578033447253 .4680023193253 .537902832253 .4261932373252 .9868011475 252.3625946045251 .7281036377251 .0617980957250 .4228057861249 .5877990723 248.3251953125247 .1013946533246 .3058929443245 .645401001244 .8200073242 244.0111999512243 .3843994141243 .0592041016243 .1719970703243 .3267059326 243.316696167243 .3052062988243 .4122009277243 .588394165243 .658203125 243.584197998243 .4326934814243 .363494873243 .4727935791243 .904296875 244.7344055176245 .5827026367246 .175201416246 .6645050049247 .1981048584 247.7946929932248 .3854064941248 .7971038818248 .866104126248 .7619018555 248.7736968994248 .7713012695248 .6374969482248 .7566986084249 .3731994629 250.1316986084250 .7339935303251 .1302947998251 .2734069824251 .2675018311 251.1484985352250 .9356994629250 .6611938477250 .3497009277250 .0115966797 249.7779998779249 .895904541249 .9351043701249 .5388946533249 .0142974854 248.5225067139248 .0769042969247 .6930999756247 .4391021729247 .3939056396 247.5158996582247 .7929992676248 .4004974365249 .4589996338250 .4447937012 250.8576965332251 .0574951172251 .4624023438251 .8540039062251 .8598937988 251.5735015869251 .2319946289251 .0229034424251 .1374053955251 .6649932861 252.5722045898253 .2449035645253 .3502044678253 .0798034668252 .6903991699 252.5464019775252 .8820037842253 .2890930176253 .3874969482253 .3638000488 253.5225982666253 .4645996094252 .7315063477252 .1302947998252 .5214996338 
252.7834014893251 .9909973145251 .2192993164251 .4638977051252 .3338012695 253.4044952393254 .6136932373255 .8040924072257 .0729064941258 .4200134277 259.687286377260 .7831115723261 .5853881836262 .0382080078262 .4512939453 263.1317138672263 .5900878906263 .309387207263 .2822875977264 .5693054199 265.904296875266 .2031860352266 .2666931152266 .8409118652267 .4266967773 267.612487793267 .8489074707268 .5660095215269 .6531982422271 .1957092285 272.4046020508272 .4737854004272 .1485900879272 .0914001465272 .253692627 272.7132873535273 .1975097656273 .4135131836273 .6246948242274 .2047119141 274.9772949219275 .958404541277 .1607055664278 .4312133789280 .1041870117 282.1559143066285 .1135864258289 .5358886719294 .4851989746300 .0502929688 304.767791748307 .087310791308 .4440002441309 .1010131836309 .4446105957 310.1184082031311 .6691894531315 .1442871094319 .5150146484323 .8005065918 328.2253112793332 .6622009277337 .1426086426341 .6129150391346 .0599975586 350.6343994141354 .9414978027358 .549987793361 .8102111816365 .0197143555 368.170501709371 .3192138672374 .4032897949377 .3941955566380 .145904541 382.4912109375384 .6026000977386 .6181945801388 .5505981445390 .4356994629 392.2723999023394 .071685791395 .8355102539397 .5723876953399 .2803955078 400.9602050781402 .6109924316404 .2319946289405 .8251953125407 .3924865723 408.9341125488410 .4511108398411 .9431152344413 .4104919434414 .8529968262 416.2708129883417 .6642150879419 .0339050293420 .3807067871421 .7055969238 423.0096130371424 .2939147949425 .5596923828426 .8081970215428 .0403137207 429.2571105957430 .4595947266431 .6487121582432 .8251953125433 .9901123047 435.1440124512436 .2875976562437 .4218139648438 .547088623439 .6643981934 440.7742004395441 .8771972656442 .9739990234444 .0651855469445 .1513977051 446.2331848145447 .3110961914448 .3857116699449 .4573974609450 .5268859863 451.5943908691452 .6606140137453 .7258911133454 .7905883789455 .8551025391 456.9197998047457 .9848022461459 .0505981445460 .117401123461 .1852111816 462.254486084463 .3251037598464 .3973999023465 .4713134766466 .5468139648 467.6239929199468 .7026977539469 .7828979492470 .8645019531471 .9475097656 473.0315856934474 .1166992188475 .2026062012476 .2890930176477 .3758850098 478.4630126953479 .549987793480 .6366882324481 .7229003906482 .8082885742 483.8926086426484 .9755859375486 .0568847656487 .1362915039488 .2134094238 489.2882080078490 .3601989746491 .4291992188492 .4949951172493 .5573120117 494.6159973145495 .6709899902496 .7195129395497 .7598876953

9.24788188934311 .9604997634914 .6680202484117 .3652896881120 .05427932739 22.7352695465125 .4083690643328 .0738296508830 .7317504882833 .38236999512 36.0257797241238 .6622085571341 .2917404174843 .9145698547446 .53075027466 49.1404685974151 .743721008354 .3406486511256 .931221008359 .51552963257 62.0934906005964 .6651611328167 .2304000854569 .7891616821372 .34124755859 74.8865509033277 .4248123168979 .9558334350682 .4792633056684 .99481964111 87.5021286010790 .00083160492 .4904937744194 .9706878662197 .44094848633 99.9008026123102 .3498001099104 .787399292107 .2132034302109 .626701355 112.0273971558114 .4148025513116 .7885971069119 .1482009888121 .4934005737 123.823600769126 .1384963989128 .4378051758130 .721206665132 .9884033203 135.2391052246137 .4730072021139 .6900024414141 .8899993896144 .0726013184 146.2378997803148 .3856964111150 .5160064697152 .6286010742154 .7236938477 
156.8011016846158 .8609924316160 .9033050537162 .9282073975164 .9355926514 166.9257965088168 .8986968994170 .8545074463172 .7933044434174 .7153015137 176.6204986572178 .5090942383180 .3809967041182 .2364044189184 .075302124 185.8977966309187 .703704834189 .4931030273191 .2657928467193 .0218048096 194.7606964111196 .4824066162198 .186706543199 .8731994629201 .5413970947 203.1911010742204 .8217010498206 .432800293208 .0234985352209 .5935058594 211.1416931152212 .6676025391214 .1697998047215 .6479034424217 .099899292 218.5252075195219 .9216003418221 .2881011963222 .6224060059223 .9228973389 225.1871948242226 .4134979248227 .599105835228 .741897583229 .8390045166 230.8881988525231 .8869018555232 .8323974609233 .7245025635234 .5603027344 235.3450927734236 .0751037598236 .7713928223237 .4400024414238 .1045074463 238.7718963623239 .4611968994240 .179397583240 .9183959961241 .6876068115 242.4165039062243 .0532989502243 .6226959229244 .1015930176244 .4241943359 244.5171966553244 .4768981934244 .4624023438244 .2687072754243 .6260986328 242.7602996826241 .9541931152241 .116394043240 .4486999512239 .6432037354 238.2436065674 236.8780059814236.0821075439235.3963012695 234.3898925781 233.4129943848232 .6526947021232 .1351013184231 .991394043231 .9868927002 232.0308990479232 .1589050293232 .382598877232 .6856994629232 .9214019775 233.1275024414233 .2931976318233 .4235992432233 .3890991211233 .5852966309 234.5050964355235 .532699585236 .1591033936236 .6371002197237 .154800415 237.6847991943238 .3527069092238 .8265991211238 .7030944824238 .383605957 238.2359008789238 .0843048096237 .678894043237 .5478973389238 .2357025146 239.0601043701239 .5397949219239 .7803039551239 .7321929932239 .5561065674 239.3657989502 239.1273040771238.8336029053238.5001068115238.0971984863 237.8428039551 238.129699707 238.3502044678 237.928894043 237.3421020508 236.8777008057236 .4821929932236 .1470947266235 .9394989014235 .8992004395 236.0175933838236 .2183990479236 .7720031738238 .0200042725239 .1531982422 239.2474975586239 .150894165239 .6985931396240 .2967987061240 .4528961182 240.4042053223240 .1943054199240 .0561065674240 .3471069336240 .9463043213 242.0565032959242 .9971923828243 .0131988525242 .6654052734242 .1483001709 241.8101959229242 .2198944092242 .7342071533242 .7360992432242 .711807251 243.2519073486243 .4685974121242 .4450073242241 .4447021484241 .9378051758 242.3567962646241 .1849060059239 .9882965088239 .8238067627240 .2890014648 241.266204834242 .5119018555243 .679901123244 .8585968018246 .0007019043 247.129196167248 .25340271249 .2398071289250 .0433959961250 .5812072754 250.866897583250 .6806945801249 .2530975342248 .541595459250 .8560028076 253.7572021484255 .3609924316256 .525604248257 .4934997559258 .2979125977 259.0776062012259 .8732910156260 .8468017578261 .900390625262 .9996948242 263.9104003906264 .433807373264 .7640075684265 .0809936523265 .4601135254 265.9460144043266 .4725952148267 .0014038086267 .5502929688268 .2554016113 269.0848083496270 .0852966309271 .3228149414272 .6817016602274 .512298584 276.8064880371279 .9840087891284 .4345092773289 .4652099609295 .4715881348 300.3230895996301 .6366882324301 .7571105957301 .970489502302 .0422973633 301.9833068848302 .8443908691306 .1040039062310 .3273925781314 .2951965332 318.4285888672322 .5982055664326 .9690856934331 .5685119629336 .2453918457 340.8996887207345 .3511962891349 .4982910156353 .3669128418357 .0215148926 
360.5380859375364 .0517883301367 .4708862305370 .8219909668373 .8793029785 376.3646850586378 .5672912598380 .7048950195382 .7443847656384 .7231140137 386.6458129883388 .5228881836390 .3604125977392 .1662902832393 .9389038086 395.6778869629397 .3829040527399 .0527038574400 .6897888184402 .2966003418 403.8736877441405 .4227905273406 .9437866211408 .4378051758409 .9049072266 411.3456115723412 .7608947754414 .1512145996415 .5180053711416 .8622131348 418.1849975586419 .4877929688420 .771697998422 .037902832423 .2875976562 424.5217895508425 .7414855957426 .9475097656428 .1408996582429 .3223876953 430.4927978516431 .6528930664432 .8034057617433 .9450073242435 .0783996582 436.2041931152437 .3232116699438 .4359130859439 .5429077148440 .6448059082 441.7423095703442 .8356933594443 .9255981445445 .0126037598446 .0971984863 447.1796875448 .2607116699449 .3405151367450 .4195861816451 .4984130859 452.5770874023453 .6560058594454 .7354125977455 .815612793456 .8966064453 457.9786987305459 .0621032715460 .1467895508461 .2327880859462 .3201904297 463.408996582464 .4991149902465 .5903930664466 .6828918457467 .7763977051 468.8709106445469 .9660949707471 .061706543472 .1578063965473 .2539978027 474.350189209475 .4460144043476 .5414123535477 .6359863281478 .7296142578 479.8218994141480 .912689209482 .0015869141483 .0884094238484 .1727905273 485.2546081543486 .333404541487 .4090881348488 .4812927246489 .5498962402 490.6146850586491 .6751098633492 .7318115234493 .7831115723

7.56936883926410 .279259681712 .9726696014415 .652239799518 .32445907593 20.9886207580623 .6448707580626 .2933902740528 .9342994689931 .56780052185 34.1940002441436 .8130798339839 .4251213073742 .0303001403844 .62868118286 47.2203903198249 .8054389953652 .3839416503954 .9558792114357 .52130126953 60.0801506042562 .6324195861865 .1780014038167 .7168426513770 .24871063232 72.7735137939575 .2909698486377 .8008728027380 .302871704182 .79670715332 85.2819595336987 .7582626342890 .2251892089892 .6822967529395 .12914276123 97.5651931762799 .98998260498102 .4029998779104 .8038024902107 .1918029785 109.5665969849111 .927696228114 .274597168116 .6067962646118 .9238967896 121.2255020142123 .5111999512125 .7807006836128 .033493042130 .2693023682 132.4878997803134 .6889953613136 .8722991943139 .0377044678141 .1847991943 143.3135986328145 .4239959717147 .5157928467149 .5890045166151 .6434020996 153.6791992188155 .6961975098157 .6945037842159 .6741943359161 .6352996826 163.5778045654165 .5019073486167 .4075927734169 .2951049805171 .1643981934 173.0155944824174 .8489990234176 .6643066406178 .4618988037180 .2416992188 182.003692627183 .7478027344185 .4741973877187 .1824951172188 .8728027344 190.5446929932192 .1981964111193 .8327026367195 .4483032227197 .0442962646 198.6204986572200 .1763000488201 .7111968994203 .2245941162204 .7158966064 206.1842041016207 .62890625209 .0487060547210 .4429931641211 .8099975586 213.1488037109214 .4573059082215 .7344055176216 .9774932861218 .1851959229 219.354598999 220.4839019775221.5700073242 222.6107025146 223.6029052734 224.5437927246225 .4306030273226 .2601928711227 .0316925049227 .7424926758 228.3959960938228 .9902954102229 .5440063477230 .0666046143230 .5798950195 231.0950927734231 .6376953125232 .224395752232 .854095459233 .5386962891 234.1795959473234 .7268981934235 .2062988281235 .554901123235 .7265014648 235.6894989014235 .4768066406235 .1611022949234 .7176055908234 .0319061279 
233.1307067871232 .1098022461231 .087600708230 .3489074707229 .6361999512 228.7451019287227 .7610015869226 .6154022217225 .4281005859224 .2093048096 223.0680999756222 .1531982422221 .4786071777221 .1815948486221 .1300048828 221.2174072266221 .4548034668221 .7946014404222 .2140960693222 .6266021729 223.1092987061223 .6878967285224 .1161956787224 .0973968506224 .1307983398 224.7180938721225 .5417938232226 .420501709227 .1436004639227 .4915008545 227.7483062744228 .18699646228 .488494873228 .3621063232228 .1011047363 227.9841003418227 .8977966309227 .7353973389227 .7191009521228 .0615997314 228.4279022217228 .5419006348228 .4801940918228 .2940063477228 .0446929932 227.7700042725227 .4615936279227 .0839996338226 .6575927734226 .1641998291 225.8706054688226 .1416931152226 .4250030518226 .2454071045225 .8912963867 225.533493042225 .2082977295224 .9461975098224 .7646026611224 .68409729 224.6929016113224 .7611999512225 .1020965576225 .9378051758226 .6983947754 226.796295166226 .7339935303227 .0187072754227 .3829956055227 .5641021729 227.749206543228 .1369018555228 .4402008057228 .4568023682228 .4656982422 228.741394043229 .1575927734229 .7731018066230 .288192749230 .4288024902 230.4237060547230 .4308929443230 .4302062988230 .3365936279230 .3692016602 230.992401123231 .31300354230 .603805542229 .7097015381229 .3500976562 229.0975952148228 .6571044922228 .3074951172228 .354095459228 .7877044678 229.6506958008230 .7402038574231 .8135986328232 .8085021973233 .5944976807 234.4817962646235 .7518005371237 .0431976318237 .9808044434238 .5545959473 238.7857055664238 .5688018799237 .713104248237 .6542053223239 .6840057373 242.4541931152244 .5861053467246 .3278961182247 .7536010742248 .9830932617 250.1703033447251 .3455963135252 .5570983887253 .6658935547254 .7046051025 255.6450958252256 .3555908203257 .0333862305257 .7698059082258 .482208252 259.2132873535259 .9811096191260 .7749938965261 .6146850586262 .5250854492 263.5114135742264 .6557006836265 .9880065918267 .4892883301269 .3507080078 271.5715942383274 .6304016113279 .0884094238284 .096496582289 .2995910645 293.3569946289294 .8472900391295 .1942138672295 .395111084295 .4740905762 295.5704040527296 .4136047363298 .9692993164302 .361114502305 .8280029297 309.4460144043313 .0277099609317 .0158996582321 .7803039551326 .7907104492 331.5939025879336 .2467956543340 .6759033203344 .9230041504348 .9663085938 352.8474121094356 .6719055176360 .3684082031363 .9099121094367 .1466064453 369.9039001465372 .3630065918374 .666809082376 .8374938965378 .9248962402 380.9360961914382 .896697998384 .8098144531386 .6875388 .5262145996390 .3265991211 392.0874938965393 .8081054688395 .4910888672397 .1394042969398 .7540893555 400.3374023438401 .8898925781403 .412902832404 .9070129395406 .3732910156 407.8125915527409 .2262878418410 .6153869629411 .9814147949413 .3254089355 414.6489868164415 .9531860352417 .2395019531418 .5087890625419 .7623901367 421.0010986328422 .2260131836423 .4378967285424 .63778686652425 .8262939453 427.0043945312428 .1726989746429 .3320007324430 .4829101562431 .6261901855 432.762298584433 .8920898438435 .0161132812436 .1347961426437 .2488098145 438.3586120605439 .4649047852440 .5679931641441 .6684875488442 .7666931152 443.8631896973444 .958404541446 .0526123047447 .1462097168448 .2395019531 449.3327941895450 .4263916016451 .5203857422452 .6151123047453 .7105102539 454.8068847656455 .9043884277457 .0028991699458 .1025085449459 .2031860352 
460.304901123461 .4075927734462 .5112915039463 .6156005859464 .7206115723 465.8261108398466 .9317932129468 .0375976562469 .1433105469470 .2488098145 471.3536987305472 .4577941895473 .5610046387474 .6629943848475 .7633972168 476.8620910645477 .9585876465479 .0530090332480 .1448059082481 .2337036133 482.3194885254483 .4020080566484 .4807128906485 .5556945801486 .6268005371 487.6936950684488 .753692627489 .8051147461

5.9486632347118 .62758255004911 .3014001846313 .9650001525916 .62030029297 19.2675495147721 .9068393707324 .538360595727 .1622009277329 .77857017517 32.3875198364334 .989261627237 .583839416540 .1714286804242 .75204086304 45.3258285522547 .8927688598650 .452991485653 .006420135555 .55311965942 58.0929985046460 .6260910034263 .152210235665 .6713333129968 .18321228027 70.6877593994173 .1846618652375 .6737213134878 .1545867919980 .62698364258 83.0904617309685 .5446929931687 .9892120361390 .4235763549892 .84731292725 95.259902954197 .66087341309100 .049697876102 .4259033203104 .7888031006 107.1380996704109 .473197937111 .7936019897114 .0988998413116 .3884963989 118.6620025635120 .9189987183123 .158996582125 .3817977905127 .5868988037 129.7738952637131 .9427032471134 .0928955078136 .2241973877138 .3365020752 140.4295043945142 .5030975342144 .5570983887146 .591506958148 .6060028076 150.6007995605152 .5758056641154 .5308990479156 .4662017822158 .3816070557 160.2774047852162 .1533966064164 .0099029541165 .8468933105167 .6645050049 169.4627075195171 .2418060303173 .0016021729174 .742401123176 .4640960693 178.1667938232179 .8502960205181 .5146942139183 .1598968506184 .7857055664 186.3919067383187 .9783935547189 .5447998047191 .0908966064192 .6161956787 194.1204986572195 .6029968262197 .0637054443198 .5014038086199 .9161071777 201.3065948486202.6723937988204.0121002197205.3251953125 206.6098022461 207.8652038574209 .0888977051210 .2799987793211 .4355926514212 .554397583 213.6329040527214 .6696929932215 .6609954834216 .6047058105217 .4969024658 218.3350067139219 .1154022217219 .8350067139220 .4920959473221 .0834960938 221.6123962402222 .074798584222 .4900054932222 .8625030518223 .2198028564 223.5646057129223 .9394073486224 .3544006348224 .8356018066225 .3874969482 225.954498291226 .4517974854226 .8032989502226 .9107055664226 .8482971191 226.7404937744226 .3972015381225 .7725982666224 .9519958496224 .1172027588 223.1972961426222 .0646972656220 .9824066162220 .3502044678219 .887802124 219.6201019287219 .1396026611217 .633605957215 .9315032959214 .4494934082 213.0953979492212 .042098999211 .2574005127210 .8807983398210 .838394165 211.0034942627211 .3533935547211 .8040008545212 .349105835212 .8992004395 213.5444030762214 .3522949219214 .9821014404214 .9595947266214 .8276062012 215.0464935303215 .5346984863216 .5802001953217 .5457000732217 .7875976562 217.8188934326218 .0341949463218 .1815032959218 .1156005859218 .0030059814 217.9586029053217 .978302002218 .0890960693218 .1730957031218 .1188049316 217.9611053467 217.7117004395 217.416305542 217.1726074219 216.9058990479 216.5599975586216 .1714019775215 .6737976074215 .1589050293214 .6067047119 214.2519073486214 .462097168214 .779800415214 .8670043945214 .8356018066 214.6349945068214 .3880004883214 .182800293214 .0027008057213 .8542938232 213.7463989258213 .6634063721213 .691696167213 .9219970703214 .1286010742 214.1580047607214 .1479034424214 .1539001465214 .2276000977214 .3155975342 
214.5924072266215 .4781036377216 .1929931641215 .9024963379215 .3473052979 214.7960968018214 .7035980225215 .9165039062217 .3240966797218 .1755981445 218.5404968262218 .141494751217 .5108032227217 .1734924316217 .1842956543 217.8262023926218 .4279937744218 .3067932129217 .7335968018216 .629196167 215.7597961426216 .1222991943216 .8213043213217 .2315979004217 .7480010986 218.5059967041219 .3919067383220 .3338012695221 .1952972412221 .7158050537 222.3964996338223 .7680053711225 .1945037842226 .1154022217226 .6880950928 226.9826049805227 .1363067627227 .3840026855228 .1472930908229 .6875231 .7525024414 233.9145965576236 .00050354237 .837600708239 .4799957275241 .0388946533 242.483001709243 .8899993896245 .1555023193246 .3249969482247 .3986053467 248.3123016357249 .2440948486250 .3435974121251 .4528045654252 .5108032227 253.5738067627254 .6557006836255 .7713928223256 .9361877441258 .1704101562 259.5516052246261 .0835876465262 .745513916264 .6875266 .7579040527269 .5649108887 273.8757019043278 .5014953613282 .6362915039285 .9027099609287 .8181152344 288.8380126953289 .2809143066289 .5573120117290 .0851135254291 .0979919434 292.9655151367295 .4407043457298 .2973937988301 .433013916304 .4334106445 307.9836120605312 .7510986328317 .9099121094322 .7557983398327 .5014038086 332.099395752336 .566986084340 .9189147949345 .120300293349 .2478942871 353.1742858887356 .8670043945360 .2663879395363 .308013916366 .0592956543 368.5549926758370 .8612060547373 .0600891113375 .1625976562377 .2078857422 379.1979980469381 .1478881836383 .0534973145384 .9155883789386 .7331848145 388.5057067871390 .2359008789391 .9274902344393 .5813903809395 .2009887695 396.7867126465398 .341003418399 .8642883301401 .3583984375402 .8241882324 404.2633972168405 .6773071289407 .0672912598408 .4348144531409 .7811889648 411.1079101562412 .4161987305413 .7070922852414 .9818115234416 .2414855957 417.4867858887418 .7189941406419 .9388122559421 .1470031738422 .3445129395 423.5321044922424 .7103881836425 .8800964355427 .0419006348428 .1965026855 429.3443908691430 .4863891602431 .6228027344432 .7543945312433 .8815917969 435.0050048828436 .125437 .2421875438 .3569030762439 .4696044922440 .5808105469 441.6907043457442 .7998046875443 .908203125445 .0163879395446 .1245117188 447.2327880859448 .3414916992449 .4508056641450 .5606079102451 .6712036133 452.7825012207453 .8945922852455 .0075073242456 .1211853027457 .2355957031 458.3504943848459 .4659118652460 .5816040039461 .6975097656462 .8135070801 463.9292907715465 .0445861816466 .1594848633467 .2735900879468 .3866882324 469.4985046387470 .6090087891471 .717590332472 .8243103027473 .9288024902 475.0307922363476 .1300048828477 .2261962891478 .3190002441479 .4083862305 480.4938964844481 .5752868652482 .6527099609483 .7253112793484 .7937011719 485.8565979004 4.3227667808536 .9985971450819 .6579513549812 .3035802841214 .94186019897 17.5720901489320 .194339752222 .8087997436525 .4155406951928 .01473045349 30.606449127233 .1908607482935 .7680206298838 .3380508422940 .90098953247 43.4569511413646 .0059089660648 .5479507446351 .0830192565953 .61117172241 56.1322784423858 .6463584899961 .1532402038663 .6528816223166 .14502716064 68.6295700073271 .1062011718873 .5746994018676 .0347213745178 .48596954346 80.928016662683 .36049652185 .7829513549888 .1949234008890 .59590911865 92.9854202270595 .3629531860497 .72794342041100 .0799026489102 .4181976318 
104.7425003052107 .0520019531109 .3463973999111 .6250991821113 .8877029419 116.1335983276118 .3622970581120 .5735015869122 .7667007446124 .9415969849 127.0977020264129 .2348022461131 .3524017334133 .4503936768135 .5283966064 137.5863037109139 .6237030029141 .6405944824143 .6369018555145 .6123046875 147.5668029785149 .50050354151 .4131011963153 .3047943115155 .1755065918 157.0252990723158 .8542022705160 .6622924805162 .4497070312164 .2164001465 165.962600708167 .6884002686169 .3937072754171 .078704834172 .7433013916 174.3876953125176 .0117034912177 .6154022217179 .1985015869180 .7611999512 182.3029937744183 .8238983154185 .3233947754186 .8014984131188 .257598877 189.6914978027191 .1026000977192 .4907073975193 .8547973633195 .1947937012 196.5095977783197 .7987060547199 .0608062744200 .2953033447201 .50050354 202.6753997803203 .8177947998204 .9264068604205 .9985046387207 .0323028564 208.0247039795208 .9734954834209 .8751983643210 .7270050049211 .525100708 212.2664031982212 .9468994141213 .5630950928214 .1123962402214 .5919036865 215.0014038086215 .337600708215 .6130981445215 .8334960938216 .0187988281 216.1768951416216 .3448944092216 .5377044678216 .8027038574217 .1683959961 217.6309967041218 .2342987061218 .5655975342218 .1128997803217 .561706543 217.6045074463217 .4120025635216 .4069976807215 .0755004883213 .7552032471 212.5677032471211 .5558013916210 .7575073242210 .5142974854210 .4792022705 210.4483032227210 .0682983398208 .68409729206 .9403991699205 .203994751 203.591506958202 .4295959473201 .5937042236201 .1938018799201 .2075042725 201.4589996338201 .8955993652202 .4765930176203 .1195983887203 .7272949219 204.3397064209204 .8746948242205 .212600708205 .1018981934204 .8578033447 204.9145050049205 .2514038086206 .0666046143206 .9273986816207 .3592071533 207.5789031982207 .8531951904208 .0715026855208 .1036987305208 .0635070801 207.9445953369207 .8466033936207 .8242034912207 .711807251207 .5328063965 207.2503051758 206.9486999512 206.6938018799 206.470993042 206.2062072754 205.8379974365205 .3928985596204 .8195037842204 .2561035156203 .7557983398 203.4488067627 203.5973052979 203.9109039307 204.1340026855 204.2947998047 204.2507019043204 .0904998779203 .904800415203 .6867980957203 .4588928223 203.2236022949202 .9983978271202 .7532043457202 .5279998779202 .2395019531 201.7230072021201 .3336029053201 .3939056396201 .5279998779201 .3816986084 201.4467926025202 .1291046143202 .7113037109202 .5534057617202 .1607971191 201.9810943604202 .3128051758203 .4134063721204 .7252044678205 .5937042236 205.8733062744205 .4476928711204 .620300293203 .6549072266203 .2897949219 204.3609924316205 .7061004639206 .2182006836206 .1226959229205 .4049987793 204.8527984619205 .18359375205 .8923034668206 .4476928711206 .9824981689 207.711807251208 .5449981689209 .4586029053210 .3278961182210 .9940948486 211.7861022949212 .9613037109214 .1681060791215 .0182952881215 .6181030273 216.0066070557216 .4723968506217 .1593017578218 .1625976562219 .7476959229 221.6638946533223 .8099975586226 .0740966797228 .1398925781230 .0650939941 231.8681030273233 .5440979004235 .1222991943236 .5742034912237 .9217987061 239.2028961182240 .4187011719241 .6784057617243 .074005127244 .4958953857 245.8766021729247 .2545928955248 .6390991211250 .0503997803251 .492401123 253.0001068115254 .6408996582256 .3948974609258 .282409668260 .3680114746 262.6189880371265 .4088134766269 .1939086914273 .125793457276 .6845092773 
279.6539001465281 .5208129883282 .7466125488283 .4601135254283 .9902038574 284.7558898926285 .7828063965287 .3517150879289 .3259887695291 .7443847656 294.5166015625297 .3851928711300 .7969055176305 .1311035156309 .8843994141 314.5678100586319 .250213623323 .8698120117328 .459197998333 .0021057129 337.4602050781341 .8442077637346 .0156860352349 .9092102051353 .5223083496 356.7716064453359 .7314147949362 .3982849121364 .8333129883367 .1408996582 369.338104248 371.4685974121 373.5362854004 375.5581970215 377.530090332 379.453704834381 .3280944824383 .1527099609384 .9309997559386 .666595459 388.3612976074390 .0184936523391 .6394042969393 .2265930176394 .7810974121 396.304901123397 .799407959399 .2662963867400 .7067871094402 .1229858398 403.5158996582404 .887298584406 .2383117676407 .5704956055408 .8847045898 410.1824951172411 .4645996094412 .732208252413 .986114502415 .2273864746 416.4566955566417 .674987793418 .8830871582420 .0816955566421 .2713928223 422.452911377423 .6270141602424 .7941894531425 .9551086426427 .1102905273 428.2603149414429 .4057922363430 .5469970703431 .6848144531432 .8193054199 433.9512023926435 .0808105469436 .2084960938437 .3346862793438 .4598083496 439.5840148926440 .707611084441 .8306884766442 .9537963867444 .0769042969 445.2002868652446 .3239135742447 .4479064941448 .5722961426449 .6972045898 450.8226928711451 .9484863281453 .0747070312454 .2012023926455 .327911377 456.4545898438457 .5810852051458 .7073974609459 .8333129883460 .9585876465 462.0830078125463 .2063903809464 .3284912109465 .4491882324466 .5682067871 467.6852111816468 .8001098633469 .9125061035471 .0223083496472 .1289978027 473.2325134277474 .332611084475 .428894043476 .5210876465477 .6091918945 478.6929016113479 .7721862793480 .8440856934481 .9068908691

2.7543048858645 .3988537788398 .03833484649710 .6677398681613 .28888988495 15.9020204544118 .5071601867721 .1045093536423 .6941108703626 .27611923218 28.8506107330331 .4177207946833 .9774818420436 .5300407409739 .07537078857 41.6136093139644 .1446914672946 .6687011718849 .1855697631851 .69533920288 54.1978683471756 .6931686401459 .1810417175361 .6614303588964 .13410186768 66.5989227294969 .0555572509871 .5038070678773 .9433135986376 .3737411499 78.7946929931681 .205772399983 .6065063476685 .9964828491288 .37510681152 90.7419433593893 .0964126586995 .4380035400497 .76614379883100 .0802993774 102.3798980713104 .6643981934106 .9332962036109 .1858978271111 .4218978882 113.6407012939115 .841796875118 .024597168120 .1889038086122 .3340988159 124.4598999023126 .5658035278128 .6515045166130 .7167053223132 .7610931396 134.7843933105136 .7864074707138 .7669067383140 .7257995605142 .6627960205 144.5778045654146 .4707946777148 .341796875150 .1905975342152 .0173950195 153.8220062256155 .604598999157 .3652038574159 .1038970947160 .8208007812 162.5157928467164 .1891937256165 .8408966064167 .471206665169 .0798034668 170.6670074463172 .2326049805173 .7765960693175 .2989959717176 .7996063232 178.2781982422179 .7348022461181 .1688995361182 .5803070068183 .9687042236 185.3338012695186 .6748962402187 .9920959473189 .2843017578190 .5514984131 191.7924957275193 .0072021484194 .1940002441195 .3526000977196 .4810028076 197.5785980225198 .6428070068199 .6726989746200 .6649932861201 .6184997559 202.5290985107203 .3952026367204 .2122955322204 .978302002205 .6882019043 206.3394012451206 .9268035889207 .4472045898207 .8963012695208 .2714996338 
208.570098877208 .788192749208 .9322967529209 .0050964355209 .0220031738 208.9866943359208 .9402008057208 .8786010742208 .891494751209 .0146942139 209.2480926514209.8341064453210.0238037109 208.9615020752 207.841506958 207.9190979004207 .9243927002206 .7592926025205 .1540985107203 .5009002686 201.9967041016201 .0518035889200 .7010955811201 .116897583201 .7378997803 202.0130004883201 .745803833200 .5213928223198 .7328033447196 .6006011963 194.646697998193 .4501953125192 .7731933594192 .4828033447192 .4980926514 192.7350006104193 .2227935791193 .9358978271194 .7198944092195 .3735961914 195.8249053955195 .9143981934195 .7223052979195 .2971954346194 .9100036621 194.8988952637195 .1669006348195 .7062072754196 .3428039551196 .9485015869 197.5092010498198 .0119018555198 .4058990479198 .5816955566198 .567199707 198.3193054199197 .9362945557197 .5478057861197 .1786956787196 .9951019287 196.8395996094196 .6649932861196 .5117950439196 .350402832196 .1571960449 195.8195037842195 .3383026123194 .7015991211194 .0558013916193 .554397583 193.3247070312193 .466796875193 .8173980713194 .1464996338194 .3917999268 194.4378967285194 .3302001953194 .1448059082193 .8672943115193 .5558929443 193.1858978271192 .8175048828192 .3549957275191 .7835998535191 .0872039795 190.0673065186189 .2781066895189 .3820953369189 .6255950928189 .2931060791 189.0437011719189 .3217010498189 .6475982666189 .6732940674189 .7386016846 190.2565002441191 .0348968506191 .8231048584192 .5977020264193 .1264953613 193.2337036133192 .9613952637192 .283203125191 .0289001465190 .4167938232 191.866394043193 .7621002197194 .7220001221195 .2021026611195 .1903991699 195.1044006348195 .2761993408195 .6358032227196 .1051025391196 .6457061768 197.3840026855198 .2133026123199 .1589050293200 .1479949951201 .1190948486 202.0852966309203 .0133972168203 .8766021729204 .5955963135205 .2368927002 205.7855987549206 .4530029297207 .3318939209208 .4925994873210 .1448974609 212.0847015381214 .2413024902216 .5229034424218 .6925048828220 .783493042 222.7552947998224 .6027069092226 .3529052734227 .9895019531229 .5505065918 231.0724945068232 .608505249234 .1941986084235 .8771972656237 .5901947021 239.2957000732 241.0010070801242.6775970459 244.3681945801246.0796051025 247.853302002249 .7521972656251 .7808990479253 .9441986084256 .2369995117 258.6931152344261 .3884887695264 .554107666267 .8030090332270 .983001709 273.7611083984275 .5899047852276 .9216918945277 .8756103516278 .674987793 279.6329956055280 .7202148438282 .1336975098283 .8565063477285 .983795166 288.5159912109291 .350402832294 .6488037109298 .445892334302 .6216125488 306.9902954102311 .5060119629316 .0382995605320 .6307067871325 .2596130371 329.8622131348334 .457611084338 .879699707343 .0401916504346 .8837890625 350.3167114258353 .4092102051356 .201385498358 .762298584361 .1818847656 363.4749145508365 .6922912598367 .8363037109369 .9291992188371 .9656982422 373.949798584375 .8800048828377 .7568054199379 .5833129883381 .3638916016 383.1000976562384 .796295166386 .4536132812388 .0754089355389 .662689209 391.2182006836392 .7431030273394 .2395019531395 .7088012695397 .1528930664 398.5730895996399 .9711914062401 .3482971191402 .7059936523404 .0452880859 405.3674926758406 .6737060547407 .9649047852409 .2420043945410 .5061035156 411.7579040527412 .9984130859414 .2282104492415 .4482116699416 .6590881348 417.8615112305419 .0559997559420 .2434082031421 .4242858887422 .5989990234 
423.7684020996424 .932800293426 .0928039551427 .2489013672428 .4016113281 429.5512084961430 .6983032227431 .8432006836432 .9862060547434 .1278076172 435.2680969238436 .4075012207437 .5461120605438 .6842956543439 .8222045898 440.9599914551442 .0976867676443 .2355041504444 .3734130859445 .5114135742 446.649597168447 .7878112793448 .9260864258450 .0643920898451 .2025146484 452.3403015137453 .4776916504454 .6145019531455 .7506103516456 .8858032227 458.0198974609459 .1527099609460 .2840881348461 .4136962891462 .5414123535 463.6669006348464 .7900085449465 .9104919434467 .0280151367468 .1423950195 469.2532958984470 .3605957031471 .4638977051472 .5629882812473 .6577148438 474.7479858398475 .8330993652476 .9137878418477 .988494873

1.1804080009463 .8214700222026 .4461798667919 .05738353729211 .66133022308 14.2572698593116 .8452606201219 .4254398345921 .9978809356724 .56270980835 27.119979858429 .6698207855232 .2122497558634 .7473793029837 .27521133423 39.7958183288642 .309158325244 .8152999877947 .3141403198249 .80570983887 52.2898788452154 .766601562557 .2357101440459 .697120666562 .15058898926 64.5959625244167 .032920837469 .4612426757871 .8805389404374 .29051971436 76.6907272338979 .080780029381 .4601974487383 .8285293579186 .18522644043 88.5297775268690 .8616333007893 .1802368164195 .4850463867297 .77546691895 100.0509033203102 .310798645104 .5546035767106 .7817993164108 .9916992188 111.1838989258113 .3578033447115 .5129013062117 .6488037109119 .7649002075 121.8609008789123 .9363021851125 .9906997681128 .0238037109130 .0352020264 132.0247039795133 .991897583135 .936706543137 .858795166139 .758102417 141.6343994141143 .4875946045145 .3175964355147 .12449646148 .9080047607 150.6683959961152 .4055023193154 .1195068359155 .8103027344157 .4781951904 159.1230010986160 .7449951172162 .3441009521163 .920501709165 .4741973877 167.0052032471168 .5135040283169 .9989929199171 .4617004395172 .9015045166 174.3182067871175 .7117004395177 .0814971924178 .4277038574179 .7498016357 181.0475006104182 .3202972412183 .5682067871184 .7902984619185 .9864959717 187.1560058594188 .2982940674189 .4122009277190 .4974060059191 .5520019531 192.575302124193 .5650024414194 .5198059082195 .436706543196 .3139953613 197.1479949951197 .9364929199198 .6750946045199 .3610992432199 .9898071289 200.5576019287201 .0596923828201 .4922027588201 .8495941162202 .1273040771 202.3229064941202 .43359375202 .4559020996202 .3880004883202 .2359008789 202.0068054199201 .7236938477201 .3950042725201 .1036071777200 .8921051025 200.7415008545200 .7554016113200 .3191986084198 .8182983398197 .3294067383 196.8704986572196 .6452941895196 .0713043213195 .0731964111193 .4886932373 191.8999938965190 .7472991943190 .5885925293192 .163192749194 .0027008057 194.9550018311195 .0316009521193 .8092041016191 .6755065918188 .6260070801 185.9273071289185 .1230926514185 .0841064453184 .9402008057184 .8771972656 184.9008026123185 .2590942383186 .2205047607187 .275604248187 .9571990967 188.2299957275187 .9853973389187 .3058013916186 .1147003174185 .1708068848 185.2312927246185 .6596069336186 .0278930664186 .5003051758187 .132598877 187.8934020996188 .707901001189 .3760986328189 .6743011475189 .6492004395 189.2935028076 188.6381988525187.699005127 186.9658050537 187.0178985596 187.233795166187 .0574951172186 .8580932617186 .8824005127186 .8997039795 186.6887969971186 .2333068848185 .4824981689184 .6533966064183 .9125061035 
183.5623931885183 .9647064209184 .6112976074185 .0220947266185 .2720947266 185.3166046143185 .1970062256184 .9716033936184 .6392974854184 .2416992188 183.7684020996183 .2424926758182 .6027984619181 .8348999023180 .953704834 179.9217071533179 .132598877178 .9743041992178 .9848022461178 .725402832 178.5041046143178 .5809020996178 .7890014648178 .887802124179 .1580047607 179.713394165180 .3218994141180 .849105835181 .2678985596181 .529296875 181.6204071045181 .5310974121181 .2250061035180 .6506958008180 .6072998047 181.8786010742183 .5283966064184 .6076965332185 .349395752185 .6755065918 185.7953948975185 .9438018799186 .1443023682186 .5063018799187 .0191040039 187.7041015625188 .5245056152189 .5063934326190 .629699707191 .853302002 192.9546966553193 .7187957764194 .3229980469194 .9199981689195 .5608062744 196.2254943848197 .0364074707198 .0711975098199 .3609008789201 .0231933594 202.9387054443205 .0787963867207 .3470001221209 .5805053711211 .7779998779 213.8598937988215 .8471984863217 .7427978516219 .554901123221 .2817993164 223.0084075928224 .811706543226 .6965026855228 .7077941895230 .7545013428 232.7893066406234 .8110961914236 .7521057129238 .6842041016240 .6284942627 242.6311950684244 .7731933594247 .0915985107249 .6593017578252 .2434997559 254.5946044922256 .9507141113259 .6803894043262 .486114502265 .2781066895 267.8313903809269 .7450866699271 .2846984863272 .512512207273 .5965881348 274.7340087891275 .912109375277 .275390625278 .8670043945280 .8068847656 283.128112793285 .7937927246288 .8182067871292 .2640991211296 .0280151367 300.0614929199304 .3241882324308 .6781921387313 .1726989746317 .7632141113 322.4140930176327 .1358032227331 .787902832336 .3017883301340 .4725036621 344.0033874512347 .1300048828350 .0140991211352 .6848144531355 .2048950195 357.5921936035359 .8915100098362 .1099853516364 .2708129883366 .3700866699 368.4125061035370 .3974914551372 .3255004883374 .2001953125376 .025604248 377.804107666379 .5398864746381 .2348937988382 .8923950195384 .5140991211 386.1026916504387 .6596069336389 .1871032715390 .686706543392 .1604003906 393.6094970703395 .0358886719396 .440612793397 .8254089355399 .191192627 400.5394897461401 .87109375403 .187286377404 .4890136719405 .7771911621 407.0527038574408 .3164978027409 .5692138672410 .8117980957412 .0447998047 413.2690124512414 .4849853516415 .6936035156416 .895111084418 .0903930664 419.2797851562420 .4639892578421 .6434020996422 .8186035156423 .9899902344 425.1581115723426 .3232116699427 .4856872559428 .6460876465429 .8045959473 430.9614868164432 .1170959473433 .2716064453434 .4254150391435 .5783996582 436.7309875488437 .8830871582439 .0349121094440 .1864929199441 .337890625 442.4890136719443 .6398925781444 .7904052734445 .940612793447 .0903015137 448.2394104004449 .3877868652450 .5353088379451 .6817932129452 .8270874023 453.9708862305455 .1133117676456 .25390625457 .3926086426458 .5291137695 459.6630859375460 .7945861816461 .9230957031463 .048614502464 .1706848145 465.2890930176466 .4035949707467 .5140075684468 .6200866699469 .721496582 470.8182983398471 .9104003906472 .9943847656474 .0687866211 $-0.336854010822 .2727839946754 .8774228096017 .47218513488810 .05881977081$ 12.6375198364315 .208290100117 .7712898254420 .3265495300322 .87420082092 25.41427040127 .9468708038330 .4720191955632 .98981857335 .50022888184 38.003341674840 .4990692138742 .9874916076745 .468471527147 .94203948975 
50.4080390930252 .8664283752455 .3170204162657 .7597389221260 .19427871704 62.620529174865 .0381164550867 .446853637769 .8463134765672 .23619842529 74.6160507202176 .9854812622179 .3439788818481 .6910934448284 .02628326416 86.3489990234488 .6586990356490 .954803466893 .236740112395 .50389862061 97.7557067871199 .99153137207102 .2108001709104 .4130020142106 .5973968506 108.7634963989110 .9108963013113 .0388031006115 .1467971802117 .2344970703 119.3013000488 121.3467025757 123.3704986572 125.3721008301 127.3511962891 129.3074951172131 .2406005859133 .1504058838135 .0364990234136 .8988037109 138.7371063232140 .5513000488142 .3412017822144 .1067962646145 .8480072021 147.5648956299149 .2574005127150 .9255065918152 .5693969727154 .1891021729 155.7846984863157 .3562011719158 .9037017822160 .4272003174161 .9268951416 163.4028015137164 .8547973633166 .2828979492167 .68699646169 .067199707 170.4230041504171 .7545928955173 .0614929199174 .3437042236175 .600692749 176.8325042725178 .0384979248179 .2185974121180 .3721923828181 .499206543 182.5988006592183 .6708984375184 .7140960693185 .728302002186 .7117004395 187.6638946533188 .5821075439189 .4656982422190 .3110046387191 .116897583 191.8791046143192 .5955963135193 .2613983154193 .8740997314194 .4279022217 194.9196929932195 .3437042236195 .696395874195 .9705963135196 .1613006592 196.2624053955196 .275894165196 .1871032715195 .9960021973195 .696395874 195.3016052246194 .8079986572194 .237701416193 .6107025146192 .9944000244 192.3560943604191 .7086029053190 .7698974609189 .096206665187 .4420928955 186.4761047363185 .9188995361185 .8849945068185 .6519012451184 .3847045898 183.0140991211181 .8659057617181 .8668060303184 .3630065918187 .3249053955 189.0579071045189 .5195007324188 .2886962891185 .7559967041181 .9508056641 178.7062072754178 .2555999756178 .7055053711178 .5760955811178 .4611968994 178.3168029785178 .512298584179 .6371002197180 .8267974854181 .4279937744 181.5249023438181 .0102996826179 .9667053223178 .1430969238176 .6237030029 176.6678009033177 .18359375177 .3936004639177 .7333068848178 .3842010498 179.2232971191180 .2259979248181 .075302124181 .4062957764181 .3264007568 180.8652954102180 .0276947021178 .717300415177 .7035064697178 .0260009766 178.5762023926178 .408706665178 .2102966309178 .3793945312178 .5437927246 178.4107971191177 .9815979004177 .195098877176 .283493042175 .3871002197 174.9335021973175 .492401123176 .3114929199176 .6721954346176 .8188018799 176.8029937744176 .6197052002176 .3516998291175 .9635925293175 .5066986084 174.9447937012174 .2987976074173 .537902832172 .6674041748171 .7543029785 170.8694000244170 .1558990479169 .7239074707169 .4738006592169 .3166046143 169.2433929443169 .2640075684169 .3946075439169 .5798034668169 .8744049072 170.2386932373170 .5579986572170 .7893981934170 .8867034912170 .883605957 170.928604126171 .1118011475171 .4232025146171 .8560943604172 .5323028564 173.5762939453174 .7628936768175 .7545928955176 .5581970215177 .0146026611 177.2384033203 177.3125 177.3748931885 177.6204986572 178.0158996582 178.6454925537 179.4570007324180 .4934997559181 .6981048584183 .0718994141184 .2794036865 184.9373931885185 .4066009521185 .9575958252186 .5930023193187 .3226013184 188.2261047363189 .3580932617190 .7182006836192 .3713989258194 .2619934082 196.3766937256198.6291046143200.8843994141 203.1248016357 205.2653961182 207.3336029053 209.3341064453211.279006958 213.1446075439215.0397949219 
217.0724945068219 .2252044678221 .5393981934223 .93359375226 .3255004883 228.6472015381230 .8119049072232 .9149017334235 .0451049805237 .258605957 239.6190948486242 .1614990234245 .0375976562247 .8155975342250 .0213012695 252.1011047363254 .5733032227257 .1070861816259 .6448974609262 .0556945801 264.0770874023265 .8573913574267 .3366088867268 .673614502269 .9859008789 271.297088623272 .7329101562274 .3147888184276 .1499023438278 .2721862793 280.6893005371283 .4448852539286 .5638122559289 .9995117188293 .7325134277 297.7171020508301 .841003418306 .1402893066310 .5559082031315 .1547851562 319.9574890137324 .8107910156329 .6408081055334 .0827026367337 .7001037598 340.8644104004343 .8479003906346 .6115112305349 .225189209351 .6991882324 354.0769958496356 .3655090332358 .591796875360 .7515869141362 .8507080078 364.8883972168366 .8667907715368 .7889099121370 .6592102051372 .4800109863 374.2561035156375 .9892883301377 .6836853027379 .3407897949380 .9637145996 382.5539855957384 .1141052246385 .6453857422387 .1500854492388 .629486084 390.0856018066391 .5192871094392 .9325866699394 .3262023926395 .7018127441 397.0602111816398 .4025878906399 .7300109863401 .0434875488402 .3439025879 403.6319885254404 .9086914062406 .1748046875407 .4309082031408 .6778869629 409.9162902832411 .1467895508412 .3699951172413 .5863952637414 .7966003418 416.0013122559417 .2007141113418 .3955993652419 .5863037109420 .7732849121 421.9569091797423 .1376037598424 .3157043457425 .491607666426 .6654968262 427.8377075195429 .0085144043430 .1781005859431 .3465881348432 .5141906738 433.6810913086434 .8471984863436 .0126953125437 .1776123047438 .3418884277 439.5056152344440 .6686096191441 .8309020996442 .9923095703444 .1528015137 445.312286377446 .4706115723447 .6275939941448 .7831115723449 .9368896484 451.0888977051452 .2388000488453 .3865966797454 .5320129395455 .6745910645 456.8145141602457 .9512023926459 .0845947266460 .2143859863461 .3403930664 462.4621887207463 .5798034668464 .6928100586465 .800994873466 .904510498 468.0022888184469 .0956115723470 .1824951172

-1.85974001884.7459689974785 3.3355529308325.9119510650638.481226921082 11.0426101684613 .5961399078416 .1419200897218 .6800003051821 .21047973633 23.7333698272726 .2487907409728 .7567291259831 .257259368933 .75035858154 36.2360801696838 .7143592834541 .1851997375543 .6485099792546 .10427856445 48.5523414611850 .9926490783753 .4249992370655 .8492698669458 .26522064209 60.6726417541563 .0712203979565 .4607086181667 .8406982421970 .21087646484 72.5707702636774 .9199829101677 .2579879760779 .5843429565481 .89845275879 84.1998062133886 .4878234863388 .7619094848691 .0214691162193 .2658996582 95.494560241797 .7068481445399 .90215301514102 .0798034668104 .2393035889 106.3799972534108.5012969971 110.6026000977112.6834030151 114.7432022095 116.78150177118 .7976989746120 .7913970947122 .7621994019124 .7097015381 126.6334991455128 .533203125130 .408706665132 .2595977783134 .0856018066 135.8865966797137 .6625061035139 .4131011963141 .1381988525142 .8379058838 144.5121002197146 .1607971191147 .783996582149 .3818054199150 .9542999268 152.5014038086154 .0234069824155 .5202026367156 .991897583158 .4385986328 159.8603057861161 .2570037842162 .6287994385163 .975402832165 .2969055176 166.5930938721167 .8639984131169 .1091003418170 .3285064697171 .5218963623 172.6889038086173 .829498291174 .9432983398176 .0299987793177 .0894927979 
178.1212005615179 .1248016357180 .0995941162181 .0453033447181 .9602050781 182.8439941406183 .6943969727184 .5102996826185 .2884979248186 .0276031494 186.7232971191187 .3733062744187 .9727020264188 .5182952881189 .004699707 189.4277038574189 .7816009521190 .0619049072190 .2628936768190 .3804931641 190.4039001465190 .3255004883190 .1396026611189 .8502960205189 .4425048828 188.9221954346188 .2655029297187 .4781951904186 .5265045166185 .3856048584 184.2503051758183 .4062042236182 .5155944824181 .1692962646179 .8247070312 178.8222961426178 .1967926025178 .0157928467177 .8513946533177 .0930023193 176.3052062988175 .8618011475176 .4669952393178 .9136962891181 .9846038818 184.7066040039185 .9405059814184 .3047027588181 .2061004639177 .7178039551 174.8775024414173 .9866027832173 .9243927002173 .7422027588173 .6313934326 173.5771942139173 .8329925537174 .721496582175 .62109375176 .0010070801 175.9010925293175 .216796875174 .0401000977172 .2841033936170 .7725982666 170.3609924316170 .4317932129170 .529296875170 .8312988281171 .4436035156 172.2400970459173 .0731964111173 .74949646173 .9842987061173 .8334960938 173.2743988037172 .4029998779171 .3050994873170 .5375061035170 .7447052002 171.1842041016171 .2525024414171 .2702026367171 .3594970703171 .4051055908 171.196105957170 .7382965088170 .0975952148169 .3704986572168 .6938934326 168.3558044434168 .6009979248169 .0177001953169 .1457061768169 .0834960938 168.9219970703168 .6613006592168 .328994751167 .9069976807167 .4073944092 166.8088989258166 .1071014404165 .3029937744164 .3899993896163 .4667053223 162.5749053955161 .8188934326161 .3692016602161 .1098937988160 .9756011963 160.9485015869160 .9915008545161 .1101074219161 .3249969482161 .5890045166 161.8545074463162 .0126037598162 .0144042969161 .8363952637161 .3722991943 161.2142944336161 .8970031738162 .9949035645164 .0764007568165 .1405944824 166.2689056396 167.3220977783168.2377929688 169.0095977783 169.4232025146 169.5727996826169 .491897583169 .3775939941169 .4172973633169 .6425933838 170.2035980225171 .0045928955172 .0561065674173 .2895050049174 .5960998535 175.741897583176 .4714050293177 .0252075195177 .5960998535178 .2501068115 179.0428009033180 .0059051514181 .18699646182 .5661010742184 .1755065918 186.0196075439188 .1333007812190 .3934936523192 .6546020508194 .9002990723 197.0563049316 199.1488952637 201.1667938232 203.1625061035 205.1363067627 207.1806030273209 .3983001709211 .7763977051214 .3444061279217 .0605926514 219.8887023926222 .5746002197224 .8321075439226 .9676055908229 .2407073975 231.6210021973234 .1338043213236 .7852935791239 .6056976318242 .3083953857 244.6150054932246 .787399292249 .1708068848251 .6054992676254 .0635986328 256.453704834258 .6134033203260 .5986938477262 .3208007812263 .8924865723 265.4009094238266 .8952941895268 .5111083984270 .1813049316271 .8893127441 273.7677001953275 .9453125278 .4339904785281 .2619934082284 .399810791 287.8823852539291 .6173095703295 .5195007324299 .5667114258303 .625213623 307.9879150391312 .9428100586318 .0555114746322 .9487915039327 .4408874512 331.2484130859334 .6112060547337 .7015991211340 .559387207343 .2604980469 345.8146057129348 .2609863281350 .6133117676352 .9012145996355 .1198120117 357.2727050781359 .3615112305361 .3884887695363 .357208252365 .2715148926 367.1346130371368 .9509887695370 .7229919434372 .4547119141374 .1480102539 375.8062133789377 .4307861328379 .0245056152380 .5887145996382 .1257019043 
383.6366882324385 .1235961914386 .5875854492388 .0303955078389 .4530944824 390.8570861816392 .2434082031393 .6131896973394 .9674987793396 .3074035645 397.633605957398 .9471130371400 .2486877441401 .5393066406402 .8193969727 404.0899963379405 .3515014648406 .6047058105407 .850189209409 .0885925293 410.3203125411 .5458984375412 .7661132812413 .9812011719415 .1917114258 416.3981018066417 .6007080078418 .799987793419 .996307373421 .1899108887 422.3812866211423 .5704956055424 .7578125425 .9435119629427 .1276855469 428.3106994629429 .492401123430 .6730957031431 .8528137207433 .0314941406 434.2091064453435 .3857116699436 .5614013672437 .7359008789438 .9092102051 440.0812988281441 .2520141602442 .4212036133443 .5887145996444 .754486084 445.9183044434447 .0799865723448 .2392883301449 .3963012695450 .5505981445 451.7019958496452 .850189209453 .9952087402455 .1365966797456 .2742004395 457.4077148438458 .5369873047459 .6617126465460 .7817077637461 .8967895508 463.0068969727464 .1117858887465 .208404541466 .294708252 -3.32715606689-.752894997597 1.816483020782 4.3762612342836.9281001091 9.472132682812 .0083703994814 .5369300842317 .0578193664619 .57114028931 22.0768909454324 .5751800537127 .0659599304229 .5493297576932 .02521896362 34.4936904907236 .9546394348139 .4080886840841 .8539009094244 .29207992554 46.7224311828649 .1449089050351 .5592689514253 .9654197692956 .36304855347 58.7520103454661 .1319198608463 .5025405883865 .8634414672968 .21430969238 70.5546569824272 .8840866088975 .2020568847777 .5081024169979 .80164337158 82.0821228027384 .3489532470786 .6015319824288 .8392486572391 .06146240234 93.2675476074295 .4568405151497 .6287231445399 .78253173828101 .9177017212 104.0335006714106 .1293029785108 .2046966553110 .2589035034112 .2914962769 114.3018035889116 .2893981934118 .2537994385120 .1943969727122 .111000061 124.0029983521125 .8701019287127 .7119979858129 .5283050537131 .3188934326 133.083404541134 .8217010498136 .533706665138 .2191925049139 .8780975342 141.5104980469143 .1161956787144 .6954040527146 .2480010986147 .7740936279 149.2736968994150 .7469940186152 .1940002441153 .6148071289155 .0093994141 156.3780059814157 .7203979492159 .0368041992160 .3269958496161 .591003418 162.8285980225164 .0397949219165 .2243041992166 .3822021484167 .5130004883 168.6166992188169 .6929016113170 .741897583171 .7630004883172 .7565002441 173.7216949463174 .6587982178175 .5670013428176 .4461975098177 .2949066162 178.1132049561178 .8984069824179 .6502075195180 .3650054932181 .0420074463 181.6759033203182 .2653961182182 .8043060303183 .2901000977183 .7158966064 184.0780944824 184.3697967529 184.5863037109 184.7212982178 184.7738037109 184.7277069092184 .5709075928184 .3022003174183 .942199707183 .4510040283 182.8504943848182 .0769042969181 .1432037354179 .9828033447178 .4653015137 177.0131072998176 .1425933838175 .4261932373174 .5104980469173 .6138000488 172.7601928711172 .0908050537171 .6425018311171 .3549041748171 .0364990234 170.9826049805171 .3952026367172 .5323028564174 .6049041748177 .1885070801 180.3730010986182 .1763000488180 .3222961426177 .1387939453174 .5621948242 172.383102417171 .0146026611170 .2608032227169 .8361053467169 .7261047363 169.7991943359170 .0767974854170 .6867980957171 .2064056396171 .3551940918 171.1091003418170 .2718048096169 .0702056885167 .5518951416166 .1071929932 165.2024993896164 .720993042164 .6701965332164 .9611968994165 .550994873 
166.2391052246166 .8056030273167 .2046966553167 .2308044434166 .9358978271 166.2763977051165 .4396972656164 .7223968506164 .2671051025164 .2971954346 164.6170043945165 .0267944336165 .321105957165 .2651977539164 .9792938232 164.5485992432164 .0626068115163 .6190032959163 .2503051758163 .0139007568 162.8251953125162 .6262054443162 .3979949951162 .1305999756161 .8350067139 161.5301055908161 .1902008057160 .8197021484160 .3845977783159 .883605957 159.2913970947158 .5903015137157 .8023986816156 .9044952393155 .9911956787 155.0724029541154 .2987060547153 .883605957153 .6661987305153 .5563964844 153.5579986572153 .6466064453153 .8036956787154 .0446929932154 .2808074951 154.4705047607154 .533203125154 .411605835154 .1163024902153 .3731994629 153.0908050537154 .2135009766155 .8565063477157 .3067932129158 .6651000977 159.9304962158161 .0142974854161 .9107055664162 .582901001162 .8520050049 162.8385009766162 .5529022217162 .1703948975161 .8907928467161 .883102417 162.3807983398163 .2212982178164 .3081054688165 .4960021973166 .6558074951 167.6986999512168 .5319976807169 .237701416169 .8688049316170 .550994873 171.3777008057172 .3659973145173 .5758056641174 .9714050293176 .5567016602 178.37109375180 .471496582182 .7187957764184 .9492034912187 .1645050049 189.3058929443191.3851013184193.3838043213195.3735961914197.3760986328 199.5173950195201 .8789978027204 .4546051025207 .2250976562210 .1475067139 213.2919006348216 .2604064941218 .5960998535220 .7781066895223 .2041931152 225.7384033203228 .3865966797231 .0637054443233 .7035064697236 .2463989258 238.6846008301241 .0572967529243 .5068969727245 .9721069336248 .4774932861 250.959197998253 .3005981445255 .4998931885257 .4285888672259 .207611084 260.9054870605262 .5875854492264 .412109375266 .2127990723267 .8573913574 269.5707092285271 .5620117188273 .8034973145276 .3310852051279 .2062988281 282.4725036621 286.0303039551289.7336120605 293.5606994629 297.2897033691 301.3953857422306 .4129943848311 .6177062988316 .4161987305320 .8671875 324.8346862793328 .3969116211331 .6054992676334 .5350952148337 .3146972656 339.938293457342 .4494934082344 .8623046875347 .2094116211349 .4833068848 351.687713623353 .824798584355 .8989868164357 .9124145508359 .8700866699 361.7746887207363 .6311950684365 .441986084367 .2114868164368 .94140625 370.6354980469372 .2952880859373 .9234924316375 .5215148926377 .0917053223 378.6351928711380 .1539916992381 .6492919922383 .1228027344384 .575592041 386.0090026855387 .4242858887388 .8223876953390 .2045898438391 .571685791 392.9247131348394 .2644958496395 .5918884277396 .9077148438398 .2127990723 399.507598877400 .7929992676402 .0696105957403 .3380126953404 .5987854004 405.8526916504407 .0999145508408 .3411865234409 .5770874023410 .8078918457 412.0340881348413 .2561950684414 .4744873047415 .6893005371416 .9010925293 418.1101074219419 .3165893555420 .520690918421 .7228088379422 .9230041504 424.1214904785425 .3185119629426 .5137939453427 .7077941895428 .900390625 430.0916137695431 .2813110352432 .4696960449433 .6565856934434 .8418884277 436.0256958008437 .2077026367438 .3877868652439 .5660095215440 .7420959473 441.9159851074443 .0874023438444 .2562866211445 .4223937988446 .5856933594 447.7456970215448 .9024963379450 .0556945801451 .2051086426452 .3504943848 453.491607666454 .6282958984455 .7603149414456 .887298584458 .009185791 459.1260986328460 .236907959461 .3428955078462 .441986084 
-4.8003988266 -2.23052811623.3235459923744 2.8648409843445.399199008942 7.92583703994810 .4447803497312 .9560899734515 .4597997665417 .9559803009 20.4446392059322 .9258308410625 .3995494842527 .8658294677730 .3246307373 32.7759704589835 .2197494506837 .655971527140 .0844993591342 .50529098511 44.9181785583547 .3230705261249 .7197418212952 .1080513000554 .48770904541 56.8585205078159 .2201309204161 .5722503662163 .9144897460966 .24646759033 68.5677185058670 .8778228759873 .1762390136775 .4624633789177 .7359085083 79.9960403442482 .2422103881884 .4738235473686 .6902313232488 .89080810547 91.0748672485493 .2417526245195 .3908004760797 .521339416599 .63271331787 101.7242965698103 .7954025269105 .8453979492107 .8735961914109 .8796005249 111.862701416113 .8224029541115 .758102417117 .6692962646119 .5556030273 121.4166030884123 .2518005371125 .060798645126 .8432998657128 .5991973877 130.3280029297132 .0294952393133 .703704834135 .350402832136 .9694061279 138.5606994629140 .1242980957141 .6602935791143 .1685028076144 .6490936279 146.1020965576147 .5276031494148 .9257049561150 .2966003418151 .6401062012 152.9564056396154 .2454986572155 .5075073242156 .7422027588157 .9497070312 159.1298065186160 .2823944092161 .4073944092162 .504699707163 .5740966797 164.6156005859165 .62890625166 .6141052246167 .571105957168 .4998016357 169.4002075195170 .2722930908171 .1157073975171 .9302978516172 .7151947021 173.470199585174 .1936035156174 .8845977783175 .5402069092176 .1591033936 176.7368927002177 .271194458177 .7563934326178 .1889038086178 .56199646 178.8706970215179 .1085968018179 .2698059082179 .3477935791179 .3365936279 179.2286071777179 .0162963867178 .7012939453178 .2949066162177 .7691040039 177.1302947998176 .3358001709175 .3874053955174 .2400970459172 .8453979492 171.5144042969170 .5467071533169 .782699585168 .9828948975168 .2156066895 167.4925994873166 .8363952637166 .3793029785166 .1515045166166 .0825958252 166.4105072021167 .2066040039168 .4297943115170 .2570953369172 .3863983154 174.7850036621176 .1678924561175 .0267944336172 .9207000732171 .1157073975 169.4344024658168 .1860046387167 .2496032715166 .6141967773166 .3628997803 166.3535003662166 .516204834167 .0158996582167 .4069976807167 .4842987061 167.1941986084166 .1690063477164 .8096008301163 .2057952881161 .5601043701 160.3654022217159 .5807952881159 .3592987061159 .5841064453160 .1477966309 160.7438964844161 .1905975342161 .4291992188161 .2100982666160 .7050933838 159.8905944824159 .0061035156158 .3730010986158 .000793457158 .0220947266 158.4519958496159 .438293457160 .1690063477159 .7695007324158 .9380950928 158.2644958496157 .7512969971157 .4385986328157 .3809967041157 .6898956299 157.7606048584157 .0885009766156 .1795959473155 .5196990967155 .0068054199 154.5740966797154 .182800293153 .8063964844153 .4015960693152 .9391937256 152.3946990967151 .7339935303150 .9891052246150 .1464996338149 .2781066895 148.4190063477147 .6900024414147 .2557067871147 .0140991211146 .9165039062 146.949005127147 .1056976318147 .3428955078147 .6585998535147 .9418945312 148.1165008545148 .1719055176148 .0675048828147 .8433074951147 .4174041748 147.4309997559148 .5055999756150 .0733032227151 .6600036621153 .1768035889 154.5505981445155 .7050018311156 .5838012695157 .1607055664157 .31590271 157.1280975342156 .5930938721155 .8509979248154 .9983062744154 .5500030518 155.1172027588156 .1614074707157 .2808990479158 .4226989746159 .4962005615 
160.4909973145161 .3307952881162 .0830993652162 .7471008301163 .4445037842 164.2852935791165 .2908935547166 .5491027832167 .99659729169 .6313018799 171.467300415173 .4920043945175 .6405944824177 .8159942627179 .9786987305 182.0735015869184 .1105041504186 .088104248188 .0395050049189 .9188995361 191.9980010986194 .5258026123197 .3087005615200 .1905975342203 .1808929443 206.2904052734209 .2606048584211 .816696167214 .2561035156216 .8399963379 219.5287017822222 .3609008789225 .1269073486227 .6600952148230 .1092071533 232.5599060059235 .0393066406237 .5821075439240 .1470031738242 .7799987793 245.4315032959248 .0565948486250 .5294036865252 .6479034424254 .5867004395 256.4653015137258 .3229980469260 .2514953613262 .1217041016263 .8586120605 265.5963134766267 .4946899414269 .5338134766271 .700012207274 .2401123047 277.4208068848280 .9360961914284 .5101928711288 .1860046387291 .9077148438 295.9876098633300 .740814209305 .6571960449310 .3171081543314 .7130126953 318.6853942871322 .3187866211325 .5893859863328 .5715026855331 .3977050781 334.0783996582336 .650604248339 .125793457341 .5267028809343 .8511962891 346.1040039062348 .2875061035350 .4060974121352 .462890625354 .4621887207 356.407409668358 .303314209360 .1525878906361 .9595947266363 .7265014648 365.4567871094367 .1520996094368 .8153076172370 .4479064941372 .0519104004 373.6288146973375 .1802978516376 .7077941895378 .212890625379 .6965942383 381.1604919434382 .6054992676384 .0328979492385 .4437866211386 .8391113281 388.2196044922389 .5864868164390 .9403991699392 .2822875977393 .6127929688 394.9325866699396 .2424926758397 .5432128906398 .8351135254400 .1189880371 401.3953857422402 .6647949219403 .9277038574405 .1848144531406 .4361877441 407.682800293408 .9245910645410 .1622009277411 .395904541412 .6260986328 413.8530883789415 .0770874023416 .2983093262417 .516998291418 .7333984375 419.9476928711421 .1599121094422 .3702087402423 .5786132812424 .7853088379 425.9901123047427 .1931152344428 .3942871094429 .5936889648430 .7911987305 431.9866027832433 .1799926758434 .3711853027435 .5600891113436 .7466125488 437.9305114746439 .1117858887440 .2901916504441 .4655151367442 .6376953125 443.8064880371444 .9718017578446 .1332092285447 .2907104492448 .4440002441 449.5928039551450 .7367858887451 .8760070801453 .0101013184454 .138885498 455.2623901367456 .3804016113457 .4895019531458 .5880126953 -6.21967792511 -3.68113493919-1.14733505249 1.377194046974 3.894018888474 6.4032378196728 .90484619140611 .398920059213 .885459899916 .36453056335 18.8361206054721 .3002891540523 .7570095062326 .2063102722228 .64812088013 31.0824699401933 .5092201232935 .9283981323238 .3398208618240 .74346160889 43.1391105651945 .5266914367747 .9059410095250 .2767295837452 .63874053955 54.9917793273957 .3354492187559 .6694908142161 .9934501647964 .30697631836 66.6095962524468 .9008636474671 .1801910400473 .4471130371175 .70099639893 77.9413070678780 .1673889160282 .3786010742284 .5742874145586 .75379943848 88.91644287109 91.0615310668993.1883697509895.29625701904 97.38452911377 99.45247650146101 .49949646103 .5248031616105 .5278015137107 .5078964233 109.4644012451111 .3968963623113 .3046035767115 .1871032715117 .0438995361 118.87449646120 .6784973145122 .4553985596124 .2050018311125 .9268035889 127.6206970215129 .2863006592130 .9234924316132 .5321044922134 .1119995117 135.6631011963137 .1855010986138 .6790008545140 .1437072754141 .5796051025 
142.9868927002144 .3656005859145 .7156982422147 .037399292148 .3307037354 149.5957946777150 .8325042725152 .0411071777153 .2212982178154 .3731994629 155.4967956543156 .5919036865157 .6584014893158 .6961975098159 .7053070068 160.6855010986161 .6369018555162 .5596008301163 .4535064697164 .3186950684 165.1553955078165 .9638061523166 .7436981201167 .495300293168 .2180023193 168.9120025635169 .5753936768170 .2086029053170 .8079071045171 .3733062744 171.8992004395172 .3843994141172 .8217010498173 .208404541173 .5361022949 173.800201416173 .9924926758174 .1082000732174 .1374969482174 .0720062256 173.9105987549173 .6531982422173 .3023986816172 .8706054688172 .3316955566 171.7061004639170 .9526062012170 .0872955322169 .1112976074168 .0522003174 167.0054016113166 .0180969238165 .150894165164 .3226928711163 .578994751 162.9149932861162 .354598999161 .9716033936161 .849395752161 .9490966797 162.4178009033163 .2756958008164 .4308929443165 .9407043457167 .4803924561 168.8079071045169 .5587005615169 .2182006836168 .3251037598167 .2825927734 166.1860961914165 .3052062988164 .4575958252163 .6569976807163 .0451049805 162.7277069092162 .7333068848163 .1398925781163 .6372070312163 .9595947266 163.7230072021162 .4683074951160 .6808013916158 .7637939453156 .945602417 155.5626983643154 .633895874154 .2805938721154 .4084014893154 .8744049072 155.4882965088155 .9938964844156 .1351013184155 .6300048828154 .7409057617 153.7012023926152 .7602996826152 .1468963623151 .8706970215151 .9178924561 152.4221954346153 .8018035889154 .8329925537154 .1278991699152 .9353027344 152.1699981689151 .6486053467151 .4134063721151 .4944000244152 .1219024658 152.4028930664151 .3858947754150 .0328979492149 .1575927734148 .4795074463 147.946395874147 .5352020264147 .1847991943146 .8495941162146 .4761962891 146.0296936035145 .4452972412144 .7774047852143 .9880981445143 .1757049561 142.3880004883141 .7044067383141 .2463989258140 .971496582140 .8795928955 140.9532928467141 .1949005127141 .537399292141 .9786987305142 .3679046631 142.6069946289142 .7409057617142 .7093963623142 .68359375142 .7144927979 143.0576934814143 .9593048096145 .2458953857146 .8175048828148 .4281005859 149.9510040283151 .224105835152 .121307373152 .6457061768152 .6690063477 152.2946014404151 .487701416150 .4181976318149 .0733032227148 .1985931396 148.7660980225149 .8842010498150 .9384002686152 .0184936523153 .0382995605 153.9900054932154 .8312072754155 .5955963135156 .2749023438156 .9676055908 157.7772979736158 .7861022949160 .1118927002161 .6641998291163 .4013977051 165.2657928467167 .1945953369169 .2109069824171 .2765045166173 .350402832 175.3932037354177 .3979949951179 .3489990234181 .2736968994183 .0218048096 184.9911956787187 .5877990723190 .4515075684193 .3244018555196 .2460021973 199.1853027344202 .0626068115204 .8208007812207 .5296020508210 .2731933594 213.0644073486216 .0305023193218 .8903961182221 .3907012939223 .7919006348 226.2727966309228 .8191986084231 .4660949707234 .1773986816237 .003692627 239.8739013672242 .7845001221245 .550994873247 .8672943115249 .9904022217 252.0670013428254 .083404541256 .1015014648258 .0530090332259 .950012207 261.8077087402263 .7031860352265 .6491088867267 .550994873269 .8218078613 272.9005126953276 .3359069824279 .7406921387283 .3028869629287 .0614929199 291.100189209295 .4851989746300 .0220031738304 .5320129395308 .8355102539 312.7477111816316 .3273010254319 .5953979492322 .6271972656325 .5054931641 
328.2426147461330 .8764038086333 .4108886719335 .862487793338 .2330932617 340.5309143066342 .7572937012344 .9179992676347 .015411377349 .054901123 351.0390014648352 .9735107422354 .8604125977356 .7048034668358 .508392334 360.2750854492362 .0061950684363 .7049865723365 .3724060059367 .0108947754 368.6217041016370 .2066955566371 .766998291373 .3044128418374 .8198852539 376.3149108887377 .7904968262379 .2479858398380 .6882019043382 .1123962402 383.5213012695384 .9158935547386 .2969970703387 .6654968262389 .0220947266 390.3676147461391 .7025146484393 .0277099609394 .3436889648395 .6510925293 396.9505004883398 .242401123399 .5274047852400 .8059997559402 .0786132812 403.3456115723404 .6076049805405 .8648071289407 .1177062988408 .366607666 409.6116943359410 .8533935547412 .0918884277413 .3275146484414 .5602111816 415.7904052734417 .0180969238418 .2434082031419 .4664001465420 .6871948242 421.9057006836423 .1221008301424 .3363037109425 .5481872559426 .7578125 427.9650878906429 .1698913574430 .3721008301431 .571685791432 .7687072754 433.9627075195435 .1536865234436 .3417053223437 .5263061523438 .7074890137 439.8851013184441 .058807373442 .2284851074443 .3940124512444 .5551147461 445.7114868164446 .8630065918448 .0094909668449 .1505126953450 .2861938477 451.4164123535452 .5403137207453 .6590881348454 .770690918 -7.64493608475 -5.11127185822 -2.59300208092 -8.7027997e-02 2.41223692894 4.9040050506597 .3882799148569 .86511039733912 .3344898223914 .79648017883 17.2510604858419 .6982707977322 .1380596160924 .5704708099426 .99542045593 29.4129009246831 .8228092193634 .2251014709536 .6196289062539 .00632858276 41.3849983215343 .7555313110446 .1176605224648 .4712409973150 .81594848633 53.1515617370655 .4776916503957 .7940483093360 .1001815795962 .39572906494 64.6801834106466 .9530715942469 .2138519287171 .4619903564573 .69687652588 75.9179229736378 .1244735717880 .3158721923882 .4914474487384 .65052032471 86.7923736572388 .9162826538191 .0215606689593 .1074676513795 .17328643799 97.2183227539199 .24185180664101 .2432022095103 .2216033936105 .1765975952 107.1072998047 109.0131988525 110.893699646 112.7481994629 114.5763015747 116.3772964478118 .1508026123119 .8964004517121 .6137008667123 .3023986816 124.9619979858126 .5924987793128 .1934967041129 .7648925781131 .3065032959 132.8182983398134 .3000946045135 .7521057129137 .1741027832138 .5662994385 139.928604126141 .2613067627142 .5643005371143 .8377990723145 .0818023682 146.2964935303147 .4817962646148 .6378936768149 .7644958496150 .8618927002 151.929901123152 .9683990479153 .9772949219154 .9566040039155 .9064025879 156.8264007568157 .7169036865158 .5780029297159 .4098052979160 .212600708 160.9866943359161 .7324066162162 .4499969482163 .1398925781163 .8018951416 164.4364013672165 .0424041748165 .6201019287166 .1667022705166 .6820068359 167.1611938477167 .6022949219167 .9985961914168 .3462982178168 .6369934082 168.8650970459169 .0218963623169 .1006011963169 .0921936035168 .9888000488 168.7890930176168 .4868011475168 .1082000732167 .6681976318167 .158706665 166.6049041748165 .9757995605165 .2673950195164 .5162963867163 .7158966064 162.8648071289161 .9965057373161 .1416015625160 .3186035156159 .5802001953 158.932800293158 .400604248158 .0614013672157 .9774017334158 .1853942871 158.6726989746159 .3986968994160 .2978057861161 .4243011475162 .4452056885 163.1885986328163 .6688995361163 .571105957163 .2501068115162 .7628936768 
162.2328948975162 .0890960693161 .675994873160 .4526062012159 .1654968262 158.4698944092158 .274307251158 .6277008057159 .3751983643160 .5231018066 160.8182983398158 .8834075928156 .1575927734153 .8486022949151 .8719024658 150.4104003906149 .4243011475148 .9732971191148 .9929962158149 .4002075195 150.1083068848151 .0910949707151 .483505249150 .3318023682148 .6598052979 147.3641052246146 .3887023926145 .8354034424145 .6477966309145 .7691955566 146.2568969727147 .2521972656147 .9304962158147 .4503936768146 .55909729 145.8813018799145 .4031066895145 .1884002686145 .2178955078145 .5637969971 145.6015014648144 .758605957143 .6228942871142 .7429046631142 .0395965576 141.5193939209141 .1430969238140 .8809967041140 .6631011963140 .4393005371 140.1354980469139 .670501709139 .0914001465138 .3471984863137 .5558013916 136.7976989746136 .1219940186135 .6562042236135 .3773956299135 .3135070801 135.4555969238135 .8029022217136 .2949066162136 .9107055664137 .4752044678 137.8881072998138 .1793060303138 .2353057861138 .3244018555138 .5419006348 138.9635009766139 .8542022705141 .078704834142 .6773071289144 .4151000977 146.0892028809147 .49659729148 .4346008301148 .9237976074148 .8470001221 148.304901123147 .2678070068145 .9593048096144 .5803985596143 .6468963623 143.8088989258144 .5187988281145 .3786010742146 .336807251147 .2828063965 148.2068023682149 .0420074463149 .8141937256150 .5048065186151 .1726989746 151.8504943848152 .7864990234154 .2696075439156 .025894165157 .8526000977 159.7147979736 161.5704040527 163.4651947021 165.3583984375 167.2855072021 169.3101043701171 .3249969482173 .2523956299175 .1562957764176 .9530029297 178.9176025391181 .3251037598183 .966506958186 .6898956299189 .4638061523 192.2660064697 195.0928955078 197.8894042969 200.7061004639203.537902832 206.3903961182 209.3397979736212.1959991455 214.7966003418 217.3123016357 219.8549041748222 .4824066162225 .2344055176228 .0904998779231 .1125030518 234.200302124237 .31199646240 .3005981445242 .9315032959245 .3600006104 247.6800994873249 .9004974365252 .0717010498254 .1757049561256 .2362976074 258.2391052246260 .196685791262 .1506958008264 .1170959473266 .3662109375 269.1600952148272 .2500915527275 .4190063477278 .7766113281282 .3583984375 286.1773986816290 .2818908691294 .5780944824299 .0755004883303 .3851013184 307.0643920898310 .4153137207313 .6361083984316 .708404541319 .6400146484 322.4433898926325 .1353149414327 .7242126465330 .2237854004332 .6382141113 334.9769897461337 .2432861328339 .4426879883341 .5781860352343 .6552124023 345.6767883301347 .6481018066349 .5718994141351 .4526977539353 .2927856445 355.0953979492356 .862487793358 .5967102051360 .299407959361 .9726867676 363.6178894043365 .2367858887366 .8305969238368 .4007873535369 .9486083984 371.475402832372 .9822998047374 .4703979492375 .9407043457377 .3942871094 378.8320922852380 .2550048828381 .6639099121383 .0596008301384 .4428100586 385.8143920898387 .1748962402388 .5250854492389 .8655090332391 .1968994141 392.5197143555393 .8345031738395 .1419067383396 .4422912598397 .7362976074 399.0242004395400 .3064880371401 .5835876465402 .8558044434404 .1235961914 405.3870849609406 .646697998407 .9025878906409 .155090332410 .4043884277 411.650604248412 .8938903809414 .1343078613415 .3720092773416 .6069946289 417.8393859863419 .0692138672420 .2963867188421 .5208129883422 .7426147461 423.9617004395425 .1778869629426 .3913879395427 .6017150879428 .8091125488 
430.0132141113431 .2141113281432 .4114990234433 .6054077148434 .7955932617 435.9818115234437 .1640930176438 .3421020508439 .5155944824440 .684387207 441.8483886719443 .0073852539444 .1610107422445 .3091125488446 .4515991211 447.5885009766448 .7196960449449 .8414001465450 .9520874023 $-9.01801013947-6.51546192169-4.0174779892-1.52838397026 .9532859921455$ 3.4275929927835 .894521236428 .35411739349410 .8063602447513 .25131034851 15.6889095306418 .1192207336420 .5421695709222 .9577903747625 .36598014832 27.7667407989530 .1599292755132 .5455398559634 .9233703613337 .29336166382 39.6552810668942 .0090484619144 .354351043746 .6910514831549 .01879882812 51.3373718261753 .646339416555 .945449829158 .2341995239360 .51221847534 62.7789802551365 .034042358467 .276786804269 .5067062377971 .72313690186 73.9255218505976 .113136291578 .2853622436580 .4414520263782 .58072662354 84.7024383544986 .8058624267688 .8902511596790 .9548568725692 .99894714355 95.0217437744197 .0225601196399 .00061798096100 .9552993774102 .8856964111 104.7913970947 106.6715011597 108.5255966187 110.352897644 112.1529006958 113.9251022339115 .6688995361117 .3840026855119 .0698013306120 .7260971069 122.3524017334123 .9485015869125 .5140991211127 .0491027832128 .5532073975 130.0263977051131 .4687042236132 .8798980713134 .2601013184135 .6092987061 136.9277038574138 .2151947021139 .4720001221140 .6981964111141 .8937988281 143.0590057373144 .1936950684145 .2980957031146 .3721923828147 .4158935547 148.4291992188149 .4120025635150 .3643951416151 .2861938477152 .1775054932 153.0382995605153 .8688049316154 .6690979004155 .4396972656156 .1808929443 156.8932037354157 .5771026611158 .2332000732158 .8621063232159 .4642028809 160.0404052734160 .5899047852161 .1139984131161 .6098022461162 .0785064697 162.5142059326162 .9167022705163 .2772979736163 .5932006836163 .8544006348 164.0554046631164 .1856994629164 .2380981445164 .2039031982164 .0780029297 163.8542938232163 .5227050781163 .1148071289162 .6587982178162 .191696167 161.745803833161 .2976989746160 .7998046875160 .2709960938159 .6945037842 159.0565032959158 .3484954834157 .5729980469156 .7501983643155 .9651947021 155.2993011475154 .7895050049154 .4810028076154 .4185028076154 .624206543 155.0261993408155 .4978942871156 .0476989746156 .7523040771157 .3701019287 157.7422027588157 .9853057861157 .9391021729157 .8244934082157 .6053924561 157.4324035645157 .8641967773157 .841796875156 .2973937988154 .5202026367 153.5724945068153 .1985931396153 .4542999268154 .2483062744155 .9288024902 156.6484985352154 .1826934814150 .8182983398148 .375146 .3656005859144 .9208068848 143.9835968018143 .4676971436143 .4127044678143 .7032928467144 .341003418 145.5944976807146 .1351013184144 .4355010986142 .2198028564140 .8739929199 139.995803833139 .5346984863139 .44090271139 .6078948975139 .9566040039 140.3526000977140 .5755004883140 .3824005127139 .9656982422139 .4967956543 139.0834960938138 .8435058594138 .6954040527138 .591796875138 .3348999023 137.7861938477137 .0756072998136 .3536987305135 .7174072266135 .2557983398 134.9555053711134 .7902984619134 .7214050293134 .6860046387134 .5845031738 134.2942047119133 .8043060303133 .0744018555132 .2568054199131 .4857025146 130.8249053955130 .3650970459130 .1101989746130 .088104248130 .2984008789 130.7357025146131 .3661956787132 .150894165132 .9772949219133 .7111053467 134.2270965576134.3549041748 134.3979034424134.6094055176135.0760955811 
135.9696960449137 .2266998291138 .9145050049140 .7761993408142 .6694946289 144.2749023438145 .3361968994145 .8769989014145 .6726989746144 .9407043457 143.6472015381142 .137802124140 .8386993408139 .8898010254139 .6143035889 139.8191986084140 .4246063232141 .2631988525142 .1511993408143 .0605010986 143.8921966553144 .6744995117145 .37890625146 .0588989258146 .6546936035 147.536605835149 .1531982422151 .0601043701152 .9528961182154 .8307952881 156.6896057129158 .4396057129160 .0655059814161 .8399963379163 .8350982666 165.945602417167 .8666992188169 .6858978271171 .504196167173 .4053955078 175.525894165177 .8222045898180 .3032073975182 .8934020996185 .5697021484 188.3155059814191 .099105835193 .9235992432196 .7682037354199 .6302947998 202.5321960449205 .3867034912208 .1327972412210 .8088989258213 .4477996826 216.1251983643218 .9378967285221 .9273071289225 .1775054932228 .5359039307 231.8540039062235 .054901123237 .988494873240 .7304992676243 .2875976562 245.7048034668248 .0509033203250 .3190002441252 .5830993652254 .7617034912 256.8446044922258 .9189147949261 .0390014648263 .312713623265 .8002929688 268.4877929688271 .3818054199274 .4906005859277 .8139953613281 .3605041504 285.1437072754289 .184387207293 .6196899414297 .8984985352301 .3700866699 304.5314941406307 .7395019531310 .8558044434313 .8374938965316 .7027893066 319.4454040527322 .0805053711324 .6220092773327 .0744018555329 .4504089355 331.7515869141333 .9865112305336 .1567077637338 .2690124512340 .3257141113 342.332611084344 .2919006348346 .2084960938348 .084197998349 .9227905273 351.725402832353 .495300293355 .2331848145356 .9415893555358 .6214904785 360.2746887207361 .9023132324363 .5058898926365 .0864868164366 .645690918 368.1842041016369 .7034912109371 .2043151855372 .6878967285374 .155090332 375.6069030762377 .0440063477378 .4672851562379 .8775939941381 .275604248 382.662109375384 .0375976562385 .4028930664386 .7585144043388 .1050109863 389.4429931641390 .7730102539392 .0956115723393 .4111022949394 .7200927734 396.0228881836397 .320098877398 .611907959399 .8987121582401 .1806945801 402.458404541403 .7319030762405 .0014038086406 .2672119141407 .529510498 408.7885131836410 .0440979004411 .2965087891412 .5458068848413 .7921142578 415.0351867676416 .275390625417 .512512207418 .7464904785419 .9773864746 421.2051086426422 .4295959473423 .6507873535424 .8684997559426 .0827026367 427.2933959961428 .5003051758429 .7033996582430 .9024963379432 .0975036621 433.2880859375434 .4743041992435 .6557922363436 .8324890137438 .0039978027 439.1702880859440 .3310852051441 .4862976074442 .6355895996443 .7792053223 444.9161071777446 .0476989746447 .1716918945

-10.3972196579 -7.90005302429 -5.41779279709-2.94728899002-.483227998018 1.973600983624 .4231891632086 .865558147439 .30069255828911 .7286195755 14.14931011216 .5627803802518 .9689693450921 .3679008483923 .75946044922 26.143629074128 .5202808380130 .889369964633 .250701904335 .6042098999 37.9496612548840 .2869186401442 .6157112121644 .9358406066947 .24697875977 49.5488891601651 .8411293029854 .1234092712456 .395229339658 .65621948242 60.9057998657263 .1435394287165 .3688125610467 .5810775756869 .77966308594 71.9639663696374 .1333007812576 .2869567871178 .4242324829180 .54438781738 82.6466369628984 .7302627563586 .7944717407288 .8384933471790 .86154937744 92.8628768920994 .8417129516696 .7972564697398 .7287979126100 .635597229 
102.5168991089104 .3721008301106 .2004013062108 .0012969971109 .7741012573 111.5183029175113 .2332992554114 .9186019897116 .5737991333118 .1984024048 119.7921981812121 .3546981812122 .8858032227124 .3852005005125 .8526992798 127.2882003784128 .6916046143130 .0628967285131 .4020996094132 .7093048096 133.9844055176135 .2277069092136 .4391021729137 .6188049316138 .7669067383 139.8834991455140 .9685058594142 .0222930908143 .0444946289144 .0355072021 144.9949951172145 .9232025146146 .8197937012147 .6849060059148 .5187072754 149.3209991455150 .092300415150 .8327026367151 .5428009033152 .2230072021 152.8740997314153 .49659729154 .0917053223154 .6602020264155 .2030029297 155.7212982178156 .2156066895156 .6871032715157 .1345062256157 .558807373 157.9553070068158 .3233032227158 .6546936035158 .9452056885159 .1853027344 159.3677978516159 .4824981689159 .5205993652159 .4747924805159 .3381958008 159.1044006348158 .7649993896158 .3363952637157 .8155975342157 .3424987793 157.0547943115156 .829498291156 .550201416156 .2321014404155 .8556060791 155.4185028076154 .9405975342154 .3058929443153 .4031982422152 .483795166 151.791595459151 .2830963135150 .9909973145150 .9013977051151 .00340271 151.2254943848151 .4951019287151 .7725982666152 .0482025146152 .2440032959 152.283706665152 .2604064941152 .1340942383152 .0001068115151 .8224029541 151.686706543151 .7989044189151 .5021972656150 .1923065186148 .6629943848 147.6809997559 147.1717987061 147.2106018066147.6907958984148.620300293 148.7584991455146 .8009033203144 .1212005615141 .950302124140 .1699066162 138.9069976807138 .0527954102137 .5738067627137 .4243011475137 .4998016357 137.8137054443138 .3992004395138 .3516998291136 .7861938477134 .9264984131 133.9226989746133 .403793335133 .1354980469133 .0982055664133 .2597961426 133.4528045654133 .5852050781133 .6385955811133 .4754943848133 .2238006592 132.8769073486132 .4947052002132 .2445068359131 .9974060059131 .7310943604 131.4248962402130 .9781951904130 .4752044678129 .9046020508129 .3675994873 129.0299072266128 .8477020264128 .7924041748128 .875793457129 .1172027588 129.308807373129 .2577972412128 .8898925781128 .070602417127 .1171035767 126.3173980713125 .6714019775125 .2456970215125 .0335006714125 .0571975708 125.3184967041125 .8172988892126 .5477981567127 .4931030273128 .6186065674 129.9358978271130 .8800964355130 .8222961426130 .5258026123130 .6463012695 131.1233978271132 .0585021973133 .4109039307135 .2259063721137 .2922058105 139.5005950928141 .4098968506142 .7261047363143 .4010009766143 .0821990967 142.1063995361140 .5269012451138 .7391967773137 .2624969482136 .1262969971 135.6255950928135 .582901001136 .0131072998136 .7691040039137 .6201934814 138.5196990967139 .3582000732140 .1652069092140 .9169006348141 .6645965576 142.4125061035143 .4232940674144 .987197876146 .8345031738148 .7720031738 150.7144012451152 .620300293154 .2330932617155 .3348999023156 .7012023926 158.9311981201161 .3677978516163 .2637023926164 .8921051025166 .5113983154 168.1773986816170 .0207977295172 .0272979736174 .2501983643176 .6425933838 179.1649932861181 .8032073975184 .5272979736187 .3096923828190 .0867004395 192.9098968506195 .8421020508198 .7846984863201 .6230010986204 .4044952393 207.1295013428209 .8401031494212 .5740966797215 .5868988037219 .1949005127 222.9730072021226 .5653991699230 .0009002686233 .1768951416236 .1524047852 238.895904541241 .4797058105244 .0007019043246 .4698944092248 .9564971924 
251.3513031006253 .6280059814255 .8556060791258 .0105895996260 .1893005371 262.4750061035264 .8651123047267 .4926147461270 .3395080566273 .3854064941 276.604888916279 .9671936035283 .6181945801287 .7192077637291 .7738037109 295.3139038086298 .6112976074301 .8775939941305 .067199707308 .113494873 311.0296936035313 .8181152344316 .4917907715319 .0676879883321 .5526123047 323.959197998326 .2914123535328 .5567016602330 .7586975098332 .9028015137 334.9926147461337 .0327148438339 .0263061523340 .9772949219342 .8880004883 344.7615966797346 .5997009277348 .4047851562350 .1781005859351 .9216003418 353.6362915039355 .324005127356 .9858093262358 .6229858398360 .236907959 361.828704834363 .3994140625364 .9501037598366 .4819030762367 .9959106445 369.4927978516370 .9737854004372 .4395141602373 .8908081055375 .3284912109 376.7532958984378 .1659851074379 .567199707380 .9574890137382 .3375854492 383.7080993652385 .0694885254386 .4223937988387 .7672119141389 .1046142578 390.4348144531391 .7583007812393 .0757141113394 .3870849609395 .6929931641 396.9937133789398 .2894897461399 .5805969238400 .8671875402 .1496887207 403.4281921387404 .7027893066405 .9736022949407 .240814209408 .504486084 409.7644958496411 .0210876465412 .2742919922413 .5239868164414 .7702026367 416.0129089355417 .2520141602418 .4876098633419 .7195129395420 .9476013184 422.1719055176423 .3923034668424 .6087036133425 .820892334427 .0289001465 428.2325134277429 .4316101074430 .6258850098431 .8153991699432 .9996948242 434.1788024902435 .3523864746436 .5202941895437 .6824035645438 .8385925293 439.9887084961441 .1328125442 .2672119141443 .3900146484 $-11.7262802124-9.25989627838-6.79788208008-4.3443441391-1.89791405201$ .54143601655962 .9736790657045 .3988380432137 .81687879562410 .22782993317 12.6316499710115 .028349876417 .4178600311319 .8001899719222 .17523002625 24.5429496765126 .9032096862829 .2559604644831 .60099988321533 .93825912476 36.2674598693838 .5885086059640 .9010810852143 .20499038696445 .49988174438 47.7855110168550 .0614318847752 .3273315429754 .5826911926356 .82714080811 59.0600700378461 .2810401916563 .489398956365 .6846008300867 .86595153809 70.0328292846772 .1845092773474 .3202972412176 .4394226074278 .5411529541 80.6246795654382 .6892166137784 .7339935302786 .7581634521588 .76097106934 90.7415695190492 .6992034912194 .6330108642696 .542266845798 .42616271973 100.283996582102 .1149978638103 .9184036255105 .6936035156107 .4401016235 109.1569976807 110.84400177 112.5003967285 114.1257019043115.7195968628 117.2816009521 118.8115005493120.3087997437 121.773399353123.2051010132 124.6036987305125 .9692001343127 .3014984131128 .6004943848129 .8665008545 131.0993041992132 .2991027832133 .466003418134 .6000976562135 .7015075684 136.7702941895137 .8065948486138 .8105010986139 .7819061279140 .720993042 141.6277008057142 .5019073486143 .3437957764144 .1531982422144 .9302062988 145.6750030518146 .3878936768147 .0691070557147 .7194061279148 .3390960693 148.9295043945149 .4909973145150 .0252990723150 .533203125151 .0166015625 151.4770050049151 .915802002152 .3352050781152 .7344055176153 .116104126 153.4752044678153 .8126983643154 .1188049316154 .3901977539154 .6154937744 154.7872009277154 .8945007324154 .9282989502154 .8802947998154 .7440032959 154.5144042969154 .1855010986153 .7725067139153 .2225036621152 .7579956055 152.6006011963152 .5489044189152 .4223022461152 .2597045898152 .0238952637 
151.7191009521151 .4156036377150 .9091949463149 .9519042969148 .9467926025 148.2648925781147 .7770996094147 .5301971436147 .4084014893147 .3419952393 147.3665924072 147.4100036621 147.4225006104 147.2982940674147.0679016113 146.7839050293146 .4969024658146 .1795043945145 .8829956055145 .5868988037 145.2301025391144 .775100708144 .0688018799143 .0567016602141 .9738006592 141.12109375140 .5429992676140 .342300415140 .2696990967140 .0830993652 139.5001068115138 .2015075684136 .5740966797134 .9571075439133 .5382995605 132.5281982422131 .8475952148131 .4765014648131 .2559051514131 .0756072998 130.8406066895130 .4739990234129 .829498291128 .6475067139127 .5225982666 127.0650024414126 .9152984619126 .7882995605126 .7730026245126 .8731994629 126.9617004395126 .9572982788126 .8946990967126 .7192001343126 .4857025146 126.1697006226125 .8137969971125 .5599975586125 .2950973511125 .0052032471 124.7060012817124 .3507003784123 .976600647123 .5279998779123 .1339035034 122.9362030029122 .885597229122 .9318008423123 .1312026978123 .5894012451 123.9990997314124 .1362991333123 .903503418123 .0522003174122 .0337982178 121.2512969971120 .640296936120 .256401062120 .0979995728120 .1638031006 120.4756011963121 .0127029419121 .8163986206122 .8602981567124 .1464004517 125.8751983643127 .1650009155126 .9629974365126 .44090271126 .5529022217 127.0617980957128 .0500030518129 .4904937744131 .3822937012133 .6286010742 136.1374969482138 .5238952637140 .3764038086141 .2834014893140 .8157958984 139.4114074707137 .4597015381135 .3899993896133 .666305542132 .3740997314 131.7572937012131 .6661987305132 .045501709132 .7483978271133 .5773010254 134.4875030518135 .3439025879136 .1972045898136 .9978027344137 .8475952148 138.7940979004139 .9407043457141 .4078063965143 .1138000488145 .0341033936 147.0238037109149 .0066986084150 .7606964111151 .7478027344152 .8549041748 155.1544952393157 .5287017822159 .1114044189160 .4777984619161 .8363952637 163.2324981689164 .7984008789166 .5359039307168 .5162963867170 .696395874 173.0662994385175 .5906982422178 .2351989746180 .961807251183 .6616973877 186.4398040771189 .404296875192 .404296875195 .2953948975198 .1376953125 200.9302062988203 .7138061523206 .4376068115209 .4944000244213 .442199707 217.5942993164221 .4373931885225 .1009979248228 .4577941895231 .588104248 234.4499969482237 .1443939209239 .8065032959242 .4458007812245 .1356964111 247.7984008789250 .3842926025252 .7772979736254 .9069061279256 .899597168 258.9757995605261 .1676940918263 .5990905762266 .2264099121269 .0303955078 271.9772033691274 .9744873047278 .1993103027281 .8306884766285 .6028137207 289.2319030762 292.7777099609296.1661071777 299.4137878418 302.5035095215 305.4491882324308 .2672119141310 .9656066895313 .5675964355316 .0758056641 318.5080871582320 .8648986816323 .1575012207325 .3869934082327 .5607910156 329.6807861328331 .7528076172333 .7788085938335 .7634887695337 .7083129883 339.616607666341 .4895935059343 .3298950195345 .1383056641346 .9169006348 348.6665039062350 .388885498352 .0848999023353 .7561035156355 .4034118652 357.0281066895358 .6311035156360 .2137145996361 .7767028809363 .3212890625 364.8482971191366 .3587036133367 .8532104492369 .3327941895370 .7980957031 372.2499084473373 .6890869141375 .1160888672376 .5317077637377 .9364929199 379.3310852051380 .7160949707382 .0918884277383 .459197998384 .8183898926 386.1698913574387 .5143127441388 .8518981934390 .183013916391 .5080871582 
392.8275146484394 .1413879395395 .4501953125396 .7539978027398 .0531921387 399.3478088379400 .638092041401 .9241027832403 .2059936523404 .4838867188 405.7578125407 .0278930664408 .2940063477409 .5563049316410 .8146972656 412.0690917969413 .3196105957414 .5661010742415 .8086853027417 .047088623 418.2814025879419 .511505127420 .7372131348421 .9585876465423 .1754150391 424.387512207425 .594909668426 .7973022461427 .9945983887429 .1866149902 430.3731994629431 .5539855957432 .7290039062433 .8980102539435 .0609130859 436.2177124023437 .3674926758438 .5116882324439 .6480102539 -13.0615901947 -10.6010904312 -8.1549654007 -5.72001886368 -3.29122304916 -.869356989861 1.545554041862 3.9535140991216 .3544960021978 .748506546021 11.1355104446413 .5155000686615 .8884201049818 .2542495727520 .61288070679 22.964290618925 .308319091827 .6449108123829 .9738693237332 .29507827759 34.6083183288636 .9134292602539 .2100906372141 .4981193542543 .77714157104 46.046871185348 .3068885803250 .5568618774452 .7962493896555 .02465057373 57.2414703369159 .4462318420461 .6382713317963 .8170089721765 .98175811768 68.1318588256870 .2665634155372 .3851623535274 .4868469238376 .5708770752 78.6364212036180 .6826400756882 .7087402343884 .713867187586 .69718933105 88.6578826904390 .5950775146592 .5079803466894 .3957672119196 .25758361816 98.0926971435599 .90032196045101 .6797027588103 .4301986694105 .1510009766 106.8415985107108 .5014038086110 .129699707111 .7259979248113 .2900009155 114.8211975098116 .3190994263117 .7835998535119 .2142028809120 .611000061 121.9735031128123 .301902771124 .5960006714125 .8556976318127 .0812988281 128.2725982666129 .4297943115130 .5529937744131 .6423034668132 .6979064941 133.7198028564134 .7082061768135 .6631011963136 .5845947266137 .4727020264 138.3273925781139 .1486968994139 .9365997314140 .6911010742141 .4122009277 142.1002960205142 .7554931641143 .3782043457143 .9691925049144 .5289001465 145.05859375145 .5592041016146 .0323944092146 .479598999146 .9031066895 147.3049926758 147.6878967285148.0547027588 148.4062957764148.745803833 149.0700073242149 .3793945312149 .6649932861149 .9219970703150 .1392974854 150.3069000244150 .4154052734150 .453994751150 .4154052734150 .2910003662 150.0825958252149 .7872009277149 .421295166148 .9790039062148 .6105041504 148.4537963867148 .3894958496148 .3016052246148 .1770935059147 .9812927246 147.7093048096147 .37109375146 .8477935791146 .008895874145 .141998291 144.5276031494144 .1143035889143 .9898986816143 .8856048584143 .6318054199 143.4174957275143 .2864990234143 .0623016357142 .5054016113141 .7882995605 141.1291046143140 .5214996338139 .9530944824139 .4219055176138 .9358978271 138.3545074463137 .6127929688136 .7353973389135 .6278991699134 .5865936279 133.8249969482133 .2169036865132 .8267059326132 .3406982422131 .5686950684 130.6831054688129 .5832977295128 .4864044189127 .3839035034126 .3772964478 125.7251968384125 .3283004761125 .1872024536124 .9928970337124 .4825973511 123.6981964111122 .7227020264121 .8293991089121 .1376037598120 .7422027588 120.6100997925120 .5758972168120 .5606002808120 .5670013428120 .6046981812 120.6007003784120 .4916992188120 .3315963745120 .1095962524119 .8539962769 119.5574035645119 .2404022217118 .9794006348118 .7241973877118 .4630966187 118.2141036987117 .9476013184117 .6800003052117 .3757019043117 .1260986328 117.0184020996117 .0382003784117 .1747970581117 .4390029907117 .8712997437 
118.2576980591 118.4234008789118.2675018311 117.6381988525116 .8454971313 116.1668014526115 .6276016235115 .3054962158115 .1863021851115 .2897033691 115.6218032837116 .193397522117 .0054016113118 .025100708119 .2515029907 120.7152023315121 .818397522121 .9437026978121 .8116989136122 .081199646 122.7082977295123 .7736968994125 .2415008545127 .0976028442129 .4075012207 132.2528991699135 .2765960693138 .2637939453139 .9239044189138 .8262023926 136.4714050293134 .1123962402131 .8025054932129 .8002929688128 .3439941406 127.8338012695127 .9105987549128 .3433074951129 .0559997559129 .9243011475 130.8751983643131 .7978057861132 .7180023193133 .5726928711134 .4864959717 135.512298584136 .68359375138 .1136016846139 .7554016113141 .6273040771 143.6721038818145 .8202972412148 .0095977783150 .1974029541152 .1015014648 153.3849029541154 .387802124155 .3578033447156 .333694458157 .3941955566 158.5489044189159 .8464050293161 .3352050781163 .0746002197165 .0485992432 167.2823944092169 .7111968994172 .2919006348174 .9859924316177 .6979980469 180.4904022217183 .3995056152186 .3477020264189 .2326965332192 .1036071777 194.9620056152197 .8775024414200 .8930053711204 .2555999756208 .2855987549 212.4998931885216 .5361022949220 .379196167223 .8365020752227 .0325927734 229.9452972412232 .6804046631235 .3955993652238 .1390991211240 .9844055176 243.9270019531247 .0375976562249 .7958068848251 .6795043945253 .2756958008 255.1470031738257 .2087097168259 .5239868164262 .0270080566264 .6961975098 267.4737854004270 .308013916273 .253112793276 .3508911133279 .7150878906 283.3995056152 287.1480102539290.6347045898293.9198913574297.0280151367 299.9838867188302 .8102111816305 .5198059082308 .1329956055310 .6563110352 313.1044921875315 .4809875488317 .794708252320 .0484008789322 .2478942871 324.3960876465326 .4977111816328 .5549926758330 .571685791332 .5498046875 334.4920043945336 .399597168338 .2745056152340 .1180114746341 .9313964844 343.7159118652345 .4729003906347 .2033081055348 .9083862305350 .5892028809 352.246887207353 .8823852539355 .496887207357 .0914001465358 .666809082 360.2239990234361 .7640075684363 .2875976562364 .7955932617366 .2886047363 367.7676086426369 .2333068848370 .6864013672372 .1272888184373 .5568847656 374.9757995605376 .3843994141377 .7832946777379 .1730957031380 .554107666 381.9270935059383 .2922058105384 .6500854492386 .0008850098387 .3453063965 388.6832885742390 .015411377391 .341796875392 .6628112793393 .9784851074 395.2893066406396 .5952148438397 .8963928223399 .1929931641400 .4851074219 401.7728881836403 .0562133789404 .3352966309405 .6101074219406 .8804931641 408.1466064453409 .4083862305410 .6658935547411 .9190063477413 .1676025391 414.411895752415 .6516113281416 .8865966797418 .1169128418419 .3424072266 420.5631103516421 .7786865234422 .9891052246424 .1942138672425 .3937988281 426.5875854492427 .7756958008428 .9577026367430 .1335144043431 .3030090332 432.4663085938433 .6232910156434 .7698974609435 .9047851562 -14.3489198685 -11.9188098907 -9.49286079407 -7.07494211197-4.6637878418 $-2.25940394402 .13817900419242 .5289590358734 .9128999710087 .290011882782$ 9.66023826599112 .0235900878914 .3799800872816 .7294101715119 .07173919678 21.4069690704323 .7349205017126 .055530548128 .3685894012530 .67400932312 32.9715118408235 .2609710693437 .5420303344739 .8145217895542 .07801818848 44.3322792053246 .5768203735448 .8113212585451 .0352096557653 .24810028076 
55.449359893857 .6384811401459 .8148002624561 .9777183532764 .12651062012 66.2605133056668 .3789367675870 .4810714721772 .5660705566474 .63314056396 76.6814498901478 .7101364135780 .7183837890682 .7052612304784 .66993713379 86.6115264892688 .5291671752990 .4219665527392 .2891311645594 .12973022461 95.9430236816497 .7281265258899 .48435211182101 .210899353102 .9069976807 104.5720977783106 .2054977417107 .806602478109 .3749008179110 .9097976685 112.4108963013113 .8777999878115 .3103027344116 .707901001118 .0705032349 119.3979034424120 .6900024414121 .9467010498123 .1679992676124 .3538970947 125.5046005249126 .6201019287127 .7004013062128 .745803833129 .7563934326 130.7324066162131 .6737060547132 .5805053711133 .4528961182134 .2908935547 135.0944976807135 .8636932373136 .5986022949137 .2991027832137 .9653930664 138.5975036621139 .1959075928139 .7608032227140 .2931976318140 .7933044434 141.262802124141 .7023010254142 .1143951416142 .5142 .8628997803143 .2048950195 143.5305938721143 .8432006836144 .1457061768144 .4423980713144 .7306976318 145.0135040283145 .2799987793145 .5269927979145 .7400054932145 .9069976807 146.0209960938146 .0682067871146 .0449066162145 .9393005371145 .7595977783 145.5055999756145 .2147979736144 .9085998535144 .6407928467144 .4378051758 144.2888946533 144.157699585144.0061950684143.7929992676143.4801940918 143.0384979248142 .4680938721141 .7485961914141 .0525970459140 .5077056885 140.1600952148140 .2368927002140 .2144012451139 .8885040283139 .5440979004 139.0966033936138 .5314025879137 .5628051758136 .3370056152135 .3123016357 134.3793029785133 .5160980225132 .7341003418132 .0252075195131 .2684936523 130.3874969482129 .4091949463128 .2133026123127 .1024017334126 .3541030884 125.7111968994125 .1470031738124 .4508972168123 .4207992554122 .3775024414 121.4160003662120 .5970993042119 .8305969238119 .2013015747118 .8666000366 118.6792984009118 .6947021484118 .5036010742117 .738899231116 .6654968262 115.4545974731114 .5212020874114 .3305969238114 .4791030884114 .4806976318 114.4863967896114 .5352020264114 .5492019653114 .5409011841114 .4558029175 114.2642974854114 .0174026489113 .7188034058113 .404800415113 .1149978638 112.8301010132112 .5972976685112 .3909988403112 .1948013306112 .0234985352 111.8373031616111 .6615982056111 .4896011353111 .3666000366111 .31199646 111.3678970337 111.5531005859 111.8143005371 112.1524963379 112.4348983765 112.5712966919112 .5077972412112 .1596984863111 .6692962646111 .1386032104 110.681602478110 .4132003784110 .3285980225110 .4695968628110 .8284988403 111.4175033569112 .2078018188113 .1213989258114 .1193008423115 .0932006836 115.8986968994116 .4050979614116 .8139038086117 .3524017334118 .1334991455 119.270401001120 .7798995972122 .5907974243124 .9121017456127 .9615020752 131.3025970459135 .0765991211137 .3560028076135 .8146972656132 .8511047363 130.3981933594128 .042098999125 .9116973877124 .4084014893124 .0510025024 124.3279037476124 .8226013184125 .5942993164126 .5231018066127 .5672988892 128.6072998047129 .6201019287130 .5148010254131 .4279937744132 .4521942139 133.6287994385135 .0229949951136 .6347961426138 .4635009766140 .537902832 142.8162994385145 .3771972656148 .721496582151 .4010009766151 .7028961182 151.3802032471151 .7922058105152 .4073944092153 .1887054443154 .1295013428 155.1920928955156 .445602417157 .9326934814159 .7153930664161 .8343963623 164.2153930664166 .75340271169 .4185028076172 .1493988037174 .9445037842 
177.7677001953180 .6186981201183 .4470977783186 .3076934814189 .1920928955 192.2398986816195 .5733947754199 .2183074951203 .2704925537207 .508102417 211.7642974854215 .7812042236219 .2684936523222 .3948974609225 .2602996826 228.0065002441230 .7404022217233 .5424041748236 .4725952148239 .5500030518 243.0240020752246 .0657958984247 .7734069824249 .1103973389250 .9342041016 252.9624023438255 .2462005615257 .712890625260 .3309936523263 .048614502 265.8327941895268 .6672973633271 .3758850098274 .3775939941278 .0286865234 281.8359069824285 .3016052246288 .5812072754291 .6824035645294 .6220092773 297.4431152344300 .1462097168302 .7616882324305 .2893981934307 .7481994629 310.1379089355312 .4695129395314 .7434997559316 .9668884277319 .1408996582 321.270690918323 .3576965332325 .4059143066327 .4164123535329 .391998291 331.3335876465333 .2430114746335 .12109375336 .9693908691338 .7885131836 340.5799865723342 .3446960449344 .0837097168345 .7980041504347 .4887084961 349.1567993164350 .8034057617352 .4292907715354 .0356140137355 .6231079102 357.1928100586358 .7453918457360 .2817993164361 .8027038574363 .3089904785 364.8012084961366 .2803039551367 .7466125488369 .2011108398370 .6441040039 372.076385498373 .4984130859374 .9106140137376 .3135070801377 .7078857422 379.0938110352380 .4718933105381 .8424072266383 .2059020996384 .5625385 .912689209 387.2567138672388 .5947875977389 .9270935059391 .25390625392 .5754089355 393.8916015625395 .202911377396 .5090942383397 .8104858398399 .1070861816 400.3989868164401 .6861877441402 .9685974121404 .246307373405 .5192871094 406.7875061035408 .0510864258409 .3099060059410 .5639953613411 .8131103516 413.0573120117414 .2966003418415 .5307006836416 .7597045898417 .9834899902 419.2018127441420 .4144897461421 .6216125488422 .8226928711424 .0179138184 425.2067871094426 .3894042969427 .5653991699428 .7351074219429 .8976135254 431.0541992188432 .2026062012

-15.6426095963 -13.2188901901 -10.8089704514-8.40962028503-6.01610803604 -3.62920188904-1.24893295765 1.124683976173 3.491616964345.851861000061 8.20536994934110 .552140235912 .8920803070115 .2251901626617 .55135917664 19.870529174822 .182550430324 .4873504638726 .7847309112529 .07456016541 31.3565998077433 .6306686401435 .8964614868238 .1537284851140 .40211105347 42.6412811279344 .8708000183147 .0902786254949 .2991981506351 .49708938599 53.6833381652855 .85742187558 .0186309814560 .1663703918562 .29988098145 64.4184875488366 .5213623046968 .6077575683670 .6768188476672 .72772216797 74.7595977783276 .7715835571378 .7627563476680 .7322311401482 .67910003662 84.6024627685586 .501388549888 .37590 .2223968505992 .0426712036193 .83499908447 95.59851074219 97.3324279785299.03592681885 100.7082977295 102.3487014771 103.956703186105 .53150177107 .0725021362108 .5792007446110 .0512008667 111.4879989624112 .8892974854114 .254699707115 .5839996338116 .8770980835 118.1337966919119 .3539962769120 .5376968384121 .6848983765122 .7957000732 123.870300293124 .9086990356125 .9110031128126 .8775024414127 .8081970215 128.7032928467129 .5628967285130 .3871002197131 .1759033203131 .9293060303 132.6475067139133.3302001953133.9777069092 134.5897979736135.1670074463 135.7093048096136 .2171936035136 .69140625137 .1324005127137 .5417022705 137.9201049805138 .2702941895138 .5935974121138 .8943023682139 .1750946045 139.44140625139 .6976928711139 .949005127140 .2006988525140 .4524993896 
140.707901001140 .9570007324141 .1961975098141 .4075927734141 .5747070312 141.6947021484141 .7550048828141 .7512969971141 .6708984375141 .5220031738 141.3061981201141 .0675048828140 .8307952881140 .5914001465140 .3605041504 140.1416015625139 .9537963867139 .753692627139 .4936981201139 .1282958984 138.6295013428138 .0339050293137 .3070983887136 .6399993896136 .124206543 135.8939971924136 .1663970947136 .2675933838136 .1009979248135 .7718963623 134.832901001133 .7057037354132 .4409942627130 .8383026123129 .3125127 .9905014038 126.8889007568125 .9289016724125 .0552978516124 .1887969971123 .2632980347 122.2902984619121 .200302124120 .1854019165119 .3944015503118 .6751022339 117.9649963379117 .1557006836116 .1456985474115 .1714019775114 .3214035034 113.6387023926113 .0478973389112 .5845031738112 .3035964966112 .1094970703 111.9816970825111 .6707992554110 .9572982788110 .0326004028109 .0771026611 108.4348983765108 .3853988647108 .6031036377108 .7331008911108 .8069992065 108.8658981323108 .8716964722108 .7956008911108 .6209030151108 .3238983154 107.9733963013 107.5888977051 107.2198028564106.9341964722 106.6927032471 106.5170974731106 .3886032104106 .2617034912106 .1620025635106 .0640029907 105.9719009399105 .8985977173105 .8490982056105 .8152999878105 .8672027588 106.0262985229106 .2382965088106 .5447006226106 .8190002441106 .9838027954 107.0435028076106 .8647994995106 .5506973267106 .1425018311105 .757598877 105.5337982178105 .4769973755105 .6644973755106 .0456008911106 .6188964844 107.3311004639108.0988006592108.8657989502 109.5731964111 110.2637023926 110.8908004761111 .5605010986112 .3085021973113 .2285003662114 .4577026367 116.0127029419117 .9157028198120 .2496032715123 .1216964722126 .2060012817 129.3339996338131 .1683044434130 .2666015625128 .1210021973126 .0227966309 123.9705963135122 .1831970215120 .9302978516120 .6007995605120 .8451004028 121.399597168122 .2304992676123 .2485961914124 .4210968018125 .6854019165 126.8599014282127 .7072982788128 .5102996826129 .5021972656130 .6627044678 132.0278015137133 .604598999135 .413192749137 .4608001709139 .7093048096 142.2588043213145 .2416992188147 .5140075684148 .0572967529147 .9237976074 148.1625061035148 .6168060303149 .2194061279149 .9591064453150 .841506958 151.8751983643153 .0569000244154 .5948944092156 .7097930908159 .1454925537 161.6678924561164 .2944946289166 .9855957031169 .7205047607172 .4671020508 175.2283935547177 .9832000732180 .7897949219183 .6398925781186 .7169036865 190.12840271193 .8582000732198 .0157928467202 .4411010742207 .1405029297 211.5021057129214 .7890930176217 .5834960938220 .321395874223 .0214996338 225.7532043457228 .5496063232231 .4418945312234 .4575958252237 .6871948242 240.56199646242 .5404052734244 .2218017578246 .1882019043248 .3408966064 250.7129058838253 .2422943115255 .9178924561258 .6795959473261 .4866027832 264.3042907715267 .0636901855270 .0315856934273 .4273986816276 .9549865723 280.2864990234283 .470703125286 .5003967285289 .3963928223292 .1796875 294.8616027832297 .4614868164299 .9848022461302 .4442138672304 .8421020508 307.1857910156309 .4772949219311 .7210998535313 .9194030762316 .0755004883 318.19140625320 .2698974609322 .312286377324 .3204956055326 .2956848145 328.2391052246330 .1516113281332 .0343017578333 .8880004883335 .7138061523 337.5126037598339 .2853088379341 .032989502342 .7567138672344 .4573059082 346.1358947754347 .7930908203349 .4302062988351 .0480041504352 .6473083496 
354.2289123535355 .7937011719357 .3424072266358 .8758850098360 .3947143555 361.8996887207363 .3915100098364 .8706970215366 .3380126953367 .7937927246 369.2387084961370 .6734008789372 .0982055664373 .5137023926374 .9204101562 376.3186035156377 .7088012695379 .0913085938380 .4664001465381 .8345947266 383.196105957384 .5510864258385 .899810791387 .2426147461388 .579498291 389.9107055664391 .2365112305392 .5567016602393 .8717041016395 .1813964844 396.4859008789397 .7854003906399 .0797119141400 .3688049316401 .6528930664 402.9318847656404 .2058105469405 .474609375406 .7383117676407 .9967956543409 .25 410.4981079102411 .740814209412 .9779968262414 .2096862793415 .4357910156 416.6560974121417 .870513916419 .0787963867420 .2809143066421 .4765930176 422.665802002423 .8482971191425 .0244140625426 .1937866211427 .3525085449 428.499206543

-16.890630722 -14.4968395233 -12.1069698334 -9.72469139099 -7.34882116318 $-4.979388237-2.61642694473-.2599569857122 .0899860858924 .433396816254$ 6.7702221870429 .10046291351311 .4240303039613 .7409200668316 .05100059509 18.3542404174820 .6504802703922 .9396495819125 .2215194702127 .49600982666 29.7628097534232 .0217895507834 .2725906372136 .5150108337438 .7486114502 40.9731292724643 .1880416870145 .3930091857947 .5874290466349 .77088165283 51.9426918029854 .1023406982456 .2490806579658 .3823089599660 .50122070312 62.6051406860464 .6931991577166 .7646331787168 .8185501098670 .85410308838 72.8703765869174 .8664703369176 .8414611816478 .7944030761780 .72435760498 82.6303634643684 .5115127563586 .3667907714888 .1953582763789 .99620819092 91.7685165405393 .5113372802795 .2238922119196 .9052581787198 .55474853516 100.1715011597101 .7548980713103 .3042984009104 .8190002441106 .2984008789 107.7421035767109 .1496963501110 .5206985474111 .8547973633113 .151802063 114.4113006592115 .6334991455116 .8180007935117 .9649963379119 .0743026733 120.1462020874121 .1807022095122 .1779022217123 .1380004883124 .0612030029 124.9476013184125 .7974014282126 .6107025146127 .3874969482128 .1280975342 128.8321990967129 .5001983643130 .1318054199130 .7272033691131 .2864990234 131.8096008301132 .2969055176132 .7485961914133 .1656036377133 .5480041504 133.8975982666134 .2147064209134 .5028991699134 .7628936768135 .0003967285 135.2176971436135 .4225006104135 .6190948486135 .8157043457136 .0180053711 136.2292022705136 .4535980225136 .6824035645136 .9143981934137 .1242980957 137.2911987305 137.4169006348 137.4810028076137.4895935059 137.4306030273 137.30859375137 .1266021729136 .9210968018136 .7104034424136 .4727935791 136.1970062256135 .9093017578135 .6367950439135 .3502960205135 .0209960938 134.6047973633134 .0888061523133 .4792022705132 .7196044922131 .9866943359 131.3690032959131 .0348968506131 .274307251131 .8273925781132 .5554046631 132.4732971191130 .6844024658128 .3197021484126 .4701004028124 .8569030762 123.1277999878121 .5126037598120 .2473983765119 .1472015381118 .1636962891 117.2516021729116 .350402832115 .464302063114 .5358963013113 .6443023682 112.8182983398112 .0117034912111 .2197036743110 .4044036865109 .5494003296 108.7484970093107 .9985961914107 .3731994629106 .8470993042106 .4216995239 106.1082992554105 .7951965332105 .4493026733104 .9980010986104 .4320983887 103.867401123103 .3926010132103 .136100769103 .1184997559103 .2453994751 103.387298584 103.4937973022 103.55909729 103.5297012329 103.3990020752 
103.141998291102 .7615966797102 .2983016968101 .7992019653101 .3631973267 101.0855026245100 .931602478100 .860496521100 .8290023804100 .7676010132 100.7115020752100 .6570968628100 .6396026611100 .6688995361100 .6906967163 100.6654968262100 .6306991577100 .6666030884100 .8041992188101 .1140975952 101.4691009521101 .7310028076101 .8833007812101 .8238983154101 .6222000122 101.3033981323100 .9629974365100 .7419967651100 .6988983154100 .9421005249 101.3777999878101 .9402008057102 .549697876103 .1435012817103 .6976013184 104.185798645104 .7578964233105 .4476013184106 .2746963501107 .1605987549 108.1942977905109 .4792022705111 .0618972778113 .0311965942115 .2983016968 117.8611984253120 .3488006592122 .4226989746123 .6539993286123 .5712966919 122.619102478121 .198600769119 .6417999268118 .37159729117 .4879989624 117.2144012451117 .4271011353118 .0306015015118 .9506988525120 .0589981079 121.3383026123122 .7772979736124 .0976028442124 .9102020264125 .6407012939 126.620300293127 .7693023682129 .1065979004130 .6582946777132 .4360046387 134.4273986816136 .5657043457138 .7696990967140 .9145050049142 .6072998047 143.6067047119144 .141998291144 .554901123144 .9519958496145 .432800293 146.0308074951146 .7808074951147 .6820068359148 .6407012939149 .9906005859 152.0894927979154 .5451049805157 .0095062256159 .5715026855162 .1907958984 164.8446044922167 .5043945312170 .1800994873172 .8491973877175 .5773010254 178.3536987305181 .338104248184 .6434936523188 .3516998291192 .5778045654 197.1627044678202 .2136993408206 .8206939697209 .9326934814212 .4824981689 215.165802002217 .8289031982220 .5323944092223 .2843017578226 .057800293 228.8560028076231 .6450958252234 .2563018799236 .5852966309238 .7738037109 241.0310058594243 .3883972168245 .9208068848248 .5839996338251 .4073028564 254.2937927246257 .2062072754260 .1510925293263 .0909118652266 .1203918457 269.2236938477272 .3721923828275 .4757080078278 .5112915039281 .4374084473 284.2634887695286 .99609375289 .642791748292 .220489502294 .7314147949297 .1875 299.5891113281301 .9429016113304 .2493896484306 .512512207308 .7333984375 310.9151916504313 .0591125488315 .167388916317 .2409973145319 .2815856934 321.2898864746323 .266998291325 .2135009766327 .1304016113329 .0181884766 330.878112793332 .7107849121334 .5170898438336 .2979125977338 .0544128418 339.7872924805341 .4975891113343 .1860961914344 .8539123535346 .5015869141 348.1304016113349 .7409057617351 .3340148926352 .9104003906354 .4708862305 356.0162963867357 .547088623359 .0639953613360 .5679016113362 .0592041016 363.5385131836365 .0061950684366 .463104248367 .9096984863369 .3463134766 370.7735900879372 .1918029785373 .6014099121375 .0028076172376 .3963012695 377.7822875977379 .1611022949380 .5328979492381 .8978881836383 .2565002441 384.6087036133385 .9547119141387 .294708252388 .62890625389 .9573059082 391.2799987793392 .5969848633393 .9085083008395 .2145080566396 .5148925781 397.8099060059399 .0994873047400 .383605957401 .6622009277402 .9353942871 404.2030944824405 .4653015137406 .7219848633407 .9729919434409 .2184143066 410.4578857422411 .6915893555412 .9193115234414 .1408996582415 .3562927246 416.5651855469417 .7676086426418 .9632873535420 .1521911621421 .3344116211 422.5090942383423 .6778869629424 .838104248 $-18.1450805664-15.7581501007-13.3844404221-11.0206899643-8.66245269775$ -6.31048679352 -3.96482205391 -1.62548398972 0.7074940204623 .034100055695 
5.3542890548717 .6680498123179 .97531223297112 .2760496139514 .57015991211 16.8575897216819 .1382007598921 .4118900299123 .6784706115725 .93781089783 28.1896400451730 .4337997436532 .6699409484934 .8978309631337 .11706161499 39.3273010253941 .5280799865743 .7189903259345 .8994483947848 .06900024414 50.2269592285252 .3727798461954 .5057106018156 .6250915527358 .73014068604 60.8200988769562 .894119262764 .9513778686566 .9909591674869 .0119934082 71.0134963989372 .9945983886774 .9542770385776 .8915786743278 .8055267334 80.6951065063582 .5593795776484 .3973007202186 .2079696655387 .99034881592 89.743583679291.466659545993.158767700294.8189773559696.44650268555 98.0405273437599 .60034179688101 .1251983643102 .6145019531104 .0675964355 105.4840011597106 .8631973267108 .2048034668109 .5084991455110 .7739028931 112.0009994507113 .1893997192114 .3391036987115 .4502029419116 .5224990845 117.5562973022118 .5514984131119 .5083999634120 .4272003174121 .3078994751 122.1509017944122 .956199646123 .7239990234124 .454498291125 .1476974487 125.8035964966126 .4224014282127 .0039978027127 .548500061128 .0556945801 128.5260009766128 .9593048096129 .3558959961129 .716293335130 .040802002 130.3307952881130 .5868988037130 .8123016357131 .0083007812131 .1804962158 131.3323059082131 .4718933105131 .6051940918131 .7416992188131 .8894042969 132.0540008545132 .2422943115132 .4476928711132 .6690063477132 .8737030029 133.0404968262133 .166305542133 .2207946777133 .2236938477133 .1712036133 133.0567932129132 .8979949951132 .7131958008132 .4998931885132 .2337036133 131.9105987549131 .5482940674131 .1589050293130 .7630004883130 .3656005859 129.9109954834129 .4066009521128 .8009033203128 .0090942383127 .1455001831 126.1899032593125 .4608001709125 .2108001709126 .1539993286129 .5904998779 131.2785949707126 .8077011108121 .2501983643119 .0317001343117 .9551010132 116.4964981079115 .0030975342113 .6785964966112 .4989013672111 .4942016602 110.6091003418109 .7786026001108 .9963989258108 .1978988647107 .4051971436 106.6167984009105 .8141021729105 .0150985718104 .2422027588103 .4919967651 102.7988967896102 .1719970703101 .6129989624101 .132598877100 .7275009155 100.4223022461100 .073196411199 .5800628662199 .0498809814598 .50727844238 98.1464767456198 .0829315185598 .1630706787198 .2857971191498 .41837310791 98.5471115112398 .6471023559698 .6800537109498 .6119232177798 .42460632324 98.1074905395597 .6587829589897 .090538024996 .3902893066495 .80963897705 95.6051330566495 .6129608154395 .7103881835995 .8100128173895 .78151702881 95.7114562988395 .6310272216895 .6403198242295 .8571701049896 .03814697266 95.9678726196395 .7697830200295 .5255966186595 .4768600463995 .91649627686 96.4908828735496 .8757629394597 .1123428344797 .1368026733497 .00611877441 96.7442092895596 .4097518920996 .0630722045995 .9351119995196 .30877685547 96.8949966430797 .4707336425898 .0035400390698 .4400405883898 .77503204346 98.9556732177799 .31056976318100 .1108016968101 .1237030029102 .1061019897 103.172996521104 .403503418105 .8880004883107 .7092971802109 .737197876 112.0052032471114 .0686035156115 .6733016968116 .7950973511117 .0307998657 116.7242965698115 .9196014404114 .8965988159114 .112701416113 .5972976685 113.5690002441113 .9244995117114 .6556015015115 .6775970459116 .8584976196 118.1751022339119 .5810012817120 .8771972656121 .829498291122 .6995010376 123.7170028687124 .8681030273126 .1843032837127 .6707000732129 .3455963135 
131.1766052246133 .1425933838135 .0404968262136 .7765960693138 .2808074951 139.3592987061140 .1800994873140 .7673034668141 .2062072754141 .7075958252 142.2919006348143 .0182037354143 .8896026611144 .899307251146 .2592926025 148.1860961914150 .436706543152 .7855987549155 .2402038574157 .7648010254 160.3267974854162 .8894042969165 .4638061523168 .0265045166170 .6318969727 173.2890930176176 .0847015381179 .0668029785182 .5305023193186 .8226928711 191.5265045166196 .366897583200 .7761993408204 .1143951416206 .9378967285 209.6954956055212 .3802032471215 .0469055176217 .6896972656220 .3191986084 222.9107055664225 .4597015381227 .9830932617230 .4503936768232 .9337005615 235.4618988037238 .0690002441240 .8294067383243 .716506958246 .7673034668 249.8670043945252 .9777984619256 .0931091309259 .1207885742262 .1054077148 265.0557861328267 .9522094727270 .8392028809273 .7036132812276 .499206543 279.2300109863281 .8923034668284 .4924926758287 .0378112793289 .5311889648 291.9786987305294 .3812866211296 .7421875299 .0621948242301 .3429870605 303.5860900879305 .7926940918307 .9642028809310 .1018066406312 .2063903809 314.2789001465316 .3200073242318 .330291748320 .3104858398322 .2611083984 324.1828918457326 .076385498327 .9425048828329 .7821044922331 .5957946777 333.3847045898335 .149597168336 .8913879395338 .6108093262340 .3089904785 341.9866027832343 .6445922852345 .2838134766346 .9049987793348 .5087890625 350.0961914062351 .6676940918353 .2242126465354 .766204834356 .2944946289 357.8096008301359 .3120117188360 .8024902344362 .2814941406363 .7495117188 365.2072143555366 .6546936035368 .0927124023369 .5216064453370 .9417114258 372.3533935547373 .7569885254375 .1528930664376 .5412902832377 .9224853516 379.2965087891380 .6637878418382 .0245056152383 .3786010742384 .7265014648 386.0681152344387 .403503418388 .7329101562390 .0563049316391 .3738098145 392.6853027344393 .9910888672395 .2909851074396 .5851135254397 .8734130859 399.1559143066400 .4327087402401 .7036132812402 .9686889648404 .2279968262 405.4812927246406 .7284851074407 .9696960449409 .2047119141410 .4332885742 411.6554870605412 .8711853027414 .0801086426415 .2821960449416 .4773864746 417.6657104492418 .8471069336420 .0176086426421 .1756896973 -19.3561496735 -16.9986591339-14.6448698044 -12.2982196808 -9.95762252808 $-7.62312602997-5.29475402832-2.9725420475-.6565179824831 .653306007385$ 3.9568819999696 .2542119026188 .54521465301510 .8298902511613 .10809993744 15.3798398971617 .6449298858619 .9033107757622 .1547603607224 .39919090271 26.6362800598128 .8659000396731 .0876693725633 .3013992309635 .50659942627 37.7030105590839 .8900794982942 .0674285888744 .2344398498546 .39065933228 48.5353507995650 .6679916381852 .7877502441454 .8940086364756 .98588943481 59.0626792907761 .1234283447363 .1673316955665 .1934127807667 .20078277588 69.1884536743271 .1554336547973 .100723266675 .0233230590876 .92220306396 78.796318054280 .644676208582 .4662017822384 .2599487304786 .0248336792 87.75995635986 89.464279174891.1369400024492.7769393920994.3835067749 95.9557266235497 .4929199218898 .99421691895100 .4590988159101 .8867034912 103.276802063104 .6285018921105 .9417037964107 .2157974243108 .4506988525 109.6460037231110 .8016967773111 .9175033569112 .9934997559114 .0297012329 115.0261993408115 .983001709116 .9004974365117 .7787017822118 .6177978516 119.4181976318120 .1798019409120 .9030990601121 .5880966187122 .2350006104 
122.8435974121123 .4143981934123 .9469985962124 .4417037964124 .8983001709 125.3169021606125 .6976013184126 .0402984619126 .3454971313126 .6129989624 126.8443984985127 .0394973755127 .2023010254127 .3332977295127 .4394989014 127.5235977173127 .5959014893127 .6615982056127 .7338027954127 .8197021484 127.9298019409128 .0702056885128 .2402038574128 .4364929199128 .6369934082 128.811706543128 .9293060303128 .9477996826128 .9046020508128 .8224029541 128.7142028809128 .5818023682128 .3948974609128 .1320953369127 .8115005493 127.4569015503127 .0288009644126 .4950027466125 .9291000366125 .439201355 124.9449996948124 .4829025269123 .8843994141123 .0226974487122 .0587997437 120.7393035889119 .6820983887119 .0662002563119 .9648971558125 .4224014282 128.7445983887122 .2284011841114 .3011016846112 .0236968994111 .2823028564 109.893699646108 .5552978516107 .2571029663106 .0686035156105 .1166000366 104.3323974609103 .6220016479102 .9735031128102 .3038024902101 .608001709 100.8713989258100 .116996765199 .3705673217898 .6695480346798 .00875854492 97.4191970825296 .8944702148496 .4213409423895 .9853820800895 .58702087402 95.3037490844794 .9688796997194 .4444122314593 .9156417846793 .4370803833 93.2024536132893 .3894271850693 .7108535766693 .902481079194 .03471374512 94.1433029174894 .1862564086994 .1703796386794 .0481185913193 .8198928833 93.4607391357492 .9845275878992 .3820419311591 .5707931518690 .91340637207 90.8000411987390 .9395294189591 .1510467529391 .3539123535291 .33483123779 91.2510528564591 .1355667114391 .1189575195391 .4512023925891 .72849273682 91.6076431274491 .3088531494190 .8846130371190 .6931228637791 .24878692627 91.9881973266692 .4305419921992 .7145385742292 .7835235595792 .68538665771 92.4679489135792 .157638549891 .7333679199291 .5328292846792 .00791168213 92.6862869262793 .2368698120193 .695732116794 .0127563476694 .20384979248 94.1594467163194 .3245315551895 .1598205566496 .2478027343897 .23045349121 98.2619705200299 .39549255371100 .6641998291102 .1848983765103 .890296936 105.8616027832107 .7230987549109 .1672973633110 .2335968018110 .6668014526 110.7182998657110 .3705978394109 .8625030518109 .5735015869109 .4688034058 109.7634963989110 .3655014038111 .278503418112 .4184036255113 .6595993042 114.9776000977116 .2855987549117 .5328979492118 .6464004517119 .7108001709 120.8063964844121 .9732971191123 .2703018188124 .6850967407126 .2257003784 127.849899292129 .5695037842131 .2366027832132 .7575073242134 .1396942139 135.2763061523136 .2203063965136 .9264984131137 .4938049316138 .095993042 138.7427062988139 .5090942383140 .4384002686141 .5879058838143 .0106048584 144.7481994629146 .7456054688148 .9266967773151 .2527008057153 .6622924805 156.1280975342158 .6000976562161 .0670013428163 .500793457165 .9532928467 168.4544067383171 .0758972168173 .7474060059176 .9264984131181 .1784973145 185.7855072021190 .1894989014194 .3018035889197 .9167022705201 .1405029297 204.0785980225206 .8153076172209 .4465026855211 .9763031006214 .4523010254 216.8571014404219 .2071990967221 .6472015381224 .2216949463226 .9326934814 229.6817016602232 .5167999268235 .4949035645238 .5989990234241 .9064025879 245.2967987061248 .7274932861252 .0507965088255 .1280975342258 .0263977051 260.8196105957263 .5487060547266 .2614135742268 .9559936523271 .6153869629 274.2466125488276 .8342895508279 .3865966797281 .8980102539284 .3735046387 286.8118896484289 .2153015137291 .5830078125293 .9164123535296 .2149963379 
298.479888916300 .7113952637302 .9101867676305 .0769958496307 .2121887207 309.31640625311 .3900146484313 .4331054688315 .4465026855317 .4305114746 319.3857116699 321.3124084473 323.2117004395 325.0840148926 326.9301147461 328.7510986328330 .5474853516332 .3204040527334 .0704040527335 .798614502 337.5057067871339 .1926879883340 .8601074219342 .5090026855344 .1400146484 345.75390625347 .3514099121348 .9331970215350 .5352 .0523986816353 .591003418 355.1164855957356 .6293029785358 .1300964355359 .6193847656361 .0976867676 362.5653076172364 .0228881836365 .4707946777366 .9093017578368 .3388977051 369.7598876953371 .1726989746372 .5773925781373 .974395752375 .3638000488 376.7460021973378 .1210021973379 .4891052246380 .8503112793382 .2048950195 383.5528869629384 .8944091797386 .2294921875387 .5582885742388 .8807067871 390.1969909668391 .5069885254392 .8110046387394 .1087036133395 .400390625 396.6860046387397 .9655151367399 .2388916016400 .5061950684401 .7672119141 403.0220031738404 .2705078125405 .5126037598406 .7481079102407 .9769897461 409.1991882324410 .4146118164411 .6228942871412 .8240966797414 .0183105469 415.2048034668416 .3851928711417 .5567932129 -20.5736999512 -18.2235393524-15.88601017-13.5578403473 -11.2348804474 $-8.91784000397-6.60675811768-4.30166387558-2.00258302689 .2904750108719$ 2.5774710178384 .858401775367 .1332049369819 .40186691284211 .66429042816 13.9204301834116 .1701507568418 .413360595720 .6498794555722 .87957000732 25.1021804809627 .3175296783429 .525249481231 .7251300811833 .9167098999 36.0996818542538 .2735099792540 .437778472942 .5918884277344 .73532104492 46.8673782348648 .98744964651 .0947494506853 .1885681152355 .26805877686 57.3324317932159 .3807296752961 .4121017456163 .4255599975665 .42014312744 67.39485168457 69.34864807129 71.28050231934 73.18934631348 75.07412719727 76.9337692260778 .7671966552780 .5733413696382 .3511581420984 .09957122803 85.8175888061587 .5041732788189 .1583709716890 .7791976928792 .36578369141 93.9172286987395 .4327316284296 .9115066528398 .3528594970799 .75608062744 101.1205978394102 .4458999634103 .7315979004104 .9770965576106 .1822967529 107.3468017578108 .4704971313109 .5532989502110 .5951004028111 .5960006714 112.5559997559113 .475402832114 .3542022705115 .1927032471115 .9910964966 116.7497024536117 .4686965942118 .148399353118 .7888031006119 .390296936 119.952796936120 .4765014648120 .9614028931121 .4076004028121 .8147964478 122.1832962036122 .5127029419122 .8030014038123 .0541000366123 .2658004761 123.4391021729123 .5739974976123 .6736984253123 .739402771123 .7777023315 123.7927017212123 .793800354123 .7883987427123 .7888031006123 .8053970337 123.848197937123 .9253005981124 .0404968262124 .1951980591124 .380897522 124.5969009399124 .7266998291124 .6373977661124 .4671020508124 .322303772 124.2037963867124 .1380996704123 .9764022827123 .56199646123 .103302002 122.8158035278122 .4150009155121 .6220016479120 .7677001953120 .1511993408 119.6182022095119 .1417999268118 .4844970703117 .5187988281116 .4553985596 115.09400177113 .9998016357113 .65599823114 .6250991821118 .3110961914 120.2537002563115 .779800415109 .9441986084107 .1242980957105 .5361022949 103.8798980713102 .3395004272101 .041801452699 .9300003051899 .05880737305 98.4166183471797.9083862304797.45467376709 96.946426391696.36354064941 95.6587295532294 .9296112060594 .2636795043993 .6512069702193 .06687927246 
92.5623931884892 .181221008391 .8503570556691 .5198669433691 .20529174805 90.9473800659290 .6590499877990 .2665634155389 .8849411010789 .56369018555 89.4437026977589 .6136627197389 .8724670410290 .02455902190 .10150146484 90.140342712490 .1176986694390 .0293502807689 .8579483032289 .59931945801 89.24548339844 88.79656219482 88.26313018799 87.63609313965 87.1552734375 87.0694503784287 .1913528442487 .370956420987 .5342178344787 .542137146 87.48262023926 87.37684631348 87.34107208252 87.52245330811 87.67096710205 87.57745361328 87.36083221436 87.09911346436 87.04202270508 87.4822769165 88.07308959961 88.47496032715 88.73552703857 88.80722808838 88.73737335205 88.564872741788 .3272705078188 .0538635253987 .9724197387788 .35452270508 88.8973770141689 .359939575289 .7365570068489 .9779434204190 .11348724365 90.1069564819390 .2743225097790 .9170227050891 .7882766723692 .67388153076 93.6000518798894 .5746231079195 .5844268798896 .628341674897 .92070007324 99.76740264893101 .6299972534103 .0196990967104 .0541000366104 .5905990601 104.8491973877104 .8391036987104 .7536010742104 .8787002563105 .182800293 105.81590271106 .7035980225107 .8121032715109 .0726013184110 .4057006836 111.7574005127113 .0606002808114 .3279037476115 .5195999146116 .6871032715 117.8516998291119 .0410003662120 .3252029419121 .679397583123 .1128997803 124.5699005127126 .0214996338127 .4580001831128 .8914031982130 .2597045898 131.4270935059132 .4407958984133 .2548065186133 .9553985596134 .6533966064 135.3867950439136 .2308959961137 .2362976074138 .4591064453139 .8807983398 141.5319061279143 .3739929199145 .4028930664147 .5886993408149 .8699035645 152.2281036377154 .6367950439157 .0175018311159 .2716064453161 .5252075195 163.8778991699166 .3672027588169 .0101013184172 .108505249176 .0099029541 180.1985931396184 .2819976807188 .233001709191 .8822937012195 .2814025879 198.3628997803201 .1770019531203 .8177032471206 .2971954346208 .6607055664 210.8858947754212 .9376068115215 .1844024658217 .9548034668220 .9557952881 223.8766937256226 .8598022461229 .9604034424233 .2229003906236 .7565002441 240.4734039307244 .3993988037248 .0971069336251 .0997009277253 .7749023438 256.4193115234259 .0163879395261 .6012878418264 .1637878418266 .7203063965 269.2673950195271 .7956848145274 .3055114746276 .7898864746279 .2499084473 281.6825866699284 .088104248286 .4645996094288 .8121948242291 .129486084 293.416809082295 .6734924316297 .8999938965300 .0960083008302 .2618103027 304.3973999023306 .503112793308 .5788879395310 .6250915527312 .6419067383 314.6299133301316 .5895080566318 .5213012695320 .4258117676322 .303894043 324.1564025879325 .9838867188327 .7874145508329 .5675048828331 .3252868652 333.0614929199334 .7768859863336 .4721984863338 .1484069824339 .8062133789 341.4462890625343 .0693054199344 .6760864258346 .2672119141347 .8434143066 349.4052124023350 .9533081055352 .4881896973354 .0104980469355 .520690918 357.0192871094358 .5067138672359 .9834899902361 .4501037598362 .9067993164 364.3540039062365 .7921142578367 .2214050293368 .6422119141370 .0548095703 371.4592895508372 .8559875488374 .2452087402375 .6268920898377 .0013122559 378.3685913086379 .7289123535381 .0822143555382 .4288024902383 .7685852051 385.1018066406386 .428314209387 .7482910156389 .0617980957390 .3688049316 391.6694946289392 .9637145996394 .2514953613395 .532989502396 .808013916 398.0765991211399 .3387145996400 .5942993164401 .8434143066403 .0856018066 
404.321105957405 .5497131348406 .7712097168407 .9855957031409 .1926879883 410.392791748411 .5857849121412 .7674865723413 .9366149902 -21.750120163 -19.428899765 -17.1111392975 -14.8001098633 -12.4947900772 $-10.1952199936-7.90143918991-5.61347198486-3.3313369751-1.0550429821$ 1.215378999713 .4799380302435 .7385659217837 .99127817153910 .23795986176 12.4785995483414 .7130403518716 .9412403106719 .1629695892321 .37816047668 23.586490631125 .7878398895327 .9818000793530 .168180465732 .34648895264 34.5164489746136 .6774711608938 .8291893005440 .9709091186543 .10214996338 45.2221603393647 .3303489685149 .4258499145551 .5079917907753 .57582855225 55.6285896301357 .6652717590359 .6849784851161 .6866912841863 .66941833496 65.6321029663167 .5736770629969 .4930572509871 .3891601562573 .26085662842 75.1070327758876 .9265670776478 .7183532714880 .4812927246182 .21424102783 83.91620635986 85.58606719971 87.22286987305 88.82552337646 90.39318847656 91.9248275756893 .4197082519594 .8768997192496 .2957687377997 .6754989624 99.01558685303100 .3152999878101 .5744018555102 .7922973633103 .9686965942 105.103302002106 .1959991455107 .24659729108 .2550964355109 .221496582 110.1460037231111 .0286026001111 .8696975708112 .6692962646113 .4278030396 114.1455001831114 .8227005005115 .459602356116 .0563964844116 .6135025024 117.1307983398117 .6088027954118 .0470962524118 .4461975098118 .8054962158 119.1253967285119 .4051971436119 .6446990967119 .8435974121120 .0009994507 120.1177978516120 .1930999756120 .2305984497120 .2305984497120 .2008972168 120.1452026367120 .0739974976119 .9943008423119 .9200973511119 .8603973389 119.8290023804119 .8309020996119 .8770980835119 .96849823120 .1016998291120 .3125 120.425201416120 .2194976807119 .9261016846119 .7085037231119 .5341033936 119.4741973877119 .3031005859118 .7419967651118 .1256027222117 .865196228 117.4587020874116 .4085006714115 .2987976074114 .5596008301113 .9653015137 113.5014038086112 .9534988403112 .1352005005110 .9757003784109 .354598999 108.1328964233108 .1612014771108 .9872970581110 .1894989014110 .5274963379 108.8608016968106 .147102356103 .2647018433100 .517700195398 .21128845215 96.391326904395 .120529174894 .251388549893 .5747528076293 .08833312988 92.7737884521592 .4970932006892 .142013549891 .6841125488391 .04595947266 90.377098083589 .805526733489 .2858734130988 .7550811767688 .30593109131 88.02757263184 87.80786895752 87.57621002197 87.34755706787 87.14290618896 86.9407424926886 .7524414062586 .5896530151486 .4547882080186 .4153213501 86.4470825195386 .5141372680786 .5390167236386 .5067672729586 .45707702637 86.3503723144586 .191963195885 .9716491699285 .6992721557685 .36929321289 84.9802169799884 .5841522216884 .2326736450283 .9946517944383 .95983886719 84.0320510864384 .133377075284 .2336273193484 .2340393066484 .18730926514 84.0836334228583 .9736099243283 .9361495971783 .8995666503983 .83673095703 83.7825164794983 .7954025268683 .9323577880984 .2518768310584 .62338256836 84.9086380004985 .0949630737385 .1327590942485 .0764236450284 .94484710693 84.8065338134884 .7392730712984 .7918319702185 .0615463256885 .41187286377 85.7631835937586 .0680465698286 .2554626464886 .391181945886 .49153137207 86.6838989257887 .0870971679787 .6543502807688 .3691101074289 .14965057373 89.9650878906290 .7676467895591 .4414901733492 .38169097994 .14037322998 96.0017929077197 .335380554298 .3534317016698 .9163131713999 .23950195312 
99.3960800170999 .60320281982100 .1061019897100 .8323974609101 .8460006714 103.0182037354104 .3285980225105 .7148971558107 .133102417108 .5382003784 109.8727035522111 .165802002112 .4196014404113 .651802063114 .8699035645 116.0924987793117 .3765029907118 .6847000122120 .0354003906121 .3677978516 122.6213989258123 .8892974854125 .2848968506126 .6588973999127 .8202972412 128.8609008789129 .754699707130 .5690002441131 .3746032715132 .2117004395 133.1562042236134 .2344055176135 .5014038086136 .9253997803138 .5151977539 140.2581939697142 .1622009277144 .2066040039146 .3468017578148 .5755004883 150.8928070068153 .1748962402155 .2537994385157 .328994751159 .5482025146 161.9506072998164 .6152038574167 .6260986328171 .0975952148174 .8069000244 178.603805542182 .3963928223186 .0348052979189 .5016021729192 .6779022217 195.5803070068198 .2601013184200 .7156066895203 .021697998205 .1665039062 207.029800415209 .1394042969212 .0431060791215 .2205963135218 .1972045898 221.2104949951224 .3148956299227 .653793335231 .3690948486235 .3531036377 239.6864013672243 .7062988281246 .6999053955249 .2415008545251 .8273010254 254.3229980469256 .8106079102259 .2956848145261 .7804870605264 .2746887207 266.7586975098269 .241394043271 .7059020996274 .1585998535276 .5892028809 279.0014038086281 .3887023926283 .7529907227286 .0899963379288 .4010009766 290.6832885742292 .9378967285295 .1630859375297 .3594970703299 .5262145996 301.6637878418303 .7716064453305 .8500976562307 .8992004395309 .9194946289 311.9111938477313 .8749084473315 .8110046387317 .720489502319 .6037902832 321.4617919922323 .2952880859325 .1050109863326 .8918151855328 .6564025879 330.399810791332 .1224975586333 .825592041335 .5096130371337 .1752929688 338.8234863281340 .4547119141342 .0697937012343 .6694030762345 .2539978027 346.8243103027348 .3807983398349 .9241943359351 .4548950195352 .9733886719 354.4802856445355 .9760131836357 .4607849121358 .9353942871360 .3999023438 361.8547058105363 .3002929688364 .7367858887366 .1646118164367 .5838928223 368.9949035645370 .3978881836371 .7927856445373 .1802062988374 .5599060059 375.9321899414377 .297088623378 .6549072266380 .0054931641381 .3489990234 382.6856079102384 .0152893066385 .3381958008386 .6542053223387 .9635009766 389.2661132812390 .5620117188391 .8512878418393 .1339111328394 .4099121094 395.679107666396 .9417114258398 .1973876953399 .4461975098400 .6879882812 401.9227905273403 .150390625404 .3706054688405 .5834960938406 .7893066406 407.9869995117409 .1784057617410 .3608093262 $-22.9330291748-20.619550705-18.3181495667-16.0255699158-13.7378902435$ -11.4558000565 -9.17932987213 -6.90850019455 -4.64331912994-2.38379192352 -.129935994744 2.118258953094 4.3607511520396.597544193268 8.828556060791 11.0537700653113 .2730598449715 .4863595962517 .6934890747119 .89432907104 22.0886306762724 .2762203216626 .4567298889228 .6299304962230 .79537010193 32.9527206420935 .101421356237 .2410392761239 .3709297180241 .49055099487 43.5991706848145 .6961097717347 .780548095749 .8517303466851 .90871810913 53.9506683349655 .9765815734957 .9855117797959 .9763908386261 .94820022583 63.8998184204165 .8301620483467 .7380828857469 .6224365234471 .48209381104 73.3158264160275 .1225433349676 .9010162353578 .6501388549880 .3687210083 82.0557022094783 .7099075317485 .330352783286 .9159164428788 .46566009521 89.9785766601691.453819274992.890487670994.2878570556695.64511108398 
96.9616928100698 .2369079589899 .47032928467100 .6614990234101 .8099975586 102.9156036377103 .9782028198104 .9974975586105 .9736022949106 .90650177 107.7962036133108 .6429977417109 .4470977783110 .2087020874110 .9281997681 111.6059036255112 .2419967651112 .837097168113 .3912963867113 .9049987793 114.3783035278114 .8115997314115 .2048034668115 .5580978394115 .8712005615 116.144203186116 .3760986328116 .5668029785116 .7151031494116 .820098877 116.8816986084116 .8988037109116 .8743972778116 .8091964722116 .7106018066 116.5836029053116 .4375991821116 .2817993164116 .1277008057115 .9859008789 115.868598938115 .7864990234115 .7427978516115 .7397003174115 .7688980103 115.831703186115 .8067016602115 .5610961914115 .2332992554114 .9318008423 114.6529998779114 .4197998047114 .0873031616113 .5123977661112 .867401123 112.3573989868111 .6902008057110 .5837020874109 .4597015381108 .6154022217 107.9927978516107 .6887969971107 .5071029663107 .4692993164106 .5820999146 103.4673995972100 .8309020996101 .2620010376102 .5006027222103 .1968994141 103.5335998535102 .9962005615101 .619499206599 .018836975195 .72221374512 92.725997924890 .5167083740289 .5815734863389 .2378997802788 .86531829834 88.5778121948288 .3857269287188 .2116165161187 .9813766479587 .65473175049 87.1735229492286 .6516723632886 .1666870117285 .7041473388785 .22538757324 84.8042526245184 .5128707885784 .2894897460984 .090682983483 .92095947266 83.7960586547983 .7193374633883 .7003936767683 .7028732299883 .71671295166 83.7175064086983 .6651382446383 .5776062011783 .4391937255983 .25611877441 83.0709686279382 .8645019531282 .6377868652382 .3880615234482 .11173248291 81.8200225830181 .5077133178781 .2461166381881 .0748214721781 .00092315674 81.0857467651481 .1962127685581 .3094863891681 .3967437744181 .33911132812 81.2220382690481 .0429382324280 .8152313232480 .6504669189580 .53434753418 80.4672393798880 .5049133300880 .6462173461980 .8735961914181 .24933624268 81.5832366943481 .727951049881 .7823028564581 .7668304443481 .7068862915 81.6038970947381 .5357971191481 .5573120117281 .6603622436581 .91249084473 82.1943893432682 .4817810058682 .7418975830182 .865509033282 .95825958252 83.03868865967 83.15096282959 83.41458892822 83.80110931396 84.35076904297 85.0074920654385 .7178573608486 .444061279387 .1484298706188 .0777130127 89.5169830322391 .0486526489392 .2410125732493 .1633911132893 .7156829834 94.03208160494 .1269836425894 .4191436767695 .3497390747196 .59581756592 97.9584884643699 .39663696289100 .8932037354102 .4093017578103 .8918991089 105.3360977173106 .7089004517108 .0355987549109 .3397979736110 .6283035278 111.9030990601113 .1723022461114 .4653015137115 .7592010498117 .0610961914 118.3310012817119 .5395965576120 .7599029541122 .0548019409123 .3352966309 124.4822006226125 .5370025635126 .4860992432127 .3871994019128 .2848968506 129.2171936035130 .2436065674131 .3827056885132 .6782073975134 .0995025635 135.6479949951137 .3162994385139 .1174926758141 .0321044922143 .0364990234 145.117401123147 .2574005127149 .3731994629151 .3652038574153 .3650054932 155.4770050049157 .7731933594160 .3146972656163 .1204986572166 .2772979736 169.6490936279173 .2118988037176 .8697052002180 .4662017822183 .967300415 187.2351074219190 .2382049561192 .9300994873195 .3845977783197 .69140625 199.8618011475201 .8881072998204 .1217041016206 .9033966064209 .9049987793 212.8114013672215 .7124023438218 .5885009766221 .7910003662225 .6750030518 
229.8937988281234 .1981964111238 .2162017822241 .5536956787244 .417098999 246.9739074707249 .3728027344251 .8141937256254 .2640991211256 .7323913574 259.2102050781261 .6875915527264 .1632995605266 .6289978027269 .0846862793 271.5249023438273 .9491882324276 .3536071777278 .7373962402281 .0975036621 283.4335021973285 .7431030273288 .0262145996290 .2811889648292 .5080871582 294.7059936523296 .875299 .0144042969301 .1246948242303 .2055969238305 .2575073242 307.2806091309309 .2755126953311 .2426147461313 .1827087402315 .0961914062 316.9840087891318 .8468017578320 .6853942871322 .5006103516324 .2930908203 326.0636901855327 .813293457329 .5425109863331 .2521972656332 .9431152344 334.615814209336 .2710876465337 .9096069336339 .5320129395341 .138885498 342.7309875488344 .3086853027345 .8727111816347 .4234008789348 .9614868164 350.4873046875352 .0014953613353 .5043029785354 .9961853027356 .4776000977 357.9487915039359 .4101867676360 .8622131348362 .3048095703363 .738494873 365.1633911133366 .5798034668367 .9879150391369 .3876953125370 .779510498 372.1635131836373 .5397949219374 .9083862305376 .2695007324377 .6231994629 378.9695129395380 .30859375381 .6405029297382 .9653015137384 .282989502 385.5938110352386 .8976135254388 .1943969727389 .4844055176390 .7674865723 392.0436096191393 .3128051758394 .5751037598395 .8302001953397 .0781860352 398.3189086914399 .5523071289400 .7782897949401 .9967956543403 .2080993652 404.4119873047405 .604309082406 .7839050293 $-24.0768508911-21.7918491364-19.510099411-17.2347106934-14.9646902084$ $-12.7001199722-10.4409799576-8.18731784821$-5.93911981583 -3.69638490677 $-1.45911800861 .77271097898482 .9990589618685 .2199649810797 .435335159302$ 9.64519691467311 .8493995666514 .0479297637916 .2405700683618 .42727088928 20.6077194213922 .781810760524 .9491405487127 .1095104217529 .2624206543 31.4075908660933 .5443992614735 .6724510192937 .7910308837939 .89965057373 41.9974594116244 .0838699340846 .1579399108948 .2189407348650 .26586914062 52.2978706359954 .3138809204156 .3129501342858 .2939300537160 .25579071045 62.1973381042564 .117462158266 .0149536132867 .8886337280369 .73729705811 71.5597000122173 .3546676635775 .1209335327176 .8573532104578 .5626373291 80.2357330322381 .8753662109483 .4805679321385 .050086975186 .58303070068 88.0782470703189 .5349502563590 .9521026611392 .3290100097793 .66477203369 94.9588623046996 .2104797363397 .4192733764698 .5846023559699 .70626068115 100.7837982178101 .817199707102 .806098938103 .7506027222104 .6507034302 105.5065994263106 .318397522107 .0864028931107 .810798645108 .4919967651 109.1304016113109 .7265014648110 .2806015015110 .7929992676111 .2642974854 111.6946029663112 .0843963623112 .4336013794112 .7426986694113 .0109024048 113.2388000488113 .4247970581113 .568901062113 .6688995361113 .7238006592 113.7325973511113 .6932983398113 .6089019775113 .4788970947113 .3121032715 113.1128997803112 .8925018311112 .6615982056112 .4274978638112 .2005996704 111.9947967529111 .8207015991111 .6781997681111 .5658035278111 .4565963745 111.3289031982111 .1433029175110 .8588027954110 .5119018555110 .1241989136 109.698600769109 .2338027954108 .7114028931108 .1418991089107 .4721984863 106.7192993164105 .8152999878104 .7287979126103 .6214981079102 .5992965698 101.9254989624101 .8056030273101 .9835968018102 .6645965576102 .1668014526 97.9278182983494 .0550689697394 .6939392089896 .4214477539197 .10453033447 
97.5317230224697 .6218795776496 .8614578247194 .4518127441491 .24224090576 88.0754470825285 .6318435668984 .9749221801885 .0279693603584 .8292388916 84.6849365234484 .5724868774484 .4555816650484 .3424301147584 .15453338623 83.8638763427783 .5135421752983 .1006927490282 .669082641682 .21222686768 81.7762985229581 .4267807006881 .147186279380 .9420471191480 .81228637695 80.7620773315480 .7981567382880 .917411804281 .0841979980581 .25955963135 81.3130264282281 .1622161865280 .8734283447380 .5416717529380 .19891357422 79.8802337646579 .5800018310579 .2964935302779 .0283126831178 .75792694092 78.5133666992278 .2787628173878 .120819091878 .0633468627978 .11151885986 78.2953872680778 .5233078002978 .7558975219778 .8598175048878 .713722229 78.4260864257878 .0995635986377 .7802886962977 .5431365966877 .40032958984 77.3480072021577 .4233932495177 .6136169433677 .8933029174878 .32202148438 78.6731491088978 .7290191650478 .6785430908278 .6215820312578 .55668640137 78.4644699096778 .4197998046978 .4550628662178 .5688476562578 .80903625488 79.092910766679 .4074325561579 .6465072631879 .7044830322379 .69019317627 79.677879333579 .7111968994179 .8646392822380 .1319427490280 .55436706543 81.097236633381 .739532470782 .4814682006883 .3684310913184 .38009643555 85.5241088867286 .6865615844787 .6679229736388 .4732971191488 .9716796875 89.2811126709 89.31440734863 89.6358413696390.8896789550892.51373291016 94.1278762817495 .790733337497 .48520660499 .12216949463100 .6666030884 102.1260986328103 .5342025757104 .9072036743106 .265296936107 .6092987061 108.943901062110 .2641983032111 .5838012695112 .8833007812114 .1710968018 115.4307022095116 .6647033691117 .8865966797119 .0903015137120 .272102356 121.3820037842122 .4421005249123 .4274978638124 .389503479125 .3615036011 126.3742980957127 .4728012085128 .6634063721129 .9815979004131 .3981933594 132.9212036133134 .5377960205136 .2566986084138 .0614013672139 .9358978271 141.8618011475143 .804397583145 .7527008057147 .6779022217149 .6369934082 151.6687011719153 .8368988037156 .2070007324158 .7770996094161 .6242980957 164.7324066162168 .1305999756171 .6981964111175 .2409973145178 .7182006836 182.0252075195185 .0879058838187 .8007049561190 .278503418192 .6383972168 194.9208984375197 .213394165199 .6138000488202 .2156982422204 .9425964355 207.6893005371 210.4698944092 213.1257019043216.1472930908 220.0811004639 224.3184967041228 .3677978516232 .2359924316235 .8955993652239 .1394042969 241.7830963135244 .1692047119246 .6436004639249 .1156005859251 .6044006348 254.1036987305256 .5952148438259 .087310791261 .5663146973264 .0386962891 266.495300293268 .9396057129271 .3646850586273 .7723999023276 .1572875977 278.5203857422280 .8579101562283 .1701965332285 .4549865723287 .7124023438 289.9410095215 292.1409912109294.3114929199296.4527893066 298.5646057129 300.6473999023302 .7012023926304 .7265014648306 .7236938477308 .6935119629 310.636505127312 .553314209314 .4447021484316 .3113098145318 .1541137695 319.9736938477321 .7709960938323 .5466003418325 .3015136719327 .0361022949 328.7514953613330 .4480895996332 .1268005371333 .7882080078335 .4328918457 337.0616149902338 .6748046875340 .2731933594341 .8572998047343 .4276123047 344.9847106934346 .5291137695348 .0613098145349 .5815124512351 .0903930664 352.5881958008354 .0754089355355 .5521850586357 .0191040039358 .4761962891 359.9238891602361 .3623962402362 .7919006348364 .2125854492365 .6246032715 
367.0281982422368 .423614502369 .8107910156371 .1900024414372 .5611877441 373.9247131348375 .2804870605376 .628692627377 .9693908691379 .3026123047 380.6285095215381 .9471130371383 .2585144043384 .562713623385 .8598022461 387.1496887207388 .4325866699389 .708190918390 .9767150879392 .2380065918 393.4919128418394 .7384033203395 .9773864746397 .2090148926398 .432800293 399.6494140625400 .8576049805402 .059387207403 .2521057129 -25.2271709442 -22.9502906799 -20.6849899292 -18.4280395508 -16.175699234 $-13.9286603928-11.6869001389-9.45044326782-7.21926689148-4.9933590889$ $-2.77270293236-.5572659969331 .6529430150993 .8579590320596 .057728767395$ 8.25226974487310 .4414701461812 .6253204345714 .8036298751816 .97632980347 19.1431598663321 .3039798736623 .458419799825 .6062602996827 .74703979492 29.8804092407232 .0057983398434 .122768402136 .2306289672938 .32880020142 40.4164886474642 .49301910444 .557479858446 .6090507507348 .64675140381 50.6696510314952 .6766586303754 .6667709350656 .6388282775958 .59172058105 60.5242309570362 .4351692199764 .3233032226666 .1873931884868 .02616119385 69.8383331298871 .6226730346773 .3778533935575 .1026611328176 .79580688477 78.4561309814580 .0823593139681 .6733779907283 .2279891967884 .74517822266 86.2238235473687 .6630096435589 .0617294311590 .4191894531291 .73452758789 93.0071029663194 .2361679077195 .4212265014696 .5617675781297 .65743255615 98.70786285499 .71288299561100 .6723022461101 .5861968994102 .4543991089 103.2772979736104 .054901123104 .7874984741105 .4755020142106 .1193008423 106.7193984985107 .2761001587107 .7901000977108 .2617034912108 .6915969849 109.0800018311109 .4273986816109 .7340011597110 .0001983643110 .225402832 110.4100036621110 .5522003174110 .6519012451110 .7061004639110 .7134017944 110.6716995239110 .5784988403110 .4356994629110 .2425003052110 .0077972412 109.7365036011109 .4420013428109 .139503479108 .8273010254108 .5114974976 108.2097015381107 .9394989014107 .6927032471107 .4654006958107 .2225036621 106.9507980347106 .6397018433106 .2583999634105 .8263015747105 .3271026611 104.7503967285104 .1150970459103 .4644012451102 .8147964478102 .0902023315 101.2927017212100 .360198974699 .2606277465898 .0404663085996 .55821228027 95.5409011840895 .7451477050896 .3695297241296 .8420028686596 .19693756104 93.1734390258890 .3849334716890 .3979721069391 .3525466918991 .86328887939 92.2082290649492 .3007583618291 .7241668701289 .8987579345787 .39051818848 84.7997894287182 .741630554281 .9389266967881 .7346115112381 .51268768311 81.3594818115281 .2728881835981 .22573089681 .214431762781 .16343688965 81.0204162597780 .7937927246180 .4285812377979 .9942626953179 .51625061035 79.024696350178 .6151580810578 .2844772338978 .0508270263777 .9260635376 77.9065170288178 .0038375854578 .2208786010778 .5477981567479 .02301025391 79.2582626342878 .8751602172978 .248741149977 .7123413085977 .22648620605 76.8077163696376 .4392471313576 .1108703613375 .8219375610475 .56060791016 75.3451538085975 .1685028076275 .0729980468875 .0762329101675 .1950378418 75.4586563110475 .8320388793976 .3593978881876 .6388397216876 .25946807861 75.6447067260775 .156806945874 .7598571777374 .4923400878974 .34834289551 74.3217773437574 .4190979003974 .63002777174 .9182281494175 .28617858887 75.5796737670975 .6657104492275 .6476593017675 .5917434692475 .5210723877 75.4329223632875 .3772888183675 .3813171386775 .4676513671975 .68874359131 
76.0079269409276 .465400695876 .7881164550876 .6943817138776 .47384643555 76.355056762776 .3186035156276 .3966598510776 .5925598144576 .94184875488 77.4308166503978 .0517730712978 .832313537679 .7927322387780 .80686187744 81.8508987426882 .8327026367283 .6355667114384 .3092422485484 .75553131104 85.0769195556685 .3247070312585 .8736572265687 .112586975188 .71852111816 90.4409179687592 .2599563598694 .1524734497195 .9518127441497 .48568725586 98.90493011475100 .3348999023101 .7601013184103 .1853027344104 .6017990112 106.0048980713107 .388999939108 .7548980713110 .0894012451111 .3905029297 112.6615982056113 .903503418115 .1100997925116 .2820968628117 .4166030884 118.5055999756119 .5650024414120 .5791015625121 .5826034546122 .5980987549 123.6632995605124 .8275985718126 .0745010376127 .4125976562128 .8289031982 130.3285064697131 .9011993408133 .5487976074135 .2566070557137 .016998291 138.8072052002140 .6062011719142 .4270935059144 .2563018799146 .1347045898 148.083404541150 .133102417152 .3410949707154 .6820983887157 .1611022949 159.9602966309 163.3016967773 166.87890625170.386505127 173.8188018799 177.0885009766180 .1497039795182 .9174957275185 .4824981689187 .9143066406 190.3016967773192 .720703125195 .1640930176197 .6911010742200 .266204834 202.8972015381205 .5973968506208 .2899932861211 .300201416214 .9573059082 218.8473968506222 .6340942383226 .3518981934229 .9329986572233 .2389068604 236.0782928467238 .6638031006241 .2512969971243 .8170013428246 .3778991699 248.9281005859251 .466796875253 .9942932129256 .508392334259 .0098876953 261.4966125488263 .9681091309266 .4219055176268 .857208252271 .2710876465 273.6629943848276 .0302124023278 .3723144531280 .6874084473282 .9750976562 285.2343139648287 .4648132324289 .6657104492291 .8374023438293 .9794921875 296.0922851562298 .1759033203300 .2307128906302 .2572021484304 .2558898926 306.2272949219308 .1722106934310 .0913085938311 .9851989746313 .8547058105 315.7007141113317 .5238037109319 .3247070312321 .104309082322 .8633117676 324.6023864746326 .3222961426328 .0238037109329 .7073059082331 .3736877441 333.0234985352334 .657409668336 .2757873535337 .879486084339 .4688110352 341.0444030762342 .6068115234344 .1564025879345 .6936950684347 .2189941406 348.7327880859350 .2354125977351 .7272033691353 .2085876465354 .6798095703 356.1411132812357 .5927124023359 .0347900391360 .4677124023361 .8916015625 363.3066101074364 .7130126953366 .1108093262367 .500213623368 .8812866211 370.2542114258371 .6191101074372 .9761047363374 .3251953125375 .666595459 377.0003051758378 .3265991211379 .6452941895380 .9566040039382 .2604980469 383.5570983887384 .8463134766386 .128112793387 .4025878906388 .669708252 389.9294128418391 .1814880371392 .4259033203393 .662689209394 .8918151855 396.1134033203 397.3275146484398.5297851562 399.7192077637 -26.3401908875 -24.0913791656-21.8456306458 -19.6059398651 -17.3713302612 $-15.1418800354-12.917550087-10.6983699799-8.4842748642-6.27525520325$ $-4.07127380371-1.87226903439 .32175499200822 .51087307934 .695026874542$ 6.8742871284489 .04852485656711 .2177801132213 .3818502426115 .54071998596 17.6940803527819 .8418807983421 .9836692810124 .1193199157726 .24827003479 28.3702907562330 .4846897125232 .5910911560134 .6887397766136 .77709960938 38.8552894592340 .9226608276442 .9782295227145 .0211906433147 .05047988892 49.0651702880951 .0640907287653 .0462303161655 .0103416442956 .95529174805 
58.8797988891660 .7826309204162 .6625099182164 .5181121826266 .34812927246 68.1511993408269 .926063537671 .6713027954173 .3856964111375 .06784057617 76.7165603637778 .3304824829179 .9085083007881 .4493026733482 .95188903809 84.4150238037185 .8378067016687 .2191162109488 .5582427978589 .85414123535 91.1062469482492 .3137130737393 .4760971069394 .5927581787195 .66342926025 96.6876068115297 .6652679443498 .5960769653399 .48013305664100 .3173980713 101.108001709101 .8522033691102 .5503997803103 .202796936103 .8099975586 104.3723983765104 .8906021118105 .3653030396105 .7968978882106 .1860961914 106.5334014893106 .8395004272107 .1044998169107 .3291015625107 .5124969482 107.6555023193107 .7557983398107 .8134994507107 .8246002197107 .7876968384 107.6988983154107 .5554962158107 .3578033447107 .1041030884106 .8040008545 106.4600982666106 .0924987793105 .7223968506105 .3356018066104 .9405975342 104.5513000488104 .179901123103 .8246002197103 .4813995361103 .1179962158 102.7389984131102 .3218002319101 .8443984985101 .3021011353100 .6707000732 99.9653091430799 .2141113281298 .4262924194397 .6514892578196 .87679290771 96.150947570895 .3418884277394 .3324813842893 .1118164062591 .30687713623 89.995529174890 .3789672851691 .0810012817490 .9590072631890 .25180053711 88.93370056152 87.65207672119 87.15833282471 87.10928344727 87.28299713135 87.4655990600687 .3111572265686 .7396926879985 .5504913330183 .95600128174 82.2692184448280 .7742614746179 .7631301879979 .1247711181678 .70086669922 78.4468002319378 .3296737670978 .3160476684678 .3837585449278 .47312927246 78.508651733478 .391876220778 .0302124023477 .5158615112376 .96404266357 76.4204025268675 .9603576660275 .59291839675 .3259429931675 .18979644775 75.1658935546975 .2840728759875 .5424728393675 .9321670532276 .60069274902 76.970848083576 .4099426269575 .5446701049874 .8935470581174 .31121063232 73.8177490234473 .4037475585973 .0392990112372 .7406082153372 .4831237793 72.2928466796972 .1462326049872 .0842437744172 .0992736816472 .23993682861 72.5348434448272 .9591369628973 .6896896362374 .1143875122173 .56025695801 72.7256393432672 .1759567260771 .7544479370171 .4852294921971 .36826324463 71.3572006225671 .4653472900471 .6703033447371 .9304733276472 .21367645264 72.4538116455172 .6073684692472 .6762390136772 .6510314941472 .58471679688 72.4750671386772 .3806381225672 .3117065429772 .3307189941472 .50820922852 72.8104705810573 .3713378906273 .7743072509873 .5733718872173 .21945953369 73.0489578247172 .9698791503972 .9995269775473 .1601562573 .46865844727 73.9366302490274 .5635299682675 .3647003173876 .3520126342877 .40950012207 78.461082458579 .3758773803780 .0321426391680 .5308074951280 .8784866333 81.2516326904381 .7580108642682 .5242004394583 .6605987548885 .10703277588 86.8264312744188 .7123184204190 .7417297363392 .6660308837994 .20925140381 95.6197280883897 .1062927246198 .59844970703100 .1016998291101 .5998001099 103.0799026489104 .5363998413105 .9636001587107 .350402832108 .6923980713 109.988899231111 .2436981201112 .4543991089113 .6136016846114 .7350997925 115.8124008179116 .8686981201117 .8990020752118 .932800293119 .9801025391 121.0832977295122 .300201416123 .5919036865124 .9494018555126 .3671035767 127.8554000854129 .3952941895130 .9866027832132 .6159973145134 .2772064209 135.9588012695137 .6439971924139 .353805542141 .087097168142 .87159729 144.7274932861146 .6661071777148 .7346954346150 .9075927734153 .1139984131 
155.6661987305158 .9458007812162 .4969024658165 .912399292169 .2613983154 172.4519958496175 .4752960205178 .2940979004180 .9486999512183 .467300415 185.9257965088188 .4093933105190 .8764953613193 .3471984863195 .8394927979 198.3861999512201 .0361938477203 .8016967773206 .7808074951210 .0708007812 213.5227050781217 .0153045654220 .4987945557223 .8793029785227 .1172943115 230.1367950439232 .9877929688235 .757598877238 .4485931396241 .108001709 243.7322998047246 .3345031738248 .9152984619251 .4756011963254 .0184936523 256.5419921875259 .0483093262261 .5343933105264 .0014038086266 .4460144043 268.8684082031271 .2658081055273 .6382141113275 .9833068848278 .3010864258 280.5900878906282 .850402832285 .0810852051287 .2822875977289 .4536132812 291.595489502293 .7077941895295 .7911987305297 .8457946777299 .8724060059 301.871307373303 .8434143066305 .7890930176307 .7094116211309 .6047973633 311.4761047363313 .3240966797315 .1495056152316 .9530944824318 .7355957031 320.4978027344322 .2401123047323 .9635925293325 .6684875488327 .3558959961 329.0260925293330 .679901123332 .3178100586333 .9403991699335 .5481872559 337.1416931152338 .721496582340 .2879943848341 .8416137695343 .3829040527 344.912109375346 .4296875347 .9360046387349 .4314880371350 .9161987305 352.3905944824353 .854888916355 .3092956543356 .7539978027358 .1893920898 359.6153869629361 .0322875977362 .4403076172363 .8395080566365 .2301025391 366.6122131348367 .9858093262369 .3511962891370 .7084960938372 .0577087402 373.3989868164 374.7325134277 376.0581970215 377.3763122559 378.6867980957 379.9896850586381 .2850036621382 .5729064941383 .8530883789385 .1258850098 386.3908996582387 .6482849121388 .8980102539390 .1398925781391 .3739929199 392.600402832393 .8185119629395 .0299072266396 .2320861816

$-27.4596595764-25.2192802429-22.9900894165-20.7688694-18.5520401001$ $-16.3402404785-14.1334104538-11.9315700531-9.73463821411-7.54258203506$ -5.35534000397 -3.17283606529-.9950370192531.178136944771 3.34667801857 5.5106458663947 .669973850259 .82468414306611 .9746303558314 .11977005005 16.2598800659218 .3948307037420 .52426910422 .6479892730724 .76552009583 26.876529693628 .9804306030331 .0767498016433 .164760589635 .24388885498 37.3132591247639 .3721694946341 .4196205139243 .4547500610445 .47650146484 47.4838409423849 .4756393432651 .450759887753 .4079513549855 .34598922729 57.2635917663659 .1594200134361 .0321502685562 .8804092407264 .70281982422 66.4979934692468 .2645263671970 .0010375976671 .7061691284273 .37850189209 75.0167770385776 .6195907592878 .1857376098679 .7138977050881 .2029800415 82.6517486572384 .0591964721785 .4242630004986 .7460479736388 .02361297607 89.2562637329190.4431686401491.5838165283292.6776199340893.7241897583

94.7231292724695 .6742630004996 .5773696899497 .4324569702198 .23956298828 98.9988327026499 .71048736572100 .3749008179100 .9925003052101 .5637969971 102.089302063102 .5698013306103 .005897522103 .3982009888103 .7477035522 104.0548019409104 .3203964233104 .5448989868104 .7289962769104 .8722991943 104.9753036499105 .0358963013105 .0540008545105 .0251998901104 .9475021362 104.8158035278104 .6265029907104 .3778991699104 .0668029785103 .7025985718 103.2889022827102 .853302002102 .4161987305101 .9599990845101 .5027999878 101.0421981812100 .572303772100 .11389923199 .6644668579199 .1988067627 98.7409973144598 .2527084350697 .7005691528397 .0666122436596 .29598236084 
95.4670562744194.6667022705193.8052902221792.7911071777391.89597320557 91.4325637817490 .9879379272590 .2005615234489 .1533966064587 .7378616333 86.6657333374 86.64254760742 86.78447723389 86.36267852783 85.78426361084 85.0274734497184 .2573165893683 .745948791583 .3299865722783 .24263000488 83.2741470336983 .0656433105582 .6574478149481 .9064331054780 .95575714111 79.8731536865278 .7399063110477 .7606277465876 .9325790405376 .31522369385 75.8966064453175 .6701507568475 .6154479980575 .7073211669975 .92221069336 76.2602691650476 .361053466875 .837471008375 .0753936767674 .41539001465 73.8199920654373 .3286209106472 .9346008300872 .6412811279372 .47315979004 72.42494964672 .5075683593872 .7335662841873 .0694503784273 .53827667236 73.7503280639673 .3123092651472 .6002120971771 .9562988281271 .35945892334 70.8418884277370 .393966674870 .0189895629969 .7115173339869 .46058654785 69.2751007080169 .1394805908269 .0698089599669 .0682373046969 .1725769043 69.4010467529369 .7363433837970 .238136291570 .4935226440470 .10418701172 69.4901123046969 .025527954168 .6680297851668 .4449462890668 .35237884521 68.3696823120168 .4823837280368 .6852111816468 .9284591674869 .182472229 69.4212875366269 .6062774658269 .7201919555769 .7319564819369 .66763305664 69.5264968872169 .3626403808669 .2026519775469 .1167602539169 .1820526123 69.38198089669 .7868881225670 .0880508422970 .0092697143669 .81101226807 69.6863632202169 .6240692138769 .6467208862369 .7866210937570 .07444763184 70.5242080688571 .1617431640671 .9819869995172 .9930572509874 .12272644043 75.3455734252976 .3412170410276 .7735519409276 .9914093017677 .23783111572 77.6207580566478 .2267227172979 .0586013793980 .194892883381 .58630371094 83.2619476318485 .1388015747187 .1189727783289 .0324630737390 .68820953369 92.2414321899493 .8231430053795 .4128570556697 .0126113891698 .60312652588 100.1745986938101 .7163009644103 .2137985229104 .6628036499106 .0587997437 107.3944015503108 .6707992554109 .8921966553111 .0569992065112 .1763000488 113.2509002686114 .3040008545115 .3522033691116 .4132003784117 .5053024292 118.6550979614119 .8989028931121 .2123031616122 .5876998901124 .0159988403 125.4999008179127 .0210037231128 .5702056885130 .1399993896131 .7245025635 133.3184051514134 .9114990234136 .5252075195138 .1708984375139 .8688049316 141.6387023926143 .4933929443145 .466796875147 .5525970459149 .74659729 152.2541046143155 .2984008789158 .5888977051161 .8524932861165 .0760040283 168.1799926758171 .1631011963173 .9752960205176 .6604003906179 .2317047119 181.7427062988184 .2599945068186 .741394043189 .1961975098191 .6499938965 194.1237030029196 .6945037842199 .3863983154202 .2041931152205 .2301025391 208.3652038574211 .5832977295214 .8311004639217 .9942016602221 .1394958496 224.2599029541227 .3117980957230 .2333984375233 .0523071289235 .81640625 238.5301971436241 .209197998243 .8553924561246 .4736938477249 .0662994385 251.6351928711254 .1815032959256 .7054138184259 .2069091797261 .6849975586 264.1391906738266 .5679016113268 .9706115723271 .3458862305273 .6932983398 276.0116882324278 .3010864258280 .5604858398282 .7903137207284 .9898071289 287.1596984863289 .2998046875291 .4106140137293 .4923095703295 .5456848145 297.5710144043299 .5690917969301 .5404968262303 .4859924316305 .4063110352 307.3020935059309 .1741027832311 .0230102539312 .8497009277314 .6547851562 316.4390869141318 .2030944824319 .9476928711321 .6734008789323 .3810119629 
325.070892334326 .7439880371328 .400604248330 .0414123535331 .6669006348 333.2777099609334 .8742980957336 .4570922852338 .0266113281339 .583190918 341.1272888184342 .6593017578344 .1795959473345 .6885070801347 .1863098145 348.6733093262350 .149810791351 .6159973145353 .0721130371354 .5183105469 355.9549865723357 .3819885254358 .7998962402360 .2084960938361 .6081848145 362.9989013672364 .3810119629365 .754486084367 .1195983887368 .4762878418 369.824798584371 .1653137207372 .4977111816373 .8222961426375 .1390075684 376.4479980469377 .749206543379 .0426940918380 .3284912109381 .6065063477 382.8768005371384 .1393127441385 .3938903809386 .6406860352387 .879486084 389.1105957031390 .3341064453391 .545501709392 .7439880371 -28.5431804657 -26.3306007385 -24.1209106445 -21.9170799255 -19.7180995941 $-17.5240402222-15.334810257-13.1504201889-10.9707603455-8.79577445984$ $-6.62538003922-4.45946598053-2.2979850769-.1408080011612 .012054920197$ 4.1607289314276 .3051290512088 .44535160064710 .5812196731612 .71277999878 14.8397302627616 .9620609283419 .0793495178221 .191469192523 .29788017273 25.3983192443827 .4921092987129 .5788707733231 .6577701568633 .72829055786 35.78947830237 .8406486511239 .8807296752941 .9088783264243 .92393112183 45.9248809814547 .9104804992749 .879600524951 .8308982849153 .76313018799 55.6749000549357 .5648612976159 .4316101074261 .2736892700263 .0897102356 64.8781433105566 .6376037597768 .3665618896570 .0636672973671 .72738647461 73.3564300537174 .9493026733476 .5047988891678 .0214614868279 .49822998047 80.9337234497182 .32700347983 .6768264770584 .9824066162186 .24265289307 87.4569015502988 .6242294311589 .7441864013790 .8160629272591 .83953857422 92.8141021728593 .739677429294 .6159210205195 .4429779052796 .220703125 96.9494628906297 .6293334960998 .2608337402398 .8442993164199 .3804397583 99.86976623535100 .3131027222100 .7113037109101 .0651016235101 .3752975464 101.6428985596101 .8687973022102 .0533981323102 .1977996826102 .3015975952 102.3659973145102 .3881988525102 .3690032959102 .3025970459102 .1881027222 102.0177993774101 .7888031006101 .4959030151101 .1360015869100 .7154998779 100.239097595299 .7285919189599 .2101135253998 .7007369995198 .22495269775 97.7264633178797 .1698379516696 .5842971801896 .0181579589895 .47936248779 94.9817504882894 .4674606323293 .8706207275493 .1678924560592 .29148864746 91.3637237548890 .5421676635789 .6689071655388 .5118179321387 .55571746826 87.37998962402 87.28923034668 86.73616790771 86.0016632080185.11869049072 84.3115768432683 .7624664306683 .2558670043982 .6097412109481 .99928283691 81.418533325280 .8403091430780 .3217315673879 .8432235717879 .65643310547 79.5696487426879 .3268127441479 .055526733478 .6456069946378 .16986083984 77.5905685424876 .8048934936575 .8796463012774 .897048950274 .09638214111 73.5118179321373 .1526870727573 .0300979614373 .0990066528373 .34516906738 73.8672027587974 .1211166381873 .4559478759872 .5123214721771 .81455993652 71.2006683349670 .703269958570 .3111572265669 .9975814819369 .78939056396 69.6749801635769 .6892471313569 .8416671752970 .0436935424870 .2036895752 70.2009963989369 .9381027221769 .4925537109468 .9551467895568 .38793182373 67.8660812377967 .4078063964867 .0327606201266 .7343063354566 .48515319824 66.2954330444366 .1473922729566 .0549926757866 .0184631347766 .03811645508 66.1335830688566 .2733306884866 .447677612366 .5108489990266 .34516143799 
66.070877075265 .8012924194365 .5765228271565 .4186325073265 .35037231445 65.3729400634865 .4838027954165 .6733627319365 .9007034301866 .145652771 66.3838882446366 .5921630859466 .7482833862366 .8100967407266 .75974273682 66.5795974731466 .3237762451266 .0625534057665 .8452529907265 .74836730957 65.7898712158265 .9892730712966 .2119522094766 .3207626342866 .35109710693 66.3358688354566 .3221969604566 .3647766113366 .498191833566 .75894165039 67.200332641667 .845283508368 .6899490356469 .7082290649470 .84662628174 72.1888198852573 .2637176513773 .5341033935573 .5692291259873 .76702880859 74.1362915039174 .7501831054775 .6031417846776 .7376022338978 .11376953125 79.7509918212981 .562919616783 .4298095703185 .2948379516687 .07626342773 88.8052673339890 .5118865966892 .208290100193 .90820312595 .59929656982 97.2741622924898 .90648651123100 .4794006348101 .9899978638103 .4516983032 104.8441009521106 .1603012085107 .4116973877108 .5892028809109 .7154006958 110.7882995605111 .8391036987112 .9014968872113 .9896011353115 .1258010864 116.3191986084117 .5837020874118 .9122009277120 .306602478121 .7501983643 123.2423019409124 .7565002441126 .2817001343127 .8115005493129 .3367004395 130.8612060547132 .3791046143133 .9120025635135 .4792938232137 .0997009277 138.7938995361140 .5809020996142 .4895935059144 .5516052246146 .8170013428 149.324005127152 .1130981445155 .0914001465158 .1490936279161 .2265014648 164.2247009277167 .1410980225169 .9163970947172 .5941925049175 .1849975586 177.7196960449180 .2471923828182 .7429046631185 .2187957764187 .6611938477 190.070098877192 .5146026611195 .0547027588197 .6905059814200 .4763946533 203.3603973389206 .3489074707209 .3869934082212 .3569946289215 .3869018555 218.554397583221 .7232055664224 .7509002686227 .6864929199230 .5594024658 233.366104126236 .1293029785238 .8462982178241 .5281066895244 .175201416 246.7931976318249 .3827972412251 .946395874254 .4842071533256 .9963989258 259.4829101562261 .9426879883264 .3754882812266 .7802124023269 .1564025879 271.5032043457273 .8205871582276 .1076965332278 .3648071289280 .5914916992 282.7880859375284 .9545898438287 .0916137695289 .1991882324291 .2781066895 293.328704834295 .3517150879297 .3476867676299 .3172912598301 .2614135742 303.1805114746305 .0754089355306 .9468994141308 .7956848145310 .6224975586 312.4280090332314 .2127990723315 .9776916504317 .7232971191319 .4501953125 321.1590881348322 .8505859375324 .5250854492326 .1835021973327 .8259887695 329.4534912109331 .066192627332 .6646118164334 .2492980957335 .8205871582 337.3789978027338 .9248962402340 .4585876465341 .9804077148343 .4906921387 344.9898986816346 .4780883789347 .9555053711349 .4224853516350 .8792114258 352.3258972168353 .7627868652355 .1900024414356 .6076049805358 .0158996582 359.4150085449360 .8052062988362 .1864013672363 .5588989258364 .9227905273 366.2781982422367 .6253051758368 .9641113281370 .2947998047371 .6174926758 372.9321899414374 .2390136719375 .537902832376 .8288879395378 .1120910645 379.387298584380 .6546020508381 .9139099121383 .1651916504384 .4085083008 385.6441040039386 .87109375388 .0914001465389 .3023071289 -29.6331291199 -27.4292106628 -25.2362003326 -23.0509395599-20.8698997498 $-18.6936702728-16.5221595764-14.3553304672-12.1930704117-10.0352802277$ $-7.88185214996-5.73264598846-3.58757090569-1.44648802280 .690653026104$ 2.8239738941194 .9534611701977 .0791931152349 .201067924511 .31910037994 
13.4330902099615 .5429401397717 .6483402252219 .7490997314521 .84474945068 23.9349594116226 .019119262728 .0967807769830 .1671600341832 .22966003418 34.2833595275936 .3274803161638 .3610000610440 .3829612731942 .39221954346 44.387691497846 .3680915832548 .3322105407750 .2786788940452 .20618057251 54.1132698059155 .9985198974657 .8604583740259 .6975784301861 .50838851929 63.2913284301865 .0449295043966 .7675933837968 .4578933715870 .11422729492 71.7352523803773 .3194198608474 .8654327392676 .3718185424877 .83738708496 79.2608108520580 .6410064697381 .9767608642683 .2671890258884 .51119232178 85.7080535888786 .856857299887 .9570770263789 .0080337524490 .00933074951 90.9605026245191 .8613815307692 .7117080688593 .5115127563594 .26080322266 94.9597702026495 .608673095796 .2079391479596 .7580566406297 .25968170166 97.7135162353598 .120391845798 .4812316894598 .7969436645599 .06861114502 99.2971420288199 .4836883544999 .629043579199 .7343597412199 .79974365234 99.8262405395599 .8120117187599 .7572708129999 .656951904399 .5092010498 99.3063964843899 .044227600198 .7166137695398 .3189773559697 .85350036621 97.3211364746196 .734786987396 .0957336425895 .516181945895 .13529968262 94.7100524902394 .0189971923893 .2466888427792 .5493164062591 .94418334961 91.4832000732491 .0249481201290 .4287185668989 .7067871093888 .82716369629 87.9038619995187 .0441665649486 .183731079185 .2467193603584 .54992675781 84.4344100952184 .4069213867284 .0620498657283 .5688934326282 .85549163818 82.0189971923881 .1873168945380 .2877731323279 .4390487670978 .74752807617 78.1581573486377 .614120483477 .0894470214876 .6046066284276 .30906677246 76.1069793701275 .8690490722775 .6920928955175 .5353927612375 .45596313477 75.5048599243275 .1943969726674 .0905303955172 .752647399971 .76142120361 71.0390472412170 .5908813476670 .3880004882870 .3891067504970 .54960632324 70.857978820870 .9499969482470 .4223098754969 .6655883789169 .03318023682 68.4723663330168 .0186462402367 .6460800170967 .3354415893667 .07434082031 66.8305435180766 .706329345766 .8143310546966 .9450531005966 .93775177002 66.8373794555766 .6169662475666 .3019638061565 .8627319335965 .34414672852 64.8287429809664 .3679885864364 .0321578979563 .7664794921963 .52196121216 63.3141098022563 .1443290710463 .0138893127462 .9312095642162 .84479904175 62.7113800048862 .6177711486862 .7116088867262 .8052787780862 .65964889526 62.5042190551862 .4783210754462 .4584999084562 .3726997375562 .31309890747 62.3472213745162 .4567604064962 .6347999572862 .8462905883863 .07284164429 63.3020896911663 .519809722963 .7181205749563 .887271881163 .90382003784 63.6334609985463 .2350616455162 .8672790527362 .5072288513262 .15998077393 61.9916610717862 .2079315185562 .5599098205662 .779708862362 .93563079834 63.0192604064963 .0662307739363 .1467399597263 .2781982421963 .47594833374 63.8615417480564 .5542907714865 .4422531127966 .4298706054767 .49313354492 68.6367263793969 .5457305908269 .898437570 .0465393066470 .27079772949 70.6479263305771 .2592163085972 .0994110107473 .2361526489374 .60530090332 76.2138214111377 .9824905395579 .8057632446381 .6706771850683 .51657104492 85.3555526733487 .1703796386788 .9716186523490 .7742233276492 .57444000244 94.3770675659296 .1235427856497 .7564315795999 .3187713623100 .8544998169 102.320602417103 .7009963989105 .0002975464106 .1962966919107 .3251037598 108.3973999023109 .4432983398110 .5164031982111 .6272964478112 .7981033325 
114.0276031494115 .3243026733116 .6819000244118 .101600647119 .570098877 121.0798034668122 .6015014648124 .1202011108125 .6285018921127 .1078033447 128.5744018555130 .0308074951131 .4969940186133 .0036010742134 .5675964355 136.2109069824137 .9542999268139 .8202056885141 .8554992676144 .0975952148 146.5205993652149 .1504058838151 .9152069092154 .7792053223157 .6920013428 160.5536956787163 .3634033203166 .0776977539168 .7239990234171 .3070068359 173.8470001221176 .370803833178 .8834991455181 .4140014648183 .8704986572 186.1593017578188 .4243927002190 .7991027832193 .2606048584195 .838104248 198.5160064697201 .3108978271204 .1808013916207 .0686950684210 .0532073975 213.1775054932216 .3435058594219 .4268951416222 .4459075928225 .3986968994 228.2901000977231 .1273040771233 .9141998291236 .6571960449239 .3596954346 242.0269012451244 .6607055664247 .2644042969249 .8388061523252 .3852996826 254.9037017822257 .3941955566259 .8564147949262 .2896118164264 .6936035156 267.0678100586269 .411895752271 .7254943848274 .0086975098276 .2611083984 278.4831848145280 .6748962402282 .8367004395284 .9689941406287 .0721130371 289.146697998291 .1932983398293 .2125854492295 .2052001953297 .1718139648 299.1131896973301 .0299987793302 .9230041504304 .7927856445306 .6402893066 308.466003418310 .2705993652312 .054901123313 .8194885254315 .5649108887 317.291809082319 .0008850098320 .6926879883322 .3677978516324 .0267028809 325.6700134277327 .2980957031328 .9114990234330 .5107116699332 .0960083008 333.6680908203335 .2272033691336 .7737121582338 .3078918457339 .8302001953 341.3409118652342 .8402099609344 .3283996582345 .8057861328347 .2724914551 348.7289123535350 .174987793351 .611114502353 .0372924805354 .4538879395 355.8609924316357 .2586975098358 .6473083496360 .0267944336361 .3974914551 362.7593994141364 .1127929688365 .4577026367366 .7943115234368 .1224975586 369.4426879883370 .7547912598372 .0586853027373 .3547058105374 .6427001953 375.9224853516377 .1943969727378 .4580993652379 .7138061523380 .9613037109 382.2011108398383 .4331970215384 .6528015137385 .859588623 $-30.6879291534-28.511680603-26.3381996155-24.1705093384-22.0075092316$ $-19.8492698669-17.6956195831-15.5465202332-13.4018201828-11.2613897324$ $-9.12508964539-6.99273395538-4.86421489716-2.73933196068-.618034005165$ 1.4998819828033 .614382028585 .7256388664257 .8335142135629 .938122749329 12.039199829114 .1367797851616 .2304496765118 .3201408386220 .40529060364 22.4856796264624 .5606002807626 .6296691894528 .69202995330 .7471408844 32.7939682006834 .8318214416536 .859519958538 .8761787414640 .88050842285 42.8714599609444 .8476409912146 .8078308105548 .7505493164150 .67446136475 52.5780105590854 .4597396850656 .3180885314958 .1514701843359 .95832824707 61.737030029363 .4860382080165 .2036590576266 .8884429931668 .5386428833 70.1529235839871 .7295837402373 .2673568725674 .7646331787176 .22025299072 77.6326980590879 .0009918212980 .3237609863381 .6001434326282 .82894134521 84.009483337485 .1407470703186 .2222671508887 .2532272338988 .23333740234 89.1620025634890 .0391235351690 .8643493652391 .637832641692 .35941314697 93.0294723510793.6481094360494.2159500122194.7333374023495.20115661621 95.6200332641695 .9910430908296 .3149871826296 .5931472778396 .82649230957 97.016326904397 .1637496948297 .2700195312597 .336357116797 .36334228516 97.35243988037 97.30198669434 97.2132720947397.080360412696.90325164795 
96.67167663574 96.3836975097796.0286331176895.6036071777395.10534667969 94.5314788818493 .8969879150493 .1675262451292 .5176086425892 .20748901367 91.8461532592891 .0575637817490 .1696014404389 .4127502441488 .76976013184 88.3409118652387 .9306335449287 .3241882324286 .6035919189585 .75042724609 84.8475494384883 .959266662683 .1522903442482 .5035324096782 .08870697021 81.9773712158281 .993446350181 .9095764160281 .5820083618280 .84895324707 79.8160476684678 .7127227783277 .6024627685576 .6372375488375 .8371963501 75.1327362060574 .5262527465873 .9982070922973 .5354919433673 .18060302734 72.9208908081172 .6742324829172 .5544586181672 .5190124511772 .62336730957 73.0829162597773 .1128234863371 .8870620727570 .3410034179769 .30912017822 68.5308227539168 .0054168701267 .7194137573267 .6220474243267 .63149261475 67.6191711425867 .4845275878967 .1138534545966 .6244506835966 .12629699707 65.6645202636765 .2839813232464 .9551086425864 .6542129516664 .35901641846 64.0090789794963 .7459983825763 .7809600830163 .8432617187563 .7212600708 63.5446281433163 .3439483642663 .0852012634362 .7104797363362 .26342010498 61.781810760561 .3398208618261 .0445289611860 .8073997497660 .55548095703 60.3221397399960 .1176414489759 .9314308166559 .7862892150959 .60346984863 59.2787704467859 .0235214233459 .1275711059659 .2849006652859 .15642929077 59.0627517700259 .2269706726159 .3976593017659 .3720207214459 .32117843628 59.345291137759 .4222602844259 .5617103576759 .7334289550859 .93529891968 60.1479606628460 .3652496337960 .5757713317960 .8110389709560 .87427902222 60.534458160460 .0345687866259 .6161384582559 .183029174858 .66244125366 58.3596992492758 .6220092773459 .0709304809659 .3438796997159 .56050872803 59.7225608825759 .8468704223659 .996089935360 .1673202514660 .33456039429 60.6812782287661 .3949203491262 .2850685119663 .1951904296964 .10521697998 64.9726791381865 .6917572021566 .1841964721766 .5466537475666 .858543396 67.2416534423867 .8000030517668 .6082992553769 .7534408569371 .1544418335 72.7571792602574 .4888610839876 .2748565673878 .1295318603580 .01828765869 81.9349136352583 .8370132446385 .7312927246187 .6268692016689 .51722717285 91.4286117553793 .2760772705194 .9695587158296 .5907287597798 .21103668213 99.77395629883101 .2555999756102 .620300293103 .8321990967104 .943901062 106.0072021484107 .0595016479108 .1539001465109 .2966003418110 .5042037964 111.7759017944113 .1090011597114 .5027999878115 .9505004883117 .4445037842 118.9741973877120 .5176010132122 .0559005737123 .5581970215125 .0024032593 126.4119033813127 .8149032593129 .2355957031130 .7012023926132 .2308959961 133.8439025879135 .5644073486137 .4053039551139 .4024963379141 .5843048096 143.9188995361146 .4100952148149 .0135040283151 .7064056396154 .4479064941 157.1524963379159 .8372955322162 .463394165165 .0516967773167 .6015930176 170.1235961914172 .628692627175 .1273040771177 .682800293180 .1349029541 182.3097991943184 .4179992676186 .6486968994188 .9499969482191 .3475952148 193.8515930176196 .4808044434199 .2227020264202 .0653991699205 .0214996338 208.0744934082211 .1902008057214 .2859954834217 .3551940918220 .3701019287 223.3289031982226 .2332000732229 .0816955566231 .883102417234 .6371002197 237.3520965576240 .0278930664242 .6707000732245 .2801971436247 .8596954346 250.4085998535252 .9284973145255 .4185028076257 .87890625260 .3092956543 262.7092895508265 .078704834267 .4172058105269 .7249145508272 .0015869141 
274.2477111816276 .463104248278 .6482849121280 .8037109375282 .9296875 285.0268859863287 .0957946777289 .1370849609291 .1513977051293 .1394042969 295.1018066406297 .0393066406298 .9526062012300 .8424987793302 .7094116211 304.5544128418306 .3778076172308 .1805114746309 .963104248311 .7261047363 313.4702148438315 .1960144043316 .9042053223318 .5952148438320 .2695922852 321.9280090332323 .5707092285325 .1983947754326 .8113098145328 .4100952148 329.9950866699331 .5668945312333 .1254882812334 .6716003418336 .2052001953 337.7268066406339 .2366943359340 .7351074219342 .2224121094343 .6986083984 345.1640930176346 .6189880371348 .0635070801349 .4978942871350 .9223022461 352.3369140625353 .7419128418355 .1373901367356 .5235900879357 .9006958008 359.2687988281360 .628112793361 .9786071777363 .3207092285364 .6543884277 365.9796142578367 .2966003418368 .6054077148369 .9060058594371 .1983947754 372.4826965332373 .7589111328375 .0267944336376 .2864990234377 .5380859375 378.7817993164380 .0168151855381 .2450866699382 .4637145996 -31.749080658 -29.5816192627 -27.4249706268 -25.2760391235 -23.1312408447 $-20.9911193848-18.8554992676-16.7243099213-14.5973501205-12.4744596481$ $-10.3554496765-8.24012470245-6.12830400467-4.01977586746-1.91441500187$ .1879809945822 2.287461996078 4.384184837341 6.478105068207 8.569301605225 10.6576099395812 .7430095672614 .8251895904516 .9040107727118 .9790096283 21.049879074123 .1160106658925 .1769409179727 .2318592071529 .2801399231 31.3208198547433 .3530693054235 .3757781982437 .3879394531239 .38829040527 41.3756599426343 .3486595153845 .305938720747 .2460403442449 .16746902466 51.0686798095752 .9480895996154 .8040695190456 .6349716186558 .43915176392 60.2149009704661 .9605903625563 .6744689941465 .3549804687567 .00035858154 68.6091308593870 .1795806884871 .7103195190473 .1997299194374 .64653778076 76.049247741777 .4067382812578 .7176666259879 .9810714721781 .19577789307 82.3610076904383 .4758071899484 .5395736694385 .5515594482486 .51136779785 87.4185028076288 .2727127075289 .0737762451289 .821701049890 .516456604 91.1583175659291 .7474975585992 .2845230102592 .7699203491293 .20446014404 93.58899668872193 .9245071411194 .2120819091894 .4529113769594 .64823913574 94.7994003295994 .9077987670994 .9748535156295 .002090454194 .99067687988 94.9422988891694 .8564834594794 .7344284057694 .5719070434694 .36820983887 94.1144104003993 .8063278198293 .4340209960992 .9909591674892 .47646331787 91.8871612548891 .2397079467890 .5339126586989 .8926696777389 .45876312256 88.99331665039 88.27941131592 87.4962310791 86.80407714844 86.19815063477 85.7082366943485 .2180099487384 .5819168090883 .84487152182 .98246002197 82.0710525512781 .1791763305780 .4121627807679 .8613204956179 .54223632812 79.5150070190479 .7076263427780 .1487579345780 .1910705566479 .10605621338 77.559989929276 .1796264648474 .9163436889673 .8692932128972 .99610900879 72.2463378906271 .6101379394571 .0645370483470 .5915832519570 .18934631348 69.8639678955169 .5851364135769 .4265136718869 .3870315551869 .47118377686 69.7403030395569 .648857116768 .6739273071367 .4460830688566 .5740737915 65.8798904418965 .283348083564 .8650436401464 .7200469970764 .64521026611 64.485763549864 .2510986328163 .8544692993263 .4332313537663 .05447006226 62.7144889831562 .4628486633362 .2327995300361 .9594306945861 .66321182251 61.3608589172461 .0964088439960 .946990966860 .8142089843860 .61280059814 
60.39690017760 .1732597351159 .9193000793559 .586910247859 .20037078857 58.781810760558 .389511108458 .0932998657257 .8352699279857 .56964111328 57.3087081909257 .0604782104556 .8223190307656 .6042594909756 .36365127563 56.0612907409755 .8485794067455 .900531768856 .033901214656 .05052185059 56.1138801574756 .3222503662156 .5132408142156 .5354003906256 .49501037598 56.4520606994656 .436111450256 .4759712219256 .5577087402356 .70846939087 56.8880996704157 .0813598632857 .2681999206557 .4195404052757 .42050933838 57.1319999694856 .7114715576256 .336219787655 .9522590637255 .54856872559 55.327991485655 .4765701293955 .7922096252456 .0514602661156 .28388977051 56.4971694946356 .7059516906756 .9419097900457 .1923408508357 .4404296875 57.8220710754458 .4584083557159 .2230415344260 .0092201232960 .76596069336 61.4802894592362 .1319198608462 .6634101867763 .1287803649963 .51950836182 63.9003982543964 .339569091865 .0553665161166 .2989883422967 .82454681396 69.4409484863371 .1327972412172 .849472045974 .6562271118276 .58702087402 78.5778198242280 .5497436523482 .5143127441484 .4700164794986 .41790771484 88.3657608032290 .258926391692 .041290283293 .7666931152395 .48063659668 97.1605911254998 .81455230713100 .304901123101 .4801025391102 .5175018311 103.5696029663104 .6382980347105 .7701034546106 .9608001709108 .2211990356 109.5444030762110 .9240036011112 .3567962646113 .8352966309115 .3546981812 116.9074020386118 .4839019775120 .0852966309121 .6240005493123 .0108032227 124.3419036865125 .7022018433127 .0959014893128 .5428924561130 .0570068359 131.6560974121133 .3582000732135 .1808929443137 .1396026611139 .2561950684 141.4996032715143 .8677062988146 .3264007568148 .8594055176151 .4324951172 153.9924926758156 .5473937988159 .0677032471161 .571105957164 .0632019043 166.5393981934169 .0007019043171 .4515075684173 .9053955078176 .2588043213 178.4109039307180 .4888000488182 .6174926758184 .7922058105187 .0361938477 189.3834991455191 .8603973389194 .4759979248197 .2552947998200 .1618041992 203.1809997559206.2752075195209.3764038086212.4739074707 215.5258026123 218.5319976807221 .4832000732224 .3818969727227 .2292022705230 .0283966064 232.7835998535235 .4976959229238 .1748962402240 .816696167243 .4261932373 246.0036010742248 .5503997803251 .0664978027253 .5520019531256 .0068969727 258.4309082031260 .8239135742263 .1856994629265 .5162963867267 .815612793 270.0840148926272 .3215026855274 .5285949707276 .7055969238278 .8530883789 280.9714050293283 .0611877441285 .1231079102287 .1577148438289 .165802002 291.1478881836293 .104888916295 .0374145508296 .9460144043298 .8315124512 300.6944885254302 .5357055664304 .3558044434306 .1553039551307 .9349975586 309.6953125311 .4370117188313 .1606140137314 .8666992188316 .5557861328 318.2283935547319 .8850097656321 .5262145996323 .1521911621324 .7637023926 326.3609924316327 .9446105957329 .5148010254331 .0718994141332 .6163024902 334.1482849121335 .6682128906337 .1763000488338 .6727905273340 .157989502 341.6319885254343 .0953063965344 .5477905273345 .9898071289347 .4216003418 348.8432922363350 .2550048828351 .6570129395353 .0494995117354 .4325866699 355.8064880371357 .1713867188358 .5273132324359 .8745117188361 .2131958008 362.5432128906363 .8648071289365 .1780090332366 .483001709367 .7796020508 369.0679931641370 .3481140137371 .6199951172372 .883605957374 .138885498 375.3862915039376 .6258850098377 .8529052734379 .066986084 
-32.7751197815 -30.6354408264 -28.4984493256 -26.3673591614 -24.2409191132 -22.1191291809-20.0017604828 -17.8887004852 -15.7797002792 -13.6745901108 -11.5731096268 -9.47501945496 -7.38011884689 -5.28811788559-3.19888710976 -1.11213099957.9721869826317 3.0543310642245.134216785431 7.212047100067 9.2875909805311 .3609600067113 .4317502975515 .4999599456817 .56501960754 19.6267604827921 .6844406127923 .737720489525 .7856693267827 .82776069641 29.8628902435331 .8903198242233 .9087905883835 .9173583984437 .91461181641 39.899410247841 .8702201843343 .8257293701245 .7643089294447 .68447113037 49.584541320851 .4628715515153 .3177604675355 .147460937556 .95027923584 58.7243804931660 .4680900573762 .1795387268163 .8571205139265 .49896240234 67.1035537719768 .6690368652370 .1940383911171 .6767807006873 .11604309082 74.5101394653375 .8580322265677 .15820312578 .4097595214879 .61138916016 80.7623977661181 .8616790771582 .9087219238383 .9026565551884 .84314727783 85.7295837402386 .5618515014687 .3395462036188 .0628204345788 .73149871826 89.3459930419989 .9063568115290 .4133529663190 .8673095703191 .2692565918 91.6198577880991 .9204330444392 .1718597412192 .3757171630992 .5330581665 92.6456832885792 .7147521972792 .7423782348692 .7299499511792 .6795425415 92.59291839692 .4708023071392 .3151779174892 .122627258391 .89456176758 91.6204605102591 .2988967895590 .9162063598690 .4667587280389 .94896697998 89.35814666748 88.72676086426 88.07521820068 87.43961334229 86.84438323975 86.252517700285 .6423263549885 .0329971313584 .4810104370183 .9409866333 83.39195251465 82.81215667725 82.1119232177781.33132171631 80.42872619629 79.4915313720778 .5943298339877 .8376464843877 .3004226684677 .01447296143 77.0112915039177 .272743225178 .0513000488378 .331192016676 .93308258057 75.0081100463973 .5323562622172 .2229766845771 .1446304321370 .25605773926 69.4780273437568 .8267593383868 .2669296264667 .7929763793967 .3669128418 66.998458862366 .6548767089866 .4017181396566 .249717712466 .15354156494 66.0355911254965 .7414169311565 .1043014526464 .3403015136763 .74100875854 63.1695899963462 .5271606445361 .9995307922461 .7978782653861 .66854858398 61.4274215698261 .1327705383360 .710098266660 .3026809692460 .00339889526 59.7688407897959 .6107101440459 .4493789672959 .1800003051858 .87902069092 58.6529617309658 .4041290283258 .0974388122657 .7909088134857 .53232955933 57.2959899902357 .0359306335456 .7626190185556 .4550704956156 .1229095459 55.7734603881855 .4338188171455 .123889923154 .8304481506354 .5419883728 54.2477912902853 .9548912048353 .6588897705153 .3727989196853 .10712814331 52.8931617736852 .7753601074252 .7933082580652 .9198112487853 .08744049072 53.2961692810153 .5028495788653 .6589813232453 .7210807800353 .67581176758 53.5377082824753 .3790016174353 .2783699035653 .2585906982453 .34886169434 53.5029487609953 .6914291381853 .833141326953 .8587608337453 .76160812378 53.5365791320853 .2523002624552 .9778404235852 .7434997558652 .58547973633 52.5098190307652 .5248794555752 .6232910156252 .7988395690953 .03205871582 53.2974014282253 .6004104614353 .9481201171954 .3152198791554 .68413162231 55.1192398071355 .6420898437556 .22809982356 .8575210571357 .47703170776 58.1125602722258 .732559204159 .3101387023959 .8496017456160 .30847930908 60.7470207214461 .1251716613861 .7773590087963 .0953483581564 .69444274902 66.2893829345767 .9414596557669 .5971069335971 .3517913818473 .29489135742 
75.319473266677 .3232879638779 .3259277343881 .3190917968883 .29400634766 85.2500610351687 .1688537597789 .0313186645590 .8566970825292 .65331268311 94.4226303100696 .2234573364397 .8253479003998 .9827804565499 .97306060791 101.0497970581102 .1628036499103 .3555984497104 .6184997559105 .945098877 107.3356018066 108.7665023804 110.2452011108 111.7522964478 113.2946014404 114.8637008667116 .4560012817118 .1039962769119 .6750030518121 .0254974365 122.3098983765123 .6597976685125 .0495986938126 .4975967407128 .0160064697 129.6143035889131 .3110046387133 .1163024902135 .0386962891137 .0874938965 139.2427978516141 .5019989014143 .8350982666146 .2234039307148 .6452026367 151.0644989014153 .4853057861155 .879699707158 .2819976807160 .7001953125 163.1204071045165 .5258026123167 .8955993652170 .2122955322172 .450302124 174.5980987549176 .682800293178 .7528991699180 .8287963867182 .9515075684 185.1517028809187 .4676971436189 .9608001709192 .6743011475195 .5603942871 198.5565948486201 .6268005371204 .7176055908207 .8146972656210 .8798980713 213.9104003906216 .8930969238219 .8258972168222 .7095947266225 .5433044434 228.332901001231 .0782012939233 .7857055664236 .4550933838239 .0914001465 241.6938018799244 .2651062012246 .804397583249 .31300354251 .7899932861 254.2360992432256 .6505126953259 .0335998535261 .3851928711263 .7054138184 265.9942932129268 .2521972656270 .4794921875272 .6765136719274 .8436889648 276.9816894531279 .0909118652281 .1719970703283 .2255859375285 .2522888184 287.2528991699 289.2280883789291.1784057617293.1046142578 295.0073852539 296.8873901367298 .7450866699300 .5816040039302 .3970947266304 .1924133301 305.9679870605307 .724609375309 .4627075195311 .183013916312 .8858032227 314.5718994141316 .2414855957317 .8953857422319 .5336914062321 .1571960449 322.7661132812324 .3608093262325 .9418029785327 .5093994141329 .0639038086 330.6057128906332 .1350097656333 .6520996094335 .1572875977336 .6509094238 338.1330871582339 .6040039062341 .0639953613342 .5133056641343 .9519958496 345.3801879883346 .7984008789348 .2065124512349 .6047973633350 .9935913086 352.3728942871353 .7428894043355 .1037902832356 .4559020996357 .7991027832 359.133605957360 .4595031738361 .7768859863363 .0857849121364 .3864135742 365.6785888672366 .9624938965368 .2379150391369 .5050964355370 .763885498 372.0147094727373 .2567138672374 .4919128418375 .7174072266 -33.8074111938 -31.6765193939-29.5565605164 -27.4445400238 -25.3366794586 -23.2334308624 -21.1345500946 -19.0398597717 -16.9490795135 -14.861989975 -12.7782897949 -10.6976900101-8.61991786957-6.54467582703 -4.47173976898 -2.4008140564 -.331759005785 1.735672950745 3.8015089035035 .865911960602 7.9287738800059 .99013805389412 .0497398376514 .1074800491316 .16291046143 18.2157707214420 .2654399871822 .31146049524 .3530101776126 .3894405365 28.4197292327930 .4430198669432 .4580917358434 .4638786315936 .45901107788 38.4421882629440 .4119110107442 .3666992187544 .3049507141146 .22499847412 48.1251716613850 .0036811828651 .8587684631353 .6885910034255 .49135971069 57.2651481628459 .0082015991260 .7185783386262 .3945503234964 .03420257568 65.63588714667 .1977386474668 .7182388305770 .1956100463971 .6284866333 73.0152206420974 .3546066284275 .6452026367276 .8859710693478 .07565307617 79.2134170532280 .2982406616281 .3294906616282 .3063735961983 .22843933105 84.0951538085984 .9062881469785 .6615371704186 .360908508387 .00435638428 
87.5921478271588 .1245193481488 .6020431518689 .0252380371189 .39501953125 89.7122573852589 .9781265258890 .1937866210990 .3606796264690 .48014831543 90.5538864135790 .5834503173890 .5709304809690 .5181808471790 .42768096924 90.3017425537190 .1423568725689 .9519271850689 .7298812866289 .47794342041 89.1880569458 88.85753631592 88.4741821289188.03106689453 87.52200317383 86.93427276611 86.31065368652 85.67149353027 85.0161819458 84.36519622803 83.7436294555783 .1742172241282 .6676177978582 .2305831909281 .7578125 81.2389373779380 .6407928466879 .8700180053779 .0026016235478 .01602172852 76.9924163818476 .0491714477575 .2534332275474 .6845397949274 .33865356445 74.23802947998 74.3537826538174.73058319092 74.68882751465 73.52937316895 71.9427566528370 .581748962469 .3710327148468 .3556671142667 .49321746826 66.7549362182666 .1210708618265 .5705032348665 .0994262695364 .6919631958 64.2881698608463 .8089599609463 .3661117553763 .0535316467362 .77714920044 62.4966316223162 .2055511474661 .8019294738861 .3669204711960 .90832901001 60.382678985659 .8152503967359 .3127403259359 .0105514526458 .77132034302 58.4862594604558 .1791191101157 .8182601928757 .4851493835457 .23107910156 57.0213699340856 .8227310180756 .6010894775456 .2852287292555 .94945907593 55.6771011352555 .3751296997155 .0392494201754 .7049789428754 .40798187256 54.1444816589453 .8731193542553 .5941810607953 .3135910034253 .02537918091 52.7181587219252 .4063301086452 .0947685241751 .7824401855551 .47354888916 51.151649475150 .8136405944850 .4709892272950 .1376495361349 .85506057739 49.6469612121649 .5472183227549 .6095695495649 .7961006164650 .07347869873 50.3749198913650 .6142997741750 .7818717956550 .8947792053250 .84635162354 50.5232505798350 .1383285522549 .8915901184149 .7748718261749 .8083114624 49.9515800476150 .2002983093350 .3690986633350 .284599304250 .09344100952 49.8813095092849 .6866912841849 .5266990661649 .4608993530349 .56184005737 49.6417007446349 .5480499267649 .4520797729549 .5457992553749 .78049087524 50.1184196472250 .5393714904851 .0115699768151 .4954299926851 .96131896973 52.4241294860852 .86565017753 .3149909973153 .7985916137754 .30144882202 54.8805999755955 .5040016174356 .1427612304756 .7747688293557 .34046936035 57.8918304443458 .4329299926859 .1934089660660 .4084701538161 .85911941528 63.3760604858464 .9632568359466 .5945968627968 .3314208984470 .21575164795 72.1880264282274 .1784515380976 .1814498901478 .1803131103580 .16519165039 82.1318893432684 .0764694213985 .9774398803787 .8499832153389 .68634033203 91.49713897705 93.3147506713994.93834686279 96.16966247555997.24598693848 98.3949127197399 .59588623047100 .8850021362102 .2417984009103 .6592025757 105.1275024414106 .6248016357108 .1508026123109 .6901016235111 .2469024658 112.8181991577114 .4011001587116 .0054016113117 .5445022583118 .9347000122 120.2723999023121 .6475982666123 .0610961914124 .5323028564126 .0680007935 127.6819000244129 .3813934326131 .1775054932133 .0684967041135 .0612945557 137.1390075684139 .2973022461141 .5131988525143 .7720947266146 .054901123 148.3394012451150 .6195068359152 .8681945801155 .145401001157 .5023040771 159.8775024414162 .2180023193164 .508102417166 .7353057861168 .9062042236 171.0108032227173 .0695037842175 .0928955078177 .096206665179 .1186065674 181.1757049561183 .2752075195185 .5912017822188 .3067016602191 .2364044189 194.2194976807 197.2566070557 200.3195953369 203.395401001206.4546966553 
209.491897583212 .4869995117215 .4398040771218 .3439025879221 .2017059326 224.0139007568226 .783203125229 .5130004883232 .2050018311234 .8623962402 237.4859924316240 .0776977539242 .637298584245 .1656036377247 .6625061035 250.1278076172252 .5615997314254 .9636993408257 .334197998259 .6730957031 261.9808044434264 .2572021484266 .5029907227268 .7182922363270 .9036865234 273.0596008301275 .1866149902277 .2854003906279 .3564147949281 .4005126953 283.4182128906285 .4100952148287 .3770141602289 .3194885254291 .2383117676 293.1340942383295 .0073852539296 .8588867188298 .6893005371300 .499206543 302.2890930176304 .0596008301305 .8113098145307 .5447998047309 .2604980469 310.9591064453312 .6409912109314 .3067016602315 .9565124512317 .5911865234 319.2107849121320 .8160095215322 .4071044922323 .9844970703325 .5484924316 327.099395752328 .6373901367330 .1630859375331 .6763916016333 .1777954102 334.6675109863336 .145690918337 .612701416339 .0686035156340 .5137023926 341.9482116699343 .3721923828344 .7860107422346 .1896972656347 .5837097168 348.9679870605350 .3428039551351 .708404541353 .0647888184354 .4122924805 355.7510070801357 .0808105469358 .4020996094359 .7148132324361 .0188903809 362.3146057129363 .6018981934364 .8807983398366 .1512145996367 .4132080078 368.6672058105369 .9132080078371 .1466064453372 .3671875 -34.8035583496 -32.7008705139 -30.6008701324 -28.5070991516 -26.4180603027 $-24.333650589-22.2535591125-20.1775608063-18.1053295135-16.0365905762$ $-13.970990181-11.9081897736-9.84788513184-7.78968000412-5.73334312439$ $-3.67846798897-1.6249320507 .42764401435852 .4792439937594 .530179023743$ 6.5802621841438 .62969970703110 .6781196594212 .7255802154514 .77153015137 16.815849304218 .8577899932920 .8970298767122 .9326095581124 .96401977539 26.9900608062729 .0099792480531 .0224094390933 .0263481140135 .02024841309 37.0028800964438 .9725494384840 .9278106689542 .8668785095244 .78810882568 46.6896286010748 .5696487426850 .4262809753452 .2575912475654 .06169891357 55.8365592956557 .5803718566959 .2910385131860 .9668197631862 .60562133789 64.2058029174865 .7652969360467 .2826538085968 .7558670043970 .18366241455 71.564178466872 .8963012695374 .1783828735475 .4095077514676 .58822631836 77.7138366699278 .7851409912179 .801620483480 .7623291015681 .66693115234 82.5147628784283 .3056869506884 .0392608642684 .7156066894585 .3345413208 85.8964614868286 .4014205932686 .8502120971787 .2431564331187 .58141326904 87.8656005859488 .097236633388 .2772598266688 .4074096679788 .48886108398 88.5236968994188 .513252258388 .4601974487388 .3661727905388 .23464202881 88.06774139404 87.86927032471 87.64148712158 87.38717651367 87.10938262939 86.8020706176886 .4654464721786 .0859832763785 .6607437133885 .17130279541 84.595848083583.97535705566 83.3212127685582.6500091552781.96878051758 81.3296813964880 .7774581909280 .3152008056679 .9406585693479 .57885742188 79.1808395385778 .6089324951277 .7555618286176 .7222595214875 .59935760498 74.4943923950273 .4953536987372 .6561584472772 .0299835205171 .59052276611 71.3471221923871 .1638870239370 .9212875366270 .4588012695369 .6116027832 68.5670013427767 .5054016113366 .4816436767665 .5734176635764 .77718353271 64.106857299863 .5344886779863 .017158508362 .5553207397562 .16101074219 61.7326202392661 .1243705749560 .5106811523460 .0302009582559 .61750030518 59.2480583190958 .9543304443458 .7151794433658 .4551506042558 .04130172729 
57.5515098571857 .086071014456 .6333198547456 .2498092651455 .90208053589 55.5819206237855 .2887115478554 .9966697692954 .7453384399454 .52400970459 54.2999191284254 .0155296325753 .6626205444353 .2470893859952 .81489944458 52.4557685852152 .1215705871651 .8347511291551 .5490913391151 .24335098267 50.9475593566950 .6479606628450 .3779106140150 .126541137749 .88079833984 49.6172218322849 .3175010681248 .988700866748 .6375312805248 .29388046265 47.9436111450247 .5684814453147 .1966590881346 .8403205871646 .54565811157 46.3308410644546 .2432098388746 .3448982238846 .5771217346246 .89469146729 47.2294998168947 .464981079147 .6183586120647 .7736816406247 .72790145874 47.2718315124546 .7349815368746 .3862800598146 .1858406066946 .15003967285 46.2485809326246 .5285911560146 .7381210327146 .6014900207546 .37522888184 46.2108993530346 .0994796752946 .0392303466846 .0882987976146 .3525390625 46.5543594360446 .388809204146 .1899490356446 .2794189453146 .54001998901 46.9531593322847 .4947700500548 .0729904174848 .6880302429249 .27481079102 49.7648315429750 .1134986877450 .3866615295450 .7336006164651 .16049957275 51.7369499206552 .4168090820353 .1465911865253 .8970108032254 .58877182007 55.3011817932156 .0508804321356 .9301986694358 .007949829159 .24580001831 60.6474494934162 .1684799194363 .7834510803265 .5011367797967 .30024719238 69.1835327148471 .1200790405373 .0899505615275 .0753631591877 .05860137939 79.033622741780 .9931411743282 .9103698730584 .7952804565486 .63244628906 88.4218597412190 .1824417114391 .7909393310593 .1243667602594 .34234619141 95.6260528564596 .9487915039198 .3675689697399 .85119628906101 .3759994507 102.9412002563104 .5056991577106 .0824966431107 .6461029053109 .2071990967 110.769203186112 .3197021484113 .8570022583115 .3555984497116 .8032989502 118.2253036499119 .654800415121 .1108016968122 .6212005615124 .1904983521 125.8326034546127 .5476989746129 .3403930664131 .2093048096133 .1537017822 135.162902832137 .2312927246139 .3414001465141 .4850006104143 .6457977295 145.8074035645147 .966003418150 .0827026367152 .2418060303154 .5261993408 156.838394165159 .0982055664161 .31300354163 .4725036621165 .5823974609 167.6425933838169 .658996582171 .6390991211173 .5899047852175 .5417938232 177.5068054199179 .4436950684181 .6125030518184 .3117980957187 .24609375 190.1741027832193 .1598968506196 .1790008545199 .2189025879202 .2568969727 205.279800415208 .2709960938211 .2254943848214 .1376953125217 .0059967041 219.8321990967222 .6157989502225 .3616943359228 .0693969727230 .7436065674 233.3834075928235 .991897583238 .5679016113241 .1132049561243 .6264953613 246.1087036133248 .55909729250 .9779968262253 .3650970459255 .7207946777 258.0450134277260 .3381958008262 .600402832264 .8323059082267 .033996582 269.2062988281271 .3494873047273 .4643859863275 .5513916016277 .6112060547 279.6445007324281 .6518859863283 .6340026855285 .5914916992287 .5250854492 289.4353942871291 .3229980469293 .1885986328295 .0327148438296 .8561096191 298.6590881348300 .4425964355302 .2067871094303 .9526062012305 .6802978516 307.3905029297309 .0837097168310 .7604064941312 .4209899902314 .0660095215 315.6957092285317 .3106079102318 .9111022949320 .4975891113322 .0703125 323.6296081543325 .1758117676326 .7092895508328 .2301940918329 .7390136719 331.2355957031332 .720489502334 .1939086914335 .6560058594337 .1069946289 338.5472106934339 .9767150879341 .395690918342 .8044128418344 .2031860352 
345.592010498346 .9713134766348 .3410949707349 .7015991211351 .0530090332 352.3953857422353 .7289123535355 .0537109375356 .3698120117357 .6773071289 358.9761962891360 .2666015625361 .5484924316362 .8218994141364 .0869140625 365.3436889648366 .591796875367 .8328857422369 .0642089844 -35.805770874 -33.7117500305 -31.6290798187 -29.554889679 -27.4849891663 -25.419719696 -23.3587493896 -21.3017997742 -19.2484703064-17.1984500885 -15.151309967-13.1066799164 -11.0641698837-9.02335643768 -6.98390293121 $-4.94540119171-2.90760111809-.8701410293581 .1670969724663 .204385042191$ 5.2416768074047 .2791128158579 .31646442413311 .3537101745613 .39041996002 15.4263801574717 .4609794616719 .4937896728521 .5239505767823 .55081939697 25.5733203887927 .5905494689929 .6012001037631 .6041202545233 .59780883789 35.5808601379437 .551620483439 .5084686279341 .4496116638243 .37322998047 45.2774505615247 .1603088378949 .0198593139650 .8540382385352 .66088104248 54.4382591247656 .1842193603557 .896629333559 .5735816955661 .21295166016 62.8129501342864 .371513366765 .8869705200267 .3573913574268 .78128814697 70.1568603515671 .4828262329172 .7576065063573 .9801177978575 .14900970459 76.2634201049877 .3222579956178 .3248596191479 .2703781127980 .15837097168 80.9882507324281 .7597427368282 .4725265502983 .1265792846783 .72183227539 84.2585220336984 .7368621826285 .1574630737385 .5207977294985 .82787322998 86.0795364379986 .2770767211986 .4217529296986 .515060424886 .55853271484 86.5540084838986 .5032577514686 .4087524414186 .2726364135786 .0983505249 85.8887100219785 .6481094360485 .3799819946385 .0900268554784 .78237915039 84.4558181762784 .1131286621183 .742469787683 .3389663696382 .8724822998 82.3196792602581 .7060928344781 .025947570880 .3169937133879 .59744262695 78.9183120727578 .3434829711977 .8813400268677 .5393600463977 .29744720459 77.1906585693476 .8004226684675 .7017898559674 .3288803100673 .05557250977 71.8739089965870 .8296890258869 .943771362369 .2500915527368 .69994354248 68.3084869384867 .8734512329167 .2655868530366 .5899200439565 .7961730957 65.0201568603564 .2966766357463 .5455207824762 .7673912048362 .05702972412 61.5259590148961 .0793113708560 .6400909423860 .2121810913159 .79235076904 59.3187294006358 .7184906005958 .0882682800357 .5139617919956 .99945068359 56.5480003356956 .1953506469755 .9196281433155 .6329193115255 .23812103271 54.7888488769554 .3327789306653 .8749084472753 .4429512023953 .0323600769 52.6692504882852 .3616409301852 .089420318651 .8694992065451 .71709823608 51.5178298950251 .1659889221250 .6843910217350 .073101043749 .47032928467 49.0289497375548 .7048683166548 .5255088806248 .3404197692947 .9952583313 47.6218109130947 .3047714233447 .0481986999546 .8512916564946 .67015075684 46.4738693237346 .1972198486345 .7807693481445 .32072830244 .90904998779 44.5125808715844 .111461639443 .7237014770543 .3616790771543 .0664100647 42.8680610656742 .7878684997642 .8677787780843 .0507202148443 .2911491394 43.5456809997643 .729911804243 .8474617004443 .9546089172443 .89022827148 43.5321807861343 .089988708542 .723209381142 .4669685363842 .35655975342 42.3704681396542 .5526084899942 .7098693847742 .6663703918542 .57186889648 42.5088996887242 .4813804626542 .4879608154342 .5652389526442 .74755096436 42.8790702819842 .7981681823742 .7172508239742 .8908386230543 .2402305603 43.7493782043544 .3914718627945 .0744094848645 .8253593444846 .66193008423 
47.2961692810147.4228096008347.4044303894 47.6120910644548.00362014771 48.6393318176349 .4406013488850 .3237915039151 .2327613830652 .08850860596 52.9535903930753 .8039703369154 .7005805969255 .711349487356 .82201004028 58.1142082214459 .5588302612361 .115100860662 .7685317993264 .492187566 .2931137085 68.1561203002970 .0702972412172 .0257720947373 .995117187575 .96365356445 77.920486450279 .8297729492281 .6927871704183 .4942626953185 .229347229 86.8980636596788 .4749374389689 .9060592651491 .2884521484492 .72119903564 94.1991119384895 .7867126464897 .4305496215899 .08883666992100 .7587966919 102.4050979614104 .0304031372105 .6112976074107 .1635971069108 .7068023682 110.2273025513111 .7319030762113 .2239990234114 .6979980469116 .1736984253 117.6594009399119 .1696014404120 .7341003418122 .3529968262124 .039100647 125.7829971313127 .5838012695129 .4394073486131 .3489990234133 .3020935059 135.2906036377137 .3056945801139 .3466949463141 .4015045166143 .4622039795 145.5249023438147 .5747070312149 .6638946533151 .8406982422154 .0433044434 156.2160949707158 .3560943604160 .4512939453162 .5072021484164 .5196075439 166.4951019287168 .4346923828170 .3509979248172 .2642974854174 .1943969727 176.1531982422178 .3162994385180 .8699951172183 .6333007812186 .4468994141 189.3361053467 192.2969970703 195.2976074219 198.2969055176 201.2895965576 204.2579040527207 .1988983154210 .1029052734212 .9700927734215 .7976074219 218.5872039795221 .3397979736224 .0569000244226 .7409057617229 .3921051025 232.0122070312234 .6009979248237 .158996582239 .6858978271242 .1815948486 244.6459960938247 .0789031982249 .4803924561251 .850402832254 .1891021729 256.4967041016258 .7735900879261 .0199890137263 .2363891602265 .4231872559 267.5809936523269 .7102050781271 .8116149902273 .8857116699275 .9331054688 277.9544067383279 .9504089355281 .9216003418283 .8685913086285 .7922058105 287.6929016113289 .5712890625291 .4280090332293 .2637023926295 .0788879395 296.8741149902298 .6499938965300 .4070129395302 .1458129883303 .8666992188 305.5703125307 .2571105957308 .9276123047310 .5820922852312 .2210998535 313.8450012207315 .4541015625317 .0488891602318 .629699707320 .1968994141 321.7506103516323 .2912902832324 .8190917969326 .3345031738327 .8375854492 329.328704834330 .808013916332 .2756958008333 .7320861816335 .1774902344 336.611907959338 .0357055664339 .449005127340 .8521118164342 .2452087402 343.6285095215345 .0021057129346 .366394043347 .7213134766349 .0671081543 350.4039916992351 .7319946289353 .0510864258354 .3616027832355 .6635131836 356.9566955566358 .241394043359 .5174865723360 .7850952148362 .0445861816 363.2961120605364 .5346984863365 .7607116699 -36.7694282532 -34.7045402527 -32.6423988342 -30.5870399475 -28.536649704 $-26.4909706116-24.4495601654-22.4120998383-20.3781509399-18.3473091125$ -16.3191299438 -14.2931499481 -12.2689304352 -10.2459497452 -8.22386074066 $-6.20212078094-4.18049287796-2.15845298767-.1359360069041 .887516021729$ 3.9117660522465 .9371500015267 .9633159637459 .99044132232712 .01795005798 14.0458402633716 .0732994079618 .1001205444320 .1252403259322 .14821052551 24.1677303314226 .1830596923828 .1926803588930 .1955604553232 .18996047974 34.1745796203636 .1475296020538 .1072311401440 .0516815185541 .9790802002 43.8873405456545 .7744903564547 .6384010314949 .4769401550351 .28802871704 53.0694007873554 .8190498352156 .5346603393658 .2143096923859 .85567092896 
61.4569702148463 .0159301757864 .5309371948265 .9998168945367 .4211730957 68.7929763793970 .1140365600671 .3825836181672 .5976409912173 .75768280029 74.8619537353575 .9092102050876 .8989181518677 .8300933837978 .70237731934 79.5150833129980 .2680282592880 .9607620239381 .5933532714882 .1656036377 82.6778564453183 .130157470783 .5232467651483 .8574295043984 .13390350342 84.35327148438 84.51712799072 84.6264419555784.68306732178 84.68830871582 84.6443481445384 .5527496337984 .416427612384 .2372894287184 .01953125 83.76564025879 83.4814529418983.17027282715 82.83963775635 82.49433135986 82.1417083740281 .7859191894581 .4188385009881 .0304412841880 .59696960449 80.0879135131879 .4848785400478 .7669906616277 .9929962158277 .21650695801 76.4979171752975 .8807983398475 .3896713256875 .0311431884874 .80750274658 74.8793869018674 .6223220825273 .336082458571 .7317733764670 .41068267822 69.2022094726668 .1280136108467 .2009735107466 .4205703735465 .75980377197 65.2315368652364 .6654129028363 .8809814453163 .0823593139662 .32567977905 61.6790390014661 .1867408752460 .6939811706560 .0542602539159 .44752120972 59.0624885559158 .736888885558 .373329162657 .9761886596757 .52421951294 57.0190200805756 .4579391479555 .8533592224155 .2340393066454 .64233016968 54.1024398803753 .6422615051353 .2278709411652 .8381614685152 .4376411438 51.9973106384351 .5203590393151 .0205688476650 .5489387512250 .10694122314 49.7097892761249 .3764495849649 .1000709533748 .8714103698748 .72629928589 48.4983711242748 .0502014160247 .4527397155846 .6723899841345 .92226028442 45.4386405944845 .1270599365245 .0573997497644 .9897193908744 .63542175293 44.2356796264643 .9165000915543 .6656684875543 .4908409118743 .33517074585 43.1836204528842 .9281883239742 .4511299133341 .9155883789141 .45785903931 41.027488708540 .6126594543540 .2226791381839 .8650398254439 .57656860352 39.3867416381839 .3135414123539 .3609199523939 .4778518676839 .60606002808 39.7140693664639 .7750511169439 .8183708190939 .8739395141639 .8556098938 39.6887283325239 .4173889160239 .089279174838 .7737007141138 .54961013794 38.4549598693838 .5301895141638 .6673316955638 .7521705627438 .82313156128 38.8849182128938 .9502601623539 .0075111389239 .0520782470739 .08135986328 39.0816307067939 .0691604614339 .1615295410239 .4904098510740 .00344085693 40.6360588073741 .3590011596742 .1002616882342 .8932609558143 .85454177856 44.5661010742244 .4967803955144 .262969970744 .4497985839844 .88188934326 45.6189117431646 .5839004516647 .6200485229548 .7214889526449 .78174972534 50.7757186889651 .6602706909252 .5039215087953 .4422187805254 .48379135132 55.7156410217357 .0956802368258 .5892105102560 .1841316223161 .83042144775 63.5438499450765 .3031234741267 .1371612548869 .0528335571371 .01197052002 72.9735107421974 .9100799560576 .7912826538178 .6085510253980 .34874725342 82.0100631713983 .5701065063585 .0923233032286 .601280212488 .12243652344 89.7206420898491 .3817367553793 .1743621826295 .0132369995196 .82494354248 98.61549377441100 .3311004639101 .9910964966103 .572303772105 .0985031128 106.6162033081108 .1120986938109 .6034011841111 .096496582112 .5960998535 114.1136016846115 .6522979736117 .2249984741118 .8535003662120 .5329971313 122.2767028809124 .0625991821125 .8851013184127 .7414016724129 .6237945557 131.528503418133 .4474029541135 .37840271137 .3321990967139 .2998962402 141.2774047852143 .2704925537145 .2765960693147 .3112030029149 .3789978027 
151.4644012451153 .5469970703155 .6148986816157 .6519012451159 .6573028564 161.6226043701163 .5561065674165 .4582061768167 .3466033936169 .2397003174 171.1781005859173 .2145996094175 .4004974365177 .7931060791180 .349105835 183.0160064697185 .7946929932188 .6802978516191 .6228942871194 .5653991699 197.5106964111200 .441696167203 .3535003662206 .2375030518209 .0908050537 211.9105987549214 .6959991455217 .4485015869220 .1676025391222 .8560943604 225.5130004883228 .1407012939230 .7375946045233 .3050994873235 .841796875 238.3480987549240 .8235015869243 .2678985596245 .6809997559248 .06300354 250.4140014648252 .7339935303255 .0234069824257 .282409668259 .511505127 261.7110900879263 .8815917969266 .0237121582268 .1377868652270 .2244873047 272.2844848633274 .3183898926276 .3268127441278 .3102111816280 .2694091797 282.2049865723284 .117401123286 .0075073242287 .8756103516289 .7225036621 291.548614502293 .3547058105295 .1411132812296 .9083862305298 .6571960449 300.3879089355302 .1010131836303 .797088623305 .4765014648307 .1398010254 308.7872009277310 .4193115234312 .0362854004313 .6387939453315 .2268981934 316.8012084961318 .3617858887319 .908996582321 .4432067871322 .9646911621 324.4735107422325 .9702148438327 .4548950195328 .9277954102330 .3891906738 331.8392028809333 .2781066895334 .7062072754336 .1236877441337 .5307006836 338.9276123047340 .3145141602341 .6915893555343 .0591125488344 .4172973633 345.766204834347 .1059875488348 .4368896484349 .7589111328351 .0719909668 352.3764038086353 .6722106934354 .9592895508356 .2379150391357 .5079040527 358.7697143555360 .0226135254361 .2684936523362 .5046081543 -37.738910675 -35.6824798584-33.6381416321 -31.6031608582 -29.5727405548 $-27.5470790863-25.5257301331-23.5082702637-21.4942207336-19.4831199646$ $-17.4744300842-15.4676504135-13.4622497559-11.4576702118-9.45343589783$ $-7.44899177551-5.44395208359-3.43780493736-1.43031895161 .5789219737053$ 2.5899538993844 .6030411720286 .6180062294018 .63492202758810 .65338993073 12.6732797622714 .693949699416 .7150306701718 .7356491088920 .75517082214 22.7724399566724 .7865295410226 .7960300445628 .7997093200730 .79590988159 32.7831306457534 .7594985961936 .7232513427738 .6723709106440 .60486984253 42.5186386108444 .4114990234446 .2812881469748 .1257095336949 .94256973267 51.7294998168953 .4843482971255 .2047309875556 .8885498046958 .53345108032 60.1374816894561 .6983413696363 .2142181396564 .6829833984466 .10301971436 67.4723663330168 .7896728515670 .0531768798871 .2618026733472 .41409301758 73.5091629028374 .5458602905375 .5235137939576 .4412765502977 .29865264893 78.0950622558678 .8302078247179 .5037307739380 .1155776977580 .66561889648 81.1540527343881 .5810165405381 .9470825195382 .2527313232482 .49889373779 82.6864166259882 .8166503906282 .8908462524482 .9106216430782 .87760162354 82.7937622070382 .6610336303782 .4820632934682 .2593231201281 .99671936035 81.6976394653381 .367332458581 .0102386474680 .6320800781280 .2357635498 79.8408508300879 .4653320312579 .0940093994178 .710243225178 .31056213379 77.8990707397577 .3529281616276 .5387725830175 .6308822631874 .7779006958 73.9992523193473 .3351669311572 .7766189575272 .3246612548871 .98243713379 71.7805709838971 .3165130615270 .1855926513768 .8020935058667 .57579040527 66.4383773803765 .3867492675864 .433868408263 .5873908996662 .85594177246 62.2914199829161 .7212409973160 .9801712036160 .237030029359 .5558013916 
58.9914016723658 .5493392944358 .1242218017657 .6123809814557 .13182067871 56.8042411804256 .5191688537656 .1917610168555 .8090782165555 .36172103882 54.8634414672954 .2891693115253 .6533889770552 .9821586608952 .29819107056 51.6433715820351 .0433616638250 .5047187805250 .0290298461949 .65135955811 49.2405815124548 .6558113098148 .0417594909747 .5399208068847 .08380889893 46.6264991760346 .2346382141145 .9700889587445 .7183113098145 .39060974121 44.9498291015644 .3612289428743 .6669006347742 .8631591796942 .12475967407 41.647178649941 .361610412641 .3054504394541 .2738418579141 .04671859741 40.7554016113340 .4578895568840 .190849304239 .9677314758339 .75848007202 39.5757293701239 .3132514953638 .904850006138 .4479789733938 .00852966309 37.5868606567437 .1815910339436 .7956085205136 .4386711120636 .140209198 35.9233894348135 .8265113830635 .8986282348636 .0108413696336 .05907821655 36.0251388549835 .8414802551335 .720279693635 .8700790405336 .05155181885 36.0231399536135 .8536796569835 .5565986633335 .1721687316934 .7495803833 34.4925117492734 .6496505737334 .9339599609435 .0550498962435 .17216110229 35.3703689575235 .5546188354535 .6543998718335 .6765098571835 .64213943481 35.5685386657735 .4225006103535 .4950218200736 .0654983520536 .84812164307 37.6247406005938 .3984489440939 .1240997314539 .8209800720240 .5068397522 40.9828186035240 .960941314740 .8615493774441 .1675300598141 .75220108032 42.642719268843 .7738685607944 .979358673146 .272048950247 .64287948608 48.8512115478549 .6376190185550 .3073005676351 .165180206352 .17023849487 53.3764495849654 .7282905578656 .1912803649957 .7411117553759 .32907104492 60.9482688903862 .5516891479564 .2520065307666 .1605300903368 .14457702637 70.0921630859471 .9962692260773 .8321609497175 .5902709960977 .25422668457 78.8275527954180 .2968368530381 .7717514038183 .2909469604584 .89343261719 86.6561965942488 .5282897949290 .5430068969792 .6006164550894 .59647369385 96.5180664062598 .2923507690499 .96383666992101 .5308990479103 .0218963623 104.5042037964105 .9769973755107 .4597015381108 .9602966309110 .4853973389 112.0429000854113 .6350021362115 .271697998116 .966796875118 .7157974243 120.5266036987122 .3681030273124 .2301025391126 .1029968262127 .9656982422 129.8278961182131 .68800354133 .5478973389135 .4291992188137 .3265991211 139.238494873141 .1717987061143 .1251983643145 .0955963135147 .0861968994 149.0856018066151 .0897979736153 .0906982422155 .0715942383157 .0283050537 158.9524993896160 .8518066406162 .7236022949164 .5915985107166 .4700012207 168.4087982178170 .4526062012172 .6047058105174 .9098968506177 .3390045166 179.8946990967182 .5742034912185 .3536071777188 .1983032227191 .0641937256 193.9454040527196 .8238983154199 .6947021484202 .5457000732205 .3748931885 208.1759033203210 .949005127213 .6925048828216 .4071044922219 .0932006836 221.750793457224 .3804016113226 .9815063477229 .553894043232 .0970001221 234.6103973389237 .0937957764239 .5466003418241 .9689025879244 .3603057861 246.721206665249 .0513000488251 .3511047363253 .620803833255 .8607025146 258.071105957260 .2525939941262 .4057006836264 .5309143066266 .628692627 268.6997070312270 .7445983887272 .763885498274 .7582092285276 .7280883789 278.6742858887280 .5972900391282 .4977111816284 .3760070801286 .233001709 288.0690002441289 .8847045898291 .6805114746293 .4572143555295 .2149047852 296.954498291298 .6762084961300 .3806152344302 .0681152344303 .7392883301 
305.3942871094307 .0338134766308 .6578979492310 .2673034668311 .8620910645 313.4426879883315 .0094909668316 .562713623318 .1026000977319 .6296081543 321.1437072754322 .6453857422324 .1348876953325 .6123962402327 .0781860352 328.532409668329 .975402832331 .4072875977332 .8284912109334 .2391052246 335.6393127441337 .0293884277338 .4096069336339 .780090332341 .1411132812 342.4927062988343 .8352050781345 .1684875488346 .4930114746347 .8085021973 349.1152038574350 .4132080078351 .7025146484352 .9831848145354 .2553100586 355.5191955566356 .7749938965358 .0179138184359 .2481994629 -38.6658210754 -36.6400985718 -34.6172485352 -32.6020317078 -30.592130661 -28.5871105194 -26.5864295959 -24.5896396637 -22.5961608887 -20.6054897308 $-18.6170101166-16.6301498413-14.6443099976-12.658829689-10.6731901169$ $-8.68667793274-6.69892120361-4.70920610428-2.71735811234-.722729980946$ 1.2746089696883 .2751719951635 .2786269187937 .2853059768689 .294622421265 11.3066902160613 .3206701278715 .3364295959517 .3528499603319 .36953926086 21.3850898742723 .3987808227525 .4089107513427 .4144401550329 .41341018677 31.4044494628933 .3854103088435 .3545989990237 .3097381591839 .24887084961 41.169639587443 .0698318481444 .9471015930246 .7990493774448 .62335968018 50.4174995422452 .1792488098153 .9060096740755 .5956802368257 .2456817627 58.8540496826260 .4182395935161 .9365310668963 .4065017700264 .82666015625 66.1947402954167 .5095596313568 .769111633369 .9724578857471 .11792755127 72.2048187255973 .2317581176874 .1982879638775 .103370666575 .94667816162 76.7274932861377 .4456329345778 .1006164550878 .6924591064579 .22091674805 79.6862716674880 .088447570880 .4281692504980 .705642700280 .92199707031 81.0778198242281 .1747283935581 .2136917114381 .1966781616281 .12510681152 81.0012435913180 .8268890380980 .6049880981480 .33789062580 .02986907959 79.6842727661179 .3068923950278 .9017486572378 .4761199951278 .02699279785 77.5854797363377 .1781921386776 .7858963012776 .384628295975 .98065185547 75.6260070800875 .1176528930774 .2240829467873 .2143478393672 .30603027344 71.4738388061570 .7552871704170 .1192169189569 .5581665039168 .99976348877 68.3850326538167 .6472930908266 .7158126831165 .6978607177764 .69106292725 63.6974601745662 .7160301208561 .7742195129460 .8971710205160 .12459945679 59.5600090026959 .0370216369658 .4039611816457 .7818717956557 .17361068726 56.637271881156 .1604881286655 .7229690551855 .3029899597254 .92073059082 54.618721008354 .3270683288654 .004051208553 .6403388977153 .21356964111 52.7047386169452 .0776901245151 .374439239550 .6694297790549 .91910171509 49.1399917602548 .3778190612847 .6911087036147 .1176300048846 .72750854492 46.314170837445 .6274604797444 .9173011779844 .4008903503443 .93743133545 43.4229316711442 .9695014953642 .6936187744142 .3873710632341 .86919021606 41.223079681440 .5239410400439 .7630805969238 .9576187133838 .26343917847 37.8135108947837 .5875282287637 .5544586181637 .5784683227537 .51321029663 37.36225128174 37.10470962524 36.7890586853 36.4569282531736.14965057373 35.9160995483435 .6869506835935 .4085998535235 .0754890441934 .68856048584 34.282360076933 .8894004821833 .5255012512233 .1925811767632 .91326904297 32.6861801147532 .5612602233932 .6440200805732 .7456016540532 .72780990601 32.5981712341332 .2343406677231 .9783992767332 .2220191955632 .54512023926 32.5957412719732 .4849700927732 .2168693542531 .8184509277331 .27176094055 
30.904430389431 .1548595428531 .5592002868731 .6795806884831 .80005073547 32.0877304077132 .3537101745632 .4765281677232 .4984893798832 .46162033081 32.3751907348632 .1462211608932 .1808891296432 .9337005615233 .92303085327 34.7892494201735 .5883293151936 .2872695922936 .8261413574237 .16691970825 37.3101882934637 .2715492248537 .3817481994637 .9149093627938 .79254150391 39.8857307434141 .1355209350642 .4373703002943 .8152198791545 .37762069702 46.7285499572847 .4301414489747 .9751091003448 .8319587707549 .84617996216 51.077850341852 .4510002136253 .9163284301855 .4551887512256 .9907913208 58.5367202758860 .0014801025461 .5690689086963 .4496688842865 .42504119873 67.332313537669 .1911926269570 .9794769287172 .6787796020574 .27899932861 75.7838821411177 .1869964599678 .5837631225680 .0304336547981 .66210174561 83.57427215576 85.69116973877 87.9414978027390.2188720703192.42378234863 94.4688568115296 .2732162475697 .8994216918999 .42185974121100 .8806991577 102.3399963379 103.8010025024 105.2878036499 106.8050994873108.3581008911 109.956703186111 .5995025635113 .297203064115 .0551986694116 .8712005615 118.7489013672120 .6607971191122 .5907974243124 .4946975708126 .3448028564 128.158493042129 .966293335131 .7774963379133 .6087036133135 .4591064453 137.3229064941 139.2079925537141.108505249 143.0231018066 144.9474029541 146.8791046143148 .8159942627150 .7539978027152 .6793060303154 .5924072266 156.4817962646158 .3509063721160 .1940002441162 .0395965576163 .9053039551 165.8303070068167 .8529052734169 .9678955078172 .2035064697174 .5491943359 177.0196990967179 .600402832182 .2626953125184 .9956970215187 .7705993652 190.5767974854193 .3925018311196 .2115936279199 .0202026367201 .8153076172 204.5895996094207 .3419036865210 .0700073242212 .7731933594215 .4517974854 218.1044006348220 .7317962646223 .3323974609225 .9062042236228 .4519042969 230.9691925049233 .4573059082235 .9158935547238 .3444061279240 .7429046631 243.1110992432245 .4492950439247 .7572937012250 .0355072021252 .2841033936 254.5036010742256 .6943054199258 .8566894531260 .99108886672263 .0983886719 265.178894043267 .2331848145269 .2619018555271 .2656860352273 .2449951172 275.2004089355277 .132598877279 .0421142578280 .9294128418282 .7951965332 284.6398925781286 .4642028809288 .2684020996290 .053314209291 .8190917969 293.5664978027295 .2958068848297 .0076904297298 .7023925781300 .3806152344 302.042388916303 .6885070801305 .3190917969306 .9346008301308 .5353088379 310.1217041016311 .6939086914313 .2524108887314 .7973937988316 .3291931152 317.8481140137319 .354309082320 .8479919434322 .3297119141323 .7992858887 325.2572937012326 .7037963867328 .1390991211329 .5635070801330 .9772033691 332.3804016113333 .7732849121335 .1561889648336 .529296875337 .8927001953 339.2467041016340.5914001465 341.9270019531343 .2535095215344 .571105957 345.8797912598347 .1796875348 .4708862305349 .7533874512351 .0274047852 352.2930908203353.5497131348354.799407959 356.0392150879 -39.5982894897 -37.5808486938 -35.5765991211 -33.5829200745 -31.594209671 $-29.6105098724-27.6312198639-25.6558303833-23.6836891174-21.7142391205$ $-19.7467803955-17.7806797028-15.8152198792-13.8496904373-11.8834199905$ $-9.91568183899-7.94590616226-5.97338914871-3.99774909019-2.01838111877$ -3.5135999e-02 1.952415943146 3.944166898727 5.940320014954 7.940511226654 9.94469642639211 .9522495269813 .96284961715 .975589752217 .98986053467 
20.0044193267822 .018350601224 .0300807952926 .0383300781228 .04125022888 30.0372104644832 .0241203308134 .0000495910635 .9627304077137 .90995025635 39.8393402099641 .7484893798843 .6349411010745 .4961318969747 .32960891724 49.1327209472750 .9030609130952 .637969970754 .3351402282755 .99192047119 57.606170654359 .1753387451260 .6974716186562 .1701583862363 .59170913696 64.9599304199266 .2733993530367 .5302200317468 .7292709350669 .86901092529 70.9485702514671 .9667434692472 .9228897094773 .8161468505974 .6460723877 75.4120788574276 .1138610839876 .7510681152377 .3235473632877 .83116912842 78.2739868164178 .652061462478 .9658432006879 .2156677246179 .40244293213 79.5269165039179 .5904464721779 .594306945879 .5402526855579 .43003845215 79.2657165527379 .049522399978 .7841033935578 .4721603393678 .11770629883 77.7244491577177 .2983779907276 .8448333740276 .3706970214875 .88065338135 75.3954925537174 .9348068237374 .4850463867274 .0302429199273 .57066345215 73.1158370971772 .5272369384871 .6666412353570 .6981201171969 .76986694336 68.8998870849668 .1235733032267 .4033966064566 .7568969726666 .03177642822 65.1226425170964 .1983032226663 .3172187805262 .5162696838461 .78681945801 61.0344505310160 .2078781127959 .3637084960958 .5495185852157 .80786132812 57.2026901245156 .6485404968356 .0454216003455 .4575614929254 .89804840088 54.3728904724153 .8971900939953 .4642295837453 .0767211914152 .73419189453 52.4295997619652 .1166381835951 .7792816162151 .4219703674351 .03327178955 50.520229339649 .7372398376548 .8899002075248 .2314910888747 .50825119019 46.5261917114345 .5120582580644 .6740303039643 .9863395690943 .45397949219 42.9263801574742 .2570495605541 .5839500427241 .0308189392140 .52365112305 39.9999389648439 .5242309570339 .1642189025938 .7690200805738 .23831176758 37.5932998657236 .8672714233436 .071571350135 .1301918029834 .33177947998 33.9478492736833 .8506698608433 .9954109191934 .2018585205134 .25714874268 34.1847686767633 .9494285583533 .569198608433 .0535011291532 .59838867188 32.4165916442932 .3290290832532 .1721191406231 .9396400451731 .58291053772 31.1775493621830 .7943897247330 .4669799804730 .2388496398930 .06464004517 29.8996200561529 .7964191436829 .8136901855529 .8389701843329 .77821922302 29.6292304992729 .3463096618729 .1641597747829 .304130554229 .51799964905 29.5636997222929 .4771804809629 .2470607757628 .9084796905528 .48204040527 28.2067604064928 .3469696044928 .6263904571528 .779779434228 .94351005554 29.2016201019329 .4451999664329 .5785694122329 .6350708007829 .64386940002 29.6297092437729 .5807209014929 .7696208953930 .4666805267331 .36844062805 32.2224006652833 .00349044833 .6772994995134 .1333503723134 .30992889404 34.2248001098633 .7578392028833 .6707382202134 .6532096862836 .06352996826 37.3698692321838 .6656494140639 .951728820841 .2645301818842 .65528869629 43.882118225144 .7063407897945 .429969787646 .3665504455647 .46794128418 48.7864913940450 .2312698364351 .7586784362853 .3266410827654 .83972167969 56.3337211608957 .7770500183159 .29645919861 .0501289367762 .89952850342 64.7340087890666 .536697387768 .2773132324269 .937637329171 .49722290039 72.9570236206174 .3061676025475 .5955886840876 .8149185180778 .32344818115 80.478103637782 .9355163574285 .4036483764687 .8851928710990 .3630065918 92.5913162231494 .3025665283295 .7681274414197 .2197494506898 .65077209473 100.100402832101 .5675964355103 .068901062104 .609703064106 .1989974976 
107.8411026001109 .5353012085111 .2882995605113 .1026992798114 .9788970947 116.9197998047118 .9125976562120 .9628982544122 .9501037598124 .7557983398 126.4910964966128 .2572937012130 .0397949219131 .8448944092133 .6674957275 135.5028991699137 .3520050049139 .2109985352141 .0765991211142 .9468994141 144.8202056885146 .6979980469148 .5776977539150 .4533996582152 .3267974854 154.1965026855156 .0446014404157 .8450012207159 .6479034424161 .4936981201 163.3997955322165 .3930053711167 .4691009521169 .6472015381171 .9237976074 174.3106994629176 .7922973633179 .3551025391181 .9862976074184 .6703033447 187.3952941895190 .1410980225192 .900100708195 .658203125198 .411605835 201.1513977051203 .8764038086206 .5821075439209 .2684020996211 .933303833 214.5764007568217 .196395874219 .7924957275222 .3632965088224 .908203125 227.4257965088229 .9156036377232 .3768005371234 .8090057373237 .211807251 239.5850982666241 .9286956787244 .2427978516246 .5274963379248 .7828979492 251.0093994141253 .2073059082255 .3771057129257 .5192871094259 .634185791 261.7225952148263 .7847900391265 .8215026855267 .8330993652269 .8204040527 271.7836914062273 .7237854004275 .6411132812277 .5361938477279 .4096069336 281.2619018555283 .0935058594284 .905090332286 .6971130371288 .469909668 290.2242126465291 .9602050781293 .6785888672295 .379699707297 .0639038086 298.7318115234300 .383605957302 .0198059082303 .6406860352305 .2467041016 306.8380126953308 .4151916504309 .978302002311 .5277099609313 .0638122559 314.5867919922316 .0968017578317 .5942993164319 .079498291320 .5524902344 322.0137939453323 .4632873535324 .9016113281326 .3288879395327 .7452087402 329.1509094238330 .5462036133331 .9313964844333 .3067016602334 .6723022461 336.0282897949337 .3749084473338 .712310791340 .0407104492341 .3599853516 342.6704101562343 .9719848633345 .2647094727346 .5487976074347 .8241882324 349.0914001465350 .3504943848351 .5964050293352 .8301086426 $-40.4824409485-38.4981689453-36.5168914795-34.5443382263-32.5776405334$ $-30.616109848-28.6590995789-26.7060394287-24.7561893463-22.8089504242$ $-20.8635292053-18.919210434-16.975189209-15.0306196213-13.0847902298$ -11.1367702484 -9.18599319458 -7.23150777817 -5.27298688889 -3.30954194069 -1.34114301205.6329500079155 2.612449884415 4.597876071936.588637828827 8.5850028991710 .5860795974712 .591859817514 .6011400222816 .61359024048 18.6276798248320 .6427097320622 .6567993164124 .6688804626526 .67678070068 28.678989410430 .673130035432 .6573295593334 .629039764436 .58605957031 38.5257606506340 .4456710815442 .3431091308644 .215408325246 .05995941162 47.8739089965849 .6547813415551 .3996391296453 .1061897277854 .7714805603 56.393421173157 .9691390991259 .4967803955160 .9735984802262 .39805984497 63.7676315307665 .0810928344766 .336219787667 .5321273803768 .66697692871 69.7401733398470 .7502365112371 .6968231201272 .578826904373 .3960723877 74.1478118896574 .8338928222775 .4538421630976 .0075988769576 .49491119385 76.9158401489377 .2702789306677 .5587081909277 .7811965942477 .93881225586 78.0319671630978 .0623321533278 .0308914184677 .9397430419977 .79049682617 77.5855484008877 .327148437577 .017990112376 .6609191894576 .25988769531 75.8184127807675 .3434829711974 .8403930664174 .3193206787173 .78955078125 73.2586898803772 .7360229492272 .2139968872171 .6849670410271 .13213348389 70.5323486328169 .8443908691469 .0438537597768 .1632537841867 .25421905518 
66.3476104736365 .4931716918964 .6841735839863 .9677581787163 .18490982056 62.1350097656261 .1020812988360 .2665290832559 .5833892822359 .04333114624 58.504600524957 .8262214660657 .0990982055756 .3809700012255 .68484115601 55.0523414611854 .4479789733953 .840541839653 .260601043752 .69166946411 52.1610183715851 .6638984680251 .2163200378450 .8375701904350 .48310852051 50.132110595749 .7798690795949 .4415817260749 .0594406127948 .64292144775 48.0489311218347 .0790596008346 .0790901184145 .4591407775944 .77265167236 43.6526794433642 .4804992675841 .5602416992240 .768978118940 .06259155273 39.4243698120138 .8079795837438 .2224807739337 .6496009826737 .10354995728 36.589420318636 .0937690734935 .620121002235 .1443099975634 .67211151123 34.1384506225633 .4855194091832 .7164192199731 .7014999389630 .84350013733 30.5278491973930 .5419692993230 .8260498046931 .165670394931 .292760849 31.2560501098631 .0363502502430 .6340599060130 .0041198730529 .44903945923 29.3326892852829 .3462104797429 .2642898559629 .103170394928 .7767791748 28.3938007354728 .0426692962627 .7582798004227 .6315002441427 .56059074402 27.4650497436527 .381000518827 .3278808593827 .2670707702627 .17797088623 27.0671997070326 .9464092254626 .8716106414826 .8804302215626 .91535949707 26.8980598449726 .8113098144526 .6244602203426 .3868808746326 .15905952454 26.0088806152326 .0166397094726 .126050949126 .2812526 .4710807800326 .66938018799 26.8512496948226 .9858798980727 .0865402221727 .1675605773927 .28086090088 27.4739398956327 .8254909515428 .4099502563529 .1259002685529 .89740943909 30.626470565831 .2807292938231 .7190799713131 .8839397430431 .75411987305 31.0228195190430 .7562103271532 .030830383333 .7839088439935 .12448120117 36.3570213317937 .5484199523938 .6779708862339 .7724990844740 .79832839966 41.7562294006342 .7095298767143 .7980308532745 .0238304138246 .46530151367 48.0481491088949 .7069091796951 .3402709960952 .8335800170954 .26512145996 55.6990585327157 .1956710815458 .8197402954160 .5233116149962 .27238082886 64.0195083618265 .7248229980567 .3604202270568 .9057388305770 .34979248047 71.6760177612372 .9317092895573 .987716674875 .388816833577 .70725250244 80.3820037841882 .9483337402385 .5224533081188 .1749572753990 .52380371094 92.1560363769593 .5000228881894 .9260482788196 .3436431884897 .7963180542 99.28119659424100 .8076019287102 .3840026855104 .0142974854105 .7053985596 107.4475021362109 .251701355111 .1143035889113 .0410003662115 .033996582 117.0821990967119 .2291030884121 .2925033569123 .0807037354124 .7781982422 126.5458984375128 .3289031982130 .1298065186131 .9472045898133 .7655029297 135.592300415137 .4152984619139 .2393951416141 .06300354142 .8876037598 144.713104248146 .5417938232148 .3695068359150 .2015075684152 .0449981689 153.8697052002155 .6269073486157 .3896942139159 .2127990723161 .0941925049 163.0541992188165 .0919036865167 .2221984863169 .4407043457171 .7496948242 174.1407012939176 .6094055176179 .1461029053181 .7404022217184 .3825073242 187.0534973145189 .7478027344192 .4496002197195 .1555938721197 .8551940918 200.5469055176203 .2252044678205 .8890075684208 .5357971191211 .1643066406 213.7729949951216 .3603057861218 .9248046875221 .4649963379223 .9799041748 226.4682006836228 .9293060303231 .3623962402233 .766998291236 .1428985596 238.4898071289240 .8076019287243 .0966033936245 .3567962646247 .588394165 249.7917022705251 .9671936035254 .1150970459256 .2362060547258 .3306884766 
260.3992919922262 .4422912598264 .4605102539266 .4541931152268 .4241027832 270.3706970215272 .2945861816274 .196105957276 .0759887695277 .9346008301 279.7726135254281 .5903930664283 .3884887695285 .1672973633286 .9273986816 288.6691894531290 .3931884766292 .0997009277293 .7893066406295 .4621887207 297.1191101074298.7601013184300.3857116699301.99609375 303.591796875 305.1730957031306 .7402038574308 .2934875488309 .833190918311 .359588623 312.8731079102314 .3736877441315 .861907959317 .337890625318 .8017883301 320.2540893555321 .6948852539323 .1243896484324 .5429992676325 .9508056641 327.3482055664328 .7352905273330 .1123962402331 .4797058105332 .8374023438 334.1856079102335 .524597168336 .8544921875338 .175201416339 .4869995117 340.7897949219342 .0838928223343 .3692016602344 .645904541345 .9143066406 347.173614502348 .425994873349 .6683959961 -41.3719902039 -39.3959693909 -37.4345817566 -35.4853096008 -33.5415611267 -31.6031703949 -29.6694602966 -27.7397708893 -25.8132991791 -23.8894004822 $-21.9671592712-20.0457992554-18.124370575-16.2019805908-14.2777099609$ $-12.3506002426-10.419839859-8.48449420929-6.54396390915-4.59740304947$ $-2.64450907707-0.684639990331 .2821969985963 .2563738822945 .237574100494$ 7.2258710861219 .22063732147211 .2216396331813 .2279100418115 .23888015747 17.2532196044919 .2699794769321 .2874603271523 .3042793273925 .31841087341 27.3280696868929 .3309307098431 .324850082433 .3072700500535 .27574920654 37.2275810241739 .1600799560541 .070449829142 .9558105468844 .81338882446 46.6401901245148 .4335098266650 .1903381347751 .9081115722753 .5838394165 55.2151718139656 .799251556458 .3339309692459 .816539764461 .2452507019 62.6176300048863 .9322090148965 .1868896484466 .3805694580167 .5115737915 68.5791168212969 .5819396972770 .5195388793971 .391036987372 .19611358643 72.9342117309673 .605056762774 .2083663940474 .7438964843875 .21148681641 75.6110000610475 .9423675537176 .2057876586976 .4013977050876 .52996826172 76.592071533276 .5891265869176 .5224227905376 .3938674926876 .20543670654 75.9595108032275 .6587066650475 .3056335449274 .9033889770574 .4556427002 73.9663467407273 .4421234130972 .888526916572 .3168869018671 .73787689209 71.1507034301870 .5631408691469 .9652328491269 .3562164306668 .71830749512 68.0336837768667 .3038330078166 .5182037353565 .6820831298864 .79637145996 63.8660202026462 .9000816345261 .9975891113361 .2934608459560 .57522964478 59.6399497985858 .7140998840357 .9403305053757 .3029212951756 .77125930786 56.2464599609455 .6199302673354 .9524002075254 .2783317565953 .60548019409 52.9707794189552 .3409881591851 .7219009399451 .1208610534750 .49866104126 49.9061584472749 .3604011535648 .8754615783748 .5020599365248 .12913131714 47.6524505615247 .1974487304746 .9138603210446 .5383911132845 .83029174805 44.910289764443 .8395881652842 .8038711547942 .0448112487841 .26612854004 40.2557296752939 .2130012512238 .3183288574237 .4967384338436 .69557952881 35.9936790466335 .4575004577634 .9687385559134 .3828811645533 .80574035645 33.3387985229532 .8607902526932 .2552795410231 .6967391967831 .35486984253 31.026779174830 .5170097351129 .8742809295729 .0781402587928 .40900039673 28.1285800933828 .1268005371128 .343259811428 .6068191528328 .72590065002 28.7050094604528 .5081405639628 .1534996032727 .6365394592327 .17907905579 27.0079593658426 .950399398826 .855539321926 .7042007446326 .43807029724 
26.131769180325 .8414592742925 .6108608245825 .4900798797625 .41880989075 25.3420200347925 .2580299377425 .1795196533225 .0930004119924 .99159049988 24.9099292755124 .845569610624 .7886600494424 .7612094879224 .72483062744 24.6675891876224 .586219787624 .4304103851324 .2652606964124 .12542915344 24.0167007446323 .9957504272524 .0413894653324 .163089752224 .33230018616 24.4999008178724 .6577301025424 .7932796478324 .9333000183125 .07563018799 25.2825202941925 .5881309509325 .9927291870126 .5486507415827 .18523025513 27.8895206451428 .5975208282529 .2359504699729 .7336006164630 .03775978088 30.0968799591129 .8108501434329 .8705806732230 .8503494262732 .17779159546 33.2875099182134 .2760200500535 .2433586120636 .1589508056637 .02119827271 37.9173889160238 .849891662639 .8861389160241 .10073089642 .47129058838 44.0686302185145 .8495101928747 .7780990600649 .5881805419950 .98683929443 52.2578392028853 .6282997131355 .0740394592356 .6345291137758 .2653503418 59.956748962461 .6693000793563 .3546104431264 .9883499145566 .54183959961 68.0090179443469 .372489929270 .6812667846771 .9203567504973 .45485687256 75.6351089477578 .1212234497180 .6129608154383 .1165237426885 .61679077148 87.8601913452189 .580642700291 .0483093261792 .5021133422993 .94432830811 95.4171066284296 .923973083598 .49067687988100 .1122970581101 .7931976318 103.5351028442105 .3273010254107 .1761016846109 .0815963745111 .0447006226 113.0670013428115 .1376037598117 .2627029419119 .3195037842121 .1901016235 122.9831008911124 .8022003174126 .6240997314128 .4483032227130 .2738952637 132.0948028564133 .9093017578135 .7075958252137 .4951019287139 .278793335 141.0585021973142 .8381958008144 .6181945801146 .3988037109148 .1824035645 149.9714050293151 .746307373153 .4824066162155 .2304992676157 .032699585 158.8896942139160 .8202056885162 .8229064941164 .908996582167 .0731964111 169.3094940186171 .6156005859173 .9971008301176 .4449005127178 .9546051025 181.5157012939184 .1139984131186 .7420959473189 .3858947754192 .040802002 194.6965026855197 .350692749199 .9969940186202 .6340942383205 .2584075928 207.8683929443210 .4615936279213 .036605835215 .5908966064218 .1233978271 220.6320037842223 .116104126225 .5738983154228 .0052947998230 .408996582 232.7850952148235 .1327972412237 .4523010254239 .7433929443242 .0063018799 244.2409057617246 .4477996826248 .6271057129250 .7792053223252 .9044952393 255.0036010742257 .0769042969259 .124786377261 .1478881836263 .1467895508 265.1217956543267 .0736083984269 .0025939941270 .9093933105272 .7944946289 274.6583862305276 .5014953613278 .3243103027280 .1275024414281 .9112854004 283.6763000488285 .4229125977287 .1514892578288 .8626098633290 .5566101074 292.23388667188293 .8948974609295 .5400085449297 .1694946289298 .7836914062 300.3830871582301 .9677124023303 .5382080078305 .0946960449306 .637512207 308.166809082309 .683013916311 .1863098145312 .6770935059314 .1553955078 315.6216125488317 .0759887695318 .5187988281319 .9501953125321 .3706054688 322.7802124023324 .179107666325 .5678100586326 .9464111328328 .3150939941 329.6741027832331 .0235900879332 .3638000488333 .6947937012335 .0166931152 336.329498291337 .633392334338 .9284973145340 .2148132324341 .4924926758 342.7618103027344 .0230102539345 .2709960938346 .5068054199 $-42.2058181763-40.2664299011-38.3302192688-36.4040489197-34.4844017029$ $-32.570350647-30.6611499786-28.7560901642-26.854309082-24.9550800323$ 
-23.057390213 -21.1603603363 -19.262960434 -17.3640995026 -15.4628200531 $-13.5579004288-11.6485395432-9.7334728241-7.81217193604-5.8834400177$ -3.9471039772 -2.00215005875 -4.8781998e-02 1.913745045662 3.884860038757 5.865001201637 .8532447814949 .84970188140911 .8530797958413 .86312961578 15.8781700134317 .8975391387919 .919149398821 .9418907165523 .96334075928 25.9818992614727 .9948501586930 .0001792907731 .9949607849133 .97679901123 35.9426498413137 .8897781372139 .8151283264241 .7156906127943 .58845901489 45.430240631147 .2382202148449 .0090789794950 .7402114868252 .42831039429 54.0710601806655 .6652297973657 .2088088989358 .6986999511760 .13328170776 61.5097198486362 .8267898559664 .0820083618265 .2745819091866 .40245819092 67.4652328491268 .4613189697369 .3905715942470 .2518997192471 .04527282715 71.7699890136772 .4260101318473 .0129470825273 .5306396484473 .97884368896 74.3573684692474 .6660079956174 .9048690795975 .0738372802775 .17372131348 75.2047805786175 .1687011718875 .0664901733474 .9004669189574 .67252349854 74.3854064941474 .0419998168973 .644943237373 .1979827880972 .70413208008 72.1683197021571 .5956268310570 .9912872314570 .366912841869 .73442077637 69.0890731811568 .4400863647567 .7717437744167 .0895767211966 .37616729736 65.6210327148464 .8553466796964 .0857391357463 .2901191711462 .43711853027 61.5156784057660 .4850883483959 .519248962458 .8433494567958 .2204208374 57.4513397216856 .6899909973155 .9784507751555 .3299598693854 .73471832275 54.1437988281253 .5126190185552 .8600196838452 .1851806640651 .50634002686 50.8586997985850 .2246284484949 .624019622848 .9954910278348 .28438186646 47.5681686401446 .9155883789146 .350170135545 .926620483445 .50075912476 44.8971900939944 .3177795410244 .0554008483943 .6500701904342 .65253829956 41.4453697204640 .3339385986339 .2807998657238 .3654212951737 .53210067749 36.7189102172935 .9205703735435 .1292991638234 .3477592468333 .53438949585 32.8289413452132 .3807296752931 .9756107330331 .3878097534230 .80221939087 30.3916397094729 .9580802917529 .2829799652128 .6812496185328 .4693107605 28.3143291473427 .9337806701727 .4711608886726 .9702892303526 .54401016235 26.3108806610126.23776054382 26.3125 26.43107032776 26.4941997528126.46587944031 26.2982196807926 .0288200378425 .6975803375225 .3772506713925 .14608955383 24.9704303741524 .8157806396524 .653669357324 .4488506317124 .22805023193 24.0126800537123 .8250102996823 .6859893798823 .5776100158723 .49175071716 23.4073104858423.32571029663 23.24179077148 23.1524696350123.08016014099 23.0285396575922 .9788398742722 .9318504333522 .873600006122 .80463981628 22.7245407104522 .5956001281722 .4691200256322 .3709106445322 .29500961304 22.2713508606 22.29528045654 22.3896598815922.5251407623322.66186904907 22.8092098236122 .9551296234123 .1278495788623 .3213195800823 .58164978027 23.9325599670424 .3602008819624 .8911590576225 .4829406738326 .14226913452 26.8151397705127 .4392395019528 .0129508972228 .4998302459728 .95285987854 29.3811607360829 .8409595489530 .3703594207830 .9521598815931 .60947036743 32.2960815429733 .0254287719733 .7512817382834 .4429817199735 .18743896484 36.0123291015637 .0476112365738 .3623504638739 .9204483032241 .69353103638 43.6207695007345 .7577705383347 .7168998718349 .0536117553750 .21260070801 51.5552711486852 .9712181091354 .4967002868756 .0959510803257 .7579498291 59.4514198303261 .1334991455162 .7851104736364 .37387847965 .89777374268 
67.3338317871168 .7776565551870 .2760467529371 .9622802734473 .9236831665 76.0864334106478 .3809661865280 .7001419067482 .9391326904385 .01313018799 86.840263366788 .4824981689590 .017013549891 .4948272705192 .99127960205 94.5295486450296 .1457366943497 .8299179077199 .56709289551101 .3584976196 103.1930007935105 .0786972046107 .0160980225109 .0029983521111 .0404968262 113.103302002115 .1744995117117 .2119979858119 .1885986328121 .1175994873 123.0311965942124 .9198989868126 .7910995483128 .6468963623130 .4772033691 132.2875061035134 .0644989014135 .820098877137 .5691070557139 .3112945557 141.0507965088142 .7891998291144 .5249938965146 .2597961426147 .9878997803 149.7127075195151 .4311065674153 .1667938232154 .9438934326156 .7760009766 158.6815948486160 .6600036621162 .7041015625164 .8099975586166 .9741973877 169.1974029541171 .4983062744173 .8652038574176 .2962036133178 .7823028564 181.3097991943183 .8730926514186 .4575042725189 .0599060059191 .6687011719 194.2821960449196 .8930053711199 .4996948242202 .0977935791204 .6856994629 207.2599945068209 .8190002441212 .3601074219214 .8815002441217 .3811950684 219.8578033447222 .3099975586224 .7368011475227 .137298584229 .5110015869 231.8574066162234 .1763000488236 .4674072266238 .7308959961240 .9667053223 243.1750946045245 .3563995361247 .5108947754249 .6389007568251 .7407989502 253.817199707255 .8684997559257 .895111084259 .8974914551261 .8764038086 263.8320007324265 .7650146484267 .6756896973269 .5647888184271 .4327087402 273.2799072266275 .1068115234276 .9139099121278 .7015991211280 .4706115723 282.2208862305283 .9533996582285 .6682128906287 .365814209289 .0465087891 290.7109069824292 .3591918945293 .9919128418295 .6091918945297 .2114868164 298.7990112305300 .3721923828301 .9312133789303 .4764099121305 .0080871582 306.5266113281308 .0320129395309 .5246887207311 .0049133301312 .4729003906 313.9289855957315 .3734130859316 .8063049316318 .2280883789319 .638885498 321.0392150879322 .4289855957323 .8086853027325 .1784057617326 .5385131836 327.888885498329 .229888916330 .561706543331 .8843994141333 .1979980469 334.5026855469335 .7984924316337 .0855102539338 .3638916016339 .6339111328 340.8948059082342 .1487121582343 .3926086426 $-43.045009613-41.1141891479-39.1998291016-37.299369812-35.405128479$ -33.5167617798 -31.6334590912 -29.7544708252 -27.8788299561 -26.0057601929 $-24.1341400146-22.263010025-20.3911399841-18.5174102783-16.6405906677$ $-14.7594099045-12.8727998734-10.979470253-9.07857036591-7.1689491272$ $-5.25009822845-3.32110905647-1.38184905052 .56825697422032 .528970956802$ 4.5005030632026 .4822487831128 .47404766082810 .4749097824112 .48427009583 14.5007200241116 .5232791900618 .550079345720 .5796699523922 .609790802 24.6384906768826 .6631793975828 .6814804077130 .6905193328932 .68753051758 34.6694793701236 .6333007812538 .5758209228540 .4937896728542 .38399887085 44.2430610656746 .0678901672447 .855049133349 .6016502380451 .30429077148 52.9603691101154 .5666389465356 .1207618713457 .6197395324759 .06158065796 60.4436111450261 .7642707824763 .0212783813564 .2135467529365 .3392791748 66.39781188965 67.38787841797 68.30912017822 69.16075897217 69.94262695312 70.6543426513771 .2957077026471 .8665771484472 .3666534423872 .79580688477 73.1536331176873 .4399108886773 .6544799804773 .797157287673 .86847686768 73.8687591552773 .7994689941473 .661827087473 .4581069946373 .19058227539 
72.8622131347772 .4761734008872 .0355224609471 .544357299871 .00553894043 70.4238891601669 .8029174804769 .1474990844768 .4709701538167 .78489685059 67.0873031616266 .3893814086965 .6713333129964 .9329223632864 .154296875 63.3022193908762 .4767494201761 .7633781433161 .0585594177260 .26586151123 59.398578643858 .4500007629457 .5478782653856 .8243408203156 .16807937622 55.4521293640154 .7436904907254 .0656089782753 .4012107849152 .7861289978 52.1625785827651 .4977188110450 .8163909912150 .077850341849 .33586883545 48.6390190124547 .9963912963947 .4883384704646 .8971900939946 .00497817993 45.0450210571344 .2116088867243 .4860382080142 .8808517456142 .29590988159 41.643550872841 .0213699340840 .5816383361840 .0130386352539 .03062820435 37.8678512573236 .7025413513235 .6010208129934 .6697502136233 .91273117065 33.3309783935532 .7882003784232 .109939575231 .4005908966130 .75752067566 30.2099494934129 .7972393035929 .4040393829328 .8997993469228 .39524078369 27.987520217927 .5658893585227 .0127105712926 .5302791595526 .29939079285 26.1322402954125 .8360691070625 .5070705413825 .1701507568424 .87462997437 24.6985607147224 .5931301116924 .5949497222924 .6336307525624 .64137077332 24.6004600524924 .4487209320124 .2409896850623 .9955692291323 .73208999634 23.5038890838623 .2887306213423 .1071796417222 .9468994140622 .77047920227 22.5947399139422 .4247398376522 .2630691528322 .1322994232222 .01890945435 21.9218902587921 .8350391387921 .7524890899721 .6727695465121 .59439086914 21.5289306640621 .4829597473121 .4362697601321 .3813991546621 .31520080566 21.2413997650121 .1617794036921 .0605697631820 .9655990600620 .89419937134 20.8414096832320 .8241004943820 .8426609039320 .9164104461721 .0249004364 21.1455192565921 .2856197357221 .4385700225821 .6256904602121 .84917068481 22.1351509094222 .5038890838622 .9370193481423 .4431591033924 .00222015381 24.6163101196325 .2594890594525 .8872604370126 .5408401489327 .20004081726 28.015420913729 .1046104431229 .9198703765930 .0016994476329 .85996055603 30.0617294311530 .4601898193430 .9658508300831 .5255508422932 .07764053345 32.6618881225633 .2380409240734 .1276206970235 .6307907104537 .45362854004 39.3505706787141 .3294181823743 .3895492553745 .2808609008846 .74110031128 48.0416297912649 .4237899780350 .8616905212452 .3902587890653 .98405075073 55.644390106257 .3440208435159 .0545387268160 .7561912536662 .41847991943 64.0296173095765 .5670928955167 .1239471435568 .7216720581170 .40086364746 72.2379226684674 .1777877807676 .2581329345778 .3763809204180 .41998291016 82.3836898803784 .1972427368285 .9005432128987 .4900436401489 .00457000732 90.5122680664192 .0759506225693 .7725067138795 .5449676513797 .34397125244 99.17938232422101 .048500061102 .9586029053104 .9144973755106 .912399292 108.9549026489111 .0142974854113 .0776977539115 .1410980225117 .1838989258 119.2135009766121 .2268981934123 .2015991211125 .1463012695127 .0539016724 128.9031066895130 .7098999023132 .4714050293134 .1976928711135 .9154052734 137.6237945557139 .3285064697141 .0290985107142 .7261962891144 .4181976318 146.1044006348147 .7929992676149 .4862976074151 .1959991455152 .9275970459 154.7185974121156 .6248931885158 .6024932861160 .603302002162 .6450042725 164.7326049805166 .8722991943169 .0937042236171 .3856964111173 .7449951172 176.161895752178 .62449646181 .1257019043183 .6533966064186 .2030029297 188.7646942139191 .3356018066193 .9089050293196 .4824981689199 .0516052246 
201.6143035889204 .1667022705206 .7068939209209 .2315979004211 .7391967773 214.2268981934216 .6936950684219 .137298584221 .5572052002223 .9517974854 226.3209991455228 .6636047363230 .979598999233 .2686004639235 .5307006836 237.7657012939239 .9738006592242 .1551971436244 .3101959229246 .4391021729 248.5424041748250 .620300293252 .6732940674254 .7019042969256 .7066040039 258.687713623260 .645904541262 .5815124512264 .4949951172266 .3869018555 268.2576904297270 .1076965332271 .9375273 .7475891113275 .5382995605277 .3100891113 279.0633850098280 .798614502282 .516204834284 .2166137695285 .8999938965 287.566986084289 .2178039551290 .8529052734292 .4725952148294 .0770874023 295.666809082297 .2420043945298 .8030090332300 .3500976562301 .883605957 303.4036865234304 .9107055664306 .4049072266307 .886505127309 .3558044434 310.8131103516312 .258605957313 .6925964355315 .1153869629316 .5270996094 317.9281921387319 .3187866211320 .6993103027322 .0697021484323 .4303894043 324.7814025879326 .1229858398327 .455291748328 .778503418330 .092590332 331.3977966309332 .6940917969333 .9815063477335 .2603149414336 .5307006836 337.7929992676339 .0419006348340 .2788085938 $-43.819568634-41.9300308228-40.0438995361-38.1693000793-36.3020095825$ -34.4408988953 -32.5851097107 -30.7338409424 -28.8860397339 -27.0408592224 -25.1970596313 -23.3535499573 -21.5090198517 -19.6620998383 -17.8115196228 -15.9556999207 -14.0935401917-12.2233800888 -10.3444499969-8.45516014099 $-6.55514383316-4.64305782318-2.71898293495-.7819089889531 .167642951012$ 3.1303110122685 .1051487922677 .0924072265629 .09070587158211 .09988021851 13.118089675915 .1447000503517 .1774196624819 .2150802612321 .25497055054 23.29538917542 25.33326911926 27.3664093017629.39147949219 31.40579986572 33.4059104919435 .3887405395537 .3507385253939 .2885284423841 .19863891602 43.0774116516144 .921600341846 .7274093627948 .491909027150 .21128082275 51.8829689025953 .5032501220755 .0699806213456 .5796508789158 .03054046631 59.4194297790560 .7451286315962 .0048484802263 .1979103088464 .32206726074 65.3771362304766 .3614196777367 .2750930786168 .117042541568 .88758850098 69.5861129760770 .2128067016670 .767440795971 .2498397827171 .65989685059 71.9970626831172 .2610931396572 .4515609741272 .5680694580172 .61109924316 72.5805892944372 .4782562255972 .3050537109472 .0636672973671 .75644683838 71.3865966796970 .9576110839870 .4732818603569 .9386367797969 .35590362549 68.7319488525468 .0659027099667 .3652267456166 .6366195678765 .89389801025 65.1453475952164 .4076538085963 .6594200134362 .8900909423862 .07983016968 61.1642684936560 .2938385009859 .6203498840358 .9805297851658 .23366165161 57.4366493225156 .6099586486855 .7944602966355 .0146903991754 .28247070312 53.5540885925352 .8357391357452 .1209907531751 .4202995300350 .78973007202 50.1567993164149 .4810714721748 .7325210571347 .8852996826247 .02534866333 46.2468109130945 .5654792785645 .1118011474644 .5507392883343 .51152038574 42.3611297607441 .3834495544440 .4794807434139 .6514282226638 .89097976685 38.1983108520537 .5510101318436 .9298400878936 .2219390869135 .33620071411 34.3382110595733 .2300300598132 .1842193603531 .3335704803530 .68055915833 30.2959995269829 .955839157129 .3784503936828 .7826404571528 .35399055481 27.9777202606227 .5895996093827 .1998996734626 .7921009063726 .38093948364 25.9817695617725 .5907592773425 .2049903869624 .8654708862324 .59413909912 
24.3638095855724.10880088806 23.8635597229 23.6235504150423.4070892334 23.2605590820323 .148500442523 .1104106903123 .0918693542523 .05771064758 22.9965591430722 .8558006286622 .6799297332822 .4765090942422 .25141906738 22.0327892303521 .818010330221 .6341800689721 .4719905853321 .31139945984 21.1598606109621 .0159206390420 .8801708221420 .7632503509520 .65456008911 20.555589675920 .4665203094520 .3881702423120 .3178005218520 .25198936462 20.1942806243920 .1500091552720 .1059608459520 .0530891418519 .99167060852 19.9210491180419 .8485603332519 .7691497802719 .6982898712219 .64619064331 19.6126995086719 .6111392974919 .6379909515419 .7017498016419 .79523086548 19.9066600799620 .0452098846420 .2013492584220 .3965301513720 .62882041931 20.9184703826921 .2800598144521 .6994209289622 .1799602508522 .71040916443 23.2853507995623 .909669876124 .5443801879925 .2662391662626 .04791069031 27.0166702270528 .4581794738829 .529 .226150512728 .6021709442128 .55191993713 28.7160205841129 .0422801971429 .4890308380129 .9425506591830 .44593048096 30.8301792144831 .5848808288633 .2072792053235 .186798095737 .10609054565 39.0377197265640 .9244804382342 .6945381164644 .2978401184145 .79272079468 47.26652908325 48.7470703125 50.3049697876 51.9175605773953.59848022461 55.3264808654857 .0777702331558 .8444404602160 .5913200378462 .3221282959 63.9967498779365 .6414031982467 .2542037963968 .8686676025470 .56968688965 72.3385467529374 .226142883376 .1512832641678 .0261001586979 .87164306641 81.6393585205183 .3428192138784 .9653625488386 .5340881347788 .07850646973 89.682899475191.4560012817493.3034667968895.1473388671997.01647949219 98.9087600708100 .831703186102 .7941970825104 .790802002106 .8293991089 108.8897018433110 .964302063113 .0551986694115 .1549987793117 .2610015869 119.3646011353121 .4452972412123 .4972991943125 .4745025635127 .3468017578 129.1392974854130 .8822937012132 .5926971436134 .2904052734135 .9772033691 137.6549072266139 .3262023926140 .9893035889142 .6477966309144 .3007049561 145.9589996338147 .625793457149 .31199646151 .0019989014152 .7657928467 154.6820068359156 .649597168158 .5890960693160 .5429992676162 .5484008789 164.6134033203166 .7671051025168 .9958953857171 .2922058105173 .6479949951 176.050201416178 .4938049316180 .9662017822183 .4645996094185 .978302002 188.5057983398191 .0397033691193 .5782012939196 .1159973145198 .6510009766 201.178894043203 .6976013184206 .2033996582208 .6943969727211 .1676940918 213.6217956543216 .0545959473218 .4649963379220 .8515014648223 .2136993408 225.5503997803227 .8614044189230 .1463012695232 .4049072266234 .6371002197 236.8430023193239 .0227050781241 .1764984131243 .3047027588245 .4075012207 247.4853057861249 .5386047363251 .5677947998253 .5731964111255 .5554046631 257.5147094727259 .4516906738261 .366607666263 .2601928711265 .132598877 266.9844970703268 .816192627270 .628112793272 .4206848145274 .19448855254 275.9497070312277 .6870117188279 .4064941406281 .1087036133282 .7940063477 284.462890625286 .1155090332287 .7522888184289 .3735961914290 .9796142578 292.570892334294 .1476135254295 .7098999023297 .2583007812298 .7929992676 300.3142089844301 .8222961426303 .3174133301304 .799987793306 .270111084 307.7280883789309 .174407959310 .6090087891312 .0322875977313 .4447021484 314.8463134766316 .2373046875317 .6181945801318 .9890136719320 .3499145508 321.7012023926323 .0430908203324 .3756103516325 .699005127327 .0133056641 
328.3186950684329 .6151123047330 .9028015137332 .1817016602333 .4522094727 334.7135925293335 .9679870605337 .2124023438 $-44.5997390747-42.719581604-40.8580818176-39.0124511719-37.1738395691$ $-35.3417510986-33.5152893066-31.6935806274-29.8754997253-28.0601005554$ $-26.2460193634-24.4320697784-22.6167392731-20.7985801697-18.976020813$ $-17.1474399567-15.3113899231-13.4661998749-11.6106796265-9.74331283569$ $-7.86332082748-5.96947097778-4.06145000458-2.13843607903-.200555995107$ 1.7525680065163 .7203710079195 .7027859687817 .6987957954419 .707872390747 11.7285099029513 .7596797943115 .7993698120117 .8460197448719 .89710998535 21.9505500793524 .0034008026126 .0530490875228 .0962295532230 .12986946106 32.1504592895534 .1545600891136 .138530731238 .0986213684140 .03116989136 41.9322395324743 .7982902526945 .6253509521547 .4101104736349 .14868164062 50.8380889892652 .4746589660654 .05580902155 .5781517028857 .03952026367 58.4369316101159 .7687416076761 .0324516296462 .2269897460963 .35047149658 64.4023666381865 .3814086914166 .2875137329167 .1199569702167 .87893676758 68.5642166137769 .175926208569 .7141189575270 .1785888671970 .56936645508 70.8858032226671 .1276092529371 .2940368652371 .3845596313571 .39936828613 71.3383789062571 .2030868530370 .994560241770 .7155685424870 .36892700195 69.9577178955169 .4853286743268 .9575576782268 .3807525634867 .75791168213 67.0950927734466 .3906936645565 .6523971557664 .8785476684664 .06722259521 63.2604293823262 .5021896362361 .7530288696360 .9878311157260 .18843841553 59.3173294067458 .481441497857 .7720985412657 .0976295471256 .3670501709 55.606998443654 .8220710754454 .0194091796953 .2135200500552 .430809021 51.6845512390150 .9253501892150 .0797805786149 .2669105529848 .6393699646 48.0482406616247 .4000892639246 .6086997985845 .5619812011744 .48480987549 43.5894699096742 .827430725142 .2281112670941 .5503807067940 .56362915039 39.4699096679738 .4457588195837 .4342193603536 .4209213256835 .49615097046 34.7419204711934 .079238891633 .4569702148432 .7810401916531 .91620063782 31.0277805328430 .208839416529 .4581604003928 .7927093505928 .26684951782 27.92288970947 27.6149597168 27.16826057434 26.7197608947826.37265014648 26.0513305664125 .7117500305225 .3646202087425 .0187797546424 .67288970947 24.3204402923623 .9852600097723 .6815299987823 .4009609222423 .14736938477 22.9074401855522 .6764202117922 .473770141622 .279850006122 .10125923157 21.9606494903621 .8403491973921 .7672500610421 .7070598602321 .6408290863 21.5582695007321 .4264602661121 .2704200744621 .0917797088620 .89110946655 20.6833000183120 .4755096435520 .2919902801520 .1297893524219 .98760986328 19.8577308654819 .7392692565919 .6304092407219 .529159545919 .43032073975 19.3387603759819 .2560997009319 .1846809387219 .1241493225119 .07579040527 19.0319595336918 .9962196350118 .9601402282718 .9125003814718 .85598945618 18.7924900054918 .7295703887918 .6730403900118 .6269702911418 .60046005249 18.5922603607218 .608680725118 .6473999023418 .7122707366918 .8000793457 18.9078693389919 .0416107177719 .2004508972219 .3950901031519 .6299495697 19.91323089620 .2546100616520 .6464195251521 .089279174821 .57811927795 22.1089496612522 .6899604797423 .3069496154824 .0011692047124 .76392936707 25.6526298522926 .7598209381127 .5133991241527 .3668498992926 .92328071594 26.8306598663326 .9304790496827 .2106895446827 .6245002746628 .07696914673 
28.5886993408229 .1056308746329 .9486293792731 .4228191375733 .21067047119 35.0357284545936 .8615608215338 .628341674840 .3458099365241 .96607971191 43.5402908325245 .0811691284246 .6157302856448 .2184486389249 .87382888794 51.5964393615753 .3682212829655 .1681594848656 .995391845758 .826171875 60.6723709106462 .5422782897964 .3166427612365 .8607406616267 .33197021484 68.9023132324270 .5329818725672 .2549972534274 .0117416381875 .74683380127 77.48226165771 79.18668365479 80.8694229126 82.52335357666 84.157371521 85.7889404296987 .4777297973689 .2781066894591 .1357192993293 .00090789795 94.8842926025496 .7855987548898 .7126083374100 .672203064102 .664100647 104.693901062106 .7535018921108 .8391036987110 .9554977417113 .0985031128 115.2667999268117 .4511032104119 .6430969238121 .8520965576123 .9489974976 125.8047027588127 .5426025391129 .2698059082130 .9757995605132 .6696929932 134.3486938477136 .0131988525137 .6645050049139 .3034057617140 .9344024658 142.5610046387144 .1932983398145 .8388977051147 .5083007812149 .2046966553 150.9826965332152 .908203125154 .8484039307156 .6685028076158 .4835968018 160.4013977051162 .4028015137164 .5001983643166 .6790008545168 .9235992432 171.225692749173 .5746002197175 .9644927979178 .3858032227180 .8343963623 183.3020019531185 .7857971191188 .2799987793190 .7819976807193 .2870941162 195.7926025391198 .2940063477200 .7890930176203 .2736053467205 .7458953857 208.2023010254210 .641494751213 .0608978271215 .4597015381217 .8358001709 220.1887054443222 .5173034668224 .8211975098227 .0997924805229 .3529968262 231.5803985596233 .7823028564235 .9584960938238 .1094055176240 .2351074219 242.3359069824244 .4120941162246 .4642028809248 .492401123250 .4971923828 252.4790039062254 .4382019043256 .375213623258 .2904052734260 .184387207 262.0574951172263 .9100036621265 .7424926758267 .5552978516269 .3487854004 271.1235961914272 .8799133301274 .6181945801276 .3388061523278 .0421142578 279.7284851074281 .3982849121283 .0520019531284 .6897888184286 .3120117188 287.9190979004289 .5111999512291 .0887145996292 .6517944336294 .2009887695 295.7362976074297 .2580871582298 .7666931152300 .262298584301 .745300293 303.2157897949 304.6741943359 306.1206970215 307.5555114746 308.979095459 310.3916015625311 .7933044434313 .184387207314 .5653076172315 .9360961914 317.2969970703 318.6481933594 319.9901123047 321.3225097656322.645904541 323.9601135254325 .265411377326 .561706543327 .8493041992329 .128112793 330.3984985352331 .6607055664332 .9094848633334 .1465148926 $-45.3053016663-43.4722290039-41.6429100037$-39.8266906738 -38.018699646 $-36.2176399231-34.4225311279-32.6324501038-30.8461894989-29.0626792908$ $-27.2804603577-25.4981498718-23.7141609192-21.9267501831-20.1343193054$ $-18.334859848-16.5269298553-14.7083997726-12.8781499863-11.0341796875$ $-9.17583656311-7.301404953-5.4107837677-3.50265908241-1.5774589777 .3656789958477$ 2.3258190155034 .3033638000496 .2968688011178 .30625152587910 .32952976227 12.3661003112814 .4134197235116 .4703006744418 .5337104797420 .60181045532 22.6711597442624 .7393398284926 .8025493621828 .8578300476130 .90118980408 32.9291496276934 .9376296997136 .9227409362838 .8804588317940 .80659103394 42.6973304748544 .5483093261746 .3560981750548 .1163406372149 .82609176636 51.4811210632353 .0790214538654 .6158103942956 .0896606445357 .49694061279 58.8364410400460 .105049133361 .3022308349662 .4254798889263 .47491073608 
64.4486923217865 .3474426269566 .1699905395566 .9171981811567 .58850097656 68.1846466064568 .7055206298869 .1513137817469 .5220794677769 .81712341309 70.0363235473670 .178436279370 .2427673339870 .2293395996170 .13748168945 69.9691925048869 .7249832153369 .4082794189569 .022323608468 .56967926025 68.0540237426867 .4826812744166 .8636627197366 .1990509033265 .49858093262 64.7612075805763 .9970016479563 .1957702636762 .3346214294461 .48120117188 60.7073402404859 .9589309692459 .2002716064558 .4304389953657 .62501907349 56.8309593200756 .0617218017655 .3155899047954 .566970825253 .81190872192 53.0367012023952 .2321701049851 .3887100219750 .528041839649 .7041015625 48.8389205932647 .8251495361346 .8710289001546 .2144508361845 .61384963989 44.9631996154844 .1442718505942 .9521903991741 .7201004028340 .75458908081 39.9025688171439 .1339683532738 .34960937537 .4678688049336 .5168800354 35.5185012817434 .4848289489733 .3835182189932 .3694305419931 .58790969849 30.9288692474430 .3497104644829 .7524108886728 .940500259428 .17048072815 27.6543693542527 .2261009216326 .7614994049126 .3451404571525 .99131011963 25.6666603088425 .3288497924824 .9986400604224 .6947307586724 .39487075806 24.0994701385523 .802040100123 .5135803222723 .2261791229222 .92569923401 22.64020919822 .3833503723122 .1394805908221 .8995609283421 .6683807373 21.4491291046121 .2521190643321 .059640884420 .8800601959220 .7287902832 20.591659545920 .4943408966120 .4056301116920 .3187103271520 .22203063965 20.0903701782219 .9434700012219 .7696895599419 .5813598632819 .38793945312 19.188959121719 .0051708221418 .842079162618 .7131004333518 .60960006714 18.5220394134518 .4372100830118 .3485603332518 .2624092102118 .19123077393 18.1254501342818 .0602092742918 .0080890655517 .9821491241517 .96690940857 17.9501399993917 .9253597259517 .8890094757117 .8434791564917 .79058074951 17.7428607940717 .7107391357417 .6961898803717 .7021694183317 .72612953186 17.7675304412817 .8262405395517 .9000091552717 .9916992187518 .1000995636 18.2331695556618 .3914299011218 .5844593048118 .8132305145319 .08315086365 19.3968505859419 .7538700103820 .1553993225120 .6009292602521 .08404922485 21.6181106567422 .1927509307922 .8195705413823 .4799194335924 .12162017822 24.6880893707325 .0249099731425 .0537605285624 .9697799682625 .02708053589 25.2131099700925 .5423393249525 .9774608612126 .4597797393827 .05409049988 27.7761993408228 .7329196929929 .9943809509331 .4824199676533 .12147903442 34.8177680969236 .4803695678738 .1273498535239 .7276115417541 .31209182739 42.8877906799344 .4737892150946 .1344795227147 .8471107482949 .6323890686 51.463871002253 .3165092468355 .2003707885757 .0972290039159 .02309036255 61.0312805175862 .9025192260764 .3805236816465 .7372970581167 .22721862793 68.7584075927770 .3561172485471 .9844131469773 .6045684814575 .23580169678 76.8503799438578 .4959716796980 .1747512817481 .8884735107483 .6245803833 85.3933715820387 .2042617797989 .0467834472790 .911132812592 .79416656494 94.6918869018696 .6111602783298 .5584564209100 .5367965698102 .5542984009 104.6093978882106 .7043991089108 .8414993286111 .0167999268113 .2310028076 115.4796981812117 .7502975464120 .0863037109122 .2910995483124 .1519012451 125.8714981079127 .6186981201129 .3412017822131 .0458068848132 .7321014404 134.391998291136 .0343017578137 .6558990479139 .2673950195140 .8728027344 142.4859008789144 .1125946045145 .7740936279147 .483795166149 .2619934082 
151.1663970947153 .0487976074154 .7402954102156 .43409729158 .2895050049 160.2487945557162 .3052978516164 .4405975342166 .6383972168168 .8925018311 171.1925048828173 .5341949463175 .9069976807178 .30859375180 .7304992676 183.1712036133185 .6251983643188 .0903015137190 .5612945557193 .0357971191 195.5090942383197 .9786987305200 .4400024414202 .8912963867205 .3287963867 207.7509002686210 .1549072266212 .5395965576214 .9031066895217 .2445983887 219.56300354221 .8576965332224 .1280975342226 .3737945557228 .5946960449 230.7906036377232 .9617004395235 .1078033447237 .2294006348239 .3265991211 241.3997039795243 .449005127245 .474899292247 .4776000977249 .4577026367 251.4154968262253 .3513031006255 .2657012939257 .1589050293259 .0314025879 260.8835144043262 .7157897949264 .528503418266 .3219909668268 .0968017578 269.853302002271 .591796875273 .3125915527275 .016204834276 .702911377 278.3731079102280 .0270996094281 .6651916504283 .287689209284 .8949890137 286.4873046875288 .0650939941289 .6283874512291 .1777038574292 .713104248 294.2351074219295 .7437133789297 .2392883301298 .7222900391300 .1926879883 301.6510009766303 .0974121094304 .5321044922305 .9555053711307 .3677062988 308.7691955566310 .1600036621311 .5405883789312 .9111022949314 .271697998 315.6225891113316 .9641113281318 .2962036133319 .6191101074320 .933013916 322.2379150391323 .5339050293324 .821105957326 .0994873047327 .3695068359 328.6304016113329 .884185791331 .1279907227 $-46.0171813965-44.19480896-42.3936882019-40.6105308533-38.8353004456$ -37.0674514771 -35.3059310913 -33.5497589111 -31.797580719 -30.0482597351 -28.3001499176 -26.5517902374 -24.8013095856 -23.0469207764 -21.2866706848 -19.5185203552 -17.7406005859-15.9507904053 -14.1475095749-12.328789711 $-10.4935398102-8.64012336731-6.76800298691-4.87605285645-2.96425104141$ $-1.03201699257 .92015999555592 .8923280239114 .8834681510936 .893091201782$ 8.91961097717310 .9619598388713 .0179700851415 .0859498977717 .16315078735 19.2472496032721 .3349895477323 .4234504699725 .5089702606227 .58805084229 29.6567192077631 .7110290527333 .7467803955135 .7596702575737 .74544143677 39.6995201110841 .6177902221743 .4956016540545 .3291206359947 .11384963989 48.8463592529350 .5224304199252 .1391296386753 .6926193237355 .18054962158 56.5995407104557 .9478797912659 .2227706909260 .4232101440461 .54713058472 62.5942115783763 .5631294250564 .4541625976665 .2666778564566 .00131988525 66.658058166567 .237579345767 .7402267456168 .1662673950268 .51608276367 68.7889633178768 .9848632812569 .1022033691469 .1400527954169 .09803009033 68.9750366210968 .7733078002968 .4936370849668 .1395492553767 .71430206299 67.2203521728566 .6623229980566 .0486679077165 .3858413696364 .67942810059 63.938339233463 .1728286743262 .4048194885361 .6067008972260 .74769973755 59.8899993896559 .0896492004458 .3156318664657 .5417900085456 .76594161987 55.9677581787155 .1595115661654 .3503799438553 .5490989685152 .76195144653 51.9839401245151 .2153205871650 .4007606506349 .4859390258848 .49364852905 47.4337806701746 .3197708129945 .1746101379444 .1170005798343 .28646087646 42.5312194824241 .7690010070840 .8892517089839 .7760391235438 .6492805481 37.7072181701736 .8506202697836 .0728683471735 .313480377234 .49483108521 33.6387786865232 .7037200927731 .7292308807430 .7702693939229 .88869094849 29.1493301391628 .5132198333727 .9445209503227 .3840999603326 .72052955627 
26.1258792877225 .7123203277625 .3781890869125 .0337791442924 .6875705719 24.36914062524 .0730991363523 .7876491546623 .5163497924823 .25091934204 22.982700347922 .724750518822 .4732398986822 .2263793945321 .97974014282 21.7236900329621 .475660324121 .2460594177221 .0179004669220 .78397941589 20.5488605499320 .3220596313520 .1085491180419 .9011898040819 .70340919495 19.5230903625519 .3593807220519 .2296104431219 .1142692565919 .01225090027 18.9047698974618 .7727699279818 .6272907257118 .453960418718 .27142906189 18.0970401763917 .9094696044917 .7026901245117 .5201892852817 .41176986694 17.347240448 17.30974960327 17.2622795105 17.16448020935 17.07395935059 17.052879333517 .0320205688516 .949630737316 .8830394744916 .90854072571 16.9536399841316 .9617900848416 .9506397247316 .9337406158416 .90566062927 16.8628807067916 .8294296264616 .8317108154316 .8591308593816 .91094970703 16.9777202606217 .053640365617 .1385402679417 .2281494140617 .32708930969 17.4403705596917 .5730209350617 .7332191467317 .923059463518 .14430999756 18.3971996307418 .6854190826419 .0071907043519 .3640708923319 .75531005859 20.1784191131620 .6374607086221 .1322898864721 .6467990875222 .17554092407 22.6031799316422 .8813991546623 .0035095214822 .8509597778322 .78525924683 23.1038093566923 .5594501495424 .028390884424 .5414199829125 .0872592926 25.7445907592826 .5447196960427 .4960994720528 .656179428129 .96619033813 31.4264602661132 .9744415283234 .5110702514636 .060550689737 .59965896606 39.1578903198240 .7403411865242 .3626708984444 .061111450245 .82966995239 47.6912307739349 .5952301025451 .4908409118753 .4031906127955 .33702850342 57.2875785827659 .2578201293961 .0928993225162 .6375007629464 .05876159668 65.5242462158267 .0055465698268 .5251693725670 .0588607788171 .592628479 73.1245193481474 .6232376098676 .1970672607477 .9360198974679 .75357055664 81.5629806518683 .3772735595785 .2041702270587 .0415420532288 .89502716064 90.7652969360492 .6448669433694 .5435028076296 .4663467407298 .42175292969 100.4190979004102 .462097168104 .5567016602106 .7032012939108 .9007034302 111.1443023682113 .4284973145115 .7366027832118 .0662994385120 .2823028564 122.248298645124 .0837020874125 .8953018188127 .6669998169129 .403793335 131.1071014404132 .7778930664134 .4201049805136 .0343933105137 .6318054199 139.2238006592140 .8209991455142 .43409729144 .0794067383145 .7696075439 147.503692627149 .3025054932151 .0635986328152 .6860961914154 .3412017822 156.1869049072158 .1484069824160 .1799926758162 .2763977051164 .4309997559 166.6390075684168 .8955993652171 .1934967041173 .5218048096175 .87840271 178.2570037842180 .6553039551183 .0697937012185 .4974975586187 .9342041016 190.3769073486192 .8209991455195 .2635955811197 .700302124200 .1287994385 202.5453948975204 .9485015869207 .3348999023209 .7035980225212 .0523071289 214.3804931641216 .6864929199218 .9700927734221 .2301940918223 .4667053223 225.6790924072227 .867401123230 .0314025879232 .1712036133234 .2870941162 236.3791046143238 .4474945068240 .4925994873242 .5146942139244 .5140991211 246.491104126248 .4461975098250 .379699707252 .2919006348254 .1831970215 256.054107666257 .9047851562259 .7356872559261 .5473022461263 .3399047852 265.1138916016266 .8695983887268 .6073913574270 .3276977539272 .0307922363 273.717010498275 .3868103027277 .0404052734278 .6781005859280 .3002929688 281.9072875977283 .4992980957285 .0765991211286 .6395874023288 .1885070801 
289.7235107422 291.2449951172 292.7532043457 294.2484130859 295.7308959961 297.2008972168298 .6585998535300 .1044921875301 .5386047363302 .9613952637 304.3731079102305 .7738952637307 .1642150879308 .5440979004309 .9139099121 311.2738952637312 .624206543313 .9650878906315 .2965087891316 .6188049316 317.9320983887319 .2363891602320 .5317077637321 .8182067871323 .0960083008 324.3653869629325 .6267089844326 .8743896484328 .1104125977 $-46.6439590454-44.8754005432-43.1111106873-41.3616104126-39.6214103699$ $-37.8891410828-36.163608551-34.4437904358-32.7281913757-31.0155200958$ $-29.3040294647-27.591999054-25.8775005341-24.1583995819-22.4327106476$ $-20.6979808807-18.9523296356-17.1931591034-15.4189500809-13.6271896362$ $-11.8168897629-9.985912323-8.13389396667-6.25917196274-4.36203098297$ $-2.44134092331-.4979900121691 .468608975413 .4569690227515 .467116832733$ 7.4969382286079 .54585266113311 .6111001968413 .691439628615 .78349971771 17.8853206634519 .99301910422 .1039295196524 .2137603759826 .31917953491 28.4155902862530 .4990806579632 .5648994445834 .6085891723636 .6254196167 38.6105690002440 .5595092773442 .4672012329144 .3296012878446 .14165115356 47.8999214172449 .5995407104551 .2377510070852 .8100509643654 .31436920166 55.7466697692957 .1056709289658 .3878784179759 .5928993225160 .717918396 61.7633590698262 .7272300720263 .6106109619164 .4122772216865 .13378143311 65.774551391666 .3362426757866 .8188476562567 .2234573364367 .55045318604 67.7994537353567 .97070312568 .0621185302768 .0729217529368 .00160217285 67.8461837768667 .6100234985467 .292823791566 .8998031616266 .43372344971 65.8988265991265 .3015975952164 .6441726684663 .934429168763 .18495941162 62.4073905944861 .6200103759860 .8515090942460 .0649108886759 .22227096558 58.373329162657 .547008514456 .7384910583555 .9368286132855 .13325119019 54.3111915588453 .4721107482952 .6047096252451 .740230560350 .88483810425 50.0453491210949 .2621192932148 .3957405090347 .3774681091346 .22219085693 44.9082412719743 .5641593933142 .3224906921441 .1576118469240 .12408065796 39.1791992187538 .2901687622137 .4006996154836 .442520141635 .48788070679 34.6097602844233 .81333160433 .1165084838932 .4561309814531 .73699951172 30.9710693359430 .1203804016129 .2642307281528 .5135192871127 .82099914551 27.1622009277326 .5604896545426 .0041294097925 .4919490814224 .98917007446 24.5478496551524 .1706295013423 .8454704284723 .5515804290823 .26530075073 22.9856090545722 .7157001495422 .4578609466622 .2081909179721 .96043014526 21.7174091339121 .4967708587621 .2833003997821 .0721492767320 .85902023315 20.633369445820 .4092102050820 .185899734519 .9549808502219 .72031974792 19.475660324119 .2279701232918 .9857997894318 .7401294708318 .50350952148 18.2839107513418 .0795497894317 .9116992950417 .7702903747617 .6592502594 17.5551300048817 .4298896789617 .2789001464817 .0911808013916 .89134025574 16.7177295684816 .5385494232216 .3141498565716 .1213493347216 .03298950195 15.9984903335615 .9992904663115 .9883699417115 .8906803131115 .80265045166 15.8327503204315 .8624200820915 .7769403457615 .7098302841215 .78931045532 15.8929195404115 .9291400909415 .9432401657115 .9579896926915 .96214962006 15.9441499710115 .9415702819815 .9881801605216 .0686893463116 .17518043518 16.2956008911116 .4166297912616 .532920837416 .6424293518116 .75299072266 16.8755092620817 .0175895690917 .182750701917 .373180389417 .586769104 
17.824630737318 .0893993377718 .379470825218 .6935901641819 .03137969971 19.3902702331519 .766319274920 .1604099273720 .5407390594520 .91596031189 21.1872291564921 .3096599578921 .3020191192621 .0082798004220 .88752937317 21.3988208770822 .1036205291722 .6993103027323 .3057403564523 .92410087585 24.6167392730725 .4319400787426 .3547801971427 .424459457428 .60499954224 29.914619445831 .3047409057632 .7037887573234 .1401290893635 .58652877808 37.0849304199238 .6455917358440 .275810241742 .0068702697843 .82329177856 45.7575416564947 .7348098754949 .6741600036651 .6146888732953 .57276153564 55.5079307556257 .3843803405859 .1577301025460 .7910499572862 .32332992554 63.8159790039165 .2794036865266 .7571411132868 .2334136962969 .70851898193 71.1825790405372 .5952529907274 .1129226684675 .891876220777 .77259063721 79.6109466552781 .4475936889683 .2813034057685 .1123962402386 .9528427124 88.7999114990290 .6516036987392 .518417358494 .4051666259896 .32737731934 98.29496765137100 .317199707102 .4020996094104 .5463027954106 .7549972534 109.0129013062111 .3169021606113 .6287002563115 .9140014648118 .1234970093 120.2126998901122 .2001037598124 .1119995117125 .9530029297127 .7388000488 129.4750061035131 .1638946533132 .8146972656134 .4275054932136 .0178070068 137.6022949219139 .19090271140 .7935943604142 .4192047119144 .0765075684 145.7472991943147 .4217987061149 .0753936768150 .6654052734152 .3173065186 154.1667938232156 .1242980957158 .1237945557160 .1815948486162 .2971954346 164.4645996094166 .6822052002168 .9412994385171 .2274017334173 .5404052734 175.8766021729178 .2339935303180 .6094970703183 .00050354185 .4026031494 187.8130950928190 .2268066406192 .6414031982195 .0518035889197 .4561004639 199.8500061035202 .2319946289204 .5989074707206 .9496002197209 .2816009521 211.5944061279213 .8861999512216 .1566009521218 .4046020508220 .6298980713 222.8321075439225 .0108947754227 .1661987305229 .2982025146231 .4066925049 233.4920043945235 .5543060303237 .5937957764239 .6107025146241 .6053924561 243.5782012939245 .529296875247 .459197998249 .3681945801251 .2566070557 253.1246948242254 .9730072021256 .8016967773258 .6112060547260 .4018859863 262.1741943359263 .928314209265 .6647033691267 .3835144043269 .0853881836 270.7703857422272 .4390869141274 .0916137695275 .728302002277 .3494873047 278.9555053711280 .5466003418282 .1229858398283 .6850891113285 .233001709 286.7672119141288 .2878112793289 .7951049805291 .2893981934292 .770904541 294.2399902344295 .6968078613297 .1418151855298 .575012207299 .9967956543 301.4075012207302 .8074035645304 .196685791305 .5757141113306 .9446105957 308.3037109375309 .6531066895310 .9930114746312 .3236083984313 .6449890137 314.9573059082316 .2607116699317 .5551147461318 .8407897949320 .1177062988 321.3862915039322 .645690918323 .8978881836325 .1401062012 $-47.2784004211-45.5221290588-43.7900810242-42.0783805847-40.3756790161$ $-38.6814994812-36.9945297241-35.3136787415-33.6372718811-31.9639091492$ $-30.2915992737-28.6185398102-26.9424800873-25.261220932-23.5723991394$ $-21.8735103607-20.1622505188-18.436000824-16.6927604675-14.9300403595$ $-13.1463499069-11.3396501541-9.50905132294-7.65309381485-5.77154302597$ -3.86356091499 -1.92952299118.0307769998908 2.016350030899 4.026770114899 6.0603928565988 .1161270141610 .1916399002112 .2851104736314 .39354991913 16.5144004821818 .6440505981420 .779230117822 .915800094625 .04984092712 
27.1767807006829 .2921390533431 .3910598754933 .4685516357435 .51964950562 37.5390510559139 .52190017741 .4627609252943 .357139587445 .19972991943 46.9865798950248 .712749481250 .3749198913651 .9686508178753 .49132919312 54.9391212463456 .3101615905857 .6013488769558 .811660766659 .93883132935 60.982700347961 .9418601989762 .8169517517163 .6073799133364 .31436157227 64.9380493164165 .4799423217865 .9407730102566 .3217315673866 .62380981445 66.8469390869166 .9916763305767 .0558395385767 .038642883366 .93686676025 66.7471237182666 .4738693237366 .1175308227565 .6836318969765 .17492675781 64.5994567871163 .9692611694363 .2737884521562 .5037994384861 .70101165771 60.9073791503960 .115791320859 .3266983032258 .5240783691457 .68486022949 56.8323707580655 .9857597351155 .1455688476654 .3170394897553 .47898101807 52.6182098388751 .7239189147950 .7763099670449 .8159599304248 .84972000122 47.9088401794447 .0613517761246 .1013107299844 .8854713439943 .52238082886 42.0912818908740 .6720695495639 .3445281982438 .0693817138736 .86431884766 35.7825813293534 .9016609191934 .1119003295933 .2453002929732 .38068008423 31.5428295135530 .813550949130 .3172092437729 .8786506652829 .3223991394 28.6941795349127 .9806995391827 .26737022426 .6227703094526 .01670074463 25.4393501281724 .8884696960424 .3840503692623 .9351902008123 .53071022034 23.1710700988822 .8523902893122 .5589694976822 .2905502319322 .03392982483 21.7697200775121 .5081291198721 .2562408447321 .0098209381120 .76775932312 20.5406093597420 .3457794189520 .1633892059319 .9855995178219 .79940032959 19.5914592742919 .3748493194619 .1422195434618 .8940105438218 .64615058899 18.3807697296118 .102750778217 .8210792541517 .5228500366217 .23133087158 16.96742057816 .7178592681916 .4890403747616 .3059692382816 .20206069946 16.1222095489516 .0194396972715 .8681201934815 .6298904418915 .36993980408 15.1519298553514 .94793033614 .7419700622614 .5747003555314 .48985958099 14.4569396972714 .4582595825214 .4556503295914 .4071702957214 .37117004395 14.4097099304214 .4516401290914 .434470176714 .4349203109714 .53032970428 14.6473102569614 .7281799316414 .7917203903214 .8529901504514 .90795040131 14.9547300338715 .0192003250115 .1285800933815 .2735996246315 .45283985138 15.6421003341715 .8218002319315 .9798202514616 .1032009124816 .21928977966 16.3607196807916 .5216693878216 .7007293701216 .8971500396717 .11005020142 17.33733940125 17.58399963379 17.84630966187 18.12321090698 18.41153907776 18.7112293243419 .0132999420219 .3184394836419 .5980396270819 .84531021118 20.0125999450720 .0687694549620 .0435104370119 .8890304565419 .90867042542 20.3634700775121 .0032291412421 .621089935322 .2555408477822 .90936088562 23.6227798461924 .4293594360425 .3140506744426 .2938899993927 .35714912415 28.5266609191929 .7665290832531 .032089233432 .342769622833 .68518829346 35.1043014526436 .6144905090338 .2265205383339 .9738082885741 .82807922363 43.7949905395545 .8148803710947 .8139801025449 .8028488159251 .78446960449 53.7155990600655 .566261291557 .3380012512259 .0025711059660 .59006881714 62.1112213134863 .5801010131865 .0449066162166 .4999237060567 .9553527832 69.4135971069370 .8605728149472 .4036636352574 .1392135620175 .96733093262 77.7935562133879 .6224365234481 .4459609985483 .2654571533285 .08365631104 86.9019927978588 .7190399169990 .5446014404392 .3816528320394 .25480651855 96.1828231811598 .17384338379100 .2365036011102 .3657989502104 .5672988892 
106.825302124109 .1382980347111 .4585037231113 .7481994629115 .9955978394 118.1603012085120 .2530975342122 .2629013062124 .1853027344126 .0385971069 127.8251037598129 .5420074463131 .2059936523132 .8249053955134 .4122924805 135.9934997559137 .574798584139 .1678924561140 .7734985352142 .3988037109 144.020904541145 .6327972412147 .2416992188148 .8329925537150 .4934997559 152.2924041748154 .1835021973156 .1389007568158 .154296875160 .2322998047 162.3652038574164 .5484924316166 .7731018066169 .0193023682171 .2891998291 173.584197998175 .9015960693178 .2391967773180 .5941009521182 .962097168 185.3401031494187 .7232971191190 .1089019775192 .4920959473194 .8706054688 197.2404022217 199.5997009277 201.9452972412 204.2760009766 206.5894927979 208.8849029541211 .1605987549213 .4160003662215 .650100708217 .8625030518 220.0525970459222 .2203979492224 .3654022217226 .4877929688228 .5874938965 230.6645965576232 .7192993164234 .7518005371236 .762298584238 .7510070801 240.7182006836242 .6643066406244 .5894012451246 .4940032959248 .37840271 250.2427978516252 .087600708253 .9131011963255 .7196044922257 .507598877 259.2771911621261 .0289001465262 .763092041264 .4797973633266 .1796875 267.8627929688269 .5296020508271 .1803894043272 .8154907227274 .4350891113 276.0394897461277 .6290893555279 .2040100098280 .7645874023282 .3111877441 283.8439941406285 .3631896973286 .8692016602288 .3620910645289 .8422851562 291.3100891113292 .7655944824294 .209197998295 .6411132812297 .0616149902 298.4710998535299 .8696899414301 .2576904297302 .6354980469304 .003112793 305.3609924316306 .7091064453308 .0479125977309 .3772888184310 .6975097656 312.0086975098313 .3109130859314 .6041870117315 .8887939453317 .1646118164 318.4320068359319 .6913146973320 .9367980957322 .1708068848 $-47.8169212341-46.1216392517-44.4314117432-42.7579917908-41.095249176$ -39.4417610168 -37.7960395813 -36.156879425 -34.5224304199 -32.89112854 $-31.2608108521-29.6293792725-27.9945106506-26.3536205292-24.7042999268$ -23.0436000824 -21.3692092896 -19.6780109406 -17.9680404663 -16.2362594604 $-14.4812898636-12.7004699707-10.8931503296-9.05722332001-7.19277381897$ $-5.29834794998-3.3747279644-1.42109799385 .56105101108552 .571891069412$ 4.6091961860666 .6724362373358 .75863361358610 .8664903640712 .99230003357 15.1339502334617 .2870903015119 .448799133321 .6141891479523 .77953910828 25.9395809173628 .0898704528830 .2248497009332 .3394699096734 .42811965942 36.4852409362838 .5054702758840 .4829597473142 .4128494262744 .28927993774 46.1081504821847 .8638687133849 .5531806945851 .170898437552 .7146987915 54.1799583435155 .5652999877956 .86677169858 .0840187072859 .21387863159 60.2570610046461 .2112693786662 .0780982971262 .856170654363 .54779052734 64.1523666381864 .6726684570365 .108818054265 .4634170532265 .73712158203 65.9311523437566 .0462112426866 .0803070068466 .0336837768665 .89996337891 65.6744766235465 .3625564575264 .962196350164 .4823226928763 .92626953125 63.3034896850662 .6356506347761 .9032287597761 .0800704956160 .23265838623 59.4273300170958 .6277694702157 .8082618713456 .9779281616256 .12757110596 55.2636909484954 .3829116821353 .5017013549852 .6234207153351 .74034118652 50.8389587402349 .8831787109448 .8493881225647 .7563591003446 .63394927979 45.5325317382844 .5819206237843 .5152282714842 .1620407104540 .67156982422 39.1825485229537 .7394981384336 .3543205261235 .0406913757333 .76351165771 
32.6434516906731 .8387794494631 .1483306884830 .3579998016429 .57959938049 28.7999992370628 .1566009521527 .8518695831327 .6157798767127 .20528030396 26.7171401977526 .1532592773425 .5647296905524 .9945106506324 .44231033325 23.9279193878223 .4438209533723 .0032596588122 .6127395629922 .27059936523 21.9657001495421 .6842193603521 .4189090728821 .1644706726120 .9135093689 20.6432399749820 .3710002899220 .1047496795719 .8420600891119 .59247016907 19.3669300079319 .1776905059819 .0171394348118 .8679008483918 .70614051819 18.5117397308318 .2764701843318 .0051403045717 .7188396453917 .45348930359 17.1809406280516 .8877601623516 .5607891082816 .1950397491515 .82761955261 15.5044803619415 .2122402191214 .9276103973414 .7035303115814 .59692955017 14.5255298614514 .4303503036514 .2784004211414 .0010004043613 .69316959381 13.438409805313 .2179498672513 .0405702590912 .9098701477112 .8275604248 12.7869501113912 .7748899459812 .7799396514912 .7891397476212 .8115901947 12.8553800582912 .9117002487212 .9765396118213 .0587100982713 .17096996307 13.2969999313413 .4239196777313 .5484600067113 .6667499542213 .78680038452 13.9116697311414 .0570402145414 .2346897125214 .4443702697814 .69116020203 14.9446296691915 .1809701919615 .3874597549415 .5383796691915 .68004989624 15.8602304458616 .0527801513716 .2520599365216 .4582500457816 .67554092407 16.9027404785217 .1399707794217 .383859634417 .6308193206817 .87742996216 18.1251792907718 .3624591827418 .5929908752418 .7909603118918 .94907951355 19.0572605133119 .1032905578619 .1447505950919 .1967601776119 .36684036255 19.7063503265420 .1814594268820 .7473506927521 .3751506805422 .03650093079 22.7451992034923 .5216808319124 .3503494262725 .2488098144526 .2088508606 27.2573394775428 .364669799829 .5046691894530 .6958999633831 .9298992157 33.246238708534 .6650199890136 .2331314086937 .9882888793939 .88385009766 41.8781814575243 .9208488464445 .9691200256347 .999858856250 .00170898438 51.9410018920953 .7950897216855 .5727005004957 .2611198425358 .87638092041 60.4210205078161 .9106712341363 .3876190185564 .8479919433666 .30938720703 67.7908172607469 .3053970336970 .88979339672 .5616073608474 .3020324707 76.0835037231477 .886573791579 .6912231445381 .4924316406283 .2861328125 85.0730285644586 .8526687622188 .6342468261790 .4165573120192 .2331237793 94.1059036254996 .0488662719798 .0707321167100 .1675033569102 .3535995483 104.6034011841106 .9199981689109 .257598877111 .5711975098113 .8569030762 116.0842971802118 .2531967163120 .3471984863122 .3618011475124 .3047027588 126.1541976929127 .9052963257129 .5796966553131 .2066955566132 .8029022217 134.3898010254135 .9725036621137 .5596008301139 .1492004395140 .7454986572 142.337097168143 .9178924561145 .5101013184147 .1204071045148 .7839050293 150.5162963867152 .3235015869154 .2185058594156 .1894989014158 .2375946045 160.3475952148162 .5001068115164 .6862030029166 .8916015625169 .1181945801 171.3739013672173 .6539001465175 .9552001953178 .2758026123180 .6101074219 182.9559936523185 .3081054688187 .6638946533190 .0186004639192 .3699951172 194.7140045166197 .0489044189199 .3715057373201 .6806030273203 .9736022949 206.2498931885208 .507598877210 .746307373212 .9647064209215 .162399292 217.3388977051 219.4938964844221.6271057129 223.7384033203225.8278045654 227.8952941895229 .9411010742231 .9653015137233 .9680023193235 .9494934082 237.9100036621239 .8497924805241 .7691955566243 .6683959961245 .5476074219 
247.4073028564249 .2476959229251 .0691070557252 .8717956543254 .6560974121 256.4223937988258 .1708984375259 .9020080566261 .6159057617263 .3129882812 264.9935913086266 .6578979492268 .3063049316269 .9390869141271 .5564880371 273.1589050293274 .746307373276 .3193054199277 .8779907227279 .4226989746 280.9536132812282 .4710083008283 .975189209285 .4664001465286 .9447937012 288.4107971191289 .8646850586291 .3066101074292 .7367858887294 .1557922363 295.5635986328296 .9606018066298 .3469848633299 .7232055664301 .0893859863 302.4457092285303 .792388916305 .129699707306 .457611084307 .7764892578 309.0863037109310 .3870849609311 .679107666312 .9621887207314 .2366943359 315.5028076172316 .7597045898318 .0094909668319 .249206543 $-48.3646697998-46.68309021-45.0292701721-43.3987083435-41.7785415649$ $-40.1684188843-38.5667114258-36.9720802307-35.3824501038-33.7961006165$ -32.2106018066 -30.6237106323 -29.0327396393 -27.4350299835 -25.8277397156 -24.2078895569 -22.5727005005 -20.9190406799-19.2444496155 -17.5459003448 $-15.8214902878-14.0686302185-12.2860898972-10.4719800949-8.62576675415$ $-6.74630403519-4.83378601074-2.88779091835-.9092339873311 .101564049721$ 3.1429309844975 .2137660980227 .3116002082829 .43449497222911 .57919025421 13.7428903579715 .9215898513818 .1116409301820 .3084106445322 .50742912292 24.70354080226 .8915805816729 .0659503936831 .2208995819133 .35063934326 35.4489707946837 .5102081298839 .5279693603541 .496929168743 .41088104248 45.2651214599647 .0538902282748 .773300170950 .4182090759351 .98556900024 53.4710197448754 .8724212646556 .1862716674857 .4114494323758 .54537963867 59.5880088806260 .5377502441461 .3955307006862 .1607589721762 .83518981934 63.4191284179763 .9149818420464 .323806762764 .6483078002964 .8900680542 65.0510406494165 .1328735351665 .1342926025465 .05551910464 .88751983643 64.6254272460964 .2722930908263 .822261810363 .2888488769562 .67807006836 62.0005493164161 .2761306762760 .4961395263759 .6528091430758 .79121017456 57.9559593200757 .1223983764656 .2739601135355 .4130706787154 .53713989258 53.6390686035252 .7041206359951 .7550010681250 .797298431449 .84909057617 48.9398498535247 .9572715759346 .8104705810545 .5459403991744 .19284057617 42.8829307556241 .7680091857940 .6059303283739 .3074989318837 .88634109497 36.3024787902834 .7836418151933 .4381294250532 .2070999145531 .10779953003 30.1660594940229 .4119396209728 .755510330228 .0715694427527 .41267967224 26.7751007080126 .2605991363525 .9705791473425 .7408103942925 .40555000305 25.0072498321524 .5443191528324 .0471897125223 .5455894470223 .04870033264 22.5818405151422 .1469402313221 .7549400329621 .4071998596221 .11124992371 20.8436508178720 .5903205871620 .3421707153320 .0935592651419 .83455085754 19.5403900146519 .2366199493418 .9361591339118 .6385097503718 .36504936218 18.1216793060317 .9122295379617 .7511501312317 .6450500488317 .52432060242 17.3367595672617 .0698795318616 .6999607086216 .3280601501516 .06673049927 15.823940277115 .5409097671515 .1843099594114 .7107801437414 .22294044495 13.8206796646113 .4720201492313 .1609096527112 .9129400253312 .75572013855 12.6359701156612 .5086202621512 .3392801284812 .0890197753911 .81552028656 11.5777502059911 .3791904449511 .2269096374511 .1183900833111 .05121994019 11.0162496566811 .0107297897311 .0352096557611 .0784101486211 .13871002197 11.2132701873811 .3078899383511 .4267396926911 .565039634711 .72033023834 
11.8856801986712 .0612697601312 .2453002929712 .4260997772212 .61328983307 12.8101501464813 .0252304077113 .2659997940113 .5296697616613 .82038974762 14.1149196624814 .3950595855714 .6503601074214 .8692598342915 .0849199295 15.3367204666115 .586739540115 .80688953416 .0200691223116 .25318908691 16.493030548116 .7348098754916 .9733104705817 .2029705047617 .42177009583 17.6327095031717 .8272991180418 .0073108673118 .1584091186518 .27300071716 18.361049652118 .4174308776918 .5077400207518 .6496105194118 .85931015015 19.18297004719 .5913906097420 .0958595275920 .6851997375521 .31826019287 21.9943904876722 .7101593017623 .4679203033424 .2842292785625 .15382003784 26.0910205841127 .0808601379428 .1119709014929 .1941699981730 .32667922974 31.5261707305932 .7870407104534 .2467803955136 .0484390258838 .03059005737 40.0597190856942 .1254806518644 .1949386596746 .2490501403848 .26462173462 50.2165718078652 .0816688537653 .8729209899955 .5817298889257 .22093963623 58.7882690429760 .3040504455661 .8003196716363 .2803611755464 .76180267334 66.2680664062567 .8119735717869 .3988037109471 .046173095772 .73769378662 74.4773864746176 .2486267089878 .0245666503979 .7993621826281 .56350708008 83.3171997070385 .0579071044986 .7932205200288 .5245132446390 .27954864502 92.0773773193493 .947128295995 .9055633544997 .95420074463100 .1206970215 102.3686981201104 .6894989014107 .0473022461109 .389503479111 .7123031616 113.9888000488116 .2185974121118 .385597229120 .4925994873122 .5509033203 124.493598938126 .256401062127 .9200973511129 .5597991943131 .1750030518 132.7808990479134 .3775024414135 .9709014893137 .5581970215139 .1412963867 140.7171020508142 .2825012207143 .8625946045145 .4674987793147 .108505249 148.800201416150 .5473022461152 .3639068604154 .2736053467156 .3143005371 158.424697876160 .5410003662162 .6802978516164 .842300415167 .0254974365 169.2409973145171 .4851074219173 .7527008057176 .0406036377178 .3428955078 180.6569061279182 .9779968262185 .3032073975187 .6286010742189 .9515991211 192.2684936523194 .5774993896196 .87550354199 .1611022949201 .4320983887203 .6875 205.9255981445208 .1457977295210 .3468017578212 .5283050537214 .6894989014 216.8303070068218 .9501037598221 .0489044189223 .1266021729225 .1831970215 227.2187042236229 .2333068848231 .2270965576233 .2001953125235 .1528930664 237.0852966309238 .9978027344240 .8905029297242 .7637023926244 .6177062988 246.4528045654248 .2691040039250 .0670928955251 .8470001221253 .6091003418 255.3536987305257 .0809936523258 .7914123535260 .4851074219262 .1624145508 263.8236999512265 .4690856934267 .0989990234268 .7137145996270 .313293457 271.8981933594273 .4686889648275 .0249938965276 .5672912598278 .0958862305 279.611114502281 .1130065918282 .6019897461284 .0783081055285 .5422058105 286.9939880371288 .4338989258289 .8622131348291 .2791137695292 .6849975586 294.0801086426295 .4646911621296 .8391113281298 .2033996582299 .558013916 300.9028930664302 .238494873303 .5647888184304 .8818969727306 .1900939941 307.4892883301308 .7796936035310 .0611877441311 .3341064453312 .5986022949 313.854888916315 .0975036621316 .3286132812 $-48.8045692444-47.1913490295-45.5844192505-43.996799469-42.4216995239$ $-40.8576393127-39.3027114868$-37.75548172 -36.2135887146 -34.6751289368 $-33.1374397278-31.5979690552-30.0538806915-28.5020999908-26.9397201538$ $-25.3632907867-23.770029068-22.1562595367-20.519569397-18.8563709259$ 
-17.1648292542 -15.441740036 -13.6860704422 -11.8952302933 -10.0690097809 -8.20556735992 -6.30550193787-4.36770296097 -2.39361095428 -.382867991924 1.6622309684753 .7412309646615 .8509540557867 .99005603790310 .15450000763 12.3420000076314 .5477304458616 .7684402465818 .9986400604221 .2341709137 23.4689502716125 .6979904174827 .9148406982430 .1137104034432 .28802108765 34.4313812255936 .5373992919938 .5993003845240 .6112709045442 .56650924683 44.4600601196346 .2854194641148 .0386581420949 .7138290405351 .30810928345 52.8161811828654 .2364501953155 .5643692016656 .799530029357 .93832015991 58.9815483093359 .926620483460 .7755088806261 .5266113281262 .1828994751 62.7437515258863 .2130012512263 .5908813476663 .8817596435564 .08661651611 64.2094192504964 .2515182495164 .2138366699264 .0962066650463 .89291000366 63.5970306396563 .1998100280862 .6928291320862 .0931510925361 .41875839233 60.6818504333559 .896060943659 .0695114135758 .2104797363357 .337059021 56.4649696350155 .5881118774454 .6988105773953 .802040100152 .88661956787 51.9423408508350 .9439697265649 .9023895263748 .8342704772947 .77000045776 46.8055915832545 .7632102966344 .5023803710943 .08789062541 .55065917969 40.0209388732938 .7038803100637 .5228996276936 .464698791535 .31399154663 33.7581291198732 .1593399047930 .8459300994929 .7390193939228 .85564994812 28.1222190856927 .4183502197326 .7879104614326 .199430465725 .66758918762 25.1850299835224 .7769508361824 .4512996673624 .1612796783423 .8466796875 23.5012702941923 .1047306060822 .6722698211722 .2200603485121 .7647895813 21.3325195312520 .9294395446820 .5679893493720 .2470092773419 .97957038879 19.734449386619 .4971904754619 .2629508972219 .0099391937318 .72974967957 18.3946304321318 .0277099609417 .6650295257617 .3231391906717 .02916908264 16.7663993835416 .5171394348116 .3103694915816 .1982192993216 .08050918579 15.8724298477215 .5716104507415 .1200704574614 .6714401245114 .41390991211 14.1850404739413 .9048795700113 .5360898971612 .9896602630612 .41823959351 11.9621496200611 .574330329911 .2481203079210 .9834995269810 .76550006866 10.5821199417110 .4061603546110 .2229099273710 .019539833079 .812299728394 9.6207237243659 .4594478607189 .3340892791759 .2463636398329 .194184303284 9.1744594573979 .184800148019 .2269811630259 .2959461212169 .388770103455 9.4995126724249 .634778976449 .8016681671149 .98920631408710 .19355964661 10.4109601974510 .6440200805710 .8884296417211 .1337003707911 .38903045654 11.6543903350811 .9350204467812 .2327499389612 .544810295112 .87032032013 13.1972799301113 .5154199600213 .8229103088414 .1197700500514 .41771030426 14.7452602386515 .0574398040815 .3087100982715 .5464296340915 .81396961212 16.0816307067916 .342220306416 .5856800079316 .8094100952117 .01349067688 17.2029495239317 .3741207122817 .5272407531717 .6595191955617 .76468086243 17.8636894226117 .9483108520518 .0706806182918 .2420997619618 .47116088867 18.7817802429219 .1597805023219 .6139297485420 .14020919820 .71939086914 21.3397598266621 .9823303222722 .660160064723 .4000301361124 .18564987183 25.0258693695125 .9132995605526 .8486003875727 .8368492126528 .87848091125 29.9886093139631 .1161003112832 .4713706970234 .288639068636 .31383895874 38.3425102233940 .4078903198242 .4835891723644 .5430297851646 .57312011719 48.5406990051350 .427169799852 .2379188537653 .9612312316955 .61500167847 57.2002105712958 .7378196716360 .2601509094261 .7719993591363 .28863143921 
64.8195190429766 .3746719360467 .9568481445369 .5820465087971 .24463653564 72.951446533274 .6868972778376 .4303283691478 .175369262779 .90998840332 81.6316299438583 .335372924885 .0285568237386 .7124328613388 .40807342529 90.1268234252991 .9015731811593 .7633132934695 .747627258397 .89356231689 100.1541976929102 .4890975952104 .8600997925107 .2253036499109 .5763015747 111.8879013062114 .1614990234116 .3862991333118 .5608978271120 .7161026001 122.7442016602124 .5334014893126 .209602356127 .8856964111129 .5348968506 131.1712036133132 .7933044434134 .4022979736135 .9989013672137 .5818939209 139.1558074951140 .7182006836142 .2895965576143 .8780059814145 .4933013916 147.1448974609148 .845993042150 .5897979736152 .4474029541154 .4900054932 156.5892944336158 .6598968506160 .733795166162 .8466033936164 .9983978271 167.1813964844169 .395904541171 .6322937012173 .8890991211176 .1593017578 178.44140625180 .7304992676183 .0245056152185 .3193054199187 .612701416 189.9010925293192 .1826019287194 .4544067383196 .7149963379198 .9622955322 201.195098877203 .4120025635205 .6121063232207 .7942047119209 .957901001 212.1024017334214 .2274017334216 .3325042725218 .4174041748220 .4821014404 222.5265045166224 .5505981445226 .554397583228 .5379943848230 .5016021729 232.4454040527234 .3694000244236 .2740020752238 .1593017578240 .025604248 241.8730010986243 .7019042969245 .5124053955247 .304901123249 .079498291 250.8367004395252 .5765991211254 .2993927002256 .0056152344257 .6953125 259.3687133789261 .0263061523262 .6682128906264 .2945861816265 .9060058594 267.5025024414269 .0844116211270 .6517944336272 .2052001953273 .7446899414 275.2705993652276 .7831115723278 .2822875977279 .7687988281281 .2426147461 282.7041015625284 .1534118652285 .591003418287 .0169067383288 .4316101074 289.8352050781291 .2280883789292 .6105957031293 .9827880859295 .3450927734 296.6976013184298 .0405883789299 .374206543300 .6984863281302 .0137939453 303.320098877304 .6174926758305 .9060058594307 .1857910156308 .4567871094 309.7196044922310 .9731140137312 .2195129395313 .4558105469 $-49.2550811768-47.6563491821-46.089679718-44.5500183105-43.0225982666$ $-41.5072402954-40.0019187927-38.504940033-37.0137481689-35.5261993408$ -34.0392913818 -32.5503196716 -31.0560207367 -29.5531997681 -28.0385093689 -26.5084095001 -24.9596290588 -23.3885002136 -21.7920303345 -20.1666908264 $-18.5100708008-16.8190498352-15.0919704437-13.3264198303-11.5215396881$ $-9.67575836182-7.78902387619-5.8606300354-3.89135193825-1.88135504723$ .16770599782472 .2547531127934 .3772058486946 .5330100059518 .71865940094 10.931079864513 .1659002304115 .419019699117 .6852798461919 .95962905884 22.2362194061324 .5091495513926 .7720108032229 .0181503295931 .24087905884 33.4329795837435 .5877914428737 .6978492736839 .7568588256841 .75751113892 43.6942405700745 .5602302551347 .3508491516149 .0600509643650 .68423080444 52.2182617187553 .6596412658755 .0042381286656 .2507514953657 .39614868164 58.4403305053759 .3814697265660 .2206382751560 .9571914672961 .59328079224 62.1293601989762 .5685806274462 .9124107360863 .1647300720263 .32778930664 63.4054794311563 .4001884460463 .3147506713963 .1507186889662 .90824127197 62.5910186767662 .1600608825761 .5730781555260 .8838195800860 .13917922974 59.3413887023958 .5014381408757 .6305389404356 .7360382080155 .82873916626 54.9191894531253 .9957084655853 .0573692321852 .1117591857951 .15414047241 
50.1594009399449 .0958786010747 .947959899946 .7023582458545 .44358062744 44.2755393981943 .0602416992241 .6970291137740 .2093696594238 .62808990479 37.0190391540535 .4492797851634 .2489891052233 .8176689147933 .32518005371 31.9210700988830 .2907199859628 .9722099304227 .896970748927 .06344985962 26.3718109130925 .7343692779525 .1614704132124 .6494197845524 .20624923706 23.8110198974623 .4492206573523 .1266193389922 .8165302276622 .50020027161 22.1736698150621 .8048000335721 .4023990631120 .9715690612820 .53461074829 20.1154193878219 .723499298119 .3709907531719 .0594806671118 .8054599762 18.5702991485618 .3409194946318 .1118698120117 .8585205078117 .55590057373 17.1549491882316 .6939697265616 .2212104797415 .80206966415 .52515029907 15.2714500427214 .9307498931914 .6005001068114 .3674802780214 .14608001709 13.8689203262313 .523300170913 .0853204727212 .6555795669612 .35019016266 12.0724096298211 .7643098831211 .3859996795710 .8911104202310 .37304973602 9.9236974716199 .5315723419199 .200208663948 .915799140938 .667634010315 8.4494342803968 .2480287551888 .0660629272467 .8917608261117 .731712818146 7.5881309509287 .468965053558 7.3788189888 7.317628860474 7.286425113678 7.2851419448857 .3138828277597 .3750548362737 .467093944557 .588401794434 7.7346010208137 .9110131263738 .1212768554698 .3568658828748 .612759590149 8.886634826669 .1779165267949 .483056068429 .7936382293710 .11415958405 10.4429302215610 .7821798324611 .1332998275811 .4917001724211 .85721969604 12.2234497070312 .5837497711212 .9432201385513 .2983598709113 .65629005432 14.0269403457614 .3806295394914 .6956901550315 .0013103485115 .33117008209 15.6530103683515 .9462795257616 .2070198059116 .4349002838116 .63677024841 16.8233509063716 .9914608001717 .1402301788317 .2710304260317 .38202095032 17.4919700622617 .6072998046917 .7522392272917 .940570831318 .17411994934 18.4719505310118 .8213195800819 .2284202575719 .6935100555420 .21356010437 20.7704296112121 .3429603576721 .9489898681622 .6089401245123 .3135509491 24.0639190673824 .8619098663325 .7130203247126 .6251106262227 .60387039185 28.6633892059329 .800220489531 .1541309356732 .8673095703134 .78216934204 36.7599182128938 .7928504943840 .8504905700742 .9106788635344 .94789123535 46.9327888488848 .8396797180250 .6706085205152 .4042015075754 .06634140015 55.6624717712457 .2148017883358 .7569999694860 .2989006042561 .86125183105 63.4259490966864 .9780883789166 .5420837402368 .1497497558669 .79165649414 71.4730072021573 .1794204711974 .8969192504976 .6163024902378 .32565307617 80.0194625854581 .6897430419983 .3437576293984 .9838485717886 .62167358398 88.26583862305 89.9366836547991.6444320678793.512413024995.67649841309 97.99323272705100 .3430023193102 .7186965942105 .0903015137107 .4526977539 109.7865982056112 .0897979736114 .3497009277116 .5643005371118 .734703064 120.7911987305122 .6651000977124 .4345016479126 .1736984253127 .8785018921 129.5608978271131 .2191925049132 .8567962646134 .4727935791136 .0673980713 137.6459960938139 .2111053467140 .7754058838142 .3486938477143 .9378051758 145.5522003174147 .2095031738148 .9203948975150 .7637939453152 .81590271 154.8995056152156 .8686065674158 .8296966553160 .8907928467163 .0218963623 165.1865997314167 .3802032471169 .591003418171 .8177947998174 .0567932129 176.3061981201178 .56300354180 .8247070312183 .0879974365185 .3504943848 187.6089935303189 .8618011475192 .1058044434194 .3399963379196 .5619049072 
198.7707977295200 .9647979736203 .1434020996205 .3050994873207 .4496002197 209.5760040283211 .6838989258213 .7727966309215 .8426971436217 .8930053711 219.9239959717221.9353942871 223.9273071289225.8997039795 227.8527984619 229.786605835231 .7012939453233 .5971069336235 .4739990234237 .3323974609 239.1723937988240 .9942932129242 .7982025146244 .5843963623246 .3531036377 248.104598999249 .8390960693251 .5567932129253 .258102417254 .9430999756 256.6120910645258 .265411377259 .9031982422261 .5256958008263 .1333007812 264.7261047363266 .3044128418267 .8684082031269 .4183959961270 .9547119141 272.4773864746273 .9867858887275 .4831848145276 .9667053223278 .4375915527 279.8963012695281 .3428955078282 .7777099609284 .2009887695285 .6130981445 287.0141906738288 .4046936035289 .7846984863291 .1546020508292 .5144958496 293.8646850586295 .2054138184296 .5368041992297 .8590087891299 .172088623 300.4762878418301 .7716064453303 .0581054688304 .3359069824305 .604888916 306.8656921387308 .1181945801309 .3569030762310 .584197998 -49.5834197998 -48.0605697632-46.5457801819-45.0534706116-43.5761184692 $-42.1121406555-40.6591110229-39.2152709961-37.7777099609-36.3440513611$ -34.9110107422 -33.4755401611 -32.0341491699-30.583240509-29.1193008423 -27.6383304596 -26.1369895935 -24.6110496521 -23.0575904846 -21.4724407196 -19.8532905579-18.1963691711 -16.5001792908 -14.761590004-12.9800300598 -11.1531600952 -9.28135490417 -7.36311912537-5.39977216721 -3.39071798325 -1.33826494217.75723397731782.8924450874335.065981864929 7.27349615097 9.51250934600811 .7777099609414 .065529823316 .3697891235418 .68584060669 21.0067901611323 .3269691467325 .638950347927 .9361495971730 .21089935303 32.4558410644534 .6634407043536 .825889587438 .9362182617240 .98653030396 42.9708099365244 .8814582824746 .7136993408248 .4605407714850 .11851119995 51.6814193725653 .1472015380954 .5105705261255 .7709007263256 .9239692688 57.9705886840858 .9076995849659 .7374992370660 .4581794738861 .07315063477 61.5818405151461 .9887886047462 .2945518493762 .5045700073262 .62022018433 62.6473503112862 .5872802734462 .4459800720262 .2253417968861 .92776107788 61.5716514587461 .0957298278860 .4282188415559 .6542205810558 .84379959106 57.9867782592857 .0937995910656 .1740417480555 .2303009033254 .27621078491 53.313480377252 .3417510986351 .3546905517650 .3409500122149 .30916976929 48.2188301086447 .0611610412645 .8001708984444 .3895606994642 .93302154541 41.5523300170940 .1464996337938 .696701049837 .191551208535 .65205001831 34.1230392456132 .4663696289131 .2785606384331 .3731994628931 .4547290802 30.2390899658228 .7057304382327 .4772090911926 .4192504882825 .58126068115 24.896350860624 .3041095733623 .798059463523 .3504009246822 .96165084839 22.6056499481222 .268350601221 .9405193328921 .6147499084521 .28465080261 20.9455394744920 .5753498077420 .1758308410619 .7471694946319 .31113052368 18.8818702697818 .4764099121118 .1063804626517 .7790393829317 .51626968384 17.2898406982417 .0795307159416 .8397407531716 .5513591766416 .17528915405 15.6807098388715 .1336898803714 .5667104721114 .070030212413 .79316043854 13.5347604751613 .1023101806612 .6493701934812 .2804098129311 .92889022827 11.5595903396611 .1758604049710 .773329734810 .3788604736310 .03050041199 9.693324089059 .353502273568 .9912376403818 .5884714126598 .174050331116 7.7726430892947 .4000339508067 .075467109686 .7865991592416 .523984909058 
6.2870497703556 .0681481361395 .8880119323735 .7422280311585 .630003929138 5.5341620445255 .4565200805665 .3994941711435 .3641700744635 .354608058929 5.3720397949225 .4181241989145 .4969158172615 .6089367866525 .755043983459 5.9332141876226 .1453962326056 .3950419425966 .6745128631596 .984095096588 7.3157420158397.667625904083 8.035078048706 8.41033744812 8.794090270996 9.1812467575079 .5743570327769 .97380828857410 .3768301010110 .78283023834 11.1892900466911 .5941095352212 .0002202987712 .4060602188112 .81095027924 13.2136201858513 .607700347913 .9937095642114 .375980377214 .77482032776 15.1548004150415 .490059852615 .7843599319516 .0397090911916 .26140975952 16.4667892456116 .6510295867916 .8121299743716 .9594402313217 .08748054504 17.21826934814 17.35778999329 17.52178955078 17.71393013 17.943359375 18.2281208038318 .5534896850618 .9181499481219 .3262290954619 .78252983093 20.2721195220920 .7765293121321 .3131008148221 .8991603851322 .52701950073 23.1980800628723 .9191703796424 .69817924525 .5482902526926 .47661018372 27.5174598693828 .6979904174830 .0613994598431 .6428108215333 .39931106567 35.28475952148 37.2600402832 39.28231811523 41.32592010498 43.36346054077 45.3670387268147 .3084983825749 .1621208190950 .9003181457552 .55469894409 54.151500701955 .7174491882357 .2789916992258 .8464889526460 .44623184204 62.0405616760363 .5904312133865 .1425018310566 .7428436279368 .37288665771 70.0354232788171 .71958160473 .4147033691475 .1119689941476 .80091094971 78.4717102050880 .1146087646581 .7358703613383 .3358993530384 .92154693604 86.4989624023488 .089561462489 .6705474853591 .4318771362393 .59308624268 95.9309082031298 .26463317871100 .6270980835102 .9925003052105 .3527984619 107.6978988647110 .0168991089112 .2983016968114 .526802063116 .6877975464 118.7595977783120 .7301025391122 .6143035889124 .4397964478126 .2133026123 127.9529037476129 .658493042131 .333404541132 .9786987305134 .5926971436 136.1831970215137 .7543029785139 .3161010742140 .8764038086142 .4452972412 144.0310058594145 .6582946777147 .3479003906149 .1423034668151 .1352996826 153.1694946289155 .053894043156 .9608001709159 .0131988525161 .12840271 163.2743988037165 .4467926025167 .6298065186169 .8262023926172 .0330047607 174.2489013672176 .4723968506178 .7006988525180 .9311981201183 .1616973877 185.3890075684187 .6114959717189 .8265075684192 .032699585194 .2281036377 196.4114990234198 .5814056396200 .7368927002202 .8769989014205 .0009002686 207.1078948975 209.1974945068 211.2691040039 213.3224945068 215.3574981689 217.3739013672219 .37159729221 .3504943848223 .3106994629225 .2521972656 227.175201416229.0796051025 230.9656982422 232.8334960938 234.6831970215 236.5149993896238 .328994751240 .1255950928241 .904800415243 .6667938232 245.4120025635247 .1405029297248 .8524932861250 .5482025146252 .2279968262 253.891998291255 .5404968262257 .173614502258 .7916870117260 .3949890137 261.9836120605263 .558013916265 .1181030273266 .6643981934268 .1969909668 269.7161865234271 .2221069336272 .7150878906274 .1953125275 .6630859375 277.1185913086278 .5621032715279 .9939880371281 .4143066406282 .8236083984 284.2218933105 285.609588623286.986907959288.354095459289.7114868164 291.0592041016292 .3973999023293 .7264099121295 .0462036133296 .3569946289 297.6588134766298 .9518127441300 .236114502301 .5115966797302 .778503418 304.0369873047305 .2864074707306 .528503418307 .7604980469 
-49.9232406616 -48.4147109985-46.9435005188 -45.5040817261-44.0792694092 $-42.6691398621-41.2711601257-39.8832397461-38.5022201538-37.1254615784$ -35.7493095398 -34.3704681396 -32.9850387573 -31.5891990662 -30.1789798737 -28.7502403259 -27.2991294861 -25.821390152 -24.3134899139 -22.7713108063 -21.19190979 -19.5716209412 -17.9082508087 -16.1988792419-14.4421796799 -12.6361198425 -10.7803096771 -8.87368869781 -6.91681718826-4.90964794159 -2.85376000404-.750172972679 1.398463964462 3.5899939537055 .820686817169 8.08720207214410 .3847599029512 .7088403701815 .0536899566717 .4136505127 19.7821197509822 .1523895263724 .5171604156526 .8688297271729 .19964027405 31.5013008117733 .7660102844235 .9851112365738 .1511688232440 .25559997559 42.2917709350644 .2515792846746 .1294784545947 .9182205200249 .61346054077 51.2090415954652 .7019081115754 .0871086120655 .3629608154356 .5258102417 57.5754013061558 .5094985961959 .3292198181260 .033760070860 .62554931641 61.1051788330161 .476280212461 .7407417297461 .903179168761 .96659088135 61.9359016418561 .8145484924361 .6068115234461 .3156394958560 .94301986694 60.4946289062559 .9317588806259 .2135581970258 .3955001831157 .52687072754 56.6124305725155 .6644897460954 .686248779353 .6833000183152 .66624832153 51.6358985900950 .6020889282249 .5800590515148 .4990692138747 .29724884033 46.0183715820344 .7072601318443 .3152389526441 .8178482055740 .2797088623 38.7853698730537 .2918281555235 .7836608886734 .2964286804232 .84460067749 31.4762992858930 .1769790649429 .2872600555429 .1885795593329 .0948600769 28.2075099945127 .0410709381126 .0009307861325 .0565605163624 .28193092346 23.6334590911923 .0848693847722 .6211490631122 .213729858421 .85132980347 21.5131607055721 .1784591674820 .8298091888420 .4737091064520 .11500930786 19.7487297058119 .3614006042518 .9457092285218 .5037002563518 .04952049255 17.58307075517 .1327991485616 .7151794433616 .342220306416 .0465297699 15.8188600540215 .6731395721415 .4521703720114 .9961204528814 .41911029816 13.8164596557613 .2027702331512 .6112604141212 .0915699005111 .71737003326 11.3607997894310 .9117698669410 .434590339669 .9923925399789 .56186580658 9.1219062805188 .6998319625858 .2841281890877 .8861517906197 .531445026398 7.1887288093576 .8591079711916 .5441708564766 .2069950103765 .867744922638 5.5309309959415 .2025160789494 .9098181724554 .6404881477364 .385980129242 4.1417059898383 .8931078910833 .6985890865333 .6045858860023 .559108972549 3.5084218978883 .4647059440613 .4307880401613 .4139630794533 .422080993652 3.455177068713 .5124650001533 .6035790443423 .7361230850223 .906732082367 4.1102671623234 .3522758483894 .6363739967354 .9581432342535 .318396091461 5.7073111534126 .1185188293466 .5481009483346 .9878149032597 .433183193207 7.8754172325138 .3185615539558 .7640304565439 .209821701059 .653696060181 10.0973396301310 .5424203872710 .9903297424311 .4410800933811 .89021015167 12.3356800079312 .7793397903413 .2201204299913 .6606397628814 .10420036316 14.5270004272514 .9142799377415 .2658596038815 .5861396789615 .86763000488 16.1114292144816 .3251094818116 .5128707885716 .6830005645816 .83724021912 16.9888095855717 .1513805389417 .3300304412817 .5319099426317 .76063919067 18.0280895233218 .325199127218 .6521205902119 .010189056419 .40475082397 19.8283901214620 .2723808288620 .7480907440221 .2659893035921 .8251991272 22.4295005798323 .0876808166523 .808240890524 .6068592071525 .49278068542 
26.5046997070327 .6678791046128 .983610153230 .4797401428232 .12575149536 33.9150810241735 .8168716430737 .7822990417539 .7912788391141 .81391143799 43.8347206115745 .8395004272547 .7442512512249 .4526214599651 .06312942505 52.65388107354 .2302589416555 .8088798522957 .3947906494159 .00128936768 60.6016693115262 .1741485595763 .74650955265 .349327087466 .97511291504 68.6261901855570 .2942886352571 .9738235473673 .6557693481475 .33122253418 76.9865036010778 .6115570068480 .2107620239381 .7796401977583 .32689666748 84.8546905517686 .3955383300887 .9778289794989 .7286834716891 .78369140625 94.0080566406296 .2834930419998 .60292053223100 .9395980835103 .2857971191 105.6264038086107 .9505996704110 .2415008545112 .4826965332114 .6585006714 116.7706985474118 .8076019287120 .7798995972122 .6906967163124 .5417022705 126.3479003906128 .1107025146129 .8329925537131 .5151977539133 .1549987793 134.7611999512136 .3424987793137 .9062042236139 .4622955322141 .0193023682 142.5879974365144 .1835021973145 .820602417147 .504699707149 .2485961914 151.0848999023153 .0623016357155 .1219024658157 .2102966309159 .3253936768 161.453704834163 .5960998535165 .7487945557167 .9122009277170 .0854034424 172.266998291174 .4557952881176 .649597168178 .846206665181 .0433044434 183.2382049561185 .4291992188187 .6138000488189 .790802002191 .9580993652 194.1148986816196 .2592926025198 .3907012939200 .5077972412202 .6100006104 204.6963043213206 .7664031982208 .8195037842210 .8554992676212 .8739929199 214.8748016357216 .8576965332218 .8227996826220 .7698059082222 .6988983154 224.6101074219226 .50340271228 .37890625230 .2366943359232 .0769042969 233.8997955322235 .7053985596237 .4938049316239 .2653045654241 .0200958252 242.7583007812244 .4801940918246 .1858062744247 .87550354249 .5494995117 251.2079925537252 .8511047363254 .479095459256 .0922851562257 .6907958984 259.2749023438260 .8447875977262 .4006958008263 .9428100586265 .4714050293 266.9866027832268 .4888000488269 .9780883789271 .4547119141272 .9189147949 274.3709106445275 .8110961914277 .2396850586278 .6567993164280 .0628967285 281.458190918282 .8428039551284 .2171936035285 .5816040039286 .9360961914 288.2810058594289 .6164855957290 .9428100586292 .2600097656293 .5682067871 294.8676147461296 .1581115723297 .4399108887298 .7130126953299 .9775085449 301.2336120605302 .4815063477303 .7155151367304 .938293457

-50.1231117249-48.6983108521-47.2838401794-45.8957595825-44.5257110596 $-43.1719589233-41.8315505981-40.5023193359-39.1806907654-37.8637695312$ -36.5475616455 -35.22838974 -33.9020805359-32.5643501282 -31.2110500336 -29.8374996185 -28.4397602081 -27.0129699707 -25.5536193848 -24.0569400787 $-22.5200691223-20.9386196136-19.3106098175-17.6322994232-15.9026699066$ $-14.1188497543-12.2808599472-10.3868103027-8.43777656555-6.43290185928$ $-4.37442111969-2.26256608963-.1007599979642 .1095719337464 .363813877106$ 6.6592888832098 .99022865295411 .3526897430413 .7398300170916 .14645957947 18.5648193359420 .9885292053223 .409109115625 .8190803527828 .20956993103 30.5722007751532 .8981285095235 .1783790588437 .4046592712439 .56777954102 41.6604995727543 .6738815307645 .6020393371647 .4366798400949 .17345809937 50.8050193786652 .3286399841353 .7380409240755 .0322113037156 .20611953735 57.2604217529358 .191551208559 .0017204284759 .688888549860 .25672149658 60.7047309875561 .0378608703661 .2570991516161 .3683891296461 .374168396 
61.2804985046461 .0908813476660 .80900955260 .4374694824259 .9737701416 59.4141082763758 .7527999877957 .9837799072357 .1276893615756 .20433044434 55.2299880981454 .2211608886753 .1825485229552 .1173896789651 .02556991577 49.9074211120648 .7780685424847 .6894416809146 .5201110839845 .14093017578 43.6679687542 .2098007202140 .7019081115739 .166019439737 .59962081909 36.0481185913134 .5334587097233 .0426788330131 .6441402435330 .33654975891 29.2062797546428 .3458499908427 .7183799743727 .2514495849626 .80248069763 26.163709640525 .4071903228824 .6034793853823 .8089199066223 .11856079102 22.5155200958322 .0041198730521 .5658397674621 .1727199554420 .81447029114 20.469310760520 .1158008575419 .7355709075919 .3386802673318 .93140983582 18.5180492401118 .0900897979717 .6485595703117 .1966400146516 .71389961243 16.1882896423315 .6590595245415 .1678600311314 .7357902526914 .389960289 14.1211900711113 .9899997711213 .7528495788613 .1262502670312 .36779975891 11.6880502700811 .03715038310 .446999549879 .9124383926399 .428978919983 8.9698848724378 .5191421508798 .0609178543097 .5940899848947 .119979858398 6.6363639831546 .1686391830445 .7166008949285 .3057641983034 .955512046814 4.6492609977724 .3723859786994 .1107330322273 .8287100791933 .546999931335 3.2722849845893 .0058391094212 .761092901232 .5243330001832 .293652057648 2.0641210079191 .8059569597241 .6057709455491 .5529979467391 .555098056793 1.5313429832461 .510769009591 .4941829442981 .4903160333631 .512246012688 1.5567419528961 .6213090419771 .7201189994811 .8667370080952 .053659915924 2.2743780612952 .5367119312292 .8472421169283 .2044649124153 .613733053207 4.0586018562324 .530014991765 .020433902745 .5225729942326 .026527881622 6.5223588943487 .0135178565987 .5018820762637 .9873518943798 .467562675476 8.9461336135869 .4292211532599 .91601181030310 .4076099395810 .90069007874 11.3926696777311 .8851404190112 .3769397735612 .8649797439613 .34457015991 13.8070297241214 .2489795684814 .6653203964215 .0627002716115 .42216014862 15.7280397415215 .9895896911616 .2160797119116 .4157791137716 .59896087646 16.7795200347916 .9646301269517 .1609096527117 .3728599548317 .6021900177 17.854209899918 .1270408630418 .4220104217518 .739669799819 .07896995544 19.443429946919 .8329505920420 .2526092529320 .7082405090321 .20499992371 21.751600265522 .3560905456523 .0272293090823 .782159805324 .62886047363 25.5993900299126 .7144508361827 .9720401763929 .3843803405830 .93901062012 32.6350288391134 .4488601684636 .3426208496138 .3004302978540 .29499053955 42.308460235644 .3535995483446 .2988204956147 .9867095947349 .57183074951 51.1714706420952 .7622108459554 .3564910888755 .9548912048357 .5576210022 59.1598205566460 .7585296630962 .359519958563 .9733314514265 .59980773926 67.2440338134868 .9007492065470 .5669479370172 .2359619140673 .89971160889 75.5483932495177 .1700134277378 .7536010742280 .2939071655381 .80304718018 83.2920227050884 .8196334838986 .4443664550888 .2030181884890 .13220214844 92.2053680419994 .3869705200296 .6439590454198 .94040679932101 .2613983154 103.5883026123105 .9072036743108 .1981964111110 .4496002197112 .6483001709 114.7974014282116 .8943023682118 .9384002686120 .9319000244122 .8657989502 124.748298645126 .5768966675128 .3513031006130 .0742034912131 .7434997559 133.3686981201134 .9645996094136 .5361938477138 .095199585139 .6479034424 141.2075958252142 .7745056152144 .3589935303145 .9443054199147 .4521942139 
149.1069030762151 .178894043153 .3856048584155 .4998016357157 .6089935303 159.7154998779161 .8240966797163 .9445953369166 .0726013184168 .2108001709 170.3563995361172 .5093994141174 .6674957275176 .8289031982178 .991394043 181.1526947021183 .3108978271185 .4640960693187 .6107025146189 .7489013672 191.8777008057193 .9956054688196 .1016998291198 .1947021484200 .2740020752 202.3386993408204 .3881988525206 .4219970703208 .4394989014210 .4405975342 212.4248962402214 .3921966553216 .3424072266218 .2754058838220 .1912994385 222.0897979736223 .971206665225 .8354034424227 .6824951172229 .5126037598 231.3258056641233 .1221923828234 .9019927979236 .6652069092238 .4120941162 240.1428070068241 .8574066162243 .5561981201245 .2393035889246 .9069976807 248.5594024658250 .1967926025251 .8191986084253 .4270935059255 .020401001 256.5994873047258 .1646118164259 .7157897949261 .2533874512262 .7774963379 264.2885131836265 .7864990234267 .271697998268 .7443847656270 .2048034668 271.6531066895273 .0895996094274 .5145874023275 .928314209277 .3309936523 278.7229003906280 .104309082281 .4754943848282 .8367004395284 .1882019043 285.5302124023286 .8627929688288 .1861877441289 .5004882812290 .8059997559 292.1026000977293 .3905029297294 .6695861816295 .9400939941297 .2019958496 298.4555053711299 .6998901367300 .9370117188302 .1640014648 $-50.3349990845-48.9232215881-47.5550003052-46.2244300842-44.9114303589$ $-43.6163482666-42.336101532-41.0681610107-39.8087387085-38.5545387268$ $-37.3012619019-36.0448493958-34.7807312012-33.5043296814-32.2109909058$ -30.895860672 -29.5544204712 -28.1817493439-26.7736797333 -25.3254909515 -23.8336200714 -22.2937908173 -20.7032394409-19.0584602356-17.357629776 -15.59815979-13.7792797089-11.899479866 -9.95905303955 -7.9576830864 -5.89680480957 -3.77734208107 -1.60195302963.6271229982376 2.905973911285 5.23099899292 7.5970492362989 .99915122985812 .430979728714 .8862400054917 .35754013062 19.837329864522 .3173503875724 .7889308929427 .2432193756129 .67070007324 32.0623397827134 .4080810546936 .6992301940938 .9257011413641 .07958984375 43.1512794494645 .1340217590347 .019111633348 .801200866750 .47282028198 52.030139923153 .4670906066954 .7814598083555 .9687881469757 .02851104736 57.957870483458 .7579116821359 .4276504516659 .9696311950760 .38463973999 60.6765518188560 .847789764460 .9033012390160 .846958160460 .68389129639 60.418949127260 .0550003051859 .596260070859 .0384712219258 .38095855713 57.6314392089856 .7881088256855 .8680610656754 .8796310424853 .83765029907 52.7622108459551 .6590614318850 .5413398742749 .3745193481448 .12297821045 46.8441200256345 .6043701171944 .2940711975142 .8219299316441 .27252960205 39.7211494445838 .1565399169936 .5967903137235 .0202407836933 .41463088989 31.9046993255630 .597930908229 .4339599609428 .3246593475327 .39138031006 26.6993198394826 .1045608520525 .5620193481425 .0426101684624 .48174095154 23.9209499359123 .28474044822 .6138191223122 .0049800872821 .45348930359 20.9776306152320 .553710937520 .1652793884319 .7971096038819 .42575073242 19.0337696075418 .6083908081118 .1551303863517 .6744194030817 .1884803772 16.7010993957516 .2239799499515 .7949800491315 .3115501403814 .67014026642 14.0010299682613 .4206304550212 .9126195907612 .4877500534112 .12771987915 11.8400897979711 .460209846510 .8138704299910 .062879562389 .35659122467 8.695674896248 .0939807891857 .5335898399357 .0133519172676 .522925853729 
6.059916019445 .6102871894845 .148939132694 .6653499603274 .158697128296 3.6549239158633 .1532039642332 .7136900424962 .3938040733342 .153603076935 1.9650210142141 .7805639505391 .5280950069431 .2745829820631 .067713022232 .8765820264816.6804839968681. 4839360117912 0.291592001915 9.85900015e-02 $-.107500001788-.267940014601-328648000956-342891007662-.361277014017$ $-.373463988304-.379673987627-372552990913-.346385985613-.298539012671$ - $228900998831-125826001167$ 1.98160000e-02 2070859968662. 2348250031471 .70844399929051 .0314149856571 .4142709970471 .8711940050132 .374443054199 2.9049720764163 .4567151069644 .0168309211734 .5763750076295 .125789165497 5.6650509834296 .191552162176 .7119741439827 .2258062362677 .73689699173 8.2551746368418 .7796726226819 .3113174438489 .84722900390610 .38444042206 10.9233102798511 .4622097015411 .9956903457612 .5190200805713 .02929973602 13.5219697952313 .9985599517814 .4574298858614 .8885002136215 .28796005249 15.6311502456715 .8955097198516 .1192607879616 .3381595611616 .55286026001 16.7698402404816 .9896602630617 .2157096862817 .4481391906717 .69238090515 17.9489994049118 .2225093841618 .5106105804418 .81117057819 .13105964661 19.4746303558319 .8444309234620 .2433300018320 .6826400756821 .17569923401 21.7285003662122 .3483295440723 .051549911523 .8527107238824 .77129936218 25.8268508911127 .0148200988828 .3440399169929 .807479858431 .40694999695 33.1266593933134 .9460296630936 .8421592712438 .7879600524940 .76499938965 42.7592201232944 .6766815185546 .4105987548848 .055660247849 .68608093262 51.3026809692452 .9180488586454 .5296707153356 .1421699523957 .75619125366 59.3708305358960 .9893684387262 .6136093139664 .2430877685565 .88374328613 67.5320129394569 .1860733032270 .8428421020572 .4975433349674 .14745330811 75.7934188842877 .3877105712978 .8797607421980 .3328475952181 .79933166504 83.3226699829184 .9454727172986 .6687927246188 .5212402343890 .49014282227 92.577713012794 .7602462768697 .0063781738399 .29370117188101 .5982971191 103.907699585106 .1934967041108 .451499939110 .6690979004112 .852897644 115.0010986328117 .1123962402119 .1847000122121 .2025985718123 .1635971069 125.0632019043126 .8897018433128 .6531066895130 .354095459132 .0019073486 133.6159057617135 .2014007568136 .7687072754138 .3233947754139 .875793457 141.4266967773142 .9873046875144 .5372009277146 .058303833147 .7272033691 149.7057952881151 .8233032227153 .9069061279155 .9813995361158 .054901123 160.1322021484162 .2162017822164 .3076019287166 .4075927734168 .5153045654 170.6305999756172 .7514038086174 .8762054443177 .0030059814179 .1293945312 181.25390625183 .3742980957185 .4895019531187 .5975036621189 .6974945068 191.7877960205193 .8675994873195 .9355926514197 .991104126200 .033203125 202.0612030029204 .0746002197206 .0729064941208 .0556030273210 .0225067139 211.9732971191213 .9080047607215 .8262023926217 .7279968262219 .6132965088 221.4821014404223 .3343048096225 .1699981689226 .9893035889228 .7922058105 230.5789031982232 .3493041992234 .1036987305235 .8421020508237 .5646972656 239.271697998240 .963104248242 .6390991211244 .3000946045245 .9459991455 247.5771026611249 .1934967041250 .7955932617252 .3833007812253 .9571075439 255.5169067383257 .0631103516258 .5957946777260 .1152038574261 .6216125488 263.1151123047264 .5960083008266 .0645141602267 .520690918268 .9649963379 270.3976135254271 .8186950684273 .2286987305274 .6276855469276 .0161132812 
277.3940124512 278.7616882324 280.1196899414281.4678955078282.8066101074 284.1359863281285 .4563903809286 .767791748288 .0703125289 .3638916016 290.6488952637291 .9252929688293 .1929016113294 .4519958496295 .7027893066 296.9454040527298 .1740112305299 .3913879395 $-50.3853912354-49.0654983521-47.7586708069-46.4829406738-45.2289810181$ $-43.9948997498-42.777141571-41.5731201172-40.3785591125-39.1899414062$ $-38.0024909973-36.8118400574-35.6130104065-34.400970459-33.1707992554$ $-31.9170799255-30.6351509094-29.3194503784-27.9657993317-26.5687294006$ $-25.1247901917-23.6289100647-22.0785198212-20.4692707062-18.7996101379$ $-17.066110611-15.2683496475-13.4039697647-11.4737596512-9.47656154633$ $-7.41443490982-5.28748703003-3.09913396835-.8508459925651 .452579975128$ 3.8082571029666 .2100191116338 .65353488922111 .1313400268613 .63768005371 16.1639099121118 .702909469621 .2450809478823 .7820091247626 .30352973938 28.8001098632831 .2614707946833 .677310943636 .0378303527838 .33237075806 40.552181243942 .6867599487344 .7288398742746 .6685600280848 .50043106079 50.2155914306651 .8104515075753 .2774696350154 .6150398254455 .81718826294 56.8842315673857 .8119888305758 .6026000976659 .2538108825759 .7693901062 60.1490898132360 .3979797363360 .5177803039660 .5144081115760 .39136123657 60.1543312072859 .8081398010359 .3563690185558 .8045082092358 .15219116211 57.4003791809156 .5599098205655 .6337585449254 .6353492736853 .57098007202 52.4548912048351 .3055801391650 .1249084472748 .9411201477147 .69107055664 46.3085784912144 .8722610473643 .4693603515642 .0167694091840 .48236083984 38.8895797729537 .2812194824235 .6876106262234 .1501388549832 .6370010376 31.0584793090829 .6180591583328 .523990631127 .6040306091326 .67843055725 25.871999740625 .2240791320824 .6404895782524 .0869293212923 .56736946106 23.0606002807622 .5699501037622 .0202198028621 .4486999511720 .91193008423 20.4042091369619 .9440002441419 .5208301544219 .126470565818 .72521018982 18.3005294799817 .8497390747117 .3833007812516 .8753795623816 .31074905396 15.72465038315 .1536197662414 .6178102493314 .1822299957313 .6846704483 12.9362697601312 .1490097045911 .4967403411910 .9148998260510 .41036987305 9.9356803894049 .4565591812138 .9210109710698 .2777223587047 .594088077545 6.9223518371586 .2740211486825 .6567878723145 .0766520500184 .551986217499 4.0656161308293 .6044499874113 .1604158878332 .7224769592292 .27020907402 1.7782080173491 .273913025856 .7528399825096 .3050009906292 2.32630000e-02 $-.158733993769-.276048988104-391656011343-0.61975902319-.850766003132$ $-.998543977737-1.12977695465-1.28520703316-1.44607400894-1.60020899773$ $-1.75046098232-1.89351403713-2.0122089386-2.09270596504-2.14342498779$ $-2.17338609695-2.18690705299-2.18921899796-2.17778801918-2.15328907967$ $-2.1085460186-2.0405600071-1.94152605534-1.80649101734-1.62953901291$ $-1.40465795994-1.12775397301-.799685001373-.4012070000179 .20030028 \mathrm{e}-02$ .6455479860306 1.233597993851 1.840116024017 2.4508149623873.05952501297 3.6679999828344 .2591738700874 .8239340782175 .3723258972175 .916439056396 6.4631500244147 .0184521675117 .5827431678778 .1558647155768 .73540687561 9.3175029754649 .90174198150610 .4845104217511 .0632295608511 .63160991669 12.1897802352912 .7330102920513 .2625904083313 .7760295867914 .26982021332 14.758830070515 .1889600753815 .5053300857515 .7702903747616 .03869056702 
16.2980308532716 .5519294738816 .8013401031517 .0457191467317 .28792953491 17.5316905975317 .780689239518 .0383205413818 .3034496307418 .56986999512 18.8492698669419 .1476306915319 .4691791534419 .8160591125520 .20225906372 20.6468505859421 .1517295837421 .7256908416722 .3831291198723 .13924026489 24.0060291290324 .99867057826 .1161708831827 .3641395568828 .7401599884 30.2398300170931 .8632698059133 .5991592407235 .4224205017137 .31187820435 39.2328605651941 .1519393920943 .0317497253444 .8206100463946 .54552078247 48.2213211059649 .8670005798351 .5033302307153 .1309204101654 .7571105957 56.3835296630958 .0113792419459 .6413917541561 .2737388610862 .90768814087 64.5476379394566 .1899566650467 .8330764770569 .4780273437571 .12180328369 72.7643280029374 .4251174926876 .0277862548877 .4847412109478 .90345001221 80.3704376220781 .892723083583 .5005035400485 .1913528442486 .97927856445 88.8641967773490 .8554000854592 .9542083740295 .1424636840897 .39726257324 99.67588806152101 .9641036987104 .2366027832106 .4919967651108 .7226028442 110.9322967529113 .12159729115 .2878036499117 .4304962158119 .5323028564 121.5839004517123 .5572967529125 .4353027344127 .2304000854128 .9615936279 130.6396026611132 .2805938721133 .8885955811135 .4721984863137 .0357971191 138.5865020752140 .1307983398141 .6822052002143 .25390625144 .8701934814 146.5885009766148 .4458007812150 .4044952393152 .4058990479154 .4333953857 156.4691925049158 .5108947754160 .5572967529162 .6092071533164 .6697998047 166.737701416168 .8139953613170 .8963012695172 .983505249175 .0733947754 177.1640014648179 .2537994385181 .3406982422183 .4235992432185 .5005950928 187.5708007812189 .6327056885191 .6853942871193 .7276000977195 .7584991455 197.7770996094199 .7828979492201 .775100708203 .7532958984205 .7169952393 207.665802002209 .5995025635211 .5178070068213 .4205932617215 .307800293 217.1790924072219 .0346069336220 .874206543222 .6979980469224 .5059051514 226.2980041504228 .0742950439229 .8348999023231 .5798950195233 .3094024658 235.0234069824236 .7221984863238 .4057006836240 .0742950439241 .7279968262 243.3670043945244 .991394043246 .6015014648248 .1974029541249 .7792053223 251.3471984863252 .9015045166254 .4423065186255 .9698028564257 .4841003418 258.9855957031260 .474395752261 .950592041263 .4144897461264 .866394043 266.3063964844267 .7348022461269 .1518859863270 .5578918457271 .9530029297 273.3374938965274 .7117004395276 .0758972168277 .4302062988278 .7749023438 280.1102905273281 .4364013672282 .7535095215284 .0616149902285 .3609008789 286.6516113281287 .9335021973289 .2067871094290 .471496582291 .7276000977 292.9754943848294 .2141113281295 .4455871582296 .6669006348 $-50.4480209351-49.1386985779-47.8801689148-46.666229248-45.4733886719$ $-44.3023681641-43.149520874-42.0118217468-40.8847999573-39.7644615173$ -38.6457290649 -37.5237808228 -36.3932418823 -35.2486915588 -34.0847206116 -32.8956184387 -31.6761608124 -30.4206295013 -29.1241703033 -27.7813205719 -26.3878498077 -24.9388103485 -23.4308204651 -21.8597106934-20.2231006622 $-18.5178394318-16.7426700592-14.8956298828-12.9766597748-10.9851198196$ -8.92224979401 -6.78883314133 -4.58746910095 -2.32044792175 8.20900034e-03 2.3946568965914 .8334431648257 .3191528320319 .84493827819812 .403840065 14.9877300262517 .5881595611620 .1958808898922 .8011398315425 .39385986328 27.9631996154830 .4987392425532 .9888992309635 .4234809875537 .79069900513 
40.0811309814542 .2833595275944 .3891906738346 .3881492614748 .27362060547 50.0364990234451 .6719207763753 .1724700927754 .5352096557655 .75466156006 56.8298301696857 .7573394775458 .5381202697859 .1709709167559 .65856170654 60.0018806457560 .2050895690960 .2712211608960 .2054786682160 .01263046265 59.6980209350659 .2675590515158 .7256011962958 .0780982971257 .32857894897 56.4808311462455 .5458412170454 .5299491882353 .4441299438552 .29594039917 51.0961799621649 .8588600158748 .5859489440947 .2911796569845 .93141174316 44.4713706970242 .9523696899441 .4286613464439 .8746299743738 .26802062988 36.6211509704634 .9332389831533 .3157806396531 .8988704681430 .5649394989 29.1872100830127 .9316101074226 .9259796142626 .073450088525 .27005958557 24.5474300384523 .9351100921623 .3682899475122 .8174991607722 .30308914185 21.8170890808121 .351079940820 .8515090942420 .3345298767119 .8263092041 19.3297405242918 .8487796783418 .4008998870818 .0084495544417 .58062934875 17.0418891906716 .487720489516 .0201206207315 .5011901855514 .80661964417 14.0647001266513 .3872699737512 .7627401351912 .2100296020511 .61198997498 10.8517398834210 .063839912419 .3672819137578 .7319231033338 .171366691589 7.6185078620917 .0420207977296 .4257860183725 .7035617828375 .00435590744 4.4279279708863 .8602869510653 .2083940505982 .5879399776462 .111205101013 $1.6815340518951 .212887048721 .76717299222950 .3926370143892 .41030008 \mathrm{e}-02$ -.399076014757 -.842031002045 -1.29041302204 -1.67585194111 - 1.9353979826 $-2.10600709915-2.21982192993-2.3280620575-2.50198602676-2.67652797699$ $-2.80510210991-2.92074394226-3.05436897278-3.19357395172-3.33300900459$ $-3.46471595764-3.586591959-3.69624209404-3.78167510033-3.84868001938$ -3.89244890213 -3.91406393051 -3.92332005501 -3.91876101494 -3.9024169445 $-3.86792802811-3.81371307373-3.7308549881-3.61285805702-3.45215010643$ $-3.23898291588-2.9672191143-2.63429498672-2.22332406044-1.71719002724$ -1.13397097588- 484351992607.1836940050125.8194580078125 1.460901021957 2.1470820903782 .8129220008853 .3991880416873 .9583640098574 .533283233643 5.118962764745 .7160701751716 .3238520622256 .9426960945137 .567949771881 8.1950702667248 .8234910964979 .45116901397710 .0747900009210 .68729972839 11.2902002334611 .8805904388412 .4582300186213 .0216598510713 .56984996796 14.1048803329514 .5902700424214 .9907197952315 .3403396606415 .67580986023 15.9932098388716 .2940597534216 .5795001983616 .8520603179917 .11240959167 17.36734008789 17.61694908142 17.86091041565 18.1000595092818.33072090149 18.5646896362318 .8113307952919 .0795192718519 .3816509246819 .72360992432 20.1181793212920 .576030731221 .1166992187521 .7420406341622 .46162986755 23.284179687524 .224260330225 .2772998809826 .4439792633127 .72604942322 29.1246700286930 .6465702056932 .2884407043534 .0288581848135 .86135864258 37.7359390258839 .6173591613841 .4909515380943 .3026313781745 .06980133057 46.7832794189548 .4579811096250 .1173706054751 .7638206481953 .40560913086 55.0448303222756 .6839981079158 .3230018615759 .9615592956561 .59894943237 63.2375602722264 .8737030029366 .5056991577168 .1354370117269 .76168823242 71.3839035034273 .004882812574 .5764694213976 .0507202148477 .49777984619 78.9800262451280 .5092468261782 .1087112426883 .7715377807685 .50933837891 87.3165512085 89.1912231445391.1836776733493.3407669067495.5842590332 97.83466339111100 .0925979614102 .3402023315104 .5813980103106 .8121032715 
109.0362014771 111.2537002563113.464302063 115.6664962769 117.8510971069 120.0173034668122 .0897979736123 .991897583125 .793296814127 .5542984009 129.2700958252130 .9479064941132 .5895996094134 .2008056641135 .7863006592 137.3529052734138 .9105987549140 .4694976807142 .0623016357143 .7104949951 145.4203948975147 .2234954834149 .0912017822151 .0173034668152 .988494873 154.9714050293156 .9658050537158 .966796875160 .975692749162 .9938964844 165.0207061768167 .0563049316169 .0989990234171 .1472930908173 .1994018555 175.2532958984177 .3074951172179 .3601074219181 .4098052979183 .4552001953 185.4949035645187 .5276947021189 .5525970459191 .5682067871193 .5738983154 195.5684051514197 .5513000488199 .521697998201 .4792022705203 .4230957031 205.353302002 207.2691040039209.1705932617 211.0572967529 212.9291992188 214.7859954834216 .6277008057218 .4541931152220 .2655029297222 .0614013672 223.8421936035225 .6076965332227 .358001709229 .0930938721230 .8132019043 232.5182037354234 .2082977295235 .8836975098237 .5442962646239 .1903991699 240.8220977783242 .4394989014244 .0428009033245 .6320953369247 .2075958252 248.7695007324250 .3179016113251 .8529968262253 .375254 .8840026855256 .3803100586 257.8640136719259 .3352966309260 .7944946289262 .2416992188263 .6771850586 265.1011047363266 .513885498267 .9157104492269 .3067016602270 .6871948242 272.0574951172273 .4177856445274 .7684020996276 .1094055176277 .4411010742 278.7637023926280 .0773010254281 .3821105957282 .6781005859283 .9653930664 285.2441101074286 .5143127441287 .7757873535289 .0288085938290 .2735900879 291.5101013184292 .7326049805293 .9440917969 $-50.323841095-49.1149597168-47.9222602844-46.7661399841-45.6361808777$ $-44.5303497314-43.4445114136-42.3755607605-41.3185195923-40.2691307068$ $-39.2218513489-38.1714401245-37.1121406555-36.0379981995-34.9433097839$ $-33.8217391968-32.6678886414-31.4753303528-30.2391700745-28.9531402588$ $-27.6131095886-26.2132701874-24.7504196167-23.2195301056-21.6184597015$ $-19.943189621-18.1928005219-16.3644790649-14.4586000443-12.4737100601$ $-10.4116001129-8.27224159241-6.0589389801-3.773209095-1.41990602016$ .99786198139193 .4736509323126 .002745151528 .5771350860611 .19050979614 13.833390235916 .4979000091619 .1733093261721 .8502597808824 .51712989807 27.16324043274 29.7766304016132.34558105469 34.858501434333 37.30308151245 39.6687507629441 .9432106018144 .1175003051846 .1798896789648 .12342834473 49.9375190734951 .6174087524453 .1540489196854 .5450286865255 .78324127197 56.8685607910257 .7961196899458 .5679283142159 .1815490722759 .64083862305 59.9458808898960 .1020088195860 .1116905212459 .9812202453659 .71524047852 59.3202018737858 .8023414611858 .1676292419457 .4226684570356 .57426071167 55.6283607482954 .5957412719753 .4837608337452 .3031005859451 .06396102905 49.7719192504948 .4403991699247 .0628585815445 .6471710205144 .1764793396 42.6572189331141 .0851097106939 .4827499389637 .8465614318836 .18825912476 34.5187606811532 .802879333531 .2128391265929 .9389495849628 .80496025085 27.6545295715326 .5945491790825 .6424808502224 .8019294738824 .05496025085 23.385530471822 .7932701110822 .2379302978521 .6993007659921 .18925094604 20.6879100799620 .2033004760719 .7031402587919 .1998691558818 .70174980164 18.1867408752417 .6515598297117 .1217498779316 .6825599670416 .20453071594 15.5500698089614 .8852100372314 .4034595489513 .8665504455613 .06282997131 
12.197830200211 .4386901855510 .720769882210 .030030250559 .330404281616 8.5833616256717 .8266658782967 .103878021246 .4284181594855 .83202123642 5.2511267662054 .642145156863 .9922161102293 .2235620021822 .502774953842 $2.0051209926611 .524127960205 .8587790131569 .2214149981737-.194780007005$ -.562026977539-1.026720047-1.46325004101 -1.77091705799 -2.05539703369 $-2.39904999733-2.75301003456-3.09670090675-3.39998102188-3.63445711136$ -3.81166291237 -3.94842600822-4.06459093094 -4.19012498856-4.31351900101 $-4.43456888199-4.55537080765-4.68121480942-4.81134796143-4.94567584991$ $-5.07688713074-5.19734716415-5.30842781067-5.39900112152-5.47439193726$ $-5.52696800232-5.56143283844-5.58600902557-5.59401607513-5.59109020233$ $-5.57369804382-5.54319810867-5.48787784576-5.39547014236-5.25642585754$ $-5.06246900558-4.8043088913-4.47533512115-4.06341505051-3.56117200851$ $-2.97211694717-2.28410696983-1.57183802128-0.91391402483-.245472997427$ .51447397470471 .2541270256041 .874161005022 .4611549377443 .081291913986 3.7128930091864 .3553671836855 .0112037658695 .6779360771186 .350953102112 7.0247321128857 .6998300552378 .3716506958019 .0402879714979 .693740844727 10.3368301391610 .9692201614411 .5896501541112 .1986598968512 .7896900177 13.3574304580713 .8899898529114 .378419876114 .8272695541415 .24594020844 15.6299600601215 .9834499359116 .3082809448216 .6153202056916 .90432929993 17.1788806915317 .4365806579617 .6687602996817 .8842601776118 .0758895874 18.2642002105718 .4559993743918 .6685104370118 .9249095916719 .22242927551 19.5721702575719 .9889698028620 .5052108764621 .1089496612521 .80365943909 22.595220565823 .4942207336424 .4945297241225 .5905208587626 .78940010071 28.0930404663129 .5070304870631 .0347595214832 .6852989196834 .461769104 36.3125801086438 .1782493591340 .0427093505941 .8636589050343 .64876937866 45.3854904174847 .0859184265148 .7687492370650 .4336395263752 .09088897705 53.7415695190455 .3888282775957 .0331611633358 .6751899719260 .31336975098 61.9513397216863 .5820388793965 .2043304443466 .8189010620168 .42362976074 70.0137329101671 .581466674873 .1188125610474 .6242904663176 .11945343018 77.6309661865279 .1730804443480 .7686691284282 .412803649984 .11463928223 85.8697891235487 .6498031616289 .5487213134891 .6623764038193 .87391662598 96.0734329223698 .28632354736100 .4981002808102 .7134017944104 .9346008301 107.1622009277109 .3979034424111 .6406021118113 .8898010254116 .1340026855 118.3937988281120 .5537033081122 .4890975952124 .3137969971126 .1235961914 127.887802124129 .6118927002131 .2969970703132 .9441986084134 .5623931885 136.1560058594137 .7402038574139 .3204956055140 .9273071289142 .5821075439 144.2812042236146 .0399017334147 .8482971191149 .7124938965151 .6190032959 153.541305542155 .4826049805157 .4346923828159 .3984069824161 .3728942871 163.3574066162165 .3515014648167 .3536987305169 .3623962402171 .3760070801 173.3925933838175 .4105987549177 .4282989502179 .4445037842181 .4575958252 183.4664001465185 .4696044922187 .4662017822189 .4546966553191 .4346008301 193.4044952393195 .3639984131197 .31199646199 .2483062744201 .1719970703 203.082901001204 .9804992676206 .8645935059208 .7346954346210 .5908050537 212.4326019287214 .2599945068216 .0729064941217 .8712005615219 .6549072266 221.4237976074223 .1781005859224 .9176025391226 .6425018311228 .3527069092 230.0482940674231 .7295074463233 .3961029053235 .0484924316236 .6865997314 
238.3105926514239 .9207000732241 .5169067383243 .0993041992244 .6681976318 246.2236938477247 .7660064697249 .2951049805250 .8112030029252 .3146057129 253.8054046631255 .2837982178256 .7499084473258 .2041015625259 .6463928223 261.0770874023262 .4964904785263 .9046936035265 .3020019531266 .6886901855 268.0650024414269 .4312133789270 .7874145508272 .1340026855273 .4711914062 274.7991027832276 .1180114746277 .4280090332278 .7291870117280 .021697998 281.3055114746282 .5808105469283 .8475952148285 .1058044434286 .3554992676 287.5969848633288 .8294067383290 .0545043945291 .2695007324 $-50.2120780945-49.0101585388-47.8671607971-46.7767105103-45.7115097046$ $-44.6727104187-43.6560707092-42.6580505371-41.67345047-40.6975097656$ $-39.7243690491-38.7482681274-37.7630195618-36.7622299194-35.7396812439$ $-34.6887016296-33.6032791138-32.4767608643-31.3035793304-30.0774002075$ $-28.7932891846-27.4455299377-26.0300807953-24.5420608521-22.9784793854$ $-21.335609436-19.6116504669-17.8041706085-15.9126901627-13.9362602234$ $-11.8758001328-9.73195552826-7.50717401505-5.20376396179-2.82575798035$ -.377202987671 2.1362450122834.708774089813 7.333106040955 10.00168037415 12.7056398391715 .4357404708918 .1816997528120 .9326705932623 .67728042603 26.4032802581829 .0987091064531 .7502803802534 .3460502624536 .87231063843 39.3178100585941 .6690597534243 .9161415100146 .04645919848 .05184936523 49.9212684631351 .6486091613853 .2248115539654 .6460304260355 .90555953979 57.0019302368257 .9310493469258 .6936912536659 .2884788513259 .71828079224 59.9843902587960 .0914382934660 .0431785583559 .845569610659 .50445175171 59.0265388488858 .4191818237357 .6894416809156 .8452987670955 .89527130127 54.8476982116753 .7129516601652 .5006294250551 .2205505371149 .88381958008 48.4954109191947 .066551208545 .5913505554244 .0755081176842 .52093887329 40.9305000305239 .3054695129437 .6542396545435 .9796791076734 .29251861572 32.6401596069331 .055730819729 .6207809448228 .4146995544427 .35383033752 26.3377208709725 .3882503509524 .5164699554423 .721189498923 .01288986206 22.3761291503921 .7932701110821 .2358093261720 .6850490570120 .14871025085 19.6077995300319 .0728206634518 .5342903137218 .007879257217 .52125930786 16.9860191345216 .3138008117715 .6137695312515 .0076799392714 .39074039459 13.6797103881812 .9718904495212 .3706903457611 .7314300537110 .9289598465 10.07526969919 .2828264236458 .5159711837777 .7641911506657 .021695137024 6.2656240463265 .5064392089844 .7394189834594 .0266089439393 .452302932739 2.9128859043122 .3252520561221 .6980010271071 .001384973526 .3484559953213 $-.161804005504-651843011379-1.2391680479-1.79751300812-2.21194291115$ $-2.57867908478-2.98631811142-3.36306190491-3.65297198296-3.9117128849$ $-4.19837379456-4.48278188705-4.75304794312-4.99858617783-5.19665193558$ $-5.36428308487-5.49974298477-5.6114192009-5.7203412056-5.82737398148$ $-5.94207000732-6.06550121307-6.19413709641-6.32654619217-6.46472597122$ $-6.6016368866-6.72957897186-6.84660100937-6.94551515579-7.02825307846$ $-7.08713197708-7.13309001923-7.17778587341-7.20592784882-7.21303081512$ $-7.21282577515-7.22209978104-7.21126794815-7.15086507797-7.03942203522$ $-6.87488794327-6.64458322525-6.33783817291-5.94672489166-5.46220111847$ $-4.88604879379-4.21585178375-3.50566196442-2.8069601059-2.08420205116$ $-1.29658401012-.515956997871 .1904429942369$.8679500222206 1.551825046539 
2.2400920391082 .9368801116943 .6446819305424 .3633389472965 .085841178894 5.8101167678836 .5332779884347 .2517471313487 .9640312194828 .655414581299 9.3324394226079 .99986171722410 .6565704345711 .3052597045911 .937512 .54841041565 13.1375799179113 .6969299316414 .2313203811614 .7433900833115 .20893955231 15.6106395721415 .9719600677516 .3208293914816 .6463699340816 .94539070129 17.21195983887 17.4372501373317.628490448 17.78359985352 17.9253692627 18.0690193176318 .2301807403618 .4295902252218 .6757297515918 .98970031738 19.3805294036919 .8725204467820 .4592800140421 .1465702056921 .92684936523 22.7986392974923 .7591991424624 .8071403503425 .9409694671627 .15929985046 28.4615001678529 .8388595581131 .3669490814233 .1272087097234 .99428939819 36.8513412475638 .7025299072340 .5187110900942 .3061485290544 .05401992798 45.7718696594247 .4696197509849 .1490097045950 .8165206909252 .47494888306 54.1274185180755 .7746696472257 .4168891906759 .0541496276960 .68976974487 62.3147888183663 .9273300170965 .5267028808667 .1074600219768 .66837310791 70.2077713012771 .7337112426873 .2519683837974 .7768173217876 .3179473877 77.8808288574279 .4842834472781 .1251068115282 .8088607788184 .53455352783 86.296043396 88.1559982299890.1737365722792.2792129516694.4021987915 96.548690795998 .7092666626100 .8884963989103 .0868988037105 .306602478 107.5492019653109 .8106002808112 .0865020752114 .3643035889116 .6380996704 118.8273010254120 .8500976562122 .7727966309124 .6533966064126 .4834976196 128.266204834130 .0028076172131 .6959991455133 .3533935547134 .9806060791 136.5915985107138 .1965942383139 .81590271141 .4696044922143 .1526947021 144.8777008057146 .6398925781148 .4494018555150 .2953033447152 .1634063721 154.0523986816155 .9555969238157 .8730010986159 .8025970459161 .7436981201 163.6954956055165 .6564025879167 .625169 .5995025635171 .5782012939173 .5596923828 175.542098999177 .5243988037179 .5048065186181 .4824066162183 .4555969238 185.4234008789 187.3845977783 189.3381958008 191.283203125 193.2187957764 195.1441955566197 .058807373198 .9618988037200 .8531036377202 .7319946289 204.5982971191206 .4514007568208 .2913970947210 .1177978516211 .9304962158 213.7294006348215 .5142974854217 .2852020264219 .0420074463220 .7846069336 222.5131072998224 .2272949219225 .9273071289227 .6132049561229 .2850036621 230.9427032471232 .5863952637234 .2162017822235 .8323059082237 .4346008301 239.0234069824240 .5986938477242 .1607055664243 .7095031738245 .2451934814 246.7680969238248 .2781066895249 .775604248251 .2606964111252 .733505249 254.1943054199255 .6430969238257 .080291748258 .5061035156259 .920501709 261.324005127262 .7167053223264 .0989074707265 .4707946777266 .832611084 268.1846008301269 .5270996094270 .8601989746272 .1842041016273 .499206543 274.8053894043276 .1028137207277 .3916015625278 .6719055176279 .9436035156 281.2067871094282 .4616088867283 .7078857422284 .9460144043286 .1759033203 287.3918151855 288.5967102051 $-49.8847503662-48.7919807434-47.7189903259-46.6888008118-45.6898612976$ $-44.7199707031-43.7743797302-42.8494911194-41.9395294189-41.0394706726$ $-40.1429405212-39.2437286377-38.3352203369-37.4104690552-36.4629096985$ $-35.4851989746-34.4711112976-33.4132614136-32.3059692383-31.1420993805$ $-29.9167499542-28.6233501434-27.2579708099-25.8148994446-24.2913398743$ $-22.6827201843-20.9875202179-19.2024993896-17.327539444-15.3609104156$ 
-13.304019928 -11.1567497253 -8.92213153839-6.60174608231 -4.20034503937 -1.72125697136.8289679884911 3.4452428817756 .1191868782048 .843954086304 11.6093597412114 .4068298339817 .2245101928720 .0521297454822 .87656021118 25.685899734528 .4663200378431 .2045993804933 .8869705200236 .49935913086 39.0289611816441 .4614791870143 .7858314514245 .9882011413648 .05981826782 49.9880409240751 .7667312622153 .385040283254 .8396110534756 .12199020386 57.2315406799358 .1626396179258 .9171791076759 .4925804138259 .89294052124 60.1187400817960 .1758689880460 .0676918029859 .8014602661159 .3829498291 58.8203811645558 .1213493347257 .2948608398456 .3494606018155 .29565811157 54.1428794860852 .9023895263751 .5850906372150 .2003898620648 .76174926758 47.2718811035245 .7458915710444 .17731857342 .5766716003440 .94470977783 39.2920494079637 .6211509704635 .9437904357934 .2670402526932 .59339904785 31.006620407129 .5969505310128 .335800170927 .1793708801326 .14530944824 25.2001590728824 .3317108154323 .5209808349622 .77057075522 .08477020264 21.4530696868920 .8567600250220 .2868099212619 .7167091369619 .13368988037 18.5166702270517 .8893909454317 .276790618916 .680040359516 .15489959717 15.5556402206414 .7360897064213 .8623399734513 .0837898254412 .32349967957 11.5685701370210 .8239097595210 .090029716499 .3448829650888 .570454597473 7.7771887779247 .000359058386 .2235012054445 .4458818435674 .682409763336 3.9279398918153 .1809039115912 .3951048851011 .6699290275571 .134433031082 $.64627897739419 .74140018 \mathrm{e}-02-.470295011997-1.05778896809-1.62879598141$ $-2.16237401962-2.67088103294-3.16558694839-3.62795710564-4.03888893127$ $-4.41013097763-4.75357103348-5.06309080124-5.33919811249-5.58893680573$ $-5.83209276199-6.06018400192-6.27307796478-6.46808099747-6.63310718536$ $-6.77880096436-6.90374708176-7.01275682449-7.12000083923-7.22711706161$ $-7.34687185287-7.47636890411-7.61235713959-7.75595283508-7.90582418442$ $-8.05481624603-8.19530296326-8.32343387604-8.43303012848-8.52333259583$ -8.58369636536 -8.63657569885 -8.70467376709-8.7535610199-8.77941799164 -8.81115913391 -8.85953807831-8.89835071564 -8.87665843964 -8.79327583313 $-8.66438770294-8.47099304199-8.19643878937-7.8341050148-7.38291120529$ $-6.83911705017-6.21178388596-5.52422809601-4.7862071991-4.01231718063$ -3.20294594765 -2.38494992256 -1.58408999443 -.800585985184 -3.8256001e-02 .71607798337941 .4760789871222 .2374129295353 .0055270195013 .779476881027 4.5595788955695 .3421940803536 .1065998077396 .8557410240177 .576842784882 8.2790355682378 .9754810333259 .66298389434810 .3473501205411 .02103996277 11.6784601211512 .3215703964212 .9445800781213 .5490999221814 .14342021942 14.6878700256315 .1447696685815 .5541000366215 .9591903686516 .33160018921 16.6631202697816 .9460296630917 .168039321917 .3409194946317 .45586967468 17.5488491058317 .6358299255417 .7386894226117 .8771190643318 .06896018982 18.3558502197318 .7272090911919 .2089900970519 .7912006378220 .48534965515 21.2724399566722 .1338901519823 .0731601715124 .0882797241225 .1736907959 26.3215808868427 .5404205322328 .7948303222730 .2143993377731 .94804954529 33.8097801208535 .6367301940937 .4630813598639 .2611198425341 .03644943237 42.7849884033244 .5093383789146 .2176895141647 .9067993164149 .58235931396 51.2456207275452 .8987503051854 .5436401367256 .1810684204157 .81200027466 59.4421806335461 .063610076962 .6729393005464 .2582626342865 .81273651123 
67.344161987368 .8651733398470 .3870162963971 .9203872680773 .46954345703 75.0402526855576 .632110595778 .2544174194379 .9036712646581 .58113098145 83.2992095947385 .0630416870186 .8954620361388 .8041915893690 .78015136719 92.8023529052794 .8675537109496 .9657669067499 .09750366211101 .2651977539 103.4675979614105 .7089996338107 .9793014526110 .2698974609112 .5581970215 114.8205032349117 .0246963501119 .1425018311121 .1802978516123 .150100708 125.0551986694126 .9057998657128 .7028961182130 .4492950439132 .153793335 133.8186035156135 .4608001709137 .088104248138 .717300415140 .3641967773 142.0296020508143 .7279052734145 .454498291147 .2174072266149 .0104980469 150.8267059326152 .6656036377154 .5200042725156 .3910064697158 .2752990723 160.1728057861162 .0818939209164 .0014038086165 .9295043945167 .8648071289 169.8054962158171 .7503051758173 .6974029541175 .6454925537177 .5932006836 179.5393981934181 .4824981689183 .4216003418185 .3551025391187 .2823028564 189.2019958496191 .1136016846193 .0158996582194 .9085998535196 .790802002 198.6620941162200 .5220031738202 .3701019287204 .2059936523206 .0294036865 207.8401031494209 .6378936768211 .4223937988213 .1936950684214 .9515075684 216.6958007812218 .4264984131220 .1434936523221 .8468017578223 .5363006592 225.212097168226 .874206543228 .5225982666230 .1573944092231 .7785949707 233.3863983154234 .9806976318236 .5617980957238 .129699707239 .6844940186 241.2263031006242 .7552947998244 .271697998245 .7754058838247 .2667999268 248.7458953857250 .2129974365251 .6681060791253 .1114959717254 .5433044434 255.9638977051257 .3732910156258 .7717895508260 .1596984863261 .537109375 262.9043884277264 .2616882324265 .6093139648266 .9475097656268 .2763977051 269.5961914062270 .9071960449272 .2094116211273 .5028991699274 .787902832 276.0643005371277 .3323974609278 .5918884277279 .8431091309281 .0857849121 282.3203125283.5458068848 284.7640075684285.9719848633 $-49.5697288513-48.4791717529-47.4565887451-46.4955711365-45.5645103455$ $-44.6651191711-43.7925300598-42.9426689148-42.1095504761-41.2875900269$ $-40.4700698853-39.6502189636-38.8209915161-37.9749183655-37.1049194336$ -36.2032394409 -35.2630500793 -34.2766609192 -33.2377204895 -32.1389503479 -30.9747009277 -29.7383708954-28.4252490997 -27.0297203064 -25.5481891632 -23.9762802124 -22.3116493225 -20.551410675 -18.6945991516 -16.7399597168 $-14.6880502701-12.5393295288-10.2960195541-7.96039390564-5.53637886047$ -3.02817201614-.441471993923 2.217583894734.941451072693 7.722045898438 10.5499601364113 .415180206316 .3065109252919 .2120494842522 .11907958984 25.013950347927 .8829402923630 .7109794616733 .4840698242236 .18635940552 38.8044013977141 .3223609924343 .7281990051346 .0069007873548 .14846038818 50.1395301818851 .9725303649953 .636440277155 .1264114379956 .43428039551 57.5580711364758 .4928512573259 .2393798828159 .7961082458560 .16627883911 60.3516197204660 .3574790954660 .1885490417559 .8519096374559 .35474014282 58.705490112357 .9131813049356 .9875297546455 .9388198852554 .77820968628 53.5172080993752 .167549133350 .7420005798349 .2509498596247 .70837020874 46.1197814941444 .4982299804742 .8439788818441 .1655807495139 .46929168701 37.7638206481936 .0642890930234 .3819198608432 .7328300476131 .13530921936 29.6529598236128 .3434104919427 .1658992767326 .0876007080125 .10463905334 24.2134399414123 .3972702026422 .6262397766121 .8984508514421 .21120071411 
20.5584392547619 .9277801513719 .3255596160918 .7524509429918 .12895965576 17.365159988416 .5726795196515 .8647203445415 .17253971114 .46181964874 13.6814603805512 .7834396362311 .8474397659310 .9674301147510 .120470047 9.29817199707 8.492639541626 7.687317848206 6.897396087646 6.125411987305 5.3710050582894 .6427960395813 .8963460922243 .0997951030732 .322120904922 $1.612663984299 .92725002765660 .214978992939-.448870003223-.988753020763$ $-1.48245799541-2.00008010864-2.51630496979-3.03291606903-3.54649591446$ $-4.04449510574-4.51822280884-4.95714378357-5.36282300949-5.7381310463$ $-6.08159208298-6.38361501694-6.65160989761-6.89453601837-7.11663198471$ $-7.32047080994-7.50279998779-7.67087984085-7.8256611824-7.96246576309$ $-8.08877658844-8.20353984833-8.31222057343-8.42298984528-8.53888034821$ $-8.66867542267-8.80949115753-8.95815753937-9.1169834137-9.28541755676$ $-9.45189762115-9.60440444946-9.74296283722-9.86894798279-9.96942234039$ $-10.0255203247-10.0824203491-10.1670303345-10.2333202362-10.2862195969$ $-10.3568096161-10.451880455-10.5443296432-10.5713701248-10.5238599777$ $-10.4327402115-10.2853002548-10.0487003326-9.72480201721-9.31706809998$ $-8.81571578979-8.22692775726-7.55787992477-6.80362606049-5.99259614944$ $-5.14300680161-4.267100811-3.39629507065-2.5313770771-1.68734097481$ -.855561971664-2.0977000e-02 .8031370043755 1.604768991472 .415241956711 3.2751989364624 .1376461982734 .9460968971255 .7219858169566 .464139938354 7.1829981803897 .9005560874948 .6151800155649 .33191490173310 .04463005066 10.7472696304311 .4400901794412 .1172199249312 .7784795761113 .42173957825 14.0210399627714 .5524301528915 .0408601760915 .5178203582815 .95285987854 16.3266906738316 .6320209503216 .8598308563217 .0155906677217 .08931922913 17.1228103637717 .1386909484917 .1692409515417 .2507591247617 .40023040771 17.657850265518 .0175991058318 .5037593841619 .1020507812519 .81274032593 20.6179199218821 .4958705902122 .4390106201223 .4342803955124 .48563957214 25.594169616726 .768970489528 .0100307464629 .4015693664631 .03265953064 32.7858810424834 .5505790710436 .3279609680238 .0925598144539 .84774017334 41.5849685668943 .3079490661645 .0184402465846 .7126007080148 .39168930054 50.0563392639251 .7037086486853 .3395118713454 .9653205871656 .58430099487 58.2042808532759 .8235702514661 .447128295963 .0364303588964 .55137634277 66.0407867431667 .547576904369 .0726699829170 .6242065429772 .2015914917 73.8080673217875 .4373779296977 .088867187578 .7564926147580 .43450164795 82.1414031982483 .8829879760785 .6613922119187 .4831771850689 .34873199463 91.2656784057693.2384872436595.2631530761797.3374328613399.46253204346 101.6380004883103 .8686981201106 .1399993896108 .4373016357110 .7352981567 113.0102996826115 .251701355117 .4334030151119 .5569000244121 .6116027832 123.5972976685125 .5232009888127 .3891983032129 .1959075928130 .9512023926 132.6585998535134 .3318939209135 .9808959961137 .6183013916139 .2604980469 140.9107971191142 .5838012695144 .2778015137146 .0003051758147 .7472991943 149.5175018311151 .3092041016153 .1181030273154 .9438934326156 .7843933105 158.6387023926160 .5055999756162 .3836975098164 .2716064453166 .1678009033 168.070602417169 .978805542171 .8905029297173 .8047943115175 .7198028564 177.6345977783179 .5476074219181 .4577026367183 .3636016846185 .2644042969 187.1587982178 189.0460968018190.9253997803 192.796005249194.6569976807 
196.5083007812198 .3489074707200 .1786956787201 .9971008301203 .8038024902 205.5984954834207 .3809967041209 .1510009766210 .9082946777212 .6528015137 214.3843994141216 .1027984619217 .8081054688219 .5001068115221 .178894043 222.8442993164224 .4965057373226 .1352996826227 .7608947754229 .3733062744 230.9725952148232 .5587005615234 .1318054199235 .6920013428237 .2393951416 238.7740020752240 .2960968018241 .8056945801243 .3029022217244 .787902832 246.2608947754247 .7218933105249 .1712036133250 .6089019775252 .0352020264 253.450302124254 .8544006348256 .2478942871257 .6307067871259 .0032958984 260.3656921387261 .7184143066263 .0614929199264 .395111084265 .7196044922 267.0351867676268 .3418884277269 .6398925781270 .9294128418272 .2103881836 273.4829101562274 .7471008301276 .0028991699277 .250213623278 .4891967773 279.7200927734280 .9428100586282 .1514892578283 .349395752 $-49.0069503784-48.0344810486-47.0857810974-46.1868400574-45.3248901367$ $-44.4976005554-43.6995697021-42.9266395569-42.1722297668-41.430480957$ $-40.6940994263-39.9558792114-39.2082595825$-38.4432106018 -37.6532402039 -36.8299407959 -35.9661903381 -35.0535697937-34.0855712891-33.0541191101 $-31.9535007477-30.7763690948-29.5180091858-28.1720504761-26.7349891663$ $-25.2017307281-23.5701007843-21.8365192413-20.0002708435-18.0594291687$ $-16.0148792267-13.8664598465-11.6167802811-9.26752853394-6.82313394547$ $-4.28715801239-1.666003942491 .0348900556563 .807034969336 .643112182617$ 9.53246879577612 .4658899307315 .430589675918 .4154396057121 .40578079224 24.3886108398427 .3479404449530 .2691097259533 .1357498168935 .93196105957 38.642158508341 .2498703002943 .7414093017646 .1005592346248 .31636810303 50.373748779352 .2649993896553 .9770507812555 .5055999755956 .84051895142 57.980751037658 .9198417663659 .6596107482960 .1975288391160 .53796005249 60.6821289062560 .636581420960 .4057884216359 .9982109069859 .42097091675 58.6841812133857 .796871185356 .7707710266155 .6162605285654 .34666061401 52.9737205505451 .5113906860449 .9735717773448 .3721313476646 .7239112854 45.0346107482943 .3220291137741 .5858993530339 .8409690856938 .09048080444 36.3469390869134 .6265602111832 .9473915100131 .3467597961429 .85157012939 28.4852199554427 .2525291442926 .1370697021525 .1185207366924 .18928909302 23.3366107940722 .5472698211721 .79192924521 .067449569720 .35747909546 19.6648406982418 .972730636618 .2935791015617 .6619491577116 .9531993866 16.0264797210715 .0573101043714 .2433900833113 .4249897003212 .50654029846 11.5457801818810 .595689773569 .6445856094368 .7161474227917 .812148094177 6.9422721862796 .0888648033145 .2330927848824 .4125041961673 .640048980713 $2.920770883562 .2528080940251 .572865962982 .79708600044253 .17250006 \mathrm{e}-02$ $-.621991991997-1.23513996601-1.85591602325-2.44681596756-2.98880290985$ $-3.49663209915-3.98706507683-4.45974302292-4.92163276672-5.37586593628$ $-5.82220888138-6.2464928627-6.63487005234-6.99341201782-7.32982587814$ $-7.63556003571-7.89966392517-8.1319026947-8.34203338623-8.52901935577$ $-8.69484806061-8.84054660797-8.97391986847-9.09621429443-9.20768737793$ $-9.31511974335-9.42008113861-9.52857303619-9.6483631134-9.77838611603$ $-9.9255695343-10.0842199326-10.2486600876-10.4254302979-10.6113796234$ $-10.7927999496-10.955160141-11.1100301743-11.258310318-11.3748102188$ $-11.4450397491-11.4813098907-11.5608901978-11.6629400253-11.7929801941$ 
-11.9579801559-12.0557603836 -12.1486501694 -12.204079628 -12.2011499405 $-12.171380043-12.0539503098-11.843460083-11.549539566-11.1893796921$ $-10.7506904602-10.2224597931-9.5834236145-8.8192358017-7.96797895432$ $-7.0704407692-6.14492893219-5.21591901779-4.28861618042-3.37162590027$ $-2.46459197998-1.5548479557-.661929011345 .18368999660021 .045711994171$ 1.9967110157012 .9329109191893 .7694749832154 .551262855535 .301164150238 6.0347580909736 .7740459442147 .5161471366888 .2656698226939 .017102241516 9.76292610168510 .5018997192411 .2256002426111 .9310302734412 .60962963104 13.2546396255513 .8626098632814 .4351396560714 .9918003082315 .4934797287 15.9191703796416 .2578506469716 .5036602020316 .6538696289116 .68325996399 16.6576004028316 .5857391357416 .5334091186516 .5520591735816 .64706039429 16.8844108581517 .2402095794717 .7532997131318 .3938694000219 .14151000977 19.9831008911120 .8899803161621 .8518905639622 .8400001525923 .87405967712 24.959129333526 .1189899444627 .3778495788628 .7562503814730 .27215957642 31.8899192810133 .566970825235 .2823905944837 .0023193359438 .72639083862 40.4430389404342 .1542205810543 .8598403930745 .5554389953647 .23949813843 48.9026107788150 .5394287109452 .1573791503953 .7658309936555 .37010955811 56.9773292541558 .586498260560 .2157211303761 .8064193725663 .28905105591 64.7488327026466 .252227783267 .7856216430769 .3589935302770 .96797180176 72.613426208574 .285438537675 .975166320877 .6700897216879 .35735321045 81.0533676147582 .7575073242284 .4759292602586 .209548950287 .97158050537 89.7811813354591 .652488708593 .5923080444395 .5991668701297 .67897033691 99.82499694824102 .0407028198104 .3082962036106 .6044006348108 .9110031128 111.2050018311113 .4786987305115 .7151031494117 .9055023193120 .0386962891 122.1072998047124 .1169967651126 .0589981079127 .9319000244129 .7442932129 131.4954071045133 .2017059326134 .8690948486136 .5124053955138 .1493988037 139.7852020264141 .43699646143 .1029052734144 .7910003662146 .499206543 148.2281036377149 .9768981934151 .742401123153 .5252990723155 .3226928711 157.1349945068158 .9602050781160 .7976989746162 .6457977295164 .5034942627 166.3688964844168 .2409057617170 .1177062988171 .9983062744173 .8809967041 175.7646942139177 .6477966309179 .529296875181 .4075927734183 .2819976807 185.1510925293187 .0142974854188 .8704071045190 .7189025879192 .558807373 194.3898010254196 .2111968994198 .0225067139199 .8231964111201 .6130981445 203.3916931152 205.1587982178 206.9140014648 208.6571960449210.3881072998 212.1067047119213 .8126983643215 .5059967041217 .1865997314218 .8544006348 220.5092926025222 .1513061523223 .7803039551225 .3964996338226 .9998016357 228.5903015137230 .1679992676231 .7328948975233 .2852020264234 .8249053955 236.3522033691237 .8670959473239 .3697052002240 .8601989746242 .3385925293 243.8052062988245 .2599945068246 .7032928467248 .1351013184249 .5556945801 250.9651947021252 .3639068604253 .7519989014255 .129699707256 .4971008301 257.8547058105259 .2025146484260 .540802002261 .8698120117263 .1897888184 264.5008850098265 .8031921387267 .0969848633268 .3822021484269 .6590881348 270.9276123047272 .187713623273 .4395141602274 .683013916275 .9180908203 277.1452026367278 .3631896973279 .574005127280 .7746887207 -48.4562911987 -47.4800186157-46.5816688538 -45.7548904419-44.9633789062 $-44.2094497681-43.4875984192-42.793170929-42.1193504333-41.4596595764$ 
$-40.8064613342-40.1519393921-39.488079071-38.8062782288-38.0985412598$ -37.3559608459 -36.5708389282 -35.7344017029 -34.8394699097 -33.8777694702 -32.8428993225 -31.7273902893 -30.5258407593 -29.2318897247 -27.8413200378 $-26.3491802216-24.7525691986-23.048160553-21.234500885-19.3100204468$ $-17.2748908997-15.1293897629-12.8753795624-10.5151195526-8.05224514008$ -5.49105215073 -2.8370718956 -9.6665002e-02 2.722599029541 5.612260818481 8.56259536743211 .5629796981814 .6014900207517 .6653194427520 .74045944214 23.8119506835926 .8641796112129 .8803195953432 .8439598083535 .73699951172 38.5433311462441 .2444801330643 .8258018493746 .2694702148448 .56324005127 50.6909713745152 .6434516906754 .4072189331155 .9764595031757 .34122085571 58.4991188049359 .4443893432660 .177871704160 .6980400085461 .00859069824 61.1120185852161 .0144500732460 .7217712402360 .2422485351659 .58452987671 58.7587013244657 .7754783630456 .6466903686555 .3846588134854 .00297164917 52.515491485650 .937221527149 .2840194702147 .5704689025945 .81457901001 44.0268592834542 .2253303527840 .4152793884338 .6109313964836 .81851959229 35.0493698120133 .3157691955631 .622909545930 .0463409423828 .65649986267 27.4058990478526 .2591800689725 .2061405181924 .2392501831123 .34848022461 22.5199604034421 .7384204864520 .9802207946820 .234029769919 .48336982727 18.7237300872817 .9401397705117 .1337299346916 .2953090667715 .37722015381 14.3359498977713 .2682895660412 .3040504455611 .3402204513510 .32143974304 9.2946777343758 .2866840362557 .3080649375926 .3587422370915 .435153961182 4.5616741180423 .6945240497592 .7860469818121 .919144988061 .145925045013 $.4626370072365-.127627000213-.714950978756-1.39520800114-2.08024907112$ $-2.70096802711-3.2830529213-3.85275006294-4.40348100662-4.92171478271$ $-5.4131731987-5.8736448288-6.30533790588-6.72110414505-7.12422180176$ $-7.51703119278-7.88894891739-8.2299156189-8.54521942139-8.83921909332$ $-9.10567569733-9.33465480804-9.53393268585-9.7087726593-9.8606338501$ $-9.99050331116-10.102930069-10.2037696838-10.2969903946-10.3858699799$ $-10.4771699905-10.5756101608-10.6871404648-10.8167200089-10.9635601044$ -11.1330795288 -11.3138303757-11.4981403351 -11.6937599182 -11.8905200958 -12.0773096085 -12.2514896393 -12.430270195 -12.6194496155 -12.7802600861 -12.8779296875 -12.9035997391 -12.8698797226 -12.9265699387 -13.3071804047 -13.6982603073 -13.6830596924-13.6277599335 -13.7609500885-13.8712501526 $-13.8910303116-13.7981796265-13.5589704514-13.2533502579-12.9522895813$ $-12.6046800613-12.1798601151-11.6069698334-10.8079595566-9.88906478882$ -8.94785022736 -7.98229789734 -7.01194190979-6.03603315353 -5.06259584427 $-4.09082984924-3.12083792686-2.16111898422-1.22385501862-.262053996325$ .7800769805908 1.7745699882512.593343973163.337007999424.083306789398 4.8307251930245 .5940799713136 .3672189712527 .1505842208867 .939153194427 8.72530746469 .50513553619410 .2710399627711 .0176200866711 .73668003082 12.4316797256513 .1014404296913 .7456197738614 .3696298599214 .93478965759 15.4165296554615 .7991304397616 .07505035416 .2247791290316 .21410942078 16.1200199127215 .969269752515 .8355998992915 .7773303985615 .81272029877 16.0207290649416 .3835201263416 .9430198669417 .6543407440218 .47135925293 19.3734893798820 .3179302215621 .3017292022722 .3074302673323 .34560966492 24.4163494110125 .5562400817926 .7940998077428 .1237792968829 .56315040588 
31.0845394134532 .6770210266134 .3231201171935 .9877510070837 .6689491272 39.3541908264241 .0447082519542 .7373199462944 .4310607910246 .12726974487 47.7962608337449 .4073905944850 .9925498962452 .5794982910254 .16603851318 55.7552413940457 .344730377258 .9377403259360 .4971504211461 .98250961304 63.4557495117264 .9655532836966 .5133209228568 .1165695190469 .76349639893 71.4534683227573 .1740188598674 .908058166576 .633926391678 .33766174316 80.0250473022581 .6844635009883 .3321380615284 .9750366210986 .62893676758 88.3256835937590.08975982666 91.9367599487393.8692321777395.90588378906 98.0267791748100 .2279968262102 .4922027588104 .7865982056107 .0986022949 109.408203125111 .7101974487113 .9907989502116 .2406997681118 .4458999634 120.5971984863122 .6903991699124 .7127990723126 .6541976929128 .5247039795 130.3238983154132 .0641021729133 .7489929199135 .3959960938137 .0281066895 138.6513977051140 .283493042141 .9244995117143 .5825958252145 .2566986084 146.949005127148 .6585998535150 .3845977783152 .1264953613153 .8834991455 155.6549987793157 .4402008057159 .2380981445161 .0476074219162 .867401123 164.6961975098166 .532699585168 .3753967285170 .2229003906172 .0736999512 173.9266967773175 .7803039551177 .6334075928179 .4846038818181 .3327941895 183.1768951416185 .0160980225186 .849105835188 .6755981445190 .4944000244 192.3052978516194 .1072998047195 .900100708197 .6831970215199 .4561004639 201.2185058594202 .9700012207204 .7102966309206 .4391937256208 .1564941406 209.8618927002211 .5552978516213 .2366027832214 .9055938721216 .5621948242 218.2062988281219 .8379974365221 .4570007324223 .0635986328224 .6575927734 226.2391052246227 .8081970215229 .3647003174230 .9089050293232 .4407958984 233.9604034424235 .4680023193236 .963394165238 .4470062256239 .9187011719 241.378692627242 .8271026611244 .2642059326245 .6898956299247 .104598999 248.5084075928249 .9015045166251 .2841033936252 .6564025879254 .0186004639 255.3710021973256 .7138977051258 .0473022461259 .3714904785260 .6867980957 261.9931945801263 .2909851074264 .5804138184265 .8612976074267 .1337890625 268.3981018066269 .6541137695270 .9018859863272 .1412963867273 .3724060059 274.5956115723275 .8106079102277 .0115966797278 .2019958496 $-47.6223907471-46.7731018066-45.9520606995-45.1885108948-44.4683303833$ $-43.7890396118-43.144569397-42.5301704407-41.9384002686-41.3624801636$ $-40.7941703796-40.2251586914-39.646938324-39.0502891541-38.4267807007$ $-37.7668304443-37.0624198914-36.3040504456-35.4843406677-34.5942687988$ -33.6273193359 -32.5753097534 -31.432800293 -30.192779541 -28.8510398865 $-27.4020309448-25.8429203033-24.1698493958-22.3814601898-20.475730896$ -18.4529209137 -16.3129291534-14.0577497482 -11.6892299652 -9.2112531662 $-6.62762403488-3.94428396225-1.166995048521 .6960200071334 .637050151825$ 7.64534902572610 .7111997604413 .8211803436316 .9634990692120 .12208938599 23.2830600738526.4281291961729.54147911072 32.60358047485 35.59693145752 38.5023307800341 .3011398315443 .9762611389246 .5087089538648 .88486099243 51.086498260553 .1042900085454 .9222793579156 .5353813171457 .93141174316 59.1091308593860 .0613098144560 .7898292541561 .2925987243761 .57418060303 61.6370697021561 .4882507324261 .1337699890160 .5829887390159 .84453964233 58.9300689697357 .8499794006356 .6181907653855 .2463798522953 .75096130371 52.1450996398950 .4475097656248 .6741905212446 .8440399169944 .97748947144 
43.088169097941 .200199127239 .317661285437 .4620704650935 .63611984253 33.8540191650432 .1259498596230 .4380702972428 .8899803161627 .58513069153 26.4297695159925 .3466205596924 .3484802246123 .4228897094722 .55822944641 21.7356700897220 .944540023820 .1582508087219 .3723907470718 .56221961975 17.7106304168716 .8075599670415 .8191404342714 .7190999984713 .55764007568 12.4031000137311 .2487602233910 .153380393989 .0725584030158 .010432243347 6.9657101631165 .9286241531374 .9252820014953 .9602069854743 .046725034714 $2.2005970478061 .364948987961 .4469839930534-.434495985508-1.19699299335$ $-1.85576200485-2.39310503006-2.90223693848-3.48405694962-4.07990503311$ $-4.666451931-5.23561286926-5.77535915375-6.29420518875-6.78463315964$ -7.24671697617 -7.67281198502 -8.06877613068 -8.44315910339-8.79836654663 $-9.13805198669-9.4565076828-9.75389099121-10.0289697647-10.2820196152$ $-10.5100002289-10.7059698105-10.8732004166-11.0145196915-11.1321601868$ -11.2289400101 -11.3105096817-11.3824996948 -11.4502401352 -11.5196695328 -11.5980796814 -11.6926202774 -11.8063201904 -11.9442901611 -12.109459877 $-12.3050003052-12.5183897018-12.7311601639-12.9375495911-13.1260299683$ $-13.3161697388-13.5172796249-13.7116098404-13.9030895233-14.0682497025$ $-14.1850500107-14.2707901001-14.2024803162-14.3230304718-15.0541801453$ -15.6684799194 -15.4790401459-15.1279497147 -15.2196998596 -15.3892498016 -15.4282302856 -15.3689804077 -15.1245298386 -14.8227396011 -14.5840597153 $-14.3119697571-13.9746704102-13.4699401855-12.6606502533-11.7075796127$ $-10.7534799576-9.76992416382-8.77260017395-7.7644739151-6.7459731102$ $-5.72319602966-4.70147323608-3.67743611336-2.64414310455-1.59606897831$ -0.48777499795 .5429469943047 1.343938946724 2.062959909439 2.817212104797 3.583720922474 .374295234685 .1825900077826 .0008201599126 .824965953827 7.6473112106328 .46404170999 .2664136886610 .0508699417110 .80920028687 11.5488395690912 .2751703262312 .9787998199513 .6634302139314 .28962039948 14.8379602432315 .2800502777115 .6144599914615 .7891798019415 .75319004059 15.6044902801515 .3415803909315 .0934295654314 .9288597106914 .87567996979 15.0790901184115 .4813404083316 .1206893920916 .9370594024717 .83735084534 18.8106403350819 .7967395782520 .8070907592821 .8348598480222 .88282012939 23.9442291259825 .0581092834526 .2572898864727 .5336093902628 .90151977539 30.3446502685531 .8598899841333 .4313697814935 .0334396362336 .66463088989 38.3115615844739 .9746017456141 .6473808288643 .3282394409245 .02605056763 46.6943588256848 .2818489074749 .839431762751 .4105186462452 .98051834106 54.5519294738856 .1163787841857 .6659507751559 .1942291259860 .69227981567 62.1870117187563 .7012710571365 .2641830444366 .8996200561568 .59339904785 70.3283767700272 .0899505615273 .861053466875 .6239318847777 .35970306396 79.0413513183680 .6501464843882 .2111129760783 .7613372802785 .32012176514 86.9158096313588 .5706787109490 .3075027465892 .1616287231494 .15783691406 96.2697372436598 .46115875244100 .7126998901102 .9960021973105 .3032989502 107.6200027466109 .9401016235112 .2539978027114 .5505981445116 .8214035034 119.0491027832121 .2306976318123 .3379974365125 .356300354127 .2923965454 129.1374969482130 .908996582132 .608001709134 .2557983398135 .8840942383 137.4971008301139 .1136932373140 .7348937988142 .3681030273144 .0139007568 145.6737976074147 .3486938477149 .0377960205150 .7420043945152 .4604034424 
154.1932067871155 .9398040771157 .6997070312159 .4718017578161 .2550964355 163.0484008789164 .8504943848166 .6596984863168 .4750976562170 .2947998047 172.1177978516173 .9423980713175 .7677001953177 .5919952393179 .4145965576 181.2339935303183 .0493927002184 .8596954346186 .6643066406188 .4622039795 190.2530059814192 .0357971191193 .8101959229195 .5756072998197 .3316040039 199.0776977539200 .8137054443202 .5390014648204 .2536010742205 .9571075439 207.6493988037209 .3300018311210 .9990997314212 .6562957764214 .3016052246 215.9347991943217 .5559997559219 .1649017334220 .7617034912222 .346206665 223.9185943604225 .478805542227 .0267944336228 .5626983643230 .0865936279 231.5984954834233 .0984039307234 .5865936279236 .06300354237 .5278015137 238.9810028076240 .4228973389241 .8536071777243 .2731018066244 .6817016602 246.0796051025247 .4669036865248 .8439025879250 .2106933594251 .5675048828 252.9147033691254 .2523040771255 .5807037354256 .8999938965258 .2103881836 259.5120849609260 .8052062988262 .0899963379263 .366394043264 .6346130371 265.8945007324267 .1462097168268 .3897094727269 .625270 .8521118164272 .071105957 273.2811889648 274.4841918945275 .6770935059 -46.7999801636 -45.9396286011-45.1680412292-44.4790306091-43.8311500549 $-43.2273788452-42.661529541-42.1283111572-41.6200294495-41.1292800903$ $-40.6474304199-40.1655502319-39.6746406555-39.1648788452-38.6273002625$ $-38.0518302917-37.4298591614-36.7514801025-36.0087203979-35.1922798157$ $-34.2950210571-33.3086090088-32.2270011902-31.0431404114-29.7522392273$ $-28.3487892151-26.829410553-25.1903591156-23.4297504425-21.5457706451$ $-19.5381202698-17.406999588-15.1537704468-12.7806901932-10.2909297943$ -7.68883323669 -4.97949981689-2.16939711571 .7342169880867 3.722687959671 6.7863368988049 .91419124603313 .0939197540316 .3120899200419 .55364990234 22.8026294708326 .041580200229 .2521400451732 .4152107238835 .51052856445 38.5186500549341 .4182395935144 .191268920946 .8165206909249 .27891159058 51.5586700439553 .6447906494155 .5206909179757 .1797103881858 .60982131958 59.8086013793960 .7696113586461 .4939689636261 .9806900024462 .23392105103 62.257400512762 .0578689575261 .6426582336461 .0209007263260 .20264816284 59.1991500854558 .0225601196356 .6862182617255 .2038993835453 .59162902832 51.8650207519550 .0436897277848 .1463813781746 .1955299377444 .21448898315 42.2228202819840 .2467384338438 .2953987121636 .3912086486834 .54029083252 32.7547988891631 .0466995239329 .4214801788327 .940849304226 .66859054565 25.5398006439224 .4986896514923 .5362606048622 .6372108459521 .78303909302 20.9497509002720 .126529693619 .2928390502918 .4449996948217 .56615066528 16.6114101409915 .5390396118214 .3339796066312 .9918699264511 .61995983124 10.311860084539 .0524921417247 .8700008392336 .7342119216925 .653470039368 4.6112051010133 .5635490417482 .5441370010381 .568135023117 .6716870069504 -.103476002812 -.853151023388 -1.67850196362 -2.48591899872 -3.21033191681 $-3.85024309158-4.39787578583-4.90898799896-5.45373678207-6.00705480576$ $-6.55815076828-7.10061597824-7.61810588837-8.11162853241-8.5772857666$ $-9.01075839996-9.40640735626-9.76858139038-10.099240303-10.4066200256$ -10.6964702606 -10.9659900665 -11.2221298218 -11.4601297379 -11.6760702133 $-11.8696603775-12.0342597961-12.1709699631-12.2814702988-12.368519783$ $-12.4336996078-12.4857997894-12.5299596786-12.5737695694-12.6266498566$ 
-12.6953697205 -12.7873897552 -12.9026498795 -13.0415802002 -13.2185697556 $-13.4507398605-13.7089300156-13.9651699066-14.185839653-14.3200101852$ $-14.4753904343-14.763999939-15.0141096115-15.0534095764-15.0828800201$ -15.2766199112 -15.5450296402 -15.7771396637 -16.2864398956 -17.4477405548 -18.2789993286 -17.7712898254 -16.9419708252 -16.6934604645 -16.660779953 -16.650390625 -16.6112499237 -16.4465808868 -16.234670639 -16.0327091217 -15.7891798019 -15.4690599442 -14.9872703552 -14.2536001205 -13.3737201691 $-12.4514102936-11.4827098846-10.4809103012-9.4517250061-8.40417003632$ $-7.34128284454-6.27614402771-5.20154809952-4.11718082428-3.03058409691$ -1.93137800694 -.913491010666 -6.4038001e-02.7121400237083 1.490980029106 2.2845609188083 .1158549785613 .9656538963324 .821253776555 .679251194 6.5356950759897 .386097908028 .2219676971449 .0402297973639 .832224845886 10.6111803054811 .3882799148612 .1491899490412 .8886604309113 .58059024811 14.2081003189114 .7391901016215 .1580095291115 .3808898925815 .34710979462 15.1380901336714 .7280302047714 .3128099441513 .9962596893313 .83442974091 14.0506296157814 .5397500991815 .2953996658316 .2462291717517 .24628067017 18.2894592285219 .3350391387920 .3823509216321 .4190597534222 .45999908447 23.5115795135524 .6001605987525 .7540798187326 .9721508026128 .27096939087 29.6402301788331 .0812091827432 .5800018310534 .1207084655835 .69921112061 37.3057098388738 .936241149940 .5812988281242 .2378501892143 .90304946899 45.5450897216847 .1312904357948 .6919288635350 .2545089721751 .81383132935 53.3719406127954 .9189186096256 .4499397277857 .9678993225159 .46691131592 60.9618301391662 .4518508911164 .0046615600665 .6947097778367 .45570373535 69.2312011718871 .022872924872 .8207397460974 .6206512451276 .42677307129 78.1406173706179 .6618881225681 .1018066406282 .5628128051884 .03964996338 85.5501708984487 .1002578735488 .6895599365290 .4272232055792 .42574310303 94.5686569213996 .7528533935598 .98297119141101 .2425003052103 .5307998657 105.8397979736108 .1656036377110 .5008010864112 .8367996216115 .1644973755 117.4681015015119 .7370986938121 .9348983765124 .0391998291126 .0482025146 127.9362030029129 .7321929932131 .4432983398133 .0901947021134 .713104248 136.3182067871137 .9228973389139 .5285949707141 .141998291142 .7635040283 144.3957977295146 .0393066406147 .6952972412149 .3643035889151 .0469970703 152.7433013916154 .4535980225156 .1772003174157 .9136962891159 .6620941162 161.4214019775163 .1903076172164 .9674072266166 .7514953613168 .5411071777 170.3350067139172 .1315002441173 .9295959473175 .7277984619177 .525100708 179.3202056885181 .1123046875182 .9002990723184 .683303833186 .4606018066 188.2315063477189 .995300293191 .7514038086193 .499206543195 .2384033203 196.9683074951198 .6887054443200 .3992004395202 .099395752203 .7890930176 205.4680938721207 .1360015869208 .7926940918210 .4380950928212 .0720062256 213.6941986084215 .3047027588216 .9033966064218 .4902038574220 .0652008057 221.6282958984223 .1795043945224 .7187957764226 .246307373227 .7619018555 229.2658996582230 .758102417232 .2388000488233 .707901001235 .1656036377 236.6119995117238 .0471954346239 .4712982178240 .8843994141242 .2868041992 243.678604126245 .0599975586246 .4311981201247 .7922973633249 .1436004639 250.4853973389251 .8177032471253 .1408996582254 .4550933838255 .7604980469 257.0573120117258 .345703125259 .6257019043260 .8974914551262 .1611022949 
263.416595459264 .6639099121265 .9031066895267 .1340942383268 .3569030762 269.5718078613270 .7786865234271 .9717102051273 .154296875 $-45.6555213928-44.9310798645-44.2397499084-43.6143188477-43.0392189026$ $-42.5118293762-42.0253601074-41.5743904114-41.1506118774-40.7462387085$ $-40.3520698547-39.9586105347-39.556350708-39.1348190308-38.6846389771$ -38.1950111389 -37.6570091248 -37.0600318909-36.3958511353 -35.6544799805 -34.8286590576 -33.9094085693 -32.8906211853 -31.7646903992 -30.5267696381 -29.1709709167 -27.6938209534 -26.0912895203 -24.3614196777 -22.502199173 $-20.5132198334-18.3945198059-16.147359848-13.7738304138-11.277009964$ -8.66099452972 -5.93088722229 -3.09275698662 -.154075995088 2.877137899399 5.9905991554269 .17626094818112 .4206104278615 .7114400863619 .03175926208 22.3671894073525 .6973209381129 .0056800842332 .2691917419435 .46932983398 38.5821418762241 .5869789123544 .4619598388747 .1847991943449 .73834991455 52.100028991754 .2588882446356 .1948394775457 .9027214050359 .36775970459 60.5891990661661 .5594902038662 .2807083129962 .7522392272962 .97845077515 62.9640312194862 .715820312562 .2417297363361 .5514602661160 .65494918823 59.5647697448758 .2922210693456 .8527603149455 .2586708068853 .52922058105 51.6782188415549 .730190277147 .7027702331545 .6251602172943 .52214813232 41.4208717346239 .3524894714437 .3308906555235 .3851089477533 .51214981079 31.7294807434130 .0515594482428 .5005397796627 .0930194854725 .83753013611 24.7132492065423 .6919307708722 .7518692016621 .8647899627721 .00795936584 20.1456604003919 .2782802581818 .3772201538117 .4298095703116 .4408493042 15.3318796157814 .0679798126212 .660750389111 .124119758619 .565113067627 8.1084165573126 .7461872100835 .5159969329834 .381955146793 .326807975769 2.3180670738221 .288174986839 .2905049920082 -.669439971447 -1.53952300549 $-2.2511279583-2.91405701637-3.63654899597-4.34968805313-5.02615785599$ $-5.65688991547-6.23394918442-6.77973604202-7.31935977936-7.85136604309$ -8.37799263 -8.8953666687 -9.38908576965 -9.86142635345 -10.3006801605 -10.7070198059 $-11.0782003403-11.4083499908-11.6965198517-11.9522399902-12.1901102066$ $-12.4165096283-12.6399002075-12.8488998413-13.032699585-13.1918201447$ -13.325799942 -13.4352798462 -13.5209197998 -13.5825796127 -13.6219701767 -13.6463403702 -13.6643104553 -13.6878595352 -13.7284698486-13.7917203903 -13.8811502457-14.002699852 -14.1485900879-14.3419103622 -14.6064901352 -14.8953199387 -15.1804895401 -15.4168796539 -15.5078296661 -15.6220903397 -15.9716501236 -16.2633800507 -16.1588191986 -16.0722999573 -16.3357601166 -16.7954406738 -17.331199646 -18.1061592102 -19.4866409302 -20.3912200928 -19.6233100891 -18.4647903442 -17.9824790955 -17.7527809143 -17.6781597137 -17.6709899902 -17.6006908417-17.4955196381 - 17.327999115-17.0897407532 -16.7591400146 -16.2961902618 -15.6605796814 -14.8958501816 -14.0475301743 -13.1180095673 -12.1274595261 -11.0878801346 -10.0218000412 -8.93540287018 $-7.83833503723-6.73422384262-5.62062501907-4.5249671936-3.45705699921$ $-2.45214605331-1.53322994709-.671648025513 .1546310037374 .9813299775124$ 1.8488680124282 .7361860275273 .6238570213324 .5154480934145 .403718948364 6.2835822105417 .1485748291027 .9965910911568 .8186492919929 .631681442261 10.4538202285811 .2650899887112 .0578699111912 .8109302520813 .52085018158 14.142470359814 .6598501205414 .9912900924715 .0496397018414 .81925010681 
14.248399734513 .554030418412 .9803400039712 .7239799499513 .00732040405 13.6929702758814 .6172800064115 .685409545916 .7628707885717 .85499000549 18.9450607299820 .0174694061321 .0562095642122 .0823192596423 .11815071106 24.1752395629925 .2796401977526 .436660766627 .6682891845728 .96698951721 30.3357505798331 .7643108367933 .2450103759834 .7717285156236 .33634185791 37.9320411682139 .5448608398441 .1679000854542 .7903900146544 .40082931519 45.989810943647 .561389923149 .1232910156250 .6757812552 .22472000122 53.7632217407255 .2886009216356 .8044815063558 .3072395324759 .80773162842 61.2816009521562 .8290710449264 .5612335205166 .3698272705168 .1647567749 69.9708709716871 .7800827026473 .5884628295975 .4371109008877 .17025756836 78.6209869384879 .9686737060581 .371932983482 .7881774902384 .23428344727 85.714988708587 .1893463134888 .8281707763790 .8140029907292 .96085357666 95.1080627441497 .3005828857499 .52223968506101 .7771987915104 .0661010742 106.3832015991108 .7272033691111 .0879974365113 .4604034424115 .8267974854 118.1755981445120 .4721984863122 .6865005493124 .7757034302126 .7032012939 128.5050964355130 .2194976807131 .8733978271133 .4990997314135 .1044006348 136.7039031982138 .3005981445139 .8988037109141 .5012054443143 .1092987061 144.7254943848146 .3513031006147 .9882965088149 .6376953125151 .300201416 152.9763946533154 .6661071777156 .3690948486158 .0845031738159 .8114013672 161.5487976074163 .2951049805165 .0493927002166 .8099975586168 .5758056641 170.3450012207172 .116897583173 .8896026611175 .662399292177 .4338989258 179.2032012939180 .9691925049182 .7312011719184 .4880981445186 .2395019531 187.9844970703189 .7225036621191 .4528961182193 .1753997803194 .8892974854 196.5942993164198 .2897949219199 .9757995605201 .6517028809203 .3173065186 204.9725036621206 .616897583208 .2503051758209 .8726959229211 .483795166 213.0836029053214 .6719055176216 .2487030029217 .8139953613219 .3677062988 220.9098052979222 .4402008057223 .959197998225 .466506958226 .9624023438 228.4467926025229 .9197998047231 .3815002441232 .8318939209234 .2713012695 235.6996002197237 .1170043945238 .5236053467239 .9196929932241 .3052062988 242.6804962158244 .0458068848245 .4010925293246 .7467956543248 .082901001 249.4098052979250 .7277069092252 .0366973877253 .3370056152254 .6287994385 255.9122009277257 .1874084473258 .4544067383259 .7134094238260 .9642028809 262.2070007324263 .4417114258264 .6683959961265 .8869018555267 .0975036621 268.2992858887269 .4939880371270 .6787109375 $-44.5218582153-43.7777290344-43.1339683533-42.5847511292-42.0830001831$ $-41.6324195862-41.2260894775-40.8580513-40.5196800232-40.2025794983$ -39.8971099854 -39.593120575 -39.2806015015 -38.9484786987 -38.5868301392 $-38.1843299866-37.7314796448-37.2172698975-36.6329193115-35.9681282043$ $-35.2151298523-34.3647499084-33.4103889465-32.3443489075-31.1613903046$ -29.8555698395 -28.4230899811 -26.8599395752 -25.1638393402 -23.3328609467 -21.3662395477 -19.2641601562 -17.027469635 -14.6584300995 -12.1595897675 $-9.53530502319-6.78995895386-3.93000102043-.9619780182842 .105483055115$ 5.2632617950448 .50034046173111 .8045902252215 .1623296737718 .55813026428 21.975519180325 .3956508636528 .7993202209532 .1645889282235 .46963882446 38.6906394958541 .8033409118744 .784881591847 .6095390319850 .25846099854 52.7067985534754 .9414215087956 .9411201477158 .6992988586460 .2017288208 
61.4466400146562 .4276084899963 .1465187072863 .6041603088463 .80490875244 63.7545700073263 .4598808288662 .9296302795462 .1730918884361 .20132064819 60.025951385558 .6599006652857 .1172409057655 .4123992919953 .56327056885 51.5864410400449 .5062294006347 .3438796997145 .1312294006342 .8971786499 40.6772384643638 .509910583536 .4178504943834 .4383201599132 .5538482666 30.7634696960429 .0999794006327 .5956306457526 .2361698150625 .01642036438 23.9124107360822 .9071006774921 .9766407012921 .0863990783720 .20624923706 19.3027000427218 .3741798400917 .396409988416 .3293399810815 .12512969971 13.7806196212812 .3241996765110 .757980346689 .09828376777 .428150177002 5.8135290145874 .342714786533 .1421151161192 .0885589122771 .09316599369 $.1494109928608-.790251970291-1.70101797581-2.58348488808-3.39559698105$ $-4.10186719894-4.75927686691-5.43828201294-6.10946321487-6.75857877731$ -7.38581800461 -7.96955490112 -8.52847290039 -9.07369995117 -9.59942531586 -10.1177301407 -10.6197900772 -11.0935602188 -11.5429201126-11.9574403763 $-12.3398199081-12.6992301941-13.0096302032-13.2460298538-13.4399900436$ -13.6190299988 -13.8009004593 -14.0118198395 -14.2116098404-14.3634004593 $-14.4857902527-14.5909795761-14.6777896881-14.7476100922-14.7940797806$ -14.8116598129 -14.8111200333 -14.8007001877-14.8022403717-14.8388996124 $-14.9031295776-14.9874000549-15.1132097244-15.2984199524-15.5317602158$ -15.8035001755 -16.088350296 -16.3610191345 -16.5870094299-16.7159194946 -16.8570194244 -17.1242008209-17.3378200531 -17.3132705688-17.3108901978 -17.5428504944 -17.9686698914-18.4977302551 -19.1683292389-20.1126403809 -20.6141700745 -20.0025806427 -19.1155490875 -18.7521591187 -18.6202201843 -18.5903301239 -18.6256809235 -18.6223907471 -18.5758895874 -18.4549198151 -18.242389679 -17.9285697937 -17.5066299438 -16.9465503693 -16.2806797028 -15.5327501297 -14.6756000519-13.7004098892 -12.6535196304-11.5867900848 $-10.4959802628-9.38916683197-8.27209568024-7.1472492218-6.04303598404$ $-4.97193193436-3.94152593613-2.9721660614-2.04435706139-1.15805399418$ -.288585007191 0.5951430201531 .4948860406882 .4154810905463 .341980934143 4.2597222328195 .1658639907846 .0549621582036 .9280018806467 .778625011444 8.6249246597299 .48499202728310 .3429002761811 .1911802291912 .0113401413 12.7899999618513 .4998397827114 .123499870314 .6110601425214 .95221996307 14.8685102462814 .0049295425412 .8501100540211 .8293399810811 .34023952484 11.9178495407113 .0232200622614 .1504802703915 .3129701614416 .44123077393 17.5530700683618 .6445007324219 .711490631120 .7460498809821 .7600402832 22.7636795043923 .7777996063224 .8290290832525 .925020217927 .08653068542 28.3130798339829 .6084804534930 .9675502777132 .3921890258833 .87049865723 35.3942108154336 .9545783996638 .5351982116740 .126670837441 .71897125244 43.3095588684144 .8901901245146 .4628105163648 .0251197814949 .57711029053 51.1236495971752 .6617088317954 .1890602111855 .7108993530357 .22700119019 58.7457809448260 .2636795043961 .8470001220763 .5631904602165 .34481048584 67.1325607299868 .9275131225670 .7194213867272 .502929687574 .28185272217 75.9546508789177 .4204025268678 .7920074462980 .1752471923881 .56623077393 82.9839935302784 .4348831176885 .9194183349687 .5494537353589 .43801879883 91.4715805053793 .5455169677795 .670898437597 .83464813232100 .0429000854 102.2950973511104 .5898971558106 .9262008667109 .2970962524111 .6965026855 
114.1119003296116 .529296875118 .929901123121 .304901123123 .5230026245 125.4448013306127 .2063980103128 .9212036133130 .5892028809132 .2297973633 133.8462982178135 .4501037598137 .0440063477138 .6334075928140 .2205047607 141.8090057373143 .400894165145 .0001068115146 .6078033447148 .2272033691 149.8583984375151 .50340271153 .161605835154 .8334960938156 .5180969238 158.2147979736159 .9223022461161 .6396942139163 .3656005859165 .0984954834 166.8374023438168 .5805969238170 .3271026611172 .075302124173 .8244018555 175.5729064941177 .320098877179 .0648040771180 .8061065674182 .5433044434 184.2754974365186 .0019989014187 .7223052979189 .4355926514191 .1416015625 192.8395996094194 .5292053223196 .2100982666197 .8818054199199 .5438995361 201.196395874202 .8386993408204 .4707946777206 .092300415207 .7032012939 209.3031005859210.8921051025 212.4700012207 214.0366973877215.5921936035 217.1363983154218 .6692047119220 .1907958984221 .7010040283223 .1999053955 224.6876068115226 .1640014648227 .629196167229 .083404541230 .5263977051 231.9586029053233 .3798980713234 .7904968262236 .1905059814237 .5800018311 238.959197998240 .3282928467241 .6873931885243 .0368041992244 .3766937256 245.7071990967247 .028503418248 .3408966064249 .6445007324250 .9396057129 252.2261962891253 .5045928955254 .7749023438256 .0369873047257 .2911987305 258.5372924805259 .7755126953261 .0056152344262 .2276916504263 .4418029785 264.6481018066265 .8464050293267 .0310058594268 .2054138184 $-43.0242996216-42.4247207642-41.8635292053-41.37733078-40.9489707947$ $-40.5755882263-40.2496795654-39.9650993347-39.7126312256-39.4834289551$ -39.267288208 -39.0534706116 -38.8314399719-38.5894584656 -38.3171806335 -38.002571106 -37.6358299255 -37.2052192688 -36.7017593384 -36.1145210266 -35.4355888367 -34.6552581787 -33.7668495178 -32.7622795105 -31.6361999512 -30.3824691772 -28.9971408844 -27.4761791229 -25.8170795441 -24.017999649 $-22.0778694153-19.9970607758-17.7759609222-15.417090416-12.9224500656$ $-10.2965202332-7.54316902161-4.66877698898-1.679517030721 .416383981705$ 4.6098208427437 .89062023162811 .2460498809814 .6638803482118 .12711906433 21.6215000152625 .1253204345728 .6223793029832 .0860900878935 .49800872803 38.8279190063542 .053848266645 .1463317871148 .0788497924850 .82918930054 53.3683815002455 .6837005615257 .748329162659 .5589981079161 .09803009033 62.366489410463 .3576507568464 .0741271972764 .5193099975664 .69641113281 64.6136093139664 .2763900756863 .6944007873562 .8767204284761 .8338508606 60.5784111022959 .1217384338457 .4799194335955 .6650199890153 .69813156128 51.5931396484449 .3793487548847 .0757789611844 .7223281860442 .34693145752 39.9982185363837 .7222595214835 .5425415039133 .5180206298831 .61805915833 29.8268203735428 .1842002868726 .7196693420425 .4013805389424 .21216964722 23.1306095123322 .1339607238821 .1988296508820 .2837009429919 .37281990051 18.4213409423817 .4035301208516 .3059806823715 .0622501373313 .61968040466 12.0420103073110 .431280136118 .7511310577397 .0302300453195 .305210113525 3.576916933062 .037265062332 .8914300203323 -5.5279002e-02 -0.97855001688 $-1.84420096874-2.68231201172-3.48933196068-4.28171396255-5.03701591492$ $-5.75432777405-6.43916320801-7.11057519913-7.76882600784-8.41299152374$ $-9.03935909271-9.6279706955-10.1933403015-10.735830307-11.2672700882$ $-11.7923202515-12.2921304703-12.7479295731$-13.1652297974 -13.5483102798 
-13.9026699066 -14.246219635 -14.5367498398 -14.7298498154 -14.8762302399 -15.0111198425 -15.1545000076 -15.3518896103 -15.5411396027 -15.6628398895 -15.7547597885 -15.8373498917-15.9048299789 -15.9628400803 -15.9992704391 -16.003490448 -15.9897603989-15.9639396667 -15.9543504715 -15.9933099747 $-16.0651092529-16.1483306885-16.2823200226-16.5040092468-16.7679195404$ $-17.0318698883-17.2940998077-17.5371608734-17.7530002594-17.9328098297$ -18.0948905945 -18.2485694885 -18.3821105957-18.4719905853 -18.5959300995 -18.7891998291 -19.0694694519-19.417219162 -19.7629394531 -20.0627098083 -20.119310379 -19.790430069-19.3808097839-19.3051395416 -19.3659992218 -19.4194793701 -19.5023994446 -19.5452003479-19.5422706604 -19.4590892792 -19.28399086 -19.0032291412 -18.6220493317-18.1309108734 -17.5440807343 -16.8864307404 -16.1086006165 -15.1684103012 -14.1387701035 -13.0955295563 $-12.0209102631-10.9222803116-9.81130504608-8.68426132202-7.57023382187$ $-6.47744178772-5.41326093674-4.39119911194-3.40469193459-2.45797395706$ -1.5380179882 -.634176015854 .2757250070572 1.220214962959 2.174324989319 3.1135261058814 .0419669151314 .9513611793525 .844594001776 .719566822052 7.5938258171088 .487068176279 .38494205474910 .2848596572911 .16835975647 12.0190000534112 .8166399002113 .5588598251314 .1683902740514 .78118991852 14.8261995315613 .7116804122912 .307550430311 .0569095611610 .49868965149 11.3520402908312 .7302799224913 .9260501861615 .1154899597216 .25550079346 17.3527202606218 .42494964619 .4618492126520 .4799194335921 .46987915039 22.4365100860623 .4027404785224 .4029407501225 .439449310326 .53520965576 27.6879806518628 .9053592681930 .1962108612131 .5681991577133 .00624084473 34.4919700622636 .0143089294437 .5600318908739 .120670318640 .68830108643 42.2603492736843 .832588195845 .4021415710446 .9655799865748 .52169036865 50.0721702575751 .6161308288653 .1506805419954 .6840705871656 .21530914307 57.7621192932159 .3347587585460 .9541511535662 .6381301879964 .36791992188 66.1261596679767 .8937683105569 .6536483764671 .3835601806673 .06279754639 74.6626434326276 .1622772216877 .5912628173878 .9869613647580 .37389373779 81.783622741783 .2400283813584 .7714920043986 .4120712280388 .18876647949 90.0792999267692 .0491561889694 .0908966064596 .1797409057698 .32592773438 100.5279998779102 .7855987549105 .1024017334107 .4700012207109 .8844985962 112.3345031738114 .8041000366117 .2750015259119 .7762985229122 .108001709 124.043800354125 .7975997925127 .5438995361129 .2407073975130 .9060974121 132.5451049805134 .1595001221135 .7579956055137 .3424072266138 .9187927246 140.4902954102142 .0612945557143 .6365966797145 .2183990479146 .8105010986 148.4138946533150 .0303955078151 .6602020264153 .3034973145154 .9598999023 156.62840271158 .3085021973159 .9985046387161 .6977996826163 .4044952393 165.1179046631166 .8361968994168 .5585021973170 .283203125172 .0095062256 173.7359008789175 .4617004395177 .1855926514178 .9069976807180 .6246948242 182.3383026123184 .0467987061185 .7496948242187 .4461975098189 .1360015869 190.8182983398192 .4927978516194 .1591033936195 .816696167197 .4651947021 199.1045074463200 .7341003418202 .3538970947203 .9635009766205 .5628051758 207.1515960693208 .7297973633210 .2971954346211 .8536987305213 .399307251 214.9338989258216 .4573974609217 .9700012207219 .4714050293220 .961807251 222.4411010742223 .9093933105225 .3668060303226 .8132019043228 .2487945557 
229.6737060547231 .0877990723232 .491394043233 .8845977783235 .2675018311 236.6401977539238 .0030059814239 .3558959961240 .6992950439242 .033203125 243.3578033447244 .6734924316245 .9803009033247 .2783966064248 .5680999756 249.8495025635251 .1226959229252 .3878936768253 .6450042725254 .8943023682 256.1355895996257 .3689880371258 .5945129395259 .8120117188261 .0215148926 262.2232971191263 .4164123535264 .6023864746265 .7786865234 $-41.5363807678-40.9071807861-40.3906593323-39.9815292358-39.6266517639$ -39.3304100037 -39.0851593018 -38.8841705322 -38.7179298401 -38.5769309998 $-38.4505310059-38.3273086548-38.1962509155-38.0449485779-37.8625602722$ $-37.6364898682-37.3564186096-37.0101890564-36.5883407593-36.0796203613$ $-35.4757003784-34.7666702271-33.9455299377-33.004070282-31.9367599487$ $-30.7373409271-29.4017906189-27.9260101318-26.3074398041-24.544210434$ $-22.6351890564-20.5806999207-18.3810405731-16.0386009216-13.5551595688$ $-10.9350996017-8.18183231354-5.30167913437-2.30002999306$.8147349953651 4.0347051620487 .3491950035110 .7471504211414 .2152795791617 .73884010315 21.3017292022724 .884910583528 .4694690704332 .0312690734935 .54808044434 38.9906005859442 .3320999145545 .5414810180748 .5867500305251 .44351959229 54.0791893005456 .4778594970758 .6109390258860 .4739799499562 .05084991455 63.3422317504964 .3432617187565 .0576782226665 .4910964965865 .64736938477 65.5351867675865 .1600723266664 .5315017700263 .6578216552762 .54983139038 61.2186393737859 .6768302917557 .9382591247656 .0171318054253 .93201065063 51.6997413635349 .3477783203146 .8992996215844 .3951606750541 .87062072754 39.381420135536 .9796104431234 .6924591064532 .5743293762230 .62258911133 28.862030029327 .2788391113325 .8573799133324 .5753707885723 .41245079041 22.3439598083521 .3457603454620 .3891105651919 .4338607788118 .47525024414 17.496019363416 .3954105377215 .0589599609413 .5500802993811 .93474006653 10.23521041878 .5168581008916 .7776060104375 .024899005893 .278693914413 $1.531970977783-8.8000001 \mathrm{e}-04-1.09133696556-1.95959997177-2.80292010307$ $-3.59788608551-4.37014198303-5.11615514755-5.85298299789-6.57962322235$ $-7.28994321823-7.98520183563-8.66583061218-9.33250617981-9.99123287201$ $-10.6297998428-11.2340602875-11.8042402267-12.3232002258-12.8423995972$ $-13.4090795517-13.9399499893-14.3627996445-14.7274599075-15.0718097687$ $-15.3917798996-15.6928300858-15.946559906-16.1263904572-16.2639694214$ $-16.3866901398-16.5133705139-16.6705493927-16.8191795349-16.9233703613$ $-17.0023097992-17.0692901611-17.1239700317-17.1688594818-17.1969890594$ $-17.2026500702-17.1959400177-17.1849193573-17.1912002563-17.2371292114$ $-17.315290451-17.4166698456-17.5658607483-17.7834091187-18.0333595276$ -18.2854499817-18.5285797119 -18.7506008148 -18.9574604034-19.1377906799 $-19.282119751-19.3865509033-19.4821205139-19.5745697021-19.6936397552$ -19.8624401093 -20.0055294037-20.080789566 -20.0787601471 -20.025390625 $-19.9336395264-19.7649803162-19.6769008636-19.7801609039-19.947769165$ $-20.1147193909-20.2712802887-20.3789196014-20.4264602661-20.3846797943$ $-20.2483692169-20.0069293976-19.6693496704-19.2315406799-18.7027397156$ $-18.089050293-17.3600006104-16.4926605225-15.5341100693-14.5367097855$ $-13.4966402054-12.4256296158-11.3289699554-10.2046699524-9.07671737671$ $-7.96002721786-6.85766601562-5.78763914108-4.7473449707-3.74437999725$ 
-2.77384591103 -1.82652795315 -.887130022049 6.27499968e-02 1.019217967987 1.9743200540542 .9203810691833 .8463490009314 .7558212280275 .646385192871 6.5412678718577 .4639639854438 .3983716964729 .33624744415310 .2742099762 11.211219787612 .1134195327812 .9608802795413 .6729202270514 .24639987946 14.1994199752813 .0615396499611 .7819499969511 .1256799697911 .13502979279 11.9046602249113 .0022802352914 .077879905715 .1650600433316 .23336982727 17.2845001220718 .3033103942919 .2956008911120 .2632007598921 .20782089233 22.1317005157523 .0552692413324 .0046501159724 .9860897064226 .01847076416 27.0975399017328 .2217006683329 .4308300018330 .7671794891432 .1823387146 33.6336593627935 .1188316345236 .6283988952638 .1581306457539 .70222854614 41.2584800720242 .8225517272944 .3905982971245 .9571304321347 .52050018311 49.0782394409250 .6314315795952 .1775588989353 .7240104675355 .27112960815 56.8373489379958 .4324913024960 .0570106506361 .7240905761763 .41862106323 65.1392669677766 .8684005737368 .5854034423870 .264373779371 .88596343994 73.4536590576274 .9511795043976 .4026794433677 .8154678344779 .21269226074 80.6293869018682 .0941772460983 .6332397460985 .2464675903386 .95610046387 88.7458572387790 .6149826049892 .5607299804794 .5583419799896 .62328338623 98.76072692871100 .9683990479103 .25105 .599899292108 .0179977417110 .485496521 112.978302002115 .4766998291117 .9663009644120 .3099975586122 .3650970459 124.2496032715126 .064201355127 .8139038086129 .5216064453131 .1898956299 132.8264007568134 .4353027344136 .0213012695137 .5903015137139 .1488952637 140.7015991211142 .2563018799143 .8150024414145 .3833007812146 .961807251 148.5532989502150 .1575927734151 .7754058838153 .4060974121155 .0491943359 156.7037963867158 .3688049316160 .0431060791161 .7254943848163 .4147949219 165.1096038818166 .8088989258168 .5113067627170 .2156982422171 .921005249 173.6262054443175 .3302001953177 .0321960449178 .7312011719180 .4266967773 182.1175994873183 .8034973145185 .4835968018187 .1575012207188 .8244018555 190.4841003418192 .1360015869193 .7796936035195 .4147949219197 .0410003662 198.6580047607200 .2655029297201 .8632049561203 .4510040283205 .0287017822 206.595993042208 .1528930664209 .6992034912211 .2348937988212 .7599029541 214.2740936279215 .7774963379217 .2700042725218 .7516937256220 .2227020264 221.682800293223 .1320953369224 .5708007812225 .9987030029227 .4161987305 228.8231048584230 .2196044922231 .6058959961232 .9819946289234 .3480987549 235.7044067383237 .0511016846238 .3881988525239 .716003418241 .0346984863 242.3446044922243 .6455993652244 .9382019043246 .2223968506247 .4983978271 248.7662963867250 .0263061523251 .2783050537252 .5225067139253 .758895874 254.9875030518256 .208190918257 .4209899902258 .6258850098259 .8232116699 261.0126037598262 .1883850098263 .354309082 -39.6396903992 -39.1634902954 -38.7312507629 -38.3836402893 -38.1018409729 -37.8826217651 -37.7177581787-37.6003494263 -37.5202102661 -37.4674491882 $-37.430770874-37.3982200623-37.3582000732-37.2976799011-37.2053413391$ $-37.0679512024-36.8748397827-36.6132316589-36.2734298706-35.8436584473$ $-35.3154411316-34.6785011292-33.9257011414-33.0486793518-32.0417518616$ $-30.8987293243-29.6153507233-28.1878299713-26.6132202148-24.8901596069$ $-23.0169506073-20.9945392609-18.8224697113-16.5038108826-14.039349556$ -11.4340801239-8.69031333923 -5.81474494934-2.81169605255 0.310487985611 
3.5447258949286 .8809399604810 .3084297180213 .8152999877917 .38633918762 21.0080108642624 .6593399047928 .3254394531231 .977750778235 .59936904907 39.1528511047442 .6164398193445 .9476509094249 .1146888732952 .08596038818 54.8226509094257 .3102912902859 .5111312866261 .42731857363 .03804016113 64.3486633300865 .3575363159266 .0679321289166 .4924011230566 .63094329834 66.4959793090866 .0900802612365 .4230194091864 .5022430419963 .33684158325 61.9387207031260 .3178405761758 .4899482727156 .4661216735854 .26791000366 51.9086685180749 .4208793640146 .8247489929244 .1682891845741 .48865890503 38.8433685302736 .2940711975133 .8875083923331 .6749706268329 .67935943604 27.951450347926 .4189605712925 .0284996032723 .7719802856422 .62655067444 21.5643692016620 .5580005645819 .5710201263418 .5597896575917 .52072906494 16.4628791809115 .2336797714213 .6368198394811 .8708295822110 .12880992889 8.3527450561526 .595829010014 .8401808738713 .0988790988921 .399145960808 -.289622008801 -1.7589789629 -2.79775905609-3.61790800095 -4.41440105438 -5.15349006653 -5.88181209564 -6.5935997963 -7.30460119247 -8.0162935257 $-8.7281370163-9.43810844421-10.1382398605-10.8304195404-11.5099897385$ $-12.1753797531-12.808429718-13.3970003128-13.8978500366-14.3902101517$ $-14.9768104553-15.5256996155-15.9129400253-16.2316093445-16.5436992645$ -16.8265800476 -17.0808792114 -17.2983608246 -17.4738693237 -17.6183204651 $-17.7444896698-17.8605709076-17.9759807587-18.0819702148-18.1704406738$ $-18.2432899475-18.300699234-18.3457698822-18.3803501129-18.404340744$ -18.4188308716 -18.4304504395 -18.4469394684 -18.4795303345 -18.5380191803 -18.6277294159 -18.7504405975 -18.9111309052 -19.1106891632 -19.3331394196 -19.5651702881 -19.7916793823 -19.9976196289-20.1846408844 -20.3456001282 -20.470539093 -20.5443592072 -20.601600647 -20.6559295654 -20.7094993591 -20.8012599945 -20.7933692932 -20.5985794067 -20.2952003479 -19.9962100983 -19.8211402893 -19.8327293396 -20.0140094757 -20.2522602081 -20.5118808746 $-20.7812995911-21.0139007568-21.1805591583-21.2696800232-21.2653808594$ $-21.1639499664-20.9629096985-20.6651000977-20.2719306946-19.7827796936$ -19.1968593597 -18.5088100433 -17.7229995728 -16.8516807556 -15.917140007 $-14.9284000397-13.9015703201-12.8297100067-11.7068595886-10.560379982$ $-9.41246032715-8.27349281311-7.16010713577-6.07322692871-5.01772785187$ -3.99427199364 -2.99326610565 -2.01391410828 -1.05497300625 -.100807003677 .85793000459671 .8131690025332 .7470390796663 .6680068969734 .570258140564 5.4787597656256 .4243288040167 .3896207809458 .361111640939 .346326828003 10.3634004592911 .3497695922912 .2831602096613 .0376901626613 .52283000946 13.5554504394512 .7495498657211 .9132795333911 .9861097335812 .43091964722 12.8963499069213 .5656995773314 .4078702926615 .3447999954216 .31580924988 17.2934398651118 .2450294494619 .1739597320620 .0806503295920 .96817016602 21.8464603424122 .7259292602523 .6287708282524 .5592899322525 .53554916382 26.5531806945827 .5978298187328 .7327804565430 .0295104980531 .41283035278 32.8208999633834 .2653312683135 .7382316589437 .2365913391138 .75938034058 40.3009605407741 .858680725143 .4262886047444 .9987907409746 .57202148438 48.1398315429749 .7056007385351 .2638511657752 .8243103027354 .3839302063 55.9583816528357 .5571708679259 .1762809753460 .8239288330162 .48793029785 64.1709213256865 .8534927368267 .5222473144569 .1577682495170 .74265289307 
72.285293579173 .778320312575 .2373886108476 .6643676757878 .08196258545 79.5158081054780 .9854507446382 .5156326293984 .1001968383885 .75160217285 87.4639282226689 .240516662691 .0844726562592 .975723266694 .94566345215 97.0021286010799 .14501190186101 .3851013184103 .7105026245106 .1235961914 108.5970001221111 .0948028564113 .5827026367116 .0167999268118 .3477020264 120.5345001221122 .581703186124 .498298645126 .3190994263128 .0820007324 129.7908935547131 .4541931152133 .0796966553134 .6692047119136 .2328033447 137.7803039551139 .3173980713140 .8545074463142 .3937988281143 .9418029785 145.4992980957147 .0691986084148 .6515045166150 .2467956543151 .8549041748 153.4750061035155 .1065979004156 .7485046387158 .400100708160 .0596923828 161.7265930176163 .399307251165 .0769958496166 .758102417168 .4418945312 170.1269989014171 .8125173 .4972991943175 .1808013916176 .8616943359178 .5395965576 180.2135009766181 .8829040527183 .5469970703185 .2053070068186 .8571929932 188.5023956299190 .1401062012191 .7700958252193 .3919067383195 .0052032471 196.6096038818198 .2050018311199 .7910003662201 .3672943115202 .933807373 204.4904022217206 .0366973877207 .5729064941209 .0986022949210 .6138000488 212.1186065674213 .6127929688215 .0964050293216 .5693969727218 .0317993164 219.4835968018220 .9248962402222 .3556060791223 .775894165225 .1858062744 226.5852966309227 .9747009277229 .3538970947230 .7232055664232 .0825958252 233.4322967529234 .7723999023236 .103302002237 .4248962402238 .7375946045 240.0413970947241 .3367004395242 .6235961914243 .9022064209245 .1726989746 246.4351959229247 .6898040771248 .9365997314250 .1757049561251 .4071044922 252.6307067871253 .846496582255 .0545043945256 .254699707257 .4472961426 258.6312866211259 .8082885742260 .9758911133 $-37.7510986328-37.2341804504-36.8428001404-36.5723190308-36.3631591797$ -36.2204208374 -36.1356391907 -36.101348877 -36.1070594788 -36.1421699524 -36.1950111389 -36.2528686523 -36.3037109375 -36.333820343 -36.3314094543 -36.2826499939 -36.1764602661 -35.9995918274 -35.7419891357 -35.3915290833 $-34.9394989014-34.3753509521-33.6918907166-32.880569458-31.935749054$ -30.8511505127 -29.6226997375 -28.2464599609 -26.7198505402 -25.0412807465 -23.2094402313 -21.2249908447 -19.0877895355 -16.8005104065 -14.3641395569 -11.7831497192 -9.05974769592 -6.20011091232 -3.20804309845 -9.1459997e-02 3.1436460018166 .4873409271249 .93080520629913 .4617795944217 .06797027588 20.7346992492724 .4450492858928 .1818904876731 .9211406707835 .64213943481 39.3100891113342 .897319793746 .3586616516149 .6545181274452 .74781036377 55.5909690856958 .1680488586460 .4410095214862 .4087486267164 .05090332031 65.3765792846766 .3897399902367 .0960693359467 .5115585327167 .63746643066 67.4851303100667 .056777954166 .3602294921965 .4014892578164 .18887329102 62.7319717407261 .0415115356459 .1302490234457 .0112495422454 .70294952393 52.2218704223649 .5983314514246 .8577308654844 .0466804504441 .20726013184 38.3935089111335 .6587905883833 .1071701049830 .8682098388728 .89127922058 27.1564407348625 .6216106414824 .2406101226822 .9934101104721 .85437965393 20.791090011619 .7686595916718 .7374305725117 .6517505645816 .49522972107 15.2292499542213 .7724103927612 .0145502090510 .126350402838 .268746376038 $6.4413728713994 .7023367881772 .9986081123351 .310057997704-.304847985506$ $-1.8367960453-3.17575097084-4.19844579697-5.04092597961-5.81534481049$ 
-6.53099298477 -7.23543119431 -7.93160486221 -8.6403799057 -9.3584690094 $-10.0895900726-10.8260202408-11.5579004288-12.2800998688-12.9769496918$ -13.6687097549 -14.3726100922 -15.0175695419-15.5220298767-15.9876403809 -16.5081005096 -16.9936294556 -17.3675498962 -17.6784801483 -17.9664001465 -18.2224807739 -18.4476604462 -18.6433296204 -18.8073806763 -18.948759079 -19.0714607239 -19.17552948 -19.2706394196 -19.3547496796 -19.4274902344 -19.4908504486 -19.5407600403 -19.5800590515 -19.6121902466 -19.6401195526 -19.6659297943 -19.6964797974-19.7360801697-19.7905406952 -19.8679199219 -19.9719905853 -20.1083106995 -20.2718906403 -20.4622192383 -20.6665592194 $-20.8781108856-21.0851192474-21.2724399567-21.4373092651-21.5709209442$ $-21.6645793915-21.7062397003-21.7154808044-21.7028408051-21.66381073$ $-21.6136703491-21.4420700073-21.0850906372-20.5915393829-19.986289978$ $-19.6438808441-19.8951702118-20.3937797546-20.8137798309-21.1862506866$ $-21.5188808441-21.7979698181-21.9977607727-22.1134300232-22.1336593628$ $-22.0592403412-21.8875198364-21.62251091-21.2664394379-20.8159408569$ $-20.2698402405-19.6346206665-18.9104690552-18.1093196869-17.2394790649$ $-16.3118095398-15.3496398926-14.318570137-13.1858301163-12.0064001083$ $-10.8283500671-9.65516662598-8.50386619568-7.37309980392-6.2683930397$ $-5.19222211838-4.14130496979-3.12093496323-2.13262200356-1.1667920351$ -.219108998775.7229899764061 1.660797953606 2.5892639160163.49929189682 4.4172778129585 .3740410804756 .3602151870737 .3701920509348 .403733253479 9.46397399902310 .5059499740611 .5015802383412 .359939575213 .01780033112 13.497070312513 .7348804473913 .8268604278613 .7362298965513 .64262962341 13.8367900848414 .2280597686814 .856229782115 .6517801284816 .50242042542 17.3834209442118 .2430706024219 .0931396484419 .9339294433620 .76623916626 21.5895404815722 .4206504821823 .277830123924 .1649093627925 .0945892334 26.0661792755127 .0788497924828 .1757907867429 .401159286530 .71009063721 32.0627593994133 .4590415954634 .8921089172436 .3603401184137 .86103057861 39.389789581340 .942661285442 .5128593444844 .0939407348645 .67882156372 47.2576599121148 .833980560350 .4030113220251 .9712104797453 .53691101074 55.110771179256 .7032089233458 .3093910217359 .9347991943461 .5701789856 63.2162704467864 .8582382202166 .484092712468 .0825729370169 .63922119141 71.1630477905372 .6498565673874 .1115493774475 .5496292114376 .98195648193 78.427597045979 .898857116781 .4152069091882 .9694900512784 .56977081299 86.2119369506887 .9005432128989 .6397399902391 .4230270385793 .28772735596 95.2489013671997 .3130187988399 .50652313232101 .8039016724104 .2011032104 106.6687011719109 .1617965698111 .6391983032114 .0615997314116 .4177017212 118.6698989868120 .8177032471122 .8386993408124 .7496032715126 .5805969238 128.3414001465130 .0417022705131 .6882019043133 .2843933105134 .8430938721 136.3815002441137 .9053039551139 .4277038574140 .9508972168142 .4824066162 144.0225067139145 .5746002197147 .1383972168148 .7147979736150 .3031005859 151.9031982422153 .5142059326155 .1354980469156 .7660980225158 .4049987793 160.0511932373161 .7035064697163 .3609008789165 .0222015381166 .6864013672 168.3522949219170 .0191040039171 .6856994629173 .3513031006175 .0149993896 176.6759033203178 .333404541179 .9868011475181 .6354064941183 .2787017822 184.9158935547186 .5467987061188 .1705932617189 .7872009277191 .395904541 
192.9965057373 194.5885925293196.1719055176197.7462005615199.3110961914 200.8665008545202 .4122924805203 .9481964111205 .474105835206 .9898071289 208.495300293209 .9906005859211 .4756011963212 .9501953125214 .4143981934 215.8681945801217 .311706543218 .7447967529220 .1674957275221 .5800018311 222.9821929932224 .3742980957225 .7563018799227 .12840271228 .4907073975 229.8432006836231 .1862945557232 .5198974609233 .8442993164235 .1596069336 236.4660949707237 .7639007568239 .0532073975240 .3343048096241 .6071014404 242.8721008301244 .1289978027245 .3782958984246 .6197967529247 .8536071777 249.0798034668250 .2984008789251 .5092010498252 .7124023438253 .907699585 255.0955963135256 .2757873535257 .4425964355258 .5997009277 -35.406288147 -35.0506210327 -34.7447090149 -34.5333595276 -34.3960113525 -34.3290901184 -34.323600769-34.371799469-34.4626083374-34.5850105286 $-34.7266693115-34.8743400574-35.0154304504-35.1355781555-35.2225608826$ -35.261920929 -35.2422409058 -35.1497383118 -34.9741287231 -34.7028808594 -34.327129364 -33.8361206055 -33.222568512 -32.4779396057 -31.5965003967 -30.5722808838 -29.4009799957-28.07929039-26.6041698456 -24.9749794006 -23.1896495819-21.2499809265 -19.1547393799-16.9078502655 -14.5088500977 $-11.9634103775-9.27201843262-6.44178295135-3.47467708588-.379090994596$ 2.8407769203196 .1751780509959 .61688327789313 .1547298431416 .77761077881 20.473220825224 .2249298095728 .0197200775131 .8314895629935 .64599990845 39.4208793640143 .1366882324246 .7321205139250 .1720809936553 .39812088013 56.3537101745659 .0277900695861 .3683815002463 .3852195739765 .05003356934 66.3796768188567 .394256591868 .0948867797968 .5085296630968 .62920379639 68.4711380004968 .032920837467 .3197937011766 .3369674682665 .08907318115 63.5866813659761 .8366889953659 .8537216186557 .6471710205155 .23817825317 52.639648437549 .8864707946847 .0010299682644 .0372581481941 .03382873535 38.0612297058135 .1546897888232 .4669685363830 .2041797637928 .22826004028 26.4608993530324 .9007091522223 .5091304779122 .2568798065221 .11046028137 20.0301303863518 .9761104583717 .9005908966116 .7494697570815 .4525604248 13.940039634712 .2243795394910 .325869560248 .3444566726686 .38836812973 $4.5156931877142 .8258941173551 .23270201683-.349730014801-1.83597195148$ -3.18291497231 -4.37370300293 -5.38935089111 -6.26460313797 -7.04113483429 $-7.7530298233-8.45740795135-9.15931987762-9.88801002502-10.6351995468$ $-11.4041996002-12.1863698959-12.960559845-13.7264404297-14.4455795288$ -15.1605195999 -15.92029953 -16.6163005829-17.1319293976 -17.5734195709 -18.017539978 -18.424779892 -18.7826309204-19.0943393707 -19.3661499023 -19.6017799377 -19.8071804047 -19.9858493805 -20.140209198 -20.2739391327 -20.3900604248 -20.4875392914 -20.572259903 -20.6446609497 -20.7067298889 $-20.7606506348-20.8029594421-20.8394908905-20.8723907471-20.9070606232$ -20.9470291138 -20.9956607819 -21.056930542 -21.1338195801 -21.2303600311 -21.350019455 -21.4951496124 -21.6593093872 -21.8405208588 -22.0296001434 $-22.2235202789-22.4104690552-22.5783100128-22.7194309235-22.8248405457$ $-22.8854808807-22.8950500488-22.8521900177-22.7594394684-22.6052398682$ $-22.402639389-22.0864601135-21.6560497284-21.1153392792-20.3539791107$ $-19.9061603546-20.3162193298-21.0212993622-21.5286197662-21.9758396149$ $-22.3512706757-22.6443595886-22.8578300476-22.9793395996-23.0130405426$ 
-22.9518108368 -22.8017692566 -22.5598697662 -22.2347297668 -21.8205299377 $-21.3181304932-20.7324008942-20.0650691986-19.3236503601-18.5139904022$ -17.642829895 -16.7401199341 - $15.7505702972-14.6173295975-13.4165000916$ $-12.2156600952-11.0144300461-9.83029079437-8.66455936432-7.51243686676$ $-6.38410282135-5.27800798416-4.2081360817-3.17960095406-2.18850493431$ $-1.2479159832-.324236005545$.6012439727783 1.5247260332112 .434231042862 3.3599989414224 .3246111869815 .3229718208316 .3628358840947 .430605888367 8.5162496566779 .59700298309310 .6447200775111 .6452102661112 .55280971527 13.4947700500514 .7557096481315 .6538000106815 .2820901870714 .64323043823 14.6309900283814 .8609199523915 .3387498855615 .997389793416 .71760940552 17.4947490692118 .2548599243219 .0229606628419 .7974090576220 .57513999939 21.3459606170722 .1307601928722 .9466705322323 .7958106994624 .68598937988 25.6245899200426 .6202106475827 .6872100830128 .8370990753230 .06143951416 31.3495197296132 .6939697265634 .0861015319835 .5230789184637 .00241851807 38.5186080932640 .0685081481941 .6431808471743 .2361297607444 .83543014526 46.4271087646548 .0152893066449 .5899009704651 .160160064752 .72272109985 54.2867507934655 .8647689819357 .4514083862359 .0540008544960 .66139984131 62.2745895385763 .8802490234465 .4702987670967 .0384063720768 .57377624512 70.0837173461971 .562782287673 .0236129760774 .4686431884875 .910987854 77.3641281127978 .8333282470780 .3338012695381 .8583908081183 .41581726074 84.9993209838986 .6113433837988 .2577362060589 .9382095336991 .68599700928 93.5238265991295 .4977493286197 .6434478759899 .92594146729102 .3071975708 104.7506027222107 .221496582109 .6853027344112 .1082992554114 .4824981689 116.7825012207118 .9989013672121 .1146011353123 .1230010986125 .0338973999 126.8554992676128 .5935058594130 .2606048584131 .8623962402133 .4151000977 134.946395874136 .4600982666137 .9718017578139 .4837036133141 .0028991699 142.5303955078144 .0684967041145 .6175994873147 .1781005859148 .7498931885 150.3325958252151 .9257049561153 .528503418155 .1405029297156 .7604064941 158.3876037598160 .0209960938161 .6596984863163 .3023071289164 .9483032227 166.5960998535168 .245300293169 .8945007324171 .5431976318173 .1902008057 174.8350067139176 .4765930176178 .1147003174179 .7481994629181 .3768005371 182.9996948242184 .6166992188186 .2270050049187 .8303985596189 .4261932373 191.0142974854192 .5941925049194 .1656036377195 .728302002197 .2819976807 198.8264007568200 .3614044189201 .8867034912203 .4024047852204 .908203125 206.404006958207 .8898010254209 .3654022217210 .8309936523212 .2863006592 213.7315063477215 .1665039062216 .591293335218 .0059967041219 .4105987549 220.8050994873222 .1896057129223 .5643005371224 .9290924072226 .2841949463 227.6298980713228 .9660949707230 .2929992676231 .6109008789232 .9197998047 234.2200012207235 .5117034912236 .7949066162238 .0700073242239 .337097168 240.5962982178241 .8477020264243 .0914001465244 .3273925781245 .5559997559 246.7769012451247 .9902954102249 .196105957250 .3943023682251 .5847930908 252.7678070068253 .9423980713255 .1103057861256 .2687072754 -33.0678100586 -32.6593513489-32.3896408081 -32.2546882629-32.1882705688 -32.1961097717 -32.2690086365 -32.3987007141 -32.5737304688 -32.7824211121 -33.0120391846 -33.248588562 -33.4790611267 -33.6884002686 -33.8639602661 $-33.9906997681-34.0568618774-34.048160553-33.9540901184-33.7617683411$ 
-33.4622688293 -33.0445594788 -32.501499176 -31.8243808746 -31.0078296661 $-30.0457000732-28.934299469-27.670129776-26.2509002686-24.6756496429$ -22.9431991577 -21.0548706055 -19.010269165 -16.8126106262 -14.4621496201 $-11.9636297226-9.31795215607-6.53112888336-3.60505795479-.547016978264$ 2.6395831108095 .9459629058849 .3666925430312 .8912401199316 .51172065735 20.2158603668223 .9921302795427 .8265991210931 .6999492645335 .59519958496 39.4762992858943 .3178100585947 .0581092834550 .6536293029854 .02639007568 57.0976409912159 .8647689819362 .2800712585464 .3438186645566 .02021789551 67.3424530029368 .3513717651469 .0491561889669 .4632797241269 .58896636963 69.4364089965869 .0025329589868 .2880401611367 .2953491210966 .0277633667 64.4926910400462 .6976203918560 .6535911560158 .3720588684155 .8702507019 53.1638793945350 .2848701477147 .259208679244 .1439208984440 .98595046997 37.8712806701734 .8739700317432 .1107902526929 .7385406494127 .66496086121 25.8517398834224 .2621707916322 .8487491607721 .5785903930720 .40395927429 19.2864093780518 .179969787617 .0568008422915 .8925600051914 .51941013336 12.7617902755710 .784049987798 .7078914642336 .5948572158814 .485515117645 $2.5300490856170 .929516017437-.502081990242-1.913367033-3.22730708122$ $-4.42491292953-5.51208591461-6.47619819641-7.34360313416-8.11975479126$ $-8.84079456329-9.5615272522-10.2918996811-11.0587100983-11.8534402847$ $-12.6859502792-13.5336999893-14.3697900772-15.1882400513-15.9561901093$ $-16.7002506256-17.4414196014-18.1142292023-18.6502094269-19.0987091064$ -19.511680603 -19.8827705383 -20.2138996124 -20.5091304779 -20.7630805969 $-20.9802494049-21.1701602936-21.3363208771-21.4825000763-21.6103305817$ $-21.7214298248-21.8151893616-21.8941192627-21.9600906372-22.0151996613$ $-22.0619392395-22.099319458-22.1334896088-22.1671295166-22.2077693939$ $-22.2618694305-22.3280792236-22.4083309174-22.5042705536-22.6191196442$ $-22.7534503937-22.9063396454-23.0706996918-23.2433605194-23.4189395905$ $-23.5970096588-23.766330719-23.9153003693-24.0347805023-24.1156597137$ $-24.1474208832-24.1217594147-24.0291595459-23.8649291992-23.6282997131$ $-23.322479248-22.9428501129-22.5035495758-22.0152397156-21.4541301727$ $-21.1667194366-21.4785804749-22.0400104523-22.5272102356-22.9675598145$ -23.3286495209-23.6108703613 -23.8033103943 -23.9109096527 -23.934709549 -23.8737201691 -23.7288398743 -23.5021305084 -23.1998100281 -22.818769455 -22.3561592102 -21.8166408539-21.1995601654 -20.5096607208 -19.748380661 -18.9200305939-18.0363998413 -17.0618896484-15.9657201767 -14.7887201309 -13.5693702698 -12.3396596909-11.1392698288 -9.94887733459-8.75259876251 -7.56690311432-6.40013790131 -5.27258205414-4.20043897629-3.18012309074 $-2.21922492981-1.29839599133-.413473010063 .46916198730471 .378851056099$ 2.3157629966743 .2864229679114 .2911820411685 .335637092596 .415513038635 7.5304780006418 .6608915328989 .78276443481410 .9009399414111 .97484970093 13.1386404037514 .4806604385415 .426969528215 .4560499191315 .14002037048 15.1307401657115 .3219900131215 .7165203094516 .2559700012216 .88375091553 17.5664405822818 .2461795806918 .9409694671619 .6527690887520 .37746047974 21.1068992614721 .8560600280822 .6374492645323 .4537391662624 .30971908569 25.2154407501226 .1786098480227 .2015800476128 .2942104339629 .4525604248 30.6795196533231 .9715690612833 .3207893371634 .7249603271536 .18154907227 
37.6856307983439 .2335281372140 .815429687542 .4223899841344 .03757095337 45.6451301574747 .2440605163648 .8193511962950 .3828201293951 .93479919434 53.4822196960455 .0403099060156 .6057891845758 .1833610534759 .76480102539 61.3481712341362 .9238586425864 .484230041566 .0268630981467 .54402923584 69.0406494140670 .5137634277371 .9726333618273 .4218826293974 .86982727051 76.3259963989377 .7921066284279 .2776412963980 .7778015136782 .29696655273 83.8304672241285 .3796386718886 .9468688964888 .534881591890 .15976715088 91.820587158293 .6524734497195 .7962799072398 .1106262207100 .4763031006 102.8880004883105 .3225021362107 .7604980469110 .1763000488112 .5634994507 114.9005966187117 .1781997681119 .3746032715121 .4717025757123 .4604034424 125.3449020386127 .1156997681128 .7978057861130 .4028930664131 .9488983154 133.4723968506134 .978805542136 .483795166137 .9889068604139 .5009002686 141.0198059082142 .5484008789144 .0865020752145 .6349029541147 .1930999756 148.7613983154150 .3390045166151 .9257965088153 .5211029053155 .124206543 156.7342071533158 .3502960205159 .9716949463161 .5971984863163 .2261047363 164.8571929932166 .4897003174168 .1226043701169 .7550964355171 .3863983154 173.0157012939174 .6421966553176 .2653961182177 .8843994141179 .4989013672 181.108001709 182.7113952637 184.3085021973 185.8990020752 187.4821929932 189.0579986572 190.625793457 192.1855010986 193.7368011475 195.279296875 196.8126983643198 .337097168199 .8520050049201 .3574981689202 .853302002 204.3394012451205.8155975342 207.2819976807 208.7384033203 210.1849060059 211.6213989258213 .0478057861214 .4642944336215 .870803833217 .2673950195 218.6540985107220 .0310058594221 .3981018066222 .7555999756224 .1035003662 225.4420928955226 .7713928223228 .0915985107229 .4028015137230 .7052001953 231.9990997314233 .2843933105234 .5615997314235 .8305969238237 .0917053223 238.3450927734239 .5908050537240 .8289031982242 .0594024658243 .2825012207 244.4980926514245 .7062988281246 .9069061279248 .1000061035249 .2855987549 250.4636993408251 .6343994141252 .7919006348253 .9400024414 $-30.2240695953-29.9847297668-29.8010406494-29.7220191956-29.7252502441$ $-29.8066806793-29.9566402435-30.1665802002-30.4244709015-30.7182006836$ $-31.0344009399-31.3585796356-31.6771202087-31.9743995667-32.2373085022$ $-32.4502792358-32.6011810303-32.6753005981-32.6619300842-32.5478782654$ $-32.324131012-31.9795799255-31.5070590973-30.8980808258-30.1472396851$ $-29.2489395142-28.1993694305-26.9959793091-25.6360797882-24.1200408936$ $-22.4458599091-20.6165599823-18.6304092407-16.4924602509-14.2011404037$ $-11.7630300522-9.17673683167-6.44984483719-3.58164405823-.580506980419$ 2.5529539585115 .8095760345469 .18682765960712 .6747198104916 .2683391571 19.9571094512923 .7324905395527 .5835990905831 .4936790466335 .45038986206 39.417690277143 .3776588439947 .2564888000551 .0252990722754 .5587310791 57.7674598693860 .6437301635763 .1168212890665 .2088165283266 .88440704346 68.1839599609469 .1914367675869 .8928375244170 .3240432739370 .47422027588 70.3462066650469 .936660766669 .2381668090868 .2556304931666 .98432159424 65.4346923828163 .6086196899461 .5199699401959 .176059722956 .59613037109 53.7928886413650 .8005485534747 .6418113708544 .3848190307641 .07331085205 37.823520660434 .7382507324231 .8946304321329 .4034595489527 .22347068787 25.3543701171923 .7299003601122 .2840900421120 .9777793884319 .75724983215 
18.5872402191217 .4157505035416 .2099094390914 .9957799911513 .53654956818 11.582759857189 .3996124267587 .1979970932014 .9746050834662 .73243188858 $.7178729772568-.796172976494-2.06222701073-3.30670809746-4.46097421646$ $-5.53867006302-6.54004096985-7.45931720734-8.30808639526-9.09033966064$ -9.83710861206 -10.5966100693 -11.3740301132 -12.1959295273 -13.0669202805 -13.98416996 -14.9253702164 -15.8313102722 -16.7048397064 -17.5184593201 -18.2775306702 -18.9768695831 -19.6028804779-20.1483898163 -20.6148891449 $-21.0176792145-21.3666191101-21.6749191284-21.9459991455-22.1783103943$ $-22.3789405823-22.5564994812-22.7122306824-22.8515491486-22.9739208221$ $-23.0821990967-23.1747207642-23.2527809143-23.3173294067-23.3689899445$ $-23.4116802216-23.4448108673-23.4768505096-23.5085697174-23.5528106689$ $-23.6178798676-23.6985206604-23.7985496521-23.9141902924-24.0449008942$ $-24.1920604706-24.3483600616-24.5087890625-24.6744709015-24.8381595612$ $-25.0028095245-25.1561698914-25.2877407074-25.3869590759-25.4484195709$ -25.4555206299 -25.4047203064 -25.273059845 -25.0603294373 -24.7574291229 $-24.3722896576-23.9665393829-23.5738105774-23.2409496307-22.9879493713$ -22.9036197662 -23.0628890991 -23.3813304901 -23.7564201355 -24.137260437 -24.4487495422 -24.6863899231 -24.8367595673 -24.9060497284 -24.9035892487 -24.8245391846 -24.6770706177 -24.4566898346 -24.1742591858 -23.8225097656 -23.397069931 -22.8990192413 -22.3266792297 -21.6801490784 -20.9604892731 $-20.1626396179-19.2870903015-18.3239994049-17.2734107971-16.1407299042$ -14.9257497787 -13.6806297302 -12.4678201675 -11.2509803772 -10.0066204071 -8.7644071579 -7.528236866 -6.33630990982 -5.20974493027 -4.14576911926 -3.15971398354 -2.23403501511 -1.3880790472-.552954018116 0.345459997654 1.2815150022512 .2459781169893 .2482120990754 .2889370918275 .375287055969 6.5147309303287 .696784019478 .89739322662410 .1212701797511 .31571006775 12.4925899505613 .5781402587914 .4103202819814 .9062700271615 .1502199173 15.356619834915 .5870504379315 .9521503448516 .4196090698216 .97208976746 17.5838108062718 .1957092285218 .8338603973419 .49197959920 .17359924316 20.8687095642121 .5906696319622 .3431396484423 .131839752223 .95756912231 24.8301105499325 .7551002502426 .7346191406227 .7738895416328 .87595939636 30.0457305908231 .2845191955632 .5896110534733 .9593696594235 .39289093018 36.8840599060138 .4292984008840 .0180702209541 .6372299194343 .27254867554 44.9027099609446 .5126419067448 .0818099975649 .6257286071851 .15726852417 52.6852798461954 .222381591855 .7655792236357 .3197708129958 .87670898438 60.4351501464861 .9861984252963 .523300170965 .0458221435566 .54691314697 68.0321426391669 .498191833570 .9539413452172 .4044036865273 .85417175293 75.3110198974676 .772598266678 .2462692260779 .7251434326281 .21363067627 82.7053680419984 .2031936645585 .7063827514687 .2177581787188 .75254821777 90.2689971923891 .9728775024494 .0940170288196 .4046478271598 .72071838379 101.0822982788103 .470703125105 .8721008301108 .2741012573110 .664100647 113.0238037109115 .3432006836117 .6031036377119 .7830963135121 .8610992432 123.8087005615125 .6060028076127 .2845993042128 .8851928711130 .4304046631 131.9532012939133 .4593048096134 .9636993408136 .4678955078137 .9770965576 139.492401123141 .0151062012142 .546005249144 .0850982666145 .6329040527 147.1891937256148 .7539978027150 .3269042969151 .907699585153 .4956970215 
155.0903930664156 .69090271158 .2964935303159 .9062042236161 .5193939209 163.1347045898164 .7516937256166 .3692016602167 .9866027832169 .6029052734 171.2174987793172 .829498291174 .4385070801176 .0435943604177 .6443939209 179.2400970459180 .8303985596182 .4145965576183 .992401123185 .5634002686 187.1271057129188 .6831054688190 .2312927246191 .7711029053193 .3025970459 194.8251953125196 .3388977051197 .8435058594199 .3388061523200 .8246002197 202.300994873203 .7677001953205 .2247924805206 .6721038818208 .1096038818 209.5372924805 210.9552001953 212.3632049561213.761505127 215.1499938965 216.528793335217 .8979949951219 .2575073242220 .6076049805221 .9481964111 223.2796020508224 .6018981934225 .9152069092227 .2196960449228 .5155029297 229.8029022217231 .0818939209232 .3527984619233 .6157073975234 .870803833 236.1181945801237 .358001709238 .5903930664239 .8153991699241 .0330047607 242.2431945801243 .4459991455244 .6414031982245 .8294067383247 .0097961426 248.1829986572249 .3480072021250 .5063934326251 .6555023193 -27.384809494 -27.0799102783 -26.926990509 -26.9227905273 -26.9942893982 -27.1478004456 -27.3733901978 -27.661989212 -28.0012397766 -28.3783798218 $-28.7796592712-29.1898403168-29.5949306488-29.9785995483-30.3274097443$ -30.6251506805 -30.8594894409-31.015209198 -31.0815200806 -31.0448493958 -30.8962802887 -30.6245002747 -30.2226600647 -29.6821193695 -28.9981403351 $-28.1650295258-27.1798801422-26.040019989-24.7439403534-23.2917308807$ $-21.6827697754-19.9194602966-18.0015392303-15.9331502914-13.7139797211$ $-11.3492803574-8.83868408203-6.188144207-3.39743590355-.473062008619$ 2.5846359729775 .768422126779 .07709407806412 .502510070816 .04247093201 19.6879405975323 .4349308013927 .2734699249331 .194269180335 .18495941162 39.2213401794443 .2839584350647 .3084297180251 .2537002563554 .96598815918 58.3438682556261 .3503990173363 .859378814765 .9477233886767 .61276245117 68.888107299869 .8797912597770 .5898971557671 .0553512573271 .25316619873 71.170486450270 .8033828735470 .1445770263769 .1916580200267 .93890380859 66.3924789428764 .5563888549862 .4402198791560 .0536384582557 .41178894043 54.5296707153351 .4370994567948 .1607398986844 .7660713195841 .30461120605 37.9011917114334 .6492996215831 .6581802368229 .1096992492726 .89509963989 24.9815807342523 .3198604583721 .8308296203620 .4707908630419 .18732070923 17.9483890533416 .7087898254415 .4079103469813 .9858703613312 .32666969299 10.302780151378 .0876035690315 .8295950889593 .5557920932771 .28998696804 -.712244987488 -2.17077088356 -3.34435892105 -4.47139215469 -5.52107810974 $-6.51233911514-7.45249319077-8.34630775452-9.19353103638-9.99764537811$ $-10.7869195938-11.592590332-12.4255599976-13.3122797012-14.2678804398$ -15.3172702789 -16.3854598999-17.3709602356-18.2897090912 -19.1290206909 $-19.8864002228-20.5657806396-21.1693897247-21.7010192871-22.1636791229$ -22.555639267 -22.8875808716 -23.1745891571 -23.422580719 -23.6350097656 -23.8192901611 -23.9833698273 -24.1290798187 -24.2617797852 -24.3808708191 $-24.4886207581-24.5830593109-24.6625900269-24.7281093597-24.7792205811$ $-24.8192806244-24.8488197327-24.8757991791-24.9031600952-24.9471797943$ $-25.0177707672-25.1094303131-25.2308807373-25.3680801392-25.5129699707$ $-25.6702404022-25.8257904053-25.9789791107-26.1372394562-26.2917995453$ -26.4432296753 -26.5835990906 -26.7006492615 -26.7860298157 -26.8350601196 
-26.8341808319 -26.7771091461 -26.6393795013 -26.4103298187 -26.0718002319 -25.5948600769 -25.1516704559-24.8800792694 -24.7385997772 -24.6588401794 $-24.6481609344-24.7767601013-24.9806098938-25.2439498901-25.5332298279$ $-25.7548408508-25.9088802338-25.9837093353-25.9919700623-25.9368591309$ -25.8235397339 -25.6608009338 -25.4418792725 -25.1715698242 -24.8449897766 $-24.4510402679-23.9891891479-23.4549598694-22.8467197418-22.1630096436$ $-21.3960895538-20.5426998138-19.6066207886-18.586479187-17.4897193909$ $-16.3182106018-15.0950803757-13.8513097763-12.5810003281-11.2855100632$ $-9.97913169861-8.66773033142-7.40115404129-6.20654392242-5.0884771347$ $-4.08140802383-3.15585207939-2.31177306175-1.49685895443-.638985991478$ .25852501392361 .1965830326082 .1803090572363 .2219939231874 .316963195801 5.4648427963266 .6640810966497 .8995981216439 .15512275695810 .40213012695 11.5696201324512 .6154899597213 .5255403518714 .2099895477314 .74586009979 15.1663503646915 .5118198394815 .9264202117916 .3911991119416 .91682052612 17.4841308593818 .0659503936818 .6714401245119 .3001403808619 .95301055908 20.6261196136521 .3262405395522 .0562400817922 .8192291259823 .61825942993 24.4587497711225 .3462295532226 .282360076927 .271970748928 .32061004639 29.4351406097430 .6215496063231 .8848495483433 .2210884094234 .63019180298 36.1064109802237 .6471405029339 .240230560340 .8698005676342 .52611160278 44.1979904174845 .8340797424347 .3753089904848 .8763694763250 .38190078735 51.8897705078153 .4071197509854 .9310684204156 .4638404846257 .99979019165 59.5368118286161 .0675010681262 .5860290527364 .0917205810565 .57846069336 67.0517730712968 .5111923217869 .9629211425871 .4134063720772 .86469268799 74.3220062255975 .781806945877 .2468490600678 .7115325927780 .17533874512 81.6356735229583 .092071533284 .5495071411186 .0129165649487 .49983978271 89.0129470825290 .6930694580192 .6852111816494 .8526077270597 .07688140869 99.35983276367101 .6839981079104 .0398025513106 .4113006592108 .7888031006 111.1540985107113 .4990997314115 .8046035767118 .0608978271120 .2602996826 122.3028030396124 .0808029175125 .7127990723127 .302696228128 .8518981934 130.382598877131 .8979034424133 .4093017578134 .9183959961136 .4306030273 137.9461975098139 .4674987793140 .9944000244142 .5278930664144 .0679016113 145.6150970459147 .1692962646148 .7306976318150 .2989959717151 .8739013672 153.4550018311155 .0415039062156 .6329040527158 .228302002159 .8269958496 161.4279022217163 .0303955078164 .633605957166 .2366943359167 .8388977051 169.4396057129171 .037902832172 .6333007812174 .2250061035175 .8126068115 177.395401001178 .9729003906180 .5446014404182 .1101989746183 .6690979004 185.220993042186 .7653961182188 .3022003174189 .8309020996191 .3513946533 192.8632965088194 .3665008545195 .8607025146197 .3459014893198 .8218994141 200.2884979248201 .7456970215203 .1934051514204 .6315002441206 .0601043701 207.4790039062208 .8881988525210 .2877960205211 .6777954102213 .0581970215 214.4290008545215 .7902984619217 .1421966553218 .4846954346219 .8179931641 221.1421966553222 .4573059082223 .7637023926225 .0612945557226 .350402832 227.6311035156228 .9037017822230 .1683044434231 .4250030518232 .6739959717 233.9154052734235 .149307251236 .3759002686237 .5950927734238 .8070983887 240.0117950439241 .209197998242 .399307251243 .5820007324244 .7574005127 245.9255981445247 .0863952637248 .2344970703249 .3733062744 
-23.9910106659 -23.8624992371 -23.7954502106 -23.8430805206 -23.9811191559 $-24.2049999237-24.5043392181-24.8697795868-25.28840065-25.7470493317$ $-26.2313709259-26.7256393433-27.2152690887-27.6834697723-28.1162796021$ $-28.4970703125-28.8131408691-29.0489692688-29.193529129-29.2331008911$ $-29.1587104797-28.9591007233-28.6275100708-28.155620575-27.53886985578$ $-26.7723293304-25.8531608582-24.7798805237-23.5508003235-22.167760849$ $-20.6293792725-18.9402809143-17.0987491608-15.1114997864-12.9759998322$ $-10.7000598907-8.28046512604-5.72551679611-3.03159093857-.206992000341$ 2.7516810894015 .8361878395089 .04934120178212 .382920265215 .83905982971 19.4095096588123 .0951690673826 .8874092102130 .782850265534 .77130889893 38.8353004455642 .9596595764247 .0867500305251 .1766586303755 .09339904785 58.7198295593361 .8735389709564 .3987884521566 .4044723510768 .02826690674 69.3102569580170 .3283767700271 .0892715454171 .6271209716871 .90779876709 71.8983078002971 .6034927368271 .0059204101670 .106727600168 .88999176025 67.3671569824265 .5361709594763 .4099998474160 .9944992065458 .30686187744 55.3602218627952 .1875686645548 .8131408691445 .3041610717841 .70761871338 38.1426506042534 .6890602111831 .5434303283728 .9435806274426 .72286987305 24.7676105499323 .0428905487121 .4966907501220 .0659809112518 .70951080322 17.387620925916 .0590496063214 .6280202865612 .9739198684711 .11270999908 9.0679426193246 .8834428787234 .6224188804632 .372215986252 .1617040038109 $-1.77874994278-3.20413088799-4.35121583939-5.43316411972-6.4226398468$ $-7.35948419571-8.26245117188-9.15011310577-10.0153598785-10.8771896362$ $-11.7349901199-12.6098804474-13.54226017-14.5331802368-15.6153001785$ $-16.7986907959-17.978219986-19.0163002014-19.9586696625-20.8016490936$ $-21.545759201-22.2104701996-22.7933101654-23.3114395142-23.7611694336$ $-24.1419792175-24.4616794586-24.7307491302-24.9572105408-25.1491298676$ $-25.3157100677-25.4654407501-25.600320816-25.727930069-25.8454093933$ $-25.9556007385-26.0543708801-26.1383895874-26.207780838-26.260969162$ $-26.3016204834-26.3291091919-26.3521595001-26.3734207153-26.4082393646$ $-26.4685897827-26.5672206879-26.7145500183-26.883310318-27.0471496582$ $-27.2001991272-27.3395900726-27.4779090881-27.6317901611-27.7847194672$ $-27.9279403687-28.0527992249-28.1557407379-28.2294406891-28.2710609436$ $-28.267370224-28.2156105042-28.0909805298-27.8807601929-27.5679397583$ $-27.0756797791-26.6335296631-26.4704303741-26.4431591034-26.4275093079$ $-26.4678707123-26.5914306641-26.7428398132-26.9191799164-27.0835609436$ $-27.1849098206-27.2355899811-27.2249298096-27.1570491791-27.0304908752$ $-26.8661308289-26.6813907623-26.4654693604-26.2081699371-25.8999404907$ $-25.5313301086-25.0984191895-24.5962200165-24.0197601318-23.3689594269$ $-22.633600235-21.8101806641-20.9028892517-19.9120502472-18.8473300934$ $-17.7224998474-16.5285205841-15.2611103058-13.9451398849-12.610329628$ $-11.2513399124-9.87254524231-8.51695728302-7.2199177742-6.03755998611$ $-5.01474523544-4.10704803467-3.26542592049-2.45187997818-1.62602496147$ $-.771062016487 .12883299589161 .0925430059432 .1349859237673 .244579076767$ 4.3970708847055 .5968260765086 .833939075478 .0839433670049 .325618743896 10.50240993511 .5747499465912 .5461597442613 .3641195297214 .06622982025 14.6630096435515 .1723804473915 .6934099197416 .2064304351816 .7422504425 
17.29648017883 17.8687896728518.4647502899219.078269958519.71718025208 20.3754806518621 .0610809326221 .7718906402622 .513809204123 .28795051575 24.0990695953424 .9506607055725 .8461399078426 .7898597717327 .78948974609 28.8495292663629 .9848308563231 .2044105529832 .5054206848133 .89160919189 35.3544616699236 .8900299072338 .4861106872640 .1198196411141 .78400039673 43.4813995361345 .1345481872646 .6504707336448 .1172714233449 .60494995117 51.095008850152 .5942687988354 .1002998352155 .6132888793957 .13006973267 58.6484107971260 .1632385253961 .6685791015663 .1610107421964 .63382720947 66.0941162109467 .5450134277368 .992607116770 .442382812571 .89431762695 73.3533172607474 .8126525878976 .2746734619177 .7301788330179 .17707061768 80.6143188476682 .0391006469783 .4640197753984 .8947067260786 .36755371094 87.91693115234 89.5911865234491.43578338623 93.4226531982495.5216293335 97.709960937599 .95971679688102 .2590026855104 .5907974243106 .9448013306 109.3030014038111.6583023071 113.9889984131 116.2855987549 118.5705032349 120.68699646122 .454498291124 .0606994629125 .6623001099127 .2255020142 128.7716064453130 .3031005859131 .8265075684133 .3457946777134 .8647003174 136.3849029541137 .9075927734139 .433807373140 .9640960693142 .4990997314 144.0393981934145 .5852966309147 .1371002197148 .6949005127150 .258605957 151.8278045654153 .4019927979154 .9806976318156 .5630950928158 .1486053467 159.7362976074161 .3255004883162 .9152984619164 .5050964355166 .0939941406 167.6815032959169 .2666931152170 .8491973877172 .4281005859174 .0030975342 175.5733032227177 .1385955811178 .6981964111180 .2518005371181 .7989959717 183.3392944336184 .8722991943186 .3979034424187 .9156036377189 .4252929688 190.9266052246192 .4194030762193 .9033050537195 .37840271196 .8444976807 198.3014984131199 .7490997314201 .1873931885202 .616394043204 .0359039307 205.4459991455206 .846496582208 .2375946045209 .6192016602210 .991394043 212.3542022705213 .7075958252215 .0516967773216 .3865966797217 .7124023438 219.029296875220 .3372039795221 .636505127222 .9272003174224 .2095031738 225.4835968018226 .7496032715228 .0077056885229 .258102417230 .5009002686 231.7362060547232 .9640960693234 .1847991943235 .3981933594236 .6045074463 237.803604126238 .9954986572240 .1802062988241 .3576965332242 .5278930664 243.69090271244 .845993042245 .9945983887247 .1342926025 $-20.5999393463-20.3927097321-20.3503093719-20.4702606201-20.6729297638$ $-20.9651508331-21.3362503052-21.7763595581-22.2722492218-22.8101291656$ $-23.3753204346-23.9514007568-24.5234508514-25.0739707947-25.5887699127$ $-26.050579071-26.4465808868-26.7607307434-26.982049942-27.0964603424$ $-27.0952396393-26.9668998718-26.7052307129-26.3018608093-25.7530899048$ $-25.0539894104-24.2030200958-23.198720932-22.041009903-20.7315101624$ $-19.2707996368-17.6629295349-15.9082803726-14.0124197006-11.9749002457$ $-9.80187416077-7.49180412292-5.05074882507-2.47629594803 .2258609980345$ 3.0587360858926 .0170040130629 .10405445098912 .3147602081315 .65287971497 19.1134109497122 .6998195648226 .4067897796630 .234230041534 .17390823364 38.2145195007342 .3380203247146 .5116882324250 .6988983154354 .82904052734 58.8813400268662 .3541412353564 .7208328247166 .4739685058668 .03736877441 69.3574981689570 .4704589843871 .3551788330172 .0165786743272 .41854095459 72.5260467529372 .3350830078171 .8289718627971 .0031585693469 .84477233887 
68.3603973388766 .5519332885764 .4284667968861 .9976387023959 .27587890625 56.2806282043553 .0443000793549 .6002197265646 .000839233442 .29285049438 38.5738601684634 .9117393493731 .5951995849628 .96771049526 .7514591217 24.7304191589422 .9164505004921 .2953701019319 .7837696075418 .33502960205 16.9143199920715 .4551601409913 .8806600570712 .0904598236110 .13241004944 8.0398902893075 .8603520393373 .6089859008791 .404785990715 -.646066009998 -2.45309996605 -3.88863110542 -5.0916261673 -6.172123909 -7.14691495895 $-8.06505489349-8.96221923828-9.87483215332-10.7959604263-11.7601099014$ $-12.7320098877-13.6984996796-14.7535495758-15.9671096802-17.2574501038$ -18.5325603485 -19.7441196442 -20.8034706116 -21.7415409088 -22.5640106201 $-23.2833099365-23.9262599945-24.4916305542-24.9940891266-25.4325904846$ $-25.8021697998-26.1097698212-26.3611602783-26.5666007996-26.7364807129$ $-26.8830795288-27.0165596008-27.1399307251-27.2632007599-27.3817691803$ $-27.4962406158-27.602060318-27.6927700043-27.7681007385-27.825920105$ -27.869140625 -27.8975791931 -27.9171791077 -27.9308300018 -27.9475002289 -27.9685707092 -28.0501594543 -28.2546195984 -28.4882602692 -28.6681194305 -28.8059406281 -28.8955993652 -28.9934406281 -29.1606292725 -29.3348808289 $-29.4654903412-29.5697994232-29.6590099335-29.7253494263-29.7632102966$ -29.7663707733 -29.7295093536-29.6428909302 -29.4989891052 -29.2786903381 -28.9451904297 -28.6221809387 -28.4082393646 -28.2940006256 -28.2723197937 $-28.3274307251-28.4793605804-28.6287994385-28.7063598633-28.7318897247$ -28.7053203583 -28.6430492401 -28.556640625 -28.4161701202 -28.1833400726 -27.934299469 -27.7386207581 -27.5404701233 -27.2945995331 -27.0004501343 -26.6496696472 -26.2397708893 -25.7639503479 -25.2178592682 -24.5981998444 -23.8960609436 -23.1041908264 -22.2278499603 -21.2662391663 -20.2293395996 -19.1210098267 -17.9347000122 -16.6719799042 -15.3507499695 -14.0019903183 $-12.6118402481-11.1749200821-9.71880722046-8.24772357941-6.93396997452$ $-5.95648002625-5.13142681122-4.30755519867-3.49522209167-2.67123508453$ -1.83334994316 -.972450017929 -3.9363001e-02 1.014721989632 2.142622947693 3.3013958930974 .4945888519295 .718484878546 .9552302360538 .19415473938 9.38751506805410 .4922895431511 .5211696624812 .4403696060213 .27266025543 14.0037403106714 .6559000015315 .2812900543215 .8700599670416 .44387054443 17.0145301818817 .5998706817618 .2008495330818 .8182506561319 .45437049866 20.1088294982920 .7847995758121 .4836692810122 .2083206176822 .96202087402 23.7471199035624 .5675392150925 .4259490966826 .3267192840627 .27742958069 28.284320831329 .3675804138230 .5401992797931 .8027400970533 .16857147217 34.6200981140136 .1507606506337 .7448616027839 .3740997314541 .02843093872 42.695590972944 .3223381042545 .8500709533747 .3324699401948 .81517028809 50.2960510253951 .7817993164153 .2712593078654 .7666816711456 .26573944092 57.767440795959 .2690696716360 .76869964662 .2538108825763 .70909118652 65.1513595581166 .5933837890668 .037246704169 .4872817993270 .94235229492 72.4052581787173 .8691635131875 .3334121704176 .7876510620178 .22473907471 79.6479263305781 .0546264648482 .4590606689583 .8653488159285 .31775665283 86.8497772216888 .4705886840890 .2186508178792 .0774765014694 .05516815186 96.139648437598 .3034362793100 .5329971313102 .8117980957105 .1287002563 107.46900177109 .817199707112 .1458969116114 .4423980713116 .6929016113 
118.7921981812120 .6264038086122 .3125991821123 .9536972046125 .5503997803 127.1230010986128 .6748046875130 .2165985107131 .7501068115133 .2803955078 134.8081970215136 .3359069824137 .8639984131139 .3937988281140 .9259033203 142.4617004395144 .0012969971145 .5457000732147 .0948944092148 .6492004395 150.2080993652151 .7716064453153 .3390960693154 .9098968506156 .4835968018 158.0592041016159 .6360931396161 .2135925293162 .7910003662164 .3675994873 165.9425964355167 .5155029297169 .0856933594170 .6524047852172 .2151947021 173.7734985352175 .3269042969176 .8746948242178 .4167938232179 .9523925781 181.4813995361183 .0032958984184 .5178985596186 .0247955322187 .5238037109 189.0146026611190 .4969940186191 .9707946777193 .4358978271194 .8921051025 196.3394012451197 .7774963379199 .2064971924200 .6262969971202 .0366973877 203.4378967285204 .8296966553206 .2122039795207 .5854034424208 .9492950439 210.3040008545211 .6493988037212 .9857025146214 .3128967285215 .6311950684 216.9405975342218 .2413024902219 .5334014893220 .8170928955222 .0924987793 223.3598022461224 .6192016602225 .870803833227 .1148071289228 .3513031006 229.5803985596230 .8022003174232 .0169067383233 .2245025635234 .4250030518 235.6183929443236 .8047943115237 .9839935303239 .1560974121240 .3209991455 241.4788970947242 .629699707243 .7680053711244 .8975067139 -16.6063194275 -16.5817699432 -16.6243190765 -16.7911605835 -17.0562496185 $-17.4145393372-17.8549594879-18.3673095703-18.9378509521-19.5524501801$ $-20.1958007812-20.8511505127-21.5029697418-22.1334095001-22.7277107239$ $-23.2683601379-23.7420806885-24.1326904297-24.4289398193-24.6167507172$ $-24.687330246-24.6293506622-24.4368190765-24.1018009186-23.6209907532$ $-22.9903106689-22.2086296082-21.2759609222-20.1923103333-18.9614200592$ $-17.5833797455-16.0646591187-14.4052600861-12.612830162-10.6852502823$ $-8.63213634491-6.44749879837-4.14203119278-1.70788395405 .8455780148506$ 3.5268020629886 .3283629417429 .25863361358612 .3122100830115 .49705982208 18.8097305297922 .2570896148725 .8360195159929 .55098915133 .39326858521 37.3594818115241 .4267311096245 .5804100036649 .7933998107954 .00180053711 58.3461418151962 .0703392028864 .3435363769565 .9609527587967 .58881378174 69.0148162841870 .2845306396571 .3511962890672 .1799926757872 .75051116943 73.01059722972 .961631774972 .5719680786171 .8467330932670 .76731872559 69.3445434570367 .5747985839865 .4721908569363 .0413208007860 .3048286438 57.2788505554253 .9999694824250 .5060997009346 .8416213989343 .03998947144 39.2179603576735 .3908195495631 .9347305297929 .2623100280826 .98158073425 24.8344097137522 .8817501068121 .1596393585219 .5896797180218 .08708953857 16.5678405761714 .959819793713 .2198400497411 .320819854749 .308330535889 $7.1989660263065 .039121150972 .8176069259640 .691888988018-1.19410002232$ $-2.87024998665-4.34405708313-5.63015413284-6.74824476242-7.74692821503$ $-8.68078327179-9.58757400513-10.5319595337-11.5345697403-12.6529102325$ $-13.8251199722-14.9664897919-16.2002506256-17.6515102386-19.139509201$ $-20.4633903503-21.672990799-22.717710495-23.6207695007-24.4022102356$ $-25.0807590485-25.7019805908-26.255569458-26.7505397797-27.1781101227$ $-27.5377902985-27.8325691223-28.0704994202-28.2594299316-28.4096107483$ $-28.5351295471-28.6486301422-28.7610607147-28.8821907043-29.0059394836$ $-29.1281299591-29.2412605286-29.340549469-29.4239597321-29.4881801605$ 
-29.5362606049 -29.5660190582 -29.5835990906 -29.5900096893 -29.5955200195 -29.583530426 -29.6413402557 -29.8807601929 -30.1520805359 -30.3304195404 -30.4533691406 -30.5045604706 -30.564699173 -30.7418193817 -30.9290008545 $-31.0453090668-31.1331996918-31.2143192291-31.2763195038-31.3142604828$ -31.326499939 -31.3079395294 -31.2598400116 -31.1849002838 -31.072769165 -30.9216098785 -30.732749939 -30.4504909515 -30.2166900635 -30.1503791809 $-30.1840400696-30.3451194763-30.4873504639-30.4795303345-30.3928108215$ $-30.2618103027-30.0995998383-29.9436206818-29.7417793274-29.4172401428$ -29.0925292969 -28.8794708252 -28.6853599548 -28.4375801086 -28.1508598328 $-27.8118095398-27.4171905518-26.9626407623-26.4415206909-25.853269577$ -25.1839599609 -24.4281101227 -23.5859298706 -22.6534996033 -21.6371707916 -20.5356903076 -19.3527202606 -18.1027507782 -16.7901802063 -15.4418296814 -14.0385503769-12.5698795319-11.0577201843 -9.45515441895-8.02365779877 -7.0642490387 -6.28430223465 -5.44424819946 -4.6128578186 -3.77111792564 -2.91957592964 -2.0739068985 -1.15800702572 -9.7278997e-02 1.039281010628 2.1884410381323 .368659019474 .570658206945 .7877469062817 .027625083923 8.2416057586679 .38580989837610 .4718799591111 .4676198959412 .3902797699 13.2288198471113 .9954395294214 .7272300720215 .4036998748816 .03846931458 16.6495800018317 .2675895690917 .890699386618 .5230503082319 .16765022278 19.8240299224920 .4972190856921 .1878795623821 .9001808166522 .63677978516 23.4002304077124 .1941795349125 .0212192535425 .8857002258326 .79453086853 27.7543506622328 .7829704284729 .8971290588431 .1189708709732 .46691894531 33.9181213378935 .4465904235837 .0310211181638 .6454887390140 .2728805542 41.8904991149943 .4805488586445 .0238800048846 .5329589843848 .02067184448 49.4958992004450 .9706192016652 .4455718994153 .9249687194855 .40771102905 56.8934783935558 .3809204101659 .8726692199761 .3502883911162 .78969955444 64.2173233032265 .6522369384867 .0926971435568 .542556762770 .00051879883 71.4688034057672 .9392166137774 .4124069213975 .8718414306677 .3083190918 78.7270965576280 .1217269897581 .5118408203182 .8985595703184 .31976318359 85.812080383387 .3761978149489 .0387268066490 .7972412109492 .66413116455 94.6391220092896 .7068023681698 .85748291016101 .0783004761103 .3535995483 105.6681976318107 .9990005493110 .3082962036112 .5711975098114 .7478027344 116.8076019287118 .7162017822120 .5048980713122 .2064971924123 .8439025879 125.4483032227127 .0246963501128 .5877990723130 .1385040283131 .6824951172 133.2205963135134 .7552032471136 .2872009277137 .8184967041139 .3497924805 140.8827972412142 .4181060791143 .9568939209145 .499206543147 .0457000732 148.5960998535150 .1504058838151 .7080993652153 .2687072754154 .8318023682 156.3963928223157 .9622039795159 .5283966064161 .0944061279162 .6593017578 164.2227935791165 .783996582167 .3424987793168 .8975067139170 .4486999512 171.9954986572173 .537399292175 .0738067627176 .604598999178 .1291046143 179.6470031738181 .1580047607182 .6618041992184 .1580047607185 .6464996338 187.1268005371188 .5989990234190 .0626983643191 .5178985596192 .9642944336 194.4019012451195 .8305053711197 .2501068115198 .6607055664200 .0621032715 201.4542999268202 .8374023438204 .2113037109205 .5760040283206 .9315032959 208.2779998779 209.6152954102 210.9436950684212.2631988525 213.5738983154 214.875793457216 .1690979004217 .453994751218 .7306060791219 .9990997314 
221.2595062256222 .5122070312223 .7570953369224 .9945983887226 .2247009277 227.4476013184228 .663192749229 .8719024658231 .0735015869232 .2680969238 233.4557952881234 .636505127235 .8101959229236 .9768981934238 .136505127 239.2891998291240 .43409729241 .5727996826242 .7026977539

$-12.6135797501-12.4971399307-12.5576295853-12.7933797836-13.1184902191$ $-13.5402898788-14.047419548-14.6292600632-15.2717599869-15.960149765$ $-16.6789302826-17.4106292725-18.1395397186-18.8470897675-19.5184497833$ $-20.1354103088-20.684709549-21.1496295929-21.5190505981-21.7785301208$ $-21.9196300507-21.9308490753-21.8068294525-21.5396595001-21.1271305084$ $-20.5653190613-19.8547096252-18.9954891205-17.9898109436-16.8413505554$ $-15.5525503159-14.1297597885-12.576210022-10.8990898132-9.09816265106$ $-7.18017196655-5.14177799225-2.99071907997-0.721844971181 .659389019012$ 4.1597781181346 .7759461402899 .51587772369412 .3781099319515 .37121009827 18.4953193664621 .7581691741925 .1605892181428 .7087898254432 .40008163452 36.2292900085440 .1816291809144 .2313613891648 .3457908630452 .4648399353 56.5784912109460 .1721000671462 .722381591864 .7108764648466 .56799316406 68.2301712036169 .7318267822371 .0218429565472 .0745468139672 .85452270508 73.3183212280373 .4475936889673 .2072830200272 .6049804687571 .63857269287 70.3033065795968 .5928115844766 .526786804264 .1222229003961 .39532089233 58.3628005981455 .0635185241751 .5401611328147 .8309593200743 .9680480957 40.0742416381836 .2319297790532 .7487983703629 .955839157127 .49109077454 25.0996608734122 .9124603271521 .0631694793719 .4595909118718 .01468086243 16.5038604736314 .685999870312 .7156801223810 .703709602368 .650446891785 6.5521860122684 .4358530044562 .298281908035 .2676939964294 -1.55235898495 $-3.20529007912-4.6950712204-6.03632116318-7.209608078-8.25873088837$ $-9.23458576202-10.1749601364-11.1225004196-12.1997299194-13.5750303268$ $-15.0692396164-16.534620285-18.0458393097-19.6450500488-21.2018508911$ $-22.5688400269-23.7697105408-24.7762794495-25.6203594208-26.3240604401$ $-26.9382591248-27.5374603271-28.0915107727-28.5876903534-29.0144901276$ $-29.3593196869-29.6383705139-29.8685092926-30.0479698181-30.1783905029$ $-30.2798900604-30.3679008484-30.4639396667-30.5929603577-30.7320194244$ $-30.8632698059-30.9843597412-31.0930900574-31.1860103607-31.2583503723$ $-31.3125591278-31.3444404602-31.3614902496-31.3672409058-31.3708496094$ $-31.3748092651-31.4372596741-31.6215305328-31.8341197968-31.991519928$ $-32.1053085327-32.1705093384-32.24451828-32.3896217346-32.5437698364$ $-32.6557807922-32.7447509766-32.8226089478-32.8847694397-32.9258117676$ $-32.9457817078-32.9403114319-32.913269043-32.8598403931-32.7883300781$ $-32.6920394897-32.5407600403-32.3163604736-32.1040000916-32.0123786926$ -32.0088310242 -32.0854187012 -32.1399688721 -32.0837593079-31.9520606995 $-31.7722606659-31.5614700317-31.3423500061-31.0837993622-30.750120163$ $-30.4165000916-30.1507892609-29.9075298309-29.647939682-29.3607196808$ $-29.0256500244-28.6415901184-28.2018795013-27.7037696838-27.1436805725$ $-26.507730484-25.7890090942-24.9829902649-24.0787506104-23.0836200714$ $-21.9955501556-20.823469162-19.5814094543-18.2777900696-16.9273891449$ $-15.527589798-14.0864601135-12.5962896347-11.0322999954-9.60520362854$ $-8.52752113342-7.61488389969-6.70963478088-5.82191801071-4.9303021431$ 
-4.03980922699 -3.14927601814 -2.20787906647 -1.16191601753 -5.6101002e-02 1.069195032122 .2251460552223 .411761999134 .6206111907965 .854506015778 7.0796980857858 .2652950286879 .40833091735810 .4772100448611 .48194026947 12.410189628613 .2742300033614 .0874300003114 .8415403366115 .54006958008 16.2065391540516 .87150955217 .5314502716118 .1896495819118 .84962081909 19.5158901214620 .191469192520 .8802204132121 .5848808288622 .30971908569 23.0567703247123 .8304595947324 .6331405639625 .4700298309326 .34511947632 27.26482009888 28.23744010925 29.2654800415 30.41979980469 31.77651977539 33.2527389526434 .7778701782236 .3446807861337 .9350204467839 .53123092651 41.1149215698242 .6829490661644 .2191810607945 .7323989868247 .22063827515 48.6912498474150 .1575698852551 .6210784912153 .0866203308154 .55363082886 56.0227699279857 .4928512573258 .9637107849160 .4232292175361 .85752105713 63.2834205627464 .7146835327166 .1533966064567 .6037826538169 .06548309326 70.5408935546972 .0228500366273 .5098114013774 .9814224243276 .42640686035 77.8467712402379 .2290115356480 .5980529785281 .9621200561583 .34799194336 84.79376983643 86.29920959473 87.88450622559 89.5513305664191.31369018555 93.1811523437595 .152481079197 .2192993164199 .3829498291101 .615196228 103.8970031738106 .2009963989108 .4835968018110 .7127990723112 .8529968262 114.9045028687116 .8395996094118 .6818008423120 .4327011108122 .1116027832 123.7509994507125 .3572998047126 .9446029663128 .5149993896130 .0744934082 131.624206543133 .1672973633134 .7048034668136 .2391052246137 .771194458 139.3032073975140 .8358001709142 .3706054688143 .907699585145 .4481048584 146.9915008545148 .5379943848150 .0872955322151 .6390991211153 .1927032471 154.7476043701156 .3032989502157 .8591003418159 .4145050049160 .9687042236 162.5213012695164 .0715026855165 .6190032959167 .1629943848168 .7030944824 170.2388000488171 .7696075439173 .2951049805174 .8148040771176 .3283996582 177.8356018066179 .3359069824180 .828994751182 .3146972656183 .7928009033 185.2628936768186 .7250061035188 .178604126189 .6239013672191 .0605010986 192.488494873193 .9075927734195 .3179016113196 .7191925049198 .1114959717 199.4947967529200 .8690948486202 .2342987061203 .5904998779204 .9376983643 206.2758026123207 .6051025391208 .9255065918210 .2371063232211 .5401000977 212.8345031738214 .1204071045215 .3979949951216 .6674041748217 .9288024902 219.1822967529220 .4281005859221 .6663970947222 .8972930908224 .1208953857 225.3374023438226 .5467987061227 .7492980957228 .9449005127230 .133605957 231.3155059814232 .4904937744233 .6585998535234 .8197937012235 .9739990234 237.1213989258238 .2619934082239 .3903045654240 .5101928711 -7.97293806076 -8.04432296753 -8.18805885315 -8.46495437622 -8.84739589691 $-9.329870224-9.9007062912-10.5489902496-11.2601900101-12.0192699432$ -12.8101196289-13.6150798798 -14.4178104401 -15.1996297836-15.9450302124 $-16.6358108521-17.2581005096-17.7952709198-18.2358493805-18.5655002594$ $-18.7756004333-18.8549995422-18.7986392975-18.5990104675-18.2544994354$ $-17.7621707916-17.1233196259-16.3395900726-15.4139699936-14.3516902924$ $-13.1576795578-11.8388795853-10.3978004456-8.84561252594-7.17851781845$ $-5.41048812866-3.53395009041-1.56088995934 .51973801851272 .698189020157$ 4.9879460334787 .3825130462659 .89633560180712 .5267095565815 .28779029846 18.1799793243421 .2159805297924 .3978900909427 .7321300506631 .22114944458 
34.8559913635338 .6333618164142 .5071792602546 .4449806213450 .32802963257 54.0516281127957 .4320487976160 .3195190429762 .8037490844765 .01605224609 66.9782867431668 .7754592895570 .3443908691471 .6681594848672 .705909729 73.4074401855573 .754608154373 .6928176879973 .2438964843872 .41361999512 71.1934280395569 .5647125244167 .5614318847765 .202842712462 .50775909424 59.4896011352556 .1934394836452 .6630592346248 .9375381469745 .04277038574 41.1255416870137 .3084106445333 .758789062530 .7271308898928 .00807952881 25.374580383323 .0236206054721 .086149215719 .4077301025417 .97372055054 16.4515800476114 .4611396789612 .3143501281710 .240870475778 .17590045929 6.1038041114814 .0527091026312 .005701065063 5.47519997e-02 -1.75643002987 -3.43029999733 -4.9579911232 -6.35306787491 -7.58433008194 -8.70265388489 $-9.74160861969-10.7571697235-11.7632102966-12.9506502151-14.6120100021$ -16.4500102997 -18.2644004822 -20.0806102753 -21.8130397797 -23.4212799072 $-24.8070392609-25.9796390533-26.9246101379-27.6910305023-28.3176994324$ -28.8717498779 -29.4518203735 -29.9970302582 -30.4901790619 -30.9142799377 -31.2474594116 -31.5166893005 -31.7493095398 -31.9300708771 -32.0517311096 $-32.1422805786-32.2107696533-32.2975387573-32.4322090149-32.580619812$ -32.7185096741 -32.8458213806 -32.9665107727 -33.0735206604 -33.1555213928 -33.2169799805 -33.2488212585 -33.264251709 -33.2682991028 -33.2761497498 -33.3044815063 -33.3645401001 -33.4694595337 -33.5933990479-33.7103118896 -33.8161506653 -33.9078788757 -33.9989089966 -34.1072883606 -34.2181587219 $-34.323009491-34.4173088074-34.4958190918-34.5591812134-34.603351593$ -34.6303291321 -34.6357116699 -34.6206588745 -34.5709190369 -34.499961853 $-34.4016304016-34.2710189819-34.1175117493-33.9658317566-33.8697013855$ -33.808681488 -33.7755203247 -33.7269210815 -33.6300582886 -33.4816398621 $-33.2826309204-33.0443611145-32.7744407654-32.4785995483-32.1585197449$ $-31.8356609344-31.5186500549-31.2157897949-30.9298496246-30.6324501038$ -30.2925605774 -29.9113998413 -29.4809303284 -28.9976291656 -28.4596996307 $-27.8573799133-27.1840801239-26.4181594849-25.542219162-24.562669754$ $-23.4884700775-22.3311100006-21.1023101807-19.8096504211-18.46159935$ $-17.0719108582-15.6699399948-14.2442798615-12.7767801285-11.3859796524$ $-10.1743297577-9.08494853973-8.07433700562-7.11228084564-6.15470600128$ $-5.20193719864-4.24199676514-3.25472593307-2.21814107895-1.14443397522$ -4.6066001e-02 1.082883000374 2.2485249042513.4496450424194.68351984024 5.9305791854867 .1603150367748 .3580751419079 .48809242248510 .56015968323 11.5624904632612 .5021896362313 .386859893814 .2102003097514 .97807025909 15.7065496444716 .4269008636517 .1303997039817 .8201904296918 .50233078003 19.1834106445319 .8671092987120 .5580902099621 .2599391937321 .97719955444 22.7125797271723 .4712905883824 .2553901672425 .0716304779125 .92155075073 26.8111305236827 .7473907470728 .7092609405529 .8057193756131 .16127967834 32.6439590454134 .1468696594235 .685680389437 .2446708679238 .80881881714 40.3650283813541 .9101791381843 .4340896606444 .9397010803246 .42245864868 47.8887786865249 .3482894897550 .8016510009852 .2545509338453 .70634078979 55.1586608886756 .609241485658 .0555915832559 .4957199096760 .92589187622 62.3531799316463 .7821006774965 .2187271118266 .6680526733468 .13134002686 69.6113586425871 .1024627685572 .6024932861374 .0950698852575 .56519317627 
76.9937667846778 .3618087768679 .6984863281281 .0312423706182 .38340759277 83.7851562585 .2377929687586 .7603073120188 .352127075290 .02426147461 91.7870788574293 .6493530273495 .6306762695397 .7394104003999 .94077301025 102.1904983521104 .456199646106 .6998977661108 .8955993652111 .0111999512 113.0514984131114 .9997024536116 .8678970337118 .6529998779120 .3705978394 122.0462036133123 .6824035645125 .2949981689126 .8851013184128 .4606933594 130.0223999023131 .574798584133 .1186981201134 .6571960449136 .19140625 137.7238006592139 .2552032471140 .7875976562142 .321105957143 .8567962646 145.3946075439146 .9347991943148 .4770965576150 .0211029053151 .5666046143 153.1127929688154 .6595001221156 .2057952881157 .7514953613159 .2958068848 160.8381958008162 .3780975342163 .9151000977165 .4485931396166 .9781036377 168.5030975342170 .0233001709171 .5381011963173 .0471954346174 .550201416 176.0467987061177 .5364990234179 .0193023682180 .4945983887181 .9624023438 183.4223937988184 .8744049072186 .3180999756187 .7534942627189 .1804962158 190.5988006592192 .0084991455193 .4093017578194 .8014068604196 .1846923828 197.5590057373198 .9243927002200 .2808990479201 .6284942627202 .9671936035 204.2971038818205 .6181945801206 .9306030273208 .2342987061209 .5294036865 210.816192627212 .0946044922213 .3648071289214 .6269073486215 .8811950684 217.1277008057218 .3665924072219 .5980987549220 .8224029541222 .0393981934 223.24949646224 .4526062012225 .6488952637226 .838394165228 .0211029053 229.1970977783230 .3663024902231 .528793335232 .6844024658233 .8330993652 234.9752960205236 .1098022461237 .2382965088238 .3583068848 -3.33150696754 -3.29812097549 -3.45260906219 -3.79405498505 -4.23092508316 $-4.7710108757-5.40238523483-6.11373186111-6.8903298378-7.71656608582$ $-8.57622623444-9.45093917847-10.3243703842-11.1771202087-11.9938001633$ -12.7554502487 -13.4484300613 -14.055439949-14.5654401779-14.9635896683 -15.2415304184 -15.3877601624 -15.3983097076 -15.2658700943 -14.9896497726 $-14.5667495728-14.0006504059-13.2938203812-12.4509401321-11.4780197144$ $-10.3844804764-9.18055152893-7.86471223831-6.43819999695-4.91060018539$ -3.3021171093 -1.60677695274 1675460040569 2.029618024826 3.975138902664 6.0159339904798 .15144062042210 .3956899642912 .7520599365215 .23558998108 17.8530406951920 .6184406280523 .5415496826226 .6197700500529 .84876060486 33.225589752236 .7510185241740 .3786582946844 .0791282653847 .72422027588 51.22573089654 .5508804321357 .5776214599660 .3661994934162 .90048980713 65.1960830688567 .3535614013769 .2801513671970 .9277801513772 .26624298096 73.2471313476673 .8436965942474 .0034484863373 .7411193847773 .06878662109 71.9804763793970 .4714126586968 .5627975463966 .2701187133863 .62125015259 60.6433410644557 .3753089904853 .865238189750 .1449203491246 .24493026733 42.2970390319838 .4189910888734 .6742782592831 .1729602813728 .02725028992 25.4290409088123 .2069206237821 .211000442519 .4182395935117 .78820991516 16.0899600982714 .0901899337811 .977970123299 .9064035415657 .867365837097 5.845531940463 .848506927491 .87310397625 -3.4504998e-02 -1.85150504112 -3.56455302238 -5.15090608597 -6.61680984497 -7.92265892029 -9.12299823761 $-10.2498598099-11.3898296356-12.6085195541-14.0405101776-15.8984899521$ -17.9541091919 -20.0424900055 -22.1069698334 -24.0416793823 -25.7692909241 $-27.1754703522-28.3032493591-29.1462001801-29.8075904846-30.4008293152$ 
-30.9420700073 -31.4804191589 -31.987039566 -32.4539299011 -32.8596496582 -33.1849403381 -33.4573898315 -33.7022285461 -33.8969802856 -34.0280303955 -34.1230697632 -34.201171875 -34.2968292236 -34.4291000366 -34.5710792542 $-34.7072410583-34.8366584778-34.9712600708-35.0968589783-35.191860199$ -35.2606582642 -35.2925605774 -35.3030281067 -35.3007698059-35.3021888733 -35.3229293823 -35.3558387756 -35.4117012024 -35.4799003601 -35.5535583496 -35.6390113831 -35.7217788696 -35.8024215698 -35.8902702332 -35.979309082 $-36.0713806152-36.1623687744-36.2387809753-36.2999801636-36.3424797058$ $-36.3692016602-36.3810005188-36.3695907593-36.3246192932-36.2553100586$ -36.1622505188 -36.0529899597 -35.922580719 -35.7885398865 -35.6802215576 -35.5732917786 -35.4739303589 -35.3630905151 -35.2164611816 -35.0379219055 -34.8132705688 -34.5483283997 -34.2511901855 -33.9355392456 -33.6099586487 -33.2773017883 -32.9428291321 -32.6106681824 -32.2934608459 -31.9713993073 -31.6183204651 -31.2315006256 -30.8019294739 -30.3264503479-29.7983703613 $-29.2251300812-28.6191692352-27.9168701172-27.0548992157-26.0768508911$ -25.0166492462 -23.8787899017-22.6708297729 -21.397769928 -20.0640106201 $-18.6903800964-17.296169281-15.8947095871-14.4847097397-13.107460022$ -11.835940361 -10.6417303085 -9.53392124176 -8.48666763306 -7.45467710495 $-6.43095684052-5.40088891983-4.36415195465-3.30667996407$-2.23495602608 -1.14384996891 -3.3971000e-02 1.085348010063 2.254316091537 3.517519950867 4.8146238327036 .0897560119637 .334304809578 .5183591842659 .648090362549 10.7150697708111 .7229700088512 .6715602874813 .5615501403814 .39385986328 15.1842498779315 .951479911816 .6938095092817 .4168205261218 .12486076355 18.8250102996819 .5212001800520 .219310760520 .9229393005421 .63767051697 22.3667507171623 .1159896850623 .8883991241524 .6903190612825 .52572059631 26.4016990661627 .325759887728 .300149917629 .3973808288630 .69434928894 32.1080207824733 .5671386718835 .0650901794436 .5851402282738 .11626815796 39.6433410644541 .1650810241742 .6717796325744 .1647987365745 .63840866089 47.0977210998548 .547428131149 .9896392822351 .4287910461452 .8649597168 54.3003005981455 .732280731257 .1598396301358 .5847511291560 .00524902344 61.426891326962 .8513908386264 .2838134765665 .7301330566467 .19190216064 68.6717071533270 .1674270629971 .6778030395573 .1961135864374 .72347259521 76.1887207031277 .5151824951278 .790176391680 .0883865356481 .41219329834 82.7809829711984 .1952514648485 .6686477661187 .199363708588 .79570007324 90.4581375122192 .1814804077194 .0469284057696 .1391067504998 .34635925293 100.5688018799102 .7942962646104 .9931030273107 .1498031616109 .2385025024 111.263999939113 .2132034302115 .0942001343116 .9020004272118 .6494979858 120.3511962891122 .0130004883123 .646697998125 .2550964355126 .8452987671 128.4190063477129 .9803924561131 .5312042236133 .0744934082134 .6116943359 136.1455993652137 .6772003174139 .2082977295140 .7395935059142 .2720031738 143.8056030273145 .3408050537146 .8771972656148 .4147949219149 .9530944824 151.4918060303153 .0303039551154 .5682067871156 .1049957275157 .6401062012 159.1730957031160 .7032928467162 .2304992676163 .75390625165 .2733001709 166.7881011963168 .2980041504169 .8025054932171 .3013000488172 .7938995361 174.2801971436175 .7595977783177 .2321014404178 .6972961426180 .1549072266 181.6049041748183 .0469055176184 .4806976318185 .9062957764187 .3235931396 
188.7324066162190 .1325073242191 .5240936279192 .9069061279194 .2810058594 195.6463928223197 .0028991699198 .3506011963199 .6896057129201 .0198059082 202.3414001465203 .6542053223204 .9584960938206 .254196167207 .541595459 208.820602417210 .0914001465211 .354095459212 .6089019775213 .8560028076 215.0953979492216 .3273925781217 .5520019531218 .7695007324219 .9799957275 221.1835021973222 .3802032471223 .5702056885224 .7534942627225 .9302978516 227.1002960205 228.2637023926 229.4203948975 230.5704040527 231.7136993408 232.850402832233 .9804992676235 .0986938477236 .2088012695

1.9988410472871 .840806961061 .6056809425351 .229581952095 .7414259910583 $0.147129997611-.541172027588-1.31193399429-2.15002703667-3.03970193863$ $-3.96417307854-4.9050579071-5.84534597397-6.76579713821-7.65025615692$ $-8.48013210297-9.2409658432-9.91592884064-10.4929895401-10.9578199387$ $-11.3023500443-11.5150499344-11.5918998718-11.5259799957-11.3176603317$ $-10.9649896622-10.4727096558-9.84329223633-9.08629417419-8.20739936829$ $-7.21592187881-6.12686777115-4.93364286423-3.63776302338-2.2574570179$ $-.823635995388 .67685699462892 .2295908927923 .8512029647835 .531929969788$ 7.2930469512949 .12985324859611 .0660400390613 .1034603118915 .26513957977 17.5598793029820 .0050296783422 .6182403564525 .3877391815228 .30665016174 31.3719005584734 .5946502685537 .9195404052741 .3375205993744 .74834823608 48.0870780944851 .3488883972254 .4667015075757 .4498596191460 .26016998291 62.8980903625565 .4586563110467 .7804489135769 .806228637771 .49298858643 72.7827377319373 .6551437377974 .0663986206174 .0198593139673 .53456878662 72.6131286621171 .2483062744169 .4669189453167 .2621002197364 .68321228027 61.767719268858 .549388885555 .0849304199251 .3986816406247 .52296066284 43.5583305358939 .6128082275435 .7064399719231 .7813796997128 .27523040771 25.7318305969223 .6252593994121 .5378093719519 .5655593872117 .66267967224 15.7620096206713 .7906799316411 .788490295419 .7658395767217 .760447025299 $5.7732281684883 .8285610675811 .9125399589542 .40870006 e-02-1.83823502064$ $-3.6407289505-5.31271314621-6.86176681519-8.24510860443-9.53405761719$ $-10.759180069-12.0295200348-13.4704799652-15.1597795486-17.2348003387$ $-19.5135192871-21.8581905365-24.1580295563-26.2768192291-28.123260498$ $-29.5406799316-30.6127109528-31.3637008667-31.9376602173-32.5175094604$ $-33.0506401062-33.5517807007-34.0167312622-34.4627304077-34.8588790894$ $-35.1908798218-35.4855308533-35.7552680969-35.9805488586-36.1473693848$ $-36.2778816223-36.3721008301-36.4823799133-36.5944900513-36.7102508545$ $-36.8463592529-36.9820404053-37.1372489929-37.2892303467-37.3950805664$ $-37.4674682617-37.4931106567-37.491519928-37.4758110046-37.4568099976$ -37.4542388916 -37.4556388855 -37.4694404602 -37.4943084717 -37.5267715454 -37.5744895935 -37.6293182373 -37.6884384155 -37.7586097717 -37.8336791992 $-37.9146385193-37.9966812134-38.0649299622-38.1194000244-38.155330658$ $-38.1771202087-38.1886100769-38.1766700745-38.132019043-38.0638198853$ -37.9722595215 -37.8651809692 -37.740650177-37.6020393372 -37.4742202759 -37.3357810974 -37.1928901672 -37.0337409973 -36.8455200195 -36.6306991577 $-36.3780097961-36.0933990479-35.779750824-35.4497489929-35.1132888794$ $-34.7705001831-34.4227409363-34.0729904175-33.7257614136-33.3726081848$ $-32.9983596802-32.5990486145-32.1653594971-31.6925792694-31.1717300415$ 
-30.6161499023 -30.0630893707 -29.4156799316 -28.5715808868 -27.6070194244 -26.573720932 -25.4632892609 -24.2813091278 -23.0327396393 -21.7211208344 $-20.364610672-18.9739894867-17.5775794983-16.1962394714-14.8346099854$ -13.5217399597 -12.2585201263-11.0685796738 -9.93068790436-8.81500339508 $-7.7175359726-6.61738395691-5.52390909195-4.43190383911-3.34059810638$ -2.23775410652 -1.12919104099 -3.9019000e-02 1.1100430488592 .404211997986 3.7469549179085 .0564599037176 .340509891517 .5680150985728 .746580123901 9.86759471893310 .9313297271711 .9366502761812 .8842296600313 .7786397934 14.626110076915 .4397697448716 .2208194732716 .979770660417 .71739006042 18.4404392242419 .1533699035619 .8621501922620 .5716705322321 .28757095337 22.0142498016422 .7585906982423 .5243091583324 .3178997039825 .14650917053 26.0181407928526 .9496898651127 .9593791961729 .0681705474930 .29768943787 31.6232891082833 .0230102539134 .4740715026935 .9537811279337 .45093154907 38.9499282836940 .4479904174841 .9347991943443 .4116516113344 .87261962891 46.3214988708547 .7596092224149 .1891098022550 .6138801574752 .03379821777 53.4519996643154 .8667602539156 .2779388427757 .6882896423359 .09714889526 60.5096015930261 .9260292053263 .3523597717364 .7927932739366 .25002288818 67.7256393432669 .2205276489370 .7345733642672 .2622299194373 .82904815674 75.3237075805776 .6191711425877 .8513336181679 .1321563720780 .43704986572 81.7827682495183 .1689071655384 .6059875488386 .0908966064587 .62930297852 89.2224884033290 .836357116792 .602256774994 .6676330566496 .86036682129 99.03491973877101 .2110977173103 .3612976074105 .4750976562107 .5353012085 109.5413970947111 .4817962646113 .3632965088115 .182800293116 .9487991333 118.670501709120 .3516998291122 .0037994385123 .6276016235125 .2313995361 126.8158035278128 .3863067627129 .9438018799131 .4924926758133 .0334014893 134.5699005127136 .1026000977137 .6338043213139 .1640014648140 .6943969727 142.2250976562143 .7565002441145 .2882995605146 .8204956055148 .3527984619 149.8847961426151 .4161987305152 .946395874154 .4750976562156 .0018005371 157.5260009766159 .0471038818160 .5650024414162 .0789031982163 .5885925293 165.0935058594166 .5935058594168 .0879974365169 .5767059326171 .0592041016 172.5354003906174 .004699707175 .4671020508176 .9221954346178 .3699035645 179.8097991943181 .241897583182 .6660003662184 .0818939209185 .4895019531 186.8887023926188 .2794036865189 .661605835191 .0352020264192 .4002075195 193.7565002441195 .104095459196 .4430999756197 .7734069824199 .0950012207 200.408203125201 .7127075195203 .0088043213204 .2964935303205 .5760040283 206.8471984863208 .1103057861209 .3654937744210 .6128997803211 .8527069092 213.0850067139214 .3099060059215 .5276031494216 .7382965088217 .9420928955 219.1390991211220 .3292999268221 .5130004883222 .6900024414223 .8605957031 225.024597168226 .1822052002227 .3330993652228 .4774932861229 .6152038574 230.7465057373231 .8704986572232 .9886016846234 .0984954834 7.3316121101387 .2905068397527 .052172183996 .6168379783636 .080812931061 5.4358868598944 .6943898200993 .8681759834292 .9724519252782 .023499011993 $1.0380179882053 .50669995 \mathrm{e}-02-.968586981297$-1.95293998718 -2.90222406387 -3.79703402519-4.6234369278 -5.36392784119-6.00630283356-6.53473615646 $-6.94382190704-7.22415304184-7.36872196198-7.36673116684-7.22435188293$ $-6.94495010376-6.52939891815-5.97671604156-5.30540704727-4.53162288666$ 
-3.6504919529-2.65713906288 -1.57114100456-0.41571700573.7972589731216 2.0438570976263 .329094886784 .6431531906135 .9977822303777 .389389038086 8.83631229400610 .3415203094511 .9279003143313 .6052398681615 .3973197937 17.3190307617219 .3896808624321 .626670837424 .0267505645826 .59098052979 29.3161201477132 .2105484008835 .2281684875538 .3401107788141 .50210952759 44.6639099121147 .8449096679751 .0088806152354 .1462287902857 .20634078979 60.1873016357463 .1203117370665 .8469772338968 .2880172729570 .37596893311 71.9991989135773 .1703796386773 .8538894653374 .0442886352573 .77799987793 73.0537796020571 .859786987370 .2226028442468 .1458969116265 .67014312744 62.8371200561559 .686389923156 .2853698730552 .6534194946348 .82733917236 44.8886795043940 .9377403259336 .9807586669933 .0407714843829 .49398994446 26.7334194183324 .3866100311322 .1220893859919 .9300594329817 .78142929077 15.7188196182313 .7417402267511 .806839942939 .8165664672857 .822550773621 $5.855426788333 .9476010799412 .130044937134 .2861849963665-1.70683598518$ -3.68328905106 -5.47556209564 -7.12008476257 -8.5940952301 -9.9723367691 $-11.2930498123-12.6606903076-14.1543598175-15.9684200287-18.4047107697$ -21.0705394745 -23.6976203918 -26.2209300995 -28.480890274 -30.3958702087 $-31.795419693-32.8064308167-33.5338783264-34.0946502686-34.6351203918$ -35.1316986084 -35.6135787964 -36.066860199 -36.5122718811 -36.9204216003 $-37.2800598145-37.616809845-37.9232711792-38.1902008057-38.4268417358$ $-38.610408783-38.7243309021-38.8364486694-38.9234085083-39.005569458$ $-39.1478385925-39.3037185669-39.4830589294-39.6644897461-39.7828216553$ -39.8510513306 -39.8621482849 -39.8375511169-39.796710968 -39.7499885559 $-39.7160301208-39.6827201843-39.6560592651-39.6385116577-39.6245307922$ -39.6271514893 -39.6462516785 -39.6771507263 -39.7281188965 -39.7902412415 -39.8574104309-39.9270896912 -39.9829902649-40.0242500305-40.0494117737 $-40.0637893677-40.0686302185-40.051410675-40.0074081421-39.9392318726$ -39.8412895203 -39.727230072 -39.5963401794 -39.4462394714 -39.2946205139 -39.1300697327 -38.9498710632 -38.7507400513 -38.5252189636 -38.2761611938 -37.997341156 -37.6923904419 -37.3619308472 -37.0169296265 -36.6680793762 -36.3123016357 -35.9477615356 -35.5763015747 -35.2032585144 -34.8222694397 $-34.4263114929-34.0115699768-33.5700492859-33.0961303711-32.584148407$ -32.040851593 -31.4789791107 -30.8350200653 -30.041519165 -29.136259079 -28.1485900879 -27.0803699493 -25.9304294586 -24.7071990967-23.4181194305 -22.075969696 -20.6997699738 -19.3137893677 -17.9336395264 -16.5621700287 -15.2157497406 -13.8982095718 -12.6353702545 -11.4138298035 -10.2200698853 $-9.04777240753-7.88478088379-6.73534822464-5.59614896774-4.46544981003$ $-3.33372306824-2.20226097107-1.073966026310 .1078649982811 .403702974319$ 2.7456629276284 .0736608505255 .3813428878786 .6453609466557 .866368770599 9.030971527110 .1405801773111 .1923799514812 .1898298263513 .13560009003 14.0344400405914 .8940296173115 .7175798416116 .5134296417217 .28314971924 18.0310192108218 .7630691528319 .4861392974920 .2050991058320 .9256401062 21.6536102294922 .3975296020523 .1620807647723 .9545402526924 .78322982788 25.6560592651426 .5928993225127 .6093196868928 .7049999237129 .89687919617 31.1667003631632 .512828826933 .9171981811535 .3548507690436 .81595993042 38.2851104736339 .7580795288141 .2244606018142 .6839103698744 .13005065918 
45.5655593872146 .9895706176848 .4046592712449 .8135681152351 .21704101562 52.617610931454 .0151290893655 .4103813171456 .8057289123558 .20158004761 59.6018791198761 .0076103210462 .4237518310563 .8544387817465 .301902771 66.7689819335968 .2543716430769 .7574691772571 .271759033272 .7991027832 74.2644805908275 .5907135009876 .8610610961978 .1497268676879 .45539855957 80.7927398681682 .1630020141683 .5764694213985 .0330429077186 .5396194458 88.0990829467889 .7083816528391 .4532928466893 .4228668212995 .50779724121 97.6096115112399 .72019195557101 .8133010864103 .8809967041105 .9049987793 107.884803772109 .8097991943111 .6847000122113 .5065994263115 .2818984985 117.0147018433118 .709602356120 .3737030029122 .0099029541123 .6237030029 125.2173995972126 .7954025269128 .3594970703129 .9132995605131 .458404541 132.9978942871134 .5325927734136 .0648956299137 .5950927734139 .1246948242 140.653503418142 .1820983887143 .7104034424145 .2382965088146 .7655029297 148.2919006348149 .8168945312151 .3403015137152 .8616943359154 .3804931641 155.8964996338157 .4091949463158 .9181976318160 .4230957031161 .9234924316 163.4190979004164 .9093933105166 .3941955566167 .8730926514169 .345703125 170.81199646172 .2713928223173 .7239074707175 .1690979004176 .6069030762 178.036895752179 .459197998180 .8735046387182 .279800415183 .6777038574 185.0675048828186 .4486999512187 .8215026855189 .1858978271190 .5417022705 191.8890075684193 .2276000977194 .557800293195 .8793945312197 .1925048828 198.4971008301199 .7933044434201 .0812072754202 .3607940674203 .6322021484 204.8955993652206 .1510009766207 .3986968994208 .6385955811209 .8710021973 211.095993042212 .3139038086213 .524597168214 .7283935547215 .9253997803 217.1157989502218 .2994995117219 .4766998291220 .6475067139221 .8119049072 222.9698944092224 .1213989258225 .2666015625226 .4051971436227 .537399292 228.6631011963229 .7825012207230 .8903961182231 .9906005859

13.388259887713 .1539297103912 .8385095596312 .3757600784311 .79547977448 11.1038999557510 .313420295729 .4360361099248 .4872579574587 .483367919922 6.4415559768685 .3806509971624 .3181037902833 .2734301090242 .263273954391 $1.306314945221 .4175220131874-.386559993029-1.09275305271-1.68462002277$ $-2.15716505051-2.5038869381-2.71501207352-2.77716207504-2.70137405396$ $-2.49544596672-2.15800094604-1.68348097801-1.0966360569-.421539008617$ .3563719987869 1.258355021477 2.236512899399 3.2455859184274.285963058472 5.3345141410836 .3966641426097 .4541559219368 .5263347625739 .60036945343 10.7068996429411 .841830253613 .0410604476914 .3120002746615 .68762969971 17.1851005554218 .8263397216820 .6322498321522 .6072597503724 .76980018616 27.1077995300329 .6402301788332 .3172302246135 .1133918762238 .01324081421 40.9882888793944 .0607299804747 .2143287658750 .4366493225153 .68618011475 56.9435806274460 .2114105224663 .3487281799366 .2764434814568 .79263305664 70.7691421508872 .2128372192473 .1920928955173 .6841735839873 .69302368164 73.2269897460972 .2335662841870 .7734680175868 .83872222966 .47930145264 63.753070831360 .6953506469757 .3934783935553 .8526992797950 .11745834351 46.2543411254942 .3488006591838 .4659805297934 .6673812866231 .17094039917 28.1662807464625 .478170394922 .9699192047120 .5852603912418 .24945068359 16.0584793090814 .0593900680512 .1392898559610 .133919715888 .132307052612 6.1494951248174 .2221379280092 .425920009613 .5730440020561 -1.56826996803 
-3.71728610992 -5.6165471077 -7.36351490021 -8.92070674896 -10.3872699738 $-11.7872200012-13.252120018-14.7973299026-16.7203903198-19.5119895935$ $-22.5625495911-25.4892902374-28.2312908173-30.584690094-32.5145683289$ $-33.8715591431-34.8402786255-35.5798110962-36.1497497559-36.6622695923$ -37.1288108826 -37.6176986694 -38.0871086121 -38.5772209167 -39.0448303223 $-39.4952201843-39.9035797119-40.2325897217-40.5662918091-40.9127616882$ $-41.2275810242-41.3941192627-41.4616508484-41.4478797913-41.4649581909$ $-41.6195487976-41.8401184082-42.0731010437-42.2689399719-42.381729126$ $-42.4276618958-42.4114303589-42.353931427-42.2760391235-42.1902999878$ $-42.1207618713-42.05701828-42.0018310547-41.9448699951-41.8784408569$ $-41.8230285645-41.7911605835-41.7909889221-41.8246917725-41.8771896362$ $-41.9288787842-41.9749908447-42.0053710938-42.0248718262-42.0363311768$ $-42.0345306396-42.0175094604-41.9896011353-41.9551010132-41.8908081055$ $-41.7772407532-41.6331100464-41.4841308594-41.3226013184-41.1564407349$ $-40.9704093933-40.760848999-40.5294799805-40.2695808411-39.9892501831$ -39.6842803955 -39.356628418 -39.0097694397 -38.6508407593 -38.2870101929 -37.9155807495 -37.5319099426 -37.1380500793 -36.7370109558 -36.3278694153 -35.9064407349 -35.469909668 -35.0143890381 -34.5373306274 -34.0360107422 -33.5006217957 -32.9179801941 -32.2664299011 -31.5222797394 -30.6864891052 $-29.7568397522-28.730260849-27.6064395905-26.4021892548-25.1354198456$ $-23.8192005157-22.4637298584-21.0846195221-19.6956996918-18.3038692474$ -16.9268398285 -15.5663299561 -14.2393302917-12.9421195984 -11.6709098816 $-10.4258403778-9.20096111298-7.99529123306-6.80354309082$-5.62491416931 $-4.45299386978-3.27866911888-2.08627104759-.855647981167 .4421370029449$ 1.7751820087433 .1127870082864 .4430880546575 .7367639541636 .992134094238 8.1910133361829 .33700561523410 .4287595748911 .4683704376212 .4608001709 13.4068098068214 .3123598098815 .1794300079316 .015279769916 .81937026978 17.5956802368218 .3506393432619 .0900497436519 .8208103179920 .54812049866 21.2798404693622 .0266799926822 .7942504882823 .5904502868724 .42436027527 25.3022708892826 .2397708892827 .2505092620828 .3311004638729 .49209022522 30.7224006652832 .0255012512233 .3845901489334 .7818183898936 .20838928223 37.6489715576239 .0985717773440 .5445594787641 .9866905212443 .41596984863 44.8358116149946 .2429084777847 .6412506103549 .0328903198250 .41862106323 51.8016510009853 .1820106506354 .5615615844755 .9421806335457 .32320022583 58.7093086242760 .1008300781261 .5032806396562 .9201202392664 .35356903076 65.8077163696367 .2774200439568 .762557983470 .2456283569371 .71262359619 73.1404724121174 .5092773437575 .8403396606477 .1568984985478 .47406768799 79.8131866455181 .1775665283282 .5783462524484 .0199966430785 .51016998291 87.0649871826288 .7017822265690 .442657470792 .3068618774494 .2615737915 96.2709426879998 .30841827393100 .3402023315102 .3574981689104 .3408966064 106.2893981934108 .1924972534110 .0539016724111 .8703994751113 .6462020874 115.3834991455117 .0852966309118 .757598877120 .4017028809122 .0236968994 123.6243972778125 .209197998126 .7789993286128 .3381958008129 .8876037598 131.4308013916132 .9683074951134 .5025939941136 .0337982178137 .5635070801 139.091506958140 .6184997559142 .1441955566143 .6687927246145 .1918945312 146.713394165148 .233001709149 .7501983643151 .2648925781152 .7765960693 
154.2850036621 155.7895965576 157.2902984619158.7864990234160.2779998779 161.7644958496163 .2454986572164 .7207946777166 .1902008057167 .6531982422 169.1096954346170 .5594024658172 .0019989014173 .4373931885174 .8654022217 176.2857055664177 .6983032227179 .1029052734180 .49949646181 .8878936768 183.2680969238184.6398925781 186.00340271 187.3583984375 188.7050933838 190.0431976318191 .3730010986192 .6943054199194 .0070953369195 .3115997314 196.6076965332197 .8954925537199 .1750946045200 .4465026855201 .7098999023 202.9653930664204 .2129974365205 .4530029297206 .6853942871207 .9104003906 209.1282043457210 .3388061523211 .5424957275212 .7393035889213 .9295043945 215.1132049561216 .2902984619217 .4611053467218 .62550354219 .783706665 220.9355010986222 .0811004639223 .2203979492224 .3531951904225 .4797058105 226.6000061035227 .7131958008228 .8208007812229 .920501709

19.4485893249519 .342290878319 .0315093994118 .5158500671417 .89525032043 17.1611309051516 .3259906768815 .4020500183114 .404720306413 .35072040558 12.2569303512611 .1428098678610 .025270462048 .9246044158947 .856718063354 6.8411707878115 .892167091375 .027263164524 .2582440376283 .600577116013 3.0621860027312 .6552119255072 .3829419612882 .2527379989622 .25797700882 2.3953440189362 .6608099937443 .051486015323 .5535991191864 .157650947571 4.8576750755315 .6517381668096 .5005869865427 .3632440567028 .228810310364 9.0760726928719 .90369510650610 .6944503784211 .4617500305212 .19859027863 12.9311704635613 .6647396087614 .4335203170815 .255829811116 .16544914246 17.1889896392818 .3512401580819 .6793003082321 .1872291564922 .89464950562 24.8017406463626 .9173507690429 .2153491973931 .6769905090334 .29946136475 37.0600090026939 .9856414794943 .0694313049346 .3059501647949 .66471099854 53.1272888183656 .6697616577160 .2201690673863 .7627716064566 .85466003418 69.0564575195370 .67299652171 .9870605468872 .8558425903373 .20334625244 73.0423431396572 .3242492675871 .0846023559669 .298271179267 .05316925049 64.4630126953161 .5444297790558 .3775596618754 .9792785644551 .39965057373 47.6837081909243 .8864517211940 .1031112670936 .4058189392132 .91854095459 29.7990798950226 .9009399414124 .1854591369621 .6312904357919 .20985984802 16.963380813614 .8687295913712 .8484296798710 .785659790048 .720299720764 6.6580080986024 .6266369819642 .651123046875 6245959997177 -1.57874798775 -3.76929211617 -5.75508880615 -7.57835483551 -9.20552158356 -10.7381095886 $-12.216509819-13.7981004715-15.5822696686-17.7769603729-20.7285003662$ -23.9641494751 -27.2160491943 -30.2180995941 -32.5713500977 -34.4221000671 -35.7530212402 -36.7078094482 -37.4372596741 -38.0065307617 -38.5194396973 -39.002658844 -39.5401191711-40.0826301575-40.6469917297-41.2238311768 $-41.8587799072-42.4027481079-42.673789978-42.9889183044-43.6169013977$ $-44.2197494507-44.4656486511-44.4500198364-44.1777305603-43.9899597168$ $-44.2502708435-44.648891449-44.9505691528-45.1557693481-45.2235717773$ -45.209941864-45.1543807983 -45.0572891235-44.9207992554 -44.7803382874 $-44.6782112122-44.594669342-44.5271186829-44.4426116943-44.3028488159$ -44.1642303467-44.070098877-44.0304107666-44.0620002747 -44.1174087524 $-44.1479187012-44.1592903137-44.1426086426-44.1224784851-44.125541687$ $-44.1110115051-44.034740448-43.9680404663-43.9846000671-43.9645004272$ $-43.7918014526-43.5751495361-43.4118614197-43.2547683716-43.0814208984$ 
-42.8809089661 -42.6398696899-42.3731193542 -42.0861206055-41.7799682617 $-41.4468193054-41.0919303894-40.7274589539-40.3535194397-39.9715194702$ -39.5804901123 -39.17552948 -38.7548599243 -38.3193283081 -37.8752212524 -37.4234085083 -36.9592208862 -36.4795913696 -35.992061615 -35.5075492859 -34.993270874 -34.4229698181 -33.7899398804 -33.0719795227 -32.2793388367 -31.4087696075 -30.425359726 -29.2946491241 -28.0814704895 -26.8504905701 $-25.578119278-24.2490692139-22.880399704-21.4867591858-20.0772705078$ $-18.6679496765-17.2629909515-15.8747901917-14.5055398941-13.1595497131$ $-11.8413200378-10.5546598434-9.29096698761-8.04662895203-6.81793403625$ $-5.60236883163-4.38239479065-3.13742589951-1.8662250042-.549721002579$ .79196697473532 .1555941104893 .5162680149084 .8346209526066 .11377620697 7.3404250144968 .5163440704359 .64233779907210 .7208995819111 .75572967529 12.7472696304313 .697440147414 .6091995239315 .4859895706216 .32696914673 17.1357707977317 .9172801971418 .6747207641619 .4180507659920 .15410995483 20.891189575221 .6427402496322 .4148101806623 .2160797119124 .05417060852 24.9368400573725 .873600006126 .8758697509827 .9408893585229 .07620048523 30.2752399444631 .5421104431232 .8633003234934 .2272415161135 .62392044067 37.0401611328138 .4685592651439 .896480560341 .3213500976642 .73382949829 44.1359901428245 .5241889953646 .9033317565948 .2760696411149 .6431312561 51.0072288513252 .3695487976153 .7329101562555 .0978507995656 .46318054199 57.832729339659 .2074317932160 .5921707153361 .9907188415563 .40505981445 64.8394927978566 .2881164550867 .7509002685569 .207450866770 .64626312256 72.065849304273 .4502410888774 .8141326904376 .1581268310577 .4945526123 78.8459167480580 .2170181274481 .6184997558683 .0573577880984 .54128265381 86.090957641687 .7214431762789 .4281311035291 .226142883393 .09091949463 95.0147018432696 .9763870239398 .9415435791100 .9017028809102 .8386001587 104.7500991821106 .6265029907108 .4692001343110 .2742996216112 .0447006226 113.7802963257115 .4841003418117 .1593017578118 .8081970215120 .4346008301 122.040802002123 .6305007935125 .2054977417126 .7693023682128 .3233032227 129.870300293131 .4111022949132 .9479980469134 .4810943604136 .0117034912 137.5399017334139 .0661010742140 .5901031494142 .112197876143 .6320953369 145.1495056152146 .6643066406148 .1761016846149 .6846923828151 .1898040771 152.6911010742154 .188293457155 .6809997559157 .1690063477158 .6519012451 160.1295013428161 .6015014648163 .0675964355164 .5276031494165 .9812011719 167.4281005859168 .8681945801170 .3011932373171 .7268981934173 .1452026367 174.5558013916175 .958694458177 .3536071777178 .7406005859180 .1194000244 181.4900970459182 .8524932861184 .2066040039185 .5523986816186 .8898925781 188.2189941406189 .5397033691190 .8520965576192 .1562042236193 .4519958496 194.7395019531196 .0189056396197 .2901000977198 .5532989502199 .80859375 201.0561065674202 .2958984375203 .5281982422204 .7530059814205 .9705047607 207.1808929443208.3842926025209.5809020996210.7707061768 211.9541015625 213.1309051514214 .3014984131215 .4656982422216 .6237030029217 .775604248 218.9212036133220 .0606994629221 .1940002441222 .3211975098223 .4418945312 224.5565948486225 .6651000977226 .7626037598227 .8527069092 26.2597007751525 .9607200622625 .5775203704825 .0424003601124 .38558006287 23.6135005950922 .7385501861621 .7730293273920 .7324600219719 .63339996338 
18.493089675917 .3305206298816 .1632003784215 .0106000900313 .88953018188 12.8183097839411 .8123502731310 .8880596160910 .058019638069 .335218429565 8.7321128845218 .2650375366217 .9312372207647 .7312698364267 .66447687149 7.7326040267947 .9247670173658 .229757308968 .649950981149 .191481590271 9.81893634796110 .5084800720211 .2261199951211 .9456501007112 .64251995087 13.2912797927913 .8876304626514 .4034500122114 .8603897094715 .23672962189 15.5753297805815 .8697299957316 .1726207733216 .4983901977516 .89452934265 17.3926105499318 .0245800018318 .8278007507319 .8178806304921 .0265007019 22.4523792266824 .1123600006125 .9939498901428 .0968093872130 .41390991211 32.9252014160235 .6608314514238 .6154403686541 .7998504638745 .19137954712 48.7722587585452 .5088500976656 .3403511047460 .3774299621663 .97414016724 66.4547500610468 .3442230224670 .1348724365271 .4717102050872 .24540710449 72.4713592529372 .0346221923871 .0216903686569 .385177612367 .25344085693 64.8314285278362 .0963897705159 .1297988891655 .9463500976652 .60176849365 49.1165390014645 .5124397277841 .8834991455138 .29965972934 .82804107666 31.5748596191428 .5374507904125 .6933002471923 .0718002319320 .63941955566 18.3484191894516 .1306190490713 .9695100784311 .808409690869 .651821136475 $7.4743738174445 .2842302322393 .0518369674680 .79474401474-1.5038189888$ $-3.73733997345-5.80858898163-7.72123908997-9.41211700439-11.0155296326$ $-12.5275001526-14.1963796616-16.1676292419-18.5760402679-21.6579608917$ $-25.0491409302-28.6550807953-31.9268302917-34.2794799805-36.039100647$ $-37.3554000854-38.3220901489-39.0527381897-39.6351699829-40.156211853$ $-40.6748199463-41.2901306152-41.9460411072-42.6727600098-43.4402389526$ $-44.3474311829-45.1457710266-45.4748802185-45.8523292542-46.7299499512$ $-47.5548095703-47.8291511536-47.7600708008-47.2860107422-46.912399292$ $-47.2427101135-47.7426986694-48.0543899536-48.2515106201-48.2732391357$ $-48.1979789734-48.1034698486-47.962928772-47.7676010132-47.5710906982$ $-47.4352302551-47.3246498108-47.2377815247-47.128200531-46.9272689819$ $-46.7160186768-46.5649795532-46.4797706604-46.4891014099-46.5280418396$ $-46.5173416138-46.4809799194-46.4091911316-46.336730957-46.319229126$ $-46.2823905945-46.1436500549-46.0262908936-46.0683288574-46.0749588013$ $-45.844379425-45.5666389465-45.3997497559-45.2484588623-45.0744781494$ $-44.8687286377-44.6093788147-44.3142204285-44.0026817322-43.6646499634$ $-43.2931289673-42.9129981995-42.5380096436-42.156211853-41.7534103394$ $-41.3368492126-40.9080696106-40.4651985168$-39.994720459 -39.510799408 $-39.0231399536-38.5273590088-38.0233192444-37.5219688416-37.0486183167$ $-36.5539703369-36.0013504028-35.3858604431-34.6852302551-33.9119110107$ $-33.0781784058-32.1294517517-30.9979305267-29.7853603363-28.5952091217$ $-27.3644790649-26.0584907532-24.7002105713-23.3035507202-21.8787097931$ $-20.4407501221-18.9953098297-17.5498008728-16.1140804291-14.6938400269$ $-13.302189827-11.9524002075-10.6293802261-9.33610725403-8.0620470047$ $-6.80129003525-5.54004096985-4.24624919891-2.92993998528-1.58454596996$ -.214291006327 1.188971996307 2.582962989807 3.9208860397345 .216592788696 6.4630479812627 .665482044228 .8239097595219 .93910598754911 .01615047455 12.0528898239113 .0478801727314 .0036001205414 .9200401306215 .80119037628 16.6487808227517 .4614601135318 .2382507324218 .9916801452619 .73576927185 
20.4808692932121 .2397804260322 .0189990997322 .8269290924123 .67033004761 24.5564403533925 .4912796020526 .4836292266827 .5330600738528 .64755058289 29.821920394931 .0608806610132 .3521690368733 .6899414062535 .06309890747 36.4599800109937 .8725013732939 .2848701477140 .6949691772542 .09033966064 43.4744300842344 .8409881591846 .1985397338947 .5495414733948 .89559936523 50.2406692504951 .585098266652 .9318199157754 .2808418273955 .62829971313 56.9789085388258 .3330688476659 .6958999633861 .0716018676862 .461769104 63.8725700378465 .2956008911166 .7347564697368 .1720428466869 .59921264648 71.0165786743272 .4140472412173 .7985610961975 .1654968261776 .52629089355 77.8970565795979 .2823867797980 .6928329467882 .1370620727583 .62109375 85.16118621826 86.77028656006 88.4411163330190.1806564331191.97534179688 93.8234634399495 .7078399658297 .6030502319399 .50277709961101 .3897018433 103.2610015869105 .1064987183106 .9264984131108 .7153015137110 .474899292 112.2039031982113 .9045028687115 .5789031982117 .2285995483118 .8573989868 120.4665985107122 .0603027344123 .6393966675125 .2078018188126 .7660980225 128.3173980713129 .8621063232131 .4022979736132 .9378967285134 .4703979492 135.99949646137 .5256958008139 .0489959717140 .5693969727142 .0867004395 143.600692749145 .1114044189146 .6183013916148 .1215057373149 .6204986572 151.1150970459152 .6051025391154 .0903015137155 .5702972412157 .0449981689 158.5140075684159 .9772949219161 .4344024658162 .8851928711164 .329498291 165.766998291167 .1976013184168 .6210021973170 .0370941162171 .4458007812 172.8466949463174 .2400054932175 .6253051758177 .0027008057178 .3719940186 179.7330932617181 .0861053467182 .4308929443183 .7673950195185 .0955963135 186.4156036377187 .7272949219189 .0308074951190 .3260040283191 .6130981445 192.891998291194 .162902832195 .4257965088196 .6806945801197 .9279022217 199.1672973633200 .3992004395201 .6237030029202 .8408050537204 .0507965088 205.2537994385206 .4499053955207 .6392974854208 .8222045898209 .9985046387 211.1685943604 212.3323974609 213.4900970459214.6416931152 215.7872009277 216.9266052246218 .0599975586219 .1873016357220 .3085021973221 .4235992432 222.532699585223 .6349945068224 .7319030762225 .8211975098

33.0755882263232 .9142494201732 .5437202453631 .9631004333531 .27457046509 30.4692001342829 .559429168728 .5576095581127 .4790191650426 .34052085876 25.1587696075423 .9532794952422 .7406806945821 .541149139420 .37031936646 19.24749946594 18.18680000305 17.20498085022 16.31471061707 15.53227043152 14.8676395416314 .3355197906513 .9342002868713 .6655397415213 .52764987946 13.5219202041613 .6365604400613 .8584899902314 .2000904083314 .6736497879 15.2282600402815 .8261804580716 .4312992095917 .0154590606717 .55129051208 18.0080394744918 .3726692199718 .6161994934118 .7496395111118 .75550079346 18.6704902648918 .5006294250518 .2957706451418 .0852108001717 .9191608429 17.8430690765417 .8955097198518 .1230106353818 .5496692657519 .21030044556 20.1143398284921 .2789802551322 .7094402313224 .4092903137226 .37335014343 28.5771808624331 .0585594177233 .8322105407736 .9006881713940 .25037002563 43.851699829147 .6591110229551 .6177787780855 .7068595886259 .49069976807 62.5305404663165 .111740112367 .5116119384869 .4392166137770 .7624130249 71.4455184936571 .29770660470 .4832916259869 .0186080932667 .02839660645 64.7790527343862 .2696609497159 .5819282531756 .7083206176853 .67855834961 
50.4970207214447 .1795005798343 .7732582092340 .325199127236 .84926986694 33.3640899658230 .1105308532727 .3627490997324 .8874607086222 .47047042847 20.1145191192617 .7990703582815 .5096197128313 .2348699569710 .95868015289 $8.6449689865116 .2786722183233 .8308830261231 .355692028999-1.16062200069$ $-3.56696200371-5.75205421448-7.74890899658-9.52246284485-11.1634502411$ $-12.6643104553-14.2980298996-16.1946792603-18.5996494293-21.9283103943$ -25.6655101776 -29.6431007385 -33.2165489197 -35.6037483215 -37.3146209717 $-38.6326408386-39.6189689636-40.3763809204-40.9852409363-41.5357818604$ $-42.1142501831-42.825088501-43.6537818909-44.6859703064-45.819480896-47.05519104$ $-48.1882591248-48.9775886536-49.7203598022-50.592628479-51.3094100952$ $-51.5708808899-51.4808692932-51.0919799805-50.7818908691-50.9356613159$ $-51.2327804565-51.4552612305-51.5932807922-51.58934021-51.4974517822$ -51.352519989 -51.1601104736 -50.9273796082 -50.6942214966 -50.5054702759 $-50.3423805237-50.2041282654-50.0520896912-49.8332099915-49.5954818726$ $-49.3934593201-49.2486000061-49.1808395386-49.1378097534-49.0549316406$ $-48.9475708008-48.8197212219-48.6964912415-48.6100006104-48.5072097778$ $-48.3398094177-48.1951789856-48.152381897-48.0862884521-47.8698806763$ $-47.6208381653-47.4504585266-47.3011894226-47.1388092041-46.9436187744$ $-46.6913414001-46.3902206421-46.0429382324-45.6549797058-45.2265892029$ $-44.8087806702-44.4563102722-44.0965690613-43.6591491699-43.1996803284$ $-42.7635383606-42.3153381348-41.8160018921-41.295211792-40.7695083618$ $-40.2422218323-39.7252006531-39.2201805115-38.735660553-38.2357711792$ -37.6845588684 -37.0704803467 -36.3733711243 -35.6034393311 -34.7584381104 -33.8101196289 -32.7286186218 -31.5732097626 -30.4054203033 -29.1906700134 -27.8993701935 -26.5462398529-25.1473693848 -23.7109699249-22.2494792938 $-20.767370224-19.2693099976-17.7684707642-16.2759494781-14.812210083$ $-13.3955802917-12.0125703812-10.6757898331-9.36418437958-8.0645608902$ $-6.76522922516-5.43142700195-4.07015800476-2.676623106-1.25614094734$ 0.1977380067111 .6295100450522 .9810020923614 .2829861640935 .548202991486 6.7766041755687 .9671201705939 .119244575510 .2394199371311 .32266044617 12.3631000518813 .3618202209514 .3146696090715 .2348203659116 .13615989685 16.9937591552717 .7830295562718 .538160324119 .2900104522720 .04430007935 20.8129405975321 .6010494232222 .4171600341823 .2662601470924 .15572929382 25.0890598297126 .0733890533427 .1101799011228 .205490112329 .35914993286 30.5767402648931 .8468399047933 .1651115417534 .5211715698235 .90642929077 37.3088111877438 .7111282348640 .108680725141 .4892387390142 .85422134399 44.1983909606945 .5317611694346 .8578109741248 .1799888610849 .50576019287 50.8325195312552 .1619300842353 .4935684204154 .8218688964856 .15058898926 57.480880737358 .8180198669460 .1665992736861 .5303993225162 .91627883911 64.3171463012765 .7341232299867 .1566772460968 .5787506103569 .99957275391 71.4095306396572 .8121566772574 .201446533275 .5863418579176 .97590637207 78.3764266967879 .7967910766681 .2448730468882 .7285003662184 .25682830811 85.8406677246187 .4733963012789 .1596908569390 .8911437988392 .66828918457 94.4788970947396 .308448791598 .1483230590899 .98461914062101 .8134994507 103.6260986328105 .4207000732107 .1900024414108 .9354019165110 .6539993286 112.3479995728114 .0178985596115 .665802002117 .2941970825118 .9048995972 
120.5008010864122 .0833969116123 .6555023193125 .2182998657126 .7738037109 128.3226928711129 .8665008545131 .4055023193132 .9403076172134 .4710998535 135.9980926514137 .5213012695139 .0406951904140 .5561065674142 .0673980713 143.5744018555145 .0771026611146 .5751953125148 .0686035156149 .5569000244 151.0402069092152 .5180969238153 .9904022217155 .4571075439156 .9178009033 158.3724975586159 .8208007812161 .2624969482162 .6976928711164 .1259002686 165.5471038818166 .9611053467168 .3675994873169 .7666931152171 .1580963135 172.5417022705173 .9174957275175 .2852935791176 .6450958252177 .9967041016 179.3403015137180 .6757049561182 .0028991699183 .3218994141184 .6327056885 185.9353942871187 .2299041748188 .516204834189 .7944946289191 .0648040771 192.3271026611193 .5816040039194 .8282012939196 .067199707197 .2985992432 198.5225067139199 .7391052246200 .9485931396202 .1510009766203 .346496582 204.5352935791205 .7174987793206 .8932037354208 .0626068115209 .2257995605 210.3827972412211 .5339050293212 .678894043213 .8180999756214 .9512023926 216.0785064697217 .199798584218 .3150939941219 .4243011475220 .5278015137 221.6251983643222 .712097168223 .7920074463 40.6593017578140 .3084411621139 .8713798522939 .2799797058138 .5643196106 37.7308998107936 .7918014526435 .7594413757334 .6489410400433 .47692871094 32.2601013183631 .0173397064229 .7656402587928 .5241603851327 .30884933472 26.1380004882825 .0259609222423 .9876194000223 .0395698547422 .19889068604 21.4741306304920 .8747100830120 .404790878320 .0637397766119 .85453987122 19.7719402313219 .8098392486619 .9492092132620 .20487022420 .59938049316 21.0669498443621 .5748291015622 .0731506347722 .5424003601122 .93320083618 23.2179794311523.3711605072 23.3499507904123.1709098815922.79219055176 22.2743492126521 .6053695678720 .8617992401120 .0681800842319 .29390907288 18.5951805114718 .0189304351817 .6263008117717 .4428291320817 .51572990417 17.856170654318 .4912700653119 .4292507171620 .6846103668222 .25052070618 24.0991497039826 .2805690765428 .8168601989731 .7059402465834 .93745040894 38.4692611694342 .2526817321846 .1865386962950 .1636581420954 .02099990845 57.6120185852160 .9250602722263 .9817504882866 .6113586425868 .67823791504 69.8926162719770 .0166320800869 .281532287667 .9478530883866 .17685699463 64.1858367919961 .9868583679259 .6667709350657 .1908683776954 .56254959106 51.7739295959548 .8239212036145 .7242889404342 .4756202697839 .10564041138 35.5015907287632 .1306190490729 .4912700653127 .1366691589424 .68548965454 22.255020141619 .8569107055717 .4629993438715 .0932397842412 .70316028595 $10.253930091867 .7302050590525 .0848507881162 .396625041962-.379581987858$ -3.02494692802 -5.41199922562 -7.56854200363 -9.47601699829-11.1957101822 -12.6704301834 -14.1939897537-15.8232898712 -18.1057891846-21.5959300995 -25.6395206451 -30.0096893311 -33.8619194031 -36.3632583618 -38.1205291748 -39.5188713074 -40.5911712646-41.4015197754-42.0679206848 -42.6483688354 $-43.2768211365-44.0577697754-45.0673599243-46.4706192017-48.042301178$ $-49.6804504395-51.2784309387-52.6753997803-53.8379402161-54.6322402954$ $-55.1105804443-55.3097801208-55.2676811218-55.0531997681-54.8239593506$ $-54.7580299377-54.7961082458-54.8982200623-54.9766807556-54.9502906799$ $-54.8444290161-54.6683692932-54.439868927-54.1755218506-53.9107398987$ $-53.6836395264-53.4762802124-53.2799415588-53.0753097534-52.8467216492$ 
$-52.6203994751-52.4084815979-52.2173995972-52.0635604858$-51.9133491516 $-51.7368011475-51.5593299866-51.3726997375-51.1925010681-51.0358581543$ $-50.8705787659-50.6882019043-50.5192985535-50.3600006104-50.195930481$ $-49.9939804077-49.7826690674-49.613079071-49.4567298889-49.2980003357$ $-49.1105804443-48.8693389893-48.5667190552-48.1913108826-47.7685813904$ $-47.2991714478-46.8502807617-46.5129089355-46.1659812927-45.6933898926$ $-45.1933708191-44.7455101013-44.2799301147-43.7369117737-43.1676902771$ $-42.5890693665-42.0255508423-41.4946899414-40.9812812805-40.480430603$ -39.957950592 -39.4034690857-38.7854614258 -38.0916404724 -37.3140296936 $-36.4393615723-35.4874992371-34.4665794373-33.3824310303-32.2407417297$ -31.0318202972 -29.753950119-28.4097900391 -27.0177707672 -25.5792694092 $-24.0998592377-22.5883407593-21.0407791138-19.4803009033-17.9159603119$ $-16.3742198944-14.8785400391-13.4406099319-12.0825300217-10.7543296814$ $-9.42650318146-8.08370780945-6.70190477371-5.29348611832-3.84363603592$ $-2.3682539463-.865783989429 .60780000686651 .9818290472033 .300127983093$ 4.5880441665655 .839097023017 .0625867843638 .2571439743049 .424390792847 10.5590200424211 .6462001800512 .6899204254213 .6794204711914 .63490009308 15.5831003189116 .4814891815217 .2848205566418 .0473098754918 .81221961975 19.5783500671420 .3583908081121 .1569995880121 .9823207855222 .83810043335 23.7320194244424 .6652297973625 .6447906494126 .6716995239327 .75148010254 28.8883094787630 .0898990631131 .3451595306432 .6535911560134 .00249099731 35.3835487365736 .7837181091338 .1799888610839 .5690498352140 .93701934814 42.2851905822843 .6079483032244 .9144897460946 .2089004516647 .50484085083 48.810970306450 .1235885620151 .4359016418552 .746368408254 .05126953125 55.3538093566956 .656108856257 .9631195068459 .2802009582560 .61326980591 61.9724884033263 .3498115539664 .7505416870166 .1640167236367 .58791351318 69.0173492431670 .4393768310571 .8580627441473 .2676162719774 .67453765869 76.0834579467877 .4999771118278 .9309997558680 .3834075927781 .86360931396 83.37754058838 84.93242645264 86.52554321289 88.16220092773 89.83564758301 91.5462570190493 .2875823974695 .0524978637796 .8331375122198 .61891174316 100.4052963257102 .1836013794103 .9511032104105 .6979980469107 .4257965088 109.1305007935110 .8139038086112 .4764022827114 .1194000244115 .7453994751 117.3554992676118 .952796936120 .537902832122 .1137008667123 .6806030273 125.2406997681126 .7940979004128 .3421936035129 .8847961426131 .4226989746 132.9557952881134 .4842987061136 .0079956055137 .5269012451139 .0410003662 140.5500030518142 .0540924072143 .5527954102145 .046295166146 .5343017578 148.0166931152149 .4934997559150 .9644012451152 .4293060303153 .8881988525 155.3406982422156 .786895752158 .2265014648159 .6595001221161 .0854949951 162.5045928955163 .9163970947165 .3209991455166 .7180938721168 .1076965332 169.4895019531170 .863494873172 .2297058105173 .5879974365174 .9382019043 176.2803955078177 .6145019531178 .9405059814180 .2584075928181 .5682067871 182.8697967529184 .1632995605185 .4488067627186 .7263031006187 .995803833 189.2572937012190 .5110931396191 .7570953369192 .9954071045194 .2261047363 195.4494018555196 .6652984619197 .8739929199199 .0756988525200 .2704925537 201.4584960938202 .6398925781203 .8148040771204 .9833984375206 .1457061768 207.3020019531 208.4523010254209.5966033936210.7351074219211.8677978516 
212.9947052002214 .1157989502215 .2310028076216 .3403015137217 .4438018799 218.5415039062219 .6327056885220 .7187042236221 .7975006104 48.2484283447348 .0429992675847 .6268005371146 .9984512329146 .2607383728 45.4045295715344 .4418601989743 .3850097656242 .2487297058141 .04970932007 39.8038101196338 .5302200317437 .2449111938535 .967491149934 .71203994751 33.4972000122132 .3355598449731 .2421493530330 .2353992462229 .33630943298 28.5491790771527 .8845901489327 .345209121726 .9323692321826 .65010070801 26.4985008239726 .4645805358926 .5282001495426 .7006301879926 .99167060852 27.3547592163127 .7628307342528 .1641597747828 .5307903289828 .80306053162 28.9375591278128 .8981208801328 .633369445828 .1431903839127 .38552093506 26.4128208160425 .2297897338923 .9095401763922 .4967403411921 .06694984436 19.6994705200218 .4486904144317 .3887996673616 .5534706115715 .99456977844 15.731690406815 .7938499450716 .1954803466816 .9496803283718 .06007003784 19.5144901275621 .3512306213423 .5895195007326 .2262001037629 .25315093994 32.6252098083536 .2978706359940 .1565589904844 .1021690368748 .09128952026 51.9886817932155 .7948417663659 .424800872862 .8108406066966 .01122283936 68.1249313354568 .2105331420967 .2353210449266 .0270233154364 .55107879639 62.9352493286161 .1690292358459 .3093490600657 .3152999877955 .18402862549 52.8802795410250 .3902511596747 .6972389221244 .7869415283241 .68027114868 38.3588600158735 .1609687805232 .4016990661629 .8519496917727 .30061912537 24.7694702148422 .3032093048119 .8524608612117 .4160709381114 .94865989685 12.393750190739 .7266693115236 .8982830047613 .980734109879 .9717239737511 -1.9373780489-4.64537286758 -7.09888696671 -9.21651744843 -11.039560318 -12.515370369 -13.8521900177-15.1006402969-17.0948104858 -20.6365394592 -24.9184398651 -29.5721302032 -33.688659668 -36.3741188049-38.3214797974 -39.9072189331 -41.1483688354-42.0882797241 -42.8320808411-43.4657897949 $-44.1268806458-44.9227104187-46.0711593628-47.8728485107-49.9389801025$ $-52.0557594299-54.1838798523-56.1991004944-57.7710494995-58.4726791382$ $-58.7125816345-58.9299316406-58.9884490967-58.7546310425-58.4275398254$ $-58.2529602051-58.1784896851-58.2681694031-58.3562011719-58.246509552$ $-58.0654602051-57.9179992676-57.7139205933-57.3758392334-57.0400085449$ $-56.8486595154-56.6707000732-56.4066696167-56.127948761-55.8864707947$ $-55.6830711365-55.5360794067-55.3725318909-55.1395797729-54.8746681213$ $-54.6159896851-54.3733215332-54.1255912781-53.8916702271-53.6938018799$ $-53.4928703308-53.2931785583-53.0973396301-52.8646583557-52.6304206848$ $-52.3955993652-52.1666488647-51.9731903076-51.7953605652-51.6182098389$ $-51.4194107056-51.1672706604-50.8544692993-50.4747009277-50.0529518127$ $-49.6052894592-49.1708297729-48.78881073-48.3890190125-47.9086799622$ $-47.3961906433-46.8942604065-46.3587417603-45.739151001-45.0871810913$ $-44.432308197-43.8123817444-43.2673492432-42.7499198914-42.2293701172$ $-41.6880912781-41.1252098083-40.5070991516-39.8155403137-39.0331382751$ -38.1310195923 -37.1730194092 -36.202129364 -35.1781196594 -34.0655517578 $-32.8720588684-31.6151409149-30.2917995453-28.9145793915-27.4814395905$ -25.9893894196 -24.4486293793 -22.8576507568 -21.2377300262 -19.6046905518 $-17.9815807343-16.3852996826-14.8839302063-13.5700597763-12.290430069$ $-10.9208698273-9.5097284317-8.07284545898-6.6121339798-5.11147499084$ 
-3.58809089661 -2.05652809143 -.552738010883 .8863469958305 2.264986991882 3.5721731185914 .8384971618656 .1006808280947 .3439159393318 .566264152527 9.75751972198510 .8976202011111 .9879999160813 .0213403701814 .01231002808 14.9751796722415 .8855495452916 .7194309234617 .5122299194318 .29660987854 19.0791301727319 .8730907440220 .6833400726321 .5195598602322 .38429069519 23.2849102020324 .2215499877925 .1994991302526 .2199897766127 .28727912903 28.4110794067429 .598770141630 .8437900543232 .1521682739333 .5047416687 34.8905181884836 .2953300476137 .6932792663639 .0784988403340 .43872070312 41.7730903625543 .0772781372144 .3554306030345 .6054115295446 .86212158203 48.1591987609949 .4675483703650 .7616310119652 .046741485653 .32302093506 54.5942993164155 .8636398315457 .1362915039158 .4174690246659 .71765136719 61.0462608337462 .4006118774463 .7890510559165 .1998214721766 .62847137451 68.0690231323269 .5063171386770 .9419937133872 .3709869384873 .797706604 75.2243118286176 .6550674438578 .0951309204179 .5494308471781 .02321624756 82.5201263427784 .0459518432685 .5999221801887 .1861190795988 .80149841309 90.4474411010792 .1220626831193 .8234863281295 .5454406738397 .28311920166 99.02852630615100 .7731018066102 .5127029419104 .2362976074105 .9441986084 107.6324996948109 .3028030396110 .9551010132112 .591003418114 .2124023438 115.820602417117 .4178009033119 .0048980713120 .5837020874122 .154800415 123.7193984985125 .2777023315126 .8302993774128 .3771972656129 .9187011719 131.4546051025132 .9850006104134 .5097045898136 .0287017822137 .5419006348 139.0491943359140 .5505065918142 .0457000732143 .5348052979145 .0178070068 146.4945983887147 .9649963379149 .4290924072150 .8867950439152 .3379974365 153.7825927734155 .2205047607156 .6515045166158 .0756988525159 .4927062988 160.9026031494162 .3052978516163 .7003936768165 .088104248166 .4682006836 167.8404998779169 .2050018311170 .5615997314171 .9102935791173 .2510070801 174.583694458175 .9084014893177 .224899292178 .533493042179 .8338928223 181.1264038086182 .4107971191183 .6871948242184 .9557952881186 .2164001465 187.4691925049188 .7142944336189 .9517974854191 .1817016602192 .4042053223 193.6192932129194 .8271942139196 .0279998779197 .2218933105198 .408996582 199.5894012451200 .7633056641201 .9308929443203 .092300415204 .2476043701 205.3968963623206 .5402984619207 .6779937744208 .8099060059209 .9360961914 211.0565948486212 .1714019775213 .2805023193214 .383895874215 .4813995361 216.5733947754217 .6596984863218 .7357940674219 .8052978516 56.6106185913156 .2220191955655 .7465209960955 .1167602539154 .36207962036 53.4889717102152 .5088691711451 .4341392517150 .279018402149 .05992889404 47.7925109863346 .4952888488845 .1834907531743 .8759689331142 .58700180054 41.3340682983440 .129470825238 .984939575237 .9239082336436 .96689987183 36.1213989257835 .3914108276434 .7839393615734 .2906112670933 .92736053467 33.6890602111833 .5678710937533 .5341300964433 .5986900329633 .76306915283 33.9957504272534 .3003807067934 .6003913879434 .8947906494135 .07445144653 35.1064605712934 .9175605773934 .438751220733 .6718902587932 .53533935547 31.1159591674829 .3885993957527 .4642295837425 .3896808624323 .26334953308 21.1877498626719 .2236309051517 .4625396728515 .940110206614 .71891021729 13.8198699951213 .2780303955113 .1082401275613 .3224802017213 .93797016144 14.9547395706216 .3999691009518 .2832508087220 .6037693023723 .35436058044 
26.4904003143329 .9771595001233 .7240905761737 .6387786865241 .70167160034 45.8001899719249 .9260902404853 .9836196899457 .9084281921462 .0241317749 64.9422531127965 .1272888183664 .1454772949263 .2897109985462 .22959136963 61.0839004516659 .8442306518658 .5206985473657 .0908088684155 .53802871704 53.808040618951 .8692283630449 .6822814941447 .1994209289644 .50506973267 41.6078186035238 .6732482910235 .77455902132 .9438095092830 .21487998962 27.5756607055725 .0779304504422 .6265392303520 .1889305114717 .68915939331 15.0820903778112 .325570106519 .3702421188356 .2762222290043 .039875030518 $-0.16092300415-3.31000900269-6.1490240097-8.57567501068-10.5693302155$ $-12.1077003479-13.4057703018-14.3468103409-15.9682998657-19.2497005463$ $-23.4125900269-28.1823501587-32.6223907471-35.674331665-37.9898300171$ -39.9025192261 -41.3792381287-42.4770889282-43.3230781555-43.9971313477 $-44.6954917908-45.4629592896-46.6971092224-48.8146781921-51.359210968$ $-54.0196800232-56.6032295227-59.0766792297-60.9235801697-61.5437316895$ $-61.6852989197-62.0091018677-62.1590499878-61.8869895935-61.5073509216$ $-61.2909202576-61.1860809326-61.2965698242-61.4018592834-61.2212905884$ $-60.9871482849-60.8821296692-60.7280883789-60.3463401794-59.9688682556$ $-59.8227310181-59.6894607544-59.3807106018-59.0575904846-58.8201408386$ $-58.6402397156-58.5539703369-58.4372787476-58.1591796875-57.8335494995$ $-57.5442199707-57.2462997437-56.9189987183-56.6164283752-56.3786506653$ $-56.1893997192-56.0195198059-55.8097000122-55.4975204468-55.1631088257$ $-54.870300293-54.6187896729-54.3993797302-54.1977386475-53.9914207458$ $-53.7643699646-53.4953308105-53.1718292236-52.8016586304-52.4011993408$ -51.9875488281 -51.5633506775 -51.1239395142 -50.6573295593 -50.1723098755 $-49.6546897888-49.0960006714-48.4878997803-47.7848701477-47.0529289246$ $-46.3111114502-45.6137695312-45.0171699524-44.4590797424-43.8951301575$ $-43.3192100525-42.7553901672-42.141330719-41.4763908386-40.7176895142$ -39.8170013428 -38.8661117554 -37.934009552 -36.9522895813 -35.8604888916 $-34.6861801147-33.4661216736-32.1833992004-30.8487300873-29.4445800781$ $-27.9531993866-26.3949394226-24.7616291046-23.0931797028-21.3878593445$ -19.6940002441 -18.003950119-16.4306106567-15.1421403885 -13.897190094 $-12.4993000031-11.0365600586-9.54934692383-8.02696323395-6.46734809875$ $-4.8995847702-3.34138298035-1.80835700035-0.301050990821 .143396019936$ 2.4757819175723 .7700059413915 .085976123816 .3951878547677 .680665016174 8.93127346038810 .1223497390711 .2587699890112 .3344202041613 .35540008545 14.32374000549 15.240130424516.1049098968516.9332809448217.74131011963 18.5415000915519 .3500595092820 .1723403930721 .0206508636521 .89546966553 22.806499481223 .7504997253424 .7349605560325 .7567291259826 .82209014893 27.9352893829329 .1071891784730 .347930908231 .6668205261233 .0411605835 34.441551208535 .85393142737 .2547798156738 .6378784179739 .99280166626 41.3170204162642 .6069183349643 .8658103942945 .079101562546 .29988861084 47.5815505981448 .8757781982450 .1412506103551 .3944282531752 .63698959351 53.8721809387255 .1061210632356 .3415985107457 .5864295959558 .84769821167 60.1390686035261 .4685897827162 .8497886657764 .2667922973665 .70603942871 67.1578826904368 .6093902587970 .0608367919971 .5074691772572 .95195770264 74.3953018188575 .8396835327177 .2885131835978 .7439727783280 .20886230469 
81.6873779296983 .1828002929784 .6969528198286 .2337722778387 .79196929932 89.3765106201290 .9856109619192 .6223297119194 .2869491577195 .97849273682 97.6874694824299 .39923858643101 .1091995239102 .8063964844104 .4913024902 106.1600036621107 .8140029907109 .4536972046111 .0799026489112 .6952972412 114.3000030518115 .8965988159117 .4849014282119 .0668029785120 .641998291 122.2114028931123 .7748031616125 .3323974609126 .8840026855128 .4295043945 129.9687042236131 .5014038086133 .0276031494134 .5469970703136 .0596008301 137.5653991699139 .0643005371140 .5561981201142 .0411987305143 .5193023682 144.9904937744146 .4548950195147 .912399292149 .3628997803150 .8065032959 152.2431945801153 .6728057861155 .0953979492156 .5108032227157 .9190063477 159.3197937012160 .7131958008162 .0989990234163 .4772949219164 .8479003906 166.2106018066167 .5655975342168 .9127044678170 .2518005371171 .5829925537 172.9062042236174 .2212982178175 .528503418176 .8276062012178 .1188049316 179.4019927979180 .6772003174181 .9445953369183 .2041015625184 .4559020996 185.6999969482186 .9364013672188 .1652984619189 .3867950439190 .6009063721 191.807800293193 .007598877194 .2003936768195 .386505127196 .5657958984 197.7386016846198 .9051055908200 .0653076172201 .2194976807202 .3675994873 203.5099945068204 .6464996338205 .7774047852206 .9026947021208 .0223999023 209.1363983154210 .2449951172211 .3479003906212 .4452972412213 .536895752 214.6230926514215 .7032012939216 .7781982422217 .8462982178 64.9787063598664 .7410888671964 .2946319580163 .6376304626562 .8716583252 61.9874992370660 .9965209960959 .9107398986858 .7439308166557 .51224136353 56.2307815551854 .9184989929253 .5878982543952 .256000518850 .93881988525 49.6576194763248 .4182090759347 .2300415039146 .1187705993745 .10995101929 44.2070503234943 .4179687542 .737998962442 .1557197570841 .68833160441 .33609008789 41.0884399414140 .919219970740 .8409805297940 .8603782653840 .96269989014 41.1556091308641 .3770599365241 .6136589050341 .7466201782241 .71773910522 41.4280395507840 .7732086181639 .7449493408238 .2642707824736 .39429092407 34.1170692443831 .5529308319128 .7863998413125 .9237804412823 .1030292511 20.391880035417 .8955192565915 .6558904647813 .7412099838312 .17636966705 10.9996995925910 .226949691779 .873897552499 .96028423309310 .49069976807 11.4876298904412 .9583101272614 .9048700332617 .3283805847220 .18424987793 23.4276294708327 .0014991760330 .8289909362834 .8857498168939 .08266067505 43.36914062547 .6303482055751 .783760070855 .8248291015658 .82472991943 59.8294792175359 .7999610900959 .5802688598659 .1380882263258 .59600067139 57.9550704956157 .2719688415556 .4970397949255 .6184005737354 .56079864502 53.2838287353551 .7018890380949 .7255592346247 .4680709838944 .94478988647 42.2101593017639 .3163909912136 .333148956333 .4003601074230 .62413024902 28.1611099243225 .8036804199223 .4224491119420 .961910247818 .36598968506 15.5890302658112 .584830284129 .353774070745 .8710741996772 .281053066254 -1.40366995335 -4.77902698517 -7.52601003647 -9.73898983002 -11.4649000168 $-12.825050354-13.8103504181-15.1933202744-17.5309906006-20.8568096161$ -25.6754207611 -30.543390274 -34.181350708 -37.1493682861 -39.5053100586 $-41.2877693176-42.5712089539-43.5025787354-44.2247581482-44.9201393127$ $-45.6857795715-46.9708404541-49.2373809814-52.1015281677-55.4008102417$ $-58.499168396-60.8209991455-62.4248695374-63.2177505493-63.6070404053$ 
$-63.9847602844-64.1655426025-64.0448608398-63.8027305603-63.6482696533$ $-63.5703392029-63.6379508972-63.6902313232-63.5718917847-63.4078598022$ $-63.3071289062-63.1608810425-62.8698387146-62.5716094971-62.4075889587$ $-62.2478218079-61.989238739-61.718208313-61.5093994141-61.3511009216$ $-61.2540817261-61.1279907227-60.8989715576-60.6315002441-60.4031410217$ $-60.1090202332-59.638420105-59.1898193359-58.9474105835-58.8254890442$ $-58.7897186279-58.6401596069-58.153629303-57.613861084-57.2742385864$ $-57.0245018005-56.804889679-56.5952796936-56.3589286804-56.1041984558$ $-55.824760437-55.4997901917-55.1381797791-54.7519187927-54.3324890137$ $-53.8845901489-53.4112014771-52.904510498-52.3972511292-51.8607406616$ $-51.2705917358-50.6161689758-49.86977005-49.080280304-48.2632904053$ $-47.4720993042-46.7513504028-46.0763816833-45.4338607788-44.8160591125$ $-44.2464408875-43.6624908447-43.0521202087-42.3575897217-41.5130805969$ -40.6079406738 -39.6904907227 -38.7137794495 -37.6343917847 -36.4814186096 -35.3033409119 -34.0823287964 -32.8296890259 -31.4916095734 -30.0126895905 $-28.4354991913-26.7756500244-25.0614395142-23.2951107025-21.5344696045$ -19.8104190826 -18.2005500793 -16.811000824 -15.4868297577 -14.1262598038 -12.6978302002 -11.1441602707 -9.53600597382 -7.91426086426 -6.29568099976 $-4.69847488403-3.12805008888-1.59166502953-.1169020012021 .25248503685$ 2.5977699756624 .0041718482975 .4108161926276 .7709178924568 .081480026245 9.32255458831810 .4991798400911 .6100502014212 .6565704345713 .64243984222 14.5759401321415 .4620504379316 .3147392272917 .1436691284217 .96101951599 18.7845497131319 .6206798553520 .4821491241521 .3708095550522 .29575920105 23.2548999786424 .2542800903325 .2892208099426 .3627490997327 .47153091431 28.6109695434629 .832799911531 .1928596496632 .6182899475134 .04159164429 35.463169097936 .8683891296438 .2507286071839 .6014900207540 .91947937012 42.2034187316943 .4543609619144 .6655807495145 .8745307922447 .11455154419 48.3590202331549 .5836410522550 .7955818176351 .9975891113353 .19379043579 54.3893089294455 .5874404907256 .7943115234458 .0140304565459 .25006103516 60.5406799316461 .9296989440963 .3700294494664 .8223037719766 .28502655029 67.7489395141669 .2142028808670 .6768722534272 .1380691528373 .59734344482 75.0550613403376 .5127563476677 .969169616779 .4238891601680 .88223266602 82.3475494384883 .8222808837985 .309288024986 .8108978271588 .33486175537 89.8788070678791.4431762695393.0440216064594.6992034912196.38069152832 98.0610122680799 .73950195312101 .4077987671103 .0667037964104 .7128982544 106.3479995728107 .9725036621109 .5874023438111 .1949005127112 .7951965332 114.3900985718115 .9794998169117 .5641021729119 .1436004639120 .7180023193 122.2867965698123 .8498001099125 .4064025879126 .956199646128 .4990997314 130.0345001221131 .5623931885133 .0825042725134 .5948028564136 .0991973877 137.5957946777139 .0845947266140 .5655975342142 .0390014648143 .5048065186 144.963104248146 .4140014648147 .8574981689149 .2935943604150 .7223968506 152.1439056396153 .5579986572154 .9647064209156 .3639068604157 .7557067871 159.1398010254160 .5164031982161 .8851928711163 .246307373164 .5995941162 165.9450073242167 .2825012207168 .6119995117169 .9337005615171 .2472991943 172.5529022217173 .8506011963175 .1403961182176 .4221954346177 .696105957 178.9622039795180 .2203979492181 .4709014893182 .7138061523183 .949005127 
185.1768035889186 .3970947266187 .6101074219188 .8157958984190 .0144958496 191.2061004639192 .3910064697193 .5691070557194 .7407073975195 .9058990479 197.0648040771198 .2176971436199 .3645019531200 .5054931641201 .6407928467 202.770401001203 .8945007324205 .0131072998206 .1262969971207 .2339019775 208.3361053467 209.4329071045210.5240936279211.6098937988212.6903076172 213.7651977539214 .8305053711215 .8896026611

74.1118698120173 .7006912231473 .2035827636772 .555099487371 .78331756592 70.8946228027369 .8995285034268 .8102111816467 .6395721435566 .40351104736 65.1163101196363 .7969589233462 .4565391540561 .1090316772559 .77291107178 58.4713096618757 .2078514099155 .9865798950254 .8347511291553 .77619171143 52.8190498352151 .9660797119151 .2133903503450 .5265884399449 .93605041504 49.4302902221749 .0166511535648 .6571693420448 .3897018432648 .21625900269 48.1442604064948 .2004814147948 .3139610290548 .5179405212448 .62702178955 48.6272506713948 .3054008483947 .5378990173346 .3187904357944 .50819015503 42.2154197692939 .3639984130936 .1275291442932 .6392707824729 .02045059204 25.4402008056621 .9707107543918 .7274894714415 .7590503692613 .13757991791 10.893560409559 .0642690658577 .6721072196966 .7289490699776 .259874820709 6.2660851478586 .7738780975347 .7853541374219 .3105115890511 .35857009888 13.8821601867716 .8390903472920 .1908607482923 .8790092468327 .86239051819 32.0615806579636 .3820304870640 .7086410522544 .8210601806648 .49811935425 51.4408187866253 .3836898803754 .5516891479555 .188339233455 .46755981445 55.6040382385355 .628341674855 .6321296691955 .5631484985455 .40996932983 55.0854797363354 .5623397827153 .6765403747652 .2990989685150 .53374099731 48.3361892700245 .7993011474642 .9409484863339 .8900909423836 .8412399292 33.9641189575231 .5524997711229 .3113498687727 .0427207946824 .68374061584 22.1896190643319 .4668292999316 .5363693237313 .296259880079 .66592502594 $5.8206701278691 .636752009392-2.28506803513-5.51144981384-8.12298202515$ -10.3010597229 -11.9456100464 -13.2155504227 -14.4142799377 -15.5581197739 $-17.9636306763-22.7500190735-28.1057891846-32.4337501526-35.9459381104$ -38.7029495239 -40.815700531-42.3169898987-43.3905410767-44.1851882935 $-44.9062995911-45.6349906921-46.8797492981-49.0853805542-52.0044403076$ $-55.7033004761-59.1797294617-61.3444290161-62.7698516846-63.8854408264$ $-64.6008300781-65.0580368042-65.3087005615-65.386932373-65.3662109375$ $-65.3470611572-65.3382034302-65.3719863892-65.4028167725-65.3830871582$ $-65.3324203491-65.2505264282-65.1340789795-64.9652862549-64.7807922363$ $-64.6031494141-64.4250793457-64.2354202271-64.0521774292-63.8912391663$ $-63.7507896423-63.6289405823-63.4971618652-63.3417015076-63.164188385$ $-63.0171585083-62.7649002075-62.2017707825-61.6593093872-61.4272689819$ $-61.342590332-61.3894691467-61.2951011658-60.6704788208-59.9782600403$ $-59.6122398376-59.3640899658-59.1365585327-58.9115715027-58.6216201782$ $-58.3130187988-58.0012702942-57.6873283386-57.3660583496-56.9906997681$ $-56.5455093384-56.0393104553-55.5295982361-55.0091400146-54.4972991943$ $-53.9603500366-53.3493118286-52.6726112366-51.8876495361-51.0446205139$ $-50.1359710693-49.2230606079-48.3302688599-47.4876289368-46.7219810486$ $-46.032749176-45.4553489685-44.9117088318-44.414981842-43.8214607239$ $-43.0861091614-42.2555809021-41.3467597961-40.3760299683-39.3241081238$ 
-38.2099609375 -37.1104698181 -35.9871292114 -34.8491096497 -33.6215896606 -32.1919593811 -30.6405601501 -28.9738197327 -27.2320899963 -25.390920639 -23.5618305206 -21.7833900452 -20.1006298065 -18.5675506592 -17.1253604889 $-15.793800354-14.411359787-12.8133602142-11.1261997223-9.44897079468$ $-7.77847194672-6.12835216522-4.51636600494-2.94808197021-1.43576705456$ -1.3567000e-02 1.404183030128 2.910125017166 4.4174189567575.846079826355 7.2117800712598 .4969263076789 .70731544494610 .8479604721111 .91969966888 12.9264297485413 .879039764414 .7836799621615 .6541099548316 .49863052368 17.3309497833318 .1681194305419 .016460418719 .891809463520 .79434013367 21.7377605438222 .7159500122123 .7402400970524 .7987594604525 .89712905884 27.0256404876728 .1604194641129 .381969451930 .7850093841632 .25609970093 33.6924285888735 .1217994689936 .529018402137 .9101295471239 .26102828979 40.5785102844241 .8620109558143 .1154899597244 .3333091735845 .53361129761 46.7248497009347 .9078903198249 .080490112350 .2440681457551 .40000152588 52.5518493652353 .70619964654 .8645591735856 .0348701477157 .21912002563 58.4099807739359 .6652984619161 .0582084655862 .5125083923363 .9701385498 65.4406967163166 .9154434204168 .3931732177769 .8708267211971 .34768676758 72.8222732543974 .2931518554775 .7611083984477 .2197799682678 .66578674316 80.1051406860481 .5381774902382 .9710998535284 .4077301025485 .85246276855 87.3193511962988 .8050231933690 .3052673339891 .8476333618293 .46530151367 95.115516662696 .7589416503998 .40331268311100 .0394973755101 .6691970825 103.2900009155104 .9029998779106 .5102996826108 .1119003296109 .7107009888 111.3058013916112 .8991012573114 .4895019531116 .0773010254117 .6613006592 119.2409973145120 .8155975342122 .3841018677123 .9460983276125 .50050354 127.047203064128 .5854034424130 .1150970459131 .6360015869133 .1481018066 134.6511993408136 .1455993652137 .6313018799139 .1083984375140 .5769958496 142.037399292143 .4897003174144 .9340057373146 .3704986572147 .7991027832 149.2200012207150 .6333007812152 .0388946533153 .4369049072154 .8273010254 156.2098999023157 .5848999023158 .9521026611160 .3114929199161 .6631011963 163.0068969727164 .3426971436165 .6705932617166 .9906005859168 .3025970459 169.6065979004170 .9028015137172 .19090271173 .471206665174 .7436065674 176.0083007812177 .2651062012178 .5142059326179 .7557067871180 .9895935059 182.216003418183 .4349975586184 .646697998185 .8511047363187 .0484008789 188.2388000488189 .4223022461190 .599105835191 .7693023682192 .9331054688 194.0906982422195 .2420043945196 .3874053955197 .5269927979198 .6607971191 199.7890014648200 .9116973877202 .0289001465203 .1407928467204 .2472991943 205.3484954834206 .4443969727207 .5348968506208 .6199951172209 .699798584 210.7743988037211 .8430023193212 .9069976807213 .9644012451 83.2509384155382 .9937362670982 .5336990356481 .8687362670981 .09736633301 80.2105102539179 .2186431884878 .1333923339876 .9671936035275 .73554992676 74.451446533273 .1324462890671 .7901229858470 .4408187866269 .09884643555 67.7836532592866 .5021133422965 .2655487060564 .0850067138762 .97401046753 61.9496002197361 .0309104919460 .1894989013759 .3867416381858 .64088058472 57.9458084106457 .310268402156 .7133789062556 .1984291076755 .77772140503 55.4869918823255 .3623695373555 .3686714172455 .5355300903355 .68722915649 55.7871398925855 .5342216491754 .7034187316953 .3205795288151 .26008987427 
48.5716514587445 .1379890441941 .1870613098136 .956329345732 .56645965576 28.2186107635523 .9872608184819 .9949398040816 .2921791076712 .96103000641 10.028889656077 .5392508506775 .5114221572883 .9626479148862 .912591934204 2.3674120903022 .3520770072942 .8763589859013 .9477629661565 .569952964783 7.70975303649910 .3320999145513 .4060401916516 .8810901641820 .70405006409 24.7976303100629 .0489196777333 .3436508178737 .4197196960441 .06583023071 44.2561111450246 .7638282775948 .7523117065450 .2009696960451 .25037002563 52.1397285461452 .9069404602153 .6411705017154 .3142395019554 .92803955078 55.3990402221755 .6884002685555 .5620002746654 .8811302185153 .67081832886 51.7836303710949 .4110107421946 .6240386962943 .5711402893140 .56642913818 37.7452888488835 .3298606872633 .1415901184131 .0709705352828 .93737983704 26.5847606658924 .007530212421 .2660198211718 .1638202667214 .59311962128 $10.655329704286 .2242140769961 .810127973557-2.21592998505-5.72096681595$ -8.58126831055 -10.7508001328 -12.3145399094 -13.2420396805-13.3459701538 $-14.9457998276-20.2324695587-26.4282894135-31.0990905762-34.7405395508$ -37.6182098389 -39.9325790405-41.7069816589-42.9938697815-43.8866500854 $-44.5850410461-45.2007904053-46.2159690857-48.0814590454-50.7055091858$ $-54.2488517761-57.7644309998-60.4273681641-62.4352798462-63.7841491699$ $-64.6810531616-65.2949981689-65.6982879639-65.9811172485-66.1644897461$ -66.306968689-66.4045181274-66.5054626465-66.5986862183-66.6751327515 $-66.7219772339-66.7191314697-66.6786804199-66.6040115356-66.5008621216$ $-66.3723602295-66.231552124-66.0961837769-65.9732437134-65.8653869629$ $-65.7577209473-65.6610870361-65.5641708374-65.4566726685-65.3338623047$ $-65.1988372803-64.9580764771-64.5155563354-64.0763168335-63.8303413391$ $-63.6915397644-63.6221313477-63.4260215759-62.8871803284-62.2890510559$ $-61.8895187378-61.5954589844-61.3637084961-61.1036682129-60.7050514221$ $-60.2816390991-59.9122314453-59.6068611145-59.4046783447-59.1158714294$ $-58.5683708191-57.93201828-57.3830795288-56.8678283691-56.3822784424$ $-55.8694000244-55.2635307312-54.5655288696-53.733039856-52.80260849$ $-51.7766990662-50.7038002014-49.6273612976-48.5987091064-47.6726303101$ $-46.8883895874-46.3050918579-45.8492889404-45.5158309937-45.0922889709$ $-44.4561080933-43.6943702698-42.820930481-41.8871002197-40.9010009766$ -39.864818573 -38.8748092651 -37.8856391907 -36.8794212341 -35.7775611877 $-34.4806518555-33.0209007263-31.3880901337-29.6177406311-27.7015094757$ -25.7631092072 -23.8571205139-22.0304393768 -20.3823699951 -18.8603096008 $-17.4931602478-16.1095294952-14.5030202866-12.788189888-11.0621204376$ -9.33822536469 -7.62915802002 -5.95564222336 -4.32627677917 -2.74375700951 $-1.23713302612 .27041798830031 .8539570569993 .4286210536964 .91579580307$ 6.3256459236157 .6474652290348 .88711452484110 .0524702072111 .1468000412 12.1738500595113 .1443500518814 .0649995803814 .9488897323615 .80582046509 16.6496505737317 .4968204498318 .356370925919 .2441806793220 .1637096405 21.1276798248322 .1334991455123 .1895103454624 .2877197265625 .43099975586 26.6101493835427 .8169498443629 .0989398956330 .5067501068131 .96603965759 33.4036102294934 .8310813903836 .2351112365737 .614540100138 .97093963623 40.2950210571341 .5822715759342 .837749481244 .0507316589445 .22927093506 46.3820114135747 .5131301879948 .6318206787149 .7422409057650 .84627151489 
51.949359893853 .0579605102554 .176761627255 .3134689331156 .47262954712 57.658481597958 .9106292724660 .2737998962461 .7004394531263 .15092849731 64.6219406127966 .1034927368267 .5930862426869 .0844573974670 .57684326172 72.0669326782273 .5527267456175 .0328674316476 .4963836669977 .93816375732 79.3612136840880 .7597808837982 .1476898193483 .5325317382884 .92162322998 86.3342819213987 .7695236206189 .2304992675890 .7338562011792 .29850769043 93.8952026367295 .4953536987397 .0998229980598 .70072174072100 .2990036011 101.8909988403103 .4794998169105 .0671005249106 .6540985107108 .2428970337 109.8327026367111 .4242019653113 .0160980225114 .6072006226116 .1962966919 117.7817001343119 .3625030518120 .9368972778122 .5044021606124 .0635986328 125.6140975952127 .1551971436128 .6867980957130 .2084960938131 .720199585 133.2220001221134 .7140960693136 .1965942383137 .6696929932139 .133605957 140.5885009766142 .0348052979143 .4723968506144 .9017944336146 .3229064941 147.7359008789149 .1410064697150 .5381011963151 .9273986816153 .3087005615 154.6822967529156 .0480041504157 .4058990479158 .7559051514160 .0979003906 161.4320983887162 .7583007812164 .0765991211165 .3869018555166 .6893005371 167.9837036133169 .2702941895170 .5489044189171 .8197021484173 .0827026367 174.3379974365 175.5856018066176 .8255004883178 .0579071045179 .2828063965 180.5003051758181 .7104949951182 .9134979248184 .1094055176185 .2982940674 186.4803924561187 .6557006836188 .8244934082189 .9866943359191 .1427001953 192.2924957275193 .4362030029194 .5742034912195 .7064056396196 .8329925537 197.9541015625199 .0697021484200 .1800994873201 .2852020264202 .3851013184 203.4797973633204 .5693054199205 .6535949707206 .7326049805207 .8063964844 208.8751068115209.9385986328210.9927978516212.0413970947

93.1324386596792 .7149200439592 .2141876220791 .5680465698290 .80283355713 89.9248428344788 .9434585571387 .8705825805786 .7174530029385 .49957275391 84.2283172607482 .9197463989381 .5863800048880 .2463226318478 .90968322754 77.5906906127976 .3016967773475 .059158325273 .8639526367272 .71089935303 71.6272430419970 .6342620849669 .6954421997168 .7521209716867 .83225250244 66.9043426513766 .0069198608465 .1036834716864 .2764434814563 .51583862305 62.9167900085462 .5131492614762 .3216209411662 .4133300781262 .57801818848 62.8902397155862 .7983589172462 .0756683349660 .6756706237858 .36629867554 55.2714691162151 .2350997924846 .552181243941 .6015090942436 .48831176758 31.4059391021726 .4545097351121 .7376899719217 .3271198272713 .30101013184 9.6982793807986 .5508890151983 .892749071121 1.726263999939 8.65100026e-02 -1.03265500069-1.59530699253-1.59113800526-1.01205301285 0.146621003747 1.861943960194 .1138358116156 .86454200744610 .0745601654113 .67090988159 17.5826492309621 .6796798706125 .8718891143829 .940429687533 .6921081543 37.1359596252440 .1239509582542 .7307205200244 .8854217529346 .71105957031 48.3736610412649 .893131256151 .357139587452 .7549400329654 .10792922974 55.3447418212956 .4247283935557 .1535606384357 .3506698608456 .75616073608 55.1502799987852 .8121795654350 .0692405700747 .1371192932144 .31060028076 41.6518592834539 .2822494506837 .1518707275435 .2818183898933 .41061019897 31.3065605163629 .0034809112526 .6617698669423 .95619964620 .78535079956 $16.9908695220912 .427760124217 .6389288902282 .858220100403-1.5139349699$ $-5.30857419968-8.23563766479-10.5636901855-11.8452501297-11.7284898758$ 
-12.810500145 -17.8638095856 -24.2792892456 -29.0114994049 -32.9338417053 -36.1762886047 -38.587020874 -40.6176490784-42.2360916138 -43.2816085815 $-44.0162887573-44.5664405823-45.3148612976-46.6716499329-48.7931404114$ $-51.8935394287-55.338760376-58.5001411438-61.1346282959-62.8556900024$ $-63.9629707336-64.8003463745-65.3840408325-65.8689727783-66.2724914551$ $-66.5882873535-66.8403930664-67.060333252-67.2533721924-67.4430770874$ $-67.6011123657-67.7002868652-67.7601318359-67.7793502808-67.7632598877$ $-67.6982727051-67.6151428223-67.5345230103-67.4595489502-67.3960266113$ $-67.3349380493-67.2876205444-67.237953186-67.1830368042-67.0999603271$ -66.9646072388 -66.7679672241-66.5016326904-66.2219085693-65.9766921997 $-65.7461700439-65.502243042-65.1976699829-64.7882080078-64.345993042$ $-63.9439201355-63.5873908997-63.3204689026-63.0146217346-62.5017204285$ $-61.9693908691-61.5225486755-61.1743087769-61.0228996277-60.7891693115$ $-60.1693382263-59.4500083923-58.9284515381-58.4591903687-58.0278587341$ $-57.5761795044-56.9838104248-56.2715187073-55.3700904846-54.3330688477$ $-53.1538009644-51.898349762-50.6096191406-49.3686485291-48.2443504333$ $-47.3087692261-46.8940200806-46.5836296082-46.2348518372-45.8195610046$ $-45.4949493408-44.9580802917-44.0669517517-43.1461601257-42.2511711121$ $-41.3924598694-40.6039390564-39.8390388489-39.0232696533-38.1157188416$ -36.9984397888 -35.6895904541 -34.1240615845 -32.3566818237-30.3676109314 -28.2783603668 -26.1407108307 -24.1214599609-22.3335399628 -20.7273693085 $-19.2921600342-17.8412399292-16.2108097076-14.4911403656-12.7538099289$ $-10.9847402573-9.21212100983-7.45167398453-5.73378419876-4.06047296524$ -2.44783592224 -.840067982674 .8163149952888 2.443833112717 3.970391988754 5.410651206976 .7612299919138 .0282068252569 .21878147125210 .33689022064 11.383959770212 .372460365313 .3042402267514 .1969804763815 .05945014954 15.9081497192416 .7600097656217 .6252002716118 .5237808227519 .45778083801 20.445940017721 .4819908142122 .5800895690923 .7285099029524 .93544006348 26.191970825227 .5045509338428 .8708705902130 .2911300659231 .73801040649 33.1742095947334 .5973205566435 .9868583679237 .3639411926338 .72998046875 40.0736808776941 .3704605102542 .621650695843 .8190193176344 .97016143799 46.0820693969747 .1637916564948 .227539062549 .279991149950 .32682037354 51.3759002685552 .4349098205653 .5108604431254 .6139984130955 .75318908691 56.9445495605558 .1964416503959 .5252304077160 .9130783081162 .34889984131 63.8177413940465 .3052368164166 .8063507080168 .3106231689569 .81764221191 71.3206329345772 .8191375732474 .3086471557675 .7816009521577 .2289276123 78.6383438110480 .0005416870181 .3347473144582 .6650085449284 .00324249268 85.3679504394586 .7620620727588 .1936492919989 .6640701293991 .174949646 92.7142333984494 .2661437988395 .8287124633897 .3900833129998 .95279693604 100.5130996704102 .073600769103 .6405029297105 .2118988037106 .7912979126 108.3762969971109 .9670028687111 .5613021851113 .15650177114 .7512969971 116.3427963257117 .9300003052119 .5102996826121 .0832977295122 .647102356 124.201499939125 .745300293127 .278503418128 .8005981445130 .3119049072 131.8121948242133 .3018035889134 .7808990479136 .2498016357137 .7088012695 139.1580963135140 .5982055664142 .0290985107143 .4512023926144 .8647003174 146.2698059082147 .666595459149 .0550994873150 .4355926514151 .8079986572 
153.1723937988154 .528793335155 .8771972656157 .2176971436158 .550201416 159.8746948242161 .1912994385162 .4998931885163 .8005981445165 .0933074951 166.3780975342167 .6549987793168 .9241027832170 .1853942871171 .4389038086 172.6847991943173 .9230957031175 .153793335176 .3771057129177 .5930023193 178.8014984131180 .0028991699181 .1972045898182 .3845977783183 .5650024414 184.7386932373185 .9058074951187 .06640625188 .220703125189 .3688049316 190.5108947754191 .6470031738192 .7774047852193 .9022979736195 .0216064453 196.1356048584197 .2442016602198 .3477020264199 .446105957200 .5393066406 201.6273956299202 .7104949951203 .7884979248204 .8614044189205 .9290924072 206.991897583208.0491027832209.1018066406210.1481933594 103.0197982788102 .7562026978102 .3001022339101 .6491012573100 .8965988159 100.034202575799 .0713424682698 .0190811157296 .8883438110495 .69374847412 94.4459381103593 .1605834960991 .848632812590 .5261611938589 .20262908936 87.8931579589886 .6078033447385 .3615493774484 .1528015136782 .98734283447 81.863006591880 .78320312579 .7143173217878 .6118621826277 .47805786133 76.2864227294975 .0649032592873 .7953567504972 .5569381713971 .3628616333 70.3351821899469 .5388870239369 .063056945869 .0129165649469 .24535369873 69.8018188476670 .0123291015669 .6013870239368 .3697967529365 .80220031738 62.2288703918557 .5931701660252 .1752014160246 .5218200683640 .7342300415 34.9827308654829 .359170913723 .9765796661418 .8925304412814 .2097902298 $9.9550867080696 .1737451553342 .8885219097140 .111818999052-2.12786507607$ -3.82195711136-4.94800901413 -5.49932384491 -5.45298719406-4.7882809639 -3.52601289749-1.68205595016 0.709743976593 3.6099679470066 .946179866791 10.6416597366314 .5819101333618 .6533699035622 .7122192382826 .58033943176 30.2708301544233 .6585083007836 .7833290100139 .5585289001542 .08079910278 44.4292907714846 .6424484252948 .7834510803250 .8553199768152 .87435913086 54.810970306456 .6361885070858 .2731781005959 .7407188415560 .12815856934 58.4764404296955 .8402481079153 .1389808654850 .3939094543547 .80072021484 45.360351562543 .1717987060541 .2036705017139 .4857292175337 .86483001709 36.1928596496634 .4537086486832 .7557907104530 .7973899841328 .4790802002 25.1952590942420 .2629508972214 .84574031839 .9124965667725 .043437004089 -6.2272999e-02 -4.57913208008 -8.12113952637 -10.4357995987 -11.7062997818 $-13.1578302383-15.4936504364-19.4390907288-25.3184890747-30.8907604218$ $-34.4148216248-36.8250007629-39.0773086548-41.0605812073-42.3617591858$ $-43.2009811401-43.8240814209-44.3726501465-45.0838088989-46.526309967$ $-49.3852500916-52.8396110535-55.9478912354-58.7201690674-60.9995384216$ $-62.6473388672-63.6604003906-64.3763198853-65.0666122437-65.6924514771$ $-66.2253036499-66.6640090942-67.0268936157-67.3432388306-67.6626205444$ $-67.9451065063-68.1692962646-68.3458786011-68.4725112915-68.5479431152$ $-68.5558929443-68.530632019-68.500793457-68.4689102173-68.4483566284$ $-68.4352493286-68.4418334961-68.4489517212-68.4526367188-68.4250488281$ $-68.3467636108-68.2316665649-68.0653076172-67.8653335571-67.6483230591$ $-67.3793182373-67.0717697144-66.7395935059-66.3622436523-65.9677581787$ $-65.5758972168-65.1765136719-64.8205032349-64.4149169922-63.8576316833$ $-63.2694511414-62.7217407227-62.2588500977-61.9406089783-61.5974502563$ $-61.0748214722-60.5041999817-60.0739593506-59.7008781433-59.369430542$ 
$-58.995929718-58.4422798157-57.7058601379-56.7270507812-55.553981781$ $-54.1995010376-52.7274589539-51.1962089539-50.1584091187-49.3094100952$ $-48.6244506836-48.1110801697-47.6880302429-47.2687492371-46.8219490051$ $-46.3581314087-45.8992385864-45.5355110168-45.2208404541-43.930141449$ $-42.7156410217-42.2667694092-41.8443908691-41.3456993103-40.716129303$ -39.8381690979 -38.7035484314 -37.252571106 -35.5056991577 -33.457901001 $-31.1729297638-28.6544399261-26.2809200287-24.4058704376-22.7688808441$ $-21.1941394806-19.6051597595-17.9177799225-16.2012500763-14.5010204315$ $-12.7433099747-10.8734502792-8.9844379425-7.16268110275-5.38864803314$ -3.6598110199-1.94435799122 -.203996002674 1.4775680303573 .020340919495 4.465775012975 .8365068435677 .1282410621648 .344092369089 .486113548279 10.5533800125111 .5563802719112 .497070312513 .3926801681514 .25500011444 15.1016302108815 .9514398574816 .818080902117 .722440719618 .67163085938 19.683660507220 .7575893402121 .9052295684823 .1186790466324 .40155029297 25.7474002838127 .1546401977528 .6003608703630 .0762901306231 .55336952209 33.0079803466834 .4292106628435 .7805404663137 .1286010742238 .53018951416 39.9169692993241 .2244110107442 .4652709960943 .638538360644 .75402069092 45.8211593627946 .850860595747 .8569908142148 .8486709594749 .83583068848 50.827850341851 .8346290588452 .8656196594253 .9315109252955 .04524993896 56.2209510803257 .4568481445358 .7650909423860 .1319084167561 .55569076538 63.0226516723664 .5149612426866 .025672912667 .5420608520569 .06133270264 70.574493408272 .081748962473 .578399658275 .0633926391676 .53948974609 77.9566879272579 .2630615234480 .5242462158281 .800079345783 .0924987793 84.4158172607485 .7729415893687 .1703567504988 .6028366088990 .07131958008 91.5631866455193 .0700988769594 .5894927978596 .1076736450297 .62998199463 99.15508270264100 .6856994629102 .2294006348103 .7851028442105 .3552017212 106.9367980957108 .5279006958110 .1258010864111 .7264022827113 .3274993896 114.9256973267116 .5195007324118 .1060028076119 .6843032837121 .2526016235 122.8104019165124 .3565979004125 .8910980225127 .4133987427128 .9237976074 130.4221954346131 .908996582133 .3845062256134 .8489074707136 .3027954102 137.746307373139 .1799926758140 .6040039062142 .0187988281143 .4246063232 144.8215026855146 .2098999023147 .5897979736148 .9613952637150 .3247070312 151.6797943115153 .0269012451154 .3657989502155 .6967926025157 .0196075439 158.3345031738159 .6412963867160 .9402008057162 .2310943604163 .5140991211 164.7891998291166 .0565032959167 .3159942627168 .5677032471169 .8117980957 171.0482025146172 .2772064209173 .4985961914174 .7127075195175 .9196014404 177.1192016602178 .311706543179 .4972991943180 .675994873181 .8480072021 183.0133056641184 .1721954346185 .3246002197186 .4709014893187 .6110992432 188.7454071045189 .8739013672190 .9967956543192 .1143035889193 .2263031006 194.3330993652195 .4347991943196 .5312957764197 .6228027344198 .7093963623 199.7910003662200 .8675994873201 .9393005371203 .0059967041204 .0675964355 205.12449646206.1764984131207.2194976807 208.2572937012 113.6116027832113 .2042007446112 .71849823112 .0966033936111 .362701416 110.5232009888109 .5863037109108 .5635986328107 .4644012451106 .3035964966 105.0901031494103 .8399963379102 .5615997314101 .269096374599 .97216796875 98.6858062744197 .4168014526496 .1763229370194 .9670104980593 .80145263672 
92.6494903564591 .4834136962990 .2830963134889 .0063095092887 .64962768555 86.1626281738384 .5906677246182 .8871612548881 .1742630004979 .42407226562 77.8479080200276 .4729766845775 .5191726684675 .103233337475 .1826171875 75.8505020141676 .5225067138776 .9233169555776 .0370635986373 .25543212891 68.9430694580163 .6327400207557 .7368011474651 .5646896362345 .29861068726 38.9809188842832 .7690505981426 .780759811421 .0951309204115 .80766010284 $10.961359977726 .5745282173162 .697798967361-.688492000103-3.52256608009$ -5.81022691727 -7.51690101624 -8.64914989471 -9.1639251709 -9.01827430725 $-8.23859977722-6.82765197754-4.82733392715-2.26805710793 .7715219855309$ 4.2264418601997 .98329496383711 .9385204315215 .9825096130419 .96903038025 23.8837509155327 .5936107635531 .1383399963434 .4330711364737 .54700088501 40.5002212524443 .3304100036646 .0808982849148 .7580108642651 .37166976929 53.9157905578656 .3833999633858 .7004890441961 .2011299133362 .4686088562 60.9166908264258 .2359199523955 .8242607116753 .3875198364351 .10480117798 48.9773788452147 .0489883422945 .3227310180743 .7847290039142 .43729019165 41.245811462440 .1749305725139 .3602409362838 .2692794799837 .03651809692 34.6331481933629 .8763504028324 .3452301025419 .5475292205814 .55718994141 $8.581271171572 .674645900726-2.54428195953-6.93914318085-11.2392997742$ -13.8607997894 -13.8902997971 -14.7412500381 -20.3590507507 -27.2524700165 -31.1425495148 -34.2515792847 -37.2533607483 -39.442489624 -40.9281082153 $-41.8835716248-42.6472816467-43.2892990112-43.6526794434-44.620929718$ $-47.2416496277-50.39894104-52.9813194275-55.5437393188-58.2333297729$ $-60.4908103943-61.8900299072-62.8277893066-63.7491607666-64.6167831421$ $-65.3441009521-65.966003418-66.4831619263-66.9145965576-67.3769226074$ $-67.8011627197-68.1645584106-68.4739532471-68.7085037231-68.8809280396$ $-68.9578933716-68.9806671143-68.9916610718-68.9954833984-69.0102767944$ $-69.0404586792-69.1041030884-69.1702804565-69.2427368164-69.2913208008$ $-69.2979431152-69.2704772949-69.1798400879-69.0355834961-68.8350601196$ $-68.5688171387-68.2508087158-67.9033737183-67.5390167236-67.1579284668$ -66.7722320557 -66.3533782959-65.930267334-65.4496536255-64.8738021851 $-64.2601318359-63.5962295532-62.9768791199-62.4203681946-61.8970603943$ -61.4592399597-61.0888404846-60.8369407654 -60.6566696167-60.4766807556 $-60.1922111511-59.6664886475-58.896030426-57.8124504089-56.4823303223$ $-54.9270401001-53.2192993164-52.0291900635-51.0678710938-50.3183403015$ $-49.7271003723-49.2180786133-48.7367095947-48.2237091064-47.6693687439$ $-47.1072502136-46.622428894-46.2533111572-45.8502998352-45.233291626$ $-44.6561088562-44.2915382385-44.0301094055-43.9444694519-43.6645889282$ $-43.0534286499-42.1194610596-40.798740387-39.1007499695-37.0199012756$ -34.603729248 -31.7614803314 -29.0223693848 -26.9379405975 -25.1411590576 $-23.310880661-21.5307407379-19.7614803314-17.9850101471-16.2875900269$ -14.5222797394 -12.5669298172 -10.5670795441 -8.64754009247 -6.7647228241 $-4.91407585144-3.08998298645-1.275297999380 .4592910110952 .018266916275$ 3.4708580970764 .8679738044746 .1884288787847 .4334120750438 .604663848877 9.68970012664810 .706270217911 .6473102569612 .5382003784213 .38922023773 14.222760200515 .0608501434315 .9188499450716 .8239307403617 .78207969666 18.8194503784219 .9314804077121 .1383209228522 .4250602722223 .80030059814 
25.2435207366926 .7527198791528 .2937908172629 .8480491638231 .38857078552 32.8852386474634 .3305511474635 .6636199951236 .9932708740238 .41999053955 39.8325614929241 .1321983337442 .3536682128943 .4957809448244 .57046127319 45.590400695846 .566688537647 .5128784179748 .4418716430749 .36499023438 50.2957801818851 .2456588745152 .2265281677253 .251388549854 .33013916016 55.4804611206156 .6954307556257 .9872589111359 .3418197631860 .76139068604 62.22893142763 .7278404235865 .2502136230566 .7779388427768 .30967712402 69.8293991088971 .3416366577172 .8382110595774 .321151733475 .81095123291 77.22913360596 78.48834228516 79.69183349609 80.92902374268 82.18460083008 83.4730072021584 .7965164184686 .1582870483487 .5549011230588 .98323059082 90.4363327026491 .9043731689593 .3805694580194 .8504180908296 .32483673096 97.8104629516699 .31021881104100 .8323974609102 .3734970093103 .93699646 105.5179977417 107.1115036011 108.7147979736 110.3211975098 111.9292984009 113.5341033936115 .1342010498116 .7263031006118 .3096008301119 .8816986084 121.4422988892122 .9903030396124 .5253982544126 .0474014282127 .5562973022 129.0525054932130 .5359954834132 .0075073242133 .4671020508134 .9156036377 136.3529968262137 .7801055908139 .1970062256140 .6042938232142 .0021057129 143.3907928467144 .7705993652146 .1417999268147 .5043029785148 .858505249 150.2042999268151 .5419006348152 .871307373154 .1925964355155 .5057067871 156.8108062744158 .1078948975159 .3970031738160 .6781005859161 .9514007568 163.2167053223164 .4743041992165 .724105835166 .9662017822168 .2006988525 169.4277954102170 .6472930908171 .8594970703173 .0644073486174 .2621002197 175.4528045654176 .636505127177 .813293457178 .9833984375180 .1468048096 181.3036956787 182.4542999268 183.5986022949 184.7368011475 185.8692016602 186.9956970215188 .1165008545189 .2319030762190 .3419036865191 .4465942383 192.5462036133193 .6407928467194 .7303924561195 .8150939941196 .8950042725 197.9698944092199 .0401000977200 .1053924561201 .1658935547202 .221496582 203.2723999023204.3179931641205.3592987061206.3946990967

124.2087020874 123.9518966675 123.5175018311122 .9027023315122 .1941986084 121.3844985962120 .4820022583119 .4973983765118 .4399032593117 .3234024048 116.1558990479114 .951499939113 .71849823112 .4713973999111 .2169036865 109.9682006836108.7288970947 107.5092010498 106.3099975586105.1446990967 103.9616012573102 .7230987549101 .396598815999 .9444580078198 .34245300293 96.5430068969794 .5651168823292 .3774719238390 .0759429931687 .66507720947 85.34879302979 83.2027511596781.50280761719 80.4157714843880.06896972656 80.6421203613381 .9098968505984 .0982589721784 .566818237380 .79611968994 74.9859695434669 .0498580932662 .8824996948256 .5451583862350 .06427001953 43.3698196411136 .6590003967330 .175710678123 .9623203277618 .15459060669 $12.770210266117 .8426351547243 .399334907532-.564311981201-3.99693894386$ $-6.88342380524-9.19330883026-10.911450386-11.9953804016-12.3945703506$ $-12.1198396683-11.1653299332-9.57195663452-7.37840604782-4.64853715897$ -1.45299804211 2.114712953568 5.944321155548 9.956650733948 14.01821994781 18.0986404418922 .078470230125 .9696693420429 .6895599365233 .28314971924 36.7320289611840 .0737190246643 .3274688720746 .5042610168549 .61394882202 52.6292915344255 .52539062558 .2217903137260 .743579864562 .14624023438 61.4626502990759 .745121002257 .9269104003956 .0111389160254 .177688598863 
52.4317588806250 .8683586120649 .4630508422948 .2350616455147 .25740814209 46.519668579146 .1600990295446 .3931694030846 .4439811706546 .03248977661 44.5845794677741 .5567016601637 .4397506713932 .4475708007826 .96986961365 $21.7146797180215 .577119827277 .527324199677-.915618002415$-9.19890785217 -14.3040599823 -14.2128696442 -13.1957397461 -14.7866897583-18.9759101868 -25.1382293701 -31.1865196228 -35.1920318604 -37.6426811218 -39.0368804932 -39.9317588806-40.9640808105 -41.9809112549-42.8377799988-43.986579895 $-46.0412902832-48.2807502747-49.89220047-51.7990608215-54.6022911072$ -57.3520889282 -59.3671798706 -60.836101532-61.9710693359-63.0329704285 $-64.0197067261-64.8485031128-65.4829177856-66.0070724487-66.611366272$ $-67.1982879639-67.6977767944-68.130241394-68.489440918-68.7652435303$ -68.898727417-68.9485931396-68.9875030518 -69.0175933838 -69.055770874 $-69.1225662231-69.2403564453-69.3724365234-69.5176620483-69.6481628418$ $-69.7468566895-69.8075027466-69.79296875-69.7011795044-69.5183792114$ $-69.2564926147-68.9366073608-68.5842590332-68.2310180664-67.8677520752$ $-67.5025863647-67.0998077393-66.6787872314-66.1874465942-65.5831375122$ -64.9038467407-64.1277618408-63.3578987122 -62.6510314941 -61.9990310669 $-61.4220504761-61.0606002808-61.1284599304-61.3177185059-61.3382606506$ $-61.1507301331-60.6498298645-59.8219299316-58.6083297729-57.0918312073$ $-55.5516891479-54.0575294495-52.8523597717-51.9296989441-51.2333602905$ -50.674659729 -50.1610488892 -49.6119117737-48.9740104675-48.2476997375 $-47.4995613098-46.8480606079-46.3909988403-46.1337394714-46.1279983521$ $-46.3857917786-46.382019043-46.500038147-46.8827095032-47.0066795349$ $-46.7182006836-46.0122299194-44.8479385376-43.2327919006-41.1770896912$ $-38.7139205933-35.847328186-32.927520752-30.2716503143-27.8823604584$ -25.7663898468 -23.7986392975 -21.8614997864 -19.948469162 -18.0786209106 $-16.1877403259-14.2158098221-12.2089500427-10.2010498047-8.213555336$ $-6.2601108551-4.34627103806-2.47588801384-.700403988361 .9098209738731$ 2.4086039066313 .8447089195255 .2023878097536 .4846172332767 .686459064484 8.7921552658089 .81610488891610 .75349044811 .6288604736312 .45833969116 13.2669897079514 .0815296173114 .9222497940115 .8184404373216 .78253936768 17.8403091430718 .9937801361120 .2607192993221 .6295890808123 .10507965088 24.6609306335426 .2855892181427 .9407901763929 .595640182531 .22456932068 32.795341491734 .2976493835435 .6967201232937 .0655899047938 .4651184082 39.8297805786141 .0992698669442 .2849617004443 .3872299194344 .41749954224 45.3856811523446 .3047904968347 .1883506774948 .0507698059148 .90621948242 49.7700004577650 .6571502685551 .5808982849152 .557201385553 .59574127197 54.7136306762755 .9061393737857 .1820907592858 .5300712585459 .94987869263 61.4237098693862 .9349403381364 .4712066650466 .0124664306667 .55387878418 69.0796890258870 .5898208618272 .0752487182673 .5375366210974 .98085784912 76.3554534912177 .6126098632878 .8185195922980 .0361633300881 .26808929443 82.5299224853583 .822410583585 .1517028808686 .5130615234487 .9049987793 89.3231124877990.7650527954192.2067337036193.6171035766695.03076934814 96.4751129150497 .9455566406299 .4467010498100 .9757995605102 .5362014771 104.1202011108105 .71900177107 .3292007446108 .9430999756110 .5582962036 112.1698989868113 .7760009766115 .373298645116 .9607009888118 .5358963013 
120.0986022949121 .6474990845123 .1825027466124 .7033996582126 .2102966309 127.7034988403129 .183303833130 .6502075195132 .1047058105133 .5471954346 134.978302002136 .3984069824137 .8079986572139 .2075042725140 .5971984863 141.9774932861143 .3486022949144 .7108001709146 .0641937256147 .4091033936 148.7454986572150 .0735015869151 .3932037354152 .7048034668154 .008102417 155.3034057617156 .5906066895157 .8699035645159 .1410980225160 .4046020508 161.6600952148162 .9078979492164 .1479949951165 .3804931641166 .6053924561 167.8229980469169 .0330963135170 .2359008789171 .4315948486172 .6201934814 173.8018035889174 .9766998291176 .1446990967177 .3061065674178 .4609985352 179.6094970703180 .7518005371181 .8878936768183 .0180969238184 .1425018311 185.2611999512186 .3744049072187 .4821929932188 .5847015381189 .6820983887 190.7745056152191 .8619995117192 .9447021484194 .0225067139195 .0955963135 196.1640014648197 .2276000977198 .286605835199 .3408050537200 .3903045654 201.4351959229202 .475402832203 .5072937012204 .5341949463

135.4566040039135 .0758056641134 .6235046387134 .0475006104133 .3699951172 132.5973052979131 .7366027832130 .7991943359129 .7928009033128 .7317047119 127.6216964722126 .4761962891125 .3023986816124 .1159973145122 .9194030762 121.724899292120 .5327987671119 .3518981934118 .1766967773117 .0223007202 115.8207015991114 .5258026123113 .0930023193111 .4800033569109 .647102356 107.5371017456 105.1592025757 102.4587020874 99.5445480346796.37445068359 93.2250366210990 .0896606445387 .4258804321385 .3240509033284 .1967086792 84.3212738037185 .5032424926888 .898300170990 .4754867553786 .26685333252 79.7909622192474 .0321578979568 .0841903686561 .7593307495155 .23175048828 48.2393493652341 .1239204406734 .2536201477127 .6503105163621 .42831039429 $15.6256799697910 .215390205385 .274260997772 .7408649921417-3.27384901047$ $-6.78447294235-9.71799659729-12.0411596298-13.7189502716-14.6772699356$ $-14.9269304276-14.4430103302-13.2745895386-11.4628696442-9.06492424011$ $-6.14301109314-2.78318190575 .91288000345234 .8680839538578 .970527648926$ 13.1738901138317 .3549900054921 .5192508697525 .5619201660229 .52419090271 33.3521690368737 .0878791809140 .7346801757844 .2954406738347 .79784011841 51.1556816101154 .3589096069357 .1744804382359 .4363517761260 .84873962402 61.1728096008360 .6894111633359 .6963806152358 .4137382507357 .11299133301 55.8317184448254 .7277717590353 .7426910400452 .9230194091852 .36632919312 51.9921302795452 .2575187683153 .5309410095254 .7062988281255 .48217010498 55.5642700195354 .7902297973652 .7184600830148 .1553688049342 .65097045898 38.6850700378433 .0732688903823 .1755008697511 .79648017883 -7.5510000e-03 $-8.78441143036-11.7419204712-11.5649900436-10.6251401901-11.5573301315$ $-18.5853996277-26.9222297668-31.2335395813-34.2389602661-36.0461502075$ -37.2106781006 -38.7950286865-40.2705192566 -41.8375205994-43.4005012512 $-44.9982910156-46.4215507507-47.1649093628-48.2347106934-50.7295303345$ $-53.6529502869-56.293170929-58.6165008545-60.1456298828-61.3620491028$ $-62.4483108521-63.2976112366-64.038520813-64.643371582-65.3807220459$ -66.1661987305 -66.816116333 -67.4163970947 -67.8891372681 -68.2202072144 $-68.3930587769-68.4476394653-68.5090789795-68.5681610107-68.6183929443$ $-68.7082138062-68.8641815186-69.0533828735-69.2979278564-69.5328826904$ $-69.7298736572-69.8844833374-69.9315490723-69.8827133179-69.7142562866$ 
$-69.4485778809-69.1298904419-68.7816162109-68.4368133545-68.0887069702$ $-67.7582626343-67.4023895264-67.060546875-66.6203308105-66.0532302856$ $-65.3532028198-64.4625778198-63.5575485229-62.6660308838-61.8894500732$ $-61.2263183594-60.9098815918-61.2910690308-61.8098182678-61.9927597046$ $-61.8736305237-61.387550354-60.4887695312-59.1435890198-57.6268997192$ -56.1072883606 -54.7146110535 -53.542678833 -52.6435203552 -51.966091156 $-51.4147491455-50.8739700317-50.2384796143-49.4445381165-48.4973983765$ $-47.4930610657-46.6150398254-46.0907707214-46.0834693909-46.6203804016$ $-47.4938583374-48.4331703186-49.3327789307-50.2286911011-50.7592582703$ $-50.7832183838-50.2871818542-49.2837791443-47.7607307434-45.7653808594$ $-43.3371315002-40.5564308167-37.5432891846-34.3251609802-31.2532806396$ -28.6843204498 -26.4018096924 -24.1926498413 -22.0792694092 -20.0110301971 $-17.949590683-15.9568195343-13.9517097473-11.8576898575-9.75831222534$ -7.68938207626 -5.66836309433 -3.74430298805 -1.92983901501 -.264872997999 1.2867850065232 .7729980945594 .1866350173955 .5161848068246 .759583950043 7.8814358711248 .9061584472669 .82393455505410 .6697301864611 .46047019958 12.2270498275813 .0038099288913 .8117704391514 .6900501251215 .64999008179 16.7264003753717 .9179496765119 .2507591247620 .7058105468822 .29454994202 23.9749393463125 .7358703613327 .5245609283429 .3010005950931 .04339981079 32.7055206298834 .294780731235 .7841911315937 .2040290832538 .56818008423 39.8675193786641 .0917510986342 .2371406555243 .296871185344 .28210067749 45.1975593566946 .0595207214446 .8779983520547 .6723518371648 .45428085327 49.2455711364750 .061660766650 .9197387695351 .8401794433652 .83013916016 53.9125595092855 .0792007446356 .3444213867257 .6913490295459 .12004852295 60.6088905334562 .1397209167563 .6960792541565 .2513504028366 .80368804932 68.3302078247169 .8329696655371 .2976226806672 .7215270996174 .09987640381 75.4223327636776 .6863403320377 .9117126464879 .1258773803780 .3429107666 81.5839385986382 .8507766723684 .1504898071385 .4799728393686 .8376083374 88.2199935913189 .6317596435591 .0381088256892 .3898086547993 .74681854248 95.1523208618296 .5935287475698 .0784530639699 .60064697266101 .1621017456 102.7537002563104 .3591995239105 .9773025513107 .5980987549109 .2199020386 110.8369979858112 .4478988647114 .0491027832115 .6393966675117 .2165985107 118.7800979614120 .3289031982121 .8628997803123 .3817977905124 .8858032227 126.3753967285127 .8507003784129 .3126068115130 .7613067627132 .1976013184 133.6217956543135 .0348052979136 .436706543137 .8282012939139 .2095031738 140.5812072754141 .9434051514143 .2964935303144 .6405944824145 .9759979248 147.3029022217148 .6212005615149 .9311981201151 .2328948975152 .5263977051 153.811706543155 .0890045166156 .3583068848157 .6197052002158 .8731994629 160.1188964844161 .3567962646162 .5872039795163 .8099975586165 .0252990723 166.2333068848167 .4338989258168 .6273956299169 .8139038086170 .9933013916 172.1658935547173 .3318023682174 .4909973145175 .6437072754176 .7899932861 177.9300994873179 .0641021729180 .1920928955181 .3141937256182 .4306030273 183.5415039062184 .6470031738185 .7471923828186 .842300415187 .9322967529 189.0175018311190 .0979003906191 .1735992432192 .2445068359193 .3108978271 194.3726043701195 .4297943115196 .4822998047197 .5303039551198 .5736999512 199.6125030518200 .6463928223201 .6761932373202 .7003936768 
146.7093048096146 .4716949463146 .0760040283145 .5191040039144 .8791046143 144.1499938965143 .3394012451142 .4577941895141 .5130004883140 .5178070068 139.4781951904138 .4066009521137 .3087005615136 .1970062256135 .0740966797 133.9506988525132 .8240966797131 .7017059326130 .5715942383129 .4432067871 128.2409973145126 .9113006592125 .396697998123 .6457977295121 .600402832 119.1996002197116 .4173965454113 .201499939109 .6074981689105 .6155014038 101.445198059197 .1514205932693 .1866226196389 .7503662109487 .35410308838 86.4447326660286 .7828369140688 .7155838012789 .5799636840887 .06059265137 82.7505111694378 .2367324829173 .2270126342867 .2592620849660 .71578979492 53.6099510192946 .1888084411639 .0527000427232 .1883010864325 .70739936829 $19.5923595428513 .810830116278 .41193485263 .371325016022-1.22054004669$ -5.3443479538 -8.91662979126 -11.8660802841 -14.1576004028 -15.7012796402 $-16.488740921-16.4874897003-15.7511901855-14.338470459-12.2880401611$ $-9.65603256226-6.51896810532-2.985744953160 .8782010078434 .975581169128$ 9.24429321289113 .5649404525817 .9183406829822 .1968402862526 .41695022583 30.5085697174134 .5118293762238 .4199485778842 .2381896972745 .97785949707 49.5593109130952 .9637794494655 .9268684387258 .2957992553760 .0608215332 61.0250511169461 .3959007263261 .1899681091360 .6002311706559 .92961883545 59.238559722958 .6881294250558 .2040481567457 .8387718200757 .64237976074 57.5910110473658 .4743003845260 .5826416015662 .9403610229565 .80386352539 68.3913574218869 .6999969482469 .6952362060567 .3473510742263 .66955947876 60.5278205871655 .5186805725146 .9816207885735 .6924896240222 .18313026428 $9.434469223022-1.49244999886-8.32800197601-9.44896507263-9.87313175201$ $-13.812040329-19.2356891632-23.4229793549-27.1879806519-30.9055995941$ -33.9568595886 -36.1574707031 -38.0009307861 -40.0700302124-41.9791793823 $-43.6011581421-44.8094902039-45.513710022-46.281211853-47.4921302795$ $-49.5417404175-53.0419311523-56.556640625-58.6679115295-60.1190109253$ $-60.9643516541-61.5019607544-62.2787895203-62.9756088257-63.6856498718$ $-64.5568389893-65.5168914795-66.4018173218-66.9579467773-67.2901763916$ $-67.4649429321-67.5058517456-67.562538147-67.6365814209-67.6987686157$ $-67.8034133911-67.9627532959-68.1903381348-68.5705871582-68.9514389038$ $-69.2347183228-69.4630813599-69.5891418457-69.5901031494-69.4150085449$ $-69.1223526001-68.7932662964-68.4508972168-68.1249465942-67.8162307739$ $-67.5389633179-67.280166626-67.0802230835-66.7840881348-66.3299713135$ $-65.6648025513-64.7083282471-63.6612701416-62.4846801758-61.5116500854$ $-61.1405982971-61.2038192749-61.6926116943-62.2714195251-62.5267791748$ $-62.426990509-61.9078598022-60.9305000305-59.4505195618-57.9680709839$ $-56.4936294556-55.1366996765-53.9905281067-53.1040611267-52.4398117065$ $-51.8920516968-51.3227005005-50.6049613953-49.6620483398-48.4960403442$ $-47.2219085693-46.0860900879-45.4796295166-45.7749290466-46.998550415$ $-48.7931594849-50.7295913696-52.5675811768-54.0672607422-55.0039482117$ $-55.3128395081-55.0134506226-54.1563987732-52.744808197-50.8167114258$ $-48.4374809265-45.6704711914-42.5363998413-39.0970611572-35.5922889709$ $-32.2738990784-29.3015995026-26.7803497314-24.4809703827-22.2502803802$ $-20.0659198761-17.9427394867-15.840180397-13.6498203278-11.4357500076$ $-9.20271492004-7.02986383438-5.02680587769-3.16500496864-1.47388803959$ 
.1001069992781 1.641991972923 3.1236588954934.5273728370675.82585477829 6.9662690162667 .9783258438118 .8646459579479 .66196918487510 .39671039581 11.1038398742711 .8236598968512 .5845203399713 .429030418414 .37709999084 15.4639196395916 .6947803497318 .0935001373319 .6455307006821 .356300354 23.1810493469225 .0981807708727 .0434303283728 .9590702056930 .82732963562 32.5996704101634 .2802505493235 .8387718200737 .2868385314938 .6449508667 39.9097518920941 .0959587097242 .2016487121643 .2189292907744 .15670013428 45.0199317932145 .822410583546 .575199127247 .2964706420948 .00080108643 48.711631774949 .4490394592350 .2334403991751 .0903701782252 .02854156494 53.0705718994154 .2131118774455 .4689292907756 .8218307495158 .26662826538 59.7798194885361 .3399581909262 .9219818115264 .4941177368266 .05341339111 67.5791320800869 .068222045970 .5052719116271 .8888015747173 .22205352783 74.5119628906275 .7605667114376 .9840469360478 .1935424804779 .40035247803 80.6271133422981 .8746032714883 .1508331298884 .4514236450285 .77546691895 87.11770629883 88.47559356689 89.8260726928791.1406784057692.4663772583 93.8366622924895 .2513122558696 .7269592285298 .2493133544999 .81701660156 101.4197006226103 .0358963013104 .6623001099106 .2900009155107 .9169006348 109.5383987427 111.1523971558 112.755897522 114.3476028442 115.925201416 117.4881973267119 .0355987549120 .5673980713122 .0831985474123 .5835037231 125.0684967041126 .5386962891127 .9947967529129 .4371948242130 .8666992188 132.2837982178133 .6891021729135 .0829925537136 .4662017822137 .8388977051 139.2017059326140 .5547943115141 .8986053467143 .2333068848144 .55909729 145.8762054443147 .1846923828148 .4848022461149 .7765045166151 .0599975586 152.3354034424153 .6026000977154 .8618927002156 .1132965088157 .3567962646 158.5926055908159 .8206939697161 .0411987305162 .254196167163 .4598999023 164.6582946777165 .8495025635167 .0335998535168 .2106933594169 .3809967041 170.5446014404171 .7015075684172 .8518981934173 .9958953857175 .133605957 176.2651977539177 .3908996582178 .5106048584179 .6246948242180 .7330932617 181.8361968994182 .9338989258184 .0265960693185 .1141967773186 .1968994141 187.2749023438 188.3480987549 189.4167022705 190.48080444434 191.5404052734 192.5955047607193 .6461029053194 .6923065186195 .7339019775196 .7711029053 197.803894043198 .8323974609199 .8527984619200 .8686981201

158.5437011719158 .2041931152157 .8023986816157 .2928009033156 .6952972412 156.0166015625155 .2631988525154 .446105957153 .5717010498152 .6535949707 151.6959075928150 .7122955322149 .7044067383148 .6840057373147 .6510925293 146.6181030273145 .5767974854144 .5357055664143 .4709014893142 .3934020996 141.2136993408139 .8833007812138 .321395874136 .4790039062134 .2671966553 131.6329040527128 .5055999756124 .8347015381120 .6249008179115 .8395996094 110.6713027954105 .112800598199 .7153472900494 .5548171997190 .49587249756 88.0461502075286 .6854400634886 .4276580810586 .267303466885 .8017578125 84.71835327148 82.5665588378978.92427062988 73.4079132080166.62875366211 59.3436584472751 .907779693644 .7504692077637 .8704299926831 .3138999939 25.0515708923318 .9773998260513 .217599868777 .6711440086362 .516360044479 $-2.26916790009-6.53308296204-10.1402101517-13.065320015-15.1771602631$ $-16.5002498627-16.9918308258-16.703119278-15.7078800201-14.0180101395$ $-11.7043600082-8.8340549469-5.49279689789-1.764582037932 .297534942627$ 
6.59352207183810 .9943103790315 .4767599105819 .8906307220524 .26461982727 28.4868297576932 .6203498840336 .6516113281240 .5786209106444 .42961883545 48.0979995727551 .6307792663654 .7732009887757 .4235191345259 .57286834717 61.1160812377962 .1554603576762 .6327018737862 .7517509460462 .7294883728 62.6469497680762 .7060394287162 .8297004699763 .1773681640663 .54537963867 64.0413284301865 .0074081420966 .8332214355570 .6533432006876 .59425354004 82.5094070434685 .6557388305786 .7357177734486 .6627731323285 .21337890625 82.9368362426878 .9344024658273 .3018112182664 .5875167846751 .72092819214 $35.8985900878916 .86259078979 .6577079892159-6.07846212387-8.73805332184$ $-11.1266098022-13.0564603806-16.2215900421-20.0175094604-24.8087291718$ -29.5674495697 -32.3407402039 -34.5263710022 -37.0674781799 -39.2630500793 $-41.0508804321-42.4247207642-43.430519104-44.2536697388-44.5165100098$ $-45.7130699158-50.0001983643-54.5588607788-57.2501296997-58.7072486877$ $-58.8097610474-58.8607292175-59.7260398865-60.9591712952-61.9964904785$ $-62.8476104736-64.0905532837-65.1635665894-65.5813064575-65.8387374878$ $-66.0030593872-66.1049423218-66.2418212891-66.3369979858-66.4137268066$ $-66.4954986572-66.5856399536-66.84765625-67.385559082-67.9665527344$ $-68.3882598877-68.6789398193-68.8387527466-68.8473968506-68.6597366333$ $-68.3386383057-68.0090103149-67.6894836426-67.368309021-67.0928573608$ $-66.8690414429-66.707611084-66.6837081909-66.5910415649-66.4179763794$ $-65.9447631836-65.0600585938-63.8968086243-62.3068084717-61.1709403992$ $-61.1066207886-61.5872917175-62.1184005737-62.5413017273-62.7887496948$ $-62.6505012512-62.1038093567-61.0652008057-59.5836410522-58.1300315857$ $-56.671749115-55.3055496216-54.1503295898-53.2703590393-52.6335411072$ $-52.1183204651-51.5602989197-50.811630249-49.7937889099-48.5035018921$ $-47.0442390442-45.6680297852-44.8753700256-45.4914512634-47.6429290771$ -50.7927703857 -53.7214698792 -56.3476104736 -58.2705612183 -59.4472503662 $-59.969669342-59.7962188721-59.0903396606-57.7914505005-55.9684791565$ $-53.6426010132-50.8860702515-47.7043991089-44.1861686707-40.4242591858$ -36.4527587891 -32.7207298279-29.699760437-27.1008796692 -24.661649704 $-22.3882598877-20.1626091003-17.9115390778-15.6016798019-13.2296600342$ $-10.771490097-8.42613601685-6.34101819992-4.4569978714-2.73667907715$ $-1.10421800613 .52125602960592 .0923969745643 .5645020008094 .916338920593$ 6.05440902717 .041419982917 .8736581802378 .5998172760019 .25486946106 9.87716197967510 .5236101150511 .2194700241112 .0210504531912 .94484996796 14.0369300842315 .301969528216 .7682495117218 .4172096252420 .25811004639 22.2359504699724 .3350391387926 .4609107971228 .5432205200230 .56191062927 32.4461593627934 .2124099731435 .8250999450737 .2972297668538 .66067123413 39.914760589641 .0797386169442 .1554489135743 .1352500915544 .03247070312 44.8459281921445 .5932693481446 .2793502807646 .9276885986347 .54764938354 48.171600341848 .8179206848149 .5181198120150 .3044509887751 .18264007568 52.1853790283253 .3032493591354 .5563812255955 .9233894348157 .39252090454 58.9386291503960 .5370292663662 .1526908874563 .7463302612365 .3157119751 66.8310470581168 .2965087890669 .6965332031271 .0370788574272 .33400726318 73.5933609008874 .8251495361376 .0384368896577 .2413406372178 .44302368164 79.6612930297980 .8951721191482 .1530227661183 .4291763305784 .72334289551 
86.0262527465887 .3297500610488 .6286773681689 .9157028198291 .21383666992 92.5433197021593 .9322280883895 .4051132202196 .9430236816498 .52484130859 100.1368026733101 .7602005005103 .3918991089105 .0234985352106 .6529006958 108.2761993408109 .8909988403111 .4947967529113 .0857009888114 .6621017456 116.2229995728117 .7677001953119 .2957992554120 .8075027466122 .3029022217 123.7826004028125 .2469024658126 .6966018677128 .1320953369129 .554397583 130.9636993408132 .3609924316133 .7465057373135 .12109375136 .4848937988 137.8385925293139 .1824035645140 .5166931152141 .8417053223143 .1578063965 144.4649963379145 .7635955811147 .053604126148 .3352966309149 .6087036133 150.8739013672152 .1311035156153 .3802032471154 .6215057373155 .8549957275 157.0807037354158 .2989044189159 .5095062256160 .7127990723161 .908706665 163.0975036621164 .2792053223165 .4539031982166 .6217041016167 .7828063965 168.9371948242170 .0852050781171 .2266998291172 .3619995117173 .4911956787 174.6143035889175 .7315979004176 .8430938721177 .9490966797179 .0496063232 180.1448059082181 .2348022461182 .3199005127183 .3999938965184 .475402832 185.5460968018186 .612197876187 .6737976074188 .7310028076189 .7837982178 190.8321990967191 .8762969971192 .9160003662193 .9512939453194 .9822998047 196.0090942383197 .0310058594198 .0491943359199 .0621032715 170.3818054199170 .1741027832169 .8321075439169 .3527069092168 .803604126 168.1811065674167 .4925994873166 .7478942871165 .9541015625165 .1233978271 164.2601928711163 .3760986328162 .4730072021161 .5605926514160 .6381072998 159.7151031494158 .7828979492157 .845703125156 .8766021729155 .8778991699 154.7604980469153 .4671020508151 .9131011963150 .033203125147 .7312927246 144.9373016357141 .5581970215137 .5265045166132 .7875061035127 .293800354 121.1153030396114 .2481002808107 .1284027199 .9030532836993 .71418762207 89.27182769775 86.05571746826 84.4729385376 84.1552886962984.82160186768 86.24526214687 .5147705078186 .3402099609480 .5216064453172 .73301696777 65.3730926513758 .2002716064551 .3652000427244 .7660217285238 .3941192627 32.1395416259825 .9035091400119 .8129291534413 .845339775098 .125047683716 $2.63272690773-2.39379310608-6.69413900375-10.2542800903-12.9105195999$ -14.7334604263 -15.7583999634 -15.965880394 -15.3776903152 -14.0512104034 $-12.0927801132-9.52938270569-6.43383789062-2.881773948671 .096439957619$ 5.3746771812449 .80125808715814 .3328399658218 .8089809417723 .22561073303 27.4573898315431 .5823993682935 .6054000854539 .5354690551843 .38323974609 47.0985908508350 .706478118954 .0396690368756 .9880485534759 .5453414917 61.6071701049863 .2334098815964 .3381195068465 .1060562133865 .66060638428 66.1786270141666 .8610305786167 .7639770507869 .1661911010770 .50382232666 71.6026229858472 .1330337524471 .3045272827174 .6409378051887 .44721221924 100.060798645102 .667098999102 .1054000854104 .2553024292105 .6277999878 103.75340271100 .910499572899 .7488937377995 .8581695556685 .67923736572 69.04750823975 45.5870895385722 .228309631356 .102052211761 -4.4526309967 -11.1518497467 -14.556189537-15.8420495987 -17.1898803711 -20.1668491364 $-23.8413295746-27.174200058-30.102350235-32.7944908142-35.1035995483$ $-37.1107902527-38.8030815125-40.0228004456-41.1039390564-42.22631073$ $-44.2031402588-48.5220298767-53.1092681885-56.1788711548-57.3220405579$ $-55.4519691467-54.0030708313-56.1146316528-59.1976089478-60.942401886$ 
$-61.9276313782-63.0808486938-63.904510498-63.7556495667-63.5741195679$ $-63.9265403748-64.3335571289-64.6116867065-64.7748413086-64.8327865601$ $-64.8198165894-64.7233428955-64.9215316772-65.7417984009-66.6574020386$ $-67.2717666626-67.64478302-67.7438964844-67.6785736084-67.4685134888$ $-67.1236495972-66.7994613647-66.5083770752-66.1774520874-65.9051132202$ $-65.7602462769-65.7448272705-65.8762664795-66.0628509521-66.4005126953$ $-66.3994369507-65.7107162476-64.4339065552-62.3136405945-60.7851982117$ $-61.0707893372-61.9626693726-62.4587516785-62.679649353-62.8439407349$ $-62.6884803772-62.0133514404-60.9076499939-59.5194091797-58.1199417114$ -56.6481285095 -55.2256584167 -54.0354194641 -53.1789207458 -52.6253204346 $-52.2271690369-51.7795791626-51.1077308655-50.1558685303-48.9690704346$ $-47.5779190063-46.1613883972-45.0842018127-45.6127700806-49.0163002014$ $-54.0977210999-57.9711608887-60.9308700562-62.9638595581-64.1675872803$ $-64.7117080688-64.5994186401-63.9691810608-62.7847900391-61.0734596252$ $-58.8461608887-56.122341156-52.9391899109-49.3635597229-45.4219207764$ $-41.2151794434-37.0248718262-33.1307907104-29.7735996246-27.1897106171$ -24.9353504181 -22.6331005096 -20.2538299561 -17.7521705627 -15.1370296478 $-12.3327102661-9.71654319763-7.64962911606-5.8339600563-4.0263428688$ $-2.25884795189-.5133000016211 .1522129774092 .6720550060274 .030353069305$ 5.155130863196 .0937871932986 .8565177917487 .4911208152778 .036803245544 8.549128532419 .1012630462659 .72106361389210 .461839675911 .3512802124 12.435580253613 .7290296554615 .2605199813817 .0117702484118 .9816608429 21.1262397766123 .4273395538325 .7611007690428 .0384197235130 .22410011292 32.2195510864334 .05900955235 .7178306579637 .2090492248538 .58555984497 39.8464202880941 .0071411132842 .0678291320843 .0274200439543 .89316177368 44.6671485900945 .3617095947345 .9849090576246 .5561294555747 .08890151978 47.6158485412648 .1603507995648 .7653999328649 .4753684997650 .29389953613 51.2512893676852 .3463211059653 .6026115417554 .9939308166556 .49673080444 58.0858306884859 .732009887761 .3885498046963 .0146408081164 .59808349609 66.0965728759867 .5279769897568 .8847732543970 .1782836914171 .43612670898 72.6663208007873 .879463195875 .0817718505976 .2787475585977 .47704315186 78.688339233479 .9122085571381 .1550827026482 .4116134643683 .68176269531 84.9550094604586 .2251892089887 .4917373657288 .7493972778390 .00930023193 91.2693710327192 .6080703735494 .110351562595 .6959533691497 .29708099365 98.9158782959100 .5416030884102 .1726989746103 .8034973145105 .4317016602 107.0532989502108 .6663970947110 .2676010132111 .855796814113 .4285964966 114.9856033325116 .5257034302118 .0490036011119 .5550994873121 .0447006226 122.5178985596123 .9755020142125 .4179992676126 .8460998535128 .2604064941 129.661605835131 .0503997803132 .4272003174133 .7928009033135 .1473999023 136.4916992188137 .8258972168139 .1504974365140 .4656982422141 .7718048096 143.0688934326144 .3574066162145 .637298584146 .9087982178148 .1719055176 149.4268951416150 .6739044189151 .9127960205153 .1439971924154 .3672943115 155.5829925537156 .7911071777157 .9918060303159 .1851959229160 .3713989258 161.5505065918162 .7225952148163 .8878936768165 .046295166166 .1981964111 167.3435058594168 .4824981689169 .6152038574170 .7416992188171 .8623046875 172.9770050049174 .0859069824175 .1891937256176 .2870025635177 .3795928955 
178.4669036865179 .5491943359180 .6266937256181 .6992950439182 .7673034668 183.8307037354184 .8896942139185 .9443054199186 .9945983887188 .0406036377 189.0823059082190 .1197967529191 .1531066895192 .1820983887193 .2068939209 194.2274932861195 .2440032959196 .2528991699197 .2577056885

182.7182006836182 .4322052002182 .0955047607181 .6696929932181 .1730957031 180.612701416179 .9947967529179 .3303985596178 .6251983643177 .8921966553 177.133895874176 .362701416175 .5773925781174 .7895965576173 .9945983887 173.2035064697172 .400100708171 .5919036865170 .7425994873169 .8592071533 168.8395996094167 .6360931396166 .1385040283164 .2976074219161 .9792938232 159.1381072998155 .6188049316151 .3901062012146 .2911987305140 .3182067871 133.3722991943125 .4609985352116 .8426971436107 .583503723198 .85904693604 91.5788879394586 .4447021484484 .1438217163184 .2829132080185 .86459350586 88.50801849365 92.11502075195 93.01769256592 87.31754302979 79.22273254395 72.428016662665 .8537826538159 .5451698303253 .3934707641647 .37137985229 41.2939109802235 .0258293151928 .7490291595522 .3281707763715 .99240016937 $9.7133493423463 .840114116669-1.21764802933-5.40591812134-8.53418159485$ $-10.8419399261-12.3999500275-13.1018600464-12.9706201553-12.016579628$ -10.4790401459-8.35528564453 -5.54856491089-2.2201359272 1.676094055176 5.93785190582310 .3634996414214 .914199829119 .3470001220723 .69988059998 27.7978706359931 .7706699371335 .6171112060539 .3805999755943 .10255050659 46.7424812316950 .3950996398953 .8770408630457 .1574783325260 .11882019043 62.6567115783764 .8074035644566 .4513473510767 .7719497680768 .79210662842 69.7847976684670 .9583816528372 .5195007324274 .986602783277 .42501068115 79.5405197143681 .1465377807679 .1825790405381 .6780395507898 .9896697998 115.5919036865116 .396697998114 .0475997925117 .9669036865121 .5186004639 120.0370025635118 .0335006714120 .7125015259120 .5774993896113 .0084991455 97.7827606201273 .5043716430746 .9317588806224 .009170532235 .873918056488 $-6.12538385391-12.8834104538-14.2138996124-13.7232198715-14.84375-16.5346908569$ $-19.6746101379-23.0821208954-25.8418998718-28.3257904053-30.7369194031$ $-32.7074203491-34.0182495117-35.416229248-37.5225296021-40.623249054$ $-45.1884613037-49.8160400391-53.2263183594-54.6513214111-52.052318573$ $-49.5079689026-52.5875892639-56.4323501587-58.2276115417-59.751750946$ $-61.1590499878-62.2782287598-61.7943191528-61.0742912292-61.5284996033$ $-62.1107711792-62.5222587585-62.8400497437-62.9320793152-62.9508399963$ $-62.8430709839-62.9420700073-63.8369407654-64.9680480957-65.7950134277$ $-66.3394927979-66.3569869995-66.0828475952-65.8382492065-65.6167068481$ $-65.3940429688-65.1524963379-64.763710022-64.4642868042-64.3500976562$ $-64.405166626-64.5521469116-65.0089874268-65.9830093384-66.6018600464$ $-66.4147567749-65.3307723999-62.9160995483-61.0846595764-61.2864608765$ $-62.0227890015-62.1603507996-62.0395507812-62.2081794739-62.0364303589$ $-61.3167991638-60.2944107056-59.2145614624-57.9209785461-56.4289512634$ $-54.9292106628-53.7200508118-52.9596214294-52.6202697754-52.5113716125$ $-52.344959259-51.9080886841-51.1856994629-50.4222297668-49.5794906616$ $-48.7429084778-47.840259552-47.077419281-52.4384689331-58.558971405$ $-62.5386695862-65.3902816772-67.2932128906-68.267250061-68.793800354$ $-68.6763534546-68.151260376-67.1078186035-65.5569763184-63.4735412598$ 
-60.8303489685 -57.6706581116 -54.1059608459 -50.1405105591 -45.9210205078 -41.5364685059 -36.9477310181 -32.8411712646 -29.9656791687 -27.6080608368 $-25.1439609528-22.6575107574-20.0132598877-17.2110290527-14.1378097534$ $-11.2888097763-9.19006824493-7.35116195679-5.36997699738-3.41377711296$ -1.50016796589.2831650078297 1.8406900167473.1951599121094.266167163849 5.1354389190675 .7893037796026 .2926759719856 .6993350982677 .071187973022 7.5145249366768 .0420494079598 .7195682525639 .57061004638710 .64887046814 11.9661598205613 .5565500259415 .4022197723417 .4940395355219 .79925918579 22.2998199462924 .8730697631827 .4071407318129 .7831306457531 .8824005127 33.7525215148935 .4384002685536 .9713516235438 .3881607055739 .68629837036 40.8667411804241 .9368095397942 .8903884887743 .7400817871144 .48220825195 45.1333007812545 .697120666546 .1955108642646 .6385002136247 .06533050537 47.493579864547 .991069793748 .6108512878449 .3580894470250 .27927017212 51.3611717224152 .6299896240254 .0545387268155 .5894393920957 .21810913086 58.9050788879460 .6110687255962 .2890205383363 .889091491765 .3611831665 66.7334976196368 .0355606079169 .2872161865270 .5135726928771 .72093200684 72.9182968139674 .1109771728575 .3033065795976 .4996337890677 .70741271973 78.9250488281280 .1578292846781 .3997726440482 .6519775390683 .90502929688 85.155273437586 .4009017944387 .639236450288 .877647399990 .08833312988 91.389511108492 .9143600463994 .532089233496 .1367263793997 .75533294678 99.37799835205101 .00340271102 .6297988892104 .2527999878105 .8697967529 107.4776992798109 .0739974976110 .6567001343112 .2240982056113 .7751998901 115.3093032837116 .8259963989118 .3255996704119 .8079986572121 .2740020752 122.7238998413124 .1585998535125 .5784988403126 .9843978882128 .3769073486 129.7568054199131 .12449646132 .4808044434133 .8258972168135 .1605072021 136.4848937988137 .7996063232139 .1047058105140 .4006958008141 .6876068115 142.9658050537144 .2353973389145 .4965057373146 .7492980957147 .9940032959 149.2306060791150 .4593048096151 .6800994873152 .8932037354154 .0988006592 155.2967987061156 .4875946045157 .6710968018158 .8473968506160 .0167999268 161.1793060303162 .3350982666163 .4842071533164 .6268005371165 .7630004883 166.8930053711168 .0167999268169 .1345977783170 .2465057373171 .3527069092 172.4532012939173 .5482940674174 .6381072998175 .7225952148176 .8020935059 177.8768005371178 .9465026855180 .0117034912181 .0722961426182 .1284942627 183.1802978516184 .2279052734185 .271194458186 .3103942871187 .3455047607 188.3764038086189 .4031982422190 .4257965088191 .4443969727192 .4588928223 193.4689025879194 .4752960205195 .4766998291

195.0569000244194 .8867950439194 .6101989746194 .2239074707193 .7843933105 193.2906951904192 .75192 .1725006104191 .5646972656190 .938293457190 .2967987061 189.6510925293189188.3507995605 187.7019958496187.0635070801 186.4158935547 185.7559967041185 .0592041016184 .3314971924183 .4703063965182 .4089050293 181.0500030518179 .3255004883177 .1159057617174 .3475036621170 .8795928955 166.6412963867161 .4685974121155 .3074035645147 .9810943604139 .4609985352 129.7127075195118 .7225036621107 .361297607495 .711776733487 .2041015625 85.8020629882887 .740798950289 .5624313354592 .0670394897594 .97718811035 95.6560974121191 .8501129150486 .0556716918980 .5448989868275 .09335327148 69.6129913330164 .0451431274458 .5175018310552 .7287406921446 .64231109619 
40.3060913085933 .4214096069326 .3548202514619 .2208499908412 .40629959106 $6.4996299743651 .672345995903-1.81959998608-4.5084400177-6.69680404663$ -8.01741123199 -8.25483131409 -7.62573385239-6.61851501465 -5.05149507523 -2.63631606102.44728899002084.2215061187748.45396327972412.88941955566 17.419780731221 .7260208129925 .867959976229 .7365894317633 .42358016968 36.915740966840 .3476791381843 .8101501464847 .3005294799850 .90053939819 54.5008201599158 .0647392272961 .4146614074764 .3890075683667 .00903320312 69.1353988647570 .8937377929772 .2291870117273 .5011367797974 .96968841553 77.1052627563580 .3337783813583 .9824066162188 .1887664794992 .58065795898 96.08917999268101 .912399292112 .6598968506121 .6716003418122 .6716003418 121.854598999124 .581199646127 .3529968262127 .2395019531126 .7860031128 128.8399047852128 .4253997803121 .7415008545108 .454002380488 .23079681396 65.0889663696344 .096401214626 .0362205505412 .755700111393 .660655021667 -2.37087011337 -5.68278598785 -7.19872522354 -8.09425354004 -10.0481300354 -12.6570301056 -15.7038002014 -18.7654590607 -21.5535697937 -23.6802597046 -24.7332992554-25.896270752 -27.7692508698 -31.1096305847 -37.4630088806 $-43.9481391907-48.1076698303-50.7245407104-51.7630996704-51.8110389709$ -51.9741096497 -52.0992202759-52.7748298645 -54.4142494202 -57.4844398499 $-60.3824882507-60.5448989868-59.838470459-59.8833808899-60.0568885803$ $-60.5172996521-61.0415992737-61.244720459-61.4395217896-61.8035202026$ $-62.085269928-62.1723594666-62.6423301697-64.0504074097-65.1853713989$ $-64.7518615723-63.9003791809-63.7653503418-63.8824310303-63.8929405212$ $-63.7361602783-63.2186317444-62.7620506287-62.660369873-62.6879882812$ $-62.6310310364-63.2422294617-65.1367034912-66.831161499-67.3165664673$ $-66.632232666-64.8022384644-63.2251586914-62.383518219-61.7649497986$ $-61.1862983704-60.6660881042-60.7094192505-60.6068115234-59.9294013977$ $-59.1947212219-58.542640686-57.4196205139-55.9597206116-54.512588501$ $-53.3680305481-52.8325691223-52.9720306396-53.4507102966-53.7759208679$ $-53.7625007629-53.4682502747-53.2836303711-53.7433891296-53.940071106$ $-54.7986602783-55.9945983887-59.9273490906-64.4784011841-67.6001205444$ $-69.7422866821-71.0167922974-71.5966567993-71.9187927246-71.8021392822$ $-71.320602417-70.4385910034-69.11769104-67.2646865845-64.7425308228$ $-61.6700401306-58.2034111023-54.3410491943-50.1755409241-45.7513084412$ $-41.1811485291-36.8791999817-33.3098983765-30.2960891724-27.6575202942$ -25.1230392456 -22.4254302979 -19.5730495453 -16.5254402161 -13.6578502655 $-11.2656402588-9.06964302063-6.84935092926-4.65949821472-2.49699091911$ -.545795023441 1.054146051407 2.3740050792693.3845100402834.148447036743 4.6519241333014 .975757122045 .2108330726625 .4251370429995 .730774879456 6.1548538208016 .7643589973457 .5831389427198 .65828418731710 .00026988983 11.6311502456713 .5495700836215 .7588996887218 .2215595245420 .90661048889 23.7337608337426 .6553993225129 .3424606323231 .4398994445833 .23210906982 34.9471511840836 .5480384826738 .038089752239 .4040794372640 .63695144653 41.7399101257342 .7112083435143 .5586013793944 .2849502563544 .90076065063 45.4149208068845 .8425788879446 .1973114013746 .5142707824746 .81840133667 47.1953811645547 .7052612304748 .3701286315949 .264369964650 .35041046143 51.6395492553753 .1004295349154 .6680603027356 .3271903991758 .04666137695 
59.8035507202161 .5816307067963 .2424888610864 .6360626220765 .89739990234 67.1378021240268 .3523483276469 .5551834106470 .7480163574271 .93657684326 73.1243667602574 .3156204223675 .5127334594776 .7205200195377 .93695068359 79.1651535034280 .4004135131881 .6418075561582 .8841705322384 .12406158447 85.3625106811586 .5995178222787 .8419799804789 .0864028930790 .41232299805 91.9011077880993 .4733428955195 .0597534179796 .6631164550898 .27356719971 99.889503479101 .5056991577103 .1196975708104 .7275009155106 .3271026611 107.9150009155 109.4897994995 111.0492019653 112.5924987793114.118598938 115.6275024414117 .1188964844118 .5932006836120 .0507965088121 .4923019409 122.918296814124 .3292999268125 .7261962891127 .1095962524128 .4801025391 129.8383026123131 .1847991943132 .5200958252133 .8448028564135 .1591033936 136.4635925293137 .7584991455139 .0440979004140 .320602417141 .588394165 142.8475036621144 .0982055664145 .3404998779146 .5747070312147 .8009033203 149.0191040039150 .229598999151 .4324951172152 .6278076172153 .8157043457 154.9963989258156 .1699066162157 .3363952637158 .49609375159 .6488952637 160.7951049805161 .9349060059163 .0682067871164 .1952972412165 .316192627 166.4311065674167 .5402069092168 .6434020996169 .741104126170 .8332977295 171.9201965332173 .0018005371174 .0783996582175 .150100708176 .2169036865 177.2790985107 178.336807251 179.3899993896 180.4389038086181.4835968018 182.5240936279 183.5605010986184.5928955078 185.621307373186.6455993652 187.6658935547188 .6822052002189 .6943969727190 .7028045654191 .7071990967 192.7044067383193 .6979064941

207.7975006104207 .5731964111207 .3117980957206 .9826965332206 .6029968262 206.1802062988205 .720993042205 .2364044189204 .7321014404204 .2205963135 203.7042999268203 .1959991455202 .69090271202 .1965026855201 .7091064453 201.2431945801200 .771697998200 .290802002199 .7742004395199 .2429046631 198.5760955811197 .716796875196 .5527954102195 .0388946533193 .0254974365 190.4741973877187 .1940002441183 .1661071777178 .1423034668172 .1483001709 164.8359985352156 .3235015869146 .1204986572134 .2662963867121 .1340026855 105.652702331594.4036788940493.9171905517697.1794204711998.19627380371 98.9471130371199 .494422912699 .4223937988397 .8617935180795 .06005859375 91.3682632446386 .9088897705182 .1629104614377 .0510864257872 .01219940186 66.7940368652361 .2548103332554 .9811401367247 .5802001953139 .49131011963 31.4140796661423 .8340396881117 .0144805908211 .542189598087 .64794921875 $4.5154042243961 .917494058609 .643719929457-635987997055-556487977505$ -.267365992069.4787029922009 2.535183906555 5.4004302024849.113597869873 13.4273099899317 .9046707153322 .4029502868726 .4547595977830 .26523017883 33.7637901306237 .029300689739 .9580497741742 .8314895629945 .84003067017 49.0238189697352 .452430725156 .0226211547959 .828128814763 .52154159546 66.9231033325269 .97460937572 .4712371826274 .5324478149476 .05629730225 77.4446792602579 .0253982543981 .2789764404384 .6356811523489 .60542297363 96.54547119141104 .4496994019113 .6850967407121 .3059997559123 .1859970093 123.3483963013124 .5680999756125 .6912994385126 .8207015991127 .8890991211 128.6324005127129 .0160064697129 .2283935547127 .1324005127120 .9420013428 110.465896606496 .3208923339879 .7526397705164 .0290985107449 .23603057861 36.6590003967326 .2983398437516 .000709533698 .6557922363286 .150889873505 
$5.4797329902654 .2406730651862 .598541021347-.434305012226$-3.89427399635 $-6.99055814743-9.52348327637-10.6838102341-11.5392904282-12.8952903748$ $-16.0674495697-23.8562107086-32.0733909607-36.6577186584-40.2205505371$ $-44.9401283264-48.0900993347-45.9709205627-43.7147598267-44.8141899109$ $-47.5120582581-52.7694587708-56.8902206421-57.2723312378-56.3853607178$ $-55.9675292969-56.1392707825-56.9206008911-57.8948516846-58.3026504517$ $-58.7673606873-59.7470092773-60.4111595154-60.0037002563-59.9920310974$ $-61.6826210022-63.3746490479-62.7751502991-61.5225982666-61.7246818542$ $-62.2791290283-62.4670906067-62.4620704651-61.8805084229-61.2703094482$ $-61.0691604614-60.9691009521-60.7622108459-61.1912193298-63.2015991211$ $-65.5417785645-67.0171203613-67.4871673584-66.8167114258-65.2387695312$ $-62.5166511536-59.8978996277-58.3784599304-57.509979248-57.6427383423$ $-57.7642593384-57.7073516846-57.556388855-57.0136985779-56.171459198$ $-55.0503387451-54.2992210388-53.3301391602-53.0575904846-54.2416496277$ $-55.7384490967-56.6081695557-57.2587394714-57.8559608459-57.7290687561$ $-60.5394515991-62.7208099365-64.3388366699-65.7528762817-67.7598419189$ $-69.9667434692-71.475151062-72.4016265869-72.8118362427-72.7910766602$ $-72.9699020386-72.9351501465$-72.6306762695 -72.0328292847 -70.9904098511 $-69.4005126953-67.0672531128-64.1418304443-60.8864898682-57.2455101013$ $-53.2871704102-49.0843887329-44.8599891663-40.6987190247-36.6132698059$ $-32.9370689392-29.9928607941-27.3798408508-24.6518306732-21.9067401886$ $-19.053730011-16.1968307495-13.4485301971-10.839630127-8.33815097809$ -5.95531797409 -3.55353689194-1.38232004642 .3064279854298 1.635710000992 2.5545289516453 .1547660827643 .4361879825593 .5195670127873 .54986000061 3.576050996783 .7367560863494 .0481348037724 .5945429801945 .386328220367 6.465878963477 .8389649391179 .5118026733411 .500100135813 .81476020813 16.4138603210419 .2551593780522 .2716903686525 .5135993957528 .48638916016 30.6305694580132 .4261894226134 .2486991882335 .9614410400437 .55588912964 39.0223083496140 .3286094665541 .4903602600142 .4938697814943 .35559844971 44.0753784179744 .6670913696345 .1401901245145 .5087089538645 .78791046143 46.0088005065946 .2002906799346 .4364585876546 .7913513183647 .36293029785 48.2436103820849 .3781814575250 .7073707580652 .190010070853 .77016067505 55.4374198913657 .1650085449258 .9325599670460 .770370483462 .46982955933 63.7984695434664 .9767837524466 .1847915649467 .37568 .5629272460969 .74906158447 70.9329071044972 .1205673217873 .3134078979574 .5140609741275 .72509765625 76.94468688966578 .1746368408279 .4092330932680 .647323608481 .88614654541 83.1243972778384 .3663635253985 .6126632690486 .8804016113388 .18279266357 89.5452804565490 .9895172119192 .497207641694 .0484771728595 .62941741943 97.2224197387798 .8240814209100 .4265975952102 .0276031494103 .6233978271 105.2113037109 106.7883987427 108.3527984619 109.9022979736 111.435798645 112.9524993896114 .452003479115 .93409729117 .3992004395118 .8476028442 120.2797012329121 .6964035034123 .0979003906124 .4852981567125 .8590011597 127.2197036743128.5679016113129.9044036865 131.229598999 132.5440063477 133.8480072021135 .1421051025136 .4264984131137 .7015991211138 .9674987793 140.2247009277141 .4732055664142 .7133026123143 .9450073242145 .1685943604 146.3842010498147 .5919952393148 .7920074463149 .9844970703151 .1694946289 
152.3471984863153 .5178070068154 .6813049316155 .8379058838156 .9877929688 158.1309051514159 .2675933838160 .3979034424161 .5218963623162 .6398010254 163.7518005371164 .8578033447165 .9579925537167 .0527038574168 .1419067383 169.225692749170 .3043060303171 .3778076172172 .4465026855173 .5102996826 174.5693969727175 .6239929199176 .6741027832177 .7200012207178 .7617034912 179.7991943359180 .8327026367181 .862197876182 .8876953125183 .9093017578 184.9270935059185 .94090271186 .9506988525187 .9566955566188 .9588928223 189.9568023682190 .9514007568191 .941192627

220.5382995605220 .4095001221220 .2050933838219 .9223937988219 .6053009033 219.2563018799218.8829956055 218.4960021973218.1018066406 217.7120056152 217.3305053711216 .9680938721216 .6221923828216 .2989044189215 .9944000244 215.716003418215 .4454040527215 .1802062988214 .8932037354214 .5861053467 214.1618041992213 .5570068359212 .6773986816211 .4588012695209 .7841033936 207.5834960938204 .7164001465201 .1163024902196 .6168060303191 .1775970459 184.5536956787176 .7498016357167 .1815032959155 .7319030762142 .158706665 125.5759963989113 .4719009399112 .8007965088115 .182800293113 .4169998169 110.5972976685108 .831703186108 .3612976074108 .6031036377108 .2942962646 105.8787002563102 .093299865797 .6140136718892 .6949768066488 .07447814941 83.6261825561579 .4240570068473 .9309921264665 .294357299855 .43215942383 46.4289703369138 .1372604370130 .5534000396724 .5170001983620 .08456993103 16.3911800384513 .7892599105811 .9663095474210 .289239883429 .437858581543 8.8344287872318 .65916919708310 .1797895431512 .8747797012316 .56505012512 21.0195503234925 .7116699218830 .2199497222933 .8474006652837 .07873916626 40.1911582946842 .9573211669945 .0198707580646 .9950408935549 .39958953857 52.158199310355 .2034988403358 .6018104553262 .5474815368766 .56606292725 70.3812026977573 .8491134643676 .5854568481478 .7826614379980 .36421203613 81.6783981323283 .0860900878984 .9558563232487 .3616867065492 .67147064209 103.5895996094115 .0953979492122 .2269973755125 .2045974731124 .7024002075 123.3638000488124 .1564025879125 .5856018066125 .5809020996125 .1408996582 125.3125991821125 .3573989868124 .8480987549122 .8723983765118 .7146987915 112.5289001465103 .256599426392 .0780029296980 .1654434204167 .73008728027 56.4089584350646 .332729339638 .4809913635333 .0829811096230 .56467056274 29.4798698425327 .4574394226125 .3158607482923 .1177101135320 .2885799408 16.5034008026112 .9558401107810 .739819526679 .3750314712528 .596151351929 $6.129352092743-1.15084803104-8.85235786438-12.6717100143-15.7184400558$ $-19.9716892242-23.541179657-25.3636894226-28.2215690613-35.2332687378$ $-43.1341018677-49.3363494873-52.413848877-50.7843513489-47.9906196594$ $-47.6090888977-48.6305389404-50.5254211426-52.4242210388-53.1975708008$ -53.9719696045 -55.476890564 -56.6327705383 -57.218170166 -57.9691696167 $-59.3376693726-60.9829902649-61.5263290405-61.1826515198-61.4882888794$ $-62.1973495483-62.636920929-62.7990989685-62.4389686584-61.8743515015$ $-61.2399597168-60.6512298584-60.5515899658-60.6692008972-60.4405593872$ $-61.3939704895-65.0132827759-68.0040130615-68.081161499-65.8036727905$ $-60.2742004395-54.8699302673-53.1094894409-52.8222999573-52.6259689331$ $-52.7762107849-54.6448898315-56.1387786865-54.0485687256-52.0878295898$ $-53.5208587646-55.2382507324-54.364151001-54.0670204163-57.2702293396$ 
$-60.2129707336-61.2508010864-62.4151611328-64.7141113281-67.2735519409$ $-69.1536483765-70.4129333496-71.6867828369-72.493057251-73.1661529541$ -73.7107467651 -73.4951629639-72.8845825195 -72.0662536621 -71.270362854 $-71.2825469971-71.4751968384-71.5285491943-71.3828964233-70.7048568726$ $-69.4247817993-67.3486404419-64.6609191895-61.7234191895-58.4737892151$ $-54.8993911743-51.0880317688-47.2323493958-43.3088302612-39.4165000916$ -35.6576004028 -32.2086296082 -29.1783294678 -26.5779705048 -24.0846500397 $-21.3638801575-18.443239212-15.3893404007-12.4309301376-9.80127620697$ $-7.3346247673-4.76390123367-2.39089107513-.465633004904 .9905620217323$ 1.788450002672 .1427519321442 .1444931030271 .930654048921 .704473972321 1.520048022271 .5133160352711 .711768031122 .1905019283292 .95912194252 4.0468521118165 .4553828239447 .1926808357249 .25929927825911 .65441989899 14.3412199020417 .2863006591820 .4094009399423 .6643104553226 .69737052917 29.1380100250231 .2612209320133 .292270660435 .1869010925336 .93645095825 38.5265808105539 .9384918212941 .1767196655342 .2348098754943 .12445068359 43.852821350144 .4322090148944 .878349304245 .2039413452145 .42993927002 45.5768318176345 .672710418745 .7591781616245 .8561210632346 .23979949951 47.2056007385348 .4873695373549 .8640899658251 .3490791320852 .91477966309 54.5537681579656 .2468605041557 .9728889465359 .7206382751561 .34860992432 62.7095108032263 .9381904602165 .150802612366 .3429412841867 .53067016602 68.715118408269 .9025421142671 .0945968627972 .2944030761773 .50263977051 74.7214126586975 .9494400024477 .1884994506878 .4308929443479 .67099761963 80.9125595092882 .1584091186583 .4127807617284 .6764678955185 .96874237061 87.30052947998 88.6737136840890.1044464111391.5796737670993.10050964355 94.6560668945396 .2263870239397 .8077468872199 .39192199707100 .9764022827 102.5567016602104 .1303024292105 .693901062107 .2456970215108 .7829971313 110.3051986694111 .8106994629113 .2994995117114 .7711029053116 .2258987427 117.664100647119 .0861968994120 .4926986694121 .8842010498123 .2613983154 124.6248016357125 .9753036499127 .3132019043128 .6394042969129 .9541015625 131.2579040527132 .5513000488133 .8347930908135 .108505249136 .3728027344 137.6280059814138 .8744049072140 .112197876141 .3414001465142 .5623931885 143.7752990723144 .9803009033146 .1773986816147 .366897583148 .5489959717 149.7236022949150 .8910980225152 .0514068604153 .2048950195154 .3515014648 155.4915008545156 .625157 .7521057129158 .8728942871159 .987701416161 .0964050293 162.1992034912163 .296295166164 .387802124165 .4738006592166 .5545043945 167.6300048828168 .7003936768169 .7657928467170 .8264007568171 .8824005127 172.933807373173 .9806976318175 .0234069824176 .0619049072177 .0964050293 178.1266937256179 .1531982422180 .1757049561181 .1943969727182 .2093048096 183.2203979492 184.2277069092 185.2312011719 186.2308044434 187.2268066406 188.2191009521189 .204498291190 .1865997314 233.5742034912233 .4145050049233 .2328948975233 .0074005127232 .75390625 232.4808044434232 .1956939697231 .9096984863231 .6293029785231 .3666992188 231.1253051758230 .9169006348230 .738494873230 .5989990234230 .4897003174 230.4161071777230 .3641052246230 .3428039551230 .3099060059230 .2642059326 230.1145935059229 .8204040527229 .2785949707228 .4454956055227 .1938934326 225.4851074219223 .1632995605220 .2077026367216 .4268035889211 .8500976562 
206.1972961426199 .5397033691191 .3997955322181 .5386047363169 .8674926758 154.8833007812142 .5027008057140 .0617980957140 .0679016113135 .2485046387 130.1759033203126 .9477996826125 .0742034912125 .9196014404126 .6146011353 124.2665023804120 .7416992188116 .2039031982111 .6052017212107 .7437973022 103.7497024536100 .505798339895 .3015594482485 .4517822265674 .5987701416 65.5104827880957 .1898498535249 .0133705139241 .6819000244135 .42473983765 31.2560691833529 .6345806121828 .4955596923825 .7163295745822 .42485046387 20.1680507659919 .1411800384520 .5354595184323 .4418392181427 .3309803009 32.1004981994636 .9191818237341 .2837181091344 .4576988220247 .07907867432 49.6045913696351 .6604003906252 .7245101928753 .6557693481455 .12022018433 57.1716804504459 .5175094604562 .438758850166 .2567825317470 .50434875488 74.7856979370178 .5281982421981 .3554611206183 .3411788940484 .82639312744 86.0191497802787 .199638366788 .9063568115290 .5294036865295 .53125762939 108.9196014404121 .6561965942124 .4956970215123 .2977981567122 .7393035889 122.112701416122 .9970016479123 .9486999512122 .5227966309120 .7492980957 120.0030975342119 .3734970093118 .3783035278117 .0149002075115 .4816970825 112.9816970825108 .2357025146101 .529403686593 .2789611816484 .05396270752 74.9854431152367 .3708572387763 .7947387695362 .061248779360 .58898162842 59.2055397033756 .1369590759352 .8803596496651 .1441497802749 .24969100952 45.2036018371641 .1495018005438 .2891502380435 .9114990234435 .0966796875 32.9183387756326 .0960597991919 .3334407806416 .4893798828114 .6106004715 $11.993800163278 .204987525941 .940147995949-6.50145101547-18.8400707245$ -30.6609897614 -37.0677108765 -39.6472702026 -37.2171287537-34.0607795715 -35.149848938 -37.644618988-40.6265106201-43.4440498352 -44.8641281128 $-45.9695205688-47.3034515381-49.2383384705-52.1575088501-54.6791305542$ $-55.3526802063-55.4076881409-56.2036895752-57.5507011414-59.0312995911$ $-60.2382888794-60.5445098877-60.5209007263-60.6373214722-60.3215904236$ $-58.8301086426-57.4322013855-58.156211853-58.543510437-55.5052490234$ $-54.2097702026-59.6265296936-65.3019866943-66.3171463013-63.1333007812$ $-55.3240203857-47.3514785767-44.9691390991-44.8742904663-43.9049110413$ $-45.2014808655-50.2660903931-53.9440002441-50.2965316772-46.7626914978$ $-51.1163597107-56.787071228-58.4454193115-59.5790405273-62.2481193542$ $-65.5270996094-68.788848877-71.3026123047-72.5014266968-72.65675354$ $-72.4800567627-72.4560928345-73.6142578125-74.6098098755-74.6885528564$ $-73.7561721802-71.624671936-69.1332473755-66.9894714355-65.6930084229$ $-65.6564865112-66.4486312866-67.2307510376-67.6720199585-67.302406311$ $-66.1480789185-64.4428405762-62.2557106018-59.7962417603-57.0783882141$ $-54.1286697388-50.9187316895-47.5923805237-44.1987991333-40.8299713135$ -37.464099884 -33.8279418945 -30.4645195007 -27.9461097717 -25.6380290985 $-23.0125694275-20.1860294342-17.045759201-13.9476900101-11.2416095734$ -8.67768573761 -5.89074087143 -3.30120205879-1.13258695602.4609169960022 $1.0671590566641 .085983037949 .7445539832115 .1628240048885-.338761001825$ -.751092016697 -.916754007339 -.822459995747 - 399206995964 .3558099865913 1.4574929475782 .909813880924 .7146220207216 .8588099479689 .322385787964 12.0755796432515 .0971603393618 .2585792541521 .4455890655524 .50584030151 27.29302978516 29.8358001709 32.15660858154 34.27751922607 36.21234893799 
37.9553489685139 .4882507324240 .8211097717341 .9420204162642 .87055969238 43.6143608093344 .1894416809144 .6189613342344 .9132499694845 .10377120972 45.1999397277845 .2316284179745 .2342185974145 .1443290710445 .37490081787 46.3933410644547 .7605209350649 .1219787597750 .5770301818852 .10134124756 53.682891845755 .3152694702156 .953258514458 .563751220760 .09357070923 61.5000114440962 .8101387023964 .0573577880965 .2639236450266 .4606628418 67.6511611938568 .8470230102570 .0488662719771 .2591094970772 .47866821289 73.7084732055774 .9479064941476 .1996612548877 .4545669555778 .70348358154 79.9556808471781 .2168273925882 .4909591674883 .7769775390685 .0899810791 86.4381713867287 .819892883389 .2429885864390 .7016830444392 .20007324219 93.7288284301895 .2733230590896 .8315963745198 .3946304321399 .96015930176 101.5226974487 103.0801010132104.6283035278 106.1656036377 107.6893005371 109.1985015869110 .6915969849112 .1685028076113 .6287002563115 .0721969604 116.4993972778117 .9105987549119 .3063964844120 .6872024536122 .0538024902 123.4066009521124 .7463989258126 .073600769127 .388999939128 .6929016113 129.9859924316131 .2686004639132 .5411071777133 .803894043135 .0574035645 136.3016967773137 .5370941162138 .7639007568139 .9822998047141 .1923980713 142.3945007324143 .5886993408144 .775100708145 .953994751147 .12550354 148.2897033691149 .4467926025150 .5968933105151 .7402038574152 .8769073486 154.0070037842155 .1307983398156 .2481994629157 .3596038818158 .4649963379 159.5644989014160 .6582946777161 .7463989258162 .8291931152163 .9066009521 164.9786987305166 .0458068848167 .108001709168 .1652984619169 .2178955078 170.2660064697171 .3096923828172 .349105835173 .3842926025174 .4154052734 175.4425964355176 .4658050537177 .4851989746178 .500793457179 .5126953125 180.520904541181 .5252990723182 .5260925293183 .5231018066184 .516494751 185.5061950684186 .4920043945187 .4745941162188 .4526977539

246.6076049805246 .5180969238246 .3865966797246 .2108001709246 .0213928223 245.8249969482245 .6298065186245 .4468994141245 .283706665245 .1519927979 245.0565032959245 .0077972412245 .0057983398245 .0576934814245 .1562957764 245.3034973145245 .4927062988245 .7292938232245 .9774017334246 .2265930176 246.4053039551246 .4682006836246 .3403015137245 .9645996094245 .2550048828 244.1535949707242 .5621948242240 .4259033203237 .6338043213234 .1351928711 229.8318023682224 .6824035645218 .7686004639212 .3020935059204 .6145935059 194.4651947021183 .9710998535175 .653793335169 .536605835166 .7949066162 164.7642974854159 .8437042236155 .0850982666153 .3731994629151 .6654052734 147.3670043945142 .5691070557137 .9355010986134 .0279998779131 .4691925049 128.2402954102123 .3011016846116 .2021026611106 .286003112896 .30268096924 88.965682983482 .0094299316473 .3011169433663 .7917709350653 .29708099365 46.8294715881350 .060409545953 .2402610778846 .8268394470238 .24761962891 33.6686515808131 .9056091308633 .5859489440937 .2398605346741 .7984085083 47.15127182007 51.9530296325755.8776893615758.74542999268 60.88256072998 62.4213409423863 .3460311889663 .4151611328163 .1697387695363 .26197814941 64.0921401977565 .4695587158267 .5802764892670 .9505310058675 .2945098877 80.3402099609484 .6931304931686 .9807128906288 .2339477539189 .41419219971 90.4554672241291 .4162826538192 .9416198730595 .2878112793100 .4353027344 110.8613967896120 .240196228122 .8242034912122 .4320983887121 .9415969849 
121.6134033203121 .804901123121 .5049972534119 .7024993896117 .5913009644 116.103302002114 .9569015503113 .8789978027113 .1959991455113 .0460968018 112.9325027466111 .6938018799108 .9712982178104 .782501220799 .95406341553 95.5249328613392 .383506774991 .0244827270590 .7786865234492 .05703735352 92.3124771118288 .9846878051884 .7992324829182 .1696624755980 .00012207031 77.341102600174 .7330627441472 .4830932617269 .7563171386766 .81874084473 62.4080810546954 .4191017150947 .200469970744 .5346603393643 .12282943726 40.9327812194836 .8599090576230 .3138504028322 .0226001739513 .01782035828 $4.534029006958-3.1022028923-8.53159141541-10.4419698715-12.2572898865$ $-17.4953098297-23.0021190643-26.077999115-28.5291404724-32.113948822$ -34.7507896423 -33.8556594849 -34.8597106934 -43.5940589905 -51.0051193237 $-48.4549789429-43.7208099365-43.1208610535-45.4054603577-50.9618186951$ -55.3033599854 -53.5654907227 -51.359210968 -53.9459915161 -55.7999801636 $-51.3999900818-47.5288009644-51.7974281311-55.1615486145-48.9575004578$ $-44.5663909912-51.8737983704-60.441280365-61.7733306885-57.6818084717$ $-49.2978897095-40.343120575-34.7653694153-31.8992290497-31.2038707733$ -35.176700592 -46.0673789978 -54.1281890869-49.0448493958-43.5446586609 $-50.1117782593-58.0616989136-56.5905418396-54.1727409363-59.1467018127$ $-65.8879928589-70.1479110718-72.6418075562-73.680847168-72.2770233154$ $-67.8034210205-64.7294006348-67.7387924194-71.2451019287-71.2773971558$ $-69.0015029907-64.2114562988-59.048248291-56.0078811646-54.63256073$ $-54.9350700378-56.6271018982-59.1522598267-60.9325790405-60.2309989929$ $-58.5970993042-57.6509590149-56.4770507812-54.4639701843-52.2714614868$ $-50.3497200012-48.1379318237-45.4588012695-42.7040405273-40.1737709045$ -37.5574989319 -34.5612792969 -31.504650116-28.7918701172 -26.2739601135 -23.8265895844 -21.2702102661 -18.5132808685 -15.664440155 -12.7585802078 -9.8441362381 -6.80392313004 -3.97213792801 -1.63160705566 -1.4153000e-02 $.3451960086823-2.3259001 e-02-.771833002567-1.75240004063-2.58194303513$ $-3.22731804848-3.55016994476-3.542771101-3.16220498085-2.41080403328$ -1.28560495377.21039900183682.072029113774.2769541740426.804313182831 9.6203470230112 .709329605115 .9303798675519 .1753997802722 .37664031982 25.4009399414128 .2503108978330 .859159469633 .2315101623535 .3864402771 37.3116798400938 .9876594543540 .4256782531741 .6220893859942 .59661102295 43.3643493652343 .9450683593844 .3680000305244 .6491813659744 .81977844238 44.9000892639244 .9233512878444 .9282684326244 .9334793090845 .22164916992 46.0872001647947 .2655906677248 .5298194885349 .8939399719251 .33312988281 52.8332786560154 .3769111633355 .921321868957 .4339218139658 .9049987793 60.2980117797961 .6328392028862 .9042015075764 .1302032470765 .34446716309 66.5514297485467 .7631835937568 .980323791570 .2062072753971 .44080352783 72.6853027343873 .938888549875 .2025375366276 .4703292846777 .73686981201 79.0084304809680 .2893676757881 .5837707519582 .8931274414184 .22534942627 85.5872116088986 .975723266688 .3956298828189 .843612670991 .3239364624 92.8292694091894 .351699829195 .8874435424897 .4294967651498 .97492980957 100.5186004639102 .0580978394103 .5895004272105 .111000061106 .6197967529 108.1147994995109 .5943984985111 .0585021973112 .5061035156113 .9376983643 115.3531036377 116.7527999878 118.1371994019119.5067977905 120.862197876 
122.2039031982123 .5326004028124 .8488006592126 .1530990601127 .4459991455 128.7279968262129 .9994049072131 .2608947754132 .5126037598133 .7548980713 134.9880981445136 .2124023438137 .4281005859138 .6354980469139 .8345947266 141.0256958008142 .2089996338143 .3847045898144 .5527954102145 .7136993408 146.867401123148 .0140075684149 .1539001465150 .2870025635151 .4136047363 152.5337982178153 .6477966309154 .7555999756155 .8574981689156 .9535064697 158.0437927246159 .1284942627160 .2077026367161 .2816925049162 .350402832 163.4140930176164 .4727935791165 .5267028809166 .5760040283167 .6206970215 168.6609039307169 .6968994141170 .7286987305171 .7563934326172 .7801971436 173.8000946045174 .816192627175 .8285980225176 .8372039795177 .842300415 178.8437042236179 .841506958180 .8356933594181 .8262939453182 .813293457 183.7969055176184 .7769012451185 .7503967285186 .7209014893

259.8211975098259 .7224121094259 .6181030273259 .495300293259 .3689880371 259.2485961914259 .1430053711259 .0635986328259 .0181884766259 .0191040039 259.0712890625259 .1860961914259 .3635864258259 .6127929688259 .9263000488 260.3071899414260 .7473144531261 .2560119629261 .798614502262 .3698120117 262.9046020508263 .3684997559263 .6928100586263 .8385009766263 .7304077148 263.3337097168262 .565612793261 .3955078125259 .7416992188257 .5491027832 254.8338928223251 .5428009033247 .9859008789245 .1212005615241 .1640014648 235.7810058594227 .8061981201214 .6390991211203 .6627044678203 .2872924805 204.2669067383197 .6058959961190 .3392944336186 .2835998535182 .7164001465 177.2964935303171 .1795043945166 .0310974121161 .6804962158159 .2966003418 156.449798584149 .7563018799141 .5608978271132 .7285003662124 .3758010864 119.2155990601113 .2833023071103 .811401367292 .6728210449278 .50846099854 69.0268173217875 .0905227661180 .4896926879969 .7142028808656 .52059173584 50.1459808349648 .1997909545950 .6772499084555 .7342605590861 .55778884888 66.9697875976670 .8064498901473 .9317016601677 .0501098632879 .08321380615 79.2575988769578 .441131591877 .7885208129976 .9526596069375 .3013381958 74.2266387939573 .8721618652375 .0511779785277 .542831420981 .01941680908 86.0798416137790 .2849273681691 .8822326660292 .4563064575293 .60104370117 94.7012710571395 .6755294799897 .40425872803100 .6411972046105 .2492980957 111.1717987061116 .5062026978119 .6240005493121 .1560974121121 .6143035889 121.3630981445120 .4895019531119 .0380020142116 .9909973145114 .735496521 112.6206970215110 .9189987183109 .730796814109 .5589981079110 .2614974976 111.5514984131112 .5740966797113 .5735015869114 .4019012451114 .6932983398 115.6485977173116 .2547988892116 .298500061117 .3127975464121 .0378036499 123.4685974121120 .581703186116 .3946990967113 .6763000488111 .4536972046 110.0074996948108 .5184020996106 .6455001831104 .104896545499 .88498687744 94.0384368896585 .5518569946377 .6112136840874 .4728469848672 .44058227539 69.4126434326265 .3679428100659 .6042404174853 .6886482238850 .01811981201 45.8567008972237 .5620689392128 .771409988421 .6996803283714 .40645027161 $4.971722126007-3.16463303566-6.21352720261-8.39337253571-14.2479400635$ $-18.8255596161-16.0863208771-15.6765804291-28.937330246-40.348651886$ -34.5643196106 -25.971660614 -24.5163593292 -27.1781101227 -35.47108078 $-42.3724098206-38.9221496582-34.4852409363-38.7482681274-41.8336906433$ $-34.3579101562-28.3279399872-35.9888687134-42.876121521-34.8420181274$ 
-27.5748100281 -34.9371910095 -44.0164985657 -44.5361595154-40.8442993164 -34.3561897278 -26.5580196381 -19.6093502045 -15.015879631 -15.3550195694 -20.5161991119-33.6670608521 -44.7834587097 -39.2878608704 -33.3958892822 $-41.916431427-49.6186714172-43.3838310242-37.5132904053-45.0521812439$ $-54.7404594421-58.558429718-60.1157188416-61.3971405029-60.0096702576$ $-52.4852409363-46.641708374-51.6187286377-57.9888496399-58.3943099976$ -55.5879592896 -48.9866104126-42.2687187195 -39.6292800903 -38.9679985046 -39.6906013489-41.9147186279-45.5500411987-48.4587593079-47.4323005676 -45.5615310669-45.938369751 -46.1849899292-44.8450202942 -43.3005981445 $-42.5181999207-41.7125282288-40.1641616821-38.4297409058-36.8994903564$ -35.1398200989 -33.1446800232 -30.6676692963 -27.9819507599-25.4120407104 -23.1660404205 -21.212770462 -19.129650116 -16.7899799347 -13.8210000992 $-10.5843696594-7.33975696564-4.27244186401-1.77133595943-.277249991894$ $-0.30871000886-1.29731202126-2.54079008102-3.90506696701-5.01620197296$ $-5.85871315002-6.3037109375-6.35628890991-6.00365400314-5.24389410019$ $-4.09328508377-2.5552239418-.6452640295031 .611276030544 .193098068237$ 7.06297779083310 .2132797241213 .5170202255216 .8773002624520 .23454093933 23.4856891632126 .593330383329 .47327995332 .1143302917534 .50514984131 36.6289596557638 .4550895690940 .0054092407241 .2766799926842 .29642105103 43.0891609191943 .6774101257344 .1032295227144 .3819389343344 .55142974854 44.6404991149944 .6887702941944 .7667694091844 .9500808715845 .33591079712 46.0159492492746 .9361495971748 .0390892028849 .2808494567950 .60886001587 52.0029983520553 .4405899047954 .887969970756 .3188896179257 .72779846191 59.0949707031260 .424240112361 .7066802978562 .9547615051364 .19339752197 65.4227218627966 .6558074951267 .8926620483469 .1376266479570 .39058685303 71.6526336669972 .9227371215874 .2005081176875 .4844512939576 .77295684814 78.0688781738379 .3725662231480 .6892700195382 .0201263427783 .37003326416 84.7426605224686 .1368713378987 .5568008422988 .9989318847790 .46569061279 91.9523620605593 .4545364379994 .9692382812596 .4902496337998 .01544189453 99.53954315186101 .0605010986102 .5743026733104 .0792007446105 .5719985962 107.0521011353108 .5174026489109 .9677963257111 .4022979736112 .8210983276 114.2240982056115 .6117019653116 .9841995239118 .3420028687119 .685798645 121.0159988403122 .3332977295123 .6380996704124 .931098938126 .212600708 127.4832000732128 .7433929443129 .9934997559131 .2339019775132 .4649047852 133.6867980957134 .8999023438136 .1044006348137 .3005981445138 .4886016846 139.6685943604140 .8408966064142 .0057067871143 .1629943848144 .3132019043 145.4562988281146 .5924987793147 .7220001221148 .8448944092149 .9613952637 151.0717010498152 .1757965088153 .2740020752154 .3663024902155 .4528961182 156.533996582157 .6096038818158 .679901123159 .7451019287160 .8052062988 161.8603057861162 .9107055664163 .9564056396164 .9974975586166 .0343017578 167.066696167168 .0950012207169 .1192016602170 .1394042969171 .1558074951 172.1685028076173 .1775054932174 .182800293175 .1844940186176 .1826934814 177.1773986816178 .1685943604179 .1562042236180 .1403961182181 .12109375 182.0982971191183 .0717926025184 .0422058105185 .0084075928 273.0289916992272 .970703125272 .9053039551272 .8313903809272 .7659912109 272.719909668272 .7025146484272 .725402832272 .7974853516272 .9306945801 
273.1314086914273 .4106140137273 .7705993652274 .2193908691274 .753692627 275.3761901855276 .0795898438276 .8651123047277 .7153015137278 .6279907227 279.5505981445280 .4429931641281 .2627868652281 .9700012207282 .524810791 282.888885498283 .0282897949282 .9104003906282 .513092041281 .8060913086 280.8132019043279 .5192871094278 .0585021973276 .7015075684274 .0685119629 268.9536132812260 .7813110352250 .1271057129241 .1062011719238 .0756988525 235.9125976562228 .7250976562221 .461807251219 .5827941895219 .0632019043 216.716796875212 .1253051758204 .2129058838196 .3455963135191 .6457977295 187.6540985107182 .4156036377176 .7436981201170 .5375061035164 .6692047119 159.8179931641152 .9683074951142 .1912994385129 .5384979248115 .7385025024 105.5726013184104 .2926025391101 .871299743789 .242469787675 .67372131348 68.5684509277367 .3080062866272 .2083663940479 .952842712487 .87828063965 93.6019134521593 .8382568359494 .1091308593899 .96032714844104 .3867034912 100.648498535295 .6774368286196 .266319274996 .6873321533291 .71893310547 86.5677185058684 .7965087890685 .151786804286 .2088623046987 .9543762207 90.7361068725693 .0691299438594 .161270141694 .9868621826296 .42948913574 98.0075607299899 .46147155762101 .5323028564104 .6196975708108 .0492019653 111.8958969116115 .5202026367118 .1741027832120 .2344970703121 .064201355 120.6430969238119 .2929992676117 .2528991699114 .6492004395111 .8094024658 108.890296936106 .302696228104 .4801025391104 .2049026489106 .070602417 108.8654022217111 .0270004272115 .1716995239123 .6969985962131 .5043029785 134.1280059814134 .6934967041136 .3708953857139 .2742004395143 .8383026123 146.9897003174145 .6277008057143 .2825012207143 .650100708143 .7590942383 141.1226959229137 .7422027588135 .1544952393132 .9479064941131 .8267974854 129.2032928467122 .3920974731114 .9327011108110 .0979995728105 .7170028687 100.56719970795 .3589706420990 .0722427368285 .5220031738381 .98030853271 77.4519805908270 .3941268920961 .527618408252 .9405899047943 .84978866577 33.7182388305725 .4770107269321 .4210891723618 .0030803680411 .40717983246 $6.3254828453067 .9399981498727 .806682109833-2.85514497757-11.4989099503$ $-6.292891025541 .2557350397111 .34819996357-2.22158408165-7.30519008636$ $-11.003490448-9.71369361877-7.00181388855-6.9678068161-5.40115976334$ $1.9148859977726 .591913223267-299719005823-6.55591678619-1.17345798016$ $5.180967807773 .551770925522 .0227049998939-.866702973843-.300294011831$ 1.0207049846653 .350866079336 .2000370025638 .034674644475 .988686084747 $2.057466030121-1.87398695946-5.31589078903-5.68030691147-6.61565923691$ $-12.8377799988-15.9008798599-8.71200180054-3.29261898994-11.2407798767$ $-20.7206001282-21.1674594879-19.7718391418-23.3822994232-25.1239891052$ $-18.3751506805-12.9423398972-18.7215995789-26.3224697113-28.3582897186$ $-26.8501091003-21.4365901947-16.3955307007-16.833480835-18.6982593536$ $-19.3318099976-20.7550392151-24.0077896118-26.7337703705-26.2356491089$ $-25.4403591156-27.754650116-30.0149402618-29.6593608856-28.9827098846$ $-29.537820816-30.3953990936-31.1690006256-31.5170307159-30.8593997955$ $-29.754360199-28.6988601685-26.9011096954-24.5089492798-22.1909999847$ $-20.4797306061-19.3100891113-18.2627506256-16.6738491058-13.9745798111$ $-10.7390804291-7.41107416153-4.14788293839-1.29157400131 .2384369969368$ $-.694519996643-2.74975800514-4.62038803101-6.34237480164-7.68336582184$ 
-8.65011882782 -9.16641235352 -9.24561023712 -8.89225578308 -8.11336135864 $-6.92759418488-5.34647607803-3.38755488396-1.078485965731 .554955005646$ 4.4874210357677 .70560598373411 .106229782114 .5951595306418 .12125968933 21.5981807708724 .9602298736628 .1032104492231 .0037994384833 .61603164673 35.9290618896537 .9082984924339 .5716896057140 .9142303466841 .97515106201 42.7898597717343 .3894081115743 .8238906860444 .1164817810144 .30699920654 44.4302597045944 .5234489440944 .6677894592344 .9277801513745 .32089996338 45.9207000732446 .6903495788647 .6455993652348 .7522697448749 .94948959351 51.2197799682652 .5373191833553 .8806800842355 .22573089656 .57070159912 57.899139404359 .2116088867260 .4957695007361 .7610511779863 .018409729 64.2708663940465 .5264205932666 .7860336303768 .053016662669 .32731628418 70.6100463867271 .9000015258873 .1971893310574 .5016632080175 .81269836426 77.1320037841878 .459548950279 .7981719970781 .1499481201282 .51661682129 83.9007873535285 .301757812586 .7220764160288 .1596069335989 .61576843262 91.0872421264692 .5723495483494 .0678787231495 .569892883397 .07554626465 98.58085632324100 .0833969116101 .579498291103 .0673980713104 .5441970825 106.0087966919107 .4592971802108 .895401001110 .3162002563111 .7218017578 113.1118011475114 .4868011475115 .8469009399117 .1925964355118 .5243988037 119.8426971436121 .1482009888122 .4412002563123 .7225036621124 .992401123 126.2515029907127 .5000991821128 .7386932373129 .9674987793131 .1871032715 132.3975067139133 .5991973877134 .7924041748135 .9772033691137 .154006958 138.3229064941139 .4841003418140 .6378936768141 .7843933105142 .9237060547 144.0561981201145 .1817932129146 .3009033203147 .4134979248148 .5198974609 149.6201934814150 .7144012451151 .8029022217152 .8856964111153 .9629974365 155.0348052979156 .1013031006157 .1625976562158 .2189941406159 .270401001 160.3170928955161 .3591003418162 .3966064453163 .4297027588164 .458404541 165.483001709166 .5036010742167 .5202026367168 .5330963135169 .542098999 170.5475006104171 .5493927002172 .5476989746173 .5424957275174 .5337982178 175.521697998176 .5063018799177 .4873962402178 .4651031494179 .4393005371 180.4102935791181 .3778991699182 .3394012451183 .2982025146 286.2976074219286 .2484130859286 .2109069824286 .1810913086286 .1733093262 286.1979064941 286.2655029297286.3876037598 286.5741882324 286.8369140625 287.1836853027287 .6253051758288 .1657104492288 .813293457289 .567199707 290.432800293291 .4017944336292 .4713134766293 .6344909668294 .8980102539 296.2163085938297 .5521850586298 .8826904297300 .1745910645301 .4139099121 302.5704956055303 .6492004395304 .6278991699305 .533996582306 .3765869141 307.1380004883307 .8653869629308 .1806030273307 .8424072266305 .8418884277 300.6534118652294 .1167907715289 .5458984375284 .4840087891278 .3208007812 271.8006896973263 .4961853027257 .4744873047258 .000213623260 .0983886719 260.433013916257 .8994140625248 .3157958984237 .7640991211230 .7644042969 225.4779052734222 .212600708219 .0124053955214 .9342041016210 .0592956543 204.338394165196 .8045959473185 .8816986084173 .2557983398161 .0175933838 149.5225067139138 .7454071045128 .1907043457115 .2488021851103 .3611984253 96.4718780517694 .94844055176100 .5921020508109 .5599975586118 .251701355 123.9271011353121 .3394012451118 .8730010986126 .7602005005133 .1062011719 125.9685974121117 .9709014893120 .4895019531122 .4942016602114 .9138031006 
105.9213027954102 .241897583100 .042198181297 .472793579195 .93280792236 95.2895431518695 .4646835327196 .2004165649497 .3737792968899 .38233184814 101.6910018921104 .0922012329106 .3009033203108 .6984024048111 .1604003906 113.631401062116 .3986968994118 .5866012573120 .3218994141120 .9617996216 120.3322982788118 .7134017944116 .1353988647112 .9005966187109 .2693023682 105.4261016846102 .032997131399 .480056762798 .70735168457100 .7711029053 104.5020980835107 .3094024658113 .2542037964127 .2695007324140 .9488067627 145.0968933105146 .6930999756151 .2653045654155 .6212005615160 .2673950195 163.5312042236163 .921005249164 .0518951416167 .5957946777170 .1728057861 166.3768005371161 .4337005615158 .0500946045156 .154296875158 .553894043 159.5404968262155 .0287017822148 .9515075684143 .1221008301137 .5274963379 131.3336029053125 .5155029297121 .1027984619116 .9194030762111 .6728973389 105.58930206399 .2881317138791 .815567016683 .5395965576274 .48779296875 65.4651870727557 .5413398742751 .6381607055746 .5789108276439 .23093032837 33.5286293029833 .0462684631332 .3286399841325 .9514293670721 .10618972778 24.8534507751529 .4557991027827 .5529098510724 .2647705078124 .11417961121 24.8882102966324 .6418399810825 .5347995758129 .8719406127935 .3338394165 41.5095596313544 .8430213928240 .0173912048334 .877788543736 .69412994385 41.2541694641145 .7369117736849 .108821868949 .114959716847 .09370040894 44.1780204772940 .7600708007838 .8886909484936 .0796890258830 .90387916565 27.7775993347233 .0765495300338 .7397308349634 .1003303527828 .03684043884 26.0023994445826 .6763496398932 .3972511291535 .881839752228 .42643928528 20.7567195892323 .9630107879627 .9507408142122 .048690795916 .8570098877 21.8258094787625 .6961097717319 .323520660411 .356650352488 .083373069763 8.18410587310812 .2655296325715 .2244901657111 .466190338136 .354427814484 5.1916861534124 .7786870002752 .534842014313 .73440200090411 .099056005478 $.4959630072117-3.93557810783-8.61868858337-9.64648723602-10.100520134$ -12.0496397018 -14.4952497482 -17.7740402222 -20.075920105 -20.0551490784 $-19.3588294983-19.2546596527-18.8586101532-18.0879592896-17.1571102142$ -16.3938503265 -15.9773902893 -15.7911901474 -14.9555397034-12.6809597015 -9.59185123444 -6.4061589241 -3.43630099297- -.763355016708 .3000499904156 -1.58279299736 -4.53483819962 -6.81448507309-8.82239246368 -10.3289604187 $-11.3693704605-11.9335002899-12.0165901184-11.6640100479-10.8688297272$ $-9.66161060333-8.0531244278-6.05830287933-3.70904302597-1.02465498447$ 1.9629969596865 .2524738311778 .74879169464112 .3744897842416 .07040977478 19.7627506256123 .3614501953126 .7612590789829 .9106693267832 .73672866821 35.2340698242237 .3538894653339 .1219711303740 .5227699279841 .60924911499 42.4417190551843 .0505294799843 .5030097961443 .8203010559144 .05004882812 44.226150512744 .3810195922944 .5778808593844 .8714294433645 .2660484314 45.8058586120646 .4795608520547 .3120498657248 .2765884399449 .32991027832 50.4654197692951 .6563606262252 .8905906677254 .1490592956555 .42607116699 56.7085990905857 .9938087463459 .2737083435160 .5498580932661 .82559967041 63.101428985664 .3813781738365 .6656875610466 .9565582275468 .25396728516 69.559150695870 .871368408272 .1909790039173 .5182571411174 .85317230225 76.1965026855577 .5477523803778 .9086837768680 .2801818847781 .66301727295 83.058448791584 .4662017822385 .8881607055787 .3226623535288 .77084350586 
90.2304763793991 .7009506225693 .1797485351694 .6640701293996 .15162658691 97.638816833599 .1236114502100 .6023025513102 .0734024048103 .5338973999 104.9829025269106 .418296814107 .8399963379109 .24659729110 .6384963989 112.0151977539113 .3771972656114 .7245025635116 .0577011108117 .3770980835 118.6830978394119 .9765014648121 .2574996948122 .5269012451123 .7848968506 125.0322036743126 .2689971924127 .4959030151128 .713104248129 .921005249 131.1199035645132 .3099975586133 .4916992188134 .6651000977135 .8305969238 136.9882049561138 .1383056641139 .2810058594140 .4165039062141 .5449981689 142.6667022705143 .7816925049144 .8903961182145 .9927062988147 .0888977051 148.1790924072149 .2635040283150 .3421936035151 .4154052734152 .4833068848 153.5458068848154 .6031951904155 .6555938721156 .7032012939157 .7460021973 158.7841033936159 .8177947998160 .8470001221161 .8719940186162 .8928985596 163.9096984863164 .9226074219165 .9315948486166 .93699646167 .9387054443 168.9369049072169 .9315948486170 .9228973389171 .9107055664172 .8952026367 173.8764038086174 .8542938232175 .8287963867176 .8000030518177 .7678985596 178.7324981689179 .6936035156180 .6517944336181 .6060028076

299.5563049316299 .5140991211299 .4996948242299 .5132141113299 .5581054688 299.6488952637299.7965087891300.0133056641300.309387207300.6971130371 301.1852111816301 .7846069336302 .5011901855303 .3435058594304 .3135070801 305.4161987305306 .6478881836308 .0097045898309 .4949951172311 .1029052734 312.8098144531314 .5893859863316 .4309997559318 .3085021973320 .2294921875 322.1788024902324 .184387207326 .2443847656328 .4013061523330 .6748046875 333.0412902832335 .5314941406337 .700012207339 .4038085938340 .0390930176 339.0068969727338 .4543151855340 .7344055176339 .9743041992331 .3359985352 320.7828063965312 .5816040039307 .5010070801305 .5148010254304 .5297851562 303.0280151367299 .9161987305294 .1567077637287 .2239074707280 .0845947266 274.3693847656271 .6596984863268 .423614502261 .6532897949253 .6714935303 246.9095001221240 .0032043457232 .3981018066222 .7400970459209 .1950073242 194.1826019287180 .6094055176169 .0988006592159 .4291992188150 .9562988281 142.3052062988137 .2310943604139 .7292022705145 .9170074463151 .8278961182 155.4528045654154 .6566925049154 .0662994385158 .3856964111161 .4696044922 156.8148040771152 .2028045654155 .0505981445156 .8775024414150 .4019927979 140.8448944092132 .332901001123 .4115982056112 .9168014526104 .3638000488 100.8865966797100 .065696716399 .97264099121101 .0711975098103 .5538024902 106.8349990845110 .3720016479112 .9686965942113 .9905014038114 .84349823 116.6303024292118 .9875030518120 .6200027466121 .7180023193122 .2337036133 121.5074996948119 .3347015381116 .0682983398111 .9029006958107 .2500991821 102.443496704198 .1558227539195 .1665420532293 .6179809570393 .464012146 95.4473266601699 .87970733643107 .3675994873118 .2470016479130 .3972930908 141.7236022949151 .5921936035159 .8863983154165 .9496002197169 .7272949219 172.1091003418174 .0541992188176 .0025024414178 .788192749180 .4884033203 179.2431945801176 .708404541173 .6098937988172 .0617980957174 .5700073242 175.6759033203171 .9064025879167 .0877990723164 .403793335162 .1475982666 158.7301940918155 .0113983154151 .9736022949148 .0625141 .6851959229134 .4676055908 128.0437927246121 .3821029663113 .3797988892104 .499298095796 .21748352051 87.8748779296979 .0153732299870 .7902221679763 .1467208862357 .21363830566 
54.5784416198752 .5982398986848 .4545516967845 .5498390197847 .40773010254 49.574638366749 .1528511047449 .0444297790550 .7886085510353 .49510955811 57.0628318786660 .492599487362 .776931762765 .5678329467871 .65309143066 75.4717025756871 .6448898315466 .5434188842866 .0076065063569 .44515991211 77.3537063598685 .3608932495188 .9850463867288 .77455902187 .06517028809 83.4933624267679 .1199264526472 .195449829160 .7358894348153 .03054046631 56.0047683715861 .7188987731963 .529991149963 .7231483459564 .49842834473 65.6512832641667 .0714035034266 .2754135131861 .425079345757 .2911605835 58.9851608276460 .7623786926356 .8954582214453 .2519683837956 .880859375 59.0933609008852 .364959716844 .4194488525441 .1254806518641 .67533874512 48.0088691711452 .2214088439946 .6165885925338 .9234390258835 .25049972534 33.7313385009832 .9785308837933 .02539062534 .3050689697333 .29602050781 26.6740894317619 .3568801879915 .9432601928713 .4695701599110 .11468982697 $6.1935582160951 .236186027527-2.17509794235-2.01110506058-1.45557296276$ $-2.71943998337-4.80080413818-8.31165218353-11.2215299606-11.5768604279$ -11.5552997589-12.110619545-11.7903900146-9.80951118469-6.94461011887 -3.98752808571 -1.64350605011 -.833730995655 -1.57942605019-3.8547809124 $-6.71332597733-9.18380737305-11.2995100021-12.8749504089-13.9563302994$ -14.5271196365 -14.6060695648 -14.2418699265 -13.4377002716 -12.2208499908 -10.5990800858 -8.58510017395 -6.2018828392 -3.46760702133-.417001008987 2.9226100444796 .49841022491510 .2571802139314 .1235904693618 .00868034363 21.8275203704825 .4820194244428 .8786201477131 .9019794464134 .56293106079 36.8125305175838 .6701087951740 .1073188781741 .2018585205142 .04027938843 42.6593589782743 .129459381143 .4772415161143 .7486190795943 .9750213623 44.1928100585944 .4395484924344 .7585601806645 .1506118774445 .64756011963 46.2458305358946 .9710693359447 .8044013977148 .7262306213449 .72888183594 50.7947196960451 .9171714782753 .0840110778854 .2888183593855 .52122116089 56.776920318658 .0478706359959 .3317298889260 .6231307983461 .92205047607 63.2258911132864 .5356216430765 .8509826660267 .1726531982468 .50137329102 69.8371429443471 .1806030273472 .5319290161173 .8914794921975 .2590637207 76.6343231201278 .0173492431679 .4082870483480 .807060241782 .21404266357 83.6290664672985 .0531082153386 .4855194091887 .9272537231489 .376953125 90.8348464965892 .2988128662193 .7675170898495 .2384490966896 .70909881592 98.1770935058699 .63939666748101 .0942993164102 .5390014648103 .9726028442 105.3929977417106 .8000030518108 .1923980713109 .5703964233110 .9335021973 112.2822036743113 .6164016724114 .9366989136116 .2434005737117 .5369033813 118.8178024292120 .0866012573121 .3438034058122 .5896987915123 .8249969482 125.0498962402126 .2649002075127 .470199585128 .666305542129 .8535003662 131.0319976807132 .2019958496133 .3639984131134 .5180053711135 .6643066406 136.8031005859137 .9346008301139 .05909729140 .1766967773141 .2875976562 142.391998291143 .4900970459144 .5820007324145 .6679992676146 .7480926514 147.8226013184148 .8916015625149 .9552001953151 .0135955811152 .0668945312 153.1152038574154 .1585998535155 .1974029541156 .2315063477157 .2611999512 158.2864990234159 .3074951172160 .3244018555161 .3372955322162 .3462982178 163.3515014648164 .3529968262165 .3509063721166 .3453063965167 .3363037109 168.3238983154169 .3081054688170 .2890014648171 .2666931152172 .241104126 
173.2124023438 174.1802978516175.1450042725176.1065063477177.0648040771 178.0200042725178 .9692993164179 .9161071777

312.7550048828312 .7362976074312 .7464904785312 .7905883789312 .8821105957 313.0327148438313 .2542114258313 .55859375313 .957611084314 .4627990723 315.0848999023315 .834197998316 .7190856934317 .7473144531318 .9244995117 320.2540893555321 .7403869629323 .3876953125325 .1889953613327 .1326904297 329.2182006836331 .4262084961333 .7648925781336 .2054138184338 .7879943848 341.4948120117344 .3909912109347 .469909668350 .7968139648354 .3678894043 358.1715087891362 .1968994141366 .2471008301370 .2179870605374 .2713012695 378.599395752383 .8283996582392 .361907959396 .7554016113388 .9585876465 377.4277954102370 .6271057129365 .633605957359 .2840881348354 .3923950195 349.6975097656345 .7770080566344 .6499023438342 .0195007324335 .2219848633 328.0035095215324 .4147949219320 .6571960449310 .9643859863300 .5798034668 293.7861022949287 .6839904785283 .5887145996277 .1413879395262 .9482116699 246.1425933838232 .1304016113220 .0321960449212 .1638946533206 .1417999268 196.0650024414187 .7913970947185 .7064056396186 .1101074219186 .9864044189 188.4230957031190 .1369018555191 .6347961426191 .8153076172191 .040802002 189.0688934326187 .6439971924189 .7848968506190 .4512939453185 .3786010742 176.1938018799163 .8677978516148 .9078979492131 .6331939697116 .5052032471 109.8226013184107 .5002975464105 .9413986206107 .014503479109 .3585968018 113.0411987305117 .4532012939121 .0597991943122 .2440032959122 .4811019897 124.1726989746125 .3805007935125 .3295974731124 .841003418124 .4128036499 123.2981033325120 .5678024292116 .5953979492111 .5109024048105 .8293991089 100.180801391695 .2320632934691 .8223266601689 .4907836914186 .82303619385 86.7566299438592 .1147994995199 .79618835449105 .3908996582113 .6852035522 130.2465057373147 .3186950684158 .9192047119166 .9111022949170 .7947998047 172.9866943359177 .4846954346181 .566696167183 .5171051025184 .6643066406 186.2487945557186 .7073059082183 .7684020996181 .3793029785182 .1217956543 183.495803833182 .4002990723180 .6183929443181 .3721008301182 .1150054932 181.9176940918180 .7570953369178 .5355072021174 .445098877167 .733795166 160.1719055176153 .5791015625146 .7606048584138 .8390960693131 .2545928955 124.7918014526117 .2025985718106 .644599914695 .588172912686 .88066101074 80.1549606323274 .7090530395571 .0924530029367 .839279174865 .71897125244 64.9917297363365 .2171478271566 .8479766845769 .5245285034272 .21398162842 75.7865829467882 .472381591888 .189178466887 .6812133789187 .11588287354 92.8474426269597 .4414596557694 .9674377441491 .17690277189 .65984344482 91.65659332275100 .2085037231109 .7677993774115 .2772979736117 .8812026978 119.0634994507117 .4990005493113 .0636978149105 .52339935391 .96463775635 80.6302413940479 .3870697021582 .7323608398490 .1575393676897 .87074279785 101.2051010132101 .914001464898 .0315475463993 .7172470092892 .53737640381 92.5245666503992 .0461273193490 .5123062133887 .9223632812585 .9884262085 88.1255493164189 .1951065063582 .9952926635776 .0156326293972 .94622039795 73.6467895507881 .2251968383887 .1467208862381 .3399734497172 .72638702393 67.6101303100664 .4578323364364 .3425521850665 .2753829956166 .58934783936 65.5142135620157 .868030548149 .1083412170443 .9147987365739 .97671890259 36.1198310852131 .8388996124326 .0471305847221 .2717895507820 .74785041809 
21.0737590789819 .0012092590314 .372509956365 .763821125031 -2.2440431118 $-4.21597909927-4.15262508392-5.26238393784-5.4110250473-4.12662887573$ -1.94093894958 -1.0826000e-02 .6877980232239-.864087998867 -3.58654499054 $-6.07478904724-8.63127613068-11.1088199615-13.3187999725-14.9389600754$ -16.0386104584 -16.6310005188 -16.7310905457 -16.400270462 -15.6361503601 -14.4538297653 -12.8693799973 -10.8692798615 -8.49082756042 -5.72664403915 $-2.63657903671 .74391400814064 .3817539215098 .25722312927212 .27029037476$ 16.3274593353320 .3421096801824 .2457904815727 .880369186431 .10441970825 33.9293289184636 .2742195129438 .1845588684139 .6319999694840 .70824050903 41.5503997802742 .1793594360442 .6764907836943 .0645103454643 .38555908203 43.6696701049843 .9486389160244 .2444381713944 .5839614868244 .97404098511 45.4419898986845 .984519958546 .6188011169447 .3380584716848 .1335105896 49.0074615478549 .9459609985450 .9543914794952 .0269088745153 .15586090088 54.3370399475155 .5609207153356 .822540283258 .1135711669959 .42021942139 60.7415809631362 .0684814453163 .4026908874564 .7416915893666 .08670806885 67.4386367797968 .7975387573270 .1650314331171 .5403671264672 .92465209961 74.3163528442475 .7156219482477 .1206588745178 .531112670979 .94593811035 81.3647537231482 .7875595092884 .2144699096785 .6458129882887 .08249664307 88.5239715576289 .9711303710991 .4222717285292 .8771667480594 .3334197998 95.7889709472797 .2417373657298 .68863677979100 .1283035278101 .557800293 102.9765014648104 .3820037842105 .774597168107 .1526031494108 .5166015625 109.8657989502111 .2008972168112 .5217971802113 .8289031982115 .1225967407 116.4032974243117 .6716003418118 .9279022217120 .1726989746121 .4063034058 122.6294021606123 .8421020508125 .0450973511126 .2384033203127 .4226989746 128.5980072021129 .7646942139130 .9230957031132 .0733947754133 .2158966064 134.350692749135 .4781951904136 .5984954834137 .7118988037138 .8184967041 139.9185028076141 .012298584142 .0997924805143 .1813049316144 .2570037842 145.3271026611146 .3916015625147 .4508056641148 .5048065186149 .5536956787 150.5977020264151 .6369018555152 .6714019775153 .7012939453154 .7268066406 155.7478942871156 .7648925781157 .7776947021158 .7864990234159 .7915039062 160.7926940918161 .7902069092162 .7841949463163 .7747039795164 .7617034912 165.7454986572166 .7259063721167 .7032012939168 .6772003174169 .6479949951 170.6157073975171 .5802001953172 .541595459173 .4998016357174 .4548034668 175.4067993164176 .3553009033177 .3011016846178 .2431945801 325.9385986328325 .8902893066325 .903503418325 .9808044434326 .1115112305 326.3143005371326 .6012878418326 .9852905273327 .4778137207328 .0914916992 328.8370056152329 .7258911133330 .766998291331 .9696960449333 .3403930664 334.8844909668336 .6097106934338 .5227966309340 .6177062988342 .8872070312 345.3330078125347 .9432067871350 .7362976074353 .7016906738356 .883392334 360.2867126465363 .9784851074367 .9812011719372 .3588867188377 .1400146484 382.3374023438387 .949798584393 .9725952148400 .3075866699407 .478302002 415.5539855957424 .854309082436 .2362060547444 .6637878418446 .3355102539 442.445892334434 .7528076172426 .4888000488419 .8507995605414 .8245849609 409.9702148438406 .8680114746407 .2152099609405 .2291870117395 .3642883301 383.9949035645378 .2073059082374 .2026062012368 .0078125361 .8738098145 357.1849975586352 .6760864258348 .3790893555342 .5238037109332 .6098022461 
319.0086975098302 .2988891602285 .0914001465269 .6274108887257 .9065856934 251.9779968262246 .5319976807237 .4425964355229 .0108032227225 .2951965332 224.6560058594225 .2321014404225 .7984924316225 .195098877223 .3134002686 219.1759033203215 .4971008301214 .9662017822213 .2568969727207 .5993041992 198.4113006592186 .0502929688170 .4824981689153 .2749023438137 .0296020508 124.5497970581116 .6732025146114 .3081970215115 .5762023926117 .0942001343 120.3632965088125 .8529968262131 .7577972412137 .449798584141 .3347930908 141.8177032471139 .8428955078135 .779006958131 .3786010742128 .4689025879 125.8404998779122 .5718994141118 .2033996582112 .0215988159105 .2593994141 99.1560211181693 .8786010742289 .7309036254986 .3752975463983 .30296325684 82.6491165161186 .3968276977591 .8218765258896 .32417297363103 .3815994263 115.5008010864129 .7825927734143 .0131988525153 .7138977051160 .3231964111 165.8816986084174 .3430023193182 .2799072266187 .4078063965191 .0189971924 193.1734924316193 .2021026611189 .0144958496184 .6499023438183 .5108032227 186.6065979004196 .632598877204 .9788970947202 .6047058105198 .8867034912 201.5617980957203 .1918945312197 .9194030762190 .7129974365186 .9013977051 182.4349975586173 .6244049072164 .1396026611157 .1300048828152 .4400024414 150.2324981689146 .2740936279137 .6414031982126 .2769012451113 .4671020508 102.054603576794 .1574172973688 .8507995605584 .9034271240281 .90928649902 79.1472930908277 .6325531005978 .5124969482481 .1548233032284 .71501159668 88.414199829191.9873733520594.8195877075296.012969970797.37460327148 101.8541030884105 .9364013672106 .1604003906105 .2058029175105 .1505966187 106.5635986328110 .6998977661115 .7679977417119 .5819015503122 .2739028931 124.2363967896124 .6239013672123 .7553024292121 .5643005371118 .8703994751 116.2043991089115 .1596984863116 .314201355120 .0985031128125 .3470001221 130.1298980713130 .9783935547124 .1806030273118 .5813980103122 .0167007446 126.9705963135127 .1971969604123 .9785003662117 .7087020874112 .4897994995 112.7301025391113 .2244033813109 .6143035889105 .1417999268101 .4729995728 100.4301986694104 .8811035156108 .9135971069106 .491897583101 .5369033813 97.5956878662194 .4096908569392 .8225784301891 .7933273315490 .61456298828 88.0255432128982 .6931915283276 .4915466308671 .2847595214867 .62615966797 66.7325210571364 .9614791870158 .5441207885751 .6312103271547 .91220092773 46.0526084899945 .7899208068841 .2776298522926 .1944293975811 .63105010986 8.2616958618168 .4683952331546 .2580652236944 .6289210319525 .011757850647 $5.9884219169625 .2794141769412 .990875005722-.3163250088669-3.98702692986$ $-7.09730482101-9.73165607452-12.3293399811-14.6924695969-16.3531703949$ $-17.440290451-18.0736198425-18.2388000488-17.9958705902-17.3307094574$ $-16.2499198914-14.7538299561-12.8295001984-10.4965295792-7.76149702072$ $-4.6690030098-1.258965969092 .4392580986026 .39145994186410 .51842021942$ 14.7330398559618 .9466094970723 .0709896087626 .9268398284930 .36932945251 33.3658905029335 .7636108398437 .6740798950239 .1038818359440 .14514923096 40.9659004211441 .6007118225142 .1252899169942 .5588188171442 .93669891357 43.2823486328143 .6273612976143 .9762916564944 .3444900512744 .74076080322 45.1859016418545 .6797599792546 .2362899780346 .8532981872647 .53337097168 48.2817001342849 .0957298278849 .988418579150 .9679298400952 .02273178101 53.1505508422954 .3428688049355 .5976104736356 .8987083435158 .22225952148 
59.5656318664660 .915039062562 .272048950263 .6328392028864 .99942779541 66.3726196289167 .7533569335969 .1432876586970 .5419235229571 .95012664795 73.3659896850674 .7890167236376 .2164764404377 .6468429565479 .07842254639 80.5095367431681 .9405899047983 .3712921142684 .802459716886 .23499298096 87.6692733764689 .1069793701290 .5468673706191 .9896316528393 .43290710449 94.8752212524496 .3142318725697 .7473297119199 .17282867432100 .5882034302 101.9925003052103 .3837966919104 .7620010376106 .1259994507107 .4757995605 108.8113021851110 .132598877111 .4399032593112 .7337036133114 .0141983032 115.2818984985116 .5373001099117 .7808990479119 .0130996704120 .2341995239 121.4449005127122 .645401001123 .8361968994125 .0175018311126 .1896972656 127.3529968262128 .5079040527129 .6544952393130 .7931060791131 .9239959717 133.0473937988134 .1634063721135 .2725067139136 .3746948242137 .4703063965 138.5594024658139 .6423950195140 .7192993164141 .7904052734142 .8558044434 143.9156951904144 .9703063965146 .0196990967147 .0639953613148 .1035003662 149.1381072998150 .1681976318151 .1936950684152 .2147979736153 .2315979004 154.2442016602 155.2528076172 156.2574005127 157.2581939697 158.2552032471 159.2485961914160 .238494873161 .224899292162 .207901001163 .1876983643 164.1641998291165 .1374969482166 .1076965332167 .074798584168 .0388946533 168.9998016357169 .9575958252170 .912399292171 .8641052246172 .8126983643 173.7583007812174 .7008056641175 .637802124176 .5724945068

338.9436950684338 .9287109375338 .9590148926339 .048614502339 .2102966309 339.4560852051 339.7994995117340.2522888184340.8280944824 341.5379943848 342.3952026367343 .4093933105344 .5931091309345 .9536132812347 .5018920898 349.2410888672351 .1853942871353 .3392944336355 .7055969238358 .2731018066 361.0545043945364 .0267028809367 .2351074219370 .6644897461374 .3879089355 378.395904541382 .7945861816387 .583190918392 .8861999512398 .7025146484 405.1655883789412 .234588623420 .1339111328428 .6976013184438 .4432983398 449.2226867676460 .9682922363473 .3006896973484 .974395752496 .5433044434 503.3163146973498 .362701416489 .3024902344483 .0481872559476 .6206970215 470.421295166465 .5855102539464 .1373901367460 .5198059082447 .4023132324 433.6473083496426 .7673034668422 .1958007812418 .713104248415 .7666015625 412.5769042969409 .3945007324404 .7258911133398 .7568969727392 .8104858398 383.1723022461365 .9945983887345 .782989502323 .3992004395305 .173614502 302.4242858887300 .1586914062285 .062286377269 .6348876953262 .8405151367 259.8854980469257 .896697998256 .6601867676255 .5908966064253 .0043029785 245.7770996094238 .2583007812234 .0323944092229 .4308013916222 .363494873 212.849899292201 .2852020264187 .93699646174 .1399993896160 .1154937744 144.3079071045132 .5124969482129 .7695007324130 .5628967285129 .5363006592 130.161605835134 .8470001221141 .7032928467151 .1427001953158 .2378997803 157.6732940674152 .9454040527145 .6316986084137 .8049926758132 .6163024902 128.2686004639124 .1791000366119 .3908004761112 .3273010254104 .9548034668 98.8345565795993 .405273437588 .4292373657284 .2949295043981 .21914672852 80.0124435424881 .3781585693484 .5098724365288 .7857666015694 .61622619629 100.7844009399109 .181098938121 .5306015015133 .9132995605142 .8430023193 152.3997955322165 .6349945068178 .4808959961188 .4671936035194 .8090057373 197.6399993896196 .512802124190 .4241943359184 .2794036865180 .7747955322 
184.475402832203 .8885040283220 .8887023926215 .6929931641206 .6938018799 210.5390014648213 .816696167205 .9654998779197 .246307373197 .1875196 .5433959961 186.5774993896176 .036605835171 .0599975586168 .3027038574168 .9640045166 168.6692962646163 .7012023926154 .9528961182139 .9002990723124 .720703125 114.7944030762107 .4559020996101 .279899597296 .1127624511791 .07553100586 87.6366882324286 .5542907714887 .6520767211991 .0712127685594 .31907653809 93.8755416870193 .1477127075296 .0607223510799 .85050201416103 .3149032593 106.7515029907109 .6204986572111 .9496994019114 .0384979248115 .3477020264 114.6977996826114 .1266021729115 .084602356116 .7061004639118 .5653991699 120.8042984009123 .6149978638128 .1466064453137 .783706665146 .6416015625 149.2922973633150 .100402832151 .0021972656152 .4828033447157 .4143981934 159.9040985107152 .6542053223146 .8654937744153 .4570007324161 .1278076172 161.546005249157 .712600708148 .5848999023139 .9425964355138 .117401123 138.2803955078137 .3952026367135 .7294006348131 .8087005615128 .470703125 128.1490936279128 .6130065918128 .608505249127 .4568023682125 .3583984375 122.6417999268119 .5402984619116 .2850036621112 .3197021484108 .4345016479 105.7015991211102 .902702331598 .600303649995 .2572631835996 .61756896973 97.1210403442490 .5973434448282 .6651611328175 .980323791570 .85334777832 71.3383483886767 .6584167480548 .5098495483429 .6685390472425 .79487991333 26.2020606994623 .3894500732420 .5763206481919 .4691295623817 .42102050781 $12.206379890446 .5307707786561 .668784976006-2.26891589165-5.86318016052$ $-9.24739265442-12.2282800674-14.8373298645-16.5925807953-17.7074508667$ $-18.4775390625-18.8345298767-18.7906494141-18.361410141-17.4715309143$ -16.163520813 -14.3749704361 -12.159239769-9.50119018555-6.45749378204 -3.05084204674.66666299104694.65457201004 8.842707633972 13.16452026367 17.5232200622621 .8221607208325 .9137191772529 .6463794708332 .81481170654 35.2206802368237 .0232391357438 .381271362339 .404430389440 .22895812988 40.8927383422941 .4641799926841 .9590492248542 .4022789001542 .81795120239 43.2304916381843 .6376686096244 .0405693054244 .4495391845744 .88180160522 45.3378410339445 .8298912048346 .3608589172446 .9356498718347 .56742095947 48.2551918029849 .0313796997149 .9123611450250 .8888702392651 .96984863281 53.137691497854 .3905906677255 .7069816589457 .0462188720758 .40913009644 59.7768211364761 .1518707275462 .5302009582563 .9139595031765 .30513763428 66.7041931152368 .1142120361369 .5335388183670 .9643402099672 .40281677246 73.8495864868275 .2993469238376 .7510528564578 .2004470825279 .64505767822 81.085662841882 .5208969116283 .9529113769585 .3820419311586 .80976867676 88.23944091797 89.669776916591.1024780273492.5350036621193.96600341797 95.3933563232496 .8140563964898 .2269515991299 .62899780273101 .0198974609 102.3973999023103 .7618026733105 .1116027832106 .4476013184107 .7689971924 109.076499939110 .3701019287111 .6502990723112 .9173965454114 .1718978882 115.4142990112116 .6448974609117 .864402771119 .0729980469120 .2711029053 121.4592971802122 .6377029419123 .8068008423124 .9669036865126 .1183013916 127.2611999512128 .3959960938129 .5229034424130 .6421051025131 .75390625 132.858505249133 .9562072754135 .0471954346136 .1316986084137 .2100067139 138.2821960449139 .3484039307140 .408996582141 .4640960693142 .5139007568 143.5583953857144 .5980072021145 .6327056885146 .6625976562147 .68800354 
148.7088012695149 .7252960205150 .7375946045151 .7456970215152 .7498931885 153.7501068115154 .7465057373155 .7391967773156 .728302002157 .7138977051 158.696105957159 .6748962402160 .6504974365161 .6230010986162 .592300415 163.5585021973164 .521697998165 .4819030762166 .4389953613167 .3932037354 168.3444061279169 .2926025391170 .237701416171 .1797943115172 .1190032959 173.054901123173 .9882049561174 .9178924561

351.9277954102351 .8442993164351 .8539123535351 .9620056152352 .1442871094 352.4230957031352 .8113098145353 .321685791353 .967010498354 .7598876953 355.7127075195356 .8367919922358 .1437988281359 .6434936523361 .3463134766 363.258392334365 .3934020996367 .7607116699370 .3616943359373 .1915893555 376.258392334379 .5481872559383 .104095459386 .9328918457391 .0981140137 395.6176147461400 .583190918406 .0286865234412 .0665893555418 .7355957031 426.1698913574434 .3886108398443 .5975952148453 .7802124023465 .1770935059 477.7695007324491 .0414123535504 .5288085938518 .8654174805533 .8917236328 547.2291259766556 .848815918558 .6506958008548 .2531738281533 .2612304688 520.7183227539509 .1058044434499 .5710144043489 .8703918457478 .4826049805 468.3788146973462 .7809143066457 .4361877441447 .7640075684438 .2691040039 433.186706543429 .8499145508428 .0722961426424 .7113037109416 .286895752 405.5318908691395 .9052124023382 .8988952637363 .4142150879346 .0151062012 339.9664001465333 .986114502318 .5759887695302 .9028930664295 .4063110352 291.1846008301286 .2806091309281 .9920043945279 .5158081055275 .3031921387 265.3685913086254 .7465057373248 .2973937988241 .9938049316232 .6640014648 221.9806976318210 .5897979736199 .4615020752189 .6622009277179 .8034973145 169.1436004639161 .1553955078159 .6074066162158 .9199066162152 .2489013672 146.0063934326145 .7281951904149 .1251068115155 .3784942627160 .2194976807 159.5193939209154 .9546051025148 .1177062988140 .6949005127134 .9969024658 129.8614959717124 .5150985718118 .6467971802111 .5540008545104 .5176010132 98.8172073364393 .5163116455187 .8577270507882 .8070907592879 .08917999268 76.8108673095776 .4291915893677 .7587966918980 .8187484741284 .88812255859 89.4123306274495 .62982940674104 .5183029175114 .635597229122 .6532974243 133.8805999756152 .900604248172 .329498291186 .2212982178194 .8941955566 199.1069030762197 .9026947021190 .1358947754181 .4716949463175 .4900054932 177.2496948242 192.5839996338 206.3643035889 205.5350036621 199.8569030762 198.3065032959197 .4055938721194 .7191925049192 .3511047363192 .7978057861 192.6479034424 188.1860046387 183.3327941895 181.1526031494 179.1555938721 176.2339019775174 .0247039795175 .2778930664173 .5193939209161 .8605957031 147.9411010742138 .3011016846129 .5480041504118 .8314971924108 .6556015015 101.544601440496 .3163604736391 .5969772338989 .4737472534292 .20648193359 95.3122329711994 .5559921264693 .4627227783294 .2695770263796 .52098846436 100.1072998047104 .360496521108 .5425033569112 .6965026855116 .3367996216 117.9776000977 116.7798995972 114.9084014893 114.3309020996 115.2481002808 116.9626998901120 .0801010132123 .8965988159131 .4002075195144 .4537963867 157.9550018311168 .4770965576176 .2221984863183 .4440002441189 .5475006104 194.4290008545197 .1403961182194 .3553009033191 .758605957194 .0547943115 196.5021972656196 .3276062012193 .0941925049185 .561706543178 .100692749 174.8816070557174 .1647949219174 .1269989014173 .4465026855170 .5325927734 
166.2785949707161 .500793457157 .6007995605154 .5894012451151 .8540039062 149.5169067383146 .7127990723143 .6587982178140 .3179931641136 .2610015869 132.7033996582129 .8636016846127 .3047027588124 .1787033081120 .8459014893 118.398399353115 .7053985596111 .8117980957106 .571296691999 .34429168701 92.5150909423889 .3426971435583 .3045883178768 .2016372680753 .77210998535 49.2501792907748 .8203315734948 .8064308166547 .3889007568442 .04351043701 33.5228500366221 .6753196716310 .955019950875 .6668310165412 .651257038116 -1.79097902775 -6.51053285599-10.176150322 -13.152009964 -15.2596302032 -16.56498909 $-17.5760002136-18.2466907501-18.5829105377-18.528459549-17.986289978$ -16.9646492004 -15.422949791 -13.392250061 -10.8869600296 -7.94629812241 $-4.61641120911-.9419900178913 .0206859111797 .21312999725311 .56361961365$ 16.0003299713120 .4307003021224 .7740097045928 .9821090698232 .49102020264 34.6811599731436 .1521797180237 .4010505676338 .4200096130439 .28802108765 40.0230712890640 .6723785400441 .2478599548341 .7733612060542 .26755142212 42.7567100524943 .2281913757343 .6773796081544 .1102409362844 .53694915771 44.9631881713945 .4023208618245 .857559204146 .33705902146 .85459136963 47.4196090698248 .0768508911148 .8522186279349 .7462692260750 .78981018066 51.9461784362853 .2044906616254 .5402793884355 .8994789123557 .27938842773 58.6615180969260 .0490303039661 .4388809204162 .834548950264 .23815917969 65.6514663696367 .0771789550868 .5145797729569 .9649505615271 .42513275146 72.8944473266674 .3674774169975 .8415832519577 .3107681274478 .76979827881 80.2207183837981 .6623611450283 .0964736938584 .5226669311585 .94425201416 87.366767883388 .7891006469790 .2134628295991 .6372070312593 .05905151367 94.4765396118295 .8868331909297 .2884216308698 .67867279053100 .0569000244 101.4215011597102 .7723007202104 .1085968018105 .4306030273106 .7381973267 108.0317993164109 .3115997314110 .5781021118111 .831703186113 .0727996826 114.3020019531115 .5195999146116 .7261962891117 .9219970703119 .1075973511 120.2833023071121 .4494018555122 .6062011719123 .7540969849124 .8934020996 126.0243988037127 .1473007202128 .262298584129 .3699035645130 .4700927734 131.5632019043132 .649597168133 .7292938232134 .8027954102135 .8699951172 136.9313964844137 .9869995117139 .0370941162140 .0818023682141 .1213989258 142.1558990479143 .1855926514144 .2106018066145 .2310028076146 .2469940186 147.2586975098148 .266204834149 .2696075439150 .2691040039151 .2646942139 152.2565002441153 .2447052002154 .2292938232155 .2104949951156 .188293457 157.1627960205158 .1340942383159 .1022949219160 .0673980713161 .0294952393 161.9886016846162 .9447937012163 .8979949951164 .8484039307165 .7958068848 166.7402954102167 .6817932129168 .6204071045169 .5559997559170 .4888000488 171.4185943604172 .3430938721173 .2655944824

364.6202087402364 .575012207364 .5900878906364 .6885070801364 .8814086914 365.1813049316365 .6026000977366 .1565856934366 .8580932617367 .717590332 368.7500915527369 .9643859863371 .3758850098372 .9909973145374 .8254089355 376.8814086914379 .1792907715381 .7242126465384 .5255126953387 .5718078613 390.8812866211394 .4278869629398 .2752990723402 .4184875488406 .9458007812 411.8551940918417 .2749938965423 .208404541429 .8233032227437 .1117858887 445.2890930176454 .2987976074464 .4247131348475 .5510864258487 .9106140137 501.3364868164515 .6414794922529 .8997192383545 .1422119141560 .5817260742 
576.7709960938598 .4088745117609 .9907836914595 .6127929688572 .1027832031 553.2883300781535 .2730712891517 .6848754883503 .1705932617494 .8353881836 489.2557067871 484.9187927246478.0907897949 461.4530944824 444.9580078125 437.0624084473433 .4032897949434 .0317993164432 .8541870117420 .8371887207 408.2543029785405 .8960876465402 .1019897461388 .0268859863372 .7850952148 363.1228027344353 .6861877441340 .0365905762327 .0143127441320 .3547973633 315.4299926758307 .991607666301 .0983886719297 .3067932129291 .9153137207 280.1148986816267 .5942077637259 .5837097168251 .970703125240 .9120025635 229.3589019775218 .4284057617209 .137298584202 .5800933838197 .6313934326 193.3898925781190 .4530944824189 .824005127186 .18409729173 .5603027344 160.2559967041154 .6651000977153 .3448028564154 .3647003174155 .637298584 154.4754943848151 .2315979004146 .3670959473140 .6531066895135 .4176025391 129.9925994873123 .5623016357116 .8993988037110 .1017990112103 .7249984741 98.5484619140693 .4693908691487 .3302993774481 .4990997314577 .06871795654 73.8077011108471 .9134063720771 .5488433837973 .07895660475 .9627532959 79.9862823486385 .1857528686590 .8767776489397 .83039093018104 .0979003906 114.6631011963136 .0789031982158 .7792053223174 .566192627185 .6566009521 192.3247070312193 .217300415186 .7050933838177 .5690002441169 .9600067139 166.6445007324172 .453704834180 .1907043457184 .1329040527184 .6354980469 179.457901001174 .8292999268178 .3739013672183 .2633972168184 .2335968018 184.4739990234185 .5756072998186 .3775939941186 .1141967773184 .8489990234 179.3251037598175 .9282989502183 .2250976562188 .6464996338182 .0099029541 171.0435028076162 .0507965088151 .4445037842136 .3334960938121 .7433013916 112.6458969116105 .632896423397 .0607070922991 .4136734008892 .68385314941 95.1855926513794.6005783081193.3792037963991.7889633178791.75662231445 95.0710983276499 .93800354004104 .8245010376109 .49659729113 .6650009155 115.8239974976115 .4179992676114 .0366973877113 .19090271113 .5188980103 115.0272979736118 .3538970947122 .2587966919129 .5137939453141 .3619995117 156.2285003662173 .3621063232190 .1851959229206 .658203125219 .9971008301 227.525604248231 .2893066406233 .6197967529233 .4140014648230 .3856964111 227.1786956787 226.2774963379 224.8852996826 220.9349060059 216.2227020264 212.532699585210 .5072021484209 .8679962158209 .695602417208 .5034942627 204.3218994141 196.0744934082 187.1233062744 179.521194458 174.3683929443 171.9671020508170 .0428009033168 .4454040527166 .0001068115163 .2536010742 160.1000976562156 .3894042969152 .8126068115149 .7317962646146 .7135925293 140.0995025635133 .9971923828132 .6318969727129 .8005065918121 .8237991333 112.7886962891104 .649902343896 .6966781616287 .4542922973679 .17149353027 74.4727630615272 .6090164184675 .2701568603575 .4034729003966 .2232131958 52.4945983886736 .2209701538121 .7786407470715 .8722600936911 .97049999237 $4.720347881317-1.70596301556-6.17451095581$-9.13554573059-11.4709596634 $-13.4344301224-15.0318403244-16.3437805176-17.2727794647-17.8005199432$ $-17.7208995819-17.1130104065-15.8924198151-14.1358699799-11.8469495773$ $-9.08659553528-5.8988699913-2.341852903371 .5341069698335 .663050174713$ 9.97953987121614 .4182701110818 .9045295715323 .3491592407227 .8754901886 31.6394290924133 .6699905395534 .9272384643636 .1806182861337 .24328994751 38.1842498779339 .0192298889239 .7619590759340 .4381484985441 .05628967285 
41.6395416259842 .2095909118742 .7493782043543 .2497406005943 .71405029297 44.1466903686544 .5554809570344 .9560089111345 .3510398864745 .75257110596 46.1749992370646 .6327514648447 .1649703979547 .809158325248 .61780929565 49.6347007751550 .8111305236852 .0889892578153 .4357490539654 .80374908447 56.1898307800357 .5768203735458 .9678993225160 .3622703552261 .76248931885 63.1728897094764 .5942764282266 .0311965942467 .4816589355568 .94843292236 70.4268417358471 .9176330566473 .4129333496174 .9117889404376 .40270996094 77.8796310424879 .3439025878980 .79213714682 .2283172607483 .65203094482 85.0678329467886 .4851684570387 .9019470214889 .3206100463990 .73857116699 92.1535568237393 .5637130737394 .9652099609496 .3572998046997 .73665618896 99.10340118408100 .4553985596101 .793296814103 .1160964966104 .4244003296 105.7180023193106 .9977035522108 .2636032104109 .5162963867110 .7563018799 111.9839019775113 .199798584114 .404296875115 .5979003906116 .7808990479 117.9537963867119 .116897583120 .2705993652121 .4151000977122 .5509033203 123.6781005859124 .7969970703125 .9079971313127 .0112991333128 .1071014404 129.1956939697130 .2772979736131 .3522949219132 .4208068848133 .4830932617 134.5393981934135 .5899047852136 .6347961426137 .6743927002138 .708694458 139.7380981445140 .7626037598141 .7823944092142 .7976989746143 .80859375 144.8152008057145 .8177032471146 .8161010742147 .8106994629148 .8014068604 149.7884979248150 .7720031738151 .7519073486152 .7285003662153 .7017059326 154.6717071533155 .6385040283156 .6022949219157 .56300354158 .5207977295 159.475692749160 .4277038574161 .3769073486162 .3231964111163 .2666931152 164.2073059082165 .1450958252166 .0800018311167 .0119934082167 .9411010742 168.867401123169 .7906036377170 .7111968994171 .62840271

377.2849121094377 .1312866211377 .0992126465377 .1972961426377 .3883056641 377.6972045898378 .1369934082378 .7206115723379 .4610900879380 .370513916 381.4620056152382 .7466125488384 .2373962402385 .9439086914387 .8789978027 390.0492858887392 .4717102051395 .1575012207398 .1104125977401 .326385498 404.8146057129408 .5574035645412 .6094055176416 .9852905273421 .7542114258 426.9392089844432 .640411377438 .895904541445 .8312072754453 .4901123047 462.0144958496471 .4313964844481 .8797912598493 .3465881348505 .8483886719 519.2727050781533 .3513793945547 .5693969727562 .021484375576 .1223754883 590.8905029297607 .1964111328613 .3856201172598 .2020263672573 .6630859375 552.8189697266533 .483581543516 .1937866211503 .2666931152496 .6129150391 492.1601867676485 .7558898926475 .6346130371459 .9914855957444 .7900085449 435.8566894531431 .6339111328431 .2847900391428 .9455871582417 .3463134766 406.1397094727403 .6422119141400 .7290039062388 .2098999023373 .734588623 365.6275024414358 .4819030762348 .111907959338 .2253112793331 .6854858398 325.6730957031318 .8357849121312 .5880126953308 .6072998047303 .0087890625 291.8807983398279 .7070007324270 .0786132812260 .9389953613250 .5570983887 240.1430053711230 .2754058838222 .3226013184216 .6697998047213 .1856994629 211.4720001221209 .8632049561206 .6175994873198 .1204986572182 .0426025391 165.2951049805156 .6293945312152 .742401123151 .2064056396150 .6625976562 148.616897583145 .804901123141 .7557067871136 .9300994873132 .2678070068 126.9798965454120 .7113037109114 .2885971069108 .0558013916102 .269203186 97.262832641692 .0806274414185 .9737930297979 .9748001098675 .04752349854 
71.0009613037167 .9314498901466 .2086334228566 .3315811157268 .1003036499 71.4098510742275 .5761032104580 .0720062255985 .4066772460991 .16561126709 99.87326812744113 .4462966919129 .1900024414145 .0402984619159 .1851043701 169.8247070312176 .0662994385176 .8928985596172 .7967071533163 .4570007324 154.2633972168152 .3177032471155 .4138946533162 .2554016113168 .2174987793 166.8336029053165 .4326934814170 .745300293177 .6820068359181 .7731933594 184.3576049805185 .4100952148185 .6445007324184 .1286010742183 .1165924072 186.0162963867191 .8545074463200 .4389953613206 .8316040039205 .0043029785 197.2655944824184 .9268951416169 .6920013428154 .4481964111139 .8937988281 127.8525009155117 .5628967285107 .4699020386100 .290603637798 .72479248047 98.5441513061595 .8489608764692 .8086700439590 .4564514160289 .74082946777 91.5761032104595 .40673828125100 .5147018433105 .4128036499108 .4974975586 109.9459991455109 .7788009644108 .9101028442108 .2570037842108 .244102478 109.3163986206111 .8261032104115 .5606994629121 .4571990967129 .8701019287 143.3742980957163 .6069946289186 .5289001465208 .8628997803228 .3648986816 244.3217010498254 .679901123256 .5463867188253 .6647949219251 .2281951904 249.1387939453249 .0507049561249 .8988952637249 .1477050781246 .3706970215 242.3968963623239 .004699707237 .5765991211237 .9066925049239 .8267974854 237.1687927246225 .4093933105211 .658996582201 .6640014648196 .7886962891 198.6567993164201 .5581970215201 .2068939209199 .2436981201197 .3092956543 194.0736999512188 .291305542182 .0294036865177 .4420013428173 .9141998291 169.3437042236165 .2904968262162 .9098968506157 .6166992188145 .4965057373 131.9727020264121 .3564987183113 .5932998657107 .3921966553101 .9197998047 96.4845581054793 .2227172851696 .4010467529397 .0979003906287 .19819641113 73.0547637939560 .0563812255948 .0594711303737 .5003585815426 .751039505 $13.965579986573 .676136016846-.402714014053-1.96513104439-4.62859201431$ -7.63429689407 -10.3987798691 -12.7848596573 -14.665309906 -15.9816904068 $-16.5687904358-16.4804897308-15.7087402344-14.3078804016-12.3320198059$ -9.82774925232 -6.8703827858-3.50658988953.20062099397184.191837787628 8.39783763885512 .7451400756817 .1431198120121 .4978694915825 .75079917908 29.3305797576931 .623600006133 .2258796691934 .6417083740235 .85113143921 36.9166603088437 .8599586486838 .7252998352139 .5165100097740 .24842834473 40.9340705871641 .5945587158242 .2080688476642 .7617111206143 .26211929321 43.7167816162144 .1277313232444 .5014610290544 .8507995605545 .19635009766 45.5458908081145 .9151611328146 .3222312927246 .7722206115747 .43619918823 48.4961509704649 .7614097595251 .0666084289652 .415180206353 .77700042725 55.1531715393156 .5317306518657 .9161987304759 .3049583435160 .70223999023 62.1110916137763 .5343589782764 .975723266666 .4345932006867 .91240692139 69.4063415527370 .9159469604572 .434570312573 .9586563110475 .47427368164 76.9732971191478 .4547271728579 .9095382690481 .3467483520582 .76849365234 84.1794967651485 .5926971435587 .0062408447388 .4220428466889 .83683013916 91.2479629516692 .6528091430794 .0478591918995 .431777954196 .80182647705 98.1578063964899 .49825286865100 .8235015869102 .1332015991103 .4279022217 104.7078018188105 .9735031128107 .2255020142108 .464302063109 .6905975342 110.9046020508112 .1071014404113 .2984008789114 .4789962769115 .6491012573 116.8093032837117 .9598007202119 .1010971069120 .2332992554121 .3569030762 
122.4720001221123 .5789031982124 .6780014038125 .7694015503126 .8535003662 127.9304962158129 .0007019043130 .0643005371131 .1215057373132 .1726989746 133.2180023193134 .257598877135 .2917938232136 .3208007812137 .3448028564 138.3639068604139 .3782958984140 .3881988525141 .3937988281142 .3950958252 143.3923034668144 .3856048584145 .375146 .3607025146147 .3426971436148 .3211975098 149.296295166150 .2680053711151 .2364959717152 .2017974854153 .1638946533 154.1230926514155 .0792999268156 .0325927734156 .9830932617157 .9308013916 158.8755950928159 .8177947998160 .7570953369161 .6938018799162 .6275939941 163.5587005615164 .4869995117165 .412399292166 .3350067139167 .2548065186 168.1717987061169 .0836029053169 .9936065674 389.5530090332 389.4378967285 389.3963012695 389.4598083496389.637298584 389.941192627 390.3861083984390.9826965332 391.7461853027392 .6856994629 393.817199707395 .1482849121396 .6955871582398 .4643859863400 .4722900391 402.7210083008405 .2336120605408 .0155944824411 .0773010254414 .407409668 418.0213928223421 .8884887695426 .0776062012430 .5900878906435 .5101928711 440.8387145996446 .696105957453 .0885009766460 .1659851074467 .9281921387 476.537689209485 .9645996094496 .3393859863507 .5766906738519 .6680297852 532.4063720703545 .6013183594558 .921875571 .7905273438583 .4094848633 592.5355834961597 .7271118164594 .7738037109579 .0822143555557 .6494750977 538.6478271484521 .2448120117507 .182800293496 .9039916992491 .0039978027 485.4747009277475 .2150878906462 .8207092285450 .5604858398439 .5130004883 431.3789978027425 .9865112305423 .2459106445419 .5362854004409 .6153869629 399.7597045898395 .2936096191390 .0972900391377 .4277038574364 .2919921875 358.7728881836354 .5893859863347 .6669006348340 .441986084333 .8418884277 327.4758911133322 .270111084317 .5651855469313 .888885498309 .0492858887 300.1890869141289 .6913146973278 .9140014648268 .4765930176259 .137298584 250.845703125242 .4575958252235 .3807983398229 .4624023438225 .3430938721 223.713104248219 .5834960938210 .0746002197196 .246307373179 .1320037842 163.4922027588154 .9436950684149 .9508056641146 .7823944092144 .7902984619 141.7975006104138 .7415008545134 .9100036621130 .8547058105126 .8276977539 122.3779983521116 .8896026611111 .1108016968105 .5434036255100 .137298584 95.07659912109 89.83567810059 84.00190734863 78.1983795166 73.09285736084 68.592491149964 .7677383422962 .121929168761 .1898498535261 .87464141846 64.3799362182667 .8670578002971 .6494827270576 .2343673706181 .77395629883 88.0498199462992.4733123779399.58699035645 113.9080963135129 .7617034912 143.4082946777154 .1558074951162 .0621032715163 .3229064941153 .1302032471 140.6961975098134 .0505981445133 .3560028076141 .7543945312151 .8625946045 155.3000030518158 .4405059814165 .2528991699172 .8977050781180 .4447937012 185.6479949951185 .7223052979183 .8072052002179 .9458007812179 .654006958 191.6015930176206 .158493042214 .5854949951219 .5518035889221 .3885955811 216.2669067383200 .9674072266182 .4069061279169 .0148010254156 .641494751 143.1804962158130 .5310974121119 .4400024414110 .9471969604106 .3106002808 103.181999206598 .3551483154393 .8884429931691 .3056030273490 .21044921875 90.2881088256892 .1962432861396 .36533355713100 .5839996338102 .2164993286 102.6585006714102 .9132003784102 .6434020996102 .3623962402102 .3162994385 102.7735977173104 .3151016235107 .1328964233111 .7350997925116 .4979019165 
126.4589996338146 .0034942627170 .2425994873195 .021697998219 .1522064209 242.3258056641258 .841003418259 .9974975586256 .3695068359258 .1781921387 260.0918884277262 .2939147949264 .3181152344265 .404296875265 .5213928223 263.7421875260 .1534118652257 .5498962402255 .8764953613258 .520111084 258.7702941895245 .8609924316230 .4790039062220 .1161956787214 .7713928223 218.9844055176225 .6067962646226 .8296966553227 .0287017822226 .9830932617 225.2371063232220 .1179962158213 .8578033447209 .7256011963205 .9194030762 203.0596923828199 .7149047852194 .9391021729187 .0092926025172 .4364929199 155.9315948486143 .3491973877133 .9665985107127 .4148025513122 .7844009399 115.4888000488110 .2002029419112 .4615020752113 .3015975952104 .3030014038 92.3357009887785 .0877838134876 .4813766479561 .77775955245 .44480133057 28.7091903686515 .2222003936810 .636819839488 .827859878544 .492418766022 $.1613560020924-4.01489019394-7.79618406296-10.789270401-13.1004400253$ -14.4597702026 -15.0154399872 -14.7769098282 -13.8245697021 -12.2468004227 $-10.1017799377-7.46130084991-4.38936376572-.9235360026362 .846271038055$ 6.8797469139111 .0536098480215 .285679817219 .3942203521723 .20125007629 26.515829086329 .1364898681631 .2209091186532 .9132804870634 .31129837036 35.5245399475136 .595001220737 .5903587341338 .5065994262739 .35678100586 40.1489105224640 .9005012512241 .5903015136742 .2041206359942 .7490196228 43.2357788085943 .6594810485844 .0225105285644 .3430709838944 .65307998657 44.952430725145 .2603797912645 .5932998657245 .901371002246 .44852828979 47.532501220748 .8479118347250 .1406097412151 .4718704223652 .81293869019 54.1652488708555 .5255393981956 .8924598693858 .2676887512259 .65322875977 61.0536308288662 .4711990356463 .9109497070365 .3715286254966 .85566711426 68.359649658269 .8841323852571 .4217224121172 .969032287674 .51304626465 76.0443725585977 .5466995239379 .0084228515680 .4411773681681 .85991668701 83.2714462280384 .6856689453186 .1011886596787 .5179672241288 .93348693848 90.3430786132891 .7453689575293 .1352996826294 .5127410888795 .87420654297 97.2203521728598 .5495071411199 .8625869751101 .1593017578102 .4404983521 103.7065963745104 .9583969116106 .1964035034107 .4213027954108 .6337966919 109.834197998111 .0232009888112 .2012023926113 .3686981201114 .5260009766 115.673500061116 .8115005493117 .9403991699119 .0603027344120 .1716995239 121.2746963501122 .3696975708123 .4569015503124 .5365982056125 .6090011597 126.6744003296127 .7331008911128 .7852935791129 .8312988281130 .871307373 131.9055938721132 .9344024658133 .9577941895134 .9763031006135 .9898071289 136.9987030029138 .0030059814139 .0030059814139 .9987945557140 .9904937744 141.978302002142 .9624023438143 .9427032471144 .9194946289145 .8928070068 146.8627929688147 .8294067383148 .7928924561149 .7532043457150 .7106018066 151.6649017334152 .616394043153 .5650939941154 .5108947754155 .4541015625 156.3945007324157 .3323059082158 .2673950195159 .199798584160 .1295013428 161.0565948486161 .9808959961162 .9024963379163 .821395874164 .7373962402 165.6506958008166 .5610046387167 .4687957764168 .3733062744 401.7860107422401 .5231018066401 .4059143066401 .4472961426401 .5971984863 401.8825073242402 .3160095215402 .9096069336403 .6763000488404 .6268920898 405.7745056152407 .1289978027408 .7034912109410 .5065002441412 .5513916016 414.8439941406417 .4021911621420 .2370910645423 .3521118164426 .7430114746 
430.4122009277434 .3363952637438 .5705871582443 .1323852539448 .0799865723 453.4335021973459 .2752990723465 .6391906738472 .6177062988480 .2481994629 488.6064147949497 .7103881836507 .5638122559518 .1273803711529 .237121582 540.7288818359552 .2531738281563 .5068969727573 .5020751953581 .5822753906 585.1201171875582 .4100952148574 .1876220703559 .2523193359542 .4722900391 526.9848022461512 .7252807617500 .5986022949490 .8916931152484 .1742858887 476.5340881348464 .1733093262451 .3287963867440 .7956848145432 .3519897461 425.8228149414420 .3330993652415 .9856872559411 .2210998535403 .1159973145 394.6845092773388 .3678894043381 .2847900391370 .3100891113359 .8158874512 353.3357849121348 .2749023438342 .240814209336 .0393981934330 .0798034668 324.5192871094320 .2550964355316 .530090332312 .8469848633308 .8510131836 304.0654907227296 .896697998284 .9927062988272 .7607116699264 .3566894531 257.6875915527250 .8444061279244 .0717010498237 .4436950684231 .7554016113 228.045501709219 .0102996826197 .5818939209175 .0310974121162 .5959014893 155.2156066895149 .4786071777144 .9396057129141 .2124938965137 .9638977051 134.1407928467130 .4575042725126 .7960968018123 .2633972168120 .2885971069 117.1140975952112 .5807037354107 .4704971313102 .316497802797 .06894683838 92.0509796142686 .9506530761781 .5703201293976 .2647476196371 .31072235107 66.7831802368262 .9067916870160 .004741668758 .4804000854558 .37488174438 59.8797683715862 .346260070865 .2070999145568 .8353271484473 .39788818359 77.6990280151480 .9346466064586 .6373825073298 .2183303833112 .4425964355 124.9344024658135 .5025939941142 .9535064697144 .1483001709135 .3957977295 124.3815994263119 .5521011353120 .1834030151126 .8813018799136 .0411071777 142.3164978027148 .7129058838157 .4259033203166 .8856964111177 .7637023926 185.6775970459186 .1125030518183 .6058044434180 .0399017334180 .7171020508 191.3699951172 204.2942962646213.2653045654219.0155944824222.0126953125 218.2973022461203 .9624938965186 .9073944092175 .4685974121165 .5063934326 154.6461029053142 .9808044434130 .0785064697118 .903503418112 .4501037598 107.9442977905103 .483901977599 .6233978271596 .2296981811593 .74111175537 92.372352600192 .3279571533293 .8351135253995 .8087463378996 .94319152832 97.6404266357497 .9742279052797 .944053649997 .6090393066497 .22048187256 97.0943679809697 .561943054298 .85846710205101 .4402008057105 .3575973511 112.6343994141124 .0003967285140 .953704834165 .2637939453191 .0117034912 212.5646057129228 .8925018311235 .9691925049240 .5019073486250 .0980987549 258.5784912109262 .4407958984264 .3500976562265 .9570922852268 .9898986816 275.8717041016277 .8370056152268 .4833068848258 .0686035156257 .263092041 257.953704834250 .8482971191240 .5838928223230 .4801940918222 .6463012695 220.2328033447222 .0865936279228 .6705932617236 .4978027344240 .9873962402 244.6109008789249 .6571960449253 .0316009521254 .2330932617252 .2238006592 244.0093994141234 .0545959473227 .0191955566219 .1546020508209 .0540008545 195.1941986084175 .7333068848157 .7187042236146 .4172058105138 .303894043 129.129699707122 .1203994751121 .532699585121 .4248962402115 .6854019165 108.1295013428101 .905899047993 .335800170980 .4465026855565 .98193359375 52.9180793762241 .5037002563531 .6874198913623 .3595600128216 .22682952881 $10.007340431214 .041738986969-1.26651000977-5.57959413528-8.98442363739$ $-11.3151302338-12.6408901215$-13.0341796875 -12.6073198318 -11.5319700241 
-9.84129142761 -7.62556314468 -4.93218183517-1.81134998798 1.659605026245 5.4215388298039 .35384845733613 .3547096252417 .2264709472720 .79479026794 24.0311508178726 .7616901397729 .0970401763931 .0190601348932 .60831069946 33.9998893737835 .2303581237836 .3666992187537 .410301208538 .38048934937 39.2783317565940 .1167411804240 .8828201293941 .5744895935142 .18397903442 42.7031097412143 .144248962443 .51869964643 .8395195007344 .12997817993 44.4063491821344 .6967811584545 .0185203552245 .3785705566445 .95370101929 46.9283599853548 .1139411926349 .3430786132850 .6204910278351 .91802978516 53.2361412048354 .563610076955 .9034118652357 .2538490295458 .61909103394 60.0018997192461 .4064598083562 .8364601135364 .2922363281265 .77615356445 67.2850265502968 .8175506591870 .3694992065471 .936111450273 .51141357422 75.0949630737376 .6380996704178 .0906906127979 .5033264160280 .9203414917 82.33762359619 83.75982666016 85.18340301514 86.60674285889 88.02638244629 89.4381713867290 .8397369384892 .2269287109493 .5989303588994 .95317077637 96.2899703979597 .6085281372198 .90960693359100 .1936035156101 .4614028931 102.7137985229103 .9515991211105 .1755981445106 .3865966797107 .5851974487 108.7720031738109 .9476013184111 .1122970581112 .2667999268113 .4112014771 114.5460968018115 .6716003418116 .7881011963117 .8957977295118 .9951019287 120.0860977173121 .1691970825122 .2444992065123 .3125124 .3731994629125 .4271011353 126.4742965698127 .5151977539128 .5498962402129 .5787963867130 .6020965576 131.6199951172132 .6327972412133 .6405944824134 .6437988281135 .6423034668 136.6365966797137 .6266021729138 .6125946045139 .5948028564140 .5731964111 141.5478973389142 .5191955566143 .4871063232144 .4515991211145 .4129943848 146.3712005615147 .3264007568148 .2785949707149 .2279968262150 .1744995117 151.1183013916152 .0594024658152 .9978027344153 .93359375154 .866897583 155.7975006104156 .7254943848157 .6510009766158 .5738983154159 .4940948486 160.4116973877161 .3265991211162 .2388000488163 .1481933594164 .0549926758 164.9591064453165 .858001709166 .7554016113 413.5284118652413 .3001098633413 .1560058594413 .1358947754413 .2456054688 413.4971008301413 .904296875414 .4768066406415 .229095459416 .1690063477 417.311706543418 .6630859375420 .2395019531422 .0445861816424 .095489502 426.3924865723428 .9580993652431 .797088623434 .9175109863438 .3091125488 441.9765930176445 .8844909668450 .0946044922454 .6105041504459 .4945983887 464.7475891113470 .4531860352476 .621307373483 .338104248490 .611907959 498.4952087402506 .979095459516 .0117797852525 .5432128906535 .3037719727 545.1566772461554 .4852905273563 .071105957569 .5419921875573 .5682983398 572.7385864258564 .7642822266553 .224609375540 .4846191406527 .6262207031 515.4146728516503 .9635009766493 .1943054199483 .2119140625474 .7785949707 465.3327026367452 .4331970215439 .9819030762431 .2561950684424 .5683898926 419.1224975586414 .0895080566408 .6610107422402 .9583129883396 .3507995605 388.9985961914380 .7936096191372 .0812988281363 .2449951172354 .8380126953 347.092010498339 .8620910645333 .4256896973327 .4418945312322 .1994934082 317.8669128418314 .7961120605312 .2901000977309 .1242980957306 .2221069336 305.2318115234301 .5289916992289 .3711853027276 .2474060059268 .5918884277 262.7430114746256 .3927001953249 .6452941895241 .895904541232 .891204834 224.670501709210 .3226928711179 .5773925781151 .2234954834144 .9512939453 
145.3894958496142 .2214050293138 .7816009521134 .9813995361130 .9960021973 126.528503418122 .579498291118 .9957962036115 .9842987061114 .0355987549 111.9445037842108 .0932998657103 .424400329698 .4824371337993 .38333892822 88.5351562583 .7562866210979 .0007095336974 .2943878173869 .69436645508 65.4063034057661 .7815093994158 .9281806945857 .0886688232456 .37134933472 56.9684410095258 .494979858460 .5438690185563 .1124114990266 .2967376709 69.8578262329174 .2496795654380 .5850067138790 .00360107422100 .9138031006 110.5044021606118 .3606033325122 .9694976807123 .1256027222116 .9002990723 109.8993988037109 .3844985962112 .2602005005116 .5220031738122 .8917007446 129.9058990479138 .0617980957147 .1638031006158 .1298980713172 .3648986816 183.5482025146185 .7140045166183 .5823059082181 .221206665181 .7406005859 188.161605835196 .6047973633204 .1844940186209 .4848937988212 .3571014404 210.0444946289198 .7975006104185 .4396057129177 .1022949219169 .7933959961 162.175201416152 .9250030518139 .2062072754126 .0516967773118 .0904006958 112.8180007935109 .1778030396106 .4265975952102 .578796386798 .93424224854 96.2633438110494 .3682785034292 .9885787963992 .3656616210992 .77306365967 93.4282379150493 .7518768310593 .8366699218893 .5515670776493 .03476715088 92.613006591892 .418663024992 .4835662841893 .5500564575297 .03579711914 101.5715026855103 .5755996704111 .3636016846132 .8406982422157 .1517944336 173.863494873186 .7532043457197 .5437927246208 .441192627224 .1690063477 238.5742034912244 .145401001246 .5180053711248 .988494873253 .2637023926 266.2922973633275 .4812011719264 .5112915039250 .7171936035249 .7559967041 249.366394043 247.4127960205 242.9013977051 233.2973022461 224.3632049561 221.5767974854221 .7230072021224 .1723937988238 .4589996338245 .266494751 252.7911987305267 .4642944336281 .6524047852289 .6870117188289 .7110900879 276.2721862793259 .9266052246251 .3690032959245 .1071929932241 .2189941406 233.0769958496211 .074005127186 .8112945557170 .3744049072157 .1772003174 144.966506958136 .1152038574131 .5691986084128 .7984008789125 .2666015625 120.7837982178114 .2058029175105 .766502380496 .1941070556686 .2045211792 78.8080902099670 .1977081298855 .4351196289140 .6042289733930 .40518951416 22.0404300689713 .775489807136 .697910785675 .8817309737206 -3.66654706001 $-6.96620607376-9.17533683777-10.311920166-10.5228300095-10.0796499252$ -8.99026679993 -7.30836582184-5.12200880051 -2.41869211197.6632289886475 4.1045989990237 .73677396774311 .4766101837215 .1415596008318 .56296920776 21.7346706390424 .5237293243426 .9858703613329 .0626697540330 .83643913269 32.4100799560533 .8006706237835 .0787086486836 .2430496215837 .32986831665 38.3288002014239 .253208160440 .0967788696340 .8724784851141 .5512008667 42.1097793579142 .5736389160242 .9710311889643 .3066101074243 .59825134277 43.8764610290544 .1786193847744 .5428581237845 .0148582458545 .64958953857 46.4961509704647 .5088005065948 .6341896057149 .8402099609451 .0807800293 52.3526611328153 .6386299133354 .941818237356 .2606506347757 .59809112549 58.9573593139660 .3413581848161 .7541694641163 .1982498168964 .67643737793 66.1852188110467 .7212219238369 .2805786132870 .8609313964872 .45526123047 74.0805587768675 .6604766845777 .1137619018678 .5213928222779 .95157623291 81.3838577270582 .8205337524484 .2586975097785 .6921768188587 .12023925781 88.5360107421989 .9392623901491 .3243865966892 .6920471191494 .0392074585 
95.3670272827196 .6749191284297 .9640579223699 .23529052734100 .4896011353 101.728302002102 .952003479104 .1621017456105 .3591003418106 .5438995361 107.7171020508108 .8793029785110 .0308990479111 .1724014282112 .3041000366 113.426399231114 .5394973755115 .643699646116 .7393035889117 .8265991211 118.9057006836119 .9769973755121 .0406036377122 .0969009399123 .1461029053 124.1884002686125 .2242965698126 .2537994385127 .2773971558128 .2951965332 129.3074035645130 .3144989014131 .3166046143132 .3137969971133 .3065032959 134.2947998047135 .2789001465136 .2590026855137 .2353057861138 .2077941895 139.1766967773140 .1421966553141 .1044006348142 .063293457143 .0191040039 143.9718017578144 .9216003418145 .8684997559146 .8126983643147 .7539978027 148.6927032471149 .6287994385150 .5623016357151 .4933013916152 .4217071533 153.3477020264154 .271194458155 .192199707156 .1107025146157 .0267028809 157.9400939941158 .8509063721159 .7590942383160 .6645965576161 .5673980713 162.4676055908163 .3648986816164 .2597045898165 .1513977051

425.228302002424 .8146972656424 .5660095215424 .5424 .5546875424 .7579040527 425.121307373425 .6556091309426 .3724060059427 .2810974121428 .3933105469 429.7171936035431 .2643127441433 .041595459435 .0606994629437 .325592041 439.8522949219442 .649810791445 .7189941406449 .0551147461452 .650390625 456.4776000977460 .5797119141464 .9668884277469 .6777954102474 .7247009277 480.1543884277485 .990814209492 .2705993652499 .0144042969506 .2127990723 513.862487793521 .8461303711530 .0991821289538 .3087158203546 .2943725586 553.4362792969559 .3873901367563 .0798950195563 .9052734375560 .5228271484 551.5153198242540 .2100830078528 .2467041016516 .5010986328504 .895690918 493.6549987793483 .6824035645473 .7944030762463 .7510070801453 .2030029297 441.7196960449431 .4327087402423 .7561950684417 .673614502412 .5017089844 407.2977905273401 .4295959473395 .4161071777388 .958190918381 .4985046387 372.5065002441363 .1785888672354 .6180114746346 .7101135254339 .4348144531 331.9154052734323 .9284057617316 .9786987305312 .2886962891309 .2897033691 307.4248962402306 .4216918945305 .8894042969305 .6265869141305 .1979064941 301.9610900879292 .5017089844281 .466003418273 .138885498265 .9952087402 259.0274047852251 .3253936768242 .4642944336230 .4799041748213 .9730072021 193.1224975586167 .0717926025145 .7680053711138 .7532958984137 .7807006836 135.6271972656132 .6141967773128 .4093017578123 .8486022949119 .505897522 115.7445983887112 .6396026611111 .2919998169109 .7480010986107 .7734985352 103.949996948299 .167686462494 .1854324340889 .2462234497184 .91441345215 80.8470001220776 .6897201538172 .5471801757868 .442520141664 .53341674805 61.0056610107458 .0710411071856 .0431709289654 .9204292297454 .96384811401 55.9599494934157 .8224716186560 .0476608276462 .0565414428764 .82634735107 69.1023330688574 .8025283813582 .4761276245190 .5849227905398 .13432312012 104.3274993896108 .0550003052109 .2127990723106 .0257034302102 .903503418 103.5951004028105 .7939987183109 .064201355113 .745300293119 .667098999 126.7481002808133 .5314025879144 .1490936279163 .1428985596179 .8609008789 184.6087036133183 .2738952637180 .1423950195178 .9674987793184 .4674072266 191.0688934326194 .3020935059195 .9266052246197 .0547943115195 .6755065918 188.9942932129181 .0977020264175 .5823059082170 .3878936768164 .9351043701 157.4284973145145 .5886993408133 .1705932617123 .7462997437116 .9824981689 
113.2624969482110 .814201355107 .81199646104 .3834991455100 .6684036255 97.1847381591894 .4529724121192 .3369064331190 .5148620605589 .44702148438 89.5988998413190 .079513549890 .2531814575290 .2558135986390 .21363067627 90.2358093261790 .4362564086990 .9634170532292 .0893173217892 .33471679688 89.9635772705193 .02089691162110 .0018997192130 .0850982666142 .8348999023 150.908203125152 .5054931641156 .1069030762169 .5139007568184 .0924987793 192.8780059814198 .6979064941203 .8231964111209 .5354003906217 .295501709 226.5621948242237 .1076965332245 .4539031982250 .1051025391249 .8686981201 244.6181945801236 .9308013916228 .5424957275222 .0948944092219 .0554046631 221.3829956055230 .4598999023243 .2232055664243 .4904022217245 .4268951416 260.7820129395278 .4442138672290 .5246887207292 .7770996094280 .7072143555 265.6568908691259 .1391906738256 .6878967285255 .7653961182252 .3805999756 243.6804962158229 .1266937256208 .6063995361188 .5559997559174 .2575073242 163.1761932373152 .7064971924144 .1148986816137 .7156066895132 .016494751 125.6186981201118 .6669006348111 .2833023071104 .131301879997 .36419677734 87.9739608764674 .1909027099659 .3066215515147 .038509368936 .21784973145 $25.2503795623815 .638859748848 .4453649520872 .904378890991-1.37046504021$ $-4.50115823746-6.51256608963-7.49735498428-7.81231117249-7.44978380203$ $-6.44948911667-4.86463022232-2.69411110878-4.9297001 \mathrm{e}-023.014816999435$ 6.3483901023869 .81602764129613 .2841100692716 .5750598907519 .68272018433 22.4844703674325 .010110855127 .1973495483429 .1145591735830 .82048988342 32.3451614379933 .7441711425835 .0232887268136 .2156982421937 .31388092041 38.3262710571339 .2543106079140 .1080284118740 .8544502258341 .46063995361 41.9598617553742 .3787994384842 .7350196838443 .053569793743 .36275100708 43.6966514587444 .1039009094244 .6260108947845 .2641792297446 .05739974976 46.9719696044948 .0058784484949 .1334800720250 .3051681518651 .51660919189 52.7503890991254 .0087089538655 .2882614135756 .5919914245657 .92107009888 59.2779312133860 .6635398864762 .0865707397563 .5554618835465 .06099700928 66.5947418212968 .1542663574269 .7364883422971 .3352966308672 .95127868652 74.5323486328176 .0272827148477 .4840774536178 .9459075927780 .40653991699 81.8674392700283 .3246231079184 .7743225097786 .2134628295987 .6368637085 89.0430068969790.427879333591.7915267944393.1322021484494.45099639893 95.7482833862397 .0253524780398 .2837219238399 .52448272705100 .7492980957 101.9590988159103 .1551971436104 .3382034302105 .5093002319106 .6688995361 107.8178024292108 .9563980103110 .0849990845111 .2041015625112 .3140029907 113.4148025513114 .5070037842115 .5905990601116 .6660003662117 .7332992554 118.7929000854119 .8449020386120 .8896026611121 .9272994995122 .9582977295 123.9826965332125 .0010986328126 .0133972168127 .0202026367128 .0214996338 129.0177001953130 .0090942383130 .995803833131 .9781036377132 .9561004639 133.9300994873134 .9002075195135 .8665924072136 .829498291137 .7890014648 138.7451934814139 .6981964111140 .6481018066141 .5950927734142 .5393066406 143.4806060791144 .4192047119145 .3551025391146 .2884979248147 .2194061279 148.1477050781149 .0735931396149 .9971008301150 .9181976318151 .8368988037 152.7532958984153 .6672058105154 .578704834155 .4877929688156 .3943939209 157.2984008789158 .199798584159 .0986938477159 .9949035645160 .8883972168 161.7794036865162 .6652984619163 .5498046875 
436.3568115234435 .9700012207435 .6755065918435 .5205993652435 .5073852539 435.646697998435 .9509887695436 .4284057617437 .0916137695437 .9465942383 439.0065002441440 .275604248441 .7673950195443 .4840087891445 .4395141602 447.6325073242450 .0813903809452 .7887878418455 .758605957458 .9801940918 462.4486083984466 .1296081543470 .0582885742474 .2320861816478 .6859130859 483.4222106934488 .4765930176493 .857208252499 .5768127441505 .6447143555 512.0089111328518 .6663208008525 .4315185547532 .2647705078538 .7593994141 544.8099975586549 .7034301758553 .2221069336554 .4434204102552 .983581543 548.4533081055540 .3991699219530 .5274047852519 .2418823242507 .5108947754 495.120300293483 .1279907227473 .2203063965463 .2987976074452 .1771850586 441.2727050781432 .0386047363424 .1676025391417 .1767883301411 .1393127441 405.8807067871400 .6129150391394 .5213012695387 .987487793380 .9436950684 372.9237976074363 .5603942871353 .858001709345 .1907958984337 .0744018555 330.0976867676323 .103302002314 .5846862793307 .4068908691303 .7279052734 302.0705871582301 .3244018555301 .8392944336303 .8923034668305 .5922851562 304.6041870117301 .1393127441294 .5534973145286 .1690979004277 .2475891113 267.9672851562259 .2936096191249 .8139038086239 .3842010498224 .7725067139 201.0838928223176 .0314025879158 .43800354145 .7225036621136 .9226074219 131.9734039307128 .9360961914126 .1300964355121 .825302124117 .1427993774 113.1393966675109 .5317993164106 .3379974365107 .8056030273106 .113899231 103.846298217899 .6459579467894 .7651901245189 .9059066772585 .30841827393 81.6210403442478 .1973876953174 .5520095825270 .9012985229567 .32006835938 63.8031806945860 .4061508178757 .4216194152855 .2854995727553 .95907974243 53.6362304687554 .2463607788156 .0037117004458 .0966606140159 .41178131104 61.4149208068865 .3151702880970 .2654724121176 .1235885620182 .20918273926 88.1177825927793.3812637329197.1554870605599.5463790893699.50340270996 99.0732269287199 .81629180908101 .214302063103 .793296814107 .4140014648 112.0001983643117 .4474029541121 .4822006226129 .5975952148149 .7519989014 169.3188934326176 .2111053467177 .2895050049174 .8647003174172 .3242950439 176.8370056152181 .4443054199180 .3130950928178 .412902832178 .1766967773 177.81590271175 .9250030518173 .2837982178170 .5839996338167 .2864074707 163.8730010986158 .349395752149 .2747039795138 .8916931152129 .0354003906 121.1218032837116 .8884963989114 .3510971069111 .9493026733109 .1896972656 104.9972000122100 .515602111896 .8924636840893 .4308166503989 .42875671387 86.5586166381886 .417266845787 .3335189819388 .1902236938589 .06667327881 89.7818908691490 .4180908203191 .1584625244191 .1544189453189 .90590667725 87.5641632080183 .613838195883 .8849792480596 .02490997314110 .3759002686 118.7285995483121 .8986968994113 .9688034058107 .7917022705115 .4880981445 127.0055999756136 .2194976807144 .7301940918152 .5458984375158 .9264984131 159.300994873165 .3849029541194 .6959075928224 .2855072021234 .4777069092 236.7774963379231 .9839935303226 .6347961426222 .0048065186216 .6031036377 214.054901123215 .9790039062225 .2682952881233 .8298034668237 .4396972656 232.5346984863244 .9391937256261 .2041931152273 .3815917969278 .4260864258 270.8146057129260 .4700927734257 .8728027344258 .0714111328257 .925201416 258.7773132324264 .4515991211263 .6416931152243 .8126983643219 .887802124 205.0449066162191 .7303924561175 .3058929443160 .4575958252149 .6959991455 
141.9622955322135 .7373962402130 .6567993164125 .4206008911119 .3401031494 111.4190979004101 .417701721290 .3943786621178 .0244216918965 .30544281006 52.5112686157238 .9863090515126 .8673000335717 .8063297271710 .96755981445 $5.5029211044311 .579960942268-1.34905004501-3.36014199257-4.65502786636$ $-5.25311994553-5.07055091858-4.23428821564-2.64241194725-.493198990822$ 2.1944160461435 .2237391471868 .44385147094711 .7333202362114 .90445995331 17.9424190521220 .7071399688723 .2368793487525 .4727096557627 .47156906128 29.2660293579130 .8823204040532 .378768920933 .7475204467835 .0383682251 36.2240791320837 .3240013122638 .3302917480539 .2567481994640 .06755828857 40.7275199890141 .2678108215341 .7198104858442 .1069908142142 .46947097778 42.8306617736843 .2140502929743 .6623115539644 .210380554244 .85282897949 45.6091690063546 .4651908874547 .4263191223148 .4728317260749 .56797027588 50.7124481201251 .8875007629453 .0956382751554 .3314285278355 .59706115723 56.8922195434658 .2189102172959 .5742607116760 .9716987609962 .42433929443 63.9183502197365 .4423370361366 .9941635131868 .572677612370 .16291046143 71.7580184936573 .3360137939574 .8839874267676 .4078979492277 .9176864624 79.4168167114380 .9085464477582 .3913803100683 .8602294921985 .31419372559 86.745811462488 .1562118530389 .540176391690 .8996582031292 .23296356201 93.5419464111394 .8280105590896 .0924072265697 .3376693725698 .56463623047 99.77565765381100 .9713973999102 .1536026001103 .3227996826104 .4803009033 105.6266021729106 .7623977661107 .8880004883109 .0039978027110 .1107025146 111.2082977295112 .2970962524113 .3774032593114 .4492034912115 .5129013062 116.5686035156117 .6166000366118 .6572036743119 .6904983521120 .716796875 121.7363967896122 .7496032715123 .7567977905124 .758102417125 .7537994385 126.7442016602127 .729598999128 .7102966309129 .6864013672130 .6582946777 131.6260070801132 .5899047852133 .5500030518134 .5066070557135 .4598999023 136.4098052979137 .3567047119138 .3005981445139 .2415924072140 .1797027588 141.1152038574142 .0480041504142 .978302002143 .9060974121144 .8314971924 145.7543945312146 .6750030518147 .5933074951148 .5092926025149 .4230041504 150.3345031738151 .2436065674152 .1504974365153 .0549926758153 .9571990967 154.8569030762155 .7541046143156 .6488037109157 .5408935547158 .4304046631 159.3173980713160 .2014007568161 .0830993652161 .9617004395 447.4352111816446 .8286132812446 .4014892578446 .1762084961446 .0802001953 446.1411132812446 .3687133789446 .7720031738447 .3604125977448 .141204834 449.1235046387450 .3132019043451 .7189941406453 .3453063965455 .2002868652 457.2854919434459 .6123962402462 .1860046387465 .0039978027468 .0603027344 471.341796875474 .8226013184478 .5112915039482 .3941955566486 .5000915527 490.8432922363495 .4291992188500 .2615966797505 .324798584510 .6174926758 516.0653076172521 .6403808594527 .1596069336532 .5347900391537 .4252929688 541.6411132812544 .6685180664546 .169128418545 .6428222656542 .6118164062 537.3916015625529 .6865234375520 .44140625510 .129699707498 .6810913086 486.2786865234474 .0982971191463 .4431152344452 .9233093262441 .516998291 431.0318908691423 .1590881348416 .6897888184410 .2846069336404 .3230895996 399.5210876465394 .5732116699388 .0567016602380 .6900939941372 .3811950684 363.2892150879353 .8806152344344 .3349914551335 .237487793326 .6564941406 318.866394043311 .9679870605306 .3586120605302 .5155944824300 .6547851562 
300.3257141113300 .7650146484302 .2047119141304 .578704834306 .1312866211 305.1166992188301 .9592895508296 .2398071289288 .7224121094279 .8853149414 269.391204834257 .9801940918245 .9369049072234 .0218048096218 .3029022217 193.8267974854169 .5567016602153 .2122039795141 .4772949219133 .1773986816 127.2684020996123 .3163986206120 .3003997803116 .2063980103111 .8748016357 107.8990020752104 .1479034424100 .5895004272103 .9991989136102 .0039978027 99.222938537694 .8767013549890 .2667236328186 .1982727050882 .48745727539 79.1609725952175 .9662628173872 .6584320068469 .3776168823266 .21788024902 63.0641403198259 .8267097473156 .8880386352554 .7015991210953 .24256134033 52.6556282043552 .9049682617254 .0674514770555 .6062507629456 .92530059814 58.8428802490262 .0890388488866 .0974502563570 .7798233032275 .72120666504 80.8263397216885 .884490966890 .4110336303794 .0088272094795 .17568969727 95.5005264282296 .4872283935597 .7165069580199 .97001647949103 .0422973633 106.8964996338111 .0559005737114 .4422988892119 .8834991455130 .0330963135 141.6074981689151 .4555969238158 .2075042725159 .7171936035158 .8903045654 159.5652008057159 .5601959229157 .7422943115156 .5117034912157 .6605072021 159.8733978271161 .0227966309161 .600402832161 .8583068848161 .2738952637 160.4367980957157 .5352935791150 .4188995361141 .5500030518132 .9882965088 125.5709991455120 .8615036011117 .6797027588114 .9425964355112 .0781021118 108.4653015137104 .138099670498 .8354721069393 .3721313476688 .79221343994 85.77065277185 .3701629638786 .5175170898488 .2315063476690 .13845062256 91.74916839693 .1583862304794 .0374526977593 .7488479614392 .12854766846 89.7094268798886 .8291091918986 .5815887451293 .18006896973100 .8179016113 105.03150177104 .961700439597 .3998031616290 .8293380737393 .36679077148 99.26586914062101 .8074035645105 .8273010254114 .0375976562120 .3217010498 118.1483001709121 .0618972778139 .8309936523161 .3088989258172 .5382995605 181.3244934082 196.1257019043206.6513977051210.4257049561 208.2035064697 206.7651062012208 .9998016357214 .7109985352222 .2050018311225 .3323974609 225.7928009033233 .5496063232244 .8287963867254 .1255950928259 .5231018066 256.9070129395252 .2602996826250 .7135009766250 .3713989258250 .7225036621 254.2386016846263 .0151062012267 .1477966309257 .2489929199240 .6596984863 225.7386932373209 .6118011475190 .6141052246172 .3200073242158 .5941925049 149.3876037598144 .7028961182141 .9770965576137 .7610931396131 .8592987061 123.9352035522114 .9364013672106 .097503662195 .9621276855583 .56799316406 69.7993087768655 .4113006591841 .7192382812529 .6168708801319 .88784980774 $13.609820365919 .2758998870855 .326806068422 .073067903519-.482645988464$ $-2.25832796097-3.11865901947-3.13297390938-2.22395205498-.578199028969$ 1.7028260231024 .4426021575937 .43224382400510 .5544204711913 .59691047668 16.5356597900419 .2392406463621 .7304897308323 .9615001678525 .98205947876 27.8078899383529 .4735298156731 .0208492279132 .4553489685133 .81764984131 35.0812606811536 .2479705810537 .3217582702638 .3090705871639 .1802406311 39.8976707458540 .4901618957540 .9840507507341 .4137191772541 .82275009155 42.2341918945342 .6758308410643 .1701507568443 .7452392578144 .39339065552 45.1284408569345 .942100524946 .843189239547 .8171195983948 .84539031982 49.9244117736851 .0416488647552 .197399139453 .3870391845754 .61177825928 55.8709297180257 .1657104492258 .4950103759859 .8680801391661 .29219818115 
62.7601699829164 .2644882202165 .8018798828167 .3714981079168 .95720672607 70.5515136718872 .1477127075273 .7336502075275 .3101730346776 .87055206299 78.4145126342879 .9449920654381 .4590988159282 .9524765014684 .42304992676 85.8651962280387 .2794265747188 .662803649990 .0170288085991 .3420791626 92.640213012793 .9139862060595 .1651229858496 .3965682983497 .60954284668 98.8064498901499 .98819732666101 .15650177102 .3121032715103 .456199646 104.589302063105 .7121963501106 .8252029419107 .9288024902109 .0233001709 110.1090011597111 .1859970093112 .2546005249113 .3147964478114 .3671035767 115.4113006592116 .4479980469117 .4772033691118 .4991989136119 .5142974854 120.5226974487121 .5248031616122 .5207977295123 .511100769124 .4959030151 125.475402832126 .4501037598127 .4200973511128 .3856964111129 .3471069336 130.3045959473131 .2583007812132 .2084960938133 .1551971436134 .0988006592 135.0393066406135 .9768066406136 .9114990234137 .8435058594138 .7727966309 139.6996002197140 .6239929199141 .5458984375142 .4654998779143 .3827972412 144.2978973389145 .2106933594146 .121307373147 .029800415147 .9362030029 148.8403015137149 .7422943115150 .6421051025151 .5395965576152 .4346923828 153.3276062012154 .2180023193155 .1058959961155 .9913024902156 .8740997314 157.7543029785158 .6320037842159 .504699707160 .3760986328 457.8757019043457 .2858886719456 .7934875488456 .452911377456 .2616882324 456.2289123535456 .3648071289456 .6756896973457 .1716003418457 .8562927246 458.7398071289459 .8239135742461 .1184997559462 .6232910156464 .3475952148 466.2880859375468 .4563903809470 .8512878418473 .4729003906476 .3110961914 479.353302002482 .5736999512485 .9643859863489 .4923095703493 .1874084473 497.0667114258501 .1116943359505 .3212890625509 .6512145996514 .1024780273 518.5620117188523 .018371582527 .2465820312531 .1998291016534 .5145874023 537.078125538 .4334106445538 .3594970703536 .5493774414532 .6121826172 526.9730224609519 .4553222656510 .6759033203500 .9096069336490 .0765075684 478.1000976562465 .754486084454 .1848144531442 .9724121094431 .8521118164 422.2619018555415 .4598999023409 .888092041403 .6442871094397 .924987793 393.7073059082388 .9486083984381 .9294128418373 .0997924805362 .978302002 352.437713623343 .0491943359334 .0303039551324 .7916870117316 .1075134277 308.0564880371302 .1137084961300 .1936035156300 .2132873535300 .3068847656 301.1784973145302 .5903015137304 .3858947754306 .1679077148307 .0015869141 305.8775939941302 .701385498297 .1148071289289 .5234985352280 .2139892578 269.0273132324255 .7362060547241 .2214050293227 .737197876210 .9152069092 187.2967071533164 .3778991699148 .1100006104136 .7232971191128 .879699707 123.1567001343118 .7649002075115 .0011978149111 .0395965576107 .172203064 103.3245010376 99.45265197754 102.3787002563100.049201965397.69264984131 94.7974777221790 .66909027186 .4587936401483 .2012634277380 .20957946777 77.0509872436573 .9246368408270 .8323669433667 .803710937564 .96523284912 62.1161994934159 .0961608886756 .303298950254 .1931800842352 .6983795166 51.9518508911151 .8690605163652 .3784484863353 .3947486877454 .81356811523 56.7428398132359 .3085708618262 .4285392761266 .2565994262770 .60809326172 75.4467926025480 .5998764038185 .8007888793990 .1368408203191 .65598297119 92.2611694335993 .5124282836994 .959396362397 .40869903564100 .3152999878 103.7227020264107 .2276992798110 .5774993896113 .4580001831112 .8118972778 
114.6390991211125 .4511032104136 .608001709141 .7229003906142 .9853973389 140.5307006836136 .970993042135 .8202056885136 .2431030273138 .7503967285 142.537399292145 .1071929932147 .7079925537150 .2196044922152 .1484069824 154.0677032471153 .7619018555148 .961807251142 .0749053955135 .6430969238 129.5110015869124 .5397033691120 .5491027832117 .2132034302114 .0207977295 111.0307006836106 .864997863899 .8290328979592 .9228897094788 .6106262207 86.24082946777 85.79019927979 87.10778045654 89.7734069824292.99076080322 95.5783691406297 .386299133397 .9729232788197 .5613937377996 .52494812012 95.0974578857494 .4999923706194 .4474411010796 .1606979370197 .84021759033 98.4420089721797 .3545532226693 .2998962402389 .4774932861388 .91574859619 88.6479873657283 .7689208984480 .9614105224687 .3918304443493 .94629669189 91.5563735961989 .9865264892692 .6449813842898 .88585662842106 .8258972168 120.5194015503155 .5254058838177 .633895874189 .2861022949191 .9862060547 191.5252990723196 .4082946777203 .0944976807210 .213104248213 .4539031982 216.6983947754221 .1873016357225 .9273986816230 .8300018311235 .2523956299 237.1109008789237 .678604126236 .6690979004236 .1578063965237 .6784057617 241.7299041748249 .3701019287254 .962600708255 .0809020996248 .8101959229 236.4078063965219 .4954071045200 .4452972412181 .9716033936167 .662399292 158.1996002197154 .3815002441152 .679397583147 .9886932373141 .8992004395 134.4954071045126 .5884017944119 .9583969116112 .0594024658100 .8321990967 87.4481735229573 .1977767944358 .671741485643 .9141387939531 .5949306488 24.1528892517118 .9159908294713 .370510101328 .5454559326174 .477108001709 $1.279348015785-.715902984142-1.70170998573-1.46126794815-.313953012228$ 1.5970779657364 .0768008232126 .8514080047619 .814731597912 .70773983002 15.5120401382418 .1042995452920 .5070590972922 .6707096099924 .64767074585 26.4397106170728 .0873107910229 .6402206420931 .0917797088632 .51287841797 33.8354682922435 .0727806091336 .211631774937 .2514915466338 .1718788147 38.9463081359939 .5920295715340 .1442604064940 .6341705322341 .10474014282 41.5800514221242 .0823287963942 .6275596618743 .2276916503943 .8847618103 44.6088714599645 .3948593139646 .2475395202647 .1608695983948 .12657165527 49.143978118950 .203689575251 .3072509765652 .4498901367253 .63319015503 54.8553009033256 .1183395385757 .420898437558 .7672080993760 .15670013428 61.5905609130963 .0667800903364 .5826187133866 .1409683227567 .72460174561 69.33123016357 70.95088195801 72.57830047607 74.20500183105 75.81773376465 77.4139785766678 .9889984130980 .540176391682 .0600204467883 .54956054688 85.0010833740286 .4186401367287 .7987213134889 .1452713012790 .45964813232 91.7444992065493 .0047302246194 .2412261962995 .4585266113396 .65706634521 97.8400268554799 .00787353516100 .1625976562101 .304901123102 .4358978271 103.556098938104 .6664962769105 .7671966553106 .8588027954107 .9414978027 109.0155029297 110.0810012817 111.1381988525 112.1872024536113 .2281036377 114.2612991333115 .2866973877116 .3048019409117 .3156967163118 .3197021484 119.3171005249120 .3080978394121 .2930984497122 .2724990845123 .2462997437 124.2151031494125 .1790008545126 .1383972168127 .09349823128 .0444946289 128.9916992188129 .9353027344130 .87550354131 .8123931885132 .746307373 133.6773071289134 .6054992676135 .5310058594136 .4539031982137 .3744049072 138.2924957275139 .2082977295140 .1219024658141 .033203125141 .9425048828 
142.8495941162143 .754699707144 .657699585145 .5587005615146 .4575958252 147.3544006348148 .249206543149 .1417999268150 .0323028564150 .920501709 151.8063964844152 .6900024414153 .571105957154 .4497070312155 .3256988525 156.1992034912157 .0699005127157 .9384002686158 .803604126 468.2590942383467 .4193115234466 .7684936523466 .3335876465466 .0328979492 465.8926086426465 .9201965332466 .1224060059466 .5057983398467 .0751037598 467.8359985352468 .791595459469 .946685791471 .3026123047472 .8630065918 474.6264953613476 .5968017578478 .7724914551481 .149810791483 .7228088379 486.4717102051489 .3707885742492 .4016113281495 .5331115723498 .7768859863 502.1391906738505 .5945129395509 .1299133301512 .6945800781516 .2680053711 519.7473144531523 .0853271484526 .1032104492528 .7044067383530 .6312866211 531.7133178711531 .6776733398530 .2761230469527 .4016723633522 .7794799805 516.7532958984509 .283203125500 .7314147949491 .3175964355481 .0903930664 470.3364868164458 .6647033691445 .8089904785433 .5097961426423 .5539855957 415.5592956543409 .312713623403 .9316101074398 .3125915527393 .2385864258 389.3645935059384 .5365905762376 .5721130371365 .9025878906352 .812286377340 330.6123046875322 .4837036133313 .7525024414305 .9624023438300 .4479064941 297.5982971191297 .5867004395299 .0999145508300 .6405944824302 .3286132812 304.3848876953306 .3218994141307 .7380981445308 .087310791306 .7280883789 303.2822875977297 .2304077148288 .9688110352278 .2302856445266 .1080932617 254.1858062744240 .5254974365223 .8143005371203 .2637023926176 .7848968506 152.3721008301138 .8730010986131 .0610961914125 .1156005859120 .2834014893 115.193901062110 .3220977783106 .2151031494102 .623497009398 .84403991699 95.0323028564597 .8684234619195 .27455902193 .4771881103591 .54596710205 88.1089935302784 .426483154381 .2246017456178 .0909423828174 .98927307129 71.9385070800869 .000411987366 .1803970336963 .4603691101160 .77774047852 58.0705604553255 .589008331353 .6196594238352 .1569099426351 .32189941406 51.0027389526451 .1841697692951 .9014091491753 .0993804931654 .74224853516 56.7800598144559 .2576103210462 .3943405151466 .2251892089870 .81365966797 75.7811279296980 .7106933593884 .8842773437587 .2489013671988 .91178131104 90.9045333862393 .1062164306695 .9330596923898 .94896697998102 .1365966797 105.2201004028107 .9673995972109 .0280990601107 .2519989014107 .5680007935 114.4105987549123 .1572036743128 .1051940918129 .5469055176127 .5276031494 124.5628967285123 .271697998123 .1977005005123 .5493011475125 .0961990356 128.0554962158131 .8917999268135 .6481018066139 .3838043213143 .5540924072 146.0220947266144 .5290985107140 .8542938232136 .5523986816131 .6730041504 126.7718963623122 .3326034546119 .0500030518115 .8849029541112 .2637023926 107.100502014298 .7831573486391 .2374877929788 .116767883387 .09477996826 86.5444335937587 .8434066772592 .3825531005997 .65412139893101 .0766983032 102.9806976318102 .9681015015102 .3813018799102 .4312973022102 .5599975586 102.6237030029101 .9884033203101 .5419998169100 .675102233999 .61517333984 98.7827072143697 .0478820800895 .0939636230594 .3012771606491 .39691162109 84.1154479980578 .389373779379 .9625930786182 .9541625976681 .15514373779 78.0046463012776 .1966018676877 .2052078247181 .3262634277392 .39058685303 110.105796814133 .4924926758155 .4221038818167 .2465057373166 .654800415 175.9801940918184 .711807251193 .9246063232197 .4353942871199 .5556945801 
202.7180023193202 .3265991211203 .6219024658206 .6620025635210 .5493011475 213.9196014404214 .6177978516215 .6851959229220 .8769073486227 .5169067383 233.2066040039238 .404800415242 .6143951416242 .4770965576234 .8600006104 221.6878051758205 .6862030029190 .1531982422179 .5354003906172 .3023071289 166.9963989258162 .6645965576156 .9723968506150 .442199707143 .6472930908 137.0852050781131 .4689941406125 .1511001587116 .7964019775105 .7230987549 91.2361526489375 .6342391967860 .9995193481448 .2929611206138 .68603134155 30.7450809478822 .9961490631116 .0610198974610 .176839828495 .434422969818 $2.1063570976260 .104785002768-.357989013195 .34439000487331 .905238986015$ 4.1458358764656 .7432551383979 .55434036254912 .2775497436514 .90054988861 17.3305091857919 .5842704772921 .6264400482223 .4989204406725 .18844032288 26.7560100555428 .250980377229 .6857299804731 .1253108978332 .49800109863 33.800369262735 .0123901367236 .0937805175837 .0553512573237 .87231063843 38.5654907226639 .1834182739339 .7507286071840 .3013000488340 .85313034058 41.4237594604542 .0205993652342 .6532707214443 .323799133344 .04288864136 44.8068618774445 .6204414367746 .4821090698247 .3934783935548 .3540802002 49.3619003295950 .4159812927251 .5143394470252 .656951904353 .84302902222 55.072830200256 .3439712524457 .6573410034259 .0120582580660 .41102981567 61.8548507690463 .3476409912164 .8942413330166 .4804229736368 .10192108154 69.7511901855571 .4239578247173 .1056289672974 .7755966186576 .42768096924 78.0507125854579 .6407470703181 .1891403198282 .6966323852584 .15795135498 85.5765228271586 .9510116577188 .2864990234489 .587051391690 .85619354248 92.100303649993.3210372924894.5229187011795.7068176269596.87545776367 98.0295867919999 .17096710205100 .300201416101 .4185028076102 .5263977051 103.6246032715104 .7135009766105 .7935028076106 .8647003174107 .9273986816 108.9817962646110 .0279006958111 .06590271112 .0959014893113 .1181030273 114.132598877 115.1398010254 116.1397018433 117.1327972412 118.1193008423 119.0994033813120 .073600769121 .0419998169122 .0050964355122 .9630966187 123.9163970947124 .865196228125 .8097000122126 .7503967285127 .6873016357 128.620803833129 .550994873130 .4781036377131 .4022979736132 .3238067627 133.2425994873134 .1589050293135 .0727996826135 .9844055176136 .8937988281 137.8011016846138 .7062072754139 .6094055176140 .5104980469141 .4096984863 142.3070068359143 .2023010254144 .095703125144 .987197876145 .8766937256 146.7642059326147 .6497039795148 .5330963135149 .4143066406150 .2933044434 151.1699981689152 .0442962646152 .9161071777153 .7854003906154 .6520996094 155.5164031982156 .3757019043157 .2337036133 477.9534912109477 .1188049316476 .3839111328475 .8095092773475 .3879089355 475.1260070801475 .0314025879475 .1080932617475 .3626098633475 .7963867188 476.4154052734477 .2189025879478 .2117004395479 .3911132812480 .7604980469 482.3149108887484 .0556945801485 .9753112793488 .071685791490 .3370056152 492.7482910156495 .2770996094497 .9016113281500 .5940856934503 .3432006836 506.1473083496508 .9668884277511 .7954101562514 .5601196289517 .2493286133 519.736328125521 .9963989258523 .8372192383525 .2020263672525 .8486938477 525.6613769531524 .4324951172521 .9727783203518 .2722167969513 .1138916016 506.7936096191499 .2265930176490 .7529907227481 .495300293471 .6630859375 462.0404968262451 .2947998047437 .7495117188424 .9986877441416 .5046081543 
410.0271911621403 .9150085449398 .4787902832393 .2582092285388 .2850952148 383.9811096191377 .9961853027368 .5257873535356 .4053955078341 .4620056152 327.3850097656318 .437713623311 .3835144043303 .5863037109297 .5191040039 295.2056884766295 .3554992676296 .3758850098298 .3830871582300 .6976928711 302.9765930176 305.4375 307.3970947266 308.2723083496307.9802856445 306.1444091797 302.300994873295 .9800109863286 .7672119141274 .049987793260 .5296020508 250.0146026611236 .8265075684216 .5466003418192 .3665008545164 .0782928467 140.2409057617130 .4913024902125 .9187011719121 .0259017944116 .410697937 110.6119995117105 .3035964966101 .40899658298 .1092071533294 .50179290771 90.8045578002992 .5437927246190 .2182693481489 .6526794433688 .88221740723 86.1548461914182 .7119216918979 .2574691772575 .8447494506872 .73805999756 69.8114700317467 .0379562377964 .3783187866261 .7426795959559 .20837020874 56.8535003662154 .7370681762752 .9795799255451 .6135406494150 .75444030762 50.3355598449750 .3472709655850 .8243217468351 .7394790649453 .03926086426 54.6353416442956 .6801185607959 .3688812255962 .7659988403367 .02403259277 71.610488891675 .8337783813579 .6950531005982 .8073883056685 .60172271729 88.5265808105591 .5229873657294 .8847503662198 .27059936523101 .6106033325 104.3789978027106 .4784011841107 .3367004395107 .3155975342108 .0796966553 110.7488021851114 .4979019165117 .1703033447118 .4045028687117 .9649963379 116.7164001465115 .870300293115 .1294021606113 .0628967285112 .1380004883 114.599899292118 .5584030151122 .5381011963127 .0916976929132 .5856933594 137.0729980469138 .5964050293138 .0955047607136 .2704925537132 .8890991211 128.3934020996123 .6773986816120 .4642028809117 .3271026611113 .1781997681 107.527099609498.7793502807691.0955581665 89.10640716553 89.41818237305 88.808731079190 .2523574829196 .36165618896103 .0363006592106 .7176971436 108.4574966431107 .7097015381106 .6787033081107 .3326034546108 .085899353 108.462600708107 .6624984741106 .7351989746105 .5111999512104 .5487976074 104.2884979248104 .1143035889103 .5025024414102 .473602294999 .42178344727 92.6389389038186 .4057464599684 .3355026245183 .4060668945381 .64707946777 79.0375671386776 .1131286621174 .8839569091876 .5525283813580 .82985687256 81.2124633789185 .0808792114398 .53740692139113 .6206970215130 .4812011719 143.2816009521159 .878692627170 .5729064941172 .9920043945176 .5330047607 178.5431060791177 .1732025146177 .1679992676178 .5346069336182 .5135955811 186.8190002441188 .4125976562191 .162399292199 .3867034912207 .9118041992 211.2548980713214 .2407073975220 .0800018311223 .6174926758220 .6300048828 213.3011016846 203.1188964844 193.3099975586189.1213989258 185.2686004639 178.350402832170 .4971008301163 .1096038818156 .4286956787150 .4559020996 145.3594055176140 .549697876135 .4053039551129 .915802002121 .7244033813 108.182601928792 .8721466064579 .4995498657266 .9399032592854 .9849395752 44.0862808227533 .6594314575224 .4074897766116 .418500900279 .906675338745 5.2426161766052 .2291829586031 .1601920127871 .5049049854282 .770101070404 4.8217759132397 .1932640075689 .78269577026412 .2858295440714 .65054988861 16.8714504241918 .93882942220 .797220230122 .507400512724 .01409912109 25.4050807952926 .7726898193428 .1196498870829 .54380035430 .96191978455 32.3743515014633 .6675987243734 .7881011962935 .7518501281736 .60121154785 37.3654289245638 .0791091918938 .7571792602539 .4113311767640 .06021881104 
40.7034606933641 .3592109680242 .0249214172442 .7132110595743 .43138122559 44.1779594421444 .9594306945845 .7781600952146 .641460418747 .55170059204 48.5111312866249 .5196609497150 .5769004821851 .6823005676352 .83422851562 54.0318489074755 .2701606750556 .5498886108457 .868438720759 .23136901855 60.6383399963462 .1030006408763 .6354484558165 .2221832275466 .86724090576 68.5539169311570 .2785491943472 .0208206176873 .7515563964875 .46240234375 77.1370468139678 .7689132690480 .3457489013781 .8720932006883 .33949279785 84.756278991786 .1198196411187 .4384231567488 .7210998535289 .97068786621 91.1972122192492 .4005889892693 .5869216918994 .7559432983495 .91074371338 97.0515823364398 .1801528930799 .29698944092100 .4031982422101 .4991989136 102.585899353103 .6633987427104 .7322006226105 .7925033569106 .8442993164 107.8880004883108 .9234008789109 .9506988525110 .9701004028111 .9815979004 112.985496521113 .9819030762114 .9711990356115 .9534988403116 .9291992188 117.8985977173118 .8619995117119 .8197021484120 .7720031738121 .7193984985 122.6620025635123 .6003036499124 .5344009399125 .4646987915126 .3914031982 127.3147964478128 .2350006104129 .1522979736130 .0668029785130 .9786987305 131.8881072998132 .7951965332133 .7001037598134 .6027984619135 .5034942627 136.4022064209137 .2989044189138 .1938018799139 .086807251139 .9781036377 140.8674926758141 .7552032471142 .6410064697143 .5249938965144 .4071960449 145.287399292146 .165802002147 .042098999147 .916305542148 .7882995605 149.6580963135150 .5254974365151 .3905029297152 .2530059814153 .1130065918 153.970199585154 .8251037598155 .6768035889

487.5842895508486 .4747009277485 .5589904785484 .8681030273484 .3128051758 483.9169006348483 .6852111816483 .6217956543483 .7297058105484 .0108947754 484.4671936035485 .0982971191485 .9046936035486 .8840026855488 .0349121094 489.3526000977490 .8327026367492 .4674987793494 .250793457496 .1752929688 498.2142028809 500.3388061523502.5241088867504.7377929688506.9587097168 509.1666870117511 .3293151855513 .4307250977515 .4044799805517 .2133789062 518.7576293945519 .9807128906520 .7457275391520 .9652099609520 .4812011719 519.1624145508516 .8947753906513 .5230712891509 .0768127441503 .4354858398 496.7861022949489 .1337890625480 .6773071289471 .5461120605461 .9920959473 452.3835144043441 .8299865723429 .4407958984418 .0455932617410 .4422912598 404.500793457398 .5611877441392 .8569030762387 .3724060059381 .5696105957 374.7847900391365 .9432983398354 .1853027344341 .0328063965328 .0740966797 316.6792907715308 .4975891113302 .2387084961296 .4890136719292 .62109375 291.8504943848293 .0255126953294 .8057861328297 .1684875488299 .9663085938 302.6264953613305 .1323852539306 .8544006348306 .9508056641305 .750793457 303.0668029785298 .7856140137293 .3215942383284 .0389099121268 .2651062012 251.8242034912239 .8614959717224 .7312011719199 .9907989502172 .9931945801 150.2772064209134 .0484008789127 .3486022949123 .3467025757116 .0821990967 108.6327972412103 .127197265699 .0632171630996 .1977920532293 .60278320312 90.214149475186 .4046707153388 .1436309814586 .7179565429787 .02654266357 86.9215316772584 .0533905029380 .098358154376 .5367431640673 .15844726562 70.1566314697367 .4230194091864 .8116073608462 .31013107359 .89292907715 57.629600524955 .5829696655353 .7871894836452 .2771415710451 .07231140137 50.2588615417549 .8067283630449 .7286186218350 .0403099060150 .75233078003 
51.8021507263253 .1225204467854 .8682594299357 .2089996337960 .14968109131 63.7174606323267 .5743103027371 .4693832397575 .3787536621179 .02768707275 82.6670837402386 .2852172851689 .9311218261793 .84570312597 .89440917969 102.2393035889105 .8324966431107 .7975006104108 .5643005371108 .2218017578 107.6715011597108 .470199585109 .6863021851110 .7726974487111 .7406997681 111.6429977417111 .091003418110 .720199585110 .1948013306109 .679901123 109.7403030396110 .7506027222113 .0031967163116 .325302124120 .595703125 125.5446014404130 .2294006348133 .1109008789134 .7713928223135 .6026000977 134.3927001953130 .3385925293125 .4339981079121 .7263031006118 .4716033936 115.5718994141111 .331703186103 .45960235696 .3330001831193 .83278656006 93.6546936035294 .0522308349696 .43213653564102 .1510009766108 .0342025757 111.0955963135111 .9842987061110 .5830993652108 .9617004395108 .2332992554 108.0734024048109 .1141967773109 .3324966431108 .525100708107 .6635971069 107.5822982788 108.1172027588 108.4791030884 107.8645019531 105.7460021973 102.439796447898 .5095977783295 .1782302856494 .84487152194 .63128662109 92.3887405395588 .725021362383 .2448730468878 .3662567138777 .23769378662 76.5355072021574 .44838714676 .4608230590887 .101280212499 .09461212158 104.9240036011107 .1364974976106 .0976028442120 .8398971558142 .6889038086 152.8798065186152 .5986022949151 .3771972656153 .0151062012154 .7966003418 156.5193939209158 .3863067627159 .962097168162 .975402832169 .0402069092 174.7286987305176 .9647979736179 .4190063477185 .4813995361191 .1569976807 191.8327026367190 .2516937256187 .7808074951186 .5117950439190 .2649993896 191.3773956299184 .2440032959174 .0650024414165 .3262023926158 .4145050049 153.7165985107150 .2855072021147 .0388031006143 .4846954346139 .1732940674 132.8162994385123 .1084976196111 .140899658298 .073806762784 .36418151855 70.9243774414157 .7780799865745 .0031394958533 .3675918579123 .05018997192 14.515689849858 .5597829818734 .694966793063 .0555279254913 .108319997787 4.2278242111216 .1530528068548 .2639303207410 .5491504669212 .76101016998 14.8066797256516 .7236499786418 .533069610620 .1738395690921 .66970062256 22.9074192047124 .026790618925 .1732406616226 .3711795806927 .72044944763 29.1838207244930 .798200607332 .2756614685133 .3370895385734 .21305084229 35.0984306335435 .9631500244136 .8096008300837 .631420135538 .42039108276 39.1829795837439 .9146003723140 .6325111389241 .3438987731942 .05590057373 42.776500701943 .5075988769544 .260601043745 .0412483215345 .86177062988 46.7267684936547 .6426811218348 .609519958549 .6312294006350 .70367050171 51.8254203796452 .99330902154 .2011299133355 .4476585388256 .73012924194 58.0542106628459 .4213714599660 .8548202514662 .3667411804263 .95243835449 65.6269073486367 .361892700269 .1456832885770 .9562225341872 .7543182373 74.5277862548876 .2580490112377 .9334335327179 .5380172729581 .07908630371 82.5516662597783 .9624176025485 .3089599609486 .6039505004987 .86289978027 89.0895767211990.2950134277391.4799270629992.64945983887 93.80372619629 94.9447174072396 .072830200297 .1891479492298 .2942428588999 .38899230957 100.4738998413101 .5495986938102 .6164016724103 .6745986938104 .7244033813 105.7658996582106 .7992019653107 .8243026733108 .8414001465109 .850402832 110.851600647111 .8451004028112 .8311004639113 .8098983765114 .7816009521 115.7466964722116 .7054977417117 .658203125118 .6053009033119 .5470962524 
120.4838027954121 .4159011841122 .3436965942123 .2674026489124 .1874008179 125.1038970947126 .0170974731126 .9273986816127 .8348007202128 .7397003174 129.641998291130 .542098999131 .4400024414132 .3358001709133 .229598999 134.1215057373135 .0115966797135 .8999023438136 .7864990234137 .6714019775 138.5547027588139 .4362945557140 .316192627141 .1945037842142 .0709991455 142.9458007812143 .8188018799144 .6900024414145 .5592041016146 .4263000488 147.2913970947148 .1542053223149 .0148010254149 .8728942871150 .7285003662 151.5816955566152 .4324035645153 .2781982422154 .1226043701 496.4902954102495 .3738098145494 .3569946289493 .5056152344492 .8066101074 492.2644958496491 .883605957491 .6653137207491 .612487793491 .7239074707 492.0008850098492 .4399108887493 .0404968262493 .797088623494 .7070007324 495.762512207496 .9570922852498 .280090332499 .7229003906501 .2763977051 502.9111938477504 .600189209506 .3121948242508 .0172119141509 .6795959473 511.2745056152512 .7614135742514 .1367797852515 .3134155273516 .2677001953 516.8892211914517 .1433105469516 .8956298828516 .0861816406514 .5803222656 512.2822265625509 .1193847656504 .970703125499 .8955993652493 .7948913574 486.8446960449479 .0397033691470 .562286377461 .4934082031451 .9725952148 442.0939941406431 .896697998421 .2875976562411 .6531982422404 .7116088867 398.8487854004392 .8450012207386 .725402832380 .4674072266373 .1065979004 363.1386108398351 .3280944824337 .8215942383324 .6337890625314 .7929077148 306.7589111328299 .4920959473293 .9296875289 .9960021973288 .3363952637 288.7709960938290 .2426147461291 .812286377293 .7189025879296 .558807373 299.6336975098302 .3203125303 .6716003418303 .0452880859300 .374786377 296.1531982422290 .8828125285 .7789916992277 .4204101562260 .0035095215 240.0695037842224 .9308929443206 .915802002179 .2657012939152 .6139984131 137.6141967773128 .6345977783123 .5043029785119 .176399231109 .2791976929 99.6304168701294 .9622879028392 .259910583590 .299392700288 .37870788574 85.2093505859484 .9160766601683 .5166625976682 .8843078613383 .57520294189 83.8086471557680 .5642929077176 .3320922851673 .0139007568469 .92460632324 67.2160568237364 .710517883362 .2586097717359 .9627609252957 .82220077515 55.9036903381354 .2013206481952 .7330589294451 .4979209899950 .50954055786 49.8110694885349 .3984794616749 .288780212449 .495948791550 .04233169556 50.9002609252952 .0446090698253 .5738906860455 .634620666558 .11302947998 60.8861198425364 .0919876098667 .7754135131871 .8193130493275 .88918304443 80.0650634765684 .1387023925888 .2781372070392 .6724700927797 .24179840088 102.5194015503106 .93409729109 .1766967773109 .865196228109 .1289978027 107.8500976562107 .5494995117107 .5743026733107 .7220001221108 .0954971313 107.8975982666107 .6608963013107 .5164031982107 .7137985229109 .3961029053 111.0897979736110 .9654998779111 .3608016968113 .729598999117 .1541976929 120.9017028809124 .7578964233127 .9309005737130 .6405944824133 .4411010742 134.2698974609131 .141494751126 .5257034302122 .7240982056119 .4149017334 117.8246994019115 .4250030518109 .1673965454103 .039703369199 .94317626953 99.03576660156100 .2583999634103 .2578964233107 .7846984863112 .173500061 114.2875976562114 .6110992432112 .9446029663109 .9452972412106 .4219970703 103.8304977417105 .0602035522107 .1750030518108 .0507965088108 .9882965088 110.4677963257111 .9207000732112 .2824020386111 .3647994995108 .3249969482 
105.1340026855104 .2715988159104 .6503982544106 .899597168108 .5217971802 106.6428985596101 .986801147594 .3678207397586 .4083709716882 .24516296387 80.1431198120180 .187637329183 .2478637695390 .2304534912195 .21591186523 85.2084426879976 .2586364746184 .6038208007897 .78785705566108 .8310012817 118.568397522124 .8407974243128 .9044952393132 .9225006104135 .5520935059 135.0019989014134 .43699646135 .921295166138 .2183990479140 .6063995361 142.6997070312143 .9689941406146 .3076019287151 .8059997559157 .8193969727 160.7375030518163 .2590026855166 .8592987061172 .0084075928181 .5847015381 187.7436981201182 .2106018066172 .5260009766165 .0570068359158 .7171020508 155.3670043945153 .2490997314151 .0587005615148 .6730041504144 .9656982422 140.1206970215134 .5249938965126 .5262985229114 .5450973511100 .4692993164 86.392158508371 .8667984008857 .1999015808143 .2374610900930 .1120891571 19.4409694671612 .176110267647 .7824401855475 .781609058385 .590766906738 6.5888710021978 .3295717239389 .9630365371711 .6011400222813 .39669036865 15.0914697647116 .7682399749818 .3696708679219 .7171192169220 .90346908569 21.7690792083722 .5029602050823 .3705902099624 .3636093139625 .60746002197 27.0506992340128 .809989929230 .4471702575731 .4983100891132 .36437988281 33.3662605285634 .380439758335 .3990402221736 .4017295837437 .3447303772 38.2489318847739 .0774612426839 .8690109252940 .6236381530841 .35427093506 42.074359893842 .7899208068843 .5198516845744 .26869964645 .05427932739 45.8800811767646 .7552680969247 .685821533248 .6772003173849 .72431182861 50.8204193115251 .9609794616753 .1405792236354 .3571586608955 .60879135132 56.8993911743258 .2324295043959 .6264686584561 .1006011962962 .68114852905 64.3916931152366 .1941528320368 .0471420288169 .9219512939571 .7837677002 73.6167602539175 .404861450277 .12612152178 .7616195678780 .31965637207 81.7898788452183 .1865615844784 .5080032348685 .7711181640687 .00272369385 88.2035827636789 .3875198364390 .5537719726691 .7072677612392 .84742736816 93.9755630493295 .0918579101696 .1968383789197 .2911224365298 .37525177002 99.44980621338100 .515296936101 .5720977783102 .620300293103 .6602020264 104.6919021606105 .7154006958106 .7305984497107 .7378005981108 .7369003296 109.7281036377110 .7114028931111 .6872024536112 .6556015015113 .6171035767 114.5717010498115 .5199966431116 .4623031616117 .3988037109118 .3300018311 119.2563018799120 .1779022217121 .095199585122 .0085983276122 .918296814 123.8246002197124 .7277984619125 .6280975342126 .5257034302127 .4208984375 128.3137054443129 .2044067383130 .0930023193130 .9797973633131 .8647003174 132.7478027344133 .6293029785134 .5092010498135 .3874969482136 .2642974854 137.1396026611138 .0133056641138 .8854980469139 .7561035156140 .6251983643 141.4925994873142 .3583068848143 .2223052979144 .0843048096144 .9445037842 145.8025054932146 .6584014893147 .5119934082148 .3632965088149 .212097168 150.0583953857150 .9019012451151 .7431945801152 .5812988281 505.3275146484503 .9172058105502 .7011108398501 .7139892578500 .8605957031 500.161895752499 .6192932129499 .2340087891499 .0057983398498 .9331970215 499.0140075684499 .2443847656499 .620300293500 .1355895996500 .7836914062 501.5557861328502 .4421081543503 .4303894043504 .508392334505 .6642150879 506.8684082031508 .0931091309509 .3075866699510 .4786987305511 .5707092285 512.5507202148513 .3792114258514 .0313720703514 .4387207031514 .5557250977 
514.3065795898513 .6436767578512 .4719848633510 .7143859863508 .2898864746 505.1113891602501 .1434020996496 .3048095703490 .6447143555484 .1206054688 476.8511962891468 .8689880371460 .3125451 .2847900391441 .8641052246432 .1496887207 422.6290893555413 .5397949219405 .245300293398 .2763061523391 .8825073242 385.9516906738379 .4733886719371 .611907959362 .1662902832350 .1476135254 336.962097168323 .8196105957312 .1911010742303 .6264953613296 .7387084961 290.1712036133284 .925994873281 .8559875488281 .5643920898284 .5006103516 287.2921142578 286.7648925781 286.316192627 289.1972961426 293.1523132324 296.3934936523297 .790802002296 .1115112305291 .4111938477283 .9031982422 275.8734130859269 .9201965332262 .1387023926247 .8726959229229 .0447998047 207.3869018555 183.9745025635160.6865997314140.8441009521 127.4557037354 118.3797988892112 .8427963257107 .629898071399 .5487136840892 .11193084717 87.7549972534285 .107986450283 .0061035156280 .7668991088977 .99172973633 78.9289627075277 .7567672729577 .0862274169977 .2050704956176 .78839874268 74.2277908325270 .9714431762768 .4004135131866 .0245132446363 .77178955078 61.563758850159 .3175506591857 .2308387756355 .4539718627953 .94729995728 52.6704406738351 .5901603698750 .6798515319849 .9508590698249 .42263031006 49.1015892028849 .0042991638249 .1492004394549 .5706901550350 .2688293457 51.2543792724652 .5706100463954 .3015213012756 .2999916076758 .4753112793 61.209819793764 .8777999877969 .1030197143673 .3751602172977 .76336669922 82.1320724487386 .5697784423891 .1614379882895 .87880706787100 .8569030762 105.0514984131107 .5473022461108 .616897583108 .4801025391107 .6834030151 107.1440963745106 .6743011475106 .4011001587106 .3507995605106 .2232971191 106.1996002197106 .2372970581106 .779800415108 .381401062109 .801399231 110.0613021851110 .3963012695112 .2170028687114 .8406982422117 .7994995117 120.8495025635123 .3777008057125 .9938964844129 .0641937256130 .7572021484 129.2852935791126 .2601013184123 .2761993408120 .5434036255118 .787902832 116.640296936112 .3376998901107 .8759994507105 .2077026367104 .220703125 105.3772964478107 .8958969116111 .2640991211114 .4588012695116 .5720977783 117.2556991577115 .5406036377110 .942199707102 .317497253495 .22651672363 95.99855804443100 .1307983398104 .6990966797109 .3986968994112 .9151000977 115.4629974365116 .5610961914116 .0254974365113 .6633987427111 .5068969727 111.0886993408112 .0395965576114 .5344009399116 .5485992432116 .7015991211 113.4822998047105 .412200927796 .3510894775490 .9680862426888 .59661865234 89.04799652190 .9673309326293 .8613891601693 .8163528442486 .88976287842 81.5373001098684 .7901077270592 .1559371948299 .73921203613106 .9977035522 112.0388031006116 .0343017578119 .4476013184121 .3562011719121 .4400024414 121.795501709124 .209197998126 .5322036743126 .5016021729126 .0886001587 126.8069000244128 .9524993896132 .4122009277136 .5547027588139 .6571044922 142.9096984863145 .4449005127149 .9324035645159 .5838928223167 .6380004883 168.0314941406165 .0527954102162 .5955963135159 .8795928955157 .4346923828 155.2015075684153 .003692627150 .6934967041147 .9248962402144 .745300293 140.9662017822135 .2563934326126 .4423980713114 .7442016602101 .0022964478 85.8012619018669 .8828964233453 .6623382568437 .0803298950223 .40059089661 15.6977996826211 .57334995279 .3920574188238 .96806716918910 .09801006317 11.7958202362112 .4275503158612 .9204301834114 .0987901687615 .43729019165 
16.9468402862518 .4288997650119 .4093093872120 .1478290557920 .55331993103 20.8117294311521 .3076190948522 .0444908142123 .1190795898424 .47245979309 26.1040992736827 .706470489528 .9746303558330 .1280593872131 .34987068176 32.5916099548333 .8387489318835 .0497894287136 .1789283752437 .23751068115 38.2009582519539 .0850181579639 .8787307739340 .6141586303741 .32976150513 42.0299797058142 .7378883361843 .4605293273944 .2169494628945 .00925064087 45.8427200317446 .7358093261747 .7099800109948 .7439804077149 .82015991211 50.9375915527352 .0933113098153 .285999298154 .515201568655 .78158950806 57.0873489379958 .4387893676859 .8319702148461 .3683509826763 .1552696228 65.0670394897566 .9933929443468 .9288635253970 .8474578857472 .73695373535 74.58119964676 .350166320878 .0222702026479 .5992431640681 .05895996094 82.4291076660283 .7172317504984 .9414291381886 .1386032104587 .31130218506 88.472236633389 .6203079223690 .758377075291 .8855285644593 .00187683105 94.1074295043995 .2021789550896 .2866287231497 .3611679077198 .42624664307 99.48240661621100 .529800415101 .568901062102 .5996017456103 .6220016479 104.636100769 105.641998291 106.6397018433107.6292037964108.6106033325 109.5840988159110 .5500030518111 .5083999634112 .459602356113 .4040985107 114.3421020508 115.2739028931 116.2001037598 117.1209030151 118.0366973877 118.9478988647119 .8548965454120 .7580032349121 .6574020386122 .5535964966 123.4467010498124 .337097168125 .224899292126 .1103973389126 .9936981201127 .875 128.7543945312129 .6320953369130 .508102417131 .3825073242132 .2554016113 133.1268005371133 .9967956543134 .8654022217135 .7326965332136 .5984954834 137.4629974365138 .3260040283139 .1875140 .0476074219140 .9060058594141 .7626953125 142.6175994873143 .470703125144 .3217010498145 .1705932617146 .0173034668 146.8616943359147 .7035980225148 .5429992676149 .3800048828150 .2120056152 151.0428009033

513.4188232422511 .9901123047510 .6586914062509 .4942016602508 .478302002 507.6129150391506 .8988037109506 .3348083496505 .9195861816505 .6495056152 505.520904541505 .5275878906505 .6636962891505 .9209899902506 .2905883789 506.7616882324507 .321685791507 .9570922852508 .6512145996509 .3901977539 510.1440124512510 .8869934082511 .5840148926512 .2062988281512 .7114257812 513.0745239258513 .2401733398513 .1840820312512 .833984375512 .154296875 511.0736999512509 .5660095215507 .532989502504 .9166870117501 .6571960449 497.6957092285493 .0184936523487 .5636901855481 .3884887695474 .4601135254 466.8915100098458 .7059936523450 .0494995117441 .0226135254431 .7903137207 422.3991088867413 .4562072754405 .6007995605398 .2022094727390 .94140625 384.0328979492378 .1628112793371 .6211853027362 .5575866699351 .1051940918 337.0555114746322 .8558044434310 .8911132812301 .0427856445292 .9966125488 286.374786377280 .2755126953275 .6690979004273 .103302002272 .8779907227 276.7301940918280 .1012878418277 .4180908203274 .8573913574277 .7632141113 281.6947021484284 .5515136719285 .2945861816282 .4309082031276 .7315063477 267.423614502257 .3309936523250 .5007019043241 .7689971924229 .1161956787 211.4170074463184 .3273010254157 .5198974609140 .5814056396128 .0740966797 115.7552032471106 .145599365299 .8336868286194 .5772705078189 .54705810547 85.1092224121181 .1691589355577 .9814987182675 .3470764160272 .73818969727 69.9652023315471 .8524169921971 .1959609985470 .5938568115269 .737449646 
68.5882110595766 .6179885864364 .490936279362 .8001403808661 .23662948608 59.5440711975157 .7987213134855 .9378089904854 .2089500427252 .87997817993 51.8223800659250 .9915313720750 .3267898559649 .7771110534749 .34014129639 49.022048950248 .8336296081548 .7872085571348 .9087181091349 .25069046021 49.8259086608950 .68400955251 .8116111755453 .2424201965354 .9275894165 56.7295494079659 .183731079162 .8400688171467 .1213531494171 .344581604 75.7414627075280 .204658508384 .7428207397589 .3673171997193 .88903808594 98.18884277344101 .8337020874104 .4542007446106 .1066970825107 .0025024414 107.1437988281106 .9524002075106 .5093994141106 .1434020996105 .998298645 105.9168014526106 .0733032227106 .2675018311106 .7412033081107 .5948028564 108.484703064109 .2620010376110 .174697876111 .7376022339113 .7241973877 115.956199646118 .2854003906120 .0031967163121 .8795013428124 .4145965576 126.262298584126 .2583999634125 .0903015137123 .3974990845121 .3554992676 119.24659729116 .9749984741114 .3047027588111 .729598999109 .8125108 .9220962524 109.7413024902111 .466003418113 .56199646115 .5906982422117 .6605987549 118.0250015259115 .5938034058109 .621498107996 .8793411254986 .40641021729 87.2067031860493 .43878936768101 .8385009766110 .4024963379115 .657699585 118.7884979248120 .3775024414120 .5007019043119 .3898010254118 .2021026611 117.6902999878118 .0092010498119 .6061019897120 .9999008179122 .2139968872 120.9098968506113 .9375106 .1808013916101 .938697814999 .6392669677799 .75007629395 100.070297241298 .4745025634896 .4432373046996 .3853607177796 .98821258545 95.8275375366296 .0437011718899 .31897735596103 .40650177106 .427696228 109.0632019043111 .2239990234112 .5712966919114 .177696228115 .9934997559118 .8125 121.1054992676119 .2304000854117 .1032028198117 .9652023315119 .6755981445 120.8924026489122 .646697998124 .9944992065127 .3494033813127 .0232009888 128.2409057617135 .2613067627142 .8379058838148 .0364990234151 .662902832 154.7200927734156 .3634033203155 .5966033936153 .7292938232151 .866394043 149.8253936768148 .2028045654146 .3352050781143 .6390991211139 .5711975098 134.0285949707125 .6447982788113 .651702880998 .9537429809682 .87078094482 65.5540466308646 .5294685363830 .282089233421 .5338897705117 .1360206604 14.2363100051913 .6660203933714 .5566902160615 .6099195480314 .8550195694 13.8683300018314 .4125003814715 .5354499816917 .2273197174118 .69556045532 19.2088794708319 .1847591400118 .9388809204118 .7494106292718 .91044044495 19.4155006408720 .3309898376521 .5539207458523 .0002899169924 .55194091797 26.0879192352327 .6183891296429 .1398792266830 .6572704315232 .17572021484 33.6331596374534 .9743995666536 .2125587463437 .3013191223138 .27048110962 39.0913581848139 .8193702697840 .5263595581141 .2107887268141 .90330886841 42.6094703674343 .34724044844 .1181907653844 .9212684631345 .78598022461 46.7454681396547 .7668609619148 .8229904174849 .9197311401451 .05550003052 52.2285881042553 .4422683715854 .6931610107455 .9838905334557 .3187789917 58.6594505310160 .1640701293962 .0120697021564 .0049133300865 .97693634033 67.957443237369 .9202270507871 .8539886474673 .7461776733475 .56902313232 77.2965774536178 .8958435058680 .3370132446381 .6582336425882 .90046691895 84.0885391235485 .2550582885786 .403182983487 .5440063476688 .67626190186 89.8006286621190.9165878295992.0225219726693.1188735961994.20456695557 95.2804794311596 .3464279174897 .4031372070398 .4508132934699 .48985290527 
100.5203018188101 .5425033569102 .5561981201103 .5615997314104 .5585021973 105.5470962524106 .5272979736107 .4992980957108 .4633026123109 .4194030762 110.3679962158111 .3093032837112 .2436981201113 .1715011597114 .0931015015 115.0090026855115 .9195022583116 .8248977661117 .7257995605118 .6224975586 119.5154037476120 .4046020508121 .2907028198122 .1737976074123 .0542984009 123.9322967529124 .8081970215125 .6819000244126 .5539016724127 .4240036011 128.2926025391129 .1596984863130 .0252990723130 .8896026611131 .7525939941 132.6143035889133 .4747924805134 .3339996338135 .1920013428136 .0487060547 136.9040985107137 .758102417138 .6107025146139 .461807251140 .3112945557 141.158996582142 .0050048828142 .8489990234143 .69090271144 .5307006836 145.3681030273146 .2030944824147 .0355987549147 .8654022217148 .6929016113 149.5171966553

521.4373168945519 .7023925781518 .1580810547516 .8425292969515 .6558837891 514.6157836914513 .7205810547512 .9683837891512 .3552856445511 .8768005371 511.5264892578511 .2972106934511 .1805114746511 .1664123535511 .2435913086 511.399810791511 .6198120117511 .888092041512 .1854858398512 .4943237305 512.7874755859513 .0405883789513 .2166137695513 .2781982422513 .1923217773 512.9262695312512 .4332275391511 .6748962402510 .5987854004509 .1640014648 507.3190002441505 .0245056152502 .2040100098498 .7838134766494 .7514953613 490.0769042969484 .7536010742478 .7427062988472 .092010498464 .8016967773 456.9559936523448 .6005859375439 .8583068848430 .8268127441421 .7009887695 412.5940856934404 .054901123396 .5574035645389 .3371887207382 .1402893066 375.2716064453369 .4715881348363 .2580871582355 .0537109375343 .234588623 325.3045043945307 .9328918457297 .3167114258289 .3348083496280 .6358947754 273.1351928711268 .7023925781265 .792388916262 .9288024902261 .1575927734 261.475189209261 .6156921387259 .294708252257 .5798950195259 .4888916016 261.6997070312261 .561706543259 .5603942871256 .0563049316251 .2550964355 245.3056945801237 .9638061523229 .9407958984217 .9494934082198 .5579071045 175.2534942627149 .9559020996127 .0535964966111 .4972000122101 .1563034058 95.4039382934691 .6544265747187 .8592224121184 .5232696533281 .00820922852 77.6297836303774 .1626434326270 .8372879028368 .1749572753965 .42357635498 62.4338798522964 .5467224121164 .0800933837963 .3549499511762 .30210876465 60.9186897277858 .8510513305756 .9425582885755 .7706794738854 .81729125977 53.8439598083552 .8447608947851 .804550170950 .8451995849650 .06822967529 49.4948806762749 .1642684936548 .9539299011248 .7953681945848 .68130111694 48.5994300842348 .5727806091348 .5999908447348 .7262992858949 .03445053101 49.5402717590350 .2984390258851 .2997589111352 .5720901489354 .11557006836 55.9117393493758 .3151817321861 .6673889160265 .5759124755969 .63638305664 73.8887481689578 .2426681518682 .663650512787 .1106872558691 .34377288818 95.2425308227598 .6686630249101 .3686981201103 .5953979492105 .3768005371 106.4088973999106 .5065994263106 .1179962158105 .9781036377106 .0008010864 106.0919036865106 .3416976929106 .6958007812107 .0977020264107 .6831970215 108.4353027344109 .2342987061110 .2156982422111 .5177001953112 .9770965576 114.7146987915116 .5277023315118 .1222000122119 .7826004028121 .7051010132 123.3193969727123 .7182006836123 .4197998047122 .6503982544121 .2833023071 119.5803985596117 .817199707116 .0212020874114 .4501037598113 .2281036377 
112.53150177113 .0193023682114 .0089035034115 .1567001343116 .0674972534 116.452003479114 .8259963989109 .7132034302101 .675903320390 .22956848145 81.9188232421983 .6952362060591 .65128326416103 .1930999756114 .3527984619 119.8100967407122 .2077026367123 .4636001587123 .6583023071123 .0409011841 122.2146987915121 .9517974854121 .9698028564122 .6479034424122 .8483963013 121.3783035278119 .0593032837116 .0001983643113 .1502990723111 .8654022217 110.8121032715109 .5746994019107 .601600647104 .8229980469103 .1261978149 103.551902771104 .251701355103 .9600982666102 .9402999878102 .8466033936 103.738899231105 .1934967041107 .087097168109 .0855026245110 .7555999756 112.5092010498113 .9680023193114 .7166976929114 .9121017456113 .1353988647 111.3460998535111 .8951034546112 .7306976318113 .0962982178113 .7531967163 115.1069030762116 .3930969238116 .3118972778117 .0205993652120 .7929992676 125.6055984497128 .2984924316131 .3688049316136 .291305542140 .7138061523 143.7353973389145 .3374023438145 .6992034912145 .4810028076145 .3948974609 144.9360046387143 .711807251141 .5122070312137 .9414978027132 .1316986084 123.4254989624111 .456001281796 .3701629638779 .287391662661 .08457946777 44.4305000305231 .8980598449723 .6332702636720 .3052806854219 .75675964355 19.3062400817918 .5930309295716 .358680725114 .1731100082413 .98433971405 15.1307001113917 .7025203704819 .7895793914819 .2127990722717 .73365974426 16.738210678116 .1282997131316 .0392494201716 .3990402221717 .20805931091 18.3561801910419 .7696208953921 .395790100123 .1233692169224 .94276046753 26.7766399383528 .6098003387530 .4451599121132 .1910781860433 .78575134277 35.2182197570836 .4065895080637 .4189300537138 .2633018493738 .9818611145 39.6641502380440 .3274917602541 .0125007629441 .7156410217342 .44564819336 43.2076301574744 .0082092285244 .8660202026445 .8019599914646 .79624176025 47.8322296142648 .9105110168550 .0299606323251 .1908798217852 .39471054077 53.6432991027854 .9403686523456 .2923507690457 .6952781677259 .25329971313 61.0734596252463 .030139923165 .009628295967 .0059814453168 .99043273926 70.9550704956172 .8817520141674 .7602767944376 .5873870849678 .25010681152 79.6265716552780 .8515701293982 .0415573120183 .1969070434684 .34046936035 85.4715194702186 .5979232788187 .7176971435588 .8317031860489 .93831634521 91.0361022949292 .1246871948293 .2031021118294 .2717132568495 .33045959473 96.3797988891697 .4200973510798 .4515380859499 .47435760498100 .4886016846 101.4943008423102 .4913024902103 .4797973633104 .4597015381105 .431098938 106.3939971924107 .3487014771108 .2954025269109 .2343978882110 .1659011841 111.0904006958112 .0082015991112 .9197006226113 .8254013062114 .7257003784 115.6209030151116 .5115966797117 .3980026245118 .2807006836119 .1597976685 120.0357971191120 .908996582121 .7796020508122 .6477966309123 .513999939 124.3783035278125 .2408981323126 .1017990112126 .9613037109127 .8195037842 128.6764068604129 .5319976807130 .3865966797131 .2400054932132 .092300415 132.9434967041133 .7935943604134 .6425018311135 .4902954102136 .336807251 137.1819000244138 .0256958008138 .8679962158139 .7086029053140 .5475006104 141.3843994141142 .2194061279143 .0520935059143 .882598877144 .7106933594 145.5363006592146 .3594055176147 .1775970459147 .9944000244 528.7031860352526 .9396972656525 .2689819336523 .7639160156522 .4005737305 521.178527832520 .094909668519 .1461181641518 .3265991211517 .6301269531 
517.0485839844516 .5733032227516 .1931762695515 .8973999023515 .6715087891 515.5025024414515 .3718261719515 .2639770508515 .1553955078515 .0275878906 514.8524780273514 .6115112305514 .2598876953513 .7614135742513 .0806884766 512.192199707511 .0440979004509 .6051025391507 .8233032227505 .6731872559 503.0968933105500 .0658874512496 .5079956055492 .3518981934487 .6130981445 482.2901000977476 .3817138672469 .8597106934462 .7825012207455 .1557922363 447.0693054199438 .5701904297429 .7817077637420 .7973022461411 .7987060547 402.9559020996394 .5394897461386 .9713134766379 .9276123047373 .3193969727 367.0452880859361 .5686035156355 .2948913574347 .5606079102335 .9765930176 315.5643005371295 .7549133301285 .8955078125278 .9155883789269 .008392334 260.6658935547257 .7491149902256 .1105957031252 .6074066162248 .9678039551 245.1139068604241 .6842956543239 .9349975586239 .0912017822239 .4313049316 239.2283935547 235.8236999512 231.2947998047 227.550994873 223.7814025879 221.2451019287216 .7769012451208 .0077056885193 .37159729168 .1472015381 140.2630004883118 .1149978638100 .09230041585 .2284469604576 .61934661865 76.8296813964879 .279579162678 .6310501098677 .0033798217874 .45641326904 71.2992172241267 .7989273071364 .1420364379961 .5028686523458 .83860015869 56.9976005554256 .597801208556 .5347709655856 .0244598388755 .13114929199 53.8212394714451 .7141799926849 .8100090026948 .8859291076748 .37395858765 47.9975395202647 .7276992797947 .5230712890647 .351150512747 .11825942993 46.9917984008847 .1083183288647 .3360900878947 .6045913696347 .83618927002 48.035301208548 .1552391052248 .2791404724148 .4526100158748 .77690124512 49.28118896484 49.9953002929750 .9432907104552 .1485404968353 .68428039551 55.607288360658 .0317192077661 .0081596374564 .454376220768 .20662689209 72.2050628662176 .3017883300880 .4407806396584 .5614929199288 .47828674316 92.0627670288195 .3136825561598 .09339904785100 .5925979614102 .9763031006 104.6899032593105 .1339035034105 .158996582105 .65599823106 .1085968018 106.4254989624106 .6934967041107 .1067962646107 .6279983521108 .1614990234 108.8379974365109 .5796966553110 .4326019287111 .4347991943112 .5413970947 113.9199981689115 .4464035034117 .0553970337118 .6719970703120 .0343017578 121.1557998657121 .5889968872121 .6352005005121 .45069885525120 .8168029785 119.7469024658118 .5462036133117 .380897522116 .3665008545115 .6171035767 115.1268997192115 .355796814115 .7098007202116 .1371002197115 .8774032593 114.4266967773110 .804901123103 .46730041594 .6225967407286 .07657623291 81.4471435546984 .7234573364393 .60874938965106 .4067993164118 .3472976685 123.1167984009124 .651802063125 .7528991699125 .8649978638125 .5370025635 124.9923019409124 .956199646124 .8439025879124 .8231964111123 .9057006836 119.7673034668116 .1472015381116 .6985015869118 .2761001587119 .4745025635 119.6425018311117 .3584976196114 .2469024658112 .0142974854110 .5933990479 109.8109970093109 .5165023804110 .2585983276110 .2500991821108 .3890991211 106.8653030396107 .0383987427108 .2846984863110 .2511978149112 .8846969604 116.0235977173118 .1075973511117 .206703186114 .5761032104111 .7011032104 109.6505966187 109.1072006226 109.4485015869 109.4253005981 109.2352981567 109.4330978394109 .7496032715110 .2835006714111 .0039978027111 .8387985229 112.8115997314111 .4195022583111 .3082962036115 .927696228121 .9037017822 128.1315002441133 .4199066162136 .4248962402138 .2877960205139 .9197998047 
140.9752960205141 .3016967773140 .6394042969138 .641494751134 .866394043 129.5359039307121 .1055984497108 .431701660293 .1981735229577 .50554656982 61.8052597045946 .4213905334534 .6159782409730 .1583900451728 .79891967773 25.4749603271521 .8701801317 .6018009185813 .9409503936813 .07378959656 14.1368398666417 .289199829119 .7341308593818 .2078990936315 .60492038727 14.1704101562513 .2455396652212 .9556598663313 .2089195251513 .92547035217 15.0490503311216 .4946498870818 .2236595153820 .1299400329622 .18836975098 24.2990093231226 .444759368928 .5943393707330 .6649799346932 .57625961304 34.2188606262235 .4878005981436 .4848785400437 .3230400085438 .04705047607 38.7202301025439 .3775787353540 .0662002563540 .7780685424841 .50959014893 42.2754516601643 .0848884582543 .9442481994644 .8583793640145 .82489013672 46.8404502868747 .9027290344249 .0097007751550 .1627693176351 .36273956299 52.6171607971253 .9313011169455 .3262100219756 .8219299316458 .44535827637 60.219730377262 .1064300537164 .0624771118266 .0574188232468 .04892730713 70.028739929271 .9743194580173 .8772735595775 .7717437744177 .48272705078 78.8095169067479 .9670562744181 .1318969726682 .2673263549883 .39573669434 84.5170364379985 .6327667236386 .7446670532287 .85073089688 .95099639893 90.0423965454191 .1253662109492 .1978607177793 .2608184814594 .31349945068 95.3567733764696.3905792236397.4154205322398.4312591552799.43831634521 100.4364013672101 .4257965088102 .4061965942103 .3777999878104 .3405990601 105.2947998047 106.2405014038 107.1779022217108.1074981689109.0294036865 109.9440994263110 .8520965576111 .7536010742112 .6492004395113 .5393981934 114.4244995117115 .3050003052116 .1812973022117 .0538024902117 .9227981567 118.7888031006119 .6520996094120 .512802124121 .3713989258122 .2279968262 123.0827026367123 .9359970093124 .7876968384125 .6381988525126 .4873962402 127.3356018066128.1826019287 129.0287017822 129.8739013672130 .7180023193 131.5612030029132 .4033966064133 .2445983887134 .0847015381134 .9237060547 135.7613983154136 .5979003906137 .4329071045138 .2662963867139 .0980987549 139.9279937744140 .7559051514141 .5816955566142 .4051971436143 .2263031006 144.0449981689144 .8609008789145 .6744995117146 .4848022461

535.8936767578533 .8178710938531 .9260864258530 .2584838867528 .7131958008 527.3037109375526 .0253295898524 .8732910156523 .8402709961522 .9187011719 522.0983886719521 .3693237305520 .7185058594520 .1331176758519 .5974121094 519.0958862305518 .6093139648518 .1190795898517 .6016845703517 .0352172852 516.3931884766515 .6516723633514 .7725830078513 .7194213867512 .4586791992 510.958190918509 .1771850586507 .0781860352504 .6213989258501 .7688903809 498.4841918945494 .7315063477490 .4666137695485 .6383972168480 .261505127 474.3333129883467 .8753051758460 .8868103027453 .4195861816445 .4984130859 437.209197998428 .6187133789419 .8364868164410 .9696960449402 .1383056641 393.4682006836385 .1321105957377 .3883056641370 .7045898438365 .8955078125 361.3570861816356 .0339050293349 .0515136719338 .9443969727325 .6318054199 308.0436096191290 .8140869141278 .8544921875269 .451385498260 .2980041504 252.9459991455249 .0218963623246 .1560058594242 .4985046387238 .383895874 233.5106964111229 .095199585226 .0019989014223 .6483001709221 .5162963867 218.9015045166215 .0563049316210 .7901000977206 .6188964844202 .5095062256 197.7541046143191 .5023040771183 .729095459170 .9396972656149 .9687957764 
126.0320968628102 .049301147582 .7420196533272 .6569366455169 .25373840332 70.6906814575273 .6014404296973 .9329376220772 .7466964721770 .35987091064 67.0565795898463 .0352210998558 .9333801269555 .4159393310551 .1153717041 47.929828643848 .5457992553748 .941268920949 .0351905822848 .56541061401 47.5921592712446 .0728988647544 .6671600341843 .9227485656743 .58148956299 43.4473800659243 .5147590637243 .6813201904343 .9024085998544 .07722854614 44.3289299011244 .7684516906745 .3714218139646 .1660003662146 .88764953613 47.3202400207547 .5648994445847 .7602310180747 .9933204650948 .39070129395 48.9655494689949 .7362213134850 .713169097951 .9148788452153 .44401931763 55.3728790283257 .6878318786660 .4408988952663 .5497703552266 .97804260254 70.6477966308674 .4186782836978 .2158737182681 .9554519653385 .52098083496 88.7898178100691 .8070678710994 .4770431518696 .9614868164199 .30062866211 101.1656036377 102.2080001831 103.1470031738 104.790802002106.1623001099 106.5264968872 106.6000976562 107.1864013672 107.9601974487108.6576004028 109.3817977905 110.0575027466110.7370986938 111.5022964478 112.3454971313 113.4259033203114 .7030029297116 .1396026611117 .524597168118 .6815032959 119.6027984619120 .1311035156120 .452796936120 .5288009644120 .2871017456 119.7022018433118 .9829025269118 .2947998047117 .6970977783117 .2485961914 116.8953018188116 .8552017212116 .7442016602116 .5035018921115 .5136032104 113.3992996216109 .6421966553103 .61389923196 .6534118652388 .5816192627 84.4294967651489 .4300308227598 .93433380127109 .7593994141119 .3227996826 123.962600708125 .9761962891127 .1091995239127 .5123977661127 .6066970825 127.5477981567127 .75127 .7142028809127 .5311965942126 .4655990601123 .4237976074 121.130897522121 .1960983276122 .2130966187122 .9654998779122 .7429962158 121.417098999119 .5218963623117 .614402771115 .9937973022114 .3000030518 113.0808029175114 .2527999878113 .8004989624111 .957901001110 .2051010132 110.0324020386111 .037399292112 .5897979736116 .4097976685125 .3554992676 132.7310028076132 .44140625127 .4560012817118 .6703033447111 .1959991455 109.6832962036110 .1999969482109 .6605987549108 .545501709107 .5914993286 106.9328994751106 .6930007935106 .3610992432105 .5385971069104 .1090011597 101.4598999023100 .5074996948103 .8248977661109 .2862014771115 .3453979492 121.3044967651125 .3615036011128 .4575958252131 .658493042134 .4004058838 136.3309936523137 .2819976807136 .94090271135 .2402038574132 .0182952881 126.5102005005118 .0772018433106 .956497192493 .4316635131878 .893409729 65.4266510009853 .9934692382846 .9555206298841 .9073181152334 .65459823608 26.9331207275419 .2369899749813 .0301198959411 .2958297729512 .26313018799 14.3010101318415 .7196397781414 .5364303588912 .5034704208411 .05910968781 10.093640327459 .7281837463389 .89154434204110 .5740995407111 .7009601593 13.214249610915 .0585002899217 .1363506317119 .4039802551321 .75638008118 24.1739807128926 .6035995483429 .0051593780531 .3631591796933 .34006118774 34.5767517089835 .4419212341336 .2522888183636 .9866485595737 .67966079712 38.3586196899439 .0646896362339 .7907905578640 .5370483398441 .31365966797 42.1312294006342 .9898796081543 .8947105407744 .8453712463445 .84589004517 46.896060943647 .9945907592849 .144809722950 .3486900329651 .61584854126 52.9517402648954 .3819503784255 .9227600097757 .5681915283259 .33430862427 61.1896286010763 .1216812133865 .1022872924867 .0859298706169 .05882263184 
70.994552612372 .8821411132874 .7156066894576 .3795089721777 .75158691406 78.9665679931680 .1440734863381 .2851409912182 .4139633178783 .53067016602 84.6439971923885 .7518997192486 .855186462487 .9519500732489 .04023742676 90.1195068359491 .1883163452192 .2470169067493 .2952728271594 .33355712891 95.3621215820396.3811798095797.3909378051898.3914489746199.38271331787 100.3647994995101 .337600708102 .3013000488103 .255897522104 .201499939 105.1383972168106 .0669021606106 .987197876107 .8996963501108 .8048019409 109.7030029297110 .5947036743111 .4804000854112 .360496521113 .235496521 114.1060028076114 .9720993042115 .834602356116 .6936035156117 .549697876 118.4029998779119 .2539978027120 .1027984619120 .949798584121 .7951965332 122.6390991211123 .4816970825124 .323097229125 .1634979248126 .0028991699 126.8414001465127 .6790008545128 .5158996582129 .3518981934130 .18699646 131.0213012695131 .8547973633132 .6873016357133 .5187072754134 .3489990234 135.1782073975136 .0059051514136 .8321990967137 .6569061279138 .4797058105 139.3005981445140 .1195068359140 .9360046387141 .7501983643142 .5619049072 143.37109375144 .1752929688144 .9781036377

542.3372802734540 .2247924805538 .19921875536 .3350219727534 .6038818359 533.0025024414531 .5247192383530 .1644897461528 .9127197266527 .7606201172 526.6959838867525 .707824707524 .7805786133523 .9011230469523 .0505981445 522.2136230469521 .3673095703520 .4940795898519 .5668945312518 .5654296875 517.458190918516 .2224121094514 .8203125513 .2241821289511 .3941040039 509.3013000488506 .9042053223504 .1740112305501 .0664978027497 .5474853516 493.5834960938489 .1466064453484 .2145996094478 .7626037598472 .800201416 466.3125915527459 .3492126465451 .9230041504444 .099395752435 .9027099609 427.4346923828418 .7668151855410 .0032958984401 .2560119629392 .6174926758 384.1462097168376 .1123962402368 .5397033691362 .4111938477359 .5098876953 356.871887207352 .1304016113344 .3913879395331 .6651000977316 .7791137695 302.9938964844289 .3895874023275 .4454040527263 .2063903809254 .3856048584 247.9691009521242 .8092041016238 .6318054199235 .1676025391231 .0341033936 225.8204956055220 .6421051025216 .2077941895211 .9987945557207 .0962982178 202.2991943359198.5966033936195.2415008545 191.166595459 185.9458007812 178.0095062256169 .063293457162 .2360992432153 .0444030762139 .0328979492 121.48300170997 .3855285644577 .182342529371 .5058517456171 .8635635376 72.3035964965873 .3221435546973 .2584533691471 .8191680908269 .17729949951 65.3021087646560 .5069198608455 .3679008483951 .0397186279345 .51343917847 38.415180206340 .8065299987842 .0812988281242 .7920303344742 .7837600708 42.2988395690941 .4748115539640 .6484184265140 .0501403808639 .71448898315 39.6708717346239 .8479499816940 .1709899902340 .6004295349141 .03873062134 41.5603485107442 .2111587524443 .0287895202644 .2074012756345 .30303955078 45.9619407653846 .4003486633346 .8350601196347 .2439804077147 .8198890686 48.5361900329649 .4124107360850 .4999504089451 .7560501098653 .28942108154 55.1769409179757 .3939285278359 .9451904296962 .7899284362865 .90039825439 69.20741271973 72.6014099121176 .0147628784279 .3612289428782 .5676574707 85.5305480957 88.2897262573290.727813720792.9916381835995.0128326416 96.8167037963998 .42273712158100 .1064987183102 .6316986084104 .8460998535 105.4088973999105 .7104034424106 .8469009399108 .0437011719109 .0348968506 
109.8016967773110 .3517990112110 .8324966431111 .4098968506112 .1179962158 113.03099823114 .1249008179115 .3575973511116 .5823974609117 .6107025146 118.4870986938119 .0966033936119 .5385971069119 .7031021118119 .6762008667 119.4708023071119 .1657028198118 .829498291118 .4777984619118 .2227020264 117.9054031372117 .6835021973117 .1983032227116 .4791030884115 .0958023071 112.8710021973109 .8590011597106 .2667999268102 .05660247894 .9548034668 91.1360092163197 .07755279541106 .0674972534113 .3251037598119 .4261016846 123.5599975586126 .1667022705127 .552696228128 .2350006104128 .7550048828 129.0525970459129 .5187072754129 .7872009277129 .9362030029129 .608505249 128.5933990479127 .4934997559126 .1011962891124 .9917984009124 .1501998901 123.37550354123 .4325027466123 .1854019165121 .7667007446120 .1258010864 121.9199981689116 .7384033203115 .8239974976115 .9828033447114 .6389007568 113.5699005127113 .3826980591114 .5175018311115 .7524032593120 .7221984863 135.262802124 148.0231018066 149.3255004883 143.670501709 130.9844055176 118.3483963013114 .8040008545113 .9962997437111 .8612976074110 .0727005005 108.297203064106 .7288970947105 .4164962769103 .8944015503101 .7666015625 99.80000305176999898 .598 .88712310791103 .8161010742108 .8873977661 113.0463027954117 .0762023926121 .5985031128125 .8385009766129 .1614990234 131.5767974854132 .7548980713132 .6929016113131 .2516021729128 .0650024414 123.8734970093117 .0028991699106 .128196716394 .2230072021584 .5443572998 75.8579711914167 .9786300659258 .7362289428745 .8554801940932 .67477035522 21.1709194183313 .380539894110 .9631996154811 .031350135811 .11036014557 11.065529823310 .297189712529 .1802511215218 .0197143554697 .073752880096 6.657546997076 .7233471870427 .3769707679758 .51066780090310 .09549045563 12.0508403778114 .2695198059116 .709199905419 .2512092590321 .88007926941 24.5283508300827 .1567993164129 .8614997863832 .1209411621133 .36845016479 34.1784095764235 .0373001098635 .8185386657736 .5586090087937 .28491973877 38.0179214477538 .7681999206539 .5324401855540 .3249893188541 .15010070801 42.0106506347742 .9100418090843 .8515701293944 .8421516418545 .88336181641 46.9764518737848 .1278991699249 .3396492004450 .6239089965851 .98307037354 53.4370498657254 .998741149956 .6570091247658 .4172515869160 .25728988647 62.1703186035264 .1274871826266 .0919723510768 .0447921752969 .955909729 71.7978820800873 .5350570678775 .1370697021576 .5714035034277 .87798309326 79.0976562580 .2586822509881 .3972091674882 .5176696777383 .6333770752 84.7428131103585 .8464126586986 .9433135986388 .0306015014689 .10871124268 90.175369262791 .2316665649492 .2766571044993 .3113327026494 .33548736572 95.3497619628996.35404205322 97.3486785888798.3335113525499.30877685547 100.2742996216101 .2304000854102 .1770019531103 .1143035889104 .0426025391 104.9621963501105 .8733978271106 .7767028809107 .6723022461108 .5608978271 109.4429016113110 .3187026978111 .1889038086112 .0539016724112 .9142990112 113.7705001831114 .6230010986115 .4720001221116 .3181991577117 .1616973877 118.0028991699118 .8421020508119 .6796035767120 .5155029297121 .3500976562 122.1836013794123 .0159988403123 .8475036621124 .6782989502125 .5082015991 126.3374023438127 .1660003662127 .9937973022128 .8209991455129 .6475067139 130.4732055664131 .2980041504132 .1219940186132 .9449005127133 .7666931152 134.5872039795135 .4064025879136 .2239074707137 .0397033691137 .8536071777 
138.6654968262139 .4750976562140 .2823028564141 .087097168141 .8890075684 142.6885986328143 .4848022461

548.7047119141546 .280090332544 .0302734375541 .9970703125540 .0775146484 538.2813110352536 .6010131836535 .0291748047533 .5551757812532 .169128418 530.8571777344529 .6065063477528 .4008789062527 .2247924805526 .0590209961 524.8853759766523 .6815795898522 .4268188477521 .0952148438519 .6630859375 518.1010131836516 .3823242188514 .4746704102512 .3475952148509 .9671020508 507.3001098633504 .3128967285500 .9728088379497 .2464904785493 .1005859375 488.5054931641483 .4266967773477 .8696899414471 .8211975098465 .2984924316 458.2976074219450 .8666992188443 .0310974121434 .8662109375426 .4186096191 417.7864074707409 .044708252400 .3066101074391 .6760864258383 .3149108887 375.3569946289368 .0938110352361 .7630004883356 .9892883301354 .7478027344 353.0069885254350 .2732849121343 .6697998047329 .812286377314 .2651062012 301.5068969727288 .9981994629275 .2626037598262 .2232055664251 .8105010986 244.4098968506240 .283996582237 .4170074463234 .5605926514230 .2315063477 222.2852020264214 .4176940918210 .2548980713206 .1194000244198 .8957977295 191.7799987793187 .046295166183 .5411987305180 .116394043175 .0639038086 166.9696960449158 .2897949219151 .6266937256144 .3984985352133 .0314941406 118.9842987061102 .419898986888 .2940063476682 .5556869506880 .8493270874 79.9428787231479 .2876892089878 .1345062255975 .9856796264671 .95850372314 66.7488632202160 .8896217346254 .9543609619148 .9556694030841 .91641998291 31.5062408447334 .7538681030336 .6241493225137 .7164611816438 .0952796936 37.9902801513737 .561100006137 .0360603332536 .618999481236 .33520889282 36.3737297058136 .6255683898937 .0434608459537 .5933990478538 .13647842407 38.7511291503939 .4434890747140 .2899208068841 .4023094177242 .52183914185 43.4396095275944 .2908096313545 .2692718505946 .1908798217846 .99966812134 47.868160247848 .9204406738350 .1536293029851 .5208511352553 .08069992065 54.9382286071857 .0584106445359 .4394989013762 .0427017211964 .86406707764 67.8291168212970 .8645935058673 .9013900756876 .861747741779 .68876647949 82.2936019897584 .6978988647586 .8377075195388 .8171920776490 .62747192383 92.3795776367294 .1468887329195 .9883270263798 .0002593994199 .98499298096 101.745300293103 .5696029663105 .822303772107 .8645019531109 .1920013428 109.9536972046110 .261100769110 .456703186110 .9324035645111 .6001968384 112.4674987793113 .4788970947114 .5994033813115 .7082977295116 .6731033325 117.5102996826118 .1597976685118 .6373977661118 .8803024292119 .0048980713 119.0880966187119 .1106033325119 .0454025269118 .9112014771118 .7718963623 118.5226974487118 .2062988281117 .616897583116 .7115020752115 .3249969482 113.2582015991110 .9885025024108 .6001968384106 .1380996704102 .9403991699 102.0463027954107 .2916030884113 .751701355117 .8173980713120 .9539031982 123.5876998901125 .7949981689127 .0911026001127 .9169006348128 .700302124 129.3453979492130 .0717926025130 .8659057617132 .1154937744132 .8894958496 131.8300018311129 .9705963135128 .3428955078126 .745300293125 .5575027466 125.0063018799125 .0164031982124 .9475021362124 .0175018311122 .6875121 .5142974854 119.4815979004117 .9576034546117 .3479995728116 .7384033203116 .1193008423 115.6865997314116 .7210998535119 .2600021362126 .1979980469141 .5928955078 155.3880004883158 .6464996338155 .0915985107147 .1143951416136 .9075012207 
127.3321990967 119.6262969971 115.3175964355112 .7309036255110 .3793029785 108.3573989868106 .7726974487104 .771598815981737680 .865371704184 .52982330322 89.9310913085993 .427452087496 .9263381958101 .0418014526105 .7936019897 110.860496521115 .8059997559120 .0888977051123 .6117019653126 .0162963867 127.447303772127 .907699585127 .0362014771124 .6541976929120 .177696228 113.1352996826105 .602302551399 .7248611450294 .5323333740290 .92487335205 81.614257812558 .9961204528835 .8742103576723 .5630302429217 .27454948425 13.6373996734611 .6449499130210 .027230262768 .7485370635997 .43029499054 6.3621158599855 .2693200111394 .3246459960943 .8428440093993 .844110012054 4.4563250541695 .5924777984627 .2195668220529 .25366592407211 .58257007599 14.1480903625516 .8287696838419 .5924091339122 .3560104370125 .0803604126 27.7460098266630 .0064601898231 .5092906951932 .605751037633 .61296081543 34.5145988464435 .3513793945336 .1449699401936 .9248886108437 .70293045044 38.4948196411139 .3049888610840 .1409416198741 .0046501159741 .90200042725 42.8378791809143 .8218307495144 .8569908142145 .9477996826247 .100730896 48.3200683593849 .6156692504950 .9933395385752 .4632110595754 .03559875488 55.6983108520557 .4524116516159 .2792396545461 .1718902587963 .10287094116 65.0431900024466 .9684600830168 .8493881225670 .6519165039172 .34372711182 73.9287033081175 .3812484741276 .73242187577 .9903335571379 .17803955078 80.3369598388781 .471679687582 .5979537963983 .7141799926884 .82321929932 85.92323303223 87.01299285889 88.09197998047 89.15895080566 90.21431732178 91.2577819824292 .2898864746193 .3108978271594 .3210983276495 .32077026367 96.3100280761797 .2890014648498 .2577819824299 .21643829346100 .1651000977 101.1039962769102 .033203125102 .9531021118103 .8639984131104 .7662963867 105.6603012085106 .5466003418107 .4256973267108 .297996521109 .1640014648 110.0243988037110 .8795013428111 .7300033569112 .5762023926113 .418800354 114.2578964233115 .0942001343115 .9279022217116 .7594985962117 .5891036987 118.417098999119 .2436981201120 .0690994263120 .8934020996121 .7169036865 122.5395965576123 .3616027832124 .1829986572125 .0038986206125 .8242034912 126.6438980103127 .4632034302128 .2817993164129 .0997924805129 .9170074463 130.733505249131 .5489959717132 .363494873133 .1768035889133 .9888000488 134.7993011475135 .608001709136 .4149017334137 .2198028564138 .0223999023 138.8226928711139 .6204986572140 .4156951904141 .2057952881141 .9945068359 554.3422241211551 .8751220703549 .4879760742547 .2559204102545 .146484375 543.1538696289541 .2692260742539 .4838867188537 .7858276367536 .1641235352 534.6030273438533 .0891723633531 .6041870117530 .1323242188528 .6516113281 527.1445922852525 .5858154297523 .955871582522 .2255859375520 .3737182617 518.3668823242516 .1823120117513 .7844238281511 .1476135254508 .2354125977 505.0208129883501 .4678955078497 .5498046875493 .2349853516488 .5014038086 483.3171081543477 .6458129883471 .5072937012464 .899810791457 .8517150879 450.3670959473442 .5036010742434 .2759094238425 .7880859375417 .084197998 408.2868041992399 .4446105957390 .7267150879382 .1875915527374 .1167907715 366.6823120117360 .2737121582355 .2770996094351 .7893981934349 .9429931641 348.341796875346 .9978027344342 .0159912109328 .5862121582313 .1987915039 301.1441955566289 .5362854004277 .0173950195264 .7308044434253 .2147064209 244.3013000488240 .7859954834239 .0603027344236 .7436981201232 .3807983398 
222.5449981689212 .7053070068208 .9833984375205 .4974975586197 .0498962402 188.3302001953182 .2639007568177 .4638977051173 .6078033447169 .0493011475 161.9485931396154 .5850982666148 .7738037109142 .362197876131 .9279022217 120.9076004028112 .4309997559105 .196701049898 .9077301025493 .92278289795 91.0005722045988 .6280364990286 .3402099609483 .4503173828178 .29630279541 72.1825790405366 .0652999877959 .5102691650454 .276371002224 .00020980835 27.7098598480230 .4548301696832 .367328643833 .7109794616734 .40845108032 34.6267585754434 .4693183898934 .1080589294433 .7116699218833 .44514083862 33.5340690612833 .854209899934 .3428497314534 .9014892578135 .43273162842 35.9833297729536 .5818290710437 .2876014709538 .1393508911139 .13203811646 40.2287101745641 .4777908325243 .0580902099644 .5708198547445 .82456970215 46.9853286743248 .2501182556249 .6394996643151 .1179504394552 .75959014893 54.6186103820856 .6593704223658 .8931198120161 .2909393310563 .84746932983 66.502372741769 .2021636962971 .8859405517674 .4911499023476 .96453857422 79.2284927368281 .2894973754983 .1073837280384 .7577667236386 .26937866211 87.88259124756 89.7085800170991.5711288452192.8851318359494.49449920654 97.35372161865100 .5919036865103 .8067016602106 .5246963501108 .1906967163 109.0761032104 109.3731994629 109.5048980713110.0605010986110.8095016479 111.7117996216112 .7335968018113 .7922973633114 .8463973999115 .782699585 116.6163024902117 .2754974365117 .7954025269118 .0936965942118 .3309020996 118.6163024902118 .8572998047118 .9697036743118 .9694976807118 .9220962524 118.7137985229118 .414100647117 .8591003418117 .0435028076115 .9327011108 114.3144989014112 .7324981689111 .0277023315110 .0691986084110 .5652008057 112.3693008423116 .3706970215120 .112197876121 .5208969116122 .3158035278 123.5820999146125 .049697876125 .8371963501126 .5428009033127 .3762969971 128.0758056641129 .2095947266130 .6042022705132 .9537963867134 .5153961182 132.8809051514130 .3188934326128 .7947998047127 .6069030762126 .8080978394 126.4057006836126 .0300979614125 .6633987427125 .0009002686124 .1160964966 121.9199981689121 .3104019165119 .4815979004118 .567199707117 .6528015137 117.9576034546 117.7758026123 118.7198028564 121.990196228 129.3892974854 143.2559967041156 .2532043457160 .8858947754160 .549697876159 .4839935303 153.8811035156140 .2729034424126 .4341964722120 .0083999634116 .5531005859 113.356300354111 .1353988647109 .4589996338107 .373001098662656668 .89019775391 72.6652297973679 .8162536621182 .4498672485485 .0223083496189 .44217681885 94.5616912841899 .7215423584104 .8416976929109 .537399292113 .6598968506 116.7016983032119 .0640029907120 .9306030273121 .7057037354120 .8592987061 118.7052001953116 .0617980957113 .2350006104111 .0050964355108 .5843963623 108.8688964844101 .206298828172 .1362075805742 .1852416992230 .45866966248 25.1469497680718 .8519306182914 .2976598739610 .817979812628 .418732643127 6.4100918769844 .8205847740173 .418540954592 .3053069114691 .682554006577 1.5121779441832 .0554599761963 .142214059834 .782323837286 .852105140686 9.23464870452911 .8633403778114 .6041498184217 .4099102020320 .2010307312 22.8812007904125 .3793392181427 .5608100891129 .353860855130 .81568908691 32.0534591674833 .1148910522534 .0761909484934 .9615592956535 .79652023315 36.613140106237 .4325790405338 .2613792419439 .1059188842839 .97124862671 40.8679084777841 .800640106242 .7817802429243 .8148002624544 .90586853027 
46.0627098083547 .2883110046448 .5935287475649 .981861114551 .46009063721 53.0335998535254 .6932601928756 .440429687558 .2546386718860 .12860107422 62.0338592529363 .9483718872165 .8430023193467 .6913070678769 .46666717529 71.136863708572 .7126922607474 .1769866943475 .5508728027376 .83717346191 78.0570068359479 .2436828613380 .3996200561581 .5422134399482 .67027282715 83.788223266684 .8949737548885 .9894790649487 .071990966888 .14084625244 89.19718170166 90.2401962280391.2710266113392.2895736694393.29654693604 94.2920227050895 .2764282226696 .2498016357497 .2124328613398 .1643371582 99.10582733154100 .0370025635100 .9582977295101 .8699035645102 .7722015381 103.6656036377104 .5504989624105 .4275970459106 .297203064107 .1598968506 108.0162963867108 .866897583109 .7121963501110 .5528030396111 .3890991211 112.2218017578113 .0512008667113 .8777008057114 .7016983032115 .5235977173 116.3436965942117 .1622009277117 .9794998169118 .7957000732119 .611000061 120.4255981445121 .2395019531122 .0529022217122 .8658981323123 .6783981323 124.4905014038125 .3022003174126 .1134033203126 .9243011475127 .7345962524 128.5442047119129 .3531951904130 .1614074707130 .9685974121131 .7747039795 132.5796051025133 .3829040527134 .1846923828134 .9846038818135 .7825012207 136.5782012939137 .3715057373138 .162399292138 .950302124139 .7359008789 140.5180969238 559.9038696289557 .1309814453554 .5217895508552 .1185302734549 .8192138672 547.6298828125545 .5405273438543 .5413208008541 .6193237305539 .7617797852 537.9525756836536 .1765136719534 .4146728516532 .6491699219530 .8587036133 529.0228271484527 .1173095703525 .1198120117523 .0031738281520 .7426147461 518.30859375515 .6743164062512 .8088989258509 .6836853027506 .2677001953 502.5313110352498 .4454040527493 .9809875488489 .1151123047483 .8228149414 478.0840148926471 .8710021973465 .200592041458 .0701904297450 .5215148926 442.5758972168434 .287689209425 .687286377416 .8734130859407 .9067077637 398.9106140137389 .9625854492381 .2340087891372 .8338012695365 .0069885254 357.8576049805351 .8382873535347 .3020935059344 .366607666343 .575592041 342.6073913574339 .7362976074333 .9975891113323 .6401977539311 .6445922852 300.5488891602290 .1065979004281 .1713867188271 .9695129395260 .7142944336 250.8603057861245 .7888031006242 .7973937988239 .8802032471235 .4989929199 228.0426940918220 .4270019531215 .3592987061210 .5131072998203 .7510986328 196.0836029053187 .8937988281180 .31199646174 .2299041748168 .5014038086 162.2250976562156 .3997955322152 .1743011475147 .0223999023137 .7059020996 128.8117980957123 .4116973877118 .7914962769113 .9521026611108 .7117996216 104.2089004517100 .36049652197 .1716995239394 .0624008178789 .86917877197 84.8113327026479 .065147399974 .0796508789169 .5915679931622 .48987960815 25.340679168727 .6208992004429 .3589706420930 .7668590545731 .7306804657 32.2466812133832 .2627906799331 .9316291809131 .3025398254430 .82913017273 31.0258903503431 .5108890533432 .0704917907732 .606719970732 .97584915161 33.2987518310533 .6539382934634 .0977096557634 .6976509094235 .56185913086 36.7227096557638 .2538795471240 .1447601318442 .1067390441944 .13756942749 45.9691390991247 .3427886962948 .7448310852150 .4456787109452 .26919937134 54.1735801696856 .1664009094258 .2795600891160 .4964408874562 .81996917725 65.2010498046967 .6110382080169 .9895935058672 .2862319946374 .45571136475 
76.4489822387778 .2295989990279 .7465667724681 .0076293945381 .92816925049 83.1404266357485 .2623672485487 .522186279389 .1815567016691 .11338043213 93.8899993896597 .09546661377100 .2301025391102 .8917999268104 .8616027832 106.1968002319107 .0469970703107 .7469024658108 .6318969727109 .603302002 110.6579971313111 .7449035645112 .8193969727113 .8538970947114 .7947006226 115.6309967041116 .3363037109116 .9192962646117 .3522033691117 .7313995361 118.1204986572118 .4601974487118 .6891021729118 .8068008423118 .837600708 118.7276992798118 .4872970581118 .0570983887117 .4104003906116 .5824966431 115.4934005737114 .4646987915113 .4980010986113 .5177001953114 .9772033691 117.0897979736120 .0925979614122 .1748962402122 .4228973389122 .3199996948 122.720703125123 .4825973511123 .9534988403124 .4617996216124 .8097000122 125.1464004517126 .6036987305128 .5258026123130 .6981964111132 .0260925293 130.7512969971128 .7041931152127 .8498001099127 .4950027466127 .1804962158 126.8672027588126 .4220962524125 .9669036865125 .5173034668124 .9914016724 124.2565994263123 .3626022339122 .4228973389120 .3960037231119 .7863998413 119.7863998413119 .6706008911119 .774597168120 .5634994507125 .1399002075 137.511505127150 .0823059082155 .6369018555157 .971206665159 .1080932617 155.5491943359145 .5500030518133 .7816925049125 .9311981201120 .7444000244 116.9934997559114 .3559036255112 .0854034424109 .43489837655557596061 .5 63.332588195867 .8779373168972 .4755935668977 .6071014404383 .00009918213 88.2063217163193.1378936767697.56301116943101.3917007446104.18409729 106.5647964478108 .6549987793110 .5008010864112 .5958023071114 .34400177 115.8015975952116 .9915008545117 .2990036011116 .3673019409114 .8874969482 105.924797058182 .8515472412158 .6210212707545 .4146118164136 .4799118042 26.56146049518 .3088607788113 .5273704528810 .580900192267 .722758769989 5.2933149337773 .2181229591371 .634312033653 .5603719949722 5.18589988e-02 .36112201213841 .3340859413152 .9018371105194 .9469709396367 .3092918396 9.92157554626512 .6278800964415 .3861503601118 .1141490936320 .7175693512 23.1299095153825 .3295307159427 .2508792877228 .9347400665330 .37663078308 31.6129093170232 .7184791564933 .7148704528834 .6254501342835 .4899597168 36.3464698791537 .1953010559138 .0470008850138 .9113197326739 .80644989014 40.7374000549341 .7171287536642 .7497787475643 .8427886962945 .00246810913 46.2337493896547 .5438919067448 .9379005432150 .418109893851 .98883056641 53.6423301696855 .3777694702157 .1778106689559 .0330810546960 .91764068604 62.8110885620164 .6838607788166 .5059127807668 .2606887817469 .92027282715 71.4933395385772 .9659118652374 .3552017211975 .6660995483476 .91562652588 78.1273117065479 .3062362670980 .4675903320381 .6110076904382 .74160003662 83.85806274414 84.96048736572 86.04859161377 87.1216888427788.18035888672 89.2245635986390.2549819946391.2721023559692.276367187593.26828765869 94.2481231689595 .2162628173896 .1728897094797 .1182708740298 .05267333984 98.9763565063599 .88970184326100 .7929992676101 .6867980957102 .5714035034 103.447303772104 .3151016235105 .1753997803106 .0286026001106 .8752975464 107.7162017822108 .5518035889109 .382598877110 .2090988159111 .0319976807 111.851600647112 .6684036255113 .4826965332114 .2950973511115 .1056976318 115.9149017334116 .7229995728117 .5300979614118 .3364028931119 .1420974731 119.947303772120 .7521972656121 .556602478122 .3609008789123 .1648025513 
123.96849823124 .7717971802125 .5748977661126 .3775024414127 .1797027588 127.981300354128 .7821044922129 .5821075439130 .3809967041131 .1788024902 131.9750976562132 .7698059082133 .5628051758134 .3536987305135 .1425018311 135.9288024902136 .7127075195137 .4940032959138 .2700958252139 .0446014404 564.7626953125561 .9439086914559 .1975708008556 .5979003906554 .1096801758 551.7244873047549 .4312744141547 .2194824219545 .0744018555542 .9830932617 540.9276123047538 .8925170898536 .8568115234534 .8034057617532 .7078857422 530.551574707528 .3071899414525 .954284668523 .4628295898520 .8107299805 517.9653930664514 .9039916992511 .5924072266508 .0068969727504 .1140136719 499.8895874023495 .303314209490 .3320007324484 .9520874023479 .1431884766 472.8922119141466 .182800293459 .0263061523451 .412109375443 .4010009766 435.0213928223426 .3385009766417 .374786377408 .2475891113398 .9920959473 389.7844848633380 .6657104492371 .8815002441363 .5108947754355 .7955932617 348.62109375342 .7692871094338 .2633056641335 .3023986816334 .8948059082 334.0538024902329 .4831848145322 .9097900391315 .9274902344307 .504486084 297.5419006348288 .4099121094282 .9739990234277 .2394104004267 .1293029785 256.9400939941250 .4777069092245 .5052032471241 .3121948242237 .5424041748 233.9190063477229 .6891021729223 .6076965332217 .2904052734212 .554901123 206.6930999756196 .6808929443186 .0771942139177 .536895752170 .5130004883 164.8522033691160 .5220947266157 .5433044434153 .7236022949145 .4710998535 137.3103027344 132.6967010498128.9485931396125.2384033203120.9826965332 116.1644973755111 .6787033081108 .3544006348105 .2276000977101 .7927017212 97.9372863769592 .5151214599687 .2843933105585 .3056488037122 .59671020508 24.1420803070125 .5143795013427 .2137203216628 .7924194335929 .98443031311 30.7435703277630 .8943004608230 .5460300445629 .6549396514928 .85627937317 29.0256195068429 .5331096649230 .0388202667230 .479009628330 .65357017517 30.7359199523930 .8534793853831 .064029693631 .4523792266832 .14416885376 33.2339096069334 .7510910034236 .5924110412638 .9176406860441 .86742019653 44.5758018493746 .2827606201247 .6411590576249 .5274314880451 .55141067505 53.50349044855 .5132713317957 .5515289306659 .6303596496661 .76216888428 63.9118881225666 .0768814086968 .1981964111370 .2399291992272 .16153717041 73.9422912597775 .5079727172976 .8033370971777 .8282928466878 .30795288086 79.1830902099681 .4873962402384 .1685867309686 .3290023803788 .55461120605 90.9427871704193 .4281387329195 .8570175170998 .15744781494100 .3850021362 102.3501968384104 .0093994141105 .4301986694106 .7725982666108 .0442962646 109.3227005005110 .5362014771111 .6641998291112 .7059020996113 .6622009277 114.5380020142115 .3037033081115 .9857025146116 .5627975464117 .0776977539 117.521697998117 .8981018066118 .1911010742118 .3856964111118 .5027999878 118.4945983887118 .3836975098118 .1427001953117 .75117 .3057022095116 .7415008545 116.3237991333115 .945098877116 .1783981323117 .3590011597118 .8550033569 120.8091964722122 .1207962036122 .3411026001122 .1965026855122 .165802002 122.1128997803121 .5380020142121 .0154037476119 .9292984009119 .8852996826 122.4746017456125 .0901031494126 .9960021973127 .7429962158126 .9542007446 126.1977005005126 .435798645126 .9604034424127 .0602035522126 .9365005493 126.5059967041126 .0206985474125 .7451019287125 .4142990112124 .7910003662 123.9849014282122 .9928970337121 .3104019165120 .7007980347120 .7007980347 
121.2947998047120 .7326965332118 .8701019287119 .9683990479129 .5762023926 140.4384002686145 .8809967041148 .9624023438150 .112197876148 .5478973389 144.5341033936138 .1788024902131 .4140014648125 .1175994873120 .7892990112 117.8227996826114 .6587982178111 .41040039064244464850525660 .46889877319 66.2550430297971 .7338485717876 .821563720781 .3806076049885 .2928237915 88.4785919189590 .5836181640692 .2353286743293 .443496704195 .85159301758 100.7593994141106 .7947998047112 .8799972534117 .4264984131119 .5544967651 118.3728027344113 .9718017578105 .107101440491 .764236450276 .75715637207 63.4389381408750 .92465972937 .4634399414126 .1216106414819 .75036048889 15.8292703628511 .538499832158 .0780563354494 .9832248687742 .435338973999 $.6828420162201-0.3923420012-.397336006165 .36808800697331 .802487015724$ 3.753402948386 .0017628669748 .48237800598111 .0314502716113 .60958003998 16.1764202117918 .6348094940220 .9818305969223 .1617698669425 .18419075012 27.0105590820328 .6328105926530 .0600204467831 .3285903930732 .45600128174 33.4483413696334 .3629684448235 .2488594055236 .1088485717836 .96152877808 37.8207511901938 .7153091430739 .6455688476640 .6282501220741 .66469955444 42.7627105712943 .9280815124545 .1634712219246 .4773292541547 .87073135376 49.3478088378950 .9097518920952 .5512619018654 .2714614868256 .05366897583 57.8910598754959 .7564697265661 .6357307434163 .492889404365 .3000869751 67.0447006225668 .6996536254970 .2734680175871 .7499313354573 .14848327637 74.4794082641675 .7548294067476 .9921493530378 .1957473754979 .37899017334 80.5412216186581 .6874771118282 .8168334960983 .9293594360485 .02543640137 86.1041564941487 .1667785644588 .2129516601689 .2439727783290 .26006317139 91.2621612548892 .2506637573293 .2261962890694 .1891174316495 .13981628418 96.0786590576297 .0059661865297 .922149658298 .827568054299 .72264862061 100.6078033447101 .4837036133102 .3506011963103 .209197998104 .0600967407 104.9038009644105 .7409973145106 .572303772107 .3981018066108 .2192001343 109.0361022949109 .8491973877110 .6591033936111 .4663009644112 .2711029053 113.0738983154113 .8751983643114 .6751022339115 .4738998413116 .2720031738 117.0693969727117 .8663024902118 .662902832119 .459197998120 .2553024292 121.0513000488121 .8471984863122 .6428985596123 .4384002686124 .2337036133 125.0288009644125 .8234024048126 .6175994873127 .4112014771128 .2039031982 128.9956970215129 .7864074707130 .5756988525131 .363494873132 .1495056152 132.9335021973133 .7153015137134 .4947967529135 .2718048096136 .0458068848 136.8173980713137 .5854949951

569.5477294922566 .4343261719563 .4724121094560 .7036743164558 .0286865234 555.450012207552 .9553833008550 .533203125548 .1682739258545 .8463134766 543.5490112305541 .2592163086538 .9564819336536 .6212768555534 .2305908203 531.7626953125529 .1926269531526 .4965820312523 .6475830078520 .6206054688 517.3867797852513 .9196777344510 .1903991699506 .1719055176501 .8363952637 497.1575012207492 .1106872559486 .6716918945480 .8222045898474 .541809082 467.824005127460 .6543884277453 .0439147949444 .9854125977436 .5437011719 427.7679138184418 .7073059082409 .3935852051399 .9280090332390 .3702087402 380.8728942871371 .516204834362 .5038146973353 .9269104004345 .903503418 338.4648132324332 .4757080078328 .3351135254325 .3472900391323 .2897033691 321.1416015625317 .9501037598313 .5143127441306 .8758850098298 .7856140137 
290.2695922852282 .8753051758278 .4028015137273 .7471923828265 .7027893066 256.8641052246250 .5467071533245 .0350036621239 .7247009277236 .3542938232 236.120803833234 .9158935547228 .8497924805221 .9268035889218 .2236938477 213.1172027588201 .9886016846189 .3520965576179 .8589935303172 .5563964844 167.0742950439163 .1678924561160 .4555969238156 .783706665149 .5108032227 141.9700012207137 .1764984131133 .4342041016130 .1127929688126 .7012023926 122.9057006836119 .5548019409117 .7734985352115 .3585968018109 .8785018921 103.873596191499 .9080963134897 .5646667480595 .2756271362322 .97150039673 23.6955699920724 .3033695220925 .8695907592827 .1933708190928 .47520065308 29.6748104095530 .5402202606230 .2128391265929 .2221508026128 .13097000122 27.8459091186527 .9291191101128 .1342296600328 .3361892700228 .39011001587 28.3921108245828 .4109706878728 .51387977628 .7630290985129 .23903083801 29.9707508087231 .0614795684832 .4587707519534 .8730697631839 .02349853516 43.0346412658745 .2184104919446 .683029174848 .5065994262750 .50473022461 52.5514907836954 .6305503845256 .6662216186558 .6671791076760 .66448974609 62.640201568664 .6058273315466 .523719787668 .3811035156270 .13954925537 71.7671508789173 .2192535400474 .4606933593875 .4922332763776 .24324035645 77.3304061889679 .3434066772581 .7305831909283 .9084930419985 .99900054932 88.0512695312589 .920486450291 .491622924893 .3093719482495 .85122680664 98.54483032227100 .7757034302102 .7194976807104 .4793014526106 .0897979736 107.681602478109 .116897583110 .2921981812111 .3240966797112 .320602417 113.2565994263114 .116897583114 .9054031372115 .605796814116 .220703125 116.7421035767117 .1731033325117 .5154037476117 .7802963257117 .9789962769 118.0892028809118 .1140975952118 .0634994507117 .9401016235117 .8255004883 117.7211990356117 .6866989136117 .6615982056117 .8613967896118 .5187988281 119.4328994751120 .8488998413122 .0727996826122 .4632034302122 .452003479 122.28099823121 .1528015137118 .0942001343114 .7518005371111 .4803009033 111.0361022949116 .8654022217122 .5215988159123 .4953994751122 .9590988159 123.0699996948123 .9761962891125 .1756973267126 .2049026489126 .7113037109 126.792098999126 .5579986572126 .2065963745125 .9449996948125 .6207962036 125.0708999634124 .3702011108123 .5626983643122 .9032974243122 .6695022583 122.2248001099122 .2838973999121 .5206985474119 .7174987793119 .3742980957 123.5655975342129 .1136932373132 .6381072998134 .9337005615135 .1811065674 135.3766937256136 .908493042136 .5191955566132 .6900024414127 .3870010376 123.5370025635120 .6668014526116 .971298217811340504844 .84904098511 37.072830200239 .266880035443 .9655189514250 .1583900451755 .78099060059 60.9727706909265 .7817535400469 .984649658273 .4123077392675 .94925689697 77.2521896362377 .6976165771576 .9469680786178 .66684722985 .87983703613 96.0223236084107 .5658035278116 .4365997314118 .8328018188116 .9047012329 112.8283004761107 .054298400999 .3651275634889 .839988708578 .77778625488 65.9786071777352 .7012100219740 .7160797119131 .1259193420423 .70903015137 18.0843105316213 .610739707959 .0553817749025 .101074218752 .356684923172 $.5773950219154-4.8190001 \mathrm{e}-03.42003598809241 .6316670179373 .415833950043$ 5.4365849494937 .6651878356939 .92937183380112 .2278299331714 .51865959167 16.7710399627718 .9859695434621 .1296901702923 .1960792541525 .1408290863 26.9175205230728 .527280807529 .9560394287131 .2173805236832 .29333114624 
33.2522697448734 .1506309509335 .0037193298335 .8500900268636 .70291900635 37.5933799743738 .5245704650939 .5126495361340 .5569915771541 .66262054443 42.8340911865244 .074779510545 .3897705078146 .7806396484448 .24988937378 49.7994804382351 .425228118953 .1259307861354 .8892707824756 .7082901001 58.5605392456160 .4301986694362 .2812385559164 .084960937565 .82834625244 67.4793701171969 .0504913330170 .5316314697371 .9381103515673 .28569030762 74.5841369628975 .845840454177 .0748519897578 .2809906005979 .46421813965 80.6284179687581 .7728195190482 .8978118896584 .0035171508885 .0896987915 86.1572799682687 .206611633388 .2387237548889 .2544326782290 .25453948975 91.2399215698292 .2111282348693 .1688919067494 .1136016845795 .04585266113 95.9660110473696 .8746032714897 .7720336914198 .6588134765699 .53540039062 100.4023971558101 .2602996826102 .1098022461102 .9513015747103 .7855987549 104.6132965088105 .4348983765106 .2510986328107 .0625991821107 .8697967529 108.6733016968109 .4735031128110 .2712020874111 .0664978027111 .8599014282 112.651802063113 .4425964355114 .2322998047115 .0214004517115 .8099975586 116.598197937117 .3861999512118 .1741027832118 .9618988037119 .7497024536 120.5374984741121 .325302124122 .1130981445122 .9008026123123 .6883010864 124.4755020142125 .262298584126 .0485992432126 .834197998127 .6190032959 128.4026031494129 .1849975586129 .9658050537130 .7449035645131 .5220031738 132.2969970703133 .0695037842133 .8395996094134 .6069946289135 .3690948486 136.1293945312

573.6641235352570 .5042724609567 .408996582564 .4506225586561 .5919189453 558.8225708008556 .1295776367553 .5009765625550 .919921875548 .3720703125 545.8377075195543 .3001098633540 .7366943359538 .1290893555535 .4517822266 532.6851196289529 .8010864258526 .7788696289523 .5883789062520 .2081298828 516.6060791016512 .7603149414508 .6390991211504 .2203063965499 .4739074707 494.37890625488 .9092102051483 .0461120605476 .7702941895470 .0667114258 462.9278869629455 .3432922363447 .3258056641438 .8674926758430 .0425109863 420.9064025879411 .5051879883401 .8612060547392 .0802001953382 .2095031738 372.4000854492362 .6978149414353 .3392944336344 .2676086426335 .9281005859 328.1041870117321 .3734130859316 .4507141113312 .4331970215308 .0824890137 304.2926940918302 .1408996582298 .4653930664291 .6455993652284 .0867919922 277.2838134766 271.7388000488 267.3102111816 262.3601989746 255.7481994629 248.7660064697243 .5010070801238 .9739074707233 .9309997559230 .9866027832 233.1354980469234 .487197876229 .2476043701222 .5729980469219 .5682983398 214.6750030518202 .7832946777189 .8063049316180 .6300048828173 .6972961426 168.2902069092164 .178604126160 .7250061035156 .6219940186149 .8883056641 142.9544067383137 .7104034424133 .5314941406130 .3946990967127 .7142028809 125.1684036255123 .0684967041122 .6985015869120 .8783035278113 .2483978271 105.0365982056100 .09230041597 .1388702392695 .3640518188524 .64492034912 24.147460937524 .4375190734925 .1685695648226 .084749221827 .02750968933 27.8746109008828 .4847602844228 .8045406341629 .0456295013427 .71806907654 26.9760398864726 .5309906005926 .3520908355726 .2972698211726 .25707054138 26.2397708892826 .2371692657526 .2984695434626 .4631595611626 .76593971252 27.13781929016 27.842699050928.78339958191 30.8765602111835.51568984985 40.3460617065442 .9900207519544 .943920135547 .1314697265649 .21049118042 
51.4185600280853 .5813217163155 .6130714416557 .5888595581159 .49237823486 61.3375587463463 .1595306396564 .9337081909266 .6636886596768 .3180770874 69.8518600463971 .2633514404372 .5535964965873 .7831192016675 .04122161865 76.4673461914178 .1449737548880 .0246429443481 .9282531738383 .75827026367 85.4026870727586 .8050003051887 .7219924926889 .0550079345791 .7942199707 94.8973693847797 .4410018920999 .73828125101 .8447036743103 .7574005127 105.6577987671107 .320098877108 .591003418109 .6720962524110 .7602996826 111.7902984619112 .7633972168113 .6699981689114 .478302002115 .1871032715 115.7750015259116 .2608032227116 .6427993774116 .9604034424117 .2386016846 117.4609985352117 .6508026123117 .8212966919117 .9742965698118 .1744003296 118.4115982056118 .646697998118 .756401062118 .8449020386118 .9929962158 119.3655014038120 .5736999512121 .8087005615122 .5453033447122 .7199020386 122.4975967407120 .5402984619115 .4164962769109 .0703964233102 .9534988403 100.7796020508107 .9045028687116 .8012008667118 .2080993652118 .1691970825 120.37550354122 .5727996826124 .2957000732125 .4933013916126 .204498291 126.4571990967126 .4721984863126 .2757034302126 .0022964478125 .6182022095 125.0979995728124 .5170974731123 .9509963989123 .449798584123 .1000976562 122.7846984863122 .6210021973122 .1679992676121 .4002990723120 .5995025635 119.9744033813120 .0352020264120 .9966964722121 .9833984375120 .9984970093 120.9987030029125 .4368972778129 .8634033203130 .1625976562128 .5807037354 126.8547973633123 .71289825441201174045343233 .290180206334 .00447845459 37.1121902465841 .6400489807146 .3141098022550 .9878311157255 .47011184692 59.3735504150462 .4156990051364 .3914108276465 .0155868530364 .71533966064 62.4690208435162 .9679985046470 .730743408282 .6667022705197 .52481079102 109.8999023438112 .8529968262111 .3716964722110 .0418014526107 .5718994141 104.726997375599 .7979583740291 .5767669677781 .0887832641670 .19132232666 58.918949127246 .7005691528335 .8777618408228 .4256191253722 .31933021545 15.354189872749 .5245618820195 .5099458694462 .9945778846741 .916458964348 1.8344269990922 .6958279609684 .1891498565675 .8089299201977 .601035118103 9.40874099731411 .2430801391613 .1438398361215 .0617198944117 .10511016846 19.1525993347221 .2646007537823 .3053493499825 .2430591583327 .03928947449 28.6235599517830 .0207691192631 .1655597686832 .150249481233 .04653167725 33.87714004517 34.71203994751 35.55366134644 36.44276046753 37.37683105469 38.3756790161139 .4339408874540 .5530700683641 .7372894287142 .98448944092 44.3018417358445 .6857604980547 .1439208984448 .674671173150 .27853012085 51.9539909362853 .6922302246155 .4892997741757 .324359893859 .1856803894 61.0392913818462 .8590507507364 .6100387573266 .2586135864367 .8203125 69.3011779785270 .719451904372 .0847167968873 .4064331054774 .69317626953 75.9486923217877 .1794662475678 .3857727050879 .5698013305780 .73140716553 81.8702926635782 .9872131347784 .0816726684685 .1551666259886 .20794677734 87.24156951904 88.25686645508 89.25504302979 90.23710632324 91.20388793945 92.1562728881893 .0948028564594 .0202484130994 .9330520629995 .83389282227 96.7231826782297 .6015396118298 .469451904399 .32758331299100 .176399231 101.0167007446101 .8488998413102 .6737976074103 .491897583104 .3040008545 105.1106033325105 .9124984741106 .7100982666107 .5039978027108 .2947998047 109.082901001109 .8687973022110 .6529998779111 .4356994629112 .217300415 
112.9981002808113 .7782974243114 .5580978394115 .3376998901116 .1172027588 116.896697998117 .6763000488118 .4561004639119 .2359008789120 .0158996582 120.7958984375121 .5759963989122 .3561019897123 .1359024048123 .9154968262 124.6946029663125 .4730987549126 .2508010864127 .0274963379127 .8029022217 128.5767974854129 .349105835130 .1194000244130 .8874969482131 .6531982422 132.4163970947133 .1766052246133 .9342041016134 .688293457

577.7103271484574 .2716064453570 .9713134766567 .8499145508564 .811706543 561.8560791016558 .9697265625556 .1390991211553 .3477783203550 .5797729492 547.8159179688545 .0377197266542 .2235717773539 .3530273438536 .4024047852 533.3491821289530 .1682739258526 .8358764648523 .3253173828519 .6118164062 515.6682128906511 .4689025879506 .987487793502 .199005127497 .0787963867 491.6036987305485 .753112793479 .5068969727472 .8507080078465 .7694091797 458.2579956055450 .3085021973441 .9328918457433 .128112793423 .9648132324 414.5047912598404 .7843017578394 .8406982422384 .7432861328374 .5491943359 364.3367004395354 .1530151367344 .1659851074334 .4154052734325 .4605102539 317.6557922363309 .916595459300 .8028869629292 .5440063477287 .9125061035 284.2421875277 .7189941406269 .7774963379263 .5173950195258 .2125854492 254.1224975586251 .0527954102246 .6320037842240 .7832946777234 .0252075195 227.8282012939224 .095993042221 .6741943359220 .0897979736220 .0507965088 221.9216003418223 .0688934326221 .3014068604217 .7583007812213 .7469940186 207.4515075684196 .8067932129185 .6439056396177 .5791931152171 .3385925293 166.5303955078162 .1611022949157 .1945037842151 .7057952881145 .3583068848 139.1464996338134 .0762939453130 .0478057861127 .2500991821125 .0080032349 122.393699646119 .9708023071118 .5636978149115 .6264038086108 .7742004395 100.867698669494 .9985885620190 .9267272949287 .0119018554725 .56007957458 24.5196304321324 .2614002227824 .481100082424 .9976406097425 .62627983093 26.2661495208726 .8488197326727 .433170318628 .2571392059326 .88320922852 25.9145298004225 .1950607299824 .7683200836224 .5425796508824 .39558029175 24.3313102722224 .2955799102824 .316829681424 .4269790649424 .63018989563 24.9471702575725 .5141105651926 .3825397491528 .0801792144831 .10288047791 34.7484397888238 .2641296386741 .6323089599644 .8870506286647 .75796890259 50.1585617065452 .3305587768654 .3990287780856 .3709411621158 .22225952148 59.9767990112361 .7209510803263 .4223518371665 .0840682983466 .69915771484 68.2270126342869 .6875534057671 .0963516235472 .5377273559674 .07350921631 75.6270217895577 .2345733642678 .8624801635780 .4986801147582 .05638122559 83.3569412231484 .447402954185 .331329345786 .6445312589 .00096893311 91.7719116210994 .330360412696 .7626266479599 .03811645508101 .160697937 103.1677017212104 .9481964111106 .4175033569107 .7036972046108 .9354019165 110.0966033936111 .2052993774112 .235496521113 .1592025757113 .9583969116 114.6063995361115 .1337966919115 .5604019165115 .9347991943116 .2732009888 116.5911026001116 .9502029419117 .3335037231117 .7457962036118 .201499939 118.6555023193119 .0594024658119 .3538970947119 .5486984253119 .7259979248 120.0698013306120 .891998291121 .8415985107122 .5493011475122 .6934967041 122.1789016724119 .7189025879114 .3735961914106 .355003356995 .53357696533 88.5019836425891 .530830383399 .40589904785107 .2636032104114 .282699585 119.00340271122 .1382980347124 .1220016479125 .1945037842125 .8519973755 
126.1358032227126 .2142028809126 .0876998901125 .8396987915125 .4632034302 124.9681015015124 .4679031372124 .0015029907123 .5766983032123 .2944030762 123.0835037231122 .987197876122 .9458999634122 .8649978638121 .9674987793 120.1470031738118 .2660980225117 .2929992676116 .6697006226114 .8490982056 113.5436019897113 .266998291115 .8823013306123 .7914962769130 .6797027588 131.1125030518127 .1763000488117110109403530 .7500801086429 .47381973267 29.6859893798831 .8643493652335 .1896095275938 .6221504211442 .40528106689 46.5250396728550 .2903099060153 .0244293212954 .6818809509355 .03691101074 54.482700347952 .8628311157252 .98744964657 .129741668765 .76516723633 80.0411987304793 .4656219482499 .40798187256101 .8928985596104 .1929016113 105.8498001099107 .3333969116106 .8163986206102 .884696960496 .32920837402 87.8123931884877 .5214767456165 .8034133911154 .0595893859944 .06789016724 34.5851707458523 .9784107208315 .0652599334710 .024530410777 .196348190308 5.5869441032414 .9416542053225 .2293171882636 .2268490791327 .27344083786 8.4343214035039 .57721233367910 .7835597991912 .1132297515913 .59998989105 15.352580070517 .2784404754619 .4002208709721 .5558605194123 .6432094574 25.61992073059 27.3617992401128.88076972961 30.07716941833 31.06406974792 31.9446506500232 .7487297058133 .5568618774434 .3827285766635 .26770019531 36.2083511352537 .2182998657238 .2933006286639 .4351997375540 .63930130005 41.8974990844743 .2159690856944 .5933609008846 .035720825247 .54356002808 49.118858337450 .7631912231452 .4707298278854 .2383804321356 .05263900757 57.9024009704659 .7660903930761 .6320381164663 .4201202392665 .04445648193 66.5732498168968 .0546798706169 .4885406494170 .8764572143672 .22441101074 73.5389404296974 .8223266601676 .0794830322377 .3101425170978 .51566314697 79.6956634521580 .8498382568481 .9787368774483 .0823898315484 .16210174561 85.21874237061 86.25379943848 87.268699646 88.26467132568 89.24320983887 90.2051925659291 .1518936157292 .08392333398493 .0022735595793 .90746307373 94.8002777099695 .681221008396 .5509796142697 .4100723266698 .25919342041 99.0988769531299 .92986297607100 .7527008057101 .5681991577102 .3768005371 103.179397583103 .9765014648104 .7687988281105 .5568008423106 .3413009644 107.1227035522107 .9013977051108 .6780014038109 .4530029297110 .2265014648 110.9991989136111 .7710037231112 .5425033569113 .3135986328114 .0847015381 114.855796814115 .6270980835116 .3985977173117 .1703033447117 .9422988892 118.7145004272119 .4869995117120 .2595977783121 .0322036743121 .8047027588 122.5771026611123 .3490982056124 .1205978394124 .8912963867125 .6610031128 126.4296035767127 .1967010498127 .962097168128 .7256011963129 .4868927002 130.245803833131 .0021972656131 .7559051514132 .5039978027133 .2503051758 581.1286010742577 .6450195312574 .2180175781570 .9174194336567 .7044067383 564.5676879883561 .4926757812558 .4661865234555 .4702758789552 .4896850586 549.5034179688546 .4942016602543 .4384765625540 .3173217773537 .1049194336 533.7811279297530 .3181762695526 .6956176758522 .883972168518 .862121582 514.6002807617510 .0775146484505 .2647094727500 .1416931152494 .6820068359 488.8673095703482 .6755065918476 .0914916992469 .0994873047461 .6893005371 453.8547058105445 .5918884277436 .9111938477427 .8117980957418 .3622131348 408.6231994629398 .6296081543388 .4242858887378 .0520935059367 .5676879883 357.003112793346 .3909912109335 .8193969727325 .4144897461315 .3500976562 
306.8096923828297 .3854980469283 .6849060059271 .1184082031266 .0822143555 260.4677124023246 .6212005615234 .3744049072230 .9750061035230 .93699646 229.5829925537226 .8988037109221 .4308013916214 .5234985352207 .5032043457 201.8329925537199 .8562927246200 .0357971191201 .8218994141204 .096206665 204.616897583205 .2424926758207 .078994751206 .9573974609202 .4454956055 195.116104126186 .5252075195177 .9342041016171 .3323974609165 .8609008789 161.4405975342156 .6546020508150 .1307983398143 .311706543137 .337097168 132.1157989502127 .4595031738123 .672203064121 .009803772118 .7379989624 115.6405029297112 .3399963379109 .2646026611105 .222503662199 .77764892578 93.2793884277385 .8561325073277 .8381500244127 .0675506591825 .29487991333 24.2205600738523 .7236194610623 .6463603973423 .860979080224 .25219917297 24.7410202026425 .2947692871125 .9294395446826 .6946296691925 .74641990662 24.6782302856423 .8306007385323 .2751903533922 .9449501037622 .7255897522 22.6198005676322 .5557994842522 .5587406158422 .6394691467322 .82859992981 23.1984596252423 .8060894012524 .7547092437726 .0388793945327 .2009601593 29.2282104492233 .1492004394537 .6847381591841 .9577713012745 .7677192688 48.6058197021550 .8927917480553 .0894393920955 .0458183288656 .82580947876 58.5358695983960 .2537193298361 .9668312072863 .6062011718865 .19933319092 66.7403106689568 .281806945869 .8526535034271 .478103637773 .23697662354 74.9440765380976 .5710601806678 .1078262329179 .4883728027380 .73166656494 81.6946029663182 .5803070068483 .6090011596784 .9617080688586 .80699157715 89.00576782227 91.3555221557693.7629928588996.1063766479598.3274230957 100.3770980835102 .236000061103 .9179000854105 .4410018921106 .8438034058 108.1567993164109 .4196014404110 .5776977539111 .6184005737112 .5113 .2186965942 113.8117980957114 .2883987427114 .6927032471115 .0581970215115 .4601974487 116.008102417116 .6537017822117 .318397522117 .9863967896118 .5654983521 119.0677032471119 .5195007324119 .8970031738120 .3275985718120 .7882003784 121.3406982422121 .8917007446122 .3929977417122 .3116989136121 .4697036743 118.8203964233113 .9928970337106 .716300964494 .2518920898483 .9672088623 82.4981231689587 .1239929199299 .2379989624112 .242401123118 .5314025879 122.0208969116124 .0357971191124 .8292007446125 .4366989136125 .6651000977 125.776802063125 .6976013184125 .4969024658125 .1649017334124 .7220001221 124.2341995239123 .7554016113123 .3827972412123 .2228012085123 .1940002441 123.2363967896123 .2741012573123 .6051025391123 .0972976685121 .3725967407 119.0861968994117 .0520019531115 .1261978149112 .646697998110 .0698013306 104.6169967651103 .8901977539117 .6211013794131 .5406951904133 .6085968018 129.7350006104121 .054397583118115373325 .2183704376225 .97884941101 26.0905609130927 .7150497436530 .10895919832 .5263595581135 .41104125977 39.1607017517142 .7215499877945 .1886711120646 .6851692199746 .99737167358 46.7303886413646 .299240112346 .5445594787646 .836360931450 .68072891235 61.998741149974 .4752883911182 .4865188598688 .9890975952195 .05795288086 100.7977981567106 .7145996094110 .6436004639111 .9944000244109 .6803970337 104.0590972995 .6429519653385 .5082931518674 .2391510009862 .35742950439 49.9955482482936 .130439758324 .1200008392317 .2082996368413 .37489032745 10.845069885259 .8409624099739 .6021509170539 .8002777099619 .981509208679 10.2179002761810 .438409805310 .7749700546311 .3766403198212 .25848960876 
13.6503801345815 .3667402267517 .5334205627419 .8276805877722 .12853050232 24.333290100126 .2101192474427 .818849563629 .0199298858629 .96075057983 30.8121490478531 .5801296234132 .3658294677733 .1806106567434 .069190979 35.0253791809136 .0576591491737 .160018920938 .3330802917539 .56703948975 40.840118408242 .1641693115243 .5326881408744 .9564590454146 .43183898926 47.9712295532249 .5745697021551 .2429809570352 .9727783203154 .75473022461 56.5857086181658 .4425811767660 .3438415527362 .1655883789163 .78147888184 65.2991867065466 .7976837158268 .2555236816469 .6694717407271 .04683685303 72.390342712473 .70395660474 .9883804321376 .2450637817477 .47263336182 78.6718368530379 .8414535522580 .9826431274482 .095283508383 .18109893799 84.2411727905385 .2773132324286 .2912826538187 .2845535278388 .25901031494 89.2156982421990 .1562271118291 .0812835693491 .9921417236392 .88932800293 93.773849487394 .6461486816495 .5070877075296 .3571624755997 .19714355469 98.0275573730598 .8492126464899 .66264343262100 .4686965942101 .2677993774 102.0608978271102 .8485031128103 .631401062104 .4100036621105 .1849975586 105.9570007324106 .7265014648107 .4938964844108 .259803772109 .0242996216 109.7880020142110 .5511016846111 .3139038086112 .076499939112 .8392028809 113.6020965576114 .365196228115 .1287002563115 .8925018311116 .6567001343 117.4213027954118 .1862030029118 .9514007568119 .7166976929120 .4820022583 121.2472991943122 .0121994019122 .7767028809123 .5404968262124 .3034973145 125.0652008057125 .8255004883126 .584197998127 .341003418128 .0955047607 128.8477020264129 .5973052979130 .3437957764131 .0877075195131 .8278961182 584.4812011719580 .7380981445577 .1201171875573 .6655883789570 .283996582 566.9719848633563 .7152099609560 .499206543557 .3068237305554 .1212158203 550.9224853516547 .6917114258544 .4069213867541 .0469970703537 .5883789062 534.0089111328530 .2836914062526 .3894042969522 .3004760742517 .9932250977 513.4420776367508 .6234130859503 .5130004883498 .0882873535492 .327911377 486.2114868164479 .7219848633472 .8431091309465 .5632019043457 .8714904785 449.7650146484441 .2409973145432 .3074951172422 .962890625413 .2757873535 403.3146972656393 .1037902832382 .686706543372 .0957946777361 .3919067383 350.5703125339 .6955871582328 .6535949707317 .4938049316305 .8511962891 293.7331848145280 .3015136719264 .6986083984250 .3775024414241 .4906005859 229.8092041016206 .0684051514188 .8852996826197 .5872039795210 .8509063721 207.8408966064 199.9230957031 194.2772064209188.0001068115 180.3690948486 175.0054931641175 .3762969971177 .9635925293179 .0872039795179 .7890930176 180.6248016357182 .738494873186 .6871948242188 .9219055176186 .2863006592 180.6378936768173 .7684020996167 .099899292161 .7064971924156 .7162017822 152.0832061768146 .550201416139 .2796020508132 .0561981201126 .5809020996 122.2582015991118 .2382965088114 .5407028198111 .1203994751107 .9627990723 104.9430007935101 .679801940997 .9933929443493 .7725524902388 .74516296387 82.7895965576275 .8881301879969 .1683502197325 .1915798187324 .206199646 23.356660842922 .816539764422 .5967903137222 .6322402954122 .85852050781 23.2268295288123 .7126693725624 .302600860624 .9475307464624 .30236053467 23.1798896789622 .2667102813721 .7052307128921 .3773097991921 .16984939575 21.0724601745621 .0266609191921 .0526905059821 .1559696197521 .37906074524 21.7682991027822 .3824195861823 .3207607269324 .3117408752425 .21808052063 
26.8619003295929 .8366909027133 .8629302978538 .473350524942 .89134979248 46.473911285449 .3740501403851 .7041091918953 .6207389831555 .26377105713 56.8660812377958 .6905517578160 .5310707092362 .1721382141163 .72257995605 65.2521820068466 .8426895141668 .5738830566470 .416152954172 .41645050049 74.330352783276 .0971298217877 .6548385620178 .824630737379 .75731658936 80.412246704181 .0333023071381 .9010009765683 .0322036743284 .58493804932 86.4377899169988 .5596771240290 .861190795993 .1631164550895 .39971923828 97.4800262451299 .42819976807101 .2275009155102 .9049987793104 .4550018311 105.9248962402107 .385597229108 .7240982056109 .8524017334110 .7956008911 111.6201019287112 .3173980713112 .8429031372113 .2531967163113 .5510025024 113.9533996582114 .7705993652115 .758102417116 .6859970093117 .5546035767 118.2829971313118 .9169998169119 .4882965088120 .0203018188120 .5662002563 121.0594024658121 .5350036621121 .9265975952122 .2384033203122 .1600036621 121.5001983643119 .5400009155115 .5752029419111 .0011978149106 .5843963623 102.37030029398 .8689498901499 .11815643311105 .9747009277114 .7931976318 119.8408966064122 .5310974121123 .9112014771124 .4683990479124 .8843994141 125.0942993164125 .1958007812125 .1612014771125 .0140991211124 .7457962036 124.3542022705123 .8532028198123 .2277984619122 .7882995605122 .8520965576 123.1065979004123 .2939987183123 .4477996826123 .6481018066123 .137802124 121.3184967041118 .7542037964116 .2423019409113 .7341003418111 .3004989624 108.6063995361104 .8139038086105 .6864013672117 .1349029541129 .146194458 132.4317016602129 .9582977295125122120343222 .3710994720523 .29593086243 22.9584598541323 .9536209106425 .7214603424127 .9664402008130 .74016952515 33.9951400756837 .1156997680739 .4093894958540 .8750686645541 .22444915771 41.1811904907241 .1111183166541 .0803489685141 .2898292541543 .66318893433 50.8959693908759 .8566398620666 .328536987373 .3004226684681 .86264038086 91.59217834473103 .1141967773113 .2332992554119 .6809997559121 .6836013794 118.6078033447112 .0584030151103 .516197204693 .0687866210981 .14946746826 67.8133087158253 .4777297973639 .9899711608928 .6203899383520 .65756034851 17.6695899963416 .9616909027116 .0627994537415 .210209846514 .14484024048 13.0961198806812 .0618896484411 .2768402099610 .9358100891111 .10344982147 11.9714603424113 .4466896057115 .6337604522718 .1296195983920 .71813964844 23.2150802612325 .2241992950426 .8730106353828 .0301799774228 .8729801178 29.6528205871630 .3743095397931 .1291694641131 .9398193359432 .84344100952 33.829101562534 .9007110595736 .044780731237 .2581787109438 .52667999268 39.8244781494141 .1568603515642 .5183296203643 .916988372845 .35129165649 46.8406105041548 .3972511291550 .0181884765651 .6994400024453 .43690872192 55.2302398681657 .0612983703658 .9279785156260 .73715972962 .40322875977 63.9852790832565 .522880554267 .0175170898468 .4668884277369 .87564086914 71.252098083572 .5971527099673 .9116134643675 .1950531005976 .44583892822 77.6641387939578 .8492507934680 .0021667480581 .1233520507882 .2145614624 83.27736663818 84.31378936768 85.32605743408 86.31585693359 87.28550720215 88.2362365722789 .16992187590 .087471008390 .9903030395591 .8790512085 92.7548217773493 .6181869506894 .470001220795 .3108367919996 .14147949219 96.9625015258897 .774696350198 .5786514282299 .37518310547100 .1649017334 100.9485015869101 .726600647102 .5000991821103 .2693023682104 .0350036621 
104.7977981567105 .5580978394106 .3163986206107 .0731964111107 .8289031982 108.5839004517109 .3383026123110 .0925979614110 .8468017578111 .6011962891 112.3559036255113 .111000061113 .8666000366114 .6225967407115 .3792037964 116.1362991333116 .893699646117 .6516036987118 .4096984863119 .1679000854 119.9261016846120 .68409729121 .4417037964122 .1986999512122 .9548034668 123.7098007202124 .4635009766125 .2154998779125 .9654998779126 .7134017944 127.4589004517128 .2017974854128 .9418029785129 .6761932373130 .408493042 587.2514038086583 .4669799805579 .731628418576 .1110229492572 .5667724609 569.0861816406565 .6541137695562 .2564086914558 .8748168945555 .4937133789 552.0914916992548 .6506958008545 .1478271484541 .5634765625537 .8726806641 534.0554199219530 .084777832525 .9409179688521 .5958862305517 .0297241211 512.2147827148507 .1317138672501 .7540893555496 .0640869141490 .0385131836 483.661895752476 .9154052734469 .7875976562462 .2652893066454 .3422851562 446.013885498437 .2821044922428 .1507873535418 .6181945801408 .7515869141 398.6260986328388 .2539978027377 .6845092773366 .9323120117356 .0846862793 345.0715026855334 .045501709322 .6268920898310 .9307861328297 .9666137695 282.8098144531266 .4408874512250 .5124969482235 .0231018066221 .803894043 205.9736938477175 .9976959229156 .5944061279176 .9846038818200 .12159729 192.7303924561178 .0317993164171 .1638031006165 .9642944336158 .6598052979 153.9850006104156 .1873016357159 .6053009033158 .836807251157 .6954956055 158.9275054932161 .0632019043164 .5590057373167 .1631011963166 .1690979004 163.113494873158 .4826965332153 .1428070068148 .4497070312143 .532699585 138.3016052246132 .5010986328125 .667098999119 .3248977661115 .0712966919 111.5999984741108 .1159973145104 .4785995483100 .226501464896 .05151367188 92.8959121704189 .7078094482485 .7305068969781 .449501037676 .77828216553 71.618583679265 .8446197509859 .8196983337423 .3479404449522 .69842910767 22.0780696868921 .6216297149721 .3695106506321 .3136291503921 .42960929871 21.6949806213422 .0945205688522 .6104106903123 .1812705993722 .60243034363 21.4917392730720 .6121902465820 .1199607849119 .8608303070119 .69420051575 19.6396503448519 .6349296569819 .7129497528119 .872909545920 .15306091309 20.5798091888421 .1781196594222 .0814990997323 .1132392883324 .29921913147 25.9420700073227 .8674297332830 .7749691009535 .0808601379439 .69358062744 43.9043807983447 .4523010253950 .0477714538652 .0449905395553 .72211837769 55.3210296630957 .2504501342859 .1632881164660 .7477111816462 .24647140503 63.725868225165 .3259735107467 .1436614990269 .1419906616271 .35476688457 73.5720062255975 .6909713745177 .3815078735478 .3539428710978 .88421630859 79.1849136352579 .5322570800880 .1500015258881 .0559234619182 .35278320312 83.9655914306685 .8845825195388 .0168075561590 .2144088745192 .42108154297 94.5182418823296 .5282211303798 .40709686279100 .1834030151101 .8308029175 103.4107971191105 .0142974854106 .4912033081107 .6901016235108 .7429962158 109.7620010376110 .5902023315111 .165802002111 .5585021973111 .8422012329 112.318397522113 .4247970581114 .7464981079115 .8648986816116 .8991012573 117.7459030151118 .4732971191119 .1572036743119 .789100647120 .4291000366 120.9757003784121 .4474029541121 .7667007446121 .9381027222121 .8336029053 121.4244995117120 .4360961914117 .8574981689116 .1265029907119 .7240982056 122.8077011108119 .4832992554116 .3046035767116 .8973007202118 .9453964233 
121.0618972778122 .7093963623123 .5378036499123 .8920974731124 .2001037598 124.3793029785124 .4766998291124 .476600647124 .3768997192124 .1651000977 123.8202972412123 .3656997681122 .6808013916122 .1760025024122 .417098999 122.8412017822123 .089302063123 .193901062123 .1604003906122 .4748001099 120.7077026367118 .2734985352115 .6782989502113 .1306991577110 .9176025391 109.5277023315109 .1768035889111 .8309020996119 .0210037231126 .6271972656 130.3217010498129 .166305542124121118 .5333121 .2000007629420 .992170333862222 .5 2324.3280696868927 .1817798614530 .1285190582332 .8768997192435 .0777015686 36.6146202087437 .1567001342837 .2420806884837 .1020584106437 .09783172607 38.0361900329640 .0639114379943 .7004814147948 .4759407043552 .27759933472 57.9117202758866 .7264099121178 .6154403686594 .13471221924109 .262802124 120.487197876127 .0139007568128 .141998291124 .6156005859118 .6113967896 109.571601867798 .5745773315485 .9872436523472 .5259323120158 .7935218811 43.5717201232931 .5744590759327 .5090198516826 .4008693695124 .21614074707 22.0417308807419 .5167102813716 .9714508056614 .4152297973612 .2777299881 10.8038396835310 .039170265210 .2824802398711 .3801803588913 .55762004852 16.3728504180919 .4284801483222 .2797508239724 .3977699279825 .91459083557 26.927589416527 .658689498928 .3840293884329 .1002101898229 .86149024963 30.6958007812531 .6220607757632 .649829864533 .7750282287634 .98212814331 36.2499008178737 .5598411560138 .8856315612840 .2320289611841 .58555984497 42.9609107971244 .3474197387745 .779571533247 .2718086242748 .8274307251 50.4403610229552 .1129684448253 .8540916442955 .6333389282257 .44602966309 59.2385101318460 .9791717529362 .6518783569364 .2479400634865 .78365325928 67.2710113525468 .7197189331170 .1328811645571 .5139007568472 .85871887207 74.1694412231475 .4420471191476 .6782836914177 .8773422241279 .04061126709 80.1689376831181 .264236450282 .3286132812583 .3641281127984 .37368011475 85.3590011596786 .3229904174887 .266876220788 .1930923461989 .10243988037 89.9967193603590 .8765182495191 .7431564331192 .5971679687593 .43958282471 94.2708892822395 .0920104980595 .9034500122196 .7061004638797 .50050354004 98.2874984741299 .0676727294999 .84184265137100 .6106033325101 .3747024536 102.1345977783102 .8910980225103 .6446990967104 .3960037231105 .1453018188 105.8933029175106 .640296936107 .3865966797108 .1324996948108 .87840271 109.6242980957 110.3705978394 111.1173019409 111.8645019531 112.6122970581 113.3607025146114 .109703064114 .8593978882115 .6094970703116 .3601989746 117.1111984253117 .8623962402118 .6136016846119 .3647994995120 .1156005859 120.8657989502121 .6153030396122 .3636016846123 .1107025146123 .8560028076 124.5995025635125 .3407974243126 .0795974731126 .8158035278127 .5488967896 128.2792053223129 .0057067871

589.9614868164585 .9395751953582 .0296020508578 .2672119141574 .5675048828 570.9254760742567 .326171875563 .754699707560 .1937255859556 .6259765625 553.0319213867549 .3922119141545 .6851806641541 .8903198242537 .984375 533.9459228516529 .7510986328525 .3776245117520 .8018188477516 .0009765625 510.9519958496505 .6332092285500 .0231933594494 .1017150879487 .8503112793 481.2520141602474 .2925109863466 .959197998459 .2431030273451 .1370849609 442.6398925781433 .7528991699424 .4812927246414 .8254089355404 .8482971191 394.6184082031384 .1543884277373 .5025024414362 .6856994629351 .7773132324 
340.7284851074329 .6069030762318 .1892089844306 .5445861816293 .8481140137 279.7992858887264 .7738952637249 .2884063721233 .6103057861218 .3943939209 202.0077972412179 .9526062012169 .0166015625186 .7012939453203 .4971008301 191.9073028564172 .3795013428160 .3226013184153 .0885009766149 .2274932861 147.9790039062148 .5751953125149 .4447021484148 .9963989258148 .3330993652 147.953704834146 .9622955322143 .9808044434141 .3780975342141 .0693969727 140.5612945557137 .3392944336132 .8300018311128 .4573974609123 .5383987427 117.6703033447112 .1824035645108 .4820022583105 .7805023193103 .5399017334 101.2723999023 98.3950805664194.8923568725690.72812652588 86.33609008789 82.0680313110477 .8575286865273 .5254669189569 .3156127929765 .31813812256 61.1999702453657 .5598297119153 .1174316406221 .5001602172921 .06130027771 20.6298294067420 .276790618920 .0445709228519 .9461097717319 .98002052307 20.1430892944320 .4344806671120 .8539791107221 .4017105102520 .64860916138 19.6945705413818 .9692001342818 .5592708587618 .3579597473118 .25853919983 18.2615203857418 .3294792175318 .481719970718 .7211208343519 .09057044983 19.6215305328420 .3243007659921 .2716007232722 .3906097412123 .68767929077 25.1959705352826 .8723602294929 .2803001403832 .8462905883837 .00503921509 41.2929115295445 .1483612060547 .9955787658750 .2958106994652 .42816162109 54.3844604492256 .1875610351657 .8421897888259 .3129005432160 .69593811035 62.0681991577163 .6011886596765 .4069137573267 .4789428710969 .88610839844 72.496650695875 .3640823364377 .5484466552778 .0275192260777 .81133270264 77.7252273559677 .80776214678 .2128829956178 .925506591880 .02498626709 81.4442291259883 .1863632202185 .1626892089887 .2764968872189 .44654846191 91.5443115234493 .5818634033295 .5028991699297 .321006774998 .99620819092 100.5976028442102 .1811981201103 .6656036377104 .9751968384106 .2490005493 107.6550979614108 .8044967651109 .3080978394109 .6029968262110 .1120986938 110.8925018311112 .1845016479113 .6573028564114 .908996582116 .0316009521 116.9488983154117 .7282028198118 .4800033569119 .2042999268119 .9449996948 120.5800018311121 .0434036255121 .3177032471121 .4169998169121 .2808990479 120.7492980957120 .2631988525119 .9365997314120 .2440032959121 .056602478 121.6977005005122 .4056015015122 .043296814121 .439201355121 .0800018311 121.5314025879122 .4571990967122 .9248962402123 .1706008911123 .3461990356 123.4653015137123 .6031036377123 .6704025269123 .5904006958123 .4136962891 123.1613998413122 .8565979004122 .4725036621122 .1822967529122 .2233963013 122.3794021606122 .5437011719122 .5693969727122 .3439025879121 .6177978516 120.0652999878118 .0258026123115 .7397994995113 .5597000122111 .7901992798 111.3003997803112 .4798965454115 .2822036743120 .7437973022126 .6593017578 131.6161956787131 .4391021729120 .01450347911811631 .53021 .57939910889 19.1920795440717 .167129516617 .3177700042718 .8645000457821 .01734924316 23.6878509521526 .8861408233629 .8709297180231 .949850082433 .46532058716 34.512271881135 .0013389587434 .6402511596734 .366210937535 .01499938965 35.9974403381337 .6692695617739 .7663688659741 .8323707580645 .57315063477 51.1618003845260 .8526496887276 .5270233154393 .70115661621108 .6072006226 120.4988021851129 .387802124133 .1941986084129 .9739990234122 .5059967041 113.5867004395102 .809600830190 .2861633300876 .5657806396561 .96192932129 49.5290412902842 .7202415466338 .5293693542534 .3595695495630 .3100605011 
26.0499000549321 .8147697448717 .4653205871613 .7055797576910 .94589042664 9.1378755569468 .4931411743169 .0484724044811 .1710996627814 .40985965729 18.3428592681921 .9124698638923 .8621997833324 .9401893615725 .68017959595 26.2557697296126 .9554405212427 .7190399169928 .5539093017629 .45648956299 30.4089794158931 .4682998657232 .6882400512733 .994560241735 .33135986328 36.6893806457538 .0480003356939 .4080085754440 .7573089599642 .10614013672 43.4504089355544 .8183212280346 .2237396240247 .682899475149 .20357894897 50.790878295952 .4602699279854 .1847915649455 .9615707397557 .76676940918 59.5795097351161 .3418693542562 .9814109802264 .5478134155366 .08070373535 67.5773010253969 .0366363525470 .4579620361371 .8364486694373 .17353057861 74.4673767089875 .7192764282276 .930252075278 .101707458579 .23513793945 80.3327178955181 .3968429565482 .4300384521583 .435401916584 .41510009766 85.37225341797 86.30844116211 87.22624206543 88.12670135498 89.01171112061 89.8820419311590 .7390213012791 .5833129882892 .4159011840893 .23742675781 94.0487365722794 .850448608495 .6433792114396 .4281311035297 .20554351807 97.9761962890698 .740928649999 .50028991699100 .2550964355101 .0057983398 101.7531967163102 .4977035522103 .2400970459103 .9805984497104 .7199020386 105.4582977295106 .1960983276106 .9336013794107 .6713027954108 .4091033936 109.1473999023109 .886100769110 .6256027222111 .3657989502112 .1066970825 112.8483963013113 .5906982422114 .3337020874115 .0772018433115 .8211975098 116.5654983521117 .3099975586118 .054397583118 .798500061119 .542098999 120.2848968506121 .0267028809121 .7671966553122 .5061035156123 .2429962158 123.9776992798124 .7099990845125 .4395980835126 .1663970947126 .8871994019 127.605796814

592.137878418588 .0797729492584 .0634155273580 .1503295898576 .3024291992 572.5067749023568 .7479248047565 .01171875561 .2797241211557 .536315918 553.7603759766549 .9345703125546 .0358886719542 .0458984375537 .9401245117 533.6992797852529 .2985839844524 .7186279297519 .9338989258514 .9257202148 509.6690063477504 .1463928223498 .3345947266492 .2179870605485 .7764892578 478.9975891113471 .8656921387464 .3725891113456 .5078125448 .2685852051 439.6524047852430 .6642150879421 .308013916411 .591003418401 .5643920898 391.297088623380 .8046875370 .1459960938359 .3353881836348 .4624023438 337.4508056641326 .3493041992315 .0490112305303 .7359924316292 .0914916992 280.5416870117268 .3612976074254 .9219970703240 .4969940186225 .19090271 210.9425964355199 .658493042195 .8695983887205 .7061004639212 .8948974609 198.3220977783177 .75050354163 .1457977295153 .0758056641151 .242401123 151.9759979248149 .55909729147 .3657073975147 .1916046143146 .7503051758 144.541305542139 .9642944336130 .5359954834122 .202796936121 .3777008057 122.0421981812119 .2331008911115 .2180023193110 .9504013062105 .8678970337 99.4661712646594 .3358993530393 .6198196411194 .2172470092893 .58014678955 92.1490631103589 .7440185546986 .4461669921982 .7309494018678 .38178253174 73.211502075267 .9802017211963 .2958602905359 .0811004638755 .45986938477 53.7482681274451 .7130203247148 .8576889038119 .7223491668719 .45471000671 19.1703395843518 .9134807586718 .713380813618 .5844898223918 .53533935547 18.5740203857418 .7085895538318 .965890884419 .4675197601318 .47419929504 17.7340297699 17.220209121716.9479503631616.83662986755 16.81467056274 
16.8949298858617 .0542507171617 .3097991943417 .6335296630918 .09210014343 18.7268600463919 .555730819720 .6167201995821 .8837394714423 .37026023865 24.9330501556426 .5250301361128 .4773597717331 .0693302154534 .38813018799 38.4150695800842 .4358100891145 .5747909545948 .2817497253451 .03973007202 53.4068489074755 .1019897460956 .4804992675857 .8309593200759 .13737869263 60.407508850161 .8200988769563 .4789199829165 .5301895141668 .05435180664 70.9202423095774 .3626937866276 .9460220336977 .0629272460976 .33763122559 76.0482025146575 .9449462890676 .149131774976 .6938705444377 .62454986572 78.8898391723680 .4877624511782 .339698791584 .384483337486 .53147125244 88.624023437590 .6758804321392 .6024780273494 .4212875366296 .06588745117 97.6195068359499 .1040802002100 .5283966064101 .9078979492103 .3128967285 104.9763031006106 .3738021851106 .8314971924107 .1411972046108 .0458984375 109.2753982544 110.8583984375 112.4860992432113.7871017456114.8779983521 115.7811965942116 .5953979492117 .3990020752118 .1865005493119 .012298584 119.7266998291120 .2241973877120 .5300979614120 .6630020142120 .6305999756 120.0774002075120 .0102005005121 .6231002808122 .5919036865118 .5574035645 115.1140975952118 .9944000244122 .9806976318123 .0400009155122 .1678009033 122.028503418122 .282699585122 .3500976562122 .4870986938122 .4940032959 122.5317001343122 .664100647122 .7630996704122 .6679992676122 .4932022095 122.292098999122 .0849990845121 .9571990967121 .8567962646121 .6961975098 121.5845031738121 .6743011475121 .6371002197121 .2929992676120 .5799026489 119.3471984863117 .8132019043116 .0248031616114 .456703186113 .2676010132 113.2235031128114 .8740005493117 .6391983032121 .7049026489125 .9697036743 131.4369049072131 .2149047852118116114302921 .4132804870617 .63726043701 14.7403097152714 .7764196395916 .166509628319 .5133705139221 .93370056152 24.2542095184326 .7112007141129 .1355495452930 .7331504821832 .42079925537 33.3836708068832 .8603286743232 .0086593627932 .0329589843832 .19469070435 32.5204582214433 .1469306945834 .1153297424336 .1333312988337 .98009109497 43.5965805053756 .2784118652372 .6748962402388 .9825668335105 .4098968506 122.1221008301133 .4627075195134 .6125030518129 .6466064453124 .4030990601 116.3795013428105 .281097412193 .0652313232480 .4135971069368 .79485321045 59.4737091064551 .7618217468345 .3122291564939 .4824295043933 .57883071899 27.7841205596921 .4869098663315 .9788904190111 .555899620068 .392316818237 6.8708000183116 .9201188087468 .95044898986812 .4477300643916 .92325019836 20.9423694610622 .7091693878223 .4538497924824 .1379909515424 .66996002197 25.4458293914826 .3299808502227 .2752094268828 .2972698211729 .30138015747 30.4018096923831 .7163696289133 .1187705993734 .5253181457535 .94131088257 37.34025955238 .7234802246140 .0713310241741 .3992500305242 .69704055786 43.9947090148945 .2916717529346 .630439758348 .0254592895549 .49856948853 51.0789909362852 .7370185852154 .4862899780356 .2941894531258 .16976165771 60.0112915039161 .7031784057663 .3192481994664 .9142990112366 .46949005127 67.9783172607469 .4431915283270 .8528366088972 .2134323120173 .52468109131 74.7889633178776 .008926391677 .1858062744178 .3220291137779 .41969299316 80.4818420410281 .5109481811582 .5108184814583 .48354339684 .4328994751 85.3603820800886 .2690429687587 .1598434448288 .035018920988 .89527130127 89.7421569824290.5762634277391.3987426757892.2101211547993.01142883301 
93.8031768798894 .5862808227595 .3612670898496 .1290664672996 .89018249512 97.6454925537198 .3955230712999 .1410903930799 .88271331787100 .6211013794 101.3567962646102 .0903015137102 .8221969604103 .5529022217104 .2827987671 105.012298584105 .7416992188106 .4711990356107 .2011032104107 .9315032959 108.6625976562109 .3945007324110 .1271972656110 .8607025146111 .5951004028 112.3302993774113 .0662994385113 .8029022217114 .5400009155115 .2774963379 116.015296936116 .7529983521117 .4906005859118 .2276000977118 .9639968872 119.6993026733120 .4332962036121 .1657028198121 .8962020874122 .62449646 123.3503036499124 .0734024048124 .7931976318125 .5102005005126 .2232971191 594.2603759766589 .9887695312585 .8159790039581 .7747192383577 .7866821289 573.8453979492569 .9360961914566 .0438232422562 .1514892578558 .2423706055 554.2971801758550 .2973022461546 .2219848633542 .0512084961537 .7634887695 533.3380126953528 .7529296875523 .987121582519 .0189819336513 .8280029297 508.3934020996502 .6958007812496 .7166137695490 .4382019043483 .8453063965 476.9238891602469 .662902832462 .0527038574454 .0871887207445 .762512207 437.0804138184428 .0451965332418 .6642150879408 .9433898926398 .9338989258 388.6975097656378 .2597045898367 .6727905273356 .9787902832346 .2603149414 335.483001709324 .6588134766313 .8468017578303 .1083068848292 .7338867188 282.9142150879273 .4483947754264 .4457092285254 .0155029297240 .558303833 227.858001709217 .8995056152212 .4781951904216 .6676940918219 .1410064697 210.0137939453196 .9898986816184 .3470001221173 .6806030273167 .8966064453 163.9972991943159 .741897583156 .1755981445153 .93359375151 .7104949951 147.9813995361141 .5794067383131 .9931945801123 .4360961914119 .3556976318 117.3476028442 114.4664993286110.8617019653106.1359024048 100.5414962769 93.6832122802788 .462333679287 .2815628051887 .6105422973687 .00554656982 85.5243988037183 .2343521118280 .2659530639676 .7433471679772 .54109954834 67.5557327270562 .3481101989757 .4145889282252 .8465690612850 .37728118896 49.3353996276948 .4093589782746 .8825798034718 .101699829117 .9729309082 17.8043594360417 .6255893707317 .4469108581517 .27190017717 .11034011841 16.9818191528316 .9070491790816 .8831806182916 .9141006469716 .10489082336 15.5657701492315 .2652502059915 .2197399139415 .2856397628815 .32964992523 15.4647197723415 .7653398513816 .1589908599916 .5563201904317 .07357978821 17.7840003967318 .7209396362319 .9391098022521 .4570693969723 .39208984375 25.1999702453626 .350170135527 .4131698608428 .9031200408931 .26955986023 35.0924110412639 .3183784484942 .828399658246 .0270996093849 .17304992676 51.805938720753 .5791091918954 .9244804382356 .2536697387757 .53606033325 58.7565498352159 .9997100830161 .2964897155863 .0489883422965 .66188812256 68.6604537963971 .7430725097774 .0016098022574 .4732513427774 .16648101807 73.940292358473 .8120422363373 .9122695922974 .3072128295975 .11531829834 76.2574462890677 .7453613281279 .508651733481 .5238723754983 .66893005371 85.7763977050887 .8312072753989 .7422332763791 .5125427246193 .08849334717 94.5478668212995 .9213333129997 .240516662698 .5443496704199 .86624908447 101.2705001831102 .5102005005103 .2142028809103 .9344024658105 .2659988403 107.0108032227109 .2632980347111 .3582992554112 .5426025391113 .3615036011 114.1971969604115 .0189971924115 .8591003418116 .6981964111117 .5469970703 118.3050994873118 .8994979858119 .3229980469119 .5615997314119 .638999939 
119.4746017456119 .7717971802121 .1930007935121 .5252990723118 .5898971558 116.4811019897118 .9691009521122 .251701355122 .8348999023122 .2463989258 121.9943008423121 .9481964111121 .9008026123121 .9023971558121 .8352966309 121.7749023438121 .7911987305121 .7800979614121 .6354980469121 .4061965942 121.0972976685120 .764503479120 .3989028931120 .1259994507120 .1818008423 120.3348999023120 .5136032104120 .5509033203120 .2633972168119 .6897964478 118.7209014893117 .5467987061116 .1604003906114 .9562988281114 .2218017578 114.3575973511115 .7968978882117 .8097991943120 .3397979736122 .5390014648 124.3552017212120 .8906021118117114112252320 .726400375371918 .11757087708 19.6303501129218 .5116500854519 .851699829120 .5813694000221 .64410972595 23.2445392608625 .5823192596427 .6321201324529 .9919891357431 .44939041138 30.8571796417229 .5842800140428 .9061908721928 .2910995483427 .6830291748 27.2996807098427 .4629402160628 .0361194610628 .682130813631 .46985054016 38.1115493774449 .557891845765 .6357879638784 .98438262939105 .6425018311 122.2407989502129 .6298065186130 .6477966309129 .4680023193124 .8114013672 116.3351974487106 .338600158795 .3991622924884 .137413024973 .99809265137 64.4568481445356 .466659545949 .2603988647542 .0059204101634 .60647964478 26.497980117819 .0687904357912 .550580024727 .5722231864935 .335176944733 5.0588579177866 .85067415237410 .2878303527814 .2726497650117 .82284927368 19.8136291503920 .9705295562721 .9609298706122 .8368606567423 .83146095276 24.9100608825726 .0553092956527 .244560241728 .3878898620629 .58184051514 30.9468193054232 .3912811279333 .8629608154335 .3404998779336 .78870010376 38.2021789550839 .5571899414140 .8624305725142 .1078987121643 .31605911255 44.4938888549845 .6895599365246 .9275588989348 .2571411132849 .73355102539 51.3198699951253 .0223312377954 .820178985656 .709548950258 .59992980957 60.3873405456562 .1072692871163 .779441833565 .4020462036166 .96797180176 68.4762420654369 .9157867431671 .2945785522572 .6193237304773 .89186859131 75.1168289184676 .2958908081177 .4317703247178 .527069091879 .5848236084 80.6080627441481 .6006088256882 .5650863647583 .5053176879984 .42315673828 85.3216934204186 .2021636962987 .0667724609487 .9164123535288 .75263214111 89.5761337280390 .3880462646591 .1890182495191 .9800109863392 .76161956787 93.5347213745194 .2998809814595 .0579528808695 .8095169067496 .55541992188 97.296180725198 .0326080322398 .7652206420999 .49472808838100 .2216033936 100.9465026855101 .6698989868102 .3921966553103 .1138000488103 .8351974487 104.5565032959105 .2781982422106 .0002975464106 .7230987549107 .4466018677 108.1710968018108 .8964004517109 .6228027344110 .3500976562111 .0783004761 111.8072967529112 .5371017456113 .2675018311113 .9983978271114 .729598999 115.4608001709116 .1919021606116 .9225006104117 .6524963379118 .381401062 119.1091003418119 .8350982666120 .5593032837121 .2811965942122 .0006027222 122.717300415123 .4309997559124 .1386032104124 .8436965942 595.9003295898591 .5985717773587 .3317871094583 .1563720703579 .0360107422 574.9575805664570 .9061279297566 .8676147461562 .82421875558 .7606811523 554.6572265625550 .4967041016546 .2576904297541 .9224243164537 .4682006836 532.8770751953528 .1262207031523 .1973876953518 .0681152344512 .7211303711 507.1347045898501 .2929992676495 .1763916016488 .7715148926482 .0617980957 475.0375061035467 .6863098145460 .0028076172451 .9804992676443 .6189880371 
434.9183044434425 .8866882324416 .5313110352406 .865814209396 .9346008301 386.8005065918376 .490814209366 .0613098145355 .5696105957345 .1087036133 334.6885070801324 .3125915527314 .1726989746304 .2280883789295 .0190124512 286.6297912598279 .3317871094274 .4223937988268 .5162963867257 .9295043945 246.908493042236 .6813964844228 .6345977783227 .1708068848226 .4187927246 224.0442962646219 .6199951172210 .3193054199199 .8188934326189 .6224975586 180.9237060547175 .558303833171 .0935058594166 .3327941895161 .1376953125 155.4476013184149 .008102417141 .9533996582134 .9234008789127 .9017028809 122.1099014282118 .2585983276114 .5494003296109 .1278991699102 .9442977905 96.0409622192490 .2270584106487 .2912673950285 .5882873535283 .65960693359 81.648857116779 .3345870971776 .5022430419973 .0927429199269 .02578735352 64.51450347959 .6113700866754 .5713691711449 .4273681640648 .03580856323 47.5409317016647 .2222900390646 .6032791137716 .6977901458716 .67094993591 16.5879192352316 .4633293151916 .2828998565716 .0264492034915 .69764995575 15.3303499221814 .9730396270814 .6297197341914 .1892004013113 .54516983032 13.1971797943113 .0960502624513 .2849702835113 .5650300979613 .72799968719 13.959719657914 .4182300567614 .9618301391615 .4330596923816 .01198959351 16.7709007263217 .7904396057119 .1388492584220 .8239898681623 .12174987793 25.117120742825 .9166297912626 .4131507873527 .1033096313528 .6949596405 32.1843681335436 .3416099548339 .9996185302743 .4810485839846 .8591003418 49.7030982971251.66884994507 53.1781692504954.6269912719755.94578933716 57.1604614257858 .31948089659 .320308685360 .7573318481463 .29843902588 66.113563537668 .4971694946370 .3078002929771 .2744064331171 .65306091309 71.695449829171 .6289978027371 .6426620483471 .8991699218872 .57737731934 73.5996398925875 .0302505493276 .7636489868278 .7906265258880 .97470092773 83.10178375244 85.16088867188 87.03880310059 88.74138641357 90.22473144531 91.5471191406292 .7551269531293 .9273529052795 .1241836547996 .28690338135 97.3149032592898 .2442626953199 .08078765869100 .2182006836101 .9990997314 104.2714004517107 .1380996704109 .6470031738110 .7496032715111 .3713989258 112.2029037476113 .0394973755113 .9029006958114 .7670974731115 .6125030518 116.3946990967117 .0932006836117 .6640014648118 .0366973877118 .3391036987 118.6075973511118 .9240036011119 .335899353119 .3740997314118 .8654022217 118.6707000732119 .4048995972120 .4434967041121 .0998001099121 .3031997681 121.3920974731121 .3911972046121 .3081970215121 .226600647121 .0786972046 120.9236984253120 .7990036011120 .6551971436120 .4405975342120 .1406021118 119.6826019287119 .1554031372118 .4420013428117 .9564971924118 .2498016357 118.7286987305119 .0596008301119 .2285995483119 .0914993286118 .7182006836 117.9925003052117 .0935974121115 .9866027832115 .0395965576114 .5093994141 114.5054016113115 .389503479116 .3523025513117 .3846969604117 .2135009766 114.789100647113112111109 .5202016 .9037990570118 .0307693481418 .71158981323 19.2554092407219 .2597293853819 .2328300476119 .1714401245119 .09387969971 19.1520500183121 .510259628323 .9131393432626 .7995605468828 .71124076843 28.2577896118226 .8557796478325 .7520008087224 .5411300659223 .35955047607 22.3227291107221 .8762302398721 .7967395782522 .1865997314523 .46401977539 24.7238197326730 .3107109069843 .731868743961 .8045997619681 .89038085938 100.4126968384112 .5756988525120 .6900024414126 .0370025635127 .2414016724 
123.7064971924116 .1430969238106 .599296569895 .5251770019585 .05686950684 75.0852203369166 .7578887939559 .009628295951 .1028709411642 .95537185669 33.6726417541524 .1869506835914 .535420417797 .4141688346864 .449934005737 4.6770238876346 .4670248031629 .08322906494111 .8485002517714 .37183952332 16.4316005706818 .0646495819119 .5837593078620 .9080600738522 .26272010803 23.6277904510524 .9727001190226 .3223304748527 .6058502197328 .88162994385 30.3096008300831 .8025798797633 .3479690551834 .9076881408736 .41767883301 37.8788986206139 .245250701940 .5331802368241 .7249603271542 .8431892395 43.8952598571844 .9290313720745 .9696884155347 .1230888366748 .46036911011 49.9539794921951 .6136894226153 .3905601501555 .2788085937557 .2056312561 59.0952301025460 .9285888671962 .6935310363864 .3906326293966 .01077270508 67.5585021972769 .0215911865270 .4120864868271 .7457962036173 .0231628418 74.2500991821375 .4287567138776 .5618820190477 .6524734497178 .70394897461 79.7194137573280 .7033462524481 .6582336425882 .588447570883 .49571228027 84.3834609985485 .2528915405386 .1063995361386 .9448699951287 .76998138428 88.5824279785289 .3834762573290 .1736984252990 .9541625976691 .72540283203 92.4883728027393 .243583679293 .9919281005994 .7339324951295 .47045898438 96.2020187377996 .929412841897 .6531219482498 .3738937377999 .09217834473 99.80863189697100 .5235977173101 .2378005981101 .9513015747102 .6647033691 103.3781967163104 .0921020508104 .8067016602105 .5220031738106 .2381973267 106.9553985596 107.6735992432108.3929977417 109.1132965088 109.8347015381 110.5569992065111 .2800979614112 .0039978027112 .728302002113 .4530029297 114.1779022217114 .9026031494115 .6268997192116 .3506011963117 .0733032227 117.7947006226118 .514503479119 .2323989868119 .9479980469120 .6611022949 121.3714981079122 .0784988403122 .7825012207123 .4823989868

597.4931030273593 .0026855469588 .5986938477584 .3098144531580 .0656738281 575.858581543571 .6743774414567 .4987182617563 .3153076172559 .1080932617 554.8590087891550 .5501708984546 .1627197266541 .6774291992537 .0748901367 532.3355712891527 .4398803711522 .3687744141517 .1030273438511 .6239929199 505.9142150879499 .9562988281493 .7349853516487 .2355041504480 .4458007812 473.354888916465 .954498291458 .2377929688450 .2037963867441 .8533935547 433.1854858398424 .1998901367414 .9195861816405 .367401123395 .5842895508 385.6224975586375 .5231018066365 .3428955078355 .150604248345 .0302124023 335.0199890137325 .1369934082315 .5823059082306 .4190063477298 .1007080078 290.780090332284 .7341918945280 .4779968262275 .7797851562268 .3944091797 260.9010925293255 .5236968994250 .0482025146244 .400100708239 .7322998047 236.6179962158233 .2288970947226 .1804962158216 .5897064209206 .853805542 198.5769042969194 .4658050537190 .4609985352182 .7384033203174 .0160980225 166.6925048828160 .6466064453155 .9423980713150 .4703063965142 .4062042236 134.4832000732129 .554397583125 .0902023315118 .3936004639111 .0826034546 104.3945007324 98.2205276489392.88659667969 88.32982635498 84.57360839844 81.599746704178 .9923934936576 .1882171630972 .4957733154368 .28639221191 63.841518402158 .9566307067953 .5904998779349 .8602905273447 .86999130249 47.29626083374 47.2150001525947.1147308349615.5487403869615.57621955872 15.5381097793615 .4353199005115 .2218198776214 .8400897979714 .26642036438 13.5568599700912 .82425975812 .1681499481211 .3355598449710 .81896972656 
10.6252202987710 .7033300399811 .043700218211 .4948301315311 .90219020844 12.3593397140512 .9348602294913 .5635204315214 .1645498275814 .83343982697 15.6007003784216 .6132793426518 .0222301483219 .7630805969221 .87365913391 23.7031803131124 .7326908111625 .4549007415826 .2484092712427 .72516059875 30.5164699554433 .9522209167537 .3670387268140 .7797393798844 .11637115479 47.0600509643649 .3529396057151 .2538299560552 .9056816101154 .34943008423 55.6539382934656 .8311080932657 .9323196411159 .3270492553761 .40861129761 63.6461486816465 .6258163452167 .2858810424868 .3998413085969 .11418914795 69.3786773681669 .3846969604569 .3509292602569 .4951705932670 .0263671875 70.9271469116272 .3545837402374 .1318435668976 .2139663696378 .46882629395 80.6523818969782 .7254180908284 .5814208984486 .2168807983487 .59638977051 88.7450027465889 .6522827148490 .5625228881891 .7409973144592 .87564849854 93.7232437133894 .4016876220794 .8153076171995 .7971725463998 .12753295898 101.0271987915103 .9677963257106 .4367980957107 .8214035034108 .7349014282 109.685798645110 .6089019775111 .5170974731112 .3970031738113 .2591018677 114.0735015869114 .8224029541115 .4739990234115 .9619979858116 .4321975708 116.9565963745117 .3021011353117 .4548034668117 .6654968262117 .8718032837 118.0945968628118 .4767990112118 .8365020752119 .3388977051119 .9111022949 120.2194976807120 .3039016724120 .2510986328120 .1305007935119 .9595031738 119.7362976074119 .5389022827119 .3173980713119 .0384979248118 .6602020264 118.1179962158117 .4851989746116 .7229995728116 .2522964478116 .4925003052 116.9708023071117 .346496582117 .5972976685117 .6651000977117 .519203186 116.9793014526116 .2092971802115 .2456970215114 .3383026123113 .7210006714 113.3781967163113 .5667037964113 .5272979736113 .0529022217111 .2144012451110 .5 109.5108 .51081071061715 .5397596359316 .0141391754217 .217769622817 .92757987976 18.2659797668518 .0892505645817 .5551605224616 .7106609344516 .11236953735 16.8365993499819 .2483196258522 .1122798919724 .2047805786124 .47978019714 23.7632198333722 .6709804534921 .2896804809619 .8310604095518 .46900939941 17.6145992279117 .2511405944817 .5799007415817 .9342002868718 .17663002014 20.5900802612326 .7633705139236 .9400787353550 .6410789489765 .46881103516 78.1254272460991 .56733703613108 .6136016846122 .2095031738126 .2073974609 122.9451980591113 .6455993652101 .705802917591 .5142211914182 .26526641846 74.8496932983467 .8507080078160 .5210494995152 .6205101013243 .5048789978 32.3146095275917 .150550842295 .3382248878483 .828489065176 .679741859436 8.4897003173839 .86982440948511 .0867500305212 .3852901458713 .8818397522 15.5632696151717 .3223094940219 .0186901092520 .7958698272722 .55637931824 24.0825004577625 .542129516626 .918529510528 .246160507229 .75769042969 31.3543090820332 .9910011291534 .6436080932636 .246089935337 .77138900757 39.1603889465340 .4327201843341 .584960937542 .6199607849143 .5391998291 44.3827590942445 .1785812377946 .0991096496647 .2660789489748 .64630126953 50.2730903625552 .0527801513753 .9460601806655 .9216194152857 .89244842529 59.8203010559161 .67494964663 .4494514465365 .1167907714866 .69452667236 68.174942016669 .5701828002970 .9056320190472 .1832275390673 .40882873535 74.5843887329175 .7123565673876 .7960510253977 .8391723632878 .84520721436 79.8188934326280 .7630767822381 .6821212768682 .5780487060583 .45420074463 84.3119964599685 .1537933349685 .980613708586 .7941284179787 .59513092041 
88.384902954189 .1640930175889 .933738708590 .6944427490291 .44711303711 92.1923065185592 .9308700561593 .6633377075294 .3905181884895 .11293792725 95.8313827514696 .5463333129997 .2584991455197 .9683532714898 .67651367188 99.3833694458100 .0895004272100 .7950973511101 .5008010864102 .206703186 102.9131011963103 .6202011108104 .3283004761105 .0373001099105 .7474975586 106.4588012695107 .1713027954107 .8849029541108 .5996017456109 .3152999878 110.0319976807110 .7493972778111 .4673995972112 .185798645112 .9044036865 113.6229019165114 .341003418115 .0585021973115 .775100708116 .4904022217 117.2041015625117 .915802002118 .6252975464119 .3320999146120 .0363006592 120.7372970581121 .4319992065122 .1240005493

598.6558227539594 .141784668589 .6564941406585 .250793457580 .8906860352 576.5637817383572 .2554931641567 .9526977539563 .638671875559 .2991943359 554.9155883789550 .4719848633545 .9489135742541 .3297119141536 .5938720703 531.7252197266526 .7030029297521 .5114135742516 .1301879883510 .544708252 504.736114502498 .6910095215492 .3933105469485 .8322143555478 .9948120117 471.8739929199464 .4609985352456 .7522888184448 .746307373440 .4495849609 431.8564147949422 .9642944336413 .8074035645404 .4240112305394 .8474121094 385.1260070801375 .3102111816365 .458404541355 .6466064453345 .9455871582 336.429901123327 .1044006348318 .1936035156309 .7640075684302 .1322937012 295.3996887207 289.8363952637 285.232208252 281.0226135254 276.2051086426 271.9111022949271 .1018066406269 .1553039551261 .7547912598253 .9871063232 248.9559020996244 .2019958496237 .6513061523229 .9284973145222 .0798034668 215.3244934082212 .6170959473208 .9342956543198 .9219970703187 .928604126 179.9989013672174 .1665039062171 .0144042969167 .2852935791159 .1374053955 150.4197998047144 .7660064697139 .2469940186131 .1604003906122 .9350967407 116.44090271110 .1632995605102 .805099487395 .821289062590 .31902313232 85.9305801391682 .4096679687579 .0667572021574 .6722030639669 .92754364014 65.1867294311560 .0310897827154 .2522888183650 .8625984191948 .47576904297 47.6206398010347 .4621009826747 .4282684326214 .6949796676614 .70131015778 14.645919799814 .5130596160914 .2221403121913 .6750097274812 .77093029022 11.6128396987910 .352120399489 .1688652038578 .3459768295297 .9252409935 7.8576731681828 .0966033935558 .5900526046759 .215380668649 .908950805664 10.6196403503411 .335280418412 .0819396972712 .8094501495413 .58559989929 14.3618898391715 .3329401016216 .7332592010518 .3513298034720 .05686950684 21.7213096618723 .230190277124 .5716800689725 .8373794555727 .32924079895 29.3813896179231 .9319705963134 .8379402160637 .989959716841 .18236160278 44.2433280944846 .9548912048349 .2826118469251 .163501739552 .73286056519 54.1652793884355 .4839782714856 .8762702941958 .2876091003459 .85134124756 61.4998016357463 .1170005798364 .6997528076265 .9382324218866 .84735870361 67.2795410156267 .3673934936567 .3204803466867 .2986526489367 .57617950439 68.3355407714869 .8149871826271 .7730865478573 .9887924194376 .29940795898 78.5157928466880 .5796737670982 .3995971679783 .9605865478585 .24398040771 86.2536468505986 .9108886718887 .5736236572388 .7006301879989 .80912017822 90.5400238037191 .0855026245191 .15429687591 .8854217529394 .5272064209 97.71798706055100 .4061965942102 .6917037964104 .386100769105 .6867980957 106.8290023804107 .8279037476108 .7555007935109 .6332015991110 .4981994629 
111.3319015503112 .1209030151112 .8313980103113 .4012985229113 .9338989258 114.5362014771115 .0411987305115 .3455963135115 .6433029175116 .0134963989 116.2946014404116 .4834976196116 .7106018066117 .2754974365117 .9872970581 118.4709014893118 .7192993164118 .7296981812118 .5593032837118 .3632965088 118.1423034668117 .9296035767117 .6941986084117 .388999939116 .9728012085 116.412399292115 .731300354114 .9330978394114 .4677963257114 .5366973877 114.893699646115 .257598877115 .5856018066115 .8525009155115 .9003982544 115.4477996826114 .6733016968113 .7631988525112 .7434997559111 .8487014771 110.9441986084110 .3963012695109 .4674987793107 .859703064107 .3000030518106 .5106 105.5105104 .510417 .7056407928515 .0678300857514 .9119901657115 .65983009338 16.2031002044716 .5118293762216 .5425300598116 .0630302429214 .78549957275 13.2499303817712 .1205301284814 .2704200744616 .8427391052219 .05707931519 20.2660903930720 .4791202545219 .6588497161918 .1915893554716 .65096092224 15.1960601806614 .198550224313 .6945800781214 .1217098236114 .81826019287 15.9531602859516 .9676494598420 .7264003753720 .7264003753723 .52730941772 33.2637481689544 .6758689880460 .9219512939586 .87969207764110 .4348983765 120.6872024536121 .6575012207113 .6384963989101 .790496826293 .25367736816 85.7158508300880 .2807464599675 .3508224487370 .0001831054763 .42205047607 54.9978294372643 .7645988464425 .224639892589 .9107513427738 .958478927612 12.2992200851412 .2864704132111 .9547595977811 .5079002380411 .39873981476 12.0996704101613 .400739669815 .170100212117 .2181606292719 .60816955566 21.802879333523 .4565391540524 .7973995208726 .1583595275927 .58840942383 29.2686100006131 .0510005950932 .8328285217334 .6158790588436 .31637954712 37.9213409423839 .3275184631340 .5810089111341 .6861686706542 .63731002808 43.4396514892644 .1233901977544 .7247085571345 .3773307800346 .26858901978 47.4856681823749 .0413284301850 .8570594787652 .7700996398954 .72721099854 56.7453117370658 .749298095760 .7080688476662 .5641517639264 .27313232422 65.8583526611367 .3430175781268 .7461929321370 .0850372314571 .36437225342 72.5876388549873 .7590026855574 .8797073364375 .954521179276 .98753356934 77.9825973510778 .9450073242279 .8775024414180 .7847671508881 .66871643066 82.5328216552783 .378486633384 .20815277185 .0228576660285 .82438659668 86.61357116699 87.39176940918 88.15962219238 88.9182662963989.6682510376 90.4105377197391 .1456375122191 .8744201660292 .5973587036193 .31527709961 94.0286788940494 .7383117675895 .4446487426896 .1483993530396 .84998321533 97.5500564575298 .2489776611398 .9472885131899 .64528656006100 .3433990479 101.0419006348101 .7409973145102 .4410018921103 .141998291103 .8441009521 104.5474014282105 .2519989014105 .9578018188106 .6649017334107 .3731002808 108.0823974609108 .7928009033109 .5038986206110 .2156982422110 .9279022217 111.6404037476112 .3527984619113 .0650024414113 .7764968872114 .4869995117 115.1962966919115 .9039001465116 .6095962524117 .31300354118 .0138015747 118.7117996216119 .4063034058120 .0977020264120 .7848968506 599.778503418595 .1008911133590 .4976196289585 .9935302734581 .526184082 577.0878295898572 .6649780273568 .2443237305563 .8106079102559 .3491821289 554.8436889648550 .2775268555545 .6334838867540 .8944702148536 .0429077148 531.0612792969525 .9326171875520 .6397094727515 .1663818359509 .4967041016 503.615814209497 .5093994141491 .1653137207484 .5718078613477 .7202148438 
470.6025085449463 .2142944336455 .5527954102447 .6166992188439 .4065856934 430.9266967773422 .1798095703413 .2041015625404 .0380859375394 .7224121094 385.3070068359375 .8407897949366 .3789978027356 .9971923828347 .7755126953 338.7732849121330 .037109375321 .6852111816313 .8088989258306 .4385070801 299.4927062988293 .7803039551290 .3052062988287 .7456970215284 .4718933105 281.5245056152279 .3793029785276 .2080993652271 .0863952637265 .2744140625 260.432800293255 .6253967285249 .5666046143242 .9207000732235 .6439971924 228.9571990967224 .4476928711218 .7940063477209 .6495056152199 .9362030029 192.4095001221186 .9029998779183 .4082946777179 .5818939209173 .2324066162 165.8768005371159 .3069000244152 .4248046875144 .3625946045136 .4120941162 129.654800415123 .0090026855115 .9131011963108 .693901062101 .8320007324 95.714149475190 .3098678588985 .1714019775479 .6226119995173 .944190979 68.2580566406262 .4149818420456 .3489685058651 .7247314453148 .96411895752 47.7205009460447 .2740592956546 .8624000549314 .1946401596114 .05237960815 13.8892097473113 .6357097625713 .1858797073412 .4195699691811 .17197036743 9.3910703659067 .4474058151256 .1021780967715 .2400641441354 .862308979034 4.9029760360725 .3131041526796 .0400500297556 .9253640174877 .809689044952 8.6960897445689 .62497520446810 .5626201629611 .4043998718312 .24726963043 13.0838699340814 .0366096496615 .3152198791516 .7320709228518 .16189956665 19.8501892089821 .9997196197524 .044639587425 .3205108642626 .41728973389 28.0293197631830 .0078506469732 .347789764435 .1294403076238 .37321853638 41.7355918884344 .837329864547 .538509368949 .5276603698751 .1520614624 52.7380409240754 .2825813293555 .9104614257857 .3358497619658 .51770019531 59.693778991761 .0407218933162 .5658988952664 .050506591865 .22575378418 65.7853088378965 .9180526733465 .7917404174865 .5276870727565 .2412109375 65.6086273193467 .4011230468869 .8246688842872 .2200927734474 .58126831055 76.7876586914178 .8074569702180 .5679168701282 .0657730102583 .28021240234 84.2292633056684 .9046478271585 .556358337486 .4555130004987 .34538269043 88.0057067871188 .5483779907288 .9256668090889 .8778228759892 .14317321777 94.8332138061597 .2210083007899 .35304260254101 .0663986206102 .5102005005 103.7124023438104 .7161026001105 .6228027344106 .4721984863107 .3188018799 108.158203125109 .0018997192109 .7690963745110 .37840271110 .9244003296 111.4190979004111 .9508972168112 .7315979004113 .408203125113 .5804977417 113.5757980347113 .685798645113 .9428024292114 .5317001343115 .365196228 116.2592010498116 .8479003906116 .756401062116 .3946990967116 .1841964722 116.0205993652115 .884803772115 .7301025391115 .4921035767115 .1323013306 114.6240997314113 .8594970703112 .7446975708111 .9819030762112 .0279998779 112.3981018066112 .7578964233113 .1303024292113 .5902023315113 .8144989014 113.2453994751112 .2863998413111 .4273986816110 .3664016724108 .9309005737 107.3683013916106.2154006958106.4000015259106.1999969482106105.8000030518105.5 105104.510310218 .7137508392315 .3815698623714 .0977096557614 .25584983826 14.0321397781414 .1967000961314 .4610700607314 .6649398803713 .06877040863 11.4040203094510 .193189620979 .79403495788612 .0705795288114 .42759037018 16.5651702880917 .7318706512516 .88651084915 .1472101211513 .60857963562 12.3009500503511 .5149803161611 .3561496734612 .083290100113 .59764957428 16.3264999389617 .4473209381120 .7264003753720 .7264003753721 .3360004425 
21.3461494445831.9760208129948.26974868774 70.9207382202192.05074310303 103.3907012939106 .7630004883102 .572601318495 .072410583589 .51508331299 85.0721664428782 .6692123413181 .0808334350680 .0087432861376 .89351654053 68.9766769409258 .2613906860445 .2337799072333 .5272216796926 .89234924316 22.7150402069118 .7935504913315 .5297803878813 .07505035411 .61431026459 11.1436195373511 .7571802139313 .3308000564615 .6970796585119 .02397918701 22.0231304168723 .2785205841124 .0051193237325 .260459899926 .8425693512 28.7831306457530 .8528404235832 .8527603149434 .8033905029336 .63481903076 38.3185195922939 .7618789672941 .0014801025442 .0489807128942 .92100143433 43.6473999023444 .2438392639244 .7579612731945 .1835403442445 .53594970703 46.3099403381347 .9223098754949 .905971527151 .795478820853 .67562866211 55.669361114557 .7266082763759 .8212318420461 .8017997741763 .49597167969 65.0342102050866 .5148162841867 .9274291992269 .2749099731470 .55933380127 71.7826690673872 .9491195678774 .0619735717875 .1261367797976 .1477432251 77.1306228637778 .0807189941479 .0008468627979 .8956909179780 .76722717285 81.6188125610482 .4519500732483 .2690734863384 .0713119506884 .860496521 85.63752746582 86.40383148193 87.16011810303 87.90753936768 88.64668273926 89.3784713745190.1034469604590.8224182128991.5358963012792.24462890625 92.9491271972793 .6500778198294 .3479690551895 .0434722900495 .7370223999 96.4292068481497 .1204071044997 .8111572265698 .5017166137799 .19257354736 99.88387298584100 .5759963989101 .2689971924101 .9632034302102 .6585006714 103.3552017212104 .0532989502104 .7526016235105 .4533004761106 .1552963257 106.8583984375107 .5625991821108 .2676010132108 .9733963013109 .6796035767 110.3861999512111 .0926971436111 .7988967896112 .5045013428113 .209197998 113.9125976562114 .6143035889115 .3141021729116 .0114974976116 .7063980103 117.3983001709118 .087097168118 .7693023682119 .448600769

600.5247192383595 .8295288086591 .1577148438586 .5535888672581 .9868164062 577.4453735352572 .9163208008568 .387512207563 .8436279297559 .271484375 554.6547241211549 .9788208008545 .2263793945540 .3825073242535 .4295043945 530.3524780273525 .1342163086519 .7603149414514 .2144165039508 .4836120605 502.5528869629496 .4111938477490 .046295166483 .449798584476 .6129150391 469.5309143066462 .1995849609454 .620513916446 .7887878418438 .7025146484 430.3745117188421 .8167114258413 .0679931641404 .1689147949395 .1646118164 386.1081848145377 .0466003418368 .0263061523359 .1271972656350 .4201049805 341.9674072266333 .8151855469326 .0216064453318 .6336975098311 .6123962402 304.4807128906298 .8098144531296 .4744873047295 .2522888184292 .9943847656 290.0804138184285 .3286132812280 .2973937988277 .6849060059274 .9959106445 271.0035095215266 .5082092285261 .2265014648255 .1437072754248 .0043029785 240.2548980713232 .7611999512225 .2035064697217 .8800048828210 .9942016602 204.6983032227199 .3612976074194 .8067932129190 .3822021484185 .8735046387 180.4517059326173 .4855041504165 .9317016602158 .4320983887151 .045501709 144.0048065186137 .1672058105130 .8195037842124 .2679977417116 .8219985962 109.1625976562 101.583000183194.28568267822 87.21705627441 80.40534210205 73.2783737182666 .2892684936559 .70507812552 .7353210449249 .63542175293 47.5212593078646 .1983909606936 .2711982727114 .0867900848413 .64083003998 13.2394199371312 .7245998382611 .9370403289810 .806090354929 .358366012573 
6.5092458724984 .4272150993352 .9752988815312 .0877931118011 .743358969688 1.845427989962 .380157947543 .286043882374 .385794162755 .450767040253 6.5794630050667 .8408899307259 .0252542495739 .96757030487110 .80035972595 11.6572198867812 .6106901168813 .7692098617615 .0659503936816 .35316085815 18.0345306396520 .6683197021523 .1616497039824 .3457107543925 .20129013062 26.6113395690928 .2899398803730 .201940536532 .6606483459535 .93196105957 39.4982299804742 .8352508544945 .7713699340847 .8121109008849 .48960113525 51.2375488281252 .9592514038154 .8085517883356 .476001739557 .72840118408 58.7960700988860 .0228500366261 .3437309265162 .8202209472764 .1206817627 64.7065277099664 .8507537841864 .6913223266664 .3203735351663 .65217971802 63.7060813903865 .7313385009868 .4581909179770 .8905410766673 .24057006836 75.4052429199277 .3508071899479 .0466995239380 .4773178100681 .64122009277 82.5804824829183 .3563766479584 .0398330688584 .7129364013785 .36089324951 85.9501266479586 .6076736450287 .4230575561588 .5952072143690 .30835723877 92.2822799682694 .2711181640696 .1764526367297 .8191528320399 .24405670166 100.4095001221101 .37449646102 .236000061103 .0214996338103 .8065032959 104.600402832105 .4586029053106 .2300033569106 .8663024902107 .3655014038 107.6643981934108 .1743011475109 .3818969727110 .4417037964110 .3877029419 110.1008987427110 .283203125110 .7007980347111 .3215026855112 .1636962891 113.2843017578 114.1022033691 113.9578018188113.5198974609 113.4136962891 113.391998291113 .3880996704113 .3388977051113 .1698989868112 .8750991821 112.4613037109111 .8468017578110 .7107009888109 .6247024536109 .3044967651 109.3994979858109 .6614990234110 .113899231110 .5354003906110 .6148986816 109.800201416108 .5494995117107 .7677001953106 .5935974121104 .695602417103 102.8000030518102 .5999984741102 .4000015259102 .1999969482102101 .8000030518 101.5999984741101 .0999984741100 .510020 .0826301574715 .9979295730612 .53756999969 11.3258800506611 .3429403305111 .4714498519911 .6092796325711 .59117984772 11.1408500671410 .283289909369 .325586318979 .23792266845710 .48134994507 11.8676996231113 .2626695632914 .5425701141413 .6793003082311 .87948989868 10.610619544989 .6378536224379 .2619686126719 .58818721771210 .73727035522 12.7107095718416 .6609706878719 .8120002746619 .8120002746619 .81200027466 21.336000442521 .336000442528 .9964694976842 .6300811767657 .85485839844 72.0132217407281 .3718109130985 .8686599731485 .5770721435582 .99458312988 81.2921829223680 .5302124023481 .7067184448283 .7769775390687 .6784286499 88.8281478881882 .3982620239373 .4369964599667 .2351303100659 .94313049316 47.6278991699235 .3145599365226 .8462696075420 .6444091796916 .2286605835 13.5853500366211 .5975799560511 .0518999099712 .0892601013214 .43922996521 18.3579292297421 .8081398010322 .719169616723 .0307197570824 .41677093506 26.2188396453928 .4829902648930 .9230804443433 .1848106384335 .3652381897 37.3213310241739 .0645599365240 .509899139441 .6981391906742 .65948867798 43.4212303161644 .0582313537644 .5736312866245 .0322799682645 .39995956421 45.4271202087445 .7945404052747 .3048400878949 .1661109924350 .8498916626 52.6211318969754 .5858306884856 .6718597412158 .8760795593360 .96300888062 62.6589393615764 .1787033081165 .6814498901467 .1143569946368 .47464752197 69.7684707641670 .9907531738372 .1519775390673 .2549819946374 .30724334717 75.3162765502976 .286132812577 .2234802246178 .1308975219779 .01307678223 
79.8720016479580 .7108306884881 .5312271118282 .3354873657283 .12496948242 83.90151214684 .6661071777385 .4203109741286 .1648330688586 .90090942383 87.6290893554788 .3503875732489 .0652313232489 .7744827270590 .47856903076 91.1782684326291 .8740005493292 .5664672851693 .2561187744193 .94360351562 94.6293334960995 .3138809204195 .9976196289196 .6810531616297 .36444854736 98.0482406616298 .7326278686599 .41793060303100 .1043014526100 .7919006348 101.4806976318102 .1709976196102 .8628005981103 .5559005737104 .25050354 104.9462966919105 .6434020996106 .3415985107107 .040802002107 .7406997681 108.4411010742109 .1417999268109 .8424987793110 .5429992676111 .2427978516 111.9418029785112 .6393966675113 .3354034424114 .0294036865114 .7210006714 115.4100036621116 .0960006714116 .7783966064117 .4576034546118 .1324005127 601.2382202148596 .4041137695591 .6328125586 .9448852539582 .2866821289 577.6505737305573 .0244140625568 .3961181641563 .7523193359559 .0795288086 554.36328125549 .5891113281544 .7418823242539 .8065185547534 .7678222656 529.6107177734524 .3209228516518 .8834838867513 .2858276367507 .513885498 501.5567932129495 .4028015137489 .0433044434482 .4695129395475 .6763916016 468.6592102051461 .4164123535453 .9482116699446 .2533874512438 .3312988281 430.1984863281421 .8655090332413 .3823852539404 .7984924316396 .1535949707 387.495513916378 .8716125488370 .3340148926361 .9448852539353 .7732849121 345.8746948242338 .30859375331 .1242980957324 .3944091797318 .0382080078 311.9565124512307 .1925964355304 .7789916992303 .384185791301 .7113952637 299.0448913574294 .4892883301289 .9195861816286 .7239074707283 .8100891113 280.0892028809275 .9812011719272 .1774902344267 .2065124512259 .3937072754 249.9176025391240 .0122070312231 .2602996826225 .4539031982220 .900604248 215.7810974121210 .6609954834205 .9985961914201 .616394043197 .44090271 192.6555938721186 .5738067627179 .8681945801172 .9897003174166 .0419006348 159.2028961182152 .4913024902146 .1645050049139 .6999969482132 .7626953125 124.6979980469115 .0641021729105 .434600830197 .2428665161189 .35077667236 80.2778091430771 .4748535156264 .1396408081156 .8301315307651 .35900115967 47.203960418743 .8223495483414 .8658304214514 .254110336313 .42492961884 12.6344995498711 .6981897354110 .376079559338 .5245685577396 .001159191132 $3.129980087281 .100028038025-.276142001152-1.10133194923-1.40364801884$ -1.28538095951 -.731305003166.1854760050774 1.36001098156 2.689661979675 4.221449851996 .0523262023937 .6849842071538 .5658483505259 .2013463974 10.0285501480110 .9942998886112 .1458101272613 .4305400848414 .7926197052 16.5162200927718 .8518791198721 .0892295837422 .5285396575923 .69289970398 25.1301498413126 .7534599304228 .5778694152830 .9177894592334 .08422088623 37.5602493286140 .8095817565943 .6844787597745 .8534698486347 .71817016602 49.5664405822851 .4694290161153 .5950889587455 .790740966858 .12726974487 60.029861450260 .9630584716861 .6581497192462 .6754913330163 .6400604248 64.1503829956164 .3132095336964 .2047271728563 .9425811767663 .60388946533 63.8955192565965 .5838775634867 .8867034912170 .1393966674872 .34449005127 74.3956069946376 .2628631591877 .8774337768679 .2517089843880 .36685943604 81.2929763793982 .0693130493282 .717071533283 .302597045983 .84845733643 84.3899078369185 .0855789184685 .9917373657287 .0878372192488 .49418640137 90.0283737182691 .6401901245193 .272186279394 .7200469970796 .00293731689 
97.0609130859497 .9382476806698 .6851501464899 .3448333740299 .97132110596 100.6287994385101 .3658981323102 .0375976562102 .6295013428103 .0137023926 103.0346984863103 .3955993652104 .7339019775105 .9573974609106 .0253982544 105.8679962158106 .302696228106 .966003418107 .6026992798108 .3238983154 109.1423034668109 .7522964478109 .8748016357109 .8143005371109 .9599990845 110.198600769110 .4116973877110 .4972991943110 .3201980591110 .0372009277 109.8179016113109 .6134033203109 .4546966553108 .7454986572106 .7518997192 105.1707000732105 .717300415106 .5994033813106 .1486968994105 .2779006958 104.4049987793103 .2545013428102 .0886993408102102102102102102102102102102 102102981816.026519775399 .7915792465218 .4371910095218 .89586353302 8.5183305740368 .4800043106088 .5639858245858 .8305988311779 .488768577576 8.3653621673588 .3682928085339 .9483461389 .5801830291759 .575242042542 9.7891349792489 .3790397644048 .2855195999157 .4633560180666 .960999011993 7.0755262374887 .8571109771739 .41003608703611 .7521896362315 .26266956329 15.8495998382616 .1543998718316 .1543998718316 .1543998718317 .47657966614 25.5482807159435 .6094093322846 .5472793579156 .5663986206163 .41278839111 67.6827926635767 .4647293090866 .5605163574268 .4610137939571 .88955688477 76.5235671997182 .3248519897590 .6979370117295 .4536972045992 .91309356689 88.5881118774481 .2320480346772 .830917358460 .9401283264247 .4377784729 35.5391311645526 .4329109191921 .1031608581517 .6390800476113 .50374984741 10.8241796493511 .3552703857413 .6305799484316 .6361103057919 .3586807251 20.7109394073521 .788360595723 .5369300842325 .7261600494428 .37833976746 31.1873493194633 .8354415893636 .3185501098638 .4299507141140 .20989990234 41.6194992065442 .7112998962443 .5447616577144 .1705513000544 .65972900391 45.0725212097245 .4820709228545 .9270706176846 .4742507934647 .1111907959 47.7785797119148 .6466789245649 .9305381774951 .5233306884853 .42197036743 55.5308494567957 .7172393798859 .8126182556261 .6163406372163 .25344085693 64.8141937255966 .2889328002967 .6766510009868 .9822235107470 .20709228516 71.3616561889672 .4553833007873 .4949264526474 .4909515380975 .4474029541 76.3717117309677 .2663116455178 .1357879638778 .9820175170979 .8080291748 80.6155014038181 .4067687988382 .1832427978582 .9469070434683 .69888305664 84.44078063965 85.1734085083 85.8980331420986.61522674561 87.32598876953 88.0307769775488 .7303695678789 .425216674890 .1159973144590 .80317687988 91.4873580932692 .1689987182692 .8486862182693 .5268402099694 .20401763916 94.8805313110495 .556922912696 .2334136962996 .910438537697 .5881729126 98.2669372558698 .9468383789199 .62808990479100 .3106994629100 .9949035645 101.6804962158102 .3676986694103 .0562973022103 .7462997437104 .4375991821 105.1299972534 105.8234024048 106.5176010132 107.2124023438 107.9074020386 108.6026000977109 .2974014282109 .9916992188110 .6849975586111 .3769989014 112.0672988892112 .7556991577113 .4415969849114 .1248016357114 .8050994873 115.4820022583116 .1521987915116 .8191986084

601.6301269531596 .7830810547591 .9547119141587 .1826171875582 .4403076172 577.7172851562573 .0017700195568 .2830810547563 .5479736328558 .7849121094 553.979309082549 .1187133789544 .1881103516539 .174621582534 .0634765625 528.8419189453523 .4954833984518 .0125732422512 .3801269531506 .5874023438 500.6234130859494 .4794921875488 .1473999023481 .6210021973474 .8960876465 
467.970489502460 .8428039551453 .5145874023445 .9862976074438 .2605895996 430.3568115234422 .2846984863414 .1039123535405 .8727111816397 .6238098145 389.3981933594381 .2474975586373 .2237854004365 .3775024414357 .7593994141 350.4313049316343 .4307861328336 .8649902344330 .7836914062325 .3534851074 320.7088012695316 .9314880371314 .1196899414311 .924987793310 .2493896484 308.0609130859304 .4834899902300 .5046081543296 .2781982422292 .1499023438 288.2048950195284 .3729858398281 .6650085449277 .503692627269 .0314941406 258.6481018066247 .7429962158238 .4264984131234 .1076965332231 .1564025879 226.69140625221 .8903045654217 .0500946045212 .5980072021208 .538192749 204.3925018311199 .4947967529193 .891494751187 .7769927979181 .257598877 174.7984008789168 .3215942383161 .9685058594155 .4243011475148 .9635925293 141.2386016846130 .5242004395119 .4283981323110 .3616027832101 .2722015381 90.0113677978579 .0875167846770 .2366333007861 .8121490478554 .00616836548 47.2464218139640 .8094711303716 .1303501129214 .6520500183113 .26206970215 11.9283599853510 .369700431828 .3500337600715 .7009611129762 .242530107498 -.534371972084 -2.39862704277 -3.58361291885 -4.27120113373 -4.46946287155 $-4.32252979279-3.79717111588-2.99016094208-1.79177796841-0.21699899435$ 1.6843149662023 .9789590835575 .9762411117556 .8348360061657 .373626232147 8.2670755386359 .28921031951910 .4965496063211 .8641004562413 .37843036652 15.0571002960216 .8499794006318 .6639194488520 .365720748921 .99731063843 23.673549652125 .4340305328427 .3782005310129 .7253894805932 .74279022217 35.9895210266138 .9677391052241 .6899108886743 .9407882690445 .95045089722 47.8113594055249 .7978210449252 .1218605041554 .7587814331158 .17729949951 61.0532684326262 .0014991760362 .2922592163162 .923969268863 .45774841309 63.8087196350164 .0179595947364 .0185089111364 .0305404663164 .2329788208 64.8512268066466 .116912841867 .8102035522569 .7389297485471 .74490356445 73.6567687988375 .4273300170976 .9610900878978 .2774429321379 .34925079346 80.2356109619180 .9725799560581 .585662841882 .1229782104582 .63488769531 83.1565017700283 .7986526489384 .6229934692485 .5760726928786 .71144104004 87.9323806762789 .2358703613390 .5555114746191 .7334136962992 .7986831665 93.693771362394 .4397964477595 .0636291503995 .5777282714896 .04679870605 96.4759826660296 .9798965454197 .521621704198 .1361770629998 .65683746338 98.6034774780398 .77982330322100 .0160980225101 .2276000977101 .43699646 101.5278015137102 .2621002197103 .0958023071103 .6893005371104 .1220016479 104.3582000732104 .6299972534105 .0002975464105 .4993972778106 .0497970581 106.4737014771106 .8523025513107106 .797996521106 .5773010254106 .5617980957 106.6778030396107 .4039993286107 .2095031738103 .8626022339100 .7788009644 101.5026016235102 .5083007812100 .961898803798 .776641845797 .37698364258 96.2114562988394 .9426498413193 .7947616577192 .6382369995191 .67697906494949796 9492908684828017.515 .891500473029 .1489448547366 .2200570106516 .168460845947 5.9423689842225 .9860639572146 .4237451553346 .0620789527896 .881978988647 6.6476988792426 .0165591239936 .7700710296636 .6045970916755 .950887203217 6.0683622360236 .3843832015995 .1000847816474 .3442168235784 .378042221069 5.0014791488656 .2189769744878 .08846378326410 .3163499832212 .87907981873 14.4929199218813 .7428503036512 .8241195678713 .8962697982816 .86911010742 22.6065006256129 .5399208068836 .8751792907743 .7139701843348 .474609375 
51.6107101440450 .6827392578150 .3547592163154 .7829589843861 .26802062988 68.1875686645577 .4011383056689 .0987167358495 .6663284301897 .60076904297 95.4703903198289 .8930130004980 .2859573364370 .0934295654358 .65250015259 46.1477088928235 .3379287719729 .2195091247624 .643060684217 .88726997375 12.9892501831112 .4750795364413 .8154602050815 .2135696411116 .89435005188 18.7589492797920 .8165092468323 .1397094726625 .7773704528828 .86989021301 32.1501808166535 .1715011596737 .9043884277340 .0748901367241 .77122879028 43.0599288940443 .9729003906244 .6377182006845 .0837402343845 .40261077881 45.6782608032246 .0099601745646 .4985694885347 .5556297302248 .4125213623 48.1707801818848 .0272789001548 .9494209289650 .4356002807652 .29948043823 54.3866996765156 .5026206970258 .5781707763760 .5019111633362 .28844070435 63.9346008300865 .4626693725666 .8818283081168 .2032470703169 .42944335938 70.5760498046971 .6589584350672 .6852111816473 .6681365966874 .61138916016 75.5229263305776 .4050903320377 .262001037678 .0957336425878 .90886688232 79.7033767700280 .4814910888781 .2448196411181 .9954986572382 .73468780518 83.46423339844 84.18489837646 84.89810180664 85.60436248779 86.30471038818 86.9995574951287 .6896667480588 .3754577636789 .0575714111389 .73638916016 90.4125595092891 .0864410400491 .7586212158292 .4294815063593 .09954833984 93.7691574096794 .4387664794995 .1086578369195 .7791900634896 .45056152344 97.12304687597 .7968063354598 .4719772338999 .1486434936599 .82688140869 100.5066986084101 .1881027222101 .8710021973102 .5552978516103 .2409973145 103.9278030396104 .6156997681105 .304397583105 .9936981201106 .6832962036 107.3730010986 108.0624008179 108.7511978149 109.4390029907 110.1256027222 110.8104019165111 .4932022095112 .1735992432112 .8510971069113 .5257034302 114.1966018677114 .8640975952115 .5270004272

601.9965209961 597.0338745117592.1229248047 587.2802734375 582.4611816406 577.6586303711572 .862121582568 .0610961914563 .2442016602558 .3997192383 553.5153808594548 .5786132812543 .5767822266538 .4970703125533 .3272705078 528.0546264648522 .6674804688517 .1541137695511 .504486084505 .7080993652 499.7568969727493 .6422119141487 .3590087891480 .9014892578474 .2681884766 467.4570922852460 .4703979492453 .3113098145445 .9797973633438 .474609375 430.8255004883423 .0513000488415 .2091064453407 .3564147949399 .5262145996 391.7634887695384 .1131896973376 .6283874512369 .3443908691362 .3109130859 355.5711975098349 .1635131836343 .2051086426337 .7409973145333 .1160888672 329.5932922363326 .5205993652323 .5022888184320 .7793884277318 .8792114258 316.7684020996313 .2933959961309 .1650085449304 .5830078125299 .9471130371 295.8427124023292 .024810791288 .6796875284 .1530151367276 .4841918945 267.3023986816 257.8893127441250.0319976807245.9824066162 242.9394989014 238.7456970215233 .8222961426227 .7718048096222 .4934997559219 .7480926514 217.366897583213 .2263946533208 .1640014648202 .5182952881196 .3470001221 190.3164978027184 .2498931885178 .1058959961171 .6441040039164 .713394165 156.8215026855147 .5610961914137 .5124969482127 .2676010132116 .1638031006 103.376800537190 .529579162678 .808456420968 .0430679321357 .65097045898 48.3745689392138 .7764091491717 .5598907470715 .1797103881812 .98062992096 $10.818779945378 .4508428573615 .6213312149051 .51980805397-1.79586696625$ $-4.32612514496-5.98960018158-6.97999000549-7.44920015335-7.48623418808$ 
-7.2261838913 -6.71867799759-6.11603784561 -5.04714107513 -3.21458005905 -1.02055895329 1.164227008823.05693602562 4.287949085236 5.259449005127 6.3529701232917 .5254502296458 .83609104156510 .279720306411 .85422992706 13.4261903762814 .9304103851316 .5635700225818 .4342803955120 .42597007751 22.3461494445824 .2962207794226 .4573898315428 .8965301513731 .77644920349 34.764369964637 .5610694885340 .1527900695842 .3380889892644 .27848815918 45.9710197448747 .8303489685150 .2007102966353 .0106201171956 .36603927612 59.3617706298861 .2432212829662 .3199310302762 .9450111389263 .29647064209 63.6142005920463 .8996391296464 .0627288818464 .3040237426864 .7674331665 65.471122741766 .5877685546967 .9703369140669 .6384887695371 .44947052002 73.1874771118274 .8211135864376 .2586135864377 .5019607543978 .50807952881 79.3339004516680 .01674652180 .5817108154381 .066261291581 .52201080322 82.0016632080182 .5611724853583 .2603683471784 .044357299884 .93788909912 85.8872299194386 .8936004638787 .9044265747188 .8247070312589 .6622467041 90.3728179931690 .9721832275491 .4700927734491 .8661880493292 .19937896729 92.4190597534292 .4801330566492 .7758636474693 .8187103271594 .93843078613 95.3478393554795 .7264862060596 .5780334472797 .3939819335997 .70230865479 97.9967422485498 .6487808227599 .3042831420999 .7454986572399 .8030166626 99.3001327514699 .0617599487399 .6950378418100 .7752990723101 .7649002075 102.3858032227102 .5660018921102 .4881973267102 .3737030029102 .3382034302 102.4007034302102 .5442962646102 .8868026733102 .359298706199 .86865997314 97.4610671997197 .3052062988397 .1437301635795 .0367507934691 .96150970459 88.4157867431685 .9668426513786 .4012527465887 .6885528564588 .020362854 88.0413589477587 .9332580566487 .3597106933685 .9151077270583 .88758087158 81.5674896240278 .7100677490275 .0525131225670 .8325195312566 .02127075195651617 8.5880479812626 .0710968971255 .206397056585 .1838130950935 .384323120117 5.431773185735 .1440238952644 .987611770634 .7141919136054 .519797801971 4.0069470405583 .5469379425052 .7627320289612 .3960740566251 .323379039764 1.3739750385281 .159819006921 .6599899530412 .7315270900734 .272229194641 6.2658119201668 .27884197235110 .1173696517911 .4863901138311 .64340019226 11.9320201873813 .5310297012315 .9220104217519 .6282501220723 .85376930237 28.4606494903632 .8622283935536 .1650695800838 .5467910766638 .7674407959 39.9351806640644 .449501037650 .7765808105557 .0495109558166 .54766845703 79.7129364013794 .1024398803799 .431640625100 .068199157795 .43405151367 86.691970825277 .8977966308668 .0508804321359 .1416511535650 .51979064941 42.3936309814534 .54380035426 .2509498596219 .8600292205816 .89060020447 15.7286300659215 .619589805616 .5300998687718 .233680725120 .68773078918 23.3761291503926 .3917407989530 .1221599578934 .0511283874537 .43463134766 40.2997398376542 .3742904663143 .8331298828144 .8609695434645 .51276016235 45.9216194152846 .1407394409246 .2589111328146 .3528404235846 .49982070923 46.8031196594247 .4184303283747 .7195396423347 .1433410644546 .76507949829 47.712051391649 .3670387268151 .2510108947853 .2972412109455 .38246917725 57.4646682739359 .4479408264261 .3248596191463 .0442008972264 .62596130371 66.0830993652367 .4253234863368 .6542663574269 .7916336059670 .86305236816 71.8755874633872 .845420837473 .7758865356474 .6752471923875 .54538726807 76.3902969360477 .2117080688578 .0122528076278 .7937698364379 .55874633789 
80.3088531494181 .0464706420981 .7728576660282 .4900283813583 .1987991333 83.9006271362384 .5960922241285 .2861709594785 .971267700286 .65209960938 87.3290634155388 .0027389526488 .6735000610489 .3419036865290 .00833129883 90.6733016967891 .3371810913192 .0004577636792 .6634521484493 .32662200928 93.9901809692494 .6545181274495 .3198089599695 .9863433837996 .65421295166 97.3235931396597 .9945297241298 .667129516699 .34136199951100 .0171966553 100.6946029663101 .3734970093102 .0538024902102 .7352981567103 .4178009033 104.1011962891104 .7852020264105 .4694976807106 .1539001465106 .8379974365 107.5214996338108 .2040023804108 .8852005005109 .5646972656110 .2421035767 110.917098999111 .5892028809112 .2582015991112 .9238967896113 .5824966431 114.237701416 602.096496582597 .1237792969592 .1652832031587 .2526245117582 .3629760742 577.4879150391572 .6171875567 .7421264648562 .8510131836557 .934387207 552.9801025391547 .9776000977542 .9146728516537 .7805175781532 .5634155273 527.2526245117521 .8375854492516 .3084716797510 .6563110352504 .8724975586 498.9501037598492 .8826904297486 .6661987305480 .2969055176473 .7745056152 467.0983886719460 .2728881836453 .3041992188446 .1925964355438 .932800293 431.5632019043424 .1101074219416 .6300964355409 .1766967773401 .7897033691 394.5103149414387 .3821105957380 .4566040039373 .7609863281367 .3453063965 361.2341003418355 .4613952637350 .1337890625345 .245300293341 .1524047852 338.2828979492335 .7025146484332 .5960998535329 .6304931641327 .7139892578 325.6568908691322 .2640075684318 .0101013184312 .9504089355307 .8286132812 303.6489868164299 .7556152344295 .2991027832290 .1229858398283 .3138122559 275.8476867676268 .6756896973262 .467010498258 .4075927734255 .1681976318 251.650894165247 .1116027832240 .1784973145233 .9891967773232 .3903045654 231.2460021973227 .0809936523221 .8374938965216 .4145965576210 .8430938721 205.5019989014200 .0048065186194 .2621002197187 .9674987793180 .6790008545 172.8298034668165 .5066070557156 .9658966064145 .716506958133 .054901123 119.12550354104 .744201660289 .8621215820375 .5789031982463 .56618881226 50.8954696655337 .9773788452118 .9454708099415 .4207801818812 .13080978394 $8.9107656478885 .453878879547 .7514179944992-3.17599201202-6.17718982697$ $-8.33924484253-9.69778823853-10.388999939-10.5607204437-10.3284502029$ $-9.88070297241-9.24549198151-8.72920703888-7.74925422668-5.76512718201$ -3.49233198166 -1.65121304989 1.10080000e-02 1.589651942253 3.046730995178 4.4144959449775 .775180816657 .2200188636788 .71376800537110 .29520988464 11.8632297515913 .2692604064914 .8152999877916 .809150695818 .96447944641 21.0506191253723 .2297306060825 .6664199829128 .2637691497831 .0430393219 33.8403396606436 .4923515319838 .9544906616241 .0328903198242 .86162948608 44.3552284240745 .9704704284748 .14926910450 .7571716308653 .60182189941 56.4691505432159 .220291137761 .3153305053762 .3382682800362 .79333877563 63.2889404296963 .6922607421964 .0232162475664 .4808731079165 .0788269043 65.8445434570366 .8825073242268 .1086578369169 .6144409179771 .24929046631 72.8142471313574 .3173065185575 .6502227783276 .8145217895577 .74105072021 78.4993209838979 .117607116779 .6271362304780 .0543212890680 .44798278809 80.8569183349681 .3071670532281 .8511734008882 .4502868652383 .13565826416 83.85341644287 84.59439849854 85.32685852051 85.98664093018 86.58862304688 
87.09557342529 87.52393341064 87.89084625244 88.17199707031 88.40646362305 88.5395431518688 .3290634155388 .5538101196390 .1361923217891 .85205841064 92.6971893310593 .2020263671993 .6003494262793 .9557266235494 .31400299072 94.7004089355595 .1432571411195 .5026016235495 .7259063720795 .63414764404 94.7654571533294 .1305465698294 .8162231445395 .8680114746196 .73229980469 97.3922729492297 .4551010131897 .359519958597 .4775314331197 .58791351318 97.6644515991297 .6007614135797 .2415466308696 .4456100463995 .28076934814 93.9379577636792 .9084091186591 .4579086303788 .9840469360485 .64470672607 80.5804367065477 .1349868774479 .2165603637782 .7758407592884 .41478729248 85.2463378906285 .1263732910284 .1861419677782 .7615432739380 .90263366699 78.6987686157276 .1490631103572 .975021362369 .2524795532265 .03028869629 60.3302803039621 .4171390533415 .248350143438 .8155088424685 .986983776093 4.9820408821114 .8884491920474 .1934437751773 .795629978183 .487272977829 3.1460919380192 .7559759616852 .1676769256591 .4629809856410 .617908000946 -.446940004826 -1.76376199722 -1.85306501389-1.91154301167-1.48670196533 -.650404989719.7152680158615 2.3618168830874.2418928146365.970115184784 7.2307648658758 .3034687042249 .16158199310310 .2125196456912 .12434959412 14.1564302444516 .3362808227518 .5765705108621 .2635002136224 .01275062561 26.1792392730728 .2713108062729 .7880496978832 .1159400939935 .73175048828 40.7825202941945 .6992988586453 .036830902165 .1339416503981 .91829681396 96.17382049561101 .8588027954100 .746002197392 .0969467163173 .26820373535 76.2474975585971 .3085327148465 .6953887939556 .4396591186546 .45341110229 37.2924613952629 .2770099639923 .1473808288619 .2351093292217 .82732963562 18.3136291503919 .7065906524722 .0900497436524 .9617195129428 .51302909851 32.9197998046937 .3353614807140 .78012847943 .4460182189945 .20217895508 46.2053413391146 .8767318725647 .1758003234947 .2952194213947 .25212097168 47.1549682617247 .0301208496146 .9483108520546 .8687400817946 .77759170532 46.5074195861845 .8348388671945 .5609092712446 .6781692504948 .43965911865 50.2624511718852 .2518005371154 .3119506835956 .3952789306658 .42882919312 60.3681793212962 .1514015197863 .7923011779865 .2856216430766 .6459197998 67.8753433227569 .000556945870 .0609436035271 .0610427856472 .01909637451 72.9386520385773 .8267135620174 .685829162675 .518966674876 .32837677002 77.1162872314577 .8848724365278 .6367034912179 .3736190795980 .09826660156 80.8119583129981 .5169296264682 .2139968872182 .9047317504983 .58965301514 84.2697296142684 .9453735351685 .6172409057686 .2856979370186 .95126342773 87.6143035888788 .2752685546988 .9345779418989 .5926589965890 .24989318848 90.9067230224691 .5634536743292 .2204666137792 .8780364990293 .53650665283 94.1960296630994 .8568801879995 .5191726684696 .183036804296 .84855651855 97.515769958598 .1846694946398 .8552474975699 .52744293213100 .2011032104 100.8761978149101 .5525970459102 .2300033569102 .908203125103 .587097168 104.2662963867104 .9455032349105 .62449646106 .3029022217106 .9803009033 107.6563034058108 .3305969238109 .0027008057109 .6723022461110 .3391036987 111.0027999878111 .6625976562112 .318901062112 .9704971313 602.1774291992597 .1105957031592 .0844116211587 .112487793582 .1588745117 577.2175292969572 .2800292969567 .3374023438562 .3803710938557 .3994140625 552.3842773438547 .3248291016542 .2109985352537 .0322265625531 .7791748047 
526.4417114258521 .0114135742515 .4791259766509 .8381958008504 .0808105469 498.2025146484492 .1972961426486 .0638122559479 .7990112305473 .4046020508 466.8808898926460 .2341918945453 .4696960449446 .5935058594439 .6072998047 432.542388916425 .4183044434418 .3059997559411 .2763977051404 .3555908203 397.5795898438390 .9928894043384 .6488037109378 .5686950684372 .8006896973 367.337097168362 .2051086426357 .4189147949352 .9844970703349 .1658935547 346.1278076172343 .390411377340 .6520996094338 .1283874512336 .3985900879 334.679107666332 .2940063477328 .5765991211322 .1200866699315 .5346069336 311.6076965332308 .1116943359303 .4016113281298 .0855102539291 .3857116699 284.5358886719278 .2945861816272 .8606872559269 .3796081543267 .2358093262 266.6238098145264 .616394043257 .6766052246250 .8928985596249 .0921020508 247.37159729241 .2312011719234 .1808929443229 .104598999224 .6768035889 220.1566009521215 .4167022705210 .2904968262204 .5415039062197 .9429016113 190.9008026123183 .8786010742175 .2335968018163 .542098999150 .1488952637 136.0912017822120 .8933029175103 .572998046986 .1140823364370 .45031738281 54.3666687011738 .3675498962419 .7311191558814 .7942800521910 .26698970795 $5.673210144043 .0158610008657-4.70269823074-8.40781497955-11.0226898193$ $-12.7136802673-13.5866298676-13.8082304001-13.5486297607-12.9321699142$ $-12.1515398026-11.2464704514-10.3791704178-9.18480873108-7.35143899918$ -5.36285114288 -3.67100691795 -2.08658099174 -.599420011044 .9117169976234 2.5027689933784 .0868539810185 .6575851440437 .2280449867258 .835668563843 10.4746904373212 .1343297958413 .8738298416115 .7010297775317 .67283058167 19.8481597900422 .2278995513924 .862230300927 .6034793853830 .40010070801 33.1349601745635 .7005081176838 .0557098388740 .055240631141 .7679901123 43.1719703674344 .5069313049345 .967079162647 .8514518737850 .54005050659 53.5522918701256 .2595100402858 .6081581115760 .4747085571361 .7126083374 62.4439010620162 .9596595764263 .5467605590864 .2488479614365 .00224304199 65.8343505859466 .8608703613368 .0135803222769 .3986129760770 .89775848389 72.3776626586973 .7957229614375 .036697387776 .1054763793976 .96237182617 77.6533966064578 .2062301635778 .6481323242279 .0035629272579 .31424713135 79.6316070556679 .9650726318480 .3611526489380 .7938613891681 .27993774414 81.7815093994182 .2834167480582 .7641296386783 .189590454183 .569190979 83.87941741943 84.14644622803 84.38562774658 84.60080718994 84.81838226318 85.047851562585 .2503814697386 .0007705688587 .9317626953189 .82718658447 90.4354934692490 .487716674890 .5901565551890 .7246017456190 .98645782471 91.3116378784291 .6278305053791 .8395767211991 .9057769775491 .87777709961 91.7537536621191 .5717391967891 .2946624755990 .9837493896590 .63070678711 90.5698394775491 .243026733492 .0070724487392 .2432174682692 .29670715332 92.41525268555 92.3079528808691.8256607055791.1881637573290.40487670898 89.33898162842 88.05087280273 86.24635314941 83.87139892578 81.02136230469 77.3485488891675 .1623535156276 .8020477294979 .8751220703181 .98322296143 83.0815811157282 .7002563476681 .3118820190479 .4950027465877 .47427368164 75.5110321044973 .3944931030370 .7331771850667 .429969787663 .4327507019 59.370010375985713 .319749832157 .907989978795 .9108052253724 .536105155945 3.0222270488742 .4732630252841 .9943530559541 .5095039606091 .190467953682 $.7808200120926-4.9562000 \mathrm{e}-02-.910546004772-1.86070799828-2.77556705475$ 
-3.4720261097 -3.44043898582 -3.27473592758 -2.7709209919-1.88715898991 -.473603010178 1.065747022629 2.4563291072853.637921094894 4.588499069214 5.580469131476 .6137299537667 .8731989860539 .53234004974411 .04061985016 12.4101800918613 .6530103683515 .0599699020416 .6295394897518 .07517051697 19.7868900299121 .680660247824 .0082302093526 .9504394531230 .88232040405 35.9029502868741 .9815406799352 .021629333565 .7794799804785 .2964630127 100.2385025024103 .445999145596 .0904998779385 .9190368652381 .49388885498 79.5287704467873 .6364135742267 .0854187011759 .2845687866249 .42364883423 39.2087287902829 .8008308410623 .0475101470921 .8038005828923 .03668022156 23.5959091186525 .1587200164828 .7044391632133 .2348899841338 .04148101807 42.5027313232445 .5188217163147 .5351905822848 .6439094543549 .00685882568 49.0952301025448 .950469970748 .7019081115748 .3612289428747 .97731018066 47.5760688781747 .2157897949246 .8077392578146 .3496208190945 .87963867188 45.3268890380945 .2555618286146 .1758804321347 .6343002319349 .33792877197 51.2454910278353 .2730484008855 .3702888488857 .4442481994659 .44065093994 61.2871894836462 .9864501953164 .5023269653365 .8685913085967 .09311676025 68.203681945869 .2499694824270 .2384033203171 .1864166259872 .09660339355 72.975311279373 .8242034912174 .6465072631875 .4440994262776 .21967315674 76.9753494262777 .7141265869178 .4379806518679 .149833679279 .85106658936 80.5441131591881 .2297897338981 .909736633382 .5844421386783 .25489807129 83.921463012784 .5847473144585 .2450790405385 .9029235839886 .55859375 87.2125167846787 .8650665283288 .5166473388789 .1675796508889 .81831359863 90.4690933227591 .1203384399491 .7722473144592 .4251708984493 .079246521 93.7347564697394 .3917617797995 .0504302978595 .7107772827196 .37288665771 97.0367279052797 .70229339698 .3694763183699 .038223266699 .70835113525 100.3797988892101 .0522003174101 .7255020142102 .3994979858103 .0737991333 103.7481002808104 .4220962524105 .0954971313105 .7678985596106 .4389038086 107.1081008911107 .775100708108 .4395980835109 .1010971069109 .7595977783 110.4143981934111 .0621032715111 .7059020996 602.046081543596 .9697875977591 .9041137695586 .8737792969581 .861328125 576.8598022461571 .8610839844566 .8580932617561 .8416748047556 .8040161133 551.7354736328546 .6276855469541 .4713134766536 .2573852539530 .9777832031 525.6239013672520 .1884765625514 .6644287109509 .0458984375503 .3272094727 497.5050048828491 .5752868652485 .5378112793479 .3911132812473 .1383972168 466.7811889648460 .3269042969453 .7793884277447 .1516113281440 .450592041 433.7059936523426 .9247131348420 .1950073242413 .5958862305407 .1484069824 400.8750915527394 .8322143555389 .0694885254383 .6091003418378 .5064086914 373.7211914062369 .3057861328365 .1325073242361 .2773132324357 .5563049316 354.0574951172351 .0210876465348 .7211914062347 .0571899414345 .8461914062 344.6105957031343 .3909912109340 .2901916504332 .607208252324 .9520874023 321.4883117676318 .8298034668313 .9645996094308 .0815124512300 .6557006836 293.3053894043287 .0650024414282 .0094909668279 .0575866699277 .7632141113 279.7023010254280 .2695007324274 .1319885254267 .1633911133264 .8984985352 262.1123046875254 .041595459245 .6351013184241 .1468963623237 .7879943848 234.0354003906230 .0870056152225 .6071929932220 .6016998291215 .0451965332 208.8323059082 201.9160003662 193.2230987549 181.7601928711 168.2431030273 
153.9857940674137 .9091949463117 .883598327697 .0998001098677 .70427703857 58.3310317993239 .6343193054219 .2817096710212 .719790458686 .898668766022 -9.7602002e-02 -6.11564493179 -10.7214899063 -14.0810403824 -16.1813697815 $-17.2712192535-17.5238609314-17.1302890778-16.326379776-15.2090797424$ $-14.0159196854-12.7009401321-11.3715400696-9.90840435028-8.3000869751$ $-6.64718389511-5.09081888199-3.59247589111-2.26905107498-.874669015408$ .80862498283392 .543149948124 .2066869735725 .8416810035717 .5074858666547 9.21230411529511 .1161098480213 .0331497192414 .6387395858816 .41657066345 18.6731491088921 .2143402099624 .030199050926 .9126491546629 .79632949829 32.5537300109935 .06835937537 .3362884521539 .2584609985440 .87651062012 42.2073783874543 .339561462444 .1505012512245 .3479995727547 .81301879883 50.5908889770552 .7435989379954 .8682289123557 .3112716674859 .47700881958 60.7282600402861 .6119384765662 .6509208679263 .5549888610864 .39122772217 65.2411804199266 .3024978637767 .5032272338968 .8806915283270 .35270690918 71.7916030883873 .164337158274 .3238525390675 .3049163818476 .09069824219 76.7238388061577 .2027282714877 .5731964111377 .8433227539178 .05767059326 78.2741088867278 .4880676269578 .752227783279 .0332870483479 .34906005859 79.6643905639679 .9598388671980 .2277832031280 .4376983642680 .61090087891 80.7230377197380 .8280410766680 .9401168823281 .1044235229581 .34947967529 81.8013076782282 .5731430053783 .8106231689585 .863838195887 .64114379883 87.8569335937587 .5363311767687 .5127487182687 .5434722900487 .70166778564 87.91510009766 88.08950042725 88.20580291748 88.175086975188.23164367676 88.8713836669989 .1287384033287 .8453369140686 .1510772705184 .61013793945 83.8159713745185 .0197067260786 .5538635253986 .8244094848686 .77433776855 86.9154891967886 .8643569946386 .5045166015685 .9662933349685 .32747650146 84.3709716796983 .0085220336981 .2897872924879 .3603897094777 .54486846924 76.0127868652375 .5094070434676 .468193054278 .1312103271579 .76367950439 80.5974807739379 .7981719970778 .1253890991276 .1163177490274 .00708007812 72.2036590576270 .2065505981467 .5116271972764 .3447113037159 .91265869141 55.632369995125510 .023900032046 .6777319908144 .8400359153753 .127918958664 $1.559839010239 .6780269742012 .1486199945211-.307060986757-.794808983803$ $-1.4262919426-2.23832988739-3.03809809685-3.71131896973-4.35717487335$ $-4.52117776871-4.20504188538-3.8644349575-3.43178510666-2.76220202446$ $-1.5417920351-.305765002966 .54645502567291 .2647140026092 .070378065109$ 2.9835929870613 .9905660152445 .079823017126 .2878398895267 .320545196533 8.3637037277229 .1921968460089 .92082595825210 .7265100479111 .47994995117 12.8333797454814 .7544403076217 .04512977619 .2412204742422 .21710014343 27.2838306427 30.396060943636 .5688400268647 .6211395263765 .66895294189 93.78740692139103 .3147964478101 .808097839488 .9918518066486 .34121704102 81.6348419189579 .2480010986376 .3327789306671 .7668228149461 .7689704895 50.1147308349638 .4542884826729 .9792404174829 .197689056430 .99934959412 30.48130035431 .1464691162135 .0465507507340 .2236099243245 .12184143066 49.1279716491751 .1425895690951 .9279785156252 .0981216430751 .77339935303 51.321571350150 .6927108764650 .0713005065949 .4104003906248 .71923828125 48.0152702331547 .3543891906746 .6882095336946 .022319793745 .48751068115 45.1649703979545 .2419509887745 .8513107299846 .9276390075748 .452709198 
50.2757110595752 .2681999206554 .3616218566956 .4591484069858 .51115036011 60.4384117126562 .1939811706563 .7230110168565 .0689773559666 .27744293213 67.3815307617268 .4214172363369 .4052810668970 .346817016671 .25045013428 72.1203308105572 .959823608473 .771072387774 .5568771362375 .31999969482 76.0628433227576 .7888031005977 .4998703002978 .1993484497178 .88861846924 79.5702362060580 .2450714111380 .914756774981 .5798110961982 .24114990234 82.8991470336983 .5543136596784 .2069778442484 .8575210571385 .5062713623 86.1535720825286 .7997817993287 .4452362060588 .0902862548888 .73528289795 89.3805084228590.0263137817490.6729278564591.3206481933691.96964263916 92.6201019287193 .2721481323293 .9259033203194 .5813903808695 .23867797852 95.897743225196 .5585327148497 .220977783297 .8849868774498 .55042266846 99.2170867919999 .88484191895100 .5533981323101 .2226028442101 .8921966553 102.5616989136103 .2310028076103 .899597168104 .5671005249105 .2332000732 105.8974990845106 .5596008301107 .21900177107 .87550354108 .5288009644 109.1781005859109 .8237991333110 .4645004272 601.9011230469596 .7498779297591 .6287841797586 .5490112305581 .4829711914 576.4262695312571 .3723754883566 .3145141602561 .2454223633556 .1572875977 551.0427856445545 .8936767578540 .7028198242535 .4616699219530 .1641845703 524.8024291992519 .3715209961513 .8646240234508 .2785949707502 .6084899902 496.8529052734491 .0090942383485 .0783996582479 .0606079102472 .9602966309 466.7803039551460 .5284118652454 .2107849121447 .8406066895441 .4227905273 434.9959106445428 .5848083496422 .2589111328416 .0870056152410 .0982971191 404.3237915039398 .8174133301393 .6308898926388 .7974853516384 .3734130859 380.3348083496376 .7366027832373 .3858032227370 .2941894531366 .8779907227 362.7825012207359 .2832946777357 .4702148438356 .7359924316356 .4526977539 356.0548095703355 .2951965332352 .2708129883344 .592590332337 .1903991699 334.854095459333 .1278076172327 .8305053711320 .4707946777310 .9942932129 301.8186035156295 .1289978027290 .1499023438287 .0751037598285 .7524108887 286.6520080566286 .7644958496282 .6939086914277 .4827880859274 .4475097656 270.687286377263 .9462890625257 .2495117188253 .1159973145250 .0670013428 247.1100006104243 .9105987549239 .9062042236235 .4501037598230 .7404022217 225.4176940918219 .3896026611211 .7082977295201 .7566986084188 .8643951416 172.4678955078153 .271697998130 .5950927734106 .85040283284 .64827728271 62.9489784240741 .1749000549317 .349510192878 .984480857849 .4872840046883 $-6.97999620438-13.0941801071-17.4138202667-20.1811904907-21.6022701263$ $-21.9378795624-21.435300827-20.3066101074-18.8246593475-17.1100997925$ $-15.4074401855-13.6691198349-11.9968099594-10.3856801987-8.82853317261$ $-7.34760904312-5.93134403229-4.55352210999-3.27057695389-1.91153597832$ -.330496013165 1.342542052269 3.0024199485784 .6613311767586 .357683181763 8.0529069900519 .72179126739511 .3955402374313 .0510101318414 .9727602005 17.4314498901420 .213239669823 .1910591125526 .2116298675529 .2252407074 32.0625801086434 .5135002136236 .6873512268138 .5969085693440 .18347167969 41.3879203796442 .3711318969743 .3061904907244 .4264411926346 .05976104736 47.7622909545948 .9947700500550 .473491668752 .6706504821855 .16324996948 57.539760589659 .5950317382861 .2389984130962 .430801391663 .16849136353 63.8819198608465 .0385437011766 .3970565795967 .9097671508869 .47476959229 
70.940986633372 .2913589477573 .4177169799874 .3286666870175 .04989624023 75.6154632568476 .0277023315476 .3206481933676 .505020141676 .62316131592 76.7421264648476 .8542327880977 .0039215087977 .1620330810577 .32974243164 77.4848327636777 .6110763549877 .6971664428777 .717910766677 .69686889648 77.6292114257877 .5816879272577 .5859680175877 .704803466877 .9919128418 78.5736465454179 .5278167724680 .8057708740282 .5071334838983 .87580108643 84.23317718506 84.18209075928 84.19418334961 84.22415924072 84.33010101318 84.4452362060584 .5238265991284 .537666320884 .4240493774484 .39512634277 84.6405181884884 .432479858483 .126388549881 .3715667724679 .87547302246 79.1930923461979 .9389190673881 .0627136230581 .4085693359481 .45356750488 81.5384521484481 .4918365478581 .2256469726680 .8138504028380 .31478881836 79.5590362548878 .4133377075277 .0683670043975 .5998611450274 .55236816406 74.103240966874 .3372116088975 .76869964677 .1028900146577 .39663696289 77.0115890502975 .8725967407274 .2773132324272 .6309661865270 .86221313477 68.9147262573266 .3734970092862 .5755615234458 .308029174854 .34941864014 50.86750030518506 .4363079071045 .9432668685913 .5148150920871 .576360940933 $-.290854007006-1.03685200214-1.5882730484-2.11258411407-2.7172191143$ $-3.50129508972-4.35155820847-5.04084300995-5.00948810577-5.61869907379$ $-4.93148183823-4.60303115845-4.36379003525-4.10781621933-3.76987099648$ -3.02883291245 -2.25969910622 -1.69878804684 -1.15172898769-.487708002329 .32240399718281 .2816480398182 .2689409255983 .2535738945014 .127949237823 4.8808331489565 .3878297805795 .6226649284365 .6988811492925 .49732208252 6.2326779365549 .01877880096412 .0466203689613 .663709640515 .4944601059 18.0692291259820 .5696392059322 .911199569726 .0734291076740 .25419998169 58.873611450293 .38672637939109 .382698059199 .9156723022593 .94859313965 87.66716003418 85.11572265625 84.0120162963983.69519805908 73.79811096191 61.6950416564951 .3652801513744 .2135009765642 .5389404296942 .88095092773 42.0935096740742 .4436912536645 .4552803039649 .8752288818454 .64546966553 57.9643096923857 .754459381156 .2702903747655 .3328514099154 .42647171021 53.4361190795952 .3754081726151 .3546791076750 .3687095642149 .39136886597 48.4306907653847 .5120506286646 .6444206237845 .8423690795945 .25648117065 44.9582405090344 .9803886413645 .400810241746 .2387809753447 .62237930298 49.3740882873551 .3000907897953 .3549385070855 .4554481506357 .56293106079 59.6223411560161 .4833602905362 .9663505554264 .234092712465 .41951751709 66.5232315063567 .5676498413168 .5561981201269 .4978027343870 .39697265625 71.2604217529372 .0905227661172 .8912200927773 .6649932861374 .41571044922 75.1458129882875 .8591766357476 .5579071044977 .2455062866277 .92343139648 78.5942916870179 .2589416503979 .9190597534280 .5750732421981 .22794342041 81.877929687582 .5255737304783 .1710891723683 .814872741784 .45716094971 85.0983123779385 .7386093139686 .3784027099687 .0179519653387 .65762329102 88.2976837158288 .9384536743289 .5801315307690 .2230072021590 .86723327637 91.5130081176892 .1604003906292 .8095626831193 .4604873657294 .11325073242 94.7677764892695 .424102783296 .0820465087996 .7415771484497 .40251922607 98.0647125244198 .727958679299 .39203643799100 .0567016602100 .7217025757 101.3865966797102 .0513000488102 .7152023315103 .3780975342104 .0394973755 104.6989974976105 .356300354106 .0109024048106 .6624984741107 .310798645 
107.9553985596 108.5925979614 109.2257995605

601.5953979492596 .4334716797591 .2786865234586 .1505126953581 .0352783203 575.928527832570 .8239746094565 .716796875560 .5999755859555 .4677734375 550.3131103516545 .1293945312539 .9102783203534 .6491088867529 .3405761719 523.978515625518 .5590209961513 .0772705078507 .5313110352501 .9176025391 496.2366027832490 .4865112305484 .6705932617478 .7894897461472 .849395752 466.8536987305460 .8121032715454 .7308959961448 .624206543442 .4906005859 436.3858032227430 .3450012207424 .4267883301418 .6713867188413 .1318054199 407.8315124512402 .8395996094398 .1936950684393 .9507141113390 .1635131836 386.8197021484384 .008605957381 .4814147949379 .2890014648376 .7974853516 373.1390075684369 .8803100586368 .8089904785368 .8168029785369 .1726989746 369.4754943848369 .0325012207366 .641998291360 .2443847656353 .8646850586 352.6055908203351 .0042114258344 .328704834335 .1000976562322 .9350891113 311.2033081055303 .1369018555297 .4558105469293 .8629150391291 .7904052734 290.6968994141289 .4472961426287 .1651916504283 .9858093262280 .4725952148 276.4014892578271 .8883972168267 .6007080078264 .0404968262261 .1552124023 258.8562011719256 .3629150391252 .8013000488248 .75244 .7151031494240 .1533050537 234.9351959229228 .3524932861220 .3256072998208 .6708068848190 .9512939453 168.8177032471142 .7559967041115 .916198730590 .8498382568466 .27306365967 $41.6804199218813 .66751956944 .148622989655-6.40715122223-14.4714097977$ $-20.4606704712-24.2999897003-26.415189743-27.061000824-26.5589008331$ $-25.1879405975-23.2150001526-20.9679107666-18.5609397888-16.3102207184$ $-14.1468801498-12.2172498703-10.4829101562-8.96068572998-7.59625101089$ $-6.30903720856-5.06027317047-3.8333671093-2.54350805283-1.1426179409$ .35811200737951 .9441709518433 .5853710174565 .3248729705816 .989057064056 8.4008827209479 .86576080322311 .5806999206513 .647390365616 .22657966614 19.1107692718522 .1644496917725 .3086109161428 .5182399749831 .46917915344 33.8848190307635 .9450912475637 .8183403015139 .3850288391140 .48666000366 41.4345283508342 .6672897338943 .831748962444 .6518402099645 .32775878906 45.7130699157746 .4787712097248 .1231193542550 .446990966853 .47937011719 56.4804306030358 .6464195251560 .1946792602561 .0145683288661 .69388961792 63.067939758364 .698806762766 .4911804199268 .2435531616269 .76167297363 71.0702362060572 .1675262451273 .070449829173 .7683792114374 .30832672119 74.6474914550874 .8564910888774 .9426803588974 .9512100219774 .98039245605 75.0065917968875 .0816497802775 .1504516601675 .2078475952175 .24514770508 75.2366409301875 .1836166381875 .0426101684674 .851707458574 .62375640869 74.4293670654374 .3076705932674 .3856735229574 .7108535766675 .34915924072 76.3048629760777 .4106903076278 .5736465454179 .5386962890680 .1647567749 80.5279388427780 .7085418701280 .7962570190480 .8813400268680 .93715667725 80.9523086547980 .9011764526480 .7345428466880 .4440383911179 .98121643066 79.1660537719777 .9615173339876 .697967529375 .8154220581175 .4528427124 75.5882186889675 .9710464477576 .1729278564576 .2721099853576 .29815673828 76.204238891676 .0401229858475 .7652664184675 .419776916574 .92384338379 74.15099334717 73.31488037109 72.36057281494 71.79522705078 71.80905151367 72.3643112182674 .0194931030375 .1556091308674 .2038879394572 .55039978027 71.1005172729569 .6708526611368 .538787841867 .0214691162164 .69207000732 
61.3579902648956 .2278709411651 .1294097900447 .176059722943 .757671356241 $2.6559019088751 .8748719692231 .533285021782-.131726995111-1.57727694511$ $-2.55834102631-3.3124859333-3.96430492401-4.5805478096-5.51785182953$ $-6.29564380646-6.73797178268-6.86975383759-5.7489991188-4.98318195343$ $-4.78881597519-4.87608385086-4.97538900375-5.01665401459-4.78484678268$ $-4.45463895798-4.05563402176-3.581594944-3.03426098824-2.33238792419$ $-1.4570800066-.527054011822 .37086799740791 .1330250501631 .758167028427$ 2.1177520751952 .1474080085751 .896911025047 .95256197452551 .013844013214 4.248661041267 .7657799720768 .8732805252089 .7029371261611 .69328022003 13.2138595581114 .8091697692917 .7472591400125 .5367507934636 .62203979492 53.2293395996196 .03263092041108 .76869964698 .8702468872190 .3971786499 90.3244171142690 .8595275878987 .7849731445372 .8434219360472 .91536712646 65.1906661987359 .7946090698256 .9103317260755 .686519622854 .86494064331 55.205780029357 .1090812683159 .9621582031263 .7944107055766 .17579650879 63.8857307434160 .3330688476658 .3939895629956 .8197898864755 .27053070068 53.8684883117752 .5032501220751 .2035903930749 .9548492431648 .76662063599 47.6433296203646 .6323585510345 .7520294189545 .1074905395544 .74565887451 44.6873016357444 .9440994262745 .618858337446 .887130737348 .53207015991 50.3597297668552 .3541908264254 .435268402156 .5600013732958 .70848083496 60.6503105163662 .1041793823263 .3267593383864 .5229873657265 .64163208008 66.697967529367 .6980667114368 .6408462524469 .5377807617270 .39405822754 71.2148437572 .0042037963972 .7655868530373 .5038833618274 .22141265869 74.9228210449275 .6099472045976 .2865982055776 .9541320800877 .61517333984 78.2706069946378 .9219818115279 .5698394775480 .2149276733480 .85765075684 81.4983367919982 .1373596191482 .7748794555783 .41127777184 .04676055908 84.68164062585 .3161773681685 .9507064819386 .5854797363387 .22077941895 87.8569030761788 .4940338134889 .1324234008889 .7722396850690 .4136505127 91.0567474365291 .7016220092892 .3482971191492 .9968185424893 .64713287354 94.2992019653394 .9529418945395 .6082229614396 .264923095796 .92283630371 97.5818023681698 .2415695190498 .9019012451299 .5625100 .2230987549100 .8833007812 101.5427017212102 .2011032104102 .8579025269103 .5129013062104 .1654968262 104.8152999878105 .462097168106 .1055984497106 .7449035645107 .3805007935 108.011100769 601.2797851562596 .0598144531590 .8601074219585 .6896972656580 .5296020508 575.3765869141570 .2263793945565 .07421875559 .9149780273554 .7432861328 549.5540161133544 .3408203125539 .0994262695533 .8234863281528 .5098266602 523.1530151367517 .7512207031512 .3002929688506 .8004150391501 .2488098145 495.6480102539489 .9973144531484 .3013000488478 .5620117188472 .7865905762 466.9796142578461 .1513061523455 .3096923828449 .4664001465443 .6231994629 437.837097168432 .1500854492426 .6120910645421 .2685852051416 .1588134766 411.3104858398406 .7909851074402 .6473999023398 .9457092285395 .7406005859 393.0663146973 390.9771118164389.4125061035 388.4139099121 387.6925964355 387.1319885254386 .5874938965386 .0520935059386 .050201416386 .7283935547 387.5672912598387 .9866027832387 .1018066406383 .6859130859379 .6115112305 377.2033081055373 .0396118164364 .0255126953352 .0729064941337 .3027038574 322.8366088867311 .6552124023303 .4989013672299 .1731872559296 .6073913574 
294.3558959961292 .5021057129290 .4536132812288 .0210876465284 .8482971191 281.400604248278 .0469970703275 .0325012207272 .4251098633270 .175201416 268.6994934082266 .9410095215263 .737701416259 .9556884766256 .3635864258 252.2350006104246 .9833984375240 .7973022461234 .0773925781223 .899597168 208.3878936768 186.2617034912 154.9275054932 122.595001220795.48719787598 $68.4951477050840 .329990386969 .283341407776-2.86979007721-14.0926103592$ $-22.188949585-27.7661590576-31.1122608185-32.5793991089-32.4146995544$ $-30.9971809387-28.6827507019-25.7831401825-22.70952034-19.5908508301$ $-16.7472896576-14.1654901505-12.0008602142-10.1869897842-8.70481586456$ $-7.46493196487-6.33800792694-5.26273488998-4.17013978958-3.03205704689$ $-1.79784202576-.4535660147671 .0289549827582 .6477689743044 .412603855133$ 6.1149058341987 .6706638336189 .26718521118210 .9051504135112 .84039974213 15.1969099044817 .8528003692620 .8645591735824 .1175098419227 .57510948181 30.7247009277333 .051200866734 .9460601806636 .6969490051338 .19160079956 39.3241081237840 .3261184692441 .449501037642 .3775291442942 .97494888306 43.3349418640143 .5797805786144 .10044097945 .1359596252446 .78189086914 48.9622993469251 .436241149953 .8800811767655 .9450988769557 .3136100769 58.5440292358460 .258930206362 .2759895324764 .5942764282266 .73087310791 68.1940383911169 .3378372192470 .4445800781271 .3969802856472 .15663909912 72.7249832153373 .0210876464873 .1439285278373 .1266632080173 .02069854736 72.9588928222772 .9263610839872 .9669799804772 .9966964721772 .97411346436 72.9212493896572 .8347167968872 .6880874633872 .4177780151472 .07398986816 71.7079467773471 .3534088134871 .0224533081170 .9391098022571 .30288696289 71.9784469604572 .8572616577173 .7768325805774 .6729431152375 .49671936035 76.1480712890676 .6713333129976 .9943923950277 .1633300781277 .28618621826 77.3377990722777 .3223419189577 .2123718261776 .9836425781276 .50792694092 75.7357330322374 .6598968505973 .1618728637771 .9312896728571 .55261230469 71.5082015991271 .5231933593871 .5534591674871 .4701919555771 .39582061768 71.2690429687571 .1009368896571 .018272399970 .9185867309670 .77059936523 70.5507507324270 .1102828979569 .6121826171969 .0573120117268 .72653198242 68.8024215698269 .175506591870 .0119705200270 .241210937569 .02612304688 67.2201690673865 .3867034912163 .8273696899462 .9164085388261 .31256103516 58.0047187805253 .3949890136747 .7469100952142 .4831504821839 .019428253173530 $1.690417051315-.766350984573-1.38487994671-2.16182899475-3.12307906151$ $-4.06984806061-5.13458490372-6.00690507889-6.79678916931-7.65280914307$ $-8.253947258-8.25196838379-7.41479682922-5.72737312317-4.62638998032$ $-4.90059280396-5.67533016205-6.19769191742-6.57639503479-6.67634105682$ $-6.59431695938-6.3587231636-6.00394582748-5.63606119156-5.07675886154$ $-4.12947416306-3.08146500587-2.19590592384-1.46528697014-.928969025612$ $-.580618977547-.359872996807-.507863998413-1.41320502758-1.61445403099$ .39552599191672 .7320029735573 .7224740982064 .4260139465335 .788829803467 8.00668621063211 .3446903228813 .3764801025415 .8482999801620 .83325958252 29.9759502410951 .6309890747191 .258651733497 .0857009887795 .85513305664 93.2981567382895 .1562728881893 .8019638061591 .3990936279383 .31684875488 76.7522888183671 .265907287667 .9626235961966 .0538330078165 .79913330078 66.5206832885767 .3808364868268 .4698104858470 .2205963134870 .83408355713 
68.2135314941464 .4663467407261 .3262710571358 .6491699218856 .70092010498 55.0936393737853 .4638290405351 .8966789245650 .4067611694349 .01356124878 47.7334594726646 .606029510545 .6539115905844 .9429893493744 .52244949341 44.3923110961944 .5736999511745 .1529998779346 .2436599731447 .70386123657 49.4223098754951 .3371391296453 .370529174855 .4692382812557 .54819869995 59.4503707885760 .9904098510762 .3210983276463 .5707511901964 .7318572998 65.8139572143666 .8258438110467 .7752838134868 .6697235107469 .51989746094 70.3304672241271 .1083679199271 .8569564819372 .5827102661173 .28807830811 73.9780273437574 .6545028686575 .3211822509875 .9794387817476 .63181304932 77.2790832519577 .9227905273478 .5633621215879 .2016220092879 .83780670166 80.4723510742281 .1054611206181 .7374191284282 .368438720782 .99883270264 83.6287765502984 .2586135864384 .8885421752985 .5188674926886 .1498336792 86.78170776367 87.41468048096 88.04898834229 88.68475341797 89.32216644287 89.9612808227590 .6022109985491 .2449417114391 .8895187377992 .53588104248 93.1839981079193 .8337631225694 .4850616455195 .1377334594795 .79163360596 96.4465332031297 .1022033691497 .758377075298 .4148178100699 .07118225098 99.7271270752100 .3823013306101 .0363006592101 .6886978149102 .3392028809 102.9872970581103 .632598877104 .2748031616104 .9134979248105 .548500061 106.1759033203106 .7988967896 600.8508300781595 .6177978516590 .3889160156585 .1781005859579 .9765014648 574.7813720703569 .5889892578564 .3961791992559 .1984863281553 .9918823242 548.7719726562543 .5341186523538 .274597168532 .9885864258527 .6740722656 522.3270263672516 .9470214844511 .5310058594506 .0808105469500 .5950012207 495.0776062012489 .5291137695483 .9556884766478 .3601074219472 .7511901855 467.133605957461 .5192871094455 .9158935547450 .3377990723444 .783203125 439.3146972656433 .9678039551428 .7972106934423 .8367004395419 .1317138672 414.6864013672410 .595489502406 .8803100586403 .6495056152400 .9172973633 398.8075866699397 .30859375396 .5885009766396 .6871948242397 .7647094727 400.5028991699403 .192199707403 .8417053223404 .0523986816404 .8861083984 405.708404541406 .6754150391407 .2594909668406 .7721862793405 .200012207 401.9977111816395 .6007080078384 .7615966797370 .1686096191353 .108795166 335.8653869629321 .0961914062309 .9155883789304 .0701904297300 .824798584 297.4789123535294 .8732910156292 .683013916290 .5927124023287 .9841003418 285.3107910156282 .8880004883280 .7452087402278 .8778991699277 .3176879883 276.5537109375275 .4201049805272 .6227111816269 .2416992188266 .1821899414 262.4483947754257 .1586914062250 .9432983398244 .9985961914236 .3090057373 224.0144958496203 .6578979492168 .7467041016130 .451095581199 .18456268311 $69.3586425781239 .102828979492 .252784967422-9.93744659424-21.2470207214$ -29.0938491821 -34.5410499573 -37.5279083252 -38.465839386 -37.4886207581 -35.1651496887 -31.8113899231 -27.9299106598 -23.9874801636 -20.1118793488 -16.713350296 -13.7367095947 -11.4086198807 -9.59612846375 -8.18558502197 $-7.08856296539-6.12651395798-5.24288082123-4.33000183105-3.36930894852$ $-2.32819604874-1.16051995754 .15986999869351 .6731779575353 .352602005005$ 5.2028799057017 .1590299606328 .95920276641810 .4924497604412 .03470993042 13.9672899246216 .3629608154319 .2648792266822 .5284404754626 .13962936401 29.4667892456131 .7977504730233 .6287918090835 .3295783996636 .78178024292 
37.9942092895539 .0321998596239 .9724807739340 .7013816833541 .26485061646 41.6922187805242 .132808685342 .6824417114343 .2184906005944 .04423904419 45.0140800476146 .4360389709548 .6766395568851 .0294914245652 .9012298584 54.7632102966356 .8952713012759 .2260589599661 .9996604919464 .47686004639 65.9380035400467 .0238037109468 .2292709350669 .3272323608470 .25109863281 70.8922195434671 .1264724731471 .0942993164170 .9413299560570 .74738311768 70.6199874877970 .5628128051870 .6226730346770 .6628799438570 .63403320312 70.5622329711970 .411407470770 .1873779296969 .8070068359469 .33100128174 68.8622512817468 .4086685180767 .9095306396567 .6741790771567 .99297332764 68.6015777587969 .2839508056670 .0151901245170 .7601394653371 .48223876953 72.1550827026472 .7338333129973 .1506500244173 .4306564331173 .62496185303 73.7102508544973 .6844024658273 .513397216873 .2070388793972 .64138031006 71.7737731933670 .63950347969 .0418014526467 .7741622924867 .70639801025 67.9526367187567 .8658828735467 .6601409912167 .3034820556666 .88414001465 66.4613265991266 .1793823242266 .2024536132866 .3615417480566 .47026062012 66.5093002319366 .3414764404366 .1001815795965 .7696304321365 .47557830811 65.3351821899465 .1415710449264 .8142700195364 .1354217529362 .98283004761 61.3170318603559 .2893486022957 .2514190673856 .0598793029854 .29685974121 50.1403999328644 .969589233439 .3232002258334 .124580383330 .5625095367422 $6.096000194553 .14030014 \mathrm{e}-02$-2.63955307007 -3.44828391075 -3.95300889015 $-4.79927206039-5.9764380455-7.24866485596-8.26945114136-9.00920200348$ $-9.94937038422-10.284529686-9.96518039703-8.41927719116-6.35992193222$ $-5.00626993179-5.6819729805-7.00338315964-7.81988286972-8.43983364105$ $-8.73636817932-8.77810001373-8.62821960449-8.33237171173-8.07159900665$ $-7.58227777481-6.53932189941-5.38072109222-4.51116800308-3.8125629425$ -3.32956600189 -2.98585295677 -2.52848792076 -2.35483908653 -2.91668891907 -3.3086309433 -2.778881073 -1.91821801662 -1.07128596306 -.142704993486 1.1055569648743 .0711529254916 .88471508026111 .1851196289110 .23789978027 11.5492897033718 .0412807464631 .9132404327454 .6798095703178 .36446380615 94.4355163574297 .0081710815498 .1396865844797 .9109268188596 .30332183838 91.4376525878985 .3100128173879 .2347335815475 .5578536987373 .52970123291 73.9402236938575 .1167526245175 .114257812574 .8043289184674 .61772155762 73.5756225585971 .0444564819367 .5956878662163 .6631698608460 .10879135132 57.7912597656256 .040458679254 .1489295959552 .3648490905850 .67752075195 49.1358299255447 .7412986755446 .5435905456545 .532508850144 .774269104 44.2942008972244 .1110610961944 .2547111511244 .7495994567945 .63970184326 46.9008216857948 .4989318847750 .3450508117752 .3218383789154 .34563827515 56.2991294860858 .131000518859 .7705001831161 .2462692260762 .58644104004 63.8036308288664 .9173202514665 .9429931640666 .8973388671967 .79174804688 68.6348037719769 .4343032836970 .1998901367270 .935272216871 .6490020752 72.3429336547973 .0227127075273 .6899337768674 .3481292724674 .99865722656 75.6436691284276 .2841415405376 .9212570190477 .5556869506878 .18797302246 78.8185195922979 .4476165771580 .0755767822380 .7025527954181 .32885742188 81.9546737670982 .5802612304783 .2058334350683 .8316726684684 .45799255371 85.0850677490285 .7131195068486 .3423385620186 .9729232788187 .60502624512 88.2387771606488 .8742675781289 .5115585327190 .150672912690 .79160308838 
91.43430328369 92.0787277221792.7247772216893.3723373413194.02124786377 94.6713333129995 .3223800659295 .9741592407296 .6264190673897 .27886962891 97.9312133789198 .5830612182699 .234100341899 .88390350342100 .5320968628 101.1782989502101 .8219985962102 .4628982544103 .1006011963103 .7348022461 104.3647003174104 .9908981323105 .6118011475

600.4146118164595 .1380004883589 .8726806641584 .6259155273579 .3862304688 574.1520996094568 .921081543563 .6909179688558 .4583129883553 .2200927734 547.9733276367542 .7139282227537 .4398193359532 .1469116211526 .834777832 521.5001831055516 .1442871094510 .7655944824505 .3669128418499 .9483947754 494.5152893066489 .0696105957483 .6184997559478 .1661987305472 .7221069336 467.292388916461 .888885498456 .520904541451 .2009887695445 .9314880371 440.7691955566435 .7578125430 .9317016602426 .3187866211421 .9562072754 417.859588623414 .1093139648410 .7488098145407 .8678894043405 .4979858398 403.7849121094402 .7746887207402 .6712036133403 .5127868652405 .7247009277 409.611114502413 .8561096191417 .592010498420 .121307373420 .5953979492 420.4349060059421 .1845092773422 .2102050781422 .816986084422 .8547973633 422.6018066406418 .3652954102407 .253692627391 .2354125977371 .6913146973 351.3067932129333 .3052062988319 .0768127441310 .6062011719305 .2049865723 300.3953857422296 .795501709294 .4353942871292 .6751098633290 .5476989746 288.4822998047286 .6243896484285 .0213012695283 .6818847656282 .5833129883 281.9175109863280 .9794921875279 .0288085938276 .6465148926274 .3646850586 271.3207092285266 .7764892578261 .2087097168255 .2223968506247 .4010925293 237.2987060547218 .5863952637184 .6260986328143 .7760009766102 .5330963135 66.1889190673816 .4037399292 -2.91941690445 -16.5400905609 -26.5105495453 $-34.7232589722-40.4550018311-43.3343582153-43.7788391113-42.1004600525$ -38.8372802734 -34.4402198792 -29.5188808441 -24.7294406891 -20.143289566 $-16.1749992371-12.8370800018-10.421380043-8.70198154449-7.44785118103$ $-6.5439581871-5.77543497086-5.09254789352-4.38590908051-3.63686990738$ -2.80314493179-1.85572302341 -.774886012077.5183519721031 2.039496898651 4.0361418724066 .7109909057628 .9987192153939 .96608829498310 .67821025848 12.2597599029514 .5087995529217 .26067924520 .4132995605523 .89022064209 27.1925792694129 .8221397399931 .9664096832333 .7298393249535 .21356964111 36.515071868937 .6215286254938 .556919097939 .2872009277339 .82654953003 40.3128089904840 .9096794128441 .4786186218341 .8972892761242 .2950592041 42.7805595397943 .6006889343344 .920898437546 .6525497436548 .49826812744 50.5946388244652 .9952201843355 .5609397888258 .3208007812560 .80223083496 62.5683288574264 .01450347965 .4344482421966 .7822036743268 .09535217285 68.9727401733468 .9762496948268 .6025314331168 .3070907592868 .05406951904 67.906806945867 .888816833568 .0173721313568 .1254577636768 .1916885376 68.1827087402367 .9776992797967 .664756774967 .2012634277366 .62329864502 66.0873794555765 .5924682617265 .1191864013764 .8586273193464 .98309326172 65.3329315185565 .7603530883866 .2735671997166 .8721084594767 .52227783203 68.2062683105568 .8396835327169 .327980041569 .7019882202169 .96533966064 70.1010665893670 .0887069702169 .9090499877969 .5592498779368 .99266815186 68.1906127929767 .2164993286166 .0557327270565 .155830383365 .00785827637 65.04678344727 64.7716064453164.30097961426 63.63814926147 62.82564926147 
61.885879516661 .3000106811561 .5846405029362 .1687507629462 .54375076294 62.7734603881862 .7742996215862 .6297111511262 .3461112976161 .92353057861 61.4299201965360 .6330490112359 .4708900451758 .2379608154356 .96086120605 55.2335891723652 .7690086364750 .0076408386247 .8314018249545 .5433807373 42.2003097534238 .1808700561533 .3673515319828 .5145301818824 .4399299621618 $2.418610095978-2.43870902061-4.03243398666-4.7544708252-5.25319719315$ $-6.30012989044-7.75347995758-9.54375267029-10.7297401428-11.6873598099$ $-12.3112697601-12.3327503204-11.6513700485-10.2098197937-8.59675884247$ -7.59692621231 -8.04250240326 -9.09285354614-10.0041799545 -10.72356987 -11.0188903809-11.0317401886 -10.8544597626-10.5076398849-10.0531797409 -9.39789581299-8.3925075531 -7.32147884369-6.51848983765 -5.89715003967 $-5.49068498611-5.20437479019-4.88290786743-4.74230194092-5.05853223801$ $-5.4860701561-5.44886398315-5.08994007111-4.43396615982-3.43014001846$ $-2.18164896965-.4040279984472 .5279049873354 .9125537872315 .48956823349$ 6.95552492141710 .2395200729418 .4382705688530 .8203392028856 .0987701416 75.9823303222792 .0101318359495 .4163665771596 .6378479003996 .12509155273 93.8824996948289 .3939285278385 .4027786254978 .8223724365277 .26849365234 77.3605728149478 .1602783203178 .5093078613378 .3068313598677 .60079193115 76.0083465576272 .8043365478568 .8296966552764 .8786926269561 .26541900635 58.645229339656 .5924491882354 .5284118652352 .5459899902350 .72484970093 49.0844306945847 .619979858446 .3712196350145 .3505096435544 .57844161987 44.0718193054243 .8483695983943 .9368591308644 .3152389526444 .97721862793 46.0179290771547 .5561790466349 .3838882446351 .2978210449253 .23896026611 55.115100860656 .9185905456558 .5900001525960 .1469192504961 .57585906982 62.8621482849164 .0049285888765 .0412368774466 .0042037963966 .90012359619 67.736747741768 .524002075269 .2767562866269 .9989089965870 .7007598877 71.3843231201272 .0551605224672 .7147369384873 .3661575317474 .01053619385 74.6498794555775 .2848892211975 .9168395996176 .5461578369177 .17359924316 77.799392700278 .4239501953179 .0474624633879 .6702194213980 .2924118042 80.9142837524481 .5360336303782 .1579132080182 .7801208496183 .40294647217 84.0265731811584 .651229858485 .2770919799885 .9043731689586 .53317260742 87.163650512787 .7958297729588 .429832458589 .0656127929789 .70320129395 90.3425369262790 .9835662841891 .6261596679792 .270233154392 .9156036377 93.5621109008894 .2095336914194 .8576202392695 .5061492919996 .15480804443 96.803298950297 .4512481689598 .0983200073298 .7441024780399 .38820648193 100.0301971436100 .6697998047101 .3063964844101 .9396972656102 .5696029663 103.1955032349103 .8135986328104 .4271011353

599.9074707031594 .6151733398589 .3242797852584 .0435791016578 .7686767578 573.4985961914568 .2318725586562 .9672241211557 .7025756836552 .4357299805 547.1646728516541 .8864135742536 .5999755859531 .3024291992525 .9943847656 520.6735839844515 .3430786133510 .0018005371504 .6547851562499 .3027038574 493.9527893066488 .6075134277483 .2763061523477 .9632873535472 .6799926758 467.4324951172462 .2344055176457 .0942077637452 .0274047852447 .0343017578 442.1706848145437 .4755859375432 .9742126465428 .6713867188424 .617401123 420.8113098145417 .3497009277414 .2488098145411 .6318054199409 .4708862305 408.0191040039407 .2620849609407 .5365905762408 .7085876465411 .2464904785 
415.0979919434419 .9071960449426 .104095459430 .8349914551430 .7702026367 429.7997131348430 .6267089844431 .6672973633432 .3629150391432 .3909912109 434.1600036621431 .9696960449421 .0867004395404 .8298034668384 .745300293 363.4894104004344 .2289123535328 .1310119629317 .2690124512309 .740814209 303.4436950684299 .0491027832296 .4059143066294 .7695922852292 .9092102051 291.2922058105289 .7685852051288 .4695129395287 .462890625286 .6184082031 285.8503112793284 .9935913086283 .8439941406282 .4088134766280 .8362121582 278.4970092773274 .8994140625270 .162689209264 .3601989746256 .628112793 248.1085968018231 .7713928223201 .6683959961161 .7725067139111 .4360961914 $64.2761688232425 .86532020569-1.85403704643-19.301399231-29.4311008453$ -38.7958106995 -45.1942596436-48.1648902893-48.4221191406-46.1687698364 $-42.1546096802-36.6613502502-30.6993999481-24.9649200439-19.61536026$ $-15.2234401703-11.6786699295-9.29128646851-7.78645420074-6.70109176636$ -5.99370288849 -5.40657997131-4.89672517776-4.39000797272 -3.83864402771 -3.21272492409 -2.47628593445-1.63688802719-0.57871901989 .7286530137062 2.4844028949745 .3218741416937 .8652768135078 .4259462356578 .803590774536 10.4083499908412 .5707197189315 .1361398696918 .0748405456521 .27895927429 24.4739608764627 .4073200225829 .9375896453931 .8765907287633 .46252059937 34.884490966836 .0899009704637 .1020317077637 .9255981445338 .56140136719 39.175220489539 .9750709533740 .6410713195840 .998600006141 .20330047607 41.4414787292541 .8323402404842 .2374610900943 .1001091003444 .63293075562 46.6421890258849 .0130882263251 .5768890380954 .1410102844256 .56438064575 58.6863594055260 .5481109619162 .2251396179263 .7463417053265 .35501861572 66.4129180908266 .2179031372165 .6096267700265 .2874374389665 .05621337891 64.9302062988364 .9268798828165 .0625305175865 .3235397338965 .67244720459 65.8368682861365 .5653991699265 .0426406860464 .4571380615263 .86703109741 63.3441009521562 .8870391845762 .5115585327162 .2627296447862 .16080856323 62.2025108337462 .3204002380462 .5889015197863 .0279998779363 .57558822632 64.2732620239364 .9668884277365 .5379104614366 .0266723632866 .36563873291 66.548271179266 .54994964666 .3614425659265 .9970779418965 .46846008301 64.7996063232464 .1090469360463 .5004997253463 .0526809692462 .84590148926 62.5737800598162 .0381393432661 .2499313354560 .284599304259 .21575164795 57.9038696289157 .0806884765657 .5731887817458 .4664115905858 .98881149292 59.3425598144559 .413089752259 .2526016235458 .8886985778858 .23514938354 57.373180389456 .1035499572854 .428009033252 .4699592590350 .6283493042 48.637279510545 .9502105712943 .2148513793940 .5616798400937 .865650177 $35.3804893493732 .4705085754428 .45660972595262214-1.59879899025$-3.51584506035 $-4.70281791687-5.64784383774-6.51753520966-7.69459915161-9.21907329559$ -11.3438901901 -13.1582899094-14.4018201828 -14.9168796539-14.6272497177 -13.6583099365 -12.5754699707 -11.6109695435 -11.0644302368 -11.172129631 $-11.705160141-12.4732999802-13.1695995331-13.380490303-13.3128900528$ $-13.1075401306-12.6497001648-11.9514398575-11.0533504486-10.012260437$ -9.0624666214 -8.3677854538 -7.89074993134 -7.57687520981 -7.36889076233 $-7.25169706345-7.25404596329-7.42706012726-7.67511796951-7.74577999115$ $-7.5543551445-6.95183801651-5.95934200287-4.67556905746-3.21172595024$ -1.32657897472 -4.8709001e-02 .3299480080605 1.7057609558115.310783863068 
10.937080383319 .3649005889931 .7542991638254 .6197891235475 .11695098877 86.6860580444389 .9943008422991 .4274673461992 .5350875854588 .69631958008 85.5688629150477 .9451828002977 .3645629882877 .165603637777 .53024291992 78.254463195878 .5562133789177 .7625198364375 .9144210815472 .19915771484 68.0040664672964 .7091827392661 .6490783691458 .9814796447856 .63660812378 54.3600997924852 .339981079150 .4821510314948 .8493003845247 .37316894531 46.1289291381845 .1165618896544 .3587913513243 .8402214050343 .59053039551 43.6298103332543 .9267196655344 .4102401733445 .2721099853546 .74171066284 48.5138816833550 .323520660452 .1758804321353 .987300872855 .75548171997 57.4388008117759 .0335998535260 .5284309387261 .8817596435563 .06262969971 64.1203079223665 .0957870483465 .9928512573266 .8213195800867 .59364318848 68.3334579467869 .0431976318469 .7350234985470 .410438537671 .07456207275 71.7288131713972 .3753662109473 .0156097412173 .6507568359474 .28191375732 74.9098587036175 .5353393554776 .1588363647576 .7808609008877 .40162658691 78.0215225219778 .6407012939579 .2594604492279 .8779525756880 .49645233154 81.1151428222781 .7342529296982 .3539962768682 .9746398925883 .59632873535 84.2192687988384 .8436203002985 .4694976806686 .0970306396586 .7262802124 87.35729217529 87.99006652832 88.62461853027 89.2608795166 89.89877319336 90.5381774902391 .1790008544991 .8210830688592 .4642333984493 .10822296143 93.7528533935594 .3978271484495 .0429000854595 .6877136230596 .33193206787 96.9751968383897 .6171188354598 .2573165893698 .8953399658299 .53082275391 100.1632995605100 .7925033569101 .4180984497102 .0391998291102 .6564025879 103.2683029175

599.3952026367 594.0723266602 588.7520751953 583.4403076172 578.1328125 572.8292236328567 .5291748047562 .232421875556 .9379882812551 .6445922852 546.3511962891541 .0557250977535 .7581787109530 .4567260742525 .1530151367 519.8463134766514 .5401000977509 .2351989746503 .9375498 .6494140625493 .378692627 488.1297912598482 .9125976562477 .7331848145472 .6030883789467 .5303039551 462.5280151367457 .6064147949452 .779510498448 .0538024902443 .4707946777 439.0658874512434 .849395752430 .8291015625427 .033996582423 .4750061035 420.2145080566417 .2791137695414 .750213623412 .6359863281411 .124786377 410.2630004883410 .3053894043411 .287689209413 .4195861816416 .7202148438 421.2135925293427 .1817016602431 .6315917969431 .0934143066430 .1214904785 432.9509887695435 .5524902344434 .7674865723432 .3359985352430 .6228942871 425.7532043457414 .0801086426398 .6264038086382 .354309082365 .2463989258 348.570098877333 .6773071289322 .3174133301313 .6459960938307 .1418151855 302.563293457299 .353302002297 .2063903809295 .4361877441294 .0284118652 292.6600952148291 .4934997559290 .6279907227289 .8992919922289 .1866149902 288.5132141113287 .7113952637286 .7264099121285 .4122924805283 .4411010742 280.5591125488276 .7521972656272 .1729125977265 .842590332257 .8399963379 243.6472930908219 .2628936768182 .4272003174130 .039199829178 .75617980957 $38.188240051275 .22517490387-15.7302103043-29.6159896851-40.7265090942$ $-48.0177688599-51.6414718628-51.9818611145-49.5039787292-44.8222694397$ -38.39012146 -31.3594799042 -24.5925598145 -18.4125900269-13.80148983-10.3051099777 $-8.06627845764-6.84780788422-6.02415418625-5.51481723785-5.11504077911$ $-4.77059221268-4.41053199768-4.02493190765-3.59003901482-3.07388901711$ 
-2.429666996 -1.64874303341 -.720282018185.3536989986897 1.569285035133 2.940829038624 .506554126746 .2663807868968 .27385520935110 .50174999237 12.9549303054815 .6700897216818 .7008399963421 .8318099975624 .80913925171 27.4966793060329 .6928501129231 .533340454133 .1218185424834 .47916030884 35.6260604858436 .6081390380937 .4865188598638 .3937110900939 .52104187012 40.3774604797440 .5223884582540 .3843193054240 .3441314697340 .36365127563 40.4822998046940 .9753494262742 .0831604003943 .6624603271545 .47660064697 47.5774917602550 .0402908325252 .5680885314954 .8041992187556 .82851028442 58.5984802246160 .1404991149961 .575618743962 .4670295715362 .37145996094 61.9454994201761 .8083992004461 .7584114074761 .6976394653361 .67055892944 61.667129516662 .0113906860463 .1258697509863 .9018898010363 .23923873901 62.1526489257861 .5039596557661 .0268898010360 .5986213684160 .23122024536 59.9243202209559 .6482315063559 .4027214050359 .196289062559 .02194976807 59.0254096984959 .2331008911159 .6204299926860 .2989311218361 .05731964111 61.7779693603562 .4480705261262 .8897514343363 .1232490539663 .12900161743 62.9326400756862 .5684509277362 .0896797180261 .5307693481461 .05442047119 60.7618408203160 .6291694641160 .8070106506360 .6750717163159 .71839904785 58.4435806274457 .2449302673356 .0923690795954 .9680213928254 .33221817017 54.6626396179255 .3525009155355 .8685188293556 .2181510925356 .26168060303 56.0377197265655 .5374794006354 .6986694335953 .5803489685152 .03134918213 50.047569274947 .3567886352543 .5130691528340 .1437683105538 .92412185669 38.2600212097236 .7909584045434 .66643142731 .5157604217527 .8580493927 $23.6015796661418 .64026069641138-2.3123281002-3.28512597084-5.50441122055$ $-6.41974592209-7.6684718132-9.19875335693-11.0525798798-13.2689800262$ -15.5091495514 -17.1555404663 -17.6585502625 -17.1691093445 -16.2450504303 -15.3338499069-14.667599678 -14.2694702148 -14.3085002899-14.5809698105 -15.0735502243 -15.574549675 -15.7285003662 -15.6594800949-15.4434099197 $-14.9314603806-14.0779399872-12.9741697311-11.6150999069-10.5112600327$ $-10.0959100723-9.95433807373-9.75671577454-9.60443210602-9.54174041748$ $-9.53860092163-9.63624095917-9.76003265381-9.82176303864-9.67290210724$ -9.11118793488 -8.09907245636 -6.59524822235 -4.89972400665 -2.94916701317 -1.628221035 -1.921620965-1.4552090168 1.864135026932 7.636259078979 12.2004404068 20.123949050933 .46958160456 .8250007629472 .7786102294981 .50213623047 85.14624786377 84.83261108398 81.8747329711978.53085327148 72.58560943604 73.3865966796973 .695457458574 .0679321289174 .4789810180774 .37777709961 73.079376220770 .8723373413167 .6249771118264 .4278335571362 .74483108521 61.0347595214858 .3688316345255 .6482696533253 .421180725151 .53226089478 49.8345909118748 .3238410949746 .9619789123545 .78794097944 .81636810303 44.0733718872143 .5795097351143 .3357696533243 .3563308715843 .61600112915 44.0931587219244 .9113311767646 .205490112347 .7795486450249 .45206069946 51.1919097900452 .9274291992254 .6525802612356 .3238105773957 .93291854858 59.4536705017160 .8461608886762 .0776100158763 .1802101135364 .17012786865 65.0680084228565 .8868331909266 .6421279907267 .3672485351668 .06558227539 68.7493133544969 .4192428588970 .0794830322370 .7308120727571 .37500762939 72.012969970772 .645927429273 .2746429443473 .9001007080174 .52284240723 75.1436233520575 .7627182006876 .3806686401476 .9976577758877 .61402893066 
78.2299804687578 .8457565307679 .4615478515680 .0776062011780 .69412231445 81.3113403320381 .9294204711982 .5485992431683 .1690063476683 .79083251953 84.4141616821385 .0391235351685 .6657562255986 .2941436767686 .92421722412 87.5560302734488 .1894836425888 .824501037689 .4609985351690 .09883880615 90.7378387451291 .3778533935592 .0186462402392 .660011291593 .30165100098 93.9432983398494 .5846328735495 .2252883911195 .8649291992296 .50315093994 97.1395568847797 .7737503051898 .4053268432699 .0338516235499 .65897369385 100.2805023193100 .8979034424101 .5074005127102 .1118011475

598.8513183594593 .5095825195588 .1663818359582 .8261108398577 .4882202148 572.1533813477566 .8223266602561 .4954833984556 .1730957031550 .8546142578 545.5399780273540 .2280273438534 .9199829102529 .6143188477524 .3146972656 519.0200805664513 .7368164062508 .4649963379503 .2132873535497 .9838867188 492.7872924805487 .6275024414482 .516998291477 .4614868164472 .4750061035 467.5649108887462 .7467041016458 .0293884277453 .4299926758448 .9560852051 444.6372070312440 .4966125488436 .5398864746432 .7690124512429 .2052001953 425.850189209422 .749786377419 .9041137695417 .3930969238415 .1895141602 413.4760131836412 .2214050293411 .7113952637411 .9324035645413 .1416015625 415.0956115723418 .2331848145422 .7590026855425 .7730102539424 .5360107422 422.7911987305426 .4111022949429 .5710144043426 .7944030762421 .8528137207 416.6622009277408 .8926086426396 .6146850586383 .0144958496372 .0010070801 361.0548095703348 .7022094727336 .6405029297325 .9348144531317 .0891113281 310.9717102051306 .5871887207302 .9117126465300 .3680114746298 .5676879883 297.2309875488295.9388122559294.799987793293.9086914062 293.2965087891 292.5981140137292 .0043029785291 .2590026855290 .2856140137288 .9366149902 287.0950012207284 .7542114258281 .7261047363278 .3717041016273 .2940979004 265.8068847656253 .4151000977235 .332901001205 .5048980713154 .4736022949 100.956398010356 .4410896301319 .32024002075 -7.84937286377 -26.0468006134 -39.7528991699-48.5579605103 -53.3088188171 -54.461730957 -52.2438392639 $-47.3915596008-40.308971405-32.1528091431-23.8849601746-16.8328895569$ -12.1891298294 -9.31910991669 -7.50181484222 -6.44616699219-5.71380090714 $-5.24515914917-4.93741416931-4.67126703262-4.43847799301-4.18597984314$ -3.92477107048 -3.60993003845 -3.14749193192 -2.63060903549-2.08819007874 $-1.70199799538-2.14662289619-1.96292901039 .60604602098463 .767842054367$ 6.1793889999398 .50311946868910 .8777904510513 .3963499069216 .24325942993 19.2277793884322 .1298809051524 .8949203491227 .3513698577929 .46899032593 31.2529792785632 .7432289123534 .0421791076735 .2185707092336 .37113952637 37.5429687538 .931079864539 .9596710205140 .0012893676839 .64614868164 39.4267692565939 .2557411193839 .2690391540539 .595420837440 .29108810425 41.3390998840342 .4707603454644 .008930206346 .2916412353548 .77820968628 50.9705314636252 .971958160454 .7206001281756 .1606407165557 .30936813354 58.0085906982458 .1229705810558 .023849487358 .162670135558 .31158065796 58.3220291137758 .3301010131858 .2290382385358 .5565490722760 .23305892944 61.5098609924360 .5428695678759 .0804595947358 .5098114013758 .17832946777 57.8577499389657 .5971794128457 .3647994995157 .1000595092856 .77838897705 56.4156608581556 .0044288635355 .6716117858955 .504470825255 .68265151978 56.37712097168 57.34096908569 58.26972961426 59.0776100158759.56726074219 
59.7891082763759 .7690696716359 .5412483215359 .1847190856958 .75846099854 58.2979393005457 .9519309997657 .8190193176357 .8535804748558 .33848953247 58.4070091247657 .1939506530855 .6084899902354 .3484497070353 .29415130615 52.5245208740252 .1573295593352 .2530403137252 .6305084228553 .05472183228 53.3451805114753 .2953796386752 .9149284362852 .2462501525951 .2268409729 49.9556999206548 .2152290344246 .0911407470743 .0468902587937 .64477920532 33.2835884094233 .620529174834 .9216613769534 .5571212768632 .85681915283 28.7301692962623 .8243198394818 .9946594238313 .815569877622 .438400030136 $.4451859891415-2.65119791031-3.85144901276-5.50570297241-7.73817300797$ $-9.34115219116-11.0735998154-12.8898801804-15.1297397614-17.5721492767$ $-19.7890605927-20.1183300018-19.6316604614-18.9748897552-18.2451190948$ $-17.7551994324-17.4264698029-17.4228897095-17.5689201355-17.8185691833$ $-18.0786304474-18.1068096161-17.9971809387-17.7768993378-17.2370491028$ $-16.3836708069-15.2585697174-13.6844797134-12.4347896576-12.1771602631$ $-12.2214603424-12.0191402435-11.8273296356-11.7406702042-11.6885204315$ $-11.7031497955-11.7121601105-11.7040100098-11.5084295273-10.9863901138$ $-10.0155496597-8.38913154602-6.51391220093-4.20262289047-2.56587505341$ -3.00687599182-3.03894996643 -6.4176999e-02 3.969786882401 6.837248802185 12.0300302505520 .4967594146728 .9198894500745 .0076103210466 .81743621826 71.6260528564571 .3467102050869 .5833969116264 .7301101684664 .58918762207 66.9411773681667 .9586410522568 .5249633789168 .6552429199268 .00846862793 66.1575698852563 .5998802185160 .6905784606958 .5184288024958 .53696060181 58.6237907409756 .5015182495153 .850589752251 .9873695373550 .3787612915 48.9106216430747 .6147308349646 .4136695861845 .371791839644 .46805953979 43.7690391540543 .3095207214443 .087329864543 .1023902893143 .36507034302 43.8894309997644 .696430206345 .806781768847 .1535911560148 .66373062134 50.2832794189551 .9347190856953 .6045188903855 .2416915893656 .83666992188 58.3568801879959 .7783889770561 .0735397338962 .2258110046463 .22861099243 64.1110229492264 .9129867553765 .6562423706166 .3723373413167 .06461334229 67.7444763183668 .4127120971769 .0717468261769 .7229537963970 .36666870117 71.0044097900471 .6365585327172 .264373779372 .8884429931673 .50964355469 74.1285629272574 .7457199096775 .3615722656275 .9764633178776 .5906829834 77.2044906616277 .8181228637778 .4318084716879 .04575347979 .66018676758 80.2753067016680 .8913116455181 .508377075282 .126678466882 .74635314941 83.3675231933683 .9902572631884 .6146316528385 .2406768798885 .86839294434 86.4977264404387 .1286468505987 .7610778808688 .3949127197389 .0299911499 89.6661834716890 .3032684326290 .9410705566491 .5793609619192 .21785736084 92.8562698364393 .4942932128994 .131553649994 .7677307128995 .40241241455 96.0352172851696 .6657180786197 .293533325297 .9182205200298 .53943634033 99.1569671630999 .76992034912100 .3787994385100 .9822006226

598.3043212891592 .9434204102587 .5770874023582 .2094726562576 .8430786133 571.4788818359566 .1182861328560 .762878418555 .4135742188550 .0709228516 544.7354736328539 .4069824219534 .0875244141528 .7767944336523 .4786987305 518.1942138672512 .9293823242507 .686706543502 .4749145508497 .2980957031 492.1669921875487 .087890625482 .0729980469477 .1304016113472 .2738952637 467.5130004883462 .862701416458 .3338012695453 .9426879883449 .7030944824 
445.6268920898441 .7280883789438 .0029907227434 .4509887695431 .0776977539 427.8877868652424 .8861083984422 .0728149414419 .4684143066417 .0667114258 414.9320983887413 .0657043457411 .5809936523410 .4837036133409 .887298584 409.736114502410 .8320922852413 .7673034668415 .129486084411 .7448120117 407.1982116699405 .4717102051403 .9942016602400 .6091918945396 .3012084961 392.6051940918386 .765411377375 .4410095215364 .3588867188357 .9284973145 352.2676086426344 .2391967773335 .2969970703326 .5957946777318 .9000854492 313.5198059082309 .4429931641306 .3005065918304 .1695861816302 .566986084 301.2943115234300 .0806884766298 .878692627297 .8008117676297 .0645141602 296.4431152344295 .8410949707294 .8399047852293 .5433959961292 .0960083008 290.3703918457288 .2532958984285 .6636047363282 .4975891113278 .0989990234 272.3761901855263 .7239074707251 .0252990723227 .5487976074185 .8283996582 $135.851303100683 .4374313354535 .947059631353 .640008926392-18.790309906$ -35.0849609375 -45.8892211914 -52.7179908752 -55.5235710144 -54.3911895752 $-49.9092597961-42.685459137-33.4159317017$-22.5761604309 -13.5767402649 $-10.1315603256-9.09263134003-7.89631986618-6.90776395798-6.02880811691$ $-5.36714506149-4.97153806686-4.69571399689-4.51223087311-4.37516212463$ $-4.23901081085-4.09285783768-3.82516288757-3.51508998871-3.18798089027$ -3.04980611801 -3.30339598656-2.84052801132 -.743497014046 2.026108026505 4.4416937828066 .7136211395269 .02369022369411 .4162702560413 .95761013031 16.6612892150919 .5082893371622 .3784999847425 .0842208862327 .47126960754 29.344659805330 .8915996551532 .2995491027833 .624580383334 .94816970825 36.2577514648437 .6040496826238 .6207084655838 .9852294921938 .91651916504 38.6128997802738 .280410766638 .167690277138 .2874717712438 .72459030151 39.4036598205640 .2674903869641 .5210189819343 .3435211181645 .40394973755 47.32791137695 49.1336898803750.7637100219752.11598968506 53.13541030884 53.8361511230554 .1461105346754 .3274612426854 .5769805908254 .7758102417 54.8890609741254 .9801406860455 .0476303100655 .4565505981456 .65201187134 57.518688201956 .9693603515656 .020919799855 .5574417114355 .30144119263 55.108261108454 .9599800109954 .8413200378454 .6497192382854 .34904098511 53.9229316711453 .3230209350652 .6188697814951 .7591400146551 .44863128662 52.5121612548854 .0340003967355 .1722793579156 .0323295593356 .47566986084 56.597518920956 .4777603149456 .1703987121655 .7692413330155 .33504104614 54.9215087890654 .6225318908754 .5103988647554 .5387001037654 .80350112915 54.7177200317453 .7593383789152 .5018310546951 .4116401672450 .54803085327 49.9891090393149 .7092704772949 .7806701660250 .0681304931650 .54481887817 50.8630485534750 .5986099243249 .9621009826749 .1188201904347 .99493026733 46.6044692993244 .8326988220242 .6613197326739 .7328109741235 .49448013306 32.3596687316932 .5895309448233 .4417190551832 .3455886840829 .58527946472 $25.1887702941919 .9939498901414 .680230140692 .438400030136-1.98720097542$ $-6.89046621323-8.5576915741-8.98812961578-9.99074840546-10.9938497543$ $-12.0209999084-13.3740100861-15.0497903824-17.0301895142-19.1090106964$ $-20.6909008026-21.2462291718-21.2737808228-21.2914009094-21.1581192017$ -20.7757701874 -20.4106292725 -20.418970108 -20.5197601318 -20.6407699585 $-20.7324008942-20.6007194519-20.4057998657-20.1440105438-19.6259708405$ $-18.9616298676-18.0695209503-16.7886600494-15.725230217-15.2073802948$ 
-14.8635902405 -14.4456501007 -14.0753803253 -13.8418798447 -13.6788597107 $-13.5828504562-13.5002098083-13.4322004318-13.2372703552-12.76101017$ -11.8803100586 -10.4559297562 -8.74772167206 -6.77696418762 -5.29502820969 $-5.08075094223-4.66273880005-2.57646894455-.3273740112781 .320999979973$ 4.71046304702812 .5907602310217 .9097309112525 .5079097747828 .57991027832 44.4180412292553 .3508796691953 .1211509704650 .1294097900454 .37847900391 58.2123908996660 .3869209289661 .5153884887761 .8058395385761 .05163955688 59.0083007812556 .0632286071852 .0516510009849 .4259681701750 .78004837036 52.7145881652852 .3645591735851 .1116790771549 .9526405334548 .80611038208 47.7078895568846 .6671791076745 .6991500854544 .8254394531244 .06451034546 43.459121704143 .0520095825242 .8526306152342 .8809204101643 .14760971069 43.664340972944 .4132881164645 .406108856246 .5953292846747 .95951080322 49.4546318054251 .0080795288152 .6008491516154 .1859893798855 .75009155273 57.2622299194358 .7146301269560 .0945510864361 .3170585632362 .28572845459 63.1103096008363 .8903198242264 .627098083565 .3420486450266 .03639221191 66.7186889648467 .3893203735468 .0511627197368 .7046127319369 .35051727295 69.9897232055770 .6229476928771 .2510986328171 .8751525878972 .49577331543 73.1138992309673 .7299270629974 .3445587158274 .9580535888775 .57083892822 76.1831436157276 .7952575683677 .4073867797978 .0197830200278 .63262176514 79.2461471557679 .86049652180 .4759063720781 .092491149981 .71042633057 82.3297729492282 .9506607055783 .5730819702184 .197128295984 .82274627686 85.4499435424886 .0786132812586 .7087173461987 .340118408287 .97268676758 88.6062469482489 .2406616210989 .8756866455190 .5111007690491 .1466217041 91.7819824218892 .4168624877993 .050918579193 .6837921142694 .31507873535 94.9444274902395 .5713882446396 .195587158296 .8165969848697 .43406677246 98.0477828979598 .6573104858499 .2586975097799 .85478210449 597.7631225586592 .379699707586 .9921264648581 .6002807617576 .2072753906 570.8151855469565 .426574707560 .0437011719554 .6685180664549 .301574707 543.9453735352538 .599609375533 .2678222656527 .9495239258522 .6508178711 517.371887207512 .1215820312506 .9017944336501 .7233886719496 .5903015137 491.5158996582486 .5054931641481 .5744934082476 .7297973633471 .9883117676 467.3583068848462 .8576049805458 .4959106445454 .2914123535450 .2620849609 446.4034118652442 .7211914062439 .2031860352435 .8489990234432 .6448974609 429.6018066406426 .6798095703423 .8808898926421 .1622009277418 .5239868164 415.9295959473413 .3678894043410 .8301086426408 .287902832405 .7833862305 403.3758850098401 .2720947266400 .9769897461399 .7750854492394 .6929931641 388.4093017578381 .8745117188375 .8870849609372 .1850891113369 .440612793 368.1864929199365 .5574035645356 .4852905273347 .9312133789345 .2185974121 343.4368896484339 .0367126465333 .1924133301326 .5795898438320 .2576904297 315.8815917969312 .800994873310 .762512207309 .2650146484307 .7988891602 306.3475952148305 .4742126465304 .7011108398303 .625302 .8788146973301 .9959106445 300.9495849609299 .1184997559297 .140411377295 .3721923828293 .5282897949 291.4047851562288 .7366943359285 .5281066895281 .6666870117277 .7239074707 271.8887939453263 .4885864258247 .1159973145217 .1970062256175 .8901977539 $116.435096740758 .8845405578620 .99081039429-5.84830188751-26.3538894653$ $-40.2732200623-50.0727500916-55.2455787659-55.7123908997-52.2017402649$ 
$-45.3522415161-35.9474906921-23.450750351-13.0276203156-10.4366502762$ $-10.5624904633-9.30945491791-8.08631515503-6.81462621689-5.71903181076$ $-5.07462596893-4.66264915466-4.57508277893-4.5457701683-4.51978683472$ $-4.48410987854-4.36461400986-4.23572301865-4.0540728569-3.79109501839$ -3.29522609711 -2.33773589134-.915807008743.9442009925842 3.022811889648 5.1959681510937 .4609289169319 .76650142669712 .0254297256514 .43603038788 17.1417903900119 .9660606384322 .7471103668225 .2540206909227 .17614936829 28.7869396209730 .3352909088131 .8131103515633 .2901115417534 .65689849854 35.8669700622636 .8183212280337 .5585289001537 .9093589782737 .69522857666 37.326030731237 .1540298461937 .1475486755437 .3602600097737 .81224060059 38.5240898132339 .5403404235840 .8466911315942 .3510894775443 .87255096436 45.378768920946 .8197288513248 .0692710876549 .0345687866249 .77407073975 50.3023605346750 .6953201293950 .9973716735851 .2316703796451 .46097946167 51.6922111511251 .9776191711452 .3449096679752 .8070297241253 .12919998169 53.075759887752 .8483695983952 .6224708557152 .4397506713952 .34278869629 52.2912216186552 .2849388122652 .2184906005952 .0433197021551 .62604904175 50.89802169849 .9481201171948 .5537300109947 .8898887634349 .28248977661 51.2080688476652 .3744583129953 .1279106140153 .4140205383353 .34894180298 53.104770660452 .7024803161652 .2624397277851 .8137702941951 .41696929932 51.1078605651950 .9230117797950 .810829162650 .7413215637250 .51287841797 49.9584503173849 .2331008911148 .4642105102547 .8084297180247 .38687896729 47.185970306447 .2506599426347 .5013313293548 .0165596008348 .32373809814 47.8681106567447 .0301017761246 .1015090942444 .9263000488343 .49666976929 41.7688598632839 .6542282104537 .3785209655835 .0557212829633 .33781051636 32.9192886352532 .3129806518629 .7080192565925 .9147090911921 .54165077209 $16.3874092102111 .30570983887-2.25132989883-8.97442817688-15.2917604446$ -16.5159492493 -15.8232097626 -16.1001491547 -16.4314899445 -16.862859726 -17.5642700195 -18.3730602264 -19.3697395325 -20.4033603668 -21.3113594055 $-22.0445404053-22.6135692596-23.3383998871-23.7841491699-23.5190696716$ $-23.1198806763-23.2003002167-23.3723201752-23.5161991119-23.5225200653$ $-23.2074108124-22.7409992218-22.237909317-21.835729599-21.6513404846$ -21.3283596039-20.5368499756 -19.541229248 -18.5615901947 -17.6802806854 $-16.9123401642-16.299030304-15.8547096252-15.5188102722-15.3120698929$ $-15.1530599594-15.0283002853-14.829750061-14.3916196823-13.6840600967$ -12.6149702072 -11.2735204697 -9.78723716736 -8.36014175415 -7.24763822556 -6.33068990707 -5.16200494766-4.02107095718 -2.22899198532.4212299883366 3.9785881042488 .92626380920415 .0416202545221 .3743495941221 .76137924194 29.5421104431231 .1243591308636 .2900199890143 .8388290405348 .76850128174 51.9753494262753 .773860931454 .4871101379453 .8887901306252 .01322937012 49.0880393981944 .3383407592841 .0924301147543 .0998802185146 .27310180664 47.4731712341347 .8289413452147 .6056709289647 .0003585815446 .33631134033 45.5964813232444 .8900299072344 .2202682495143 .6263694763243 .14125061035 42.7988586425842 .634071350142 .6840209960942 .9490203857443 .43693161011 44.1267395019545 .0172615051346 .0861091613847 .3252792358448 .69729995728 50.1437187194851 .648849487353 .1653785705654 .6844902038656 .1724281311 57.6230392456159 .0532798767160 .3217315673861 .2615890502962 .04735946655 
62.8264198303263 .5663909912164 .2871398925864 .9896621704165 .67793273926 66.3548965454167 .0216827392667 .6798095703168 .3293304443468 .97158050537 69.6069183349670 .236602783270 .861473083571 .4824829101672 .10056304932 72.7162780761773 .330360412673 .9431686401474 .5551528930775 .1665725708 75.7777328491276 .3888702392677 .0001983642677 .6119537353578 .22431182861 78.8374862670979 .4516372680780 .0669097900480 .683456420981 .30135345459 81.9206924438582 .5415191650483 .1638565063583 .7876968383884 .41298675537 85.0397033691485 .6677169799886 .2969436645586 .9272232055787 .55841064453 88.1903381347788 .8227767944389 .4554824829190 .0882186889690 .720703125 91.3526229858491 .9836120605592 .6133422851693 .2413864135793 .86741638184 94.4909820556695 .1117095947395 .7291793823296 .3430328369196 .95304870605 97.5583419799898 .1595001220798 .75496673584

597.2208862305591 .8289794922586 .4235229492581 .007019043575 .5885009766 570.1697998047564 .7540283203559 .3441772461553 .9428710938548 .5518798828 543.173828125537 .8095092773532 .4625854492527 .1342773438521 .8302001953 516.5527954102511 .3102111816506 .1064147949500 .9520874023495 .8534851074 490.8232116699485 .8691101074481 .0060119629476 .2434082031471 .5974121094 467.0788879395462 .7049865723458 .4873962402454 .4443969727450 .5968017578 446.9291992188443 .4366149902440 .107208252436 .9382019043433 .903503418 430.9988098145428 .1654052734425 .3859863281422 .5772094727419 .7112121582 416.6864013672413 .467010498409 .9591064453406 .1445922852401 .8985900879 397.3711853027391 .6221923828383 .6683959961376 .5006103516373 .3688049316 370.6989135742365 .6727905273360 .7239074707357 .1005859375354 .8352050781 353.396697998351 .2939147949345 .8015136719340 .891998291339 .5120849609 338.9563903809337 .417388916334 .1563110352327 .5985107422321 .207611084 318.4263000488317 .3319091797316 .9931030273316 .5694885254314 .4855957031 312.3308105469312 .4443969727312 .8653869629312 .2940979004311 .6235961914 310.1465148926307 .8739929199304 .5495910645301 .2511901855299 .138885498 297.2294921875 294.4729003906 291.2698059082 288.2716064453 285.0380859375 281.4053955078276 .6592102051270 .2862854004258 .6737976074237 .6360931396 202.8780059814148 .798706054791 .3992462158247 .4427490234413 .38239955902 -12.7622699738 -31.9706707001-45.4140892029 -53.4840087891 -56.2415390015 $-54.3355712891-48.7472190857-40.3234405518-29.7123508453-20.4720001221$ $-16.4143791199-14.5221395493-12.3144197464-10.1924295425-8.12240886688$ $-6.41430282593-5.24414396286-4.58627080917-4.65885210037-4.86721086502$ $-4.76636505127-4.64660596848-4.57665920258-4.51042890549-4.39782190323$ $-4.05378484726-3.37141704559-2.40543007851-1.09537899494 .4526239931583$ 2.2431139945984 .2518057823186 .3552231788648 .49812698364310 .60247993469 12.7993202209515 .1800899505617 .6848297119120 .1765193939222 .49447059631 24.4775009155326 .2550392150927 .9768505096429 .6657600402831 .3478603363 32.8371696472234 .0087394714434 .9613304138235 .7760391235436 .2989616394 36.35895919836 .2023506164636 .0977210998536 .0554199218836 .12672042847 36.3687095642136 .8455390930237 .5271682739338 .4428596496639 .50986099243 40.6718101501541 .8946914672943 .0929908752444 .1925086975145 .09540176392 45.8671417236346 .5113296508847 .0332489013747 .4327087402347 .76292037964 48.1143493652348 .4530906677248 .7288703918548 .9195518493749 .11672973633 
49.3090400695849 .3931808471749 .4799804687549 .5401916503949 .53715133667 49.5335197448749 .5722007751549 .6958312988349 .8196716308649 .91751098633 49.6928710937548 .8464698791547 .7471618652346 .6311492919946 .26058959961 47.4823303222749 .1035614013750 .0111999511750 .429130554250 .3607711792 50.0080490112349 .5855598449749 .0879707336448 .5930900573748 .1176109314 47.7042503356947 .3410682678247 .0163002014246 .7583618164146 .66244888306 46.5705184936546 .252090454145 .8436203002945 .3524589538644 .88541030884 44.6063499450744 .4799003601144 .5442008972244 .734378814745 .06076049805 45.1952285766644 .7964210510344 .0707588195843 .1883201599142 .09378051758 40.7694396972739 .2187614440937 .3723411560135 .6660385131834 .24842834473 32.8730697631831 .6002197265629 .6299304962226 .5122203826922 .70121002197 $18.2045097351113 .325940132148 .390237808228-5.88460206985-14.2479295731$ $-21.1183204651-22.9374008179-22.2950496674-21.6648693085-21.0234794617$ -20.8145294189 -20.8509807587 -21.1649398804 -21.6039600372 -22.1582698822 -22.8437309265 -23.5163192749 -24.2833995819-25.1755409241 -25.7924804688 $-25.7397708893-25.5276508331-25.7090091705-26.0252799988-26.4336605072$ -26.5527992249 -25.9177703857-24.9469203949-23.8680801392 -23.3974208832 $-24.4297790527-25.3473091125-24.5833892822-23.1162490845-21.7411308289$ -20.4444999695 -19.3710308075 -18.5169696808 -17.800579071 -17.2354698181 -16.9121208191 -16.6954498291 -16.5214004517-16.3416004181 -15.9883098602 -15.5111503601 -14.9167098999-13.9867696762 -12.4515695572 -10.5713500977 -8.73504543304 -7.3710308075 -6.94203281403 -6.65481281281 -5.47730302811 -3.80910992622 -1.327278971672.258955955505 6.89445686340311 .31748008728 14.2829504013117 .6982498168922 .5508098602328 .6464691162134 .97188186646 40.247909545943 .999580383346 .4458885192947 .5361518859947 .34135055542 45.9436492919943 .617599487340 .3315200805738 .2136497497639 .52375030518 42.0248603820843 .6236610412644 .6909599304245 .1139106750545 .06777954102 44.830780029344 .4496688842844 .0261306762743 .5812606811543 .15863037109 42.793380737342 .5327110290542 .4132995605542 .4910011291542 .75458908081 43.2105598449743 .8392295837444 .634208679245 .5918693542546 .72045135498 47.9791488647549 .3233718872150 .7344398498552 .1771583557153 .63520050049 55.07505035456 .4864883422957 .8543701171959 .0825805664160 .06473922729 60.9094696044961 .7123489379962 .4731597900463 .2096481323263 .92370986938 64.6234436035265 .3094482421965 .9845733642666 .6492233276467 .30432891846 67.9507675170968 .5894622802769 .2214889526469 .8481369018670 .47026062012 71.0891036987371 .7051773071372 .3194427490272 .9321670532273 .54399108887 74.1550979614374 .7658767700275 .376533508375 .9873275756876 .59844207764 77.2101211547977 .8225097656278 .435829162679 .0501708984479 .66570281982 80.2824935913180 .9006500244181 .5201797485482 .1411285400482 .76345825195 83.3871536254984 .012138366784 .6383209228585 .2655868530385 .89380645752 86.52282714844 87.15247344971 87.78251647949 88.41272735596 89.04286193848 89.6726379394590 .3017425537190 .929832458591 .5565719604592 .18153381348 92.8043899536193 .4246978759894 .0420913696394 .6561431884895 .26651000977 95.8729934692496 .4751586914197 .0690231323297 .65728759766 596.7219238281591 .3029174805585 .8767089844580 .4392700195574 .9967041016 569.5521850586564 .1102294922558 .673828125553 .2465820312547 .8306884766 
542.4296875537 .0446166992531 .6804199219526 .337890625521 .0247192383 515.7423706055510 .5014038086505 .304901123500 .1661071777495 .0898132324 490.091796875485 .1784973145480 .3678894043475 .6676025391471 .0974121094 466.6661071777462 .3940124512458 .2915039062454 .3797912598450 .6823120117 447.1754150391443 .8482971191440 .6817932129437 .6838989258434 .8002929688 432.0411071777429 .3004150391426 .5916137695423 .7365112305420 .7582092285 417.4023132324413 .7150878906409 .395111084404 .5693054199398 .8132019043 392.7125854492384 .084197998369 .7979125977357 .6131896973356 .9475097656 359.1578063965357 .3988952637355 .0509033203352 .2713012695349 .995513916 347.684387207345 .7575073242343 .1495056152340 .9896850586339 .6029968262 339.0274963379339 .5419921875338 .1293029785331 .7268066406324 .958404541 323.6346130371324 .1570129395325 .2153930664325 .1297912598321 .9388122559 319.5288085938321 .5150146484324 .5639038086325 .2395935059324 .3909912109 321.4509887695317 .4895019531312 .3711853027307 .4494934082304 .4085083008 301.3530883789297 .2904052734293 .2991943359290 .5653991699288 .0281982422 284.6763916016280 .4201965332275 .0938110352265 .5853881836250 .12550354 222.8529052734177 .6118927002126 .029197692979 .3390808105538 .22576141357 $4.648431777954-20.7573890686-38.749710083-49.8673210144-55.1260490417$ -55.6235084534 -51.9395294189-45.5740699768 -37.9338912964 -30.4816093445 -24.6399402618 -20.0018005371 -16.1903991699-12.9304800034-9.91635131836 -7.3464717865 -5.37007713318 -4.24699306488-4.39258718491 -4.91508722305 $-4.84122180939-4.6395277977-4.59449005127-4.51096200943-4.35750484467$ -3.98832201958 -3.30057692528 -2.36357188225 -1.11745297909 0.337424993515 1.9644019603733 .7789249420175 .6929688453677 .6752238273629 .652746200562 11.6562995910613 .6644401550315 .6866102218617 .6586208343519 .64513969421 21.6359996795723 .6091499328625 .5088100433327 .3310794830329 .14878082275 30.7374706268331 .9381008148232 .8977584838933 .769119262734 .42226028442 34.8023605346734 .9728088378935 .0217208862335 .0127296447834 .98601913452 35.035438537635 .250419616735 .6138610839836 .1647987365736 .86629867554 37.6998405456538 .6282196044939 .5721702575740 .5024108886741 .34297943115 42.1230697631842 .8337402343843 .4546890258843 .9607887268144 .40390014648 44.8828887939545 .2858810424845 .4996604919445 .6136817932145 .74496841431 45.9069900512746 .0629310607946 .2710304260346 .4905509948746 .66931915283 46.7571792602546 .8567390441947 .0773811340347 .3102607727147 .6177406311 47.5875091552746 .7271995544445 .7249107360845 .1565513610845 .12596893311 45.966659545946 .9733200073247 .3864097595247 .4000282287646 .97484970093 46.3308982849145 .7707595825245 .2027511596744 .7011909484944 .24620819092 43.8394584655843 .4643898010343 .0384101867742 .7131881713942 .69046020508 42.739540100142 .6010208129942 .4038581848142 .1206893920941 .84125900269 41.701450347941 .6474494934141 .7256202697841 .8376197814941 .9334487915 41.8964195251541 .6106796264641 .093608856240 .3651084899939 .43894958496 38.3140792846737 .0613708496135 .5670585632334 .1611099243233 .04996109009 31.6010494232229 .2807407379226 .2869396209723 .0168704986619 .1947593689 $14.320859909069 .340804100037-3.02857804298-11.3448896408-20.5317497253$ $-27.1502990723-29.1030406952-28.6978397369-27.472650528-25.9239692688$ $-24.9004707336-24.265920639-24.0400505066-24.1270294189-24.3803405762$ 
-24.8147201538 -25.3557605743 -26.0307102203 -26.8335494995 -27.4310894012 $-27.5542602539-27.5608100891-27.9180698395-28.3742809296-29.0389194489$ -29.2998600006 -28.401599884 -27.1390705109-25.6896400452 -25.1084308624 $-27.0723991394-28.926279068-28.0924091339-26.310880661-24.7762203217$ -23.230140686 -21.9415607452 -20.8021392822 -19.6951694489 -18.8749294281 -18.4458198547 -18.2644405365 -18.0659103394 -17.8560390472 -17.5378894806 -17.1591396332 -16.8960990906 -16.2042503357-14.5331201553 -12.4467201233 $-10.2564697266-8.7120847702-8.78554821014-9.14460086823-8.36780261993$ $-6.97817611694-4.59074783325-1.656309962271 .1343400478364 .062660217285$ 7.16745805740411 .0905895233215 .8117704391521 .4172992706327 .28260993958 32.5229988098136 .709678649939 .640350341841 .1717796325741 .46133041382 40.7173004150439 .4191284179738 .1298484802237 .4183006286637 .89072036743 39.1000900268640 .4990692138741 .8179016113342 .6609115600643 .11191177368 43.3140716552743 .2813682556243 .1517486572342 .927871704142 .6798286438 42.4393997192442 .2672195434642 .2009582519542 .3087081909242 .57077026367 42.9933891296443 .5630416870144 .2729797363345 .1320495605546 .15726852417 47.3088493347248 .5507507324249 .8679809570351 .2306594848652 .61917114258 53.9959983825755 .3382110595756 .6070594787657 .7742309570358 .80572128296 59.7303009033260 .5764884948761 .3647193908762 .1214714050362 .85065078735 63.5637207031264 .2608566284264 .9452667236365 .6175384521566 .27879333496 66.9300765991267 .5726318359468 .2076034545968 .8365783691469 .46041870117 70.0805969238370 .6976699829171 .3126831054771 .9259567260772 .53814697266 73.1494979858473 .7603988647574 .3710708618274 .9817733764675 .59272003174 76.2041168212976 .8161468505977 .4290008544978 .0427932739378 .65765380859 79.2736816406279 .8909530639680 .5094985961981 .1293334960981 .75042724609 82.3727798461982 .9962768554783 .6208572387784 .2463989257884 .87277984619 85.4998397827186 .1273880004986 .7552337646587 .3831100463988 .01081085205 88.6380386352589 .2644882202189 .8898162841890 .5137023925891 .13572692871 91.7555465698292 .3727264404392 .9869232177793 .5976791381894 .20469665527 94.8077392578195 .4059219360495 .9998703002996 .58798217773 596.2236938477590 .8059082031585 .366027832579 .9055786133574 .4395141602 568.9702148438563 .5017700195558 .0388793945552 .5848999023547 .1431274414 541.7171020508536 .3088989258530 .9235229492525 .5629272461520 .2343139648 514.9412231445509 .6929931641504 .4952087402499 .3598022461494 .2943115234 489.3128967285484 .424987793479 .6467895508474 .9891052246470 .4697875977 466.1007080078461 .9005126953457 .8817138672454 .0690917969450 .4912109375 447.1207885742443 .9413146973440 .9323120117438 .0822143555435 .3566894531 432.753112793430 .1766967773427 .6046142578424 .8727111816421 .9431152344 418.563293457414 .6701049805409 .9867858887404 .4543151855398 .058013916 391.1083984375381 .6588134766368 .1409912109357 .2496948242355 .9945983887 358.5628967285358 .7319030762357 .7178955078355 .3534851074352 .8382873535 351.56640625350 .8395080566348 .5079956055346 .0999145508344 .7623901367 344.7343139648346 .8078918457347 .221496582341 .945098877335 .8772888184 334.2889099121334 .7033081055335 .2149963379333 .8042907715328 .5100097656 325.7225952148332 .0722961426340 .1290893555342 .8262939453341 .645690918 336.2572021484 329.5573120117323.8245849609 318.1955871582312 .1787109375 
305.8623046875299 .7355957031294 .6662902832291 .8225097656289 .8922119141 287.7428894043284 .7373046875280 .5538024902272 .8887939453258 .9952087402 236.0276947021199 .6461029053155 .5675964355109 .911399841364 .86805725098 $23.73411941528-9.39222240448-30.6347808838-43.974899292-52.2241783142$ $-55.7493209839-54.6638412476-50.5177383423-44.8320808411-38.1810913086$ -31.9415798187 -25.9437904358 -20.8320808411 -16.4103603363 -12.3287601471 -8.63497257233 -5.25513076782 -3.11513590813 -3.25712299347-4.15532016754 $-4.4177031517-4.46329879761-4.46978378296-4.37969493866-4.1563949585$ -3.72919511795 -3.0083630085 -2.07826089859- -.966111004353.3504639863968 1.938104033473 .6876690387735 .4824337959297 .313926219949 .115278244019 10.8592901229912 .522419929514 .0608301162715 .3970499038716 .91789054871 18.9435691833521 .1243495941223 .0895099639924 .9268398284926 .69043922424 28.2566509246829 .5495491027830 .6557903289831 .6875400543232 .57315063477 33.2459983825733 .703258514433 .9140701293933 .9508781433133 .8599395752 33.7399902343833 .7134590148933 .7781906127934 .0059013366734 .37953186035 34.9078903198235 .5551910400436 .2750205993737 .0445899963437 .81277084351 38.5853996276939 .3381805419940 .0454101562540 .6775207519541 .25556945801 41.8114013671942 .2738990783742 .5738792419442 .772319793742 .93257904053 43.1044692993243 .2955017089843 .5278892517143 .7637596130443 .96992111206 44.1059684753444 .2395210266144 .4391517639244 .6468009948744 .8510093689 44.792549133344 .1803703308143 .5109901428243 .1726112365743 .1099281311 43.4959106445343 .8459396362343 .8070106506343 .4944686889642 .83438110352 42.0592498779341 .4200706481940 .8564796447840 .4491195678740 .12973022461 39.8500518798839 .5933990478539 .2892684936539 .0594406127939 .02587890625 39.0670089721739 .0257415771538 .9563598632838 .8467102050838 .73955154419 38.7058105468838 .7166709899938 .8034591674838 .8675193786638 .86111068726 38.7727584838938 .5280799865738 .1423416137737 .5942687988336 .8618888855 35.9580993652334 .9122695922933 .651088714632 .3090286254930 .97794914246 29.089000701926 .2820491790822 .8417396545419 .0718994140614 .7732000351 $9.4168033599853 .58745598793-10.9054803848-21.1942806244-29.4787502289$ -34.5261688232 -35.7601890564 -34.9917907715 -33.5229110718 -31.5236797333 $-29.4544906616-27.8111190796-27.1926193237-27.0441398621-26.9011306763$ -26.9365291595 -27.2811908722 -27.8263492584 -28.5059509277-29.0562400818 $-29.1604804993-29.2518196106-29.7463207245-30.3289203644-30.9176292419$ -31.0807209015 -30.2812004089-29.1869297028 -28.2132091522 -27.9883403778 $-29.3184890747-30.5749797821-30.2257404327-29.0178699493-27.5993595123$ -26.0573005676 -24.6307907104-23.1620807648 -21.4655208588 -20.1683998108 -19.8808193207 -19.9492301941 -19.7168006897-19.3687591553 -18.9501991272 -18.4795894623 -17.999130249 -17.1751308441 -15.7414798737 -14.0250501633 $-12.3204402924-11.2235498428-11.4032096863-11.7003898621-10.8848695755$ $-9.40790271759-7.38740491867-5.15843391418-2.95495796204-.456075996161$ 2.5707180500036 .40008306503311 .1025495529216 .2913208007821 .75421905518 26.8847808837931 .0584297180234 .2519302368236 .105751037636 .89390945435 36.771621704136 .3522987365736 .059150695835 .9135704040536 .38021850586 37.1845207214438 .3721008300839 .7421112060540 .7665710449241 .51465988159 41.9876213073742 .2315406799342 .3234100341842 .295478820842 .20806884766 
42.0959892272942 .0084304809641 .9965591430742 .1366806030342 .40254974365 42.7961311340343 .3117408752443 .9484710693444 .7185401916545 .6348991394 46.6719703674347 .8142013549849 .0372390747150 .3167381286651 .62895965576 52.9371681213454 .2110404968355 .4169006347756 .5531196594257 .59086990356 58.5504913330159 .4300804138260 .2461090087961 .0261116027861 .77479171753 62.503349304263 .2128295898463 .9072608947864 .5873565673865 .2550201416 65.9113464355566 .5580062866267 .1962738037167 .8279113769568 .45393371582 69.0759201049869 .69448089670 .3107528686570 .9250717163171 .53816986084 72.150253295972 .7617568969773 .372909545973 .9839935302774 .59516906738 75.2067108154375 .8187637329176 .4315338134877 .0450973510777 .65965270996 78.2752227783278 .8919219970779 .5097503662180 .128761291580 .74889373779 81.3701324462981 .9923934936582 .6156005859483 .2396392822383 .86437988281 84.4896469116285 .1153106689585 .7410964965886 .3668365478586 .99226379395 87.6171035766688 .2410430908288 .8637695312589 .484931945890 .10414886475 90.7210464477591 .335243225191 .9463577270592 .5539703369193 .15775299072 93.7575073242294.3528289794994.9396820068495.52069854736 595.805480957590 .3549804688584 .8944091797579 .4155273438573 .9270019531 568.4329833984562 .9390258789557 .4489746094551 .9680175781546 .4987182617 541.0460205078535 .6115112305530 .2015991211524 .8178100586519 .4688720703 514.1572265625508 .8945007324503 .6848144531498 .5426940918493 .4736938477 488.4952087402483 .6141967773478 .8503112793474 .2117919922469 .7200927734 465.3839111328461 .2276916504457 .2600097656453 .5123901367450 .0156860352 446.7409057617443 .6737976074440 .7867126465438 .0635070801435 .471496582 433.0306091309430 .6206054688428 .2573852539425 .7172851562423 .0451049805 419.8403015137416 .1676940918411 .5069885254405 .8716125488399 .1509094238 391.8504943848383 .8345947266374 .7997131348368 .632598877368 .3515014648 370.6152954102371 .8388061523372 .0421142578370 .2767944336368 .4530944824 368.4338989258368 .1546936035364 .2054138184360 .207611084358 .3056945801 357.4841918945358 .8955993652359 .2432861328355 .4765930176350 .9638061523 349.4964904785348 .5306091309347 .6624145508345 .9547119141340 .8223876953 339.246307373349 .7280883789361 .579498291365 .2669067383363 .8389892578 355.9484863281346 .0643005371338 .7117004395331 .229309082321 .1915893555 311.1203918457303 .1571960449296 .9601135254293 .6169128418291 .8569946289 290.6517944336288 .9555969238285 .8098144531278 .9909057617265 .542388916 245.6096954346218 .3426055908183 .2521057129141 .289901733495 .35028839111 48.412029266367 .85897397995 -18.2984008789 -35.2950592041 -47.6399307251 $-54.4921607971-56.1706809998-54.3628807068-50.2158889771-44.4134788513$ -38.0802497864 -31.4607791901 -25.4695301056 -19.9475193024 -14.8354797363 $-10.1997299194-5.62557220459-2.50873804092-2.41623902321-3.41244602203$ -3.82389497757 -4.11527681351-4.19007492065 -4.0694527626 -3.79560399055 -3.27966499329 -2.49814295769 -1.56298398972 -.527253985405.6927869915962 2.279254913334 .0327868461615 .7241811752327 .3997879028328 .998203277588 10.4749803543111 .8064603805512 .9655199050913 .7780399322514 .85029983521 16.7962608337418 .9836006164620 .8237800598122 .5352993011524 .14289093018 25.609029769926 .9988403320328 .2812595367429 .5163497924830 .65258979797 31.6380290985132 .3747100830132 .7694396972732 .8548507690432 .70132064819 
32.4221305847232 .1685981750531 .9813404083331 .9294490814232 .0202293396 32.2681503295932 .6599082946833 .1682891845733 .7847290039134 .47257995605 35.222930908236 .0003890991236 .7822799682637 .5467796325738 .25569152832 38.8837203979539 .4214210510339 .8490409851140 .1845893859940 .42858123779 40.6352005004940 .8300285339441 .0298118591341 .1994895935141 .3556098938 41.4856681823741 .6015396118241 .7281303405841 .814308166541 .82389068604 41.7052917480541 .3896102905341 .0419616699240 .8236808776940 .63798904419 40.5310211181640 .3037910461439 .8775215148939 .2441101074238 .36307907104 37.4791488647536 .7689514160236 .2921714782736 .0590400695835 .95338821411 35.8586311340335 .7521286010735 .6317214965835 .5344390869135 .49058914185 35.4917106628435 .488418579135 .5006904602135 .5248718261735 .55680847168 35.6233901977535 .694759368935 .8096313476635 .8744010925335 .85047149658 35.7422103881835 .5215301513735 .2347488403334 .8659400939934 .38996124268 33.7450103759832 .8906402587931 .7426605224630 .27807998665728 .49684906006 26.1243400573723 .0651092529319 .3451690673815 .0483503341710 .07592964172 $3.949018955231-2.99362611771-22.3008708954-33.3252105713-39.2231216431$ $-42.1166801453-42.7868690491-41.8119506836-40.2713699341-37.9735794067$ $-34.9557914734-32.2823104858-30.9954109192-30.3893795013-29.6500606537$ $-29.166349411-29.2210693359-29.4717102051-29.9205493927-30.3766708374$ $-30.4614200592-30.6197395325-31.2508296967-31.9407596588-32.4687194824$ $-32.6004104614-32.0281295776-31.3064193726-30.9702091217-30.974199295$ $-31.2287597656-31.4920692444-31.4939899445-31.0409202576-30.056640625$ $-28.7027702332-27.2741394043-25.6715908051-23.6239395142-21.9985408783$ $-21.7883300781-21.9155197144-21.4549293518-20.8913993835-20.2435302734$ $-19.491859436-18.6355209351-17.6076202393-16.4978504181-15.4084396362$ $-14.4652996063-13.874830246-13.9441099167-13.8826704025-12.7220697403$ $-11.1587200165-9.55934238434-7.80799484253-5.78312492371-3.30115509033$ -.3126499950893.396121025085 7.79738187789912 .6346797943117 .7787399292 22.6673393249526 .7313404083329 .9742107391432 .0591316223133 .31204986572 33.8125915527334 .0067100524934 .2681198120134 .5400886535635 .12879943848 35.9020996093837 .0050392150938 .2520408630439 .2899703979540 .17565917969 40.8301887512241 .2808113098141 .5652503967341 .7061309814541 .77206039429 41.7781295776441 .7749290466341 .8145790100141 .9864082336442 .25582122803 42.6245193481443 .0917282104543 .6653900146544 .3485908508345 .15216827393 46.0765495300347 .1218910217348 .2600517272949 .4575386047450 .68761062622 51.9202117919953 .1300315856954 .2865600585955 .3919715881356 .42464828491 57.3948783874558 .2936401367259 .1350593566959 .9385490417560 .70611953735 61.4501609802262 .1710205078162 .8749389648463 .562080383364 .23578643799 64.8967437744165 .5475082397566 .1890029907266 .8235931396567 .45202636719 68.0762481689568 .6966934204169 .3146896362369 .9305114746170 .54495239258 71.1582183837971 .7707672119172 .382812572 .9946517944373 .60648345947

74.2185287475674 .8309631347775 .4439697265676 .0576705932676 .67220306396 77.2876205444377 .9040298461978 .5214309692479 .1398468017679 .75926208496 80.3796234130981 .0008621215881 .622909545982 .2456436157282 .86891937256 83.492607116784 .1165237426884 .7404632568485 .3641967773485 .98750305176 86.610076904387 .2316589355587 .8519134521588 .4704895019589 .08702087402 
89.7011489868290.3124618530390.9206085205191.5251770019592.12584686279 92.7224121093893 .3139801025493 .9012069702194 .48248291016

595.3895874023589 .9492797852584 .4782714844578 .9772949219573 .4666137695 567.9484863281562 .4282226562556 .9110717773551 .4013061523545 .9030761719 540.420715332534 .9570922852529 .5178833008524 .1060791016518 .7296142578 513.3925170898508 .1051940918502 .8739013672497 .7114868164492 .6260070801 487.632598877482 .7412109375477 .9690856934473 .3276062012468 .8353881836 464.5039978027460 .3583984375456 .4154052734452 .7008972168449 .2417907715 446.0172119141443 .0126037598440 .2112121582437 .5956115723435 .1492004395 432.8702087402430 .6917114258428 .5992126465426 .4533996582424 .2354125977 421.6516113281418 .6535949707414 .7943115234409 .9518127441404 .0851135254 396.7738037109390 .7750854492388 .5281982422389 .8818054199395 .5668029785 401.7619018555404 .5180969238405 .7008972168406 .2362976074406 .3764038086 406.3453063965 404.4555969238397.4309997559390.3738098145 388.0122070312 385.8121948242379 .8593139648374 .3474121094373 .253692627372 .8452148438 370.8937988281368 .4688110352366 .6377868652366 .1173095703367 .6809997559 372.4740905762381 .870513916391 .0158996582394 .6408081055392 .475402832 382.5409851074369 .4468994141356 .9757080078344 .1882019043330 .2735900879 317.3761901855308 .6224975586302 .195098877297 .0515136719293 .9407958984 292.9660949707292 .037902832289 .5557861328283 .6553955078272 .2225952148 257.2275085449239 .1687927246213 .6779022217176 .5561065674131 .5446929932 $82.415458679236 .608100891111 .261976003647-24.7500095367-41.1573486328$ $-50.7985992432-55.5590591431-56.1621398926-53.6395111084-48.7160797119$ $-42.6126708984-35.7261314392-29.1452407837-22.8391399384-17.1004009247$ $-11.9301099777-7.32932281494-4.12066221237-3.21488499641-3.42421793938$ -3.56413602829 -3.75322294235 -3.79475498199 -3.65905594826 -3.31744098663 -2.69804310799 -1.75257003307-.695315003395 3491770029068 1.542346954346 3.096599102024 .8045167922976 .4098229408267 .9361219406139 .347929954529 10.5979204177911 .6567201614412 .54380035413 .2469596862814 .16506004333 15.6618499755917 .3644790649418 .8912906646720 .3416099548321 .71805953979 23.0637302398724 .4514007568425 .8470096588127 .2486095428528 .63883972168 29.9926204681431 .0768909454331 .6612892150931 .7986602783231 .5060005188 31.012620925930 .5628890991230 .1655693054229 .8820209503229 .72480964661 29.7262191772529 .8825702667230 .2023200988830 .6739902496331 .28318977356 32.0078392028832 .8162918090833 .6803283691434 .5651817321835 .4037399292 36.1446304321336 .7932586669937 .3063697814937 .7186012268138 .01934051514 38.2342185974138 .4335212707538 .5959205627438 .7073593139638 .79169082642 38.8372192382838 .8566284179738 .8747406005938 .8397598266638 .74555969238 38.6218185424838 .4256591796938 .217910766638 .0417404174837 .75122070312 37.3688201904336 .8114585876536 .0205001831135 .0373115539633 .79512023926 32.6416511535631 .8790702819831 .5317306518631 .650669097931 .90998077393 31.9874706268331 .98612022431 .9624404907231 .928569793731 .91822052002 31.9309291839631 .9777202606232 .0674400329632 .188899993932 .33097839355 32.4966888427732 .6569290161132 .817520141632 .9172096252432 .91801834106 32.8124809265132 .5526199340832 .289058685332 .1418991088931 .95453071594 31.597860336330 .9323692321829 .8010692596428 .1823596954326 .10865020752 
23.4299201965320 .0308399200415 .9126195907611 .064649581915 .442508220673 -1.20642900467 -20.3726406097 -31.6500797272 -41.6805114746 -47.3098297119 $-49.8725318909-51.032749176-50.7403488159-48.8322486877-45.7897491455$ $-42.2626495361-38.8044586182-36.0628814697-34.0681800842-32.6645088196$ -31.662279129 -31.0714702606 -30.7441196442 -30.7803401947 -31.0697898865 -31.2914791107 -31.689950943 -32.4480400085 -33.3070983887 -34.1775894165 -34.6478309631 -34.1823005676 -33.5471687317 -33.274520874 -33.0426712036 $-32.8245201111-32.6688613892-32.54114151-32.3687210083-31.9852790833$ -31.1560897827 -29.8195095062 -28.2946891785 -26.8298797607 -25.6095294952 $-24.8652591705-24.2199497223-23.336019516-22.4045600891-21.3705806732$ -20.276720047 -19.2304191589-18.2008495331 -17.2643203735 -16.5578708649 -15.9988899231 -15.5429296494 -15.3445701599 -14.8397703171 -13.5284996033 -12.0772104263 -10.9369697571 -9.69692611694 -8.00044059753 -5.75010681152 -2.86730504036.6692320108414 4.9265999794019.632838249207 14.87115001678 19.8362503051823 .6898498535226 .7815208435128 .9939594268830 .53792953491 31.4950695037832 .1523017883332 .7961006164633 .3846511840834 .10538101196 34.9193000793535 .9713401794437 .1209297180238 .1798896789639 .14548110962 39.9159202575740 .516880035440 .9499702453641 .2413215637241 .42369842529 41.5282287597741 .5946197509841 .682479858441 .8754501342842 .14469909668 42.4909591674842 .9154396057143 .4251708984444 .0185699462944 .69622039795 45.4974098205646 .4682807922447 .5437088012748 .6648597717349 .81576156616 50.9724006652852 .1177711486853 .2280502319354 .3026504516655 .32215881348 56.2916107177757 .1999702453658 .0580787658758 .875560760559 .65707015991 60.4117889404361 .1418190002461 .8526611328162 .5456390380963 .22394180298 63.8889312744164 .5430679321365 .1876983642665 .8250274658266 .45607757568 67.0826263427767 .7053070068468 .325332641668 .9430389404369 .55918884277 70.1740264892670 .7880020141671 .4013214111372 .0143127441472 .62712860107 73.2400436401473 .8531875610474 .4667663574275 .0809020996175 .69570159912 76.311248779376 .9276275634877 .5448532104578 .1629333496178 .78185272217 79.4015426635780 .0219726562580 .6430587768681 .2646713256881 .88667297363 82.508926391683 .131278991783 .7535018920984 .3753890991284 .99671173096 85.6171798706186 .2365264892686 .8544387817487 .4705505371188 .08451080322 88.6959686279389 .3045272827189 .9098434448290 .5114822387791 .10915374756 91.7026367187592 .2916107177792 .8719406127993 .44618225098

595.0895996094589 .6104736328584 .1179199219578 .6002807617573 .0679931641 567.5258178711561 .979675293556 .434387207550 .8953857422545 .3660888672 539.8521118164534 .3555908203528 .8834838867523 .4379882812518 .0283813477 512.6574707031507 .3375854492502 .0733032227496 .879486084491 .7623901367 486.7394104004481 .8179931641477 .0184020996472 .3483886719467 .8313903809 463.4742126465459 .3099060059455 .3547973633451 .6347045898448 .1666870117 444.9447937012441 .9543151855439 .1907043457436 .6400146484434 .2933044434 432.145111084430 .1608886719428 .3406066895426 .5889892578424 .9219055176 423.0979919434421 .1599121094418 .6022033691415 .5111083984411 .391204834 404.8801879883401 .9119873047406 .4143066406415 .3771972656426 .3320922852 436.1922912598440 .596496582443 .136505127446 .8497009277448 .5812072754 448.1712036133443 .8764953613433 .1408996582421 .9486083984418 .0848083496 
413.2019958496399 .0409851074387 .125793457388 .138885498391 .794708252 389.9891052246387 .5770874023386 .6153869629389 .1018981934399 .041809082 411.0844116211419 .108001709424 .6112976074427 .4530944824424 .4829101562 413.4354858398397 .2284851074379 .3129882812359 .9161071777341 .1448059082 325.657409668316 .1177062988309 .9187927246303 .1773071289298 .112701416 296.2807006836295 .3681945801293 .0935974121288 .7661132812279 .9482116699 268.8082885742258 .032989502240 .2386016846208 .5780029297167 .0028991699 $119.351501464870 .3635482788125 .7108001709-9.87607765198-31.667470932$ $-44.463760376-52.4173812866-55.7663192749-54.8552284241-50.8245582581$ $-45.1462783813-38.277130127-31.4225406647-24.7009296417-18.6310100555$ -13.3547201157 -9.14760684967-6.15895414352 -4.46476793289 -3.72297406197 $-3.35649800301-3.29365706444-3.16805505753-2.95171999931-2.54025793076$ -1.87384903431-.877551019192.2984800040722 1.4480509758 2.769692897797 4.3742427825936 .019392013557 .5085539817818 .86221885681210 .06715965271 11.0854797363311 .9274101257312 .6463603973413 .3636102676414 .1856098175 15.1555500030516 .2371807098417 .3166999816918 .3943805694619 .4504108429 20.6096191406221 .9621105194123 .4496593475324 .9934406280526 .54904937744 28.18297004729 .5236606597930 .2757205963130 .4980792999330 .14998054504 29.5319309234628 .9564094543528 .4016990661627 .9128093719527 .5355091095 27.30584907532 27.24575996399 27.38809967041 27.72468948364 28.25274085999 28.9487304687529 .7767295837430 .7078208923331 .6912002563532 .67182922363 33.56486892734 .3278694152834 .8960113525435 .3166389465335 .61766052246 35.8459587097236 .0482788085936 .1859512329136 .2358818054236 .20914840698 36.1171188354535 .9874610900935 .8619918823235 .7233200073235 .55908966064 35.4052810668935 .2421112060535 .0549507141134 .8511886596734 .48649978638 33.9419898986833 .1859283447332 .1638984680230 .9291400909429 .47493934631 28.1656894683827 .3806190490727 .1148490905827 .4492206573527 .93136978149 28.1059608459528 .1686496734628 .215749740628 .2459201812728 .28115081787 28.3362808227528 .4444999694828 .6010398864728 .8052997589129 .0431098938 29.3106708526629 .56702995329 .8044109344529 .9722690582330 .04602050781 30.0097293853829 .7627906799329 .5460700988829 .5908603668229 .62571907043 29.479009628328 .9488105773927 .8112792968826 .0805206298823 .8491897583 20.9511203765917 .3171691894512 .927289962777 .5466580390931 .730334997177 -5.11600780487 -25.4374694824 -37.3943786621 -48.0845489502 -53.7565689087 $-56.7253799438-58.9464416504-59.3175582886-57.1154403687-53.5942497253$ $-49.9607505798-46.0329818726-41.8952407837-38.2180213928-35.5736198425$ -33.8316192627 -32.5552787781 -31.8624191284-31.6678104401 -31.7490501404 -32.1028709412 -32.6787490845 -33.4752311707 -34.4372711182 -35.6496887207 -36.5124092102 -36.2374305725 -35.6136283875 -35.2404899597 -34.7987518311 -34.3019485474 -33.8269195557 -33.4229393005 -33.2115707397 -33.270450592 -33.0768089294 -32.0214004517 -30.7667102814 -30.0781402588 -29.3493690491 -28.0706195831 -26.6715507507 -25.4288806915 -24.0544605255 -22.426410675 $-20.8886394501-19.7258892059-18.8853302002-18.1805591583-17.6553001404$ $-17.2244701385-16.7472991943-16.2151908875-15.4116201401-14.1182003021$ $-12.838640213-12.0445098877-11.1537303925-9.67887210846-7.63913202286$ $-4.94655323029-1.627951025962 .3862209320077 .03068017959612 .50666999817$ 
17.758930206321 .5169391632124 .4442005157526 .7164096832328 .44919013977 29.6938591003430 .6704406738331 .5711708068832 .3719482421933 .25688934326 34.160289764435 .2120780944836 .3215103149437 .3824081420938 .38483047485 39.2193984985439 .9161682128940 .4603385925340 .864540100141 .14331817627 41.3281097412141 .459819793741 .5889396667541 .8010101318442 .06581115723 42.3917617797942 .7759208679243 .2284317016643 .745819091844 .31587982178 45.0062103271545 .9004287719746 .9043693542547 .9402084350649 .00965881348 50.0937690734951 .1782684326252 .2450790405353 .2893104553254 .28762054443 55.245819091856 .1529808044457 .0164489746157 .8409385681258 .6296081543 59.3913993835460 .1267509460460 .8426589965861 .5392189025962 .22116088867 62.8889808654863 .5461387634364 .1934127807664 .8335266113365 .46716308594 66.0963134765666 .721397399967 .3437728881867 .9636535644568 .58186340332 69.1986007690469 .8143386840870 .4292831420971 .0437164306671 .65786743164 72.2719497680772 .8861083984473 .5005493164174 .1153869628974 .73072814941 75.3466491699275 .9632263183676 .580497741777 .1984634399477 .81709289551 78.4363327026479 .0561370849679 .6764297485480 .2970886230580 .91799163818 81.53897857666 82.15989685059 82.7805480957 83.4007263183684.02017974854 84.6386795043985.25592041016 85.87159729004 86.4853591918987.09687042236 87.7057571411188.311660766688.91423034668 89.51304626465 90.10781097412 90.6983413696391 .2837524414191 .8647308349692 .43961334229

594.7930297852589 .3319702148583 .8317260742578 .2924804688572 .7387084961 567.1727294922561 .5999755859556 .026184082550 .4559936523544 .8941040039 539.3450927734533 .8126831055528 .3026123047522 .8184204102517 .367980957 511.9562072754506 .5934143066501 .2860107422496 .0469970703490 .8846130371 485.8139038086480 .8447875977475 .9941101074471 .2727966309466 .7015075684 462.2925109863458 .0743103027454 .0660095215450 .2912902832446 .7705078125 443.5038146973440 .4888000488437 .7189025879435 .1700134277432 .861114502 430.7886962891428 .9630126953427 .3757019043426 .0444030762424 .9740905762 424.1530151367423 .6236877441423 .0910949707422 .5134887695420 .6954956055 416.2797851562416 .5520935059426 .8687133789440 .9056091309452 .1332092285 461.1093139648468 .558013916474 .9931030273481 .229888916484 .0158996582 482.5927124023475 .583404541461 .0956115723445 .5591125488436 .1789855957 425.3929138184407 .8604125977394 .365814209394 .6719055176399 .3290100098 400.4317932129401 .6181945801405 .2001953125413 .2515869141428 .541809082 444.9660949707457 .250793457465 .0017089844467 .1614990234463 .1347961426 452.0235900879434 .3021850586410 .8862915039384 .3525085449358 .3969116211 337.6918029785326 .6083068848319 .9783935547313 .050201416306 .8812866211 302.1303100586299 .1026916504297 .7092895508295 .5118103027289 .3052978516 281.1108093262272 .2851867676257 .7874145508232 .5556030273197 .2478027344 $152.7471923828102 .786796569852 .190319061289 .332235336304-17.6826190948$ $-34.703578949-46.1143989563-52.5163002014-53.6358795166-50.6394805908$ $-45.4342002869-38.7083206177-31.8673706055-25.0874900818-19.0151596069$ $-13.8222904205-9.85287952423-6.9099612236-5.03274917603-3.8630130291$ $-3.13268089294-2.77407503128-2.37339305878-1.95172703266-1.44046401978$ -.793425023556 -7.7468999e-02.9185280203819 2.471615076065 4.273716926575 6.0487580299387 .6918821334849 .06147384643610 .2258901596111 .19029045105 
11.9744901657112 .6253995895413 .1802701950113 .7238502502414 .28868961334 14.9208402633715 .5642204284716 .1961002349916 .8264293670717 .3888092041 18.195940017719 .5477695465121 .1639404296922 .7796192169224 .39418983459 26.0200805664127 .3837108612128 .2450294494628 .6079902648928 .42926025391 27.9374904632627 .3384304046626 .6799602508526 .0259208679225 .43818092346 24.9963798522924 .7285499572824 .7028293609624 .9084300994925 .35800933838 26.01840972926 .8553791046127 .8340606689528 .8996505737330 .01626968384 31.1392707824732 .0722312927232 .5826301574732 .8843994140633 .13988113403 33.3607902526933 .5977096557633 .7461700439533 .7266693115233 .56954956055 33.2915611267132 .9695701599132 .691680908232 .4373512268132 .19926071167 31.9953498840331 .8076591491731 .6089706420931 .4019794464131 .02342987061 30.3700008392329 .5377902984628 .4888591766427 .281810760526 .05138015747 24.9457206726124 .1727504730223 .8460597991923 .9255790710424 .12779998779 24.2438297271724 .3121109008824 .3778896331824 .4661407470724 .55109024048 24.6578998565724 .8264102935825 .0525608062725 .3556709289625 .70690917969 26.0819396972726 .4491901397726 .7833995819127 .054899215727 .24320030212 27.3369293212927 .2968292236327 .2689304351827 .3875007629427 .47035980225 27.3730792999326 .8859996795725 .8220806121824 .1497802734421 .87398910522 $18.9163703918515 .2089004516610 .716569900515 .305984973907-.683402001858$ $-6.98768901825-30.0712394714-41.2357215881-51.3243713379-57.8636207581$ $-62.0269699097-64.512046814-64.9056472778-63.0609703064-59.8842201233$ $-56.5256996155-52.4728317261-47.6273994446-42.5685386658-37.6502494812$ -34.1039390564 -33.0420799255 -33.0098381042 -32.8829803467 -32.9143409729 -33.2290687561 -33.7643013 -34.3956184387 -35.2434387207 -36.4514312744 -37.4367599487 -37.5541992188 -37.2543411255 -36.9216003418 -36.4089012146 -35.7453308105 -34.9677200317 -34.0428390503 -33.4896392822 -33.7729415894 $-34.0573692322-33.5317497253-32.7677688599-32.241809845-31.5166397095$ -30.3463592529 -28.9811496735 -27.8235702515 -26.246389389 -23.5026302338 -20.9829902649-20.012960434 -19.6754302979-19.2024097443 -18.7637195587 $-18.3211307526-17.7623405457-17.0986404419-16.2584495544-15.1688899994$ $-14.1521701813-13.3776502609-12.4610500336-11.0759801865$-9.18157196045 $-6.68161821365-3.67035603523-0.19571800534 .1276531219489 .949104309082$ 15.6569004058819 .6197891235422 .6158294677724 .9716491699226 .81607055664 28.2627792358429 .4696102142330 .607559204131 .6209297180232 .57934951782 33.5194206237834 .5903816223135 .7062988281236 .7962799072337 .831199646 38.7266502380439 .4930686950740 .1048889160240 .5814018249540 .93296813965 41.1878089904841 .3749389648441 .5453796386741 .7701797485442 .03062057495 42.3347206115742 .6843910217343 .0884399414143 .5479202270544 .06613922119 44.6896591186545 .4710388183646 .3558197021547 .2941513061548 .27616882324 49.2892303466850 .3167800903351 .339420318652 .3502502441453 .325050354 54.26604080255 .1635398864756 .0228614807156 .8450698852557 .63423156738 58.3959693908759 .1326217651459 .8491096496660 .5470695495661 .23012924194 61.8997306823762 .5586700439563 .2082099914663 .8506088256864 .48677825928 65.1184234619165 .7461090087966 .370948791566 .9932785034267 .61379241943 68.2327117919968 .8504867553769 .4673309326270 .0835266113370 .69925689697 71.3147888183671 .9302291870172 .5457916259873 .1615676879973 .77770233154 
74.39423370361 75.0112533569375.628768920976.2468109130976.86533355713 77.4843063354578 .1036682128978 .7233428955179 .343193054279 .96312713623 80.5829772949281 .2026214599681 .8218307495182 .4404220581183 .05815124512 83.6747665405384 .2900085449284 .9035568237385 .5150909423886 .12423706055 86.7306671142687 .3340301513787 .9339523315488 .5300369262789 .12200164795 89.7096710205190 .292686462490 .8669204711991 .4348526001

594.6459960938589 .1400146484583 .6171875578 .0626220703572 .4879760742 566.8980712891561 .2990112305555 .6956787109550 .0936889648544 .4970092773 538.9110717773533 .3389282227527 .7872924805522 .258605957516 .7620849609 511.3012084961505 .8876037598500 .5260009766495 .2308959961490 .0085144043 484.8754882812479 .8393859863474 .9191894531470 .121887207465 .4728088379 460.9809875488456 .678314209452 .5762023926448 .7069091797445 .0840148926 441.7239074707438 .6254882812435 .7897949219433 .1711120605430 .8287963867 428.7461853027426 .9948120117425 .5336914062424 .5103149414423 .8839111328 423.8870849609424 .5108032227425 .8801879883427 .7388000488429 .9844055176 429.9119873047433 .1683044434445 .8193969727459 .5286865234466 .925201416 472.6614990234481 .1162109375488 .7694091797495 .0473937988497 .9065856934 496.079498291487 .7421875470 .678314209451 .3554992676436 .9612121582 423.3197021484406 .1170959473393 .3900146484392 .596496582397 .208190918 401.0729980469407 .3440856934416 .0484924316429 .2680969238448 .8461914062 468.2333068848483 .7309875488493 .2632141113495 .0353088379489 .8555908203 478.9677124023460 .6524963379434 .5682067871405 .4396972656376 .5896911621 352.7235107422339 .7692871094331 .9731140137324 .5934143066318 .3463134766 311.2242126465306 .033996582304 .9772033691304 .0927124023299 .5985107422 292.8822021484283 .7096862793269 .9490966797249 .3704071045220 .1656951904 180.9463043213134 .407104492282 .9394302368234 .874290466311 .414222955704 $-21.9347496033-38.2190093994-46.8688392639-49.4624099731-47.5934104919$ $-43.0321884155-36.7740211487-30.268819809-23.7738304138-18.0305995941$ $-13.1432199478-9.44676017761-6.74421787262-4.86514616013-3.63524198532$ $-2.73467206955-2.05591392517-1.25409495831-.440295010805 .2372689992189$ .86128997802731 .3374119997022 .1169929504394 .0016069412236 .204862117767 7.9879789352429 .58879947662410 .865059852611 .7791404724112 .4610004425 12.9456796646113 .4668798446713 .9110298156714 .2682504653914 .60258960724 14.9163103103615 .211290359515 .448940277115 .6403398513815 .75481987 16.2333507537817 .4875106811519 .1044502258320 .6766605377222 .23294067383 23.7698192596425 .0798797607426 .0492191314726 .604770660426 .68086051941 26.4123001098625 .839910507225 .108119964624 .2885208129923 .48287010193 22.8293895721422 .3578796386722 .1738395690922 .2584991455122 .63364982605 23.2619991302524 .0987396240225 .1117000579826 .2284297943127 .42152023315 28.6948604583729 .7502593994130 .1918792724630 .3881206512530 .60047912598 30.7770900726331 .0041408538831 .1258697509831 .0169906616230 .73727989197 30.2951602935829 .8020095825229 .3895893096929 .0250701904328 .69127082825 28.4100494384828 .1246490478527 .8669700622627 .6336593627927 .25852012634 26.5466499328625 .5950508117724 .4005794525123 .2683792114322 .49921035767 21.8160896301321 .2310009002720 .655199050920 .2639808654820 .07682991028 20.0975494384820 .2629203796420 .3974094390920 .5458202362120 .68000030518 
20.8493595123321 .0871505737321 .412179946921 .8312397003222 .31179046631 22.8045902252223 .2848491668723 .7361793518124 .1369400024424 .47002029419 24.7472190856924 .9688396453925 .1579895019525 .3264102935825 .39015960693 25.2805595397924 .8116092681923 .8888893127422 .3593196868920 .17995071411 $17.2915191650413 .655670166029 .2438383102424 .008786201477-1.66495800018$ -7.62944602966 -33.726348877-44.5608596802 -53.4647293091-60.7892990112 $-65.824256897-68.3209762573-68.789352417-67.5570983887-65.0767974854$ $-62.2569999695-58.5433502197-53.6021385193-47.9055709839-41.1129188538$ -35.6995201111 -34.4393615723 -34.6861801147 -34.4105110168 -34.3448905945 -34.601890564 -35.0728607178 -35.5298194885 -36.1729812622 -37.2128410339 -38.1558189392 -38.5756416321 -38.6132011414 -38.3961601257 -37.8836593628 -37.1822090149 -36.2878417969-34.9799118042 -34.0660095215 -34.3609313965 -34.8828010559-34.7725486755 -34.3896408081 -33.8516082764 -33.0609397888 $-32.1099205017-30.9628391266-30.0044193268-28.3997802734-24.8609008789$ -21.6251392365 -20.8913097382 -20.9266605377 -20.4996299744 -20.0055809021 -19.3742103577 -18.6792793274 -17.9882698059-17.2591991425 -16.4749698639 -15.6457004547 -14.7420797348 -13.6583299637 -12.2825298309-10.5018997192 $-8.1887588501-5.37628984451-2.291366100311 .7601300477987 .852046966553$ 13.9048795700118 .0350608825721 .1698894500723 .6307697296125 .5913105011 27.1668090820328 .5074806213429 .7797298431430 .9320907592831 .9741897583 32.9901199340834 .1376800537135 .2993392944336 .4245910644537 .48983001709 38.4211502075239 .2305908203139 .880439758340 .3998908996640 .80374145508 41.1097412109441 .3431091308641 .5447502136241 .7788085937542 .03036880493 42.3131408691442 .6288909912142 .9909896850643 .4062194824243 .89345169067 44.4625701904345 .1323585510345 .8868484497146 .7152786254947 .60903930664 48.5550117492749 .5340003967350 .514511108451 .4883499145552 .43212890625 53.3480606079154 .2267189025955 .0718917846755 .8843917846756 .66646957397 57.4237518310558 .1569099426358 .8716392517159 .5682983398460 .25135040283 60.9213409423861 .5816001892162 .2327919006362 .8773803710963 .51591110229 64.1501617431664 .7804718017665 .4079818725666 .0329132080166 .65595245361 67.2772827148467 .8973464965868 .516326904369 .1345214843869 .7520904541 70.3692932128970 .9862518310571 .6031570434672 .2200927734472 .83721160889 73.4545516967874 .0721969604574 .6901626586975 .308448791575 .92704772949 76.5459136962977 .1649703979577 .7841415405378 .4033432006879 .02245330811 79.6413116455180 .2597808837980 .8776702880981 .4947814941482 .11089324951 82.72573089683 .3390731811583 .9505767822384 .5599517822385 .16683959961 85.77091217041 86.37180328369 86.9691696167 87.56260681152 88.15186309814 88.736740112389 .3163681030389 .8914871215890 .46040344238 594.5029296875589 .0225219727583 .4943847656577 .9185180664572 .3231201172 566.7094726562561 .0833129883555 .450012207549 .8145141602544 .1815795898 538.5557861328532 .9411010742527 .3430175781521 .7653198242516 .2155761719 510.6987915039505 .2244873047499 .7992858887494 .4349975586489 .1398010254 483.9274902344478 .8075866699473 .7956848145468 .9016113281464 .1460876465 459.5421142578455 .1164855957450 .8866882324446 .8778076172443 .1072998047 439.5918884277436 .3387145996433 .3469848633430 .5869140625428 .1101074219 425.9142150879424 .0786132812422 .5947875977421 .6231079102421 .1607055664 
421.5203857422422 .7113037109425 .2948913574429 .3187866211435 .612487793 444.8445129395453 .7777099609458 .5386962891460 .8150939941462 .6395874023 463.6854858398464 .5338134766464 .9771118164465 .2796936035464 .7438049316 465.3421020508459 .8398132324440 .8443908691419 .4194946289407 .0810852051 397.557800293385 .9111938477377 .3345031738376 .0028991699379 .6322021484 387.0302124023397 .6159973145408 .2568969727423 .5777893066449 .1011047363 472.2865905762482 .8529968262486 .7763977051488 .949005127485 .137298584 472.2571105957453 .024810791431 .6323852539409 .2132873535388 .8236083984 370.8982849121355 .666809082344 .0221862793336 .9831848145331 .4592895508 324.8131103516319 .5262145996316 .800201416314 .1227111816309 .0280151367 301.7781066895293 .0094909668280 .4731140137260 .0985107422233 .775100708 202.771697998164 .887298584119 .235900878971 .1131134033225 .87738037109 $-10.2890100479-29.9090805054-39.0018386841-42.3144607544-41.1796913147$ -37.5542106628 -32.1391601562 -26.2376194 -20.2578697205 -15.1644697189 -10.8513402939 -7.66491222382 -5.36464691162 -3.72928404808 -2.61710500717 -1.89043903351 -1.11694896221.32462000846861.84373998642 2.794492959976 3.5314021110534 .2168769836435 .0947499275216 .7590918540958 .692379951477 10.2002201080311 .572959899912 .87259006513 .6888504028313 .78814029694 13.7633800506614 .2572097778314 .7506904602114 .931079864515 .02698993683 15.11456966415 .1529798507715 .0270299911514 .8229904174814 .78960037231 15.1500501632716 .0473804473917 .3182697296118 .7337303161620 .18405914307 21.6732997894323 .0417499542224 .1483802795424 .9172592163125 .17416000366 25.0435905456524 .5204391479523 .7277393341122 .7366409301821 .69816970825 20.8203601837220 .1443004608219 .7999801635719 .7681598663320 .07327079773 20.6654090881321 .5002593994122 .519880294823 .6445598602324 .8263092041 25.9953899383526 .9584007263227 .4774208068827 .7519607543927 .93263053894 28.0375099182128 .1264495849628 .0990505218527 .8856296539327 .51435089111 27.0044307708726 .4417705535925 .9271202087425 .4484195709225 .00326919556 24.5980491638224 .1943607330323 .8465995788623 .5907802581823 .21611022949 22.5114593505921 .4098606109619 .5880508422918 .1454792022718 .16227912903 18.3357391357417 .8172302246116 .8864307403615 .9426002502415 .35556983948 15.5161695480315 .9798297882116 .2462997436516 .4515991210916 .62791061401 16.8402099609417 .1732501983617 .6231899261518 .2080993652318 .85737037659 19.4801502227820 .0805797576920 .6682090759321 .2199401855521 .71221923828 22.1687908172622 .5843791961722 .928079605123 .2043399810823 .33628082275 23.2863597869922 .934080123922 .1823997497620 .8672199249318 .87899017334 $16.1963691711412 .743220329288 .5061521530153 .276382923126-2.44117593765$ -29.5576896667 -38.9248504639-48.9221496582 -58.2310600281 -64.5475692749 $-68.6782989502-71.1270523071-71.9909515381-71.4284133911-69.7730026245$ $-67.4770126343-64.3306274414-60.3944091797-55.2904510498-48.45470047$ $-42.3538589478-39.1666717529-37.5594902039-36.5840301514-36.1499099731$ -36.253528595 -36.7254905701 -37.2002906799 -37.7994194031 -38.5808296204 $-39.3299102783-39.7655181885-39.9202919006-39.7639007568-39.3086509705$ -38.6594390869 -37.8230705261 -36.7513618469 -35.9593391418 -35.9551010132 -36.2013511658 -36.1310997009-35.8394317627 -35.3246116638 -34.5830688477 $-33.6579093933-32.5639305115-31.4060993195-29.6629600525-26.7669296265$ 
-24.1458892822 -23.1812705994 -22.838180542 -22.3069992065 -21.6134204865 -20.5691394806 -19.5783405304 -18.9756908417 -18.4684391022 -17.8077907562 $-16.9886703491-15.992099762-14.8044500351-13.4584503174-11.7785997391$ $-9.54116725922-6.74042081833-3.35169601441 .0084520578386 .963054180145$ 12.8067302703916 .8331203460719 .9075298309322 .4675998687724 .57175064087 26.2825603485127 .7068290710428 .9436702728330 .0921096801831 .3268699646 32.5695800781233 .8277397155835 .0572090148936 .2251892089837 .31238174438 38.2719306945839 .1057891845739 .7898101806640 .3450393676840 .7806892395 41.1188507080141 .3780899047941 .5981597900441 .832729339642 .07389068604 42.3330307006842 .6173706054742 .9389495849643 .3110694885343 .75033950806 44.2542800903344 .8379592895545 .4869689941446 .1970405578646 .99060058594 47.8857192993248 .8301506042549 .7691497802750 .7008209228551 .60739135742 52.490230560353 .3420982360854 .1657295227154 .9609298706155 .73038101196 56.4772109985457 .2033691406257 .9124107360858 .6058692932159 .28667068481 59.9561195373560 .6165313720761 .268970489561 .9152107238862 .55601882935 63.1926918029863 .8256797790564 .4558868408265 .0835494995165 .70924377441 66.33315277166 .9556808471767 .5769882202168 .1973724365268 .81699371338 69.4360733032270 .0547332763770 .6731567382871 .2914581298871 .90975189209 72.5280685424873 .1465072631873 .765068054274 .3837738037175 .00257873535 75.6214675903376 .2403564453176 .8591918945377 .4778594970778 .09623718262 78.7142181396579 .3316268920979 .9483032226680 .5640182495181 .17858886719 81.7917709350682 .4032669067483 .01284027183 .6201400756884 .22485351562 84.8266372680785 .4251403808686 .0200271606486 .6109237670987 .1975402832 87.7797317504988 .357147216888 .9256668090889 .48769378662

594.5410766602589 .0098266602583 .4581298828577 .8685302734572 .2526855469 566.6154785156560 .9625244141555 .2985839844549 .6292114258543 .958190918 538.2908935547532 .6303100586526 .9827880859521 .3510131836515 .7434082031 510.1632995605504 .6213989258499 .1224975586493 .6794128418488 .2981872559 482.9937133789477 .7728881836472 .6528015137467 .6398010254462 .7571105957 458.0120849609453 .4357910156449 .040802002444 .8562011719440 .890411377 437.1711120605433 .6954040527430 .4825134277427 .4928894043424 .7998046875 422.3677978516420 .3312988281418 .6321105957417 .5315856934416 .9106140137 417.3118896484418 .4685058594421 .6115112305426 .6170959473435 .1520996094 451.308013916462 .9643859863457 .3406982422446 .8616027832443 .0534057617 439.3138122559431 .7952880859424 .1502990723418 .0039978027414 .195892334 417.1137084961415 .6755065918397 .2054138184377 .104309082369 .5924987793 365.771697998360 .1915893555356 .4758911133354 .8793029785357 .9768981934 368.2174987793381 .4151000977391 .4061889648405 .5817871094433 .3620910645 458.2304077148463 .5465087891461 .8953857422464 .3315124512461 .6664123535 447.3663024902429 .8630065918416 .5176086426404 .7713928223396 .2127075195 386.5932922363370 .3518066406355 .5187988281349 .0405883789345 .2131958008 340.3436889648335 .2659912109329 .9284973145324 .6272888184318 .5592956543 311.7831115723303 .584197998291 .1560058594269 .2981872559243 .4721069336 219.5137939453190 .161895752151 .9438018799106 .954696655353 .23727035522 $6.550608158112-16.2932796478-26.8325099945-31.9634799957-32.0267105103$ -29.7489299774 -25.3805198669-20.1702404022 -14.8778896332 -10.5980901718 
-7.26155281067 -4.85194921494 -3.04194903374-1.71907103062 -.713091015816 -.118538998067.76454502344132.8574259281164.896668910985.886836051941 6.5106739997867 .3727941513068 .53783226013210 .1467399597211 .69106006622 12.6522197723413 .369560241714 .3807001113915 .0459804534914 .64861011505 14.2176303863514 .7289400100715 .4173803329515 .6559896469115 .62724018097 15.465720176715 .117959976214 .5843400955214 .2350902557414 .33104038239 14.6839504241915 .1516704559315 .8624095916716 .959129333518 .29833030701 19.7866001129221 .266189575222 .5998191833523 .6022796630924 .05042076111 24.0617294311523 .5160007476822 .6117305755621 .4088706970220 .08946990967 18.9885807037418 .115379333517 .6280403137217 .499019622817 .7423992157 18.3059692382819 .1336803436320 .1491203308121 .2522602081322 .36256980896 23.3350791931224 .150249481224 .7234001159725 .0817508697525 .23184013367 25.2219295501725 .1315898895324 .9180297851624 .5857696533224 .13458061218 23.5823192596422 .9825897216822 .3886108398421 .8112792968821 .24025917053 20.6908397674620 .1145896911619 .5899906158419 .1950092315718 .65616989136 17.8428897857716 .4758090972913 .9419097900411 .8659400939912 .16460037231 12.9032001495412 .4458303451511 .62740993510 .7031202316310 .09109020233 10.5953598022511 .3835201263411 .7947301864612 .110110282912 .36849975586 12.681150436413 .1579704284713 .7865104675314 .538260459915 .33917999268 16.0883693695116 .811449050917 .5579109191918 .2802295684818 .94757080078 19.5732307434120 .1445999145520 .6370697021521 .0378799438521 .26672935486 21.2952499389621 .0615997314520 .5273094177219 .5216102600117 .88526916504 $15.5025596618712 .330639839178 .3420524597173 .4253718853-1.78607404232$ -31.7021808624 -40.4485282898 -50.9013710022-61.3066902161 -66.7471466064 $-70.0031967163-72.6500167847-74.0230865479-74.2693328857-73.5173034668$ $-71.8410491943-69.4024200439-66.6290664673-62.6407699585-56.5121307373$ $-50.1127090454-44.7720909119-40.8767585754-38.9324493408-38.2465400696$ $-38.2872009277-38.7285194397-39.211730957-39.733291626-40.2407989502$ $-40.7044296265-41.0323791504-41.1838798523-41.0718383789-40.7317008972$ $-40.2204399109-39.5893211365-38.9134788513-38.3476104736-38.0007705688$ -37.782989502 -37.5421791077 -37.2022399902 -36.6851501465 -35.9629898071 -35.0556793213 -33.9029083252 -32.4785804749 -30.7874507904 -28.8973808289 -27.1772098541 -25.9981098175 -25.1492595673 -24.4344100952 -23.5799999237 $-22.1827907562-20.8632602692-20.2733192444-19.8629493713-19.1753807068$ $-18.311170578-17.2238903046-15.9640302658-14.6543102264-13.0123796463$ -10.7991600037 -7.88549995422 -4.04107809067.5996180176735 6.284452915192 11.7633695602415 .6758699417118 .8288307189921 .5756092071523 .86879920959 25.6871204376227 .1693191528328 .3363399505629 .4460391998330 .8619594574 32.3160209655833 .6840286254934 .9897804260336 .2009391784737 .30696105957 38.2791290283239 .1208496093839 .8211593627940 .3937683105540 .84394836426 41.1955490112341 .4683189392141 .6954116821341 .9245109558142 .1487197876 42.382530212442 .6331901550342 .9161109924343 .2406387329143 .62712097168 44.0684089660644 .5787696838445 .1465187072845 .7601699829146 .46276855469 47.303710937548 .2059402465849 .0924797058149 .9764404296950 .83864974976 51.6811294555752 .4995307922453 .2945594787654 .0674514770554 .81885910034 55.5521507263256 .2679214477556 .9696998596257 .658069610658 .33589935303 
59.0038299560559 .6641006469760 .3172988891660 .9650993347261 .60795974731 62.2470893859962 .8827285766663 .5156898498564 .1461486816464 .77461242676 65.4012374877966 .026367187566 .6501693725667 .2729034423867 .89470672607 68.5158233642669 .1363601684669 .7564773559670 .3762893676870 .99590301514 71.6153488159272 .2347183227572 .8540115356473 .4732437133874 .09239196777 74.7114181518675 .3302612304775 .9488372802776 .5670928955177 .1848526001 77.802032470778 .4184722900479 .0339965820379 .6484222412180 .26154327393 80.8731079101681 .4828796386782 .0905685424882 .695869445883 .29846954346 83.8980407714884 .4942169189585 .0867004394585 .6751327514686 .25917053223 86.838729858487 .4129028320387 .9825134277388 .54577636719 594.5833740234589 .084777832583 .5305175781577 .9197998047572 .2841186523 566.6235961914560 .9434204102555 .2487792969549 .5441894531543 .8341064453 538.1229248047532 .4141845703526 .7133178711521 .0236816406515 .3521118164 509.7031860352504 .0853881836498 .5049133301492 .9718017578487 .4938049316 482.0824890137476 .7467041016471 .4995117188466 .349609375461 .3150939941 456.407409668451 .6492919922447 .0544128418442 .6467895508438 .4429931641 434.4605102539430 .7066955566427 .187286377423 .8775024414420 .8281860352 418.0311889648415 .5721130371413 .4349060059411 .8017883301410 .6679992676 410.3627929688410 .8422851562412 .905090332416 .6630859375423 .6459960938 435.7286071777441 .217010498429 .986114502414 .1690063477406 .4930114746 400.2395019531389 .9523925781380 .1180114746374 .4099121094372 .7192077637 374.9081115723374 .5636901855362 .9431152344350 .4978942871346 .016204834 344.3700866699340 .8085021973338 .1495056152338 .0681152344342 .1207885742 352.5791931152364 .4729919434371 .2601928711380 .8693847656401 .3562927246 420.8384094238429 .3055114746431 .7084960938431 .0304870605426 .3016967773 415.7853088379405 .5409851074400 .862701416399 .0054016113397 .928314209 392.9023132324379 .5531005859366 .0745849609360 .8510131836358 .655090332 355.8418884277350 .7687988281341 .2456970215332 .2821960449329 .2865905762 326.5820007324318 .6470031738304 .9621887207282 .2066955566256 .5950927734 233.6965942383207 .1452026367171 .8757019043129 .17599487379 .97738647461 $35.524330139167 .669141769409-8.89991474152-17.2167701721$-19.9746894836 -19.7746105194 -16.7565307617 -11.9981002808 -7.07505607605-4.12491321564 -2.30120801926 -1.04706704617 7.40299970e-02 1.299842953682 2.476675987244 3.3859190940864 .7130351066597 .2464938163769 .4173107147229 .580381393433 9.2752437591559 .9075822830211 .2855195999113 .6826000213615 .57030010223 15.3717603683514 .6342601776114 .6387701034514 .6606197357214 .2172498703 13.9195499420214 .3602695465115 .2032499313416 .2308101654116 .7078704834 15.833809852614 .5834398269713 .7875795364413 .5503702163714 .13234996796 14.7560195922914 .6936998367314 .687399864215 .4301004409816 .6558303833 18.1982898712219 .8730792999321 .4940891265922 .7792701721223 .48214912415 23.6387405395522 .9943904876721 .8678302764920 .3771800994918 .7287902832 17.3575992584216 .2896099090615 .6682796478315 .4579296112115 .65359020233 16.1904106140117 .011299133318 .0107097625719 .0785503387520 .10741996765 20.9662094116221 .6819992065422 .1703300476122 .4601097106922 .51814079285 22.3758792877222 .13567924521 .7847499847421 .3276596069320 .78075027466 20.1272106170719 .4357109069818 .7792091369618 .1143608093317 .41419029236 
16.6704597473115 .8465204238914 .998080253614 .1531600952113 .10247993469 11.711350440989 .6546564102176 .5045709609993 .7010240554812 .63992190361 2.4861381053922 .7051930427553 .0822620391853 .4610741138464 .0191822052 4.9746351242075 .9944548606876 .7317447662357 .3069009780887 .760151863098 8.2664747238169 .0355243682869 .94130039215110 .8378601074211 .73834991455 12.6176500320413 .4790000915514 .3873996734615 .2890100479116 .13097953796 16.9175701141417 .628070831318 .2629508972218 .8339996337919 .20196914673 19.2406406402619 .0847892761218 .8665790557918 .3293704986617 .26617050171 $15.4004697799712 .418540000928 .5995016098024 .10944890976-.597990989685$ $-29.6960792542-38.6016807556-48.3192901611-57.8899803162-64.8270797729$ $-69.5518569946-72.8151016235-74.8269882202-75.8925476074-76.0045394897$ $-75.2405319214-73.6524124146-71.2344970703-67.5178909302-61.9656715393$ $-55.3820610046-48.6671905518-43.2988586426-41.1772003174-40.7955207825$ $-40.9043312073-41.2875595093-41.5073394775-41.7084503174-41.9858818054$ $-42.2481193542-42.3961982727-42.4825401306-42.4853096008-42.3471412659$ $-41.996509552-41.5445404053-41.0242385864-40.4698982239-39.9857292175$ -39.5199813843 -39.1069984436 -38.6750183105 -38.0959205627 -37.3569488525 $-36.4316902161-35.2718200684-33.8512001038-32.3830299377-30.916759491$ $-29.5556106567-28.4706707001-27.5538005829-26.9557800293-26.1972103119$ $-24.6984004974-23.1745204926-22.2229995728-21.4828796387-20.6520805359$ $-19.6921405792-18.5610599518-17.291519165-15.919719696-14.2286500931$ $-12.0143995285-9.05163288116-5.14781713486-.5819690227514 .774207115173$ 9.97455024719214 .1982898712217 .8602409362820 .9284191131623 .45022010803 25.4024391174326 .9456405639628 .2076206207329 .4042491912830 .83124923706 32.3050804138233 .7318992614735 .0927505493236 .3418312072837 .46643066406 38.4385604858439 .2720298767139 .9674606323240 .5359497070340 .98263168335 41.333431243941 .6119194030841 .8419990539642 .0559310913142 .25629043579 42.457588195842 .6704483032242 .9104003906243 .1874084472743 .51906967163 43.9034690856944 .3527717590344 .8602905273445 .42755888989346 .07809829712 46.8379096984947 .656810760548 .4809188842849 .3075904846250 .11798095703 50.914199829151 .6928596496652 .4548606872653 .2004394531253 .93075180054 54.6472091674855 .3509292602556 .0434989929256 .7259597778357 .39974975586 58.0657806396558 .725311279359 .3790893554760 .0281486511260 .67300033569 61.3144111633361 .952701568662 .5883903503463 .2216987609963 .85298156738 64.4824066162165 .1102294921965 .7366333007866 .3618164062566 .98594665527 67.6092071533268 .2317428588968 .8536682128969 .4751129150470 .09615325928 70.7168426513771 .3372573852571 .9573898315472 .5772705078173 .1968536377 73.8161163330174 .4349975585975 .053436279375 .6713333129976 .28856658936 76.9050292968877 .5205688476678 .1350326538178 .7482223510779 .35994720459 79.9699935913180 .5780792236381 .1839370727581 .7873229980582 .38787078857 82.9852905273483.5792236328184.16934967041 84.75533294678 85.33688354492 85.9138793945386 .4860229492287 .0491333007887 .60555267334

594.8359985352589 .2813720703583 .7028808594578 .0803222656572 .4254760742 566.7421264648561 .0355224609555 .3098754883549 .5700073242543 .8198242188 538.0637207031532 .3046264648526 .5479736328520 .7968139648515 .0576782227 509.3341064453503 .6351013184497 .9649963379492 .3344116211486 .7489013672 
481.220703125475 .7561035156470 .3687133789465 .0643005371459 .8613891602 454.7683105469449 .8055114746444 .979095459440 .3187866211435 .8367919922 431.5516052246427 .4619140625423 .5794067383419 .8670959473416 .3835144043 413.099395752410 .1012878418407 .3301086426404 .9855041504403 .0238037109 401.7308044434401 .0393981934401 .2793884277402 .4948120117404 .1329956055 407.0892028809404 .8642883301390 .8107910156374 .2244873047365 .5943908691 358.3138122559347 .7166137695338 .9520874023336 .1918029785336 .5462036133 337.1253967285337 .009185791332 .8266906738328 .4107055664326 .8002929688 325.8356933594322 .7973937988320 .7107849121322 .4224853516327 .2070922852 336.516204834345 .7687988281348 .8942871094352 .8481140137363 .9572143555 376.4902038574388 .7561035156396 .3432922363393 .3193969727387 .0703125 381.8057861328379 .3793945312382 .3363952637387 .0245056152390 .3792114258 389.5650024414380 .8330078125371 .0497131348368 .1973876953367 .3320007324 366.570892334362 .942199707351 .3342895508341 .1492004395342 .5812072754 343.9536132812335 .5028991699320 .2179870605296 .729095459270 .3522033691 246.483795166219 .7388000488186 .0446014404147 .5102996826106 .62567 .36711120605 $35.0561981201211 .68381977081-1.06078195572-6.43141078949-8.08629226685$ $-6.7657828331-2.965276002881 .1206589937212 .6743819713593 .335925102234$ 3.8533029556274 .3235120773325 .2891287803656 .4963650703437 .706869125366 9.25296306610111 .7532796859713 .5591602325412 .7971801757811 .74359989166 12.2406797409113 .6955795288116 .6302204132118 .8284797668517 .6309299469 15.6187496185314 .7091102600114 .1253404617313 .8023900985713 .82647037506 14.194410324115 .0517101287816 .6505908966117 .5785198211716 .1556892395 14.2688398361213 .374409675613 .21181011214 .0772104263314 .89274024963 14.3915195465113 .8864297866814 .4246397018415 .5414600372317 .10730934143 18.9339103698720 .7830200195322 .4504508972223 .5726699829123 .8763999939 23.0149803161621 .3957500457819 .4874401092517 .5417900085415 .96175003052 14.7625303268414 .0430498123213 .77563953413 .9225502014214 .42920017242 15.2287998199516 .1971492767317 .2089290618918 .1822605133118 .95809936523 19.5461292266819 .8734302520819 .964780807519 .8549499511719 .57653045654 19.2174797058118 .7505397796618 .1840991973917 .5296897888216 .76944923401 15.979729652415 .2456102371214 .4869604110713 .6496095657312 .69859027863 11.6038198471110 .339619636548 .9089355468757 .1920318603525 .123611927032 $2.527086019516-.928628027439-4.2534031868-6.74246311188-8.03444290161$ -7.37588787079 -5.80769777298 -4.05463981628 -2.23529195786-.807226002216 .41955301165581 .4879239797592 .3890180587773 .1150190830233 .895008087158 5.0112161636356 .162423133857 .1205801963818 .038622856149 .013927459717 10.0378503799411 .1376495361312 .2266798019413 .2537298202514 .2127199173 15.0591697692915 .8183097839416 .5491600036617 .0667495727517 .15835952759 17.1067790985117 .1917304992717 .0471305847216 .4987506866515 .1553401947 $12.469280242929 .0464973449715 .3261032104491 .441319942474-25.2021102905$ -32.9669494629 -43.1433105469 -52.0984992981 -60.2227897644-66.8490600586 $-71.1938171387-74.0287399292-76.2005386353-77.4223175049-77.6646194458$ -76.9253082275 -74.6254730225 -70.9359512329-65.9259414673 -59.6679611206 $-52.3181610107-46.0926895142-43.9270401001-43.6394195557-43.5468406677$ $-43.7705612183-43.6957206726-43.6224212646-43.7577400208-43.9179191589$ 
$-43.9435195923-43.9795417786-44.0916786194-44.1450881958-43.9534492493$ $-43.6166114807-43.1359710693-42.5410308838-41.9280090332-41.3062896729$ $-40.7546882629-40.1948204041-39.5246696472-38.7310295105-37.7807884216$ -36.6743507385 -35.3867683411 -34.0918197632 -32.849861145 -31.6887302399 $-30.6701507568-29.7958507538-29.3308506012-28.7234401703-27.3032608032$ -25.687210083 -24.3783607483 -23.1818809509 -22.1061096191 -21.0611801147 $-19.9042205811-18.6216392517-17.1462097168-15.3478002548-13.0788602829$ $-10.2003602982-6.48199892044-2.091196060183 .0155038833628 .230939865112$ 13.0007295608517 .2684192657520 .6663799285923 .4026794433625 .45903968811 27.0414295196528 .3847999572829 .6541805267331 .0654602050832 .52914810181 33.9880599975635 .3738708496136 .6401290893637 .7647781372138 .72386932373 39.5349998474140 .2117195129440 .7621803283741 .1932411193841 .53213882446 41.8057403564542 .0266685485842 .2164916992242 .3839492797942 .54713821411 42.715961456342 .9092102050843 .1345710754443 .4113311767643 .74024963379 44.1375885009844 .6004905700745 .1422882080145 .7542495727546 .43368911743 47.1634902954147 .9142417907748 .677730560349 .4301986694350 .17443847656 50.9098510742251 .6355590820352 .3521308898953 .0595283508353 .75846862793 54.4492492675855 .132389068655 .8084907531756 .4781494140657 .1420211792 57.8007812558 .4549789428759 .1052398681659 .7519683837960 .3956489563 61.0365295410261 .6749687194862 .3111190795962 .9452590942463 .57751083374 64.2081069946364 .8371582031265 .4648818969766 .0914077758866 .71691894531 67.3415069580167 .9653472900468 .5885009765669 .2110671997169 .83309173584 70.4546432495171 .0756912231471 .696289062572 .3163833618272 .9359664917 73.5549774169974 .1733322143674 .7909393310575 .4077072143676 .02352142334 76.6382217407277 .2516632080177 .863693237378 .4740829467879 .08262634277 79.6890869140680 .2931976318480 .894676208581 .4932174682682 .08853149414 82.680252075283 .2680969238383 .851707458584 .4308166503985 .0053024292 85.5743026733486 .1386566162186 .69657897949 595.0930175781589 .578125583 .9998168945578 .3571166992572 .6837768555 566.978515625561 .2454223633555 .4893188477549 .713684082543 .9229736328 538.1204833984532 .3098144531526 .4949951172520 .6795043945514 .8687133789 509.0667114258503 .2803955078497 .5148925781491 .7785949707486 .0777893066 480.4218139648474 .8179016113469 .2760925293463 .803894043458 .4140930176 453.1160888672447 .922088623442 .8392944336437 .8926086426433 .1021118164 428.4684143066423 .9883117676419 .6658935547415 .4881896973411 .4703979492 407.5928955078403 .8828125400 .3164978027396 .9761047363393 .8764953613 391.067199707388 .580291748386 .1411132812383 .7684936523379 .6411132812 373.0115966797364 .2372131348353 .0119934082341 .8460083008332 .5382080078 324.2797851562316 .4896850586310 .8992004395308 .3653869629307 .5694885254 307.5466003418307 .8082885742306 .0278015137304 .5661010742305 .0928039551 305.2041015625303 .6416931152303 .0911865234305 .7807006836310 .4075012207 316.9887084961322 .8999938965325 .4119873047327 .6785888672333 .1455078125 341.2470092773351 .7597961426359 .1091003418356 .1086120605350 .9728088379 349.8570861816352 .3593139648357 .415802002363 .3056030273369 .6146850586 372.990814209369 .9106140137365 .5976867676364 .837310791365 .5697021484 367.9255065918367 .8775024414361 .5227050781356 .7990112305361 .4755859375 
364.1879882812354 .2344970703336 .3330993652312 .6849975586286 .3757019043 261.0559082031234 .095199585204 .4689941406171 .8460998535133 .3919067383 93.5498275756857 .3154907226628 .5507392883313 .395500183116 .931581020355 4.7124099731454 .9107580184945 .819591045387 .4043049812328 .497239112854 9.35367107391410 .0992698669410 .5759401321410 .4588403701810 .6364402771 11.9211502075213 .3966703414914 .4619398117114 .793729782114 .06474971771 13.4267396926913 .9960498809815 .3942604064917 .5527095794718 .94734954834 17.9695701599116 .2196693420415 .0555696487414 .3173599243214 .12508010864 14.272219657914 .5801000595115 .2762804031416 .3409595489516 .79966926575 15.7493495941214 .2852697372413 .3856697082513 .1239700317413 .5330696106 13.876110076913 .5419902801513 .303959846513 .8706502914414 .99853992462 16.548690795918 .4049301147520 .4319992065422 .515899658224 .53613090515 25.3903408050523 .7891101837221 .1443500518818 .7065105438216 .48382949829 14.7802600860613 .5429496765112 .783169746412 .4782199859612 .59527015686 13.0703401565613 .843259811414 .7718601226815 .7353696823116 .6603603363 17.4011402130117 .8821506500217 .9261398315417 .6959991455117 .35584068298 16.9227790832516 .46176910415 .9131402969415 .2258501052914 .45586013794 13.6352996826212 .7799596786511 .9142198562611 .0034799575810 .01819038391 8.8609695434577 .477836132055 .8022089004523 .7771980762481 .498232960701 -.914421975613 -3.58145403862 -6.69799995422 -9.77094173431 -12.3501300812 $-13.82654953-13.629940033-12.2022600174-10.2285499573-8.12431716919$ $-6.38757419586-4.8945851326-3.57002806664-2.3599460125-1.28785705566$ -.1523170024161.283972978592 2.60759305954 3.4243330955514.175508022308 5.2506480216986 .4861078262337 .789159774789 .08383560180710 .3235502243 11.4842901229912 .498600006113 .3997602462814 .2001800537114 .79673957825 15.1095800399815 .2995195388815 .5011901855515 .4992799758915 .11509990692 14.0634403228812 .017950057989 .4101543426516 .5861301422123 .637679100037 $-22.4587593079-30.3764705658-38.2868385315-46.2671890259-54.1280517578$ $-61.3354911804-66.954498291-71.1964263916-74.8534927368-77.5042266846$ -78.8708877563 -78.9910964966 -77.2072372437 -73.9625167847-69.7130584717 $-64.1692123413-57.1338386536-50.8162612915-47.7425918579-46.4248085022$ $-45.795501709-45.6149787903-45.4447402954-45.3938484192-45.5040283203$ $-45.6786308289-45.783908844-45.90417099-46.0515708923-46.1522598267$ $-46.0829315186-45.8185806274-45.2877006531-44.5785293579-43.8027305603$ $-43.0241394043-42.3713989258-41.7277603149-40.986869812-40.1494102478$ -39.184261322 -38.1192893982 -36.9473800659 -35.7797889709 -34.6724891663 -33.6099281311 -32.605381012 -31.6894302368 -30.9788208008 -30.2372398376 -29.1713504791 -27.8201904297 -26.2935390472 -24.7504692078 -23.4872207642 -22.3619499207 -21.1643009186 -19.8272590637 -18.25922966 -16.3768291473 -14.07833004 -11.336139679 -8.08853530884 -4.02103900909 1.429584026337 7.248351097107 12.5022096633917 .1921901702920 .8818893432623 .7742500305225 .91514968872 27.4858894348128 .7014102935829 .8718490600631 .3974208831832 .99723052979 34.4868011474635 .867328643837 .1036300659238 .1902999877939 .1157913208 39.8954315185540 .5411682128941 .0651702880941 .4770889282241 .79946899414 42.0519104003942 .247211456342 .4024391174342 .5291709899942 .64580154419 42.7653083801342 .9059104919443 .0780715942443 .2997093200743 .57696914673 
43.9245796203644 .3455009460444 .850028991745 .4156494140646 .03823852539 46.7002296447847 .3799514770548 .0752296447848 .7657318115249 .45325088501 50.1416587829650 .8296813964851 .5163002014252 .2009811401452 .88264083862 53.5610313415554 .2351303100654 .9052581787155 .5710601806656 .23295974731 56.891048431457 .5457191467358 .1972084045458 .8457908630459 .49171829224 60.1351699829160 .7763214111361 .415321350162 .052310943662 .68740081787 63.3207702636763 .9525184631364 .5828170776465 .211776733465 .83957672119 66.4663009643667 .0920867919967 .7170028686568 .3411636352568 .9645614624 69.5872879028370 .2093276977570 .8307113647571 .4513931274472 .07134246826 72.6905136108473 .3088302612373 .9262237548874 .5425720214875 .15776824951 75.7716827392676 .3841476440476 .9950408935577 .6041488647578 .21124267578 78.8161163330179 .4185028076280 .018142700280 .6147232055781 .20794677734 81.7975082397582 .3831024169982 .9643783569383 .5410766601684 .11311340332 84.6801910400485 .2381286621185 .78922271729

595.5864257812590 .01171875584 .4094238281578 .7573852539573 .0667724609 567.3402709961561 .5820922852555 .7958984375549 .9854125977544 .1538696289 538.3051147461532 .4415283203526 .5676269531520 .6857299805514 .8010864258 508.9169921875503 .0400085449497 .1741027832491 .3270874023485 .5039978027 479.7135009766473 .9610900879468 .2561035156462 .6041870117457 .0156860352 451.4971008301446 .0582885742440 .7015075684435 .4497070312430 .3234863281 425.3139038086420 .4067993164415 .6098022461410 .915802002406 .3099060059 401.7620849609397 .2656860352392 .8034057617388 .345489502383 .9307861328 379.3438110352374 .7150878906369 .2112121582362 .9697875977354 .0940856934 340.1769104004326 .6590881348319 .9328918457314 .5262145996305 .290802002 296.9223022461292 .6646118164290 .2286987305287 .3810119629285 .4578857422 285.0203857422285 .2561035156284 .2276916504283 .6997070312284 .9396972656 286.1159973145286 .2449951172286 .9487915039290 .1423950195293 .9224853516 297.3989868164300 .3272094727303 .1185913086305 .5798950195308 .000213623 312.0697937012319 .5494995117325 .794708252324 .0043029785321 .4595947266 323.8387145996328 .2886962891331 .9009094238336 .6430969238344 .1737976074 350.7092895508353 .2549133301353 .9348144531354 .7864074707356 .5739135742 361.5519104004366 .6117858887368 .1860961914369 .8012084961376 .7618103027 378.9383850098367 .2605895996347 .6976013184324 .4392089844298 .862487793 272.344909668246 .4515991211221 .9951019287194 .153793335156 .9696960449 116.726898193479 .161407470747 .6010589599629 .7393093109120 .69535064697 16.8320903778116 .3556194305414 .5390796661413 .3689298629814 .00436019897 15.1510496139516 .2732906341616 .8300495147715 .8109397888214 .84181976318 15.9270000457817 .0685596466116 .5604400634815 .7249698638915 .48056983948 15.7516803741516 .622489929217 .8644199371318 .9347305297919 .3819694519 18.9015407562317 .8412494659416 .7191791534416 .0380096435516 .13923072815 16.612379074117 .0081405639617 .2466201782217 .2311191558817 .05643081665 16.6222801208516 .0425891876215 .2679195404114 .5806303024314 .09657001495 13.8349504470813 .6775102615413 .8447103500414 .5008602142315 .52954006195 17.0161399841318 .7999191284220 .8636608123823 .0610198974625 .56467056274 26.7281093597424 .4382705688520 .9587306976318 .2558097839415 .88191986084 14.1340904235812 .9340000152612 .136930465711 .7861299514811 .83699035645 
12.2447299957312 .9402999877913 .8224296569814 .75934982315 .59265995026 16.2218399047916 .4890995025616 .2030792236315 .6621103286715 .11598968506 14.5245800018313 .962329864513 .3358697891212 .5254096984911 .65268039703 10.781209945689 .8516674041758 .8388700485237 .7437157630926 .563852787018 $5.1933569908143 .5830268859861 .561293005943-.945136010647-3.68502497673$ $-6.29887914658-8.89610385895-11.5082197189-13.9471797943-16.0867595673$ -17.4374809265 -17.7343292236 -16.980890274-15.37541008 -13.4034700394 -11.580739975 $-9.88241863251-8.32602024078-6.87539720535-5.4933347702-4.09881496429$ $-2.46393299103-1.04460203648-.3584409952160 .2654770016671 .443385958672$ 2.8395950794224 .288658142095 .7886209487927 .2720341682438 .634165763855 9.81038379669210 .7890796661411 .6337604522712 .3406200408912 .91508960724 13.3635396957413 .6364603042613 .6589002609313 .3191299438512 .52845001221 $11.176329612739 .4336805343637 .4972410202035 .220016956329-18.3281402588$ -25.963350296 -32.7333106995 -39.9017791748 -47.1783790588 -54.1879997253 $-60.5215606689-66.2996368408-72.0649108887-76.7406082153-79.3268432617$ $-80.0606689453-78.5157165527-75.4418106079-71.8495635986-67.075302124$ $-60.9341888428-55.068901062-51.3026809692-48.9198799133-47.5879707336$ $-47.0471916199-46.8533401489-46.9606895447-47.166519165-47.4517707825$ $-47.7152404785-47.9791984558-48.1479988098-48.2483787537-48.2165489197$ $-47.9682502747-47.3571281433-46.5321884155-45.635269165-44.7281799316$ $-43.9859008789-43.2639808655-42.4468193054-41.5697593689-40.598739624$ -39.5745391846 -38.4951591492 -37.4210395813 -36.3804206848 -35.3563690186 $-34.3532218933-33.341758728-32.316860199-31.2829608917-30.3928794861$ -29.3387794495 -27.7705593109 -26.1594600677 -24.8761196136-23.6707706451 -22.389629364 -20.9708003998 -19.2855205536-17.3160991669 -14.9686403275 $-12.2591600418-9.32532596588-5.43596982956 .45605999231346 .912230014801$ 12.6208696365417 .6413307189921 .4983596801824 .4254302978526 .60264968872 28.1920509338429 .3190994262730 .4064807891832 .01757812533 .70664978027 35.1747398376536 .5071601867737 .6857681274438 .7125587463439 .59379959106 40.334259033240 .9434700012241 .4355697631841 .8211708068842 .1176109314 42.3360214233442 .4926300048842 .6023597717342 .6792411804242 .7425994873 42.8054504394542 .888950347943 .0034294128443 .1695404052743 .39387893677 43.693080902144 .0680618286144 .5296707153345 .0563011169445 .63888931274 46.2474708557146 .8594093322847 .477958679248 .1007614135748 .73389053345 49.37736892750 .0300903320350 .6888809204151 .3527908325252 .01852035522 52.6858901977553 .3517417907754 .0166397094754 .6789817810155 .33929824829 55.9968910217356 .6521797180257 .3049011230557 .9553718566958 .6035194397 59.2495002746659 .8933296203660 .5351295471261 .174938201961 .81287002563 62.4489898681663 .083431243963 .7163009643664 .3477172851664 .9778213501 65.6066818237366 .2344436645566 .8611526489367 .4869079589868 .11173248291 68.7356719970769 .3587265014669 .9809265136770 .6022262573271 .22258758545 71.8419570922972 .4602813720773 .0774612426873 .6934204101674 .3080368042 74.9211883544975 .5327301025476 .1425170898476 .7503509521577 .3560333252 77.9593429565478 .5600433349679 .1578369140679 .7524871826280 .34368133545 80.9311065673881 .5144882202182 .0934829711982 .6678085327183 .23741912842 83.8014526367284 .360763549884 .91354370117 
596.0844116211590 .5565185547584 .9580078125579 .2877807617573 .5811157227 567.8348999023562 .0524291992556 .2371826172550 .3922119141544 .520690918 538.6253051758532 .708984375526 .7750244141520 .8256835938514 .8654174805 508.8973083496502 .9263916016496 .9569091797490 .9946899414485 .0448913574 479.1135864258473 .2066955566467 .3304138184461 .4905090332455 .6932983398 449.9448852539444 .2499084473438 .612487793433 .0439147949427 .5563964844 422.1408996582416 .7943115234411 .5032043457406 .2565917969401 .0176086426 395.7517089844390 .4248962402385 .0252990723379 .4435119629373 .6563110352 367.4226074219360 .7471923828352 .986114502344 .020904541332 .7896118164 318.2568969727305 .4096069336298 .1243896484292 .6069946289284 .8479919434 277.8804931641274 .5455932617272 .792388916270 .8434143066269 .237701416 268.7785949707269 .0497131348268 .9609985352269 .3204040527270 .5791015625 272.0232849121272 .9888000488274 .3948059082277 .1238098145279 .7688903809 281.7976989746283 .696685791285 .6520996094287 .4349060059288 .8085021973 291.0394897461296 .0304870605301 .4393920898303 .8233947754305 .5888061523 307.5898132324309 .6708068848311 .7990112305315 .5469055176322 .674987793 330.5757141113335 .9515075684339 .1677856445339 .8078918457341 .3469848633 347.8207092285356 .8135986328365 .2856140137372 .0780029297377 .3008117676 376.1758117676365 .4989929199347 .5504150391323 .403503418297 .2645874023 273.3909912109251 .9028930664233 .0829925537210 .0502929688175 .0301055908 136.811706543105 .096900939976 .6718292236350 .153320312531 .35861968994 25.8057708740225 .2741909027122 .3106403350819 .7992706298819 .21125984192 19.6586799621620 .2240200042720 .3226699829119 .4415092468318 .47130966187 18.6427097320618 .9085407257118 .3622493743917 .8893795013418 .12643051147 19.0447006225620 .5495491027822 .0306396484422 .7974090576222 .9496307373 22.5136299133321 .589290618920 .1124095916719 .2811203002920 .29775047302 21.7184104919422 .3785800933822 .1860008239720 .8606204986619 .83219909668 20.2505702972420 .6882400512719 .6444702148418 .114120483416 .90737915039 16.1576690673815 .9177799224916 .1692790985116 .6441802978517 .38431930542 18.6963291168220 .2919101715122 .0949401855523 .9447307586725 .53469085693 25.8990993499823 .7824497222920 .6697692871118 .0453090667715 .77987003326 14.1304998397813 .0018596649212 .2049798965511 .7709598541311 .72420978546 12.0097303390512 .5732297897313 .3732404708914 .3690299987815 .16250038147 15.3363103866615 .090820312514 .5626602172913 .8766803741513 .17798995972 12.460339546211 .7598304748511 .0054798126210 .107819557199 .166927337646 8.2275695800787 .2016868591316 .0654377937324 .811907768253 .394191026688 $1.83887898922 .1864800006151-1.91569304466-4.71858787537-7.73150396347$ -10.5346803665 -13.116350174 -15.5355300903 -17.6697406769-19.4211406708 -20.6313991547 -20.9667205811 -20.5136604309-19.2670707703 -17.5663204193 $-15.8725004196-14.167140007-12.5736503601-11.0359096527-9.55883598328$ $-8.09961605072-6.56600093842-5.23591184616-4.36642313004-3.52628302574$ $-2.33144903183-.920337021351 .61217600107192 .277551889424 .093040943146$ 5.7493720054636 .9299402236947 .8524928092968 .7721176147469 .629062652588 10.3799600601210 .9934101104711 .3871097564711 .5051097869911 .33580970764 10.8741397857710 .017939567579 .0020341873178 .0721406936655 .751955986023 $-10.1269702911-17.8926696777-25.4320297241-32.7160682678-39.7591400146$ 
-46.5102310181 -52.3547210693 -58.7621307373 -67.9147567749 -75.9910430908 -79.469543457-80.1802368164 -78.4725799561 -75.1733627319-71.4090881348 $-66.8319473267-61.6430397034-56.6590805054-53.0897293091-50.5094299316$ $-48.8877601624-48.1555900574-48.0356292725-48.3094596863-48.6817588806$ $-49.1139411926-49.5277290344-49.9009017944-50.1618003845-50.2910881042$ $-50.22397995-49.9173812866-49.2851905823-48.4343185425-47.486831665$ $-46.5127296448-45.6339683533-44.7749404907-43.8833999634-42.962348938$ $-41.9799118042-40.9720191956-39.9531707764-38.9381904602-37.9487304688$ -36.9487190247 -35.9211807251 -34.803478241 -33.5828285217 -32.2793388367 -30.849319458 -29.4801807404 -28.3557300568 -27.2777309418 -26.1411800385 -24.9249095917 -23.56731987 -22.0157699585 -20.2035198212 -18.0853290558 -15.5853595734 -12.6934900284 -9.38604736328 -5.12828397751.7450169920921 7.2550539970413 .4933996200618 .9241600036622 .6754894256625 .39098930359 27.5459098815929 .2010498046930 .4888305664131 .7003192901633 .18885040283 34.7016906738336 .0636482238837 .2918281555238 .3826293945339 .33898162842 40.1585807800340 .8493804931641 .4153404235841 .8686408996642 .21694946289 42.4737892150942 .6485900878942 .7560615539642 .8112297058142 .83002853394 42.8316688537642 .8318099975642 .8517112731942 .9043083190943 .00981140137 43.1770782470743 .4221305847243 .7473983764644 .1625404357944 .65464019775 45.2257995605545 .8082809448246 .335800170946 .8589782714847 .41646957397 47.9999618530348 .6050682067949 .2278518676849 .8637809753450 .51023101807 51.1631889343351 .8214111328152 .4810409545953 .1417617797953 .80175018311 54.4609985351655 .1186408996655 .7747497558656 .4289588928257 .08135986328 57.7317886352558 .3802909851159 .0267982482959 .6713600158760 .31394958496 60.9546508789161 .5935096740762 .2305984497162 .8660087585463 .4998588562 64.1322326660264 .7632293701265 .3929519653366 .0214614868266 .64881896973 67.2750625610467 .9002304077168 .5243072509869 .1473388671969 .7692565918 70.3900375366271 .009620666571 .6279602050872 .2449569702172 .86054992676 73.47460937574 .0870132446374 .6976318359475 .3063278198275 .91291809082 76.5171966552777 .1189498901477 .7179718017678 .3139801025478 .90670776367 79.4958801269580 .081192016680 .6623764038181 .2390975952181 .8111114502 82.378341674882 .9404983520583 .493446350184 .03942108154 596.8422851562591 .2521972656585 .6311035156579 .9550170898574 .2338256836 568.4694213867562 .6643066406556 .8215942383550 .9434814453545 .0328979492 539.0922241211533 .1234741211527 .1298217773521 .1129150391515 .0765991211 509.0232849121502 .957611084496 .8825073242490 .803314209484 .7237854004 478.6489868164472 .5834960938466 .5317993164460 .4988098145454 .487701416 448.5032958984442 .5469970703436 .6239013672430 .7322998047424 .8764038086 419.0481872559413 .2572937012407 .4627075195401 .654296875395 .766998291 389.7810974121383 .611114502377 .2900085449370 .5860900879363 .5078125 355.7088928223347 .282989502337 .6987915039327 .0401916504315 .3452148438 302.8765869141291 .7968139648283 .1937866211276 .3763122559269 .7695922852 264.4558105469261 .4941101074259 .783996582258 .5891113281257 .8810119629 257.6770935059257 .9952087402258 .4811096191259 .2864990234260 .2377929688 261.3857116699262 .7601013184264 .2605895996266 .1950073242267 .8659973145 269.3309936523270 .6236877441271 .9938049316273 .2911071777274 .4560852051 
276.2749938965279 .5487976074284 .2401123047290 .4200134277295 .6852111816 296.266998291295 .7112121582296 .4056091309299 .0173950195305 .0950927734 312.3221130371318 .7287902832323 .536895752324 .2369995117325 .7869873047 333.3453979492343 .7781982422355 .6856079102365 .2630004883368 .1264038086 364.5491027832356 .5421142578342 .5566101074320 .1644897461296 .2641906738 275.9278869629257 .4772949219240 .9618988037220 .4653930664187 .275604248 152.5292053223129 .2960968018106 .128303527873 .0917282104545 .12292098999 36.8462486267135 .4018898010330 .8606700897227 .2524299621625 .39616012573 24.5298995971724 .0187492370623 .5776500701923 .205850601222 .81341934204 22.6158294677722 .5383300781222 .5614204406723 .0365295410224 .12409973145 25.7856807708727 .6155300140429 .2411594390929 .8018398284929 .64814949036 29.4757995605528 .8518791198727 .2618293762226 .5225906372128 .26333999634 30.3118190765431 .1864204406731 .0518302917529 .0141792297427 .28914070129 28.3077297210729 .2751598358227 .6772003173825 .4166202545223 .59300041199 22.1636104583721 .4702701568621 .1352291107220 .7738208770820 .9079208374 21.9639396667523 .4337902069124 .9750709533726 .0974807739326 .35063934326 25.5279998779323 .4662494659420 .9362201690718 .6669692993216 .78339004517 15.3215703964214 .1786098480213 .3042001724212 .7058496475212 .49773979187 12.6012496948212 .9649295806913 .5439300537114 .4342203140315 .05836963654 14.7339000701914 .0185804367113 .3326902389512 .5512599945111 .75351047516 10.9205799102810 .087690353399 .211028099068 .1958894729617 .158992767334 6.0611410140994 .9300651550293 .7280640602112 .290775060654 .5968009829521 $-1.29647600651-3.05011200905-5.11507892609-7.96552705765-11.0131998062$ $-13.8284101486-16.3994808197-18.7064495087-20.620759964-22.0737400055$ $-23.0185909271-23.3072891235-22.9958591461-22.1009101868-20.7862796783$ $-19.3448104858-17.7887802124-16.2797603607-14.7896404266-13.3464097977$ $-11.9701900482-10.6585302353-9.45715808868-8.3628282547-7.26699304581$ $-6.06467580795-4.71162223816-3.18824696541-1.48582398891 .5052189826965$ 2.3430659770973 .4972450733184 .4306259155275 .5667409896856 .619177818298 7.5258021354688 .2404365539558 .7124738693248 .9748287200939 .019407272339 8.8911561965948 .4494056701667 .8761978149417 .7705860137945 .881926059723 $-2.59898900986-9.9792470932-18.001789093-25.7121391296-32.3481292725$ $-38.6149406433-43.6412010193-50.4019508362-62.7650985718-74.018119812$ $-78.3741531372-78.5845184326-76.3668518066-72.3864212036-68.2598724365$ $-63.9941596985-59.9706001282-56.3304100037-53.4720993042-51.2898292542$ $-49.7449493408-48.9848098755-48.9440307617-49.3737602234-49.9326591492$ $-50.5683403015-51.158870697-51.6933784485-52.0489387512-52.2287101746$ $-52.0870094299-51.6759490967-51.017288208-50.1592216492-49.2107810974$ $-48.2004089355-47.2101898193-46.229511261-45.269569397-44.3077087402$ $-43.2967987061-42.2971191406-41.3142700195-40.3462600708-39.3879394531$ -38.3809509277 -37.3176002502 -36.1247291565 -34.7920799255 -33.2812004089 $-31.3247699738-29.6051998138-28.9031791687-28.3661003113-27.3648109436$ $-26.1320209503-24.6807098389-22.9897403717-21.0438709259-18.75922966$ $-16.0731201172-12.8330001831-8.88839530945-4.146299839021 .665642976761$ 8.00289154052714 .4429502487220 .1301097869923 .7451095581126 .26803016663 28.4821796417230 .262699127231 .7892208099433 .1576309204134 .49935913086 
35.7775497436536 .9926795959538 .1107902526939 .1147689819340 .00283813477 40.7629585266141 .4068794250541 .9284706115742 .3436012268142 .6467590332 42.8580093383842 .9779014587443 .0274581909243 .018138885542 .96944046021 42.9017410278342 .8313407897942 .7828903198242 .7682495117242 .81079864502 42.9176597595243 .106311798143 .3780403137243 .7431983947844 .1904296875 44.7412986755445 .2978210449245 .7544784545946 .2025985717846 .71175003052 47.2550506591847 .8267707824748 .4254417419449 .0422210693449 .67612075806 50.3189392089850 .9701118469251 .6245193481452 .2822418212952 .94041824341 53.5992584228554 .2572097778354 .9144706726155 .5702400207556 .22468185425 56.8773612976157 .5283699035658 .1774787902858 .8247489929259 .47005081177 60.1134605407760 .7549591064561 .3946304321362 .0325393676862 .66873931885 63.3033599853563 .9364395141664 .5680923461965 .1983566284265 .82730865479 66.4549636840867 .081336975167 .7064437866268 .3302764892668 .95279693604 69.5740127563570 .1938095092870 .8121566772571 .428993225172 .04419708252 72.6576919555773 .2693634033273 .8790664672974 .4866790771575 .09201812744 75.694900512776 .2951202392676 .8924636840877 .4866867065478 .07750701904 78.6646804809679 .2478866577179 .8268966674880 .401367187580 .97106933594 81.5359268188582 .0950927734482 .6495132446383 .19731903076 597.6052856445592 .0692749023586 .4564208984580 .7650146484575 .0313110352 569.2504882812563 .4249267578557 .5563964844551 .6469726562545 .6989746094 539.7141113281533 .6943969727527 .641784668521 .5582885742515 .4462280273 509.3082885742503 .1474914551496 .9668884277490 .7698059082484 .5599975586 478.3405151367472 .1152954102465 .8869018555459 .6589050293453 .4320983887 447.2099914551440 .9910888672434 .7780151367428 .5633850098422 .3485107422 416.1221008301409 .8882141113403 .6017150879397 .2398986816390 .7405090332 384.0723876953377 .1564025879369 .9773864746362 .3598937988354 .2504882812 345.4307861328335 .8557128906325 .3539123535313 .837310791302 .0545043945 290.1694946289279 .4448852539271 .2922058105264 .790802002259 .3320007324 255.2984924316252 .8943939209251 .4803924561250 .6965026855250 .4562988281 250.4649047852250 .7935943604251 .4380950928252 .245803833253 .0805053711 254.0839996338255 .3488006592256 .6655883789258 .0264892578259 .1939086914 260.2102966309261 .1976013184262 .1955871582263 .2969970703264 .5436096191 266.2146911621268 .8724975586273 .0855102539279 .1724853516284 .3380126953 285.7546081543285 .4888000488285 .8316955566287 .8103942871292 .1108093262 297.5029907227303 .2995910645308 .6612854004311 .9383850098315 .638092041 322.3291931152330 .7437133789339 .1423950195346 .3174133301351 .2297058105 351.1700134277344 .9189147949334 .9761962891322 .4667053223307 .5093078613 288.8815002441268 .7702026367248 .1092071533224 .2521057129193 .8574981689 164.8108062744146 .1145019531126 .368797302296 .7888183593869 .41261291504 55.9687309265149 .2198104858442 .4846687316937 .1615715026933 .57099914551 31.2217807769829 .5882492065428 .7377490997328 .6133499145529 .02879905701 30.1946697235131 .4795207977331 .8874397277832 .859508514435 .61315917969 38.5349998474140 .0130310058640 .9459686279341 .1503791809140 .8256187439 40.945171356240 .9024200439540 .4661293029840 .8073310852142 .03623962402 43.3491706848144 .6237792968845 .1867103576744 .064590454142 .98025131226 43.2876281738343 .2714385986341 .4409103393638 .9174003601136 .356300354 
33.9286003112831 .8661098480229 .8590507507327 .4722805023226 .05514907837 27.0104694366528 .7363891601629 .9775905609130 .4516696929929 .76704978943 28.0191497802724 .8814697265621 .8515701293920 .255580902119 .20189094543 17.9521903991716 .7238292694115 .6570901870714 .7891502380414 .31140041351 14.14157009125 14.1871500015314.37926959991 14.66849040985 14.74536037445 14.2667999267613 .5214004516612 .707409858711 .8336095809910 .94274997711 10.005749702459 .0827770233158 .0898008346566 .9096918106085 .672391891479 $4.3331727981573 .0506269931791 .97765994072 .5423570275307-1.71714198589$ $-4.2309718132-6.38885116577-8.57591915131-11.1425504684-13.8445501328$ $-16.5034694672-18.9679107666-21.060300827-22.7324695587-23.9613494873$ $-24.7419300079-25.016620636-24.8521308899-24.2071094513-23.2173309326$ $-22.0446796417-20.7214107513-19.3896598816-18.0481395721-16.7462501526$ $-15.5145597458-14.3733501434-13.2600498199-12.1676301956-11.0421600342$ $-9.85854911804-8.58988380432-7.17236614227-5.59972906113-3.86371994019$ -2.19835495949- -902760028839.3408749997616 1.9168800115593 .368197917938 4.35170888990085 .058409214025 .5816650390625 .9487199783336 .187705993652 6.3402137756356 .3672900199896 .3233919143686 .5632448196415 .158565998077 .0861269980669 -6.52341985703 -12.9773302078 -19.5352897644 -25.1745204926 $-30.54088974-35.6586990356-43.491859436-57.5891609192-70.5602722168$ $-75.7206726074-75.6995620728-71.7982406616-66.346786499-62.2511482239$ $-58.9192695618-56.2919807434-54.1879997253-52.4278793335-50.9926605225$ $-49.9495010376-49.4442901611-49.5191001892-50.0231208801-50.8456802368$ $-51.7417182922-52.5320510864-53.2310218811-53.7421607971-54.0007896423$ $-53.8129997253-53.3008308411-52.5719299316-51.6739501953-50.7018890381$ $-49.6633796692-48.628868103-47.5938987732-46.5811882019-45.5646514893$ $-44.4976615906-43.4683799744-42.5439605713-41.6455192566-40.7104911804$ -39.7017402649 -38.6013183594 -37.3756599426 -36.0152816772 -34.4812202454 $-32.6980285645-31.1766300201-30.3712692261-29.708820343-28.6359100342$ $-27.2704296112-25.6924495697-23.8679103851-21.7711791992-19.3083992004$ $-16.4082698822-12.8223199844-8.40109443665-3.334508895872 .568973064423$ 8.79176616668714 .8945798873920 .3400402069124 .1394691467326 .90453910828 29.2436790466331 .192590713532 .8636398315434 .2980117797935 .60496902466 36.7711296081537 .8836593627938 .917129516639 .8471794128440 .67168045044 41.3819618225141 .9807090759342 .4631195068442 .8359985351643 .09497070312 43.2534599304243 .3146095275943 .2973594665543 .2161293029843 .09144973755 42.9461402893142 .7987098693842 .67494964642 .5886802673342 .56325912476 42.6064682006842 .7352485656742 .9491691589443 .2558898925843 .6449508667 44.1182518005444 .6076507568445 .0461502075245 .4857788085945 .96995925903 46.4882888793947 .0357589721747 .6132698059148 .2200889587448 .84748077393 49.4846305847250 .1307487487850 .7819786071851 .4375915527352 .09508895874 52.754051208553 .412948608454 .0716400146554 .7292785644555 .38584136963 56.040878295956 .6943817138757 .3460807800357 .9959716796958 .64390945435 59.2899398803759 .9339981079160 .5761604309161 .2164497375561 .85494995117 62.4917182922463 .1268310546963 .7603492736864 .3923263549865 .02281188965 65.6518173217866 .2793731689566 .9054565429767 .5300827026468 .15321350098 68.7748031616269 .3947982788170 .0131607055770 .6297836303771 .24462127686 
71.8575363159272 .4684600830173 .0772399902373 .6837615966874 .28784942627 74.8893280029375 .488006591876 .0836868286176 .6761169433677 .26503753662 77.8501968383878 .4313278198279 .0081634521579 .5803833007880 .14778900146 80.7102966308681 .2676773071381 .8157577514682 .35675048828

598.6489257812593 .0499267578587 .4166259766581 .7236938477575 .9796142578 570.1848754883564 .3408203125558 .4489746094552 .5106811523546 .5275268555 540.5006713867534 .4318847656528 .3223876953522 .173828125515 .9879760742 509.7668151855503 .512512207497 .2276000977490 .9140930176484 .5752868652 478.2124023438471 .8291931152465 .425201416459 .0042114258452 .5635986328 446.1069030762439 .6274108887433 .12890625426 .5971984863420 .0369873047 413.4234924316406 .7666015625400 .0032043457393 .1234130859386 .0444946289 378.7650146484371 .1637878418363 .2551879883354 .8546142578345 .9851989746 336.4493103027326 .2752990723315 .4444885254303 .8807067871292 .3221130371 280.8095092773270 .5972900391262 .966796875257 .1712036133252 .6894073486 249.6244049072247 .6557006836246 .5796966553246 .2012023926246 .178604126 246.1988067627246 .4317016602247 .0390014648247 .7640075684248 .43409729 249.1587982178250 .116897583251 .1000061035252 .0679016113252 .932800293 253.825302124254 .708404541255 .5948028564256 .6846923828258 .2410888672 260.3015136719262 .8774108887266 .4140014648271 .0505981445275 .2825012207 277.9348144531279 .3739929199280 .7466125488282 .0812072754283 .8512878418 287.1740112305 292.3723144531298.549987793 304.3215942383310 .1878967285 316.484588623322 .4472961426324 .9827880859327 .3978881836334 .3333129883 339.4906921387336 .6650085449332 .4237060547331 .2809143066325 .3570861816 307.7907104492283 .5380859375256 .1604003906227 .2637023926198 .7247009277 173.563293457157 .158493042140 .8865966797117 .933403015194 .95570373535 78.3108367919965 .6475677490255 .8338203430248 .7654418945343 .54890060425 39.9822502136237 .2302093505935 .9959182739336 .4294395446838 .24628829956 41.4544410705644 .5420188903845 .8636703491246 .5090293884346 .65832138062 46.0805511474645 .3051300048844 .8110389709544 .6064987182644 .42636871338 42.9823188781742 .8271408081150 .9325294494656 .2464103698760 .40063858032 60.7423515319862 .4331512451264 .0428619384864 .0855865478563 .3941116333 62.6984481811561 .4411888122659 .3566017150956 .5260009765653 .15460968018 49.5174903869645 .8202705383342 .0779991149937 .710659027134 .56240081787 35.0674018859936 .5755691528337 .1565208435136 .9752197265635 .59181976318 33.1229705810529 .1721591949525 .5537490844724 .3814792633123 .79177093506 22.2622604370120 .6920890808119 .3383007049618 .1622009277317 .40780067444 16.8604507446316 .5136508941716 .2259292602515 .8017702102715 .25823974609 14.6363897323613 .8913497924812 .9427003860511 .9200897216810 .94299983978 9.9300756454478 .9884843826297 .9338989257816 .6052861213685 .124372005463 3.3608489036561 .706900000572 .5236660242081 -1.06041204929-3.76207399368 $-6.76925182343-9.25114917755-11.5046596527-13.7575902939-16.0297393799$ -18.4301795959-20.6863307953 -22.527759552 -23.9641609192 -25.0285606384 $-25.7136707306-26.0116901398-25.9670391083-25.5485095978-24.8506603241$ $-23.9740791321-22.9448604584-21.87541008-20.7732696533-19.6928901672$ $-18.6512794495-17.6760292053-16.7026100159-15.7011899948-14.6582202911$ $-13.564740181-12.4092903137-11.1443195343-9.81391239166-8.47625923157$ 
-7.13153219223 -5.80594682693 -4.31124591827 -2.3338060379 -.477573990822 .62923198938371 .3727879524232 .0115520954132 .5234990119932 .963885068893 3.3705639839173 .7728641033174 .0276207923894 .4110140800483 .334136962891 $-.231435999274-5.02923202515-10.0031900406-15.0104999542-19.2131595612$ $-23.6227092743-28.5720100403-36.2756996155-50.2302284241-63.1751899719$ $-68.3402481079-68.3843917847-63.6616210938-57.7050018311-54.4531097412$ $-52.470790863-51.4257392883-50.8202209473-50.3257484436-49.8336410522$ $-49.4678115845-49.3472595215-49.5069618225-50.1082496643-51.2241096497$ $-52.4651603699-53.5867195129-54.5563087463-55.185760498-55.492729187$ $-55.2303085327-54.5740509033-53.7776985168-52.8317108154-51.8532791138$ $-50.8310089111-49.8076286316-48.7780990601-47.7507781982-46.7226905823$ $-45.6266403198-44.5853004456-43.6977386475-42.8407592773-41.9088401794$ $-40.8959693909-39.7794494629-38.5471687317-37.2112998962-35.8144302368$ -34.4137611389 -33.1505889893 -32.1279792786 -31.1204891205 -29.844499588 -28.3374099731 -26.6433506012 -24.679189682 -22.405620575 -19.7359008789 -16.6034202576 -12.8220901489-8.21268844604 -2.81125402451 3.367254018784 9.62417602539115 .2333202362120 .0703697204623 .9264907836927 .02580070496 29.6175003051831 .7619094848633 .5593910217335 .0522804260336 .36791992188 37.5073814392138 .5907783508339 .5880088806240 .4790496826241 .27608108521 41.958419799842 .5403099060142 .9931983947843 .3386802673343 .55067825317 43.6579589843843 .6504096984943 .5591316223143 .3947410583543 .18381881714 42.9522514343342 .7191009521542 .5155792236342 .3525009155342 .25830078125 42.2359390258842 .3056907653842 .461078643842 .7095985412643 .0323600769 43.4177207946843 .8395004272544 .2739601135344 .7280502319345 .2059211731 45.7117309570346 .2435111999546 .8073196411147 .40708160448 .03052902222 48.6628608703649 .3060302734449 .9550895690950 .60979080251 .26715087891 51.9268684387252 .5869789123553 .2473907470753 .9069709777854 .56575012207 55.2231101989755 .8790588378956 .5332489013757 .1856689453157 .83612823486 58.484649658259 .1311492919959 .7756805419960 .418251037661 .05892181396 61.6977500915562 .3347892761262 .9701004028363 .6036987304764 .23565673828 64.8659591674865 .4946365356466 .121658325266 .7470169067467 .37069702148 67.9926605224668 .6128311157269 .231163024969 .8475723266670 .46199798584 71.0743331909271 .6844863891672 .2923202514672 .897743225173 .50054931641 74.1006317138774 .6977691650475 .2917633056675 .882392883376 .46939849854 77.0525588989377 .6315917968878 .2062530517678 .776229858479 .34134674072 79.9015197753980 .4559326171981 .0055465698281 .54847717285 599.6983032227594 .1608276367588 .5410766602582 .8367919922577 .0848999023 571.2786865234565 .4190063477559 .5065917969553 .5421142578547 .5266113281 541.4605712891535 .3455200195529 .1818237305522 .9711303711516 .7139892578 510.4124145508504 .0674133301497 .6810913086491 .254486084484 .7898864746 478.2875976562471 .7499084473465 .1755065918458 .5664978027451 .9190063477 445.2343139648438 .5050964355431 .7311096191424 .8995056152418 .0083007812 411.0362854004403 .9830932617396 .7951965332389 .450012207381 .8869934082 374.0822143555365 .9559936523357 .4855041504348 .5718994141339 .1784057617 329.2594909668318 .7959899902307 .9274902344296 .6812133789285 .6239013672 275.0284118652265 .6447143555258 .3440856934252 .7832946777248 .7928924561 
246.2261962891244 .9152984619244 .4246063232244 .4205932617244 .4976043701 244.1044006348243 .9015045166244 .5977935791245 .4199066162245 .7635040283 246.0668945312246 .7189941406247 .4821929932248 .2415924072249 .0202941895 249.8638000488250 .7743988037251 .7913970947253 .0556945801254 .7268981934 256.8609008789259 .5939941406262 .8523864746266 .7593994141270 .8724975586 274.9177856445278 .3457946777280 .9309082031281 .6925048828279 .6155090332 279.9453125288 .2811889648298 .1583862305302 .1885986328306 .1972961426 316.7499084473325 .4737854004323 .1484069824320 .7880859375327 .4884033203 335.850189209340 .2312927246344 .9573974609350 .9661865234349 .2738952637 331.383392334302 .9289855957269 .9790039062236 .8524017334206 .9143066406 182.0597991943165 .3616027832150 .7671966553133 .1985931396114 .8854980469 98.1946334838982 .9608535766670 .249588012760 .9662590026955 .49826049805 51.7993202209547 .6280784606945 .6973915100148 .2669486999552 .97986984253 57.572410583561 .7796707153365 .2431869506868 .7913513183672 .86363220215 72.664337158272 .9751205444371 .5849227905368 .5762634277372 .07245635986 73.8478393554777 .4533386230580 .6044769287181 .6796188354582 .87906646729 82.5370864868285 .2923736572388 .2553863525487 .8332138061586 .04467010498 85.0655899047983 .5815200805780 .8723831176877 .2419433593872 .672706604 67.6423797607462 .8096809387258 .0425605773953 .0952415466349 .2387008667 47.955780029347 .7048416137747 .2297592163146 .3082504272544 .27944946289 41.4555397033737 .9843292236334 .8100090026933 .000278472931 .41333961487 28.7050399780326 .0904903411924 .4719905853323 .1814594268821 .96932029724 20.9252395629920 .1484794616719 .4341392517118 .5386009216317 .56019020081 16.5175495147715 .4535303115814 .2393903732313 .0116195678711 .94097995758 10.910710334789 .9998350143438 .9417800903327 .4933128356935 .663914203644 3.253669977188 .8964840173721 -1.08734202385 -3.31231188774 -5.99994897842 -8.8454208374 -11.3253297806 -13.4319400787 -15.521730423 -17.5971794128 -19.6773204803 -21.6280593872 -23.1794700623 -24.3629302979 -25.2684803009 -25.8978805542 -26.2484607697 -26.347530365 -26.1721096039-25.7770195007 $-25.2041702271-24.4927997589-23.7208003998-22.9026508331-22.0861797333$ $-21.2789802551-20.5144996643-19.7299098969-18.8964996338-18.0128803253$ -17.0804004669 -16.0995197296 -15.0442895889-13.9786701202 -12.9365901947 -11.8940696716 -10.9509897232 -9.65707015991 -7.57539510727-5.48586893082 $-4.061191082-3.00616502762-2.12317705154-1.36900305748-.685720980167$ -7.1797997e-02.4701769948006.7945050001144.9668409824371. 2887569963932 $-2.26495409012-5.59886217117-9.00424194336-12.4897298813-15.4733200073$ -18.4255905151 -21.1264801025 -26.1846904755 -36.9952888489-47.3072090149 -51.5147399902 -51.8349609375 -48.992061615 -45.661190033 -44.7068595886 $-45.0094108582-45.8682403564-46.8228797913-47.6198806763-48.0956306458$ $-48.2117805481-48.3149108887-48.5959815979-49.3567199707-50.8823394775$ $-52.5904502869-54.2665100098-55.6671218872-56.36536026-56.6127891541$ $-56.2662506104-55.4557914734-54.5490684509-53.5659217834-52.6059799194$ $-51.6414489746-50.6740188599-49.6947898865-48.7109985352-47.7250404358$ $-46.7266998291-45.7582588196-44.8422889709-43.939540863-43.0168914795$ $-42.0292396545-40.9329605103-39.7440986633-38.463809967-37.1836395264$ -35.9485397339 -34.7384109497 -33.6073989868 -32.3938903809 -30.999540329 
-29.4135398865 -27.5869407654 -25.4668598175 -22.9877300262 -20.1191997528 -16.8114299774 -13.0090999603 -8.7563867569-3.43022608757 3.821504116058 10.9164400100715 .8391799926819 .7424297332823 .3314990997326 .52166938782 29.3717803955131 .7945899963433 .7271614074735 .3030891418536 .67374038696 37.8505401611338 .9679908752439 .9950904846240 .9160385131841 .73038101196 42.4368896484443 .0295982360843 .4884300231943 .8178100585943 .99893188477 44.0518684387243 .97697830243 .8022499084543 .547439575243 .24024963379 42.9131202697842 .5877304077142 .2975006103542 .0553512573241 .88882827759 41.8014488220241 .8104591369641 .9091606140142 .1023292541542 .36891174316 42.6975097656243 .0793495178243 .4943695068443 .9449806213444 .42058944702 44.9222106933645 .4538612365746 .0161514282246 .6092185974147 .22520065308 47.8545608520548 .4957008361849 .1441612243749 .7988891601650 .45706939697 51.1180000305251 .7797889709552 .442108154353 .1038589477553 .76488876343 54.4246101379455 .0829505920455 .7395706176856 .3944091796957 .04726028442 57.6981391906758 .3469390869158 .9936981201259 .6384010314960 .28113937378 60.9219017028861 .5607604980562 .1977500915562 .8328895568863 .46622848511 64.0977478027364 .7274627685565 .3553466796965 .9814071655366 .60558319092 67.2278518676867 .8481369018668 .4664077758869 .0825729370169 .69654846191 70.3082733154370 .9176177978571 .5244979858472 .128768920972 .73030853271 73.3289489746173 .924522399974 .5168228149475 .1056365966875 .69072723389 76.2718582153376 .8487930297977 .4212722778377 .9890136718878 .55182647705 79.1097030639679 .6623535156280 .2056198120180 .74170684814 601.0455932617595 .4462280273589 .8095703125584 .1090698242578 .3519897461 572.5374145508566 .6649780273560 .7352294922554 .7476196289548 .703125 542.6015014648536 .4436035156530 .2293701172523 .9600219727517 .6356201172 511.2575073242504 .8258056641498 .3427124023491 .8074035645485 .2225952148 478.5862121582471 .9009094238465 .1625976562458 .3742980957451 .5282897949 444.6275939941437 .6596984863430 .6276855469423 .5118103027416 .315612793 409.0083007812401 .5983886719394 .0245056152386 .2807006836378 .2969055176 370.0728149414361 .5260009766352 .6662902832343 .4065856934333 .7385864258 323.6762084961313 .2202148438302 .5989990234291 .8551025391281 .5289001465 271.9205932617263 .4389038086256 .4132080078250 .9573974609247 .1266021729 244.7805938721243 .8471069336243 .6923980713243 .8200073242243 .8316040039 243.0090942383242 .366897583243 .1024017334244 .0110015869244 .1166992188 244.1371002197244 .6006011963245 .2127990723245 .9208068848246 .7077026367 247.616897583248 .670501709250 .0399932861251 .6479034424253 .5055999756 255.8197021484258 .7504882812261 .9896850586265 .3778991699269 .5562133789 275.1600036621280 .7481994629285 .1570129395286 .9491882324283 .4534912109 282.5505065918293 .9829101562307 .1586914062308 .4385986328310 .9906921387 326.9674987793338 .7958984375331 .9242858887324 .5504150391330 .5676879883 342.2019042969353 .4533996582362 .7016906738369 .9226074219367 .5284118652 348.1810913086318 .3999023438283 .330291748247 .4393005371216 .0312042236 190.058303833171 .608001709157 .0975036621143 .6632995605130 .1208953857 115.028297424399 .8345336914186 .1337585449275 .3082962036169 .81240081787 66.5439834594761 .4956207275459 .2966690063563 .9109306335470 .68305969238 75.81392669678 81.24681091309 87.3346328735490.8584899902398.37748718262 
102.0226974487 103.123703002997.6848297119190.7740325927794.83630371094 104.6240997314108 .236000061111 .6209030151109 .085899353109 .5661010742 109.1250991821112 .5708999634115 .3551025391113 .332901001110 .2667999268 109.0243988037107 .4483032227104 .161903381399 .7502365112394 .07025909424 87.8899765014682 .1895217895576 .5855636596771 .2459869384866 .80695343018 63.6830596923861 .6007995605559 .7887687683157 .844169616755 .12971115112 52.1214218139649 .3831787109446 .9152488708544 .5421714782741 .70259857178 37.5700607299833 .5135498046931 .32854080229 .7692699432428 .04491043091 26.5278396606425 .3299808502224 .194269180322 .849119186421 .46537971497 20.0172901153618 .4920902252216 .8034496307415 .2188100814814 .00821971893 13.0262403488212 .1936302185111 .182299613959 .7893495559697 .726585865021 $4.7377271652221 .304043054581-2.04525589943-5.08585691452-7.55609989166$ $-9.66307830811-11.7816801071-13.8755302429-16.0925807953-18.1854000092$ $-20.0007400513-21.5352497101-22.7504501343-23.7478809357-24.571390152$ -25.2252197266 -25.6762599945 -25.9591999054 -26.0385494232 -25.9547195435 -25.7053909302 -25.3347892761 -24.8987197876 -24.4039802551-23.8865699768 $-23.3522205353-22.8335399628-22.2831802368-21.6752300262-21.0158596039$ -20.2955703735 -19.5391101837-18.7238006592 -17.9112091064 -17.1163597107 -16.3325099945 -15.7720403671 -14.8340101242 -12.8950395584-10.7759895325 $-9.12803268433-7.74562501907-6.57990121841-5.57887506485-4.66469478607$ $-3.89504909515-3.28845596313-3.01987290382-3.15651702881-3.99681591988$ $-5.64923286438-7.70054006577-9.75105476379-11.7525501251-13.5623102188$ $-15.2154798508-15.624830246-17.6195201874-24.3720703125-31.2795791626$ -34.1542015076 -35.0605201721 -34.7983703613 -34.4713897705 -35.6677398682 $-37.587020874-39.5439109802-41.6545600891-43.6631393433-45.228931427$ $-46.0936317444-46.5626792908-47.0913887024-47.9880599976-49.6780509949$ $-51.9285087585-54.4799499512-56.4835014343-57.2360191345-57.0620307922$ $-56.4530487061-55.5836906433-54.6706085205-53.7412605286-52.8754806519$ $-52.0290412903-51.1734809875-50.3115196228-49.4277000427-48.5551185608$ $-47.6960411072-46.8309516907-45.8880615234-44.9350891113-44.0152587891$ $-43.0571899414-42.0037994385-40.8867797852-39.696849823-38.5012893677$ -37.3426017761 -36.1517181396 -34.916519165 -33.5710411072 -32.1054801941 $-30.4552097321-28.5267505646-26.2652492523-23.5833892822-20.4925003052$ $-17.0049190521-13.1164598465-9.16733646393-4.097349166873 .844263076782$ 11.4901199340815 .6327295303318 .6998405456522 .0650405883825 .28989982605 28.419710159331 .0962009429933 .1874198913634 .8228416442936 .32252120972 37.6589202880938 .9119491577140 .0673103332541 .0933418273942 .00494003296 42.7874908447343 .4513816833543 .9382591247644 .2830390930244 .43450164795 44.4396591186544 .2858886718844 .0188484191943 .6593589782743 .24420166016 42.8120613098142 .385040283242 .0052795410241 .679821014441 .44424819946 41.2933387756341 .2481307983441 .295619964641 .4417991638241 .66728973389 41.9589691162142 .3131294250542 .7116012573243 .1548118591343 .62722015381 44.1320686340344 .6698799133345 .236190795945 .8251113891646 .43539047241 47.0624694824247 .7030181884848 .3515510559149 .0071601867749 .66648864746 50.3289985656750 .9925804138251 .6569290161152 .3208007812552 .98408126831 53.64606857354 .3066902160654 .9655799865755 .6226806640656 .27775955256 .930809021 
57.5817413330158 .2305603027358 .8772697448759 .5218811035260 .16445922852 60.8050003051861 .4435615539662 .0801200866762 .7147407531763 .34737014771 63.9780616760364 .6067428588965 .2334213256865 .8580169677766 .48055267334 67.1009063720767 .7190628051868 .3349075317468 .9484176635769 .55947113037 70.1679992675870 .773857116771 .3769836425871 .9772033691472 .57438659668 73.1683578491273 .7589416503974 .3459167480574 .9290771484475 .50817871094 76.0829925537176 .6532821655377 .2188034057677 .7793197631878 .33484649658 78.8845367431679 .4293670654379 .96748352051

602.4000244141596 .8696289062591 .2526245117585 .5457763672579 .7866210938 573.9666137695568 .0850830078562 .1412963867556 .1345825195550 .0650024414 543.9318237305537 .7352294922531 .4749755859525 .1514892578518 .7645263672 512.3151245117505 .8024902344499 .2283935547492 .5914001465485 .8930969238 479.1311035156472 .3066101074465 .4155883789458 .4585876465451 .4289855957 444.326385498437 .1406860352429 .8702087402422 .4999084473415 .0267028809 407.4287109375399 .7034912109391 .8100891113383 .7326965332375 .4295959473 366.884185791358 .059387207348 .9455871582339 .5148010254329 .7473144531 319.7185974121309 .4601135254299 .1953125289 .0224914551279 .3652038574 270.5282897949262 .6596984863256 .0620117188250 .779006958247 .016998291 244.6168060303243 .4340057373242 .9360961914242 .6157073975242 .221496582 241.4378967285240 .8999938965241 .3323059082242 .041305542242 .4792938232 242.8524932861243 .307800293243 .8975067139244 .7220001221245 .6602020264 246.6036987305247 .8251953125249 .7429046631251 .9151000977254 .1584014893 256.8500976562260 .1221008301263 .4294128418266 .3472900391270 .692199707 278.3736877441287 .1521911621294 .6648864746299 .8935852051302 .0736083984 305.8106079102316 .349395752327 .9804992676332 .0480957031338 .9162902832 358.8193054199371 .2703857422357 .4273071289343 .3116149902351 .4379882812 367.5694885254379 .6557922363385 .2781066895381 .4027099609369 .0777893066 350.1937866211324 .1401062012290 .4248962402255 .1755981445224 .1125030518 197.7115936279178 .2382049561163 .5048980713151 .5402984619140 .6842956543 128.5505981445115 .9204025269103 .998397827194 .137283325288 .18744659424 84.4418869018680 .8269729614380 .0208206176884 .1921997070389 .97160339355 94.49417877197100 .3956985474110 .0641021729119 .9095001221124 .9291992188 128.1165008545132 .1439971924134 .0599060059134 .9839935303135 .6540985107 137.4226074219141 .6083068848143 .4338989258142 .9671020508144 .1029968262 146.0619049072146 .3273010254144 .7176971436140 .8589019775136 .7902069092 134.4049987793131 .9671020508128 .1900939941123 .3077011108117 .2764968872 110.6641998291104 .007698059197 .1562271118290 .1184768676884 .0179901123 80.526786804278 .0637664794974 .9105834960971 .5965270996168 .02797698975 64.5696563720761 .8610610961959 .7336311340358 .0689582824755 .29212188721 49.904430389444 .3176803588940 .7388687133838 .1290092468335 .92126083374 34.0632400512732 .3945198059130 .7400798797628 .7611999511726 .82356071472 25.2321891784723 .4355792999320 .8185100555418 .4179191589417 .20266914368 16.4820308685315 .6897497177114 .7830200195313 .8053598403911 .92498016357 $8.4025144577033 .793977975845-1.66907000542-6.17914199829-7.7978720665$ $-8.51767730713-10.2046804428-12.4368896484-15.2616300583-17.8278007507$ $-19.2416992188-20.1597099304-21.1057090759-22.0022792816-22.8405799866$ 
-23.5937099457 -24.2262096405 -24.7441997528 -25.1217193604 -25.3722305298 -25.4854698181 -25.4871501923 -25.4069690704 -25.2565994263 -25.0655193329 -24.8377609253 -24.6018505096 -24.3215293884 -23.9782104492 -23.572719574 $-23.09623909-22.5724906921-22.0074100494-21.4300708771-20.8582496643$ $-20.274520874-19.7412490845-18.8879508972-17.3523292542-15.5710096359$ -13.9840297699 -12.5166301727-11.2273397446 -10.0738697052 -9.00564956665 -8.10067558289 -7.38370895386 -7.05241203308 -7.20757102966 -7.96559476852 $-9.7171421051-11.3154296875-12.0035495758-12.4325504303-13.1640501022$ -13.8550195694 -13.9374198914 -14.9552698135 -19.0615196228 -23.6189804077 -25.844329834 -27.3769607544 -28.0274295807 -28.5396003723 -29.4055404663 -30.494550705 -31.8944206238 -34.0126686096 -37.3150596619-40.4998893738 $-42.5092697144-43.8399391174-44.8913192749-46.0226287842-47.3834609985$ $-49.801700592-54.2808418274-57.8946800232-57.9507598877-56.5658683777$ -55.566619873 -54.7057914734 -53.9505195618 -53.241230011 -52.5837211609 $-51.9406204224-51.2710800171-50.5802993774-49.8866004944-49.1862602234$ -48.4465408325 -47.6505889893-46.7757492065 -45.8572387695-44.9345817566 $-43.98046875-42.9660797119-41.9059410095-40.799041748-39.6759796143$ -38.5670204163 -37.3882598877 -36.1095504761 -34.6964912415 -33.1308708191 -31.3975200653 -29.4702606201 -27.1597099304 -24.2644691467 -20.9047298431 -17.1559906006 -13.0520401001-8.68962287903 -3.50200200081 3.293108940125 9.64811325073213 .4109201431316 .3483791351319 .7217006683323 .20192909241 26.7338504791329 .7676506042531 .8639106750533 .4869613647535 .18788909912 36.8202896118238 .3136901855539 .6874885559140 .9297294616742 .01678085327 42.9589691162143 .7408905029344 .3118705749544 .6882400512744 .84059143066 44.7986106872644 .5668601989744 .1934700012243 .7206802368243 .18669891357 42.6402893066442 .1071701049841 .6319885253941 .2252807617240 .92078018188 40.7145996093840 .6222305297940 .631561279340 .7421417236340 .9387512207 41.2076492309641 .5441894531241 .9327888488842 .3701515197842 .84268951416 43.350868225143 .8916587829644 .4597511291545 .050228118945 .66064834595 46.2879219055246 .928989410447 .5785789489748 .2353401184148 .89627075195 49.5604896545450 .2260208129950 .8924102783251 .5584297180252 .22385025024 52.8880004882853 .5507698059154 .21176910454 .870948791555 .52806091309 56.1831092834556 .8359718322857 .4866790771558 .1352005004958 .78155136108 59.4257583618260 .0678482055760 .7078285217361 .345699310361 .98147964478 62.6151390075763 .2466812133863 .8760681152364 .5032730102565 .12825012207 65.7509536743266 .3713226318466 .9892807006867 .6047897338968 .21775817871 68.8281097412169 .4357528686570 .0405883789170 .6425094604571 .24137878418 71.8370666503972 .429412841873 .0182418823273 .6033630371174 .18456268311 74.7616119384875 .3342895507875 .9023818969776 .4656372070377 .02387237549 77.5770721435578 .12578 .6634902954179 .19474029541 604.0667724609598 .4769287109592 .8472900391587 .1505126953581 .3922729492 575.5703735352569 .6832275391563 .7296142578557 .707824707551 .6173706055 545.4570922852539 .2269287109532 .9254760742526 .5534057617520 .1094970703 513.594909668507 .0079040527500 .350189209493 .6188964844486 .816192627 479.9375915527472 .9854125977465 .9525146484458 .8414916992451 .6420898438 444.3568115234436 .9713134766429 .4883117676421 .8882141113414 .1740112305 
406.3193969727398 .3294067383390 .1654968262381 .8268127441373 .2746887207 364.5082092285355 .5022888184346 .2640075684336 .7916870117327 .0768127441 317.2355041504307 .3024902344297 .5104064941287 .9176940918278 .8934020996 270.661895752263 .3409118652257 .125252 .0588989258248 .2765045166245 .6067962646 243.8473052979242 .662902832241 .6101989746240 .724395752240 .0610961914 239.6941070557239.7926940918240.2355041504 240.9898071289 241.7854003906 242.3034973145242 .8952026367243 .8157958984244 .9248046875245 .9432983398 247.4497070312250 .1515960693253 .1257019043256 .1729125977259 .3505859375 262.6818847656266 .4303894043269 .5614929199274 .699005127283 .9408874512 294.7344970703304 .3403930664313 .934387207324 .0964050293334 .5557861328 345.003112793353 .6885070801358 .8075866699365 .9036865234384 .74609375 397.390411377380 .6405944824362 .9631958008372 .3887939453387 .3283996582 394.6487121582394 .1003112793378 .3828125356 .8836975098340 .3045959473 319.8673095703289 .9977111816257 .68359375228 .283996582202 .8641052246 183.0626068115168 .0798034668156 .6071929932147 .1522064209137 .7012939453 128.4230041504119 .5027008057111 .8815994263106 .3974990845102 .7985992432 101.0640029907101 .5390014648104 .4051971436109 .3665008545113 .6607971191 120.5183029175133 .4947052002145 .0032958984148 .0946960449150 .5323944092 160.411605835169 .1490936279169 .5984039307169 .0229949951174 .3479003906 178.741104126174 .891998291170 .700302124174 .6748046875178 .4772033691 175.2727966309170 .1062011719165 .574798584161 .2444000244157 .9403991699 154.6011047363150 .6212005615145 .7848968506139 .6246032715132 .7256011963 125.4639968872117 .8279037476109 .4728012085102 .331596374599 .27203369141 96.6099014282291 .6140823364386 .5137329101681 .9383010864378 .45757293701 75.59570312573 .1587066650471 .7495422363369 .1408615112362 .97792053223 56.3079109191951 .6938209533748 .0865402221745 .4388504028343 .37916946411 41.2683792114339 .1449699401936 .5476989746134 .0153999328632 .18383026123 30.1086997985826 .6733798980723 .516880035422 .2287406921421 .52421951294 20.5135002136219 .4948902130118 .8112907409717 .1775398254413 .42061042786 $8.2419605255131 .39265704155-4.22273015976-5.07964801788-4.8590388298$ $-6.55854082108-9.05470752716-12.4853200912-15.5487804413-16.7245998383$ -17.3001499176 -18.2078208923 -19.1396102905 -20.0822505951 -21.0300693512 $-21.8911991119-22.7029495239-23.4024391174-24.0113506317-24.4990692139$ $-24.8886108398-25.1850605011-25.4022808075-25.5635604858-25.6669101715$ $-25.7450504303-25.7695808411-25.7222595215-25.6035308838-25.396150589$ -25.128610611 -24.8117599487 -24.4658107758 -24.0945892334 -23.6526794434 $-23.084859848-22.2981204987-21.2283000946-19.9374408722-18.5680007935$ -17.1690006256 -15.8725204468 -14.6579303741 -13.5194501877 -12.5538902283 -11.763879776 -11.3223304749 -11.3629798889-11.8903503418 -13.5566396713 -14.9688796997 -14.769780159-14.2410297394-14.3003501892 -14.5461902618 -14.9609699249 -15.9239902496-18.2800006866 -21.0424404144-22.9362602234 $-24.6652297974-25.5216293335-25.984500885-25.7688503265-25.5634498596$ -25.9988498688 -27.4968395233 -31.3907794952 -35.6532783508 -38.6354293823 $-40.9689903259-42.6968193054-44.1059684753-45.1047210693-47.0819206238$ $-52.549030304-57.2227592468-56.6988105774-54.6452293396-53.7149505615$ $-52.9461708069-52.4560203552-52.0598602295-51.6793708801-51.2813186646$ 
-50.855670929 -50.4407501221 -49.99451828 -49.5091896057-48.9004707336 $-48.1977806091-47.4195404053-46.5769805908-45.6752586365-44.736289978$ $-43.7670707703-42.7752799988-41.7442703247-40.6837005615-39.6095199585$ $-38.4496994019-37.1744194031-35.74243927-34.1198997498-32.3043708801$ -30.361530304 -28.0120201111 -24.9419498444 -21.3670005798 -17.4008598328 -13.0043201447 -8.10192584991 -2.89667010307 2.439970016479 7.254981994629 10.5881004333513 .4809503555316 .7711296081520 .1968994140623 .85154914856 27.0404396057129 .2067203521731 .0342102050833 .1833915710435 .299949646 37.1725997924838 .8289299011240 .3751106262241 .7680892944342 .95323181152 43.9457588195844 .6312294006345 .0729103088445 .2210388183645 .13296890259 44.8084983825744 .3179092407243 .7164611816443 .0493011474642 .37759017944 41.7268714904841 .1541481018140 .663219451940 .2991905212440 .04531097412 39.9211692810139 .9076309204140 .0013809204140 .18862152140 .44968032837 40.7818412780841 .1652297973641 .601280212442 .0742912292542 .58578872681 43.128341674843 .6988296508844 .2922286987344 .9054412841845 .53443145752 46.1766395568846 .827430725147 .4855995178248 .1480598449748 .81396102905 49.4812889099150 .149551391650 .8175010681251 .4848709106452 .15097045898 52.8156394958553 .4785308837954 .1395416259854 .7984695434655 .45528030396 56.1098785400456 .7622604370157 .4123992919958 .0602989196858 .70598983765 59.3494491577159 .9907188415560 .629749298161 .2665710449261 .90113830566 62.5334396362363 .1634292602563 .7910804748564 .4163436889665 .03914642334 65.6594467163166 .2771835327166 .8922805786167 .5046691894568 .1142578125 68.720977783269 .3247222900469 .9253997802770 .5228881835971 .1170501709 71.707733154372 .294776916572 .8780136108473 .4572067260774 .03220367432 74.6027297973675 .1686096191475 .7296066284276 .2855224609476 .83637237549 77.3813171386777 .9214172363378 .45472717285 605.7420043945600 .228515625594 .6251220703588 .9276733398583 .1740112305 577.3538208008571 .4650268555565 .5054931641559 .4733276367553 .3671264648 547.1849975586540 .9265136719534 .5900268555528 .1754760742521 .6817016602 515.1090087891508 .4556884766501 .7226867676494 .9071960449488 .0101013184 481.0273132324473 .9594116211466 .8005981445459 .5508117676452 .2020874023 444.7538146973437 .1955871582429 .5260925293421 .7322998047413 .8118896484 405.7491149902397 .5416870117389 .1715087891380 .633392334371 .9125976562 363.0021972656353 .9071044922344 .634185791335 .2106018066325 .6453857422 316.0535888672306 .5010986328297 .1624145508288 .1440124512279 .6860046387 272.0010986328265 .1271972656259 .2405090332254 .3014984131250 .395904541 247.3365020752244 .9940032959243 .1246032715241 .4075927734240 .06590271 239.1983032227 238.7232055664 238.6333007812 238.9145050049 239.5052947998 240.2077941895240 .7377929688241 .3238067627242 .1694030762243 .3251953125 244.7523956299247 .0220031738250 .7154998779254 .8191986084259 .254699707 263.3316040039265 .859588623269 .2825927734275 .3564147949283 .3158874512 292.3879089355 302.533203125312 .2741088867324 .3309936523341 .3539123535 358.5616149902373 .0718994141380 .8973999023376 .8186035156372 .4961853027 380.1335144043386 .915802002381 .8019104004373 .9368896484371 .9251098633 371.2760925293371 .3692932129366 .2244873047350 .6994018555332 .5913085938 318.8261108398302 .9234008789277 .9666137695249 .6197052002223 .2254943848 
200.0072021484182 .5420074463169 .1298065186158 .6307067871150 .1790008545 142.0395050049134 .6945037842128 .1446075439122 .9944992065120 .4921035767 119.2587966919118 .1131973267118 .2801971436121 .1538009644126 .9702987671 135.4089050293146 .5798950195160 .2355041504169 .8141937256168 .5603027344 167.7062988281178 .2854003906189 .0278930664189 .3869018555186 .6125030518 188.3347015381189 .7722930908187 .8240966797186 .3088989258188 .5364990234 190.0077972412187 .8643951416184 .6448974609182 .6307067871180 .4692993164 176.8957977295172 .8990936279170 .0939941406166 .345199585159 .3238983154 151.4494934082144 .779800415137 .9022979736130 .049697876123 .5756988525 121.3935012817118 .2220001221109 .118103027399 .9436264038195 .61814880371 93.3295669555790 .1296691894586 .6370925903383 .5782318115279 .65795898438 73.6950683593867 .5148773193462 .943641662659 .2420005798356 .45948028564 54.2684593200751 .9527206420949 .4920806884846 .6056709289643 .69152832031 41.1257400512738 .3766593933134 .9380187988331 .7883701324529 .89100074768 28.4563808441226 .769319534325 .2359600067124 .2629795074522 .66378974915 19.35895919814 .752980232248 .9052448272714 .12315082552 .848896026611 $2.289712905884-.135882005095-3.36140799522-6.85141086578-9.85841655731$ $-11.545999527-12.660900116-13.8367395401-15.003279686-16.2136993408$ $-17.4328994751-18.6143798828-19.7628307343-20.8482704163-21.8476104736$ $-22.7191791534-23.4963302612-24.2041893005-24.8261909485-25.3539905548$ $-25.8041400909-26.2215595245-26.575340271-26.8426399231-27.021490097$ $-27.1005096436-27.09141922-27.0161991119-26.883430481-26.7025508881$ $-26.4238796234-26.0312805176-25.5053901672-24.7857303619-23.876209259$ $-22.7690296173-21.5347309113-20.3241691589-19.138759613-18.0358104706$ $-17.0779399872-16.3130493164-15.8092298508-15.6536798477-15.7439203262$ $-16.1697998047-16.610080719-16.8962593079-17.1047801971-17.2972507477$ $-17.7181892395-18.4637107849-19.3431491852-20.5859394073-21.9586906433$ $-23.2549095154-24.6134605408-25.5131893158-25.9034690857-25.7487297058$ $-25.4810390472-25.5893192291-26.6406097412-29.1334991455-32.3995513916$ $-35.7945289612-38.8998908997-41.0035705566-42.4921188354-43.4668693542$ $-44.8553886414-47.8494911194-50.5766410828-51.3101005554-51.056930542$ $-50.6055297852-50.169670105-50.1819610596-50.2477111816-50.1123008728$ $-49.9118995667-49.8312988281-49.7871398926-49.6480293274-49.4052505493$ $-48.9910011292-48.4224586487-47.746799469-46.9821891785-46.138961792$ $-45.2445983887-44.3504486084-43.4420089722-42.4940681458-41.5023384094$ $-40.4782600403-39.3624191284-38.1209487915-36.7112007141-35.0994491577$ $-33.2450904846-31.1333198547-28.6077098846-25.4864597321-21.8642196655$ $-17.7929096222-13.2615995407-8.28572463989-3.292520046231 .65728700161$ 5.9342188835148 .62331581115710 .933070182813 .4676198959416 .1515007019 19.1745605468822 .0096092224124 .4769096374526 .9911193847729 .99315071106 32.9848213195835 .3486518859937 .3375015258839 .3065605163641 .12434005737 42.691268920943 .9791908264244 .8624114990245 .3922004699745 .55599975586 45.4093589782744 .9935989379944 .3763313293543 .6331596374542 .81895828247 42.0080299377441 .2327499389640 .553298950239 .9814987182639 .56372070312 39.2791290283239 .1342201232939 .1147804260339 .2156906127939 .41535186768 39.6850318908740 .0220184326240 .4111900329640 .850311279341 .32788085938 
41.8425788879442 .3883285522542 .9614486694343 .5573310852144 .17282104492 44.8036193847745 .4471397399946 .0994300842346 .7590103149447 .42295837402 48.0903396606448 .7592506408749 .4291000366250 .0986900329650 .7677116394 51.4354515075752 .1017494201752 .7662391662653 .4288291931254 .08930969238 54.7476501464855 .403739929256 .0575904846256 .7091407775957 .35840988159 58.0053901672458 .6500701904359 .2924385070859 .9324989318860 .57022094727 61.2055702209561 .8385086059662 .4690093994163 .0970115661663 .72245025635 64.345291137764 .9654464721765 .5828781127966 .1975021362366 .80922698975 67.4180221557668 .0237579345768 .6263809204169 .2257690429769 .82182312012 70.4144210815471 .0034027099671 .5886535644572 .1699371337972 .74713134766 73.3200073242273 .8883666992274 .4520263671975 .0107269287175 .56433105469 76.1128311157276 .6560287475677 .1897430419977 .71617126465 607.7407836914602 .1713867188596 .5607299805590 .8800048828585 .133972168 579.3192749023573 .4329223633567 .4722290039561 .4343261719555 .3173828125 549.1190795898542 .8383789062536 .4730834961530 .0233154297523 .4866943359 516.8641967773510 .1530151367503 .3544921875496 .4645996094489 .4849853516 482.4100036621475 .2410888672467 .9707946777460 .6007995605453 .1209106445 445.5331115723437 .8251953125429 .9993896484422 .0412902832413 .9540100098 405.7217102051397 .3481140137388 .820892334380 .1449890137371 .3150024414 362.3319091797 353.2181091309 343.9855957031334.688293457325.3392944336 316.0645141602306 .9150085449298 .0534973145289 .5620117188281 .6159973145 274.3642883301 267.8855895996262.3103942871257.4949035645 253.4284973145 249.9326934814246 .9898986816244 .4199066162242 .0077972412240 .1455993652 238.9810028076238 .383102417238 .1201934814238 .153793335238 .4214019775 238.8311004639239 .2480926514239 .7911987305240 .4631958008241 .5693054199 243.1972045898245 .9176025391250 .0238037109255 .4694976807262 .0293884277 267.7341918945269 .8026123047272 .8992919922281 .7648925781292 .1098937988 299.8348999023 307.4827880859315.5219116211327.4381103516348.0043029785 368.6440124512385 .1361999512392 .1471862793379 .8692016602363 .9920043945 359.1708984375358 .454498291363 .9916992188366 .7312011719353 .3616943359 337.4117126465330 .2629089355323 .2655944824312 .4483947754300 .9700927734 290.5866088867278 .1530151367258 .1303100586235 .637802124213 .8265075684 194.0072937012179 .4954986572168 .1539001465158 .4682006836150 .5406036377 143.0861053467136 .8816986084132 .0921936035129 .1210021973129 .3536071777 130.5278015137129 .8125130 .3793945312134 .2245025635140 .9385070801152 .320602417 164.7714996338176 .0352020264182 .9544067383178 .4837036133174 .6773986816 184.4481048584194 .6065979004193 .213394165188 .8354949951188 .216003418 188.1367950439189 .012298584190 .321105957190 .2982025146190 .1125946045 190.2964019775190 .5513000488191 .8040924072192 .0567016602188 .5736999512 184.6826934814183 .7684936523181 .4738006592173 .9501037598165 .2781982422 159.4105072021154 .112701416147 .7176055908142 .4197998047141 .1520996094 138.2476959229126 .7904968262115 .2004013062111 .7141036987109 .8072967529 105.0761032104100 .05439758395 .0968627929789 .9819412231484 .23742675781 78.8521575927774 .8608932495171 .7956008911169 .2923965454167 .00126647949 64.3826293945361 .5877113342358 .3934593200754 .987869262751 .581199646 48.1323394775444 .860488891641 .8680114746139 .3427581787137 .06924819946 
34.6329383850132 .4300498962430 .9316596984929 .162599563626 .36261940002 22.8626804351818 .7726001739515 .1198902130113 .1395797729511 .26659011841 $7.8148040771484 .002076148987 .6666479706764-2.25728392601-4.59106206894$ $-6.50509691238-8.18627929688-9.7349281311-11.3161201477-12.8998603821$ $-14.4305400848-15.9615898132-17.4384498596-18.8377094269-20.0985603333$ -21.2680797577 -22.3904495239 -23.4153709412 -24.3285102844 -25.1428508759 $-25.9263706207-26.6457901001-27.2410907745-27.7281608582-28.1277809143$ $-28.3949298859-28.5879306793-28.6799106598-28.6566200256-28.6046791077$ -28.4109191895 -28.1719894409 -27.7985591888 -27.188129425 -26.4034690857 -25.3814697266 -24.3473491669 -23.310710907 -22.3640804291 -21.5332603455 -20.8437995911 -20.3176994324 -20.0353507996 -19.7633800507 -19.0772705078 $-18.7282600403-19.7808895111-21.1072902679-21.747800827-22.4281406403$ -23.4936904907 -24.4498901367 -25.0346603394 -25.5933799744 -26.3071899414 -27.1223392487 -27.5993690491 -27.8288707733 -27.8266296387 -27.7572402954 -27.8407993317 -28.3569507599 -29.1917495728 -30.9587192535 -34.3372688293 -37.7393417358 -39.8333816528 -41.1545295715 -42.0577011108-42.6257896423 $-42.6223106384-42.905090332-44.6994781494-46.3629798889-46.5465011597$ $-46.4360694885-46.9414482117-47.461151123-47.6359596252-47.8062591553$ -48.2652015686 -48.6723709106-48.8382492065 -48.8058700562 -48.6098518372 -48.240398407-47.7025489807 -47.0374107361 -46.2892990112 -45.5012283325 $-44.7088890076-43.8957290649-43.0290908813-42.1180992126-41.157459259$ $-40.101600647-38.9209709167-37.5636787415-36.0024185181-34.1472206116$ -31.9055595398 -29.2289295197 -26.0910491943 -22.4693908691 -18.3607196808 $-13.8743000031-9.05752468109-4.237983226780 .6193919777874 .644976139069$ 6.8039550781258 .2670106887829 .70886611938511 .3171901702913 .29281997681 15.8333396911619 .041439056422 .4263000488326 .3489398956330 .00667953491 32.781810760535 .34724044837 .9411506652840 .3366699218842 .34160995483 44.0124893188545 .1064300537145 .7116889953645 .870819091845 .64670944214 45.1211013793944 .3605804443443 .4618301391642 .4859886169441 .52260971069 40.6106910705639 .8256301879939 .1712417602538 .7139015197838 .41143035889 38.2694396972738 .2704200744638 .3995704650938 .6318511962938 .92250061035 39.2780303955139 .6791801452640 .1273002624540 .6097106933641 .12791824341 41.6759414672942 .2512397766142 .8490905761743 .4663009643644 .09851074219 44.7431793212945 .3966712951746 .0573005676346 .7223205566447 .39073944092 48.0607681274448 .7317504882849 .4025611877450 .0727806091350 .74179840088 51.4093589782752 .0751304626552 .7389717102153 .4007301330654 .06031036377 54.7176589965855 .3727111816456 .0254783630456 .6758995056257 .32398986816 57.9696884155358 .6130409240759 .2539596557659 .8924484252960 .52845001221 61.1619300842361 .7928199768162 .4210700988863 .0466194152863 .66941070557 64.2893524169964 .9064025878965 .5204772949266 .1315231323266 .73943328857 67.3441390991267 .9455718994168 .5436325073269 .1382064819369 .72920227051 70.3164520263770 .8998413085971 .4791870117272 .0543289184672 .62507629395 73.1912536621173 .7526397705174 .3090515136774 .8603134155375 .40644073486 75.9466400146576 .4819488525477 .0104598999 609.7495727539604 .2637939453598 .6859741211593 .0109863281587 .2766113281 581.4713134766575 .5916137695569 .6342773438563 .5958862305557 .4738769531 
551.265625544 .9691162109538 .5823974609532 .104675293525 .533996582518 .8704833984 512.1115722656505 .2579956055498 .3060913086491 .2562866211484 .1040039062 476.8492126465469 .486114502462 .0140991211454 .4263916016446 .7221069336 438.8935852051430 .9401855469422 .854095459414 .6354064941406 .2778015137 397.7825012207389 .1496887207380 .3836975098371 .495300293362 .491607666 353.4071960449344 .2645874023335 .1264038086326 .0307006836317 .079498291 308.3471984863299 .9390869141291 .9548034668284 .4616088867277 .5407104492 271.3724060059266 .2207946777261 .6636962891257 .3982849121253 .4528961182 249.9371032715246 .6522064209243 .3348999023240 .7321014404239 .4582977295 238.8869018555238 .3952941895238 .0825958252238 .0045013428238 .0975952148 238.2760009766238 .6105041504239 .0249023438239 .8135070801241 .0453948975 243.3495941162246 .8847961426253 .2077941895264 .1405029297273 .7594909668 276.1904907227278 .9222106934288 .3996887207298 .3859863281303 .0573120117 305.9395141602309 .9584960938318 .371887207334 .7542114258350 .8124084473 360.6557006836362 .4119873047353 .7448120117340 .1733093262328 .4179992676 320.8706054688320 .8955993652320 .1928100586309 .7116088867295 .5390930176 285.3160095215278 .1018066406272 .0130004883265 .6463012695256 .0928955078 244.7389068604232 .2035980225218 .4423065186202 .7017059326187 .2850036621 175.1071014404164 .846496582155 .9203033447148 .3381958008141 .6763000488 136.3751983643132 .4225006104130 .258102417130 .3179016113131 .4750976562 132.5196990967135 .2393951416141 .5847015381148 .699005127153 .875158 .2355041504 163.5690002441166 .5619049072164 .1367034912162 .4967956543168 .1564941406 174.400604248175 .2113952637174 .2494049072175 .0377960205176 .1504058838 176.8647003174178 .2057952881180 .6437988281183 .3970031738185 .7951965332 188.2512054443190 .4160003662190 .9942016602188 .8771057129186 .7915039062 187.9839019775187 .4080963135180 .5484008789172 .137298584166 .5489044189 162.1761932373157 .8428955078154 .3800048828153 .2498931885150 .9983978271 144.6461029053137 .6027984619133 .1602935791128 .3217010498120 .2688980103 112.3578033447107 .5646972656103 .135101318496 .0934371948289 .81072235107 87.1627273559685 .7187271118283 .8237686157281 .5310592651478 .5541229248 75.2511978149471 .5369796752967 .4932708740263 .3926506042559 .40575027466 55.896488189752 .7359008789149 .885601043747 .1748695373544 .4831199646 42.0152587890639 .9470710754437 .8260612487835 .0829887390132 .09949874878 28.8351306915325 .5647602081323 .0185909271220 .2017097473116 .48769950867 12.710229873669 .2190961837776 .0246157646183 .3722519874570 .977774977684 -1.25050294399 -3.29673790932 -5.3434510231 -7.36046504974 -9.30358409882 $-11.2358598709-13.1338100433-14.9380702972-16.613910675-18.1974201202$ $-19.7189693451-21.1417198181-22.4304695129-23.6116199493-24.7976398468$ -25.9230308533 -26.8628692627 -27.6792297363 -28.4301109314 -29.0197601318 $-29.4757404327-29.7710704803-29.9067592621-30.0274105072-30.0870990753$ -30.1656093597 -30.1941699982-29.9715003967-29.4897098541-28.7251796722 -27.8161697388 -26.9512195587-26.3421592712 -25.8071403503 -25.1790790558 -24.6678390503 -24.5475997925 -24.4257793427 -24.0281505585 -24.0335597992 -25.0160903931 -26.3539791107 -27.2780208588 -28.1396102905 -29.1689090729 -29.964799881 -30.4309597015 -30.7306098938 -31.0818595886 -31.4116401672 -31.4403991699 -31.2760391235 -30.9059391022 -30.5280303955 -30.3588504791 
-30.3888702393 -30.8968696594 -32.3612098694 -35.4180908203 -38.4672584534 -39.720741272 -40.1377487183-40.418598175 -40.1618995667 -39.3167304993 -38.9393501282 -39.8087615967-41.0670700073-41.4922714233-41.6487083435 $-42.2809715271-43.0751991272-43.8574981689-44.8119812012-46.1482505798$ $-47.2684898376-47.5754013062-47.5740585327-47.7072792053-47.6734199524$ $-47.2475395203-46.653049469-46.0927009583-45.4944000244-44.8143997192$ $-44.0832214355-43.3224411011-42.5110702515-41.6379013062-40.6641998291$ -39.5607910156 -38.2786598206 -36.7772293091 -34.979598999-32.8488998413 $-30.2505493164-27.0260791779-23.3228092194-19.2188491821-14.8126602173$ $-10.1827201843-5.53349399567-.9059770107272 .7400588989264 .292781829834$ 4.8547081947335 .2538390159615 .7945189476016 .8357682228099 .36367225647 14.2869100570719 .3444099426322 .9248695373526 .0085506439229 .33263969421 32.8302688598636 .2450218200739 .3123397827141 .8945693969744 .02458953857 45.3821907043546 .0516510009846 .1815681457545 .8620605468845 .19506072998 44.2661399841343 .1945800781242 .0459403991740 .9108200073239 .85321044922 38.9648094177238 .2438392639237 .7430686950737 .4325790405337 .32255935669 37.3763008117737 .5519981384337 .8273391723638 .1585807800338 .54479980469 38.9698486328139 .4323501586939 .9230995178240 .4444885253940 .99557113647 41.5724487304742 .171451568642 .7893905639643 .4221115112344 .06718826294 44.7210083007845 .3819885253946 .0473709106446 .7162208557147 .38671875 48.0582695007348 .7297096252449 .400669097950 .070449829150 .73884963989 51.4054908752452 .0702514648452 .7329292297453 .3934898376554 .05179977417 54.7078399658255 .3615608215356 .0129203796456 .6619110107457 .30849075317 57.9526214599658 .5942611694359 .2333793640159 .8699111938560 .50379943848 61.1349792480561 .7633781433162 .3889312744163 .011581420963 .63124084473 64.2478332519564 .8612976074265 .4715728759866 .078536987366 .68218231201 67.2823791503967 .8790588378968 .4721069335969 .0614471435569 .64692687988 70.2284317016670 .8057937622171 .3788604736371 .9474563598672 .51139831543 73.0705108642673 .6246032714874 .1735076904374 .7172698974675 .25567626953 75.784591674876 .30621337891

612.0902709961606 .553527832600 .9738769531595 .3225708008589 .6030273438 583.8112182617577 .9423828125571 .9934082031565 .9597167969559 .8383789062 553.6262207031547 .3209838867540 .9199829102534 .4227905273527 .8264160156 521.1317138672514 .3350830078507 .4378967285500 .4354858398493 .3295898438 486.1140136719478 .7901916504471 .3510131836463 .7979125977456 .1225891113 448.3270874023440 .4028930664432 .3525085449424 .1690063477415 .8558044434 407.4100036621398 .8362121582390 .1411132812381 .3308105469372 .429901123 363.4483947754354 .438293457345 .4179992676336 .4731140137327 .6383056641 319.0226135254310 .6856079102302 .7178039551295 .2074890137288 .157989502 281.5591125488275 .6492919922270 .8229980469266 .4435119629262 .003112793 257.702911377253 .7940979004250 .0301055908246 .0422058105242 .8222045898 241.3220977783240 .5467071533239 .5794067383238 .8103942871238 .3466949463 238.1094055176238 .0016937256238 .0395050049238 .1266021729238 .5301055908 239.199798584240 .8464050293243 .3218994141248 .9895019531262 .0993041992 274.7058105469277 .9917907715280 .1129150391288 .3767089844295 .5333862305 295.8843994141294 .7478027344295 .2705078125298 .5205078125307 .3945007324 
315.8374938965317 .7882995605315 .2698059082312 .1577148438305 .2618103027 292.337097168280 .4061889648273 .0107116699266 .6469116211260 .4223937988 253.1430053711244 .3618011475237 .8023986816235 .737701416233 .3435058594 223.7183990479213 .3488006592207 .5428924561201 .4532012939191 .2189025879 179.9342956543169 .9476013184160 .5484924316152 .1609039307144 .8101043701 138.6757965088133 .896194458130 .3193054199128 .0993041992126 .9327011108 127.3578033447129 .6493988037133 .8791046143141 .824798584147 .9277038574 145.6464996338141 .3630981445140 .6119995117140 .6094970703141 .3802032471 142.7276000977144 .0509033203145 .8805999756148 .4716033936151 .5117034912 155.0514984131158 .3314056396159 .0525970459160 .3854980469165 .6340942383 171.5968017578175 .8070983887179 .1916046143181 .0482025146181 .5382995605 181.0415039062180 .6082000732183 .1315002441184 .2117004395179 .0021057129 172.3153076172167 .8912963867164 .5384063721162 .2360992432160 .7048950195 159.6311035156158 .6824035645158 .8963012695157 .7216033936153 .1566925049 146.3540039062136 .1490936279126 .4798965454122 .5127029419118 .7141036987 110.5027008057103 .3411026001101 .4063034058101 .327903747699 .79016113281 97.6169891357494 .2472915649490 .0926208496185 .5424728393680 .65454864502 75.9729003906271 .5256500244167 .7476119995164 .432060241761 .29256057739 58.3520393371655 .5698814392152 .9127883911150 .3506698608447 .80350112915 44.999858856242 .1426582336439 .2196083068836 .1318511962933 .05587005615 29.7054195404126 .14586067222 .4457206726118 .6234207153315 .10729980469 12.146019935619 .4935569763186 .8077650070194 .1422181129461 .536893963814 $-.990768015385-3.36441707611-5.68159484863-7.88759183884-10.063170433$ $-12.1793403625-14.155960083-16.0568695068-17.7843208313-19.4521503448$ $-21.1005592346-22.7424793243-24.2880592346-25.5462703705-26.6336593628$ $-27.7355899811-28.7384300232-29.6182899475-30.3096294403-30.7894001007$ $-31.1234493256-31.2420902252-31.3592891693-31.4864292145-31.4471893311$ $-31.3220806122-30.9736690521-30.4167900085-29.9427509308-29.8119602203$ $-29.6930809021-29.2523803711-28.8969192505-29.089509964-29.4542808533$ $-29.8680896759-30.5130405426-31.4447994232-32.5828704834-33.5523986816$ $-34.4654083252-35.2692718506-35.9259490967-36.5266418457-36.9153785706$ $-37.0129699707-36.8783302307-36.412021637-35.718711853-34.7730903625$ $-33.8340606689-33.2132301331-33.0027198792-33.512588501-34.8165588379$ $-37.3161582947-39.5633201599-39.7533988953-39.1565284729-38.7699203491$ $-38.0857391357-37.1797409058-36.4490509033-36.0120506287-36.0077400208$ $-36.091178894-36.4047698975-37.1108016968-38.1354789734-39.5144996643$ $-41.1894493103-43.3097190857-45.0617294312-45.5530090332-45.6396598816$ $-46.1631317139-46.4984703064-46.25989151-45.8331184387-45.5327301025$ $-45.1763801575-44.6429901123-44.0338897705-43.4008293152-42.7095184326$ $-41.9376411438-41.05809021-40.0432701111-38.8420791626-37.413848877$ $-35.7022018433-33.7453308105-31.2898006439-28.0562896729-24.3380203247$ $-20.304599762-16.0480594635-11.6257400513-7.29812097549-3.04382991791$ .1675740033388 1.196169018745 1.15956401825.8415510058403.6265310049057 .98076200485233 .0019609928138 .69009113311815 .1035699844418 .85618019104 22.0716896057126 .2274208068830 .4629898071334 .737861633338 .7887802124 41.8534889221244 .2569198608445 .695030212446 .3749809265146 .5008392334 
46.0008010864345 .1833801269544 .0736999511742 .8281898498541 .50130081177 40.1843795776438 .9738693237337 .9788208007837 .188339233436 .67248916626 36.3833312988336 .3358306884836 .4739303588936 .711349487337 .04256820679 37.4194602966337 .8427314758338 .293941497838 .7733802795439 .27222061157 39.7965087890640 .3495101928740 .927040100141 .5261116027842 .14360046387 42.7758293151943 .4202384948744 .0735015869144 .7338600158745 .39881134033 46.0672302246146 .7375106811547 .4088897705148 .080360412648 .75141906738 49.4214897155850 .0902290344250 .7573394775451 .4226188659752 .08591842651 52.7471008300853 .4061203002954 .0628585815454 .7173194885355 .36941146851 56.019119262756 .6663589477557 .3111305236857 .9533386230558 .59294891357 59.2298812866259 .8640594482460 .4954109191961 .1238708496161 .74934005737 62.3717689514262 .9910583496163 .607139587464 .2199325561564 .82936096191 65.4353637695366 .0378570556666 .6367797851667 .2320327758867 .8235168457 68.4111709594768 .994842529369 .5744171142670 .1497573852570 .72071838379 71.2871170043971 .8488235473672 .4056320190472 .9573822021573 .50390625 74.0452728271574 .5806732177775 .111183166575 .63487243652 614.4426879883608 .9962158203603 .4564208984597 .8176269531592 .1168212891 586.3422851562580 .4893188477574 .5532836914568 .5297851562562 .4152832031 556.2059936523549 .8991699219543 .4921875536 .9838256836530 .3715820312 523.6555786133516 .832824707509 .9036865234502 .8648986816495 .7164916992 488.4541931152481 .077911377473 .5824890137465 .9679870605458 .2290039062 450.3659057617442 .3742980957434 .2550964355426 .0067138672417 .6318054199 409.133605957400 .517791748391 .7969970703382 .9819946289374 .1022949219 365.1773986816356 .2611999512347 .3883972168338 .6383972168330 .066192627 321.7644042969313 .8099060059306 .2663879395299 .2210998535292 .6177062988 286.469909668280 .8970031738276 .0501098633271 .5556945801267 .0830993652 262.7289123535258 .682800293254 .7765960693250 .8591003418247 .5529937744 245.3511047363243 .6772003174241 .9026031494240 .4114990234239 .5697937012 239.06640625238 .5944976807238 .2223052979237 .9051055908237 .7933044434 237.9456939697238 .5935974121239 .6622009277242 .9250030518250 .2835998535 258.3362121582 263.8587036133267.2802124023 269.2633056641 268.9183044434 266.0375061035263 .0231018066262 .5692138672263 .0286865234264 .057800293 265.7365112305269 .1434020996270 .4349975586263 .5591125488254 .8847045898 250.0814056396245 .6038970947240 .0596008301234 .5005950928227 .5305023193 221.0435943604215 .9114990234212 .5196990967211 .6172943115210 .0335998535 203.5892028809196 .7830963135192 .7767028809188 .7973937988181 .5016021729 172.7740936279164 .6307067871156 .3726959229148 .1109924316140 .6069946289 134.4730987549129 .6770019531126 .1917037964123 .6445999146121 .7897033691 121.4725036621122 .7916030884125 .7755966187130 .7093048096133 .2615966797 130.3421936035125 .6691970825122 .8881988525122 .3085021973123 .2521972656 124.4708023071124 .6965026855124 .9088973999125 .2670974731127 .8088989258 133.545501709139 .3927001953142 .5635986328145 .8013000488151 .0650024414 156.6696929932160 .7581939697163 .6871032715165 .250793457165 .8932037354 166.217300415166 .4983978271167 .5359954834168 .2364959717167 .2268981934 165.3274993896163 .2442016602161 .6645965576161 .5411987305161 .9541931152 161.9915008545162 .8273010254165 .4631958008166 .862701416165 .2097015381 
160.995300293154 .6132049561148 .1988067627143 .3309020996137 .6936035156 130.1342010498123 .4873962402119 .9177017212118 .3695983887117 .3394012451 115.5225982666111 .4461975098106 .1513977051100 .221000671494 .14360809326 88.8593826293984 .0903396606480 .0991668701276 .6976699829173 .42378234863 70.3072967529367 .2547912597764 .2379608154361 .3597297668558 .5259513855 55.6546211242752 .8360900878949 .9873695373546 .9493484497143 .74098968506 40.3218803405836 .7639999389632 .8899002075228 .4621200561524 .35799980164 21.4035491943418 .794019699115 .7417697906512 .474559783949 .244156837463 $6.1688032150273 .349338054657 .7084450125694-1.64699697495-4.04980707169$ $-6.77518701553-9.33051109314-11.3549804688-13.1759996414-15.2632703781$ $-17.4768505096-19.6942996979-21.7316894531-23.2031707764-24.456489563$ $-25.9226398468-27.4771595001-29.1154308319-30.5636806488-31.7168292999$ -32.3584098816 -32.0470809937 -31.549079895 -31.1700401306 -30.8677692413 -31.098859787 -31.4070205688 -31.6479797363 -32.0428085327 -32.5316009521 -32.9328689575 -33.1015205383 -33.321269989 -33.9070510864 -34.7358589172 -35.6926803589-36.7463111877-38.073009491 -39.3985404968 -40.3939208984 $-41.211101532-41.7122993469-42.1850509644-43.0879211426-43.71875-43.4160194397$ $-42.6730194092-41.917930603-40.8506088257-39.2009086609-37.5343208313$ -36.3963508606 -35.8167304993 -35.9472885132 -36.6665306091 -38.126789093 $-39.2835197449-39.1463508606-38.4230384827-37.6160392761-36.6304397583$ $-35.4609794617-34.1156997681-32.6354598999-31.5290107727-31.0919208527$ $-31.2911701202-32.0965614319-33.3766899109-35.019821167-37.029460907$ -39.3066711426-41.2308502197-42.2388496399-42.880771637-43.6759109497 $-44.2878913879-44.486240387-44.4902687073-44.486541748-44.3800086975$ $-44.1043586731-43.712348938-43.2528686523-42.7050209045-42.0566902161$ $-41.2831916809-40.3649406433-39.2557487488-37.9157104492-36.3042106628$ -34.4059104919 -32.0268287659-28.9833393097-25.4747104645 -21.6152000427 -17.577829361 -13.4618797302 -9.54531097412 -6.01647281647 -3.43673300743 $-2.51454401016-2.53223395348-2.98507499695-3.51005291939-3.61391210556$ -2.57150506973.32603499293335.24701595306412.83703994751 20.12759971619 24.1457099914627 .7873191833533 .6466903686539 .2957496643142 .36243057251 44.3699493408245 .9665794372646 .8063812255946 .8318099975646 .12895965576 45.0839118957543 .7960815429742 .3577117919940 .8390197753939 .33718109131 37.9735183715836 .85659027135 .998050689735 .5015487670935 .28068161011 35.3222503662135 .5659103393635 .8934288024936 .2929496765136 .72119903564 37.1800003051837 .6578407287638 .1531295776438 .6596794128439 .1861000061 39.7401390075740 .317241668740 .9152297973641 .5311012268142 .16152954102 42.8041191101143 .4555282592844 .1142196655344 .7775993347245 .44469833374 46.1137809753446 .7842407226647 .4549484252948 .1255111694348 .7952003479 49.4637985229550 .1308708190950 .7962799072351 .4597892761252 .12129974365 52.780689239553 .4379005432154 .0928192138754 .7454299926855 .3956413269 56.043380737356 .688610076957 .3312301635757 .9711914062558 .60839080811 59.242748260559 .8741798400960 .5025901794461 .1278915405361 .75001144409 62.3688507080162 .9843406677263 .596401214664 .204940795964 .80991363525 65.4112167358466 .0087966918966 .6025772094767 .1924667358467 .77837371826 68.3601913452168 .9378128051869 .5111007690470 .0799179077170 .6441192627 
71.2035293579171 .7580184936572 .3074035644572 .8515472412173 .39051818848 73.924102783274 .4481887817474 .9649810791

617.1320800781611 .6403198242606 .1049804688600 .4967041016594 .8184204102 589.0654296875583 .2321777344577 .3142700195571 .3065185547565 .2047729492 559.0048217773552 .7041015625546 .2988891602539 .7885131836533 .1696777344 526.4429931641519 .6049194336512 .6566772461505 .5939941406498 .4182128906 491.124206543483 .713104248476 .1794128418468 .5245056152460 .7430114746 452.8369140625444 .8026123047436 .6430969238428 .3584899902419 .9534912109 411.4350891113402 .8100891113394 .0982971191385 .3096008301376 .4843139648 367.638092041358 .8399963379350 .1177978516341 .5682067871333 .2329101562 325.220703125317 .5922851562310 .4226074219303 .7853088379297 .6391906738 292.0144042969286 .7486877441281 .7994995117277 .071685791272 .5693969727 268.2919921875264 .2807922363260 .5289001465257 .0275878906253 .7895965576 250.8081054688248 .0541992188245 .3726043701243 .1766052246241 .9181976318 241.0695953369240 .1383972168239 .2890930176238 .508895874237 .854095459 237.4577941895 237.2496032715 237.0516052246 237.4255981445 237.849395752 239.7570037842246 .1719970703250 .445098877246 .1811981201239 .2052001953 234.2454071045230 .3780059814229 .5189056396228 .5070037842223 .3766021729 220.2232971191226 .8699035645232 .0171051025221 .2749938965210 .546295166 214.3108062744219 .4777069092218 .1273956299214 .0639953613206 .3338928223 199.3769989014 197.3992004395 197.0588989258196.1757049561 194.7770996094 191.6753997803188 .0691986084184 .3914031982180 .0007019043173 .8394012451 166.5803070068159 .7270050049152 .4143066406144 .478805542136 .8177032471 130.396697998125 .2097015381121 .5520019531118 .8208999634116 .4811019897 114.9517974854114 .274597168114 .0351028442114 .1262969971113 .3116989136 111.8743972778109 .8309020996107 .6800003052106 .6480026245107 .048500061 107.883102417107 .9972000122107 .78099823106 .2189025879106 .9477005005 113.4789962769121 .2876968384126 .9378967285131 .9300994873136 .6450958252 140.6683044434143 .6027984619145 .316192627145 .9786987305146 .4221038818 147.558807373148 .5704956055148 .0576934814147 .9358062744150 .6710968018 153.5798034668154 .1340026855154 .5924072266156 .4860992432158 .6273040771 159.8730926514161 .7973937988165 .3905029297168 .8950042725171 .3717041016 171.6654968262170 .5117950439167 .3751068115161 .6775970459155 .595993042 150.7835998535146 .2749938965141 .5885009766137 .7321929932136 .0404968262 134.024597168128 .9268951416122 .1882019043114 .5930023193107 .2488021851 101.484497070396 .986053466893 .0339279174889 .5608978271586 .06134033203 82.5628204345779 .1159591674875 .691818237372 .541152954169 .53880310059 66.5940628051863 .7036209106460 .7726783752457 .7158584594754 .50777816772 51.1279907226647 .6194801330643 .8088798522939 .1812782287634 .69047927856 31.6354007720928 .7286891937325 .11914062521 .339639663717 .59712982178 13.9789896011410 .673749923717 .7438678741465 .3637580871583 .028925895691 -4.6319999e-02 -2.99428701401 -5.07305288315 -7.1573882103 -9.9321346283 -12.8296699524 -15.552740097 -17.8772201538 -19.4857997894-20.9886398315 -22.8633403778 -24.9879894257-27.3898601532 -29.7252006531 -31.8257808685 -32.916179657 -32.330039978 -30.8757705688 -29.4952297211 -28.8994197845 $-29.5713195801-31.0144805908-32.3620414734-33.5744400024-34.6494216919$ 
-35.588508606 -36.4677009583 -37.3944015503 -38.4839401245 -39.7206802368 $-41.1390190125-42.7277297974-44.706199646-46.452671051-47.4975891113$ $-48.0963897705-48.2264289856-48.4872207642-49.5282096863-50.2748908997$ $-49.5001602173-48.1848182678-47.1312408447-45.7144317627-43.4647483826$ $-41.1898117065-39.6521987915-38.6620483398-38.2938613892-38.3222084045$ -38.6113204956 -38.7838783264 -38.5359916687 -37.9218292236 -36.9590911865 -35.7276382446 -34.3042106628 -32.6037788391 -30.3280105591 -28.4024200439 $-27.3564891815-27.1760292053-28.0179595947-29.4058094025-31.0521297455$ -32.981010437 -35.0227203369 -36.9409713745 -38.4422607422 -39.6626205444 $-40.7676887512-41.6670913696-42.3649711609-42.8590202332-43.187210083$ $-43.3480911255-43.3521614075-43.2104682922-42.9448318481-42.5508995056$ $-42.0314903259-41.3668518066-40.5470199585-39.5303115845-38.2883911133$ -36.7643699646 -34.9145812988 -32.6550102234 -29.900850296 -26.7112598419 $-23.0851402283-19.290599823-15.4700098038-12.0054998398-9.2034702301$ $-7.21075820923-6.26817512512-6.08498907089-6.41676616669-6.90253019333$ $-7.08256292343-6.67087602615-6.49318790436-3.453713893897 .541411876678$ 18.8886508941723 .0097103118926 .6751308441234 .3704490661641 .47838973999 44.4325485229545 .5576705932646 .6576309204147 .1428909301846 .86111831665 46.0038795471244 .8396492004443 .390480041541 .7974815368740 .12049102783 38.4694595336936 .9389114379935 .6502990722734 .7252311706534 .2854309082 34.2149314880434 .3905410766634 .7348098754935 .1430587768635 .60354995728 36.0761413574236 .5646286010737 .0649299621637 .5731887817438 .08639907837 38.6138992309639 .1682205200239 .7433700561540 .3390197753940 .9518699646 41.5792808532742 .2186698913642 .8671188354543 .522880554244 .18368911743 44.8483810424845 .5154495239346 .1840782165546 .8533515930247 .52265930176 48.1914482116748 .8593101501549 .5259208679250 .1910018920950 .85437011719 51.5158500671452 .1753501892152 .832729339653 .4879188537654 .14078903198 54.7913208007855 .4393806457556 .0849113464456 .7277984619157 .36798095703 58.0053215026958 .6397514343359 .2711486816459 .8994293212960 .52447891235 61.1462211608961 .7645492553762 .3793792724662 .9906387329163 .59823989868 64.2021102905364 .8021926879965 .3983917236365 .990646362366 .57890319824 67.1630325317467 .7429733276468 .3186035156268 .88979339669 .45644378662 70.0183868408270 .5755081176871 .127647399971 .67465972972 .21640014648 72.7529373168973 .2834930419973 .809158325274 .32801055908 619.8350830078614 .4396972656608 .951171875603 .3621826172597 .7102050781 591.9827880859586 .1741943359580 .2794189453574 .2929077148568 .2100830078 562.0269165039555 .7393798828549 .3447265625542 .8411254883536 .2260742188 529.4993286133522 .6583251953515 .7031860352508 .6311950684501 .4425048828 494.133605957486 .7047119141479 .1523132324471 .4767150879463 .675201416 455.7489013672447 .6972961426439 .5231018066431 .2297973633422 .8223876953 414.3111877441405 .7055053711397 .0263061523388 .2894897461379 .5331115723 370.783203125362 .1007995605353 .5278015137345 .1494140625337 .0288085938 329.2546081543321 .8978881836315 .0356140137308 .749786377303 .0394897461 297.995513916293 .1376037598288 .0928955078283 .1557006836278 .5808105469 274.362701416270 .466003418266 .9541015625263 .9136962891260 .8010864258 257.1546020508253 .4683074951250 .2496032715247 .6240997314245 .7525024414 
244.2733001709242 .7958984375241 .4066925049240 .1260070801238 .9324951172 237.8495941162236 .8329925537235 .94140625234 .7740936279233 .4458007812 233.6123046875236 .9138031006238 .6643066406233 .9642944336227 .0863037109 221.4474029541217 .420501709215 .0848999023212 .3177032471207 .0092010498 203.9633026123207 .349899292210 .1578979492203 .6945037842198 .3670959473 202.8768005371208 .5612030029207 .5491027832202 .8954925537196 .5075073242 191.1222991943189 .4636993408189 .1056976318188 .346496582187 .3047943115 185.6387023926183 .3365020752179 .9597930908175 .3943023682169 .7431030273 163.2657928467156 .0563049316148 .5782012939141 .5131072998134 .4674987793 127.1772994995121 .0634002686117 .551902771114 .9195022583111 .8985977173 108.8460006714105 .5669021606102 .042701721298 .5392608642695 .8588180542 95.0384216308694 .7257919311592 .8744506835991 .416427612392 .37201690674 93.9288864135794.4984970092894.5380630493293.8869018554795.03880310059 100.2236022949106 .9989013672112 .908996582118 .0604019165122 .4151992798 125.5699005127127 .3415985107127 .6250991821125 .7260971069124 .6484985352 127.3339996338 130.3681945801 130.7270965576131.3249053955 134.0648956299 137.7902069092141 .0162963867143 .9600982666146 .8876037598149 .6790008545 151.9011993408154 .8791046143159 .6510009766165 .9745941162174 .37449646 180.2899017334178 .9143981934174 .4691925049170 .7998962402168 .546295166 170.0596923828170 .8818054199167 .1889953613161 .9654998779157 .633895874 153.0018005371146 .578704834138 .2391967773127 .8989028931118 .4436035156 113.0742034912109 .7248001099106 .348197937102 .963096618799 .03897857666 94.8869628906290 .8575973510786 .945030212483 .482841491780 .33531951904 77.3526000976674 .4288635253971 .4495773315468 .3754882812565 .10510253906 61.7492904663158 .373180389454 .973911285451 .6640090942448 .04616928101 43.7618484497139 .2315406799334 .8604202270530 .5821609497126 .45384979248 22.4229602813718 .4277496337915 .0483503341712 .9579896926911 .09228992462 8.4191846847535 .6956090927123 .45792889595 .7750430107117 -3.35065507889 $-7.46204996109-10.1080102921-12.0826797485-13.9982595444-16.0067596436$ -18.3360691071 -20.9863605499-23.9233093262 -27.0178699493 -30.3461799622 $-32.358581543-31.728969574-29.4309501648-26.3725891113-24.8679103851$ -27.0966796875 -30.662530899 -33.0830192566 -34.8562698364 -36.3449783325 -37.7184410095 -39.1905784607-40.7562789917-42.3815803528 -44.0921211243 $-45.980140686-48.2165794373-51.2540016174-53.7953491211-54.6230201721$ $-54.6555290222-54.5522384644-54.59400177-55.1060409546-55.2665405273$ $-54.2167892456-52.6002883911-50.9869194031-49.0614700317-46.6734199524$ $-44.305229187-42.5287704468-41.210269928-40.3735389709-39.7930984497$ -39.3800506592 -39.0050582886 -38.4717102051 -37.7617683411 -36.7318687439 -35.4041595459 -33.8307914734 -31.9506206512 -29.7461395264 -27.7323703766 -25.9981899261 -25.1649799347 -26.0146408081 -27.3663806915 -28.3936500549 -29.6696605682 -31.4040603638 -33.272228241 -34.8611106873 -36.3381996155 -37.7997589111 -39.1168518066-40.2144889832-41.1109085083-41.7731895447 $-42.2225990295-42.4866790771-42.5766792297-42.5031700134-42.2654418945$ $-41.8765487671-41.3223991394-40.5977706909-39.6738586426-38.5279083252$ $-37.1123313904-35.3890190125-33.3414306641-30.9397792816-28.1046390533$ $-24.6697101593-21.0245399475-17.4584407806-14.3163499832-11.8897104263$ 
-10.1491498947 -9.31952571869 -9.08720302582 -9.43089199066 -9.79973316193 $-9.36394786835-8.35654067993-7.06849479675-3.106873989116 .361765861511$ 16.6613597869923 .1862602233929 .7623996734638 .9724502563546 .84524154663 49.8943595886250 .1158981323248 .8898010253947 .3421096801846 .6319694519 45.787391662644 .4401283264242 .8633193969741 .1665306091339 .39374923706 37.6318092346235 .934158325234 .3396415710433 .2255210876533 .00603866577 33.2496795654333 .5886688232434 .0265388488834 .4960212707534 .99568939209 35.4981117248536 .0078201293936 .5211296081537 .0374603271537 .55440139771 38.0828399658238 .6349601745639 .2066802978539 .7982788085940 .4068107605 41.0297012329141 .6646690368742 .3087615966842 .9604682922443 .61745834351 44.2787704467844 .9427490234445 .6087684631346 .2757110595746 .94313812256 47.6103210449248 .2769393920948 .942520141649 .606861114550 .2696685791 50.93080902151 .5900688171452 .2473602294952 .9025306701753 .55548858643 54.2061195373554 .8543281555255 .556 .1430206298856 .7832717895557 .42065048218 58.0550384521558 .6863212585459 .3143692016659 .9390907287660 .56037902832 61.1781311035261 .7922401428262 .4026412963963 .0092391967863 .61196899414 64.2107696533264 .8055496215865 .3962631225665 .9828109741266 .56513977051 67.1431503295967 .7167587280368 .2858428955168 .8502883911169 .40998077393 69.9647674560570 .5145416259871 .0591430664171 .5984573364372 .13256835938 72.6613006591873 .180526733473 .69248962402 622.8770751953617 .4428710938611 .9650268555606 .4138183594600 .791809082 595.0939941406589 .3142700195583 .4475708008577 .4877929688571 .4302978516 565.2700805664559 .0037841797552 .6276245117546 .1401977539539 .5385131836 532.8228149414525 .9899291992519 .0410766602511 .9726867676504 .7862854004 497.4779052734490 .0487060547482 .4952087402474 .8190917969467 .0179138184 459.0940856934451 .0481872559442 .8840026855434 .6069946289426 .2231140137 417.7456970215409 .18359375400 .5629882812391 .8971862793383 .2314147949 374.5860900879366 .0313110352357 .5968017578349 .3822937012341 .4371032715 333.8649902344326 .7110900879320 .082611084314 .0538024902308 .625793457 304.0271911621299 .5362854004294 .541809082289 .5665893555285 .0472106934 280.9359130859277 .1496887207273 .7554931641270 .9873962402267 .9607849121 263.8039855957259 .5621948242256 .1192932129253 .2095031738250 .7312011719 248.5668029785246 .4998016357244 .5498962402242 .7778930664241 .0184020996 239.2454071045237 .4499053955235 .9815063477234 .4532928467233 .2019042969 232.3899993896232 .3164978027231 .2955932617227 .8372039795223 .2362060547 218.6224060059214 .4055023193210 .8005981445207 .3587036133204 .1528930664 202.162399292201 .4611968994201 .4503936768200 .3092041016200 .3545074463 203.8394012451206 .7035980225204 .1228027344199 .3231964111195 .0272979736 191.2895050049189 .213394165187 .9705047607186 .9689941406186 .0413970947 184.9963989258183 .0574035645179 .3094940186174 .5007019043169 .258605957 163.2265930176155 .4817962646147 .4524993896141 .1557006836134 .7398071289 126.7665023804119 .6566009521115 .9817962646113 .1727981567109 .5632019043 104.860397338998 .6138534545992 .2153701782286 .3777389526482 .6076965332 82.53587341309 83.1439666748 81.28711700439 79.8242034912181.39929962158 83.587753295984 .5972290039185 .3892517089886 .2954025268688 .10784912109 91.4528121948295 .91326904297100 .9070968628105 .5978012085109 .4438018799 
111.890296936112 .8312988281112 .0488967896108 .1872024536105 .6149978638 109.3482971191114 .2042007446115 .8522033691117 .2654037476119 .2939987183 122.3569030762127 .0865020752131 .8271942139135 .2082061768138 .0605926514 140.6591033936144 .1490936279149 .3314056396157 .1210021973169 .9709014893 179.9761047363177 .8258972168172 .6593017578172 .0236053467174 .3173065186 182.2050018311188 .8323974609187 .6148071289182 .6398925781176 .6855926514 169.2803039551161 .3385009766152 .2299957275140 .6049957275130 .4284057617 126.0173034668123 .4145965576119 .9672012329116 .3153991699111 .3498001099 106.3630981445101 .761802673397 .4849929809693 .856727600190 .56767272949 87.5168914794984 .6124572753981 .6415863037178 .5528869628975 .20184326172 71.7986297607468 .4968872070365 .4724884033263 .466659545960 .75214004517 55.3927497863849 .4141502380444 .494419097939 .9035797119135 .58153915405 31.4349498748827 .0489006042523 .4158191680921 .6422405242920 .27325057983 18.0660705566415 .5927600860612 .954219818129 .6482172012334 .397480010986 -.680368006229 -3.05186200142-4.88396120071 -7.32039690018 -9.95126247406 -12.7772903442 -15.7765703201 -19.0346698761 -22.4543800354-26.5479106903 $-29.4221401215-29.1963596344-27.3935699463-24.2338695526-22.4564609528$ -25.9090309143 -30.6015892029 -33.2765884399 -35.445110321 -37.3199615479 -39.0855903625 -41.1272392273-43.1577301025 -45.1267700195-47.3046417236 $-49.7133903503-52.5639610291-56.6068000793-59.9283905029-60.7831306458$ $-60.7222709656-60.7176895142-60.5997886658-60.3623580933-59.7444381714$ $-58.2763214111-56.3200912476-54.0769386292-51.6262588501-49.2509803772$ $-46.9625511169-45.0888214111-43.5331611633-42.2906417847-41.2714996338$ $-40.3766212463-39.5922889709-38.8453903198-38.0309791565$-36.9662399292 -35.6525993347 -34.0593605042 -32.2629814148 -30.4881401062 -28.4519100189 $-25.7738494873-24.0175991058-24.6753406525-26.1409606934-26.6729793549$ $-27.2852401733-28.6842498779-30.3297996521-31.8295192719-33.3691902161$ -35.0998802185 -36.7684898376 -38.2039604187 -39.4224586487-40.3814086914 $-41.0927810669-41.6002693176-41.8908309937-41.9938011169-41.900138855$ $-41.6362304688-41.1839904785-40.5497398376-39.7102508545-38.655670166$ -37.3573608398 -35.7851600647 -33.9467391968 -31.8810195923 -29.3876094818 -26.1631393433 -22.7148303986 -19.4077701569 -16.4621505737 -14.153550148 $-12.5423002243-11.810210228-11.6711301804-12.1015701294-12.2123098373$ $-10.927980423-8.76472377777-5.5808339119-.5324890017517 .061318874359$ 16.189029693625 .2922496795734 .4735984802243 .9560089111351 .48529052734 54.5762481689554 .4692382812551 .233398437547 .347789764446 .08491134644 45.2975807189943 .8344116210942 .1733703613340 .4312896728538 .62779998779 36.8269195556635 .0836105346733 .3051300048832 .0699806213432 .03483963013 32.5146408081132 .9377098083533 .4367294311533 .9463195800834 .46585083008 34.9881515502935 .5071716308636 .0278396606436 .5455284118737 .06391906738 37.590400695838 .1392097473138 .7057495117239 .2921218872139 .8948097229 40.5119590759341 .1411018371641 .7797012329142 .4261093139643 .07830047607 43.7351303100644 .3951988220245 .0576705932645 .7216186523446 .38642883301 47.0514411926347 .7162208557148 .3803482055749 .0434989929249 .70539855957 50.3658218383851 .0245780944851 .681499481252 .3364486694352 .9892616272 53.6398391723654 .2880096435554 .9336814880455 .5766906738356 .21691894531 
56.8542289733957 .4884796142658 .1195411682158 .7472991943459 .37160873413 59.9923706054760 .6094818115261 .2228202819861 .832309722962 .43787002563 63.0394210815463 .6368789672964 .2302017211964 .8193130493265 .4041519165 65.9846420288166 .5606994628967 .132247924867 .6991882324268 .26141357422 68.8188095092869 .3712615966869 .9186325073270 .4608230590870 .99770355225 71.5293579101672 .0550308227572 .5758285522573 .08982849121

625.9345092773620 .6021118164615 .1776123047609 .6527709961604 .0646972656 598.4005737305592 .6544799805586 .8208007812580 .8936157227574 .8671875 568.7374267578562 .4995117188556 .1505737305549 .688293457543 .1102905273 536.4160766602529 .6038208008522 .6735229492515 .6232299805508 .4533996582 501.1615905762493 .7486877441486 .2125854492478 .5544128418470 .7739868164 462.8734130859454 .8550109863446 .7232055664438 .4848937988430 .1473999023 421.7244873047413 .2279052734404 .6817932129396 .104888916387 .5361022949 379.0043945312370 .5681152344362 .270904541354 .191192627346 .390411377 338.9534912109331 .9464111328325 .4548950195319 .5534057617314 .2633056641 309.7018127441305 .3182067871300 .7065124512296 .1129150391291 .7760925293 287.7872924805284 .0710144043280 .6397094727277 .5815124512274 .2269897461 270.0454101562265 .8641052246262 .4088134766259 .3609008789256 .5385131836 253.8856048584251 .3475952148248 .941696167246 .7050933838244 .4978942871 242.2642974854240 .0807952881238 .0540008545236 .2247924805234 .7232055664 233.2182006836231.9803009033230.3356018066 227.5742034912 224.4562988281 220.9609985352217 .1918945312213 .8170928955210 .804397583208 .4620056152 206.5102996826204 .713394165203 .9593048096204 .282699585205 .4418029785 207.886505127208 .7962036133206 .0877990723202 .4326019287199 .1188049316 196.0196990967 193.8639984131 192.1497039795 191.00050354190 .0830993652 188.9356994629186 .6528015137182 .1757965088176 .9916992188172 .6184997559 167.7026062012160 .5370025635152 .8273010254146 .1614990234139 .3603973389 131.6405944824124 .4740982056119 .2042999268114 .9672012329111 .4859008789 106.1050033569 96.16397094727 86.51664733887 81.06629180908 78.5608291626 77.9087829589877 .6926727294976 .3633422851675 .5521011352576 .6282119751 78.2773437579 .2398071289180 .2371978759881 .4308166503982 .8596572876 84.96935272217 87.8531417846791.9705429077196.2200622558699.38036346436 101.290802002101 .7421035767100 .777198791597 .9857482910296 .37557220459 98.85051727295102 .5830993652104 .8144989014106 .7266998291108 .9321975708 111.9396972656116 .1728973389120 .5025024414123 .6118011475125 .948600769 127.5690994263129 .8321990967133 .6300048828140 .4400939941151 .9617004395 161.6145935059163 .1141052246162 .4006958008164 .2747039795169 .6053924561 180.0214996338189 .4237976074193 .204498291192 .349105835187 .9385070801 180.7563018799171 .6954956055162 .3869934082154 .6446075439148 .3345947266 143.883102417139 .7812042236134 .825302124129 .279006958122 .4125976562 115.9720993042111 .2434005737107 .1381988525103 .332496643199 .8680267334 96.7367630004993 .8610305786191 .0888977050888 .1145477294984 .5551071167 80.8820495605577 .4787063598674 .4565887451272 .0758819580168 .99430847168 64.0683212280358 .515350341853 .6076393127449 .1017417907744 .92221832275 40.9820404052737 .159881591834 .0326118469232 .2052001953130 .67086982727 28.5303192138725 .881420135522 .4750194549618 .4936904907213 .74363040924 
9.2436408996586 .3856759071353 .743020057678 .4149279892445 -3.03282594681 $-6.24594211578-9.37153530121-12.6741895676-16.0759391785-19.651309967$ $-22.6060009003-24.0916595459-24.9402103424-25.8954296112-27.1402702332$ -28.9529895782 -31.0909900665 -33.1921081543 -35.3248100281 -37.4577713013 -39.6528282166 -42.0005302429-44.1822891235 -45.9801712036-48.2014007568 $-51.4401702881-55.2024803162-59.3455810547-62.7691116333-64.7002334595$ $-65.7840881348-66.3307876587-66.2901611328-65.6251602173-64.3254470825$ $-62.2361793518-59.6871795654-56.8364601135-53.9510192871-51.4602394104$ $-49.18227005-47.2059402466-45.4998703003-44.1052017212-42.8725509644$ $-41.5538101196-40.3862495422-39.5944404602-38.8426895142-37.833820343$ -36.6263198853 -35.1928100586 -33.632648468 -32.1112289429-29.6705303192 $-25.1768703461-21.7141094208-22.4368190765-24.4654693604-25.3912506104$ -26.1234092712 -27.1912708282 -28.4919204712 -29.855840683 -31.3713798523 -33.1307601929 -34.9272689819 -36.5554008484 -38.0048789978 -39.1813812256 $-40.1075706482-40.7928581238-41.2463188171-41.4851493835-41.5137214661$ $-41.3493881226-40.9866409302-40.430229187-39.6694412231-38.6962203979$ $-37.4992408752-36.0569992065-34.3870582581-32.5039215088-30.2213306427$ -27.3037891388 -24.1532306671 -21.112569809-18.3034801483 -15.8791399002 -14.1739797592 -13.6706800461 -13.7743701935 -14.1665000916-13.8723697662 $-11.8025197983-8.89651298523-6.28769683838-1.856114029887 .773725986481$ 19.3904495239330 .0462398529139 .5242996215845 .8278388977150 .16352081299 54.4244689941455 .9526901245151 .9703903198246 .947120666545 .2773399353 44.4815597534242 .9981498718341 .3231201171939 .5912284851137 .8341217041 36.1158218383834 .4843482971232 .9627113342331 .9324703216631 .79309082031 32.1158103942932 .5175399780333 .0054206848133 .5131683349634 .03953933716 34.5594100952135 .0780601501535 .5939292907736 .1075096130436 .61906051636 37.1394004821837 .681358337438 .2413406372138 .820449829139 .41596984863 40.0258407592840 .6479415893641 .279720306441 .9197692871142 .565990448 43.2174491882343 .8726196289144 .5308113098145 .1909484863345 .85250854492 46.5147018432647 .1771507263247 .839290618948 .5008506774949 .16143035889 49.8208312988350 .4787597656251 .1350708007851 .7895507812552 .44203186035 53.0923385620153 .7403411865254 .3858604431255 .028739929255 .66881942749 56.3059616088956 .9399795532257 .5707588195858 .1981391906758 .8219909668 59.4421615600660 .0585708618260 .6710815429761 .2796211242761 .88407897949 62.4844017028863 .080501556463 .6723289489764 .2598114013764 .84290313721 65.4215011596765 .9955825805766 .5650482177767 .1298217773467 .68979644775 68.2448730468868 .7949523925869 .3399276733469 .8796768188570 .41410064697 70.9433135986371 .4671325683671 .9814834594772 .48858642578 629.3289794922623 .9652099609618 .5579833984613 .0778808594607 .5272216797 601.9010009766596 .1926879883590 .3969726562584 .5073852539578 .5186157227 572.4251708984566 .2235717773559 .9097290039553 .4816894531546 .9368286133 540.2753295898533 .4943847656526 .5955200195519 .5759277344512 .4373779297 505.1770935059497 .7968139648490 .294708252482 .6730041504474 .9318847656 467.0744018555459 .1039123535451 .0252075195442 .8469848633434 .576385498 426.2294006348417 .8165893555409 .3648071289400 .8900146484392 .4338989258 384.0199890137375 .7101135254367 .540802002359 .5898132324351 .9028930664 
344.5703125337 .6459960938331 .216796875325 .325592041320 .013885498315 .3429870605 311.0010986328306 .9478149414302 .9578857422299 .0065917969295 .1770019531 291.3334960938287.6834106445284.1841125488280.5910949707276.6492004395 272.7226867676269 .3345031738266 .1708984375263 .0017089844259 .924987793 256.9866943359254 .1441955566251 .5435028076249 .0030975342246 .5422973633 244.1479034424241 .8175964355239 .675201416237 .8591003418236 .1912994385 234.6517944336233 .2675933838231 .7402954102229 .8446960449227 .1425933838 224.1616973877221 .6654968262219 .6983947754218 .2944946289216 .790802002 214.5041046143212 .9642028809213 .1392059326214 .19140625215 .2769927979 215.1533050537213 .0343933105210 .084197998207 .2209014893204 .4658966064 202.1450042725200 .2805023193199 .0523071289198 .0397033691196 .4483947754 193.8332977295189 .0131072998183 .7555999756180 .3699951172176 .1636962891 169.262802124161 .5937957764154 .3227996826147 .2265930176140 .0733947754 133.037399292126 .2121963501120 .1279983521116 .4811019897111 .212600708 99.4595108032287 .8117904663182 .946853637780 .8112182617278 .48809051514 77.1864776611376 .3024673461975 .990936279376 .4438400268677 .1955871582 77.8107070922978 .4784469604579 .3471221923880 .2852630615281 .35884094238 83.0452270507886 .3268432617289 .7754669189592 .1268463134893 .50890350342 93.731163024993 .2268218994192 .3817672729592 .0822982788193 .00463104248 94.7848434448296 .8657531738399 .18480682373101 .596496582104 .3143997192 107.4097976685110 .388999939112 .7082977295114 .3246002197114 .9036026001 115.7718963623117 .8220977783121 .8127975464129 .032699585136 .7185058594 142.0641021729146 .7828979492151 .2490997314157 .4488983154167 .6763000488 178.1687927246186 .4026031494190 .6855010986189 .4337005615184 .0242004395 175.5032958984167 .2597961426164 .4429016113162 .7386932373158 .6128997803 153.6748962402148 .0211029053141 .2619018555132 .6811981201124 .459602356 119.2857971191115 .3015975952111 .3354034424107 .8721008301104 .6924972534 101.837402343899 .1863098144596 .3006515502992 .5835113525488 .72637176514 85.2506027221781 .940849304278 .714141845775 .144386291570 .98178100586 66.4942932128962 .1053199768157 .9279098510754 .0905303955150 .65427017212 47.6877708435145 .2602996826243 .3199195861841 .6009597778339 .5597114563 36.6722106933632 .3897705078127 .4436607360823 .0250701904319 .0447807312 15.5830898284912 .315690040598 .4409799575814 .606665134431 .276633024216 -1.90898299217 -5.21123600006 -8.50538921356 -11.4080095291 -14.3347997665 -17.6255302429 -21.3811397552 -26.7972106934 -31.2870597839-31.4759197235 -30.9295692444 -32.3636894226 -34.3907203674 -36.696559906 -39.2209510803 $-41.7610206604-44.2600708008-46.2354888916-48.4813995361-52.2707481384$ $-56.4876289368-60.5412483215-64.3666687012-67.7666320801-70.3529663086$ $-71.6366195679-71.8563232422-70.8692626953-68.9307098389-66.1619491577$ $-62.8691596985-59.2684898376-55.8890991211-53.2974700928-51.0655288696$ $-49.1733703613-47.506690979-46.0676498413-44.7414016724-43.0788993835$ $-41.5775108337-40.7834892273-40.1223106384-39.2227096558-38.1685218811$ -36.9377708435 -35.4868392944 -34.0399589539 -31.4694690704 -25.7868499756 -21.0668792725 -21.690120697 -23.9039592743 -25.0348892212 -26.0050392151 -26.7766990662 -27.6342697144 -28.7430095673 -30.1504192352 -31.8477191925 $-33.6540184021-35.3733711243-36.9262504578-38.2367782593-39.2909011841$ 
$-40.103351593-40.6648483276-41.0102310181-41.127620697-41.0465087891$ $-40.7542991638-40.266658783-39.5734786987-38.675151825-37.5672111511$ -36.2366981506 -34.6806602478 -32.8994903564 -30.784160614 -28.1768302917 $-25.3682003021-22.6122398376-19.9886894226-17.4964694977-15.6915102005$ -15.3461103439 -15.510720253 -15.6682901382 -15.0740098953 -12.495639801 -9.26163387299 -7.55905818939 -3.03614997864 9.737277030945 24.37635040283 35.8971481323244 .3371696472246 .6361083984447 .513389587452 .60205078125 55.7856407165551 .5786209106445 .9977798461944 .2677001953143 .44390106201 41.9143295288140 .2936897277838 .6391105651937 .0078315734935 .45018005371 34.0639610290532 .9361305236832 .1843185424831 .8989105224631 .9698009491 32.2620086669932 .7017707824733 .1832008361833 .6950912475634 .20087051392 34.7049598693835 .2094688415535 .7118606567436 .2141799926836 .72520065308 37.2591514587437 .8107681274438 .3814888000538 .9683609008839 .56980895996 40.1836013793940 .8075485229541 .4401283264242 .079521179242 .72465133667 43.3741912841844 .0273017883344 .6830215454145 .340679168745 .99956130981 46.6591415405347 .3188896179247 .9784202575748 .6373710632349 .29541015625 49.9522705078150 .6077194213951 .2615318298351 .9134788513252 .56340026855 53.211071014453 .8563194274954 .4989585876555 .1388015747155 .7756690979 56.4094009399457 .0398216247657 .6667594909758 .2900810241758 .90962982178 59.5252914428760 .1369209289660 .7444610595761 .347789764461 .94683837891 62.5415382385363 .131839752263 .7176589965864 .2989501953164 .87566375732 65.4477233886766 .0150833129966 .5776596069367 .1353607177767 .68811035156 68.2358093261768 .7783584594769 .3156509399469 .8476104736370 .37433624268 70.8950805664171 .4109725952171 .92009735107

632.7407836914627 .4833984375622 .1359863281616 .6892700195611 .1801147461 605.5955810547599 .9298706055594 .1768188477588 .3303833008582 .3848266602 576.3350830078570 .176574707563 .9061889648557 .5211181641551 .0194091797 544.4005737305537 .662902832530 .8073120117523 .8317871094516 .7379760742 509.5242919922502 .1918945312494 .7406005859487 .1722106934479 .4881896973 471.691986084463 .7878112793455 .7813110352447 .6812133789439 .4963989258 431.2414855957422 .9301147461414 .5851135254406 .2268066406397 .8895874023 389.6032104492381 .4159851074373 .370513916365 .5257873535357 .9378051758 350.6653137207343 .7644958496337 .3062133789331 .3518066406325 .9932861328 321.3075866699317 .1682128906313 .6170043945310 .2172851562306 .7582092285 303.1149902344298 .8208007812294 .6690063477291 .2974853516288 .0422973633 284.3731994629280 .6340026855277 .0804138184273 .5777893066270 .032989502 266.5523071289263 .2141113281260 .0210876465257 .1690063477254 .4842071533 251.9541015625249 .5142059326247 .0569000244244 .724105835242 .5231933594 240.6119995117239 .1121063232238 .3845062256238 .8518066406238 .69090271 235.9745941162232 .9347991943231 .7794036865231 .5222015381231 .6531066895 230.7617034912227 .3063049316224 .0350036621223 .495803833224 .3773956299 226.4002075195227 .2306060791224 .4019012451220 .6233062744217 .8292999268 215.2003936768212 .7725067139210 .7973022461209 .6519927979208 .7200012207 207.1336975098204 .7731933594201 .3126983643197 .4815979004194 .2073974609 189.3374938965180 .7530975342171 .5180969238164 .400100708157 .9922027588 151.1589050293144 .0984954834137 .0547027588130 .5252075195125 .4711990356 
119.8408966064111 .5719985962102 .406898498593 .5238189697386 .46183776855 82.9644470214881 .4024581909280 .2103881835979 .6590805053779 .88562011719 80.2217636108480 .102951049880 .0413436889680 .2848663330180 .66568756104 81.2299880981482 .2966995239384 .4291687011786 .7410812377988 .35257720947 89.325477600189 .4037704467889 .2473678588989 .0993499755989 .04824829102 89.566963195890 .5297470092892 .0910263061594 .1430282592896 .24495697021 98.30993652344100 .4446029663102 .3559036255103 .7726974487104 .6859970093 104.8591995239105 .0102996826105 .8656997681107 .1966018677109 .0019989014 113.032699585120 .1541976929127 .8874969482132 .6056060791137 .4808044434 145.9835968018156 .1428985596166 .4541015625174 .2357025146175 .9329986572 173.341003418168 .3339996338163 .6974945068162 .9427947998162 .9801025391 161.5858001709159 .1759033203157 .0003051758152 .7019042969143 .2014007568 133.0993041992126 .5226974487121 .5447006226117 .4794006348114 .1318969727 110.9839019775108 .0989990234105 .2386016846102 .11689758398 .50357055664 94.7846832275491 .3352584838987 .9130630493284 .4628372192480 .94635009766 77.1912765502973 .3983688354569 .639373779366 .0044326782262 .74769973755 59.921310424857 .5847702026455 .5776481628453 .8304290771552 .34651947021 51.1950988769548 .7160301208543 .188751220736 .4958915710430 .21273040771 24.8538894653321 .3485507965118 .5128192901615 .6033296585112 .74472045898 $9.6965227127086 .5473999977113 .165925979614-.306661993265$-3.550978899 $-7.0833067894-11.007809639-15.8105602264-21.9081306458-26.7769203186$ $-28.3210506439-28.7256507874-30.3362808228-32.5857887268-35.017539978$ -37.6778411865 -40.5404701233-43.7153015137 -47.2904815674 -50.6809997559 -53.3214797974 -56.3902511597-61.3579597473 -66.7416534424 -71.2240982056 $-74.7481231689-76.7313613892-77.2175979614-76.0577392578-73.5909881592$ -70.1476287842-66.012588501 -61.4138908386 -57.3471298218 -54.7712516785 $-52.825969696-51.2845306396-49.9133911133-48.4455795288-46.9986190796$ $-45.1625595093-43.45154953-42.56275177-41.9057502747-41.1082496643-40.181098938$ -39.0203018188 -37.6038093567 -35.924079895 -33.363571167-29.1840000153 $-25.6263504028-24.9414196014-25.5856704712-26.3101100922-27.0083904266$ $-27.2452106476-27.5275497437-28.277759552-29.498790741-31.2240200043$ $-33.1102790833-34.8201293945-36.3652305603-37.6777114868-38.7640800476$ $-39.6134109497-40.2312507629-40.626209259-40.8014183044-40.768119812$ $-40.5266990662-40.0844497681-39.4409599304-38.5966796875-37.5518989563$ -36.300491333 -34.8288002014 -33.1303100586 -31.1663093567 -28.8404407501 -26.3705005646 -23.9292392731 -21.5860290527 -19.4529094696-17.8792095184 -17.3247394562 -17.1322193146-16.8681507111 -15.9729795456-13.7108402252 $-10.6915302277-7.93327283859-1.457677960413 .7616500854530 .17420005798$ 40.9263305664147 .2413101196348 .5210800170948 .7574310302752 .32609939575 54.5250282287650 .2155914306644 .6119689941442 .7973213195841 .98526000977 40.5501899719239 .0593414306637 .585239410436 .1653900146534 .83673095703 33.7049789428732 .843471527132 .2464790344231 .9837398529131 .96781921387 32.1739807128932 .5477409362832 .9782600402833 .4492683410633 .91865921021 34.39405822754 34.87421035767 35.3592796325735.84815979004 36.34931182861 36.8723297119137 .4139785766637 .9744606018138 .5514297485439 .14307022095 39.7475013732940 .3624610900940 .9866790771541 .6182785034242 .25634002686 
42.8994293212943 .5468406677244 .1974601745644 .8507003784245 .50569152832 46.1619796752946 .8188781738347 .4760513305748 .1329917907748 .78939819336 49.4449195861850 .0992889404350 .7522087097251 .4034805297952 .05284118652 52.700061798153 .3449211120653 .9872207641654 .6267395019555 .26327896118 55.896629333556 .5266304016157 .1530685424857 .7758216857958 .39468002319 59.0095481872659 .6202697753960 .2267799377460 .8289299011261 .42668914795 62.019950866762 .608680725163 .1928100585963 .7722892761264 .34706878662 64.9170989990265 .4823303222766 .042686462466 .5980987548867 .14849090576 67.693778991768 .2338790893668 .7687072753969 .2981872558669 .82244873047 70.3413162231470 .8507766723671 .35304260254 636.4846191406631 .2034912109625 .8798828125620 .4846801758615 .020324707 609.4818115234603 .8624267578598 .1569824219592 .3587036133586 .4622802734 580.4622192383574 .354309082568 .1345825195561 .8012695312555 .3516235352 548.7858276367542 .1019287109535 .3012695312528 .3822021484521 .3466186523 514.1928710938506 .9234008789499 .5379943848492 .0390014648484 .4287109375 476.7106933594468 .890411377460 .9732055664452 .9690856934444 .8864135742 436.7410888672428 .5452880859420 .3232116699412 .0922851562403 .8873901367 395.7341918945387 .6781921387379 .7546081543372 .0180053711364 .5192871094 357.3023986816350 .4097900391343 .9043884277337 .8546142578332 .3515930176 327.5145874023323 .4964904785320 .438293457317 .8222045898315 .1477050781 311.867401123307 .2070007324302 .4764099121299 .1140136719296 .1021118164 292.5860900879288 .9435119629285 .1972045898281 .3145141602277 .330291748 273.3359069824269 .5967102051266 .1094970703263 .1672058105260 .5379943848 258.2166137695255 .9524993896253 .5697021484251 .1685943604248 .6399993896 246.5843963623245 .0178985596244 .6383056641246 .4698944092247 .699005127 245.096206665242 .2942047119242 .5023956299243 .6311950684244 .7742004395 244.4537963867240 .1273956299235 .5886993408234 .3097991943234 .7868041992 237.6979980469239 .6139984131236 .3067016602231 .903793335229 .2321929932 227.1065979004225 .1416015625223 .4978027344222 .5265045166221 .4174957275 219.5505065918217 .3515930176215 .2117004395212 .570098877209 .0818939209 203.6253967285193 .9577026367183 .7230072021176 .9376983643170 .8948974609 163.9337005615156 .8811950684149 .9093933105143 .1269073486136 .6311035156 130.5756072998126 .265296936120 .3649978638108 .120597839496 .46092987061 91.7132186889689 .5552673339887 .4560470581186 .2706298828186 .03021240234 85.9436569213985 .0543670654384 .1306610107483 .6721420288183 .48351287842 83.7402572631884 .3526916503985 .4121627807686 .5905227661187 .50106048584 88.1371383667 88.16886901855 88.09512329102 88.10195922852 88.14746856689 88.44217681885 89.011436462490.0935974121191.502372741792.92748260498 94.2531967163195 .4295578002996 .3231887817496 .8626937866297 .03386688232 96.9417419433696 .6229934692496 .6215667724696 .2713165283293 .90367889404 94.15191650391101 .5335006714110 .2255020142113 .8375015259117 .2493972778 123.8752975464132 .3013000488142 .8571929932151 .7610015869154 .974105835 155.3489990234154 .8533935547154 .3401031494155 .0419006348156 .1425933838 157.4183959961158 .4454956055160 .5213928223159 .2814941406149 .7431945801 138.4452972412130 .946105957125 .4066009521121 .6498031616118 .7473983765 115.675201416112 .6286010742109 .393699646106 .1137008667102 .6996002197 
99.27520751953 95.9335632324292.59581756592 89.21183013916 85.87819671631 82.5413513183679 .3138732910276 .1715621948273 .2436294555770 .70887756348 68.54965972966 .8242797851665 .2803878784263 .7849807739362 .36698913574 61.6429100036659 .4434700012253 .0904998779345 .2689895629937 .52270126343 30.8822708129927 .3952102661125 .2189102172923 .3916893005421 .59049987793 18.6649608612115 .3829603195211 .708259582527 .8050351142884 .102744102478 -2.5092000e-02 -4.3149061203 -9.12892723083 -14.4550800323 -19.077129364 $-22.3199806213-24.7103500366-27.2081794739-29.7738800049-32.367401123$ $-35.1986618042-38.3766212463-42.0550384521-47.0255813599-51.6176109314$ $-53.4279212952-55.842628479-62.2139892578-69.2053222656-74.76927948$ $-79.1319732666-81.6062316895-82.3494873047-81.0544662476-78.1241836548$ $-74.1404266357-69.3420028687-63.9156303406-59.0481300354-56.0799713135$ $-54.396068573-53.5268211365-52.8199005127-51.4107284546-49.5519104004$ $-47.4226493835-45.5172691345-44.4905395508-43.8427581787-43.2472190857$ $-42.5228004456-41.4191513062-39.9085884094-37.9368591309-35.712600708$ -33.6214103699 -31.6996898651 -29.8682899475 -28.7031497955 -28.7109107971 $-28.9981498718-28.6925697327-28.5178794861-28.9140300751-29.8519001007$ $-31.4386196136-33.2336082458-34.7920303345-36.2071304321-37.4397506714$ $-38.4719810486-39.3063697815-39.9233093262-40.3357009888-40.5315208435$ $-40.5267295837-40.3134002686-39.9040794373-39.2945213318-38.4898986816$ $-37.4894218445-36.2909812927-34.8883209229-33.2605514526-31.4258804321$ $-29.3515300751-27.1849308014-25.0390701294-23.031539917-21.3519592285$ $-20.0272293091-19.2094707489-18.5502490997-17.8406391144-16.6896305084$ $-14.8625802994-11.7955198288-7.49863910675$.9063140153885 18.0311794281 35.1245994567944 .1474304199248 .7766685485850 .355880737350 .71036911011 52.4504394531252 .6680183410647 .8992614746142 .5790481567440 .96157836914 40.2434501647938 .9604988098137 .6744918823236 .4438705444335 .30344009399 34.2506599426333 .3733711242732 .721679687532 .2786788940432 .0668296814 32.0446815490732 .1998405456532 .4939308166532 .8539199829133 .26726150513 33.6889991760334 .1274986267134 .5790596008335 .0425910949735 .51657867432 36.0061607360836 .5173683166537 .0475502014237 .5967292785638 .16260910034 38.7435302734439 .3375701904339 .9427795410240 .5577812194841 .18091964722 41.8111801147542 .447269439743 .0883598327643 .7333908081144 .381690979 45.0323982238845 .6849517822346 .3386917114346 .9931411743247 .64783096313 48.3023490905848 .9563102722249 .6094093322850 .2613105773950 .91173934937 51.560409545952 .2070693969752 .8514595031753 .4933395385754 .13246154785 54.7686004638755 .4015312194856 .0310592651456 .6569595336957 .27907943726 57.8972091674858 .5112609863359 .1210289001559 .7264709472760 .32741928101 60.9238395690961 .5156402587962 .1027793884362 .6851882934663 .2628288269 63.835659027164 .4036331176864 .9667129516665 .5248107910266 .07791900635 66.6259307861367 .16880035467 .7064437866268 .2387771606468 .7657699585 69.287521362369 .8033065795970 .3142776489370 .81852722168 640.2468261719635 .0759277344629 .8181762695624 .4633789062619 .0477294922 613.5587158203607 .9904174805602 .3367919922596 .5921020508590 .7503051758 584.8063964844578 .7554931641572 .5946044922566 .3209228516559 .9326171875 553.4293212891546 .8098754883540 .0751953125533 .2244873047526 .2595214844 
519.1793823242511 .9866027832504 .6813964844497 .2668151855489 .7453918457 482.121307373474 .3999938965466 .5881958008458 .6948852539450 .7301025391 442.7078857422434 .6426086426426 .554901123418 .4648132324410 .4010925293 402.391998291394 .4732971191386 .6834106445379 .0632019043371 .6625061035 364.5119934082357 .6608886719351 .134185791344 .9802856445339 .2307128906 333.8313903809329 .5682067871327 .2513122559325 .8461914062324 .5628051758 322.2513122559317 .5306091309312 .31640625308 .2573852539304 .6657104492 300.9706115723297 .2171936035293 .4902038574289 .4761962891284 .8048095703 280.0848999023275 .8937072754272 .1948852539269 .2810974121266 .9435119629 265.1577148438263 .3908081055261 .1523132324258 .6264038086255 .8894958496 253.4420928955251 .2713012695250 .2879943848251 .3343048096252 .1813964844 251.1497039795250 .128692627250 .8558044434252 .1273040771252 .8475036621 252.0744934082248 .7351989746245 .0769042969243 .5339050293243 .4904937744 245.2415008545246 .3845977783244 .3477935791241 .5066070557239 .7787017822 238.8943939209239 .116897583239 .1878051758237 .9949951172235 .8813018799 232.9627990723229 .866897583227 .1109924316224 .0321960449220 .3650970459 215.3041992188 208.2716064453200.4226989746 192.8466033936185.396697998 177.9640045166170 .5847015381163 .1934967041155 .7985992432148 .6278076172 142.3675994873137 .6777954102131 .7557067871122 .0409011841112 .0115966797 105.4459991455101 .042701721297 .7629318237395 .5227279663194 .16259765625 93.1097030639691 .6820373535290 .2898864746189 .2478485107488 .55290222168 88.29147338867 88.30207061768 88.59426879883 88.96758270264 89.260887146 89.486473083589.4021987915 89.2798614502 89.2408065795989.21639251709 89.31816864014 89.5680007934690.1687088012790.9376296997191.69346618652 92.2898864746192 .6200180053792 .6854934692492 .4441680908292 .01260375977 91.4544067382890 .764228820890 .2008819580189 .0978927612386 .98815917969 87.0055389404391.9360885620198.26434326172 101.8943023682 105.3184967041 110.657699585117 .3906021118125 .2547988892131 .8547973633133 .4826965332 134.2518005371137 .1602935791140 .4515991211143 .0487976074145 .6602935791 148.9967956543152 .5200042725155 .87159729155 .3647003174146 .967300415 136.5411987305129 .9828948975125 .6850967407123 .5793991089121 .9092025757 118.7198028564115 .106300354111 .7698974609108 .5839996338105 .4189987183 102.296501159799.1822967529396.0475311279392.91356658936 89.88481903076 86.9762573242284 .2639236450281 .7382965087979 .4994201660277 .68621826172 76.2335662841875 .1910629272574 .1248016357472 .83690643331171 .15738677979 68.8516235351665 .3982772827160 .1026382446353 .7111511230546 .99885940552 41.1670989990237 .6335601806635 .3092994689933 .319610595731 .14882087708 27.7479305267323 .8621807098419 .6641197204615 .4305801391612 .03001976013 $8.2040843963623 .084784030914-2.32227706909-7.41926193237-12.1233301163$ $-15.9205904007-19.2343292236-22.3352203369-25.2716293335-28.4535503387$ $-31.7880992889-35.1698608398-38.9093818665-43.2900314331-47.6817893982$ $-51.5325889587-56.3664093018-63.807598114-71.663482666-78.4782562256$ $-83.8041229248-86.6291427612-87.4603271484-85.9996185303-82.6626968384$ $-78.2580871582-73.0401306152-67.3619384766-61.9664993286-57.4710617065$ $-55.0010299683-56.040309906-57.2255592346-55.2895202637-52.2948112488$ $-49.7097015381-47.5659713745-46.2146492004-45.4901695251-45.4770698547$ 
$-45.3495407104-44.2213401794-42.5573501587-40.6885108948-38.9657096863$ -37.5034217834 -35.9652099609 -34.2539405823 -32.7288017273 -32.1446113586 -31.960729599 -31.4959793091 -31.1692008972 -31.2315597534 -31.7615604401 -32.8178787231 -34.0860710144 -35.308429718 -36.4805984497 -37.5363311768 -38.46144104 -39.2138786316 -39.788608551-40.1702308655 -40.3578910828 $-40.3495903015-40.1455192566-39.7474784851-39.1566085815-38.3737182617$ -37.402381897-36.2415809631 -34.8975296021 -33.3657493591 -31.6734008789 -29.8008708954 -27.8783397675 -25.9934005737 -24.2626495361 -22.8159503937 -21.5809707642 -20.6507205963 -19.7362804413 -18.762430191 -17.3762607574 -15.1126804352 -11.4687700272 -6.59982490542.566977024078 20.51100921631 37.5134582519544 .9886093139648 .4210510253950 .7689208984451 .75719070435 51.8333892822350 .0114517211944 .9481811523440 .0751495361338 .70426177979 38.1976318359437 .1401710510336 .1256103515635 .1881790161134 .34748077393 33.6071701049832 .9980392456132 .5548706054732 .2590599060132 .12363052368 32.1204185485832 .2448806762732 .472091674832 .7698898315433 .12192153931 33.4982109069833 .9004287719734 .3213310241734 .7616310119635 .21826934814 35.6944198608436 .1923484802236 .7099800109937 .2467117309637 .80059814453 38.3698081970238 .9527206420939 .5473403930740 .1525001525940 .76651000977 41.3884506225642 .0169601440442 .6512718200743 .2902297973643 .93318939209 44.5792007446345 .2276992797945 .8779106140146 .5294113159247 .18154907227 47.8339691162148 .4861793518149 .1378517150949 .7885704040550 .43804931641 51.0859298706151 .7319488525452 .3757781982453 .0171699523953 .6558303833 54.2915191650454 .923969268855 .5529899597256 .1783103942956 .79977035522 57.4171409606958 .0303306579658 .6391296386759 .2434616088959 .8431892395 60.4382514953661 .0285606384361 .6140708923362 .1947402954162 .77051925659 63.3413696289163 .9072608947864 .4681472778365 .024002075265 .57476806641 66.120391845766 .6608123779367 .1959762573267 .7258529663168 .25032043457 68.7695693969769 .2834701538169 .7880020141670 .28542327881 644.3322143555639 .1461181641633 .9188842773628 .6220092773623 .2581176758 617.8225708008612 .3090209961606 .7119750977601 .025390625595 .2437133789 589.3615722656583 .3745727539577 .2791748047571 .0731201172564 .7543945312 558.3229980469551 .7775878906545 .1196289062538 .3483276367531 .4658203125 524.4716796875517 .3682861328510 .1570129395502 .8405151367495 .4222106934 487.9061889648480 .2990112305472 .6064147949464 .8388061523457 .0050964355 449.120513916441 .1976013184433 .2576904297425 .3185119629417 .4078063965 409.5505065918401 .7799072266394 .1311035156386 .6365966797379 .3421020508 372.2702941895365 .4790039062358 .9659118652352 .7579040527346 .9065856934 341.0809936523336 .575012207334 .74609375334 .0819091797333 .7221069336 332.3125915527327 .8942871094322 .5109863281317 .8298034668313 .4090881348 309.2150878906305 .2049865723301 .3846130371297 .1588134766291 .7850036621 286.291595459281 .7604064941277 .9692993164275 .2471923828273 .3203125 272.1889038086271 .1152954102269 .3645019531267 .1391906738264 .7219848633 261.9559936523258 .7821960449256 .515411377255 .5787963867255 .9002075195 256.7296142578257 .8558044434258 .9451904297259 .5043945312258 .9512939453 257.4215087891255 .2301025391252 .891998291251 .5117950439250 .8303070068 250.9828033447251 .2301025391250 .596496582249 .8484954834249 .3354034424 
249.574005127251 .7384033203253 .3193054199251 .9024047852248 .9761962891 245.2548980713241 .1824951172237 .4178924561233 .5722961426229 .5433959961 225.3016967773221 .5158996582216 .6882019043208 .8356018066200 .1251068115 192.2292938232184 .3824005127176 .4515991211168 .6764984131161 .1018981934 154.1634979248147 .8112030029141 .4591064453135 .1083068848128 .2953033447 120.8401031494114 .2475967407109 .7562026978106 .4729003906103 .8630981445 101.760398864799 .7584381103598 .02622222996 .5163497924895 .32151031494 94.5244598388793 .9790115356493 .6347427368293 .4096679687593 .18409729004 93.0039291381892 .6853485107492 .3983230590892 .1630783081191 .96267700195 91.9068984985491 .9084167480592 .0727233886792 .2510910034292 .36609649658 92.2821426391691 .9003372192491 .2345733642690 .2906723022589 .25842285156 88.2535629272587 .2482528686586 .3727035522585 .5902023315485 .23441314697 85.900802612387 .93051910490 .9345779418994 .1207427978597 .74266815186 102.1624984741106 .9138031006111 .4636001587114 .9313964844114 .5866012573 114.8310012817119 .8986968994125 .8823013306129 .8582000732133 .6156005859 138.4653015137142 .7801971436145 .6672058105145 .1410064697138 .3276062012 129.9969940186125 .5626983643122 .9740982056122 .6298980713122 .3955993652 119.365196228115 .6738967896112 .6249008179109 .7446975708106 .8998031616 104.1192016602101 .279502868798 .4645385742295 .6790924072393 .03704071045 90.5385665893688 .3023605346786 .3287506103584 .7133865356483 .53912353516 82.7209167480582 .3012771606481 .8089065551880 .9799575805779 .04975891113 75.010330200270 .1545333862366 .0272216796961 .7549400329656 .85943984985 52.4015502929749 .0789909362846 .494701385544 .2069206237841 .40705871582 37.2244911193832 .233539581326 .9418201446522 .1771202087419 .0590801239 $15.8304004669210 .317339897164 .357748985291-.502871990204-5.03858089447$ $-9.04441738129-12.7046203613-16.1994094849-19.5929908752-23.4498996735$ -27.3780994415 -31.0191192627 -34.6975288391 -38.253238678 -42.5331993103 $-48.8213500977-56.2898597717-64.5013809204-73.1611633301-81.7061767578$ -88.3532485962 -91.5344161987 -91.9142227173 -90.064453125 -86.5587997437 $-82.0189208984-76.7707519531-71.2054519653-65.7468414307-60.004360199$ $-56.4905090332-58.7211303711-61.1861495972-58.5305290222-54.6060791016$ $-51.7807693481-49.4434509277-47.848449707-47.0424804688-47.5029907227$ $-47.9418716431-46.8640708923-45.3069496155-43.852558136-42.450668335$ $-41.1027984619-39.698009491-38.3135108948-37.0019493103-36.1062698364$ -35.5094795227 -35.0058784485 -34.6488685608 -34.3945198059 -34.3872718811 $-34.7451896667-35.380821228-36.1770401001-37.05260849-37.8890304565$ $-38.6580505371-39.2934303284-39.7861289978-40.1114692688-40.2625617981$ $-40.2344284058-40.0210800171-39.623790741-39.0397186279-38.2698402405$ -37.3184890747 -36.185710907 -34.8905296326 -33.4373588562 -31.8700904846 -30.163690567 -28.4460792542 -26.7765903473 -25.2242908478 -23.8966808319 $-22.6906299591-21.6842498779-20.6326198578-19.5316905975-17.8229198456$ -14.8788099289-10.5854196548 -5.30238199234 3.67467188835121 .13793945312 37.9991493225144 .7021598815947 .7686614990251 .1084289550852 .42750930786 50.9805908203147 .4775505065942 .1717605590837 .40974044836 .10005950928 35.9337501525935 .1948394775434 .5127410888733 .8992309570333 .36602020264 32.9351997375532 .5931396484432 .3520011901932 .2055091857932 .15412139893 
32.1842994689932 .2911186218332 .4636802673332 .7038803100632 .99839019775 33.3305282592833 .6988792419434 .0902290344234 .5081787109434 .94704055786 35.4091682434135 .8929100036636 .397460937536 .9211006164637 .46237945557 38.0193290710438 .5905303955139 .1741294860839 .7689590454140 .37345123291 40.9866409301841 .6072311401442 .234371185342 .8669586181643 .50423812866 44.1452789306644 .7894401550345 .4359283447346 .0842285156246 .73366928101 47.3838195800848 .0341491699248 .6842689514249 .333709716849 .98215103149 50.6291694641151 .2744789123551 .9177093505952 .5585594177253 .19672012329 53.8319206237854 .463871002255 .0923309326255 .7170295715356 .33779907227 56.9543914794957 .566680908258 .1744689941458 .7776794433659 .37614822388 59.9698295593360 .5586204528861 .1424903869661 .7213897705162 .29528045654 62.864120483463 .4279098510763 .9865989685164 .5401687622165 .08857727051 65.6317825317466 .1697463989366 .702430725167 .229766845767 .75173187256 68.2684631347768 .7792510986369 .2852630615269 .7845916748 648.4376831055643 .3643798828638 .2083740234632 .9586791992627 .6503295898 622.2716064453616 .8170166016611 .2807006836605 .6572265625599 .940612793 594.1262207031588 .208984375582 .1862792969576 .0551147461569 .8142700195 563.4633178711557 .0015258789550 .4301147461543 .7487792969536 .9595947266 530.0629882812523 .0612182617515 .9559936523508 .7503967285501 .4479980469 494.0534973145486 .5728149414479 .0130004883471 .383392334463 .6942138672 455.9585876465448 .1908874512440 .4093933105432 .6333007812424 .8861083984 417.1933898926409 .5830078125402 .0885009766394 .736907959387 .5681152344 380.6062011719373 .8963928223367 .4577026367361 .3301086426355 .5606079102 350.0870056152345 .8111877441343 .6058959961342 .4725952148341 .5516967773 339.895904541336 .366394043331 .7463989258326 .7828979492321 .7439880371 317.029510498312 .5726928711308 .3312988281303 .6187133789297 .6021118164 291.562713623286 .8414001465283 .1687011719280 .7481994629279 .3340148926 278.7644042969278 .4440917969277 .8190917969276 .7049865723275 .1505126953 272.265411377267 .2770996094262 .6943054199260 .2556152344260 .3409118652 263.1618041992266 .3262939453267 .5787963867267 .3223876953265 .6452026367 263.3923034668260 .9522094727258 .7171936035257 .4006958008256 .4374084473 256.1470031738256 .3902893066256 .4006958008256 .6123962402256 .8806152344 257.5577087402259 .3692016602260 .4743041992259 .3760986328256 .7691040039 253.3768005371249 .5207061768245 .7303009033241 .8233947754237 .678894043 233.9317932129230 .9586029053227 .1654968262221 .1773071289213 .6927947998 205.620803833197 .2675018311189 .0359039307180 .8896942139172 .8114013672 165.1654052734158 .3397064209152 .2980041504146 .7425994873140 .8137969971 133.7489013672126 .8309020996122 .0048980713118 .2626037598114 .8268966675 111.8308029175109 .1461029053106 .8832015991104 .993598938103 .395401001 102.1268005371101 .0824966431100 .19390106299 .4288711547998 .73866271973 98.1380386352597 .5575332641697 .0484466552796 .6200714111396 .25187683105 96.0030136108495 .7665786743295 .5590591430795 .2797317504994 .88751220703 94.2646331787193 .2906494140691 .9858932495190 .309288024988 .70599365234 87.5822601318486 .6807327270585 .7867965698285 .4129028320385 .9532623291 86.6254272460987 .1039199829187 .9968719482489 .8943328857492 .58406066895 95.7248764038198 .63553619385101 .2507019043103 .1881027222103 .3291015625 
104.6258010864109 .1551971436114 .6651992798119 .0971984863123 .2261962891 127.5883026123130 .9649963379132 .3352050781131 .3359069824126 .4568023682 120.956199646118 .1588973999116 .7947998047117 .234703064117 .7485961914 116.292098999114 .0529022217111 .8421020508109 .5783004761107 .2413024902 104.8487014771102 .388603210499 .930381774997 .5229873657295 .2544631958 93.1752319335991 .3703002929789 .8833999633888 .7732391357486 .86799621582 85.3440017700284 .1248016357482 .9056015014681 .6864013671980 .16239929199 78.638397216877 .5400466918973 .2935867309669 .5264129638765 .62803649902 61.9636993408259 .186798095756 .947959899955 .4843292236352 .99071884155 47.6066017150940 .7458305358933 .2625999450726 .9115295410223 .68828010559 20.9383907318116 .0586891174310 .68317031866 .1806898117071 .939934968948 $-1.94078695774-5.64025211334-9.39842510223-13.1999101639-17.3281707764$ $-21.6096401215-25.7727508545-29.9286594391-34.1658782959-39.3952789307$ $-46.389831543-54.454410553-62.7303009033-72.1503829956-84.3292236328$ $-94.1376876831-96.5791473389-95.3112335205-93.01146698-89.5482635498$ $-85.1974563599-80.2486495972-75.0510101318-69.8254470825-64.6895065308$ $-61.283531189-61.6223716736-62.1939811707-59.6184501648-56.0993118286$ $-53.1657600403-50.7764587402-49.3106803894-48.6369400024-48.93724823$ $-49.3415107727-48.7622718811-47.8140487671-46.9319801331-45.9424705505$ $-44.6812515259-43.3635482788-42.2458114624-41.1396102905-40.0028381348$ $-39.109249115-38.7474403381-38.4329605103-37.6849517822-36.9551391602$ $-36.7453804016-36.8885803223-37.2956085205-37.868938446-38.462310791$ $-39.0417098999-39.5309791565-39.9168815613-40.1615715027-40.2592086792$ $-40.1925392151-39.958480835$-39.5494194031 -38.9651184082 -38.202129364 $-37.2652511597-36.1529006958-34.8832397461-33.4532012939-31.9426403046$ $-30.3958492279-28.8580303192-27.34375-25.9089508057-24.6334209442-23.4321994781$ $-22.3336906433-21.1785392761-19.9719600677-18.0448303223-14.7803602219$ $-10.2585201263-4.738111019133 .88004302978519 .5675106048635 .38888168335$ 44.3294982910249 .8335113525452 .5014801025452 .4276084899950 .74592971802 46.9377288818440 .4144210815434 .6791915893633 .345558166533 .50576019287 33.1611404418932 .8806190490732 .6058998107932 .3796310424832 .24314117432 32.1570205688532 .1270103454632 .1401901245132 .1668090820332 .22290039062 32.3134117126532 .4381408691432 .6289901733432 .8753204345733 .16999816895 33.5073699951233 .8756294250534 .2743301391634 .6976699829135 .14570999146 35.615928649936 .1070404052736 .6174888610837 .1457595825237 .69017028809 38.2493515014638 .8216094970739 .4058418273940 .0005111694340 .60469055176 41.217079162641 .8368301391642 .4627799987843 .0941810607943 .73001861572 44.3696708679245 .0122413635345 .6571998596246 .3037986755446 .95158004761 47.5999107360848 .2484092712448 .8964996337949 .5438308715850 .18994903564 50.8345108032251 .4770812988352 .1173706054752 .7549896240253 .38967895508 54.0210914611854 .6489791870155 .2730407714855 .8931007385356 .50888061523 57.120250701957 .7270088195858 .3290596008358 .9262504577659 .51852035522 60.1057701110860 .6879692077661 .265071868961 .8370399475162 .40386962891 62.9655189514263 .5219917297464 .0732498168964 .6192932128965 .16005706787 65.6955413818466 .225723266666 .7505264282267 .269943237367 .78414916992 68.2930221557668 .7926177978569 .28515625 
652.8538818359647 .7741699219642 .655090332637 .4691772461632 .2192993164 626.9011230469621 .5087890625616 .0374755859610 .4812011719604 .8347167969 599.0930175781593 .2517700195587 .3079223633581 .2589111328575 .1032104492 568.8408203125562 .4711303711555 .9954833984549 .4138183594542 .728515625 535.9398803711529 .05078125522 .0631103516514 .9799804688507 .8055114746 500.5440979004493 .2025146484485 .7869873047478 .307800293470 .7738037109 463.1993103027455 .5967102051447 .9848937988440 .3806152344432 .8073120117 425.2875061035417 .8474121094410 .5161132812403 .3190917969396 .2900085449 389.4567871094382 .8504943848376 .5297851562370 .5367126465365 .0288085938 360.0992126465356 .0820007324353 .234588623351 .0456848145348 .9090881348 346.546295166343 .7457885742340 .0736083984335 .129699707329 .7233886719 324.5408935547319 .4041137695314 .4270019531308 .9780883789302 .2366943359 295.8295898438291 .1821899414287 .8453063965285 .924987793285 .0534057617 285.0100097656285 .4440917969286 .0051879883286 .2525939941285 .9750061035 284.1307983398278 .8517150879273 .1073913574269 .5260009766268 .5490112305 272.012298584276 .078704834276 .6586914062275 .3641052246272 .6991882324 269.3612976074266 .0516967773263 .3222961426261 .9284973145261 .2969055176 261.1943054199261 .5303039551261 .8594055176262 .3981018066262 .9070129395 263.4303894043264 .1268005371264 .219909668263 .3619995117261 .4892883301 258.9013061523255 .7572937012252 .387298584248 .8442993164244 .9241943359 241.2841033936238 .2234039307234 .8318023682230 .6593933105225 .0509033203 217.4019012451208 .9456939697200 .8013000488192 .5769958496184 .108001709 176.0641021729169 .0352020264162 .8730010986157 .1701049805151 .3896942139 144.8565979004138 .5182952881133 .9617004395130 .1461029053126 .2705993652 122.6952972412119 .4548034668116 .6302032471114 .3244018555112 .4179992676 110.7485961914109 .2918014526107 .9399032593106 .7123031616105 .5879974365 104.6138000488103 .7198028564102 .960899353102 .2994003296101 .7302017212 101.3123016357100 .8636016846100 .381202697899 .7634811401498 .97422790527 97.9221191406296 .4974212646594 .7376632690492 .520919799890 .50570678711 89.32875823975 88.57039642334 87.77649688721 87.49273681641 88.35926818848 89.0666580200288 .5164489746188 .0217514038188 .745956420990 .07527160645 91.6523437593 .1496200561594 .3898391723695 .6875762939596 .9249420166 99.03447723389102 .1846008301106 .0365982056110 .1100006104113 .9104995728 117.1083984375118 .9033966064118 .5257034302116 .4903030396113 .0106964111 109.8696975708108 .7244033813108 .8467025757110 .0833969116111 .261100769 111.56199646111 .1295013428110 .0355987549108 .5074005127106 .7279968262 104.7670974731102 .7098007202100 .632301330698 .598350524996 .7038269043 94.9980926513793 .5797729492292 .4849777221791 .7733917236391 .13520050049 89.9160003662188 .6968002319387 .4776000976686 .2583999633884 .73439788818 83.5151977539181 .9912033081180 .4691467285276 .6770935058673 .22743225098 70.2243499755967 .9245071411166 .0606384277365 .3687133789163 .2808303833 57.1717605590849 .1956481933640 .311389923132 .5832099914628 .81049919128 25.9597606658921 .2121601104716 .3898105621312 .269800186168 .550065994263 $5.2929048538211 .804044961929-2.11541199684-6.36218881607-10.7338495255$ $-15.2051696777-19.7893104553-24.6336307526-29.9319896698-36.1534004211$ $-43.502948761-51.6279602051-59.555519104-69.1869888306-84.2975234985$ 
-96.7325973511 -98.9048233032 -96.7439117432 -94.6030807495 -91.6658096313 -87.7822723389 -83.4299316406 -78.7222213745 -74.0662765503-69.9671401978 -66.6694869995 -64.5492172241-62.6476783752-60.0908203125 -57.1795310974 $-54.1734809875-51.801700592-50.5996513367-50.25730896-50.3481216431$ $-50.5155792236-50.379119873-50.054561615-49.6848716736-49.058719635$ $-47.8768997192-46.5907402039-45.7325706482-44.8241691589-43.5579605103$ $-42.4292106628-42.0940208435-41.7824211121-40.5770606995-39.3474082947$ -38.7632293701 -38.5001182556 -38.5583114624 -38.8375892639-39.1726989746 $-39.5541687012-39.8811798096-40.1467399597-40.2975692749-40.3282585144$ $-40.2134208679-39.9483299255-39.5214118958-38.930519104-38.1703796387$ -37.2451705933 -36.1485786438 -34.904800415 -33.483341217 -32.0123214722 $-30.5734500885-29.1491603851-27.7035007477-26.2973003387-25.0163497925$ -23.7713794708 -22.6004505157 -21.3316898346 -20.0409698486 -18.029750824 $-14.7613601685-9.99875545502-4.102138996124 .7679238319419 .3362903595$ 34.1817398071345 .017990112351 .8973083496153 .0581512451251 .10010147095 49.3921318054245 .8068885803238 .5498695373532 .1741790771530 .84523010254 31.3257904052731 .2740592956531 .3382701873831 .3337001800531 .37430000305 31.5023002624531 .6777095794731 .8866291046132 .0540695190432 .14881896973 32.1990203857432 .2659301757832 .3616905212432 .5220909118732 .7378692627 33.0058517456133 .3218612670933 .6713905334534 .0559082031234 .46485137939 34.9003295898435 .3569297790535 .8351402282736 .3322906494136 .84772109985 37.3795089721737 .9266815185538 .4875488281239 .0611190795939 .64590835571 40.2410087585440 .8451118469241 .4573593139642 .0765800476142 .70198822021 43.3325691223143 .9676094055244 .6062011718845 .2477493286145 .8914604187 46.5368194580147 .1831398010347 .8299598693848 .4766883850149 .1229095459 49.7680892944350 .4118804931651 .0537986755451 .6935081481952 .33058166504 52.9647407531753 .5955886840854 .2228889465354 .8462791442955 .46561050415 56.0805511474656 .69099044857 .2966804504457 .8975486755458 .49343109131 59.084259033259 .6699409484960 .2504386901960 .8257102966361 .39574050903 61.9605102539162 .5200119018663 .0742301940963 .6231613159264 .16678619385 64.7051086425865 .2380981445365 .7657318115266 .2879867553766 .80486297607 67.3165130615267 .8222579956168 .3232727050868 .81768035889 657.2916259766652 .326171875647 .2833251953642 .1506958008636 .9625854492 631.7081298828626 .382019043620 .979309082615 .4946899414609 .9227905273 604.2592163086598 .4990844727592 .6403198242586 .6796875580 .6165771484 574.4503173828568 .1809082031561 .809387207555 .3366088867548 .7642822266 542.0936279297535 .3272705078528 .4675292969521 .517578125514 .481628418 507.3644104004500 .1722106934492 .9122009277485 .5935058594478 .2258911133 470.8218994141463 .395111084455 .9617919922448 .5397033691441 .1489868164 433.812286377426 .5520935059419 .3962097168412 .3684082031405 .4999084473 398.8211975098392 .3640136719386 .1926879883380 .3476867676375 .00390625 370.2645874023366 .142791748362 .812713623359 .7590942383356 .6365966797 353.6387023926350 .6713867188347 .1469116211342 .4277038574337 .0221862793 331.4117126465325 .5494995117319 .5008850098312 .934387207305 .3597106934 298.6398925781294 .453704834291 .8835144043290 .6419067383290 .438293457 291.0530090332292 .3330993652293 .8507080078295 .5144042969297 .2788085938 
298.155090332297 .3586120605294 .6781005859289 .3731994629285 .4166870117 286.7623901367288 .8179931641287 .4194946289284 .250793457280 .3070983887 275.7854919434270 .7179870605266 .782989502265 .829498291266 .1120910645 266.2467956543266 .5150146484266 .7640075684267 .099609375267 .4255981445 267.5604858398267 .5859069824267 .2387084961266 .2742004395264 .8059997559 262.700012207260 .1047973633257 .2438049316254 .1472015381250 .8630981445 247.6174926758244 .6226043701241 .4969024658237 .7769927979232 .9196929932 226.2821960449218 .7449951172211 .3923034668203 .6940002441195 .254699707 186.9192047119179 .483795166172 .7957000732166 .6282958984160 .6994934082 154.6298065186148 .9647979736144 .5124053955140 .7037963867137 .241897583 133.8795928955130 .2947998047126 .9490966797124 .2695999146122 .0413970947 120.1116027832118 .3460006714116 .5587005615114 .8529968262113 .339302063 112.0074996948110 .8305969238109 .8190994263108 .9412002563108 .1999969482 107.6411972046107 .0544967651106 .3933029175105 .570098877104 .4825973511 103.1266021729101 .421897888299 .4056167602597 .1257934570395 .0495223999 93.5693435668992 .4985504150491 .6171569824291 .159461975191 .44635009766 91.5373306274490 .7392883300889 .8483200073289 .7142105102589 .95664978027 90.337051391690 .6904067993290 .8898391723691 .5304336547992 .68952941895 94.415039062596 .9064636230599 .77903747559103 .0326004028106 .0690994263 108.1860961914108 .7603988647107 .2142028809104 .241996765199 .40072631836 96.0727691650497 .54856109619100 .6383972168103 .3009033203105 .5782012939 106.9616012573107 .6479034424107 .4916000366106 .6798019409105 .4880981445 104.0090026855102 .368598938100 .657798767198 .9723510742297 .39703369141 96.0145263671994 .895919799894 .1035919189593 .6652069091892 .65920257568 91.1352005004990 .2208023071389 .3063964843888 .3919982910287 .78240203857 87.1727981567486 .563201904385 .9711990356482 .5516662597779 .55431365967 76.98354339674 .9185485839873 .1461029052771 .9114379882869 .48348999023 64.2908935546957 .3979187011749 .6824493408242 .5322189331137 .42929840088 32.8233909606926 .7672500610421 .1671504974417 .415870666514 .64988994598 $12.6714696884210 .057310104375 .596982002258 .5153229832649-4.22048091888$ -8.91189002991 -13.6023797989-18.7037391663 -24.4875602722 -31.2555503845 -39.4580688477-48.0641288757 -55.9800300598 -65.6277999878 -79.611541748 -91.3934707642 -95.4571990967 -95.4121398926 -94.1277694702 -92.1436767578 $-89.5353775024-86.1765670776-82.0608215332-77.7844085693-73.9971313477$ $-70.3854370117-67.3460083008-64.4941177368-61.5699310303-58.5168495178$ $-54.7262992859-51.7926712036-51.325958252-51.8483314514-52.0862503052$ $-52.1844711304-52.1150283813-51.9720001221-51.7250518799-51.2045593262$ $-50.2840805054-49.2501106262-48.4172210693-47.4827308655-46.2303504944$ -44.965549469-44.0930099487-43.3157997131-42.2886581421 -41.2801589966 -40.5385704041 -39.9971313477 -39.7808609009 -39.7945594788 -39.9210700989 $-40.1184387207-40.3003387451-40.4459381104-40.5033302307-40.4622688293$ $-40.2947502136-39.9941596985-39.5446090698-38.9432411194-38.1806182861$ -37.2610397339 -36.1795692444 -34.9561500549 -33.5869598389 -32.1667289734 -30.7583808899-29.3388996124 -27.865819931 -26.4086799622 -25.0620307922 -23.7529201508 -22.4900493622 -21.1346797943 -19.6944103241 -17.6067199707 $-14.4575500488-9.39211845398-1.952746033678 .80323982238825 .48883056641$ 
41.3962516784749 .4748306274452 .871089935352 .233261108448 .94356155396 45.9108390808141 .7462882995635 .2980690002429 .9500598907528 .9678401947 29.6249599456829 .8005790710429 .9905490875230 .1250801086430 .32906913757 30.7061004638731 .168729782131 .6720294952432 .0489311218332 .12728118896 32.0959281921432 .1296997070332 .2097511291532 .3579483032232 .56254959106 32.8214111328133 .1270103454633 .4680595397933 .8423690795934 .24192047119 34.6662101745635 .1115989685135 .5775299072336 .0624198913636 .56531906128 37.0849990844737 .6203498840338 .1700897216838 .7331314086939 .3081817627 39.8942604064940 .4901313781741 .0949096679741 .7074203491242 .32685852051 42.9521598815943 .5826110839844 .2172393798844 .8554000854545 .4962310791 46.1391792297446 .7834892272947 .4286689758348 .0740318298348 .71915054321 49.363418579150 .0064506530850 .6477203369151 .2868499755951 .92338180542 52.5569915771553 .1872711181653 .8139610290554 .4366989135755 .05525970459 55.6693496704156 .2788200378456 .8834381103557 .4831008911158 .07764053345 58.6669998168959 .2510795593359 .8298492431660 .4032707214460 .97132873535 61.5340194702162 .0913314819362 .6432685852163 .1898384094263 .73104095459 64.266876220764 .7973403930765 .3224182128965 .8421096801866 .35639953613 66.8654937744167 .3692703247167 .8638916015668 .3515625 662.0247192383657 .0618286133652 .0618286133646 .9982910156641 .8745727539 636.6870117188631 .4301757812626 .0999145508620 .6906738281615 .1978149414 609.6165771484603 .9431762695598 .174621582592 .3087158203586 .3444213867 580.2811889648574 .1193847656567 .8602294922561 .5040893555555 .053527832 548.5095825195541 .8753051758535 .1527709961528 .3455810547521 .4581298828 514.4946899414507 .4621887207500 .3670043945493 .2188110352486 .0263061523 478.8027038574471 .5595092773464 .3139038086457 .0806884766449 .8807983398 442.7327880859435 .6604919434428 .6859130859421 .8371887207415 .1379089355 408.6300048828402 .3351135254396 .329498291390 .6246948242385 .3573913574 380.6200866699376 .2821044922372 .4009094238368 .6516113281364 .7380981445 360.970703125357 .4956970215353 .7903137207349 .2827148438343 .9912109375 337.9332885742331 .2568054199324 .1632080078316 .6900939941308 .5349121094 301.4715881348297 .5212097168295 .587097168294 .9991149902295 .6217041016 296.9825134277298 .9592895508301 .2396850586304 .0111999512307 .5436096191 311.0278930664314 .9400939941316 .1181945801310 .2343139648303 .712097168 302.5448913574301 .8367919922298 .150604248293 .3399047852288 .3680114746 282.9721984863276 .4945068359271 .4660949707270 .7500915527271 .588104248 271.6064147949271 .6010131836271 .4303894043271 .1770935059270 .9443054199 270.5238037109270 .004699707269 .2437133789268 .232208252266 .9191894531 265.1937866211263 .1304016113260 .8135986328258 .2972106934255 .6822967529 252.9505004883250 .0503997803246 .8780975342243 .1873016357238 .6963043213 233.1107940674226 .7861022949220 .4904937744213 .5791015625205 .5384979248 197.275894165189 .5858001709182 .3242950439175 .399597168169 .1179046631 163.4747924805158 .5057983398154 .2324981689150 .4781036377147 .5095977783 144.5751953125140 .8932952881137 .3101959229134 .4842987061132 .0375976562 129.8807067871127 .8444976807125 .6748962402123 .6166000366121 .7957992554 120.1894989014118 .7304992676117 .4694976807116 .3268966675115 .3728027344 114.6523971558113 .9887008667113 .334602356112 .4247970581111 .1141967773 
109.4822006226107 .5649032593105 .5143966675103 .4027023315101 .3899002075 99.5693817138798 .0514297485496 .9029617309696 .0656127929795 .53753662109 94.9476165771594 .1545028686593 .2722167968892 .5491867065491 .9197769165 91.364677429290 .8754730224690 .3573684692490 .2666931152390 .7237701416 91.8096923828193 .5887527465895 .7344436645598 .13928222656100 .1143035889 101.1283035278100 .75640106298 .547439575295 .0199966430788 .91232299805 84.9237136840888 .239952087493 .6382827758897 .38349151611100 .4887008667 102.7005004883104 .075302124104 .6381988525104 .4625015259103 .8426971436 102.8102035522101 .5668029785100 .183197021598 .8043136596797 .50174713135 96.3800506591895 .4945907592894 .9103088378994 .6449737548894 .71865844727 93.5736007690492 .6592025756890 .8303985595790 .2208023071389 .61119842529 88.6968002319387 .4776000976686 .563201904385 .6488037109484 .49743652344 82.1457214355580 .1750488281278 .2326278686576 .1826400756873 .43334960938 69.5743408203164 .8150482177759 .5036392211953 .6510200500547 .4287109375 40.7996215820333 .1497192382826 .4603195190422 .3966503143319 .96072006226 18.8145999908417 .0776004791312 .453969955446 .8737068176272 .118834018707 -2.61172890663 -7.25836706161 -12.335269928 -18.2702007294 -25.1975307465 -33.83852005 -42.8945503235 -51.021030426 -59.7358207703 -70.8932266235 $-81.3436126709-88.3218765259-92.4258575439-93.404586792-92.4314727783$ $-90.8695526123-88.4029006958-84.7157287598-80.6227035522-76.8565368652$ $-73.0962371826-69.7090835571-66.4970703125-63.4353981018-60.3531303406$ -56.117729187 -52.8251419067 -52.8404083252 -53.7867393494 -53.8941383362 $-53.8885383606-53.7925682068-53.6125183105-53.3070487976-52.8196105957$ $-52.1624717712-51.3631591797-50.5130386353-49.528968811-48.3614883423$ $-47.1127090454-45.8197288513-44.5730705261-43.6687583923-42.852809906$ $-41.995059967-41.3160400391-40.9268913269-40.7364311218-40.6823997498$ $-40.7212982178-40.7635307312-40.7966384888-40.7589607239-40.6458587646$ $-40.4225387573-40.0838890076-39.6091308594-38.9950294495-38.2275886536$ $-37.3129997253-36.24243927-35.0444297791-33.7206306458-32.3258285522$ $-30.8797607422-29.3902397156-27.81483078-26.2492408752-24.8090801239$ $-23.3964595795-22.0528507233-20.5930690765-19.036239624-16.8009300232$ -13.7774600983 -8.57840442657-.022213999182 12.2517299652130 .95371055603 47.1654701232951 .5186500549350 .3245201110847 .6381797790543 .73305892944 40.1786003112836 .4384307861331 .7971305847228 .1379909515427 .6664390564 28.3674392700228 .5705108642628 .8246192932129 .0425701141429 .36418914795 29.9312896728530 .5920104980531 .3120498657231 .8539695739731 .93173027039 31.8542404174831 .8989791870131 .9853591918932 .1415901184132 .35427093506 32.6159095764232 .924251556433 .2624816894533 .6330184936534 .02516937256 34.4412307739334 .876258850135 .3314018249535 .8046112060536 .29587936401 36.8039016723637 .3280296325737 .8669815063538 .4198989868238 .98546981812 39.5628204345740 .150669097940 .748191833541 .3541603088441 .96780014038 42.5879898071343 .2139892578143 .8447608947844 .4796485900945 .11769866943 45.7583503723146 .4007301330647 .0443382263247 .6884002685548 .33245849609 48.975860595749 .6181793212950 .2588005065950 .8973808288651 .53337097168 52.1664505004952 .7961616516153 .4222412109454 .0442695617754 .66205978394 55.2752799987855 .8837585449256 .4872589111357 .0856704711957 .67884063721 
58.2667007446358 .8491401672459 .4261398315459 .9976692199760 .56372833252 61.1242904663161 .6793785095262 .2290191650462 .7731895446863 .3119392395 63.8452491760364 .3731536865264 .89565277165 .4127502441465 .92443847656 66.4309234619166 .9315490722767 .4275131225667 .91693878174 666.7805786133661 .9326171875657 .0128173828652 .0084228516646 .9520263672 641.8341064453636 .6499023438631 .395324707626 .0653076172620 .6552124023 615.1610717773609 .5786743164603 .9058837891598 .1400756836592 .2805786133 586.3267822266580 .2794189453574 .1394042969567 .9077148438561 .5866088867 555.1776123047548 .6834716797542 .1068115234535 .4509887695528 .7203979492 521.919921875515 .0554199219508 .134185791501 .1646118164494 .1560974121 487.1200866699480 .0690002441473 .0173034668465 .9805908203458 .9764099121 452.0238037109445 .1429138184438 .3554992676431 .6857910156425 .1583862305 418.8059082031412 .6517944336406 .7532043457401 .1440124512395 .8949890137 391.0975952148386 .5120849609382 .0292053223377 .5848083496373 .1424865723 368.8270874023364 .6997070312360 .6217041016356 .4260864258351 .3269958496 344.362701416336 .6271972656329 .1929931641321 .6029052734313 .312286377 306.0085144043301 .2065124512298 .7796020508299 .0534057617300 .7939147949 302.7723999023305 .200592041307 .9816894531311 .3174133301315 .286895752 319.5404968262323 .6742858887325 .2359008789321 .8268127441316 .7998962402 314.436706543312 .0071105957307 .701385498302 .6429138184297 .1044921875 291.2680969238285 .1953125280 .3995056152278 .6643981934278 .3337097168 277.6940917969276 .9801025391276 .1105957031275 .1408996582274 .1155090332 273.0161132812271 .8729858398270 .7062072754269 .5534057617268 .3396911621 266.9417114258265 .366394043263 .532409668261 .520111084259 .3411865234 256.9202880859254 .2485046387251 .200302124247 .6712036133243 .6083984375 238.7447967529233 .3193969727227 .5885925293221 .2057952881213 .9933929443 206.3639068604198 .8726959229191 .3430023193183 .6524963379176 .8488006592 171.7380981445167 .5187988281163 .4783935547159 .7671051025156 .6289978027 153.612197876150 .2548065186147 .0363006592144 .5014953613142 .1685943604 139.7030944824137 .2557983398134 .883895874132 .6553039551130 .6690063477 128.8643951416127 .1809997559125 .6532974243124 .2270965576123 .0186004639 122.1083984375121 .425201416121 .0848999023120 .3976974487118 .7274017334 116.6678009033114 .6277999878112 .6222991943110 .6932983398108 .7117004395 106.5941009521104 .6342010498103 .195098877102 .0376968384101 .0832977295 100.174598693899 .1682128906298 .0970230102596 .9181213378995 .64576721191 94.3943328857493 .1837234497192 .0563125610491 .1917266845790 .63649749756 90.7829666137792 .1803131103593 .9915618896595 .6360321044996 .72030639648 96.7933120727595 .7503585815493 .3139801025489 .9503784179785 .41213226318 82.8401336669985 .3265762329189 .7422409057693 .4976730346796 .79295349121 99.31453704834101 .1337966919102 .1087036133102 .3945999146102 .1313018799 101.4362030029100 .474197387799 .3474807739398 .1979827880997 .10148620605 96.1669235229595 .432060241794 .9611511230594 .7512893676894 .81690979004 95.1103363037193 .8784027099692 .6592025756891 .1352005004990 .52559661865 89.6111984252989 .0016021728588 .3919982910287 .7824020385786 .86799621582 85.4031295776483 .5073776245181 .5481185913179 .3924865722777 .00523376465 74.096961975171 .0794372558668 .1579589843863 .8490982055757 .18783950806 
49.2663688659741 .2406005859434 .0189018249528 .0225601196323 .88129043579 22.29409027120 .7038593292216 .9342002868712 .313850402838 .050679206848 $3.75387096405-.644545018673-5.51826381683-11.2714004517-17.8984794617$ $-25.6385002136-33.935798645-42.292098999-50.358631134-58.1532096863$ $-67.2233734131-79.3477401733-89.8906402588$-93.5801467896 -93.586769104 -92.2788696289 -89.7594604492 -86.3628616333-82.4639129639-78.6973724365 $-74.9164276123-71.4500732422-68.2522964478-65.3770294189-62.7688217163$ $-60.1331100464-58.0224685669-56.9222183228-56.3414115906-55.8671798706$ $-55.5307693481-55.2818603516-55.0477790833-54.7142410278-54.2854385376$ $-53.7145309448-53.0179100037-52.2046508789-51.2891082764-50.2901916504$ $-49.271648407-48.3794403076-47.2953300476-45.6299209595-44.029838562$ $-43.0294494629-42.3411407471-41.8679008484-41.5635795593-41.3841896057$ $-41.2946395874-41.2268981934-41.1582603455-41.0394706726-40.8582305908$ $-40.5840911865-40.2077789307-39.7089309692-39.0811309814-38.3097991943$ -37.3961982727 -36.3318786621 -35.1361999512 -33.8117408752 -32.376411438 -30.8345603943 -29.214220047 -27.5210094452 -25.8451404572 -24.2876701355 $-22.770280838-21.3092308044-19.7652702332-18.1372299194-15.8988304138$ -12.7167396545 -7.74513292313-.491091012955 10.4520702362127 .82737922668 41.8964500427243 .7500915527340 .0420188903835 .6616401672431 .90600013733 30.8393192291330 .2914009094228 .2298793792726 .4405803680426 .5154209137 27.1169204711927 .4514598846427 .8204708099428 .1863002777128 .6429901123 29.2611293792729 .9478092193630 .6445007324231 .180730819731 .38101959229 31.4421997070331 .5452594757131 .6763591766431 .8650608062732 .09878921509 32.379329681432 .6992111206133 .0458297729533 .4176483154333 .8084602356 34.2187194824234 .6465415954635 .0922584533735 .5555915832536 .03615951538 36.5336608886737 .0472488403337 .5761909484938 .1194992065438 .67613983154 39.2451515197839 .8254089355540 .4159889221241 .015769958541 .6238899231 42.2392311096242 .8610191345243 .4881706237844 .119979858444 .75545120239 45.3939399719246 .0345382690446 .6766891479547 .3195686340347 .96266937256 48.6052703857449 .2469215393149 .8869590759350 .5250091552751 .16048049927 51.7930488586452 .4221992492753 .0476493835453 .6689910888754 .28598022461 54.898300170955 .5057601928756 .1081085205156 .7052497863857 .29700088501 57.8833198547458 .4640808105559 .0392799377459 .6088790893660 .17288970947 60.7312889099161 .2841186523461 .8313903808662 .3731384277362 .90938949585 63.4401588439963 .9654808044464 .4853591918964 .9998168945365 .50888061523 66.0127563476666 .5113830566467 .0009384155367 .4836807251 671.8140869141666 .9771728516662 .1060180664657 .1751708984652 .1884765625 647.1430053711642 .0341796875636 .8583984375631 .6107788086626 .2872924805 620.883972168615 .3972167969609 .8245239258604 .1638183594598 .4144287109 592.5759887695586 .6489257812580 .6345214844574 .5338745117568 .3491821289 562.0822143555555 .7357177734549 .3123779297542 .8156738281536 .2498779297 529.6196289062522 .9315185547516 .1915283203509 .4085083008502 .5907897949 495.750213623488 .8970031738482 .0462036133475 .2105102539468 .4078979492 461.6535949707454 .9688110352448 .3695068359441 .8822021484435 .5232849121 429.3234863281423 .2886962891417 .471496582411 .8965148926406 .5824890137 401.6315917969396 .7491149902391 .7264099121386 .6976013184381 .8280029297 
377.0924987793372 .3587036133367 .7477111816363 .591003418358 .4619140625 350.6173095703341 .9863891602334 .3656921387326 .8163146973318 .6141967773 311.2330932617305 .6234130859302 .504699707303 .2294006348305 .7616882324 308.0911865234310 .8471984863314 .0866088867317 .7561950684321 .729309082 325.5311889648328 .2766113281329 .4111938477328 .6659851074326 .3980102539 323.9700927734320 .7874145508316 .8687133789312 .0504150391306 .0971069336 300.1639099121295 .0147094727291 .0317077637288 .2020874023286 .1784057617 284.3642883301 282.6726989746280.9193115234 279.0707092285 277.2159118652 275.3204040527273 .5288085938271 .9379882812270 .6083068848269 .5007019043 268.4117126465267 .2598876953265 .8544006348264 .2106933594262 .3176879883 260.1206054688257 .6268005371254 .7548980713251 .4181976318247 .6524963379 243.3903045654238 .5973968506233 .3014984131227 .4360961914221 .1620941162 214.4510040283207 .4934997559200 .2012939453192 .2115020752185 .0101013184 180.1912994385176 .3347015381172 .2864074707168 .512802124165 .1011047363 161.9243011475158 .9304046631156 .2124023438154 .0921020508151 .999206543 149.3836975098146 .6710968018144 .2176971436141 .9656982422139 .9075927734 138.0281066895136 .1591949463134 .3672027588132 .6383972168131 .1029052734 129.8905029297129 .0760040283128 .9815979004128 .5879058838126 .7264022827 124.4026031494122 .3506011963120 .3703994751118 .5206985474116 .568397522 114.2145004272111 .9406967163110 .2562026978108 .860496521107 .6458969116 106.5360031128105 .4156036377104 .1334991455102 .5591964722100 .7854003906 99.011573791597 .2827529907295 .6575927734494 .2135314941492 .75467681885 92.0317230224693 .0408325195394 .4730072021595 .3570632934695 .64044952393 94.9769210815493 .4825515747191 .044776916588 .4089584350685 .99907684326 84.8951034545985 .9441528320388 .3502502441491 .3534469604594 .41398620605 96.9297027587998 .85885620117100 .0279998779100 .5307006836100 .4932022095 99.9942016601699 .2343215942498 .2744369506897 .2944335937596 .33455657959 95.5318374633894 .8852386474694 .470848083594 .2463836669994 .22863006592 94.3421936035294 .5816268920993 .8784027099692 .9639968872192 .04959869385 90.8303985595790 .2208023071389 .3063964843888 .3919982910287 .78240203857 86.9333267211985 .1277770996183 .3155364990281 .3944702148479 .49600982666 77.4549865722775 .5143966674874 .2632064819371 .4459304809664 .93300628662 56.9825782775949 .7267608642642 .5225791931234 .5867004394528 .05155944824 25.0394706726123 .0223407745420 .0428009033216 .7443103790313 .3646402359 $9.7624206542975 .9231982231141 .461742997169-3.92716193199-10.0484600067$ $-16.5993003845-23.7448596954-32.0676307678-40.1654281616-45.9008789062$ $-53.9326095581-70.5534591675-86.3240737915-92.2056808472-93.5394897461$ $-92.7026672363-90.0791473389-86.8760299683-83.1029586792-79.4381637573$ $-75.783493042-72.527130127-69.6542129517-67.1204528809-65.1842269897$ $-64.292427063-63.4084014893-61.1231117249-58.8692398071-57.7279090881$ $-57.0422401428-56.5947113037-56.2896995544-55.9209098816$-55.5084190369 $-54.9685707092-54.3228302002-53.5428695679-52.6982803345-51.8668518066$ $-51.069229126-50.6429595947-49.787071228-47.435218811-45.0394210815$ $-43.8803596497-43.1924705505-42.6512298584-42.2910614014-42.0264511108$ $-41.8408088684-41.6800689697-41.5266799927-41.3331985474-41.0915107727$ $-40.7679405212-40.3562393188-39.8324508667$-39.1912689209-38.4154281616 
-37.5030899048 -36.4435005188 -35.2403907776 -33.8928794861 -32.3955802917 $-30.724149704-28.9502792358-27.0967597961-25.2694206238-23.5674705505$ $-21.9035701752-20.3531208038-18.7152900696-17.041809082-14.7634801865$ $-11.4218797684-6.85874223709-1.310464978226 .68133306503320 .43988990784$ 31.6829605102532 .1020812988328 .1790008544923 .934429168720 .83470916748 22.3198509216324 .8488292694125 .0306396484424 .8952102661125 .38154983521 25.9350299835226 .4337997436526 .9397296905527 .4565296173128 .01498031616 28.6271400451729 .2466201782229 .833839416530 .3202590942430 .6612701416 30.899759292631 .0998497009331 .2938995361331 .5334491729731 .80843925476 32.1202011108432 .4608688354532 .8199501037633 .1984481811533 .59009170532 33.9978103637734 .41992187534 .8582496643135 .3128089904835 .7840385437 36.27190017736 .775951385537 .2956008911137 .83007812538 .37841033936 38.9397392272939 .5129394531240 .0971488952640 .6912002563541 .29426956177 41.9051818847742 .5231513977143 .1470108032243 .7760810852144 .40921020508 45.0457992553745 .6848182678246 .3257102966346 .9675407409747 .60980987549 48.2517013549848 .8927688598649 .5322799682650 .1698417663650 .8048210144 51.4368782043552 .0654602050852 .6902999877953 .3109092712453 .92707824707 54.5384597778355 .1448707580655 .7460212707556 .3418388366756 .93212890625 57.5168495178258 .0958786010758 .6692314147959 .2368392944359 .79874038696 60.3549385070860 .9054603576761 .450328826961 .9896011352562 .52331924438 63.0514907836963 .5741806030364 .0914001464864 .6032028198265 .10958862305 65.6108016967866 .1062088012766 .5970077514667 .08139038086

676.8713989258672 .1489257812667 .3610229492662 .4943847656657 .5800170898 652.6093139648647 .5786132812642 .484375637 .3223876953632 .088684082 626.7800292969621 .3922729492615 .9240722656610 .3729858398604 .7385864258 599.0205078125593 .2194213867587 .3363037109581 .3726196289575 .3306274414 569.2119140625563 .0195922852556 .7562255859550 .4252929688544 .0311279297 537.5781860352531 .0728149414524 .5209960938517 .9307861328511 .3107910156 504.6708068848498 .021697998491 .3756103516484 .7459106445478 .1469116211 471.5939025879465 .1030883789458 .69140625452 .3770141602446 .1798095703 440.1106872559434 .1777038574428 .4041137695422 .8120117188417 .384185791 412.1564941406406 .9179992676401 .5239868164396 .0812988281390 .6553955078 385.3843994141380 .4259033203375 .5278930664370 .5809020996364 .6784057617 356.6742858887347 .9057006836339 .491607666331 .3320922852323 .2721862793 316.0663146973310 .6802062988307 .6065979004307 .7905883789309 .8819885254 312.2760925293315 .1882019043318 .7897033691322 .7301025391326 .7901000977 330.332611084332 .5245056152333 .8432006836334 .0952148438333 .2626037598 331.4957885742328 .8281860352325 .9942016602321 .8344116211314 .937286377 308.1624145508304 .0975952148301 .1091003418297 .9753112793294 .8402099609 291.8171081543288 .9678955078286 .1853942871283 .3948059082280 .6296081543 277.8955078125275 .2416992188273 .0412902832271 .5942993164270 .6571044922 269.9498901367269 .2312011719268 .1442871094266 .745513916265 .0026855469 262.9242858887260 .5094909668257 .7431030273254 .5778045654251 .0930023193 247.2828063965243 .0375976562238 .3173065186233 .1681060791227 .6287994385 221.7770996094215 .700302124209 .1703948975202 .0041046143195 .2332000732 189.8377990723185 .216003418180 .8672943115176 .8939971924173 .3961029053 
170.2653961182167 .31590271164 .7613983154162 .8014984131160 .8701019287 158.5554962158156 .0655975342153 .5731964111151 .2760925293149 .354598999 147.5525970459145 .5648956299143 .5054931641141 .4635925293139 .5115966797 137.7245025635136 .4674072266136 .2218017578135 .8652954102134 .3229064941 132.2879943848130 .2611999512128 .2350006104126 .2587966919124 .1701965332 121.8735961914119 .6416015625117 .8319015503116 .2916030884114 .9498977661 113.7698974609112 .7433013916111 .4406967163109 .4169998169107 .0970001221 104.8924026489102 .7904968262100 .860198974699 .1047363281297 .52897644043 96.5702514648496 .8060913085997 .3693771362397 .5089874267697 .12814331055 95.9597702026494 .2163619995191 .8534164428789 .6601867675887 .95052337646 87.0209732055787 .6559219360489 .1494903564591 .3393096923893 .87566375732 95.995948791597 .6887664794998 .726837158299 .2137374877999 .17552185059 98.7345962524498 .0231170654397 .1386566162196 .2227020263795 .33492279053 94.5911178588993 .9892425537193 .5857162475693 .3234634399493 .19381713867 93.0990676879992 .9328079223692 .8751602172993 .0737686157293 .26289367676 93.038360595791.1352005004990.8303985595790.41737365723 88.76363372803 86.9278030395585 .2556228637783 .6236267089881 .9915771484480 .46351623535 78.9710235595777 .5858306884876 .3943634033273 .9272994995168 .8662109375 62.7127914428757 .1236991882350 .7727890014642 .4309616088934 .5486907959 29.4930000305226 .0065307617223 .0459709167520 .4492206573517 .80764961243 $15.0638799667412 .291040420538 .7373208999633 .611726045609-2.29762506485$ -8.39375495911 -15.194729805 -23.0776100159 -31.2887592316 -38.9165802002 $-48.8492202759-64.4270324707-79.3733215332-87.1586074829-90.5102462769$ $-90.8435897827-89.0244979858-86.1110916138-82.5181808472-79.1022872925$ $-75.7583465576-72.8796005249-70.4368972778-68.313117981-66.7788925171$ $-65.9961166382-64.9799194336-62.9414100647-60.7116584778-59.2762985229$ $-58.3777809143-57.7755393982-57.3547782898-56.9474487305-56.528968811$ $-56.0195388794-55.4175682068-54.665019989-53.8515396118-53.0189399719$ $-52.2083587646-51.5469398499-50.4483909607-48.3679389954-46.2078590393$ $-44.8346710205-43.9348602295-43.3255615234-42.9080085754-42.5800895691$ $-42.3231697083-42.0928611755-41.8704681396-41.6180000305-41.3230895996$ $-40.958240509-40.5132789612-39.9674110413-39.3120613098-38.5310287476$ $-37.6169509888-36.5594596863-35.3451881409-33.9669494629-32.3981208801$ $-30.6105594635-28.6747608185-26.6149501801-24.5866203308-22.6877593994$ -20.8642292023 -19.2366600037-17.5779895782 -15.7935304642 -13.5198602676 $-10.476770401-6.6810002327-1.768695950514 .29527282714812 .68669986725$ 19.9749107360822 .2120304107721 .8129501342819 .5044498443617 .78446006775 19.2845191955621 .6968307495122 .8237495422423 .4573402404824 .23262023926 24.8910102844225 .4883098602326 .1104202270526 .7213001251227 .32333946228 27.9387207031228 .5219898223929 .0672302246129 .5619792938229 .96101951599 30.2945899963430 .563550949130 .8170108795231 .1331195831331 .47834014893 31.8351001739532 .2038497924832 .5817108154332 .9695510864333 .36616897583 33.7735481262234 .1928787231434 .6255683898935 .073379516635 .53657913208 36.0162315368736 .5117416381837 .0232009887737 .5496902465838 .09059906006 38.6449813842839 .2118911743239 .7903709411640 .3793792724640 .97797012329 41.5850105285642 .199638366742 .8207015991243 .4473915100144 .07859039307 
44.7135696411145 .3513107299845 .9911384582546 .6321411132847 .2737197876 47.9150581359948 .5556411743249 .1947097778349 .8318405151450 .46636962891 51.097938537651 .7259712219252 .3501586914152 .9700317382853 .58535003662 54.1957588195854 .801059722955 .4009895324755 .9954299926856 .58420181274 57.167270660457 .7445182800358 .3159484863358 .8815193176359 .4412689209 59.9951896667560 .5433502197361 .0857696533261 .6225090026962 .15362930298 62.6791610717863 .1991691589463 .7136917114364 .2227783203164 .72646331787 65.2249832153365 .7182922363366 .202713012766 .68044281006 682.1859741211677 .483215332672 .7490234375667 .9595947266663 .1193237305 658.2258911133653 .2755737305648 .265625643 .1917724609638 .0510253906 632.8397827148627 .5549926758622 .1948242188616 .7573242188611 .2421264648 605.6486816406599 .9780883789594 .2313232422588 .4097900391582 .5156860352 576.5509033203570 .5181884766564 .4205932617558 .2614135742552 .0446777344 545.7750244141539 .4583129883533 .100402832526 .708984375520 .2916259766 513.8579711914507 .4172058105500 .9811096191494 .5603942871488 .1687927246 481.8179931641475 .5234069824469 .2966918945463 .1542053223457 .1104125977 451.1640930176445 .3139953613439 .5614013672433 .9211120605428 .3387145996 422.8142089844417 .2399902344411 .5701904297405 .8226928711399 .9162902832 394.1789855957389 .0056152344383 .7656860352377 .9061889648371 .1531066895 363.1424865723354 .3526000977345 .2343139648336 .3016967773328 .1012878418 321.2661132812316 .4808044434313 .8721008301313 .3775939941314 .4060058594 316.359588623319 .2141113281323 .0812988281327 .3830871582331 .4216918945 334.7921142578336 .6690063477337 .7843017578338 .4446105957338 .2730102539 337.1747131348 335.3035888672 333.7370910645 330.7059020996323.7101135254 316.700012207313 .705291748311 .3768920898307 .7712097168303 .7755126953 299.5762023926295 .5190124512291 .6422119141287 .8680114746284 .3353881836 280.9663085938277 .6612854004275 .0278015137273 .4692993164272 .5885009766 272.063293457271 .5877075195270 .6568908691269 .3758850098267 .6994018555 265.6484069824263 .2380065918260 .5065002441257 .4104003906254 .0827026367 250.5653991699246 .7754058838242 .7171936035238 .2696990967233 .4703063965 228.3343048096223 .1112976074217 .5467987061211 .5196990967205 .441192627 199.5009002686194 .0142059326189 .2819976807185 .1450042725181 .6369934082 178.5722961426175 .633102417173 .0818939209171 .1324005127169 .3441925049 167.4273986816165 .4131011963163 .1380004883160 .9208068848159 .1625976562 157.3565063477155 .1797943115152 .8677978516150 .5507049561148 .3072967529 146.0525970459144 .3049926758143 .7153015137143 .2492980957142 .025894165 140.4062042236138 .4678039551136 .345993042134 .141494751131 .9013061523 129.7346954346127 .6834030151125 .8581008911124 .2294998169122 .8006973267 121.5337982178120 .5505981445119 .2294998169116 .8818969727114 .1976013184 111.7406997681109 .4091033936107 .2777023315105 .4241027832103 .9703979492 102.9651031494102 .4998016357102 .1569976807101 .5787963867100 .6384963989 99.1326370239397 .3294372558695 .1045608520593 .0792694091891 .42658996582 90.4041671752990 .6444015502991 .5738601684693 .0477371215894 .80146789551 96.2631530761797 .4582672119198 .1512832641698 .4085617065498 .22131347656 97.6853179931696 .924247741796 .0071563720795 .0930175781294 .20349884033 93.4805068969792 .8760299682692 .466941833592 .1532974243291 .92363739014 
92.3544006347792 .6592025756892 .6592025756892 .3544006347792 .35440063477 92.0495986938592 .0495986938589 .7648391723688 .5641937255987 .17022705078 85.6265106201284 .1493835449282 .7166366577181 .3785095214880 .15724945068 78.968193054277 .6712417602575 .9821166992273 .5703277587970 .16953277588 66.1196212768662 .4176406860457 .3544387817449 .3231391906740 .85720825195 34.1423301696829 .0589008331325 .7872295379623 .593820571921 .48657035828 19.4979991912817 .7342090606715 .1223201751710 .452549934394 .833639144897 -.835429012775 -7.24053907394 -14.4942398071 -23.0687503815 -33.3584289551 $-45.306640625-59.1534881592-71.8075866699-80.6551895142-85.9904937744$ $-87.6425476074-86.7867507935-84.1181869507-80.6292037964-77.6262435913$ $-74.9077301025-72.6678237915-70.7562789917-69.05909729-67.644241333$ $-66.3963088989-65.0579071045-63.4906311035-61.852230072-60.5203514099$ $-59.4930114746-58.748840332-58.232219696-57.7656707764-57.3435516357$ $-56.8613891602-56.2882804871-55.5466918945-54.7042617798-53.807510376$ $-52.8220100403-51.7322616577-50.4097595215-48.8153495789-47.179901123$ $-45.7497291565-44.6176300049-43.9101982117-43.4399490356-43.0543212891$ $-42.7493400574-42.4657592773-42.19190979-41.8901596069-41.5519485474$ $-41.1491508484-40.6747016907-40.1055297852-39.4351387024-38.6449584961$ -37.7256088257 -36.6680488586 -35.4424514771 -34.0463104248 -32.4250411987 $-30.5557498932-28.4871902466-26.2292308807-23.9261608124-21.7249698639$ -19.7111492157-18.081829071 -16.5117301941 -14.6740503311-12.6301803589 $-10.3086700439-7.20832014084-2.452933073042 .3950099945076 .118009090424$ 9.57629489898713 .9691801071217 .5177593231217 .681499481217 .36072921753 18.3003292083719 .6604595184320 .9064693450921 .9796791076723 .00469970703 23.8438701629624 .6268692016625 .3397502899226 .0023803710926 .62005996704 27.2233390808127 .7869205474928 .3238792419428 .8229808807429 .26460075378 29.6585903167729 .9875297546430 .3096599578930 .7093791961731 .12760925293 31.5311203002931 .9325103759832 .3321990966832 .7329216003433 .13666915894 33.5462989807133 .964420318634 .3933181762734 .8356208801335 .29214096069 35.7646598815936 .252788543736 .7570610046437 .2766304016137 .81108856201 38.3595314025938 .921039581339 .4947395324740 .0794792175340 .67440032959 41.2782592773441 .8902282714842 .5090217590343 .1338806152343 .7635383606 44.3973388671945 .0340805053745 .6731681823746 .3135299682646 .95463943481 47.5955390930248 .2357482910248 .8744506835949 .5112113952650 .14532089233 50.7764091491751 .4038696289152 .0274009704652 .646488189753 .26092910767 53.8703002929754 .4744415283255 .0730590820355 .6660690307656 .25325012207 56.8345909118757 .4099807739357 .9794197082558 .5428695678759 .10039138794 59.6519813537660 .1977005004960 .7375984191961 .2717514038161 .80020904541 62.3230400085462 .8403091430763 .3520812988363 .8583908081164 .35930633545 64.8550796508865 .3451232910265 .8306274414166 .30980682373 687.525390625682 .9351196289678 .2866821289673 .5657958984668 .8018188477 663.9874267578659 .1198120117654 .1962280273649 .2133789062644 .1679077148 639.0573120117633 .8781738281628 .6293945312623 .3087768555617 .9165039062 612.4517822266606 .9157714844601 .3095703125595 .6345825195589 .8930053711 584.0866699219578 .2186889648572 .2916259766566 .3088989258560 .2747192383 554.1932983398548 .0701293945541 .9111938477535 .7230224609529 .5131835938 
523.2896728516517 .061706543510 .8381958008504 .6300048828498 .4464111328 492.2995910645486 .1989135742480 .1564941406474 .1803894043468 .2856140137 462.4530029297456 .6738891602450 .9360046387445 .2437133789439 .5354003906 433.7936096191427 .9772949219422 .0463867188416 .0227050781409 .8684082031 403.8297119141398 .1632080078392 .3960876465386 .2525024414379 .2470092773 370.7011108398361 .404510498352 .0187988281342 .6980895996333 .5708007812 326.259185791322 .5038146973320 .8514099121320 .0629882812320 .196685791 321.1272888184323 .3435974121327 .6171875332 .5401000977336 .5249938965 339.6026000977341 .291595459342 .2287902832342 .6973876953342 .5552978516 341.6570129395340 .2717895508338 .9642944336336 .7573852539332 .6491088867 328.2810974121325 .3070068359322 .1254882812317 .6693115234312 .5502929688 307.2019042969302 .0427856445297 .1687011719292 .5361022949288 .4879150391 284.8277893066281 .5194091797278 .9688110352277 .2551879883276 .1282043457 275.3676147461274 .6904907227273 .7188110352272 .4331054688270 .7196960449 268.6173095703266 .0965881348263 .2601013184260 .0851135254256 .7723999023 253.4268951416250 .046005249246 .7310028076243 .1107940674238 .9111022949 234.328704834229 .5097961426224 .4566955566219 .1136016846213 .5287017822 207.9029998779202 .4875946045197 .7169036865193 .5717010498190 .0312957764 186.9490966797184 .1333007812181 .6862030029179 .6914978027177 .966506958 176.3157958984174 .7503051758173 .179901123171 .499206543169 .636505127 167.4810028076164 .9477996826162 .3052062988159 .828994751157 .4924926758 155.2781982422153 .466003418152 .4306945801151 .592300415150 .3392944336 148.8045043945146 .9093017578144 .7252960205142 .3309936523139 .9716949463 137.9017944336135 .9974060059134 .1817932129132 .4750976562130 .9319000244 129.5101013184128 .2330932617126 .6601028442124 .3748016357121 .7995986938 119.2874984741116 .8760986328114 .6529006958112 .7245025635111 .224899292 110.0740966797109 .3892974854108 .6379013062107 .4017028809105 .8635025024 104.0576019287102 .121498107999 .9952697753998 .0283966064596 .41278839111 95.2582168579194 .9686508178795 .2089462280395 .9020233154396 .8092880249 97.5736923217898 .1622695922998 .3689727783298 .2495727539197 .7573928833 97.0028610229596 .0621032714895 .0287094116294 .027618408293 .09548187256 92.3345870971792 .0495986938592 .0495986938592 .0495986938592 .04959869385 92.0495986938592 .3544006347792 .3544006347792 .3544006347792 .35440063477 91.7447967529391 .7447967529389 .0016021728586 .1150207519584 .76290893555 83.3393020629981 .9495468139680 .618438720779 .4199371337978 .32440185547 77.2946166992276 .050216674874 .3718414306672 .3710174560569 .84147644043 67.0646209716864 .3460388183660 .0569381713952 .7718696594244 .50038146973 37.3021888732931 .5969791412428 .2608699798626 .2938308715824 .56720924377 23.01038932821 .4399509429919 .1579303741515 .4163599014310 .79518032074 $5.871451854706 .2206050008535-6.24424695969-14.6551704407-25.5271701813$ $-38.1780090332-53.3522987366-66.9403686523-75.81640625-81.636756897$ $-84.0528869629-83.728012085-80.719581604-76.9141235352-74.8041381836$ $-73.2758865356-71.7619018555-70.3343734741-69.0240631104-67.7342834473$ $-66.4100799561-65.087348938-63.6612701416-62.2822685242-61.0999298096$ $-60.0716896057-59.3284301758-58.7954483032-58.3341598511-57.9245986938$ $-57.5059318542-56.9632492065-56.1481399536-55.1898498535-54.2028999329$ 
-53.0929489136 -51.84141922 -50.5170211792 -49.0901603699-47.6775817871 $-46.3633995056-45.2136688232-44.436958313-43.8955116272-43.4630012512$ $-43.1136016846-42.7897186279-42.4748916626-42.1357002258-41.7608909607$ $-41.3272018433-40.8247299194-40.2341194153-39.5469589233-38.746761322$ -37.8245391846 -36.7701301575 -35.5543518066 -34.1673698425 -32.5363082886 -30.6267700195 -28.465719223 -26.0407600403 -23.4468994141 -20.6942100525 $-18.3029193878-16.9555492401-15.7840795517-13.9880104065-12.2655801773$ -11.1474103928 -8.84552192688 -3.38578510284 1.678293943405 3.614546060562 5.305366992958 .83938980102512 .7044496536314 .4220399856615 .1206703186 16.3902492523217 .7422599792519 .1541805267320 .6002597808821 .8681602478 22.9359893798823 .8362693786624 .6162300109925 .308660507225 .92915916443 26.5191402435327 .0706405639627 .6001605987528 .1067409515428 .58505058289 29.0366306304929 .4496192932129 .8607902526930 .312429428130 .77202033997 31.2157993316731 .648370742832 .0709190368732 .4871101379432 .90018081665 33.3139114379933 .7327194213934 .1592292785634 .597511291535 .04856109619 35.5151901245135 .9970817565936 .4953498840337 .0091209411637 .53828811646 38.0818710327138 .6390991210939 .208988189739 .7905006408740 .38262176514 40.9841804504441 .5942115783742 .2114601135342 .8350601196343 .46377182007 44.0967903137244 .732978820845 .3716087341346 .0116500854546 .65246963501 47.29312896729 47.93310165405 48.5715293884349.2079811096249.84170913696 50.4723205566451 .0992202758851 .7220611572352 .3403511047452 .95383834839 53.5621299743754 .165039062554 .762279510555 .3537597656255 .93928909302 56.5188217163157 .0922508239757 .6596107482958 .2208786010758 .77608108521 59.3252601623559 .8684692382860 .4057693481460 .9372482299861 .46298980713 61.9830513000562 .4975204467863 .0064582824763 .5099601745664 .00804901123 64.5010070800864 .9888534545965 .4679489135765 .94053649902

693.0996704102688 .5374145508683 .9467773438679 .3060913086674 .6198120117 669.8864746094665 .1032714844660 .2681884766655 .378112793650 .4304199219 645.4224853516640 .3518066406635 .2169799805630 .0164794922624 .7498779297 619.417175293614 .0192260742608 .5571289062603 .0322875977597 .4468994141 591.8029785156586 .103515625580 .3510131836574 .5490112305568 .7012939453 562.8123168945556 .8870849609550 .9310302734544 .9503173828538 .9517211914 532.9426269531526 .9304199219520 .9232788086514 .9298095703508 .9578857422 503.0168151855497 .112701416491 .2540893555485 .4428100586479 .6910095215 473.9678955078468 .2579040527462 .5327148438456 .7990112305450 .992401123 445.1003112793439 .0960998535432 .9551086426426 .7188110352420 .3811950684 414.0437927246407 .7822875977401 .4184875488395 .0274963379387 .8258972168 378.8528137207369 .1973876953359 .8929138184350 .6781921387341 .0351867676 333.4498901367330 .6553955078329 .6015014648328 .0401000977327 .1853942871 327.258392334329 .1137084961333 .816986084339 .0078125342 .5863952637 345.1597900391346 .4339904785346 .9519958496346 .8505859375346 .2208862305 345.2651062012344 .0013122559342 .6406860352341 .1700134277340 .1184082031 338.5051879883335 .5162963867331 .5065917969326 .6931152344320 .9671020508 314.8992919922308 .6372070312302 .5076904297297 .186706543292 .9656066895 289.5646972656286 .6127929688284 .1737976074282 .2356872559280 .7569885254 279.5975036621278 .578704834277 .4486999512276 .0809020996274 .3147888184 
272.1231079102269 .4309997559266 .4208068848262 .9974975586259 .5390930176 256.1600952148252 .9120941162250 .1846923828247 .2640991211243 .6757049561 239.6750946045235 .2843017578230 .6076965332225 .775604248220 .733795166 215.6652069092210 .6896057129206 .1217956543202 .0455932617198 .4812927246 195.4058990479192 .7046966553190 .3650054932188 .3509979248186 .666305542 185.2053985596183 .9593963623182 .9757995605181 .7438964844179 .7532958984 177.2720947266 174.524597168 171.7062988281 169.1817016602 166.9031066895 164.8686981201163 .1246948242161 .7032012939160 .4358978271159 .0657043457 157.5019989014155 .5834960938153 .3717041016150 .862701416148 .4141998291 146.4105072021144 .5753936768142 .7281951904140 .9452972412139 .2675018311 137.6302032471135 .9759979248134 .1647949219132 .066192627129 .754196167 127.3133010864124 .8908004761122 .638999939120 .6499023438119 .0456008911 117.7426986694116 .873298645115 .8792037964114 .1677017212112 .2163009644 110.2538986206108 .2442016602106 .0920028687104 .0569000244102 .3343963623 100.9721984863100 .169502258399 .7473373413199 .6687011718899 .75293731689 99.766189575299 .6752929687599 .2971267700298 .6924896240297 .79138946533 96.7092437744195 .4972686767694 .2570190429793 .1223068237392 .08541107178 91.2724914550890 .6178131103590 .1790618896589 .8547973632889 .56255340576 89.2739028930791 .4400024414192 .0495986938592 .0495986938591 .74479675293 91.7447967529391 .7447967529390 .5255966186589 .6111984252988 .0871963501 85.3440017700282 .6007995605579 .2480010986376 .5109405517675 .44429016113 74.4338226318473 .2788162231471 .7748031616270 .0831832885768 .11350250244 65.8919982910263 .5550689697359 .8435516357453 .5916404724146 .3251914978 39.5525588989333 .9122085571330 .6434497833328 .7165794372627 .0726108551 25.665250778223 .9988708496121 .8855400085419 .0806903839115 .58267021179 $11.536339759836 .6501522064211 .090680956841-6.27903413773-16.0351009369$ $-28.4506702423-44.8612594604-60.4019203186-70.6918792725-77.0939025879$ $-80.1293029785-80.006362915-76.6323623657-72.7690429688-71.5859832764$ $-71.1430130005-70.2429428101-69.3074035645-68.3656768799-67.3209991455$ $-66.104309082-64.8122406006-63.445640564-62.1915206909-61.1519203186$ $-60.2969284058-59.6556091309-59.1388206482-58.6779518127-58.2524909973$ $-57.8516082764-57.3068695068-56.405418396-55.3345718384-54.2666282654$ $-53.1031990051-51.8255996704-50.5195617676-49.1991500854-47.9186096191$ $-46.7168807983-45.6532897949-44.8716201782-44.2795410156-43.8101196289$ $-43.427318573-43.0709381104-42.7265090942-42.356918335-41.9540214539$ $-41.4926795959-40.9660491943-40.352230072-39.6464805603-38.8285713196$ $-37.8952293396-36.8344688416-35.6221389771-34.2583198547-32.6563110352$ $-30.7895107269-28.5963306427-26.0539302826-23.2482395172-20.0694503784$ $-17.3931808472-16.3470497131-15.6171197891-13.9214696884-12.3257303238$ -11.9267702103 -10.5095500946-4.83090782166 .7734060287476 2.354515075684 3.4146780967715 .8763499259958 .69690608978310 .7668104171812 .45880031586 14.2695999145515 .9603996276917 .7021598815919 .3903293609620 .84930038452 22.1069507598923 .1127300262523 .9328193664624 .6360797882125 .24686050415 25.8216991424626 .3621101379426 .8905601501527 .4069309234627 .91897964478 28.4241695404128 .923690795929 .4214496612529 .9203090667730 .41292953491 30.8920593261731 .3556003570631 .8018093109132 .2347183227532 .65829086304 
33.0773315429733 .4976997375533 .9226913452134 .3578186035234 .80424880981 35.2661018371635 .7428703308136 .2364196777336 .7457199096737 .27093887329 37.8110313415538 .3652496337938 .9326591491739 .5120391845740 .10251998901 40.7026786804241 .3117294311541 .9281616210942 .5512390136743 .17951965332 43.8123283386244 .4483108520545 .0868797302245 .7268295288146 .36761856079 47.0081787109447 .6480407714848 .2862815856948 .9224700927749 .55582046509 50.185970306450 .8122596740751 .4343795776452 .0517883300852 .66426086426 53.2713699340853 .8729591369654 .4687309265155 .058589935355 .64234161377 56.2199592590356 .7913513183657 .3565406799357 .9155006408758 .46828842163 59.0149497985859 .5555610656760 .0901794433660 .6189002990761 .14183044434 61.6590499877962 .1706390380962 .6766815185563 .1772689819363 .67247009277 64.1625595092864 .6470031738365 .1270217895565 .60083770752 698.6994018555694 .246887207689 .7437133789685 .1749267578680 .5679931641 675.9171142578671 .2202148438666 .4750976562661 .6796875656 .8314819336 651.9285888672646 .9683837891641 .950012207636 .8715820312631 .7335205078 626.5352172852621 .2780151367615 .9628295898610 .5911865234605 .1651000977 599.6868286133594 .1588134766588 .5841064453582 .9661254883577 .3082885742 571.6151123047565 .8909301758560 .1411743164554 .37109375548 .5872802734 542.7952270508537 .0023193359531 .2141113281525 .4384155273519 .6804199219 513.9494018555508 .2448120117502 .5721130371496 .9266967773491 .3146057129 485.7047119141480 .0801086426474 .4002075195468 .6445922852462 .7771911621 456.7861938477450 .6462097168444 .3261108398437 .8687133789431 .2720031738 424.5474853516417 .7249145508410 .7709960938403 .7471923828396 .1344909668 387.3212890625378 .1105041504369 .2934875488360 .7055053711352 .2005004883 345.7051086426343 .2554016113341 .6711120605337 .9114074707335 .0152893066 335.6802062988338 .691986084343 .3052062988347 .8345947266350 .370513916 351.7640991211352 .138885498351 .834197998350 .8995056152349 .5728149414 348.3016052246346 .9772033691345 .6492919922344 .6729125977344 .1076049805 343.0314025879340 .7482910156337 .4737854004333 .9724121094329 .2809143066 322.7242126465315 .2239990234307 .3174133301300 .8351135254297 .596496582 295.4718017578292 .6517944336289 .9100036621287 .7627868652285 .9970092773 284.600402832283 .3771972656282 .067199707280 .5797119141278 .7482910156 276.433013916273 .4841003418270 .1370849609266 .3706970215262 .5823974609 258.8793945312255 .4430999756252 .7304992676250 .1024932861247 .2317962646 244.1083984375240 .538192749236 .6163024902232 .3213043213227 .8112030029 223.2225952148218 .6295013428214 .2315979004210 .2185974121206 .8352966309 203.9118041992201 .2467956543198 .9053955078197 .0195007324195 .4687957764 194.0865936279192 .8917999268191 .7660064697190 .3822937012188 .4479064941 186.0738983154183 .5433044434180 .9774017334178 .5144042969176 .2920074463 174.3377990723172 .5529937744170 .9915008545169 .55859375168 .2247009277 166.7265930176164 .7037963867162 .3842010498159 .8983001709157 .4803924561 155.3768005371153 .403793335151 .4517059326149 .5352020264147 .6678924561 145.8175964355143 .9837036133142 .1246948242140 .1562042236138 .0184936523 135.5724029541133 .0800933838130 .8385925293128 .8217010498127 .112701416 125.6158981323124 .3162994385122 .8945999146121 .024597168119 .0280990601 117.1961975098115 .2729034424112 .9568023682110 .6517028809108 .75050354 
107.1381988525105 .8888015747104 .8818969727104 .0798034668103 .3743972778 102.6465988159101 .8452987671100 .857002258399 .7099990844798 .34454345703 96.8637924194395 .3014907836993 .7944335937592 .4783172607491 .32734680176 90.4125671386789 .7172317504989 .3082885742289 .0476608276488 .77921295166 88.4924316406288 .0777282714887 .5158615112388 .087196350190 .22080230713 90.2208023071389 .6111984252988 .3919982910286 .563201904383 .21040344238 79.8575973510776 .5047988891674 .0615005493272 .8924026489371 .82447814941 70.7825469970769 .6395874023468 .2481994628966 .6916427612364 .89209747314 62.852951049860 .608119964657 .4009590148952 .3539581298846 .53858184814 40.8714599609435 .9183502197332 .7098503112830 .5642700195328 .94762039185 27.5707893371626 .0095100402824 .2337207794222 .0108108520519 .34041976929 $16.1401100158712 .283109664927 .8599691390992 .28499007225-4.50905418396$ -14.8494100571 -31.2047195435-48.4814300537-63.2797889709 -73.5938186646 -76.5768127441 -75.7549972534 -73.1465988159-70.1925506592-69.103553772 $-68.704536438-68.278213501-67.8069381714-67.2799835205-66.5904006958$ $-65.6031036377-64.3914413452-62.8824882507-61.5420303345-60.7955207825$ $-60.2828483582-59.761680603-59.254070282-58.7622299194-58.2706794739$ $-57.769859314-57.137260437-56.2424888611-55.195728302-54.0992698669$ -52.9286994934 -51.6804695129-50.4239997864 -49.1849594116-47.994228363 $-46.865940094-45.8681793213-45.1339988708-44.5607910156-44.0872306824$ $-43.6867599487-43.3102989197-42.9416007996-42.5494613647-42.1222610474$ $-41.6383399963-41.0878295898-40.4524002075-39.7237510681-38.8830604553$ -37.9309616089-36.8558311462 -35.6542282104 -34.3207397461 -32.8030700684 -31.121389389-29.0726795197 -26.4320697784 -23.5008907318 -20.4694309235 $-17.9912109375-16.8806800842-16.072719574-14.5982303619-13.0170497894$ -11.5823001862 -9.69844245911 -6.61245012283 -3.26582407951 -.701811015606 1.4377110004433 .4806718826295 .5750889778147 .75734996795710 .03081035614 12.2870702743514 .3768701553316 .4422206878718 .3848896026620 .02005958557 21.402139663722 .4741592407223 .3053092956523 .9997806549124 .59243965149 25.1371898651125 .6564807891826 .1864795684826 .7193908691427 .26412010193 27.819759368928 .3897590637228 .9600601196329 .5158805847230 .05344009399 30.5682201385531 .0616397857731 .5299301147531 .9785995483432 .41247177124 32.8371200561533 .2592391967833 .6831588745134 .1155395507834 .55813980103 35.0159301757835 .4887390136735 .9787292480536 .4849510192937 .00764083862 37.5457000732438 .0984001159738 .6646385192939 .2432785034239 .83324813843 40.4332313537641 .0421981811541 .6587905883842 .2820510864342 .91064071655 43.5437393188544 .1800804138244 .818920135545 .4591484069846 .10010910034 46.740798950247 .3806610107448 .0188217163148 .6547813415549 .28778839111 49.9174499511750 .5430984497151 .1644287109451 .7808990478552 .39225006104 52.9981002807653 .5982589721754 .1924591064554 .7805786132855 .362449646 55.9380416870156 .5072708129957 .0701599121157 .6267089843858 .17697906494 58.7210197448759 .2589111328159 .7907485961960 .3166313171460 .83665847778 61.3509292602561 .8595504760762 .3625984191962 .860210418763 .35243988037 63.8395996093864 .3216934204164 .7952270507865 .26246643066 704.5100097656700 .0930786133695 .6514282227691 .1647949219686 .6384277344 682.0712890625677 .4616699219672 .8082275391668 .1088867188663 .3618774414 
658.5654296875653 .7172851562648 .8167724609643 .862487793638 .8546142578 633.7929077148628 .678527832623 .5123291016618 .2960205078613 .0314941406 607.7208862305602 .3670043945596 .9724731445591 .5408935547586 .0756225586 580.5806884766575 .0603027344569 .5194702148563 .9630126953558 .396484375 552.8245239258547 .2537231445541 .6873779297536 .1323852539530 .5916748047 525.0739135742519 .5731811523514 .0908813477508 .6148986816503 .1484985352 497.6531066895492 .125793457486 .5053100586480 .7687988281474 .8846130371 468.8599853516462 .645111084456 .207611084449 .5562133789442 .6904907227 435.5947875977428 .212890625420 .6604003906412 .912689209404 .8482055664 396.2510070801387 .7446899414379 .6628112793372 .1762084961365 .4815063477 360.0192871094357 .4497070312355 .0220031738349 .333190918345 .0633850098 346.5946044922350 .5130004883354 .5911865234358 .1534118652359 .5981140137 359.7066040039358 .8735961914357 .3363037109355 .0892028809352 .8500061035 351.1282958984349 .7156982422348 .4433898926347 .3295898438346 .308013916 344.9937133789343 .2051086426340 .9317016602339 .05859375335 .8698120117 329.7745056152322 .0165100098313 .1683044434305 .7283935547303 .1809997559 302.0986938477299 .1561889648296 .1524963379293 .8526916504291 .950012207 290.4497070312289 .0819091797287 .6046142578285 .9437866211284 .0895080566 281.7457885742278 .6448059082275 .042388916270 .8174133301266 .4204101562 261.995513916258 .0461120605255 .1522064209252 .8388977051250 .7420959473 248.4875946045245 .7532958984242 .5579071045238 .803604126234 .7501068115 230.6237945557226 .4358062744222 .3334960938218 .5146026611215 .3063049316 212.4683990479 209.81300354207.5055999756205.8007965088204.4161071777 203.0193939209201 .6533966064200 .0944061279198 .3013000488196 .3249053955 194.2382049561192 .2321014404190 .1674957275187 .9015045166185 .6643981934 183.6768951416181 .8576965332180 .2048034668178 .6945953369177 .3977966309 175.9517974854173 .8632965088171 .5009002686169 .1069030762166 .7214050293 164.4839019775162 .334197998160 .2514953613158 .208404541156 .1477050781 154.120803833152 .1614990234150 .2294006348148 .3157958984146 .2595062256 143.7770996094141 .2595977783139 .0523986816137 .0507965088135 .2872924805 133.5774993896131 .8076019287129 .9465026855127 .9708023071126 .0260009766 124.3104019165122 .4664001465119 .9598999023117 .4315032959115 .3956985474 113.5662994385111 .948097229110 .4040985107108 .931098938107 .4936981201 106.0541992188104 .59400177103 .0047988892101 .320297241299 .46478271484 97.5513687133895 .5734024047993 .736610412692 .1859436035290 .87519836426 89.901786804289 .2076034545988 .8685531616288 .7074890136788 .462890625 88.13059234619 87.57967376709 86.78238677979 85.6915512085 84.31516265869 82.6341934204184 .7343978881882 .2959976196379 .2480010986376 .19999694824 73.1143569946371 .5680999755970 .160713195868 .9626998901467 .85675811768 66.733673095765 .5831680297964 .2758865356462 .8224296569861 .02220916748 58.939449310356 .6052093505953 .6874198913649 .8326988220245 .49732971191 41.1903495788637 .2126388549834 .1837005615231 .8756809234630 .19973945618 28.8381309509327 .4022197723425 .9037094116224 .1311798095722 .08481025696 19.6304798126216 .7413997650113 .47428989419 .525083541875 .726881980896 $-1.51596605778-15.8414697647-33.5213890076-52.62940979-67.4934234619$ $-71.369758606-70.1584014893-68.9398803711-67.3957138062-66.3945770264$ 
-65.9051437378 -65.826133728 -65.8845291138-65.8627929688-65.6012573242 $-64.9322967529-63.9216194153-62.3458595276-60.9212303162-60.39112854$ $-60.1114692688-59.6377983093-59.1163101196-58.582649231-58.0034599304$ $-57.3769302368-56.6502304077-55.787651062-54.8082199097-53.7385482788$ -52.602481842 -51.4193305969-50.2361183167-49.0667915344-47.9490509033 $-46.8921318054-45.9668006897-45.2986793518-44.7683105469-44.305431366$ $-43.8993797302-43.5105400085-43.1260414124-42.7164993286-42.27135849$ $-41.7676582336-41.1968193054-40.5386314392-39.7857398987-38.9151191711$ -37.9328308105 -36.8209190369 -35.6023292542 -34.2592391968 -32.8171691895 -31.3580093384 -29.4775791168 -26.8347797394 -23.9447193146 -21.2968597412 -19.1644706726 -17.9259796143 -17.0068302155 -15.7811403275 -14.1216096878 $-11.281829834-8.6428976059-8.03994655609-7.26403284073-4.0897321701$ -.6324189901351.192499995232 2.9239130020145.21880197525 7.686569213867 10.2587699890112 .7642402648915 .2732200622617 .5207691192619 .31513977051 20.743379592921 .8327903747622 .6873092651423 .3822708129923 .96503067017 24.4785594940224 .9736194610625 .4978694915826 .0419998168926 .6229801178 27.2286300659227 .8625106811528 .5024108886729 .1136894226129 .69820022583 30.2499198913630 .7697792053231 .2580394744931 .7208499908432 .16397857666 32.5935592651433 .0170097351133 .4390106201233 .8689193725634 .30796813965 34.7629394531235 .232978820835 .7210693359436 .2258911132836 .74781036377 37.2856216430737 .8384094238338 .4051704406738 .9844589233439 .57537078857 40.1762695312540 .7863388061541 .4039001464842 .0282516479542 .65774917603 43.2917709350643 .928848266644 .5684089660645 .2091407775945 .85054016113 46.4914703369147 .1314697265647 .7695693969748 .4053382873549 .03797912598 49.6670989990250 .2920417785650 .9124908447351 .527900695852 .13803863525 52.7424888610853 .341098785453 .9335594177254 .5198211669955 .09965896606 55.6730804443456 .2400093078656 .8004798889257 .3544807434157 .90208816528 58.4433784484958 .9784393310559 .5073814392160 .0302886962960 .54730987549 61.0585289001561 .5640792846762 .0640487670962 .558589935363 .04774856567 63.5318717956564 .0104217529364 .484657287664 .95282745361

710.3463745117706 .0355834961701 .6817016602697 .2697143555692 .8248291016 688.3424072266683 .8214111328679 .2606201172674 .6585083008670 .013671875 665.3245849609660 .5899047852655 .8087158203650 .979675293646 .103515625 641.1796875636 .2094726562631 .1937866211626 .1342773438621 .0327758789 615.8917236328610 .7135009766605 .5009765625600 .2576293945594 .9865112305 589.6917724609584 .3773193359579 .0477294922573 .7067871094568 .3601074219 563.010925293557 .6647949219552 .3234863281546 .9923706055541 .6729736328 536.3720703125531 .080871582525 .7974853516520 .5048217773515 .1976928711 509.8371887207504 .4018859863498 .8551940918493 .1814880371487 .3429870605 481.325012207475 .0824890137468 .5874023438461 .7945861816454 .6705932617 447.1859130859439 .3092956543431 .2318115234422 .9739990234414 .5618896484 405.9450073242397 .9146118164390 .9336853027384 .8970947266379 .704498291 374.9508056641371 .1968994141367 .4645080566362 .7637939453359 .7222900391 360.5551147461363 .3562011719366 .7376098633369 .4519042969370 .3492126465 369.6473083496367 .058013916363 .5433044434359 .490814209355 .8758850098 353.8281860352352 .4223022461350 .9183959961349 .4059143066347 .9891967773 
346.5172119141344 .7504882812342 .9451904297341 .2043151855338 .7688903809 335.173614502329 .6599121094321 .5869140625314 .1850891113310 .6153869629 308.5029907227305 .6195983887302 .7195129395300 .379699707298 .5104980469 297.1260986328295 .8035888672294 .1148986816292 .2627868652290 .4685058594 288.2206115723285 .2185058594281 .496887207276 .6904907227271 .3511962891 265.5801086426260 .5734863281257 .9346923828256 .458404541255 .1221923828 253.6045074463251 .3166046143248 .520904541245 .3215942383241 .820098877 238.0305023193234 .2021942139230 .7617034912227 .4777984619224 .1360931396 221.0610046387218 .5146942139216 .3619995117214 .7512969971213 .395401001 211.9165039062210 .321395874208 .4273071289206 .2884979248203 .9597015381 201.9344024658200 .7070007324199 .429901123197 .3155975342194 .9640960693 192.8686981201190 .9396057129189 .1882019043187 .5756072998186 .1322021484 184.6071929932182 .7225036621180 .5800933838178 .1949005127175 .7471923828 173.4653930664171 .242401123169 .0910949707166 .9651031494164 .7731933594 162.5903930664160 .4396972656158 .3135986328156 .2261047363154 .0509033203 151.620803833149 .1985015869147 .0258026123145 .0646972656143 .3955993652 141.6246032715139 .4277038574137 .108795166134 .8811950684132 .7754058838 130.8209075928128 .7633972168126 .3470993042123 .9587020874122 .0049972534 120.1527023315118 .2272033691116 .1849975586114 .0297012329111 .8607025146 109.7998962402107 .7602996826105 .6524963379103 .4692993164101 .1527023315 98.7833175659296 .3701934814594 .1668930053792 .3163223266690 .82067871094 89.8612899780389 .2641677856489 .0068664550888 .9266281127988 .69438171387 88.2674026489387 .5218200683686 .4356536865284 .9716110229583 .15724182129 80.9950714111378 .6182632446376 .1001434326273 .6488265991271 .40479278564 69.3778305053767 .7161865234466 .2698669433665 .0256271362363 .8617401123 62.5599212646561 .2931289672960 .1548309326258 .9025917053257 .22813034058 55.2086181640652 .8479995727550 .1948394775447 .0441093444843 .7089881897 40.3824310302737 .1877708435134 .5791587829632 .432758331330 .80883979797 29.4746894836428 .1460094451926 .8384704589825 .4179496765123 .86569976807 22.0505008697519 .9675006866517 .5630092620814 .9047002792412 .19773006439 $7.200979232788-1.66833794117$-15.8952598572 -37.5229492188 -56.2142105103 $-62.0031585693-62.1105690002-62.3931388855-62.395740509-62.2592391968$ $-62.2465896606-62.9222793579-63.7379188538-64.3010177612-64.5146636963$ $-64.2328262329-63.5276298523-62.3097000122-61.1094703674-60.4323997498$ $-59.9308013916-59.3628807068-58.7533416748-58.1397895813-57.4912910461$ $-56.7930908203-56.0332107544-55.1768188477-54.2404785156-53.2182998657$ $-52.139541626-51.0348396301-49.9353294373-48.8636283875-47.8450813293$ $-46.9020500183-46.0788192749-45.4434509277-44.9219703674-44.4687004089$ -44.0617980957 -43.6696510315-43.2769699097 -42.8569984436-42.3975105286 $-41.8786392212-41.2878189087-40.6062507629-39.8218917847-38.9139709473$ -37.8797683716 -36.699760437-35.4095306396 -34.0045318604 -32.6092987061 -31.341709137-29.6608390808 -27.0851306915 -24.3180007935 -22.0052394867 -20.1685791016 -18.972700119-18.0988101959-17.3549098969-15.8640203476 $-12.4827003479-9.49018096924-8.78748703003-8.39542102814-6.80265378952$ $-4.48816919327-2.13166499138 .26669600605962 .7777628898625 .415400028229$ 8.20843410491911 .0860395431514 .1851301193216 .9310493469218 .74391937256 
20.0609798431421 .1633396148722 .0541992187522 .771699905423 .35535049438 23.850370407124 .3209209442124 .8239307403625 .3632507324225 .98406028748 26.6474399566727 .3449592590328 .053710937528 .7231903076229 .35460090637 29.9410400390630 .4857807159430 .9907302856431 .4649391174331 .9158706665 32.3495101928732 .7722206115733 .1911582946833 .617599487334 .05353927612 34.5060310363834 .9747009277335 .4622497558635 .9674491882336 .49040985107 37.0297889709537 .5845718383838 .1534881591838 .7351303100639 .32833099365 39.9315795898440 .54380035441 .1634902954141 .7896690368742 .42092132568 43.0564002990743 .6948089599644 .3353996276944 .9770317077645 .61904144287 46.2604217529346 .9006195068447 .5387496948248 .1743202209548 .80656814575 49.4350891113350 .0592498779350 .678710937551 .2929496765151 .90172958374 52.5046501159753 .1015510559153 .6921501159754 .2763595581154 .85401916504 55.4251289367755 .9895896911656 .5474700927757 .098770141657 .64358901978 58.1819915771558 .7140808105559 .2399902343859 .7598190307660 .27370071411 60.7817497253461 .2841110229561 .7808990478562 .2722396850662 .75825119019 63.2392387390163 .71525955264 .1829299926864 .64453125

716.3685302734712 .1002197266707 .8107299805703 .4818115234699 .1190795898 694.7222290039690 .2902832031685 .8229980469681 .3189086914676 .7769775391 672.1962890625667 .575378418662 .9141235352658 .2111816406653 .4672851562 648.6821289062643 .8568725586638 .9923706055634 .0905151367629 .1528930664 624.1820068359619 .1804199219614 .1508789062609 .0966796875604 .0211181641 598.9279174805593 .8206176758588 .7036132812583 .580078125578 .455078125 573.3305053711568 .2116699219563 .0985717773557 .9959716797552 .9022216797 547.8237304688542 .7454833984537 .6677246094532 .5626220703527 .4279174805 522.2144775391516 .9008178711511 .458190918505 .9027099609500 .1622924805 494.2213134766 488.0177001953481.5444946289474.7004089355 467.4374084473 459.7025146484451 .5150146484442 .9097900391433 .9725036621425 .3006896973 416.7538146973408 .9895935059402 .3884887695396 .9142150879392 .5140075684 388.5198059082384 .1065979004379 .8634033203377 .1463928223375 .7843933105 375.7633056641376 .8999023438379 .0161132812380 .9396972656381 .7132873535 380.6610107422376 .738494873371 .25365 .436706543360 .3171081543357 .4818115234 355.6581115723353 .441986084351 .4361877441349 .6682128906347 .9729003906 346.1838989258344 .2775878906342 .0625339 .8844909668338 .5964050293336 .0516967773 330.1832885742323 .7236938477319 .2464904785315 .7102966309312 .5621032715 309.9621887207307 .7217102051305 .903503418304 .5935058594303 .2656860352 301.4071044922299 .4700927734297 .7813110352295 .9061889648293 .4354858398 289.7535095215284 .3319091797277 .9183044434270 .8400878906264 .9982910156 262.4863891602261 .6250915527260 .6390991211259 .4919128418257 .5975036621 254.9664001465252 .1549987793249 .046005249245 .4799957275241 .9893035889 239.1985015869236 .4606018066232 .8979034424229 .5283050537227 .0892028809 225.1602020264223 .8202972412222 .5079956055220 .8547058105218 .8865966797 216.6280975342214 .2682952881211 .7023010254209 .6497039795208 .9752960205 208.3152008057206 .3291015625203 .9378967285201 .804397583199 .7469024658 197.9017944336196 .1992950439194 .5677032471192 .9412994385191 .2465057373 189.3403015137186 .9756011963184 .4972991943182 .2149963379180 .004196167 177.875793457175 .7086029053173 .4057006836171 .0397949219168 .6613006592 
166.3146972656163 .9824981689161 .6596069336159 .2698059082156 .9423065186 154.7776947021152 .7794036865151 .1295013428149 .3099975586146 .8094940186 144.1441955566141 .7068939209139 .3683929443137 .0449066162134 .7447052002 132.4178924561130 .1961975098128 .3217926025126 .4142990112124 .2304992676 121.8031997681119 .1349029541116 .4070968628113 .8600997925111 .3516998291 108.7991027832106 .2005996704103 .489402771100 .73300170997 .94068145752 95.3013916015692 .9954986572391 .2878265380990 .4101409912190 .09265136719 89.98845672607 89.91972351074 89.60764312744 88.99952697754 88.00538635254 86.5830307006884 .7401580810582 .4829483032279 .8534317016676 .97367858887 73.9356231689570 .9457473754968 .1937408447365 .8277511596764 .07161712646 62.6696701049861 .4548110961960 .2707214355558 .8354301452657 .45133972168 56.3993301391655 .2611999511753 .6260490417551 .651641845749 .24361038208 46.6798095703143 .9639816284241 .2591896057138 .7299995422436 .26541900635 34.1595306396532 .280830383330 .7721004486129 .4940795898428 .25419998169 27.1158790588425 .951869964624 .7886295318623 .4969005584722 .06929969788 20.3701896667518 .3298301696815 .7940797805812 .266280174268 .787528991699 .2072139978409-20.5407009125 -41.0478515625 -48.8759384155 -51.9624099731 $-55.0526695251-56.8303489685-57.7358589172-58.3763198853-59.7874603271$ $-61.2949104309-62.4323692322-63.1622886658-63.3257217407-62.9854316711$ $-62.2307510376-61.2777900696-60.3806304932-59.5354804993-58.7960586548$ $-58.1032485962-57.4294204712-56.7455482483-56.0205802917-55.2535400391$ $-54.4171104431-53.5252685547-52.5638198853-51.5655593872-50.5507698059$ $-49.5498008728-48.5801506042-47.6729202271-46.8558998108-46.1339302063$ $-45.5337104797-45.0200500488-44.5797805786-44.1826286316-43.7942199707$ $-43.4003791809-42.9739990234-42.5043907166-41.9726104736-41.363861084$ $-40.6581497192-39.842048645-38.8948287964-37.8110809326-36.5643692017$ $-35.1940193176-33.7024612427-32.1824302673-30.8701896667-29.3213100433$ -26.9509906769-24.5357208252 -22.6692790985-21.1372890472 -19.9677505493 -19.035200119-18.5303497314 -17.3341293335 -13.8120498657 -10.4058198929 -8.88321685791 -8.09364509583 -8.02241230011 -7.36261320114-4.95932722092 -2.05717396736.4624350070953 3.0775020122536.01284122467 9.145275115967 12.7998304367116 .0517406463617 .9664802551319 .2766895294220 .47192955017 21.4417190551822 .2034091949522 .808029174823 .295059204123 .73055076599 24.1768798828124 .7011604309125 .3647499084526 .1116695404126 .88072013855 27.6422691345228 .3573398590129 .024480819729 .641189575230 .20667076111 30.727539062531 .2113094329831 .6670207977332 .101150512732 .52124023438 32.9349288940433 .3583488464433 .7917594909734 .2435989379934 .7127494812 35.2019996643135 .709819793736 .2359809875536 .7791404724137 .33779144287 37.9108390808138 .4963798522939 .0935401916539 .7003211975140 .31597137451 40.93862152141 .5675811767642 .2011604309142 .8387489318843 .47882843018 44.1208610534744 .7635612487845 .4064102172946 .0483016967846 .68878173828 47.3269004821847 .9622383117748 .5940093994149 .2218284606949 .84505844116 50.4633903503451 .0763015747151 .6835594177252 .2847595214852 .87976074219 53.4682998657254 .0502891540554 .6255798339855 .1941719055255 .7560005188 56.3111190795956 .8595581054757 .4014091491757 .9367599487358 .46572875977 58.9884605407759 .5050392150960 .0156517028860 .5204010009861 .01945877075 
61.5129318237362 .000980377262 .4837112426862 .9614410400463 .4337310791 63.9018287658764 .36401367188

722.4163208008718 .249206543714 .0469970703709 .7944946289705 .5142822266 701.2034912109696 .861328125692 .4876708984688 .0819702148683 .6433105469 679.1713256836674 .6646728516670 .1234130859665 .546875660 .9354248047 656.2888793945651 .608581543646 .8955078125642 .1513061523637 .3778076172 632.5772705078627 .7526245117622 .9063720703618 .0418701172613 .1622924805 608.2714233398603 .3721923828598 .4691162109593 .5645141602588 .6627197266 583.7653198242578 .8759155273573 .9948120117569 .1267700195564 .2666015625 559.4157714844554 .5584716797549 .6873168945544 .7788696289539 .8223266602 534.7819824219529 .640625524 .3740844727518 .981628418513 .4052734375 507.6167907715501 .5559082031495 .196105957488 .4413146973481 .2420043945 473.495300293465 .1630859375455 .9653930664445 .5712890625435 .8312988281 428.2255859375421 .0107116699412 .2843017578404 .7716064453400 .8265991211 398.2171020508395 .5386047363393 .0566101074391 .1731872559390 .2526855469 390.446685791390 .9671936035391 .4772033691392 .3019104004393 .7275085449 393.4053955078388 .8995056152382 .1636962891374 .9941101074368 .3641052246 363.4715881348359 .7319030762356 .4349975586353 .7330932617351 .7766113281 350.0521850586348 .0127868652345 .6922912598343 .0035095215340 .8407897949 339.5947875977338 .2206115723335 .8629150391332 .2662963867327 .9100036621 323.7286987305320 .4750976562318 .0017089844315 .9950866699314 .25312 .5819091797 310.8728027344309 .1029052734307 .4226989746305 .9483947754304 .6986083984 303.7290039062300 .9750976562294 .3734130859286 .4101867676279 .136505127 273.3283081055270 .2182922363268 .8380126953267 .7641906738266 .6812133789 265.1625976562262 .7692871094259 .5751037598256 .2202148438252 .7987976074 249.5587005615247 .0016937256244 .4188995361240 .9114074707237 .5731048584 235.2303924561 233.6013031006233.0162963867 232.2312927246230.0520935059 227.3488006592224 .7472991943222 .2642974854219 .9210968018218 .0892028809 217.0957946777216 .1654968262214 .5310974121212 .495300293210 .3173980713 208.1363067627206 .2218017578204 .4523925781202 .7350006104201 .0442962646 199.3038024902197 .4053039551195 .1679992676192 .8193969727190 .6015930176 188.483001709186 .5348052979184 .4488983154181 .9275970459179 .2456970215 176.6394042969174 .0942993164171 .6376953125169 .2438964844166 .8305053711 164.4815979004162 .2308959961160 .0856018066158 .137298584156 .0390930176 153.4936981201150 .7998962402148 .225402832145 .6968994141143 .1806945801 140.7277984619138 .3173980713136 .0303039551133 .9353942871131 .757598877 129.362197876126 .7322998047123 .8932037354120 .9750976562118 .1231994629 115.2763977051112 .4097976685109 .5021972656106 .5314025879103 .504699707 100.428497314597 .3445129394594 .2095870971791 .9417572021591 .51878356934 91.8505020141691 .9524078369191 .8504180908291 .3552169799890 .47682189941 89.1939315795987 .4400329589885 .164482116782 .4470977783279 .36418914795 76.0061035156272 .4572067260768 .8845672607465 .3695220947362 .4520111084 60.7846107482959 .6684188842858 .5751609802257 .4656486511256 .13869094849 54.7985000610453 .5656013488852 .2004508972250 .405139923148 .26699829102 45.7420196533243 .1679496765140 .6655502319338 .4133796691936 .6565284729 34.9687118530333 .1575813293531 .4186401367229 .9650802612328 .71320915222 
27.59885025024 26.6124095916725.6574993133524.7498703002923.8120098114 22.780340194721 .5559101104719 .8318290710417 .23961067214 .86573982239 $13.934789657599 .445013046265-4.21482801437-20.2705192566$-31.8410205841 $-40.7541885376-47.1690483093-51.2673988342-53.4508399963-54.795009613$ $-56.584400177-58.4243507385-60.2600784302-61.6693382263-62.2462081909$ $-62.2173309326-61.7007789612-60.8198318481-59.7945785522-58.7378883362$ $-57.8945007324-57.168548584-56.4771995544-55.7919082642-55.0725402832$ $-54.3226890564-53.5261306763-52.6906394958-51.8066291809-50.8980407715$ $-49.9795684814-49.0793914795-48.2210083008-47.4280014038-46.7229499817$ $-46.0914306641-45.5456695557-45.0640792847-44.646900177-44.2676086426$ $-43.8894309998-43.4977493286-43.0688095093-42.5910186768-42.0487785339$ $-41.4231796265-40.6930084229-39.8441810608-38.859249115-37.7259292603$ $-36.4287796021-34.9674911499-33.3325386047-31.5417709351-29.5978393555$ $-27.6938209534-25.986120224-24.4510593414-23.0583305359-21.7604904175$ $-20.6109409332-19.4906692505-18.4076499939-16.7054691315-13.4510698318$ $-10.1610603333-8.10719585419-6.9579539299-6.89761400223-6.70831489563$ $-5.46107196808-3.63895702362-1.67427599430 .6075869798663 .513134002686$ 6.84368801116910 .6748304367114 .2022199630716 .5583992004418 .28010940552 19.7004604339620 .827909469621 .6902198791522 .3316001892122 .82735061646 23.2149906158423 .5337390899723 .9740505218524 .7492198944125 .64768981934 26.4902706146227 .2917003631628 .0332603454628 .7213497161929 .35704994202 29.9392700195330 .473009109530 .9656906127931 .4204902648931 .85020065308 32.264369964632 .6715316772533 .0903091430733 .5221710205133 .97452926636 34.4463691711434 .9395294189535 .4523506164635 .9841194152836 .5331993103 37.0979614257837 .6769599914638 .2683296203638 .8708496093839 .48271942139 40.1028594970740 .7296409606941 .3621292114341 .9988517761242 .63901138306 43.2812995910643 .9250488281244 .5691184997645 .2129096984945 .85544967651 46.4962005615247 .1343193054247 .7693405151448 .4005508422949 .02753829956 49.6497001647950 .2667312622150 .8781204223651 .4836502075252 .08293151855 52.6758384704653 .2621002197353 .8416709899954 .4143791198754 .98025894165 55.5392494201756 .0914192199756 .6367988586457 .1755104064957 .70763015747 58.2333106994658 .7526817321859 .2658805847259 .7730598449760 .27436828613 60.7699699401961 .2600097656261 .7446212768662 .2239494323762 .69832992554 63.1678390502963 .6292304992764 .08483123779

728.6234130859724 .5050048828720 .3693237305716 .1998291016712 .0023803711 707.7775878906703 .5255126953699 .2457275391694 .9381713867690 .6027832031 686.239074707681 .8466186523677 .4251708984672 .9744262695668 .4948730469 663.9865722656659 .4508056641654 .8884277344650 .3013916016645 .69140625 641.0609130859636 .4127197266631 .7493286133627 .0744018555622 .3906860352 617.7022094727613 .0114746094608 .3226928711603 .6375732422598 .9603881836 594.2913818359589 .6337890625584 .9873046875580 .3585205078575 .7354736328 571.1182250977566 .4860229492561 .8306884766557 .1265258789552 .3673095703 547.5228271484542 .5983886719537 .5498046875532 .3814697266527 .0241699219 521.4708862305515 .6301269531509 .4858093262502 .9219055176495 .9202880859 488.3051147461480 .0252990723470 .8175048828459 .6506958008449 .0551147461 441.8031005859434 .6644897461423 .7593078613413 .7092895508408 .9971008301 
406.7797851562405 .6520080566405 .3633117676404 .291809082403 .3522949219 403.6184997559403 .7712097168402 .9211120605402 .3586120605403 .8920898438 403.9957885742399 .1690063477392 .2102050781385 .0498046875377 .6358947754 371.1051025391365 .3319091797360 .6471862793357 .3505859375355 .1286010742 353.2749938965351 .0899047852348 .4383850098345 .6561889648343 .1796875 340.7730102539339 .574005127340 .2392883301340 .3089904785337 .1513061523 333.0654907227330 .1494140625327 .6752929688325 .7134094238323 .8677062988 321.6874084473319 .7142028809318 .237487793317 .0180053711315 .8182983398 314.7443847656314 .7355041504312 .7484130859305 .4945068359296 .9093017578 290.0958862305284 .908203125281 .4945068359278 .8746948242276 .400390625 274.2633056641272 .7304992676271 .1888122559268 .0512084961264 .4024963379 261.0264892578258 .0711975098255 .7059020996253 .0977935791249 .4738006592 245.7743988037243 .2185974121241 .6860961914241 .6591033936241 .3623046875 238.8164978027235 .5975952148232 .93699646230 .5135040283228 .459197998 226.7651062012225 .1979064941223 .6607055664222 .1703033447220 .4750061035 218.3554992676216 .1844024658214 .2949066162212 .5021972656210 .7270965576 208.9512023926207 .0821990967205 .1148071289202 .975402832200 .7810974121 198.6522979736196 .5906066895194 .7819976807192 .7677001953190 .0809936523 187.1846923828184 .4367980957181 .7680053711179 .225692749176 .7667999268 174.2835998535171 .845703125169 .4382019043167 .0594024658164 .7295074463 162.3226013184159 .8000030518157 .18699646154 .5484008789151 .9075012207 149.2684020996146 .679901123144 .1352996826141 .6437072754139 .1996002197 136.7037963867134 .1417999268131 .4449005127128 .6067962646125 .6493988037122 .625 119.543296814116 .4543991089113 .3356018066110 .1918029785107 .0030975342 103.7676010132100 .499298095796 .8376998901494 .1595306396594 .0911026001 94.8532867431694 .9045410156294 .6315231323293 .8563919067492 .60133361816 90.993721008388 .8758010864386 .2009963989383 .0614929199279 .59422302246 75.8267822265671 .8447418212967 .7846069335963 .5770683288660 .14052963257 58.5083808898957 .6117286682156 .5903205871655 .5557518005454 .38010025024 53.0716209411651 .5897712707549 .8778610229547 .8109016418545 .45283126831 42.734649658239 .9909591674837 .38784027135 .2610015869134 .034740448 32.9919586181631 .5052604675329 .9211292266828 .6006202697827 .41926002502 26.4388008117725 .5906105041524 .7665405273424 .0135898590123 .2518196106 22.4449291229221 .5128307342520 .2131004333517 .7576599121115 .73927021027 $15.8657503128114 .179710388187 .696061134338-2.63484692574-16.590839386$ -30.2884597778 -39.3748893738 -45.5041618347 -48.9927597046 -51.0248298645 $-53.1494102478-55.1427497864-57.5018997192-59.4519004822-60.4020195007$ $-60.6376495361-60.3450088501-59.5979194641-58.5946311951-57.5078887939$ -56.6859092712 -55.9815406799-55.3050498962 -54.6561889648 -53.970199585 $-53.2675209045-52.5290412903-51.7672691345-50.9720115662-50.1662406921$ $-49.3511009216-48.5600585938-47.8133010864-47.1238288879-46.5120391846$ $-45.9662094116-45.4856910706-45.0588493347-44.6815185547-44.3244514465$ $-43.9584617615-43.5707397461-43.1399612427-42.6551094055-42.1034698486$ $-41.4618415833-40.709148407-39.8290596008-38.8108100891-37.631980896$ -36.292350769 -34.7491111755 -32.9831199646 -30.9703598022 -28.4459705353 $-26.2014808655-25.0969009399-24.3357505798-23.3018703461-22.1827602386$ 
-21.0615005493 -19.6875991821 -17.9152393341 -15.6417798996 -12.6409101486 -9.51998901367 -6.82636976242 -5.05194997787 -4.66802310944-4.87974214554 $-5.01987218857-4.7334151268-3.74492907524-1.943390011790 .867879986763$ 4.3725481033338 .31035995483412 .0634002685514 .9571104049717 .21150970459 18.9479408264220 .242599487321 .2096004486121 .913089752222 .44055938721 22.8304004669223 .0702896118223 .4472103118924 .3041496276925 .30208969116 26.1696701049826 .9839496612527 .7345504760728 .4266605377229 .07271003723 29.6679992675830 .2194404602130 .719730377231 .1699695587231 .58592987061 31.9902801513732 .3926315307632 .809989929233 .2432403564533 .69934082031 34.1767807006834 .6766395568835 .1972198486335 .7369918823236 .29452133179 36.8673591613837 .4544105529838 .0531311035238 .662670135539 .28073120117 39.9065895080640 .5382499694841 .1750907897941 .8154106140142 .45866012573 43.1034011840843 .7491302490244 .3946495056245 .03947830245 .6826210022 46.3236198425346 .9616203308147 .5962104797448 .2266616821348 .85263824463 49.4735183715850 .0890197753950 .698661804251 .3022193908751 .89934921265 52.4899101257353 .073661804253 .6505508422954 .2204513549854 .78339004517 55.3393096923855 .8883094787656 .4304389953656 .9657897949257 .49449920654 58.0166893005458 .5325393676859 .0421600341859 .5457496643160 .04344940186 60.5354499816961 .0218811035261 .502929687561 .9787101745662 .44958114624 62.9151191711463 .3766098022563 .83235931396

734.8560791016730 .8331298828726 .7830810547722 .6907958984718 .5761108398 714.4371948242710 .2744750977706 .0885009766701 .8790283203697 .6464233398 693.3905029297689 .111328125684 .8088989258680 .4829711914676 .1345214844 671.7631835938667 .3707885742662 .9581298828658 .5270996094654 .0795898438 649.6181030273645 .145324707640 .6641235352636 .1779785156631 .6895751953 627.2031860352622 .7208862305618 .2465820312613 .7817993164609 .330078125 604.8911743164600 .4674072266596 .0590209961591 .671081543587 .2899780273 582.9100952148578 .5134277344574 .0885009766569 .6143188477565 .0778198242 560.4683227539555 .7891235352551 .0072021484546 .1151123047541 .0560913086 535.8103027344530 .2937011719524 .4644775391518 .2286987305511 .5237121582 504.2488098145496 .2937011719487 .6477966309478 .3724060059468 .9352111816 459.3649902344449 .7496948242440 .0734863281430 .4601135254421 .2106933594 414.9512023926414 .0203857422415 .0809020996414 .7596130371413 .953704834 413.4836120605412 .6644897461411 .1390991211409 .687713623409 .1364135742 407.6093139648403 .0161132812397 .2990112305392 .354095459386 .6391906738 379.8562011719372 .9696044922367 .1900024414363 .182800293360 .7380065918 358.7320861816356 .2344055176353 .2435913086350 .7652893066348 .0545959473 343.500213623341 .1000061035343 .854095459346 .9890136719346 .2466125488 343.8070068359341 .591003418339 .3147888184336 .9939880371334 .5887145996 332.1383056641330 .2278137207329 .3503112793328 .716796875327 .5733947754 326.1541137695324 .6600952148321 .6153869629315 .8078918457308 .9610900879 302.487487793297 .6488952637295 .7486877441292 .8977966309285 .5385131836 278.8670959473277 .9757995605278 .6274108887276 .6897888184273 .6373901367 270.4067077637267 .7799072266266 .4325866699264 .3817138672259 .5354919434 254.2434997559250 .8706054688248 .9902954102248 .6163024902248 .1884002686 246.1143035889243 .4622955322241 .1112976074238 .9266967773236 .929397583 
235.1101074219233 .3233947754231 .4387054443229 .474395752227 .5576019287 225.712600708223 .891204834222 .112701416220 .3414001465218 .5341033936 216.6728057861214 .7194061279212 .6956939697210 .5628051758208 .4120941162 206.3009033203204 .2210998535202 .2611999512200 .1190032959197 .5388031006 194.774597168192 .0467987061189 .3562927246186 .7355041504184 .1558074951 181.570098877178 .9889984131176 .3997955322173 .7955932617171 .1983032227 168.5971984863165 .9891052246163 .3605041504160 .691696167157 .9911956787 155.2740020752152 .5641021729149 .8701934814147 .1627960205144 .4228973389 141.6896057129139 .0444030762136 .3690948486133 .4958953857130 .4801940918 127.3470993042124 .12449646120 .9150009155117 .7013015747114 .4806976318 111.2770996094108 .1156005859105 .0207977295101 .94560241799 .70722198486 99.2433624267699 .4120635986399 .0797119140698 .3851394653397 .1780090332 95.490936279393 .425369262790 .9051666259887 .8878784179784 .4499206543 80.6727828979576 .6109924316472 .3371505737367 .9541397094763 .4833984375 59.8366012573257 .9663009643656 .9007911682155 .8142089843854 .7293510437 53.513259887752 .1067581176850 .423130035448 .4311408996646 .07329940796 43.4193000793540 .413360595737 .2888908386234 .1131095886231 .61862945557 30.6055698394830 .021339416528 .9900398254427 .8142395019526 .72439002991 25.7226295471224 .850240707424 .0659408569323 .3105602264422 .60080909729 21.8801097869921 .1671009063720 .4410400390619 .4752101898217 .95414924622 16.7348899841316 .7447204589815 .823479652410 .926779747012 .191911935806 -10.1563301086 -23.3085308075 -32.955280304 -39.764339447 -43.9736785889 $-46.6851005554-49.0974311829-51.2750282288-53.6896095276-55.7461509705$ $-56.9731788635-57.5333595276-57.5681800842-57.1786499023-56.5195617676$ $-55.7284317017-55.0664787292-54.467880249-53.890209198-53.3162384033$ $-52.7126617432-52.0875701904-51.4380989075-50.7692909241-50.0789299011$ $-49.3826293945-48.6854400635-48.0089797974-47.3684005737-46.7687797546$ $-46.2208404541-45.738658905-45.3509292603-45.0119400024-44.6844100952$ $-44.355091095-44.0039100647-43.6201896667-43.1879615784-42.696811676$ $-42.1361312866-41.4814109802-40.7095909119-39.8066482544-38.7600708008$ -37.5501403809 -36.1666908264 -34.5796890259 -32.772190094 -30.7257709503 -28.3854007721 -26.37225914 -25.2161502838 -24.4225692749 -23.5079593658 $-22.4608707428-21.3397293091-19.8396396637-17.8271903992-15.3507099152$ $-12.2007303238-8.67702198029-4.79056119919-2.04731607437-2.30730199814$ -3.81636691093 -4.90624809265 -5.65266895294 -5.8299407959-4.81626605988 -1.96374499798 1.887400031096.07403182983410.1689500808713.55288982391 16.2945804595918 .2587394714419 .6718902587920 .7512798309321 .54952049255 22.1643199920722 .6294403076222 .9926605224623 .4537601470924 .23686027527 25.1312999725325 .9593791961726 .7419891357427 .4696102142328 .15138053894 28.7897796630929 .3922004699729 .9715900421130 .492250442530 .91827011108 31.3023796081531 .6942596435532 .0942611694332 .5140495300332 .95341873169 33.4171218872133 .9035797119134 .4134216308634 .9444999694835 .49514007568 36.0633697509836 .6467208862337 .2436103820837 .8516197204638 .46950912476 39.0951995849639 .727680206340 .3652191162141 .0069885253941 .65155029297 42.2982101440442 .9457588195843 .5935897827144 .2407188415544 .8865814209 45.5303115844746 .1714286804246 .8091812133847 .4431495666548 .07266998291 
48.697399139449 .3167610168549 .9304885864350 .5381088256851 .13945007324 51.7341384887752 .3220901489352 .9030609130953 .4770202636754 .04384994507 54.6035881042555 .1562004089455 .7018013000556 .2404212951756 .77220916748 57.2972793579157 .8157882690458 .3278999328658 .8337707519559 .33359146118 59.8275108337460 .3157386779860 .798408508361 .2757110595761 .74779891968 62.2150306701762 .6775207519563 .1321296691963 .58126068115

741.2211914062737 .2521972656733 .2697143555729 .2592773438725 .2269287109 721.1737060547717 .1002197266713 .0070800781708 .8950805664704 .7642822266 700.6154785156696 .448425293692 .263671875688 .0612182617683 .8419189453 679.6062011719675 .3555297852671 .0905761719666 .8139038086662 .5272216797 658.2329101562653 .9340820312649 .6334838867645 .3348999023641 .0407714844 636.7554931641632 .4807128906628 .2205200195623 .9755859375619 .7495727539 615.5413818359611 .3532714844607 .1840209961603 .0394897461598 .9022216797 594.7653808594590 .609375586 .4260864258582 .1948242188577 .9071044922 573.5562744141569 .1585083008564 .6754760742560 .11328125555 .4055175781 550.5502929688545 .4373168945540 .0427856445534 .2327270508527 .928527832 521.1267700195513 .5670166016505 .9328918457499 .0924072266490 .8269958496 478.548614502466 .0350952148457 .6339111328449 .4088134766436 .6594848633 426.2159118652424 .3375854492425 .2522888184424 .5065002441423 .3547973633 421.9974975586420 .1640014648418 .2101135254415 .8302001953412 .775390625 409.0994873047404.366394043 399.7022094727 396.7549133301 393.4017028809 387.9903869629381 .7200927734376 .2640075684371 .6301879883368 .1795959473 365.3912963867362 .8034973145360 .6090087891359 .7202148438358 .3627929688 352.6455078125348 .6897888184351 .8920898438356 .5105895996357 .3711853027 356.7236022949355 .5280151367353 .2796936035350 .9417114258348 .0389099121 345.621887207343 .8655090332343 .2294006348343 .1445922852341 .8587036133 339.841003418336 .3575134277332 .4064025879328 .8569030762324 .8767089844 319.5244140625314 .2644958496312 .7307128906309 .7431030273298 .4632873535 288.4100036621288 .3673095703290 .2148132324288 .7185974121286 .2803955078 283.388885498280 .6802062988279 .0043945312276 .7045898438270 .549987793 264.1032104492260 .0075073242257 .279510498256 .1430969238255 .2579040527 253.5072021484251 .3394012451249 .5885925293247 .7969055176245 .7285003662 243.4779968262241 .3753051758239 .2528076172236 .8562927246234 .6436004639 233.037902832231 .5608978271229 .8878936768228 .1242980957226 .2583007812 224.3074035645222 .2714996338220 .1665039062217 .9918060303215 .8007965088 213.6405029297211 .4600067139209 .2861938477207 .0115966797204 .6092987061 202.0955963135199 .4898071289196 .8256988525194 .1490020752191 .4611053467 188.7487030029186 .0101013184183 .2265930176180 .3997039795177 .5690002441 174.7899932861172 .1051025391169 .4611053467166 .783493042164 .0594024658 161.2937011719158 .4832000732155 .6441040039152 .7545928955149 .7834014893 146.8780975342144 .2122955322141 .5397949219138 .5982055664135 .4875030518 132.2767028809128 .995300293125 .7498016357122 .5258026123119 .2956008911 116.1563034058113 .1474990845110 .4461975098108 .2282028198106 .6240997314 105.7677993774105 .1054992676104 .1315002441102 .7974014282101 .0477981567 98.9088134765696 .4109268188593 .5129089355590 .2239227294986 .56260681152 82.5649414062578 .3068389892673 .8556671142669 .3835906982464 .91738128662 
61.1752586364758 .9541282653857 .4952888488856 .1646118164154 .93429946899 53.598068237352 .0394401550350 .1609382629447 .9225997924845 .28445053101 42.3167381286638 .9601097106935 .4836883544931 .7238998413128 .69000053406 27.5647792816227 .073799133326 .3006496429425 .4943695068424 .67053031921 23.8331794738823 .0741691589422 .3288993835421 .6211395263720 .89443969727 20.1160297393819 .3792800903318 .7141799926818 .1902008056617 .72522926331 17.2903499603316 .7399692535414 .812740325939 .4255371093751 .331037998199 -8.43310260773 -18.9285907745 -27.6056194305 -34.457408905 -39.1729316711 $-42.3639602661-45.0638885498-47.3024597168-49.5250701904-51.4540405273$ $-52.8478012085-53.7442588806-54.1379508972-54.1369094849-53.9451599121$ $-53.5884399414-53.1999893188-52.7655296326-52.3165283203-51.8492584229$ $-51.3465499878-50.8227996826-50.2797203064-49.722820282-49.1494789124$ $-48.5754508972-47.9994697571-47.4387817383-46.898311615-46.3894195557$ $-45.9087486267-45.493850708-45.1987380981-44.9412994385-44.6596488953$ $-44.3569107056-44.0201187134-43.6394805908-43.2055397034-42.7066497803$ $-42.1369781494-41.4688796997-40.6820411682-39.7598190308-38.6944198608$ -37.4603881836 -36.0475692749 -34.4439888 -32.6448097229 -30.743719101 -28.8250904083 $-27.1198406219-25.7630290985-24.6476898193-23.6331195831-22.5668392181$ $-21.436170578-19.9593391418-18.0066509247-15.4489202499-12.1371803284$ $-8.29065704346-3.49873590469-0.14475800097-1.0460100174-3.4485270977$ $-4.98992681503-6.23407411575-7.21359920502-6.83881807327-4.01547384262$ .01112200040374 .2676749229438 .52764892578112 .257430076615 .3839302063 17.5478096008319 .1004199981720 .3236904144321 .2236595153821 .94144058228 22.5223293304423 .0606307983423 .6244602203424 .3019199371325 .03552055359 25.7803802490226 .5130100250227 .2078304290827 .867740631128 .49271011353 29.0899295806929 .6854190826430 .2198505401630 .6262893676830 .98871040344 31.3784809112531 .7812900543232 .2079086303732 .657508850133 .1322593689 33.6313705444334 .154159545934 .6988601684635 .2627716064535 .84426116943 36.4399185180737 .0485992431637 .6671600341838 .294788360638 .92892074585 39.5689392089840 .2128295898440 .860069274941 .5090904235842 .15940856934 42.8097915649443 .4597892761244 .1083908081144 .7551918029845 .39931869507 46.0403709411646 .6776390075747 .3107299804747 .939029693648 .5622215271 49.1797599792549 .7914009094250 .3967018127450 .9954795837451 .58744049072 52.1724700927752 .7503585815453 .3210906982453 .8845596313554 .44081115723 54.9898605346755 .5317687988356 .0666503906256 .5946197509857 .11582946777 57.6304206848158 .1385993957558 .6405105590859 .1363601684659 .62630844116 60.1105804443460 .5893096923861 .0627212524461 .5309410095261 .99436950684 62.4525985717862 .9069213867263 .35569000244

747.6115112305743 .7313232422739 .8319091797735 .8983764648731 .9475708008 727.979309082723 .9942016602719 .9932861328715 .9776000977711 .9476928711 707.9041748047703 .8477783203699 .7791137695695 .6981201172691 .6062011719 687.5037841797683 .3925170898679 .2733154297675 .1486816406671 .020324707 666.8912963867662 .7644042969658 .642578125654 .5297241211650 .4282836914 646.3425292969642 .2741699219638 .2271118164634 .2017211914630 .201171875 626.2244262695622 .2728881836618 .3450927734614 .4451293945610 .5562133789 606.6696166992602 .7661743164598 .8284912109594 .852722168590 .8361816406 
586.7786865234582 .690612793578 .5513916016574 .3621826172570 .0758056641 565.6801757812561 .0756835938556 .2147827148550 .9426269531545 .1384887695 538.7993774414531 .7672729492525 .0477294922519 .3483276367511 .1947937012 497.4696960449483 .2774047852473 .5999145508465 .0056152344454 .6495056152 445.487701416440 .695892334438 .2963867188435 .746307373433 .209197998 430.749206543428 .0674133301425 .1348876953421 .5429077148416 .8811950684 411.6781921387405 .8566894531400 .7786865234397 .0508117676394 .3269042969 392.9892883301390 .7929992676387 .308013916383 .0219116211376 .9216918945 371.7594909668370 .3192138672370 .8525085449373 .9274902344376 .3118896484 372.9437866211369 .458190918370 .2766113281372 .5578918457373 .5226135254 373.704498291372 .8566894531370 .8629150391368 .682800293365 .8099060059 362.9833068848360 .6762084961359 .0513916016358 .200592041357 .3534851074 355.4884033203351 .3792114258347 .8322143555347 .3446044922346 .924987793 343.3222045898337 .6857910156331 .951385498325 .6355895996318 .0273132324 312.1870117188311 .017791748310 .5299987793307 .0982971191303 .2182006836 300.9531860352297 .9856872559291 .6221923828285 .1209106445280 .488494873 276.1518859863271 .1029968262267 .1007080078266 .091796875265 .478302002 262.4403076172259 .304107666258 .5559997559257 .8671875255 .1197052002 251.817199707249 .2639007568246 .9739990234244 .6614074707242 .6096038818 240.9848022461239 .4853057861237 .7980957031235 .9635009766233 .9685974121 231.8867034912229 .7657012939227 .5733032227225 .295501709223 .0016937256 220.7194976807218 .4188995361216 .1544952393213 .8820953369211 .5753936768 209.2252044678 206.7223968506204.0870056152 201.4064025879 198.6658935547 195.8632965088192 .9976959229190 .0415039062186 .9956970215183 .8719940186 180.8699951172178 .1920928955175 .62159729172 .9566040039170 .2221069336 167.4190063477164 .5471038818161 .6201019287158 .6251983643155 .5476989746 152.5688934326149 .8822937012147 .1676025391144 .0455932617140 .7454986572 137.462600708134 .175201416130 .9436950684127 .7726974487124 .6218032837 121.6014022827118 .7567977905116 .3441009521114 .5254974365113 .2276992798 112.6784973145111 .8926010132110 .0686035156107 .7982025146105 .4334030151 102.850700378499 .9912567138796 .8172988891693 .3012466430789 .47807312012 85.3536071777381 .0133666992276 .5161590576272 .0663909912167 .78980255127 64.0587005615261 .3728103637759 .3350410461457 .7157211303756 .29549026489 54.7571716308653 .0077896118250 .9180603027348 .4476013183645 .52452850342 42.2367706298838 .5638198852534 .803710937531 .0499191284227 .92432975769 26.1789493560825 .1276092529324 .2160892486623 .4768905639622 .71866035461 21.9647502899221 .271060943620 .585309982319 .9163799285919 .16283035278 18.2185707092317 .2967491149916 .5189094543516 .1377391815216 .32366943359 16.2175807952915 .2458200454712 .640780448917 .2620000839230 .314523011446 -7.72190093994 -16.2915992737 -24.4630699158 -31.485370636 -35.9978599548 -39.0934295654 -41.7393913269-43.8519210815 -45.5801811218-47.1457710266 $-48.7757301331-50.0944290161-50.6600799561-50.8862113953-51.1181907654$ $-51.2112617493-51.1240501404-50.8973808289-50.6032104492-50.2608718872$ $-49.8801002502-49.4710502625-49.0519599915-48.6208190918-48.1836891174$ $-47.7435913086-47.2926101685-46.8454093933-46.4073905945-45.9964294434$ -45.6373901367-45.3339004517-45.0938911438 -44.8703994751-44.6187705994 
$-44.33411026-44.0063591003-43.6280288696-43.1899490356-42.6836891174$ $-42.1031990051-41.424369812-40.6259613037-39.6966590881-38.6262016296$ -37.3984603882 -36.0002593994 -34.4363708496 -32.6919784546 -30.9207191467 $-29.2075805664-27.601940155-26.2177791595-24.9659805298-23.8457298279$ $-22.7547607422-21.5868091583-20.2159690857-18.5947608948-16.3162307739$ -12.8962802887 -8.95265007019-4.83894205093 -2.08394002914 -2.37856793404 $-4.0026512146-5.39726114273-6.56953907013-7.2702050209-6.74762201309$ $-4.17121887207-.5108870267873 .416847944267 .41135501861611 .12452030182$ 14.3847103118916 .7869091033918 .5918197631819 .9542293548620 .95948982239 21.753690719622 .4130706787123 .0385704040523 .6333103179924 .26457023621 24.9077491760325 .5882701873826 .277269363426 .9310703277627 .55936050415 28.1648006439228 .7478694915829 .3125991821329 .8249397277830 .24727058411 30.6340999603331 .0360908508331 .4519195556631 .8919792175332 .35535812378 32.8456916809133 .3608207702633 .9003105163634 .4615097045935 .04169082642 35.6385612487836 .2488098144536 .8707504272537 .5014801025438 .1397895813 38.7834281921439 .4315185546940 .0823898315440 .7353286743241 .38909912109 42.043109893842 .6963806152343 .3484191894543 .9984207153344 .6459312439 45.2902412414645 .9309616088946 .5674514770547 .1993484497147 .82611083984 48.4474182128949 .0628013610849 .6720008850150 .2746200561550 .87052154541 51.45940017752 .0411682128952 .6156387329153 .1828193664653 .74261856079 54.2950897216854 .84025955255 .3782196044955 .9090805053756 .43297958374 56.950061798157 .4605102539157 .9645118713458 .4622383117758 .95391082764 59.4396896362359 .9197998046960 .3944206237860 .8637390136761 .32793045044 61.7873687744162 .2422103881862 .6894416809163 .1315612793

754.1071777344750 .2852783203746 .4536132812742 .5999145508738 .7299804688 734.8455810547730 .9479980469727 .0382080078723 .1176147461719 .1868896484 715.2474975586711 .2996826172707 .344909668703 .3831787109699 .4161987305 695.444519043691 .4697875977687 .4935302734683 .5181274414679 .5455932617 675.5789794922671 .6212768555667 .6760253906663 .7462768555659 .8353881836 655.9470825195652 .0833129883648 .2473754883644 .4400024414640 .6636962891 636.9172973633633 .2022705078629 .5158081055625 .862121582622 .2230224609 618.5916137695614 .9451293945611 .2617797852607 .5510253906603 .8225708008 600.075012207 596.3209838867592.5471191406 588.765625 584.9315185547 581.0477294922577 .0095825195572 .7830810547568 .200012207563 .1517944336 557.5230712891551 .3220214844544 .5363769531538 .2708740234530 .0540161133 515.981628418501 .3960876465490 .2593078613480 .9523925781473 .7833862305 467.3984069824460 .261505127453 .5903930664448 .207611084443 .8197937012 440.2196960449436 .7750854492433 .0609130859428 .4020080566422 .854309082 416.5899047852409 .7945861816403 .3750915527397 .655090332394 .4827880859 396.298614502399 .0668029785399 .8995056152396 .9696044922388 .0741882324 380.5958862305381 .1512145996386 .5577087402394 .1448974609400 .916595459 400.5179138184398 .4706115723396 .8388061523395 .0860900879395 .0144958496 394.1184997559391 .996887207389 .9036865234388 .966796875387 .5436096191 386.4478149414384 .786895752382 .9807128906381 .6462097168380 .2267150879 378.6888122559374 .753692627371 .736907959373 .2109985352374 .2062988281 371.3142089844365 .8959960938356 .9060974121348 .1948852539345 .3035888672 
343.8201904297341 .1140136719337 .9417114258332 .6947021484327 .7626953125 326.4823913574323 .1702880859312 .2655029297300 .6282043457295 .8046875 292.9204101562286 .2225952148280 .9426879883279 .0322875977277 .3475036621 272.4978942871268 .1854858398268 .2406921387268 .0657958984264 .6802978516 260.3768920898257 .5454101562255 .18800354253 .06300354251 .1697998047 249.4391021729247 .7301940918245 .9154052734243 .961807251241 .7937927246 239.5202026367237 .2772979736234 .9532928467232 .5679931641230 .1058044434 227.6219024658225 .1898956299222 .9033966064220 .708404541218 .487701416 216.2088012695213 .7469024658211 .157699585208 .5458068848205 .8007049561 202.9320983887199 .9362030029196 .8271942139193 .6318969727190 .2987060547 187.1235961914184 .4432983398181 .9071960449179 .2236022949176 .4696044922 173.6403045654170 .7303924561167 .7624053955164 .7382965088161 .6593933105 158.641494751155 .9095001221153 .0749969482149 .6902008057146 .2071075439 142.9013977051139 .6795959473136 .5131988525133 .4165039062130 .3526000977 127.4665985107124 .7636032104122 .4857025146120 .7848968506119 .5597000122 119.1967010498118 .4147033691115 .9798965454112 .9465026855110 .1242980957 107.1651992798104 .0255966187100 .671501159797 .0097732543993 .10668182373 88.9278030395584 .595291137780 .1266326904375 .7629470825271 .70037078857 68.0336532592864 .9131622314562 .3221817016660 .3875007629458 .70363998413 56.9159088134854 .9579582214452 .6924781799350 .0444412231446 .90045166016 43.3545494079639 .3965110778835 .3699684143131 .5655307769828 .32727050781 25.8601894378724 .1102905273422 .8754806518621 .9285793304421 .06739997864 20.2564792633119 .5841007232718 .9256000518818 .3128108978317 .59789085388 16.6158905029315 .6398801803614 .8140802383414 .373600006114 .76910018921 $14.7268495559713 .1875400543210 .111880302434 .988862037659-1.13977599144$ $-7.60571098328-14.5101804733-22.0200901031-28.8248691559-33.0382385254$ $-36.0241508484-38.7271881104-40.8123016357-42.1520195007-43.3661384583$ $-45.1438293457-46.717048645-47.3726005554-47.7413597107-48.3120384216$ $-48.7727584839-48.9685401917-48.9801712036-48.8675804138-48.655090332$ -48.3978691101 -48.1150016785-47.8235702515 -47.5345115662 -47.2454986572 $-46.9460601807-46.6149597168-46.2753982544-45.9379997253-45.6310195923$ -45.3971595764 -45.1935997009-44.9917907715-44.7810707092-44.5464897156 $-44.2728385925-43.9513511658-43.5720901489-43.1290206909-42.6129112244$ $-42.0213890076-41.3313102722-40.5255088806-39.5941009521-38.5293617249$ -37.3232917786 -35.9674987793 -34.4773902893 -32.8285293579 -31.1589698792 -29.5505104065 -28.0104103088 -26.5951309204 -25.2698707581 -24.0706501007 $-22.9072608948-21.7010192871-20.3795795441-19.0579605103-17.1153907776$ $-13.7622699738-10.1543798447-7.25376605988-5.31577014923-4.7968249321$ $-5.20032691956-5.98797798157-6.70360517502-6.76297807693-5.8881149292$ -3.63877701759-.5134099721912.936129093176.623154163361 10.26091957092 13.550669670116 .1192893981918 .109230041519 .5855693817120 .68988990784 21.5594406127922 .2689609527622 .9374694824223 .5457897186324 .14211082458 24.7305698394825 .3685493469226 .0123996734626 .6256103515627 .22366905212 27.8111190795928 .3756809234628 .9011096954329 .3896999359129 .83462905884 30.2587394714430 .6832008361831 .1174392700231 .5751495361332 .05620956421 32.5655097961433 .1002197265633 .6592216491734 .2398986816434 .83837127686 
35.4528007507336 .0788993835436 .7155113220237 .3590583801338 .00883865356 38.662250518839 .3187599182139 .9765815734940 .6352806091341 .29360961914 41.9511604309142 .6070518493743 .2608604431243 .9118995666544 .55978012085 45.2038993835445 .843891143846 .479209899947 .109508514447 .73432922363 48.3533401489348 .9661407470749 .5724792480550 .1720390319850 .7646484375 51.3500709533751 .9281997680752 .4989013671953 .0621604919453 .61795043945 54.1663093566954 .7072906494155 .2410011291555 .7675399780356 .28709030151 56.7997894287157 .3058280944857 .8054199218858 .2987289428758 .7859916687 59.2673797607459 .7431411743260 .2134284973160 .6784782409761 .13843917847 61.5937194824262 .0439796447862 .4904899597262 .93165969849

760.6273803711756 .8870239258753 .1350708008749 .3568115234745 .5667114258 741.7650146484737 .9534912109734 .1334228516730 .3062133789726 .4730834961 722.6356201172718 .7946166992714 .9511108398711 .1060791016707 .2611083984 703.4169921875699 .5759277344695 .7393188477691 .9099731445688 .0900268555 684.2827758789680 .4915161133676 .7194824219672 .9703979492669 .2473144531 665.553894043661 .8922119141658 .2653198242654 .673828125651 .1198730469 647.602722168644 .1229248047640 .6782836914637 .2725219727633 .8873291016 630.5120849609627 .1271972656623 .7086791992620 .2769165039616 .8444213867 613.419128418610 .0134277344606 .6273193359603 .2728881836599 .9251708984 596.5817871094593 .1738891602589 .6713867188585 .9340209961581 .9014282227 577.2067871094571 .7050170898564 .2395019531554 .0938720703543 .1398925781 532.4071044922521 .31640625508 .7950134277497 .958404541492 .2626037598 487.3371887207479 .6117858887470 .6174926758462 .1004943848455 .382598877 451.3345947266447 .9613037109443 .4932861328438 .0129089355432 .0882873535 425.3680114746417 .3478088379409 .0035095215401 .1795959473396 .6180114746 397.1666870117401 .6427001953410 .3486938477412 .866394043399 .3052062988 387.875213623394 .9094848633408 .7279052734419 .4153137207427 .8645935059 431.7260131836432 .874206543431 .4495849609428 .088104248425 .6838989258 421.9291992188415 .1723937988411 .2026977539414 .4883117676418 .9801025391 422.024810791423 .6910095215424 .9371032715425 .1246032715420 .6971130371 416.2684936523414 .9565124512414 .058013916411 .3001098633407 .4758911133 403.8850097656399 .5527038574393 .6445922852387 .9031982422383 .3703918457 379.4176025391375 .8882141113372 .2356872559368 .6589050293366 .0599060059 365.2228088379361 .2193908691349 .5328979492335 .0398864746322 .0495910645 311.9621887207305 .0317993164299 .7767028809293 .0947875977286 .503692627 281.6683044434278 .608001709277 .8146057129276 .8111877441273 .5322875977 269.5118103027266 .5132141113264 .2023925781262 .1115112305260 .1669921875 258.3062133789256 .4013061523254 .4228057861252 .3249053955249 .9304962158 247.4255981445244 .9373016357242 .4053039551239 .9174041748237 .3115997314 234.4311065674231 .7010040283229 .5368041992227 .5498962402225 .3529052734 223.0480041504220 .5946960449218 .0691070557215 .625212 .99949646210 .0088043213 206.8441009521203 .6369934082200 .3798065186197 .0726928711193 .9091949463 191.0924987793188 .4080047607185 .6629943848182 .870300293180 .0095977783 177.0870056152174 .1087036133171 .100402832168 .0791931152165 .0552062988 162.1347045898159 .0222015381155 .3728027344151 .7378997803148 .5565948486 145.5274047852142 .433303833139 .3612976074136 .3258056641133 .4557952881 
130.8148040771128 .5312042236126 .7259979248125 .3037033081124 .387298584 123.1225967407120 .7845993042117 .8863983154114 .856300354111 .6781997681 108.4142990112104 .9810028076101 .29720306497 .3977813720793 .25290679932 88.9664764404384 .5660934448280 .2728424072376 .2724685668972 .56421661377 69.2984237670966 .4542312622164 .1797790527362 .1687393188560 .12239074707 57.9689598083555 .5886497497652 .8531303405849 .5896492004445 .86573028564 41.6569213867237 .2240715026932 .6539688110428 .6397705078125 .97500991821 24.0785694122322 .5007896423321 .2140693664620 .0424003601119 .02363967896 18.242610931417 .5987892150917 .0382404327416 .4840908050515 .85295009613 15.2030897140514 .5654802322414 .1366701126114 .1295795440713 .60241985321 $11.752059936528 .5687265396123 .707724094391-1.6793949604-6.92355680466$ $-12.4263401031-18.5537796021-24.4607200623-29.0769004822-32.7833404541$ -35.8616981506 -38.2296905518 -39.7948493958 -41.1135902405 -42.6565284729 -43.9964408875 -44.7847595215-45.3515396118 -45.9479904175-46.4850692749 -46.9182395935 -47.1788291931-47.2021903992-47.0933113098-46.9467010498 $-46.782169342-46.624710083-46.4840011597-46.3716087341-46.2338104248$ $-46.0095405579-45.7624282837-45.5431518555-45.3501014709-45.1888885498$ $-45.0323410034-44.8643112183-44.671131134-44.4451293945-44.1770095825$ $-43.8536491394-43.4692382812-43.016960144-42.4904212952-41.8860702515$ $-41.1867980957-40.3771209717-39.4509010315-38.3983001709-37.2207603455$ -35.9107894897 -34.4838981628 -32.9338912964 -31.3527107239-29.8057098389 $-28.2937908173-26.8634204865-25.4941806793-24.2256698608-22.9927101135$ $-21.7350997925-20.4065494537-18.9819202423-17.0923500061-14.2670097351$ $-11.3993797302-9.16273021698-7.50008916855-6.74675893784-6.51420402527$ $-6.73482084274-6.96884012222-6.62402200699-5.64455890656-3.71296906471$ -1.06351196766 2.3095870018016.0756859779369.860447883606 13.29084014893 15.7862997055117 .6938095092819 .1981105804420 .3652896881121 .29766082764 22.057750701922 .7411003112823 .3469905853323 .9240493774424 .48418045044 25.0768299102825 .6759395599426 .2653694152826 .8474292755127 .4236907959 27.9775905609128 .4932804107728 .9812908172629 .4353504180929 .87854003906 30.3248291015630 .7798595428531 .2596797943131 .7632102966332 .29531097412 32.8528594970733 .4345588684134 .0370407104534 .6562614440935 .28974914551 35.933319091836 .5853691101137 .2426490783737 .9041481018138 .56764984131 39.2325096130439 .8972587585440 .5614395141641 .2240791320841 .88481140137 42.5429191589443 .1980705261243 .8497200012244 .4975090026945 .14096069336 45.7797508239746 .4134101867747 .0416488647547 .6640281677248 .28028869629 48.8900489807149 .4931106567450 .089149475150 .6780395507851 .25955963135 51.8336601257352 .4001884460452 .9591712951753 .5105705261254 .05448150635 54.5909194946355 .1200408935555 .6419715881356 .1568603515656 .66489028931 57.1662597656257 .6611709594758 .1498184204158 .6324386596759 .10921096802 59.5803909301860 .0461387634360 .5067100524960 .9622611999561 .41318893433 61.8596801757862 .29882812562 .7332611084 767.2269287109763 .5479125977759 .8629150391756 .161315918752 .4495239258 748.7291259766745 .0021972656741 .2702026367737 .5347290039733 .7974243164 730.0596923828726 .3226928711722 .5880737305718 .8568115234715 .1306762695 711.4108886719707 .7000732422703 .9995727539700 .3126831055696 .6417236328 
692.9901733398689 .3618164062685 .7595825195682 .1876831055678 .6489868164 675.1469726562671 .6840209961668 .2626953125664 .8839111328661 .549621582 658.2587280273655 .0117797852651 .8067016602648 .6475830078645 .5153198242 642.3973999023639 .2769775391636 .1292724609632 .9818725586629 .8510131836 626.7523193359623 .700378418620 .7081298828617 .7885742188614 .9340820312 612.1447753906609 .3720703125606 .6110229492603 .6959838867600 .6593017578 596.8754882812592 .1279296875585 .0139770508572 .5895996094559 .5966186523 551.87890625543 .8598022461530 .1093139648517 .5305786133511 .833404541 506.9635925293498 .6864929199489 .0029907227478 .9179992676470 .0187988281 464.9899902344460 .9789123535455 .5892028809449 .9039001465444 .4967041016 438.2731933594430 .075592041421 .550994873413 .8562011719408 .4177856445 406.3059082031409 .891204834424 .1702880859434 .7348937988421 .5274963379 410.0758056641424 .1878051758444 .3517150879456 .2243041992464 .0939941406 469.1553955078469 .7146911621465 .5111999512459 .1646118164454 .4012145996 448.1760864258437 .6600036621430 .8327026367435 .4396972656445 .6170043945 455.4336853027464 .2323913574471 .6925964355474 .0378112793467 .7237854004 460.2137145996459 .8743896484459 .5075073242451 .6583862305443 .3316040039 439.2333984375436 .3891906738434 .6943969727432 .2237854004425 .2988891602 418.1818847656414 .196105957411 .5625410 .7594909668410 .325592041409 .5570983887 405.5481872559395 .4932861328381 .6236877441363 .4887084961346 .7880859375 338.113494873330 .3414001465316 .1705932617303 .1306152344297 .0586853027 293.5481872559289 .8243103027286 .5299987793283 .0840148926279 .7773132324 276.9605102539274 .3616027832271 .9870910645269 .7015991211267 .5705871582 265.4070129395263 .3045959473260 .9545898438258 .2384033203255 .3466949463 252.5238037109249 .7599029541247 .1930999756244 .5233001709241 .3999938965 238.4788970947236 .4425048828234 .5953063965232 .3305053711229 .899307251 227.3372955322 224.7953033447222.4862060547220.0178070068216.9803009033 213.6986999512210 .4606933594207 .2082977295204 .0043945312200 .8957977295 197.9317016602195 .0614013672192 .2241973877189 .3860931396186 .5041046143 183.5800018311180 .6179046631177 .6320953369174 .6681060791171 .6710968018 168.6154022217165 .3314056396161 .5236968994157 .7684020996154 .6744995117 151.7767028809148 .6853942871145 .6083068848142 .5411987305139 .6269989014 136.9291992188134 .5092926025132 .4490966797130 .5989074707128 .936706543 127.1196975708125 .0250015259122 .5261001587119 .5442962646116 .3209991455 113.0749969482109 .6837005615106 .0660018921102 .263000488398 .19167327881 93.9908294677789 .6515808105585 .3872528076281 .3619232177777 .60353088379 74.2720336914171 .2883529663168 .758926391666 .4532928466864 .20372009277 61.9053115844759 .4606399536156 .6989898681653 .393280029349 .58797836304 45.223499298140 .4650993347235 .1525993347230 .3879508972227 .39730072021 25.2499408721923 .0955009460421 .2254695892319 .6118202209518 .24662017822 17.30434036255 16.62430953979 16.10457038879 15.71560955048 15.49633979797 15.2859401702914 .9699096679714 .5105600357113 .9659900665312 .84317016602 $10.812450408947 .8437089920043 .48991394043-1.21543502808-5.55130004883$ -10.0137395859 -14.8342399597 -19.8357391357-24.8067493439 -29.3727493286 -33.0598182678 -35.8916282654 -37.861530304 -39.2758712769-40.5078201294 $-41.5708885193-42.4767494202-43.2568588257-43.8587112427-44.405040741$ 
$-45.0234909058-45.5054092407-45.6721916199-45.6912117004-45.6735801697$ $-45.6348304749-45.60131073-45.5884284973-45.6182899475-45.6147117615$ $-45.4800109863-45.3140792847-45.2002601624-45.0939712524-44.9745407104$ $-44.839969635-44.6926689148-44.5117797852-44.2925415039-44.0227394104$ $-43.6939506531-43.3000602722-42.8372688293-42.2985191345-41.6819610596$ $-40.9742088318-40.1639900208-39.2465782166-38.2100105286-37.0629882812$ -35.7940597534 -34.4328994751 -32.9722290039 -31.460439682 -29.9390201569 -28.424079895 -26.9809894562 -25.5866203308 -24.2697296143 -22.9766902924 $-21.6747493744-20.2838897705-18.680059433-16.8500099182-14.653380394$ $-12.5023298264-10.713549614-9.25310516357-8.34787082672-7.76266098022$ -7.53486299515 -7.30556488037-6.62901210785 -5.53266477585 -3.86138606071 $-1.513378977781 .8810729980475 .7324380874639 .60343360900913 .10638046265$ 15.4862899780317 .2868099212618 .8079204559320 .0189609527620 .99294090271 21.7786903381322 .4576892852823 .0452308654823 .6124706268324 .15369987488 24.7165603637725 .2829093933125 .8607997894326 .4399299621627 .01538085938 27.5746994018628 .0964393615728 .5942306518629 .0577602386529 .51452064514 29.9782505035430 .4554805755630 .9597702026431 .4885101318432 .04655075073 32.629878997833 .2364807128933 .8630294799834 .5041007995635 .15781021118 35.8190917968836 .486888885537 .1575889587437 .8305702209538 .50362014771 39.1762809753439 .8473091125540 .5163116455141 .1825904846241 .84579086304 42.5054817199743 .1612892150943 .8129081726144 .459960937545 .10216140747 45.739120483446 .3705711364746 .9961509704647 .6155586242748 .2285118103 48.8347206115749 .4339714050350 .0260086059650 .6107101440451 .18788909912 51.7574882507352 .3194389343352 .8737182617253 .4203491210953 .95941162109 54.4909706115755 .0151710510355 .5321502685556 .0420799255456 .54515075684 57.0415496826257 .5315208435158 .0152397155858 .4929695129458 .96488189697 59.4312515258859 .8922386169460 .3481216430760 .7990417480561 .24541091919 61.686939239562 .1249008178762 .55773925781

773.8499145508770 .2443237305766 .6345825195763 .0062866211759 .3712158203 755.7305297852752 .0864257812748 .4404907227744 .7947998047741 .1508789062 737.5104980469733 .8751220703730 .2463989258726 .625793457723 .0153198242 719.4163208008715 .8317260742712 .2634887695708 .7150878906705 .1890869141 701.6895751953698 .2197875977694 .7836914062691 .3848876953688 .0266113281 684.7122192383681 .4437866211678 .2244262695675 .0543823242671 .9357299805 668.8676147461665 .8502807617662 .8817749023659 .9645996094657 .0822753906 654.2230834961651 .3696289062648 .4943847656645 .6317138672642 .8024291992 640.0278930664637 .3283081055634 .7244873047632 .237121582629 .8698120117 627.6309814453625 .4829101562623 .4041748047621 .2694702148619 .0098266602 616.2852172852612 .9287719727608 .0930786133601 .2286987305592 .5485839844 581.4614868164569 .2319946289556 .3101806641544 .315612793535 .2318115234 527.1021728516518 .5040283203509 .4512023926500 .2820129395491 .3030090332 482.7080078125475 .2308044434469 .4668884277464 .8287963867461 .1933898926 457.3630981445451 .7167053223446 .4533081055444 .1788024902442 .0866088867 437.2452087402438 .2802124023452 .7106018066468 .1373901367471 .0389099121 474.2007141113488 .2786865234505 .2690124512518 .7794189453525 .4077148438 520.4982910156508 .8013916016492 .7060852051477 .1608886719469 .6270141602 
462.5905151367452 .2730102539444 .4603881836440 .6770935059447 .6994018555 472.8728942871498 .7643127441511 .6913146973515 .6275024414513 .0875244141 506.8391113281499 .5179138184492 .053314209486 .116607666481 .0761108398 477.228302002474 .8598022461473 .7470092773471 .4722900391465 .491394043 459.3913879395457 .208190918456 .9176940918456 .9552001953456 .8453063965 456.1910095215453 .4625854492447 .640411377439 .2536010742429 .9455871582 418.2854919434402 .1241149902383 .3472900391361 .1597900391340 .8551940918 328.1897888184318 .5610961914307 .8676147461299 .2325134277295 .0564880371 292.5957946777289 .3421020508286 .0242919922282 .8920898438279 .9689941406 277.3799133301274 .9566955566272 .7139892578270 .1427001953266 .720703125 263.1184082031259 .925201416256 .9999084473254 .3361053467251 .679397583 248.836807251246 .18359375244 .0404968262241 .9873962402239 .5885925293 236.9322967529234 .0014953613231 .2005004883228 .9208984375226 .5879974365 223.6923065186220 .5216064453217 .3040924072214 .0778961182210 .9069061279 207.7881011963204 .7693023682201 .8108062744198 .9084014893196 .0357055664 193.1394042969190 .2189025879187 .2660980225184 .2913970947181 .3016967773 178.3300933838175 .4907989502172 .4064025879168 .6463012695164 .8538970947 161.5666046143158 .4535980225155 .2673950195152 .0877990723148 .9219055176 145.8715057373142 .9813995361140 .2924041748137 .895904541135 .6327056885 133.4929962158131 .3789978027129 .1472015381126 .7183990479123 .9358978271 120.9216995239117 .8618011475114 .6481018066111 .2158966064107 .5670013428 103.619300842399 .4909591674895 .2053833007890 .9383773803786 .8770904541 83.0652999877979 .6275787353576 .5146331787173 .8367614746171 .39629364014 69.1014862060566 .7956771850664 .3078231811561 .5316390991258 .27611160278 54.507389068650 .1171112060545 .2390518188539 .9626388549834 .98683166504 31.0244598388727 .753969192524 .6994705200222 .0055904388419 .82803916931 18.0843391418516 .8996105194116 .157850265515 .6282997131315 .33602046967 15.2551403045715 .2764101028415 .3468399047915 .0637197494514 .19095039368 12.7260198593110 .677900314338 .0650053024294 .629845142365 .8745040297508 -2.88472294807 -6.8486161232 -11.2132701874 -15.9626197815 -20.902469635 -25.8283500671 -30.3996105194 -33.9692001343 -35.8605499268 -36.9465713501 -38.091178894 -39.1594009399-40.2030792236-41.1816482544-42.0125198364 $-42.757900238-43.4888191223-44.094619751-44.4544410706-44.6666603088$ $-44.8017082214-44.8926811218-44.9629211426-45.0289497375-45.1015586853$ -45.1337203979-45.0754013062-44.984500885-44.9109611511-44.8312301636 $-44.734790802-44.6148109436-44.4730491638-44.2960395813-44.0750389099$ $-43.8003311157-43.4614906311-43.0561904907-42.5805397034-42.0295295715$ $-41.4003982544-40.684841156-39.8746185303-38.9642601013-37.9423408508$ -36.8160896301 -35.5773086548 -34.264881134 -32.8973693848 -31.4566707611 -29.9284496307 -28.3831195831 -26.9191799164 -25.5024604797 -24.1346206665 -22.7855892181 -21.4477996826 -20.0284404755 -18.4464797974-16.7912101746 $-14.9934501648-13.2876501083-11.8115501404-10.502790451-9.5346288681$ -8.7512178421 -8.18653202057 -7.59234619141 -6.67976379395 -5.44204616547 -3.71172904968 -1.38000798225 1.8148610591895.4321231842049.082666397095 12.4068002700814 .8854799270616 .8331508636518 .4098205566419 .66699028015 20.6564197540321 .4377498626722 .0998992919922 .6688098907523 .21310997009 
23.7369899749824 .2815608978324 .8365707397525 .4128608703626 .00045967102 26.5942001342827 .174589157127 .7152194976828 .2285308837928 .70858955383 29.1804199218829 .6613197326730 .1584892272930 .686319351231 .24093055725 31.8262596130432 .4374008178733 .0708999633833 .7228584289634 .3871383667 35.0614204406735 .7407493591336 .4238891601637 .1076202392637 .7912902832 38.473079681439 .1526412963939 .8289794921940 .5018806457541 .17084121704 41.835659027142 .4959983825743 .1516799926843 .8024291992244 .44802093506 45.088169097945 .7226486206146 .3511581420946 .9734687805247 .58926010132 48.1983299255448 .8003807067949 .3952789306649 .9827690124550 .56277084351 51.1351089477551 .6997604370152 .2566413879452 .80580902153 .347240448 53.8810691833554 .40737152154 .9262886047455 .4379692077655 .94261932373 56.4403991699256 .9315490722757 .4162788391157 .8947982788158 .36737060547 58.8341903686559 .2955017089859 .7514991760360 .2024497985860 .64854049683 61.0901412963961 .527481079161 .9577903747662 .38380050659

780.526184082776 .9843139648773 .4396972656769 .8842773438766 .3239746094 762.7612304688759 .1978759766755 .6361083984752 .0778808594748 .5250244141 744.9793701172741 .4426879883737 .9169921875734 .4036254883730 .9052734375 727.4232788086723 .9611816406720 .5211181641717 .1068725586713 .7216186523 710.3693847656707 .0540161133703 .7791748047700 .5490112305697 .366394043 694.2346801758691 .1563110352688 .1334838867685 .1674194336682 .2592163086 679.4088134766676 .616027832673 .8793945312671 .2006225586668 .5640869141 665.9600219727663 .3712158203660 .7659912109658 .1873779297655 .6547851562 653.2003173828650 .8414916992648 .6154174805646 .5391235352644 .6367797852 642.9133300781641 .3472290039639 .8892211914638 .4561767578636 .8762817383 635.1356201172633 .1942749023631 .0485229492630 .6398925781626 .7033081055 612.2568969727595 .5628051758583 .4965820312572 .0527954102559 .0401000977 546.9398803711537 .8358764648529 .830871582522 .479309082514 .1729736328 502.6818847656492 .1444091797486 .1608886719482 .816986084481 .0899047852 479.9637145996477 .1046142578475 .9773864746480 .2666015625484 .1340026855 479.5598144531478 .1224060059490 .4067993164507 .8281860352525 .9603881836 543.2626953125555 .149597168565 .0737304688576 .8936767578580 .612121582 565.8961181641541 .3225708008513 .2225952148487 .5481872559477 .183807373 472.687286377466 .0469970703460 .0582885742447 .2633056641447 .0524902344 482.1646118164521 .1735839844538 .5626831055545 .3685913086549 .4108886719 546.8383789062533 .7094116211520 .2758789062517 .3270263672517 .1856079102 514.383972168511 .936706543510 .0393066406507 .411895752502 .7478942871 498.938293457499 .3503112793500 .9502868652501 .1387023926500 .7909851074 499.7803039551498 .8277893066497 .7551879883497 .0133056641499 .3385925293 494.6932067871472 .3620910645442 .4172058105413 .0292053223385 .705291748 365.9830932617349 .4061889648331 .0744934082316 .7300109863310 .8656921387 308.1940917969303 .5602111816299 .013885498294 .7059020996290 .7276000977 287.4473876953284 .4435119629281 .8554992676278 .9852905273274 .9547119141 270.7485046387267 .2582092285264 .1452941895261 .3633117676258 .8182983398 256.4686889648254 .1884002686251 .9275970459249 .5453033447246 .9640045166 244.1761932373240 .941192627237 .8497924805235 .4638977051233 .1230010986 230.3195037842227 .2861938477224 .1367034912220 .9342956543217 .7783966064 
214.6557006836211 .6094055176208 .6150970459205 .6743011475202 .7707061768 199.8639984131196 .9510040283194 .0196075439191 .0675964355188 .0657043457 185.1248016357182 .5088043213179 .6938934326176 .0921936035172 .3338928223 168.8504943848165 .4606933594162 .1266937256158 .8285064697155 .5216064453 152.2680969238149 .0749969482146 .0274047852143 .220703125140 .5845947266 138.0881958008135 .6632995605133 .2565002441130 .7940063477128 .2093963623 125.5150985718122 .7263031006119 .7913970947116 .6448974609113 .2089004517 109.3936004639 105.3087997437 101.034797668596.7680664062592.62956237793 88.7224884033285 .1684570312581 .9341430664179 .1837997436576 .71071624756 74.4992675781272 .2873535156269 .8366470336967 .1095962524463 .91110992432 60.2211494445855 .8890419006351 .1077308654846 .2075996398941 .22700881958 36.2996788024931 .6397495269827 .20270919823 .4686698913620 .6443901062 18.5901699066217 .1995296478316 .2619895935115 .6357297897315 .29281044006 15.2053298950215 .2671899795515 .5822896957415 .5085000991814 .52474021912 12.9816503524811 .147660255438 .9982004165656 .469151020053 .610409021378 $.2483099997044-3.51900291443-7.70469999313-12.309220314-17.0347003937$ -21.9067306519 -27.0123100281 -31.1696605682 -33.032661438 -34.0098609924 -35.3352012634 -36.5996818542 -37.869468689-39.1019287109-40.1994018555 $-41.1956710815-42.0600204468-42.7807617188-43.3454704285-43.7866096497$ $-44.0929298401-44.3237991333-44.4837112427-44.5952186584-44.6688690186$ $-44.7021598816-44.6982192993-44.6636390686-44.6069297791-44.5290184021$ $-44.4380111694-44.3206596375-44.1773605347-43.99559021-43.7688713074$ $-43.4854888916-43.1349105835-42.7157287598-42.226978302-41.6635818481$ $-41.0237312317-40.3016281128-39.4921188354-38.5896110535-37.5803108215$ -36.4732093811 -35.252571106 -33.9617195129 -32.6418914795 -31.2437496185 -29.704240799-28.1354293823 -26.6630992889-25.2233009338 -23.811000824 $-22.4183502197-21.0569095612-19.6706905365-18.1923503876-16.7178497314$ $-15.2104196548-13.7837600708-12.4881000519-11.2889604568-10.3268404007$ $-9.44230937958-8.65421104431-7.80190896988-6.70071315765-5.31539297104$ -3.43225193024 -1.04783701897 1.962012052536 5.288503170013 8.613562583923 11.7225999832214 .2990198135416 .4288196563718 .0647392272919 .33148956299 20.2999191284221 .0431594848621 .6719799041722 .2057209014922 .72963905334 23.2360992431623 .7804698944124 .3411197662424 .9367504119925 .55126953125 26.1774902343826 .7957191467327 .3633003234927 .9029293060328 .40217971802 28.891189575229 .388259887729 .9024600982730 .4535598754931 .03447914124 31.6487293243432 .2899513244632 .9512481689533 .6293106079134 .31615066528 35.0102615356435 .7062416076736 .4032287597737 .098350524937 .7910118103 38.4799613952639 .1647415161139 .8449783325240 .5202903747641 .19070053101 41.8558082580642 .515758514443 .1701698303243 .8191413879444 .46226882935 45.0995788574245 .7307090759346 .3555603027346 .9738082885747 .58531951904 48.1898002624548 .78710937549 .3770217895549 .9594116210950 .53413009644 51.1011085510351 .660289764452 .2116584777852 .7552299499553 .29104995728 53.8192291259854 .3398818969754 .8531303405855 .3591804504455 .85818099976 56.3503799438556 .8359489440957 .315151214657 .7881889343358 .25534057617 58.7167892456159 .1727981567459 .6235694885360 .0693702697860 .51037979126 60.946990966861 .3789787292561 .8075790405362 .231300354 
787.2249755859 783.7479248047 780.2734985352 776.7883300781 773.30078125 769.8137207031766 .3289794922762 .8489990234759 .375793457755 .9113769531 752.457824707749 .016784668745 .5908813477742 .1815185547738 .7913208008 735.4224853516732 .0786743164728 .762512207725 .4780273438722 .2288208008 719.0189819336715 .8530883789712 .7346191406709 .6677246094706 .6555175781 703.7011108398700 .8068847656697 .9750976562695 .2067871094692 .5032958984 689.8645019531687 .2897949219684 .7794799805682 .3366088867679 .9431152344 677.5847167969675 .249206543672 .9096069336670 .6071166992668 .3635864258 666.2119140625664 .1779785156662 .2984008789660 .6005249023659 .1090087891 657.8408813477656 .7805175781655 .9033203125655 .1323852539654 .3530273438 653.5413208008652 .5319213867651 .7161865234651 .5361938477647 .4652099609 635.4301147461620 .5872192383607 .8334960938594 .8385009766579 .8425292969 565.7504882812555 .8422241211548 .3081054688541 .6090698242533 .6400146484 522.9193725586513506 .9424133301504 .1077880859503 .8269958496504 .2886962891 502.6680908203504 .169708252513 .4918212891523 .1024780273526 .299987793 529.0872802734537 .3209228516550 .5075073242567 .6832885742583 .4752197266 592.73828125597 .1917114258600 .8339233398598 .2125854492585 .129699707 561.3591918945526 .3220825195494 .4124145508482 .5299987793481 .4879150391 484.4136047363484 .827911377470 .3317871094465 .1339111328491 .1195068359 524.0449829102544 .7517700195557 .3731079102566 .1871948242568 .3754882812 559.8698730469549 .7725830078546 .9191894531546 .8118896484545 .992980957 544.5670166016542 .5465698242539 .7053222656535 .4818115234532 .6790161133 533.8098144531535 .6026000977536 .1116943359535 .7437744141534 .5485839844 535.0336914062538 .4890136719544 .1599731445551 .7260742188549 .7415771484 528.2070922852495 .8275146484461 .6336975098429 .3511962891405 .4189147949 384.2190856934361 .6264953613343 .44140625333 .6633911133327 .5191040039 320.3900146484313 .6353149414307 .4888916016302 .0166931152297 .3688964844 293.2536010742289 .7294921875286 .2944946289282 .275604248278 .186706543 274.4767150879271 .1852111816268 .3471069336265 .95498655723264 .0969848633 262.2178039551259 .8129882812257 .128112793254 .4777984619251 .7115936279 248.5811004639245 .5003051758242 .766204834240 .0653991699237 .1300964355 234.0610961914230 .9134063721227 .7315063477224 .5895996094221 .4797973633 218.4284973145215 .4210968018212 .4568939209209 .5339050293206 .6333007812 203.7442932129200 .8594055176197 .9674987793195 .0655975342192 .2088928223 189.479095459186 .5955963135183 .2111053467179 .6334991455176 .154006958 172.6750030518169 .2478942871165 .8329925537162 .3596038818158 .8468017578 155.2604980469151 .7722015381148 .5850067139145 .6183013916142 .7635040283 140.0363006592137 .4855957031135 .0193939209132 .5648040771130 .1246032715 127.5983963013124 .9757003784122 .2746963501119 .1936035156115 .4133987427 111.2474975586106 .9853973389102 .710601806698 .4699325561594 .43527984619 90.7628784179787 .4373779296984 .6327590942482 .201873779380 .13519287109 78.099891662675 .8404388427773 .2803802490270 .1561431884866 .55728912354 62.4028511047457 .8466987609953 .1897392272948 .1270790100142 .66907119751 36.8705215454130 .4893894195625 .073940277121 .9577598571819 .96516036987 18.288509368917 .0164508819616 .1188507080115 .5732297897315 .3501996994 15.3543796539315 .531669616715 .4351396560714 .6613397598313 .44147968292 
11.9473495483410 .23001956948 .2276306152345 .8502349853522 .989253997803 -.360922992229 -4.14074897766 -8.29700088501 -12.6850700378 -17.2537708282 -21.9736995697 -25.9976596832 -28.4485702515 -30.185300827 -31.9657993317 -33.6418304443 -35.2951698303 -36.8572998047 -38.2318916321 -39.4591407776 $-40.5553894043-41.4738616943-42.237159729-42.8776702881-43.3770103455$ $-43.7520599365-43.9975891113-44.1405296326-44.2314605713-44.2754516602$ $-44.294921875-44.2852210999-44.2444114685-44.1715888977-44.0734481812$ -43.946521759-43.7910194397 -43.5974197388 -43.3599205017-43.0655288696 $-42.7004890442-42.266708374-41.7637786865-41.188331604-40.5393104553$ -39.8114814758 -39.0004692078 -38.1001014709 -37.1006202698 -36.0006599426 -34.7878913879 -33.4899597168 -32.1180496216 -30.678850174 -29.1823997498 $-27.6637992859-26.1816196442-24.7189998627-23.2801303864-21.8718891144$ -20.5136108398 -19.1715297699-17.8073692322 -16.4844608307 -15.2019701004 -13.9868497849-12.8471899033 -11.7581100464 -10.775270462 -9.80465316772 $-8.83558273315-7.77527809143-6.52412605286-5.03403520584-3.20263004303$ -.915935993195 2.0710179805765.314774036407 8.476893424988 11.46189975739 14.0114603042616 .1627502441417 .7900505065919 .0140094757119 .92793083191 20.6124897003221 .1811408996621 .6714992523222 .1657791137722 .66447067261 23.2130298614523 .7966899871824 .430040359525 .0910396575925 .76354026794 26.4261207580627 .0362491607727 .6101608276428 .1398200988828 .65193939209 29.1672897338929 .6989002227830 .2720909118730 .879110336331 .52343940735 32.1960296630932 .8859710693433 .589569091834 .2983283996635 .01057815552 35.721401214636 .430110931437 .1343193054237 .8338317871138 .52764129639 39.2157287597739 .8978004455640 .5738792419441 .2439613342341 .90800094604 42.5660591125543 .2180404663143 .8639488220244 .5036392211945 .13703155518 45.7639198303246 .3841781616246 .9976196289147 .6040191650448 .20323944092 48.7950515747149 .3793601989749 .9559898376550 .5248794555751 .08591842651 51.6391181945852 .1844406127952 .7219505310153 .2516899108953 .77378845215 54.288360595754 .7955818176355 .2956008911155 .7886314392156 .27487945557 56.7545585632357 .2279396057157 .6952095031758 .1566390991258 .612449646 59.0629005432159 .5082092285259 .9486083984460 .3843193054260 .81573104858 61.2430610656761 .6636886596762 .0804901123

793.9525146484790 .5397949219787 .128112793783 .7109985352780 .294128418 776.8803710938773 .4719238281770 .071105957766 .6804199219763 .301574707 759.9370727539756 .5888061523753 .2592773438749 .9500732422746 .6646728516 743.4050292969740 .1751708984736 .9780883789733 .8187255859730 .7003173828 727.628112793724 .6060180664721 .6383056641718 .7288818359715 .8809814453 713.0977172852710 .3812866211707 .7338256836705 .1566162109702 .6505737305 700.216003418697 .8521118164695 .5601196289693 .3455810547691 .1879272461 689.0684204102686 .9802856445684 .8975219727682 .8627929688680 .8941040039 679.0330810547677 .2996826172675 .7432250977674 .3817138672673 .2592773438 672.3781738281671 .7609863281671 .3759155273671 .2077026367671 .1707763672 671.1594848633670 .8596801758670 .0004272461667 .9935302734663 .3098144531 654.8571166992643 .4487304688630 .4506835938615 .9113769531599 .8043212891 584.9445800781574 .4702148438566 .419921875559 .2196044922552 .3773193359 544.4808959961537 .0991210938531 .673828125528 .7271728516529 .2152709961 
531.0125732422529 .9215698242531 .9334106445543 .3499755859556 .5925292969 566.5415039062574 .883972168580 .1029052734586 .7938842773597 .9078979492 607.5446777344612 .1862792969611 .6557006836606 .2930908203596 .1434936523 585.3753051758566 .2797241211529 .9672851562498 .0881958008489 .3409118652492 .3125 502.6423950195509 .4594116211495 .4094848633483 .9495849609493 .6188049316 512.6307983398534 .0482788086554 .3748779297569 .979675293578 .4044189453 577.9663085938574 .0529785156572 .040222168571 .1306152344571 .4595947266 571.3666992188569 .3967285156566 .8480834961563 .6530151367561 .3765258789 561.733581543563 .2520751953564 .4564819336565 .6351928711564 .7191772461 566.0364990234572 .4458007812579 .6431884766586 .0869750977582 .9724731445 563.3184204102533 .1657714844498 .6088867188464 .4960021973439 .1387939453 417.1871032715 393.3965148926 373.1871032715 359.4060058594 349.2362060547 339.0809936523329 .8869934082321 .4366149902313 .8865966797307 .696105957 302.4772033691297 .7463989258293 .6211853027289 .6680908203285 .7998962402 281.966796875278 .321685791275 .3225097656272 .9590148926271 .362487793 269.7445068359267 .2405090332264 .4739990234262 .0040893555259 .4142150879 256.5064086914253 .4197998047250 .2678070068247 .1016998291243 .9472961426 240.7980041504237 .6363983154234 .4819030762231 .3625946045228 .2792053223 225.2447052002222 .2483062744219 .2682037354216 .3312072754213 .4288024902 210.5608062744207 .7344055176204 .9324951172202 .179901123199 .4004058838 196.5028991699193 .4785003662190 .2346038818186 .8580932617183 .4319000244 179.9499969482176 .5314025879173 .0359954834169 .4073944092165 .6558074951 161.7247009277157 .8567047119154 .3287963867150 .9683990479147 .6286010742 144.5731964111141 .8957977295139 .4909973145137 .1708984375134 .8869934082 132.5413970947130 .1282958984127 .7618026733124 .9770965576121 .2434997559 117.1027984619112.975402832108.71900177 104.3212966919100.0532989502 96.1913833618292 .766876220789 .9504089355587 .6039199829185 .7138671875 83.9919891357482 .0987472534279 .7817764282276 .6994323730573 .06436157227 69.0188598632864 .6939926147560 .2825317382855 .391738891649 .85813903809 43.4097213745135 .3987884521528 .223209381124 .4813404083322 .25806999207 20.0033893585218 .2560195922916 .9953708648716 .1531600952115 .72570037842 15.5444602966315 .4757204055815 .2988901138314 .8331298828114 .08271980286 13.035160064711 .7153596878110 .061960220348 .0463809967045 .58073091507 $2.679500102997-.614696025848-4.25999307632-8.12308502197-12.1668596268$ -16.2045707703 -19.9521408081 -23.0456790924 -25.6792106628 -28.045879364 $-30.2358608246-32.4022789001-34.3412513733-35.9963188171-37.4156417847$ -38.7675285339 -39.9836807251-41.0086212158-41.8909301758-42.5678100586 $-43.0809402466-43.3965797424-43.5677185059-43.6844215393-43.7478408813$ $-43.7869300842-43.7969512939-43.7663803101-43.6996192932-43.5931510925$ $-43.4538116455-43.283000946-43.0739707947-42.8225288391-42.5143585205$ $-42.1333808899-41.6843986511-41.1671791077-40.5806617737-39.9245414734$ -39.1926994324 -38.3810195923 -37.482421875 -36.4878311157 -35.3953781128 $-34.1832504272-32.8635406494-31.4165496826-29.91381073-28.4550209045$ -26.987449646 -25.5008602142 -24.019859314 -22.5639591217 -21.1558208466 $-19.8179302216-18.5352592468-17.2886104584-16.1102294922-14.9904603958$ $-13.9312696457-12.9096097946-11.892250061-10.9057598114-9.86845970154$ 
-8.76962852478 -7.5552148819-6.16823005676-4.58409118652 -2.79161691666 -.5925869941712.3781230449685.583933830261 8.62869739532511.5029001236 13.986740112316 .0734806060817 .6146507263218 .74197959919 .56473922729 20.1648693084720 .6544609069821 .0838603973421 .5520706176822 .04112052917 22.6158599853523 .2411804199223 .9394607543924 .6786594390925 .41399002075 26.1360797882126 .7894992828427 .3993492126527 .9542407989528 .48546981812 29.0160102844229 .5618991851830 .1596794128430 .7952995300331 .47071075439 32.1754608154332 .8918190002433 .6182289123534 .3453102111835 .07173919678 35.7937202453636 .5102615356437 .2203598022537 .9232788085938 .61928939819 39.3078002929739 .989540100140 .6640090942441 .3320007324241 .99304962158 42.6477813720743 .295761108443 .9374389648444 .5723915100145 .20083999634 45.822410583546 .4371986389247 .0448684692447 .6453895568848 .23851013184 48.8241500854549 .4021186828649 .9723701477150 .5347709655851 .08930969238 51.6359481811552 .1747283935552 .7056617736853 .2288703918553 .74443054199 54.2525291442954 .7532806396555 .2469215393155 .7335891723656 .21356964111 56.6870384216357 .1542701721257 .6154708862358 .0709190368758 .52082061768 58.9654617309659 .4050292968859 .8397903442460 .2699584960960 .69591903687 61.117469787661 .5358390808161 .94958114624

800.7006835938797 .3441772461793 .9965820312790 .645690918787 .296875 783.9539794922780 .6190795898777 .294921875773 .983581543770 .6876220703 767.4091186523764 .1503295898760 .9135742188757 .7011108398754 .5161743164 751.3615722656748 .2412719727745 .1588745117742 .1193237305739 .1267089844 736.1862182617733 .3021850586730 .4791259766727 .7208251953725 .0305175781 722.411315918719 .8654174805717 .3947753906715 .000793457712 .6843261719 710.4456176758708 .2841186523706 .2017211914704 .2017822266702 .2672729492 700.3848876953698 .5394897461696 .7000732422694 .9132080078693 .2031860352 691.6055908203690 .147277832688 .8701171875687 .8040771484686 .9821777344 686.4251708984686 .1384277344686 .1096801758686 .2974243164686 .6337890625 686.9166259766686 .9464111328686 .0070800781683 .6223754883679 .6834716797 673.6030883789664 .6107177734651 .6264038086636 .3624267578620 .853515625 606.5811157227595 .2512207031585 .9591064453577 .8991699219572 .1430053711 569.3433227539566 .6007080078560 .9525756836556 .6356201172558 .1959838867 560.9837036133559 .5294189453559 .8450927734567 .4771728516577 .3015136719 584.9114990234591 .4522705078597 .6705932617603 .6536254883611 .3709716797 616.8834838867617 .5922241211613 .0601806641601 .5526123047586 .1743164062 569.2249145508547 .658203125517 .7645874023495 .7114868164498 .9234924316 510.5320129395517 .0214233398517 .2313842773505 .1726989746490 .2063903809 480.8724975586483 .729095459509 .7178955078542 .2576293945565 .356628418 580.6054077148586 .1879272461587 .0233764648587 .9210205078588 .3109741211 589.2866821289589 .4052734375587 .3530273438585 .2528076172585 .0349731445 584.6533203125582 .1047973633581 .3424072266586 .6416015625592 .1452026367 591.2177734375591 .1763916016597 .4722290039601 .7327880859597 .0703735352 584.6116943359565 .6527709961539 .954284668507 .7843017578476 .1528930664 454.833404541436 .9468078613416 .7792053223397 .8924865723382 .6581115723 369.8862915039358 .879699707348 .4685974121336 .6122131348325 .7651062012 318.6931152344313 .0827941895306 .9400024414301 .7554016113297 .9201049805 
294.2903137207289 .908203125285 .5260009766282 .1452026367279 .6253967285 277.7395019531275 .9468994141273 .6994934082271 .3866882324269 .4495849609 267.3171081543264 .3982849121261 .0374145508257 .5459899902254 .032699585 250.7111053467247 .5090026855244 .3455047607241 .2187957764238 .1163024902 235.0552978516232 .0556945801229 .0805053711226 .0899047852223 .1340942383 220.2198944092217 .3623962402214 .596496582211 .8892974854209 .2487030029 206.5332946777203 .6466064453200 .6179962158197 .3692016602194 .0274963379 190.6172027588187 .1674957275183 .8896026611180 .4779968262176 .7061004639 172.7519073486168 .7232971191164 .6918945312160 .7828063965156 .8657073975 152.7216033936149 .0382995605146 .4506072998144 .3244934082142 .1112060547 139.8775024414137 .5623931885135 .1714935303132 .7147979736129 .9019012451 126.4215011597122 .6344985962118 .9010009766114 .8496017456110 .1200027466 105.3952026367 101.260902404897.6930999755994.8819274902392.6547088623 90.971397399989 .6434936523488 .4738082885786 .6785812377983 .35655975342 79.3433609008875 .2808532714871 .1744918823267 .1786422729562 .86014938354 58.0568695068451 .8432998657243 .1155815124534 .705360412629 .28903007507 25.5178203582822 .3747406005919 .9421596527118 .1985301971417 .02242088318 16.3274898529115 .9608402252215 .7324695587215 .5545196533215 .25304985046 14.8226499557514 .1779003143313 .2451200485211 .9959802627610 .38537979126 $8.2872247695925 .8100209236152 .965572118759-.133239999413-3.28671693802$ $-6.6725268364-10.4742097855-14.3163995743-17.6516895294-20.7182407379$ $-23.5128803253-26.2038993835-29.0943603516-31.6446609497-33.4254608154$ $-34.8965492249-36.5383491516-38.1252403259-39.5278396606-40.7229499817$ $-41.5847396851-42.2051582336-42.596321106-42.797870636-42.9417610168$ $-43.0338897705-43.1080207825-43.1464118958-43.130859375-43.0673599243$ $-42.9615898132-42.8160400391-42.6342811584-42.4103012085-42.1420211792$ $-41.8157806396-41.4178314209-40.9528999329-40.4211883545-39.8239593506$ -39.1633300781 -38.4301490784 -37.6191291809 -36.7208099365 -35.7295303345 $-34.6418685913-33.4398612976-32.1141090393-30.6413803101-29.1131095886$ $-27.6258602142-26.1420097351-24.6421604156-23.1448192596-21.6729297638$ $-20.2651500702-18.9416809082-17.7035293579-16.5713500977-15.5269899368$ $-14.5595302582-13.6439599991-12.727399826-11.7748699188-10.7714796066$ $-9.67300319672-8.4622631073-7.11144781113-5.58055877686-3.85917305946$ -1.92491996288.34995898604393.160727977753 6.15475320816 9.059597015381 11.8091402053814 .2291498184216 .2336997985817 .6140098571818 .56471061707 19.2444095611619 .7283992767320 .108119964620 .4645099639920 .90501022339 21.4032993316722 .0040607452422 .6870594024723 .4799594879224 .3279209137 25.1579704284725 .953960418726 .6560802459727 .2929592132627 .864320755 28.4044208526628 .9427509307929 .5008697509830 .1256904602130 .79491043091 31.5023899078432 .2381896972732 .9799499511733 .7253684997634 .4662399292 35.2020606994635.9299697876 36.6500091552737.36128997803 38.06404876709 38.7583198547439 .4443702697840 .1225891113340 .7931709289641 .45652008057 42.112720489542 .7621002197343 .4045982360844 .0403900146544 .6693611145 45.2915306091345 .9067497253446 .5149383544947 .1159400939947 .70962142944 48.2958412170448 .8744697570849 .4454116821350 .0085411071850 .56383895874 51.1112289428751 .6507492065452 .1824111938552 .7062797546453 .22243118286 
53.731029510554 .2321891784754 .7260894775455 .2129211425855 .69289016724 56.1662292480556 .6331481933657 .0939216613857 .5487594604557 .99792098999 58.4416389465358 .8801803588959 .313758850159 .7426414489760 .16703033447 60.5872993469261 .0037193298361 .4137687683161 .82049179077 807.4545288086804 .1621704102800 .8740234375797 .5855712891794 .3023071289 791.0275268555787 .7634277344784 .5128173828781 .2780761719778 .0615844727 774.8657836914771 .6928100586768 .5454711914765 .42578125762 .3375854492 759.2835083008756 .2683105469753 .2954711914750 .3707275391747 .4982299805 744.6837158203741 .9315185547739 .2463989258736 .6323242188734 .0924072266 731.6295776367729 .2463989258726 .9442749023724 .72497558599722 .5889892578 720.5371704102718 .5687255859716 .6851806641714 .888671875713 .1666259766 711.5101928711709 .8978881836708 .2894287109706 .7379760742705 .2672729492 703.9157104492702 .7022705078701 .6760864258700 .8590087891700 .2930908203 699.9912109375699 .9603271484700 .1748046875700 .5646972656701 .0319824219 701.3416748047701 .3394775391700 .4478149414698 .1373901367694 .5936889648 690.107421875682 .7404785156670 .008605957655 .1514282227641 .3992919922 628.3284301758616 .4050292969606 .095703125597 .2852783203591 .770690918 592.575012207593 .8062133789588 .2506103516583 .3505249023585 .8679199219 588.9539794922586 .6915283203584 .8867797852587 .8521728516592 .3297119141 595.5070800781598 .7103271484604 .825012207610 .8590698242615 .4473876953 617.9810791016616 .5806274414608 .8900146484592 .4465942383571 .3256835938 547.7377929688525 .2178955078504 .7301940918494 .6636047363508 .9443054199 526.4848022461526 .5397949219518 .5133056641507 .6995849609491 .3422851562 466.4110107422455 .4154968262484 .2398986816525 .1604003906553 .0147094727 573.958984375585 .838684082591 .6362304688596 .3958129883598 .7993774414 600.9434204102601 .8864746094600 .4392700195599 .4168701172602 .1627807617 604.2396240234599.7288208008 597.2954101562 606.3643188477615.5836181641 613.919921875610 .7681884766613 .1834716797610 .8508911133593 .8010253906 571.0554199219552 .8142700195532 .8231201172505 .6954040527480 .5179138184 466.0884094238453 .7015075684438 .0318908691422 .058013916406 .047088623 391.6978149414379 .9038085938368 .0523986816352 .9100036621339 .2124023438 331.7312927246326 .0766906738318 .737701416311 .8803100586307 .1007080078 302.9659118652297 .8118896484293 .025390625289 .4819030762286 .5651855469 284.0544128418281 .8450927734279 .800994873277 .9396972656276 .4943847656 274.6723937988271 .6856994629268 .1289978027264 .469909668260 .7849121094 257.4089050293254 .1873931885251 .0366973877247 .9611968994244 .891204834 241.8684997559238 .9176025391235 .9730987549232 .9785003662229 .9909973145 227.0182037354224 .1517028809221 .4329071045218 .8191986084216 .2646942139 213.6484985352210 .8746032715207 .8782043457204 .5890045166201 .1324005127 197.6356048584194 .2042999268191 .0890960693187 .8428955078184 .0449066162 180.0166015625176 .0142059326171 .9369049072167 .7601928711163 .4197998047 158.5955047607154 .3101043701151 .6885070801149 .6800994873147 .3943023682 145.0941009521142 .7032928467140 .18699646137 .4900054932134 .5433959961 131.2926940918127 .8265991211124 .4356002808120 .5660018921115 .5755004883 110.4446029663106 .014503479102 .299003601199 .5123596191497 .48168945312 95.9965362548894 .8894577026494 .2256088256892 .8500823974689 .34647369385 
85.08888244629 81.08390808105 77.1170196533273.41387939453 69.46092987061 65.2948303222759 .665451049850 .9617309570341 .9610290527335 .07807159424 29.5638694763225 .2427692413322 .0544605255119 .7690601348918 .26848983765 17.2895507812516 .7045097351116 .3202095031716 .0945796966615 .88416004181 15.6577901840215 .3153400421114 .7814798355113 .9855098724412 .77433013916 11.007639884958 .833085060126 .3726119995123 .7544159889221 .263761043549 $-1.55317294598-5.16490221024-8.98793888092-12.3492898941-15.5594701767$ $-18.5863609314-21.5721302032-24.9726696014-28.0426101685-30.0293598175$ $-31.7324295044-33.8027801514-35.8508300781-37.7431602478-39.2933197021$ $-40.315120697-40.9609603882-41.3947792053-41.6717681885-41.8893890381$ $-42.0564994812-42.1867904663-42.2726783752-42.2822990417-42.2340583801$ $-42.1352806091-41.9925689697-41.8010787964-41.5654716492-41.2817001343$ $-40.9387512207-40.5252685547-40.0463905334-39.4991798401-38.8921089172$ $-38.2255516052-37.4901695251-36.6795196533-35.789150238-34.8067398071$ $-33.7167701721-32.5089797974-31.1693897247-29.687379837-28.1477603912$ $-26.6359004974-25.1249294281-23.6196994781-22.1240901947-20.6563205719$ $-19.2441997528-17.9069900513-16.7125205994-15.6923904419-14.8051204681$ $-13.9797401428-13.1706895828-12.3307600021-11.4132699966-10.3997297287$ $-9.24697589874-7.9520111084-6.48184394836-4.81038093567-2.93923902512$ $-.8232510089871 .5315550565724 .1737837791446 .9489231109629 .724528312683$ 12.3442497253414 .6481103897116 .5077209472717 .698940277118 .47513008118 19.0196304321319 .3806591033919 .6287803649919 .8918399810820 .28820037842 20.7818393707321 .4480400085422 .2316799163823 .1530399322524 .14570045471 25.0751304626525 .9438209533726 .6819705963127 .3335704803527 .90979957581 28.440010070828 .9749698638929 .5423393249530 .1973896026630 .91078948975 31.6516704559332 .4094886779833 .1674690246633 .9224586486834 .66938018799 35.4068908691436 .134899139436 .8521385192937 .5600509643638 .25759887695 38.9465789794939 .6261711120640 .2980804443440 .9616203308141 .6181602478 42.2670898437542 .9093704223643 .5444602966344 .1729698181244 .79441833496 45.4091415405346 .0167198181246 .6173095703147 .2105598449747 .79652023315 48.3749313354548 .9457702636749 .5088691711450 .0642089843850 .61169052124 51.1513404846251 .6831207275452 .2071304321352 .7233810424853 .23202896118 53.7331504821854 .2269592285254 .7135696411155 .1932296752955 .66609954834 56.1324691772556 .592498779357 .0464897155857 .4946403503457 .93724060059 58.3744888305758 .8066711425859 .2340011596759 .6567382812560 .07508850098 60.4894409179760 .8996391296461 .3068504333561 .70973968506 814.2274169922810 .9816894531807 .7512817383804 .5241088867801 .3035888672 798.0938720703794 .8975830078791 .7175292969788 .5560913086785 .4157714844 782.2991943359779 .2083740234776 .146484375773 .1157226562770 .1198730469 767.1619873047764 .2470092773761 .3790283203758 .5634155273755 .8051757812 753.1102294922750 .4835205078747 .9291992188745 .4519042969743 .0545043945 740.7401123047738 .5108032227736 .3682861328734 .3140869141732 .348815918 730.4735107422728 .6873168945726 .9915161133725 .3887939453723 .8676757812 722.4199829102721 .0209960938719 .6312866211718 .2990112305717 .0507202148 715.9172973633714 .9219970703714 .1030883789713 .4920043945713 .1143188477 712.9954223633713 .1165161133713 .4697265625713 .9412231445714 .4495239258 
714.7371826172714 .608581543713 .6298217773711 .3444213867707 .9061279297 703.2014160156696 .0256958008684 .813293457671 .971496582659 .8101196289 647.8309936523636 .1505126953625 .450012207616 .7124023438610 .8516845703 608.6373901367607 .700012207605 .4885864258603 .9423828125605 .5770874023 606.9066162109604 .603515625602 .3131713867604 .1301269531607 .2199707031 610.0474243164612 .4055175781613 .0435180664613 .5551147461614 .9810791016 616.1481933594616 .4285888672608 .9080810547585 .157409668556 .8161010742 533.9411010742516 .9899291992505 .4425964355503 .2981872559515 .1705932617 527.4284057617530 .1342163086524 .94921875510 .5596008301489 .0844116211 461.094909668446 .7504882812468 .5296020508504 .7155151367534 .1300048828 559.0620727539577 .8732299805590 .8759155273598 .528503418602 .8643798828 607.4274902344610 .928527832612 .3447265625613 .9788818359617 .6411743164 620.4403076172619 .4589233398619 .8480834961626 .9467163086632 .8969116211 630.299987793623 .8134155273616 .2061157227603 .4384765625582 .8756103516 559.4650268555539 .3422241211522 .1350097656504 .9450073242491 .0151977539 482.859588623474 .1900024414460 .7713012695445 .6112976074430 .0931091309 415.2815856934401 .3055114746386 .587890625370 .1960144043356 .0223999023 348.5108947754342 .8609008789334 .753692627325 .999786377317 .433013916 310.1418151855305 .0651855469301 .1094055176297 .5187072754294 .2088012695 290.9349975586288 .0947875977285 .9511108398284 .1921081543282 .5263977051 280.4767150879277 .5888061523274 .2239074707270 .7185058594267 .2016906738 263.903503418260 .7392883301257 .6870117188254 .7095947266251 .7380981445 248.7971954346245 .8941040039242 .9635009766239 .9635925293236 .9160003662 233.7857055664230 .8063049316228 .1880950928225 .7241973877223 .2380065918 220.7252044678218 .1974945068215 .3578948975211 .8979949951208 .1638031006 204.4319000244200 .9010009766197 .8679046631194 .7888031006191 .2174987793 187.3885955811183 .4396057129179 .3811035156175 .2604064941170 .862701416 165.9555053711161 .463394165158 .2675933838155 .6757965088153 .0926055908 150.5498962402147 .9676971436145 .2778015137142 .4028930664139 .3605957031 136.0926055908132 .6558074951129 .1000976562125 .056602478120 .1893997192 115.087600708110 .2519989014106 .2279968262103 .6899032593101 .9914016724 100.600097656299 .4464111328198 .440010070896 .8008270263793 .6678237915 89.8586730957 86.04145812988 82.1711730957 78.34140777588 74.21588134766 69.6192932128963 .8206710815455 .9502906799347 .5286216735840 .24203109741 33.8242111206128 .4492206573524 .3614501953121 .6991100311319 .97296905518 18.7024192810117 .8436603546117 .2551708221416 .9119796752916 .68733978271 16.5557594299316 .425079345716 .2593593597416 .058240890515 .37837982178 13.7338600158711 .621250152599 .423472404487 .1515460014344 .916526794434 $2.381226062775-.741263985634-4.10516405106-7.28451299667-10.4064598083$ $-13.4279603958-16.4154491425-19.4776096344-22.4271392822-25.1348495483$ $-27.7454299927-30.3835697174-33.0004310608-35.631439209-37.7272796631$ $-38.7235908508-39.2002906799-39.6703605652-40.0617980957-40.4238586426$ $-40.728351593-40.9546394348-41.1078796387-41.1776390076-41.1641387939$ $-41.0825309753-40.943611145-40.7499504089-40.5053291321-40.2157096863$ -39.8623199463 -39.4356117249 -38.9415092468 -38.3805809021 -37.7626495361 $-37.0876693726-36.3455696106-35.5374488831-34.6604003906-33.7141609192$ 
-32.6406402588 -31.3674201965 -29.9570999146 -28.4676990509 -26.940530777 -25.4377193451 -23.9396896362 -22.4557495117 -20.9837493896 -19.5302906036 -18.1016693115 -16.6786804199 -15.4557104111 -14.6254796982 -13.9682998657 $-13.286190033-12.5677995682-11.7708597183-10.8687200546-9.84268856049$ -8.64982700348 -7.26106500626 -5.66637182236 -3.8449549675 -1.83303105831 .33867698907852 .671473979955 .2189469337467 .87542104721110 .603099823 13.1359195709215 .1645402908316 .7305793762217 .7912406921418 .48089027405 18.9121208190919 .1509494781519 .262620925919 .4173202514619 .73180961609 20.2064990997320 .9774894714421 .9194793701223 .0058307647724 .16464996338 25.2052593231226 .1298809051526 .8955497741727 .5512104034428 .11886978149 28.6281299591129 .1260108947829 .6788005828930 .3848495483431 .16539955139 31.9387607574532 .709259033233 .4704017639234 .2229194641134 .96453094482 35.6953887939536 .4148101806637 .123180389437 .8209381103538 .50856018066 39.186939239539 .856449127240 .5179595947341 .1716804504441 .81824874878 42.457729339643 .0904808044443 .7164382934644 .3357505798344 .94828033447 45.5540008544946 .15275955246 .7444801330647 .3289909362847 .90615081787 48.4758796691949 .0380210876549 .5925216674850 .1392707824750 .67826843262 51.2094802856451 .7329406738352 .2486801147552 .7568092346253 .2574005127 53.7506217956554 .2365913391154 .7155189514255 .1875801086455 .65301132202 56.1120109558156 .5648307800357 .0117111206157 .4528694152857 .88859176636 58.3190917968858 .7446403503459 .165451049859 .5817909240759 .9938583374 60.402061462460 .8066215515161 .2051811218361 .60091018677 820.983581543817 .8012695312814 .6259155273811 .4552001953808 .2943115234 805.1467285156802 .0150146484798 .9019775391795 .8104858398792 .7426757812 789.7017211914786 .6892700195783 .7089233398780 .7628173828777 .8549804688 774.9885864258772 .169128418769 .4003295898766 .6885986328764 .0386962891 761.4570922852758 .9484863281756 .5180053711754 .1693725586751 .9064941406 749.731628418747 .647277832745 .6547241211743 .7559204102741 .9506835938 740.241027832738 .6253051758737 .1060180664735 .6853027344734 .3516845703 733.0969238281731 .896484375730 .7108154297729 .5853881836728 .5397949219 727.6052246094726 .7990112305726 .1591186523725 .7125854492725 .4810180664 725.4857177734725 .6959228516726 .1077270508726 .5847167969727 .0665893555 727.2714233398727 .0311889648725 .9719848633723 .7169189453720 .1098022461 714.6118774414707 .2634887695697 .6599731445686 .9091186523676 .3115234375 665.4052734375654 .2603149414643 .9868164062635 .9307861328629 .5772705078 623.1970825195619 .0040893555619 .4951171875621 .1113891602621 .3629760742 620.6685791016618 .4968261719616 .7498779297618 .6151123047621 .8248291016 625.9193725586628 .4437866211624 .9614257812620 .1647949219618 .5681152344 617.3123779297617 .6917724609610 .2208862305580 .6076049805548 .1129760742 528.5463867188517 .1688232422512 .4105834961513 .4375517 .8919067383522 .5667114258 528.2907714844526 .6727905273509 .5851135254486 .7018127441462 .8890991211 450.3139038086463 .6409912109489 .2417907715514 .4201049805540 .0651855469 563.7310180664582 .4630737305593 .5205078125600 .6284790039609 .1295776367 616.51171875621 .857421875626 .3577270508630 .6030883789634 .5153808594 638.0994873047641 .7991943359646 .1671142578648 .0034790039644 .5936889648 634.2301025391614 .9058227539592 .0676879883571 .1292724609551 .9821166992 
534.0469970703519 .7268066406511 .4476928711506 .1093139648501 .571685791 496.1817016602486 .1182861328472 .7432861328457 .9442138672441 .2547912598 423.292388916405 .8157958984388 .958190918375 .0079956055367 .212890625 360.9353027344352 .141998291341 .9812927246330 .058807373319 .3229980469 313.900604248310 .5163879395306 .512512207302 .7410888672298 .7312927246 295.1079101562292 .6283874512290 .5501098633288 .2909851074285 .7955932617 282.9762878418279 .87890625276 .6659851074273 .4078063965270 .2658081055 267.2249145508264 .3223876953261 .4765930176258 .6164855957255 .7476959229 252.8986968994250 .0059967041247 .0312957764243 .9841003418240 .7335968018 237.645904541235 .0684051514232 .6627960205230 .1569976807227 .6488037109 225.2805023193222 .5632019043218 .9940032959215 .1007995605211 .2523040771 207.6246948242204 .5941009521201 .6596984863198 .3795928955194 .8343048096 190.9718933105186 .8948059082182 .8406066895178 .5742034912173 .8484954834 169.316192627165 .5149993896162 .1835021973159 .1367950439156 .2667999268 153.4109039307150 .5135040283147 .4680938721144 .2819976807140 .9154968262 137.3195037842133 .4288024902129 .1717071533124 .5212020874119 .681602478 114.6587982178110 .401802063108 .0166015625106 .4708023071104 .9672012329 103.5261001587101 .899299621699 .8498229980597 .129051208593 .9087600708 90.3679962158286 .5255966186582 .4520492553777 .8953475952172 .62023925781 66.5430526733459 .6278305053752 .2650108337445 .1188888549838 .3780708313 32.3136596679727 .4494400024424 .3299598693822 .2908897399920 .61784934998 19.4568996429418 .6057796478318 .0711307525617 .7352790832517 .57987976074 17.5477504730217 .5846195220917 .8248691558817 .5885200500516 .07250976562 14.0582704544112 .1412601470910 .119440078748 .0157594680795 .695722103119 $3.120080947876 .3456650078297-2.48691105843-5.3653049469-8.22272586823$ $-11.0483102798-13.6376895905-16.3865509033-19.7819309235-23.2727909088$ $-26.4323291779-29.4742794037-32.690990448-35.2537307739-36.2890090942$ $-36.726600647-37.3573799133-37.9418411255-38.5208511353-39.0156593323$ $-39.3604812622-39.5898704529-39.7326087952-39.7896118164-39.7456207275$ $-39.6330795288-39.4414405823-39.192199707-38.9014892578-38.5432395935$ $-38.1141014099-37.6171607971-37.0449485779-36.4149017334-35.7185707092$ $-34.9700698853-34.1719093323-33.3041191101-32.3767204285-31.2943191528$ $-29.9552402496-28.4880695343-27.0094795227-25.5154590607-24.0425205231$ $-22.5812606812-21.1493492126-19.731470108-18.3237991333-16.9374103546$ $-15.4798297882-14.2521600723-13.5736999512-13.0851297379-12.4820299149$ $-11.8135795593-11.0366802216-10.1267595291-9.09444046021-7.86280488968$ $-6.40271282196-4.71320676804-2.77014398575-.6605529785161 .528918981552$ 3.8376660346986 .3190879821788 .87704086303711 .5474996566813 .96368026733 15.709890365617 .0116405487117 .9956798553518 .6527690887519 .02920913696 19.1903800964419 .2075099945119 .2078495025619 .3368301391619 .77953910828 20.7075996398921 .9424400329623 .2469902038624 .5323791503925 .64030075073 26.5809192657527 .3535003662127 .9796600341828 .5052890777628 .98633956909 29.4678897857730 .0295906066930 .7826690673831 .5961494445832 .3720703125 33.1373901367233 .88867187534 .6257591247635 .3529891967836 .06692886353 36.7706298828137 .4621315002438 .1442604064938 .8158302307139 .47945022583 40.1341781616240 .7821197509841 .4224205017142 .0566101074242 .68386077881 
43.3051910400443 .9198684692444 .5284500122145 .1303291320845 .72578048706 46.3143310546946 .8960990905847 .4706916809148 .0381393432648 .59817123413 49.1507911682149 .6958312988350 .2332916259850 .7630615234451 .28520965576 51.7996902465852 .30664062552 .8060607910253 .2981185913153 .78290939331 54.2606391906754 .7314300537155 .1955299377455 .6531105041556 .10441970825 56.54965972956 .989120483457 .4229812622157 .8515396118258 .27500152588 58.6936492919959 .1076889038159 .5173683166559 .9229087829660 .32469940186 60.7226104736361 .1177291870161 .50881958008 827.7573242188824 .612121582821 .4874267578818 .3724975586815 .2681274414 812.1793212891809 .1087036133806 .0595092773803 .0341796875800 .0354003906 797.0659179688794 .1279296875791 .2246704102788 .3588867188785 .5344848633 782.7548828125780 .0255126953777 .3507080078774 .7368164062772 .1892089844 769.7139892578767 .3167114258765 .0018920898762 .7741088867760 .63671875 758.5922241211756 .6431274414754 .7905273438753 .0360717773751 .3801879883 749.8240966797748 .3665771484747 .0104980469745 .758972168744 .5991821289 743.5220947266742 .5031738281741 .5075073242740 .5712280273739 .7097167969 738.9486083984738 .3070068359737 .8134155273737 .4993286133737 .3746948242 737.4639892578737 .7265014648738 .1566162109738 .6198120117739 .0424194336 739.1657714844738 .8032836914737 .6361083984735 .3391723633731 .5792236328 725.9202880859718 .7930297852709 .9412231445700 .3032836914690 .5697021484 680.3433837891669 .8146972656660 .2655029297653 .3543701172647 .4481811523 641.201171875636 .9603271484636 .4036254883637 .0825805664636 .5297241211 635.2869873047633 .6608886719633 .0468139648634 .861328125638 .3380737305 643.500793457647 .3939208984647 .3067016602644 .1240844727638 .6286010742 631.9373779297624 .8485717773611 .2280273438582 .646484375552 .8226928711 533.4929199219522 .2222290039518 .0643920898517 .3278198242518 .603515625 520.4135131836522 .4812011719519 .1604003906502 .7739868164483 .6423034668 469.5159912109463 .1258850098470 .1180114746484 .6198120117502 .3667907715 523.9384155273546 .1848754883566 .1362304688580 .938293457593 .1358032227 606.416015625618 .7172241211627 .670715332634 .6702270508640 .9724731445 646.8944702148652 .6168212891657 .6478271484662 .3269042969664 .0438232422 661.9412231445649 .887512207620 .1665039062588 .8375854492569 .3303222656 557.0222167969549 .7935180664544 .225402832536 .0842895508528 .7150878906 523.3532714844519 .4699707031518 .2423095703512 .2598266602494 .0067138672 470.5159912109447 .0620117188425 .9425964355409 .478302002396 .2520141602 385.9320068359377 .0986938477368 .6593933105359 .037109375346 .5255126953 334.6434936523327 .0704956055321 .8790893555316 .9790039062312 .4432983398 307.8554992676303 .6145935059300 .2889099121297 .4294128418294 .5592041016 291.6695861816288 .6769104004285 .6556091309282 .5456848145279 .4379882812 276.4583129883273 .5986938477270 .9370117188268 .3019104004265 .5025939941 262.6585083008259 .8919067383257 .0939025879254 .2158966064251 .2478027344 248.0962982178245 .0393981934242 .2991943359239 .6714935303237 .0070953369 234.3603057861231 .7734985352228 .928604126225 .5442047119221 .9064025879 218.2845001221214 .8175964355211 .6735992432208 .6954956055205 .7388000488 202.5050048828198 .612197876194 .3946990967190 .1739959717185 .837600708 181.2796936035176 .7814025879172 .7279052734168 .9747924805165 .5346984863 
162.3123931885159 .1336975098155 .9593963623152 .6983947754149 .3289031982 145.8088989258142 .0563964844138 .0065002441133 .7218017578129 .1663970947 124.5212020874119 .8365020752115 .7546005249113 .0220031738110 .9904022217 109.1608963013107 .3392028809105 .3199996948103 .0724029541100 .3828964233 97.3490829467893 .9309005737390 .0764770507885 .8946914672981 .15371704102 75.7065124511769 .7712936401463 .273441314756 .4851799011249 .65073013306 42.9488182067936 .8632011413631 .7251396179227 .9316005706825 .15456962585 23.0673503875721 .5543308258120 .3698692321819 .5483608245819 .01697921753 18.7277908325218 .6173591613818 .6397495269818 .7972793579118 .59789085388 17.4889602661115 .955289840714 .3832702636712 .6807899475110 .87211990356 $8.9105939865116 .7691631317144 .478024005892 .020581960678-.547042012215$ -3.12276101112 -5.76183700562 -8.47461795807-11.4900102615 -14.9472503662 $-18.5567893982-21.9331798553-25.1404094696-28.3045406342-30.8892593384$ -32.3789596558 -33.3440513611 -34.2981414795 -35.2026405334 -36.1354904175 $-36.9096488953-37.3632011414-37.6407203674-37.8822097778-38.0347900391$ -38.0722808838 -38.0146713257 -37.8466300964 -37.6017303467 -37.3129081726 -36.9521713257 -36.5348396301 -36.0469818115 -35.4696311951 -34.8204994202 -34.0851402283 -33.3099594116 -32.554649353 -31.7180194855 -30.7116603851 -29.5411396027 -28.2040405273 -26.7693099976 -25.3169803619-23.868850708 $-22.445230484-21.0455093384-19.6998004913-18.3819007874-17.085269928$ -15.8182897568 -14.5432596207-13.460559845 -12.7624597549-12.2162399292 -11.6113996506 -10.9393596649-10.1580600739 -9.2476682663 -8.19038581848 -6.92798519135 -5.42723417282 -3.69508695602 -1.70879995823.4368650019169 2.67511010175 .0072259902957 .4321260452279 .8826799392712 .34088039398 14.5341396331816 .1884002685517 .4510803222718 .401300430319 .06155014038 19.4518795013419 .6037693023719 .578470230119 .4126396179219 .09503936768 19.2700996398920 .6431694030822 .4539108276423 .998329162625 .36528015137 26.4842491149927 .3919696807928 .132879257228 .7053108215329 .09853935242 29.4937496185330 .077920913730 .7613506317131 .4888305664132 .23812866211 32.9775199890133 .7100601196334 .4314384460435 .1422004699735 .84138870239 36.529441833537 .2069206237837 .8743591308638 .5329093933139 .1830406189 39.8259391784740 .4618682861341 .0917510986341 .7155990600642 .33395004272 42.9466705322343 .5539398193444 .1554908752444 .7512702941945 .34103012085 45.9245681762746 .501678466847 .072128295947 .6357498168948 .19234085083 48.7417793273949 .2839202880949 .8186988830650 .3460311889650 .86589050293 51.3782615661651 .8831901550352 .3806915283252 .8708992004453 .35387039185 53.8297882080154 .2987899780354 .7610397338955 .2167510986355 .66611099243 56.1093597412156 .5467109680256 .9784011840857 .4046592712457 .8257598877 58.241909027158 .6533813476659 .0603713989359 .4631500244159 .86191940308 60.2570686340360 .6488304138261 .0349617004461 .418800354 834.4940795898 831.4099121094 828.3355712891 825.270324707 822.2191162109 819.1857299805816 .1727905273813 .1834716797810 .2208251953807 .2869262695 804.3848266602801 .5170898438798 .6868896484795 .8967285156793 .1511230469 790.453125787 .8087158203785 .2222290039782 .7003173828780 .2484130859 777.8729858398775 .579284668773 .3726196289771 .257019043769 .236328125 767.3126220703765 .4887695312763 .7655029297762 .1447753906760 .6264038086 
759.212097168757 .9000244141756 .6937866211755 .5968017578754 .595703125 753.6801147461752 .8295288086752 .0114746094751 .2503051758750 .5524291992 749.9428100586749 .4403076172749 .0703125748 .8615722656748 .8167114258 748.9625854492749 .2473144531749 .6776123047750 .1041870117750 .4821166992 750.5349121094750 .1193237305748 .885925293746 .6098022461742 .9321289062 737.4354248047730 .5294189453721 .9815063477712 .8378295898703 .5017700195 693.9345703125684 .4431152344675 .8502197266670 .0228881836665 .3245239258 660.204284668656 .2523193359653 .9063720703652 .2805175781650 .5349731445 648.9782714844648 .3939208984648 .9072265625650 .8762817383654 .3480834961 660.0545043945665 .5982055664670 .1444702148670 .7944946289663 .916809082 652.0095214844636 .6436157227616 .6375732422590 .3084106445564 .6724243164 544.7247924805530 .7985229492523 .5114135742519 .8574829102518 .950012207 518.3948974609516 .611328125511 .3411865234497 .7479858398484 .1622924805 480.0190124512479 .7457885742480 .5101013184485 .486907959495 .4108886719 509.7875976562526 .7526855469545 .2949829102563 .6176757812581 .8590698242 600.9428100586617 .7802124023630 .1719970703640 .1881713867649 .2650146484 657.2678222656664 .3291015625670 .0634155273675 .2489013672677 .2337036133 676.9384155273665 .4086914062630 .434387207593 .707824707575 .4724731445 568.6591186523570 .838684082574 .4757080078565 .7019042969554 .6292724609 547.7448730469544 .0465698242550 .0534057617550 .7111206055530 .4755859375 502.1845092773474 .7633056641449 .8154907227432 .6462097168419 .3168029785 405.3945922852393 .0643920898384 .153503418375 .225189209363 .3763122559 351.797088623342 .9957885742335 .6034851074329 .0604858398323 .2904968262 317.8353881836313 .0982055664308 .8653869629304 .9717102051301 .395904541 298.0252075195294 .8067016602291 .7034912109288 .5625285 .5078125282 .6524047852 279.9656066895277 .5129089355275 .0328063965272 .2846069336269 .475402832 266.8135986328264 .1618041992261 .4554138184258 .6290893555255 .621307373 252.5677032471249 .6009063721246 .6869049072243 .8139038086240 .9257049561 237.9839935303234 .9683074951231 .8363037109228 .6351013184225 .4031982422 222.1761016846218 .9496002197215 .8442993164213 .0675964355210 .0321044922 206.0903930664201 .7528991699197 .3916015625192 .9512023926188 .5258026123 184.1463012695179 .9640960693175 .9678039551172 .2265014648168 .6649932861 165.1408996582161 .6638031006158 .1499938965154 .5634002686150 .8645935059 146.9844970703142 .8506011963138 .5614013672134 .0780029297129 .6248931885 125.3511962891121 .4747009277118 .2852020264115 .5724029541113 .2555999756 111.051902771108 .7309036255106 .266998291103 .5072021484100 .4474029541 97.01614379883 93.14611816406 88.92034912109 84.17289733887 78.81757354736 73.0460128784266 .8713836669960 .4621505737353 .9813919067447 .62163162231 41.8434791564936 .7061805725132 .3299789428728 .8178100585926 .23064994812 24.3070507049622 .668670654321 .4643001556420 .6172008514420 .07156944275 19.7980499267619 .6570301055919 .5503902435319 .2812309265118 .54974937439 17.5224304199216 .3027095794714 .906640052813 .4340295791611 .84848022461 10.171839714058 .3162593841556 .2234988212593 .9472229480741 .654489994049 $-855714023113-3.80056405067-7.03238582611-10.3397598267-13.7403697968$ $-17.0715904236-20.222820282-23.1366004944-25.6380901337-27.6380805969$ $-29.255569458-30.6384601593-31.8708190918-33.1433792114-34.2018089294$ 
-34.7967300415 -35.1872406006 -35.5871200562 -35.8854789734 -36.0456809998 $-36.0567207336-35.9062690735-35.6556892395-35.3623390198-35.0284805298$ $-34.6596603394-34.2089996338-33.6500892639-32.9802513123-32.1927986145$ $-31.3906898499-30.6546001434-29.8297901154-28.7322292328-27.4741191864$ $-26.1825809479-24.8296203613-23.4457302094-22.0561695099-20.6806907654$ $-19.3621692657-18.1293392181-16.9601707458-15.8110399246-14.7126197815$ $-13.6690101624-12.7428798676-11.9781398773-11.2986001968-10.6274700165$ $-9.91289901733-9.1010017395-8.1646604538-7.07275009155-5.79277086258$ $-4.3019361496-2.56236195564-.5690150260931 .6105099916463 .89997792244$ 6.2442941665658 .6176824569710 .9338397979713 .1504096984915 .12827014923 16.7518692016618 .0473499298119 .0226306915319 .7115898132320 .1578502655 20.3612594604520 .3740291595520 .2117404937719 .6326694488519 .65726089478 21.4243202209523 .6491909027125 .253910064726 .5765399932927 .63331031799 28.4654903411929 .159669876129 .6779994964629 .9636497497630 .28474998474 30.9629306793231 .7341995239332 .3977508544933 .0522994995133 .73281097412 34.4138793945335 .0924682617235 .7629089355536 .4244003295937 .07577896118 37.7196311950738 .3547592163138 .9841308593839 .6065597534240 .22449874878 40.8368606567441 .4454307556242 .0491600036642 .6492195129443 .24457168579 43.8358192443844 .4220504760745 .0034790039145 .5793609619146 .1496887207 46.7139091491747 .2719497680747 .8233909606948 .3681488037148 .9059715271 49.436798095749 .9604415893650 .4769210815450 .9861106872651 .48807144165 51.9827613830652 .470291137752 .9506988525453 .4241294860853 .89065933228 54.3505096435554 .8037796020555 .2507209777855 .6914901733456 .12633895874 56.5554389953656 .979080200257 .3974304199257 .8107795715358 .21932983398 58.6233596801859 .0230598449759 .4186897277859 .8104400634860 .19871139526 60.5833702087460 .9654693603561 .34386062622

841.2462158203838 .1898193359835 .1583862305832 .1428222656829 .141418457 826.1597290039823 .2008056641820 .2678222656817 .3635253906814 .4904785156 811.6516723633808 .8496704102806 .087890625803 .3687133789800 .6965942383 798.0751953125795 .5101928711793 .0062255859790 .5698852539788 .2072143555 785.9241943359783 .7268066406781 .6198120117779 .6079711914777 .694519043 775.8820800781774 .1729736328772 .5681762695771 .069519043769 .6766967773 768.3911743164767 .2113037109766 .1406860352765 .1832275391764 .3251953125 763.5560913086762 .859375762 .2122192383761 .6160888672761 .0568847656 760.5712280273760 .1884155273759 .9240722656759 .8032226562759 .826171875 760.0145263672760 .3244018555760 .753112793761 .1782226562761 .5405273438 761.614074707761 .2470703125760 .132019043758 .0225219727754 .5709228516 749.4030761719742 .6541137695734 .0126953125724 .9451293945716 .231628418 707.7235717773699 .7888793945692 .6497192383687 .2415771484682 .8121948242 678.0001220703673 .7116699219670 .6693115234667 .8602294922664 .575012207 662.209777832661 .9827270508663 .1240234375665 .1785888672668 .4918823242 673.6561279297679 .4379882812684 .6560058594686 .7675170898683 .9451293945 673.6149291992654 .3635864258630 .4141235352603 .4639892578577 .8010864258 556.4298706055539 .5089111328529 .8173217773524 .1857910156520 .9232788086 518.6566162109515 .8508300781511 .7590026855503 .634185791496 .2349853516 492.6748962402489 .5020141602485 .8562011719484 .5020141602488 .9212036133 
497.2755126953 506.6767883301521.1068115234544.0391845703 569.8374023438 593.1148071289613 .1771850586629 .0786132812642 .6831054688655 .155090332 665.796081543674 .0734863281680 .2822265625685 .2197265625687 .3109130859 686.4996948242675 .370300293645 .4398803711611 .7822875977587 .4005126953 575.5794067383581 .4916992188590 .2343139648587 .2329101562580 .1760253906 575.8574829102574 .2344970703576 .7429199219575 .1359863281561 .6353149414 539.1226196289509 .6011962891480 .7573852539460 .1397094727443 .3034057617 426.6351928711411 .438293457398 .9248962402387 .921295166377 .1531066895 367.3792114258359 .9895019531352 .6593933105343 .3815002441334 .7276916504 328.4305114746323 .3393859863318 .3001098633313 .4352111816309 .0179138184 305.0539855957301 .5498962402298 .3038024902294 .9371948242291 .7412109375 288.9655151367286 .4273986816283 .9598999023281 .4594116211278 .8197937012 276.1622924805273 .624206543271 .1636047363268 .7600097656266 .1646118164 263.1008911133259 .8583068848256 .7242126465253 .6204071045250 .5749053955 247.4745941162244 .2122955322241 .0489959717238 .1611938477235 .367401123 232.4340057373229.3766021729 226.2593994141223.1571960449220.18800354 216.9868011475213 .133895874208 .9046020508204 .5545043945200 .1468048096 195.7673950195191 .4185943604187 .1515960693182 .9859924316179 .0447998047 175.2223052979171 .4143066406167 .6499023438163 .8811950684160 .0769042969 156.225402832152 .2485961914148 .0708007812143 .7875976562139 .3442993164 134.9738006592130 .8047027588126 .8760986328123 .3936004639120 .2309036255 117.450302124114 .8598022461112 .2251968384109 .5205001831106 .6192016602 103.4806976318100 .008201599196 .1557922363391 .9115829467887 .2243270874 82.0345001220776 .4983825683670 .6461181640664 .6147384643658 .50138092041 52.5115394592346 .9521903991741 .8195991516137 .2845001220733 .39614105225 30.2839794158927 .7686100006125 .5757694244423 .8402996063222 .52687072754 21.5946102142321 .1002292633120 .7972602844220 .5531291961720 .30209922791 19.7201900482218 .9477100372317 .9707107543916 .8336296081515 .67014980316 14.4839897155813 .3539896011412 .0027704238910 .131079673777 .980936050415 $5.7936692237853 .352896928787 .5143769979477-2.54873895645-5.69153594971$ -8.88386058807 -12.0354995728 -15.0455799103 -17.8355197906 -20.392660141 $-22.633939743-24.6366291046-26.3598594666-27.8704605103-29.3271598816$ -30.5634803772 -31.440290451 -32.1254692078 -32.7842407227 -33.3147201538 -33.653678894 -33.7588996887 -33.5737190247 -33.2607498169 -32.9797286987 $-32.7078285217-32.460849762-32.1181793213-31.5794906616-30.8716106415$ -30.0244102478 -29.170999527 -28.4099807739 -27.5629291534 -26.4405994415 -25.179769516 -23.9472694397 -22.699180603 -21.4174003601 -20.1087799072 $-18.7602291107-17.4997997284-16.4528808594-15.4973402023-14.5144996643$ -13.564160347 -12.6584196091 -11.7998199463 -11.023349762 -10.2719802856 -9.53081607819-8.75388336182 -7.86851787567-6.87275123596 -5.73950481415 $-4.46674013138-3.0616209507-1.388139963150 .6930580139162 .982794046402$ 5.2924151420597 .6093502044689 .90276432037412 .0947799682614 .1462802887 15.997099876417 .5640792846718 .8708095550519 .8895092010520 .6531791687 21.2010002136221 .548200607321 .7357101440421 .79380035421 .70252037048 22.1535205841123 .8531608581525 .8370990753227 .1867504119928 .21513938904 29.0936603546129 .8223209381130 .4234199523930 .8898696899431 .20384025574 
31.5595092773432 .1534996032732 .8188209533733 .428569793734 .02328872681 34.6359100341835 .2579002380435 .8774185180736 .4936294555737 .10403060913 37.7091598510738 .3095588684138 .9056816101139 .498470306440 .08813858032 40.6754493713441 .2603607177741 .8432998657242 .423969268843 .00239944458 43.5780792236344 .1507415771544 .7198410034245 .284881591845 .8454208374 46.4009017944346 .9510002136247 .4952697753948 .033481597948 .5652885437 49.0905685424849 .6091117858950 .1208305358950 .6256103515651 .12342834473 51.6142692565952 .0981407165552 .5750694274953 .0451583862353 .50849151611 53.9651908874554 .4154205322354 .8593215942455 .2970809936555 .72890090942 56.1549797058156 .5755195617756 .9907684326257 .4009284973157 .80624008179 58.2069396972758 .6032600402858 .995399475159 .3836288452159 .7681388855 60.1492881774960 .5273208618260 .9001007080161 .27112960815 847.9431152344844 .944519043841 .958190918838 .9849853516836 .0297241211 833.0961303711830 .1873779297827 .3067016602824 .4567871094821 .6403198242 818.8604736328816 .1196899414813 .4215087891810 .7681884766808 .1647949219 805.6143798828803 .1232910156800 .6956787109798 .3389282227796 .0582885742 793.8607788086791 .7517700195789 .7365112305787 .8193969727786 .0040283203 784.2927246094782 .6879882812781 .190612793779 .8024291992778 .5228881836 777.3536987305776 .2924804688775 .3435058594774 .5098266602773 .7791137695 773.1400756836772 .580078125772 .0858764648771 .637878418771 .201171875 770.8240966797770 .5457763672770 .3717041016770 .3250732422770 .4019165039 770.6270751953770 .9536743164771 .3922729492771 .8222045898772 .2119140625 772.3452148438772 .1220703125771 .2282104492769 .482421875766 .4906005859 762.0006713867755 .7512817383747 .2194213867737 .9799804688729 .0775756836 721.2943725586715 .0618896484709 .8875732422705 .3214111328700 .6674194336 695.4655761719690 .270324707686 .0720214844682 .1929931641677 .6367797852 674.262878418674 .2260742188675 .9077148438678 .0161132812681 .3748779297 686.0009765625690 .9520874023695 .2767944336697 .7415771484698 .801574707 692.6444702148673 .515625648 .088684082621 .0120849609594 .2280273438 570.0123291016550 .2786254883538 .1334228516530 .5034790039525 .2780151367 521.766418457518 .5698242188516 .0942993164513 .5482177734510 .6055908203 505.379699707498 .7403869629492 .6293029785487 .3671875486 .9534912109 489.7814025879492 .1726989746502 .5914001465528 .0200195312558 .3900146484 584.1853027344607 .1555786133626 .9279174805643 .921081543659 .4271850586 672.4055175781681 .7849121094688 .2368774414693 .0114135742694 .2489013672 692.2459716797682 .8508300781661 .6234130859636 .1909790039608 .9694824219 590.6865844727594 .7119140625604 .0180053711604 .591796875602 .9658203125 602.7717285156601 .9160766602598 .5015869141592 .5551757812585 .7686157227 571.8834228516544 .1693725586513 .4989013672489 .5698852539468 .3266906738 448.2782897949430 .2601013184413 .7641906738399 .9609069824389 .8120117188 381.9309997559376 .1801147461369 .7721862793358 .8756103516347 .8876037598 340.7210083008334 .6978149414328 .3916015625322 .5820922852317 .3688049316 312.9523925781309 .1101074219305 .5906066895301 .9530944824298 .5042114258 295.6918029785293 .1387023926290 .4870910645287 .8469848633285 .2934875488 282.7998046875280 .3840026855278 .032989502275 .8369140625273 .403503418 270.2775878906266 .8859863281263 .6549987793260 .4175109863257 .2626953125 
254.0702972412250 .6338043213247 .3880004883244 .6766967773242 .1293029785 239.3493041992236 .4474945068233 .4978027344230 .4069976807227 .1679992676 223.6976928711219 .9069976807215 .8583984375211 .6195068359207 .279800415 202.9532012939198 .6273040771194 .3271026611190 .0859985352186 .0308990479 182.0301055908177 .9976959229173 .9602050781169 .8993988037165 .8849029541 161.9125976562157 .917098999153 .7337036133149 .4394989014144 .9729003906 140.5487060547136 .296005249132 .2138977051128 .4573974609124 .9425964355 121.7827987671118 .8089981079115 .8566970825112 .8953018188109 .8076019287 106.543296814103 .015098571899 .1655273437594 .9616928100690 .38757324219 85.4160232543980 .1484069824274 .6054992675868 .917686462463 .19298934937 57.5542297363352 .2355003356947 .2252998352142 .7005386352538 .63998031616 35.0988502502432 .0124282836929 .2386608123826 .8622703552224 .88220024109 23.4724502563522 .738140106222 .3963603973422 .095840454121 .77432060242 21.1716899871820 .4356002807619 .5448703765918 .5655307769817 .68453025818 16.8262805938716 .1643791198715 .2562904357913 .595179557811 .57161045074 $9.5008401870737 .1703472137454 .5489749908451 .73497402668-1.17376697063$ $-4.09180307388-6.95264720917-9.76203632355-12.4673595428-15.0801000595$ $-17.4895706177-19.6968898773-21.6588802338-23.3899497986-24.98320961$ $-26.3706607819-27.5442409515-28.545879364-29.4716491699-30.2157096863$ $-30.7234897614-30.9415607452-30.7712898254-30.4489498138-30.2130908966$ $-30.0041999817-29.8524398804-29.6194496155-29.1535797119-28.4706401825$ $-27.6429290771-26.7896099091-25.9293193817-25.0077705383-23.8819599152$ $-22.6392097473-21.5118408203-20.4100494385-19.2630195618-18.0900802612$ $-16.8189792633-15.6461496353-14.7792301178-14.016289711-13.1684598923$ $-12.329460144-11.5003795624-10.6773300171-9.88209819794-9.07785511017$ $-8.27878475189-7.42283296585-6.44651508331-5.3711180687-4.17311382294$ $-2.86093497276-1.5073980093 .12073600292212 .2589030265814 .596499919891$ 6.8672690391549 .10651588439911 .3001804351813 .3747596740715 .30941009521 17.0619106292718 .5958900451719 .910219192520 .9825191497821 .84494018555 22.5261802673323 .0641803741523 .4969692230223 .958290100124 .56826972961 25.4940109252926 .9560298919728 .4476795196529 .3849906921430 .09514045715 30.7990093231231 .4024391174331 .9016799926832 .3251495361332 .69638061523 33.0826110839833 .5484504699734 .0556907653834 .5841598510735 .12125015259 35.6663589477536 .2167091369636 .7667617797937 .317241668737 .86801147461 38.4180984497138 .9687881469739 .519111633340 .0705413818440 .62211990356 41.175079345741 .7283592224142 .2827491760342 .8370399475143 .39152908325 43.9449501037644 .4972000122145 .0471115112345 .5942687988346 .13777923584 46.677169799847 .211780548147 .7411994934148 .2649993896548 .7829208374 49.2946510314949 .800079345750 .2989997863850 .7913703918551 .27708053589 51.7561607360852 .2285614013752 .6943588256853 .1535797119153 .60634994507 54.052738189754 .4929313659754 .9270286560155 .3552589416555 .777759552 56.194751739556 .6063995361357 .012969970757 .4146308898957 .81164932251 58.2042083740258 .5925712585458 .9769210815459 .3575210571359 .73453903198 60.1083488464460 .4788513183660 .8470306396561 .21181869507 854.6530761719851 .6729125977848 .7216796875845 .7916259766842 .8787231445 839.9893798828 837.1268920898 834.2943115234 831.4946289062828.7305297852 
826.0048828125823 .3206787109820 .6810302734818 .088684082815 .5482788086 813.0635986328810 .6400756836808 .2830200195805 .9989013672803 .7937011719 801.673828125799 .6453857422797 .7131958008795 .8820800781794 .1550292969 792.5349731445791 .0239257812789 .6228027344788 .3330078125787 .1544799805 786.0880737305785 .132019043784 .2896728516783 .5642089844782 .9439086914 782.4185791016781 .9771728516781 .6068115234781 .2808227539780 .9616088867 780.6926879883780 .5090942383780 .4180908203780 .4375780 .5681152344780 .8289794922 781.1896972656781 .6516113281782 .1301269531782 .5833129883782 .8604736328 782.8549194336782 .3483886719781 .1688842773778 .9956054688775 .5928955078 770.3109130859762 .6804199219753 .4671020508742 .4088745117733 .290222168 729.5836791992727 .5003051758724 .4774780273720 .0219116211713 .2532958984 705.7915039062699 .0239257812693 .0372924805687 .7379760742684 .0457763672 683.7680053711685 .5076293945688 .1489257812692 .0111083984696 .7578125 701.266418457704 .9191894531707 .4608154297707 .897277832702 .7036132812 688.3524169922666 .9901733398640 .7288208008612 .9509887695586 .7581787109 564.5264282227549 .76171875539 .8027954102533 .196105957528 .4852905273 523.3278808594520 .2050170898520 .1900024414519 .9489746094516 .9649047852 512.2139282227507 .7650146484501 .8471069336492 .5267944336486 .0466918945 488.5881958008500 .3103942871520 .8264770508547 .154296875575 .6102294922 602.794921875625 .5874023438645 .3338012695662 .1749267578676 .1810302734 686.8992919922694 .2741088867699 .0228881836700 .044921875697 .2210083008 689.9351806641675 .6812133789658 .5346069336641 .8701782227628 .5347900391 623.9818115234623 .7180786133621 .9782714844620 .6450805664620 .6663818359 618.9224853516614 .3978881836608 .4636230469601 .4125976562589 .9075927734 569.678894043544 .2108764648518 .1854858398492 .6588134766469 .4016113281 448.3335876465429 .345703125413 .7817993164403 .0969848633395 .529296875 389.4085083008382 .9059143066374 .2775878906364 .917388916355 .9053955078 347.2872009277339 .1552124023331 .9346008301326 .2614135742321 .7326049805 317.5874023438313 .7347106934309 .9294128418306 .2865905762303 .1487121582 300.3051147461297 .3208007812294 .4206848145291 .8623962402289 .466796875 287.0571899414284 .6734008789282 .3340148926279 .8060913086276 .8514099121 273.641204834270 .3664855957267 .0718994141263 .9099121094260 .7503967285 257.4833068848254 .3805999756251 .6087036133248 .9732971191246 .2178955078 243.3815002441240 .5451965332237 .4878997803234 .0818023682230 .4490966797 226.6311035156222 .6641998291218 .5426025391214 .3110046387210 .0738067627 205.8251953125201 .5765991211197 .3495025635193 .2169952393189 .0820007324 184.899597168180 .6255950928176 .179397583171 .8567962646167 .9259033203 164.0449981689159 .8560028076155 .4781951904150 .9122924805146 .3433074951 141.8977050781137 .5928039551133 .5592956543129 .7436065674126 .2333984375 122.9120025635119 .6425018311116 .4125976562113 .1648025513109 .8080978394 106.2238006592102 .38559722998 .2351684570393 .791160583589 .02937316895 84.0284271240278 .8138504028373 .4890594482468 .1430969238362 .86413955688 57.79965972952 .9595298767148 .4601402282744 .2763099670440 .48128890991 36.9817008972233 .7169799804730 .6673297882127 .6996898651125 .51172065735 24.8203296661424 .7164993286124 .3626594543523 .8626308441223 .06234931946 22.1656799316421 .1916694641120 .2342090606719 .4978294372618 .85909080505 
18.3542003631617 .6662502288816 .3917407989514 .7614803314212 .98017978668 10.910389900218 .4351434707645 .7767248153693 .098226070404 .4806239902973 -1.93865597248 -4.40403795242 -7.10701322556 -9.84007263184-12.3226900101 -14.6198797226 -16.7373790741 -18.6454696655 -20.3696708679 -21.9224796295 -23.2877197266 -24.490940094 -25.549369812 -26.3995704651 -27.0065307617 -27.3299694061 -27.3384799957 -27.1814594269-27.0217208862 -26.8561992645 $-26.7009506226-26.5145702362-26.2247505188-25.7017593384-25.0304393768$ $-24.2706794739-23.2867107391-22.2339305878-21.1138191223-19.9097900391$ -18.8858299255 -17.9701194763 -17.0225296021 -16.0473499298 -15.0054702759 $-14.0263204575-13.2363395691-12.5168800354-11.750459671-10.9720697403$ $-10.1776800156-9.36248016357-8.53594493866-7.68274307251-6.82345294952$ $-5.8893198967-4.82712507248-3.65892100334-2.35133004189-.933577001095$ 0.5659949779512 .2904319763184 .3402829170236 .5311422348028 .692826271057 10.815600395212 .8781995773314 .8378601074216 .6625595092818 .34152030945 19.8501091003421 .1864204406722 .3292694091823 .3150596618724 .15694999695 24.9126892089825 .6264991760326 .4498291015627 .4897499084528 .60963058472 29.7967090606730 .8257694244431 .5618591308632 .171310424832 .72716140747 33.2115783691433 .6141510009833 .9770698547434 .3230094909734 .66790008545 35.0535392761235 .4581985473635 .8899993896536 .3452491760336 .8073387146 37.2750511169437 .7479896545438 .2265892028838 .7104301452639 .19960021973 39.6939811706540 .1934700012240 .698101043741 .2076110839841 .72185897827 42.2403411865242 .7626609802243 .2880401611343 .8157691955644 .34490966797 44.8744812011745 .4035491943445 .9310188293546 .4561500549346 .97793960571 47.4958915710448 .009201049848 .5176010131849 .0205192565949 .51784133911 50.0092201232950 .4945793151950 .9737396240251 .4466705322351 .91329956055 52.3736495971752 .82770919853 .2755584716853 .7172508239754 .15288925171 54.5826110839855 .0065307617255 .4248390197855 .8376693725656 .24523162842 56.6476898193457 .0452804565457 .4381713867257 .8266105651958 .21078109741 58.5909309387258 .9672508239759 .3399696350159 .7092895507860 .07553863525 60.4389381408760 .7975082397561 .15486907959

861.2918701172858 .3654174805855 .4531860352852 .5579223633849 .6837768555 846.8350219727844 .0145874023841 .2260742188838 .4721069336835 .7557983398 833.0800170898830 .4470825195827 .8612060547825 .3245239258822 .8419799805 820.416809082818 .0554199219815 .7620849609813 .5443115234811 .4072265625 809.3577880859 807.4019165039805.5444946289803.7901000977802.1422119141 800.6030273438799 .1751098633797 .8587036133796 .6558227539795 .5654907227 794.5891113281793 .7244262695792 .9746704102792 .3422851562791 .8167724609 791.388671875791 .0460205078790 .7777709961790 .5549926758790 .3411254883 790.1715087891790 .0734863281790 .0543823242790 .1325073242790 .3090820312 790.6077270508791 .0029296875791 .5042724609792 .0443115234792 .5955200195 793.0413818359793 .299621582793 .2058105469792 .6306152344791 .3148193359 789.0786132812785 .3527832031779 .5623168945771 .2719116211758 .5728759766 747.5401000977745 .146484375745 .0244750977742 .7730712891738 .4619140625 730.608581543721 .0568847656712 .07421875703 .7299804688697 .1348876953 693.5872802734693 .7056274414696 .2031860352699 .2545776367703 .0360717773 707.5114746094712 .0120849609715 .1892700195716 .6973876953714 .708984375 
708.638671875699 .0571289062683 .3568115234659 .9193115234632 .9722290039 606.2858886719582 .3909301758565 .296081543553 .196105957545 .2396240234 539.5053100586532 .1483154297527 .2567138672527 .2543945312528 .4682006836 528.1329956055526 .1118164062524 .7556762695519 .3560791016503 .592590332 491.2734069824496 .5195922852509 .736114502523 .140625542 .1063232422570 .329284668 600.6784057617626 .1926269531648 .4857788086666 .0410766602679 .8881835938 691.1890869141698 .9962158203703 .9110717773705 .2266845703702 .512878418 697.0908203125688 .6909790039679 .6718139648674 .6795043945668 .5712890625 656.5051269531645 .073425293638 .6823120117635 .0919799805633 .5092163086 631.7429199219627 .7905883789621 .9525146484613 .0953979492601 .4556274414 588.0170288086569 .5225219727543 .7816772461515 .6724853516489 .9749145508 466.5344848633445 .6910095215429 .0537109375417 .5551147461409 .0743103027 401.5510864258394 .6890869141388 .6518859863381 .5867919922371 .2857055664 360.4479980469350 .8876037598342 .7467956543336 .9934997559332 .178314209 327.0957946777322 .4717102051318 .3814086914314 .7702026367311 .3382873535 307.9265136719304 .4952087402301 .2782897949298 .6517028809296 .2511901855 293.7459106445291 .2073059082288 .5754089355285 .8409118652283 .020690918 280.0089111328276 .7803039551273 .5033874512270 .4201049805267 .4341125488 264.4783935547261 .5781860352258 .6615905762255 .7734069824252 .899597168 250.0223999023247 .2395019531244 .2420959473240 .7870025635237 .0758972168 233.2433929443 229.3115997314 225.2989044189 221.2243041992 217.1188964844 212.9745941162208 .8193054199204 .6427001953200 .4875030518196 .2830963135 192.038192749187 .6629943848182 .9664001465178 .4255065918174 .5102996826 170.678604126166 .4075012207161 .9026947021157 .1876983643152 .3932952881 147.6459960938143 .050994873138 .7518005371134 .6929931641130 .8970947266 127.25340271123 .6835021973120 .1882019043116 .7736968994113 .3146972656 109.6703033447105 .8374023438101 .753097534297 .4429626464892 .8828125 88.1396331787183 .2365264892678 .2525711059673 .2759780883868 .33865356445 63.5678405761758 .9287986755454 .5183181762750 .3019714355546 .35000991821 42.5733718872138 .9340591430735 .40974044831 .6692790985128 .80306053162 28.0627803802528 .0249290466327 .441469192526 .6707401275625 .56442070007 24.3050899505623 .0198307037421 .9283008575421 .2775192260720 .83761024475 20.422639846819 .8367595672618 .9065303802517 .6622905731216 .20104026794 14.3914699554412 .092940330519 .597998619087 .1357789039614 .768355846405 $2.706765890121 .5469549894333-2.10845303535-4.84143304825-7.22744178772$ -9.48762512207 -11.6771297455 -13.7294998169 -15.590470314 -17.2643203735 -18.7849693298 -20.112329483 -21.244310379 -22.148519516 -22.8179397583 $-23.2570400238-23.5045604706-23.5851898193-23.5608596802-23.442949295$ $-23.2599506378-23.0343608856-22.8069591522-22.60820961-22.4361991882$ -21.902469635 -20.6485290527 -19.1843700409 -17.9810504913 -17.0042190552 -16.2040691376 -15.480890274-14.7294197083-13.9646501541-13.1787204742 $-12.4013595581-11.6695899963-10.9546899796-10.2179899216-9.46256923676$ $-8.65832710266-7.80978679657-6.93063306808-6.01616811752-5.09294891357$ $-4.09900617599-2.9836640358-1.71183395386-.2637470066551 .338132023811$ 3.0347399711614 .8430638313296 .7508721351628 .71384334564210 .7110004425 12.684399604814 .6114797592216 .4524993896518 .1830501556419 .80105018616 
21.2983093261722 .6657600402823 .9019107818625 .0198593139626 .02771949768 27.0250606536928 .0340690612829 .148300170930 .4355602264431 .63166999817 32.51284027133 .1914482116733 .8338699340834 .3852996826234 .81887054443 35.1865310668935 .4899101257335 .7712593078636 .0518188476636 .33451080322 36.641189575236 .9603309631337 .3017692565937 .6615295410238 .03050994873 38.4106597900438 .8018684387239 .2039794921939 .6168098449740 .04042053223 40.4747200012240 .9192810058641 .3739204406741 .8378601074242 .31069946289 42.7914009094243 .2793807983443 .7733383178744 .2724304199244 .77518844604 45.2805213928245 .7870292663646 .2934913635346 .7988014221247 .30186080933 47.8019104003948 .298130035448 .7900314331149 .2770996093849 .75904083252 50.2355995178250 .7065811157251 .1718482971251 .6312904357952 .08488845825 52.5325698852552 .9743881225653 .4103317260753 .84049988779354 .26493835449 54.6837997436555 .0971488952655 .5051803588955 .9080009460456 .30582809448 56.698799133357 .0871200561557 .4709701538157 .850589752258 .22611999512 58.5978393554758 .9658889770559 .3305206298859 .6919212341360 .05039978027 60.4058990478560 .7593002319361 .10966110229 867.9412231445865 .0236816406862 .138671875859 .2794189453856 .4401245117 853.6276855469850 .8452758789848 .096496582845 .3839111328842 .7106933594 840.0797119141837 .4937133789834 .9561157227832 .4697265625830 .0391845703 827.6680297852 825.3619995117823.1264038086 820.9677124023 818.891784668 816.9050292969815 .0136108398813 .2222290039811 .5355834961809 .9569091797 808.4887695312807 .1328735352805 .8903198242804 .7620239258803 .7476196289 802.8477783203802 .0607299805801 .3892211914800 .8355712891800 .3897094727 800.0427856445799 .7838134766799 .6022949219799 .4686279297799 .3447875977 799.2620849609799 .2382202148799 .2841186523799 .4144287109799 .63671875 799.9716796875800 .4094238281800 .9573974609801 .5755004883802 .2401733398 802.8743896484803 .4022827148803 .7183837891803 .6821899414803 .2108154297 802.1428222656800 .4083862305798 .1527099609792 .6760864258780 .7410888672 769.1436157227764 .4130249023762 .0579833984758 .8217163086754 .0004882812 746.5670776367737 .1600952148726 .8862915039716 .5220947266706 .6442871094 701.5029296875705 .4548950195711 .6806030273713 .4971923828714 .9108886719 718.8217163086723 .1746826172726 .5708007812727 .4896850586722 .7537841797 714.9812011719705 .9984130859693 .2196044922675 .4398193359653 .5192260742 628.4467163086604 .4702758789586 .1182861328572 .1801147461562 .5645751953 554.9617919922546 .5947875977540 .6165771484538 .9038696289539 .7279052734 541.5020141602542 .0374145508539 .5985107422533 .0095825195520 .9276733398 512.7631835938518 .3087768555528 .9785766602537 .5236816406550 .3515014648 573.4838256836601 .8192749023630 .4213256836656 .1500854492673 .7932739258 686.7623901367696 .9110717773703 .9185791016708 .6552124023710 .4940185547 709.2866210938706 .5341186523701 .9652099609697 .5811767578695 .1431274414 689.4467773438678 .100402832664 .8140258789653 .7354125977646 .5897216797 644.9271240234644 .2360229492640 .2868041992633 .8687133789624 .3051147461 612.9586791992600 .5629882812584 .3648071289562 .3291015625536 .3256225586 508.7780151367482 .9896850586462 .1025085449445 .5657043457433 .2236022949 423.3363952637414 .7186889648407 .3819885254400 .7832946777393 .486114502 383.7521057129373 .3098144531364 .0107116699356 .3096923828351 .0368041992 
345.7809143066337 .9888916016330 .8277893066327 .0220031738324 .2159118652 320.3168945312316 .1091003418312 .2280883789308 .7351989746305 .8388977051 303.2236022949300 .5188903809297 .7427978516294 .8551025391291 .9400939941 288.9688110352285 .9172973633282 .7862854004279 .6585998535276 .7130126953 273.9436950684271 .3228149414268 .6099853516265 .5534973145262 .3909912109 259.3309936523256 .3436889648253 .4689941406250 .4589996338247 .1378936768 243.5527038574239 .6730957031235 .7229003906231 .8903961182228 .0428924561 224.1026000977220 .0924072266216 .0281982422211 .9194030762207 .7985992432 203.6262969971199 .4286956787195 .1067047119190 .5774993896186 .1307067871 181.9931945801177 .8690948486173 .4279022217168 .7295074463163 .8251953125 158.770904541153 .5825958252148 .5798950195144 .087600708139 .8840026855 135.8316955566131 .8995056152128 .0619049072124 .3303985596120 .7245025635 117.1333007812113 .4216003418109 .5849990845105 .5623016357101 .3756027222 96.9975433349692 .4897613525487 .876533508383 .2221832275478 .5952835083 74.012557983469 .5588912963965 .1811599731460 .9064483642656 .73723983765 52.7081794738848 .7901916503944 .9785995483441 .272598266637 .63554000854 34.7535095214833 .3581809997632 .5727500915531 .5560302734430 .36383056641 28.8373603820827 .0812206268325 .0666503906223 .4823398590123 .06164932251 23.0343704223622 .7752799987822 .3099098205621 .509620666520 .4405708313 19.1041698455817 .4333400726315 .3846397399913 .1381597518910 .85219955444 $8.6389522552496 .619806766514 .5275659561162 .160080909729-.226937994361$ $-2.30592989922-4.34549808502-6.57553720474-8.77797603607-10.7378101349$ $-12.5074796677-14.1223897934-15.5400495529-16.7453899384-17.7241001129$ -18.4356002808 -18.9807395935 -19.435760498 -19.7445907593 -19.8841991425 -19.8549995422 -19.6921291351-19.4092006683 -18.916059494-18.8657398224 -20.067779541 -20.5075397491 -18.1338100433 -15.3660001755 -14.3484296799 -13.986240387 -13.5111904144 -13.0080404282 -12.4322004318 -11.8320598602 $-11.2170801163-10.5746803284-9.94071674347-9.27407169342-8.55424213409$ $-7.79040384293-6.93554401398-6.00892591476-5.03558683395-4.03239107132$ $-3.03818702698-2.00328207016-.904776990414 .40866601467132 .104626893997$ 3.9704020023355 .7707738876347 .5566711425789 .34550094604511 .12154960632 12.9346103668214 .7479696273816 .5246601104718 .2429504394519 .8740901947 21.4366207122822 .9267597198524 .3378696441725 .677459716826 .92116928101 28.0388793945329 .1918106079130 .5033397674631 .8798599243233 .23294067383 34.3753318786635 .1634101867735 .7349586486836 .2316894531236 .65393829346 36.981719970737 .2370414733937 .4497909545937 .6466484069837 .85205078125 38.0620193481438 .2900009155338 .5265808105538 .7752914428739 .03839111328 39.3154182434139 .6068992614739 .9139709472740 .2369308471740 .57624816895 40.9318084716841 .3035583496141 .6908798217842 .0930290222242 .50917053223 42.938201904343 .3790893554743 .8305282592844 .2912712097244 .7597618103 45.2345886230545 .7139892578146 .1966094970746 .6806106567447 .16493988037 47.64802169848 .1291694641148 .6071701049849 .0816802978549 .55191040039 50.0176887512250 .4785804748550 .9344596862851 .3851013183651 .83044052124 52.2703514099152 .7048416137753 .1338500976653 .5574188232453 .9755897522 54.3884315490754 .7959899902355 .1984214782755 .5958099365255 .98831939697 56.3760910034256 .7592811584557 .1380691528357 .5126304626557 .88315963745 
58.2498397827158 .6128807067958 .9724617004459 .3287887573259 .6820602417 60.0325698852560 .3805313110460 .7240600585961 .06692886353 874.5051879883871 .63671875868 .7844238281865 .9520263672863 .1436767578 860.3637084961857 .6151733398854 .9016113281852 .2260131836849 .5911254883 847.0001831055844 .4556884766841 .9614257812839 .5197753906837 .1356811523 834.8123168945832 .5559082031830 .3712158203828 .2650146484826 .2427978516 824.3112792969822 .4760742188820 .7423706055819 .1143798828817 .5955810547 816.1879272461814 .8937988281813 .7133789062812 .6481933594811 .6973266602 810.8616943359810 .1386108398809 .5310058594809 .0402832031808 .6583251953 808.3767700195 808.1845092773 808.0722045898 808.0120849609 807.9686279297 807.9608764648807 .9998168945808 .0966796875808 .2703857422808 .5322875977 808.9027099609809 .3817138672809 .9788208008810 .6765136719811 .4547729492 812.2758789062813 .0590820312813 .7692871094814 .2241821289814 .4990844727 814.4243774414814 .1259155273814 .7772827148812 .4409179688802 .5274047852 791.3508300781784 .2711791992778 .6859130859773 .6851806641768 .1574707031 761.4094238281753 .3765869141743 .7041015625733 .6760864258722 .4816894531 716.2250976562723 .3740234375732 .4512939453732 .5145263672731 .5994873047 734.8721923828738 .7056274414741 .6657714844740 .9060058594732 .0344848633 720.673828125710 .6281738281699 .548828125687 .654296875672 .0056152344 650.4711303711628 .1762695312609 .4710083008594 .0806884766582 .75573 .6643066406 564.6146850586557 .5546264648553 .1734008789551 .8057861328553 .940612793 555.1520996094550 .9119262695544 .4962158203539 .2719726562537 .1663818359 542.8911132812550 .9365844727555 .9025268555565 .3466796875584 .1633911133 609.6229248047639 .9329833984667 .6229248047684 .4495239258695 .303527832 703.2589111328708 .9190063477713 .6094970703716 .7354125977717 .567199707 717.0979003906715 .0897216797712 .2672729492709 .0927734375702 .9797973633 694.356628418683 .1981811523670 .2150878906660 .1624755859658 .239074707 657.9008178711653 .2772216797646 .0192871094635 .3256835938623 .176574707 610.1417236328594 .8041992188576 .7598266602554 .7545776367527 .716796875 500.992401123480 .3030090332463 .4729919434449 .483795166438 .2904968262 428.8829040527420 .5562133789412 .5473022461404 .3167114258395 .236114502 386.1401977539377 .8392944336370 .6329040527365 .6463012695359 .9757995605 349.8676147461340 .4533081055336 .5827026367334 .058013916329 .2937927246 324.2919921875320 .2031860352316 .4800109863313 .3146972656310 .384185791 307.3966064453304 .3969116211301 .2587890625298 .0693054199294 .8020935059 291.5816040039288 .5412902832285 .645690918282 .8916931152280 .2710876465 277.854888916275 .2645874023272 .0679016113268 .6849060059265 .4567871094 262.3151855469259 .3312988281256 .3143920898253 .1831970215249 .8126068115 245.9597015381242 .0316009521238 .3769073486234 .7391052246230 .9709014893 227.1040039062223 .1378936768219 .0977020264215 .0364074707210 .9481964111 206.8605041504 202.7400970459198.5693969727 194.3079986572189.9073028564 185.3645019531180 .6625061035175 .7908935547170 .746307373165 .5018005371 159.9496002197154 .5516967773149 .8177947998145 .4140930176141 .0516052246 136.8238067627132 .7489013672128 .800994873125 .0115966797121 .2899017334 117.5030975342113 .6512985229109 .6699981689105 .5837020874101 .3510971069 97.0406570434692 .6703872680788 .2957916259883 .9885025024479 .7345123291 
75.6308822631871 .5429229736367 .4759216308663 .4259796142659 .37567901611 55.3899612426851 .5069618225147 .8328590393144 .5937004089441 .85866165161 39.7670898437538 .0746192932136 .4424514770534 .7583007812532 .77037811279 30.5604991912827 .9059600830125 .8175697326725 .4807395935125 .67082023621 25.4263191223124 .978590011624 .2207393646223 .1802291870121 .86952972412 20.2909107208318 .5051498413116 .5342407226614 .4330196380612 .27742958069 10.143150329598 .0400362014775 .9881138801574 .0204191207892 .29603099823 $.4943880140781-1.71073400974-3.95038795471-5.90397405624-7.70828199387$ $-9.38597679138-10.8838796616-12.1706199646-13.2203998566-13.9917497635$ $-14.6191701889-15.2548704147-15.7523298264-16.0628509521-16.1781005859$ $-16.1053504944-15.8872404099-15.2247495651-15.1459503174-17.3745193481$ $-18.6849899292-15.4580402374-11.750289917-11.0485496521-11.1640100479$ $-10.8574895859-10.5226097107-10.0649595261-9.56520557404-9.05859375$ $-8.52254867554-7.99814414978-7.40576887131-6.71333217621-5.8987569809$ $-4.94771003723-3.91072392464-2.83264493942-1.72837305069-.643020987511$ .49125099182131 .6082600355152 .9761219024664 .8974490165716 .928921222687 8.71225452423110 .3807802200312 .0174303054813 .6267004013115 .27748966217 16.928569793718 .563060760520 .163160324121 .7054100036623 .20553970337 24.6717395782526 .1275901794427 .5876693725629 .0103092193630 .28877067566 31.6023292541533 .1561889648434 .6972808837935 .9854087829637 .02582168579 37.7797584533738 .300369262738 .6877098083538 .9706497192439 .18022155762 39.335800170939 .4564895629939 .5659484863339 .6859893798839 .81538009644 39.9651794433640 .121929168740 .2814788818440 .4509391784740 .63724899292 40.84138107341 .0646591186541 .3088302612341 .5742111206141 .86148071289 42.1698188781742 .4990386962942 .8475303649943 .2146606445343 .59854888916 43.9982109069844 .4117889404344 .8378791809145 .2745285034245 .72006988525 46.1724090576246 .6299018859947 .090408325247 .5526504516648 .01480865479 48.4760208129948 .9349594116249 .3911514282249 .8437690734950 .2925491333 50.7370605468851 .1771087646551 .6124992370652 .0430908203152 .46878814697 52.8895187377953 .3052597045953 .7159881591854 .1217613220254 .52256011963 54.9184989929255 .3096199035655 .6960792541556 .0779609680256 .45539855957 56.8285293579157 .197540283257 .5625610351657 .9237899780358 .2813911438 58.6355514526458 .9864387512259 .3342704772959 .6792297363360 .02156829834 60.3612785339460 .6991310119661 .03427886963

881.0775146484878 .2089233398875 .3754272461872 .5717163086869 .7902832031 867.0385742188864 .3195800781861 .6370849609858 .9937133789856 .3925170898 853.8364868164851 .3284912109848 .871887207846 .4694824219844 .1259155273 841.8444824219839 .6312255859837 .4909057617835 .4298706055833 .4544067383 831.5701293945829 .7833251953828 .0983886719826 .5200805664825 .0512695312 823.6943969727822 .4509887695821 .3218994141820 .3079833984819 .4083862305 818.6237182617817 .9517822266817 .3936157227816 .9481811523816 .6121826172 816.3826904297816 .2443237305816 .1821289062816 .1796875816 .2144165039 816.2811889648816 .362487793816 .4915771484816 .6976928711816 .9915161133 817.3900756836817 .9016113281818 .5377197266819 .2932128906820 .1602172852 821.1148071289822 .1093139648823 .1066894531823 .9995727539824 .7764282227 825.2849121094825.5986938477825.907409668 823.9108886719816.9478149414 
808.1730957031 801.1967773438 794.8433227539789.2568969727 783.7001953125 776.7869873047770 .0725708008764 .9395751953759 .9733276367753 .5715942383 750.5186767578755 .7470703125761 .8671264648761 .813293457760 .7706298828 762.8599243164765 .0568847656765 .1923217773759 .7617797852743 .5720214844 726.0322265625715 .1405029297706 .3278808594697 .2307128906685 .4584960938 668.8071899414650 .2374267578631 .7296142578615 .1676025391603 .2313842773 593.2891845703583 .5261230469574 .7448730469567 .2561035156562 .6049804688 561.8106079102561 .0697021484557 .1522216797553 .1533813477551 .19140625 551.9326171875557 .0977172852563 .1367797852569 .0255737305580 .029296875 600.8151855469627 .8339233398657 .7993774414683 .8812255859698 .1671142578 705.6995239258709 .9420166016713 .4038696289719 .1104125977724 .3048095703 726.3505249023726 .8120727539726 .3646850586724 .8215942383722 .6508789062 718.2490844727710 .5452270508700 .7218017578690 .0377197266681 .1317138672 677.4357910156674 .6525268555668 .5734863281659 .3566894531645 .8419799805 631.6652832031619 .7269287109606 .9282226562590 .4761962891570 .8092041016 547.9990844727524 .0933227539501 .3328857422481 .2181091309465 .6424865723 453.4302062988443 .8330078125435 .1296081543425 .9238891602416 .8359069824 407.6943969727399 .091003418391 .0604858398383 .746307373377 .9205932617 371.3317871094362 .1174926758353 .3396911621347 .6369934082343 .1088867188 337.578704834332 .1729125977328 .1037902832324 .4921875320 .9924926758 317.6852111816314 .4692993164311 .2655029297307 .8671875304 .3460998535 300.6263122559297 .0870056152294 .1651000977291 .5317077637288 .9042053223 286.3194885254283 .7875061035281 .0557861328277 .8604125977274 .4656066895 271.1047058105267 .8615112305264 .9036865234261 .9926147461258 .9645996094 255.7375030518252 .1231994629248 .4167022705244 .8549041748241 .3081054688 237.7312011719234 .0395050049230 .1396942139226 .1473999023222 .1622924805 218.1873931885214 .2434997559210 .3572998047206 .5780944824202 .5312042236 197.8827056885192 .9427032471188 .0191040039183 .045501709177 .9962005615 172.724899292167 .0727996826161 .4539031982156 .2626037598151 .3719940186 146.6145019531142 .0359039307137 .7113037109133 .5657958984129 .6143951416 125.7854995728121 .9364013672118 .0551986694114 .0827026367110 .047996521 105.9254989624101 .767799377497 .5840530395593 .4433288574289 .41870117188 85.5014724731481 .7526092529378 .0014038085974 .202842712470 .34851837158 66.3424606323262 .3495903015158 .4335708618254 .7807693481451 .66397094727 48.8748397827146 .4829406738344 .2808189392142 .0901794433639 .90364837646 37.4922714233434 .9377403259332 .2745895385730 .1741199493429 .33679008484 29.0149707794228 .547439575227 .9570407867427 .1264400482226 .06411933899 24.7192897796623 .2035007476821 .611740112319 .8713607788117 .93968963623 15.8318300247213 .5458097457911 .377960205089 .5800895690927 .948129177094 $6.3286371231084 .5859971046452 .58686208725 .5678949952126-1.20850896835$ -2.91423201561 -4.66983985901-6.30343914032 -7.66428613663 -8.78746700287 -9.65913963318 -10.4087696075 -11.139749527 -11.7575798035 -12.2352399826 $-12.542429924-12.6647100449-12.6395702362-12.3647603989-12.5256900787$ -13.9570503235 -14.6030302048 -12.3875398636 -9.75821399689-8.89992046356 $-8.70419216156-8.38462352753-8.03273868561-7.58941411972-7.12648820877$ $-6.66237020493-6.20233201981-5.81451892853-5.34576177597-4.66802120209$ 
-3.78247690201 -2.66224694252 -1.45073199272 - 296451985836.8874269723892 2.1699020862583 .5176839828494 .838127136236 .3758668899548 .363247871399 10.3424701690711 .8976202011113 .2854003906214 .7225399017316 .17610931396 17.6715202331519 .1827201843320 .6935901641822 .190500259423 .65267944336 25.0857505798326 .4737892150927 .9336109161429 .5836601257331 .2767906189 32.8726501464834 .4523811340336 .1174888610837 .6688308715838 .88623809814 39.8269081115740 .4677085876540 .873470306441 .1364517211941 .28894042969 41.3850593566941 .4375915527341 .4657402038641 .4851188659741 .51956176758 41.5674400329641 .6401710510341 .7193183898941 .7926101684641 .87302017212 41.9727592468342 .092639923142 .2359504699742 .4035797119142 .59761047363 42.8177299499543 .0640182495143 .3353996276943 .6306114196843 .94837188721 44.2868499755944 .6445999145545 .0196304321345 .4102210998545 .81415176392 46.2295188903846 .6538391113347 .0853004455647 .5213813781747 .96067047119 48.4009819030848 .8414382934649 .2804489135749 .7175598144550 .15176010132 50.5828514099151 .0102500915551 .4338493347251 .8533401489352 .26863098145 52.6795387268153 .0860404968353 .4880218505953 .8854904174854 .27841186523 54.6668205261255 .0507507324255 .4302787780855 .8054695129456 .17644119263 56.5432701110856 .9061012268157 .265071868957 .6203308105557 .97203063965 58.3203392028858 .6654205322359 .0074386596759 .3465881347759 .6830406189 60.0170516967860 .3488197326760 .6765785217361 .00423049927

887.5524291992884 .7271728516881 .9197998047879 .1350097656876 .3767089844 873.6489868164870 .9555053711868 .2993164062865 .6837158203863 .1112060547 860.5853881836858 .108581543855 .6845703125853 .3156738281851 .0067749023 848.7612304688846 .584777832844 .4821166992842 .459777832840 .5231933594 838.6787719727 836.9321289062 835.2877197266 833.7498779297832.3217163086 831.0053710938829 .8026733398828 .7139282227827 .7399291992826 .8795166016 826.1334228516825 .4995727539824 .9776000977824 .5634155273824 .2584838867 824.0651855469823 .9641723633823 .9357910156823 .9727172852824 .0681152344 824.1928710938824 .3057250977824 .4575805664824 .6887207031825 .0059814453 825.4240722656825 .9597167969826 .6207885742827 .420715332828 .3463745117 829.4049072266830 .546875831 .7686157227832 .9821777344834 .1040039062 834.9412841797835 .1776733398834 .2169189453831 .7418212891827 .3967285156 821.6704101562815 .8181762695809 .82421875804 .4807739258799 .2072753906 792.3828735352787 .0587158203786 .4735717773787 .2379760742786 .63671875 786.8792114258789 .2844238281791 .5347290039791 .6854248047791 .2698974609 792.4182739258792 .1538696289788 .6035766602778 .8330078125756 .358215332 733.1019287109720 .6475830078712 .4752197266705 .1314697266697 .3250732422 686.4505004883672 .4490966797654 .8580932617637 .3923950195624 .8082275391 614.1810913086603 .8903808594594 .1757202148584 .2796020508575 .6008911133 569.9868774414566 .3756103516563 .2199707031562 .0181884766562 .1240234375 563.9838867188568 .2736816406575 .0382080078585 .2293701172600 .4420166016 624.0772705078651 .1740722656678 .2249145508700 .9282226562712 .4321289062 717.8560180664719 .6967163086721 .2899169922727 .5518188477733 .8925170898 735.9998168945736 .5189819336736 .4166259766735 .3253173828734 .0850830078 730.9616699219724 .4943847656716 .7307128906710 .1455078125703 .9299926758 698.9208984375693 .3018188477685 .7081298828675 .2089233398659 .6096801758 
643.5336303711631 .7360229492620 .2971191406604 .3552856445586 .6328735352 568.3200073242547 .854675293524 .1411743164501 .0032958984483 .5347900391 469.6760864258459 .0810852051450 .3316040039440 .4511108398430 .7901000977 421.6122131348412 .850189209404 .4425048828396 .4787902832389 .3680114746 382.3084106445375 .1419067383367 .7286987305360 .2211914062352 .9036865234 345.7489013672339 .7279968262335 .5773925781332 .3052062988328 .6850891113 325.0748901367321 .8239135742318 .3830871582314 .6765136719310 .7799072266 306.6221008301302 .8096923828299 .9584960938297 .4736938477294 .8602905273 292.208190918289 .437713623286 .4880065918283 .2860107422279 .9354858398 276.496307373273 .1716918945270 .24609375267 .4320068359264 .5235900879 261.4495849609258 .0997924805254 .6063995361251 .1143951416247 .62840271 244.2131958008240 .7008056641236 .8932952881232 .9859924316229 .1098022461 225.2655029297221 .4698028564217 .741104126214 .2261962891210 .3610992432 205.5500946045200 .3816070557195 .3641967773190 .3251953125185 .3011932373 180.1013031006174 .5218963623168 .8278961182163 .2599945068157 .8227996826 152.5171966553147 .5438995361142 .966796875138 .7086029053134 .6361999512 130.6674957275126 .7314987183122 .7928009033118 .7919006348114 .7725982666 110.6969985962106 .62840271102 .55439758398 .5684509277394 .75466156006 91.1007766723687 .6603088378984 .2892303466880 .8972930908277 .2893371582 73.3354873657269 .2563095092865 .2811508178761 .623321533258 .52893066406 55.7758293151953 .3121414184650 .8448982238848 .1880416870145 .43054962158 42.5685501098639 .8257102966337 .3451805114735 .3151588439933 .88571929932 32.8582496643132 .0018615722731 .1849403381330 .2171993255629 .08776092529 27.6961593627926 .197269439724 .7454395294223 .1842403411921 .4176902771 19.4156894683817 .0644893646214 .8157796859713 .1815595626811 .7201795578 10.060420036328 .3291797637946 .5479211807254 .7801671028143 .21502494812 $1.640570998192-.146117001772-1.85638105869-3.25805711746-4.44455480576$ $-5.41736698151-6.25489616394-7.02501916885-7.73240995407-8.40674591064$ $-8.95637512207-9.32495307922-9.58048057556-9.78859233856-10.0060100555$ $-10.2126703262-10.0382099152-9.13422298431-7.98557090759-7.08759593964$ $-6.40463876724-5.92807817459-5.50940704346-5.00318002701-4.49040603638$ $-4.00314807892-3.57088589668$-3.27363109589 -2.87539100647 -2.19408202171 -1.25100398064 -6.9129998e-03 1.3487379550932.560029983521 3.841399908066 5.334569931036 .897293090828 .40414714813210 .0038604736311 .90244007111 13.7019996643114 .9847002029416 .1084995269817 .3901500701918 .7058506012 20.0679702758821 .4583301544222 .8582496643124 .2654399871825 .65867042542 27.0509796142628 .3844795227129 .8555603027331 .6657791137733 .60623931885 35.5010795593337 .3626213073739 .1536598205640 .6833381652841 .80498886108 42.578399658243 .0754318237343 .36677169843 .5149803161643 .56319046021 43.5557098388743 .5102386474643 .4450607299843 .3764610290543 .32472991943 43.2907104492243 .2863197326743 .2894592285243 .2824592590343 .28192901611 43.3021392822343 .3441581726143 .4120407104543 .5083198547443 .63412094116 43.79059982343 .9765701293944 .1921310424844 .4348182678244 .70415878296 44.9973411560145 .3134002685545 .6496009826746 .004459381146 .37517929077 46.7598686218347 .1555709838947 .5603713989347 .9713287353548 .38695907593 48.8047294616749 .2237014770549 .6420898437550 .0593910217350 .47452926636 
50.8872299194351 .2969398498551 .7034683227552 .1065292358452 .50597000122 52.9016304016153 .2934112548853 .681221008354 .065010070854 .44474029541 54.8204002380455 .1920204162655 .5596199035655 .9232788085956 .28305053711 56.6390304565456 .9913215637257 .3400497436557 .6853294372658 .02732086182 58.3661384582558 .7019615173359 .0349311828659 .365230560359 .69300842285 60.0185203552260 .3417396545460 .6633300781260 .98258972168 894.0330200195891 .1990966797888 .4022827148885 .6386108398882 .8991699219 880.1915283203877 .5187988281874 .8845825195872 .2918701172869 .7435913086 867.2426757812864 .7921142578862 .3948974609860 .0540771484857 .7739868164 855.5581054688853 .4119873047851 .3403930664849 .3494262695847 .4448242188 845.6322021484843 .9174804688842 .3048706055840 .7988891602839 .4019165039 838.1165771484 836.9439697266835.8847045898 834.9390869141 834.1063842773 833.3864746094 832.7777709961 832.2786254883 831.8853759766 831.6002197266 831.4243164062831 .3408813477831 .3338012695831 .3956298828831 .5150756836 831.6655273438831 .80859375831 .9871826172832 .2343139648832 .5626831055 832.9868164062833 .5241699219834 .1898193359834 .9940795898835 .940612793 837.0247802734838 .2241210938839 .5048217773840 .8098144531841 .9901123047 842.9152832031843 .0385742188841 .957824707839 .9843139648836 .8361816406 832.8223266602828 .1295166016822 .9448852539818 .1586303711813 .5034179688 808.3483276367 804.9088745117804.8668823242 806.5026245117 807.9528808594 809.0692749023810 .9119873047812 .1879882812812 .8032836914812 .9437866211 812.7791137695810 .0618286133803 .8834228516791 .6491699219769 .1948242188 745.4746704102728 .0979003906716 .6094970703713 .3510742188712 .204284668 707.111328125697 .5355834961680 .9556884766662 .7540283203648 .4010009766 636.178894043626 .0930786133616 .5930786133606 .1951293945594 .8444213867 582.371887207573 .4279174805572 .3358764648574 .8809204102575 .233215332 576.9555053711583 .4730224609594 .7816162109612 .0189819336632 .6245727539 653.5731811523674 .592590332696 .1237182617714 .3427734375725 .6817016602 732.4771118164735 .2620849609737 .2156982422741 .4373168945745 .3853759766 746.772277832746 .7736206055746 .0269165039744 .5729980469742 .821105957 740.0708007812735 .5059204102730 .912902832728 .0996704102724 .7233886719 719.8391113281713 .3057250977705 .6619262695695 .4268798828680 .7396850586 664.4636230469648 .7426757812633 .9871826172619 .8909301758605 .2258300781 587.6036987305567 .8218994141547 .2692871094525 .6538085938504 .3768005371 486.1878967285473 .5685119629464 .0374145508455 .0111083984446 .2214050293 437.0067138672427 .7864074707418 .4591064453409 .5032043457401 .6452026367 394.8016052246389 .0733947754382 .5721130371373 .8876953125364 .1890869141 354.1047058105345 .9652099609341 .7844848633339 .1129150391335 .8960876465 332.604888916329 .5805053711326 .1452941895321 .838104248317 .333404541 313.0719909668309 .2752990723306 .2426147461303 .5585021973300 .8485107422 298.0639038086295 .1054077148291 .9985961914288 .6787109375285 .2699890137 281.8035888672278 .4519958496275 .4392089844272 .6274108887269 .9804077148 267.1849060059263 .8666992188260 .3594055176256 .9536132812253 .5760955811 250.2512969971246 .8565979004243 .2425994873239 .5218963623235 .7680969238 232.0220947266228 .3339996338224 .6714019775221 .0572967529217 .1062011719 212.4573974609 207.4727020264 202.4938964844 197.4772033691 192.4468994141 
187.2875976562 181.8952941895176.2886962891 170.6058959961164 .7877044678 158.7140045166153 .0769958496148 .4644927979144 .3011932373140 .108001709 135.9588012695131 .8811035156127 .8300018311123 .7668991089119 .7145996094 115.6154022217111 .5425033569107 .5037994385103 .590301513799 .88971710205 96.4146804809693 .2096328735490 .2338027954187 .5313568115284 .42701721191 80.2195205688575 .721397399971 .6338119506867 .9766387939564 .90659332275 62.2740592956560 .1226196289157 .7575988769554 .5197410583551 .03945159912 47.7937698364344 .8694992065442 .3479995727540 .18080902138 .44731140137 37.0006790161135 .7957000732434 .7261009216333 .5746917724632 .33246994019 30.912250518829 .4459095001228 .0354690551826 .5869293212925 .03915023804 23.2420597076421 .0143108367918 .8153190612817 .0842494964615 .49964046478 13.8033504486112 .092149734510 .357899665838 .6771154403697 .144743919373 $5.5952210426333 .9291799068452 .330324888229 .9524880051613-.249527007341$ $-1.25778305531-2.12666201591-2.87830209732-3.65776109695-4.6556968689$ $-5.56425905228-6.10114812851-6.48370885849-6.83402299881-6.93972492218$ $-6.76691818237-6.47662687302-6.02693319321-5.45736408234-4.7019982338$ -3.87995004654 -3.42737102509 -3.03551793098 -2.32694005966 -1.58730196953 $-1.03047394753-.576122999191-0.19363899529 .28566500544551 .008708000183$ 1.9752010107043 .1902461051944 .5250692367555 .8345999717717 .255544185638 8.88750362396210 .533340454111 .9598398208613 .3556003570614 .95849990845 16.4720401763917 .6740894317618 .7766208648719 .9540004730221 .16708946228 22.4212608337423 .7053794860825 .0105094909726 .3413200378427 .69107055664 29.0728092193630 .4800090789832 .0450515747133 .8866195678735 .89646911621 37.9594497680740 .036411285442 .1423110961943 .8503990173344 .75115966797 45.2193984985445 .5459289550845 .7235603332545 .7818717956545 .74720001221 45.6513900756845 .5135498046945 .3623886108445 .2080802917545 .07577133179 44.9636688232444 .8797302246144 .8054084777844 .7270088195844 .65655899048 44.6049690246644 .5760803222744 .5764198303244 .6070289611844 .67079925537 44.7675094604544 .8975296020545 .0596885681245 .252651214645 .47489929199 45.7243499755945 .9993286132846 .2974586486846 .6167182922446 .95442962646 47.3082695007347 .6751708984448 .0529289245648 .4383811950748 .82981872559 49.2245216369649 .6214408874550 .0186080932650 .4155197143650 .81098175049 51.2047500610451 .5961799621651 .9851303100652 .3712196350152 .75434875488 53.1342887878453 .5109405517653 .8841705322354 .2539215087954 .62009048462 54.982700347955 .3416786193855 .6970901489356 .0489387512256 .39728164673 56.7421684265157 .0837211608957 .4219818115257 .7570991516158 .08917999268 58.4183387756358 .7447395324759 .068500518859 .3897781372159 .70875167847 60.0256195068460 .3405494689960 .6519012451260 .96366882324 900.4066162109897 .6101074219894 .8325195312892 .0797119141889 .3552246094 886.6633300781884 .0073242188881 .390625878 .8162231445876 .2871704102 873.8065185547871 .3765258789869 .0009765625866 .6823730469864 .4254760742 862.2330932617860 .1110839844858 .0637207031856 .0972290039854 .2169799805 852.4290161133850 .7382202148849 .1491088867847 .6658935547846 .2910766602 845.0269165039843 .8745727539842 .8342285156841 .9061889648841 .0897216797 840.3842773438839 .7880859375839 .2999267578838 .9157104492838 .6365966797 838.4619140625 838.3803100586 838.3790283203838.4467163086838.5686035156 
838.7246704102838 .8856201172839 .0825805664839 .3364257812839 .6641845703 840.0792236328840 .6035766602841 .2503051758842 .0368041992842 .9639282227 844.0297241211845 .2086791992846 .4498901367847 .6890869141848 .7587890625 849.5737304688849 .7465209961848 .9241943359847 .4071044922845 .0935058594 842.1057739258838 .4802246094834 .4365844727830 .5576171875827 .0338745117 823.9102783203821 .9888916016821 .2437744141821 .6851806641822 .9085083008 824.2454223633825 .7938232422827 .2548828125829 .4149169922829 .9398193359 828.6486206055823 .7573242188815 .041015625802 .4857177734781 .5396118164 758.8961181641737 .9566040039722 .8359985352722 .8751831055727 .1405029297 726.3231811523720 .6604003906705 .5996704102687 .575012207672 .1154174805 658.5739746094649 .2052001953640 .2578125629 .799987793617 .7614746094 601.4744262695589 .0930786133589 .7882080078593 .9187011719592 .5864868164 593.8134765625602 .8734130859618 .4249267578641 .8811035156666 .0739746094 682.7678222656697 .0505981445712 .9755859375727 .5706176758739 .9552001953 749.201171875753 .9166870117756 .4105224609757 .9611816406758 .7559204102 758.5584716797757 .481628418755 .6237182617753 .2529907227750 .4987182617 747.753112793744 .9694824219742 .7838745117742 .9729003906742 .165222168 738.1190185547732 .0861206055725 .7338867188717 .1838989258705 .3159179688 690.8203735352672 .0883178711654 .022277832640 .6060180664626 .6815795898 607.4641113281586 .796081543569 .1962280273551 .1325073242528 .5410766602 507.1908874512492 .6452026367481 .2395019531472 .1383972168464 .1416015625 454.3819885254444 .2601013184433 .8096923828423 .6441955566414 .9075927734 407.7276000977402 .5924072266396 .908996582387 .9187011719377 .0215148926 364.8994140625354 .4046020508349 .5220031738346 .725402832343 .0698852539 339.7308959961336 .800994873333 .4732055664328 .8550109863323 .9328918457 319.7821960449316 .062286377312 .7947998047309 .8066101074306 .9122924805 303.9744873047300 .8483886719297 .5799865723294 .0928955078290 .5614013672 287.0155944824283 .5852966309280 .432800293277 .5307006836275 .0562133789 272.474609375269 .1776123047265 .6820068359262 .4234008789259 .195098877 255.970703125252 .6986999512249 .2861022949245 .7772064209242 .1600952148 238.5016937256234 .8865966797231 .2082061768227 .391998291223 .3242950439 218.9174041748214 .2490997314209 .4210968018204 .4732055664199 .4461975098 194.3296966553189 .1349945068183 .7644042969178 .2162017822172 .3009033203 165.6893005371159 .428894043154 .6678009033150 .4535980225145 .9676055908 141.5796051025137 .3359985352133 .1837005615129 .0471038818124 .9141998291 120.7228012085116 .5639038086112 .4515991211108 .5214004517104 .8423995972 101.454696655398 .3808975219795 .5872268676893 .3661727905390 .65416717529 86.2645797729581 .4996032714877 .418533325273 .7878417968870 .71824645996 68.1155624389666 .2018814086963 .9812698364360 .3450508117756 .39968109131 52.9671096801849 .8991813659747 .2568283081144 .9656181335442 .99195098877 41.2827682495139 .8004302978538 .4691314697337 .1054115295435 .737449646 34.2803611755432 .8209381103531 .4025306701729 .9826908111628 .59148025513 27.0100593566924 .992670059222 .9051303863521 .0688896179219 .31596946716 17.5798091888415 .8430595397914 .0682296752912 .3798704147310 .80941963196 9.3084850311287 .8023939132696 .3369698524485 .0056538581853 .799336910248 2.7840061187741 .8851530551911 .147881984711 .3225229978561 -.943978011608 
-2.15928196907 -2.84430503845 -3.28416204453 -3.64839410782 -3.72115302086 -3.44812893867 -3.09656095505 -2.84012794495 -2.49589705467 -1.7985149622 $-1.03419399261-.710776984692-.351637989283 .53968697786331 .48049902916$ 2.1124029159552 .6445538997653 .1880190372473 .8088181018834 .585806846619 5.5432829856876 .6581659317027 .9247469902049 .30444335937510 .80393981934 12.4681301116914 .0627803802515 .3052396774316 .4427394866917 .71426963806 18.9528198242220 .1277999877921 .2637901306222 .3838291168223 .51754951477 24.6865596771225 .8843097686827 .1032505035428 .3655109405529 .67493057251 31.0740509033232 .5782814025934 .239669799836 .0667114257838 .05741882324 40.1795196533242 .3539085388244 .6839904785246 .5545310974147 .31579971313 47.5780105590847 .8221511840847 .930389404347 .91992187547 .82379150391 47.6407508850147 .4179382324247 .1846694946346 .9547615051346 .7483291626 46.5607490539646 .3996009826746 .2525215148946 .1107406616245 .98112106323 45.8677787780845 .7779197692945 .7183494567945 .6914901733445 .69871902466 45.7417182922445 .8194885253945 .9323997497646 .0779304504446 .25577163696 46.4628791809146 .698379516646 .9591712951747 .2436790466347 .54864120483 47.8719406127948 .2099800109948 .5606307983448 .9202804565449 .2872505188 49.6584396362350 .0328598022550 .4083213806250 .7843513488851 .15964889526 51.5339698791551 .906669616752 .2775382995652 .6462593078653 .01264190674 53.3764801025453 .7376213073754 .0959281921454 .4512901306254 .80361938477 55.1528587341355 .4989585876555 .8419189453156 .1817283630456 .518409729 56.8520317077657 .182621002257 .5102615356457 .8350296020558 .15703964233 58.4763793945358 .7932014465359 .1076087951759 .4197502136259 .72975921631 60.0378494262760 .3439788818460 .6487503051860 .95151901245 906.7835083008903 .969909668901 .1947021484898 .4552001953895 .7415771484 893.0614013672890 .4176025391887 .8140258789885 .2532958984882 .7385864258 880.2728271484877 .8585205078875 .4990844727873 .1973876953870 .9575195312 868.7827148438866 .6782836914864 .6486206055862 .6995849609860 .8366699219 859.0651855469857 .390625855 .8167114258854 .3477172852852 .9857788086 851.7335205078850 .5913696289849 .5596923828848 .6386108398847 .8270874023 847.1245727539846 .5289916992846 .0390014648845 .6510009766845 .3638916016 845.174987793845 .0784301758845 .0670166016845 .1259765625845 .239074707 845.3892822266845 .5482177734845 .7437133789845 .9885864258846 .2985839844 846.6870727539847 .1738891602847 .7769165039848 .5068969727849 .3737792969 850.36328125851 .4647827148852 .6088256836853 .7438964844854 .716796875 855.4144897461855 .6279296875855 .1021118164854 .0493774414852 .4116821289 850.2791748047847 .6071166992844 .6157836914841 .6430053711839 .0452880859 837.0451049805835 .6215820312834 .8768920898834 .7147827148835 .0720825195 835.921875836 .934387207838 .962097168843 .1707763672845 .1676025391842 .2780151367 834.6998901367 824.2807006836 811.5922241211 791.0471801758 768.6951293945 749.5194091797735 .3441772461734 .5789794922739 .1273803711740 .0104980469 736.3928833008724 .5308227539709 .2435302734694 .553527832681 .736328125 674.1881103516666 .794128418655 .1776733398643 .0117797852633 .3732910156 626.9069824219624 .9013061523624 .2531738281620 .8643798828620 .9332885742 629.5164794922645 .3627929688668 .2905883789690 .6641235352705 .4448852539 717.260925293730 .8259887695744 .7708129883757 .9149169922768 .3535766602 
772.9639282227774 .1630859375774 .4171142578773 .4871826172771 .4290161133 768.6453857422765 .4423217773761 .9312133789758 .4193725586755 .6323242188 753.4196777344752 .2133789062752 .9487304688753 .0662231445750 .9462890625 747.396484375743 .0974121094737 .3253173828729 .8809204102719 .2056884766 703.9177246094687 .4274902344671 .4127807617653 .5006713867630 .9801025391 607.9852294922589 .475402832573 .1049194336556 .6812133789539 .8463745117 522.5684204102506 .8606872559495 .3995056152485 .7525024414474 .4707946777 462.8005065918451 .2477111816439 .7836914062429 .0184936523420 .2853088379 414.4607849121409 .0535888672401 .9970092773392 .7172851562380 .4991149902 368.9679870605361 .8833007812356 .6312866211350 .6192016602345 .496307373 342.2789001465339 .207611084334 .9602966309330 .4397888184326 .3894042969 322.691986084319 .3591003418316 .2177124023313 .1672973633310 .070892334 306.765411377303 .2961120605299 .5953979492295 .8526916504292 .0905151367 288.4341125488285 .0885009766282 .0325012207279 .3891906738276 .7594909668 273.6947937012270 .5049133301267 .4815979004264 .4818115234261 .4418029785 258.3398132324255 .0908966064251 .7324981689248 .249206543244 .6750030518 241.0964050293237 .404800415233 .5469055176229 .5081939697225 .2191009521 220.7353973389216 .0632019043211 .224899292206 .2937927246201 .3083953857 196.287902832191 .2252044678186 .1930999756180 .6457061768174 .0753936768 167.5838928223162 .1938018799157 .2733001709152 .2386016846147 .4080047607 143.0428009033138 .8683929443134 .6280975342130 .3563995361126 .0137023926 121.6761016846117 .3505020142113 .2444992065109 .5320968628106 .1364974976 103.0022964478100 .116600036697 .5506668090894 .6026992797990 .57122802734 86.247901916582 .3396072387778 .8008728027375 .7216720581173 .01815032959 70.7421417236368 .2128982543964 .7640686035261 .0629806518657 .68124008179 54.6086006164651 .9230804443449 .5287818908747 .4077491760345 .50968933105 43.817520141642 .2648506164640 .7362289428739 .2435913085937 .7325592041 36.2415618896534 .7926101684633 .3590698242231 .9348907470730 .40033912659 28.5986194610626 .7046203613324 .9280490875223 .1756992340121 .44400024414 19.6571903228817 .6984691619915 .8693399429314 .4143800735513 .10348033905 11.6737699508710 .242440223698 .9122991561897 .6920919418336 .661402225494 5.7357158660894 .9099760055543 .9982919692992 .7692570686341 .549118041992 .6171159744263 -5.1406998e-02 -.421088010073 -.429365992546 -4.2536002e-02 .4268180131912 .73482698202131 .0735820531851 .6096190214162 .197326898575 2.5732080936433 .0133419036873 .8055300712594 .6755800247195 .377966880798 6.0236201286326 .6875610351567 .4043898582468 .2163419723519 .138562202454 10.1882400512711 .3847799301112 .7635898590114 .2263298034715 .68183994293 17.0312004089418 .1782608032219 .2250709533720 .3069801330621 .39468002319 22.4697208404523 .5496807098424 .6153907775925 .6875801086426 .81262969971 27.9583892822329 .0950298309330 .2787799835231 .549879074132 .94269943237 34.4763412475636 .1523094177237 .9826507568439 .9482688903842 .04568099976 44.192378997846 .3546600341848 .1085891723649 .0409507751549 .50357055664 49.7954292297449 .9160881042549 .8938484191949 .7476196289149 .4856300354 49.170478820848 .8771095275948 .589839935348 .3164710998548 .05818939209 47.8275184631347 .6158103942947 .4191093444847 .2389907836947 .07489013672 46.9340286254946 .824630737346 .747909545946 .7069091796946 .70178985596 
46.7335014343346 .8010406494146 .9035491943447 .0395698547447 .20729827881 47.404991149947 .6303215026947 .8810615539648 .1543693542548 .44758987427 48.7573013305749 .0809288024949 .4148902893149 .7571983337450 .10474014282 50.4563407897950 .8097915649451 .1645393371651 .5192909240751 .87377929688 52.2273216247652 .5797500610452 .9306907653853 .2799797058153 .62736129761 53.9726791381854 .3157386779854 .6564407348654 .9946403503455 .33026885986 55.66323089655 .9935188293556 .3210601806656 .645919799856 .9680480957 57.2875099182157 .604351043757 .9186286926358 .2304191589458 .53982162476 58.8469200134359 .1518516540559 .4547195434659 .7556495666560 .05484008789 60.3524093627960 .6468391418560 .94219970703

913.0458984375910 .2631225586907 .5001220703904 .7634887695902 .0568237305 899.3839111328 896.7482299805 894.1530761719 891.6016235352 889.0963745117 886.640625884 .2368164062881 .8881835938879 .5977172852877 .3692016602 875.2056884766873 .1127929688871 .0941772461869 .1560058594867 .3031005859 865.5410766602863 .8745727539862 .307800293860 .8444213867859 .4868164062 858.2368164062 857.0955200195856.0626220703 855.1381835938 854.3209838867 853.6104125977853 .00390625852 .5003051758852 .0961303711851 .7888183594 851.5728759766851 .4473266602851 .4094848633851 .4431762695851 .5316162109 851.6605834961851 .8037719727851 .9812011719852 .200012207852 .4755249023 852.8192749023853 .2512817383853 .7872924805854 .4362792969855 .207824707 856.0842285156857 .0590820312858 .0626831055859 .0587158203859 .9147949219 860.5297851562860 .8082275391860 .5822753906859 .9622192383858 .8483276367 857.3759765625855 .5634765625853 .5535888672851 .512512207849 .6826171875 848.3206787109 847.2313232422 846.4324951172 845.8107299805 845.3729248047 845.2023925781845 .419921875846 .7924194336851 .6182861328855 .3521118164 853.0745239258847 .3596191406840 .2086791992826 .4165039062801 .496887207 776.0194702148758 .3867797852749 .1616210938749 .1284790039752 .4837036133 753.5123291016750 .6295776367741 .4694213867728 .7158813477714 .734375702 .359375 696.0650024414690 .0217285156677 .8408813477666 .7681274414665 .3986206055 665.6422119141660 .8892211914655 .7150268555651 .2224731445650 .9058227539 658.6290893555672 .3515014648691 .4083862305710 .3856811523723 .7609863281 735.3399047852748 .8618164062762 .6071777344776 .232421875787 .0302734375 791.0364990234791 .5023193359791 .1511230469789 .1098022461785 .2221069336 780.6853027344776 .3153076172772 .1627197266768 .0695800781764 .682800293 761.9641113281760 .6334838867761 .1812133789762 .0942993164762 .3469238281 761.4979248047759 .728515625757 .0490722656754 .5615234375749 .1790771484 739.5280761719724 .7985839844704 .2130126953681 .2587280273655 .3192749023 631.5654907227612 .4102783203596 .2783203125585 .0808105469573 .1323242188 554.3474731445535 .7257080078523 .0847167969511 .0606079102497 .229309082 483.1463012695470 .2427062988458 .3066101074445 .925994873435 .1405029297 427.3699951172420 .9302978516415 .1337890625407 .9570007324396 .8197937012 385.2557067871376 .6068115234368 .7464904785360 .0061950684352 .4158935547 348.1271057129344 .9231872559340 .938293457336 .9476928711333 .0866088867 329.3846130371325 .9953918457322 .7156066895319 .5646057129316 .3197937012 312.8905029297309 .2766113281305 .3568115234301 .3096923828297 .1686096191 293.1935119629289 .6123046875286 .3959960938283 .482208252280 .6801147461 
277.834197998274 .9892883301272 .2373962402269 .5050048828266 .7027893066 263.7719116211260 .6599121094257 .384185791254 .0027008057250 .5153045654 246.9720001221243 .3061065674239 .4817962646235 .5016937256231 .3247070312 226.975692749222 .4476013184217 .7680969238212 .9804992676208 .1390991211 203.2512969971198 .3950958252193 .8000030518188 .7821960449182 .6434020996 176.2138977051170 .2895965576164 .595199585158 .9450073242153 .6958007812 149.1611938477144 .8908996582140 .4696044922136 .0220947266131 .4833984375 126.9418029785122 .3529968262117 .9984970093114 .1258010864110 .5736999512 107.227897644 104.0087966919 100.846000671497.5282135009893.92196655273 90.2101135253986 .5954437255983 .169219970780 .0679321289177 .1608505249 74.3858566284271 .5219726562568 .3951263427765 .1692428588962 .00178146362 59.0067710876556 .3172798156753 .8703308105551 .6666984558149 .66250991821 47.8097190856946 .087329864544 .4066886901942 .7927818298341 .20764160156 39.6708488464438 .1730690002436 .6926193237335 .1877403259333 .64065170288 32.0183410644530 .3400993347228 .6769199371326 .9936294555725 .31270980835 23.5658302307121 .5367202758819 .6133708953918 .2262306213416 .9617099762 15.4821195602414 .0153598785412 .6450996398911 .3949003219610 .34848022461 9.4045352935798 .5174865722667 .5599298477176 .4532799720765 .30872297287 4.2155408859253 .3812611103063 .0091640949253 .0438020229343 .456739902496 4.020772933964 .4818830490114 .8860020637515 .2571787834175 .636703968048 6.0475320816046 .5597620010387 .217644214637 .9447660446178 .665926933289 9.41612529754610 .2110204696711 .0288200378411 .8506698608412 .71706008911 13.6832504272514 .7884502410916 .0972595214817 .4344406127918 .59671020508 19.6716995239320 .7352008819621 .7423095703122 .7193698883123 .69018936157 24.66688991906725 .6615390777626 .6546802520827 .6724090576228 .75581932068 29.8584995269830 .9232406616232 .0435905456533 .2773284912134 .6455116272 36.1614189147937 .8221092224139 .6245307922441 .5420417785643 .57004928589 45.5798912048347 .4674797058149 .0648117065450 .2462882995651 .03895950317 51.4932899475151 .691268920951 .6800117492751 .5070915222251 .17702102661 50.7802810668950 .4313087463450 .0923385620149 .7564888000549 .43856811523 49.1497611999548 .8858909606948 .6446609497148 .4251213073748 .22035980225 48.0403518676847 .8901481628447 .7730102539147 .6903495788647 .64437866211 47.6347885131847 .6623191833547 .7251281738347 .8231506347747 .95378875732 48.1162681579648 .3076400756848 .5262985229548 .7688102722249 .0329208374 49.3146705627449 .6117210388249 .9200210571350 .2377586364750 .56147003174 50.8901214599651 .2212715148951 .5544891357451 .8883590698252 .22269821167 52.556781768852 .8904495239353 .2233085632353 .5552101135353 .88584899902 54.2150611877454 .5426292419454 .8684196472255 .1922607421955 .51404953003 55.8336906433156 .1511001586956 .4662284851156 .7790489196857 .0895614624 57.3977508544957 .7036399841358 .0073013305758 .3087501525958 .60807037354 58.9053611755459 .2006988525459 .4942016601659 .7859497070360 .07614135742 60.3647193908760 .6521797180260 .93801879883

919.3090820312916.5015258789913.7327880859911.0020141602908.2980957031 905.6286010742902 .9965820312900 .4055175781897 .8583984375895 .3579711914 892.9072875977 890.5089111328 888.1657714844 885.8809814453 883.6578979492881.5 879.4119873047877 .3981933594875 .4639282227873 .6141967773871 .8538208008 
870.1879272461868 .6199951172867 .1539916992865 .7918701172864 .5355224609 863.3853759766862 .3416137695861 .4038085938860 .5706787109859 .8411254883 859.2128295898 858.6840820312 858.2515258789 857.9116821289 857.6594848633 857.4943237305857 .4133300781857 .4036865234857 .4503173828857 .5416259766 857.6577758789857 .8046875857 .9752197266858 .1920776367858 .4727783203 858.8300170898859 .2783203125859 .8231811523860 .4763793945861 .2191162109 862.046081543862 .9016723633863 .7482910156864 .4943847656865 .0524902344 865.3884887695865 .3903808594865 .1115722656864 .4854125977863 .6130981445 862.5134887695861 .2941894531860 .0526733398858 .9028930664858 .0330810547 857.2406005859856 .5286865234855 .7219238281854 .8051147461853 .6572265625 851.9655761719851 .1444702148852 .5313110352855 .8892822266861 .7645263672 867.2357788086871 .6068725586860 .854309082816 .7011108398772 .6314697266 758.728515625759 .0709838867764 .3659057617770 .4500732422772 .4625244141 769.9771118164760 .2108154297746 .3978881836730 .3563232422716 .0745239258 708.6928710938702 .4749145508692 .5076293945684 .4077148438683 .26171875 683.1287841797679 .9971923828676 .1989135742674 .2020874023676 .0678100586 683.8809814453695 .7634277344711 .3154296875727 .2545166016739 .9437255859 752.0640258789765 .1553955078778 .1669921875790 .9664916992801 .1522216797 806.3798828125 808.1768188477 807.6331787109 804.6489868164 798.9586181641 792.7282714844788 .51171875784 .7050170898779 .946472168775 .2634887695 770.6923217773768 .1840209961770 .3259887695773 .8920898438775 .6710205078 776.5322265625776 .7213134766776 .9431152344778 .6538696289777 .8602905273 771.5343017578756 .0424194336727 .7708740234697 .6865234375675 .0142211914 656.8939208984640 .1735229492624 .4951171875609 .5435791016594 .5067749023 578.6994018555563 .9957275391553 .9520263672542 .349609375523 .6962280273 504.5871887207490 .8178100586479 .2616882324467 .0281066895455 .1752929688 443.9070129395434 .158996582426 .7112121582419 .3095092773409 .5542907715 399.4112854004391 .5791931152383 .5454101562373 .2568054199363 .6265869141 356.9920959473352 .0728149414347 .6777954102343 .7352905273339 .9200134277 336.2449951172332 .7456054688329 .358001709326 .0963134766322 .7510986328 319.2796020508315 .5968933105311 .475189209307 .0516052246302 .2658996582 297.6987915039294 .0166931152290 .8056945801287 .6849975586284 .7239990234 281.9366149902279 .2814941406276 .7336120605274 .2593078613271 .7813110352 269.1021118164266 .0203857422262 .7294921875259 .421295166256 .032409668 252.5525970459248 .9508972168245 .1961975098241 .2991027832237 .2355041504 233.016204834228 .6358032227224 .1105957031219 .4696044922214 .7386016846 209.912399292 205.1186065674200.445098877 195.5693969727 190.2019042969 184.3587036133178.2644958496172.1446990967 166.2785949707 160.8421936035 155.9420013428151 .2747955322146 .5861968994141 .8930053711137 .1307067871 132.3596038818127 .5656967163122 .9580993652118 .7033996582114 .7440032959 111.0612030029107 .4850997925103 .956199646100 .484397888296 .9845199585 93.55029296875 90.14055633545 86.80679321289 83.70159912109 80.67990112305 77.7105636596774 .7743225097771 .7596893310568 .7735671997165 .81642150879 62.9533882141160 .3454399108957 .9283218383855 .7129211425853 .65203857422 51.6908111572349 .8266983032248 .0188407897946 .2801513671944 .61277008057 43.0116500854541 .4711799621639 .9566688537638 .445171356236 .9444694519 
35.4205093383833 .8790702819832 .316818237330 .7317600250229 .16049957275 27.5831298828125 .9752597808824 .3373203277622 .6369705200220 .93973922729 19.2736091613817 .68400955216 .2068099975614 .895990371713 .83265972137 12.9277896881112 .1575498580911 .320030212410 .166700363168 .964735031128 7.9457230567937 .1859917640696 .8564581871036 .9004697799687 .227066993713 7.7472991943368 .3296785354618 .7868566513068 .9482030868539 .081807136536 9.4189357757579 .91660499572810 .5877799987811 .3036098480211 .9400100708 12.6816101074213 .6743898391714 .6625699996915 .416609764116 .13302993774 16.9901409149217 .9716300964419 .1068592071520 .2420291900621 .24447059631 22.1907501220723 .1240997314524 .0373992919924 .9188899993925 .78803062439 26.6760997772227 .5860195159928 .5068492889429 .4566707611130 .45442008972 31.4761905670232 .4973983764633 .5798683166534 .7744903564536 .0982093811 37.5704803466839 .1774215698240 .9178695678742 .7570686340344 .68867874146 46.5813713073748 .3509101867749 .9442901611351 .251258850152 .25185012817 52.8885993957553 .2072296142653 .2404899597253 .0625686645552 .71303939819 52.2661209106451 .8473091125551 .4380989074751 .047988891650 .68099975586 50.3509597778350 .0506210327149 .7769699096749 .5272598266649 .29500961304 49.0863990783748 .9061813354548 .7566604614348 .6411705017148 .56050109863 48.516460418748 .5085487365748 .5368194580148 .6001586914148 .69747161865 48.8270797729548 .9871215820349 .1752395629949 .3886909484949 .62459945679 49.8794097900450 .1503105163650 .433460235650 .7267417907751 .0267791748 51.3323783874551 .641189575251 .9526901245152 .2655181884852 .57947921753 52.8938789367753 .2085418701253 .5230903625553 .8373603820854 .15102005005 54.4639205932654 .7757797241255 .0864601135355 .3957481384355 .70352935791 56.0096511840856 .314041137756 .6165809631356 .9172592163157 .21598815918 57.5127792358457 .807621002258 .1005287170458 .3915405273458 .68069076538 58.9680595397959 .2537193298359 .5377502441459 .8202400207560 .10134124756 60.3811302185160 .6582298278860 .93674087524

925.4525756836922 .6688232422919 .9052124023917 .1696166992914 .4644165039 911.794128418909 .1616210938906 .5703125904 .0230712891901 .5228881836 899.0723876953 896.6743164062 894.3314819336 892.0468139648 889.8237304688 887.6652832031885 .5764770508883 .5607910156881 .6239013672879 .7700805664 878.0045166016876 .3314819336874 .7548828125873 .2780761719871 .9030151367 870.6314086914869 .463684082868 .3997802734867 .4390869141866 .5800170898 865.821472168865 .1608276367864 .5961303711864 .1234741211863 .7404174805 863.4412231445863 .2244262695863 .0858764648863 .0170288086863 .0043945312 863.0410766602863 .1137084961863 .2130126953863 .3192138672863 .4614257812 863.6619262695863 .9276123047864 .2692871094864 .6915283203865 .2064208984 865.7962036133866 .4600830078867 .1533813477867 .849609375868 .4904785156 869.0059204102 869.392578125 869.5665283203 869.5739135742 869.3491210938 868.9802856445868 .4865112305867 .919128418867 .3671264648866 .7985839844 866.3681030273865 .8425292969865 .3435058594864 .5281982422863 .4263916016 861.7401733398858 .6436157227856 .1873779297854 .4409179688857 .4556884766 871.3577270508886 .4788818359900 .9713134766895 .0875244141836 .8032226562 778.0123901367767 .4282226562774 .2628173828781 .6143188477789 .3267211914 791.6270751953788 .7542114258778 .3272705078763 .2515869141745 .3856201172 
728.5552978516718 .7593994141711 .5518798828703 .6821899414697 .7036132812 694.6484985352692 .9796142578691 .8931274414691 .8704223633694 .0313720703 698.8223876953706 .771484375717 .0985717773729 .518371582742 .6660766602 755.2941894531767 .7108154297779 .9031982422792 .0399169922803 .7086181641 813.7730712891821 .0040283203824 .7224731445824 .8978881836821 .4943237305 814.5242919922807 .3751220703803 .6563720703800 .9229125977795 .4876098633 789.4113769531783 .2567749023779 .5200195312782 .9077758789788 .3626708984 790.8720703125792 .9697265625795 .2761230469798 .1392822266803 .647277832 806.1467895508802 .7817993164789 .3212280273758 .0668945312724 .9641723633 705.981628418691 .5689697266674 .4044799805656 .9725952148635 .7958984375 615.6397094727601 .8306274414590 .5142211914582 .5908203125572 .1420898438 550.7028808594528 .4205932617515 .2575073242503 .8396911621491 .3940124512 478.5415039062463 .5748901367449 .8622131348439 .3136901855430 .2352905273 421.0212097168412 .3594970703405 .6270141602398 .0877075195387 .229309082 376.3005065918367 .6594848633360 .6716918945355 .325012207351 .0538024902 346.9797973633343 .2073059082339 .5437927246335 .8570861816332 .5212097168 329.1860046387325 .8359985352322 .2179870605317 .9287109375313 .157989502 307.8313903809302 .7742919922298 .9921875295 .6606140137292 .1311035156 288.9309082031286 .1200866699283 .6326904297281 .229888916278 .8515930176 276.5733947754274 .0474853516270 .9891967773267 .704498291264 .520690918 261.2491149902257 .865814209254 .3569946289250 .6884002686246 .8860015869 242.9304962158238 .8311004639234 .6049957275230 .2476959229225 .7769927979 221.1737060547216 .3948059082211 .5343017578206 .5361938477201 .5576934814 196.8049926758191 .7059020996185 .8224945068179 .6604003906173 .8370056152 168.2577972412162 .9519958496157 .8739929199152 .8822937012147 .9486999512 142.9505004883137 .9577026367132 .9418029785128 .033996582123 .28099823 118.7862014771114 .6464996338110 .7005004883106 .9289016724103 .3262023926 99.8671112060596 .5505828857493 .2272415161189 .9546737670986 .83840179443 83.763252258380 .7422027587977 .7801208496174 .857841491772 .00797271729 69.2093429565466 .5137405395564 .0310668945361 .7073783874559 .5556602478 57.4902000427255 .4503898620653 .4619789123551 .5344696044949 .69647979736 47.9487800598146 .2903594970744 .7078590393143 .1840286254941 .69195175171 40.2362785339438 .7853202819837 .3377990722735 .8664283752434 .39458847046 32.9494895935131 .5598201751730 .3927001953129 .0489406585727 .03256034851 24.890840530423 .0191307067921 .2953891754219 .6923294067418 .29277038574 17.1798591613816 .2690792083715 .5842199325614 .8377799987813 .64190006256 12.4341402053811 .5844402313211 .0275096893310 .8253097534210 .87290000916 11.0430297851611 .3661899566711 .9309597015412 .4066801071212 .40625953674 12.367250442512 .6430501937913 .1093301773113 .7897701263414 .53178024292 15.1025295257615 .7989301681516 .9212703704818 .0320091247618 .71652030945 19.3163108825720 .0909900665320 .9427394866921 .8713493347222 .80648994446 23.6852703094524 .530199050925 .3435802459726 .1433906555226 .92803001404 27.7161006927528 .5218391418529 .3489208221430 .1906890869131 .05904960632 31.9544200897232 .8875694274933 .8607788085934 .9076194763236 .0503692627 37.3118705749538 .7100601196340 .2328109741241 .880020141643 .61151885986 45.4245910644547 .2199707031248 .9348411560150 .5339088439951 .94467926025 
53.1219711303753 .9772911071854 .461071014454 .5568008422954 .3585395813 53.9936904907253 .5343093872153 .0695610046452 .6115798950252 .18144989014 51.7866096496651 .4320411682151 .1131210327150 .819198608450 .55136108398 50.3008499145550 .0747909545949 .8727912902849 .6999092102149 .5580291748 49.4498596191449 .3763504028349 .3386306762749 .3361511230549 .36907958984 49.435821533249 .5357017517149 .6663284301849 .8260688781750 .01168060303 50.2207717895550 .4493217468350 .6948585510350 .9531593322851 .22233963013 51.4987602233951 .7814216613852 .067798614552 .3575210571352 .64918899536 52.9426383972253 .2372016906753 .5327110290553 .8287887573254 .12525939941 54.4217910766654 .718189239555 .0141983032255 .3096199035655 .6042098999 55.8978500366256 .1903305053756 .4815597534256 .7714118957557 .05981063843 57.3466682434157 .631969451957 .9156608581558 .1977310180758 .47821044922 58.757118225159 .0344886779859 .3103904724159 .5848884582559 .85805130005 60.1299896240260 .4006881713960 .6705017089860 .93904876709 931.5944213867928 .7786865234926 .0015869141923 .2639770508920 .553894043 917.8787231445915 .2415161133912 .6456298828910 .0938110352907 .5891113281 905.133972168902 .7312011719900 .3834838867898 .0935058594895 .8649291992 893.7003173828891 .6043701172889 .5808105469887 .6345214844885 .7700805664 883.9918823242882 .3046264648880 .7114257812879 .216003418877 .8198242188 876.524597168875 .3305053711874 .237487793873 .2446899414872 .350402832 871.5529785156870 .8497924805870 .2385253906869 .7152709961869 .2770996094 868.9188842773868 .637512207868 .4282226562868 .2849121094868 .1983032227 868.1635742188 868.1696777344 868.2003173828 868.231628418 868.2899780273 868.3942260742868 .5521240234868 .7727050781869 .059387207869 .4227294922 869.8513793945870 .3438110352870 .8723754883871 .4147949219871 .9412841797 872.4047241211872 .8112182617873 .1118774414873 .3369750977873 .4525756836 873.5145263672873 .5405883789873 .5570068359873 .6088256836873 .6331176758 873.6824951172873 .5955810547873 .3743286133872 .8173828125871 .832824707 870.3969726562868 .3369750977866 .9987182617867 .1829223633872 .477722168 886.1845092773901 .4528808594913 .7758789062907 .1326293945863 .3793945312 817.8662719727802 .7321166992802 .0383911133804 .4869995117807 .2730712891 807.0156860352803 .2155761719794 .2916259766781 .0435180664763 .548828125 745.7650146484732 .1351928711721 .5717163086713 .1951293945707 .3001708984 704.1331787109703 .0313720703703 .4321289062706 .2468261719711 .4567871094 718.3948974609726 .8516235352736 .3690185547747 .1998291016758 .8442993164 770.734375782 .262878418792 .2938232422802 .7548828125815 .4766845703 827.7719726562837 .0084228516842 .7379760742844 .3831176758841 .6193237305 834.0656738281826 .4348754883823 .8455200195822 .4672241211817 .1727294922 810.5432739258804 .8145141602801 .2708740234803 .0178222656807 .1007080078 809.3615112305 812.1987304688 817.5172729492 824.225402832 832.1342773438 837.7346191406838 .8198852539831 .8145141602813 .0142822266789 .4854125977 765.4185180664741 .867980957718 .1920776367694 .24609375670 .3538208008 648.3405761719629 .7659301758614 .5789794922603 .4948730469591 .9772949219 575.8455810547559 .4959106445547 .3925170898535 .0668945312519 .8015136719 503.4089050293486 .428314209470 .2388916016455 .7012023926443 .3044128418 433.2951965332424 .7721862793416 .9672851562408 .4843139648398 .2044067383 
387.7738037109378 .7315979004370 .8514099121364 .3333129883359 .0899963379 354.6694946289350 .7189025879346 .5618896484342 .395690918338 .8305969238 335.56640625332 .6151123047329 .3728027344324 .8760986328319 .7456054688 314.4732971191309 .4515991211305 .2590942383301 .2821044922296 .9060974121 293.0468139648290 .4039916992288 .2655944824285 .8966064453283 .4313964844 280.9590148926278 .3081970215275 .3677062988272 .3034973145269 .3042907715 266.2150878906262 .9446105957259 .5293884277255 .9546051025252 .2467956543 248.3955993652244 .4122009277240 .3453063965236 .1652984619231 .8641967773 227.3706054688222 .6401977539217 .6549987793212 .3056945801207 .1096038818 202.4069061279197 .658706665192 .5294036865186 .9792022705181 .0885925293 175.2285003662169 .7682037354164 .4949035645159 .3007049561154 .1544036865 148.9492034912143 .7095947266138 .3903961182133 .0765991211127 .8367004395 122.8282012939118 .1713027954113 .8150024414109 .8345031738106 .137802124 102.67520141699 .4150695800896 .1449127197392 .9081497192489 .73770141602 86.6079406738383 .5483016967880 .5831909179777 .7220535278374 .97241210938 72.3051605224669 .7609863281267 .398719787665 .2009429931663 .20212173462 61.2167091369659 .0654792785656 .9118804931654 .8933105468852 .98733901978 51.1887702941949 .4927101135347 .893558502246 .3727111816444 .907371521 43.4940414428742 .1106109619140 .7454681396539 .3691291809137 .99747085571 36.6347198486335 .325469970734 .1227188110432 .6940689086930 .74863052368 28.6289997100826 .6751308441224 .8686008453423 .1807804107721 .67724990845 20.4306793212919 .3887500762918 .5356807708717 .6861495971716 .60877037048 15.5978202819814 .9086503982514 .5443000793514 .6087503433214 .76270008087 14.6996097564714 .6870698928814 .960280418415 .2418603897115 .27363014221 15.3062801361115 .5691003799416 .0110492706316 .6363506317117 .33233070374 17.9751796722418 .730680465719 .7547607421920 .7685909271221 .51297950745 22.1695709228522 .9049396514923 .6683406829824 .4546604156525 .2375202179 25.9837303161626 .7050800323527 .3904495239328 .0687007904128 .76382064819 29.4749393463130 .2030200958330 .94817924531 .7063407897932 .48484039307 33.2872009277334 .1329193115235 .0305290222236 .0057792663637 .07577896118 38.2527809143139 .557750701940 .978370666542 .5139617919944 .13283157349 45.8225097656247 .524829864549 .1906394958550 .798690795952 .29077911377 53.648571014454 .8470001220755 .6134605407755 .6619110107455 .33700942993 54.9489288330154 .4949684143154 .0351104736353 .573940277153 .13790130615 52.7364006042552 .383789062552 .0643692016651 .7669296264651 .49177932739 51.2352905273451 .000278472950 .7862510681250 .5970497131350 .436668396 50.3067283630450 .2101593017650 .1471595764250 .118999481250 .12501907349 50.1651191711450 .2378501892150 .3419609069850 .4751281738350 .6349105835 50.8183403015151 .0219192504951 .242748260551 .4769401550351 .72232818604 51.9755287170452 .235351562552 .4994812011752 .7674293518153 .0379486084 53.3108482360853 .5855102539153 .8617897033754 .1393089294454 .41788101196 54.6971817016654 .9770011901955 .2570381164655 .5370903015155 .81689071655 56.0962791442956 .3750190734956 .6530113220256 .9300689697357 .20610809326 57.481021881157 .754749298158 .027210235658 .2984008789158 .56829071045 58.8368911743259 .104209899959 .3703002929759 .6352005004959 .89897155762 60.1617088317960 .4234504699760 .6829490661660 .94432067871 
937.6132202148934 .8140258789932 .0352172852929 .2849731445926 .5659790039 923.8818969727921 .2359008789918 .6312255859916 .0704956055913 .5565795898 911.0922851562908 .6798706055906 .3223266602904 .0219116211901 .7822265625 899.6057739258 897.4970703125 895.4594116211 893.4976196289 891.6154785156 889.8181152344 888.1091918945 886.4921875 884.9705200195883.5454101562 882.2186279297880 .9899902344879 .859375878 .8256835938877 .8870849609 877.0416870117876 .286315918875 .6187133789875 .0344848633874 .5308837891 874.1024169922873 .7457275391873 .4539794922873 .2244873047873 .0490112305 872.9240112305872 .8413085938872 .7847290039872 .7285766602872 .6915283203 872.6865844727872 .7202148438872 .8043212891872 .9417724609873 .1422729492 873.3989868164873 .713684082874 .0720214844874 .4566040039874 .8635253906 875.2557983398875 .658203125876 .0291137695876 .4130859375876 .7860107422 877.1917114258 877.6486206055 878.145324707 878.7432250977 879.3087158203 879.9083251953880 .3162231445880 .5479736328880 .4337158203879 .8322143555 879.2451171875 878.9594726562 880.1176757812 883.5643920898 890.3687133789 901.0560302734911 .1268920898916 .3281860352911 .2592163086890 .2844848633 865.1049194336847 .0112915039834 .5159912109828 .016418457824 .2810058594 820.3427124023815 .2379760742807 .8305053711797 .0676879883781 .2872924805 763.8547973633747 .5114746094733 .5651245117723 .9733276367717 .8809204102 714.8364257812714 .678527832716 .6115722656721 .133605957728 .2022705078 736.5391845703745 .3314819336754 .3643798828764 .166809082774 .7213134766 786.0087280273797 .1953125805 .6552124023814 .7252807617828 .3135986328 841.9130249023852 .3729248047859 .6577148438862 .9774169922862 .4055175781 856.4193115234850 .174987793849 .7561035156848 .2053833008840 .6583862305 832.7218017578828 .3259277344826 .6220703125827 .0111083984828 .5706176758 829.7661132812833 .1052246094840 .9509887695850 .7105712891860 .2438964844 868.6840209961 875.2205810547 877.2758178711 875.7459716797 864.2451782227 835.5189208984801 .0582275391767 .8482055664736 .6102294922709 .545715332 684.8922729492659 .9896240234638 .2692871094622 .0034179688608 .3173828125 597.2470703125586 .8063964844576 .1199951172563 .8701782227547 .4976806641 529.1129150391511 .3010864258493 .2894897461475 .1500854492459 .3579101562 447.4661865234437 .7471923828427 .8615112305418 .2337036133408 .6229858398 399.0676879883390 .0974121094381 .9021911621374 .5056152344368 .0611877441 362.9269104004357 .9949951172352 .7775878906348 .1029968262344 .5758972168 341.7756958008339 .3305969238336 .3760070801331 .7235107422326 .4389038086 321.5315856934316 .725189209312 .2395935059307 .765411377302 .7031860352 298.265411377295.5472106934293.4100952148 290.7372131348 287.9335021973 285.1152954102282 .2284851074279 .3965148926276 .563293457273 .7665100098 270.8776855469267 .7799072266264 .4844970703260 .999786377257 .345489502 253.5800933838249 .7241973877245 .8265991211241 .8303985596237 .7052001953 233.3652038574228 .75390625223 .7630004883218 .1649932861212 .5805053711 207.5531005859 202.8314971924198.3684997559193.6154937744 187.8713989258 181.8937988281176 .4411010742171 .1016998291165 .7899017334160 .4871063232 155.0845947266149 .6071014404143 .9781036377138 .2740936279132 .5820007324 127.0226974487121 .7416992188116 .9518966675112 .8099975586109 .1410980225 105.6808013916102 .374702453699 .0460815429795 .7393112182692 .47615814209 
89.25537109375 86.17246246338 83.20362091064 80.39185333252 77.71671295166 75.1634063720772 .7505111694370 .506416320868 .413917541566 .5479888916 64.6480865478562 .4303092956560 .1773681640658 .1222686767656 .18585968018 54.3591384887752 .6485595703151 .0452995300349 .5404815673848 .10335159302 46.7363510131845 .4104003906244 .118030548142 .8303985595741 .54652023315 40.2516212463438 .9258499145537 .5425682067935 .9866218566934 .19108963013 32.259899139430 .3333492279128 .4606704711926 .669439315825 .04718017578 23.63365936279 22.40818977356 21.3002204895 20.29231071472 19.33311080933 18.5307102203417 .9961700439517 .7592296600318 .0036506652818 .25070953369 17.9882698059117 .6702194213917 .6408901214617 .7070407867417 .80026054382 17.9707202911418 .2621192932118 .6845092773419 .2400207519519 .90020942688 20.6306190490721 .4385299682622 .3078804016123 .1770496368423 .98101997375 24.7361106872625 .4747905731226 .1782894134526 .8564891815227 .50632095337 28.1309890747128 .7358703613329 .2990303039629 .8669605255130 .47440910339 31.1063098907531 .7501392364532 .4098205566433 .0759582519533 .7620010376 34.4693489074735 .2213706970236 .0265312194836 .9088401794437 .88135910034 38.9548988342340 .144248962441 .4408187866242 .8465194702144 .33763885498 45.9052391052247 .5134391784749 .1334609985450 .7408103942952 .28544998169 53.7481002807655 .2123107910256 .226421356256 .2822494506855 .92074966431 55.5928916931255 .1972312927254 .7821693420454 .3629417419453 .94760894775 53.564029693653 .2250099182152 .9206809997652 .6297683715852 .3602104187 52.1059913635351 .8703498840351 .6503181457551 .4520416259851 .27859115601 51.1330184936551 .0178909301850 .9347000122150 .8845214843850 .86772155762 50.8839797973650 .9327011108451 .0123481750551 .1212196350151 .25653839111 51.4158210754451 .5952682495151 .7923507690452 .0028991699252 .22505187988 52.4552497863852 .6925392150952 .9345092773453 .1808509826753 .43025970459 53.6826591491753 .9374389648454 .19448089654 .4534301757854 .71406936646 54.9761085510355 .2392997741755 .5033111572355 .7679405212456 .03289031982 56.2979698181256 .562919616756 .8276100158757 .0918312072857 .35546875 57.6183815002457 .8804893493758 .1416816711458 .4019393920958 .66119003296 58.9194412231459 .1766700744659 .4329109191959 .6881904602159 .94253921509 60.1960296630960 .4486389160260 .7005882263260 .95164108276

943.628112793940 .7902832031937 .9907226562935 .2313232422932 .4993896484 929.8026123047927.1436767578924.5258789062921.9520263672919.424621582 916.9464111328914 .5197143555912 .1472167969909 .8311767578907 .575012207 905.3812866211903 .25390625901 .196105957899 .2122802734897 .3065795898 895.4829711914893 .7457885742892 .0979003906890 .5424804688889 .0808105469 887.7145996094886 .4434814453885 .2672729492884 .184387207883 .1928100586 882.2904052734881 .4738769531880 .7404174805880 .0856933594879 .5062866211 878.9970092773878 .5535888672878 .1699829102877 .8427734375877 .5646972656 877.3328857422 877.1390991211 876.9744873047 876.8229980469 876.6843261719 876.5527954102876 .4458007812876 .3793945312876 .3566894531876 .3840942383 876.4605712891876 .5894165039876 .766418457876 .982421875877 .2459716797 877.541809082877 .8950805664878 .2918701172878 .771484375879 .3342285156 880.0150146484880 .8319702148881 .7778930664882 .8776855469884 .0316772461 885.2346191406 886.3162841797 887.2116699219 887.8303833008 887.9937744141 
888.3856811523 889.2083129883 891.3851928711 895.5051269531901.3186035156 909.8262939453916 .7686157227919 .0927734375918 .3400878906911 .7482299805 899.3430175781 881.3560791016 861.8134765625 849.6151733398 841.5142211914 834.3818969727827 .6373291016819 .3775024414809 .128112793795 .6505126953 780.2119140625764 .4492797852750 .3679199219740 .7006225586734 .7794189453 731.978515625732 .2487792969734 .8941040039739 .9904785156747 .2056884766 755.5267944336764 .1271972656772 .5142211914780 .2760009766789 .2147827148 801.196105957813 .7777709961824 .0822753906834 .1323242188845 .3651733398 856.5220947266866 .6666259766874 .7683105469879 .8067016602882 .520690918 882.6594848633882 .303527832884 .4741821289881 .2249755859864 .3986206055 848.8366699219848 .3988037109852 .2338867188852 .2615966797851 .6978759766 852.4531860352856 .2736816406864 .5219726562875 .2858276367887 .0010986328 899.5744018555912 .9968261719924 .9996948242933 .5708007812928 .4443969727 901.2203979492863 .0371704102823 .0225219727784 .7904052734751 .3032836914 720.0844726562690 .2814941406664 .0241699219643 .9069824219627 .5526733398 611.8381958008598 .3787841797588 .8690795898579 .5982055664569 .1931152344 555.897277832536 .9680786133516 .0698852539496 .9428100586479 .6946105957 464.5586853027451 .6438903809440 .6687927246430 .7387084961420 .5140075684 410.5333862305401 .1530151367392 .6023864746385 .4212036133378 .7513122559 371.738494873364 .4321899414357 .0899963379351 .3098144531348 .8814086914 347.6169128418345 .3684997559342 .2896118164337 .9429016113333 .0603027344 328.4596862793323 .9216918945319 .6000061035315 .1752929688310 .4241027832 306.0524902344302 .4681091309299 .2712097168295 .9075012207292 .5076904297 289.2768859863286 .1889953613283 .2947998047280 .5581970215277 .8667907715 275.1448974609272 .3601074219269 .3312988281265 .8342895508262 .1270141602 258.4469909668254 .7407989502251 .021194458247 .2294006348243 .3112030029 239.2035064697234 .8925018311230 .0798950195224 .4364929199218 .5166015625 212.7241973877207 .4783935547203 .2301025391198 .9833984375193 .7772979736 188.2176971436182 .8898010254177 .575302124172 .2489013672166 .8583068848 161.3128967285155 .6342926025149 .7731018066143 .7519073486137 .6591949463 131.5352020264125 .3548965454119 .8725967407115 .8572006226112 .489402771 109.0498962402105 .6339035034102 .134597778398 .6476287841895 .20527648926 91.8479995727588 .6764907836985 .681503295982 .9023666381880 .3041229248 77.8544692993275 .556221008373 .3980636596771 .3666076660269 .466796875 67.533897399965 .4005432128963 .2379112243761 .2018089294459 .27201080322 57.4577217102155 .7536888122654 .1574592590352 .6646804809651 .26462936401 49.9434509277348 .6772003173847 .4472389221246 .2228698730544 .99301147461 43.7440109252942 .4180107116740 .9886589050339 .436248779337 .70838928223 35.8745002746633 .9677391052232 .0193786621130 .0757293701228 .27082061768 26.7491397857725 .3967094421424 .1086997985822 .972660064721 .99810028076 21.2439498901420 .7675895690920 .5515308380120 .6608791351320 .76403045654 20.5368404388420 .2338199615520 .0941104888920 .0821990966820 .16506004333 20.367540359520 .6896800994921 .1125106811521 .6545696258522 .31094932556 23.0587291717523 .8573894500724 .6716194152825 .490230560326 .28673934937 27.0701293945327 .8232307434128 .4986400604229 .0775909423829 .6047706604 30.1227607727130 .6265201568631 .1068897247331 .5927200317432 .10731124878 
32.6425094604533 .1899490356433 .7495193481434 .3167991638234 .90167999268 35.5075492858936 .1539993286136 .8521995544437 .6217613220238 .47872161865 39.4283599853540 .4812889099141 .6355018615742 .892990112344 .24362945557 45.6811294555747 .1842002868748 .7329216003450 .3020286560151 .85721969604 53.3516082763754 .7574806213455 .7769889831556 .0979995727556 .0385093689 55.8799209594755 .6219406127955 .315849304254 .9730186462454 .61793899536 54.2720909118753 .9612998962453 .6753883361853 .4091110229553 .15781021118 52.9152183532752 .6845283508352 .4657402038652 .2636413574252 .08304977417 51.9264106750551 .7978591918951 .698379516651 .6304702758851 .59402084351 51.5899505615251 .6171188354551 .6749801635751 .7613296508851 .87414932251 52.0105018615752 .1671600341852 .3412208557152 .5289993286152 .7283706665 52.936111450253 .1511383056653 .3712882995653 .5961608886753 .82468032837 54.0566902160654 .291709899954 .529579162654 .7700195312555 .01277923584 55.2575798034755 .5041389465355 .7521400451756 .0013389587456 .25143051147 56.5021896362356 .7533302307157 .0047111511257 .2560615539657 .50727081299 57.7581596374558 .0086288452158 .2585296630958 .5078315734958 .75643157959 59.0043106079159 .2514381408759 .4978218078659 .743438720759 .98834991455 60.2325782775960 .4761581420960 .7178993225160 .96197128296 949.5186767578946 .6900024414943 .8817138672941 .1024169922938 .3541870117 935.6408081055932 .9652099609930 .3303222656927 .7390136719925 .1937255859 922.6970825195920 .2514038086917 .8591918945915 .5228271484913 .2451171875 911.028503418908 .8768920898906 .7932739258904 .7816772461902 .8458862305 900.9899902344899 .2177734375897 .5321044922895 .9359741211894 .4307861328 893.0178833008 891.6967773438 890.4672241211 889.3272705078 888.2747802734 887.3071899414 886.4208984375 885.6129150391 884.8784179688 884.2138061523 883.6135864258883 .0739135742882 .5880737305882 .1530151367881 .7600097656 881.4074707031881 .0856933594880 .7935180664880 .5266723633880 .2700195312 880.0006713867879 .7423706055879 .5153808594879 .3192749023879 .162902832 879.0504760742878 .9840698242878 .9713134766879 .003112793879 .1069946289 879.2697143555879 .5374755859879 .8969116211880 .4080200195881 .0737915039 881.9398193359883 .0269775391884 .3272705078885 .8767089844887 .5676269531 889.4229125977 891.2478027344 893.0084838867 894.5819702148 895.7622070312 897.1503295898 898.7327880859901.1813964844904.700378418909.0335083008 915.0839233398920 .1380004883921 .3707885742922 .2396850586924 .7022705078 921.3679199219904 .0551757812882 .4862060547868 .5316772461857 .4866943359 847.8458251953839 .2420043945829 .4694213867818 .9937133789807 .4760131836 794.7723999023780 .9284057617768 .4274902344759 .8552856445754 .6298828125 752.2091064453752 .645324707755 .3856201172760 .3068847656766 .8323974609 774.4241943359782 .5311889648790 .5106811523796 .9583740234804 .7598876953 817.3897094727 830.9337768555 842.7706298828 853.3862304688 861.6450195312 869.5969238281878 .694519043887 .4282836914894 .4310302734900 .2036743164 906.015625910 .0758056641913 .5551757812909 .463684082885 .6732788086 863.8934936523866 .7993164062874 .9912719727874 .3452148438872 .9298706055 874.106628418878 .2816162109885 .9561767578896 .9008178711910 .1473999023 926.0629272461945 .2321166992963 .3850097656977 .8640136719979 .4304199219 959.5200805664923 .9619140625880 .7687988281835 .2706298828793 .7543945312 
756.5557861328721 .4099121094690 .9902954102667 .607421875647 .2387084961 624.6671142578605 .9180908203596 .4354248047590 .795715332586 .6791992188 579.1638183594560 .4656982422538 .7443847656520 .9270019531503 .3584899902 485.3599853516469 .020111084456 .4869995117445 .6835021973433 .8370056152 422.6893920898412 .6604919434403 .5957946777396 .0484008789388 .4916992188 379.5152893066370 .3757019043361 .6958007812355 .3200073242354 .0425109863 354.011505127351 .4656982422347 .8916931152343 .782989502339 .3086853027 335.0185852051330 .8357849121326 .8804016113322 .9567871094319 .0390930176 314.8208007812310 .2594909668305 .6156005859301 .1267089844297 .0946044922 293.4548950195290 .2233886719287 .2648925781284 .4740905762281 .7905883789 279.145690918276 .6079101562273 .8038024902270 .298614502266 .5739135742 263.0281066895259 .5025939941255 .9750061035252 .37890625248 .6665039062 244.7673034668240 .7626037598236 .2136993408230 .6985931396224 .7174987793 218.3473968506212 .4797973633208 .1157989502204 .0357055664199 .2239990234 194.1392059326189 .0256958008183 .8155975342178 .62109375173 .2346038818 167.5868988037161 .7039031982155 .6347961426149 .4002075195143 .0404968262 136.5735015869129 .7145996094123 .6396026611119 .6405029297116 .4114990234 112.8190002441109 .189201355105 .4031982422101 .594200134397 .89000701904 94.3269195556691 .0490493774488 .0064773559685 .2713165283282 .74376678467 80.3997421264678 .207733154376 .1260223388774 .1281509399472 .15854644775 70.1799011230568 .1657028198266 .1498031616264 .1821594238362 .29175949097 60.5133590698258 .842639923157 .2690010070855 .8029289245654 .44139099121 53.1665992736851 .9494895935150 .7698211669949 .5897598266648 .39323043823 47.1699790954645 .865089416544 .4522705078142 .927730560341 .27947998047 39.5146408081137 .6264801025435 .6527404785233 .5943298339831 .63570022583 30.0020809173628 .5137691497827 .0314292907725 .7264709472724 .65759086609 23.879110336323 .401300430323 .1357402801523 .0195598602322 .91765022278 22.7481708526622 .5552101135322 .4061298370422 .3457393646222 .41049957275 22.6060504913322 .936040878323 .3806591033923 .9328403472924 .58296966553 25.3186702728326 .0982704162626 .8777198791527 .6615600585928 .43890953064 29.1999397277829 .9409294128430 .5933399200431 .1001300811831 .53517913818 31.971260070832 .3938598632832 .8065490722733 .2226104736333 .6466293335 34.0830688476634 .5285110473634 .9853897094735 .4498291015635 .93119049072 36.4299507141136 .9649391174337 .5433311462438 .1867294311538 .91022109985 39.7195510864340 .6195487976141 .6148300170942 .7076110839843 .89992904663 45.1944389343346 .5769500732448 .0419502258349 .5500488281251 .0904083252 52.5465507507353 .8158988952654 .8120117187555 .4526290893655 .79563903809 55.8955307006855 .828689575255 .670478820855 .4424209594755 .17224884033 54.8893203735454 .6175193786654 .3608093261754 .1237602233953 .89834976196 53.6716499328653 .4515190124553 .2380218505953 .0369796752952 .85316085815 52.6898994445852 .551479339652 .4396591186552 .3570899963452 .30437088013 52.2824592590352 .2907905578652 .3287506103552 .3946304321352 .48625946045 52.601139068652 .7358703613352 .8879203796453 .0534706115753 .23070907593 53.4163703918553 .6095809936553 .808170318654 .0119209289654 .2197303772 54.4315795898454 .6469917297454 .8658599853555 .08789062555 .31288909912 55.5405197143655 .7705307006856 .0025787353556 .2364006042556 .47166061401 
56.7081298828156 .9454803466857 .1835517883357 .4220504760757 .6608505249 57.8997116088958 .1385498046958 .3771591186558 .615509033258 .85345840454 59.0909805297959 .3279991149959 .5645103454659 .800498962460 .03596115112 60.2709388732960 .5053710937560 .739398956360 .97285079956

955.4030151367952 .5297851562949 .6937866211946 .8980712891944 .1298217773 941.3961181641938 .6998291016936 .0438842773933 .4310302734930 .8635864258 928.3441772461925 .8748779297923 .4583740234921 .096496582918 .7922973633 916.5477905273914 .3665771484912 .2515258789910 .2062988281908 .2346801758 906.3402099609904 .5266113281902 .7965698242901 .1533203125899 .5977172852 898.1309814453896 .7529296875895 .4625854492894 .2581787109893 .1370849609 892.096496582891 .1323852539890 .2415771484889 .4185180664888 .6597900391 887.9594116211887 .3131713867886 .7147827148886 .1602172852885 .6420288086 885.1569213867 884.6970214844 884.262878418 883.8482055664 883.4439697266 883.0355224609882 .6286010742882 .2266235352881 .8428955078881 .4912719727 881.1773071289880 .903503418880 .6807861328880 .5098876953880 .4197998047 880.4144287109880 .5396728516880 .8070068359881 .2739257812881 .9664916992 882.9337768555884 .2052001953885 .7954711914887 .7285766602889 .9498291016 892.4525146484895 .0861206055897 .7769775391900 .2938842773902 .4058837891 904.4564208984906 .3701171875908 .6544799805911 .8084716797915 .0913085938 918.708190918921 .1354980469920 .4694824219920 .7631225586924 .3228759766 923.6895141602911 .598815918894 .6937255859881 .0609741211869 .0303955078 858.4990844727848 .7808837891838 .7653198242828 .6912231445818 .0618286133 806.9213867188794 .8906860352784 .3067016602778 .0089111328774 .4904174805 772.8668823242773 .3571777344775 .9677734375780 .4232177734786 .6041259766 793.8643188477801 .3538818359809 .1567993164816 .8568115234825 .6619262695 836.9428710938848 .4567260742857 .7874755859865 .637512207872 .5427856445 879.5145263672 887.9149780273 897.2227172852906.737121582914.7581787109 918.8801269531920 .4321289062922 .1959228516917 .6683959961900 .3839111328 884.7495727539884 .3991699219888 .4852905273888 .5513916016888 .3275146484 890.2808227539894 .8369140625902 .3295288086912 .9152832031926 .459777832 943.1314086914962 .9611206055982 .82037353521000 .4229736331009 .906982422 1007.346008301985.1032714844935.8253173828 879.2700195312 833.9302978516 793.5543212891752 .4005737305715 .7470703125689 .1616821289665 .231628418 638.1032714844616 .1287841797606 .9788208008603 .6865844727598 .8585205078 591.1920166016577 .2816162109561 .0061035156546 .4661254883530 .2943115234 511.1369018555492 .365814209477 .1901855469463 .6104125977448 .808013916 435.1870117188425 .041809082415 .7124938965404 .5676879883393 .4964904785 384.1937866211375 .7822875977368 .2421875363 .1883850098362 .1036987305 361.7539978027358 .4702148438354 .0161132812349 .5815124512345 .1575927734 341.0083007812337 .2016906738333 .9213867188330 .8691101074327 .7514953613 323.6907958984318 .1961975098312 .1017150879306 .2452087402301 .2980957031 297.5838012695294 .462890625291 .4028930664288 .4577941895285 .6770935059 282.9974975586280 .375277 .5383911133274 .1398925781270 .5911865234267 .2742919922 264.0109863281260 .6965026855257 .2962036133253 .7716064453250 .066192627 246.1667938232241 .7720947266236 .6096038818230 .9295043945224 .8672943115 219.0756988525214 .2288970947209 .6896972656204 .8041992188199 .8103942871 
194.7859039307189 .7411956787184 .8894042969179 .7510070801173 .9248046875 167.7698974609161 .5531005859155 .2395935059148 .8621063232142 .3686065674 135.6302032471129 .5343933105124 .9546966553121 .0731964111117 .1700973511 113.2076034546108 .943397522104 .6648025513100 .577499389696 .74597167969 93.3169326782290 .2348937988387 .5307464599685 .0841369628982 .82276153564 80.7232666015678 .7281875610476 .789756774974 .8302688598672 .87264251709 70.9091110229568 .9710922241267 .0762634277365 .2464294433663 .52696990967 61.9104995727560 .3946495056258 .9786987304757 .6610298156756 .42436981201 55.2460098266654 .1030387878452 .9649009704651 .8090896606450 .61343002319 49.3449096679747 .9760398864746 .5097389221244 .9347496032743 .23923873901 41.4016113281239 .4558906555237 .4269294738835 .4369506835933 .62017822266 31.8743495941230 .105539321928 .52380943329827 .2924003601126 .43063926697 25.9816398620625 .7239398956325 .4762401580825 .2508792877224 .99976921082 24.7824497222924 .6004905700724 .4978904724124 .5511207580624 .74585914612 25.0830802917525 .5445003509526 .1055698394826 .750490188627 .4645690918 28.2157802581828 .9638500213629 .7114696502730 .4472503662131 .16107940674 31.8360691070632 .4288291931232 .8997611999533 .2990188598633 .67625045776 34.0349502563534 .3837013244634 .7271499633835 .0724487304735 .41913986206 35.7711105346736 .1291694641136 .4915008544936 .8654212951737 .25263977051 37.6673812866238 .1183891296438 .6237792968839 .1999282836939 .85234832764 40.5889701843341 .4120292663642 .3198204040543 .3305511474644 .45391082764 45.6908302307147 .0528106689548 .4902114868249 .9829216003451 .41107940674 52.691131591853 .8021202087454 .6545600891155 .2850990295455 .65565872192 55.816970825255 .8439712524455 .7631301879955 .6132392883355 .41767883301 55.2078018188554 .9919281005954 .7884788513254 .5872001647954 .38129043579 54.1751899719253 .9710311889653 .7742195129453 .5908012390153 .42399978638 53.2791213989353 .1578216552753 .0637207031252 .997211456352 .96014022827 52.9516487121652 .9718894958553 .0188217163153 .0909309387253 .18544006348 53.2994499206553 .4302597045953 .5744590759353 .7301292419453 .89432907104 54.0661201477154 .2436103820854 .4265403747654 .6140098571854 .80596160889 55.0020294189555 .2020988464455 .4059410095255 .6133117675855 .8239402771 56.037528991756 .2537307739356 .4722595214856 .6927795410256 .91501998901 57.1386489868257 .3634605407757 .5891609191957 .8155784606958 .04246139526 58.2696914672958 .4970512390158 .724468231258 .9517898559659 .17897033691 59.4058990478559 .6325683593859 .8589286804260 .0849685668960 .31069946289 60.5360717773460 .7600593566960 .98675918579

961.1638793945958 .2922973633955 .4409179688952 .6185302734949 .8265991211 947.0689697266944 .3483886719941 .6677246094939 .0294189453936 .4357910156 933.8892822266931 .3922119141928 .9465942383926 .5546264648924 .2189941406 921.9417114258919 .7258300781917 .5739135742915 .4898071289913 .4766235352 911.5377807617909 .6768798828907 .8967285156906 .1998901367904 .5874023438 903.0606079102901 .6187744141900 .2609863281898 .9851074219897 .7883300781 896.6674194336895 .6182250977894 .6365966797893 .7172241211892 .8560180664 892.0468139648 891.2852783203 890.5648803711 889.8814697266 889.227722168 888.6005249023887 .9915771484887 .4005737305886 .8187255859886 .2459716797 885.680480957885 .1124267578884 .5258789062883 .9459838867883 .3909301758 
882.8638916016882 .3668212891881 .9204711914881 .5236206055881 .2177124023 880.9987182617880 .9362182617881 .0399780273881 .3939208984882 .0169067383 882.9887695312884 .3300170898886 .0933837891888 .3001708984890 .9368286133 894.0095825195 897.378112793900.9923706055904.5178833008907.6229248047 910.2847290039912 .1475830078913 .883972168916 .4840698242918 .7426757812 920.4227294922920 .9780883789918 .6895141602917 .0042114258918 .0952758789 917.2045288086910 .2973022461899 .673828125888 .5490112305877 .040222168 866.5382080078856 .6256103516846 .8657226562837 .3706054688827 .5115966797 817.7742919922807 .7473144531799 .4896850586795 .5753173828793 .9509277344 793.0454101562793 .7197875977796 .0692138672800 .1353759766806 .0197753906 812.8031005859819 .4235839844826 .698425293835 .584777832845 .0708007812 854.3120727539 862.6663208008 868.4166259766 873.3527832031 879.2608032227 885.940612793893 .7583007812902 .8079223633913 .5922241211922 .1730957031 922.991394043920 .8406982422920 .4663085938917 .3803100586909 .8983764648 902.3637695312898 .3745727539896 .9611206055897 .094909668898 .8690185547 901.9730224609907 .0233764648913 .8953857422923 .5194702148936 .2095947266 951.9118041992969 .6865234375988 .48498535161006 .8029785161021 .335998535 1035.7359619141030 .376953125983 .387512207923 .5784301758878 .3441772461 835.4777832031787 .6843261719744 .5260009766713 .3302001953686 .6342773438 657.4984741211635 .2208251953626 .416015625622 .9498901367614 .3090209961 604.1968994141593 .6364135742581 .5573730469569 .7559814453555 .6644287109 537.4633178711518 .1326293945501 .3059997559484 .633605957466 .5600891113 450.2579956055439 .4782104492429 .1701049805413 .5668029785398 .6754150391 389.0060119629382 .2739868164376 .8663024902373 .3893127441372 .0163879395 370.2237854004365 .5682983398359 .9956970215355 .1608886719350 .7171020508 346.6679077148343 .0874023438340 .3223876953337 .6232910156334 .7275085449 330.9226074219325 .2431945801318 .7811889648312 .2887878418306 .4460144043 302.3830871582299 .1282958984295 .7099914551292 .5444946289289 .629699707 286.8388977051284 .0375976562281 .0857849121277 .8070068359274 .4672851562 271.3870849609268 .3457946777265 .2074890137261 .9702148438258 .6112976074 255.0442047119251 .2064056396246 .988494873242 .3005981445237 .1614990234 231.6643981934226 .0986022949220 .7449035645215 .5635986328210 .3995056152 205.2823028564200 .2006072998195 .2384033203190 .7048950195185 .8793945312 180.0175933838173 .7297058105167 .50390625161 .2041015625154 .9046936035 148.6051940918142 .2483062744136 .2789001465131 .0319976807126 .2772979736 121.8347015381117 .4297027588112 .5877990723107 .7606964111103 .2393035889 99.07711791992 95.45290374756 92.29270172119 89.64013671875 87.27184295654 85.1390762329183 .160720825281 .2530136108479 .3904266357477 .47451019287 75.5437393188573 .6322631835971 .7627792358469 .9451980590868 .20269012451 66.5599365234465 .0155792236363 .5673408508362 .2148017883360 .94435882568 59.7465896606458 .5984802246157 .4833793640156 .37849044855 .25714111328 54.0927505493252 .8658981323251 .5580902099650 .1605415344248 .66572189331 47.0436782836945 .2761993408243 .3976783752441 .4424896240239 .44855880737 37.4632797241235 .4802703857433 .4614791870131 .6496696472230 .25061988831 29.2546691894528 .7473697662428 .4401302337628 .0563697814927 .69342041016 27.3446102142327 .0353393554726 .7718791961726 .6223907470726 .66688919067 
26.8699607849127 .2087192535427 .6634807586728 .2207107543928 .85316085815 29.5379104614330 .2473297119130 .9583702087431 .6603107452432 .34062957764 32.9840087890633 .574081420934 .0951805114734 .5409812927234 .9224281311 35.2599296569835 .5652008056635 .8547782897936 .1313285827636 .40264892578 36.6688194274936 .9338989257837 .1985702514637 .461780548137 .73028182983 38.0053405761738 .2995491027838 .6198081970238 .9832382202139 .40475845337 39.8922309875540 .4555816650441 .097091674841 .8050117492742 .61771011353 43.546451568644 .6137809753445 .8577690124547 .2013702392648 .64583969116 50.0796813964851 .4495086669952 .7154502868753 .7751502990754 .6471786499 55.2659111022955 .6745491027855 .9073410034255 .9937705993755 .97940063477 55.8850593566955 .7456893920955 .5788688659755 .4118690490755 .2373008728 55.0531997680754 .8633804321354 .6704597473154 .4803085327154 .29959106445 54.1318206787153 .9828109741253 .8545913696353 .7511405944853 .67319869995 53.6228485107453 .5995712280353 .6035881042553 .6332092285253 .68695068359 53.7623100280853 .856441497853 .9669113159254 .0903701782254 .22515106201 54.3683700561554 .5193099975654 .6761093139654 .8386802673355 .00614929199 55.1785583496155 .3555793762255 .5371513366755 .7230300903355 .91302871704 56.1068382263256 .3041915893656 .5046997070356 .7080917358456 .91397094727 57.1221008300857 .3320999145557 .5437507629457 .7567214965857 .97082901001 58.1857910156258 .4014701843358 .6176185607958 .8341598510759 .05089950562 59.2677688598659 .484649658259 .7015190124559 .9182815551860 .13492965698 60.3514404296960 .5677604675360 .7838897705160 .99980163574 966.9160766602963 .9948730469961 .1091918945958 .2634277344955 .4445800781 952.6594848633949 .9110107422947 .2017211914944 .533996582941 .9102172852 939.3327026367936.8034057617934.3245849609931.8980102539929.5263061523 927.2111206055 924.9556274414922.7620239258920.6337280273918.5734863281 916.5850219727914 .6713867188912 .8350830078911 .0789794922909 .4036865234 907.8107910156906 .2990112305904 .8673706055903 .5134887695902 .2343139648 901.026184082899 .8845825195898 .8051147461897 .7819213867896 .8104858398 895.8845825195894 .9995117188894 .1481933594893 .3267211914892 .5275268555 891.7473144531890 .9785766602890 .2191162109889 .4614868164888 .7083129883 887.954284668 887.1945800781 886.4185180664 885.6403808594 884.8732299805 884.1196289062883 .378112793882 .6782226562882 .0377807617881 .4807128906 881.0043945312880 .6848754883880 .5631713867880 .7139892578881 .1799926758 882.0399169922 883.3344116211 885.1317749023 887.4688720703 890.3712768555 893.8521728516 897.8267211914902.2437133789906.7443847656 911.1810913086 914.7495727539916 .3331298828917 .3024902344918 .9464111328919 .9973754883 920.0081176758918 .9951171875916 .6536254883914 .4851074219913 .8590087891 912.5939941406907 .5979003906900 .2387084961891 .1773071289880 .9031982422 871.145324707861 .8026733398852 .9796142578844 .5330200195836 .196105957 828.3823242188820 .9838867188815 .2681884766812 .5504150391811 .5524902344 811.426574707812 .5106201172815 .0098876953819 .0429077148824 .8966064453 831.1226806641836 .0374755859841 .3801879883848 .516418457856 .018371582 863.1326293945869 .078125873 .3052978516877 .2510986328881 .8859863281 887.3798217773 893.9124755859901.4058227539910.0728149414916.8065795898 918.5264282227918.026184082918.4033813477917.9456787109913.6231079102 
908.1243896484904.3314819336901.8276977539901.8820800781904.5452880859 908.7741699219913 .9197998047919 .162109375926 .3040161133936 .9622802734 950.2901000977965 .9318847656983 .35388183591001 .2399902341019 .000976562 1036.8630371091040 .7919921881018 .366027832979 .5565185547933 .5369873047 883.8297119141 833.2484741211 785.9984130859746.6331787109 713.708984375 688.8828125671 .8001098633660 .9030761719653 .311706543643 .6234130859 632.2597045898617 .0510864258601 .2036132812587 .8049926758574 .2479858398 560.4342041016545 .2786865234528 .1329956055509 .3507080078489 .3284912109 470.9794006348457 .5660095215444 .1596069336425 .5871887207408 .2178039551 397.096496582390 .5422058105387 .2556152344385 .3197937012382 .900604248 378.9855041504372 .4943847656365 .6384887695360 .4021911621356 .0404968262 351.9982910156348 .342590332345 .1702880859341 .8398132324337 .7294006348 333.4953918457330.0351867676 325.9426879883 319.9509887695 313.740814209 308.620300293304 .2055969238300 .225189209296 .7037963867293 .6926879883 290.8887023926287 .9713134766284 .9613037109281 .7557983398278 .5596923828 275.5375976562272 .5526123047269 .5192871094266 .4036865234263 .1686096191 259.7481994629256 .0855102539252 .1979980469248 .0755004883243 .4978027344 238.1627044678232 .4734954834226 .9174041748221 .4192047119216 .025604248 210.7021026611205 .3121032715200 .1676025391195 .6589050293191 .0043029785 185.488494873179 .5370025635173 .4734954834167 .3025054932161 .0720062256 154.8657989502148 .6976013184142 .69090271137 .0821990967131 .7158966064 126.6240997314121 .5887985229116 .1723022461110 .8102035522105 .8285980225 101.310096740797.4357910156294.1877670288191.59377288818 89.36039733887 87.4029769897585 .6118011474683 .7968292236382 .0040817260780 .13268280029 78.2233734130976 .3685531616274 .5810165405372 .8615570068471 .21943664551 69.6595230102568 .1855621337966 .8007736206165 .5036773681664 .29360961914 63.1445083618262 .0297698974660 .9420509338459 .8668708801358 .77838897705 57.6452713012756 .4628105163655 .2160301208553 .8983497619652 .550 .9758605957 49.3003196716347 .5019416809145 .5708389282243 .5468215942441 .47455978394 39.3732490539637 .3090896606435 .4483985900933 .9435386657732 .79692077637 32.0401191711431 .4679603576730 .8722496032730 .3314094543529 .87126922607 29.4578609466629 .0171909332328 .7377395629928 .8077297210729 .06425094604 29.3711891174329 .7798309326230 .3222007751530 .9401607513431 .58098983765 32.2363815307632 .8884887695333 .528179168734 .1414299011234 .71374893188 35.2307891845735 .6933288574236 .0915603637736 .4364509582536 .73252105713 36.989810943637 .225868225137 .4425697326737 .6475791931237 .84069061279 38.0261306762738 .2037887573238 .3745117187538 .542270660438 .70960998535 38.8854217529339 .0770988464439 .2981185913139 .5628318786639 .87874984741 40.2577209472740 .7005615234441 .2000083923341 .7998313903842 .51770019531 43.4050903320344 .516460418745 .7787208557147 .1850509643648 .65665054321 50.1518783569351 .604080200252 .8828201293953 .9890403747654 .8451385498 55.4850196838455 .9203910827656 .1793708801356 .2967491149956 .30199050903 56.2356796264656 .121368408255 .9981117248555 .8559188842855 .69548034668 55.5222702026455 .3417282104555 .1595001220754 .9828910827654 .81571960449 54.6642684936554 .5307807922454 .4197616577154 .3319892883354 .27006912231 54.233398437554 .2227210998554 .236190795954 .2727890014654 .32992935181 
54.4051818847754 .4960517883354 .5995788574254 .7140693664654 .83697891235 54.9675483703655 .1042213439955 .2468605041555 .394809722955 .54806900024 55.7064514160255 .8698310852156 .0381011962956 .2109909057656 .3882598877 56.5695800781256 .754608154356 .9430389404357 .1344604492257 .32862091064 57.5251312255957 .7237281799357 .9240913391158 .125980377258 .32912063599 58.5333290100158 .7383613586458 .9440803527859 .1502990722759 .35692977905 59.5638198852559 .770931243959 .9781494140660 .1854591369660 .39279174805 60.6000785827660 .8064193725661 .01585006714 972.5474243164969 .6204223633966 .712890625963 .8339233398960 .9846801758 958.1690063477955.3889770508952.6473999023949.9467163086947.2890014648 944.6765136719942 .1110229492939 .5947265625937 .1292724609934 .7169799805 932.3596191406930.0596923828927.819519043925.6422119141923.5302734375 921.4869995117919 .5155029297917 .617980957915 .7974243164914 .053894043 912.3889770508910 .8013916016909 .290222168907 .8522949219906 .4846191406 905.1829223633903 .9423828125902 .7581787109901 .6245117188900 .5358886719 899.4860839844 898.469909668 897.4802856445 896.5126953125 895.5598754883 894.617980957893 .6799926758892 .7432861328891 .8004760742890 .8527832031 889.8928222656 888.9235229492 887.9417114258 886.9525756836 885.9592285156 884.9666137695883 .9661254883882 .9989013672882 .0883178711881 .2534790039 880.4727783203879 .8549804688879 .4395141602879 .3223266602879 .5280761719 880.1729736328881 .2777099609882 .9641113281885 .2474975586888 .2197265625 891.874206543896 .2006225586901 .1436157227906 .4080200195912 .0670166016 916.3989257812917 .6840820312917 .657409668918 .3020019531918 .3198242188 917.1591186523915 .4083862305913 .5280761719911 .6422119141909 .6898803711 907.3007202148903 .1118164062897 .4204101562890 .0357055664881 .4779052734 873.0504150391864 .803894043857 .1821289062850 .1796264648843 .6901245117 838.0308837891 833.2479248047829.8125 827.9447021484 827.3228759766 827.7495727539 829.2415771484831 .9340209961835 .7791748047841 .2211303711846 .549621582 849.6370849609 852.6746826172 857.254699707 862.1005859375 866.779296875 870.919128418874 .3812866211877 .7327270508881 .1663818359885 .1702270508 889.8690185547 895.0106811523900.2496948242904.7487182617907.9896240234 910.3259887695912 .8101806641913 .9882202148911 .0228271484906 .848815918 904.1663208008902 .592590332903 .3577880859906 .1715698242910 .6287841797 915.4885253906918 .7833862305923 .2907104492931 .3983154297942 .2230224609 955.5593261719970 .7653808594986 .39691162111003 .3889770511020 .427978516 1032.202026367 1037.9749755861025.963989258986.0150146484932.9260253906 881.5941772461831 .9064941406785 .0344238281749 .4630126953731 .94140625 721.5042114258707 .2672119141693 .3491210938680 .4566040039665 .5369873047 642.7498779297619 .88671875602 .9393920898589 .0432739258579 .4523925781 568.3668212891551 .8601074219532 .7321166992512 .8101806641493 .5570983887 477.8952026367462 .0166931152441 .7139892578423 .0414123535410 .5426025391 402.7775878906399 .6583862305397 .6328125392 .9696044922386 .8485107422 378.9902038574371 .3114013672365 .9136962891361 .4280090332357 .1986999512 353.2117919922349 .370300293345 .2732849121339 .9619140625335 .3613891602 334.2188110352332 .7695922852327 .7901000977321 .6332092285315 .6210021973 309.9703063965305 .3052062988301 .3884887695298 .1437072754295 .2377929688 
292.1307983398289 .0103149414285 .8468017578282 .7022094727279 .6557922363 276.6510925293273 .653503418270 .6101989746267 .4726867676264 .1881103516 260.7261047363257 .1040039062253 .4530944824249 .3114929199244 .0843963623 238.3695068359232 .7613067627227 .1197052002221 .5760040283216 .0821990967 210.4239044189205 .0391998291200 .4196014404195 .838394165190 .683303833 185.1864929199179 .4143066406173 .4365997314167 .3256988525161 .1858062744 155.108505249149 .0659942627143 .1741943359137 .3448028564131 .6743011475 125.9822006226119 .8701019287113 .9453964233108 .4697036743103 .5885009766 99.3610687255995 .8666763305793 .2287368774491 .134483337489 .55423736572 88.01293182373 86.321853637784.5280838012782.67180633545 80.87315368652 79.1238021850677 .4651336669975 .8637466430774 .3379364013772 .869140625 71.4750900268670 .1538391113368 .9130401611367 .7572021484466 .65580749512 65.5701293945364 .5038986206163 .4507408142162 .3860702514661 .27782058716 60.1301803588958 .9311904907257 .6780395507856 .3613090515154 .94847106934 53.4058990478551 .6839103698749 .754470825247 .6712989807145 .53369140625 43.4050483703641 .391319274939 .5602188110437 .9912681579636 .6838684082 35.6331405639634 .7538108825733 .9262695312533 .2037010192932 .61742019653 32.0934906005931 .4815006256131 .0604190826431 .1198806762731 .38163948059 31.6191902160631 .9526290893632 .4528999328633 .0241012573233 .60083007812 34.1835517883334 .7645301818835 .3274497985835 .8655891418536 .36363983154 36.8132896423337 .2136192321837 .5610313415537 .859519958538 .11228942871 38.32524108887 38.51332092285 38.67554092407 38.82144927979 38.94871139526 39.0628013610839 .1617317199739 .2483100891139 .3235588073739 .39152908325 39.4572486877439 .5293083190939 .6162986755439 .7333602905339 .88563156128 40.0888404846240 .3399581909240 .6313400268641 .0140495300341 .49290847778 42.1744689941443 .1283912658744 .2907714843845 .7055702209547 .26010131836 48.9211997985850 .5946006774952 .083560943653 .4064598083554 .47299957275 55.3134613037155 .9336700439556 .3498992919956 .5940093994156 .69586181641 56.7039108276456 .6423416137756 .5630302429256 .4523315429756 .31491851807 56.1576805114755 .989681243955 .8156089782755 .6438789367755 .47811889648 55.32534027155 .1877517700255 .0703887939554 .9740791320854 .90176010132 54.852958679254 .8286209106454 .8270683288654 .8474197387754 .8872795105 54.9443817138755 .0164489746155 .1006698608455 .1955604553255 .29870986938 55.4095382690455 .5265884399455 .6498603820855 .7787513732955 .91334915161 56.0534782409756 .1991195678756 .3501014709556 .5062408447356 .66724014282 56.8328399658257 .0026283264257 .1763305664157 .3535003662157 .53387832642 57.7170410156257 .90275955258 .0906295776458 .2804412841858 .47185897827 58.6647109985458 .8586997985859 .053710937559 .2495002746659 .44596099854 59.6429405212459 .8403587341360 .0381011962960 .2361183166560 .43432998657 60.6327018737860 .8311080932661 .02962875366 978.1680908203975.1868286133972.2387695312969.330078125966.4475708008 963.5977172852960 .7827758789958 .0056152344955 .2681884766952 .5728759766 949.9215087891947.3159790039944.7581787109 942.2498779297939.7929077148 937.3889160156935 .040222168932 .7490234375930 .5181274414928 .3497924805 926.2471923828924 .2130737305922 .2495727539920 .3593139648918 .5424804688 916.8007202148915 .132019043913 .5355834961912 .0081176758910 .5460205078 
909.1450195312907 .799621582906 .5045776367905 .2537841797904 .041809082 902.861328125901 .7072753906900 .5723876953899 .4517211914898 .3378295898 897.2265014648 896.1107788086 894.9876098633 893.8502807617892.6978149414 891.5244750977890 .3338012695889 .1220092773887 .8944091797886 .6508178711 885.396484375 884.1314086914882.8828735352 881.6704711914880.5093994141 879.3890991211 878.4149169922 877.6563720703 877.1845703125 877.0391845703 877.3267822266 878.1021728516 879.4771118164 881.5042114258 884.2725219727 887.8126831055 892.1370239258 897.221496582902.9171142578909.3228759766 914.132019043914 .9984130859914 .1729125977913 .8568725586913 .1505737305 911.7064208984910 .0145263672908 .357421875906 .4489135742904 .2432861328 901.5371704102897 .8338012695893 .2260131836887 .1298217773880 .0753173828 872.7689819336865 .666015625859 .280090332853 .7877197266849 .5673828125 846.2188720703 843.2584838867841.3239135742 841.0054931641 841.4193725586 841.9193115234843 .1907958984845 .7976074219849 .0510864258852 .5922241211 855.7393798828857 .7894287109859 .6741943359862 .4025878906865 .2811279297 867.9611816406870 .5095825195872 .6447143555874 .7006225586876 .7374267578 878.9946289062881 .7835083008884 .7045288086887 .6655273438890 .7968139648 893.7308959961896 .7174072266899 .7376708984901 .6168823242901 .2075195312 899.9735107422 899.2221069336 899.1594848633900.5485839844903.1127929688 906.6447753906910 .0313720703911 .995300293914 .7083740234920 .3319091797 928.5454711914939 .8123168945951 .8784790039961 .5861816406974 .7979125977 996.46838378911020 .4039916991040 .2380371091044 .2039794921021 .138000488 978.5233154297924 .958190918870 .6016845703825 .3107299805794 .825378418 786.7523803711782 .0557861328763 .2139282227740 .2136230469719 .5095825195 696.4840698242665 .6646728516636 .1394042969617 .0173950195603 .694519043 592.7490234375580 .9478759766565 .8087768555549 .0380859375532 .2069091797 515.5512695312500 .371887207484 .3214111328464 .7713012695446 .3048095703 432.3901977539422 .0263977051415 .0304870605408 .7608032227400 .599395752 392.099609375384 .3026123047377 .4655151367371 .795501709366 .8182983398 362.2565002441357 .9301147461353 .7847900391349 .5625344 .7803039551341 .0419921875 339.7475891113338 .3707885742334 .4674072266329 .0069885254322 .8255004883 316.6742858887311 .5523071289307 .1976013184303 .4234008789300 .0127868652 296.5921020508293 .2525939941289 .9910888672286 .7921142578283 .6962890625 280.666809082277 .6452941895274 .6236877441271 .5621948242268 .3829956055 265.0162963867261 .5053100586257 .9039001465253 .8860931396249 .0861968994 243.7631988525238 .1802062988232 .4732055664226 .8898925781221 .3607025146 215.841003418210 .5453033447205 .7442932129201 .0527954102196 .0242004395 190.770401001185 .2516021729179 .4864959717173 .5717010498167 .5722961426 161.5346069336155 .4174957275149 .2393035889142 .9925994873136 .9261016846 130.6775054932123 .6754989624116 .9119033813111 .1044998169105 .9505996704 101.222000122197 .3021926879994 .4858932495192 .5616073608491 .68235015869 90.7664337158288 .8971710205186 .8123168945385 .0139389038183 .40242767334 81.8662033081180 .4015197753978 .963172912677 .5665588378976 .21896362305 74.9219970703173 .6768264770572 .4937362670971 .3813323974670 .31189727783 69.2530364990268 .2046890258867 .1623611450266 .1076431274465 .01294708252 63.8832702636762 .7061691284261 .4890518188560 .2238998413158 .91598129272 
57.5898094177256 .0293807983454 .0160903930751 .8009414672949 .61539840698 47.4915199279845 .5006294250543 .6682281494142 .0546493530340 .61840057373 39.38544082642 38.30075836182 37.30752944946 36.44171142578 35.69432067871 35.0289001464834 .3740081787133 .9095687866233 .8077392578133 .90307998657 34.050640106234 .3015708923334 .6863517761235 .1462211608935 .6252784729 36.1173896789636 .6079292297437 .086498260537 .5402908325237 .96155929565 38.3399391174338 .6772193908738 .9684791564939 .2175102233939 .42404174805 39.5934410095239 .7340507507339 .8468704223639 .9384307861340 .00761032104 40.0581398010340 .0885391235440 .1009216308640 .0957489013740 .07619094849 40.0460205078140 .0125198364339 .982139587439 .9668617248539 .97343063354 40.0211791992240 .0946693420440 .1803092956540 .3251190185540 .54151153564 40.9893417358441 .7531013488842 .8113212585444 .2711791992245 .96321868896 47.815429687549 .722511291551 .4397392272952 .9682998657254 .2290802002 55.2446289062556 .0088882446356 .5518302917556 .9060783386257 .1014213562 57.1769599914657 .1667900085457 .1219787597757 .0360908508356 .91883087158 56.7768096923856 .6198997497656 .4536399841356 .2863388061556 .1222114563 55.9682693481455 .8271408081155 .7039909362855 .5998611450255 .51792907715 55.4577903747655 .420619964655 .4048004150455 .4097099304255 .43301010132 55.4727210998555 .526649475155 .5922889709555 .6681709289655 .7522315979 55.8438796997155 .9419403076256 .0463714599656 .1567611694356 .27317810059 56.3955802917556 .5238800048856 .6580200195356 .7977714538656 .94289016724 57.093048095757 .247909545957 .4071388244657 .570308685357 .73712921143 57.9071807861358 .0801696777358 .2557296752958 .4336090087958 .61346054077 58.7950782775958 .9781684875559 .1625709533759 .3480110168559 .53440856934 59.7215690612859 .9093818664660 .0977287292560 .2865295410260 .47570037842 60.6651382446360 .8540496826261 .04639053345 983.6716918945980 .6771240234977 .7014160156974 .7536010742971 .8344726562 968.9473876953966 .0944824219963 .2783813477960 .5009155273957 .7642822266 955.0706176758952 .4213256836949 .8181762695947 .262878418944 .7573242188 942.3026733398939 .901184082937 .5546875935 .2659912109933 .0371704102 930.8709106445928 .7698974609926 .7360229492924 .7717285156922 .8771972656 921.0535888672919 .2990722656917 .612487793915 .9901733398914 .4285888672 912.9227294922911 .4669799805910 .0557861328908 .6826171875907 .3411865234 906.0244750977904 .7269287109903 .4409179688902 .1610717773900 .8801269531 899.5930786133 898.2932128906 896.9769287109 895.6373901367 894.2734985352 892.8792114258 891.4569702148 890.0017700195 888.5200195312 887.0103759766 885.4818725586883 .9381713867882 .3958740234880 .859375879 .3535766602 877.8607177734876 .5004882812875 .3397216797874 .4556274414873 .8604736328 873.6956787109 873.9912109375 874.9053955078 876.4597167969 878.8057250977 881.9498291016885 .9470214844890 .7971191406896 .227722168902 .6477050781 907.4957885742908 .1544799805907 .0327148438906 .3767700195905 .4130859375 904.2208862305902.920715332901.5396118164 899.8956298828 897.7514038086 895.1676025391 891.8505249023 887.883605957 882.8400878906 877.0980224609 870.9987182617864 .9893188477859 .6284790039855 .546081543853 .4295043945 852.349609375850 .9204101562850 .1569213867851 .1602172852852 .5853 .037109375 853.8754272461856 .1561279297858 .5092163086859 .8911743164860 .8905029297 
862.0889282227863 .2310791016864 .5543212891865 .8348999023866 .9998168945 868.0678710938868 .8333740234869 .5045776367870 .0556030273870 .5755004883 871.3505249023872 .3259277344873 .6052246094875 .4531860352877 .6378173828 880.2944946289882 .9105834961885 .4769897461887 .7042236328889 .57421875 891.2211303711892 .7506713867894 .8121948242897 .0037231445899 .2512207031 901.1657714844902 .1688842773903 .7642211914907 .5123901367913 .4025268555 922.7564086914932.5269775391937.1080932617946.8803710938971.768371582 1001.8159790041027 .7230224611042 .7750244141038 .1970214841013 .437988281 966.9296264648915 .1201171875876 .8076171875851 .5062866211848 .708984375 847.1624145508 823.7634277344 792.9456176758 762.7548828125730 .6193847656 692.2949829102 657.2993774414 635.1422119141 618.8580932617603.4937133789 589.6561279297575 .8187255859561 .8469238281548 .89898668164535 .4857788086 521.7979125977506 .7955932617489 .1765136719471 .7077941895456 .5028991699 443.1604003906431 .3468933105420 .3590087891408 .796295166398 .2456054688 390.7054138184384 .4888916016378 .1766967773372 .4483032227367 .3646850586 362.7188110352358 .4381103516354 .4277038574350 .6553955078347 .5299987793 345.3518981934343 .087890625339 .7680053711335 .2791137695329 .4967041016 323.4047851562318 .2224121094313 .5314025879309 .2022094727305 .2049865723 301.2817077637297 .6250915527294 .1806945801290 .9151000977287 .7630004883 284.6585083008 281.5705871582 278.483795166 275.4140930176272.282409668 268.9826049805265 .5191040039261 .8438110352257 .8335876465253 .4358978271 248.5583953857243 .1181945801237 .4499969482231 .9183959961226 .4752960205 221.2164001465216 .1316070557211 .2185974121206 .3683013916201 .358795166 196.2203063965190 .8778076172185 .3578948975179 .7037963867173 .854095459 167.8289031982161 .6054992676155 .213104248148 .7651062012142 .5673980713 135.9841003418128 .2353057861120 .6091003418114 .3093032837108 .7404022217 103.227699279898 .6522369384895 .3936462402393 .2698898315492 .97103118896 92.7097625732490 .9144973754988 .8995132446387 .4000701904386 .08130645752 84.7828063964883 .5299530029382 .2483596801880 .9870681762779 .75787353516 78.5582427978577 .3872375488376 .2588806152375 .1728286743274 .11876678467 73.0707473754972 .0268478393670 .9822921752969 .9212493896568 .82195281982 67.6903762817466 .5097579956165 .29770660464 .0455017089862 .77151107788 61.5889205932660 .1503601074258 .0817718505955 .7918090820353 .62979888916 51.5376815795949 .578128814747 .7539787292546 .1030693054244 .59225082397 43.2322998046942 .0076217651440 .8859596252439 .8874092102138 .96725082397 38.164619445837 .4819793701236 .9702301025436 .6709518432636 .54787063599 36.5701408386236 .7143402099636 .959259033237 .2764091491737 .637840271 38.0232200622638 .4151611328138 .8000106811539 .1671218872139 .50790023804 39.8152198791540 .0873489379940 .3207397460940 .5167694091840 .67652130127 40.801338195840 .8978309631340 .9644813537641 .0084915161141 .02605056763 41.0226211547940 .9938697814940 .9444313049340 .8709793090840 .77978134155 40.6693496704140 .5508308410640 .4232406616240 .3017692565940 .18896865845 40.115379333540 .0481796264639 .9745407104539 .9246292114339 .91788864136 40.0822982788140 .5418281555241 .4745903015143 .0258407592844 .98072052002 47.0769309997649 .177600860651 .0696487426852 .7504310607954 .15449905396 55.2935409545956 .1680603027356 .8046684265157 .2532501220757 .52434921265 
57.6609497070357 .692939758357 .6781806945857 .6115112304757 .51189041138 57.3825912475657 .2357292175357 .075748443656 .9123802185156 .74924087524 56.5942001342856 .4495201110856 .3209609985456 .20940017756 .11838912964 56.0474586486855 .9980812072855 .9686393737855 .9587287902855 .96612930298 55.9890708923356 .0255203247156 .0731697082556 .1307411193856 .19630050659 56.2694396972756 .3490905761756 .4352989196856 .5277481079156 .62657165527 56.731719970756 .8432083129956 .9609489440957 .0847511291557 .21434020996 57.3494606018157 .4897003173857 .634769439757 .7842102050857 .93772888184 58.09487152158 .2553710937558 .418811798158 .5849418640158 .75336837769 58.9239082336459 .0962104797459 .2701301574759 .4453697204659 .62181091309 59.799240112359 .9775581359960 .1566009521560 .3362884521560 .51649856567 60.6971893310560 .8781394958561 .05953979492 989.1625976562 986.1099853516983.0885009766980.1049194336977.1463012695 974.2188720703971 .325012207968 .4666748047965 .6458740234962 .8648071289 960.1251831055957 .4285888672954 .7766113281952 .1707763672949 .6126098633 947.103515625944 .6453857422942 .2399291992939 .8895263672937 .5961303711 935.3623046875933 .1904296875931 .0822143555929 .0399169922927 .0634765625 925.1538696289923 .3092041016921 .5280151367919 .8062744141918 .1403198242 916.5247192383914 .9536743164913 .4213256836911 .9202880859910 .4448242188 908.9868774414907 .5407104492906 .0983886719904 .6544189453903 .201171875 901.7335205078900 .2440795898898 .7291259766897 .1818847656895 .6002197266 893.9785766602892 .3173828125890 .6132202148888 .8696289062887 .0858154297 885.2706298828883 .4262695312881 .5654296875879 .6956787109877 .826171875 875.9428710938874 .1536865234872 .5355224609871 .146484375870 .022277832 869.2725219727868 .957824707869 .2081298828870 .0889282227871 .7271118164 874.1881713867877 .4744873047881 .6091918945886 .2553710938891 .3818969727 895.3969116211896 .6364746094896 .4946289062896 .1903076172895 .5968017578 894.8568725586894 .0103759766893 .0394287109891 .7354125977889 .9962768555 887.8134765625885 .0996704102881 .8773803711877 .8870239258873 .3422241211 868.3521118164863.1973876953 858.0463867188 854.4788818359 854.1574707031 855.1005859375855 .451171875856 .0020751953857 .3905029297858 .8082275391 859.6234130859 860.4259033203861.9190063477863.1531982422 863.5150756836 863.5759887695863 .7448730469863 .9483032227864 .1586303711864 .2130126953 864.2039794922864 .0504150391863 .5341186523862 .896484375862 .2935791016 861.3977050781859 .9465942383858 .7700195312858 .7421875859 .5123291016 860.55078125862 .3677978516865 .1555175781868 .9318847656873 .3941040039 877.8966064453881 .4000244141884 .1890258789886 .8652954102889 .0601806641 890.8159790039892 .2064819336892 .9014282227894 .1472167969897 .0358886719 901.7395019531909 .275390625917 .2874145508922 .9329833984932 .6348876953 951.3701782227976 .31988525391004 .5180053711028 .9410400391040 .083007812 1035.9079589841013 .896972656982 .6954956055951 .9990234375927 .6082763672 917.9592285156908 .1251831055886 .8991699219855 .9031982422813 .2249145508 768.8134765625729 .8107299805694 .3297729492661 .7177124023634 .2177124023 615.1062011719600 .7659912109587 .1832885742574 .854675293563 .137512207 551.0062255859538 .3311767578524 .4168701172508 .4440002441491 .824005127 475.8175964355460 .3887939453446 .6711120605433 .8594055176421 .0358886719 
409.6256103516 400.4895935059392.6773986816 385.2066955566378.4903869629 372.8976135254368 .0806884766363 .7066955566359 .7719116211356 .0556945801 352.6628112793349 .8829956055347 .0856933594343 .7394104004339 .7547912598 334.7146911621329 .2890930176324 .3717956543319 .6419067383315 .1246948242 310.7092895508306 .1171875301 .8873901367298 .3774108887295 .1567993164 291.9191894531288 .691986084285 .4639892578282 .2236022949278 .938293457 275.678314209272 .5148925781269 .2200012207265 .6064147949261 .6904907227 257.3893127441252 .6800994873247 .4642028809241 .9998931885236 .5959014893 231.2962036133226 .2178039551221 .2738037109216 .4862976074211 .6806030273 206.6522979736201 .5281982422196 .304397583191 .0023956299185 .6882019043 180.0968933105173 .9972991943167 .6455993652161 .2828979492154 .991897583 149.0583953857142 .528793335134 .3818969727126 .03150177118 .7182998657 112.0029983521105 .46209716899 .9234466552795 .7468566894592 .98075866699 92.3778305053792 .261863708591 .4331436157290 .5847930908289 .77731323242 88.9357833862387 .9435272216886 .8701400756885 .7693328857484 .64601135254 83.5172576904382 .3906173706181 .2893905639680 .2071533203179 .13208007812 78.0719299316477 .0172729492275 .9585800170974 .8946609497173 .80841064453 72.6773071289171 .5104217529370 .3013763427769 .0547714233467 .75763702393 66.434150695865 .1334762573263 .6211395263761 .6697311401459 .53738021851 57.4583816528355 .439590454153 .5367088317951 .7417602539150 .09033966064 48.5439682006847 .1037483215345 .7728385925344 .5412216186543 .4100189209 42.3522300720241 .4164581298840 .6322097778340 .0007514953639 .54977035522 39.2570991516139 .127929687539 .1331901550339 .2354316711439 .41292953491 39.644119262739 .9132995605540 .1956100463940 .4813690185540 .75613021851 41.0146713256841 .2475204467841 .453678131141 .6279983520541 .77175140381 41.8837814331141 .9655113220242 .0192108154342 .0447692871142 .04568862915 42.0202217102141 .9709701538141 .8956604003941 .7966117858941 .67235946655 41.5266609191941 .3598594665541 .1796302795440 .9864997863840 .79040145874 40.6009216308640 .447128295940 .2952194213940 .1333503723139 .96186065674 39.7888107299839 .6538391113339 .5225601196340 .0658607482941 .98509979248 44.4801292419446 .8368797302249 .0795707702651 .0781097412152 .83850097656 54.306499481255 .5095405578656 .4562110900957 .1686592102157 .67430877686 57.9979400634858 .171871185358 .2343902587958 .2398910522558 .18935012817 58.1017417907757 .9823989868257 .8421897888257 .6868095397957 .52540969849 57.3623809814557 .205211639457 .0567016601656 .9223518371656 .80342102051 56.7033500671456 .621929168756 .5606002807656 .5179595947356 .49367141724 56.4856796264656 .4924087524456 .5119400024456 .5422096252456 .58206176758 56.6297988891656 .6850395202656 .746929168756 .8155288696356 .89065933228 56.9724311828657 .0609397888257 .1561012268157 .2579612731957 .36624145508 57.4807701110857 .6012001037657 .7272109985457 .8584403991757 .99446868896 58.1349601745658 .2794799804758 .4277191162158 .5792617797958 .73382949829 58.891048431459 .0506706237859 .2123718261759 .3759498596259 .54111862183 59.707729339659 .8755493164160 .0444793701260 .2143211364760 .38499832153 60.5563507080160 .7282600402860 .9000587463461 .0756111145 994.5418701172991 .4689941406988 .4140014648985 .3858032227982 .3850097656 979.4146118164976 .4763793945973 .5728759766970 .705871582967 .8770751953 
965.0883789062962 .3411254883959 .6367797852956 .9768066406954 .3626708984 951.7954711914949 .2770996094946 .8090209961944 .3933105469942 .0319213867 939.7269287109937 .4807128906935 .2944946289933 .1705932617931 .108581543 929.109375927.1704711914925.2905883789923.4652709961921.6907958984 919.9611206055918 .2705078125916 .6123046875914 .9796142578913 .3654174805 911.7623291016910 .1633911133908 .5612182617906 .94921875905 .3201293945 903.6677856445901 .9857177734900 .2683105469898 .5097045898896 .7064208984 894.853515625892 .9497070312890 .9921264648888 .9824829102886 .9199829102 884.8109741211882 .6569213867880 .4680175781878 .2526855469876 .0134277344 873.7261962891871 .4935302734869 .3803710938867 .4498291016865 .7291870117 864.3319091797863 .294921875862 .7675170898862 .7899780273863 .5219726562 865.0269775391867 .3024291992870 .4149169922873 .856628418877 .3709716797 880.3383178711882 .3502197266883 .5297851562884 .0678710938884 .1821899414 884.1019287109883 .8237304688883 .3303833008882 .532409668881 .3707275391 879.825012207877 .7952270508875 .3480224609872 .348815918868 .9083862305 865.0391235352860 .9404296875856 .2244262695853 .0911254883853 .9708251953 856.2871704102857 .8756713867859 .3676147461860 .799621582861 .9755859375 862.9896850586863 .708984375864 .3883056641864 .6472167969864 .4605102539 863.9362792969863 .2819213867862 .5396728516861 .8027954102861 .0004882812 860.1837768555859 .153503418857 .6171264648855 .8612060547854 .3120117188 852.3414916992849 .2130737305846 .4251708984845 .4661254883845 .4718017578 845.4207763672846 .5814208984849 .5609741211854 .1094970703860 .0256958008 866.0581054688870 .6586914062874 .3435058594877 .708984375880 .2440795898 882.0264282227883 .2056884766883 .8629150391884 .9448242188887 .3350830078 891.1007080078 897.2064208984 904.7880249023913.4108276367924.5217285156 936.2738037109953 .578918457980 .00787353521007 .2930297851027 .791992188 1040.6490478521045 .0140380861038 .8649902341019 .762023926996 .6262207031 979.359375961 .6859130859945 .3555908203918 .3027954102867 .2136230469 812.3192138672772 .0255737305736 .0167236328692 .4329833984654 .2537841797 631.2416992188615 .1389160156600 .3159179688587 .7130737305575 .7929077148 564.0748291016552 .5380859375539 .8402709961525 .5634765625509 .8570861816 493.466796875477 .0526123047462 .3439025879448 .5914916992435 .1882019043 423.0704040527411 .9895935059402 .1232910156393 .1599121094385 .390411377 379.1640930176373 .9531860352369 .3464050293365 .1780090332361 .1084899902 357.3024902344353 .9404907227350 .6527099609347 .1784057617343 .3945007324 339.0687866211334 .4556884766329 .9848937988325 .5014953613321 .1044921875 316.5331115723311 .3960876465306 .5389099121302 .8099060059299 .5242004395 296.0971984863292 .7043151855289 .3164978027285 .9103088379282 .3982849121 278.9760131836275 .8861083984272 .7409973145269 .216003418265 .3521118164 261.0681152344256 .4082946777251 .4039001465246 .1916046143240 .9586029053 235.8108062744230 .8961029053226 .1248931885221 .4976959229216 .8016967773 211.7727966309206 .6316986084201 .4685058594196 .2908935547191 .2301025391 185.87109375179 .7476959229173 .3598022461167 .1488952637161 .0023040771 155.2949066162148 .9295959473140 .6900939941131 .9862060547123 .9149017334 116.1137008667108 .5873031616101 .689498901495 .9250335693492 .21131896973 91.1986007690491 .6854705810592 .2418670654392 .6447372436592 .59336853027 
92.1892013549891 .4633865356490 .5413131713989 .6020965576288 .59127807617 87.53589630127 86.47489929199 85.43769836426 84.39644622803 83.30403900146 82.1998291015681 .0992507934680 .0031890869178 .8970870971777 .75463867188 76.568771362375 .3389892578174 .0663528442472 .7460937571 .36322784424 69.913917541568 .4117584228566 .7791290283264 .9649963378963 .04172897339 61.0897407531759 .1586303710957 .3232917785655 .5737113952653 .95455169678 52.412521362350 .9394302368249 .5461997985848 .2118911743246 .96212005615 45.7687988281244 .6889190673843 .7696189880443 .0023994445842 .40237045288 41.9589385986341 .67927169841 .5329895019541 .4860992431641 .52347946167 41.6232604980541 .7694702148441 .9386787414642 .121650695842 .30364990234 42.4786911010742 .6374015808142 .7772293090842 .8930091857942 .9842300415 43.0497283935543 .0886917114343 .1030197143643 .0905113220243 .05500030518 42.9926414489742 .9076690673842 .7954711914142 .6610107421942 .49983978271 42.3193588256842 .1156692504941 .9011001586941 .6704292297441 .4380607605 41.2078094482441 .0200195312540 .8286094665540 .640491485640 .42218017578 40.1776313781739 .9268608093339 .3982086181639 .6427688598641 .83470153809 44.6942405700747 .1314086914149 .419639587451 .4465599060153 .2084312439 54.6848182678255 .8899917602556 .8715705871657 .6182594299358 .15795135498 58.508510589658 .708419799858 .7890396118258 .8102188110458 .76927185059 58.6905517578158 .5766105651958 .4406089782758 .2869186401458 .12602996826 57.9614295959557 .8014183044457 .6482086181657 .5078811645557 .3812789917 57.2722702026457 .1804008483957 .1074295043957 .0518608093357 .01361083984 56.9906692504956 .9816894531256 .9848709106456 .9983711242757 .02112960815 57.0516586303757 .0896911621157 .1344604492257 .1861190795957 .24454879761 57.3099212646557 .3823318481457 .46176910457 .5482292175357 .64152145386 57.7414093017657 .8476295471257 .9597816467358 .077560424858 .20048904419 58.328269958558 .4604187011758 .5966682434158 .7365417480558 .87979125977 59.0259819030859 .1748886108459 .3261413574259 .4795494079659 .63478851318 59.7917213439959 .9500808715860 .1097412109460 .2705001831160 .43227005005 60.5948791503960 .7582702636760 .9221305847261 .08675003052 999.9066772461996 .7725830078993 .6668701172990 .5974121094987 .551574707 984.5352783203981 .5502929688978 .5986938477975 .6823730469972 .8029785156 969.962097168967 .1610717773964 .401184082961 .6838989258959 .0103759766 956.3818969727953 .7999267578951 .2656860352948 .7813720703946 .3485717773 943.9691772461941 .645324707939 .378112793937 .1691894531935 .018371582 932.9260253906930 .8897094727928 .9074707031926 .9750976562925 .0880126953 923.2406005859921.4265136719919.6389770508917.8707275391916.1146240234 914.3626708984912 .6080932617910 .8427124023909 .0601196289907 .2523803711 905.4135131836903 .5358886719901 .6143188477899 .6422729492897 .616027832 895.5297241211 893.3818969727 891.1688232422 888.891418457 886.5482177734 884.1431274414881.6790771484879.1594238281876.5872802734873.9614868164 871.2650756836868 .5737915039865 .9495239258863 .4384155273861 .0838012695 858.9625244141857 .1276245117855 .6879272461854 .7103881836854 .3311157227 854.6367797852855 .6887817383857 .6127929688859 .9138183594862 .3939819336 864.9088745117867 .1431884766869 .1096801758870 .5004882812871 .458190918 872.1574707031872 .5883178711872 .7401733398872 .5783081055872 .082824707 
871.237121582 869.9929199219 868.4000244141 866.417175293 864.1184082031 861.5012817383858 .7197265625855 .798828125854 .1041259766855 .0698242188 857.2349853516 859.1755981445 860.9326171875 862.3267211914 863.3928222656 864.2056274414864 .6597900391864 .7510986328864 .4069824219863 .6547241211 862.5598144531861 .1234130859859 .5443115234858 .0814819336856 .7034301758 855.477722168854 .0501098633852 .0612182617849 .7763061523847 .4464111328 844.7537841797841 .3754882812838 .3737792969836 .7542114258836 .1116943359 835.969909668837 .1209106445840 .0053710938844 .4647827148850 .1273193359 855.953918457860 .6256713867864 .7114257812868 .8126831055872 .1403198242 874.0833740234875 .1677856445875 .4710083008876 .1071166992877 .8463134766 880.8084716797886 .0305175781893 .4780883789903 .2208862305914 .5407714844 926.6661987305942 .1461791992963 .8170166016986 .89611816411003 .484008789 1019.382019043 1037.529052734 1048.2419433591043.671020508 1029.941040039 1017.210998535 1004.122009277993.799987793971.3676147461921.3441772461 863.1549072266812 .9932861328767 .3383789062723 .2067871094684 .3668823242 656.1072998047634 .6663818359616 .3842773438601 .3618774414588 .3311767578 576.8756713867567 .0346069336556 .5858154297543 .1298828125527 .9835205078 512.3895874023496 .2121887207479 .5809936523463 .5722961426448 .9732971191 435.6401062012423 .6029052734412 .611907959402 .5654907227393 .8345947266 386.500213623380 .2890930176374 .9301147461370 .1160888672365 .6086120605 361.4938964844357 .8402099609354 .3673095703350 .7827148438347 .1286010742 343.1541137695339 .0421142578334 .9717102051330 .9071044922327 .0860900879 322.8447875977317 .4949035645312 .1636047363307 .8557128906304 .0450134277 300.3251037598296 .7058105469293 .1516113281289 .6250915527286 .0728149414 282.634185791279 .4176025391276 .195098877272 .7463989258268 .958190918 264.6671142578260 .0374145508255 .1602935791250 .1123046875244 .9530944824 239.8907012939235 .1970977783230 .6472930908226 .0935058594221 .420501709 216.4822998047211 .4006958008206 .2391967773201 .0729980469196 .008102417 190.6900024414184 .7767028809178 .6085968018172 .4689941406166 .3103027344 160.2599029541153 .6363983154145 .7749023438137 .450302124129 .4687957764 121.3722991943112 .9814987183104 .427398681695 .7176208496189 .92420196533 90.2431793212993 .0241470336994 .7127380371195 .7948608398496 .16805267334 96.0053863525495 .4563674926894 .6692886352593 .8258514404392 .87785339355 91.8407211303790 .8052673339889 .861053466888 .87695312587 .70652770996 86.4820938110485 .3125076293984 .161132812582 .9813537597781 .75229644775 80.4824829101679 .162246704177 .7757568359476 .3350067138774 .83113861084 73.2486267089871 .6157836914169 .9275207519568 .1464309692466 .32508850098 64.4751129150462 .6355514526460 .8827018737859 .2101593017657 .65195083618 56.1469802856454 .6820907592853 .2549591064551 .8288307189950 .45064163208 49.1255798339847 .8945388793946 .8288803100645 .9175796508845 .17578887939 44.5904502868744 .1644706726143 .8706588745143 .683040618943 .58523178101 43.5560684204143 .581050872843 .6387710571343 .7201995849643 .80992889404 43.9025192260743 .9875297546444 .0623283386244 .120540618944 .16133117676 44.1817283630444 .1811103820844 .1587982177744 .1137809753444 .04690170288 43.9565582275443 .8442611694343 .7083892822343 .5512809753443 .37221908569 43.175640106242 .9622306823742 .7404289245642 .510330200242 .28197860718 
42.0650787353541 .8890304565441 .7246589660641 .5690689086941 .4102897644 41.2536010742241 .1243591308640 .9720802307141 .4906806945843 .37808990479 45.8347206115748 .1215400695850 .2860603332552 .2172508239753 .91424942017 55.3280105590856 .4939308166557 .4407196044958 .1750717163158 .71189117432 59.0722007751559 .2802009582559 .3726692199759 .3978004455659 .36088943481 59.2836799621659 .1711387634359 .0347213745158 .8801116943458 .71673965454 58.548961639458 .3843002319358 .2255516052258 .0782394409257 .9436416626 57.8252410888757 .7229118347257 .6382293701257 .5699386596757 .51792907715 57.4804306030357 .4561500549357 .4434890747157 .4407501220757 .44702148438 57.4609909057657 .4824295043957 .5107498168957 .5461196899457 .58850860596 57.6380882263257 .6950492858957 .7593116760357 .8309593200757 .909740448 57.9955215454158 .0879402160658 .1866798400958 .2913703918558 .40158081055 58.5169792175358 .6371002197358 .7616195678758 .8901100158759 .02225875854 59.1576690673859 .2960510253959 .4370689392159 .5804786682159 .72597885132 59.8733711242760 .0224113464460 .1729393005460 .3247604370160 .47774124146 60.6317100524960 .7864990234460 .9416007995661 .10074996948

1005.1669921881002 .005004883998 .8607788086995 .7416992188992 .6486206055 989.5836791992986 .5491943359983 .546875980 .5784912109977 .6456298828 974.7495727539971 .8919067383969 .0734863281966 .2957763672963 .5598754883 960.8668823242958 .2183227539955 .6151123047953 .0588989258950 .5516967773 948.0947875977945 .6903076172943 .3389282227941 .0422973633938 .7996826172 936.611328125934 .4743041992932 .3867797852930 .3438720703928 .3414916992 926.3729248047 924.4323120117922.5123291016920.6057128906 918.7047119141 916.8016967773914 .8889160156912 .9586791992911 .0036010742909 .0161743164 906.9893188477904 .916015625902 .7896118164900 .6043701172898 .3549194336 896.0364990234893 .6452026367891 .1782836914888 .6342773438886 .0128173828 883.3143920898880 .5451049805877 .6968994141874 .7689208984871 .7579956055 868.6546020508865 .5112304688862 .3778076172859 .2902832031856 .2954711914 853.4442138672850 .7869873047848 .4027099609846 .3524780273844 .7645263672 843.6973876953843 .3526000977843 .9392700195845 .1309204102846 .9237060547 849.1185302734851 .5864257812854 .1492919922856 .3046875858 .1690063477 859.6857299805860 .8552856445861 .7023925781862 .2100830078862 .424987793 862.3239746094861 .8869018555861 .1760253906860 .171081543858 .9810791016 857.5999755859 856.3375854492 855.5192871094 855.3690185547 856.1732177734 857.6215209961859 .32421875860 .9671020508862 .1973876953863 .0161132812 863.5778808594863 .6727294922863 .353515625862 .5629272461861 .434387207 859.9187011719857 .9270019531855 .7954101562853 .8787231445852 .0947265625 850.6079711914848 .9686889648846 .7744750977844 .2127075195841 .382019043 838.3665771484835.3225708008 832.6547241211 830.7369995117829.7711791992 829.8142700195831 .161315918833 .8239135742837 .7064208984842 .3701782227 847.3137817383851 .6525268555855 .8560791016860 .7258300781864 .7802734375 867.0869140625868 .1434936523868 .1372070312868 .0103759766868 .6328125 870.9052124023875 .796081543883 .3685302734893 .5120239258905 .5562744141 919.4517822266 934.8898925781951.5469970703968.2827758789977.9069824219 990.38470458981014 .2689819341035 .1920166021042 .4969482421041 .12097168 1037.8470458981031 .5019531251027 .7099609381012 .260986328969 .8408813477 
914.9857177734857 .8826904297802 .5070800781757 .2633056641719 .5020751953 686.0985717773658 .9497070312635 .6881713867616 .6560058594601 .3256835938 589.1881713867580 .2930297852571 .2031860352558 .5687255859544 .1837768555 530.2844238281514 .9478149414497 .0927124023479 .1713867188463 .2774047852 448.8590087891435 .8731994629424 .1129150391413 .2359924316403 .5068054199 394.7356872559387 .1615905762380 .7640991211375 .2513122559370 .2857971191 365.812286377361 .8988952637358 .2337036133354 .5025939941350 .7994995117 346.984588623343 .1492919922339 .3918151855335 .6718139648332 .3988037109 328.6105957031323 .3349914551317 .8021850586313 .0191040039308 .628112793 304.5270080566300 .6697998047296 .9450073242293 .3505859375289 .8139953613 286.3584899902282 .9646911621279 .5564880371276 .0911865234272 .353302002 268.0745849609263 .4910888672258 .7489013672253 .8524017334248 .7807006836 243.8155975342239 .3213043213234 .9324035645230 .3910064697225 .7216949463 220.8780059814215 .8896026611210 .7369995117205 .5196075439200 .3536071777 195.0171966553189 .336807251183 .4176940918177 .3450012207171 .0711975098 164.5628967285157 .6669006348150 .2904052734142 .5287017822134 .8316955566 126.6917037964117 .7767028809108 .590103149498 .2322616577191 .01786804199 92.4093933105596 .4542236328198 .3430175781299 .69174957275100 .2705001831 100.254997253499 .8785934448299 .1781082153398 .4343185424897 .5348815918 96.5346374511795 .5382995605594 .6154327392693 .6540069580192 .37127685547 91.0202178955189 .7285614013788 .4460525512787 .1235733032285 .74780273438 84.3887634277382 .9474868774481 .4131088256879 .7929000854578 .1314163208 76.4266967773474 .6983032226672 .9550170898471 .1798706054769 .40226745605 67.6172103881865 .8601531982464 .1870193481462 .5897789001561 .10000991821 59.6689605712958 .2736206054756 .8453903198255 .3301200866753 .8000793457 52.3268013000550 .9604797363349 .7558708190948 .711360931447 .83903121948 47.1250190734946 .5618209838946 .1308517456145 .8095016479545 .5837097168 45.4305114746145 .3388900756845 .2883491516145 .2710189819345 .2710609436 45.2833900451745 .2968482971245 .3084907531745 .3112297058145 .30332946777 45.2811698913645 .2430686950745 .1881217956545 .1141395568845 .02230834961 44.9099807739344 .7798995971744 .6294898986844 .4632492065444 .27949142456 44.0856208801343 .8811492919943 .6782493591343 .4757995605543 .28865814209 43.1206893920943 .002090454142 .909599304242 .8462104797442 .82207870483 42.8489608764643 .0356903076243 .4806518554744 .3740692138745 .85438156128 47.7034606933649 .6489791870151 .5885200500553 .3370399475154 .88758087158 56.1892089843857 .2594299316458 .1376190185558 .8225784301859 .33451080322 59.681781768859 .8866310119659 .9775009155360 .0007095336959 .95998001099 59.8800888061559 .7635002136259 .6235084533759 .4643287658759 .29650115967 59.1232604980558 .9528388977158 .7872314453158 .6324310302758 .48917007446 58.3612709045458 .2482910156258 .1520309448258 .0711288452158 .00569152832 57.9539489746157 .9148292541557 .8868217468357 .8684310913157 .85884094238 57.8568916320857 .8624305725157 .8749885559157 .8947601318457 .92177963257 57.9562492370657 .9983482360858 .0480804443458 .1054687558 .17031860352 58.2424507141158 .3215789794958 .4073181152358 .4993591308658 .59720993042 58.7005882263258 .8089790344258 .9221000671459 .0394706726159 .16080093384 59.2856407165559 .4137382507359 .5447082519559 .6783294677759 .81423950195 
59.9522705078160 .0921287536660 .233680725160 .3766899108960 .52101898193 60.6664810180760 .8130302429260 .9602508544961 .10852813721

1010.4099731451007 .1849975591003 .9860229491000 .820007324997 .6773071289 994.5615844727991 .4749755859988 .4193725586985 .3963012695982 .4072265625 979.4534912109976.536315918973.6566772461970.8156738281968.0145874023 965.2542724609962 .5358886719959 .8605957031957 .2299804688954 .6453857422 952.1082763672949 .6204833984947 .1823120117944 .7952270508942 .458190918 940.171081543937 .9310302734935 .7354736328933 .5797119141931 .4589233398 929.3668823242 927.2971191406925.2423706055 923.1951293945 921.1475219727 919.0913696289917 .0194702148914 .9232177734912 .7952880859910 .6276855469 908.4133911133906 .1445922852903 .8151245117901 .4180297852898 .9481201172 896.3997192383 893.7689819336 891.0521240234 888.2471923828 885.3524169922 882.3685302734879 .3013916016876 .1353149414872 .8610229492869 .4771728516 865.9768066406862 .3964233398858 .7747802734855 .1362915039851 .5250244141 847.9666137695844 .5067749023841 .1832275391838 .0490722656835 .203918457 832.7205200195830 .953918457830 .1143188477830 .1873168945831 .3986206055 833.4331054688836 .1871948242839 .3599243164842 .2800292969844 .98828125 847.2393798828849 .0966796875850 .5900878906851 .7504882812852 .6284179688 853.2451171875853 .6126708984853 .7849121094853 .7614135742853 .6593017578 853.483215332853 .5891113281854 .2307128906855 .0728759766856 .1480102539 857.3557739258 858.7260131836 860.0764160156 860.9854125977 861.4943847656 861.6934204102861 .4716186523860 .801574707859 .7218017578858 .2863769531 856.5443725586854 .5222167969852 .3776245117850 .2753295898848 .2484130859 846.3696899414844 .3792114258842 .0037231445839 .3159179688836 .3563232422 833.3704833984 830.5192260742 828.0307006836 826.1644287109 825.1209716797 825.1854248047826 .3892822266828 .8087158203832 .1162719727836 .1829223633 840.6682128906845 .0659790039849 .7238769531854 .8737182617859 .2279052734 861.6696777344862 .6300048828862 .3151245117861 .2755737305859 .5441894531 860.0078735352865 .919128418874 .9577026367885 .1829833984897 .1101074219 910.8483886719924 .5626831055937 .4840698242949 .7086181641960 .2244873047 974.6362304688996 .89691162111019 .1589965821032 .5369873051039 .637939453 1042.1810302731041 .1850585941040 .8699951171032 .1120605471006 .182983398 965.3947143555911 .0126953125852 .1508789062798 .18359375751 .8599853516 716.3958740234686 .6087036133657 .8900146484633 .3549194336615 .2473754883 601.6831054688590 .8436279297580 .8671264648569 .7543945312557 .7271728516 545.2733764648530 .9876708984513 .612487793495 .5299072266478 .8656921387 463.4422912598449 .2459106445436 .2601013184424 .7351074219414 .0769042969 403.4937133789 394.1553039551387.099609375 381.2922973633 375.8583068848 370.9354858398366 .4789123535362 .3414916992358 .3254089355354 .4650878906 350.6726074219346 .9718017578343 .3450012207339 .7796936035336 .3734130859 332.5396118164327 .7072143555322 .5338134766317 .69140625313 .0556945801 308.6603088379304 .5445861816300 .7084960938297 .0592956543293 .4682006836 289.9157104492 286.3839111328282.8153991699279.1758117676275.3540039062 271.1931152344266 .7977905273262 .2181091309257 .5020141602252 .6710968018 247.9190979004243 .4817962646239 .0872039795234 .5222930908229 .8356018066 225.0245056152220 .0899963379215 .0072937012209 .8128051758204 .5827026367 
199.2210998535193.6069946289187.7673034668181.6887969971 175.3307037354 168.7342987061161 .916595459154 .8309936523147 .4138946533139 .5858001709 131.3612976074122 .8382034302114 .6605987549107 .3899002075102 .4729003906 101.5948028564102 .6279983521103 .6417007446104 .6445999146105 .1178970337 105.1988983154104 .8337020874104 .1787033081103 .4476013184102 .5680007935 101.646697998100 .695899963499 .6415634155398 .5193099975697 .22982025146 95.826736450294 .3591537475692 .8691024780391 .3148574829189 .73448181152 88.2952270507886 .775527954184 .9950103759883 .1171112060581 .27639007568 79.4485626220777 .6325836181675 .835792541574 .0471878051872 .28401947021 70.5386962890668 .8388137817467 .2155609130965 .6764221191464 .24535369873 62.9079513549861 .6887092590360 .3572998046958 .6792488098156 .91548156738 55.2938919067453 .8068618774452 .4919395446851 .3382797241250 .35403060913 49.5235404968348 .8398513793948 .2850418090847 .842639923147 .49758911133 47.2305717468347 .0298690795946 .8784294128446 .7675590515146 .6830291748 46.6189193725646 .5645790100146 .5162696838446 .4665718078646 .41321182251 46.3515281677246 .279998779346 .1961288452146 .0988388061545 .98738861084 45.8612098693845 .7211685180745 .5677680969245 .4036788940445 .23133087158 45.0560913085944 .8827781677244 .7208099365244 .5762710571344 .46139907837 44.3847007751544 .3671188354544 .4050292968844 .506278991744 .69018936157 44.9639701843345 .4493789672946 .2033615112347 .2094802856448 .56612014771 50.0905609130951 .7085189819353 .3586006164654 .8399581909256 .1593208313 57.2723388671958 .1954689025958 .9655494689959 .5834388732960 .04298019409 60.3584289550860 .5383491516160 .6142387390160 .6235389709560 .57313919067 60.4827308654860 .3575706481960 .2089118957560 .0421791076759 .86650848389 59.6859283447359 .5076103210459 .3340988159259 .1705818176359 .01818084717 58.8801689147958 .756420135558 .6484107971258 .5550613403358 .47631835938 58.4106903076258 .3571014404358 .3142395019558 .2807312011758 .25587081909 58.2386398315458 .2289505004958 .226421356258 .2312698364358 .24361038208 58.2636108398458 .2915306091358 .3273086547958 .3710517883358 .42250061035 58.4815483093358 .5478401184158 .6210784912158 .7008590698258 .78678894043 58.8785018920958 .9755401611359 .077560424859 .1841087341359 .29487991333 59.4094200134359 .5274696350159 .6486206054759 .7726402282759 .89915847778 60.0280113220260 .1588706970260 .2915992736860 .4259300231960 .56175994873 60.6988410949760 .8370094299360 .9758911132861 .11906814575

1015.5560302731012 .2979736331009 .0549926761005 .8350219731002 .640014648 999.4713745117996.3305053711993.2191772461990.1389770508987.0913696289 984.0772705078981 .0980834961978 .1544799805975 .2478027344972 .3787841797 969.5484008789966 .7576904297964 .0076904297961 .2996826172958 .6353149414 956.0153808594953 .4417114258950 .9141845703948 .4343261719946 .0004272461 943.612487793941 .2667236328938 .9611206055936 .6901245117934 .44921875 932.231628418930.0308837891927.8394775391925.6502075195923.4545288086 921.2448730469919 .012878418916 .750793457914 .4503173828912 .1035766602 909.7028808594907 .2412109375904 .7106933594902 .1055297852899 .4185791016 896.6453857422893 .7802124023890 .8204956055887 .7614135742884 .6029052734 881.3422241211877 .9907226562874 .5192871094870 .9174194336867 .1785888672 863.3060302734859 .3140258789855 .2429199219851 .0919189453846 .917175293 
842.7050170898838 .5189208984834 .3419799805830 .2514038086826 .278503418 822.5477294922819 .3035888672816 .8853149414815 .8040771484816 .5053710938 818.7244873047821 .9091186523825 .6649780273829 .2088012695832 .5064697266 835.3002929688837 .669128418839 .7172241211841 .4379272461842 .9310302734 844.207824707 845.3342895508 846.3472290039 847.2368164062 848.1384277344 849.0446166992850 .1987915039851 .8543701172853 .5380859375855 .0264282227 856.2482299805 857.3670043945 858.208984375 858.6777954102 858.82421875 858.6948242188858 .2109985352857 .3466796875856 .1171264648854 .5413818359 852.7363891602850 .8837280273848 .9125976562846 .8032226562844 .6278076172 842.426574707 840.1209106445 837.6362304688 834.9805297852 832.1264038086 829.3201904297 826.7053222656 824.4697875977 822.7573852539821.8007202148 821.8228759766822 .8272705078824 .8270874023827 .6524047852831 .1638793945 835.2689819336 839.7276000977844.5200195312 849.5889892578 853.9716796875 856.625 857.7368774414857 .4843139648855 .919921875852 .3134155273851 .2600097656 858.0430908203868 .0673217773877 .6577758789888 .2286987305900 .575012207 912.5103759766922 .2753295898932 .4348754883945 .2620849609961 .3643798828 979.6635742188998 .78271484381015 .0670166021027 .546997071035 .208984375 1038.8420410161041 .6259765621038 .4830322271028 .9980468751005 .216003418 959.6311035156903 .4235229492844 .2620239258790 .2973022461751 .3596191406 718.9298095703684 .3963012695654 .0844116211632 .4849853516615 .9598999023 601.1887207031589 .0026245117578 .7719116211568 .7744750977557 .919921875 544.8297119141528 .9442749023511 .7702941895494 .8720092773478 .6856079102 463.3353881836449 .270690918437 .1737976074425 .6933898926413 .4219970703 402.3627929688394 .5047912598388 .2177124023382 .1195983887376 .5812988281 371.4609069824366 .7142944336362 .2865905762358 .1547851562354 .258605957 350.5437011719346 .9359130859343 .312286377339 .5945129395335 .607208252 331.279296875326 .6647033691321 .987487793317 .3068847656312 .7463989258 308.4403991699304 .4895935059300 .7551879883297 .0429077148293 .3692016602 289.7001037598285 .9834899902282 .1594848633278 .2365112305274 .190612793 269.9903869629265 .5679931641261 .0331115723256 .4585876465251 .9031066895 247.4770050049243 .0247955322238 .4203033447233 .7122955322228 .9181976318 224.0151977539218 .9983062744213 .8509979248208 .5948944092203 .1929931641 197.6062927246191 .7861022949185 .6858062744179 .3166046143172 .7425994873 166.0175018311159 .1486053467151 .9306030273143 .9221038818135 .7848052979 127.9508972168121 .3470001221117 .8559036255115 .5048980713112 .1900024414 109.8152999878109 .6891021729110 .2181015015110 .4772033691110 .4925994873 110.1266021729109 .5040969849108 .8015975952108 .0669021606107 .4657974243 106.6931991577105 .3567962646104 .0124969482102 .5680999756101 .1507034302 99.4179229736397 .4319076538195 .5163803100693 .5951080322392 .00453948975 90.3701934814588 .3583526611386 .2473678588984 .2617263793982 .31754302979 80.41880035478 .56752777176 .7452774047974 .9730300903373 .24069976807 71.5714721679769 .9788131713968 .4762115478567 .0845336914165 .79161834717 64.6972427368263 .4467506408761 .6474418640159 .7199401855558 .01097106934 56.4383506774955 .0355415344253 .7957916259852 .7138900756851 .78387069702 50.9925498962450 .3293304443449 .7767982482949 .3238906860448 .9514503479 48.6507415771548 .4050712585448 .2072906494148 .0432281494147 .90771102905 
47.7895393371647 .6852111816447 .5864105224647 .4908409118747 .3929901123 47.2912101745647 .1825599670447 .065841674846 .9403915405346 .80577850342 46.663509368946 .5146789550846 .3631515502946 .212478637746 .06951141357 45.9409713745145 .8373184204145 .7681808471745 .7472305297945 .7864112854 45.9001197814946 .1053504943846 .4155197143646 .8520698547447 .41492080688 48.1517105102549 .0865287780850 .1775588989351 .4357910156252 .7714805603 54.1352500915555 .4458389282256 .5834808349657 .5950202941958 .47386932373 59.2414398193459 .896629333560 .4263000488360 .8168411254961 .08055114746 61.223068237361 .2716484069861 .2602882385361 .1926307678261 .08726882935 60.9481201171960 .7876281738360 .6097183227560 .4242095947360 .23400115967 60.0466499328659 .8638916015659 .6911010742259 .5289001464859 .38063812256 59.2458992004459 .1262893676859 .0205688476658 .9288787841858 .84968185425 58.7821197509858 .7249107360858 .6768798828158 .6373901367258 .60554885864 58.5813217163158 .5644111633358 .5550498962458 .5533981323258 .55963897705 58.5740013122658 .5964889526458 .6271514892658 .6658096313558 .71228027344 58.7662811279358 .8274497985858 .8954505920458 .9698410034259 .05028915405 59.136299133359 .2275695800859 .3236007690459 .4240989685159 .52859115601 59.6368293762259 .7483901977559 .8630294799859 .9803581237860 .10020065308 60.22224044860 .3462982177760 .4721183776960 .5995903015160 .72843170166 60.8586502075260 .9897384643661 .12216949463

1020.6849975591017 .3610229491014 .0590209961010 .7890014651007 .539001465 1004.3150024411001 .117980957997 .9486083984994 .8090820312991 .7005004883 988.6237792969985 .5802001953982 .5703735352979 .5952758789976 .6560058594 973.753112793970 .8875732422968 .0604248047965 .2728271484962 .5258789062 959.8209228516 957.1588134766954.5399780273951.9650268555949.4323120117 946.9412231445944 .4882202148942 .0704956055939 .6826782227937 .3198852539 934.9755249023932 .642578125930 .3139038086927 .9815063477925 .6378173828 923.2741699219920 .8828735352918 .4555053711915 .9840698242913 .4600830078 910.8760986328908 .2241821289905 .4973754883902 .6884155273899 .7910766602 896.7993774414893 .7084960938890 .5140991211887 .2125854492883 .8016967773 880.2811279297876 .6594848633872 .9052124023868 .9998168945864 .9418945312 860.7302856445856 .3767700195851 .9061279297847 .3187255859842 .6519775391 837.8997192383833 .1063232422828 .2623901367823 .4329833984818 .6049804688 813.8602905273809 .2357177734804 .6630249023801 .8364257812802 .4506835938 805.2813720703809 .2763061523813 .7896118164817 .7753295898821 .3754882812 824.4025268555827 .0388793945829 .4312744141831 .5900878906833 .5581054688 835.3966064453837 .1718139648838 .9044799805840 .5628051758842 .2589111328 844.0100708008845 .9547119141848 .2327270508850 .5363769531852 .7872924805 854.4749755859855 .1992797852855 .3947143555855 .415222168855 .2326049805 854.8629760742854 .2584228516853 .3843994141852 .2172241211850 .7003173828 848.9860839844847 .1796264648845 .2401733398843 .1508178711840 .9149169922 838.6212158203 836.2379150391 833.7443847656 831.1793212891 828.5089111328 825.9232177734823 .5549926758821 .5355834961820 .013671875819 .1284179688 819.0969238281819 .867980957821 .4957275391823 .8441162109826 .8458251953 830.4758300781834 .5856933594839 .0383300781843 .6845703125847 .9989013672 851.5366821289853 .7791748047854 .1251220703852 .8027954102849 .5823974609 
848.6577148438854 .436706543862 .8845825195870 .5911865234878 .7841796875 888.4105834961 897.9454956055 906.2479248047915.4307861328926.7730712891 940.7686767578958 .4143066406977 .3828125994 .9285278321010 .75402832 1023.0629882811031 .8590087891038 .3470458981040 .9040527341037 .557006836 1022.653015137989 .9578857422944 .2349853516892 .2490234375840 .7354736328 795.8217163086755 .4105224609716 .7700195312681 .9155273438654 .8366699219 632.9016723633613 .1995849609597 .7105102539587 .037902832578 .173828125 568.2734985352556 .4669189453542 .3740234375526 .7708129883509 .8982849121 493.2031860352477 .7793884277463 .5197143555450 .9425048828438 .675994873 425.4350891113413 .1947021484403 .8041992188396 .1159057617389 .0707092285 382.6842956543376 .8103027344371 .4088134766366 .4042053223361 .8505859375 357.7402954102353 .9180908203350 .2033996582346 .4778137207342 .6499023438 338.7365112305334 .6762084961330 .4190063477325 .890411377321 .2379150391 316.7156982422312 .3812866211308 .3005065918304 .3897094727300 .5303955078 296.7078857422292 .9143066406289 .0882873535285 .1942138672281 .2598876953 277.2486877441273 .1312866211268 .8212890625264 .4159851074259 .9872131348 255.5379943848251 .1302032471246 .6546936035242 .0567932129237 .3704986572 232.5805969238227 .6905059814222 .6894989014217 .5563964844212 .3150024414 206.9344024658201 .396697998195 .6358032227189 .5868988037183 .2404937744 176.5673065186169 .7904052734163 .0579986572156 .033996582148 .3224029541 140.6311950684133 .3034057617127 .4889984131124 .2285003662121 .5942993164 118.6511993408116 .3218002319116 .0931015015116 .6723022461116 .5161972046 116.1300964355115 .7781982422115 .2637023926114 .4550018311113 .8424987793 114.0799026489113 .846496582111 .8775024414109 .772102356108 .487197876 107.2623977661 105.0386962891 102.2814025879 99.74044036865 97.34087371826 95.3262863159293.4265136718891.31491088867 89.15173339844 87.05821228027 85.0183334350683 .0374526977581 .1182785034279 .2556381225677 .45832824707 75.7199935913174 .0547866821372 .4709930419970 .9733734130969 .57135009766 68.2516403198267 .0335235595765 .680946350163 .9582481384362 .12353897095 60.4105491638258 .8101081848157 .359939575256 .0527915954654 .89828109741 53.8842201232953 .0046997070352 .2470893859951 .5992698669451 .04951858521 50.5835113525450 .1917114257849 .8610687255949 .5834999084549 .34712982178 49.1457710266148 .9694595336948 .8136711120648 .6703491210948 .53657913208 48.4065895080648 .2787094116248 .1493606567448 .0181083679247 .88346099854 47.7465896606447 .6082000732447 .4717788696347 .3406181335447 .22132873535 47.120391845747 .0480499267647 .014511108447 .0337104797447 .11915969849 47.28728866577 47.55405044556 47.9422988891648.4712982177749.15100097656 49.9904098510750 .9540290832552 .0394287109453 .1897583007854 .36153030396 55.5389099121156 .732559204157 .7641487121658 .45940017759 .04975891113 59.7228698730560 .3722305297960 .910011291561 .3400802612361 .6466217041 61.8443908691461 .9387092590361 .9529991149961 .9116706848161 .82064056396 61.693641662661 .5364303588961 .3595008850161 .1677207946860 .96932983398 60.7678489685160 .5695800781260 .3766593933160 .1935501098660 .02112960815 59.8621406555259 .7163887023959 .5850791931259 .4672393798859 .36278915405 59.2704505920459 .189308166559 .118301391659 .0563087463459 .00281143188 58.9570198059158 .918941497858 .8883399963458 .8654785156258 .85054016113 
58.8436698913658 .8451690673858 .8549804687558 .8732109069858 .89962005615 58.9340896606458 .976280212459 .0258903503459 .0825500488359 .14583969116 59.215400695859 .2907905578659 .3716316223159 .4574699401959 .5479888916 59.6427307128959 .7414093017659 .843608856259 .9490699768160 .05744171143 60.1684684753460 .2818603515660 .3974304199260 .5149116516160 .63415908813 60.7549285888760 .8770217895561 .0002212524461 .1279296875 1025.7249755861022 .3610229491019 .0109863281015 .6829833981012 .37701416 1009.096008301 1005.840026855 1002.611022949999.4099121094996.23828125 993.0969238281989 .9865722656986 .9083251953983 .8629150391980 .8508911133 977.8732299805974 .9306030273972 .0239868164969 .1544799805966 .3229980469 963.5305175781960 .7780761719958 .0656738281955 .3936767578952 .7600708008 950.1644287109947 .6024169922945 .0712890625942 .5651855469940 .0797119141 937.6071777344935 .1417236328932 .6749267578930 .1998291016927 .707824707 925.1912841797922 .6416015625920 .05078125917 .4102172852914 .7122192383 911.9479980469909 .1107788086906 .1920776367903 .1859741211900 .0844726562 896.8831787109893.575012207 890.1577148438 886.6248168945 882.9769287109 879.2094116211 875.3366699219 871.3208007812 867.146484375 862.8015136719 858.2937011719 853.6171875 848.8079833984843.8458251953 838.7808837891 833.5803833008 828.3195800781 822.9478149414 817.5905761719 812.1456298828 806.7299804688801 .3109130859795 .2731933594791 .2177124023791 .8145141602 794.9985961914799 .287109375804 .1550292969808 .1450805664811 .6870727539 814.7044067383817 .3613891602819 .9282836914822 .3496704102824 .6842041016 826.9602050781829 .2691040039831 .5922851562833 .8629760742836 .1726074219 838.5435791016841 .0123901367843 .6528930664846 .2852172852849 .1696166992 851.3197021484851 .8325805664851 .6040039062851 .3809204102850 .982421875 850.4760131836849 .8306274414849 .0258178711848 .0023803711846 .6414794922 845.0623168945843 .3065795898841 .3853759766839 .3325805664837 .1431274414 834.8884277344 832.5607299805 830.1594238281 827.7473754883 825.2979125977 822.9724731445820 .838684082819 .0390014648817 .6873779297816 .882019043 816.7617797852817 .3062744141818 .5535888672820 .4591064453822 .9412231445 826.0178833008829 .5369873047833 .3944702148837 .3482055664841 .2984008789 845.4401855469848 .5570068359849 .5131835938849 .0601806641847 .2666015625 846.87890625851 .208190918857 .2493286133862 .5255126953868 .1956176758 875.1005859375882 .5454101562890 .2736816406898 .9631958008908 .2235717773 920.0604858398936 .8391723633955 .4556274414972 .8184814453989 .8847045898 1005.7559814451019 .51030 .2879638671036 .5400390621036 .5799560551027 .720947266 1008.239013672978 .3864746094941 .0177001953896 .0750732422845 .3927001953 795.1522827148751 .1026000977713 .5546875681 .5272216797654 .8228149414 630.2305297852610 .4572143555597 .6342163086587 .5034790039577 .2280273438 566.6594848633555 .2700805664541 .7783813477525 .405090332508 .1481933594 492.4880065918477 .9447021484464 .5625915527451 .5969848633437 .8403930664 424.9655151367414 .1789855957404 .8456115723396 .5751953125389 .1857910156 382.4739074707376 .3724975586370 .7553100586365 .7027893066361 .2623901367 357.1908874512353 .2381896973349 .365814209345 .4791870117341 .5849914551 337.7226867676333 .6820068359329 .3348083496324 .8540039062320 .5108032227 316.2556152344312 .0703125307 .9715881348303 .9162902832299 .9342956543 
296.0250854492292 .1441040039288 .2327880859284 .2926940918280 .2814025879 276.1897888184271 .9465026855267 .625213623263 .283203125258 .896697998 254.4931030273250 .0213012695245 .4651031494240 .8023071289236 .0028076172 231.0841064453226 .0776062012220 .9635925293215 .758102417210 .4295959473 204.962600708199 .2814025879193 .3542022705187 .1076049805180 .3916931152 173.5592956543166 .7915039062159 .9604034424152 .6280975342145 .3932037354 138.44090271132 .425201416128 .0930023193124 .7302017212122 .6399002075 121.493598938121 .8498001099122 .587097168122 .1377029419121 .548500061 121.4204025269121 .2902984619120 .7316970825120 .4908981323121 .6461029053 122.397102356120 .3519973755117 .6789016724116 .1399993896114 .1539993286 110.6485977173106 .9073028564103 .7333984375100 .933799743798 .53600311279 96.2904129028394 .066543579191 .8587799072389 .680107116787 .54630279541 85.4849777221783 .497070312581 .5833129882879 .7493362426877 .98681640625 76.3054809570374 .7118606567473 .1965332031271 .7608337402370 .35801696777 68.9512176513767 .4721832275465 .8654327392664 .1978912353562 .544921875 60.9516601562559 .4784393310558 .1273612976156 .9160804748555 .83586120605 54.8810691833554 .0435905456553 .311248779352 .6763610839852 .12596130371 51.6527290344251 .244979858450 .8956298828150 .5935897827150 .33319091797 50.1040496826249 .9022712707549 .718608856249 .5509300231949 .39239883423 49.2420692443849 .0956192016648 .9534492492748 .8137016296448 .67869186401 48.5490417480548 .429969787648 .3247604370148 .242610931448 .18962097168 48.1797790527348 .2219085693448 .3351898193448 .5303306579648 .83200073242 49.2509002685549 .8187103271550 .5437202453651 .4441490173352 .51501846313 53.6989212036154 .9557495117256 .1505813598657 .2298583984458 .20481872559 59.2044982910260 .011299133360 .3289718627960 .5636291503961 .05424880981 61.5780296325761 .9782218933162 .2988395690962 .5102882385362 .63386154175 62.6732215881362 .6455192565962 .5685882568462 .4475898742762 .29484939575 62.1152801513761 .9194488525461 .7109909057661 .4982604980561 .28377914429 61.0738105773960 .8697814941460 .6760215759360 .4929809570360 .32326889038 60.1664695739760 .023719787659 .893978118959 .777198791559 .67213821411 59.577980041559 .4937400817959 .4184303283759 .3516006469759 .29254150391 59.2413291931259 .1977615356459 .1621208190959 .1345710754459 .11531829834 59.1045989990259 .102401733459 .1087799072359 .1235504150459 .14654922485 59.1774902343859 .2160110473659 .2617988586459 .3143997192459 .37350082397 59.4385910034259 .5093803405859 .5853385925359 .6661911010759 .75144958496 59.8408393859959 .9339218139660 .0304603576760 .1300392150960 .23247146606 60.3373908996660 .4446601867760 .5539588928260 .6651611328160 .77798843384 60.892440795961 .007949829161 .12506103516

1030.7449951171027 .3139648441023 .9019775391020 .5200195311017 .156005859 1013.8159790041010 .4990234381007 .2080078121003 .9439697271000 .708007812 997.4995117188994.3206176758991.171875988.0537719727984.9672241211 981.9127197266978 .8909912109975 .9030151367972 .9494018555970 .0313720703 967.1494750977964 .3048095703961 .496887207958 .7260742188955 .9901733398 953.2882080078 950.6157836914947.9700927734945.3452148438942.7359008789 940.1353759766937 .5366821289934 .9324951172932 .3148803711929 .6760864258 927.0078125924 .3021240234921 .5501708984918 .7440185547915 .8753051758 
912.9360961914909 .9185180664906 .8150024414903 .6185302734900 .3222045898 896.9202880859893 .4072875977889 .7789916992886 .0311889648882 .1619873047 878.1702880859874 .0651245117869 .8186035156865 .4182128906860 .842590332 856.0762939453851 .1356201172846 .0515136719840 .8142700195835 .4522094727 829.9583740234824 .3765258789818 .7072143555813 .0228271484807 .3328857422 801.7418823242796 .3109130859790 .9979248047787 .5186767578787 .5816040039 789.8956298828793 .3590698242797 .3615722656800 .7667236328803 .8311157227 806.5153808594808 .9938964844811 .4537963867813 .9379882812816 .4614257812 819.0272216797821 .6926879883824 .432800293827 .1350708008829 .8656005859 832.6594238281835 .4802246094838 .3314208984841 .1248168945843 .8798828125 845.9564819336846 .7526245117846 .8223876953846 .6846923828846 .3411865234 845.8582763672845 .2368774414844 .4702148438843 .5147094727842 .2926025391 840.8419189453839 .1895141602837 .3574829102835 .3922119141833 .3106079102 831.1605224609828 .9534301758826 .7111816406824 .4827270508822 .2783203125 820.1967773438818 .305480957816 .7014160156815 .4940795898814 .7285766602 814.5170288086814 .8186035156815 .6699829102817 .0559082031818 .9564819336 821.3530273438824 .1799926758827 .2786865234830 .4998779297833 .8269042969 837.1907958984839.8656005859840.9583740234841.1312866211840.6680908203 840.9099731445843 .9733886719847 .9904785156851 .9973144531856 .4318237305 861.5272827148867 .5670166016874 .6550292969882 .8278198242891 .834777832 902.8989257812917 .6011962891933 .8302001953949 .1923828125965 .6171875 983.99511718751001 .7940063481016 .4400024411026 .8780517581032 .260009766 1031.7760009771023 .6420288091009 .026000977989 .2385864258954 .2086181641 895.3255004883832 .2601928711783 .676574707744 .2095947266710 .8945922852 682.2017822266655 .5681762695632 .8292236328614 .4683227539599 .2694702148 587.1112060547577 .5017700195569 .7902832031559 .7969970703543 .1901855469 524.4857788086507 .4570922852491 .5208129883476 .5297851562462 .254699707 448.7084960938436 .0946044922424 .5600891113414 .047088623404 .5979919434 396.103302002388 .471496582381 .6088867188375 .412109375369 .8843994141 364.9771118164360 .5004882812356 .2130126953352 .1138000488348 .1148986816 344.212890625340 .3682861328336 .4400024414332 .3608093262328 .1942138672 324.0314941406319 .8662109375315 .674407959311 .4491882324307 .1770019531 302.9960021973299 .0362854004295 .1524963379291 .2142028809287 .2373046875 283.2044067383279.1075134277274.9137878418270.6570129395 266.3604125977 262.0104064941257 .6177062988253 .1694030762248 .6678924561244 .0370941162 239.1737976074234 .1800994873229 .1683044434224 .0899047852218 .9364013672 213.6911010742208 .3188934326202 .7635040283197 .0014038086190 .9066925049 184.3782043457177 .6157073975170 .6585998535163 .7035980225156 .6660003662 149.6143035889142 .3609008789135 .6732025146130 .6849975586127 .1194000244 125.2137985229124 .6172027588125 .1062011719125 .8611984253126 .0596008301 126.2712020874126 .8565979004127 .6010971069128 .3316955566129 .3278045654 131.0679931641132 .5588989258132 .6681976318131 .1734008789127 .3003005981 122.0222015381116 .1699981689110 .8063964844107 .2593994141104 .5130004883 101.837402343899 .2938766479596 .8199234008894 .4376602172992 .12664031982 89.888397216887 .7427902221785 .6886672973683 .718612670981 .83763122559 80.0383071899478 .32309722976 .6969985961975 .1443481445373 .66072845459 
72.188476562570 .6942062377969 .1799163818467 .6032867431666 .01246643066 64.4157562255962 .8476791381861 .3777008056660 .0085296630958 .76248168945 57.6321907043556 .6180992126555 .7122688293554 .9080390930254 .19789886475 53.5737609863353 .0279388427752 .5519599914652 .1384086608951 .77864837646 51.4658508300851 .1907310485850 .9482994079650 .7299003601150 .53260040283 50.3500099182150 .1808815002450 .0211181640649 .8714218139649 .73009109497 49.6002388000549 .4827995300349 .3840789794949 .3081092834549 .26512908936 49.2625312805249 .3147888183649 .4328117370649 .6347503662149 .93416976929 50.3519515991250 .9019088745151 .6088905334552 .487171173153 .55736923218 54.8323516845756 .245529174857 .7933387756359 .1404495239359 .97341918945 60.5868988037161 .2615394592361 .7929115295462 .015491485662 .17155075073 62.4772491455162 .8119010925363 .0751686096263 .2733497619663 .3903503418 63.4385299682663 .4190406799363 .3447189331163 .2266006469763 .07089996338 62.8879089355562 .6831016540562 .4652214050362 .2383384704662 .00931167603 61.7808685302761 .5580711364761 .342491149961 .13755035460 .94380187988 60.7632408142160 .595569610660 .441539764460 .3002815246660 .17155075073 60.0542793273959 .9476394653359 .8507881164659 .7627906799359 .68328857422 59.6116714477559 .5480117797959 .4921989440959 .444469451959 .40504074097 59.3740692138759 .3518104553259 .3382301330659 .3334007263259 .33708953857 59.3492012023959 .3693809509359 .3973312377959 .4326896667559 .47507095337 59.5240898132359 .5793113708559 .6403694152859 .7067985534759 .77827835083 59.854351043759 .9347190856960 .0189590454160 .1067810058660 .1978187561 60.2918395996160 .3885192871160 .4876403808660 .5889396667560 .6922492981 60.797298431460 .9039001464861 .0119590759361 .12474822998 1035.6860351561032 .2089843751028 .745971681025 .3020019531021 .87902832 1018.4780273441015 .0989990231011 .7449951171008 .4149780271005 .111999512 1001.835021973998 .5861816406995 .3651733398992 .1729736328989 .0098266602 985.8765869141982 .7739868164979 .7025756836976 .6633300781973 .6569213867 970.6837768555967 .7451171875964 .8400268555961 .9688720703959 .1290893555 956.3195800781953 .5358276367950 .7747192383948 .030090332945 .2971191406 942.5681152344939 .837097168937 .095703125934 .337097168931 .5526123047 928.7349853516925 .8751220703922 .9655761719919 .9970703125916 .9625854492 913.8530273438910 .6616821289907 .3795776367904 .0015258789900 .5189208984 896.9279174805 893.2208862305 889.3963012695 885.4476928711 881.3762207031 877.1776123047872 .864074707868 .4091186523863 .8161010742859 .0443725586 854.0703125848 .9146728516843 .6270141602838 .1837768555832 .6256713867 826.9395141602821 .1818237305815 .361328125809 .5535888672803 .8579711914 798.4157104492793 .5612182617789 .6981811523787 .3231811523786 .9398193359 788.1522216797790 .4108276367793 .1102905273795 .4375797 .6674804688799 .8388061523 802.0452270508804 .1987304688806 .5076293945809 .0531005859811 .799987793 814.6821289062817 .6121826172820 .5499267578823 .4990844727826 .5319213867 829.5305175781832 .4818725586835 .2086791992837 .635925293839 .5112304688 840.698425293841 .2905883789841 .458984375841 .3001708984840 .9353027344 840.3880004883839 .669128418838 .7741699219837 .6685791016836 .3560180664 834.8278198242833 .1226806641831 .2932739258829 .3593139648827 .3665771484 825.3386230469 823.2916870117821.2822875977819.3176269531817.479675293 
815.7985229492814 .3690185547813 .2642211914812 .5148925781812 .2022705078 812.2670288086812 .7271118164813 .5955810547814 .8353881836816 .4818115234 818.4940795898820 .7567138672823 .1962890625825 .6558837891827 .833984375 829.6162109375830 .5424194336831 .0883789062831 .6975708008832 .5562133789 834.5059814453837 .0283203125840 .3427124023844 .1569824219848 .1760253906 853.1475219727859 .5552978516867 .3659057617876 .4544067383887 .1428833008 899.7105712891913.5189819336926.6895751953941.8986206055 961.3939819336 981.3206787109998 .08612060551012 .3460083011023 .3859863281030 .891967773 1033.7089843751030 .5699462891025 .6839599611002 .210998535941 .9556274414 872.8593139648822 .823425293781 .9688720703746 .6691894531716 .521484375 686.0017700195658 .7432861328633 .4876708984612 .8234863281598 .6754760742 588.2335205078582 .7163085938575 .553527832559 .6168212891540 .3930053711 522.5598144531505 .1570129395488 .3512878418473 .0679016113459 .791809082 447.4197998047435 .1499023438423 .4744873047412 .8369140625403 .2026977539 394.6383972168387 .0358886719380 .265411377374 .2481079102368 .824005127 363.8613891602359 .1543884277354 .7508850098350 .5415039062346 .4974060059 342.5900878906338 .717010498335 .004486084331 .2351074219327 .3190002441 323.2840881348319 .1084899902314 .8446044922310 .4150085449306 .0639038086 302.0443115234298 .1293029785294 .1260986328290 .0964050293286 .0155029297 281.8934936523277 .7233886719273 .5008850098269 .2290039062264 .8982849121 260.5161132812256 .0701904297251 .6022033691246 .9714050293242 .0270996094 236.9774017334231 .991897583226 .9851989746221 .9044036865216 .7317962646 211.4373931885206 .0057067871200 .4434967041194 .6136016846188 .4394989014 181.8397064209174 .6239929199167 .275894165159 .9770965576152 .6587982178 144.6759033203137 .2324981689131 .9499053955128 .2845001221126 .6561965942 126.4411010742126 .9387969971127 .9231033325128 .9949035645130 .2926940918 131.7684936523133 .5964050293135 .887802124138 .3733062744140 .8764953613 142.9759979248144 .9438018799144 .3672027588138 .108505249129 .7707977295 121.9064025879115 .0839996338111 .0819015503108 .2193984985105 .1221008301 102.226501464899 .4615478515696 .8447036743294 .3774871826292 .03356170654 89.8149337768687 .6981201171985 .6693496704183 .7314071655381 .88471984863 80.1275863647578 .4592971801876 .8589172363375 .3217620849673 .80291748047 72.2704162597770 .7372436523469 .1806716918967 .6265029907266 .06950378418 64.5405273437563 .0912094116261 .7208900451760 .4549484252959 .28828811646 58.225719451957 .2625885009856 .3948593139655 .6187782287654 .9291305542 54.3191490173353 .783069610653 .3135795593352 .9036712646552 .54656982422 52.2316284179751 .9548797607451 .706188201951 .4839286804251 .28052902222 51.0960617065450 .9254684448250 .770919799850 .6299705505450 .50743865967 50.403598785450 .3269195556650 .2804985046450 .2773895263750 .32331085205 50.4362907409750 .6246109008850 .9100914001551 .3023681640651 .82497024536 52.4844017028853 .3077201843354 .2999916076755 .4805488586456 .87765884399 58.4179496765160 .1744384765661 .6516189575262 .3022994995162 .6234588623 63.035720825263 .3629188537663 .5805091857963 .7523307800363 .90850067139 64.0579376220764 .1728363037164 .2526397705164 .273017883364 .24491119385 64.1625518798864 .0369262695363 .8734817504963 .6795387268163 .46413040161 63.2318992614762 .9908790588462 .7443313598662 .498458862362 .25542831421 
62.0196495056261 .7922897338961 .5762596130461 .3718681335461 .18074035645 61.0024604797460 .8376007080160 .6852493286160 .5451316833560 .41622161865 60.2977409362860 .1889305114760 .0889511108459 .997489929259 .91402816772 59.8386802673359 .7713317871159 .7122497558659 .6616287231459 .61965942383 59.5865097045959 .5621986389259 .5467491149959 .5399818420459 .54172134399 59.5516891479559 .5695381164659 .5949707031259 .6275291442959 .66690826416 59.7126007080159 .7643203735459 .8215408325259 .8839797973659 .95114898682 60.0227584838960 .0983810424860 .1777496337960 .260459899960 .34629058838 60.4348793029860 .5260696411160 .6195411682160 .7151412963960 .81256866455 60.9118499755961 .0123596191461 .11471176147

1040.6059570311037 .0620117191033 .5340576171030 .0319824221026 .547973633 1023.0839843751019 .6420288091016 .2219848631012 .825988771009 .453979492 1006.1079711911002 .786987305999 .4918212891996 .2235717773992 .9826049805 989.7692260742986 .5839233398983 .4276733398980 .3010253906977 .2045288086 974.1389160156971 .1044921875968 .1008911133965 .1279296875962 .1832275391 959.2650756836956.3690795898953.4921264648950.6276855469947.770690918 944.9141845703942 .0512084961939 .1743774414936 .2761230469933 .3485717773 930.3837280273927 .3734741211924 .3095703125921 .1840209961917 .9885253906 914.7150878906911 .3563232422907 .9044799805904 .3530883789900 .6956176758 896.9262695312893 .0399780273889 .0333251953884 .9025268555880 .646484375 876.2653808594871 .7672119141867 .1348876953862 .3659057617857 .4310302734 852.3057861328847 .0145874023841 .5894775391836 .0316162109830 .3668823242 824.6154785156818 .8184204102813 .0352783203807 .3338012695801 .8864746094 796.8234863281792 .606628418789 .5654907227787 .6937255859787 .3568725586 788.0786132812789 .8419189453791 .6732177734792 .3118286133793 .0120239258 794.7694091797796 .7990722656798 .2565917969799 .9609985352802 .5491943359 805.5098266602808 .3919067383811 .2841796875814 .2312011719817 .2221069336 820.2860717773823 .3228149414826 .2581176758828 .9187011719831 .2064208984 833.0878295898834 .4282836914835 .3184814453835 .742980957835 .7827148438 835.5827026367835 .1569824219834 .5549926758833 .766784668832 .7788696289 831.5991821289830 .2239990234828 .6832885742827 .0114135742825 .2456054688 823.4332275391821 .5969238281819 .7642211914817 .9727172852816 .2501831055 814.6309204102813 .1403198242811 .8485107422810 .8245849609810 .07421875 809.6497192383809 .4658203125809 .5432128906809 .8681030273810 .3900756836 811.1923828125812 .2891845703813 .5902099609815 .1466064453816 .6854858398 818.0029296875819 .1475830078819 .8276977539820 .532409668821 .4262695312 822.4348754883823 .9500732422825 .9058837891828 .5787963867831 .8325195312 835.403503418839 .7589111328845 .2299804688852 .2111206055860 .983215332 871.0233154297882 .1699829102894 .4577026367907 .8231201172923 .3339233398 941.5687255859960 .3399047852976 .7905883789992 .72808837891009 .133972168 1024.4160156251036 .8160400391043 .3940429691042 .0329589841024 .16394043 982.0745239258928 .0933837891875 .6420898438828 .5894165039791 .9434204102 757.8945922852716 .5599975586677 .8585205078649 .5928955078628 .1447753906 611.9036254883599 .503112793591 .0477294922582 .9735107422570 .8598022461 555.3336181641537 .0590820312518 .3723754883501 .3768005371486 .216796875 472.6892089844459 .6174926758446 .0773010254432 .8830871582420 .9354858398 
410.187713623400 .7849121094392 .5156860352385 .166595459378 .6322021484 372.7337036133367 .2892150879362 .1131896973357 .3133850098352 .7672119141 348.4884033203344 .4560852051340 .6705932617337 .386505127334 .1260986328 330.4277038574326 .4943847656322 .3866882324318 .1426086426313 .736907959 309.3410949707 305.1603088379301 .0668945312296 .958190918292 .8410949707 288.7011108398284 .547088623280 .3721923828276 .1608886719271 .9100036621 267.5967102051263 .1972045898258 .7193908691254 .1770935059249 .4584960938 244.4542999268239 .403503418234 .5355072021229 .6790008545224 .6858978271 219.5724029541214 .3074035645208 .9729003906203 .6645965576198 .1865997314 192.4432983398185 .9862976074178 .395401001170 .2595062256161 .8005981445 153.3755950928144 .8108978271137 .0576019287131 .7440948486128 .334197998 127.0640029907127 .3327026367128 .2507019043129 .7462005615131 .4528045654 133.5189971924135 .8262939453138 .6504974365142 .175994873145 .8946990967 149.8329925537152 .7891998291153 .5453948975151 .3240966797144 .9427032471 136.5045928955128 .3271942139121 .1945037842116 .1479034424112 .1754989624 108.4604034424105 .070602417101 .956001281799 .1017990112396 .45365905762 93.9986190795991 .7116012573289 .5441818237387 .4386978149485 .4273223877 83.5309066772581 .7348403930780 .0295867919978 .394256591876 .81379699707 75.2615203857473 .709129333572 .1693420410270 .6273269653369 .09838867188 67.5755310058666 .0822830200264 .649696350163 .2831001281762 .00368881226 60.8095092773459 .7075195312558 .6951484680257 .7719116210956 .93701934814 56.1902389526455 .5243682861354 .9356117248554 .4175796508853 .96601867676 53.572269439753 .2251014709552 .9196510314952 .6465797424352 .40328979492 52.1832199096751 .9859199523951 .8073692321851 .6493988037151 .5104598999 51.3953208923351 .3055000305251 .2491493225151 .2310104370151 .26316833496 51.3535308837951 .517990112351 .767719268852 .1206092834552 .59035873413 53.1924095153853 .9397201538154 .8425788879455 .9100990295457 .128490448 58.4895782470759 .9811897277861 .6480598449763 .0679092407263 .83457946777 64.2535171508864 .5968627929764 .8554229736365 .0312194824265 .14610290527 65.2152786254965 .2369537353565 .2375183105565 .2119522094765 .14457702637 65.0393524169964 .8925018310564 .7111968994164 .5007934570364 .26711273193 64.0178680419963 .7574806213463 .4925003051863 .226001739562 .96300125122 62.7053909301862 .4566497802762 .2177391052261 .9908409118761 .77616882324 61.5748405456561 .386440277161 .2112312316961 .0483703613360 .89743041992 60.757530212460 .6278686523460 .5078010559160 .3965415954660 .29384994507 60.1992797851660 .1129493713460 .0348091125559 .9650917053259 .90399932861 59.8516616821359 .808319091859 .7738914489759 .748458862359 .73176956177 59.7237281799359 .7239913940459 .7322692871159 .7481994628959 .77141952515 59.8015289306659 .8381195068459 .8808288574259 .9291992187559 .98289871216 60.0414695739760 .1046104431260 .1718902587960 .243030548160 .31763839722 60.3954811096260 .4762115478560 .5596313476660 .6454505920460 .73350143433 60.8234786987360 .9151916503961 .0087013244661 .10710144043

1045.4560546881041 .8609619141038 .2779541021034 .7130126951031 .166015625 1027.6379394531024 .1309814451020 .6439819341017 .1799926761013 .739013672 1010.3200073241006 .9260253911003 .5560302731000 .210998535996 .8900756836 993.5950927734990 .3259887695987 .0834960938983 .867980957980 .6802978516 
977.5205078125974 .3894042969971 .2858886719968 .2100830078965 .1591796875 962.1317749023959 .1232299805956 .1298828125953 .1456298828950 .1652832031 947.1815795898944 .1881713867941 .1771240234938 .1416015625935 .0729980469 931.9641723633928 .8067016602925 .5930786133922 .3145751953918 .9641113281 915.5327148438912 .0142211914908 .4000854492904 .6854858398900 .8626098633 896.9277954102892 .8745117188888 .7014770508884 .4041137695879 .9838867188 875.4395141602870 .7816162109865 .9943847656861 .080078125856 .012878418 850.7821044922845 .4008178711839 .8994750977834 .2874755859828 .5961303711 822.86328125817 .1317749023811 .5067138672806 .0524291992801 .0006713867 796.4398803711792 .7698974609790 .2650756836788 .8148193359788 .6035766602 789.128112793790 .5396728516791 .6848144531790 .9420166016790 .3441772461 791.707824707793 .4680175781794 .0927734375795 .0639038086797 .4329833984 800.2564697266802 .8081054688805 .4357910156808 .2346191406811 .1317138672 814.1135253906817 .0291748047819 .8654174805822 .4381103516824 .6754150391 826.5587158203828 .0181884766829 .0775146484829 .7006835938829 .950378418 829.9373779297829 .6665039062829 .2034301758828 .5374145508827 .6680297852 826.6166992188825 .3980102539824 .0296020508822 .5283203125820 .9431762695 819.3209838867817 .6879882812816 .0648803711814 .4921875812 .9926757812 811.5764160156810 .2446289062809 .0607299805808 .0588989258807 .2567138672 806.6840209961806 .2775268555806 .057800293805 .8734130859805 .665222168 805.5220947266805 .5994262695805 .9329223633806 .6165161133807 .4000854492 808.0225830078808 .5739746094808 .8900146484809 .3839111328810 .2211303711 811.2642822266812 .6851196289814 .4168701172816 .7766113281819 .6793823242 823.0908203125827 .1978759766831 .9155883789837 .991027832846 .1483764648 855.575378418865 .5618896484877 .0687866211891 .0659179688906 .7816772461 923.0025024414939 .6262207031954 .809387207971 .3762207031991 .522277832 1012.3070068361031 .535034181043 .9389648441043 .1879882811030 .750976562 1011.437988281980 .7470703125934 .6428222656885 .3010864258847 .4409790039 808.1057739258754 .9650268555704 .9052124023670 .707824707646 .1461791992 626.3712768555611 .4934082031598 .9835205078588 .2896118164579 .2562255859 568.3842773438551 .74609375532 .9697875977516 .4041137695500 .7034912109 485.8828125471 .6170959473456 .5828857422442 .0006103516428 .984588623 417.2217102051407 .0444030762398 .1536865234390 .1724853516383 .0787963867 376.6325073242370 .738494873365 .1505126953359 .8677062988354 .7847900391 349.9833068848345 .7767028809342 .1170959473339 .2799072266336 .6003112793 333.2403869629329 .5148010254325 .5361938477321 .3215026855316 .9641113281 312.5700073242308 .2228088379303 .9267883301299 .6818847656295 .4657897949 291.2495117188287 .0440063477282 .8313903809278 .6181030273274 .3966064453 270.0875854492265 .6664123535261 .1198120117256 .4809875488251 .7124938965 246.7124023438241 .7144012451236 .9727935791232 .2420043945227 .2998046875 222.2330932617216 .9815979004211 .7138061523206 .6233062744201 .4062042236 196.0601043701189 .8730010986182 .1654052734173 .3670043945163 .5686950684 153.4729003906143 .7050018311135 .5995941162130 .566192627127 .966003418 127.3343963623128 .0258026123129 .3665924072131 .3043060303133 .5121002197 136.1470031738139 .0773925781142 .5780029297146 .8430023193151 .5469970703 156.9506072998160 .43699646159 .3769989014155 .2118988037149 .2422943115 
141.9768066406134 .4967956543127 .4415969849121 .3342971802116 .0983963013 111.6107025146107 .7235031128104 .25340271101 .164901733498 .33464050293 95.7608337402393 .3981170654391 .1793823242289 .0053482055786 .9330368042 84.9978637695383 .1692733764681 .4340972900479 .7718429565478 .1625213623 76.5913009643675 .0333862304773 .4969863891671 .9639434814570 .45084381104 68.9532928466867 .4872589111366 .0720672607464 .7114486694363 .42544174194 62.2108612060561 .077289581360 .0231018066459 .04994964658 .16220092773 57.3634605407756 .6474914550856 .0148696899455 .4575691223154 .97264099121 54.5508384704654 .17731857353 .8489990234453 .55551910453 .29521942139 53.0607490539652 .8532295227152 .667549133352 .5073394775452 .36994171143 52.2619590759352 .1842384338452 .1467285156252 .1527404785252 .21649169922 52.3434104919452 .5519981384352 .8502006530853 .2580604553253 .78688812256 54.4502487182655 .2623710632356 .2184181213457 .3302688598658 .55641937256 59.8517608642661 .216098785462 .6956787109464 .014373779364 .95113372803 65.594306945865 .9953231811566 .2381210327166 .3769836425866 .43329620361 66.420066833566 .3522109985466 .2591705322366 .1381835937565 .98504638672 65.8039703369165 .5910415649465 .3537368774465 .0958862304764 .82290649414 64.5404129028364 .2525634765663 .9643211364763 .6786499023463 .39918136597 63.1277389526462 .8666610717862 .6168708801362 .3797187805262 .1554107666 61.9444885253961 .7466087341361 .5616798400961 .3889808654861 .22792816162 61.0777587890660 .9376487731960 .8070793151960 .6852798461960 .57213973999 60.467208862360 .370670318660 .2824592590360 .2028312683160 .13193893433 60.0699615478560 .0170402526959 .9731597900459 .9383087158259 .91231918335 59.8950004577659 .8861007690459 .8852615356459 .8922004699759 .90647125244 59.9277610778859 .9556083679259 .9896888732960 .0295295715360 .07481002808 60.1250610351660 .1800117492760 .2391891479560 .3023490905860 .36907958984 60.4391593933160 .5122184753460 .5880699157760 .6664199829160 .74708938599 60.8297805786160 .9145011901961 .0006103515661 .08877182007 1050.285034181046 .6230468751042 .9720458981039 .3459472661035 .734985352 1032.1419677731028 .5679931641025 .0140380861021 .4810180661017 .968017578 1014.4769897461011 .0079956051007 .5620117191004 .1380004881000 .736999512 997.3587036133994 .0045776367990 .6746826172987 .3693847656984 .0892944336 980.8344116211977 .6052856445974 .401184082971 .2216796875968 .0640258789 964.9266967773961 .8051147461958 .6953735352955 .5916748047952 .4885253906 949.3790283203946 .2562866211943 .1134033203939 .9426269531936 .736328125 933.4868774414930 .1865844727926 .8275146484923 .4019165039919 .9019165039 916.3201293945912 .6491699219908 .8826293945905 .0139770508901 .0377197266 896.9489135742892 .7437133789888 .4193115234883 .9738769531879 .4077148438 874.7230224609869 .926574707865 .0147705078859 .9946289062854 .8413696289 849.5314941406844 .0961914062838 .5643920898832 .9567871094827 .30078125 821.6514282227816 .0526733398810 .6246948242805 .4470825195800 .7349853516 796.6265869141793 .3970947266791 .3087768555790 .2225952148790 .3189697266 790.858581543791 .4036254883791 .6312255859791 .0745239258790 .6777954102 791.3748779297792 .3057861328792 .4945068359792 .9431762695794 .3961791992 796.2531738281798 .0372924805800 .0775756836802 .633972168805 .4331054688 808.2194824219 810.9528198242 813.5994873047 816.0493774414 818.2152099609 
820.0996704102821 .6154785156822 .7811889648823 .5460205078823 .9672241211 824.1068115234823 .9843139648823 .6478881836823 .1019897461822 .3612060547 821.4453125820 .3676147461819 .1525268555817 .8181152344816 .4094848633 814.9729003906813 .5291137695812 .1030883789810 .7285766602809 .4348754883 808.1929931641807 .0045166016805 .8936767578804 .8552246094803 .9415283203 803.1868286133802 .582824707802 .2534179688801 .7526855469800 .6831054688 799.4475097656798 .4061279297797 .7515869141797 .8071289062798 .0874023438 798.1569824219798 .1229248047797 .8389282227797 .9063720703798 .8065185547 800.0834960938801 .4384765625803 .0548095703805 .1696777344807 .8596801758 811.2053222656815 .1909790039819 .8062744141825 .544128418832 .8869018555 841.4100952148850 .6948852539861 .5551147461874 .6616821289889 .11328125 904.2100830078919 .4793701172934 .0549926758950 .6513061523970 .9833984375 993.02862548831014 .8989868161031 .078002931036 .4279785161035 .097045898 1029.130004883 1015.913024902 994.1668701172961.2691040039917.9874267578 867.3048095703 812.0488891602 757.2440795898 704.8569946289 663.2009277344 640.4138183594625 .0723266602609 .32421875596 .4931030273587 .1834716797 578.63671875567 .3754882812552 .5762939453534 .3157958984515 .4542236328 498.3070068359482 .0780029297466 .0881958008450 .8306884766436 .9388122559 424.3391113281413 .3947143555403 .8281860352395 .2235107422387 .503692627 380.4287109375374 .0224914551368 .3405151367362 .8240966797356 .6285095215 350.7619934082346 .3652954102342 .9284057617340 .3776855469338 .1980895996 335.6077880859332 .495300293328 .5985107422324 .3051147461319 .9371948242 315.4992980957311 .0640869141306 .638092041302 .2752075195297 .9515991211 293.6415100098289 .3537902832285 .0788879395280 .8532104492276 .703704834 272.4483947754267 .9448852539263 .2984008789258 .636505127253 .9194946289 249.0648040771244 .2100067139239 .4765930176234 .7145996094229 .7769927979 224.7142028809219 .508605957214 .3179016113209 .279296875204 .1826019287 198.9969024658193 .0554962158185 .9665985107177 .2955932617166 .3614044189 154.3854980469141 .9141998291132 .0821990967128 .3650054932127 .7610015869 127.9553985596129 .0137023926130 .5904998779132 .7095031738135 .1732940674 138.0628967285141 .2830047607144 .971206665149 .1069030762154 .0527038574 160.665802002164 .9208984375163 .116897583158 .2102050781152 .3587036133 145.8348999023138 .8894042969131 .8291015625125 .3505020142119 .4442977905 114.4225997925110 .1137008667106 .3289031982102 .998596191499 .99849700928 97.2997131347794.8320922851692.5376510620190.33542633057 88.25115203857 86.2962188720784 .4514236450282 .699363708581 .0218734741279 .39797210693 77.8175506591876 .2597198486374 .7273788452173 .2072219848671 .70953369141 70.232566833568 .7875900268667 .3852462768666 .0307769775464 .73808288574 63.5070304870662 .345138549861 .2531814575260 .234230041559 .29776000977 58.4498291015657 .6883010864357 .0204811096256 .4339103698755 .92407989502 55.4816284179755 .0893592834554 .7430992126554 .4341201782254 .15961837769 53.9133987426853 .6963386535653 .5049018859953 .3417282104553 .20516967773 53.1013908386253 .0333099365253 .0093688964853 .0346908569353 .12118911743 53.2764091491753 .5157318115253 .8498001098654 .2950401306254 .86547851562 55.5695610046456 .4222717285257 .4092407226658 .533340454159 .76042938232 61.0857391357462 .4411697387763 .8023490905865 .0583267211966 .0327835083 
66.7680969238367 .2221527099667 .4697570800867 .5954132080167 .61042785645 67.5342864990267 .3882369995167 .2112426757867 .0023117065466 .77049255371 66.5161132812566 .2415924072365 .950889587465 .6483306884865 .33798217773 65.0244598388764 .7108764648464 .4013900756864 .0980072021563 .80371856689 63.5196113586463 .2475204467862 .9878196716362 .7414817810162 .50836181641 62.2887611389262 .082168579161 .8883590698261 .7065696716361 .53620910645 61.3765182495161 .2267608642661 .0864410400460 .9549217224160 .83208084106 60.7175788879460 .6115493774460 .5140304565460 .4251785278360 .34521865845 60.2742385864360 .2124214172460 .1596794128460 .1160392761260 .08127975464 60.0552711486860 .0376815795960 .0282516479560 .0266113281260 .03239822388 60.0452613830660 .0647583007860 .0905609130960 .1222190856960 .15938186646 60.2016410827660 .2486495971760 .2999992370660 .3554191589460 .41450881958 60.4770317077660 .5426292419460 .6111106872660 .6821708679260 .75563049316 60.8311805725160 .9086303710960 .9881896972761 .07276153564 1055.0529785161051 .3349609381047 .6269531251043 .9350585941040 .259033203 1036.5999755861032 .9580078121029 .3349609381025 .7309570311022 .145996094 1018.5809936521015 .0369873051011 .5130004881008 .0089721681004 .526977539 1001.065002441997 .625994 .2067871094990 .8107299805987 .4373168945984 .0864868164 980.7587890625977 .453125974 .1693115234970 .9041748047967 .6567993164964 .421875 961.1964111328957 .9735107422954 .7487182617951 .5142211914948 .2644042969 944.9912719727941 .6881713867938 .3469848633934 .9608764648931 .521484375 928.0220947266924 .454284668920 .8115234375917 .0855712891913 .270690918 909.3594970703905.3472290039901.227722168 896.9978027344 892.6530151367 888.1926269531883 .6146850586878 .9215698242874 .1152954102869 .2031860352 864.1881713867859.0883178711 853.8743286133848.517578125843.0609741211 837.5388183594 831.9780883789826.4030761719 820.8862915039815.4611206055 810.2706298828805 .3676147461800 .9821166992797 .2122802734794 .2965087891 792.4365234375791 .5233154297791 .8607177734792 .3729858398792 .1240844727 791.7357788086791 .791015625792 .025390625792 .2709960938792 .444519043 792.2382202148792 .1237792969792 .4882202148793 .2250976562794 .1215820312 795.4971923828797 .6901855469800 .2136230469802 .6516723633805 .095703125 807.5236816406 809.834777832 811.9365844727 813.7850952148 815.3037719727 816.5045776367817 .3571166992817 .8947143555818 .1618041992818 .1635742188 817.9439697266817 .5098266602816 .891418457816 .1005859375815 .151184082 814.075012207812 .8939208984811 .6505737305810 .3839111328809 .1123046875 807.8557128906806 .6469116211805 .5020751953804 .4227294922803 .3845214844 802.3269042969 801.200378418 800.0800170898 799.0794067383798.1989135742 797.6973876953796 .8848876953795 .087890625792 .9893798828791 .080078125 789.5999755859 789.116027832 788.9552001953 788.5266113281 788.0396118164 787.2119140625786 .8353271484787 .6959838867789 .0463256836790 .3394165039 791.8872070312793 .8773803711796 .4268188477799 .7285766602803 .7393188477 808.4555053711814 .0197753906820 .575012207828 .1801757812836 .8828735352 846.9722290039858 .6130981445871 .4862060547885 .201171875899 .8043212891 914.2886962891930.4857788086949.4583129883969.9896240234991.3228759766 1010.3579711911022 .8590087891031 .4210205081036 .1629638671036 .555053711 1038.8809814451025 .795043945982 .0925292969925 .8508300781874 .546875 
819.2316894531 749.6522216797689.5991821289660.2775268555 643.6475830078 625.2534790039609 .6489257812597 .6472167969587 .9547729492580 .4224243164 570.3046875551 .6182250977530 .1445922852510 .9548034668492 .6885070801475 .4375 459.3891906738444 .8143920898431 .6223144531420 .083404541409 .875793457 400.5292053223392 .095703125384 .3147888184377 .2189025879371 .3266906738 365.2847900391357 .7171020508350 .9122009277346 .5578918457343 .6818847656 341.5060119629339 .6037902832337 .6377868652335 .0899963379331 .3320007324 327.0223083496322 .6805114746318 .2132873535313 .7094116211309 .1868896484 304.7237854004300 .2980041504295 .892791748291 .520111084287 .1711120605 282.8695068359278 .7045898438274 .4695129395269 .9194946289265 .2713928223 260.6734008789256 .0506896973251 .3697967529246 .6607971191241 .9167938232 237.0879058838232 .1186065674227 .038192749221 .867401123216 .6788024902 211.5554962158206 .4293060303201 .3112945557195 .6699981689189 .4272003174 181.1941986084169 .5950927734156 .424697876141 .9768981934130 .6997070312 127.912902832128 .6737976074129 .1053009033130 .2693939209131 .9011993408 133.99949646136 .5299987793139 .4615020752142 .7277069092146 .3462982178 150.0191955566154 .4514007568161 .3560943604166 .116897583164 .3117980957 159.536605835154 .4230957031148 .5444030762141 .9297027588135 .0514984131 128.4134063721122 .1743011475116 .8361968994112 .1977005005108 .1336975098 104.6165008545101 .458801269598 .6492233276496 .0726699829193 .7073135376 91.4888916015689 .4115676879987 .4540863037185 .605751037683 .84858703613 82.168251037680 .5410766601678 .9617080688577 .4076309204175 .88320159912 74.3729934692472 .8876571655371 .4251403808669 .9935226440468 .60102844238 67.2501678466865 .9537200927764 .7093276977563 .5260200500562 .40296936035 61.3460884094260 .3626403808659 .4631195068458 .6599311828657 .96529006958 57.3637695312556 .8386383056656 .3790893554755 .9703483581555 .60882949829 55.2866096496655 .000560760554 .7441291809154 .5190391540554 .32067871094 54.1535110473654 .0150299072353 .9129981994653 .8503494262753 .83625030518 53.8742103576753 .9771995544454 .1500816345254 .4097785949754 .76383972168 55.2305183410655 .8218803405856 .5465011596757 .4216690063558 .42222976685 59.552871704160 .7869491577162 .1714096069363 .567378997864 .88034820557 66.0808868408267 .0706634521567 .8494873046968 .3335571289168 .60475921631 68.7190780639668 .6928329467868 .556083679268 .3346405029368 .07997131348 67.7886810302767 .4824066162167 .1601409912166 .8287429809666 .49014282227 66.1473312377965 .804130554265 .4629821777365 .1274490356464 .79929351807 64.4810791015664 .1738662719763 .8792304992763 .597511291563 .32947158813 63.0750083923362 .8342895507862 .6069183349662 .3926200866762 .19075012207 62.0007781982461 .8219108581561 .6535797119161 .4949684143161 .34574890137 61.2052993774461 .0735893249560 .9502716064560 .8355598449760 .72943115234 60.632118225160 .5437507629460 .4644699096760 .3943595886260 .33338928223 60.2815208435160 .2385902404860 .204380035460 .1786384582560 .16104888916 60.1513214111360 .1490287780860 .1538696289160 .1653900146560 .18328094482 60.2070693969760 .2364501953160 .2709808349660 .3103408813560 .35411071777 60.4020385742260 .4537086486860 .5088996887260 .5672302246160 .62852859497 60.6924781799360 .7589111328160 .8274993896560 .898300170960 .97060012817 61.04515075684 
1059.8000488281056 .0140380861052 .2370605471048 .4820556641044 .739990234 1041.0129394531037 .3029785161033 .6099853521029 .9339599611026 .276977539 1022.6370239261019 .0159912111015 .4130249021011 .830017091008 .265014648 1004.7189941411001 .192016602997 .684387207994 .1968994141990 .7294921875 987.2821044922983 .8552856445980 .4476928711977 .0590209961973 .686706543 970.328918457966 .9812011719963 .6400146484960 .2990722656956 .9534301758 953.5961303711950 .2208251953946 .8201904297943 .3873291016939 .9149780273 936.3958129883932 .8223266602929 .1871948242925 .4835205078921 .7037963867 917.8416137695913 .8901977539909 .8438720703905 .6973266602901 .4462280273 897.0866088867892 .6165161133888 .0341186523883 .3405151367878 .5369873047 873.6284790039868 .6212768555863 .5250244141858 .3547973633853 .0936889648 847.7230834961842 .2813720703836 .7979736328831 .3076171875825 .8375854492 820.4578857422815 .2152709961810 .2258911133805 .5670166016801 .4058837891 797.8665771484795 .104309082793 .2819213867792 .3557128906792 .5394287109 792.8325805664792 .4047851562792 .0048828125792 .108581543792 .4598999023 792.959777832793 .0640258789792 .2789916992791 .3500976562790 .953918457 790.9284057617791 .2858886719792 .1948852539793 .7672119141795 .6674194336 797.5435791016799 .541015625801 .7518920898803 .9630737305805 .9508056641 807.7125854492809 .17578125810 .361328125811 .2473144531811 .856628418 812.1948242188812 .2824707031812 .1475830078811 .8062744141811 .2811889648 810.5922241211809 .7567749023808 .8035888672807 .75390625806 .6491088867 805.5239868164804 .3881225586803 .266784668802 .1744995117801 .1098022461 800.1427001953799 .3552856445798 .434387207797 .080078125795 .5952148438 794.2578735352793 .0136108398791 .9406738281790 .5795288086788 .5250854492 786.2012939453783 .9924926758782 .1469726562781 .0200805664780 .2111816406 779.3526000977778 .5250244141777 .6320800781777 .1934814453777 .6749267578 778.6691894531779 .8098754883781 .270324707783 .1594848633785 .6223754883 788.7990722656792 .7476196289797 .5443725586802 .9431762695808 .7725830078 815.4329223633823 .3248291016832 .3745727539842 .6171264648853 .8723754883 865.9342041016879 .5103759766894 .5933837891910 .8267211914928 .1348266602 946.393371582965 .9078979492985 .85131835941003 .4680175781019 .611999512 1033.5610351561044 .8470458981053 .9680175781048 .3129882811018 .072021484 974.2716064453929 .6563720703875 .7210083008803 .3499755859735 .9177856445 694.9655761719669 .2655029297651 .3261108398635 .1558227539614 .1110839844 596.3939819336587 .7777709961579 .4570922852563 .6002197266543 .9647216797 524.1057128906504 .5651855469485 .2749938965467 .412689209452 .4554138184 439.1234130859427 .1047973633416 .2979125977406 .1351928711396 .8167114258 388.2731933594380 .3819885254373 .358001709365 .9530944824356 .8994140625 349.3315124512346 .0907897949344 .7337036133343 .1073913574341 .3554077148 339.3942871094336 .8931884766333 .4324951172329 .4119873047325 .1559143066 320.7080993652316 .1553955078311 .5419006348306 .9892883301302 .471496582 297.992401123293 .5398864746289 .1032104492284 .6686096191280 .2188110352 275.791809082271 .4339904785267 .0645141602262 .5981140137258 .0780029297 253.495300293248 .8576965332244 .1954040527239 .3912963867234 .3515014648 229.1858978271223 .9685974121218 .6750946045213 .279296875208 .0014038086 203.1585998535198 .1320953369192 .5420074463184 .8368988037173 .2955932617 
160.1240997314146 .9064025879136 .6069030762132 .5108032227131 .6248016357 131.4407043457132 .120803833133 .4058074951135 .2769012451137 .6076965332 140.3657073975143 .4512939453146 .7747039795150 .1502990723154 .091293335 159.4152069092163 .1770019531162 .4703063965159 .3264007568155 .2151947021 150.0941925049143 .899597168137 .1882019043130 .5290985107124 .1220016479 118.5904998779113 .7323989868109 .5358963013105 .9139022827102 .6835021973 99.7985687255997 .1623077392694 .7527084350692 .5172424316490 .44037628174 88.48937988281 86.64906311035 84.90017700195 83.22785949707 81.60814666748 80.0351028442478 .4895172119176 .972511291575 .4728622436573 .99729919434 72.5456771850671 .1238632202169 .7374801635768 .3897628784267 .08891296387 65.8351898193464 .6350097656263 .4883995056262 .3997611999561 .37231063843 60.4065589904859 .5493316650458 .8511085510358 .2582817077657 .72489929199 57.2506790161156 .8264999389656 .4501190185556 .1160316467355 .81948852539 55.5546112060555 .3215293884355 .1148605346754 .9400215148954 .79679870605 54.6916618347254 .6299400329654 .6188316345254 .6630783081154 .77259063721 54.9535713195855 .2194900512755 .5794410705656 .0500411987356 .64461898804 57.3773002624558 .2678298950259 .2923583984460 .4524497985861 .73001861572 63.1422309875564 .5643997192465 .9026718139667 .1159591674868 .12103271484 68.9178466796969 .4291534423869 .7113265991269 .7892532348669 .70184326172 69.4949493408269 .1948623657268 .8553619384868 .4818115234468 .10266113281 67.7177963256867 .336639404366 .9574966430766 .5814437866266 .21102142334 65.8482666015665 .4950637817465 .1529235839864 .8229904174864 .50634002686 64.2033615112363 .9145317077663 .6397399902363 .3789901733463 .13188934326 62.8981285095262 .6771316528362 .4683494567962 .2710990905862 .08470916748 61.9085693359461 .7420387268161 .5847587585461 .436241149961 .29644012451 61.1651382446361 .0424804687560 .9285316467360 .8234405517660 .72739028931 60.6404304504460 .5626907348660 .4940795898460 .4345817565960 .38397979736 60.3421211242760 .3087081909260 .2834701538160 .2660598754960 .25613021851 60.253341674860 .2572708129960 .2675704956160 .2838516235460 .30574035645 60.3328399658260 .36481857360 .4012908935560 .441959381160 .48645019531 60.5345001220760 .5857887268160 .6400909423860 .697120666560 .756690979 60.8184700012260 .8823013305760 .9484710693461 .01976013184

1064.4949951171060 .6490478521056 .8120117191052 .9899902341049 .180053711 1045.3859863281041 .6059570311037 .8420410161034 .0939941411030 .362060547 1026.6469726561022 .9489746091019 .2670288091015 .6030273441011 .95501709 1008.3229980471004 .7089843751001 .112976074997 .5330810547993 .9713745117 990.4271240234986 .9008178711983 .3911132812979 .8977050781976 .4177856445 972.9501953125969 .4899291992966 .0338134766962 .5755004883959 .1105957031 955.6317138672952 .1331787109948 .6074829102945 .0482788086941 .4478149414 937.799621582934 .0961303711930 .330871582926 .4962768555922 .5864868164 918.5944213867914 .5145874023910 .3413085938906 .0703125901 .6973266602 897.2199707031 892.6359863281 887.9458007812 883.1503295898 878.2526245117 873.258605957 868.1754760742 863.0145263672 857.7896728516 852.4982910156 847.1331787109841 .7285766602836 .3040161133830 .9036865234825 .5501708984 820.321472168815 .2520141602810 .458984375805 .9976196289802 .0131835938 798.6030883789795 .8676147461793 .9235229492792 .7719116211792 .6279296875 
792.7376098633792 .4020996094792 .1232299805792 .1859130859792 .4534301758 793.1099853516793 .2952880859792 .0823974609790 .5595092773789 .6383056641 789.1154174805789 .1016845703789 .588684082790 .4849853516791 .6992797852 792.9697265625794 .4923706055796 .4387817383798 .473815918800 .2763061523 801.8959960938 803.2556152344804.3762207031 805.25 805.8732910156 806.2423706055 806.3745727539806 .299621582806 .0247192383805 .5723876953804 .9630126953 804.2208862305803 .3684082031802 .4240112305801 .4243164062800 .3983154297 799.3740234375798 .3673706055797 .3707275391796 .3406982422795 .3812255859 794.7219848633793 .8599243164792 .2755737305790 .4542236328788 .8148803711 787.1494140625785 .444519043783 .5546264648781 .4036254883779 .1262207031 776.9083251953774 .8800048828773 .1981201172771 .7822265625770 .522277832 769.4871826172768 .6536865234768 .2122802734768 .2590942383768 .7711791992 769.6837768555771 .0344848633772 .8369750977775 .2073974609778 .2260742188 781.981628418786 .6989135742791 .8977050781797 .0911865234802 .9359130859 810.0311279297818 .0797119141827 .0469970703836 .848815918847 .2951049805 859.2608032227 873.6865844727 889.5546875 905.2130737305 922.0018920898 940.0139160156959 .5283203125979 .78448486331000 .8070068361021 .166992188 1038.2910156251048 .6929931641048 .1579589841035 .3179931641009 .659973145 975.9812011719928 .1522827148860 .2750854492791 .4293212891738 .9166870117 700.9528198242680 .3348999023664 .1790771484635 .2144165039608 .8812255859 596.6090087891587 .4509887695573 .8593139648557 .4838867188538 .4813232422 517.713684082495 .925201416475 .8139953613460 .2560119629447 .0942993164 434.8684082031423 .4472961426412 .3688049316401 .8897094727392 .3333129883 383.4263000488375 .158996582366 .9671936035357 .3716125488349 .5604858398 347.2319946289346 .6888122559345 .0234069824343 .1690979004340 .9952087402 338.3818969727335 .2354125977331 .5502929688327 .4223937988322 .9606018066 318.3587036133313 .6781921387309 .0606079102304 .4729919434299 .9352111816 295.4169921875290 .9046936035286 .3580932617281 .6445922852277 .0430908203 272.883605957268 .7944946289264 .4447937012259 .9961853027255 .4553985596 250.8392944336246 .2292938232241 .453704834236 .3648986816231 .120803833 225.8527984619220 .4980010986214 .8941040039209 .4895019531204 .8898925781 200.1455993652194 .8699951172187 .6790924072176 .6932067871164 .6578979492 153.8267059326144 .9732971191139 .216003418135 .8876953125134 .4049987793 134.2783966064135 .0007019043136 .4627075195138 .4485015869140 .875143 .6401062012 146.6094970703149 .6988983154152 .8222961426156 .0673065186158 .4627075195 158.9799957275157 .904800415155 .1441955566150 .8231964111145 .0303955078 138.3679962158131 .667098999125 .2490997314119 .7081985474114 .8776016235 110.68409729107 .021697998103 .7358016968100 .799896240298 .11786651611 95.6786727905393 .4341278076291 .3626022338989 .4264526367287 .6081237793 85.8788986206184 .2266235351682 .6205673217881 .0603103637779 .52247619629 78.0124816894576 .5188217163175 .0485305786173 .602676391672 .1849822998 70.8022003173869 .4546432495168 .1511917114366 .8896408081165 .67841339111 64.5145797729563 .4039115905862 .3482818603561 .3339996337960 .43349075317 59.7302894592359 .139228820858 .5905113220258 .1003417968857 .6600112915 57.2683906555256 .9220695495656 .6163902282756 .3450508117756 .10412979126 55.8866615295455 .6999511718855 .5473403930755 .4364814758355 .37118911743 
55.3588905334555 .4025497436555 .5119895935155 .6910514831555 .95341873169 56.3051490783756 .7652702331557 .3440093994158 .0636901855558 .95090103149 59.988559722961 .1929206848162 .5192604064963 .9788894653365 .44917297363 66.8587036132868 .131698608469 .1637268066469 .9778976440470 .49269104004 70.7658081054770 .7828216552770 .6080703735470 .3182678222769 .92952728271 69.5091781616269 .0584869384868 .6162567138768 .1776123046967 .7557220459 67.3456878662166 .9442291259866 .555099487366 .1766891479565 .81215667725 65.4601593017665 .1230697631864 .7997970581164 .4916992187564 .19770812988 63.9184417724663 .6528282165563 .4010009765663 .1619911193862 .93558883667 62.7208595275962 .5174293518162 .3244209289662 .1414909362861 .96789169312 61.8034706115761 .6477203369161 .500701904361 .3621902465861 .23239898682 61.1113395690960 .9992218017660 .8961296081560 .802169799860 .71738815308 60.6417503356960 .5751495361360 .5174598693860 .4684410095260 .42786026001 60.3954010009860 .3707695007360 .3535995483460 .3435707092360 .34024810791 60.3433494567960 .3524093627960 .3671302795460 .3870811462460 .4119682312 60.4413795471260 .475028991760 .51255035460 .5536994934160 .59812927246 60.6456298828160 .6959114074760 .7487907409760 .8039588928260 .86145019531 60.9205589294460 .98205184937

1069.167968751065 .2550048831061 .3489990231057 .4599609381053 .583007812 1049.7199707031045 .8699951171042 .035034181038 .2139892581034 .406982422 1030.6159667971026 .839965821023 .078002931019 .3319702151015 .601013184 1011.8839721681008 .1829833981004 .495971681000 .823974609997 .1680908203 993.5269165039989 .9008789062986 .2891845703982 .6912841797979 .1043701172 975.5272216797971 .9550170898968 .3847045898964 .8106079102961 .227722168 957.6295166016954 .0098876953950 .3619995117946 .6790161133942 .9545288086 939.1812133789935.352722168931.4619750977927.5026855469923.46868889648 919.3541259766915.1531982422910.8618164062906.4750976562901.9907226562 897.4060058594892 .7205810547887 .9345703125883 .0509033203878 .0728149414 873.0081176758867 .8643188477862 .6544799805857 .3947143555852 .0891723633 846.7387695312841 .3748168945836 .0175170898830 .7061157227825 .4711914062 820.3759155273815 .4655151367810 .825378418806 .5255737305802 .6520996094 799.2993774414796 .4907226562794 .2819824219792 .8068237305792 .3579711914 792.3162231445792 .0507202148791 .8552856445791 .8314819336791 .9083251953 792.1342163086791 .9525146484790 .8040161133789 .3455200195788 .2058105469 787.387878418787 .0399169922787 .0834960938787 .5067138672788 .2122192383 789.1035766602790 .287902832791 .8118286133793 .4566040039794 .9783935547 796.378112793797 .5894775391798 .6143188477799 .4180908203800 .0054931641 800.3610229492800 .5045776367800 .4495239258800 .2108764648799 .8027954102 799.2484130859798 .5673828125797 .7817993164796 .9080810547795 .971496582 794.9880981445794 .0238037109793 .1536865234792 .2581787109791 .2133789062 790.1580200195789 .2448730469788 .1290893555786 .4931030273784 .6071166992 782.7368164062780 .766784668778 .6920776367776 .516784668774 .1931152344 771.8554077148769 .5607299805767 .3452148438765 .3690795898763 .6010742188 762.0576782227760 .8286743164759 .8903808594759 .2833251953759 .0831298828 759.295715332759 .9702758789761 .1447753906762 .7908935547764 .9799804688 767.7844238281771 .2542724609775 .5015258789780 .1889038086785 .0145874023 
790.4188232422796 .8524169922804 .0734863281812 .0552978516820 .5288085938 829.3909912109839 .0510253906849 .2573242188861 .6173095703877 .8300170898 895.6851806641913.5485229492932.325378418951.3395996094972.305480957 996.11187744141017 .7399902341032 .792968751041 .589965821043 .749023438 1035.4289550781012 .992004395973 .649597168915 .3217773438849 .4708251953 786.7230834961735 .4370727539707 .5355834961686 .9459838867659 .7064208984 634.0839233398615 .1799926758600 .4990234375587 .4271240234573 .1915893555 554.6840209961532 .8043212891507 .7956848145484 .7958984375468 .8353881836 456.046295166443 .8183898926431 .9212036133419 .6567993164407 .7486877441 396.6559143066386 .5426940918377 .9476013184370 .2799987793362 .6677856445 356.4208984375352 .5946960449349 .9707946777347 .5281982422345 .203704834 342.7525024414340 .1361999512337 .1756896973333 .7294921875329 .5501098633 324.9585876465320 .2933044434315 .5762023926310 .9172973633306 .2904968262 301.7098999023297 .1534118652292 .6156921387288 .0520935059283 .4132995605 278.900390625274 .6926879883270 .5588989258266 .233001709261 .7856140137 257.2344055176252 .5959014893247 .9127960205243 .0796051025238 .0153961182 232.8123931885227 .5614929199222 .24659729216 .824798584211 .5682067871 206.8190002441201 .8880004883196 .2895965576189 .2138977051179 .4649963379 169.1519012451159 .7048950195151 .3887939453145 .2304992676140 .7015991211 137.9951934814136 .8616027832136 .8094024658137 .6605072021139 .1481933594 141.1475067139143 .4864044189146 .033493042148 .653503418150 .9290008545 152.6562042236154 .1300964355155 .3110961914155 .7176055908154 .4479980469 151.1808013916145 .5791931152138 .7572937012131 .7749938965125 .2276000977 120.0386962891115 .6128005981111 .5734024048107 .9324035645104 .6328964233 101.653900146598 .9486312866296 .4936599731494 .2542724609492 .19976806641 90.2914123535288 .5052032470786 .805526733485 .1785964965883 .5937582 .04737091064 80.5186309814579 .0120468139677 .5211181640676 .0514526367274 .6067199707 73.1903228759871 .80776214670 .460517883369 .1539764404367 .88861083984 66.6692581176865 .4970169067464 .3764801025463 .3119201660262 .30448150635 61.4036407470760 .6610183715860 .0247993469259 .4492607116758 .93534851074 58.474891662658 .0667381286657 .7059898376557 .3905105590857 .11711883545 56.8715400695856 .6361999511756 .4290885925356 .263259887756 .14234161377 56.0699806213456 .0509605407756 .0885505676356 .1896705627456 .35894012451 56.606578826956 .9395103454657 .3744010925357 .922569274958 .61296081543 59.4665603637760 .498741149961 .7488098144563 .149978637764 .68419647217 66.2435531616267 .7464828491269 .0969772338970 .1816329956171 .01735687256 71.5346832275471 .7735137939571 .7078170776471 .4226531982471 .02039337158 70.5296936035270 .0261993408269 .5099182128969 .0108337402368 .52877044678 68.0750122070367 .6425323486367 .2264099121166 .8270263671966 .44184112549 66.0719985961965 .7167816162165 .3767166137765 .0515289306664 .74120330811 64.4453430175864 .1636123657263 .8954582214463 .6404190063563 .39786148071 63.1672286987362 .9478988647562 .7393112182662 .5408287048362 .35203933716 62.1723899841362 .0017089843861 .8396492004461 .6862182617261 .54135894775 61.4051818847761 .2777900695861 .1593093872161 .0498886108460 .94953918457 60.8583717346260 .7762489318860 .7031402587960 .6388511657760 .58319854736 60.5359001159760 .4966888427760 .4652481079160 .4412498474160 .42435073853 
60.4141807556260 .4103813171460 .4125709533760 .4204216003460 .43352127075 60.4515609741260 .4741592407260 .5010414123560 .5318298339860 .56628036499 60.6040611267160 .644950866760 .6886711120660 .7350311279360 .78371810913 60.834548950260 .8879394531260 .94647979736

1073.8000488281069 .8229980471065 .8540039061061 .8969726561057 .952026367 1054.0190429691050 .0980224611046 .1910400391042 .2960205081038 .415039062 1034.546997071030 .6920166021026 .8509521481023 .0230102541019 .208007812 1015.4050292971011 .6160278321007 .8389892581004 .075988771000 .325012207 996.5866088867992 .8615112305989 .1478881836985 .4458007812981 .7523193359 978.0662841797974 .3831176758970 .700012207967 .0109863281963 .3120117188 959.5961303711955 .8579101562952 .0902709961948 .2871704102944 .4417114258 940.5474853516936 .5980224609932 .5872192383928 .5084838867924 .3563842773 920.1254882812915 .8112792969911 .4091186523906 .9155883789902 .3286132812 897.6467285156 892.8699951172 887.9995117188 883.0394287109877.9935302734 872.8709716797867 .6793823242862 .4351806641857 .1525878906851 .8452758789 846.5161132812841 .1992797852835 .9091796875830 .6906738281825 .5673828125 820.5994262695815 .8212280273811 .3090820312807 .1235961914803 .3186035156 799.9686889648797 .0733032227794 .614074707792 .8209838867792 .0675048828 791.8021240234791 .5283203125791 .3461303711791 .1735229492790 .9425048828 790.6018066406789 .9915161133789 .0103149414787 .8314819336786 .6821899414 785.6934204102785 .0612182617784 .7462768555784 .7659912109785 .0932006836 785.6958007812786 .5698852539787 .6364746094788 .8314208984790 .0104980469 791.151184082792 .1743774414793 .0607910156793 .7523193359794 .2587280273 794.5648803711794 .6823120117794 .6187133789794 .3856811523793 .9973144531 793.4708862305792 .8247070312792 .0772094727791 .2443847656790 .3469238281 789.3795776367788 .4324951172787 .6389770508786 .7921142578785 .6973876953 784.4755859375783 .2133789062781 .7733764648780 .0986938477778 .2067260742 776.1779174805773 .9935302734771 .6953735352769 .3198242188766 .8685302734 764.4235229492762 .021484375759 .6903076172757 .5347290039755 .5712280273 753.8408813477752 .4196166992751 .3005981445750 .5208129883750 .1049194336 750.1002197266750 .5595703125751 .5161743164752 .9522705078754 .9234008789 757.4697875977760 .5714111328764 .2481079102768 .3723144531772 .8718261719 777.920715332783 .733215332790 .1644287109797 .309387207804 .8170166016 812.5601196289820 .1810913086826 .0250854492834 .5347900391850 .8146972656 869.8192749023887 .3510742188905 .2490844727921 .7918701172940 .5612182617 964.7158813477988 .66900634771007 .6160278321023 .6199951171038 .66394043 1043.5419921881030 .7519531251001 .468017578957 .5239868164900 .6630859375 832.6580810547770 .7681274414734 .858215332710 .496887207686 .1176147461 663.1151123047638 .4097900391616 .8242797852602 .2593994141588 .4398803711 569.9744873047547 .9141235352520 .9943237305495 .5931091309478 .8551940918 465.6413879395452 .940612793440 .5141906738427 .0343017578413 .7652893066 401.3851013184390 .3918151855381 .7441101074374 .766998291369 .2948913574 364.5221862793358 .8963012695353 .8143005371350 .3215026855347 .4342041016 344.6637878418341 .924987793339 .00390625335 .6326904297331 .3583068848 326.6599121094321 .986114502317 .2542114258312 .5790100098307 .9310913086 303.3229980469298 .7470092773294 .2080993652289 .7055053711285 .2467041016 
280.8768920898276 .5987854004272 .3272094727267 .9399108887263 .4462890625 258.8494873047254 .149597168249 .3553009033244 .4496002197239 .4302978516 234.3137054443229.1206054688 223.900894165 218.7330932617213.6302032471 208.6614074707 203.3943939209 197.3778076172 190.4729003906 182.1674041748 173.4515991211164 .8764038086156 .8936004639150 .4555053711145 .2608947754 141.6455993652139 .4669952393138 .5744934082138 .7451019287139 .6685028076 141.1820068359143 .0549926758145 .0984039307147 .211807251148 .9512023926 149.7274017334150 .5050964355152 .0437011719153 .174697876152 .7891998291 150.4223022461145 .1492004395138 .4355010986131 .5151977539125 .0067977905 120.2171020508116 .1893005371112 .2686004639108 .6756973267105 .3774032593 102.3715972999 .6594314575297 .2044372558694 .9857330322392 .96376800537 91.0990371704189 .3602294921987 .6993331909286 .1087036132884 .54567718506 83.0154724121181 .4900665283279 .9805068969778 .4851989746177 .00952148438 75.5613937377974 .1415100097772 .7576599121171 .4087066650470 .10095977783 68.8332977294967 .6109466552766 .4360275268665 .3145065307664 .25653076172 63.2745895385762 .3838996887261 .5992088317960 .9082298278860 .29708099365 59.7568702697859 .2740516662658 .8473091125558 .4694709777858 .13948822021 57.8583488464457 .6045989990257 .3506202697857 .124160766656 .94480133057 56.811798095756 .728370666556 .6986808776956 .7244110107456 .81187820435 56.9643096923857 .1909103393657 .4968910217357 .8989295959558 .40531921387 59.0490303039659 .8436317443860 .8484497070362 .129459381163 .60107040405 65.2224731445366 .880577087468 .51757812569 .9791870117271 .15045166016 72.0351867675872 .5185317993272 .6845016479572 .5019683837972 .07288360596 71.5528335571370 .9575271606470 .3814926147569 .8126983642669 .27224731445 68.7629470825268 .2907028198267 .8494110107467 .4284973144567 .02941894531 66.6444091796966 .2769470214865 .923263549865 .5856170654365 .26174926758 64.9529113769564 .6574172973664 .3758468627964 .1068191528363 .85046005249 63.6056404113863 .3722686767663 .1494293212962 .9369087219262 .73392868042 62.5403594970762 .3555908203162 .1796417236362 .0121192932161 .85319900513 61.7027511596761 .5610198974661 .4280014038161 .3038902282761 .18877029419 61.0826988220260 .9856910705660 .8976898193460 .8185806274460 .74822998047 60.6864013671960 .6328697204660 .587329864560 .5495109558160 .51906967163 60.4956893920960 .4789695739760 .4686393737860 .4642601013260 .4655418396 60.4720497131360 .4835281372160 .4995613098160 .5199012756360 .54417037964 60.5721397399960 .6034584045460 .6379394531260 .6752700805760 .71529006958 60.757678985660 .8025093078660 .8490295410260 .89802932739 1078.4079589841074 .3659667971070 .3270263671066 .3029785161062 .28894043 1058.2860107421054 .2939453121050 .3129882811046 .3449707031042 .387939453 1038.4429931641034 .5100097661030 .5880126951026 .6779785161022 .778991699 1018.8909912111015 .0139770511011 .1469726561007 .2910156251003 .445983887 999.6115722656995 .7874755859991 .9727783203988 .1671142578984 .367980957 980.5737915039976 .7808837891972 .9860229492969 .1840820312965 .3706054688 961.5394287109957 .6848144531953 .8004760742949 .8800048828945 .9174194336 941.9061889648937 .8405151367933 .7141113281929 .5216064453925 .2573242188 920.9168701172916 .4957275391911 .9904785156907 .3978881836902 .7172241211 897.9467773438 893.0886230469 888.1434936523 883.1171264648 878.0139160156 
872.8436889648867 .6154174805862 .344909668857 .0474243164851 .7412109375 846.4398193359841 .1688842773835 .9448242188830 .8082275391825 .7921142578 820.9337768555816 .2642822266811 .8477172852807 .7501220703803 .999206543 800.6494750977797 .7094726562795 .2169189453793 .2963867188792 .1552124023 791.4963989258790 .9998779297790 .6303710938790 .2512817383789 .7526245117 789.0844116211788 .2725830078787 .2355957031786 .108215332784 .9450073242 783.8427734375783 .0153198242782 .4365844727782 .1563110352782 .1646118164 782.4591064453782 .9827270508783 .6865844727784 .5042724609785 .36328125 786.2329101562787 .0266113281787 .7233886719788 .2667236328788 .6593017578 788.8803710938788 .9401855469788 .8353881836788 .5800170898788 .1806030273 787.6547851562787 .0150756836786 .2794799805785 .4622192383784 .5784301758 783.6353759766782 .6892700195781 .8076782227780 .8524169922779 .7000732422 778.3690185547776 .9041748047775 .2838134766773 .4694213867771 .4810791016 769.3090209961766 .966003418764 .5092163086761 .9893188477759 .4334106445 756.891784668754 .3911132812751 .9569702148749 .6577758789747 .5352172852 745.6583251953744 .0670776367742 .7863769531741 .8331298828741 .23828125 741.0374755859741 .2833251953742 .0034179688743 .2161254883744 .9412231445 747.2135009766749 .9739990234753 .2352905273756 .9268798828760 .9807739258 765.5454101562770 .6452026367776 .30078125782 .6862792969789 .614074707 797.2982177734804 .3090820312808 .8906860352815 .7200927734829 .117980957 845.4738769531861 .424621582877 .5720214844893 .4661254883911 .3248901367 933.0869140625955 .3499755859974 .2993164062993 .21179199221014 .520019531 1026.9229736331019 .260986328999 .1188964844973 .8729248047932 .9509277344 866.8306274414801 .2335205078763 .5051879883738 .4912719727713 .4580078125 688.3557128906661 .5651245117636 .825378418618 .1094970703601 .580871582 583.3005981445562 .0906982422536 .045715332510 .804107666491 .4859008789 475.511505127461 .8893127441448 .7280883789433 .8547058105419 .4432983398 407.0180969238396 .1936035156386 .9867858887379 .5805053711373 .87109375 368.6424865723362 .933013916357 .4945068359353 .3380126953349 .9750976562 346.809387207343 .7450866699340 .5234069824336 .9472045898332 .7015991211 328.1034851074323 .4443969727318 .7311096191314 .0534057617309 .4014892578 304.7940063477300 .2286987305295 .7117919922291 .2668151855286 .8981933594 282.595703125278 .3796081543274 .0947875977269 .604888916265 .000793457 260.328704834255 .5581970215250 .6694946289245 .7153015137240 .7369995117 235.7015075684230 .5621032715225 .3885040283220 .2216033936215 .0758056641 210.0845947266204 .7832946777198 .8495941162192 .4093017578185 .1732940674 177.5139007568169 .3264007568161 .3110046387154 .49609375148 .7277069092 144.4492950439141 .5294036865139 .9893035889139 .5735015869139 .991897583 141.0500946045142 .4891967773144 .1351928711145 .8079071045147 .1862030029 147.9156036377148 .6360931396149 .7882995605150 .587097168150 .0930023193 147.9107971191143 .4261016846137 .6555938721131 .524307251125 .6445007324 120.8973007202116 .7544021606112 .8694992065109 .2807998657105 .9787979126 102.9672012329100 .258300781297 .821571350195 .6391983032293 .66780853271 91.8659210205190 .1885681152388 .5781326293987 .0260086059685 .49244689941 83.9763183593882 .4496536254980 .9278030395579 .4202880859477 .93245697021 76.4747161865275 .048683166573 .660438537672 .3103332519571 .00173950195 
69.7356109619168 .5147323608467 .3435134887766 .2260971069365 .17581176758 64.2025909423863 .3077888488862 .5029411315961 .779430389461 .13750076294 60.5698394775460 .0622406005959 .6120910644559 .2122993469258 .86080932617 58.5541801452658 .2776985168558 .013809204157 .7795906066957 .58815002441 57.4421501159757 .3452110290557 .3003311157257 .3102302551357 .37897872925 57.5100593566957 .7100791931257 .9844894409258 .3460388183658 .80371856689 59.3850708007860 .0980911254961 .0492897033762 .3474502563563 .88425064087 65.5870971679767 .3669433593869 .1625823974670 .7739105224672 .07231140137 73.0217895507873 .4433670043973 .4839935302773 .1548233032272 .55906677246 71.9028930664171 .2101516723670 .56166839669 .9483337402369 .38349151611 68.8640594482468 .3924102783267 .9570693969767 .5453262329167 .15557861328 66.780830383366 .422157287666 .0771865844765 .7463836669965 .42881774902 65.1245117187564 .8328933715864 .5536270141664 .2861862182664 .03014373779 63.7849082946863 .5500984191963 .3252105712963 .1098709106462 .90364074707 62.7062797546462 .5174713134862 .3371391296462 .1651382446362 .00156021118 61.8464088439961 .6998291015661 .5619697570861 .432899475161 .31275939941 61.2015609741261 .0993385314961 .0059814453160 .9214286804260 .84548187256 60.7779808044460 .7186393737860 .6672210693460 .6234207153360 .58692932129 60.5574188232460 .5345306396560 .5179710388260 .5073394775460 .50231933594 60.5025405883860 .5077018737860 .5174293518160 .5314483642660 .54943084717 60.5711212158260 .5961799621660 .6244316101160 .6555709838960 .68941879272 60.7256698608460 .7641410827660 .8053092956560 .85163879395

1082.9849853521078 .8759765621074 .7729492191070 .6800537111066 .595947266 1062.5229492191058 .4589843751054 .4060058591050 .3630371091046 .329956055 1042.3079833981038 .2960205081034 .2939453121030 .3020019531026 .317993164 1022.3449707031018 .3800048831014 .424011231010 .4760131841006 .536987305 1002.606994629998 .684387207994 .7691040039990 .8607177734986 .9567260742 983.0557861328979 .1541748047975 .2493286133971 .3358764648967 .4099731445 963.4652709961959 .4970092773955 .4984741211951 .4641113281947 .3875732422 943.2634277344939 .0855102539934 .8483886719930 .546875926 .1760864258 921.7318725586917 .2103271484912 .608581543907 .9244995117903 .1574707031 898.3068237305 893.3751220703 888.3643188477 883.2805175781 878.1286010742 872.9201049805867 .6633300781862 .3760986328857 .0698242188851 .7705078125 846.4948120117841 .2684936523836 .1005859375831 .037109375826 .1085205078 821.3441162109816 .7581787109812 .4141235352808 .3745727539804 .6544189453 801.2952880859798 .334777832795 .8723144531793 .8776245117792 .3782958984 791.2788696289790 .4573974609789 .7946166992789 .1422119141788 .4133300781 787.5338745117786 .5482177734785 .4282836914784 .249206543783 .0372924805 781.8698120117780 .9105224609780 .1419067383779 .6320800781779 .3704833984 779.3643798828779 .5678100586779 .9329833984780 .4229736328780 .9774780273 781.5676269531782 .1060180664782 .5866699219782 .9520874023783 .2034301758 783.3120117188783 .2850952148783 .11328125782 .8079833984782 .3726196289 781.8208007812781 .1619873047780 .4119873047779 .5833129883778 .6898803711 777.7493896484776 .7598876953775 .7291870117774 .6021728516773 .3563842773 771.938293457770 .338684082768 .5629272461766 .612121582764 .4879150391 762.1859130859759 .7307739258757 .1729125977754 .5521850586751 .9038696289 
749.268371582746 .6729125977744 .1494750977741 .7476806641739 .5145874023 737.5156860352735 .7824707031734 .3405761719733 .2230224609732 .4619140625 732.0850219727732 .1196289062732 .6055297852733 .5722045898735 .0277099609 736.9998168945739 .4428100586742 .356628418745 .6887207031749 .37890625 753.3809814453757 .6649780273762 .4766235352768 .1486206055774 .5509033203 782.2459716797789 .4978027344794 .2651977539800 .2655029297810 .5618896484 823.200378418836 .5648193359850 .8765258789865 .9244995117882 .5073852539 900.8093261719920 .3013916016938 .116027832956 .9251098633980 .0316162109 996.190612793992 .5963134766980 .0681762695971 .8433227539948 .8416748047 891.9099121094830 .4426879883794 .4357299805766 .9193725586737 .9689941406 710.4611816406682 .8510742188656 .75633 .8193969727613 .2808227539594 .2327880859 574.3770751953550 .3538208008525 .9210205078503 .937713623484 .7864990234 470.0159912109456 .366607666440 .3822021484425 .0816955566412 .9317016602 402.5463867188392 .8270874023384 .4497070312377 .6181030273371 .5700073242 365.9985046387360 .8948059082356 .5392150879352 .7384033203349 .1253051758 345.637512207341 .9627075195338 .0729980469333 .8176879883329 .3266906738 324.7150878906320 .0286865234315 .3662109375310 .7164916992306 .1211853027 301.5823059082297 .1052856445292 .7074890137288 .3873901367284 .1191101074 279.9436950684275 .6701965332271 .1057128906266 .4060058594261 .6713867188 256.8485107422251 .8977966309246 .9078979492241 .9644012451236 .9873046875 231.8898925781226 .7303924561221 .504699707216 .2819976807211 .275100708 206.1107025146200 .4606933594194 .5028076172188 .0637054443181 .0345001221 172.8616943359164 .6031036377157 .4346923828151 .2026977539146 .4949951172 143.0762023926141 .050201416140 .1667938232140 .1365966797140 .7855072021 141.8350982666143 .1264953613144 .4617004395145 .7053070068146 .6988067627 147.5388946533148 .112197876148 .1502075195147 .0736999512144 .8182067871 141.1371002197136 .5099945068131 .4575958252126 .3140029907121 .6088027954 117.2603988647 113.3298034668 109.7322006226106.4304962158 103.4195022583 100.732597351198 .3339385986396 .2080993652394 .3095169067492 .59211730957 90.9974670410289 .4522018432687 .9525833129986 .4412536621184 .93184661865 83.39217376709 81.84631347656 80.31951904297 78.81371307373 77.34358978271 75.9088363647574 .5160827636773 .164337158271 .857002258370 .5944519043 69.3794479370168 .2161636352567 .1077117919966 .0640106201265 .09371948242 64.1957778930763 .3767700195362 .6330108642661 .9666290283261 .37181091309 60.8373603820860 .3617286682159 .9364509582559 .558319091859 .21940994263 58.9159507751558 .6409606933658 .4000511169458 .1964187622158 .03551864624 57.9220314025957 .8587188720757 .8489799499557 .8954696655358 .00162887573 58.1722412109458 .4123001098658 .7326698303259 .1394691467359 .66342163086 60.2899284362861 .1721305847262 .4396514892663 .9844818115265 .71130371094 67.559989929269 .4822311401471 .2975387573272 .8489837646573 .89935302734 74.2231826782274 .017723083573 .4805831909272 .749588012771 .9974899292 71.2457733154370 .5562667846769 .9261703491269 .3572998046968 .84922027588 68.3916320800867 .9770431518667 .5834426879967 .2137603759866 .8557434082 66.5131530761766 .1813125610465 .8623809814565 .5542373657265 .25803375244 64.9725036621164 .6981582641664 .4339904785264 .1801834106463 .93592071533 63.7012214660663 .475448608463 .2585906982463 .0501403808662 .85013961792 
62.6582412719762 .4745712280362 .2989501953162 .1316184997661 .97253036499 61.8219413757361 .6799011230561 .5465888977161 .4220504760761 .30633926392 61.1994400024461 .1012992858961 .0117683410660 .9307403564560 .85800170898 60.7933082580660 .7364006042560 .6870307922460 .6448402404860 .60956954956 60.5808410644560 .5583686828660 .5417709350660 .5307617187560 .52494049072 60.5240516662660 .5276985168560 .5356483459560 .5475502014260 .56315994263 60.582168579160 .6043701171960 .6294898986860 .6573486328160 .68762969971 60.7204093933160 .7549285888760 .79201889038 1087.538940431083 .3649902341079 .1910400391075 .0300292971070 .876953125 1066.7330322271062 .5970458981058 .4709472661054 .3530273441050 .244995117 1046.1450195311042 .0539550781037 .9720458981033 .8969726561029 .831054688 1025.7709960941021 .7189941411017 .674011231013 .6350097661009 .603027344 1005.5770263671001 .557006836997 .542175293993 .5319824219989 .5244140625 985.5178833008981 .5093994141977 .4959106445973 .4730224609969 .4365234375 965.3809814453961 .3012695312957 .1917114258953 .046081543948 .8596191406 944.6259155273940 .3400878906935 .9965820312931 .5911254883927 .1187133789 922.5764160156917 .9602050781913 .2686157227908 .499206543903 .6527709961 898.7288208008893 .7308959961888 .661315918883 .5270996094878 .3338012695 873.0928955078867 .8140869141862 .5136108398857 .2056274414851 .9135131836 846.6567993164841 .4597167969836 .3394165039831 .3309936523826 .4650878906 821.7659301758817 .2564697266812 .9788818359808 .9813842773805 .2827758789 801.9182128906798 .9360961914796 .4019775391794 .2536010742792 .5064086914 791.0836181641789 .940612793788 .9735717773788 .0316162109787 .0601196289 785.9777832031784 .8306884766783 .6008300781782 .3408813477781 .0621948242 779.8278198242778 .7410888672777 .8106079102777 .1010131836776 .6005859375 776.3280029297776 .23828125776 .3051147461776 .4921264648776 .7587890625 777.0693969727777 .3629760742777 .6215820312777 .7994995117777 .8909301758 777.866394043777 .7293701172777 .466796875777 .0878295898776 .5908813477 775.9882202148775 .2847290039774 .4932861328773 .6226196289772 .6848754883 771.6915283203770 .6190795898769 .4677734375768 .2105102539766 .8289794922 765.2921142578763 .5635986328761 .6561279297759 .5767211914757 .3328857422 754.9193725586752 .3704223633749 .720703125747 .0114746094744 .282409668 741.5640258789738 .8878173828736 .2872924805733 .8063964844731 .4841918945 729.3739013672727 .5081787109725 .9312133789724 .6630249023723 .7324829102 723.1679077148723 .0067749023723 .2709960938723 .9931030273725 .1796264648 726.8530883789728 .9907226562731 .5936889648734 .6448974609738 .1729736328 741.7642822266744 .9412841797748 .6403808594753 .7824707031759 .8427124023 766.5913696289773 .2249755859778 .6486206055784 .6104736328793 .1174926758 803.0875244141814 .022277832825 .9202270508838 .104675293851 .3822021484 866.553527832883 .6448974609902 .2963256836922 .0972900391942 .7117919922 958.8054199219964 .0836791992963 .55078125960 .0889892578945 .4138183594 910.1815185547866 .3776245117826 .940612793790 .0278930664757 .0532836914 727.2465209961699 .9102172852673 .4783935547646 .8657226562622 .4984130859 602.3605957031583 .0177001953560 .2714233398536 .1655883789512 .3037719727 491.1057128906476 .3431091309463 .1155090332446 .5241088867430 .5220947266 418.1123046875407 .5848999023397 .7941894531388 .9967956543381 .504486084 
375.0011901855369 .1471862793363 .9630126953359 .432800293355 .3100891113 351.3905029297347 .5506896973343 .5375061035339 .3793945312334 .9590148926 330.4140930176325 .8221130371321 .1770019531316 .5299987793311 .8908081055 307.2927856445302 .7632141113298 .3335876465293 .9811096191289 .6807861328 285.4060974121281 .157409668276 .8176879883272 .287689209267 .6311950684 262.8859863281258 .0490112305253 .1067962646248 .1239929199243 .161895752 238.1723937988233 .103805542227 .9712982178222 .7794036865217 .571395874 212.4398956299 207.2483062744 201.879699707 196.307800293 190.3565063477 183.6239013672175 .4250946045166 .9732055664159 .4031982422152 .7843933105 147.7003936768143 .9237976074141 .5717010498140 .3786010742140 .0532989502 140.408203125141 .19090271142 .2402954102143 .3356018066144 .4430999756 145.4149932861146 .1029968262146 .3894042969146 .0010070801144 .6555938721 142.4835968018139 .2144012451135 .2906036377130 .9472045898126 .3279037476 121.895401001117 .629699707113 .6911010742110 .0805969238106 .7664031982 103.7473983765101 .082801818898 .7372817993296 .6899337768694 .88934326172 93.2819824218891 .7894668579190 .3355026245188 .8991470336987 .40627288818 85.8868865966884 .3246917724682 .7436370849681 .1864089965879 .65741729736 78.1709671020576 .7268066406275 .3288497924873 .9766311645572 .67134094238 71.4141464233470 .2062988281269 .0517196655367 .9532470703166 .91703796387 65.949501037665 .0493011474664 .2207565307663 .4617195129462 .77476882935 62.1548004150461 .5954895019561 .0932502746660 .6416091918960 .23559951782 59.8687095642159 .5407600402859 .2463912963958 .9895286560158 .76972961426 58.5910606384358 .4586906433158 .3749198913658 .3431587219258 .36552047729 58.4450416564958 .5856094360458 .7915916442959 .0717201232959 .43260955811 59.8954010009860 .4603691101161 .2661094665562 .4281196594263 .87668991089 65.5439605712967 .3847274780369 .3607864379971 .3947830200273 .49131011963 74.9164886474674 .8813400268674 .1580886840873 .3888397216872 .55742645264 71.7687301635771 .0175170898470 .3416213989369 .7332763671969 .19415283203 68.716239929268 .2900085449267 .9042510986367 .5425186157267 .20115661621 66.8690872192466 .5479736328166 .2354202270565 .9321365356465 .63768005371 65.3522872924865 .0759429931664 .8085403442464 .5499572753964 .30003356934 64.0585174560563 .8252716064563 .6001014709563 .3828811645563 .17348098755 62.9718704223662 .7779884338462 .5918998718362 .413650512762 .24338150024 62.0812301635761 .9273490905861 .7819099426361 .6449813842861 .51670074463 61.397041320861 .2860488891661 .1836090087961 .0896492004461 .00397872925 60.9264602661160 .8568305969260 .7948608398460 .7402687072860 .69277954102 60.652069091860 .6178398132360 .5897598266660 .5674896240260 .55075073242 60.5391693115260 .5324707031260 .5303001403860 .5323905944860 .53842926025 60.5481605529860 .5613098144560 .5776481628460 .5969314575260 .61896896362 60.6434402465860 .6701583862360 .6997108459560 .7343788147 1092.0710449221087 .8270263671083 .5880126951079 .3570556641075 .134033203 1070.9189453121066 .711059571062 .5109863281058 .3189697271054 .134033203 1049.9580078121045 .7879638671041 .6251037 .4689941411033 .3189697271029 .173950195 1025.035034181020 .9010009771016 .7719726561012 .6469726561008 .526977539 1004.4099731451000 .29699707996 .1859741211992 .0759887695987 .9655761719 983.8513793945979 .7313232422975 .6005859375971 .455871582967 .2916259766 
963.1032714844958 .8850097656954 .6317749023950 .3380737305945 .9987182617 941.6087036133937 .1632080078932 .6580200195928 .0891113281923 .4536132812 918.7484130859913 .9722900391909 .1235961914904 .2036132812899 .2125244141 894.1546020508889 .032409668883 .8538818359878 .6245117188873 .3569946289 868.0601196289862 .7517700195857 .4443969727852 .162109375846 .9196777344 841.7470703125836 .6618041992831 .6962280273826 .8712768555822 .2183837891 817.7631225586813 .5336914062809 .5609741211805 .8704223633802 .496887207 799.4636230469796 .8239135742794 .5173950195792 .5548706055790 .8674926758 789.4252929688788 .1439819336786 .9127197266785 .69921875784 .4274291992 783.1256713867781 .765625780 .3955078125779 .0313110352777 .7144775391 776.5161743164775 .4448242188774 .5634765625773 .8554077148773 .3422851562 772.9918823242772 .7885131836772 .7022094727772 .6942749023772 .741027832 772.7883300781772 .8250732422772 .8035888672772 .7219238281772 .5457763672 772.2797241211771 .9058227539771 .4318237305770 .8519287109770 .1754150391 769.4044799805768 .5474243164767 .6096191406766 .5941772461765 .5122070312 764.3361206055763 .0650024414761 .6738891602760 .1566162109758 .4838867188 756.6331787109754 .6077270508752 .4118041992750 .0562133789747 .5477294922 744.9163818359742 .190612793739 .4075927734736 .6044921875733 .8123168945 731.0629882812728 .3927001953725 .8450927734723 .4481811523721 .2379150391 719.2559814453717 .5531005859716 .1436767578715 .0477905273714 .3029785156 713.9501953125714 .0028076172714 .483215332715 .4047241211716 .7883300781 718.6234130859720 .9193725586723 .6397705078726 .950012207730 .19921875 732.4901123047735 .262878418739 .9724121094745 .5358276367751 .1552124023 757.0277099609763 .0653076172769 .4091186523776 .6431274414784 .5745239258 793.4553833008802 .9371948242812 .0903930664822 .3466796875834 .5698242188 849.3654174805 867.8920288086 887.6165771484904.4948120117919.8270263672 933.8322753906942 .5430297852940 .3939819336930 .1525878906916 .0366821289 891.3422851562850 .9575805664806 .7395019531770 .7136230469739 .2352294922 712.5477294922687 .3389282227658 .7667236328631 .8447265625610 .5260009766 590.6829833984568 .3062744141544 .8391113281520 .078918457497 .6052856445 482.8714904785469 .8806152344452 .7887878418436 .3693847656423 .5286865234 412.4638061523402 .3407897949393 .2828063965385 .3605041504378 .4201965332 372.3147888184366 .9392089844362 .2221069336357 .8940124512353 .6936035156 349.5487976074345 .2211914062340 .7815856934336 .1502990723331 .4684143066 326.8377990723322 .2012023926317 .5582885742312 .9277038574308 .3388977051 303.8181152344299 .422088623295 .0896911621290 .7825927734286 .4749145508 282.1346130371 277.7355041504 273.2738037109 268.700012207 263.9736022949 259.1405944824254 .2265930176249 .2648925781244 .2740020752239 .2505950928 234.1849060059229 .0791015625223 .9402008057218 .7805023193213 .5782928467 208.374206543203 .2519989014197 .9104003906192 .1127929688185 .4757995605 177.1734008789168 .4766998291160 .5039978027153 .4783935547148 .167098999 144.2584075928141 .7713928223140 .3818054199139 .8468017578139 .9918060303 140.5863952637141 .479598999142 .4317016602143 .4006958008144 .2579040527 144.800201416144 .8390960693144 .2472991943142 .7769012451140 .629196167 137.5771942139134 .0182037354130 .0928955078125 .9255981445121 .8649978638 117.7901992798113 .9136962891110 .2376022339106 .8989028931103 .9091033936 
101.299896240299 .041580200297 .0894775390695 .4029464721793 .90866088867 92.5458831787191 .2183227539189 .8574676513788 .3705978393686 .80709075928 85.2005920410283 .58705902182 .0025634765680 .4531707763778 .95240020752 77.4996795654376 .0976333618274 .7458267211973 .4442596435572 .1939163208 70.9950103759869 .8505935668968 .7625427246167 .7342605590866 .76982879639 65.8687362670965 .0345535278364 .2650527954163 .5611495971762 .91968917847 62.3359489440961 .8074111938561 .3277206420960 .8940696716360 .49962997437 60.145790100159 .8281707763759 .54965972959 .3090705871659 .10985946655 58.9562606811558 .84960937558 .7940292358458 .7904014587458 .84254074097 58.9527397155859 .1253089904859 .3684501647959 .686241149960 .10660934448 60.6219787597761 .3424491882362 .3349800109963 .6078796386765 .12457275391 66.8701324462968 .8252792358470 .9139709472773 .3750076293975 .10050964355 74.8005981445373 .7299499511772 .8937683105572 .0394668579171 .26989746094 70.5755462646569 .9470977783269 .3986129760768 .9094009399468 .48464202881 68.101562567 .7582397460967 .4350967407267 .1298065185566 .82791137695 66.5336380004966 .2436294555765 .9598464965865 .6815567016665 .40986633301 65.144668579164 .8864517211964 .6350631713964 .390769958564 .15337371826 63.9230804443463 .6996917724663 .4834213256863 .274131774963 .07205963135 62.8771400451762 .6896591186562 .509620666562 .337329864562 .17287063599 62.0164794921961 .8682708740261 .7284088134861 .5969505310161 .47394943237 61.359371185361 .2531585693461 .1552009582561 .0653800964460 .98348999023 60.9093399047960 .8426704406760 .7832603454660 .7307815551860 .6849899292 60.6455497741760 .612171173160 .5845298767160 .5623397827160 .54523849487 60.5329818725660 .5251884460460 .5216598510760 .522041320860 .52611160278 60.5335693359460 .5442504882860 .5578613281260 .5742416381860 .59307861328 60.6144409179760 .6375885009860 .66333007812 1096.5789794921092 .2719726561087 .9620361331083 .6629638671079 .369995117 1075.0830078121070 .8029785161066 .5300292971062 .2629394531058 .003051758 1053.7490234381049 .51045 .2569580081041 .0200195311036 .7869873051032 .557006836 1028.332031251024 .1099853521019 .8909912111015 .674011231011 .460021973 1007.247985841003.036987305998.8275756836994.6168212891990.4038696289 986.1859741211981 .9611206055977 .7247924805973 .473815918969 .2034301758 964.9086303711960 .584777832956 .2266235352951 .8292236328947 .387512207 942.8970947266938 .3533935547933 .7529296875929 .091796875924 .3679199219 919.5783081055914 .7227783203909 .7999267578904 .8115234375899 .7584228516 894.645324707889 .475402832884 .2567138672878 .9954833984873 .7039794922 868.3922119141 863.0764770508 857.7709960938 852.4959106445847.2695922852 842.1165771484837 .0584106445832 .1207275391827 .3267822266822 .7031860352 818.2753295898814 .0657958984810 .1010131836806 .4019775391802 .9990844727 799.9022216797797 .143371582794 .6787719727792 .5079956055790 .5775146484 788.862121582787 .296081543785 .8018798828784 .354675293782 .8900146484 781.4234008789779 .9306030273778 .4459838867776 .9818115234775 .571105957 774.2567138672773 .053527832772 .0081176758771 .1110839844770 .3817138672 769.7958984375769 .3458862305769 .0040283203768 .7435302734768 .5385131836 768.3522949219768 .167175293767 .9470825195767 .6829223633767 .3466796875 766.9368286133766 .4364013672765 .848815918765 .1666870117764 .3958129883 
763.5354003906762 .5902709961761 .5625760 .4512939453759 .2592773438757 .967590332 756.5681762695755 .0457763672753 .3895263672751 .5847167969749 .6096801758 747.4711303711745 .1663208008742 .7119750977740 .1165161133737 .4094848633 734.6146240234731 .7653808594728 .897277832726 .0397949219723 .2260742188 720.4904785156717 .8715209961715 .3955078125713 .098815918711 .0145263672 709.1887207031707 .6389770508706 .3936767578705 .4821166992704 .942199707 704.7863769531705 .0396118164705 .7083740234706 .8134155273708 .3378295898 710.2786865234712 .6049194336715 .3439941406718 .0708007812720 .3178710938 722.9902954102726 .9837036133731 .6972045898736 .7396850586742 .3201293945 748.3477783203754 .541015625760 .7211303711767 .1224975586774 .462890625 782.2916259766790 .2072753906798 .9907226562809 .1677856445821 .4010009766 835.9193725586851 .9439086914868 .6826171875885 .983581543902 .8532714844 914.8701782227916 .7388916016912 .6124267578904 .6068115234886 .6442871094 853.7274780273813 .6901245117776 .6990966797744 .4547729492719 .4743041992 696.2103271484669 .8577270508643 .9420776367621 .201171875599 .7974243164 577.530090332554 .6343994141530 .6834106445508 .4692077637491 .6368103027 476.558013916459 .724609375443 .7171936035430 .0133972168417 .8342895508 407.0004882812397 .4327087402389 .0946044922381 .8518981934375 .5773925781 370.0788879395365 .1622924805360 .6012878418356 .0947875977351 .6181030273 346.9985961914342 .2831115723337 .459197998332 .6377868652327 .8891906738 323.1778869629318 .4903869629313 .8489074707309 .290802002304 .8031005859 300.384185791296 .0161132812291 .687713623287 .3576049805282 .9981079102 278.6120910645274 .1908874512269 .6636047363264 .9356079102260 .0869140625 255.1835021973250 .2299041748245 .2427978516240 .2131958008235 .1392974854 230.0377044678224 .9114990234219 .7814025879214 .6604003906209 .5503997803 204.5346984863199 .2111053467193 .2776031494186 .4848937988178 .2070007324 169.4026947021160 .733505249153 .1029968262147 .8665008545144 .2095947266 141.7138977051140 .2234039307139 .5576019287139 .55909729140 .021697998 140.7955932617141 .6716003418142 .5558013916143 .304901123143 .717300415 143.5979003906142 .8569030762141 .3105010986139 .1224060059136 .1656951904 132.7723999023129 .0979003906125 .2897033691121 .6634979248117 .9197998047 113.9523010254110 .1029968262106 .762298584103 .8507995605101 .3529968262 99.2191085815497 .3897323608495 .8228530883894 .4523086547993 .23284912109 92.1151885986390 .8972167968889 .3470764160287 .6631469726686 .00112915039 84.3576812744182 .7550125122181 .1941604614379 .6846771240278 .22643280029 76.8227462768675 .4727478027374 .1765213012772 .9342117309671 .7455291748 70.61215972969 .5351104736368 .5157928466867 .5565185546966 .65689086914 65.818916320865 .0408020019564 .3228836059663 .6622695922963 .05643081665 62.5023498535261 .9955596923861 .5334701538161 .1113090515160 .72980880737 60.3862380981460 .082450866759 .8176994323759 .59487152159 .41691970825 59.2857017517159 .2045898437559 .1749114990259 .1996803283759 .28104019165 59.4220809936559 .6297607421959 .9086303710960 .2812004089460 .75819015503 61.3703193664662 .1316108703663 .131271362364 .4152297973665 .94848632812 67.7458724975669 .6831436157271 .7480392456173 .2038726806673 .22206115723 72.5585708618271 .8704986572371 .1406097412170 .4873428344769 .8904800415 69.3622970581168 .8982391357468 .4931793212968 .13979339667 .82584381104 
67.5400619506867 .2661666870167 .0011367797966 .7354507446366 .47132873535 66.2077865600665 .9460525512765 .6868820190465 .430938720765 .17919158936 64.9318466186564 .6895523071364 .4523773193464 .2207183837963 .99464035034 63.7744483947863 .5602493286163 .3523101806663 .1507911682162 .95594024658 62.7679595947362 .5871009826762 .4135704040562 .2476196289162 .08940887451 61.939170837461 .7969703674361 .6629600524961 .5371208190961 .4194984436 61.309989929261 .2085304260361 .114959716861 .0291404724160 .95085144043 60.879878997860 .8159713745160 .7588691711460 .7083091735860 .66397094727 60.6255798339860 .5928382873560 .5654487609960 .5430984497160 .52550888062 60.5123481750560 .5033988952660 .498329162660 .496929168760 .49890899658 60.5040893554760 .5122184753460 .5231094360460 .5364685058660 .55210113525 60.5706291198760 .59418869019 1101.0729980471096 .6939697271092 .3179931641087 .9489746091083 .58605957 1079.2290039061074 .8759765621070 .5300292971066 .1889648441061 .853027344 1057.5209960941053 .1949462891048 .8719482421044 .5529785161040 .238037109 1035.9239501951031 .6130371091027 .3039550781022 .995971681018 .689025879 1014.3820190431010 .075988771005 .7689819341001 .460998535997 .1511230469 992.8375854492988 .5178222656984 .1898193359979 .8499755859975 .4951782227 971.1207275391966 .7224731445962 .2955932617957 .8353881836953 .3372802734 948.7965698242944 .2094116211939 .5712890625934 .8792724609930 .1301269531 925.3220214844920 .4525146484915 .5219116211910 .5291748047905 .4771118164 900.3660888672895 .2022705078889 .9882202148884 .7332763672879 .4428710938 874.1306152344868 .8048095703863 .4830932617858 .1777954102852 .9102172852 847.6956787109842 .5593261719837 .5187988281832 .6005249023827 .82421875 823.2155151367818 .795715332814 .5864868164810 .6115722656806 .8854980469 803.4348754883800 .2551879883797 .3712158203794 .7443237305792 .3814697266 790.2293701172788 .2670288086786 .4448242188784 .7078857422783 .0385742188 781.3809814453779 .7490234375778 .1130981445776 .5037841797774 .9274291992 773.4080200195771 .9769287109770 .6434936523769 .4467773438768 .3759155273 767.4515991211766 .6527709961765 .9772949219765 .4019165039764 .9038696289 764.4647827148764 .0512695312763 .6511230469763 .2288208008762 .7791137695 762.272277832761 .7083129883761 .0668945312760 .3510742188759 .5499267578 758.6671142578757 .6989135742756 .6461181641755 .5100708008754 .2836914062 752.9691162109751 .5484008789750 .0189819336748 .362487793746 .5709838867 744.6331787109742 .5383911133740 .2888793945737 .8828735352735 .3369750977 732.662109375729 .8842163086727 .0253295898724 .1160888672721 .1884155273 718.2714233398715 .3978271484712 .598815918709 .9085083008707 .3555297852 704.9766235352702 .7976074219700 .8541870117699 .1715698242697 .783996582 696.713684082695 .9921875695 .6348266602695 .6682128906696 .0930175781 696.928527832698 .1422119141699 .7241210938701 .5986938477703 .7011108398 705.9763183594708 .3981933594711 .1870117188714 .5684814453718 .5299072266 723.141418457728 .3375244141734 .0405273438739 .7794189453745 .0479125977 750.3804931641756 .6314697266763 .4788818359770 .9630126953779 .0673217773 787.8156738281797 .4854125977807 .4381103516819 .5958251953835 .8942871094 853.9899291992870 .8795776367884 .458984375890 .1160888672889 .5017700195 883.1798706055868 .3223876953844 .4932861328813 .7709960938779 .9390869141 
747.9865722656724 .3184814453703 .1566772461679 .8712158203656 .2072143555 632.3502807617608 .8973999023586 .1898803711563 .8828735352541 .1040039062 519.6239013672501 .0945129395483 .9919128418467 .291595459451 .450592041 436.6101074219423 .1983032227411 .5643920898401 .4471130371392 .7271118164 385.2279052734378 .8067016602373 .2135925293368 .174407959363 .3977966309 358.5776062012353 .729888916348 .7864074707343 .8247070312338 .8037109375 333.8168029785328 .9094848633324 .0705871582319 .3111877441314 .6380004883 310.1028137207305 .6354980469301 .1824951172296 .7681884766292 .4142150879 288.0745849609283 .7262878418279 .3555908203274 .9602966309270 .4577026367 265.7290039062260 .8825073242255 .9956054688251 .0554046631246 .0767974854 241.053894043235 .9822998047230 .879699707225 .7595062256220 .6392059326 215.5680999756210 .5438995361205 .588394165200 .3208007812194 .2868041992 187.2942047119178 .9709014893170 .0160980225160 .7543945312152 .6036071777 147.4759979248144 .0133972168141 .4956054688139 .9685058594139 .2451019287 139.1697998047139 .5646972656140 .2749938965141 .1190032959141 .9586029053 142.6405029297142 .9817047119142 .8029937744142 .0213928223140 .4172058105 138.191696167135 .1405944824131 .7274017334128 .074798584124 .3519973755 121.0142974854117 .5089035034113 .5410995483109 .6564025879106 .4441986084 103.6844024658101 .336402893199 .3612289428797 .6581497192496 .21369934082 94.947410583593 .8294372558692 .8668899536191 .7649078369190 .16828918457 88.402763366786 .7215194702185 .0618896484483 .4485473632881 .88255310059 80.3669967651478 .9065475463977 .5030136108476 .1568527221774 .86744689941 73.6347427368272 .4574127197371 .3361587524470 .2707138061569 .26136016846 68.3088073730567 .4123687744166 .5729064941465 .7886886596765 .05905151367 64.3822021484463 .7554512023963 .1772689819362 .6432189941462 .15283966064 61.7016105651961 .2910690307660 .9184188842860 .5860481262260 .293800354 60.043949127259 .8394508361859 .6814308166559 .5740699768159 .51760101318 59.5159912109459 .5699615478559 .6827316284259 .8591117858960 .10317993164 60.4282302856460 .8603096008361 .3642196655361 .8874893188562 .56332015991 63.5132904052764 .7612533569366 .3458862304768 .0205764770569 .49845123291 70.5641098022570 .9629364013770 .875137329170 .5056533813569 .98146820068 69.5018310546969 .0559234619168 .6561737060568 .3070297241267 .99961090088 67.7314834594767 .4918518066467 .2704086303767 .048126220766 .8267288208 66.599052429266 .3676910400466 .1324691772565 .894950866765 .65657806396 65.4183197021565 .1815338134864 .9467926025464 .7149276733464 .48638153076 64.2616577148464 .041152954163 .8252601623563 .6143608093363 .40877914429 63.2089004516663 .0150184631362 .8275184631362 .646629333562 .47269821167 62.3059616088962 .1466598510761 .994979858461 .8510704040561 .71503067017 61.586910247861 .4667091369661 .3543891906761 .2498397827161 .15296936035 61.0635910034260 .9815406799360 .9066009521560 .8385696411160 .77714920044 60.7221183776960 .6731796264660 .6300811767660 .592491149960 .56016921997 60.532779693660 .5101013183660 .4917907714860 .4776306152360 .46731185913 60.4606399536160 .4573211669960 .4571990966860 .4599990844760 .46559143066 60.4736404418960 .484241485660 .4966201782260 .51161956787 1105.5439453121101 .1030273441096 .6569824221092 .2199707031087 .786010742 1083.3580322271078 .9329833981074 .5140380861070 .0980224611065 .687011719 
1061.279052734 1056.8740234381052.472045898 1048.0729980471043.675048828 1039.2790527341034 .8830566411030 .4870605471026 .0909423831021 .693969727 1017.2960205081012 .8969726561008 .495971681004 .09197998999 .6837768555 995.2711791992990 .8513793945986 .4224853516981 .9813842773977 .5247802734 973.0490112305968 .549621582964 .0223999023959 .4630126953954 .8673706055 950.2307739258945 .5501098633940 .8209228516936 .0413208008931 .2075195312 926.3189697266921 .3734130859916 .3715820312911 .3129272461906 .200378418 901.0355224609895 .8234863281890 .5684814453885 .2788696289879 .9616699219 874.6286010742869 .2896118164863 .9603271484858 .6541137695853 .3895263672 848.1837158203 843.0568237305 838.0288696289833.1207885742 828.3541870117 823.7490844727819 .3270263672815 .1049804688811 .1040039062807 .334777832 803.8168945312800 .5438842773797 .5286865234794 .7457275391792 .1928710938 789.8322753906787 .6417236328785 .5858154297783 .6254272461781 .7443237305 779.9014892578778 .1016235352776 .3228149414774 .5839233398772 .8884887695 771.2548217773769 .7019042969768 .2401123047766 .8944091797765 .6605834961 764.5527954102763 .5568847656762 .6715087891761 .8771972656761 .1583251953 760.4959716797759 .8668212891759 .2556152344758 .6356811523757 .9974975586 757.3176269531756 .5908203125755 .7998046875754 .9434814453754 .0106811523 753.0020141602751 .9113769531750 .7382202148749 .479309082748 .1284179688 746.6820068359745 .1292724609743 .462890625741 .671875739 .7457275391 737.6802978516735 .4658203125733 .1079711914730 .6038818359727 .9711303711 725.2194213867722 .3734130859719 .4528808594716 .4860229492713 .5017700195 710.5280151367707 .5966186523704 .7354125977701 .9776000977699 .3502197266 696.8870849609694 .6124267578692 .559387207690 .7526245117689 .2255859375 687.9987792969687 .1024780273686 .5494995117686 .3659057617686 .5490722656 687.1148071289688 .0283203125689 .2807006836690 .7813720703692 .4691162109 694.4600830078696 .7517700195699 .4114990234702 .5281982422706 .0787963867 710.2473144531714 .9340820312719 .9362792969724 .9650268555729 .6635742188 734.4616699219739 .9470825195746 .2235717773753 .5250854492761 .1292724609 768.4058227539775 .7443237305783 .8093261719793 .6530151367806 .0488891602 820.7067260742837 .0139770508851 .6658935547860 .633605957863 .7689819336 860.0424804688849 .9216918945833 .8433227539811 .9274291992783 .8068847656 754.8834228516731 .2634887695709 .9849853516689 .1287841797667 .1224975586 642.0040283203616 .4838256836593 .3591918945571 .366027832548 .7022705078 527.3997192383510 .0364074707493 .6104125977475 .7974853516458 .4818115234 442.5851135254428 .2087097168415 .9267883301405 .3840026855396 .2901916504 388.5132141113381 .8969116211376 .2164001465371 .2623901367366 .4634094238 361.199798584355 .8298950195350 .547088623345 .3293151855340 .1036071777 334.9312133789329 .8584899902324 .8828125320 .0343933105315 .3125915527 310.7330932617306 .2372131348301 .7770080566297 .3594970703292 .9896850586 288.6447143555 284.2976074219279.9237976074275.5003051758270.9801940918 266.3017883301261 .516204834256 .6561889648251 .7339019775246 .7662963867 241.7532043457236 .7071075439231 .6233978271226 .5077056885221 .3457946777 216.0946044922210 .9635925293206 .2368011475201 .311706543195 .7276000977 188.978302002180 .1992950439170 .7198028564161 .4445037842153 .3325958252 147.7911071777143 .9234924316141 .282699585139 .7129974365138 .9597930908 
138.8730926514139 .2570953369139 .9656982422140 .8105926514141 .6567993164 142.3500976562142 .7057952881142 .5424041748141 .7373962402140 .0785980225 137.7071075439134 .4936981201130 .8874053955127 .0742034912123 .2109985352 119.6229019165116 .0025024414112 .3156967163108 .8414001465105 .8986968994 103.3901977539 101.257896423399.4534072876 97.8997726440496.56111907959 95.3712921142694.2916107177793.28112792969 92.1367568969790.63530731201 88.97619628906 87.32613372803 85.68359375 84.0765533447382.50881195068 80.9946899414179 .5351181030378 .1360321044976 .7961578369175 .51611328125 74.2945632934673 .1302032470772 .0223007202170 .9697570800869 .97167205811 69.0274581909268 .1359100341867 .2966537475666 .5078735351665 .76851654053 65.0767593383864 .4307632446363 .8288993835463 .2684593200762 .74895095825 62.267860412661 .8261795043961 .4227294921961 .0595016479560 .73720932007 60.4581298828160 .2248191833560 .0390892028859 .9043083190959 .82162857056 59.7941818237359 .8227005004959 .9097290039160 .0563201904360 .26549911499 60.537948608460 .8858184814561 .2480010986361 .5746002197361 .93133926392 62.3562316894563 .1369590759364 .6216201782266 .2123413085967 .41356658936 68.3227691650468 .7718276977568 .9231872558668 .8342971801868 .56289672852 68.3073730468868 .0688018798867 .8516387939567 .6498565673867 .46015930176 67.2828979492267 .1187667846766 .9576416015666 .7890090942466 .61241912842 66.4241561889666 .2266387939566 .0210037231465 .8089523315465 .59275054932 65.373466491765 .1530685424864 .9321670532264 .7121276855564 .49339294434 64.2769088745164 .0630874633863 .8526992797963 .6461296081563 .44401168823 63.2467117309663 .0547981262262 .868579864562 .6885490417562 .51494979858 62.3481788635362 .1884117126562 .0359611511261 .8908805847261 .75339889526 61.623470306461 .5011901855561 .3864593505961 .2792701721261 .17947006226 61.0869293212961 .0014801025460 .9229316711460 .8510704040560 .78567123413 60.7264709472760 .6732215881360 .6256484985460 .5834884643660 .54647064209 60.5143089294460 .486740112360 .4635009765660 .444339752260 .42897033691 60.4172096252460 .4087905883860 .4035301208560 .4012107849160 .4016418457 60.4045410156260 .4097290039160 .417831420960 .43088150024

1110.0100097661105 .4949951171100 .9830322271096 .4749755861091 .972045898 1087.4730224611082 .9770507811078 .4840087891073 .9940185551069 .508056641 1065.0240478521060 .5419921881056 .0610351561051 .582031251047 .103027344 1042.6230468751038 .1440429691033 .6619873051029 .1800537111024 .693969727 1020.2059936521015 .7160034181011 .2210083011006 .7230224611002 .218994141 997.708984375993 .1912231445988 .6635742188984 .1232299805979 .5673217773 974.9921875970 .3942871094965 .7694702148961 .1137084961956 .4232788086 951.6939697266946 .9227294922942 .1058959961937 .2415771484932 .3270263672 927.3613891602922 .3430786133917 .2734985352912 .1520996094906 .9824829102 901.7661132812896 .5090942383891 .2149047852885 .8928833008880 .5491943359 875.1964111328 869.8430786133 864.5054931641 859.1953125853.9312744141 848.7282714844843 .6063842773838 .5828857422833 .6782226562828 .9108886719 824.2993774414 819.8626708984815.6149291992 811.5739746094807.7459716797 804.1484985352800 .7706298828797 .6251220703794 .6860961914791 .9564208984 789.4005737305787 .0034179688784 .736328125782 .569519043780 .491394043 778.4671020508776 .5028076172774 .5759887695772 .7026977539770 .8806152344 
769.1240234375767 .4462890625765 .8527832031764 .3637695312762 .9730224609 761.6945800781760 .5145874023759 .4340820312758 .4364013672757 .5092163086 756.637512207755 .8001708984754 .9860229492754 .1697998047753 .3444824219 752.4865722656751 .5925292969750 .6431884766749 .6372070312748 .5618896484 747.4155883789746 .19140625744 .8850708008743 .4935302734742 .0076904297 740.4252929688738 .734375736 .9312133789735 .0043945312732 .9473266602 730.7562255859728 .4257202148725 .9611206055723 .3621826172720 .6447143555 717.8184204102714 .9052734375711 .9243164062708 .9008789062705 .8615112305 702.8325195312699 .8436889648696 .9213867188694 .0969238281691 .3955078125 688.848815918686 .4802856445684 .3225708008682 .3975219727680 .736328125 679.3585205078678 .2932739258677 .55078125677 .1558227539677 .1010131836 677.4014282227678 .0214233398678 .9616699219680 .1608886719681 .5509033203 683.2606201172685 .330078125687 .7827148438690 .6668701172693 .9998779297 697.8765869141702 .0269775391706 .196472168710 .383605957714 .628112793 719.1290283203724 .1422119141729 .866027832736 .8295288086743 .8800048828 749.8225708008755 .8635864258763 .3861083984771 .8585205078780 .2219848633 790.6243896484804 .8961791992818 .9686889648829 .1090698242834 .891418457 833.733215332828 .0916748047820 .0148925781806 .3482055664784 .8964233398 760.2050170898737 .0999145508715 .1967773438695 .8807983398675 .3740844727 649.5375976562623 .1226806641600 .3253173828578 .4359130859555 .4221801758 533.8903198242517 .6774291992502 .5610046387483 .7734069824465 .1116027832 448.4212036133433 .2449035645420 .3750915527409 .412902832399 .883605957 391.8084106445384 .9418029785379 .0473022461374 .0946044922369 .2432861328 363.6185913086357 .8479919434352 .2854919434346 .816986084341 .3504943848 335.9555053711330 .6942138672325 .5658874512320 .6279907227315 .8407897949 311.202911377306 .6718139648302 .2106018066297 .8055114746293 .4324951172 289.080291748284 .7271118164280 .3476867676275 .8953857422271 .3591918945 266.7398986816262 .0198059082257 .1929016113252 .2911987305247 .3258972168 242.3247070312237 .3081970215232 .2599945068227 .1584014893221 .9859008789 216.5926055908211 .3554992676206 .8099975586202 .1150054932196 .8822937012 190.362701416181 .1869049072171 .2776947021162 .1273040771154 .1132965088 148.1739044189143 .8930969238141 .1356048584139 .5270996094138 .7778930664 138.7162017822139 .1392974854139 .8896942139140 .7830963135141 .6847991943 142.466003418142 .9214019775142 .8975982666142 .1853027344140 .541305542 138.0971069336134 .5805969238130 .6237030029126 .3295974731121 .9850006104 117.9785995483114 .1696014404110 .8700027466107 .9393997192105 .3750991821 103.1647033691101 .261802673399 .6321411132898 .2095184326296 .95536804199 95.8061828613394 .7030868530393 .5720596313592 .3440628051890 .94947052002 89.43488311768 87.85146331787 86.23667907715 84.64350128174 83.07917785645 81.5698699951280 .1146926879978 .7224502563577 .3913421630976 .1223526001 74.9136962890673 .7635192871172 .6702194213971 .6316528320370 .64605712891 69.7117004394568 .8266525268667 .9893264770567 .1979904174866 .45049285889 65.7458724975665 .0813903808664 .4570999145563 .869838714663 .32102966309 62.8081893920962 .333709716861 .8967895507861 .5000991821361 .14524078369 60.8342399597260 .5706787109460 .3555793762260 .1934814453160 .084400177 60.0326004028360 .0368118286160 .1008110046460 .2189483642660 .39567947388 
60.6091804504460 .8681182861361 .0999794006361 .2681503295961 .39804840088 61.3961410522561 .7462997436563 .0858192443864 .5905532836965 .58959960938 66.3184509277366 .6879730224666 .8986434936567 .0226135253967 .0654296875 67.086631774967 .0604934692467 .0295333862366 .973358154366 .89962005615 66.8107070922966 .7193298339866 .6157379150466 .4990692138766 .36625671387 66.2172775268666 .053436279365 .8779067993265 .6918716430765 .49870300293 65.2993011474665 .0962905883864 .8902969360464 .6830825805764 .47524261475 64.2680130004964 .061943054263 .8580093383863 .6567802429263 .45901107788 63.2652397155863 .0760993957562 .8920402526962 .7135581970262 .54103851318 62.3748512268162 .2152786254962 .0625686645561 .9169006347761 .77841949463 61.647178649961 .5232315063561 .4065513610861 .2970809936561 .19472885132 61.0993804931661 .0108718872160 .9290313720760 .8536682128960 .78456115723 60.7214889526460 .6641807556260 .6124191284260 .5659217834560 .52444839478 60.487720489560 .4555091857960 .4275207519560 .4035606384360 .38333892822 60.3666801452660 .3533401489360 .3431205749560 .3358306884860 .33127975464 60.3292083740260 .3296813964860 .3319396972760 .33681106567

1114.4520263671109 .8769531251105 .2950439451100 .7189941411096 .145996094 1091.5760498051087 .0080566411082 .4429931641077 .8800048831073 .318969727 1068.7590332031064 .1999511721059 .6409912111055 .082031251050 .522949219 1045.9620361331041 .3990478521036 .8339843751032 .2650146481027 .692993164 1023.1160278321018 .5349731451013 .9489746091009 .3579711911004 .760009766 1000.155029297995 .5413818359990 .917175293986 .2797241211981 .6267089844 976.9547729492972 .2608032227967 .541015625962 .7913818359958 .008972168 953.1896972656948 .330871582943 .4295043945938 .483581543933 .4910888672 928.4514770508923 .3635253906918 .2286987305913 .0473022461907 .8228149414 902.5573120117897 .2565917969891 .9248046875886 .5706787109881 .2011108398 875.8273925781870 .458984375865 .1102294922859 .7935180664854 .5252075195 849.3204956055844 .1967163086839 .1712036133834 .2609863281829 .484375 824.8563842773820 .3950195312816 .1107177734812 .0197143555808 .1251831055 804.4401245117800 .9562988281797 .6796875794 .5930786133791 .6926879883 788.9552001953786 .3651123047783 .9019775391781 .5432128906779 .2780151367 777.0817871094774 .9553222656772 .8826293945770 .871887207768 .9205932617 767.0380249023765 .231628418763 .5064697266761 .8740844727760 .3317871094 758.887878418757 .5330810547756 .2669067383755 .076171875753 .9514160156 752.8787841797751 .8425292969750 .8302001953749 .8231201172748 .8109741211 747.7758178711746 .7103881836745 .5991210938744 .4370117188743 .212097168 741.9207763672740 .5546264648739 .1088256836737 .5770874023735 .9530029297 734.2301025391732 .4011230469730 .4591064453728 .3983764648726 .2111816406 723.8975219727721 .4525146484718 .8834228516716 .1904296875713 .3889160156 710.4876708984707 .5076293945704 .4652709961701 .3848876953698 .2899780273 695.2055053711692 .1591186523689 .1754760742686 .2844238281683 .5095825195 680.8812255859678 .4219970703676 .1624145508674 .1232910156672 .3342285156 670.8123779297669 .5853271484668 .6614990234668 .0626831055667 .7825927734 667.8325805664668 .1845703125668 .8270263672669 .7338867188670 .8674926758 672.3162231445674 .1143188477676 .2824707031678 .8215942383681 .8939819336 685.795715332689 .7698974609693 .1370849609696 .4633178711700 .1641845703 
704.2479858398708 .7479858398713 .7916870117719 .6318969727725 .5941772461 731.0139770508736 .8275756836744 .2114257812751 .8543701172758 .8493041992 766.9423828125777 .8602905273788 .7896728516796 .3770751953801 .4976196289 803.7108764648803 .9927978516803 .0397949219796 .7185058594780 .6779174805 759.6929931641738 .6281738281717 .7930908203698 .9224853516678 .8593139648 654.5228881836629 .7636108398608 .3170166016587 .108581543563 .1804199219 540.2684936523522 .8275756836507 .0328063965489 .0036010742471 .0270080566 454.2373962402438 .5687866211424 .9349060059413 .2929992676403 .4320983887 395.0773925781387 .8989868164381 .6824951172376 .2860107422371 .0658874512 365.4125061035359 .6588134766353 .9202880859348 .2302856445342 .5134887695 336.8528137207331 .3823852539326 .0976867676321 .059387207316 .2121887207 311.5331115723306 .986114502302 .5227050781298 .124206543293 .7481079102 289.3854980469285.0202026367280.6416931152 276.2320861816 271.7442932129 267.1304931641262 .4161071777257 .6206970215252 .7404022217247 .7543029785 242.7411956787237 .7763977051232 .7958068848227 .7413024902222 .6275939941 217.4344940186212 .3553924561207 .6611022949202 .7277984619197 .1127929688 190.2696990967181 .2872009277171 .5628967285162 .0679016113153 .7174987793 147.9530944824143 .8954925537141 .1553955078139 .5493011475138 .8090057373 138.7816009521139 .2626037598140 .0953979492141 .084197998142 .1141052246 143.0458984375143 .7006988525143 .9270935059143 .4129943848141 .9062042236 139.3782958984135 .537902832131 .0363006592125 .9203033447120 .7977981567 116.5326004028112 .7852020264109 .6917037964107 .1633987427104 .9711990356 103.070098877101 .402397155899 .9391632080198 .6242065429797 .42180633545 96.2815017700295 .1414794921993 .9445037841892 .682342529391 .30256652832 89.8424682617288 .3018569946386 .7146072387785 .1398696899483 .58883666992 82.0892105102580 .642860412679 .2605667114377 .940567016676 .68491363525 75.4908981323274 .3566436767673 .2794113159272 .2563400268671 .28468322754 70.3616333007869 .4845275878968 .6507873535267 .8581466674867 .10408782959 66.3873214721765 .7055664062565 .0586624145564 .4448165893663 .86539840698 63.3198089599662 .8103981018162 .3381195068461 .9058494567961 .5163192749 61.1719818115260 .8765182495160 .6317710876560 .4417610168560 .30722045898 60.2314300537160 .2132301330660 .2546997070360 .3489303588960 .49655914307 60.6713485717860 .8718795776461 .0347290039161 .1032714843861 .12810897827 61.1309204101661 .4198188781762 .3684310913163 .4564094543564 .21732330322 64.711219787664 .7940979003964 .8759613037165 .2751235961965 .7161026001 65.9849929809666 .1479797363366 .2585525512766 .3174209594766 .33982086182 66.3311614990266 .3060607910266 .2588806152366 .1891326904366 .09752655029 65.9850082397565 .8539886474665 .7074966430765 .5475463867265 .37738800049 65.1984329223665 .0132980346764 .8229827880964 .6293563842864 .43327331543 64.2361526489364 .0386962890663 .8421287536663 .6470718383863 .45454025269 63.265071868963 .079521179262 .8983192443862 .7221488952662 .55131912231 62.3863792419462 .2275314331162 .0751609802261 .9293594360461 .79037857056 61.6582489013761 .5330810546961 .4148101806661 .3034591674861 .19890975952 61.1010894775461 .0098304748560 .9250183105560 .8464508056660 .77391815186 60.7072181701760 .6461296081560 .590408325260 .5398216247660 .49412155151 60.4530487060560 .4163894653360 .3838691711460 .3552894592360 .33041000366 
60.3090400695860 .2909507751560 .2759590148960 .2638702392660 .25450897217 60.2476196289160 .2430000305260 .2413291931260 .24448013306

1118.8959960941114 .245971681109 .5980224611104 .953002931100 .311035156 1095.6700439451091 .0310058591086 .3940429691081 .7569580081077 .121948242 1072.4870605471067 .8509521481063 .214965821058 .578002931053 .938964844 1049.296997071044 .6519775391040 .004028321035 .3509521481030 .692993164 1026.0290527341021 .3599853521016 .6840209961012 .002014161007 .312011719 1002.614013672997.9058837891993.1870727539988.4547729492983.7070922852 978.9407958984974 .1530761719969 .3406982422964 .5959 .628112793954 .7216186523 949.7780761719944 .7946166992939 .7702026367934 .7023925781929 .5916137695 924.4365234375919 .239074707913 .9998779297908 .7227783203903 .4094848633 898.0667724609 892.6981201172 887.3126220703 881.9165039062 876.5214233398 871.1358032227865 .7739257812860 .4467773438855 .1705932617849 .9586181641 844.8275146484839 .7927856445834 .8701171875830 .0756835938825 .4227294922 820.9271850586816 .5972290039812 .4475708008808 .4782714844804 .7017822266 801.108215332797 .7048950195794 .4739990234791 .4152832031788 .5075073242 785.7404174805783 .0971069336780 .5595703125778 .1201782227775 .7578735352 773.4746704102771 .2545166016769 .1049804688767 .0198974609765 .0067138672 763.0689086914761 .2088012695759 .4351196289757 .7435302734756 .1409912109 754.6182861328753 .1760253906751 .8021240234750 .4893188477749 .2255249023 747.9973144531746 .7943115234745 .5989990234744 .4036254883743 .1901245117 741.9525756836740 .6749267578739 .3524169922737 .9722290039736 .5296020508 735.0155029297733 .423828125731 .7482299805729 .9807739258728 .1165771484 726.1475830078724 .0687866211721 .8748168945719 .5607299805717 .1265869141 714.5698242188711 .8975830078709 .1116943359706 .2263183594703 .2498168945 700.2014160156697 .0969238281693 .9581298828690 .8067016602687 .6657714844 684.5612182617681 .5159301758678 .5579833984675 .7102050781673 .0012817383 670.4528198242668 .0936889648665 .9434204102664 .0300292969662 .3682250977 660.9840698242659 .883972168659 .0886230469658 .5913085938658 .4055786133 658.5053100586658 .8748779297659 .5167236328660 .4102783203661 .6085205078 663.1099243164664 .9675292969667 .1422119141669 .8704223633673 .6812133789 677.4921264648680 .2360839844682 .8795166016686 .1857299805689 .8654785156 693.8745117188698 .1998291016702 .796081543707 .6182861328712 .6569213867 718.3773193359725 .7061157227733 .2230224609739 .8541259766746 .583190918 754.2838134766761 .6721191406766 .0927124023770 .0568237305774 .8673706055 779.4343261719783 .3831787109782 .6168823242771 .5637207031754 .8474121094 736.8375854492717 .2816162109698 .6328735352678 .9650268555656 .75390625 634.2161865234614 .1754150391593 .678527832569 .2705078125546 .1273193359 528.5272216797512 .1290893555494 .3564147949476 .6359863281459 .6359863281 444.175201416430 .1659851074417 .8124084473407 .4468078613398 .599609375 390.8948974609384 .1552124023378 .1889038086372 .578704834367 .0364074707 361.442199707355 .5504150391349 .5553894043343 .5144042969337 .5531921387 331.8723144531326 .4314880371321 .3118896484316 .4223937988311 .7282104492 307.1866149902302 .7261962891298 .3348083496293 .9572143555289 .5856018066 285.2109069824280 .8233947754276 .441986084272 .0020141602267 .4034118652 262.7179870605257 .9706115723253 .1266021729248 .1345977783243 .112701416 
238.1809997559233 .2447967529228 .2050933838223 .1710968018218 .2144927979 213.2705993652208 .3647003174203 .0744018555196 .9900970459189 .820602417 181.0971069336171 .6446990967161 .8959960938153 .2808990479147 .745803833 143.9644012451141 .2725982666139 .6945953369139 .0001983643139 .0473022461 139.6324005127140 .5955047607141 .749206543142 .9508972168144 .1056060791 145.0032043457145 .561706543145 .4546966553144 .3227996826141 .99609375 137.9351959229132 .662902832126 .2508010864120 .0859985352115 .5113983154 111.9670028687109 .1544036865106 .8678970337104 .9536972046103 .3044967651 101.8286972046100 .484596252499 .23325347998 .0318374633896 .85984802246 95.6611785888794 .4062728881893 .0898284912191 .69335937590 .23023986816 88.702560424887 .1348571777385 .5810928344784 .0435562133882 .55767059326 81.1216812133879 .7520370483478 .4451065063577 .2045822143676 .02677154541 74.9096832275473 .8496475219772 .8432998657271 .8867492675870 .97657775879 70.1090393066469 .2806167602568 .4886779785267 .7293930053767 .0022277832 66.3034820556665 .6348037719764 .9933471679764 .3826828002963 .80195999146 63.2555389404362 .744979858462 .274410247861 .8478813171461 .46778106689 61.1396102905360 .8640098571860 .6469688415560 .4872093200760 .38909912109 60.3492393493760 .3697814941460 .4402313232460 .5626106262260 .70449066162 60.8677291870160 .9878005981461 .006141662661 .0283508300861 .18386077881 61.5012092590362 .0799484252962 .7176895141663 .2294616699263 .55958938599 63.3935203552263 .3278617858963 .9067497253464 .6078262329165 .02751159668 65.3236312866265 .5470428466865 .6913070678765 .7969436645565 .85453796387 65.8899917602565 .8913803100665 .8651733398465 .8102493286165 .73246765137 65.6320800781265 .5140686035265 .3793869018665 .2323226928765 .07375335693 64.9069366455164 .7326431274464 .5532379150464 .3694763183664 .18315124512 63.9950218200763 .8065299987863 .6184005737363 .4317893981963 .24737167358 63.0660705566462 .8884086608962 .7151107788162 .546600341862 .38341903687 62.2258415222262 .0742301940961 .9287910461461 .7897186279361 .65711975098 61.5310783386261 .4116096496661 .298690795961 .1922798156761 .09228897095 60.998611450260 .9110908508360 .8295898437560 .7538909912160 .68383026123 60.6191902160660 .5597610473660 .5052909851160 .4555702209560 .41035842896 60.3694610595760 .3325996398960 .2996101379460 .2702484130960 .24435043335 60.2216682434160 .2020797729560 .1853485107460 .1713485717860 .15982055664 60.1507987976160 .1435890197860 .13898086548

1123.3170166021118 .6090087891113 .8919677731109 .1789550781104 .467041016 1099.7559814451095 .046997071090 .3380126951085 .629028321080 .920043945 1076.2099609381071 .4990234381066 .7860107421062 .0720214841057 .354003906 1052.6319580081047 .9069824221043 .1760253911038 .4399414061033 .697021484 1028.9479980471024 .1920166021019 .4290161131014 .6569824221009 .87701416 1005.0880126951000 .288024902995 .4771728516990 .6524047852985 .8121948242 980.953918457976 .0748291016971 .1723022461966 .2429199219961 .2841186523 956.2927246094951 .2670288086946 .204284668941 .103515625935 .9630126953 930.7830810547925 .563293457920 .3054199219915 .0103149414909 .6818237305 904.3223266602898 .9379272461893 .5327148438888 .1151733398882 .6920776367 877.2736206055871 .8690795898866 .4907836914861 .1502075195855 .8612060547 850.6373901367845 .492980957840 .4432983398835 .5012207031830 .6823120117 
825.9973754883821 .4609985352817 .0795288086812 .8654174805808 .8187866211 804.948425293801 .2476806641797 .7194824219794 .3524169922791 .142578125 788.0759887695785 .1428222656782 .3306884766779 .6256713867777 .0206298828 774.5003051758772 .0637207031769 .6994018555767 .4102172852765 .1907958984 763.0449829102760 .9736938477758 .9782714844757 .0626220703755 .2239990234 753.4655151367751 .7802734375750 .1674194336748 .6173095703747 .1234130859 745.6751708984744 .2617797852742 .8726806641741 .4945068359740 .1177978516 738.7282714844737 .3181762695735 .8737182617734 .3883056641732 .8502197266 731.2531738281729 .587890625727 .8480834961726 .0256958008724 .1146850586 722.1077880859720 .0001220703717 .7849731445715 .4603271484713 .0206298828 710.4683837891707 .8012695312705 .0272216797702 .1486816406699 .178894043 696.1262817383693 .0084228516689 .8397827148686 .6406860352683 .4312133789 680.2324829102677 .0687866211673 .9616699219670 .9371948242668 .0172119141 665.2285766602662 .5919799805660 .1345214844657 .8743286133655 .8377075195 654.0385131836652 .5001220703651 .2290039062650 .2435302734649 .5399169922 649.1298217773648 .9910888672649 .1090698242649 .4951171875650 .1436157227 651.0770874023652 .2982177734653 .8444213867655 .7274780273658 .1021118164 661.2008056641664 .3560180664666 .9586791992669 .5269165039672 .5399169922 675.8654785156679 .4757080078683 .2274780273687 .0645751953691 .0853271484 695.198425293700 .2277832031707 .0648193359714 .2286987305720 .6248168945 726.4487304688732 .2186889648737 .5634765625742 .0858764648746 .8411865234 751.6567993164756 .6419067383761 .4061889648762 .954284668757 .8864746094 747.3311157227731 .8018188477713 .3275756836695 .0814819336676 .0228271484 655.5498046875634 .6082763672614 .104675293593 .0413208008570 .7113037109 550.8234863281537 .7675170898524 .1353759766502 .8002929688480 .9218139648 464.1286010742449 .8631896973436 .1821899414423 .5151062012412 .2886962891 402.4689941406393 .9880981445386 .6032104492380 .1752929688374 .361907959 368.9354858398363 .4744873047357 .2268066406350 .7228088379344 .3023986816 338.0297851562332 .1267089844326 .5562133789321 .3717956543316 .4697875977 311.7933959961307 .283203125302 .837310791298 .4548950195294 .0846862793 289.7090148926285 .3236999512280 .9093933105276 .4383850098271 .9490966797 267.4722900391262 .9389953613258 .2738037109253 .4878997803248 .5617980957 243.5776977539238 .6141052246233 .6226043701228 .5444946289223 .4969024658 218.5209960938213 .5144042969208 .5227966309203 .1672973633197 .2944946289 190.3645019531181 .3934020996171 .7299957275162 .3070983887154 .0097045898 148.2238006592144 .1555023193141 .4423065186139 .9039001465139 .3152008057 139.5160064697140 .2693023682141 .4369049072142 .8271026611144 .2895050049 145.6690979004146 .8446960449147 .7646942139148 .1817016602147 .9611968994 146.3280029297142 .2610931396136 .1329040527127 .6757965088119 .7070999146 115.0820999146112 .0665969849109 .5180969238107 .4004974365105 .6074981689 104.0877990723102 .6912002563101 .3927993774100 .12969970798 .88416290283 97.6277465820396 .3377227783294 .9919586181693 .598770141692 .14627075195 90.6487426757889 .1045227050887 .538917541585 .9859771728584 .45655059814 82.9781570434681 .553428649980 .1963424682678 .9045867919977 .68057250977 76.5206069946375 .4220428466874 .3806228637773 .3922729492272 .45234680176 71.556503295970 .7001419067469 .878761291569 .0888366699268 .32597351074 
67.5889129638766 .8741378784266 .1829071044965 .5137786865264 .87001037598 64.252517700263 .6663093566963 .1150588989362 .6037712097262 .13790893555 61.7208709716861 .3584594726661 .0523414611860 .8079910278360 .62456893921 60.5050315856960 .4464607238860 .4490509033260 .5041999816960 .60808181763 60.7365417480560 .8840599060160 .9974288940461 .0070114135761 .05195999146 61.2367591857961 .5040817260761 .9159011840862 .3304786682162 .6841506958 62.9302597045962 .864540100162 .8951492309663 .3463897705163 .91487884521 64.3424072265664 .6807785034264 .9485473632865 .1523208618265 .30653381348 65.4151077270565 .489959716865 .5291671752965 .5366592407265 .51439666748 65.4662933349665 .3944625854565 .3024063110465 .1921463012765 .06706237793 64.9287033081164 .7798767089864 .6218185424864 .456748962464 .28574371338 64.1106109619163 .9323310852163 .7524604797463 .5718307495163 .39176940918 63.2129592895563 .0365104675362 .8629302978562 .6930999755962 .52738952637 62.3664703369162 .2105903625562 .0602302551361 .9155197143661 .7767791748 61.6440505981461 .5175285339461 .3971595764261 .2830314636261 .17504119873 61.0731811523460 .9773292541560 .8873901367260 .8031997680760 .724609375 60.6514205932660 .5834503173860 .5205192565960 .4623908996660 .40887069702 60.3597297668560 .3147697448760 .2737617492760 .2365303039660 .20286941528 60.1725997924860 .1455192565960 .1214790344260 .1002883911160 .08180999756 60.0657806396560 .0520095825260 .0412101745660 .03511810303

1127.7480468751122 .9639892581118 .1800537111113 .3990478521108 .618041992 1103.8380126951099 .0579833981094 .2769775391089 .495971681084 .713989258 1079.9310302731075 .1450195311070 .3570556641065 .5649414061060 .770019531 1055.9689941411051 .163940431046 .3530273441041 .535034181036 .708984375 1031.8769531251027 .0360107421022 .1859741211017 .328002931012 .458984375 1007.5809936521002 .692016602997 .7907714844992 .8756713867987 .9453735352 982.9973144531978 .0294189453973 .0388793945968 .0231933594962 .9799804688 957.9063110352952 .80078125947 .6608886719942 .486328125937 .2753295898 932.0286865234926 .7459716797921 .4296264648916 .0800170898910 .7015991211 905.2965698242899 .8712768555894 .4295043945888 .9799194336883 .5281982422 878.0853271484872 .6591186523867 .2620239258861 .9038696289856 .5983886719 851.3577270508 846.1951904297841.1243286133836.1569824219831.3073120117 826.5842895508822 .0012207031817 .5626831055813 .2803955078809 .1527709961 805.1887817383801 .3809204102797 .733581543794 .2349853516790 .8843994141 787.6688232422784 .5814819336781 .6124267578778 .7498779297775 .9890136719 773.3162841797770 .7318115234768 .2241210938765 .795715332763 .4398803711 761.1594238281758 .9528198242756 .8198852539754 .7630004883752 .7780761719 750.8673706055749 .0236816406747 .2465209961745 .5264282227743 .8585205078 742.2327880859740 .6400756836739 .0712280273737 .5139160156735 .9598999023 734.3958129883732 .8145141602731 .2023925781729 .5532226562727 .8551025391 726.1016235352724 .2830200195722 .392578125720 .4227294922718 .3666992188 716.2183227539713 .9721069336711 .6232299805709 .1693115234706 .6068725586 703.9384155273701 .162902832698 .2880859375695 .3173217773692 .2628173828 689.1328125685 .9437866211682 .7092285156679 .4478759766676 .1782836914 672.9202880859669 .6959838867666 .5260009766663 .4346923828660 .4423217773 657.5744018555654 .8500976562652 .2949829102649 .9262695312647 .7681884766 
645.8334960938644 .1444091797642 .7064819336641 .5377807617640 .6354980469 640.012512207639 .6497802734639 .5324707031639 .6740112305640 .0731811523 640.7434082031641 .6782226562642 .9210205078644 .5145263672646 .4398803711 648.6776123047651 .1090698242653 .6652832031656 .3190917969659 .1995849609 662.2573852539665 .5354003906668 .908996582672 .2817993164675 .7534179688 679.1052856445683 .2940063477689 .4060058594695 .9863891602702 .1270141602 707.6417236328712 .3087158203716 .9326782227722 .5225830078728 .3547973633 732.4799804688736 .3745117188740 .0095825195741 .9224243164741 .4116821289 735.9962158203722 .8552856445705 .8411865234688 .7808227539670 .6953735352 652.045715332632 .5095825195611 .5540161133590 .8112792969571 .6585083008 555.3989868164546 .5385131836535 .7803955078512 .0180053711487 .0805053711 470.6448059082456 .9938964844442 .9996032715430 .0180053711417 .9005126953 406.9059143066397 .3664855957389 .1770019531382 .2518920898376 .2685852051 370.9549865723365 .4590148926358 .7459106445351 .6354980469344 .812713623 338.2272033691332 .1271057129326 .4410095215321 .216003418316 .3417053223 311.7365112305307 .2864990234302 .8577880859298 .4643859863294 .0924987793 289.7275085449285 .3534851074280 .9364013672276 .395904541271 .871887207 267.5104064941263 .1225891113258 .5203857422253 .7908935547248 .9355926514 243.9895935059238 .9860992432233 .9190979004228 .7808990479223 .6083068848 218.4281005859213 .2624969482208 .1620025635202 .8394012451197 .2747039795 190.5471954346181 .2982940674171 .4465942383162 .5187988281154 .6517944336 148.6936035156144 .3229064941141 .6101989746140 .220703125139 .8056945801 140.2236022949141 .1907043457142 .5926055908144 .2534942627146 .0368041992 147.74659729149 .3672027588150 .8842926025151 .9387969971152 .7635040283 151.7575073242147 .5375061035140 .9568939209130 .8825073242121 .3943023682 116.5279998779113 .483001709110 .7991027832108 .7233963013106 .9679031372 105.431602478104 .0271987915102 .6728973389101 .33119964699 .96869659424 98.5869674682697 .1633529663195 .7025833129994 .2005920410292 .66179656982 91.0935821533289 .5090408325287 .9194030761786 .3578262329184 .82608032227 83.3547973632881 .9399566650480 .597381591879 .3218078613378 .11557006836 76.9741134643675 .8946914672974 .8721771240273 .9027786254972 .98023223877 72.1005477905371 .2571029663170 .4451370239369 .659736633368 .89505767822 68.1502227783267 .4194030761766 .7063827514666 .0080490112365 .33009338379 64.6729431152364 .0442886352563 .4486503601162 .8933715820362 .38513946533 61.928009033261 .5307617187561 .1929588317960 .9233283996660 .71744155884 60.5799903869660 .505020141660 .4921493530360 .5333595275960 .62075042725 60.7435684204160 .8959693908761 .0213813781761 .0561294555761 .10723876953 61.2828712463461 .5206184387261 .8395500183162 .1708908081162 .47325134277 62.7228507995662 .8238716125562 .9482192993263 .1812095642163 .49412918091 63.8305511474664 .1550598144564 .435821533264 .6681518554764 .85597991943 64.9969863891665 .1026229858465 .1694869995165 .2062301635765 .21125793457 65.1903991699265 .1439132690465 .0764312744164 .9888076782264 .88503265381 64.7660064697364 .6350021362364 .492889404364 .3422775268664 .18408966064 64.0204772949263 .8523406982463 .6815185546963 .5088310241763 .33576965332 63.1630706787162 .9919204711962 .8229103088462 .656951904362 .49449920654 62.3362503051862 .1824913024962 .0337104797461 .8901214599661 .75202178955 
61.6195182800361 .4927787780861 .3718299865761 .2567405700761 .14746856689 61.0439987182660 .9462509155360 .8541183471760 .7674903869660 .68619918823 60.6101112365760 .5390396118260 .4728088378960 .4112205505460 .3540802002 60.3011894226160 .25236892760 .2073898315460 .1660995483460 .12829971313 60.0938301086460 .0625114440960 .034179687560 .0086898803759 .98588180542 59.9655303955159 .947689056459 .9316596984959 .91822814941

1132.155029297 1127.3149414061122.463989258 1117.6140136721112 .765014648 1107.9160156251103 .0660400391098 .214965821093 .3630371091088 .508056641 1083.6519775391078 .7919921881073 .9289550781069 .0610351561064 .188964844 1059.3110351561054 .4270019531049 .5369873051044 .6379394531039 .732055664 1034.8170166021029 .8929443361024 .9589843751020 .0150146481015 .060974121 1010.0969848631005 .1199951171000 .130981445995 .128112793990 .1099243164 985.0744018555980 .0197143555974 .9437866211969 .8441162109964 .7186279297 959.5648803711954 .3817138672949 .1671142578943 .920715332938 .6411132812 933.3295898438927 .9857177734922 .6118774414917 .2092285156911 .7816772461 906.3317871094900 .8654785156895 .3870849609889 .9041748047884 .4232788086 878.9536132812873 .5036010742868 .0842285156862 .7056274414857 .3793945312 852.1176757812846 .9321289062841 .8353881836836 .8378295898831 .9525756836 827.1870117188822 .5532226562818 .0551147461813 .7020874023809 .4937744141 805.4365234375801 .5253295898797 .7623291016794 .1395874023790 .6549072266 787.2993774414784 .0667114258780 .94921875777 .9379272461775 .0277709961 772.2094726562769 .4805297852766 .832824707764 .2656860352761 .7744140625 759.358581543757 .0159912109754 .7457275391752 .5471801758750 .4177246094 748.3563842773746 .3577880859744 .4197998047742 .5349121094740 .6976928711 738.8997802734737 .1331787109735 .3889770508733 .6572265625731 .9290771484 730.1937255859728 .4426879883726 .6646118164724 .8521118164722 .9942016602 721.0842285156719 .1118774414717 .0712890625714 .9536743164712 .7537231445 710.4641113281708 .0814819336705 .5999145508703 .0192260742700 .3356933594 697.5527954102694 .6702270508691 .6956176758688 .6326293945685 .4929199219 682.2847290039679 .0230712891675 .7210083008672 .3955078125669 .0637817383 665.7446289062662 .4583740234659 .2243041992656 .0648803711652 .9996948242 650.0521240234647 .2404785156644 .5886230469642 .1124267578639 .8347167969 637.7672729492635 .9309082031634 .3316040039632 .9849853516631 .8916015625 631.0626831055630 .482421875630 .1392822266630 .0404052734630 .1862182617 630.5803833008631 .2216186523632 .1364746094633 .3532104492634 .7937011719 636.4472045898638 .4188232422640 .7139282227643 .2609863281646 .0894165039649 .0625 652.1539916992655 .3316040039658 .4752197266661 .6665039062664 .9376831055 668.8681030273674 .1060180664679 .8991699219685 .6442260742690 .9735717773 695.44921875700 .0219116211705 .5656738281711 .167175293715 .7664794922 719.5966186523722 .8422851562724 .8986206055724 .6701049805720 .3804931641 709.2979125977694 .6168823242679 .7838745117663 .9683227539647 .0714111328 629.1549072266610 .2990722656592 .1815185547576 .2114257812562 .385925293 551.3231201172538 .5673828125520 .1397705078500 .2431030273482 .3728027344 466.1200866699451 .0006103516437 .0090026855424 .1391906738412 .1585998535 401.0974121094391 .6485900879384 .320892334378 .2773132324372 .8800048828 367.1718139648359 .9331970215352 .2514038086344 .9901123047338 .1192016602 
331.8315124512326 .0568847656320 .8136901855316 .0061035156311 .5722045898 307.2669067383302 .8074035645298 .345489502293 .9715881348289 .636505127 285.3107910156280 .9483032227276 .5014953613272 .0650024414267 .7084960938 263.312286377258 .7260131836254 .0084991455249 .1721038818244 .2268981934 239.2055053711234.0829925537228.8645935059223.5001068115 217.911895752 212.3898010254207 .2436065674201 .9716949463196 .1802978516189 .1977996826 180.0558929443170 .4757995605161 .8175964355154 .2266998291148 .4817962646 144.2630004883141 .7525024414140 .6450958252140 .5052032471141 .1849060059 142.4207000732144 .0964050293146 .032699585148 .1938018799150 .5045928955 152.9241943359155 .4514007568157 .4945983887158 .8036956787157 .791595459 152.9622955322145 .8184051514136 .5393066406127 .5682983398121 .2344970703 116.4723968506113 .2953033447111 .1055984497109 .1913986206107 .5325012207 105.970199585104 .4663009644102 .9223022461101 .361099243299 .78280639648 98.1825637817496 .5557785034294 .9109268188593 .2500381469791 .58728027344 89.93306732178 88.30082702637 86.71003723145 85.16771697998 83.69407653809 82.2879180908280 .9572830200279 .6986083984478 .5100708007877 .38778686523 76.327713012775 .324913024974 .374862670973 .4712066650472 .60885620117 71.7805404663170 .980056762770 .2012100219769 .4368972778368 .68492889404 67.9391326904367 .2031707763766 .4756698608465 .761306762765 .06214904785 64.3871688842863 .7441902160663 .1417083740262 .5877189636262 .08863067627 61.6547889709561 .2866401672460 .9918403625560 .7666206359960 .61376953125 60.5257987976160 .4982604980560 .5249481201260 .5966682434160 .71937942505 60.8951988220261 .047569274961 .0935783386261 .1447792053261 .30947113037 61.5387916564961 .8291511535662 .1565704345762 .5252609252962 .83559036255 62.9123306274462 .9277000427263 .0513305664163 .2297782897963 .47806930542 63.7647094726664 .0255966186564 .2586822509864 .4536972045964 .6120223999 64.7348632812564 .8235397338964 .8811492919964 .9093017578164 .91059875488 64.886863708564 .8408432006864 .7743301391664 .6900329589864 .58952331543 64.475303649964 .34877777164 .2121734619164 .0667800903363 .91460037231 63.7568092346263 .5951881408763 .4307289123563 .2649688720763 .09870147705 62.9332199096762 .769119262762 .60742187562 .4485702514662 .29333877563 62.142021179261 .9951705932661 .8529891967861 .7158393859961 .58382034302 61.457168579161 .3358917236361 .2201194763261 .10979080261 .00495910645 60.9055290222260 .8114395141660 .7225685119660 .638809204160 .56002044678 60.4860382080160 .416709899960 .3518486022960 .2912788391160 .23482131958 60.1822891235460 .1335182189960 .0883407592860 .0465583801360 .00804901123 59.9726409912159 .9401893615759 .9105491638259 .8835792541559 .85905075073 59.836780548159 .8175315856959 .8028717041

1136.578002931131 .6610107421126 .7440185551121 .8270263671116 .91003418 1111.9930419921107 .0729980471102 .1519775391097 .2290039061092 .302978516 1087.3740234381082 .4420166021077 .504028321072 .5620117191067 .614990234 1062.660034181057 .6989746091052 .7299804691047 .7530517581042 .766967773 1037.7709960941032 .7659912111027 .751022 .7239990231017 .6859741211012 .637023926 1007.5750122071002 .500976562997 .4119262695992 .3082275391987 .1876831055 982.048828125976 .8897094727971 .7081298828966 .5026855469961 .2711181641 956.012512207950.7250976562945.4088745117940.0626831055934.6879272461 
929.2843017578923.8546142578918.3997192383912.9240112305907.4296264648 901.9224853516896 .4067993164890 .8900756836885 .3781738281879 .8801879883 874.4038696289868 .959777832863 .5571289062858 .2067871094852 .919921875 847.7070922852842 .5800170898837 .5479125977832 .6226196289827 .8104858398 823.1226806641818 .5618896484814 .1373901367809 .8474731445805 .6989746094 801.6865234375797 .8131713867794 .0717163086790 .4608764648786 .9733276367 783.6041259766780 .3469238281777 .194519043774 .1428833008771 .18359375 768.3148803711765 .5288696289762 .8251953125760 .1978149414757 .6463012695 755.1672973633752 .7589111328750 .419921875748 .1461791992745 .9370117188 743.7861938477741 .6917724609739 .6463012695737 .645324707735 .680480957 733.7451171875731 .8308105469729 .9287109375728 .0308837891726 .1267089844 724.2089233398722 .2661743164720 .291809082718 .2747192383716 .2083129883 714.0830078125711 .8922729492709 .6278076172707 .2844848633704 .8555297852 702.3377075195699 .7260742188697 .020324707694 .2180175781691 .3225097656 688.3342285156685 .2606201172682 .1057128906678 .8806762695675 .5933227539 672.2578125668 .8861083984665 .4946289062662 .0988769531658 .7166137695 655.3665771484652 .0670166016648 .838684082645 .6998291016642 .6724243164 639.7733764648637 .0253295898634 .4423828125632 .046875629 .8493041992 627.8693237305626 .1126098633624 .5947875977623 .3162841797622 .2894287109 621.4998168945620 .938293457620 .6063232422620 .5017700195620 .6226806641 620.9708862305621 .5427856445622 .3656005859623 .382019043624 .582824707 626.0891113281627 .9854125977630 .3637084961633 .2479248047636 .3286743164 639.358215332642 .3488769531645 .3743286133648 .5087280273651 .9193725586 655.7448120117660 .1696777344665 .0733032227670 .3654785156675 .6243286133 680.3322753906685 .1334838867690 .4044799805695 .6787109375700 .5546875 704.6740112305707 .6807250977709 .1563720703707 .9608764648703 .3945922852 693.9077148438681 .6226806641669 .3121948242655 .7772827148640 .6040039062 624.6942138672608 .7946166992593 .727722168580 .7893066406568 .2689819336 553.8679199219539 .2155761719527 .2866210938514 .0681762695495 .9942016602 477.099609375460 .2506103516444 .8953857422430 .9630126953418 .4567871094 406.1091003418395 .2694091797387 .3074035645380 .7283935547374 .7629089355 368.5635070801360 .7567138672352 .5302124023344 .9301147461337 .7807922363 331.3345947266325 .4816894531320 .236114502315 .4801940918311 .1885986328 307.0231933594302 .5548095703298 .0663146973293 .7226867676289 .4298095703 285.1755981445280 .9122009277276 .6207885742272 .3052978516267 .9348144531 263.4879150391258 .8676147461254 .1212005615249 .2483978271244 .2682037354 239.2082061768 234.0305938721 228.7183074951 223.2144012451 217.3061981201 211.424697876206 .1571960449200 .654800415194 .3404998779187 .0352020264 178.1024017334168 .8246002197160 .3518066406153 .0166015625147 .7014007568 144.0494995117142 .0205993652141 .2859954834141 .4530029297142 .4232025146 143.9237060547145 .9062042236148 .1502075195150 .7521057129153 .6999969482 156.9055938721160 .3782958984163 .353805542165 .2178955078164 .6701049805 160.1678924561152 .8923950195144 .3294067383135 .6210021973127 .3671035767 120.8492965698117 .0436019897114 .3679962158112 .0924987793110 .1675033569 108.3424987793106 .6109008789104 .8115005493102 .9866027832101 .1743011475 99.35495758057 97.5312271118295.7115173339893.9013824462992.11609649658 
90.3725128173888 .6737518310587 .0438613891685 .4791793823284 .00164794922 82.6025314331181 .2842330932680 .0415878295978 .8697280883877 .76486968994 76.7229232788175 .7380218505974 .8074035644573 .9221878051873 .07945251465 72.2680892944371 .4831085205170 .7145080566469 .9540710449269 .19866943359 68.4382400512767 .6806030273466 .9213562011766 .1689987182665 .4252166748 64.7019424438564 .0072708129963 .353240966862 .7479782104562 .20180892944 61.7301216125561 .3293609619161 .0127105712960 .7705802917560 .6085395813 60.5147399902360 .480609893860 .4993591308660 .561939239560 .66717147827 60.8367004394561 .0073699951261 .0726509094261 .152618408261 .33015823364 61.5598602294961 .8526191711462 .1955490112362 .6311798095762 .98109817505 62.9837913513262 .900810241762 .9483108520563 .0521202087463 .23371887207 63.4622802734463 .6823196411163 .8980789184664 .0872726440464 .25116729736 64.3846817016664 .4881820678764 .5628433227564 .6091690063564 .62978363037 64.6253814697364 .5988769531264 .5511322021564 .4850463867264 .40155792236 64.3034133911164 .1916198730564 .0687103271563 .9357109069863 .79492950439 63.6473693847763 .4950714111363 .3389396667563 .1806907653863 .02108001709 62.8614997863862 .7025909423862 .5454101562562 .3904418945362 .23847961426 62.0898704528861 .9451904296961 .8046684265161 .6687011718861 .53741073608 61.4110603332561 .2896995544461 .1734390258861 .0622901916560 .95629882812 60.8553810119660 .7595291137760 .6686210632360 .5825805664160 .50127029419 60.4245681762760 .3523101806660 .2843513488860 .2205200195360 .16064834595 60.1045989990260 .052181243960 .0032615661659 .9576606750559 .91527175903 59.8759193420459 .8394889831559 .8058395385759 .7748603820859 .74631881714 59.7202987670959 .6961097717359 .6745300293

1140.9770507811136 .0069580081131 .0229492191126 .038940431121 .055053711 1116.0689697271111 .082031251106 .0920410161101 .0980224611096 .102050781 1091.1009521481086 .0959472661081 .086059571076 .0699462891071 .047973633 1066.0190429691060 .9809570311055 .9360351561050 .8819580081045 .817993164 1040.7430419921035 .6579589841030 .5620117191025 .4539794921020 .335021973 1015.203979492 1010.0590209961004.901977539999.7299804688994.5432739258 989.3400878906 984.1192016602978.8790893555973.617980957968.3347167969 963.0272827148957 .6951293945952 .3369140625946 .9525756836941 .5415039062 936.1049194336930.6430053711925.1583251953919.6520996094914.1281738281 908.5895996094903 .0415039062897 .4882202148891 .9364013672886 .3922729492 880.8640136719875 .3594970703869 .8876953125864 .4581298828859 .0803833008 853.7650146484848 .5213012695843 .3602905273838 .290222168833 .3217163086 828.4606933594823 .7166137695819 .0925292969814 .5955810547810 .2255859375 805.9874267578801 .8776245117797 .8978881836794 .0432739258790 .3123779297 786.6995239258783 .200378418779 .8101806641776 .5233154297773 .3353271484 770.2402954102767 .2352294922764 .3142700195761 .4752807617758 .7136230469 756.0270996094753 .4121704102750 .8665161133748 .387512207745 .971496582 743.616027832741 .3161010742739 .0681762695736 .8662719727734 .7053222656 732.5781860352730 .478515625728 .3986206055726 .3303833008724 .2664794922 722.1975097656720 .1157226562718 .0112915039715 .8770141602713 .7026977539 711.481628418709 .2044067383706 .8651123047704 .4553222656701 .9703979492 699.4036865234696 .7528076172694 .0125732422691 .1840209961688 .2645263672 
685.2578735352682 .165222168678 .9934082031675 .746887207672 .4362182617 669.0689697266665 .6583862305662 .2161254883658 .7567749023655 .2954711914 651.8483886719648 .4332275391645 .0667114258641 .7683105469638 .5548706055 635.4473266602632 .4611206055629 .6171875626 .9293212891624 .4174804688 622.0925292969619 .9719848633618 .0625616 .3779907227614 .9204101562613 .7011108398 612.7072753906611 .9315185547611 .3721923828611 .0297241211610 .893371582 610.9597167969611 .2208862305611 .6898803711612 .3272705078613 .1185913086 614.135925293615 .3513793945617 .3577270508620 .8018188477624 .4951782227 627.3148803711629.9583740234632.9611816406 636.1439208984639.4268188477 642.9251708984646 .8707885742651 .2083129883655 .9293823242660 .8604736328 665.6599731445670 .5952758789675 .9854736328681 .2310180664685 .8325195312 689.5620727539692 .2534790039693 .3452148438692 .4240722656688 .6879272461 680.4887695312670 .0062866211658 .9138183594646 .6398925781633 .0919799805 619.1638183594605 .6915893555592 .9609985352581 .4746704102569 .6240234375 556.6069946289544 .1644287109533 .7662963867522 .5079956055507 .5992126465 489.9117126465470 .6523132324452 .6070861816438 .1520996094425 .5892028809 412.9472961426401 .3400878906391 .9598999023383 .8812866211376 .649810791 369.4791870117361 .12109375352 .5534973145344 .5971069336337 .2253112793 330.6369018555324 .7231140137319 .4693908691314 .7359008789310 .4137878418 306.249786377301 .9242858887297 .5942077637293 .3313903809289 .1184997559 284.9577941895280 .8009033203276 .6317138672272 .4031066895268 .0658874512 263.5978088379258 .9353027344254 .1190948486249 .1401062012244 .0570068359 238.9405975342233 .7156066895228 .3321075439222 .7789001465217 .0155029297 211.1394958496205 .2922058105199 .0438995361192 .113494873184 .4609069824 175.6782073975166 .6504974365157 .987197876150 .6741027832146 .2420959473 143.6770935059142 .3309936523142 .0731964111142 .633895874143 .9125061035 145.68699646147 .9671936035150 .6649017334153 .7787017822157 .2115936279 160.9488983154164 .9286956787168 .7191009521172 .1047058105173 .5509033203 171.846496582166 .0549926758154 .4913024902142 .2178955078133 .5057067871 127.0149002075122 .4420013428118 .8389968872115 .8331985474113 .3794021606 111.1457977295109 .1019973755107 .0007019043104 .8793029785102 .7731018066 100.6909027198 .6300964355596 .6032791137794 .6138534545992 .68376922607 90.8291931152389 .051483154387 .3645095825285 .7694702148484 .28201293945 82.890068054281 .5820312580 .3542022705179 .1970291137778 .10784912109 77.0815582275476 .1137237548875 .200897216874 .3354110717873 .51280212402 72.7219161987371 .9553680419971 .20117187570 .4481887817469 .69100952148 68.9185714721768 .1382980346767 .3461608886766 .5518264770565 .76300048828 64.9887619018664 .2388687133863 .5280303955162 .8656692504962 .2681312561 61.7558097839461 .3245391845760 .9846992492760 .7296791076760 .56457138062 60.4742813110460 .4448814392160 .4638404846260 .5172500610460 .58526992798 60.6462898254460 .7472496032760 .9146614074761 .1228408813561 .34128189087 61.5766906738361 .8493995666562 .1552391052262 .5061988830662 .77376174927 62.8129386901962 .7731781005962 .7990913391162 .8673400878963 .00239181519 63.1785316467363 .3701095581163 .5680389404363 .7501602172963 .91529846191 64.0543365478564 .1682128906264 .2550430297964 .3161621093864 .35220336914 64.364540100164 .3545608520564 .323661804264 .2736129760764 .20583343506 
64.1222763061564 .0244064331163 .9142684936563 .793251037663 .66337966919 63.5259094238363 .3827400207563 .2349586486863 .0842018127462 .9313583374 62.7778091430762 .6242294311562 .4717407226662 .3208198547462 .17232131958 62.0265998840361 .8843002319361 .7456283569361 .611049652161 .48067092896 61.3548202514661 .2335281372161 .1169891357461 .0051918029860 .89820861816 60.7959899902360 .6985511779860 .6057891845760 .5176391601660 .43397903442 60.3547096252460 .2796897888260 .2087898254460 .1418495178260 .07873916626 60.0193099975659 .9633903503459 .9108810424859 .861610412659 .81547927856 59.7723312377959 .7320709228559 .6945800781259 .6597213745159 .62731170654 59.5971603393659 .5701217651459 .54759979248

1145.3979492191140 .3509521481135 .3020019531130 .2519531251125 .201049805 1120.1479492191115 .0930175781110 .0340576171104 .9709472661099 .905029297 1094.8339843751089 .7569580081084 .6750488281079 .5870361331074 .490966797 1069.3879394531064 .2760009771059 .1560058591054 .0250244141048 .885009766 1043.7330322271038 .5710449221033 .3959960941028 .2099609381023 .010986328 1017.7999877931012 .5750122071007 .3369750981002 .083984375996 .8167724609 991.5333862305986 .2327880859980 .9141235352975 .5756225586970 .2166748047 964.8353881836959 .4318847656954 .0045776367948 .5540161133943 .0795288086 937.5825195312932 .0634155273926 .5247802734920 .9677734375915 .3967285156 909.8137207031904 .2244873047898 .6326293945893 .0452270508887 .4675292969 881.9074707031876 .3723144531870 .8707885742865 .4113769531860 .0034790039 854.6563110352849 .3787231445844 .1807250977839 .0695800781834 .0554199219 829.1428222656824 .3411254883819 .6522216797815 .0833740234810 .6337280273 806.3082885742802 .1038208008798 .022277832794 .0593261719790 .2141723633 786.4819946289782 .8596801758779 .3430786133775 .9271850586772 .6088256836 769.382019043766 .2448120117763 .1912231445760 .2191772461757 .3239746094 754.5034790039751 .7534179688749 .071105957746 .4534301758743 .8961791992 741.3969116211738 .950012207736 .5524291992734 .1975708008731 .8809814453 729.5960083008727 .3366088867725 .095703125722 .8657836914720 .6400756836 718.4097290039716 .1674194336713 .9038696289711 .6123046875709 .2827758789 706.9091186523704 .4818725586701 .9954833984699 .442199707696 .8175048828 694.1151123047691 .3330078125688 .4666748047685 .5172119141682 .482421875 679.3665161133676 .1704711914672 .9016113281669 .5637817383666 .1674194336 662.7197265625659 .2332763672655 .7188720703652 .1904296875648 .6618041992 645.1483154297641 .6663208008638 .2313842773634 .8619995117631 .573425293 628.3850708008625 .311706543622 .3726806641619 .5806884766616 .9550170898 614.5048828125612 .2479248047610 .1895751953608 .3441772461606 .7130126953 605.307800293604 .1157836914603 .1322021484602 .3516845703601 .779296875 601.3944091797601 .1953735352601 .1654052734601 .32421875601 .6400146484 602.1016235352602 .7758789062603 .424987793605 .0073242188608 .7874145508 612.8751220703615 .4152832031617 .7526855469620 .7852783203624 .0048828125 627.2133789062630 .5128173828634 .1657104492638 .0872802734642 .2426147461 646.7620849609651 .4735107422656 .4702148438661 .8475952148666 .9387817383 671.0908203125674 .3137817383676 .6126098633677 .55078125677 .0557861328 674.1845703125667 .270324707658 .1616210938647 .9885864258636 .7542114258 624.8109741211612 .80078125601 .5266113281590 .5883178711579 .86328125 
569.1461181641558 .9196777344549 .017578125539 .3123168945528 .8311157227 517.3170166016502 .8186035156483 .1321105957463 .4426879883448 .4169006348 435.2315979004421 .4108886719408 .7189941406397 .7179870605387 .9511108398 379.1510925293370 .5718078613361 .4841003418352 .5333862305344 .258392334 336.6405029297329 .9115905762323 .9111938477318 .6589050293313 .915802002 309.5220947266305 .3353881836301 .1459960938296 .9927978516292 .8146972656 288.6607055664284 .5950927734280 .545501709276 .5181884766272 .3923034668 268.0968017578263 .620513916258 .8909912109253 .9954071045248 .8735046387 243.6484985352238 .43699646233 .1224060059227 .616897583221 .9947967529 216.3704071045210 .4445953369203 .9506988525196 .9806976318189 .5791931152 181.6062927246172 .9400939941164 .0980072021155 .4282989502148 .3791046143 144.9326019287143 .4734039307142 .7839050293143 .0653076172144 .038192749 145.6600036621147 .7149963379150 .3058013916153 .4315948486156 .9971923828 160.7796020508164 .8338928223169 .0113067627173 .208694458177 .7478942871 180.9031982422182 .1230010986178 .5641021729165 .1132965088149 .9174957275 140.5684051514133 .504196167127 .6988983154123 .2391967773119 .7291030884 116.8470993042114 .2171020508111 .7656021118109 .2894973755106 .8860015869 104.4831008911102 .132301330699 .8225936889697 .5752334594795 .38622283936 93.28980255127 91.30348205566 89.42682647705 87.6795501709 86.05082702637 84.5535888671983 .1686935424881 .8674392700280 .6490783691479 .50095367432 78.420623779377 .4052429199276 .4488983154375 .5520706176874 .70362854004 73.9033966064573 .134490966872 .3928298950271 .6589202880970 .92149353027 70.1703567504969 .390480041568 .5891571044967 .7577209472766 .92063903809 66.0848617553765 .2617111206164 .4542999267663 .67927169862 .95087051392 62.2933197021561 .7346801757861 .2677497863860 .911128997860 .64947128296 60.4894981384360 .4103393554760 .3908309936560 .4149398803760 .46472167969 60.5156097412160 .4919395446860 .5306091308660 .7841606140161 .09395980835 61.3371009826761 .5737609863361 .8241195678762 .0677108764662 .28971099854 62.4582405090362 .5397491455162 .5758285522562 .6156997680762 .67060852051 62.7760696411162 .9165382385363 .08356857363 .2669105529863 .43933868408 63.6025505065963 .7432289123563 .8633308410663 .9589195251564 .03118896484 64.0799102783264 .1059036254964 .1102371215864 .0937271118264 .05806732178 64.004180908263 .9341201782263 .8489494323763 .7509002685563 .64107894897 63.5217399597263 .3939399719263 .2597389221263 .1200904846262 .97679901123 62.8306694030862 .6831893920962 .5349998474162 .387271881162 .24048995972 62.095569610661 .9528694152861 .813060760561 .6763801574761 .54330825806 61.4140014648461 .288780212461 .1677207946861 .0510292053260 .93872833252 60.83090972960 .727539062560 .6286697387760 .5341911315960 .44406890869 60.3582191467360 .2765312194860 .1988983154360 .1251983642660 .05530929565 59.9890899658259 .9264183044459 .8671493530359 .8111686706559 .7583694458 59.7086181640659 .6618194580159 .6178588867259 .5766410827659 .53805923462 59.5019302368259 .4683494567959 .4366302490259 .40758895874

1149.7960205081144 .6970214841139 .5830078121134 .4670410161129 .349975586 1124.2299804691119 .1070556641113 .9809570311108 .8499755861103 .713989258 1098.5729980471093 .4270019531088 .2740478521083 .1140136721077 .947021484 1072.7709960941067 .586059571062 .3909912111057 .1870117191051 .970947266 
1046.7440185551041 .5059814451036 .2550048831030 .9919433591025 .715942383 1020.4270019531015 .1240234381009 .8079833981004 .476989746999 .1309814453 993.7695922852988 .391784668982 .9965820312977 .5831298828972 .1505126953 966.6975708008961 .2243041992955 .729675293950 .2144165039944 .6779174805 939.1217041016933 .5463867188927 .9545898438922 .3477172852916 .729309082 911.1021728516905 .4713134766899 .8405761719894 .2163696289888 .6041259766 883.0106811523877 .4431762695871 .9097900391866 .4185791016860 .9777832031 855.5966186523850 .2825927734845 .0452880859839 .8911132812834 .8291015625 829.8640136719825 .0034790039820 .25815 .609375811 .0817871094806 .671081543 802.3751220703798 .1951293945794 .1281738281790 .1735229492786 .3270874023 782.5866699219778 .9484863281775 .4086303711771 .9638061523768 .6096801758 765.3433227539762 .1602172852759 .0573730469756 .0308837891753 .0778198242 750.1942138672747 .3767700195744 .621887207741 .92578125739 .2846069336 736.6937255859734 .1489868164731 .6450195312729 .1765136719726 .7376098633 724.3226928711721 .924987793719 .5375976562717 .1538696289714 .7659301758 712.3666992188709 .9475097656707 .5015258789705 .0197143555702 .4957885742 699.9210205078697 .2901000977694 .5955200195691 .833190918688 .9971923828 686.0861206055683 .0955810547680 .0270996094676 .8790283203673 .6552124023 670.3571777344666 .9918212891663 .5634155273660 .0812988281656 .5529785156 652.9901123047649 .4025878906645 .8037719727642 .2067260742638 .6254272461 635.075378418631 .571105957628 .1295776367624 .7653808594621 .4962768555 618.3361206055615 .3027954102612 .4083862305609 .6705932617607 .0985717773 604.7083740234602 .5059814453600 .5042724609598 .7053222656597 .1198730469 595.7374267578594 .5543212891593 .5645751953592 .7670288086592 .1503295898 591.7125244141591 .4376831055591 .3239135742591 .3837280273591 .6312866211 592.1104736328592 .7794799805594 .2725219727597 .2711181641600 .5847167969 603.0438232422605 .4318237305608 .3148193359611 .4970703125614 .9741210938 618.4611816406621 .8557739258625 .3225708008628 .9644165039632 .9926147461 637.4780273438642 .2412109375647 .1024169922651 .6107788086655 .4077758789 658.3654174805660 .4573974609661 .3555297852660 .799621582658 .2628173828 652.6951904297645 .1248779297636 .294921875626 .4705200195616 .1157836914 605.9102783203596 .5748291016587 .3491821289577 .7971191406568 .5026855469 560.0092773438551 .832824707543 .7899169922535 .2963256836526 .0643920898 514.3162841797498 .4262084961481 .0765991211464 .5969848633448 .5147094727 431.4876098633415 .7695007324403 .9010009766393 .4753112793382 .8243103027 372.4487915039362 .3086853027352 .7601928711344 .0513916016336 .1704101562 329.2284851074323 .1243896484317 .871887207313 .1604003906308 .753112793 304.5816955566300 .429107666296 .3323059082292 .169708252288 .0289916992 284.0340881348280 .1094970703276 .2681884766272 .2966003418268 .0120849609 263.4786987305258 .6868896484253 .7021026611248 .4826965332243 .1289978027 237.7624969482232 .2592926025226 .5343017578220 .6907958984214 .7326049805 208.404006958 201.5742034912 194.3820953369 187.0908050537179.3085021973 170.3567962646161 .4071960449153 .6047058105147 .6387939453144 .666305542 143.6157073975143 .5059051514144 .2700958252145 .6551971436147 .6251983643 150.016998291152 .899307251156 .254196167159 .9889984131163 .966293335 168.1006011963172 .2667999268176 .370803833180 .2736053467183 .3217926025 
185.1707000732183 .0341033936174 .141204834162 .1280975342149 .541305542 138.3677062988131 .354598999126 .5167999268123 .2116012573120 .5975036621 117.4822998047114 .4050979614111 .5684967041108 .886100769106 .2238006592 103.6182022095101 .077598571898 .6081771850696 .2100067138793 .92938995361 91.7897109985489 .7982025146587 .9886398315486 .3312683105584 .82290649414 83.4438934326282 .1480331420980 .9336929321379 .7871475219778 .70886993408 77.6965103149476 .7474975585975 .8614273071375 .0302505493274 .25142669678 73.5096130371172 .7969818115272 .0919265747171 .3786087036170 .641746521 69.8609771728569 .0380630493268 .1580200195367 .2652969360466 .39402770996 65.5303268432664 .6616668701263 .8134918212963 .0091209411662 .28316116333 61.6665496826261 .160018920960 .7911796569860 .5341415405360 .38528060913 60.3245086669960 .3181304931660 .3549613952660 .4196090698260 .49518966675 60.5607490539660 .67229080260 .8665809631361 .099750518861 .31890869141 61.5300903320361 .7466201782261 .9381294250562 .0916900634862 .21342086792 62.2818603515662 .3323287963962 .3746604919462 .4197692871162 .51433944702 62.640480041562 .7979202270562 .9740905761763 .1443214416563 .30632019043 63.4493103027363 .5737304687563 .6759986877463 .7569084167563 .8155708313 63.8528289794963 .8689002990763 .8647804260363 .8413314819363 .79978942871 63.7415390014663 .6679801940963 .5808296203663 .4815216064563 .37192153931 63.253349304263 .1276206970262 .9958801269562 .85979080262 .72026062012 62.5787010192962 .4358596801862 .2928581237862 .150249481262 .0089302063 61.8692893981961 .7320289611861 .5974082946861 .4659385681261 .33777999878 61.2132911682161 .0925712585460 .9758491516160 .8631591796960 .75461959839 60.6502189636260 .5500297546460 .453960418760 .3620109558160 .27407073975 60.1901092529360 .1099891662660 .0336303710959 .9609107971259 .89170837402 59.8259315490759 .7634391784759 .7041282653859 .6479110717859 .59468841553 59.544361114559 .4968299865759 .4520301818859 .4098396301359 .3701210022 59.3326988220259 .2985191345259 .26882171631

1154.2209472661149 .0439453121143 .8649902341138 .6850585941133 .503051758 1128.3170166021123 .1280517581117 .9339599611112 .7359619141107 .531982422 1102.3220214841097 .1070556641091 .8840332031086 .6540527341081 .415039062 1076.167968751070 .9110107421065 .6440429691060 .3669433591055 .07800293 1049.7779541021044 .464965821039 .1400146481033 .8020019531028 .451049805 1023.0859985351017 .7080078121012 .3150024411006 .908020021001 .486999512 996.0501708984990 .5974731445985 .1281738281979 .641784668974 .1378173828 968.6151733398963 .0740966797957 .5139160156951 .9354248047946 .3383789062 940.7244262695935 .0938720703929 .4497070312923 .7932128906918 .1281738281 912.4567260742906 .7841796875901 .114074707895 .4525146484889 .8040771484 884.1760864258878 .5748291016873 .0078125867 .4827270508862 .0070800781 856.5894775391851 .2369995117845 .9583129883840 .7590942383835 .6480712891 830.6290283203825 .7094116211820 .8909301758816 .1796264648811 .5748901367 807.0809936523802 .6958007812798 .421081543794 .25390625790 .1939697266 786.2380981445782 .3842163086778 .6292114258774 .9697265625771 .4030151367 767.9249267578764 .5330200195761 .2227783203757 .9918212891754 .8358764648 751.7520751953748 .7365112305745 .7854003906742 .8952026367740 .0618286133 737.2811889648734 .5487060547731 .8602294922729 .2100830078726 .5936279297 
724.0048828125721 .4384765625718 .8881835938716 .3474731445713 .8098754883 711.2681884766708 .7158203125706 .1442260742703 .5469970703700 .9157714844 698.2445068359695 .5247802734692 .7517700195689 .9182128906687 .020690918 684.0535888672681 .0156860352677 .9033203125674 .7180175781671 .4583129883 668.1284179688664 .729675293661 .2689819336657 .7504272461654 .1832275391 650.5739746094646 .9340820312643 .2728271484639 .6027832031635 .9359741211 632.2858886719628 .6666870117625 .0919189453621 .5775756836618 .1370239258 614.7871704102611 .5404052734608 .4140014648605 .4185791016602 .5712280273 599.8801879883597 .3610229492595 .0186157227592 .8662719727590 .9052734375 589.1466064453587 .5803833008586 .2072143555585 .0167236328584 .0073242188 583.171081543582 .5170288086582 .0247192383581 .6809082031581 .5355224609 581.6256713867582 .0458984375582 .8817138672584 .2498779297586 .2196044922 588.5065917969590 .7830810547593 .1987304688595 .8272094727598 .8461303711 602.5510864258606 .3461303711609 .7263183594612 .9741821289616 .2756958008 619.8369750977623 .9437255859628 .2169189453632 .2261962891635 .9661254883 639.3298950195642 .0927734375644 .1002197266645 .0131225586644 .3621826172 642.0161132812637 .5258178711631 .3939208984623 .9606933594615 .6231079102 606.8516845703598 .2006225586590 .4495849609582 .8422851562574 .6994018555 566.7407226562559 .6881103516553 .0955810547546 .854675293540 .4412841797 533.4362792969524 .8927001953514 .4354248047500 .9364013672483 .8523864746 464.513092041443 .5780029297424 .8042907715411 .5187072754400 .2827148438 387.6770935059375 .3099975586363 .9389953613353 .6821899414344 .4312133789 336.0698852539328 .8320007324322 .4932861328317 .1806030273312 .4974060059 308.1554870605303 .9937133789299 .8088989258295 .6326904297291 .3868103027 287.2048950195283 .249206543279 .4059143066275 .7484130859271 .9588928223 267.7358093262263 .216003418258 .3931884766253 .2913970947247 .8722991943 242.3332977295236 .7575073242231 .0494995117225 .0532073975218 .7942047119 212.2561950684205 .4174041748198 .3735961914191 .0290985107183 .9286956787 176.2230987549166 .9707946777158 .2707977295151 .8361968994147 .386505127 144.983001709144 .1891021729144 .5027008057145 .720703125147 .4795074463 149.771697998152 .4575958252155 .5572052002159 .0119934082162 .7819976807 166.7899017334170 .8802947998174 .8959960938178 .5729980469181 .3683013916 183.4284973145184 .9078979492184 .2752075195180 .8146057129172 .9826965332 157.6929931641142 .1658935547133 .9039001465128 .9384002686125 .9304962158 123.755897522120 .3449020386116 .8740005493113 .8041992188110 .9020004272 107.9960021973105 .15599823102 .391403198299 .7132873535297 .11070251465 94.6335525512792 .3058624267690 .1877136230588 .3180999755986 .655128479 85.1430206298883 .7542572021582 .4474334716881 .2206802368280 .06233215332 78.9728469848677 .954376220777 .002510070876 .1222534179775 .30210876465 74.5452804565473 .8299713134873 .1541290283272 .4851837158271 .81009674072 71.0998382568470 .3274383544969 .4980621337968 .5768127441467 .6335067749 66.7187728881865 .8023681640664 .8651809692463 .9409484863363 .06240844727 62.2558097839461 .5624694824261 .0110397338960 .6377296447860 .40555953979 60.280269622860 .2354812622160 .2398490905860 .2884101867760 .37033843994 60.4897689819360 .6743392944360 .8682098388760 .9878005981461 .10887908936 61.2793388366761 .4556083679261 .6352500915561 .791019439761 .90623092651 
61.9926795959562 .0414199829162 .0744209289662 .0979614257862 .13856887817 62.2364311218362 .3703002929762 .5306510925362 .7036094665562 .87094116211 63.0310897827163 .1740493774463 .3007583618263 .4072608947863 .49425888062 63.5605010986363 .6064605712963 .632118225163 .6380805969263 .62509918213 63.5940399169963 .546310424863 .4829406738363 .4057807922463 .31594848633 63.2154808044463 .1054306030362 .9877815246662 .8634910583562 .73432922363 62.6011199951262 .4653396606462 .3276710510362 .189319610662 .05078887939 61.9130287170461 .7764282226661 .6417312622161 .5091705322361 .3793296814 61.2523612976161 .1286697387761 .0083389282260 .8916511535660 .77864074707 60.6694793701260 .5641403198260 .4627304077160 .3651695251560 .2714805603 60.1815910339460 .0954513549860 .012969970759 .9340591430759 .85861968994 59.7865600585959 .7177810668959 .6521682739359 .5896606445359 .5301399231 59.4735603332559 .4198112487859 .3688392639259 .3205604553259 .27490997314 59.2317390441959 .1911582946859 .1525306701759 .11666107178 1158.6219482421153 .3950195311148 .1529541021142 .9079589841137 .661010742 1132.410034181127 .1550292971121 .8950195311116 .6300048831111 .359008789 1106.082031251100 .7979736331095 .5059814451090 .207031251084 .899047852 1079.5810546881074 .254028321068 .9169921881063 .5679931641058 .208007812 1052.8349609381047 .4499511721042 .0529785161036 .6419677731031 .218017578 1025.7790527341020 .328002931014 .8619995121009 .3809814451003 .885986328 998.3762817383992 .8511962891987 .3103027344981 .7532958984976 .1798706055 970.5894775391964 .9824829102959 .3585205078953 .7183227539948 .0618896484 942.3911132812936 .7066040039931 .0106811523925 .3052978516919 .5936279297 913.8781738281908 .1635742188902 .4536743164896 .7537231445891 .0687255859 885.4047851562879 .768371582874 .1663818359868 .6060180664863 .0941162109 857.6386108398 852.2459716797 846.9243774414 841.6791992188 836.5181274414 831.4447021484826 .4655761719821 .582824707816 .8012084961812 .1212158203 807.545715332803 .0739746094798 .7069702148794 .4428100586790 .2811279297 786.2191772461782 .2556762695778 .387512207774 .6121826172770 .9268798828 767.3284301758763 .8137817383760 .3795776367757 .0228271484753 .7399291992 750.5275878906747 .382019043744 .2994995117741 .276184082738 .3079223633 735.3903808594732 .5192260742729 .6896972656726 .8969726562724 .1358032227 721.4008789062718 .6868286133715 .9879150391713 .2977294922710 .6102294922 707.9185791016705 .2163696289702 .4959716797699 .7512207031696 .973815918 694.158203125691 .2965087891688 .3842773438685 .4144897461682 .3843994141 679.2885742188676 .1264038086672 .8942871094669 .5941772461666 .2249145508 662.7904052734659 .2926025391655 .737487793652 .1298217773648 .4774780273 644.7877807617641 .0706176758637 .3353271484633 .5933227539629 .8562011719 626.1362915039622 .4473266602618 .8015136719615 .2139282227611 .6970214844 608.2664794922604 .9340820312601 .7155761719598 .6212768555595 .666809082 592.8602294922590 .2156982422587 .7387084961585 .4412231445583 .3253173828 581.400390625579 .6602783203578 .1057128906576 .7288818359575 .5272827148 574.4982910156573 .643371582572 .9581298828572 .4351806641572 .1259765625 572.0596923828572 .3532104492573 .0833740234574 .1358032227575 .5656738281 577.2741088867579 .1560058594581 .2589111328583 .4066162109586 .0609130859 589.7047119141593 .6715698242597 .4724121094601 .0169067383604 .2030029297 
607.4011230469610 .9603271484614 .4716796875617 .5364990234620 .4025268555 623.2084960938625 .6740112305627 .549621582628 .503112793628 .1727294922 626.3255004883622 .3961791992617 .1483154297611 .049987793604 .1610717773 596.7041015625589 .3325805664582 .8491210938576 .607421875570 .026184082 563.5656738281557 .6688232422552 .4752807617548 .3488769531544 .4890136719 540.1464233398535 .3391723633530 .0742797852520 .5938110352503 .6387939453 481.8992919922458 .2272033691436 .8948974609421 .2869873047407 .8157958984 393.2992858887379 .004486084366 .4118041992355 .5414123535345 .6924133301 336.7363891602328 .9462890625322 .2442932129316 .7047119141312 .0050964355 307.8317871094303 .7821960449299 .3731079102294 .915802002290 .5032043457 286.221496582282 .1987915039278 .3681945801274 .8008117676271 .1570129395 267.1505126953262 .8074035645258 .0181884766252 .7579956055246 .8968963623 240.9105987549235 .2263031006229 .4055023193223 .0888061523216 .3450927734 209.1571044922201 .8056030273194 .5722961426187 .0803985596179 .2393951416 170.8607025146161 .6929931641153 .8069000244149 .1616973877146 .5655975342 145.25390625145 .0735015869145 .8798065186147 .4931030273149 .5596008301 152.0637969971154 .8800964355158 .0213012695161 .4889984131165 .1932983398 169.0691070557172 .9295959473176 .6264953613179 .7933959961182 .0043029785 183.5926055908185 .1257019043185 .7606964111183 .9535980225177 .1392974854 161.5372009277144 .782699585135 .6302032471130 .4342041016127 .2319030762 124.9458999634121 .964302063118 .8656005859115 .8212966919112 .8226013184 109.7714996338106 .7213973999103 .7538986206100 .871299743798 .08925628662 95.4149398803792 .8354110717890 .5254974365288 .660720825287 .05407714844 85.5391616821384 .1247329711982 .784881591881 .5239562988380 .33458709717 79.2200469970778 .1810226440477 .21791839676 .3335571289175 .52175140381 74.7826919555774 .0987396240273 .4629669189572 .8426513671972 .21856689453 71.5506896972770 .7991561889669 .9741363525469 .0545730590868 .08847045898 67.1016235351666 .0953979492265 .0812683105564 .0802307128963 .12644958496 62.2341194152861 .4179801940960 .7829399108960 .4464797973660 .28372955322 60.1889610290560 .1598510742260 .1742210388260 .2320404052760 .32297897339 60.4615287780860 .6548004150460 .842220306460 .9766502380461 .09255981445 61.2324714660661 .3812484741261 .5254211425861 .6481399536161 .73603820801 61.7963905334561 .8249092102161 .8317909240761 .811519622861 .82598114014 61.945869445862 .1119384765662 .2816200256362 .4534606933662 .61822891235 62.7746696472262 .9166984558163 .0439796447863 .1531410217363 .24433898926 63.3160705566463 .3687400817963 .4018287658763 .416019439763 .41154098511 63.3894309997663 .3505516052263 .2961883544963 .2277107238863 .1464805603 63.0541496276962 .9519996643162 .8417091369662 .7244186401462 .6016998291 62.4744796752962 .3441390991262 .2114295959562 .0774803161661 .94289016724 61.8085594177261 .6749191284261 .5426788330161 .4121704101661 .28392028809 61.1581306457561 .0352210998560 .915321350160 .7986984252960 .68542098999 60.5756797790560 .4694709777860 .366909027160 .2679405212460 .17261123657 60.0808410644559 .9926300048859 .9078598022559 .8264999389659 .74845123291 59.6736297607459 .6019592285259 .533340454159 .4677200317459 .40502166748 59.3451690673859 .2881202697859 .2337989807159 .1821708679259 .13317108154 59.0866508483959 .0424880981459 .0017700195358 .96556854248 
1163.0539550781157 .751152 .4449462891147 .1369628911141 .8249511721136 .510009766 1131.1899414061125 .8649902341120 .5340576171115 .1970214841109 .853027344 1104.5019531251099 .1429443361093 .7750244141088 .3990478521083 .012939453 1077.6159667971072 .2089843751066 .7910156251061 .3599853521055 .91796875 1050.4630126951044 .9940185551039 .5119628911034 .0169677731028 .508056641 1022.9840087891017 .4470214841011 .8959960941006 .330017091000 .749023438 995.1538696289989 .5435791016983 .9182128906978 .2777099609972 .6215820312 966.9506225586961 .2642822266955 .5640258789949 .8497924805944 .1234130859 938.3856811523932 .6390991211926 .8850708008921 .1273193359915 .3679199219 909.611328125903 .8610839844898 .1223754883892 .3997802734886 .6992797852 881.0266113281875 .3884277344869 .7913208008864 .2416992188858 .7470703125 853.3131103516847 .9475708008842 .6552734375837 .4432983398832 .3148803711 827.2764892578822 .329284668817 .478515625812 .7239990234808 .0690917969 803.5125732422799 .0560913086794 .6976928711790 .4375786 .2728881836782 .203125 778.225402832774 .3375854492770 .5371704102766 .8212280273763 .1870727539 759.6314086914756 .1514892578752 .7437744141749 .4052734375746 .132019043 742.9201049805739 .7658081055736 .6649169922733 .6130981445730 .6057739258 727.6384887695724 .7061157227721 .8037719727718 .9262084961716 .0682983398 713.2241821289710 .3884887695707 .5551147461704 .7174072266701 .8692016602 699.0034790039696.1143188477693.1940917969 690.2373046875 687.2368164062 684.1881103516681 .0850830078677 .9251098633674 .7034301758671 .4193725586 668.0701293945664 .657409668661 .180480957657 .643371582654 .0477905273 650.3999023438646 .7036743164642 .9672851562639 .1970825195635 .4027709961 631.5930786133627 .7788085938623 .9708251953620 .1807250977616 .421081543 612.7036743164609 .0427246094605 .4492797852601 .9387207031598 .5211791992 595.2122192383592 .0208129883588 .9619750977586 .0430297852583 .2777099609 580.6707763672578 .234375575 .9697265625573 .8867797852571 .9807739258 570.2551269531568 .7031860352567 .3256225586566 .1193847656565 .083984375 564.2297973633563 .5590820312563 .1140136719562 .9033203125563 .0053710938 563.5032958984564 .272277832565 .3179931641566 .6110839844568 .1312255859 569.8629760742571 .529296875573 .7219238281577 .0681152344580 .9705810547 585.1005249023589 .0800170898592 .3181762695595 .2808837891598 .3792114258 601.1790161133603 .3496704102605 .3461914062607 .5437011719609 .5739135742 611.1774902344612 .041015625611 .9110107422610 .4993286133607 .0222167969 602.4428710938597 .4567871094591 .9448242188585 .8510742188579 .7858886719 574.4392700195569 .2844238281564 .1049194336559 .1751098633554 .4984741211 550.7330932617548 .6599121094547 .2266845703545 .4235229492543 .3278808594 542.0123901367536 .1209716797520 .5130004883499 .6227111816476 .9531860352 454.0176086426434 .6695861816417 .657409668400 .6022033691385 .3646850586 371.7315979004359 .216796875347 .8385009766337 .9979858398329 .5852966309 322.4354858398316 .615814209311 .6099853516307 .5307006836303 .5551147461 298.9115905762294 .1052856445289 .5126953125285 .0848999023280 .9324951172 277.0848083496273 .6000976562270 .1755065918266 .4144897461262 .2568969727 257.495300293252 .099899292245 .8200073242239 .3354034424233 .3345031738 227.2254943848220 .4745025635213 .1358032227205 .2888946533197 .195602417 189.6369934082181 .8628997803173 .3993988037164 .8721008301156 .4526977539 
149.8565063477146 .9550933838146 .0393981934145 .670501709146 .1979980469 147.5117950439149 .4317932129151 .708404541154 .317199707157 .1649932861 160.2756958008163 .68359375167 .2483978271170 .9028015137174 .4313049316 177.7100982666180 .4609985352182 .2664031982183 .8735046387185 .8945007324 186.5838012695184 .3058013916177 .040802002161 .6300964355145 .5045013428 136.7294006348131 .5296936035127 .9654998779125 .5582962036123 .1210021973 120.6224975586117 .724899292114 .6336975098111 .4417037964108 .2408981323 105.1106033325102 .06890106299 .1405715942496 .3272171020593 .54531097412 91.0692672729589 .1829528808687 .5871429443486 .0211868286184 .5541229248 83.1588134765681 .8418807983480 .6046524047979 .4467468261778 .37389373779 77.3846130371176 .4865570068475 .6717987060574 .9455108642674 .28714752197 73.6949386596773 .127372741772 .5728683471771 .9646835327171 .25486755371 70.4576263427769 .542823791568 .5509414672967 .4812927246166 .36982727051 65.276367187564 .2042236328163 .1886787414662 .2388114929261 .33155822754 60.6284713745160 .3171501159760 .1994514465360 .112438201960 .09016036987 60.1110191345260 .1743087768660 .2723693847760 .4050292968860 .56795883179 60.7337303161660 .8936386108461 .0372695922961 .1705894470261 .29476165771 61.4108390808161 .5083618164161 .5789413452161 .6232185363861 .63468933105 61.6240997314561 .5699081420961 .560691833561 .6973114013761 .88526153564 62.0559005737362 .2250404357962 .3861808776962 .5379981994662 .67794036865 62.8042793273962 .9143600463963 .0078392028863 .0831604003963 .14044952393 63.1791114807163 .1995506286663 .2019386291563 .1870117187563 .15565109253 63.1088294982963 .047988891662 .9742202758862 .889228820862 .7940788269 62.6905593872162 .5796012878462 .4628715515162 .3411483764662 .21591949463 62.0878105163661 .9580497741761 .8271408081161 .6960601806661 .56520080566 61.4353294372661 .3067283630461 .1800117492761 .0553512573260 .93320083618 60.8136901855560 .6971397399960 .5836105346760 .4733085632360 .36626052856 60.2625999450760 .1622810363860 .0653610229559 .9717903137259 .8815612793 59.7946014404359 .7108688354559 .6302909851159 .5527992248559 .47832107544 59.4067916870159 .3381500244159 .2723503112859 .2093391418559 .14907836914 59.091518402159 .0366401672458 .9843902587958 .9346504211458 .88758850098 58.8425903320358 .80047988892

1167.4630126951162 .1109619141156 .7430419921151 .3719482421145 .996948242 1140.6180419921135 .2340087891129 .8439941411124 .4489746091119 .04699707 1113.6369628911108 .2199707031102 .7939453121097 .3599853521091 .916015625 1086.4630126951080 .9990234381075 .5229492191070 .0369873051064 .537963867 1059.0269775391053 .5030517581047 .964965821042 .4150390621036 .849975586 1031.2719726561025 .6800537111020 .0729980471014 .453002931008 .817993164 1003.169006348997 .5062866211991 .8289794922986 .137512207980 .4320068359 974.7122192383968 .9788818359963 .232421875957 .4733886719951 .7028198242 945.9219970703940 .1320800781934 .3353881836928 .5336914062922 .7299194336 916.9268188477911 .128112793905 .3375854492899 .5596923828893 .7990722656 888.0612182617882 .3516235352876 .6762084961871 .0413818359865 .4531860352 859.9185180664854 .4423828125849 .0322265625843 .6923217773838 .4290771484 833.2457885742828 .1478881836823 .1370849609818 .217590332813 .3898925781 808.6567993164804 .0175170898799 .4735107422795 .0233154297790 .6669921875 
786.4025878906782 .229309082778 .1448974609774 .1475830078770 .2348022461 766.404296875762 .6531982422758 .9788818359755 .3784790039751 .848815918 748.3862304688744 .9876098633741 .6489257812738 .3660888672735 .1351928711 731.9517211914728 .8109741211725 .7086181641722 .6397705078719 .5994873047 716.5825805664713 .5842895508710 .5989990234707 .6212768555704 .6453857422 701.665222168698 .6746826172695 .6674804688692 .6373291016689 .5775756836 686.4829101562683 .3466796875680 .1649169922676 .9315795898673 .6447753906 670.2999267578666 .8967285156663 .4326782227659 .9097290039656 .3273925781 652.6895141602648 .9979248047645 .2581787109641 .4749755859637 .655090332 633.8051757812629 .9340820312626 .0501708984622 .1635131836618 .2844848633 614.4238891602610 .5936279297606 .8046875603 .0701904297599 .4008789062 595.8107299805592 .3095092773588 .9114990234585 .6254272461582 .4650268555 579.4376220703576 .5557861328573 .8247070312571 .2551879883568 .8496704102 566.6168212891564 .5551147461562 .6688842773560 .9547729492559 .4124755859 558.0426025391556 .8458862305555 .8358764648555 .0189208984554 .4249267578 554.0725708008553 .9962768555554 .2487182617554 .7470703125555 .4846191406 556.4595947266557 .6823120117559 .1201171875560 .658203125562 .6054077148 565.23828125568 .548828125572 .5939941406576 .6989135742580 .07421875583 .076171875 586.0933837891588 .5874023438590 .1354980469591 .4266967773592 .9644165039 594.3815917969595 .3864135742595 .7271728516595 .1406860352593 .6286010742 590.9193725586587 .3234863281582 .951171875578 .3851928711574 .2916259766 570.2103271484565 .8176879883561 .4282226562557 .2905883789553 .6331787109 550.6290283203548 .6212158203548 .0261230469548 .1135253906548 .1179199219 547.8352050781547 .268371582543 .0501708984531 .9649047852516 .8798828125 501.0812072754480 .9039916992453 .4349975586427 .6213989258410 .9733886719 397.5104064941381 .4551086426365 .157989502350 .8988037109339 .2640991211 330.6556091309323 .6357116699317 .062286377311 .3508911133307 .1130065918 303.1527099609298 .2420959473293 .1471862793288 .3847045898283 .8200073242 279.4064025879275 .4289855957272 .2535095215269 .2367858887265 .6751098633 261.6098937988256 .857208252251 .3535003662245 .0177001953238 .2649993896 231.4403076172224 .4944000244217 .2877960205209 .4131011963200 .6401062012 191.6118011475183 .0628051758174 .7530059814166 .8002929688159 .4570007324 152.9196014404148 .2994995117146 .3728942871146 .0399017334146 .4058990479 147.4931030273149 .2151947021151 .3811035156153 .7319946289156 .3224029541 159.1678924561162 .2427062988165 .5469055176168 .9530029297172 .3798065186 175.62840271178 .5422058105180 .9208984375182 .3829040527183 .9855041504 187.1045074463188 .1004943848183 .1398925781173 .3751068115158 .383895874 143.8392944336136 .2261047363131 .8706054688128 .6815948486126 .4899978638 124.5711975098122 .5140991211119 .5585021973116 .2147979736112 .9050979614 109.617401123106 .4033966064103 .2778015137100 .275398254497 .39346313477 94.6135025024492 .1148071289190 .0717391967888 .2988510131886 .62436676025 85.0593872070383 .5778198242282 .1862030029380 .8779373168979 .6595993042 78.5336685180777 .5043106079176 .5769119262775 .7495727539175 .02503204346 74.3902206420973 .8402175903373 .3389205932672 .8662567138772 .33748626709 71.6966629028370 .9424667358470 .0133285522568 .9691925048867 .82479858398 66.6214370727565 .4488983154364 .3192520141663 .2649192810162 .29515838623 
61.4173698425360 .7371292114360 .3667602539160 .1814689636260 .06995010376 60.0311584472760 .0422782897960 .1007118225160 .195449829160 .31916046143 60.4655685424860 .6248893737860 .7861785888760 .9386787414661 .07178115845 61.1868095397961 .2897682189961 .3749885559161 .4357299804761 .47203826904 61.481441497861 .4723205566461 .4408912658761 .4487686157261 .55765914917 61.7114295959561 .8666000366262 .0235595703162 .1760406494162 .32236099243 62.4580383300862 .5820808410662 .6912918090862 .7853507995662 .86248016357 62.9227218627962 .9651718139662 .9902496337962 .9977989196862 .98862838745 62.9632415771562 .9227600097762 .8682403564562 .8009300231962 .72219085693 62.6332702636762 .5356407165562 .430389404362 .3189697265662 .20227813721 62.0816307067961 .9577713012761 .8317909240761 .7042808532761 .576171875 61.4478797912661 .3201599121161 .1933517456161 .0680007934660 .94437026978 60.8228988647560 .7037315368760 .5872001647960 .4733886718860 .36252975464 60.2546501159760 .1498908996660 .0482597351159 .9497909545959 .85446166992 59.762279510559 .6731910705659 .5871505737359 .5041084289659 .42401885986 59.3468093872159 .2724418640159 .2008705139259 .1320610046459 .06597137451 59.0025787353558 .9418716430758 .8838310241758 .8284187316958 .77555084229 58.7251281738358 .6783981323258 .6362991333 1171.9060058591166 .4780273441161 .0479736331155 .6149902341150 .177001953 1144.7349853521139 .2879638671133 .8349609381128 .3751122 .9090576171117 .435058594 1111.953002931106 .4620361331100 .9620361331095 .4520263671089 .932983398 1084.4019775391078 .8599853521073 .3070068361067 .7409667971062 .162963867 1056.5720214841050 .9680175781045 .3499755861039 .7180175781034 .072998047 1028.4129638671022 .7399902341017 .0529785161011 .3519897461005 .637023926 999.9088134766994 .1666870117988 .411315918982 .6428833008976 .8615112305 971.0681152344965 .2628173828959 .4470214844953 .6212158203947 .7871704102 941.946105957936 .1002807617930 .2512207031924 .4022216797918 .5554199219 912.7150268555906 .8837890625901 .0667114258895 .267578125889 .4918823242 883.7446899414878 .0316162109872 .3582763672866 .7305908203861 .1549072266 855.6361083984850 .1806030273844 .7924194336839 .477722168834 .2393188477 829.0822143555824 .0079956055819 .0208129883814 .1207885742809 .3109741211 804.5905151367799 .9609985352795 .4210205078790 .9710083008786 .6093139648 782.3353271484778 .1469726562774 .0427856445770 .0205078125766 .078125 762.2130126953758 .4226074219754 .7042236328751 .0546875747 .4708862305 743.94921875740 .4860229492737 .0772705078733 .7188110352730 .4061889648 727.1348266602723 .9003295898720 .6978149414717 .5225830078714 .3698120117 711.234375708 .1112060547704 .9951171875701 .8803100586698 .7612304688 695.632019043692 .486328125689 .3187866211686 .1229248047682 .8936767578679 .625 676.3131103516672 .9528198242669 .5419921875666 .0769042969662 .5573730469 658.9813232422655 .3505859375651 .6651000977647 .9284057617644 .1423950195 640.3129272461636 .4434814453632 .5413208008628 .6124267578624 .6649780273 620.7072143555616 .7484130859612 .7984008789608 .8673706055604 .9663696289 601.1060180664597 .2982788086593 .5534057617589 .8845214844586 .30078125 582.815612793579 .4370117188576 .1782226562573 .0457763672570 .0521850586 567.2017822266564 .5057983398561 .9663085938559 .5922241211557 .3834838867 555.3468017578553 .4801025391551 .7841186523550 .262878418548 .9179077148 
547.7631835938546 .8029174805546 .0609741211545 .5565185547545 .2952270508 545.3120117188545 .5610961914546 .0560302734546 .7849121094547 .7526855469 548.9821166992550 .4804077148552 .2963256836554 .2797851562556 .8983764648 560.6503295898564 .5817871094567 .8695068359570 .8289794922573 .796081543 576.1677246094577 .3521118164578 .07421875578 .9323730469579 .6370239258 579.9415283203579 .7437133789578 .6705932617576 .9840087891574 .8973999023 572.1857299805568 .383972168564 .6347045898562 .3189697266560 .0150756836 556.4833984375552 .8453979492549 .7058105469547 .2592163086545 .8928222656 545.5183105469546 .0775756836547 .2197265625548 .4810180664549 .1348876953 548.3936767578545 .3073120117539 .2763061523530 .6586303711522 .7053833008 507.9714050293476 .4815979004443 .8481140137426 .7269897461412 .9959106445 392.9620056152373 .7479858398356 .7983093262342 .6883850098332 .9732055664 325.2412109375317 .588104248310 .9552001953306 .4732055664302 .3575134277 297.2171020508291 .9645080566287 .1895141602282 .5573120117278 .0433044434 274.0512084961271 .1488037109268 .4234008789264 .8211975098260 .6694030762 255.6929931641250 .0646972656243 .7890930176236 .7313995361229 .0391998291 220.7290039062212 .6266937256204 .0099029541194 .4770050049184 .7415924072 175.3011016846166 .8106994629160 .0052947998154 .7160949707150 .5971984863 147.9481964111146 .6730041504146 .5928039551147 .4288024902148 .9371032715 150.945098877153 .2357025146155 .5827026367158 .1092987061160 .9237976074 163.9237976074167 .0908050537170 .2994995117173 .479095459176 .4553985596 179.0635070801181 .2550964355182 .5767974854184 .0556945801187 .7525024414 188.3179016113180 .1694030762168 .008102417154 .2725067139142 .021697998 135.8589935303132 .3771972656129 .4754943848127 .4306030273125 .841003418 124.0329971313120 .9983978271117 .516998291114 .2090988159110 .9046020508 107.6615982056104 .5073013306101 .469596862898 .5831298828195 .86373901367 93.3746032714891 .1497726440489 .1512069702187 .3191375732485 .63046264648 84.0391464233482 .5509414672981 .1523590087979 .8531875610478 .65746307373 77.5698471069376 .5992889404375 .7434234619175 .0088577270574 .38227081299 73.8618316650473 .4132690429773 .0150527954172 .5940628051872 .07891082764 71.3835296630970 .42494964669 .284317016668 .049667358466 .7811126709 65.5557403564564 .39257812563 .3219604492262 .3689002990761 .55884933472 60.9216499328660 .4805183410660 .2006683349660 .0401916503959 .97423934937 59.9671897888260 .0127601623560 .0961990356460 .2090797424360 .34321975708 60.4924812316960 .6518096923860 .8066596984960 .9441184997661 .06148910522 61.1626396179261 .2427902221761 .3001098632861 .3385009765661 .35472106934 61.362171173161 .3679084777861 .3961791992261 .4690208435161 .57447052002 61.7036094665561 .8446807861361 .986751556462 .1262702941962 .25667953491 62.3771286010762 .484100341862 .5772399902362 .6546211242762 .71614074707 62.7607994079662 .7888603210462 .800079345762 .7950782775962 .77436065674 62.7388114929262 .6894912719762 .6274185180762 .5540313720762 .47032165527 62.3778381347762 .277488708562 .1707687377962 .0584716796961 .94194030762 61.8218002319361 .6992301940961 .5747413635361 .4492988586461 .32329177856 61.1975097656261 .0722389221260 .9481315612860 .8253707885760 .70444869995 60.5855293273960 .4689483642660 .3548011779860 .2433509826760 .13460922241 60.0287704467859 .9258117675859 .8258209228559 .7287597656259 .63465881348 
59.5434684753459 .4551811218359 .3697395324759 .2871017456159 .20722961426 59.1300888061559 .0556411743258 .9838905334558 .9147911071858 .8483581543 58.7845802307158 .7234497070358 .6649818420458 .6090698242258 .55596923828 58.5050582885758 .45724105835

1176.3260498051170 .8520507811165 .3609619141159 .8659667971154 .366943359 1148.8630371091143 .3530273441137 .8370361331132 .3149414061126 .78503418 1121.2469482421115 .7010498051110 .1469726561104 .582031251099 .008056641 1093.4229736331087 .828002931082 .2209472661076 .6020507811070 .970947266 1065.328002931059 .6710205081054 .0019531251048 .3179931641042 .621948242 1036.9110107421031 .1870117191025 .4489746091019 .6970214841013 .932006836 1008.1530151371002 .361999512996 .5571289062990 .7399291992984 .9105834961 979.0698242188973 .2178955078967 .3557739258961 .4846191406955 .6052246094 949.7191772461943 .828125937 .9338989258932 .0385131836926 .1445922852 920.2548217773914 .3726196289908 .5009765625902 .6444091797896 .8068237305 890.9929199219885 .207824707879 .4564208984873 .7443237305868 .0767211914 862.4594726562856 .897277832851 .3961181641845 .9594726562840 .5930786133 835.299621582830 .0834960938824 .946472168819 .8922119141814 .9210205078 810.0355224609805 .2354125977800 .5219116211795 .8939819336791 .3524169922 786.8955078125782 .5228881836778 .2329711914774 .0244750977769 .895324707 765.8436279297761 .8668823242757 .9630126953754 .1290893555750 .362487793 746.6597290039743 .0177001953739 .4324951172735 .9002075195732 .4166870117 728.977722168725 .5784301758722 .2144775391718 .8812866211715 .57421875 712.2885131836709 .0191040039705 .7614135742702 .5098876953699 .2595825195 696.0048828125692 .7402954102689 .459777832686 .1583251953682 .8295288086 679.4691162109676 .071105957672 .6323852539669 .1481933594665 .6165771484 662.0344238281658 .4014282227654 .716003418650 .9799194336647 .1936035156 643.3602294922639 .4821166992635 .5640258789631 .6102294922627 .6267700195 623.6198730469619 .5972290039615 .5662231445611 .5358276367607 .5151977539 603.5139770508599 .5429077148595 .6115112305591 .7312011719587 .9116821289 584.1652832031580 .5006713867576 .9301757812573 .4619140625570 .1077270508 566.8745117188563 .7733764648560 .8095703125557 .9931030273555 .3270874023 552.8198242188550 .4733276367548 .2935791016546 .2816772461544 .4401245117 542.7739868164541 .2869873047539 .9901123047538 .890625538 .00390625537 .3466796875 536.9163208008536 .7322998047536 .7780761719537 .0609741211537 .5822143555 538.3427124023539 .3966064453540 .7656860352542 .416015625544 .3264770508 546.7678222656550 .1093139648553 .5482788086556 .1853027344558 .5784301758 561.1712036133563 .2744140625564 .3068847656564 .6989135742564 .7723999023 564.6655273438564 .5844116211564 .2191162109563 .3217163086561 .9378051758 559.8353881836557 .3521118164554 .6610717773552 .1364746094550 .2727050781 548.4331054688545 .9694213867543 .4906005859541 .4672241211540 .1939697266 539.9636230469540 .6049804688542 .0687255859544 .0280761719546 .2432861328 547.8511962891548 .162109375547 .1605834961544 .1953735352539 .8568725586 534.7880859375523 .7843017578502 .9572143555476 .9367980957450 .4201049805 425.4612121582403 .9717102051385 .0006103516366 .6903076172350 .3698120117 337.0788879395326 .1520080566317 .4812011719310 .5230102539305 .2287902832 300.6120910645295 .5498046875290 .6401062012285 .9573974609281 .4242858887 
277.3021850586273 .6778869629270 .7120056152267 .7315063477263 .8471984863 259.2869873047253 .8601989746247 .9349060059241 .7272949219234 .4846954346 225.7926940918215 .9609069824205 .6107025146195 .2492980957185 .6463012695 176.1963043213166 .3278045654158 .0673065186153 .3054962158150 .6363067627 148.624206543147 .4488067627147 .1555938721147 .6315002441148 .8905029297 150.691696167152 .7012023926154 .8892059326157 .2108001709159 .7144012451 162.4418029785165 .3262939453168 .3282012939171 .3336029053174 .2523956299 176.9662017822179 .3372955322181 .362197876182 .8562927246184 .2982940674 186.7180023193185 .4174041748175 .6907958984163 .1885070801151 .9683074951 142.824005127137 .2328033447133 .4053039551130 .4734039307128 .2993927002 126.4983978271124 .5538024902121 .7461013794118 .556602478115 .345199585 112.1054000854108 .8920974731105 .7416992188102 .708503723199 .82290649414 97.109931945894 .5720291137792 .2400817871190 .0847473144588 .10163879395 86.2726898193484 .5503921508882 .9397583007881 .4286117553780 .02816009521 78.7423934936577 .5792007446376 .5466613769575 .6460189819374 .88218688965 74.245399475173 .7288131713973 .3115692138772 .9722137451272 .67371368408 72.4034194946371 .8764038085970 .7849731445369 .4427566528368 .11711883545 66.8082199096765 .5665130615264 .403739929263 .3442993164162 .41501998901 61.638950347961 .0103492736860 .5467681884860 .2195091247660 .01842880249 59.9215011596759 .8898200988859 .9154396057159 .9815101623560 .08053970337 60.2026405334560 .3437194824260 .4971199035660 .6536598205660 .80242919922 60.9322319030861 .0317916870161 .1090507507361 .1710281372161 .21995162964 61.254878997861 .2822990417561 .2991905212461 .3230400085461 .38055038452 61.4608802795461 .567520141661 .6918106079161 .8209190368761 .95082092285 62.0740890502962 .1893997192462 .2927818298362 .3837013244662 .45994949341 62.5213699340862 .5667800903362 .5964202880962 .6098289489762 .6077003479 62.5902214050362 .5583915710462 .5129814147962 .4551086425862 .38592910767 62.3065414428762 .2182388305762 .1220397949262 .0192298889261 .91070175171 61.7976188659761 .6807289123561 .5610389709561 .439170837461 .315990448 61.191959381161 .0677795410260 .9438400268660 .8207092285260 .69865036011 60.578128814760 .4593086242760 .3425712585460 .2280082702660 .11587905884 60.0062484741259 .8992881774959 .7949905395559 .6934585571359 .59466934204 59.4986801147559 .40541839659 .3149108886759 .2270889282259 .14196014404 59.0594711303758 .9795989990258 .9023590087958 .82770919858 .75566101074 58.686241149958 .6194496154858 .5553207397558 .4938507080158 .43497848511 58.3786697387758 .3263702392658 .278881073

1180.7819824221175 .2330322271169 .6810302731164 .1259765621158 .5660400391153 1147.4289550781141 .8520507811136 .2679443361130 .6760253911125 .074951172 1119.4670410161113 .8489990231108 .2220458981102 .5839843751096 .936035156 1091.2769775391085 .6059570311079 .9229736331074 .2290039061068 .520996094 1062.8010253911057 .0679931641051 .3210449221045 .5610351561039 .7869873051034 1028.1989746091022 .3850097661016 .5570068361010 .716979981004 .864013672 998.9995117188993 .1226806641987 .2348022461981 .3361816406975 .4279785156 969.5106811523963 .5858154297957 .6541137695951 .7175292969945 .7772827148 939.8358764648933 .8947143555927 .9567260742922 .0241699219916 .1005249023 910.1887207031904 .2927856445898 .4163818359892 .5642089844886 .7407226562 
880.9506835938875 .1994018555869 .491394043863 .8322753906858 .2263793945 852.6790161133847 .1937866211841 .7755126953836 .4268798828831 .1522216797 825.9528808594820 .8322143555815 .7905883789810 .8308105469805 .9522094727 801.1563720703796 .4426269531791 .8112792969787 .2614135742782 .7927246094 778.4036254883774 .0930175781769 .859375765 .7009277344761 .6152954102 757.6002807617753 .6533203125749 .7719116211745 .9528198242742 .1926269531 738.4879150391734 .8344726562731 .2283935547727 .6652832031724 .1406860352 720.6500854492717 .1890258789713 .7528076172710 .337097168706 .9368896484 703.5474853516700 .1640014648696 .7813110352693 .3942260742689 .9973754883 686.5853881836683 .1530151367679 .6947021484676 .2061767578672 .6823730469 669.1201171875665 .5150146484661 .8657836914658 .1693725586654 .4259033203 650.6339111328646 .7952880859642 .9105834961638 .9829101562635 .0142822266 631.0098266602626 .9727783203622 .9097290039618 .8259277344614 .7286987305 610.6253051758606 .5239868164602 .4334716797598 .3627929688594 .3220214844 590.3201904297586 .3682250977582 .4750976562578 .6525268555574 .9083862305 571.2548828125567 .69921875564 .253112793560 .9224243164557 .7186889648 554.6464233398551 .7158813477548 .9301757812546 .2979736328543 .8217773438 541.5078125539 .3593139648537 .3803710938535 .5773925781533 .9536132812 532.5197143555531 .2822265625530 .2512817383529 .4420166016528 .8499755859 528.491027832528 .3587036133528 .4644165039528 .8145141602529 .4005126953 530.2813720703531 .4810180664533 .0214233398534 .9669189453537 .3131713867 540.1934814453543 .0181884766544 .953918457546 .6702880859548 .7708740234 550.5208740234551 .453125551 .6610107422551 .0534057617550 .1934814453 549.7208251953549 .2227172852548 .5349121094547 .3947753906545 .0900878906 542.7194824219541 .1085205078539 .7114868164538 .0601196289536 .4049072266 534.8975219727533 .6002807617532 .6652832031532 .3967285156532 .999206543 534.3806152344536 .4251098633538 .9252929688541 .7756958008544 .3449707031 546.1115112305547 .0526123047546 .6530151367544 .6934204102540 .6967773438 533.4174194336525 .5374145508509 .9417114258477 .6525878906443 .2027893066 420.7510986328401 .7605895996380 .620513916361 .425201416343 .4106140137 328.5799865723318 .2355957031310 .4837036133304 .5155944824299 .2268981934 294.1466064453289 .1943054199284 .4547119141280 .1614074707276 .6787109375 273.5945129395270 .5389099121267 .1452941895262 .6859130859257 .5310058594 251.2870941162244 .4120941162237 .6468963623229 .6320037842220 .0025024414 209.0393981934197 .0699005127185 .4819946289176 .2949981689167 .8963012695 158.4434051514151 .0272064209148 .3125147 .8377990723147 .2863006592147 .3560028076 147.9445953369148 .9803924561150 .6016998291152 .4846954346154 .3697967529 156.3907928467158 .6717987061161 .1266021729163 .7449951172166 .4734954834 169.2823944092 172.0608062744174 .7144927979177 .1714019775179 .3215026855 181.1651000977182 .758102417183 .6148986816184 .0256958008181 .0570983887 170.9470977783159 .3719940186151 .1575927734144 .6407012939139 .0966949463 134.6959075928131 .5812072754129 .1595001221126 .9817962646124 .7976989746 122.2369995117119 .4187011719116 .3925018311113 .2545013428110 .1061019897 106.9934997559103 .986000061101 .103996276998 .3706207275495 .78369903564 93.3552780151491 .0780105590888 .954238891686 .974327087485 .10195159912 83.3510589599681 .7065277099680 .1852416992278 .790039062577 .53144836426 
76.420486450275 .4568634033274 .6489486694373 .9848327636773 .45585632324 73.047576904372 .7395706176872 .4985733032272 .4015502929772 .01235961914 70.8292236328169 .3605575561568 .0176315307666 .7098083496165 .48178100586 64.3489990234463 .3178405761762 .4179916381861 .6625595092861 .04555892944 60.5704612731960 .2215805053759 .9923095703159 .8636283874559 .80348968506 59.8061714172459 .8526687622159 .9370498657260 .0480918884360 .1810798645 60.3277587890660 .4822998046960 .6409606933660 .7836799621660 .88721084595 60.9701614379961 .0455207824761 .1099090576261 .1646118164161 .20697021484 61.2256813049361 .245819091861 .2937507629461 .3604316711461 .45162963867 61.559429168761 .6747703552261 .794639587461 .909591674862 .0189704895 62.1175804138262 .2051200866762 .2789115905862 .338871002262 .38364028931 62.41341018677 62.42766952515 62.42694854736 62.4114608764662.38199996948 62.3393592834562 .2844696044962 .2184982299862 .1423683166562 .05741119385 61.9644508361861 .8648605346761 .7593307495161 .6491203308161 .53483963013 61.4175682067961 .2978210449261 .1765213012761 .0540504455660 .93119049072 60.8082504272560 .6858711242760 .5642700195360 .4439582824760 .32508850098 60.2080612182660 .0929603576759 .9800796508859 .8694686889659 .76132965088 59.6556510925359 .5525703430259 .4520492553759 .3541488647559 .25883102417 59.1661109924359 .0759506225658 .9883499145558 .9032707214458 .820728302 58.7407112121658 .663219451958 .5882797241258 .5159301757858 .44617843628 58.3790893554758 .3146896362358 .2529182434158 .1940994262758 .13764190674 58.08449172974

1185.2170410161179 .6230468751174 .0119628911168 .3959960941162 .776000977 1157.1500244141151 .5179443361145 .8800048831140 .2340087891134 .581054688 1128.9200439451123 .251117 .5699462891111 .8809814451106 .1810302731100 .470947266 1094.7490234381089 .0159912111083 .2709960941077 .5140380861071 .744995117 1065.9620361331060 .1669921881054 .3580322271048 .5360107421042 .701049805 1036.8520507811030 .9909667971025 .1159667971019 .2290039061013 .328979492 1007.4169921881001 .494018555995 .5595703125989 .6149902344983 .6608276367 977.6978759766 971.7271728516965.7498779297959.767578125953.7816772461 947.7937011719941 .8057250977935 .8197021484929 .8380737305923 .8635253906 917.8988037109911 .9470214844906 .0119018555900 .0969848633894 .2064208984 888.3446044922882 .5158081055876 .7249755859870 .9763183594865 .2750854492 859.6251220703 854.0314941406 848.4973754883 843.0274047852 837.6239013672 832.2907714844827 .0294799805821 .8430786133816 .7321777344811 .6989135742 806.7432861328801 .8668212891797 .0686035156792 .3494873047787 .7084960938 783.1458129883778 .6596069336774 .2495117188769 .9135742188765 .6508178711 761.4584960938757 .334777832753 .2772827148749 .2835083008745 .3502807617 741.4744262695737 .6524047852733 .8801879883730 .1539916992726 .4694213867 722.8220214844719 .2072753906715 .6209716797712 .0584716797708 .5153808594 704.987121582701 .4691162109697 .9564208984694 .4442749023690 .9276733398 687.4019165039683 .8612060547680 .3012695312676 .7166137695673 .1032714844 669.4567260742 665.7741088867 662.051574707 658.2877197266 654.4802246094 650.6290283203646 .7332763672642 .794921875638 .8142089844634 .7943725586 630.7376708984626 .6483154297622 .530090332618 .3886108398614 .2293701172 610.0590209961605 .8842773438601 .7130737305597 .5537109375593 .4144897461 
589.3049926758585 .2338256836581 .2114257812577 .2459716797573 .348815918 569.5274047852565 .7930908203562 .1530151367558 .6179199219555 .1942138672 551.8920898438548 .716796875545 .6777954102542 .7791137695540 .0291137695 537.4307861328534 .991394043532 .7147216797530 .6063232422528 .6719970703 526.9174804688525 .3508300781523 .9794921875522 .8109130859521 .8558959961 521.1143798828520 .5958862305520 .3037109375520 .2462768555520 .4345092773 520.8712158203521 .5939941406522 .6248779297524 .0029907227525 .7600708008 527.7990112305530 .1566162109532 .4254760742534 .219909668535 .7896728516 537.2883911133538 .5178833008539 .2943725586539 .3322143555538 .2611083984 536.8201904297535 .6768188477534 .6245117188533 .5770263672532 .1483154297 529.8369140625527 .7603759766526 .8322753906526 .2432861328525 .4647827148 524.6436157227523 .8264160156523 .2874755859523 .1019287109523 .5095214844 524.8455810547526 .8552246094529 .3306274414532 .2271728516535 .4506835938 538.6947021484541 .6591796875544 .2318725586546 .1157226562546 .5308227539 544.7125854492541 .4412231445537 .2683105469526 .2924804688503 .6312866211 475.6105041504450 .0564880371425 .3581848145398 .5356140137373 .327911377 351.9790039062334 .4736022949321 .1889953613311 .5144042969305 .5981140137 300.5903930664294 .0804138184287 .8073120117282 .6221008301278 .4530944824 275.6091003418273 .137298584270 .1499023438266 .3453979492261 .2651977539 255.2227935791247 .7915039062239 .395401001230 .2931976318220 .2156982422 209.8087005615 198.8347015381 187.5756988525 177.149597168168.657699585 161.2951965332153 .9577026367148 .5231018066146 .5868988037146 .5648040771 146.9629058838147 .8856048584149 .1824035645150 .7097930908152 .3453063965 154.0673980713155 .8833007812157 .850692749160 .024597168162 .3672943115 164.8448028564167 .395401001169 .9757995605172 .4942932129174 .8619995117 177.0092010498178 .8388061523180 .3132019043181 .3959960938181 .3518066406 180.0236053467176 .0296020508167 .4306945801158 .2471008301151 .3845977783 145.596496582140 .5355072021136 .1354980469132 .8345947266130 .2075958252 127.7882003784125 .4691009521122 .9430999756120 .278503418117 .3904037476 114.3590011597111 .2895965576108 .2328033447105 .2627029419102 .3880004883 99.6335678100696 .9935989379994 .4801025390692 .089569091889 .83117675781 87.6984024047985 .6754837036183 .7717437744181 .980751037680 .31983184814 78.7960586547977 .4225234985476 .2133789062575 .1687164306674 .29654693604 73.5841979980573 .0247268676872 .5927429199272 .2602386474671 .98946380615 71.7631301879971 .2862091064570 .2466735839868 .9580688476667 .6921081543 66.4490127563565 .2761611938564 .1862716674863 .2044296264662 .3416595459 61.6151313781761 .0136909484960 .5402793884360 .1815299987859 .93378829956 59.7800292968859 .6989707946859 .6816101074259 .7114295959559 .78215026855 59.882678985660 .0075798034760 .1482086181660 .2998390197860 .45523834229 60.6004791259860 .7182388305760 .8203811645560 .9162483215360 .9984588623 61.0590591430761 .1025695800861 .1309814453161 .1586799621661 .20283889771 61.2615394592361 .342361450261 .4375381469761 .5429496765161 .65409851074 61.7620086669961 .8650093078661 .9583892822362 .0414505004962 .1117401123 62.1690101623562 .2118797302262 .240509033262 .2542800903362 .25373077393 62.2388992309662 .2106399536162 .169509887762 .1165313720762 .05263137817 61.978790283261 .8961601257361 .8056297302261 .7083511352561 .60514068604 
61.497070312561 .3848114013761 .2693405151461 .1512184143161 .03128814697 60.9099998474160 .7880516052260 .6658096313560 .5438613891660 .42248916626 60.3021392822360 .183029174860 .0655212402359 .9497489929259 .83599090576 59.7243118286159 .6149101257359 .5078010559159 .4031105041559 .30081939697 59.2010002136259 .1036109924359 .0086898803758 .9161911010758 .82612991333 58.7384910583558 .6532897949258 .5705299377458 .490238189758 .41244125366 58.3371810913158 .2645187377958 .1945190429758 .127231597958 .06259918213 58.0006790161157 .9431304931657 .8906288147

1189.6889648441184 .0209960941178 .3499755861172 .6760253911166 .99597168 1161.3110351561155 .6199951171149 .921997071144 .2159423831138 .503051758 1132.7810058591127 .0500488281121 .3100585941115 .5600585941109 .798950195 1104.0279541021098 .245971681092 .4520263671086 .6459960941080 .82800293 1074.9980468751069 .1540527341063 .2979736331057 .4300537111051 .547973633 1045.6529541021039 .7449951171033 .8239746091027 .8909912111021 .945007324 1015.9879760741010 .0189819341004 .039978027998 .049621582992 .0501098633 986.0418701172980 .026184082974 .0037231445967 .9760131836961 .9442138672 955.9102172852949 .8754272461943 .8419799805937 .8118286133931 .7874755859 925.7711181641919 .7659301758913 .7744140625907 .8001708984901 .8468017578 895.9177856445890 .0175170898884 .1497802734878 .3192138672872 .5297241211 866.7860717773 861.0921020508 855.4520874023 849.8690185547 844.3472900391 838.8889770508 833.4979248047 828.1751708984 822.9240112305 817.7446289062 812.6392211914807 .6077880859802 .6519775391797 .7713012695792 .9663696289 788.2365112305783 .5817260742779 .0009155273774 .4935302734770 .0579223633 765.6928100586761 .3963012695757 .1663208008753 .0004882812748 .8966064453 744.8515014648740 .8621826172736 .924987793733 .0363769531729 .192199707 725.3883056641721 .6204223633717 .8840942383714 .174987793710 .4887084961 706.8209228516703 .167175293699 .5230712891695 .8840942383692 .2454223633 688.6022949219684 .9501953125681 .2841186523677 .5994262695673 .891418457 670.1566162109666 .3903808594662 .5906982422658 .7536010742654 .8784179688 650.9627075195647 .007019043643 .0103759766638 .9746704102634 .9005737305 630.791015625626 .6478881836622 .4758911133618 .2780151367614 .0598754883 609.8264770508605 .5842285156601 .3394165039597 .0994873047592 .8723144531 588.6655883789584 .4885864258580 .3493041992576 .2576293945572 .2213745117 568.2512817383564 .3546142578560 .5418701172556 .8201293945553 .1995239258 549.6862182617546 .2902832031543 .0167236328539 .8751220703536 .8696289062 534.0084228516531 .295715332528 .73828125526 .3411865234524 .1099243164 522.0512084961520 .1702880859518 .4755249023516 .9733886719515 .6705932617 514.5759277344513 .6920776367513 .0270996094512 .5877075195512 .3792114258 512.4188842773512 .7103271484513 .2816162109514 .1381835938515 .2954711914 516.7749023438518 .4456176758520 .2534790039522 .0532226562523 .8088989258 525.315612793526 .2817993164526 .9215698242527 .4779052734527 .361328125 526.0335083008524 .1893920898522 .4102172852520 .7130126953519 .1721801758 517.5487060547515 .3408813477513 .5073852539512 .9157714844512 .8928222656 512.9401245117513 .0274047852512 .8577270508512 .8676147461513 .258972168 514.2321166992516 .1223144531518 .551574707521 .2578735352524 .298828125 527.6431274414531 .3104248047535 .2011108398539 .1610107422542 .9094848633 
545.6403198242546 .4321899414545 .3804931641542 .1660766602535 .0012817383 524.6516113281508 .3503112793484 .2280883789455 .2265930176422 .963104248 391.4509887695365 .875345 .044708252326 .7770080566313 .7242126465306 .7908935547 301.9937133789294 .2124023438286 .3475036621281 .003112793276 .8190002441 274.4562988281272 .3599853516269 .262512207265 .2673034668259 .6152954102 252.3083953857 243.0935974121232.0973968506220.0384979248 207.8213043213 197.0885009766187 .0971984863177 .7891998291169 .4479980469162 .1981964111 156.2910003662151 .4226989746148 .1824035645146 .6871948242146 .629699707 147.4792022705148 .9279937744150 .6884002686152 .474899292154 .0182952881 155.545501709157 .3213043213159 .233795166161 .291595459163 .475402832 165.774597168168 .1138000488170 .4425048828172 .6757049561174 .7449035645 176.5471954346178 .003692627178 .9207000732179 .2761993408178 .3612060547 175.7178039551171 .3999938965165 .003692627158 .2203979492152 .0572052002 146.4472045898141 .6649017334137 .478805542134 .1837005615131 .3894958496 128.7971038818126 .3482971191123 .8057022095121 .189201355118 .381401062 115.4554977417112 .4765014648109 .4862976074106 .5571975708103 .6910018921 100.91069793798 .2171936035295 .6238632202193 .1297073364390 .74089050293 88.46029663086 86.28022766113 84.21639251709 82.26289367676 80.44573974609 78.771766662677 .2628173828175 .9385681152374 .7939529418973 .84517669678 73.0693664550872 .4669570922971 .9930572509871 .6098937988371 .24169158936 70.802459716870 .2027816772569 .3483734130968 .3225936889667 .20533752441 66.0618972778364 .9664230346763 .9395103454663 .0144615173362 .19805145264 61.5028991699260 .922851562560 .4599418640160 .1026992797959 .84545898438 59.6760101318459 .5784988403359 .5453491210959 .5607681274459 .61988067627 59.7110900878959 .8292808532759 .9646797180260 .1119804382360 .26110839844 60.4069213867260 .5402488708560 .6635704040560 .7801589965860 .87850952148 60.9423103332560 .9884910583561 .0305213928261 .0684204101661 .11130905151 61.1649093627961 .2395286560161 .3292007446361 .4280395507861 .53165054321 61.6320381164661 .7282218933161 .8152694702161 .8929100036661 .95849990845 62.0118904113862 .0516281127962 .0778388977162 .0898590087962 .0881690979 62.0727691650462 .0444183349662 .0036888122661 .9514083862361 .88856124878 61.8159484863361 .7347488403361 .6456909179761 .5499610900961 .4482383728 61.3416404724161 .2307205200261 .1165008544960 .999439239560 .88042068481 60.7598304748560 .6384315490760 .5164985656760 .3946990966860 .27323150635 60.1526298522960 .0330390930259 .914901733459 .7982788085959 .68350982666 59.5706405639659 .4598884582559 .3512611389259 .2448997497659 .14080047607 59.0390205383358 .9395408630458 .8423881530858 .7475509643658 .65502929688 58.5648384094258 .4769897460958 .3915100097758 .3084182739358 .22779083252 58.1496696472258 .0741195678758 .0012283325257 .931079864557 .86362838745 57.7993011474657 .7375297546457 .67932891846 1194.1390380861188 .4279785161182 .6999511721176 .9659423831171 .228027344 1165.4840087891159 .7340087891153 .9770507811148 .2130126951142 .439941406 1136.6590576171130 .8690185551125 .0689697271119 .2600097661113 .439941406 1107.6090087891101 .7669677731095 .9129638671090 .0479736331084 .171020508 1078.2810058591072 .379028321066 .4639892581060 .5360107421054 .595947266 1048.6429443361042 .6770019531036 .6989746091030 .7089843751024 .708007812 
1018.6939697271012 .669982911006 .6359863281000 .59197998994 .5393066406 988.4791259766982 .4119873047976 .3392944336970 .2623901367964 .1826782227 958.1016845703952 .0214233398945 .9434814453939 .8699951172933 .8034057617 927.7459716797921 .700378418915 .6696777344909 .6567993164903 .6649169922 897.6976928711891 .7589111328885 .8521728516879 .9818725586874 .1516113281 868.3657226562 862.6273193359 856.9409790039851.3090820312 845.7357788086 840.2230834961834 .7744750977829 .3909912109824 .0756225586818 .8286743164 813.6522827148808 .5466918945803 .5133056641798 .5518188477793 .6630249023 788.8461303711784 .1015014648779 .4282226562774 .8256835938770 .2924804688 765.8275756836761 .4290161133757 .094909668752 .8228759766748 .6112060547 744.4564208984740 .3557128906736 .305480957732 .3026123047728 .342590332 724.4215698242720 .5355224609716 .6796875712 .8500976562709 .0424194336 705.2523803711701 .4758300781697 .708190918693 .9451904297690 .1826171875 686.4157104492682 .6400756836678 .8513183594675 .0449829102671 .2166748047 667.3632202148663 .4805908203659 .5667114258655 .6182250977651 .6347045898 647.6137695312643 .5562744141639 .4616088867635 .3311767578631 .1660766602 626.9691162109622 .7421264648618 .489074707614 .2136230469609 .9204711914 605.6146240234601 .3018798828596 .9885253906592 .6812133789588 .387512207 584.1146850586579 .8715820312575 .6657714844571 .5064697266567 .4014892578 563.3604736328559 .3906860352555 .5023193359551 .7017211914547 .9989013672 544.4000244141540 .9144287109537 .5476074219534 .3084716797531 .2017822266 528.2357177734525 .4146118164522 .7457885742520 .2343139648517 .88671875 515.7089233398513 .707824707511 .8895874023510 .2618103027508 .8297119141 507.6011047363506 .580291748505 .7742919922505 .1900024414504 .8337097168 504.7182922363504 .8515930176505 .2442932129505 .9067993164506 .8236083984 508.0039978027509 .31640625510 .6972045898512 .1102294922513 .4910888672 514.6340942383515 .3029174805515 .6259155273515 .7650146484515 .3355712891 513.9818115234512 .0133056641509 .684387207507 .4632873535505 .9137878418 504.4841918945502 .5538024902500 .9305114746500 .2002868652500 .1813049316 500.7914123535501 .5599060059501 .8876037598502 .3739929199503 .4978942871 505.153503418507 .3273010254509 .8447875977512 .5283203125515 .4246826172 518.4509887695522 .0720825195526 .6989746094531 .8685302734537 .0841064453 541.6879272461544 .9561157227546 .3934936523545 .5131835938542 .9401855469 538.3453979492529 .5435180664515 .9420166016493 .1050109863457 .9580078125 420.3052978516388 .625360 .7995910645334 .4688110352314 .5050048828305 .5035095215 300.4836120605292 .6727905273285 .0013122559280 .0267944336276 .3850097656 273.6494140625271 .0658874512267 .7550964355263 .5557861328257 .8027038574 249.4967041016236 .8833007812221 .9535980225207 .2601928711193 .8692016602 183.6015930176175 .3659057617168 .0559997559161 .7359008789156 .3818054199 152.2938995361149 .391204834147 .6784973145147 .2030029297147 .6573944092 148.9575042725150 .7483978271152 .4602966309154 .0863037109155 .5854034424 157.0919952393158 .7601928711160 .5597991943162 .4766998291164 .4813995361 166.5628051758168 .6526031494170 .6967926025172 .6170959473174 .3446044922 175.7705993652176 .8070068359177 .245803833176 .9862976074175 .520401001 172.4785003662168 .43409729163 .266998291157 .7749938965152 .4463043213 147.2559051514142 .770401001138 .8403930664135 .5352935791132 .6230010986 
129.9297027588 127.3901977539124.8330001831 122.2363967896 119.4770965576 116.6213989258113 .7073974609110 .7739028931107 .8759002686105 .0143966675 102.208999633899 .4629364013796 .7895507812594 .1906127929791 .67446136475 89.2457427978586 .9077529907284 .6742172241282 .5490570068480 .55809020996 78.715118408277 .0507278442475 .5950698852574 .3381271362373 .29232025146 72.4365768432671 .7712936401471 .2405624389670 .7953491210970 .34710693359 69.8173675537169 .2010726928768 .4231491088967 .5437927246166 .56300354004 65.5320205688564 .5358886718863 .5924606323262 .7387390136761 .97782897949 61.324920654360 .7740592956560 .3288383483959 .979358673159 .72138977051 59.5444183349659 .4381103515659 .3942108154359 .4005393981959 .45098114014 59.5354690551859 .6480903625559 .7799186706559 .9244613647560 .07279968262 60.2222595214860 .3645896911660 .5002517700260 .6262702941960 .73360061646 60.8134193420460 .8777008056660 .9366798400960 .9852981567461 .01871871948 61.0602912902861 .137561798161 .2313499450761 .3277206420961 .42514038086 61.5187797546461 .6074600219761 .6878089904861 .7591094970761 .81914901733 61.8675918579161 .9030685424861 .9256782531761 .9347305297961 .93069076538 61.913509368961 .8839187622161 .8423690795961 .7897491455161 .72681045532 61.6544685363861 .5736694335961 .4852294921961 .3901596069361 .28918075562 61.1832695007361 .0730514526460 .95940017760 .8428611755460 .72420120239 60.6038818359460 .4825401306260 .3605804443460 .2385406494160 .11669921875 59.995540618959 .8752593994159 .7562294006359 .6385993957559 .52264022827 59.4084510803259 .2962188720759 .1859817504959 .0778694152858 .97188949585 58.8680915832558 .766460418758 .6670608520558 .5698585510358 .47486877441 58.382110595758 .2916183471758 .2034111022958 .1175498962458 .03408050537 57.9530982971257 .8746795654357 .7989196777357 .7259292602557 .6556892395 57.5882987976157 .5256805419957 .46839904785

1198.628051758 1192.8449707031187.057983398 1181.2679443361175.472045898 1169.6700439451163 .8630371091158 .0479736331152 .2249755861146 .394042969 1140.5550537111134 .707031251128 .8489990231122 .9809570311117 .102050781 1111.2130126951105 .3120117191099 .4010009771093 .4770507811087 .541992188 1081.5939941411075 .6350097661069 .6619873051063 .6779785161057 .681030273 1051.6710205081045 .6490478521039 .6159667971033 .5710449221027 .514038086 1021.4459838871015 .3690185551009 .2810058591003 .184997559997 .0814819336 990.9705200195984 .8538208008978 .7321777344972 .6077270508966 .4810791016 960.3544921875954 .2293701172948 .1079101562941 .9918212891935 .8837280273 929.7855834961923 .7003173828917 .6303710938911 .578918457905 .5485839844 899.5432128906893 .5659179688887 .620300293881 .7103271484875 .8389892578 870.0106201172864 .2280273438858 .495300293852 .8148193359847 .1904296875 841.6237182617836 .1181030273830 .674621582825 .2960205078819 .9824829102 814.7365722656809 .5582275391804 .4489746094799 .4083862305794 .4376831055 789.5360107422784 .7037963867779 .9401245117775 .2448120117770 .6162719727 766.0537109375761 .5551757812757 .1192016602752 .7432861328748 .4254760742 744.1630249023739 .9528808594735 .7918701172731 .6763916016727 .602722168 723.5667114258719 .5642089844715 .591003418711 .6431884766707 .7163696289 703.8063964844699 .9091186523696 .0203857422692 .1361083984688 .2520751953 684.364074707680 .4677734375676 .5590209961672 .6339111328668 .6881713867 
664.7191772461660 .7230224609656 .6979980469652 .6412963867648 .5524291992 644.4293823242640 .2730102539636 .082824707631 .8604736328627 .6066894531 623.3244018555619 .0153808594614 .68359375610 .3319702148605 .9656982422 601.5889282227597 .2072143555592 .8264770508588 .4534301758584 .0946044922 579.7573852539575 .4495849609571 .1787719727566 .9536743164562 .7816772461 558.671875554 .6312866211550 .6696777344546 .7932739258543 .0115966797 539.3306884766535 .7598266602532 .3040771484528 .9724731445525 .7700195312 522.7045288086519 .7810058594517 .0065917969514 .3869018555511 .9281921387 509.6372070312507 .5197143555505 .5827026367503 .8323974609502 .2749938965 500.9166870117499 .7633056641498 .8203125498 .0952148438497 .5916137695 497.3201904297497 .2846984863497 .4867858887497 .9328918457498 .5892028809 499.4616088867500 .441192627501 .4729919434502 .4956970215503 .4356994629 504.1691894531504 .5726013184504 .6318054199504 .3414916992503 .6243896484 502.4013061523500 .5768127441497 .9909057617495 .4525146484494 .0014038086 492.8676147461491 .2549133301489 .8836975098488 .9511108398488 .7236938477 489.5780944824490 .7643127441491 .4240112305492 .3068847656494 .0531921387 496.1990966797498 .4755859375500 .8916931152503 .4252929688506 .0900878906 508.7159118652512 .1881103516517 .2376708984523 .1851196289529 .2824707031 535.2235717773540 .5778808594544 .6948852539546 .7791137695547 .3436889648 546.1630249023542 .4509277344539 .162902832526 .1146850586493 .2249145508 453.5643005371418 .3662109375384 .6123962402350 .2608947754322 .8930969238 309.2684936523301 .5162963867291 .5562133789283 .2726135254278 .5911865234 275.3862915039272 .242401123269 .1146850586265 .8536071777261 .0114135742 254.4299926758243 .9978942871227 .6027069092209 .5240936279193 .6031036377 180.1636962891170 .9232025146164 .4042053223159 .0131988525155 .0301971436 151.7904968262149 .5639038086148 .2510986328147 .8367004395148 .2752990723 149.3462982178151 .029296875152 .879699707154 .3399963379155 .6912994385 157.1560058594158 .6452026367160 .2124023438161 .8553924561163 .5984954834 165.3952941895167 .2342071533169 .0447998047170 .7882995605172 .3719024658 173.7436981201174 .7653045654175 .3740997314175 .3515930176174 .625172 .942199707 170.0178985596166 .3883972168162 .0482940674157 .4102020264152 .6219024658 147.8945007324143 .8070983887140 .1042938232136 .8489990234133 .8943023682 131.1587982178128 .5693054199125 .9878005981123 .3928985596120 .6578979492 117.8525009155114 .9938964844112 .1094970703109 .2368011475106 .3766021729 103.5438995361100 .744499206597 .9917526245195 .2898635864392 .64832305908 90.0754013061587 .5782089233485 .1730804443482 .8668136596780 .69101715088 78.6577529907276 .8170471191475 .2086105346773 .8181533813572 .67318725586 71.7328872680771 .00083160470 .4083328247169 .8945236206169 .39189147949 68.8255615234468 .205360412667 .4839935302766 .6939926147565 .82093811035 64.9098129272564 .0240097045963 .1735916137762 .3978118896561 .69797897339 61.092491149960 .5761108398460 .1548805236859 .8198318481459 .56842041016 59.3921012878459 .2830886840859 .2344093322859 .2355003356959 .28105163574 59.3610191345259 .470291137759 .5997810363859 .7441291809159 .89413070679 60.0476684570360 .1969490051360 .3400497436560 .470569610660 .58631134033 60.6845092773460 .7686309814560 .8452491760360 .9057502746660 .93505859375 60.9701995849661 .0525016784761 .1504402160661 .2432518005461 .33504104614 
61.4216384887761 .502651214661 .5755996704161 .6398086547961 .69327926636 61.7357292175361 .7658309936561 .7836608886761 .7885894775461 .78099822998 61.760879516661 .7288589477561 .6854209899961 .6313018798861 .56729888916 61.4941711425861 .4128799438561 .3241081237861 .2288894653361 .12783050537 61.0219192504960 .9116706848160 .7980117797960 .6813697814960 .56259155273 60.4420089721760 .3203506469760 .1979103088460 .0753097534259 .95275878906 59.8307685852159 .7095108032259 .5894012451259 .4705314636259 .35322952271 59.2375602722259 .1237297058159 .0117607116758 .9017982482958 .79383850098 58.6879615783758 .5841407775958 .4824409484958 .3828392028858 .28535842896 58.1900291442958 .0968589782758 .0059318542557 .917270660457 .83097839355 57.7471389770557 .6658401489357 .5872192382857 .5113906860457 .43835830688 57.3686103820857 .3016090393157 .23844146729

1203.095947266 1197.2709960941191.428955078 1185.5799560551179.728027344 1173.8699951171168 .0050048831162 .1330566411156 .2530517581150 .364990234 1144.4689941411138 .5629882811132 .6479492191126 .7230224611120 .786987305 1114.8409423831108 .8830566411102 .9150390621096 .9339599611090 .942016602 1084.9379882811078 .921997071072 .8940429691066 .8540039061060 .801025391 1054.7370605471048 .6610107421042 .5729980471036 .4739990231030 .364013672 1024.2440185551018 .1149902341011 .9760131841005 .828979492999 .6752929688 993.5151977539987 .3499755859981 .1810913086975 .0098876953968 .8378295898 962.6663818359956 .4976806641950 .3333740234944 .1754760742938 .0263061523 931.8881225586925 .7633056641919 .6544799805913 .5645141602907 .4962158203 901.4525146484895 .4368286133889 .4522094727883 .5023803711877 .5902099609 871.7194824219865 .8928833008860 .114074707854 .3853759766848 .7100830078 843.0900878906837 .5283203125832 .0255737305826 .584777832821 .2062988281 815.8922119141810 .6427001953805 .4592285156800 .3416137695795 .2907714844 790.3062744141785 .3886108398780 .5366821289775 .7506713867771 .0291137695 766.37109375761 .7747802734757 .2387695312752 .7609863281748 .3392944336 743.9708862305739 .6533813477735 .3831787109731 .1572265625726 .9713745117 722.8220214844718 .705078125714 .6165771484710 .5524291992706 .5084838867 702.4807128906698 .4649047852694 .4575195312690 .4542236328686 .4512939453 682.444519043678 .4301147461674 .4038696289670 .3627929688666 .3026733398 662.2208862305658 .1143188477653 .9813232422649 .8192138672645 .6278076172 641.4055175781637 .1527709961632 .8698730469628 .5579223633624 .2180175781 619.8526000977615 .4638061523611 .0549926758606 .6295166016602 .1915283203 597.7454833984593 .2965087891588 .8502807617584 .4127197266579 .9906005859 575.5905151367571 .219909668566 .885925293562 .5969848633558 .3599853516 554.1838989258550 .0750732422546 .0430908203542 .0938720703538 .2368164062 534.4774780273530 .825012207527 .2847900391523 .8654174805520 .5717773438 517.4119873047514 .3911132812511 .5162963867508 .7929992676506 .2284851074 503.8280029297501 .5986938477499 .5461120605497 .6771850586495 .996887207 494.5118103027493 .2267150879492 .1476135254491 .2789916992490 .6260070801 490.1918029785489 .9815063477489 .9865112305490 .2091064453490 .6106872559 491.1812133789491 .8416137695492 .5412902832493 .2072143555493 .7710876465 494.1541137695494 .2477111816494 .0198974609493 .4096984863492 .6012878418 491.7493896484490 .3770141602487 .9794921875485 .4928894043483 .9147949219 
482.7499084473481 .4926147461480 .4234008789479 .6943054199479 .5256958008 480.1885986328481 .2674865723482 .2112121582483 .4383850098485 .2887878418 487.4544067383489 .712890625492 .0132141113494 .3019104004496 .6809997559 499.1525878906502 .563293457507 .6512145996513 .7498168945520 .012512207 526.5963745117533 .5737304688539 .9716796875544 .9436035156548 .358215332 549.510925293549 .2487182617548 .6729736328540 .5244140625518 .2592773438 487.3937988281454 .0736999512418 .467010498381 .3868103027348 .9885864258 326.658203125309 .9256896973293 .4432067871280 .7416992188275 .1538085938 272.3136901855269 .0132141113266 .0736999512263 .7645874023258 .8579101562 248.1322937012232 .8551025391213 .7886962891194 .7993927002180 .2653045654 168.9282989502160 .1669006348154 .2218017578151 .1022033691149 .6723022461 148.5641021729148 .0518951416148 .0115966797148 .5588989258149 .8123016357 151.4096069336153 .141494751154 .8190002441156 .2171020508157 .5254974365 158.8753051758160 .2601928711161 .6842041016163 .146194458164 .6784973145 166.2397003174167 .81199646169 .3336029053170 .7608947754172 .0135955811 173.028503418173 .6936950684173 .9255065918173 .5744934082172 .5281066895 170.724899292167 .9980010986164 .7297058105160 .991897583156 .9582977295 152.762802124148 .5720977783144 .779800415141 .271697998138 .0989990234 135.1629943848132 .4196929932129 .8029937744127 .2113037109124 .6129989624 121.9192962646119 .1677017212116 .3592987061113 .5160980225110 .6610031128 107.7962036133104 .9324035645102 .077499389699 .2436828613396 .43800354004 93.6718826293990 .9548187255988 .2987136840885 .7177886962983 .224609375 80.8485565185578 .6097335815476 .5736923217874 .7856597900473 .24524688721 72.0011978149470 .9909210205170 .1993865966869 .5631866455168 .99571228027 68.4515533447367 .8651962280367 .2483062744166 .5678176879965 .84409332275 65.0621414184664 .2568664550863 .4660911560162 .7047500610462 .00429916382 61.3682289123560 .8132896423360 .3365707397559 .9438705444359 .62884140015 59.3899803161659 .2204589843859 .1148300170959 .0664596557659 .06742858887 59.1117210388259 .1910209655859 .2995681762759 .4292106628459 .57461929321 59.7277297973659 .8854904174860 .0412406921460 .1913490295460 .32973098755 60.4562911987360 .5676498413160 .6664199829160 .7535514831560 .82390975952 60.8719596862860 .9221611022961 .0005302429261 .0895500183161 .17641067505 61.2607116699261 .339839935361 .4129905700761 .4780807495161 .5344581604 61.5805511474661 .6159896850661 .6396903991761 .6516609191961 .65132904053 61.6390991210961 .6148986816461 .5793914794961 .5329399108961 .47631835938 61.4101905822861 .3353385925361 .2525711059661 .1626396179261 .06637954712 60.9644889831560 .8577919006360 .7468681335460 .6325187683160 .51522827148 60.3957214355560 .2744216918960 .1519393920960 .0286483764659 .90507888794 59.7814903259359 .6583518981959 .5358695983959 .4143981933659 .294090271 59.1752395629959 .0579185485858 .9423217773458 .8284988403358 .71657943726 58.6065483093358 .4985008239758 .3924293518158 .288360595758 .18630981445 58.0862998962457 .9883384704657 .8924903869657 .7988014221257 .70734024048 57.6182098388757 .5314903259357 .4473190307657 .3658294677757 .28713989258 57.2112998962457 .1384696960457 .0707893371657 .00876998901 1207.6030273441201 .707031251195 .8079833981189 .9050292971183 .99597168 1178.0810546881172 .1610107421166 .2320556641160 .296997071154 .353027344 
1148.4000244141142 .4379882811136 .4670410161130 .4859619141124 .494018555 1118.4919433591112 .4790039061106 .4539794921100 .4189453121094 .37097168 1088.312011719 1082.240966797 1076.1590576171070.0639648441063.958007812 1057.839965821051 .711059571045 .5699462891039 .4189453121033 .258056641 1027.0870361331020 .9069824221014 .7180175781008 .5219726561002 .320007324 996.1115112305989 .8992919922983 .6840820312977 .4675292969971 .250793457 965.0358276367958 .8240966797952 .6176757812946 .4185180664940 .2288208008 934.05078125927 .8869018555921 .7393188477915 .6110229492909 .5045166016 903.4226074219897 .3685302734891 .344909668885 .3552246094879 .4019775391 873.4890136719867 .6185302734861 .7938842773856 .0172119141850 .2916870117 844.6188964844839 .0015869141833 .4409179688827 .9390258789822 .4967041016 817.1159057617811.796875 806.541015625801.3480834961 796.2194213867 791.1541748047786 .1530151367781 .2152099609776 .3405151367771 .5277709961 766.7764282227762 .0844726562757 .4506835938752 .8728027344748 .3491210938 743.8767700195739 .4534912109735 .0759277344730 .741027832726 .4448852539 722.1840209961717 .9545288086713 .7523803711709 .5737915039705 .4146118164 701.2709960938697 .1389770508693 .0150146484688 .8952026367684 .7756958008 680.6527709961676 .5228881836672 .3823242188668 .2280273438664 .0562133789 659.8646850586655 .6505737305651 .4124755859647 .1480712891642 .8571166992 638.5380859375634 .1920776367629 .8187866211625 .419921875620 .9959106445 616.5496826172612 .0828857422607 .5991821289603 .1013183594598 .5933837891 594.0797119141589 .5651245117585 .0546875580 .5543823242576 .0703735352 571.6090087891567 .1773071289562 .7821044922558 .4312744141554 .1314697266 549.8911743164545 .7166748047541 .6168823242537 .5980224609533 .6685180664 529.8344116211526 .1041870117522 .4835205078518 .9804077148515 .600402832 512.3508911133509 .2373046875506 .2668151855503 .4448852539500 .7782897949 498.2728881836495 .9349060059493 .7703857422491 .7851867676489 .9848937988 488.3749084473486 .9601135254485 .7450866699484 .7331848145483 .9280090332 483.3283996582482 .9375915527482 .7399902344482 .737487793482 .8851013184 483.1724853516483 .5289001465483 .9224853516484 .2692871094484 .5043945312 484.567199707484 .3815002441483 .9262084961483 .0950927734482 .1697998047 481.571685791480 .6509094238478 .6604003906476 .5422973633475 .0120849609 473.8064880371472 .8096923828472 .0723876953471 .613494873471 .5257873535 471.8682861328472 .6220092773473 .6671142578475 .082611084476 .8593139648 478.8363952637480 .9411010742483 .0524902344485 .1227111816487 .3789978027 489.892791748493 .2663879395498 .096496582503 .8547973633509 .599395752 516.2650756836524 .3602294922532 .6267089844540 .2114257812546 .2775878906 549.546875550 .892578125550 .6754150391545 .6583862305534 .8286132812 515.7620849609487 .9649963379454 .6689147949418 .6565856934383 .1968994141 351.7726135254324 .5268859863299 .0183105469280 .7338867188273 .0064086914 269.3756103516 265.4753112793 261.5705871582 259.1052856445 253.261505127 238.2868041992218 .9779052734199 .0731964111180 .7404022217168 .720993042 160.0742034912151 .9499053955146 .6750030518145 .4862060547146 .2801055908 146.9082946777147 .8874053955148 .8571014404150 .0796966553151 .9116973877 153.8121032715155 .4389038086156 .8798980713158 .2397003174159 .49659729 160.7223052979161 .9306945801163 .1683959961164 .4196014404165 .721206665 
167.021697998168 .3168945312169 .5361022949170 .649307251171 .5677947998 172.2456054688172 .5738983154172 .4954071045171 .8981933594170 .6822052002 168.883102417166 .3901977539163 .4662017822160 .1154937744156 .5269927979 152.8343963623149 .1201019287145 .6374969482142 .3186950684139 .2767944336 136.4111022949133 .7073974609131 .1018981934128 .5130004883125 .9272994995 123.2736968994120 .5759963989117 .81199646115 .0045013428112 .1607971191 109.2871017456106 .3887023926103 .4760971069100 .559501647997 .64943695068 94.758926391691 .8991165161189 .0858993530386 .3326568603583 .65725708008 81.0849761962978 .6433105468876 .3851165771574 .3715286254972 .6628036499 71.327423095770 .2809906005969 .4521179199268 .7653884887768 .14775085449 67.5646514892666 .9646224975666 .3519363403365 .6966323852565 .0178527832 64.3071365356463 .5872993469262 .8821792602562 .201869964661 .575050354 61.0013198852560 .4993209838960 .0641899108959 .7044792175359 .41360855103 59.1928710937559 .0357017517158 .9387092590358 .8958892822358 .90074920654 58.9478416442959 .0293197631859 .1400909423859 .2719497680759 .42049026489 59.5776290893659 .7403907775959 .9018402099660 .0591888427760 .20623016357 60.3430099487360 .4658813476660 .5755996704160 .6702499389660 .75207901001 60.8242988586460 .8935699462960 .9685897827161 .0461387634361 .12482833862 61.2013587951761 .2725791931261 .3375701904361 .3941802978561 .4421005249 61.4799308776961 .5074691772561 .5237388610861 .5288200378461 .52220916748 61.5042495727561 .4749488830661 .4348793029861 .3844299316461 .32426834106 61.2550811767661 .1775207519561 .0924301147561 .000419616760 .90237045288 60.79882812560 .6906585693460 .5783500671460 .4627189636260 .34415817261 60.2234306335460 .1008796691959 .9771690368759 .8525810241759 .7276802063 59.6027107238859 .4781303405859 .3541183471759 .2310600280859 .10908126831 58.9884910583558 .8693313598658 .751819610658 .6359901428258 .52198028564 58.4097785949758 .2994804382358 .1910591125558 .0845718383857 .97999954224 57.8773994445857 .776790618957 .6782112121657 .5817413330157 .487449646 57.3954391479557 .3058280944857 .2187614440957 .1343688964857 .05281066895 56.9741287231456 .8989105224656 .8266105651956 .75841903687

1212.0889892581206 .1529541021200 .1999511721194 .2399902341188 .276977539 1182.3070068361176 .3310546881170 .3470458981164 .3559570311158 .357055664 1152.3499755861146 .3330078121140 .3060302731134 .2700195311128 .223999023 1122.1669921881116 .0989990231110 .0209960941103 .9310302731097 .828979492 1091.7159423831085 .5920410161079 .4560546881073 .3089599611067 .150024414 1060.9799804691054 .7989501951048 .6070556641042 .4060058591036 .193969727 1029.9730224611023 .7440185551017 .5059814451011 .2630004881005 .013000488 998.7581787109992 .5986 .2398071289979 .9788208008973 .7183227539967 .4603271484 961.2064208984954 .9586181641948 .7186279297942 .4887695312936 .2714233398 930.0684814453923 .8823852539917 .7155761719911 .5709838867905 .4509887695 899.3582763672 893.295715332 887.2661743164 881.2722167969 875.3170776367 869.4027709961 863.5327148438 857.7086181641 851.9332885742 846.2084960938 840.5366821289834 .9188842773829 .3572998047823 .8526000977818 .4066772461 813.0197753906807 .6931762695802 .4270019531797 .2222290039792 .0783081055 786.9959106445781 .9741210938777 .0131225586772 .111328125767 .2684936523 762.4827880859757 .753112793753 .0770874023748 .453125743 .8787841797 
739.3513793945734 .8681030273730 .4259033203726 .0211791992721 .6505126953 717.3098754883712 .9959716797708 .7047119141704 .4320068359700 .174621582 695.928527832691 .6901855469687 .4559936523683 .2224731445678 .9860229492 674.7432861328670 .4907836914666 .2260131836661 .9453735352657 .6472167969 653.3284301758648 .9880981445644 .6240844727640 .236328125635 .8236083984 631.38671875626 .9257202148622 .4418945312617 .9362792969613 .411315918 608.8687744141604 .3118286133599 .7432861328595 .167175293590 .5875244141 586.0087280273581 .4359741211576 .8745117188572 .3303222656567 .809387207 563.3184814453558 .8640136719554 .4534301758550 .0930175781545 .791015625 541.5532836914537 .388671875533 .3027954102529 .3043212891525 .3986816406 521.5944213867517 .8969116211514 .3142700195510 .8515930176507 .5166931152 504.3145141602501 .2524108887498 .3353881836495 .5708007812492 .9634094238 490.5202026367488 .2459106445486 .1471862793484 .2282104492482 .4949951172 480.9504089355479 .5997009277478 .4432983398477 .4848937988476 .7192077637 476.1474914551475 .7520141602475 .5282897949475 .437286377475 .4603881836 475.5436096191475 .649810791475 .7120056152475 .6697998047475 .4789123535 475.079498291474 .4523010254473 .5288085938472 .4974060059471 .5003051758 470.4201965332469 .0732116699467 .7130126953466 .6582946777465 .7605895996 464.9382019043464 .3375854492464 .0523986816463 .9591064453464 .0466003418 464.4869995117465 .4176025391466 .8028869629468 .604888916470 .5268859863 472.3145141602474 .1358947754476 .1232910156478 .4280090332481 .1311950684 484.4497070312488 .6741943359493 .5000915527498 .3413085938504 .5928955078 513.2861938477522 .9243774414532 .4602050781540 .7456054688546 .7778930664 550.6967163086552 .2194824219550 .9487915039545 .4680175781533 .1724853516 512.1627197266484 .4027099609452 .4601135254416 .7026977539378 .9077148438 342.3717041016309 .8248901367286 .5459899902276 .0463867188270 .1138000488 263.1079101562255 .8867034912249 .2409973145240 .1826934814224 .4774932861 205.733001709187 .200302124171 .1091003418160 .3701934814152 .8804016113 146.9954986572143 .6679992676143 .5926971436145 .3439025879147 .2550964355 149.3229980469151 .0805053711152 .8112030029154 .7554016113156 .5982055664 158.1116943359159 .4096069336160 .5821075439161 .6645965576162 .6900024414 163.6779937744164 .6856994629165 .7014007568166 .7451019287167 .7769927979 168.782699585169 .7059936523170 .5074005127171 .1186981201171 .4842987061 171.5301055908171 .188293457170 .4013061523169 .0867004395167 .304397583 165.0072937012162 .3450012207159 .3571929932156 .1652984619152 .8840942383 149.5720977783146 .3777008057143 .2850952148140 .3894042969137 .6300048828 134.9938964844132 .429397583129 .8815002441127 .3310012817124 .7269973755 122.0773010254119 .361000061116 .585899353113 .7524032593110 .8657989502 107.9303970337104 .9570999146101 .956100463998 .9404907226695 .92517089844 92.9244384765689 .9573364257887 .0394134521584 .1934585571381 .43800354004 78.8003463745176 .3071899414173 .9717636108472 .0114288330170 .66664886475 69.6754608154368 .8199234008868 .0812530517667 .4048461914166 .77374267578 66.1477737426865 .5277862548864 .8893814086964 .2454376220763 .58934020996 62.9379005432162 .3025093078661 .694061279361 .1310615539660 .61682128906 60.1641502380459 .7718315124559 .4459190368759 .1828117370658 .98334884644 58.8428802490258 .7587394714458 .7256317138758 .7384605407758 .79169082642 
58.8787384033258 .9942092895559 .1309204101659 .284179687559 .44689941406 59.6154098510759 .7834396362359 .948101043760 .1039085388260 .25028991699 60.3837509155360 .5039787292560 .6087608337460 .702980041560 .78844070435 60.8671989440960 .9437408447361 .0163803100661 .0881996154861 .15703964233 61.2197990417561 .2756805419961 .3231506347761 .3617706298861 .39059066772 61.4093589782761 .4173393249561 .4145889282261 .4007110595761 .37606811523 61.3406600952161 .2950706481961 .2396392822361 .1750297546461 .10182189941 61.0206985473660 .9323806762760 .8375015258860 .7368087768660 .63090896606 60.5205307006860 .4062004089460 .2886199951260 .1682586669960 .04573822021 59.9214782714859 .7960281372159 .6697502136259 .5431213378959 .41641998291 59.2900505065959 .1642494201759 .0393295288158 .915451049858 .79288101196 58.6717109680258 .5521087646558 .4341316223158 .3178901672458 .2033996582 58.0907211303757 .9798698425357 .8708610534757 .7637214660657 .65845870972 57.5551300048857 .4537811279357 .3544807434157 .2573089599657 .16239929199 57.0698699951256 .9798507690456 .8925209045456 .8080482482956 .72649002075 56.6480789184656 .575191497856 .50828933716 1216.6140136721210 .6090087891204 .5999755861198 .5880126951192 .568969727 1186.5460205081180 .5150146481174 .4770507811168 .4320068361162 .37902832 1156.3170166021150 .245971681144 .1660156251138 .0760498051131 .975952148 1125.8649902341119 .7440185551113 .6120605471107 .4689941411101 .314941406 1095.1500244141088 .9739990231082 .7860107421076 .5870361331070 .376953125 1064.156005859 1057.925048828 1051.682983398 1045.432006836 1039.171020508 1032.9019775391026 .6251020 .3400268551014 .049011231007 .754028321001 .45300293 995.1505737305988 .8461303711982 .5416259766976 .2382202148969 .9379882812 963.6425170898957 .3538818359951 .0737304688944 .8043212891938 .5474853516 932.3057250977926.0811767578919.8762207031913.6932983398907.5349121094 901.403503418895 .3016967773889 .2322998047883 .1973876953877 .2000732422 871.2423095703865 .3270263672859 .4556884766853 .6312866211847 .8552246094 842.1298217773836 .4558105469830 .8355712891825 .2698974609819 .7603149414 814.3071289062 808.9113769531 803.5737304688 798.2946777344 793.0740966797 787.9124145508782 .8087158203777 .7631225586772 .7744140625767 .8421020508 762.9644775391758 .1406860352753 .3685302734748 .6461791992743 .9713745117 739.341796875734 .7545776367730 .2067260742725 .6950073242721 .2161254883 716.766418457712 .3422851562707 .9401855469703 .5562133789699 .1870117188 694.828918457690 .4785766602686 .1325073242681 .7874145508677 .4398803711 673.087097168668 .7257080078664 .3532714844659 .9669189453655 .5648193359 651.1444091797646 .7047729492642 .2440185547637 .7622070312633 .2583007812 628.7332763672624 .1868286133619 .6206054688615 .0355224609610 .4337768555 605.817199707601 .1889038086596 .5515136719591 .9088745117587 .2645874023 582.6232299805577 .9893798828573 .3684082031568 .765625564 .1868286133 559.6384277344555 .1264038086550 .6580200195546 .239074707541 .8776245117 537.579284668533 .3522949219529 .2025146484525 .1378173828521 .1638793945 517.2888793945513 .5181884766509 .859588623506 .3182067871502 .9014892578 499.6146850586496 .4645996094493 .4566040039490 .5968933105487 .8911132812 485.3450927734482 .9641113281480 .7536010742478 .7179870605476 .8623962402 475.1895141602473 .7030944824472 .4024963379471 .2903137207470 .3580932617 
469.6070861816469 .015411377468 .5798034668468 .2600097656468 .0422973633 467.8729858398467 .7236022949467 .5343017578467 .2587890625466 .8604125977 466.2966003418465 .5589904785464 .6093139648463 .4934082031462 .0429077148 460.7008056641459 .8807983398459 .2520141602458 .6651000977458 .1018981934 457.4143981934456 .8469848633456 .6254882812456 .5403137207456 .4417114258 456.6358032227457 .3858032227458 .5952148438460 .2687988281462 .0527954102 463.4979858398465 .0570983887467 .0176086426469 .4020080566472 .25390625 475.5051879883479 .1278991699483 .0559997559486 .8486938477492 .1568908691 500.4838867188510 .6422119141521 .2974853516531 .8419189453541 .0006713867 547.734375551 .2896118164551 .8493041992549 .5554199219542 .3665161133 528.7064819336507 .8666992188480 .9440002441447 .6455078125407 .4612121582 366.1975097656328 .5851135254298 .145904541280 .7860107422270 .0310058594 259.3301086426249 .1735992432238 .1811065674224 .9226989746208 .8352966309 192.0522003174176 .4187927246163 .3686981201154 .0708007812147 .912902832 144.4342956543143 .3760070801144 .2855072021146 .567199707149 .2530059814 152.057800293154 .3347015381156 .3479003906158 .2021026611159 .7769012451 161.1072998047162 .1831970215163 .1253967285163 .9405059814164 .7138061523 165.4441070557166 .2032012939166 .9595947266167 .7382965088168 .4916992188 169.212600708169 .8410949707170 .3482971191170 .6676940918170 .7572021484 170.5552062988170 .0068969727169 .086807251167 .7263031006165 .9954986572 163.8509979248161 .4172973633158 .7100982666155 .8385009766152 .8972015381 149.9145050049147 .0014953613144 .1405944824141 .4300994873138 .8050994873 136.2733001709133 .7875976562131 .3094940186128 .8220062256126 .2776031494 123.6837997437121 .0130004883118 .2717971802115 .4453964233112 .545501709 109.5696029663106 .5337982178103 .4447021484100 .320999145597 .17849731445 94.0351791381890 .9156188964887 .834686279384 .8261032104581 .89849853516 79.0854873657276 .4056015014673 .8059997558671 .617881774970 .23670196533 69.2466278076268 .3192520141667 .5096130371166 .7688064575266 .08177947998 65.4241485595764 .7886886596764 .1557693481463 .5335998535262 .91661071777 62.3152008056661 .736751556461 .1873397827160 .6821289062560 .22079086304 59.8163299560559 .4650802612359 .1749992370658 .9411506652858 .76662826538 58.6461181640658 .5787887573258 .5592002868758 .5834999084558 .64630889893 58.7416915893658 .8646583557159 .00822830259 .1682395935159 .33755111694 59.5129890441959 .6879005432159 .8602409362860 .0243301391660 .17966079712 60.3222389221260 .4524002075260 .5673599243260 .6711006164660 .76509094238 60.8496894836460 .9274406433160 .9978904724161 .0645790100161 .12554168701 61.1793289184661 .2256202697861 .263248443661 .2920188903861 .31106948853 61.3203315734961 .3191719055261 .3077392578161 .2857284545961 .253490448 61.2111015319861 .1590614318861 .0977706909261 .0277900695860 .94972991943 60.8641891479560 .7718505859460 .6732902526960 .5692596435560 .4602394104 60.3470115661660 .2299880981460 .1099090576259 .9871482849159 .86235809326 59.7358703613359 .6082992553759 .4798889160259 .3511810302759 .22238922119 59.0939483642658 .9660415649458 .8390312194858 .7130012512258 .58826065063 58.4648590087958 .3430099487358 .2227096557658 .1040992736857 .98719024658 57.8720397949257 .7586402893157 .647041320857 .5372314453157 .42924880981 57.3231391906757 .2189598083557 .1167793273957 .0166893005456 .91881942749 
56.8233108520556 .7303085327156 .6399993896556 .5525703430256 .46805953979 56.3871688842856 .3093681335456 .23588943481

1221.1190185551215 .0749511721209 .0140380861202 .9460449221196 .8751190 .79699707 1184.7130126951178 .6219482421172 .5240478521166 .4169921881160 .302001953 1154.1779785161148 .0450439451141 .9029541021135 .751129 .5870361331123 .41394043 1117.2299804691111 .035034181104 .8289794921098 .6130371091092 .385009766 1086.1469726561079 .8979492191073 .6379394531067 .3680419921061 .087036133 1054.796997071048 .4969482421042 .1889648441035 .8730468751029 .547973633 1023.2180175781016 .8809814451010 .5410156251004 .195983887997 .8491210938 991.5014038086985 .1539916992978 .80859375972 .4669189453966 .1304931641 959.8012695312953 .4813842773947 .1724853516940 .8765869141934 .5961914062 928.333190918922 .0899047852915 .8687133789909 .6718139648903 .5015869141 897.3604736328 891.2509765625 885.1751708984 879.1356811523 873.1345825195 867.1743164062861 .2562866211855 .3833007812849 .5565795898843 .7783203125 838.0493774414832 .3718261719826 .7462768555821 .1743164062815 .6561889648 810.1934204102804 .7858276367799 .434387207794 .1387939453788 .8994750977 783.7158203125778 .5875854492773 .5137939453768 .4938964844763 .5264282227 758.6102905273753 .7435302734748 .9246826172744 .151184082739 .421081543 734.731628418730 .0800170898725 .4630126953720 .8776245117716 .3204956055 711.7880859375707 .2769165039702 .7836303711698 .3046875693 .8369140625 689.3767700195684 .9213256836680 .4672241211676 .0114135742671 .5512695312 667.0838012695662 .6068115234658 .1174926758653 .6143798828649 .0952758789 644.5590820312640 .0045166016635 .4312744141630 .8389892578626 .2280273438 621.5985717773616 .9522094727612 .2896728516607 .6132202148602 .924621582 598.2266235352593 .5219726562588 .8142700195584 .1071777344579 .4047241211 574.7114868164570 .032409668565 .3726806641560 .7376708984556 .1334838867 551.5657958984547 .0415039062542 .5662841797538 .1475830078533 .791015625 529.5042724609525 .2932128906521 .165222168517 .1262207031513 .1837158203 509.3428955078505 .6116943359501 .9949951172498 .5000915527495 .1318054199 491.8971862793488 .8009033203485 .8494873047483 .0476074219480 .4017028809 477.9155883789475 .595703125473 .4448852539471 .4685974121469 .6679992676 468.0473022461466 .6036987305465 .3393859863464 .2449951172463 .3186950684 462.540802002461 .9031982422461 .3735046387460 .933013916460 .5401916504 460.1637878418459 .7603149414459 .2862854004458 .7166137695458 .0116882324 457.1795043945456 .1998901367455 .0472106934453 .6756896973452 .4635009766 451.6893005371451 .1596069336450 .658996582450 .129486084449 .5440063477 449.0389099121448 .7724914551448 .6286010742448 .5539855957448 .7099914551 449.3023071289450 .2670898438451 .5441894531452 .9288024902454 .1689147949 455.6210021973457 .5765991211459 .996887207462 .7445983887465 .7833862305 469.3280944824472 .8114013672475 .5425109863479 .4158935547485 .921295166 495.0003051758506 .7080078125519 .7772827148532 .7836303711542 .8322753906 546.8073120117547 .7227172852548 .2980957031546 .5427246094541 .0911254883 528.1918945312503 .3103942871471 .5515136719438 .3359069824401 .3218078613 358.6492004395317 .8073120117285 .679901123262 .7817077637252 .6755981445 245.141204834230 .4102935791212 .8470001221194 .191696167177 .2584075928 164.4089050293154 .7655029297148 .3997955322144 .7492980957143 .375793457 
144.0440979004146 .4553985596149 .6970062256152 .8628997803155 .954498291 158.5111999512160 .637298584162 .3182067871163 .595993042164 .5516052246 165.2592010498165 .8444061279166 .3276977539166 .7911987305167 .2406005859 167.7198028564168 .207901001168 .7104034424169 .1905975342169 .629196167 169.9804992676170 .2084960938170 .2653961182170 .1054992676169 .6900939941 168.9694976807167 .9373931885166 .5493927002164 .8571929932162 .849105835 160.6009979248158 .1437988281155 .550994873152 .8970031738150 .2075958252 147.5518951416144 .9306030273142 .4055938721139 .9391937256137 .5352935791 135.1578063965132 .778793335130 .3764953613127 .9157028198125 .3897018433 122.7740020752120 .0660018921117 .2511978149114 .3367996216111 .3209991455 108.2192993164105 .0404968262101 .805702209598 .5342330932695 .24890136719 91.9771728515688 .7412261962985 .5744476318482 .4982070922979 .54946899414 76.7535629272574 .127372741771 .8943786621170 .2967681884869 .07647705078 68.011016845767 .0891876220766 .2595977783265 .509628295964 .80561828613 64.1442337036163 .5047798156762 .8928489685162 .3012390136761 .7371711731 61.2023010253960 .7022705078160 .2444114685159 .8308486938559 .46863937378 59.1572494506858 .9010810852158 .6978988647558 .5491218566958 .45125961304 58.4030609130958 .4000511169458 .4386711120658 .5138511657758 .62031173706 58.7529907226658 .9056701660259 .0739097595259 .2513504028359 .43437957764 59.6170997619659 .7970809936559 .9693298339860 .132671356260 .28345108032 60.4216995239360 .545200347960 .6563301086460 .7558212280360 .84387969971 60.9217910766660 .9899902343861 .0510787963961 .1041984558161 .14915084839 61.1856307983461 .2131195068461 .231449127261 .2401695251561 .23920059204 61.2282104492261 .2073287963961 .1763992309661 .1357688903861 .08555984497 61.0262718200760 .9582710266160 .8821411132860 .7984008789160 .70766067505 60.6105194091860 .5075683593860 .3994407653860 .2866783142160 .169921875 60.0496406555259 .9264488220259 .8007698059159 .6731796264659 .54404067993 59.4138603210459 .2829589843859 .1517715454159 .0205688476658 .88972091675 58.7594490051358 .6300392150958 .5016517639258 .3745002746658 .24869155884 58.1243782043558 .0016098022557 .8804893493757 .761020660457 .64326095581 57.5272216796957 .4129104614357 .3003501892157 .1895713806257 .08060073853 56.9735183715856 .8683891296456 .7653198242256 .6644515991256 .56589889526 56.4698486328156 .3764991760356 .2860298156756 .198520660456 .11428070068 56.035850524955 .96374130249 1225.6629638671219 .5510253911213 .4360351561207 .3170166021201 .192016602 1195.0620117191188 .9260253911182 .7819824221176 .6309814451170 .472045898 1164.3050537111158 .129028321151 .9439697271145 .751139 .5460205081133 .331054688 1127.1070556641120 .8719482421114 .6269531251108 .370971681102 .104003906 1095.8270263671089 .538940431083 .2409667971076 .9329833981070 .614013672 1064.2860107421057 .9479980471051 .6009521481045 .245971681038 .884033203 1032.5140380861026 .1379394531019 .7570190431013 .3720092771006 .984008789 1000.593994141994 .2036743164987 .8143920898981 .4274902344975 .044921875 968.6680908203962 .2990722656955 .9395141602949 .5913696289943 .2567138672 936.9376220703930 .6361083984924 .3543701172918 .0947265625911 .8590698242 905.6500244141899 .4694213867893 .319519043887 .2025756836881 .12109375 875.0764770508869 .0714111328863 .1069946289857 .1859130859851 .3090209961 
845.4785766602 839.6954956055 833.9614868164 828.2772216797822.6441040039 817.0626220703811 .5338745117806 .0579223633800 .6356201172795 .2666015625 789.9514160156784 .6892700195779 .4802246094774 .3231811523769 .217590332 764.1619262695759 .1553955078754 .1959838867749 .2822875977744 .412109375 739.5833740234734 .7933959961730 .0399169922725 .319519043720 .6295776367 715.9669189453711 .3281860352706 .7103271484702 .1099243164697 .5236206055 692.9483032227688 .3809204102683 .8184814453679 .2581787109674 .6970214844 670.1323852539665 .5618286133660 .983215332656 .3939208984651 .7927856445 647.1776733398642 .5480957031637 .9022827148633 .2404785156628 .5620727539 623.8677978516619 .1577148438614 .4332275391609 .6953125604 .9459838867 600.1870117188595 .421081543590 .6508789062585 .8798217773581 .1110839844 576.3491210938571 .5979003906566 .862121582562 .1469116211557 .4570922852 552.7985839844548 .1771240234543 .5986938477539 .0689697266534 .5952148438 530.1824951172525 .8385009766521 .5684814453517 .3801269531513 .2786254883 509.2713012695505 .3638000488501 .5629882812497 .874206543494 .304107666 490.8576965332487 .5414123535484 .3599853516481 .3194885254478 .4244995117 475.6806945801473 .0922851562470 .6644897461468 .4005126953466 .3048095703 464.3782958984462 .6246032715461 .0397949219459 .6258850098458 .3717041016 457.2763977051456 .3186035156455 .4921875454 .7652893066454 .1238098145 453.5289001465452 .9556884766452 .3673095703451 .7287902832451 .0198059082 450.2002868652449 .2890930176448 .2763977051447 .1935119629446 .0491027832 445.0168151855444 .1698913574443 .4808044434442 .8494873047442 .2542114258 441.7008972168441 .2172851562440 .8541870117440 .632598877440 .5932006836 440.7856140137441 .2708129883441 .9403991699442 .7077026367443 .604888916 444.6455993652445 .9914855957447 .8398132324449 .9867858887452 .2680969238 454.8994140625458 .3198852539461 .6423950195463 .5942077637466 .3133850098 470.9364929199478 .4690856934490 .1907043457504 .0356140137518 .8837890625 531.1920166016535 .4254150391537 .1743774414540 .6055297852543 .2952880859 545.2565917969539 .1267700195516 .5031738281486 .7119140625461 .8005065918 430.725189209384 .6408081055335 .4432067871289 .9872131348255 .4754943848 244.971496582239 .7097930908222 .0317993164201 .5558013916181 .7030029297 164.6168060303154 .1352996826147 .9311981201144 .4026947021143 .3825073242 143.8869018555146 .0513000488149 .7984008789154 .0428924561157 .6269989014 160.8023071289163 .4192047119165 .4517059326166 .8199005127167 .6421051025 168.1502990723168 .3800964355168 .5652008057168 .6855010986168 .8309020996 168.9897003174169 .1903076172169 .4082946777169 .6419067383169 .8542022705 170.0260009766170 .1139984131170 .0870056152169 .9042053223169 .5269927979 168.929901123168 .0691986084166 .954498291165 .5460968018163 .8977050781 161.9927062988159 .9024963379157 .6464996338155 .2850952148152 .8771057129 150.4365997314148 .0278930664145 .6354980469143 .3152008057141 .0260009766 138.7814025879136 .5426940918134 .2911071777132 .0019073486129 .6421051025 127.201499939124 .6473007202121 .9813995361119 .1794967651116 .2550964355 113.1962966919110 .0280990601106 .7526016235103 .401901245199 .99388885498 96.559852600193 .132537841889 .7382431030386 .4184112548883 .20205688477 80.1394882202177 .2793121337974 .6967163085972 .4491729736370 .61055755615 69.1019210815467 .8517990112366 .798973083565 .8703689575265 .04768371582 
64.2896881103563 .5931205749562 .9371604919462 .3243293762261 .74605941772 61.2059593200760 .7036285400460 .2410392761259 .8232612609959 .44947814941 59.1262817382858 .8508186340358 .6284217834558 .4551200866758 .3338508606 58.2599182128958 .2335090637258 .2494010925358 .3051414489758 .39533996582 58.5153694152858 .6602287292558 .8238983154359 .0023002624559 .18891143799 59.3807411193859 .5714912414659 .7593994140659 .9390182495160 .10969161987 60.2671394348160 .4119300842360 .541580200260 .6575698852560 .7597694397 60.8486709594760 .9257011413660 .9908409118761 .0462989807161 .09159088135 61.1275596618761 .1539802551361 .1709213256861 .1783714294461 .17618179321 61.1644210815461 .1429405212461 .1119384765661 .0713806152361 .02164077759 60.9628791809160 .8955802917560 .8201484680260 .7370986938560 .64696884155 60.5502891540560 .4476699829160 .3396110534760 .2267799377460 .10960006714 59.9887504577659 .8646087646559 .7378082275459 .6086997985859 .47785949707 59.3456001281759 .2124290466359 .0786285400458 .9446487426858 .81069946289 58.677181243958 .5442314147958 .4122085571358 .2811889648458 .15143966675 58.0230102539157 .8960800170957 .7706794738857 .64690017757 .52473068237 57.4042510986357 .285438537657 .1683311462457 .0529289245656 .93925094604 56.8273582458556 .7173004150456 .6091613769556 .5030403137256 .39907836914 56.297428131156 .1982688903856 .1017990112356 .00822830255 .91762924194 55.8307418823255 .7470817565955 .66790008545

1230.1860351561224 .0360107421217 .8699951171211 .6979980471205 .521972656 1199.339965821193 .1519775391186 .957031251180 .754028321174 .543945312 1168.3249511721162 .0989990231155 .8630371091149 .6180419921143 .363037109 1137.0980224611130 .8239746091124 .538940431118 .2440185551111 .938964844 1105.6240234381099 .2979736331092 .9620361331086 .6159667971080 .260009766 1073.8940429691067 .5190429691061 .1350097661054 .7419433591048 .342041016 1041.9339599611035 .5200195311029 .0999755861022 .6749877931016 .247009277 1009.8159790041003 .383972168996 .9517211914990 .5209960938984 .0933227539 977.6701049805971 .2534179688964 .8447265625958 .4459228516952 .0587768555 945.6854858398939 .3276977539932 .9876708984926 .6674194336920 .3690795898 914.0947265625907 .8463745117901 .6259155273895 .4357910156889 .2775878906 883.1536865234877 .0657958984871 .0159301758865 .0053710938859 .036315918 853.1098022461847 .2279052734841 .3912963867835 .6016845703829 .8596191406 824.1665039062 818.5225830078 812.9290771484 807.3861083984 801.8942871094 796.4534301758791 .0639038086785 .7249145508780 .4365844727775 .1978149414 770.0081787109764 .8660888672759 .7708740234754 .7205810547749 .7141723633 744.7490844727739 .8234863281734 .9351806641730 .0817260742725 .2600708008 720.4677734375715 .7017211914710 .9589233398706 .2365722656701 .5311279297 696.8399047852692 .1597290039687 .4877929688682 .821105957678 .1572875977 673.4935302734668 .8275756836664 .1566772461659 .479309082654 .7932128906 650.0969848633645 .3889770508640 .6685180664635 .9343261719631 .1865234375 626.4244995117621 .6491088867616 .8605957031612 .0601806641607 .2489013672 602.4285888672597 .6010131836592 .7689208984587 .9346923828583 .1016235352 578.2730712891573 .4528198242568 .6450195312563 .8538818359559 .0844726562 554.3413696289549 .6303710938544 .9564208984540 .3256835938535 .7435302734 531.2163696289526 .7498168945522 .3505859375518 .0241699219513 .7777099609 
509.6163024902505 .5472106934501 .5754089355497 .7080078125493 .9497070312 490.3074035645486 .7856140137483 .3905944824480 .1265869141476 .999786377 474.013885498471 .1748962402468 .4859924316465 .9527893066463 .5773010254 461.3645019531459 .3142089844457 .429901123455 .7073974609454 .1477050781 452.7405090332451 .4825134277450 .3562011719449 .3521118164448 .4455871582 447.6198120117446 .8453979492446 .0975952148445 .3497009277444 .571685791 443.7485961914442 .8510131836441 .8940124512440 .8677062988439 .8290100098 438.7940979004437 .8153991699436 .9630126953436 .1805114746435 .4545898438 434.7893066406434 .1495056152433 .5819091797433 .1101989746432 .7887878418 432.641204834432 .7550048828433 .2485046387433 .7526855469433 .9594116211 434.2750854492435 .0516052246436 .1372070312437 .3906860352438 .6982116699 439.9368896484441 .654510498444 .5466003418447 .4988098145449 .2745056152 451.5310974121455 .7077026367462 .2390136719471 .7651062012483 .0299987793 494.5392150879504 .8414001465511 .8322143555517 .5722045898524 .0017700195 530.6911010742537 .5615844727536 .2473144531518 .1757202148492 .4346008301 467.849395752435 .9635009766389 .375213623337 .720489502291 .2921142578 255.2770996094238 .0782012939227 .1114959717209 .7357940674190 .7655029297 172.5843963623157 .5605010986148 .7597961426144 .4985046387143 .050994873 143.7763061523145 .7951049805149 .1826934814153 .9192962646158 .9084014893 163.0684967041166 .5099029541169 .0428009033170 .7902069092171 .6361999512 171.8410949707171 .7696075439171 .4750976562171 .2070007324170 .9597015381 170.7823028564170 .6587982178170 .5897064209170 .5507049561170 .5278015137 170.4895019531170 .4107971191170 .2574005127169 .9967956543169 .5993041992 169.029296875168 .2707977295167 .2906951904166 .0993041992164 .6748046875 163.0545959473161 .2398071289159 .2785949707157 .1981964111155 .0404968262 152.8529968262150 .6472015381148 .4613037109146 .2935943604144 .1775054932 142.0850067139140 .0177001953137 .9443054199135 .8441009521133 .6900939941 131.4515991211129 .1094055176126 .6336975098124 .0174026489121 .2389984131 118.304901123115 .2063980103111 .966003418108 .591796875105 .1173019409 101.5664978027 97.9771118164194.3891296386790.8381729126 87.37065887451 84.0262832641680 .8554611206177 .9213027954175 .2874069213972 .9483795166 70.9590911865269 .26088714667 .8418426513766 .6527862548865 .6121673584 64.7012634277363 .8778610229563 .1360092163162 .4535713195861 .83026123047 61.255020141660 .7293891906760 .2490997314559 .8155899047959 .42881011963 59.0892410278358 .7986793518158 .5564918518158 .3644409179758 .22071838379 58.1260108947858 .0772514343358 .0733909606958 .1102485656758 .18487167358 58.2923393249558 .4280509948758 .58705902158 .7636795043958 .95357131958 59.1507797241259 .3518981933659 .5513191223159 .7467308044459 .93341064453 60.1100616455160 .2730903625560 .4224205017160 .5560188293560 .67449951172 60.777488708560 .8656311035260 .9398193359461 .0005683898961 .04936981201 61.0864486694361 .1129302978561 .1289596557661 .1349716186561 .13111114502 61.1175804138261 .0945205688561 .0620307922461 .0203285217360 .96955871582 60.9100685119660 .8421096801860 .7661590576260 .682621002260 .59199905396 60.4947891235460 .3915290832560 .282779693660 .1690101623560 .05083847046 59.9286994934159 .8031692504959 .6746788024959 .5437393188559 .41075134277 59.2761993408259 .1404190063559 .0038681030358 .8668212890658 .72969055176 
58.5926895141658 .4561691284258 .3203201293958 .1853981018158 .05155181885 57.9189682006857 .7877388000557 .6580200195357 .5298118591357 .40319824219 57.2782096862857 .1548690795957 .0331687927256 .9131507873556 .79479980469 56.67815017756 .5632209777856 .4501113891656 .3388786315956 .2296295166 56.1225204467856 .0176887512255 .9153404235855 .8156585693455 .7188911438 55.6250991821355 .5346488952655 .4502296447855 .37237167358 1234.7469482421228 .5319824221222 .3129882811216 .0909423831209 .863037109 1203.6300048831197 .3909912111191 .1450195311184 .8919677731178 .631958008 1172.3630371091166 .086059571159 .8000488281153 .5050048831147 .201049805 1140.8869628911134 .5639648441128 .2299804691121 .8869628911115 .534057617 1109.1700439451102 .796997071096 .413940431090 .0209960941083 .619018555 1077.20703125 1070.786010742 1064.355957031 1057.9189453121051.473999023 1045.0219726561038 .5639648441032 .1009521481025 .6340332031019 .163024902 1012.6900024411006 .21697998999 .7434082031993 .2719726562986 .803894043 980.3408813477973 .8845214844967 .4365234375960 .9984741211954 .5725708008 948.1605834961941 .7642822266935 .3858032227929 .0269165039922 .6898193359 916.3762817383910 .0883789062903 .828125897 .5972290039891 .3975830078 885.2313842773879 .0999145508873 .0051879883866 .9484863281860 .9318237305 854.9559936523849 .0228271484843 .1331787109837 .2885742188831 .4895019531 825.737121582820 .0319213867814 .3748168945808 .7658081055803 .2056884766 797.6942138672792 .231628418786 .8173217773781 .4511108398776 .1322021484 770.8601074219765 .6334838867760 .4514160156755 .3123168945750 .2147216797 745.1566772461740 .13671875735 .1519165039730 .2006225586725 .2799072266 720.387512207715 .5203857422710 .6760253906705 .8513793945701 .0437011719 696.2501220703691 .4677124023686 .6937866211681 .92578125677 .1614990234 672.3980712891667 .633605957662 .8654785156658 .0925292969653 .3123168945 648.5239868164643 .7257080078638 .917175293634 .0972290039629 .2659301758 624.4229125977619 .5687866211614 .703918457609 .8297119141604 .9467163086 600.0573730469595 .162902832590 .2661743164585 .3693847656580 .4760131836 575.588684082570 .7116088867565 .8483886719561 .0034179688556 .1810913086 551.3861083984546 .6237182617541 .8989257812537 .2172851562532 .583984375 528.0054931641523 .4866943359519 .0344238281514 .6536254883510 .3512878418 506.1323852539502 .003692627497 .9703063965494 .0386962891490 .2138061523 486.5018005371482 .9071960449479 .4359130859476 .0921020508472 .8811950684 469.8071899414466 .8750915527464 .0881958008461 .4515075684458 .967010498 456.6391906738454 .467590332452 .4555053711450 .5983886719448 .8973999023 447.341796875445 .9294128418444 .6424865723443 .4740905762442 .400604248 441.4088134766440 .4729919434439 .5726013184438 .6871032715437 .7908935547 436.8774108887435 .9216003418434 .941192627433 .9175109863432 .904296875 431.9195861816430 .9729919434430 .0947875977429 .2561035156428 .4650878906 427.7107849121426 .9697875977426 .2846984863425 .6921081543425 .2286071777 424.8991088867424 .7981872559425 .1647033691425 .486114502425 .2340087891 425.0432128906425 .5535888672426 .2974853516426 .8541870117427 .3615112305 427.7137145996428 .5285949707430 .7132873535433 .250213623434 .8870849609 437.1037902832441 .2228088379446 .7312927246453 .482208252460 .9776916504 467.5773010254474 .7937927246483 .7604980469493 .3884887695502 .3245849609 
510.6787109375518 .7551879883520 .3690795898507 .7916870117486 .3598022461 461.2615966797426 .9574890137381 .4211120605332 .7365112305290 .6032104492 256.3388061523232 .6593017578214 .4031066895196 .158203125179 .525894165 164.4347991943153 .1221008301146 .5513000488143 .7478942871143 .7270050049 145.81300354149 .029800415153 .4051971436158 .7447052002164 .2196960449 168.8618927002172 .5090942383174 .9188995361176 .0713043213176 .2227020264 175.6725006104175 .000793457174 .2648010254173 .6132965088173 .0523986816 172.5874023438172 .2093048096171 .8892974854171 .6136016846171 .3524932861 171.0829925537170 .7749023438170 .4019012451169 .9322052002169 .3444061279 168.6056060791167 .7100982666166 .6260986328165 .3728027344163 .9273986816 162.3318023682160 .5818939209158 .7270965576156 .7891998291154 .8027954102 152.8103027344150 .8115997314148 .8412017822146 .8887023926144 .9886016846 143.1036987305141 .237701416139 .3515014648137 .4288024902135 .4344940186 133.3388977051131 .1181030273128 .7369995117126 .1884002686123 .4400024414 120.5067977905117 .3666000366114 .0558013916110 .5712966919106 .9630966187 103.252098083599 .4931869506895 .7314300537192 .0127105712988 .39671325684 84.9213562011781 .6483078002978 .6168289184675 .895370483473 .45851135254 71.3425521850669 .5064468383867 .9475784301866 .6223220825265 .46373748779 64.459129333563 .562778472962 .7695503234962 .0525512695361 .41054153442 60.8291397094760 .308170318659 .8409385681259 .4267692565959 .06391906738 58.7507591247658 .4884986877458 .2745208740258 .1110305786157 .99444961548 57.9264602661157 .902481079157 .9226493835457 .9815406799358 .07717895508 58.2038383483958 .3575210571358 .5328407287658 .7243003845258 .92761993408 59.1365203857459 .3481407165559 .5562515258859 .7593803405859 .95203018188 60.1338081359960 .3004913330160 .4524993896560 .5874481201260 .70595932007 60.8075103759860 .8926506042560 .962478637761 .0172500610461 .05865097046 61.0868797302261 .1035385131861 .1087493896561 .1034812927261 .08792877197 61.062641143861 .0278587341360 .9838790893660 .9309997558660 .86948013306 60.7997016906760 .7219810485860 .6367988586460 .5445594787660 .44577026367 60.3409194946360 .2304916381860 .1150283813559 .9949989318859 .8709602356 59.7433204650959 .6126403808659 .4792900085459 .3437881469759 .2064704895 59.0678215026958 .9281311035258 .7878494262758 .6472206115758 .50662994385 58.3662910461458 .2265281677258 .0875015258857 .9494781494157 .81256866455 57.6769790649457 .5427589416557 .4100608825757 .27888107357 .14933013916 57.0213584899956 .8950309753456 .7703399658256 .6473007202156 .52590179443 56.4061584472756 .2881393432656 .171878814756 .0574684143155 .94501876831 55.8346900939955 .7266006469755 .6209716796955 .518001556455 .41793060303 55.3208389282255 .2275199890155 .1375007629455 .05207061768 1239.288940431233 .0360107421226 .7679443361220 .4940185551214 .215942383 1207.9329833981201 .6440429691195 .3480224611189 .0450439451182 .734985352 1176.4169921881170 .0909423831163 .7559814451157 .4119873051151 .058959961 1144.6979980471138 .3260498051131 .9449462891125 .5539550781119 .154052734 1112.7440185551106 .3239746091099 .8950195311093 .4560546881087 .008056641 1080.5510253911074 .086059571067 .6120605471061 .1309814451054 .641967773 1048.1469726561041 .6469726561035 .1409912111028 .6319580081022 .119995117 1015.6060180661009 .0910034181002 .577026367996 .065612793989 .5579223633 
983.0551757812976 .5595092773970 .0723876953963 .5955810547957 .1309204102 950.6804199219944 .2454833984937 .8284301758931 .4307861328925 .0546875 918.7020263672912 .3745117188906 .0737915039899 .8021240234893 .5607299805 887.3519287109 881.1766967773 875.0371704102 868.9343261719 862.8699951172 856.844909668850 .8609008789844 .9185180664839 .0192871094833 .1638183594 827.3527832031821 .5869140625815 .8670043945810 .1929931641804 .565612793 798.984375793 .4500732422787 .9614868164782 .5191040039777 .1215209961 771.7686157227766 .4589233398761 .1917724609755 .9655151367750 .7788696289 745.6301269531740 .5173950195735 .4387207031730 .3919067383725 .3745117188 720.3845214844715 .4188842773710 .4755249023705 .5515136719700 .6441040039 695.7509155273690 .8690795898685 .9962158203681 .1298217773676 .2678833008 671.4077758789666 .5477294922661 .6854858398656 .8198242188651 .948425293 647.0706787109642 .1851806641637 .2911987305632 .387878418627 .4755859375 622.5537719727617 .6232299805612 .6843261719607 .7379760742602 .7855834961 597.8287963867592 .8693237305587 .9094238281582 .9517822266577 .9990844727 573.0546875568 .1220092773563 .2047729492558 .3070068359553 .4331054688 548.5872802734543 .7750244141539 .0004272461534 .2694702148529 .5866699219 524.958190918520 .3889160156515 .8853149414511 .4519958496507 .0958862305 502.8214111328498 .6354980469494 .5426025391490 .5492858887486 .6599121094 482.8807067871479 .2156982422475 .6706848145472 .2492980957468 .9569091797 465.7968139648462 .7742004395459 .8916931152457 .1541137695454 .5631103516 452.1231079102449 .8334960938447 .6972961426445 .7102966309443 .8729858398 442.1763916016440 .6167907715439 .1801147461437 .8576965332436 .6315917969 435.4877929688434 .4070129395433 .3706054688432 .3637084961431 .3655090332 430.3720092773429 .365814209428 .3577880859427 .3405151367426 .3439941406 425.3854980469424 .4556884766423 .5704956055422 .7109069824421 .8898010254 421.0864868164420 .2807006836419 .4920043945418 .7383117676418 .0548095703 417.4458007812416 .9873046875416 .787109375416 .5899047852416 .1726989746 415.8268127441415 .9508972168416 .2968139648416 .5751037598416 .8554077148 417.2388916016417 .9404907227419 .3469848633421 .1683959961422 .5116882324 424.396697998427 .6795043945431 .5842895508436 .2309875488440 .9039001465 444.837890625450 .0089111328456 .9280090332465 .587097168475 .6691894531 483.9093017578487 .1380004883486 .5795898438482 .0986022949469 .5343017578 444.9797058105410 .4072875977368 .7723999023325 .5969848633285 .6846923828 251.5774993896227 .9201049805207 .5030975342184 .2857971191164 .9579925537 153.9925994873148 .1468048096145 .0800933838144 .5453033447146 .1015014648 149.3663024902153 .7689971924159 .0050048828164 .4967956543170 .0173034668 175.0800018311178 .9795074463180 .9727020264181 .3388977051180 .3746032715 178.8027038574177 .5628051758176 .5104980469175 .6148986816174 .842300415 174.1703948975173 .5816040039173 .0556030273172 .5706939697172 .1024932861 171.6260986328171 .1150970459170 .5458984375169 .8910980225169 .133605957 168.2471008301167 .2274017334166 .0529937744164 .7382049561163 .2729949951 161.6885070801159 .9916992188158 .221496582156 .4046936035154 .5679016113 152.7456054688150 .9403076172149 .1764984131147 .4459991455145 .7631988525 144.1002960205142 .4467926025140 .7684020996139 .0424041748137 .2312011719 135.3018035889133 .2238006592130 .9615936279128 .495803833125 .7909011841 
122.8589019775119 .6882019043116 .3024978638112 .7006988525108 .9384994507 105.052696228101 .10459899997 .152061462493 .250282287689 .46868896484 85.8484725952182 .4557037353579 .3191299438576 .4976501464873 .96489715576 71.7381286621169 .7878723144568 .1076202392666 .6607666015665 .39888763428 64.3033065795963 .3357582092362 .4868087768661 .730880737361 .06324005127 60.4687194824259 .944889068659 .4827613830659 .0808715820358 .73427963257 58.4419517517158 .201728820858 .0123710632357 .8731689453157 .78213119507 57.7386283874557 .7395095825257 .7832412719757 .8653984069857 .98295974731 58.1306686401458 .3039588928258 .4975090026958 .7056198120158 .9236907959 59.1456909179759 .3682212829659 .5856513977159 .7958297729559 .99407958984 60.1793785095260 .3483810424860 .5009384155360 .6352005004960 .7515296936 60.8495216369660 .9298782348660 .9934082031261 .0408592224161 .07350921631 61.0921211242761 .0980987548861 .0920104980561 .0749282836961 .0472984314 61.0098609924360 .9629402160660 .9070701599160 .8425788879460 .76987075806 60.6893386840860 .6013908386260 .5064697265660 .4050407409760 .2975692749 60.1845512390160 .0664482116759 .943778991759 .8170013427759 .68661117554 59.5530204772959 .4167213439959 .2780990600659 .1376113891658 .99559020996 58.8524589538658 .7085304260358 .564170837458 .4196586608958 .27532958984 58.1313781738357 .9881095886257 .8456802368257 .7043190002457 .56415939331 57.4253501892157 .2879600524957 .1521186828657 .0178298950256 .88515090942 56.7540893554756 .6246604919456 .4968490600656 .370670318656 .24612045288 56.1232109069856 .0019798278855 .8824882507355 .7648200988855 .64907836914 55.5354194641155 .4239807128955 .3149909973155 .2086296081555 .10514831543 55.0046386718854 .907501220754 .8164710998554 .73220825195

1243.8659667971237 .5500488281231 .2309570311224 .9079589841218 .581054688 1212.2480468751205 .9090576171199 .5639648441193 .2130126951186 .854003906 1180.4870605471174 .1130371091167 .7299804691161 .3380126951154 .937988281 1148.5290527341142 .1099853521135 .6820068361129 .2449951171122 .798950195 1116.343017578 1109.878051758 1103.402954102 1096.920043945 1090.427978516 1083.9270019531077 .4169921881070 .9000244141064 .3759765621057 .844970703 1051.3079833981044 .7650146481038 .2180175781031 .6669921881025 .114013672 1018.5599975591012 .0050048831005 .45098877998 .9000854492992 .3529052734 985.8112182617979 .2764282227972 .7504882812966 .2349853516959 .7318725586 953.2426757812946 .7692871094940 .3134765625933 .8770751953927 .4619140625 921.0695800781914 .7022094727908 .3610839844902 .0482177734895 .7650146484 889.5131835938 883.2943115234877.1096191406 870.9605102539864.8483886719 858.7741699219852 .7393798828846 .7446899414840 .7913208008834 .8795166016 829.0106201172823 .1845703125817 .4025878906811 .6644287109805 .9705810547 800.3209228516 794.7158203125 789.1544189453783.6367797852 778.1619873047 772.7299194336767 .338684082761 .98828125756 .6768188477751 .4030761719 746.1655273438740 .9625244141735 .7919921875730 .6520996094725 .5405883789 720.4553833008715 .3942260742710 .354309082705 .3336181641700 .329284668 695.3394165039690 .3610229492685 .3922119141680 .4304199219675 .4735717773 670.5197753906665 .567199707660 .6137695312655 .6580810547650 .6984863281 645.7343139648640 .7639160156635 .7871704102630 .8032226562625 .8123168945 620.8140258789615 .8090820312610 .7979125977605 .7816772461600 .7614135742 
595.7390136719590 .7158813477585 .6945800781580 .6773071289575 .6671142578 570.6666259766565 .6796264648560 .7094726562555 .7600708008550 .8355712891 545.9404296875541 .0789794922536 .2561035156531 .4768066406526 .7457885742 522.0687866211517 .4506225586512 .8969726562508 .412902832504 .0046081543 499.6766052246495 .4352111816491 .2849121094487 .2318115234483 .2803039551 479.4360046387475 .702911377472 .0863037109468 .5895996094465 .2179870605 461.974395752458 .863494873455 .8877868652453 .0519104004450 .357208252 447.808013916445 .4034118652443 .1470031738441 .0342102051439 .0663146973 437.2341918945435 .5357055664433 .9573974609432 .4927062988431 .1250915527 429.8434143066428 .6317138672427 .4743041992426 .3609924316425 .2731018066 424.2113037109423 .1585083008422 .1268920898421 .1076965332420 .1180114746 419.1672058105418 .2442932129417 .3646850586416 .5025024414415 .6805114746 414.857208252414 .0346069336413 .1853942871412 .3417053223411 .4533081055 410.6039123535409 .7349853516408 .9237976074408 .2297973633407 .6942138672 407.4115905762 407.3601989746 407.3811035156407.3269958496 407.5556945801 408.3684082031409 .4655151367410 .4262084961411 .3254089355412 .0564880371 413.1188049316415 .1478881836417 .6803894043420 .7489013672423 .9054870605 426.4305114746429 .8190002441433 .9114074707439 .7720031738449 .1069946289 456.0242919922453 .407409668448 .3125915527448 .8789978027442 .4242858887 418.1126098633385 .6684875488351 .80859375316 .371307373279 .5734863281 245.5682983398222 .1307067871201 .3069000244174 .6513977051153 .2626953125 146.0213012695145 .0762939453144 .9010925293146 .6585998535149 .6813049316 153.9801025391159 .5066986084165 .3659973145170 .6295013428175 .5099945068 180.3759002686183 .9931945801185 .2781066895184 .915802002183 .208694458 181.0395965576179 .571105957178 .3417053223177 .2772979736176 .3722991943 175.5328063965174 .7850036621174 .0825958252173 .4230957031172 .7722930908 172.1166992188171 .4259033203170 .6855010986169 .8677978516168 .9635925293 167.9472961426166 .8220062256165 .5655059814164 .1981964111162 .7068939209 161.1282958984159 .4649963379157 .7608032227156 .040802002154 .3273010254 152.6555023193151 .025100708149 .4638061523147 .9512023926146 .4929962158 145.054397583143 .6282043457142 .1703033447140 .6643981934139 .0587005615 137.3246002197 135.4174041748 133.2989044189130.9440002441 128.2987976074 125.3883972168122 .1866989136118 .7289962769114 .9949035645111 .0665969849 106.9802017212102 .818199157798 .6446380615294 .5326309204190 .56601715088 86.7792587280383 .2581176757880 .0034408569377 .0814132690474 .45720672607 72.142303466870 .1024169921968 .3211135864366 .7703933715865 .4123916626 64.232978820863 .1933708190962 .2873992919961 .4871406555260 .78873062134 60.1739883422959 .6400794982959 .1755409240758 .7779693603558 .44095993042 58.1621704101657 .9389610290557 .7685699462957 .6506195068457 .58145141602 57.5613212585457 .5853500366257 .6530914306657 .7585296630957 .89957809448 58.0696296691958 .2647590637258 .4785690307658 .7055091857958 .94049072266 59.1769599914659 .4119415283259 .6387481689559 .8563690185560 .05889892578 60.2467498779360 .4157714843860 .5667991638260 .6977691650460 .80936813354 60.9015808105560 .9748802185161 .0305404663161 .0689888000561 .09196090698 61.0999488830661 .094730377261 .0767707824761 .0475311279361 .00743103027 60.9575119018660 .8981285095260 .8300209045460 .7535781860460 .66931152344 
60.5776596069360 .4790611267160 .3740005493260 .2629394531260 .1463508606 60.0247306823759 .8985214233459 .7682189941459 .6342391967859 .49708938599 59.3571395874 59.2148513793959.07057189941 58.92473983765 58.77766036987 58.629749298158 .4812507629458 .3325500488358 .1838798522958 .03554916382 57.8877410888757 .7407608032257 .5947113037157 .4498291015657 .30620956421 57.1640205383357 .023300170956 .8841705322356 .7466201782256 .61069869995 56.4763984680256 .3437556 .2127113342356 .083290100155 .955490112355 .82931137085 55.704799652155 .5819816589455 .4609718322855 .3418388366755 .22476959229 55.1099014282254 .9974403381354 .8875808715854 .7805900573754 .67652893066 54.5762405395554 .4792709350654 .38690948486 1248.4239501951242 .0720214841235 .7049560551229 .332031251222 .956054688 1216.5739746091210 .1870117191203 .7939453121197 .3940429691190 .988037109 1184.5729980471178 .1510009771171 .7209472661165 .2829589841158 .83605957 1152.3800048831145 .9160156251139 .4420166021132 .9589843751126 .468017578 1119.9670410161113 .457031251106 .9389648441100 .4110107421093 .875976562 1087.331054688 1080.779052734 1074.219970703 1067.6540527341061.081054688 1054.5019531251047 .917968751041 .3299560551034 .7390136721028 .145996094 1021.5510253911014 .9569702151008 .3640136721001 .773986816995 .1873168945 988.6068115234982 .0333862305975 .4689941406968 .915222168962 .3734741211 955.8458251953949 .3338012695942 .8394165039936 .3638916016929 .9094238281 923.4774780273917 .0698852539910 .6881713867904 .3339233398898 .0084228516 891.713684082885 .4506225586879 .2208251953873 .0253295898866 .8654174805 860.7420043945854 .6564941406848 .6093139648842 .6019287109836 .6343994141 830.707824707824 .8222045898818 .9786987305813 .1768798828807 .4176025391 801.7003173828796 .025390625790 .3922119141784 .80078125779 .2501831055 773.7401733398768 .2692871094762 .8372192383757 .4423828125752 .0836791992 746.7593994141741 .4683227539736 .2083740234730 .9780273438725 .7747802734 720.5974121094715 .4428710938710 .3095703125705 .1948852539700 .0966796875 695.0128173828689 .9409790039684 .8790283203679 .8248291016674 .7763061523 669.7316894531664 .6892700195659 .6475219727654 .6047973633649 .5598144531 644.5115966797639 .4592285156634 .4019775391629 .3397827148624 .2725219727 619.1998901367614 .1226806641609 .0413818359603 .9570922852598 .8709106445 593.7844848633588 .6995239258583 .6181030273578 .5427246094573 .4760131836 568.4210205078563 .3806762695558 .3588867188553 .3590087891548 .3850708008 543.4412841797538 .5321044922533 .6616821289528 .8353271484524 .0573120117 519.3328857422514 .6668701172510 .0649108887505 .5314941406501 .0725097656 496.6924133301492 .3973083496488 .1913146973484 .0804138184480 .0685119629 476.1611938477472 .361907959468 .675994873465 .1062011719461 .6577148438 458.3328857422455 .1362915039452 .070098877449 .1386108398446 .3432922363 443.6881103516441 .1726989746438 .8001098633436 .5668029785434 .4736022949 432.5133056641430 .6831054688428 .9724121094427 .3742980957425 .8760986328 424.4671936035423 .1355895996421 .8678894043420 .6564025879419 .487487793 418.3601989746417 .263885498416 .2049865723415 .1794128418414 .1929016113 413.2504882812412 .3439025879411 .479888916410 .6384887695409 .8201904297 409.0107116699408 .2231140137407 .4135131836406 .5997009277405 .6684875488 404.5888061523403 .3745117188402 .1975097656401 .2083129883400 .425201416 
400.1353149414400 .5946044922400 .8359985352399 .8334960938399 .3854064941 401.0616149902403 .1065979004404 .0953979492404 .3248901367403 .7080993652 403.2956848145404 .1697998047405 .8883056641408 .6517944336411 .5492858887 413.3566894531415 .428314209418 .3681945801422 .5010986328428 .8518981934 432.4130859375428 .2356872559421 .5060119629415 .6036071777403 .9786071777 379.6206054688351 .832611084329 .7388916016306 .3055114746274 .1311950684 240.5756072998213 .4797058105189 .5081939697167 .2145996094151 .1627960205 145.2142028809145 .0921936035146 .8007965088150 .0973052979154 .1604003906 159.3486022949165 .99659729172 .3892059326176 .6945037842180 .0475006104 183.3377075195185 .5086975098185 .6343994141184 .6443023682183 .4458007812 182.0773925781180 .8197937012179 .6324005127178 .5473937988177 .550201416 176.6278076172175 .7655944824174 .9427032471174 .1437988281173 .349105835 172.5415039062171 .7001037598170 .8106994629169 .8536987305168 .8202056885 167.6925048828166 .4712982178165 .1434936523163 .7230987549162 .2062988281 160.6221923828158 .9817962646157 .3262939453155 .6856994629154 .0785980225 152.5377960205151 .0709075928149 .7062072754148 .4156036377147 .1800994873 145.9738006592144 .7799072266143 .5603027344142 .2901000977140 .9174041748 139.4051055908137 .6988067627135 .7485046387133 .5233001709130 .9727935791 128.1011962891124 .8765029907121 .3326034546117 .4665985107113 .3529968262 109.0423965454 104.6290969849 100.199302673395.8428726196391.66325378418 87.6956710815484 .028877258380 .6582336425877 .6341705322374 .93134307861 72.547012329170 .4393386840868 .5696563720766 .9251403808665 .48513793945 64.2291564941463 .1237792968862 .1600608825761 .3155403137260 .58226013184 59.9432411193859 .3933296203658 .9202690124558 .5207214355558 .18655014038 57.9156608581557 .703258514457 .5475502014257 .4459381103557 .39604187012 57.3960494995157 .4423599243257 .5326805114757 .6619911193857 .82672119141 58.0207786560158 .2391014099158 .4752693176358 .7230110168558 .97665023804 59.2293205261259 .4773788452159 .7145309448259 .9389190673860 .14543151855 60.3339691162160 .5015907287660 .6487503051860 .7742118835460 .87873840332 60.9628295898461 .027210235661 .0730514526461 .1011810302761 .11304092407 61.1095390319861 .092208862361 .0618515014661 .0198707580660 .9669303894 60.9041290283260 .8319892883360 .7513389587460 .6626281738360 .56650161743 60.4633903503460 .3538284301860 .2382812560 .1172485351659 .99119949341 59.8606109619159 .7259216308659 .587608337459 .4460906982459 .30183029175 59.1551589965859 .0065383911158 .8562889099158 .7048110961958 .55237960815 58.3993797302258 .2460594177258 .0927581787157 .9396781921457 .78712081909 57.6352500915557 .4843292236357 .3344917297457 .1859016418557 .03865814209 56.8929290771556 .7487297058156 .6061515808156 .4651985168556 .32592010498 56.1882705688556 .0522804260355 .9179115295455 .7851486206155 .65399932861 55.5244407653855 .3965492248555 .2703094482455 .1458702087455 .02326965332 54.9026908874554 .7842788696354 .6682395935154 .5547714233454 .44412994385 54.3363990783754 .231998443654 .1336784362854 .04222106934 1253.0169677731246 .6030273441240 .1860351561233 .7659912111227 .342041016 1220.9119873051214 .4780273441208 .0369873051201 .589965821195 .135986328 1188.6750488281182 .2060546881175 .7290039061169 .2449951171162 .751953125 1156.2509765621149 .7409667971143 .2230224611136 .6960449221130 .16003418 
1123.6149902341117 .0620117191110 .51103 .9300537111097 .3509521481090 .765014648 1084.1710205081077 .5699462891070 .9620361331064 .3480224611057 .729003906 1051.1040039061044 .4770507811037 .8449707031031 .2130126951024 .578979492 1017.9450073241011 .3129882811004 .684020996998 .0593261719991 .4403076172 984.8286743164978 .2260131836971 .6337890625965 .0537719727958 .4876708984 951.9370727539945 .4038696289938 .8895263672932 .3956298828925 .923828125 919.4760131836913 .0532836914906 .6572875977900 .2896118164893 .9514160156 887.6439819336 881.3687744141 875.1267700195 868.919128418 862.7465209961 856.6104125977850 .5109863281844 .4495849609838 .426574707832 .4426879883 826.4979858398820 .5935058594814 .7288208008808 .9047241211803 .1206054688 797.3770141602791 .6729736328786 .0090942383780 .383972168774 .7974853516 769.2485961914763 .7366943359758 .2603149414752 .8184814453747 .4097900391 742.0328979492736 .6859130859731 .3673706055726 .0753173828720 .8079223633 715.5631103516710 .3389282227705 .1331787109699 .9439697266694 .7691040039 689.606628418684 .454284668679 .3104858398674 .1732177734669 .0405883789 663.911315918658 .7838134766653 .6567993164648 .5288696289643 .3994750977 638.2673950195633 .1326293945627 .9942016602622 .8527832031617 .7078857422 612.5604858398607 .4108886719602 .2603759766597 .1099243164591 .9611206055 586.815612793581 .6757202148576 .5433959961571 .4216918945566 .3129882812 561.2208862305556 .1483154297551 .0989990234546 .0765991211541 .0852050781 536.1290893555531 .2122802734526 .3397216797521 .515625516 .7448730469 512.0322875977507 .3829040527502 .8013916016498 .2930908203493 .8623962402 489.5150146484485 .2549133301481 .0877075195477 .0172119141473 .048614502 469.1852111816465 .4317932129461 .7911071777458 .267791748454 .8641052246 451.584197998448 .4301147461445 .4059143066442 .5130004883439 .7554016113 437.1328125434 .6484069824432 .2991027832430 .0864868164428 .0038146973 426.0492858887424 .2138061523422 .4914855957420 .871887207419 .3457946777 417.904296875416 .5354003906415 .2349853516413 .9899902344412 .8024902344 411.6614074707410 .5733032227409 .5332946777408 .5433959961407 .6058044434 406.7120056152405 .8724975586405 .0582885742404 .2676086426403 .4931030273 402.7825012207402 .0570983887401 .358001709400 .5274963379399 .4469909668 398.308807373397 .3165893555396 .4218139648395 .6011962891395 .2518920898 396.1372070312396 .8298950195395 .1954956055394 .108001709396 .2998962402 398.9260864258399 .7467041016399 .4974060059397 .7225036621395 .916595459 395.9461975098397 .0396118164399 .7719116211402 .537109375403 .5291137695 404.5050964355406 .0697021484408 .1026000977411 .113494873411 .4961853027 407.2768859863398 .5844116211384 .3160095215366 .2101135254342 .6005859375 320.6340026855309 .4732055664296 .0636901855267 .6409912109234 .6638031006 204.7221069336178 .9535980225162 .6298980713152 .9562988281147 .7855987549 147.0722045898149 .4514007568153 .7545013428158 .578704834164 .3869934082 171.7850952148178 .3614959717181 .6295928955183 .350692749184 .9055938721 185.5001983643184 .5511932373183 .1894989014182 .7886047363182 .4248046875 181.5225982666180 .5179 .4691925049178 .4542999268177 .4936065674176 .566192627 175.654296875174 .7514038086173 .8379058838172 .9060058594171 .9362030029 170.9216003418169 .8448028564168 .7024993896167 .4777984619166 .1761932373 164.7834014893163 .3177032471161 .7722015381160 .1804046631158 .549697876 
156.9257965088155 .3399963379153 .8217010498152 .4044036865151 .0948028564 149.920501709148 .8372039795147 .8168945312146 .8347015381145 .8771057129 144.8979034424143 .8811950684142 .7584075928141 .5030975342140 .0316009521 138.2906951904136 .2355041504133 .803894043130 .9998016357127 .7525024414 124.12840271120 .1158981323115 .8059997559111 .2479019165106 .5595016479 101.833000183197 .1936798095792 .7643203735488 .5804824829184 .76712036133 81.2818298339878 .1714172363375 .4050064086972 .964706420970 .7996673584 68.8558502197367 .1334075927765 .6220321655364 .2977828979563 .12808990479 62.1078109741261 .2159194946360 .4450607299859 .7763404846259 .2049407959 58.7167510986358 .3083381652857 .9705200195357 .7005195617757 .49338912964 57.3462181091357 .2569618225157 .2217292785657 .239669799857 .30545043945 57.4178810119657 .5701103210457 .7595481872657 .9783096313558 .22204971313 58.4825782775958 .7539596557659 .0289802551359 .3001785278359 .56372070312 59.8117103576760 .04380035460 .2528686523460 .4411811828660 .60462188721 60.7453498840360 .8623695373560 .9569816589461 .0307006835961 .0838508606 61.1183891296461 .1346397399961 .134490966861 .1185302734461 .08855056763 61.0452308654860 .9901809692460 .9240493774460 .8481292724660 .7629699707 60.6695518493760 .5683517456160 .4601097106960 .3452987670960 .22451019287 60.098209381159 .966930389459 .8311195373559 .691268920959 .54780960083 59.4011993408259 .2518310546959 .1001586914158 .9464988708558 .79127120972 58.634769439758 .4773788452158 .3193511962958 .1610412597758 .00265884399 57.8445396423357 .6868515014657 .5298805236857 .3737602233957 .2187557 .06492996216 56.9124794006356 .7614898681656 .6120796203656 .4642601013256 .31811904907 56.1736602783256 .0308914184655 .8898010253955 .7503700256355 .61256027222 55.4763603210455 .3417701721255 .2087593078655 .0773811340354 .94765090942 54.8196792602554 .6935310363854 .5693588256854 .4472999572854 .32759094238 54.210380554254 .0959701538153 .9844207763753 .8765602111853 .77196884155 53.67190170288

1257.5909423831251 .1409912111244 .6779785161238 .2089843751231 .738037109 1225.2609863281218 .7790527341212 .2919921881205 .7979736331199 .297973633 1192.7910156251186 .2760009771179 .754028321173 .2239990231166 .687011719 1160.1409912111153 .5870361331147 .0240478521140 .453002931133 .874023438 1127.2860107421120 .6899414061114 .086059571107 .4739990231100 .853027344 1094.2249755861087 .589965821080 .9479980471074 .3000488281067 .645996094 1060.9859619141054 .3220214841047 .6550292971040 .9849853521034 .312988281 1027.6400146481020 .9680175781014 .2979736331007 .6300048831000 .96697998 994.3099975586987 .6602783203981 .0194702148974 .3892822266967 .7711181641 961.1666259766954 .5775146484948 .0054931641941 .4519042969934 .9185791016 928.4067993164921 .9185180664915 .4547729492909 .0170288086902 .606628418 896.2249755859889 .8732299805883 .5526123047877 .2637939453871 .0081787109 864.7863769531858 .5994873047852 .4481201172846 .3331298828840 .254699707 834.2138061523828 .2103881836822 .2454223633816 .3184814453810 .4301757812 804.5803222656798 .7687988281792 .995300293787 .2598876953781 .5615844727 775.9003295898770 .2747802734764 .6846923828759 .1286010742753 .6057739258 748.1146850586742 .6541137695737 .2224731445731 .8181762695726 .4396972656 721.0850830078715 .7526245117710 .4404296875705 .146484375699 .8690185547 
694.6060180664689 .3555297852684 .1157836914678 .8850708008673 .6618041992 668.4440917969663 .2307128906658 .0200805664652 .8112792969647 .6032714844 642.3950195312637 .1857299805631 .9752807617626 .7631835938621 .5496826172 616.3347167969611 .1190185547605 .9030151367600 .6879272461595 .4746704102 590.2650756836585 .0607299805579 .8635253906574 .67578125569 .5001831055 564.3392944336559 .1962280273554 .0739135742548 .9760131836543 .9061889648 538.8681030273533 .866027832528 .9036254883523 .9857788086519 .116394043 514.3004760742509 .5421142578504 .846496582500 .2178039551495 .6612854004 491.1812133789486 .7828063965482 .469909668478 .2479858398474 .120300293 470.0921936035466 .1661987305462 .3472900391458 .6376953125455 .041809082 451.5614929199448 .2008972168444 .9617919922441 .8479003906438 .8609008789 436.0043945312433 .2785949707430 .6867980957428 .2268066406425 .8999023438 423.7012023926421 .6289978027419 .6758117676417 .8367004395416 .1033935547 414.4678955078412 .9231872559411 .4601135254410 .0745849609408 .7579040527 407.5101928711406 .324798584405 .2045898438404 .146697998403 .1510925293 402.2174987793401 .342010498400 .5263977051399 .7562866211399 .0275878906 398.3508911133397 .7550964355397 .2106933594396 .7276916504396 .2557983398 395.7692871094395 .4905090332395 .7424926758395 .9047851562395 .3439025879 394.9491882324395 .5603027344396 .1086120605395 .3288879395394 .8024902344 395.895904541397 .2709960938397 .7609863281397 .3500976562395 .4603881836 393.4808044434393 .0906982422393 .6679992676395 .1615905762396 .3020935059 395.6412963867394 .6011962891393 .6181945801393 .0432128906394 .172088623 393.087310791387 .5085144043376 .6516113281359 .2431945801340 .0620117188 322.1702880859308 .0071105957299 .0285949707286 .3186950684259 .912109375 228.3170013428199 .7312011719176 .1455993652161 .516204834153 .4228973389 149.9033050537149 .7243041992152 .1797027588156 .6604003906161 .9553070068 168.1488952637175 .1764068604181 .1123046875184 .0240936279185 .1925964355 185.788192749185 .62840271184 .4734954834183 .2733001709182 .7776947021 182.4019012451181 .7277069092180 .8845062256179 .9898071289179 .0583953857 178.1219940186177 .1737060547176 .2140960693175 .2357940674174 .2341003418 173.2008972168172 .1278991699171 .0079040527169 .8320007324168 .5960998535 167.2906036377165 .9176940918164 .4705963135162 .9617004395161 .3914031982 159.7861938477158 .1595001221156 .5523986816154 .9925994873153 .5377960205 152.2597045898151 .1246032715150 .12109375149 .2241973877148 .4042053223 147.6401062012146 .9120941162146 .1824035645145 .4257965088144 .5803070068 143.608505249142 .4149932861140 .929901123139 .0856018066136 .7975006104 134.0643005371130 .8206939697127 .1171035767122 .9518966675118 .4195022583 113.6022033691108 .6091003418103 .549499511798 .5853118896593 .86013793945 89.43148040771 85.45555877686 81.86470794678 78.68602752686 75.88265228271 73.3888015747171 .165603637769 .167266845767 .3877487182665 .81484985352 64.4282226562563 .1987495422462 .121791839661 .1830787658760 .3717918396 59.6705207824759 .0725784301858 .5641288757358 .140899658257 .7931098938 57.5181503295957 .3099517822357 .1664199829157 .0839996337957 .05997848511 57.0917816162157 .1753005981457 .3074989318857 .4826316833557 .69628143311 57.9412498474158 .2115402221758 .4990692138758 .7964706420959 .09564971924 59.3881416320859 .6687812805259 .9291801452660 .1683387756360 .38037872314 
60.5665702819860 .7240715026960 .8553504943860 .9612388610861 .0432510376 61.1039505004961 .1440010070861 .1652908325261 .1684608459561 .15502166748 61.1258583068861 .0824203491261 .0256881713960 .9570884704660 .87747955322 60.7881393432660 .689731597960 .5833206176860 .4694404602160 .34889984131 60.2221908569360 .089988708559 .9527206420959 .8109893798859 .66519165039 59.5158691406259 .3633995056259 .2082595825259 .0508193969758 .89149856567 58.7306213378958 .5685501098658 .4055900573758 .2420806884858 .07825088501 57.9144210815457 .7508010864357 .5876808166557 .425220489557 .26366043091 57.1031494140656 .9438781738356 .7859497070356 .6295204162656 .47463989258 56.3214187622156 .1698799133356 .0200805664155 .8720016479555 .72565078735 55.5810012817455 .4380302429255 .2966995239355 .1569786071855 .01885986328 54.8823089599654 .7473793029854 .6140594482454 .4824714660654 .35266113281 54.2248001098654 .0989990234453 .9754905700753 .8544387817453 .73612976074 53.6206207275453 .5083389282253 .4019584655853 .30242156982

1262.1960449221255 .6879882811249 .1760253911242 .6619873051236 .142944336 1229.6199951171223 .0920410161216 .5579833981210 .0190429691203 .473022461 1196.9210205081190 .3609619141183 .7939453121177 .2199707031170 .637939453 1164.0489501951157 .4510498051150 .8449707031144 .2320556641137 .609985352 1130.9799804691124 .3420410161117 .6960449221111 .0419921881104 .380004883 1097.7120361331091 .0360107421084 .3540039061077 .6660156251070 .972045898 1064.2729492191057 .5710449221050 .8640136721044 .1550292971037 .444946289 1030.7340087891024 .0240478521017 .3150024411010 .6099853521003 .908996582 997.2141723633990 .5266113281983 .8477783203977 .1796264648970 .5233154297 963.8806762695957 .253112793950 .6422119141944 .0493774414937 .4766235352 930.9248046875924 .3959960938917 .8909912109911 .4113769531904 .958190918 898.5330200195892 .1365966797885 .7702026367879 .4348144531873 .1312255859 866.8602294922860 .6228027344854 .4193725586848 .250793457842 .1173706055 836.0197753906829 .958190918823 .9332275391817 .9445800781811 .992980957 806.0780029297 800.1997070312 794.3577880859 788.5521240234 782.7819824219 777.0471801758771 .3468017578765 .6801757812760 .0463256836754 .4443969727 748.8729248047743 .330871582737 .8167114258732 .3292236328726 .8665161133 721.4273071289716 .0095825195710 .6119995117705 .2327270508699 .8696289062 694.5211791992689 .1854858398683 .8610839844678 .5463256836673 .2396240234 667.9392700195662 .6444091797657 .353515625652 .0654907227646 .7794189453 641.4948120117636 .2105712891630 .9268188477625 .6431274414620 .3596191406 615.0762939453609 .794128418604 .5134887695599 .2355957031593 .9613037109 588.6923828125583 .4304199219578 .1774291992572 .9354858398567 .7072143555 562.4949951172557 .3018798828552 .1309204102546 .9854736328541 .8690185547 536.7852172852531 .7377929688526 .7307128906521 .7683105469516 .8546142578 511.9939880371507 .1908874512502 .449798584497 .7749023438493 .171295166 488.642791748484 .1944885254479 .8299865723475 .5545959473471 .3711853027 467.2847900391463 .2980041504459 .4153137207455 .6387023926451 .9721984863 448.4176940918444 .9787902832441 .6572875977438 .4567871094435 .3788146973 432.4270935059429 .6021118164426 .9072875977424 .3410949707421 .9053039551 419.5960083008417 .4122009277415 .3479003906413 .3988952637411 .558807373 409.8205871582408 .1795959473406 .6270141602405 .1617126465403 .774597168 
402.4682922363401 .2355041504400 .080291748398 .9984130859397 .9910888672 397.0567016602396 .1929931641395 .399597168394 .6755981445394 .0252075195 393.4630126953393 .008605957392 .6755981445392 .4641113281392 .4606933594 392.7283935547393 .424407959395 .0145874023396 .4314880371396 .4808044434 396.2703857422396 .645111084397 .1418151855397 .2343139648397 .4407958984 397.2857055664396 .9301147461396 .8067932129395 .7486877441393 .4985046387 391.578704834391 .1054992676391 .3015136719391 .6249084473390 .93359375 389.0692138672385 .7319946289381 .2098083496377 .0433044434375 .7857055664 373.841796875367 .5927124023357 .1571960449340 .2471008301323 .317199707 312.4733886719303 .6416015625292 .6019897461276 .6329040527250 .2451019287 220.6517944336195 .7348022461175 .334197998161 .8383026123154 .0173034668 151.2946014404152 .0290985107154 .7530059814159 .2678070068164 .903793335 171.0693969727177 .1448059082182 .1410064697184 .8518981934185 .9864959717 186.2247009277185 .6900939941184 .6358947754183 .5861053467182 .8128051758 182.2144927979181 .6369934082180 .9846954346180 .2611999512179 .4465942383 178.5670928955177 .6253967285176 .6432037354175 .6150054932174 .5464019775 173.4337005615172 .2765045166171 .0715026855169 .813293457168 .5012969971 167.1275024414165 .6968994141164 .2023010254162 .658706665161 .0646057129 159.4486999512157 .8211975098156 .2272033691154 .6831970215153 .283203125 152.1329040527151 .158203125150 .3063964844149 .5724029541148 .9329071045 148.3665008545147 .8560028076147 .362197876146 .8672943115146 .3005981445 145.641998291144 .7566986084143 .5895996094142 .0126037598139 .9078979492 137.2866973877 134.0442047119130.2646026611 125.9367980957 121.1772994995 116.0996017456110 .8061981201105 .4126968384100 .077598571894 .97644805908 90.2693328857486 .1392822265682 .4963836669979 .2848968505976 .42883300781 73.8710708618271 .580642700269 .5305023193467 .6997909545966 .07127380371 64.6252136230563 .3369712829662 .2047805786161 .2174491882360 .36381149292 59.6253890991258 .9961090087958 .4611701965358 .0166397094757 .65227127075 57.3653297424357 .1500511169457 .0035896301356 .923271179256 .90509033203 56.9476394653357 .0451393127457 .1957397460957 .3918113708557 .62995147705 57.9010009765658 .1997604370158 .5159416198758 .8428497314559 .16967010498 59.4878387451259 .7895088195860 .0639305114760 .3124084472760 .52587127686 60.7091789245660 .8572998046960 .9755516052261 .066970825261 .1333694458 61.1790084838961 .2039299011261 .2107810974161 .1996688842861 .17226028442 61.129188537661 .0719184875561 .0013504028360 .9189605712960 .8256187439 60.7226905822860 .6109008789160 .4913711547960 .3646888732960 .23173141479 60.0930099487359 .9492301940959 .8008804321359 .6485214233459 .49259185791 59.3336181640659 .1719818115259 .0081481933658 .8424491882358 .67530822754 58.5070190429758 .3379516601658 .1683502197357 .9985504150457 .82875823975 57.6592712402357 .4902610778857 .3219985961957 .1546287536656 .98836898804 56.8233413696356 .6597099304256 .4975700378456 .3370399475156 .17818069458 56.0210800170955 .8657302856455 .7121696472255 .5603904724155 .41038131714 55.2621002197355 .115509033254 .9705810546954 .8272590637254 .68553161621 54.5453605651954 .4067916870154 .269809722954 .1345291137754 .00096893311 53.8693313598653 .739681243953 .6122817993253 .4872589111353 .36491012573 53.2452888488853 .1292114257853 .0162696838452 .90766906738 
1266.7840576171260 .2409667971253 .6829833981247 .1219482421240 .557983398 1233.9890136721227 .4150390621220 .8370361331214 .2519531251207 .661010742 1201.0639648441194 .461059571187 .8499755861181 .2320556641174 .607055664 1167.9739990231161 .3330078121154 .6850585941148 .0290527341141 .365966797 1134.6939697271128 .0150146481121 .328002931114 .6330566411107 .932006836 1101.2230224611094 .5080566411087 .7860107421081 .0589599611074 .326049805 1067.5889892581060 .8470458981054 .1030273441047 .3559570311040 .608032227 1033.8590087891027 .1109619141020 .3649902341013 .6220092771006 .882995605 1000.151000977993.4257202148986.7092895508980.0031738281973.3090209961 966.628112793959 .962097168953 .3125946 .6806030273940 .0681762695933 .4763183594 926.9066772461920 .3604125977913 .838684082907 .3427734375900 .8739013672 894.4329223633888 .0208129883881 .6384887695875 .2869873047868 .9669189453 862.6790161133856 .4237060547850 .2017822266844 .013671875837 .8599853516 831.7404785156825 .6561889648819 .606628418813 .5924072266807 .6129760742 801.6690063477795 .7595825195789 .8850097656784 .0443725586778 .2376708984 772.463684082766 .7224121094761 .012512207755 .3333129883749 .6832885742 744.0620117188738 .467590332732 .8989868164727 .354675293721 .8333129883 716.3331298828710 .8524780273705 .3900756836699 .9439697266694 .5128173828 689.0946044922683 .6879882812678 .2916870117672 .9041748047667 .5239868164 662.1500244141656 .7811279297651 .4163208008646 .0546264648640 .6956787109 635.3388061523629 .9837036133624 .6303710938619 .2788085938613 .9291992188 608.5822753906603 .2387695312597 .899597168592 .5659179688587 .2391967773 581.9210205078576 .6135253906571 .3184814453566 .0385742188560 .776184082 555.5341796875550 .315612793545 .1234130859539 .9611206055534 .8322143555 529.7404174805524 .6892089844519 .6831054688514 .7255859375509 .8214111328 504.9739990234500 .188293457495 .4679870605490 .8181152344486 .2420959473 481.7449951172477 .3299865723473 .0021972656468 .7643127441464 .6211853027 460.575012207456 .6300964355452 .7882995605449 .053314209445 .4267883301 441.9122009277438 .5111083984435 .2271118164432 .0614929199429 .0181884766 426.0979919434423 .3044128418420 .6366882324418 .0969848633415 .6823120117 413.3922119141411 .2221984863409 .1689147949407 .2272033691405 .3916015625 403.657989502402 .020111084400 .4761047363399 .0205078125397 .6539916992 396.3727111816395 .1781921387394 .0686035156393 .0444030762392 .1037902832 391.2478027344390 .4724121094389 .7950134277389 .2265014648388 .7896118164 388.4985961914388 .3981933594388 .5029907227388 .9346008301389 .729309082 391.0364074707393 .0397033691394 .9917907715396 .2406921387397 .0228881836 397.8568115234398 .5862121582398 .7478942871398 .9100952148399 .1064147949 398.6010131836397 .1347045898394 .2655029297389 .7713012695386 .4059143066 386.6271057129387 .6372070312387 .1939086914385 .3850097656383 .6578063965 379.0068054199368 .2333984375357 .5328979492352 .6922912598349 .761505127 345.9638061523339 .6191101074327 .7583007812315 .7402954102307 .8342895508 299.3349914551286 .7351989746268 .2821960449240 .6148071289212 .0139007568 189.8811035156172 .4496002197160 .6914978027153 .7465057373151 .4631958008 152.6988983154156 .3524017334161 .6280975342167 .5563964844173 .5090942383 178.5198059082182 .5408935547185 .0946960449186 .3639068604186 .4172973633 185.6175994873184 .2727050781182 .9781951904182 .3972015381182 .0359954834 
181.5881958008181 .0816955566180 .4561004639179 .7174072266178 .8762054443 177.9472045898176 .9559020996175 .8983001709174 .7794952393173 .6036071777 172.3798980713171 .1058959961169 .7821044922168 .4073944092166 .9794006348 165.5007019043163 .9694061279162 .3963928223160 .7854003906159 .1607971191 157.5377960205155 .9571075439154 .4430999756153 .1004943848152 .0457000732 151.1903076172150 .4703979492149 .8798980713149 .3972015381149 .008605957 148.6923980713148 .4228057861148 .1784973145147 .9058990479147 .5722045898 147.0404968262146 .2397003174144 .9884033203143 .1260986328140 .6513977051 137.4275970459133 .5612030029129 .079498291124 .0951004028118 .7609024048 113.172996521107 .4569015503101 .725898742796 .0836334228590 .9513168335 86.80728912354 83.26365661621 80.02528381348 77.10015106201 74.45841217041 72.0883407592869 .9723968505968 .0849761962966 .3941268920964 .88597106934 63.5389595031762 .3516883850161 .3151092529360 .4164009094259 .63788986206 58.9723396301358 .4057502746657 .9337997436557 .546451568657 .24131011963 57.012271881156 .8573684692456 .7730598449756 .7565116882356 .80493164062 56.9137992858957 .079521179257 .2956504821857 .5568389892657 .8549118042 58.1827087402358 .5304412841858 .8894882202159 .248329162659 .59692001343 59.9235305786160 .2145004272560 .4718513488860 .6885490417560 .86735916138 61.0036087036161 .1046791076761 .1782302856461 .2262496948261 .2541809082 61.2623596191461 .2531700134361 .2269096374561 .1846618652361 .12720108032 61.0556106567460 .9709205627460 .8744583129960 .7672195434660 .65055084229 60.525249481260 .3925018310560 .2529182434160 .1074714660659 .95664978027 59.8012390136759 .6416893005459 .4786300659259 .3124694824259 .14374923706 58.9728317260758 .8001708984458 .6260986328158 .4510192871158 .27521133423 58.0990104675357 .9226493835457 .7464408874557 .5705795288157 .39530944824 57.2208099365257 .047298431456 .8749389648456 .7038688659756 .53424072266 56.3661689758356 .1997413635356 .0350494384855 .8721313476655 .71105957031 55.5518188476655 .3944396972755 .2388992309655 .0851593017654 .9331817627 54.7829093933154 .6343193054254 .4873199462954 .3419189453154 .19805908203 54.0557785034253 .9150581359953 .7759895324753 .6386108398453 .50307846069 53.3694992065453 .2380790710453 .1089782714852 .9824485778852 .85857009888 52.7377815246652 .6225318908752 .51401901245

1271.4010009771264 .8000488281258 .1960449221251 .589965821244 .979980469 1238.366943359 1231.748046875 1225.1251218 .495971681211 .8609619141205 .220947266 1198.5729980471191 .9189453121185 .2590332031178 .5909423831171 .916015625 1165.2330322271158 .542968751151 .8459472661145 .1409912111138 .428955078 1131.7089843751124 .9820556641118 .2469482421111 .5059814451104 .758056641 1098.004028321091 .2440185551084 .4780273441077 .707031251070 .931030273 1064.1519775391057 .3690185551050 .5849609381043 .7989501951037 .012939453 1030.2270507811023 .4439697271016 .6640014651009 .8880004881003 .117980957 996.3560180664989 .6021118164982 .8583984375976 .1262817383969 .4072875977 962.7028808594956 .0145874023949 .3436279297942 .6915283203936 .0595703125 929.44921875922 .8615112305916 .2977905273909 .758972168903 .2462158203 896.7603759766890 .3026733398883 .8737182617877 .4744262695871 .1052246094 864.7669067383858 .4600219727852 .1851806641845 .9426269531839 .7330932617 833.5563964844 827.4132080078 821.3032836914 815.2271728516 809.1845703125 
803.1757202148 797.200012207 791.2576293945785.3477783203 779.4703979492 773.6246948242767 .8101806641762 .0260009766756 .2713012695750 .5449829102 744.8461914062739 .1737060547733 .5263061523727 .9025878906722 .3012695312 716.7208251953711 .1597900391705 .6168212891700 .0900878906694 .5786132812 689.0803222656683 .5941772461678 .1187744141672 .6528930664667 .1951293945 661.7443847656656 .2998046875650 .8604125977645 .4254760742639 .9945068359 634.5668945312629 .142578125623 .7213745117618 .3037719727612 .8895874023 607.4797973633602 .0748291016596 .6760864258591 .2841796875585 .9011230469 580.5280761719575 .167175293569 .8203735352564 .4899902344559 .1782836914 553.8884277344548 .6229248047543 .3848266602538 .1774902344533 .0042724609 527.8687133789522 .7742919922517 .7249755859512 .7244873047507 .7770080566 502.8862915039498 .0566101074493 .2916870117488 .5961914062483 .9735107422 479.428314209474 .9638977051470 .5846862793466 .2936096191462 .0947875977 457.9906921387453 .9851074219450 .0798034668446 .2782897949442 .5820007324 438.9939880371435 .5161132812432 .1512145996428 .9013061523425 .7699890137 422.7585144043419 .870300293417 .1054077148414 .4661865234411 .9509887695 409.5596923828407 .2890014648405 .1362915039403 .0979003906401 .1687011719 399.3468017578397 .6254882812396 .0056152344394 .4804992676393 .0535888672 391.7192993164390 .4820861816389 .3377075195388 .2900085449387 .3341064453 386.4776000977385 .7106018066385 .0721130371384 .5748901367384 .2589111328 384.1195068359384 .2471008301384 .6423950195385 .4309082031386 .5870056152 388.1857910156390 .1384887695392 .3118896484394 .5184020996396 .6412963867 398.3352050781399 .451385498399 .3273925781398 .4099121094398 .0718078613 396.5570068359393 .3843994141389 .1160888672383 .2450866699378 .4190979004 378.2763061523378 .8251037598376 .9609985352374 .7565002441374 .2435913086 370.0909118652355 .5317077637340 .182800293332 .7614135742328 .9617919922 327.4495849609325 .7308959961319 .5208129883312 .1541137695305 .2390136719 295.3793029785280 .2280883789259 .4244995117230 .9320983887203 .0384979248 183.350692749168 .7727050781158 .8442993164153 .0072021484151 .2678985596 152.9649047852157 .5350952148163 .6893005371170 .020904541175 .783203125 179.8338928223182 .7696075439185 .1016998291186 .4671936035186 .4304962158 185.5509033203183 .9763946533182 .4889984131182 .0666046143181 .9304962158 181.5655059814181 .1271057129180 .5614013672179 .8726043701179 .070098877 178.1567993164177 .1681060791176 .0914001465174 .9373016357173 .7140045166 172.4398040771171 .1123962402169 .7369995117168 .3141937256166 .8433074951 165.3287963867163 .7684936523162 .1755065918160 .5520019531158 .9255981445 157.3094940186155 .7528076172154 .2754058838152 .9866943359152 .0039978027 151.238494873150 .6199035645150 .1486968994149 .7969055176149 .5572052002 149.4069976807149 .3309936523149 .3148040771149 .3007965088149 .2716064453 149.1000061035148 .7212982178147 .8822021484146 .3672027588144 .0722045898 140.8540039062136 .8717041016132 .221496582127 .0450973511121 .4826965332 115.6382980347109 .6384963989103 .60160064797 .5102462768691 .99365234375 87.7882766723684 .2510223388780 .9057388305777 .8742675781275 .13761138916 72.6752471923870 .4891510009868 .5369033813566 .7808227539165 .21160125732 63.8072204589862 .5652503967361 .4775085449260 .5304908752459 .70716094971 58.9999809265158 .3954887390157 .8893585205157 .4721603393657 .14152145386 
56.892299652156 .7220115661656 .6284408569356 .6076011657756 .65813064575 56.7739181518656 .9525413513257 .185829162657 .4692192077657 .79298019409 58.1503410339458 .5301017761258 .9239997863859 .3180007934659 .70330047607 60.0609016418560 .374019622860 .6454086303760 .8627510070861 .03454971313 61.1546707153361 .2345504760761 .2877006530861 .3154983520561 .32461929321 61.3152008056661 .2894592285261 .2475395202661 .1901397705161 .11798095703 61.0318603515660 .9328804016160 .8222503662160 .7010116577160 .57054138184 60.4316902160660 .2856903076260 .1332092285259 .9752197265659 .81230163574 59.6452102661159 .4744491577159 .3006286621159 .1241989135758 .94565963745 58.7653884887758 .583839416558 .4013290405358 .2182312011758 .03480911255 57.8513984680257 .6682090759357 .4855194091857 .3034896850657 .12237930298 56.9423294067456 .763530731256 .5860900878956 .4101791381856 .23588180542 56.0633201599155 .8925514221255 .7236518859955 .55664062555 .39155960083 55.2284011840855 .0671501159754 .9077987670954 .7502899169954 .59457015991 54.440570831354 .2882614135754 .13755035453 .988418579153 .84080886841 53.694759368953 .550220489553 .4072990417553 .2660102844253 .12651062012 52.9888916015652 .8533592224152 .7200393676852 .5892181396552 .4609413147 52.3359794616752 .2139511108452 .09598922729

1276.0009765621269 .3649902341262 .7170410161256 .0649414061249 .411010742 1242.7530517581236 .0909423831229 .4229736331222 .7509765621216 .072998047 1209.3890380861202.698974609 1196.0019531251189.2989501951182.58996582 1175.8730468751169 .1490478521162 .417968751155 .6800537111148 .935058594 1142.1820068361135 .4229736331128 .6560058591121 .8819580081115 .102050781 1108.3160400391101 .5229492191094 .7239990231087 .9200439451081 .112060547 1074.2979736331067 .4820556641060 .6619873051053 .839965821047 .016967773 1040.1939697271033 .3719482421026 .5520019531019 .7349853521012 .92199707 1006.114990234 999.3156738281992.5244750977985.7432861328 978.9735717773 972.2166137695965 .4738769531958 .7468261719952 .0366821289945 .3452148438 938.6729736328932 .0219116211925 .3928222656918 .7869262695912 .2053222656 905.6486816406899 .1184082031892 .6151123047886 .1392822266879 .6923217773 873.2741088867866 .8856811523860 .5274047852854 .1998901367847 .9033813477 841.6386108398835 .4052124023829 .2037963867823 .0344238281816 .897277832 810.792175293804 .7194824219798 .678527832792 .6696166992786 .6917724609 780.745300293774 .8292236328768 .9431762695763 .0863037109757 .2581176758 751.4572143555745 .6829833984739 .9343261719734 .2100830078728 .5092163086 722.830078125717 .1716918945711 .5324707031705 .9111938477700 .3062744141 694.7166748047689 .1408081055683 .5773925781678 .0252075195672 .483215332 666.9500732422661 .424987793655 .9069213867650 .3950805664644 .8889160156 639.387878418633 .8916015625628 .4000244141622 .9130249023617 .4309082031 611.953918457606 .4827880859601 .0181884766595 .5610961914590 .1126708984 584.6743774414579 .2478027344573 .8347167969568 .4370727539563 .0573120117 557.6975708008552 .3604736328547 .0490112305541 .7659301758536 .5142822266 531.2974243164526 .1187744141520 .981628418515 .8900146484510 .8469848633 505.8569946289500 .9233093262496 .0504150391491 .2414855957486 .5010986328 481.8324890137477 .2401123047472 .7268981934468 .2973937988463 .9540100098 459.7008972168455 .5401916504451 .4754943848447 .508392334443 .6420898438 
439.878112793436 .2190856934432 .6669006348429 .2243041992425 .8933105469 422.6773986816419 .5781860352416 .5992126465413 .7412109375411 .0068969727 408.3952026367405 .9068908691403 .5393981934401 .2911987305399 .1592102051 397.1398925781395 .2309875488393 .4284973145391 .7318115234390 .1373901367 388.6465148926387 .2567138672385 .9703063965384 .7856140137383 .7047119141 382.7244873047381 .8523864746381 .0815124512380 .458404541380 .0104064941 379.7674865723379 .7336120605379 .9827880859380 .5403137207381 .4710083008 382.7882080078384 .432800293386 .3406066895388 .5823974609391 .0244140625 393.7925109863396 .986907959399 .0303039551398 .1718139648395 .1517028809 390.4101867676384 .4679870605378 .9977111816374 .0093994141370 .3819885254 366.7956848145361 .6046142578356 .5162963867353 .1243896484351 .6722106934 353.517791748352 .5657043457342 .7880859375331 .188293457323 .9672851562 319.7709960938317 .7576904297316 .3179016113312 .3626098633306 .7391052246 300.3693847656289 .5292053223271 .7809143066248 .7953033447220 .454498291 194.1867980957176 .6439056396164 .4423980713156 .5296020508152 .1571960449 151.3715057373153 .8903045654158 .946395874165 .5612030029172 .713104248 178.8262023926182 .0964050293184 .0236968994185 .6446990967186 .6063995361 186.4812927246185 .624206543184 .2736053467182 .9678955078182 .3562927246 181.9954071045181 .5982971191181 .1614990234180 .6197967529179 .9734954834 179.1972961426178 .3040924072177 .3056030273176 .2084960938175 .0270996094 173.7709960938172 .4575958252171 .0890045166169 .674697876168 .2153015137 166.7136993408165 .1728973389163 .5944061279161 .9891052246160 .3625946045 158.7404022217157 .1396942139155 .6078033447154 .1744995117152 .9360046387 152.0066070557151 .3003997803150 .7584075928150 .37550354150 .1233062744 149.9981994629149 .9788970947150 .061706543150 .2326965332150 .4418029785 150.6506958008150 .8199005127150 .9624938965150 .682800293149 .6472930908 147.6363067627144 .3146057129140 .0979003906135 .2966003418129 .966003418 124.2240982056118 .1856002808111 .9933013916105 .772697448799 .63966369629 94.0425109863389 .478233337485 .5605926513781 .9956283569378 .79026031494 75.9225234985473 .3638763427771 .0808868408269 .0484619140667 .22492218018 65.5969772338964 .1366271972762 .8412704467861 .7003593444860 .70175933838 59.8296813964859 .0759201049858 .4273414611857 .8804893493757 .42639160156 57.0635910034256 .7870407104556 .5953788757356 .4859886169456 .45610046387 56.5032997131356 .62263107356 .8100814819357 .0584907531757 .36140060425 57.7101287841858 .0960083007858 .5091400146558 .9396781921459 .3741607666 59.8012809753460 .1961593627960 .5402717590360 .8306083679261 .04735946655 61.2063217163161 .3077697753961 .3628501892161 .3922882080161 .3981590271 61.3874816894561 .3599891662661 .3174591064561 .2597007751561 .18703079224 61.1000518798860 .9993286132860 .8859710693460 .7611007690460 .6258392334 60.4815597534260 .3291587829660 .1699295043960 .0045509338459 .83406829834 59.659038543759 .4803009033259 .2983207702659 .1137695312558 .9270401001 58.7386817932158 .5490493774458 .3586006164658 .1675987243757 .97647094727 57.7854118347257 .5947494506857 .4046897888257 .2154808044457 .02727890015 56.8402900695856 .6546516418556 .4705200195356 .2879905700756 .10720825195 55.9282302856455 .7511596679755 .576030731255 .402900695855 .23176956177 55.0626716613854 .8955688476654 .7304496765154 .5672607421954 .40594100952 
54.2464485168554 .0886993408253 .9326286315953 .7781600952153 .62525177002 53.4738388061553 .3239593505953 .1755409240753 .0286903381352 .88341903687 52.7398681640652 .5981216430752 .4583511352552 .3207092285252 .18545913696 52.0526313781751 .9226493835451 .7977485656751 .67934036255

1280.6269531251273 .9360351561267 .2430419921260 .546997071253 .848999023 1247.1469726561240 .4410400391233 .7309570311227 .0159912111220 .295043945 1213.5689697271206 .836059571200 .0980224611193 .3540039061186 .603027344 1179.8449707031173 .0799560551166 .3089599611159 .5310058591152 .74597168 1145.9539794921139 .1550292971132 .3499755861125 .5379638671118 .718994141 1111.8950195311105 .0639648441098 .2280273441091 .3859863281084 .540039062 1077.6899414061070 .836059571063 .9799804691057 .120971681050 .261962891 1043.4019775391036 .542968751029 .6860351561022 .8330078121015 .982971191 1009.1400146481002 .302978516995 .4749145508988 .6563720703981 .8491210938 975.0543212891968 .2733154297961 .5078125954 .758605957948 .0272827148 941.3151245117934 .6232910156927 .9528198242921 .3048706055914 .6801757812 908.080078125901 .5051269531894 .9561157227888 .4338989258881 .9390869141 875.4724121094869 .0341186523862 .6248168945856 .2451171875849 .8950195312 843.5751953125837 .2855834961831 .0267944336824 .7985229492818 .6011962891 812.4345703125806 .2990722656800 .1939697266794 .1196289062788 .0753173828 782.0609741211776 .0759887695770 .1199951172764 .1920776367758 .2918701172 752.4182739258746 .5706176758740 .7476806641734 .9487915039729 .1724853516 723.4180297852717 .6837158203711 .9683837891706 .2711181641700 .5902709961 694.9248046875689 .2733764648683 .6348876953678 .0081787109672 .3922729492 666.7860107422661 .1887207031655 .5991210938650 .0170288086644 .4415283203 638.8726196289633 .3095092773627 .7525024414622 .2014160156616 .6566162109 611.1182861328605 .5875244141600 .0645141602594 .55078125589 .0469970703 583.5549926758578 .0759277344572 .6118164062567 .1644287109561 .7362060547 556.3291015625550 .9459228516545 .5891723633540 .26171875534 .9666137695 529.7067260742524 .4855957031519 .3063964844514 .1727294922509 .0880126953 504.0559997559499 .0801086426494 .1643066406489 .3120117188484 .5274047852 479.8135070801475 .1745910645470 .6135864258466 .1344909668461 .7398071289 457.4334106445453 .2172851562449 .094909668445 .0675048828441 .1383972168 437.3085021973433 .5808105469429 .9567871094426 .4392089844423 .0302124023 419.7327880859416 .5494995117413 .4834899902410 .5361938477407 .7105102539 405.0064086914402 .4247131348399 .9643859863397 .6238098145395 .4014892578 393.2939147949391 .3005981445389 .4166870117387 .6440124512385 .9776000977 384.4211120605382 .9703063965381 .6299133301380 .3960876465379 .2742004395 378.2567138672377 .359588623376 .5679931641375 .9437866211375 .5109863281 375.3068847656375 .3149108887375 .6169128418376 .2052001953377 .1440124512 378.411895752379 .9945983887381 .7406005859383 .8194885254386 .0866088867 388.6883850098392 .4938049316394 .4137878418391 .9950866699386 .1695861816 376.6787109375366 .9133911133360 .2325134277355 .7723083496355 .1701965332 353.2627868652 343.5657043457333.6007995605 329.1984863281328.2670898438 331.5568847656334 .1206054688330 .8176879883325 .3948059082320 .1578063965 315.7998046875312 .6394958496309 .8594970703305 .9526062012300 .3656005859 293.4359130859281.7815856934262.379486084238.6300964355 211.9019012451 
187.3424072266 170.7424926758 159.6920928955153.3878936768151.0283966064 151.7057037354154 .9304046631160 .2073974609166 .8343048096174 .4512023926 180.9129943848183 .8285064697185 .1757049561186 .3047943115186 .8289031982 186.5428009033185 .7850036621184 .7413024902183 .6515960693182 .8153076172 182.1378936768181 .6345062256181 .1811065674180 .6437988281180 .0182952881 179.2604064941178 .3766021729177 .370300293176 .253692627175 .0538024902 173.7731018066172 .4322052002171 .0343933105169 .5930023193168 .1091003418 166.586807251165 .0308074951163 .4423980713161 .8345031738160 .2113952637 158.6024017334157 .0213928223155 .5218963623154 .1320037842152 .9403076172 152.0471038818151 .3813018799150 .891204834150 .5717926025150 .3899993896 150.3489990234150 .4203948975150 .6183929443150 .9268951416151 .3180999756 151.7406005859152 .1918029785152 .790802002152 .9976959229152 .4365997314 150.7503967285147 .4257049561143 .0718994141138 .2008056641132 .7890930176 126.9185028076120 .7474975586114 .4144973755108 .1206970215102 .0579986572 96.4342727661191 .4649963378987 .065147399983 .207313537679 .80254364014 76.7993621826274 .1469879150471 .7683563232469 .6546173095767 .75842285156 66.0666732788164 .5449066162163 .1899909973161 .9894485473660 .93099975586 60.0034790039159 .1959609985458 .4968986511257 .9021186828657 .40419006348 57.0016899108956 .6912307739356 .4710197448756 .340408325256 .29537963867 56.3353004455656 .4534988403356 .647048950256 .907230377257 .22785949707 57.5991592407258 .0121994018658 .4566612243758 .9222488403359 .39569091797 59.8644294738860 .306228637760 .6980209350661 .0143585205161 .22842025757 61.3637199401961 .4397697448761 .4736518859961 .4817504882861 .46812820435 61.4387702941961 .3941802978561 .3350601196361 .2618408203161 .17387008667 61.0722084045460 .9568710327160 .8292007446360 .6901206970260 .54088973999 60.3828315734960 .2169494628960 .0445289611859 .8663291931259 .68339920044 59.4963302612359 .3059806823759 .1128387451258 .9175682067958 .72058105469 58.5224304199258 .3234481811558 .1240997314557 .9246406555257 .72546005249 57.5267715454157 .3288803100657 .1319503784256 .9362297058156 .74184036255 56.5489883422956 .3577613830656 .1683082580655 .9807090759355 .79507064819 55.6114196777355 .4298591613855 .2503890991255 .0730400085454 .89781951904 54.7247009277354 .5536689758354 .3846588134854 .217639923154 .05252838135 53.8892593383853 .7277297973653 .5678901672453 .4096298217853 .25291824341 53.0976791381852 .9439086914152 .791568756152 .6407394409252 .49140930176 52.3437309265152 .1977386474652 .0536499023451 .9115791320851 .7717590332 51.6342391967851 .4997406005951 .3679084777851 .23976898193 1285.2359619141278.510986328 1271.774047852 1265.035034181258.293945312 1251.5489501951244 .8000488281238 .046997071231 .288940431224 .526977539 1217.7590332031210 .9849853521204 .2060546881197 .4200439451190 .62902832 1183.8310546881177 .0260009771170 .214965821163 .3979492191156 .573974609 1149.743041992 1142.906005859 1136.0620117191129.2120361331122.354980469 1115.4930419921108 .6251101 .7519531251094 .8740234381087 .9909667971081 .104003906 1074.2139892581067 .3210449221060 .4260253911053 .5300292971046 .634033203 1039.7390136721032 .8459472661025 .9560546881019 .0700073241012 .190002441 1005.317016602998 .4520263672991 .5963134766984 .7514038086977 .9188842773 971.0999145508964 .295715332957 .5076293945950 .7368164062943 .9844970703 
937.2520141602930.540222168923.8502197266917.182800293910.5388793945 903.9193725586897 .3251953125890 .7564697266884 .2144165039877 .6989746094 871.2111816406864 .7512207031858 .3195800781851 .9165039062845 .5424194336 839.1973266602832 .8817138672826 .5952758789820 .3386230469814 .1115112305 807.9141235352 801.7459716797 795.607421875 789.4978027344 783.4169921875 777.3645019531771 .3400268555765 .3427124023759 .3723144531753 .4276733398 747.5081787109741 .6129760742735 .7412109375729 .8916015625724 .0634155273 718.2551879883712 .4661254883706 .6947021484700 .9400024414695 .2008056641 689.4760131836683 .7645874023678 .0654907227672 .3776855469666 .7003173828 661.0325927734655 .3737792969649 .7233276367644 .0805053711638 .4453125 632.8173217773627 .196472168621 .5831298828615 .9772949219610 .3795166016 604.7902832031599 .2105102539593 .6412963867588 .0836181641582 .5388793945 577.0084838867571 .4943847656565 .9984741211560 .5225830078555 .0692138672 549.640625544 .2393798828538 .8682861328533 .5302734375528 .2280883789 522.9652099609517 .7443847656512 .5693969727507 .4432983398502 .3698120117 497.3522033691 492.3942871094 487.4991149902 482.6708984375 477.9122924805 473.2276000977468 .6193847656464 .0917053223459 .646697998455 .2880859375 451.017791748446 .8388977051442 .7528076172438 .7623901367434 .8687133789 431.0744018555427 .3808898926423 .7909851074420 .3067016602416 .9312133789 413.666809082410 .5172119141407 .4840087891404 .5704956055401 .7770080566 399.1054077148396 .5545959473394 .1245117188391 .8133850098389 .6193847656 387.5414123535385 .5766906738383 .7255859375381 .9856872559380 .3586120605 378.8424072266377 .4397888184376 .1494140625374 .9731140137373 .9064025879 372.962310791372 .1350097656371 .4750061035371 .013092041370 .7702941895 370.7481994629370 .986907959371 .4974975586372 .2894897461373 .3551940918 374.6413879395376 .0654907227377 .617401123379 .1989135742380 .6636047363 382.0900878906381 .0488891602375 .3258056641366 .2998046875355 .1394958496 345.453704834341 .321685791340 .2210998535340 .1989135742338 .1697998047 330.7247924805322 .812713623318 .7066040039317 .8693847656319 .6812133789 321.9678955078321 .3577880859318 .9114074707315 .0848083496310 .7652893066 308.0476074219305 .0853881836300 .1094055176293 .3218994141285 .0259094238 272.5690002441253 .3218994141230 .9405975342207 .521697998185 .3639068604 166.6585998535153 .4972991943149 .4844055176150 .1876983643152 .0363006592 155.6210021973160 .9257965088167 .341003418174 .2514953613180 .1746063232 183.5254974365 185.3993988037186.5776062012 187.0388031006 186.7135925293 185.9640960693184 .9893951416183 .9010009766183 .0222015381182 .2467041016 181.6775054932181 .2129974365180 .6719055176180 .0447998047179 .2821960449 178.3936004639177 .3787994385176 .2519073486175 .0305938721173 .7281036377 172.3661956787170 .9494018555169 .4906005859167 .9918060303166 .459197998 164.896697998163 .3081054688161 .7050018311160 .0944061279158 .5028076172 156.9481964111155 .4788970947154 .1282043457152 .9723052979152 .1092071533 151.4694976807151 .0133972168150 .7301025391150 .5910949707150 .5942993164 150.7147979736150 .9752044678151 .3614959717151 .8760986328152 .5263061523 153.2398071289154 .0025024414154 .4313049316154 .2062988281152 .8406066895 149.7857055664145 .6277008057140 .8267974854135 .4326934814129 .5303955078 123.2777023315116 .8592987061110 .4841003418104 .34989929298 .56652069092 
93.3476562588 .6334533691484 .5077819824280 .9029235839877 .76264190674 75.0155334472772 .5603408813570 .3771820068468 .403739929266 .63553619385 65.0442962646563 .6208305358962 .3483886718861 .2197494506860 .22674942017 59.3579902648958 .6002502441457 .9508094787657 .4012985229556 .95227050781 56.6004714965856 .3456497192456 .1871109008856 .1221313476656 .14923095703 56.2627105712956 .4580993652356 .7272682189957 .0623016357457 .4536781311 57.8907318115258 .363418579158 .8594093322859 .3682403564559 .87685012817 60.3718910217360 .8457984924361 .2190399169961 .4052009582561 .48881912231 61.538639068661 .5546493530361 .5474510192961 .5187110900961 .47428894043 61.4141082763761 .3399696350161 .2516288757361 .1490898132361 .03290176392 60.9032897949260 .7614212036160 .6083106994660 .4452018737860 .27349853516 60.0942306518659 .9087295532259 .7177810668959 .5224990844759 .32347869873 59.1216201782258 .9173812866258 .7114715576258 .5042915344258 .29639816284 58.0881195068457 .8799209594757 .6720504760757 .4648704528857 .25859069824 57.0534896850656 .8497390747156 .6475410461456 .4470100402856 .2483291626 56.0515708923355 .8568496704155 .6642112731955 .4737510681255 .28549957275 55.0994796752954 .9157104492254 .7341995239354 .5549087524454 .37781906128 54.2028808593854 .0300292968853 .8591995239353 .6902999877953 .52325820923 53.3579597473153 .194339752253 .0322799682652 .8717498779352 .71263885498 52.5549507141152 .3986511230552 .2437782287652 .0903396606451 .93843841553 51.7881393432651 .6396293640151 .4930000305251 .348499298151 .20615005493 51.0663414001550 .9310302734450 .80186080933

1289.8680419921283 .089965821276 .3100585941269 .5279541021262 .744018555 1255.957031251249 .1660156251242 .370971681235 .5720214841228 .767944336 1221.9589843751215 .1440429691208 .3239746091201 .4990234381194 .666992188 1187.8299560551180 .9859619141174 .1359863281167 .2790527341160 .416992188 1153.5479736331146 .671997071139 .7910156251132 .9029541021126 .010009766 1119.1109619141112 .2060546881105 .2960205081098 .3809814451091 .462036133 1084.538940431077 .6130371091070 .6839599611063 .7530517581056 .822021484 1049.8900146481042 .9589843751036 .0300292971029 .1040039061022 .182006836 1015.2659912111008 .3560180661001 .453979492994 .5612792969987 .6791992188 980.8090209961973 .9520263672967 .1093139648960 .2822265625953 .4719848633 946.6796875939 .9066162109933 .1536254883926 .4215087891919 .7114257812 913.0239868164906 .3601074219899 .7205810547893 .1057739258886 .5164794922 879.9528808594873 .4157714844866 .9055175781860 .4224243164853 .9666137695 847.5388183594841 .138671875834 .7669067383828 .4232788086822 .1080932617 815.8212280273809 .5631103516803 .3331298828797 .1314697266790 .9577026367 784.8118286133778 .6931762695772 .6016845703766 .5366210938760 .4973754883 754.4835205078748 .4940795898742 .5283203125736 .5853881836730 .6644287109 724.7644042969718 .8842773438713 .0230712891707 .1796875701 .3530883789 695.5422973633689 .74609375683 .963684082678 .1942138672672 .4365844727 666.6900024414660 .9539794922655 .227722168649 .5106201172643 .8024291992 638.1027832031632 .4116210938626 .7288818359621 .0546264648615 .3892822266 609.7332763672604 .0872802734598 .4520874023592 .8287963867587 .2183227539 581.6220703125576 .0416259766570 .4785766602564 .9348144531559 .4124145508 553.9133300781548 .4401245117542 .9951171875537 .5811157227532 .2008056641 
526.8569946289521 .5526733398516 .291015625511 .0751037598505 .9081115723 500.7937011719495 .7348022461490 .7351074219485 .7976989746480 .9262084961 476.1236877441471 .3937988281466 .7391967773462 .1635131836457 .6690979004 453.259185791448 .9357910156444 .7016906738440 .5582885742436 .5082092285 432.5524902344428 .6935119629424 .932800293421 .2730102539417 .7160949707 414.2651977539410 .9229125977407 .6926879883404 .5769042969401 .5786132812 398.6990966797395 .9401855469393 .3019104004390 .783996582388 .3862915039 386.1062927246383 .9447021484381 .8978881836379 .9677124023378 .150604248 376.4498901367374 .8619995117373 .3913879395372 .0340881348370 .7947998047 369.6644897461368 .6608886719367 .7741088867367 .0545043945366 .5202941895 366.1958007812366 .0718994141366 .1784973145366 .5096130371367 .0585021973 367.8021850586368 .6705932617369 .62109375370 .4348144531371 .0437927246 370.7001037598368 .9831848145364 .5333862305355 .7496032715344 .9966125488 334.1684875488326 .0830993652325 .1083984375326 .5195922852325 .8301086426 323.9108886719320 .4263916016316 .7301940918314 .3364868164313 .1984863281 312.7208862305312 .8851928711312 .9540100098312 .0538024902309 .0136108398 305.1543884277302 .9750061035299 .888092041293 .7235107422285 .4523925781 275.7987060547262 .8270874023244 .6333007812224 .3296051025204 .3121948242 184.6667938232163 .9846954346148 .5937957764146 .2810974121149 .2796936035 151.9252929688155 .8861999512161 .2030944824167 .0494995117172 .9859924316 178.266998291182 .2839050293185 .1251983643186 .6761932373187 .2781982422 186.9712982178186 .1311950684185 .0334014893183 .8905944824183 .0175933838 182.3049926758181 .7595977783181 .2651062012180 .6932983398180 .0399932861 179.2552032471178 .349105835177 .3238983154176 .1855926514174 .9490966797 173.6304931641172 .2570037842170 .8302001953169 .3636016846167 .8600006104 166.3258056641164 .7664031982163 .1853027344161 .5959014893160 .00390625 158.4376983643156 .9120941162155 .4763946533154 .158996582153 .0343933105 152.1898040771151 .5661010742151 .1298980713150 .8681945801150 .7537994385 150.7825012207150 .9223937988151 .2006988525151 .5944976807152 .1802062988 153.0088043213153 .9022064209154 .7272949219155 .2070007324155 .1925048828 154.1571044922151 .5359039307147 .7682952881143 .1795959473137 .863494873 131.9844970703125 .7239990234119 .271697998112 .8243026733106 .5492019653 100.599998474195 .1523895263790 .2019195556685 .8868103027382 .11628723145 78.8557662963976 .0380630493273 .5036163330171 .2477798461969 .18327331543 67.3202667236365 .641738891664 .1300888061562 .77190017761 .55929946899 60.4922599792559 .553298950258 .7305603027358 .0192985534757 .41164016724 56.9086799621656 .5092697143656 .2128486633356 .021488189755 .93098068237 55.9418411254956 .0464706420956 .241210937556 .5162582397556 .86354064941 57.2723503112857 .7309684753458 .2291297912658 .7523193359459 .29209136963 59.8348808288660 .3680381774960 .9078598022561 .3330497741761 .50458145142 61.5588188171461 .600448608461 .6077308654861 .5896911621161 .55027008057 61.4925384521561 .419361114561 .3310089111361 .2288703918561 .11206054688 60.9819183349660 .8381500244160 .6823310852160 .5152893066460 .33847045898 60.1532211303759 .9606781005959 .7622184753459 .5586509704659 .35111999512 59.1402511596758 .9269599914658 .7117309570358 .4952697753958 .27798080444 58.0604209899957 .8429298400957 .6259498596257 .4097213745157 .1946105957 
56.9808006286656 .7685813903856 .5580596923856 .3494606018156 .1428604126 55.9384307861355 .7361984252955 .5362815856955 .3386993408255 .14350891113 54.9507102966354 .760330200254 .5723381042554 .3867301940954 .20344924927 54.0224494934153 .8436584472753 .6670112609953 .4924201965353 .31977081299 53.148998260552 .9799499511752 .8125686645552 .6467094421452 .48234939575 52.3193588256852 .1577415466351 .9974288940451 .8384704589851 .68085098267 51.5246696472251 .369979858451 .2169609069851 .0656700134350 .91637039185 50.7690582275450 .6243896484450 .4820594787650 .34296035767 1294.4840087891287 .671997071280 .8499755861274 .0260009771267 .198974609 1260.3699951171253 .5379638671246 .7020263671239 .8609619141233 .016967773 1226.1669921881219 .3129882811212 .453002931205 .5880126951198 .717041016 1191.8409423831184 .9580078121178 .0699462891171 .1750488281164 .274047852 1157.3680419921150 .4549560551143 .5360107421136 .6120605471129 .682006836 1122.745971681115 .8050537111108 .8590087891101 .9079589841094 .95300293 1087.9940185551081 .0319824221074 .0679931641067 .1020507811060 .135009766 1053.1669921881046 .2010498051039 .2359619141032 .2740478521025 .316040039 1018.3640136721011 .4180297851004 .479003906997 .5499267578990 .6306762695 983.7230224609976 .8278808594969 .9470214844963 .0811157227956 .231628418 949.3992919922942 .5858154297935 .7913818359929 .017578125922 .2647705078 915.5341186523908 .8259887695902 .1412963867895 .4805297852888 .8444213867 882.2329101562875 .6469726562869 .0866088867862 .5524291992856 .0446166992 849.5634765625843 .1093139648836 .6820068359830 .2819213867823 .9091186523 817.5634155273811 .2454223633804 .9545288086798 .6909790039792 .4544067383 786.2446289062780 .0612792969773 .9041748047767 .7725830078761 .6663818359 755.5845947266749 .5269165039743 .4921875737 .4799804688731 .4893188477 725.5194091797719 .5692749023713 .637878418707 .7244262695701 .8278198242 695.9472045898690 .0814819336684 .2301025391678 .3919067383672 .5662841797 666.7526245117660 .950012207655 .1580200195649 .3762817383643 .6041870117 637.8419189453632 .0891113281626 .3458862305620 .612487793614 .8892211914 609.1765136719603 .4750976562597 .7858276367592 .109375586 .4473876953580 .80078125 575.1712036133569 .5601806641563 .9696044922558 .4014282227552 .8574829102 547.3405151367541 .8524780273536 .3961181641530 .9741210938525 .5891113281 520.2440795898514 .9418945312509 .6856994629504 .4783935547499 .3234863281 494.2237854004489 .1828918457484 .2036132812479 .2896118164474 .4435119629 469.6690063477464 .9685974121460 .3458862305455 .8027954102451 .3427124023 446.9671020508442 .679107666438 .4796142578434 .3713989258430 .3552856445 426.43359375422 .6077880859418 .8804016113415 .2532958984411 .7296142578 408.3121032715405 .0042114258401 .8084106445398 .7282104492395 .7650146484 392.9212036133390 .1971130371387 .5932922363385 .1093139648382 .7442932129 380.4978027344378 .3681030273376 .3557128906374 .4587097168372 .6784973145 371.0134887695369 .4655151367368 .0328979492366 .7160949707365 .5103149414 364.4240112305363 .4495849609362 .6282958984361 .9899902344361 .5335083008 361.2547912598361 .1554870605361 .2343139648361 .4483032227361 .7732849121 362.0997924805362 .3677978516362 .2901000977361 .7448120117359 .9128112793 356.4046936035350 .6207885742341 .7239074707332 .0535888672322 .8225097656 316.3981933594315 .1726989746315 .5855102539314 .7103881836313 .5704040527 
312.2085876465310 .9916992188310 .1086120605308 .7796936035307 .1098937988 305.762512207305 .1097106934304 .2127990723301 .7113952637298 .2680969238 295.0231933594290 .7973022461284 .9342041016277 .0260925293266 .7045898438 253.5395050049236 .4257049561217 .7850036621199 .0424041748180 .4378051758 162.3148956299148 .8571014404145 .5774993896147 .6080932617151 .1893005371 156.0446929932161 .028793335166 .2115936279171 .6340026855176 .7830963135 181.1609954834184 .6251983643186 .561706543187 .3323059082187 .1186981201 186.182800293184 .7987060547183 .449005127182 .7559051514182 .2984924316 181.8173980713181 .300994873180 .6972961426180 .00390625179 .1903076172 178.262298584177 .213104248176 .0570983887174 .8094024658173 .4851989746 172.1060028076170 .6770935059169 .2106018066167 .7102050781166 .1829986572 164.6342010498163 .0690002441161 .4990997314159 .9329986572158 .3950958252 156.9031982422155 .4981994629154 .2111053467153 .1096038818152 .2776031494 151.6605987549151 .2357940674150 .9841003418150 .8845977783150 .9199981689 151.0570068359151 .3005981445151 .6148071289152 .1620941162153 .0767059326 154.0780944824154 .9859008789155 .5648956299155 .6309967041154 .8544006348 152.786895752149 .5755004883145 .2086029053139 .9812011719134 .1912994385 127.967300415121 .5262985229115 .0157012939108 .604598999102 .4811019897 96.8291320800891 .6839370727587 .2534637451283 .3948287963980 .07623291016 77.2169189453174 .6221389770572 .2784423828170 .1172103881868 .1450881958 66.3522262573264 .728103637763 .2630882263261 .9531898498560 .79782867432 59.7800102233958 .8830986022958 .1034317016657 .4299392700256 .86668014526 56.412528991756 .0689811706555 .8386802673355 .7186203002955 .70851898193 55.8013610839855 .9918594360456 .2702217102156 .6265602111857 .04978179932 57.5267715454158 .0462188720758 .5932197570859 .1564216613859 .72035980225 60.2708206176860 .7987785339461 .2184906005961 .4411811828661 .54899978638 61.6080398559661 .6221809387261 .6035804748561 .5560188293561 .48974990845 61.4053497314561 .3057594299361 .1910095214861 .0614585876560 .91783905029 60.760608673160 .5910682678260 .410430908260 .2200317382860 .02143859863 59.8157691955659 .6044998168959 .3884391784759 .16880035458 .94622039795 58.7216110229558 .4954986572358 .2685890197858 .0413017272957 .8141784668 57.5875587463457 .361888885557 .1374092102156 .9144706726156 .69322967529 56.4739685058656 .2567901611356 .0418815612855 .8293304443455 .61923980713 55.4116592407255 .2066497802755 .0042190551854 .804409027154 .60718154907 54.4125404357954 .220428466854 .0308189392153 .8436508178753 .65882873535 53.476280212453 .2959098815953 .1176300048852 .9412994384852 .76683044434 52.5940704345752 .4229507446352 .2533187866252 .0851287841851 .9182510376 51.7526893615751 .5883407592851 .4252700805751 .2634201049851 .10290145874 50.9437408447350 .7861099243250 .6300811767650 .4758491516150 .32344055176 50.1732101440450 .026779174849 .88600921631

1299.1199951171292 .2569580081285 .3919677731278 .5269775391271 .659057617 1264.788940431257 .9160156251251 .038940431244 .1579589841237 .272949219 1230.3840332031223 .4899902341216 .5909423831209 .6870117191202 .777954102 1195.8630371091188 .9420166021182 .0159912111175 .0830078121168 .145019531 1161.2020263671154 .2519531251147 .296997071140 .336059571133 .369995117 1126.3979492191119 .4210205081112 .4389648441105 .453002931098 .462036133 
1091.4680175781084 .4709472661077 .4709472661070 .4699707031063 .468017578 1056.464965821049 .4630126951042 .4630126951035 .4659423831028 .472045898 1021.4840087891014 .502014161007 .5269775391000 .560974121993 .6046142578 986.6594848633979 .7266845703972 .8076171875965 .9030151367959 .0142211914 952.1420898438945 .2880249023938 .4525756836931 .6370239258924 .841796875 918.0678710938911 .3156738281904 .5861206055897 .8795776367891 .1967163086 884.5377197266877 .9031982422871 .2932739258864 .7086181641858 .1491699219 851.6154785156845 .1074829102838 .6254882812832 .1696166992825 .7401123047 819.3366088867812 .9597167969806 .6090087891800 .2846069336793 .986328125 787.7139282227781 .4672241211775 .2457885742769 .0493774414762 .8775024414 756.7293701172750 .604675293744 .5028076172738 .4229736328732 .3643798828 726.3262939453720 .3076782227714 .3079833984708 .326171875702 .3615112305 696.4127807617690 .4796142578684 .5609130859678 .6560058594672 .7642822266 666.8848876953661 .017578125655 .1616821289649 .3170166016643 .4827880859 637.6594848633631 .8466186523626 .0444946289620 .2531738281614 .4733886719 608.7053222656602 .9498901367597 .2075195312591 .4796142578585 .7669067383 580.0709838867574 .3931884766568 .7352294922563 .0985717773557 .4854125977 551.8975219727546 .3372802734540 .8068847656535 .3088989258529 .845703125 524.4199829102519 .0347290039513 .6926269531508 .3965148926503 .1492919922 497.9541931152492 .8140869141487 .7325134277482 .7119140625477 .7557067871 472.8666992188468 .0481872559463 .3027038574458 .633392334454 .0425109863 449.532989502445 .1064147949440 .765411377436 .5112915039432 .3461914062 428.2713012695424 .2886047363420 .399597168416 .6065979004412 .9117126465 409.3176879883405 .8275146484402 .4444885254399 .1713867188396 .0116882324 392.9672851562390 .0405883789387 .2326965332384 .5440063477381 .9750976562 379.524597168377 .1933898926374 .9789123535372 .882598877370 .9016113281 369.0382995605367 .2896118164365 .657989502364 .1398010254362 .7365112305 361.441192627360 .2593994141359 .1755981445358 .2312011719357 .4547119141 356.832611084356 .3530883789356 .0010986328355 .7752990723355 .5974121094 355.4526977539355 .1553039551354 .6680908203353 .6012878418351 .8944091797 348.8935852051344 .3526000977338 .3247070312330 .7359008789323 .0625915527 316.0527954102310 .8371887207308 .2349853516306 .9695129395305 .8016052246 305.1889038086305 .2421875305 .396697998305 .2430114746304 .2018127441 301.9627075195299 .5427856445297 .9233093262296 .2827148438293 .916595459 290.6806945801286 .3564147949281 .1311035156275 .8276062012268 .7063903809 258.2189025879245 .1820983887229 .307800293211 .9275970459193 .6343994141 175.959197998160 .8733978271149 .9987945557145 .6195068359146 .0377044678 150.0160980225155 .4472045898160 .0092010498164 .5514068604169 .8522033691 175.1298980713180 .0187988281184 .0476074219186 .270904541187 .2135925293 187.0959014893186 .1567993164184 .5930938721183 .0921936035182 .5585021973 182.2957000732181 .8251037598181 .2835998535180 .6463928223179 .9085998535 179.0634002686178 .1069030762177 .033203125175 .8607025146174 .6083984375 173.2852020264171 .9085998535170 .4850006104169 .0267028809167 .5377960205 166.0249023438164 .4945983887162 .9515075684161 .408706665159 .8730010986 158.3695068359156 .9127960205155 .5431976318154 .2855072021153 .2023010254 152.3704071045151 .7498931885151 .3300933838151 .0872039795150 .9976043701 
151.0355072021151 .1627960205151 .3798980713151 .6148071289152 .0574951172 152.9212036133153 .9282073975154 .870300293155 .5426025391155 .6791992188 155.0944976807153 .5823974609150 .9181976318146 .8182983398141 .7270965576 136.1042022705130 .0148010254123 .6677017212117 .1753997803110 .6836013794 104.372596740798.447959899993.13812255859 88.66803741455 84.87536621094 81.5685272216878 .648300170975 .9527969360473 .4837722778371 .19058227539 69.0773773193467 .1478576660265 .3862762451263 .8025398254462 .38164901733 61.130580902160 .0259017944359 .0492210388258 .1955413818457 .4501991272 56.8195495605556 .3053398132355 .9086799621655 .6360702514655 .48249053955 55.4494285583555 .5278701782255 .7126693725655 .9922904968356 .35615921021 56.791709899957 .2848892211957 .8229484558158 .3903808593858 .97190856934 59.5499610900960 .100170135560 .5949211120661 .0036811828661 .29372024536 61.4800605773961 .575199127261 .6029396057161 .5876693725661 .53826904297 61.4665718078661 .374721527161 .2652893066461 .1396598815960 .99781036377 60.8414306640660 .6708908081160 .4879302978560 .29380035460 .09001922607 59.8782196044959 .659591674859 .4356307983459 .2072296142658 .97560882568 58.7414283752458 .5056381225658 .2687606811558 .0315208435157 .79431915283 57.557750701957 .3221092224157 .0878601074256 .8552284240756 .62456130981 56.3959999084556 .1698112487855 .9460792541555 .7250099182155 .50661087036 55.291019439755 .0782089233454 .8682594299354 .661128997854 .45682907104 54.2553100585954 .0565414428753 .8604583740253 .6669807434153 .47603988647 53.2875099182153 .1013183593852 .9173316955652 .7354393005452 .55550003052 52.3773994445852 .2010002136252 .0261917114351 .8528099060151 .68082046509 51.5100708007851 .3405494689951 .172149658251 .0049209594750 .83879852295 50.6739006042550 .5102081298850 .3478889465350 .1870002746650 .02774047852 49.870121002249 .7146911621149 .5612297058149 .41046142578

1303.7399902341296 .8439941411289 .9379882811283 .0310058591276 .123046875 1269.2120361331262 .2979736331255 .3809814451248 .461059571241 .536987305 1234.6090087891227 .6760253911220 .7380371091213 .7950439451206 .848022461 1199.8950195311192 .9370117191185 .9730224611179 .004028321172 .029052734 1165.0489501951158 .0629882811151 .0710449221144 .0749511721137 .072021484 1130.0649414061123 .0529785161116 .0360107421109 .0140380861101 .989013672 1094.9599609381087 .9279785161080 .8929443361073 .8570556641066 .819946289 1059.7819824221052 .7449951171045 .7099609381038 .6770019531031 .649047852 1024.6240234381017 .6060180661010 .5949707031003 .593017578996 .599609375 989.6173706055 982.6469116211975.6895751953968.74639899258961.8184204102 954.9066162109948 .0123291016941 .1359863281934 .2788085938927 .4412231445 920.624206543913 .8281860352907 .0540771484900 .3021240234893 .5728149414 886.8665161133880 .1837158203873 .5247192383866 .8900146484860 .2794799805 853.6937866211847 .1326904297840 .5966796875834 .0858154297827 .6002197266 821.1398925781814 .705078125808 .2954711914801 .9113769531795 .5524902344 789.2188110352782 .9099121094776 .6254882812770 .3654785156764 .1292724609 757.9165039062751 .7266235352745 .5587768555739 .412902832733 .287902832 727.1832885742 721.0980834961 715.0316772461 708.9832763672 702.9520874023 696.9373168945690 .9381713867684 .9539794922678 .9840698242673 .0277709961 667.0847167969661 .154296875655 .2360839844649 .3297729492643 .4351806641 
637.5521850586 631.6809082031625.8212890625 619.973815918 614.1386108398 608.3165283203602 .5081176758596 .7139892578590 .9354248047585 .1732788086 579.4290161133573 .7039794922567 .9998168945562 .3181152344556 .6605834961 551.0294799805545 .4266967773539 .8546142578534 .3154296875528 .8115844727 523.3458251953517 .9207763672512 .5388793945507 .2033996582501 .9166870117 496.6820983887491 .5020141602486 .3800964355481 .3185119629476 .3208007812 471.3893127441466 .5274047852461 .7373962402457 .0223999023452 .3843078613 447.8262023926443 .349395752438 .9566040039434 .6488952637430 .4284057617 426.2961120605422 .2542114258418 .3037109375414 .4471130371410 .6863098145 407.0242919922403 .4635009766400 .0076904297396 .6593017578393 .4223937988 390.2984924316387 .2908935547384 .4000854492381 .6276855469378 .9737854004 376.4379882812374 .0203857422371 .7197875977369 .5361938477367 .4681091309 365.5158996582363 .6780090332361 .9541931152360 .3421936035358 .8402099609 357.4436035156356 .149810791354 .9468078613353 .8620910645352 .9202880859 352.1000061035351 .3908996582350 .7616882324350 .201385498349 .6260070801 348.9996032715348 .1488037109346 .991394043345 .229309082342 .7055969238 339.1106872559334 .1632995605328 .3564147949321 .6664123535315 .1946105957 309.563293457304.854888916301.8996887207 299.9213867188298.5755004883 298.1361083984298 .2716064453298 .4802856445298 .2431945801297 .1583862305 295.1575012207292 .7905883789290 .8514099121288 .8839111328286 .3806152344 283.1644897461279 .061706543274 .1090087891268 .4833984375261 .1518859863 250.8088989258238 .2232055664223 .5729980469207 .4109954834189 .9714050293 173.0812072754158 .2154998779147 .436706543143 .8838043213144 .8027038574 148.6190948486153 .7854003906157 .8545074463162 .0113067627167 .3992004395 173.1477050781178 .7991027832183 .5433959961185 .9864959717186 .9710998535 186.9523010254186 .1094970703184 .7967987061183 .5001068115182 .8211975098 182.3551025391181 .8114013672181 .2032928467180 .5209960938179 .75178 .8621063232 177.87159729176 .7812957764175 .6033935547174 .349395752173 .0308990479 171.6631011963170 .2519989014168 .8090057373167 .3383026123165 .8470001221 164.3412017822162 .8269958496161 .3157043457159 .8161010742158 .349395752 156.9326019287155 .5989990234154 .3778076172153 .3134002686152 .4611053467 151.8170013428151 .4080963135151 .1835021973151 .1040039062151 .1472930908 151.278503418151 .4851989746151 .7328033447152 .1074066162152 .679901123 153.4445953369154 .4429016113155 .2682037354155 .5196075439155 .1618041992 154.0464019775151 .804901123147 .9573059082143 .0695953369137 .6831054688 131.8386993408125 .7041015625119 .3404998779112 .8714981079106 .3940963745 99.9727706909294 .2843093872190 .0697937011786 .6310272216883 .38291168213 80.3735809326277 .535438537674 .8875885009872 .4129333496170 .12167358398 68.0241012573266 .1097106933664 .3872299194362 .8462982177761 .48545837402 60.2850799560559 .2230415344258 .2908210754457 .4669609069856 .76292037964 56.1826896667555 .7290611267155 .4095687866255 .2203216552755 .1615486145 55.2243881225655 .4017181396555 .681499481256 .0512504577656 .49739837646 57.0041999816957 .5574188232458 .1398811340358 .7344512939559 .32246017456 59.8762702941960 .3704299926860 .7987594604561 .1376800537161 .38074111938 61.5028114318861 .5404891967861 .5348587036161 .4904289245661 .41973114014 61.3241882324261 .2083206176861 .0730895996160 .9205093383860 .75183105469 
60.5686492919960 .3725013732960 .1651992797959 .9482116699259 .72340011597 59.4919281005959 .2554512023959 .0148391723658 .7713813781758 .52573013306 58.2788887023958 .0313606262257 .7839088439957 .5369300842357 .2910118103 57.0464706420956 .8037605285656 .5630912780856 .3248100280856 .08906936646 55.8560905456555 .6259689331155 .398860931455 .1747817993254 .9538192749 54.7359695434654 .5212287902854 .309570312554 .1009483337453 .89532089233 53.6925888061553 .4926910400453 .2955093383853 .1009407043552 .90884017944 52.7191314697352 .5316390991252 .346260070852 .162811279351 .9811706543 51.8011894226151 .6227493286151 .4456787109451 .2699203491251 .09531021118 50.9218406677250 .7493896484450 .577980041550 .4075584411650 .23820877075 50.0699195861849 .9028396606449 .7370109558149 .5726203918549 .40967178345 49.248458862349 .0902404785248 .93712997437

1308.378051758 1301.4320068361294.484985352 1287.537963867 1280.588989258 1273.6390380861266 .6850585941259 .7290039061252 .7690429691245 .806030273 1238.8389892581231 .8680419921224 .8919677731217 .9119873051210 .927001953 1203.9370117191196 .9410400391189 .9410400391182 .9350585941175 .923950195 1168.9079589841161 .8859863281154 .8590087891147 .8270263671140 .78894043 1133.7469482421126 .6989746091119 .6479492191112 .5909423831105 .531005859 1098.4680175781091 .4010009771084 .332031251077 .2609863281070 .188964844 1063.1169433591056 .0450439451048 .9749755861041 .9079589841034 .843994141 1027.7840576171020 .7299804691013 .6829833981006 .643981934999 .6143798828 992.5949707031985 .5869750977978 .5916748047971 .6099853516964 .6431274414 957.6917724609950 .7573242188943 .8402099609936 .9415283203930 .0618286133 923.2019042969916 .3624267578909 .5438232422902 .7465209961895 .9711303711 889.2178955078 882.4874267578 875.7797241211869.0953979492 862.4343261719 855.7971191406849 .1834716797842 .5941772461836 .0289916992829 .48828125 822.9719238281816 .4799804688810 .0125732422803 .5698242188797 .1514282227 790.7573852539784 .3875732422778 .0416259766771 .7191772461765 .4202270508 759.1439819336752 .8903198242746 .6583251953740 .4478149414734 .2579956055 728.0883789062721 .9381713867715 .8067016602709 .6931762695703 .5972290039 697.5178833008691 .4545288086685 .4066162109679 .3732299805673 .3541870117 667.348815918661 .3569946289655 .3779907227649 .4119262695643 .4583129883 637.5172119141631 .588684082625 .6730957031619 .7703857422613 .8812866211 608.0062866211602 .1461181641596 .3012695312590 .4730834961584 .6624755859 578.8709106445573 .0994873047567 .3499755859561 .6237792969555 .9229125977 550.2490844727544 .6044921875538 .9910888672533 .4113769531527 .8676147461 522.362121582516 .8975830078511 .4767150879506 .1021118164500 .7763061523 495.5024108887490 .2828979492485 .1207885742480 .0187988281474 .979888916 470.0064086914465 .1017150879460 .2677001953455 .5075073242450 .8230895996 446.2171020508441 .6911010742437 .2474060059432 .8872070312428 .612487793 424.4242858887420 .3244018555416 .3143005371412 .3958129883408 .571105957 404.8428039551401 .2138061523397 .6871032715394 .2658081055390 .9533996582 387.7521972656384 .6648864746381 .6929016113378 .837310791376 .0990905762 373.4773864746370 .9731140137368 .584197998366 .3116149902364 .1524963379 362.1079101562360 .1748046875358 .3530883789356 .638885498355 .0299072266 353.5205993652352 .1051025391350 .7708129883349 .5327148438348 .408203125 
347.3696899414346 .4129943848345 .4873046875344 .5885925293343 .6054077148 342.5213928223341 .1429138184339 .4280090332337 .1181945801334 .1119995117 330.2926940918325 .4578857422320 .1228027344314 .2486877441308 .6310119629 303.6979064941299 .4487915039296 .3403930664294 .0972900391292 .734588623 292.1119995117291 .6913146973291 .2681884766290 .4950866699289 .2372131348 287.7023010254285 .8746948242283 .9891052246281 .870513916279 .2467956543 276.1064147949272 .5869140625268 .1406860352262 .2612915039254 .5798034668 244.3824005127232 .2648925781218 .6340026855203 .7124023438187 .3446960449 171.3240966797156 .4956970215145 .6226959229142 .8106994629144 .1519012451 147.321105957151 .5263061523154 .7734985352158 .6759033203164 .4441986084 170.9649047852177 .5323028564182 .8874969482185 .4624938965186 .3753967285 186.4510040283185 .8408966064184 .9570007324183 .9608001709183 .1188049316 182.3616943359181 .679397583181 .0037994385180 .2810974121179 .4851989746 178.56300354177 .5467987061176 .4483947754175 .2729034424174 .0240936279 172.716796875171 .3643951416169 .9730987549168 .5518951416167 .1063995361 165.6428070068164 .1681060791162 .6876983643161 .2138061523159 .75390625 158.3289031982156 .9535980225155 .6591033936154 .4743041992153 .4291992188 152.5540924072151 .8863067627151 .4875030518151 .2814025879151 .209197998 151.2552032471151 .3885040283151 .599395752151 .8807067871152 .2198944092 152.5153961182153 .0018005371153 .9801025391154 .8793029785155 .1851959229 154.9266967773154 .0437011719152 .0960998535148 .533203125143 .9604034424 138.9503936768133 .4387054443127 .6128997803121 .4853973389115 .1498031616 108.7090988159101 .991302490296 .0381164550892 .0209732055788 .80116271973 85.4712371826282 .3144912719779 .2841491699276 .4115371704173 .72015380859 71.207443237368 .9236984252966 .8382263183664 .9787368774463 .31438064575 61.8439102172960 .5483207702659 .3965492248558 .3832206726157 .47528839111 56.6902999877956 .0404701232955 .5268096923855 .1601409912154 .93445968628 54.8502197265654 .8971405029355 .0670318603555 .3464088439955 .72174835205 56.1775207519556 .6970291137757 .2635002136257 .8586502075258 .46352005005 59.0595207214459 .6237792968860 .1312599182160 .5798912048360 .95840072632 61.2425918579161 .387561798161 .4438285827661 .4560203552261 .42224121094 61.3556785583561 .2591400146561 .1377105712960 .9939498901460 .83084869385 60.6502609252960 .4545402526960 .2453689575260 .0250205993759 .79494857788 59.5572586059659 .3131294250559 .0642700195358 .8115882873558 .55643081665 58.2994499206558 .0416717529357 .7836112976157 .5260505676357 .26940155029 57.0142593383856 .7609291076756 .5098800659256 .261299133356 .01554870605 55.772739410455 .5331306457555 .2967605590855 .0637893676854 .83420181274 54.6080818176354 .3853492736854 .1660308837953 .9500312805253 .7373008728 53.5277404785253 .3212509155353 .1177101135352 .9169998168952 .71897888184 52.5234909057652 .3304214477552 .1395683288651 .9508209228551 .76398086548 51.5789184570351 .3954391479551 .2134399414151 .0327415466350 .85324859619 50.6748199462950 .4974098205650 .3208999633850 .1453018188549 .97055053711 49.7967109680249 .6237716674849 .4518508911149 .2809982299849 .11137008667 48.9429702758848 .7762603759848 .6110801696848 .44799041748 1312.9990234381306 .0209960941299 .0340576171292 .046997071285 .057983398 1278.0679931641271 .0760498051264 .0799560551257 .082031251250 .081054688 
1243.0760498051236 .0670166021229 .0539550781222 .0360107421215 .014038086 1207.9870605471200 .9549560551193 .917968751186 .8769531251179 .829956055 1172.7779541021165 .7209472661158 .6590576171151 .5909423831144 .519042969 1137.4420166021130 .3599853521123 .2740478521116 .1829833981109 .088989258 1101.9909667971094 .8900146481087 .7869873051080 .6820068361073 .574951172 1066.468994141 1059.3630371091052.258056641 1045.1550292971038.056030273 1030.961059571023 .8720092771016 .7890014651009 .7139892581002 .648010254 995.5913696289988 .5460205078981 .512878418974 .4929199219967 .487121582 960.4963989258953 .5219116211946 .5640869141939 .6240844727932 .7025146484 925.7999267578918 .9168701172912 .0541992188905 .2119750977898 .3909301758 891.5911254883884 .8131713867878 .0571899414871 .3237304688864 .6126098633 857.9243774414851 .2592163086844 .6171875837 .9984130859831 .4033203125 824.8317260742818 .2838134766811 .7595214844805 .258972168798 .7821044922 792.3291015625785 .8994140625779 .492980957773 .1096191406766 .7490234375 760.4105834961754 .0944213867747 .799621582741 .5261230469735 .2728881836 729.0399169922722 .826171875716 .6312255859710 .4544067383704 .2952270508 698.1527709961692 .0266723633685 .9163818359679 .8214111328673 .741027832 667.674987793661 .6231079102655 .5848999023649 .5601806641643 .5490112305 637.5512084961631 .5668945312625 .5963745117619 .6400146484613 .6981811523 607.7714233398601 .8604736328595 .9661254883590 .0894165039584 .2313232422 578.3931884766572 .576171875566 .7821044922561 .0123291016555 .2686157227 549.5526733398543 .8668212891538 .2128295898532 .5930175781527 .0095825195 521.4649047852515 .9616088867510 .5018005371505 .0885009766499 .7240905762 494.4112854004489 .1525878906483 .9509887695478 .808807373473 .7291870117 468.7142944336463 .7672119141458 .8898010254454 .0852050781449 .3550109863 444.7019958496440 .1275024414435 .6339111328431 .2221984863426 .8945007324 422.6516113281418 .495300293414 .4267883301410 .4482116699406 .5611877441 402.7685852051399 .0729064941395 .4773864746391 .9848022461388 .5987854004 385.3214111328382 .1559143066379 .103302002376 .1654052734373 .3424987793 370.6348876953368 .0422973633365 .5639038086363 .1990966797360 .9464111328 358.8045959473356 .7717895508354 .8456115723353 .0231018066351 .2991943359 349.6691894531348 .1225891113346 .6459960938345 .2457885742343 .9324035645 342.6767883301341 .467010498340 .2600097656339 .0414123535337 .713104248 336.224395752334 .4462890625332 .3038024902329 .6512145996326 .3584899902 322.4577941895317 .8359985352312 .8901977539307 .7137145996302 .7380981445 298.3234863281294 .4031066895291 .2968139648288 .9101867676287 .3605957031 286.3728942871285 .6217041016284 .7767028809283 .4360046387281 .9179992676 280.362701416278 .7507019043277 .158203125275 .2901000977272 .9457092285 270.1366882324266 .829498291262 .5661010742256 .9612121582249 .4418945312 239.2082977295 227.2391052246214.1595001221200.163192749 185.3513031006 170.9447021484158 .0005950928148 .4253997803144 .7855987549144 .5993041992 146.2510070801148 .8327026367150 .7884979248154 .1894073486160 .7454071045 168.5364990234176 .0563964844181 .9833984375184 .5556030273185 .3359069824 185.5050964355185 .1721954346184 .6354064941183 .8753967285183 .0435943604 182.1678924561181 .3970947266180 .6661987305179 .9044952393179 .0803985596 178.146194458177 .1253967285176 .0274963379174 .8594055176173 .6260070801 
172.338394165171 .0090942383169 .6437988281168 .2512969971166 .8367004395 165.4067993164163 .9680938721162 .5272064209161 .0944976807159 .6793060303 158.2987060547156 .9682006836155 .713394165154 .5603942871153 .5310058594 152.6519012451151 .9776000977151 .5872955322151 .3941955566151 .329498291 151.37840271151 .5083007812151 .720199585152 .0028076172152 .3146972656 152.6197052002153 .058303833153 .8007965088154 .4736022949154 .6936950684 154.3992004395153 .4570007324151 .6056976318148 .4808044434144 .4747009277 139.9216003418134 .8553009033129 .4315032959123 .6657028198117 .6388015747 111.4703979492105 .206802368299 .5483703613395 .2207183837991 .53511810303 87.9271163940484 .4859313964881 .1901016235478 .065292358475 .10214233398 72.336776733469 .8317718505967 .5658569335965 .5607376098663 .77711105347 62.1941299438560 .8001098632859 .5628814697358 .4674682617257 .47053146362 56.598079681455 .8742904663155 .2998809814554 .8851585388254 .62422943115 54.51520919854 .5473709106454 .7104797363354 .9902000427255 .37126159668 55.8371009826756 .3692283630456 .9499092102157 .5587692260758 .17721939087 58.783901214659 .3606491088959 .8835716247660 .3493995666560 .74285888672 61.0461006164661 .2282104492261 .3220481872661 .356029510561 .33650970459 61.2763900756861 .1796302795461 .0540313720760 .9021911621160 .72916030884 60.5368614196860 .3288002014260 .1067314147959 .8734283447359 .63042068481 59.3799896240259 .123321533258 .8622207641658 .5976104736358 .33086013794 58.0626792907757 .794078826957 .5256195068457 .2580718994156 .99185943604 56.7276000976656 .4655990600656 .2063217163155 .9499702453655 .69688034058 55.4471817016655 .2010993957554 .9586601257354 .7199897766154 .48508834839 54.2539901733454 .0266113281253 .8029098510753 .5828018188553 .36616897583 53.152908325252 .9428710937552 .7359008789152 .5318717956552 .33060073853 52.1319007873551 .9356307983451 .7416000366251 .5496292114351 .3595199585 51.1711502075250 .9842796325750 .7988204956150 .6145515441950 .43140029907 50.2491798400950 .0678482055749 .8872909545949 .7075004577649 .52838897705 49.350028991749 .1723899841348 .9955711364748 .819610595748 .64464950562 48.470699310348 .2980194091848 .1274414062547 .96129989624

1317.6340332031310 .6080322271303 .582031251296 .5560302731289 .527954102 1282.4990234381275 .4680175781268 .4350585941261 .3990478521254 .359985352 1247.317016602 1240.270996094 1233.220947266 1226.166015625 1219.108032227 1212.0450439451204 .9770507811197 .9050292971190 .8270263671183 .744995117 1176.6579589841169 .5660400391162 .4689941411155 .3669433591148 .260009766 1141.1490478521134 .0329589841126 .9129638671119 .7879638671112 .66003418 1105.5279541021098 .3929443361091 .2559814451084 .1169433591076 .977050781 1069.836059571062 .6960449221055 .5560302731048 .4189453121041 .28503418 1034.1550292971027 .0310058591019 .9119873051012 .8010253911005 .697998047 998.6052246094991 .5225830078984 .4517822266977 .3936157227970 .3491210938 963.3192138672 956.3046875 949.3065185547942.325378418935.3619995117 928.4169921875921 .4907836914914 .5842285156907 .6973266602900 .8306884766 893.9848022461887 .1599121094880 .3560180664873 .5737304688866 .8131103516 860.0745849609853 .358215332846 .6643066406839 .9927978516833 .3438720703 826.7178955078820 .1148071289813 .5344848633806 .9774169922800 .4431762695 793.9318847656787 .4434814453780 .9779052734774 .5347290039768 .1137084961 
761.7145996094755 .3372802734748 .9810791016742 .6458129883736 .3308105469 730.0358276367723 .7600097656717 .503112793711 .2642822266705 .0432739258 698.8394165039692 .6522216797686 .4810791016680 .3256835938674 .1854858398 668.0603027344661 .9498291016655 .8536987305649 .7719726562643 .7044067383 637.651184082631 .6124267578625 .5883178711619 .579284668613 .5858154297 607.6083984375601 .6478271484595 .7047729492589 .7805175781583 .8756713867 577.9918823242572 .1303100586566 .2922973633560 .4794921875554 .6936035156 548.9362792969543 .2097167969537 .5155029297531 .8560791016526 .2335205078 520.6500854492515 .108215332509 .6101074219504 .1585083008498 .7557067871 493.404296875488 .1068115234482 .8659973145477 .6842041016472 .5642089844 467.5082092285462 .5191955566457 .5989990234452 .7503967285447 .975189209 443.2757873535438 .6535949707434 .1109924316429 .6488037109425 .2691040039 420.9725952148416 .7611083984412 .6358032227408 .5983886719404 .6509094238 400.7956848145397 .0351867676393 .3724975586389 .8104858398386 .3523864746 383.0004882812379 .7578125376 .625793457373 .6059875488370 .699005127 367.9047851562365 .2236022949362 .6539916992360 .1955871582357 .8460998535 355.6044921875353 .4678039551351 .433013916349 .4963989258347 .6517028809 345.8942871094344 .2102050781342 .5867004395341 .0191040039339 .5165100098 338.0414123535336 .587097168335 .104888916333 .5963134766331 .9519042969 330.1322021484328 .0289001465325 .5968933105322 .7388916016319 .3428039551 315.513092041311 .1575927734306 .6151123047301 .9324951172297 .4223937988 293.3309936523289 .6517944336286 .641204834284 .1903991699282 .4096069336 281.0422973633279 .9135131836278 .7095947266276 .9541015625275 .1253051758 273.4919128418271 .9621887207270 .609588623269 .0885925293267 .1181945801 264.6437988281261 .5150146484257 .3283081055251 .9598999023244 .6790924072 234.5462036133222 .8186950684210 .25197 .178604126183 .9324951172171 .4640045166 160.8177032471152 .6020965576147 .9400939941145 .8128051758145 .7064056396 146.8695068359147 .8520965576150 .8034973145157 .8421020508166 .2523040771 174.0476989746180 .2339019775182 .8524932861183 .6923980713184 .1661987305 184.1038970947183 .8589019775183 .3363037109182 .5773925781181 .7095031738 180.9331054688180 .1707000732179 .3789978027178 .5417938232177 .6074981689 176.5997009277175 .5131988525174 .3627929688173 .1519927979171 .8927001953 170.5930023193169 .2606048584167 .9022979736166 .524597168165 .1331939697 163.7357025146162 .3379974365160 .9512023926159 .5834960938158 .2510070801 156.9671936035155 .75390625154 .6336975098153 .628692627152 .758102417 152.0881958008151 .7044067383151 .516998291151 .4506072998151 .4958953857 151.6168060303151 .8134002686152 .0773010254152 .3932037354152 .7754974365 153.2048950195153 .6808929443154 .0352935791154 .0776977539153 .6609039307 152.5661010742150 .7416992188148 .0556945801144 .6367950439140 .5980987549 136.0234069824131 .0832977295125 .7705001831120 .1600036621114 .4639968872 108.8388977051103 .551803588998 .8322219848694 .5042266845790 .49205780029 86.7265319824283 .1137924194379 .6871337890676 .4238128662173 .37103271484 70.6438217163168 .1997680664166 .0708236694364 .1917037963962 .52146911621 61.0508308410659 .7210693359458 .5355987548857 .4429206848156 .4785118103 55.6830101013255 .0518112182654 .5926704406754 .3008003234954 .1693611145 54.1883583068854 .3456611633354 .6258697509855 .0133399963455 .48925018311 
56.0349998474156 .6305007934657 .2551307678257 .8892097473158 .51081848145 59.1036911010759 .6446800231960 .1259002685560 .5252799987860 .84106826782 61.0578308105561 .1905212402361 .248050689761 .2428016662661 .18865966797 61.0911788940460 .960800170960 .800228118960 .616909027160 .41247940063 60.1920204162659 .9569396972759 .7108116149959 .4549293518159 .19189834595 58.922851562558 .6496810913158 .3732986450258 .0951309204157 .81586837769 57.5365905761757 .2578392028856 .9804191589456 .7047805786156 .43151855469 56.1609611511255 .8935890197855 .6295890808155 .3693199157755 .1128692627 54.8604812622154 .6121406555254 .3680114746154 .1279907226653 .89213943481 53.6603202819853 .4324989318853 .2084999084552 .9882316589452 .77149963379 52.5581588745152 .3480110168552 .1408691406251 .9365692138751 .73487091064 51.5356101989751 .3385505676351 .1435394287150 .9503211975150 .75875854492 50.5686302185150 .3797988891650 .1920394897550 .0052795410249 .81930923462 49.6341094970749 .449501037649 .2655105590849 .0820312548 .89912033081 48.7167205810548 .5349502563548 .3538017272948 .1734199523947 .99382019043 47.8153381347747 .6379203796447 .46192932129

1322.254028321315 .1960449221308 .1300048831301 .0649414061293 .999023438 1286.9320068361279 .8630371091272 .7919921881265 .7180175781258 .641967773 1251.5629882811244 .4799804691237 .3929443361230 .3020019531223 .208007812 1216.1090087891209 .0059814451201 .8979492191194 .7860107421187 .668945312 1180.546997071173 .4210205081166 .2900390621159 .1540527341152 .012939453 1144.8669433591137 .7180175781130 .5639648441123 .4050292971116 .243041992 1109.078002931101 .910034181094 .7390136721087 .5660400391080 .391967773 1073.2180175781066 .042968751058 .8699951171051 .6979980471044 .530029297 1037.3649902341030.204956055 1023.051025391 1015.9039916991008.765014648 1001.635009766994 .5156860352987 .407409668980 .3112182617973 .2280883789 966.158996582959 .1049194336952 .0662841797945 .0443725586938 .0394287109 931.0521850586924 .0831298828917 .1328125910 .2014770508903 .2899169922 896.3978881836889 .5264282227882 .6751708984875 .8447265625869 .0350952148 862.2468261719855.4799194336848.7346801758 842.0109863281835.309387207 828.6295776367821 .9722290039815 .3369750977808 .7241210938802 .1334228516 795.5651245117789 .0189819336782 .495300293775 .9932861328769 .5133056641 763.0546875756 .6174926758750 .201171875743 .805480957737 .4301147461 731.0742797852724 .7379150391718 .4202880859712 .1212158203705 .8397827148 699.5758056641 693.328918457 687.0983276367 680.8839111328 674.6854248047 668.5023803711662 .3347167969656 .1820068359650 .0443725586643 .9218139648 637.8142700195631 .7222290039625 .645690918619 .5850830078613 .5410766602 607.5140991211601 .5048217773595 .5142211914589 .5430908203583 .5925292969 577.6638183594571 .7581787109565 .8770141602560 .0219116211554 .1942749023 548.3961791992542 .6292724609536 .8956298828531 .1970214844525 .5357055664 519.9138793945514 .3339233398508 .7976989746503 .3081970215497 .8673095703 492.4778137207487 .1418151855481 .8622131348476 .6411132812471 .4812011719 466.3844909668461 .354095459456 .3913879395451 .4995117188446 .6798095703 441.9348144531437 .2656860352432 .6748046875428 .1630859375423 .7323913574 419.383392334415 .1178894043410 .9370117188406 .8424072266402 .8356933594 398.9194030762395 .0956115723391 .367401123387 .7372131348384 .2084960938 
380.7832946777377 .4648132324374 .25390625371 .1528015137368 .1614990234 365.2809143066362 .5098876953359 .8482055664357 .2941894531354 .8463134766 352.5018005371350 .258392334348 .1116027832346 .0574951172344 .0888061523 342.1995849609340 .3768005371338 .6083068848336 .8817138672335 .191986084 333.5119934082331 .8306884766330 .1113891602328 .3406066895326 .4392089844 324.3559875488322 .0237121582319 .3844909668316 .3965148926312 .9742126465 309.2229003906305 .1264953613300 .8977050781296 .629486084292 .4894104004 288.6731872559285 .1960144043282 .2344055176279 .7145996094277 .7105102539 276.0228881836274 .5285949707273 .013885498271 .1864929199269 .3584899902 267.6935119629266 .172088623264 .7728881836263 .2749023438261 .4520874023 259.1871032715256 .4090881348252 .4470062256246 .6916046143239 .1416015625 229.5955047607218 .7380981445207 .0771026611195 .1528015137183 .3567962646 172.4718017578163 .1903991699155 .6347045898150 .6985015869147 .6678009033 146.5534973145146 .9965057373148 .1235046387151 .220993042157 .2653045654 164.4629058838171 .288192749176 .8668060303179 .8688964844181 .413192749 182.270904541182 .5482025146182 .5382995605182 .1999053955181 .6197052002 180.8885040283180 .1779022217179 .4420013428178 .6717071533177 .8468017578 176.9358978271175 .9523925781174 .8950042725173 .7740020752172 .5971069336 171.3730926514170 .1112976074168 .8175048828167 .4998931885166 .1638031006 164.8161010742163 .4636993408162 .1138000488160 .775894165159 .4593048096 158.1779937744156 .9454956055155 .7794036865154 .7001037598153 .7265930176 152.8775939941152 .2200012207151 .8379974365151 .6439056396151 .5684967041 151.5995025635151 .7064056396151 .8845062256152 .1179046631152 .4093017578 152.7554016113153 .0816040039153 .3712005615153 .4969940186153 .362701416 152.8251953125151 .6864013672149 .9714050293147 .5690002441144 .5856018066 141.0375061035136 .9985046387132 .6047973633127 .826499939122 .7127990723 117.4802017212112 .1966018677107 .0109024048102 .149200439597 .45915222168 93.1010437011789 .0140991210985 .0250701904381 .2272109985477 .62516021729 74.2675018310571 .3033294677768 .6991195678766 .4659500122164 .51920318604 62.8105812072861 .2948989868259 .8680992126558 .5718994140657 .3858795166 56.3308410644555 .4622611999554 .7781486511254 .2816581726153 .9644317627 53.8161010742253 .8251800537153 .978939056454 .2614593505954 .65631103516 55.1443214416555 .7050285339456 .3182601928756 .9608306884857 .61375045776 58.2532005310158 .8640708923359 .4238204956159 .9210891723660 .33599853516 60.6699104309160 .9097290039161 .0668411254961 .1425895690961 .14836883545 61.0977210998560 .9981307983460 .8609886169460 .6905784606960 .49559020996 60.2785110473660 .0449600219759 .7967681884859 .5375900268659 .26893997192 58.9933700561558 .7120895385758 .4269790649458 .1389808654857 .84952926636 57.5593299865757 .2695007324256 .9805908203156 .6934204101656 .40845108032 56.1263084411655 .8473205566455 .5719795227155 .3004798889255 .03316116333 54.7701301574754 .5116004943854 .2575798034754 .0081596374553 .76327133179 53.5228996276953 .2868995666553 .0551795959552 .8275794982952 .60390853882 52.3839797973652 .1675796508851 .9545097351151 .7445297241251 .53742980957 51.3329505920451 .1309013366750 .9310302734450 .7331390380950 .5369682312 50.3423690795950 .1490898132349 .9570007324249 .7658500671449 .57555007935 49.3859100341849 .19684982349 .0082397460948 .8200492858948 .63219070435 
48.4446792602548 .2574996948248 .0706901550347 .8842887878447 .69841003418 47.5130615234447 .3284492492747 .1449813842846 .96524047852

1326.8840332031319 .7800292971312 .6760253911305 .5729980471298 .469970703 1291.3649902341284 .2590332031277 .1510009771270 .0400390621262 .927001953 1255.8110351561248 .6920166021241 .5699462891234 .4429931641227 .312988281 1220.1800537111213 .0419921881205 .8990478521198 .7519531251191 .600952148 1184.4449462891177 .2840576171170 .1190185551162 .9489746091155 .775024414 1148.5959472661141 .4129638671134 .2259521481127 .0340576171119 .838989258 1112.6400146481105 .4389648441098 .2349853521091 .0279541021083 .821044922 1076.6130371091069 .4040527341062 .1970214841054 .9909667971047 .787963867 1040.5889892581033 .3940429691026 .2039794921019 .0219726561011 .846984863 1004.681030273 997.5241699219990.3784179688983.2443237305 976.1228027344 969.0147705078961 .921081543954 .8425292969947 .7797851562940 .7333984375 933.7042236328926 .6923828125919 .6989135742912 .7235107422905 .7670288086 898.8295288086891 .9116821289885 .0134887695878 .1353759766871 .2772827148 864.4398193359 857.6229248047 850.8270263672 844.0518798828 837.2980957031 830.565612793823 .8546142578817 .165222168810 .4973754883803 .8513793945 797.2271118164790 .6243286133784 .0435180664777 .4840087891770 .9459228516 764.4290161133757 .9332275391751 .4581298828745 .0032958984738 .5686035156 732.1536254883725 .7578125719 .3809814453713 .0225830078706 .6823120117 700.3596191406694 .0540771484687 .765625681 .4937133789675 .2379760742 668.9984130859662 .7747192383656 .5667114258650 .3745727539644 .1981201172 638.0377197266631 .8933105469625 .7655029297619 .6544189453613 .5607910156 607.4851074219 601.4281005859595.390625 589.3737182617 583.378112793 577.4052124023571 .4561767578565 .5325927734559 .6356201172553 .7672119141 547.9285888672542 .1220092773536 .3489990234530 .6118164062524 .912109375 519.2523193359513 .6343994141508 .0606079102502 .5333862305497 .0548095703 491.6274108887486 .2532958984480 .9352111816475 .6751098633470 .4755859375 465.3388061523460 .2672119141455 .2627868652450 .3280029297445 .4643859863 440.6742858887435 .9590148926431 .3205871582426 .7601013184422 .279296875 417.87890625413 .5604858398409 .3251953125405 .1745910645401 .1101989746 397.1340942383393 .2485961914389 .4562072754385 .7596130371382 .1617126465 378.6646118164375 .2710876465371 .9826049805368 .8006896973365 .7258911133 362.7585144043359 .8978881836357 .1431884766354 .4927978516351 .9447937012 349.49609375347 .1438903809344 .8829040527342 .7091064453340 .6137084961 338.591003418336 .6265869141334 .7141113281332 .8298034668330 .9638061523 329.0903930664327 .2070922852325 .271697998323 .2778015137321 .1578063965 318.8775024414316 .3803100586313 .6138000488310 .5697021484307 .1727905273 303.5440063477299 .6624145508295 .7060852051291 .7308044434287 .8684082031 284.2605895996280 .9224853516278 .0100097656275 .4270019531273 .2365112305 271.2814941406269 .4767150879267 .7421875265 .9447937012264 .2055969238 262.524810791260 .9327087402259 .3770141602257 .749786377255 .9192962646 253.6976013184251 .1333007812247 .2933044434241 .1607055664233 .467300415 224.7015991211214 .9815979004204 .4091033936193 .6856994629183 .2263031006 173.553604126165 .1732940674158 .150100708153 .1813964844149 .8365020752 148.2810058594148 .4179992676149 .9716033936153 .1354980469157 .7501068115 
163.1273040771168 .4429931641173 .1432952881176 .4835968018178 .7527008057 180.0444946289180 .629699707180 .8334960938180 .6674041748180 .3079986572 179.7696075439179 .179901123178 .5155029297177 .7962036133177 .0108032227 176.1383972168175 .1945953369174 .175994873173 .0964050293171 .9609985352 170.7803039551169 .5617980957168 .31300354167 .0404968262165 .7512969971 164.4510040283163 .1479949951161 .8482971191160 .5625159 .2989044189158 .0709991455 156.8910980225155 .7758026123154 .7422027588153 .81199646152 .9985046387 152.3603973389151 .9730987549151 .7601013184151 .6605072021151 .6674957275 151.75050354151 .900604248152 .0955963135152 .325302124152 .587600708 152.7966003418152 .9181976318152 .8621063232152 .5695953369151 .9306945801 150.778503418149 .1602020264146 .9747009277144 .3175048828141 .1766967773 137.6365966797133 .7740936279129 .5975952148125 .0938034058120 .2688980103 115.1288986206109 .8654022217104 .816200256399 .9644470214895 .46411895752 91.0972824096786 .7139816284282 .4527435302778 .481163024974 .86562347412 71.7120819091868 .9949569702166 .6772003173864 .7342071533263 .06430053711 61.5370788574260 .0122413635358 .5633697509857 .2623901367256 .14934921265 55.2274589538654 .5079383850153 .9816017150953 .6435012817453 .47875976562 53.4775314331153 .6275291442953 .9112281799354 .3144187927254 .81457901001 55.3925018310556 .0250015258856 .6886405944857 .3630905151458 .0235786438 58.6548805236859 .2341690063559 .7508506774960 .1839485168560 .53541183472 60.7916412353560 .9638404846261 .0492286682161 .0608711242761 .009349823 60.9028892517160 .7563209533760 .5731582641660 .3654289245660 .13436889648 59.8875312805259 .62583160459 .3537712097259 .0723800659258 .78450012207 58.4911689758358 .1943511962957 .8949394226157 .5943908691457 .29346084595 56.9932403564556 .6943206787156 .3975601196356 .1034088134855 .81253814697 55.5252609252955 .2420997619654 .9632492065454 .6890716552754 .41962814331 54.1551704406753 .8956604003953 .6412010192953 .3916587829653 .14701843262 52.9071006774952 .6717796325752 .440841674852 .2140617370651 .9912109375 51.772048950251 .5563201904351 .3437551 .1341018676850 .9270782470750 .72248077393 50.5199813842850 .3194084167550 .1204605102549 .922988891649 .72668838501 49.5314407348649 .3369903564549 .1432418823248 .9499588012748 .7571105957 48.5644912719748 .3721199035648 .1798400878947 .987728118947 .79570007324 47.6038208007847 .4121017456147 .2206306457547 .029441833546 .83876037598 46.6486396789646 .45922851562

1331.4990234381324 .3630371091317 .2209472661310 .0799560551302 .938964844 1295.796997071288 .6550292971281 .5100097661274 .3630371091267 .213989258 1260.0620117191252 .9079589841245 .751238 .5889892581231 .4239501951224 .255004883 1217.0830078121209 .9060058591202 .7249755861195 .5400390621188 .349975586 1181.1560058591173 .957031251166 .754028321159 .5460205081152 .333984375 1145.1180419921137 .8969726561130 .6729736331123 .4449462891116 .213012695 1108.9790039061101 .7419433591094 .5019531251087 .2609863281080 .020019531 1072.7779541021065 .5369873051058 .296997071051 .0600585941043 .826049805 1036.5959472661029 .3719482421022 .1539916991014 .9429931641007 .739990234 1000.54699707993 .3638916016986 .1920166016979 .0322875977971 .8853759766 964.7525024414957 .633972168950 .5307006836943 .4431762695936 .3723144531 929.3181152344922 .2813720703915 .2622070312908 .2612915039901 .2786865234 
894.3150024414887 .370300293880 .4448242188873 .5388183594866 .6525878906 859.7863769531852 .9404296875846 .1146240234839 .309387207832 .5247192383 825.7611083984819 .0183105469812 .2965698242805 .5960083008798 .9166259766 792.2583007812785 .6212768555779 .0053710938772 .4105224609765 .8364257812 759.2830810547752 .7501831055746 .2376708984739 .7448730469733 .2719116211 726.8179931641720 .3831787109713 .9669189453707 .5687866211701 .1885986328 694.8259887695688 .4807739258682 .1525268555675 .841003418669 .546081543 663.267578125657 .0056152344650 .7600097656644 .5308837891638 .3184814453 632.1229858398625 .9448242188619 .7841796875613 .6419067383607 .518371582 601.4146118164595 .3311157227589 .2689819336583 .2291259766577 .2127075195 571.2211303711565 .2554931641559 .3173828125553 .4083862305547 .530090332 541.6840820312535 .8723754883530 .0966796875524 .3591918945518 .6616210938 513.0062866211507 .395111084501 .8305969238496 .3146057129490 .8497009277 485.437713623480 .0813903809474 .7827148438469 .5440063477464 .3673095703 459.2551879883454 .2094116211449 .2320861816444 .3251037598439 .4906005859 434.7297973633430 .044708252425 .4361877441420 .9060974121416 .4552001953 412.0849914551407 .7963867188403 .5909118652399 .4700012207395 .4354858398 391.4895019531387 .6344909668383 .8725891113380 .2067871094376 .638885498 373.1718139648369 .8063964844366 .5445861816363 .386505127360 .3327941895 357.3822937012354 .5346069336351 .7872009277349 .1384887695346 .5848083496 344.1229858398341 .7474060059339 .4533081055337 .2318115234335 .0761108398 332.9736938477330 .9150085449328 .8796081543326 .8536071777324 .8154907227 322.7533874512320 .6383972168318 .4533996582316 .1585998535313 .7232055664 311.1046142578308 .2492980957305 .1654052734301 .8131103516298 .2825927734 294.5939025879290 .8522949219287 .1225891113283 .4843139648280 .0456848145 276.8270874023273 .9323120117271 .299987793268 .9650878906266 .8219909668 264.812713623262 .9234008789261 .0621032715259 .2745056152257 .5425109863 255.8309936523254 .1492004395252 .3762969971250 .4029998779248 .0489044189 245.1853942871241 .1477966309235 .2742004395228 .1417999268220 .0756988525 211.288192749 201.8388061523 192.2474975586182.9747924805 174.3576049805 166.8312988281160 .4360046387155 .6239013672152 .2427062988150 .4568023682 150.3188018799151 .7182006836154 .3544006348158 .0771026611162 .2528991699 166.4777069092170 .5256958008173 .6726989746176 .1002044678177 .6293945312 178.4588928223178 .871307373178 .9250946045178 .7583007812178 .4024047852 177.941192627177 .37159729176 .7353057861176 .0173034668175 .2068023682 174.316696167173 .3520965576172 .3229980469171 .2391052246170 .1083984375 168.9405059814167 .7416992188166 .5198974609165 .2812042236164 .032699585 162.7816925049161 .5357055664160 .3041992188159 .0960998535157 .9235992432 156.7989044189155 .7373046875154 .7554016113153 .8740997314153 .1130065918 152.504699707152 .0984954834151 .8446960449151 .7097015381151 .6775970459 151.7203063965151 .8227996826151 .9629974365152 .1195068359152 .2772979736 152.3650054932152 .3392944336152 .136505127151 .7059936523150 .9718933105 149.8139038086148 .2639007568146 .2555999756143 .8491973877141 .0229949951 137.8735961914134 .4609985352130 .8495941162127 .1514968872122 .8882980347 117.547996521111 .8729019165106 .5907974243101 .668502807697 .34174346924 92.9971466064588 .066551208583 .1607284545978 .8408889770575 .024559021 
71.752510070868 .970001220766 .6228103637764 .7358703613363 .29217147827 61.9026794433660 .1754798889258 .4525909423857 .0431289672955 .89714050293 54.9654502868754 .2378005981453 .6989097595253 .345291137753 .16785049438 53.1565093994153 .302040100153 .5874900817953 .9984397888254 .51277923584 55.1087799072355 .7635192871156 .4505195617757 .1496505737357 .8341293335 58.4886589050359 .0896186828659 .6263198852560 .0794410705660 .44664001465 60.7145500183160 .8936309814560 .9825782775960 .9929313659760 .93239974976 60.8128395080660 .6509704589860 .4520683288660 .2282791137759 .98212051392 59.7205390930259 .4451293945359 .1597709655858 .8657798767158 .56563949585 58.2604789733957 .9521217346257 .6415290832557 .3301010131857 .01861953735 56.7081985473656 .3994598388756 .0932693481455 .7901000976655 .49063110352 55.1952285766654 .9044113159254 .6183815002454 .3374900817954 .06185913086 53.7916603088453 .5268898010353 .2676010131853 .0136795043952 .76502990723 52.521480560352 .2828292846752 .0488395690951 .8192405700751 .59378051758 51.3721313476651 .1540412902850 .9391593933150 .7272300720250 .51792144775 50.3109893798850 .1061096191449 .9030494689949 .7015113830649 .50130081177 49.3021316528349 .1038589477548 .9062118530348 .7090797424348 .51222991943 48.3156089782748 .1190299987847 .9224700927747 .7257881164647 .52902984619 47.3321189880447 .1351203918546 .9379997253446 .7408714294446 .54375076294 46.3468093872146 .1500015258845 .95611953735

1336.120971681328 .9420166021321 .7629394531314 .5849609381307 .407958984 1300.2290039061293 .0500488281285 .8690185551278 .6870117191271 .501953125 1264.3149414061257 .1251249 .9329833981242 .7370605471235 .5379638671228 .334960938 1221.1280517581213 .917968751206 .703002931199 .4840087891192 .260986328 1185.0340576171177 .8020019531170 .5660400391163 .3260498051156 .081054688 1148.832031251141 .578002931134 .3210449221127 .0610351561119 .796020508 1112.5290527341105 .2590332031097 .9870605471090 .7130126951083 .437988281 1076.1629638671068 .8879394531061 .6149902341054 .3439941411047 .074951172 1039.8110351561032 .5510253911025 .2979736331018 .0510253911010 .812988281 1003.583007812996 .3626098633989 .1533203125981 .9553833008974 .7700195312 967.5980224609960 .4396972656953 .296081543946 .1677246094939 .0551147461 931.9588012695924 .8792114258917 .8167114258910 .771484375903 .7443237305 896.7352294922889 .7443237305882 .7719116211875 .8184814453868 .8842163086 861.9691162109855 .0736083984848 .1978149414841 .3419189453834 .5059204102 827.6903076172820 .8950195312814 .1201171875807 .3657836914800 .6323852539 793.9194946289787 .2274169922780 .5560302734773 .9052734375767 .2750854492 760.6655273438754 .0759887695747 .5067138672740 .9570922852734 .4271240234 727.9165039062721 .4249267578714 .9519042969708 .4973144531702 .0609130859 695.6422729492689 .2415161133682 .8579711914676 .4918212891670 .1428222656 663.8107299805657 .4957275391651 .1978149414644 .9169921875638 .6536865234 632.4080200195626 .1804199219619 .9713134766613 .7813110352607 .6109008789 601.4609985352595 .3322143555589 .2255859375583 .1422119141577 .0828857422 571.0491943359565 .0422973633559 .0634765625553 .1146240234547 .1967773438 541.3120117188535 .4619140625529 .6483154297523 .8729858398518 .1381225586 512.4456176758506 .7973937988501 .1958007812495 .6427001953490 .140411377 484.6910095215479 .2968139648473 .9596862793468 .6823120117463 .4660949707 
458.3138122559453 .2268066406448 .2077026367443 .2579040527438 .379486084 433.5736999512428 .8424987793424 .1867980957419 .6081848145415 .1076965332 410.6864929199406 .3456115723402 .0863037109397 .9100036621393 .8183898926 389.813293457385 .8967895508382 .071105957378 .3387145996374 .7015075684 371.1618041992367 .720703125364 .3800048828361 .1395874023358 .0000915527 354.9602966309352 .0195922852349 .1755065918346 .4262084961343 .7673950195 341.1961975098338 .7059936523336 .2925109863333 .9455871582331 .6596069336 329.4198913574327 .2189941406325 .0362854004322 .8633117676320 .6737060547 318.4569091797316 .1846923828313 .8429870605311 .4041137695308 .8511047363 306.1465148926303 .2351074219300 .1460876465296 .8438110352293 .4172058105 289.8771057129286 .3114929199282 .761505127279 .2911071777275 .9834899902 272.8457946777269 .9674072266267 .2908935547264 .8587036133262 .592590332 260.4555969238258 .4439086914256 .4896850586254 .612197876252 .7689056396 250.9358062744249 .1116027832247 .1609954834244 .987701416242 .3607025146 239.0677032471234 .8507995605229 .4335021973223 .0491943359215 .7407989502 207.8269958496199.3988037109 190.887298584182.6293945312174.9073028564 168.1365966797162 .3323974609157 .8679046631154 .6573944092152 .8603973389 152.4669952393153 .4517974854155 .4833068848158 .3737030029161 .6996002197 165.1305999756168 .5093994141171 .2825927734173 .5720062256175 .1372070312 176.1416931152176 .7543029785177 .004699707177 .0314025879176 .841506958 176.5180969238176 .0617980957175 .5283966064174 .8952026367174 .1587982178 173.334197998172 .4315032959171 .4615936279170 .4349975586169 .3607025146 168.2478942871167 .1040039062165 .9364013672164 .7521972656163 .5581054688 162.362197876161 .1716003418159 .996307373158 .8442993164157 .7285003662 156.6589050293155 .6522979736154 .7225952148153 .891494751153 .1824035645 152.6036071777152 .1748046875151 .8766021729151 .6986999512151 .6183929443 151.6080932617151 .649307251151 .7192993164151 .7864990234151 .8325042725 151.796295166151 .6439056396151 .320602417150 .7779998779149 .9723968506 148.8045959473147 .3121032715145 .4228057861143 .2061004639140 .6065979004 137.7465057373134 .6560974121131 .399597168128 .258895874124 .4047012329 118.8569030762112 .8405990601107 .4144973755102 .370697021598 .13918304443 93.8206634521588 .4881973266683 .1477279663178 .6925430297974 .81504058838 71.5408325195368 .8056716918966 .4801025390664 .6172714233463 .26277923584 61.9879684448260 .1262283325258 .2877693176356 .8773002624555 .71517944336 54.7730903625554 .0406608581553 .4820594787653 .1073112487852 .91064071655 52.8815383911153 .0196113586453 .3017883300853 .7210006713954 .24827957153 54.8647994995155 .5427093505956 .2556304931656 .9813385009857 .69121932983 58.3706207275458 .9933395385759 .5509986877460 .0237693786660 .40576934814 60.6809806823760 .8616600036660 .9438896179260 .9424209594760 .86447143555 60.7233314514260 .5419998168960 .3233604431260 .0821990966859 .81943130493 59.5430297851659 .2535285949758 .9551391601658 .6486396789658 .33654022217 58.019809722957 .7002296447857 .3787307739357 .0567016601656 .7349281311 56.4145698547456 .0962409973155 .7808418273955 .4688796997155 .16106033325 54.8577384948754 .5594902038654 .2664985656753 .9791717529353 .69755935669 53.4218902587953 .1521110534752 .8882789611852 .6302413940452 .37789154053 52.1309890747151 .8893203735451 .6525993347251 .4205017089851 .19271850586 
50.9688987731950 .7487297058150 .5318298339850 .3179016113350 .10655975342 49.8975486755449 .6904792785649 .4851493835449 .2811889648449 .07841873169 48.8765182495148 .6753501892148 .4745903015148 .2741699218848 .07381057739 47.873458862347 .6729316711447 .4721794128447 .2710914611847 .06967163086 46.8678283691446 .6656494140646 .4630699157746 .2602005004946 .0570602417 45.853790283245 .6505393981945 .44725036621

1340.7280273441333 .5179443361326 .3010253911319 .0870361331311 .874023438 1304.6590576171297 .4439697271290 .2280273441283 .0109863281275 .791015625 1268.5689697271261 .3449707031254 .1180419921246 .8879394531239 .654052734 1232.417968751225 .1779785161217 .9339599611210 .6860351561203 .433959961 1196.1779785161188 .917968751181 .6529541021174 .3850097661167 .112060547 1159.8349609381152 .5529785161145 .2679443361137 .9780273441130 .685058594 1123.3879394531116 .0889892581108 .7860107421101 .4809570311094 .175048828 1086.8669433591079 .5579833981072 .251064 .9429931641057 .6379394531050 .33605957 1043.0369873051035 .7430419921028 .4539794921021 .171997071013 .896972656 1006.630981445999.3737792969992.1270751953984.8914794922977.6677246094 970.4564819336963 .258605957956 .075012207948 .9058837891941 .7520751953 934.6137695312 927.4915771484920.385925293913.2971191406906.225402832 899.171081543892 .1345825195885 .1159057617878 .1154785156871 .133605957 864.1702880859857 .2260131836850 .3005981445843 .3945922852836 .5081176758 829.6412963867822 .794128418815 .9669799805809 .1599731445802 .3732299805 795.606628418788 .8605957031782 .1345825195775 .4291992188768 .7438964844 762.0789794922755 .4338989258748 .8088989258742 .2036743164735 .617980957 729.051574707722 .5042724609715 .9758300781709 .4658813477702 .9744262695 696.5009765625690 .045715332683 .608215332677 .1884155273670 .7860717773 664.4016113281658 .0346069336651 .6853027344645 .3538818359639 .0405883789 632.7457275391626 .4697265625620 .2130126953613 .9760131836607 .7595825195 601.5642700195595 .3909912109589 .2407226562583 .1141967773577 .0128173828570 .9375 564.8897094727558 .8707885742552 .8823242188546 .9255981445541 .0023193359 535.114074707529 .2628173828523 .450378418517 .6782836914511 .9489135742 506.263885498500 .6254882812495 .0356140137489 .496307373484 .0096130371 478.577911377473 .2027893066467 .8866882324462 .6315002441457 .4393005371 452.3117980957447 .2513122559442 .2590942383437 .337310791432 .4872131348 427.7105102539423 .0082092285418 .3819885254413 .8324890137409 .3612060547 404.9689025879400 .6568908691396 .4262084961392 .2785949707388 .2155151367 384.2390136719380 .3505859375376 .5530090332372 .8475036621369 .2366943359 365.7210998535362 .3026123047358 .9808044434355 .7565917969352 .6282958984 349.5956115723346 .6556091309343 .8063964844341 .0437011719338 .3641967773 335.7612915039333 .2301940918330 .7615966797328 .3483886719325 .9779968262 323.6408081055321 .3210144043319 .0061950684316 .6770019531314 .3181152344 311.9093017578309 .434387207306 .8771057129304 .2218933105301 .4415893555 298.49609375295 .4082946777292 .1659851074288 .8280944824285 .4187927246 281.9927062988278 .5918884277275 .2579956055272 .0526123047268 .9859008789 266.1163024902263 .4140014648260 .9020080566258 .5361022949256 .2937011719 254.1638946533252 .1076965332250 .112197876248 .1472930908246 .1734924316 244.1817932129242 .0402984619239 .6578979492236 .8141021729233 .325302124 
229.1313934326224 .0254974365218 .1925048828211 .604095459204 .496307373 197.0191040039189 .4799957275182 .1625976562175 .2935028076169 .208694458 163.9732971191159 .8484039307156 .8211975098155 .0395965576154 .4393005371 155.0359954834156 .5184936523158 .7093048096161 .3105010986164 .066192627 166.833404541169 .2398986816171 .3103027344172 .8320007324173 .9203033447 174.6410980225175 .0424041748175 .2077026367175 .1629943848174 .9696960449 174.6371002197174 .2035980225173 .6587982178173 .0021972656172 .2498016357 171.4161071777170 .5110931396169 .5480041504168 .5346069336167 .4819946289 166.3966064453165 .2870941162164 .1600036621163 .0231933594161 .8840942383 160.750793457159 .6322937012158 .5375061035157 .4777069092156 .4635009766 155.5095062256154 .6293945312153 .8414001465153 .1651000977152 .5989074707 152.157699585151 .8262023926151 .603805542151 .4691009521151 .3981018066 151.3690032959151 .358505249151 .3339996338151 .2698059082151 .1195983887 150.8441009521150 .4071960449149 .7689971924148 .8946075439147 .7162017822 146.2460021973144 .4347991943142 .3229064941139 .8867034912137 .1795959473 134.2026062012130 .9972991943127 .6484985352123 .6022033691118 .2901992798 112.5076980591106 .9953994751101 .775802612397 .0929489135792 .3942565918 87.2300567627 82.1809463501 77.86730957031 74.14694976807 71.05213928223 68.4510421752966 .2201538085964 .3063735961962 .5580596923860 .97241973877 59.4600715637258 .0541801452656 .7666091918955 .6315803527854 .69454956055 53.9416198730553 .3577804565452 .9516983032252 .7274589538652 .67591094971 52.7977409362853 .0745811462453 .4977188110454 .0393905639654 .67470169067 55.3770103454656 .1158981323256 .8687095642157 .6038093566958 .30690002441 58.9520988464459 .5303497314560 .0220298767160 .4159393310560 .69784927368 60.8756599426360 .9413681030360 .9160995483460 .8109283447360 .64064025879 60.4319992065460 .1900291442959 .9280204772959 .6476707458559 .35522079468 59.0516090393158 .7399291992258 .421180725158 .0972900390657 .76932144165 57.4388008117757 .1067085266156 .7743911743256 .4426383972256 .11264038086 55.7849998474155 .4606704711955 .1401786804254 .8242683410654 .51330947876 54.2078781127953 .908199310353 .6146583557153 .3273506164653 .04647827148 52.7719802856452 .5038909912152 .2420310974151 .9862709045451 .73633956909 51.4919586181651 .2528190612851 .0185317993250 .7887611389250 .56309127808 50.3411483764650 .1225204467849 .9068603515649 .6937599182149 .48291015625 49.2739105224649 .0665092468348 .8603210449248 .6551589965848 .45066833496 48.2467117309648 .0429611206147 .8393096923847 .6355094909747 .43146896362 47.22702026367 47.0220909118746.8165702819846.6104583740246.40365982056 46.1962318420445 .9881286621145 .7794494628945 .5702095031745 .36053848267 45.14994812012 44.94145965576

1345.3389892581338 .0870361331330 .8349609381323 .586059571316 .33605957 1309.0870361331301 .8370361331294 .5849609381287 .3330078121280 .078979492 1272.8229980471265 .5639648441258 .3039550781251 .0400390621243 .772949219 1236.5030517581229 .2299804691221 .953002931214 .671997071207 .387939453 1200.0989990231192 .8070068361185 .5100097661178 .2089843751170 .904052734 1163.5949707031156 .2810058591148 .9639892581141 .6419677731134 .317016602 1126.9880371091119 .6560058591112 .3210449221104 .9840087891097 .645019531 1090.3039550781082 .9630126951075 .6219482421068 .2819824221060 .942993164 
1053.6070556641046 .2729492191038 .9439697271031 .620971681024 .302978516 1016.9929809571009 .6900024411002 .395996094995 .112487793987 .8391723633 980.5770874023973 .3270874023966 .0900268555958 .866394043951 .6567993164 944.4619140625937 .2819824219930 .1176757812922 .9691162109915 .8367919922 908.7208862305901 .6220703125894 .540222168887 .4755859375880 .4287109375 873.3997192383866 .388671875859 .3961181641852 .421875845 .4663696289 838.5300292969831 .6126708984824 .7144775391817 .8358764648810 .9769287109 804.1378173828797 .3184814453790 .5191040039783 .7396850586776 .9805297852 770.2410888672763 .5219116211756 .8223266602750 .1427001953743 .4827880859 736.8425292969730 .2213745117723 .6195068359717 .0366210938710 .4724121094 703.9268798828697 .3997802734690 .8911132812684 .4005126953677 .9281005859 671.4738769531665 .0377197266658 .6198120117652 .2202148438645 .8389892578 639.4766845703633.1334228516 626.8098144531620.5061035156 614.2230834961 607.9611816406601 .7213745117595 .5042114258589 .3107299805583 .141784668 576.9987792969570 .8825073242564 .7943725586558 .7357788086552 .7081298828 546.7128295898540 .7512817383534 .8256225586528 .9370117188523 .0874023438 517.2786254883511 .5126037598505 .7909851074500 .1160888672494 .4895019531 488.9135131836483 .3898010254477 .9206848145472 .5079040527467 .1535949707 461.859588623456 .6278991699451 .4602050781446 .3587036133441 .3245849609 436.3599853516431 .466003418426 .6445007324421 .8963012695417 .2229919434 412.6253967285408 .1047973633403 .661895752399 .2979125977395 .013885498 390.8113098145386 .69140625382 .6559143066378 .7062988281374 .8446960449 371.0725097656367 .3918151855363 .8031005859360 .3081054688356 .9064025879 353.5986938477350 .383392334347 .2598876953344 .2253112793341 .2778015137 338.4125976562335 .6268005371332 .9132995605330 .2679138184327 .6803894043 325.1449890137322 .6485900879320 .1831054688317 .7325134277315 .2867126465 312.8270874023310 .3418884277307 .8131103516305 .2269897461302 .5714111328 299.8313903809296 .9943847656294 .0257873535290 .9540100098287 .7641906738 284.5093078613281 .200012207277 .8851013184274 .5946044922271 .3615112305 268.2356872559265 .2188110352262 .3616943359259 .637298584257 .0732116699 254.6343994141252 .3085021973250 .0778045654247 .908706665245 .7870941162 243.6880950928241 .5635070801239 .3981018066237 .0612945557234 .4790039062 231.4884033203227 .9371032715223 .8307037354219 .0263977051213 .6721954346 207.7046051025201 .3515930176194 .716293335188 .0444946289181 .5570068359 175.4436035156169 .9983978271165 .2742004395161 .516998291158 .6943054199 156.9548950195156 .188293457156 .4223937988157 .4109039307159 .0352935791 161.0576934814163 .2518005371165 .5061950684167 .512298584169 .3105926514 170.7032928467171 .7846984863172 .5561981201173 .0545043945173 .3323974609 173.4069061279173 .3379974365173 .1192016602172 .7859954834172 .3282012939 171.7545013428171 .0774993896170 .316696167169 .4806060791168 .5843048096 167.6354064941166 .6455993652165 .6217041016164 .5724945068163 .5050964355 162.4270019531161 .3466033936160 .2709960938159 .2102050781158 .1717071533 157.1676025391156 .2066955566155 .3031005859154 .4678955078153 .7149963379 153.0601043701152 .5005950928152 .0471954346151 .6875151 .4217071533151 .2292022705 151.091293335150 .9848937988150 .8881072998150 .7675018311150 .5982971191 150.3392944336149 .9548950195149 .4187927246148 .696395874147 .7642059326 
146.5612945557145 .100402832143 .3215026855141 .2666015625138 .9114074707 136.2570037842133 .2615966797129 .8856964111126 .0664978027121 .6831970215 116.6358032227111 .1979980469105 .674697876100 .187698364394 .91493225098 89.8103408813584 .9758377075280 .455360412676 .549667358473 .16649627686 70.4274368286168 .1430130004966 .1106872558664 .246932983462 .09606170654 60.2184600830159 .0244903564558 .0449409484956 .8699493408255 .74803161621 54.7958602905354 .0032005310153 .3706398010352 .90512847952 .63436889648 52.5378608703652 .6366195678752 .8978385925353 .3241081237853 .87649917603 54.5332908630455 .2612800598156 .0287895202656 .8101081848157 .57109832764 58.2983818054258 .9614486694359 .5553092956560 .0579109191960 .46348953247 60.7554893493760 .9262199401960 .9649505615260 .8981399536160 .7543182373 60.5509681701760 .3135910034260 .0465011596759 .7633399963459 .46451950073 59.1560783386258 .8381996154858 .5135498046958 .1827697753957 .84745025635 57.5085601806657 .1674690246656 .8251495361356 .4828796386756 .14151000977 55.8022117614755 .4656105041555 .1327400207554 .8040695190454 .48043823242 54.1622009277353 .8499717712453 .5439682006853 .2446289062552 .95198059082 52.6662788391152 .387420654352 .1154289245651 .8501091003451 .59128952026 51.3386802673351 .091941833550 .850719451950 .6145782470750 .38314819336 50.1559295654349 .9325408935549 .712471008349 .4953804016149 .28076934814 49.0683403015148 .8576087951748 .6483497619648 .4401206970248 .23271942139 48.0257797241247 .8191490173347 .6124916076747 .405689239547 .19849014282 46.9908103942946 .7824287414646 .5733413696346 .3633689880446 .15253067017 45.9407196044945 .7279891967845 .5143013000545 .2997093200745 .08427047729 44.86801910444 .6512413024944 .43363952637

1349.9360351561342 .6519775391335 .3649902341328 .0799560551320 .795043945 1313.5109863281306 .2259521481298 .9410400391291 .6540527341284 .365966797 1277.0760498051269 .7840576171262 .4899902341255 .1929931641247 .892944336 1240.5909423831233 .285034181225 .9749755861218 .6619873051211 .345947266 1204.0250244141196 .6999511721189 .3719482421182 .038940431174 .702026367 1167.3609619141160.015991211 1152.6660156251145 .3129882811137 .956054688 1130.5949707031123 .2309570311115 .8649902341108 .4949951171101 .1240234381093 .75 1086.3769531251079 .0030517581071 .629028321064 .2569580081056 .886962891 1049.5190429691042 .1560058591034 .796997071027 .4449462891020 .098022461 1012.7600097661005 .429016113998 .1085205078990 .7974853516983 .4974975586 976.208984375968 .932800293961 .6694946289954 .4196777344947 .1840209961 939.9627075195932 .7564086914925 .5653076172918 .3897705078911 .2302856445 904.0869750977896 .9603271484889 .8502807617882 .7573242188875 .6817016602 868.6234741211861 .5831298828854 .5607299805847 .5565185547840 .5706787109 833.6035766602826 .6552734375819 .7260131836812 .8157958984805 .924987793 799.0537719727792 .2020874023785 .3701171875778 .5579223633771 .7655029297 764.9927978516758 .2399291992751 .5067138672744 .7930908203738 .0988769531 731.4243164062724 .7687988281718 .1323852539711 .5150146484704 .9165039062 698.3366699219691 .7755126953685 .2329711914678 .708984375672 .2036132812 665.7169189453659 .2487792969652 .7996826172646 .3698120117639 .9592895508 633.5686035156627 .1981201172620 .8483276367614 .5197753906608 .2131958008 601.9293212891595 .6688842773589 .4329223633583 .2222290039577 .037902832 
570.8812255859564 .7531738281558 .6552734375552 .5889282227546 .5552978516 540.5562133789534 .5930175781528 .6672973633522 .7811279297516 .9357299805 511.1333007812505 .3753967285499 .6642150879494 .0013122559488 .3887939453 482.8283081055477 .3221130371471 .871887207466 .4796142578461 .1470947266 455.8763122559450 .6687927246445 .5266113281440 .4511108398435 .4440917969 430.5068969727425 .6411132812420 .8475952148416 .1278991699411 .4827880859 406.9136047363402 .4208984375398 .0058898926393 .6694030762389 .4128112793 385.2370910645381 .1437988281377 .1340942383373 .2099914551369 .3723144531 365.6232910156361 .9630126953358 .3931884766354 .9132080078351 .5237121582 348.2229919434345 .0107116699341 .883392334338 .8396911621335 .874786377 332.9854125977330 .1650085449327 .4088134766324 .7077941895322 .0553894043 319.4403991699316 .8536987305314 .282409668311 .7150878906309 .1379089355 306.537902832303 .9023132324301 .2172851562298 .4750976562295 .6642150879 292.7778015137289 .7956848145286 .7356872559283 .5914001465280 .3991088867 277.1776123047273 .9531860352270 .7488098145267 .5946044922264 .533203125 261.5624084473258 .7073059082255 .9631958008253 .3531951904250 .8524932861 248.4519958496246 .1275024414243 .8535003662241 .6116943359239 .3854064941 237.1233062744234 .7967987061232 .3027038574229 .5643005371226 .4795074463 222.9277954102218 .9344024658214 .4105987549209 .462600708204 .0697021484 198.3834991455192 .4862976074186 .5715026855180 .8209991455175 .396194458 170.5319061279166 .2924957275162 .8591003418160 .2301940918158 .5196075439 157.62840271157 .5713043213158 .1676025391159 .3184967041160 .842300415 162.5529937744164 .3414001465165 .9963989258167 .5180969238168 .7718048096 169.7987976074170 .5715026855171 .1230926514171 .4813995361171 .6595001221 171.6809997559171 .5554046631171 .3063049316170 .9306030273170 .4333953857 169.8311004639169 .1419067383168 .375793457167 .5473937988166 .6647033691 165.7395935059164 .7787017822163 .791595459162 .7848968506161 .7671051025 160.7454986572159 .728302002158 .7239990234157 .7411956787156 .7897949219 155.879196167155 .0205993652154 .2250061035153 .5012054443152 .8621063232 152.3047943115151 .8368988037151 .4481964111151 .1381072998150 .887802124 150.6824951172150 .4989013672150 .3152008057150 .1016998291149 .8311004639 149.4710998535148 .9873046875148 .3583984375147 .5532073975146 .550201416 145.3058013916143 .8157043457142 .0457000732139 .9916992188137 .6222991943 134.9098968506131 .8229064941128 .2624969482124 .1781005859119 .6246032715 114.5354003906109 .1210021973103 .495597839497 .7706832885792 .18364715576 86.95823669434 82.30265808105 78.19673156738 74.74945831299 71.85500335693 69.6660537719767 .9026565551866 .2821273803764 .6651992797962 .73218917847 60.9788703918559 .6448593139658 .500839233457 .3009681701756 .12390899658 55.1056594848654 .2538681030353 .5439605712952 .9958915710452 .64031982422 52.4769287109452 .5340194702152 .7771911621153 .1932296752953 .75366973877 54.4332885742255 .1931991577155 .989810943656 .8002090454157 .59111022949 58.3427085876559 .0183792114359 .6181716918960 .1246299743760 .53797912598 60.8575515747161 .035720825261 .0185012817460 .8808288574260 .68941116333 60.4502487182660 .1832313537659 .8917884826759 .5870399475159 .2698097229 58.9451217651458 .6131210327158 .2756004333557 .9331398010357 .58673095703 57.2373199462956 .8860397338956 .5338783264256 .1820907592855 .83148956299 
55.4833106994655 .1381988525454 .7971916198754 .460800170954 .1298789978 53.8048095703153 .4862289428753 .1743392944352 .8696098327652 .57207107544 52.281951904351 .9991416931251 .7236518859951 .4552688598651 .1937713623 50.9388313293550 .6900901794450 .4471397399950 .2094993591349 .97674179077 49.7482986450249 .5237693786649 .3025817871149 .0843315124548 .86848831177 48.654708862348 .4425010681248 .2315711975148 .021480560347 .81200027466 47.6027488708547 .393550872847 .1840705871646 .974189758346 .76364135742 46.5523300170946 .3400688171446 .1267890930245 .9123497009345 .69675064087 45.4798889160245 .2617912292545 .0424308776944 .8218688964844 .60015106201 44.3773803710944 .1525993347243 .92905044556

1354.5329589841347 .2099609381339 .8879394531332 .5679931641325 .249023438 1317.9310302731310 .6120605471303 .292968751295 .9730224611288 .651000977 1281.328002931274 .0030517581266 .6760253911259 .3459472661252 .014038086 1244.6789550781237 .3409423831229 .9990234381222 .6540527341215 .306030273 1207.953002931200 .5970458981193 .2370605471185 .8730468751178 .50402832 1171.1319580081163 .7550048831156 .3740234381148 .9899902341141 .600952148 1134.2089843751126 .8129882811119 .413940431112 .0129394531104 .609008789 1097.203979492 1089.7979736331082.390991211 1074.9840087891067.578979492 1060.1750488281052 .7740478521045 .3759765621037 .9830322271030 .594970703 1023.2130126951015 .8389892581008 .4719848631001 .114013672993 .7659301758 986.4279785156979.1011962891971.7860717773964.4832763672957.1934814453 949.917175293942 .6547851562935 .4067993164928 .1735229492920 .955078125 913.7521972656906 .5650024414899 .3936767578892 .2387695312885 .1002197266 877.978515625870 .8737182617863 .7860717773856 .716003418849 .6635742188 842.6292114258835 .6129150391828 .6149291992821 .6356811523814 .6751098633 807.733581543800 .8112182617793 .9080200195787 .0241699219780 .1600952148 773.3154296875766 .4902954102759 .6848144531752 .8989257812746 .1326293945 739.3856811523732 .6583251953725 .9501953125719 .2614135742712 .5916748047 705.9412231445699 .3095703125692 .6970214844686 .1033935547679 .5286865234 672.9730224609666 .4365844727659 .9193115234653 .4215698242646 .9437255859 640.4857788086634 .0482788086627 .6317749023621 .2365112305614 .86328125 608.5125732422602 .1854248047595 .8823242188589 .6041870117583 .3521728516 577.1273193359570 .930480957564 .7631225586558 .6262207031552 .5214233398 546.4498901367540 .4132080078534 .412902832528 .4506225586522 .5277099609 516.6461181641510 .8074951172505 .0136108398499 .2662963867493 .567199707 487.9183959961482 .3214111328476 .7784118652471 .2908935547465 .861114502 460.4902954102455 .1806945801449 .9336853027444 .7511901855439 .6347045898 434.5857849121429 .6058044434424 .6961975098419 .858001709415 .092590332 410.4006958008405 .7835083008401 .2417907715396 .7764892578392 .3883972168 388.078704834383 .8482055664379 .6982116699375 .6296081543371 .6441955566 367.7427062988363 .9267883301360 .196685791356 .5538024902352 .9974060059 349.5281066895346 .1441040039342 .8450012207339 .6275939941336 .4902954102 333.428314209330 .4388122559327 .5150146484324 .6525878906321 .8427124023 319.079498291316 .3518981934313 .6523132324310 .9681091309308 .2900085449 305.6052856445302 .9028930664300 .1724853516297 .4017028809294 .5864868164 291.7150878906288 .7898864746285 .7945861816282 .7471923828279 .6346130371 
276.4930114746273 .3356018066270 .1812133789267 .0405883789263 .9429016113 260.9313964844257 .9920043945255 .1410980225252 .37890625249 .7355957031 247.1826934814244.7169036865242.3103942871 239.9400939941 237.5877990723 235.2447052002232 .8544006348230 .3901062012227 .7671966553224 .9237060547 221.7978973389218 .2940979004214 .449005127210 .1759033203205 .5962982178 200.6920013428195 .5901031494190 .3233032227185 .0628967285179 .9557037354 175.1307067871170 .7942047119166 .9821014404163 .8585968018161 .4024963379 159.7346038818158 .7456054688158 .4674072266158 .7454071045159 .521194458 160.6372070312161 .9371032715163 .3426971436164 .6690063477165 .9342956543 167.0193023682167 .9577026367168 .6920013428169 .258605957169 .6681976318 169.9172058105170 .0095977783169 .9553985596169 .7799072266169 .475402832 169.0511932373 168.5196075439 167.9015960693 167.2042999268 166.4443054199 165.6280059814164 .7682952881163 .871307373162 .9468994141162 .0018005371 161.0444030762160 .0821075439159 .1224975586158 .1743927002157 .2451934814 156.3446044922155 .4804992676154 .6627960205153 .9008026123153 .2005004883 152.5722045898152 .0130004883151 .5301055908151 .112197876150 .7588043213 150.4517059326150 .179397583149 .9185943604149 .650100708149 .3455963135 148.9804992676148 .5260925293147 .9526977539147 .2395019531146 .3544006348 145.2819061279143 .9821929932142 .4499053955140 .6569976807138 .5657958984 136.1224060059133 .2931976318130 .0653076172126 .3500976562122 .1019973755 117.3864974976112 .2021026611106 .6703033447100 .86859893894 .9736328125 89.1731491088983 .850311279379 .3432769775475 .5476913452172 .67883300781 70.4720001220769 .0567398071368 .0418395996166 .9740676879965 .8392868042 64.325897216862 .7343482971261 .0583801269559 .5023498535258 .12080001831 56.884628295955 .7783393859954 .7891883850153 .9433898925853 .24993133545 52.775669097952 .5074691772552 .5097885131852 .7209014892653 .12620925903 53.6885795593354 .3919906616255 .1811294555756 .0067901611356 .8482093811 57.6683502197358 .4434394836459 .1236305236859 .718330383360 .21508026123 60.6153907775960 .9407501220761 .1128387451261 .0413703918560 .84135818481 60.6106910705660 .3369293212960 .0406303405859 .7247009277359 .39825820923 59.0626983642658 .7219696044958 .3760910034258 .0260086059657 .67216110229 57.3149604797456 .9553413391156 .5942001342856 .2325210571355 .87155914307 55.5121116638255 .1554985046454 .8022994995154 .453678131154 .1100692749 53.772460937553 .4411087036153 .1167793273952 .7996101379452 .4901008606 52.1882514953651 .8942794799851 .6080818176351 .3296203613351 .05865859985 50.7949409484950 .5381317138750 .2877807617250 .0435104370149 .80472183228 49.5709800720249 .3416481018149 .1162910461448 .8942604064948 .67514038086 48.4583091735848 .2434196472248 .0299186706547 .817520141647 .60572814941 47.3943214416547 .1828613281246 .9711990356446 .7589683532746 .54607009888 46.3321990966846 .1172904968345 .9011192321845 .6836395263745 .46469116211 45.244281768845 .0222892761244 .7987709045444 .5736503601144 .34703063965 44.1189193725643 .8893089294443 .6585807800343 .42625045776 1359.1169433591351 .7629394531344 .4050292971337 .0520019531329 .697998047 1322.345947266 1314.994018555 1307.640991211 1300.287963867 1292.933959961 1285.578002931278 .2209472661270 .8609619141263 .4990234381256 .135009766 1248.7679443361241 .3979492191234 .0250244141226 .6479492191219 .267944336 
1211.8840332031204 .4969482421197 .1049804691189 .7099609381182 .311035156 1174.9069824221167 .4990234381160 .0870361331152 .6710205081145 .250976562 1137.828002931130 .4010009771122 .9699707031115 .5369873051108 .102050781 1100.663940431093 .2259521481085 .7860107421078 .3470458981070 .907958984 1063.4709472661056 .0360107421048 .6040039061041 .1770019531033 .75402832 1026.3370361331018.926025391 1011.5230102541004.12902832 996.7435302734 989.3679199219982.0028076172974.6489868164967.3071289062959.9774169922 952.6607055664945 .357421875938 .0681152344930 .7927246094923 .5319824219 916.2860107422909 .0552978516901 .8400268555894 .6403808594887 .4567260742 880.2894287109873 .1384277344866 .0042114258858 .8869018555851 .7869873047 844.7044067383837 .6395874023830 .5927734375823 .5640869141816 .5540161133 809.5623779297 802.5897216797 795.6358032227 788.7011108398 781.7857055664 774.8895874023768 .012878418761 .1558227539754 .3181762695747 .5740 .7012939453 733.921875727 .1621704102720 .4218139648713 .7006835938706 .9989013672 700.3165283203693 .6533813477687 .0095825195680 .3850708008673 .780090332 667.1947021484660 .6290893555654 .0836181641647 .5582885742641 .0537109375 634.5703125628 .1082763672621 .6682739258615 .2509155273608 .8568115234 602.4866943359596 .141418457589 .8218994141583 .5291137695577 .2637939453 571.0272827148564 .8208007812558 .6455078125552 .5026245117546 .3934936523 540.3195800781534 .2824707031528 .2836303711522 .3245239258516 .4067993164 510.5322875977504 .7025146484498 .9193115234493 .1842956543487 .4993896484 481.8660888672476 .2864990234470 .7619934082465 .2947998047459 .8861083984 454.5379943848449 .2518005371444 .029510498438 .8723144531433 .7820129395 428.7596130371423 .8067932129418 .924407959414 .1138000488409 .3756103516 404.7113037109400 .1211853027395 .6064147949391 .1675109863386 .8056030273 382.5212097168378 .315612793374 .1895141602370 .1441040039366 .1802978516 362.2992858887358 .5010986328354 .7872009277351 .1564025879347 .609588623 344.1448059082340 .7615966797337 .4570007324334 .229309082331 .074005127 327.9880981445324 .9655151367322 .0017089844319 .0888977051316 .2207946777 313.388092041310 .5828857422307 .7951049805305 .0150146484302 .2329101562 299.4381103516296 .6228027344293 .7763977051290 .8955993652287 .9721069336 285.0089111328281 .9978942871278 .9508972168275 .8638916016272 .758605957 269.6471862793266 .5422973633263 .4560852051260 .408203125257 .4266052246 254.5070037842251 .6613006592248 .8910980225246 .2142944336243 .6138000488 241.0863952637238 .6076049805236 .1596069336233 .720993042231 .2776031494 228.7846984863226 .212600708223 .4987945557220 .5856018066217 .4427032471 214.0065002441210 .2993011475206 .2704925537202 .0111999512197 .5386047363 192.9306945801188 .2180023193183 .5305023193178 .9839935303174 .6903991699 170.8054962158167 .3764038086164 .5285949707162 .2512054443160 .6215057373 159.5711975098159 .1165008545159 .1452941895159 .5984954834160 .3605041504 161.3173065186162 .3903961182163 .4481964111164 .4826965332165 .4105987549 166.2420959473166 .9371948242167 .5034942627167 .9273071289168 .2111968994 168.3518981934168 .3562011719168 .2335968018167 .9877929688167 .6251068115 167.1593933105166 .6065063477165 .9757995605165 .2812042236164 .5303955078 163.7348937988162 .9013977051162 .0393066406161 .1553955078160 .2579956055 159.3540039062158 .4514007568157 .5574035645156 .6800994873155 .8269958496 
155.0063934326154 .2252960205153 .4925994873152 .8119049072152 .19140625 151.628692627151 .1284942627150 .6813049316150 .2848968506149 .9235992432 149.5863952637149 .2523040771148 .9024963379148 .5124969482148 .057800293 147.5142974854146 .853805542146 .0558929443145 .0921936035143 .9454956055 142.586807251140 .999206543139 .1602935791137 .0106048584134 .4886016846 131.5617980957128 .2030944824124 .3623962402119 .9970016479115 .1672973633 109.8802032471104 .223899841398 .2435073852592 .1485900878986 .11408233643 80.6794967651476 .2117385864372 .7107467651470 .55161285469 .27351379395 68.8226089477568 .761306762768 .4283905029367 .8293075561566 .69640350342 65.1190872192462 .996231079160 .9053688049359 .4481506347758 .23720932007 56.9510917663655 .7237510681254 .642440795953 .7367286682153 .07638931274 52.6712417602552 .5822906494152 .7507591247653 .1375999450753 .7060585022 54.4202995300355 .2304916381856 .081329345756 .95117187557 .80150985718 58.5960884094259 .2731895446859 .8480300903360 .316551208560 .67866897583 60.9396095275961 .0522499084560 .9676589965860 .7620086669960 .50545883179 60.2053985595759 .8832015991259 .5424308776959 .1952896118258 .8416595459 58.4855690002458 .1263008117757 .7641601562557 .3992996215857 .03168869019 56.6622009277356 .2915191650455 .9206886291555 .550918579155 .18307876587 54.8184700012254 .4577407836954 .1020507812553 .7518806457553 .40816879272 53.0712585449252 .7418518066452 .4201202392652 .1065101623551 .80102920532 51.5038909912151 .2149200439550 .9340896606450 .6610984802250 .39569091797 50.1374816894549 .8860015869149 .6407890319849 .4012489318849 .16688156128 48.9370002746648 .7111206054748 .4885292053248 .2687988281248 .05123901367 47.8354606628447 .6208915710447 .4071998596247 .1938591003446 .98064041138 46.7671089172446 .5530509948746 .3381614685146 .1222686767645 .90512084961 45.6866111755445 .466518402145 .2448081970245 .0213203430244 .7960395813 44.5688705444344 .3398284912144 .1088905334543 .8760986328143 .64152908325 43.4052581787143 .165878295942 .92684173584

1363.697998047 1356.3060302731348.9160156251341.527954102 1334.141967773 1326.7559814451319 .370971681311 .9859619141304 .5999755861297 .213012695 1289.8249511721282 .4360351561275 .0439453121267 .6510009771260 .255004883 1252.8559570311245 .4549560551238 .0500488281230 .6429443361223 .232055664 1215.8170166021208 .3979492191200 .9759521481193 .5500488281186 .119995117 1178.6850585941171 .2469482421163 .8039550781156 .3570556641148 .906005859 1141.4510498051133 .9930419921126 .5310058591119 .0670166021111 .598999023 1104.1300048831096 .6590576171089 .1870117191081 .714965821074 .244018555 1066.7729492191059 .3050537111051 .8389892581044 .3769531251036 .920043945 1029.4680175781022 .0219726561014 .5830078121007 .151977539999 .7291870117 992.3159790039984 .9130249023977 .5206298828970 .1395874023962 .7705078125 955.4138183594948 .0698242188940 .7393188477933 .4223022461926 .1193847656 918.8306884766911 .5568847656904 .2979125977897 .0540771484889 .8258056641 882.61328125875 .4166870117868 .236328125861 .0723266602853 .9254150391 846.7952880859839 .6826782227832 .5875244141825 .5103149414818 .4511108398 811.4102783203804 .3878173828797 .3840942383790 .3991699219783 .4332885742 776.4865722656769 .5593261719762 .651184082755 .7625732422748 .893371582 742.0438232422735 .2136230469728 .4028930664721 .6116943359714 .8400878906 
708.0880737305701 .3555908203694 .6428222656687 .9495239258681 .2761230469 674.6223754883667 .9888916016661 .3756713867654 .7830200195648 .2111206055 641.6605834961635 .1317138672628 .6248779297622 .1408081055615 .6799926758 609.2429199219602 .8306274414596 .4436035156590 .0831298828583 .7496948242 577.4447021484571 .1688842773564 .9235839844558 .7100219727552 .5294189453 546.3829956055540 .2722167969534 .198425293528 .1630859375522 .1680297852 516.2144775391510 .3041992188504 .4386901855498 .6198120117492 .8489990234 487.1282043457481 .4588012695475 .8428039551470 .2815856934464 .7771911621 459.3309020996453 .9446105957448 .6195983887443 .3577880859438 .1604003906 433.0291137695427 .9648132324422 .9690856934418 .0429992676413 .1878051758 408.4041137695403 .6931152344399 .0552062988394 .491607666390 .0026855469 385.5893859863381 .2521057129376 .9920043945372 .809387207368 .7055969238 364.6807861328360 .7363891602356 .8721923828353 .0891113281349 .3864135742 345.7644958496342 .2215881348338 .7572937012335 .3684082031332 .0538024902 328.8086853027325 .6307067871322 .5137023926319 .4537963867316 .4432067871 313.4767150879310 .5454101562307 .6426086426304 .7587890625301 .8858032227 299.0150146484296 .137298584293 .2467041016290 .333404541287 .3967895508 284.4271850586281 .4316101074278 .4017028809275 .3515014648272 .2773132324 269.1961975098266 .1122131348263 .0404052734259 .9930114746256 .9796142578 254.0175018311251 .1076049805248 .2680053711245 .4907989502242 .7884979248 240.1463928223237 .567199707235 .0265045166232 .5151977539230 .0045013428 227.4803009033224 .9039001465222 .25390625219 .4810028076216 .5343933105 213.4080963135210 .0525054932206 .4971008301202 .6853942871198 .7185974121 194.6063995361190 .4216003418186 .1748046875181 .9759063721177 .912399292 174.0718994141170 .5854034424167 .4821929932164 .8869934082162 .7644042969 161.1903991699160 .0962982178159 .5184020996159 .3486938477159 .5471038818 160.024307251160 .6976928711161 .5021057129162 .3238983154163 .1620941162 163.9311981201164 .6551055908165 .2915039062165 .8363952637166 .2485046387 166.5401000977166 .7091064453166 .7519989014166 .6708068848166 .4707946777 166.163192749165 .7559967041165 .2646026611164 .6961975098164 .0650024414 163.3771972656162 .6446990967161 .8733062744161 .0727996826160 .249206543 159.4109039307158 .5643005371157 .7169952393156 .875793457156 .0478057861 155.2398986816154 .4589996338153 .7111968994153 .0037994385152 .3390960693 151.7241973877151 .1558074951150 .6383056641150 .1618041992149 .724899292 149.3115997314148 .9134063721148 .5095062256148 .0838928223147 .6132965088 147.0760955811146 .4494018555145 .7077026367144 .8309020996143 .7920074463 142.5744934082141 .154296875139 .5057983398137 .6109924316135 .3934020996 132.7944030762129 .775100708126 .3226013184122 .3927001953117 .9693984985 113.0737991333107 .7241973877101 .985801696895 .923271179289 .72088623047 83.5662765502977 .8940277099673 .1597290039169 .8741226196368 .56083679199 68.5682067871169 .3704605102570 .3112030029370 .7730026245170 .73319244385 69.8853073120168 .3378067016665 .8177185058663 .2113800048861 .58927154541 60.2244491577158 .5916404724157 .0224800109955 .6221618652354 .42512893677 53.5504417419452 .9750595092852 .7782707214452 .884628295953 .24510955811 53.8037986755454 .529159545955 .3538589477556 .2306785583557 .12826919556 57.996929168758 .8003005981459 .4575195312559 .9966392517160 .42321014404 
60.7251510620160 .9005813598660 .9424400329660 .8508911132860 .65303039551 60.3817100524960 .0573883056659 .7107315063559 .3464088439958 .9793510437 58.6086997985858 .2376518249557 .8655281066957 .4914207458557 .11573028564 56.7377090454156 .3583793640155 .9782600402855 .598350524955 .22003173828 54.8440208435154 .4718704223654 .1040382385353 .7419204711953 .38579940796 53.0368003845252 .6950912475652 .3614883422952 .0360298156751 .71921920776 51.410991668751 .1114997863850 .8205986022950 .5381317138750 .26385879517 49.9973793029849 .7383689880449 .4862403869649 .2405891418549 .00069046021 48.7660789489748 .5359687805248 .3098793029848 .0870094299347 .8669090271 47.6488304138247 .4323806762747 .2168998718347 .0020713806246 .78731918335 46.572399139446 .3568496704146 .1404991149945 .9229507446345 .70410919189 45.4836692810145 .2615394592345 .0374984741244 .811519622844 .5834197998 44.3531990051344 .1207695007343 .8861389160243 .64926910443 .41020965576 43.1690406799342 .925640106242 .6805610656742 .43305969238 1368.2650146481360 .8430175781353 .4189453121345 .9980468751338 .578979492 1331.1610107421323 .7430419921316 .3249511721308 .9069824221301 .489013672 1294.0689697271286 .6479492191279 .2249755861271 .8000488281264 .373046875 1256.9429931641249 .5109863281242 .0760498051234 .6369628911227 .1960449221219 .75 1212.3010253911204 .8480224611197 .3919677731189 .9310302731182 .465942383 1174.9969482421167 .5240478521160 .0460205081152 .5639648441145 .078979492 1137.5889892581130 .0970458981122 .6009521481115 .1020507811107 .600952148 1100.0980224611092 .5939941411085 .089965821077 .5849609381070 .08203125 1062.5799560551055 .0810546881047 .5839843751040 .0920410161032 .604980469 1025.1240234381017 .6489868161010 .1820068361002 .721984863995 .2717895508 987.8311157227980 .400390625972 .9805908203965 .5720214844958 .1754760742 950.7910766602943 .4197998047936 .0614013672928 .7166748047921 .3856811523 914.0689697266906 .7667236328899 .4791870117892 .2066040039884 .9492797852 877.7075805664870 .481628418863 .271484375856 .0780029297848 .9011230469 841.7410888672834 .5983886719827 .4730834961820 .3654785156813 .2760009766 806.2047119141 799.1516723633792.1173706055 785.1019287109 778.1052856445 771.1279296875764 .1696777344757 .2310180664750 .3115844727743 .4116821289 736.5313720703729 .670715332722 .8295288086716 .0081787109709 .2067260742 702.4249267578695 .6630859375688 .9213256836682 .1995239258675 .4981079102 668.8170776367662 .1569824219655 .5178833008648 .9002075195642 .3040771484 635.7305297852629 .1795043945622 .6517944336616 .1478881836609 .6685180664 603.2142944336596 .7861938477590 .3848876953584 .0115966797577 .6671142578 571.3524169922565 .0687255859558 .817199707552 .5989990234546 .4155273438 540.2680053711534 .1578979492528 .0864868164522 .055480957516 .0662841797 510.120513916504 .2193908691498 .3649902344492 .55859375486 .8020935059 481.0968017578475 .4446105957469 .8468933105464 .3055114746458 .8218994141 453.3976135254448 .0340881348442 .7331848145437 .4957885742432 .3239135742 427.2181091309422 .1802062988417 .2109069824412 .3116149902407 .4826965332 402.7257080078398 .040802002393 .429107666388 .8908996582384 .4270935059 380.037902832375 .7243041992371 .4865112305367 .325592041363 .241607666 359.2355957031355 .3071899414351 .4573974609347 .6850891113343 .9909057617 340.3727111816336 .8304138184333 .3609924316329 .963104248326 .6325073242 
323.3667907715320 .1604003906317 .0093994141313 .9071960449310 .8483886719 307.8255004883304 .8317871094301 .8597106934298 .9013061523295 .949798584 292.996887207290 .037902832287 .0650024414284 .0768127441281 .0674133301 278.0405883789274 .9928894043271 .9335021973268 .862487793265 .790802002 262.7233886719259 .6715087891256 .6453857422253 .6520996094250 .703704834 247.8034057617244 .9633026123242 .1790924072239 .4571075439236 .7861938477 234.1663970947231 .5796051025229 .0146026611226 .4470062256223 .8591003418 221.2225952148218 .5164031982215 .7062072754212 .7518005371209 .6555938721 206.3916015625202 .9736938477199 .3697967529195 .6564025879191 .8648986816 188.0390014648184 .1936035156180 .411895752176 .7630004883173 .3195953369 170.1806945801167 .37550354164 .9846038818163 .0021057129161 .4835968018 160.3780059814159 .6920013428159 .3618927002159 .3594970703159 .612701416 160.0550994873160 .629196167161 .2480926514161 .9024963379162 .5406951904 163.1622924805163 .7333068848164 .2350006104164 .6278991699164 .916305542 165.0924072266165 .1560058594165 .1031036377164 .9416046143164 .6782989502 164.3229064941163 .8856964111163 .3751983643162 .8025970459162 .1748962402 161.5021972656160 .7910003662160 .0498046875159 .2848968506158 .5039978027 157.713104248156 .9194030762156 .1286010742155 .3477935791154 .5823059082 153.8386993408153 .121307373152 .4365997314151 .7859954834151 .1750030518 150.6007995605150 .0657958984149 .561706543149 .0859069824148 .6246948242 148.1690063477147 .7008056641147 .2044067383146 .6595001221146 .0453948975 145.3417053223144 .524597168143 .5746002197142 .4671936035141 .1851959229 139.7059020996138 .0043945312136 .0650939941133 .8029937744131 .1390075684 128.0606994629124 .552696228120 .5915985107116 .1557998657111 .2682037354 105.9425964355100 .246299743794 .2502593994188 .0849761962981 .89814758301 75.9092788696370 .1796569824266 .4779968261766 .7203369140668 .8034362793 70.9984512329172 .9667587280374 .2237167358474 .7270736694374 .08516693115 72.5349731445370 .0189132690467 .2079696655364 .9711380004962 .92073822021 60.7724189758358 .7338294982956 .9009284973155 .3453483581554 .20922088623 53.4495811462453 .1121406555253 .1428108215353 .4576110839853 .99900054932 54.7240791320855 .5636291503956 .4602699279857 .377231597958 .24573135376 59.0319900512759 .6536102294960 .1419486999560 .5155715942460 .75799942017 60.8686599731460 .861740112360 .7420310974160 .5303192138760 .23765945435 59.8880805969259 .5189094543559 .1341896057158 .74916839658 .36277008057 57.9779205322357 .5932693481457 .2077217102156 .8212203979556 .43291854858 56.0437507629455 .6541709899955 .2653198242254 .8785209655854 .49468994141 54.1152915954653 .7409515380953 .3729515075753 .0116806030352 .65813827515 52.3125686645551 .9756698608451 .6474990844751 .3284683227551 .01847076416 50.7176208496150 .4256706237850 .1424789428749 .8676910400449 .60091018677 49.3417282104549 .0895805358948 .8439598083548 .6041908264248 .36970901489 48.1397399902347 .9137115478547 .690849304247 .4706115722747 .25223922729 47.035289764446 .8190689086946 .6032295227146 .3871803283746 .17065811157 45.9531707763745 .7345390319845 .5143890380945 .2925910949745 .06885910034 44.8430709838944 .6150588989344 .3847312927244 .1519508361843 .91672897339 43.6789283752443 .438610076943 .1957092285242 .9502906799342 .7024307251 42.4522285461442 .1977882385341 .94282150269 
1372.8270263671365 .3699951171357 .9129638671350 .4599609381343 .008056641 1335.5579833981328 .1090087891320 .6590576171313 .2089843751305 .759033203 1298.3079833981290 .8559570311283 .4019775391275 .9470214841268 .489013672 1261.0290527341253 .5660400391246 .0999755861238 .6309814451231 .159057617 1223.6839599611216 .2049560551208 .7220458981201 .2349853521193 .744018555 1186.2490234381178 .7490234381171 .245971681163 .7380371091156 .225952148 1148.7089843751141 .1889648441133 .6660156251126 .1379394531118 .609008789 1111.0760498051103 .5419921881096 .0059814451088 .4689941411080 .932006836 1073.3959960941065 .8599853521058 .3270263671050 .796997071043 .270996094 1035.7490234381028 .2320556641020 .7219848631013 .2180175781005 .721984863 998.234375990 .7559814453983 .2871704102975 .828918457968 .3812255859 960.9450073242953 .520690918946 .108581543938 .7092895508931 .3228759766 923.950012207916 .5908203125909 .2454833984901 .9144897461894 .5980834961 887.2965698242880 .0100708008872 .7387695312865 .4832763672858 .2437744141 851.0206298828843 .8137817383836 .6240844727829 .4514160156822 .296081543 815.1585083008808 .0388793945800 .9373779297793 .8543701172786 .7899169922 779.7442016602772 .7175292969765 .7098999023758 .7216796875751 .7529296875 744.8035888672737 .8737792969730 .9638061523724 .0734863281717 .2031860352 710.3527832031703 .5227050781696 .7125854492689 .9227905273683 .1533813477 676.4047851562669 .6771850586662 .9708251953656 .2858886719649 .6229248047 642.9821777344636 .3641967773629 .7694702148623 .1987304688616 .6522827148 610.1309204102603 .6353759766597 .1663818359590 .7249755859584 .3120117188 577.9282836914571 .575012207565 .2531738281558 .9639282227552 .7086181641 546.4882202148540 .3041992188534 .1578979492528 .0507202148521 .9838867188 515.9592285156509 .9779052734504 .0415039062498 .1517028809492 .3099060059 486.517791748480 .7767028809475 .0885009766469 .454498291463 .8764038086 458.3555908203452 .8937072754447 .4920959473442 .1521911621436 .8753967285 431.6630859375426 .5162963867421 .4366149902416 .4245910645411 .4815979004 406.6083068848401 .8057861328397 .0744934082392 .4153137207387 .8284912109 383.3150024414378 .874786377374 .5087890625370 .2168884277366 .0003051758 361.8584899902357 .7926940918353 .8020935059349 .8876953125346 .0484008789 342.2844848633338 .5942077637334 .9772033691331 .4305114746327 .9531860352 324.5411987305321 .1922912598317 .9010925293314 .6643981934311 .4758911133 308.3309020996305 .2225952148302 .1449890137299 .0914001465296 .0548095703 293.0296936035290 .008605957286 .9881896973283 .9610900879280 .9277038574 277.8814086914274 .8273010254271 .7604064941268 .6900939941265 .6145935059 262.5448913574259 .4840087891256 .4418029785253 .4259033203250 .4423065186 247.5019073486244 .6049957275241 .7626037598238 .9685974121236 .2306060791 233.5354003906230 .8845977783228 .258895874225 .6515045166223 .0379943848 220.4044036865217 .7265930176214 .9877929688212 .1652984619209 .225402832 206.1802978516203 .0084991455199 .7312927246196 .3119049072192 .8298950195 189.3058013916185 .7855072021182 .2734069824178 .842300415175 .5435943604 172.4329986572169 .5968017578167 .040802002164 .832901001162 .9658050537 161.5130004883160 .404296875159 .646697998159 .1914978027159 .0395965576 159.1186981201159 .37449646159 .7640991211160 .2093963623160 .7149963379 161.2339019775161 .761505127162 .2543029785162 .7005004883163 .0576019287 
163.328704834163 .4980926514163 .5675964355163 .533493042163 .4010009766 163.1755981445162 .8641052246162 .4759979248162 .0177001953161 .5160 .9284973145 160.3132019043159 .6591949463158 .975402832158 .266998291157 .541595459 156.804397583156 .0621948242155 .3199005127154 .5838928223153 .8583984375 153.1493988037152 .4598999023151 .7958984375151 .1575012207150 .5498046875 149.9691009521149 .4179992676148 .8876953125148 .3766021729147 .870803833 147.3630065918146 .8354949951146 .2752075195145 .6622009277144 .9786987305 144.2046051025143 .3191986084142 .3027038574141 .1338043213139 .7928009033 138.2606048584136 .5086975098134 .5343933105132 .2382965088129 .5395050049 126.4328994751122 .9233016968118 .9773025513114 .5916976929109 .7736968994 104.555702209598 .9864425659293 .1738128662187 .1829376220781 .14433288574 75.2481613159268 .9629135131865 .0175476074266 .5296478271570 .19278717041 73.3367385864376 .2718124389678 .4693222045979 .488838195878 .95655059814 77.209823608474 .7069625854571 .8083267211968 .9725875854566 .18125152588 63.4514808654860 .8735618591358 .4889183044456 .5090904235855 .08797073364 54.1707305908253 .6859283447353 .5779304504453 .8058395385754 .28633117676 55.01284027155 .8647918701256 .7951202392657 .7424201965358 .58826065063 59.3355407714859 .8941307067960 .3060913085960 .6132392883360 .78984832764 60.8449707031260 .7898292541560 .6363601684660 .3955497741760 .07545089722 59.7002296447859 .3116798400958 .9098587036158 .5091209411658 .10906982422 57.710800170957 .3140487670956 .9165306091356 .5187683105556 .11954116821 55.7198982238855 .3204803466854 .9222717285254 .5269813537654 .13521957397 53.7489318847753 .3683586120652 .9951705932652 .6293792724652 .27227020264 51.9237594604551 .5846900939951 .2548904418950 .9348106384350 .62419891357 50.323108673150 .0312614440949 .748329162649 .4740295410249 .20777130127 48.9492416381848 .69768142748 .4527282714848 .2135200500547 .97961044312 47.7500801086447 .5244598388747 .3018112182647 .0816688537646 .86315917969 46.6458587646546 .4290084838946 .2122688293545 .994979858445 .77690887451 45.5575103759845 .3366203308145 .1138610839844 .8890800476144 .66199111938 44.4325103759844 .2004203796443 .965679168743 .7281417846743 .48778915405 43.2445411682142 .9984092712442 .7493591308642 .4974288940442 .2427482605 41.9850997924841 .7251892089841 .46203994751

1377.3759765621369 .8890380861362 .3990478521354 .913940431347 .431030273 1339.9489746091332 .4680175781324 .9870605471317 .5059814451310 .025024414 1302.542968751295 .0600585941287 .5760498051280 .089965821272 .602050781 1265.1120605471257 .6190185551250 .1230468751242 .6240234381235 .121948242 1227.6169433591220 .1080322271212 .5949707031205 .078002931197 .557983398 1190.0319824221182 .5030517581174 .9689941411167 .4310302731159 .889038086 1152.3420410161144 .7919921881137 .2370605471129 .6789550781122 .118041992 1114.5550537111106 .9890136721099 .4210205081091 .8520507811084 .282958984 1076.7139892581069 .1450195311061 .5789794921054 .0150146481046 .453979492 1038.8969726561031 .3459472661023 .7999877931016 .2600097661008 .728027344 1001.20300293993.6871948242986.180480957978.6837768555971.1973266602 963.7218017578956 .2576293945948 .8054199219941 .3651733398933 .9376220703 926.5228881836919 .1215209961911 .7335205078904 .3596191406896 .9995727539 889.6541748047882.323425293875.0076293945 867.7069702148 860.4221191406 
853.1528930664845 .9000854492838 .6638183594831 .4442749023824 .2418212891 817.0568237305809 .8895263672802 .7401123047795 .6088867188788 .4962158203 781.4019775391774 .3267822266767 .2703857422760 .2335205078753 .2158813477 746.2178955078739 .2393798828732 .2808227539725 .3419799805718 .4235229492 711.5250854492704 .6469726562697 .7893066406690 .9522705078684 .1359863281 677.3408813477670 .5670776367663 .8151245117657 .0850219727650 .3771972656 643.692199707637 .0305786133630 .3927001953623 .7791748047617 .1906738281 610.6278076172604 .0913696289597 .5819702148591 .1007080078584 .6483154297 578.2258300781571 .8342285156565 .4744873047559 .1478271484552 .8552856445 546.5983886719540 .378112793534 .1958007812528 .0526733398521 .9506225586 515.8903198242509 .8738098145503 .9021911621497 .9772033691492 .1000061035 486.2724914551480 .4959106445474 .7719116211469 .1017150879463 .4870910645 457.9294128418452 .4302062988446 .9905090332441 .6122131348436 .2961120605 431.0439147949425 .8565063477420 .7354125977415 .6812133789410 .6951904297 405.7778930664400 .9305114746396 .1534118652391 .4473876953386 .8128051758 382.2503051758377 .7600097656373 .342590332368 .9979858398364 .7268981934 360.5289916992356 .4049987793352 .3544006348348 .3778076172344 .4739990234 340.6433105469336 .8839111328333 .1954956055329 .5755004883326 .0227050781 322.5335083008319 .1058044434315 .7348937988312 .4176025391309 .1482849121 305.9227905273302 .7349853516299 .579498291296 .4505004883293 .342010498 290.2491149902287 .1655883789284 .0884094238281 .0120849609277 .9359130859 274.8559875488271 .774597168268 .6900024414265 .607208252262 .5271911621 259.4567871094256 .3999023438253 .3636016846250 .353805542247 .3760070801244 .4375 241.5402069092238 .6903991699235 .8851928711233 .1278991699230 .4096984863 227.7286987305225 .070602417222 .4272003174219 .7799987793217 .1145935059 214.4134063721211 .6600952148208 .8408966064205 .933303833202 .9459075928 199.8666992188196 .712600708193 .470993042190 .1920928955186 .8988037109 183.6302032471180 .4082946777177 .2778930664174 .2742004395171 .4472045898 168.862197876166 .524307251164 .4732055664162 .7207946777161 .3200073242 160.2200012207159 .4098052979158 .8665924072158 .591003418158 .5265960693 158.6248016357158 .8556976318159 .1734008789159 .5626068115159 .9837036133 160.420501709160 .8370056152161 .2174072266161 .529800415161 .7711029053 161.925201416161 .9931030273161 .9689025879161 .8583068848161 .662399292 161.3887023926161 .0428924561160 .6320037842160 .1638946533159 .6448059082 159.0827026367158 .4830932617157 .8535003662157 .1990966797156 .5265960693 155.8408050537155 .1477050781154 .4515991211153 .758102417153 .070602417 152.3941955566151 .7312011719151 .0863037109150 .4597015381149 .8549041748 149.2689056396 148.7028961182148.1495056152147.6058959961 147.0605010986 146.5052032471145 .9248962402145 .3065948486144 .6329040527143 .8865966797 143.0498962402142 .1027984619141 .0276031494139 .803604126138 .412902832 136.8356018066135 .0487976074133 .0444030762130 .7362060547128 .0431976318 124.9693984985121 .5074996948117 .6455993652113 .3747024536108 .717300415 103.69390106298 .3780517578192 .8492736816487 .2368316650481 .68669891357 76.4104537963971 .4446868896568 .6249771118269 .8469390869173 .08924102783 76.5632095336980 .1761627197382 .9056015014683 .8199996948282 .90560150146 82.0579986572379 .2798233032276 .1920928955173 .0463714599669 .82247161865 
66.6253433227563 .4954681396560 .3633384704657 .7450103759856 .1633605957 55.2104415893654 .5461311340354 .2446403503454 .3236694335954 .71475982666 55.4077415466356 .2701492309657 .2427101135358 .228939056459 .04639053345 59.7313499450760 .211219787660 .5295600891160 .7463188171460 .84621047974 60.839988708560 .7365608215360 .5373001098660 .2580604553259 .9058303833 59.5039787292559 .0928497314558 .67465972958 .2600212097257 .8475189209 57.437358856257 .0284996032756 .6190795898456 .2093505859455 .79851150513 55.387699127254 .9776992797954 .5697708129954 .1655311584553 .76594924927 53.3727188110452 .9864196777352 .6084213256852 .238979339651 .87907028198 51.5287208557151 .1885414123550 .8583602905350 .5384597778350 .22850036621 49.9284400939949 .6378593444849 .3563995361349 .0835990905848 .81888961792 48.5618095397948 .31166839648 .0679588317947 .8299217224147 .59698104858 47.36832046509 47.14334106445 46.9211997985846.7013206481946.48286056519 46.2653198242246 .0479583740245 .8303794860845 .6119117736845 .3922996521 45.1710090637244 .9478492736844 .7224388122644 .4946289062544 .26412963867 44.0308799743743 .794639587443 .555389404343 .3129692077643 .06739044189 42.8185501098642 .5664901733442 .3111495971742 .052600860641 .79096984863 41.5263404846241 .2563514709540 .98495864868 1381.9169921881374 .3959960941366 .8751359 .3590087891351 .8449707031344 .33203125 1336.8199462891329 .3079833981321 .796997071314 .285034181306 .772949219 1299.2600097661291 .745971681284 .2299804691276 .7120361331269 .192016602 1261.6689453121254 .1440429691246 .6159667971239 .0839843751231 .548950195 1224.0100097661216 .4680175781208 .921997071201 .3719482421193 .817016602 1186.2580566411178 .6939697271171 .1259765621163 .5539550781155 .977050781 1148.3959960941140 .8110351561133 .2230224611125 .6309814451118 .036010742 1110.4389648441102 .8389892581095 .2380371091087 .6369628911080 .03503418 1072.4339599611064 .8339843751057 .2359619141049 .6409912111042 .050048828 1034.4639892581026 .8819580081019 .3070068361011 .7379760741004 .177001953 996.6237792969989 .0795288086981 .5446166992974 .0194702148966 .5048828125 959.0012207031951 .5089111328944 .0281982422936 .5595703125929 .103515625 921.6602172852914 .2299804688906 .8134155273899 .4102783203892 .0213012695 884.6467285156877 .2866210938869 .9415283203862 .6115112305855 .2971801758 847.9985961914840 .7163085938833 .4505004883826 .2014770508818 .9697265625 811.7551879883804 .5587158203797 .3798828125790 .2194213867783 .0775146484 775.954284668768 .8499755859761 .7650146484754 .69921875747 .6530761719 740.6265869141733 .6201171875726 .633605957719 .6674194336712 .7213745117 705.796081543698 .891418457692 .0078125685 .1452026367678 .3041992188 671.4849243164664 .6876831055657 .912902832651 .1608886719644 .4323120117 637.7272949219631 .0468139648624 .3909912109617 .7608032227611 .1569213867 604.5797729492598 .0302734375591 .5095214844585 .0181274414578 .5570068359 572.1273193359565 .7299194336559 .366027832553 .0366821289546 .7432861328 540.4868164062534 .2686767578528 .0900878906521 .9523925781515 .8568725586 509.8052062988503 .798614502497 .8384094238491 .9262084961486 .0633850098 480.2513122559474 .4914855957468 .7854003906463 .1346130371457 .5401916504 452.0038146973446 .5264892578441 .1098937988435 .7550048828430 .4632873535 425.2356872559420 .0734863281414 .9775085449409 .9489135742404 .9883117676 
400.0965881348395 .2742919922390 .5220947266385 .8403015137381 .2297058105 376.6900939941372 .2222900391367 .8258972168363 .5017089844359 .2491149902 355.0687866211350 .9601135254346 .9233093262342 .9574890137339 .062713623 335.2372131348331 .4808044434327 .7908935547324 .1665039062320 .6041870117 317.1021118164313 .6560058594310 .2630004883306 .9180908203303 .6173095703 300.3555908203297 .1278076172293 .9292907715290 .7543945312287 .599395752 284.4583129883281 .3294067383278 .2070922852275 .092010498271 .9794921875 268.8727111816265 .7690124512262 .6734008789259 .5855102539256 .5118103027 253.4542999268250 .4190979004247 .4109039307244 .43359375241 .4933929443 238.5908966064235 .7324066162232 .9136047363230 .1387023926227 .3981018066 224.6920928955222 .0065002441219 .3361053467216 .6641998291213 .9806060791 211.2702026367208 .5182952881205 .7191925049202 .8551940918199 .9365997314 196.9470977783193 .9145050049190 .8307037354187 .7373046875184 .6383972168 181.5847015381178 .6020050049175 .720703125172 .9606933594170 .3641052246 167.9889984131165 .828994751163 .9196014404162 .2633056641160 .9174041748 159.8273010254158 .9911956787158 .386505127158 .0229034424157 .8486022949 157.8227996826157 .9313964844158 .1459960938158 .4418029785158 .7716064453 159.1248016357159 .4613952637159 .774597168160 .0350036621160 .2400054932 160.3717956543160 .4313049316160 .4109039307160 .3148956299160 .1427001953 159.8999023438159 .591293335159 .2221984863158 .7996063232158 .3285064697 157.8162994385157 .2675933838156 .6894989014156 .0861968994155 .4640960693 154.8271026611154 .1808929443153 .5287017822152 .87550354152 .2238006592 151.5782928467150 .9400024414150 .3135986328149 .6979064941149 .0968017578 148.5061035156147 .9277038574147 .3536071777146 .7819976807146 .2010040283 145.6045074463144 .9772949219144 .3085021973143 .5811004639142 .7805938721 141.8889007568140 .8890991211139 .7631988525138 .4933929443137 .0610961914 135.450302124133 .6381072998131 .6219024658129 .3202972412126 .6684036255 123.6613006592120 .2965011597116 .5650024414112 .4692993164108 .0329971313 103.2816009521 98.2993392944393.14948272705 88.04509735107 83.14057922363 78.8938903808675 .7231979370174 .1958236694374 .7850265502976 .98281860352 80.2051162719782 .2959976196384 .1248016357485 .3440017700285 .95359802246 85.3440017700283 .5821609497180 .4290084838977 .1369781494173 .70523834229 70.1664962768666 .6144790649462 .8409500122159 .6305007934657 .81412124634 56.7028808593855 .7139816284255 .1306495666554 .9853706359955 .2172203064 55.8773117065456 .7865409851157 .8674812316958 .9220886230559 .68278884888 60.2363891601660 .5796890258860 .7826805114760 .893138885560 .90845870972 60.8509483337460 .6930084228560 .4404182434160 .1034202575759 .71458816528 59.2929496765158 .8661689758358 .4378700256358 .0116081237857 .58856964111 57.1656799316456 .7439384460456 .3208312988355 .8973693847755 .47330856323 55.04965972954 .6280593872154 .2092514038153 .7956809997653 .38771057129 52.9877395629952 .5957298278852 .2136001586951 .8410415649451 .47938156128 51.1281585693450 .7881584167550 .458850860650 .1405105590849 .83259963989 49.5349311828649 .2469902038648 .9682197570848 .6981697082548 .43601989746 48.1814193725647 .9334411621147 .6917495727547 .455360412647 .22391891479 46.9964218139646 .7724189758346 .5509414672946 .3315010070846 .11315917969 45.8954811096245 .6776313781745 .4592208862345 .2395782470745 .018409729 
44.7951812744144 .5696907043544 .3415489196844 .1106185913143 .87662887573 43.6394805908243 .3989715576243 .1550712585442 .907649993942 .65668869019 42.4021301269542 .143978118941 .8822097778341 .6168785095241 .34814071655 41.0756912231440 .8004302978540 .52111816406 1386.4449462891378 .8940429691371 .3420410161363 .7950439451356 .251348 .706054688 1341.163940431333 .6219482421326 .0810546881318 .538940431310 .996948242 1303.4549560551295 .9110107421288 .3649902341280 .8179931641273 .267944336 1265.7170410161258 .1619873051250 .6040039061243 .0439453121235 .479980469 1227.9119873051220 .339965821212 .7650146481205 .1850585941197 .600952148 1190.0129394531182 .4200439451174 .8220214841167 .2199707031159 .613037109 1152.0019531251144 .3869628911136 .7679443361129 .1450195311121 .520019531 1113.8909912111106 .2600097661098 .6269531251090 .9940185551083 .359985352 1075.7259521481068 .0930175781060 .461059571052 .8330078121045 .20703125 1037.586059571029 .9689941411022 .3579711911014 .7529907231007 .156005859 999.5654907227991 .983581543984 .4107055664976 .8472290039969 .2938232422 961.7506713867954 .2186279297946 .6976928711939 .1884155273931 .6912231445 924.2064208984916 .7343139648909 .2753295898901 .8295288086894 .3975219727 886.979309082879 .575378418872 .1860961914864 .8115844727857 .4523925781 850.1088256836842 .7808837891835 .4694213867828 .1743164062820 .8961181641 813.6351928711806 .391784668799 .1661987305791 .9586181641784 .7694091797 777.598815918770 .4472045898763 .3146972656756 .2014160156749 .1077880859 742.0341186523734 .9802246094727 .946472168720 .9331054688713 .9404296875 706.9683227539700 .0172729492693 .0875854492686 .1793212891679 .2927856445 672.428527832665 .5866699219658 .7677001953651 .9719848633645 .2000732422 638.4523925781631 .7294921875625 .0319213867618 .3604736328611 .7156982422 605.0983886719598 .5092163086591 .9489746094585 .4188232422578 .9193725586 572.4517822266566 .0170288086559 .6160888672553 .2501831055546 .9204101562 540.6279296875534 .3740844727528 .1599731445521 .987121582515 .8563842773 509.7697143555503 .7279968262497 .7329101562491 .7856140137485 .8876953125 480.0403137207474 .2450866699468 .503112793462 .816192627457 .1852111816 451.611907959446 .0972900391440 .6427001953435 .2492980957429 .9184875488 424.6510925293419 .4483947754414 .3110046387409 .2403869629404 .2367858887 399.3013916016 394.434387207389.6368103027 384.9085998535 380.2506103516 375.662689209371 .1452941895366 .6983947754362 .3222961426358 .0165100098 353.7814941406349 .6164855957345 .5219116211341 .4963989258337 .5403137207 333.6517028809329 .8305053711326 .0741882324322 .3818054199318 .7503967285 315.1781921387311 .6614074707308 .1972961426304 .7815856934301 .4106140137 298.0798950195294 .7849121094291 .5216064453288 .2851867676285 .0722045898 281.8778991699278 .7004089355275 .5354003906272 .3828125269 .2394104004 266.1069030762262 .9838867188259 .8734130859256 .7757873535253 .6952056885 250.6340942383247 .5962982178244 .5861053467241 .6060943604238 .6614074707 235.7525024414232 .883895874230 .0525970459227 .2610015869224 .5023956299 221.775100708219 .0691986084216 .37840271213 .691192627210 .9974060059 208.286895752205 .5476074219202 .7763061523199 .961807251197 .1107940674 194.2162017822191 .2978973389188 .3578033447185 .4228973389182 .5048065186 179.6390991211176 .8522033691174 .1696014404171 .6116027832169 .2084960938 
166.99949646164 .9880981445163 .1985015869161 .6354980469160 .3305969238 159.2552032471158 .4066009521157 .7684936523157 .3395996094157 .0845947266 156.9745941162156 .9936065674157 .1163024902157 .3182983398157 .5630950928 157.8325042725158 .0979003906158 .3475036621158 .5588989258158 .7265930176 158.8345031738158 .8820037842158 .8609008789158 .7743988037158 .620300293 158.403503418158 .1266021729157 .7946929932157 .4127044678156 .9857025146 156.5191955566156 .0180969238155 .4878997803154 .9329071045154 .3583068848 153.7677001953153 .1656951904152 .5550994873151 .9402008057151 .3226928711 150.7064971924150 .0924072266149 .4835968018148 .8795928955148 .2825927734 147.6894989014147 .100692749146 .5097961426145 .9138946533145 .3031005859 144.6705932617144 .0034942627143 .2910003662142 .5182037354141 .6710968018 140.7339935303139 .6903991699138 .5247039795137 .2196960449135 .7597961426 134.1269989014132 .3103027344130 .3105926514128 .0523986816125 .4608001709 122.5509033203119 .3196029663115 .7701034546111 .9013977051107 .7535018921 103.350898742798.7953720092894.15588378906 89.66416168213 85.47141265869 82.0988693237379 .9063034057678 .9024124145579 .4603500366281 .1637878418 83.920059204184 .7343978881886 .25839996338117 .957603454687 .78240203857 88.0871963501 87.30139923096 84.36279296875 81.14897155762 77.66999053955 73.9737014770570 .1761322021566 .2979583740262 .8667106628460 .47574996948 58.7208900451757 .2504692077656 .2526588439955 .7711181640655 .78834915161 56.3999481201257 .4040298461958 .7342185974159 .9783897399960 .57051086426 60.844451904361 .0030899047961 .0602912902861 .0473785400460 .97647857666 60.8887710571360 .7025184631360 .3539009094259 .9242782592859 .49678039551 59.0635986328158 .6304016113358 .1992111206157 .7671394348157 .33441925049 56.8995399475156 .4631805419956 .0248413085955 .5856208801355 .14622116089 54.708141326954 .2731018066453 .8424797058153 .4183998107953 .00180053711 52.5946006774952 .1972503662151 .8111495971751 .4362983703651 .07357025146 50.7226791381850 .3839607238850 .056919097949 .7415008544949 .4370803833 49.1432609558148 .8593406677248 .5846595764248 .3185501098648 .06019973755 47.8090400695847 .5642089843847 .3252182006847 .0912094116246 .86167907715 46.6357994079646 .4130096435546 .1924400329645 .9735412597745 .75545120239 45.5376396179245 .3193283081145 .1000900268644 .8792304992744 .65645980835 44.4312095642144 .2033081054743 .9723396301343 .7381782531743 .50054931641 43.2593803405843 .0144615173342 .765769958542 .5131683349642 .256690979 41.996231079141 .7318382263241 .4634704589841 .1912117004440 .91519927979 40.6355514526440 .3494606018140 .06111907959 1390.9630126951383 .3800048831375 .7979736331368 .2209472661360 .645996094 1353.0720214841345 .51337 .9289550781330 .3580322271322 .7869873051315 .21496582 1307.6429443361300 .0699462891292 .4949951171284 .9189453121277 .340942383 1269.7600097661262 .1770019531254 .589965821247 .0009765621239 .407958984 1231.8110351561224 .211059571216 .6070556641208 .9980468751201 .385009766 1193.7669677731186 .1450195311178 .5179443361170 .8859863281163 .251155 .609008789 1147.9639892581140 .3139648441132 .6610107421125 .0050048831117 .344970703 1109.6829833981102 .0190429691094 .3530273441086 .6860351561079 .020019531 1071.3540039061063 .6889648441056 .0269775391048 .3669433591040 .71105957 1033.0589599611025 .4129638671017 .7719726561010 .1380004881002 .510986328 
994.8920288086987 .2813720703979 .6796875972 .0875854492964 .5053710938 956.9337158203949 .3729248047941 .8231811523934 .2852172852926 .7592163086 919.2454833984911 .7443847656904 .2562866211896 .7814941406889 .3203125 881.8729858398874 .4398803711867 .0214233398859 .6176757812852 .2293701172 844.8565063477837 .4995727539830 .1588745117822 .8350830078815 .5280761719 808.2385253906 800.9664916992793.7125244141 786.4766235352 779.2592163086 772.0607299805764 .8812866211757 .7211914062750 .5806884766743 .4600219727 736.359375729 .2791137695722 .2191772461715 .1801147461708 .1619873047 701.165222168694 .1898803711687 .236328125680 .3051147461673 .3961791992 666.5101928711659 .6475219727652 .8084716797645 .9937133789639 .2036132812 632.4387817383625 .6998291016618 .9874267578612 .3021240234605 .6447753906 599.0161743164592 .4169921875585 .8482055664579 .3107299805572 .8054199219 566.3333740234559 .8956298828553 .4932250977547 .1273193359540 .7988891602 534.5095214844528 .2600097656522 .0518798828515 .8862304688509 .7644958496 503.6878967285497 .6578979492491 .6756896973485 .7427062988479 .8601989746 474.0296020508468 .2520141602462 .5291137695456 .8617858887451 .2518005371 445.700012207440 .2077941895434 .7762145996429 .4065856934424 .0997924805 418.8569030762413 .6787109375408 .56640625403 .5205078125398 .5419006348 393.6308898926388 .7883911133384 .0145874023379 .3099060059374 .6742858887 370.1084899902365 .611907959361 .1850891113356 .8273925781352 .5393066406 348.3197937012344 .1693115234340 .0864868164336 .0715026855332 .1225891113 328.2395019531324 .4200134277320 .6632995605316 .9666137695313 .3281860352 309.7448120117306 .2138977051302 .7318115234299 .2951965332295 .9000854492 292.5426025391289 .2192077637285 .9255065918282 .6588134766279 .4147033691 276.1921081543272 .9866027832269 .7987976074266 .625213623263 .4677124023 260.3241882324257 .1978149414254 .0879974365250 .9983978271247 .9302978516 244.8869934082241 .87159729238 .8861999512235 .9351043701233 .0180969238 230.1394042969227 .2958984375224 .4902954102221 .7158966064218 .9727020264 216.2514038086213 .5478057861210 .8522033691208 .1567993164205 .4548950195 202.7359924316200 .0005950928197 .2378997803194 .4582977295191 .653793335 188.8455963135186 .0319061279183 .2407989502180 .479598999177 .7792053223 175.1551971436172 .6360015869170 .2445983887167 .9987030029165 .9279022217 164.0357055664162 .3520965576160 .8672943115159 .6049041748158 .5446014404 157.6985015869157 .0404968262156 .5682983398156 .2552032471156 .0843963623 156.0341949463156 .0762023926156 .1941986084156 .3567962646156 .5502929688 156.7474060059156 .9387054443157 .1015930176157 .2321014404157 .3135070801 157.346206665157 .3204040527157 .2389068604157 .0982971191156 .9024963379 156.6528015137156 .3533935547156 .0079956055155 .620803833155 .1967926025 154.7395935059154 .2543945312153 .7444000244153 .2145996094152 .6674957275 152.1074981689151 .5361938477150 .9575958252150 .3724975586149 .7845001221 149.1934051514148 .6024932861148 .0099945068147 .4187927246146 .8247070312 146.228805542145 .6239929199145 .0088043213144 .3728942871143 .7111053467 143.0104064941142 .2622070312141 .4517059326140 .567199707139 .5933074951 138.5162963867137 .3206939697135 .9924926758134 .5164031982132 .8766937256 131.0682983398129 .1035003662126 .9054031372124 .4005966187121 .6129989624 118.5491027832115 .2158966064111 .6129989624107 .7966995239103 .7873001099 
99.7184219360495 .6470108032291 .8301467895588 .3627929687585 .66075134277 84.0249099731483 .3745498657283 .911132812585 .3339462280386 .86799621582 88.3919982910289 .0016021728589 .9160003662190 .2208023071390 .52559661865 89.9160003662187 .8991470336984 .9772109985481 .6167602539177 .87317657471 73.9603195190470 .1353073120166 .6324462890663 .6823806762761 .23728942871 59.2313690185557 .7300300598156 .756698608456 .496658325257 .06386947632 58.2122192382859 .7663993835461 .1235618591361 .5313987731961 .544921875 61.526371002261 .4096298217861 .2384109497161 .0369491577160 .88626861572 60.6451492309660 .2121009826759 .7092399597259 .2693710327158 .84365081787 58.4117393493757 .9825401306257 .5426712036157 .0990600585956 .64860153198 56.1941490173355 .7370986938555 .2785186767654 .8211593627954 .36574172974 53.9156303405853 .4712409973153 .0359191894552 .6096611022952 .19527053833 51.7923507690451 .402900695851 .0262107849150 .663501739550 .31388092041 49.9778099060149 .6543388366749 .3433494567949 .0439186096248 .75542831421 48.4770507812548 .2078018188547 .9470405578647 .6935882568447 .44704055786 47.2061805725146 .9707603454646 .7396392822346 .5125999450746 .28860092163 46.0673103332545 .8477592468345 .6295204162645 .4116516113345 .19372177124 44.9748687744144 .7547187805244 .5325393676844 .308040618944 .0806388855 43.850170135543 .6162300109943 .3786811828643 .1372489929242 .89186096191 42.6423606872642 .3886795043942 .1307296752941 .8685188293541 .60200119019 41.3311614990241 .0560188293540 .7766304016140 .4931793212940 .20531082153 39.9140892028839 .6180305481

1395.4680175781387 .8559570311380 .2430419921372 .6359863281365 .031982422 1357.4289550781349 .828002931342 .2270507811334 .6269531251327 .026977539 1319.4270019531311 .8260498051304 .2239990231296 .6199951171289 .015991211 1281.4090576171273 .7989501951266 .1879882811258 .5729980471250 .954956055 1243.3330078121235 .7080078121228 .0789794921220 .4460449221212 .808959961 1205.1669921881197 .5200195311189 .8690185551182 .2130126951174 .552001953 1166.8859863281159 .214965821151 .5400390621143 .8609619141136 .177978516 1128.4899902341120 .8000488281113 .1070556641105 .4110107421097 .713989258 1090.0150146481082 .3160400391074 .6169433591066 .9189453121059 .223022461 1051.5290527341043 .8389892581036 .1519775391028 .4709472661020 .794006348 1013.1240234381005 .460021973997 .8040161133990 .1558837891982 .5162963867 974.8858032227967 .2647094727959 .6538085938952 .0532226562944 .4635009766 936.8848876953929 .3179931641921 .762878418914 .2202148438906 .6901245117 899.1729736328 891.6688842773 884.1785888672 876.7020874023 869.2398071289 861.792175293854 .359375846 .9420776367839 .5404052734832 .1547241211 824.7855834961817 .4331054688810 .0977783203802 .7797851562795 .4799194336 788.1978149414780 .9343261719773 .6893920898766 .4636230469759 .2572021484 752.0703125744 .9033203125737 .7564697266730 .6300048828723 .5241699219 716.4392700195709 .3756103516702 .3333740234695 .3129882812688 .3148193359 681.3391113281674 .3859863281667 .4564208984660 .5502929688653 .6683959961 646.8110961914639 .9790039062633 .1727294922626 .392578125619 .6395263672 612.9141235352606 .2169799805599 .5490722656592 .9110717773586 .3040161133 579.7285766602573 .1857910156566 .676574707560 .2022094727553 .7634277344 547.3613891602 540.9973144531534.6723022461528.3875732422 522.1444091797 
515.9437866211509 .7872009277503 .6758117676497 .6109924316491 .5939025879 485.6260070801479 .708404541473 .842590332468 .0296020508462 .270904541 456.5675964355450 .9211120605445 .3323059082439 .8027954102434 .3333129883 428.925201416423 .5793151855418 .2966918945413 .0780944824407 .9247131348 402.8369140625397 .8157043457392 .8612976074387 .974609375383 .1557006836 378.4052124023373 .7229003906369 .1094055176364 .5643005371360 .0877990723 355.6795959473351 .3398132324347 .0675964355342 .8630065918338 .7250061035 334.6534118652330 .6467895508326 .7047119141322 .8251953125319 .0073852539 315.2488098145311 .5479125977307 .9017028809304 .3081054688300 .7636108398 297.2655029297293 .8100891113290 .3941040039287 .0143127441283 .6671142578 280.3499145508277 .0592041016273 .7934875488270 .5498046875267 .3276062012 264.124786377260 .941986084257 .7780151367254 .6342010498251 .5110015869 248.4102020264245 .333404541242 .2825927734239 .2604064941236 .2684020996 233.3096923828230 .3847961426227 .496307373224 .6425018311221 .8249053955 219.0388946533216 .2834014893213 .5522003174210 .8408966064208 .1428985596 205.4515991211202 .7624969482200 .0679931641197 .3688049316194 .658706665 191.9452056885189 .2263031006186 .516204834183 .8191070557181 .1544036865 178.533493042175 .9770050049173 .5023040771171 .1302947998168 .8820953369 166.7722015381164 .8213043213163 .0372924805161 .4389038086160 .0234069824 158.8023986816157 .7669067383156 .9208984375156 .2481994629155 .7409973145 155.3807067871155 .1520996094155 .0352020264155 .007598877155 .0509033203 155.1423034668155 .2669067383155 .4024047852155 .5384979248155 .6562042236 155.7498931885155 .8056030273155 .821395874155 .7890014648155 .7093048096 155.5787963867155 .4002075195155 .1737060547154 .9028930664154 .5901947021 154.2393035889153 .8538970947153 .4373931885152 .9936981201152 .5260009766 152.0379943848151 .5319061279151 .0110931396150 .4772033691149 .9329071045 149.3791046143148 .8180999756148 .25147 .6766967773147 .0971984863146 .512802124 145.9203948975145 .3200073242144 .7059020996144 .0755004883143 .4203948975 142.7350006104142 .0081939697141 .2313995361140 .391998291139 .4786987305 138.4783935547137 .3778991699136 .1645965576134 .8249053955133 .3466949463 131.7149963379129 .9320983887128 .0061035156125 .8776016235123 .4851989746 120.8520965576117 .9805984497114 .888999939111 .5789031982108 .1110992432 104.5142974854100 .915000915597 .3876266479594 .1384887695391 .30634307861 89.13189697266 87.86519622803 87.39627838135 87.85076141357 88.97754669189 90.7697830200291 .4400024414192 .3544006347792 .0495986938592 .35440063477 92.3544006347791 .1352005004989 .9160003662188 .5616302490285 .63744354248 81.8071670532277 .6796035766673 .8077392578170 .1794204711966 .97431182861 64.130722045961 .7088012695359 .6806716918957 .9036216735857 .04639053345 57.7936897277859 .2775497436560 .7478103637761 .9173812866262 .32104110718 62.3150711059662 .1363601684661 .8326606750561 .4648513793961 .08023071289 60.7611694335960 .3966712951759 .9310493469259 .4416389465359 .02489089966 58.6350784301858 .2183990478557 .7904014587457 .3455886840856 .88763046265 56.4188194274955 .9423103332555 .4622306823754 .9807701110854 .50151062012 54.0262603759853 .5581512451253 .0985488891652 .6501388549852 .21369171143 51.7912406921451 .3829689025950 .9901390075750 .6124191284250 .25032043457 49.9031715393149 .5708198547449 .2523803710948 .9472007751548 .65427017212 
48.37261962891 48.10121917725 47.8388900756847.58473968506 47.33752822876 47.0965805053746 .860771179246 .629608154346 .4021606445346 .1780090332 45.9563598632845 .7367591857945 .518421173145 .3008499145545 .08324813843 44.8651084899944 .6456604003944 .4244613647544 .2008209228543 .97443008423 43.7447204589843 .5115089416543 .2743911743243 .0332603454642 .78781890869 42.5380210876542 .2837104797442 .0248489379941 .7613410949741 .49319839478 41.2203712463440 .9429092407240 .6607818603540 .3740806579640 .08300018311 39.7876510620139 .484798431439 .17892074585

1399.961059571392 .3179931641384 .6770019531377 .0410156251369 .406982422 1361.7760009771354 .1459960941346 .5159912111338 .8879394531331 .259033203 1323.6309814451316 .0009765621308 .370971681300 .7399902341293 .107055664 1285.4720458981277 .8339843751270 .1939697271262 .5510253911254 .905029297 1247.2559814451239 .6020507811231 .9449462891224 .2840576171216 .618041992 1208.9470214841201 .2719726561193 .5920410161185 .9069824221178 .217041016 1170.5219726561162 .8220214841155 .1169433591147 .4079589841139 .693969727 1131.9770507811124 .2559814451116 .5310058591108 .8039550781101 .074951172 1093.3449707031085 .6130371091077 .8819580081070 .1510009771062 .421020508 1054.6939697271046 .9689941411039 .2480468751031 .5310058591023 .818969727 1016.1119995121008 .4119873051000 .718994141993 .0336914062985 .3563232422 977.6876220703970 .0280151367962 .3779296875954 .7379150391947 .1082763672 939.4895019531931.882019043924.2858886719916.7017822266909.1298828125 901.5706787109894 .0244750977886 .491394043878 .9719238281871 .4663085938 863.9749755859856 .4984130859849 .0369262695841 .5908813477834 .1605834961 826.7465820312819 .3491210938811 .9685058594804 .6052246094797 .2595825195 789.9320068359782 .6226806641775 .3319702148768 .0604248047760 .8079833984 753.5753173828746 .362487793739 .169921875731 .9976806641724 .8466186523 717.7163696289710 .6074829102703 .5203857422696 .4553222656689 .4127807617 682.3928833008675 .3963012695668 .4232788086661 .4744262695654 .5499267578 647.6505126953640 .7766723633633 .9290771484627 .1082763672620 .3148193359 613.5493774414606 .8128051758600 .1058959961593 .4293212891586 .783996582 580.1707763672573 .5905761719567 .0446166992560 .5335083008554 .0584716797 547.6204833984541 .220703125534 .8604125977528 .5404052734522 .2620849609 516.0266723633509 .8352966309503 .6892089844497 .5896911621491 .5378112793 485.5350952148479 .5824890137473 .6814880371467 .8333129883462 .0390014648 456.2997131348450 .6170043945444 .9914855957439 .4248962402433 .9177856445 428.471496582423 .0869140625417 .7650146484412 .5065002441407 .3124084473 402.1832885742397 .1199035645392 .1228027344387 .1925048828382 .3293151855 377.5335998535372 .8055114746368 .145111084363 .5523986816359 .0274963379 354.5698852539350 .1796875345 .8562927246341 .599395752337 .407989502 333.2820129395329 .2200012207325 .2215881348321 .2847900391317 .408996582 313.5917053223309 .8316955566306 .1263122559302 .4735107422298 .8703918457 295.3143920898291 .8026123047288 .3316955566284 .8992004395281 .5017089844 278.1373901367274 .8026123047271 .4966125488268 .2160949707264 .9613037109 261.7296142578258 .5219116211255 .3365020752252 .1750030518249 .0366973877 245.9234924316242 .8361968994239 .7763061523236 .7458953857233 .74609375 230.7796936035227 .846496582224 .9496002197222 .0867004395219 .2599029541 
216.4649963379213 .7017974854210 .9649047852208 .2512969971205 .5563049316 202.8739929199200 .2026977539197 .5354003906194 .87550354192 .2165985107 189.5682983398186 .9270935059184 .308807373181 .7147064209179 .1640930176 176.6645050049174 .2355041504171 .8905029297169 .6468048096167 .5214996338 165.5260925293163 .6797027588161 .9857940674160 .462600708159 .1045074463 157.9257049561156 .9132995605156 .0733032227155 .3889007568154 .8563995361 154.4570007324154 .178894043154 .0037994385153 .9140014648153 .8928985596 153.920501709153 .9839019775154 .0626983643154 .1484069824154 .2229003906 154.2817993164154 .3110961914154 .3096923828154 .2682037354154 .1880950928 154.0643005371153 .899597168153 .6927947998153 .4468994141153 .1634063721 152.845199585152 .4951019287152 .1159057617151 .7109069824151 .2823028564 150.833404541150 .3656005859149 .8820037842149 .383102417148 .87159729 148.3473968506147 .8128967285147 .266998291146 .7120056152146 .145904541 145.5704040527144 .9817047119144 .3804016113143 .7602996826143 .1199951172 142.4506988525141 .7483062744141 .0019989014140 .2046051025139 .3441925049 138.4114074707 137.3937988281 136.2807006836135.0601043701 133.721206665 132.2539978027130 .6457061768128 .8990936279127 .0211029053124 .9722976685 122.707901001120 .2477035522117 .5856018066114 .7514038086111 .7438964844 108.6371994019105 .448600769102 .313598632899 .2822570800896 .54591369629 94.2148513793992 .4355926513791 .3839035034290 .9676818847791 .31302642822 92.1428070068493 .4520797729593 .8784027099694 .1831970214894 .18319702148 94.1831970214894 .1831970214893 .8784027099693 .2394790649491 .50955200195 89.0620117187585 .2994918823281 .1045913696377 .2763519287173 .62536621094 70.3000183105567 .2650833129964 .5843200683662 .2287712097259 .83985900879 58.4715194702159 .2897300720260 .8753395080662 .0070190429762 .87673187256 63.2522087097263 .2502098083562 .92465972962 .3950996398961 .78087997437 61.1503982543960 .6105613708560 .0867500305259 .6208686828659 .18775177002 58.8236808776958 .4881706237858 .0850486755457 .6519508361857 .19338989258 56.7126808166556 .2183494567955 .7127609252955 .2046890258854 .69490814209 54.190429687553 .6914291381853 .2033004760752 .7259483337452 .2635307312 51.8155517578151 .3850212097250 .9710311889650 .575469970750 .19710922241 49.8367614746149 .49301910449 .1658096313548 .8536911010748 .55585098267 48.270919799847 .9976081848147 .7347106933647 .4806594848647 .2345199585 46.9946517944346 .7604789733946 .5305099487346 .3044891357446 .0811882019 45.860488891645 .6413993835445 .4237289428745 .206611633344 .98973083496 44.7722587585444 .5537910461444 .3335304260344 .1110801696843 .88576126099 43.6572418212943 .4249801635743 .1887817382842 .948238372842 .70325088501 42.4535598754942 .1991004943841 .939731597941 .6754188537641 .4061088562 41.1317901611340 .8524513244640 .5680999755940 .2787704467839 .98453903198 39.6856193542539 .3815994262739 .0736999511738 .76021957397

1404.4410400391396 .7700195311389 .0989990231381 .4350585941373 .772949219 1366.1130371091358 .4539794921350 .796997071343 .1400146481335 .484008789 1327.8270263671320 .1700439451312 .5119628911304 .8530273441297 .192016602 1289.5290527341281 .8640136721274 .1960449221266 .5260009771258 .852050781 1251.1739501951243 .4930419921235 .8079833981228 .1180419921220 .423950195 1212.7259521481205 .0219726561197 .3129882811189 .5989990231181 .880004883 
1174.1560058591166 .4270019531158 .6929931641150 .9539794921143 .21105957 1135.4630126951127 .711059571119 .9560546881112 .1979980471104 .437011719 1096.6750488281088 .9110107421081 .1469726561073 .3830566411065 .619995117 1057.8590087891050 .0999755861042 .3439941411034 .5930175781026 .844970703 1019.1030273441011 .3670043951003 .637023926995 .9141235352988 .19921875 980.4926147461972 .7944946289965 .1057128906957 .4262695312949 .7572021484 942.0983886719934 .4505004883926 .8137817383919 .1885986328911 .575378418 903.9744262695896 .3859863281888 .8104858398881 .2482910156873 .6998291016 866.1652832031858 .645324707851 .1400756836843 .6500854492836 .1754760742 828.7172241211821 .2750244141813 .8496704102806 .44140625799 .05078125 791.6779174805784 .3233032227776 .9874267578769 .6702880859762 .3724975586 755.0944213867747 .8361816406740 .5983276367733 .3809204102726 .1845703125 719.0095825195711 .8560791016704 .724609375697 .6154174805690 .5288696289 683.4652709961676 .4252929688669 .4094238281662 .4177856445655 .451171875 648.5100097656641 .5947875977634 .7061767578627 .8447875977621 .0111083984 614.2061157227607 .4301757812600 .684387207593 .9694213867587 .2860717773 580.6353149414574 .0180053711567 .4349975586560 .887512207554 .3762207031 547.9025268555541 .4671020508535 .0714111328528 .7161865234522 .4030761719 516.1326904297509 .9065856934503 .7257995605497 .5916137695491 .5051879883 485.4677124023479 .4802856445473 .5443115234467 .6607971191461 .8310852051 456.0560913086450 .337310791444 .6754150391439 .0718994141433 .5274963379 428.0433959961422 .620300293417 .2594909668411 .9614868164406 .7272949219 401.5573120117396 .4525146484391 .4130859375386 .4400024414381 .532989502 376.6929931641371 .9195861816367 .2135009766362 .5740966797358 .0018005371 353.4960021973349 .0567932129344 .6834106445340 .375793457336 .1329040527 331.954498291327 .8392944336323 .7868041992319 .7952880859315 .8641052246 311.9910888672308 .174987793304 .4135131836300 .7048034668297 .0463867188 293.4359130859289 .8707885742286 .3482971191282 .8660888672279 .421295166 276.0120849609272 .6357116699269 .2909851074265 .9755859375262 .6889038086 259.4292907715256 .196685791252 .9902038574249 .8101959229246 .6564941406 243.5299987793240 .4313964844237 .3618011475234 .3227996826231 .3152008057 228.3412017822225 .400894165222 .4965057373219 .6268005371216 .7929992676 213.9925994873211 .2247924805208 .4862060547205 .7740936279203 .0854034424 200.4158935547197 .7642974854195 .1264038086192 .504699707189 .8963012695 187.3079986572 184.7404022217 182.2042999268 179.7042999268177 .2543945312 174.863494873172 .5462036133170 .3152008057168 .18359375166 .1660003662 164.2722015381162 .5166015625160 .9035949707159 .4454040527158 .1403961182 156.9962005615156 .0054016113155 .1692047119154 .4759979248153 .9201049805 153.4871063232153 .1656036377152 .9400939941152 .795501709152 .7171936035 152.6878967285152 .6956939697152 .7234039307152 .762298584152 .7973022461 152.8229064941152 .8273010254152 .8081970215152 .7574005127152 .6748962402 152.5561065674152 .4026031494152 .2127075195151 .9888000488151 .7312011719 151.4427032471151 .1248016357150 .7801055908150 .4105987549150 .0184936523 149.6058959961149 .1741027832148 .7252044678148 .2597045898147 .779296875 147.2839050293146 .7747955322146 .2516021729145 .7151031494145 .1640014648 144.5988006592144 .0167999268143 .4174957275142 .796005249142 .1499938965 
141.4725952148140 .7590026855140 .0003967285139 .1896972656138 .3170013428 137.3733062744136 .3484954834135 .2324981689134 .0160980225132 .6891937256 131.2449951172129 .6730041504127 .9751968384126 .1541976929124 .1923980713 122.0652999878119 .7835006714117 .3361968994114 .7543029785112 .0462036133 109.2755966187106 .4730987549103 .743598938101 .153900146598 .83567047119 96.9019622802795 .421173095794 .5257873535294 .1412200927794 .33706665039 94.9046173095795 .7839126586996 .6871871948297 .3403930664196 .92639923096 96.3168029785295 .7071990966895 .0976028442495 .0479278564593 .39385223389 91.0761413574287 .7628936767684 .017303466880 .4011764526476 .88201904297 73.5961837768670 .5448532104567 .8272018432665 .4232864379963 .2640914917 62.0037384033262 .3300094604563 .282649993964 .0041732788164 .53830718994 64.6778182983464 .5003967285263 .9393615722763 .1266899108962 .2066116333 61.2983398437560 .5225791931259 .8515510559159 .371368408258 .99562072754 58.6857490539658 .4057884216358 .0254402160657 .5817985534757 .09912109375 56.5856399536156 .0553512573255 .5134086608954 .9696083068854 .42681884766 53.8916091918953 .3658599853552 .8539810180752 .3572006225651 .87852096558 51.4184112548850 .9787483215350 .5592994689950 .1609001159749 .78274154663 49.4247398376549 .085659027148 .7646598815948 .4603004455648 .17116165161 47.8957099914647 .6322212219247 .3792304992747 .1348800659246 .89796066284 46.6666908264246 .4402389526446 .2171211242745 .9968795776445 .77843093872 45.5615081787145 .3453598022545 .1297111511244 .913928985644 .69765090942 44.4802284240744 .2612190246644 .0399589538643 .8160095214843 .58871841431 43.3577995300343 .1226882934642 .8832092285242 .638950347942 .38983154297 42.1355895996141 .8761787414641 .611469268841 .3414497375541 .06605148315 40.785289764440 .4991493225140 .2076797485439 .9109115600639 .60892105103 39.3019409179738.9900817871138.66973876953 38.34563064575

1408.9069824221401 .207031251393 .5100097661385 .8170166021378 .126953125 1370.4389648441362 .7530517581355 .0679931641347 .3840332031339 .699951172 1332.0159912111324 .3310546881316 .6459960941308 .9599609381301 .270996094 1293.5810546881285 .8890380861278 .1929931641270 .4949951171262 .793945312 1255.0889892581247 .3800048831239 .6669921881231 .9499511721224 .228027344 1216.5009765621208 .7690429691201 .0319824221193 .2900390621185 .541992188 1177.788940431170 .0310058591162 .2669677731154 .4990234381146 .725952148 1138.9479980471131 .1660156251123 .3800048831115 .5909423831107 .798950195 1100.0050048831092 .2089843751084 .4129638671076 .6159667971068 .819946289 1061.0250244141053 .2320556641045 .4420166021037 .6550292971029 .873046875 1022.0949707031014 .3229980471006 .556030273998 .7966918945991 .0443115234 983.2999267578975.5637207031967.8361816406960.1179199219952.4094238281 944.7108764648937 .0230102539929 .3458251953921 .6798706055914 .0255737305 906.3831787109898 .753112793891 .1354980469883 .5308837891875 .9398193359 868.362487793860 .7993164062853 .2506713867845 .7172241211838 .1989135742 830.696472168823 .2100830078815 .7404174805808 .2874755859800 .8521728516 793.4345703125786 .0352172852778 .6541748047771 .292175293763 .9494018555 756.6262817383749 .3231201172742 .0402832031734 .7783203125727 .5374145508 720.3178100586713 .1201171875705 .944519043698 .7913818359691 .661315918 684.5543823242677 .471496582670 .412902832663 .3790283203656 .3704833984 
649.3876953125 642.4312744141635.5020141602628.6002197266621.7266845703 614.8820800781608 .067199707601 .2827148438594 .5294799805587 .8082275391 581.1198730469574 .4655761719567 .8458862305561 .2619018555554 .7144775391 548.2050170898541 .7340698242535 .3029785156528 .9127807617522 .5646972656 516.2595825195509 .9988098145503 .7833862305497 .6145935059491 .4934997559 485.4213867188479 .3992004395473 .428314209467 .5097045898461 .6447143555 455.834197998450 .079498291444 .3814086914438 .7413024902433 .1597900391 427.6382141113422 .1771850586416 .7778015137411 .440612793406 .1666870117 400.9565124512395 .8106994629390 .7297058105385 .7142028809380 .7643127441 375.8806152344371 .0628967285366 .311706543361 .6265869141357 .0079040527 352.4549865723347 .9678955078343 .5459899902339 .1890869141334 .8963928223 330.667388916326 .5008850098322 .3965148926318 .3526916504314 .3687133789 310.4425048828306 .5730895996302 .758392334298 .996887207295 .2861938477 291.624206543288 .0089111328284 .437713623280 .9086914062277 .4191894531 273.9678039551270 .5517883301267 .1704101562263 .8212890625260 .5042114258 257.2171020508253 .9602966309250 .7322998047247 .5337982178244 .3639984131 241.2238006592238 .1134033203235 .033706665231 .9857940674228 .9703063965 225.9891967773223 .0424957275220 .1322937012217 .2574005127214 .4192962646 211.6157989502208 .8468933105206 .1098937988203 .4028930664200 .724105835 198.0699005127195 .4409942627192 .8329925537190 .2503967285187 .6896972656 185.1593017578182 .658203125180 .1981048584177 .7814941406175 .4219970703 173.1259002686170 .9067993164168 .7745056152166 .7402038574164 .8162994385 163.0095977783161 .3334960938159 .7893981934158 .3892059326157 .1287994385 156.0166015625155 .0435943604154 .2127075195153 .5113983154152 .9367980957 152.474395752152 .1159057617151 .8466949463151 .654296875151 .525604248 151.4456939697151 .4040985107151 .3852996826151 .3820953369151 .3800964355 151.3751068115151 .3553009033151 .3191070557151 .2579956055151 .1721038818 151.0563049316150 .911895752150 .7362976074150 .5316009521150 .2973022461 150.0354003906149 .7469024658149 .43359375149 .0970001221148 .7384033203 148.3598022461147 .9615020752147 .5453948975147 .1112976074146 .6607055664 146.1927947998145 .7089996338145 .207901001144 .69090271144 .1555023193 143.6029968262143 .029800415142 .4362030029141 .816696167141 .1703033447 140.4895019531139 .7713012695139 .0066986084138 .1903991699137 .31300354 136.3672943115135 .3439941406134 .2351074219133 .0328063965131 .7286071777 130.3180999756128 .7937011719127 .1569976807125 .4039001465123 .5382995605 121.5510025024119 .4487991333117 .210899353114 .8788986206112 .4542999268 110.0055007935107 .5510025024105 .1902999878102 .9709014893100 .9974975586 99.3591613769598 .08872222997 .292556762796 .8872222900496 .94687652588 97.27174377441 97.8174972534298.3878936767698.7995529174899.04212188721 98.1455993652397 .5360031127996 .9263992309696 .4017333984494 .67872619629 92.4292984008889 .6412506103586 .4874572753983 .2217407226679 .92700958252 76.794647216873 .8615570068471 .2413330078169 .0295181274467 .35265350342 66.3312377929766 .1020889282266 .2907104492266 .5250167846766 .69747161865 66.5223312377966 .0578231811565 .1984634399464 .0726928710962 .84412002563 61.5989799499560 .504459381159 .6732788085959 .2230186462458 .97549057007 58.7391281127958 .4608612060558 .0615692138757 .5870780944857 .06663131714 
56.5068893432655 .9324302673355 .344169616754 .7589988708554 .17636871338 53.6068382263253 .0498886108452 .512271881151 .9933586120651 .49760055542 51.0239791870150 .5752906799350 .1500511169449 .7496109008849 .37213897705 49.0177001953148 .684291839648 .3709716796948 .0756797790547 .7967414856 47.5322189331147 .2799491882347 .0382881164646 .8048591613846 .57844161987 46.3567390441946 .1390495300345 .9234695434645 .7097511291545 .49652862549 45.2838211059645 .0707092285244 .8572006225644 .6426391601644 .42684173584 44.2092018127443 .989391326943 .7667694091843 .5409584045443 .31137084961 43.0776596069342 .8393402099642 .5961990356442 .3478813171442 .09424972534 41.8351211547941 .5704193115241 .3000488281241 .0239791870140 .74219894409 40.4546890258840 .1614799499539 .8626098632839 .5581207275439 .24810028076 38.9328002929738 .6117706298838 .2863807678237 .95470809937

1413.3609619141405 .6340332031397 .9069824221390 .1870117191382 .469970703 1374.7550048831367 .0419921881359 .3289794921351 .6180419921343 .906982422 1336.1960449221328 .4849853521320 .7729492191313 .0589599611305 .343994141 1297.6269531251289 .9069824221282 .1850585941274 .4599609381266 .730957031 1258.9990234381251 .2629394531243 .5229492191235 .7779541021228 .027954102 1220.2740478521212 .5140380861204 .7490234381196 .9780273441189 .202026367 1181.4200439451173 .6330566411165 .839965821158 .042968751150 .239990234 1142.4320068361134 .6199951171126 .8029785161118 .9830322271111 .16003418 1103.3349609381095 .5069580081087 .6779785161079 .8489990231072 .020019531 1064.1920166021056 .3649902341048 .5400390621040 .7189941411032 .901000977 1025.0880126951017 .2800292971009 .4769897461001 .681030273993 .8911743164 986.1090698242978 .3348999023970 .5690917969962 .8120727539955 .0645141602 947.3265991211939 .598815918931 .8814697266924 .1751098633916 .4799194336 908.7963867188901 .1248168945893 .4655151367885 .8189086914878 .1856079102 870.5656738281862 .959777832855 .3682250977847 .7913208008840 .2296142578 832.6834716797825 .1533203125817 .6395263672810 .142578125802 .6630249023 795.2009277344787 .757019043780 .3314819336772 .9249267578765 .5375976562 758.169921875750 .8220825195743 .4948730469736 .1884155273728 .9033203125 721.6395263672714 .3978271484707 .1785888672699 .9819946289692 .80859375 685.6588134766678 .5330810547671 .4321899414664 .3563232422657 .3060302734 650.2819213867643 .2847290039636 .3148193359629 .3729248047622 .4597167969 615.5758056641608 .7219238281601 .8989257812595 .1074829102588 .3485107422 581.6229248047574 .9315185547568 .2750854492561 .6547851562555 .0714111328 548.5261230469542 .0197143555535 .5534057617529 .1281738281522 .7451171875 516.4052734375510 .1098937988503 .8598937988497 .6565856934491 .5008850098 485.3941955566479 .3374023438473 .3316955566467 .378112793461 .4779052734 455.6318969727449 .8414916992444 .1073913574438 .4309082031432 .812713623 427.25390625421 .7551879883416 .3176879883410 .9418029785405 .628692627 400.3786010742395 .1924133301390 .0703125385 .0132141113380 .0210876465 375.0943908691370 .2331848145365 .4378051758360 .7078857422356 .0437927246 351.4447937012346 .9111022949342 .4418945312338 .0372009277333 .6960144043 329.4180908203325 .2022094727321 .0477905273316 .953704834312 .9190063477 308.941986084305 .0219116211301 .1565856934297 .3447875977293 .5844116211 289.8738098145286 .2107849121282 .5935974121279 .020111084275 .4883117676 
271.9966125488268 .5429992676265 .1264953613261 .745300293258 .3985900879 255.0850067139251 .804397583248 .5554962158245 .3385009766242 .1528015137 238.9989013672235 .8768005371232 .7870941162229 .7306060791226 .7079925537 223.7205963135220 .7687988281217 .8540039062214 .9759063721212 .1354980469 209.3314971924206 .5639038086203 .8309936523201 .1316986084198 .4647064209 195.8280029297193 .2220001221190 .6446990967188 .099105835185 .5845947266 183.1071014404180 .6681060791178 .2760925293175 .9353027344173 .6558074951 171.4445953369169 .311706543167 .2664031982165 .3175048828163 .474899292 161.7449035645160 .1371002197158 .6539001465157 .3029937744156 .0825958252 154.9969024658154 .0404052734153 .2129058838152 .5054016113151 .9134063721 151.4257049561151 .033996582150 .7263031006150 .4913024902150 .3177947998 150.1927032471150 .1065063477150 .0460968018150 .004196167149 .9687957764 149.9349975586149 .8930969238149 .8401947021149 .7691955566149 .6791992188 149.5655975342149 .4284973145149 .2655944824149 .0778045654148 .8643951416 148.6266937256148 .3650054932148 .0805053711147 .7740936279147 .4467926025 147.0995941162146 .7328948975146 .3475036621145 .9434051514145 .5211029053 145.0802001953144 .62109375144 .1428070068143 .6454925537143 .1277008057 142.5894012451142 .0281066895141 .4429931641140 .8300018311140 .1871948242 139.508895874138 .7913970947138 .0278930664137 .2127075195136 .3385009766 135.3986053467134 .3858032227133 .2926940918132 .1138000488130 .841796875 129.4745025635128 .0057983398126 .4375124 .7678985596123 .0066986084121 .1541976929 119.2153015137117 .1774978638115 .0728988647112 .9115982056110 .7457962036 108.6029968262106 .5533981323104 .6492996216102 .9569015503101 .5513000488 100.446701049899 .7138595581199 .2935562133899 .2169189453199 .34526824951 99.6161422729599 .91063690186100 .09400177100 .143501281799 .94494628906 99.4889526367298 .689872741797 .496513366795 .8566436767693 .82214355469 91.3709869384888 .644386291585 .741210937582 .7530364990279 .87454986572 77.1695175170974 .7471923828172 .7526092529371 .3106231689570 .32790374756 69.8977584838969 .6912231445369 .5599136352569 .3915634155368 .84676361084 68.0132369995166 .8178329467865 .3578491210963 .7911682128962 .16550827026 60.5234298706159 .3470611572359 .1697196960459 .2925109863359 .07712936401 58.7036590576258 .2320404052757 .6914787292557 .1078186035256 .48970031738 55.85630035455 .214000701954 .5774192810153 .9496612548853 .33932876587 52.7480812072852 .1807708740251 .6381912231451 .1231689453150 .63565826416 50.177040100149 .7464599609449 .3440399169948 .9682617187548 .61812973022 48.2917213439947 .9872093200747 .7024497985847 .4350395202647 .18284988403 46.9431991577146 .7141189575246 .4929008483946 .2779998779346 .0669708252 45.8587989807145 .6515808105545 .4448585510345 .2373886108445 .02907943726 44.8192291259844 .6078186035244 .3944206237844 .1788711547943 .96075820923 43.7397918701243 .5154609680243 .2873992919943 .0550613403342 .81816101074 42.5761985778842 .3289985656742 .0761909484941 .8176803588941 .55326080322 41.2829017639241 .0064888000540 .7240409851140 .4355010986340 .14093017578 39.8403282165539 .533760070839 .2212715148938 .9029502868738 .5791015625 38.2498207092337 .911128997837 .56806182861 1417.7979736331410 .0439453121402 .2919921881394 .5450439451386 .802001953 1379.0600585941371 .3199462891363 .5810546881355 .8430175781348 .105957031 
1340.3680419921332 .6300048831324 .8919677731317 .1519775391309 .41003418 1301.6660156251293 .9200439451286 .1710205081278 .4189453121270 .66394043 1262.9050292971255 .1409912111247 .3740234381239 .6020507811231 .824951172 1224.042968751216 .2550048831208 .4620361331200 .663940431192 .859008789 1185.0489501951177 .2330322271169 .4110107421161 .5839843751153 .751953125 1145.913940431138 .0720214841130 .2249755861122 .3740234381114 .520019531 1106.6629638671098 .8039550781090 .9429931641083 .082031251075 .218994141 1067.3580322271059 .4969482421051 .6390380861043 .7829589841035 .930053711 1028.0810546881020 .2369995121012 .3989868161004 .565979004996 .739074707 988.9196777344981 .1077270508973 .3037719727965 .5083007812957 .7219238281 949.9447021484942 .1774291992934 .4202270508926 .6735229492918 .9376831055 911.2133178711903 .5004882812895 .7999267578888 .1115722656880 .4362182617 872.7741088867865 .1256713867857 .491394043849 .8715820312842 .2667236328 834.6771850586827 .1035766602819 .5463256836812 .0054931641804 .4818725586 796.9758911133789 .4879150391782 .0181884766774 .5673217773767 .1356811523 759.723815918752 .3319702148744 .9605712891737 .6099853516730 .2808837891 722.9733886719715 .6881103516708 .4254150391701 .1856079102693 .9691772461 686.7769165039679 .6088256836672 .4656982422665 .3480224609658 .2562866211 651.1912231445644 .1530761719637 .1428833008630 .1610717773623 .2083129883 616.2852172852609 .3925170898602 .5311279297595 .7017211914588 .9050292969 582.1420898438575 .4138183594568 .7208251953562 .0642089844555 .4448242188 548.8637695312542 .3218994141535 .8203735352529 .3599853516522 .9420776367 516.5676269531510 .2376098633503 .9530944824497 .7153015137491 .5250854492 485.3839111328479 .292388916473 .2520141602467 .2634887695461 .3281860352 455.4469909668449 .62109375443 .8511962891438 .1384887695432 .483795166 426.888092041421 .3521118164415 .8768005371410 .4625854492405 .1106872559 399.8211975098394 .5950927734389 .4327087402384 .3345031738379 .3008117676 374.3319091797369 .4280090332364 .5892028809359 .8153991699355 .1068115234 350.462890625345 .883605957341 .3684082031336 .9171142578332 .5289916992 328.2036132812323 .9399108887319 .737487793315 .594909668311 .5116882324 307.4862060547303 .5174865723299 .6040039062295 .7443847656291 .9370117188 288.1801147461284 .4719848633280 .8110046387277 .1954956055273 .6234130859 270.0936889648266 .6041870117263 .154296875259 .7420043945256 .3670043945 253.0276947021249 .7239074707246 .4544067383243 .2192993164240 .0178985596 236.8502960205233 .7165985107230 .6170959473227 .5525054932224 .5231933594 221.5305023193218 .5744934082215 .6567993164212 .7770996094209 .9364013672 207.1340026855204 .3701019287201 .6437988281198 .9542999268196 .3013000488 193.6831054688191 .1015014648188 .5540924072186 .0453948975183 .5738983154 181.1464996338178 .7635955811176 .4340057373174 .1602935791171 .9523925781 169.8153991699167 .7584075928165 .7886962891163 .9136962891162 .1417999268 160.4774017334158 .9290924072157 .4974060059156 .1896972656155 .0025024414 153.9407958984152 .9972991943152 .1735992432151 .4597015381150 .853302002 150.3430023193149 .9228057861149 .5812072754149 .3088989258149 .0957946777 148.9306030273148 .804901123148 .7070007324148 .6304931641148 .5644073486 148.504699707148 .441696167148 .3735046387148 .2926025391148 .1983947754 148.0856933594147 .9548950195147 .8027038574147 .6300048828147 .4351959229 
147.2192993164146.9819946289146.7238006592146.4452972412146.1468048096 145.8289031982145 .4915008545145 .1351928711144 .7593994141144 .3645935059 143.9497070312143 .5151977539143 .0594024658142 .5830993652142 .0838012695 141.56199646141 .0146026611140 .4416046143139 .8385009766139 .2041931152 138.5330047607137 .8222961426137 .0653991699136 .2584075928135 .3943939209 134.4680023193133 .4734039307132 .4044036865131 .2572021484130 .025604248 128.7095031738127 .3037033081125 .8134994507124 .2351989746122 .5843963623 120.8607025146119 .0781021118117 .2238006592115 .3333969116113 .408203125 111.4990005493109 .6237030029107 .8422012329106 .193901062104 .7248001099 103.4954986572102 .5031967163101 .8128967285101 .3564987183101 .1723022461 101.1339035034101 .2005004883101 .2810974121101 .2748031616101 .1669006348 100.8655014038100 .353897094799 .5494232177798 .4249114990296 .91763305664 95.0892105102592 .9340209960990 .543388366787 .9805526733485 .33865356445 82.7800598144580 .3687133789178 .2038574218876 .3966369628975 .07150268555 74.115371704173 .560958862373 .1924133300872 .8933029174872 .42400360107 71.4687576293970 .1697463989368 .5874633789166 .8185577392664 .96946716309 63.0837593078661 .0254096984959 .5373687744159 .5257606506359 .87308120728 59.5696296691959 .0716781616258 .5173301696857 .8837203979557 .22243881226 56.5271606445355 .824920654355 .1171607971254 .4235801696853 .74380874634 53.089561462452 .4598617553751 .8612709045451 .2926788330150 .75793075562 50.2554817199749 .7873611450249 .3513984680248 .9480400085448 .57466125488 48.2302398681647 .9120101928747 .6178092956547 .3449287414647 .09048843384 46.8519897460946 .6261711120646 .4109001159746 .2028884887746 .00054931641 45.8008918762245 .6030197143645 .4045906066945 .2053718566945 .00381088257 44.8001213073744 .5934410095244 .3840484619144 .1715202331543 .9559211731 43.7369308471743 .5143508911143 .2877998352143 .0569686889642 .82139968872 42.5807685852142 .3346710205142 .0829010009841 .8251304626541 .56126022339 41.2911186218341 .014648437540 .7318000793540 .4425506591840 .14691925049 39.8448982238839 .5365715026939 .2219696044938 .9011688232438 .57424926758 38.2415504455637 .9025192260737 .5587196350137 .2080116272

1422.2249755861414 .4439697271406 .663940431398 .8909912111391 .12097168 1383.3530273441375 .5870361331367 .8220214841360 .0579833981352 .295043945 1344.5319824221336 .7679443361329 .0030517581321 .2370605471313 .468994141 1305.6989746091297 .9270019531290 .1510009771282 .3730468751274 .590942383 1266.8050537111259 .0150146481251 .2209472661243 .421997071235 .616943359 1227.8079833981219 .9930419921212 .171997071204 .3459472661196 .512939453 1188.6750488281180 .8299560551172 .9799804691165 .1230468751157 .261962891 1149.3940429691141 .5219726561133 .6450195311125 .7640380861117 .87902832 1109.9899902341102 .0999755861094 .207031251086 .3129882811078 .41796875 1070.5229492191062 .629028321054 .7370605471046 .8459472661038 .958984375 1031.0749511721023 .1950073241015 .3200073241007 .45098877999 .5878295898 991.7313232422983 .8817138672976 .0399169922968 .2061157227960 .3809204102 952.5648193359944 .7581176758936 .9611816406929 .174621582921 .3983764648 913.6334228516905 .8798217773898 .137878418890 .4083251953882 .6912841797 874.987121582867 .2965087891859 .6196899414851 .9572753906844 .3095703125 836.6771850586 829.0604248047821.4597167969 813.8754272461 806.3082885742 
798.7584838867791 .2266235352783 .7130737305776 .2183837891768 .7429199219 761.287109375753 .8513793945746 .4362182617739 .0418701172731 .669128418 724.3181152344716 .9893798828709 .6837158203702 .4008789062695 .141784668 687.9069824219680 .6967773438673 .5117797852666 .3524780273659 .2197265625 652.1135864258645 .0350952148637 .9846191406630 .9630126953623 .970703125 617.008605957610 .0772705078603 .1776123047596 .3101806641589 .4760131836 582.67578125575 .9105834961569 .1810302734562 .4882202148555 .8328857422 549.2161254883542 .6389160156536 .1021118164529 .6068115234523 .1539916992 516.7446899414510 .3800964355504 .0610961914497 .7887878418491 .5640869141 485.3883972168479 .2623901367473 .187286377467 .1640014648461 .1939086914 455.2775878906449 .4162902832443 .6108093262437 .8622131348432 .1712036133 426.5389099121420 .9659118652415 .4530944824410 .0010986328404 .6106872559 399.2825012207394 .0170898438388 .8147888184383 .6762084961378 .6015930176 373.5913085938368 .6453857422363 .7640991211358 .9472961426354 .1951904297 349.5072937012344 .8835144043340 .3234863281335 .8269958496331 .3931884766 327.0217895508322 .7119140625318 .4630126953314 .2738952637310 .1438903809 306.0718078613302 .0567016602298 .0971069336294 .1918945312290 .3395080566 286.5386047363282 .7875976562279 .0851135254275 .4294128418271 .8192138672 268.2529907227264 .729309082261 .2473144531257 .8055114746254 .4031066895 251.0390930176247 .7129058838244 .4234924316241 .1708068848237 .953994751 234.7733001709231 .6284942627228 .5198974609225 .4477996826222 .4127044678 219.4156036377216 .4568023682213 .537399292210 .657699585207 .8184051514 205.0193023682202 .2608032227199 .5426025391196 .8643951416194 .2263946533 191.6277008057189 .0697937012186 .5522003174184 .0778961182181 .6473999023 179.2657012939176 .9346923828174 .6609954834172 .4483032227170 .3036956787 168.2328033447166 .2424926758164 .3394012451162 .5290985107160 .8186035156 159.2115936279157 .7142028809156 .3276062012155 .0563049316153 .8984069824 152.8558959961151 .9241027832151 .1022033691150 .3829956055149 .7626953125 149.2326965332148 .7864074707148 .4147033691148 .1089935303147 .8605957031 147.6596069336147 .4983978271147 .3670043945147 .2590942383147 .1656036377 147.0820007324147 .0001983643146 .9176025391146 .8276977539146 .729095459 146.6172027588146 .4915008545146 .3489990234146 .1896972656146 .0117950439 145.8157043457145 .6006011963145 .3666992188145 .1138000488144 .8421020508 144.5514984131144 .2416992188143 .9127960205143 .5643005371143 .1958007812 142.8065948486142 .3963928223141 .9638977051141 .508895874141 .0299072266 140.5261993408139 .9956970215139 .4375138 .8482971191138 .2263031006137 .567199707 136.8681945801136 .1242980957135 .3312072754134 .4841003418133 .5780029297 132.6085968018131 .5708007812130 .4622039795129 .2779998779128 .0189971924 126.6819000244125 .2720031738123 .7889022827122 .2451019287120 .645401001 119.0040969849117 .3228988647115 .6239013672113 .9120025635112 .2240982056 110.5821990967109 .0261001587107 .5915985107106 .3069000244105 .2154006958 104.3155975342103 .6449966431103 .1602020264102 .8725967407102 .6971969604 102.5878982544102 .4899978638102 .3377990723102 .1035003662101 .7198028564 101.1585006714100 .35289764499 .2883834838997 .9151229858496 .28249359131 94.381278991792 .2861633300890 .036827087487 .7235488891685 .4596862793 83.31712341309 81.39433288574 79.75720977783 78.50746917725 77.56170654297 
76.9386062622176 .5241165161176 .3223724365275 .7872772216874 .31416320801 72.4081268310570 .4494476318468 .4335708618266 .4202117919964 .4408416748 62.5028190612861 .0769500732460 .6687507629460 .5815010070860 .15798950195 59.5844688415558 .9185905456558 .1887092590357 .4232902526956 .63367080688 55.8442192077655 .0610389709554 .2999687194853 .5634193420452 .85942077637 52.1889190673851 .5557899475150 .9602203369150 .4041290283249 .88679122925 49.4087104797448 .968189239548 .5643005371148 .1945991516147 .85688018799 47.5482902526947 .2657012939547 .0061492919946 .7660217285246 .54248046875 46.3317298889246 .1312904357945 .9375190734945 .748470306445 .56100082397 45.373889923145 .1847991943444 .9932785034244 .7978897094744 .59875106812 44.3952407836944 .1875991821343 .9757003784243 .759620666543 .53929901123 43.3146018981943 .0853004455642 .8511199951242 .6117095947342 .36680984497 42.1159896850641 .859100341841 .5958290100141 .3261108398441 .04973983765 40.7667198181240 .4769515991240 .1805000305239 .8773193359439 .56748962402 39.2510414123538 .9280700683638 .5986099243238 .2627983093337 .92095947266 37.5732002258337 .2152404785236 .85237121582

1426.6330566411418 .8270263671411 .0229492191403 .2239990231395 .427978516 1387.6350097661379 .8439941411372 .0529785161364 .2640380861356 .474975586 1348.6860351561340 .8969726561333 .1059570311325 .3139648441317 .520996094 1309.7249755861301 .9270019531294 .1251286 .3210449221278 .5129394531270 .699951172 1262.8840332031255 .0629882811247 .2370605471239 .4060058591231 .568969727 1223.7270507811215 .8780517581208 .0240478521200 .163940431192 .29699707 1184.4239501951176 .5450439451168 .660034181160 .7690429691152 .871948242 1144.9699707031137 .0629882811129 .1510009771121 .2349853521113 .316040039 1105.3929443361097 .4689941411089 .5419921881081 .6149902341073 .687011719 1065.7600097661057 .8330078121049 .9090576171041 .9870605471034 .067993164 1026.1529541021018 .2420043951010 .3369750981002 .437011719994 .5432128906 986.6561889648978 .7766723633970 .9047851562963 .0410766602955 .1862182617 947.3402709961939 .5040283203931 .6776733398923 .8615112305916 .0560913086 908.26171875900 .4791259766892 .7083129883884 .9495849609877 .203918457 869.4713134766 861.7523193359854.0476074219 846.357421875 838.6823120117 831.0225830078823 .37890625815 .7515258789808 .1409301758800 .5477294922 792.9724121094785 .4152832031777 .8770751953770 .3579711914762 .8585205078 755.3792114258747 .9204711914740 .4827880859733 .0667114258725 .6724243164 718.3007202148710 .9520263672703 .6265869141696 .325012207689 .0479736328 681.7957763672674 .5692138672667 .3685302734660 .1945800781653 .0479125977 645.9290161133638 .8383789062631 .7769775391624 .7454223633617 .7443237305 610.7744140625603 .8364868164596 .9312744141590 .0595703125583 .2222900391 576.4202270508569 .6541137695562 .924987793556 .2338256836549 .5814208984 542.9686279297536 .3966064453529 .8662109375523 .3786010742516 .9345703125 510.5354003906504 .1818847656497 .8750915527491 .6159973145485 .4057922363 479.2452087402473 .1355895996467 .0776977539461 .0726928711455 .1213989258 449.2249145508443 .3840026855437 .5997009277431 .8727111816426 .2040100098 420.5942993164415 .0444030762409 .554901123404 .1267089844398 .7601013184 393.4559020996388 .2142944336383 .0360107422377 .9211120605372 .8700866699 367.8829956055362 .9601135254358 .1011047363353 .3063964844348 .5755004883 
343.9083862305339 .3046875334 .7640991211330 .2858886719325 .8699951172 321.5152893066317 .221496582312 .987487793308 .812713623304 .6958007812 300.6361999512296 .6325073242292 .6836853027288 .7885131836284 .9457092285 281.1539001465277 .4117126465273 .7181091309270 .0712890625266 .470489502 262.9142150879259 .4016113281255 .9311981201252 .5028076172249 .1148071289 245.766998291242 .4582977295239 .1885070801235 .9568939209232 .7635955811 229.6080932617226 .4907989502223 .411895752220 .3717956543217 .37109375 214.4104003906211 .4907073975208 .612197876205 .7758026123202 .9817047119 200.2301940918197 .521697998194 .8560028076192 .2341003418189 .6551055908 187.1213989258184 .6322021484182 .19140625179 .7987060547177 .4597930908 175.1757049561172 .9528961182170 .7940979004168 .7062072754166 .6932067871 164.7613983154162 .9161071777161 .1618041992159 .5043945312157 .9463043213 156.4931030273155 .1441955566153 .9044036865152 .770401001151 .7447052002 150.8217010498150 .0014953613149 .2763977051148 .6441955566148 .0960998535 147.6271972656147 .2286987305146 .8937072754146 .6139984131146 .3813018799 146.1887054443146 .0272979736145 .8917999268145 .7734985352145 .6687011719 145.5695953369145 .4739990234145 .37550354145 .2729034424145 .1613006592 145.0402069092144 .9060058594144 .7586975098144 .595993042144 .4178924561 144.2230072021144 .0113067627143 .7821044922143 .5350036621143 .2700042725 142.9860992432142 .6833953857142 .3607025146142 .0180053711141 .6537017822 141.2678985596140 .858795166140 .4263000488139 .9683990479139 .4850006104 138.9734039307138 .4331970215137 .8609008789137 .2555999756136 .6128997803 135.9308929443135 .2048034668134 .4317932129133 .6074066162132 .7279052734 131.7901000977130 .7897033691129 .7259979248128 .5946960449127 .398399353 126.1339035034124 .8088989258123 .4217987061121 .987197876120 .5050964355 118.9984970093117 .4716033936115 .945098877114 .4164962769112 .9219970703 111.4753036499110 .1079025269108 .8470001221107 .706703186106 .7242965698 105.8860015869105 .2304000854104 .7098999023104 .3443984985104 .0581970215 103.8186035156103 .5869979858103 .3227005005102 .9934997559102 .5350036621 101.9329986572101 .1242980957100 .116500854598 .8664779663197 .41015625 95.7227401733493 .8779067993291 .9084625244189 .8894805908287 .90075683594 86.0067291259884 .2943267822382 .7986297607481 .594589233480 .63787078857 79.9649581909279 .4734268188579 .3208312988378 .7408599853576 .8551864624 74.4991073608472 .2957229614370 .1191482543968 .0177536010766 .0908203125 64.4287261962963 .1148681640662 .2063789367761 .536411285460 .88331985474 60.2121505737359 .4242591857958 .5709190368757 .6880912780856 .78784179688 55.9034385681255 .0363502502454 .2039108276453 .4056510925352 .64981079102 51.9354782104551 .2669105529850 .6427307128950 .0653800964449 .53266906738 49.0455207824748 .600860595748 .1978492736847 .8328895568847 .50347137451 47.205909729 46.9364395141646.69163131714 46.4670600891146.25968933105 46.0649490356445 .8802680969245 .7013397216845 .526229858445 .35126113892 45.1753005981444 .9956016540544 .8119010925344 .6225395202644 .42784118652 44.2271308898944 .020919799843 .8091201782243 .5920486450243 .36978149414 43.1423110961942 .9095802307142 .6713600158742 .4274482727142 .17755889893 41.9213905334541 .6587409973141 .3893890380941 .1132011413640 .83008956909 40.5399589538640 .2428092956539 .9386405944839 .6274986267139 .30941009521 
38.9844818115238 .6527290344238 .3142890930237 .9692192077637 .61791992188 37.2598190307636 .8965606689536 .52585983276

1431.0310058591423 .1989746091415 .3680419921407 .5450439451399 .723999023 1391.9050292971384 .0889892581376 .2740478521368 .4589843751360 .645019531 1352.8310546881345 .0169677731337 .2010498051329 .3840332031321 .564941406 1313.7440185551305 .9200439451298 .0930175781290 .2619628911282 .427978516 1274.589965821266 .7469482421258 .9000244141251 .046997071243 .188964844 1235.3260498051227 .4560546881219 .5810546881211 .6989746091203 .811035156 1195.9160156251188 .0150146481180 .1070556641172 .1929931641164 .272949219 1156.3470458981148 .4150390621140 .4780273441132 .5360107421124 .588989258 1116.6390380861108 .6850585941100 .7290039061092 .7700195311084 .810058594 1076.8489990231068 .8890380861060 .9289550781052 .9699707031045 .014038086 1037.0600585941029 .1090087891021 .1630249021013 .2219848631005 .284973145 997.3549194336989 .4309082031981 .513671875973 .6040039062965 .7020874023 957.8084716797949 .9238891602942 .0482177734934 .1823120117926 .3264160156 918.4807128906910 .6458740234902 .8225708008895 .0108032227887 .2111206055 879.423828125 871.649597168 863.888671875 856.141784668 848.4093017578 840.6917724609832 .9893798828825 .3029174805817 .6326293945809 .9791259766 802.3427734375794 .7243041992787 .1240234375779 .5422973633771 .9797973633 764.4370117188756 .9143066406749 .4124145508741 .9315795898734 .4722900391 727.0349731445719 .6206054688712 .2291259766704 .8610839844697 .5173950195 690.1983032227682 .9044799805675 .6362915039668 .3944702148661 .1796875 653.9923706055646 .8331298828639 .7026977539632 .6016845703625 .5308837891 618.491027832611 .4824829102604 .5064697266597 .5634155273590 .6541748047 583.7797241211576 .9407958984570 .1381835938563 .3729248047556 .645690918 549.9575805664543 .309387207536 .7022094727530 .1367797852523 .6143188477 517.1356201172510 .7016906738504 .3136901855497 .9725036621491 .6789855957 485.4342956543479 .2392883301473 .0952148438467 .0026855469460 .963104248 454.9768981934449 .0454101562443 .1691894531437 .3493041992431 .5864868164 425.8818054199420 .2355957031414 .6489868164409 .1224060059403 .6567077637 398.2522888184392 .9097900391387 .629486084382 .4119873047377 .2575073242 372.1665039062367 .138885498362 .175201416357 .2749938965352 .4386901855 347.665802002342 .9563903809338 .3099975586333 .7265014648329 .205291748 324.74609375320 .3481140137316 .0108947754311 .7334899902307 .515411377 303.3555908203299 .2532958984295 .2073059082291 .2168884277287 .2807006836 283.3978881836279.5671081543275.7872009277272.0570983887 268.3754882812 264.741607666261 .1541137695257 .6122131348254 .1147003174250 .6609954834 247.2501983643243 .8815002441240 .5543060303237 .2682037354234 .0223999023 230.8170013428227 .6515960693224 .5263061523221 .441192627218 .3968048096 215.3936004639212 .4320068359209 .5130004883206 .6369018555203 .8045959473 201.0166015625 198.2733001709 195.575302124192.9230041504 190.317199707 187.7583007812185 .2478027344182 .7861938477180 .3764038086178 .0195007324 175.7194976807173 .4785003662171 .3014068604169 .1912994385167 .153503418 165.1920013428163 .3115997314161 .5169067383159 .8114929199158 .1999969482 156.6844024658155 .2686004639153 .9526062012152 .7389068604151 .6253967285 150.6128997803149 .6972961426148 .8771057129148 .146697998147 .5028076172 
146.9385986328146 .4488067627146 .0265045166145 .6651000977145 .3576049805 145.0966033936144 .8760070801144 .6880950928144 .5276947021144 .3874969482 144.2635040283144 .1492004395144 .0417938232143 .9358978271143 .829498291 143.7182006836143 .6011047363143 .4745941162143 .338104248143 .1891937256 143.0274047852142 .8511047363142 .6598968506142 .4524993896142 .2286987305 141.9875030518141 .728302002141 .4503936768141 .1528015137140 .8348999023 140.4956054688140 .1340026855139 .7489013672139 .3395996094138 .9044952393 138.4429016113137 .9526977539137 .4329986572136 .8811950684136 .2958984375 135.6739044189135 .0130004883134 .3099975586133 .5617980957132 .7655944824 131.9179992676131 .0169067383130 .0592956543129 .0447998047127 .9709014893 126.8401031494125 .6513977051124 .4108963013123 .120300293121 .7900009155 120.424697876119 .0419998169117 .6505966187116 .2671966553114 .8974990845 113.5650024414112 .2852020264111 .077003479109 .9609985352108 .9440002441 108.0478973389107 .2646026611106 .6126022339106 .0669021606105 .6349029541 105.2667007446104 .9315032959104 .6035995483104 .2488021851103 .8379974365 103.3237991333102 .6884994507101 .8880004883100 .929199218899 .78307342529 98.4695663452196 .970558166595 .34179687593 .6103134155391 .83708190918 90.0785064697388 .3890991210986 .8407211303785 .4517135620184 .27983856201 83.2898330688582 .4996032714881 .8254165649481 .2733764648480 .33271789551 78.4815063476676 .2259521484473 .9842071533271 .7845611572369 .70041656494 67.8306732177766 .2594375610464 .8924636840863 .7751388549862 .79981994629 61.8815498352161 .013111114560 .053291320859 .0379600524958 .01150131226 56.9900588989355 .9997596740755 .0445899963454 .1352081298853 .2727394104 52.4617195129451 .702289581350 .9963607788150 .3433990478549 .74401092529 49.1966018676848 .7005386352548 .2530212402347 .8517799377447 .49314880371 47.1733398437546 .8884010314946 .6334915161146 .4047889709546 .19707870483 46.0069007873545 .8291702270545 .6609001159745 .497489929245 .3366394043 45.1745109558145 .0097389221244 .8395309448244 .6634712219244 .47998046875 44.2893486022944 .091098785443 .8857803344743 .6735610961943 .45484924316 43.2299499511742 .9989891052242 .7620697021542 .5190887451242 .26990127563 42.0143089294441 .7520484924341 .482978820841 .2068595886240 .92361831665 40.6330986022940 .3353309631340 .0302391052239 .7178802490239 .39826965332 39.0715103149438 .7376289367738 .3967208862338 .0488891601637 .69424819946 37.3331718444836 .9657783508336 .5874900817936 .20391082764 1435.410034181427 .5539550781419 .7010498051411 .8520507811404 .006958008 1396.163940431388 .3229980471380 .4830322271372 .6450195311364 .806030273 1356.9670410161349 .1280517581341 .2869873051333 .4449462891325 .602050781 1317.7550048831309 .9060058591302 .0539550781294 .1979980471286 .338012695 1278.4739990231270 .6049804691262 .7320556641254 .8530273441246 .968017578 1239.078002931231 .1820068361223 .2790527341215 .3699951171207 .453979492 1199.5310058591191 .6020507811183 .6660156251175 .7230224611167 .774047852 1159.8179931641151 .8570556641143 .8900146481135 .917968751127 .941040039 1119.9589843751111 .9739990231103 .9859619141095 .9949951171088 .003051758 1080.0100097661072 .0159912111064 .0219726561056 .0300292971048 .03894043 1040.0500488281032 .0649414061024 .0830078121016 .1060180661008 .132995605 1000.166015625 992.2052001953984.2506713867976.3032226562 968.36328125 
960.4312744141952 .5078735352944 .5932006836936 .6879272461928 .7922973633 920.9066772461913 .0316772461905 .1679077148897 .3154296875889 .474609375 881.6461181641873 .8303833008866 .0280151367858 .2391967773850 .4645996094 842.7047729492834 .9600830078827 .2310791016819 .5181274414811 .8217773438 804.1427001953796 .4813232422788 .8378295898781 .2130126953773 .607421875 766.021484375758 .4556884766750 .9108276367743 .3870239258735 .8848876953 728.4050292969720 .9478149414713 .5137939453706 .1035766602698 .7177734375 691.3568725586684 .0214233398676 .7119750977669 .4290771484662 .1735229492 654.9456787109647 .7462768555640 .5761108398633 .4357299805626 .3256835938 619.246887207612 .200012207605 .1857299805598 .2048950195591 .2583007812 584.3466796875577 .4708862305570 .6317749023563 .8302001953557 .0670166016 550.3432006836543 .6594848633537 .0170288086530 .4166259766523 .8591918945 517.345703125510 .8772888184504 .4547119141498 .0790100098491 .7511901855 485.4721069336479 .2427062988473 .0642089844466 .9371948242460 .8629150391 454.842010498448 .8754882812442 .9642028809437 .1091003418431 .3106994629 425.570098877419 .8877868652414 .2648010254408 .7015075684403 .1987915039 397.7568969727392 .3765869141387 .0581054688381 .8020935059376 .6086120605 371.478302002366 .4110107422361 .4071960449356 .4666137695351 .5895996094 346.7756958008342 .0249938965337 .3370056152332 .7117919922328 .1488037109 323.6476135254319 .207611084314 .8284912109310 .509185791306 .2495117188 302.0483093262297 .9049072266293 .8185119629289 .7880859375285 .8128967285 281.8918151855278 .0237121582274 .2077941895270 .4431152344266 .728302002 263.0628051758259 .4454040527255 .87550354252 .3518981934248 .8740997314 245.441192627242 .0525970459238 .7075958252235 .4057006836232 .1463012695 228.929397583225 .7545928955222 .6217956543219 .5312042236216 .4832000732 213.4781036377210 .516494751207 .599105835204 .7263946533201 .899307251 199.1183013916196 .3840942383193 .6976928711191 .0592041016188 .4703063965 185.9308929443183 .4434051514181 .0079956055178 .6280059814176 .303894043 174.0401000977171 .8377990723169 .7021026611167 .6351928711165 .641998291 163.7256011963161 .8901062012160 .1392974854158 .4759979248156 .9040985107 155.4244995117154 .0406951904152 .7518005371151 .5603942871150 .463394165 149.4620056152148 .5513000488147 .7308959961146 .9947052002146 .3403930664 145.7611999512145 .2532958984144 .8096008301144 .4250030518144 .0928955078 143.8070983887143 .5617980957143 .350402832143 .1683044434143 .0084991455 142.8679046631142 .7398986816142 .6222991943142 .5093994141142 .3997955322 142.2888031006142 .1752929688142 .0556030273141 .9290008545141 .7924957275 141.6457061768141 .4864044189141 .3139038086141 .1269989014140 .924697876 140.7061004639140 .4700927734140 .2160949707139 .9425964355139 .6492004395 139.334197998138 .9971923828138 .6363983154138 .2512969971137 .8399047852 137.4019012451136 .9349975586136 .4385986328135 .9100036621135 .3484039307 134.7505950928134 .1152954102133 .4394989014132 .720993042131 .9575958252 131.1466064453130 .2870941162129 .3764038086128 .4154968262127 .4020996094 126.3399963379125 .227897644124 .0735015869122 .8769989014121 .6505966187 120.3964996338119 .1321029663117 .8610992432116 .604598999115 .3690032959 114.1738967896113 .0304031372111 .9507980347110 .9511032104110 .029800415 109.2048034668108 .4617996216107 .8187026978107 .251701355106 .776802063 
106.3491973877105 .9513015747105 .5547027588105 .129699707104 .6573028564 104.0976028442103 .4430999756102 .6511001587101 .7375030518100 .6734008789 99.4813385009898 .136016845796 .688888549895 .1544494628993 .58167266846 92.0092697143690 .4809265136789 .0569992065487 .7389602661186 .58072662354 85.529441833584 .6098022460983 .6768264770582 .6386871337981 .33679962158 79.632537841877 .6634902954175 .5312881469773 .3964004516671 .37171936035 69.5376892089867 .9648666381866 .5706863403365 .3508529663164 .198387146 63.0488090515161 .9105186462460 .7234611511259 .5384788513258 .36489868164 57.2222900390656 .1263809204155 .0815582275454 .0939788818453 .16540908813 52.2981491088951 .4920997619650 .7486190795950 .0661010742249 .44541931152 48.8835182189948 .380020141647 .9306716918947 .5329895019547 .18220901489 46.8737716674846 .6030197143646 .3640899658246 .1528091430745 .96289825439 45.7908096313545 .6305313110445 .4791183471745 .3312606811545 .18473052979 45.0352096557644 .8814010620144 .7202415466344 .5513992309644 .37319946289 44.1860885620143 .9896087646543 .7844810485843 .5710601806643 .3498916626 43.1215400695842 .8861885070842 .644248962442 .3955802917542 .14028930664 41.8781318664641 .6090087890641 .3327102661141 .0491218566940 .7580909729 40.4595794677740 .1535110473639 .8399200439539 .5187988281239 .19025039673 38.8542900085438 .5110397338938 .1605300903337 .8029518127437 .438331604 37.0671310424836 .6887092590336 .3048706054735 .91315841675

1439.7790527341431 .8979492191424 .0190429691416 .1469726561408 .277954102 1400.4110107421392 .5460205081384 .6820068361376 .8189697271368 .95703125 1361.0939941411353 .2299804691345 .3649902341337 .4990234381329 .630004883 1321.7600097661313 .8859863281306 .0080566411298 .1269531251290 .241943359 1282.3520507811274 .4580078121266 .5579833981258 .6529541021250 .741943359 1242.8249511721234 .9019775391226 .9730224611219 .0360107421211 .093017578 1203.1419677731195 .1850585941187 .2199707031179 .2490234381171 .270996094 1163.2860107421155 .2960205081147 .2989501951139 .2960205081131 .28894043 1123.2769775391115 .2600097661107 .2409667971099 .2180175781091 .193969727 1083.167968751075 .1409912111067 .1140136721059 .0880126951051 .062011719 1043.038940431035 .0190429691027 .0019531251018 .9890136721010 .979980469 1002.976989746994 .9788208008986 .987121582979 .0020751953971 .0242919922 963.0540771484955 .0919799805947 .1384887695939 .1939697266931 .2587890625 923.3336181641915 .4185180664907 .5142822266899 .6212768555891 .7398071289 883.870300293876 .0134277344868 .1694946289860 .3391113281852 .5227050781 844.7208862305836 .9340820312829 .1627197266821 .4072265625813 .6682739258 805.9465942383798 .2423095703790 .5560913086782 .8884887695775 .2399291992 767.6110839844760 .0025024414752 .4146728516744 .8480834961737 .3034057617 729.7808837891722 .2811889648714 .8051147461707 .3527832031699 .924987793 692.5223999023685 .1453857422677 .794921875670 .4710083008663 .1746826172 655.9066162109648 .667175293641 .4572143555634 .2772827148627 .1281738281 620.0106811523612 .9252929688605 .8729248047598 .854309082591 .8701782227 584.9213867188578 .0089111328571 .1331787109564 .2952880859557 .4962158203 550.7365722656544 .0173950195537 .3395996094530 .7041015625524 .1118164062 517.5635986328511 .0604858398504 .6033935547498 .1932067871491 .8309936523 485.5174865723479 .2538146973473 .0408935547466 .8793945312460 .7705993652 
454.7149963379448 .7138061523442 .7674865723436 .8772888184431 .0436096191 425.2673950195419 .5492858887413 .8901977539408 .2904968262402 .7510986328 397.2721862793391 .8546142578386 .4985046387381 .204498291375 .9726867676 370.8037109375365 .6975097656360 .6543884277355 .6742858887350 .7573852539 345.9034118652341 .1123962402336 .3840026855331 .7182006836327 .1145019531 322.5726013184318 .092010498313 .6722106934309 .3125915527305 .0126953125 300.7715148926296 .5888061523292 .4634094238288 .3948974609284 .3821105957 280.4242858887276 .520690918272 .6704101562268 .8724060059265 .1260070801 261.4302062988257 .7843017578254 .1875250 .6390075684247 .1381072998243 .6840057373 240.2763061523236 .9140930176233 .5971984863230 .3249053955227 .0971069336 223.9132995605220 .7736968994217 .6782989502214 .6273040771211 .6210021973 208.6600036621205 .7449951172202 .8764038086200 .0552062988197 .2819976807 194.5576019287191 .8829956055189 .2588043213186 .6864013672184 .1663970947 181.7008056641179 .2904968262176 .93800354174 .6446075439172 .4136962891 170.2469940186168 .1483001709166 .120300293164 .1663970947162 .2899017334 160.4938964844158 .7814025879157 .1546020508155 .6165924072154 .1679992676 152.8112030029151 .5455932617150 .3721923828149 .2890014648148 .2958068848 147.3890991211146 .567199707145 .8255004883145 .1609039307144 .5684051514 144.0435943604143 .5809936523143 .1755065918142 .8215942383142 .5137023926 142.2467041016142 .0146942139141 .813293457141 .636505127141 .4810028076 141.3412017822141 .2144927979141 .0959014893140 .9833984375140 .8728942871 140.7626953125140 .6493988037140 .5316925049140 .4067993164140 .2736053467 140.1300964355139 .9750976562139 .8072052002139 .6251983643139 .4279022217 139.2142944336138 .9832000732138 .7333984375138 .4638977051138 .1734008789 137.8609008789137 .5249938965137 .1647033691136 .778503418136 .3656005859 135.9241027832135 .4530029297134 .9506072998134 .4154052734133 .8455047607 133.2391967773132 .5944976807131 .9096069336131 .1829071045130 .4125976562 129.5980987549128 .7377929688127 .832901001126 .8824005127125 .8896026611 124.8550033569123 .7845001221122 .6806030273121 .5523986816120 .404800415 119.2493972778118 .0936965942116 .9524002075115 .834602356114 .7542037964 113.7211990356112 .7440032959111 .8337020874110 .9896011353110 .2213973999 109.5194015503108 .8893966675108 .3197021484107 .8156967163107 .3496017456 106.9029006958106 .4521026611105 .9697036743105 .4448013306104 .8562011719 104.1877975464103 .4045028687102 .5215988159101 .5289993286100 .4337997437 99.2182998657297 .9180068969796 .5463562011795 .1329116821393 .69994354248 92.2886123657290 .9499893188589 .6728134155388 .4793777465887 .33978271484 86.2790069580185 .1433868408283 .8513565063582 .4003677368280 .69957733154 78.8476715087976 .8377227783274 .7870635986372 .8410263061571 .04712677002 69.482276916568 .0893783569366 .900253295965 .6936264038164 .2712097168 62.8019790649461 .3952598571860 .0409202575758 .7304916381857 .47312927246 56.2761497497655 .1428794860854 .0783309936553 .0834999084552 .15995025635 51.3073692321850 .5260391235449 .8146591186549 .1728210449248 .59777832031 48.0876617431647 .6382408142147 .245540618946 .9044494628946 .60902023315 46.3540496826246 .1325683593845 .9398193359445 .7687683105545 .61531066895 45.4730415344245 .3385505676345 .2063102722245 .073799133344 .93658828735 44.7932090759344 .6405410766644 .4782218933144 .3046112060544 .12020874023 
43.9246788024943 .718891143843 .503349304243 .2788200378443 .0460395813 42.805389404342 .5574111938542 .3021583557142 .0397911071841 .77021026611 41.49330902141 .2090110778840 .9171104431240 .6175804138240 .31032943726 39.9953498840339 .6726112365739 .3421897888239 .0041084289638 .65847015381 38.3053283691437 .9448204040537 .5770301818837 .2020912170436 .82038879395 36.4320907592836 .0323486328135 .62710189819

1444.1280517581436 .2249755861428 .3239746091420 .4279785161412 .536010742 1404.6459960941396 .7569580081388 .8699951171380 .9840087891373 .098022461 1365.211059571357 .3239746091349 .4350585941341 .5450439451333 .651977539 1325.7569580081317 .8580322271309 .9560546881302 .0500488281294 .140014648 1286.2249755861278 .3050537111270 .3800048831262 .4479980471254 .510986328 1246.5679931641238 .6180419921230 .6610107421222 .6979980471214 .727050781 1206.7490234381198 .7640380861190 .7709960941182 .7709960941174 .765014648 1166.7509765621158 .7309570311150 .7039794921142 .671997071134 .634033203 1126.5909423831118 .542968751110 .4919433591102 .4379882811094 .380981445 1086.322998047 1078.262939453 1070.203002931062.1429443361054.083984375 1046.0260009771037 .9709472661029 .9189453121021 .8699951171013 .825012207 1005.786010742997 .7509765625989 .7224121094981 .700012207973 .6845092773 965.6762695312957 .67578125949 .68359375941 .700012207933 .7255249023 925.7606201172917 .8057861328909 .8615112305901 .9279785156894 .0059814453 886.095703125878 .1978149414870 .3126220703862 .4409179688854 .582824707 846.739074707838 .9102783203831 .0968017578823 .2990722656815 .5178222656 807.7534790039800 .0067138672792 .2777709961784 .5676269531776 .8762817383 769.2047729492761 .5535888672753 .9230957031746 .3140258789738 .7266845703 731.1619262695723 .6198730469716 .1016235352708 .607421875701 .137878418 693.6937255859686 .2753295898678 .883605957671 .5189819336664 .1821289062 656.8735961914649 .5942993164642 .3444824219635 .1254272461627 .9371948242 620.7808837891613 .6569824219606 .5665893555599 .5100708008592 .4885864258 585.5026855469578 .5532226562571 .6409301758564 .766784668557 .9315185547 551.1361083984544 .3814086914537 .6682739258530 .9976806641524 .3704223633 517.7874145508511 .2496948242504 .7579956055498 .3133850098491 .9166870117 485.5689086914479 .2708129883473 .0234985352466 .8276062012460 .6842956543 454.5942077637448 .5582885742442 .5773010254436 .6520080566430 .783203125 424.9717102051419 .2181091309413 .5231933594407 .887512207402 .3117980957 396.796295166391 .3418884277385 .9486083984380 .6171875375 .3476867676 370.1406860352364 .9961853027359 .9146118164354 .8958129883349 .9397888184 345.0466918945340 .2163085938335 .4484863281330 .7432861328326 .1000061035 321.5185852051316 .9985046387312 .5394897461308 .1408081055303 .8020935059 299.5226135254295 .3019104004291 .1391906738287 .0339050293282 .9852905273 278.992401123275 .0548095703271 .1715087891267 .3418884277263 .5650939941 259.8405151367256 .1672058105252 .5447998047248 .9721984863245 .4492034912 241.9747924805238 .5487060547235 .1701049805231 .8388061523228 .5540008545 225.3157958984222 .1237030029218 .9777984619215 .8778076172212 .8242950439 209.8173980713206 .8576965332203 .9454956055201 .0818023682198 .266998291 195.5021972656192 .7879943848190 .1257019043187 .5157012939184 .9598999023 182.458694458180 .0144958496177 .6277008057175 .3011932373173 .0359954834 
170.8354034424168 .7006988525166 .6354980469164 .6417999268162 .7230072021 160.8813018799159 .1195068359157 .4400939941155 .8446960449154 .3356018066 152.9131011963151 .5791931152150 .3323974609149 .1743011475148 .1016998291 147.1152038574146 .2106018066145 .3869934082144 .6394042969143 .9658050537 143.3609008789142 .8213043213142 .341796875141 .9179992676141 .5449981689 141.2178955078140 .9319000244140 .6817932129140 .4636993408140 .2720947266 140.1038970947139 .953704834139 .8191986084139 .695602417139 .5807952881 139.470703125139 .3638000488139 .2561950684139 .146697998139 .0323944092 138.911895752138 .7830047607138 .6443023682138 .4942016602138 .3314056396 138.1544952393137 .9622039795137 .75340271137 .5265960693137 .2808990479 137.0146026611136 .7270050049136 .4161987305136 .0816955566135 .7216033936 135.3352050781134 .9207000732134 .4774017334134 .0032958984133 .4976043701 132.9582977295132 .3843994141131 .774307251131 .1264038086130 .4400024414 129.7135009766128 .9474029541128 .1401062012127 .2937011719126 .4072036743 125.4850997925124 .5269012451123 .5398025513122 .5248031616121 .4916992188 120.4434967041119 .3918991089118 .3419036865117 .3065032959116 .2919998169 115.3100967407114 .3687973022113 .4740982056112 .6362991333111 .8520965576 111.1328964233110 .4647979736109 .8551025391109 .2883987427108 .7715988159 108.2787017822107 .7987976074107 .3091964722106 .7841033936106 .2222976685 105.6120986938104 .9382019043104 .160697937103 .3061981201102 .3659973145 101.3490982056100 .232299804799 .0473632812597 .7985916137796 .50489807129 95.1740264892693 .8378067016692 .5473937988391 .2718811035290 .02414703369 88.777206420987 .5828018188586 .3056564331184 .8884963989383 .35508728027 81.6625366210979 .8763427734477 .9562301635776 .0147094726674 .14102935791 72.379882812570 .8074035644569 .3855514526468 .2194595336966 .98245239258 65.3456573486363 .6232490539662 .0473899841360 .5482902526959 .10929870605 57.7477989196856 .4513587951755 .2348594665554 .093608856253 .03361129761 52.0536117553751 .1540298461950 .3354492187549 .595008850148 .93368148804 48.3463706970247 .8319091796947 .3842391967846 .9987602233946 .6694984436 46.388809204146 .151371002245 .9483604431245 .7751197814945 .6231918335 45.4886283874545 .3640098571845 .2460784912145 .1287002563545 .00941848755 44.8834991455144 .7495002746644 .6042213439944 .4472999572844 .27714920044 44.094310760543 .8986091613843 .6910018920943 .4722595214843 .24319839478 43.0049095153842 .757808685342 .5027694702142 .2397994995141 .96937942505 41.6913108825741 .4057502746641 .1124687194840 .8114814758340 .50260925293 40.1859092712439 .8612594604539 .5287590026939 .1883811950738 .84024047852 38.4843597412138 .1208915710437 .7498703002937 .3714790344236 .98577880859 36.5932388305736 .1932106018135 .7875595092835 .3737411499 1448.4670410161440 .5400390621432 .6149902341424 .6970214841416 .781982422 1408.8690185551400 .9580078121393 .0479736331385 .1390380861377 .229003906 1369.3189697271361 .4090576171353 .495971681345 .582031251337 .666015625 1329.745971681321 .8239746091313 .8969726561305 .9659423831298 .031005859 1290.0909423831282 .1459960941274 .1949462891266 .2380371091258 .275024414 1250.3060302731242 .3289794921234 .3459472661226 .3549804691218 .357055664 1210.3509521481202 .3380126951194 .3179931641186 .288940431178 .25402832 1170.211059571162 .1619873051154 .1049804691146 .042968751137 .974975586 
1129.9010009771121 .8229980471113 .7409667971105 .6550292971097 .566040039 1089.4749755861081 .3819580081073 .288940431065 .1960449221057 .103027344 1049.0109863281040 .9210205081032 .8330078121024 .7490234381016 .669006348 1008.5930175781000 .521972656992 .4561767578984 .3967285156976 .3436279297 968.2974853516960 .2589111328952 .2280273438944 .2055053711936 .1917724609 928.1876220703920 .1931152344912 .2088012695904 .2351074219896 .2725830078 888.3217163086880 .3828735352872 .4567260742864 .5435791016856 .6441040039 848.7589111328840 .8881225586833 .0327148438825 .1928710938817 .3695068359 809.5628051758801 .7736206055794 .0023193359786 .2495117188778 .5158081055 770.8018188477763 .1079711914755 .4351196289747 .7833862305740 .1538085938 732.5466918945724 .9625854492717 .4022827148709 .8662719727702 .3551025391 694.8695068359687 .4099731445679 .9771728516672 .5717773438665 .194519043 657.8458251953650 .5264282227643 .237121582635 .978515625628 .7512207031 621.5562133789614 .3939208984607 .2653198242600 .171081543593 .112121582 586.0889282227579 .1024780273572 .1536254883565 .2431030273558 .3718261719 551.5405273438544 .7501831055538 .0015869141531 .2957763672524 .6334838867 518.0156860352511 .4432067871504 .9169921875498 .4378967285492 .0068054199 485.6246032715479 .2922058105473 .0105895996466 .7803955078460 .6026916504 454.4780883789448 .4077148438442 .3919067383436 .4318847656430 .5281982422 424.6816101074418 .8927001953413 .1622924805407 .4909057617401 .8792114258 396.3276062012390 .8367004395385 .4067993164380 .0385131836374 .7319030762 369.4876098633364 .3055114746359 .1860961914354 .1293029785349 .1353149414 344.2037963867339 .3351135254334 .5289001465329 .7851867676325 .1034851074 320.4837036133315 .9254150391311 .428314209306 .9919128418302 .6156921387 298.2991943359294 .0419921875289 .8434143066285 .7027893066281 .6196899414 277.5932922363273 .6229858398269 .708190918265 .8482055664262 .0422973633 258.2901000977254 .5906982422250 .9436035156247 .3480987549243 .8038024902 240.3099975586236 .8661956787233 .4718933105230 .1268005371226 .8302001953 223.5821075439220 .3820037842217 .2301025391214 .1262054443211 .070602417 208.0634002686205 .1053009033202 .1965026855199 .3379058838196 .5299987793 193.7738037109191 .0702056885188 .4199981689185 .8244018555183 .2846069336 180.8016967773178 .3775024414176 .0131072998173 .7106933594171 .4716033936 169.2984924316167 .1929931641165 .157699585163 .1949005127161 .3069000244 159.4960021973157 .7640991211156 .1134033203154 .5449981689153 .0605926514 151.6604003906150 .3453979492149 .1147003174147 .9685058594146 .9046936035 145.9228057861145 .0196075439144 .1934051514143 .4403991699142 .7579956055 142.141998291141 .5888977051141 .0944976807140 .6544952393140 .2648010254 139.9205932617139 .6181030273139 .3522949219139 .1195983887138 .9152069092 138.7357940674138 .5769042969138 .4355926514138 .3079071045138 .191192627 138.0818939209137 .9779052734137 .8759002686137 .7740936279137 .6696014404 137.5610046387137 .4458007812137 .3226013184137 .1893005371137 .0449066162 136.8874969482136 .716003418136 .5289001465136 .324798584136 .1024932861 135.8605957031135 .5979003906135 .31300354135 .0048065186134 .6719970703 134.313293457133 .9275970459133 .5137023926133 .0702056885132 .596206665 132.0903015137131 .5514984131130 .9786071777130 .3706970215129 .7272033691 129.0471954346128 .3314056396127 .5791015625126 .792098999125 .970703125 
125.1182022095124 .2358016968123 .3289031982122 .400100708121 .4565963745 120.5026016235119 .5466003418118 .5948028564117 .6557006836116 .7365036011 115.8445968628114 .9876022339114 .1694030762113 .397102356112 .6697998047 111.9921035767111 .3571014404110 .7648010254110 .2052993774109 .6773986816 109.1647033691 108.6564025879108.1360015869107.5848007202 106.9990997314 106.3682022095105 .6815032959104 .9154968262104 .0835037231103 .181098938 102.2149963379101 .1755981445100 .075202941998 .91127777197 .69801330566 96.4452819824295 .1638870239393 .8723831176892 .568778991791 .27297973633 89.9598007202188 .6419067382887 .2535934448285 .7607803344784 .18678283691 82.5132064819380 .7757873535278 .9404067993277 .0814132690475 .25718688965 73.5067672729571 .9032592773470 .4151687622169 .0780868530367 .67445373535 66.01088714664 .2697830200262 .6104698181261 .0166206359959 .48302841187 58.0233688354556 .6440010070855 .3488311767654 .13867187553 .01599884033 51.9823417663651 .0373497009350 .182201385549 .4143714904848 .73403167725 48.1364517211947 .6188316345247 .1749305725146 .7984886169446 .48281860352 46.218891143846 .0002708435145 .8171195983945 .6638488769545 .5315284729 45.4155807495145 .308319091845 .2061195373545 .1027107238844 .99549102783 44.8796310424844 .7536811828644 .6143798828144 .4614791870144 .29336166382 44.1107406616243 .9134788513243 .7027702331543 .4794616699243 .24465179443 42.9995498657242 .7448196411142 .4814605712942 .2096900939941 .93004989624 41.6425018310541 .3471908569341 .0440292358440 .732978820840 .41399002075 40.0869789123539 .7519798278839 .4089813232439 .058029174838 .69918823242 38.3325386047437 .9581794738837 .5761985778837 .1867294311536 .7899017334 36.3861198425335 .9755401611335 .55315017735 .12519836426

1452.7860107421444 .8389892581436 .8929443361428 .953002931421 .015991211 1413.0799560551405 .1469726561397 .214965821389 .2829589841381 .350952148 1373.4189453121365 .4849853521357 .5489501951349 .6120605471341 .67199707 1333.7290039061325 .7819824221317 .832031251309 .8759765621301 .916992188 1293.9520263671285 .9809570311278 .0050048831270 .0229492191262 .034057617 1254.038940431246 .0360107421238 .0260009771230 .0080566411221 .983032227 1213.9499511721205 .9090576171197 .8599853521189 .8029785161181 .739013672 1173.6669921881165 .5889892581157 .5030517581149 .4110107421141 .312011719 1133.2080078121125 .0989990231116 .9849853521108 .8680419921100 .746948242 1092.6240234381084 .4990234381076 .3719482421068 .2449951171060 .119018555 1051.9930419921043 .8680419921035 .745971681027 .6259765621019 .510009766 1011.3980102541003 .291015625995 .188293457987 .0916748047979 .0012207031 970.9174194336962 .8405761719954 .7714233398946 .7102050781938 .6575927734 930.6140136719922 .5800170898914 .5557861328906 .5421142578898 .5391845703 890.5479125977882 .5684204102874 .6011962891866 .6469726562858 .7061157227 850.779296875842 .8668823242834 .9697265625827 .0880126953819 .2224731445 811.3737182617803 .542175293795 .7285766602787 .9334716797780 .1574707031 772.4011230469764 .6649169922756 .9495849609749 .2556762695741 .5839233398 733.9345092773726 .3084716797718 .7062988281711 .1284790039703 .5758056641 696.048828125688 .5480957031681 .0745239258673 .6284179688666 .2105712891 658.8217163086651 .4624023438644 .1334228516636 .8353881836629 .5690917969 622.3352050781615 .1345214844607 .9677734375600 .8358154297593 .739074707 
586.6787109375579 .6552734375572 .6696777344565 .7227783203558 .8154296875 551.9481811523545 .1221923828538 .3381958008531 .5969848633524 .8997192383 518.2470092773511 .6398010254505 .0788879395498 .5653076172492 .0997924805 485.6832885742479 .3164978027473 .0004882812466 .7359924316460 .5238952637 454.3649902344448 .2600097656442 .2098083496436 .2150878906430 .2767028809 424.395111084418 .5711975098412 .8056030273407 .0987854004401 .4515075684 395.8641052246390 .337310791384 .8711853027379 .4666137695374 .1234130859 368.8422851562363 .6232910156358 .4668884277353 .3728027344348 .3414001465 343.3725891113338 .4664001465333 .6227111816328 .8414916992324 .1224060059 319.4653930664314 .8699951172310 .3360900879305 .8630065918301 .4507141113 297.0985107422292 .8060913086288 .5729064941284 .3984985352280 .2821960449 276.2235107422272 .2219848633268 .2770080566264 .3880004883260 .5542907715 256.775604248253 .050994873249 .3804016113245 .7628936768242 .1981964111 238.6856994629235 .2250061035231 .8155975342228 .4571990967225 .1492004395 221.8916931152218 .68409729215 .5265960693212 .4188995361209 .3614959717 206.3544006348 203.3981018066200.4929046631 197.6396942139194.8388977051 192.091506958189 .3983001709186 .7604064941184 .1786956787181 .6546936035 179.1891937256176 .7843017578174 .4407043457172 .1609039307169 .9456939697 167.7978057861165 .7185058594163 .7102050781161 .774597168159 .9138946533 158.1298065186156 .4239044189154 .7978973389153 .2525024414151 .7890930176 150.4073944092149 .1083984375147 .8905029297146 .754196167145 .6970062256 144.7187042236143 .8157043457142 .9868927002142 .2283935547141 .5382995605 140.9122009277140 .3473968506139 .8397064209139 .3858032227138 .9813995361 138.6226959229138 .3058929443138 .0265960693137 .7814025879137 .56590271 137.3771972656 137.2106018066137.0637969971 136.9324951172136.8146972656 136.7062072754136 .6053009033136 .5084075928136 .4138946533136 .3186950684 136.221206665136 .1188964844136 .0101928711135 .8932037354135 .7662963867 135.6278991699135 .4765014648135 .3106994629135 .12890625134 .9299926758 134.7124023438134 .4750061035134 .216293335133 .9351959229133 .6302947998 133.3007965088132 .9450073242132 .5623016357132 .1511993408131 .7111053467 131.2407989502130 .7393035889130 .2062988281129 .6405029297129 .0424041748 128.4109039307127 .7474975586127 .0512008667126 .324798584125 .5680999756 124.7852020264123 .976600647123 .1482009888122 .3013000488121 .443397522 120.5772018433119 .710899353118 .8487014771117 .9980010986117 .1647033691 116.3539962769115 .5726013184114 .8220977783114 .1090011597113 .4304962158 112.7917022705112 .1844024658111 .6115036011111 .0599975586110 .5288009644 110.00340271109 .4769973755108 .9368972778108 .3713989258107 .7732009888 107.1271972656106 .4337997437105 .677696228104 .867401123103 .9896011353 103.0594024658102 .0712966919101 .027999877999 .9161682128998 .75093841553 97.5478820800896 .2910537719794 .9778594970793 .624862670992 .27742004395 90.8984909057689 .4898529052788 .0229568481486 .5132217407284 .95073699951 83.302879333581 .6153564453179 .8329772949278 .0265731811576 .22145843506 74.4542617797972 .8056564331171 .2062835693469 .6633300781268 .09171295166 66.4598617553764 .7906723022563 .116630554261 .4718399047959 .86492156982 58.3295593261756 .8726196289155 .5064010620154 .2260818481453 .04111099243 51.9521598815950 .9599914550850 .0690002441449 .273849487348 .57804870605 
47.9725990295447 .4564094543547 .0201492309646 .6563491821346 .35778045654 46.1121101379445 .9139709472745 .7505989074745 .6176185607945 .50400161743 45.4057617187545 .3143005371145 .2262115478545 .1348915100145 .03773117065 44.9299392700244 .8099517822344 .6747093200744 .5238113403344 .35594940186 44.1716804504443 .9712409973143 .7557296752943 .5264091491743 .28430175781 43.0310401916542 .7672615051342 .4943389892642 .2124404907241 .9224281311 41.6241798400941 .3181190490741 .0040016174340 .6819992065440 .35190963745 40.0138282775939 .6676483154339 .3134689331138 .9512405395538 .58113098145 38.2030906677237 .8173408508337 .4238815307637 .0229110717836 .61449050903 36.1991004943835 .7760810852135 .3473205566434 .91025161743

1457.0959472661449 .1259765621441 .1569824221433 .1960449221425 .237060547 1417.2800292971409 .3249511721401 .370971681393 .4169921881385 .463012695 1377.5080566411369 .5520019531361 .5939941411353 .6340332031345 .671020508 1337.7039794921329 .7340087891321 .7600097661313 .7800292971305 .796020508 1297.8070068361289 .8110351561281 .8100585941273 .8020019531265 .787963867 1257.7659912111249 .7370605471241 .7010498051233 .6560058591225 .604003906 1217.542968751209 .4739990231201 .3979492191193 .3129882811185 .219970703 1177.1199951171169 .0119628911160 .8959960941152 .7740478521144 .645996094 1136.5109863281128 .370971681120 .2270507811112 .078002931103 .925048828 1095.7700195311087 .6120605471079 .4520263671071 .2919921881063 .131958008 1054.9720458981046 .8129882811038 .6560058591030 .5009765621022 .348999023 1014.200988771006 .057006836997 .9183959961989 .7847290039981 .6569824219 973.5355224609965 .420715332957 .3131713867949 .2135009766941 .1220703125 933.0393066406 924.9658203125916.9019775391908.8483276367900.8052978516 892.7734985352884 .7534179688876 .7454223633868 .7501831055860 .7681884766 852.799987793844 .8461303711836 .9072265625828 .9838256836821 .0762939453 813.1854858398805 .3118896484797 .4561157227789 .6187744141781 .8004760742 774.0020141602766 .2235107422758 .4658813477750 .7299194336743 .0159301758 735.3245239258727 .6566162109720 .012512207712 .3931274414704 .7988891602 697.2305908203689 .6887817383682 .1741943359674 .6873779297667 .2291259766 659.799987793652 .4008178711645 .0322265625637 .6948852539630 .3895874023 623.1168823242615 .8778076172608 .6729125977601 .5029296875594 .3687133789 587.2708740234580 .2105102539573 .1881713867566 .2047729492559 .2609863281 552.3579101562545 .49609375538 .676574707531 .9000854492525 .1677246094 518.4799804688511 .8380126953505 .242401123498 .6942138672492 .1942138672 485.7432861328479 .3421936035472 .9919128418466 .6931152344460 .446685791 454.2533874512448 .1141967773442 .029510498436 .0003967285430 .0273132324 424.111114502418 .2522888184412 .4516906738406 .7098083496401 .0273132324 395.404510498389 .8421020508384 .3403930664378 .899810791373 .5205993652 368.2033996582362 .9480895996357 .7551879883352 .6246948242347 .5567016602 342.5513000488337 .6084899902332 .7280883789327 .9104003906323 .1549987793 318.4617919922313 .8304138184309 .2607116699304 .7522888184300 .3049926758 295.9183044434291 .5918884277287 .3254089355283 .1182861328278 .9702148438 274.8806152344270 .8490905762266 .875262 .9580993652259 .0978088379255 .2935943604 251.5451049805247 .8518066406244 .2131958008240 .6289978027237 .0986022949 233.62159729230 .1976928711226 .8265075684223 .507598877220 .2409973145 
217.0261993408213 .8632965088210 .7521972656207 .6930999756204 .6862030029 201.7317962646198 .8303070068195 .9824981689193 .1887969971190 .4501037598 187.7671966553185 .141204834182 .5731048584180 .0641021729177 .6154022217 175.2283935547172 .9044952393170 .6452941895168 .4523010254166 .3271942139 164.271697998162 .2875061035160 .3762054443158 .5395050049156 .779006958 155.095703125153 .491104126151 .9654998779150 .5198974609149 .154006958 147.8681030273146 .6609039307145 .5325012207144 .4806976318143 .5045013428 142.6013946533141 .7696990967141 .0063018799140 .308807373139 .6739044189 139.0986022949 138.579498291 138.1132049561 137.6961975098 137.3249053955 136.9956970215136 .7048034668136 .4488983154136 .2239990234136 .0270996094 135.8542938232135 .7028045654135 .5688018799135 .4499969482135 .3428039551 135.2449035645135 .1531982422135 .0655975342134 .9792938232134 .8923950195 134.8025054932134 .707901001134 .6063995361134 .4967041016134 .3766937256 134.2451019287134 .1002044678133 .9407043457133 .7651062012133 .5720062256 133.3601074219133 .1280975342132 .8746948242132 .5986938477132 .2991027832 131.9745941162131 .6244049072131 .2474060059130 .8426971436130 .4096984863 129.9476013184129 .4561004639128 .9344940186128 .3831939697127 .8016967773 127.1912994385126 .5520019531125 .8859024048125 .1937026978124 .4786987305 123.7422027588122 .9887008667122 .2205963135121 .4430999756120 .6598968506 119.8764038086119 .0973968506118 .3279037476117 .5729980469116 .8363037109 116.1231002808115 .4343032837114 .7743988037114 .1411972046113 .537399292 112.9577026367112 .4019012451111 .8609008789111 .3312988281110 .8024978638 110.2679977417109 .7188034058109 .1448974609108 .5390014648107 .8899002075 107.1967010498 106.4499969482 105.6528015137 104.7970962524103.8907012939 102.9322967529101 .9180984497100 .836700439599 .69772338866798 .50874328613 97.2510833740295.9135131835994.5186309814593.0958328247191.64647674561 90.1666336059688 .6563034057687 .1598129272585 .6334991455184 .03800201416 82.4004592895580 .6619796752978 .873466491777 .0578536987375 .25247192383 73.5322875976671 .8342971801870 .1666183471768 .5155334472766 .86340332031 65.213867187563 .5423583984461 .8730697631860 .2352409362858 .65205001831 57.1378517150955 .7046394348154 .3600196838453 .1113815307651 .96640014648 50.9262504577649 .9985809326249 .178848266648 .4697189331147 .86180114746 47.35070037842 46.92667007446 46.58002090454 46.30160903931 46.07651901245 45.8987617492745 .7562103271545 .6427307128945 .547298431445 .4651184082 45.3877792358445 .3116302490245 .2301292419445 .1406784057645 .03847122192 44.9221000671444 .7884597778344 .6373786926344 .4674606323244 .27959060669 44.0739097595243 .8518600463943 .6146507263243 .3636817932143 .10060119629 42.8263511657742 .5423507690442 .2490386962941 .9473114013741 .63722991943 41.3191795349140 .9930992126540 .6590614318840 .3170089721739 .96691894531 39.6087989807139 .2426414489738 .8684883117738 .4864006042538 .09643936157 37.6986999511737 .2932891845736 .8803100585936 .4599113464436 .03248977661 35.598209381135 .151931762734 .70022964478 1461.3859863281453 .3959960941445 .4090576171437 .4260253911429 .447021484 1421.4689941411413 .4930419921405 .5169677731397 .5419921881389 .566040039 1381.5889892581373 .6109619141365 .6309814451357 .6479492191349 .661987305 1341.6729736331333 .6789550781325 .6810302731317 .6779785161309 .670043945 
1301.6560058591293 .6359863281285 .6099853521277 .5770263671269 .536010742 1261.4890136721253 .4339599611245 .370971681237 .3000488281229 .219970703 1221.1319580081213 .0360107421204 .9310302731196 .8179931641188 .697021484 1180.5679931641172 .4300537111164 .2860107421156 .1340332031147 .974975586 1139.8100585941131 .6400146481123 .4639892581115 .2840576171107 .098999023 1098.9110107421090 .7209472661082 .5290527341074 .3349609381066 .140991211 1057.9470214841049 .754028321041 .5620117191033 .3719482421025 .185058594 1017.002014161008 .8220214841000 .645996094992 .4755859375984 .3106079102 976.1514892578967 .9989013672959 .8532714844951 .7150878906943 .5850219727 935.4631958008927 .3502807617919 .246887207911 .1533813477903 .0703735352 894.9982910156886 .9376831055878 .8889770508870 .8530273438862 .8297729492 854.8203735352846 .8250732422838 .8446044922830 .8795166016822 .9301757812 814.9974975586807 .0819091797799 .1840820312791 .3046875783 .4442749023 775.603515625767 .7830200195759 .983215332752 .2050170898744 .4489135742 736.7155761719729 .0059204102721 .3200073242713 .658996582706 .0233764648 698.4138183594690 .830871582683 .2755126953675 .7479248047668 .2493286133 660.7800292969653 .3408203125645 .9324951172638 .5557861328631 .2114868164 623.9000854492616 .6223754883609 .3792114258602 .1713256836594 .9993896484 587.8643188477580 .7667236328573 .7075195312566 .6876220703559 .7075195312 552.7683105469545 .8707275391539 .015625532 .2036743164525 .4359741211 518.7133178711512 .036315918505 .4060058594498 .8232116699492 .2886962891 485.8034057617479 .3680114746472 .9833068848466 .6502075195460 .3695983887 454.141998291447 .9684143066441 .8494873047435 .7858886719429 .7784118652 423.8276977539417 .9342956543412 .0989990234406 .3222045898400 .6047973633 394.9469909668389 .349395752383 .8124084473378 .3363952637372 .9218139648 367.5689086914362 .2778930664357 .0491943359351 .8828125346 .7789916992 341.7377929688336 .759185791331 .8431091309326 .9898071289322 .1989135742 317.4703979492312 .8039855957308 .1997070312303 .6570129395299 .1759033203 294.7557983398290 .3966064453286 .0979003906281 .8594055176277 .6806945801 273.5613098145269 .5008850098265 .4989929199261 .5552978516257 .6694030762 253.8408966064250 .0691986084246 .3542938232242 .6954040527239 .0924072266 235.5446929932232 .0520935059228 .6141967773225 .2308044434221 .9013977051 218.6260070801215 .4042053223212 .2362060547209 .1217041016206 .0610046387 203.0541992188 200.1018066406 197.2039031982 194.3614044189191.5744934082 188.8444061279186 .1714935303183 .5570983887181 .0019073486178 .5074005127 176.0742950439173 .704498291171 .3986053467169 .1587982178166 .9857940674 164.8816070557162 .8473052979160 .8847045898158 .9949035645157 .179397583 155.4394989014153 .7758026123152 .1896057129150 .6808013916149 .2503967285 147.8975067139146 .6226959229145 .4241943359144 .3022003174143 .254196167 142.279800415141 .3760070801140 .5417022705139 .7736053467139 .0697937012 138.4270019531137 .8428039551137 .3137054443136 .8370056152136 .4091949463 136.0270996094135 .6875135 .3867950439135 .1219024658134 .8890075684134 .6855010986 134.5074005127134 .3522033691134 .2160949707134 .0970001221133 .9911956787 133.8964996338133 .8097991943133 .7290039062133 .6511993408133 .5747070312 133.4967041016133 .4156951904133 .329498291133 .2362976074133 .1343994141 133.0222930908132 .8983001709132 .7608032227132 .6085968018132 .4400024414 
132.2539978027132 .0489959717131 .8238983154131 .5773925781131 .3087005615 131.016494751130 .6999053955130 .3582000732129 .9904937744129 .5962982178 129.1750946045128 .7265930176128 .25050354127 .7472991943127 .2166976929 126.6604003906126 .0780029297125 .4722976685124 .84349823124 .1952972412 123.5283966064122 .8473968506122 .1538009644121 .452796936120 .7468032837 120.0409011841119 .3384017944118 .6435012817117 .9601974487117 .290802002 116.6397018433116 .0065994263115 .3955993652114 .8034973145114 .2332000732 113.6787033081113 .1410980225112 .6115036011112 .0885009766111 .5621032715 111.0272979736110 .4757995605109 .8992004395109 .2922973633108 .6453018188 107.9576034546107 .2193984985106 .4345016479105 .5942993164104 .7045974731 103.7610015869102 .7604980469101 .6937026978100 .561599731499 .37030792236 98.0998001098696 .7458801269595 .3125991821393 .8293533325292 .29252624512 90.7285919189589 .197402954187 .7583923339886 .3346176147584 .80587768555 83.2028274536181 .4578781127979 .6392898559677 .7721176147575 .8828125 74.0809936523472 .2948303222770 .5665130615268 .8734436035267 .22453308105 65.5960083007863 .9386291503962 .2844810485860 .6388206481959 .03102111816 57.4635810852155 .9686813354554 .5542602539153 .2366905212452 .02973175049 50.9364318847749 .9731597900449 .1284103393648 .4115104675347 .80550003052 47.30828857422 46.90533065796 46.58229064941 46.32957839966 46.12680053711 45.9715881347745 .8484001159745 .753070831345 .6728210449245 .60401916504 45.5375404357945 .4699707031245 .3949394226145 .3096809387245 .20988082886 45.0937881469744 .9588699340844 .8045997619644 .6301383972244 .43603134155 44.2229614257843 .9920806884843 .7451591491743 .4833602905343 .2088508606 42.9224014282242 .6259117126542 .3196601867742 .0049285888741 .68164825439 41.3505096435541 .0112609863340 .6642303466840 .3091697692939 .94623947144 39.5752792358439 .196430206338 .8095893859938 .4149208068838 .01237869263 37.6021499633837 .1842308044436 .7588310241736 .3259811401435 .88615036011 35.4387092590334 .9855194091834 .52402114868

1465.6669921881457 .6560058591449 .6469726561441 .6440429691433 .644042969 1425.6459960941417 .6490478521409 .6529541021401 .6569824221393 .66003418 1385.6619873051377 .6619873051369 .660034181361 .6550292971353 .646972656 1345.6340332031337 .6180419921329 .5959472661321 .5699462891313 .536987305 1305.4990234381297 .4549560551289 .4040527341281 .3459472661273 .280029297 1265.207031251257 .1259765621249 .0360107421240 .9389648441232 .83203125 1224.7170410161216 .5930175781208 .4599609381200 .3189697271192 .168945312 1184.0109863281175 .8449707031167 .6710205081159 .4890136721151 .301025391 1143.1049804691134 .9040527341126 .6970214841118 .4859619141110 .270019531 1102.0500488281093 .8270263671085 .6020507811077 .3751069 .1479492191060 .920043945 1052.6920166021044 .4659423831036 .2409667971028 .0190429691019 .79901123 1011.583007812 1003.37097168995.1638793945986.9616699219978.7653198242 970.575012207962 .3912963867954 .2147827148946 .0458984375937 .8853149414 929.733215332921.5903930664913.4572143555905.3341064453 897.2216796875 889.1207275391 881.0313720703 872.9545288086 864.8903808594856.8399047852 848.8032836914840 .7813720703832 .7744750977824 .7836303711816 .8090209961 808.8516235352800 .9119262695792 .9904174805785 .0880126953777 .2050170898 769.3422851562761 .5006103516753 .6802978516745 .8823242188738 .1071166992 
730.3554077148722 .6279907227714 .9254150391707 .2484130859699 .5974731445 691.9735717773684 .3773193359676 .8090820312669 .2700195312661 .7606201172 654.2814941406646 .8333740234639 .4174194336632 .0338134766624 .6834716797 617.3671875610 .0858154297602 .8397216797595 .6301269531588 .4575805664 581.3228149414574 .2266845703567 .1699829102560 .1536254883553 .1782226562 546.2446289062539 .3538208008532 .5064086914525 .7034912109518 .9456176758 512.2337036133505 .5685119629498 .9511108398492 .3819885254485 .8622131348 479.3923950195472 .9735107422466 .6061096191460 .2911987305454 .0293884277 447.8215942383441 .6683959961435 .5705871582429 .5288085938423 .5437927246 417.6159057617411 .7461853027405 .9348144531400 .182800293394 .4902038574 388.8577880859383 .2858886719377 .7749023438372 .3252868652366 .937286377 361.6112060547356 .3472900391351 .1458129883346 .0068054199340 .9303894043 335.916809082330 .9659118652326 .0776977539321 .2522888184316 .4895019531 311.7890930176307 .1510009766302 .575012207298 .0610961914293 .608795166 289.2178955078 284.888092041280.6192932129276.4108886719272.2627868652 268.1745910645264 .1459960938260 .1765136719256 .2659912109252 .4140014648 248.620300293244 .8843994141241 .2061004639237 .5848999023234 .0207061768 230.5130004883227 .0615997314223 .666305542220 .3267059326217 .0428009033 213.8143005371210 .641204834207 .5234069824204 .4611053467201 .454498291 198.5037994385195 .6094055176192 .7718048096189 .9915924072187 .2695007324 184.6062011719182 .0025939941179 .4597930908176 .9786987305174 .5603942871 172.2062988281169 .9172973633167 .6950073242165 .5404968262163 .4550018311 161.4400939941159 .4967041016157 .6260986328155 .8292999268154 .1074981689 152.4609069824150 .8905944824149 .3963928223147 .9788970947146 .6372070312 145.3715057373144 .1804046631143 .0635070801142 .0187988281141 .0453948975 140.1410980225139 .3040924072138 .5319061279137 .8224945068137 .1730041504 136.5809936523136 .0435943604135 .5579071045135 .1210021973134 .7297973633 134.3813934326134 .0722961426133 .7998962402133 .5603942871133 .3513031006 133.1688995361133 .0108032227132 .8733978271132 .7543945312132 .6504058838 132.55909729132 .4774932861132 .403503418132 .334197998132 .2677001953 132.2015075684132 .133895874132 .0625131 .9859008789131 .9017944336131 .80909729 131.7057037354131 .5903930664131 .4615020752131 .3177947998131 .157699585 130.9801940918130 .7837982178130 .5675964355130 .3303985596130 .0713043213 129.7893066406129 .4839019775129 .1542053223128 .8000030518128 .420501709 128.0160980225127 .5864028931127 .1318969727126 .6528015137126 .1502990723 125.6249008179125 .0784988403124 .5121994019123 .9285964966123 .3291015625 122.7172012329122 .0948028564121 .4656982422120 .8326034546120 .1987991333 119.5675964355118 .9418029785118 .3246002197117 .7174987793117 .1234970093 116.5425033569115 .976600647115 .4237976074114 .8851013184114 .3564987183 113.8371963501113 .3214035034112 .8061981201112 .2846984863111 .751701355 111.2005996704110 .62449646110 .0185012817109 .3752975464108 .6923980713 107.9635009766 107.1882019043106.3618011475 105.4841003418 104.5529022217 103.5626983643102 .5062026978101 .3805007935100 .183502197398 .90696716309 97.5482025146596 .0995483398494 .5649566650492 .9385070800891 .20008087158 89.57495117188 88.30967712402 87.09407043457 85.6368713378984.02868652344 82.2451782226680 .3559570312578 .3944168090876 .4039535522574 .49263000488 
72.6304931640670 .8679122924869 .1779785156267 .551193237365 .9600982666 64.3522872924862 .7357292175361 .0939483642659 .4605407714857 .84967041016 56.2915306091354 .8074493408253 .4153099060152 .1393203735450 .98949050903 49.99065017749 .1277389526448 .4014396667547 .8019104003947 .32955169678 46.9602203369146 .6680107116746 .4446487426846 .2707099914646 .14007949829 46.0364494323745 .95590972945 .8885612487845 .829521179245 .77025985718 45.7073593139645 .6346702575745 .5498199462945 .4483604431245 .32907867432 45.189178466845 .0286598205644 .846401214644 .643421173144 .42016983032 44.1782608032243 .919219970743 .6447105407743 .356719970743 .05644989014 42.7456893920942 .425079345742 .0958099365241 .758090972941 .41249847412 41.05900955240 .6977996826240 .3288002014239 .9520187377939 .56742858887 39.1750183105538 .7748184204138 .3668403625537 .9511489868237 .52782058716 37.0969200134336 .6585693359436 .2128791809135 .7602386474635 .30080032349 34.8293914794934 .35285949707 1469.9279785161461 .9000244141453 .8719482421445 .8499755861437 .829956055 1429.8120117191421 .7960205081413 .7790527341405 .7619628911397 .744995117 1389.7259521481381 .7049560551373 .6810302731365 .6550292971357 .624023438 1349.5889892581341 .5500488281333 .5059814451325 .4560546881317 .400024414 1309.3380126951301 .2690429691293 .1929931641285 .1099853521277 .019042969 1268.9200439451260 .8129882811252 .6970214841244 .5729980471236 .439941406 1228.296997071220 .1459960941211 .9849853521203 .8160400391195 .637939453 1187.4510498051179 .2550048831171 .0520019531162 .8409423831154 .621948242 1146.3969726561138 .1650390621129 .9270019531121 .6839599611113 .436035156 1105.1839599611096 .9289550781088 .671997071080 .4119873051072 .151000977 1063.8890380861055 .6269531251047 .3659667971039 .1070556641030 .848999023 1022.5939941411014 .341979981006 .093994141997 .8496704102989 .6104125977 981.3765258789973 .1486206055964 .9268798828956 .7122192383948 .504699707 940.3051757812932 .114074707923 .9318237305915 .758972168907 .5958862305 899.4434204102 891.3020019531883.1721801758 875.0546264648 866.9495849609 858.8579101562850 .7802124023842 .716796875834 .6685180664826 .6358032227 818.6195068359810 .620300293802 .6386108398794 .6752929688786 .7307739258 778.8059082031770 .9011230469763 .0173950195755 .155090332747 .3151245117 739.4979858398731 .7047119141723 .9354858398716 .1915283203708 .4730834961 700.7808837891693 .116027832685 .4786987305677 .8698730469670 .2902832031 662.7407226562655 .2216186523647 .7338867188640 .2783203125632 .8554077148 625.4661865234618 .1112060547610 .7913208008603 .5073242188596 .2598266602 589.0496826172581 .8776855469574 .7445068359567 .6511230469560 .5980834961 553.5864257812546 .6168823242539 .6901855469532 .8071899414525 .9688110352 519.1757202148512 .4287719727505 .7287902832499 .0765075684492 .4728088379 485.9184875488479 .4142150879472 .9609985352466 .5592956543460 .2102050781 453.9142150879447 .6722106934441 .4848937988435 .3529052734429 .2768859863 423.257598877417 .2955932617411 .3915100098405 .5458984375399 .7594909668 394.0325012207388 .3656005859382 .759185791377 .2137145996371 .7294006348 366.3067932129360 .946105957355 .6476135254350 .4114990234345 .2380065918 340.1271972656335 .0793151855330 .0942077637325 .172088623320 .3128967285 315.5166015625310 .7831115723306 .1123046875301 .5039978027296 .958190918 
292.4744873047288 .0528869629283 .6931152344279 .3949890137275 .1581115723 270.982208252266 .8671875262 .812713623258 .8186035156254 .8842926025 251.0097961426247 .1947021484243 .4387969971239 .7415924072236 .1031036377 232.5227966309229 .0005950928225 .5361938477222 .1293945312218 .7799072266 215.487701416212 .2525024414209 .0744018555205 .9532012939202 .8892974854 199.8825073242196 .9333953857194 .042098999191 .209197998188 .4351043701 185.7205963135183 .066192627180 .4729003906177 .9414978027175 .4730987549 173.0684967041170 .7290039062168 .4553985596166 .2492980957164 .1114044189 162.0431060791160 .0453033447158 .1192016602156 .2655944824154 .4853057861 152.7792053223151 .1475067139149 .591003418148 .1092987061146 .7028961182 145.3706054688144 .1127929688142 .9277038574141 .8152008057140 .7731018066 139.8007049561138 .8954925537138 .0565032959137 .2807006836136 .566696167 135.9114990234135 .3130950928134 .7686004639134 .2754974365133 .8309936523 133.4322967529133 .0765991211132 .7608032227132 .4821014404132 .2373046875 132.0238037109131 .8381958008131 .6779937744131 .5399017334131 .4214935303 131.3195953369131 .2319946289131 .1557006836131 .0885009766131 .0276031494 130.971206665130 .916595459130 .862197876130 .8056030273130 .745300293 130.6790924072130 .6054992676130 .5229034424130 .4297027588130 .3244018555 130.2055053711130 .0717926025129 .9219970703129 .7548980713129 .5693054199 129.3643035889129 .1389007568128 .8923034668128 .6239013672128 .3330993652 128.0196075439127 .682800293127 .3231964111126 .9403991699126 .5352020264 126.1074981689125 .658996582125 .1897964478124 .7021026611124 .1966018677 123.6760025024123 .1412963867122 .5958023071122 .0409011841121 .4800033569 120.9150009155120 .3488006592119 .7837982178119 .2220993042118 .6660995483 118.1165008545117 .5757980347117 .0428009033116 .5198974609116 .0039978027 115.4968032837114 .9934997559114 .4944992065113 .9938964844113 .4899978638 112.9763031006112 .4489974976111 .9022979736111 .3302993774110 .7288970947 110.0914993286109 .4160003662108 .6959991455107 .9308013916107 .115196228 106.2477035522105 .3248977661104 .341003418103 .2912979126102 .1677017212 100.966903686599 .6828765869198 .3270492553796 .873741149995 .31664276123 93.6623077392691 .8269271850690 .1489791870189 .0486221313588 .00157165527 86.5636291503984 .9250106811583 .0276565551880 .9947433471778 .89367675781 76.750976562574 .749588012772 .8311004638771 .0918273925869 .46080780029 67.897186279366 .3788528442464 .8401794433663 .2846412658761 .6552696228 60.0098190307658 .3490600585956 .7238388061555 .1532211303753 .67414855957 52.3212509155351 .1036415100150 .0680503845249 .1817283630448 .45526123047 47.872211456347 .435970306447 .1120605468846 .8585205078146 .67245864868 46.5286712646546 .4229202270546 .3349800109946 .265899658246 .206199646 46.1515502929746 .0941009521546 .0303306579645 .9550399780345 .86531829834 45.7577896118245 .630580902145 .4818992614745 .3110389709545 .11775970459 44.902488708544 .6663894653344 .4105911254944 .1372489929243 .84764862061 43.5443382263243 .228240966842 .901641845742 .5649490356442 .21979141235 41.8661308288641 .5049209594741 .1358985900940 .7594985961940 .37545013428 39.983951568639 .5847892761239 .1781005859438 .7637290954638 .34183120728 37.9123191833537 .4753684997637 .0309410095236 .5792083740236 .12020874023 35.6543884277335 .1810989379934 .7021598815934 .21506881714 
1474.1820068361466 .1330566411458 .0849609381450 .0439453121442 .005004883 1433.9680175781425 .9320068361417 .8959960941409 .8590087891401 .821044922 1393.7819824221385 .7399902341377 .6949462891369 .6469726561361 .594970703 1353.5379638671345 .4770507811337 .4090576171329 .336059571321 .256958008 1313.1710205081305 .078002931296 .9770507811288 .8690185551280 .753051758 1272.629028321264 .495971681256 .3540039061248 .203002931240 .04296875 1231.8730468751223 .6939697271215 .5059814451207 .3079833981199 .102050781 1190.8859863281182 .6619873051174 .4289550781166 .1879882811157 .938964844 1149.6839599611141 .4210205081133 .1519775391124 .8780517581116 .598999023 1108.3149414061100 .0279541021091 .7370605471083 .4449462891075 .150024414 1066.8549804691058 .5589599611050 .2629394531041 .9689941411033 .676025391 1025.3850097661017 .0980224611008 .8129882811000 .531982422992 .2562255859 983.9849853516975 .7194213867967 .459777832959 .2067871094950 .9609985352 942.7227172852934 .4924926758926 .2708740234918 .0584716797909 .8557128906 901.6630859375893 .4813842773885 .3110961914877 .1527099609869 .0068969727 860.874206543852 .7551879883844 .6505126953836 .5606079102828 .4865112305 820.4284057617812 .3873901367804 .3640136719796 .358581543788 .3720703125 780.4052734375772 .4584960938764 .5327758789756 .6284790039748 .7465820312 740.8878173828733 .0526733398725 .2418823242717 .4564208984709 .6964111328 701.9631958008694 .257019043686 .578918457678 .9293823242671 .309387207 663.7194213867656 .1602783203648 .6328125641 .1375732422633 .6754760742 626.2473144531618 .853515625611 .4951171875604 .1729125977596 .8873901367 589.6395263672582 .4301757812575 .2598876953568 .1295166016561 .0399780273 553.9918823242546 .9862060547540 .0236206055533 .1049194336526 .2310180664 519.4025268555512 .6204223633505 .8854064941499 .1983947754492 .5599975586 485.9710083008479 .4323120117472 .9447021484466 .5087890625460 .1253967285 453.7952880859447 .5191040039441 .2976074219435 .1315917969429 .0215148926 422.9682006836416 .9721069336411 .033996582405 .1542053223399 .3337097168 393.5725097656387 .8714904785382 .2308959961376 .6512145996371 .1328125 365.6760864258360 .2811889648354 .9486999512349 .6785888672344 .4711914062 339.3265075684334 .2449951172329 .2264099121324 .2712097168319 .3789978027 314.5501098633309 .7842102051305 .0815124512300 .4417114258295 .8648986816 291.3508911133286 .8995056152282 .5105895996278 .1839904785273 .9194946289 269.7168884277265 .5759887695261 .4966125488257 .4783935547253 .5213012695249 .625 245.7893066406242 .0140075684238 .2987060547234 .6434020996231 .0476074219 227.5113067627224 .0343017578220 .6161956787217 .2570953369213 .9566955566 210.7149047852207 .5317993164204 .4071960449201 .3414001465198 .3343048096 195.3863983154192 .4978027344189 .6690979004186 .900604248184 .1929931641 181.5469055176178 .9629974365176 .442199707173 .9853973389171 .5933990479 169.2671966553167 .0077972412164 .8162994385162 .6936035156160 .6405944824 158.6582946777156 .7474975586154 .908996582153 .1434020996151 .4512939453 149.8327026367148 .2882995605146 .8175964355145 .4207000732144 .0968017578 142.8455963135141 .6660003662140 .5570983887139 .5173950195138 .5457000732 137.6401977539136 .7993011475136 .0207977295135 .3029022217134 .6430969238 134.0393981934133 .4891052246132 .9900054932132 .5393066406132 .1343994141 131.7727966309131 .4514007568131 .1678009033130 .9187927246130 .7019042969 
130.5139007568130 .3524932861130 .2142944336130 .0971984863129 .9978942871 129.9143066406129 .8435058594129 .7832946777129 .7310028076129 .6846923828 129.6417999268129 .600692749129 .558807373129 .5148010254129 .4664001465 129.4122009277129 .3502960205129 .279296875129 .1976013184129 .1040039062 128.9967956543128 .8751068115128 .7375030518128 .5829925537128 .4105987549 128.2194976807128 .0086975098127 .7779998779127 .5264968872127 .2542037964 126.9605026245126 .6460037231126 .3102035522125 .9541015625125 .577796936 125.1825027466124 .7687988281124 .3384017944123 .8923034668123 .4324035645 122.9602966309122 .4781036377121 .9876022339121 .4910964966120 .9905014038 120.4878005981119 .9850006104119 .4832992554118 .9845962524118 .4891967773 117.9983978271117 .5114974976117 .0294036865116 .5500030518116 .0735015869 115.5969009399115 .1192016602114 .6362991333114 .1458969116113 .6434020996 113.1249008179112 .585899353112 .0212020874111 .4272003174110 .7981033325 110.1313018799109 .4216003418108 .6666030884107 .8617019653107 .0038986206 106.089302063105 .112701416104 .068901062102 .9514007568101 .7546005249 100.47789764499 .1228485107497 .6840896606496 .1598129272594 .56878662109 92.9050827026491 .3878021240290 .2589492797989 .121513366787 .65354919434 85.92825317383 83.83297729492 81.58080291748 79.28201293945 76.97368621826 74.8642272949272 .9270172119171 .2461166381869 .7275009155368 .28330993652 66.8777389526465 .4330673217863 .9405403137262 .348628997860 .69651031494 58.9859199523957 .2768096923855 .6054000854554 .0232315063552 .5906791687 51.3095397949250 .2150688171449 .2969703674348 .5785789489748 .02978897095 47.6343307495147 .3602294921947 .1613502502447 .0226898193446 .9109992981 46.8258094787646 .7529602050846 .6916007995646 .6345405578646 .5779800415 46.5160789489746 .4455718994146 .3614006042546 .2615089416546 .14218902588 46.0024299621645 .8399505615245 .654850006145 .4463310241745 .21553039551 44.9630889892644 .6907310485844 .4002113342344 .0933189392143 .77230834961 43.4385490417543 .0941200256342 .7397994995142 .3770599365242 .00614929199 41.6278610229541 .2421798706140 .8493499755940 .4492988586440 .04201889038 39.6274604797439 .2055892944338 .7763786315938 .3398094177237 .8959197998 37.4447288513236 .9862899780336 .5206794738836 .047988891635 .56858825684 35.0825805664134 .584819793734 .08240890503

1478.4160156251470 .3509521481462 .2869873051454 .2270507811446 .170043945 1438.1140136721430 .0579833981422 .0030517581413 .9470214841405 .889038086 1397.8299560551389 .7679443361381 .703002931373 .6340332031365 .560058594 1357.4809570311349 .3969726561341 .3070068361333 .211059571325 .109008789 1316.9990234381308 .8819580081300 .7569580081292 .6240234381284 .483032227 1276.3330078121268 .1739501951260 .0059814451251 .8289794921243 .641967773 1235.4449462891227 .2390136721219 .0229492191210 .796997071202 .562011719 1194.3170166021186 .0639648441177 .8020019531169 .5310058591161 .253051758 1152.9670410161144 .6739501951136 .3740234381128 .0689697271119 .758056641 1111.4420166021103 .1230468751094 .8000488281086 .4739990231078 .145996094 1069.8170166021061 .4870605471053 .1569824221044 .828002931036 .51028 .173950195 1019.8499755861011 .5289916991003 .211975098994 .8989868164986 .5905761719 978.2874755859969.9899902344961.6989135742 953.4144897461945.137512207 936.8682250977928 .607421875920 .3554077148912 .1127929688903 .8801879883 
895.6583251953887 .4475097656879 .2484741211871 .0618286133862 .8881225586 854.7279052734846 .5817871094838 .4506225586830 .3348999023822 .2352905273 814.1524047852806 .0869750977798 .0399169922790 .0114746094782 .0026245117 774.0139160156766 .0462036133758 .0999755859750 .1762695312742 .2755737305 734.3988037109726 .5463867188718 .7191162109710 .9177856445703 .1433105469 695.3961181641687 .6768798828679 .9868164062672 .326171875664 .6959228516 657.0966796875649 .5291748047641 .9943847656634 .492980957627 .0255737305 619.5930175781612 .1959838867604 .8353881836597 .5119018555590 .2263183594 582.979309082575 .7717285156568 .6043701172561 .4780883789554 .3934936523 547.3515014648540 .3527832031533 .3983154297526 .4887695312519 .6248779297 512.8074951172506 .0374145508499 .3153991699492 .6422119141486 .0187072754 479.4454956055472 .9234008789466 .4531860352460 .0356140137453 .6712036133 447.3609924316441 .1054077148434 .9053955078428 .7614135742422 .6741027832 416.6440124512410 .6719970703404 .758392334398 .9039001465393 .1088867188 387.3739929199381 .6994934082376 .0859985352370 .5338134766365 .0433044434 359.6148071289354 .2486877441348 .945098877343 .7043151855338 .5266113281 333.4119873047328 .3606872559323 .3728027344318 .4483947754313 .5874938965 308.7901000977304 .0563049316299 .3858947754294 .7789916992290 .2354125977 285.7550964355281 .337890625276 .9837036133272 .6924133301268 .4638977051 264.2979125977 260.1943054199256.1531066895 252.1737976074 248.2565002441 244.400894165240 .6067962646236 .8739013672233 .2023010254229 .5915985107 226.041595459222 .5522003174219 .1233062744215 .7545928955212 .4463043213 209.1979064941206 .0097045898202 .8815002441199 .8135986328196 .8058929443 193.8589019775190 .9725036621188 .1475067139185 .383895874182 .6826019287 180.0438995361177 .4687042236174 .9575958252172 .5113983154170 .1307983398 167.8168945312165 .5702972412163 .3921051025161 .2830047607159 .2438049316 157.2754058838155 .3782958984153 .5532989502151 .8005981445150 .120803833 148.5137939453146 .9799957275145 .5187988281144 .1304016113142 .8137054443 141.5686035156140 .3934936523139 .2881011963138 .25050354137 .2799072266 136.374206543135 .5321960449134 .7514953613134 .0305938721133 .3672027588 132.7593994141132 .204498291131 .7006072998131 .2451019287130 .8354034424 130.4691009521130 .1434936523129 .8560943604129 .6040039062129 .3847045898 129.1952972412129 .0332946777128 .8957977295128 .7805023193128 .6844024658 128.6051940918128 .5402069092128 .4873962402128 .4438018799128 .4078063965 128.3766937256128 .3488006592128 .3218994141128 .2942047119128 .2637023926 128.228805542128 .1878051758128 .1392059326128 .0814056396128 .0131072998 127.932800293127 .8394012451127 .7315979004127 .6085968018127 .4692001343 127.3126983643127 .1381988525126 .9455032349126 .7337036133126 .5028991699 126.2526016235125 .9832992554125 .6946029663125 .3874969482125 .06199646 124.7194976807124 .3601989746123 .986000061123 .5973968506123 .1965026855 122.7843017578122 .3629989624121 .9336013794121 .4983978271121 .0585021973 120.6156997681120 .1713027954119 .7258987427119 .2813034058118 .8366012573 118.3936004639117 .950302124117 .508102417117 .0641021729116 .619102478 116.1695022583115 .7152023315115 .2518997192114 .7783966064114 .2900009155 113.7841033936113 .2562026978112 .7024002075112 .1188964844111 .5007019043 110.8451004028110 .1468963623109 .4031982422108 .6093978882107 .7617034912 
106.855796814105 .8864974976104 .8497009277103 .7396011353102 .5521011353 101.286697387799.9396286010798.5273513793997.0565872192495.5803604126 94.1448211669992 .7987518310591 .5849533081190 .338867187588 .87561798096 87.0502014160284 .6687469482482 .043380737379 .4572906494176 .97561645508 74.8345794677772 .9509506225671 .4057693481470 .0738525390668 .7963104248 67.5465011596766 .218193054264 .8089370727563 .258789062561 .60837173462 59.8323402404858 .0280609130956 .2220115661654 .5088310241752 .97443008423 51.6031494140650 .4506988525449 .4989700317448 .8075408935548 .31336975098 47.971679687547 .7564315795947 .6121788024947 .5227508544947 .43967819214 47.37150955247 .3071784973147 .2455902099647 .1828498840347 .1160697937 47.0423011779846 .9572410583546 .8577384948746 .7407112121646 .60404968262 46.4457206726146 .2647705078146 .0603485107445 .8327598571845 .58226013184 45.3103408813545 .0180587768644 .7078514099144 .3809509277344 .04019165039 43.6865386962943 .3225898742742 .9487800598142 .5670204162642 .17729949951 41.7807197570841 .3770217895540 .9667282104540 .549530029340 .12559890747 39.6946907043539 .2569007873538 .8120384216338 .3601989746137 .90124893188 37.43532943726 36.9623413085936.48244094849 35.99562072754 35.50228881836 35.0017890930234 .4958381652833 .98205184937

1482.6429443361474 .5589599611466 .4759521481458 .3990478521450 .3239746091442 .25 1434.1760253911426 .1020507811418 .0269775391409 .9499511721401 .87097168 1393.788940431385 .703002931377 .6140136721369 .5190429691361 .418945312 1353.3129882811345 .2010498051337 .082031251328 .9560546881320 .822998047 1312.6820068361304 .5329589841296 .3751288 .2089843751280 .0329589841271 .848999023 1263.6550292971255 .4510498051247 .2370605471239 .0129394531230 .779052734 1222.535034181214 .2810058591206 .0179443361197 .7449951171189 .463012695 1181.1710205081172 .870971681164 .5620117191156 .245971681147 .922973633 1139.5920410161131 .2550048831122 .9129638671114 .5660400391106 .213989258 1097.8580322271089 .4990234381081 .1379394531072 .7760009771064 .411987305 1056.046997071047 .6829833981039 .3199462891030 .9589843751022 .598999023 1014.2420043951005 .888977051997 .5385742188989 .1931152344980 .8524169922 972.5172119141964 .1879272461955 .8651123047947 .5493164062939 .241027832 930.9409790039922 .6494750977914 .3671264648906 .0944824219897 .8325195312 889.5812988281881 .3416137695873 .1140136719864 .8992919922856 .6979980469 848.5106201172840 .337890625832 .1807250977824 .0394287109815 .9147949219 807.8074951172799 .7185058594791 .6480712891783 .5974121094775 .5667114258 767.5568847656759 .5689086914751 .6032714844743 .6608276367735 .7421875 727.8480834961719 .9791870117712 .1364746094704 .3206176758696 .5322875977 688.7722167969681 .0411987305673 .3400268555665 .6693725586658 .0299072266 650.4224853516642 .8480224609635 .3070068359627 .8004150391620 .3287963867 612.8931274414605 .4940795898598 .1323852539590 .8087768555583 .5241699219 576.2791748047569 .0747070312561 .9114990234554 .7902832031547 .7119140625 540.6770019531533 .6865234375526 .7412109375519 .8416748047512 .9890136719 506.1836853027499 .4266967773492 .7185974121486 .0603027344479 .4525146484 472.8959960938466 .3913879395459 .9395141602453 .5409851074447 .196685791 440.9071960449434 .6731872559428 .4952087402422 .3741149902416 .3102111816 410.3044128418404 .3570861816398 .4689025879392 .6401977539386 .8717041016 
381.1636962891375 .5166931152369 .9310913086364 .4071960449358 .9454956055 353.5462036133348 .2095947266342 .9360046387337 .7255859375332 .5786132812 327.4950866699322 .4753112793317 .5192871094312 .6272888184307 .7990112305 303.0347900391298 .3345031738293 .6982116699289 .125793457284 .6173095703 280.1726074219275 .7916870117271 .474395752267 .2206115723263 .0303039551 258.9034118652254 .8395996094250 .8390045166246 .9011993408243 .0263061523 239.2140045166235 .4640960693231 .7765960693228 .1513061523224 .5879974365 221.0865936279217 .6470031738214 .2689971924210 .9526062012207 .6976928711 204.5043029785201 .3724060059198 .3020935059195 .2935028076192 .3468017578 189.4622955322186 .6403045654183 .8809967041181 .1851959229178 .5532073975 175.9857025146173 .4833068848171 .0466003418168 .6764068604166 .3735046387 164.1385040283161 .9723052979159 .87550354157 .8486938477155 .8928070068 154.0079956055152 .1949005127150 .4537963867148 .7850036621147 .188293457 145.6640014648144 .2113952637142 .8305053711141 .520401001140 .2807006836 139.1101074219138 .0079956055136 .9727020264136 .0032043457135 .0977020264 134.2550048828133 .4730072021132 .75132 .0838928223131 .4729003906130 .9147033691 130.4071044922129 .9477996826129 .5345001221129 .1647033691128 .8359985352 128.5458984375128 .2917022705128 .0709991455127 .8809967041127 .7193984985 127.5832977295127 .4703979492127 .3778991699127 .3038024902127 .2450027466 127.199798584127 .165397644127 .1399002075127 .1207962036127 .1064987183 127.0944976807127 .0833969116127 .0708999634127 .0556030273127 .035697937 127.0096969604126 .9758987427126 .9330978394126 .8798980713126 .8151016235 126.7373962402126 .6461029053126 .5399017334126 .4184036255126 .2804031372 126.1259002686125 .9539031982125 .7647018433125 .557800293125 .3333969116 125.0915985107124 .832901001124 .5576019287124 .2667999268123 .960899353 123.6411972046123 .3086013794122 .9646987915122 .6102981567122 .2472000122 121.8764038086121 .4993972778121 .117401123120 .731300354120 .342300415 119.9505996704119 .5571975708119 .1614990234118 .763999939118 .3635025024 117.9600982666117 .551902771117 .1384963989116 .7174987793116 .2880020142 115.8469009399115 .3925018311114 .9215011597114 .431098938113 .9177017212 113.3777999878112 .8077011108112 .2033004761111 .5612030029110 .876701355 110.1464004517109 .3656005859108 .5300979614107 .6352005005106 .6764984131 105.6491012573104 .5504989624103 .3759994507102 .1287002563100 .806602478 99.4322433471798 .0123672485496 .6121902465895 .2650222778393 .96248626709 92.7391967773491 .5149917602590 .3042831420988 .5563278198285 .61660003662 82.3351135253979 .3810272216876 .7363586425874 .6365127563572 .91783905029 71.5869293212970 .5126571655369 .4733734130968 .420196533267 .2534866333 65.9486465454164 .444053649962 .7746810913160 .9270286560158 .99842834473 57.032501220755 .1551818847753 .4824485778852 .0025291442950 .77997970581 49.8089599609449 .1564102172948 .7383384704648 .4693412780848 .3215713501 48.2299880981448 .1792602539148 .1275215148948 .0756416320848 .0106010437 47.9379615783747 .8597793579147 .7741012573247 .6792602539147 .57194900513 47.4487915039147 .3079910278347 .1467704772946 .964279174846 .75875091553 46.5303802490246 .2786598205646 .0046691894545 .7091903686545 .39393997192 45.0607109069844 .711360931444 .3481903076243 .9726905822843 .58703994751 43.1921310424842 .7895507812542 .3796386718841 .9632682800341 .54042053223 
41.1114006042540 .676059722940 .2344207763739 .7863388061539 .3317489624 38.8705482482938 .4026908874537 .92815017737 .4468803405836 .95891189575 36.4642410278335 .9629402160635 .4553108215334 .9414291381834 .41616821289 33.88690948486 1486.8520507811478 .7530517581470 .6550292971462 .5600585941454 .468017578 1446.3759765621438 .285034181430 .1929931641422 .0989990231414 .00402832 1405.9060058591397 .8039550781389 .6979980471381 .5880126951373 .473022461 1365.3509521481357 .2239990231349 .0889892581340 .9479980471332 .798950195 1324.6419677731316 .4780273441308 .3039550781300 .1219482421291 .931030273 1283.7299804691275 .5200195311267 .2989501951259 .0689697271250 .82800293 1242.5770263671234 .3160400391226 .0439453121217 .7619628911209 .469970703 1201.1689453121192 .8570556641184 .5369873051176 .207031251167 .869018555 1159.5219726561151 .167968751142 .8060302731134 .4379882811126 .064941406 1117.6850585941109 .3010253911100 .9129638671092 .5209960941084 .126953125 1075.7309570311067 .3330078121058 .9339599611050 .5360107421042 .136962891 1033.7399902341025 .3449707031016 .9520263671008 .5620117191000 .174987793 991.7924194336983 .4144287109975 .0413208008966 .6738891602958 .3126220703 949.9581298828941 .6107788086933 .2714233398924 .9404296875916 .6182861328 908.3057861328900 .0034790039891 .7119140625883 .4315185547875 .1630859375 866.9074707031858 .6649780273850 .4362792969842 .2222290039834 .0233154297 825.8402709961817 .6740112305809 .5249023438801 .3939819336793 .2816772461 785.1889038086777 .1162719727769 .0645751953761 .0346069336753 .0270996094 745.0427246094737 .0822753906729 .146484375721 .2360229492713 .3518066406 705.4945068359697 .6649780273689 .8637695312682 .0919189453674 .3499755859 666.6389160156658 .9592285156651 .311706543643 .6973266602636 .1166992188 628.5706787109621 .0601196289613 .5855712891606 .1478881836598 .7479248047 591.3864135742584 .0639038086576 .7813720703569 .5396118164562 .3392944336 555.1812744141548 .0662841797540 .9951171875533 .9685058594526 .9873046875 520.0521850586513 .1638793945506 .3232116699499 .5310974121492 .7880859375 486.0950012207479 .4525146484472 .8613891602466 .3223876953459 .8362121582 453.403503418447 .0250854492440 .7015991211434 .43359375428 .2218017578 422.0668945312415 .9693908691409 .9299926758403 .949005127398 .0273132324 392.1651916504386 .3633117676380 .6220092773374 .9418029785369 .3230895996 363.766204834358 .2716064453352 .8395996094347 .4703979492342 .1644897461 336.9219055176331 .7431030273326 .6279907227321 .5769042969316 .5899047852 311.6672058105306 .808807373302 .0148010254297 .2853088379292 .620300293 288.0198059082283 .4838867188279 .0123901367274 .6052856445270 .2627868652 265.9844970703261 .7705993652257 .6207885742253 .5352935791249 .5137939453 245.5561981201241 .6625061035237 .8325042725234 .0661010742230 .3632049561 226.7236022949223 .1472930908219 .6340942383216 .1840057373212 .7967071533 209.4723968506206 .2108001709203 .0122070312199 .8762969971196 .8034057617 193.7933959961190 .8468017578187 .9635009766185 .1439056396182 .3883972168 179.6974029541177 .0711975098174 .5106048584172 .0158996582169 .5877990723 167.2268981934164 .9338989258162 .7093048096160 .553894043158 .4680938721 156.4524993896154 .5077056885152 .633895874150 .8316040039149 .1007995605 147.4418029785145 .8544006348144 .3385925293142 .8937072754141 .5196990967 
140.2156066895138 .9810028076137 .8146057129136 .7156982422135 .6826934814 134.7147979736133 .8099975586132 .9671936035132 .1844940186131 .4602966309 130.7924957275130 .1793060303129 .6186981201129 .1085968018128 .646697998 128.2308959961127 .8588027954127 .5279998779127 .2362976074126 .9810028076 126.7599029541126 .5701980591126 .4096984863126 .2757034302126 .1660003662 126.077796936126 .0091018677125 .9571990967125 .9199981689125 .8949966431 125.8804016113125 .8737030029125 .8731002808125 .8765029907125 .8821029663 125.887802124125 .8923034668125 .8936004639125 .890296936125 .8807983398 125.8638000488125 .8378982544125 .801902771125 .7546005249125 .6951980591 125.6224975586125 .5361022949125 .4347991943125 .3186035156125 .1865997314 125.0389022827124 .8750991821124 .695602417124 .5001983643124 .2894973755 124.0635986328123 .8236999512123 .5699005127123 .3035964966123 .0252990723 122.7365036011122 .4376983643122 .1305999756121 .8158035278121 .4944000244 121.1675033569120 .8355026245120 .4992980957120 .1585998535119 .8143997192 119.4654006958119 .1122970581118 .7531967163118 .3884963989118 .0158004761 117.6352005005117 .2437973022116 .8412017822116 .4244995117115 .992401123 115.5416030884115 .070098877114 .5745010376114 .0518035889113 .4983978271 112.9105987549112 .2846984863111 .6164016724110 .9017028809110 .1360015869 109.3150024414108 .4337005615107 .4882965088106 .4738006592105 .3899993896 104.2322998047103 .0096969604101 .7197036743100 .390098571899 .01843261719 97.6588668823296 .3302688598695 .0287780761793 .7715072631892 .50428771973 91.4502029418989 .7347564697386 .3341827392682 .468612670979 .15077209473 76.3732833862374 .4083862304773 .0325469970772 .0248565673871 .2222366333 70.4282836914169 .5815963745168 .5915603637767 .4098663330165 .96868133545 64.2983322143662 .3745689392160 .3155593872158 .1365394592356 .04829025269 54.176620483452 .5351982116751 .2621192932150 .291580200249 .70391082764 49.3873596191449 .1945495605549 .1119117736849 .0615310668949 .03361129761 48.9975509643648 .9467811584548 .8691596984948 .7737503051848 .67041015625 48.5544395446848 .4295196533248 .2902793884348 .1358909606947 .96305847168 47.7709083557147 .5572586059647 .3218688964847 .063751220746 .78356170654 46.4813690185546 .1588516235445 .8168487548845 .4578895568845 .08308029175 44.6953201293944 .2955589294443 .8864593505943 .4684791564943 .04364013672 42.6119194030842 .1745414733941 .731170654341 .2823905944840 .82778167725 40.3675498962439 .9013481140139 .4292297363338 .9509201049838 .46646881104 37.9756813049337 .4786186218336 .9751510620136 .4653511047435 .94916915894 35.4269485473634 .8980102539134 .3639106750533 .82244110107

1491.0539550781482 .9379882811474 .8220214841466 .7120361331458 .603027344 1450.4949951171442 .3859863281434 .2760009771426 .1650390621418 .051025391 1409.9339599611401 .8129882811393 .6879882811385 .5570068361377 .421020508 1369.2790527341361 .1300048831352 .9730224611344 .8089599611336 .637939453 1328.4580078121320 .2690429691312 .0720214841303 .8649902341295 .649047852 1287.4229736331279 .1870117191270 .9399414061262 .6839599611254 .416015625 1246.1379394531237 .8489990231229 .5500488281221 .2399902341212 .920043945 1204.5889892581196 .2490234381187 .8990478521179 .538940431171 .171020508 1162.7939453121154 .410034181146 .0169677731137 .6180419921129 .213012695 1120.8020019531112 .3850097661103 .964965821095 .5400390621087 .113037109 
1078.6829833981070 .2509765621061 .8179931641053 .3850097661044 .951049805 1036.5190429691028 .0880126951019 .6589965821011 .2319946291002 .807983398 994.3884887695985 .9730224609977 .5620727539969 .1566162109960 .7567749023 952.3635864258943 .9774169922935 .5985717773927 .2280273438918 .8662719727 910.513671875902 .171081543893 .8391723633885 .5181884766877 .208984375 868.9121704102860 .6284790039852 .358581543844 .1030273438835 .862487793 827.6378173828819 .4296264648811 .2387695312803 .0659179688794 .9118041992 786.7769165039778 .6622924805770 .5684814453762 .4965820312754 .4470825195 746.4207763672738 .4185180664730 .4409179688722 .4887695312714 .5629882812 706.6643066406698 .7932739258690 .951171875683 .1383056641675 .3555908203 667.6038208008659 .8837280273652 .196105957644 .5416870117636 .9213867188 629.3358764648621 .7860717773614 .2725830078606 .7962036133599 .3577880859 591.9578857422584 .5974731445577 .2772827148569 .9981079102562 .7606201172 555.565612793548 .4138793945541 .3062133789534 .2432861328527 .2260742188 520.2551269531513 .3312988281506 .4552001953499 .6276855469492 .849609375 486.1216125488479 .4443054199472 .8186950684466 .2452087402459 .724609375 453.2578125446 .8452148438440 .487701416434 .1857910156427 .9401855469 421.7515869141415 .6203918457409 .5474853516403 .5331115723397 .5780944824 391.6827087402385 .8475952148380 .0733032227374 .3601074219368 .7085876465 363.1191101074357 .5918884277352 .1276855469346 .7262878418341 .3883972168 336.1141967773330 .9039001465325 .757598877320 .6758117676315 .6582946777 310.7055969238305 .8175964355300 .9945068359296 .2363891602291 .5433959961 286.9154052734282 .3526000977277 .854888916273 .4224853516269 .0552062988 264.753112793260 .5161132812256 .3442077637252 .2373962402248 .1954956055 244.2187042236240 .3065948486236 .4593963623232 .6768035889228 .9588012695 225.3052978516221 .7162017822218 .19140625214 .7308959961211 .3343963623 208.0021972656204 .7339019775201 .529800415198 .3898010254195 .3139953613 192.3023071289189 .3551940918186 .4725952148183 .6549072266180 .9024047852 178.2153930664175 .5942993164173 .0397033691170 .5518035889168 .1313018799 165.7787017822163 .4945068359161 .279296875159 .1334991455157 .0576019287 155.0520935059153 .1172943115151 .25340271149 .4608001709147 .7393951416 146.0894012451144 .5102996826143 .0023040771141 .5646057129140 .1970977783 138.8986968994137 .6688995361136 .5066070557135 .4109954834134 .3805999756 133.4145050049132 .5110015869131 .6687011719130 .8860015869130 .1613006592 129.4925994873128 .8782958984128 .3162994385127 .8046035767127 .3412017822 126.9238967896126 .5504989624126 .2186965942125 .9263000488125 .6708984375 125.4502029419125 .2617034912125 .1032028198124 .9720993042124 .8662033081 124.7829971313124 .7203979492124 .6757965088124 .6472015381124 .6321029663 124.6287994385124 .6346969604124 .6483001709124 .6671981812124 .6897964478 124.7141036987124 .7386016846124 .7613983154124 .7811965942124 .7960968018 124.8051986694124 .8067016602124 .7997970581124 .7829971313124 .7556991577 124.7166976929124 .6652984619124 .6007995605124 .5229034424124 .4307022095 124.3244018555124 .2035980225124 .0684967041123 .9188995361123 .7555007935 123.5783004761123 .3880996704123 .1853027344122 .9709014893122 .7453994751 122.509803772122 .2649002075122 .0115966797121 .7507019043121 .4829025269 121.2088012695120 .9287033081120 .6430969238120 .3517990112120 .054901123 
119.7515029907119 .4415969849119 .1237030029118 .7974014282118 .460899353 118.1137008667117 .7536010742117 .379699707116 .9897003174116 .5822982788 116.154800415115 .7052001953115 .2305984497114 .7282028198114 .1947021484 113.6266021729113 .0199966431112 .3706970215111 .6745986938110 .9270019531 110.1234970093109 .2591018677108 .3305969238107 .3330001831106 .266998291 105.1290969849103 .9282989502102 .6649017334101 .3595962524100 .0193023682 98.669082641697 .3275070190495 .9716415405394 .6037521362393 .16912078857 91.7055969238389 .6161193847786 .2894363403382 .4428329467878 .63868713379 75.5794525146574 .1212463378973 .4308471679772 .8321228027372 .31481170654 71.759353637771 .1115798950270 .2903671264669 .2382125854567 .88781738281 66.235771179264 .2390670776462 .0095100402859 .5804290771557 .22071838379 55.0845794677753 .2415313720751 .9221191406250 .9898490905850 .47866821289 50.2786903381350 .1782684326250 .1559486389250 .1413307189950 .1240196228 50.0730094909749 .9958610534749 .8909111022949 .7643508911149 .62174987793 49.4646415710449 .2978706359949 .1177597045948 .9223403930748 .70998001099 48.4786682128948 .2276611328147 .9555892944347 .6626091003447 .3483581543 47.0138397216846 .6597709655846 .2877388000545 .8994216918945 .49655914307 45.0813598632844 .655269622844 .2204399108943 .7777404785243 .32880020142 42.8739089965842 .4139900207541 .9489784240741 .4791603088441 .00434112549 40.5244712829640 .039340972939 .54882812539 .0527610778838 .55102157593 38.0434799194337 .5300598144537 .0106887817436 .4853401184135 .95397949219 35.4168395996134 .8739204406734 .3202209472733 .7632598877 1495.2399902341487 .1099853521478 .9799804691470 .8540039061462 .729003906 1454.6049804691446 .4799804691438 .3530273441430 .2239990231422 .093017578 1413.957031251405 .8170166021397 .6729736331389 .5219726561381 .365966797 1373.2020263671365 .0319824221356 .8540039061348 .667968751340 .473022461 1332.2700195311324 .0579833981315 .836059571307 .6049804691299 .364013672 1291.1120605471282 .8509521481274 .578002931266 .2950439451258 .000976562 1249.6960449221241 .3800048831233 .0520019531224 .7139892581216 .365966797 1208.0069580081199 .6369628911191 .2580566411182 .8690185551174 .470947266 1166.0629882811157 .6479492191149 .2249755861140 .7950439451132 .358032227 1123.9150390621115 .4659423831107 .0129394531098 .5560302731090 .094970703 1081.6309814451073 .1660156251064 .6979980471056 .2299804691047 .761962891 1039.2939453121030 .8270263671022 .3619995121013 .8989868161005 .437988281 996.9813232422988 .5280761719980 .0795288086971 .6358032227963 .1976928711 954.7656860352946 .3405151367937 .9224243164929 .5123291016921 .1107177734 912.7180786133904 .3353271484895 .9628295898887 .6011962891879 .2512207031 870.9133911133862 .5883789062854 .2769775391845 .9799194336837 .6978149414 829.4313964844821 .1815185547812 .9487915039804 .7338867188796 .5377197266 788.3609008789780 .2042236328772 .0684204102763 .954284668755 .8627929688 747.7944946289739 .7501831055731 .7307128906723 .7368774414715 .7694702148 707.8292236328699 .9168701172692 .0335083008684 .1796264648676 .3560180664 668.5634765625660 .8029174805653 .075012207645 .3804931641637 .7202758789 630.0952148438622 .5059204102614 .9533081055607 .4381103516599 .9609985352 592.5228271484585 .1243286133577 .7661743164570 .4494018555563 .1744995117 555.9423828125548 .7537841797541 .6094970703534 .5101928711527 .4567871094 
520.4498291016513 .4901733398506 .5784912109499 .7156982422492 .9023132324 486.1393127441479 .4271850586472 .7668151855466 .1586914062459 .6037902832 453.1026000977446 .6560058594440 .2644042969433 .9285888672427 .6492004395 421.4270019531415 .2622070312409 .1557922363403 .1080932617397 .1199035645 391.19140625385 .3233032227379 .5161132812373 .7702941895368 .0862121582 362.4643859863356 .9049987793351 .4086914062345 .9755859375340 .6061096191 335.3005981445330 .0592956543324 .8823852539319 .7702026367314 .7229003906 309.7406005859304 .8234863281299 .9718933105295 .1856994629290 .4652099609 285.8103027344281 .2213134766276 .6979980469272 .2406921387267 .8493041992 263.5238037109259 .2643127441255 .0708007812250 .9432983398246 .8816070557 242.8858032227238 .9559020996235 .0917053223231 .2933044434227 .5605010986 223.8932952881220 .2917022705216 .7554931641213 .2846069336209 .8791046143 206.5388031006203 .2637939453200 .0541992188196 .9096984863193 .8307037354 190.8170013428187 .8688964844184 .9864959717182 .1701965332179 .4199981689 176.7364044189174 .1195983887171 .570098877169 .0883026123166 .6744995117 164.3291931152162 .0529022217159 .8460998535157 .7088928223155 .6419067383 153.645401001151 .7196044922149 .8647003174148 .0809020996146 .3679962158 144.7261047363143 .154800415141 .654006958140 .2229003906138 .8614044189 137.5684051514136 .3435058594135 .1853027344134 .0930938721133 .0655975342 132.1016998291131 .1999053955130 .358795166129 .5767974854128 .8524017334 128.1837005615127 .5690994263127 .0065994263126 .4944000244126 .0304031372 125.6126022339125 .238899231124 .9070968628124 .6149978638124 .3603973389 124.1410980225123 .9545974731123 .7990036011123 .6715011597123 .5702972412 123.4926986694123 .4367980957123 .4000015259123 .3805999756123 .3759002686 123.3843002319123 .4033966064123 .4313964844123 .4662017822123 .5063018799 123.5494003296123 .5941009521123 .6387023926123 .6817016602123 .7213973999 123.7565994263123 .7858963013123 .8081970215123 .8221969604123 .8272018433 123.8218002319123 .8058013916123 .7779998779123 .7382965088123 .6858978271 123.6207962036123 .5425033569123 .4514007568123 .3471984863123 .2304000854 123.1008987427122 .9597015381122 .8067016602122 .6428985596122 .4685974121 122.2848968506122 .0920028687121 .8908004761121 .6818008423121 .4654006958 121.2422027588121 .0121002197120 .7754974365120 .5317001343120 .2808990479 120.0217971802119 .7545013428119 .4772033691119 .1895980835118 .8896026611 118.577003479118 .2493972778117 .9063034058117 .5451965332117 .165397644 116.7639007568116 .3395996094115 .8891983032115 .4104995728114 .9000015259 114.3546981812113 .770401001113 .1432037354112 .4686965942111 .7421035767 110.9592971802110 .115196228109 .2070999146108 .2302017212107 .1860961914 106.070602417104 .8933029175103 .6526031494102 .3656997681101 .0388031006 99.6787033081198 .3015365600696 .8609924316495 .3628921508893 .6623916626 91.6754074096789 .2113037109486 .1305465698282 .6521911621178 .70221710205 75.5166778564574 .5170669555774 .3762435913174 .0538787841873 .77754974365 73.4454727172972 .9820938110472 .3483428955171 .4446716308670 .23203277588 68.6454772949266 .6215972900464 .2695999145561 .6057395935158 .88790893555 56.3068809509354 .1882514953652 .8434600830152 .0694198608451 .69591903687 51.5612792968851 .5060501098651 .4969787597751 .4819908142151 .44184112549 51.3537597656251 .2274284362851 .0802803039650 .9052391052250 .71171951294 
50.5006103515650 .2825889587450 .0508995056249 .8063507080149 .54552841187 49.2683181762748 .9724998474148 .6581687927248 .3241996765147 .97135925293 47.5994987487847 .2102508544946 .8041915893646 .3836593627945 .94960021973 45.5047302246145 .0498390197844 .5875015258844 .1181106567443 .64361953735 43.1639595031742 .6803207397542 .1923217773441 .700469970741 .20431900024 40.7039794921940 .1990203857439 .6894416809139 .1748695373538 .65528106689 38.1304092407237 .6002197265637 .0645103454636 .523300170935 .97644042969 35.4241600036634 .8657684326234 .302600860633 .73263931274 1499.4200439451491 .2740478521483 .129028321474 .9880371091466 .848022461 1458.7080078121450 .5660400391442 .4229736331434 .2779541021426 .12902832 1417.9749755861409 .8170166021401 .6529541021393 .4830322271385 .306030273 1377.1219482421368 .9310302731360 .7309570311352 .5229492191344 .305053711 1336.0789794921327 .8430175781319 .5980224611311 .3420410161303 .076049805 1294.7989501951286 .5119628911278 .2139892581269 .9040527341261 .583007812 1253.2509765621244 .9069824221236 .5520019531228 .1860351561219 .808959961 1211.4210205081203 .0229492191194 .6140136721186 .1949462891177 .766967773 1169.329956055 1160.884033203 1152.430053711 1143.968017578 1135.51127 .025024414 1118.5439453121110 .0579833981101 .5679931641093 .0739746091084 .577026367 1076.077026367 1067.574951172 1059.072998047 1050.568969727 1042.066040039 1033.5629882811025 .0620117191016 .5620117191008 .065002441999 .5709228516 991.0802001953982 .5936279297974 .1116943359965 .6350708008957 .1644287109 948.7000732422940 .2426757812931 .7930297852923 .3516235352914 .9188842773 906.4957885742898 .082824707889 .6804199219881 .2894287109872 .9105224609 864.5441894531856.19140625 847.8527832031839.5291137695 831.2208251953 822.9290771484814 .6544189453806 .3975830078798 .1593017578789 .9401855469 781.741394043773 .5634765625765 .4072875977757 .2736206055749 .1632080078 741.0769042969733 .0155029297724 .9797973633716 .9705810547708 .9887695312 701.0349731445693 .1102294922685 .2150878906677 .350402832669 .5170898438 661.7158813477653 .9475097656646 .212890625638 .5128173828630 .8479003906 623.2191162109615 .6270751953608 .0728149414600 .5568847656593 .0802001953 585.643371582578 .2473754883570 .8928222656563 .5803222656556 .3109130859 549.0852050781541 .9041137695534 .7681884766527 .678527832520 .6353759766 513.6397705078506 .6924133301499 .7940063477492 .9453125486 .1470947266 479.3999938965472 .7048034668466 .0621032715459 .4726867676452 .9371948242 446.4563903809440 .0307922363433 .6611022949427 .3479003906421 .092010498 414.8937988281408 .7539978027402 .6730957031396 .6517028809390 .6901855469 384.7893066406378 .9494018555373 .1711120605367 .4547119141361 .8006896973 356.2095031738350 .6813964844345 .2168884277339 .8163146973334 .479888916 329.2078857422324 .000793457318 .8587036133313 .7818908691308 .7705993652 303.825012207298 .9451904297294 .1315002441289 .3839111328284 .7026977539 280.087890625275 .5396118164271 .0578918457266 .642791748262 .2944946289 258.0130004883253 .7982940674249 .6504058838245 .5693054199241 .5549926758 237.6076049805233 .7268981934229 .912902832226 .1656036377222 .4848937988 218.870803833215 .3233032227211 .8421936035208 .4275054932205 .0792999268 201.7973937988198 .5820007324195 .4329071045192 .3502960205189 .334197998 186.3847961426183 .5021972656180 .6865997314177 .9382019043175 .2572937012 
172.6441955566170 .099105835167 .6224060059165 .2144927979162 .8757019043 160.6065063477158 .4069976807156 .2776031494154 .2185974121152 .2301940918 150.3126983643148 .4658966064146 .6900939941144 .9851074219143 .350692749 141.786605835140 .2924957275138 .8677978516137 .5121002197136 .2245025635 135.004196167133 .8502960205132 .7617950439131 .7375030518130 .7761993408 129.8766021729129 .0372009277128 .2566070557127 .533203125126 .8653030396 126.2511978149125 .689201355125 .1772994995124 .7136993408124 .2963027954 123.9232025146123 .592300415123 .3015975952123 .0486984253122 .8315963745 122.6481018066122 .4960021973122 .3730010986122 .2770996094122 .2059020996 122.1574020386122 .1292037964122 .1194000244122 .1257019043122 .1463012695 122.1789016724122 .2219009399122 .2730026245122 .3308029175122 .3929977417 122.4583969116122 .5250015259122 .5915985107122 .6561965942122 .7179031372 122.775100708122 .8268966675122 .8716964722122 .908996582122 .9375122 .956703186 122.9655990601122 .9641036987122 .9512023926122 .9270019531122 .8909988403 122.8433990479122 .7838973999122 .7129974365122 .6305007935122 .5371017456 122.432800293122 .318397522122 .1941986084122 .0606994629121 .918296814 121.7676010132121 .6089019775121 .4424972534121 .2686004639121 .0869979858 120.8979034424120 .7005996704120 .4947967529120 .2795028687120 .0542984009 119.8175964355119 .5688018799119 .3062973022119 .0291976929118 .7358016968 118.4251022339118 .0953979492117 .7453994751117 .3730010986116 .976600647 116.5535964966116 .1017990112115 .6176986694115 .0983963013114 .5397033691 113.9377975464113 .2881011963112 .585899353111 .8271026611111 .0065994263 110.1218032837109 .1684036255108 .1468963623107 .0548019409105 .8975982666 104.6762008667 103.3983001709 102.0707015991 100.6864013672 99.25319671631 97.7242279052796 .0957565307694 .2165374755992 .0107116699289 .49925231934 86.5988616943483 .4926834106480 .1805572509877 .5052490234476 .40986633301 76.0834808349675 .8548965454175 .711776733475 .5378417968875 .26831054688 74.8268585205174 .1222686767673 .0830307006871 .6185226440469 .63316345215 67.2118835449264 .3691864013761 .2420310974157 .8264312744155 .07004928589 53.9942092895553 .6984481811553 .470291137753 .3502197265653 .26301956177 53.1979713439953 .1119499206553 .0021705627452 .8529090881352 .6689491272 52.4506492614752 .2058792114351 .9439697265651 .6679992675851 .38563156128 51.0930213928250 .7889785766650 .4720001220750 .1403808593849 .7933807373 49.4297790527349 .0495796203648 .6524085998548 .2390213012747 .80995178223 47.3665199279846 .9100990295446 .4422111511245 .9647407531745 .47900009155 44.9868698120144 .4891395568843 .9872817993243 .4815292358442 .97267913818 42.4606018066441 .9454994201741 .4271087646540 .9052886962940 .37976837158 39.8502998352139 .3166503906238 .7785797119138 .235908508337 .68846893311 37.1360893249536 .5786590576236 .0160598754935 .4483985900934 .8755607605 34.2926788330133 .70738983154 1503.5849609381495 .4270019531487 .2690429691479 .1140136721470 .958984375 1462.8039550781454 .6469726561446 .4880371091438 .3260498051430 .16003418 1421.9890136721413 .8129882811405 .6300048831397 .4410400391389 .244018555 1381.038940431372 .8270263671364 .6049804691356 .3751348 .1350097661339 .885009766 1331.6259765621323 .3559570311315 .0760498051306 .7860107421298 .484008789 1290.1710205081281 .8459472661273 .5100097661265 .1629638671256 .802978516 
1248.4320068361240 .0500488281231 .6560058591223 .251214 .8339843751206 .406005859 1197.9680175781189 .5200195311181 .0610351561172 .5939941411164 .116943359 1155.6319580081147 .1390380861138 .6390380861130 .1319580081121 .619018555 1113.1009521481104 .5770263671096 .0500488281087 .5190429691078 .984985352 1070.4499511721061 .9119873051053 .3740234381044 .8349609381036 .296020508 1027.7590332031019 .2230224611010 .6890258791002 .156982422993 .6287841797 985.104309082976 .5842285156968 .0689697266959 .5595092773951 .0560913086 942.559387207934 .0701293945925 .588684082917 .116027832908 .6524047852 900.1987304688891 .7556152344883 .3234863281874 .9033813477866 .4957885742 858.1015014648849 .7213134766841 .3557739258833 .0057983398824 .6721191406 816.3554077148808 .0563964844799 .7758789062791 .5147705078783 .2736206055 775.053527832766 .8549804688758 .6791992188750 .5266113281742 .3981933594 734.2946777344726 .2171020508718 .166015625710 .1425170898702 .1469726562 694.1807861328686 .2443237305678 .3386230469670 .4641723633662 .6223144531 654.813293457647 .0383911133639 .2979736328631 .5933227539623 .9246826172 616.2932739258608 .6998291016601 .1450195312593 .6295166016586 .1541748047 578.7199707031571 .3272705078563 .9771728516556 .6702880859549 .407409668 542.1892700195535 .0167236328527 .8903198242520 .8109130859513 .7791748047 506.7959899902499 .861907959492 .9778137207486 .1442871094479 .3620910645 472.6319885254465 .9545898438459 .3305969238452 .7607116699446 .2456054688 439.7858886719433 .3822937012427 .0354003906420 .7457885742414 .5140991211 408.3409118652402 .2268066406396 .1723937988390 .1781005859384 .2445068359 378.3721008301372 .5614013672366 .8128051758361 .1270141602355 .5039978027 349.9446105957 344.4489135742 339.0173950195 333.650390625 328.3482971191 323.1112060547317 .9396057129312 .8337097168307 .7937927246302 .8200073242 297.9125976562293 .071685791288 .2976989746283 .5905151367278 .9504089355 274.3774108887269 .8717956543265 .43359375261 .0628967285256 .7597961426 252.524307251248 .3563995361244 .2563018799240 .2238006592236 .2590942383 232.362197876228 .5328979492224 .7713012695221 .0773010254217 .4508972168 213.8921051025210 .400894165206 .9770965576203 .620803833200 .3318939209 197.1105957031193 .9566040039190 .8701934814187 .8513946533184 .9002990723 182.016998291179 .2017059326176 .454498291173 .7756958008171 .1654052734 168.6240997314166 .1519012451163 .7490997314161 .4160003662159 .1529998779 156.9600982666154 .8377075195152 .7859039307150 .804901123148 .8948974609 147.0556030273145 .2872009277143 .5892944336141 .9620056152140 .4046020508 138.9170074463137 .4983978271136 .1484069824134 .8659057617133 .6504974365 132.5009002686131 .4163970947130 .3954925537129 .4373016357128 .5402984619 127.7033004761126 .924697876126 .2030029297125 .5366973877124 .9240036011 124.3631973267123 .8525009155123 .3901977539122 .9741973877122 .6026992798 122.2735977173121 .9850006104121 .734703064121 .5208969116121 .3411026001 121.1934967041121 .0757980347120 .986000061120 .9217987061120 .881401062 120.8623962402120 .8628997803120 .8806991577120 .914100647120 .9607009888 121.0190963745121 .0868988037121 .1628036499121 .2445983887121 .3309020996 121.4198989868121 .5102005005121 .6000976562121 .6885986328121 .7739028931 121.8552017212121 .931098938122 .0009002686122 .0632019043122 .1176986694 122.1632995605122 .1996994019122 .2261962891122 .2425994873122 .2484970093 
122.2440032959 122.2286987305 122.2029037476 122.1666030884 122.1202011108 122.0636978149121 .9975967407121 .9220962524121 .837600708121 .7444000244 121.6427993774121 .5329971313121 .4150009155121 .289100647121 .1547012329 121.0120010376120 .8599014282120 .6985015869120 .5262985229120 .3430023193 120.1468963623119 .9374008179119 .7127990723119 .4725036621119 .2145004272 118.9384002686118 .6418991089118 .3245010376117 .9838027954117 .618598938 117.2260971069116 .8042984009116 .349899292115 .8598022461115 .3300018311 114.7565994263114 .1350021362113 .4606018066112 .7291030884111 .935798645 111.0779037476110 .1511993408109 .1555023193108 .0886001587106 .952796936 105.7491989136104 .4769973755103 .1436004639101 .7275009155100 .2382965088 98.6192626953196 .882812594 .9189529418992 .6664733886790 .21439361572 87.548553466884 .8975601196382 .3970031738380 .3514785766679 .08567810059 78.3869705200278 .0937576293978 .0173492431677 .9679031372177 .8650970459 77.6281814575277 .1332015991276 .3309020996175 .046180725173 .18271636963 70.7870483398467 .819198608464 .4431610107460 .3710289001557 .02872085571 56.0893898010356 .0487785339455 .7683792114355 .5667304992755 .38679122925 55.2045593261755 .0122184753454 .7927207946854 .5593299865754 .29098129272 53.9854507446353 .6525192260753 .3109092712452 .9569816589452 .60108184814 52.2369117736851 .8654899597251 .4835090637251 .0908584594750 .68534088135 50.2669792175349 .8345108032249 .3885498046948 .928710937548 .45624923706 47.9715003967347 .4763793945346 .971538543746 .4593009948745 .94025039673 45.4166183471744 .8886413574244 .3580284118743 .824630737343 .28945159912 42.7520217895542 .212749481241 .6710700988841 .1270103454640 .58005905151 40.0300903320339 .4766693115238 .9196510314938 .3586692810137 .79364013672 37.2242317199736 .6503601074236 .0717697143635 .4885902404834 .90005111694 34.3071784973133 .70822906494

1507.7449951171499 .5729980471491 .4010009771483 .2320556641475 .063964844 1466.8940429691458 .7230224611450 .5489501951442 .370971681434 .1879882811426 1417.8050537111409 .6040039061401 .3950195311393 .1789550781384 .953979492 1376.7199707031368 .4770507811360 .2249755861351 .9620361331343 .689941406 1335.4069824221327 .1130371091318 .8089599611310 .4930419921302 .166015625 1293.828002931285 .4770507811277 .1149902341268 .7399902341260 .354003906 1251.9549560551243 .5450439451235 .1230468751226 .6889648441218 .244018555 1209.7869873051201 .3199462891192 .8409423831184 .3530273441175 .854980469 1167.3480224611158 .832031251150 .3070068361141 .7760009771133 .237060547 1124.6920166021116 .1409912111107 .5839843751099 .0240478521090 .458984375 1081.8909912111073 .3210449221064 .7490234381056 .1750488281047 .600952148 1039.026000977 1030.453002931021.8800048831013.3090209961004.739990234 996.1740722656987 .6115722656979 .0532226562970 .4995117188961 .9509887695 953.4083862305944 .8723144531936 .3433227539927 .8220214844919 .3090209961 910.8049926758902 .3106079102893 .8264160156885 .3532714844876 .8920288086 868.4429931641 860.0070800781 851.5850830078 843.1779174805 834.7858886719 826.4102172852818 .0512695312809 .7100830078801 .387512207793 .0839233398 784.8004760742776 .5380249023768 .2973022461760 .0791015625751 .8842163086 743.7136230469735 .5679931641727 .4481811523719 .3552246094711 .2896728516 703.2526245117695 .2446899414687 .266784668679 .3197021484671 .4041748047 
663.5213012695655 .6716918945647 .8562011719640 .0756225586632 .3306884766 624.6223144531616 .9514160156609 .3184204102601 .7244262695594 .1699829102 586.6561279297579 .1832885742571 .7526245117564 .3646240234557 .0200195312 549.7197265625542 .4644165039535 .2548217773528 .0916748047520 .9758300781 513.9078979492506 .8886108398499 .9187927246492 .9989929199486 .1300964355 479.3125915527472 .5474853516465 .8352050781459 .1765136719452 .5722045898 446.0227966309439 .5289916992433 .0914001465426 .7106018066420 .3873901367 414.1221923828407 .9157104492401 .7684020996395 .6810913086389 .6539916992 383.6878051758377 .782989502371 .9400939941366 .1596069336360 .441986084 354.7875976562349 .1969909668343 .6702880859338 .208190918332 .8109130859 327.4789123535322 .2121887207317 .011505127311 .8768920898306 .8086853027 301.8070983887296 .8724060059292 .0047912598287 .2045898438282 .4718933105 277.8068847656273 .2096862793268 .6806030273264 .2196044922259 .8268127441 255.5025024414251 .2465057373247 .05909729242 .9402008057238 .8898010254 234.908203125230 .9951934814227 .1508026123223 .375219 .6678924561216 .029296875 212.4593048096208.957901001205.5249023438202.1605072021 198.8645019531 195.6371002197192 .4779968262189 .3876037598186 .3657073975183 .4125061035 180.5281066895177 .712600708174 .9660949707172 .2888031006169 .6809997559 167.1427001953164 .6743927002162 .2760009766159 .9479980469157 .6903991699 155.5034942627153 .3874053955151 .3421936035149 .3679046631147 .4647064209 145.6322937012143 .870803833142 .1797943115140 .55909729139 .0081939697 137.5267028809136 .1139984131134 .7696075439133 .492401123132 .2819061279 131.1369018555130 .0565032959129 .0395050049128 .0847930908127 .1910018921 126.3567962646125 .5808029175124 .8616027832124 .1974029541123 .5868988037 123.0280990601122 .5195007324122 .0593032837121 .6455001831121 .2764968872 120.9501037598120 .6645965576120 .4178009033120 .2080001831120 .0327987671 119.8905029297119 .7789001465119 .6959991455119 .6396026611119 .608001709 119.5988006592119 .6101989746119 .6401977539119 .6867980957119 .7481002808 119.822303772119 .9073028564120 .001701355120 .1034011841120 .2109985352 120.3227005005120 .4371032715120 .5525970459120 .6679000854120 .7816009521 120.8927001953120 .9997024536121 .1019973755121 .1983032227121 .2880020142 121.3702011108121 .4445037842121 .5100021362121 .5668029785121 .6141967773 121.6522979736121 .6806030273121 .6994018555121 .7085037231121 .7082977295 121.6985015869121 .6797027588121 .6519012451121 .6153030396121 .570098877 121.5164031982121 .4543991089121 .3837966919121 .3047027588121 .2165985107 121.1193008423121 .0121002197120 .8944015503120 .7650985718120 .6234970093 120.4682998657120 .298500061120 .1128005981119 .9103012085119 .6893997192 119.4493026733119 .1884002686118 .9057998657118 .5995025635118 .2682037354 117.9093017578117 .5206985474117 .0991973877116 .6417007446116 .1440963745 115.6024017334115 .012298584114 .3690032959113 .668296814112 .9056015015 112.077796936111 .1809997559110 .2139968872109 .1747970581108 .06300354 106.8792037964105 .619102478104 .2857971191102 .8598022461101 .3407974243 99.6915130615297 .9036636352595 .9344863891693 .7407226562591 .43578338623 89.037803649986 .7767562866284 .7581100463983 .0490264892681 .87899017334 81.1094665527380 .7744216918980 .7319488525480 .7652587890680 .80657196045 80.7573394775480 .5117721557679 .9886169433678 .9717712402377 .32795715332 
75.0860595703172 .1235961914168 .6992568969764 .8495330810561 .57558059692 60.0345306396559 .3269615173358 .7297401428258 .2786598205657 .89014053345 57.5473709106457 .2014999389656 .8519897460956 .4829292297456 .09392166138 55.6800498962455 .2497787475654 .8120689392154 .3692092895553 .92737960815 53.4828681945853 .0342597961452 .5799903869652 .1182594299351 .64817810059 51.1684112548850 .6787300109950 .1785202026449 .6682090759349 .14794158936 48.6186790466348 .0813217163147 .5370292663646 .9872207641646 .43291091919 45.8755683898945 .3157882690444 .7546997070344 .1924095153843 .62948989868 43.0657196044942 .50112152141 .9353485107441 .3681182861340 .79909133911 40.2278709411639 .654159545939 .0776290893638 .4979782104537 .91493988037 37.328258514436 .7376785278336 .1429786682135 .5441207885734 .9408416748 34.3283882141133 .71445846558

1511.8929443361503 .7089843751495 .5260009771487 .3449707031479 .162963867 1470.9799804691462 .7950439451454 .6049804691446 .4119873051438 .213012695 1430.0080566411421 .7960205081413 .5760498051405 .3480224611397 .112060547 1388.8669433591380 .6120605471372 .3480224611364 .0729980471355 .787963867 1347.4930419921339 .1860351561330 .8690185551322 .5400390621314 .198974609 1305.8470458981297 .4830322271289 .1059570311280 .7180175781272 .317016602 1263.9029541021255 .4770507811247 .038940431238 .5889892581230 .125976562 1221.6519775391213 .1669921881204 .6700439451196 .1619873051187 .642944336 1179.1149902341170 .5770263671162 .0290527341153 .4739990231144 .91003418 1136.3389892581127 .7619628911119 .1779785161110 .5889892581101 .994995117 1093.3959960941084 .7950439451076 .1899414061067 .5830078121058 .973999023 1050.3640136721041 .754028321033 .1429443361024 .5340576171015 .926025391 1007.320007324998.7161254883990.1154785156981.5187988281972.9265136719 964.3391113281955 .7572021484947 .1815795898938 .6126708984930 .0512695312 921.4979858398912 .9534301758904 .4182128906895 .8931274414887 .3787841797 878.8759765625870 .3856201172861 .9080810547853 .4442749023844 .9951171875 836.5609741211 828.1431274414 819.7421264648 811.3585205078 802.9935302734 794.6475830078786 .3217163086778 .016784668769 .733581543761 .4729003906 753.2357177734745 .0225830078736 .8347167969728 .6727905273720 .5375976562 712.4301757812704 .3510742188696 .3015136719688 .2819213867680 .2932739258 672.3366088867664 .4127197266656 .5220947266648 .6658935547640 .8447875977 633.0596923828625 .3112792969617 .6005249023609 .9279174805602 .2946166992 594.7011108398587 .1483764648579 .6370239258572 .1679077148564 .7416992188 557.3593139648550 .0214233398542 .7286987305535 .4819946289528 .2819824219 521.1293945312514 .0250854492506 .9696044922499 .9637145996493 .0082092285 486.1036987305479 .2508850098472 .4505004883465 .7031860352459 .0098876953 452.3710021973445 .7872009277439 .2590942383432 .7874145508426 .3728027344 420.0158996582413 .7171936035407 .4773864746401 .2969970703395 .1766967773 389.1169128418383 .1181945801377 .1810913086371 .3062133789365 .4938049316 359.7445983887354 .0588989258348 .4371948242342 .8799133301337 .387512207 331.9601135254326 .5982971191321 .3023986816316 .0728149414310 .9097900391 305.8135986328300 .7846069336295 .8229980469290 .9289855957286 .1029968262 281.3450927734276 .6556091309272 .0344848633267 .482208252262 .9986877441 258.5842895508254 .2389068604249 .9629058838245 .7561035156241 .6186981201 
237.5507965088233 .5523986816229 .6235046387225 .7642059326221 .974395752 218.254196167214 .6035003662211 .0223999023207 .5108032227204 .0686035156 200.6959991455197 .3928070068194 .1591033936190 .9947967529187 .8999938965 184.8748016357181 .9192047119179 .033203125176 .2171020508173 .4707946777 170.7946014404168 .1885986328165 .6529998779163 .1878051758160 .7933959961 158.4696960449156 .2169952393154 .0354003906151 .9250030518149 .8858032227 147.9176940918146 .0207977295144 .1949005127142 .4398040771140 .7552032471 139.1408996582137 .5960998535136 .1206970215134 .7138061523133 .375132 .1031036377 130.8975982666129 .7572937012128 .6813964844127 .6686019897126 .7177963257 125.8276977539124 .9970016479124 .2241973877123 .5080032349122 .8469009399 122.2390975952121 .6831970215121 .1774978638120 .720199585120 .3096008301 119.9438018799119 .6210021973119 .3395004272119 .0970993042118 .8920974731 118.7223968506118 .5863037109118 .4814987183118 .4061965942118 .3583984375 118.3363037109118 .337600708118 .3606033325118 .4031982422118 .4637985229 118.5401992798118 .6306991577118 .7333984375118 .8468017578118 .9688034058 119.0980987549119 .2328033447119 .37159729119 .5129013062119 .6554031372 119.7976989746119 .9386978149120 .077003479120 .2118988037120 .3421020508 120.4671020508120 .5857009888120 .6977996826120 .8022994995120 .8991012573 120.987701416121 .0679016113121 .1393966675121 .2022018433121 .2559967041 121.3011016846121 .3374023438121 .3649978638121 .3839035034121 .394203186 121.3960037231121 .3891983032121 .3739013672121 .3496017456121 .3164978027 121.2738037109121 .2213973999121 .158203125121 .0839004517120 .9972000122 120.8974990845120 .783203125120 .6538009644120 .507598877120 .3441009521 120.1614990234119 .9593963623119 .736000061119 .4906997681119 .2211990356 118.9266967773118 .6043014526118 .2521972656117 .8666000366117 .4449996948 116.9828033447116 .4763031006115 .9209976196115 .3122024536114 .6457977295 113.9171981812113 .1231994629112 .2601013184111 .3254013062110 .3177032471 109.2333984375108 .0743026733106 .8308029175105 .5084991455104 .0850982666 102.5667037964100 .922401428299 .1484909057697 .2450027465895 .18913269043 93.0981521606490 .9784927368289 .0173263549887 .3047866821385 .8630065918 84.81845855713 84.10633850098 83.78922271729 83.7449188232483.8161315918 83.9536666870184 .0497665405384 .0173568725683 .7622985839883 .10785675049 81.8725662231479 .88169097976 .9633636474673 .5535583496170 .10218811035 67.0366363525464 .8097610473663 .2260513305762 .1290092468361 .35192871094 60.7036514282260 .1555900573759 .6289710998559 .1168403625558 .59083938599 58.0573692321857 .5207595825256 .9782485961956 .4347496032755 .89144134521 55.3553695678754 .8210296630954 .2880516052253 .7535095214853 .21662902832 52.6753082275452 .1291198730551 .5766983032251 .0181694030850 .45286178589 49.8815116882349 .3041000366248 .7219085693448 .1352806091347 .54587936401 46.9540405273446 .3614006042545 .7680282592845 .1752014160244 .58259963989 43.9909400939943 .3996505737342 .8089103698742 .2180786132841 .62702178955 41.0351181030340 .4421310424839 .8475494384839 .251110076938 .65235900879 38.0510787963937 .4468383789136 .8394393920936 .2284812927235 .61391067505 34.9948806762734 .372070312533 .74398040771 1516.035034181507 .839965821499 .6450195311491 .4520263671483 .258056641 1475.0620117191466 .8630371091458 .660034181450 .4510498051442 .235961914 
1434.0140380861425 .7840576171417 .546997071409 .3000488281401 .043945312 1392.7790527341384 .5030517581376 .2170410161367 .9210205081359 .613037109 1351.2939453121342 .964965821334 .6230468751326 .2700195311317 .905029297 1309.5269775391301 .1369628911292 .7349853521284 .3199462891275 .891967773 1267.4510498051258 .9980468751250 .5319824221242 .0529785161233 .562988281 1225.0600585941216 .5450439451208 .0179443361199 .4799804691190 .932006836 1182.3730468751173 .8039550781165 .2259521481156 .6390380861148 .04296875 1139.4399414061130 .8299560551122 .2139892581113 .5909423831104 .963989258 1096.332031251087 .6960449221079 .0560302731070 .413940431061 .7700195311053 .125 1044.4780273441035 .8310546881027 .1850585941018 .5399780271009 .895996094 1001.255004883992 .6162719727983 .9810180664975 .3499755859966 .7235107422 958.1021728516949 .4869995117940 .8781738281932 .2766113281923 .6829223633 915.0974731445906 .521484375897 .9553222656889 .3997802734880 .8555297852 872.3234863281863 .8040771484855 .2985229492846 .8071899414838 .3311157227 829.8707885742821 .4274291992813 .0014038086804 .5938110352796 .2053833008 787.8369140625779 .4893798828771 .1635742188762 .8604736328754 .5806884766 746.3250732422738 .0947875977729 .8905029297721 .7130737305713 .5634155273 705.4423217773697 .3507080078689 .2894287109681 .2592163086673 .2609863281 665.295715332657 .364074707649 .4669799805641 .6052856445633 .7797851562 625.9910888672618 .2401733398610 .5280151367602 .8551025391595 .2222900391 587.6304931641580 .0803222656572 .5725708008565 .1080932617557 .6876831055 550.3118896484542 .981628418535 .6975708008528 .4605102539521 .2711181641 514.1301269531507 .0382080078499 .9961853027493 .004699707486 .0643920898 479.1760864258472 .3405151367465 .5581054688458 .8298950195452 .1561889648 445.537902832438 .9754943848432 .4697875977426 .0212097168419 .6304931641 413.2983093262407 .0252075195400 .811706543394 .6585083008388 .5658874512 382.5347900391376 .5653991699370 .6585083008364 .8145141602359 .0338134766 353.3168945312347 .6643981934342 .0765075684336 .553894043331 .0967102051 325.7054138184320 .3804931641315 .1223144531309 .9310913086304 .8073120117 299.7510070801294 .7627868652289 .8428039551284 .9913024902280 .2084960938 275.4946899414270 .8500976562266 .274810791261 .7691955566257 .3333129883 252.967300415248 .671295166244 .4454040527240 .2897949219236 .204498291 232.1894989014228 .2449035645224 .370803833220 .5670928955216 .8338928223 213.1712036133209 .5789031982206 .0570983887202 .6056976318199 .2247009277 195.9141998291192 .6739959717189 .5043029785186 .4049987793183 .3760986328 180.4178009033177 .5299987793174 .7129058838171 .966506958169 .2908935547 166.6862030029164 .1526947021161 .6903076172159 .2991027832156 .9794006348 154.7310943604152 .5543060303150 .4490966797148 .4154052734146 .4530944824 144.5621032715142 .7422027588140 .9933013916139 .3148040771137 .7066040039 136.1678924561134 .6983947754133 .2973022461131 .9640045166130 .6976013184 129.4972991943128 .3619995117127 .2909011841126 .2826004028125 .3360977173 124.4501037598123 .6233978271122 .8544998169122 .141998291121 .4844970703 120.8803024292120 .3280029297119 .8258972168119 .3723983765118 .9655990601 118.6039962769118 .285697937118 .0089035034117 .771697998117 .5724029541 117.4091033936117 .279800415117 .1827011108117 .1158981323117 .0774002075 117.0653991699117 .0779037476117 .1131973267117 .1691970825117 .2442016602 
117.3361968994 117.4436035156 117.5644989014 117.697303772 117.8399963379 117.9913024902118 .1494979858118 .31300354118 .4804000854118 .6502990723 118.8214035034118 .992401123119 .1622009277119 .3298034668119 .4940032959 119.6541976929119 .8093032837119 .9589004517120 .1022033691120 .2388000488 120.3682022095120 .490196228120 .6043014526120 .7105026245120 .8085021973 120.8983001709120 .9798965454121 .0531005859121 .1178970337121 .1743011475 121.2221984863121 .2615966797121 .292098999121 .3134994507121 .3255996704 121.327796936121 .3196029663121 .300201416121 .2689971924121 .224899292 121.167098999121 .0943984985121 .0056991577120 .900100708120 .7764968872 120.6337966919120 .4710998535120 .2872009277120 .081199646119 .8511962891 119.5960998535119 .3131027222119 .0002975464118 .6540985107118 .2714004517 117.8479995728117 .3799972534116 .8628997803116 .292098999115 .6635971069 114.9729995728114 .2169036865113 .3917999268112 .4949035645111 .5242004395 110.4759979248109 .3503036499108 .1398010254106 .8451004028105 .4541015625 103.9656982422102 .3686981201100 .657897949298 .8571014404396 .96394348145 95.0704116821393 .2111968994191 .5019683837990 .0299835205188 .79591369629 87.8767471313587 .2436828613386 .9554367065486 .9138107299887 .01303100586 87.20601654053 87.39929199219 87.53742980957 87.53009033203 87.31442260742 86.8802108764685 .4999008178782 .3517990112378 .5816497802775 .1287689209 71.9859237670969 .4726333618267 .4285278320365 .904998779364 .77850341797 63.837051391663 .0361099243262 .2809982299861 .5690002441460 .87080001831 60.1865005493259 .5062599182158 .834819793758 .1726799011257 .52040100098 56.880020141656 .2482681274455 .6226387023955 .0014610290554 .38248062134 53.7646102905353 .1461906433152 .5266685485851 .904998779351 .28120040894 50.654850006150 .0264587402349 .3963012695348 .7650985717848 .13360977173 47.5024604797446 .8725585937546 .2442092895545 .6180610656744 .99404907227 44.3723793029843 .7526893615743 .1347808837942 .5181884765641 .90246963501 41.2871704101640 .6717796325740 .0559005737339 .4390907287638 .82094955444 38.2011108398437 .5791893005436 .9547882080136 .3275299072335 .69720840454 35.0633506774934 .4213600158733 .778881073 1520.167968751511 .9639892581503 .7590332031495 .5550537111487 .349975586 1479.1419677731470 .9300537111462 .7120361331454 .4890136721446 .258056641 1438.0200195311429 .7729492191421 .5169677731413 .2509765621404 .975952148 1396.6899414061388 .3929443361380 .086059571371 .7669677731363 .437011719 1355.0959472661346 .7419433591338 .3769531251329 .9990234381321 .609008789 1313.207031251304 .7910156251296 .3620605471287 .9210205081279 .465942383 1270.9990234381262 .5179443361254 .0240478521245 .5169677731236 .998046875 1228.4659423831219 .921997071211 .3659667971202 .7979736331194 .218994141 1185.6300048831177 .0300292971168 .4210205081159 .8020019531151 .175048828 1142.5400390621133 .8969726561125 .2480468751116 .5920410161107 .931030273 1099.2650146481090 .5949707031081 .9210205081073 .2440185551064 .563964844 1055.8830566411047 .1999511721038 .5169677731029 .8339843751021 .151000977 1012.4699707031003 .791015625995 .1137695312986 .4401245117977 .7700805664 969.1046142578960 .4437866211951 .7888183594943 .1397705078934 .4979858398 925.8635864258917 .237487793908 .6204833984900 .0131835938891 .4163208008 882.8305053711 874.2565917969 865.6953125 857.1475219727 848.614074707 
840.095703125831 .5930786133823 .1071166992814 .6384887695806 .1881713867 797.7570800781789 .3458862305780 .9556884766772 .5872192383764 .2412719727 755.9188842773747 .6207275391739 .3477172852731 .1008300781722 .8809814453 714.6890258789706 .5255737305698 .3919067383690 .2885742188682 .2166137695 674.1768188477666 .1702270508658 .1973266602650 .2592163086642 .356628418 634.4902954102626 .6611938477618 .8701782227611 .1179199219603 .4052734375 595.7329711914588 .1019287109580 .5125732422572 .9661865234565 .4631958008 558.0045166016550 .5905761719543 .2225952148535 .9010009766528 .6265869141 521.4000854492514 .2224121094507 .0939025879500 .0155029297492 .9879150391 486.0116882324479 .0877075195472 .2166137695465 .3991088867458 .6358032227 451.9273071289445 .2742919922438 .6774902344432 .137512207425 .6549072266 419.2304992676412 .8646850586406 .5582885742400 .3116149902394 .1253967285 388.000213623381 .9366149902375 .9350891113369 .9961853027364 .120513916 358.3085021973352 .5604858398346 .8772888184341 .2590026855335 .7062072754 330.2193908691324 .7988891602319 .445098877314 .1585083008308 .9393920898 303.7880859375298 .7049865723293 .6903076172288 .7443847656283 .8677062988 279.0603027344274 .3225097656269 .654510498265 .0567016602260 .5291137695 256.0719909668251 .6855010986247 .3699035645243 .1251068115238 .9514007568 234.8488006592230 .8173980713226 .8571929932222 .9683990479219 .150894165 215.404800415211 .7301025391208 .1266021729204 .5946044922201 .1340026855 197.7445983887194 .4266052246191 .179901123188 .0045013428184 .9004058838 181.8677062988178 .9062957764176 .0164031982173 .1979980469170 .4510040283 167.7756958008165 .1719970703162 .6401062012160 .1799926758157 .7917022705 155.4754943848153 .2310943604151 .0587005615148 .9582061768146 .9295959473 144.9727020264143 .0872955322141 .2731018066139 .5301055908137 .8574981689 136.2552032471134 .7225036621133 .258895874131 .8636016846130 .5359954834 129.275100708128 .0802001953126 .9501037598125 .8841018677124 .8806991577 123.9390029907123 .0577011108122 .235496521121 .4709014893120 .762802124 120.1094970703119 .5096969604118 .9617004395118 .4639968872118 .0149993896 117.6128997803117 .2563018799116 .9431991577116 .6719970703116 .44090271 116.2481994629116 .0919036865115 .9703979492115 .8816986084115 .8240966797 115.7956008911115 .7946014404115 .8190002441115 .8672027588115 .9371032715 116.0271987915116 .1353988647116 .2602005005116 .3996963501116 .5523986816 116.7163009644116 .8900985718117 .0718994141117 .260597229117 .4542999268 117.6520004272117 .8519973755118 .0532989502118 .2546005249118 .4550018311 118.6532974243118 .8487014771119 .0401992798119 .2273025513119 .4091033936 119.5854034424119 .7552032471119 .9186019897120 .0749969482120 .2240982056 120.3656997681120 .4998016357120 .6259002686120 .744102478120 .8541030884 120.9559020996121 .0492019653121 .1339035034121 .2097015381121 .2760009766 121.332901001121 .3793029785121 .4151000977121 .439201355121 .4509963989 121.4494018555121 .4337997437121 .4027023315121 .3555984497121 .2910995483 121.2086029053121 .1067962646120 .9852981567120 .8425979614120 .6781997681 120.4897994995120 .276802063120 .0358963013119 .7654037476119 .4614028931 119.1209030151118 .739402771118 .3131027222117 .8375015259117 .3082962036 116.7211990356116 .0725021362115 .3582992554114 .5758972168113 .7212982178 112.793800354111 .7881011963110 .7057037354109 .5384979248108 .2895965576 
106.949798584105 .5214996338104 .004699707102 .3968963623100 .7352981567 99.0187988281297 .3318023681695 .693778991794 .1975326538192 .90705108643 91.8334426879991 .0385284423890 .496932983490 .2485961914190 .22001647949 90.3268966674890 .5488662719790 .7918777465891 .0393981933691 .20110321045 91.2472229003991 .4268493652390 .5905075073287 .3405838012783 .32861328125 79.8912429809676 .7128372192474 .0228500366271 .7370986938569 .89588928223 68.4254379272567 .1685028076266 .0995101928765 .0949401855564 .169921875 63.2882499694862 .4438018798861 .6110382080160 .8001899719260 .01110076904 59.2415618896558 .4900283813557 .753349304257 .0290298461956 .31465911865 55.6084594726654 .9084510803254 .2135696411153 .5222702026452 .83403015137 52.1478614807151 .4637489318850 .7812614440950 .1009216308649 .42264175415 48.7473106384348 .0748901367247 .4063491821346 .7414588928246 .0809211731 45.424240112344 .7716903686544 .1226005554243 .4768295288142 .83366012573 42.1927299499541 .5533790588440 .9151611328140 .2775115966839 .64002990723 39.0021705627438 .3636283874537 .7238082885737 .0824089050336 .43881988525 35.792831420935 .1434288024934 .4908599853533 .83395004272

1524.296997071516 .0830078121507 .8690185551499 .6550292971491 .438964844 1483.2199707031474 .9949951171466 .7640380861458 .5260009771450 .280029297 1442.0250244141433 .7609863281425 .4870605471417 .2020263671408 .906982422 1400.6009521481392 .2829589841383 .9539794921375 .6140136721367 .260986328 1358.8969726561350 .5200195311342 .1300048831333 .7280273441325 .313964844 1316.8859863281308 .4439697271299 .9899902341291 .5219726561283 .041015625 1274.5460205081266 .0379638671257 .5159912111248 .9809570311240 .432983398 1231.8719482421223 .2989501951214 .7130126951206 .1159667971197 .506958008 1188.8859863281180 .2559814451171 .6149902341162 .964965821154 .306030273 1145.6379394531136 .9630126951128 .2810058591119 .5920410161110 .896972656 1102.1970214841093 .4919433591084 .7829589841076 .0710449221067 .355957031 1058.6390380861049 .9200439451041 .1999511721032 .4799804691023 .760009766 1015.0410156251006 .323974609997 .6085205078988 .8959960938980 .1870117188 971.4821166992962 .7819213867954 .0867919922945 .3978271484936 .7155151367 928.0404052734919 .3734741211910 .7152099609902 .0665283203893 .4281005859 884.8005981445876 .1848144531867 .5814819336858 .9915771484850 .4157104492 841.8549194336833 .3095703125824 .7811279297816 .2697143555807 .7766113281 799.3026733398790 .8485717773782 .4155273438774 .0040893555765 .6154174805757 .25 748.908996582740 .5933227539732 .3035888672724 .0410766602715 .8065795898 707.6008911133699 .4249267578691 .2794189453683 .1655273438675 .0839233398 667.0355224609659 .0211791992651 .041809082643 .0980834961635 .1909179688 627.3212280273619 .4896850586611 .6973266602603 .9447021484596 .2327270508 588.5620727539580 .9337158203573 .3482055664565 .8065185547558 .3092041016 550.8571777344543 .4511108398536 .0916748047528 .7799072266521 .5161743164 514.3012695312507 .1359863281500 .0210876465492 .9572143555485 .9450073242 478.9851074219472 .0783996582465 .225402832458 .4269104004451 .6835021973 444.9957885742438 .3644104004431 .7901000977425 .2734069824418 .8150939941 412.4155883789406 .0757141113399 .7959899902393 .5768127441387 .4189147949 381.3228149414375 .2890930176369 .3183898926363 .4111022949357 .5676879883 351.7887878418346 .0748901367340 .4263000488334 .8435974121329 .3272094727 
323.8776855469318 .4952087402313 .1802978516307 .9334106445302 .7549133301 297.6448974609292 .604095459287 .632598877282 .7308044434277 .8989868164 273.137512207268 .4462890625263 .8259887695259 .2767028809254 .7985992432 250.3917999268246 .0567016602241 .7931976318237 .6015014648233 .4817962646 229.43409729225 .4584960938221 .5550994873217 .7238006592213 .9647979736 210.2779998779206 .6634979248203 .1212005615199 .6511993408196 .25340271 192.9277954102189 .6743011475186 .4931030273183 .3840942383180 .3473052979 177.3827056885174 .4904022217171 .6703033447168 .9225006104166 .2469940186 163.6439971924161 .1134033203158 .6551971436156 .2695007324153 .9562988281 151.7156066895149 .5471954346147 .4512023926145 .4273071289143 .4754943848 141.5953979492139 .7868041992138 .0493927002136 .382598877134 .7861938477 133.2592926025131 .8016052246130 .4120941162129 .0903015137127 .8351974487 126.6457977295125 .5213012695124 .4606018066123 .462600708122 .5261001587 121.6499023438120 .8327026367120 .073097229119 .3699035645118 .7216033936 118.126701355117 .5838012695117 .0912017822116 .6473999023116 .2508010864 115.8999023438115 .5929031372115 .3281021118115 .1038970947114 .9185028076 114.7701034546114 .6570968628114 .5775985718114 .5299987793114 .512298584 114.5229034424114 .5597991943114 .62159729114 .7061004639114 .8117980957 114.9367980957115 .0795974731115 .2382965088115 .4113006592115 .5968017578 115.7934036255115 .9993972778116 .2135009766116 .4338989258116 .6595001221 116.8887023926117 .1205978394117 .3535995483117 .5868988037117 .8191986084 118.0497970581118 .2777023315118 .5021972656118 .7223968506118 .93800354 119.1482009888119 .3526992798119 .5509033203119 .7425994873119 .9273986816 120.1050033569120 .2752990723120 .4378967285120 .5924987793120 .7390975952 120.8772964478121 .0067977905121 .1271972656121 .2381973267121 .3392028809 121.4297027588121 .5091018677121 .5765991211121 .631401062121 .6725006104 121.6992034912121 .7104034424121 .7052993774121 .682800293121 .6423034668 121.5828018188121 .5037994385121 .4040985107121 .2829971313121 .1387023926 120.9699020386120 .7739028931120 .5484008789120 .2895965576119 .9942016602 119.6578979492119 .2766036987118 .8460006714118 .3618011475117 .8202972412 117.2173995972116 .5501022339115 .8152999878115 .0100021362114 .132598877 113.179901123112 .1511993408111 .0429992676109 .8556976318108 .5878982544 107.2405014038105 .8227005005104 .3373031616102 .8190994263101 .2817001343 99.7824935913198 .3557662963997 .0539398193495 .9335021972795 .004737854 94.3098907470793 .8368835449293 .6112365722793 .5763473510793 .68218994141 93.8946228027394 .1460571289194 .3954467773494 .5589599609494 .59192657471 94.4919509887793 .4982833862390 .7824935913187 .3583679199284 .1330871582 81.0540390014678 .3202667236375 .8810195922973 .8221130371172 .07222747803 70.564598083569 .2445068359468 .0182037353566 .886299133365 .81777191162 64.8024063110463 .8153305053762 .8618698120161 .9397888183661 .04637908936 60.1772499084559 .3298683166558 .5007400512757 .6881408691456 .88930130005 56.1029205322355 .3269081115754 .5603294372653 .8016281127953 .05025863647 52.3051910400451 .5663299560550 .8332214355550 .106029510549 .38478851318 48.6696510314947 .9608116149947 .2582206726146 .5619697570845 .87171173096 45.1872291564944 .5079994201743 .8335304260343 .1632118225142 .49639892578 41.8325500488341 .1710014343340 .5112686157239 .8527717590339 .1950302124 
38.5375404357937 .8798103332537 .2213211059636 .5614891052235 .89989852905 35.2358016967834 .5647811889633 .89427185059

1528.4200439451520 .1979980471511 .9759521481503 .7530517581495 .527954102 1487.296997071479 .0610351561470 .8170166021462 .5649414061454 .302978516 1446.0319824221437 .751429 .4580078121421 .1540527341412 .8389892581404 .512939453 1396.1739501951387 .8239746091379 .461059571371 .086059571362 .697998047 1354.2979736331345 .8850097661337 .4580078121329 .0179443361320 .564941406 1312.0980224611303 .6180419921295 .1230468751286 .6149902341278 .093017578 1269.5579833981261 .0080566411252 .4449462891243 .8680419921235 .279052734 1226.6760253911218 .0610351561209 .4329833981200 .7939453121192 .142944336 1183.4809570311174 .8089599611166 .1269531251157 .4360351561148 .735961914 1140.0279541021131 .3129882811122 .589965821113 .8620605471105 .126953125 1096.3879394531087 .6440429691078 .8959960941070 .1459960941061 .391967773 1052.6369628911043 .8809814451035 .1240234381026 .3659667971017 .609985352 1008.8540039061000 .099975586991 .3491210938982 .6008300781973 .8563842773 965.1165161133956 .3814086914947 .6520996094938 .9291992188930 .2133178711 921.5051879883912 .8057250977904 .1154785156895 .4354248047886 .7659912109 878.1080932617869 .4627075195860 .8303833008852 .2119750977843 .6083984375 835.0205078125826 .4489746094817 .8947753906809 .3588256836800 .8416748047 792.3447265625783 .8685302734775 .4140014648766 .9821777344758 .5737304688 750.1898193359741 .8311157227733 .4985961914725 .1931762695716 .916015625 708.6676025391700 .44921875692 .2614135742684 .1052856445675 .9816894531 667.8914794922659 .8353881836651 .8145141602643 .8294067383635 .8812255859 627.9705810547620 .0985107422612 .2656860352604 .4729003906596 .7208862305 589.0106201172581 .3427734375573 .7180786133566 .1373291016558 .6013793945 551.1109008789543 .6666259766536 .2692871094528 .9196777344521 .6185302734 514.366394043507 .1642150879500 .012512207492 .9119873047485 .863494873 478.8677062988471 .925201416465 .0365905762458 .2026977539451 .4241027832 444.7015991211438 .0356140137431 .4267883301424 .8758850098418 .383605957 411.9504089355405 .5769958496399 .263885498393 .0118103027386 .821105957 380.6925964355374 .6267089844368 .6241149902362 .6852111816356 .8106079102 351.000793457345 .2561950684339 .5773925781333 .9648132324328 .4190063477 322.9403991699317 .5293884277312 .1864013672306 .9118041992301 .7060852051 296.5696105957291 .5028076172286 .5057983398281 .5791931152276 .7231140137 271.9378967285267 .2237854004262 .5812988281258 .0103149414253 .5113983154 249.0845031738244 .7299957275240 .4479064941236 .2384033203232 .1016998291 228.0377960205224 .0467987061220 .1287994385216 .2837982178212 .5119018555 208.8130950928 205.1875 201.6349029541 198.1553955078 194.7490997314191.415802002 188.1555023193184 .9683990479181 .8542022705178 .8130950928175 .8450927734 172.9501037598170 .1280975342167 .379196167164 .7033996582162 .100692749 159.5709991455157 .1145019531154 .7310028076152 .4205932617150 .1831054688 148.0184936523145 .9266052246143 .9073028564141 .9602966309140 .0852966309 138.2821044922136 .550201416134 .8890991211133 .2984924316131 .7774963379 130.3256988525128 .9420928955127 .6261978149126 .3769989014125 .1934967041 124.074798584123 .0198974609122 .0274963379121 .0967025757120 .2259979248 119.4143981934118 .6604003906117 .9626998901117 .3199005127116 .7305984497 
116.193397522115 .7065963745115 .2688980103114 .8786010742114 .5341033936 114.2339019775113 .9764022827113 .7596969604113 .5823974609113 .4427032471 113.3389968872113 .2695007324113 .2325973511113 .2264022827113 .2492980957 113.2995986938113 .37550354113 .4751968384113 .5972976685113 .7396011353 113.9009017944114 .0792007446114 .2731018066114 .4805984497114 .7005996704 114.931098938115 .1708984375115 .418296814115 .6720962524115 .9308013916 116.1932983398116 .4581985474116 .7245025635116 .9909973145117 .2568969727 117.5211029053117 .7829971313118 .0416030884118 .2964019775118 .5466003418 118.7919998169119 .0317001343119 .2657012939119 .4932022095119 .7141036987 119.9279022217120 .1343994141120 .3332977295120 .5242004395120 .706703186 120.8805007935121 .0453033447121 .200302124121 .3453979492121 .479598999 121.6025009155121 .7132034302121 .8109970093121 .8949966431121 .9644012451 122.0182037354122 .0556030273122 .0758972168122 .0783996582122 .0623016357 122.0271987915121 .9718017578121 .8960037231121 .7974014282121 .6753997803 121.5263977051121 .3485031128121 .1376037598120 .8901977539120 .6019973755 120.2687988281119 .8863983154119 .4507980347118 .9581985474118 .4054031372 117.7890014648117 .1070022583116 .3562011719115 .5360031128114 .6433029175 113.6789016724112 .6405029297111 .529800415110 .3495025635109 .1011962891 107.8006973267106 .4501037598105 .0869979858103 .7202987671102 .4028015137 101.1598968506100 .032798767199 .0601577758898 .2539596557697 .6477432251 97.2308273315497 .0201568603596 .9753265380997 .0599288940497 .24070739746 97.45507812597 .6439285278397 .7160797119197 .5263137817496 .88065338135 95.6008911132893 .4819488525490 .8300933837987 .9675674438585 .04863739014 82.3553924560579 .859092712477 .6601867675875 .7132797241273 .98915100098 72.4509963989371 .0135421752969 .6877365112368 .4318466186567 .24611663818 66.1009826660265 .0033569335963 .9438018798862 .9215393066461 .9295501709 60.9664192199760 .0279502868759 .1123580932658 .2169685363857 .33996963501 56.4795989990255 .6341285705654 .8022918701253 .9827194213953 .17454910278 52.3768615722751 .5892601013250 .8111991882350 .0426712036149 .28321838379 48.5330009460447 .7914695739747 .0586395263746 .3337898254445 .61669921875 44.9065399169944 .2028198242243 .5047187805242 .8116188049342 .12279129028 41.4375991821340 .7554206848140 .0756988525439 .3978309631338 .72135162354 38.0455818176337 .3700904846236 .6940498352136 .0171089172435 .33795166016 34.6562995910633 .97138977051

1532.538940431524 .3120117191516 .082031251507 .8509521481499 .616943359 1491.3759765621483 .129028321474 .8719482421466 .6049804691458 .32800293 1450.0400390621441 .7409667971433 .4300537111425 .1080322271416 .772949219 1408.4260253911400 .0660400391391 .6939697271383 .3089599611374 .911987305 1366.5009765621358 .0770263671349 .6400146481341 .1889648441332 .723999023 1324.2449951171315 .7530517581307 .245971681298 .7259521481290 .191040039 1281.6419677731273 .078002931264 .5009765621255 .910034181247 .303955078 1238.6860351561230 .0529785161221 .4079589841212 .7509765621204 .081054688 1195.3990478521186 .7060546881178 .0030517581169 .288940431160 .566040039 1151.8330078121143 .0930175781134 .3439941411125 .5880126951116 .824951172 1108.0570068361099 .2829589841090 .504028321081 .7209472661072 .933959961 1064.1450195311055 .3530273441046 .5600585941037 .7650146481028 .969970703 
1020.1760253911011 .3820190431002 .590026855993 .7991943359985 .0117797852 976.227722168967 .4478759766958 .6727294922949 .9027709961941 .1392211914 932.3822021484923 .6329956055914 .8920288086906 .1602172852897 .4381103516 888.7266235352880 .0266113281871 .338684082862 .6638183594854 .0029296875 845.3563842773836 .7255859375828 .1110839844819 .5137939453810 .9345703125 802.3743896484793 .8341064453785 .3145751953776 .8167724609768 .3416137695 759.8900146484751 .4628295898743 .0609741211734 .6854248047726 .3369750977 718.0169067383709 .7257080078701 .4644775391693 .2341918945685 .0357055664 676.8698120117668 .737487793660 .6395874023652 .5769042969644 .5502929688 636.5607910156628 .6090698242620 .6962280273612 .8225708008604 .9893798828 597.1973266602589 .4470825195581 .7395019531574 .075378418566 .4553833008 558.8806152344551 .3513793945543 .8687133789536 .4331054688529 .0455932617 521.7067260742514 .417175293507 .1777038574499 .9891052246492 .8518981934 485.766998291478 .7348022461471 .7562866211464 .8320922852457 .9627075195 451.1488037109444 .3911132812437 .6903076172431 .0469970703424 .4617919922 417.9353027344411 .4682922363405 .0613098145398 .7149047852392 .4296875 386.2062072754380 .0451965332373 .9471130371367 .9125976562361 .9421081543 356.0361938477350 .1954040527344 .4202880859338 .7113037109333 .0690002441 327.4937133789321 .9862060547316 .5466003418311 .1755981445305 .8735046387 300.6408081055295 .4778137207290 .3850097656285 .362701416280 .4112854004 275.5310974121270 .7224121094265 .9855041504261 .3208007812256 .7283935547 252.208694458247 .7617950439243 .3880004883239 .0874023438234 .8601989746 230.7064971924226 .6264953613222 .6201019287218 .6876068115214 .828994751 211.0442047119207 .333404541203 .6965942383200 .1336975098196 .6448059082 193.2297973633189 .8887023926186 .6215057373183 .4282989502180 .308807373 177.2633056641 174.291595459171.3937988281 168.5697021484165.8195037842 163.1430969238160 .5404052734158 .011505127155 .5563964844153 .1748962402 150.866897583148 .6325073242146 .4714050293144 .3834075928142 .3683929443 140.4261016846138 .5561981201136 .758102417135 .0316925049133 .3762969971 131.7913970947130 .2763977051128 .8305053711127 .4531021118126 .1432037354 124.900100708123 .7228012085122 .6101989746121 .5613021851120 .5751037598 119.6501998901118 .785697937117 .9801025391117 .2321014404116 .5406036377 115.9039993286115 .3208999634114 .7901000977114 .3097991943113 .8787994385 113.4953994751113 .158203125112 .8656005859112 .6159973145112 .407699585 112.2393035889112 .1091003418112 .0154037476111 .9565963745111 .931098938 111.9371032715111 .9730987549112 .0372009277112 .1279983521112 .243598938 112.3824996948112 .5429000854112 .723197937112 .9216003418113 .1368026733 113.366897583113 .6106033325113 .8659973145114 .1318969727114 .4067001343 114.6890029907114 .9774017334115 .2707977295115 .5677032471115 .8672027588 116.1679992676116 .4692001343116 .7697982788117 .0690002441117 .3657989502 117.6596984863117 .9498977661118 .2359008789118 .516998291118 .7928009033 119.0627975464119 .3265991211119 .5837020874119 .8338012695120 .0764007568 120.3113021851120 .5378036499120 .7556991577120 .9644012451121 .1633987427 121.3520965576121 .5299987793121 .6962966919121 .8503036499121 .9912033081 122.1183013916122 .2306976318122 .3274993896122 .408203125122 .4719009399 122.5183029175122 .5466003418122 .5565032959122 .5470962524122 .5179977417 
122.4671020508122 .3935012817122 .2938995361122 .1659011841122 .0054016113 121.8087997437121 .5716018677121 .2894973755120 .9587020874120 .5751037598 120.1354980469119 .6365966797119 .0762023926118 .4518966675117 .7621002197 117.0056991577116 .181602478115 .2900009155114 .3318023682113 .3085021973 112.2258987427111 .087600708109 .9093017578108 .6993026733107 .486000061 106.2863006592105 .1352005005104 .0609970093103 .0880966187102 .2497024536 101.5516967773101 .019203186100 .6430969238100 .4356994629100 .3603973389 100.3900985718100 .4870986938100 .6085968018100 .6717987061100 .6029968262 100.209701538199 .3412933349698 .0402221679796 .1577529907293 .90618133545 91.3606872558688 .6468582153386 .0497131347783 .5687026977581 .30822753906 79.2345581054777 .3537216186575 .630722045974 .0213775634872 .51864624023 71.0953521728569 .7451934814568 .4487075805767 .2059936523466 .00863647461 64.8540420532263 .7364807128962 .6539382934661 .6024894714460 .58044052124 59.58488008288658 .6142692565957 .6662292480556 .7393493652355 .83155822754 54.9417190551854 .068080902153 .2098999023452 .3658905029351 .53561019897 50.7182502746649 .9134292602549 .1205787658748 .3392295837447 .56882095337 46.8087081909246 .0582199096745 .3165893554744 .5830001831143 .85670852661 43.1368408203142 .4227409362841 .7135505676341 .0087394714440 .30754852295 39.6094703674338 .9138603210438 .2201004028337 .527618408236 .83560180664 36.1434707641635 .4500198364334 .7509918212934 .05355834961 1536.6579589841528 .4250488281520 .1889648441511 .9510498051503 .708984375 1495.4589843751487 .1999511721478 .9300537111470 .6490478521462 .355957031 1454.0510253911445 .7340087891437 .4050292971429 .0629882811420 .708007812 1412.3409423831403 .9599609381395 .5660400391387 .1590576171378 .739013672 1370.3050537111361 .8570556641353 .3959960941344 .9210205081336 .431030273 1327.927001953 1319.4090576171310.875976562 1302.328979492 1293.766967773 1285.191040039 1276.5999755861267.994995117 1259.375 1250.740966797 1242.093994141 1233.4320068361224 .7569580081216 .0689697271207 .3690185551198 .656005859 1189.9320068361181 .1970214841172 .4520263671163 .6960449221154 .931030273 1146.1569824221137 .3751128 .5849609381119 .788940431110 .9859619141102 .177001953 1093.3630371091084 .5439453121075 .7220458981066 .8959960941058 .067016602 1049.237060547 1040.405029297 1031.572998047 1022.7399902341013.906982422 1005.07598877996.246887207987.419921875978.5961303711969.7761230469 960.9605712891952 .1500854492943 .3455200195934 .5474853516925 .7567749023 916.9741821289908 .2005004883899 .4364013672890 .6826782227881 .9401855469 873.209777832864 .4921264648855 .7882080078847 .098815918838 .4248046875 829.7670898438821 .1265258789812 .5040283203803 .900390625795 .3165893555 786.7534790039778 .2122192383769 .6936035156761 .1984863281752 .7279052734 744.2827148438735 .8637695312727 .4724121094719 .1090087891710 .7747802734 702.470703125694 .1975708008685 .9564208984677 .7479858398669 .573425293 661.4332885742653 .3286743164645 .2603149414637 .2291870117629 .2362060547 621.2822265625613 .3677978516605 .4940185547597 .6613769531589 .8709716797 582.1234741211574 .4196777344566 .7603759766559 .1463012695551 .5781860352 544.0568237305536 .582824707529 .1569824219521 .7802734375514 .453125 507.1762084961499 .9504089355492 .7763977051485 .6546936035478 .5862121582 471.5715026855464 .6112060547457 .7060852051450 .8568115234444 .0639038086 
437.3280944824 430.6500854492424.0303955078417.4697875977410.9686889648 404.5280151367398 .1481018066391 .8298034668385 .5734863281379 .3799133301 373.2495117188367 .183013916361 .1807861328355 .2437133789349 .371887207 343.5663146973337 .8270874023332 .1549987793326 .5504150391321 .013885498 315.5458068848310 .1469116211304 .8172912598299 .5575866699294 .3681945801 289.2496032715284 .2019958496279 .2258911133274 .3215942383269 .4895019531 264.729888916260 .0432128906255 .429397583250 .8890075684246 .4221954346 242.0292053223237 .7102050781233 .4653015137229 .2946929932225 .1985015869 221.1768951416217 .2299041748213 .3576049805209 .5599975586205 .8372039795 202.1891021729 198.6159057617 195.117401123191.6936950684188.3448028564 185.070602417181 .87109375178 .746307373175 .6961975098172 .720703125 169.8197937012166 .9934997559164 .2416992188161 .5644989014158 .9617004395 156.4333953857153 .9794006348151 .5997009277149 .2940979004147 .0625144 .9046936035 142.8204956055140 .8096923828138 .8719024658137 .0068969727135 .2140045166 133.4931030273131 .8433074951130 .2642059326128 .7550964355127 .3153991699 125.9441986084124 .6406021118123 .4038009644122 .2329025269121 .126701355 120.0842971802119 .1044998169118 .1862030029117 .3281021118116 .5290985107 115.7878036499115 .102897644114 .4729995728113 .8968963623113 .3730010986 112.9000015259112 .4763031006112 .1006011963111 .7714004517111 .4869995117 111.2461013794111 .0469970703110 .8881988525110 .7680969238110 .6852035522 110.637802124110 .62449646110 .6434020996110 .6930999756110 .7717971802 110.8780975342111 .0102005005111 .1666030884111 .3454971313111 .5454025269 111.7646026611112 .0016021729112 .254699707112 .5224990845112 .8031997681 113.0955963135113 .3980026245113 .709197998114 .0276031494114 .3522033691 114.6812973022115 .0141983032115 .3492965698115 .6859970093116 .0229034424 116.3594970703116 .6945037842117 .0274963379117 .3573989868117 .6838989258 118.0062026978118 .3237991333118 .6359024048118 .9423980713119 .2425003052 119.5358963013119 .8220977783120 .1005020142120 .3707962036120 .6324996948 120.8849029541121 .1276016235121 .3600006104121 .5812988281121 .7910995483 121.9884033203122 .1726989746122 .3430023193122 .4988021851122 .6390991211 122.7634963989122 .8713989258122 .9625015259123 .0361022949123 .092300415 123.1298980713123 .1489028931123 .1472015381123 .1238021851123 .075302124 122.9992980957122 .8914031982122 .7479019165122 .564201355122 .3360977173 122.0597991943121 .7314987183121 .348197937120 .9072036743120 .4066009521 119.8449020386119 .2209014893118 .5343017578117 .7850036621116 .9739990234 116.1039962769115 .1765975952114 .2007980347113 .179397583112 .1307983398 111.0606994629109 .9975967407108 .9531021118107 .9581985474107 .0330963135 106.1978988647105 .4770965576104 .8731994629104 .4045028687104 .0600967407 103.8492965698103 .7362976074103 .6958999634103 .6878967285103 .6791000366 103.5800018311103 .3326034546102 .7975006104101 .8378982544100 .5314025879 98.7967987060596 .7585830688594 .4371566772591 .9406967163189 .48719787598 87.0675811767684 .8012695312582 .65820312580 .6615905761778 .79415130615 77.0334625244175 .3761978149473 .7940521240272 .2898864746170 .84351348877 69.4578323364368 .1205062866266 .832443237365 .5864562988364 .38202667236 63.2147598266662 .083431243960 .9851188659759 .9181289672958 .88021850586 57.8694686889656 .8838882446355 .9216804504454 .9810791015654 .06066894531 
53.1590690612852 .2751808166551 .4080390930250 .5567283630449 .72050094604 48.898441314748 .0898590087947 .2937698364346 .5094108581545 .7357711792 44.9719696044944 .217071533243 .4701805114742 .7304801940941 .99713897705 41.2694587707540 .5467109680239 .828258514439 .1134910583538 .40169143677 37.6923599243236 .9844512939536 .2775497436535 .5698585510334 .86045074463 34.14904022217 1540.7740478521532 .538940431524 .2979736331516 .0550537111507 .806030273 1499.5460205081491 .2760009771482 .9919433591474 .6970214841466 .387939453 1458.0660400391449 .7309570311441 .3830566411433 .0209960941424 .645996094 1416.2580566411407 .8559570311399 .4399414061391 .0109863281382 .567993164 1374.1109619141365 .6400146481357 .1540527341348 .6540527341340 .140014648 1331.6109619141323 .0670166021314 .5080566411305 .9350585941297 .345947266 1288.7419433591280 .1240234381271 .4909667971262 .8430175781254 .180053711 1245.5030517581236 .8120117191228 .1070556641219 .3890380861210 .657958984 1201.9150390621193 .160034181184 .3929443361175 .6149902341166 .827026367 1158.0290527341149 .2220458981140 .4069824221131 .5830078121122 .751953125 1113.913940431105 .0699462891096 .2209472661087 .3669433591078 .508056641 1069.6459960941060 .7810058591051 .9129638671043 .042968751034 .172973633 1025.3020019531016 .4310302731007 .560974121998 .6920776367989 .8255004883 980.9616699219972 .1013793945963 .245300293954 .3939819336945 .5485229492 936.708984375927 .8767700195919 .0523071289910 .2365112305901 .4301757812 892.6340942383883 .8488769531875 .0756835938866 .3151245117857 .5681152344 848.8355102539 840.1182250977 831.4171142578 822.7329711914 814.0667724609 805.4196166992796 .7921142578788 .1854248047779 .6002807617771 .0380249023 762.4990844727753 .9849243164745 .49609375737 .0336914062728 .598815918 720.1920166016711 .8145751953703 .4672851562695 .151184082686 .8671264648 678.616027832670 .3986816406662 .2161865234654 .069519043645 .9592285156 637.8864135742629 .8516845703621 .8563232422613 .9008178711605 .9860229492 598.1127929688590 .2819213867582 .4943237305574 .7506103516567 .051574707 559.3980712891551 .7907714844544 .2305297852536 .7177734375529 .2537231445 521.838684082514 .4736938477507 .1592102051499 .8959960938492 .6848144531 485.5263061523478 .4211120605471 .3699951172464 .3735961914457 .4325866699 450.5476074219443 .7193908691436 .9483947754430 .2355041504423 .5812072754 416.9862060547410 .4511108398403 .9765014648397 .5631103516391 .2114868164 384.9222106934378 .6960144043372 .533203125366 .4346008301360 .4006958008 354.4321899414348 .529510498342 .6932067871336 .9237976074331 .2218933105 325.587890625320 .0224914551314 .5260009766309 .0989990234303 .7420043945 298.4554138184293 .2396850586288 .0952148438283 .0223999023278 .021697998 273.0934143066268 .2380065918263 .4556884766258 .746887207254 .1118011475 249.5507965088245 .0641021729240 .6519012451236 .3144989014232 .0520019531 227.8645019531223 .7523040771219 .7153930664215 .75390625211 .8679046631 208.0574035645204 .3226013184200 .6632995605197 .0796966553193 .5715942383 190.1392059326186 .7823028564183 .5010070801180 .2951965332177 .1649017334 174.1101074219171 .1307067871168 .2265930176165 .3979034424162 .6445007324 159.966293335157 .3632965088154 .8352966309152 .3822937012150 .004196167 147.7008056641145 .4718933105143 .3173980713141 .2368927002139 .2301940918 
137.2969055176135 .436706543133 .6490020752131 .9333953857130 .2893981934 128.7162017822127 .2132034302125 .7797012329124 .4149017334123 .1177978516 121.8876037598120 .7233963013119 .6240005493118 .5884017944117 .6154022217 116.7040023804115 .8529968262115 .0609970093114 .3267974854113 .6491012573 113.0266036987112 .457901001111 .9415969849111 .4764022827111 .0608978271 110.6934967041110 .3729019165110 .0975036621109 .8658981323109 .6766967773 109.5281982422109 .4189987183109 .3476028442109 .3123016357109 .3117980957 109.3442993164109 .4084014893109 .5024032593109 .6249008179109 .7741012573 109.9485015869110 .1464996338110 .3666000366110 .6070022583110 .8664016724 111.1428985596111 .4353027344111 .7417984009112 .0610961914112 .3915023804 112.7319030762113 .0805969238113 .4365005493113 .7981033325114 .1644973755 114.5342025757114 .9064025879115 .279800415115 .6537017822116 .0270004272 116.3990020752116 .7687988281117 .1356964111117 .4990005493117 .8581008911 118.2124023438118 .5613021851118 .904296875119 .2407989502119 .5701980591 119.8921966553120 .2060012817120 .5112991333120 .8074035645121 .0936965942 121.3696975708121 .6345977783121 .887802124122 .1287002563122 .3563995361 122.5702972412122 .7696990967122 .9541015625123 .1227035522123 .2754974365 123.4119033813123 .5317993164123 .6350021362123 .7209014893123 .7891998291 123.8378982544123 .8660964966123 .8703994751123 .8480987549123 .7947998047 123.7064971924123 .5789031982123 .4074020386123 .1885986328122 .9185028076 122.5951004028122 .2155990601121 .7789993286121 .283996582120 .7306976318 120.1188964844119 .4498977661118 .7249984741117 .9481964111117 .1223983765 116.2561035156115 .3550033569114 .4338989258113 .5026016235112 .581199646 111.6847991943110 .8330993652110 .0459976196109 .3348007202108 .7192993164 108.198097229107 .7833023071 107.462600708 107.2395019531 107.0822982788 106.9733963013106 .8660964966106 .7238998413106 .4773025513106 .0698013306 105.4116973877 104.3935012817 103.0875015259 101.457199096799.57009887695 97.419647216895 .1031494140692 .7594299316490 .4094696044988 .1467666626 85.9607696533283 .883369445881 .9032897949280 .0189285278378 .22273254395 76.5015716552774 .8523330688573 .2649536132871 .7378463745170 .26403808594 68.8421173095767 .4679336547966 .1401290893664 .8557586669963 .61333847046 62.410438537661 .2453384399460 .1156616210959 .0195007324257 .95436096191 56.9184913635355 .9094390869154 .9257507324253 .9653015136753 .02695846558 52.1090393066451 .2105598449750 .3301391601649 .4668502807648 .61944961548 47.7869796752946 .9682617187546 .1623001098645 .3679008483944 .58419036865 43.8100013732943 .0445709228542 .2868614196841 .5362281799340 .79179000854 40.0529594421439 .3189811706538 .5892486572337 .8631210327137 .13965988159 36.4182701110835 .6970291137734 .9718513488834 .24946975708 1544.8950195311536 .6560058591528 .4129638671520 .1650390621511 .91003418 1503.6400146481495 .3580322271487 .0610351561478 .751470 .4239501951462 .084960938 1453.7309570311445 .3640136721436 .9820556641428 .5870361331420 .177001953 1411.754028321403 .3160400391394 .8649902341386 .3990478521377 .918945312 1369.4239501951360 .9150390621352 .3900146481343 .8509521481335 .29699707 1326.7270507811318 .1419677731309 .5419921881300 .9270019531292 .296020508 1283.6500244141274 .9890136721266 .3120117191257 .620971681248 .915039062 1240.1939697271231 .4599609381222 .711059571213 .9499511721205 .175048828 
1196.3879394531187 .589965821178 .7800292971169 .9589843751161 .12902832 1152.2879638671143 .4389648441134 .5810546881125 .7159423831116 .843017578 1107.9639892581099 .0789794921090 .1889648441081 .2939453121072 .395019531 1063.4930419921054 .5880126951045 .6810302731036 .7719726561027 .862060547 1018.953002931010 .0430297851001 .135009766992 .2288208008983 .3248291016 974.4240722656965 .5272827148956 .6350708008947 .7479858398938 .8671875 929.9931030273921 .1265869141912 .2686157227903 .4196777344894 .580871582 885.7529907227876 .936706543868 .1328735352859 .3425292969850 .5665283203 841.8057250977833 .0609130859824 .3330078125815 .6229858398806 .9318847656 798.2606201172789 .6099243164780 .9808959961772 .3745117188763 .7916870117 755.233581543746 .7009277344738 .1948242188729 .7161254883721 .2656860352 712.8447265625704 .4541015625696 .0947265625687 .7675170898679 .4733886719 671.2133789062662 .9882202148654 .7990112305646 .646484375638 .5316772461 630.4552001953622 .4180908203614 .4212036133606 .4652099609598 .5510864258 590.6796264648582 .8515014648575 .0676879883567 .3286743164559 .6356201172 551.9888916016544 .3895263672536 .8380126953529 .3352050781521 .8817749023 514.4785766602507 .1263122559499 .8254089355492 .5768127441485 .3811950684 478.2391967773471 .1516113281464 .1188049316457 .1416931152450 .2208862305 443.3569946289436 .5508117676429 .8027954102423 .1137084961416 .4841918945 409.9148864746403 .4063110352396 .9591064453390 .5740966797384 .2517089844 377.9926147461371 .7973937988365 .6666870117359 .6010131836353 .6011047363 347.6672973633341 .8002929688336 .0006103516330 .2688903809324 .6054992676 319.0111083984313 .486114502308 .0311889648302 .646697998297 .333190918 292.091003418286 .9206848145281 .8226928711276 .7973937988271 .8452148438 266.9664001465262 .1614074707257 .4306030273252 .7742004395248 .1927032471 243.6860961914239 .2548065186234 .8990020752230 .6188964844226 .4145965576 222.2863006592218 .2341003418214 .258102417210 .3583984375206 .5350952148 202.788192749199 .1177062988195 .5236053467192 .0059051514188 .5646972656 185.199798584181 .9113006592178 .6990966797175 .563293457172 .503692627 169.5202941895166 .6130065918163 .7816925049161 .0265960693158 .3473052979 155.7438964844153 .2160949707150 .7640991211148 .3874053955146 .0861053467 143.8598022461141 .7084960938139 .6315002441137 .62890625135 .7001037598 133.8446960449132 .0621948242130 .3522033691128 .7138977051127 .146697998 125.6499023438124 .2229003906122 .8646011353121 .5743026733120 .3509979248 119.1937026978118 .1013031006117 .0728988647116 .1072998047115 .2032012939 114.3595962524113 .5751037598112 .8485031128112 .1785964966111 .5640029907 111.0033035278110 .495300293110 .0385971069109 .6316986084109 .2733001709 108.9619979858108 .6961975098108 .4748001099108 .2959976196108 .1585998535 108.0608978271108 .0016021729107 .9792022705107 .9922027588108 .0389022827 108.1181030273108 .2279968262108 .3673019409108 .5342025757108 .7273025513 108.9449005127109 .1856994629109 .4478988647109 .7301025391110 .0306015015 110.3480987549110 .6807022095111 .0272979736111 .3861999512111 .7559967041 112.1352996826112 .5229034424112 .9172973633113 .3173980713113 .7219009399 114.1297988892114 .5399017334114 .9512023926115 .3628005981115 .7738037109 116.1832962036116 .5906982422116 .9950027466117 .3955993652117 .7919006348 118.1831970215118 .5688018799118 .9483032227119 .3208999634119 .6862030029 
120.0436019897120 .3924026489120 .7321014404121 .06199646121 .3815002441 121.6900024414121 .9869003296122 .2713012695122 .5428009033122 .8004989624 123.0439987183123 .2726974487123 .4862976074123 .6843032837123 .866897583 124.0336990356124 .1849975586124 .3199005127124 .4384994507124 .5386962891 124.6197967529124 .6780014038124 .710899353124 .7137985229124 .6827011108 124.6131973267124 .5006027222124 .3416976929124 .1326980591123 .8720016479 123.5571975708123 .1878967285122 .7633972168122 .2845993042121 .7516021729 121.1671981812120 .5326004028119 .8535003662119 .1322021484118 .3792037964 117.5982971191116 .8053970337116 .0073013306115 .2229995728114 .4634017944 113.7450027466113 .0820999146112 .4824981689111 .9609985352111 .5119018555 111.1449966431110 .842300415110 .6053009033110 .4033966064110 .2277984619 110.025100708109 .7594985962109 .37840271108 .8408966064108 .0907974243 107.0374984741105 .7406997681104 .1652984619102 .3667984009100 .334197998 98.1466064453195 .9038085937593 .6183471679791 .3768768310589 .16845703125 87.0355529785284 .9691925048882 .9790267944381 .0618133544979 .21086120605 77.4273605346775 .7024993896574 .0385208129972 .4286499023470 .87431335449 69.371238708567 .9197463989366 .5170898437565 .1624526977563 .85367965698 62.5890617370661 .3664016723660 .1834297180259 .0377197265657 .92694091797 56.8485794067455 .8005790710454 .7806205749553 .7870101928752 .81779098511 51.8714981079150 .9464912414650 .0414581298849 .1549491882348 .28572845459 47.4324302673346 .5938606262245 .7687416076744 .9560089111344 .15444946289 43.3631591796942 .581050872841 .8073883056641 .0412292480540 .28195953369 39.5287704467838 .7810707092338 .0382614135737 .2993202209536 .56393051147 35.8296508789135 .095008850134 .35980987549

1549.0119628911540 .7790527341532 .5360107421524 .2840576171516 .021972656 1507.7430419921499 .4479980471491 .1359863281482 .8089599611474 .465942383 1466.1080322271457 .7359619141449 .3480224611440 .9470214841432 .531005859 1424.0999755861415 .6550292971407 .1960449221398 .7220458981390 .234008789 1381.7299804691373 .2120361331364 .6779785161356 .1300048831347 .564941406 1338.9859619141330 .3909912111321 .7800292971313 .1529541021304 .510986328 1295.8530273441287 .1789550781278 .4899902341269 .785034181261 .063964844 1252.3289794921243 .5789794921234 .8139648441226 .0360107421217 .243041992 1208.4370117191199 .6190185551190 .7879638671181 .9460449221173 .093017578 1164.2290039061155 .3549804691146 .4720458981137 .5799560551128 .680053711 1119.7729492191110 .8590087891101 .9379882811093 .0109863281084 .079956055 1075.1440429691066 .2049560551057 .2619628911048 .3170166021039 .369995117 1030.421997071021 .4730224611012 .5239868161003 .57598877994 .6298828125 985.6857299805976 .7443237305967 .8065185547958 .8729858398949 .9445800781 941.0219116211932 .1057739258923 .1970825195914 .2965698242905 .4050292969 896.5233764648887 .6522827148878 .7927856445869 .9456176758861 .1116943359 852.2918701172 843.4871826172 834.6986083984 825.9268188477 817.1726074219 808.4373779297 799.7218017578 791.0269775391 782.3538208008 773.7031860352 765.0762939453756 .4738769531747 .8970947266739 .3469238281730 .82421875 722.3300170898713 .8651733398705 .4310302734697 .0280151367688 .6572875977 680.3200073242672 .0170288086663 .7490234375655 .5170288086647 .3220214844 639.1649169922631 .0463256836622 .9672851562614 .9287109375606 .9312744141 
598.9760742188591 .0637207031583 .1948852539575 .3707275391567 .5916137695 559.8585205078552 .1721191406544 .5333251953536 .9426879883529 .4011230469 521.9091186523514 .4675292969507 .0769958496499 .7383117676492 .4522094727 485.2192077637478 .0401000977470 .9157104492463 .8464050293456 .8328857422 449.8760986328442 .9765014648436 .1347045898429 .3515014648422 .6274108887 415.9631958008409 .3594055176402 .8167114258396 .3356933594389 .9171142578 383.5614013672377 .2694091797371 .041595459364 .8786010742358 .7810058594 352.7495117188346 .7846069336340 .8868103027335 .0567932129329 .2951049805 323.6022949219317 .9789123535312 .4254150391306 .9424133301301 .5303955078 296.1899108887290 .921295166285 .725189209280 .6018981934275 .5520019531 270.5757141113265 .673614502260 .8458862305256 .0931091309251 .4154968262 246.813293457242 .2868041992237 .8365020752233 .4622039795229 .1645050049 224.9434051514220 .7989959717216 .7315063477212 .7409973145208 .8276062012 204.9915008545201 .2324066162197 .5507049561193 .946105957190 .4187927246 186.9687042236183 .5957946777180 .3000946045177 .0814971924173 .9400024414 170.87550354167 .8880004883164 .9774017334162 .1436004639159 .3865966797 156.7061004639154 .1022033691151 .5747070312149 .1235046387146 .7483062744 144.449005127142 .2252960205140 .0769958496138 .003692627136 .0050964355 134.0807952881132 .2303009033130 .4530029297128 .7485046387127 .1160964966 125.5550994873124 .0647964478122 .6443023682121 .2928009033120 .0094985962 118.7934036255117 .6433029175116 .5584030151115 .5374984741114 .579498291 113.6832962036112 .8475036621112 .0709991455111 .3526000977110 .69090271 110.0847015381109 .532699585109 .0335006714108 .5857009888108 .1882019043 107.8394012451 107.5380020142 107.2825012207 107.0718002319 106.9040985107 106.7783966064106 .6929016113106 .6464996338106 .6374969482106 .6647033691 106.7263031006106 .8211975098106 .9476013184107 .1043014526107 .2894973755 107.5018997192107.7397994995 108.0018005371 108.2863006592 108.5919036865 108.9168014526109 .259803772109 .6190032959109 .9933013916110 .3809967041 110.7807998657111 .1910018921111 .6106033325112 .0380020142112 .4720993042 112.9115982056113 .3554000854113 .8022003174114 .2511978149114 .7011032104 115.1512985229115 .6006011963116 .0484008789116 .4936981201116 .9358978271 117.3740997314 117.8077011108 118.236000061 118.6584014893119.0742034912 119.4829025269119 .8836975098120 .2760009766120 .6593017578121 .0328979492 121.3961029053121 .748298645122 .0888977051122 .4171981812122 .7325973511 123.0345001221123 .3224029541123 .5960006714123 .8547973633124 .0988006592 124.3281021118124 .5426025391124 .7425003052124 .9272994995125 .0969009399 125.2496032715125 .3843994141125 .4977035522125 .5869979858125 .6474990845 125.6751022339125 .665397644125 .6137008667125 .5170974731125 .37159729 125.1763000488124 .9290008545124 .6299972534124 .2789993286123 .8775024414 123.4264984131122 .9291992188122 .3876037598121 .8074035645121 .192199707 120.5509033203119 .889503479119 .2197036743118 .5506973267117 .8949966431 117.2646026611 116.6690979004 116.1212005615 115.6237030029 115.1872024536 114.8044967651114 .4798965454114 .1952972412113 .9459991455113 .7074966431 113.4682998657113 .1837997437112 .8201980591112 .3363037109111 .6924972534 110.8600006104109 .778503418108 .4794998169106 .94090271105 .199798584 103.2566986084101 .169799804798 .9987792968896 .7679061889694 .53714752197 
92.3123092651490 .1290588378987 .9878005981485 .9037704467883 .87558746338 81.905967712479 .9943923950278 .1398162841876 .3424072265674 .60090637207 72.9155426025471 .2854919433669 .7105484008868 .1899719238366 .72276306152 65.3077087402363 .9429893493762 .6265907287661 .3561897277860 .12905883789 58.942798614557 .794361114556 .6815681457555 .6014709472754 .55223083496 53.5312118530352 .5368385314951 .5668716430750 .6199111938549 .69401168823 48.7878990173347 .8998184204147 .028598785446 .1726303100645 .33086013794 44.5018692016643 .6847305297942 .8782005310142 .0815391540541 .29364013672 40.513950347939 .7415504455638 .9759788513238 .2165412902837 .46250915527 36.7133407592835 .9665489196835 .2188796997134 .47536087036 1553.1440429691544 .910034181536 .671997071528 .4169921881520 .146972656 1511.8559570311503 .546997071495 .2189941411486 .8740234381478 .514038086 1470.1369628911461 .7449951171453 .3370361331444 .9160156251436 .479003906 1428.0269775391419 .5600585941411 .0789794921402 .5830078121394 .071044922 1385.5450439451377 .0030517581368 .4449462891359 .8719482421351 .282958984 1342.6779785161334 .0570068361325 .4210205081316 .7679443361308 .098999023 1299.4129638671290 .711059571281 .9940185551273 .2600097661264 .510986328 1255.7469482421246 .9670410161238 .171997071229 .3630371091220 .53894043 1211.703002931202 .8520507811193 .9899902341185 .1149902341176 .229003906 1167.332031251158 .4239501951149 .5069580081140 .5810546881131 .645996094 1122.703002931113 .754028321104 .796997071095 .8339843751086 .865966797 1077.8929443361068 .9169921881059 .9360351561050 .953002931041 .967041016 1032.9799804691023 .9920043951015 .004028321006 .015991211997 .0294189453 988.0446166992979 .0623168945970 .0833740234961 .1085205078952 .1381835938 943.1735839844934 .2152709961925 .2642211914916 .3209228516907 .3864135742 898.4616088867889 .5471801758880 .6439819336871 .7531738281862 .8754882812 854.0117797852845 .1630859375836 .3302001953827 .5142211914818 .7156982422 809.9359741211801 .1760253906792 .4368286133783 .7191162109775 .0239868164 766.3524780273757 .7058105469749 .0844726562740 .4899902344731 .9230957031 723.3848266602714 .8759155273706 .3975830078697 .9509277344689 .5366210938 681.1555786133672 .8093261719664 .4981079102656 .2233276367647 .9854736328 639.7857055664631 .6248168945623 .5037231445615 .4230957031607 .3842163086 599.3873901367591 .4337768555583 .5241699219575 .6591796875567 .8397216797 560.06640625552 .3400878906544 .6616821289537 .0316772461529 .4509277344 521.9202270508514 .4398803711507 .0111083984499 .6343994141492 .3103942871 485.0398864746477 .8234863281470 .6619873047463 .5559997559456 .5060119629 449.5129089355442 .5773010254435 .699798584428 .8811035156422 .121887207 415.4227905273408 .7843933105402 .2073974609395 .6924133301389 .2401123047 382.8510131836376 .5257873535370 .2652893066364 .0698852539357 .9403076172 351.8770141602345 .8807983398339 .9520874023334 .0917053223328 .299987793 322.5775146484316 .924987793311 .3428955078305 .8317871094300 .3922119141 295.0246887207289 .7296142578284 .507598877279 .3590087891274 .2843933105 269.2840881348264 .3586120605259 .5082092285254 .7333984375250 .0343933105 245.411605835240 .8652954102236 .3957061768232 .0030975342227 .6878051758 223.449798584219 .2893066406215 .2064971924211 .2015075684207 .2743988037 203.4252929688 199.6542053223195.9611053467192.3460998535188.80909729 
185.3502044678181 .9691925049178 .6661987305175 .441192627172 .2940063477 169.2245941162166 .233001709163 .3190002441160 .4824981689157 .7236022949 155.0419006348152 .4375149 .9102020264147 .4597015381145 .0859985352142 .7886962891 140.5675964355138 .4223022461136 .3527069092134 .3582000732132 .4384002686 130.5928039551128 .8209075928127 .1221008301125 .4956970215123 .9410018921 122.4571990967121 .0436019897119 .6992034912118 .4231033325117 .2144012451 116.0719985962114 .9949035645113 .9819030762113 .0318984985112 .1437988281 111.3163986206110 .5483016968109 .8385009766109 .1856002808108 .5884017944 108.0454025269107 .5556030273107 .1175003052106 .7297973633106 .3910980225 106.1001968384105 .8556976318105 .6561965942105 .5003967285105 .3869018555 105.3143005371105 .2813034058105 .2863998413105 .3283004761105 .4055023193 105.5167007446105 .6602020264105 .8348999023106 .0390014648106 .2712020874 106.5298995972106 .8137969971107 .1211013794107 .4505004883107 .8003997803 108.1692962646108 .5557022095108 .9580993652109 .375109 .8050003052110 .24659729 110.6985015869111 .1593017578111 .6277008057112 .1024017334112 .5822982788 113.0661010742113 .5529022217114 .0413970947114 .5308990479115 .0201034546 115.5084991455115 .9947967529116 .4785995483116 .9588012695117 .4347991943 117.9057998657118 .3712005615118 .8301010132119 .2820968628119 .7264022827 120.1623001099120 .589302063121 .0065994263121 .4135971069121 .8097000122 122.1941986084122 .5664978027122 .9261016846123 .2724990845123 .6051025391 123.9237976074124 .2284011841124 .5187988281124 .7954025269125 .0579986572 125.3072967529125 .5425033569125 .763999939125 .9699020386126 .1592025757 126.3284988403126 .4750976562126 .5943984985126 .6820983887126 .7337036133 126.7446975708126 .7121963501126 .6323013306126 .5046005249126 .327003479 126.1006011963125 .825302124125 .5036010742125 .1364974976124 .728302002 124.28099823123 .8010025024123 .2917022705122 .7621002197122 .2172012329 121.6680984497121 .1216964722120 .5889968872120 .0786972046119 .5979003906 119.1557998657118 .7518997192118 .393699646118 .0709991455117 .7869033813 117.5199966431117 .2648010254116 .9954986572116 .7033996582116 .3494033813 115.9093017578115 .3471984863114 .623298645113 .7285995483112 .6196975708 111.3182983398109 .7917022705108 .084197998106 .1986999512104 .1762008667 102.057098388799 .8615036010797 .640342712495 .3981018066493 .1728515625 90.9653167724688 .7965393066486 .6671905517684 .585243225182 .55284118652 80.5720672607478 .6457290649476 .7742996215874 .9601364135773 .20366668701 71.5060272216869 .8675231933668 .287666320866 .7660827636765 .30081939697 63.8903694152862 .5319900512761 .2231712341359 .9609489440958 .74222183228 57.5642585754456 .4239006042555 .3187408447354 .2458610534753 .20323181152 52.1882781982451 .1992988586450 .2340316772549 .2909812927248 .36819076538 47.4642982482946 .577571868945 .7068099975644 .8504791259844 .00756835938 43.1767082214442 .3571014404341 .547569274940 .7475090026939 .95592880249 39.1724586486838 .396339416537 .6271018981936 .8642311096236 .10591888428 35.351009368934 .59674072266 1557.2709960941549 .0539550781540 .8260498051532 .5679931641524 .286987305 1515.9820556641507 .6560058591499 .3110351561490 .9470214841482 .567016602 1474.1700439451465 .7580566411457 .3310546881448 .8879394531440 .431030273 1431.9580078121423 .4699707031414 .9659423831406 .4479980471397 .912963867 
1389.363037109 1380.7979736331372.2159423831363.6190185551355.0050048831346.375 1337.7290039061329 .0660400391320 .3859863281311 .6899414061302 .977050781 1294.2480468751285 .5019531251276 .7399902341267 .9620361331259 .16796875 1250.3580322271241 .5329589841232 .6929931641223 .8389892581214 .970947266 1206.0889892581197 .1939697271188 .2860107421179 .3669433591170 .437011719 1161.4949951171152 .5439453121143 .5830078121134 .6130371091125 .635009766 1116.6500244141107 .6569824221098 .6579589841089 .6529541021080 .642944336 1071.6280517581062 .6099853521053 .5880126951044 .5639648441035 .537963867 1026.5100097661017 .4819946291008 .453979492999 .4271240234990 .4016113281 981.3781738281972 .3579101562963 .3413085938954 .3292236328945 .3223876953 936.3215942383927 .3278198242918 .3414916992909 .3637695312900 .3956298828 891.4376220703882 .4907836914873 .5560302734864 .6342773438855 .7263183594 846.8333129883837 .955871582829 .0952758789820 .2521972656811 .4279174805 802.6232299805793 .8391723633785 .0767211914776 .3369140625767 .6204833984 758.9290771484750 .2631835938741 .6240844727733 .012512207724 .4296875 715.8765258789707 .3540039062698 .8630981445690 .4049072266681 .9802246094 673.5900878906665 .2355957031656 .9174194336648 .6365966797640 .3939819336 632.1904296875624 .0269165039615 .9041748047607 .8231811523599 .7849121094 591.7899169922583 .8389282227575 .9329833984568 .0728149414560 .2592163086 552.4926757812544 .7744140625537 .1047973633529 .4846801758521 .9146728516 514.3958129883506 .928314209499 .5133056641492 .1513061523484 .8429870605 477.5891113281470 .390411377463 .2473144531456 .1606140137449 .1311035156 442.1592102051435 .2457885742428 .3915100098421 .5968933105414 .862701416 408.1895141602401 .5780029297395 .0286865234388 .5425109863382 .1199035645 375.761505127369 .4679870605363 .2401123047357 .0781860352350 .9831848145 344.9555053711338 .9957885742333 .1047058105327 .2828063965321 .5307006836 315.8489990234310 .2380981445304 .6987915039299 .2315063477293 .8367919922 288.5151977539283 .2672119141278 .0932006836272 .9938049316267 .9693908691 263.0203857422258 .1473083496253 .350402832248 .6300048828243 .9864959717 239.4203033447234 .9315032959230 .5204925537226 .1873931885221 .9324951172 217.7559967041213 .6578979492209 .6383972168205 .6974945068201 .8354949951 198.0523071289194 .3479003906190 .7223968506187 .1757049561183 .7077941895 180.3188018799177 .0084991455173 .7769927979170 .6240997314167 .5498046875 164.5540008545161 .6365966797158 .7975006104156 .036605835153 .353805542 150.7489013672148 .2216949463145 .7720031738143 .3997039795141 .1044006348 138.8858947754136 .7438049316134 .6777954102132 .6873931885130 .7722015381 128.9317016602127 .1652984619125 .4722976685123 .8520965576122 .3039016724 120.8268966675119 .4203033447118 .0832977295116 .8146972656115 .6138000488 114.4793014526113 .4103012085112 .4055023193111 .4639968872110 .5845031738 109.7658004761109 .0066986084108 .3059005737107 .6623001099107 .0745010376 106.5411987305106 .0612030029105 .6332015991105 .2559967041104 .9280014038 104.6482009888104 .4151000977104 .2276000977104 .0840988159103 .9834976196 103.9243011475103 .9052963257103 .9251022339103 .9823989868104 .0756988525 104.2036972046104 .3649978638104 .5581970215104 .7817001343105 .0343017578 105.3143997192105 .6205978394105 .9513015747106 .3050994873106 .6803970337 107.0757980347 107.4897003174107.9207992554108.3673019409 108.8280029297 
109.3013000488 109.7858963013 110.2802963257 110.7834014893 111.2936019897 111.8098983765112 .3310012817112 .855796814113 .383102417113 .9120025635 114.4412994385114 .9702987671115 .4979019165116 .0233001709116 .5456008911 117.0641021729117 .5779037476118 .0863037109118 .5886001587119 .0839996338 119.5718994141120 .0515975952120 .5223007202120 .9834976196121 .4344024658 121.87449646122 .3031005859122 .7197036743123 .1237030029123 .5148010254 123.8925018311124 .2567977905124 .6073989868124 .9448013306125 .2690963745 125.5804977417125 .8795013428126 .1659011841126 .4397964478126 .6994018555 126.943901062127 .1698989868127 .3747024536127 .5535964966127 .7023010254 127.8167037964127 .8916015625127 .9247970581127 .9122009277127 .8536987305 127.7475967407127 .5953979492127 .3973999023127 .15650177126 .8746032715 126.5558013916126 .2032012939125 .8224029541125 .4180984497124 .9972991943 124.5661010742124 .1324996948123 .7041015625123 .2875976562122 .8912963867 122.5183029175122 .1754989624121 .8600006104121 .5755004883121 .3116989136 121.0667037964120 .8220977783120 .5684967041120 .2826004028119 .9490966797 119.5418014526119 .0386962891118 .4123001099117 .6305007935116 .6855010986 115.5478973389114 .2304992676112 .71849823111 .0365982056109 .1885986328 107.2065963745 105.1176986694102.9425964355 100.7164001465 98.45231628418 96.1804428100693 .9086685180791 .6573562622189 .4310913085987 .24159240723 85.0922775268682 .9899063110480 .9374389648478 .9394073486376 .99820709229 75.1172866821373 .2978973388771 .5423889160269 .8503570556668 .22250366211 66.6568984985465 .1523666381863 .7061309814562 .3154602050860 .97732925415 59.6881904602158 .4451408386257 .2444305419956 .0834693908754 .9587097168 53.8679695129452 .8080902099651 .7772293090850 .7726898193449 .79288101196 48.8354911804247 .8991203308146 .9817581176846 .0821914672945 .19866943359 44.3301506042543 .4751205444342 .6327209472741 .8016586303740 .9813117981 40.1706008911139 .3691902160638 .5762786865237 .7917900085437 .01519012451 36.2456588745135 .4820213317934 .72370147705

1561.4389648441553 .2340087891545 .0030517581536 .7359619141528 .439941406 1520.1169433591511 .7729492191503 .4079589841495 .0250244141486 .6251478 .208984375 1469.7760009771461 .3289794921452 .8649902341444 .3869628911435 .891967773 1427.3830566411418 .8570556641410 .3160400391401 .7590332031393 .187011719 1384.5970458981375 .9919433591367 .3690185551358 .7309570311350 .076049805 1341.4040527341332 .7139892581324 .0090332031315 .285034181306 .546020508 1297.7879638671289 .0150146481280 .2239990231271 .4169921881262 .593017578 1253.754028321244 .8979492191236 .0279541021227 .1419677731218 .241943359 1209.328002931200 .4010009771191 .461059571182 .5080566411173 .543945312 1164.5689697271155 .5830078121146 .5880126951137 .5830078121128 .568969727 1119.546997071110 .5179443361101 .4830322271092 .4410400391083 .392944336 1074.3409423831065 .2840576171056 .2239990231047 .1610107421038 .094970703 1029.0279541021019 .9600219731010 .8920288091001 .823974609992 .7576293945 983.6926879883974 .6309814453965 .5720825195956 .5181884766947 .4686279297 938.4254760742929 .3881835938920 .3593139648911 .3375854492902 .326171875 893.3239135742 884.3336791992 875.3541259766 866.388671875 857.4356079102 848.4984741211839 .5756835938830 .671081543821 .782409668812 .9138793945 804.0634155273795 .2351074219786 .426574707777 .642578125768 .8803710938 
760.1447753906751 .4329833984742 .75734 .0925292969725 .4661254883716 .8671264648 708.3012695312699 .7647094727691 .2634887695682 .7935180664674 .3607788086 665.9611206055657 .6008911133649 .2752075195640 .9909057617632 .742980957 624.5383300781616 .3717041016608 .2501220703600 .1682128906592 .1331176758 584.1390991211576 .1937255859568 .2907714844560 .438293457552 .629699707 544.8729858398537 .1616821289529 .5037841797521 .8927001953514 .3364868164 506.8284912109499 .3768920898491 .974609375484 .6303100586477 .3367004395 470.1023864746462 .9201049805455 .798614502448 .7302856445441 .7242126465 434.7724914551427 .8844909668421 .0520935059414 .2849121094407 .5744018555 400.9305114746394 .3446044922387 .8265991211381 .3677978516374 .9783935547 368.6494140625362 .3911132812356 .1944885254350 .0698852539344 .0080871582 338.0197143555332 .0953979492326 .2456970215320 .4612121582314 .7526855469 309.1104125977 303.5452880859298.0476074219292.6282043457 287.2773132324 282.0057067871276 .8037109375271 .6820983887266 .6307983398261 .6608886719 256.7622070312251 .9458007812247 .2012939453242 .5397949219237 .9508972168 233.445602417229 .0133056641224 .6652984619220 .3907012939216 .2006988525 212.0845947266208 .0532073975204 .0959014893200 .2236938477196 .4255981445 192.712600708189 .0738067627185 .5202026367182 .0406951904178 .6463012695 175.3260955811172 .0908050537168 .9295043945165 .8529968262162 .8502960205 159.9322052002157 .0877075195154 .3276062012151 .6408996582149 .0381011963 146.5084075928144 .0621948242141 .6887054443139 .3981018066137 .1795959473 135.0433959961132 .9785003662130 .9949951172129 .0820007324127 .2491989136 125.4858016968123 .801399231122 .1849975586120 .6460037231119 .1735992432 117.776802063116 .4448013306115 .1865005493113 .9912033081112 .8673019409 111.8044967651110 .8106002808109 .8757019043109 .0073013306108 .1957015991 107.4478988647106 .754699707106 .1227035522105 .5428009033105 .0214996338 104.5500030518104 .1343994141103 .7662963867103 .4512023926103 .1813964844 102.9617996216102 .7851028442102 .6558990479102 .5672988892102 .523399353 102.5177001953102 .5539016724102 .6258010864102 .7368011475102 .8812026978 103.0616989136103 .2730026245103 .5174026489103 .7901000977104 .0926971436 104.4210968018104 .7761993408105 .1544036865105 .556098938105 .9779968262 106.4203033447106 .8800964355107 .3569030762107 .8485031128108 .3539962769 108.87159729109 .4001998901109 .9382019043110 .4841995239111 .0373001099 111.5958023071112 .158996582112 .7251968384113 .2939987183113 .8634033203 114.4335021973115 .0021972656115 .5698013306116 .1340026855116 .6955032349 117.2518005371 117.8038024902 118.3490982056118.8884963989 119.4197006226 119.9437026978120 .457901001120 .9636001587121 .4580993652121 .9429016113 122.4152984619122 .8768997192123 .3248977661123 .7614974976124 .1837997437 124.5944976807124 .9907989502125 .3759994507125 .7474975586126 .1087036133 126.4570999146126 .7957992554127 .12159729127 .4365997314127 .7359008789 128.0204925537128 .2828979492128 .5240020752128 .7333068848128 .913192749 129.0514984131129 .1535949707129 .2073974609129 .2216033936129 .1855926514 129.1107940674128 .9884033203128 .8312988281128 .6324005127128 .4055023193 128.1448974609127 .8648986816127 .5621032715127 .2499008179126 .9283981323 126.608001709126 .2930984497125 .9880981445125 .7021026611125 .4301986694 125.1849975586124 .9511032104124 .7416000366124 .5316009521124 .3305969238 
124.1073989868123 .8645019531123 .568901062123 .207901001122 .7615966797 122.2082977295121 .537399292120 .7053985596119 .7304000854118 .556602478 117.2316970825115 .7158966064114 .0553970337112 .2210006714110 .2621994019 108.1850967407106 .0147018433103 .7774963379101 .482498168999 .16654205322 96.8268432617294 .4985504150492 .1742095947389 .8825988769587 .61576080322 85.3960189819383 .2166290283281 .0950317382879 .0256881713977 .02245330811 75.0800628662173 .2090988159271 .4036636352569 .6708526611368 .00390625 66.4065780639664 .8717269897563 .4004783630461 .9859313964860 .62757873535 59.319061279358 .0591201782256 .842079162655 .6665000915554 .52740097046 53.4235687255952 .3506507873551 .3077011108450 .2909812927249 .29975891113 48.3307914733947 .3834800720246 .4550209045445 .5448799133344 .65071868896 43.7719917297442 .9067993164142 .0546302795441 .2140312194840 .38452911377 39.5651893615738 .755718231237 .955631256137 .1649398803736 .38352966309 35.6115798950234 .84645843506 1565.6529541021557 .4539794921549 .214965821540 .9339599611532 .609985352 1524.2659912111515 .8979492191507 .5140380861499 .1099853521490 .691040039 1482.254028321473 .8029785161465 .3330078121456 .8499755861448 .348999023 1439.8349609381431 .3020019531422 .7569580081414 .1920166021405 .613037109 1397.0159912111388 .4050292971379 .7740478521371 .129028321362 .463989258 1353.785034181345 .086059571336 .3730468751327 .6390380861318 .890014648 1310.120971681301 .3380126951292 .5340576171283 .7159423831274 .878051758 1266.0260009771257 .1550292971248 .2709960941239 .3680419921230 .452026367 1221.5190429691212 .5739746091203 .6130371091194 .6409912111185 .654052734 1176.6569824221167 .6469726561158 .6269531251149 .5959472661140 .556030273 1131.5059814451122 .4489746091113 .3830566411104 .3100585941095 .229980469 1086.1459960941077 .0550537111067 .9599609381058 .8599853521049 .759033203 1040.6529541021031 .5460205081022 .4379882811013 .3289794921004 .219970703 995.1123046875986 .0059204102976 .9022216797967 .8012695312958 .7044067383 949.6124267578940 .5255737305931 .4456787109922 .3723754883913 .3076782227 904.2515258789895 .205871582886 .1701049805877 .1472167969868 .1356201172 859.1389770508850 .1555175781841 .1890869141832 .2374267578823 .3051147461 814.3892822266805 .4951782227796 .6193847656787 .767578125778 .9359130859 770.1304931641761 .3469238281752 .5921020508743 .8610229492735 .1610107422 726.4865112305717 .8453979492709 .2313842773700 .6533203125692 .1041259766 683.5930175781675 .1124267578666 .6721801758658 .2640991211649 .8986206055 641.5668945312633 .2797241211625 .0277709961616 .8225708008608 .6541137695 600.5341796875592 .4525756836584 .4213256836576 .4296875568 .4902954102 560.5919189453552 .7474975586544 .9453735352537 .1989135742529 .4959716797 521.8502807617514 .2495117188506 .707611084499 .2117919922491 .7764892578 484.3883056641477 .0621948242469 .7844848633462 .5704040527455 .4059143066 448.3063964844441 .2576904297434 .275604248427 .3453063965420 .4831848145 413.6741027832406 .9346923828400 .2493896484393 .6351928711387 .0762939453 380.5900878906374 .1603088379367 .8045959473361 .5065002441355 .2840881348 349.120300293343 .0336914062337 .0067138672331 .0585021973325 .1709899902 319.3635864258313 .6181030273307 .9541015625302 .3529052734296 .8346862793 291.3801879883286 .0098876953280 .7044067383275 .4844055176270 .3298950195 
265.2620849609260 .2605895996255 .3468017578250 .5245 .741897583241 .0514984131 236.4505004883231 .9176940918227 .4750976562223 .1009979248218 .8175964355 214.6031951904210 .4797973633206 .4257049561202 .4629058838198 .5693969727 194.7673950195191 .0348052979187 .3937988281183 .8222045898180 .3421020508 176.9313964844173 .6121063232170 .3621063232167 .2033996582164 .1136932373 161.1152038574158 .1855010986155 .3466949463152 .5765075684149 .8968048096 147.2855072021144 .7642059326142 .3108062744139 .9468994141137 .6504974365 135.4427947998133 .3020019531131 .2489929199129 .2621002197127 .3619003296 125.526802063123 .7770004272122 .0912017822120 .4891967773118 .9496994019 117.4921035767116 .0958023071114 .7790985107113 .5218963623112 .3422012329 111.2201004028110 .172996521109 .1817016602108 .2627029419107 .3973999023 106.6017990112105 .8578033447105 .1806030273104 .5529022217103 .9893035889 103.4730987549103 .0180969238102 .6082992554102 .2568969727101 .9485015869 101.6958007812101 .4840011597101 .3249969482101 .2046966553101 .1344985962 101.1008987427101 .1145019531101 .1624984741101 .2548980713101 .3793029785 101.5454025269101 .7412033081101 .9756011963102 .2373962402102 .5347976685 102.8571014404103 .2117004395103 .5887985229103 .9949035645104 .4208984375 104.8727035522105 .3415985107105 .832901001106 .3388977051106 .8637008667 107.4007034302107 .9532012939108 .515296936109 .0897979736109 .6715011597 110.2624969482110 .8584976196111 .4609985352112 .0662994385112 .6754989624 113.2855987549113 .8970031738114 .507598877115 .1173019409115 .7244033813 116.3284988403116 .9285964966117 .5236968994118 .1131973267118 .6959991455 119.2718963623119 .839302063120 .3984985352120 .9476013184121 .4875030518 122.0157012939122 .5335998535123 .0388031006123 .532699585124 .0131988525 124.4820022583124 .9373016357125 .3811035156125 .8123016357126 .2328033447 126.6421966553127 .0419006348127 .4313964844127 .8115997314128 .1804962158 128.5381011963128 .879699707129 .2048950195129 .5054016113129 .7819061279 130.0233001709130 .2326049805130 .3981933594130 .525894165130 .6062011719 130.6472930908130 .6427001953130 .6016998291130 .5211029053130 .4095001221 130.2675018311130 .1015014648129 .9160003662129 .7151947021129 .5068054199 129.2928924561129 .0829925537128 .8771972656128 .6840057373128 .5021972656 128.3352966309128 .1817016602128 .0361938477127 .8981018066127 .7503967285 127.5949020386127 .4014968872127 .176399231126 .8756027222126 .5100021362 126.0295028687125 .4543991089124 .7298965454123 .8789978027122 .8520965576 121.6779022217120 .3201980591118 .8188018799117 .1418991089115 .3313980103 113.3672027588111 .3003005981109 .1141967773106 .8582000732104 .523399353 102.152496337999 .7434768676897 .3270568847794 .9076690673892 .50327301025 90.1240463256887 .7768096923885 .4766693115283 .2217330932681 .03115081787 78.8961334228576 .8382568359474 .8429565429772 .9320907592871 .08651733398 69.3263778686567 .6297988891666 .0142517089864 .4573211669962 .97367858887 61.5420494079660 .1745986938558 .8521881103557 .5847892761256 .35575866699 55.1732902526954 .0232887268152 .9125785827651 .8293609619150 .77936172485 49.7527008056648 .7542304992747 .7756004333546 .8208808898945 .88299942017 44.9653892517144 .0620307922443 .1758804321342 .3018417358441 .44253921509 40.5936584472739 .7576904296938 .9309005737338 .115798950237 .30918121338 36.5148887634335 .7316589355534 .95999145508 
1569.9160156251561 .7060546881553 .4479980471545 .1409912111536 .782958984 1528.4210205081520 .0269775391511 .6259765621503 .1979980471494 .762939453 1486.3020019531477 .8330078121469 .339965821460 .8389892581452 .314941406 1443.7810058591435 .2249755861426 .6590576171418 .0699462891409 .470947266 1400.8480224611392 .2159423831383 .5579833981374 .8919677731366 .199951172 1357.4980468751348 .7709960941340 .0340576171331 .2709960941322 .496948242 1313.6989746091304 .8890380861296 .0560302731287 .2099609381278 .342041016 1269.4620361331260 .5600585941251 .6450195311242 .711059571233 .764038086 1224.7989501951215 .8210449221206 .828002931197 .8210449221188 .802001953 1179.7690429691170 .7259521481161 .6689453121152 .6049804691143 .526977539 1134.4439697271125 .3470458981116 .2469482421107 .1340332031098 .020996094 1088.8929443361079 .7690429691070 .6300048831061 .4969482421052 .348999023 1043.211059571034 .0570068361024 .9150390621015 .7579956051006 .614990234 997.4575805664988 .3181762695979 .1627197266970 .0291137695960 .8792724609 951.7545776367942 .6135253906933 .5010986328924 .3723144531915 .2755737305 906.1624145508897 .0853271484887 .9912719727878 .9373168945869 .8662719727 860.8391113281851 .7951049805842 .7987060547833 .7855224609824 .8239135742 815.8455810547806 .9229125977797 .9835205078789 .1038818359780 .2077026367 771.3754272461762 .5266113281753 .7459106445744 .9487915039736 .223815918 727.4826049805718 .8175048828710 .1364135742701 .5354003906692 .9185180664 684.3856201172675 .8369140625667 .3759765625658 .899597168650 .5144042969 642.114074707633 .8084106445625 .4879150391617 .2650756836609 .0278930664 600.8917236328592 .7410888672584 .6945800781576 .6340942383568 .680480957 560.7133178711552 .8557128906544 .9846801758537 .2261962891529 .4545288086 521.7979125977514 .1282958984506 .576385498499 .0119018555491 .5675964355 484.1108093262476 .7767944336469 .4305114746462 .2095031738454 .9764099121 447.8710021973440 .75390625433 .7669067383426 .7683105469419 .9023132324 413.0249938965406 .2827148438399 .5293884277392 .9133911133386 .2865905762 379.7995910645373 .3021850586366 .9468994141360 .5815124512354 .3605041504 348.1297912598342 .0458068848335 .9523925781330 .0079040527324 .0545043945 318.2521972656312 .44140625306 .7838134766301 .1181030273295 .6076049805 290.0895080566284 .7283935547279 .3601074219274 .150604248268 .9346008301 263.8788146973258 .816986084253 .916595459249 .0108947754244 .2677001953 239.5198059082234 .9351959229230 .3466033936225 .9217987061221 .4936065674 217.2295074463212 .9627075195208 .8601074219204 .7554016113200 .8146972656 196.8726043701193 .0941009521189 .3148040771185 .6986999512182 .0823059082 178.62840271175 .1748962402171 .883102417168 .592300415165 .4622039795 162.333694458159 .3650054932156 .3984069824153 .5906066895150 .7854003906 148.1376953125145 .4931945801143 .0048980713140 .5202026367138 .1900939941 135.8643035889133 .6911010742131 .5225982666129 .504699707127 .4917984009 125.6270980835123 .7677001953122 .0537033081120 .3452987671118 .7789993286 117.2185974121115 .7966003418114 .380897522113 .0996017456111 .8245010376 110.6797027588109 .5412979126108 .5286026001107 .5223999023106 .6371002197 105.7583999634104 .9957962036104 .2398986816103 .5950012207102 .9569015503 102.4250030518101 .8998031616101 .4757995605101 .0587997437100 .7378005981 100.4240036011100 .201202392699 .9858932495199 .8565292358499 .73486328125 
99.694053649999 .6613464355599 .7042770385799 .7557601928799 .87748718262 100.0083007812100 .2039031982100 .4091033936100 .6732025146100 .9477005005 101.275100708101 .6136016846101 .9985961914102 .3955001831102 .8324966431 103.2818984985103 .7649002075104 .2610015869104 .783996582105 .3208007812 105.8777999878106 .4489974976107 .0341033936107 .6339035034108 .2412033081 108.8638000488109 .4878997803110 .1277008057110 .7634963989111 .4151992798 112.057800293112 .7165985107113 .3616027832114 .0229034424114 .6660003662 115.3255996704115 .9629974365116 .616897583117 .2451019287117 .8897018433 118.5052032471119 .1371002197119 .7368011475120 .352897644120 .9338989258 121.5311965942122 .091003418122 .6669998169123 .2034988403123 .7561035156 124.2680969238124 .7962036133125 .2837982178125 .7876968384126 .2526016235 126.7349014282127 .179901123127 .644203186128 .0715942383128 .521194458 128.9297027588129 .3634033203129 .745300293130 .154296875130 .4949951172 130.862701416131 .1434020996131 .4496002197131 .654296875131 .8827056885 132.0036010742132 .1481018066132 .1882019043132 .2537994385132 .2247009277 132.2241973877132 .1425933838132 .0928955078131 .9781036377131 .8984069824 131.7705993652131 .6806030273131 .5585021973131 .4759063721131 .3724060059 131.3079986572131 .2247924805131 .1772003174131 .0997009277131 .050994873 130.9459991455130 .8598937988130 .6764984131130 .5010070801130 .1748962402 129.8460998535129 .3108062744128 .7637023926127 .9599990845127 .141998291 126.0287017822124 .9019012451123 .4661026001122 .0167999268120 .2713012695 118.5090026855116 .4897994995114 .4458999634112 .2086029053109 .9355010986 107.5453033447 105.1106033325 102.6370010376 100.1129989624 97.61981964111 95.0739669799892 .6152267456190 .1042327880987 .7237930297985 .29402923584 83.0270080566480 .716232299878 .5892486572376 .4258499145574 .45504760742 72.4553298950270 .6447219848668 .8111267089867 .153602600165 .47747802734 63.9588813781762 .424808502261 .0279693603559 .618030548158 .32556915283 57.0215988159255 .8173599243254 .602821350153 .4728507995652 .33354187012 51.2662391662650 .1905593872149 .1764183044448 .1547317504947 .18572998047 46.2099418640145 .279300689744 .3424797058143 .4444503784242 .54077911377 41.6707496643140 .7955703735439 .9500389099139 .0996208190938 .27614974976 37.4471817016636 .6448402404835 .8485183715835 .06135177612 
col_river_CA 
node, X_coord, Y_coord, elev, comment

$12482, \overline{5} 96534.3 \overline{1}, 104370.70,104.792$, Columbia Rive 12285, 596433.39,104231.62, 104.792, Columbia River 12286, 595992.12,104614.80,104.803, Columbia River $12284,595951.49,104523.32,104.803$, Columbia River 12091,595572.12,104852.50,104.813, Columbia River $12089,595401.68,104682.81,104.813$, Columbia River 11893, 595408.62,105217.60,104.825, Columbia River 11892, 594973.44,105016.13,104.825, Columbia River $11683,595122.50,105856.50,104.845$, Columbia River $11682,594707.50,105719.16,104.845$, Columbia River 11467, 595043.00, 106412.70,104.859, Columbia River 11466, 594648.63,106422.49,104.859, Columbia River $11241,595261.12,107077.90,104.875$, Columbia River $11239,594823.18,107222.68,104.875$, Columbia River $11240,595416.88,107553.00,104.9$, Columbia River $11003,594979.56,107701.14,104.9$, Columbia River 11005, 595610.81, 108013.00,104.926, Columbia River 11004, 595196. 23, 108194.48, 104.926, Columbia River 10996, 595864.31, 108556.80, 104.955, Columbia River $10765,595272.05,108798.81,104.955$, Columbia River 10991,596142.31, 109395.10, 105.008, Columbia River $10757,595402.98,109504.50,105.008$, Columbia River 10990, 596140.62,110095.10,105.048, Columbia River 10753,595510.75,110091.23,105.048, Columbia River 10981,596116.62,110893.30,105.105, Columbia River 10752, 595480.88,110871.40,105.105, Columbia River 10973, 596007.38, 111584.80, 105.143, Columbia River $10743,595348.86,111479.38,105.143$, Columbia River 10970, 595836.31, 112465.30,105.194, Columbia River 10735, 595208.06, 112277.04,105.194, Columbia River 10969,595537.38,113207.30,105.243, Columbia River $10731,595045.63,113016.06,105.243$, Columbia River 10968,595253.69,113954.60,105.29, Columbia River $10727,594945.13,113845.80,105.29$, Columbia River 10729, 595116.00, 114435.30,105.312, Columbia River $10726,594908.81,114362.64,105.312$, Columbia River 10728, 594978.38,114916.00,105.334, Columbia River 10493, 594781.81, 114864.99,105.334, Columbia River 10730, 594932.50, 115076.20, 105.344, Columbia River 10495, 594748.06, 115026.02,105.344, Columbia River $10734,594886.56,115236.40,105.363$, Columbia River $10732,594710.69,115185.23,105.363$, Columbia River 10972, 594840.69, 115396.60, 105.383, Columbia River 10971, 594671.50, 115368.01, 105.383, Columbia River 11212, 594823.69, 115629.10, 105.41, Columbia River 10974,594613.56, 115618.80, 105.41, Columbia River 11213,594806.69,115861.60, 105.437, Columbia River $11210,594564.62,115847.84,105.437$, Columbia River 11438,594789.69,116094.10,105.463, Columbia River 11435, 594513.94, 116076.88, 105.463, Columbia River 11656, 594769.35, 116321.35, 105.496, Columbia River 11436, 594473.06, 116299.05, 105.496, Columbia River 11657,594756.81, 116564.05, 105.543, Columbia River $11437,594414.12,116575.58,105.543$, Columbia River $11658,594775.12,116791.30,105.587$, Columbia River 11439, 594367.82, 116835.81, 105.587, Columbia River
Post McNary Riverfest Post McNary Riverfest Post McNary Riverfest Post McNary Riverfest Post McNary Riverfest Post McNary Riverfest Post McNary Riverfest Post McNary Riverfest Post McNary Riverfest Post McNary Riverfest Post McNary Riverfest Post McNary Riverfest Post McNary Riverfest Post McNary Riverfest Post McNary Riverfest Post McNary Riverfest

Post McNary Riverfest Post McNary Riverfest Post McNary Riverfest Post McNary Riverfest Post McNary Riverfest Post McNary Riverfest Post McNary Riverfest Post McNary Riverfest Post McNary Riverfest Post McNary Riverfest Post McNary Riverfest Post McNary Riverfest Post McNary Riverfest Post McNary Riverfest Post McNary Riverfest Post McNary Riverfest Post McNary Riverfest Post McNary Riverfest Post McNary Riverfest Post McNary Riverfest Post McNary Riverfest Post McNary Riverfest Post McNary Riverfest Post McNary Riverfest Post McNary Riverfest Post McNary Riverfest Post McNary Riverfest Post McNary Riverfest Post McNary Riverfest Post McNary Riverfest Post McNary Riverfest Post McNary Riverfest Post McNary Riverfest Post McNary Riverfest Post McNary Riverfest Post McNary Riverfest Post McNary Riverfest Post McNary Riverfest Post McNary Riverfest Post McNary Riverfest 
$11659,594816.81,117054.70,105.627$, Columbia River $11440,594342.31,117123.87,105.627$, Columbia River 11660, 594858.44,117318.10, 105.654, Columbia River $11654,594315.00,117402.86,105.654$, Columbia River $11870,594900.12,117581.50,105.682$, Columbia River $11867,594314.88,117680.05,105.682$, Columbia River $12068,594941.49,117859.63,105.711$, Columbia River 11868, 594353.56, 117917.93, 105.711, Columbia River 12069, 594959.60,118135.19,105.75, Columbia River $11869,594397.63,118135.88,105.75$, Columbia River 12070,594931.38, 118415.90, 105.789, Columbia River 11871, 594434.50, 118364.70, 105.789, Columbia River 12071, 594905.44, 118667.20, 105.824, Columbia River 11872 , 594472.43, 118624.14, 105.824, Columbia River 12072, 594879.44,118918.50,105.868, Columbia River 12066, 594512.13,118883.59,105.868, Columbia River 12267, 594853.50, 119169.80,105.917, Columbia River 12264,594544.62,119135.77,105.917, Columbia River 12461, 594826.03, 119398. 29,105.96, Columbia River 12265, 594596.38, 119400.65, 105.96, Columbia River 12462, 594850.17,119629.35,106.002, Columbia River 12266, 594644.44, 119665.52, 106.002, Columbia River 12463, 594887.12,119863.00, 106.044, Columbia River 12268, 594679.87, 119894.16, 106.044, Columbia River 12464, 594924.50, 120093.34, 106.086, Columbia River 12269,594683.12,120119.57,106.086, Columbia River 12465, 594961.94,120323.66,106.135, Columbia River $12459,594680.93,120372.17,106.135$, Columbia River 12659, 594999.31, 120554.00, 106.188, Columbia River 12656, 594676.93,120608.46,106.188, Columbia River 12848,595040.12,120817.53,106.247, Columbia River 12657, 594627.75, 120891.46,106.247, Columbia River 12849,595081.00,121081.07,106.3, Columbia River 12658,594580.44,121156.33,106.3, Columbia River $12850,595121.81,121344.60,106.353$, Columbia River $12660,594543.94,121430.27,106.353$, Columbia River 12851,595161.31, 121608.30, 106.401, Columbia River $12661,594534.75,121706.02,106.401$, Columbia River 12852, 595200.88, 121872. $00,106.448$, Columbia River 12846, 594509.25, 121974.52,106.448, Columbia River $13040,595240.38,122135.70,106.495$, Columbia River 13037, 594494.62, 122203.16,106.495, Columbia River 13228, 595259.16, 122368.30, 106.528, Columbia River $13038,594486.24,122378.21,106.528$, Columbia River $13229,595257.34,122598.32,106.558$, Columbia River $13039,594468.81,122575.01,106.558$, Columbia River 13230, 595242.62, 122833.50, 106.588, Columbia River 13041,594458.62, 122798.99,106.588, Columbia River 13231,595231.88,123099.93,106.634, Columbia River $13042,594455.37,123074.92,106.634$, Columbia River 13232,595221.12,123366.37,106.684, Columbia River 13226, 594464.81, 123350.86,106.684, Columbia River 13421,595210.38, 123632.80, 106.734, Columbia River 13418,594468.81, 123606.87, 106.734, Columbia River 13621,595186.50, 123864.80, 106.783, Columbia River $13419,594471.00,123798.88,106.783$, Columbia River 13622,595162.69,124096.80, 106.832, Columbia River
Post McNary Riverfest Post McNary Riverfest Post McNary Riverfest Post McNary Riverfest Post McNary Riverfest Post McNary Riverfest Post McNary Riverfest Post McNary Riverfest Post McNary Riverfest Post McNary Riverfest Post McNary Riverfest Post McNary Riverfest Post McNary Riverfest Post McNary Riverfest Post McNary Riverfest Post McNary Riverfest Post McNary Riverfest Post McNary Riverfest Post McNary Riverfest Post McNary Riverfest Post McNary Riverfest Post McNary Riverfest Post McNary Riverfest Post McNary Riverfest Post McNary Riverfest Post McNary Riverfest Post McNary Riverfest Post McNary Riverfest Post McNary Riverfest Post McNary Riverfest Post McNary Riverfest Post McNary Riverfest Post McNary Riverfest Post McNary Riverfest Post McNary Riverfest Post McNary Riverfest Post McNary Riverfest Post McNary Riverfest Post McNary Riverfest Post McNary Riverfest Post McNary Riverfest Post McNary Riverfest Post McNary Riverfest Post McNary Riverfest Post McNary Riverfest Post McNary Riverfest Post McNary Riverfest Post McNary Riverfest Post McNary Riverfest Post McNary Riverfest Post McNary Riverfest Post McNary Riverfest Post McNary Riverfest Post McNary Riverfest Post McNary Riverfest Post McNary Riverfest Post McNary Riverfest 
$13420,594482.24,124036.20,106.832$, Columbia River 13623,595138.81, 124328.80,106.881, Columbia River $13422,594480.81,124266.27,106.881$, Columbia River 13624,595107.31, 124593.60,106.954, Columbia River 13423, 594533.44,124518.49,106.954, Columbia River $13625,595075.81,124858.40,107.028$, Columbia River $13610,594618.63,124806.96,107.028$, Columbia River 13803, 595044.31, 125123.20,107.074, Columbia River 13796, 594711.12,125086.37,107.074, Columbia River 13968,595016.29, 125355.60,107.112, Columbia River 13797,594745.38,125341.12,107.112, Columbia River 13969,595021.84,125585.42,107.149, Columbia River 13798, 594783.31, 125592.25, 107.149, Columbia River 13970,595037.62,125820.40,107.175, Columbia River $13799,594812.13,125837.94,107.175$, Columbia River 13971,595054.88, 126086.50, 107.204, Columbia River 13800, 594857.69,126095.20,107.204, Columbia River $13972,595072.06,126352.60,107.254$, Columbia River 13801, 594899.56, 126361.51,107.254, Columbia River 13973, 595089.31, 126618.70, 107.312, Columbia River $13802,594936.07,126620.57,107.312$, Columbia River 13974,595109.34, 126887.52,107.373, Columbia River 13804,594903.18,126894.92,107.373, Columbia River 13975,595116.48,127153.74,107.454, Columbia River 13966, 594863.12,127142.08,107.454, Columbia River 14120, 595103.00, 127417.40,107.534, Columbia River $14117,594812.13,127403.74,107.534$, Columbia River 14252, 595092.06, 127650.47,107.606, Columbia River $14118,594783.31,127637.82,107.606$, Columbia River $14253,595081.12,127883.53,107.678$, Columbia River 14119,594747.19,127864.63,107.678, Columbia River $14254,595070.19,128116.60,107.763$, Columbia River 14121,594712.93,128102.33,107.763, Columbia River 14255,595056.69,128380.39,107.89, Columbia River 14122,594651.00,128363.77,107.89, Columbia River 14256,595050.99,128651.92,108.021, Columbia River $14250,594592.75,128646.96,108.021$, Columbia River 14380,595060.69,128915.70,108.147, Columbia River $14377,594536.25,128937.39,108.147$, Columbia River $14494,595070.75,129115.44,108.234$, Columbia River 14378, 594526.37,129151.53,108.234, Columbia River 14495, 595080.75, 129315.16,108.32, Columbia River 14379,594518.37,129343.91,108.32, Columbia River 14496,595090.81, 129514.90,108.368, Columbia River 14381, 594517.56, 129552.61, 108.368, Columbia River 14497, 595102.60, 129810.56, 108.427, Columbia River $14382,594494.69,129848.70,108.427$, Columbia River 14498, 595119.60,130103.65,108.486, Columbia River $14492,594482.62,130061.44,108.486$, Columbia River 14586,595041.19,130401.90,108.534, Columbia River 14583, 594486.93, 130246.99, 108.534, Columbia River 14662, 594952.44,130688.46, 108.591, Columbia River 14584, 594450.43, 130545.64, 108.591, Columbia River 14663, 594863.75, 130975.03, 108.67, Columbia River 14585, 594403.13,130835.24,108.67, Columbia River 14664,594775.00, 131261.59, 108.748, Columbia River $14587,594357.56,131126.64,108.748$, Columbia River
Post McNary Riverfest Post McNary Riverfest Post McNary Riverfest Post McNary Riverfest Post McNary Riverfest Post McNary Riverfest Post McNary Riverfest Post McNary Riverfest Post McNary Riverfest Post McNary Riverfest Post McNary Riverfest Post McNary Riverfest Post McNary Riverfest Post McNary Riverfest Post McNary Riverfest Post McNary Riverfest Post McNary Riverfest Post McNary Riverfest Post McNary Riverfest Post McNary Riverfest Post McNary Riverfest Post McNary Riverfest Post McNary Riverfest Post McNary Riverfest Post McNary Riverfest Post McNary Riverfest Post McNary Riverfest Post McNary Riverfest Post McNary Riverfest Post McNary Riverfest Post McNary Riverfest Post McNary Riverfest Post McNary Riverfest Post McNary Riverfest Post McNary Riverfest Post McNary Riverfest Post McNary Riverfest Post McNary Riverfest Post McNary Riverfest Post McNary Riverfest Post McNary Riverfest Post McNary Riverfest Post McNary Riverfest Post McNary Riverfest Post McNary Riverfest Post McNary Riverfest Post McNary Riverfest Post McNary Riverfest Post McNary Riverfest Post McNary Riverfest Post McNary Riverfest Post McNary Riverfest Post McNary Riverfest Post McNary Riverfest Post McNary Riverfest Post McNary Riverfest Post McNary Riverfest 
$14665,594712.62,131451.27,108.8$, Columbia River - Post McNary Riverfest
$14588,594325.12,131331.30,108.8$, Columbia River - Post McNary Riverfest $14666,594663.08,131643.50,108.856$, Columbia River - Post McNary Riverfest $14661,594287.25,131532.30,108.856$, Columbia River - Post McNary Riverfest 14730,594587.81,131830.59,108.911, Columbia River - Post McNary Riverfest $14729,594258.43,131669.91,108.911$, Columbia River - Post McNary Riverfest $14660,594491.62,132005.92,108.956$, Columbia River - Post McNary Riverfest 14659,594169.94,131823.77,108.956, Columbia River - Post McNary Riverfest $14581,594395.38,132181.27,109.001$, Columbia River - Post McNary Riverfest 14578,594096.00,132019.32,109.001, Columbia River - Post McNary Riverfest $14580,594299.19,132356.59,109.045$, Columbia River - Post McNary Riverfest $14488,594023.81,132185.87,109.045$, Columbia River - Post McNary Riverfest 14582,594219.00,132502.73,109.067, Columbia River - Post McNary Riverfest 14500,593936.38,132340.04,109.067, Columbia River - Post McNary Riverfest $14589,594138.88,132648.86,109.09$, Columbia River - Post McNary Riverfest $14575,593850.69,132490.60,109.09$, Columbia River - Post McNary Riverfest $14657,594058.69,132795.00,109.112$, Columbia River - Post McNary Riverfest 14652,593779.56,132639.34,109.112, Columbia River - Post McNary Riverfest 14727,593994.56,132911.91,109.13,Columbia River - Post McNary Riverfest $14653,593717.63,132758.39,109.13$, Columbia River - Post McNary Riverfest 14728,593930.44,133028.80,109.148, Columbia River - Post McNary Riverfest 14654,593662.94,132881.07,109.148, Columbia River - Post McNary Riverfest $14656,593866.31,133145.70,109.166$, Columbia River - Post McNary Riverfest 14655,593620.93,133007.37,109.166, Columbia River - Post McNary Riverfest 14574,593778.37,133299.00,109.187, Columbia River - Post McNary Riverfest 14573,593545.00,133122.30,109.187, Columbia River - Post McNary Riverfest $14480,593613.18,133426.49,109.202$, Columbia River - Post McNary Riverfest $14478,593465.42,133231.81,109.202$, Columbia River - Post McNary Riverfest 14479,593440.19,133543.70,109.218, Columbia River - Post McNary Riverfest 14364,593349.63,133402.91,109.218, Columbia River - Post McNary Riverfest $14481,593272.19,133652.17,109.232$, Columbia River - Post McNary Riverfest $14366,593198.06,133541.70,109.232$, Columbia River - Post McNary Riverfest $14483,593104.12,133760.62,109.246$, Columbia River - Post McNary Riverfest $14472,593041.00,133669.62,109.246$, Columbia River - Post McNary Riverfest $14568,592936.12,133869.09,109.255$, Columbia River - Post McNary Riverfest 14567,592880.38,133781.24,109.255, Columbia River - Post McNary Riverfest 14471,592796.06,133959.50,109.264, Columbia River - Post McNary Riverfest $14470,592731.69,133866.85,109.264$, Columbia River - Post McNary Riverfest $14355,592656.06,134049.89,109.272$, Columbia River - Post McNary Riverfest 14352,592590.19,133950.62,109.272, Columbia River - Post McNary Riverfest 14354,592516.00,134140.30,109.277, Columbia River - Post McNary Riverfest $14225,592443.32,134027.18,109.277$, Columbia River - Post McNary Riverfest $14357,592347.12,134248.70,109.282$, Columbia River - Post McNary Riverfest $14356,592274.63,134164.87,109.282$, Columbia River - Post McNary Riverfest 14468,592211.80,134393.16,109.288, Columbia River - Post McNary Riverfest 14349,592109.19,134295.47,109.288, Columbia River - Post McNary Riverfest 14467,592079.00,134542.80,109.293, Columbia River - Post McNary Riverfest 14466,591933.94,134418.74,109.293, Columbia River - Post McNary Riverfest 14348,591926.50,134719.39,109.3,Columbia River - Post McNary Riverfest 14347,591748.31,134562.93,109.3, Columbia River - Post McNary Riverfest 14219,591774.00,134896.00,109.308, Columbia River - Post McNary Riverfest $14216,591531.95,134692.64,109.308$, Columbia River - Post McNary Riverfest 14218,591621.50,135072.59,109.315, Columbia River - Post McNary Riverfest $14084,591351.76,134836.83,109.315$, Columbia River - Post McNary Riverfest $14220,591534.38,135173.53,109.32$, Columbia River - Post McNary Riverfest 14100,591297.44,134968.10,109.32, Columbia River - Post McNary Riverfest 14236,591447.25,135274.47,109.329, Columbia River - Post McNary Riverfest 
$14213,591250.37,135101.20,109.329$, Columbia River 14345,591360.12,135375.41,109.338, Columbia River 14344,591201.50,135234.28,109.338, Columbia River 14212,591263.67,135473.88,109.348, Columbia River 14211,591151.81, 135365.96,109.348, Columbia River 14078,591177.60,135574.94,109.357, Columbia River 14075,591082.19,135495.79,109.357, Columbia River 14077, 591109.50, 135686.30, 109.366, Columbia River 13922, 591016.18,135627.46,109.366, Columbia River 14079, 591017.44, 135825.27, 109.378, Columbia River 13944,590920.38,135761.56,109.378, Columbia River 14101,590925.44,135964.23,109.393, Columbia River 14072, 590824.56, 135897.47, 109.393, Columbia River 14209, 590833.38, 136103.20,109.407, Columbia River 14208,590728.75, 136035.19,109.407, Columbia River 14071,590741.38,136242.17,109.422, Columbia River $14070,590620.87,136160.15,109.422$, Columbia River 13916, 590649.38, 136381.12, 109.437, Columbia River 13913, 590509.44,136288.72,109.437, Columbia River 13915, 590557.38, 136520.09, 109.453, Columbia River $13740,590390.69,136417.29,109.453$, Columbia River 13917,590446.94,136686.86,109.472, Columbia River $13768,590268.25,136574.04,109.472$, Columbia River 13945,590336.56, 136853.64,109.492, Columbia River 13910, 590171.12,136745.27,109.492, Columbia River 14068, 590226.12, 137020.41, 109.512, Columbia River 14067,590095.76,136913.79,109.512, Columbia River 13909, 590078.31, 137155.84, 109.532, Columbia River 13908, 589962.18,137011.14,109.532, Columbia River 13734,589920.25,137268.06,109.552, Columbia River 13731,589804.43,137116.79,109.552, Columbia River 13733, 589751.81, 137380.30, 109.572, Columbia River $13542,589648.71,137234.28,109.572$, Columbia River 13735,589614.62,137475.00,109.589, Columbia River 13581,589516.91, 137337.77,109.589, Columbia River 13774,589477.50,137569.70,109.606, Columbia River 13772,589377.31,137431.45,109.606, Columbia River 13947,589340.31,137664.41,109.623, Columbia River 13946,589236.85, 137516.26, 109.623, Columbia River $13775,589175.75,137778.03,109.653$, Columbia River 13773, 589069.15, 137625.83, 109.653, Columbia River 13770,589011.19,137891.67,109.683, Columbia River 13582, 588892.35, 137724.24, 109.683, Columbia River 13769, 588846.62,138005.30,109.714, Columbia River $13577,588719.70,137818.74,109.714$, Columbia River 13620, 588681.38, 138117.97,109.756, Columbia River 13576, 588534.71, 137907.25, 109.756, Columbia River 13619,588516.06,138230.62,109.8, Columbia River 13417,588362.54,138006.06,109.8, Columbia River $13617,588350.81,138343.30,109.846$, Columbia River 13416, 588180.12,138102.30, 109.846, Columbia River 13618, 588213.00, 138437.03, 109.892, Columbia River 13616, 588056.50, 138213.50, 109.892, Columbia River 13809,588075.19,138530.77, 109.938, Columbia River 13724,587926.53, 138323.94, 109.938, Columbia River $13903,587937.38,138624.50,109.984$, Columbia River 13902,587791.37, 138416.94, 109.984, Columbia River
Post McNary Riverfest Post McNary Riverfest Post McNary Riverfest Post McNary Riverfest Post McNary Riverfest Post McNary Riverfest Post McNary Riverfest Post McNary Riverfest Post McNary Riverfest Post McNary Riverfest Post McNary Riverfest Post McNary Riverfest Post McNary Riverfest Post McNary Riverfest Post McNary Riverfest Post McNary Riverfest Post McNary Riverfest Post McNary Riverfest Post McNary Riverfest Post McNary Riverfest Post McNary Riverfest Post McNary Riverfest Post McNary Riverfest Post McNary Riverfest Post McNary Riverfest Post McNary Riverfest Post McNary Riverfest Post McNary Riverfest Post McNary Riverfest Post McNary Riverfest Post McNary Riverfest Post McNary Riverfest Post McNary Riverfest Post McNary Riverfest Post McNary Riverfest Post McNary Riverfest Post McNary Riverfest Post McNary Riverfest Post McNary Riverfest Post McNary Riverfest Post McNary Riverfest Post McNary Riverfest Post McNary Riverfest Post McNary Riverfest Post McNary Riverfest Post McNary Riverfest Post McNary Riverfest Post McNary Riverfest Post McNary Riverfest Post McNary Riverfest Post McNary Riverfest Post McNary Riverfest Post McNary Riverfest Post McNary Riverfest Post McNary Riverfest Post McNary Riverfest Post McNary Riverfest 
13723, 587772.00, 138737.00,110.039, Columbia River 13722, 587636.80, 138545.78,110.039, Columbia River 13536, 587606.69, 138849.50,110.095, Columbia River 13529,587478.05, 138670.43,110.095, Columbia River 13535, 587441.31, 138962.00,110.151, Columbia River $13336,587312.59,138775.34,110.151$, Columbia River $13537,587310.27,139060.81,110.196$, Columbia River $13534,587142.45,138869.75,110.196$, Columbia River 13728, 587194.69,139185.39,110.244, Columbia River 13727,586989.52,138973.99,110.244, Columbia River 13906,587071.38, 139297.09,110.279, Columbia River 13905, 586860.33, 139084.07,110.279, Columbia River 13980, 586974.88, 139389.06,110.306, Columbia River 13904, 586756.18,139178.26,110.306, Columbia River $13812,586878.31,139481.03,110.334$, Columbia River 13810,586668.45, 139271.51, 110.334, Columbia River $13811,586781.81,139573.00,110.361$, Columbia River 13628, 586568.74, 139352.09,110.361, Columbia River $13813,586637.00,139710.97,110.402$, Columbia River 13629,586417.12,139488.72,110.402, Columbia River 13814,586492.19,139848.94,110.437, Columbia River 13630, 586278.12,139634.40,110.437, Columbia River 13632, 586347.38, 139986.91,110.469, Columbia River 13631,586126.49,139761.96,110.469, Columbia River 13434, 586227.54,140102.88,110.495, Columbia River 13433,585990.87, 139875.26,110.495, Columbia River 13426,586100.03,140224.02,110.522, Columbia River 13242, 585833.43, 139986.74, 110.522, Columbia River $13425,586000.81,140347.73,110.547$, Columbia River $13235,585679.68,140101.85,110.547$, Columbia River $13427,585898.52,140490.11,110.567$, Columbia River $13424,585582.68,140255.23,110.567$, Columbia River $13626,585793.65,140622.20,110.584$, Columbia River $13526,585453.13,140361.52,110.584$, Columbia River 13720, 585696.50, 140754.27,110.602, Columbia River $13719,585354.31,140489.55,110.602$, Columbia River $13901,585615.67,140858.92,110.615$, Columbia River 13718, 585273.49,140594.05,110.615, Columbia River 13899, 585534.88, 140966.14,110.629, Columbia River $13717,585172.74,140691.31,110.629$, Columbia River 13898, 585448.88, 141070.78, 110.644, Columbia River 13716, 585061.11, 140777.69,110.644, Columbia River $13900,585349.51,141209.17,110.662$, Columbia River $13897,584952.61,140920.12,110.662$, Columbia River 14066, 585244.99,141342.40,110.68, Columbia River $14065,584874.92,141055.31,110.68$, Columbia River 14207, 585135.30, 141491.11,110.7, Columbia River 14206, 584768.23,141195.92,110.7, Columbia River $14337,585019.57,141622.12,110.718$, Columbia River $14201,584657.05,141337.35,110.718$, Columbia River 14334, 584893.53, 141771.20, 110.761, Columbia River 14199, 584524.16, 141469.72,110.761, Columbia River 14333, 584764.92,141917.68, 110.804, Columbia River $14197,584387.60,141612.97,110.804$, Columbia River 14335,584620.42,142092.89,110.854, Columbia River $14331,584242.80,141803.05,110.854$, Columbia River 14460,584470.81, 142268.09, 110.905, Columbia River
Post McNary Riverfest Post McNary Riverfest Post McNary Riverfest Post McNary Riverfest Post McNary Riverfest Post McNary Riverfest Post McNary Riverfest Post McNary Riverfest Post McNary Riverfest Post McNary Riverfest Post McNary Riverfest Post McNary Riverfest Post McNary Riverfest Post McNary Riverfest Post McNary Riverfest Post McNary Riverfest Post McNary Riverfest Post McNary Riverfest Post McNary Riverfest Post McNary Riverfest Post McNary Riverfest Post McNary Riverfest Post McNary Riverfest Post McNary Riverfest Post McNary Riverfest Post McNary Riverfest Post McNary Riverfest Post McNary Riverfest Post McNary Riverfest Post McNary Riverfest Post McNary Riverfest Post McNary Riverfest Post McNary Riverfest Post McNary Riverfest Post McNary Riverfest Post McNary Riverfest Post McNary Riverfest Post McNary Riverfest Post McNary Riverfest Post McNary Riverfest Post McNary Riverfest Post McNary Riverfest Post McNary Riverfest Post McNary Riverfest Post McNary Riverfest Post McNary Riverfest Post McNary Riverfest Post McNary Riverfest Post McNary Riverfest Post McNary Riverfest Post McNary Riverfest Post McNary Riverfest Post McNary Riverfest Post McNary Riverfest Post McNary Riverfest Post McNary Riverfest Post McNary Riverfest 
14458, 584152.31, 141996.75, 110.905, Columbia River 14563, 584313.42,142445.89,110.957, Columbia River 14561, 584063.68, 142221.26,110.957, Columbia River 14650,584232.31, 142541.23,110.985, Columbia River $14648,583958.75,142369.67,110.985$, Columbia River $14726,584174.46,142657.20,111.014$, Columbia River $14724,583862.29,142524.99,111.014$, Columbia River 14782, 584129.43, 142768.01, 111.046, Columbia River $14781,583802.77,142628.87,111.046$, Columbia River 14832,584063.29,142922.04,111.091, Columbia River $14779,583720.28,142769.19,111.091$, Columbia River 14827,583999.67,143086.39,111.138, Columbia River 14777, 583631.98,142920.94,111.138, Columbia River 14826, 583933.54,143235.26,111.184, Columbia River 14775, 583554.24,143076.72,111.184, Columbia River $14830,583827.61,143500.71,111.283$, Columbia River $14828,583448.74,143356.31,111.283$, Columbia River 14875, 583719.11, 143766.15, 111.382, Columbia River 14873,583361.44,143617.78,111.382, Columbia River $14896,583628.65,144021.30,111.471$, Columbia River $14895,583274.06,143964.42,111.471$, Columbia River 14913,583640.31, 144141.92,111.508, Columbia River 14909, 583245.00, 144114.97,111.508, Columbia River $14924,583639.01,144252.22,111.544$, Columbia River 14910, 583215.87,144231.09,111.544, Columbia River 14912,583640.35, 144367.69,111.582, Columbia River $14911,583176.38,144355.02,111.582$, Columbia River 14894, 583640.06, 144493.04,111.626, Columbia River 14893, 583121.19, 144484.07,111.626, Columbia River $14867,583644.92,144628.73,111.675$, Columbia River 14865,583064.69,144613.67,111.675, Columbia River 14866,583644.62,144759.24,111.721, Columbia River $14818,583000.87,144750.53,111.721$, Columbia River $14868,583645.50,144956.38,111.813$, Columbia River $14819,582920.25,144960.71,111.813$, Columbia River $14869,583648.90,145153.50,111.926$, Columbia River $14820,582872.19,145149.15,111.926$, Columbia River $14870,583649.77,145368.66,112.015$, Columbia River $14821,582826.47,145310.86,112.015$, Columbia River $14871,583658.64,145513.95,112.064$, Columbia River 14822, 582807.47,145411.58,112.064, Columbia River $14872,583618.60,145679.88,112.122$, Columbia River $14823,582792.65,145502.56,112.122$, Columbia River $14825,583578.50,145843.20,112.204$, Columbia River $14824,582736.45,145616.29,112.204$, Columbia River $14774,583537.12,146004.64,112.289$, Columbia River 14773, 582645.08,145773.11,112.289, Columbia River $14712,583495.69,146166.06,112.373$, Columbia River 14710,582476.21, 145906.96,112.373, Columbia River $14711,583454.31,146327.50,112.455$, Columbia River 14634, 582325.39, 146038.98,112.455, Columbia River $14713,583404.56,146521.23,112.533$, Columbia River 14635, 582219.53, 146201.99, 112.533, Columbia River 14714,583354.88, 146714.97,112.61, Columbia River 14636, 582135.47, 146381.30,112.61, Columbia River 14715,583305.12,146908.70,112.688, Columbia River 14637,582189.07,146544.31,112.688, Columbia River
Post McNary Riverfest Post McNary Riverfest Post McNary Riverfest Post McNary Riverfest Post McNary Riverfest Post McNary Riverfest Post McNary Riverfest Post McNary Riverfest Post McNary Riverfest Post McNary Riverfest Post McNary Riverfest Post McNary Riverfest Post McNary Riverfest Post McNary Riverfest Post McNary Riverfest Post McNary Riverfest Post McNary Riverfest Post McNary Riverfest Post McNary Riverfest Post McNary Riverfest Post McNary Riverfest Post McNary Riverfest Post McNary Riverfest Post McNary Riverfest Post McNary Riverfest Post McNary Riverfest Post McNary Riverfest Post McNary Riverfest Post McNary Riverfest Post McNary Riverfest Post McNary Riverfest Post McNary Riverfest Post McNary Riverfest Post McNary Riverfest Post McNary Riverfest Post McNary Riverfest Post McNary Riverfest Post McNary Riverfest Post McNary Riverfest Post McNary Riverfest Post McNary Riverfest Post McNary Riverfest Post McNary Riverfest Post McNary Riverfest Post McNary Riverfest Post McNary Riverfest Post McNary Riverfest Post McNary Riverfest Post McNary Riverfest Post McNary Riverfest Post McNary Riverfest Post McNary Riverfest Post McNary Riverfest Post McNary Riverfest Post McNary Riverfest Post McNary Riverfest Post McNary Riverfest 
$14716,583122.82,147145.33,112.865$, Columbia River $14638,582241.53,146707.23,112.865$, Columbia River $14717,582775.66,147369.05,113.083$, Columbia River $14639,582272.22,146917.28,113.083$, Columbia River 14641,582433.58, 147597.95,113.21, Columbia River 14640, 582279.37, 147377.40,113.21, Columbia River 14554, 582165.40, 147776. 28, 113.404, Columbia River 14553, 581978.25, 147513.23,113.404, Columbia River 14449, 581935.89, 147921.08, 113.586, Columbia River $14447,581762.31,147627.32,113.586$, Columbia River 14448,581706.38, 148045.30,113.766, Columbia River $14320,581524.62,147708.79,113.766$, Columbia River 14450, 581559.38, 148123.80, 113.883, Columbia River 14321,581398.13,147821.42,113.883, Columbia River 14451,581412.38, 148202.30,113.963, Columbia River $14322,581271.68,147941.32,113.963$, Columbia River 14324, 581265.38, 148280.80, 114.007, Columbia River 14323,581134.11, 148036.76, 114.007, Columbia River 14190, 581084.06,148377.62,114.06, Columbia River 14189,580956.97, 148169.56, 114.06, Columbia River 14049, 580902.69, 148474.47,114.104, Columbia River $14047,580797.81,148287.54,114.104$, Columbia River 14048, 580721.38, 148571.30, 114.129, Columbia River $13881,580614.18,148401.62,114.129$, Columbia River 14050, 580602.08, 148668.42,114.147, Columbia River 13882, 580478. 24, 148517.61, 114.147, Columbia River 14051,580467.32,148775.85,114.167, Columbia River 13883, 580346.44,148624.92,114.167, Columbia River 13885, 580319.68, 148883.27,114.184, Columbia River $13884,580198.45,148750.05,114.184$, Columbia River 13703,580205.42,149000.72,114.198, Columbia River 13702, 580080.20, 148869.32,114.198, Columbia River $13509,580085.95,149125.92,114.213$, Columbia River 13506, 579943.12,148991.24,114.213, Columbia River 13507, 579961.39,149238.21, 114.221, Columbia River $13313,579771.62,149116.59,114.221$, Columbia River 13508, 579876.05, 149484.19,114.225, Columbia River 13314, 579633.57,149409.69,114.225, Columbia River 13510, 579832.02,149722.42,114.231, Columbia River 13315, 579472.01, 149807.89,114.231, Columbia River $13511,579934.81,149991.59,114.239$, Columbia River 13316, 579323.08, 150229.65,114.239, Columbia River $13512,580029.29,150226.96,114.264$, Columbia River $13475,579309.01,150418.79,114.264$, Columbia River $13671,580121.13,150446.85,114.302$, Columbia River 13670, 579273.19, 150549.93, 114.302, Columbia River 13853, 580148.60,150664.19,114.338, Columbia River $13852,579221.07,150715.51,114.338$, Columbia River 14019,580160.81, 150833.43, 114.379, Columbia River 14018, 579185.95, 150841.30, 114.379, Columbia River 14161,580178.10,151000.08,114.42, Columbia River 14160,579183.43,150907.28, 114.42, Columbia River 14295, 580094.94,151174.49,114.468, Columbia River 14294, 579208.10, 150971.45, 114.468, Columbia River $14420,579887.65,151448.82,114.557$, Columbia River 14293,579200.09,151028.04,114.557, Columbia River $14418,579626.18,151694.84,114.676$, Columbia River
Post McNary Riverfest Post McNary Riverfest Post McNary Riverfest Post McNary Riverfest Post McNary Riverfest Post McNary Riverfest Post McNary Riverfest Post McNary Riverfest Post McNary Riverfest Post McNary Riverfest Post McNary Riverfest Post McNary Riverfest Post McNary Riverfest Post McNary Riverfest Post McNary Riverfest Post McNary Riverfest Post McNary Riverfest Post McNary Riverfest Post McNary Riverfest Post McNary Riverfest Post McNary Riverfest Post McNary Riverfest Post McNary Riverfest Post McNary Riverfest Post McNary Riverfest Post McNary Riverfest Post McNary Riverfest Post McNary Riverfest Post McNary Riverfest Post McNary Riverfest Post McNary Riverfest Post McNary Riverfest Post McNary Riverfest Post McNary Riverfest Post McNary Riverfest Post McNary Riverfest Post McNary Riverfest Post McNary Riverfest Post McNary Riverfest Post McNary Riverfest Post McNary Riverfest Post McNary Riverfest Post McNary Riverfest Post McNary Riverfest Post McNary Riverfest Post McNary Riverfest Post McNary Riverfest Post McNary Riverfest Post McNary Riverfest Post McNary Riverfest Post McNary Riverfest Post McNary Riverfest Post McNary Riverfest Post McNary Riverfest Post McNary Riverfest Post McNary Riverfest Post McNary Riverfest 
$14292,579110.54,151169.80,114.676$, Columbia River 14417,579393.12,151920.20,114.812, Columbia River 14291, 578948.49,151463.79, 114.812, Columbia River $14419,579223.38,152080.33,114.894$, Columbia River 14416,578824.88, 151703.69,114.894, Columbia River $14530,579053.62,152240.47,114.969$, Columbia River 14529,578719.31, 151916.40,114.969, Columbia River $14619,578883.88,152400.59,115.05$, Columbia River 14618,578619.25,152121.87,115.05, Columbia River 14696, 578808.08, 152463.16, 115. 088, Columbia River 14695,578582.38, 152227.27, 115.088, Columbia River 14760, 578739.96, 152538.60, 115.127, Columbia River 14759, 578538.32,152354.40, 115.127, Columbia River $14812,578679.62,152619.20,115.166$, Columbia River $14811,578485.69,152452.63,115.166$, Columbia River $14860,578576.50,152750.14,115.23$, Columbia River $14810,578375.06,152592.37,115.23$, Columbia River 14858, 578473.44, 152881.06, 115.299, Columbia River 14809, 578263.13, 152712.26,115.299, Columbia River 14857, 578370.31, 153012.00, 115.389, Columbia River 14808, 578147.63,152835.77,115.389, Columbia River 14859,578267.19, 153142.94,115.478, Columbia River 14856,578056.06, 152976.48,115.478, Columbia River 14889, 578164.00, 153273.86,115.52, Columbia River 14888, 577953.69,153109.95,115.52, Columbia River 14908, 578060.88, 153404.80, 115.559, Columbia River $14907,577844.57,153239.29,115.559$, Columbia River 14923, 577936.08, 153566.35, 115.608, Columbia River 14906, 577690.80, 153368.74, 115.608, Columbia River $14921,577811.34,153720.20,115.655$, Columbia River 14905,577539.75, 153476.26,115.655, Columbia River 14920, 577678.81, 153866.30, 115.702, Columbia River $14904,577401.25,153588.15,115.702$, Columbia River $14922,577534.06,154004.33,115.75$, Columbia River $14919,577246.60,153695.45,115.75$, Columbia River 14929,577389.38, 154142.38, 115.799, Columbia River 14928,577080.02, 153838.79,115.799, Columbia River 14931,577244.62,154280.41,115.857, Columbia River 14930, 576938.42,153958.17, 115.857, Columbia River 14927, 577099.94, 154418.44, 115.916, Columbia River 14926, 576768.55, 154055.56, 115.916, Columbia River 14917,576955.19, 154556.47,115.975, Columbia River 14916, 576594.14, 154164.76, 115.975, Columbia River 14901, 576810.50, 154694.50, 116.082, Columbia River $14900,576432.08,154257.28,116.082$, Columbia River $14881,576578.87,154919.87,116.279$, Columbia River 14880, 576291.01, 154294.31, 116.279, Columbia River $14848,576290.53,155000.90,116.358$, Columbia River 14838, 576088.39, 154344.05, 116.358, Columbia River $14847,576022.81,155076.80,116.432$, Columbia River $14799,575827.72,154431.83,116.432$, Columbia River 14846,575701.39,155165.07,116.52, Columbia River 14798, 575526.05, 154512.08, 116.52, Columbia River 14845,575349.04,155271.40, 116.646, Columbia River $14797,575407.46,154550.65,116.646$, Columbia River $14844,575050.81,155187.00,116.835$, Columbia River $14796,575332.30,154567.48,116.835$, Columbia River
Post McNary Riverfest Post McNary Riverfest Post McNary Riverfest Post McNary Riverfest Post McNary Riverfest Post McNary Riverfest Post McNary Riverfest Post McNary Riverfest Post McNary Riverfest Post McNary Riverfest Post McNary Riverfest Post McNary Riverfest Post McNary Riverfest Post McNary Riverfest Post McNary Riverfest Post McNary Riverfest Post McNary Riverfest Post McNary Riverfest Post McNary Riverfest Post McNary Riverfest Post McNary Riverfest Post McNary Riverfest Post McNary Riverfest Post McNary Riverfest Post McNary Riverfest Post McNary Riverfest Post McNary Riverfest Post McNary Riverfest Post McNary Riverfest Post McNary Riverfest Post McNary Riverfest Post McNary Riverfest Post McNary Riverfest Post McNary Riverfest Post McNary Riverfest Post McNary Riverfest Post McNary Riverfest Post McNary Riverfest Post McNary Riverfest Post McNary Riverfest Post McNary Riverfest Post McNary Riverfest Post McNary Riverfest Post McNary Riverfest Post McNary Riverfest Post McNary Riverfest Post McNary Riverfest Post McNary Riverfest Post McNary Riverfest Post McNary Riverfest Post McNary Riverfest Post McNary Riverfest Post McNary Riverfest Post McNary Riverfest Post McNary Riverfest Post McNary Riverfest Post McNary Riverfest 
$14843,574834.12,154933.73,117.053$, Columbia River 14795, 575239.09, 154574.21, 117.053, Columbia River $14842,574617.50,154680.47,117.298$, Columbia River 14794,574765.25, 154551.95,117.298, Columbia River 14841,574400.81,154427.20,117.402, Columbia River $14793,574510.75,154335.78,117.402$, Columbia River 14840,574293.80,154300.22,117.406, Columbia River $14792,574410.76,154200.71,117.406$, Columbia River 14839, 574184.21, 154173.21, 117.41, Columbia River 14791,574328.89,154067.44,117.41, Columbia River $14790,574087.50,154038.50,117.413$, Columbia River 14789,574270.48, 153921.01, 117.413, Columbia River 14738, 573998.38, 153897.67,117.424, Columbia River $14737,574234.66,153749.65,117.424$, Columbia River 14674,573909.25, 153756.83,117.436, Columbia River 14673, 574206.33, 153577.05, 117.436, Columbia River $14597,573820.12,153616.00,117.447$, Columbia River 14596, 574147.31, 153408.75, 117.447, Columbia River 14508, 573731.00, 153475.17,117.459, Columbia River $14507,574111.62,153227.59,117.459$, Columbia River $14395,573641.94,153334.33,117.462$, Columbia River 14394,574085.00, 153053.69,117.462, Columbia River $14393,573552.81,153193.50,117.464$, Columbia River 14270,574004.45, 152908.62,117.464, Columbia River 14392, 573454.94,153038.80,117.466, Columbia River 14269,573901.24, 152755.87,117.466, Columbia River 14391,573357.00, 152884.11,117.483, Columbia River $14268,573743.01,152620.39,117.483$, Columbia River $14267,573259.12,152729.41,117.531$, Columbia River 14266, 573579.15,152478.43,117.531, Columbia River 14133,573109.31, 152572.53,117.587, Columbia River $14132,573374.44,152320.58,117.587$, Columbia River $13991,572959.44,152415.67,117.645$, Columbia River $13990,573223.50,152174.80,117.645$, Columbia River 13989, 572809.62,152258.80,117.721, Columbia River $13825,573050.88,152030.85,117.721$, Columbia River $13988,572694.50,152138.27,117.779$, Columbia River $13824,572922.88,151920.67,117.779$, Columbia River 13987, 572579.31, 152017.73, 117.837, Columbia River 13823, 572802.06, 151808.67,117.837, Columbia River $13822,572464.19,151897.20,117.89$, Columbia River 13821, 572679.89, 151689.03,117.89, Columbia River 13640,572324.58, 151752.76, 117.931, Columbia River 13639,572551.68,151541.10, 117.931, Columbia River 13445, 572187.49,151610.89, 117.971, Columbia River 13444, 572432.68, 151400.98, 117.971, Columbia River 13443, 572068.50, 151448.41, 118.012, Columbia River 13253, 572314.49, 151264.29,118.012, Columbia River 13442, 571976.56, 151309.41, 118.045, Columbia River 13252,572215.13,151156.79,118.045, Columbia River $13441,571884.56,151170.41,118.076$, Columbia River 13251, 572109.06, 151017.34, 118.076, Columbia River 13250, 571792.62,151031.41,118.103, Columbia River 13249,572010.30, 150881.78, 118.103, Columbia River 13060, 571682. 25, 150864.64, 118.135, Columbia River $13059,571890.19,150729.34,118.135$, Columbia River $12872,571571.88,150697.86,118.168$, Columbia River
Post McNary Riverfest Post McNary Riverfest Post McNary Riverfest Post McNary Riverfest Post McNary Riverfest Post McNary Riverfest Post McNary Riverfest Post McNary Riverfest Post McNary Riverfest Post McNary Riverfest Post McNary Riverfest Post McNary Riverfest Post McNary Riverfest Post McNary Riverfest Post McNary Riverfest Post McNary Riverfest Post McNary Riverfest Post McNary Riverfest Post McNary Riverfest Post McNary Riverfest Post McNary Riverfest Post McNary Riverfest Post McNary Riverfest Post McNary Riverfest Post McNary Riverfest Post McNary Riverfest Post McNary Riverfest Post McNary Riverfest Post McNary Riverfest Post McNary Riverfest Post McNary Riverfest Post McNary Riverfest Post McNary Riverfest Post McNary Riverfest Post McNary Riverfest Post McNary Riverfest Post McNary Riverfest Post McNary Riverfest Post McNary Riverfest Post McNary Riverfest Post McNary Riverfest Post McNary Riverfest Post McNary Riverfest Post McNary Riverfest Post McNary Riverfest Post McNary Riverfest Post McNary Riverfest Post McNary Riverfest Post McNary Riverfest Post McNary Riverfest Post McNary Riverfest Post McNary Riverfest Post McNary Riverfest Post McNary Riverfest Post McNary Riverfest Post McNary Riverfest Post McNary Riverfest 
$12871,571782.25,150562.22,118.168$, Columbia River 12683,571461.50,150531.09,118.189, Columbia River $12681,571684.56,150383.72,118.189$, Columbia River 12495, 571387.19, 150420.42,118.203, Columbia River 12493, 571606.19, 150272.89,118.203, Columbia River $12299,571312.81,150309.77,118.217$, Columbia River $12297,571524.25,150154.81,118.217$, Columbia River 12296, 571238.50, 150199.09,118.231, Columbia River 12102, 571449.50, 150045.80,118.231, Columbia River $12295,571113.44,150043.06,118.251$, Columbia River $12101,571305.82,149907.59,118.251$, Columbia River 12294, 570988.38, 149887.03,118.271, Columbia River 12099,571175.57,149737.19,118.271, Columbia River 12100, 570863.31, 149731.00,118.291, Columbia River 12098,571069.77,149578.93,118.291, Columbia River 11902, 570759.06, 149600.94,118.308, Columbia River $11900,570970.32,149437.66,118.308$, Columbia River 11695, 570654.88, 149470.86, 118.324, Columbia River $11693,570883.88,149302.37,118.324$, Columbia River $11692,570550.62,149340.80,118.342$, Columbia River 11478,570769.35, 149169.89,118.342, Columbia River 11691,570425.20,149182.18,118.365, Columbia River $11477,570631.67,149025.27,118.365$, Columbia River 11690,570307.51, 149031.30,118.387, Columbia River 11476,570486.27,148869.27,118.387, Columbia River $11475,570166.62,148880.41,118.404$, Columbia River $11474,570355.48,148705.56,118.404$, Columbia River 11249, 570049.88, 148761.44,118.418, Columbia River $11248,570238.76,148583.10,118.418$, Columbia River 11016, 569933.12,148642.47,118.432, Columbia River 11015,570128.92,148446.48,118.432, Columbia River $11014,569816.38,148523.50,118.446$, Columbia River $10776,570011.74,148338.12,118.446$, Columbia River $11013,569699.69,148404.53,118.46$, Columbia River $10775,569881.42,148231.79,118.46$, Columbia River 11012, 569583.00, 148285.56, 118.479, Columbia River 10774, 569759.89,148116.79,118.479, Columbia River 10773, 569466.31, 148166.59,118.501, Columbia River $10772,569632.45,148007.68,118.501$, Columbia River 10535, 569345.25, 148043.27, 118.522, Columbia River $10534,569519.02,147892.29,118.522$, Columbia River $10306,569224.25,147919.92,118.546$, Columbia River 10305, 569394.97,147750.93,118.546, Columbia River $10304,569103.19,147796.59,118.57$, Columbia River $10082,569271.61,147587.89,118.57$, Columbia River 10303, 568978.94, 147694.89, 118.593, Columbia River $10081,569157.47,147484.22,118.593$, Columbia River $10302,568854.75,147593.20,118.615$, Columbia River $10080,569035.18,147388.47,118.615$, Columbia River $10079,568730.50,147491.50,118.635$, Columbia River 10078,568929.29, 147258.00, 118.635, Columbia River $9861,568601.56,147385.91,118.651$, Columbia River 9860,568799.04,147140.11,118.651, Columbia River 9648,568472.56,147280.30,118.667, Columbia River 9647, 568679.64,147026.14,118.667, Columbia River $9646,568343.62,147174.70,118.683$, Columbia River 9434,568562.61,146903.57,118.683, Columbia River
Post McNary Riverfest Post McNary Riverfest Post McNary Riverfest Post McNary Riverfest Post McNary Riverfest Post McNary Riverfest Post McNary Riverfest Post McNary Riverfest Post McNary Riverfest Post McNary Riverfest Post McNary Riverfest Post McNary Riverfest Post McNary Riverfest Post McNary Riverfest Post McNary Riverfest Post McNary Riverfest Post McNary Riverfest Post McNary Riverfest Post McNary Riverfest Post McNary Riverfest Post McNary Riverfest Post McNary Riverfest Post McNary Riverfest Post McNary Riverfest Post McNary Riverfest Post McNary Riverfest Post McNary Riverfest Post McNary Riverfest Post McNary Riverfest Post McNary Riverfest Post McNary Riverfest Post McNary Riverfest Post McNary Riverfest Post McNary Riverfest Post McNary Riverfest Post McNary Riverfest Post McNary Riverfest Post McNary Riverfest Post McNary Riverfest Post McNary Riverfest Post McNary Riverfest Post McNary Riverfest Post McNary Riverfest Post McNary Riverfest Post McNary Riverfest Post McNary Riverfest Post McNary Riverfest Post McNary Riverfest Post McNary Riverfest Post McNary Riverfest Post McNary Riverfest Post McNary Riverfest Post McNary Riverfest Post McNary Riverfest Post McNary Riverfest Post McNary Riverfest Post McNary Riverfest 
$9645,568178.88,147039.80,118.704$, Columbia River $9433,568380.85,146796.33,118.704$, Columbia River 9644, 568014.12,146904.91,118.722, Columbia River 9432, 568187.53,146681.64,118.722, Columbia Rive 9431, 567849.38, 146770.00, 118.74, Columbia River 9430, 567992.47,146573.87,118.74, Columbia River $9222,567743.44,146712.73,118.75$, Columbia River 9221, 567897.33, 146475.97, 118.75, Columbia River $9017,567637.56,146655.47,118.791$, Columbia River $9016,567811.79,146375.46,118.791$, Columbia River $8821,567531.62,146598.20,118.834$, Columbia River 8820, 567700.78, 146297.27,118.834, Columbia River 8633, 567355.69, 146503.06, 118.906, Columbia River 8632, 567522.74,146196.18,118.906, Columbia River 8446,567179.81, 146407.94,119.006, Columbia River $8442,567350.64,146094.82,119.006$, Columbia River $8445,567003.88,146312.80,119.108$, Columbia River $8249,567165.07,146009.22,119.108$, Columbia River $8444,566827.94,146217.67,119.209$, Columbia River 8248, 566971.50, 145951.35, 119.209, Columbia River $8443,566652.06,146122.53,119.326$, Columbia River $8246,566777.94,145877.68,119.326$, Columbia River $8247,566476.12,146027.41,119.445$, Columbia River $8245,566563.93,145789.96,119.445$, Columbia River 8041, 566346.94, 145995.08, 119.525, Columbia River 8039, 566418.92,145736.30,119.525, Columbia River 7838, 566217.81, 145962.73, 119.633, Columbia River 7836, 566293.85, 145688.71, 119.633, Columbia River $7629,566088.62,145930.41,119.757$, Columbia River 7628, 566164.44,145640.59,119.757, Columbia River 7419,565861.69,145876.03,119.974, Columbia River 7418,565936.81, 145567.47,119.974, Columbia River $7202,565634.75,145821.67,120.059$, Columbia River $7201,565713.57,145513.73,120.059$, Columbia River $7191,565407.81,145767.30,120.13$, Columbia River 6976, 565487.49,145453.01,120.13, Columbia River 7190,565220.73,145720.24,120.182, Columbia River 6966,565295.21,145414.85,120.182, Columbia River $7189,565012.97,145670.59,120.239$, Columbia River $6964,565036.68,145310.48,120.239$, Columbia River $6965,564823.31,145672.50,120.291$, Columbia River 6963,564784.11,145286.27,120.291, Columbia River 6738, 564594.19,145716.67,120.338, Columbia River $6736,564519.61,145312.27,120.338$, Columbia River $6732,564365.12,145760.83,120.383$, Columbia River $6509,564288.45,145366.97,120.383$, Columbia River 6502, 564136.00, 145805.00, 120.405, Columbia River $6501,564071.84,145426.05,120.405$, Columbia River $6277,563903.69,145849.67,120.423$, Columbia River $6275,563836.13,145533.68,120.423$, Columbia River $6273,563671.31,145894.33,120.442$, Columbia River $6054,563603.81,145590.08,120.442$, Columbia River $6271,563439.00,145939.00,120.463$, Columbia River 6052,563372.50, 145729.29,120.463, Columbia River $6272,563021.00,146081.59,120.529$, Columbia River $6269,562967.69,145928.47,120.529$, Columbia River $6498,562600.31,146237.70,120.595$, Columbia River
Post McNary Riverfest Post McNary Riverfest Post McNary Riverfest Post McNary Riverfest Post McNary Riverfest Post McNary Riverfest Post McNary Riverfest Post McNary Riverfest Post McNary Riverfest Post McNary Riverfest Post McNary Riverfest Post McNary Riverfest Post McNary Riverfest Post McNary Riverfest Post McNary Riverfest Post McNary Riverfest Post McNary Riverfest Post McNary Riverfest Post McNary Riverfest Post McNary Riverfest Post McNary Riverfest Post McNary Riverfest Post McNary Riverfest Post McNary Riverfest Post McNary Riverfest Post McNary Riverfest Post McNary Riverfest Post McNary Riverfest Post McNary Riverfest Post McNary Riverfest Post McNary Riverfest Post McNary Riverfest Post McNary Riverfest Post McNary Riverfest Post McNary Riverfest Post McNary Riverfest Post McNary Riverfest Post McNary Riverfest Post McNary Riverfest Post McNary Riverfest Post McNary Riverfest Post McNary Riverfest Post McNary Riverfest Post McNary Riverfest Post McNary Riverfest Post McNary Riverfest Post McNary Riverfest Post McNary Riverfest Post McNary Riverfest Post McNary Riverfest Post McNary Riverfest Post McNary Riverfest Post McNary Riverfest Post McNary Riverfest Post McNary Riverfest Post McNary Riverfest Post McNary Riverfest 


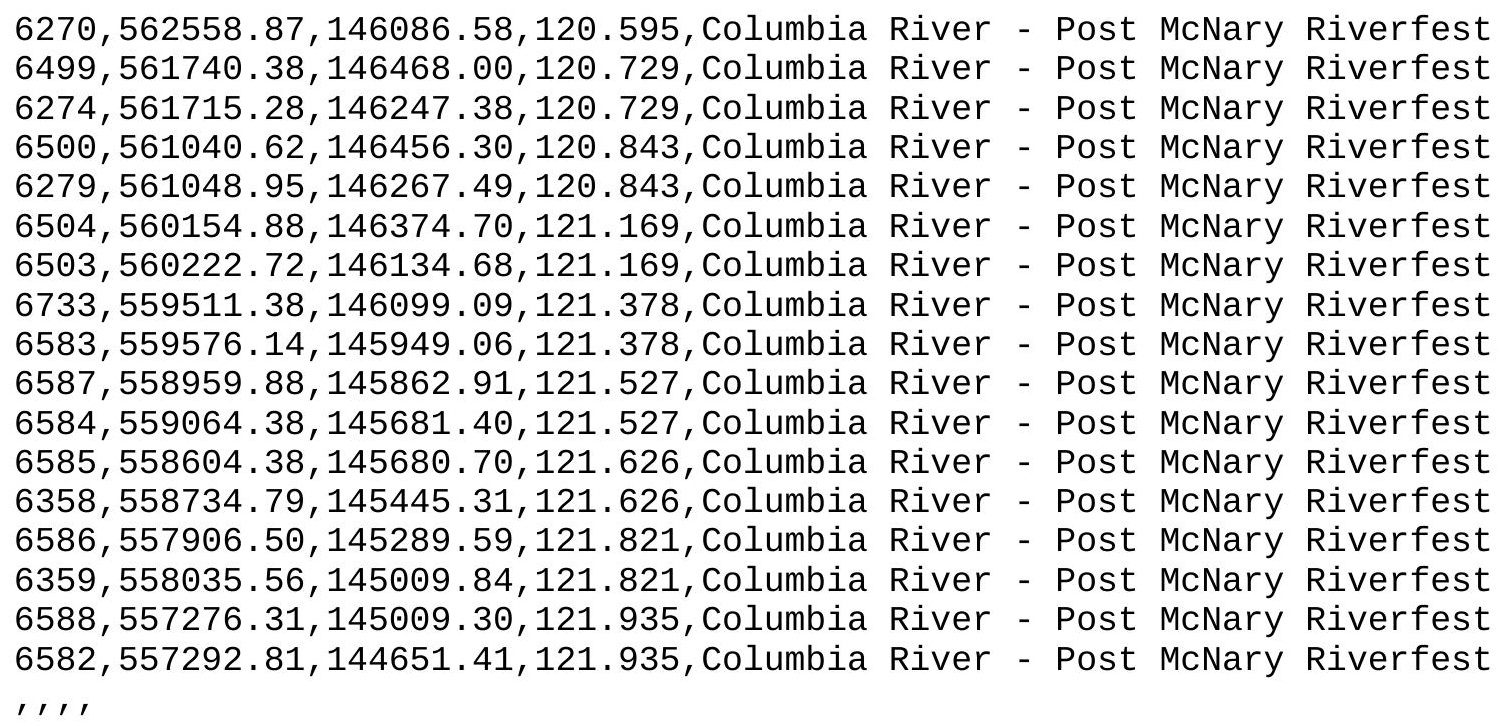


elem_nod_CA 


\begin{tabular}{|c|c|c|c|}
\hline node & X_coord & Y_coord & note: from sac04d created July 1,2004 \\
\hline 1 & 567354.94 & 135783.27 & \\
\hline 2 & 567438.31 & 135783.27 & \\
\hline 3 & 567354.94 & 135866.59 & \\
\hline 4 & 567438.31 & 135866.59 & \\
\hline 5 & 567271.62 & 135783.27 & \\
\hline 6 & 567271.62 & 135866.59 & \\
\hline 7 & 567354.94 & 135699.92 & \\
\hline 8 & 567271.62 & 135699.92 & \\
\hline 9 & 567438.31 & 135699.92 & \\
\hline 10 & 567521.62 & 135783.27 & \\
\hline 11 & 567521.62 & 135699.92 & \\
\hline 12 & 567521.62 & 135866.59 & \\
\hline 13 & 567354.94 & 135949.92 & \\
\hline 14 & 567271.62 & 135949.92 & \\
\hline 15 & 567438.31 & 135949.92 & \\
\hline 16 & 567521.62 & 135949.92 & \\
\hline 17 & 567188.31 & 135783.27 & \\
\hline 18 & 567188.31 & 135699.92 & \\
\hline 19 & 567188.31 & 135866.59 & \\
\hline 20 & 567188.31 & 135949.92 & \\
\hline 21 & 567354.94 & 135616.59 & \\
\hline 22 & 567271.62 & 135616.59 & \\
\hline 23 & 567438.31 & 135616.59 & \\
\hline 24 & 567188.31 & 135616.59 & \\
\hline 25 & 567521.62 & 135616.59 & \\
\hline 26 & 567604.94 & 135783.27 & \\
\hline 27 & 567604.94 & 135866.59 & \\
\hline 28 & 567604.94 & 135699.92 & \\
\hline 29 & 567604.94 & 135616.59 & \\
\hline 30 & 567604.94 & 135949.92 & \\
\hline 31 & 567354.94 & 136033.27 & \\
\hline 32 & 567271.62 & 136033.27 & \\
\hline 33 & 567438.31 & 136033.27 & \\
\hline 34 & 567188.31 & 136033.27 & \\
\hline 35 & 567521.62 & 136033.27 & \\
\hline 36 & 567604.94 & 136033.27 & \\
\hline 37 & 567104.94 & 135783.27 & \\
\hline 38 & 567104.94 & 135866.59 & \\
\hline 39 & 567104.94 & 135699.92 & \\
\hline 40 & 567104.94 & 135616.59 & \\
\hline 41 & 567104.94 & 135949.92 & \\
\hline 42 & 567104.94 & 136033.27 & \\
\hline 43 & 567354.94 & 135533.27 & \\
\hline 44 & 567438.31 & 135533.27 & \\
\hline 45 & 567271.62 & 135533.27 & \\
\hline 46 & 567188.31 & 135533.27 & \\
\hline 47 & 567521.62 & 135533.27 & \\
\hline 48 & 567104.94 & 135533.27 & \\
\hline 49 & 567604.94 & 135533.27 & \\
\hline 50 & 567688.31 & 135783.27 & \\
\hline 51 & 567688.31 & 135866.59 & \\
\hline 52 & 567688.31 & 135699.92 & \\
\hline 53 & 567688.31 & 135949.92 & \\
\hline 54 & 567688.31 & 135616.59 & \\
\hline 55 & 567688.31 & 135533.27 & \\
\hline 56 & 567688.31 & 136033.27 & \\
\hline
\end{tabular}




\begin{tabular}{|c|c|c|c|}
\hline node & X_coord & Y_coord & note: from sac04d created July 1, 2004 \\
\hline 57 & $5 \overline{6} 7354.94$ & $1 \overline{3} 6116.59$ & \\
\hline 58 & 567438.31 & 136116.59 & \\
\hline 59 & 567271.62 & 136116.59 & \\
\hline 60 & 567188.31 & 136116.59 & \\
\hline 61 & 567521.62 & 136116.59 & \\
\hline 62 & 567104.94 & 136116.59 & \\
\hline 63 & 567604.94 & 136116.59 & \\
\hline 64 & 567688.31 & 136116.59 & \\
\hline 65 & 567021.62 & 135783.27 & \\
\hline 66 & 567021.62 & 135866.59 & \\
\hline 67 & 567021.62 & 135699.92 & \\
\hline 68 & 567021.62 & 135949.92 & \\
\hline 69 & 567021.62 & 135616.59 & \\
\hline 70 & 567021.62 & 135533.27 & \\
\hline 71 & 567021.62 & 136033.27 & \\
\hline 72 & 567021.62 & 136116.59 & \\
\hline 73 & 567354.94 & 135449.92 & \\
\hline 74 & 567271.62 & 135449.92 & \\
\hline 75 & 567438.31 & 135449.92 & \\
\hline 76 & 567521.62 & 135449.92 & \\
\hline 77 & 567188.31 & 135449.92 & \\
\hline 78 & 567104.94 & 135449.92 & \\
\hline 79 & 567604.94 & 135449.92 & \\
\hline 80 & 567021.62 & 135449.92 & \\
\hline 81 & 567688.31 & 135449.92 & \\
\hline 82 & 567771.62 & 135783.27 & \\
\hline 83 & 567771.62 & 135699.92 & \\
\hline 84 & 567771.62 & 135866.59 & \\
\hline 85 & 567771.62 & 135949.92 & \\
\hline 86 & 567771.62 & 135616.59 & \\
\hline 87 & 567771.62 & 136033.27 & \\
\hline 88 & 567771.62 & 135533.27 & \\
\hline 89 & 567771.62 & 135449.92 & \\
\hline 90 & 567771.62 & 136116.59 & \\
\hline 91 & 567354.94 & 136199.92 & \\
\hline 92 & 567271.62 & 136199.92 & \\
\hline 93 & 567438.31 & 136199.92 & \\
\hline 94 & 567521.62 & 136199.92 & \\
\hline 95 & 567188.31 & 136199.92 & \\
\hline 96 & 567104.94 & 136199.92 & \\
\hline 97 & 567604.94 & 136199.92 & \\
\hline 98 & 567021.62 & 136199.92 & \\
\hline 99 & 567688.31 & 136199.92 & \\
\hline 100 & 567771.62 & 136199.92 & \\
\hline 101 & 566938.31 & 135783.27 & \\
\hline 102 & 566938.31 & 135699.92 & \\
\hline 103 & 566938.31 & 135866.59 & \\
\hline 104 & 566938.31 & 135949.92 & \\
\hline 105 & 566938.31 & 135616.59 & \\
\hline 106 & 566938.31 & 136033.27 & \\
\hline 107 & 566938.31 & 135533.27 & \\
\hline 108 & 566938.31 & 135449.92 & \\
\hline 109 & 566938.31 & 136116.59 & \\
\hline 110 & 566938.31 & 136199.92 & \\
\hline 111 & 567354.94 & 135366.59 & \\
\hline 112 & 567271.62 & 135366.59 & \\
\hline
\end{tabular}




\begin{tabular}{|c|c|c|c|}
\hline node & X_coord & Y_coord & note: from sac04d created July 1, 2004 \\
\hline 113 & $5 \overline{6} 7438.31$ & $1 \overline{3} 5366.59$ & \\
\hline 114 & 567188.31 & 135366.59 & \\
\hline 115 & 567521.62 & 135366.59 & \\
\hline 116 & 567604.94 & 135366.59 & \\
\hline 117 & 567104.94 & 135366.59 & \\
\hline 118 & 567021.62 & 135366.59 & \\
\hline 119 & 567688.31 & 135366.59 & \\
\hline 120 & 566938.31 & 135366.59 & \\
\hline 121 & 567771.62 & 135366.59 & \\
\hline 122 & 567854.94 & 135783.27 & \\
\hline 123 & 567854.94 & 135866.59 & \\
\hline 124 & 567854.94 & 135699.92 & \\
\hline 125 & 567854.94 & 135616.59 & \\
\hline 126 & 567854.94 & 135949.92 & \\
\hline 127 & 567854.94 & 136033.27 & \\
\hline 128 & 567854.94 & 135533.27 & \\
\hline 129 & 567854.94 & 136116.59 & \\
\hline 130 & 567854.94 & 135449.92 & \\
\hline 131 & 567854.94 & 135366.59 & \\
\hline 132 & 567854.94 & 136199.92 & \\
\hline 133 & 567354.94 & 136283.27 & \\
\hline 134 & 567271.62 & 136283.27 & \\
\hline 135 & 567438.31 & 136283.27 & \\
\hline 136 & 567188.31 & 136283.27 & \\
\hline 137 & 567521.62 & 136283.27 & \\
\hline 138 & 567604.94 & 136283.27 & \\
\hline 139 & 567104.94 & 136283.27 & \\
\hline 140 & 567021.62 & 136283.27 & \\
\hline 141 & 567688.31 & 136283.27 & \\
\hline 142 & 566938.31 & 136283.27 & \\
\hline 143 & 567771.62 & 136283.27 & \\
\hline 144 & 567854.94 & 136283.27 & \\
\hline 145 & 566854.94 & 135783.27 & \\
\hline 146 & 566854.94 & 135866.59 & \\
\hline 147 & 566854.94 & 135699.92 & \\
\hline 148 & 566854.94 & 135616.59 & \\
\hline 149 & 566854.94 & 135949.92 & \\
\hline 150 & 566854.94 & 136033.27 & \\
\hline 151 & 566854.94 & 135533.27 & \\
\hline 152 & 566854.94 & 136116.59 & \\
\hline 153 & 566854.94 & 135449.92 & \\
\hline 154 & 566854.94 & 135366.59 & \\
\hline 155 & 566854.94 & 136199.92 & \\
\hline 156 & 566854.94 & 136283.27 & \\
\hline 157 & 567354.94 & 135283.27 & \\
\hline 158 & 567438.31 & 135283.27 & \\
\hline 159 & 567271.62 & 135283.27 & \\
\hline 160 & 567188.31 & 135283.27 & \\
\hline 161 & 567521.62 & 135283.27 & \\
\hline 162 & 567104.94 & 135283.27 & \\
\hline 163 & 567604.94 & 135283.27 & \\
\hline 164 & 567688.31 & 135283.27 & \\
\hline 165 & 567021.62 & 135283.27 & \\
\hline 166 & 566938.31 & 135283.27 & \\
\hline 167 & 567771.62 & 135283.27 & \\
\hline 168 & 566854.94 & 135283.27 & \\
\hline
\end{tabular}




\begin{tabular}{|c|c|c|c|}
\hline node & X_coord & Y_coord & note: from sac04d created July 1,2004 \\
\hline 169 & $5 \overline{6} 7854.94$ & $1 \overline{3} 5283.27$ & \\
\hline 170 & 567938.31 & 135783.27 & \\
\hline 171 & 567938.31 & 135866.59 & \\
\hline 172 & 567938.31 & 135699.92 & \\
\hline 173 & 567938.31 & 135949.92 & \\
\hline 174 & 567938.31 & 135616.59 & \\
\hline 175 & 567938.31 & 135533.27 & \\
\hline 176 & 567938.31 & 136033.27 & \\
\hline 177 & 567938.31 & 136116.59 & \\
\hline 178 & 567938.31 & 135449.92 & \\
\hline 179 & 567938.31 & 136199.92 & \\
\hline 180 & 567938.31 & 135366.59 & \\
\hline 181 & 567938.31 & 135283.27 & \\
\hline 182 & 567938.31 & 136283.27 & \\
\hline 183 & 567354.94 & 136366.59 & \\
\hline 184 & 567438.31 & 136366.59 & \\
\hline 185 & 567271.62 & 136366.59 & \\
\hline 186 & 567188.31 & 136366.59 & \\
\hline 187 & 567521.62 & 136366.59 & \\
\hline 188 & 567104.94 & 136366.59 & \\
\hline 189 & 567604.94 & 136366.59 & \\
\hline 190 & 567688.31 & 136366.59 & \\
\hline 191 & 567021.62 & 136366.59 & \\
\hline 192 & 566938.31 & 136366.59 & \\
\hline 193 & 567771.62 & 136366.59 & \\
\hline 194 & 566854.94 & 136366.59 & \\
\hline 195 & 567854.94 & 136366.59 & \\
\hline 196 & 567938.31 & 136366.59 & \\
\hline 197 & 566771.62 & 135783.27 & \\
\hline 198 & 566771.62 & 135866.59 & \\
\hline 199 & 566771.62 & 135699.92 & \\
\hline 200 & 566771.62 & 135949.92 & \\
\hline 201 & 566771.62 & 135616.59 & \\
\hline 202 & 566771.62 & 135533.27 & \\
\hline 203 & 566771.62 & 136033.27 & \\
\hline 204 & 566771.62 & 136116.59 & \\
\hline 205 & 566771.62 & 135449.92 & \\
\hline 206 & 566771.62 & 136199.92 & \\
\hline 207 & 566771.62 & 135366.59 & \\
\hline 208 & 566771.62 & 135283.27 & \\
\hline 209 & 566771.62 & 136283.27 & \\
\hline 210 & 566771.62 & 136366.59 & \\
\hline 211 & 567354.94 & 135199.92 & \\
\hline 212 & 567271.62 & 135199.92 & \\
\hline 213 & 567438.31 & 135199.92 & \\
\hline 214 & 567521.62 & 135199.92 & \\
\hline 215 & 567188.31 & 135199.92 & \\
\hline 216 & 567104.94 & 135199.92 & \\
\hline 217 & 567604.94 & 135199.92 & \\
\hline 218 & 567021.62 & 135199.92 & \\
\hline 219 & 567688.31 & 135199.92 & \\
\hline 220 & 567771.62 & 135199.92 & \\
\hline 221 & 566938.31 & 135199.92 & \\
\hline 222 & 566854.94 & 135199.92 & \\
\hline 223 & 567854.94 & 135199.92 & \\
\hline 224 & 566771.62 & 135199.92 & \\
\hline
\end{tabular}




\begin{tabular}{|c|c|c|c|}
\hline node & X_coord & Y_coord & note: from sac04d created July 1, 2004 \\
\hline 225 & $5 \overline{6} 7938.31$ & $1 \overline{3} 5199.92$ & \\
\hline 226 & 568021.62 & 135783.27 & \\
\hline 227 & 568021.62 & 135699.92 & \\
\hline 228 & 568021.62 & 135866.59 & \\
\hline 229 & 568021.62 & 135949.92 & \\
\hline 230 & 568021.62 & 135616.59 & \\
\hline 231 & 568021.62 & 136033.27 & \\
\hline 232 & 568021.62 & 135533.27 & \\
\hline 233 & 568021.62 & 135449.92 & \\
\hline 234 & 568021.62 & 136116.59 & \\
\hline 235 & 568021.62 & 136199.92 & \\
\hline 236 & 568021.62 & 135366.59 & \\
\hline 237 & 568021.62 & 136283.27 & \\
\hline 238 & 568021.62 & 135283.27 & \\
\hline 239 & 568021.62 & 135199.92 & \\
\hline 240 & 568021.62 & 136366.59 & \\
\hline 241 & 567354.94 & 136449.92 & \\
\hline 242 & 567271.62 & 136449.92 & \\
\hline 243 & 567438.31 & 136449.92 & \\
\hline 244 & 567521.62 & 136449.92 & \\
\hline 245 & 567188.31 & 136449.92 & \\
\hline 246 & 567104.94 & 136449.92 & \\
\hline 247 & 567604.94 & 136449.92 & \\
\hline 248 & 567021.62 & 136449.92 & \\
\hline 249 & 567688.31 & 136449.92 & \\
\hline 250 & 567771.62 & 136449.92 & \\
\hline 251 & 566938.31 & 136449.92 & \\
\hline 252 & 566854.94 & 136449.92 & \\
\hline 253 & 567854.94 & 136449.92 & \\
\hline 254 & 566771.62 & 136449.92 & \\
\hline 255 & 567938.31 & 136449.92 & \\
\hline 256 & 568021.62 & 136449.92 & \\
\hline 257 & 566688.31 & 135783.27 & \\
\hline 258 & 566688.31 & 135699.92 & \\
\hline 259 & 566688.31 & 135866.59 & \\
\hline 260 & 566688.31 & 135949.92 & \\
\hline 261 & 566688.31 & 135616.59 & \\
\hline 262 & 566688.31 & 136033.27 & \\
\hline 263 & 566688.31 & 135533.27 & \\
\hline 264 & 566688.31 & 135449.92 & \\
\hline 265 & 566688.31 & 136116.59 & \\
\hline 266 & 566688.31 & 136199.92 & \\
\hline 267 & 566688.31 & 135366.59 & \\
\hline 268 & 566688.31 & 136283.27 & \\
\hline 269 & 566688.31 & 135283.27 & \\
\hline 270 & 566688.31 & 135199.92 & \\
\hline 271 & 566688.31 & 136366.59 & \\
\hline 272 & 566688.31 & 136449.92 & \\
\hline 273 & 567354.94 & 135116.59 & \\
\hline 274 & 567271.62 & 135116.59 & \\
\hline 275 & 567438.31 & 135116.59 & \\
\hline 276 & 567188.31 & 135116.59 & \\
\hline 277 & 567521.62 & 135116.59 & \\
\hline 278 & 567604.94 & 135116.59 & \\
\hline 279 & 567104.94 & 135116.59 & \\
\hline 280 & 567021.62 & 135116.59 & \\
\hline
\end{tabular}




\begin{tabular}{|c|c|c|c|}
\hline node & X_coord & Y_coord & note: from sac04d created July 1, 2004 \\
\hline 281 & $5 \overline{6} 7688.31$ & $1 \overline{3} 5116.59$ & \\
\hline 282 & 566938.31 & 135116.59 & \\
\hline 283 & 567771.62 & 135116.59 & \\
\hline 284 & 567854.94 & 135116.59 & \\
\hline 285 & 566854.94 & 135116.59 & \\
\hline 286 & 566771.62 & 135116.59 & \\
\hline 287 & 567938.31 & 135116.59 & \\
\hline 288 & 566688.31 & 135116.59 & \\
\hline 289 & 568021.62 & 135116.59 & \\
\hline 290 & 568104.94 & 135783.27 & \\
\hline 291 & 568104.94 & 135866.59 & \\
\hline 292 & 568104.94 & 135699.92 & \\
\hline 293 & 568104.94 & 135616.59 & \\
\hline 294 & 568104.94 & 135949.92 & \\
\hline 295 & 568104.94 & 136033.27 & \\
\hline 296 & 568104.94 & 135533.27 & \\
\hline 297 & 568104.94 & 136116.59 & \\
\hline 298 & 568104.94 & 135449.92 & \\
\hline 299 & 568104.94 & 135366.59 & \\
\hline 300 & 568104.94 & 136199.92 & \\
\hline 301 & 568104.94 & 136283.27 & \\
\hline 302 & 568104.94 & 135283.27 & \\
\hline 303 & 568104.94 & 136366.59 & \\
\hline 304 & 568104.94 & 135199.92 & \\
\hline 305 & 568104.94 & 135116.59 & \\
\hline 306 & 568104.94 & 136449.92 & \\
\hline 307 & 567354.94 & 136533.27 & \\
\hline 308 & 567271.62 & 136533.27 & \\
\hline 309 & 567438.31 & 136533.27 & \\
\hline 310 & 567188.31 & 136533.27 & \\
\hline 311 & 567521.62 & 136533.27 & \\
\hline 312 & 567604.94 & 136533.27 & \\
\hline 313 & 567104.94 & 136533.27 & \\
\hline 314 & 567021.62 & 136533.27 & \\
\hline 315 & 567688.31 & 136533.27 & \\
\hline 316 & 566938.31 & 136533.27 & \\
\hline 317 & 567771.62 & 136533.27 & \\
\hline 318 & 567854.94 & 136533.27 & \\
\hline 319 & 566854.94 & 136533.27 & \\
\hline 320 & 566771.62 & 136533.27 & \\
\hline 321 & 567938.31 & 136533.27 & \\
\hline 322 & 566688.31 & 136533.27 & \\
\hline 323 & 568021.62 & 136533.27 & \\
\hline 324 & 568104.94 & 136533.27 & \\
\hline 325 & 566604.94 & 135783.27 & \\
\hline 326 & 566604.94 & 135866.59 & \\
\hline 327 & 566604.94 & 135699.92 & \\
\hline 328 & 566604.94 & 135616.59 & \\
\hline 329 & 566604.94 & 135949.92 & \\
\hline 330 & 566604.94 & 136033.27 & \\
\hline 331 & 566604.94 & 135533.27 & \\
\hline 332 & 566604.94 & 136116.59 & \\
\hline 333 & 566604.94 & 135449.92 & \\
\hline 334 & 566604.94 & 135366.59 & \\
\hline 335 & 566604.94 & 136199.92 & \\
\hline 336 & 566604.94 & 136283.27 & \\
\hline
\end{tabular}




\begin{tabular}{|c|c|c|c|}
\hline node & X_coord & Y_coord & note: from sac04d created July 1, 2004 \\
\hline 337 & $5 \overline{6} 6604.94$ & $1 \overline{3} 5283.27$ & \\
\hline 338 & 566604.94 & 136366.59 & \\
\hline 339 & 566604.94 & 135199.92 & \\
\hline 340 & 566604.94 & 135116.59 & \\
\hline 341 & 566604.94 & 136449.92 & \\
\hline 342 & 566604.94 & 136533.27 & \\
\hline 343 & 567354.94 & 135033.27 & \\
\hline 344 & 567438.31 & 135033.27 & \\
\hline 345 & 567271.62 & 135033.27 & \\
\hline 346 & 567188.31 & 135033.27 & \\
\hline 347 & 567521.62 & 135033.27 & \\
\hline 348 & 567104.94 & 135033.27 & \\
\hline 349 & 567604.94 & 135033.27 & \\
\hline 350 & 567688.31 & 135033.27 & \\
\hline 351 & 567021.62 & 135033.27 & \\
\hline 352 & 566938.31 & 135033.27 & \\
\hline 353 & 567771.62 & 135033.27 & \\
\hline 354 & 566854.94 & 135033.27 & \\
\hline 355 & 567854.94 & 135033.27 & \\
\hline 356 & 567938.31 & 135033.27 & \\
\hline 357 & 566771.62 & 135033.27 & \\
\hline 358 & 566688.31 & 135033.27 & \\
\hline 359 & 568021.62 & 135033.27 & \\
\hline 360 & 566604.94 & 135033.27 & \\
\hline 361 & 568104.94 & 135033.27 & \\
\hline 362 & 568188.31 & 135783.27 & \\
\hline 363 & 568188.31 & 135866.59 & \\
\hline 364 & 568188.31 & 135699.92 & \\
\hline 365 & 568188.31 & 135949.92 & \\
\hline 366 & 568188.31 & 135616.59 & \\
\hline 367 & 568188.31 & 135533.27 & \\
\hline 368 & 568188.31 & 136033.27 & \\
\hline 369 & 568188.31 & 136116.59 & \\
\hline 370 & 568188.31 & 135449.92 & \\
\hline 371 & 568188.31 & 136199.92 & \\
\hline 372 & 568188.31 & 135366.59 & \\
\hline 373 & 568188.31 & 135283.27 & \\
\hline 374 & 568188.31 & 136283.27 & \\
\hline 375 & 568188.31 & 136366.59 & \\
\hline 376 & 568188.31 & 135199.92 & \\
\hline 377 & 568188.31 & 136449.92 & \\
\hline 378 & 568188.31 & 135116.59 & \\
\hline 379 & 568188.31 & 135033.27 & \\
\hline 380 & 568188.31 & 136533.27 & \\
\hline 381 & 567354.94 & 136616.59 & \\
\hline 382 & 567438.31 & 136616.59 & \\
\hline 383 & 567271.62 & 136616.59 & \\
\hline 384 & 567188.31 & 136616.59 & \\
\hline 385 & 567521.62 & 136616.59 & \\
\hline 386 & 567104.94 & 136616.59 & \\
\hline 387 & 567604.94 & 136616.59 & \\
\hline 388 & 567688.31 & 136616.59 & \\
\hline 389 & 567021.62 & 136616.59 & \\
\hline 390 & 566938.31 & 136616.59 & \\
\hline 391 & 567771.62 & 136616.59 & \\
\hline 392 & 566854.94 & 136616.59 & \\
\hline
\end{tabular}




\begin{tabular}{|c|c|c|c|}
\hline node & X_coord & Y_coord & note: from sac04d created July 1, 2004 \\
\hline 393 & $5 \overline{6} 7854.94$ & $1 \overline{3} 6616.59$ & \\
\hline 394 & 567938.31 & 136616.59 & \\
\hline 395 & 566771.62 & 136616.59 & \\
\hline 396 & 566688.31 & 136616.59 & \\
\hline 397 & 568021.62 & 136616.59 & \\
\hline 398 & 566604.94 & 136616.59 & \\
\hline 399 & 568104.94 & 136616.59 & \\
\hline 400 & 568188.31 & 136616.59 & \\
\hline 401 & 566521.62 & 135783.27 & \\
\hline 402 & 566521.62 & 135866.59 & \\
\hline 403 & 566521.62 & 135699.92 & \\
\hline 404 & 566521.62 & 135949.92 & \\
\hline 405 & 566521.62 & 135616.59 & \\
\hline 406 & 566521.62 & 135533.27 & \\
\hline 407 & 566521.62 & 136033.27 & \\
\hline 408 & 566521.62 & 136116.59 & \\
\hline 409 & 566521.62 & 135449.92 & \\
\hline 410 & 566521.62 & 136199.92 & \\
\hline 411 & 566521.62 & 135366.59 & \\
\hline 412 & 566521.62 & 135283.27 & \\
\hline 413 & 566521.62 & 136283.27 & \\
\hline 414 & 566521.62 & 136366.59 & \\
\hline 415 & 566521.62 & 135199.92 & \\
\hline 416 & 566521.62 & 136449.92 & \\
\hline 417 & 566521.62 & 135116.59 & \\
\hline 418 & 566521.62 & 135033.27 & \\
\hline 419 & 566521.62 & 136533.27 & \\
\hline 420 & 566521.62 & 136616.59 & \\
\hline 421 & 567354.94 & 134949.92 & \\
\hline 422 & 567271.62 & 134949.92 & \\
\hline 423 & 567438.31 & 134949.92 & \\
\hline 424 & 567521.62 & 134949.92 & \\
\hline 425 & 567188.31 & 134949.92 & \\
\hline 426 & 567104.94 & 134949.92 & \\
\hline 427 & 567604.94 & 134949.92 & \\
\hline 428 & 567021.62 & 134949.92 & \\
\hline 429 & 567688.31 & 134949.92 & \\
\hline 430 & 567771.62 & 134949.92 & \\
\hline 431 & 566938.31 & 134949.92 & \\
\hline 432 & 566854.94 & 134949.92 & \\
\hline 433 & 567854.94 & 134949.92 & \\
\hline 434 & 566771.62 & 134949.92 & \\
\hline 435 & 567938.31 & 134949.92 & \\
\hline 436 & 568021.62 & 134949.92 & \\
\hline 437 & 566688.31 & 134949.92 & \\
\hline 438 & 566604.94 & 134949.92 & \\
\hline 439 & 568104.94 & 134949.92 & \\
\hline 440 & 566521.62 & 134949.92 & \\
\hline 441 & 568188.31 & 134949.92 & \\
\hline 442 & 568271.62 & 135783.27 & \\
\hline 443 & 568271.62 & 135699.92 & \\
\hline 444 & 568271.62 & 135866.59 & \\
\hline 445 & 568271.62 & 135949.92 & \\
\hline 446 & 568271.62 & 135616.59 & \\
\hline 447 & 568271.62 & 136033.27 & \\
\hline 448 & 568271.62 & 135533.27 & \\
\hline
\end{tabular}




\begin{tabular}{|c|c|c|c|}
\hline node & X_coord & Y_coord & note: from sac04d created July 1,2004 \\
\hline 449 & $5 \overline{6} 8271.62$ & $1 \overline{3} 5449.92$ & \\
\hline 450 & 568271.62 & 136116.59 & \\
\hline 451 & 568271.62 & 136199.92 & \\
\hline 452 & 568271.62 & 135366.59 & \\
\hline 453 & 568271.62 & 136283.27 & \\
\hline 454 & 568271.62 & 135283.27 & \\
\hline 455 & 568271.62 & 135199.92 & \\
\hline 456 & 568271.62 & 136366.59 & \\
\hline 457 & 568271.62 & 136449.92 & \\
\hline 458 & 568271.62 & 135116.59 & \\
\hline 459 & 568271.62 & 136533.27 & \\
\hline 460 & 568271.62 & 135033.27 & \\
\hline 461 & 568271.62 & 134949.92 & \\
\hline 462 & 568271.62 & 136616.59 & \\
\hline 463 & 567354.94 & 136699.92 & \\
\hline 464 & 567271.62 & 136699.92 & \\
\hline 465 & 567438.31 & 136699.92 & \\
\hline 466 & 567521.62 & 136699.92 & \\
\hline 467 & 567188.31 & 136699.92 & \\
\hline 468 & 567104.94 & 136699.92 & \\
\hline 469 & 567604.94 & 136699.92 & \\
\hline 470 & 567021.62 & 136699.92 & \\
\hline 471 & 567688.31 & 136699.92 & \\
\hline 472 & 567771.62 & 136699.92 & \\
\hline 473 & 566938.31 & 136699.92 & \\
\hline 474 & 566854.94 & 136699.92 & \\
\hline 475 & 567854.94 & 136699.92 & \\
\hline 476 & 566771.62 & 136699.92 & \\
\hline 477 & 567938.31 & 136699.92 & \\
\hline 478 & 568021.62 & 136699.92 & \\
\hline 479 & 566688.31 & 136699.92 & \\
\hline 480 & 566604.94 & 136699.92 & \\
\hline 481 & 568104.94 & 136699.92 & \\
\hline 482 & 566521.62 & 136699.92 & \\
\hline 483 & 568188.31 & 136699.92 & \\
\hline 484 & 568271.62 & 136699.92 & \\
\hline 485 & 566438.31 & 135783.27 & \\
\hline 486 & 566438.31 & 135699.92 & \\
\hline 487 & 566438.31 & 135866.59 & \\
\hline 488 & 566438.31 & 135949.92 & \\
\hline 489 & 566438.31 & 135616.59 & \\
\hline 490 & 566438.31 & 136033.27 & \\
\hline 491 & 566438.31 & 135533.27 & \\
\hline 492 & 566438.31 & 135449.92 & \\
\hline 493 & 566438.31 & 136116.59 & \\
\hline 494 & 566438.31 & 136199.92 & \\
\hline 495 & 566438.31 & 135366.59 & \\
\hline 496 & 566438.31 & 136283.27 & \\
\hline 497 & 566438.31 & 135283.27 & \\
\hline 498 & 566438.31 & 135199.92 & \\
\hline 499 & 566438.31 & 136366.59 & \\
\hline 500 & 566438.31 & 136449.92 & \\
\hline 501 & 566438.31 & 135116.59 & \\
\hline 502 & 566438.31 & 136533.27 & \\
\hline 503 & 566438.31 & 135033.27 & \\
\hline 504 & 566438.31 & 134949.92 & \\
\hline
\end{tabular}




\begin{tabular}{|c|c|c|c|}
\hline node & X_coord & Y_coord & note: from sac04d created July 1, 2004 \\
\hline 505 & $5 \overline{6} 6438.31$ & $1 \overline{3} 6616.59$ & \\
\hline 506 & 566438.31 & 136699.92 & \\
\hline 507 & 567354.94 & 134866.59 & \\
\hline 508 & 567271.62 & 134866.59 & \\
\hline 509 & 567438.31 & 134866.59 & \\
\hline 510 & 567188.31 & 134866.59 & \\
\hline 511 & 567521.62 & 134866.59 & \\
\hline 512 & 567604.94 & 134866.59 & \\
\hline 513 & 567104.94 & 134866.59 & \\
\hline 514 & 567021.62 & 134866.59 & \\
\hline 515 & 567688.31 & 134866.59 & \\
\hline 516 & 566938.31 & 134866.59 & \\
\hline 517 & 567771.62 & 134866.59 & \\
\hline 518 & 567854.94 & 134866.59 & \\
\hline 519 & 566854.94 & 134866.59 & \\
\hline 520 & 566771.62 & 134866.59 & \\
\hline 521 & 567938.31 & 134866.59 & \\
\hline 522 & 566688.31 & 134866.59 & \\
\hline 523 & 568021.62 & 134866.59 & \\
\hline 524 & 568104.94 & 134866.59 & \\
\hline 525 & 566604.94 & 134866.59 & \\
\hline 526 & 566521.62 & 134866.59 & \\
\hline 527 & 568188.31 & 134866.59 & \\
\hline 528 & 566438.31 & 134866.59 & \\
\hline 529 & 568271.62 & 134866.59 & \\
\hline 530 & 568354.94 & 135783.27 & \\
\hline 531 & 568354.94 & 135866.59 & \\
\hline 532 & 568354.94 & 135699.92 & \\
\hline 533 & 568354.94 & 135616.59 & \\
\hline 534 & 568354.94 & 135949.92 & \\
\hline 535 & 568354.94 & 136033.27 & \\
\hline 536 & 568354.94 & 135533.27 & \\
\hline 537 & 568354.94 & 136116.59 & \\
\hline 538 & 568354.94 & 135449.92 & \\
\hline 539 & 568354.94 & 135366.59 & \\
\hline 540 & 568354.94 & 136199.92 & \\
\hline 541 & 568354.94 & 136283.27 & \\
\hline 542 & 568354.94 & 135283.27 & \\
\hline 543 & 568354.94 & 136366.59 & \\
\hline 544 & 568354.94 & 135199.92 & \\
\hline 545 & 568354.94 & 135116.59 & \\
\hline 546 & 568354.94 & 136449.92 & \\
\hline 547 & 568354.94 & 136533.27 & \\
\hline 548 & 568354.94 & 135033.27 & \\
\hline 549 & 568354.94 & 136616.59 & \\
\hline 550 & 568354.94 & 134949.92 & \\
\hline 551 & 568354.94 & 134866.59 & \\
\hline 552 & 568354.94 & 136699.92 & \\
\hline 553 & 567354.94 & 136783.27 & \\
\hline 554 & 567271.62 & 136783.27 & \\
\hline 555 & 567438.31 & 136783.27 & \\
\hline 556 & 567188.31 & 136783.27 & \\
\hline 557 & 567521.62 & 136783.27 & \\
\hline 558 & 567604.94 & 136783.27 & \\
\hline 559 & 567104.94 & 136783.27 & \\
\hline 560 & 567021.62 & 136783.27 & \\
\hline
\end{tabular}




\begin{tabular}{|c|c|c|c|}
\hline node & X_coord & Y_coord & note: from sac04d created July 1, 2004 \\
\hline 561 & $5 \overline{6} 7688.31$ & $1 \overline{3} 6783.27$ & \\
\hline 562 & 566938.31 & 136783.27 & \\
\hline 563 & 567771.62 & 136783.27 & \\
\hline 564 & 567854.94 & 136783.27 & \\
\hline 565 & 566854.94 & 136783.27 & \\
\hline 566 & 566771.62 & 136783.27 & \\
\hline 567 & 567938.31 & 136783.27 & \\
\hline 568 & 566688.31 & 136783.27 & \\
\hline 569 & 568021.62 & 136783.27 & \\
\hline 570 & 568104.94 & 136783.27 & \\
\hline 571 & 566604.94 & 136783.27 & \\
\hline 572 & 566521.62 & 136783.27 & \\
\hline 573 & 568188.31 & 136783.27 & \\
\hline 574 & 566438.31 & 136783.27 & \\
\hline 575 & 568271.62 & 136783.27 & \\
\hline 576 & 568354.94 & 136783.27 & \\
\hline 577 & 566354.94 & 135783.27 & \\
\hline 578 & 566354.94 & 135866.59 & \\
\hline 579 & 566354.94 & 135699.92 & \\
\hline 580 & 566354.94 & 135616.59 & \\
\hline 581 & 566354.94 & 135949.92 & \\
\hline 582 & 566354.94 & 136033.27 & \\
\hline 583 & 566354.94 & 135533.27 & \\
\hline 584 & 566354.94 & 136116.59 & \\
\hline 585 & 566354.94 & 135449.92 & \\
\hline 586 & 566354.94 & 135366.59 & \\
\hline 587 & 566354.94 & 136199.92 & \\
\hline 588 & 566354.94 & 136283.27 & \\
\hline 589 & 566354.94 & 135283.27 & \\
\hline 590 & 566354.94 & 136366.59 & \\
\hline 591 & 566354.94 & 135199.92 & \\
\hline 592 & 566354.94 & 135116.59 & \\
\hline 593 & 566354.94 & 136449.92 & \\
\hline 594 & 566354.94 & 136533.27 & \\
\hline 595 & 566354.94 & 135033.27 & \\
\hline 596 & 566354.94 & 136616.59 & \\
\hline 597 & 566354.94 & 134949.92 & \\
\hline 598 & 566354.94 & 134866.59 & \\
\hline 599 & 566354.94 & 136699.92 & \\
\hline 600 & 566354.94 & 136783.27 & \\
\hline 601 & 567354.94 & 134783.27 & \\
\hline 602 & 567438.31 & 134783.27 & \\
\hline 603 & 567271.62 & 134783.27 & \\
\hline 604 & 567188.31 & 134783.27 & \\
\hline 605 & 567521.62 & 134783.27 & \\
\hline 606 & 567104.94 & 134783.27 & \\
\hline 607 & 567604.94 & 134783.27 & \\
\hline 608 & 567688.31 & 134783.27 & \\
\hline 609 & 567021.62 & 134783.27 & \\
\hline 610 & 566938.31 & 134783.27 & \\
\hline 611 & 567771.62 & 134783.27 & \\
\hline 612 & 566854.94 & 134783.27 & \\
\hline 613 & 567854.94 & 134783.27 & \\
\hline 614 & 567938.31 & 134783.27 & \\
\hline 615 & 566771.62 & 134783.27 & \\
\hline 616 & 566688.31 & 134783.27 & \\
\hline
\end{tabular}




\begin{tabular}{|c|c|c|c|}
\hline node & X_coord & Y_coord & note: from sac04d created July 1, 2004 \\
\hline 617 & $5 \overline{6} 8021.62$ & $1 \overline{3} 4783.27$ & \\
\hline 618 & 566604.94 & 134783.27 & \\
\hline 619 & 568104.94 & 134783.27 & \\
\hline 620 & 568188.31 & 134783.27 & \\
\hline 621 & 566521.62 & 134783.27 & \\
\hline 622 & 566438.31 & 134783.27 & \\
\hline 623 & 568271.62 & 134783.27 & \\
\hline 624 & 566354.94 & 134783.27 & \\
\hline 625 & 568354.94 & 134783.27 & \\
\hline 626 & 568438.31 & 135783.27 & \\
\hline 627 & 568438.31 & 135866.59 & \\
\hline 628 & 568438.31 & 135699.92 & \\
\hline 629 & 568438.31 & 135949.92 & \\
\hline 630 & 568438.31 & 135616.59 & \\
\hline 631 & 568438.31 & 135533.27 & \\
\hline 632 & 568438.31 & 136033.27 & \\
\hline 633 & 568438.31 & 136116.59 & \\
\hline 634 & 568438.31 & 135449.92 & \\
\hline 635 & 568438.31 & 136199.92 & \\
\hline 636 & 568438.31 & 135366.59 & \\
\hline 637 & 568438.31 & 135283.27 & \\
\hline 638 & 568438.31 & 136283.27 & \\
\hline 639 & 568438.31 & 136366.59 & \\
\hline 640 & 568438.31 & 135199.92 & \\
\hline 641 & 568438.31 & 136449.92 & \\
\hline 642 & 568438.31 & 135116.59 & \\
\hline 643 & 568438.31 & 135033.27 & \\
\hline 644 & 568438.31 & 136533.27 & \\
\hline 645 & 568438.31 & 136616.59 & \\
\hline 646 & 568438.31 & 134949.92 & \\
\hline 647 & 568438.31 & 136699.92 & \\
\hline 648 & 568438.31 & 134866.59 & \\
\hline 649 & 568438.31 & 134783.27 & \\
\hline 650 & 568438.31 & 136783.27 & \\
\hline 651 & 567354.94 & 136866.59 & \\
\hline 652 & 567438.31 & 136866.59 & \\
\hline 653 & 567271.62 & 136866.59 & \\
\hline 654 & 567188.31 & 136866.59 & \\
\hline 655 & 567521.62 & 136866.59 & \\
\hline 656 & 567104.94 & 136866.59 & \\
\hline 657 & 567604.94 & 136866.59 & \\
\hline 658 & 567688.31 & 136866.59 & \\
\hline 659 & 567021.62 & 136866.59 & \\
\hline 660 & 566938.31 & 136866.59 & \\
\hline 661 & 567771.62 & 136866.59 & \\
\hline 662 & 566854.94 & 136866.59 & \\
\hline 663 & 567854.94 & 136866.59 & \\
\hline 664 & 567938.31 & 136866.59 & \\
\hline 665 & 566771.62 & 136866.59 & \\
\hline 666 & 566688.31 & 136866.59 & \\
\hline 667 & 568021.62 & 136866.59 & \\
\hline 668 & 566604.94 & 136866.59 & \\
\hline 669 & 568104.94 & 136866.59 & \\
\hline 670 & 568188.31 & 136866.59 & \\
\hline 671 & 566521.62 & 136866.59 & \\
\hline 672 & 566438.31 & 136866.59 & \\
\hline
\end{tabular}




\begin{tabular}{|c|c|c|c|}
\hline node & X_coord & Y_coord & note: from sac04d created July 1,2004 \\
\hline 673 & $5 \overline{6} 8271.62$ & $1 \overline{3} 6866.59$ & \\
\hline 674 & 566354.94 & 136866.59 & \\
\hline 675 & 568354.94 & 136866.59 & \\
\hline 676 & 568438.31 & 136866.59 & \\
\hline 677 & 566271.62 & 135783.27 & \\
\hline 678 & 566271.62 & 135866.59 & \\
\hline 679 & 566271.62 & 135699.92 & \\
\hline 680 & 566271.62 & 135949.92 & \\
\hline 681 & 566271.62 & 135616.59 & \\
\hline 682 & 566271.62 & 135533.27 & \\
\hline 683 & 566271.62 & 136033.27 & \\
\hline 684 & 566271.62 & 136116.59 & \\
\hline 685 & 566271.62 & 135449.92 & \\
\hline 686 & 566271.62 & 136199.92 & \\
\hline 687 & 566271.62 & 135366.59 & \\
\hline 688 & 566271.62 & 135283.27 & \\
\hline 689 & 566271.62 & 136283.27 & \\
\hline 690 & 566271.62 & 136366.59 & \\
\hline 691 & 566271.62 & 135199.92 & \\
\hline 692 & 566271.62 & 136449.92 & \\
\hline 693 & 566271.62 & 135116.59 & \\
\hline 694 & 566271.62 & 135033.27 & \\
\hline 695 & 566271.62 & 136533.27 & \\
\hline 696 & 566271.62 & 136616.59 & \\
\hline 697 & 566271.62 & 134949.92 & \\
\hline 698 & 566271.62 & 136699.92 & \\
\hline 699 & 566271.62 & 134866.59 & \\
\hline 700 & 566271.62 & 134783.27 & \\
\hline 701 & 566271.62 & 136783.27 & \\
\hline 702 & 566271.62 & 136866.59 & \\
\hline 703 & 567354.94 & 134699.92 & \\
\hline 704 & 567271.62 & 134699.92 & \\
\hline 705 & 567438.31 & 134699.92 & \\
\hline 706 & 567521.62 & 134699.92 & \\
\hline 707 & 567188.31 & 134699.92 & \\
\hline 708 & 567104.94 & 134699.92 & \\
\hline 709 & 567604.94 & 134699.92 & \\
\hline 710 & 567021.62 & 134699.92 & \\
\hline 711 & 567688.31 & 134699.92 & \\
\hline 712 & 567771.62 & 134699.92 & \\
\hline 713 & 566938.31 & 134699.92 & \\
\hline 714 & 566854.94 & 134699.92 & \\
\hline 715 & 567854.94 & 134699.92 & \\
\hline 716 & 566771.62 & 134699.92 & \\
\hline 717 & 567938.31 & 134699.92 & \\
\hline 718 & 568021.62 & 134699.92 & \\
\hline 719 & 566688.31 & 134699.92 & \\
\hline 720 & 566604.94 & 134699.92 & \\
\hline 721 & 568104.94 & 134699.92 & \\
\hline 722 & 566521.62 & 134699.92 & \\
\hline 723 & 568188.31 & 134699.92 & \\
\hline 724 & 568271.62 & 134699.92 & \\
\hline 725 & 566438.31 & 134699.92 & \\
\hline 726 & 566354.94 & 134699.92 & \\
\hline 727 & 568354.94 & 134699.92 & \\
\hline 728 & 566271.62 & 134699.92 & \\
\hline
\end{tabular}




\begin{tabular}{|c|c|c|c|}
\hline node & X_coord & Y_coord & note: from sac04d created July 1, 2004 \\
\hline 729 & $5 \overline{6} 8438.31$ & $1 \overline{3} 4699.92$ & \\
\hline 730 & 568521.62 & 135783.27 & \\
\hline 731 & 568521.62 & 135699.92 & \\
\hline 732 & 568521.62 & 135866.59 & \\
\hline 733 & 568521.62 & 135949.92 & \\
\hline 734 & 568521.62 & 135616.59 & \\
\hline 735 & 568521.62 & 136033.27 & \\
\hline 736 & 568521.62 & 135533.27 & \\
\hline 737 & 568521.62 & 135449.92 & \\
\hline 738 & 568521.62 & 136116.59 & \\
\hline 739 & 568521.62 & 136199.92 & \\
\hline 740 & 568521.62 & 135366.59 & \\
\hline 741 & 568521.62 & 136283.27 & \\
\hline 742 & 568521.62 & 135283.27 & \\
\hline 743 & 568521.62 & 135199.92 & \\
\hline 744 & 568521.62 & 136366.59 & \\
\hline 745 & 568521.62 & 136449.92 & \\
\hline 746 & 568521.62 & 135116.59 & \\
\hline 747 & 568521.62 & 136533.27 & \\
\hline 748 & 568521.62 & 135033.27 & \\
\hline 749 & 568521.62 & 134949.92 & \\
\hline 750 & 568521.62 & 136616.59 & \\
\hline 751 & 568521.62 & 136699.92 & \\
\hline 752 & 568521.62 & 134866.59 & \\
\hline 753 & 568521.62 & 136783.27 & \\
\hline 754 & 568521.62 & 134783.27 & \\
\hline 755 & 568521.62 & 134699.92 & \\
\hline 756 & 568521.62 & 136866.59 & \\
\hline 757 & 567354.94 & 136949.92 & \\
\hline 758 & 567271.62 & 136949.92 & \\
\hline 759 & 567438.31 & 136949.92 & \\
\hline 760 & 567521.62 & 136949.92 & \\
\hline 761 & 567188.31 & 136949.92 & \\
\hline 762 & 567104.94 & 136949.92 & \\
\hline 763 & 567604.94 & 136949.92 & \\
\hline 764 & 567021.62 & 136949.92 & \\
\hline 765 & 567688.31 & 136949.92 & \\
\hline 766 & 567771.62 & 136949.92 & \\
\hline 767 & 566938.31 & 136949.92 & \\
\hline 768 & 566854.94 & 136949.92 & \\
\hline 769 & 567854.94 & 136949.92 & \\
\hline 770 & 566771.62 & 136949.92 & \\
\hline 771 & 567938.31 & 136949.92 & \\
\hline 772 & 568021.62 & 136949.92 & \\
\hline 773 & 566688.31 & 136949.92 & \\
\hline 774 & 566604.94 & 136949.92 & \\
\hline 775 & 568104.94 & 136949.92 & \\
\hline 776 & 566521.62 & 136949.92 & \\
\hline 777 & 568188.31 & 136949.92 & \\
\hline 778 & 568271.62 & 136949.92 & \\
\hline 779 & 566438.31 & 136949.92 & \\
\hline 780 & 566354.94 & 136949.92 & \\
\hline 781 & 568354.94 & 136949.92 & \\
\hline 782 & 566271.62 & 136949.92 & \\
\hline 783 & 568438.31 & 136949.92 & \\
\hline 784 & 568521.62 & 136949.92 & \\
\hline
\end{tabular}




\begin{tabular}{|c|c|c|c|}
\hline node & X_coord & Y_coord & note: from sac04d created July 1, 2004 \\
\hline 785 & $5 \overline{6} 6188.31$ & $1 \overline{3} 5783.27$ & \\
\hline 786 & 566188.31 & 135699.92 & \\
\hline 787 & 566188.31 & 135866.59 & \\
\hline 788 & 566188.31 & 135949.92 & \\
\hline 789 & 566188.31 & 135616.59 & \\
\hline 790 & 566188.31 & 136033.27 & \\
\hline 791 & 566188.31 & 135533.27 & \\
\hline 792 & 566188.31 & 135449.92 & \\
\hline 793 & 566188.31 & 136116.59 & \\
\hline 794 & 566188.31 & 136199.92 & \\
\hline 795 & 566188.31 & 135366.59 & \\
\hline 796 & 566188.31 & 136283.27 & \\
\hline 797 & 566188.31 & 135283.27 & \\
\hline 798 & 566188.31 & 135199.92 & \\
\hline 799 & 566188.31 & 136366.59 & \\
\hline 800 & 566188.31 & 136449.92 & \\
\hline 801 & 566188.31 & 135116.59 & \\
\hline 802 & 566188.31 & 136533.27 & \\
\hline 803 & 566188.31 & 135033.27 & \\
\hline 804 & 566188.31 & 134949.92 & \\
\hline 805 & 566188.31 & 136616.59 & \\
\hline 806 & 566188.31 & 136699.92 & \\
\hline 807 & 566188.31 & 134866.59 & \\
\hline 808 & 566188.31 & 136783.27 & \\
\hline 809 & 566188.31 & 134783.27 & \\
\hline 810 & 566188.31 & 134699.92 & \\
\hline 811 & 566188.31 & 136866.59 & \\
\hline 812 & 566188.31 & 136949.92 & \\
\hline 813 & 567354.94 & 134616.59 & \\
\hline 814 & 567271.62 & 134616.59 & \\
\hline 815 & 567438.31 & 134616.59 & \\
\hline 816 & 567188.31 & 134616.59 & \\
\hline 817 & 567521.62 & 134616.59 & \\
\hline 818 & 567604.94 & 134616.59 & \\
\hline 819 & 567104.94 & 134616.59 & \\
\hline 820 & 567021.62 & 134616.59 & \\
\hline 821 & 567688.31 & 134616.59 & \\
\hline 822 & 566938.31 & 134616.59 & \\
\hline 823 & 567771.62 & 134616.59 & \\
\hline 824 & 567854.94 & 134616.59 & \\
\hline 825 & 566854.94 & 134616.59 & \\
\hline 826 & 566771.62 & 134616.59 & \\
\hline 827 & 567938.31 & 134616.59 & \\
\hline 828 & 566688.31 & 134616.59 & \\
\hline 829 & 568021.62 & 134616.59 & \\
\hline 830 & 568104.94 & 134616.59 & \\
\hline 831 & 566604.94 & 134616.59 & \\
\hline 832 & 566521.62 & 134616.59 & \\
\hline 833 & 568188.31 & 134616.59 & \\
\hline 834 & 566438.31 & 134616.59 & \\
\hline 835 & 568271.62 & 134616.59 & \\
\hline 836 & 568354.94 & 134616.59 & \\
\hline 837 & 566354.94 & 134616.59 & \\
\hline 838 & 566271.62 & 134616.59 & \\
\hline 839 & 568438.31 & 134616.59 & \\
\hline 840 & 566188.31 & 134616.59 & \\
\hline
\end{tabular}




\begin{tabular}{|c|c|c|c|}
\hline node & X_coord & Y_coord & note: from sac04d created July 1, 2004 \\
\hline 841 & $5 \overline{6} 8521.62$ & $1 \overline{3} 4616.59$ & \\
\hline 842 & 568604.94 & 135783.27 & \\
\hline 843 & 568604.94 & 135866.59 & \\
\hline 844 & 568604.94 & 135699.92 & \\
\hline 845 & 568604.94 & 135616.59 & \\
\hline 846 & 568604.94 & 135949.92 & \\
\hline 847 & 568604.94 & 136033.27 & \\
\hline 848 & 568604.94 & 135533.27 & \\
\hline 849 & 568604.94 & 136116.59 & \\
\hline 850 & 568604.94 & 135449.92 & \\
\hline 851 & 568604.94 & 135366.59 & \\
\hline 852 & 568604.94 & 136199.92 & \\
\hline 853 & 568604.94 & 136283.27 & \\
\hline 854 & 568604.94 & 135283.27 & \\
\hline 855 & 568604.94 & 136366.59 & \\
\hline 856 & 568604.94 & 135199.92 & \\
\hline 857 & 568604.94 & 135116.59 & \\
\hline 858 & 568604.94 & 136449.92 & \\
\hline 859 & 568604.94 & 136533.27 & \\
\hline 860 & 568604.94 & 135033.27 & \\
\hline 861 & 568604.94 & 136616.59 & \\
\hline 862 & 568604.94 & 134949.92 & \\
\hline 863 & 568604.94 & 134866.59 & \\
\hline 864 & 568604.94 & 136699.92 & \\
\hline 865 & 568604.94 & 136783.27 & \\
\hline 866 & 568604.94 & 134783.27 & \\
\hline 867 & 568604.94 & 136866.59 & \\
\hline 868 & 568604.94 & 134699.92 & \\
\hline 869 & 568604.94 & 134616.59 & \\
\hline 870 & 568604.94 & 136949.92 & \\
\hline 871 & 567354.94 & 137033.27 & \\
\hline 872 & 567271.62 & 137033.27 & \\
\hline 873 & 567438.31 & 137033.27 & \\
\hline 874 & 567188.31 & 137033.27 & \\
\hline 875 & 567521.62 & 137033.27 & \\
\hline 876 & 567604.94 & 137033.27 & \\
\hline 877 & 567104.94 & 137033.27 & \\
\hline 878 & 567021.62 & 137033.27 & \\
\hline 879 & 567688.31 & 137033.27 & \\
\hline 880 & 566938.31 & 137033.27 & \\
\hline 881 & 567771.62 & 137033.27 & \\
\hline 882 & 567854.94 & 137033.27 & \\
\hline 883 & 566854.94 & 137033.27 & \\
\hline 884 & 566771.62 & 137033.27 & \\
\hline 885 & 567938.31 & 137033.27 & \\
\hline 886 & 566688.31 & 137033.27 & \\
\hline 887 & 568021.62 & 137033.27 & \\
\hline 888 & 568104.94 & 137033.27 & \\
\hline 889 & 566604.94 & 137033.27 & \\
\hline 890 & 566521.62 & 137033.27 & \\
\hline 891 & 568188.31 & 137033.27 & \\
\hline 892 & 566438.31 & 137033.27 & \\
\hline 893 & 568271.62 & 137033.27 & \\
\hline 894 & 568354.94 & 137033.27 & \\
\hline 895 & 566354.94 & 137033.27 & \\
\hline 896 & 566271.62 & 137033.27 & \\
\hline
\end{tabular}




\begin{tabular}{|c|c|c|c|}
\hline node & X_coord & Y_coord & note: from sac04d created July 1,2004 \\
\hline 897 & $5 \overline{6} 8438.31$ & $1 \overline{3} 7033.27$ & \\
\hline 898 & 566188.31 & 137033.27 & \\
\hline 899 & 568521.62 & 137033.27 & \\
\hline 900 & 568604.94 & 137033.27 & \\
\hline 901 & 566104.94 & 135783.27 & \\
\hline 902 & 566104.94 & 135866.59 & \\
\hline 903 & 566104.94 & 135699.92 & \\
\hline 904 & 566104.94 & 135616.59 & \\
\hline 905 & 566104.94 & 135949.92 & \\
\hline 906 & 566104.94 & 136033.27 & \\
\hline 907 & 566104.94 & 135533.27 & \\
\hline 908 & 566104.94 & 136116.59 & \\
\hline 909 & 566104.94 & 135449.92 & \\
\hline 910 & 566104.94 & 135366.59 & \\
\hline 911 & 566104.94 & 136199.92 & \\
\hline 912 & 566104.94 & 136283.27 & \\
\hline 913 & 566104.94 & 135283.27 & \\
\hline 914 & 566104.94 & 136366.59 & \\
\hline 915 & 566104.94 & 135199.92 & \\
\hline 916 & 566104.94 & 135116.59 & \\
\hline 917 & 566104.94 & 136449.92 & \\
\hline 918 & 566104.94 & 136533.27 & \\
\hline 919 & 566104.94 & 135033.27 & \\
\hline 920 & 566104.94 & 136616.59 & \\
\hline 921 & 566104.94 & 134949.92 & \\
\hline 922 & 566104.94 & 134866.59 & \\
\hline 923 & 566104.94 & 136699.92 & \\
\hline 924 & 566104.94 & 136783.27 & \\
\hline 925 & 566104.94 & 134783.27 & \\
\hline 926 & 566104.94 & 136866.59 & \\
\hline 927 & 566104.94 & 134699.92 & \\
\hline 928 & 566104.94 & 134616.59 & \\
\hline 929 & 566104.94 & 136949.92 & \\
\hline 930 & 566104.94 & 137033.27 & \\
\hline 931 & 567354.94 & 134533.27 & \\
\hline 932 & 567438.31 & 134533.27 & \\
\hline 933 & 567271.62 & 134533.27 & \\
\hline 934 & 567188.31 & 134533.27 & \\
\hline 935 & 567521.62 & 134533.27 & \\
\hline 936 & 567104.94 & 134533.27 & \\
\hline 937 & 567604.94 & 134533.27 & \\
\hline 938 & 567688.31 & 134533.27 & \\
\hline 939 & 567021.62 & 134533.27 & \\
\hline 940 & 566938.31 & 134533.27 & \\
\hline 941 & 567771.62 & 134533.27 & \\
\hline 942 & 566854.94 & 134533.27 & \\
\hline 943 & 567854.94 & 134533.27 & \\
\hline 944 & 567938.31 & 134533.27 & \\
\hline 945 & 566771.62 & 134533.27 & \\
\hline 946 & 566688.31 & 134533.27 & \\
\hline 947 & 568021.62 & 134533.27 & \\
\hline 948 & 566604.94 & 134533.27 & \\
\hline 949 & 568104.94 & 134533.27 & \\
\hline 950 & 568188.31 & 134533.27 & \\
\hline 951 & 566521.62 & 134533.27 & \\
\hline 952 & 566438.31 & 134533.27 & \\
\hline
\end{tabular}




\begin{tabular}{|c|c|c|c|}
\hline node & X_coord & Y_coord & note: from sac04d created July 1, 2004 \\
\hline 953 & $5 \overline{6} 8271.62$ & $1 \overline{3} 4533.27$ & \\
\hline 954 & 566354.94 & 134533.27 & \\
\hline 955 & 568354.94 & 134533.27 & \\
\hline 956 & 568438.31 & 134533.27 & \\
\hline 957 & 566271.62 & 134533.27 & \\
\hline 958 & 566188.31 & 134533.27 & \\
\hline 959 & 568521.62 & 134533.27 & \\
\hline 960 & 566104.94 & 134533.27 & \\
\hline 961 & 568604.94 & 134533.27 & \\
\hline 962 & 568688.31 & 135783.27 & \\
\hline 963 & 568688.31 & 135866.59 & \\
\hline 964 & 568688.31 & 135699.92 & \\
\hline 965 & 568688.31 & 135949.92 & \\
\hline 966 & 568688.31 & 135616.59 & \\
\hline 967 & 568688.31 & 135533.27 & \\
\hline 968 & 568688.31 & 136033.27 & \\
\hline 969 & 568688.31 & 136116.59 & \\
\hline 970 & 568688.31 & 135449.92 & \\
\hline 971 & 568688.31 & 136199.92 & \\
\hline 972 & 568688.31 & 135366.59 & \\
\hline 973 & 568688.31 & 135283.27 & \\
\hline 974 & 568688.31 & 136283.27 & \\
\hline 975 & 568688.31 & 136366.59 & \\
\hline 976 & 568688.31 & 135199.92 & \\
\hline 977 & 568688.31 & 136449.92 & \\
\hline 978 & 568688.31 & 135116.59 & \\
\hline 979 & 568688.31 & 135033.27 & \\
\hline 980 & 568688.31 & 136533.27 & \\
\hline 981 & 568688.31 & 136616.59 & \\
\hline 982 & 568688.31 & 134949.92 & \\
\hline 983 & 568688.31 & 136699.92 & \\
\hline 984 & 568688.31 & 134866.59 & \\
\hline 985 & 568688.31 & 134783.27 & \\
\hline 986 & 568688.31 & 136783.27 & \\
\hline 987 & 568688.31 & 136866.59 & \\
\hline 988 & 568688.31 & 134699.92 & \\
\hline 989 & 568688.31 & 136949.92 & \\
\hline 990 & 568688.31 & 134616.59 & \\
\hline 991 & 568688.31 & 134533.27 & \\
\hline 992 & 568688.31 & 137033.27 & \\
\hline 993 & 567354.94 & 137116.59 & \\
\hline 994 & 567438.31 & 137116.59 & \\
\hline 995 & 567271.62 & 137116.59 & \\
\hline 996 & 567188.31 & 137116.59 & \\
\hline 997 & 567521.62 & 137116.59 & \\
\hline 998 & 567104.94 & 137116.59 & \\
\hline 999 & 567604.94 & 137116.59 & \\
\hline 1000 & 567688.31 & 137116.59 & \\
\hline 1001 & 567021.62 & 137116.59 & \\
\hline 1002 & 566938.31 & 137116.59 & \\
\hline 1003 & 567771.62 & 137116.59 & \\
\hline 1004 & 566854.94 & 137116.59 & \\
\hline 1005 & 567854.94 & 137116.59 & \\
\hline 1006 & 567938.31 & 137116.59 & \\
\hline 1007 & 566771.62 & 137116.59 & \\
\hline 1008 & 566688.31 & 137116.59 & \\
\hline
\end{tabular}




\begin{tabular}{|c|c|c|c|}
\hline node & X_coord & Y_coord & note: from sac04d created July 1, 2004 \\
\hline 1009 & $5 \overline{6} 8021.62$ & $1 \overline{3} 7116.59$ & \\
\hline 1010 & 566604.94 & 137116.59 & \\
\hline 1011 & 568104.94 & 137116.59 & \\
\hline 1012 & 568188.31 & 137116.59 & \\
\hline 1013 & 566521.62 & 137116.59 & \\
\hline 1014 & 566438.31 & 137116.59 & \\
\hline 1015 & 568271.62 & 137116.59 & \\
\hline 1016 & 566354.94 & 137116.59 & \\
\hline 1017 & 568354.94 & 137116.59 & \\
\hline 1018 & 568438.31 & 137116.59 & \\
\hline 1019 & 566271.62 & 137116.59 & \\
\hline 1020 & 566188.31 & 137116.59 & \\
\hline 1021 & 568521.62 & 137116.59 & \\
\hline 1022 & 566104.94 & 137116.59 & \\
\hline 1023 & 568604.94 & 137116.59 & \\
\hline 1024 & 568688.31 & 137116.59 & \\
\hline 1025 & 566021.62 & 135783.27 & \\
\hline 1026 & 566021.62 & 135866.59 & \\
\hline 1027 & 566021.62 & 135699.92 & \\
\hline 1028 & 566021.62 & 135949.92 & \\
\hline 1029 & 566021.62 & 135616.59 & \\
\hline 1030 & 566021.62 & 135533.27 & \\
\hline 1031 & 566021.62 & 136033.27 & \\
\hline 1032 & 566021.62 & 136116.59 & \\
\hline 1033 & 566021.62 & 135449.92 & \\
\hline 1034 & 566021.62 & 136199.92 & \\
\hline 1035 & 566021.62 & 135366.59 & \\
\hline 1036 & 566021.62 & 135283.27 & \\
\hline 1037 & 566021.62 & 136283.27 & \\
\hline 1038 & 566021.62 & 136366.59 & \\
\hline 1039 & 566021.62 & 135199.92 & \\
\hline 1040 & 566021.62 & 136449.92 & \\
\hline 1041 & 566021.62 & 135116.59 & \\
\hline 1042 & 566021.62 & 135033.27 & \\
\hline 1043 & 566021.62 & 136533.27 & \\
\hline 1044 & 566021.62 & 136616.59 & \\
\hline 1045 & 566021.62 & 134949.92 & \\
\hline 1046 & 566021.62 & 136699.92 & \\
\hline 1047 & 566021.62 & 134866.59 & \\
\hline 1048 & 566021.62 & 134783.27 & \\
\hline 1049 & 566021.62 & 136783.27 & \\
\hline 1050 & 566021.62 & 136866.59 & \\
\hline 1051 & 566021.62 & 134699.92 & \\
\hline 1052 & 566021.62 & 136949.92 & \\
\hline 1053 & 566021.62 & 134616.59 & \\
\hline 1054 & 566021.62 & 134533.27 & \\
\hline 1055 & 566021.62 & 137033.27 & \\
\hline 1056 & 566021.62 & 137116.59 & \\
\hline 1057 & 567354.94 & 134449.92 & \\
\hline 1058 & 567271.62 & 134449.92 & \\
\hline 1059 & 567438.31 & 134449.92 & \\
\hline 1060 & 567521.62 & 134449.92 & \\
\hline 1061 & 567188.31 & 134449.92 & \\
\hline 1062 & 567104.94 & 134449.92 & \\
\hline 1063 & 567604.94 & 134449.92 & \\
\hline 1064 & 567021.62 & 134449.92 & \\
\hline
\end{tabular}




\begin{tabular}{|c|c|c|c|}
\hline node & X_coord & Y_coord & note: from sac04d created July 1,2004 \\
\hline 1065 & $5 \overline{6} 7688.31$ & $1 \overline{3} 4449.92$ & \\
\hline 1066 & 567771.62 & 134449.92 & \\
\hline 1067 & 566938.31 & 134449.92 & \\
\hline 1068 & 566854.94 & 134449.92 & \\
\hline 1069 & 567854.94 & 134449.92 & \\
\hline 1070 & 566771.62 & 134449.92 & \\
\hline 1071 & 567938.31 & 134449.92 & \\
\hline 1072 & 568021.62 & 134449.92 & \\
\hline 1073 & 566688.31 & 134449.92 & \\
\hline 1074 & 566604.94 & 134449.92 & \\
\hline 1075 & 568104.94 & 134449.92 & \\
\hline 1076 & 566521.62 & 134449.92 & \\
\hline 1077 & 568188.31 & 134449.92 & \\
\hline 1078 & 568271.62 & 134449.92 & \\
\hline 1079 & 566438.31 & 134449.92 & \\
\hline 1080 & 566354.94 & 134449.92 & \\
\hline 1081 & 568354.94 & 134449.92 & \\
\hline 1082 & 566271.62 & 134449.92 & \\
\hline 1083 & 568438.31 & 134449.92 & \\
\hline 1084 & 568521.62 & 134449.92 & \\
\hline 1085 & 566188.31 & 134449.92 & \\
\hline 1086 & 566104.94 & 134449.92 & \\
\hline 1087 & 568604.94 & 134449.92 & \\
\hline 1088 & 566021.62 & 134449.92 & \\
\hline 1089 & 568688.31 & 134449.92 & \\
\hline 1090 & 568771.62 & 135783.27 & \\
\hline 1091 & 568771.62 & 135699.92 & \\
\hline 1092 & 568771.62 & 135866.59 & \\
\hline 1093 & 568771.62 & 135949.92 & \\
\hline 1094 & 568771.62 & 135616.59 & \\
\hline 1095 & 568771.62 & 136033.27 & \\
\hline 1096 & 568771.62 & 135533.27 & \\
\hline 1097 & 568771.62 & 135449.92 & \\
\hline 1098 & 568771.62 & 136116.59 & \\
\hline 1099 & 568771.62 & 136199.92 & \\
\hline 1100 & 568771.62 & 135366.59 & \\
\hline 1101 & 568771.62 & 136283.27 & \\
\hline 1102 & 568771.62 & 135283.27 & \\
\hline 1103 & 568771.62 & 135199.92 & \\
\hline 1104 & 568771.62 & 136366.59 & \\
\hline 1105 & 568771.62 & 136449.92 & \\
\hline 1106 & 568771.62 & 135116.59 & \\
\hline 1107 & 568771.62 & 136533.27 & \\
\hline 1108 & 568771.62 & 135033.27 & \\
\hline 1109 & 568771.62 & 134949.92 & \\
\hline 1110 & 568771.62 & 136616.59 & \\
\hline 1111 & 568771.62 & 136699.92 & \\
\hline 1112 & 568771.62 & 134866.59 & \\
\hline 1113 & 568771.62 & 136783.27 & \\
\hline 1114 & 568771.62 & 134783.27 & \\
\hline 1115 & 568771.62 & 134699.92 & \\
\hline 1116 & 568771.62 & 136866.59 & \\
\hline 1117 & 568771.62 & 136949.92 & \\
\hline 1118 & 568771.62 & 134616.59 & \\
\hline 1119 & 568771.62 & 137033.27 & \\
\hline 1120 & 568771.62 & 134533.27 & \\
\hline
\end{tabular}




\begin{tabular}{|c|c|c|c|}
\hline node & X_coord & Y_coord & note: from sac04d created July 1,2004 \\
\hline 1121 & $5 \overline{6} 8771.62$ & $1 \overline{3} 4449.92$ & \\
\hline 1122 & 568771.62 & 137116.59 & \\
\hline 1123 & 567354.94 & 137199.92 & \\
\hline 1124 & 567271.62 & 137199.92 & \\
\hline 1125 & 567438.31 & 137199.92 & \\
\hline 1126 & 567521.62 & 137199.92 & \\
\hline 1127 & 567188.31 & 137199.92 & \\
\hline 1128 & 567104.94 & 137199.92 & \\
\hline 1129 & 567604.94 & 137199.92 & \\
\hline 1130 & 567021.62 & 137199.92 & \\
\hline 1131 & 567688.31 & 137199.92 & \\
\hline 1132 & 567771.62 & 137199.92 & \\
\hline 1133 & 566938.31 & 137199.92 & \\
\hline 1134 & 566854.94 & 137199.92 & \\
\hline 1135 & 567854.94 & 137199.92 & \\
\hline 1136 & 566771.62 & 137199.92 & \\
\hline 1137 & 567938.31 & 137199.92 & \\
\hline 1138 & 568021.62 & 137199.92 & \\
\hline 1139 & 566688.31 & 137199.92 & \\
\hline 1140 & 566604.94 & 137199.92 & \\
\hline 1141 & 568104.94 & 137199.92 & \\
\hline 1142 & 566521.62 & 137199.92 & \\
\hline 1143 & 568188.31 & 137199.92 & \\
\hline 1144 & 568271.62 & 137199.92 & \\
\hline 1145 & 566438.31 & 137199.92 & \\
\hline 1146 & 566354.94 & 137199.92 & \\
\hline 1147 & 568354.94 & 137199.92 & \\
\hline 1148 & 566271.62 & 137199.92 & \\
\hline 1149 & 568438.31 & 137199.92 & \\
\hline 1150 & 568521.62 & 137199.92 & \\
\hline 1151 & 566188.31 & 137199.92 & \\
\hline 1152 & 566104.94 & 137199.92 & \\
\hline 1153 & 568604.94 & 137199.92 & \\
\hline 1154 & 566021.62 & 137199.92 & \\
\hline 1155 & 568688.31 & 137199.92 & \\
\hline 1156 & 568771.62 & 137199.92 & \\
\hline 1157 & 565938.31 & 135783.27 & \\
\hline 1158 & 565938.31 & 135699.92 & \\
\hline 1159 & 565938.31 & 135866.59 & \\
\hline 1160 & 565938.31 & 135949.92 & \\
\hline 1161 & 565938.31 & 135616.59 & \\
\hline 1162 & 565938.31 & 136033.27 & \\
\hline 1163 & 565938.31 & 135533.27 & \\
\hline 1164 & 565938.31 & 135449.92 & \\
\hline 1165 & 565938.31 & 136116.59 & \\
\hline 1166 & 565938.31 & 136199.92 & \\
\hline 1167 & 565938.31 & 135366.59 & \\
\hline 1168 & 565938.31 & 136283.27 & \\
\hline 1169 & 565938.31 & 135283.27 & \\
\hline 1170 & 565938.31 & 135199.92 & \\
\hline 1171 & 565938.31 & 136366.59 & \\
\hline 1172 & 565938.31 & 136449.92 & \\
\hline 1173 & 565938.31 & 135116.59 & \\
\hline 1174 & 565938.31 & 136533.27 & \\
\hline 1175 & 565938.31 & 135033.27 & \\
\hline 1176 & 565938.31 & 134949.92 & \\
\hline
\end{tabular}




\begin{tabular}{|c|c|c|c|}
\hline node & X_coord & Y_coord & note: from sac04d created July 1, 2004 \\
\hline 1177 & $5 \overline{6} 5938.31$ & $1 \overline{3} 6616.59$ & \\
\hline 1178 & 565938.31 & 136699.92 & \\
\hline 1179 & 565938.31 & 134866.59 & \\
\hline 1180 & 565938.31 & 136783.27 & \\
\hline 1181 & 565938.31 & 134783.27 & \\
\hline 1182 & 565938.31 & 134699.92 & \\
\hline 1183 & 565938.31 & 136866.59 & \\
\hline 1184 & 565938.31 & 136949.92 & \\
\hline 1185 & 565938.31 & 134616.59 & \\
\hline 1186 & 565938.31 & 137033.27 & \\
\hline 1187 & 565938.31 & 134533.27 & \\
\hline 1188 & 565938.31 & 134449.92 & \\
\hline 1189 & 565938.31 & 137116.59 & \\
\hline 1190 & 565938.31 & 137199.92 & \\
\hline 1191 & 567354.94 & 134366.59 & \\
\hline 1192 & 567271.62 & 134366.59 & \\
\hline 1193 & 567438.31 & 134366.59 & \\
\hline 1194 & 567188.31 & 134366.59 & \\
\hline 1195 & 567521.62 & 134366.59 & \\
\hline 1196 & 567604.94 & 134366.59 & \\
\hline 1197 & 567104.94 & 134366.59 & \\
\hline 1198 & 567021.62 & 134366.59 & \\
\hline 1199 & 567688.31 & 134366.59 & \\
\hline 1200 & 566938.31 & 134366.59 & \\
\hline 1201 & 567771.62 & 134366.59 & \\
\hline 1202 & 567854.94 & 134366.59 & \\
\hline 1203 & 566854.94 & 134366.59 & \\
\hline 1204 & 566771.62 & 134366.59 & \\
\hline 1205 & 567938.31 & 134366.59 & \\
\hline 1206 & 566688.31 & 134366.59 & \\
\hline 1207 & 568021.62 & 134366.59 & \\
\hline 1208 & 568104.94 & 134366.59 & \\
\hline 1209 & 566604.94 & 134366.59 & \\
\hline 1210 & 566521.62 & 134366.59 & \\
\hline 1211 & 568188.31 & 134366.59 & \\
\hline 1212 & 566438.31 & 134366.59 & \\
\hline 1213 & 568271.62 & 134366.59 & \\
\hline 1214 & 568354.94 & 134366.59 & \\
\hline 1215 & 566354.94 & 134366.59 & \\
\hline 1216 & 566271.62 & 134366.59 & \\
\hline 1217 & 568438.31 & 134366.59 & \\
\hline 1218 & 566188.31 & 134366.59 & \\
\hline 1219 & 568521.62 & 134366.59 & \\
\hline 1220 & 568604.94 & 134366.59 & \\
\hline 1221 & 566104.94 & 134366.59 & \\
\hline 1222 & 566021.62 & 134366.59 & \\
\hline 1223 & 568688.31 & 134366.59 & \\
\hline 1224 & 565938.31 & 134366.59 & \\
\hline 1225 & 568771.62 & 134366.59 & \\
\hline 1226 & 568854.94 & 135783.27 & \\
\hline 1227 & 568854.94 & 135866.59 & \\
\hline 1228 & 568854.94 & 135699.92 & \\
\hline 1229 & 568854.94 & 135616.59 & \\
\hline 1230 & 568854.94 & 135949.92 & \\
\hline 1231 & 568854.94 & 136033.27 & \\
\hline 1232 & 568854.94 & 135533.27 & \\
\hline
\end{tabular}




\begin{tabular}{|c|c|c|c|}
\hline node & X_coord & Y_coord & note: from sac04d created July 1, 2004 \\
\hline 1233 & $5 \overline{6} 8854.94$ & $1 \overline{3} 6116.59$ & \\
\hline 1234 & 568854.94 & 135449.92 & \\
\hline 1235 & 568854.94 & 135366.59 & \\
\hline 1236 & 568854.94 & 136199.92 & \\
\hline 1237 & 568854.94 & 136283.27 & \\
\hline 1238 & 568854.94 & 135283.27 & \\
\hline 1239 & 568854.94 & 136366.59 & \\
\hline 1240 & 568854.94 & 135199.92 & \\
\hline 1241 & 568854.94 & 135116.59 & \\
\hline 1242 & 568854.94 & 136449.92 & \\
\hline 1243 & 568854.94 & 136533.27 & \\
\hline 1244 & 568854.94 & 135033.27 & \\
\hline 1245 & 568854.94 & 136616.59 & \\
\hline 1246 & 568854.94 & 134949.92 & \\
\hline 1247 & 568854.94 & 134866.59 & \\
\hline 1248 & 568854.94 & 136699.92 & \\
\hline 1249 & 568854.94 & 136783.27 & \\
\hline 1250 & 568854.94 & 134783.27 & \\
\hline 1251 & 568854.94 & 136866.59 & \\
\hline 1252 & 568854.94 & 134699.92 & \\
\hline 1253 & 568854.94 & 134616.59 & \\
\hline 1254 & 568854.94 & 136949.92 & \\
\hline 1255 & 568854.94 & 137033.27 & \\
\hline 1256 & 568854.94 & 134533.27 & \\
\hline 1257 & 568854.94 & 137116.59 & \\
\hline 1258 & 568854.94 & 134449.92 & \\
\hline 1259 & 568854.94 & 134366.59 & \\
\hline 1260 & 568854.94 & 137199.92 & \\
\hline 1261 & 567354.94 & 137283.27 & \\
\hline 1262 & 567271.62 & 137283.27 & \\
\hline 1263 & 567438.31 & 137283.27 & \\
\hline 1264 & 567188.31 & 137283.27 & \\
\hline 1265 & 567521.62 & 137283.27 & \\
\hline 1266 & 567604.94 & 137283.27 & \\
\hline 1267 & 567104.94 & 137283.27 & \\
\hline 1268 & 567021.62 & 137283.27 & \\
\hline 1269 & 567688.31 & 137283.27 & \\
\hline 1270 & 566938.31 & 137283.27 & \\
\hline 1271 & 567771.62 & 137283.27 & \\
\hline 1272 & 567854.94 & 137283.27 & \\
\hline 1273 & 566854.94 & 137283.27 & \\
\hline 1274 & 566771.62 & 137283.27 & \\
\hline 1275 & 567938.31 & 137283.27 & \\
\hline 1276 & 566688.31 & 137283.27 & \\
\hline 1277 & 568021.62 & 137283.27 & \\
\hline 1278 & 568104.94 & 137283.27 & \\
\hline 1279 & 566604.94 & 137283.27 & \\
\hline 1280 & 566521.62 & 137283.27 & \\
\hline 1281 & 568188.31 & 137283.27 & \\
\hline 1282 & 566438.31 & 137283.27 & \\
\hline 1283 & 568271.62 & 137283.27 & \\
\hline 1284 & 568354.94 & 137283.27 & \\
\hline 1285 & 566354.94 & 137283.27 & \\
\hline 1286 & 566271.62 & 137283.27 & \\
\hline 1287 & 568438.31 & 137283.27 & \\
\hline 1288 & 566188.31 & 137283.27 & \\
\hline
\end{tabular}




\begin{tabular}{|c|c|c|c|}
\hline node & X_coord & Y_coord & note: from sac04d created July 1, 2004 \\
\hline 1289 & $5 \overline{6} 8521.62$ & $1 \overline{3} 7283.27$ & \\
\hline 1290 & 568604.94 & 137283.27 & \\
\hline 1291 & 566104.94 & 137283.27 & \\
\hline 1292 & 566021.62 & 137283.27 & \\
\hline 1293 & 568688.31 & 137283.27 & \\
\hline 1294 & 565938.31 & 137283.27 & \\
\hline 1295 & 568771.62 & 137283.27 & \\
\hline 1296 & 568854.94 & 137283.27 & \\
\hline 1297 & 565854.94 & 135783.27 & \\
\hline 1298 & 565854.94 & 135866.59 & \\
\hline 1299 & 565854.94 & 135699.92 & \\
\hline 1300 & 565854.94 & 135616.59 & \\
\hline 1301 & 565854.94 & 135949.92 & \\
\hline 1302 & 565854.94 & 136033.27 & \\
\hline 1303 & 565854.94 & 135533.27 & \\
\hline 1304 & 565854.94 & 136116.59 & \\
\hline 1305 & 565854.94 & 135449.92 & \\
\hline 1306 & 565854.94 & 135366.59 & \\
\hline 1307 & 565854.94 & 136199.92 & \\
\hline 1308 & 565854.94 & 136283.27 & \\
\hline 1309 & 565854.94 & 135283.27 & \\
\hline 1310 & 565854.94 & 136366.59 & \\
\hline 1311 & 565854.94 & 135199.92 & \\
\hline 1312 & 565854.94 & 135116.59 & \\
\hline 1313 & 565854.94 & 136449.92 & \\
\hline 1314 & 565854.94 & 136533.27 & \\
\hline 1315 & 565854.94 & 135033.27 & \\
\hline 1316 & 565854.94 & 136616.59 & \\
\hline 1317 & 565854.94 & 134949.92 & \\
\hline 1318 & 565854.94 & 134866.59 & \\
\hline 1319 & 565854.94 & 136699.92 & \\
\hline 1320 & 565854.94 & 136783.27 & \\
\hline 1321 & 565854.94 & 134783.27 & \\
\hline 1322 & 565854.94 & 136866.59 & \\
\hline 1323 & 565854.94 & 134699.92 & \\
\hline 1324 & 565854.94 & 134616.59 & \\
\hline 1325 & 565854.94 & 136949.92 & \\
\hline 1326 & 565854.94 & 137033.27 & \\
\hline 1327 & 565854.94 & 134533.27 & \\
\hline 1328 & 565854.94 & 137116.59 & \\
\hline 1329 & 565854.94 & 134449.92 & \\
\hline 1330 & 565854.94 & 134366.59 & \\
\hline 1331 & 565854.94 & 137199.92 & \\
\hline 1332 & 565854.94 & 137283.27 & \\
\hline 1333 & 567354.94 & 134283.27 & \\
\hline 1334 & 567438.31 & 134283.27 & \\
\hline 1335 & 567271.62 & 134283.27 & \\
\hline 1336 & 567188.31 & 134283.27 & \\
\hline 1337 & 567521.62 & 134283.27 & \\
\hline 1338 & 567104.94 & 134283.27 & \\
\hline 1339 & 567604.94 & 134283.27 & \\
\hline 1340 & 567688.31 & 134283.27 & \\
\hline 1341 & 567021.62 & 134283.27 & \\
\hline 1342 & 566938.31 & 134283.27 & \\
\hline 1343 & 567771.62 & 134283.27 & \\
\hline 1344 & 566854.94 & 134283.27 & \\
\hline
\end{tabular}




\begin{tabular}{|c|c|c|c|}
\hline node & X_coord & Y_coord & note: from sac04d created July 1, 2004 \\
\hline 1345 & $5 \overline{6} 7854.94$ & $1 \overline{3} 4283.27$ & \\
\hline 1346 & 567938.31 & 134283.27 & \\
\hline 1347 & 566771.62 & 134283.27 & \\
\hline 1348 & 566688.31 & 134283.27 & \\
\hline 1349 & 568021.62 & 134283.27 & \\
\hline 1350 & 566604.94 & 134283.27 & \\
\hline 1351 & 568104.94 & 134283.27 & \\
\hline 1352 & 568188.31 & 134283.27 & \\
\hline 1353 & 566521.62 & 134283.27 & \\
\hline 1354 & 566438.31 & 134283.27 & \\
\hline 1355 & 568271.62 & 134283.27 & \\
\hline 1356 & 566354.94 & 134283.27 & \\
\hline 1357 & 568354.94 & 134283.27 & \\
\hline 1358 & 568438.31 & 134283.27 & \\
\hline 1359 & 566271.62 & 134283.27 & \\
\hline 1360 & 566188.31 & 134283.27 & \\
\hline 1361 & 568521.62 & 134283.27 & \\
\hline 1362 & 566104.94 & 134283.27 & \\
\hline 1363 & 568604.94 & 134283.27 & \\
\hline 1364 & 568688.31 & 134283.27 & \\
\hline 1365 & 566021.62 & 134283.27 & \\
\hline 1366 & 565938.31 & 134283.27 & \\
\hline 1367 & 568771.62 & 134283.27 & \\
\hline 1368 & 565854.94 & 134283.27 & \\
\hline 1369 & 568854.94 & 134283.27 & \\
\hline 1370 & 568938.31 & 135783.27 & \\
\hline 1371 & 568938.31 & 135866.59 & \\
\hline 1372 & 568938.31 & 135699.92 & \\
\hline 1373 & 568938.31 & 135949.92 & \\
\hline 1374 & 568938.31 & 135616.59 & \\
\hline 1375 & 568938.31 & 135533.27 & \\
\hline 1376 & 568938.31 & 136033.27 & \\
\hline 1377 & 568938.31 & 136116.59 & \\
\hline 1378 & 568938.31 & 135449.92 & \\
\hline 1379 & 568938.31 & 136199.92 & \\
\hline 1380 & 568938.31 & 135366.59 & \\
\hline 1381 & 568938.31 & 135283.27 & \\
\hline 1382 & 568938.31 & 136283.27 & \\
\hline 1383 & 568938.31 & 136366.59 & \\
\hline 1384 & 568938.31 & 135199.92 & \\
\hline 1385 & 568938.31 & 136449.92 & \\
\hline 1386 & 568938.31 & 135116.59 & \\
\hline 1387 & 568938.31 & 135033.27 & \\
\hline 1388 & 568938.31 & 136533.27 & \\
\hline 1389 & 568938.31 & 136616.59 & \\
\hline 1390 & 568938.31 & 134949.92 & \\
\hline 1391 & 568938.31 & 136699.92 & \\
\hline 1392 & 568938.31 & 134866.59 & \\
\hline 1393 & 568938.31 & 134783.27 & \\
\hline 1394 & 568938.31 & 136783.27 & \\
\hline 1395 & 568938.31 & 136866.59 & \\
\hline 1396 & 568938.31 & 134699.92 & \\
\hline 1397 & 568938.31 & 136949.92 & \\
\hline 1398 & 568938.31 & 134616.59 & \\
\hline 1399 & 568938.31 & 134533.27 & \\
\hline 1400 & 568938.31 & 137033.27 & \\
\hline
\end{tabular}




\begin{tabular}{|c|c|c|c|}
\hline node & X_coord & Y_coord & note: from sac04d created July 1, 2004 \\
\hline 1401 & $5 \overline{6} 8938.31$ & $1 \overline{3} 7116.59$ & \\
\hline 1402 & 568938.31 & 134449.92 & \\
\hline 1403 & 568938.31 & 137199.92 & \\
\hline 1404 & 568938.31 & 134366.59 & \\
\hline 1405 & 568938.31 & 134283.27 & \\
\hline 1406 & 568938.31 & 137283.27 & \\
\hline 1407 & 567354.94 & 137366.59 & \\
\hline 1408 & 567438.31 & 137366.59 & \\
\hline 1409 & 567271.62 & 137366.59 & \\
\hline 1410 & 567188.31 & 137366.59 & \\
\hline 1411 & 567521.62 & 137366.59 & \\
\hline 1412 & 567104.94 & 137366.59 & \\
\hline 1413 & 567604.94 & 137366.59 & \\
\hline 1414 & 567688.31 & 137366.59 & \\
\hline 1415 & 567021.62 & 137366.59 & \\
\hline 1416 & 566938.31 & 137366.59 & \\
\hline 1417 & 567771.62 & 137366.59 & \\
\hline 1418 & 566854.94 & 137366.59 & \\
\hline 1419 & 567854.94 & 137366.59 & \\
\hline 1420 & 567938.31 & 137366.59 & \\
\hline 1421 & 566771.62 & 137366.59 & \\
\hline 1422 & 566688.31 & 137366.59 & \\
\hline 1423 & 568021.62 & 137366.59 & \\
\hline 1424 & 566604.94 & 137366.59 & \\
\hline 1425 & 568104.94 & 137366.59 & \\
\hline 1426 & 568188.31 & 137366.59 & \\
\hline 1427 & 566521.62 & 137366.59 & \\
\hline 1428 & 566438.31 & 137366.59 & \\
\hline 1429 & 568271.62 & 137366.59 & \\
\hline 1430 & 566354.94 & 137366.59 & \\
\hline 1431 & 568354.94 & 137366.59 & \\
\hline 1432 & 568438.31 & 137366.59 & \\
\hline 1433 & 566271.62 & 137366.59 & \\
\hline 1434 & 566188.31 & 137366.59 & \\
\hline 1435 & 568521.62 & 137366.59 & \\
\hline 1436 & 566104.94 & 137366.59 & \\
\hline 1437 & 568604.94 & 137366.59 & \\
\hline 1438 & 568688.31 & 137366.59 & \\
\hline 1439 & 566021.62 & 137366.59 & \\
\hline 1440 & 565938.31 & 137366.59 & \\
\hline 1441 & 568771.62 & 137366.59 & \\
\hline 1442 & 565854.94 & 137366.59 & \\
\hline 1443 & 568854.94 & 137366.59 & \\
\hline 1444 & 568938.31 & 137366.59 & \\
\hline 1445 & 565771.62 & 135783.27 & \\
\hline 1446 & 565771.62 & 135866.59 & \\
\hline 1447 & 565771.62 & 135699.92 & \\
\hline 1448 & 565771.62 & 135949.92 & \\
\hline 1449 & 565771.62 & 135616.59 & \\
\hline 1450 & 565771.62 & 135533.27 & \\
\hline 1451 & 565771.62 & 136033.27 & \\
\hline 1452 & 565771.62 & 136116.59 & \\
\hline 1453 & 565771.62 & 135449.92 & \\
\hline 1454 & 565771.62 & 136199.92 & \\
\hline 1455 & 565771.62 & 135366.59 & \\
\hline 1456 & 565771.62 & 135283.27 & \\
\hline
\end{tabular}




\begin{tabular}{|c|c|c|c|}
\hline node & X_coord & Y_coord & note: from sac04d created July 1,2004 \\
\hline 1457 & $5 \overline{6} 5771.62$ & $1 \overline{3} 6283.27$ & \\
\hline 1458 & 565771.62 & 136366.59 & \\
\hline 1459 & 565771.62 & 135199.92 & \\
\hline 1460 & 565771.62 & 136449.92 & \\
\hline 1461 & 565771.62 & 135116.59 & \\
\hline 1462 & 565771.62 & 135033.27 & \\
\hline 1463 & 565771.62 & 136533.27 & \\
\hline 1464 & 565771.62 & 136616.59 & \\
\hline 1465 & 565771.62 & 134949.92 & \\
\hline 1466 & 565771.62 & 136699.92 & \\
\hline 1467 & 565771.62 & 134866.59 & \\
\hline 1468 & 565771.62 & 134783.27 & \\
\hline 1469 & 565771.62 & 136783.27 & \\
\hline 1470 & 565771.62 & 136866.59 & \\
\hline 1471 & 565771.62 & 134699.92 & \\
\hline 1472 & 565771.62 & 136949.92 & \\
\hline 1473 & 565771.62 & 134616.59 & \\
\hline 1474 & 565771.62 & 134533.27 & \\
\hline 1475 & 565771.62 & 137033.27 & \\
\hline 1476 & 565771.62 & 137116.59 & \\
\hline 1477 & 565771.62 & 134449.92 & \\
\hline 1478 & 565771.62 & 137199.92 & \\
\hline 1479 & 565771.62 & 134366.59 & \\
\hline 1480 & 565771.62 & 134283.27 & \\
\hline 1481 & 565771.62 & 137283.27 & \\
\hline 1482 & 565771.62 & 137366.59 & \\
\hline 1483 & 567354.94 & 134199.92 & \\
\hline 1484 & 567271.62 & 134199.92 & \\
\hline 1485 & 567438.31 & 134199.92 & \\
\hline 1486 & 567521.62 & 134199.92 & \\
\hline 1487 & 567188.31 & 134199.92 & \\
\hline 1488 & 567104.94 & 134199.92 & \\
\hline 1489 & 567604.94 & 134199.92 & \\
\hline 1490 & 567021.62 & 134199.92 & \\
\hline 1491 & 567688.31 & 134199.92 & \\
\hline 1492 & 567771.62 & 134199.92 & \\
\hline 1493 & 566938.31 & 134199.92 & \\
\hline 1494 & 566854.94 & 134199.92 & \\
\hline 1495 & 567854.94 & 134199.92 & \\
\hline 1496 & 566771.62 & 134199.92 & \\
\hline 1497 & 567938.31 & 134199.92 & \\
\hline 1498 & 568021.62 & 134199.92 & \\
\hline 1499 & 566688.31 & 134199.92 & \\
\hline 1500 & 566604.94 & 134199.92 & \\
\hline 1501 & 568104.94 & 134199.92 & \\
\hline 1502 & 566521.62 & 134199.92 & \\
\hline 1503 & 568188.31 & 134199.92 & \\
\hline 1504 & 568271.62 & 134199.92 & \\
\hline 1505 & 566438.31 & 134199.92 & \\
\hline 1506 & 566354.94 & 134199.92 & \\
\hline 1507 & 568354.94 & 134199.92 & \\
\hline 1508 & 566271.62 & 134199.92 & \\
\hline 1509 & 568438.31 & 134199.92 & \\
\hline 1510 & 568521.62 & 134199.92 & \\
\hline 1511 & 566188.31 & 134199.92 & \\
\hline 1512 & 566104.94 & 134199.92 & \\
\hline
\end{tabular}




\begin{tabular}{|c|c|c|c|}
\hline node & X_coord & Y_coord & note: from sac04d created July 1, 2004 \\
\hline 1513 & $5 \overline{6} 8604.94$ & $1 \overline{3} 4199.92$ & \\
\hline 1514 & 566021.62 & 134199.92 & \\
\hline 1515 & 568688.31 & 134199.92 & \\
\hline 1516 & 568771.62 & 134199.92 & \\
\hline 1517 & 565938.31 & 134199.92 & \\
\hline 1518 & 565854.94 & 134199.92 & \\
\hline 1519 & 568854.94 & 134199.92 & \\
\hline 1520 & 565771.62 & 134199.92 & \\
\hline 1521 & 568938.31 & 134199.92 & \\
\hline 1522 & 569021.62 & 135783.27 & \\
\hline 1523 & 569021.62 & 135699.92 & \\
\hline 1524 & 569021.62 & 135866.59 & \\
\hline 1525 & 569021.62 & 135949.92 & \\
\hline 1526 & 569021.62 & 135616.59 & \\
\hline 1527 & 569021.62 & 136033.27 & \\
\hline 1528 & 569021.62 & 135533.27 & \\
\hline 1529 & 569021.62 & 135449.92 & \\
\hline 1530 & 569021.62 & 136116.59 & \\
\hline 1531 & 569021.62 & 136199.92 & \\
\hline 1532 & 569021.62 & 135366.59 & \\
\hline 1533 & 569021.62 & 136283.27 & \\
\hline 1534 & 569021.62 & 135283.27 & \\
\hline 1535 & 569021.62 & 135199.92 & \\
\hline 1536 & 569021.62 & 136366.59 & \\
\hline 1537 & 569021.62 & 136449.92 & \\
\hline 1538 & 569021.62 & 135116.59 & \\
\hline 1539 & 569021.62 & 136533.27 & \\
\hline 1540 & 569021.62 & 135033.27 & \\
\hline 1541 & 569021.62 & 134949.92 & \\
\hline 1542 & 569021.62 & 136616.59 & \\
\hline 1543 & 569021.62 & 136699.92 & \\
\hline 1544 & 569021.62 & 134866.59 & \\
\hline 1545 & 569021.62 & 136783.27 & \\
\hline 1546 & 569021.62 & 134783.27 & \\
\hline 1547 & 569021.62 & 134699.92 & \\
\hline 1548 & 569021.62 & 136866.59 & \\
\hline 1549 & 569021.62 & 136949.92 & \\
\hline 1550 & 569021.62 & 134616.59 & \\
\hline 1551 & 569021.62 & 137033.27 & \\
\hline 1552 & 569021.62 & 134533.27 & \\
\hline 1553 & 569021.62 & 134449.92 & \\
\hline 1554 & 569021.62 & 137116.59 & \\
\hline 1555 & 569021.62 & 137199.92 & \\
\hline 1556 & 569021.62 & 134366.59 & \\
\hline 1557 & 569021.62 & 137283.27 & \\
\hline 1558 & 569021.62 & 134283.27 & \\
\hline 1559 & 569021.62 & 134199.92 & \\
\hline 1560 & 569021.62 & 137366.59 & \\
\hline 1561 & 567354.94 & 137449.92 & \\
\hline 1562 & 567271.62 & 137449.92 & \\
\hline 1563 & 567438.31 & 137449.92 & \\
\hline 1564 & 567521.62 & 137449.92 & \\
\hline 1565 & 567188.31 & 137449.92 & \\
\hline 1566 & 567104.94 & 137449.92 & \\
\hline 1567 & 567604.94 & 137449.92 & \\
\hline 1568 & 567021.62 & 137449.92 & \\
\hline
\end{tabular}




\begin{tabular}{|c|c|c|c|}
\hline node & X_coord & Y_coord & note: from sac04d created July 1, 2004 \\
\hline 1569 & $5 \overline{6} 7688.31$ & $1 \overline{3} 7449.92$ & \\
\hline 1570 & 567771.62 & 137449.92 & \\
\hline 1571 & 566938.31 & 137449.92 & \\
\hline 1572 & 566854.94 & 137449.92 & \\
\hline 1573 & 567854.94 & 137449.92 & \\
\hline 1574 & 566771.62 & 137449.92 & \\
\hline 1575 & 567938.31 & 137449.92 & \\
\hline 1576 & 568021.62 & 137449.92 & \\
\hline 1577 & 566688.31 & 137449.92 & \\
\hline 1578 & 566604.94 & 137449.92 & \\
\hline 1579 & 568104.94 & 137449.92 & \\
\hline 1580 & 566521.62 & 137449.92 & \\
\hline 1581 & 568188.31 & 137449.92 & \\
\hline 1582 & 568271.62 & 137449.92 & \\
\hline 1583 & 566438.31 & 137449.92 & \\
\hline 1584 & 566354.94 & 137449.92 & \\
\hline 1585 & 568354.94 & 137449.92 & \\
\hline 1586 & 566271.62 & 137449.92 & \\
\hline 1587 & 568438.31 & 137449.92 & \\
\hline 1588 & 568521.62 & 137449.92 & \\
\hline 1589 & 566188.31 & 137449.92 & \\
\hline 1590 & 566104.94 & 137449.92 & \\
\hline 1591 & 568604.94 & 137449.92 & \\
\hline 1592 & 566021.62 & 137449.92 & \\
\hline 1593 & 568688.31 & 137449.92 & \\
\hline 1594 & 568771.62 & 137449.92 & \\
\hline 1595 & 565938.31 & 137449.92 & \\
\hline 1596 & 565854.94 & 137449.92 & \\
\hline 1597 & 568854.94 & 137449.92 & \\
\hline 1598 & 565771.62 & 137449.92 & \\
\hline 1599 & 568938.31 & 137449.92 & \\
\hline 1600 & 569021.62 & 137449.92 & \\
\hline 1601 & 565688.31 & 135783.27 & \\
\hline 1602 & 565688.31 & 135699.92 & \\
\hline 1603 & 565688.31 & 135866.59 & \\
\hline 1604 & 565688.31 & 135949.92 & \\
\hline 1605 & 565688.31 & 135616.59 & \\
\hline 1606 & 565688.31 & 136033.27 & \\
\hline 1607 & 565688.31 & 135533.27 & \\
\hline 1608 & 565688.31 & 135449.92 & \\
\hline 1609 & 565688.31 & 136116.59 & \\
\hline 1610 & 565688.31 & 136199.92 & \\
\hline 1611 & 565688.31 & 135366.59 & \\
\hline 1612 & 565688.31 & 136283.27 & \\
\hline 1613 & 565688.31 & 135283.27 & \\
\hline 1614 & 565688.31 & 135199.92 & \\
\hline 1615 & 565688.31 & 136366.59 & \\
\hline 1616 & 565688.31 & 136449.92 & \\
\hline 1617 & 565688.31 & 135116.59 & \\
\hline 1618 & 565688.31 & 136533.27 & \\
\hline 1619 & 565688.31 & 135033.27 & \\
\hline 1620 & 565688.31 & 134949.92 & \\
\hline 1621 & 565688.31 & 136616.59 & \\
\hline 1622 & 565688.31 & 136699.92 & \\
\hline 1623 & 565688.31 & 134866.59 & \\
\hline 1624 & 565688.31 & 136783.27 & \\
\hline
\end{tabular}




\begin{tabular}{|c|c|c|c|}
\hline node & X_coord & Y_coord & note: from sac04d created July 1, 2004 \\
\hline 1625 & $5 \overline{6} 5688.31$ & $1 \overline{3} 4783.27$ & \\
\hline 1626 & 565688.31 & 134699.92 & \\
\hline 1627 & 565688.31 & 136866.59 & \\
\hline 1628 & 565688.31 & 136949.92 & \\
\hline 1629 & 565688.31 & 134616.59 & \\
\hline 1630 & 565688.31 & 137033.27 & \\
\hline 1631 & 565688.31 & 134533.27 & \\
\hline 1632 & 565688.31 & 134449.92 & \\
\hline 1633 & 565688.31 & 137116.59 & \\
\hline 1634 & 565688.31 & 137199.92 & \\
\hline 1635 & 565688.31 & 134366.59 & \\
\hline 1636 & 565688.31 & 137283.27 & \\
\hline 1637 & 565688.31 & 134283.27 & \\
\hline 1638 & 565688.31 & 134199.92 & \\
\hline 1639 & 565688.31 & 137366.59 & \\
\hline 1640 & 565688.31 & 137449.92 & \\
\hline 1641 & 567354.94 & 134116.59 & \\
\hline 1642 & 567271.62 & 134116.59 & \\
\hline 1643 & 567438.31 & 134116.59 & \\
\hline 1644 & 567188.31 & 134116.59 & \\
\hline 1645 & 567521.62 & 134116.59 & \\
\hline 1646 & 567604.94 & 134116.59 & \\
\hline 1647 & 567104.94 & 134116.59 & \\
\hline 1648 & 567021.62 & 134116.59 & \\
\hline 1649 & 567688.31 & 134116.59 & \\
\hline 1650 & 566938.31 & 134116.59 & \\
\hline 1651 & 567771.62 & 134116.59 & \\
\hline 1652 & 567854.94 & 134116.59 & \\
\hline 1653 & 566854.94 & 134116.59 & \\
\hline 1654 & 566771.62 & 134116.59 & \\
\hline 1655 & 567938.31 & 134116.59 & \\
\hline 1656 & 566688.31 & 134116.59 & \\
\hline 1657 & 568021.62 & 134116.59 & \\
\hline 1658 & 568104.94 & 134116.59 & \\
\hline 1659 & 566604.94 & 134116.59 & \\
\hline 1660 & 566521.62 & 134116.59 & \\
\hline 1661 & 568188.31 & 134116.59 & \\
\hline 1662 & 566438.31 & 134116.59 & \\
\hline 1663 & 568271.62 & 134116.59 & \\
\hline 1664 & 568354.94 & 134116.59 & \\
\hline 1665 & 566354.94 & 134116.59 & \\
\hline 1666 & 566271.62 & 134116.59 & \\
\hline 1667 & 568438.31 & 134116.59 & \\
\hline 1668 & 566188.31 & 134116.59 & \\
\hline 1669 & 568521.62 & 134116.59 & \\
\hline 1670 & 568604.94 & 134116.59 & \\
\hline 1671 & 566104.94 & 134116.59 & \\
\hline 1672 & 566021.62 & 134116.59 & \\
\hline 1673 & 568688.31 & 134116.59 & \\
\hline 1674 & 565938.31 & 134116.59 & \\
\hline 1675 & 568771.62 & 134116.59 & \\
\hline 1676 & 568854.94 & 134116.59 & \\
\hline 1677 & 565854.94 & 134116.59 & \\
\hline 1678 & 565771.62 & 134116.59 & \\
\hline 1679 & 568938.31 & 134116.59 & \\
\hline 1680 & 565688.31 & 134116.59 & \\
\hline
\end{tabular}




\begin{tabular}{|c|c|c|c|}
\hline node & X_coord & Y_coord & note: from sac04d created July 1, 2004 \\
\hline 1681 & $5 \overline{6} 9021.62$ & $1 \overline{3} 4116.59$ & \\
\hline 1682 & 569104.94 & 135783.27 & \\
\hline 1683 & 569104.94 & 135866.59 & \\
\hline 1684 & 569104.94 & 135699.92 & \\
\hline 1685 & 569104.94 & 135616.59 & \\
\hline 1686 & 569104.94 & 135949.92 & \\
\hline 1687 & 569104.94 & 136033.27 & \\
\hline 1688 & 569104.94 & 135533.27 & \\
\hline 1689 & 569104.94 & 136116.59 & \\
\hline 1690 & 569104.94 & 135449.92 & \\
\hline 1691 & 569104.94 & 135366.59 & \\
\hline 1692 & 569104.94 & 136199.92 & \\
\hline 1693 & 569104.94 & 136283.27 & \\
\hline 1694 & 569104.94 & 135283.27 & \\
\hline 1695 & 569104.94 & 136366.59 & \\
\hline 1696 & 569104.94 & 135199.92 & \\
\hline 1697 & 569104.94 & 135116.59 & \\
\hline 1698 & 569104.94 & 136449.92 & \\
\hline 1699 & 569104.94 & 136533.27 & \\
\hline 1700 & 569104.94 & 135033.27 & \\
\hline 1701 & 569104.94 & 136616.59 & \\
\hline 1702 & 569104.94 & 134949.92 & \\
\hline 1703 & 569104.94 & 134866.59 & \\
\hline 1704 & 569104.94 & 136699.92 & \\
\hline 1705 & 569104.94 & 136783.27 & \\
\hline 1706 & 569104.94 & 134783.27 & \\
\hline 1707 & 569104.94 & 136866.59 & \\
\hline 1708 & 569104.94 & 134699.92 & \\
\hline 1709 & 569104.94 & 134616.59 & \\
\hline 1710 & 569104.94 & 136949.92 & \\
\hline 1711 & 569104.94 & 137033.27 & \\
\hline 1712 & 569104.94 & 134533.27 & \\
\hline 1713 & 569104.94 & 137116.59 & \\
\hline 1714 & 569104.94 & 134449.92 & \\
\hline 1715 & 569104.94 & 134366.59 & \\
\hline 1716 & 569104.94 & 137199.92 & \\
\hline 1717 & 569104.94 & 137283.27 & \\
\hline 1718 & 569104.94 & 134283.27 & \\
\hline 1719 & 569104.94 & 137366.59 & \\
\hline 1720 & 569104.94 & 134199.92 & \\
\hline 1721 & 569104.94 & 134116.59 & \\
\hline 1722 & 569104.94 & 137449.92 & \\
\hline 1723 & 567354.94 & 137533.27 & \\
\hline 1724 & 567271.62 & 137533.27 & \\
\hline 1725 & 567438.31 & 137533.27 & \\
\hline 1726 & 567188.31 & 137533.27 & \\
\hline 1727 & 567521.62 & 137533.27 & \\
\hline 1728 & 567604.94 & 137533.27 & \\
\hline 1729 & 567104.94 & 137533.27 & \\
\hline 1730 & 567021.62 & 137533.27 & \\
\hline 1731 & 567688.31 & 137533.27 & \\
\hline 1732 & 566938.31 & 137533.27 & \\
\hline 1733 & 567771.62 & 137533.27 & \\
\hline 1734 & 567854.94 & 137533.27 & \\
\hline 1735 & 566854.94 & 137533.27 & \\
\hline 1736 & 566771.62 & 137533.27 & \\
\hline
\end{tabular}




\begin{tabular}{|c|c|c|c|}
\hline node & X_coord & Y_coord & note: from sac04d created July 1,2004 \\
\hline 1737 & $5 \overline{6} 7938.31$ & $1 \overline{3} 7533.27$ & \\
\hline 1738 & 566688.31 & 137533.27 & \\
\hline 1739 & 568021.62 & 137533.27 & \\
\hline 1740 & 568104.94 & 137533.27 & \\
\hline 1741 & 566604.94 & 137533.27 & \\
\hline 1742 & 566521.62 & 137533.27 & \\
\hline 1743 & 568188.31 & 137533.27 & \\
\hline 1744 & 566438.31 & 137533.27 & \\
\hline 1745 & 568271.62 & 137533.27 & \\
\hline 1746 & 568354.94 & 137533.27 & \\
\hline 1747 & 566354.94 & 137533.27 & \\
\hline 1748 & 566271.62 & 137533.27 & \\
\hline 1749 & 568438.31 & 137533.27 & \\
\hline 1750 & 566188.31 & 137533.27 & \\
\hline 1751 & 568521.62 & 137533.27 & \\
\hline 1752 & 568604.94 & 137533.27 & \\
\hline 1753 & 566104.94 & 137533.27 & \\
\hline 1754 & 566021.62 & 137533.27 & \\
\hline 1755 & 568688.31 & 137533.27 & \\
\hline 1756 & 565938.31 & 137533.27 & \\
\hline 1757 & 568771.62 & 137533.27 & \\
\hline 1758 & 568854.94 & 137533.27 & \\
\hline 1759 & 565854.94 & 137533.27 & \\
\hline 1760 & 565771.62 & 137533.27 & \\
\hline 1761 & 568938.31 & 137533.27 & \\
\hline 1762 & 565688.31 & 137533.27 & \\
\hline 1763 & 569021.62 & 137533.27 & \\
\hline 1764 & 569104.94 & 137533.27 & \\
\hline 1765 & 565604.94 & 135783.27 & \\
\hline 1766 & 565604.94 & 135866.59 & \\
\hline 1767 & 565604.94 & 135699.92 & \\
\hline 1768 & 565604.94 & 135616.59 & \\
\hline 1769 & 565604.94 & 135949.92 & \\
\hline 1770 & 565604.94 & 136033.27 & \\
\hline 1771 & 565604.94 & 135533.27 & \\
\hline 1772 & 565604.94 & 136116.59 & \\
\hline 1773 & 565604.94 & 135449.92 & \\
\hline 1774 & 565604.94 & 135366.59 & \\
\hline 1775 & 565604.94 & 136199.92 & \\
\hline 1776 & 565604.94 & 136283.27 & \\
\hline 1777 & 565604.94 & 135283.27 & \\
\hline 1778 & 565604.94 & 136366.59 & \\
\hline 1779 & 565604.94 & 135199.92 & \\
\hline 1780 & 565604.94 & 135116.59 & \\
\hline 1781 & 565604.94 & 136449.92 & \\
\hline 1782 & 565604.94 & 136533.27 & \\
\hline 1783 & 565604.94 & 135033.27 & \\
\hline 1784 & 565604.94 & 136616.59 & \\
\hline 1785 & 565604.94 & 134949.92 & \\
\hline 1786 & 565604.94 & 134866.59 & \\
\hline 1787 & 565604.94 & 136699.92 & \\
\hline 1788 & 565604.94 & 136783.27 & \\
\hline 1789 & 565604.94 & 134783.27 & \\
\hline 1790 & 565604.94 & 136866.59 & \\
\hline 1791 & 565604.94 & 134699.92 & \\
\hline 1792 & 565604.94 & 134616.59 & \\
\hline
\end{tabular}




\begin{tabular}{|c|c|c|c|}
\hline node & X_coord & Y_coord & note: from sac04d created July 1, 2004 \\
\hline 1793 & $5 \overline{6} 5604.94$ & $1 \overline{3} 6949.92$ & \\
\hline 1794 & 565604.94 & 137033.27 & \\
\hline 1795 & 565604.94 & 134533.27 & \\
\hline 1796 & 565604.94 & 137116.59 & \\
\hline 1797 & 565604.94 & 134449.92 & \\
\hline 1798 & 565604.94 & 134366.59 & \\
\hline 1799 & 565604.94 & 137199.92 & \\
\hline 1800 & 565604.94 & 137283.27 & \\
\hline 1801 & 565604.94 & 134283.27 & \\
\hline 1802 & 565604.94 & 137366.59 & \\
\hline 1803 & 565604.94 & 134199.92 & \\
\hline 1804 & 565604.94 & 134116.59 & \\
\hline 1805 & 565604.94 & 137449.92 & \\
\hline 1806 & 565604.94 & 137533.27 & \\
\hline 1807 & 567354.94 & 134033.27 & \\
\hline 1808 & 567438.31 & 134033.27 & \\
\hline 1809 & 567271.62 & 134033.27 & \\
\hline 1810 & 567188.31 & 134033.27 & \\
\hline 1811 & 567521.62 & 134033.27 & \\
\hline 1812 & 567104.94 & 134033.27 & \\
\hline 1813 & 567604.94 & 134033.27 & \\
\hline 1814 & 567688.31 & 134033.27 & \\
\hline 1815 & 567021.62 & 134033.27 & \\
\hline 1816 & 566938.31 & 134033.27 & \\
\hline 1817 & 567771.62 & 134033.27 & \\
\hline 1818 & 566854.94 & 134033.27 & \\
\hline 1819 & 567854.94 & 134033.27 & \\
\hline 1820 & 567938.31 & 134033.27 & \\
\hline 1821 & 566771.62 & 134033.27 & \\
\hline 1822 & 566688.31 & 134033.27 & \\
\hline 1823 & 568021.62 & 134033.27 & \\
\hline 1824 & 566604.94 & 134033.27 & \\
\hline 1825 & 568104.94 & 134033.27 & \\
\hline 1826 & 568188.31 & 134033.27 & \\
\hline 1827 & 566521.62 & 134033.27 & \\
\hline 1828 & 566438.31 & 134033.27 & \\
\hline 1829 & 568271.62 & 134033.27 & \\
\hline 1830 & 566354.94 & 134033.27 & \\
\hline 1831 & 568354.94 & 134033.27 & \\
\hline 1832 & 568438.31 & 134033.27 & \\
\hline 1833 & 566271.62 & 134033.27 & \\
\hline 1834 & 566188.31 & 134033.27 & \\
\hline 1835 & 568521.62 & 134033.27 & \\
\hline 1836 & 566104.94 & 134033.27 & \\
\hline 1837 & 568604.94 & 134033.27 & \\
\hline 1838 & 568688.31 & 134033.27 & \\
\hline 1839 & 566021.62 & 134033.27 & \\
\hline 1840 & 565938.31 & 134033.27 & \\
\hline 1841 & 568771.62 & 134033.27 & \\
\hline 1842 & 565854.94 & 134033.27 & \\
\hline 1843 & 568854.94 & 134033.27 & \\
\hline 1844 & 568938.31 & 134033.27 & \\
\hline 1845 & 565771.62 & 134033.27 & \\
\hline 1846 & 565688.31 & 134033.27 & \\
\hline 1847 & 569021.62 & 134033.27 & \\
\hline 1848 & 565604.94 & 134033.27 & \\
\hline
\end{tabular}




\begin{tabular}{|c|c|c|c|}
\hline node & X_coord & Y_coord & note: from sac04d created July 1, 2004 \\
\hline 1849 & $5 \overline{6} 9104.94$ & $1 \overline{3} 4033.27$ & \\
\hline 1850 & 569188.31 & 135783.27 & \\
\hline 1851 & 569188.31 & 135866.59 & \\
\hline 1852 & 569188.31 & 135699.92 & \\
\hline 1853 & 569188.31 & 135949.92 & \\
\hline 1854 & 569188.31 & 135616.59 & \\
\hline 1855 & 569188.31 & 135533.27 & \\
\hline 1856 & 569188.31 & 136033.27 & \\
\hline 1857 & 569188.31 & 136116.59 & \\
\hline 1858 & 569188.31 & 135449.92 & \\
\hline 1859 & 569188.31 & 136199.92 & \\
\hline 1860 & 569188.31 & 135366.59 & \\
\hline 1861 & 569188.31 & 135283.27 & \\
\hline 1862 & 569188.31 & 136283.27 & \\
\hline 1863 & 569188.31 & 136366.59 & \\
\hline 1864 & 569188.31 & 135199.92 & \\
\hline 1865 & 569188.31 & 136449.92 & \\
\hline 1866 & 569188.31 & 135116.59 & \\
\hline 1867 & 569188.31 & 135033.27 & \\
\hline 1868 & 569188.31 & 136533.27 & \\
\hline 1869 & 569188.31 & 136616.59 & \\
\hline 1870 & 569188.31 & 134949.92 & \\
\hline 1871 & 569188.31 & 136699.92 & \\
\hline 1872 & 569188.31 & 134866.59 & \\
\hline 1873 & 569188.31 & 134783.27 & \\
\hline 1874 & 569188.31 & 136783.27 & \\
\hline 1875 & 569188.31 & 136866.59 & \\
\hline 1876 & 569188.31 & 134699.92 & \\
\hline 1877 & 569188.31 & 136949.92 & \\
\hline 1878 & 569188.31 & 134616.59 & \\
\hline 1879 & 569188.31 & 134533.27 & \\
\hline 1880 & 569188.31 & 137033.27 & \\
\hline 1881 & 569188.31 & 137116.59 & \\
\hline 1882 & 569188.31 & 134449.92 & \\
\hline 1883 & 569188.31 & 137199.92 & \\
\hline 1884 & 569188.31 & 134366.59 & \\
\hline 1885 & 569188.31 & 134283.27 & \\
\hline 1886 & 569188.31 & 137283.27 & \\
\hline 1887 & 569188.31 & 137366.59 & \\
\hline 1888 & 569188.31 & 134199.92 & \\
\hline 1889 & 569188.31 & 137449.92 & \\
\hline 1890 & 569188.31 & 134116.59 & \\
\hline 1891 & 569188.31 & 134033.27 & \\
\hline 1892 & 569188.31 & 137533.27 & \\
\hline 1893 & 567354.94 & 137616.59 & \\
\hline 1894 & 567438.31 & 137616.59 & \\
\hline 1895 & 567271.62 & 137616.59 & \\
\hline 1896 & 567188.31 & 137616.59 & \\
\hline 1897 & 567521.62 & 137616.59 & \\
\hline 1898 & 567104.94 & 137616.59 & \\
\hline 1899 & 567604.94 & 137616.59 & \\
\hline 1900 & 567688.31 & 137616.59 & \\
\hline 1901 & 567021.62 & 137616.59 & \\
\hline 1902 & 566938.31 & 137616.59 & \\
\hline 1903 & 567771.62 & 137616.59 & \\
\hline 1904 & 566854.94 & 137616.59 & \\
\hline
\end{tabular}




\begin{tabular}{|c|c|c|c|}
\hline node & X_coord & Y_coord & note: from sac04d created July 1, 2004 \\
\hline 1905 & $5 \overline{6} 7854.94$ & $1 \overline{3} 7616.59$ & \\
\hline 1906 & 567938.31 & 137616.59 & \\
\hline 1907 & 566771.62 & 137616.59 & \\
\hline 1908 & 566688.31 & 137616.59 & \\
\hline 1909 & 568021.62 & 137616.59 & \\
\hline 1910 & 566604.94 & 137616.59 & \\
\hline 1911 & 568104.94 & 137616.59 & \\
\hline 1912 & 568188.31 & 137616.59 & \\
\hline 1913 & 566521.62 & 137616.59 & \\
\hline 1914 & 566438.31 & 137616.59 & \\
\hline 1915 & 568271.62 & 137616.59 & \\
\hline 1916 & 566354.94 & 137616.59 & \\
\hline 1917 & 568354.94 & 137616.59 & \\
\hline 1918 & 568438.31 & 137616.59 & \\
\hline 1919 & 566271.62 & 137616.59 & \\
\hline 1920 & 566188.31 & 137616.59 & \\
\hline 1921 & 568521.62 & 137616.59 & \\
\hline 1922 & 566104.94 & 137616.59 & \\
\hline 1923 & 568604.94 & 137616.59 & \\
\hline 1924 & 568688.31 & 137616.59 & \\
\hline 1925 & 566021.62 & 137616.59 & \\
\hline 1926 & 565938.31 & 137616.59 & \\
\hline 1927 & 568771.62 & 137616.59 & \\
\hline 1928 & 565854.94 & 137616.59 & \\
\hline 1929 & 568854.94 & 137616.59 & \\
\hline 1930 & 568938.31 & 137616.59 & \\
\hline 1931 & 565771.62 & 137616.59 & \\
\hline 1932 & 565688.31 & 137616.59 & \\
\hline 1933 & 569021.62 & 137616.59 & \\
\hline 1934 & 565604.94 & 137616.59 & \\
\hline 1935 & 569104.94 & 137616.59 & \\
\hline 1936 & 569188.31 & 137616.59 & \\
\hline 1937 & 565521.62 & 135783.27 & \\
\hline 1938 & 565521.62 & 135866.59 & \\
\hline 1939 & 565521.62 & 135699.92 & \\
\hline 1940 & 565521.62 & 135949.92 & \\
\hline 1941 & 565521.62 & 135616.59 & \\
\hline 1942 & 565521.62 & 135533.27 & \\
\hline 1943 & 565521.62 & 136033.27 & \\
\hline 1944 & 565521.62 & 136116.59 & \\
\hline 1945 & 565521.62 & 135449.92 & \\
\hline 1946 & 565521.62 & 136199.92 & \\
\hline 1947 & 565521.62 & 135366.59 & \\
\hline 1948 & 565521.62 & 135283.27 & \\
\hline 1949 & 565521.62 & 136283.27 & \\
\hline 1950 & 565521.62 & 136366.59 & \\
\hline 1951 & 565521.62 & 135199.92 & \\
\hline 1952 & 565521.62 & 136449.92 & \\
\hline 1953 & 565521.62 & 135116.59 & \\
\hline 1954 & 565521.62 & 135033.27 & \\
\hline 1955 & 565521.62 & 136533.27 & \\
\hline 1956 & 565521.62 & 136616.59 & \\
\hline 1957 & 565521.62 & 134949.92 & \\
\hline 1958 & 565521.62 & 136699.92 & \\
\hline 1959 & 565521.62 & 134866.59 & \\
\hline 1960 & 565521.62 & 134783.27 & \\
\hline
\end{tabular}




\begin{tabular}{|c|c|c|c|}
\hline node & X_coord & Y_coord & note: from sac04d created July 1,2004 \\
\hline 1961 & $5 \overline{6} 5521.62$ & $1 \overline{3} 6783.27$ & \\
\hline 1962 & 565521.62 & 136866.59 & \\
\hline 1963 & 565521.62 & 134699.92 & \\
\hline 1964 & 565521.62 & 136949.92 & \\
\hline 1965 & 565521.62 & 134616.59 & \\
\hline 1966 & 565521.62 & 134533.27 & \\
\hline 1967 & 565521.62 & 137033.27 & \\
\hline 1968 & 565521.62 & 137116.59 & \\
\hline 1969 & 565521.62 & 134449.92 & \\
\hline 1970 & 565521.62 & 137199.92 & \\
\hline 1971 & 565521.62 & 134366.59 & \\
\hline 1972 & 565521.62 & 134283.27 & \\
\hline 1973 & 565521.62 & 137283.27 & \\
\hline 1974 & 565521.62 & 137366.59 & \\
\hline 1975 & 565521.62 & 134199.92 & \\
\hline 1976 & 565521.62 & 137449.92 & \\
\hline 1977 & 565521.62 & 134116.59 & \\
\hline 1978 & 565521.62 & 134033.27 & \\
\hline 1979 & 565521.62 & 137533.27 & \\
\hline 1980 & 565521.62 & 137616.59 & \\
\hline 1981 & 567354.94 & 133949.92 & \\
\hline 1982 & 567271.62 & 133949.92 & \\
\hline 1983 & 567438.31 & 133949.92 & \\
\hline 1984 & 567521.62 & 133949.92 & \\
\hline 1985 & 567188.31 & 133949.92 & \\
\hline 1986 & 567104.94 & 133949.92 & \\
\hline 1987 & 567604.94 & 133949.92 & \\
\hline 1988 & 567021.62 & 133949.92 & \\
\hline 1989 & 567688.31 & 133949.92 & \\
\hline 1990 & 567771.62 & 133949.92 & \\
\hline 1991 & 566938.31 & 133949.92 & \\
\hline 1992 & 566854.94 & 133949.92 & \\
\hline 1993 & 567854.94 & 133949.92 & \\
\hline 1994 & 566771.62 & 133949.92 & \\
\hline 1995 & 567938.31 & 133949.92 & \\
\hline 1996 & 568021.62 & 133949.92 & \\
\hline 1997 & 566688.31 & 133949.92 & \\
\hline 1998 & 566604.94 & 133949.92 & \\
\hline 1999 & 568104.94 & 133949.92 & \\
\hline 2000 & 566521.62 & 133949.92 & \\
\hline 2001 & 568188.31 & 133949.92 & \\
\hline 2002 & 568271.62 & 133949.92 & \\
\hline 2003 & 566438.31 & 133949.92 & \\
\hline 2004 & 566354.94 & 133949.92 & \\
\hline 2005 & 568354.94 & 133949.92 & \\
\hline 2006 & 566271.62 & 133949.92 & \\
\hline 2007 & 568438.31 & 133949.92 & \\
\hline 2008 & 568521.62 & 133949.92 & \\
\hline 2009 & 566188.31 & 133949.92 & \\
\hline 2010 & 566104.94 & 133949.92 & \\
\hline 2011 & 568604.94 & 133949.92 & \\
\hline 2012 & 566021.62 & 133949.92 & \\
\hline 2013 & 568688.31 & 133949.92 & \\
\hline 2014 & 568771.62 & 133949.92 & \\
\hline 2015 & 565938.31 & 133949.92 & \\
\hline 2016 & 565854.94 & 133949.92 & \\
\hline
\end{tabular}




\begin{tabular}{|c|c|c|c|}
\hline node & X_coord & Y_coord & note: from sac04d created July 1, 2004 \\
\hline 2017 & $5 \overline{6} 8854.94$ & $1 \overline{3} 3949.92$ & \\
\hline 2018 & 565771.62 & 133949.92 & \\
\hline 2019 & 568938.31 & 133949.92 & \\
\hline 2020 & 569021.62 & 133949.92 & \\
\hline 2021 & 565688.31 & 133949.92 & \\
\hline 2022 & 565604.94 & 133949.92 & \\
\hline 2023 & 569104.94 & 133949.92 & \\
\hline 2024 & 565521.62 & 133949.92 & \\
\hline 2025 & 569188.31 & 133949.92 & \\
\hline 2026 & 569271.62 & 135783.27 & \\
\hline 2027 & 569271.62 & 135699.92 & \\
\hline 2028 & 569271.62 & 135866.59 & \\
\hline 2029 & 569271.62 & 135949.92 & \\
\hline 2030 & 569271.62 & 135616.59 & \\
\hline 2031 & 569271.62 & 136033.27 & \\
\hline 2032 & 569271.62 & 135533.27 & \\
\hline 2033 & 569271.62 & 135449.92 & \\
\hline 2034 & 569271.62 & 136116.59 & \\
\hline 2035 & 569271.62 & 136199.92 & \\
\hline 2036 & 569271.62 & 135366.59 & \\
\hline 2037 & 569271.62 & 136283.27 & \\
\hline 2038 & 569271.62 & 135283.27 & \\
\hline 2039 & 569271.62 & 135199.92 & \\
\hline 2040 & 569271.62 & 136366.59 & \\
\hline 2041 & 569271.62 & 136449.92 & \\
\hline 2042 & 569271.62 & 135116.59 & \\
\hline 2043 & 569271.62 & 136533.27 & \\
\hline 2044 & 569271.62 & 135033.27 & \\
\hline 2045 & 569271.62 & 134949.92 & \\
\hline 2046 & 569271.62 & 136616.59 & \\
\hline 2047 & 569271.62 & 136699.92 & \\
\hline 2048 & 569271.62 & 134866.59 & \\
\hline 2049 & 569271.62 & 136783.27 & \\
\hline 2050 & 569271.62 & 134783.27 & \\
\hline 2051 & 569271.62 & 134699.92 & \\
\hline 2052 & 569271.62 & 136866.59 & \\
\hline 2053 & 569271.62 & 136949.92 & \\
\hline 2054 & 569271.62 & 134616.59 & \\
\hline 2055 & 569271.62 & 137033.27 & \\
\hline 2056 & 569271.62 & 134533.27 & \\
\hline 2057 & 569271.62 & 134449.92 & \\
\hline 2058 & 569271.62 & 137116.59 & \\
\hline 2059 & 569271.62 & 137199.92 & \\
\hline 2060 & 569271.62 & 134366.59 & \\
\hline 2061 & 569271.62 & 137283.27 & \\
\hline 2062 & 569271.62 & 134283.27 & \\
\hline 2063 & 569271.62 & 134199.92 & \\
\hline 2064 & 569271.62 & 137366.59 & \\
\hline 2065 & 569271.62 & 137449.92 & \\
\hline 2066 & 569271.62 & 134116.59 & \\
\hline 2067 & 569271.62 & 137533.27 & \\
\hline 2068 & 569271.62 & 134033.27 & \\
\hline 2069 & 569271.62 & 133949.92 & \\
\hline 2070 & 569271.62 & 137616.59 & \\
\hline 2071 & 567354.94 & 137699.92 & \\
\hline 2072 & 567271.62 & 137699.92 & \\
\hline
\end{tabular}




\begin{tabular}{|c|c|c|c|}
\hline node & X_coord & Y_coord & note: from sac04d created July 1, 2004 \\
\hline 2073 & $5 \overline{6} 7438.31$ & $1 \overline{3} 7699.92$ & \\
\hline 2074 & 567521.62 & 137699.92 & \\
\hline 2075 & 567188.31 & 137699.92 & \\
\hline 2076 & 567104.94 & 137699.92 & \\
\hline 2077 & 567604.94 & 137699.92 & \\
\hline 2078 & 567021.62 & 137699.92 & \\
\hline 2079 & 567688.31 & 137699.92 & \\
\hline 2080 & 567771.62 & 137699.92 & \\
\hline 2081 & 566938.31 & 137699.92 & \\
\hline 2082 & 566854.94 & 137699.92 & \\
\hline 2083 & 567854.94 & 137699.92 & \\
\hline 2084 & 566771.62 & 137699.92 & \\
\hline 2085 & 567938.31 & 137699.92 & \\
\hline 2086 & 568021.62 & 137699.92 & \\
\hline 2087 & 566688.31 & 137699.92 & \\
\hline 2088 & 566604.94 & 137699.92 & \\
\hline 2089 & 568104.94 & 137699.92 & \\
\hline 2090 & 566521.62 & 137699.92 & \\
\hline 2091 & 568188.31 & 137699.92 & \\
\hline 2092 & 568271.62 & 137699.92 & \\
\hline 2093 & 566438.31 & 137699.92 & \\
\hline 2094 & 566354.94 & 137699.92 & \\
\hline 2095 & 568354.94 & 137699.92 & \\
\hline 2096 & 566271.62 & 137699.92 & \\
\hline 2097 & 568438.31 & 137699.92 & \\
\hline 2098 & 568521.62 & 137699.92 & \\
\hline 2099 & 566188.31 & 137699.92 & \\
\hline 2100 & 566104.94 & 137699.92 & \\
\hline 2101 & 568604.94 & 137699.92 & \\
\hline 2102 & 566021.62 & 137699.92 & \\
\hline 2103 & 568688.31 & 137699.92 & \\
\hline 2104 & 568771.62 & 137699.92 & \\
\hline 2105 & 565938.31 & 137699.92 & \\
\hline 2106 & 565854.94 & 137699.92 & \\
\hline 2107 & 568854.94 & 137699.92 & \\
\hline 2108 & 565771.62 & 137699.92 & \\
\hline 2109 & 568938.31 & 137699.92 & \\
\hline 2110 & 569021.62 & 137699.92 & \\
\hline 2111 & 565688.31 & 137699.92 & \\
\hline 2112 & 565604.94 & 137699.92 & \\
\hline 2113 & 569104.94 & 137699.92 & \\
\hline 2114 & 565521.62 & 137699.92 & \\
\hline 2115 & 569188.31 & 137699.92 & \\
\hline 2116 & 569271.62 & 137699.92 & \\
\hline 2117 & 565438.31 & 135783.27 & \\
\hline 2118 & 565438.31 & 135699.92 & \\
\hline 2119 & 565438.31 & 135866.59 & \\
\hline 2120 & 565438.31 & 135949.92 & \\
\hline 2121 & 565438.31 & 135616.59 & \\
\hline 2122 & 565438.31 & 136033.27 & \\
\hline 2123 & 565438.31 & 135533.27 & \\
\hline 2124 & 565438.31 & 135449.92 & \\
\hline 2125 & 565438.31 & 136116.59 & \\
\hline 2126 & 565438.31 & 136199.92 & \\
\hline 2127 & 565438.31 & 135366.59 & \\
\hline 2128 & 565438.31 & 136283.27 & \\
\hline
\end{tabular}




\begin{tabular}{|c|c|c|c|}
\hline node & X_coord & Y_coord & note: from sac04d created July 1, 2004 \\
\hline 2129 & $5 \overline{6} 5438.31$ & $1 \overline{3} 5283.27$ & \\
\hline 2130 & 565438.31 & 135199.92 & \\
\hline 2131 & 565438.31 & 136366.59 & \\
\hline 2132 & 565438.31 & 136449.92 & \\
\hline 2133 & 565438.31 & 135116.59 & \\
\hline 2134 & 565438.31 & 136533.27 & \\
\hline 2135 & 565438.31 & 135033.27 & \\
\hline 2136 & 565438.31 & 134949.92 & \\
\hline 2137 & 565438.31 & 136616.59 & \\
\hline 2138 & 565438.31 & 136699.92 & \\
\hline 2139 & 565438.31 & 134866.59 & \\
\hline 2140 & 565438.31 & 136783.27 & \\
\hline 2141 & 565438.31 & 134783.27 & \\
\hline 2142 & 565438.31 & 134699.92 & \\
\hline 2143 & 565438.31 & 136866.59 & \\
\hline 2144 & 565438.31 & 136949.92 & \\
\hline 2145 & 565438.31 & 134616.59 & \\
\hline 2146 & 565438.31 & 137033.27 & \\
\hline 2147 & 565438.31 & 134533.27 & \\
\hline 2148 & 565438.31 & 134449.92 & \\
\hline 2149 & 565438.31 & 137116.59 & \\
\hline 2150 & 565438.31 & 137199.92 & \\
\hline 2151 & 565438.31 & 134366.59 & \\
\hline 2152 & 565438.31 & 137283.27 & \\
\hline 2153 & 565438.31 & 134283.27 & \\
\hline 2154 & 565438.31 & 134199.92 & \\
\hline 2155 & 565438.31 & 137366.59 & \\
\hline 2156 & 565438.31 & 137449.92 & \\
\hline 2157 & 565438.31 & 134116.59 & \\
\hline 2158 & 565438.31 & 137533.27 & \\
\hline 2159 & 565438.31 & 134033.27 & \\
\hline 2160 & 565438.31 & 133949.92 & \\
\hline 2161 & 565438.31 & 137616.59 & \\
\hline 2162 & 565438.31 & 137699.92 & \\
\hline 2163 & 567354.94 & 133866.59 & \\
\hline 2164 & 567271.62 & 133866.59 & \\
\hline 2165 & 567438.31 & 133866.59 & \\
\hline 2166 & 567188.31 & 133866.59 & \\
\hline 2167 & 567521.62 & 133866.59 & \\
\hline 2168 & 567604.94 & 133866.59 & \\
\hline 2169 & 567104.94 & 133866.59 & \\
\hline 2170 & 567021.62 & 133866.59 & \\
\hline 2171 & 567688.31 & 133866.59 & \\
\hline 2172 & 566938.31 & 133866.59 & \\
\hline 2173 & 567771.62 & 133866.59 & \\
\hline 2174 & 567854.94 & 133866.59 & \\
\hline 2175 & 566854.94 & 133866.59 & \\
\hline 2176 & 566771.62 & 133866.59 & \\
\hline 2177 & 567938.31 & 133866.59 & \\
\hline 2178 & 566688.31 & 133866.59 & \\
\hline 2179 & 568021.62 & 133866.59 & \\
\hline 2180 & 568104.94 & 133866.59 & \\
\hline 2181 & 566604.94 & 133866.59 & \\
\hline 2182 & 566521.62 & 133866.59 & \\
\hline 2183 & 568188.31 & 133866.59 & \\
\hline 2184 & 566438.31 & 133866.59 & \\
\hline
\end{tabular}




\begin{tabular}{|c|c|c|c|}
\hline node & X_coord & Y_coord & note: from sac04d created July 1, 2004 \\
\hline 2185 & $5 \overline{6} 8271.62$ & $1 \overline{3} 3866.59$ & \\
\hline 2186 & 568354.94 & 133866.59 & \\
\hline 2187 & 566354.94 & 133866.59 & \\
\hline 2188 & 566271.62 & 133866.59 & \\
\hline 2189 & 568438.31 & 133866.59 & \\
\hline 2190 & 566188.31 & 133866.59 & \\
\hline 2191 & 568521.62 & 133866.59 & \\
\hline 2192 & 568604.94 & 133866.59 & \\
\hline 2193 & 566104.94 & 133866.59 & \\
\hline 2194 & 566021.62 & 133866.59 & \\
\hline 2195 & 568688.31 & 133866.59 & \\
\hline 2196 & 565938.31 & 133866.59 & \\
\hline 2197 & 568771.62 & 133866.59 & \\
\hline 2198 & 568854.94 & 133866.59 & \\
\hline 2199 & 565854.94 & 133866.59 & \\
\hline 2200 & 565771.62 & 133866.59 & \\
\hline 2201 & 568938.31 & 133866.59 & \\
\hline 2202 & 565688.31 & 133866.59 & \\
\hline 2203 & 569021.62 & 133866.59 & \\
\hline 2204 & 569104.94 & 133866.59 & \\
\hline 2205 & 565604.94 & 133866.59 & \\
\hline 2206 & 565521.62 & 133866.59 & \\
\hline 2207 & 569188.31 & 133866.59 & \\
\hline 2208 & 565438.31 & 133866.59 & \\
\hline 2209 & 569271.62 & 133866.59 & \\
\hline 2210 & 569354.94 & 135783.27 & \\
\hline 2211 & 569354.94 & 135866.59 & \\
\hline 2212 & 569354.94 & 135699.92 & \\
\hline 2213 & 569354.94 & 135616.59 & \\
\hline 2214 & 569354.94 & 135949.92 & \\
\hline 2215 & 569354.94 & 136033.27 & \\
\hline 2216 & 569354.94 & 135533.27 & \\
\hline 2217 & 569354.94 & 136116.59 & \\
\hline 2218 & 569354.94 & 135449.92 & \\
\hline 2219 & 569354.94 & 135366.59 & \\
\hline 2220 & 569354.94 & 136199.92 & \\
\hline 2221 & 569354.94 & 136283.27 & \\
\hline 2222 & 569354.94 & 135283.27 & \\
\hline 2223 & 569354.94 & 136366.59 & \\
\hline 2224 & 569354.94 & 135199.92 & \\
\hline 2225 & 569354.94 & 135116.59 & \\
\hline 2226 & 569354.94 & 136449.92 & \\
\hline 2227 & 569354.94 & 136533.27 & \\
\hline 2228 & 569354.94 & 135033.27 & \\
\hline 2229 & 569354.94 & 136616.59 & \\
\hline 2230 & 569354.94 & 134949.92 & \\
\hline 2231 & 569354.94 & 134866.59 & \\
\hline 2232 & 569354.94 & 136699.92 & \\
\hline 2233 & 569354.94 & 136783.27 & \\
\hline 2234 & 569354.94 & 134783.27 & \\
\hline 2235 & 569354.94 & 136866.59 & \\
\hline 2236 & 569354.94 & 134699.92 & \\
\hline 2237 & 569354.94 & 134616.59 & \\
\hline 2238 & 569354.94 & 136949.92 & \\
\hline 2239 & 569354.94 & 137033.27 & \\
\hline 2240 & 569354.94 & 134533.27 & \\
\hline
\end{tabular}




\begin{tabular}{|c|c|c|c|}
\hline node & X_coord & Y_coord & note: from sac04d created July 1, 2004 \\
\hline 2241 & $5 \overline{6} 9354.94$ & $1 \overline{3} 7116.59$ & \\
\hline 2242 & 569354.94 & 134449.92 & \\
\hline 2243 & 569354.94 & 134366.59 & \\
\hline 2244 & 569354.94 & 137199.92 & \\
\hline 2245 & 569354.94 & 137283.27 & \\
\hline 2246 & 569354.94 & 134283.27 & \\
\hline 2247 & 569354.94 & 137366.59 & \\
\hline 2248 & 569354.94 & 134199.92 & \\
\hline 2249 & 569354.94 & 134116.59 & \\
\hline 2250 & 569354.94 & 137449.92 & \\
\hline 2251 & 569354.94 & 137533.27 & \\
\hline 2252 & 569354.94 & 134033.27 & \\
\hline 2253 & 569354.94 & 137616.59 & \\
\hline 2254 & 569354.94 & 133949.92 & \\
\hline 2255 & 569354.94 & 133866.59 & \\
\hline 2256 & 569354.94 & 137699.92 & \\
\hline 2257 & 567354.94 & 137783.27 & \\
\hline 2258 & 567271.62 & 137783.27 & \\
\hline 2259 & 567438.31 & 137783.27 & \\
\hline 2260 & 567188.31 & 137783.27 & \\
\hline 2261 & 567521.62 & 137783.27 & \\
\hline 2262 & 567604.94 & 137783.27 & \\
\hline 2263 & 567104.94 & 137783.27 & \\
\hline 2264 & 567021.62 & 137783.27 & \\
\hline 2265 & 567688.31 & 137783.27 & \\
\hline 2266 & 566938.31 & 137783.27 & \\
\hline 2267 & 567771.62 & 137783.27 & \\
\hline 2268 & 567854.94 & 137783.27 & \\
\hline 2269 & 566854.94 & 137783.27 & \\
\hline 2270 & 566771.62 & 137783.27 & \\
\hline 2271 & 567938.31 & 137783.27 & \\
\hline 2272 & 566688.31 & 137783.27 & \\
\hline 2273 & 568021.62 & 137783.27 & \\
\hline 2274 & 568104.94 & 137783.27 & \\
\hline 2275 & 566604.94 & 137783.27 & \\
\hline 2276 & 566521.62 & 137783.27 & \\
\hline 2277 & 568188.31 & 137783.27 & \\
\hline 2278 & 566438.31 & 137783.27 & \\
\hline 2279 & 568271.62 & 137783.27 & \\
\hline 2280 & 568354.94 & 137783.27 & \\
\hline 2281 & 566354.94 & 137783.27 & \\
\hline 2282 & 566271.62 & 137783.27 & \\
\hline 2283 & 568438.31 & 137783.27 & \\
\hline 2284 & 566188.31 & 137783.27 & \\
\hline 2285 & 568521.62 & 137783.27 & \\
\hline 2286 & 568604.94 & 137783.27 & \\
\hline 2287 & 566104.94 & 137783.27 & \\
\hline 2288 & 566021.62 & 137783.27 & \\
\hline 2289 & 568688.31 & 137783.27 & \\
\hline 2290 & 565938.31 & 137783.27 & \\
\hline 2291 & 568771.62 & 137783.27 & \\
\hline 2292 & 568854.94 & 137783.27 & \\
\hline 2293 & 565854.94 & 137783.27 & \\
\hline 2294 & 565771.62 & 137783.27 & \\
\hline 2295 & 568938.31 & 137783.27 & \\
\hline 2296 & 565688.31 & 137783.27 & \\
\hline
\end{tabular}




\begin{tabular}{|c|c|c|c|}
\hline node & X_coord & Y_coord & note: from sac04d created July 1, 2004 \\
\hline 2297 & $5 \overline{6} 9021.62$ & $1 \overline{3} 7783.27$ & \\
\hline 2298 & 569104.94 & 137783.27 & \\
\hline 2299 & 565604.94 & 137783.27 & \\
\hline 2300 & 565521.62 & 137783.27 & \\
\hline 2301 & 569188.31 & 137783.27 & \\
\hline 2302 & 565438.31 & 137783.27 & \\
\hline 2303 & 569271.62 & 137783.27 & \\
\hline 2304 & 569354.94 & 137783.27 & \\
\hline 2305 & 565354.94 & 135783.27 & \\
\hline 2306 & 565354.94 & 135866.59 & \\
\hline 2307 & 565354.94 & 135699.92 & \\
\hline 2308 & 565354.94 & 135616.59 & \\
\hline 2309 & 565354.94 & 135949.92 & \\
\hline 2310 & 565354.94 & 136033.27 & \\
\hline 2311 & 565354.94 & 135533.27 & \\
\hline 2312 & 565354.94 & 136116.59 & \\
\hline 2313 & 565354.94 & 135449.92 & \\
\hline 2314 & 565354.94 & 135366.59 & \\
\hline 2315 & 565354.94 & 136199.92 & \\
\hline 2316 & 565354.94 & 136283.27 & \\
\hline 2317 & 565354.94 & 135283.27 & \\
\hline 2318 & 565354.94 & 136366.59 & \\
\hline 2319 & 565354.94 & 135199.92 & \\
\hline 2320 & 565354.94 & 135116.59 & \\
\hline 2321 & 565354.94 & 136449.92 & \\
\hline 2322 & 565354.94 & 136533.27 & \\
\hline 2323 & 565354.94 & 135033.27 & \\
\hline 2324 & 565354.94 & 136616.59 & \\
\hline 2325 & 565354.94 & 134949.92 & \\
\hline 2326 & 565354.94 & 134866.59 & \\
\hline 2327 & 565354.94 & 136699.92 & \\
\hline 2328 & 565354.94 & 136783.27 & \\
\hline 2329 & 565354.94 & 134783.27 & \\
\hline 2330 & 565354.94 & 136866.59 & \\
\hline 2331 & 565354.94 & 134699.92 & \\
\hline 2332 & 565354.94 & 134616.59 & \\
\hline 2333 & 565354.94 & 136949.92 & \\
\hline 2334 & 565354.94 & 137033.27 & \\
\hline 2335 & 565354.94 & 134533.27 & \\
\hline 2336 & 565354.94 & 137116.59 & \\
\hline 2337 & 565354.94 & 134449.92 & \\
\hline 2338 & 565354.94 & 134366.59 & \\
\hline 2339 & 565354.94 & 137199.92 & \\
\hline 2340 & 565354.94 & 137283.27 & \\
\hline 2341 & 565354.94 & 134283.27 & \\
\hline 2342 & 565354.94 & 137366.59 & \\
\hline 2343 & 565354.94 & 134199.92 & \\
\hline 2344 & 565354.94 & 134116.59 & \\
\hline 2345 & 565354.94 & 137449.92 & \\
\hline 2346 & 565354.94 & 137533.27 & \\
\hline 2347 & 565354.94 & 134033.27 & \\
\hline 2348 & 565354.94 & 137616.59 & \\
\hline 2349 & 565354.94 & 133949.92 & \\
\hline 2350 & 565354.94 & 133866.59 & \\
\hline 2351 & 565354.94 & 137699.92 & \\
\hline 2352 & 565354.94 & 137783.27 & \\
\hline
\end{tabular}




\begin{tabular}{|c|c|c|c|}
\hline node & X_coord & Y_coord & note: from sac04d created July 1, 2004 \\
\hline 2353 & $5 \overline{6} 7354.94$ & $1 \overline{3} 3783.27$ & \\
\hline 2354 & 567438.31 & 133783.27 & \\
\hline 2355 & 567271.62 & 133783.27 & \\
\hline 2356 & 567188.31 & 133783.27 & \\
\hline 2357 & 567521.62 & 133783.27 & \\
\hline 2358 & 567104.94 & 133783.27 & \\
\hline 2359 & 567604.94 & 133783.27 & \\
\hline 2360 & 567688.31 & 133783.27 & \\
\hline 2361 & 567021.62 & 133783.27 & \\
\hline 2362 & 566938.31 & 133783.27 & \\
\hline 2363 & 567771.62 & 133783.27 & \\
\hline 2364 & 566854.94 & 133783.27 & \\
\hline 2365 & 567854.94 & 133783.27 & \\
\hline 2366 & 567938.31 & 133783.27 & \\
\hline 2367 & 566771.62 & 133783.27 & \\
\hline 2368 & 566688.31 & 133783.27 & \\
\hline 2369 & 568021.62 & 133783.27 & \\
\hline 2370 & 566604.94 & 133783.27 & \\
\hline 2371 & 568104.94 & 133783.27 & \\
\hline 2372 & 568188.31 & 133783.27 & \\
\hline 2373 & 566521.62 & 133783.27 & \\
\hline 2374 & 566438.31 & 133783.27 & \\
\hline 2375 & 568271.62 & 133783.27 & \\
\hline 2376 & 566354.94 & 133783.27 & \\
\hline 2377 & 568354.94 & 133783.27 & \\
\hline 2378 & 568438.31 & 133783.27 & \\
\hline 2379 & 566271.62 & 133783.27 & \\
\hline 2380 & 566188.31 & 133783.27 & \\
\hline 2381 & 568521.62 & 133783.27 & \\
\hline 2382 & 566104.94 & 133783.27 & \\
\hline 2383 & 568604.94 & 133783.27 & \\
\hline 2384 & 568688.31 & 133783.27 & \\
\hline 2385 & 566021.62 & 133783.27 & \\
\hline 2386 & 565938.31 & 133783.27 & \\
\hline 2387 & 568771.62 & 133783.27 & \\
\hline 2388 & 565854.94 & 133783.27 & \\
\hline 2389 & 568854.94 & 133783.27 & \\
\hline 2390 & 568938.31 & 133783.27 & \\
\hline 2391 & 565771.62 & 133783.27 & \\
\hline 2392 & 565688.31 & 133783.27 & \\
\hline 2393 & 569021.62 & 133783.27 & \\
\hline 2394 & 565604.94 & 133783.27 & \\
\hline 2395 & 569104.94 & 133783.27 & \\
\hline 2396 & 569188.31 & 133783.27 & \\
\hline 2397 & 565521.62 & 133783.27 & \\
\hline 2398 & 565438.31 & 133783.27 & \\
\hline 2399 & 569271.62 & 133783.27 & \\
\hline 2400 & 565354.94 & 133699.92 & \\
\hline 2401 & 569354.94 & 133783.27 & \\
\hline 2402 & 569438.31 & 135783.27 & \\
\hline 2403 & 569438.31 & 135866.59 & \\
\hline 2404 & 569438.31 & 135699.92 & \\
\hline 2405 & 569438.31 & 135949.92 & \\
\hline 2406 & 569438.31 & 135616.59 & \\
\hline 2407 & 569438.31 & 135533.27 & \\
\hline 2408 & 569438.31 & 136033.27 & \\
\hline
\end{tabular}




\begin{tabular}{|c|c|c|c|}
\hline node & X_coord & Y_coord & note: from sac04d created July 1, 2004 \\
\hline 2409 & $5 \overline{6} 9438.31$ & $1 \overline{3} 6116.59$ & \\
\hline 2410 & 569438.31 & 135449.92 & \\
\hline 2411 & 569438.31 & 136199.92 & \\
\hline 2412 & 569438.31 & 135366.59 & \\
\hline 2413 & 569438.31 & 135283.27 & \\
\hline 2414 & 569438.31 & 136283.27 & \\
\hline 2415 & 569438.31 & 136366.59 & \\
\hline 2416 & 569438.31 & 135199.92 & \\
\hline 2417 & 569438.31 & 136449.92 & \\
\hline 2418 & 569438.31 & 135116.59 & \\
\hline 2419 & 569438.31 & 135033.27 & \\
\hline 2420 & 569438.31 & 136533.27 & \\
\hline 2421 & 569438.31 & 136616.59 & \\
\hline 2422 & 569438.31 & 134949.92 & \\
\hline 2423 & 569438.31 & 136699.92 & \\
\hline 2424 & 569438.31 & 134866.59 & \\
\hline 2425 & 569438.31 & 134783.27 & \\
\hline 2426 & 569438.31 & 136783.27 & \\
\hline 2427 & 569438.31 & 136866.59 & \\
\hline 2428 & 569438.31 & 134699.92 & \\
\hline 2429 & 569438.31 & 136949.92 & \\
\hline 2430 & 569438.31 & 134616.59 & \\
\hline 2431 & 569438.31 & 134533.27 & \\
\hline 2432 & 569438.31 & 137033.27 & \\
\hline 2433 & 569438.31 & 137116.59 & \\
\hline 2434 & 569438.31 & 134449.92 & \\
\hline 2435 & 569438.31 & 137199.92 & \\
\hline 2436 & 569438.31 & 134366.59 & \\
\hline 2437 & 569438.31 & 134283.27 & \\
\hline 2438 & 569438.31 & 137283.27 & \\
\hline 2439 & 569438.31 & 137366.59 & \\
\hline 2440 & 569438.31 & 134199.92 & \\
\hline 2441 & 569438.31 & 137449.92 & \\
\hline 2442 & 569438.31 & 134116.59 & \\
\hline 2443 & 569438.31 & 134033.27 & \\
\hline 2444 & 569438.31 & 137533.27 & \\
\hline 2445 & 569438.31 & 137616.59 & \\
\hline 2446 & 569438.31 & 133949.92 & \\
\hline 2447 & 569438.31 & 137699.92 & \\
\hline 2448 & 569438.31 & 133866.59 & \\
\hline 2449 & 569438.31 & 133783.27 & \\
\hline 2450 & 569438.31 & 137783.27 & \\
\hline 2451 & 567354.94 & 137866.59 & \\
\hline 2452 & 567438.31 & 137866.59 & \\
\hline 2453 & 567271.62 & 137866.59 & \\
\hline 2454 & 567188.31 & 137866.59 & \\
\hline 2455 & 567521.62 & 137866.59 & \\
\hline 2456 & 567104.94 & 137866.59 & \\
\hline 2457 & 567604.94 & 137866.59 & \\
\hline 2458 & 567688.31 & 137866.59 & \\
\hline 2459 & 567021.62 & 137866.59 & \\
\hline 2460 & 566938.31 & 137866.59 & \\
\hline 2461 & 567771.62 & 137866.59 & \\
\hline 2462 & 566854.94 & 137866.59 & \\
\hline 2463 & 567854.94 & 137866.59 & \\
\hline 2464 & 567938.31 & 137866.59 & \\
\hline
\end{tabular}




\begin{tabular}{|c|c|c|c|}
\hline node & X_coord & Y_coord & note: from sac04d created July 1, 2004 \\
\hline 2465 & $5 \overline{6} 6771.62$ & $1 \overline{3} 7866.59$ & \\
\hline 2466 & 566688.31 & 137866.59 & \\
\hline 2467 & 568021.62 & 137866.59 & \\
\hline 2468 & 566604.94 & 137866.59 & \\
\hline 2469 & 568104.94 & 137866.59 & \\
\hline 2470 & 568188.31 & 137866.59 & \\
\hline 2471 & 566521.62 & 137866.59 & \\
\hline 2472 & 566438.31 & 137866.59 & \\
\hline 2473 & 568271.62 & 137866.59 & \\
\hline 2474 & 566354.94 & 137866.59 & \\
\hline 2475 & 568354.94 & 137866.59 & \\
\hline 2476 & 568438.31 & 137866.59 & \\
\hline 2477 & 566271.62 & 137866.59 & \\
\hline 2478 & 566188.31 & 137866.59 & \\
\hline 2479 & 568521.62 & 137866.59 & \\
\hline 2480 & 566104.94 & 137866.59 & \\
\hline 2481 & 568604.94 & 137866.59 & \\
\hline 2482 & 568688.31 & 137866.59 & \\
\hline 2483 & 566021.62 & 137866.59 & \\
\hline 2484 & 565938.31 & 137866.59 & \\
\hline 2485 & 568771.62 & 137866.59 & \\
\hline 2486 & 565854.94 & 137866.59 & \\
\hline 2487 & 568854.94 & 137866.59 & \\
\hline 2488 & 568938.31 & 137866.59 & \\
\hline 2489 & 565771.62 & 137866.59 & \\
\hline 2490 & 565688.31 & 137866.59 & \\
\hline 2491 & 569021.62 & 137866.59 & \\
\hline 2492 & 565604.94 & 137866.59 & \\
\hline 2493 & 569104.94 & 137866.59 & \\
\hline 2494 & 569188.31 & 137866.59 & \\
\hline 2495 & 565521.62 & 137866.59 & \\
\hline 2496 & 565438.31 & 137866.59 & \\
\hline 2497 & 569271.62 & 137866.59 & \\
\hline 2498 & 565354.94 & 137866.59 & \\
\hline 2499 & 569354.94 & 137866.59 & \\
\hline 2500 & 569438.31 & 137866.59 & \\
\hline 2501 & 565271.62 & 135783.27 & \\
\hline 2502 & 565271.62 & 135866.59 & \\
\hline 2503 & 565271.62 & 135699.92 & \\
\hline 2504 & 565271.62 & 135949.92 & \\
\hline 2505 & 565271.62 & 135616.59 & \\
\hline 2506 & 565271.62 & 135533.27 & \\
\hline 2507 & 565271.62 & 136033.27 & \\
\hline 2508 & 565271.62 & 136116.59 & \\
\hline 2509 & 565271.62 & 135449.92 & \\
\hline 2510 & 565271.62 & 136199.92 & \\
\hline 2511 & 565271.62 & 135366.59 & \\
\hline 2512 & 565271.62 & 135283.27 & \\
\hline 2513 & 565271.62 & 136283.27 & \\
\hline 2514 & 565271.62 & 136366.59 & \\
\hline 2515 & 565271.62 & 135199.92 & \\
\hline 2516 & 565271.62 & 136449.92 & \\
\hline 2517 & 565271.62 & 135116.59 & \\
\hline 2518 & 565271.62 & 135033.27 & \\
\hline 2519 & 565271.62 & 136533.27 & \\
\hline 2520 & 565271.62 & 136616.59 & \\
\hline
\end{tabular}




\begin{tabular}{|c|c|c|c|}
\hline node & X_coord & Y_coord & note: from sac04d created July 1,2004 \\
\hline 2521 & $5 \overline{6} 5271.62$ & $1 \overline{3} 4949.92$ & \\
\hline 2522 & 565271.62 & 136699.92 & \\
\hline 2523 & 565271.62 & 134866.59 & \\
\hline 2524 & 565271.62 & 134783.27 & \\
\hline 2525 & 565271.62 & 136783.27 & \\
\hline 2526 & 565271.62 & 136866.59 & \\
\hline 2527 & 565271.62 & 134699.92 & \\
\hline 2528 & 565271.62 & 136949.92 & \\
\hline 2529 & 565271.62 & 134616.59 & \\
\hline 2530 & 565271.62 & 134533.27 & \\
\hline 2531 & 565271.62 & 137033.27 & \\
\hline 2532 & 565271.62 & 137116.59 & \\
\hline 2533 & 565271.62 & 134449.92 & \\
\hline 2534 & 565271.62 & 137199.92 & \\
\hline 2535 & 565271.62 & 134366.59 & \\
\hline 2536 & 565271.62 & 134283.27 & \\
\hline 2537 & 565271.62 & 137283.27 & \\
\hline 2538 & 565271.62 & 137366.59 & \\
\hline 2539 & 565271.62 & 134199.92 & \\
\hline 2540 & 565271.62 & 137449.92 & \\
\hline 2541 & 565271.62 & 134116.59 & \\
\hline 2542 & 565271.62 & 134033.27 & \\
\hline 2543 & 565271.62 & 137533.27 & \\
\hline 2544 & 565271.62 & 137616.59 & \\
\hline 2545 & 565271.62 & 133949.92 & \\
\hline 2546 & 565271.62 & 137699.92 & \\
\hline 2547 & 565271.62 & 133866.59 & \\
\hline 2548 & 565271.62 & 133616.59 & \\
\hline 2549 & 565271.62 & 137783.27 & \\
\hline 2550 & 565271.62 & 137866.59 & \\
\hline 2551 & 567354.94 & 133699.92 & \\
\hline 2552 & 567271.62 & 133699.92 & \\
\hline 2553 & 567438.31 & 133699.92 & \\
\hline 2554 & 567521.62 & 133699.92 & \\
\hline 2555 & 567188.31 & 133699.92 & \\
\hline 2556 & 567104.94 & 133699.92 & \\
\hline 2557 & 567604.94 & 133699.92 & \\
\hline 2558 & 567021.62 & 133699.92 & \\
\hline 2559 & 567688.31 & 133699.92 & \\
\hline 2560 & 567771.62 & 133699.92 & \\
\hline 2561 & 566938.31 & 133699.92 & \\
\hline 2562 & 566854.94 & 133699.92 & \\
\hline 2563 & 567854.94 & 133699.92 & \\
\hline 2564 & 566771.62 & 133699.92 & \\
\hline 2565 & 567938.31 & 133699.92 & \\
\hline 2566 & 568021.62 & 133699.92 & \\
\hline 2567 & 566688.31 & 133699.92 & \\
\hline 2568 & 566604.94 & 133699.92 & \\
\hline 2569 & 568104.94 & 133699.92 & \\
\hline 2570 & 566521.62 & 133699.92 & \\
\hline 2571 & 568188.31 & 133699.92 & \\
\hline 2572 & 568271.62 & 133699.92 & \\
\hline 2573 & 566438.31 & 133699.92 & \\
\hline 2574 & 566354.94 & 133699.92 & \\
\hline 2575 & 568354.94 & 133699.92 & \\
\hline 2576 & 566271.62 & 133699.92 & \\
\hline
\end{tabular}




\begin{tabular}{|c|c|c|c|}
\hline node & X_coord & Y_coord & note: from sac04d created July 1, 2004 \\
\hline 2577 & $5 \overline{6} 8438.31$ & $1 \overline{3} 3699.92$ & \\
\hline 2578 & 568521.62 & 133699.92 & \\
\hline 2579 & 566188.31 & 133699.92 & \\
\hline 2580 & 566104.94 & 133699.92 & \\
\hline 2581 & 568604.94 & 133699.92 & \\
\hline 2582 & 566021.62 & 133699.92 & \\
\hline 2583 & 568688.31 & 133699.92 & \\
\hline 2584 & 568771.62 & 133699.92 & \\
\hline 2585 & 565938.31 & 133699.92 & \\
\hline 2586 & 565854.94 & 133699.92 & \\
\hline 2587 & 568854.94 & 133699.92 & \\
\hline 2588 & 565771.62 & 133699.92 & \\
\hline 2589 & 568938.31 & 133699.92 & \\
\hline 2590 & 569021.62 & 133699.92 & \\
\hline 2591 & 565688.31 & 133699.92 & \\
\hline 2592 & 565604.94 & 133699.92 & \\
\hline 2593 & 569104.94 & 133699.92 & \\
\hline 2594 & 565521.62 & 133699.92 & \\
\hline 2595 & 569188.31 & 133699.92 & \\
\hline 2596 & 569271.62 & 133699.92 & \\
\hline 2597 & 569354.94 & 133699.92 & \\
\hline 2598 & 565521.62 & 133616.59 & \\
\hline 2599 & 569438.31 & 133699.92 & \\
\hline 2600 & 569521.62 & 135783.27 & \\
\hline 2601 & 569521.62 & 135699.92 & \\
\hline 2602 & 569521.62 & 135866.59 & \\
\hline 2603 & 569521.62 & 135949.92 & \\
\hline 2604 & 569521.62 & 135616.59 & \\
\hline 2605 & 569521.62 & 136033.27 & \\
\hline 2606 & 569521.62 & 135533.27 & \\
\hline 2607 & 569521.62 & 135449.92 & \\
\hline 2608 & 569521.62 & 136116.59 & \\
\hline 2609 & 569521.62 & 136199.92 & \\
\hline 2610 & 569521.62 & 135366.59 & \\
\hline 2611 & 569521.62 & 136283.27 & \\
\hline 2612 & 569521.62 & 135283.27 & \\
\hline 2613 & 569521.62 & 135199.92 & \\
\hline 2614 & 569521.62 & 136366.59 & \\
\hline 2615 & 569521.62 & 136449.92 & \\
\hline 2616 & 569521.62 & 135116.59 & \\
\hline 2617 & 569521.62 & 136533.27 & \\
\hline 2618 & 569521.62 & 135033.27 & \\
\hline 2619 & 569521.62 & 134949.92 & \\
\hline 2620 & 569521.62 & 136616.59 & \\
\hline 2621 & 569521.62 & 136699.92 & \\
\hline 2622 & 569521.62 & 134866.59 & \\
\hline 2623 & 569521.62 & 136783.27 & \\
\hline 2624 & 569521.62 & 134783.27 & \\
\hline 2625 & 569521.62 & 134699.92 & \\
\hline 2626 & 569521.62 & 136866.59 & \\
\hline 2627 & 569521.62 & 136949.92 & \\
\hline 2628 & 569521.62 & 134616.59 & \\
\hline 2629 & 569521.62 & 137033.27 & \\
\hline 2630 & 569521.62 & 134533.27 & \\
\hline 2631 & 569521.62 & 134449.92 & \\
\hline 2632 & 569521.62 & 137116.59 & \\
\hline
\end{tabular}




\begin{tabular}{|c|c|c|c|}
\hline node & X_coord & Y_coord & note: from sac04d created July 1, 2004 \\
\hline 2633 & $5 \overline{6} 9521.62$ & $1 \overline{3} 7199.92$ & \\
\hline 2634 & 569521.62 & 134366.59 & \\
\hline 2635 & 569521.62 & 137283.27 & \\
\hline 2636 & 569521.62 & 134283.27 & \\
\hline 2637 & 569521.62 & 134199.92 & \\
\hline 2638 & 569521.62 & 137366.59 & \\
\hline 2639 & 569521.62 & 137449.92 & \\
\hline 2640 & 569521.62 & 134116.59 & \\
\hline 2641 & 569521.62 & 137533.27 & \\
\hline 2642 & 569521.62 & 134033.27 & \\
\hline 2643 & 569521.62 & 133949.92 & \\
\hline 2644 & 569521.62 & 137616.59 & \\
\hline 2645 & 569521.62 & 137699.92 & \\
\hline 2646 & 569521.62 & 133866.59 & \\
\hline 2647 & 569521.62 & 137783.27 & \\
\hline 2648 & 569521.62 & 133783.27 & \\
\hline 2649 & 569521.62 & 133699.92 & \\
\hline 2650 & 569521.62 & 137866.59 & \\
\hline 2651 & 567354.94 & 137949.92 & \\
\hline 2652 & 567271.62 & 137949.92 & \\
\hline 2653 & 567438.31 & 137949.92 & \\
\hline 2654 & 567521.62 & 137949.92 & \\
\hline 2655 & 567188.31 & 137949.92 & \\
\hline 2656 & 567104.94 & 137949.92 & \\
\hline 2657 & 567604.94 & 137949.92 & \\
\hline 2658 & 567021.62 & 137949.92 & \\
\hline 2659 & 567688.31 & 137949.92 & \\
\hline 2660 & 567771.62 & 137949.92 & \\
\hline 2661 & 566938.31 & 137949.92 & \\
\hline 2662 & 566854.94 & 137949.92 & \\
\hline 2663 & 567854.94 & 137949.92 & \\
\hline 2664 & 566771.62 & 137949.92 & \\
\hline 2665 & 567938.31 & 137949.92 & \\
\hline 2666 & 568021.62 & 137949.92 & \\
\hline 2667 & 566688.31 & 137949.92 & \\
\hline 2668 & 566604.94 & 137949.92 & \\
\hline 2669 & 568104.94 & 137949.92 & \\
\hline 2670 & 566521.62 & 137949.92 & \\
\hline 2671 & 568188.31 & 137949.92 & \\
\hline 2672 & 568271.62 & 137949.92 & \\
\hline 2673 & 566438.31 & 137949.92 & \\
\hline 2674 & 566354.94 & 137949.92 & \\
\hline 2675 & 568354.94 & 137949.92 & \\
\hline 2676 & 566271.62 & 137949.92 & \\
\hline 2677 & 568438.31 & 137949.92 & \\
\hline 2678 & 568521.62 & 137949.92 & \\
\hline 2679 & 566188.31 & 137949.92 & \\
\hline 2680 & 566104.94 & 137949.92 & \\
\hline 2681 & 568604.94 & 137949.92 & \\
\hline 2682 & 566021.62 & 137949.92 & \\
\hline 2683 & 568688.31 & 137949.92 & \\
\hline 2684 & 568771.62 & 137949.92 & \\
\hline 2685 & 565938.31 & 137949.92 & \\
\hline 2686 & 565854.94 & 137949.92 & \\
\hline 2687 & 568854.94 & 137949.92 & \\
\hline 2688 & 565771.62 & 137949.92 & \\
\hline
\end{tabular}




\begin{tabular}{|c|c|c|c|}
\hline node & X_coord & Y_coord & note: from sac04d created July 1, 2004 \\
\hline 2689 & $5 \overline{6} 8938.31$ & $1 \overline{3} 7949.92$ & \\
\hline 2690 & 569021.62 & 137949.92 & \\
\hline 2691 & 565688.31 & 137949.92 & \\
\hline 2692 & 565604.94 & 137949.92 & \\
\hline 2693 & 569104.94 & 137949.92 & \\
\hline 2694 & 565521.62 & 137949.92 & \\
\hline 2695 & 569188.31 & 137949.92 & \\
\hline 2696 & 569271.62 & 137949.92 & \\
\hline 2697 & 565438.31 & 137949.92 & \\
\hline 2698 & 565354.94 & 137949.92 & \\
\hline 2699 & 569354.94 & 137949.92 & \\
\hline 2700 & 565271.62 & 137949.92 & \\
\hline 2701 & 569438.31 & 137949.92 & \\
\hline 2702 & 569521.62 & 137949.92 & \\
\hline 2703 & 565188.31 & 135783.27 & \\
\hline 2704 & 565188.31 & 135699.92 & \\
\hline 2705 & 565188.31 & 135866.59 & \\
\hline 2706 & 565188.31 & 135949.92 & \\
\hline 2707 & 565188.31 & 135616.59 & \\
\hline 2708 & 565188.31 & 136033.27 & \\
\hline 2709 & 565188.31 & 135533.27 & \\
\hline 2710 & 565188.31 & 135449.92 & \\
\hline 2711 & 565188.31 & 136116.59 & \\
\hline 2712 & 565188.31 & 136199.92 & \\
\hline 2713 & 565188.31 & 135366.59 & \\
\hline 2714 & 565188.31 & 136283.27 & \\
\hline 2715 & 565188.31 & 135283.27 & \\
\hline 2716 & 565188.31 & 135199.92 & \\
\hline 2717 & 565188.31 & 136366.59 & \\
\hline 2718 & 565188.31 & 136449.92 & \\
\hline 2719 & 565188.31 & 135116.59 & \\
\hline 2720 & 565188.31 & 136533.27 & \\
\hline 2721 & 565188.31 & 135033.27 & \\
\hline 2722 & 565188.31 & 134949.92 & \\
\hline 2723 & 565188.31 & 136616.59 & \\
\hline 2724 & 565188.31 & 136699.92 & \\
\hline 2725 & 565188.31 & 134866.59 & \\
\hline 2726 & 565188.31 & 136783.27 & \\
\hline 2727 & 565188.31 & 134783.27 & \\
\hline 2728 & 565188.31 & 134699.92 & \\
\hline 2729 & 565188.31 & 136866.59 & \\
\hline 2730 & 565188.31 & 136949.92 & \\
\hline 2731 & 565188.31 & 134616.59 & \\
\hline 2732 & 565188.31 & 137033.27 & \\
\hline 2733 & 565188.31 & 134533.27 & \\
\hline 2734 & 565188.31 & 134449.92 & \\
\hline 2735 & 565188.31 & 137116.59 & \\
\hline 2736 & 565188.31 & 137199.92 & \\
\hline 2737 & 565188.31 & 134366.59 & \\
\hline 2738 & 565188.31 & 137283.27 & \\
\hline 2739 & 565188.31 & 134283.27 & \\
\hline 2740 & 565188.31 & 134199.92 & \\
\hline 2741 & 565188.31 & 137366.59 & \\
\hline 2742 & 565188.31 & 137449.92 & \\
\hline 2743 & 565188.31 & 134116.59 & \\
\hline 2744 & 565188.31 & 137533.27 & \\
\hline
\end{tabular}




\begin{tabular}{|c|c|c|c|}
\hline node & X_coord & Y_coord & note: from sac04d created July 1, 2004 \\
\hline 2745 & $5 \overline{6} 5188.31$ & $1 \overline{3} 4033.27$ & \\
\hline 2746 & 565104.94 & 133949.92 & \\
\hline 2747 & 565188.31 & 137616.59 & \\
\hline 2748 & 565188.31 & 137699.92 & \\
\hline 2749 & 565021.62 & 133866.59 & \\
\hline 2750 & 565188.31 & 137783.27 & \\
\hline 2751 & 565021.62 & 133616.59 & \\
\hline 2752 & 565271.62 & 133366.59 & \\
\hline 2753 & 565021.62 & 133366.59 & \\
\hline 2754 & 565521.62 & 133366.59 & \\
\hline 2755 & 565188.31 & 137866.59 & \\
\hline 2756 & 565188.31 & 137949.92 & \\
\hline 2757 & 567354.94 & 133616.59 & \\
\hline 2758 & 567271.62 & 133616.59 & \\
\hline 2759 & 567438.31 & 133616.59 & \\
\hline 2760 & 567188.31 & 133616.59 & \\
\hline 2761 & 567521.62 & 133616.59 & \\
\hline 2762 & 567604.94 & 133616.59 & \\
\hline 2763 & 567104.94 & 133616.59 & \\
\hline 2764 & 567021.62 & 133616.59 & \\
\hline 2765 & 567688.31 & 133616.59 & \\
\hline 2766 & 566938.31 & 133616.59 & \\
\hline 2767 & 567771.62 & 133616.59 & \\
\hline 2768 & 567854.94 & 133616.59 & \\
\hline 2769 & 566854.94 & 133616.59 & \\
\hline 2770 & 566771.62 & 133616.59 & \\
\hline 2771 & 567938.31 & 133616.59 & \\
\hline 2772 & 566688.31 & 133616.59 & \\
\hline 2773 & 568021.62 & 133616.59 & \\
\hline 2774 & 568104.94 & 133616.59 & \\
\hline 2775 & 566604.94 & 133616.59 & \\
\hline 2776 & 566521.62 & 133616.59 & \\
\hline 2777 & 568188.31 & 133616.59 & \\
\hline 2778 & 566438.31 & 133616.59 & \\
\hline 2779 & 568271.62 & 133616.59 & \\
\hline 2780 & 568354.94 & 133616.59 & \\
\hline 2781 & 566354.94 & 133616.59 & \\
\hline 2782 & 566271.62 & 133616.59 & \\
\hline 2783 & 568438.31 & 133616.59 & \\
\hline 2784 & 566188.31 & 133616.59 & \\
\hline 2785 & 568521.62 & 133616.59 & \\
\hline 2786 & 568604.94 & 133616.59 & \\
\hline 2787 & 566104.94 & 133616.59 & \\
\hline 2788 & 566021.62 & 133616.59 & \\
\hline 2789 & 568688.31 & 133616.59 & \\
\hline 2790 & 565938.31 & 133616.59 & \\
\hline 2791 & 568771.62 & 133616.59 & \\
\hline 2792 & 568854.94 & 133616.59 & \\
\hline 2793 & 565854.94 & 133616.59 & \\
\hline 2794 & 565771.62 & 133616.59 & \\
\hline 2795 & 568938.31 & 133616.59 & \\
\hline 2796 & 565688.31 & 133616.59 & \\
\hline 2797 & 569021.62 & 133616.59 & \\
\hline 2798 & 569104.94 & 133616.59 & \\
\hline 2799 & 565604.94 & 133616.59 & \\
\hline 2800 & 569188.31 & 133616.59 & \\
\hline
\end{tabular}




\begin{tabular}{|c|c|c|c|}
\hline node & X_coord & Y_coord & note: from sac04d created July 1, 2004 \\
\hline 2801 & $5 \overline{6} 9271.62$ & $1 \overline{3} 3616.59$ & \\
\hline 2802 & 569354.94 & 133616.59 & \\
\hline 2803 & 569438.31 & 133616.59 & \\
\hline 2804 & 565604.94 & 133449.92 & \\
\hline 2805 & 569521.62 & 133616.59 & \\
\hline 2806 & 569604.94 & 135783.27 & \\
\hline 2807 & 569604.94 & 135866.59 & \\
\hline 2808 & 569604.94 & 135699.92 & \\
\hline 2809 & 569604.94 & 135616.59 & \\
\hline 2810 & 569604.94 & 135949.92 & \\
\hline 2811 & 569604.94 & 136033.27 & \\
\hline 2812 & 569604.94 & 135533.27 & \\
\hline 2813 & 569604.94 & 136116.59 & \\
\hline 2814 & 569604.94 & 135449.92 & \\
\hline 2815 & 569604.94 & 135366.59 & \\
\hline 2816 & 569604.94 & 136199.92 & \\
\hline 2817 & 569604.94 & 136283.27 & \\
\hline 2818 & 569604.94 & 135283.27 & \\
\hline 2819 & 569604.94 & 136366.59 & \\
\hline 2820 & 569604.94 & 135199.92 & \\
\hline 2821 & 569604.94 & 135116.59 & \\
\hline 2822 & 569604.94 & 136449.92 & \\
\hline 2823 & 569604.94 & 136533.27 & \\
\hline 2824 & 569604.94 & 135033.27 & \\
\hline 2825 & 569604.94 & 136616.59 & \\
\hline 2826 & 569604.94 & 134949.92 & \\
\hline 2827 & 569604.94 & 134866.59 & \\
\hline 2828 & 569604.94 & 136699.92 & \\
\hline 2829 & 569604.94 & 136783.27 & \\
\hline 2830 & 569604.94 & 134783.27 & \\
\hline 2831 & 569604.94 & 136866.59 & \\
\hline 2832 & 569604.94 & 134699.92 & \\
\hline 2833 & 569604.94 & 134616.59 & \\
\hline 2834 & 569604.94 & 136949.92 & \\
\hline 2835 & 569604.94 & 137033.27 & \\
\hline 2836 & 569604.94 & 134533.27 & \\
\hline 2837 & 569604.94 & 137116.59 & \\
\hline 2838 & 569604.94 & 134449.92 & \\
\hline 2839 & 569604.94 & 134366.59 & \\
\hline 2840 & 569604.94 & 137199.92 & \\
\hline 2841 & 569604.94 & 137283.27 & \\
\hline 2842 & 569604.94 & 134283.27 & \\
\hline 2843 & 569604.94 & 137366.59 & \\
\hline 2844 & 569604.94 & 134199.92 & \\
\hline 2845 & 569604.94 & 134116.59 & \\
\hline 2846 & 569604.94 & 137449.92 & \\
\hline 2847 & 569604.94 & 137533.27 & \\
\hline 2848 & 569604.94 & 134033.27 & \\
\hline 2849 & 569604.94 & 137616.59 & \\
\hline 2850 & 569604.94 & 133949.92 & \\
\hline 2851 & 569604.94 & 133866.59 & \\
\hline 2852 & 569604.94 & 137699.92 & \\
\hline 2853 & 569604.94 & 137783.27 & \\
\hline 2854 & 569604.94 & 133783.27 & \\
\hline 2855 & 569604.94 & 137866.59 & \\
\hline 2856 & 569604.94 & 133699.92 & \\
\hline
\end{tabular}




\begin{tabular}{|c|c|c|c|}
\hline node & X_coord & Y_coord & note: from sac04d created July 1, 2004 \\
\hline 2857 & $5 \overline{6} 9604.94$ & $1 \overline{3} 3616.59$ & \\
\hline 2858 & 569604.94 & 137949.92 & \\
\hline 2859 & 567354.94 & 138033.27 & \\
\hline 2860 & 567271.62 & 138033.27 & \\
\hline 2861 & 567438.31 & 138033.27 & \\
\hline 2862 & 567188.31 & 138033.27 & \\
\hline 2863 & 567521.62 & 138033.27 & \\
\hline 2864 & 567604.94 & 138033.27 & \\
\hline 2865 & 567104.94 & 138033.27 & \\
\hline 2866 & 567021.62 & 138033.27 & \\
\hline 2867 & 567688.31 & 138033.27 & \\
\hline 2868 & 566938.31 & 138033.27 & \\
\hline 2869 & 567771.62 & 138033.27 & \\
\hline 2870 & 567854.94 & 138033.27 & \\
\hline 2871 & 566854.94 & 138033.27 & \\
\hline 2872 & 566771.62 & 138033.27 & \\
\hline 2873 & 567938.31 & 138033.27 & \\
\hline 2874 & 566688.31 & 138033.27 & \\
\hline 2875 & 568021.62 & 138033.27 & \\
\hline 2876 & 568104.94 & 138033.27 & \\
\hline 2877 & 566604.94 & 138033.27 & \\
\hline 2878 & 566521.62 & 138033.27 & \\
\hline 2879 & 568188.31 & 138033.27 & \\
\hline 2880 & 566438.31 & 138033.27 & \\
\hline 2881 & 568271.62 & 138033.27 & \\
\hline 2882 & 568354.94 & 138033.27 & \\
\hline 2883 & 566354.94 & 138033.27 & \\
\hline 2884 & 566271.62 & 138033.27 & \\
\hline 2885 & 568438.31 & 138033.27 & \\
\hline 2886 & 566188.31 & 138033.27 & \\
\hline 2887 & 568521.62 & 138033.27 & \\
\hline 2888 & 568604.94 & 138033.27 & \\
\hline 2889 & 566104.94 & 138033.27 & \\
\hline 2890 & 566021.62 & 138033.27 & \\
\hline 2891 & 568688.31 & 138033.27 & \\
\hline 2892 & 565938.31 & 138033.27 & \\
\hline 2893 & 568771.62 & 138033.27 & \\
\hline 2894 & 568854.94 & 138033.27 & \\
\hline 2895 & 565854.94 & 138033.27 & \\
\hline 2896 & 565771.62 & 138033.27 & \\
\hline 2897 & 568938.31 & 138033.27 & \\
\hline 2898 & 565688.31 & 138033.27 & \\
\hline 2899 & 569021.62 & 138033.27 & \\
\hline 2900 & 569104.94 & 138033.27 & \\
\hline 2901 & 565604.94 & 138033.27 & \\
\hline 2902 & 565521.62 & 138033.27 & \\
\hline 2903 & 569188.31 & 138033.27 & \\
\hline 2904 & 565438.31 & 138033.27 & \\
\hline 2905 & 569271.62 & 138033.27 & \\
\hline 2906 & 569354.94 & 138033.27 & \\
\hline 2907 & 565354.94 & 138033.27 & \\
\hline 2908 & 565271.62 & 138033.27 & \\
\hline 2909 & 569438.31 & 138033.27 & \\
\hline 2910 & 565188.31 & 138033.27 & \\
\hline 2911 & 569521.62 & 138033.27 & \\
\hline 2912 & 569604.94 & 138033.27 & \\
\hline
\end{tabular}




\begin{tabular}{|c|c|c|c|}
\hline node & X_coord & Y_coord & note: from sac04d created July 1, 2004 \\
\hline 2913 & $5 \overline{6} 5104.94$ & $1 \overline{3} 5783.27$ & \\
\hline 2914 & 565104.94 & 135866.59 & \\
\hline 2915 & 565104.94 & 135699.92 & \\
\hline 2916 & 565104.94 & 135616.59 & \\
\hline 2917 & 565104.94 & 135949.92 & \\
\hline 2918 & 565104.94 & 136033.27 & \\
\hline 2919 & 565104.94 & 135533.27 & \\
\hline 2920 & 565104.94 & 136116.59 & \\
\hline 2921 & 565104.94 & 135449.92 & \\
\hline 2922 & 565104.94 & 135366.59 & \\
\hline 2923 & 565104.94 & 136199.92 & \\
\hline 2924 & 565104.94 & 136283.27 & \\
\hline 2925 & 565104.94 & 135283.27 & \\
\hline 2926 & 565104.94 & 136366.59 & \\
\hline 2927 & 565104.94 & 135199.92 & \\
\hline 2928 & 565104.94 & 135116.59 & \\
\hline 2929 & 565104.94 & 136449.92 & \\
\hline 2930 & 565104.94 & 136533.27 & \\
\hline 2931 & 565104.94 & 135033.27 & \\
\hline 2932 & 565104.94 & 136616.59 & \\
\hline 2933 & 565104.94 & 134949.92 & \\
\hline 2934 & 565104.94 & 134866.59 & \\
\hline 2935 & 565104.94 & 136699.92 & \\
\hline 2936 & 565104.94 & 136783.27 & \\
\hline 2937 & 565104.94 & 134783.27 & \\
\hline 2938 & 565104.94 & 136866.59 & \\
\hline 2939 & 565104.94 & 134699.92 & \\
\hline 2940 & 565104.94 & 134616.59 & \\
\hline 2941 & 565104.94 & 136949.92 & \\
\hline 2942 & 565104.94 & 137033.27 & \\
\hline 2943 & 565104.94 & 134533.27 & \\
\hline 2944 & 565104.94 & 137116.59 & \\
\hline 2945 & 565104.94 & 134449.92 & \\
\hline 2946 & 565104.94 & 134366.59 & \\
\hline 2947 & 565104.94 & 137199.92 & \\
\hline 2948 & 565104.94 & 137283.27 & \\
\hline 2949 & 565104.94 & 134283.27 & \\
\hline 2950 & 565104.94 & 137366.59 & \\
\hline 2951 & 565104.94 & 134199.92 & \\
\hline 2952 & 565104.94 & 134116.59 & \\
\hline 2953 & 565104.94 & 137449.92 & \\
\hline 2954 & 565104.94 & 137533.27 & \\
\hline 2955 & 565104.94 & 137616.59 & \\
\hline 2956 & 565021.62 & 134116.59 & \\
\hline 2957 & 565104.94 & 137699.92 & \\
\hline 2958 & 565104.94 & 137783.27 & \\
\hline 2959 & 564771.62 & 133866.59 & \\
\hline 2960 & 564771.62 & 134116.59 & \\
\hline 2961 & 564771.62 & 133616.59 & \\
\hline 2962 & 565104.94 & 137866.59 & \\
\hline 2963 & 564771.62 & 133366.59 & \\
\hline 2964 & 565271.62 & 133116.59 & \\
\hline 2965 & 565521.62 & 133116.59 & \\
\hline 2966 & 565021.62 & 132866.59 & \\
\hline 2967 & 564771.62 & 132616.59 & \\
\hline 2968 & 565771.62 & 133366.59 & \\
\hline
\end{tabular}




\begin{tabular}{|c|c|c|c|}
\hline node & X_coord & Y_coord & note: from sac04d created July 1, 2004 \\
\hline 2969 & $5 \overline{6} 5771.62$ & $1 \overline{3} 3116.59$ & \\
\hline 2970 & 565771.62 & 133449.92 & \\
\hline 2971 & 565104.94 & 137949.92 & \\
\hline 2972 & 565104.94 & 138033.27 & \\
\hline 2973 & 567354.94 & 133533.27 & \\
\hline 2974 & 567438.31 & 133533.27 & \\
\hline 2975 & 567271.62 & 133366.59 & \\
\hline 2976 & 567188.31 & 133533.27 & \\
\hline 2977 & 567521.62 & 133366.59 & \\
\hline 2978 & 567104.94 & 133533.27 & \\
\hline 2979 & 567604.94 & 133533.27 & \\
\hline 2980 & 567688.31 & 133533.27 & \\
\hline 2981 & 567021.62 & 133366.59 & \\
\hline 2982 & 566938.31 & 133533.27 & \\
\hline 2983 & 567771.62 & 133366.59 & \\
\hline 2984 & 566854.94 & 133533.27 & \\
\hline 2985 & 567854.94 & 133533.27 & \\
\hline 2986 & 567938.31 & 133533.27 & \\
\hline 2987 & 566771.62 & 133366.59 & \\
\hline 2988 & 566688.31 & 133533.27 & \\
\hline 2989 & 568021.62 & 133366.59 & \\
\hline 2990 & 566604.94 & 133533.27 & \\
\hline 2991 & 568104.94 & 133533.27 & \\
\hline 2992 & 568188.31 & 133533.27 & \\
\hline 2993 & 566521.62 & 133366.59 & \\
\hline 2994 & 566438.31 & 133533.27 & \\
\hline 2995 & 568271.62 & 133366.59 & \\
\hline 2996 & 566354.94 & 133533.27 & \\
\hline 2997 & 568354.94 & 133533.27 & \\
\hline 2998 & 568438.31 & 133533.27 & \\
\hline 2999 & 566271.62 & 133366.59 & \\
\hline 3000 & 566188.31 & 133533.27 & \\
\hline 3001 & 568521.62 & 133366.59 & \\
\hline 3002 & 566104.94 & 133533.27 & \\
\hline 3003 & 568604.94 & 133533.27 & \\
\hline 3004 & 568688.31 & 133533.27 & \\
\hline 3005 & 566021.62 & 133366.59 & \\
\hline 3006 & 565938.31 & 133449.92 & \\
\hline 3007 & 568771.62 & 133366.59 & \\
\hline 3008 & 565854.94 & 133533.27 & \\
\hline 3009 & 568854.94 & 133533.27 & \\
\hline 3010 & 568938.31 & 133533.27 & \\
\hline 3011 & 565771.62 & 133533.27 & \\
\hline 3012 & 565688.31 & 133533.27 & \\
\hline 3013 & 569021.62 & 133366.59 & \\
\hline 3014 & 569104.94 & 133533.27 & \\
\hline 3015 & 569188.31 & 133533.27 & \\
\hline 3016 & 569271.62 & 133366.59 & \\
\hline 3017 & 569354.94 & 133533.27 & \\
\hline 3018 & 569438.31 & 133533.27 & \\
\hline 3019 & 569521.62 & 133366.59 & \\
\hline 3020 & 569604.94 & 133449.92 & \\
\hline 3021 & 569688.31 & 135783.27 & \\
\hline 3022 & 569688.31 & 135866.59 & \\
\hline 3023 & 569688.31 & 135699.92 & \\
\hline 3024 & 569688.31 & 135949.92 & \\
\hline
\end{tabular}




\begin{tabular}{|c|c|c|c|}
\hline node & X_coord & Y_coord & note: from sac04d created July 1, 2004 \\
\hline 3025 & $5 \overline{6} 9688.31$ & $1 \overline{3} 5616.59$ & \\
\hline 3026 & 569688.31 & 135533.27 & \\
\hline 3027 & 569688.31 & 136033.27 & \\
\hline 3028 & 569688.31 & 136116.59 & \\
\hline 3029 & 569688.31 & 135449.92 & \\
\hline 3030 & 569688.31 & 136199.92 & \\
\hline 3031 & 569688.31 & 135366.59 & \\
\hline 3032 & 569688.31 & 135283.27 & \\
\hline 3033 & 569688.31 & 136283.27 & \\
\hline 3034 & 569688.31 & 136366.59 & \\
\hline 3035 & 569688.31 & 135199.92 & \\
\hline 3036 & 569688.31 & 136449.92 & \\
\hline 3037 & 569688.31 & 135116.59 & \\
\hline 3038 & 569688.31 & 135033.27 & \\
\hline 3039 & 569688.31 & 136533.27 & \\
\hline 3040 & 569688.31 & 136616.59 & \\
\hline 3041 & 569688.31 & 134949.92 & \\
\hline 3042 & 569688.31 & 136699.92 & \\
\hline 3043 & 569688.31 & 134866.59 & \\
\hline 3044 & 569688.31 & 134783.27 & \\
\hline 3045 & 569688.31 & 136783.27 & \\
\hline 3046 & 569688.31 & 136866.59 & \\
\hline 3047 & 569688.31 & 134699.92 & \\
\hline 3048 & 569688.31 & 136949.92 & \\
\hline 3049 & 569688.31 & 134616.59 & \\
\hline 3050 & 569688.31 & 134533.27 & \\
\hline 3051 & 569688.31 & 137033.27 & \\
\hline 3052 & 569688.31 & 137116.59 & \\
\hline 3053 & 569688.31 & 134449.92 & \\
\hline 3054 & 569688.31 & 137199.92 & \\
\hline 3055 & 569688.31 & 134366.59 & \\
\hline 3056 & 569688.31 & 134283.27 & \\
\hline 3057 & 569688.31 & 137283.27 & \\
\hline 3058 & 569688.31 & 137366.59 & \\
\hline 3059 & 569688.31 & 134199.92 & \\
\hline 3060 & 569688.31 & 137449.92 & \\
\hline 3061 & 569688.31 & 134116.59 & \\
\hline 3062 & 569688.31 & 134033.27 & \\
\hline 3063 & 569688.31 & 137533.27 & \\
\hline 3064 & 569688.31 & 137616.59 & \\
\hline 3065 & 569688.31 & 133949.92 & \\
\hline 3066 & 569688.31 & 137699.92 & \\
\hline 3067 & 569688.31 & 133866.59 & \\
\hline 3068 & 569688.31 & 133783.27 & \\
\hline 3069 & 569688.31 & 137783.27 & \\
\hline 3070 & 569688.31 & 137866.59 & \\
\hline 3071 & 569688.31 & 133699.92 & \\
\hline 3072 & 569688.31 & 137949.92 & \\
\hline 3073 & 569688.31 & 133616.59 & \\
\hline 3074 & 569688.31 & 133533.27 & \\
\hline 3075 & 569688.31 & 138033.27 & \\
\hline 3076 & 567354.94 & 138116.59 & \\
\hline 3077 & 567438.31 & 138116.59 & \\
\hline 3078 & 567271.62 & 138116.59 & \\
\hline 3079 & 567188.31 & 138116.59 & \\
\hline 3080 & 567521.62 & 138116.59 & \\
\hline
\end{tabular}




\begin{tabular}{|c|c|c|c|}
\hline node & X_coord & Y_coord & note: from sac04d created July 1, 2004 \\
\hline 3081 & $5 \overline{6} 7104.94$ & $1 \overline{3} 8116.59$ & \\
\hline 3082 & 567604.94 & 138116.59 & \\
\hline 3083 & 567688.31 & 138116.59 & \\
\hline 3084 & 567021.62 & 138116.59 & \\
\hline 3085 & 566938.31 & 138116.59 & \\
\hline 3086 & 567771.62 & 138116.59 & \\
\hline 3087 & 566854.94 & 138116.59 & \\
\hline 3088 & 567854.94 & 138116.59 & \\
\hline 3089 & 567938.31 & 138116.59 & \\
\hline 3090 & 566771.62 & 138116.59 & \\
\hline 3091 & 566688.31 & 138116.59 & \\
\hline 3092 & 568021.62 & 138116.59 & \\
\hline 3093 & 566604.94 & 138116.59 & \\
\hline 3094 & 568104.94 & 138116.59 & \\
\hline 3095 & 568188.31 & 138116.59 & \\
\hline 3096 & 566521.62 & 138116.59 & \\
\hline 3097 & 566438.31 & 138116.59 & \\
\hline 3098 & 568271.62 & 138116.59 & \\
\hline 3099 & 566354.94 & 138116.59 & \\
\hline 3100 & 568354.94 & 138116.59 & \\
\hline 3101 & 568438.31 & 138116.59 & \\
\hline 3102 & 566271.62 & 138116.59 & \\
\hline 3103 & 566188.31 & 138116.59 & \\
\hline 3104 & 568521.62 & 138116.59 & \\
\hline 3105 & 566104.94 & 138116.59 & \\
\hline 3106 & 568604.94 & 138116.59 & \\
\hline 3107 & 568688.31 & 138116.59 & \\
\hline 3108 & 566021.62 & 138116.59 & \\
\hline 3109 & 565938.31 & 138116.59 & \\
\hline 3110 & 568771.62 & 138116.59 & \\
\hline 3111 & 565854.94 & 138116.59 & \\
\hline 3112 & 568854.94 & 138116.59 & \\
\hline 3113 & 568938.31 & 138116.59 & \\
\hline 3114 & 565771.62 & 138116.59 & \\
\hline 3115 & 565688.31 & 138116.59 & \\
\hline 3116 & 569021.62 & 138116.59 & \\
\hline 3117 & 565604.94 & 138116.59 & \\
\hline 3118 & 569104.94 & 138116.59 & \\
\hline 3119 & 569188.31 & 138116.59 & \\
\hline 3120 & 565521.62 & 138116.59 & \\
\hline 3121 & 565438.31 & 138116.59 & \\
\hline 3122 & 569271.62 & 138116.59 & \\
\hline 3123 & 565354.94 & 138116.59 & \\
\hline 3124 & 569354.94 & 138116.59 & \\
\hline 3125 & 569438.31 & 138116.59 & \\
\hline 3126 & 565271.62 & 138116.59 & \\
\hline 3127 & 565188.31 & 138116.59 & \\
\hline 3128 & 569521.62 & 138116.59 & \\
\hline 3129 & 565104.94 & 138116.59 & \\
\hline 3130 & 569604.94 & 138116.59 & \\
\hline 3131 & 569688.31 & 138116.59 & \\
\hline 3132 & 565021.62 & 135783.27 & \\
\hline 3133 & 565021.62 & 135866.59 & \\
\hline 3134 & 565021.62 & 135699.92 & \\
\hline 3135 & 565021.62 & 135949.92 & \\
\hline 3136 & 565021.62 & 135616.59 & \\
\hline
\end{tabular}




\begin{tabular}{|c|c|c|c|}
\hline node & X_coord & Y_coord & note: from sac04d created July 1, 2004 \\
\hline 3137 & $5 \overline{6} 5021.62$ & $1 \overline{3} 5533.27$ & \\
\hline 3138 & 565021.62 & 136033.27 & \\
\hline 3139 & 565021.62 & 136116.59 & \\
\hline 3140 & 565021.62 & 135449.92 & \\
\hline 3141 & 565021.62 & 136199.92 & \\
\hline 3142 & 565021.62 & 135366.59 & \\
\hline 3143 & 565021.62 & 135283.27 & \\
\hline 3144 & 565021.62 & 136283.27 & \\
\hline 3145 & 565021.62 & 136366.59 & \\
\hline 3146 & 565021.62 & 135199.92 & \\
\hline 3147 & 565021.62 & 136449.92 & \\
\hline 3148 & 565021.62 & 135116.59 & \\
\hline 3149 & 565021.62 & 135033.27 & \\
\hline 3150 & 565021.62 & 136533.27 & \\
\hline 3151 & 565021.62 & 136616.59 & \\
\hline 3152 & 565021.62 & 134949.92 & \\
\hline 3153 & 565021.62 & 136699.92 & \\
\hline 3154 & 565021.62 & 134866.59 & \\
\hline 3155 & 565021.62 & 134783.27 & \\
\hline 3156 & 565021.62 & 136783.27 & \\
\hline 3157 & 565021.62 & 136866.59 & \\
\hline 3158 & 565021.62 & 134699.92 & \\
\hline 3159 & 565021.62 & 136949.92 & \\
\hline 3160 & 565021.62 & 134616.59 & \\
\hline 3161 & 565021.62 & 134533.27 & \\
\hline 3162 & 565021.62 & 137033.27 & \\
\hline 3163 & 565021.62 & 137116.59 & \\
\hline 3164 & 565021.62 & 134449.92 & \\
\hline 3165 & 565021.62 & 137199.92 & \\
\hline 3166 & 565021.62 & 134366.59 & \\
\hline 3167 & 565021.62 & 134283.27 & \\
\hline 3168 & 565021.62 & 137283.27 & \\
\hline 3169 & 565021.62 & 137366.59 & \\
\hline 3170 & 565021.62 & 134199.92 & \\
\hline 3171 & 565021.62 & 137449.92 & \\
\hline 3172 & 565021.62 & 137533.27 & \\
\hline 3173 & 565021.62 & 137616.59 & \\
\hline 3174 & 565021.62 & 137699.92 & \\
\hline 3175 & 564854.94 & 134199.92 & \\
\hline 3176 & 565021.62 & 137783.27 & \\
\hline 3177 & 565021.62 & 137866.59 & \\
\hline 3178 & 564521.62 & 133866.59 & \\
\hline 3179 & 564271.62 & 133616.59 & \\
\hline 3180 & 564521.62 & 134116.59 & \\
\hline 3181 & 564771.62 & 134366.59 & \\
\hline 3182 & 564521.62 & 134366.59 & \\
\hline 3183 & 564854.94 & 134366.59 & \\
\hline 3184 & 564021.62 & 133366.59 & \\
\hline 3185 & 565021.62 & 137949.92 & \\
\hline 3186 & 564021.62 & 132616.59 & \\
\hline 3187 & 565521.62 & 132866.59 & \\
\hline 3188 & 566021.62 & 132866.59 & \\
\hline 3189 & 565521.62 & 132616.59 & \\
\hline 3190 & 564771.62 & 131866.59 & \\
\hline 3191 & 564021.62 & 131866.59 & \\
\hline 3192 & 565521.62 & 131866.59 & \\
\hline
\end{tabular}




\begin{tabular}{|c|c|c|c|}
\hline node & X_coord & Y_coord & note: from sac04d created July 1, 2004 \\
\hline 3193 & $5 \overline{6} 5021.62$ & $1 \overline{3} 8033.27$ & \\
\hline 3194 & 565021.62 & 138116.59 & \\
\hline 3195 & 567271.62 & 133116.59 & \\
\hline 3196 & 567521.62 & 133116.59 & \\
\hline 3197 & 567021.62 & 132616.59 & \\
\hline 3198 & 567771.62 & 132616.59 & \\
\hline 3199 & 566771.62 & 133116.59 & \\
\hline 3200 & 568021.62 & 133116.59 & \\
\hline 3201 & 566521.62 & 133116.59 & \\
\hline 3202 & 568271.62 & 133116.59 & \\
\hline 3203 & 566271.62 & 132616.59 & \\
\hline 3204 & 568521.62 & 132616.59 & \\
\hline 3205 & 568771.62 & 132866.59 & \\
\hline 3206 & 569021.62 & 133116.59 & \\
\hline 3207 & 569271.62 & 133116.59 & \\
\hline 3208 & 569521.62 & 133116.59 & \\
\hline 3209 & 569771.62 & 133366.59 & \\
\hline 3210 & 569771.62 & 133116.59 & \\
\hline 3211 & 569771.62 & 133449.92 & \\
\hline 3212 & 569771.62 & 133533.27 & \\
\hline 3213 & 569771.62 & 135783.27 & \\
\hline 3214 & 569771.62 & 135699.92 & \\
\hline 3215 & 569771.62 & 135866.59 & \\
\hline 3216 & 569771.62 & 135949.92 & \\
\hline 3217 & 569771.62 & 135616.59 & \\
\hline 3218 & 569771.62 & 136033.27 & \\
\hline 3219 & 569771.62 & 135533.27 & \\
\hline 3220 & 569771.62 & 135449.92 & \\
\hline 3221 & 569771.62 & 136116.59 & \\
\hline 3222 & 569771.62 & 136199.92 & \\
\hline 3223 & 569771.62 & 135366.59 & \\
\hline 3224 & 569771.62 & 136283.27 & \\
\hline 3225 & 569771.62 & 135283.27 & \\
\hline 3226 & 569771.62 & 135199.92 & \\
\hline 3227 & 569771.62 & 136366.59 & \\
\hline 3228 & 569771.62 & 136449.92 & \\
\hline 3229 & 569771.62 & 135116.59 & \\
\hline 3230 & 569771.62 & 136533.27 & \\
\hline 3231 & 569771.62 & 135033.27 & \\
\hline 3232 & 569771.62 & 134949.92 & \\
\hline 3233 & 569771.62 & 136616.59 & \\
\hline 3234 & 569771.62 & 136699.92 & \\
\hline 3235 & 569771.62 & 134866.59 & \\
\hline 3236 & 569771.62 & 136783.27 & \\
\hline 3237 & 569771.62 & 134783.27 & \\
\hline 3238 & 569771.62 & 134699.92 & \\
\hline 3239 & 569771.62 & 136866.59 & \\
\hline 3240 & 569771.62 & 136949.92 & \\
\hline 3241 & 569771.62 & 134616.59 & \\
\hline 3242 & 569771.62 & 137033.27 & \\
\hline 3243 & 569771.62 & 134533.27 & \\
\hline 3244 & 569771.62 & 134449.92 & \\
\hline 3245 & 569771.62 & 137116.59 & \\
\hline 3246 & 569771.62 & 137199.92 & \\
\hline 3247 & 569771.62 & 134366.59 & \\
\hline 3248 & 569771.62 & 137283.27 & \\
\hline
\end{tabular}




\begin{tabular}{|c|c|c|c|}
\hline node & X_coord & Y_coord & note: from sac04d created July 1, 2004 \\
\hline 3249 & $5 \overline{6} 9771.62$ & $1 \overline{3} 4283.27$ & \\
\hline 3250 & 569771.62 & 134199.92 & \\
\hline 3251 & 569771.62 & 137366.59 & \\
\hline 3252 & 569771.62 & 137449.92 & \\
\hline 3253 & 569771.62 & 134116.59 & \\
\hline 3254 & 569771.62 & 137533.27 & \\
\hline 3255 & 569771.62 & 134033.27 & \\
\hline 3256 & 569771.62 & 133949.92 & \\
\hline 3257 & 569771.62 & 137616.59 & \\
\hline 3258 & 569771.62 & 137699.92 & \\
\hline 3259 & 569771.62 & 133866.59 & \\
\hline 3260 & 569771.62 & 137783.27 & \\
\hline 3261 & 569771.62 & 133783.27 & \\
\hline 3262 & 569771.62 & 133699.92 & \\
\hline 3263 & 569771.62 & 137866.59 & \\
\hline 3264 & 569771.62 & 137949.92 & \\
\hline 3265 & 569771.62 & 133616.59 & \\
\hline 3266 & 569771.62 & 138033.27 & \\
\hline 3267 & 569771.62 & 138116.59 & \\
\hline 3268 & 567354.94 & 138199.92 & \\
\hline 3269 & 567271.62 & 138199.92 & \\
\hline 3270 & 567438.31 & 138199.92 & \\
\hline 3271 & 567521.62 & 138199.92 & \\
\hline 3272 & 567188.31 & 138199.92 & \\
\hline 3273 & 567104.94 & 138199.92 & \\
\hline 3274 & 567604.94 & 138199.92 & \\
\hline 3275 & 567021.62 & 138199.92 & \\
\hline 3276 & 567688.31 & 138199.92 & \\
\hline 3277 & 567771.62 & 138199.92 & \\
\hline 3278 & 566938.31 & 138199.92 & \\
\hline 3279 & 566854.94 & 138199.92 & \\
\hline 3280 & 567854.94 & 138199.92 & \\
\hline 3281 & 566771.62 & 138199.92 & \\
\hline 3282 & 567938.31 & 138199.92 & \\
\hline 3283 & 568021.62 & 138199.92 & \\
\hline 3284 & 566688.31 & 138199.92 & \\
\hline 3285 & 566604.94 & 138199.92 & \\
\hline 3286 & 568104.94 & 138199.92 & \\
\hline 3287 & 566521.62 & 138199.92 & \\
\hline 3288 & 568188.31 & 138199.92 & \\
\hline 3289 & 568271.62 & 138199.92 & \\
\hline 3290 & 566438.31 & 138199.92 & \\
\hline 3291 & 566354.94 & 138199.92 & \\
\hline 3292 & 568354.94 & 138199.92 & \\
\hline 3293 & 566271.62 & 138199.92 & \\
\hline 3294 & 568438.31 & 138199.92 & \\
\hline 3295 & 568521.62 & 138199.92 & \\
\hline 3296 & 566188.31 & 138199.92 & \\
\hline 3297 & 566104.94 & 138199.92 & \\
\hline 3298 & 568604.94 & 138199.92 & \\
\hline 3299 & 566021.62 & 138199.92 & \\
\hline 3300 & 568688.31 & 138199.92 & \\
\hline 3301 & 568771.62 & 138199.92 & \\
\hline 3302 & 565938.31 & 138199.92 & \\
\hline 3303 & 565854.94 & 138199.92 & \\
\hline 3304 & 568854.94 & 138199.92 & \\
\hline
\end{tabular}




\begin{tabular}{|c|c|c|c|}
\hline node & X_coord & Y_coord & note: from sac04d created July 1, 2004 \\
\hline 3305 & $5 \overline{6} 5771.62$ & $1 \overline{3} 8199.92$ & \\
\hline 3306 & 568938.31 & 138199.92 & \\
\hline 3307 & 569021.62 & 138199.92 & \\
\hline 3308 & 565688.31 & 138199.92 & \\
\hline 3309 & 565604.94 & 138199.92 & \\
\hline 3310 & 569104.94 & 138199.92 & \\
\hline 3311 & 565521.62 & 138199.92 & \\
\hline 3312 & 569188.31 & 138199.92 & \\
\hline 3313 & 569271.62 & 138199.92 & \\
\hline 3314 & 565438.31 & 138199.92 & \\
\hline 3315 & 565354.94 & 138199.92 & \\
\hline 3316 & 569354.94 & 138199.92 & \\
\hline 3317 & 565271.62 & 138199.92 & \\
\hline 3318 & 569438.31 & 138199.92 & \\
\hline 3319 & 569521.62 & 138199.92 & \\
\hline 3320 & 565188.31 & 138199.92 & \\
\hline 3321 & 565104.94 & 138199.92 & \\
\hline 3322 & 569604.94 & 138199.92 & \\
\hline 3323 & 565021.62 & 138199.92 & \\
\hline 3324 & 569688.31 & 138199.92 & \\
\hline 3325 & 569771.62 & 138199.92 & \\
\hline 3326 & 564938.31 & 135783.27 & \\
\hline 3327 & 564938.31 & 135699.92 & \\
\hline 3328 & 564938.31 & 135866.59 & \\
\hline 3329 & 564938.31 & 135949.92 & \\
\hline 3330 & 564938.31 & 135616.59 & \\
\hline 3331 & 564938.31 & 136033.27 & \\
\hline 3332 & 564938.31 & 135533.27 & \\
\hline 3333 & 564938.31 & 135449.92 & \\
\hline 3334 & 564938.31 & 136116.59 & \\
\hline 3335 & 564938.31 & 136199.92 & \\
\hline 3336 & 564938.31 & 135366.59 & \\
\hline 3337 & 564938.31 & 136283.27 & \\
\hline 3338 & 564938.31 & 135283.27 & \\
\hline 3339 & 564938.31 & 135199.92 & \\
\hline 3340 & 564938.31 & 136366.59 & \\
\hline 3341 & 564938.31 & 136449.92 & \\
\hline 3342 & 564938.31 & 135116.59 & \\
\hline 3343 & 564938.31 & 136533.27 & \\
\hline 3344 & 564938.31 & 135033.27 & \\
\hline 3345 & 564938.31 & 134949.92 & \\
\hline 3346 & 564938.31 & 136616.59 & \\
\hline 3347 & 564938.31 & 136699.92 & \\
\hline 3348 & 564938.31 & 134866.59 & \\
\hline 3349 & 564938.31 & 136783.27 & \\
\hline 3350 & 564938.31 & 134783.27 & \\
\hline 3351 & 564938.31 & 134699.92 & \\
\hline 3352 & 564938.31 & 136866.59 & \\
\hline 3353 & 564938.31 & 136949.92 & \\
\hline 3354 & 564938.31 & 134616.59 & \\
\hline 3355 & 564938.31 & 137033.27 & \\
\hline 3356 & 564938.31 & 134533.27 & \\
\hline 3357 & 564938.31 & 134449.92 & \\
\hline 3358 & 564938.31 & 137116.59 & \\
\hline 3359 & 564938.31 & 137199.92 & \\
\hline 3360 & 564938.31 & 134366.59 & \\
\hline
\end{tabular}




\begin{tabular}{|c|c|c|c|}
\hline node & X_coord & Y_coord & note: from sac04d created July 1, 2004 \\
\hline 3361 & $5 \overline{6} 4938.31$ & $1 \overline{3} 7283.27$ & \\
\hline 3362 & 564938.31 & 134283.27 & \\
\hline 3363 & 564938.31 & 137366.59 & \\
\hline 3364 & 564938.31 & 137449.92 & \\
\hline 3365 & 564938.31 & 137533.27 & \\
\hline 3366 & 564938.31 & 137616.59 & \\
\hline 3367 & 564938.31 & 137699.92 & \\
\hline 3368 & 564938.31 & 137783.27 & \\
\hline 3369 & 564938.31 & 137866.59 & \\
\hline 3370 & 564938.31 & 137949.92 & \\
\hline 3371 & 564271.62 & 134116.59 & \\
\hline 3372 & 564021.62 & 134116.59 & \\
\hline 3373 & 564271.62 & 134366.59 & \\
\hline 3374 & 564771.62 & 134449.92 & \\
\hline 3375 & 564604.94 & 134449.92 & \\
\hline 3376 & 564854.94 & 134449.92 & \\
\hline 3377 & 564521.62 & 134616.59 & \\
\hline 3378 & 564271.62 & 134616.59 & \\
\hline 3379 & 564604.94 & 134616.59 & \\
\hline 3380 & 563271.62 & 133366.59 & \\
\hline 3381 & 563271.62 & 132616.59 & \\
\hline 3382 & 563271.62 & 134116.59 & \\
\hline 3383 & 564938.31 & 138033.27 & \\
\hline 3384 & 563271.62 & 131866.59 & \\
\hline 3385 & 566271.62 & 131866.59 & \\
\hline 3386 & 564765.38 & 131365 & \\
\hline 3387 & 564003.69 & 131359.7 & \\
\hline 3388 & 565516.5 & 131365 & \\
\hline 3389 & 563166.81 & 131112.91 & \\
\hline 3390 & 566267.5 & 131375.8 & \\
\hline 3391 & 564938.31 & 138116.59 & \\
\hline 3392 & 564938.31 & 138199.92 & \\
\hline 3393 & 567021.62 & 131866.59 & \\
\hline 3394 & 567771.62 & 131866.59 & \\
\hline 3395 & 568521.62 & 131866.59 & \\
\hline 3396 & 569271.62 & 132616.59 & \\
\hline 3397 & 569271.62 & 131866.59 & \\
\hline 3398 & 569271.62 & 132866.59 & \\
\hline 3399 & 569521.62 & 132866.59 & \\
\hline 3400 & 569771.62 & 132866.59 & \\
\hline 3401 & 569854.94 & 133366.59 & \\
\hline 3402 & 569854.94 & 133199.92 & \\
\hline 3403 & 569854.94 & 133449.92 & \\
\hline 3404 & 569854.94 & 133033.27 & \\
\hline 3405 & 569854.94 & 132866.59 & \\
\hline 3406 & 570021.62 & 133116.59 & \\
\hline 3407 & 570021.62 & 133033.27 & \\
\hline 3408 & 570021.62 & 133199.92 & \\
\hline 3409 & 569854.94 & 133533.27 & \\
\hline 3410 & 569854.94 & 133616.59 & \\
\hline 3411 & 569854.94 & 135783.27 & \\
\hline 3412 & 569854.94 & 135866.59 & \\
\hline 3413 & 569854.94 & 135699.92 & \\
\hline 3414 & 569854.94 & 135616.59 & \\
\hline 3415 & 569854.94 & 135949.92 & \\
\hline 3416 & 569854.94 & 136033.27 & \\
\hline
\end{tabular}




\begin{tabular}{|c|c|c|c|}
\hline node & X_coord & Y_coord & note: from sac04d created July 1, 2004 \\
\hline 3417 & $5 \overline{6} 9854.94$ & $1 \overline{3} 5533.27$ & \\
\hline 3418 & 569854.94 & 136116.59 & \\
\hline 3419 & 569854.94 & 135449.92 & \\
\hline 3420 & 569854.94 & 135366.59 & \\
\hline 3421 & 569854.94 & 136199.92 & \\
\hline 3422 & 569854.94 & 136283.27 & \\
\hline 3423 & 569854.94 & 135283.27 & \\
\hline 3424 & 569854.94 & 136366.59 & \\
\hline 3425 & 569854.94 & 135199.92 & \\
\hline 3426 & 569854.94 & 135116.59 & \\
\hline 3427 & 569854.94 & 136449.92 & \\
\hline 3428 & 569854.94 & 136533.27 & \\
\hline 3429 & 569854.94 & 135033.27 & \\
\hline 3430 & 569854.94 & 136616.59 & \\
\hline 3431 & 569854.94 & 134949.92 & \\
\hline 3432 & 569854.94 & 134866.59 & \\
\hline 3433 & 569854.94 & 136699.92 & \\
\hline 3434 & 569854.94 & 136783.27 & \\
\hline 3435 & 569854.94 & 134783.27 & \\
\hline 3436 & 569854.94 & 136866.59 & \\
\hline 3437 & 569854.94 & 134699.92 & \\
\hline 3438 & 569854.94 & 134616.59 & \\
\hline 3439 & 569854.94 & 136949.92 & \\
\hline 3440 & 569854.94 & 137033.27 & \\
\hline 3441 & 569854.94 & 134533.27 & \\
\hline 3442 & 569854.94 & 137116.59 & \\
\hline 3443 & 569854.94 & 134449.92 & \\
\hline 3444 & 569854.94 & 134366.59 & \\
\hline 3445 & 569854.94 & 137199.92 & \\
\hline 3446 & 569854.94 & 137283.27 & \\
\hline 3447 & 569854.94 & 134283.27 & \\
\hline 3448 & 569854.94 & 137366.59 & \\
\hline 3449 & 569854.94 & 134199.92 & \\
\hline 3450 & 569854.94 & 134116.59 & \\
\hline 3451 & 569854.94 & 137449.92 & \\
\hline 3452 & 569854.94 & 137533.27 & \\
\hline 3453 & 569854.94 & 134033.27 & \\
\hline 3454 & 569854.94 & 137616.59 & \\
\hline 3455 & 569854.94 & 133949.92 & \\
\hline 3456 & 569854.94 & 133866.59 & \\
\hline 3457 & 569854.94 & 137699.92 & \\
\hline 3458 & 569854.94 & 137783.27 & \\
\hline 3459 & 569854.94 & 133783.27 & \\
\hline 3460 & 569854.94 & 137866.59 & \\
\hline 3461 & 569854.94 & 133699.92 & \\
\hline 3462 & 569854.94 & 137949.92 & \\
\hline 3463 & 569854.94 & 138033.27 & \\
\hline 3464 & 569854.94 & 138116.59 & \\
\hline 3465 & 569854.94 & 138199.92 & \\
\hline 3466 & 567354.94 & 138283.27 & \\
\hline 3467 & 567271.62 & 138283.27 & \\
\hline 3468 & 567438.31 & 138283.27 & \\
\hline 3469 & 567188.31 & 138283.27 & \\
\hline 3470 & 567521.62 & 138283.27 & \\
\hline 3471 & 567604.94 & 138283.27 & \\
\hline 3472 & 567104.94 & 138283.27 & \\
\hline
\end{tabular}




\begin{tabular}{|c|c|c|c|}
\hline node & X_coord & Y_coord & note: from sac04d created July 1,2004 \\
\hline 3473 & $5 \overline{6} 7021.62$ & $1 \overline{3} 8283.27$ & \\
\hline 3474 & 567688.31 & 138283.27 & \\
\hline 3475 & 566938.31 & 138283.27 & \\
\hline 3476 & 567771.62 & 138283.27 & \\
\hline 3477 & 567854.94 & 138283.27 & \\
\hline 3478 & 566854.94 & 138283.27 & \\
\hline 3479 & 566771.62 & 138283.27 & \\
\hline 3480 & 567938.31 & 138283.27 & \\
\hline 3481 & 566688.31 & 138283.27 & \\
\hline 3482 & 568021.62 & 138283.27 & \\
\hline 3483 & 568104.94 & 138283.27 & \\
\hline 3484 & 566604.94 & 138283.27 & \\
\hline 3485 & 566521.62 & 138283.27 & \\
\hline 3486 & 568188.31 & 138283.27 & \\
\hline 3487 & 566438.31 & 138283.27 & \\
\hline 3488 & 568271.62 & 138283.27 & \\
\hline 3489 & 568354.94 & 138283.27 & \\
\hline 3490 & 566354.94 & 138283.27 & \\
\hline 3491 & 566271.62 & 138283.27 & \\
\hline 3492 & 568438.31 & 138283.27 & \\
\hline 3493 & 566188.31 & 138283.27 & \\
\hline 3494 & 568521.62 & 138283.27 & \\
\hline 3495 & 568604.94 & 138283.27 & \\
\hline 3496 & 566104.94 & 138283.27 & \\
\hline 3497 & 566021.62 & 138283.27 & \\
\hline 3498 & 568688.31 & 138283.27 & \\
\hline 3499 & 565938.31 & 138283.27 & \\
\hline 3500 & 568771.62 & 138283.27 & \\
\hline 3501 & 568854.94 & 138283.27 & \\
\hline 3502 & 565854.94 & 138283.27 & \\
\hline 3503 & 565771.62 & 138283.27 & \\
\hline 3504 & 568938.31 & 138283.27 & \\
\hline 3505 & 565688.31 & 138283.27 & \\
\hline 3506 & 569021.62 & 138283.27 & \\
\hline 3507 & 569104.94 & 138283.27 & \\
\hline 3508 & 565604.94 & 138283.27 & \\
\hline 3509 & 565521.62 & 138283.27 & \\
\hline 3510 & 569188.31 & 138283.27 & \\
\hline 3511 & 565438.31 & 138283.27 & \\
\hline 3512 & 569271.62 & 138283.27 & \\
\hline 3513 & 569354.94 & 138283.27 & \\
\hline 3514 & 565354.94 & 138283.27 & \\
\hline 3515 & 565271.62 & 138283.27 & \\
\hline 3516 & 569438.31 & 138283.27 & \\
\hline 3517 & 565188.31 & 138283.27 & \\
\hline 3518 & 569521.62 & 138283.27 & \\
\hline 3519 & 569604.94 & 138283.27 & \\
\hline 3520 & 565104.94 & 138283.27 & \\
\hline 3521 & 565021.62 & 138283.27 & \\
\hline 3522 & 569688.31 & 138283.27 & \\
\hline 3523 & 564938.31 & 138283.27 & \\
\hline 3524 & 569771.62 & 138283.27 & \\
\hline 3525 & 569854.94 & 138283.27 & \\
\hline 3526 & 564854.94 & 135783.27 & \\
\hline 3527 & 564854.94 & 135866.59 & \\
\hline 3528 & 564854.94 & 135699.92 & \\
\hline
\end{tabular}




\begin{tabular}{|c|c|c|c|}
\hline node & X_coord & Y_coord & note: from sac04d created July 1, 2004 \\
\hline 3529 & $5 \overline{6} 4854.94$ & $1 \overline{3} 5616.59$ & \\
\hline 3530 & 564854.94 & 135949.92 & \\
\hline 3531 & 564854.94 & 136033.27 & \\
\hline 3532 & 564854.94 & 135533.27 & \\
\hline 3533 & 564854.94 & 136116.59 & \\
\hline 3534 & 564854.94 & 135449.92 & \\
\hline 3535 & 564854.94 & 135366.59 & \\
\hline 3536 & 564854.94 & 136199.92 & \\
\hline 3537 & 564854.94 & 136283.27 & \\
\hline 3538 & 564854.94 & 135283.27 & \\
\hline 3539 & 564854.94 & 136366.59 & \\
\hline 3540 & 564854.94 & 135199.92 & \\
\hline 3541 & 564854.94 & 135116.59 & \\
\hline 3542 & 564854.94 & 136449.92 & \\
\hline 3543 & 564854.94 & 136533.27 & \\
\hline 3544 & 564854.94 & 135033.27 & \\
\hline 3545 & 564854.94 & 136616.59 & \\
\hline 3546 & 564854.94 & 134949.92 & \\
\hline 3547 & 564854.94 & 134866.59 & \\
\hline 3548 & 564854.94 & 136699.92 & \\
\hline 3549 & 564854.94 & 136783.27 & \\
\hline 3550 & 564854.94 & 134783.27 & \\
\hline 3551 & 564854.94 & 136866.59 & \\
\hline 3552 & 564854.94 & 134699.92 & \\
\hline 3553 & 564854.94 & 134616.59 & \\
\hline 3554 & 564854.94 & 136949.92 & \\
\hline 3555 & 564854.94 & 137033.27 & \\
\hline 3556 & 564854.94 & 134533.27 & \\
\hline 3557 & 564854.94 & 137116.59 & \\
\hline 3558 & 564854.94 & 137199.92 & \\
\hline 3559 & 564854.94 & 137283.27 & \\
\hline 3560 & 564854.94 & 137366.59 & \\
\hline 3561 & 564854.94 & 137449.92 & \\
\hline 3562 & 564854.94 & 137533.27 & \\
\hline 3563 & 564854.94 & 137616.59 & \\
\hline 3564 & 564854.94 & 137699.92 & \\
\hline 3565 & 564854.94 & 137783.27 & \\
\hline 3566 & 564854.94 & 137866.59 & \\
\hline 3567 & 564854.94 & 137949.92 & \\
\hline 3568 & 564854.94 & 138033.27 & \\
\hline 3569 & 564021.62 & 134366.59 & \\
\hline 3570 & 563521.62 & 134366.59 & \\
\hline 3571 & 564021.62 & 134616.59 & \\
\hline 3572 & 564771.62 & 134533.27 & \\
\hline 3573 & 564688.31 & 134533.27 & \\
\hline 3574 & 564688.31 & 134616.59 & \\
\hline 3575 & 564521.62 & 134699.92 & \\
\hline 3576 & 564604.94 & 134699.92 & \\
\hline 3577 & 564354.94 & 134699.92 & \\
\hline 3578 & 564271.62 & 134866.59 & \\
\hline 3579 & 564021.62 & 134866.59 & \\
\hline 3580 & 564354.94 & 134866.59 & \\
\hline 3581 & 564688.31 & 134699.92 & \\
\hline 3582 & 562521.62 & 133366.59 & \\
\hline 3583 & 562521.62 & 132616.59 & \\
\hline 3584 & 562521.62 & 134116.59 & \\
\hline
\end{tabular}




\begin{tabular}{|c|c|c|c|}
\hline node & X_coord & Y_coord & note: from sac04d created July 1,2004 \\
\hline 3585 & $5 \overline{6} 2521.62$ & $1 \overline{13} 1866.59$ & \\
\hline 3586 & 563271.62 & 134866.59 & \\
\hline 3587 & 562521.62 & 134866.59 & \\
\hline 3588 & 563521.62 & 134866.59 & \\
\hline 3589 & 564854.94 & 138116.59 & \\
\hline 3590 & 562512.38 & 131112.91 & \\
\hline 3591 & 567018.62 & 131236.3 & \\
\hline 3592 & 564854.94 & 138199.92 & \\
\hline 3593 & 564854.94 & 138283.27 & \\
\hline 3594 & 567769.62 & 131107.5 & \\
\hline 3595 & 568520.62 & 130839.3 & \\
\hline 3596 & 569271.62 & 131116.59 & \\
\hline 3597 & 569521.62 & 132616.59 & \\
\hline 3598 & 569521.62 & 132116.59 & \\
\hline 3599 & 570021.62 & 131866.59 & \\
\hline 3600 & 570021.62 & 131116.59 & \\
\hline 3601 & 570021.62 & 132116.59 & \\
\hline 3602 & 569771.62 & 132616.59 & \\
\hline 3603 & 569854.94 & 132699.92 & \\
\hline 3604 & 569938.31 & 133366.59 & \\
\hline 3605 & 569938.31 & 133283.27 & \\
\hline 3606 & 569938.31 & 133449.92 & \\
\hline 3607 & 570021.62 & 133283.27 & \\
\hline 3608 & 569938.31 & 133533.27 & \\
\hline 3609 & 569938.31 & 132949.92 & \\
\hline 3610 & 569938.31 & 132866.59 & \\
\hline 3611 & 570021.62 & 132949.92 & \\
\hline 3612 & 569938.31 & 132783.27 & \\
\hline 3613 & 570104.94 & 133116.59 & \\
\hline 3614 & 570104.94 & 133199.92 & \\
\hline 3615 & 570104.94 & 133033.27 & \\
\hline 3616 & 570104.94 & 132949.92 & \\
\hline 3617 & 570104.94 & 133283.27 & \\
\hline 3618 & 569938.31 & 133616.59 & \\
\hline 3619 & 569938.31 & 133699.92 & \\
\hline 3620 & 569938.31 & 135783.27 & \\
\hline 3621 & 569938.31 & 135866.59 & \\
\hline 3622 & 569938.31 & 135699.92 & \\
\hline 3623 & 569938.31 & 135949.92 & \\
\hline 3624 & 569938.31 & 135616.59 & \\
\hline 3625 & 569938.31 & 135533.27 & \\
\hline 3626 & 569938.31 & 136033.27 & \\
\hline 3627 & 569938.31 & 136116.59 & \\
\hline 3628 & 569938.31 & 135449.92 & \\
\hline 3629 & 569938.31 & 136199.92 & \\
\hline 3630 & 569938.31 & 135366.59 & \\
\hline 3631 & 569938.31 & 135283.27 & \\
\hline 3632 & 569938.31 & 136283.27 & \\
\hline 3633 & 569938.31 & 136366.59 & \\
\hline 3634 & 569938.31 & 135199.92 & \\
\hline 3635 & 569938.31 & 136449.92 & \\
\hline 3636 & 569938.31 & 135116.59 & \\
\hline 3637 & 569938.31 & 135033.27 & \\
\hline 3638 & 569938.31 & 136533.27 & \\
\hline 3639 & 569938.31 & 136616.59 & \\
\hline 3640 & 569938.31 & 134949.92 & \\
\hline
\end{tabular}




\begin{tabular}{|c|c|c|c|}
\hline node & X_coord & Y_coord & note: from sac04d created July 1, 2004 \\
\hline 3641 & $5 \overline{6} 9938.31$ & $1 \overline{3} 6699.92$ & \\
\hline 3642 & 569938.31 & 134866.59 & \\
\hline 3643 & 569938.31 & 134783.27 & \\
\hline 3644 & 569938.31 & 136783.27 & \\
\hline 3645 & 569938.31 & 136866.59 & \\
\hline 3646 & 569938.31 & 134699.92 & \\
\hline 3647 & 569938.31 & 136949.92 & \\
\hline 3648 & 569938.31 & 134616.59 & \\
\hline 3649 & 569938.31 & 134533.27 & \\
\hline 3650 & 569938.31 & 137033.27 & \\
\hline 3651 & 569938.31 & 137116.59 & \\
\hline 3652 & 569938.31 & 134449.92 & \\
\hline 3653 & 569938.31 & 137199.92 & \\
\hline 3654 & 569938.31 & 134366.59 & \\
\hline 3655 & 569938.31 & 134283.27 & \\
\hline 3656 & 569938.31 & 137283.27 & \\
\hline 3657 & 569938.31 & 137366.59 & \\
\hline 3658 & 569938.31 & 134199.92 & \\
\hline 3659 & 569938.31 & 137449.92 & \\
\hline 3660 & 569938.31 & 134116.59 & \\
\hline 3661 & 569938.31 & 134033.27 & \\
\hline 3662 & 569938.31 & 137533.27 & \\
\hline 3663 & 569938.31 & 137616.59 & \\
\hline 3664 & 569938.31 & 133949.92 & \\
\hline 3665 & 569938.31 & 137699.92 & \\
\hline 3666 & 569938.31 & 133866.59 & \\
\hline 3667 & 569938.31 & 133783.27 & \\
\hline 3668 & 569938.31 & 137783.27 & \\
\hline 3669 & 569938.31 & 137866.59 & \\
\hline 3670 & 569938.31 & 137949.92 & \\
\hline 3671 & 569938.31 & 138033.27 & \\
\hline 3672 & 569938.31 & 138116.59 & \\
\hline 3673 & 569938.31 & 138199.92 & \\
\hline 3674 & 569938.31 & 138283.27 & \\
\hline 3675 & 567354.94 & 138366.59 & \\
\hline 3676 & 567438.31 & 138366.59 & \\
\hline 3677 & 567271.62 & 138366.59 & \\
\hline 3678 & 567188.31 & 138366.59 & \\
\hline 3679 & 567521.62 & 138366.59 & \\
\hline 3680 & 567104.94 & 138366.59 & \\
\hline 3681 & 567604.94 & 138366.59 & \\
\hline 3682 & 567688.31 & 138366.59 & \\
\hline 3683 & 567021.62 & 138366.59 & \\
\hline 3684 & 566938.31 & 138366.59 & \\
\hline 3685 & 567771.62 & 138366.59 & \\
\hline 3686 & 566854.94 & 138366.59 & \\
\hline 3687 & 567854.94 & 138366.59 & \\
\hline 3688 & 567938.31 & 138366.59 & \\
\hline 3689 & 566771.62 & 138366.59 & \\
\hline 3690 & 566688.31 & 138366.59 & \\
\hline 3691 & 568021.62 & 138366.59 & \\
\hline 3692 & 566604.94 & 138366.59 & \\
\hline 3693 & 568104.94 & 138366.59 & \\
\hline 3694 & 568188.31 & 138366.59 & \\
\hline 3695 & 566521.62 & 138366.59 & \\
\hline 3696 & 566438.31 & 138366.59 & \\
\hline
\end{tabular}




\begin{tabular}{|c|c|c|c|}
\hline node & X_coord & Y_coord & note: from sac04d created July 1, 2004 \\
\hline 3697 & $5 \overline{6} 8271.62$ & $1 \overline{3} 8366.59$ & \\
\hline 3698 & 566354.94 & 138366.59 & \\
\hline 3699 & 568354.94 & 138366.59 & \\
\hline 3700 & 568438.31 & 138366.59 & \\
\hline 3701 & 566271.62 & 138366.59 & \\
\hline 3702 & 566188.31 & 138366.59 & \\
\hline 3703 & 568521.62 & 138366.59 & \\
\hline 3704 & 566104.94 & 138366.59 & \\
\hline 3705 & 568604.94 & 138366.59 & \\
\hline 3706 & 568688.31 & 138366.59 & \\
\hline 3707 & 566021.62 & 138366.59 & \\
\hline 3708 & 565938.31 & 138366.59 & \\
\hline 3709 & 568771.62 & 138366.59 & \\
\hline 3710 & 565854.94 & 138366.59 & \\
\hline 3711 & 568854.94 & 138366.59 & \\
\hline 3712 & 568938.31 & 138366.59 & \\
\hline 3713 & 565771.62 & 138366.59 & \\
\hline 3714 & 565688.31 & 138366.59 & \\
\hline 3715 & 569021.62 & 138366.59 & \\
\hline 3716 & 565604.94 & 138366.59 & \\
\hline 3717 & 569104.94 & 138366.59 & \\
\hline 3718 & 569188.31 & 138366.59 & \\
\hline 3719 & 565521.62 & 138366.59 & \\
\hline 3720 & 565438.31 & 138366.59 & \\
\hline 3721 & 569271.62 & 138366.59 & \\
\hline 3722 & 565354.94 & 138366.59 & \\
\hline 3723 & 569354.94 & 138366.59 & \\
\hline 3724 & 569438.31 & 138366.59 & \\
\hline 3725 & 565271.62 & 138366.59 & \\
\hline 3726 & 565188.31 & 138366.59 & \\
\hline 3727 & 569521.62 & 138366.59 & \\
\hline 3728 & 565104.94 & 138366.59 & \\
\hline 3729 & 569604.94 & 138366.59 & \\
\hline 3730 & 569688.31 & 138366.59 & \\
\hline 3731 & 565021.62 & 138366.59 & \\
\hline 3732 & 564938.31 & 138366.59 & \\
\hline 3733 & 569771.62 & 138366.59 & \\
\hline 3734 & 564854.94 & 138366.59 & \\
\hline 3735 & 569854.94 & 138366.59 & \\
\hline 3736 & 569938.31 & 138366.59 & \\
\hline 3737 & 564771.62 & 135783.27 & \\
\hline 3738 & 564771.62 & 135866.59 & \\
\hline 3739 & 564771.62 & 135699.92 & \\
\hline 3740 & 564771.62 & 135949.92 & \\
\hline 3741 & 564771.62 & 135616.59 & \\
\hline 3742 & 564771.62 & 135533.27 & \\
\hline 3743 & 564771.62 & 136033.27 & \\
\hline 3744 & 564771.62 & 136116.59 & \\
\hline 3745 & 564771.62 & 135449.92 & \\
\hline 3746 & 564771.62 & 136199.92 & \\
\hline 3747 & 564771.62 & 135366.59 & \\
\hline 3748 & 564771.62 & 135283.27 & \\
\hline 3749 & 564771.62 & 136283.27 & \\
\hline 3750 & 564771.62 & 136366.59 & \\
\hline 3751 & 564771.62 & 135199.92 & \\
\hline 3752 & 564771.62 & 136449.92 & \\
\hline
\end{tabular}




\begin{tabular}{|c|c|c|c|}
\hline node & X_coord & Y_coord & note: from sac04d created July 1, 2004 \\
\hline 3753 & $5 \overline{6} 4771.62$ & $1 \overline{3} 5116.59$ & \\
\hline 3754 & 564771.62 & 135033.27 & \\
\hline 3755 & 564771.62 & 136533.27 & \\
\hline 3756 & 564771.62 & 136616.59 & \\
\hline 3757 & 564771.62 & 134949.92 & \\
\hline 3758 & 564771.62 & 136699.92 & \\
\hline 3759 & 564771.62 & 134866.59 & \\
\hline 3760 & 564771.62 & 134783.27 & \\
\hline 3761 & 564771.62 & 136783.27 & \\
\hline 3762 & 564771.62 & 136866.59 & \\
\hline 3763 & 564771.62 & 134699.92 & \\
\hline 3764 & 564771.62 & 136949.92 & \\
\hline 3765 & 564771.62 & 134616.59 & \\
\hline 3766 & 564771.62 & 137033.27 & \\
\hline 3767 & 564771.62 & 137116.59 & \\
\hline 3768 & 564771.62 & 137199.92 & \\
\hline 3769 & 564771.62 & 137283.27 & \\
\hline 3770 & 564771.62 & 137366.59 & \\
\hline 3771 & 564771.62 & 137449.92 & \\
\hline 3772 & 564771.62 & 137533.27 & \\
\hline 3773 & 564771.62 & 137616.59 & \\
\hline 3774 & 564771.62 & 137699.92 & \\
\hline 3775 & 564771.62 & 137783.27 & \\
\hline 3776 & 564771.62 & 137866.59 & \\
\hline 3777 & 564771.62 & 137949.92 & \\
\hline 3778 & 564771.62 & 138033.27 & \\
\hline 3779 & 564771.62 & 138116.59 & \\
\hline 3780 & 563771.62 & 134616.59 & \\
\hline 3781 & 563771.62 & 134866.59 & \\
\hline 3782 & 564521.62 & 134783.27 & \\
\hline 3783 & 564604.94 & 134783.27 & \\
\hline 3784 & 564438.31 & 134783.27 & \\
\hline 3785 & 564688.31 & 134783.27 & \\
\hline 3786 & 564438.31 & 134866.59 & \\
\hline 3787 & 564271.62 & 134949.92 & \\
\hline 3788 & 564104.94 & 134949.92 & \\
\hline 3789 & 564354.94 & 134949.92 & \\
\hline 3790 & 564021.62 & 135116.59 & \\
\hline 3791 & 563771.62 & 135116.59 & \\
\hline 3792 & 564104.94 & 135116.59 & \\
\hline 3793 & 564438.31 & 134949.92 & \\
\hline 3794 & 561771.62 & 133366.59 & \\
\hline 3795 & 561771.62 & 132616.59 & \\
\hline 3796 & 561771.62 & 134116.59 & \\
\hline 3797 & 561771.62 & 131866.59 & \\
\hline 3798 & 561771.62 & 134866.59 & \\
\hline 3799 & 562093.88 & 131123.59 & \\
\hline 3800 & 563271.62 & 135616.59 & \\
\hline 3801 & 562521.62 & 135616.59 & \\
\hline 3802 & 563521.62 & 135366.59 & \\
\hline 3803 & 561771.62 & 135616.59 & \\
\hline 3804 & 564771.62 & 138199.92 & \\
\hline 3805 & 564771.62 & 138283.27 & \\
\hline 3806 & 564771.62 & 138366.59 & \\
\hline 3807 & 568713.81 & 130624.7 & \\
\hline 3808 & 569260.88 & 130490.6 & \\
\hline
\end{tabular}




\begin{tabular}{|c|c|c|c|}
\hline node & X_coord & Y_coord & note: from sac04d created July 1, 2004 \\
\hline 3809 & $5 \overline{7} 0012$ & $1 \overline{3} 0361.9$ & \\
\hline 3810 & 569771.62 & 132366.59 & \\
\hline 3811 & 570021.62 & 132366.59 & \\
\hline 3812 & 570771.62 & 131866.59 & \\
\hline 3813 & 570771.62 & 131116.59 & \\
\hline 3814 & 570521.62 & 132116.59 & \\
\hline 3815 & 570763 & 130168.8 & \\
\hline 3816 & 570271.62 & 132366.59 & \\
\hline 3817 & 570021.62 & 132616.59 & \\
\hline 3818 & 570021.62 & 132699.92 & \\
\hline 3819 & 570021.62 & 132783.27 & \\
\hline 3820 & 570021.62 & 133366.59 & \\
\hline 3821 & 570021.62 & 133449.92 & \\
\hline 3822 & 570021.62 & 133533.27 & \\
\hline 3823 & 570104.94 & 133366.59 & \\
\hline 3824 & 570021.62 & 133616.59 & \\
\hline 3825 & 570021.62 & 132866.59 & \\
\hline 3826 & 570104.94 & 132866.59 & \\
\hline 3827 & 570188.31 & 133116.59 & \\
\hline 3828 & 570188.31 & 133199.92 & \\
\hline 3829 & 570188.31 & 133033.27 & \\
\hline 3830 & 570188.31 & 133283.27 & \\
\hline 3831 & 570188.31 & 132949.92 & \\
\hline 3832 & 570188.31 & 132866.59 & \\
\hline 3833 & 570188.31 & 133366.59 & \\
\hline 3834 & 570021.62 & 133699.92 & \\
\hline 3835 & 570021.62 & 133783.27 & \\
\hline 3836 & 570021.62 & 135783.27 & \\
\hline 3837 & 570021.62 & 135699.92 & \\
\hline 3838 & 570021.62 & 135866.59 & \\
\hline 3839 & 570021.62 & 135949.92 & \\
\hline 3840 & 570021.62 & 135616.59 & \\
\hline 3841 & 570021.62 & 136033.27 & \\
\hline 3842 & 570021.62 & 135533.27 & \\
\hline 3843 & 570021.62 & 135449.92 & \\
\hline 3844 & 570021.62 & 136116.59 & \\
\hline 3845 & 570021.62 & 136199.92 & \\
\hline 3846 & 570021.62 & 135366.59 & \\
\hline 3847 & 570021.62 & 136283.27 & \\
\hline 3848 & 570021.62 & 135283.27 & \\
\hline 3849 & 570021.62 & 135199.92 & \\
\hline 3850 & 570021.62 & 136366.59 & \\
\hline 3851 & 570021.62 & 136449.92 & \\
\hline 3852 & 570021.62 & 135116.59 & \\
\hline 3853 & 570021.62 & 136533.27 & \\
\hline 3854 & 570021.62 & 135033.27 & \\
\hline 3855 & 570021.62 & 134949.92 & \\
\hline 3856 & 570021.62 & 136616.59 & \\
\hline 3857 & 570021.62 & 136699.92 & \\
\hline 3858 & 570021.62 & 134866.59 & \\
\hline 3859 & 570021.62 & 136783.27 & \\
\hline 3860 & 570021.62 & 134783.27 & \\
\hline 3861 & 570021.62 & 134699.92 & \\
\hline 3862 & 570021.62 & 136866.59 & \\
\hline 3863 & 570021.62 & 136949.92 & \\
\hline 3864 & 570021.62 & 134616.59 & \\
\hline
\end{tabular}




\begin{tabular}{|c|c|c|c|}
\hline node & X_coord & Y_coord & note: from sac04d created July 1,2004 \\
\hline 3865 & $5 \overline{7} 0021.62$ & $1 \overline{3} 7033.27$ & \\
\hline 3866 & 570021.62 & 134533.27 & \\
\hline 3867 & 570021.62 & 134449.92 & \\
\hline 3868 & 570021.62 & 137116.59 & \\
\hline 3869 & 570021.62 & 137199.92 & \\
\hline 3870 & 570021.62 & 134366.59 & \\
\hline 3871 & 570021.62 & 137283.27 & \\
\hline 3872 & 570021.62 & 134283.27 & \\
\hline 3873 & 570021.62 & 134199.92 & \\
\hline 3874 & 570021.62 & 137366.59 & \\
\hline 3875 & 570021.62 & 137449.92 & \\
\hline 3876 & 570021.62 & 134116.59 & \\
\hline 3877 & 570021.62 & 137533.27 & \\
\hline 3878 & 570021.62 & 134033.27 & \\
\hline 3879 & 570021.62 & 133949.92 & \\
\hline 3880 & 570021.62 & 137616.59 & \\
\hline 3881 & 570021.62 & 137699.92 & \\
\hline 3882 & 570021.62 & 133866.59 & \\
\hline 3883 & 570021.62 & 137783.27 & \\
\hline 3884 & 570021.62 & 137866.59 & \\
\hline 3885 & 570021.62 & 137949.92 & \\
\hline 3886 & 570021.62 & 138033.27 & \\
\hline 3887 & 570021.62 & 138116.59 & \\
\hline 3888 & 570021.62 & 138199.92 & \\
\hline 3889 & 570021.62 & 138283.27 & \\
\hline 3890 & 570021.62 & 138366.59 & \\
\hline 3891 & 567354.94 & 138449.92 & \\
\hline 3892 & 567271.62 & 138616.59 & \\
\hline 3893 & 567438.31 & 138449.92 & \\
\hline 3894 & 567521.62 & 138616.59 & \\
\hline 3895 & 567188.31 & 138449.92 & \\
\hline 3896 & 567104.94 & 138449.92 & \\
\hline 3897 & 567604.94 & 138449.92 & \\
\hline 3898 & 567021.62 & 138616.59 & \\
\hline 3899 & 567688.31 & 138449.92 & \\
\hline 3900 & 567771.62 & 138616.59 & \\
\hline 3901 & 566938.31 & 138449.92 & \\
\hline 3902 & 566854.94 & 138449.92 & \\
\hline 3903 & 567854.94 & 138449.92 & \\
\hline 3904 & 566771.62 & 138616.59 & \\
\hline 3905 & 567938.31 & 138449.92 & \\
\hline 3906 & 568021.62 & 138616.59 & \\
\hline 3907 & 566688.31 & 138449.92 & \\
\hline 3908 & 566604.94 & 138449.92 & \\
\hline 3909 & 568104.94 & 138449.92 & \\
\hline 3910 & 566521.62 & 138616.59 & \\
\hline 3911 & 568188.31 & 138449.92 & \\
\hline 3912 & 568271.62 & 138616.59 & \\
\hline 3913 & 566438.31 & 138449.92 & \\
\hline 3914 & 566354.94 & 138449.92 & \\
\hline 3915 & 568354.94 & 138449.92 & \\
\hline 3916 & 566271.62 & 138616.59 & \\
\hline 3917 & 568438.31 & 138449.92 & \\
\hline 3918 & 568521.62 & 138616.59 & \\
\hline 3919 & 566188.31 & 138449.92 & \\
\hline 3920 & 566104.94 & 138449.92 & \\
\hline
\end{tabular}




\begin{tabular}{|c|c|c|c|}
\hline node & X_coord & Y_coord & note: from sac04d created July 1, 2004 \\
\hline 3921 & $5 \overline{6} 8604.94$ & $1 \overline{3} 8449.92$ & \\
\hline 3922 & 566021.62 & 138616.59 & \\
\hline 3923 & 568688.31 & 138449.92 & \\
\hline 3924 & 568771.62 & 138616.59 & \\
\hline 3925 & 565938.31 & 138449.92 & \\
\hline 3926 & 565854.94 & 138449.92 & \\
\hline 3927 & 568854.94 & 138449.92 & \\
\hline 3928 & 565771.62 & 138616.59 & \\
\hline 3929 & 568938.31 & 138449.92 & \\
\hline 3930 & 569021.62 & 138616.59 & \\
\hline 3931 & 565688.31 & 138449.92 & \\
\hline 3932 & 565604.94 & 138449.92 & \\
\hline 3933 & 569104.94 & 138449.92 & \\
\hline 3934 & 565521.62 & 138616.59 & \\
\hline 3935 & 569188.31 & 138449.92 & \\
\hline 3936 & 569271.62 & 138616.59 & \\
\hline 3937 & 565438.31 & 138449.92 & \\
\hline 3938 & 565354.94 & 138449.92 & \\
\hline 3939 & 569354.94 & 138449.92 & \\
\hline 3940 & 565271.62 & 138616.59 & \\
\hline 3941 & 569438.31 & 138449.92 & \\
\hline 3942 & 569521.62 & 138616.59 & \\
\hline 3943 & 565188.31 & 138449.92 & \\
\hline 3944 & 565104.94 & 138449.92 & \\
\hline 3945 & 569604.94 & 138449.92 & \\
\hline 3946 & 565021.62 & 138616.59 & \\
\hline 3947 & 569688.31 & 138449.92 & \\
\hline 3948 & 569771.62 & 138616.59 & \\
\hline 3949 & 564938.31 & 138449.92 & \\
\hline 3950 & 564854.94 & 138449.92 & \\
\hline 3951 & 569854.94 & 138449.92 & \\
\hline 3952 & 564771.62 & 138616.59 & \\
\hline 3953 & 569938.31 & 138449.92 & \\
\hline 3954 & 570021.62 & 138616.59 & \\
\hline 3955 & 564688.31 & 135783.27 & \\
\hline 3956 & 564688.31 & 135699.92 & \\
\hline 3957 & 564688.31 & 135866.59 & \\
\hline 3958 & 564688.31 & 135949.92 & \\
\hline 3959 & 564688.31 & 135616.59 & \\
\hline 3960 & 564688.31 & 136033.27 & \\
\hline 3961 & 564688.31 & 135533.27 & \\
\hline 3962 & 564688.31 & 135449.92 & \\
\hline 3963 & 564688.31 & 136116.59 & \\
\hline 3964 & 564688.31 & 136199.92 & \\
\hline 3965 & 564688.31 & 135366.59 & \\
\hline 3966 & 564688.31 & 136283.27 & \\
\hline 3967 & 564688.31 & 135283.27 & \\
\hline 3968 & 564688.31 & 135199.92 & \\
\hline 3969 & 564688.31 & 136366.59 & \\
\hline 3970 & 564688.31 & 136449.92 & \\
\hline 3971 & 564688.31 & 135116.59 & \\
\hline 3972 & 564688.31 & 136533.27 & \\
\hline 3973 & 564688.31 & 135033.27 & \\
\hline 3974 & 564688.31 & 134949.92 & \\
\hline 3975 & 564688.31 & 136616.59 & \\
\hline 3976 & 564688.31 & 136699.92 & \\
\hline
\end{tabular}




\begin{tabular}{|c|c|c|c|}
\hline node & X_coord & Y_coord & note: from sac04d created July 1,2004 \\
\hline 3977 & 564688.31 & 134866.59 & \\
\hline 3978 & 564688.31 & 136783.27 & \\
\hline 3979 & 564688.31 & 136866.59 & \\
\hline 3980 & 564688.31 & 136949.92 & \\
\hline 3981 & 564688.31 & 137033.27 & \\
\hline 3982 & 564688.31 & 137116.59 & \\
\hline 3983 & 564688.31 & 137199.92 & \\
\hline 3984 & 564688.31 & 137283.27 & \\
\hline 3985 & 564688.31 & 137366.59 & \\
\hline 3986 & 564688.31 & 137449.92 & \\
\hline 3987 & 564688.31 & 137533.27 & \\
\hline 3988 & 564688.31 & 137616.59 & \\
\hline 3989 & 564688.31 & 137699.92 & \\
\hline 3990 & 564688.31 & 137783.27 & \\
\hline 3991 & 564688.31 & 137866.59 & \\
\hline 3992 & 564688.31 & 137949.92 & \\
\hline 3993 & 564688.31 & 138033.27 & \\
\hline 3994 & 564688.31 & 138116.59 & \\
\hline 3995 & 564688.31 & 138199.92 & \\
\hline 3996 & 564521.62 & 134866.59 & \\
\hline 3997 & 564604.94 & 134866.59 & \\
\hline 3998 & 564521.62 & 134949.92 & \\
\hline 3999 & 564271.62 & 135033.27 & \\
\hline 4000 & 564188.31 & 135033.27 & \\
\hline 4001 & 564354.94 & 135033.27 & \\
\hline 4002 & 564188.31 & 135116.59 & \\
\hline 4003 & 564438.31 & 135033.27 & \\
\hline 4004 & 564021.62 & 135366.59 & \\
\hline 4005 & 564104.94 & 135283.27 & \\
\hline 4006 & 564188.31 & 135199.92 & \\
\hline 4007 & 564521.62 & 135033.27 & \\
\hline 4008 & 561021 & 133371.41 & \\
\hline 4009 & 561021 & 132625.7 & \\
\hline 4010 & 561021.62 & 134116.59 & \\
\hline 4011 & 561418 & 131864 & \\
\hline 4012 & 561021.62 & 134866.59 & \\
\hline 4013 & 561696.88 & 131370.41 & \\
\hline 4014 & 561021.62 & 135616.59 & \\
\hline 4015 & 563271.62 & 136366.59 & \\
\hline 4016 & 562521.62 & 136366.59 & \\
\hline 4017 & 564021.62 & 135616.59 & \\
\hline 4018 & 563771.62 & 135866.59 & \\
\hline 4019 & 564021.62 & 135866.59 & \\
\hline 4020 & 563771.62 & 136116.59 & \\
\hline 4021 & 561771.62 & 136366.59 & \\
\hline 4022 & 561021.62 & 136366.59 & \\
\hline 4023 & 564688.31 & 138283.27 & \\
\hline 4024 & 564688.31 & 138366.59 & \\
\hline 4025 & 564688.31 & 138449.92 & \\
\hline 4026 & 570271.62 & 132616.59 & \\
\hline 4027 & 571521.62 & 131866.59 & \\
\hline 4028 & 571521.62 & 131116.59 & \\
\hline 4029 & 570771.62 & 132616.59 & \\
\hline 4030 & 570521.62 & 132616.59 & \\
\hline 4031 & 571021.62 & 132366.59 & \\
\hline 4032 & 571021.62 & 132616.59 & \\
\hline
\end{tabular}




\begin{tabular}{|c|c|c|c|}
\hline node & X_coord & Y_coord & note: from sac04d created July 1, 2004 \\
\hline 4033 & $5 \overline{7} 1271.62$ & $1 \overline{3} 2366.59$ & \\
\hline 4034 & 571521.62 & 130366.6 & \\
\hline 4035 & 571160 & 129879.1 & \\
\hline 4036 & 571514.12 & 129868.3 & \\
\hline 4037 & 570188.31 & 132699.92 & \\
\hline 4038 & 570104.94 & 132783.27 & \\
\hline 4039 & 570104.94 & 133449.92 & \\
\hline 4040 & 570104.94 & 133533.27 & \\
\hline 4041 & 570104.94 & 133616.59 & \\
\hline 4042 & 570188.31 & 133449.92 & \\
\hline 4043 & 570104.94 & 133699.92 & \\
\hline 4044 & 570271.62 & 133116.59 & \\
\hline 4045 & 570271.62 & 133199.92 & \\
\hline 4046 & 570271.62 & 133033.27 & \\
\hline 4047 & 570271.62 & 133283.27 & \\
\hline 4048 & 570271.62 & 132949.92 & \\
\hline 4049 & 570271.62 & 133366.59 & \\
\hline 4050 & 570271.62 & 132866.59 & \\
\hline 4051 & 570271.62 & 133449.92 & \\
\hline 4052 & 570104.94 & 133783.27 & \\
\hline 4053 & 570104.94 & 133866.59 & \\
\hline 4054 & 570104.94 & 135783.27 & \\
\hline 4055 & 570104.94 & 135866.59 & \\
\hline 4056 & 570104.94 & 135699.92 & \\
\hline 4057 & 570104.94 & 135616.59 & \\
\hline 4058 & 570104.94 & 135949.92 & \\
\hline 4059 & 570104.94 & 136033.27 & \\
\hline 4060 & 570104.94 & 135533.27 & \\
\hline 4061 & 570104.94 & 136116.59 & \\
\hline 4062 & 570104.94 & 135449.92 & \\
\hline 4063 & 570104.94 & 135366.59 & \\
\hline 4064 & 570104.94 & 136199.92 & \\
\hline 4065 & 570104.94 & 136283.27 & \\
\hline 4066 & 570104.94 & 135283.27 & \\
\hline 4067 & 570104.94 & 136366.59 & \\
\hline 4068 & 570104.94 & 135199.92 & \\
\hline 4069 & 570104.94 & 135116.59 & \\
\hline 4070 & 570104.94 & 136449.92 & \\
\hline 4071 & 570104.94 & 136533.27 & \\
\hline 4072 & 570104.94 & 135033.27 & \\
\hline 4073 & 570104.94 & 136616.59 & \\
\hline 4074 & 570104.94 & 134949.92 & \\
\hline 4075 & 570104.94 & 134866.59 & \\
\hline 4076 & 570104.94 & 136699.92 & \\
\hline 4077 & 570104.94 & 136783.27 & \\
\hline 4078 & 570104.94 & 134783.27 & \\
\hline 4079 & 570104.94 & 136866.59 & \\
\hline 4080 & 570104.94 & 134699.92 & \\
\hline 4081 & 570104.94 & 134616.59 & \\
\hline 4082 & 570104.94 & 136949.92 & \\
\hline 4083 & 570104.94 & 137033.27 & \\
\hline 4084 & 570104.94 & 134533.27 & \\
\hline 4085 & 570104.94 & 137116.59 & \\
\hline 4086 & 570104.94 & 134449.92 & \\
\hline 4087 & 570104.94 & 134366.59 & \\
\hline 4088 & 570104.94 & 137199.92 & \\
\hline
\end{tabular}




\begin{tabular}{|c|c|c|c|}
\hline node & X_coord & Y_coord & note: from sac04d created July 1,2004 \\
\hline 4089 & $5 \overline{7} 0104.94$ & $1 \overline{3} 7283.27$ & \\
\hline 4090 & 570104.94 & 134283.27 & \\
\hline 4091 & 570104.94 & 137366.59 & \\
\hline 4092 & 570104.94 & 134199.92 & \\
\hline 4093 & 570104.94 & 134116.59 & \\
\hline 4094 & 570104.94 & 137449.92 & \\
\hline 4095 & 570104.94 & 137533.27 & \\
\hline 4096 & 570104.94 & 134033.27 & \\
\hline 4097 & 570104.94 & 137616.59 & \\
\hline 4098 & 570104.94 & 133949.92 & \\
\hline 4099 & 570104.94 & 137699.92 & \\
\hline 4100 & 570104.94 & 137783.27 & \\
\hline 4101 & 570104.94 & 137866.59 & \\
\hline 4102 & 570104.94 & 137949.92 & \\
\hline 4103 & 570104.94 & 138033.27 & \\
\hline 4104 & 570104.94 & 138116.59 & \\
\hline 4105 & 570104.94 & 138199.92 & \\
\hline 4106 & 570104.94 & 138283.27 & \\
\hline 4107 & 570104.94 & 138366.59 & \\
\hline 4108 & 570104.94 & 138533.27 & \\
\hline 4109 & 567271.62 & 138866.59 & \\
\hline 4110 & 567021.62 & 138866.59 & \\
\hline 4111 & 567521.62 & 138866.59 & \\
\hline 4112 & 567771.62 & 138866.59 & \\
\hline 4113 & 566771.62 & 138866.59 & \\
\hline 4114 & 568021.62 & 138866.59 & \\
\hline 4115 & 566521.62 & 138866.59 & \\
\hline 4116 & 568271.62 & 138866.59 & \\
\hline 4117 & 566271.62 & 138866.59 & \\
\hline 4118 & 568521.62 & 138866.59 & \\
\hline 4119 & 566021.62 & 138866.59 & \\
\hline 4120 & 568771.62 & 138866.59 & \\
\hline 4121 & 565771.62 & 138866.59 & \\
\hline 4122 & 569021.62 & 138866.59 & \\
\hline 4123 & 565521.62 & 138866.59 & \\
\hline 4124 & 569271.62 & 138866.59 & \\
\hline 4125 & 565271.62 & 138866.59 & \\
\hline 4126 & 569533.5 & 138858.75 & \\
\hline 4127 & 565021.62 & 138866.59 & \\
\hline 4128 & 569795.31 & 138850.91 & \\
\hline 4129 & 564771.62 & 138866.59 & \\
\hline 4130 & 570057.19 & 138843.06 & \\
\hline 4131 & 564521.62 & 138616.59 & \\
\hline 4132 & 564521.62 & 138866.59 & \\
\hline 4133 & 564604.94 & 138449.92 & \\
\hline 4134 & 570271.62 & 138616.59 & \\
\hline 4135 & 570311.12 & 138841.92 & \\
\hline 4136 & 570271.62 & 138533.27 & \\
\hline 4137 & 564604.94 & 135783.27 & \\
\hline 4138 & 564604.94 & 135866.59 & \\
\hline 4139 & 564604.94 & 135699.92 & \\
\hline 4140 & 564604.94 & 135616.59 & \\
\hline 4141 & 564604.94 & 135949.92 & \\
\hline 4142 & 564604.94 & 136033.27 & \\
\hline 4143 & 564604.94 & 135533.27 & \\
\hline 4144 & 564604.94 & 136116.59 & \\
\hline
\end{tabular}




\begin{tabular}{|c|c|c|c|}
\hline node & X_coord & Y_coord & note: from sac04d created July 1, 2004 \\
\hline 4145 & $5 \overline{6} 4604.94$ & $1 \overline{3} 5449.92$ & \\
\hline 4146 & 564604.94 & 135366.59 & \\
\hline 4147 & 564604.94 & 136199.92 & \\
\hline 4148 & 564604.94 & 136283.27 & \\
\hline 4149 & 564604.94 & 135283.27 & \\
\hline 4150 & 564604.94 & 136366.59 & \\
\hline 4151 & 564604.94 & 135199.92 & \\
\hline 4152 & 564604.94 & 135116.59 & \\
\hline 4153 & 564604.94 & 136449.92 & \\
\hline 4154 & 564604.94 & 136533.27 & \\
\hline 4155 & 564604.94 & 135033.27 & \\
\hline 4156 & 564604.94 & 136616.59 & \\
\hline 4157 & 564604.94 & 134949.92 & \\
\hline 4158 & 564604.94 & 136699.92 & \\
\hline 4159 & 564604.94 & 136783.27 & \\
\hline 4160 & 564604.94 & 136866.59 & \\
\hline 4161 & 564604.94 & 136949.92 & \\
\hline 4162 & 564604.94 & 137033.27 & \\
\hline 4163 & 564604.94 & 137116.59 & \\
\hline 4164 & 564604.94 & 137199.92 & \\
\hline 4165 & 564604.94 & 137283.27 & \\
\hline 4166 & 564604.94 & 137366.59 & \\
\hline 4167 & 564604.94 & 137449.92 & \\
\hline 4168 & 564604.94 & 137533.27 & \\
\hline 4169 & 564604.94 & 137616.59 & \\
\hline 4170 & 564604.94 & 137699.92 & \\
\hline 4171 & 564604.94 & 137783.27 & \\
\hline 4172 & 564604.94 & 137866.59 & \\
\hline 4173 & 564604.94 & 137949.92 & \\
\hline 4174 & 564604.94 & 138033.27 & \\
\hline 4175 & 564604.94 & 138116.59 & \\
\hline 4176 & 564604.94 & 138199.92 & \\
\hline 4177 & 564604.94 & 138283.27 & \\
\hline 4178 & 564271.62 & 135116.59 & \\
\hline 4179 & 564354.94 & 135116.59 & \\
\hline 4180 & 564438.31 & 135116.59 & \\
\hline 4181 & 564271.62 & 135199.92 & \\
\hline 4182 & 564521.62 & 135116.59 & \\
\hline 4183 & 564271.62 & 135366.59 & \\
\hline 4184 & 564188.31 & 135449.92 & \\
\hline 4185 & 564271.62 & 135449.92 & \\
\hline 4186 & 564188.31 & 135533.27 & \\
\hline 4187 & 564271.62 & 135283.27 & \\
\hline 4188 & 560495.31 & 133468 & \\
\hline 4189 & 560645.5 & 133038.8 & \\
\hline 4190 & 560162.69 & 133929.3 & \\
\hline 4191 & 560271.62 & 134866.59 & \\
\hline 4192 & 560269.88 & 135608.41 & \\
\hline 4193 & 560262.31 & 136369 & \\
\hline 4194 & 563271.62 & 137116.59 & \\
\hline 4195 & 562521.62 & 137116.59 & \\
\hline 4196 & 564021.62 & 136366.59 & \\
\hline 4197 & 564021.62 & 136116.59 & \\
\hline 4198 & 563771.62 & 136616.59 & \\
\hline 4199 & 564021.62 & 136616.59 & \\
\hline 4200 & 563771.62 & 136866.59 & \\
\hline
\end{tabular}




\begin{tabular}{|c|c|c|c|}
\hline node & X_coord & Y_coord & note: from sac04d created July 1,2004 \\
\hline 4201 & $5 \overline{6} 1771.62$ & $1 \overline{3} 7116.59$ & \\
\hline 4202 & 564271.62 & 135616.59 & \\
\hline 4203 & 564271.62 & 135533.27 & \\
\hline 4204 & 564188.31 & 135699.92 & \\
\hline 4205 & 564271.62 & 135699.92 & \\
\hline 4206 & 564188.31 & 135783.27 & \\
\hline 4207 & 564271.62 & 135866.59 & \\
\hline 4208 & 564271.62 & 135783.27 & \\
\hline 4209 & 564188.31 & 135949.92 & \\
\hline 4210 & 564271.62 & 135949.92 & \\
\hline 4211 & 564188.31 & 136033.27 & \\
\hline 4212 & 561021.62 & 137116.59 & \\
\hline 4213 & 560271.62 & 137116.59 & \\
\hline 4214 & 564604.94 & 138366.59 & \\
\hline 4215 & 570354.94 & 132783.27 & \\
\hline 4216 & 570354.94 & 132866.59 & \\
\hline 4217 & 570438.31 & 132783.27 & \\
\hline 4218 & 572271.62 & 131866.59 & \\
\hline 4219 & 572271.62 & 131116.59 & \\
\hline 4220 & 571521.62 & 132616.59 & \\
\hline 4221 & 571271.62 & 132616.59 & \\
\hline 4222 & 571771.62 & 132366.59 & \\
\hline 4223 & 571771.62 & 132616.59 & \\
\hline 4224 & 572021.62 & 132366.59 & \\
\hline 4225 & 572271.62 & 130366.6 & \\
\hline 4226 & 570771.62 & 132866.59 & \\
\hline 4227 & 570688.31 & 132783.27 & \\
\hline 4228 & 570688.31 & 132866.59 & \\
\hline 4229 & 570604.94 & 132783.27 & \\
\hline 4230 & 570854.94 & 132783.27 & \\
\hline 4231 & 570854.94 & 132866.59 & \\
\hline 4232 & 570938.31 & 132783.27 & \\
\hline 4233 & 570521.62 & 132866.59 & \\
\hline 4234 & 570438.31 & 132866.59 & \\
\hline 4235 & 570604.94 & 132866.59 & \\
\hline 4236 & 571021.62 & 132866.59 & \\
\hline 4237 & 570938.31 & 132866.59 & \\
\hline 4238 & 571104.94 & 132783.27 & \\
\hline 4239 & 571104.94 & 132866.59 & \\
\hline 4240 & 571188.31 & 132783.27 & \\
\hline 4241 & 572275.81 & 129492.8 & \\
\hline 4242 & 570188.31 & 133533.27 & \\
\hline 4243 & 570188.31 & 133616.59 & \\
\hline 4244 & 570188.31 & 133699.92 & \\
\hline 4245 & 570271.62 & 133533.27 & \\
\hline 4246 & 570188.31 & 133783.27 & \\
\hline 4247 & 570354.94 & 133116.59 & \\
\hline 4248 & 570354.94 & 133199.92 & \\
\hline 4249 & 570354.94 & 133033.27 & \\
\hline 4250 & 570354.94 & 133283.27 & \\
\hline 4251 & 570354.94 & 132949.92 & \\
\hline 4252 & 570354.94 & 133366.59 & \\
\hline 4253 & 570354.94 & 133449.92 & \\
\hline 4254 & 570354.94 & 133533.27 & \\
\hline 4255 & 570188.31 & 133866.59 & \\
\hline 4256 & 570188.31 & 133949.92 & \\
\hline
\end{tabular}




\begin{tabular}{|c|c|c|c|}
\hline node & X_coord & Y_coord & note: from sac04d created July 1,2004 \\
\hline 4257 & $5 \overline{7} 0188.31$ & $1 \overline{3} 5783.27$ & \\
\hline 4258 & 570188.31 & 135866.59 & \\
\hline 4259 & 570188.31 & 135699.92 & \\
\hline 4260 & 570188.31 & 135949.92 & \\
\hline 4261 & 570188.31 & 135616.59 & \\
\hline 4262 & 570188.31 & 135533.27 & \\
\hline 4263 & 570188.31 & 136033.27 & \\
\hline 4264 & 570188.31 & 136116.59 & \\
\hline 4265 & 570188.31 & 135449.92 & \\
\hline 4266 & 570188.31 & 136199.92 & \\
\hline 4267 & 570188.31 & 135366.59 & \\
\hline 4268 & 570188.31 & 135283.27 & \\
\hline 4269 & 570188.31 & 136283.27 & \\
\hline 4270 & 570188.31 & 136366.59 & \\
\hline 4271 & 570188.31 & 135199.92 & \\
\hline 4272 & 570188.31 & 136449.92 & \\
\hline 4273 & 570188.31 & 135116.59 & \\
\hline 4274 & 570188.31 & 135033.27 & \\
\hline 4275 & 570188.31 & 136533.27 & \\
\hline 4276 & 570188.31 & 136616.59 & \\
\hline 4277 & 570188.31 & 134949.92 & \\
\hline 4278 & 570188.31 & 136699.92 & \\
\hline 4279 & 570188.31 & 134866.59 & \\
\hline 4280 & 570188.31 & 134783.27 & \\
\hline 4281 & 570188.31 & 136783.27 & \\
\hline 4282 & 570188.31 & 136866.59 & \\
\hline 4283 & 570188.31 & 134699.92 & \\
\hline 4284 & 570188.31 & 136949.92 & \\
\hline 4285 & 570188.31 & 134616.59 & \\
\hline 4286 & 570188.31 & 134533.27 & \\
\hline 4287 & 570188.31 & 137033.27 & \\
\hline 4288 & 570188.31 & 137116.59 & \\
\hline 4289 & 570188.31 & 134449.92 & \\
\hline 4290 & 570188.31 & 137199.92 & \\
\hline 4291 & 570188.31 & 134366.59 & \\
\hline 4292 & 570188.31 & 134283.27 & \\
\hline 4293 & 570188.31 & 137283.27 & \\
\hline 4294 & 570188.31 & 137366.59 & \\
\hline 4295 & 570188.31 & 134199.92 & \\
\hline 4296 & 570188.31 & 137449.92 & \\
\hline 4297 & 570188.31 & 134116.59 & \\
\hline 4298 & 570188.31 & 134033.27 & \\
\hline 4299 & 570188.31 & 137533.27 & \\
\hline 4300 & 570188.31 & 137616.59 & \\
\hline 4301 & 570188.31 & 137699.92 & \\
\hline 4302 & 570188.31 & 137783.27 & \\
\hline 4303 & 570188.31 & 137866.59 & \\
\hline 4304 & 570188.31 & 137949.92 & \\
\hline 4305 & 570188.31 & 138033.27 & \\
\hline 4306 & 570188.31 & 138116.59 & \\
\hline 4307 & 570188.31 & 138199.92 & \\
\hline 4308 & 570188.31 & 138283.27 & \\
\hline 4309 & 570188.31 & 138366.59 & \\
\hline 4310 & 570188.31 & 138449.92 & \\
\hline 4311 & 570271.62 & 138449.92 & \\
\hline 4312 & 567271.62 & 139116.59 & \\
\hline
\end{tabular}




\begin{tabular}{|c|c|c|c|}
\hline node & X_coord & Y_coord & note: from sac04d created July 1,2004 \\
\hline 4313 & $5 \overline{6} 7021.62$ & $1 \overline{3} 9116.59$ & \\
\hline 4314 & 567521.62 & 139116.59 & \\
\hline 4315 & 566771.62 & 139116.59 & \\
\hline 4316 & 567771.62 & 139116.59 & \\
\hline 4317 & 568021.62 & 139116.59 & \\
\hline 4318 & 566521.62 & 139116.59 & \\
\hline 4319 & 568271.62 & 139116.59 & \\
\hline 4320 & 566271.62 & 139116.59 & \\
\hline 4321 & 568521.62 & 139116.59 & \\
\hline 4322 & 566021.62 & 139116.59 & \\
\hline 4323 & 568771.62 & 139116.59 & \\
\hline 4324 & 565771.62 & 139116.59 & \\
\hline 4325 & 569021.62 & 139116.59 & \\
\hline 4326 & 565521.62 & 139116.59 & \\
\hline 4327 & 569271.62 & 139116.59 & \\
\hline 4328 & 565271.62 & 139116.59 & \\
\hline 4329 & 569545.31 & 139100.91 & \\
\hline 4330 & 565021.62 & 139116.59 & \\
\hline 4331 & 569819.06 & 139085.22 & \\
\hline 4332 & 564771.62 & 139116.59 & \\
\hline 4333 & 570092.75 & 139069.53 & \\
\hline 4334 & 564521.62 & 139116.59 & \\
\hline 4335 & 570350.56 & 139067.23 & \\
\hline 4336 & 564271.62 & 138616.59 & \\
\hline 4337 & 564271.62 & 138866.59 & \\
\hline 4338 & 564521.62 & 138366.59 & \\
\hline 4339 & 564438.31 & 138449.92 & \\
\hline 4340 & 564438.31 & 138366.59 & \\
\hline 4341 & 564354.94 & 138449.92 & \\
\hline 4342 & 564271.62 & 139116.59 & \\
\hline 4343 & 570521.62 & 138616.59 & \\
\hline 4344 & 570565 & 138840.78 & \\
\hline 4345 & 570438.31 & 138533.27 & \\
\hline 4346 & 570608.38 & 139064.95 & \\
\hline 4347 & 570354.94 & 138449.92 & \\
\hline 4348 & 564521.62 & 135783.27 & \\
\hline 4349 & 564521.62 & 135866.59 & \\
\hline 4350 & 564521.62 & 135699.92 & \\
\hline 4351 & 564521.62 & 135949.92 & \\
\hline 4352 & 564521.62 & 135616.59 & \\
\hline 4353 & 564521.62 & 135533.27 & \\
\hline 4354 & 564521.62 & 136033.27 & \\
\hline 4355 & 564521.62 & 136116.59 & \\
\hline 4356 & 564521.62 & 135449.92 & \\
\hline 4357 & 564521.62 & 136199.92 & \\
\hline 4358 & 564521.62 & 135366.59 & \\
\hline 4359 & 564521.62 & 135283.27 & \\
\hline 4360 & 564521.62 & 136283.27 & \\
\hline 4361 & 564521.62 & 136366.59 & \\
\hline 4362 & 564521.62 & 135199.92 & \\
\hline 4363 & 564521.62 & 136449.92 & \\
\hline 4364 & 564521.62 & 136533.27 & \\
\hline 4365 & 564521.62 & 136616.59 & \\
\hline 4366 & 564521.62 & 136699.92 & \\
\hline 4367 & 564521.62 & 136783.27 & \\
\hline 4368 & 564521.62 & 136866.59 & \\
\hline
\end{tabular}




\begin{tabular}{|c|c|c|c|}
\hline node & X_coord & Y_coord & note: from sac04d created July 1,2004 \\
\hline 4369 & $5 \overline{6} 4521.62$ & $1 \overline{3} 6949.92$ & \\
\hline 4370 & 564521.62 & 137033.27 & \\
\hline 4371 & 564521.62 & 137116.59 & \\
\hline 4372 & 564521.62 & 137199.92 & \\
\hline 4373 & 564521.62 & 137283.27 & \\
\hline 4374 & 564521.62 & 137366.59 & \\
\hline 4375 & 564521.62 & 137449.92 & \\
\hline 4376 & 564521.62 & 137533.27 & \\
\hline 4377 & 564521.62 & 137616.59 & \\
\hline 4378 & 564521.62 & 137699.92 & \\
\hline 4379 & 564521.62 & 137783.27 & \\
\hline 4380 & 564521.62 & 137866.59 & \\
\hline 4381 & 564521.62 & 137949.92 & \\
\hline 4382 & 564521.62 & 138033.27 & \\
\hline 4383 & 564521.62 & 138116.59 & \\
\hline 4384 & 564521.62 & 138199.92 & \\
\hline 4385 & 564521.62 & 138283.27 & \\
\hline 4386 & 564354.94 & 135199.92 & \\
\hline 4387 & 564438.31 & 135199.92 & \\
\hline 4388 & 564354.94 & 135283.27 & \\
\hline 4389 & 564354.94 & 135366.59 & \\
\hline 4390 & 564354.94 & 135449.92 & \\
\hline 4391 & 564354.94 & 135533.27 & \\
\hline 4392 & 559733.5 & 134390.59 & \\
\hline 4393 & 559551.12 & 134916.41 & \\
\hline 4394 & 559389.81 & 135636.7 & \\
\hline 4395 & 559508.19 & 136354.09 & \\
\hline 4396 & 559521.62 & 137116.59 & \\
\hline 4397 & 563271.62 & 137866.59 & \\
\hline 4398 & 562521.62 & 137866.59 & \\
\hline 4399 & 564021.62 & 137116.59 & \\
\hline 4400 & 564021.62 & 136866.59 & \\
\hline 4401 & 563771.62 & 137366.59 & \\
\hline 4402 & 564021.62 & 137366.59 & \\
\hline 4403 & 563771.62 & 137616.59 & \\
\hline 4404 & 561771.62 & 137866.59 & \\
\hline 4405 & 564188.31 & 136283.27 & \\
\hline 4406 & 564271.62 & 136366.59 & \\
\hline 4407 & 564271.62 & 136283.27 & \\
\hline 4408 & 564188.31 & 136199.92 & \\
\hline 4409 & 564188.31 & 136449.92 & \\
\hline 4410 & 564271.62 & 136449.92 & \\
\hline 4411 & 564188.31 & 136533.27 & \\
\hline 4412 & 564271.62 & 136116.59 & \\
\hline 4413 & 564271.62 & 136199.92 & \\
\hline 4414 & 564271.62 & 136033.27 & \\
\hline 4415 & 564271.62 & 136616.59 & \\
\hline 4416 & 564271.62 & 136533.27 & \\
\hline 4417 & 564188.31 & 136699.92 & \\
\hline 4418 & 564271.62 & 136699.92 & \\
\hline 4419 & 564188.31 & 136783.27 & \\
\hline 4420 & 561021.62 & 137866.59 & \\
\hline 4421 & 564354.94 & 135616.59 & \\
\hline 4422 & 564354.94 & 135699.92 & \\
\hline 4423 & 564354.94 & 135783.27 & \\
\hline 4424 & 564354.94 & 135866.59 & \\
\hline
\end{tabular}




\begin{tabular}{|c|c|c|c|}
\hline node & X_coord & Y_coord & note: from sac04d created July 1,2004 \\
\hline 4425 & $5 \overline{6} 4354.94$ & $1 \overline{3} 5949.92$ & \\
\hline 4426 & 564354.94 & 136033.27 & \\
\hline 4427 & 560271.62 & 137866.59 & \\
\hline 4428 & 559521.62 & 137866.59 & \\
\hline 4429 & 570438.31 & 132949.92 & \\
\hline 4430 & 573021.62 & 131866.59 & \\
\hline 4431 & 573021.62 & 131116.59 & \\
\hline 4432 & 572271.62 & 132616.59 & \\
\hline 4433 & 572021.62 & 132616.59 & \\
\hline 4434 & 572521.62 & 132366.59 & \\
\hline 4435 & 572521.62 & 132616.59 & \\
\hline 4436 & 572771.62 & 132366.59 & \\
\hline 4437 & 573021.62 & 130366.6 & \\
\hline 4438 & 571521.62 & 132866.59 & \\
\hline 4439 & 571438.31 & 132783.27 & \\
\hline 4440 & 571438.31 & 132866.59 & \\
\hline 4441 & 571354.94 & 132783.27 & \\
\hline 4442 & 571604.94 & 132783.27 & \\
\hline 4443 & 571604.94 & 132866.59 & \\
\hline 4444 & 571688.31 & 132783.27 & \\
\hline 4445 & 571271.62 & 132866.59 & \\
\hline 4446 & 571188.31 & 132866.59 & \\
\hline 4447 & 571354.94 & 132866.59 & \\
\hline 4448 & 571771.62 & 132866.59 & \\
\hline 4449 & 571688.31 & 132866.59 & \\
\hline 4450 & 571854.94 & 132783.27 & \\
\hline 4451 & 571854.94 & 132866.59 & \\
\hline 4452 & 571938.31 & 132783.27 & \\
\hline 4453 & 573021.62 & 129616.6 & \\
\hline 4454 & 570771.62 & 132949.92 & \\
\hline 4455 & 570688.31 & 132949.92 & \\
\hline 4456 & 570854.94 & 132949.92 & \\
\hline 4457 & 570604.94 & 132949.92 & \\
\hline 4458 & 570938.31 & 132949.92 & \\
\hline 4459 & 570521.62 & 132949.92 & \\
\hline 4460 & 571021.62 & 132949.92 & \\
\hline 4461 & 571104.94 & 132949.92 & \\
\hline 4462 & 571188.31 & 132949.92 & \\
\hline 4463 & 572271.62 & 128866.6 & \\
\hline 4464 & 573021.62 & 128866.6 & \\
\hline 4465 & 570271.62 & 133616.59 & \\
\hline 4466 & 570271.62 & 133699.92 & \\
\hline 4467 & 570271.62 & 133783.27 & \\
\hline 4468 & 570354.94 & 133616.59 & \\
\hline 4469 & 570271.62 & 133866.59 & \\
\hline 4470 & 570438.31 & 133116.59 & \\
\hline 4471 & 570438.31 & 133199.92 & \\
\hline 4472 & 570438.31 & 133033.27 & \\
\hline 4473 & 570438.31 & 133283.27 & \\
\hline 4474 & 570438.31 & 133366.59 & \\
\hline 4475 & 570438.31 & 133449.92 & \\
\hline 4476 & 570438.31 & 133533.27 & \\
\hline 4477 & 570438.31 & 133616.59 & \\
\hline 4478 & 570271.62 & 133949.92 & \\
\hline 4479 & 570271.62 & 134033.27 & \\
\hline 4480 & 570271.62 & 135783.27 & \\
\hline
\end{tabular}




\begin{tabular}{|c|c|c|c|}
\hline node & X_coord & Y_coord & note: from sac04d created July 1,2004 \\
\hline 4481 & $5 \overline{7} 0271.62$ & $1 \overline{3} 5699.92$ & \\
\hline 4482 & 570271.62 & 135866.59 & \\
\hline 4483 & 570271.62 & 135949.92 & \\
\hline 4484 & 570271.62 & 135616.59 & \\
\hline 4485 & 570271.62 & 136033.27 & \\
\hline 4486 & 570271.62 & 135533.27 & \\
\hline 4487 & 570271.62 & 135449.92 & \\
\hline 4488 & 570271.62 & 136116.59 & \\
\hline 4489 & 570271.62 & 136199.92 & \\
\hline 4490 & 570271.62 & 135366.59 & \\
\hline 4491 & 570271.62 & 136283.27 & \\
\hline 4492 & 570271.62 & 135283.27 & \\
\hline 4493 & 570271.62 & 135199.92 & \\
\hline 4494 & 570271.62 & 136366.59 & \\
\hline 4495 & 570271.62 & 136449.92 & \\
\hline 4496 & 570271.62 & 135116.59 & \\
\hline 4497 & 570271.62 & 136533.27 & \\
\hline 4498 & 570271.62 & 135033.27 & \\
\hline 4499 & 570271.62 & 134949.92 & \\
\hline 4500 & 570271.62 & 136616.59 & \\
\hline 4501 & 570271.62 & 136699.92 & \\
\hline 4502 & 570271.62 & 134866.59 & \\
\hline 4503 & 570271.62 & 136783.27 & \\
\hline 4504 & 570271.62 & 134783.27 & \\
\hline 4505 & 570271.62 & 134699.92 & \\
\hline 4506 & 570271.62 & 136866.59 & \\
\hline 4507 & 570271.62 & 136949.92 & \\
\hline 4508 & 570271.62 & 134616.59 & \\
\hline 4509 & 570271.62 & 137033.27 & \\
\hline 4510 & 570271.62 & 134533.27 & \\
\hline 4511 & 570271.62 & 134449.92 & \\
\hline 4512 & 570271.62 & 137116.59 & \\
\hline 4513 & 570271.62 & 137199.92 & \\
\hline 4514 & 570271.62 & 134366.59 & \\
\hline 4515 & 570271.62 & 137283.27 & \\
\hline 4516 & 570271.62 & 134283.27 & \\
\hline 4517 & 570271.62 & 134199.92 & \\
\hline 4518 & 570271.62 & 137366.59 & \\
\hline 4519 & 570271.62 & 137449.92 & \\
\hline 4520 & 570271.62 & 134116.59 & \\
\hline 4521 & 570271.62 & 137533.27 & \\
\hline 4522 & 570271.62 & 137616.59 & \\
\hline 4523 & 570271.62 & 137699.92 & \\
\hline 4524 & 570271.62 & 137783.27 & \\
\hline 4525 & 570271.62 & 137866.59 & \\
\hline 4526 & 570271.62 & 137949.92 & \\
\hline 4527 & 570271.62 & 138033.27 & \\
\hline 4528 & 570271.62 & 138116.59 & \\
\hline 4529 & 570271.62 & 138199.92 & \\
\hline 4530 & 570271.62 & 138283.27 & \\
\hline 4531 & 570271.62 & 138366.59 & \\
\hline 4532 & 570354.94 & 138366.59 & \\
\hline 4533 & 567271.62 & 139366.59 & \\
\hline 4534 & 567521.62 & 139366.59 & \\
\hline 4535 & 567021.62 & 139366.59 & \\
\hline 4536 & 566771.62 & 139366.59 & \\
\hline
\end{tabular}




\begin{tabular}{|c|c|c|c|}
\hline node & X_coord & Y_coord & note: from sac04d created July 1, 2004 \\
\hline 4537 & $5 \overline{6} 7771.62$ & $1 \overline{3} 9366.59$ & \\
\hline 4538 & 566521.62 & 139366.59 & \\
\hline 4539 & 568021.62 & 139366.59 & \\
\hline 4540 & 568271.62 & 139366.59 & \\
\hline 4541 & 566271.62 & 139366.59 & \\
\hline 4542 & 568521.62 & 139366.59 & \\
\hline 4543 & 566021.62 & 139366.59 & \\
\hline 4544 & 568771.62 & 139366.59 & \\
\hline 4545 & 565771.62 & 139366.59 & \\
\hline 4546 & 569021.62 & 139366.59 & \\
\hline 4547 & 565521.62 & 139366.59 & \\
\hline 4548 & 569271.62 & 139366.59 & \\
\hline 4549 & 565271.62 & 139366.59 & \\
\hline 4550 & 569557.19 & 139343.06 & \\
\hline 4551 & 565021.62 & 139366.59 & \\
\hline 4552 & 569842.75 & 139319.53 & \\
\hline 4553 & 564771.62 & 139366.59 & \\
\hline 4554 & 570128.31 & 139296 & \\
\hline 4555 & 564521.62 & 139366.59 & \\
\hline 4556 & 570390.06 & 139292.56 & \\
\hline 4557 & 564271.62 & 139366.59 & \\
\hline 4558 & 570651.75 & 139289.14 & \\
\hline 4559 & 564021.62 & 138616.59 & \\
\hline 4560 & 564021.62 & 138866.59 & \\
\hline 4561 & 564271.62 & 138366.59 & \\
\hline 4562 & 564354.94 & 138366.59 & \\
\hline 4563 & 564188.31 & 138449.92 & \\
\hline 4564 & 564188.31 & 138366.59 & \\
\hline 4565 & 564104.94 & 138449.92 & \\
\hline 4566 & 564021.62 & 139116.59 & \\
\hline 4567 & 564438.31 & 138283.27 & \\
\hline 4568 & 564354.94 & 138283.27 & \\
\hline 4569 & 564021.62 & 139366.59 & \\
\hline 4570 & 570521.62 & 138366.59 & \\
\hline 4571 & 570771.62 & 138616.59 & \\
\hline 4572 & 570771.62 & 138366.59 & \\
\hline 4573 & 570818.94 & 138839.62 & \\
\hline 4574 & 570438.31 & 138366.59 & \\
\hline 4575 & 570866.19 & 139062.67 & \\
\hline 4576 & 570913.5 & 139285.7 & \\
\hline 4577 & 564438.31 & 135783.27 & \\
\hline 4578 & 564438.31 & 135699.92 & \\
\hline 4579 & 564438.31 & 135866.59 & \\
\hline 4580 & 564438.31 & 135949.92 & \\
\hline 4581 & 564438.31 & 135616.59 & \\
\hline 4582 & 564438.31 & 136033.27 & \\
\hline 4583 & 564438.31 & 135533.27 & \\
\hline 4584 & 564438.31 & 135449.92 & \\
\hline 4585 & 564438.31 & 136116.59 & \\
\hline 4586 & 564438.31 & 136199.92 & \\
\hline 4587 & 564438.31 & 135366.59 & \\
\hline 4588 & 564438.31 & 136283.27 & \\
\hline 4589 & 564438.31 & 135283.27 & \\
\hline 4590 & 564438.31 & 136366.59 & \\
\hline 4591 & 564438.31 & 136449.92 & \\
\hline 4592 & 564438.31 & 136533.27 & \\
\hline
\end{tabular}




\begin{tabular}{|c|c|c|c|}
\hline node & X_coord & Y_coord & note: from sac04d created July 1, 2004 \\
\hline 4593 & $5 \overline{6} 4438.31$ & $1 \overline{3} 6616.59$ & \\
\hline 4594 & 564438.31 & 136699.92 & \\
\hline 4595 & 564438.31 & 136783.27 & \\
\hline 4596 & 564438.31 & 136866.59 & \\
\hline 4597 & 564438.31 & 136949.92 & \\
\hline 4598 & 564438.31 & 137033.27 & \\
\hline 4599 & 564438.31 & 137116.59 & \\
\hline 4600 & 564438.31 & 137199.92 & \\
\hline 4601 & 564438.31 & 137283.27 & \\
\hline 4602 & 564438.31 & 137366.59 & \\
\hline 4603 & 564438.31 & 137449.92 & \\
\hline 4604 & 564438.31 & 137533.27 & \\
\hline 4605 & 564438.31 & 137616.59 & \\
\hline 4606 & 564438.31 & 137699.92 & \\
\hline 4607 & 564438.31 & 137783.27 & \\
\hline 4608 & 564438.31 & 137866.59 & \\
\hline 4609 & 564438.31 & 137949.92 & \\
\hline 4610 & 564438.31 & 138033.27 & \\
\hline 4611 & 564438.31 & 138116.59 & \\
\hline 4612 & 564438.31 & 138199.92 & \\
\hline 4613 & 558821.62 & 136155.59 & \\
\hline 4614 & 558542.62 & 136520.41 & \\
\hline 4615 & 558521.12 & 137421.59 & \\
\hline 4616 & 558338.81 & 138258.5 & \\
\hline 4617 & 563271.62 & 138616.59 & \\
\hline 4618 & 562521.62 & 138616.59 & \\
\hline 4619 & 564021.62 & 137866.59 & \\
\hline 4620 & 564021.62 & 137616.59 & \\
\hline 4621 & 563771.62 & 138116.59 & \\
\hline 4622 & 564021.62 & 138116.59 & \\
\hline 4623 & 563771.62 & 138366.59 & \\
\hline 4624 & 561771.62 & 138616.59 & \\
\hline 4625 & 564188.31 & 137033.27 & \\
\hline 4626 & 564271.62 & 137116.59 & \\
\hline 4627 & 564271.62 & 137033.27 & \\
\hline 4628 & 564188.31 & 136949.92 & \\
\hline 4629 & 564188.31 & 137199.92 & \\
\hline 4630 & 564271.62 & 137199.92 & \\
\hline 4631 & 564188.31 & 137283.27 & \\
\hline 4632 & 564271.62 & 136866.59 & \\
\hline 4633 & 564271.62 & 136949.92 & \\
\hline 4634 & 564271.62 & 136783.27 & \\
\hline 4635 & 564271.62 & 137366.59 & \\
\hline 4636 & 564271.62 & 137283.27 & \\
\hline 4637 & 564188.31 & 137449.92 & \\
\hline 4638 & 564271.62 & 137449.92 & \\
\hline 4639 & 564188.31 & 137533.27 & \\
\hline 4640 & 561021.62 & 138616.59 & \\
\hline 4641 & 564354.94 & 136366.59 & \\
\hline 4642 & 564354.94 & 136283.27 & \\
\hline 4643 & 564354.94 & 136449.92 & \\
\hline 4644 & 564354.94 & 136199.92 & \\
\hline 4645 & 564354.94 & 136533.27 & \\
\hline 4646 & 564354.94 & 136116.59 & \\
\hline 4647 & 564354.94 & 136616.59 & \\
\hline 4648 & 564354.94 & 136699.92 & \\
\hline
\end{tabular}




\begin{tabular}{|c|c|c|c|}
\hline node & X_coord & Y_coord & note: from sac04d created July 1, 2004 \\
\hline 4649 & $5 \overline{6} 4354.94$ & $1 \overline{3} 6783.27$ & \\
\hline 4650 & 560271.62 & 138616.59 & \\
\hline 4651 & 559521.62 & 138616.59 & \\
\hline 4652 & 558542.62 & 138794.91 & \\
\hline 4653 & 570521.62 & 133033.27 & \\
\hline 4654 & 573771.62 & 131866.59 & \\
\hline 4655 & 573771.62 & 131116.59 & \\
\hline 4656 & 573021.62 & 132616.59 & \\
\hline 4657 & 572771.62 & 132616.59 & \\
\hline 4658 & 573271.62 & 132366.59 & \\
\hline 4659 & 573271.62 & 132616.59 & \\
\hline 4660 & 573521.62 & 132366.59 & \\
\hline 4661 & 573771.62 & 130366.6 & \\
\hline 4662 & 572271.62 & 132866.59 & \\
\hline 4663 & 572188.31 & 132783.27 & \\
\hline 4664 & 572188.31 & 132866.59 & \\
\hline 4665 & 572104.94 & 132783.27 & \\
\hline 4666 & 572354.94 & 132783.27 & \\
\hline 4667 & 572354.94 & 132866.59 & \\
\hline 4668 & 572438.31 & 132783.27 & \\
\hline 4669 & 572021.62 & 132866.59 & \\
\hline 4670 & 571938.31 & 132866.59 & \\
\hline 4671 & 572104.94 & 132866.59 & \\
\hline 4672 & 572521.62 & 132866.59 & \\
\hline 4673 & 572438.31 & 132866.59 & \\
\hline 4674 & 572604.94 & 132783.27 & \\
\hline 4675 & 572604.94 & 132866.59 & \\
\hline 4676 & 572688.31 & 132783.27 & \\
\hline 4677 & 573771.62 & 129616.6 & \\
\hline 4678 & 571521.62 & 132949.92 & \\
\hline 4679 & 571438.31 & 132949.92 & \\
\hline 4680 & 571604.94 & 132949.92 & \\
\hline 4681 & 571354.94 & 132949.92 & \\
\hline 4682 & 571688.31 & 132949.92 & \\
\hline 4683 & 571271.62 & 132949.92 & \\
\hline 4684 & 571771.62 & 132949.92 & \\
\hline 4685 & 571854.94 & 132949.92 & \\
\hline 4686 & 571938.31 & 132949.92 & \\
\hline 4687 & 573771.62 & 128866.6 & \\
\hline 4688 & 570771.62 & 133033.27 & \\
\hline 4689 & 570688.31 & 133033.27 & \\
\hline 4690 & 570854.94 & 133033.27 & \\
\hline 4691 & 570604.94 & 133033.27 & \\
\hline 4692 & 570938.31 & 133033.27 & \\
\hline 4693 & 571021.62 & 133033.27 & \\
\hline 4694 & 571104.94 & 133033.27 & \\
\hline 4695 & 571188.31 & 133033.27 & \\
\hline 4696 & 571271.62 & 133033.27 & \\
\hline 4697 & 571514.12 & 128634.5 & \\
\hline 4698 & 572271.62 & 128116.6 & \\
\hline 4699 & 571521.62 & 128116.6 & \\
\hline 4700 & 573026.88 & 128119.5 & \\
\hline 4701 & 573771.62 & 128116.6 & \\
\hline 4702 & 570354.94 & 133699.92 & \\
\hline 4703 & 570354.94 & 133783.27 & \\
\hline 4704 & 570354.94 & 133866.59 & \\
\hline
\end{tabular}




\begin{tabular}{|c|c|c|c|}
\hline node & X_coord & Y_coord & note: from sac04d created July 1, 2004 \\
\hline 4705 & $5 \overline{7} 0438.31$ & $1 \overline{3} 3699.92$ & \\
\hline 4706 & 570354.94 & 133949.92 & \\
\hline 4707 & 570521.62 & 133116.59 & \\
\hline 4708 & 570521.62 & 133199.92 & \\
\hline 4709 & 570521.62 & 133283.27 & \\
\hline 4710 & 570521.62 & 133366.59 & \\
\hline 4711 & 570521.62 & 133449.92 & \\
\hline 4712 & 570521.62 & 133533.27 & \\
\hline 4713 & 570521.62 & 133616.59 & \\
\hline 4714 & 570521.62 & 133699.92 & \\
\hline 4715 & 570354.94 & 134033.27 & \\
\hline 4716 & 570354.94 & 134116.59 & \\
\hline 4717 & 570354.94 & 135783.27 & \\
\hline 4718 & 570354.94 & 135866.59 & \\
\hline 4719 & 570354.94 & 135699.92 & \\
\hline 4720 & 570354.94 & 135616.59 & \\
\hline 4721 & 570354.94 & 135949.92 & \\
\hline 4722 & 570354.94 & 136033.27 & \\
\hline 4723 & 570354.94 & 135533.27 & \\
\hline 4724 & 570354.94 & 136116.59 & \\
\hline 4725 & 570354.94 & 135449.92 & \\
\hline 4726 & 570354.94 & 135366.59 & \\
\hline 4727 & 570354.94 & 136199.92 & \\
\hline 4728 & 570354.94 & 136283.27 & \\
\hline 4729 & 570354.94 & 135283.27 & \\
\hline 4730 & 570354.94 & 136366.59 & \\
\hline 4731 & 570354.94 & 135199.92 & \\
\hline 4732 & 570354.94 & 135116.59 & \\
\hline 4733 & 570354.94 & 136449.92 & \\
\hline 4734 & 570354.94 & 136533.27 & \\
\hline 4735 & 570354.94 & 135033.27 & \\
\hline 4736 & 570354.94 & 136616.59 & \\
\hline 4737 & 570354.94 & 134949.92 & \\
\hline 4738 & 570354.94 & 134866.59 & \\
\hline 4739 & 570354.94 & 136699.92 & \\
\hline 4740 & 570354.94 & 136783.27 & \\
\hline 4741 & 570354.94 & 134783.27 & \\
\hline 4742 & 570354.94 & 136866.59 & \\
\hline 4743 & 570354.94 & 134699.92 & \\
\hline 4744 & 570354.94 & 134616.59 & \\
\hline 4745 & 570354.94 & 136949.92 & \\
\hline 4746 & 570354.94 & 137033.27 & \\
\hline 4747 & 570354.94 & 134533.27 & \\
\hline 4748 & 570354.94 & 137116.59 & \\
\hline 4749 & 570354.94 & 134449.92 & \\
\hline 4750 & 570354.94 & 134366.59 & \\
\hline 4751 & 570354.94 & 137199.92 & \\
\hline 4752 & 570354.94 & 137283.27 & \\
\hline 4753 & 570354.94 & 134283.27 & \\
\hline 4754 & 570354.94 & 137366.59 & \\
\hline 4755 & 570354.94 & 134199.92 & \\
\hline 4756 & 570354.94 & 137449.92 & \\
\hline 4757 & 570354.94 & 137533.27 & \\
\hline 4758 & 570354.94 & 137616.59 & \\
\hline 4759 & 570354.94 & 137699.92 & \\
\hline 4760 & 570354.94 & 137783.27 & \\
\hline
\end{tabular}




\begin{tabular}{|c|c|c|c|}
\hline node & X_coord & Y_coord & note: from sac04d created July 1, 2004 \\
\hline 4761 & $5 \overline{7} 0354.94$ & $1 \overline{3} 7866.59$ & \\
\hline 4762 & 570354.94 & 137949.92 & \\
\hline 4763 & 570354.94 & 138033.27 & \\
\hline 4764 & 570354.94 & 138116.59 & \\
\hline 4765 & 570354.94 & 138199.92 & \\
\hline 4766 & 570354.94 & 138283.27 & \\
\hline 4767 & 570438.31 & 138283.27 & \\
\hline 4768 & 567271.62 & 139616.59 & \\
\hline 4769 & 567021.62 & 140116.59 & \\
\hline 4770 & 567521.62 & 139616.59 & \\
\hline 4771 & 567771.62 & 140116.59 & \\
\hline 4772 & 566771.62 & 139616.59 & \\
\hline 4773 & 566521.62 & 139616.59 & \\
\hline 4774 & 568028.12 & 139600.81 & \\
\hline 4775 & 566271.62 & 140116.59 & \\
\hline 4776 & 568284.62 & 139585.02 & \\
\hline 4777 & 568580.12 & 139974.5 & \\
\hline 4778 & 566021.62 & 139616.59 & \\
\hline 4779 & 568885.81 & 139751.73 & \\
\hline 4780 & 565771.62 & 139616.59 & \\
\hline 4781 & 569116.38 & 139549.09 & \\
\hline 4782 & 565521.62 & 140116.59 & \\
\hline 4783 & 569403.94 & 139539.03 & \\
\hline 4784 & 565271.62 & 139616.59 & \\
\hline 4785 & 569712 & 139514.28 & \\
\hline 4786 & 565021.62 & 139616.59 & \\
\hline 4787 & 570020 & 139489.52 & \\
\hline 4788 & 564771.62 & 140116.59 & \\
\hline 4789 & 570328.06 & 139464.77 & \\
\hline 4790 & 564521.62 & 139866.59 & \\
\hline 4791 & 570542.75 & 139486.58 & \\
\hline 4792 & 564271.62 & 139616.59 & \\
\hline 4793 & 570757.38 & 139508.39 & \\
\hline 4794 & 564021.62 & 139616.59 & \\
\hline 4795 & 570972.06 & 139530.2 & \\
\hline 4796 & 564021.62 & 138366.59 & \\
\hline 4797 & 563521.62 & 138866.59 & \\
\hline 4798 & 564104.94 & 138366.59 & \\
\hline 4799 & 563771.62 & 139116.59 & \\
\hline 4800 & 564271.62 & 138283.27 & \\
\hline 4801 & 564188.31 & 138283.27 & \\
\hline 4802 & 564104.94 & 138199.92 & \\
\hline 4803 & 563771.62 & 139366.59 & \\
\hline 4804 & 564354.94 & 138199.92 & \\
\hline 4805 & 564271.62 & 138199.92 & \\
\hline 4806 & 563771.62 & 139616.59 & \\
\hline 4807 & 570521.62 & 138283.27 & \\
\hline 4808 & 570688.31 & 138283.27 & \\
\hline 4809 & 571021.62 & 138616.59 & \\
\hline 4810 & 571021.62 & 138366.59 & \\
\hline 4811 & 571053.12 & 138848.62 & \\
\hline 4812 & 570771.62 & 138116.59 & \\
\hline 4813 & 571021.62 & 138116.59 & \\
\hline 4814 & 570688.31 & 138116.59 & \\
\hline 4815 & 571084.69 & 139080.64 & \\
\hline 4816 & 571116.19 & 139312.67 & \\
\hline
\end{tabular}




\begin{tabular}{|c|c|c|c|}
\hline node & X_coord & Y_coord & note: from sac04d created July 1, 2004 \\
\hline 4817 & $5 \overline{7} 1155.25$ & $1 \overline{3} 9559$ & \\
\hline 4818 & 564354.94 & 136866.59 & \\
\hline 4819 & 564354.94 & 136949.92 & \\
\hline 4820 & 564354.94 & 137033.27 & \\
\hline 4821 & 564354.94 & 137116.59 & \\
\hline 4822 & 564354.94 & 137199.92 & \\
\hline 4823 & 564354.94 & 137283.27 & \\
\hline 4824 & 564354.94 & 137366.59 & \\
\hline 4825 & 564354.94 & 137449.92 & \\
\hline 4826 & 564354.94 & 137533.27 & \\
\hline 4827 & 564354.94 & 137616.59 & \\
\hline 4828 & 564354.94 & 137699.92 & \\
\hline 4829 & 564354.94 & 137783.27 & \\
\hline 4830 & 564354.94 & 137866.59 & \\
\hline 4831 & 564354.94 & 137949.92 & \\
\hline 4832 & 564354.94 & 138033.27 & \\
\hline 4833 & 564354.94 & 138116.59 & \\
\hline 4834 & 557813 & 136810.09 & \\
\hline 4835 & 557813 & 137421.59 & \\
\hline 4836 & 557813 & 138033.2 & \\
\hline 4837 & 563271.62 & 139366.59 & \\
\hline 4838 & 562521.62 & 139366.59 & \\
\hline 4839 & 563521.62 & 139366.59 & \\
\hline 4840 & 561771.62 & 139366.59 & \\
\hline 4841 & 564188.31 & 137783.27 & \\
\hline 4842 & 564271.62 & 137866.59 & \\
\hline 4843 & 564271.62 & 137783.27 & \\
\hline 4844 & 564188.31 & 137699.92 & \\
\hline 4845 & 564188.31 & 137949.92 & \\
\hline 4846 & 564271.62 & 137949.92 & \\
\hline 4847 & 564188.31 & 138033.27 & \\
\hline 4848 & 564271.62 & 137616.59 & \\
\hline 4849 & 564271.62 & 137699.92 & \\
\hline 4850 & 564271.62 & 137533.27 & \\
\hline 4851 & 564271.62 & 138116.59 & \\
\hline 4852 & 564271.62 & 138033.27 & \\
\hline 4853 & 561021.62 & 139366.59 & \\
\hline 4854 & 560271.62 & 139366.59 & \\
\hline 4855 & 559521.62 & 139366.59 & \\
\hline 4856 & 558531.88 & 139374.3 & \\
\hline 4857 & 558167.12 & 139020.3 & \\
\hline 4858 & 558070.5 & 139309.91 & \\
\hline 4859 & 570604.94 & 133116.59 & \\
\hline 4860 & 574521.62 & 131866.59 & \\
\hline 4861 & 574521.62 & 131116.59 & \\
\hline 4862 & 573771.62 & 132616.59 & \\
\hline 4863 & 573521.62 & 132616.59 & \\
\hline 4864 & 574021.62 & 132366.59 & \\
\hline 4865 & 574021.62 & 132616.59 & \\
\hline 4866 & 574271.62 & 132366.59 & \\
\hline 4867 & 574521.62 & 130366.6 & \\
\hline 4868 & 573021.62 & 132866.59 & \\
\hline 4869 & 572938.31 & 132783.27 & \\
\hline 4870 & 572938.31 & 132866.59 & \\
\hline 4871 & 572854.94 & 132783.27 & \\
\hline 4872 & 573104.94 & 132783.27 & \\
\hline
\end{tabular}




\begin{tabular}{|c|c|c|c|}
\hline node & X_coord & Y_coord & note: from sac04d created July 1,2004 \\
\hline 4873 & $5 \overline{7} 3104.94$ & $1 \overline{3} 2866.59$ & \\
\hline 4874 & 573188.31 & 132783.27 & \\
\hline 4875 & 572771.62 & 132866.59 & \\
\hline 4876 & 572688.31 & 132866.59 & \\
\hline 4877 & 572854.94 & 132866.59 & \\
\hline 4878 & 573271.62 & 132866.59 & \\
\hline 4879 & 573188.31 & 132866.59 & \\
\hline 4880 & 573354.94 & 132783.27 & \\
\hline 4881 & 573354.94 & 132866.59 & \\
\hline 4882 & 573438.31 & 132783.27 & \\
\hline 4883 & 574521.62 & 129616.6 & \\
\hline 4884 & 572271.62 & 132949.92 & \\
\hline 4885 & 572188.31 & 132949.92 & \\
\hline 4886 & 572354.94 & 132949.92 & \\
\hline 4887 & 572104.94 & 132949.92 & \\
\hline 4888 & 572438.31 & 132949.92 & \\
\hline 4889 & 572021.62 & 132949.92 & \\
\hline 4890 & 572521.62 & 132949.92 & \\
\hline 4891 & 572604.94 & 132949.92 & \\
\hline 4892 & 572688.31 & 132949.92 & \\
\hline 4893 & 574521.62 & 128866.6 & \\
\hline 4894 & 571521.62 & 133033.27 & \\
\hline 4895 & 571438.31 & 133033.27 & \\
\hline 4896 & 571604.94 & 133033.27 & \\
\hline 4897 & 571354.94 & 133033.27 & \\
\hline 4898 & 571688.31 & 133033.27 & \\
\hline 4899 & 571771.62 & 133033.27 & \\
\hline 4900 & 571854.94 & 133033.27 & \\
\hline 4901 & 571938.31 & 133033.27 & \\
\hline 4902 & 572021.62 & 133033.27 & \\
\hline 4903 & 574521.62 & 128116.6 & \\
\hline 4904 & 570771.62 & 133116.59 & \\
\hline 4905 & 570688.31 & 133116.59 & \\
\hline 4906 & 570854.94 & 133116.59 & \\
\hline 4907 & 570938.31 & 133116.59 & \\
\hline 4908 & 571021.62 & 133116.59 & \\
\hline 4909 & 571104.94 & 133116.59 & \\
\hline 4910 & 571188.31 & 133116.59 & \\
\hline 4911 & 571271.62 & 133116.59 & \\
\hline 4912 & 571354.94 & 133116.59 & \\
\hline 4913 & 572265.12 & 127357.7 & \\
\hline 4914 & 571514.12 & 127561.6 & \\
\hline 4915 & 573016.12 & 127357.7 & \\
\hline 4916 & 573771.62 & 127366.6 & \\
\hline 4917 & 574521.62 & 127366.6 & \\
\hline 4918 & 570438.31 & 133783.27 & \\
\hline 4919 & 570438.31 & 133866.59 & \\
\hline 4920 & 570438.31 & 133949.92 & \\
\hline 4921 & 570521.62 & 133783.27 & \\
\hline 4922 & 570438.31 & 134033.27 & \\
\hline 4923 & 570604.94 & 133199.92 & \\
\hline 4924 & 570604.94 & 133283.27 & \\
\hline 4925 & 570604.94 & 133366.59 & \\
\hline 4926 & 570604.94 & 133449.92 & \\
\hline 4927 & 570604.94 & 133533.27 & \\
\hline 4928 & 570604.94 & 133616.59 & \\
\hline
\end{tabular}




\begin{tabular}{|c|c|c|c|}
\hline node & X_coord & Y_coord & note: from sac04d created July 1, 2004 \\
\hline 4929 & $5 \overline{7} 0604.94$ & $1 \overline{3} 3699.92$ & \\
\hline 4930 & 570604.94 & 133783.27 & \\
\hline 4931 & 570438.31 & 134116.59 & \\
\hline 4932 & 570438.31 & 134199.92 & \\
\hline 4933 & 570438.31 & 135783.27 & \\
\hline 4934 & 570438.31 & 135866.59 & \\
\hline 4935 & 570438.31 & 135699.92 & \\
\hline 4936 & 570438.31 & 135949.92 & \\
\hline 4937 & 570438.31 & 135616.59 & \\
\hline 4938 & 570438.31 & 135533.27 & \\
\hline 4939 & 570438.31 & 136033.27 & \\
\hline 4940 & 570438.31 & 136116.59 & \\
\hline 4941 & 570438.31 & 135449.92 & \\
\hline 4942 & 570438.31 & 136199.92 & \\
\hline 4943 & 570438.31 & 135366.59 & \\
\hline 4944 & 570438.31 & 135283.27 & \\
\hline 4945 & 570438.31 & 136283.27 & \\
\hline 4946 & 570438.31 & 136366.59 & \\
\hline 4947 & 570438.31 & 135199.92 & \\
\hline 4948 & 570438.31 & 136449.92 & \\
\hline 4949 & 570438.31 & 135116.59 & \\
\hline 4950 & 570438.31 & 135033.27 & \\
\hline 4951 & 570438.31 & 136533.27 & \\
\hline 4952 & 570438.31 & 136616.59 & \\
\hline 4953 & 570438.31 & 134949.92 & \\
\hline 4954 & 570438.31 & 136699.92 & \\
\hline 4955 & 570438.31 & 134866.59 & \\
\hline 4956 & 570438.31 & 134783.27 & \\
\hline 4957 & 570438.31 & 136783.27 & \\
\hline 4958 & 570438.31 & 136866.59 & \\
\hline 4959 & 570438.31 & 134699.92 & \\
\hline 4960 & 570438.31 & 136949.92 & \\
\hline 4961 & 570438.31 & 134616.59 & \\
\hline 4962 & 570438.31 & 134533.27 & \\
\hline 4963 & 570438.31 & 137033.27 & \\
\hline 4964 & 570438.31 & 137116.59 & \\
\hline 4965 & 570438.31 & 134449.92 & \\
\hline 4966 & 570438.31 & 137199.92 & \\
\hline 4967 & 570438.31 & 134366.59 & \\
\hline 4968 & 570438.31 & 134283.27 & \\
\hline 4969 & 570438.31 & 137283.27 & \\
\hline 4970 & 570438.31 & 137366.59 & \\
\hline 4971 & 570438.31 & 137449.92 & \\
\hline 4972 & 570438.31 & 137533.27 & \\
\hline 4973 & 570438.31 & 137616.59 & \\
\hline 4974 & 570438.31 & 137699.92 & \\
\hline 4975 & 570438.31 & 137783.27 & \\
\hline 4976 & 570438.31 & 137866.59 & \\
\hline 4977 & 570438.31 & 137949.92 & \\
\hline 4978 & 570438.31 & 138033.27 & \\
\hline 4979 & 570438.31 & 138116.59 & \\
\hline 4980 & 570438.31 & 138199.92 & \\
\hline 4981 & 570521.62 & 138199.92 & \\
\hline 4982 & 567235.38 & 140618.5 & \\
\hline 4983 & 566267.5 & 140645.7 & \\
\hline 4984 & 567773.88 & 140555.41 & \\
\hline
\end{tabular}




\begin{tabular}{|c|c|c|c|}
\hline node & X_coord & Y_coord & note: from sac04d created July 1, 2004 \\
\hline 4985 & $5 \overline{6} 8509$ & $1 \overline{4} 0531.7$ & \\
\hline 4986 & 565521.62 & 140866.59 & \\
\hline 4987 & 569668.62 & 139883.91 & \\
\hline 4988 & 569219.12 & 140267.2 & \\
\hline 4989 & 569536.31 & 139711.47 & \\
\hline 4990 & 564771.62 & 140866.59 & \\
\hline 4991 & 569866.75 & 139685.48 & \\
\hline 4992 & 570197.31 & 139659.52 & \\
\hline 4993 & 570527.75 & 139633.53 & \\
\hline 4994 & 564021.62 & 140116.59 & \\
\hline 4995 & 564021.62 & 140866.59 & \\
\hline 4996 & 564021.62 & 139866.59 & \\
\hline 4997 & 570695.38 & 139680.58 & \\
\hline 4998 & 570862.94 & 139727.66 & \\
\hline 4999 & 571030.56 & 139774.7 & \\
\hline 5000 & 563521.62 & 139866.59 & \\
\hline 5001 & 571194.25 & 139805.34 & \\
\hline 5002 & 570604.94 & 138199.92 & \\
\hline 5003 & 570604.94 & 138116.59 & \\
\hline 5004 & 571271.62 & 138616.59 & \\
\hline 5005 & 571271.62 & 138366.59 & \\
\hline 5006 & 571287.38 & 138857.61 & \\
\hline 5007 & 571271.62 & 138116.59 & \\
\hline 5008 & 571303.19 & 139098.61 & \\
\hline 5009 & 570771.62 & 138033.27 & \\
\hline 5010 & 570688.31 & 138033.27 & \\
\hline 5011 & 570938.31 & 138033.27 & \\
\hline 5012 & 571021.62 & 137866.59 & \\
\hline 5013 & 571271.62 & 137866.59 & \\
\hline 5014 & 570938.31 & 137866.59 & \\
\hline 5015 & 570604.94 & 138033.27 & \\
\hline 5016 & 571318.94 & 139339.62 & \\
\hline 5017 & 571338.44 & 139587.8 & \\
\hline 5018 & 571357.94 & 139835.95 & \\
\hline 5019 & 563271.62 & 140116.59 & \\
\hline 5020 & 562521.62 & 140116.59 & \\
\hline 5021 & 561771.62 & 140116.59 & \\
\hline 5022 & 561021.62 & 140116.59 & \\
\hline 5023 & 560271.62 & 140116.59 & \\
\hline 5024 & 559521.62 & 140116.59 & \\
\hline 5025 & 558671.31 & 140039.5 & \\
\hline 5026 & 558262.38 & 139744.2 & \\
\hline 5027 & 570688.31 & 133199.92 & \\
\hline 5028 & 575271.62 & 131866.59 & \\
\hline 5029 & 575271.62 & 131116.59 & \\
\hline 5030 & 574521.62 & 132616.59 & \\
\hline 5031 & 574271.62 & 132616.59 & \\
\hline 5032 & 574771.62 & 132116.59 & \\
\hline 5033 & 575271.62 & 132116.59 & \\
\hline 5034 & 574771.62 & 132616.59 & \\
\hline 5035 & 575271.62 & 130366.6 & \\
\hline 5036 & 573771.62 & 132866.59 & \\
\hline 5037 & 574021.62 & 132866.59 & \\
\hline 5038 & 573688.31 & 132783.27 & \\
\hline 5039 & 573688.31 & 132866.59 & \\
\hline 5040 & 573604.94 & 132783.27 & \\
\hline
\end{tabular}




\begin{tabular}{|c|c|c|c|}
\hline node & X_coord & Y_coord & note: from sac04d created July 1, 2004 \\
\hline 5041 & $5 \overline{7} 3521.62$ & $1 \overline{3} 2866.59$ & \\
\hline 5042 & 573438.31 & 132866.59 & \\
\hline 5043 & 573604.94 & 132866.59 & \\
\hline 5044 & 574271.62 & 132866.59 & \\
\hline 5045 & 575271.62 & 129616.6 & \\
\hline 5046 & 573021.62 & 132949.92 & \\
\hline 5047 & 572938.31 & 132949.92 & \\
\hline 5048 & 573104.94 & 132949.92 & \\
\hline 5049 & 572854.94 & 132949.92 & \\
\hline 5050 & 573188.31 & 132949.92 & \\
\hline 5051 & 572771.62 & 132949.92 & \\
\hline 5052 & 573271.62 & 132949.92 & \\
\hline 5053 & 573354.94 & 132949.92 & \\
\hline 5054 & 573438.31 & 132949.92 & \\
\hline 5055 & 575271.62 & 128866.6 & \\
\hline 5056 & 572271.62 & 133033.27 & \\
\hline 5057 & 572188.31 & 133033.27 & \\
\hline 5058 & 572354.94 & 133033.27 & \\
\hline 5059 & 572104.94 & 133033.27 & \\
\hline 5060 & 572438.31 & 133033.27 & \\
\hline 5061 & 572521.62 & 133033.27 & \\
\hline 5062 & 572604.94 & 133033.27 & \\
\hline 5063 & 572688.31 & 133033.27 & \\
\hline 5064 & 572771.62 & 133033.27 & \\
\hline 5065 & 575271.62 & 128116.6 & \\
\hline 5066 & 571521.62 & 133116.59 & \\
\hline 5067 & 571438.31 & 133116.59 & \\
\hline 5068 & 571604.94 & 133116.59 & \\
\hline 5069 & 571688.31 & 133116.59 & \\
\hline 5070 & 571771.62 & 133116.59 & \\
\hline 5071 & 571854.94 & 133116.59 & \\
\hline 5072 & 571938.31 & 133116.59 & \\
\hline 5073 & 572021.62 & 133116.59 & \\
\hline 5074 & 572104.94 & 133116.59 & \\
\hline 5075 & 575271.62 & 127366.6 & \\
\hline 5076 & 570771.62 & 133199.92 & \\
\hline 5077 & 570854.94 & 133199.92 & \\
\hline 5078 & 570938.31 & 133199.92 & \\
\hline 5079 & 571021.62 & 133199.92 & \\
\hline 5080 & 571104.94 & 133199.92 & \\
\hline 5081 & 571188.31 & 133199.92 & \\
\hline 5082 & 571271.62 & 133199.92 & \\
\hline 5083 & 571354.94 & 133199.92 & \\
\hline 5084 & 571438.31 & 133199.92 & \\
\hline 5085 & 572254.38 & 126730.1 & \\
\hline 5086 & 571514.12 & 127062.7 & \\
\hline 5087 & 573005.38 & 126467.2 & \\
\hline 5088 & 573771.62 & 126616.6 & \\
\hline 5089 & 574518.19 & 126622.8 & \\
\hline 5090 & 575271.62 & 126616.6 & \\
\hline 5091 & 570521.62 & 133866.59 & \\
\hline 5092 & 570521.62 & 133949.92 & \\
\hline 5093 & 570521.62 & 134033.27 & \\
\hline 5094 & 570604.94 & 133866.59 & \\
\hline 5095 & 570521.62 & 134116.59 & \\
\hline 5096 & 570688.31 & 133283.27 & \\
\hline
\end{tabular}




\begin{tabular}{|c|c|c|c|}
\hline node & X_coord & Y_coord & note: from sac04d created July 1, 2004 \\
\hline 5097 & $5 \overline{7} 0688.31$ & $1 \overline{3} 3366.59$ & \\
\hline 5098 & 570688.31 & 133449.92 & \\
\hline 5099 & 570688.31 & 133533.27 & \\
\hline 5100 & 570688.31 & 133616.59 & \\
\hline 5101 & 570688.31 & 133699.92 & \\
\hline 5102 & 570688.31 & 133783.27 & \\
\hline 5103 & 570688.31 & 133866.59 & \\
\hline 5104 & 570521.62 & 134199.92 & \\
\hline 5105 & 570521.62 & 134283.27 & \\
\hline 5106 & 570521.62 & 135783.27 & \\
\hline 5107 & 570521.62 & 135699.92 & \\
\hline 5108 & 570521.62 & 135866.59 & \\
\hline 5109 & 570521.62 & 135949.92 & \\
\hline 5110 & 570521.62 & 135616.59 & \\
\hline 5111 & 570521.62 & 136033.27 & \\
\hline 5112 & 570521.62 & 135533.27 & \\
\hline 5113 & 570521.62 & 135449.92 & \\
\hline 5114 & 570521.62 & 136116.59 & \\
\hline 5115 & 570521.62 & 136199.92 & \\
\hline 5116 & 570521.62 & 135366.59 & \\
\hline 5117 & 570521.62 & 136283.27 & \\
\hline 5118 & 570521.62 & 135283.27 & \\
\hline 5119 & 570521.62 & 135199.92 & \\
\hline 5120 & 570521.62 & 136366.59 & \\
\hline 5121 & 570521.62 & 136449.92 & \\
\hline 5122 & 570521.62 & 135116.59 & \\
\hline 5123 & 570521.62 & 136533.27 & \\
\hline 5124 & 570521.62 & 135033.27 & \\
\hline 5125 & 570521.62 & 134949.92 & \\
\hline 5126 & 570521.62 & 136616.59 & \\
\hline 5127 & 570521.62 & 136699.92 & \\
\hline 5128 & 570521.62 & 134866.59 & \\
\hline 5129 & 570521.62 & 136783.27 & \\
\hline 5130 & 570521.62 & 134783.27 & \\
\hline 5131 & 570521.62 & 134699.92 & \\
\hline 5132 & 570521.62 & 136866.59 & \\
\hline 5133 & 570521.62 & 136949.92 & \\
\hline 5134 & 570521.62 & 134616.59 & \\
\hline 5135 & 570521.62 & 137033.27 & \\
\hline 5136 & 570521.62 & 134533.27 & \\
\hline 5137 & 570521.62 & 134449.92 & \\
\hline 5138 & 570521.62 & 137116.59 & \\
\hline 5139 & 570521.62 & 137199.92 & \\
\hline 5140 & 570521.62 & 134366.59 & \\
\hline 5141 & 570521.62 & 137283.27 & \\
\hline 5142 & 570521.62 & 137366.59 & \\
\hline 5143 & 570521.62 & 137449.92 & \\
\hline 5144 & 570521.62 & 137533.27 & \\
\hline 5145 & 570521.62 & 137616.59 & \\
\hline 5146 & 570521.62 & 137699.92 & \\
\hline 5147 & 570521.62 & 137783.27 & \\
\hline 5148 & 570521.62 & 137866.59 & \\
\hline 5149 & 570521.62 & 137949.92 & \\
\hline 5150 & 570521.62 & 138033.27 & \\
\hline 5151 & 570521.62 & 138116.59 & \\
\hline 5152 & 566884.19 & 140928.41 & \\
\hline
\end{tabular}




\begin{tabular}{|c|c|c|}
\hline node & X_coord & Y_coord \\
\hline 5153 & $5 \overline{6} 6339.38$ & $1 \overline{14} 1053.3$ \\
\hline 5154 & 565521.38 & 141183.8 \\
\hline 5155 & 564765.38 & 141192.91 \\
\hline 5156 & 570021.56 & 139856.7 \\
\hline 5157 & 564021.62 & 141616.59 \\
\hline 5158 & 570374.56 & 139829.5 \\
\hline 5159 & 570727.5 & 139802.3 \\
\hline 5160 & 570848.06 & 139874.59 \\
\hline 5161 & 563271.62 & 140866.59 \\
\hline 5162 & 563271.62 & 141616.59 \\
\hline 5163 & 570968.56 & 139946.91 \\
\hline 5164 & 571089.12 & 140019.2 \\
\hline 5165 & 571233.31 & 140051.67 \\
\hline 5166 & 571377.44 & 140084.12 \\
\hline 5167 & 571521.62 & 138616.59 \\
\hline 5168 & 571521.62 & 138366.59 \\
\hline 5169 & 571521.62 & 138866.59 \\
\hline 5170 & 571521.62 & 138116.59 \\
\hline 5171 & 571521.62 & 139116.59 \\
\hline 5172 & 571521.62 & 137866.59 \\
\hline 5173 & 571521.62 & 139366.59 \\
\hline 5174 & 570771.62 & 137949.92 \\
\hline 5175 & 570688.31 & 137949.92 \\
\hline 5176 & 570854.94 & 137949.92 \\
\hline 5177 & 570604.94 & 137949.92 \\
\hline 5178 & 570854.94 & 137866.59 \\
\hline 5179 & 571021.62 & 137783.27 \\
\hline 5180 & 571188.31 & 137783.27 \\
\hline 5181 & 570938.31 & 137783.27 \\
\hline 5182 & 571271.62 & 137616.59 \\
\hline 5183 & 571521.62 & 137616.59 \\
\hline 5184 & 571188.31 & 137616.59 \\
\hline 5185 & 570854.94 & 137783.27 \\
\hline 5186 & 571521.62 & 139616.59 \\
\hline 5187 & 571521.62 & 139866.59 \\
\hline 5188 & 571521.62 & 140116.59 \\
\hline 5189 & 562521.62 & 140866.59 \\
\hline 5190 & 561771.62 & 140866.59 \\
\hline 5191 & 561021.62 & 140866.59 \\
\hline 5192 & 560271.62 & 140866.59 \\
\hline 5193 & 559518.88 & 140876.41 \\
\hline 5194 & 559175.62 & 140672.5 \\
\hline 5195 & 570771.62 & 133283.27 \\
\hline 5196 & 575521.62 & 131866.59 \\
\hline 5197 & 575521.62 & 131116.59 \\
\hline 5198 & 575521.62 & 132116.59 \\
\hline 5199 & 575521.62 & 130616.6 \\
\hline 5200 & 574521.62 & 132866.59 \\
\hline 5201 & 574771.62 & 132866.59 \\
\hline 5202 & 575021.62 & 132366.59 \\
\hline 5203 & 575271.62 & 132366.59 \\
\hline 5204 & 575021.62 & 132616.59 \\
\hline 5205 & 575521.62 & 132366.59 \\
\hline 5206 & 575021.62 & 132866.59 \\
\hline 5207 & 576021.62 & 130366.6 \\
\hline 5208 & 576021.62 & 129616.6 \\
\hline
\end{tabular}

note: from sac04d created July 1, 2004 


\begin{tabular}{|c|c|c|c|}
\hline node & X_coord & Y_coord & note: from sac04d created July 1,2004 \\
\hline 5209 & $5 \overline{7} 6021.62$ & $1 \overline{3} 0616.6$ & \\
\hline 5210 & 573771.62 & 133116.59 & \\
\hline 5211 & 574021.62 & 133116.59 & \\
\hline 5212 & 573688.31 & 133033.27 & \\
\hline 5213 & 574271.62 & 133116.59 & \\
\hline 5214 & 573604.94 & 132949.92 & \\
\hline 5215 & 573521.62 & 132949.92 & \\
\hline 5216 & 574521.62 & 133116.59 & \\
\hline 5217 & 576021.62 & 128866.6 & \\
\hline 5218 & 573021.62 & 133033.27 & \\
\hline 5219 & 572938.31 & 133033.27 & \\
\hline 5220 & 573104.94 & 133033.27 & \\
\hline 5221 & 572854.94 & 133033.27 & \\
\hline 5222 & 573188.31 & 133033.27 & \\
\hline 5223 & 573271.62 & 133033.27 & \\
\hline 5224 & 573354.94 & 133033.27 & \\
\hline 5225 & 573438.31 & 133033.27 & \\
\hline 5226 & 573521.62 & 133033.27 & \\
\hline 5227 & 576021.62 & 128116.6 & \\
\hline 5228 & 572271.62 & 133116.59 & \\
\hline 5229 & 572188.31 & 133116.59 & \\
\hline 5230 & 572354.94 & 133116.59 & \\
\hline 5231 & 572438.31 & 133116.59 & \\
\hline 5232 & 572521.62 & 133116.59 & \\
\hline 5233 & 572604.94 & 133116.59 & \\
\hline 5234 & 572688.31 & 133116.59 & \\
\hline 5235 & 572771.62 & 133116.59 & \\
\hline 5236 & 572854.94 & 133116.59 & \\
\hline 5237 & 576021.62 & 127366.6 & \\
\hline 5238 & 571521.62 & 133199.92 & \\
\hline 5239 & 571604.94 & 133199.92 & \\
\hline 5240 & 571688.31 & 133199.92 & \\
\hline 5241 & 571771.62 & 133199.92 & \\
\hline 5242 & 571854.94 & 133199.92 & \\
\hline 5243 & 571938.31 & 133199.92 & \\
\hline 5244 & 572021.62 & 133199.92 & \\
\hline 5245 & 572104.94 & 133199.92 & \\
\hline 5246 & 572188.31 & 133199.92 & \\
\hline 5247 & 576021.62 & 126616.6 & \\
\hline 5248 & 570854.94 & 133283.27 & \\
\hline 5249 & 570938.31 & 133283.27 & \\
\hline 5250 & 571021.62 & 133283.27 & \\
\hline 5251 & 571104.94 & 133283.27 & \\
\hline 5252 & 571188.31 & 133283.27 & \\
\hline 5253 & 571271.62 & 133283.27 & \\
\hline 5254 & 571354.94 & 133283.27 & \\
\hline 5255 & 571438.31 & 133283.27 & \\
\hline 5256 & 571521.62 & 133283.27 & \\
\hline 5257 & 573241.38 & 126107.8 & \\
\hline 5258 & 573756.38 & 125989.8 & \\
\hline 5259 & 574325.12 & 125882.5 & \\
\hline 5260 & 575279.88 & 125855.7 & \\
\hline 5261 & 576021.62 & 125866.6 & \\
\hline 5262 & 570604.94 & 133949.92 & \\
\hline 5263 & 570604.94 & 134033.27 & \\
\hline 5264 & 570604.94 & 134116.59 & \\
\hline
\end{tabular}




\begin{tabular}{|c|c|c|c|}
\hline node & X_coord & Y_coord & note: from sac04d created July 1,2004 \\
\hline 5265 & $5 \overline{7} 0688.31$ & $1 \overline{3} 3949.92$ & \\
\hline 5266 & 570604.94 & 134199.92 & \\
\hline 5267 & 570771.62 & 133366.59 & \\
\hline 5268 & 570771.62 & 133449.92 & \\
\hline 5269 & 570771.62 & 133533.27 & \\
\hline 5270 & 570771.62 & 133616.59 & \\
\hline 5271 & 570771.62 & 133699.92 & \\
\hline 5272 & 570771.62 & 133783.27 & \\
\hline 5273 & 570771.62 & 133866.59 & \\
\hline 5274 & 570771.62 & 133949.92 & \\
\hline 5275 & 570604.94 & 134283.27 & \\
\hline 5276 & 570604.94 & 134366.59 & \\
\hline 5277 & 570604.94 & 135783.27 & \\
\hline 5278 & 570604.94 & 135866.59 & \\
\hline 5279 & 570604.94 & 135699.92 & \\
\hline 5280 & 570604.94 & 135616.59 & \\
\hline 5281 & 570604.94 & 135949.92 & \\
\hline 5282 & 570604.94 & 136033.27 & \\
\hline 5283 & 570604.94 & 135533.27 & \\
\hline 5284 & 570604.94 & 136116.59 & \\
\hline 5285 & 570604.94 & 135449.92 & \\
\hline 5286 & 570604.94 & 135366.59 & \\
\hline 5287 & 570604.94 & 136199.92 & \\
\hline 5288 & 570604.94 & 136283.27 & \\
\hline 5289 & 570604.94 & 135283.27 & \\
\hline 5290 & 570604.94 & 136366.59 & \\
\hline 5291 & 570604.94 & 135199.92 & \\
\hline 5292 & 570604.94 & 135116.59 & \\
\hline 5293 & 570604.94 & 136449.92 & \\
\hline 5294 & 570604.94 & 136533.27 & \\
\hline 5295 & 570604.94 & 135033.27 & \\
\hline 5296 & 570604.94 & 136616.59 & \\
\hline 5297 & 570604.94 & 134949.92 & \\
\hline 5298 & 570604.94 & 134866.59 & \\
\hline 5299 & 570604.94 & 136699.92 & \\
\hline 5300 & 570604.94 & 136783.27 & \\
\hline 5301 & 570604.94 & 134783.27 & \\
\hline 5302 & 570604.94 & 136866.59 & \\
\hline 5303 & 570604.94 & 134699.92 & \\
\hline 5304 & 570604.94 & 134616.59 & \\
\hline 5305 & 570604.94 & 136949.92 & \\
\hline 5306 & 570604.94 & 137033.27 & \\
\hline 5307 & 570604.94 & 134533.27 & \\
\hline 5308 & 570604.94 & 137116.59 & \\
\hline 5309 & 570604.94 & 134449.92 & \\
\hline 5310 & 570604.94 & 137199.92 & \\
\hline 5311 & 570604.94 & 137283.27 & \\
\hline 5312 & 570604.94 & 137366.59 & \\
\hline 5313 & 570604.94 & 137449.92 & \\
\hline 5314 & 570604.94 & 137533.27 & \\
\hline 5315 & 570604.94 & 137616.59 & \\
\hline 5316 & 570604.94 & 137699.92 & \\
\hline 5317 & 570604.94 & 137783.27 & \\
\hline 5318 & 570604.94 & 137866.59 & \\
\hline 5319 & 566057.62 & 141352 & \\
\hline 5320 & 565521.38 & 141492 & \\
\hline
\end{tabular}




\begin{tabular}{|c|c|c|c|}
\hline node & X_coord & Y_coord & note: from sac04d created July 1, 2004 \\
\hline 5321 & $5 \overline{6} 4765.38$ & 141536.2 & \\
\hline 5322 & 564014.38 & 142083.41 & \\
\hline 5323 & 563147.38 & 142483.09 & \\
\hline 5324 & 570720.62 & 140122.56 & \\
\hline 5325 & 570842.31 & 140181.09 & \\
\hline 5326 & 570964 & 140239.64 & \\
\hline 5327 & 562521.31 & 141620.91 & \\
\hline 5328 & 562512.5 & 142465.3 & \\
\hline 5329 & 571085.69 & 140298.17 & \\
\hline 5330 & 571231 & 140320.98 & \\
\hline 5331 & 571376.31 & 140343.78 & \\
\hline 5332 & 571521.62 & 140366.59 & \\
\hline 5333 & 571771.62 & 138616.59 & \\
\hline 5334 & 571771.62 & 138366.59 & \\
\hline 5335 & 571771.62 & 138866.59 & \\
\hline 5336 & 571771.62 & 138116.59 & \\
\hline 5337 & 571771.62 & 139116.59 & \\
\hline 5338 & 571771.62 & 137866.59 & \\
\hline 5339 & 571771.62 & 139366.59 & \\
\hline 5340 & 571771.62 & 137616.59 & \\
\hline 5341 & 571771.62 & 139616.59 & \\
\hline 5342 & 570771.62 & 137866.59 & \\
\hline 5343 & 570688.31 & 137866.59 & \\
\hline 5344 & 570771.62 & 137783.27 & \\
\hline 5345 & 571021.62 & 137699.92 & \\
\hline 5346 & 571104.94 & 137699.92 & \\
\hline 5347 & 570938.31 & 137699.92 & \\
\hline 5348 & 571104.94 & 137616.59 & \\
\hline 5349 & 570854.94 & 137699.92 & \\
\hline 5350 & 571271.62 & 137366.59 & \\
\hline 5351 & 571521.62 & 137366.59 & \\
\hline 5352 & 571188.31 & 137366.59 & \\
\hline 5353 & 571771.62 & 137366.59 & \\
\hline 5354 & 571132.75 & 137533.27 & \\
\hline 5355 & 571132.75 & 137449.92 & \\
\hline 5356 & 571077.19 & 137533.27 & \\
\hline 5357 & 570771.62 & 137699.92 & \\
\hline 5358 & 571771.62 & 139866.59 & \\
\hline 5359 & 571771.62 & 140116.59 & \\
\hline 5360 & 571771.62 & 140366.59 & \\
\hline 5361 & 561760.62 & 141628.5 & \\
\hline 5362 & 561031.81 & 141654.2 & \\
\hline 5363 & 560269.88 & 141423.59 & \\
\hline 5364 & 559765.69 & 141262.59 & \\
\hline 5365 & 570854.94 & 133366.59 & \\
\hline 5366 & 575688.31 & 131616.59 & \\
\hline 5367 & 575771.62 & 131866.59 & \\
\hline 5368 & 575854.94 & 131616.59 & \\
\hline 5369 & 575688.31 & 131366.59 & \\
\hline 5370 & 575771.62 & 132116.59 & \\
\hline 5371 & 575771.62 & 131116.59 & \\
\hline 5372 & 575771.62 & 130866.59 & \\
\hline 5373 & 575854.94 & 131366.59 & \\
\hline 5374 & 575771.62 & 132366.59 & \\
\hline 5375 & 576021.62 & 130866.59 & \\
\hline 5376 & 574771.62 & 133116.59 & \\
\hline
\end{tabular}




\begin{tabular}{|c|c|c|c|}
\hline node & X_coord & Y_coord & note: from sac04d created July 1,2004 \\
\hline 5377 & $5 \overline{7} 5021.62$ & $1 \overline{3} 3116.59$ & \\
\hline 5378 & 575271.62 & 132616.59 & \\
\hline 5379 & 575521.62 & 132616.59 & \\
\hline 5380 & 575271.62 & 132866.59 & \\
\hline 5381 & 575771.62 & 132616.59 & \\
\hline 5382 & 575271.62 & 133116.59 & \\
\hline 5383 & 576771.62 & 130366.6 & \\
\hline 5384 & 576771.62 & 129616.6 & \\
\hline 5385 & 576521.62 & 130616.6 & \\
\hline 5386 & 576771.62 & 128866.6 & \\
\hline 5387 & 576271.62 & 130866.59 & \\
\hline 5388 & 573771.62 & 133366.59 & \\
\hline 5389 & 574021.62 & 133366.59 & \\
\hline 5390 & 573521.62 & 133116.59 & \\
\hline 5391 & 573604.94 & 133199.92 & \\
\hline 5392 & 573521.62 & 133199.92 & \\
\hline 5393 & 573604.94 & 133283.27 & \\
\hline 5394 & 574271.62 & 133366.59 & \\
\hline 5395 & 574521.62 & 133366.59 & \\
\hline 5396 & 574771.62 & 133366.59 & \\
\hline 5397 & 576771.62 & 128116.6 & \\
\hline 5398 & 573021.62 & 133116.59 & \\
\hline 5399 & 572938.31 & 133116.59 & \\
\hline 5400 & 573104.94 & 133116.59 & \\
\hline 5401 & 573188.31 & 133116.59 & \\
\hline 5402 & 573271.62 & 133116.59 & \\
\hline 5403 & 573354.94 & 133116.59 & \\
\hline 5404 & 573438.31 & 133116.59 & \\
\hline 5405 & 576771.62 & 127366.6 & \\
\hline 5406 & 572271.62 & 133199.92 & \\
\hline 5407 & 572354.94 & 133199.92 & \\
\hline 5408 & 572438.31 & 133199.92 & \\
\hline 5409 & 572521.62 & 133199.92 & \\
\hline 5410 & 572604.94 & 133199.92 & \\
\hline 5411 & 572688.31 & 133199.92 & \\
\hline 5412 & 572771.62 & 133199.92 & \\
\hline 5413 & 572854.94 & 133199.92 & \\
\hline 5414 & 572938.31 & 133199.92 & \\
\hline 5415 & 576771.62 & 126616.6 & \\
\hline 5416 & 571604.94 & 133283.27 & \\
\hline 5417 & 571688.31 & 133283.27 & \\
\hline 5418 & 571771.62 & 133283.27 & \\
\hline 5419 & 571854.94 & 133283.27 & \\
\hline 5420 & 571938.31 & 133283.27 & \\
\hline 5421 & 572021.62 & 133283.27 & \\
\hline 5422 & 572104.94 & 133283.27 & \\
\hline 5423 & 572188.31 & 133283.27 & \\
\hline 5424 & 572271.62 & 133283.27 & \\
\hline 5425 & 576771.62 & 125866.6 & \\
\hline 5426 & 570938.31 & 133366.59 & \\
\hline 5427 & 571021.62 & 133366.59 & \\
\hline 5428 & 571104.94 & 133366.59 & \\
\hline 5429 & 571188.31 & 133366.59 & \\
\hline 5430 & 571271.62 & 133366.59 & \\
\hline 5431 & 571354.94 & 133366.59 & \\
\hline 5432 & 571438.31 & 133366.59 & \\
\hline
\end{tabular}




\begin{tabular}{|c|c|c|c|}
\hline node & X_coord & Y_coord & note: from sac04d created July 1,2004 \\
\hline 5433 & $5 \overline{7} 1521.62$ & $1 \overline{3} 3366.59$ & \\
\hline 5434 & 571604.94 & 133366.59 & \\
\hline 5435 & 574475.31 & 125667.9 & \\
\hline 5436 & 575269.31 & 125351.4 & \\
\hline 5437 & 576021.62 & 125116.6 & \\
\hline 5438 & 576771.62 & 125116.6 & \\
\hline 5439 & 570688.31 & 134033.27 & \\
\hline 5440 & 570688.31 & 134116.59 & \\
\hline 5441 & 570688.31 & 134199.92 & \\
\hline 5442 & 570771.62 & 134033.27 & \\
\hline 5443 & 570688.31 & 134283.27 & \\
\hline 5444 & 570854.94 & 133449.92 & \\
\hline 5445 & 570854.94 & 133533.27 & \\
\hline 5446 & 570854.94 & 133616.59 & \\
\hline 5447 & 570854.94 & 133699.92 & \\
\hline 5448 & 570854.94 & 133783.27 & \\
\hline 5449 & 570854.94 & 133866.59 & \\
\hline 5450 & 570854.94 & 133949.92 & \\
\hline 5451 & 570854.94 & 134033.27 & \\
\hline 5452 & 570688.31 & 134366.59 & \\
\hline 5453 & 570688.31 & 134449.92 & \\
\hline 5454 & 570688.31 & 135783.27 & \\
\hline 5455 & 570688.31 & 135866.59 & \\
\hline 5456 & 570688.31 & 135699.92 & \\
\hline 5457 & 570688.31 & 135949.92 & \\
\hline 5458 & 570688.31 & 135616.59 & \\
\hline 5459 & 570688.31 & 135533.27 & \\
\hline 5460 & 570688.31 & 136033.27 & \\
\hline 5461 & 570688.31 & 136116.59 & \\
\hline 5462 & 570688.31 & 135449.92 & \\
\hline 5463 & 570688.31 & 136199.92 & \\
\hline 5464 & 570688.31 & 135366.59 & \\
\hline 5465 & 570688.31 & 135283.27 & \\
\hline 5466 & 570688.31 & 136283.27 & \\
\hline 5467 & 570688.31 & 136366.59 & \\
\hline 5468 & 570688.31 & 135199.92 & \\
\hline 5469 & 570688.31 & 136449.92 & \\
\hline 5470 & 570688.31 & 135116.59 & \\
\hline 5471 & 570688.31 & 135033.27 & \\
\hline 5472 & 570688.31 & 136533.27 & \\
\hline 5473 & 570688.31 & 136616.59 & \\
\hline 5474 & 570688.31 & 134949.92 & \\
\hline 5475 & 570688.31 & 136699.92 & \\
\hline 5476 & 570688.31 & 134866.59 & \\
\hline 5477 & 570688.31 & 134783.27 & \\
\hline 5478 & 570688.31 & 136783.27 & \\
\hline 5479 & 570688.31 & 136866.59 & \\
\hline 5480 & 570688.31 & 134699.92 & \\
\hline 5481 & 570688.31 & 136949.92 & \\
\hline 5482 & 570688.31 & 134616.59 & \\
\hline 5483 & 570688.31 & 134533.27 & \\
\hline 5484 & 570688.31 & 137033.27 & \\
\hline 5485 & 570688.31 & 137116.59 & \\
\hline 5486 & 570688.31 & 137199.92 & \\
\hline 5487 & 570688.31 & 137283.27 & \\
\hline 5488 & 570688.31 & 137366.59 & \\
\hline
\end{tabular}




\begin{tabular}{|c|c|c|c|}
\hline node & X_coord & Y_coord & note: from sac04d created July 1,2004 \\
\hline 5489 & $5 \overline{7} 0688.31$ & $1 \overline{3} 7449.92$ & \\
\hline 5490 & 570688.31 & 137533.27 & \\
\hline 5491 & 570688.31 & 137616.59 & \\
\hline 5492 & 570688.31 & 137699.92 & \\
\hline 5493 & 570688.31 & 137783.27 & \\
\hline 5494 & 562773.62 & 143179.7 & \\
\hline 5495 & 562399.81 & 143086.3 & \\
\hline 5496 & 570713.69 & 140442.83 & \\
\hline 5497 & 570836.56 & 140487.59 & \\
\hline 5498 & 570959.38 & 140532.36 & \\
\hline 5499 & 571082.25 & 140577.12 & \\
\hline 5500 & 561924.12 & 142457.7 & \\
\hline 5501 & 561890.12 & 143035.3 & \\
\hline 5502 & 571228.75 & 140590.28 & \\
\hline 5503 & 571375.12 & 140603.44 & \\
\hline 5504 & 571521.62 & 140616.59 & \\
\hline 5505 & 571771.62 & 140616.59 & \\
\hline 5506 & 572021.62 & 138616.59 & \\
\hline 5507 & 572021.62 & 138366.59 & \\
\hline 5508 & 572021.62 & 138866.59 & \\
\hline 5509 & 572021.62 & 138116.59 & \\
\hline 5510 & 572021.62 & 139116.59 & \\
\hline 5511 & 572021.62 & 137866.59 & \\
\hline 5512 & 572021.62 & 139366.59 & \\
\hline 5513 & 572021.62 & 137616.59 & \\
\hline 5514 & 572021.62 & 139616.59 & \\
\hline 5515 & 572021.62 & 137366.59 & \\
\hline 5516 & 572021.62 & 139866.59 & \\
\hline 5517 & 571021.62 & 137616.59 & \\
\hline 5518 & 570938.31 & 137616.59 & \\
\hline 5519 & 570854.94 & 137616.59 & \\
\hline 5520 & 571021.62 & 137533.27 & \\
\hline 5521 & 570771.62 & 137616.59 & \\
\hline 5522 & 571271.62 & 137283.27 & \\
\hline 5523 & 571188.31 & 137283.27 & \\
\hline 5524 & 571438.31 & 137283.27 & \\
\hline 5525 & 571521.62 & 137116.59 & \\
\hline 5526 & 571771.62 & 137116.59 & \\
\hline 5527 & 571438.31 & 137116.59 & \\
\hline 5528 & 571104.94 & 137366.59 & \\
\hline 5529 & 571104.94 & 137283.27 & \\
\hline 5530 & 571077.19 & 137449.92 & \\
\hline 5531 & 572021.62 & 137116.59 & \\
\hline 5532 & 571021.62 & 137449.92 & \\
\hline 5533 & 572021.62 & 140116.59 & \\
\hline 5534 & 572021.62 & 140366.59 & \\
\hline 5535 & 572021.62 & 140616.59 & \\
\hline 5536 & 561465.38 & 142576.59 & \\
\hline 5537 & 570938.31 & 133449.92 & \\
\hline 5538 & 576021.62 & 131866.59 & \\
\hline 5539 & 576021.62 & 131616.59 & \\
\hline 5540 & 576021.62 & 132116.59 & \\
\hline 5541 & 576021.62 & 131366.59 & \\
\hline 5542 & 576021.62 & 132366.59 & \\
\hline 5543 & 576021.62 & 131116.59 & \\
\hline 5544 & 576021.62 & 132616.59 & \\
\hline
\end{tabular}




\begin{tabular}{|c|c|c|c|}
\hline node & X_coord & Y_coord & note: from sac04d created July 1, 2004 \\
\hline 5545 & $5 \overline{7} 6271.62$ & $1 \overline{13} 1116.59$ & \\
\hline 5546 & 575021.62 & 133366.59 & \\
\hline 5547 & 575271.62 & 133366.59 & \\
\hline 5548 & 575521.62 & 132866.59 & \\
\hline 5549 & 575771.62 & 132866.59 & \\
\hline 5550 & 575521.62 & 133116.59 & \\
\hline 5551 & 576021.62 & 132866.59 & \\
\hline 5552 & 575521.62 & 133366.59 & \\
\hline 5553 & 577521.62 & 130366.6 & \\
\hline 5554 & 577521.62 & 129616.6 & \\
\hline 5555 & 576771.62 & 131116.59 & \\
\hline 5556 & 576521.62 & 131116.59 & \\
\hline 5557 & 577021.62 & 130616.6 & \\
\hline 5558 & 577521.62 & 130616.6 & \\
\hline 5559 & 577021.62 & 131116.59 & \\
\hline 5560 & 577521.62 & 128866.6 & \\
\hline 5561 & 577521.62 & 128116.6 & \\
\hline 5562 & 573771.62 & 133616.59 & \\
\hline 5563 & 574021.62 & 133616.59 & \\
\hline 5564 & 573521.62 & 133366.59 & \\
\hline 5565 & 573521.62 & 133283.27 & \\
\hline 5566 & 573604.94 & 133449.92 & \\
\hline 5567 & 573521.62 & 133449.92 & \\
\hline 5568 & 573604.94 & 133533.27 & \\
\hline 5569 & 574271.62 & 133616.59 & \\
\hline 5570 & 573438.31 & 133199.92 & \\
\hline 5571 & 573438.31 & 133283.27 & \\
\hline 5572 & 574521.62 & 133616.59 & \\
\hline 5573 & 574771.62 & 133616.59 & \\
\hline 5574 & 575021.62 & 133616.59 & \\
\hline 5575 & 577521.62 & 127366.6 & \\
\hline 5576 & 573021.62 & 133199.92 & \\
\hline 5577 & 573104.94 & 133199.92 & \\
\hline 5578 & 573188.31 & 133199.92 & \\
\hline 5579 & 573271.62 & 133199.92 & \\
\hline 5580 & 573354.94 & 133199.92 & \\
\hline 5581 & 577521.62 & 126616.6 & \\
\hline 5582 & 572354.94 & 133283.27 & \\
\hline 5583 & 572438.31 & 133283.27 & \\
\hline 5584 & 572521.62 & 133283.27 & \\
\hline 5585 & 572604.94 & 133283.27 & \\
\hline 5586 & 572688.31 & 133283.27 & \\
\hline 5587 & 572771.62 & 133283.27 & \\
\hline 5588 & 572854.94 & 133283.27 & \\
\hline 5589 & 572938.31 & 133283.27 & \\
\hline 5590 & 573021.62 & 133283.27 & \\
\hline 5591 & 577521.62 & 125866.6 & \\
\hline 5592 & 571688.31 & 133366.59 & \\
\hline 5593 & 571771.62 & 133366.59 & \\
\hline 5594 & 571854.94 & 133366.59 & \\
\hline 5595 & 571938.31 & 133366.59 & \\
\hline 5596 & 572021.62 & 133366.59 & \\
\hline 5597 & 572104.94 & 133366.59 & \\
\hline 5598 & 572188.31 & 133366.59 & \\
\hline 5599 & 572271.62 & 133366.59 & \\
\hline 5600 & 572354.94 & 133366.59 & \\
\hline
\end{tabular}




\begin{tabular}{|c|c|c|c|}
\hline node & X_coord & Y_coord & note: from sac04d created July 1,2004 \\
\hline 5601 & $5 \overline{7} 7521.62$ & $1 \overline{2} 5116.6$ & \\
\hline 5602 & 571021.62 & 133449.92 & \\
\hline 5603 & 571104.94 & 133449.92 & \\
\hline 5604 & 571188.31 & 133449.92 & \\
\hline 5605 & 571271.62 & 133449.92 & \\
\hline 5606 & 571354.94 & 133449.92 & \\
\hline 5607 & 571438.31 & 133449.92 & \\
\hline 5608 & 571521.62 & 133449.92 & \\
\hline 5609 & 571604.94 & 133449.92 & \\
\hline 5610 & 571688.31 & 133449.92 & \\
\hline 5611 & 575623.31 & 124922.2 & \\
\hline 5612 & 576020.31 & 124632.5 & \\
\hline 5613 & 576795.62 & 124294.2 & \\
\hline 5614 & 577490.12 & 124353.6 & \\
\hline 5615 & 570771.62 & 134116.59 & \\
\hline 5616 & 570771.62 & 134199.92 & \\
\hline 5617 & 570771.62 & 134283.27 & \\
\hline 5618 & 570854.94 & 134116.59 & \\
\hline 5619 & 570771.62 & 134366.59 & \\
\hline 5620 & 570938.31 & 133533.27 & \\
\hline 5621 & 570938.31 & 133616.59 & \\
\hline 5622 & 570938.31 & 133699.92 & \\
\hline 5623 & 570938.31 & 133783.27 & \\
\hline 5624 & 570938.31 & 133866.59 & \\
\hline 5625 & 570938.31 & 133949.92 & \\
\hline 5626 & 570938.31 & 134033.27 & \\
\hline 5627 & 570938.31 & 134116.59 & \\
\hline 5628 & 570771.62 & 134449.92 & \\
\hline 5629 & 570771.62 & 134533.27 & \\
\hline 5630 & 570771.62 & 135783.27 & \\
\hline 5631 & 570771.62 & 135699.92 & \\
\hline 5632 & 570771.62 & 135866.59 & \\
\hline 5633 & 570771.62 & 135949.92 & \\
\hline 5634 & 570771.62 & 135616.59 & \\
\hline 5635 & 570771.62 & 136033.27 & \\
\hline 5636 & 570771.62 & 135533.27 & \\
\hline 5637 & 570771.62 & 135449.92 & \\
\hline 5638 & 570771.62 & 136116.59 & \\
\hline 5639 & 570771.62 & 136199.92 & \\
\hline 5640 & 570771.62 & 135366.59 & \\
\hline 5641 & 570771.62 & 136283.27 & \\
\hline 5642 & 570771.62 & 135283.27 & \\
\hline 5643 & 570771.62 & 135199.92 & \\
\hline 5644 & 570771.62 & 136366.59 & \\
\hline 5645 & 570771.62 & 136449.92 & \\
\hline 5646 & 570771.62 & 135116.59 & \\
\hline 5647 & 570771.62 & 136533.27 & \\
\hline 5648 & 570771.62 & 135033.27 & \\
\hline 5649 & 570771.62 & 134949.92 & \\
\hline 5650 & 570771.62 & 136616.59 & \\
\hline 5651 & 570771.62 & 136699.92 & \\
\hline 5652 & 570771.62 & 134866.59 & \\
\hline 5653 & 570771.62 & 136783.27 & \\
\hline 5654 & 570771.62 & 134783.27 & \\
\hline 5655 & 570771.62 & 134699.92 & \\
\hline 5656 & 570771.62 & 136866.59 & \\
\hline
\end{tabular}




\begin{tabular}{|c|c|c|c|}
\hline node & X_coord & Y_coord & note: from sac04d created July 1, 2004 \\
\hline 5657 & $5 \overline{7} 0771.62$ & $1 \overline{3} 6949.92$ & \\
\hline 5658 & 570771.62 & 134616.59 & \\
\hline 5659 & 570771.62 & 137033.27 & \\
\hline 5660 & 570771.62 & 137116.59 & \\
\hline 5661 & 570771.62 & 137199.92 & \\
\hline 5662 & 570771.62 & 137283.27 & \\
\hline 5663 & 570771.62 & 137366.59 & \\
\hline 5664 & 570771.62 & 137449.92 & \\
\hline 5665 & 570771.62 & 137533.27 & \\
\hline 5666 & 563271.62 & 143866.59 & \\
\hline 5667 & 562499.5 & 143786.91 & \\
\hline 5668 & 563708 & 143494 & \\
\hline 5669 & 564021.62 & 143866.59 & \\
\hline 5670 & 561760.88 & 143488.91 & \\
\hline 5671 & 570706.81 & 140763.09 & \\
\hline 5672 & 570830.81 & 140794.09 & \\
\hline 5673 & 570954.81 & 140825.09 & \\
\hline 5674 & 571078.81 & 140856.09 & \\
\hline 5675 & 571226.44 & 140859.59 & \\
\hline 5676 & 561287 & 143094.8 & \\
\hline 5677 & 561414.38 & 143417.59 & \\
\hline 5678 & 571374 & 140863.09 & \\
\hline 5679 & 571521.62 & 140866.59 & \\
\hline 5680 & 571771.62 & 140866.59 & \\
\hline 5681 & 572021.62 & 140866.59 & \\
\hline 5682 & 572271.62 & 138616.59 & \\
\hline 5683 & 572271.62 & 138366.59 & \\
\hline 5684 & 572271.62 & 138866.59 & \\
\hline 5685 & 572271.62 & 138116.59 & \\
\hline 5686 & 572271.62 & 139116.59 & \\
\hline 5687 & 572271.62 & 137866.59 & \\
\hline 5688 & 572271.62 & 139366.59 & \\
\hline 5689 & 572271.62 & 137616.59 & \\
\hline 5690 & 572271.62 & 139616.59 & \\
\hline 5691 & 572271.62 & 137366.59 & \\
\hline 5692 & 572271.62 & 139866.59 & \\
\hline 5693 & 572271.62 & 137116.59 & \\
\hline 5694 & 572271.62 & 140116.59 & \\
\hline 5695 & 570938.31 & 137533.27 & \\
\hline 5696 & 570854.94 & 137533.27 & \\
\hline 5697 & 570938.31 & 137449.92 & \\
\hline 5698 & 571271.62 & 137199.92 & \\
\hline 5699 & 571188.31 & 137199.92 & \\
\hline 5700 & 571354.94 & 137199.92 & \\
\hline 5701 & 571104.94 & 137199.92 & \\
\hline 5702 & 571354.94 & 137116.59 & \\
\hline 5703 & 571521.62 & 137033.27 & \\
\hline 5704 & 571438.31 & 137033.27 & \\
\hline 5705 & 571688.31 & 137033.27 & \\
\hline 5706 & 571771.62 & 136866.59 & \\
\hline 5707 & 572021.62 & 136866.59 & \\
\hline 5708 & 571688.31 & 136866.59 & \\
\hline 5709 & 571354.94 & 137033.27 & \\
\hline 5710 & 571021.62 & 137366.59 & \\
\hline 5711 & 571021.62 & 137283.27 & \\
\hline 5712 & 571021.62 & 137199.92 & \\
\hline
\end{tabular}




\begin{tabular}{|c|c|c|c|}
\hline node & X_coord & Y_coord & note: from sac04d created July 1, 2004 \\
\hline 5713 & $5 \overline{7} 2271.62$ & $1 \overline{3} 6866.59$ & \\
\hline 5714 & 570938.31 & 137366.59 & \\
\hline 5715 & 572271.62 & 140366.59 & \\
\hline 5716 & 572271.62 & 140616.59 & \\
\hline 5717 & 572271.62 & 140866.59 & \\
\hline 5718 & 560395.12 & 143001.3 & \\
\hline 5719 & 560344.12 & 143298.59 & \\
\hline 5720 & 571021.62 & 133533.27 & \\
\hline 5721 & 576271.62 & 131866.59 & \\
\hline 5722 & 576271.62 & 131616.59 & \\
\hline 5723 & 576271.62 & 132116.59 & \\
\hline 5724 & 576271.62 & 131366.59 & \\
\hline 5725 & 576271.62 & 132366.59 & \\
\hline 5726 & 576271.62 & 132616.59 & \\
\hline 5727 & 576271.62 & 132866.59 & \\
\hline 5728 & 576521.62 & 131366.59 & \\
\hline 5729 & 575271.62 & 133616.59 & \\
\hline 5730 & 575521.62 & 133616.59 & \\
\hline 5731 & 575771.62 & 133116.59 & \\
\hline 5732 & 576021.62 & 133116.59 & \\
\hline 5733 & 575771.62 & 133366.59 & \\
\hline 5734 & 576271.62 & 133116.59 & \\
\hline 5735 & 575771.62 & 133616.59 & \\
\hline 5736 & 577771.62 & 130366.6 & \\
\hline 5737 & 577771.62 & 129866.6 & \\
\hline 5738 & 577771.62 & 130616.6 & \\
\hline 5739 & 578271.62 & 129616.6 & \\
\hline 5740 & 578271.62 & 128866.6 & \\
\hline 5741 & 578271.62 & 129866.6 & \\
\hline 5742 & 576771.62 & 131366.59 & \\
\hline 5743 & 577021.62 & 131366.59 & \\
\hline 5744 & 577271.62 & 130866.59 & \\
\hline 5745 & 577521.62 & 130866.59 & \\
\hline 5746 & 577271.62 & 131116.59 & \\
\hline 5747 & 577771.62 & 130866.59 & \\
\hline 5748 & 577271.62 & 131366.59 & \\
\hline 5749 & 578271.62 & 128116.6 & \\
\hline 5750 & 578271.62 & 127366.6 & \\
\hline 5751 & 573771.62 & 133866.59 & \\
\hline 5752 & 574021.62 & 133866.59 & \\
\hline 5753 & 573521.62 & 133616.59 & \\
\hline 5754 & 573521.62 & 133533.27 & \\
\hline 5755 & 573604.94 & 133699.92 & \\
\hline 5756 & 573521.62 & 133699.92 & \\
\hline 5757 & 573604.94 & 133783.27 & \\
\hline 5758 & 574271.62 & 133866.59 & \\
\hline 5759 & 573438.31 & 133366.59 & \\
\hline 5760 & 573438.31 & 133449.92 & \\
\hline 5761 & 573438.31 & 133533.27 & \\
\hline 5762 & 574521.62 & 133866.59 & \\
\hline 5763 & 573354.94 & 133283.27 & \\
\hline 5764 & 573354.94 & 133366.59 & \\
\hline 5765 & 574771.62 & 133866.59 & \\
\hline 5766 & 575021.62 & 133866.59 & \\
\hline 5767 & 575271.62 & 133866.59 & \\
\hline 5768 & 578271.62 & 126616.6 & \\
\hline
\end{tabular}




\begin{tabular}{|c|c|c|}
\hline node & X_coord & Y_coord \\
\hline 5769 & $5 \overline{7} 3104.94$ & $1 \overline{3} 3283.27$ \\
\hline 5770 & 573188.31 & 133283.27 \\
\hline 5771 & 573271.62 & 133283.27 \\
\hline 5772 & 578271.62 & 125866.6 \\
\hline 5773 & 572438.31 & 133366.59 \\
\hline 5774 & 572521.62 & 133366.59 \\
\hline 5775 & 572604.94 & 133366.59 \\
\hline 5776 & 572688.31 & 133366.59 \\
\hline 5777 & 572771.62 & 133366.59 \\
\hline 5778 & 572854.94 & 133366.59 \\
\hline 5779 & 572938.31 & 133366.59 \\
\hline 5780 & 573021.62 & 133366.59 \\
\hline 5781 & 573104.94 & 133366.59 \\
\hline 5782 & 578271.62 & 125116.6 \\
\hline 5783 & 571771.62 & 133449.92 \\
\hline 5784 & 571854.94 & 133449.92 \\
\hline 5785 & 571938.31 & 133449.92 \\
\hline 5786 & 572021.62 & 133449.92 \\
\hline 5787 & 572104.94 & 133449.92 \\
\hline 5788 & 572188.31 & 133449.92 \\
\hline 5789 & 572271.62 & 133449.92 \\
\hline 5790 & 572354.94 & 133449.92 \\
\hline 5791 & 572438.31 & 133449.92 \\
\hline 5792 & 578271.62 & 124366.6 \\
\hline 5793 & 571104.94 & 133533.27 \\
\hline 5794 & 571188.31 & 133533.27 \\
\hline 5795 & 571271.62 & 133533.27 \\
\hline 5796 & 571354.94 & 133533.27 \\
\hline 5797 & 571438.31 & 133533.27 \\
\hline 5798 & 571521.62 & 133533.27 \\
\hline 5799 & 571604.94 & 133533.27 \\
\hline 5800 & 571688.31 & 133533.27 \\
\hline 5801 & 571771.62 & 133533.27 \\
\hline 5802 & 577167.5 & 123860.3 \\
\hline 5803 & 577570.38 & 123658.9 \\
\hline 5804 & 578273.38 & 123624 \\
\hline 5805 & 570854.94 & 134199.92 \\
\hline 5806 & 570854.94 & 134283.27 \\
\hline 5807 & 570854.94 & 134366.59 \\
\hline 5808 & 570938.31 & 134199.92 \\
\hline 5809 & 570854.94 & 134449.92 \\
\hline 5810 & 571021.62 & 133616.59 \\
\hline 5811 & 571021.62 & 133699.92 \\
\hline 5812 & 571021.62 & 133783.27 \\
\hline 5813 & 571021.62 & 133866.59 \\
\hline 5814 & 571021.62 & 133949.92 \\
\hline 5815 & 571021.62 & 134033.27 \\
\hline 5816 & 571021.62 & 134116.59 \\
\hline 5817 & 571021.62 & 134199.92 \\
\hline 5818 & 570854.94 & 134533.27 \\
\hline 5819 & 570854.94 & 134616.59 \\
\hline 5820 & 570854.94 & 135783.27 \\
\hline 5821 & 570854.94 & 135866.59 \\
\hline 5822 & 570854.94 & 135699.92 \\
\hline 5823 & 570854.94 & 135616.59 \\
\hline 5824 & 570854.94 & 135949.92 \\
\hline
\end{tabular}




\begin{tabular}{|c|c|c|c|}
\hline node & X_coord & Y_coord & note: from sac04d created July 1,2004 \\
\hline 5825 & $5 \overline{7} 0854.94$ & $1 \overline{3} 6033.27$ & \\
\hline 5826 & 570854.94 & 135533.27 & \\
\hline 5827 & 570854.94 & 136116.59 & \\
\hline 5828 & 570854.94 & 135449.92 & \\
\hline 5829 & 570854.94 & 135366.59 & \\
\hline 5830 & 570854.94 & 136199.92 & \\
\hline 5831 & 570854.94 & 136283.27 & \\
\hline 5832 & 570854.94 & 135283.27 & \\
\hline 5833 & 570854.94 & 136366.59 & \\
\hline 5834 & 570854.94 & 135199.92 & \\
\hline 5835 & 570854.94 & 135116.59 & \\
\hline 5836 & 570854.94 & 136449.92 & \\
\hline 5837 & 570854.94 & 136533.27 & \\
\hline 5838 & 570854.94 & 135033.27 & \\
\hline 5839 & 570854.94 & 136616.59 & \\
\hline 5840 & 570854.94 & 134949.92 & \\
\hline 5841 & 570854.94 & 134866.59 & \\
\hline 5842 & 570854.94 & 136699.92 & \\
\hline 5843 & 570854.94 & 136783.27 & \\
\hline 5844 & 570854.94 & 134783.27 & \\
\hline 5845 & 570854.94 & 136866.59 & \\
\hline 5846 & 570854.94 & 134699.92 & \\
\hline 5847 & 570854.94 & 136949.92 & \\
\hline 5848 & 570854.94 & 137033.27 & \\
\hline 5849 & 570854.94 & 137116.59 & \\
\hline 5850 & 570854.94 & 137199.92 & \\
\hline 5851 & 570854.94 & 137283.27 & \\
\hline 5852 & 570854.94 & 137366.59 & \\
\hline 5853 & 570854.94 & 137449.92 & \\
\hline 5854 & 563271.62 & 144616.59 & \\
\hline 5855 & 562447.69 & 144395.91 & \\
\hline 5856 & 563521.62 & 144116.59 & \\
\hline 5857 & 564021.62 & 144116.59 & \\
\hline 5858 & 563521.62 & 144616.59 & \\
\hline 5859 & 564060.44 & 143474.44 & \\
\hline 5860 & 564271.62 & 143866.59 & \\
\hline 5861 & 564271.62 & 144116.59 & \\
\hline 5862 & 570531.19 & 141038.59 & \\
\hline 5863 & 570679.56 & 141062.27 & \\
\hline 5864 & 570828 & 141085.92 & \\
\hline 5865 & 570976.44 & 141109.59 & \\
\hline 5866 & 571156.69 & 141122.45 & \\
\hline 5867 & 571336.94 & 141135.31 & \\
\hline 5868 & 571517.19 & 141148.16 & \\
\hline 5869 & 571782.69 & 141146.84 & \\
\hline 5870 & 572048.12 & 141145.55 & \\
\hline 5871 & 572313.62 & 141144.23 & \\
\hline 5872 & 572526.12 & 138614.03 & \\
\hline 5873 & 572495.56 & 138365.27 & \\
\hline 5874 & 572524.62 & 138864.89 & \\
\hline 5875 & 572464.94 & 138116.5 & \\
\hline 5876 & 572523.12 & 139115.73 & \\
\hline 5877 & 572434.38 & 137867.73 & \\
\hline 5878 & 572521.62 & 139366.59 & \\
\hline 5879 & 572463.44 & 137617.36 & \\
\hline 5880 & 572521.62 & 139616.59 & \\
\hline
\end{tabular}




\begin{tabular}{|c|c|c|c|}
\hline node & X_coord & Y_coord & note: from sac04d created July 1, 2004 \\
\hline 5881 & $5 \overline{7} 2492.56$ & $1 \overline{3} 7366.97$ & \\
\hline 5882 & 572521.62 & 139866.59 & \\
\hline 5883 & 572521.62 & 137116.59 & \\
\hline 5884 & 572521.62 & 140116.59 & \\
\hline 5885 & 572521.62 & 136866.59 & \\
\hline 5886 & 572521.62 & 140366.59 & \\
\hline 5887 & 571271.62 & 137116.59 & \\
\hline 5888 & 571188.31 & 137116.59 & \\
\hline 5889 & 571104.94 & 137116.59 & \\
\hline 5890 & 571021.62 & 137116.59 & \\
\hline 5891 & 571271.62 & 137033.27 & \\
\hline 5892 & 571521.62 & 136949.92 & \\
\hline 5893 & 571438.31 & 136949.92 & \\
\hline 5894 & 571604.94 & 136949.92 & \\
\hline 5895 & 571354.94 & 136949.92 & \\
\hline 5896 & 571604.94 & 136866.59 & \\
\hline 5897 & 571771.62 & 136616.59 & \\
\hline 5898 & 572021.62 & 136616.59 & \\
\hline 5899 & 571688.31 & 136616.59 & \\
\hline 5900 & 572271.62 & 136616.59 & \\
\hline 5901 & 571632.75 & 136783.27 & \\
\hline 5902 & 571632.75 & 136699.92 & \\
\hline 5903 & 571577.19 & 136783.27 & \\
\hline 5904 & 571271.62 & 136949.92 & \\
\hline 5905 & 570938.31 & 137283.27 & \\
\hline 5906 & 570938.31 & 137199.92 & \\
\hline 5907 & 570938.31 & 137116.59 & \\
\hline 5908 & 572521.62 & 136616.59 & \\
\hline 5909 & 572521.62 & 140616.59 & \\
\hline 5910 & 572521.62 & 140866.59 & \\
\hline 5911 & 572548.81 & 141116.56 & \\
\hline 5912 & 559706.88 & 142941.91 & \\
\hline 5913 & 559610.12 & 143340.5 & \\
\hline 5914 & 560259.12 & 143867.8 & \\
\hline 5915 & 559521.62 & 143866.59 & \\
\hline 5916 & 571104.94 & 133616.59 & \\
\hline 5917 & 576521.62 & 131866.59 & \\
\hline 5918 & 576521.62 & 131616.59 & \\
\hline 5919 & 576521.62 & 132116.59 & \\
\hline 5920 & 576521.62 & 132366.59 & \\
\hline 5921 & 576521.62 & 132616.59 & \\
\hline 5922 & 576521.62 & 132866.59 & \\
\hline 5923 & 576521.62 & 133116.59 & \\
\hline 5924 & 576771.62 & 131616.59 & \\
\hline 5925 & 575521.62 & 133866.59 & \\
\hline 5926 & 575771.62 & 133866.59 & \\
\hline 5927 & 576021.62 & 133366.59 & \\
\hline 5928 & 576271.62 & 133366.59 & \\
\hline 5929 & 576021.62 & 133616.59 & \\
\hline 5930 & 576521.62 & 133366.59 & \\
\hline 5931 & 576021.62 & 133866.59 & \\
\hline 5932 & 578021.62 & 130366.6 & \\
\hline 5933 & 578021.62 & 130116.6 & \\
\hline 5934 & 578021.62 & 130616.6 & \\
\hline 5935 & 578271.62 & 130116.6 & \\
\hline 5936 & 578021.62 & 130866.59 & \\
\hline
\end{tabular}




\begin{tabular}{|c|c|c|c|}
\hline node & X_coord & Y_coord & note: from sac04d created July 1,2004 \\
\hline 5937 & $5 \overline{7} 8521.62$ & $1 \overline{2} 9616.6$ & \\
\hline 5938 & 578521.62 & 129116.6 & \\
\hline 5939 & 578521.62 & 129866.6 & \\
\hline 5940 & 579021.62 & 128866.6 & \\
\hline 5941 & 579021.62 & 128116.6 & \\
\hline 5942 & 579021.62 & 129116.6 & \\
\hline 5943 & 578521.62 & 130116.6 & \\
\hline 5944 & 577021.62 & 131616.59 & \\
\hline 5945 & 577271.62 & 131616.59 & \\
\hline 5946 & 577521.62 & 131116.59 & \\
\hline 5947 & 577771.62 & 131116.59 & \\
\hline 5948 & 577521.62 & 131366.59 & \\
\hline 5949 & 578021.62 & 131116.59 & \\
\hline 5950 & 577521.62 & 131616.59 & \\
\hline 5951 & 579021.62 & 127366.6 & \\
\hline 5952 & 579021.62 & 126616.6 & \\
\hline 5953 & 573771.62 & 134116.59 & \\
\hline 5954 & 574021.62 & 134116.59 & \\
\hline 5955 & 573521.62 & 133866.59 & \\
\hline 5956 & 573521.62 & 133783.27 & \\
\hline 5957 & 573604.94 & 133949.92 & \\
\hline 5958 & 573521.62 & 133949.92 & \\
\hline 5959 & 573604.94 & 134033.27 & \\
\hline 5960 & 574271.62 & 134116.59 & \\
\hline 5961 & 573438.31 & 133616.59 & \\
\hline 5962 & 573438.31 & 133699.92 & \\
\hline 5963 & 573438.31 & 133783.27 & \\
\hline 5964 & 574521.62 & 134116.59 & \\
\hline 5965 & 573354.94 & 133449.92 & \\
\hline 5966 & 573354.94 & 133533.27 & \\
\hline 5967 & 573354.94 & 133616.59 & \\
\hline 5968 & 574771.62 & 134116.59 & \\
\hline 5969 & 573271.62 & 133366.59 & \\
\hline 5970 & 573271.62 & 133449.92 & \\
\hline 5971 & 575021.62 & 134116.59 & \\
\hline 5972 & 575271.62 & 134116.59 & \\
\hline 5973 & 575521.62 & 134116.59 & \\
\hline 5974 & 579021.62 & 125866.6 & \\
\hline 5975 & 573188.31 & 133366.59 & \\
\hline 5976 & 579021.62 & 125116.6 & \\
\hline 5977 & 572521.62 & 133449.92 & \\
\hline 5978 & 572604.94 & 133449.92 & \\
\hline 5979 & 572688.31 & 133449.92 & \\
\hline 5980 & 572771.62 & 133449.92 & \\
\hline 5981 & 572854.94 & 133449.92 & \\
\hline 5982 & 572938.31 & 133449.92 & \\
\hline 5983 & 573021.62 & 133449.92 & \\
\hline 5984 & 573104.94 & 133449.92 & \\
\hline 5985 & 573188.31 & 133449.92 & \\
\hline 5986 & 579021.62 & 124366.6 & \\
\hline 5987 & 571854.94 & 133533.27 & \\
\hline 5988 & 571938.31 & 133533.27 & \\
\hline 5989 & 572021.62 & 133533.27 & \\
\hline 5990 & 572104.94 & 133533.27 & \\
\hline 5991 & 572188.31 & 133533.27 & \\
\hline 5992 & 572271.62 & 133533.27 & \\
\hline
\end{tabular}




\begin{tabular}{|c|c|c|c|}
\hline node & X_coord & Y_coord & note: from sac04d created July 1,2004 \\
\hline 5993 & $5 \overline{7} 2354.94$ & $1 \overline{3} 3533.27$ & \\
\hline 5994 & 572438.31 & 133533.27 & \\
\hline 5995 & 572521.62 & 133533.27 & \\
\hline 5996 & 579021.62 & 123616.6 & \\
\hline 5997 & 571188.31 & 133616.59 & \\
\hline 5998 & 571271.62 & 133616.59 & \\
\hline 5999 & 571354.94 & 133616.59 & \\
\hline 6000 & 571438.31 & 133616.59 & \\
\hline 6001 & 571521.62 & 133616.59 & \\
\hline 6002 & 571604.94 & 133616.59 & \\
\hline 6003 & 571688.31 & 133616.59 & \\
\hline 6004 & 571771.62 & 133616.59 & \\
\hline 6005 & 571854.94 & 133616.59 & \\
\hline 6006 & 577895.81 & 123225 & \\
\hline 6007 & 578407.19 & 122977 & \\
\hline 6008 & 579021.62 & 122866.6 & \\
\hline 6009 & 570938.31 & 134283.27 & \\
\hline 6010 & 570938.31 & 134366.59 & \\
\hline 6011 & 570938.31 & 134449.92 & \\
\hline 6012 & 571021.62 & 134283.27 & \\
\hline 6013 & 570938.31 & 134533.27 & \\
\hline 6014 & 571104.94 & 133699.92 & \\
\hline 6015 & 571104.94 & 133783.27 & \\
\hline 6016 & 571104.94 & 133866.59 & \\
\hline 6017 & 571104.94 & 133949.92 & \\
\hline 6018 & 571104.94 & 134033.27 & \\
\hline 6019 & 571104.94 & 134116.59 & \\
\hline 6020 & 571104.94 & 134199.92 & \\
\hline 6021 & 571104.94 & 134283.27 & \\
\hline 6022 & 570938.31 & 134616.59 & \\
\hline 6023 & 570938.31 & 134699.92 & \\
\hline 6024 & 570938.31 & 135783.27 & \\
\hline 6025 & 570938.31 & 135866.59 & \\
\hline 6026 & 570938.31 & 135699.92 & \\
\hline 6027 & 570938.31 & 135949.92 & \\
\hline 6028 & 570938.31 & 135616.59 & \\
\hline 6029 & 570938.31 & 135533.27 & \\
\hline 6030 & 570938.31 & 136033.27 & \\
\hline 6031 & 570938.31 & 136116.59 & \\
\hline 6032 & 570938.31 & 135449.92 & \\
\hline 6033 & 570938.31 & 136199.92 & \\
\hline 6034 & 570938.31 & 135366.59 & \\
\hline 6035 & 570938.31 & 135283.27 & \\
\hline 6036 & 570938.31 & 136283.27 & \\
\hline 6037 & 570938.31 & 136366.59 & \\
\hline 6038 & 570938.31 & 135199.92 & \\
\hline 6039 & 570938.31 & 136449.92 & \\
\hline 6040 & 570938.31 & 135116.59 & \\
\hline 6041 & 570938.31 & 135033.27 & \\
\hline 6042 & 570938.31 & 136533.27 & \\
\hline 6043 & 570938.31 & 136616.59 & \\
\hline 6044 & 570938.31 & 134949.92 & \\
\hline 6045 & 570938.31 & 136699.92 & \\
\hline 6046 & 570938.31 & 134866.59 & \\
\hline 6047 & 570938.31 & 134783.27 & \\
\hline 6048 & 570938.31 & 136783.27 & \\
\hline
\end{tabular}




\begin{tabular}{|c|c|c|c|}
\hline node & X_coord & Y_coord & note: from sac04d created July 1, 2004 \\
\hline 6049 & $5 \overline{7} 0938.31$ & $1 \overline{3} 6866.59$ & \\
\hline 6050 & 570938.31 & 136949.92 & \\
\hline 6051 & 570938.31 & 137033.27 & \\
\hline 6052 & 563372.5 & 145729.294 & \\
\hline 6053 & 562463.6309 & 145301.3522 & \\
\hline 6054 & 563603.8051 & 145590.0811 & \\
\hline 6055 & 561760.88 & 144421.91 & \\
\hline 6056 & 561710.0066 & 145366.59 & \\
\hline 6057 & 563771.62 & 144366.59 & \\
\hline 6058 & 564021.62 & 144366.59 & \\
\hline 6059 & 563771.62 & 144616.59 & \\
\hline 6060 & 564271.62 & 144366.59 & \\
\hline 6061 & 563704.5 & 144930.23 & \\
\hline 6062 & 563720.69 & 145243.86 & \\
\hline 6063 & 563864.19 & 144908.5 & \\
\hline 6064 & 564343.06 & 143596.45 & \\
\hline 6065 & 564390.69 & 143731.53 & \\
\hline 6066 & 564412.94 & 143454.86 & \\
\hline 6067 & 564555.25 & 143587.77 & \\
\hline 6068 & 564521.62 & 143866.59 & \\
\hline 6069 & 564580.12 & 143727.17 & \\
\hline 6070 & 564521.62 & 144116.59 & \\
\hline 6071 & 564521.62 & 144366.59 & \\
\hline 6072 & 570355.5 & 141314.09 & \\
\hline 6073 & 570528.38 & 141330.42 & \\
\hline 6074 & 570701.19 & 141346.77 & \\
\hline 6075 & 570874 & 141363.09 & \\
\hline 6076 & 571086.94 & 141385.3 & \\
\hline 6077 & 571299.88 & 141407.52 & \\
\hline 6078 & 571512.81 & 141429.73 & \\
\hline 6079 & 571793.75 & 141427.11 & \\
\hline 6080 & 572074.69 & 141424.48 & \\
\hline 6081 & 572355.62 & 141421.86 & \\
\hline 6082 & 572575.94 & 141366.53 & \\
\hline 6083 & 572780.62 & 138611.47 & \\
\hline 6084 & 572719.44 & 138363.94 & \\
\hline 6085 & 572777.62 & 138863.17 & \\
\hline 6086 & 572658.31 & 138116.39 & \\
\hline 6087 & 572774.62 & 139114.89 & \\
\hline 6088 & 572597.12 & 137868.86 & \\
\hline 6089 & 572771.62 & 139366.59 & \\
\hline 6090 & 572655.31 & 137618.11 & \\
\hline 6091 & 572771.62 & 139616.59 & \\
\hline 6092 & 572713.44 & 137367.34 & \\
\hline 6093 & 572771.62 & 139866.59 & \\
\hline 6094 & 572771.62 & 137116.59 & \\
\hline 6095 & 572771.62 & 140116.59 & \\
\hline 6096 & 572771.62 & 136866.59 & \\
\hline 6097 & 572771.62 & 140366.59 & \\
\hline 6098 & 572771.62 & 136616.59 & \\
\hline 6099 & 572771.62 & 140616.59 & \\
\hline 6100 & 571188.31 & 137033.27 & \\
\hline 6101 & 571104.94 & 137033.27 & \\
\hline 6102 & 571021.62 & 137033.27 & \\
\hline 6103 & 571188.31 & 136949.92 & \\
\hline 6104 & 571521.62 & 136866.59 & \\
\hline
\end{tabular}




\begin{tabular}{|c|c|c|c|}
\hline node & X_coord & Y_coord & note: from sac04d created July 1,2004 \\
\hline 6105 & $5 \overline{7} 1438.31$ & $1 \overline{3} 6866.59$ & \\
\hline 6106 & 571354.94 & 136866.59 & \\
\hline 6107 & 571271.62 & 136866.59 & \\
\hline 6108 & 571521.62 & 136783.27 & \\
\hline 6109 & 571771.62 & 136533.27 & \\
\hline 6110 & 571688.31 & 136533.27 & \\
\hline 6111 & 571938.31 & 136533.27 & \\
\hline 6112 & 572021.62 & 136366.59 & \\
\hline 6113 & 572271.62 & 136366.59 & \\
\hline 6114 & 571938.31 & 136366.59 & \\
\hline 6115 & 571604.94 & 136616.59 & \\
\hline 6116 & 571604.94 & 136533.27 & \\
\hline 6117 & 571577.19 & 136699.92 & \\
\hline 6118 & 572521.62 & 136366.59 & \\
\hline 6119 & 571521.62 & 136699.92 & \\
\hline 6120 & 571188.31 & 136866.59 & \\
\hline 6121 & 572771.62 & 136366.59 & \\
\hline 6122 & 572771.62 & 140866.59 & \\
\hline 6123 & 572783.94 & 141088.89 & \\
\hline 6124 & 572796.31 & 141311.2 & \\
\hline 6125 & 559248.31 & 142780.5 & \\
\hline 6126 & 559036.12 & 143279.7 & \\
\hline 6127 & 558771.62 & 143866.59 & \\
\hline 6128 & 560271.62 & 144616.59 & \\
\hline 6129 & 559445.5093 & 144631.0873 & \\
\hline 6130 & 560828 & 144162.7 & \\
\hline 6131 & 561177.88 & 144434.8 & \\
\hline 6132 & 558771.62 & 144616.59 & \\
\hline 6133 & 571188.31 & 133699.92 & \\
\hline 6134 & 576771.62 & 131866.59 & \\
\hline 6135 & 576771.62 & 132116.59 & \\
\hline 6136 & 576771.62 & 132366.59 & \\
\hline 6137 & 576771.62 & 132616.59 & \\
\hline 6138 & 576771.62 & 132866.59 & \\
\hline 6139 & 576771.62 & 133116.59 & \\
\hline 6140 & 576771.62 & 133366.59 & \\
\hline 6141 & 577021.62 & 131866.59 & \\
\hline 6142 & 575771.62 & 134116.59 & \\
\hline 6143 & 576021.62 & 134116.59 & \\
\hline 6144 & 576271.62 & 133616.59 & \\
\hline 6145 & 576521.62 & 133616.59 & \\
\hline 6146 & 576271.62 & 133866.59 & \\
\hline 6147 & 576771.62 & 133616.59 & \\
\hline 6148 & 576271.62 & 134116.59 & \\
\hline 6149 & 578271.62 & 130366.6 & \\
\hline 6150 & 578271.62 & 130616.6 & \\
\hline 6151 & 578271.62 & 130866.59 & \\
\hline 6152 & 578521.62 & 130366.6 & \\
\hline 6153 & 578271.62 & 131116.59 & \\
\hline 6154 & 578771.62 & 129616.6 & \\
\hline 6155 & 578771.62 & 129366.6 & \\
\hline 6156 & 578771.62 & 129866.6 & \\
\hline 6157 & 579021.62 & 129366.6 & \\
\hline 6158 & 578771.62 & 130116.6 & \\
\hline 6159 & 579771.62 & 128866.6 & \\
\hline 6160 & 579771.62 & 128116.6 & \\
\hline
\end{tabular}




\begin{tabular}{|c|c|c|c|}
\hline node & X_coord & Y_coord & note: from sac04d created July 1, 2004 \\
\hline 6161 & $5 \overline{7} 9521.62$ & $1 \overline{2} 9116.6$ & \\
\hline 6162 & 579771.62 & 127366.6 & \\
\hline 6163 & 579271.62 & 129366.6 & \\
\hline 6164 & 578771.62 & 130366.6 & \\
\hline 6165 & 577271.62 & 131866.59 & \\
\hline 6166 & 577521.62 & 131866.59 & \\
\hline 6167 & 577771.62 & 131366.59 & \\
\hline 6168 & 578021.62 & 131366.59 & \\
\hline 6169 & 577771.62 & 131616.59 & \\
\hline 6170 & 578271.62 & 131366.59 & \\
\hline 6171 & 577771.62 & 131866.59 & \\
\hline 6172 & 579771.62 & 126616.6 & \\
\hline 6173 & 579771.62 & 125866.6 & \\
\hline 6174 & 573771.62 & 134366.59 & \\
\hline 6175 & 573521.62 & 134116.59 & \\
\hline 6176 & 573521.62 & 134366.59 & \\
\hline 6177 & 574021.62 & 134366.59 & \\
\hline 6178 & 573521.62 & 134033.27 & \\
\hline 6179 & 574271.62 & 134366.59 & \\
\hline 6180 & 573438.31 & 133866.59 & \\
\hline 6181 & 573438.31 & 133949.92 & \\
\hline 6182 & 573438.31 & 134033.27 & \\
\hline 6183 & 574521.62 & 134366.59 & \\
\hline 6184 & 573354.94 & 133699.92 & \\
\hline 6185 & 573354.94 & 133783.27 & \\
\hline 6186 & 573354.94 & 133866.59 & \\
\hline 6187 & 574771.62 & 134366.59 & \\
\hline 6188 & 573271.62 & 133533.27 & \\
\hline 6189 & 573271.62 & 133616.59 & \\
\hline 6190 & 573271.62 & 133699.92 & \\
\hline 6191 & 575021.62 & 134366.59 & \\
\hline 6192 & 573188.31 & 133533.27 & \\
\hline 6193 & 575271.62 & 134366.59 & \\
\hline 6194 & 575521.62 & 134366.59 & \\
\hline 6195 & 575771.62 & 134366.59 & \\
\hline 6196 & 579771.62 & 125116.6 & \\
\hline 6197 & 579771.62 & 124366.6 & \\
\hline 6198 & 572604.94 & 133533.27 & \\
\hline 6199 & 572688.31 & 133533.27 & \\
\hline 6200 & 572771.62 & 133533.27 & \\
\hline 6201 & 572854.94 & 133533.27 & \\
\hline 6202 & 572938.31 & 133533.27 & \\
\hline 6203 & 573021.62 & 133533.27 & \\
\hline 6204 & 573104.94 & 133533.27 & \\
\hline 6205 & 579771.62 & 123616.6 & \\
\hline 6206 & 571938.31 & 133616.59 & \\
\hline 6207 & 572021.62 & 133616.59 & \\
\hline 6208 & 572104.94 & 133616.59 & \\
\hline 6209 & 572188.31 & 133616.59 & \\
\hline 6210 & 572271.62 & 133616.59 & \\
\hline 6211 & 572354.94 & 133616.59 & \\
\hline 6212 & 572438.31 & 133616.59 & \\
\hline 6213 & 572521.62 & 133616.59 & \\
\hline 6214 & 572604.94 & 133616.59 & \\
\hline 6215 & 579771.62 & 122866.6 & \\
\hline 6216 & 571271.62 & 133699.92 & \\
\hline
\end{tabular}




\begin{tabular}{|c|c|c|c|}
\hline node & $X$ coord & Y coord & note: from sac04d created July 1, 2004 \\
\hline 6217 & $5 \overline{7} 1354.94$ & $1 \overline{3} 3699.92$ & \\
\hline 6218 & 571438.31 & 133699.92 & \\
\hline 6219 & 571521.62 & 133699.92 & \\
\hline 6220 & 571604.94 & 133699.92 & \\
\hline 6221 & 571688.31 & 133699.92 & \\
\hline 6222 & 571771.62 & 133699.92 & \\
\hline 6223 & 571854.94 & 133699.92 & \\
\hline 6224 & 571938.31 & 133699.92 & \\
\hline 6225 & 578717.12 & 122574.2 & \\
\hline 6226 & 579120 & 122248.8 & \\
\hline 6227 & 579786.31 & 122217.8 & \\
\hline 6228 & 571021.62 & 134366.59 & \\
\hline 6229 & 571021.62 & 134449.92 & \\
\hline 6230 & 571021.62 & 134533.27 & \\
\hline 6231 & 571104.94 & 134366.59 & \\
\hline 6232 & 571021.62 & 134616.59 & \\
\hline 6233 & 571188.31 & 133783.27 & \\
\hline 6234 & 571188.31 & 133866.59 & \\
\hline 6235 & 571188.31 & 133949.92 & \\
\hline 6236 & 571188.31 & 134033.27 & \\
\hline 6237 & 571188.31 & 134116.59 & \\
\hline 6238 & 571188.31 & 134199.92 & \\
\hline 6239 & 571188.31 & 134283.27 & \\
\hline 6240 & 571188.31 & 134366.59 & \\
\hline 6241 & 571021.62 & 134699.92 & \\
\hline 6242 & 571021.62 & 134783.27 & \\
\hline 6243 & 571021.62 & 135783.27 & \\
\hline 6244 & 571021.62 & 135699.92 & \\
\hline 6245 & 571021.62 & 135866.59 & \\
\hline 6246 & 571021.62 & 135949.92 & \\
\hline 6247 & 571021.62 & 135616.59 & \\
\hline 6248 & 571021.62 & 136033.27 & \\
\hline 6249 & 571021.62 & 135533.27 & \\
\hline 6250 & 571021.62 & 135449.92 & \\
\hline 6251 & 571021.62 & 136116.59 & \\
\hline 6252 & 571021.62 & 136199.92 & \\
\hline 6253 & 571021.62 & 135366.59 & \\
\hline 6254 & 571021.62 & 136283.27 & \\
\hline 6255 & 571021.62 & 135283.27 & \\
\hline 6256 & 571021.62 & 135199.92 & \\
\hline 6257 & 571021.62 & 136366.59 & \\
\hline 6258 & 571021.62 & 136449.92 & \\
\hline 6259 & 571021.62 & 135116.59 & \\
\hline 6260 & 571021.62 & 136533.27 & \\
\hline 6261 & 571021.62 & 135033.27 & \\
\hline 6262 & 571021.62 & 134949.92 & \\
\hline 6263 & 571021.62 & 136616.59 & \\
\hline 6264 & 571021.62 & 136699.92 & \\
\hline 6265 & 571021.62 & 134866.59 & \\
\hline 6266 & 571021.62 & 136783.27 & \\
\hline 6267 & 571021.62 & 136866.59 & \\
\hline 6268 & 571021.62 & 136949.92 & \\
\hline 6269 & 562967.691 & 145928.472 & \\
\hline 6270 & 562558.8651 & 146086.5751 & \\
\hline 6271 & 563439 & 145939 & \\
\hline 6272 & 563021 & 146081.59 & \\
\hline
\end{tabular}




\begin{tabular}{|c|c|c|c|}
\hline node & X_coord & Y_coord & note: from sac04d created July 1, 2004 \\
\hline 6273 & $5 \overline{6} 3671.31$ & $1 \overline{4} 5894.33$ & \\
\hline 6274 & 561715.2801 & 146247.3821 & \\
\hline 6275 & 563836.1321 & 145533.684 & \\
\hline 6276 & 563873.38 & 145200.39 & \\
\hline 6277 & 563903.69 & 145849.67 & \\
\hline 6278 & 561021.62 & 145366.59 & \\
\hline 6279 & 561048.9531 & 146267.487 & \\
\hline 6280 & 564021.62 & 144616.59 & \\
\hline 6281 & 564271.62 & 144616.59 & \\
\hline 6282 & 564023.88 & 144886.77 & \\
\hline 6283 & 564521.62 & 144616.59 & \\
\hline 6284 & 564026.12 & 145156.92 & \\
\hline 6285 & 564765.38 & 143435.3 & \\
\hline 6286 & 564767.44 & 143579.06 & \\
\hline 6287 & 564769.56 & 143722.83 & \\
\hline 6288 & 564771.62 & 143866.59 & \\
\hline 6289 & 564771.62 & 144116.59 & \\
\hline 6290 & 564771.62 & 144366.59 & \\
\hline 6291 & 564771.62 & 144616.59 & \\
\hline 6292 & 570179.88 & 141589.59 & \\
\hline 6293 & 570377.12 & 141598.59 & \\
\hline 6294 & 570574.38 & 141607.59 & \\
\hline 6295 & 570771.62 & 141616.59 & \\
\hline 6296 & 571017.19 & 141648.16 & \\
\hline 6297 & 571262.81 & 141679.73 & \\
\hline 6298 & 571508.38 & 141711.3 & \\
\hline 6299 & 571804.81 & 141707.36 & \\
\hline 6300 & 572101.19 & 141703.44 & \\
\hline 6301 & 572397.62 & 141699.5 & \\
\hline 6302 & 572603.12 & 141616.5 & \\
\hline 6303 & 572808.62 & 141533.5 & \\
\hline 6304 & 573035.12 & 138608.91 & \\
\hline 6305 & 572943.38 & 138362.61 & \\
\hline 6306 & 573030.62 & 138861.47 & \\
\hline 6307 & 572851.62 & 138116.3 & \\
\hline 6308 & 573026.12 & 139114.03 & \\
\hline 6309 & 572759.88 & 137870 & \\
\hline 6310 & 573021.62 & 139366.59 & \\
\hline 6311 & 572847.12 & 137618.86 & \\
\hline 6312 & 573021.62 & 139616.59 & \\
\hline 6313 & 572934.38 & 137367.73 & \\
\hline 6314 & 573021.62 & 139866.59 & \\
\hline 6315 & 573021.62 & 137116.59 & \\
\hline 6316 & 573021.62 & 140116.59 & \\
\hline 6317 & 573021.62 & 136866.59 & \\
\hline 6318 & 573021.62 & 140366.59 & \\
\hline 6319 & 573021.62 & 136616.59 & \\
\hline 6320 & 573021.62 & 140616.59 & \\
\hline 6321 & 573021.62 & 136366.59 & \\
\hline 6322 & 573021.62 & 140866.59 & \\
\hline 6323 & 571104.94 & 136949.92 & \\
\hline 6324 & 571104.94 & 136866.59 & \\
\hline 6325 & 571438.31 & 136783.27 & \\
\hline 6326 & 571354.94 & 136783.27 & \\
\hline 6327 & 571271.62 & 136783.27 & \\
\hline 6328 & 571188.31 & 136783.27 & \\
\hline
\end{tabular}




\begin{tabular}{|c|c|c|c|}
\hline node & X_coord & Y_coord & note: from sac04d created July 1,2004 \\
\hline 6329 & $5 \overline{7} 1438.31$ & $1 \overline{3} 6699.92$ & \\
\hline 6330 & 571771.62 & 136449.92 & \\
\hline 6331 & 571688.31 & 136449.92 & \\
\hline 6332 & 571854.94 & 136449.92 & \\
\hline 6333 & 571604.94 & 136449.92 & \\
\hline 6334 & 571854.94 & 136366.59 & \\
\hline 6335 & 572021.62 & 136283.27 & \\
\hline 6336 & 572104.94 & 136283.27 & \\
\hline 6337 & 571938.31 & 136283.27 & \\
\hline 6338 & 572271.62 & 136116.59 & \\
\hline 6339 & 572521.62 & 136116.59 & \\
\hline 6340 & 572104.94 & 136199.92 & \\
\hline 6341 & 571854.94 & 136283.27 & \\
\hline 6342 & 571521.62 & 136616.59 & \\
\hline 6343 & 571521.62 & 136533.27 & \\
\hline 6344 & 571521.62 & 136449.92 & \\
\hline 6345 & 572771.62 & 136116.59 & \\
\hline 6346 & 571438.31 & 136616.59 & \\
\hline 6347 & 571104.94 & 136783.27 & \\
\hline 6348 & 573021.62 & 136116.59 & \\
\hline 6349 & 573019.12 & 141061.23 & \\
\hline 6350 & 573016.62 & 141255.86 & \\
\hline 6351 & 573014.12 & 141450.5 & \\
\hline 6352 & 558551.69 & 142950.41 & \\
\hline 6353 & 557995.38 & 143151 & \\
\hline 6354 & 558026.5 & 143617 & \\
\hline 6355 & 558026.5 & 144350.7 & \\
\hline 6356 & 560271.62 & 145366.59 & \\
\hline 6358 & 558734.7902 & 145445.3056 & \\
\hline 6359 & 558035.5608 & 145009.8359 & \\
\hline 6360 & 571271.62 & 133783.27 & \\
\hline 6361 & 577021.62 & 132116.59 & \\
\hline 6362 & 577021.62 & 132366.59 & \\
\hline 6363 & 577021.62 & 132616.59 & \\
\hline 6364 & 577021.62 & 132866.59 & \\
\hline 6365 & 577021.62 & 133116.59 & \\
\hline 6366 & 577021.62 & 133366.59 & \\
\hline 6367 & 577021.62 & 133616.59 & \\
\hline 6368 & 577271.62 & 132116.59 & \\
\hline 6369 & 576021.62 & 134366.59 & \\
\hline 6370 & 576271.62 & 134366.59 & \\
\hline 6371 & 576521.62 & 133866.59 & \\
\hline 6372 & 576771.62 & 133866.59 & \\
\hline 6373 & 576521.62 & 134116.59 & \\
\hline 6374 & 577021.62 & 133866.59 & \\
\hline 6375 & 576521.62 & 134366.59 & \\
\hline 6376 & 578521.62 & 130616.6 & \\
\hline 6377 & 578521.62 & 130866.59 & \\
\hline 6378 & 578521.62 & 131116.59 & \\
\hline 6379 & 578771.62 & 130616.6 & \\
\hline 6380 & 578521.62 & 131366.59 & \\
\hline 6381 & 579021.62 & 129616.6 & \\
\hline 6382 & 579021.62 & 129866.6 & \\
\hline 6383 & 579021.62 & 130116.6 & \\
\hline 6384 & 579271.62 & 129616.6 & \\
\hline 6385 & 579021.62 & 130366.6 & \\
\hline
\end{tabular}




\begin{tabular}{|c|c|c|c|}
\hline node & X_coord & Y_coord & note: from sac04d created July 1, 2004 \\
\hline 6386 & $5 \overline{80} 521.62$ & $1 \overline{2} 8866.6$ & \\
\hline 6387 & 580521.62 & 128116.6 & \\
\hline 6388 & 579771.62 & 129616.6 & \\
\hline 6389 & 579521.62 & 129616.6 & \\
\hline 6390 & 580021.62 & 129366.6 & \\
\hline 6391 & 580021.62 & 129616.6 & \\
\hline 6392 & 580271.62 & 129366.6 & \\
\hline 6393 & 580521.62 & 127366.6 & \\
\hline 6394 & 580521.62 & 126616.6 & \\
\hline 6395 & 579021.62 & 130616.6 & \\
\hline 6396 & 577521.62 & 132116.59 & \\
\hline 6397 & 577771.62 & 132116.59 & \\
\hline 6398 & 578021.62 & 131616.59 & \\
\hline 6399 & 578271.62 & 131616.59 & \\
\hline 6400 & 578021.62 & 131866.59 & \\
\hline 6401 & 578521.62 & 131616.59 & \\
\hline 6402 & 578021.62 & 132116.59 & \\
\hline 6403 & 580521.62 & 125866.6 & \\
\hline 6404 & 580521.62 & 125116.6 & \\
\hline 6405 & 573771.62 & 134616.59 & \\
\hline 6406 & 573521.62 & 134616.59 & \\
\hline 6407 & 574021.62 & 134616.59 & \\
\hline 6408 & 573438.31 & 134116.59 & \\
\hline 6409 & 573438.31 & 134283.27 & \\
\hline 6410 & 573271.62 & 134366.59 & \\
\hline 6411 & 573271.62 & 134616.59 & \\
\hline 6412 & 573271.62 & 134283.27 & \\
\hline 6413 & 574271.62 & 134616.59 & \\
\hline 6414 & 574521.62 & 134616.59 & \\
\hline 6415 & 573354.94 & 133949.92 & \\
\hline 6416 & 573354.94 & 134033.27 & \\
\hline 6417 & 573354.94 & 134116.59 & \\
\hline 6418 & 574771.62 & 134616.59 & \\
\hline 6419 & 573271.62 & 133783.27 & \\
\hline 6420 & 573271.62 & 133866.59 & \\
\hline 6421 & 573271.62 & 133949.92 & \\
\hline 6422 & 575021.62 & 134616.59 & \\
\hline 6423 & 573188.31 & 133616.59 & \\
\hline 6424 & 573188.31 & 133699.92 & \\
\hline 6425 & 573188.31 & 133783.27 & \\
\hline 6426 & 575271.62 & 134616.59 & \\
\hline 6427 & 573104.94 & 133616.59 & \\
\hline 6428 & 575521.62 & 134616.59 & \\
\hline 6429 & 575771.62 & 134616.59 & \\
\hline 6430 & 576021.62 & 134616.59 & \\
\hline 6431 & 580521.62 & 124366.6 & \\
\hline 6432 & 580521.62 & 123616.6 & \\
\hline 6433 & 572688.31 & 133616.59 & \\
\hline 6434 & 572771.62 & 133616.59 & \\
\hline 6435 & 572854.94 & 133616.59 & \\
\hline 6436 & 572938.31 & 133616.59 & \\
\hline 6437 & 573021.62 & 133616.59 & \\
\hline 6438 & 580521.62 & 122866.6 & \\
\hline 6439 & 572021.62 & 133699.92 & \\
\hline 6440 & 572104.94 & 133699.92 & \\
\hline 6441 & 572188.31 & 133699.92 & \\
\hline
\end{tabular}




\begin{tabular}{|c|c|c|c|}
\hline node & X_coord & Y_coord & note: from sac04d created July 1,2004 \\
\hline 6442 & $5 \overline{7} 2271.62$ & $1 \overline{3} 3699.92$ & \\
\hline 6443 & 572354.94 & 133699.92 & \\
\hline 6444 & 572438.31 & 133699.92 & \\
\hline 6445 & 572521.62 & 133699.92 & \\
\hline 6446 & 572604.94 & 133699.92 & \\
\hline 6447 & 572688.31 & 133699.92 & \\
\hline 6448 & 580521.62 & 122116.6 & \\
\hline 6449 & 571354.94 & 133783.27 & \\
\hline 6450 & 571438.31 & 133783.27 & \\
\hline 6451 & 571521.62 & 133783.27 & \\
\hline 6452 & 571604.94 & 133783.27 & \\
\hline 6453 & 571688.31 & 133783.27 & \\
\hline 6454 & 571771.62 & 133783.27 & \\
\hline 6455 & 571854.94 & 133783.27 & \\
\hline 6456 & 571938.31 & 133783.27 & \\
\hline 6457 & 572021.62 & 133783.27 & \\
\hline 6458 & 579460.88 & 121690.9 & \\
\hline 6459 & 580003.31 & 121443 & \\
\hline 6460 & 580521.62 & 121366.6 & \\
\hline 6461 & 571104.94 & 134449.92 & \\
\hline 6462 & 571104.94 & 134533.27 & \\
\hline 6463 & 571104.94 & 134616.59 & \\
\hline 6464 & 571188.31 & 134449.92 & \\
\hline 6465 & 571104.94 & 134699.92 & \\
\hline 6466 & 571271.62 & 133866.59 & \\
\hline 6467 & 571271.62 & 133949.92 & \\
\hline 6468 & 571271.62 & 134033.27 & \\
\hline 6469 & 571271.62 & 134116.59 & \\
\hline 6470 & 571271.62 & 134199.92 & \\
\hline 6471 & 571271.62 & 134283.27 & \\
\hline 6472 & 571271.62 & 134366.59 & \\
\hline 6473 & 571271.62 & 134449.92 & \\
\hline 6474 & 571104.94 & 134783.27 & \\
\hline 6475 & 571104.94 & 134866.59 & \\
\hline 6476 & 571104.94 & 135783.27 & \\
\hline 6477 & 571104.94 & 135866.59 & \\
\hline 6478 & 571104.94 & 135699.92 & \\
\hline 6479 & 571104.94 & 135616.59 & \\
\hline 6480 & 571104.94 & 135949.92 & \\
\hline 6481 & 571104.94 & 136033.27 & \\
\hline 6482 & 571104.94 & 135533.27 & \\
\hline 6483 & 571104.94 & 136116.59 & \\
\hline 6484 & 571104.94 & 135449.92 & \\
\hline 6485 & 571104.94 & 135366.59 & \\
\hline 6486 & 571104.94 & 136199.92 & \\
\hline 6487 & 571104.94 & 136283.27 & \\
\hline 6488 & 571104.94 & 135283.27 & \\
\hline 6489 & 571104.94 & 136366.59 & \\
\hline 6490 & 571104.94 & 135199.92 & \\
\hline 6491 & 571104.94 & 135116.59 & \\
\hline 6492 & 571104.94 & 136449.92 & \\
\hline 6493 & 571104.94 & 136533.27 & \\
\hline 6494 & 571104.94 & 135033.27 & \\
\hline 6495 & 571104.94 & 136616.59 & \\
\hline 6496 & 571104.94 & 134949.92 & \\
\hline 6497 & 571104.94 & 136699.92 & \\
\hline
\end{tabular}




\begin{tabular}{|c|c|c|c|}
\hline node & X_coord & Y_coord & note: from sac04d created July 1, 2004 \\
\hline 6498 & $5 \overline{6} 2600.31$ & $1 \overline{4} 6237.7$ & \\
\hline 6499 & 561740.38 & 146468 & \\
\hline 6500 & 561040.62 & 146456.3 & \\
\hline 6501 & 564071.8442 & 145426.0505 & \\
\hline 6502 & 564136 & 145805 & \\
\hline 6503 & 560222.7193 & 146134.684 & \\
\hline 6504 & 560154.88 & 146374.7 & \\
\hline 6505 & 564272.06 & 144866.72 & \\
\hline 6506 & 564520.25 & 144846.67 & \\
\hline 6507 & 564272.5 & 145116.84 & \\
\hline 6508 & 564768.44 & 144826.62 & \\
\hline 6509 & 564288.4491 & 145366.97 & \\
\hline 6510 & 565025.31 & 143441.56 & \\
\hline 6511 & 565024.06 & 143583.23 & \\
\hline 6512 & 565022.88 & 143724.92 & \\
\hline 6513 & 565021.62 & 143866.59 & \\
\hline 6514 & 565021.62 & 144116.59 & \\
\hline 6515 & 565021.62 & 144366.59 & \\
\hline 6516 & 565021.62 & 144616.59 & \\
\hline 6517 & 565019.31 & 144849.36 & \\
\hline 6518 & 570132.69 & 141877.16 & \\
\hline 6519 & 569976.69 & 141765.23 & \\
\hline 6520 & 569905.06 & 142000.84 & \\
\hline 6521 & 570345.69 & 141873.64 & \\
\hline 6522 & 570558.62 & 141870.11 & \\
\hline 6523 & 570771.62 & 141866.59 & \\
\hline 6524 & 571018.69 & 141887.64 & \\
\hline 6525 & 571265.75 & 141908.69 & \\
\hline 6526 & 571512.81 & 141929.73 & \\
\hline 6527 & 571789.75 & 141917.11 & \\
\hline 6528 & 572066.75 & 141904.52 & \\
\hline 6529 & 572343.69 & 141891.91 & \\
\hline 6530 & 573237.56 & 138639.27 & \\
\hline 6531 & 573192.19 & 138389.44 & \\
\hline 6532 & 573218.75 & 138906.44 & \\
\hline 6533 & 573146.88 & 138139.62 & \\
\hline 6534 & 573199.94 & 139173.62 & \\
\hline 6535 & 573101.5 & 137889.8 & \\
\hline 6536 & 573181.12 & 139440.8 & \\
\hline 6537 & 573158.19 & 137632.06 & \\
\hline 6538 & 573213.19 & 139681.34 & \\
\hline 6539 & 573214.94 & 137374.33 & \\
\hline 6540 & 573245.25 & 139921.88 & \\
\hline 6541 & 573271.62 & 137116.59 & \\
\hline 6542 & 573277.31 & 140162.42 & \\
\hline 6543 & 573271.62 & 136866.59 & \\
\hline 6544 & 573275.44 & 140397.14 & \\
\hline 6545 & 573271.62 & 136616.59 & \\
\hline 6546 & 573273.5 & 140631.88 & \\
\hline 6547 & 573271.62 & 136366.59 & \\
\hline 6548 & 573271.62 & 140866.59 & \\
\hline 6549 & 573271.62 & 136116.59 & \\
\hline 6550 & 573261.19 & 141027.89 & \\
\hline 6551 & 571354.94 & 136699.92 & \\
\hline 6552 & 571271.62 & 136699.92 & \\
\hline 6553 & 571188.31 & 136699.92 & \\
\hline
\end{tabular}




\begin{tabular}{|c|c|c|c|}
\hline node & X_coord & Y_coord & note: from sac04d created July 1,2004 \\
\hline 6554 & $5 \overline{7} 1354.94$ & $1 \overline{3} 6616.59$ & \\
\hline 6555 & 571771.62 & 136366.59 & \\
\hline 6556 & 571688.31 & 136366.59 & \\
\hline 6557 & 571604.94 & 136366.59 & \\
\hline 6558 & 571521.62 & 136366.59 & \\
\hline 6559 & 571771.62 & 136283.27 & \\
\hline 6560 & 572021.62 & 136199.92 & \\
\hline 6561 & 571938.31 & 136199.92 & \\
\hline 6562 & 571854.94 & 136199.92 & \\
\hline 6563 & 572271.62 & 135866.59 & \\
\hline 6564 & 572521.62 & 135866.59 & \\
\hline 6565 & 572021.62 & 136116.59 & \\
\hline 6566 & 572188.31 & 136033.27 & \\
\hline 6567 & 572021.62 & 136033.27 & \\
\hline 6568 & 572188.31 & 135866.59 & \\
\hline 6569 & 572771.62 & 135866.59 & \\
\hline 6570 & 571771.62 & 136199.92 & \\
\hline 6571 & 571438.31 & 136533.27 & \\
\hline 6572 & 571438.31 & 136449.92 & \\
\hline 6573 & 571438.31 & 136366.59 & \\
\hline 6574 & 573021.62 & 135866.59 & \\
\hline 6575 & 571354.94 & 136533.27 & \\
\hline 6576 & 573271.62 & 135866.59 & \\
\hline 6577 & 573250.75 & 141189.2 & \\
\hline 6578 & 573240.31 & 141350.5 & \\
\hline 6579 & 557265.81 & 143215.3 & \\
\hline 6580 & 557276.62 & 143655.2 & \\
\hline 6581 & 557280.81 & 144134.2 & \\
\hline 6582 & 557292.81 & 144651.41 & \\
\hline 6583 & 559576.1366 & 145949.0577 & \\
\hline 6584 & 559064.3804 & 145681.3989 & \\
\hline 6585 & 558604.38 & 145680.7 & \\
\hline 6586 & 557906.5 & 145289.59 & \\
\hline 6587 & 558959.88 & 145862.91 & \\
\hline 6588 & 557276.31 & 145009.3 & \\
\hline 6589 & 571354.94 & 133866.59 & \\
\hline 6590 & 577271.62 & 132366.59 & \\
\hline 6591 & 577271.62 & 132616.59 & \\
\hline 6592 & 577271.62 & 132866.59 & \\
\hline 6593 & 577271.62 & 133116.59 & \\
\hline 6594 & 577271.62 & 133366.59 & \\
\hline 6595 & 577271.62 & 133616.59 & \\
\hline 6596 & 577271.62 & 133866.59 & \\
\hline 6597 & 577521.62 & 132366.59 & \\
\hline 6598 & 576271.62 & 134616.59 & \\
\hline 6599 & 576521.62 & 134616.59 & \\
\hline 6600 & 576771.62 & 134116.59 & \\
\hline 6601 & 577021.62 & 134116.59 & \\
\hline 6602 & 576771.62 & 134366.59 & \\
\hline 6603 & 577271.62 & 134116.59 & \\
\hline 6604 & 576771.62 & 134616.59 & \\
\hline 6605 & 578771.62 & 130866.59 & \\
\hline 6606 & 578771.62 & 131116.59 & \\
\hline 6607 & 578771.62 & 131366.59 & \\
\hline 6608 & 579021.62 & 130866.59 & \\
\hline 6609 & 578771.62 & 131616.59 & \\
\hline
\end{tabular}




\begin{tabular}{|c|c|c|c|}
\hline node & X_coord & Y_coord & note: from sac04d created July 1, 2004 \\
\hline 6610 & $5 \overline{7} 9271.62$ & $1 \overline{2} 9866.6$ & \\
\hline 6611 & 579271.62 & 130116.6 & \\
\hline 6612 & 579271.62 & 130366.6 & \\
\hline 6613 & 579521.62 & 129866.6 & \\
\hline 6614 & 579271.62 & 130616.6 & \\
\hline 6615 & 581271.62 & 128866.6 & \\
\hline 6616 & 581271.62 & 128116.6 & \\
\hline 6617 & 580521.62 & 129616.6 & \\
\hline 6618 & 580271.62 & 129616.6 & \\
\hline 6619 & 580771.62 & 129116.6 & \\
\hline 6620 & 581271.62 & 129116.6 & \\
\hline 6621 & 580771.62 & 129616.6 & \\
\hline 6622 & 581271.62 & 127366.6 & \\
\hline 6623 & 579771.62 & 129866.6 & \\
\hline 6624 & 580021.62 & 129866.6 & \\
\hline 6625 & 580271.62 & 129866.6 & \\
\hline 6626 & 581271.62 & 126616.6 & \\
\hline 6627 & 581271.62 & 125866.6 & \\
\hline 6628 & 579271.62 & 130866.59 & \\
\hline 6629 & 577771.62 & 132366.59 & \\
\hline 6630 & 578021.62 & 132366.59 & \\
\hline 6631 & 578271.62 & 131866.59 & \\
\hline 6632 & 578521.62 & 131866.59 & \\
\hline 6633 & 578271.62 & 132116.59 & \\
\hline 6634 & 578771.62 & 131866.59 & \\
\hline 6635 & 578271.62 & 132366.59 & \\
\hline 6636 & 581271.62 & 125116.6 & \\
\hline 6637 & 581271.62 & 124366.6 & \\
\hline 6638 & 573771.62 & 134866.59 & \\
\hline 6639 & 573521.62 & 134866.59 & \\
\hline 6640 & 574021.62 & 134866.59 & \\
\hline 6641 & 573271.62 & 134866.59 & \\
\hline 6642 & 574271.62 & 134866.59 & \\
\hline 6643 & 573354.94 & 134199.92 & \\
\hline 6644 & 573271.62 & 134199.92 & \\
\hline 6645 & 573188.31 & 134366.59 & \\
\hline 6646 & 573188.31 & 134283.27 & \\
\hline 6647 & 573188.31 & 134533.27 & \\
\hline 6648 & 573021.62 & 134616.59 & \\
\hline 6649 & 573021.62 & 134866.59 & \\
\hline 6650 & 573021.62 & 134533.27 & \\
\hline 6651 & 573188.31 & 134199.92 & \\
\hline 6652 & 574521.62 & 134866.59 & \\
\hline 6653 & 574771.62 & 134866.59 & \\
\hline 6654 & 573271.62 & 134033.27 & \\
\hline 6655 & 573271.62 & 134116.59 & \\
\hline 6656 & 575021.62 & 134866.59 & \\
\hline 6657 & 573188.31 & 133866.59 & \\
\hline 6658 & 573188.31 & 133949.92 & \\
\hline 6659 & 573188.31 & 134033.27 & \\
\hline 6660 & 575271.62 & 134866.59 & \\
\hline 6661 & 573104.94 & 133699.92 & \\
\hline 6662 & 573104.94 & 133783.27 & \\
\hline 6663 & 573104.94 & 133866.59 & \\
\hline 6664 & 575521.62 & 134866.59 & \\
\hline 6665 & 573021.62 & 133699.92 & \\
\hline
\end{tabular}




\begin{tabular}{|c|c|c|c|}
\hline node & X_coord & Y_coord & note: from sac04d created July 1,2004 \\
\hline 6666 & $5 \overline{7} 5771.62$ & $1 \overline{3} 4866.59$ & \\
\hline 6667 & 576021.62 & 134866.59 & \\
\hline 6668 & 576271.62 & 134866.59 & \\
\hline 6669 & 581271.62 & 123616.6 & \\
\hline 6670 & 581271.62 & 122866.6 & \\
\hline 6671 & 572771.62 & 133699.92 & \\
\hline 6672 & 572854.94 & 133699.92 & \\
\hline 6673 & 572938.31 & 133699.92 & \\
\hline 6674 & 581271.62 & 122116.6 & \\
\hline 6675 & 572104.94 & 133783.27 & \\
\hline 6676 & 572188.31 & 133783.27 & \\
\hline 6677 & 572271.62 & 133783.27 & \\
\hline 6678 & 572354.94 & 133783.27 & \\
\hline 6679 & 572438.31 & 133783.27 & \\
\hline 6680 & 572521.62 & 133783.27 & \\
\hline 6681 & 572604.94 & 133783.27 & \\
\hline 6682 & 572688.31 & 133783.27 & \\
\hline 6683 & 572771.62 & 133783.27 & \\
\hline 6684 & 581273.88 & 121350 & \\
\hline 6685 & 571438.31 & 133866.59 & \\
\hline 6686 & 571521.62 & 133866.59 & \\
\hline 6687 & 571604.94 & 133866.59 & \\
\hline 6688 & 571688.31 & 133866.59 & \\
\hline 6689 & 571771.62 & 133866.59 & \\
\hline 6690 & 571854.94 & 133866.59 & \\
\hline 6691 & 571938.31 & 133866.59 & \\
\hline 6692 & 572021.62 & 133866.59 & \\
\hline 6693 & 572104.94 & 133866.59 & \\
\hline 6694 & 580282.12 & 120854.1 & \\
\hline 6695 & 580666.62 & 120506 & \\
\hline 6696 & 581258.38 & 120513.2 & \\
\hline 6697 & 571188.31 & 134533.27 & \\
\hline 6698 & 571188.31 & 134616.59 & \\
\hline 6699 & 571188.31 & 134699.92 & \\
\hline 6700 & 571271.62 & 134533.27 & \\
\hline 6701 & 571188.31 & 134783.27 & \\
\hline 6702 & 571354.94 & 133949.92 & \\
\hline 6703 & 571354.94 & 134033.27 & \\
\hline 6704 & 571354.94 & 134116.59 & \\
\hline 6705 & 571354.94 & 134199.92 & \\
\hline 6706 & 571354.94 & 134283.27 & \\
\hline 6707 & 571354.94 & 134366.59 & \\
\hline 6708 & 571354.94 & 134449.92 & \\
\hline 6709 & 571354.94 & 134533.27 & \\
\hline 6710 & 571188.31 & 134866.59 & \\
\hline 6711 & 571188.31 & 134949.92 & \\
\hline 6712 & 571188.31 & 135783.27 & \\
\hline 6713 & 571188.31 & 135866.59 & \\
\hline 6714 & 571188.31 & 135699.92 & \\
\hline 6715 & 571188.31 & 135949.92 & \\
\hline 6716 & 571188.31 & 135616.59 & \\
\hline 6717 & 571188.31 & 135533.27 & \\
\hline 6718 & 571188.31 & 136033.27 & \\
\hline 6719 & 571188.31 & 136116.59 & \\
\hline 6720 & 571188.31 & 135449.92 & \\
\hline 6721 & 571188.31 & 136199.92 & \\
\hline
\end{tabular}




\begin{tabular}{|c|c|c|c|}
\hline node & X_coord & Y_coord & note: from sac04d created July 1,2004 \\
\hline 6722 & $5 \overline{7} 1188.31$ & $1 \overline{3} 5366.59$ & \\
\hline 6723 & 571188.31 & 135283.27 & \\
\hline 6724 & 571188.31 & 136283.27 & \\
\hline 6725 & 571188.31 & 136366.59 & \\
\hline 6726 & 571188.31 & 135199.92 & \\
\hline 6727 & 571188.31 & 136449.92 & \\
\hline 6728 & 571188.31 & 135116.59 & \\
\hline 6729 & 571188.31 & 135033.27 & \\
\hline 6730 & 571188.31 & 136533.27 & \\
\hline 6731 & 571188.31 & 136616.59 & \\
\hline 6732 & 564365.12 & 145760.83 & \\
\hline 6733 & 559511.38 & 146099.09 & \\
\hline 6734 & 564518.94 & 145076.75 & \\
\hline 6735 & 564765.31 & 145036.67 & \\
\hline 6736 & 564519.6113 & 145312.2665 & \\
\hline 6737 & 565017 & 145082.11 & \\
\hline 6738 & 564594.19 & 145716.67 & \\
\hline 6739 & 565285.19 & 143447.83 & \\
\hline 6740 & 565280.69 & 143587.42 & \\
\hline 6741 & 565276.12 & 143727 & \\
\hline 6742 & 565271.62 & 143866.59 & \\
\hline 6743 & 565271.62 & 144116.59 & \\
\hline 6744 & 565271.62 & 144366.59 & \\
\hline 6745 & 565271.62 & 144616.59 & \\
\hline 6746 & 565270.19 & 144872.08 & \\
\hline 6747 & 565268.69 & 145127.55 & \\
\hline 6748 & 570085.56 & 142164.73 & \\
\hline 6749 & 569833.38 & 142236.45 & \\
\hline 6750 & 570314.25 & 142148.69 & \\
\hline 6751 & 569773.56 & 141940.86 & \\
\hline 6752 & 569677.44 & 142124.52 & \\
\hline 6753 & 569581.25 & 142308.17 & \\
\hline 6754 & 570542.94 & 142132.64 & \\
\hline 6755 & 570771.62 & 142116.59 & \\
\hline 6756 & 571020.12 & 142127.11 & \\
\hline 6757 & 571268.69 & 142137.64 & \\
\hline 6758 & 571517.19 & 142148.16 & \\
\hline 6759 & 571774.75 & 142126.88 & \\
\hline 6760 & 572032.25 & 142105.59 & \\
\hline 6761 & 572289.81 & 142084.3 & \\
\hline 6762 & 573439.94 & 138669.64 & \\
\hline 6763 & 573441 & 138416.3 & \\
\hline 6764 & 573406.81 & 138951.42 & \\
\hline 6765 & 573442 & 138162.95 & \\
\hline 6766 & 573373.75 & 139233.22 & \\
\hline 6767 & 573443.06 & 137909.61 & \\
\hline 6768 & 573340.62 & 139515 & \\
\hline 6769 & 573469.25 & 137645.27 & \\
\hline 6770 & 573404.75 & 139746.09 & \\
\hline 6771 & 573495.44 & 137380.94 & \\
\hline 6772 & 573468.81 & 139977.17 & \\
\hline 6773 & 573521.62 & 137116.59 & \\
\hline 6774 & 573532.94 & 140208.27 & \\
\hline 6775 & 573521.62 & 136866.59 & \\
\hline 6776 & 573529.19 & 140427.7 & \\
\hline 6777 & 573521.62 & 136616.59 & \\
\hline
\end{tabular}




\begin{tabular}{|c|c|c|c|}
\hline node & X_coord & Y_coord & note: from sac04d created July 1, 2004 \\
\hline 6778 & $5 \overline{7} 3525.38$ & $1 \overline{4} 0647.16$ & \\
\hline 6779 & 573521.62 & 136366.59 & \\
\hline 6780 & 573521.62 & 140866.59 & \\
\hline 6781 & 573521.62 & 136116.59 & \\
\hline 6782 & 573503.25 & 140994.56 & \\
\hline 6783 & 573521.62 & 135866.59 & \\
\hline 6784 & 573484.88 & 141122.53 & \\
\hline 6785 & 571271.62 & 136616.59 & \\
\hline 6786 & 571271.62 & 136533.27 & \\
\hline 6787 & 571688.31 & 136283.27 & \\
\hline 6788 & 571604.94 & 136283.27 & \\
\hline 6789 & 571521.62 & 136283.27 & \\
\hline 6790 & 571438.31 & 136283.27 & \\
\hline 6791 & 571688.31 & 136199.92 & \\
\hline 6792 & 571938.31 & 136116.59 & \\
\hline 6793 & 571854.94 & 136116.59 & \\
\hline 6794 & 571771.62 & 136116.59 & \\
\hline 6795 & 572271.62 & 135783.27 & \\
\hline 6796 & 572188.31 & 135783.27 & \\
\hline 6797 & 572438.31 & 135783.27 & \\
\hline 6798 & 572521.62 & 135616.59 & \\
\hline 6799 & 572771.62 & 135616.59 & \\
\hline 6800 & 572438.31 & 135616.59 & \\
\hline 6801 & 571938.31 & 136033.27 & \\
\hline 6802 & 572104.94 & 135949.92 & \\
\hline 6803 & 572021.62 & 135949.92 & \\
\hline 6804 & 572104.94 & 135866.59 & \\
\hline 6805 & 571938.31 & 135949.92 & \\
\hline 6806 & 572104.94 & 135783.27 & \\
\hline 6807 & 573021.62 & 135616.59 & \\
\hline 6808 & 571688.31 & 136116.59 & \\
\hline 6809 & 571354.94 & 136449.92 & \\
\hline 6810 & 571354.94 & 136366.59 & \\
\hline 6811 & 571354.94 & 136283.27 & \\
\hline 6812 & 573271.62 & 135616.59 & \\
\hline 6813 & 571271.62 & 136449.92 & \\
\hline 6814 & 573521.62 & 135616.59 & \\
\hline 6815 & 573466.5 & 141250.5 & \\
\hline 6816 & 571438.31 & 133949.92 & \\
\hline 6817 & 577521.62 & 132616.59 & \\
\hline 6818 & 577521.62 & 132866.59 & \\
\hline 6819 & 577521.62 & 133116.59 & \\
\hline 6820 & 577521.62 & 133366.59 & \\
\hline 6821 & 577521.62 & 133616.59 & \\
\hline 6822 & 577521.62 & 133866.59 & \\
\hline 6823 & 577521.62 & 134116.59 & \\
\hline 6824 & 577771.62 & 132616.59 & \\
\hline 6825 & 576521.62 & 134866.59 & \\
\hline 6826 & 576771.62 & 134866.59 & \\
\hline 6827 & 577021.62 & 134366.59 & \\
\hline 6828 & 577271.62 & 134366.59 & \\
\hline 6829 & 577021.62 & 134616.59 & \\
\hline 6830 & 577521.62 & 134366.59 & \\
\hline 6831 & 577021.62 & 134866.59 & \\
\hline 6832 & 579021.62 & 131116.59 & \\
\hline 6833 & 579021.62 & 131366.59 & \\
\hline
\end{tabular}




\begin{tabular}{|c|c|c|c|}
\hline node & X_coord & Y_coord & note: from sac04d created July 1,2004 \\
\hline 6834 & $5 \overline{7} 9021.62$ & $1 \overline{13} 1616.59$ & \\
\hline 6835 & 579271.62 & 131116.59 & \\
\hline 6836 & 579021.62 & 131866.59 & \\
\hline 6837 & 579521.62 & 130116.6 & \\
\hline 6838 & 579521.62 & 130366.6 & \\
\hline 6839 & 579521.62 & 130616.6 & \\
\hline 6840 & 579771.62 & 130116.6 & \\
\hline 6841 & 579521.62 & 130866.59 & \\
\hline 6842 & 581521.62 & 128866.6 & \\
\hline 6843 & 581521.62 & 128366.6 & \\
\hline 6844 & 581521.62 & 129116.6 & \\
\hline 6845 & 582021.62 & 128116.6 & \\
\hline 6846 & 582021.62 & 127366.6 & \\
\hline 6847 & 582021.62 & 128366.6 & \\
\hline 6848 & 580521.62 & 129866.6 & \\
\hline 6849 & 580771.62 & 129866.6 & \\
\hline 6850 & 581021.62 & 129366.6 & \\
\hline 6851 & 581271.62 & 129366.6 & \\
\hline 6852 & 581021.62 & 129616.6 & \\
\hline 6853 & 581521.62 & 129366.6 & \\
\hline 6854 & 581021.62 & 129866.6 & \\
\hline 6855 & 582021.62 & 126616.6 & \\
\hline 6856 & 580021.62 & 130116.6 & \\
\hline 6857 & 580271.62 & 130116.6 & \\
\hline 6858 & 580521.62 & 130116.6 & \\
\hline 6859 & 582021.62 & 125866.6 & \\
\hline 6860 & 582021.62 & 125116.6 & \\
\hline 6861 & 579521.62 & 131116.59 & \\
\hline 6862 & 578021.62 & 132616.59 & \\
\hline 6863 & 578271.62 & 132616.59 & \\
\hline 6864 & 578521.62 & 132116.59 & \\
\hline 6865 & 578771.62 & 132116.59 & \\
\hline 6866 & 578521.62 & 132366.59 & \\
\hline 6867 & 579021.62 & 132116.59 & \\
\hline 6868 & 578521.62 & 132616.59 & \\
\hline 6869 & 582021.62 & 124366.6 & \\
\hline 6870 & 582021.62 & 123616.6 & \\
\hline 6871 & 573771.62 & 135116.59 & \\
\hline 6872 & 573521.62 & 135116.59 & \\
\hline 6873 & 574021.62 & 135116.59 & \\
\hline 6874 & 573271.62 & 135116.59 & \\
\hline 6875 & 574271.62 & 135116.59 & \\
\hline 6876 & 573021.62 & 135116.59 & \\
\hline 6877 & 574521.62 & 135116.59 & \\
\hline 6878 & 573188.31 & 134116.59 & \\
\hline 6879 & 573104.94 & 134366.59 & \\
\hline 6880 & 573104.94 & 134283.27 & \\
\hline 6881 & 573104.94 & 134449.92 & \\
\hline 6882 & 573104.94 & 134199.92 & \\
\hline 6883 & 573021.62 & 134449.92 & \\
\hline 6884 & 572938.31 & 134616.59 & \\
\hline 6885 & 572938.31 & 134533.27 & \\
\hline 6886 & 572938.31 & 134783.27 & \\
\hline 6887 & 572771.62 & 134866.59 & \\
\hline 6888 & 572771.62 & 135116.59 & \\
\hline 6889 & 572771.62 & 134783.27 & \\
\hline
\end{tabular}




\begin{tabular}{|c|c|c|c|}
\hline node & X_coord & Y_coord & note: from sac04d created July 1,2004 \\
\hline 6890 & $5 \overline{7} 2938.31$ & $1 \overline{3} 4449.92$ & \\
\hline 6891 & 573104.94 & 134116.59 & \\
\hline 6892 & 574771.62 & 135116.59 & \\
\hline 6893 & 575021.62 & 135116.59 & \\
\hline 6894 & 575271.62 & 135116.59 & \\
\hline 6895 & 573104.94 & 133949.92 & \\
\hline 6896 & 573104.94 & 134033.27 & \\
\hline 6897 & 575521.62 & 135116.59 & \\
\hline 6898 & 573021.62 & 133783.27 & \\
\hline 6899 & 573021.62 & 133866.59 & \\
\hline 6900 & 573021.62 & 133949.92 & \\
\hline 6901 & 575771.62 & 135116.59 & \\
\hline 6902 & 572938.31 & 133783.27 & \\
\hline 6903 & 576021.62 & 135116.59 & \\
\hline 6904 & 576271.62 & 135116.59 & \\
\hline 6905 & 576521.62 & 135116.59 & \\
\hline 6906 & 582021.62 & 122866.6 & \\
\hline 6907 & 582021.62 & 122116.6 & \\
\hline 6908 & 572854.94 & 133783.27 & \\
\hline 6909 & 582021.62 & 121366.6 & \\
\hline 6910 & 572188.31 & 133866.59 & \\
\hline 6911 & 572271.62 & 133866.59 & \\
\hline 6912 & 572354.94 & 133866.59 & \\
\hline 6913 & 572438.31 & 133866.59 & \\
\hline 6914 & 572521.62 & 133866.59 & \\
\hline 6915 & 572604.94 & 133866.59 & \\
\hline 6916 & 572688.31 & 133866.59 & \\
\hline 6917 & 572771.62 & 133866.59 & \\
\hline 6918 & 572854.94 & 133866.59 & \\
\hline 6919 & 582021.62 & 120616.6 & \\
\hline 6920 & 571521.62 & 133949.92 & \\
\hline 6921 & 571604.94 & 133949.92 & \\
\hline 6922 & 571688.31 & 133949.92 & \\
\hline 6923 & 571771.62 & 133949.92 & \\
\hline 6924 & 571854.94 & 133949.92 & \\
\hline 6925 & 571938.31 & 133949.92 & \\
\hline 6926 & 572021.62 & 133949.92 & \\
\hline 6927 & 572104.94 & 133949.92 & \\
\hline 6928 & 572188.31 & 133949.92 & \\
\hline 6929 & 580886.5 & 120063.9 & \\
\hline 6930 & 581227.38 & 119862.4 & \\
\hline 6931 & 582017.62 & 119939.9 & \\
\hline 6932 & 571271.62 & 134616.59 & \\
\hline 6933 & 571271.62 & 134699.92 & \\
\hline 6934 & 571271.62 & 134783.27 & \\
\hline 6935 & 571354.94 & 134616.59 & \\
\hline 6936 & 571271.62 & 134866.59 & \\
\hline 6937 & 571438.31 & 134033.27 & \\
\hline 6938 & 571438.31 & 134116.59 & \\
\hline 6939 & 571438.31 & 134199.92 & \\
\hline 6940 & 571438.31 & 134283.27 & \\
\hline 6941 & 571438.31 & 134366.59 & \\
\hline 6942 & 571438.31 & 134449.92 & \\
\hline 6943 & 571438.31 & 134533.27 & \\
\hline 6944 & 571438.31 & 134616.59 & \\
\hline 6945 & 571271.62 & 134949.92 & \\
\hline
\end{tabular}




\begin{tabular}{|c|c|c|c|}
\hline node & X_coord & Y_coord & note: from sac04d created July 1,2004 \\
\hline 6946 & $5 \overline{7} 1271.62$ & $1 \overline{3} 5033.27$ & \\
\hline 6947 & 571271.62 & 135783.27 & \\
\hline 6948 & 571271.62 & 135699.92 & \\
\hline 6949 & 571271.62 & 135866.59 & \\
\hline 6950 & 571271.62 & 135949.92 & \\
\hline 6951 & 571271.62 & 135616.59 & \\
\hline 6952 & 571271.62 & 136033.27 & \\
\hline 6953 & 571271.62 & 135533.27 & \\
\hline 6954 & 571271.62 & 135449.92 & \\
\hline 6955 & 571271.62 & 136116.59 & \\
\hline 6956 & 571271.62 & 136199.92 & \\
\hline 6957 & 571271.62 & 135366.59 & \\
\hline 6958 & 571271.62 & 136283.27 & \\
\hline 6959 & 571271.62 & 135283.27 & \\
\hline 6960 & 571271.62 & 135199.92 & \\
\hline 6961 & 571271.62 & 136366.59 & \\
\hline 6962 & 571271.62 & 135116.59 & \\
\hline 6963 & 564784.1051 & 145286.2731 & \\
\hline 6964 & 565036.6751 & 145310.483 & \\
\hline 6965 & 564823.31 & 145672.5 & \\
\hline 6966 & 565295.2051 & 145414.8485 & \\
\hline 6967 & 565545.12 & 143454.09 & \\
\hline 6968 & 565537.31 & 143591.59 & \\
\hline 6969 & 565529.44 & 143729.09 & \\
\hline 6970 & 565521.62 & 143866.59 & \\
\hline 6971 & 565521.62 & 144116.59 & \\
\hline 6972 & 565521.62 & 144366.59 & \\
\hline 6973 & 565521.62 & 144616.59 & \\
\hline 6974 & 565521 & 144894.8 & \\
\hline 6975 & 565520.44 & 145173 & \\
\hline 6976 & 565487.4855 & 145453.0122 & \\
\hline 6977 & 570038.38 & 142452.3 & \\
\hline 6978 & 569761.75 & 142472.06 & \\
\hline 6979 & 570282.81 & 142423.73 & \\
\hline 6980 & 569485.12 & 142491.83 & \\
\hline 6981 & 570527.19 & 142395.16 & \\
\hline 6982 & 569570.38 & 142116.5 & \\
\hline 6983 & 569449.75 & 142248.2 & \\
\hline 6984 & 569329.12 & 142379.89 & \\
\hline 6985 & 569208.5 & 142511.59 & \\
\hline 6986 & 570771.62 & 142366.59 & \\
\hline 6987 & 571021.62 & 142366.59 & \\
\hline 6988 & 571271.62 & 142366.59 & \\
\hline 6989 & 571521.62 & 142366.59 & \\
\hline 6990 & 571759.69 & 142336.62 & \\
\hline 6991 & 571997.81 & 142306.67 & \\
\hline 6992 & 572235.88 & 142276.7 & \\
\hline 6993 & 573642.38 & 138700 & \\
\hline 6994 & 573689.81 & 138443.14 & \\
\hline 6995 & 573594.94 & 138996.41 & \\
\hline 6996 & 573737.25 & 138186.27 & \\
\hline 6997 & 573547.56 & 139292.8 & \\
\hline 6998 & 573784.69 & 137929.41 & \\
\hline 6999 & 573500.12 & 139589.2 & \\
\hline 7000 & 573780.31 & 137658.47 & \\
\hline 7001 & 573596.31 & 139810.83 & \\
\hline
\end{tabular}




\begin{tabular}{|c|c|c|c|}
\hline node & X_coord & Y_coord & note: from sac04d created July 1, 2004 \\
\hline 7002 & $5 \overline{7} 3776$ & $1 \overline{3} 7387.53$ & \\
\hline 7003 & 573692.44 & 140032.47 & \\
\hline 7004 & 573771.62 & 137116.59 & \\
\hline 7005 & 573788.62 & 140254.09 & \\
\hline 7006 & 573771.62 & 136866.59 & \\
\hline 7007 & 573782.94 & 140458.27 & \\
\hline 7008 & 573771.62 & 136616.59 & \\
\hline 7009 & 573777.31 & 140662.42 & \\
\hline 7010 & 573771.62 & 136366.59 & \\
\hline 7011 & 573771.62 & 140866.59 & \\
\hline 7012 & 573771.62 & 136116.59 & \\
\hline 7013 & 573745.31 & 140961.23 & \\
\hline 7014 & 573771.62 & 135866.59 & \\
\hline 7015 & 573719 & 141055.86 & \\
\hline 7016 & 573771.62 & 135616.59 & \\
\hline 7017 & 573692.69 & 141150.5 & \\
\hline 7018 & 571604.94 & 136199.92 & \\
\hline 7019 & 571521.62 & 136199.92 & \\
\hline 7020 & 571438.31 & 136199.92 & \\
\hline 7021 & 571354.94 & 136199.92 & \\
\hline 7022 & 571604.94 & 136116.59 & \\
\hline 7023 & 571854.94 & 136033.27 & \\
\hline 7024 & 571771.62 & 136033.27 & \\
\hline 7025 & 571688.31 & 136033.27 & \\
\hline 7026 & 572271.62 & 135699.92 & \\
\hline 7027 & 572188.31 & 135699.92 & \\
\hline 7028 & 572354.94 & 135699.92 & \\
\hline 7029 & 572104.94 & 135699.92 & \\
\hline 7030 & 572354.94 & 135616.59 & \\
\hline 7031 & 572521.62 & 135366.59 & \\
\hline 7032 & 572771.62 & 135366.59 & \\
\hline 7033 & 572438.31 & 135366.59 & \\
\hline 7034 & 573021.62 & 135366.59 & \\
\hline 7035 & 572382.75 & 135533.27 & \\
\hline 7036 & 572382.75 & 135449.92 & \\
\hline 7037 & 572327.19 & 135533.27 & \\
\hline 7038 & 571854.94 & 135949.92 & \\
\hline 7039 & 572021.62 & 135866.59 & \\
\hline 7040 & 571938.31 & 135866.59 & \\
\hline 7041 & 572021.62 & 135783.27 & \\
\hline 7042 & 571854.94 & 135866.59 & \\
\hline 7043 & 572021.62 & 135699.92 & \\
\hline 7044 & 573271.62 & 135366.59 & \\
\hline 7045 & 571604.94 & 136033.27 & \\
\hline 7046 & 573521.62 & 135366.59 & \\
\hline 7047 & 573771.62 & 135366.59 & \\
\hline 7048 & 571521.62 & 134033.27 & \\
\hline 7049 & 577771.62 & 132866.59 & \\
\hline 7050 & 577771.62 & 133116.59 & \\
\hline 7051 & 577771.62 & 133366.59 & \\
\hline 7052 & 577771.62 & 133616.59 & \\
\hline 7053 & 577771.62 & 133866.59 & \\
\hline 7054 & 577771.62 & 134116.59 & \\
\hline 7055 & 577771.62 & 134366.59 & \\
\hline 7056 & 578021.62 & 132866.59 & \\
\hline 7057 & 576771.62 & 135116.59 & \\
\hline
\end{tabular}




\begin{tabular}{|c|c|c|c|}
\hline node & X_coord & Y_coord & note: from sac04d created July 1,2004 \\
\hline 7058 & 577021.62 & 135116.59 & \\
\hline 7059 & 577271.62 & 134616.59 & \\
\hline 7060 & 577521.62 & 134616.59 & \\
\hline 7061 & 577271.62 & 134866.59 & \\
\hline 7062 & 577771.62 & 134616.59 & \\
\hline 7063 & 577271.62 & 135116.59 & \\
\hline 7064 & 579271.62 & 131366.59 & \\
\hline 7065 & 579271.62 & 131616.59 & \\
\hline 7066 & 579271.62 & 131866.59 & \\
\hline 7067 & 579521.62 & 131366.59 & \\
\hline 7068 & 579271.62 & 132116.59 & \\
\hline 7069 & 579771.62 & 130366.6 & \\
\hline 7070 & 579771.62 & 130616.6 & \\
\hline 7071 & 579771.62 & 130866.59 & \\
\hline 7072 & 580021.62 & 130366.6 & \\
\hline 7073 & 579771.62 & 131116.59 & \\
\hline 7074 & 581771.62 & 128866.6 & \\
\hline 7075 & 581771.62 & 128616.6 & \\
\hline 7076 & 581771.62 & 129116.6 & \\
\hline 7077 & 582021.62 & 128616.6 & \\
\hline 7078 & 581771.62 & 129366.6 & \\
\hline 7079 & 582271.62 & 128116.6 & \\
\hline 7080 & 582271.62 & 127616.6 & \\
\hline 7081 & 582271.62 & 128366.6 & \\
\hline 7082 & 582771.62 & 127366.6 & \\
\hline 7083 & 582771.62 & 126616.6 & \\
\hline 7084 & 582771.62 & 127616.6 & \\
\hline 7085 & 582271.62 & 128616.6 & \\
\hline 7086 & 580771.62 & 130116.6 & \\
\hline 7087 & 581021.62 & 130116.6 & \\
\hline 7088 & 581271.62 & 129616.6 & \\
\hline 7089 & 581521.62 & 129616.6 & \\
\hline 7090 & 581271.62 & 129866.6 & \\
\hline 7091 & 581771.62 & 129616.6 & \\
\hline 7092 & 581271.62 & 130116.6 & \\
\hline 7093 & 582771.62 & 125866.6 & \\
\hline 7094 & 580271.62 & 130366.6 & \\
\hline 7095 & 580521.62 & 130366.6 & \\
\hline 7096 & 580771.62 & 130366.6 & \\
\hline 7097 & 582771.62 & 125116.6 & \\
\hline 7098 & 582771.62 & 124366.6 & \\
\hline 7099 & 579771.62 & 131366.59 & \\
\hline 7100 & 578271.62 & 132866.59 & \\
\hline 7101 & 578521.62 & 132866.59 & \\
\hline 7102 & 578771.62 & 132366.59 & \\
\hline 7103 & 579021.62 & 132366.59 & \\
\hline 7104 & 578771.62 & 132616.59 & \\
\hline 7105 & 579271.62 & 132366.59 & \\
\hline 7106 & 578771.62 & 132866.59 & \\
\hline 7107 & 582771.62 & 123616.6 & \\
\hline 7108 & 582771.62 & 122866.6 & \\
\hline 7109 & 574021.62 & 135366.59 & \\
\hline 7110 & 574271.62 & 135366.59 & \\
\hline 7111 & 574521.62 & 135366.59 & \\
\hline 7112 & 574771.62 & 135366.59 & \\
\hline 7113 & 573021.62 & 134366.59 & \\
\hline
\end{tabular}




\begin{tabular}{|c|c|c|c|}
\hline node & X_coord & Y_coord & note: from sac04d created July 1, 2004 \\
\hline 7114 & $5 \overline{7} 3021.62$ & $1 \overline{3} 4283.27$ & \\
\hline 7115 & 573021.62 & 134199.92 & \\
\hline 7116 & 573021.62 & 134116.59 & \\
\hline 7117 & 572938.31 & 134366.59 & \\
\hline 7118 & 572854.94 & 134616.59 & \\
\hline 7119 & 572854.94 & 134533.27 & \\
\hline 7120 & 572854.94 & 134699.92 & \\
\hline 7121 & 572854.94 & 134449.92 & \\
\hline 7122 & 572771.62 & 134699.92 & \\
\hline 7123 & 572688.31 & 134866.59 & \\
\hline 7124 & 572688.31 & 134783.27 & \\
\hline 7125 & 572688.31 & 135116.59 & \\
\hline 7126 & 572688.31 & 135283.27 & \\
\hline 7127 & 572688.31 & 134699.92 & \\
\hline 7128 & 572854.94 & 134366.59 & \\
\hline 7129 & 573021.62 & 134033.27 & \\
\hline 7130 & 575021.62 & 135366.59 & \\
\hline 7131 & 575271.62 & 135366.59 & \\
\hline 7132 & 575521.62 & 135366.59 & \\
\hline 7133 & 575771.62 & 135366.59 & \\
\hline 7134 & 572938.31 & 133866.59 & \\
\hline 7135 & 572938.31 & 133949.92 & \\
\hline 7136 & 572938.31 & 134033.27 & \\
\hline 7137 & 576021.62 & 135366.59 & \\
\hline 7138 & 576271.62 & 135366.59 & \\
\hline 7139 & 576521.62 & 135366.59 & \\
\hline 7140 & 576771.62 & 135366.59 & \\
\hline 7141 & 582771.62 & 122116.6 & \\
\hline 7142 & 582771.62 & 121366.6 & \\
\hline 7143 & 582771.62 & 120616.6 & \\
\hline 7144 & 572271.62 & 133949.92 & \\
\hline 7145 & 572354.94 & 133949.92 & \\
\hline 7146 & 572438.31 & 133949.92 & \\
\hline 7147 & 572521.62 & 133949.92 & \\
\hline 7148 & 572604.94 & 133949.92 & \\
\hline 7149 & 572688.31 & 133949.92 & \\
\hline 7150 & 572771.62 & 133949.92 & \\
\hline 7151 & 572854.94 & 133949.92 & \\
\hline 7152 & 582761.38 & 120001.9 & \\
\hline 7153 & 571604.94 & 134033.27 & \\
\hline 7154 & 571688.31 & 134033.27 & \\
\hline 7155 & 571771.62 & 134033.27 & \\
\hline 7156 & 571854.94 & 134033.27 & \\
\hline 7157 & 571938.31 & 134033.27 & \\
\hline 7158 & 572021.62 & 134033.27 & \\
\hline 7159 & 572104.94 & 134033.27 & \\
\hline 7160 & 572188.31 & 134033.27 & \\
\hline 7161 & 572271.62 & 134033.27 & \\
\hline 7162 & 571354.94 & 134699.92 & \\
\hline 7163 & 571354.94 & 134783.27 & \\
\hline 7164 & 571354.94 & 134866.59 & \\
\hline 7165 & 571438.31 & 134699.92 & \\
\hline 7166 & 571354.94 & 134949.92 & \\
\hline 7167 & 571521.62 & 134116.59 & \\
\hline 7168 & 571521.62 & 134199.92 & \\
\hline 7169 & 571521.62 & 134283.27 & \\
\hline
\end{tabular}




\begin{tabular}{|c|c|c|c|}
\hline node & X_coord & Y_coord & note: from sac04d created July 1, 2004 \\
\hline 7170 & $5 \overline{7} 1521.62$ & $1 \overline{3} 4366.59$ & \\
\hline 7171 & 571521.62 & 134449.92 & \\
\hline 7172 & 571521.62 & 134533.27 & \\
\hline 7173 & 571521.62 & 134616.59 & \\
\hline 7174 & 571521.62 & 134699.92 & \\
\hline 7175 & 571354.94 & 135033.27 & \\
\hline 7176 & 571354.94 & 135116.59 & \\
\hline 7177 & 571354.94 & 135783.27 & \\
\hline 7178 & 571354.94 & 135866.59 & \\
\hline 7179 & 571354.94 & 135699.92 & \\
\hline 7180 & 571354.94 & 135616.59 & \\
\hline 7181 & 571354.94 & 135949.92 & \\
\hline 7182 & 571354.94 & 136033.27 & \\
\hline 7183 & 571354.94 & 135533.27 & \\
\hline 7184 & 571354.94 & 136116.59 & \\
\hline 7185 & 571354.94 & 135449.92 & \\
\hline 7186 & 571354.94 & 135366.59 & \\
\hline 7187 & 571354.94 & 135283.27 & \\
\hline 7188 & 571354.94 & 135199.92 & \\
\hline 7189 & 565012.9657 & 145670.5872 & \\
\hline 7190 & 565220.7314 & 145720.2372 & \\
\hline 7191 & 565407.81 & 145767.3 & \\
\hline 7192 & 565790.12 & 143416.53 & \\
\hline 7193 & 565783.94 & 143566.55 & \\
\hline 7194 & 565777.81 & 143716.58 & \\
\hline 7195 & 565771.62 & 143866.59 & \\
\hline 7196 & 565771.62 & 144116.59 & \\
\hline 7197 & 565771.62 & 144366.59 & \\
\hline 7198 & 565771.62 & 144616.59 & \\
\hline 7199 & 565757.19 & 144914.17 & \\
\hline 7200 & 565742.75 & 145211.75 & \\
\hline 7201 & 565713.5736 & 145513.727 & \\
\hline 7202 & 565634.75 & 145821.67 & \\
\hline 7203 & 570032.81 & 142673.73 & \\
\hline 7204 & 569765.06 & 142686.91 & \\
\hline 7205 & 570279.06 & 142654.69 & \\
\hline 7206 & 569497.31 & 142700.08 & \\
\hline 7207 & 570525.31 & 142635.64 & \\
\hline 7208 & 569229.56 & 142713.27 & \\
\hline 7209 & 570771.62 & 142616.59 & \\
\hline 7210 & 568983.25 & 142578.77 & \\
\hline 7211 & 568998.31 & 142757.69 & \\
\hline 7212 & 571021.62 & 142616.59 & \\
\hline 7213 & 571271.62 & 142616.59 & \\
\hline 7214 & 571521.62 & 142616.59 & \\
\hline 7215 & 571763.69 & 142596.61 & \\
\hline 7216 & 572005.75 & 142576.64 & \\
\hline 7217 & 572247.81 & 142556.67 & \\
\hline 7218 & 572495.31 & 142443.91 & \\
\hline 7219 & 572504.06 & 142668.14 & \\
\hline 7220 & 574014.69 & 137731.64 & \\
\hline 7221 & 574014.06 & 137504.23 & \\
\hline 7222 & 573843.06 & 139767.91 & \\
\hline 7223 & 573906 & 139950.23 & \\
\hline 7224 & 574013.5 & 137276.83 & \\
\hline 7225 & 573968.88 & 140132.56 & \\
\hline
\end{tabular}




\begin{tabular}{|c|c|c|c|}
\hline node & X_coord & Y_coord & note: from sac04d created July 1,2004 \\
\hline 7226 & $5 \overline{7} 4012.88$ & $1 \overline{3} 7049.42$ & \\
\hline 7227 & 574031.81 & 140314.89 & \\
\hline 7228 & 574015.81 & 136821.81 & \\
\hline 7229 & 574028.06 & 140487.95 & \\
\hline 7230 & 574018.69 & 136594.2 & \\
\hline 7231 & 574024.25 & 140661.03 & \\
\hline 7232 & 574021.62 & 136366.59 & \\
\hline 7233 & 574020.5 & 140834.09 & \\
\hline 7234 & 574021.62 & 136116.59 & \\
\hline 7235 & 574003.06 & 140925.8 & \\
\hline 7236 & 574021.62 & 135866.59 & \\
\hline 7237 & 573985.62 & 141017.5 & \\
\hline 7238 & 574021.62 & 135616.59 & \\
\hline 7239 & 573968.19 & 141109.2 & \\
\hline 7240 & 571521.62 & 136116.59 & \\
\hline 7241 & 571438.31 & 136116.59 & \\
\hline 7242 & 571521.62 & 136033.27 & \\
\hline 7243 & 571771.62 & 135949.92 & \\
\hline 7244 & 571688.31 & 135949.92 & \\
\hline 7245 & 571604.94 & 135949.92 & \\
\hline 7246 & 572271.62 & 135616.59 & \\
\hline 7247 & 572188.31 & 135616.59 & \\
\hline 7248 & 572104.94 & 135616.59 & \\
\hline 7249 & 572021.62 & 135616.59 & \\
\hline 7250 & 572271.62 & 135533.27 & \\
\hline 7251 & 572521.62 & 135283.27 & \\
\hline 7252 & 572438.31 & 135283.27 & \\
\hline 7253 & 572354.94 & 135366.59 & \\
\hline 7254 & 572327.19 & 135449.92 & \\
\hline 7255 & 572354.94 & 135283.27 & \\
\hline 7256 & 572271.62 & 135449.92 & \\
\hline 7257 & 571771.62 & 135866.59 & \\
\hline 7258 & 571938.31 & 135783.27 & \\
\hline 7259 & 571854.94 & 135783.27 & \\
\hline 7260 & 571938.31 & 135699.92 & \\
\hline 7261 & 571771.62 & 135783.27 & \\
\hline 7262 & 571938.31 & 135616.59 & \\
\hline 7263 & 571521.62 & 135949.92 & \\
\hline 7264 & 571604.94 & 134116.59 & \\
\hline 7265 & 578021.62 & 133116.59 & \\
\hline 7266 & 578021.62 & 133366.59 & \\
\hline 7267 & 578021.62 & 133616.59 & \\
\hline 7268 & 578021.62 & 133866.59 & \\
\hline 7269 & 578021.62 & 134116.59 & \\
\hline 7270 & 578021.62 & 134366.59 & \\
\hline 7271 & 578021.62 & 134616.59 & \\
\hline 7272 & 578271.62 & 133116.59 & \\
\hline 7273 & 577021.62 & 135366.59 & \\
\hline 7274 & 577271.62 & 135366.59 & \\
\hline 7275 & 577521.62 & 134866.59 & \\
\hline 7276 & 577771.62 & 134866.59 & \\
\hline 7277 & 577521.62 & 135116.59 & \\
\hline 7278 & 578021.62 & 134866.59 & \\
\hline 7279 & 577521.62 & 135366.59 & \\
\hline 7280 & 579521.62 & 131616.59 & \\
\hline 7281 & 579521.62 & 131866.59 & \\
\hline
\end{tabular}




\begin{tabular}{|c|c|c|c|}
\hline node & X_coord & Y_coord & note: from sac04d created July 1, 2004 \\
\hline 7282 & $5 \overline{7} 9521.62$ & $1 \overline{3} 2116.59$ & \\
\hline 7283 & 579771.62 & 131616.59 & \\
\hline 7284 & 579521.62 & 132366.59 & \\
\hline 7285 & 580021.62 & 130616.6 & \\
\hline 7286 & 580021.62 & 130866.59 & \\
\hline 7287 & 580021.62 & 131116.59 & \\
\hline 7288 & 580271.62 & 130616.6 & \\
\hline 7289 & 580021.62 & 131366.59 & \\
\hline 7290 & 582021.62 & 128866.6 & \\
\hline 7291 & 582021.62 & 129116.6 & \\
\hline 7292 & 582021.62 & 129366.6 & \\
\hline 7293 & 582271.62 & 128866.6 & \\
\hline 7294 & 582021.62 & 129616.6 & \\
\hline 7295 & 582521.62 & 128116.6 & \\
\hline 7296 & 582521.62 & 127866.6 & \\
\hline 7297 & 582521.62 & 128366.6 & \\
\hline 7298 & 582771.62 & 127866.6 & \\
\hline 7299 & 582521.62 & 128616.6 & \\
\hline 7300 & 583021.62 & 127366.6 & \\
\hline 7301 & 583021.62 & 126866.6 & \\
\hline 7302 & 583021.62 & 127616.6 & \\
\hline 7303 & 583521.62 & 126616.6 & \\
\hline 7304 & 583521.62 & 125866.6 & \\
\hline 7305 & 583521.62 & 126866.6 & \\
\hline 7306 & 583021.62 & 127866.6 & \\
\hline 7307 & 582521.62 & 128866.6 & \\
\hline 7308 & 581021.62 & 130366.6 & \\
\hline 7309 & 581271.62 & 130366.6 & \\
\hline 7310 & 581521.62 & 129866.6 & \\
\hline 7311 & 581771.62 & 129866.6 & \\
\hline 7312 & 581521.62 & 130116.6 & \\
\hline 7313 & 582021.62 & 129866.6 & \\
\hline 7314 & 581521.62 & 130366.6 & \\
\hline 7315 & 583521.62 & 125116.6 & \\
\hline 7316 & 580521.62 & 130616.6 & \\
\hline 7317 & 580771.62 & 130616.6 & \\
\hline 7318 & 581021.62 & 130616.6 & \\
\hline 7319 & 583521.62 & 124366.6 & \\
\hline 7320 & 583521.62 & 123616.6 & \\
\hline 7321 & 580021.62 & 131616.59 & \\
\hline 7322 & 578521.62 & 133116.59 & \\
\hline 7323 & 578771.62 & 133116.59 & \\
\hline 7324 & 579021.62 & 132616.59 & \\
\hline 7325 & 579271.62 & 132616.59 & \\
\hline 7326 & 579021.62 & 132866.59 & \\
\hline 7327 & 579521.62 & 132616.59 & \\
\hline 7328 & 579021.62 & 133116.59 & \\
\hline 7329 & 583521.62 & 122866.6 & \\
\hline 7330 & 583521.62 & 122116.6 & \\
\hline 7331 & 574271.62 & 135616.59 & \\
\hline 7332 & 574521.62 & 135616.59 & \\
\hline 7333 & 574771.62 & 135616.59 & \\
\hline 7334 & 575021.62 & 135616.59 & \\
\hline 7335 & 572938.31 & 134283.27 & \\
\hline 7336 & 572938.31 & 134199.92 & \\
\hline 7337 & 572938.31 & 134116.59 & \\
\hline
\end{tabular}




\begin{tabular}{|c|c|c|c|}
\hline node & X_coord & Y_coord & note: from sac04d created July 1,2004 \\
\hline 7338 & $5 \overline{7} 2854.94$ & $1 \overline{3} 4283.27$ & \\
\hline 7339 & 572771.62 & 134616.59 & \\
\hline 7340 & 572771.62 & 134533.27 & \\
\hline 7341 & 572771.62 & 134449.92 & \\
\hline 7342 & 572771.62 & 134366.59 & \\
\hline 7343 & 572688.31 & 134616.59 & \\
\hline 7344 & 572604.94 & 134866.59 & \\
\hline 7345 & 572604.94 & 134783.27 & \\
\hline 7346 & 572632.75 & 134949.92 & \\
\hline 7347 & 572577.19 & 134949.92 & \\
\hline 7348 & 572632.75 & 135033.27 & \\
\hline 7349 & 572604.94 & 134699.92 & \\
\hline 7350 & 572604.94 & 135116.59 & \\
\hline 7351 & 572577.19 & 135033.27 & \\
\hline 7352 & 572604.94 & 135199.92 & \\
\hline 7353 & 572521.62 & 135199.92 & \\
\hline 7354 & 572604.94 & 134616.59 & \\
\hline 7355 & 572771.62 & 134283.27 & \\
\hline 7356 & 575271.62 & 135616.59 & \\
\hline 7357 & 575521.62 & 135616.59 & \\
\hline 7358 & 575771.62 & 135616.59 & \\
\hline 7359 & 576021.62 & 135616.59 & \\
\hline 7360 & 572854.94 & 134033.27 & \\
\hline 7361 & 572854.94 & 134116.59 & \\
\hline 7362 & 576271.62 & 135616.59 & \\
\hline 7363 & 576521.62 & 135616.59 & \\
\hline 7364 & 576771.62 & 135616.59 & \\
\hline 7365 & 577021.62 & 135616.59 & \\
\hline 7366 & 583521.62 & 121366.6 & \\
\hline 7367 & 583521.62 & 120616.6 & \\
\hline 7368 & 583551.69 & 119970.9 & \\
\hline 7369 & 572354.94 & 134033.27 & \\
\hline 7370 & 572438.31 & 134033.27 & \\
\hline 7371 & 572521.62 & 134033.27 & \\
\hline 7372 & 572604.94 & 134033.27 & \\
\hline 7373 & 572688.31 & 134033.27 & \\
\hline 7374 & 572771.62 & 134033.27 & \\
\hline 7375 & 571688.31 & 134116.59 & \\
\hline 7376 & 571771.62 & 134116.59 & \\
\hline 7377 & 571854.94 & 134116.59 & \\
\hline 7378 & 571938.31 & 134116.59 & \\
\hline 7379 & 572021.62 & 134116.59 & \\
\hline 7380 & 572104.94 & 134116.59 & \\
\hline 7381 & 572188.31 & 134116.59 & \\
\hline 7382 & 572271.62 & 134116.59 & \\
\hline 7383 & 572354.94 & 134116.59 & \\
\hline 7384 & 571438.31 & 134783.27 & \\
\hline 7385 & 571438.31 & 134866.59 & \\
\hline 7386 & 571438.31 & 134949.92 & \\
\hline 7387 & 571521.62 & 134783.27 & \\
\hline 7388 & 571438.31 & 135033.27 & \\
\hline 7389 & 571604.94 & 134199.92 & \\
\hline 7390 & 571604.94 & 134283.27 & \\
\hline 7391 & 571604.94 & 134366.59 & \\
\hline 7392 & 571604.94 & 134449.92 & \\
\hline 7393 & 571604.94 & 134533.27 & \\
\hline
\end{tabular}




\begin{tabular}{|c|c|c|c|}
\hline node & X_coord & Y_coord & note: from sac04d created July 1,2004 \\
\hline 7394 & $5 \overline{7} 1604.94$ & $1 \overline{3} 4616.59$ & \\
\hline 7395 & 571604.94 & 134699.92 & \\
\hline 7396 & 571604.94 & 134783.27 & \\
\hline 7397 & 571438.31 & 135116.59 & \\
\hline 7398 & 571438.31 & 135199.92 & \\
\hline 7399 & 571438.31 & 135783.27 & \\
\hline 7400 & 571438.31 & 135866.59 & \\
\hline 7401 & 571438.31 & 135699.92 & \\
\hline 7402 & 571438.31 & 135949.92 & \\
\hline 7403 & 571438.31 & 135616.59 & \\
\hline 7404 & 571438.31 & 135533.27 & \\
\hline 7405 & 571438.31 & 136033.27 & \\
\hline 7406 & 571438.31 & 135449.92 & \\
\hline 7407 & 571438.31 & 135366.59 & \\
\hline 7408 & 571438.31 & 135283.27 & \\
\hline 7409 & 566035.19 & 143378.97 & \\
\hline 7410 & 566030.69 & 143541.52 & \\
\hline 7411 & 566026.12 & 143704.05 & \\
\hline 7412 & 566021.62 & 143866.59 & \\
\hline 7413 & 566021.62 & 144116.59 & \\
\hline 7414 & 566021.62 & 144366.59 & \\
\hline 7415 & 566021.62 & 144616.59 & \\
\hline 7416 & 565993.38 & 144933.55 & \\
\hline 7417 & 565965.06 & 145250.52 & \\
\hline 7418 & 565936.81 & 145567.47 & \\
\hline 7419 & 565861.69 & 145876.03 & \\
\hline 7420 & 570027.19 & 142895.16 & \\
\hline 7421 & 569768.31 & 142901.75 & \\
\hline 7422 & 570275.38 & 142885.64 & \\
\hline 7423 & 569509.44 & 142908.34 & \\
\hline 7424 & 570523.5 & 142876.11 & \\
\hline 7425 & 569250.56 & 142914.92 & \\
\hline 7426 & 570771.62 & 142866.59 & \\
\hline 7427 & 569013.38 & 142936.61 & \\
\hline 7428 & 571021.62 & 142866.59 & \\
\hline 7429 & 568757.94 & 142645.92 & \\
\hline 7430 & 568767.06 & 142802.11 & \\
\hline 7431 & 568776.19 & 142958.28 & \\
\hline 7432 & 571271.62 & 142866.59 & \\
\hline 7433 & 571521.62 & 142866.59 & \\
\hline 7434 & 571767.62 & 142856.61 & \\
\hline 7435 & 572013.69 & 142846.62 & \\
\hline 7436 & 572259.69 & 142836.62 & \\
\hline 7437 & 572512.88 & 142892.36 & \\
\hline 7438 & 572754.69 & 142611.09 & \\
\hline 7439 & 572760.31 & 142779.59 & \\
\hline 7440 & 572766 & 142948.09 & \\
\hline 7441 & 574244.69 & 137533.86 & \\
\hline 7442 & 574247.81 & 137350 & \\
\hline 7443 & 574250.94 & 137166.12 & \\
\hline 7444 & 574185.94 & 139946.59 & \\
\hline 7445 & 574215.62 & 140089.62 & \\
\hline 7446 & 574245.31 & 140232.67 & \\
\hline 7447 & 574254.06 & 136982.27 & \\
\hline 7448 & 574275 & 140375.7 & \\
\hline 7449 & 574259.94 & 136777.05 & \\
\hline
\end{tabular}




\begin{tabular}{|c|c|c|c|}
\hline node & X_coord & Y_coord & note: from sac04d created July 1,2004 \\
\hline 7450 & $5 \overline{7} 4273.12$ & $1 \overline{40517.67}$ & \\
\hline 7451 & 574265.75 & 136571.81 & \\
\hline 7452 & 574271.19 & 140659.62 & \\
\hline 7453 & 574271.62 & 136366.59 & \\
\hline 7454 & 574269.31 & 140801.59 & \\
\hline 7455 & 574271.62 & 136116.59 & \\
\hline 7456 & 574260.75 & 140890.36 & \\
\hline 7457 & 574271.62 & 135866.59 & \\
\hline 7458 & 574252.25 & 140979.12 & \\
\hline 7459 & 574243.69 & 141067.89 & \\
\hline 7460 & 571688.31 & 135866.59 & \\
\hline 7461 & 571604.94 & 135866.59 & \\
\hline 7462 & 571521.62 & 135866.59 & \\
\hline 7463 & 572188.31 & 135533.27 & \\
\hline 7464 & 572104.94 & 135533.27 & \\
\hline 7465 & 572021.62 & 135533.27 & \\
\hline 7466 & 571938.31 & 135533.27 & \\
\hline 7467 & 572188.31 & 135449.92 & \\
\hline 7468 & 572438.31 & 135199.92 & \\
\hline 7469 & 572354.94 & 135199.92 & \\
\hline 7470 & 572271.62 & 135366.59 & \\
\hline 7471 & 572271.62 & 135283.27 & \\
\hline 7472 & 572271.62 & 135199.92 & \\
\hline 7473 & 572188.31 & 135366.59 & \\
\hline 7474 & 571688.31 & 135783.27 & \\
\hline 7475 & 571854.94 & 135699.92 & \\
\hline 7476 & 571771.62 & 135699.92 & \\
\hline 7477 & 571854.94 & 135616.59 & \\
\hline 7478 & 571688.31 & 135699.92 & \\
\hline 7479 & 571854.94 & 135533.27 & \\
\hline 7480 & 571688.31 & 134199.92 & \\
\hline 7481 & 578271.62 & 133366.59 & \\
\hline 7482 & 578271.62 & 133616.59 & \\
\hline 7483 & 578271.62 & 133866.59 & \\
\hline 7484 & 578271.62 & 134116.59 & \\
\hline 7485 & 578271.62 & 134366.59 & \\
\hline 7486 & 578271.62 & 134616.59 & \\
\hline 7487 & 578271.62 & 134866.59 & \\
\hline 7488 & 578521.62 & 133366.59 & \\
\hline 7489 & 577271.62 & 135616.59 & \\
\hline 7490 & 577521.62 & 135616.59 & \\
\hline 7491 & 577771.62 & 135116.59 & \\
\hline 7492 & 578021.62 & 135116.59 & \\
\hline 7493 & 577771.62 & 135366.59 & \\
\hline 7494 & 578271.62 & 135116.59 & \\
\hline 7495 & 577771.62 & 135616.59 & \\
\hline 7496 & 579771.62 & 131866.59 & \\
\hline 7497 & 579771.62 & 132116.59 & \\
\hline 7498 & 579771.62 & 132366.59 & \\
\hline 7499 & 580021.62 & 131866.59 & \\
\hline 7500 & 579771.62 & 132616.59 & \\
\hline 7501 & 580271.62 & 130866.59 & \\
\hline 7502 & 580271.62 & 131116.59 & \\
\hline 7503 & 580271.62 & 131366.59 & \\
\hline 7504 & 580521.62 & 130866.59 & \\
\hline 7505 & 580271.62 & 131616.59 & \\
\hline
\end{tabular}




\begin{tabular}{|c|c|c|c|}
\hline node & X_coord & Y_coord & note: from sac04d created July 1, 2004 \\
\hline 7506 & $5 \overline{8} 2271.62$ & $1 \overline{2} 9116.6$ & \\
\hline 7507 & 582271.62 & 129366.6 & \\
\hline 7508 & 582271.62 & 129616.6 & \\
\hline 7509 & 582521.62 & 129116.6 & \\
\hline 7510 & 582271.62 & 129866.6 & \\
\hline 7511 & 582771.62 & 128116.6 & \\
\hline 7512 & 582771.62 & 128366.6 & \\
\hline 7513 & 582771.62 & 128616.6 & \\
\hline 7514 & 583021.62 & 128116.6 & \\
\hline 7515 & 582771.62 & 128866.6 & \\
\hline 7516 & 583271.62 & 127366.6 & \\
\hline 7517 & 583271.62 & 127116.6 & \\
\hline 7518 & 583271.62 & 127616.6 & \\
\hline 7519 & 583521.62 & 127116.6 & \\
\hline 7520 & 583271.62 & 127866.6 & \\
\hline 7521 & 583771.62 & 126616.6 & \\
\hline 7522 & 583771.62 & 126116.6 & \\
\hline 7523 & 583771.62 & 126866.6 & \\
\hline 7524 & 584271.62 & 125866.6 & \\
\hline 7525 & 584271.62 & 125116.6 & \\
\hline 7526 & 584271.62 & 126116.6 & \\
\hline 7527 & 583771.62 & 127116.6 & \\
\hline 7528 & 583271.62 & 128116.6 & \\
\hline 7529 & 582771.62 & 129116.6 & \\
\hline 7530 & 581271.62 & 130616.6 & \\
\hline 7531 & 581521.62 & 130616.6 & \\
\hline 7532 & 581771.62 & 130116.6 & \\
\hline 7533 & 582021.62 & 130116.6 & \\
\hline 7534 & 581771.62 & 130366.6 & \\
\hline 7535 & 582271.62 & 130116.6 & \\
\hline 7536 & 581771.62 & 130616.6 & \\
\hline 7537 & 584271.62 & 124366.6 & \\
\hline 7538 & 580771.62 & 130866.59 & \\
\hline 7539 & 581021.62 & 130866.59 & \\
\hline 7540 & 581271.62 & 130866.59 & \\
\hline 7541 & 584271.62 & 123616.6 & \\
\hline 7542 & 584271.62 & 122866.6 & \\
\hline 7543 & 580271.62 & 131866.59 & \\
\hline 7544 & 578771.62 & 133366.59 & \\
\hline 7545 & 579021.62 & 133366.59 & \\
\hline 7546 & 579271.62 & 132866.59 & \\
\hline 7547 & 579521.62 & 132866.59 & \\
\hline 7548 & 579271.62 & 133116.59 & \\
\hline 7549 & 579771.62 & 132866.59 & \\
\hline 7550 & 579271.62 & 133366.59 & \\
\hline 7551 & 584271.62 & 122116.6 & \\
\hline 7552 & 584271.62 & 121366.6 & \\
\hline 7553 & 574521.62 & 135866.59 & \\
\hline 7554 & 574771.62 & 135866.59 & \\
\hline 7555 & 575021.62 & 135866.59 & \\
\hline 7556 & 575271.62 & 135866.59 & \\
\hline 7557 & 572854.94 & 134199.92 & \\
\hline 7558 & 572771.62 & 134199.92 & \\
\hline 7559 & 572688.31 & 134533.27 & \\
\hline 7560 & 572688.31 & 134449.92 & \\
\hline 7561 & 572688.31 & 134366.59 & \\
\hline
\end{tabular}




\begin{tabular}{|c|c|c|c|}
\hline node & X_coord & Y_coord & note: from sac04d created July 1, 2004 \\
\hline 7562 & $5 \overline{7} 2688.31$ & $1 \overline{3} 4283.27$ & \\
\hline 7563 & 572604.94 & 134533.27 & \\
\hline 7564 & 572521.62 & 134866.59 & \\
\hline 7565 & 572521.62 & 134783.27 & \\
\hline 7566 & 572521.62 & 134949.92 & \\
\hline 7567 & 572521.62 & 134699.92 & \\
\hline 7568 & 572521.62 & 135033.27 & \\
\hline 7569 & 572521.62 & 134616.59 & \\
\hline 7570 & 572521.62 & 135116.59 & \\
\hline 7571 & 572438.31 & 135116.59 & \\
\hline 7572 & 572521.62 & 134533.27 & \\
\hline 7573 & 572688.31 & 134199.92 & \\
\hline 7574 & 575521.62 & 135866.59 & \\
\hline 7575 & 575771.62 & 135866.59 & \\
\hline 7576 & 576021.62 & 135866.59 & \\
\hline 7577 & 576271.62 & 135866.59 & \\
\hline 7578 & 572771.62 & 134116.59 & \\
\hline 7579 & 576521.62 & 135866.59 & \\
\hline 7580 & 576771.62 & 135866.59 & \\
\hline 7581 & 577021.62 & 135866.59 & \\
\hline 7582 & 577271.62 & 135866.59 & \\
\hline 7583 & 584271.62 & 120616.6 & \\
\hline 7584 & 584271.62 & 119866.6 & \\
\hline 7585 & 572438.31 & 134116.59 & \\
\hline 7586 & 572521.62 & 134116.59 & \\
\hline 7587 & 572604.94 & 134116.59 & \\
\hline 7588 & 572688.31 & 134116.59 & \\
\hline 7589 & 571771.62 & 134199.92 & \\
\hline 7590 & 571854.94 & 134199.92 & \\
\hline 7591 & 571938.31 & 134199.92 & \\
\hline 7592 & 572021.62 & 134199.92 & \\
\hline 7593 & 572104.94 & 134199.92 & \\
\hline 7594 & 572188.31 & 134199.92 & \\
\hline 7595 & 572271.62 & 134199.92 & \\
\hline 7596 & 572354.94 & 134199.92 & \\
\hline 7597 & 572438.31 & 134199.92 & \\
\hline 7598 & 571521.62 & 134866.59 & \\
\hline 7599 & 571521.62 & 134949.92 & \\
\hline 7600 & 571521.62 & 135033.27 & \\
\hline 7601 & 571604.94 & 134866.59 & \\
\hline 7602 & 571521.62 & 135116.59 & \\
\hline 7603 & 571688.31 & 134283.27 & \\
\hline 7604 & 571688.31 & 134366.59 & \\
\hline 7605 & 571688.31 & 134449.92 & \\
\hline 7606 & 571688.31 & 134533.27 & \\
\hline 7607 & 571688.31 & 134616.59 & \\
\hline 7608 & 571688.31 & 134699.92 & \\
\hline 7609 & 571688.31 & 134783.27 & \\
\hline 7610 & 571688.31 & 134866.59 & \\
\hline 7611 & 571521.62 & 135199.92 & \\
\hline 7612 & 571521.62 & 135283.27 & \\
\hline 7613 & 571521.62 & 135783.27 & \\
\hline 7614 & 571521.62 & 135699.92 & \\
\hline 7615 & 571521.62 & 135616.59 & \\
\hline 7616 & 571521.62 & 135533.27 & \\
\hline 7617 & 571521.62 & 135449.92 & \\
\hline
\end{tabular}




\begin{tabular}{|c|c|c|c|}
\hline node & X_coord & Y_coord & note: from sac04d created July 1,2004 \\
\hline 7618 & $5 \overline{7} 1521.62$ & $1 \overline{3} 5366.59$ & \\
\hline 7619 & 566280.19 & 143341.41 & \\
\hline 7620 & 566277.31 & 143516.47 & \\
\hline 7621 & 566274.5 & 143691.53 & \\
\hline 7622 & 566271.62 & 143866.59 & \\
\hline 7623 & 566271.62 & 144116.59 & \\
\hline 7624 & 566271.62 & 144366.59 & \\
\hline 7625 & 566271.62 & 144616.59 & \\
\hline 7626 & 566229.5 & 144952.92 & \\
\hline 7627 & 566187.44 & 145289.27 & \\
\hline 7628 & 566164.4434 & 145640.5932 & \\
\hline 7629 & 566088.62 & 145930.41 & \\
\hline 7630 & 570021.62 & 143116.59 & \\
\hline 7631 & 569771.62 & 143116.59 & \\
\hline 7632 & 570271.62 & 143116.59 & \\
\hline 7633 & 569521.62 & 143116.59 & \\
\hline 7634 & 570521.62 & 143116.59 & \\
\hline 7635 & 569271.62 & 143116.59 & \\
\hline 7636 & 570771.62 & 143116.59 & \\
\hline 7637 & 569028.44 & 143115.53 & \\
\hline 7638 & 571021.62 & 143116.59 & \\
\hline 7639 & 568785.31 & 143114.47 & \\
\hline 7640 & 571271.62 & 143116.59 & \\
\hline 7641 & 568532.69 & 142713.09 & \\
\hline 7642 & 568535.81 & 142846.53 & \\
\hline 7643 & 568539 & 142979.97 & \\
\hline 7644 & 568542.12 & 143113.41 & \\
\hline 7645 & 571521.62 & 143116.59 & \\
\hline 7646 & 571771.62 & 143116.59 & \\
\hline 7647 & 572021.62 & 143116.59 & \\
\hline 7648 & 572271.62 & 143116.59 & \\
\hline 7649 & 572521.62 & 143116.59 & \\
\hline 7650 & 572771.62 & 143116.59 & \\
\hline 7651 & 573014.12 & 142778.3 & \\
\hline 7652 & 573016.62 & 142891.06 & \\
\hline 7653 & 573019.12 & 143003.83 & \\
\hline 7654 & 573021.62 & 143116.59 & \\
\hline 7655 & 574474.69 & 137336.09 & \\
\hline 7656 & 574481.56 & 137195.77 & \\
\hline 7657 & 574488.44 & 137055.42 & \\
\hline 7658 & 574495.31 & 136915.09 & \\
\hline 7659 & 574528.88 & 140125.3 & \\
\hline 7660 & 574525.31 & 140229.03 & \\
\hline 7661 & 574521.75 & 140332.77 & \\
\hline 7662 & 574518.19 & 140436.5 & \\
\hline 7663 & 574504.06 & 136732.27 & \\
\hline 7664 & 574518.19 & 140547.36 & \\
\hline 7665 & 574512.88 & 136549.42 & \\
\hline 7666 & 574518.19 & 140658.23 & \\
\hline 7667 & 574521.62 & 136366.59 & \\
\hline 7668 & 574518.19 & 140769.09 & \\
\hline 7669 & 574521.62 & 136116.59 & \\
\hline 7670 & 574518.5 & 140854.92 & \\
\hline 7671 & 574518.88 & 140940.77 & \\
\hline 7672 & 574519.19 & 141026.59 & \\
\hline 7673 & 571604.94 & 135783.27 & \\
\hline
\end{tabular}




\begin{tabular}{|c|c|c|c|}
\hline node & X_coord & Y_coord & note: from sac04d created July 1,2004 \\
\hline 7674 & 572104.94 & 135449.92 & \\
\hline 7675 & 572021.62 & 135449.92 & \\
\hline 7676 & 571938.31 & 135449.92 & \\
\hline 7677 & 571854.94 & 135449.92 & \\
\hline 7678 & 572104.94 & 135366.59 & \\
\hline 7679 & 572354.94 & 135116.59 & \\
\hline 7680 & 572271.62 & 135116.59 & \\
\hline 7681 & 572188.31 & 135283.27 & \\
\hline 7682 & 572188.31 & 135199.92 & \\
\hline 7683 & 572188.31 & 135116.59 & \\
\hline 7684 & 572104.94 & 135283.27 & \\
\hline 7685 & 571604.94 & 135699.92 & \\
\hline 7686 & 571771.62 & 135616.59 & \\
\hline 7687 & 571688.31 & 135616.59 & \\
\hline 7688 & 571771.62 & 135533.27 & \\
\hline 7689 & 571604.94 & 135616.59 & \\
\hline 7690 & 571771.62 & 135449.92 & \\
\hline 7691 & 571771.62 & 134283.27 & \\
\hline 7692 & 578521.62 & 133616.59 & \\
\hline 7693 & 578521.62 & 133866.59 & \\
\hline 7694 & 578521.62 & 134116.59 & \\
\hline 7695 & 578521.62 & 134366.59 & \\
\hline 7696 & 578521.62 & 134616.59 & \\
\hline 7697 & 578521.62 & 134866.59 & \\
\hline 7698 & 578521.62 & 135116.59 & \\
\hline 7699 & 578771.62 & 133616.59 & \\
\hline 7700 & 577521.62 & 135866.59 & \\
\hline 7701 & 577771.62 & 135866.59 & \\
\hline 7702 & 578021.62 & 135366.59 & \\
\hline 7703 & 578271.62 & 135366.59 & \\
\hline 7704 & 578021.62 & 135616.59 & \\
\hline 7705 & 578521.62 & 135366.59 & \\
\hline 7706 & 578021.62 & 135866.59 & \\
\hline 7707 & 580021.62 & 132116.59 & \\
\hline 7708 & 580021.62 & 132366.59 & \\
\hline 7709 & 580021.62 & 132616.59 & \\
\hline 7710 & 580271.62 & 132116.59 & \\
\hline 7711 & 580021.62 & 132866.59 & \\
\hline 7712 & 580521.62 & 131116.59 & \\
\hline 7713 & 580521.62 & 131366.59 & \\
\hline 7714 & 580521.62 & 131616.59 & \\
\hline 7715 & 580771.62 & 131116.59 & \\
\hline 7716 & 580521.62 & 131866.59 & \\
\hline 7717 & 582521.62 & 129366.6 & \\
\hline 7718 & 582521.62 & 129616.6 & \\
\hline 7719 & 582521.62 & 129866.6 & \\
\hline 7720 & 582771.62 & 129366.6 & \\
\hline 7721 & 582521.62 & 130116.6 & \\
\hline 7722 & 583021.62 & 128366.6 & \\
\hline 7723 & 583021.62 & 128616.6 & \\
\hline 7724 & 583021.62 & 128866.6 & \\
\hline 7725 & 583271.62 & 128366.6 & \\
\hline 7726 & 583021.62 & 129116.6 & \\
\hline 7727 & 583521.62 & 127366.6 & \\
\hline 7728 & 583521.62 & 127616.6 & \\
\hline 7729 & 583521.62 & 127866.6 & \\
\hline
\end{tabular}




\begin{tabular}{|c|c|c|c|}
\hline node & X_coord & Y_coord & note: from sac04d created July 1, 2004 \\
\hline 7730 & $5 \overline{8} 3771.62$ & $1 \overline{2} 7366.6$ & \\
\hline 7731 & 583521.62 & 128116.6 & \\
\hline 7732 & 584021.62 & 126616.6 & \\
\hline 7733 & 584021.62 & 126366.6 & \\
\hline 7734 & 584021.62 & 126866.6 & \\
\hline 7735 & 584271.62 & 126366.6 & \\
\hline 7736 & 584021.62 & 127116.6 & \\
\hline 7737 & 584521.62 & 125866.6 & \\
\hline 7738 & 584521.62 & 125366.6 & \\
\hline 7739 & 584521.62 & 126116.6 & \\
\hline 7740 & 585021.62 & 125116.6 & \\
\hline 7741 & 585021.62 & 124366.6 & \\
\hline 7742 & 585021.62 & 125366.6 & \\
\hline 7743 & 584521.62 & 126366.6 & \\
\hline 7744 & 584021.62 & 127366.6 & \\
\hline 7745 & 583521.62 & 128366.6 & \\
\hline 7746 & 583021.62 & 129366.6 & \\
\hline 7747 & 581521.62 & 130866.59 & \\
\hline 7748 & 581771.62 & 130866.59 & \\
\hline 7749 & 582021.62 & 130366.6 & \\
\hline 7750 & 582271.62 & 130366.6 & \\
\hline 7751 & 582021.62 & 130616.6 & \\
\hline 7752 & 582521.62 & 130366.6 & \\
\hline 7753 & 582021.62 & 130866.59 & \\
\hline 7754 & 585021.62 & 123616.6 & \\
\hline 7755 & 581021.62 & 131116.59 & \\
\hline 7756 & 581271.62 & 131116.59 & \\
\hline 7757 & 581521.62 & 131116.59 & \\
\hline 7758 & 585021.62 & 122866.6 & \\
\hline 7759 & 585021.62 & 122116.6 & \\
\hline 7760 & 580521.62 & 132116.59 & \\
\hline 7761 & 579021.62 & 133616.59 & \\
\hline 7762 & 579271.62 & 133616.59 & \\
\hline 7763 & 579521.62 & 133116.59 & \\
\hline 7764 & 579771.62 & 133116.59 & \\
\hline 7765 & 579521.62 & 133366.59 & \\
\hline 7766 & 580021.62 & 133116.59 & \\
\hline 7767 & 579521.62 & 133616.59 & \\
\hline 7768 & 585021.62 & 121366.6 & \\
\hline 7769 & 585021.62 & 120616.6 & \\
\hline 7770 & 574771.62 & 136116.59 & \\
\hline 7771 & 575021.62 & 136116.59 & \\
\hline 7772 & 575271.62 & 136116.59 & \\
\hline 7773 & 575521.62 & 136116.59 & \\
\hline 7774 & 572604.94 & 134449.92 & \\
\hline 7775 & 572604.94 & 134366.59 & \\
\hline 7776 & 572604.94 & 134283.27 & \\
\hline 7777 & 572604.94 & 134199.92 & \\
\hline 7778 & 572521.62 & 134449.92 & \\
\hline 7779 & 572438.31 & 134866.59 & \\
\hline 7780 & 572438.31 & 134783.27 & \\
\hline 7781 & 572438.31 & 134949.92 & \\
\hline 7782 & 572438.31 & 134699.92 & \\
\hline 7783 & 572438.31 & 135033.27 & \\
\hline 7784 & 572438.31 & 134616.59 & \\
\hline 7785 & 572438.31 & 134533.27 & \\
\hline
\end{tabular}




\begin{tabular}{|c|c|c|c|}
\hline node & X_coord & Y_coord & note: from sac04d created July 1, 2004 \\
\hline 7786 & $5 \overline{7} 2354.94$ & $1 \overline{3} 5033.27$ & \\
\hline 7787 & 572438.31 & 134449.92 & \\
\hline 7788 & 575771.62 & 136116.59 & \\
\hline 7789 & 576021.62 & 136116.59 & \\
\hline 7790 & 576271.62 & 136116.59 & \\
\hline 7791 & 576521.62 & 136116.59 & \\
\hline 7792 & 576771.62 & 136116.59 & \\
\hline 7793 & 577021.62 & 136116.59 & \\
\hline 7794 & 577271.62 & 136116.59 & \\
\hline 7795 & 577521.62 & 136116.59 & \\
\hline 7796 & 585209.81 & 119955.4 & \\
\hline 7797 & 584791.38 & 119444 & \\
\hline 7798 & 585240.81 & 119103.1 & \\
\hline 7799 & 572521.62 & 134199.92 & \\
\hline 7800 & 571854.94 & 134283.27 & \\
\hline 7801 & 571938.31 & 134283.27 & \\
\hline 7802 & 572021.62 & 134283.27 & \\
\hline 7803 & 572104.94 & 134283.27 & \\
\hline 7804 & 572188.31 & 134283.27 & \\
\hline 7805 & 572271.62 & 134283.27 & \\
\hline 7806 & 572354.94 & 134283.27 & \\
\hline 7807 & 572438.31 & 134283.27 & \\
\hline 7808 & 572521.62 & 134283.27 & \\
\hline 7809 & 571604.94 & 134949.92 & \\
\hline 7810 & 571604.94 & 135033.27 & \\
\hline 7811 & 571604.94 & 135116.59 & \\
\hline 7812 & 571688.31 & 134949.92 & \\
\hline 7813 & 571604.94 & 135199.92 & \\
\hline 7814 & 571771.62 & 134366.59 & \\
\hline 7815 & 571771.62 & 134449.92 & \\
\hline 7816 & 571771.62 & 134533.27 & \\
\hline 7817 & 571771.62 & 134616.59 & \\
\hline 7818 & 571771.62 & 134699.92 & \\
\hline 7819 & 571771.62 & 134783.27 & \\
\hline 7820 & 571771.62 & 134866.59 & \\
\hline 7821 & 571771.62 & 134949.92 & \\
\hline 7822 & 571604.94 & 135283.27 & \\
\hline 7823 & 571604.94 & 135366.59 & \\
\hline 7824 & 571604.94 & 135533.27 & \\
\hline 7825 & 571604.94 & 135449.92 & \\
\hline 7826 & 566529.19 & 143294 & \\
\hline 7827 & 566526.69 & 143484.86 & \\
\hline 7828 & 566524.12 & 143675.73 & \\
\hline 7829 & 566521.62 & 143866.59 & \\
\hline 7830 & 566521.62 & 144116.59 & \\
\hline 7831 & 566521.62 & 144366.59 & \\
\hline 7832 & 566521.62 & 144616.59 & \\
\hline 7833 & 566493.56 & 144924.16 & \\
\hline 7834 & 566465.5 & 145231.7 & \\
\hline 7835 & 566433.8157 & 145426.9161 & \\
\hline 7836 & 566293.8514 & 145688.706 & \\
\hline 7837 & 566481.3356 & 145545.918 & \\
\hline 7838 & 566217.81 & 145962.73 & \\
\hline 7839 & 570021.62 & 143366.59 & \\
\hline 7840 & 569771.62 & 143366.59 & \\
\hline 7841 & 570271.62 & 143366.59 & \\
\hline
\end{tabular}




\begin{tabular}{|c|c|c|c|}
\hline node & X_coord & Y_coord & note: from sac04d created July 1, 2004 \\
\hline 7842 & $5 \overline{6} 9521.62$ & $1 \overline{4} 3366.59$ & \\
\hline 7843 & 570521.62 & 143366.59 & \\
\hline 7844 & 569271.62 & 143366.59 & \\
\hline 7845 & 570771.62 & 143366.59 & \\
\hline 7846 & 569026.19 & 143365.89 & \\
\hline 7847 & 571021.62 & 143366.59 & \\
\hline 7848 & 568780.75 & 143365.17 & \\
\hline 7849 & 571271.62 & 143366.59 & \\
\hline 7850 & 568535.31 & 143364.47 & \\
\hline 7851 & 571521.62 & 143366.59 & \\
\hline 7852 & 568382.5 & 142744.73 & \\
\hline 7853 & 568347.75 & 142862.67 & \\
\hline 7854 & 568312.94 & 142980.59 & \\
\hline 7855 & 568278.19 & 143098.53 & \\
\hline 7856 & 568276 & 143354.55 & \\
\hline 7857 & 571771.62 & 143366.59 & \\
\hline 7858 & 572021.62 & 143366.59 & \\
\hline 7859 & 572271.62 & 143366.59 & \\
\hline 7860 & 572521.62 & 143366.59 & \\
\hline 7861 & 572771.62 & 143366.59 & \\
\hline 7862 & 573021.62 & 143366.59 & \\
\hline 7863 & 573263.06 & 142794.09 & \\
\hline 7864 & 573265.94 & 142901.59 & \\
\hline 7865 & 573268.75 & 143009.09 & \\
\hline 7866 & 573271.62 & 143116.59 & \\
\hline 7867 & 573271.62 & 143366.59 & \\
\hline 7868 & 574731.38 & 137301.86 & \\
\hline 7869 & 574738.25 & 137160.38 & \\
\hline 7870 & 574745.12 & 137018.91 & \\
\hline 7871 & 574752 & 136877.42 & \\
\hline 7872 & 574758.56 & 136707.14 & \\
\hline 7873 & 574775.25 & 140151 & \\
\hline 7874 & 574774.06 & 140245.44 & \\
\hline 7875 & 574772.94 & 140339.86 & \\
\hline 7876 & 574771.75 & 140434.3 & \\
\hline 7877 & 574771.12 & 140535.47 & \\
\hline 7878 & 574765.06 & 136536.88 & \\
\hline 7879 & 574770.56 & 140636.66 & \\
\hline 7880 & 574771.62 & 136366.59 & \\
\hline 7881 & 574769.94 & 140737.83 & \\
\hline 7882 & 574767.88 & 140818 & \\
\hline 7883 & 574765.81 & 140898.19 & \\
\hline 7884 & 574763.75 & 140978.36 & \\
\hline 7885 & 572021.62 & 135366.59 & \\
\hline 7886 & 571938.31 & 135366.59 & \\
\hline 7887 & 571854.94 & 135366.59 & \\
\hline 7888 & 571771.62 & 135366.59 & \\
\hline 7889 & 572021.62 & 135283.27 & \\
\hline 7890 & 572271.62 & 135033.27 & \\
\hline 7891 & 572188.31 & 135033.27 & \\
\hline 7892 & 572104.94 & 135199.92 & \\
\hline 7893 & 572104.94 & 135116.59 & \\
\hline 7894 & 572104.94 & 135033.27 & \\
\hline 7895 & 572021.62 & 135199.92 & \\
\hline 7896 & 571688.31 & 135533.27 & \\
\hline 7897 & 571688.31 & 135449.92 & \\
\hline
\end{tabular}




\begin{tabular}{|c|c|c|c|}
\hline node & X_coord & Y_coord & note: from sac04d created July 1, 2004 \\
\hline 7898 & 571688.31 & 135366.59 & \\
\hline 7899 & 571854.94 & 134366.59 & \\
\hline 7900 & 578771.62 & 133866.59 & \\
\hline 7901 & 578771.62 & 134116.59 & \\
\hline 7902 & 578771.62 & 134366.59 & \\
\hline 7903 & 578771.62 & 134616.59 & \\
\hline 7904 & 578771.62 & 134866.59 & \\
\hline 7905 & 578771.62 & 135116.59 & \\
\hline 7906 & 578771.62 & 135366.59 & \\
\hline 7907 & 579021.62 & 133866.59 & \\
\hline 7908 & 577771.62 & 136116.59 & \\
\hline 7909 & 578021.62 & 136116.59 & \\
\hline 7910 & 578271.62 & 135616.59 & \\
\hline 7911 & 578521.62 & 135616.59 & \\
\hline 7912 & 578271.62 & 135866.59 & \\
\hline 7913 & 578771.62 & 135616.59 & \\
\hline 7914 & 578271.62 & 136116.59 & \\
\hline 7915 & 580271.62 & 132366.59 & \\
\hline 7916 & 580271.62 & 132616.59 & \\
\hline 7917 & 580271.62 & 132866.59 & \\
\hline 7918 & 580521.62 & 132366.59 & \\
\hline 7919 & 580271.62 & 133116.59 & \\
\hline 7920 & 580771.62 & 131366.59 & \\
\hline 7921 & 580771.62 & 131616.59 & \\
\hline 7922 & 580771.62 & 131866.59 & \\
\hline 7923 & 581021.62 & 131366.59 & \\
\hline 7924 & 580771.62 & 132116.59 & \\
\hline 7925 & 582771.62 & 129616.6 & \\
\hline 7926 & 582771.62 & 129866.6 & \\
\hline 7927 & 582771.62 & 130116.6 & \\
\hline 7928 & 583021.62 & 129616.6 & \\
\hline 7929 & 582771.62 & 130366.6 & \\
\hline 7930 & 583271.62 & 128616.6 & \\
\hline 7931 & 583271.62 & 128866.6 & \\
\hline 7932 & 583271.62 & 129116.6 & \\
\hline 7933 & 583521.62 & 128616.6 & \\
\hline 7934 & 583271.62 & 129366.6 & \\
\hline 7935 & 583771.62 & 127616.6 & \\
\hline 7936 & 583771.62 & 127866.6 & \\
\hline 7937 & 583771.62 & 128116.6 & \\
\hline 7938 & 584021.62 & 127616.6 & \\
\hline 7939 & 583771.62 & 128366.6 & \\
\hline 7940 & 584271.62 & 126616.6 & \\
\hline 7941 & 584271.62 & 126866.6 & \\
\hline 7942 & 584271.62 & 127116.6 & \\
\hline 7943 & 584521.62 & 126616.6 & \\
\hline 7944 & 584271.62 & 127366.6 & \\
\hline 7945 & 584771.62 & 125866.6 & \\
\hline 7946 & 584771.62 & 125616.6 & \\
\hline 7947 & 584771.62 & 126116.6 & \\
\hline 7948 & 585021.62 & 125616.6 & \\
\hline 7949 & 584771.62 & 126366.6 & \\
\hline 7950 & 585271.62 & 125116.6 & \\
\hline 7951 & 585271.62 & 124366.6 & \\
\hline 7952 & 585271.62 & 125366.6 & \\
\hline 7953 & 585271.62 & 123866.6 & \\
\hline
\end{tabular}




\begin{tabular}{|c|c|c|c|}
\hline node & X_coord & Y_coord & note: from sac04d created July 1,2004 \\
\hline 7954 & 585271.62 & 125616.6 & \\
\hline 7955 & 584771.62 & 126616.6 & \\
\hline 7956 & 584271.62 & 127616.6 & \\
\hline 7957 & 583771.62 & 128616.6 & \\
\hline 7958 & 583271.62 & 129616.6 & \\
\hline 7959 & 581771.62 & 131116.59 & \\
\hline 7960 & 582021.62 & 131116.59 & \\
\hline 7961 & 582271.62 & 130616.6 & \\
\hline 7962 & 582521.62 & 130616.6 & \\
\hline 7963 & 582271.62 & 130866.59 & \\
\hline 7964 & 582771.62 & 130616.6 & \\
\hline 7965 & 582271.62 & 131116.59 & \\
\hline 7966 & 585771.62 & 123616.6 & \\
\hline 7967 & 585771.62 & 122866.6 & \\
\hline 7968 & 585771.62 & 123866.6 & \\
\hline 7969 & 581271.62 & 131366.59 & \\
\hline 7970 & 581521.62 & 131366.59 & \\
\hline 7971 & 581771.62 & 131366.59 & \\
\hline 7972 & 585771.62 & 122116.6 & \\
\hline 7973 & 585771.62 & 121366.6 & \\
\hline 7974 & 580771.62 & 132366.59 & \\
\hline 7975 & 579271.62 & 133866.59 & \\
\hline 7976 & 579521.62 & 133866.59 & \\
\hline 7977 & 579771.62 & 133366.59 & \\
\hline 7978 & 580021.62 & 133366.59 & \\
\hline 7979 & 579771.62 & 133616.59 & \\
\hline 7980 & 580271.62 & 133366.59 & \\
\hline 7981 & 579771.62 & 133866.59 & \\
\hline 7982 & 585771.62 & 120616.6 & \\
\hline 7983 & 585771.62 & 119866.6 & \\
\hline 7984 & 575021.62 & 136366.59 & \\
\hline 7985 & 575271.62 & 136366.59 & \\
\hline 7986 & 575521.62 & 136366.59 & \\
\hline 7987 & 575771.62 & 136366.59 & \\
\hline 7988 & 572521.62 & 134366.59 & \\
\hline 7989 & 572438.31 & 134366.59 & \\
\hline 7990 & 572354.94 & 134866.59 & \\
\hline 7991 & 572354.94 & 134783.27 & \\
\hline 7992 & 572354.94 & 134949.92 & \\
\hline 7993 & 572354.94 & 134699.92 & \\
\hline 7994 & 572354.94 & 134616.59 & \\
\hline 7995 & 572354.94 & 134533.27 & \\
\hline 7996 & 572354.94 & 134449.92 & \\
\hline 7997 & 572271.62 & 134949.92 & \\
\hline 7998 & 572354.94 & 134366.59 & \\
\hline 7999 & 576021.62 & 136366.59 & \\
\hline 8000 & 576271.62 & 136366.59 & \\
\hline 8001 & 576521.62 & 136366.59 & \\
\hline 8002 & 576771.62 & 136366.59 & \\
\hline 8003 & 577021.62 & 136366.59 & \\
\hline 8004 & 577271.62 & 136366.59 & \\
\hline 8005 & 577521.62 & 136366.59 & \\
\hline 8006 & 577771.62 & 136366.59 & \\
\hline 8007 & 585771.62 & 119116.6 & \\
\hline 8008 & 585349.19 & 118374.9 & \\
\hline 8009 & 585771.62 & 118366.6 & \\
\hline
\end{tabular}




\begin{tabular}{|c|c|c|c|}
\hline node & X_coord & Y_coord & note: from sac04d created July 1, 2004 \\
\hline 8010 & $5 \overline{7} 1938.31$ & $1 \overline{3} 4366.59$ & \\
\hline 8011 & 572021.62 & 134366.59 & \\
\hline 8012 & 572104.94 & 134366.59 & \\
\hline 8013 & 572188.31 & 134366.59 & \\
\hline 8014 & 572271.62 & 134366.59 & \\
\hline 8015 & 571688.31 & 135033.27 & \\
\hline 8016 & 571688.31 & 135116.59 & \\
\hline 8017 & 571688.31 & 135199.92 & \\
\hline 8018 & 571771.62 & 135033.27 & \\
\hline 8019 & 571688.31 & 135283.27 & \\
\hline 8020 & 571854.94 & 134449.92 & \\
\hline 8021 & 571854.94 & 134533.27 & \\
\hline 8022 & 571854.94 & 134616.59 & \\
\hline 8023 & 571854.94 & 134699.92 & \\
\hline 8024 & 571854.94 & 134783.27 & \\
\hline 8025 & 571854.94 & 134866.59 & \\
\hline 8026 & 571854.94 & 134949.92 & \\
\hline 8027 & 571854.94 & 135033.27 & \\
\hline 8028 & 566778.12 & 143246.61 & \\
\hline 8029 & 566775.94 & 143453.27 & \\
\hline 8030 & 566773.81 & 143659.94 & \\
\hline 8031 & 566771.62 & 143866.59 & \\
\hline 8032 & 566771.62 & 144116.59 & \\
\hline 8033 & 566771.62 & 144366.59 & \\
\hline 8034 & 566771.62 & 144616.59 & \\
\hline 8035 & 566757.56 & 144895.38 & \\
\hline 8036 & 566743.56 & 145174.14 & \\
\hline 8037 & 566718.627 & 145358.6877 & \\
\hline 8038 & 566802.6028 & 145522.6841 & \\
\hline 8039 & 566418.9247 & 145736.3028 & \\
\hline 8041 & 566346.94 & 145995.08 & \\
\hline 8042 & 566901.948 & 145756.0799 & \\
\hline 8043 & 570021.62 & 143616.59 & \\
\hline 8044 & 569771.62 & 143616.59 & \\
\hline 8045 & 570271.62 & 143616.59 & \\
\hline 8046 & 569521.62 & 143616.59 & \\
\hline 8047 & 570521.62 & 143616.59 & \\
\hline 8048 & 569271.62 & 143616.59 & \\
\hline 8049 & 570771.62 & 143616.59 & \\
\hline 8050 & 569023.88 & 143616.23 & \\
\hline 8051 & 571021.62 & 143616.59 & \\
\hline 8052 & 568776.19 & 143615.89 & \\
\hline 8053 & 571271.62 & 143616.59 & \\
\hline 8054 & 568528.44 & 143615.53 & \\
\hline 8055 & 571521.62 & 143616.59 & \\
\hline 8056 & 568273.81 & 143610.58 & \\
\hline 8057 & 571771.62 & 143616.59 & \\
\hline 8058 & 568232.38 & 142776.36 & \\
\hline 8059 & 568159.69 & 142878.8 & \\
\hline 8060 & 568086.94 & 142981.23 & \\
\hline 8061 & 568014.25 & 143083.67 & \\
\hline 8062 & 568016.69 & 143344.64 & \\
\hline 8063 & 568019.19 & 143605.62 & \\
\hline 8064 & 572021.62 & 143616.59 & \\
\hline 8065 & 572271.62 & 143616.59 & \\
\hline 8066 & 572521.62 & 143616.59 & \\
\hline
\end{tabular}




\begin{tabular}{|c|c|c|c|}
\hline node & X_coord & Y_coord & note: from sac04d created July 1,2004 \\
\hline 8067 & $5 \overline{7} 2771.62$ & $1 \overline{4} 3616.59$ & \\
\hline 8068 & 573021.62 & 143616.59 & \\
\hline 8069 & 573271.62 & 143616.59 & \\
\hline 8070 & 573511.94 & 142809.91 & \\
\hline 8071 & 573515.19 & 142912.14 & \\
\hline 8072 & 573518.38 & 143014.36 & \\
\hline 8073 & 573521.62 & 143116.59 & \\
\hline 8074 & 573521.62 & 143366.59 & \\
\hline 8075 & 573521.62 & 143616.59 & \\
\hline 8076 & 574988.12 & 137267.64 & \\
\hline 8077 & 574995 & 137125.02 & \\
\hline 8078 & 575001.81 & 136982.39 & \\
\hline 8079 & 575008.69 & 136839.77 & \\
\hline 8080 & 575013 & 136682.05 & \\
\hline 8081 & 575017.31 & 136524.31 & \\
\hline 8082 & 575021.62 & 140176.7 & \\
\hline 8083 & 575022.81 & 140261.84 & \\
\hline 8084 & 575024.06 & 140346.97 & \\
\hline 8085 & 575025.25 & 140432.11 & \\
\hline 8086 & 575024.06 & 140523.59 & \\
\hline 8087 & 575022.81 & 140615.08 & \\
\hline 8088 & 575021.62 & 140706.56 & \\
\hline 8089 & 575017.19 & 140781.09 & \\
\hline 8090 & 575012.69 & 140855.61 & \\
\hline 8091 & 575008.25 & 140930.14 & \\
\hline 8092 & 571938.31 & 135283.27 & \\
\hline 8093 & 571854.94 & 135283.27 & \\
\hline 8094 & 571771.62 & 135283.27 & \\
\hline 8095 & 571938.31 & 135199.92 & \\
\hline 8096 & 572188.31 & 134949.92 & \\
\hline 8097 & 572104.94 & 134949.92 & \\
\hline 8098 & 572021.62 & 135116.59 & \\
\hline 8099 & 572021.62 & 135033.27 & \\
\hline 8100 & 572021.62 & 134949.92 & \\
\hline 8101 & 571938.31 & 135116.59 & \\
\hline 8102 & 571938.31 & 134449.92 & \\
\hline 8103 & 579021.62 & 134116.59 & \\
\hline 8104 & 579021.62 & 134366.59 & \\
\hline 8105 & 579021.62 & 134616.59 & \\
\hline 8106 & 579021.62 & 134866.59 & \\
\hline 8107 & 579021.62 & 135116.59 & \\
\hline 8108 & 579021.62 & 135366.59 & \\
\hline 8109 & 579021.62 & 135616.59 & \\
\hline 8110 & 579271.62 & 134116.59 & \\
\hline 8111 & 578021.62 & 136366.59 & \\
\hline 8112 & 578271.62 & 136366.59 & \\
\hline 8113 & 578521.62 & 135866.59 & \\
\hline 8114 & 578771.62 & 135866.59 & \\
\hline 8115 & 578521.62 & 136116.59 & \\
\hline 8116 & 579021.62 & 135866.59 & \\
\hline 8117 & 578521.62 & 136366.59 & \\
\hline 8118 & 580521.62 & 132616.59 & \\
\hline 8119 & 580521.62 & 132866.59 & \\
\hline 8120 & 580521.62 & 133116.59 & \\
\hline 8121 & 580771.62 & 132616.59 & \\
\hline 8122 & 580521.62 & 133366.59 & \\
\hline
\end{tabular}




\begin{tabular}{|c|c|c|c|}
\hline node & X_coord & Y_coord & note: from sac04d created July 1, 2004 \\
\hline 8123 & $5 \overline{8} 1021.62$ & $1 \overline{13} 1616.59$ & \\
\hline 8124 & 581021.62 & 131866.59 & \\
\hline 8125 & 581021.62 & 132116.59 & \\
\hline 8126 & 581271.62 & 131616.59 & \\
\hline 8127 & 581021.62 & 132366.59 & \\
\hline 8128 & 583021.62 & 129866.6 & \\
\hline 8129 & 583021.62 & 130116.6 & \\
\hline 8130 & 583021.62 & 130366.6 & \\
\hline 8131 & 583271.62 & 129866.6 & \\
\hline 8132 & 583021.62 & 130616.6 & \\
\hline 8133 & 583521.62 & 128866.6 & \\
\hline 8134 & 583521.62 & 129116.6 & \\
\hline 8135 & 583521.62 & 129366.6 & \\
\hline 8136 & 583771.62 & 128866.6 & \\
\hline 8137 & 583521.62 & 129616.6 & \\
\hline 8138 & 584021.62 & 127866.6 & \\
\hline 8139 & 584021.62 & 128116.6 & \\
\hline 8140 & 584021.62 & 128366.6 & \\
\hline 8141 & 584271.62 & 127866.6 & \\
\hline 8142 & 584021.62 & 128616.6 & \\
\hline 8143 & 584521.62 & 126866.6 & \\
\hline 8144 & 584521.62 & 127116.6 & \\
\hline 8145 & 584521.62 & 127366.6 & \\
\hline 8146 & 584771.62 & 126866.6 & \\
\hline 8147 & 584521.62 & 127616.6 & \\
\hline 8148 & 585021.62 & 125866.6 & \\
\hline 8149 & 585021.62 & 126116.6 & \\
\hline 8150 & 585021.62 & 126366.6 & \\
\hline 8151 & 585271.62 & 125866.6 & \\
\hline 8152 & 585021.62 & 126616.6 & \\
\hline 8153 & 585438.31 & 124866.6 & \\
\hline 8154 & 585521.62 & 125116.6 & \\
\hline 8155 & 585604.94 & 124866.6 & \\
\hline 8156 & 585438.31 & 124616.6 & \\
\hline 8157 & 585521.62 & 125366.6 & \\
\hline 8158 & 585521.62 & 124366.6 & \\
\hline 8159 & 585521.62 & 124116.6 & \\
\hline 8160 & 585604.94 & 124616.6 & \\
\hline 8161 & 585521.62 & 125616.6 & \\
\hline 8162 & 585771.62 & 124116.6 & \\
\hline 8163 & 585521.62 & 125866.6 & \\
\hline 8164 & 585021.62 & 126866.6 & \\
\hline 8165 & 584521.62 & 127866.6 & \\
\hline 8166 & 584021.62 & 128866.6 & \\
\hline 8167 & 583521.62 & 129866.6 & \\
\hline 8168 & 582021.62 & 131366.59 & \\
\hline 8169 & 582271.62 & 131366.59 & \\
\hline 8170 & 582521.62 & 130866.59 & \\
\hline 8171 & 582771.62 & 130866.59 & \\
\hline 8172 & 582521.62 & 131116.59 & \\
\hline 8173 & 583021.62 & 130866.59 & \\
\hline 8174 & 582521.62 & 131366.59 & \\
\hline 8175 & 586021.62 & 123616.6 & \\
\hline 8176 & 586021.62 & 123116.6 & \\
\hline 8177 & 586021.62 & 123866.6 & \\
\hline 8178 & 586521.62 & 122866.6 & \\
\hline
\end{tabular}




\begin{tabular}{|c|c|c|c|}
\hline node & X_coord & Y_coord & note: from sac04d created July 1, 2004 \\
\hline 8179 & $5 \overline{8} 6521.62$ & $1 \overline{2} 2116.6$ & \\
\hline 8180 & 586521.62 & 123116.6 & \\
\hline 8181 & 586021.62 & 124116.6 & \\
\hline 8182 & 581521.62 & 131616.59 & \\
\hline 8183 & 581771.62 & 131616.59 & \\
\hline 8184 & 582021.62 & 131616.59 & \\
\hline 8185 & 586521.62 & 121366.6 & \\
\hline 8186 & 586521.62 & 120616.6 & \\
\hline 8187 & 581021.62 & 132616.59 & \\
\hline 8188 & 579521.62 & 134116.59 & \\
\hline 8189 & 579771.62 & 134116.59 & \\
\hline 8190 & 580021.62 & 133616.59 & \\
\hline 8191 & 580271.62 & 133616.59 & \\
\hline 8192 & 580021.62 & 133866.59 & \\
\hline 8193 & 580521.62 & 133616.59 & \\
\hline 8194 & 580021.62 & 134116.59 & \\
\hline 8195 & 586521.62 & 119866.6 & \\
\hline 8196 & 586521.62 & 119116.6 & \\
\hline 8197 & 575269.56 & 136511.77 & \\
\hline 8198 & 575521.94 & 136524.36 & \\
\hline 8199 & 575774.31 & 136536.97 & \\
\hline 8200 & 576026.69 & 136549.56 & \\
\hline 8201 & 572271.62 & 134866.59 & \\
\hline 8202 & 572271.62 & 134783.27 & \\
\hline 8203 & 572271.62 & 134699.92 & \\
\hline 8204 & 572271.62 & 134616.59 & \\
\hline 8205 & 572271.62 & 134533.27 & \\
\hline 8206 & 572271.62 & 134449.92 & \\
\hline 8207 & 572188.31 & 134866.59 & \\
\hline 8208 & 576275.19 & 136562.8 & \\
\hline 8209 & 576523.69 & 136576.03 & \\
\hline 8210 & 576772.19 & 136589.27 & \\
\hline 8211 & 577022 & 136598.38 & \\
\hline 8212 & 577271.81 & 136607.48 & \\
\hline 8213 & 577521.62 & 136616.59 & \\
\hline 8214 & 577778.44 & 136615.91 & \\
\hline 8215 & 578035.25 & 136615.22 & \\
\hline 8216 & 586521.62 & 118366.6 & \\
\hline 8217 & 585349.19 & 117584.6 & \\
\hline 8218 & 585771.62 & 117616.6 & \\
\hline 8219 & 586521.62 & 117616.6 & \\
\hline 8220 & 572021.62 & 134449.92 & \\
\hline 8221 & 572104.94 & 134449.92 & \\
\hline 8222 & 572188.31 & 134449.92 & \\
\hline 8223 & 571771.62 & 135116.59 & \\
\hline 8224 & 571771.62 & 135199.92 & \\
\hline 8225 & 571854.94 & 135116.59 & \\
\hline 8226 & 571938.31 & 134533.27 & \\
\hline 8227 & 571938.31 & 134616.59 & \\
\hline 8228 & 571938.31 & 134699.92 & \\
\hline 8229 & 571938.31 & 134783.27 & \\
\hline 8230 & 571938.31 & 134866.59 & \\
\hline 8231 & 571938.31 & 134949.92 & \\
\hline 8232 & 571938.31 & 135033.27 & \\
\hline 8233 & 567027.12 & 143199.2 & \\
\hline 8234 & 567025.31 & 143421.67 & \\
\hline
\end{tabular}




\begin{tabular}{|c|c|c|}
\hline node & X_coord & Y_coord \\
\hline 8235 & $5 \overline{6} 7023.44$ & $1 \overline{4} 3644.12$ \\
\hline 8236 & 567021.62 & 143866.59 \\
\hline 8237 & 567021.62 & 144116.59 \\
\hline 8238 & 567021.62 & 144366.59 \\
\hline 8239 & 567021.62 & 144616.59 \\
\hline 8240 & 567021.62 & 144866.59 \\
\hline 8241 & 567021.62 & 145116.59 \\
\hline 8242 & 567021.62 & 145366.59 \\
\hline 8243 & 567027.4454 & 145544.1254 \\
\hline 8244 & 567091.19 & 145779.67 \\
\hline 8245 & 566563.9279 & 145789.9568 \\
\hline 8246 & 566777.9408 & 145877.6843 \\
\hline 8247 & 566476.12 & 146027.41 \\
\hline 8248 & 566971.504 & 145951.3524 \\
\hline 8249 & 567165.0672 & 146009.2245 \\
\hline 8250 & 570021.62 & 143866.59 \\
\hline 8251 & 569771.62 & 143866.59 \\
\hline 8252 & 570271.62 & 143866.59 \\
\hline 8253 & 569521.62 & 143866.59 \\
\hline 8254 & 570521.62 & 143866.59 \\
\hline 8255 & 569271.62 & 143866.59 \\
\hline 8256 & 570771.62 & 143866.59 \\
\hline 8257 & 569021.62 & 143866.59 \\
\hline 8258 & 571021.62 & 143866.59 \\
\hline 8259 & 568771.62 & 143866.59 \\
\hline 8260 & 571271.62 & 143866.59 \\
\hline 8261 & 568521.62 & 143866.59 \\
\hline 8262 & 571521.62 & 143866.59 \\
\hline 8263 & 568271.62 & 143866.59 \\
\hline 8264 & 571771.62 & 143866.59 \\
\hline 8265 & 568021.62 & 143866.59 \\
\hline 8266 & 572021.62 & 143866.59 \\
\hline 8267 & 568082.19 & 142808 \\
\hline 8268 & 567971.56 & 142894.94 \\
\hline 8269 & 567860.94 & 142981.86 \\
\hline 8270 & 567750.31 & 143068.8 \\
\hline 8271 & 567757.44 & 143334.73 \\
\hline 8272 & 567764.5 & 143600.66 \\
\hline 8273 & 567771.62 & 143866.59 \\
\hline 8274 & 572271.62 & 143866.59 \\
\hline 8275 & 572521.62 & 143866.59 \\
\hline 8276 & 572771.62 & 143866.59 \\
\hline 8277 & 573021.62 & 143866.59 \\
\hline 8278 & 573271.62 & 143866.59 \\
\hline 8279 & 573521.62 & 143866.59 \\
\hline 8280 & 573760.88 & 142825.7 \\
\hline 8281 & 573764.44 & 142922.67 \\
\hline 8282 & 573768.06 & 143019.62 \\
\hline 8283 & 573771.62 & 143116.59 \\
\hline 8284 & 573771.62 & 143366.59 \\
\hline 8285 & 573771.62 & 143616.59 \\
\hline 8286 & 573771.62 & 143866.59 \\
\hline 8287 & 575244.81 & 137233.41 \\
\hline 8288 & 575251.69 & 137089.64 \\
\hline 8289 & 575258.5 & 136945.86 \\
\hline 8290 & 575265.38 & 136802.09 \\
\hline
\end{tabular}

note: from sac04d created July 1, 2004 


\begin{tabular}{|c|c|c|c|}
\hline node & X_coord & Y_coord & note: from sac04d created July 1, 2004 \\
\hline 8291 & $5 \overline{7} 5267.44$ & $1 \overline{3} 6656.92$ & \\
\hline 8292 & 575268 & 140202.41 & \\
\hline 8293 & 575271.62 & 140278.23 & \\
\hline 8294 & 575275.19 & 140354.08 & \\
\hline 8295 & 575278.81 & 140429.91 & \\
\hline 8296 & 575277 & 140511.7 & \\
\hline 8297 & 575275.19 & 140593.5 & \\
\hline 8298 & 575273.38 & 140675.3 & \\
\hline 8299 & 575266.5 & 140744.17 & \\
\hline 8300 & 575259.69 & 140813.03 & \\
\hline 8301 & 575252.81 & 140881.91 & \\
\hline 8302 & 571854.94 & 135199.92 & \\
\hline 8303 & 572104.94 & 134866.59 & \\
\hline 8304 & 572021.62 & 134866.59 & \\
\hline 8305 & 572021.62 & 134533.27 & \\
\hline 8306 & 579271.62 & 134366.59 & \\
\hline 8307 & 579271.62 & 134616.59 & \\
\hline 8308 & 579271.62 & 134866.59 & \\
\hline 8309 & 579271.62 & 135116.59 & \\
\hline 8310 & 579271.62 & 135366.59 & \\
\hline 8311 & 579271.62 & 135616.59 & \\
\hline 8312 & 579271.62 & 135866.59 & \\
\hline 8313 & 579521.62 & 134366.59 & \\
\hline 8314 & 578292.06 & 136614.53 & \\
\hline 8315 & 578535.25 & 136615.22 & \\
\hline 8316 & 578771.62 & 136116.59 & \\
\hline 8317 & 579021.62 & 136116.59 & \\
\hline 8318 & 578771.62 & 136366.59 & \\
\hline 8319 & 579271.62 & 136116.59 & \\
\hline 8320 & 578778.44 & 136615.91 & \\
\hline 8321 & 580771.62 & 132866.59 & \\
\hline 8322 & 580771.62 & 133116.59 & \\
\hline 8323 & 580771.62 & 133366.59 & \\
\hline 8324 & 581021.62 & 132866.59 & \\
\hline 8325 & 580771.62 & 133616.59 & \\
\hline 8326 & 581271.62 & 131866.59 & \\
\hline 8327 & 581271.62 & 132116.59 & \\
\hline 8328 & 581271.62 & 132366.59 & \\
\hline 8329 & 581521.62 & 131866.59 & \\
\hline 8330 & 581271.62 & 132616.59 & \\
\hline 8331 & 583271.62 & 130116.6 & \\
\hline 8332 & 583271.62 & 130366.6 & \\
\hline 8333 & 583271.62 & 130616.6 & \\
\hline 8334 & 583521.62 & 130116.6 & \\
\hline 8335 & 583271.62 & 130866.59 & \\
\hline 8336 & 583771.62 & 129116.6 & \\
\hline 8337 & 583771.62 & 129366.6 & \\
\hline 8338 & 583771.62 & 129616.6 & \\
\hline 8339 & 584021.62 & 129116.6 & \\
\hline 8340 & 583771.62 & 129866.6 & \\
\hline 8341 & 584271.62 & 128116.6 & \\
\hline 8342 & 584271.62 & 128366.6 & \\
\hline 8343 & 584271.62 & 128616.6 & \\
\hline 8344 & 584521.62 & 128116.6 & \\
\hline 8345 & 584271.62 & 128866.6 & \\
\hline 8346 & 584771.62 & 127116.6 & \\
\hline
\end{tabular}




\begin{tabular}{|c|c|c|c|}
\hline node & X_coord & Y_coord & note: from sac04d created July 1, 2004 \\
\hline 8347 & $5 \overline{8} 4771.62$ & $1 \overline{2} 7366.6$ & \\
\hline 8348 & 584771.62 & 127616.6 & \\
\hline 8349 & 585021.62 & 127116.6 & \\
\hline 8350 & 584771.62 & 127866.6 & \\
\hline 8351 & 585271.62 & 126116.6 & \\
\hline 8352 & 585271.62 & 126366.6 & \\
\hline 8353 & 585271.62 & 126616.6 & \\
\hline 8354 & 585521.62 & 126116.6 & \\
\hline 8355 & 585271.62 & 126866.6 & \\
\hline 8356 & 585771.62 & 125116.6 & \\
\hline 8357 & 585771.62 & 124866.6 & \\
\hline 8358 & 585771.62 & 125366.6 & \\
\hline 8359 & 585771.62 & 124616.6 & \\
\hline 8360 & 585771.62 & 125616.6 & \\
\hline 8361 & 585771.62 & 124366.6 & \\
\hline 8362 & 585771.62 & 125866.6 & \\
\hline 8363 & 586021.62 & 124366.6 & \\
\hline 8364 & 585771.62 & 126116.6 & \\
\hline 8365 & 585271.62 & 127116.6 & \\
\hline 8366 & 584771.62 & 128116.6 & \\
\hline 8367 & 584271.62 & 129116.6 & \\
\hline 8368 & 583771.62 & 130116.6 & \\
\hline 8369 & 582271.62 & 131616.59 & \\
\hline 8370 & 582521.62 & 131616.59 & \\
\hline 8371 & 582771.62 & 131116.59 & \\
\hline 8372 & 583021.62 & 131116.59 & \\
\hline 8373 & 582771.62 & 131366.59 & \\
\hline 8374 & 583271.62 & 131116.59 & \\
\hline 8375 & 582771.62 & 131616.59 & \\
\hline 8376 & 586271.62 & 123616.6 & \\
\hline 8377 & 586271.62 & 123366.6 & \\
\hline 8378 & 586271.62 & 123866.6 & \\
\hline 8379 & 586521.62 & 123366.6 & \\
\hline 8380 & 586271.62 & 124116.6 & \\
\hline 8381 & 586771.62 & 122866.6 & \\
\hline 8382 & 586771.62 & 122366.6 & \\
\hline 8383 & 586771.62 & 123116.6 & \\
\hline 8384 & 587271.62 & 122116.6 & \\
\hline 8385 & 587271.62 & 121366.6 & \\
\hline 8386 & 587271.62 & 122366.6 & \\
\hline 8387 & 586771.62 & 123366.6 & \\
\hline 8388 & 586271.62 & 124366.6 & \\
\hline 8389 & 581771.62 & 131866.59 & \\
\hline 8390 & 582021.62 & 131866.59 & \\
\hline 8391 & 582271.62 & 131866.59 & \\
\hline 8392 & 587271.62 & 120616.6 & \\
\hline 8393 & 587271.62 & 119866.6 & \\
\hline 8394 & 581271.62 & 132866.59 & \\
\hline 8395 & 579771.62 & 134366.59 & \\
\hline 8396 & 580021.62 & 134366.59 & \\
\hline 8397 & 580271.62 & 133866.59 & \\
\hline 8398 & 580521.62 & 133866.59 & \\
\hline 8399 & 580271.62 & 134116.59 & \\
\hline 8400 & 580771.62 & 133866.59 & \\
\hline 8401 & 580271.62 & 134366.59 & \\
\hline 8402 & 587271.62 & 119116.6 & \\
\hline
\end{tabular}




\begin{tabular}{|c|c|c|}
\hline node & X_coord & Y_coord \\
\hline 8403 & $5 \overline{8} 7271.62$ & $1 \overline{18366.6}$ \\
\hline 8404 & 575522.25 & 136682.12 \\
\hline 8405 & 575777 & 136707.33 \\
\hline 8406 & 576031.81 & 136732.53 \\
\hline 8407 & 576278.81 & 136759 \\
\hline 8408 & 572188.31 & 134783.27 \\
\hline 8409 & 572188.31 & 134699.92 \\
\hline 8410 & 572188.31 & 134616.59 \\
\hline 8411 & 572188.31 & 134533.27 \\
\hline 8412 & 572104.94 & 134783.27 \\
\hline 8413 & 576525.81 & 136785.45 \\
\hline 8414 & 576772.81 & 136811.92 \\
\hline 8415 & 577022.44 & 136830.14 \\
\hline 8416 & 577272 & 136848.38 \\
\hline 8417 & 577521.62 & 136866.59 \\
\hline 8418 & 577785.25 & 136865.22 \\
\hline 8419 & 578048.81 & 136863.84 \\
\hline 8420 & 578312.44 & 136862.47 \\
\hline 8421 & 587271.62 & 117616.6 \\
\hline 8422 & 585380.19 & 116840.8 \\
\hline 8423 & 585771.62 & 116866.6 \\
\hline 8424 & 586521.62 & 116866.6 \\
\hline 8425 & 587271.62 & 116866.6 \\
\hline 8426 & 572104.94 & 134533.27 \\
\hline 8427 & 572021.62 & 134616.59 \\
\hline 8428 & 572021.62 & 134699.92 \\
\hline 8429 & 572021.62 & 134783.27 \\
\hline 8430 & 567268.19 & 143155.73 \\
\hline 8431 & 567269.31 & 143392.69 \\
\hline 8432 & 567270.5 & 143629.64 \\
\hline 8433 & 567271.62 & 143866.59 \\
\hline 8434 & 567271.62 & 144116.59 \\
\hline 8435 & 567271.62 & 144366.59 \\
\hline 8436 & 567271.62 & 144616.59 \\
\hline 8437 & 567271.62 & 144866.59 \\
\hline 8438 & 567271.62 & 145116.59 \\
\hline 8439 & 567271.62 & 145366.59 \\
\hline 8440 & 567285.56 & 145603.73 \\
\hline 8441 & 567299.44 & 145840.86 \\
\hline 8442 & 567350.635 & 146094.8154 \\
\hline 8443 & 566652.06 & 146122.53 \\
\hline 8444 & 566827.94 & 146217.67 \\
\hline 8445 & 567003.88 & 146312.8 \\
\hline 8446 & 567179.81 & 146407.94 \\
\hline 8447 & 570021.62 & 144116.59 \\
\hline 8448 & 569771.62 & 144116.59 \\
\hline 8449 & 570271.62 & 144116.59 \\
\hline 8450 & 569521.62 & 144116.59 \\
\hline 8451 & 570521.62 & 144116.59 \\
\hline 8452 & 569271.62 & 144116.59 \\
\hline 8453 & 570771.62 & 144116.59 \\
\hline 8454 & 569021.62 & 144116.59 \\
\hline 8455 & 571021.62 & 144116.59 \\
\hline 8456 & 568771.62 & 144116.59 \\
\hline 8457 & 571271.62 & 144116.59 \\
\hline 8458 & 568521.62 & 144116.59 \\
\hline
\end{tabular}




\begin{tabular}{|c|c|c|c|}
\hline node & X_coord & Y_coord & note: from sac04d created July 1,2004 \\
\hline 8459 & $5 \overline{7} 1521.62$ & $1 \overline{4} 4116.59$ & \\
\hline 8460 & 568271.62 & 144116.59 & \\
\hline 8461 & 571771.62 & 144116.59 & \\
\hline 8462 & 568021.62 & 144116.59 & \\
\hline 8463 & 572021.62 & 144116.59 & \\
\hline 8464 & 567771.62 & 144116.59 & \\
\hline 8465 & 572271.62 & 144116.59 & \\
\hline 8466 & 567509.25 & 143112.27 & \\
\hline 8467 & 567513.38 & 143363.7 & \\
\hline 8468 & 567517.5 & 143615.16 & \\
\hline 8469 & 567521.62 & 143866.59 & \\
\hline 8470 & 567521.62 & 144116.59 & \\
\hline 8471 & 572521.62 & 144116.59 & \\
\hline 8472 & 572771.62 & 144116.59 & \\
\hline 8473 & 573021.62 & 144116.59 & \\
\hline 8474 & 573271.62 & 144116.59 & \\
\hline 8475 & 573521.62 & 144116.59 & \\
\hline 8476 & 573771.62 & 144116.59 & \\
\hline 8477 & 574009.88 & 142829.67 & \\
\hline 8478 & 574013.81 & 142925.31 & \\
\hline 8479 & 574017.69 & 143020.95 & \\
\hline 8480 & 574021.62 & 143116.59 & \\
\hline 8481 & 574021.62 & 143366.59 & \\
\hline 8482 & 574021.62 & 143616.59 & \\
\hline 8483 & 574021.62 & 143866.59 & \\
\hline 8484 & 574021.62 & 144116.59 & \\
\hline 8485 & 575576.81 & 137336.08 & \\
\hline 8486 & 575558.75 & 137170.69 & \\
\hline 8487 & 575540.62 & 137005.28 & \\
\hline 8488 & 575522.56 & 136839.89 & \\
\hline 8489 & 575383.56 & 140104.94 & \\
\hline 8490 & 575517.12 & 140166.3 & \\
\hline 8491 & 575624.5 & 140067.25 & \\
\hline 8492 & 575519.5 & 140238.52 & \\
\hline 8493 & 575521.94 & 140310.75 & \\
\hline 8494 & 575524.31 & 140382.97 & \\
\hline 8495 & 575523.12 & 140460.36 & \\
\hline 8496 & 575521.88 & 140537.73 & \\
\hline 8497 & 575520.69 & 140615.12 & \\
\hline 8498 & 575514.06 & 140686.84 & \\
\hline 8499 & 575507.38 & 140758.55 & \\
\hline 8500 & 575500.75 & 140830.27 & \\
\hline 8501 & 572104.94 & 134616.59 & \\
\hline 8502 & 579521.62 & 134616.59 & \\
\hline 8503 & 579521.62 & 134866.59 & \\
\hline 8504 & 579521.62 & 135116.59 & \\
\hline 8505 & 579521.62 & 135366.59 & \\
\hline 8506 & 579521.62 & 135616.59 & \\
\hline 8507 & 579521.62 & 135866.59 & \\
\hline 8508 & 579521.62 & 136116.59 & \\
\hline 8509 & 579771.62 & 134616.59 & \\
\hline 8510 & 578548.81 & 136863.84 & \\
\hline 8511 & 578785.25 & 136865.22 & \\
\hline 8512 & 579021.62 & 136366.59 & \\
\hline 8513 & 579271.62 & 136366.59 & \\
\hline 8514 & 579021.62 & 136616.59 & \\
\hline
\end{tabular}




\begin{tabular}{|c|c|c|c|}
\hline node & X_coord & Y_coord & note: from sac04d created July 1,2004 \\
\hline 8515 & $5 \overline{7} 9521.62$ & $1 \overline{3} 6366.59$ & \\
\hline 8516 & 579021.62 & 136866.59 & \\
\hline 8517 & 581021.62 & 133116.59 & \\
\hline 8518 & 581021.62 & 133366.59 & \\
\hline 8519 & 581021.62 & 133616.59 & \\
\hline 8520 & 581271.62 & 133116.59 & \\
\hline 8521 & 581021.62 & 133866.59 & \\
\hline 8522 & 581521.62 & 132116.59 & \\
\hline 8523 & 581521.62 & 132366.59 & \\
\hline 8524 & 581521.62 & 132616.59 & \\
\hline 8525 & 581771.62 & 132116.59 & \\
\hline 8526 & 581521.62 & 132866.59 & \\
\hline 8527 & 583521.62 & 130366.6 & \\
\hline 8528 & 583521.62 & 130616.6 & \\
\hline 8529 & 583521.62 & 130866.59 & \\
\hline 8530 & 583771.62 & 130366.6 & \\
\hline 8531 & 583521.62 & 131116.59 & \\
\hline 8532 & 584021.62 & 129366.6 & \\
\hline 8533 & 584021.62 & 129616.6 & \\
\hline 8534 & 584021.62 & 129866.6 & \\
\hline 8535 & 584271.62 & 129366.6 & \\
\hline 8536 & 584021.62 & 130116.6 & \\
\hline 8537 & 584521.62 & 128366.6 & \\
\hline 8538 & 584521.62 & 128616.6 & \\
\hline 8539 & 584521.62 & 128866.6 & \\
\hline 8540 & 584771.62 & 128366.6 & \\
\hline 8541 & 584521.62 & 129116.6 & \\
\hline 8542 & 585021.62 & 127366.6 & \\
\hline 8543 & 585021.62 & 127616.6 & \\
\hline 8544 & 585021.62 & 127866.6 & \\
\hline 8545 & 585271.62 & 127366.6 & \\
\hline 8546 & 585021.62 & 128116.6 & \\
\hline 8547 & 585521.62 & 126366.6 & \\
\hline 8548 & 585521.62 & 126616.6 & \\
\hline 8549 & 585521.62 & 126866.6 & \\
\hline 8550 & 585771.62 & 126366.6 & \\
\hline 8551 & 585521.62 & 127116.6 & \\
\hline 8552 & 586021.62 & 125116.6 & \\
\hline 8553 & 586021.62 & 124866.6 & \\
\hline 8554 & 586021.62 & 125366.6 & \\
\hline 8555 & 586021.62 & 124616.6 & \\
\hline 8556 & 586021.62 & 125616.6 & \\
\hline 8557 & 586021.62 & 125866.6 & \\
\hline 8558 & 586021.62 & 126116.6 & \\
\hline 8559 & 586271.62 & 124616.6 & \\
\hline 8560 & 586021.62 & 126366.6 & \\
\hline 8561 & 585521.62 & 127366.6 & \\
\hline 8562 & 585021.62 & 128366.6 & \\
\hline 8563 & 584521.62 & 129366.6 & \\
\hline 8564 & 584021.62 & 130366.6 & \\
\hline 8565 & 582521.62 & 131866.59 & \\
\hline 8566 & 582771.62 & 131866.59 & \\
\hline 8567 & 583021.62 & 131366.59 & \\
\hline 8568 & 583271.62 & 131366.59 & \\
\hline 8569 & 583021.62 & 131616.59 & \\
\hline 8570 & 583521.62 & 131366.59 & \\
\hline
\end{tabular}




\begin{tabular}{|c|c|c|c|}
\hline node & X_coord & Y_coord & note: from sac04d created July 1, 2004 \\
\hline 8571 & $5 \overline{8} 3021.62$ & $1 \overline{3} 1866.59$ & \\
\hline 8572 & 586521.62 & 123616.6 & \\
\hline 8573 & 586521.62 & 123866.6 & \\
\hline 8574 & 586521.62 & 124116.6 & \\
\hline 8575 & 586771.62 & 123616.6 & \\
\hline 8576 & 586521.62 & 124366.6 & \\
\hline 8577 & 587021.62 & 122866.6 & \\
\hline 8578 & 587021.62 & 122616.6 & \\
\hline 8579 & 587021.62 & 123116.6 & \\
\hline 8580 & 587271.62 & 122616.6 & \\
\hline 8581 & 587021.62 & 123366.6 & \\
\hline 8582 & 587521.62 & 122116.6 & \\
\hline 8583 & 587521.62 & 121616.6 & \\
\hline 8584 & 587521.62 & 122366.6 & \\
\hline 8585 & 588021.62 & 121366.6 & \\
\hline 8586 & 588021.62 & 120616.6 & \\
\hline 8587 & 588021.62 & 121616.6 & \\
\hline 8588 & 587521.62 & 122616.6 & \\
\hline 8589 & 587021.62 & 123616.6 & \\
\hline 8590 & 586521.62 & 124616.6 & \\
\hline 8591 & 582021.62 & 132116.59 & \\
\hline 8592 & 582271.62 & 132116.59 & \\
\hline 8593 & 582521.62 & 132116.59 & \\
\hline 8594 & 588021.62 & 119866.6 & \\
\hline 8595 & 588021.62 & 119116.6 & \\
\hline 8596 & 581521.62 & 133116.59 & \\
\hline 8597 & 580021.62 & 134616.59 & \\
\hline 8598 & 580271.62 & 134616.59 & \\
\hline 8599 & 580521.62 & 134116.59 & \\
\hline 8600 & 580771.62 & 134116.59 & \\
\hline 8601 & 580521.62 & 134366.59 & \\
\hline 8602 & 581021.62 & 134116.59 & \\
\hline 8603 & 580521.62 & 134616.59 & \\
\hline 8604 & 588021.62 & 118366.6 & \\
\hline 8605 & 588021.62 & 117616.6 & \\
\hline 8606 & 575779.69 & 136877.7 & \\
\hline 8607 & 576036.88 & 136915.5 & \\
\hline 8608 & 576282.38 & 136955.2 & \\
\hline 8609 & 576527.88 & 136994.89 & \\
\hline 8610 & 572104.94 & 134699.92 & \\
\hline 8611 & 576773.38 & 137034.59 & \\
\hline 8612 & 577022.81 & 137061.92 & \\
\hline 8613 & 577272.19 & 137089.27 & \\
\hline 8614 & 577521.62 & 137116.59 & \\
\hline 8615 & 577792.06 & 137114.53 & \\
\hline 8616 & 578062.44 & 137112.47 & \\
\hline 8617 & 578332.88 & 137110.41 & \\
\hline 8618 & 578562.44 & 137112.47 & \\
\hline 8619 & 588021.62 & 116866.6 & \\
\hline 8620 & 585503.12 & 116434.6 & \\
\hline 8621 & 585771.62 & 116116.6 & \\
\hline 8622 & 586521.62 & 116116.6 & \\
\hline 8623 & 587271.62 & 116116.6 & \\
\hline 8624 & 588021.62 & 116116.6 & \\
\hline 8625 & 567521.62 & 144366.59 & \\
\hline 8626 & 567521.62 & 144616.59 & \\
\hline
\end{tabular}




\begin{tabular}{|c|c|c|c|}
\hline node & X_coord & Y_coord & note: from sac04d created July 1, 2004 \\
\hline 8627 & $5 \overline{6} 7521.62$ & $1 \overline{4} 4866.59$ & \\
\hline 8628 & 567521.62 & 145116.59 & \\
\hline 8629 & 567521.62 & 145366.59 & \\
\hline 8630 & 567514.69 & 145634.33 & \\
\hline 8631 & 567507.69 & 145902.06 & \\
\hline 8632 & 567522.7351 & 146196.1821 & \\
\hline 8633 & 567355.69 & 146503.06 & \\
\hline 8634 & 570021.62 & 144366.59 & \\
\hline 8635 & 569771.62 & 144366.59 & \\
\hline 8636 & 570271.62 & 144366.59 & \\
\hline 8637 & 569521.62 & 144366.59 & \\
\hline 8638 & 570521.62 & 144366.59 & \\
\hline 8639 & 569271.62 & 144366.59 & \\
\hline 8640 & 570771.62 & 144366.59 & \\
\hline 8641 & 569021.62 & 144366.59 & \\
\hline 8642 & 571021.62 & 144366.59 & \\
\hline 8643 & 568771.62 & 144366.59 & \\
\hline 8644 & 571271.62 & 144366.59 & \\
\hline 8645 & 568521.62 & 144366.59 & \\
\hline 8646 & 571521.62 & 144366.59 & \\
\hline 8647 & 568271.62 & 144366.59 & \\
\hline 8648 & 571771.62 & 144366.59 & \\
\hline 8649 & 568021.62 & 144366.59 & \\
\hline 8650 & 572021.62 & 144366.59 & \\
\hline 8651 & 567771.62 & 144366.59 & \\
\hline 8652 & 572271.62 & 144366.59 & \\
\hline 8653 & 572521.62 & 144366.59 & \\
\hline 8654 & 572771.62 & 144366.59 & \\
\hline 8655 & 573021.62 & 144366.59 & \\
\hline 8656 & 573271.62 & 144366.59 & \\
\hline 8657 & 573521.62 & 144366.59 & \\
\hline 8658 & 573771.62 & 144366.59 & \\
\hline 8659 & 574021.62 & 144366.59 & \\
\hline 8660 & 574258.81 & 142833.62 & \\
\hline 8661 & 574263.06 & 142927.95 & \\
\hline 8662 & 574267.38 & 143022.27 & \\
\hline 8663 & 574271.62 & 143116.59 & \\
\hline 8664 & 574271.62 & 143366.59 & \\
\hline 8665 & 574271.62 & 143616.59 & \\
\hline 8666 & 574271.62 & 143866.59 & \\
\hline 8667 & 574271.62 & 144116.59 & \\
\hline 8668 & 574271.62 & 144366.59 & \\
\hline 8669 & 575908.88 & 137438.73 & \\
\hline 8670 & 575865.81 & 137251.72 & \\
\hline 8671 & 575822.75 & 137064.72 & \\
\hline 8672 & 575499.06 & 140007.47 & \\
\hline 8673 & 575731.88 & 139968.19 & \\
\hline 8674 & 575766.19 & 140130.2 & \\
\hline 8675 & 575865.44 & 140029.56 & \\
\hline 8676 & 575767.38 & 140198.81 & \\
\hline 8677 & 575964.62 & 139928.91 & \\
\hline 8678 & 575768.62 & 140267.42 & \\
\hline 8679 & 575769.81 & 140336.03 & \\
\hline 8680 & 575769.19 & 140409.02 & \\
\hline 8681 & 575768.62 & 140481.98 & \\
\hline 8682 & 575768 & 140554.97 & \\
\hline
\end{tabular}




\begin{tabular}{|c|c|c|c|}
\hline node & X_coord & Y_coord & note: from sac04d created July 1,2004 \\
\hline 8683 & $5 \overline{7} 5761.56$ & $1 \overline{4} 0629.53$ & \\
\hline 8684 & 575755.12 & 140704.08 & \\
\hline 8685 & 575748.69 & 140778.64 & \\
\hline 8686 & 579771.62 & 134866.59 & \\
\hline 8687 & 579771.62 & 135116.59 & \\
\hline 8688 & 579771.62 & 135366.59 & \\
\hline 8689 & 579771.62 & 135616.59 & \\
\hline 8690 & 579771.62 & 135866.59 & \\
\hline 8691 & 579771.62 & 136116.59 & \\
\hline 8692 & 579771.62 & 136366.59 & \\
\hline 8693 & 580021.62 & 134866.59 & \\
\hline 8694 & 578792.06 & 137114.53 & \\
\hline 8695 & 579021.62 & 137116.59 & \\
\hline 8696 & 579279.19 & 136586.11 & \\
\hline 8697 & 579536.81 & 136555.64 & \\
\hline 8698 & 579286.81 & 136805.64 & \\
\hline 8699 & 579794.38 & 136525.16 & \\
\hline 8700 & 579294.38 & 137025.16 & \\
\hline 8701 & 581271.62 & 133366.59 & \\
\hline 8702 & 581271.62 & 133616.59 & \\
\hline 8703 & 581271.62 & 133866.59 & \\
\hline 8704 & 581521.62 & 133366.59 & \\
\hline 8705 & 581271.62 & 134116.59 & \\
\hline 8706 & 581771.62 & 132366.59 & \\
\hline 8707 & 581771.62 & 132616.59 & \\
\hline 8708 & 581771.62 & 132866.59 & \\
\hline 8709 & 582021.62 & 132366.59 & \\
\hline 8710 & 581771.62 & 133116.59 & \\
\hline 8711 & 583771.62 & 130616.6 & \\
\hline 8712 & 583771.62 & 130866.59 & \\
\hline 8713 & 583771.62 & 131116.59 & \\
\hline 8714 & 584021.62 & 130616.6 & \\
\hline 8715 & 583771.62 & 131366.59 & \\
\hline 8716 & 584271.62 & 129616.6 & \\
\hline 8717 & 584271.62 & 129866.6 & \\
\hline 8718 & 584271.62 & 130116.6 & \\
\hline 8719 & 584521.62 & 129616.6 & \\
\hline 8720 & 584271.62 & 130366.6 & \\
\hline 8721 & 584771.62 & 128616.6 & \\
\hline 8722 & 584771.62 & 128866.6 & \\
\hline 8723 & 584771.62 & 129116.6 & \\
\hline 8724 & 585021.62 & 128616.6 & \\
\hline 8725 & 584771.62 & 129366.6 & \\
\hline 8726 & 585271.62 & 127616.6 & \\
\hline 8727 & 585271.62 & 127866.6 & \\
\hline 8728 & 585271.62 & 128116.6 & \\
\hline 8729 & 585521.62 & 127616.6 & \\
\hline 8730 & 585271.62 & 128366.6 & \\
\hline 8731 & 585771.62 & 126616.6 & \\
\hline 8732 & 585771.62 & 126866.6 & \\
\hline 8733 & 585771.62 & 127116.6 & \\
\hline 8734 & 586021.62 & 126616.6 & \\
\hline 8735 & 585771.62 & 127366.6 & \\
\hline 8736 & 586271.62 & 125116.6 & \\
\hline 8737 & 586271.62 & 124866.6 & \\
\hline 8738 & 586271.62 & 125366.6 & \\
\hline
\end{tabular}




\begin{tabular}{|c|c|c|c|}
\hline node & X_coord & Y_coord & note: from sac04d created July 1, 2004 \\
\hline 8739 & $5 \overline{8} 6271.62$ & $1 \overline{2} 5616.6$ & \\
\hline 8740 & 586271.62 & 125866.6 & \\
\hline 8741 & 586271.62 & 126116.6 & \\
\hline 8742 & 586271.62 & 126366.6 & \\
\hline 8743 & 586521.62 & 124866.6 & \\
\hline 8744 & 586271.62 & 126616.6 & \\
\hline 8745 & 585771.62 & 127616.6 & \\
\hline 8746 & 585271.62 & 128616.6 & \\
\hline 8747 & 584771.62 & 129616.6 & \\
\hline 8748 & 584271.62 & 130616.6 & \\
\hline 8749 & 582771.62 & 132116.59 & \\
\hline 8750 & 583021.62 & 132116.59 & \\
\hline 8751 & 583271.62 & 131616.59 & \\
\hline 8752 & 583521.62 & 131616.59 & \\
\hline 8753 & 583271.62 & 131866.59 & \\
\hline 8754 & 583771.62 & 131616.59 & \\
\hline 8755 & 583271.62 & 132116.59 & \\
\hline 8756 & 586771.62 & 123866.6 & \\
\hline 8757 & 586771.62 & 124116.6 & \\
\hline 8758 & 586771.62 & 124366.6 & \\
\hline 8759 & 587021.62 & 123866.6 & \\
\hline 8760 & 586771.62 & 124616.6 & \\
\hline 8761 & 587271.62 & 122866.6 & \\
\hline 8762 & 587271.62 & 123116.6 & \\
\hline 8763 & 587271.62 & 123366.6 & \\
\hline 8764 & 587521.62 & 122866.6 & \\
\hline 8765 & 587271.62 & 123616.6 & \\
\hline 8766 & 587771.62 & 122116.6 & \\
\hline 8767 & 587771.62 & 121866.6 & \\
\hline 8768 & 587771.62 & 122366.6 & \\
\hline 8769 & 588021.62 & 121866.6 & \\
\hline 8770 & 587771.62 & 122616.6 & \\
\hline 8771 & 588271.62 & 121366.6 & \\
\hline 8772 & 588271.62 & 120866.6 & \\
\hline 8773 & 588271.62 & 121616.6 & \\
\hline 8774 & 588771.62 & 120616.6 & \\
\hline 8775 & 588771.62 & 119866.6 & \\
\hline 8776 & 588771.62 & 120866.6 & \\
\hline 8777 & 588271.62 & 121866.6 & \\
\hline 8778 & 587771.62 & 122866.6 & \\
\hline 8779 & 587271.62 & 123866.6 & \\
\hline 8780 & 586771.62 & 124866.6 & \\
\hline 8781 & 582271.62 & 132366.59 & \\
\hline 8782 & 582521.62 & 132366.59 & \\
\hline 8783 & 582771.62 & 132366.59 & \\
\hline 8784 & 588771.62 & 119116.6 & \\
\hline 8785 & 588771.62 & 118366.6 & \\
\hline 8786 & 581771.62 & 133366.59 & \\
\hline 8787 & 580271.62 & 134866.59 & \\
\hline 8788 & 580521.62 & 134866.59 & \\
\hline 8789 & 580771.62 & 134366.59 & \\
\hline 8790 & 581021.62 & 134366.59 & \\
\hline 8791 & 580771.62 & 134616.59 & \\
\hline 8792 & 581271.62 & 134366.59 & \\
\hline 8793 & 580771.62 & 134866.59 & \\
\hline 8794 & 588771.62 & 117616.6 & \\
\hline
\end{tabular}




\begin{tabular}{|c|c|c|c|}
\hline node & X_coord & Y_coord & note: from sac04d created July 1, 2004 \\
\hline 8795 & $5 \overline{8} 8771.62$ & $1 \overline{16866.6}$ & \\
\hline 8796 & 576104.88 & 137124.14 & \\
\hline 8797 & 576365.38 & 137192.31 & \\
\hline 8798 & 576625.88 & 137260.48 & \\
\hline 8799 & 576886.38 & 137328.66 & \\
\hline 8800 & 577098.12 & 137341.3 & \\
\hline 8801 & 577309.88 & 137353.95 & \\
\hline 8802 & 577521.62 & 137366.59 & \\
\hline 8803 & 577785.25 & 137365.22 & \\
\hline 8804 & 578048.81 & 137363.84 & \\
\hline 8805 & 578312.44 & 137362.47 & \\
\hline 8806 & 578573.19 & 137367.12 & \\
\hline 8807 & 578833.94 & 137371.78 & \\
\hline 8808 & 588771.62 & 116116.6 & \\
\hline 8809 & 586098.62 & 115582.3 & \\
\hline 8810 & 586529.88 & 115294.8 & \\
\hline 8811 & 587271.62 & 115366.6 & \\
\hline 8812 & 588021.62 & 115366.6 & \\
\hline 8813 & 588771.62 & 115366.6 & \\
\hline 8814 & 567771.62 & 144616.59 & \\
\hline 8815 & 567771.62 & 144866.59 & \\
\hline 8816 & 567771.62 & 145116.59 & \\
\hline 8817 & 567771.62 & 145366.59 & \\
\hline 8818 & 567743.81 & 145664.92 & \\
\hline 8819 & 567715.94 & 145963.27 & \\
\hline 8820 & 567700.7775 & 146297.272 & \\
\hline 8821 & 567531.62 & 146598.2 & \\
\hline 8822 & 570021.62 & 144616.59 & \\
\hline 8823 & 569771.62 & 144616.59 & \\
\hline 8824 & 570271.62 & 144616.59 & \\
\hline 8825 & 569521.62 & 144616.59 & \\
\hline 8826 & 570521.62 & 144616.59 & \\
\hline 8827 & 569271.62 & 144616.59 & \\
\hline 8828 & 570771.62 & 144616.59 & \\
\hline 8829 & 569021.62 & 144616.59 & \\
\hline 8830 & 571021.62 & 144616.59 & \\
\hline 8831 & 568771.62 & 144616.59 & \\
\hline 8832 & 571271.62 & 144616.59 & \\
\hline 8833 & 568521.62 & 144616.59 & \\
\hline 8834 & 571521.62 & 144616.59 & \\
\hline 8835 & 568271.62 & 144616.59 & \\
\hline 8836 & 571771.62 & 144616.59 & \\
\hline 8837 & 568021.62 & 144616.59 & \\
\hline 8838 & 572021.62 & 144616.59 & \\
\hline 8839 & 572271.62 & 144616.59 & \\
\hline 8840 & 572521.62 & 144616.59 & \\
\hline 8841 & 572771.62 & 144616.59 & \\
\hline 8842 & 573021.62 & 144616.59 & \\
\hline 8843 & 573271.62 & 144616.59 & \\
\hline 8844 & 573521.62 & 144616.59 & \\
\hline 8845 & 573771.62 & 144616.59 & \\
\hline 8846 & 574021.62 & 144616.59 & \\
\hline 8847 & 574271.62 & 144616.59 & \\
\hline 8848 & 574507.81 & 142837.59 & \\
\hline 8849 & 574512.44 & 142930.59 & \\
\hline 8850 & 574517 & 143023.59 & \\
\hline
\end{tabular}




\begin{tabular}{|c|c|c|c|}
\hline node & X_coord & Y_coord & note: from sac04d created July 1, 2004 \\
\hline 8851 & $5 \overline{7} 4521.62$ & $1 \overline{4} 3116.59$ & \\
\hline 8852 & 574521.62 & 143366.59 & \\
\hline 8853 & 574521.62 & 143616.59 & \\
\hline 8854 & 574521.62 & 143866.59 & \\
\hline 8855 & 574521.62 & 144116.59 & \\
\hline 8856 & 574521.62 & 144366.59 & \\
\hline 8857 & 574521.62 & 144616.59 & \\
\hline 8858 & 576240.88 & 137541.41 & \\
\hline 8859 & 576172.88 & 137332.77 & \\
\hline 8860 & 575614.62 & 139910 & \\
\hline 8861 & 575839.25 & 139869.14 & \\
\hline 8862 & 576063.88 & 139828.27 & \\
\hline 8863 & 576015.31 & 140094.09 & \\
\hline 8864 & 576106.38 & 139991.86 & \\
\hline 8865 & 576015.31 & 140159.09 & \\
\hline 8866 & 576197.44 & 139889.64 & \\
\hline 8867 & 576015.31 & 140224.09 & \\
\hline 8868 & 576288.5 & 139787.41 & \\
\hline 8869 & 576015.31 & 140289.09 & \\
\hline 8870 & 576015.31 & 140357.66 & \\
\hline 8871 & 576015.31 & 140426.23 & \\
\hline 8872 & 576015.31 & 140494.8 & \\
\hline 8873 & 576009.06 & 140572.2 & \\
\hline 8874 & 576002.88 & 140649.59 & \\
\hline 8875 & 575996.62 & 140727 & \\
\hline 8876 & 580021.62 & 135116.59 & \\
\hline 8877 & 580021.62 & 135366.59 & \\
\hline 8878 & 580021.62 & 135616.59 & \\
\hline 8879 & 580021.62 & 135866.59 & \\
\hline 8880 & 580021.62 & 136116.59 & \\
\hline 8881 & 580021.62 & 136366.59 & \\
\hline 8882 & 580036.81 & 136555.64 & \\
\hline 8883 & 580271.62 & 135116.59 & \\
\hline 8884 & 579094.62 & 137376.42 & \\
\hline 8885 & 579341.94 & 137243.14 & \\
\hline 8886 & 579551.94 & 136744.69 & \\
\hline 8887 & 579817.12 & 136683.73 & \\
\hline 8888 & 579567.12 & 136933.73 & \\
\hline 8889 & 580051.94 & 136744.69 & \\
\hline 8890 & 579589.19 & 137109.88 & \\
\hline 8891 & 581521.62 & 133616.59 & \\
\hline 8892 & 581521.62 & 133866.59 & \\
\hline 8893 & 581521.62 & 134116.59 & \\
\hline 8894 & 581771.62 & 133616.59 & \\
\hline 8895 & 581521.62 & 134366.59 & \\
\hline 8896 & 582021.62 & 132616.59 & \\
\hline 8897 & 582021.62 & 132866.59 & \\
\hline 8898 & 582021.62 & 133116.59 & \\
\hline 8899 & 582271.62 & 132616.59 & \\
\hline 8900 & 582021.62 & 133366.59 & \\
\hline 8901 & 584021.62 & 130866.59 & \\
\hline 8902 & 584021.62 & 131116.59 & \\
\hline 8903 & 584021.62 & 131366.59 & \\
\hline 8904 & 584271.62 & 130866.59 & \\
\hline 8905 & 584021.62 & 131616.59 & \\
\hline 8906 & 584521.62 & 129866.6 & \\
\hline
\end{tabular}




\begin{tabular}{|c|c|c|c|}
\hline node & X_coord & Y_coord & note: from sac04d created July 1,2004 \\
\hline 8907 & $5 \overline{8} 4521.62$ & $1 \overline{3} 0116.6$ & \\
\hline 8908 & 584521.62 & 130366.6 & \\
\hline 8909 & 584771.62 & 129866.6 & \\
\hline 8910 & 584521.62 & 130616.6 & \\
\hline 8911 & 585021.62 & 128866.6 & \\
\hline 8912 & 585021.62 & 129116.6 & \\
\hline 8913 & 585021.62 & 129366.6 & \\
\hline 8914 & 585271.62 & 128866.6 & \\
\hline 8915 & 585021.62 & 129616.6 & \\
\hline 8916 & 585521.62 & 127866.6 & \\
\hline 8917 & 585521.62 & 128116.6 & \\
\hline 8918 & 585521.62 & 128366.6 & \\
\hline 8919 & 585771.62 & 127866.6 & \\
\hline 8920 & 585521.62 & 128616.6 & \\
\hline 8921 & 586021.62 & 126866.6 & \\
\hline 8922 & 586021.62 & 127116.6 & \\
\hline 8923 & 586021.62 & 127366.6 & \\
\hline 8924 & 586271.62 & 126866.6 & \\
\hline 8925 & 586021.62 & 127616.6 & \\
\hline 8926 & 586521.62 & 125116.6 & \\
\hline 8927 & 586521.62 & 125366.6 & \\
\hline 8928 & 586521.62 & 125616.6 & \\
\hline 8929 & 586521.62 & 125866.6 & \\
\hline 8930 & 586521.62 & 126116.6 & \\
\hline 8931 & 586521.62 & 126366.6 & \\
\hline 8932 & 586521.62 & 126616.6 & \\
\hline 8933 & 586771.62 & 125116.6 & \\
\hline 8934 & 586521.62 & 126866.6 & \\
\hline 8935 & 586021.62 & 127866.6 & \\
\hline 8936 & 585521.62 & 128866.6 & \\
\hline 8937 & 585021.62 & 129866.6 & \\
\hline 8938 & 584521.62 & 130866.59 & \\
\hline 8939 & 583021.62 & 132366.59 & \\
\hline 8940 & 583271.62 & 132366.59 & \\
\hline 8941 & 583521.62 & 131866.59 & \\
\hline 8942 & 583771.62 & 131866.59 & \\
\hline 8943 & 583521.62 & 132116.59 & \\
\hline 8944 & 584021.62 & 131866.59 & \\
\hline 8945 & 583521.62 & 132366.59 & \\
\hline 8946 & 587021.62 & 124116.6 & \\
\hline 8947 & 587021.62 & 124366.6 & \\
\hline 8948 & 587021.62 & 124616.6 & \\
\hline 8949 & 587271.62 & 124116.6 & \\
\hline 8950 & 587021.62 & 124866.6 & \\
\hline 8951 & 587521.62 & 123116.6 & \\
\hline 8952 & 587521.62 & 123366.6 & \\
\hline 8953 & 587521.62 & 123616.6 & \\
\hline 8954 & 587771.62 & 123116.6 & \\
\hline 8955 & 587521.62 & 123866.6 & \\
\hline 8956 & 588021.62 & 122116.6 & \\
\hline 8957 & 588021.62 & 122366.6 & \\
\hline 8958 & 588021.62 & 122616.6 & \\
\hline 8959 & 588271.62 & 122116.6 & \\
\hline 8960 & 588021.62 & 122866.6 & \\
\hline 8961 & 588521.62 & 121366.6 & \\
\hline 8962 & 588521.62 & 121116.6 & \\
\hline
\end{tabular}




\begin{tabular}{|c|c|c|c|}
\hline node & X_coord & Y_coord & note: from sac04d created July 1, 2004 \\
\hline 8963 & $5 \overline{8} 8521.62$ & $1 \overline{2} 1616.6$ & \\
\hline 8964 & 588771.62 & 121116.6 & \\
\hline 8965 & 588521.62 & 121866.6 & \\
\hline 8966 & 589021.62 & 120616.6 & \\
\hline 8967 & 589021.62 & 119866.6 & \\
\hline 8968 & 589021.62 & 120866.6 & \\
\hline 8969 & 589021.62 & 119366.6 & \\
\hline 8970 & 589021.62 & 121116.6 & \\
\hline 8971 & 588521.62 & 122116.6 & \\
\hline 8972 & 588021.62 & 123116.6 & \\
\hline 8973 & 587521.62 & 124116.6 & \\
\hline 8974 & 587021.62 & 125116.6 & \\
\hline 8975 & 582521.62 & 132616.59 & \\
\hline 8976 & 582771.62 & 132616.59 & \\
\hline 8977 & 583021.62 & 132616.59 & \\
\hline 8978 & 589521.62 & 119116.6 & \\
\hline 8979 & 589521.62 & 118366.6 & \\
\hline 8980 & 589521.62 & 119366.6 & \\
\hline 8981 & 589521.62 & 117616.6 & \\
\hline 8982 & 582021.62 & 133616.59 & \\
\hline 8983 & 580521.62 & 135116.59 & \\
\hline 8984 & 580771.62 & 135116.59 & \\
\hline 8985 & 581021.62 & 134616.59 & \\
\hline 8986 & 581271.62 & 134616.59 & \\
\hline 8987 & 581021.62 & 134866.59 & \\
\hline 8988 & 581521.62 & 134616.59 & \\
\hline 8989 & 581021.62 & 135116.59 & \\
\hline 8990 & 589521.62 & 116866.6 & \\
\hline 8991 & 589521.62 & 116116.6 & \\
\hline 8992 & 576448.38 & 137429.42 & \\
\hline 8993 & 576723.88 & 137526.08 & \\
\hline 8994 & 576999.38 & 137622.73 & \\
\hline 8995 & 577173.5 & 137620.69 & \\
\hline 8996 & 577347.5 & 137618.64 & \\
\hline 8997 & 577521.62 & 137616.59 & \\
\hline 8998 & 577778.44 & 137615.91 & \\
\hline 8999 & 578035.25 & 137615.22 & \\
\hline 9000 & 578292.06 & 137614.53 & \\
\hline 9001 & 578583.88 & 137621.77 & \\
\hline 9002 & 578875.81 & 137629.02 & \\
\hline 9003 & 579167.69 & 137636.27 & \\
\hline 9004 & 589521.62 & 115366.6 & \\
\hline 9005 & 586766.12 & 114663.3 & \\
\hline 9006 & 587271.62 & 114616.6 & \\
\hline 9007 & 588021.62 & 114616.6 & \\
\hline 9008 & 588771.62 & 114616.6 & \\
\hline 9009 & 589521.62 & 114616.6 & \\
\hline 9010 & 568021.62 & 144866.59 & \\
\hline 9011 & 568021.62 & 145116.59 & \\
\hline 9012 & 568021.62 & 145366.59 & \\
\hline 9013 & 568003.06 & 145648.81 & \\
\hline 9014 & 567984.5 & 145931.05 & \\
\hline 9015 & 567965.94 & 146213.27 & \\
\hline 9016 & 567811.7931 & 146375.4643 & \\
\hline 9017 & 567637.56 & 146655.47 & \\
\hline 9018 & 568010.6329 & 146317.3173 & \\
\hline
\end{tabular}




\begin{tabular}{|c|c|c|c|}
\hline node & X_coord & Y_coord & note: from sac04d created July 1, 2004 \\
\hline 9019 & $5 \overline{7} 0021.62$ & $1 \overline{4} 4866.59$ & \\
\hline 9020 & 569771.62 & 144866.59 & \\
\hline 9021 & 570271.62 & 144866.59 & \\
\hline 9022 & 569521.62 & 144866.59 & \\
\hline 9023 & 570521.62 & 144866.59 & \\
\hline 9024 & 569271.62 & 144866.59 & \\
\hline 9025 & 570771.62 & 144866.59 & \\
\hline 9026 & 569021.62 & 144866.59 & \\
\hline 9027 & 571021.62 & 144866.59 & \\
\hline 9028 & 568771.62 & 144866.59 & \\
\hline 9029 & 571271.62 & 144866.59 & \\
\hline 9030 & 568521.62 & 144866.59 & \\
\hline 9031 & 571521.62 & 144866.59 & \\
\hline 9032 & 568271.62 & 144866.59 & \\
\hline 9033 & 571771.62 & 144866.59 & \\
\hline 9034 & 572021.62 & 144866.59 & \\
\hline 9035 & 572271.62 & 144866.59 & \\
\hline 9036 & 572521.62 & 144866.59 & \\
\hline 9037 & 572771.62 & 144866.59 & \\
\hline 9038 & 573021.62 & 144866.59 & \\
\hline 9039 & 573271.62 & 144866.59 & \\
\hline 9040 & 573521.62 & 144866.59 & \\
\hline 9041 & 573771.62 & 144866.59 & \\
\hline 9042 & 574021.62 & 144866.59 & \\
\hline 9043 & 574271.62 & 144866.59 & \\
\hline 9044 & 574521.62 & 144866.59 & \\
\hline 9045 & 574760.75 & 142794.12 & \\
\hline 9046 & 574764.38 & 142901.61 & \\
\hline 9047 & 574768 & 143009.11 & \\
\hline 9048 & 574771.62 & 143116.59 & \\
\hline 9049 & 574771.62 & 143366.59 & \\
\hline 9050 & 574771.62 & 143616.59 & \\
\hline 9051 & 574771.62 & 143866.59 & \\
\hline 9052 & 574771.62 & 144116.59 & \\
\hline 9053 & 574771.62 & 144366.59 & \\
\hline 9054 & 574771.62 & 144616.59 & \\
\hline 9055 & 574771.62 & 144866.59 & \\
\hline 9056 & 576531.38 & 137666.53 & \\
\hline 9057 & 576267.31 & 140031.2 & \\
\hline 9058 & 576375.12 & 139848.84 & \\
\hline 9059 & 576267.31 & 140105.53 & \\
\hline 9060 & 576482.88 & 139666.5 & \\
\hline 9061 & 576267.31 & 140179.88 & \\
\hline 9062 & 576590.69 & 139484.14 & \\
\hline 9063 & 576267.31 & 140254.2 & \\
\hline 9064 & 576267.31 & 140329.72 & \\
\hline 9065 & 576267.31 & 140405.22 & \\
\hline 9066 & 576267.31 & 140480.73 & \\
\hline 9067 & 576237.94 & 140550.19 & \\
\hline 9068 & 576208.5 & 140619.64 & \\
\hline 9069 & 576179.12 & 140689.09 & \\
\hline 9070 & 580271.62 & 135366.59 & \\
\hline 9071 & 580271.62 & 135616.59 & \\
\hline 9072 & 580271.62 & 135866.59 & \\
\hline 9073 & 580271.62 & 136116.59 & \\
\hline 9074 & 580271.62 & 136366.59 & \\
\hline
\end{tabular}




\begin{tabular}{|c|c|c|c|}
\hline node & X_coord & Y_coord & note: from sac04d created July 1, 2004 \\
\hline 9075 & $5 \overline{80} 279.19$ & $1 \overline{3} 6586.11$ & \\
\hline 9076 & 580286.81 & 136805.64 & \\
\hline 9077 & 580521.62 & 135366.59 & \\
\hline 9078 & 579389.44 & 137461.14 & \\
\hline 9079 & 579611.25 & 137286.03 & \\
\hline 9080 & 579839.88 & 136842.3 & \\
\hline 9081 & 580067.12 & 136933.73 & \\
\hline 9082 & 579836.44 & 136976.59 & \\
\hline 9083 & 580294.38 & 137025.16 & \\
\hline 9084 & 579833.06 & 137110.91 & \\
\hline 9085 & 581771.62 & 133866.59 & \\
\hline 9086 & 581771.62 & 134116.59 & \\
\hline 9087 & 581771.62 & 134366.59 & \\
\hline 9088 & 582021.62 & 133866.59 & \\
\hline 9089 & 581771.62 & 134616.59 & \\
\hline 9090 & 582271.62 & 132866.59 & \\
\hline 9091 & 582271.62 & 133116.59 & \\
\hline 9092 & 582271.62 & 133366.59 & \\
\hline 9093 & 582521.62 & 132866.59 & \\
\hline 9094 & 582271.62 & 133616.59 & \\
\hline 9095 & 584271.62 & 131116.59 & \\
\hline 9096 & 584271.62 & 131366.59 & \\
\hline 9097 & 584271.62 & 131616.59 & \\
\hline 9098 & 584521.62 & 131116.59 & \\
\hline 9099 & 584271.62 & 131866.59 & \\
\hline 9100 & 584771.62 & 130116.6 & \\
\hline 9101 & 584771.62 & 130366.6 & \\
\hline 9102 & 584771.62 & 130616.6 & \\
\hline 9103 & 585021.62 & 130116.6 & \\
\hline 9104 & 584771.62 & 130866.59 & \\
\hline 9105 & 585271.62 & 129116.6 & \\
\hline 9106 & 585271.62 & 129366.6 & \\
\hline 9107 & 585271.62 & 129616.6 & \\
\hline 9108 & 585521.62 & 129116.6 & \\
\hline 9109 & 585271.62 & 129866.6 & \\
\hline 9110 & 585771.62 & 128116.6 & \\
\hline 9111 & 585771.62 & 128366.6 & \\
\hline 9112 & 585771.62 & 128616.6 & \\
\hline 9113 & 586021.62 & 128116.6 & \\
\hline 9114 & 585771.62 & 128866.6 & \\
\hline 9115 & 586271.62 & 127116.6 & \\
\hline 9116 & 586271.62 & 127366.6 & \\
\hline 9117 & 586271.62 & 127616.6 & \\
\hline 9118 & 586521.62 & 127116.6 & \\
\hline 9119 & 586271.62 & 127866.6 & \\
\hline 9120 & 586771.62 & 125366.6 & \\
\hline 9121 & 586771.62 & 125616.6 & \\
\hline 9122 & 586771.62 & 125866.6 & \\
\hline 9123 & 586771.62 & 126116.6 & \\
\hline 9124 & 586771.62 & 126366.6 & \\
\hline 9125 & 586771.62 & 126616.6 & \\
\hline 9126 & 586771.62 & 126866.6 & \\
\hline 9127 & 587021.62 & 125366.6 & \\
\hline 9128 & 586771.62 & 127116.6 & \\
\hline 9129 & 586271.62 & 128116.6 & \\
\hline 9130 & 585771.62 & 129116.6 & \\
\hline
\end{tabular}




\begin{tabular}{|c|c|c|c|}
\hline node & X_coord & Y_coord & note: from sac04d created July 1,2004 \\
\hline 9131 & 585271.62 & 130116.6 & \\
\hline 9132 & 584771.62 & 131116.59 & \\
\hline 9133 & 583271.62 & 132616.59 & \\
\hline 9134 & 583521.62 & 132616.59 & \\
\hline 9135 & 583771.62 & 132116.59 & \\
\hline 9136 & 584021.62 & 132116.59 & \\
\hline 9137 & 583771.62 & 132366.59 & \\
\hline 9138 & 584271.62 & 132116.59 & \\
\hline 9139 & 583771.62 & 132616.59 & \\
\hline 9140 & 587271.62 & 124366.6 & \\
\hline 9141 & 587271.62 & 124616.6 & \\
\hline 9142 & 587271.62 & 124866.6 & \\
\hline 9143 & 587521.62 & 124366.6 & \\
\hline 9144 & 587271.62 & 125116.6 & \\
\hline 9145 & 587771.62 & 123366.6 & \\
\hline 9146 & 587771.62 & 123616.6 & \\
\hline 9147 & 587771.62 & 123866.6 & \\
\hline 9148 & 588021.62 & 123366.6 & \\
\hline 9149 & 587771.62 & 124116.6 & \\
\hline 9150 & 588271.62 & 122366.6 & \\
\hline 9151 & 588271.62 & 122616.6 & \\
\hline 9152 & 588271.62 & 122866.6 & \\
\hline 9153 & 588521.62 & 122366.6 & \\
\hline 9154 & 588271.62 & 123116.6 & \\
\hline 9155 & 588771.62 & 121366.6 & \\
\hline 9156 & 588771.62 & 121616.6 & \\
\hline 9157 & 588771.62 & 121866.6 & \\
\hline 9158 & 589021.62 & 121366.6 & \\
\hline 9159 & 588771.62 & 122116.6 & \\
\hline 9160 & 589188.31 & 120366.6 & \\
\hline 9161 & 589271.62 & 120616.6 & \\
\hline 9162 & 589354.94 & 120366.6 & \\
\hline 9163 & 589188.31 & 120116.6 & \\
\hline 9164 & 589271.62 & 120866.6 & \\
\hline 9165 & 589271.62 & 119866.6 & \\
\hline 9166 & 589271.62 & 119616.6 & \\
\hline 9167 & 589354.94 & 120116.6 & \\
\hline 9168 & 589271.62 & 121116.6 & \\
\hline 9169 & 589521.62 & 119616.6 & \\
\hline 9170 & 589271.62 & 121366.6 & \\
\hline 9171 & 588771.62 & 122366.6 & \\
\hline 9172 & 588271.62 & 123366.6 & \\
\hline 9173 & 587771.62 & 124366.6 & \\
\hline 9174 & 587271.62 & 125366.6 & \\
\hline 9175 & 582771.62 & 132866.59 & \\
\hline 9176 & 583021.62 & 132866.59 & \\
\hline 9177 & 583271.62 & 132866.59 & \\
\hline 9178 & 589771.62 & 119116.6 & \\
\hline 9179 & 589771.62 & 118616.6 & \\
\hline 9180 & 589771.62 & 119366.6 & \\
\hline 9181 & 590271.62 & 118366.6 & \\
\hline 9182 & 590271.62 & 117616.6 & \\
\hline 9183 & 590271.62 & 118616.6 & \\
\hline 9184 & 589771.62 & 119616.6 & \\
\hline 9185 & 590271.62 & 116866.6 & \\
\hline 9186 & 582271.62 & 133866.59 & \\
\hline
\end{tabular}




\begin{tabular}{|c|c|c|c|}
\hline node & X_coord & Y_coord & note: from sac04d created July 1,2004 \\
\hline 9187 & $5 \overline{80} 0771.62$ & $1 \overline{3} 5366.59$ & \\
\hline 9188 & 581021.62 & 135366.59 & \\
\hline 9189 & 581271.62 & 134866.59 & \\
\hline 9190 & 581521.62 & 134866.59 & \\
\hline 9191 & 581271.62 & 135116.59 & \\
\hline 9192 & 581771.62 & 134866.59 & \\
\hline 9193 & 581271.62 & 135366.59 & \\
\hline 9194 & 590271.62 & 116116.6 & \\
\hline 9195 & 590271.62 & 115366.6 & \\
\hline 9196 & 576821.88 & 137791.67 & \\
\hline 9197 & 577112.38 & 137916.8 & \\
\hline 9198 & 577248.81 & 137900.06 & \\
\hline 9199 & 577385.19 & 137883.33 & \\
\hline 9200 & 577521.62 & 137866.59 & \\
\hline 9201 & 577771.62 & 137866.59 & \\
\hline 9202 & 578021.62 & 137866.59 & \\
\hline 9203 & 578271.62 & 137866.59 & \\
\hline 9204 & 578594.62 & 137876.42 & \\
\hline 9205 & 578917.69 & 137886.27 & \\
\hline 9206 & 579240.69 & 137896.09 & \\
\hline 9207 & 579437 & 137679.12 & \\
\hline 9208 & 590271.62 & 114616.6 & \\
\hline 9209 & 587033.12 & 113924 & \\
\hline 9210 & 587534.12 & 113857.9 & \\
\hline 9211 & 588021.62 & 113866.6 & \\
\hline 9212 & 588771.62 & 113866.6 & \\
\hline 9213 & 589521.62 & 113866.6 & \\
\hline 9214 & 590271.62 & 113866.6 & \\
\hline 9215 & 568271.62 & 145116.59 & \\
\hline 9216 & 568271.62 & 145366.59 & \\
\hline 9217 & 568262.38 & 145632.7 & \\
\hline 9218 & 568253.06 & 145898.81 & \\
\hline 9219 & 568243.81 & 146164.92 & \\
\hline 9220 & 568333.4299 & 146313.2601 & \\
\hline 9221 & 567897.3309 & 146475.9724 & \\
\hline 9222 & 567743.44 & 146712.73 & \\
\hline 9224 & 568350.8899 & 146574.9643 & \\
\hline 9225 & 570021.62 & 145116.59 & \\
\hline 9226 & 569771.62 & 145116.59 & \\
\hline 9227 & 570271.62 & 145116.59 & \\
\hline 9228 & 569521.62 & 145116.59 & \\
\hline 9229 & 570521.62 & 145116.59 & \\
\hline 9230 & 569271.62 & 145116.59 & \\
\hline 9231 & 570771.62 & 145116.59 & \\
\hline 9232 & 569021.62 & 145116.59 & \\
\hline 9233 & 571021.62 & 145116.59 & \\
\hline 9234 & 568771.62 & 145116.59 & \\
\hline 9235 & 571271.62 & 145116.59 & \\
\hline 9236 & 568521.62 & 145116.59 & \\
\hline 9237 & 571521.62 & 145116.59 & \\
\hline 9238 & 571771.62 & 145116.59 & \\
\hline 9239 & 572021.62 & 145116.59 & \\
\hline 9240 & 572271.62 & 145116.59 & \\
\hline 9241 & 572521.62 & 145116.59 & \\
\hline 9242 & 572771.62 & 145116.59 & \\
\hline 9243 & 573021.62 & 145116.59 & \\
\hline
\end{tabular}




\begin{tabular}{|c|c|c|c|}
\hline node & X_coord & Y_coord & note: from sac04d created July 1, 2004 \\
\hline 9244 & $5 \overline{7} 3271.62$ & $1 \overline{4} 5116.59$ & \\
\hline 9245 & 573521.62 & 145116.59 & \\
\hline 9246 & 573771.62 & 145116.59 & \\
\hline 9247 & 574021.62 & 145116.59 & \\
\hline 9248 & 574271.62 & 145116.59 & \\
\hline 9249 & 574521.62 & 145116.59 & \\
\hline 9250 & 574771.62 & 145116.59 & \\
\hline 9251 & 575013.69 & 142750.67 & \\
\hline 9252 & 575016.31 & 142872.64 & \\
\hline 9253 & 575019 & 142994.62 & \\
\hline 9254 & 575021.62 & 143116.59 & \\
\hline 9255 & 575021.62 & 143366.59 & \\
\hline 9256 & 575021.62 & 143616.59 & \\
\hline 9257 & 575021.62 & 143866.59 & \\
\hline 9258 & 575021.62 & 144116.59 & \\
\hline 9259 & 575021.62 & 144366.59 & \\
\hline 9260 & 575021.62 & 144616.59 & \\
\hline 9261 & 575021.62 & 144866.59 & \\
\hline 9262 & 575021.62 & 145116.59 & \\
\hline 9263 & 576519.31 & 139968.3 & \\
\hline 9264 & 576643.88 & 139705.81 & \\
\hline 9265 & 576519.31 & 140051.97 & \\
\hline 9266 & 576768.38 & 139443.34 & \\
\hline 9267 & 576519.31 & 140135.62 & \\
\hline 9268 & 576892.94 & 139180.86 & \\
\hline 9269 & 576519.31 & 140219.3 & \\
\hline 9270 & 576519.31 & 140301.75 & \\
\hline 9271 & 576519.31 & 140384.2 & \\
\hline 9272 & 576519.31 & 140466.66 & \\
\hline 9273 & 576466.75 & 140528.17 & \\
\hline 9274 & 576414.25 & 140589.69 & \\
\hline 9275 & 576361.69 & 140651.2 & \\
\hline 9276 & 580521.62 & 135616.59 & \\
\hline 9277 & 580521.62 & 135866.59 & \\
\hline 9278 & 580521.62 & 136116.59 & \\
\hline 9279 & 580521.62 & 136366.59 & \\
\hline 9280 & 580521.62 & 136616.59 & \\
\hline 9281 & 580521.62 & 136866.59 & \\
\hline 9282 & 580521.62 & 137116.59 & \\
\hline 9283 & 580771.62 & 135616.59 & \\
\hline 9284 & 579633.31 & 137462.17 & \\
\hline 9285 & 579829.62 & 137245.2 & \\
\hline 9286 & 580055.69 & 137106.44 & \\
\hline 9287 & 580274.94 & 137236.27 & \\
\hline 9288 & 580044.25 & 137279.12 & \\
\hline 9289 & 580494.12 & 137366.09 & \\
\hline 9290 & 580032.81 & 137451.83 & \\
\hline 9291 & 582021.62 & 134116.59 & \\
\hline 9292 & 582021.62 & 134366.59 & \\
\hline 9293 & 582021.62 & 134616.59 & \\
\hline 9294 & 582271.62 & 134116.59 & \\
\hline 9295 & 582021.62 & 134866.59 & \\
\hline 9296 & 582521.62 & 133116.59 & \\
\hline 9297 & 582521.62 & 133366.59 & \\
\hline 9298 & 582521.62 & 133616.59 & \\
\hline 9299 & 582771.62 & 133116.59 & \\
\hline
\end{tabular}




\begin{tabular}{|c|c|c|c|}
\hline node & X_coord & Y_coord & note: from sac04d created July 1, 2004 \\
\hline 9300 & $5 \overline{8} 2521.62$ & $1 \overline{3} 3866.59$ & \\
\hline 9301 & 584521.62 & 131366.59 & \\
\hline 9302 & 584521.62 & 131616.59 & \\
\hline 9303 & 584521.62 & 131866.59 & \\
\hline 9304 & 584771.62 & 131366.59 & \\
\hline 9305 & 584521.62 & 132116.59 & \\
\hline 9306 & 585021.62 & 130366.6 & \\
\hline 9307 & 585021.62 & 130616.6 & \\
\hline 9308 & 585021.62 & 130866.59 & \\
\hline 9309 & 585271.62 & 130366.6 & \\
\hline 9310 & 585021.62 & 131116.59 & \\
\hline 9311 & 585521.62 & 129366.6 & \\
\hline 9312 & 585521.62 & 129616.6 & \\
\hline 9313 & 585521.62 & 129866.6 & \\
\hline 9314 & 585771.62 & 129366.6 & \\
\hline 9315 & 585521.62 & 130116.6 & \\
\hline 9316 & 586021.62 & 128366.6 & \\
\hline 9317 & 586021.62 & 128616.6 & \\
\hline 9318 & 586021.62 & 128866.6 & \\
\hline 9319 & 586271.62 & 128366.6 & \\
\hline 9320 & 586021.62 & 129116.6 & \\
\hline 9321 & 586521.62 & 127366.6 & \\
\hline 9322 & 586521.62 & 127616.6 & \\
\hline 9323 & 586521.62 & 127866.6 & \\
\hline 9324 & 586771.62 & 127366.6 & \\
\hline 9325 & 586521.62 & 128116.6 & \\
\hline 9326 & 587021.62 & 125616.6 & \\
\hline 9327 & 587021.62 & 125866.6 & \\
\hline 9328 & 587021.62 & 126116.6 & \\
\hline 9329 & 587021.62 & 126366.6 & \\
\hline 9330 & 587021.62 & 126616.6 & \\
\hline 9331 & 587021.62 & 126866.6 & \\
\hline 9332 & 587021.62 & 127116.6 & \\
\hline 9333 & 587271.62 & 125616.6 & \\
\hline 9334 & 587021.62 & 127366.6 & \\
\hline 9335 & 586521.62 & 128366.6 & \\
\hline 9336 & 586021.62 & 129366.6 & \\
\hline 9337 & 585521.62 & 130366.6 & \\
\hline 9338 & 585021.62 & 131366.59 & \\
\hline 9339 & 583521.62 & 132866.59 & \\
\hline 9340 & 583771.62 & 132866.59 & \\
\hline 9341 & 584021.62 & 132366.59 & \\
\hline 9342 & 584271.62 & 132366.59 & \\
\hline 9343 & 584021.62 & 132616.59 & \\
\hline 9344 & 584521.62 & 132366.59 & \\
\hline 9345 & 584021.62 & 132866.59 & \\
\hline 9346 & 587521.62 & 124616.6 & \\
\hline 9347 & 587521.62 & 124866.6 & \\
\hline 9348 & 587521.62 & 125116.6 & \\
\hline 9349 & 587771.62 & 124616.6 & \\
\hline 9350 & 587521.62 & 125366.6 & \\
\hline 9351 & 588021.62 & 123616.6 & \\
\hline 9352 & 588021.62 & 123866.6 & \\
\hline 9353 & 588021.62 & 124116.6 & \\
\hline 9354 & 588271.62 & 123616.6 & \\
\hline 9355 & 588021.62 & 124366.6 & \\
\hline
\end{tabular}




\begin{tabular}{|c|c|c|c|}
\hline node & X_coord & Y_coord & note: from sac04d created July 1, 2004 \\
\hline 9356 & $5 \overline{8} 8521.62$ & $1 \overline{2} 2616.6$ & \\
\hline 9357 & 588521.62 & 122866.6 & \\
\hline 9358 & 588521.62 & 123116.6 & \\
\hline 9359 & 588771.62 & 122616.6 & \\
\hline 9360 & 588521.62 & 123366.6 & \\
\hline 9361 & 589021.62 & 121616.6 & \\
\hline 9362 & 589021.62 & 121866.6 & \\
\hline 9363 & 589021.62 & 122116.6 & \\
\hline 9364 & 589271.62 & 121616.6 & \\
\hline 9365 & 589021.62 & 122366.6 & \\
\hline 9366 & 589521.62 & 120616.6 & \\
\hline 9367 & 589521.62 & 120366.6 & \\
\hline 9368 & 589521.62 & 120866.6 & \\
\hline 9369 & 589521.62 & 120116.6 & \\
\hline 9370 & 589521.62 & 121116.6 & \\
\hline 9371 & 589521.62 & 119866.6 & \\
\hline 9372 & 589521.62 & 121366.6 & \\
\hline 9373 & 589771.62 & 119866.6 & \\
\hline 9374 & 589521.62 & 121616.6 & \\
\hline 9375 & 589021.62 & 122616.6 & \\
\hline 9376 & 588521.62 & 123616.6 & \\
\hline 9377 & 588021.62 & 124616.6 & \\
\hline 9378 & 587521.62 & 125616.6 & \\
\hline 9379 & 583021.62 & 133116.59 & \\
\hline 9380 & 583271.62 & 133116.59 & \\
\hline 9381 & 583521.62 & 133116.59 & \\
\hline 9382 & 590021.62 & 119116.6 & \\
\hline 9383 & 590021.62 & 118866.6 & \\
\hline 9384 & 590021.62 & 119366.6 & \\
\hline 9385 & 590271.62 & 118866.6 & \\
\hline 9386 & 590021.62 & 119616.6 & \\
\hline 9387 & 590521.62 & 118366.6 & \\
\hline 9388 & 590521.62 & 117866.6 & \\
\hline 9389 & 590521.62 & 118616.6 & \\
\hline 9390 & 591021.62 & 117616.6 & \\
\hline 9391 & 591021.62 & 116866.6 & \\
\hline 9392 & 591021.62 & 117866.6 & \\
\hline 9393 & 590521.62 & 118866.6 & \\
\hline 9394 & 590021.62 & 119866.6 & \\
\hline 9395 & 591021.62 & 116116.6 & \\
\hline 9396 & 582521.62 & 134116.59 & \\
\hline 9397 & 581021.62 & 135616.59 & \\
\hline 9398 & 581271.62 & 135616.59 & \\
\hline 9399 & 581521.62 & 135116.59 & \\
\hline 9400 & 581771.62 & 135116.59 & \\
\hline 9401 & 581521.62 & 135366.59 & \\
\hline 9402 & 582021.62 & 135116.59 & \\
\hline 9403 & 581521.62 & 135616.59 & \\
\hline 9404 & 591021.62 & 115366.6 & \\
\hline 9405 & 591021.62 & 114616.6 & \\
\hline 9406 & 577139.94 & 138237.06 & \\
\hline 9407 & 577279.12 & 138221.31 & \\
\hline 9408 & 577418.25 & 138205.58 & \\
\hline 9409 & 577557.44 & 138189.83 & \\
\hline 9410 & 577783.06 & 138189.39 & \\
\hline 9411 & 578008.69 & 138188.97 & \\
\hline
\end{tabular}




\begin{tabular}{|c|c|c|c|}
\hline node & X_coord & Y_coord & note: from sac04d created July 1,2004 \\
\hline 9412 & $5 \overline{7} 8234.31$ & $1 \overline{3} 8188.53$ & \\
\hline 9413 & 578541.06 & 138149.36 & \\
\hline 9414 & 578847.88 & 138110.2 & \\
\hline 9415 & 579154.69 & 138071.03 & \\
\hline 9416 & 591021.62 & 113866.6 & \\
\hline 9417 & 587228.12 & 113369.5 & \\
\hline 9418 & 587546.38 & 113071.7 & \\
\hline 9419 & 588021.62 & 113116.6 & \\
\hline 9420 & 588771.62 & 113116.6 & \\
\hline 9421 & 589521.62 & 113116.6 & \\
\hline 9422 & 590271.62 & 113116.6 & \\
\hline 9423 & 591021.62 & 113116.6 & \\
\hline 9424 & 568521.62 & 145366.59 & \\
\hline 9425 & 568521.62 & 145616.59 & \\
\hline 9426 & 568521.62 & 145866.59 & \\
\hline 9427 & 568521.62 & 146116.59 & \\
\hline 9428 & 568527.38 & 146365.89 & \\
\hline 9429 & 568533.06 & 146615.2 & \\
\hline 9430 & 567992.4671 & 146573.8671 & \\
\hline 9431 & 567849.38 & 146770 & \\
\hline 9432 & 568187.5324 & 146681.6416 & \\
\hline 9433 & 568380.8499 & 146796.334 & \\
\hline 9434 & 568562.6072 & 146903.5672 & \\
\hline 9435 & 570021.62 & 145366.59 & \\
\hline 9436 & 569771.62 & 145366.59 & \\
\hline 9437 & 570271.62 & 145366.59 & \\
\hline 9438 & 569521.62 & 145366.59 & \\
\hline 9439 & 570521.62 & 145366.59 & \\
\hline 9440 & 569271.62 & 145366.59 & \\
\hline 9441 & 570771.62 & 145366.59 & \\
\hline 9442 & 569021.62 & 145366.59 & \\
\hline 9443 & 571021.62 & 145366.59 & \\
\hline 9444 & 568771.62 & 145366.59 & \\
\hline 9445 & 571271.62 & 145366.59 & \\
\hline 9446 & 571521.62 & 145366.59 & \\
\hline 9447 & 571771.62 & 145366.59 & \\
\hline 9448 & 572021.62 & 145366.59 & \\
\hline 9449 & 572271.62 & 145366.59 & \\
\hline 9450 & 572521.62 & 145366.59 & \\
\hline 9451 & 572771.62 & 145366.59 & \\
\hline 9452 & 573021.62 & 145366.59 & \\
\hline 9453 & 573271.62 & 145366.59 & \\
\hline 9454 & 573521.62 & 145366.59 & \\
\hline 9455 & 573771.62 & 145366.59 & \\
\hline 9456 & 574021.62 & 145366.59 & \\
\hline 9457 & 574271.62 & 145366.59 & \\
\hline 9458 & 574521.62 & 145366.59 & \\
\hline 9459 & 574771.62 & 145366.59 & \\
\hline 9460 & 575021.62 & 145366.59 & \\
\hline 9461 & 575266.62 & 142707.2 & \\
\hline 9462 & 575268.31 & 142843.67 & \\
\hline 9463 & 575269.94 & 142980.12 & \\
\hline 9464 & 575271.62 & 143116.59 & \\
\hline 9465 & 575271.62 & 143366.59 & \\
\hline 9466 & 575271.62 & 143616.59 & \\
\hline 9467 & 575271.62 & 143866.59 & \\
\hline
\end{tabular}




\begin{tabular}{|c|c|c|c|}
\hline node & X_coord & Y_coord & note: from sac04d created July 1, 2004 \\
\hline 9468 & $5 \overline{7} 5271.62$ & $1 \overline{4} 4116.59$ & \\
\hline 9469 & 575271.62 & 144366.59 & \\
\hline 9470 & 575271.62 & 144616.59 & \\
\hline 9471 & 575271.62 & 144866.59 & \\
\hline 9472 & 575271.62 & 145116.59 & \\
\hline 9473 & 575271.62 & 145366.59 & \\
\hline 9474 & 576771.31 & 139905.41 & \\
\hline 9475 & 576912.56 & 139562.8 & \\
\hline 9476 & 576771.31 & 139998.41 & \\
\hline 9477 & 577053.88 & 139220.2 & \\
\hline 9478 & 576771.31 & 140091.41 & \\
\hline 9479 & 577195.12 & 138877.59 & \\
\hline 9480 & 576771.31 & 140184.41 & \\
\hline 9481 & 576771.31 & 140273.8 & \\
\hline 9482 & 576771.31 & 140363.2 & \\
\hline 9483 & 576771.31 & 140452.59 & \\
\hline 9484 & 576695.62 & 140506.16 & \\
\hline 9485 & 576619.88 & 140559.73 & \\
\hline 9486 & 576544.19 & 140613.3 & \\
\hline 9487 & 580771.62 & 135866.59 & \\
\hline 9488 & 580771.62 & 136116.59 & \\
\hline 9489 & 580771.62 & 136366.59 & \\
\hline 9490 & 580771.62 & 136616.59 & \\
\hline 9491 & 580771.62 & 136866.59 & \\
\hline 9492 & 580771.62 & 137116.59 & \\
\hline 9493 & 580753.31 & 137366.27 & \\
\hline 9494 & 581021.62 & 135866.59 & \\
\hline 9495 & 580255.44 & 137447.36 & \\
\hline 9496 & 580466.69 & 137615.59 & \\
\hline 9497 & 580236 & 137658.47 & \\
\hline 9498 & 580735 & 137615.92 & \\
\hline 9499 & 582271.62 & 134366.59 & \\
\hline 9500 & 582271.62 & 134616.59 & \\
\hline 9501 & 582271.62 & 134866.59 & \\
\hline 9502 & 582521.62 & 134366.59 & \\
\hline 9503 & 582271.62 & 135116.59 & \\
\hline 9504 & 582771.62 & 133366.59 & \\
\hline 9505 & 582771.62 & 133616.59 & \\
\hline 9506 & 582771.62 & 133866.59 & \\
\hline 9507 & 583021.62 & 133366.59 & \\
\hline 9508 & 582771.62 & 134116.59 & \\
\hline 9509 & 584771.62 & 131616.59 & \\
\hline 9510 & 584771.62 & 131866.59 & \\
\hline 9511 & 584771.62 & 132116.59 & \\
\hline 9512 & 585021.62 & 131616.59 & \\
\hline 9513 & 584771.62 & 132366.59 & \\
\hline 9514 & 585271.62 & 130616.6 & \\
\hline 9515 & 585271.62 & 130866.59 & \\
\hline 9516 & 585271.62 & 131116.59 & \\
\hline 9517 & 585521.62 & 130616.6 & \\
\hline 9518 & 585271.62 & 131366.59 & \\
\hline 9519 & 585771.62 & 129616.6 & \\
\hline 9520 & 585771.62 & 129866.6 & \\
\hline 9521 & 585771.62 & 130116.6 & \\
\hline 9522 & 586021.62 & 129616.6 & \\
\hline 9523 & 585771.62 & 130366.6 & \\
\hline
\end{tabular}




\begin{tabular}{|c|c|c|c|}
\hline node & X_coord & Y_coord & note: from sac04d created July 1, 2004 \\
\hline 9524 & $5 \overline{8} 6271.62$ & $1 \overline{2} 8616.6$ & \\
\hline 9525 & 586271.62 & 128866.6 & \\
\hline 9526 & 586271.62 & 129116.6 & \\
\hline 9527 & 586521.62 & 128616.6 & \\
\hline 9528 & 586271.62 & 129366.6 & \\
\hline 9529 & 586771.62 & 127616.6 & \\
\hline 9530 & 586771.62 & 127866.6 & \\
\hline 9531 & 586771.62 & 128116.6 & \\
\hline 9532 & 587021.62 & 127616.6 & \\
\hline 9533 & 586771.62 & 128366.6 & \\
\hline 9534 & 587271.62 & 125866.6 & \\
\hline 9535 & 587271.62 & 126116.6 & \\
\hline 9536 & 587271.62 & 126366.6 & \\
\hline 9537 & 587271.62 & 126616.6 & \\
\hline 9538 & 587271.62 & 126866.6 & \\
\hline 9539 & 587271.62 & 127116.6 & \\
\hline 9540 & 587271.62 & 127366.6 & \\
\hline 9541 & 587521.62 & 125866.6 & \\
\hline 9542 & 587271.62 & 127616.6 & \\
\hline 9543 & 586771.62 & 128616.6 & \\
\hline 9544 & 586271.62 & 129616.6 & \\
\hline 9545 & 585771.62 & 130616.6 & \\
\hline 9546 & 585271.62 & 131616.59 & \\
\hline 9547 & 583771.62 & 133116.59 & \\
\hline 9548 & 584021.62 & 133116.59 & \\
\hline 9549 & 584271.62 & 132616.59 & \\
\hline 9550 & 584521.62 & 132616.59 & \\
\hline 9551 & 584271.62 & 132866.59 & \\
\hline 9552 & 584771.62 & 132616.59 & \\
\hline 9553 & 584271.62 & 133116.59 & \\
\hline 9554 & 587771.62 & 124866.6 & \\
\hline 9555 & 587771.62 & 125116.6 & \\
\hline 9556 & 587771.62 & 125366.6 & \\
\hline 9557 & 588021.62 & 124866.6 & \\
\hline 9558 & 587771.62 & 125616.6 & \\
\hline 9559 & 588271.62 & 123866.6 & \\
\hline 9560 & 588271.62 & 124116.6 & \\
\hline 9561 & 588271.62 & 124366.6 & \\
\hline 9562 & 588521.62 & 123866.6 & \\
\hline 9563 & 588271.62 & 124616.6 & \\
\hline 9564 & 588771.62 & 122866.6 & \\
\hline 9565 & 588771.62 & 123116.6 & \\
\hline 9566 & 588771.62 & 123366.6 & \\
\hline 9567 & 589021.62 & 122866.6 & \\
\hline 9568 & 588771.62 & 123616.6 & \\
\hline 9569 & 589271.62 & 121866.6 & \\
\hline 9570 & 589271.62 & 122116.6 & \\
\hline 9571 & 589271.62 & 122366.6 & \\
\hline 9572 & 589521.62 & 121866.6 & \\
\hline 9573 & 589271.62 & 122616.6 & \\
\hline 9574 & 589771.62 & 120616.6 & \\
\hline 9575 & 589771.62 & 120366.6 & \\
\hline 9576 & 589771.62 & 120866.6 & \\
\hline 9577 & 589771.62 & 120116.6 & \\
\hline 9578 & 589771.62 & 121116.6 & \\
\hline 9579 & 589771.62 & 121366.6 & \\
\hline
\end{tabular}




\begin{tabular}{|c|c|c|c|}
\hline node & X_coord & Y_coord & note: from sac04d created July 1,2004 \\
\hline 9580 & $5 \overline{8} 9771.62$ & $1 \overline{2} 1616.6$ & \\
\hline 9581 & 590021.62 & 120116.6 & \\
\hline 9582 & 589771.62 & 121866.6 & \\
\hline 9583 & 589271.62 & 122866.6 & \\
\hline 9584 & 588771.62 & 123866.6 & \\
\hline 9585 & 588271.62 & 124866.6 & \\
\hline 9586 & 587771.62 & 125866.6 & \\
\hline 9587 & 583271.62 & 133366.59 & \\
\hline 9588 & 583521.62 & 133366.59 & \\
\hline 9589 & 583771.62 & 133366.59 & \\
\hline 9590 & 590271.62 & 119116.6 & \\
\hline 9591 & 590271.62 & 119366.6 & \\
\hline 9592 & 590271.62 & 119616.6 & \\
\hline 9593 & 590521.62 & 119116.6 & \\
\hline 9594 & 590271.62 & 119866.6 & \\
\hline 9595 & 590771.62 & 118366.6 & \\
\hline 9596 & 590771.62 & 118116.6 & \\
\hline 9597 & 590771.62 & 118616.6 & \\
\hline 9598 & 591021.62 & 118116.6 & \\
\hline 9599 & 590771.62 & 118866.6 & \\
\hline 9600 & 591271.62 & 117616.6 & \\
\hline 9601 & 591271.62 & 117116.6 & \\
\hline 9602 & 591271.62 & 117866.6 & \\
\hline 9603 & 591771.62 & 116866.6 & \\
\hline 9604 & 591771.62 & 116116.6 & \\
\hline 9605 & 591771.62 & 117116.6 & \\
\hline 9606 & 591271.62 & 118116.6 & \\
\hline 9607 & 590771.62 & 119116.6 & \\
\hline 9608 & 590271.62 & 120116.6 & \\
\hline 9609 & 591771.62 & 115366.6 & \\
\hline 9610 & 582771.62 & 134366.59 & \\
\hline 9611 & 581271.62 & 135866.59 & \\
\hline 9612 & 581521.62 & 135866.59 & \\
\hline 9613 & 581771.62 & 135366.59 & \\
\hline 9614 & 582021.62 & 135366.59 & \\
\hline 9615 & 581771.62 & 135616.59 & \\
\hline 9616 & 582271.62 & 135366.59 & \\
\hline 9617 & 581771.62 & 135866.59 & \\
\hline 9618 & 591771.62 & 114616.6 & \\
\hline 9619 & 591771.62 & 113866.6 & \\
\hline 9620 & 577167.56 & 138557.33 & \\
\hline 9621 & 577309.44 & 138542.58 & \\
\hline 9622 & 577451.31 & 138527.81 & \\
\hline 9623 & 577593.19 & 138513.06 & \\
\hline 9624 & 577794.44 & 138512.2 & \\
\hline 9625 & 577995.69 & 138511.33 & \\
\hline 9626 & 578196.94 & 138510.47 & \\
\hline 9627 & 578487.56 & 138422.3 & \\
\hline 9628 & 578778.12 & 138334.14 & \\
\hline 9629 & 579068.69 & 138245.97 & \\
\hline 9630 & 591771.62 & 113116.6 & \\
\hline 9631 & 587679.88 & 112660.9 & \\
\hline 9632 & 588131.81 & 112214.3 & \\
\hline 9633 & 588771.62 & 112366.6 & \\
\hline 9634 & 589521.62 & 112366.6 & \\
\hline 9635 & 590271.62 & 112366.6 & \\
\hline
\end{tabular}




\begin{tabular}{|c|c|c|c|}
\hline node & X_coord & Y_coord & note: from sac04d created July 1, 2004 \\
\hline 9636 & $5 \overline{9} 1021.62$ & $1 \overline{1} 2366.6$ & \\
\hline 9637 & 591771.62 & 112366.6 & \\
\hline 9638 & 568771.62 & 145616.59 & \\
\hline 9639 & 568771.62 & 145866.59 & \\
\hline 9640 & 568771.62 & 146116.59 & \\
\hline 9641 & 568775.44 & 146366.12 & \\
\hline 9642 & 568779.25 & 146615.67 & \\
\hline 9643 & 568783.06 & 146865.2 & \\
\hline 9644 & 568014.12 & 146904.91 & \\
\hline 9645 & 568178.88 & 147039.8 & \\
\hline 9646 & 568343.62 & 147174.7 & \\
\hline 9647 & 568679.6406 & 147026.1446 & \\
\hline 9648 & 568472.56 & 147280.3 & \\
\hline 9649 & 568828.4544 & 146949.4387 & \\
\hline 9650 & 570021.62 & 145616.59 & \\
\hline 9651 & 569771.62 & 145616.59 & \\
\hline 9652 & 570271.62 & 145616.59 & \\
\hline 9653 & 569521.62 & 145616.59 & \\
\hline 9654 & 570521.62 & 145616.59 & \\
\hline 9655 & 569271.62 & 145616.59 & \\
\hline 9656 & 570771.62 & 145616.59 & \\
\hline 9657 & 569021.62 & 145616.59 & \\
\hline 9658 & 571021.62 & 145616.59 & \\
\hline 9659 & 571271.62 & 145616.59 & \\
\hline 9660 & 571521.62 & 145616.59 & \\
\hline 9661 & 571771.62 & 145616.59 & \\
\hline 9662 & 572021.62 & 145616.59 & \\
\hline 9663 & 572271.62 & 145616.59 & \\
\hline 9664 & 572521.62 & 145616.59 & \\
\hline 9665 & 572771.62 & 145616.59 & \\
\hline 9666 & 573021.62 & 145616.59 & \\
\hline 9667 & 573271.62 & 145616.59 & \\
\hline 9668 & 573521.62 & 145616.59 & \\
\hline 9669 & 573771.62 & 145616.59 & \\
\hline 9670 & 574021.62 & 145616.59 & \\
\hline 9671 & 574271.62 & 145616.59 & \\
\hline 9672 & 574521.62 & 145616.59 & \\
\hline 9673 & 574771.62 & 145616.59 & \\
\hline 9674 & 575021.62 & 145616.59 & \\
\hline 9675 & 575271.62 & 145616.59 & \\
\hline 9676 & 575511.62 & 142734.88 & \\
\hline 9677 & 575514.94 & 142862.11 & \\
\hline 9678 & 575518.31 & 142989.36 & \\
\hline 9679 & 575521.62 & 143116.59 & \\
\hline 9680 & 575521.62 & 143366.59 & \\
\hline 9681 & 575521.62 & 143616.59 & \\
\hline 9682 & 575521.62 & 143866.59 & \\
\hline 9683 & 575521.62 & 144116.59 & \\
\hline 9684 & 575521.62 & 144366.59 & \\
\hline 9685 & 575521.62 & 144616.59 & \\
\hline 9686 & 575521.62 & 144866.59 & \\
\hline 9687 & 575521.62 & 145116.59 & \\
\hline 9688 & 575521.62 & 145366.59 & \\
\hline 9689 & 575521.62 & 145616.59 & \\
\hline 9690 & 576977.75 & 139735.47 & \\
\hline 9691 & 577098.44 & 139444.92 & \\
\hline
\end{tabular}




\begin{tabular}{|c|c|c|c|}
\hline node & X_coord & Y_coord & note: from sac04d created July 1, 2004 \\
\hline 9692 & $5 \overline{7} 6992.19$ & $1 \overline{3} 9840.22$ & \\
\hline 9693 & 577219.06 & 139154.38 & \\
\hline 9694 & 577006.56 & 139944.95 & \\
\hline 9695 & 577339.75 & 138863.83 & \\
\hline 9696 & 577021 & 140049.7 & \\
\hline 9697 & 577018.62 & 140154.41 & \\
\hline 9698 & 577016.25 & 140259.09 & \\
\hline 9699 & 577013.88 & 140363.8 & \\
\hline 9700 & 581021.62 & 136116.59 & \\
\hline 9701 & 581021.62 & 136366.59 & \\
\hline 9702 & 581021.62 & 136616.59 & \\
\hline 9703 & 581021.62 & 136866.59 & \\
\hline 9704 & 581021.62 & 137116.59 & \\
\hline 9705 & 581012.44 & 137366.42 & \\
\hline 9706 & 581003.31 & 137616.27 & \\
\hline 9707 & 581271.62 & 136116.59 & \\
\hline 9708 & 580439.19 & 137865.09 & \\
\hline 9709 & 580716.69 & 137865.59 & \\
\hline 9710 & 580994.12 & 137866.09 & \\
\hline 9711 & 582521.62 & 134616.59 & \\
\hline 9712 & 582521.62 & 134866.59 & \\
\hline 9713 & 582521.62 & 135116.59 & \\
\hline 9714 & 582771.62 & 134616.59 & \\
\hline 9715 & 582521.62 & 135366.59 & \\
\hline 9716 & 583021.62 & 133616.59 & \\
\hline 9717 & 583021.62 & 133866.59 & \\
\hline 9718 & 583021.62 & 134116.59 & \\
\hline 9719 & 583271.62 & 133616.59 & \\
\hline 9720 & 583021.62 & 134366.59 & \\
\hline 9721 & 585021.62 & 131866.59 & \\
\hline 9722 & 585021.62 & 132116.59 & \\
\hline 9723 & 585021.62 & 132366.59 & \\
\hline 9724 & 585271.62 & 131866.59 & \\
\hline 9725 & 585021.62 & 132616.59 & \\
\hline 9726 & 585521.62 & 130866.59 & \\
\hline 9727 & 585521.62 & 131116.59 & \\
\hline 9728 & 585521.62 & 131366.59 & \\
\hline 9729 & 585771.62 & 130866.59 & \\
\hline 9730 & 585521.62 & 131616.59 & \\
\hline 9731 & 586021.62 & 129866.6 & \\
\hline 9732 & 586021.62 & 130116.6 & \\
\hline 9733 & 586021.62 & 130366.6 & \\
\hline 9734 & 586271.62 & 129866.6 & \\
\hline 9735 & 586021.62 & 130616.6 & \\
\hline 9736 & 586521.62 & 128866.6 & \\
\hline 9737 & 586521.62 & 129116.6 & \\
\hline 9738 & 586521.62 & 129366.6 & \\
\hline 9739 & 586771.62 & 128866.6 & \\
\hline 9740 & 586521.62 & 129616.6 & \\
\hline 9741 & 587021.62 & 127866.6 & \\
\hline 9742 & 587021.62 & 128116.6 & \\
\hline 9743 & 587021.62 & 128366.6 & \\
\hline 9744 & 587271.62 & 127866.6 & \\
\hline 9745 & 587021.62 & 128616.6 & \\
\hline 9746 & 587521.62 & 126116.6 & \\
\hline 9747 & 587521.62 & 126366.6 & \\
\hline
\end{tabular}




\begin{tabular}{|c|c|c|c|}
\hline node & X_coord & Y_coord & note: from sac04d created July 1, 2004 \\
\hline 9748 & $5 \overline{8} 7521.62$ & $1 \overline{2} 6616.6$ & \\
\hline 9749 & 587521.62 & 126866.6 & \\
\hline 9750 & 587521.62 & 127116.6 & \\
\hline 9751 & 587521.62 & 127366.6 & \\
\hline 9752 & 587521.62 & 127616.6 & \\
\hline 9753 & 587771.62 & 126116.6 & \\
\hline 9754 & 587521.62 & 127866.6 & \\
\hline 9755 & 587021.62 & 128866.6 & \\
\hline 9756 & 586521.62 & 129866.6 & \\
\hline 9757 & 586021.62 & 130866.59 & \\
\hline 9758 & 585521.62 & 131866.59 & \\
\hline 9759 & 584021.62 & 133366.59 & \\
\hline 9760 & 584271.62 & 133366.59 & \\
\hline 9761 & 584521.62 & 132866.59 & \\
\hline 9762 & 584771.62 & 132866.59 & \\
\hline 9763 & 584521.62 & 133116.59 & \\
\hline 9764 & 585021.62 & 132866.59 & \\
\hline 9765 & 584521.62 & 133366.59 & \\
\hline 9766 & 588021.62 & 125116.6 & \\
\hline 9767 & 588021.62 & 125366.6 & \\
\hline 9768 & 588021.62 & 125616.6 & \\
\hline 9769 & 588271.62 & 125116.6 & \\
\hline 9770 & 588021.62 & 125866.6 & \\
\hline 9771 & 588521.62 & 124116.6 & \\
\hline 9772 & 588521.62 & 124366.6 & \\
\hline 9773 & 588521.62 & 124616.6 & \\
\hline 9774 & 588771.62 & 124116.6 & \\
\hline 9775 & 588521.62 & 124866.6 & \\
\hline 9776 & 589021.62 & 123116.6 & \\
\hline 9777 & 589021.62 & 123366.6 & \\
\hline 9778 & 589021.62 & 123616.6 & \\
\hline 9779 & 589271.62 & 123116.6 & \\
\hline 9780 & 589021.62 & 123866.6 & \\
\hline 9781 & 589521.62 & 122116.6 & \\
\hline 9782 & 589521.62 & 122366.6 & \\
\hline 9783 & 589521.62 & 122616.6 & \\
\hline 9784 & 589771.62 & 122116.6 & \\
\hline 9785 & 589521.62 & 122866.6 & \\
\hline 9786 & 590021.62 & 120616.6 & \\
\hline 9787 & 590021.62 & 120366.6 & \\
\hline 9788 & 590021.62 & 120866.6 & \\
\hline 9789 & 590021.62 & 121116.6 & \\
\hline 9790 & 590021.62 & 121366.6 & \\
\hline 9791 & 590021.62 & 121616.6 & \\
\hline 9792 & 590021.62 & 121866.6 & \\
\hline 9793 & 590271.62 & 120366.6 & \\
\hline 9794 & 590021.62 & 122116.6 & \\
\hline 9795 & 589521.62 & 123116.6 & \\
\hline 9796 & 589021.62 & 124116.6 & \\
\hline 9797 & 588521.62 & 125116.6 & \\
\hline 9798 & 588021.62 & 126116.6 & \\
\hline 9799 & 583521.62 & 133616.59 & \\
\hline 9800 & 583771.62 & 133616.59 & \\
\hline 9801 & 584021.62 & 133616.59 & \\
\hline 9802 & 590521.62 & 119366.6 & \\
\hline 9803 & 590521.62 & 119616.6 & \\
\hline
\end{tabular}




\begin{tabular}{|c|c|c|c|}
\hline node & X_coord & Y_coord & note: from sac04d created July 1, 2004 \\
\hline 9804 & $5 \overline{9} 0521.62$ & $1 \overline{19866.6}$ & \\
\hline 9805 & 590771.62 & 119366.6 & \\
\hline 9806 & 590521.62 & 120116.6 & \\
\hline 9807 & 591021.62 & 118366.6 & \\
\hline 9808 & 591021.62 & 118616.6 & \\
\hline 9809 & 591021.62 & 118866.6 & \\
\hline 9810 & 591271.62 & 118366.6 & \\
\hline 9811 & 591021.62 & 119116.6 & \\
\hline 9812 & 591521.62 & 117616.6 & \\
\hline 9813 & 591521.62 & 117366.6 & \\
\hline 9814 & 591521.62 & 117866.6 & \\
\hline 9815 & 591771.62 & 117366.6 & \\
\hline 9816 & 591521.62 & 118116.6 & \\
\hline 9817 & 592021.62 & 116866.6 & \\
\hline 9818 & 592021.62 & 116366.6 & \\
\hline 9819 & 592021.62 & 117116.6 & \\
\hline 9820 & 592521.62 & 116116.6 & \\
\hline 9821 & 592521.62 & 115366.6 & \\
\hline 9822 & 592521.62 & 116366.6 & \\
\hline 9823 & 592021.62 & 117366.6 & \\
\hline 9824 & 591521.62 & 118366.6 & \\
\hline 9825 & 591021.62 & 119366.6 & \\
\hline 9826 & 590521.62 & 120366.6 & \\
\hline 9827 & 592521.62 & 114616.6 & \\
\hline 9828 & 583021.62 & 134616.59 & \\
\hline 9829 & 581521.62 & 136116.59 & \\
\hline 9830 & 581771.62 & 136116.59 & \\
\hline 9831 & 582021.62 & 135616.59 & \\
\hline 9832 & 582271.62 & 135616.59 & \\
\hline 9833 & 582021.62 & 135866.59 & \\
\hline 9834 & 582521.62 & 135616.59 & \\
\hline 9835 & 582021.62 & 136116.59 & \\
\hline 9836 & 592521.62 & 113866.6 & \\
\hline 9837 & 592521.62 & 113116.6 & \\
\hline 9838 & 577484.38 & 138850.06 & \\
\hline 9839 & 577629 & 138836.3 & \\
\hline 9840 & 577805.88 & 138835 & \\
\hline 9841 & 577982.75 & 138833.7 & \\
\hline 9842 & 578159.62 & 138832.41 & \\
\hline 9843 & 578434 & 138695.23 & \\
\hline 9844 & 578708.31 & 138558.08 & \\
\hline 9845 & 578982.69 & 138420.91 & \\
\hline 9846 & 592521.62 & 112366.6 & \\
\hline 9847 & 588419.31 & 111649.5 & \\
\hline 9848 & 588758.31 & 111657.5 & \\
\hline 9849 & 589521.62 & 111616.6 & \\
\hline 9850 & 590271.62 & 111616.6 & \\
\hline 9851 & 591021.62 & 111616.6 & \\
\hline 9852 & 591771.62 & 111616.6 & \\
\hline 9853 & 592521.62 & 111616.6 & \\
\hline 9854 & 569021.62 & 145866.59 & \\
\hline 9855 & 569021.62 & 146116.59 & \\
\hline 9856 & 569023.56 & 146366.36 & \\
\hline 9857 & 569025.44 & 146616.12 & \\
\hline 9858 & 569027.38 & 146865.89 & \\
\hline 9859 & 569098.5456 & 147015.7701 & \\
\hline
\end{tabular}




\begin{tabular}{|c|c|c|c|}
\hline node & X_coord & Y_coord & note: from sac04d created July 1, 2004 \\
\hline 9860 & $5 \overline{6} 8799.0389$ & $1 \overline{4} 7140.1115$ & \\
\hline 9861 & 568601.56 & 147385.91 & \\
\hline 9863 & 569187.8313 & 147276.4871 & \\
\hline 9864 & 570021.62 & 145866.59 & \\
\hline 9865 & 569771.62 & 145866.59 & \\
\hline 9866 & 570271.62 & 145866.59 & \\
\hline 9867 & 569521.62 & 145866.59 & \\
\hline 9868 & 570521.62 & 145866.59 & \\
\hline 9869 & 569271.62 & 145866.59 & \\
\hline 9870 & 570771.62 & 145866.59 & \\
\hline 9871 & 571021.62 & 145866.59 & \\
\hline 9872 & 571271.62 & 145866.59 & \\
\hline 9873 & 571521.62 & 145866.59 & \\
\hline 9874 & 571771.62 & 145866.59 & \\
\hline 9875 & 572021.62 & 145866.59 & \\
\hline 9876 & 572271.62 & 145866.59 & \\
\hline 9877 & 572521.62 & 145866.59 & \\
\hline 9878 & 572771.62 & 145866.59 & \\
\hline 9879 & 573021.62 & 145866.59 & \\
\hline 9880 & 573271.62 & 145866.59 & \\
\hline 9881 & 573521.62 & 145866.59 & \\
\hline 9882 & 573771.62 & 145866.59 & \\
\hline 9883 & 574021.62 & 145866.59 & \\
\hline 9884 & 574271.62 & 145866.59 & \\
\hline 9885 & 574521.62 & 145866.59 & \\
\hline 9886 & 574771.62 & 145866.59 & \\
\hline 9887 & 575021.62 & 145866.59 & \\
\hline 9888 & 575271.62 & 145866.59 & \\
\hline 9889 & 575521.62 & 145866.59 & \\
\hline 9890 & 575756.62 & 142762.53 & \\
\hline 9891 & 575761.62 & 142880.55 & \\
\hline 9892 & 575766.62 & 142998.58 & \\
\hline 9893 & 575771.62 & 143116.59 & \\
\hline 9894 & 575771.62 & 143366.59 & \\
\hline 9895 & 575771.62 & 143616.59 & \\
\hline 9896 & 575771.62 & 143866.59 & \\
\hline 9897 & 575771.62 & 144116.59 & \\
\hline 9898 & 575771.62 & 144366.59 & \\
\hline 9899 & 575771.62 & 144616.59 & \\
\hline 9900 & 575771.62 & 144866.59 & \\
\hline 9901 & 575771.62 & 145116.59 & \\
\hline 9902 & 575771.62 & 145366.59 & \\
\hline 9903 & 575771.62 & 145616.59 & \\
\hline 9904 & 575771.62 & 145866.59 & \\
\hline 9905 & 577184.25 & 139565.53 & \\
\hline 9906 & 577284.31 & 139327.05 & \\
\hline 9907 & 577213.06 & 139682.02 & \\
\hline 9908 & 577384.31 & 139088.55 & \\
\hline 9909 & 577241.81 & 139798.52 & \\
\hline 9910 & 577270.62 & 139915 & \\
\hline 9911 & 577265.88 & 140035 & \\
\hline 9912 & 577261.19 & 140155 & \\
\hline 9913 & 577256.44 & 140275 & \\
\hline 9914 & 581271.62 & 136366.59 & \\
\hline 9915 & 581271.62 & 136616.59 & \\
\hline 9916 & 581271.62 & 136866.59 & \\
\hline
\end{tabular}




\begin{tabular}{|c|c|c|c|}
\hline node & X_coord & Y_coord & note: from sac04d created July 1,2004 \\
\hline 9917 & $5 \overline{8} 1271.62$ & $1 \overline{3} 7116.59$ & \\
\hline 9918 & 581271.62 & 137366.59 & \\
\hline 9919 & 581271.62 & 137616.59 & \\
\hline 9920 & 581271.62 & 137866.59 & \\
\hline 9921 & 581521.62 & 136366.59 & \\
\hline 9922 & 580441.94 & 138153.3 & \\
\hline 9923 & 580718.5 & 138141.06 & \\
\hline 9924 & 580995.06 & 138128.83 & \\
\hline 9925 & 581271.62 & 138116.59 & \\
\hline 9926 & 582771.62 & 134866.59 & \\
\hline 9927 & 582771.62 & 135116.59 & \\
\hline 9928 & 582771.62 & 135366.59 & \\
\hline 9929 & 583021.62 & 134866.59 & \\
\hline 9930 & 582771.62 & 135616.59 & \\
\hline 9931 & 583271.62 & 133866.59 & \\
\hline 9932 & 583271.62 & 134116.59 & \\
\hline 9933 & 583271.62 & 134366.59 & \\
\hline 9934 & 583521.62 & 133866.59 & \\
\hline 9935 & 583271.62 & 134616.59 & \\
\hline 9936 & 585271.62 & 132116.59 & \\
\hline 9937 & 585271.62 & 132366.59 & \\
\hline 9938 & 585271.62 & 132616.59 & \\
\hline 9939 & 585521.62 & 132116.59 & \\
\hline 9940 & 585271.62 & 132866.59 & \\
\hline 9941 & 585771.62 & 131116.59 & \\
\hline 9942 & 585771.62 & 131366.59 & \\
\hline 9943 & 585771.62 & 131616.59 & \\
\hline 9944 & 586021.62 & 131116.59 & \\
\hline 9945 & 585771.62 & 131866.59 & \\
\hline 9946 & 586271.62 & 130116.6 & \\
\hline 9947 & 586271.62 & 130366.6 & \\
\hline 9948 & 586271.62 & 130616.6 & \\
\hline 9949 & 586521.62 & 130116.6 & \\
\hline 9950 & 586271.62 & 130866.59 & \\
\hline 9951 & 586771.62 & 129116.6 & \\
\hline 9952 & 586771.62 & 129366.6 & \\
\hline 9953 & 586771.62 & 129616.6 & \\
\hline 9954 & 587021.62 & 129116.6 & \\
\hline 9955 & 586771.62 & 129866.6 & \\
\hline 9956 & 587271.62 & 128116.6 & \\
\hline 9957 & 587271.62 & 128366.6 & \\
\hline 9958 & 587271.62 & 128616.6 & \\
\hline 9959 & 587521.62 & 128116.6 & \\
\hline 9960 & 587271.62 & 128866.6 & \\
\hline 9961 & 587771.62 & 126366.6 & \\
\hline 9962 & 587771.62 & 126616.6 & \\
\hline 9963 & 587771.62 & 126866.6 & \\
\hline 9964 & 587771.62 & 127116.6 & \\
\hline 9965 & 587771.62 & 127366.6 & \\
\hline 9966 & 587771.62 & 127616.6 & \\
\hline 9967 & 587771.62 & 127866.6 & \\
\hline 9968 & 588021.62 & 126366.6 & \\
\hline 9969 & 587771.62 & 128116.6 & \\
\hline 9970 & 587271.62 & 129116.6 & \\
\hline 9971 & 586771.62 & 130116.6 & \\
\hline 9972 & 586271.62 & 131116.59 & \\
\hline
\end{tabular}




\begin{tabular}{|c|c|c|c|}
\hline node & X_coord & Y_coord & note: from sac04d created July 1,2004 \\
\hline 9973 & 585771.62 & $1 \overline{3} 2116.59$ & \\
\hline 9974 & 584271.62 & 133616.59 & \\
\hline 9975 & 584521.62 & 133616.59 & \\
\hline 9976 & 584771.62 & 133116.59 & \\
\hline 9977 & 585021.62 & 133116.59 & \\
\hline 9978 & 584771.62 & 133366.59 & \\
\hline 9979 & 585271.62 & 133116.59 & \\
\hline 9980 & 584771.62 & 133616.59 & \\
\hline 9981 & 588271.62 & 125366.6 & \\
\hline 9982 & 588271.62 & 125616.6 & \\
\hline 9983 & 588271.62 & 125866.6 & \\
\hline 9984 & 588521.62 & 125366.6 & \\
\hline 9985 & 588271.62 & 126116.6 & \\
\hline 9986 & 588771.62 & 124366.6 & \\
\hline 9987 & 588771.62 & 124616.6 & \\
\hline 9988 & 588771.62 & 124866.6 & \\
\hline 9989 & 589021.62 & 124366.6 & \\
\hline 9990 & 588771.62 & 125116.6 & \\
\hline 9991 & 589271.62 & 123366.6 & \\
\hline 9992 & 589271.62 & 123616.6 & \\
\hline 9993 & 589271.62 & 123866.6 & \\
\hline 9994 & 589521.62 & 123366.6 & \\
\hline 9995 & 589271.62 & 124116.6 & \\
\hline 9996 & 589771.62 & 122366.6 & \\
\hline 9997 & 589771.62 & 122616.6 & \\
\hline 9998 & 589771.62 & 122866.6 & \\
\hline 9999 & 590021.62 & 122366.6 & \\
\hline 10000 & 589771.62 & 123116.6 & \\
\hline 10001 & 590271.62 & 120616.6 & \\
\hline 10002 & 590271.62 & 120866.6 & \\
\hline 10003 & 590271.62 & 121116.6 & \\
\hline 10004 & 590271.62 & 121366.6 & \\
\hline 10005 & 590271.62 & 121616.6 & \\
\hline 10006 & 590271.62 & 121866.6 & \\
\hline 10007 & 590271.62 & 122116.6 & \\
\hline 10008 & 590521.62 & 120616.6 & \\
\hline 10009 & 590271.62 & 122366.6 & \\
\hline 10010 & 589771.62 & 123366.6 & \\
\hline 10011 & 589271.62 & 124366.6 & \\
\hline 10012 & 588771.62 & 125366.6 & \\
\hline 10013 & 588271.62 & 126366.6 & \\
\hline 10014 & 583771.62 & 133866.59 & \\
\hline 10015 & 584021.62 & 133866.59 & \\
\hline 10016 & 584271.62 & 133866.59 & \\
\hline 10017 & 590771.62 & 119616.6 & \\
\hline 10018 & 590771.62 & 119866.6 & \\
\hline 10019 & 590771.62 & 120116.6 & \\
\hline 10020 & 591021.62 & 119616.6 & \\
\hline 10021 & 590771.62 & 120366.6 & \\
\hline 10022 & 591271.62 & 118616.6 & \\
\hline 10023 & 591271.62 & 118866.6 & \\
\hline 10024 & 591271.62 & 119116.6 & \\
\hline 10025 & 591521.62 & 118616.6 & \\
\hline 10026 & 591271.62 & 119366.6 & \\
\hline 10027 & 591771.62 & 117616.6 & \\
\hline 10028 & 591771.62 & 117866.6 & \\
\hline
\end{tabular}




\begin{tabular}{|c|c|c|c|}
\hline node & X_coord & Y_coord & note: from sac04d created July 1, 2004 \\
\hline 10029 & $5 \overline{9} 1771.62$ & $1 \overline{18116.6}$ & \\
\hline 10030 & 592021.62 & 117616.6 & \\
\hline 10031 & 591771.62 & 118366.6 & \\
\hline 10032 & 592271.62 & 116866.6 & \\
\hline 10033 & 592271.62 & 116616.6 & \\
\hline 10034 & 592271.62 & 117116.6 & \\
\hline 10035 & 592521.62 & 116616.6 & \\
\hline 10036 & 592271.62 & 117366.6 & \\
\hline 10037 & 592771.62 & 116116.6 & \\
\hline 10038 & 592771.62 & 115616.6 & \\
\hline 10039 & 592771.62 & 116366.6 & \\
\hline 10040 & 593271.62 & 115366.6 & \\
\hline 10041 & 593271.62 & 114616.6 & \\
\hline 10042 & 593271.62 & 115616.6 & \\
\hline 10043 & 592771.62 & 116616.6 & \\
\hline 10044 & 592271.62 & 117616.6 & \\
\hline 10045 & 591771.62 & 118616.6 & \\
\hline 10046 & 591271.62 & 119616.6 & \\
\hline 10047 & 590771.62 & 120616.6 & \\
\hline 10048 & 593271.62 & 113866.6 & \\
\hline 10049 & 583271.62 & 134866.59 & \\
\hline 10050 & 581771.62 & 136366.59 & \\
\hline 10051 & 582021.62 & 136366.59 & \\
\hline 10052 & 582271.62 & 135866.59 & \\
\hline 10053 & 582521.62 & 135866.59 & \\
\hline 10054 & 582271.62 & 136116.59 & \\
\hline 10055 & 582771.62 & 135866.59 & \\
\hline 10056 & 582271.62 & 136366.59 & \\
\hline 10057 & 593271.62 & 113116.6 & \\
\hline 10058 & 593271.62 & 112366.6 & \\
\hline 10059 & 577549.56 & 139022.73 & \\
\hline 10060 & 577738.5 & 139031.48 & \\
\hline 10061 & 577927.38 & 139040.25 & \\
\hline 10062 & 578116.31 & 139049 & \\
\hline 10063 & 593271.62 & 111616.6 & \\
\hline 10064 & 588604.12 & 111064.2 & \\
\hline 10065 & 588941.12 & 110585.1 & \\
\hline 10066 & 589410.19 & 110738.4 & \\
\hline 10067 & 590271.62 & 110866.6 & \\
\hline 10068 & 591021.62 & 110866.6 & \\
\hline 10069 & 591771.62 & 110866.6 & \\
\hline 10070 & 592521.62 & 110866.6 & \\
\hline 10071 & 593271.62 & 110866.6 & \\
\hline 10072 & 569271.62 & 146116.59 & \\
\hline 10073 & 569271.62 & 146366.59 & \\
\hline 10074 & 569271.62 & 146616.59 & \\
\hline 10075 & 569271.62 & 146866.59 & \\
\hline 10076 & 569275.94 & 147110.47 & \\
\hline 10077 & 569280.19 & 147354.33 & \\
\hline 10078 & 568929.288 & 147258.0026 & \\
\hline 10079 & 568730.5 & 147491.5 & \\
\hline 10080 & 569035.1805 & 147388.4655 & \\
\hline 10081 & 569157.4745 & 147484.2233 & \\
\hline 10082 & 569271.6143 & 147587.8915 & \\
\hline 10083 & 570021.62 & 146116.59 & \\
\hline 10084 & 569771.62 & 146116.59 & \\
\hline
\end{tabular}




\begin{tabular}{|c|c|c|c|}
\hline node & X_coord & Y_coord & note: from sac04d created July 1, 2004 \\
\hline 10085 & $5 \overline{7} 0271.62$ & $1 \overline{4} 6116.59$ & \\
\hline 10086 & 569521.62 & 146116.59 & \\
\hline 10087 & 570521.62 & 146116.59 & \\
\hline 10088 & 570771.62 & 146116.59 & \\
\hline 10089 & 571021.62 & 146116.59 & \\
\hline 10090 & 571271.62 & 146116.59 & \\
\hline 10091 & 571521.62 & 146116.59 & \\
\hline 10092 & 571771.62 & 146116.59 & \\
\hline 10093 & 572021.62 & 146116.59 & \\
\hline 10094 & 572271.62 & 146116.59 & \\
\hline 10095 & 572521.62 & 146116.59 & \\
\hline 10096 & 572771.62 & 146116.59 & \\
\hline 10097 & 573021.62 & 146116.59 & \\
\hline 10098 & 573271.62 & 146116.59 & \\
\hline 10099 & 573521.62 & 146116.59 & \\
\hline 10100 & 573771.62 & 146116.59 & \\
\hline 10101 & 574021.62 & 146116.59 & \\
\hline 10102 & 574271.62 & 146116.59 & \\
\hline 10103 & 574521.62 & 146116.59 & \\
\hline 10104 & 574771.62 & 146116.59 & \\
\hline 10105 & 575021.62 & 146116.59 & \\
\hline 10106 & 575271.62 & 146116.59 & \\
\hline 10107 & 575521.62 & 146116.59 & \\
\hline 10108 & 575771.62 & 146116.59 & \\
\hline 10109 & 576001.62 & 142790.2 & \\
\hline 10110 & 576008.31 & 142899 & \\
\hline 10111 & 576014.94 & 143007.8 & \\
\hline 10112 & 576021.62 & 143116.59 & \\
\hline 10113 & 576021.62 & 143366.59 & \\
\hline 10114 & 576021.62 & 143616.59 & \\
\hline 10115 & 576021.62 & 143866.59 & \\
\hline 10116 & 576021.62 & 144116.59 & \\
\hline 10117 & 576021.62 & 144366.59 & \\
\hline 10118 & 576021.62 & 144616.59 & \\
\hline 10119 & 576021.62 & 144866.59 & \\
\hline 10120 & 576021.62 & 145116.59 & \\
\hline 10121 & 576021.62 & 145366.59 & \\
\hline 10122 & 576021.62 & 145616.59 & \\
\hline 10123 & 576021.62 & 145866.59 & \\
\hline 10124 & 576021.62 & 146116.59 & \\
\hline 10125 & 577390.69 & 139395.59 & \\
\hline 10126 & 577470.12 & 139209.16 & \\
\hline 10127 & 577433.88 & 139523.83 & \\
\hline 10128 & 577477.12 & 139652.06 & \\
\hline 10129 & 577520.31 & 139780.3 & \\
\hline 10130 & 577513.19 & 139915.59 & \\
\hline 10131 & 577506.12 & 140050.91 & \\
\hline 10132 & 577499 & 140186.2 & \\
\hline 10133 & 581521.62 & 136616.59 & \\
\hline 10134 & 581521.62 & 136866.59 & \\
\hline 10135 & 581521.62 & 137116.59 & \\
\hline 10136 & 581521.62 & 137366.59 & \\
\hline 10137 & 581521.62 & 137616.59 & \\
\hline 10138 & 581521.62 & 137866.59 & \\
\hline 10139 & 581521.62 & 138116.59 & \\
\hline 10140 & 581771.62 & 136616.59 & \\
\hline
\end{tabular}




\begin{tabular}{|c|c|c|c|}
\hline node & X_coord & Y_coord & note: from sac04d created July 1, 2004 \\
\hline 10141 & $5 \overline{80} 0444.62$ & $1 \overline{3} 8441.5$ & \\
\hline 10142 & 580720.31 & 138416.53 & \\
\hline 10143 & 580995.94 & 138391.56 & \\
\hline 10144 & 581271.62 & 138366.59 & \\
\hline 10145 & 581521.62 & 138366.59 & \\
\hline 10146 & 583021.62 & 135116.59 & \\
\hline 10147 & 583021.62 & 135366.59 & \\
\hline 10148 & 583021.62 & 135616.59 & \\
\hline 10149 & 583271.62 & 135116.59 & \\
\hline 10150 & 583021.62 & 135866.59 & \\
\hline 10151 & 583521.62 & 134116.59 & \\
\hline 10152 & 583521.62 & 134366.59 & \\
\hline 10153 & 583521.62 & 134616.59 & \\
\hline 10154 & 583771.62 & 134116.59 & \\
\hline 10155 & 583521.62 & 134866.59 & \\
\hline 10156 & 585521.62 & 132366.59 & \\
\hline 10157 & 585521.62 & 132616.59 & \\
\hline 10158 & 585521.62 & 132866.59 & \\
\hline 10159 & 585771.62 & 132366.59 & \\
\hline 10160 & 585521.62 & 133116.59 & \\
\hline 10161 & 586021.62 & 131366.59 & \\
\hline 10162 & 586021.62 & 131616.59 & \\
\hline 10163 & 586021.62 & 131866.59 & \\
\hline 10164 & 586271.62 & 131366.59 & \\
\hline 10165 & 586021.62 & 132116.59 & \\
\hline 10166 & 586521.62 & 130366.6 & \\
\hline 10167 & 586521.62 & 130616.6 & \\
\hline 10168 & 586521.62 & 130866.59 & \\
\hline 10169 & 586771.62 & 130366.6 & \\
\hline 10170 & 586521.62 & 131116.59 & \\
\hline 10171 & 587021.62 & 129366.6 & \\
\hline 10172 & 587021.62 & 129616.6 & \\
\hline 10173 & 587021.62 & 129866.6 & \\
\hline 10174 & 587271.62 & 129366.6 & \\
\hline 10175 & 587021.62 & 130116.6 & \\
\hline 10176 & 587521.62 & 128366.6 & \\
\hline 10177 & 587521.62 & 128616.6 & \\
\hline 10178 & 587521.62 & 128866.6 & \\
\hline 10179 & 587771.62 & 128366.6 & \\
\hline 10180 & 587521.62 & 129116.6 & \\
\hline 10181 & 588021.62 & 126616.6 & \\
\hline 10182 & 588021.62 & 126866.6 & \\
\hline 10183 & 588021.62 & 127116.6 & \\
\hline 10184 & 588021.62 & 127366.6 & \\
\hline 10185 & 588021.62 & 127616.6 & \\
\hline 10186 & 588021.62 & 127866.6 & \\
\hline 10187 & 588021.62 & 128116.6 & \\
\hline 10188 & 588271.62 & 126616.6 & \\
\hline 10189 & 588021.62 & 128366.6 & \\
\hline 10190 & 587521.62 & 129366.6 & \\
\hline 10191 & 587021.62 & 130366.6 & \\
\hline 10192 & 586521.62 & 131366.59 & \\
\hline 10193 & 586021.62 & 132366.59 & \\
\hline 10194 & 584521.62 & 133866.59 & \\
\hline 10195 & 584771.62 & 133866.59 & \\
\hline 10196 & 585021.62 & 133366.59 & \\
\hline
\end{tabular}




\begin{tabular}{|c|c|c|c|}
\hline node & X_coord & Y_coord & note: from sac04d created July 1, 2004 \\
\hline 10197 & $5 \overline{8} 5271.62$ & $1 \overline{3} 3366.59$ & \\
\hline 10198 & 585021.62 & 133616.59 & \\
\hline 10199 & 585521.62 & 133366.59 & \\
\hline 10200 & 585021.62 & 133866.59 & \\
\hline 10201 & 588521.62 & 125616.6 & \\
\hline 10202 & 588521.62 & 125866.6 & \\
\hline 10203 & 588521.62 & 126116.6 & \\
\hline 10204 & 588771.62 & 125616.6 & \\
\hline 10205 & 588521.62 & 126366.6 & \\
\hline 10206 & 589021.62 & 124616.6 & \\
\hline 10207 & 589021.62 & 124866.6 & \\
\hline 10208 & 589021.62 & 125116.6 & \\
\hline 10209 & 589271.62 & 124616.6 & \\
\hline 10210 & 589021.62 & 125366.6 & \\
\hline 10211 & 589521.62 & 123616.6 & \\
\hline 10212 & 589521.62 & 123866.6 & \\
\hline 10213 & 589521.62 & 124116.6 & \\
\hline 10214 & 589771.62 & 123616.6 & \\
\hline 10215 & 589521.62 & 124366.6 & \\
\hline 10216 & 590021.62 & 122616.6 & \\
\hline 10217 & 590021.62 & 122866.6 & \\
\hline 10218 & 590021.62 & 123116.6 & \\
\hline 10219 & 590271.62 & 122616.6 & \\
\hline 10220 & 590021.62 & 123366.6 & \\
\hline 10221 & 590521.62 & 120866.6 & \\
\hline 10222 & 590521.62 & 121116.6 & \\
\hline 10223 & 590521.62 & 121366.6 & \\
\hline 10224 & 590521.62 & 121616.6 & \\
\hline 10225 & 590521.62 & 121866.6 & \\
\hline 10226 & 590521.62 & 122116.6 & \\
\hline 10227 & 590521.62 & 122366.6 & \\
\hline 10228 & 590771.62 & 120866.6 & \\
\hline 10229 & 590521.62 & 122616.6 & \\
\hline 10230 & 590021.62 & 123616.6 & \\
\hline 10231 & 589521.62 & 124616.6 & \\
\hline 10232 & 589021.62 & 125616.6 & \\
\hline 10233 & 588521.62 & 126616.6 & \\
\hline 10234 & 584021.62 & 134116.59 & \\
\hline 10235 & 584271.62 & 134116.59 & \\
\hline 10236 & 584521.62 & 134116.59 & \\
\hline 10237 & 591021.62 & 119866.6 & \\
\hline 10238 & 591021.62 & 120116.6 & \\
\hline 10239 & 591021.62 & 120366.6 & \\
\hline 10240 & 591271.62 & 119866.6 & \\
\hline 10241 & 591021.62 & 120616.6 & \\
\hline 10242 & 591521.62 & 118866.6 & \\
\hline 10243 & 591521.62 & 119116.6 & \\
\hline 10244 & 591521.62 & 119366.6 & \\
\hline 10245 & 591771.62 & 118866.6 & \\
\hline 10246 & 591521.62 & 119616.6 & \\
\hline 10247 & 592021.62 & 117866.6 & \\
\hline 10248 & 592021.62 & 118116.6 & \\
\hline 10249 & 592021.62 & 118366.6 & \\
\hline 10250 & 592271.62 & 117866.6 & \\
\hline 10251 & 592021.62 & 118616.6 & \\
\hline 10252 & 592521.62 & 116866.6 & \\
\hline
\end{tabular}




\begin{tabular}{|c|c|c|c|}
\hline node & X_coord & Y_coord & note: from sac04d created July 1,2004 \\
\hline 10253 & $5 \overline{9} 2521.62$ & $1 \overline{1} 7116.6$ & \\
\hline 10254 & 592521.62 & 117366.6 & \\
\hline 10255 & 592771.62 & 116866.6 & \\
\hline 10256 & 592521.62 & 117616.6 & \\
\hline 10257 & 593021.62 & 116116.6 & \\
\hline 10258 & 593021.62 & 115866.6 & \\
\hline 10259 & 593021.62 & 116366.6 & \\
\hline 10260 & 593271.62 & 115866.6 & \\
\hline 10261 & 593021.62 & 116616.6 & \\
\hline 10262 & 593521.62 & 115366.6 & \\
\hline 10263 & 593521.62 & 114866.6 & \\
\hline 10264 & 593521.62 & 115616.6 & \\
\hline 10265 & 594021.62 & 114616.6 & \\
\hline 10266 & 593978.1282 & 114033.3187 & \\
\hline 10267 & 594021.62 & 114866.6 & \\
\hline 10268 & 593521.62 & 115866.6 & \\
\hline 10269 & 593021.62 & 116866.6 & \\
\hline 10270 & 592521.62 & 117866.6 & \\
\hline 10271 & 592021.62 & 118866.6 & \\
\hline 10272 & 591521.62 & 119866.6 & \\
\hline 10273 & 591021.62 & 120866.6 & \\
\hline 10274 & 593992.6254 & 113203.5837 & \\
\hline 10275 & 583521.62 & 135116.59 & \\
\hline 10276 & 582021.62 & 136616.59 & \\
\hline 10277 & 582271.62 & 136616.59 & \\
\hline 10278 & 582521.62 & 136116.59 & \\
\hline 10279 & 582771.62 & 136116.59 & \\
\hline 10280 & 582521.62 & 136366.59 & \\
\hline 10281 & 583021.62 & 136116.59 & \\
\hline 10282 & 582521.62 & 136616.59 & \\
\hline 10283 & 594021.62 & 112366.6 & \\
\hline 10284 & 594021.62 & 111616.6 & \\
\hline 10285 & 577671.06 & 139227.98 & \\
\hline 10286 & 577872.06 & 139246.78 & \\
\hline 10287 & 578073 & 139265.61 & \\
\hline 10288 & 594021.62 & 110866.6 & \\
\hline 10289 & 589442.38 & 110062.4 & \\
\hline 10290 & 590271.62 & 110116.6 & \\
\hline 10291 & 591021.62 & 110116.6 & \\
\hline 10292 & 591771.62 & 110116.6 & \\
\hline 10293 & 592521.62 & 110116.6 & \\
\hline 10294 & 593271.62 & 110116.6 & \\
\hline 10295 & 594021.62 & 110116.6 & \\
\hline 10296 & 569521.62 & 146366.59 & \\
\hline 10297 & 569521.62 & 146616.59 & \\
\hline 10298 & 569521.62 & 146866.59 & \\
\hline 10299 & 569524.5 & 147112.5 & \\
\hline 10300 & 569527.31 & 147358.42 & \\
\hline 10301 & 569530.19 & 147604.33 & \\
\hline 10302 & 568854.75 & 147593.2 & \\
\hline 10303 & 568978.94 & 147694.89 & \\
\hline 10304 & 569103.19 & 147796.59 & \\
\hline 10305 & 569394.9698 & 147750.929 & \\
\hline 10306 & 569224.25 & 147919.92 & \\
\hline 10307 & 569591.6915 & 147752.7129 & \\
\hline 10308 & 570021.62 & 146366.59 & \\
\hline
\end{tabular}




\begin{tabular}{|c|c|c|c|}
\hline node & X_coord & Y_coord & note: from sac04d created July 1, 2004 \\
\hline 10309 & $5 \overline{6} 9771.62$ & $1 \overline{4} 6366.59$ & \\
\hline 10310 & 570271.62 & 146366.59 & \\
\hline 10311 & 570521.62 & 146366.59 & \\
\hline 10312 & 570771.62 & 146366.59 & \\
\hline 10313 & 571021.62 & 146366.59 & \\
\hline 10314 & 571271.62 & 146366.59 & \\
\hline 10315 & 571521.62 & 146366.59 & \\
\hline 10316 & 571771.62 & 146366.59 & \\
\hline 10317 & 572021.62 & 146366.59 & \\
\hline 10318 & 572271.62 & 146366.59 & \\
\hline 10319 & 572521.62 & 146366.59 & \\
\hline 10320 & 572771.62 & 146366.59 & \\
\hline 10321 & 573021.62 & 146366.59 & \\
\hline 10322 & 573271.62 & 146366.59 & \\
\hline 10323 & 573521.62 & 146366.59 & \\
\hline 10324 & 573771.62 & 146366.59 & \\
\hline 10325 & 574021.62 & 146366.59 & \\
\hline 10326 & 574271.62 & 146366.59 & \\
\hline 10327 & 574521.62 & 146366.59 & \\
\hline 10328 & 574771.62 & 146366.59 & \\
\hline 10329 & 575021.62 & 146366.59 & \\
\hline 10330 & 575271.62 & 146366.59 & \\
\hline 10331 & 575521.62 & 146366.59 & \\
\hline 10332 & 575771.62 & 146366.59 & \\
\hline 10333 & 576021.62 & 146366.59 & \\
\hline 10334 & 576258.5 & 142786.23 & \\
\hline 10335 & 576262.88 & 142896.36 & \\
\hline 10336 & 576267.25 & 143006.47 & \\
\hline 10337 & 576271.62 & 143116.59 & \\
\hline 10338 & 576271.62 & 143366.59 & \\
\hline 10339 & 576271.62 & 143616.59 & \\
\hline 10340 & 576271.62 & 143866.59 & \\
\hline 10341 & 576271.62 & 144116.59 & \\
\hline 10342 & 576271.62 & 144366.59 & \\
\hline 10343 & 576271.62 & 144616.59 & \\
\hline 10344 & 576271.62 & 144866.59 & \\
\hline 10345 & 576271.62 & 145116.59 & \\
\hline 10346 & 576271.62 & 145366.59 & \\
\hline 10347 & 576271.62 & 145616.59 & \\
\hline 10348 & 576271.62 & 145866.59 & \\
\hline 10349 & 576271.62 & 146116.59 & \\
\hline 10350 & 576271.62 & 146366.59 & \\
\hline 10351 & 577603.69 & 139424.47 & \\
\hline 10352 & 577659.56 & 139542.66 & \\
\hline 10353 & 577715.44 & 139660.84 & \\
\hline 10354 & 577771.31 & 139779.03 & \\
\hline 10355 & 577766 & 139900.31 & \\
\hline 10356 & 577760.62 & 140021.59 & \\
\hline 10357 & 577755.31 & 140142.88 & \\
\hline 10358 & 581771.62 & 136866.59 & \\
\hline 10359 & 581771.62 & 137116.59 & \\
\hline 10360 & 581771.62 & 137366.59 & \\
\hline 10361 & 581771.62 & 137616.59 & \\
\hline 10362 & 581771.62 & 137866.59 & \\
\hline 10363 & 581771.62 & 138116.59 & \\
\hline 10364 & 581771.62 & 138366.59 & \\
\hline
\end{tabular}




\begin{tabular}{|c|c|c|c|}
\hline node & X_coord & Y_coord & note: from sac04d created July 1, 2004 \\
\hline 10365 & $5 \overline{8} 2021.62$ & $1 \overline{3} 6866.59$ & \\
\hline 10366 & 580447.38 & 138729.7 & \\
\hline 10367 & 580722.12 & 138692 & \\
\hline 10368 & 580996.88 & 138654.3 & \\
\hline 10369 & 581271.62 & 138616.59 & \\
\hline 10370 & 581521.62 & 138616.59 & \\
\hline 10371 & 581771.62 & 138616.59 & \\
\hline 10372 & 583271.62 & 135366.59 & \\
\hline 10373 & 583271.62 & 135616.59 & \\
\hline 10374 & 583271.62 & 135866.59 & \\
\hline 10375 & 583521.62 & 135366.59 & \\
\hline 10376 & 583271.62 & 136116.59 & \\
\hline 10377 & 583771.62 & 134366.59 & \\
\hline 10378 & 583771.62 & 134616.59 & \\
\hline 10379 & 583771.62 & 134866.59 & \\
\hline 10380 & 584021.62 & 134366.59 & \\
\hline 10381 & 583771.62 & 135116.59 & \\
\hline 10382 & 585771.62 & 132616.59 & \\
\hline 10383 & 585771.62 & 132866.59 & \\
\hline 10384 & 585771.62 & 133116.59 & \\
\hline 10385 & 586021.62 & 132616.59 & \\
\hline 10386 & 585771.62 & 133366.59 & \\
\hline 10387 & 586271.62 & 131616.59 & \\
\hline 10388 & 586271.62 & 131866.59 & \\
\hline 10389 & 586271.62 & 132116.59 & \\
\hline 10390 & 586521.62 & 131616.59 & \\
\hline 10391 & 586271.62 & 132366.59 & \\
\hline 10392 & 586771.62 & 130616.6 & \\
\hline 10393 & 586771.62 & 130866.59 & \\
\hline 10394 & 586771.62 & 131116.59 & \\
\hline 10395 & 587021.62 & 130616.6 & \\
\hline 10396 & 586771.62 & 131366.59 & \\
\hline 10397 & 587271.62 & 129616.6 & \\
\hline 10398 & 587271.62 & 129866.6 & \\
\hline 10399 & 587271.62 & 130116.6 & \\
\hline 10400 & 587521.62 & 129616.6 & \\
\hline 10401 & 587271.62 & 130366.6 & \\
\hline 10402 & 587771.62 & 128616.6 & \\
\hline 10403 & 587771.62 & 128866.6 & \\
\hline 10404 & 587771.62 & 129116.6 & \\
\hline 10405 & 588021.62 & 128616.6 & \\
\hline 10406 & 587771.62 & 129366.6 & \\
\hline 10407 & 588271.62 & 126866.6 & \\
\hline 10408 & 588271.62 & 127116.6 & \\
\hline 10409 & 588271.62 & 127366.6 & \\
\hline 10410 & 588271.62 & 127616.6 & \\
\hline 10411 & 588271.62 & 127866.6 & \\
\hline 10412 & 588271.62 & 128116.6 & \\
\hline 10413 & 588271.62 & 128366.6 & \\
\hline 10414 & 588521.62 & 126866.6 & \\
\hline 10415 & 588271.62 & 128616.6 & \\
\hline 10416 & 587771.62 & 129616.6 & \\
\hline 10417 & 587271.62 & 130616.6 & \\
\hline 10418 & 586771.62 & 131616.59 & \\
\hline 10419 & 586271.62 & 132616.59 & \\
\hline 10420 & 584771.62 & 134116.59 & \\
\hline
\end{tabular}




\begin{tabular}{|c|c|c|c|}
\hline node & X_coord & Y_coord & note: from sac04d created July 1, 2004 \\
\hline 10421 & $5 \overline{8} 5021.62$ & $1 \overline{3} 4116.59$ & \\
\hline 10422 & 585271.62 & 133616.59 & \\
\hline 10423 & 585521.62 & 133616.59 & \\
\hline 10424 & 585271.62 & 133866.59 & \\
\hline 10425 & 585771.62 & 133616.59 & \\
\hline 10426 & 585271.62 & 134116.59 & \\
\hline 10427 & 588771.62 & 125866.6 & \\
\hline 10428 & 588771.62 & 126116.6 & \\
\hline 10429 & 588771.62 & 126366.6 & \\
\hline 10430 & 589021.62 & 125866.6 & \\
\hline 10431 & 588771.62 & 126616.6 & \\
\hline 10432 & 589271.62 & 124866.6 & \\
\hline 10433 & 589271.62 & 125116.6 & \\
\hline 10434 & 589271.62 & 125366.6 & \\
\hline 10435 & 589521.62 & 124866.6 & \\
\hline 10436 & 589271.62 & 125616.6 & \\
\hline 10437 & 589771.62 & 123866.6 & \\
\hline 10438 & 589771.62 & 124116.6 & \\
\hline 10439 & 589771.62 & 124366.6 & \\
\hline 10440 & 590021.62 & 123866.6 & \\
\hline 10441 & 589771.62 & 124616.6 & \\
\hline 10442 & 590271.62 & 122866.6 & \\
\hline 10443 & 590271.62 & 123116.6 & \\
\hline 10444 & 590271.62 & 123366.6 & \\
\hline 10445 & 590521.62 & 122866.6 & \\
\hline 10446 & 590271.62 & 123616.6 & \\
\hline 10447 & 590771.62 & 121116.6 & \\
\hline 10448 & 590771.62 & 121366.6 & \\
\hline 10449 & 590771.62 & 121616.6 & \\
\hline 10450 & 590771.62 & 121866.6 & \\
\hline 10451 & 590771.62 & 122116.6 & \\
\hline 10452 & 590771.62 & 122366.6 & \\
\hline 10453 & 590771.62 & 122616.6 & \\
\hline 10454 & 591021.62 & 121116.6 & \\
\hline 10455 & 590771.62 & 122866.6 & \\
\hline 10456 & 590271.62 & 123866.6 & \\
\hline 10457 & 589771.62 & 124866.6 & \\
\hline 10458 & 589271.62 & 125866.6 & \\
\hline 10459 & 588771.62 & 126866.6 & \\
\hline 10460 & 584271.62 & 134366.59 & \\
\hline 10461 & 584521.62 & 134366.59 & \\
\hline 10462 & 584771.62 & 134366.59 & \\
\hline 10463 & 591271.62 & 120116.6 & \\
\hline 10464 & 591271.62 & 120366.6 & \\
\hline 10465 & 591271.62 & 120616.6 & \\
\hline 10466 & 591521.62 & 120116.6 & \\
\hline 10467 & 591271.62 & 120866.6 & \\
\hline 10468 & 591771.62 & 119116.6 & \\
\hline 10469 & 591771.62 & 119366.6 & \\
\hline 10470 & 591771.62 & 119616.6 & \\
\hline 10471 & 592021.62 & 119116.6 & \\
\hline 10472 & 591771.62 & 119866.6 & \\
\hline 10473 & 592271.62 & 118116.6 & \\
\hline 10474 & 592271.62 & 118366.6 & \\
\hline 10475 & 592271.62 & 118616.6 & \\
\hline 10476 & 592521.62 & 118116.6 & \\
\hline
\end{tabular}




\begin{tabular}{|c|c|c|c|}
\hline node & X_coord & Y_coord & note: from sac04d created July 1, 2004 \\
\hline 10477 & $5 \overline{9} 2271.62$ & $1 \overline{18866.6}$ & \\
\hline 10478 & 592771.62 & 117116.6 & \\
\hline 10479 & 592771.62 & 117366.6 & \\
\hline 10480 & 592771.62 & 117616.6 & \\
\hline 10481 & 593021.62 & 117116.6 & \\
\hline 10482 & 592771.62 & 117866.6 & \\
\hline 10483 & 593271.62 & 116116.6 & \\
\hline 10484 & 593271.62 & 116366.6 & \\
\hline 10485 & 593271.62 & 116616.6 & \\
\hline 10486 & 593521.62 & 116116.6 & \\
\hline 10487 & 593271.62 & 116866.6 & \\
\hline 10488 & 593771.62 & 115366.6 & \\
\hline 10489 & 593771.62 & 115116.6 & \\
\hline 10490 & 593771.62 & 115616.6 & \\
\hline 10491 & 594021.62 & 115116.6 & \\
\hline 10492 & 593771.62 & 115866.6 & \\
\hline 10493 & 594781.81 & 114864.9851 & \\
\hline 10495 & 594748.0622 & 115026.0186 & \\
\hline 10496 & 594584.101 & 113100.1027 & \\
\hline 10497 & 594255.25 & 115065.42 & \\
\hline 10498 & 594247.31 & 115213.53 & \\
\hline 10499 & 594488.94 & 115097.59 & \\
\hline 10500 & 593771.62 & 116116.6 & \\
\hline 10501 & 593271.62 & 117116.6 & \\
\hline 10502 & 592771.62 & 118116.6 & \\
\hline 10503 & 592271.62 & 119116.6 & \\
\hline 10504 & 591771.62 & 120116.6 & \\
\hline 10505 & 591271.62 & 121116.6 & \\
\hline 10506 & 594614.88 & 112362.8 & \\
\hline 10507 & 583771.62 & 135366.59 & \\
\hline 10508 & 582271.62 & 136866.59 & \\
\hline 10509 & 582521.62 & 136866.59 & \\
\hline 10510 & 582771.62 & 136366.59 & \\
\hline 10511 & 583021.62 & 136366.59 & \\
\hline 10512 & 582771.62 & 136616.59 & \\
\hline 10513 & 583271.62 & 136366.59 & \\
\hline 10514 & 582771.62 & 136866.59 & \\
\hline 10515 & 594771.62 & 111616.6 & \\
\hline 10516 & 594771.62 & 110866.6 & \\
\hline 10517 & 577816.69 & 139453.33 & \\
\hline 10518 & 578029.69 & 139482.2 & \\
\hline 10519 & 594771.62 & 110116.6 & \\
\hline 10520 & 589302.88 & 109633.3 & \\
\hline 10521 & 590204.12 & 109171.9 & \\
\hline 10522 & 591021.62 & 109366.6 & \\
\hline 10523 & 591771.62 & 109366.6 & \\
\hline 10524 & 592521.62 & 109366.6 & \\
\hline 10525 & 593271.62 & 109366.6 & \\
\hline 10526 & 594021.62 & 109366.6 & \\
\hline 10527 & 594759.31 & 109259.7 & \\
\hline 10528 & 569771.62 & 146616.59 & \\
\hline 10529 & 569771.62 & 146866.59 & \\
\hline 10530 & 569773.06 & 147114.55 & \\
\hline 10531 & 569774.5 & 147362.52 & \\
\hline 10532 & 569775.94 & 147610.47 & \\
\hline 10533 & 569863.0613 & 147788.9758 & \\
\hline
\end{tabular}




\begin{tabular}{|c|c|c|c|}
\hline node & X_coord & Y_coord & note: from sac04d created July 1,2004 \\
\hline 10534 & $5 \overline{6} 9519.0226$ & $1 \overline{4} 7892.2869$ & \\
\hline 10535 & 569345.25 & 148043.27 & \\
\hline 10537 & 569919.317 & 148026.7457 & \\
\hline 10538 & 570021.62 & 146616.59 & \\
\hline 10539 & 570271.62 & 146616.59 & \\
\hline 10540 & 570521.62 & 146616.59 & \\
\hline 10541 & 570771.62 & 146616.59 & \\
\hline 10542 & 571021.62 & 146616.59 & \\
\hline 10543 & 571271.62 & 146616.59 & \\
\hline 10544 & 571521.62 & 146616.59 & \\
\hline 10545 & 571771.62 & 146616.59 & \\
\hline 10546 & 572021.62 & 146616.59 & \\
\hline 10547 & 572271.62 & 146616.59 & \\
\hline 10548 & 572521.62 & 146616.59 & \\
\hline 10549 & 572771.62 & 146616.59 & \\
\hline 10550 & 573021.62 & 146616.59 & \\
\hline 10551 & 573271.62 & 146616.59 & \\
\hline 10552 & 573521.62 & 146616.59 & \\
\hline 10553 & 573771.62 & 146616.59 & \\
\hline 10554 & 574021.62 & 146616.59 & \\
\hline 10555 & 574271.62 & 146616.59 & \\
\hline 10556 & 574521.62 & 146616.59 & \\
\hline 10557 & 574771.62 & 146616.59 & \\
\hline 10558 & 575021.62 & 146616.59 & \\
\hline 10559 & 575271.62 & 146616.59 & \\
\hline 10560 & 575521.62 & 146616.59 & \\
\hline 10561 & 575771.62 & 146616.59 & \\
\hline 10562 & 576021.62 & 146616.59 & \\
\hline 10563 & 576271.62 & 146616.59 & \\
\hline 10564 & 576515.44 & 142782.27 & \\
\hline 10565 & 576517.5 & 142893.7 & \\
\hline 10566 & 576519.56 & 143005.16 & \\
\hline 10567 & 576521.62 & 143116.59 & \\
\hline 10568 & 576521.62 & 143366.59 & \\
\hline 10569 & 576521.62 & 143616.59 & \\
\hline 10570 & 576521.62 & 143866.59 & \\
\hline 10571 & 576521.62 & 144116.59 & \\
\hline 10572 & 576521.62 & 144366.59 & \\
\hline 10573 & 576521.62 & 144616.59 & \\
\hline 10574 & 576521.62 & 144866.59 & \\
\hline 10575 & 576521.62 & 145116.59 & \\
\hline 10576 & 576521.62 & 145366.59 & \\
\hline 10577 & 576521.62 & 145616.59 & \\
\hline 10578 & 576521.62 & 145866.59 & \\
\hline 10579 & 576521.62 & 146116.59 & \\
\hline 10580 & 576521.62 & 146366.59 & \\
\hline 10581 & 576521.62 & 146616.59 & \\
\hline 10582 & 577885.25 & 139561.47 & \\
\hline 10583 & 577953.75 & 139669.62 & \\
\hline 10584 & 578022.31 & 139777.77 & \\
\hline 10585 & 578018.75 & 139885.02 & \\
\hline 10586 & 578015.12 & 139992.28 & \\
\hline 10587 & 578011.56 & 140099.53 & \\
\hline 10588 & 582021.62 & 137116.59 & \\
\hline 10589 & 582021.62 & 137366.59 & \\
\hline 10590 & 582021.62 & 137616.59 & \\
\hline
\end{tabular}




\begin{tabular}{|c|c|c|c|}
\hline node & X_coord & Y_coord & note: from sac04d created July 1, 2004 \\
\hline 10591 & $5 \overline{8} 2021.62$ & $1 \overline{3} 7866.59$ & \\
\hline 10592 & 582021.62 & 138116.59 & \\
\hline 10593 & 582021.62 & 138366.59 & \\
\hline 10594 & 582021.62 & 138616.59 & \\
\hline 10595 & 582271.62 & 137116.59 & \\
\hline 10596 & 580470.62 & 138917.64 & \\
\hline 10597 & 580310.38 & 138844.44 & \\
\hline 10598 & 580309.81 & 139001.88 & \\
\hline 10599 & 580736.94 & 138890.48 & \\
\hline 10600 & 581003.31 & 138863.34 & \\
\hline 10601 & 581269.62 & 138836.2 & \\
\hline 10602 & 581516.69 & 138809.78 & \\
\hline 10603 & 581763.69 & 138783.38 & \\
\hline 10604 & 582010.69 & 138756.97 & \\
\hline 10605 & 583521.62 & 135616.59 & \\
\hline 10606 & 583521.62 & 135866.59 & \\
\hline 10607 & 583521.62 & 136116.59 & \\
\hline 10608 & 583771.62 & 135616.59 & \\
\hline 10609 & 583521.62 & 136366.59 & \\
\hline 10610 & 584021.62 & 134616.59 & \\
\hline 10611 & 584021.62 & 134866.59 & \\
\hline 10612 & 584021.62 & 135116.59 & \\
\hline 10613 & 584271.62 & 134616.59 & \\
\hline 10614 & 584021.62 & 135366.59 & \\
\hline 10615 & 586021.62 & 132866.59 & \\
\hline 10616 & 586021.62 & 133116.59 & \\
\hline 10617 & 586021.62 & 133366.59 & \\
\hline 10618 & 586271.62 & 132866.59 & \\
\hline 10619 & 586021.62 & 133616.59 & \\
\hline 10620 & 586521.62 & 131866.59 & \\
\hline 10621 & 586521.62 & 132116.59 & \\
\hline 10622 & 586521.62 & 132366.59 & \\
\hline 10623 & 586771.62 & 131866.59 & \\
\hline 10624 & 586521.62 & 132616.59 & \\
\hline 10625 & 587021.62 & 130866.59 & \\
\hline 10626 & 587021.62 & 131116.59 & \\
\hline 10627 & 587021.62 & 131366.59 & \\
\hline 10628 & 587271.62 & 130866.59 & \\
\hline 10629 & 587021.62 & 131616.59 & \\
\hline 10630 & 587521.62 & 129866.6 & \\
\hline 10631 & 587521.62 & 130116.6 & \\
\hline 10632 & 587521.62 & 130366.6 & \\
\hline 10633 & 587771.62 & 129866.6 & \\
\hline 10634 & 587521.62 & 130616.6 & \\
\hline 10635 & 588021.62 & 128866.6 & \\
\hline 10636 & 588021.62 & 129116.6 & \\
\hline 10637 & 588021.62 & 129366.6 & \\
\hline 10638 & 588271.62 & 128866.6 & \\
\hline 10639 & 588021.62 & 129616.6 & \\
\hline 10640 & 588521.62 & 127116.6 & \\
\hline 10641 & 588521.62 & 127366.6 & \\
\hline 10642 & 588521.62 & 127616.6 & \\
\hline 10643 & 588521.62 & 127866.6 & \\
\hline 10644 & 588521.62 & 128116.6 & \\
\hline 10645 & 588521.62 & 128366.6 & \\
\hline 10646 & 588521.62 & 128616.6 & \\
\hline
\end{tabular}




\begin{tabular}{|c|c|c|c|}
\hline node & X_coord & Y_coord & note: from sac04d created July 1, 2004 \\
\hline 10647 & $5 \overline{8} 8771.62$ & $1 \overline{2} 7116.6$ & \\
\hline 10648 & 588521.62 & 128866.6 & \\
\hline 10649 & 588021.62 & 129866.6 & \\
\hline 10650 & 587521.62 & 130866.59 & \\
\hline 10651 & 587021.62 & 131866.59 & \\
\hline 10652 & 586521.62 & 132866.59 & \\
\hline 10653 & 585021.62 & 134366.59 & \\
\hline 10654 & 585271.62 & 134366.59 & \\
\hline 10655 & 585521.62 & 133866.59 & \\
\hline 10656 & 585771.62 & 133866.59 & \\
\hline 10657 & 585521.62 & 134116.59 & \\
\hline 10658 & 586021.62 & 133866.59 & \\
\hline 10659 & 585521.62 & 134366.59 & \\
\hline 10660 & 589021.62 & 126116.6 & \\
\hline 10661 & 589021.62 & 126366.6 & \\
\hline 10662 & 589021.62 & 126616.6 & \\
\hline 10663 & 589271.62 & 126116.6 & \\
\hline 10664 & 589021.62 & 126866.6 & \\
\hline 10665 & 589521.62 & 125116.6 & \\
\hline 10666 & 589521.62 & 125366.6 & \\
\hline 10667 & 589521.62 & 125616.6 & \\
\hline 10668 & 589771.62 & 125116.6 & \\
\hline 10669 & 589521.62 & 125866.6 & \\
\hline 10670 & 590021.62 & 124116.6 & \\
\hline 10671 & 590021.62 & 124366.6 & \\
\hline 10672 & 590021.62 & 124616.6 & \\
\hline 10673 & 590271.62 & 124116.6 & \\
\hline 10674 & 590021.62 & 124866.6 & \\
\hline 10675 & 590521.62 & 123116.6 & \\
\hline 10676 & 590521.62 & 123366.6 & \\
\hline 10677 & 590521.62 & 123616.6 & \\
\hline 10678 & 590771.62 & 123116.6 & \\
\hline 10679 & 590521.62 & 123866.6 & \\
\hline 10680 & 591021.62 & 121366.6 & \\
\hline 10681 & 591021.62 & 121616.6 & \\
\hline 10682 & 591021.62 & 121866.6 & \\
\hline 10683 & 591021.62 & 122116.6 & \\
\hline 10684 & 591021.62 & 122366.6 & \\
\hline 10685 & 591021.62 & 122616.6 & \\
\hline 10686 & 591021.62 & 122866.6 & \\
\hline 10687 & 591271.62 & 121366.6 & \\
\hline 10688 & 591021.62 & 123116.6 & \\
\hline 10689 & 590521.62 & 124116.6 & \\
\hline 10690 & 590021.62 & 125116.6 & \\
\hline 10691 & 589521.62 & 126116.6 & \\
\hline 10692 & 589021.62 & 127116.6 & \\
\hline 10693 & 584521.62 & 134616.59 & \\
\hline 10694 & 584771.62 & 134616.59 & \\
\hline 10695 & 585021.62 & 134616.59 & \\
\hline 10696 & 591521.62 & 120366.6 & \\
\hline 10697 & 591521.62 & 120616.6 & \\
\hline 10698 & 591521.62 & 120866.6 & \\
\hline 10699 & 591771.62 & 120366.6 & \\
\hline 10700 & 591521.62 & 121116.6 & \\
\hline 10701 & 592021.62 & 119366.6 & \\
\hline 10702 & 592021.62 & 119616.6 & \\
\hline
\end{tabular}




\begin{tabular}{|c|c|c|c|}
\hline node & X_coord & Y_coord & note: from sac04d created July 1, 2004 \\
\hline 10703 & $5 \overline{9} 2021.62$ & $1 \overline{19866.6}$ & \\
\hline 10704 & 592271.62 & 119366.6 & \\
\hline 10705 & 592021.62 & 120116.6 & \\
\hline 10706 & 592521.62 & 118366.6 & \\
\hline 10707 & 592521.62 & 118616.6 & \\
\hline 10708 & 592521.62 & 118866.6 & \\
\hline 10709 & 592771.62 & 118366.6 & \\
\hline 10710 & 592521.62 & 119116.6 & \\
\hline 10711 & 593021.62 & 117366.6 & \\
\hline 10712 & 593021.62 & 117616.6 & \\
\hline 10713 & 593021.62 & 117866.6 & \\
\hline 10714 & 593271.62 & 117366.6 & \\
\hline 10715 & 593021.62 & 118116.6 & \\
\hline 10716 & 593492.62 & 116366.67 & \\
\hline 10717 & 593463.69 & 116616.73 & \\
\hline 10718 & 593434.69 & 116866.8 & \\
\hline 10719 & 593713.69 & 116366.73 & \\
\hline 10720 & 593426.69 & 117116.34 & \\
\hline 10721 & 594021.62 & 115366.6 & \\
\hline 10722 & 594021.62 & 115616.6 & \\
\hline 10723 & 594021.62 & 115866.6 & \\
\hline 10724 & 594239.44 & 115361.63 & \\
\hline 10725 & 594021.62 & 116116.6 & \\
\hline 10726 & 594908.8138 & 114362.6446 & \\
\hline 10727 & 594945.1265 & 113845.8027 & \\
\hline 10728 & 594978.38 & 114916 & \\
\hline 10729 & 595116 & 114435.3 & \\
\hline 10730 & 594932.5 & 115076.2 & \\
\hline 10731 & 595045.6259 & 113016.0582 & \\
\hline 10732 & 594710.69 & 115185.23 & \\
\hline 10733 & 594473.12 & 115227.13 & \\
\hline 10734 & 594886.56 & 115236.4 & \\
\hline 10735 & 595208.0575 & 112277.0433 & \\
\hline 10736 & 594457.31 & 115356.67 & \\
\hline 10737 & 593934.69 & 116366.8 & \\
\hline 10738 & 593418.69 & 117365.87 & \\
\hline 10739 & 593021.62 & 118366.6 & \\
\hline 10740 & 592521.62 & 119366.6 & \\
\hline 10741 & 592021.62 & 120366.6 & \\
\hline 10742 & 591521.62 & 121366.6 & \\
\hline 10743 & 595348.8632 & 111479.3758 & \\
\hline 10744 & 584021.62 & 135616.59 & \\
\hline 10745 & 582521.62 & 137116.59 & \\
\hline 10746 & 582771.62 & 137116.59 & \\
\hline 10747 & 583021.62 & 136616.59 & \\
\hline 10748 & 583271.62 & 136616.59 & \\
\hline 10749 & 583021.62 & 136866.59 & \\
\hline 10750 & 583521.62 & 136616.59 & \\
\hline 10751 & 583021.62 & 137116.59 & \\
\hline 10752 & 595480.88 & 110871.4 & \\
\hline 10753 & 595510.747 & 110091.2298 & \\
\hline 10754 & 578110.88 & 139580.3 & \\
\hline 10755 & 578436.81 & 139487.3 & \\
\hline 10756 & 578474.38 & 139569.05 & \\
\hline 10757 & 595402.9848 & 109504.4971 & \\
\hline 10758 & 590120.5 & 108327.2 & \\
\hline
\end{tabular}




\begin{tabular}{|c|c|c|}
\hline node & X_coord & Y_coord \\
\hline 10759 & $5 \overline{9} 1021.62$ & 108616.6 \\
\hline 10760 & 591771.62 & 108616.6 \\
\hline 10761 & 592521.62 & 108616.6 \\
\hline 10762 & 593271.62 & 108616.6 \\
\hline 10763 & 594169.88 & 108610.2 \\
\hline 10764 & 594663.12 & 108501.9 \\
\hline 10765 & 595272.045 & 108798.8079 \\
\hline 10766 & 570021.62 & 146866.59 \\
\hline 10767 & 570021.62 & 147116.59 \\
\hline 10768 & 570021.62 & 147366.59 \\
\hline 10769 & 570021.62 & 147616.59 \\
\hline 10770 & 570036.5 & 147851 \\
\hline 10771 & 570051.44 & 148085.39 \\
\hline 10772 & 569632.4482 & 148007.6776 \\
\hline 10773 & 569466.31 & 148166.59 \\
\hline 10774 & 569759.8869 & 148116.7896 \\
\hline 10775 & 569881.4164 & 148231.7878 \\
\hline 10776 & 570011.7446 & 148338.1222 \\
\hline 10777 & 570271.62 & 146866.59 \\
\hline 10778 & 570521.62 & 146866.59 \\
\hline 10779 & 570771.62 & 146866.59 \\
\hline 10780 & 571021.62 & 146866.59 \\
\hline 10781 & 571271.62 & 146866.59 \\
\hline 10782 & 571521.62 & 146866.59 \\
\hline 10783 & 571771.62 & 146866.59 \\
\hline 10784 & 572021.62 & 146866.59 \\
\hline 10785 & 572271.62 & 146866.59 \\
\hline 10786 & 572521.62 & 146866.59 \\
\hline 10787 & 572771.62 & 146866.59 \\
\hline 10788 & 573021.62 & 146866.59 \\
\hline 10789 & 573271.62 & 146866.59 \\
\hline 10790 & 573521.62 & 146866.59 \\
\hline 10791 & 573771.62 & 146866.59 \\
\hline 10792 & 574021.62 & 146866.59 \\
\hline 10793 & 574271.62 & 146866.59 \\
\hline 10794 & 574521.62 & 146866.59 \\
\hline 10795 & 574771.62 & 146866.59 \\
\hline 10796 & 575021.62 & 146866.59 \\
\hline 10797 & 575271.62 & 146866.59 \\
\hline 10798 & 575521.62 & 146866.59 \\
\hline 10799 & 575771.62 & 146866.59 \\
\hline 10800 & 576021.62 & 146866.59 \\
\hline 10801 & 576271.62 & 146866.59 \\
\hline 10802 & 576521.62 & 146866.59 \\
\hline 10803 & 576772.31 & 142778.3 \\
\hline 10804 & 576772.06 & 142891.06 \\
\hline 10805 & 576771.88 & 143003.83 \\
\hline 10806 & 576771.62 & 143116.59 \\
\hline 10807 & 576771.62 & 143366.59 \\
\hline 10808 & 576771.62 & 143616.59 \\
\hline 10809 & 576771.62 & 143866.59 \\
\hline 10810 & 576771.62 & 144116.59 \\
\hline 10811 & 576771.62 & 144366.59 \\
\hline 10812 & 576771.62 & 144616.59 \\
\hline 10813 & 576771.62 & 144866.59 \\
\hline 10814 & 576771.62 & 145116.59 \\
\hline
\end{tabular}




\begin{tabular}{|c|c|c|c|}
\hline node & X_coord & Y_coord & note: from sac04d created July 1, 2004 \\
\hline 10815 & $5 \overline{7} 6771.62$ & $1 \overline{4} 5366.59$ & \\
\hline 10816 & 576771.62 & 145616.59 & \\
\hline 10817 & 576771.62 & 145866.59 & \\
\hline 10818 & 576771.62 & 146116.59 & \\
\hline 10819 & 576771.62 & 146366.59 & \\
\hline 10820 & 576771.62 & 146616.59 & \\
\hline 10821 & 576771.62 & 146866.59 & \\
\hline 10822 & 578192.12 & 139678.41 & \\
\hline 10823 & 578273.31 & 139776.5 & \\
\hline 10824 & 578271.5 & 139869.73 & \\
\hline 10825 & 578269.69 & 139962.97 & \\
\hline 10826 & 578267.88 & 140056.2 & \\
\hline 10827 & 582271.62 & 137366.59 & \\
\hline 10828 & 582271.62 & 137616.59 & \\
\hline 10829 & 582271.62 & 137866.59 & \\
\hline 10830 & 582289.12 & 138118.61 & \\
\hline 10831 & 582306.62 & 138370.64 & \\
\hline 10832 & 582324.12 & 138622.66 & \\
\hline 10833 & 582280.12 & 138747.23 & \\
\hline 10834 & 582521.62 & 137366.59 & \\
\hline 10835 & 580493.88 & 139105.56 & \\
\hline 10836 & 580309.19 & 139159.3 & \\
\hline 10837 & 580751.81 & 139088.98 & \\
\hline 10838 & 580173.31 & 138959.17 & \\
\hline 10839 & 580148.94 & 139086.11 & \\
\hline 10840 & 580124.5 & 139213.03 & \\
\hline 10841 & 581009.75 & 139072.39 & \\
\hline 10842 & 581267.69 & 139055.8 & \\
\hline 10843 & 581511.69 & 139002.98 & \\
\hline 10844 & 581755.75 & 138950.16 & \\
\hline 10845 & 581999.81 & 138897.33 & \\
\hline 10846 & 582236.06 & 138871.83 & \\
\hline 10847 & 583771.62 & 135866.59 & \\
\hline 10848 & 583771.62 & 136116.59 & \\
\hline 10849 & 583771.62 & 136366.59 & \\
\hline 10850 & 584021.62 & 135866.59 & \\
\hline 10851 & 583807.94 & 136683.3 & \\
\hline 10852 & 584271.62 & 134866.59 & \\
\hline 10853 & 584271.62 & 135116.59 & \\
\hline 10854 & 584271.62 & 135366.59 & \\
\hline 10855 & 584521.62 & 134866.59 & \\
\hline 10856 & 584271.62 & 135616.59 & \\
\hline 10857 & 586271.62 & 133116.59 & \\
\hline 10858 & 586271.62 & 133366.59 & \\
\hline 10859 & 586271.62 & 133616.59 & \\
\hline 10860 & 586521.62 & 133116.59 & \\
\hline 10861 & 586271.62 & 133866.59 & \\
\hline 10862 & 586771.62 & 132116.59 & \\
\hline 10863 & 586771.62 & 132366.59 & \\
\hline 10864 & 586771.62 & 132616.59 & \\
\hline 10865 & 587021.62 & 132116.59 & \\
\hline 10866 & 586771.62 & 132866.59 & \\
\hline 10867 & 587271.62 & 131116.59 & \\
\hline 10868 & 587271.62 & 131366.59 & \\
\hline 10869 & 587271.62 & 131616.59 & \\
\hline 10870 & 587521.62 & 131116.59 & \\
\hline
\end{tabular}




\begin{tabular}{|c|c|c|c|}
\hline node & X_coord & Y_coord & note: from sac04d created July 1, 2004 \\
\hline 10871 & $5 \overline{8} 7271.62$ & $1 \overline{3} 1866.59$ & \\
\hline 10872 & 587771.62 & 130116.6 & \\
\hline 10873 & 587771.62 & 130366.6 & \\
\hline 10874 & 587771.62 & 130616.6 & \\
\hline 10875 & 588021.62 & 130116.6 & \\
\hline 10876 & 587771.62 & 130866.59 & \\
\hline 10877 & 588271.62 & 129116.6 & \\
\hline 10878 & 588271.62 & 129366.6 & \\
\hline 10879 & 588271.62 & 129616.6 & \\
\hline 10880 & 588521.62 & 129116.6 & \\
\hline 10881 & 588271.62 & 129866.6 & \\
\hline 10882 & 588771.62 & 127366.6 & \\
\hline 10883 & 588771.62 & 127616.6 & \\
\hline 10884 & 588771.62 & 127866.6 & \\
\hline 10885 & 588771.62 & 128116.6 & \\
\hline 10886 & 588771.62 & 128366.6 & \\
\hline 10887 & 588771.62 & 128616.6 & \\
\hline 10888 & 588771.62 & 128866.6 & \\
\hline 10889 & 589021.62 & 127366.6 & \\
\hline 10890 & 588771.62 & 129116.6 & \\
\hline 10891 & 588271.62 & 130116.6 & \\
\hline 10892 & 587771.62 & 131116.59 & \\
\hline 10893 & 587271.62 & 132116.59 & \\
\hline 10894 & 586771.62 & 133116.59 & \\
\hline 10895 & 585271.62 & 134616.59 & \\
\hline 10896 & 585521.62 & 134616.59 & \\
\hline 10897 & 585771.62 & 134116.59 & \\
\hline 10898 & 586021.62 & 134116.59 & \\
\hline 10899 & 585771.62 & 134366.59 & \\
\hline 10900 & 586271.62 & 134116.59 & \\
\hline 10901 & 585771.62 & 134616.59 & \\
\hline 10902 & 589271.62 & 126366.6 & \\
\hline 10903 & 589271.62 & 126616.6 & \\
\hline 10904 & 589271.62 & 126866.6 & \\
\hline 10905 & 589521.62 & 126366.6 & \\
\hline 10906 & 589271.62 & 127116.6 & \\
\hline 10907 & 589771.62 & 125366.6 & \\
\hline 10908 & 589771.62 & 125616.6 & \\
\hline 10909 & 589771.62 & 125866.6 & \\
\hline 10910 & 590021.62 & 125366.6 & \\
\hline 10911 & 589771.62 & 126116.6 & \\
\hline 10912 & 590271.62 & 124366.6 & \\
\hline 10913 & 590271.62 & 124616.6 & \\
\hline 10914 & 590271.62 & 124866.6 & \\
\hline 10915 & 590521.62 & 124366.6 & \\
\hline 10916 & 590271.62 & 125116.6 & \\
\hline 10917 & 590771.62 & 123366.6 & \\
\hline 10918 & 590771.62 & 123616.6 & \\
\hline 10919 & 590771.62 & 123866.6 & \\
\hline 10920 & 591021.62 & 123366.6 & \\
\hline 10921 & 590771.62 & 124116.6 & \\
\hline 10922 & 591271.62 & 121616.6 & \\
\hline 10923 & 591271.62 & 121866.6 & \\
\hline 10924 & 591271.62 & 122116.6 & \\
\hline 10925 & 591271.62 & 122366.6 & \\
\hline 10926 & 591271.62 & 122616.6 & \\
\hline
\end{tabular}




\begin{tabular}{|c|c|c|c|}
\hline node & X_coord & Y_coord & note: from sac04d created July 1, 2004 \\
\hline 10927 & $5 \overline{9} 1271.62$ & $1 \overline{2} 2866.6$ & \\
\hline 10928 & 591271.62 & 123116.6 & \\
\hline 10929 & 591521.62 & 121616.6 & \\
\hline 10930 & 591271.62 & 123366.6 & \\
\hline 10931 & 590771.62 & 124366.6 & \\
\hline 10932 & 590271.62 & 125366.6 & \\
\hline 10933 & 589771.62 & 126366.6 & \\
\hline 10934 & 589271.62 & 127366.6 & \\
\hline 10935 & 584771.62 & 134866.59 & \\
\hline 10936 & 585021.62 & 134866.59 & \\
\hline 10937 & 585271.62 & 134866.59 & \\
\hline 10938 & 591771.62 & 120616.6 & \\
\hline 10939 & 591771.62 & 120866.6 & \\
\hline 10940 & 591771.62 & 121116.6 & \\
\hline 10941 & 592021.62 & 120616.6 & \\
\hline 10942 & 591771.62 & 121366.6 & \\
\hline 10943 & 592271.62 & 119616.6 & \\
\hline 10944 & 592271.62 & 119866.6 & \\
\hline 10945 & 592271.62 & 120116.6 & \\
\hline 10946 & 592521.62 & 119616.6 & \\
\hline 10947 & 592271.62 & 120366.6 & \\
\hline 10948 & 592771.62 & 118616.6 & \\
\hline 10949 & 592771.62 & 118866.6 & \\
\hline 10950 & 592771.62 & 119116.6 & \\
\hline 10951 & 593021.62 & 118616.6 & \\
\hline 10952 & 592771.62 & 119366.6 & \\
\hline 10953 & 593271.62 & 117616.6 & \\
\hline 10954 & 593271.62 & 117866.6 & \\
\hline 10955 & 593271.62 & 118116.6 & \\
\hline 10956 & 593410.69 & 117615.4 & \\
\hline 10957 & 593271.62 & 118366.6 & \\
\hline 10958 & 593655.75 & 116616.87 & \\
\hline 10959 & 593597.81 & 116867 & \\
\hline 10960 & 593581.81 & 117116.07 & \\
\hline 10961 & 593847.81 & 116617 & \\
\hline 10962 & 593565.75 & 117365.13 & \\
\hline 10963 & 594220.75 & 115612.5 & \\
\hline 10964 & 594202 & 115863.37 & \\
\hline 10965 & 594183.31 & 116114.23 & \\
\hline 10966 & 594419.88 & 115608.41 & \\
\hline 10967 & 594109.31 & 116366.57 & \\
\hline 10968 & 595253.69 & 113954.6 & \\
\hline 10969 & 595537.38 & 113207.3 & \\
\hline 10970 & 595836.31 & 112465.3 & \\
\hline 10971 & 594671.4957 & 115368.0094 & \\
\hline 10972 & 594840.69 & 115396.6 & \\
\hline 10973 & 596007.38 & 111584.8 & \\
\hline 10974 & 594613.5635 & 115618.7973 & \\
\hline 10975 & 594035.38 & 116618.9 & \\
\hline 10976 & 593549.75 & 117614.2 & \\
\hline 10977 & 593271.62 & 118616.6 & \\
\hline 10978 & 592771.62 & 119616.6 & \\
\hline 10979 & 592271.62 & 120616.6 & \\
\hline 10980 & 591771.62 & 121616.6 & \\
\hline 10981 & 596116.62 & 110893.3 & \\
\hline 10982 & 584271.62 & 135866.59 & \\
\hline
\end{tabular}




\begin{tabular}{|c|c|c|c|}
\hline node & X_coord & Y_coord & note: from sac04d created July 1, 2004 \\
\hline 10983 & $5 \overline{8} 2771.62$ & $1 \overline{3} 7366.59$ & \\
\hline 10984 & 583021.62 & 137366.59 & \\
\hline 10985 & 583271.62 & 136866.59 & \\
\hline 10986 & 583521.62 & 136866.59 & \\
\hline 10987 & 583271.62 & 137116.59 & \\
\hline 10988 & 583844.19 & 137000 & \\
\hline 10989 & 583271.62 & 137366.59 & \\
\hline 10990 & 596140.62 & 110095.1 & \\
\hline 10991 & 596142.31 & 109395.1 & \\
\hline 10992 & 578511.94 & 139650.81 & \\
\hline 10993 & 578844 & 139492.41 & \\
\hline 10994 & 578837.88 & 139557.81 & \\
\hline 10995 & 578831.81 & 139623.23 & \\
\hline 10996 & 595864.31 & 108556.8 & \\
\hline 10997 & 589764.31 & 108045.4 & \\
\hline 10998 & 591021.62 & 107866.6 & \\
\hline 10999 & 591771.62 & 107866.6 & \\
\hline 11000 & 592521.62 & 107866.6 & \\
\hline 11001 & 593271.62 & 107866.6 & \\
\hline 11002 & 594157.88 & 107876.5 & \\
\hline 11003 & 594979.5575 & 107701.1378 & \\
\hline 11004 & 595196.2307 & 108194.481 & \\
\hline 11005 & 595610.81 & 108013 & \\
\hline 11006 & 570271.62 & 147116.59 & \\
\hline 11007 & 570271.62 & 147366.59 & \\
\hline 11008 & 570271.62 & 147616.59 & \\
\hline 11009 & 570281.56 & 147856.19 & \\
\hline 11010 & 570291.5 & 148095.8 & \\
\hline 11011 & 570301.44 & 148335.39 & \\
\hline 11012 & 569583 & 148285.56 & \\
\hline 11013 & 569699.69 & 148404.53 & \\
\hline 11014 & 569816.38 & 148523.5 & \\
\hline 11015 & 570128.9156 & 148446.4812 & \\
\hline 11016 & 569933.12 & 148642.47 & \\
\hline 11017 & 570354.0328 & 148453.2712 & \\
\hline 11018 & 570521.62 & 147116.59 & \\
\hline 11019 & 570771.62 & 147116.59 & \\
\hline 11020 & 571021.62 & 147116.59 & \\
\hline 11021 & 571271.62 & 147116.59 & \\
\hline 11022 & 571521.62 & 147116.59 & \\
\hline 11023 & 571771.62 & 147116.59 & \\
\hline 11024 & 572021.62 & 147116.59 & \\
\hline 11025 & 572271.62 & 147116.59 & \\
\hline 11026 & 572521.62 & 147116.59 & \\
\hline 11027 & 572771.62 & 147116.59 & \\
\hline 11028 & 573021.62 & 147116.59 & \\
\hline 11029 & 573271.62 & 147116.59 & \\
\hline 11030 & 573521.62 & 147116.59 & \\
\hline 11031 & 573771.62 & 147116.59 & \\
\hline 11032 & 574021.62 & 147116.59 & \\
\hline 11033 & 574271.62 & 147116.59 & \\
\hline 11034 & 574521.62 & 147116.59 & \\
\hline 11035 & 574771.62 & 147116.59 & \\
\hline 11036 & 575021.62 & 147116.59 & \\
\hline 11037 & 575271.62 & 147116.59 & \\
\hline 11038 & 575521.62 & 147116.59 & \\
\hline
\end{tabular}




\begin{tabular}{|c|c|c|c|}
\hline node & X_coord & Y_coord & note: from sac04d created July 1, 2004 \\
\hline 11039 & $5 \overline{7} 5771.62$ & $1 \overline{4} 7116.59$ & \\
\hline 11040 & 576021.62 & 147116.59 & \\
\hline 11041 & 576271.62 & 147116.59 & \\
\hline 11042 & 576521.62 & 147116.59 & \\
\hline 11043 & 576771.62 & 147116.59 & \\
\hline 11044 & 577013.31 & 142758.53 & \\
\hline 11045 & 577016.06 & 142877.89 & \\
\hline 11046 & 577018.88 & 142997.23 & \\
\hline 11047 & 577021.62 & 143116.59 & \\
\hline 11048 & 577021.62 & 143366.59 & \\
\hline 11049 & 577021.62 & 143616.59 & \\
\hline 11050 & 577021.62 & 143866.59 & \\
\hline 11051 & 577021.62 & 144116.59 & \\
\hline 11052 & 577021.62 & 144366.59 & \\
\hline 11053 & 577021.62 & 144616.59 & \\
\hline 11054 & 577021.62 & 144866.59 & \\
\hline 11055 & 577021.62 & 145116.59 & \\
\hline 11056 & 577021.62 & 145366.59 & \\
\hline 11057 & 577021.62 & 145616.59 & \\
\hline 11058 & 577021.62 & 145866.59 & \\
\hline 11059 & 577021.62 & 146116.59 & \\
\hline 11060 & 577021.62 & 146366.59 & \\
\hline 11061 & 577021.62 & 146616.59 & \\
\hline 11062 & 577021.62 & 146866.59 & \\
\hline 11063 & 577021.62 & 147116.59 & \\
\hline 11064 & 578549.5 & 139732.56 & \\
\hline 11065 & 578538.69 & 139826.02 & \\
\hline 11066 & 578527.81 & 139919.45 & \\
\hline 11067 & 578517 & 140012.91 & \\
\hline 11068 & 582521.62 & 137616.59 & \\
\hline 11069 & 582521.62 & 137866.59 & \\
\hline 11070 & 582556.62 & 138120.64 & \\
\hline 11071 & 582591.62 & 138374.69 & \\
\hline 11072 & 582626.62 & 138628.73 & \\
\hline 11073 & 582549.5 & 138737.52 & \\
\hline 11074 & 582472.31 & 138846.31 & \\
\hline 11075 & 582771.62 & 137616.59 & \\
\hline 11076 & 580517.12 & 139293.5 & \\
\hline 11077 & 580308.62 & 139316.73 & \\
\hline 11078 & 580766.62 & 139287.47 & \\
\hline 11079 & 580100.12 & 139339.97 & \\
\hline 11080 & 581016.19 & 139281.44 & \\
\hline 11081 & 580036.31 & 139073.91 & \\
\hline 11082 & 579988.06 & 139170.34 & \\
\hline 11083 & 579939.88 & 139266.77 & \\
\hline 11084 & 579891.62 & 139363.2 & \\
\hline 11085 & 581265.69 & 139275.41 & \\
\hline 11086 & 581506.75 & 139196.17 & \\
\hline 11087 & 581747.81 & 139116.94 & \\
\hline 11088 & 581988.88 & 139037.7 & \\
\hline 11089 & 582192.06 & 138996.41 & \\
\hline 11090 & 582395.19 & 138955.09 & \\
\hline 11091 & 584021.62 & 136116.59 & \\
\hline 11092 & 584021.62 & 136366.59 & \\
\hline 11093 & 584094.19 & 136750 & \\
\hline 11094 & 584271.62 & 136116.59 & \\
\hline
\end{tabular}




\begin{tabular}{|c|c|c|c|}
\hline node & X_coord & Y_coord & note: from sac04d created July 1, 2004 \\
\hline 11095 & $5 \overline{8} 4166.75$ & $1 \overline{3} 7133.39$ & \\
\hline 11096 & 584521.62 & 135116.59 & \\
\hline 11097 & 584521.62 & 135366.59 & \\
\hline 11098 & 584521.62 & 135616.59 & \\
\hline 11099 & 584771.62 & 135116.59 & \\
\hline 11100 & 584521.62 & 135866.59 & \\
\hline 11101 & 586521.62 & 133366.59 & \\
\hline 11102 & 586521.62 & 133616.59 & \\
\hline 11103 & 586521.62 & 133866.59 & \\
\hline 11104 & 586771.62 & 133366.59 & \\
\hline 11105 & 586521.62 & 134116.59 & \\
\hline 11106 & 587021.62 & 132366.59 & \\
\hline 11107 & 587021.62 & 132616.59 & \\
\hline 11108 & 587021.62 & 132866.59 & \\
\hline 11109 & 587271.62 & 132366.59 & \\
\hline 11110 & 587021.62 & 133116.59 & \\
\hline 11111 & 587521.62 & 131366.59 & \\
\hline 11112 & 587521.62 & 131616.59 & \\
\hline 11113 & 587521.62 & 131866.59 & \\
\hline 11114 & 587771.62 & 131366.59 & \\
\hline 11115 & 587521.62 & 132116.59 & \\
\hline 11116 & 588021.62 & 130366.6 & \\
\hline 11117 & 588021.62 & 130616.6 & \\
\hline 11118 & 588021.62 & 130866.59 & \\
\hline 11119 & 588271.62 & 130366.6 & \\
\hline 11120 & 588021.62 & 131116.59 & \\
\hline 11121 & 588521.62 & 129366.6 & \\
\hline 11122 & 588521.62 & 129616.6 & \\
\hline 11123 & 588521.62 & 129866.6 & \\
\hline 11124 & 588771.62 & 129366.6 & \\
\hline 11125 & 588521.62 & 130116.6 & \\
\hline 11126 & 589021.62 & 127616.6 & \\
\hline 11127 & 589021.62 & 127866.6 & \\
\hline 11128 & 589021.62 & 128116.6 & \\
\hline 11129 & 589021.62 & 128366.6 & \\
\hline 11130 & 589021.62 & 128616.6 & \\
\hline 11131 & 589021.62 & 128866.6 & \\
\hline 11132 & 589021.62 & 129116.6 & \\
\hline 11133 & 589271.62 & 127616.6 & \\
\hline 11134 & 589021.62 & 129366.6 & \\
\hline 11135 & 588521.62 & 130366.6 & \\
\hline 11136 & 588021.62 & 131366.59 & \\
\hline 11137 & 587521.62 & 132366.59 & \\
\hline 11138 & 587021.62 & 133366.59 & \\
\hline 11139 & 585521.62 & 134866.59 & \\
\hline 11140 & 585771.62 & 134866.59 & \\
\hline 11141 & 586021.62 & 134366.59 & \\
\hline 11142 & 586271.62 & 134366.59 & \\
\hline 11143 & 586021.62 & 134616.59 & \\
\hline 11144 & 586521.62 & 134366.59 & \\
\hline 11145 & 586021.62 & 134866.59 & \\
\hline 11146 & 589521.62 & 126616.6 & \\
\hline 11147 & 589521.62 & 126866.6 & \\
\hline 11148 & 589521.62 & 127116.6 & \\
\hline 11149 & 589771.62 & 126616.6 & \\
\hline 11150 & 589521.62 & 127366.6 & \\
\hline
\end{tabular}




\begin{tabular}{|c|c|c|c|}
\hline node & X_coord & Y_coord & note: from sac04d created July 1, 2004 \\
\hline 11151 & $5 \overline{9} 0021.62$ & $1 \overline{2} 5616.6$ & \\
\hline 11152 & 590021.62 & 125866.6 & \\
\hline 11153 & 590021.62 & 126116.6 & \\
\hline 11154 & 590271.62 & 125616.6 & \\
\hline 11155 & 590021.62 & 126366.6 & \\
\hline 11156 & 590521.62 & 124616.6 & \\
\hline 11157 & 590521.62 & 124866.6 & \\
\hline 11158 & 590521.62 & 125116.6 & \\
\hline 11159 & 590771.62 & 124616.6 & \\
\hline 11160 & 590521.62 & 125366.6 & \\
\hline 11161 & 591021.62 & 123616.6 & \\
\hline 11162 & 591021.62 & 123866.6 & \\
\hline 11163 & 591021.62 & 124116.6 & \\
\hline 11164 & 591271.62 & 123616.6 & \\
\hline 11165 & 591021.62 & 124366.6 & \\
\hline 11166 & 591521.62 & 121866.6 & \\
\hline 11167 & 591521.62 & 122116.6 & \\
\hline 11168 & 591521.62 & 122366.6 & \\
\hline 11169 & 591521.62 & 122616.6 & \\
\hline 11170 & 591521.62 & 122866.6 & \\
\hline 11171 & 591521.62 & 123116.6 & \\
\hline 11172 & 591521.62 & 123366.6 & \\
\hline 11173 & 591771.62 & 121866.6 & \\
\hline 11174 & 591521.62 & 123616.6 & \\
\hline 11175 & 591021.62 & 124616.6 & \\
\hline 11176 & 590521.62 & 125616.6 & \\
\hline 11177 & 590021.62 & 126616.6 & \\
\hline 11178 & 589521.62 & 127616.6 & \\
\hline 11179 & 585021.62 & 135116.59 & \\
\hline 11180 & 585271.62 & 135116.59 & \\
\hline 11181 & 585521.62 & 135116.59 & \\
\hline 11182 & 592021.62 & 120866.6 & \\
\hline 11183 & 592021.62 & 121116.6 & \\
\hline 11184 & 592021.62 & 121366.6 & \\
\hline 11185 & 592271.62 & 120866.6 & \\
\hline 11186 & 592021.62 & 121616.6 & \\
\hline 11187 & 592521.62 & 119866.6 & \\
\hline 11188 & 592521.62 & 120116.6 & \\
\hline 11189 & 592521.62 & 120366.6 & \\
\hline 11190 & 592771.62 & 119866.6 & \\
\hline 11191 & 592521.62 & 120616.6 & \\
\hline 11192 & 593021.62 & 118866.6 & \\
\hline 11193 & 593021.62 & 119116.6 & \\
\hline 11194 & 593021.62 & 119366.6 & \\
\hline 11195 & 593271.62 & 118866.6 & \\
\hline 11196 & 593021.62 & 119616.6 & \\
\hline 11197 & 593447.69 & 117865.8 & \\
\hline 11198 & 593484.62 & 118116.2 & \\
\hline 11199 & 593521.62 & 118366.6 & \\
\hline 11200 & 593623.69 & 117865 & \\
\hline 11201 & 593521.62 & 118616.6 & \\
\hline 11202 & 593760.88 & 116867.2 & \\
\hline 11203 & 593736.88 & 117115.8 & \\
\hline 11204 & 593712.81 & 117364.4 & \\
\hline 11205 & 593961.38 & 116871.23 & \\
\hline 11206 & 593688.81 & 117613 & \\
\hline
\end{tabular}




\begin{tabular}{|c|c|c|}
\hline node & X_coord & Y_coord \\
\hline 11207 & $5 \overline{9} 4382.44$ & $1 \overline{15860.13}$ \\
\hline 11208 & 594345 & 116111.87 \\
\hline 11209 & 594283.94 & 116366.34 \\
\hline 11210 & 594564.6222 & 115847.8392 \\
\hline 11211 & 594222.94 & 116620.8 \\
\hline 11212 & 594823.69 & 115629.1 \\
\hline 11213 & 594806.69 & 115861.6 \\
\hline 11214 & 594161.88 & 116875.27 \\
\hline 11215 & 593799.75 & 117864.2 \\
\hline 11216 & 593521.62 & 118866.6 \\
\hline 11217 & 593021.62 & 119866.6 \\
\hline 11218 & 592521.62 & 120866.6 \\
\hline 11219 & 592021.62 & 121866.6 \\
\hline 11220 & 584521.62 & 136116.59 \\
\hline 11221 & 583021.62 & 137616.59 \\
\hline 11222 & 583271.62 & 137616.59 \\
\hline 11223 & 583521.62 & 137116.59 \\
\hline 11224 & 583880.5 & 137316.7 \\
\hline 11225 & 583521.62 & 137366.59 \\
\hline 11226 & 584239.31 & 137516.8 \\
\hline 11227 & 583521.62 & 137616.59 \\
\hline 11228 & 578825.69 & 139688.64 \\
\hline 11229 & 579251.12 & 139497.5 \\
\hline 11230 & 579201.38 & 139546.56 \\
\hline 11231 & 579151.62 & 139595.64 \\
\hline 11232 & 579101.88 & 139644.7 \\
\hline 11233 & 590633.31 & 107401.6 \\
\hline 11234 & 591008.81 & 107337.3 \\
\hline 11235 & 591771.62 & 107116.6 \\
\hline 11236 & 592521.62 & 107116.6 \\
\hline 11237 & 593271.62 & 107116.6 \\
\hline 11238 & 594021.62 & 107116.6 \\
\hline 11239 & 594823.1775 & 107222.6783 \\
\hline 11240 & 595416.88 & 107553 \\
\hline 11241 & 595261.12 & 107077.9 \\
\hline 11242 & 570521.62 & 147366.59 \\
\hline 11243 & 570521.62 & 147616.59 \\
\hline 11244 & 570526.56 & 147861.39 \\
\hline 11245 & 570531.56 & 148106.2 \\
\hline 11246 & 570536.5 & 148351 \\
\hline 11247 & 570599.061 & 148532.8771 \\
\hline 11248 & 570238.7562 & 148583.0998 \\
\hline 11249 & 570049.88 & 148761.44 \\
\hline 11251 & 570664.9485 & 148816.3714 \\
\hline 11252 & 570771.62 & 147366.59 \\
\hline 11253 & 571021.62 & 147366.59 \\
\hline 11254 & 571271.62 & 147366.59 \\
\hline 11255 & 571521.62 & 147366.59 \\
\hline 11256 & 571771.62 & 147366.59 \\
\hline 11257 & 572021.62 & 147366.59 \\
\hline 11258 & 572271.62 & 147366.59 \\
\hline 11259 & 572521.62 & 147366.59 \\
\hline 11260 & 572771.62 & 147366.59 \\
\hline 11261 & 573021.62 & 147366.59 \\
\hline 11262 & 573271.62 & 147366.59 \\
\hline 11263 & 573521.62 & 147366.59 \\
\hline
\end{tabular}

note: from sac04d created July 1, 2004 


\begin{tabular}{|c|c|c|c|}
\hline node & X_coord & Y_coord & note: from sac04d created July 1, 2004 \\
\hline 11264 & $5 \overline{7} 3771.62$ & $1 \overline{4} 7366.59$ & \\
\hline 11265 & 574021.62 & 147366.59 & \\
\hline 11266 & 574271.62 & 147366.59 & \\
\hline 11267 & 574521.62 & 147366.59 & \\
\hline 11268 & 574771.62 & 147366.59 & \\
\hline 11269 & 575021.62 & 147366.59 & \\
\hline 11270 & 575271.62 & 147366.59 & \\
\hline 11271 & 575521.62 & 147366.59 & \\
\hline 11272 & 575771.62 & 147366.59 & \\
\hline 11273 & 576021.62 & 147366.59 & \\
\hline 11274 & 576271.62 & 147366.59 & \\
\hline 11275 & 576521.62 & 147366.59 & \\
\hline 11276 & 576771.62 & 147366.59 & \\
\hline 11277 & 577021.62 & 147366.59 & \\
\hline 11278 & 577254.38 & 142738.77 & \\
\hline 11279 & 577260.12 & 142864.7 & \\
\hline 11280 & 577265.88 & 142990.66 & \\
\hline 11281 & 577271.62 & 143116.59 & \\
\hline 11282 & 577271.62 & 143366.59 & \\
\hline 11283 & 577271.62 & 143616.59 & \\
\hline 11284 & 577271.62 & 143866.59 & \\
\hline 11285 & 577271.62 & 144116.59 & \\
\hline 11286 & 577271.62 & 144366.59 & \\
\hline 11287 & 577271.62 & 144616.59 & \\
\hline 11288 & 577271.62 & 144866.59 & \\
\hline 11289 & 577271.62 & 145116.59 & \\
\hline 11290 & 577271.62 & 145366.59 & \\
\hline 11291 & 577271.62 & 145616.59 & \\
\hline 11292 & 577271.62 & 145866.59 & \\
\hline 11293 & 577271.62 & 146116.59 & \\
\hline 11294 & 577271.62 & 146366.59 & \\
\hline 11295 & 577271.62 & 146616.59 & \\
\hline 11296 & 577271.62 & 146866.59 & \\
\hline 11297 & 577271.62 & 147116.59 & \\
\hline 11298 & 577271.62 & 147366.59 & \\
\hline 11299 & 578805.81 & 139782.3 & \\
\hline 11300 & 578785.94 & 139875.94 & \\
\hline 11301 & 578766.06 & 139969.59 & \\
\hline 11302 & 582771.62 & 137866.59 & \\
\hline 11303 & 582824.12 & 138122.66 & \\
\hline 11304 & 582876.62 & 138378.73 & \\
\hline 11305 & 582929.12 & 138634.8 & \\
\hline 11306 & 582818.88 & 138727.8 & \\
\hline 11307 & 582708.62 & 138820.8 & \\
\hline 11308 & 582598.38 & 138913.8 & \\
\hline 11309 & 583021.62 & 137866.59 & \\
\hline 11310 & 580515.25 & 139411.44 & \\
\hline 11311 & 580311.19 & 139440.7 & \\
\hline 11312 & 580729.81 & 139398.22 & \\
\hline 11313 & 580107.06 & 139469.97 & \\
\hline 11314 & 580944.38 & 139385.02 & \\
\hline 11315 & 579903 & 139499.23 & \\
\hline 11316 & 581158.94 & 139371.8 & \\
\hline 11317 & 579678.12 & 139407.97 & \\
\hline 11318 & 579669.12 & 139515.02 & \\
\hline 11319 & 584271.62 & 136366.59 & \\
\hline
\end{tabular}




\begin{tabular}{|c|c|c|}
\hline node & X_coord & Y_coord \\
\hline 11320 & $5 \overline{8} 4380.5$ & $1 \overline{3} 6816.7$ \\
\hline 11321 & 584489.31 & 137266.8 \\
\hline 11322 & 584521.62 & 136366.59 \\
\hline 11323 & 584598.19 & 137716.91 \\
\hline 11324 & 584771.62 & 135366.59 \\
\hline 11325 & 584771.62 & 135616.59 \\
\hline 11326 & 584771.62 & 135866.59 \\
\hline 11327 & 585021.62 & 135366.59 \\
\hline 11328 & 584771.62 & 136116.59 \\
\hline 11329 & 586771.62 & 133616.59 \\
\hline 11330 & 586771.62 & 133866.59 \\
\hline 11331 & 586771.62 & 134116.59 \\
\hline 11332 & 587021.62 & 133616.59 \\
\hline 11333 & 586771.62 & 134366.59 \\
\hline 11334 & 587271.62 & 132616.59 \\
\hline 11335 & 587271.62 & 132866.59 \\
\hline 11336 & 587271.62 & 133116.59 \\
\hline 11337 & 587521.62 & 132616.59 \\
\hline 11338 & 587271.62 & 133366.59 \\
\hline 11339 & 587771.62 & 131616.59 \\
\hline 11340 & 587771.62 & 131866.59 \\
\hline 11341 & 587771.62 & 132116.59 \\
\hline 11342 & 588021.62 & 131616.59 \\
\hline 11343 & 587771.62 & 132366.59 \\
\hline 11344 & 588271.62 & 130616.6 \\
\hline 11345 & 588271.62 & 130866.59 \\
\hline 11346 & 588271.62 & 131116.59 \\
\hline 11347 & 588521.62 & 130616.6 \\
\hline 11348 & 588271.62 & 131366.59 \\
\hline 11349 & 588771.62 & 129616.6 \\
\hline 11350 & 588771.62 & 129866.6 \\
\hline 11351 & 588771.62 & 130116.6 \\
\hline 11352 & 589021.62 & 129616.6 \\
\hline 11353 & 588771.62 & 130366.6 \\
\hline 11354 & 589271.62 & 127866.6 \\
\hline 11355 & 589271.62 & 128116.6 \\
\hline 11356 & 589271.62 & 128366.6 \\
\hline 11357 & 589271.62 & 128616.6 \\
\hline 11358 & 589271.62 & 128866.6 \\
\hline 11359 & 589271.62 & 129116.6 \\
\hline 11360 & 589271.62 & 129366.6 \\
\hline 11361 & 589521.62 & 127866.6 \\
\hline 11362 & 589271.62 & 129616.6 \\
\hline 11363 & 588771.62 & 130616.6 \\
\hline 11364 & 588271.62 & 131616.59 \\
\hline 11365 & 587771.62 & 132616.59 \\
\hline 11366 & 587271.62 & 133616.59 \\
\hline 11367 & 585771.62 & 135116.59 \\
\hline 11368 & 586021.62 & 135116.59 \\
\hline 11369 & 586271.62 & 134616.59 \\
\hline 11370 & 586521.62 & 134616.59 \\
\hline 11371 & 586271.62 & 134866.59 \\
\hline 11372 & 586771.62 & 134616.59 \\
\hline 11373 & 586271.62 & 135116.59 \\
\hline 11374 & 589771.62 & 126866.6 \\
\hline 11375 & 589771.62 & 127116.6 \\
\hline
\end{tabular}

note: from sac04d created July 1, 2004 


\begin{tabular}{|c|c|c|c|}
\hline node & X_coord & Y_coord & note: from sac04d created July 1, 2004 \\
\hline 11376 & $5 \overline{8} 9771.62$ & $1 \overline{2} 7366.6$ & \\
\hline 11377 & 590021.62 & 126866.6 & \\
\hline 11378 & 589771.62 & 127616.6 & \\
\hline 11379 & 590271.62 & 125866.6 & \\
\hline 11380 & 590271.62 & 126116.6 & \\
\hline 11381 & 590271.62 & 126366.6 & \\
\hline 11382 & 590521.62 & 125866.6 & \\
\hline 11383 & 590271.62 & 126616.6 & \\
\hline 11384 & 590771.62 & 124866.6 & \\
\hline 11385 & 590771.62 & 125116.6 & \\
\hline 11386 & 590771.62 & 125366.6 & \\
\hline 11387 & 591021.62 & 124866.6 & \\
\hline 11388 & 590771.62 & 125616.6 & \\
\hline 11389 & 591271.62 & 123866.6 & \\
\hline 11390 & 591271.62 & 124116.6 & \\
\hline 11391 & 591271.62 & 124366.6 & \\
\hline 11392 & 591521.62 & 123866.6 & \\
\hline 11393 & 591271.62 & 124616.6 & \\
\hline 11394 & 591771.62 & 122116.6 & \\
\hline 11395 & 591771.62 & 122366.6 & \\
\hline 11396 & 591771.62 & 122616.6 & \\
\hline 11397 & 591771.62 & 122866.6 & \\
\hline 11398 & 591771.62 & 123116.6 & \\
\hline 11399 & 591771.62 & 123366.6 & \\
\hline 11400 & 591771.62 & 123616.6 & \\
\hline 11401 & 592021.62 & 122116.6 & \\
\hline 11402 & 591771.62 & 123866.6 & \\
\hline 11403 & 591271.62 & 124866.6 & \\
\hline 11404 & 590771.62 & 125866.6 & \\
\hline 11405 & 590271.62 & 126866.6 & \\
\hline 11406 & 589771.62 & 127866.6 & \\
\hline 11407 & 585271.62 & 135366.59 & \\
\hline 11408 & 585521.62 & 135366.59 & \\
\hline 11409 & 585771.62 & 135366.59 & \\
\hline 11410 & 592271.62 & 121116.6 & \\
\hline 11411 & 592271.62 & 121366.6 & \\
\hline 11412 & 592271.62 & 121616.6 & \\
\hline 11413 & 592521.62 & 121116.6 & \\
\hline 11414 & 592271.62 & 121866.6 & \\
\hline 11415 & 592771.62 & 120116.6 & \\
\hline 11416 & 592771.62 & 120366.6 & \\
\hline 11417 & 592771.62 & 120616.6 & \\
\hline 11418 & 593021.62 & 120116.6 & \\
\hline 11419 & 592771.62 & 120866.6 & \\
\hline 11420 & 593271.62 & 119116.6 & \\
\hline 11421 & 593271.62 & 119366.6 & \\
\hline 11422 & 593271.62 & 119616.6 & \\
\hline 11423 & 593521.62 & 119116.6 & \\
\hline 11424 & 593271.62 & 119866.6 & \\
\hline 11425 & 593697.69 & 118115.8 & \\
\hline 11426 & 593771.62 & 118366.6 & \\
\hline 11427 & 593771.62 & 118616.6 & \\
\hline 11428 & 593910.69 & 118115.4 & \\
\hline 11429 & 593771.62 & 118866.6 & \\
\hline 11430 & 593938.69 & 117118.49 & \\
\hline 11431 & 593915.94 & 117365.74 & \\
\hline
\end{tabular}




\begin{tabular}{|c|c|c|c|}
\hline node & X_coord & Y_coord & note: from sac04d created July 1, 2004 \\
\hline 11432 & $5 \overline{9} 3893.25$ & $1 \overline{17} 613$ & \\
\hline 11433 & 594140.5 & 117121.18 & \\
\hline 11434 & 593981.94 & 117863.99 & \\
\hline 11435 & 594513.9386 & 116076.8811 & \\
\hline 11436 & 594473.0573 & 116299.0501 & \\
\hline 11437 & 594414.1243 & 116575.5838 & \\
\hline 11438 & 594789.69 & 116094.1 & \\
\hline 11439 & 594367.8165 & 116835.8082 & \\
\hline 11440 & 594342.31 & 117123.87 & \\
\hline 11441 & 594070.56 & 118114.98 & \\
\hline 11442 & 593771.62 & 119116.6 & \\
\hline 11443 & 593271.62 & 120116.6 & \\
\hline 11444 & 592771.62 & 121116.6 & \\
\hline 11445 & 592271.62 & 122116.6 & \\
\hline 11446 & 584771.62 & 136366.59 & \\
\hline 11447 & 583271.62 & 137866.59 & \\
\hline 11448 & 583521.62 & 137866.59 & \\
\hline 11449 & 583822.8829 & 137480.7873 & \\
\hline 11450 & 584118.9915 & 137636.2087 & \\
\hline 11451 & 583785.9429 & 137624.2674 & \\
\hline 11452 & 584373.856 & 137807.103 & \\
\hline 11453 & 583774.7143 & 137798.6532 & \\
\hline 11454 & 579073 & 139738.56 & \\
\hline 11455 & 579464.62 & 139452.73 & \\
\hline 11456 & 579435.25 & 139530.8 & \\
\hline 11457 & 579405.88 & 139608.84 & \\
\hline 11458 & 579376.5 & 139686.91 & \\
\hline 11459 & 579327.44 & 139762.59 & \\
\hline 11460 & 590343.62 & 106779.3 & \\
\hline 11461 & 590686.88 & 106393.1 & \\
\hline 11462 & 591771.62 & 106366.6 & \\
\hline 11463 & 592521.62 & 106366.6 & \\
\hline 11464 & 593271.62 & 106366.6 & \\
\hline 11465 & 594021.62 & 106366.6 & \\
\hline 11466 & 594648.6259 & 106422.4918 & \\
\hline 11467 & 595043 & 106412.7 & \\
\hline 11468 & 570771.62 & 147616.59 & \\
\hline 11469 & 570771.62 & 147866.59 & \\
\hline 11470 & 570771.62 & 148116.59 & \\
\hline 11471 & 570771.62 & 148366.59 & \\
\hline 11472 & 570785.06 & 148637.66 & \\
\hline 11473 & 570798.56 & 148908.73 & \\
\hline 11474 & 570355.4817 & 148705.5649 & \\
\hline 11475 & 570166.62 & 148880.41 & \\
\hline 11476 & 570486.2691 & 148869.267 & \\
\hline 11477 & 570631.6726 & 149025.2676 & \\
\hline 11478 & 570769.3548 & 149169.8926 & \\
\hline 11479 & 571021.62 & 147616.59 & \\
\hline 11480 & 571271.62 & 147616.59 & \\
\hline 11481 & 571521.62 & 147616.59 & \\
\hline 11482 & 571771.62 & 147616.59 & \\
\hline 11483 & 572021.62 & 147616.59 & \\
\hline 11484 & 572271.62 & 147616.59 & \\
\hline 11485 & 572521.62 & 147616.59 & \\
\hline 11486 & 572771.62 & 147616.59 & \\
\hline 11487 & 573021.62 & 147616.59 & \\
\hline
\end{tabular}




\begin{tabular}{|c|c|c|c|}
\hline node & X_coord & Y_coord & note: from sac04d created July 1, 2004 \\
\hline 11488 & $5 \overline{7} 3271.62$ & $1 \overline{4} 7616.59$ & \\
\hline 11489 & 573521.62 & 147616.59 & \\
\hline 11490 & 573771.62 & 147616.59 & \\
\hline 11491 & 574021.62 & 147616.59 & \\
\hline 11492 & 574271.62 & 147616.59 & \\
\hline 11493 & 574521.62 & 147616.59 & \\
\hline 11494 & 574771.62 & 147616.59 & \\
\hline 11495 & 575021.62 & 147616.59 & \\
\hline 11496 & 575271.62 & 147616.59 & \\
\hline 11497 & 575521.62 & 147616.59 & \\
\hline 11498 & 575771.62 & 147616.59 & \\
\hline 11499 & 576021.62 & 147616.59 & \\
\hline 11500 & 576271.62 & 147616.59 & \\
\hline 11501 & 576521.62 & 147616.59 & \\
\hline 11502 & 576771.62 & 147616.59 & \\
\hline 11503 & 577021.62 & 147616.59 & \\
\hline 11504 & 577271.62 & 147616.59 & \\
\hline 11505 & 577495.38 & 142719 & \\
\hline 11506 & 577504.12 & 142851.53 & \\
\hline 11507 & 577512.88 & 142984.06 & \\
\hline 11508 & 577521.62 & 143116.59 & \\
\hline 11509 & 577521.62 & 143366.59 & \\
\hline 11510 & 577521.62 & 143616.59 & \\
\hline 11511 & 577521.62 & 143866.59 & \\
\hline 11512 & 577521.62 & 144116.59 & \\
\hline 11513 & 577521.62 & 144366.59 & \\
\hline 11514 & 577521.62 & 144616.59 & \\
\hline 11515 & 577521.62 & 144866.59 & \\
\hline 11516 & 577521.62 & 145116.59 & \\
\hline 11517 & 577521.62 & 145366.59 & \\
\hline 11518 & 577521.62 & 145616.59 & \\
\hline 11519 & 577521.62 & 145866.59 & \\
\hline 11520 & 577521.62 & 146116.59 & \\
\hline 11521 & 577521.62 & 146366.59 & \\
\hline 11522 & 577521.62 & 146616.59 & \\
\hline 11523 & 577521.62 & 146866.59 & \\
\hline 11524 & 577521.62 & 147116.59 & \\
\hline 11525 & 577521.62 & 147366.59 & \\
\hline 11526 & 577521.62 & 147616.59 & \\
\hline 11527 & 579044.06 & 139832.44 & \\
\hline 11528 & 579015.19 & 139926.3 & \\
\hline 11529 & 583061.94 & 138084.2 & \\
\hline 11530 & 583102.31 & 138301.83 & \\
\hline 11531 & 583142.62 & 138519.44 & \\
\hline 11532 & 583299.81 & 138045.75 & \\
\hline 11533 & 580513.38 & 139529.36 & \\
\hline 11534 & 580313.69 & 139564.66 & \\
\hline 11535 & 580692.94 & 139508.98 & \\
\hline 11536 & 580114 & 139599.97 & \\
\hline 11537 & 580872.56 & 139488.58 & \\
\hline 11538 & 579914.31 & 139635.27 & \\
\hline 11539 & 581052.12 & 139468.2 & \\
\hline 11540 & 579660.06 & 139622.05 & \\
\hline 11541 & 584625.25 & 136751.7 & \\
\hline 11542 & 584728.81 & 137136.8 & \\
\hline 11543 & 584832.44 & 137521.91 & \\
\hline
\end{tabular}




\begin{tabular}{|c|c|c|c|}
\hline node & X_coord & Y_coord & note: from sac04d created July 1, 2004 \\
\hline 11544 & $5 \overline{8} 4869.94$ & $1 \overline{3} 6686.7$ & \\
\hline 11545 & 585021.62 & 135616.59 & \\
\hline 11546 & 585021.62 & 135866.59 & \\
\hline 11547 & 585021.62 & 136116.59 & \\
\hline 11548 & 585271.62 & 135616.59 & \\
\hline 11549 & 585021.62 & 136366.59 & \\
\hline 11550 & 587021.62 & 133866.59 & \\
\hline 11551 & 587021.62 & 134116.59 & \\
\hline 11552 & 587021.62 & 134366.59 & \\
\hline 11553 & 587271.62 & 133866.59 & \\
\hline 11554 & 587021.62 & 134616.59 & \\
\hline 11555 & 587521.62 & 132866.59 & \\
\hline 11556 & 587521.62 & 133116.59 & \\
\hline 11557 & 587521.62 & 133366.59 & \\
\hline 11558 & 587771.62 & 132866.59 & \\
\hline 11559 & 587521.62 & 133616.59 & \\
\hline 11560 & 588021.62 & 131866.59 & \\
\hline 11561 & 588021.62 & 132116.59 & \\
\hline 11562 & 588021.62 & 132366.59 & \\
\hline 11563 & 588271.62 & 131866.59 & \\
\hline 11564 & 588021.62 & 132616.59 & \\
\hline 11565 & 588521.62 & 130866.59 & \\
\hline 11566 & 588521.62 & 131116.59 & \\
\hline 11567 & 588521.62 & 131366.59 & \\
\hline 11568 & 588771.62 & 130866.59 & \\
\hline 11569 & 588521.62 & 131616.59 & \\
\hline 11570 & 589021.62 & 129866.6 & \\
\hline 11571 & 589021.62 & 130116.6 & \\
\hline 11572 & 589021.62 & 130366.6 & \\
\hline 11573 & 589271.62 & 129866.6 & \\
\hline 11574 & 589021.62 & 130616.6 & \\
\hline 11575 & 589521.62 & 128116.6 & \\
\hline 11576 & 589521.62 & 128366.6 & \\
\hline 11577 & 589521.62 & 128616.6 & \\
\hline 11578 & 589521.62 & 128866.6 & \\
\hline 11579 & 589521.62 & 129116.6 & \\
\hline 11580 & 589521.62 & 129366.6 & \\
\hline 11581 & 589521.62 & 129616.6 & \\
\hline 11582 & 589771.62 & 128116.6 & \\
\hline 11583 & 589521.62 & 129866.6 & \\
\hline 11584 & 589021.62 & 130866.59 & \\
\hline 11585 & 588521.62 & 131866.59 & \\
\hline 11586 & 588021.62 & 132866.59 & \\
\hline 11587 & 587521.62 & 133866.59 & \\
\hline 11588 & 586021.62 & 135366.59 & \\
\hline 11589 & 586271.62 & 135366.59 & \\
\hline 11590 & 586521.62 & 134866.59 & \\
\hline 11591 & 586771.62 & 134866.59 & \\
\hline 11592 & 586521.62 & 135116.59 & \\
\hline 11593 & 587021.62 & 134866.59 & \\
\hline 11594 & 586521.62 & 135366.59 & \\
\hline 11595 & 590021.62 & 127116.6 & \\
\hline 11596 & 590021.62 & 127366.6 & \\
\hline 11597 & 590021.62 & 127616.6 & \\
\hline 11598 & 590271.62 & 127116.6 & \\
\hline 11599 & 590021.62 & 127866.6 & \\
\hline
\end{tabular}




\begin{tabular}{|c|c|c|c|}
\hline node & X_coord & Y_coord & note: from sac04d created July 1, 2004 \\
\hline 11600 & $5 \overline{9} 0521.62$ & $1 \overline{2} 6116.6$ & \\
\hline 11601 & 590521.62 & 126366.6 & \\
\hline 11602 & 590521.62 & 126616.6 & \\
\hline 11603 & 590771.62 & 126116.6 & \\
\hline 11604 & 590521.62 & 126866.6 & \\
\hline 11605 & 591021.62 & 125116.6 & \\
\hline 11606 & 591021.62 & 125366.6 & \\
\hline 11607 & 591021.62 & 125616.6 & \\
\hline 11608 & 591271.62 & 125116.6 & \\
\hline 11609 & 591021.62 & 125866.6 & \\
\hline 11610 & 591521.62 & 124116.6 & \\
\hline 11611 & 591521.62 & 124366.6 & \\
\hline 11612 & 591521.62 & 124616.6 & \\
\hline 11613 & 591771.62 & 124116.6 & \\
\hline 11614 & 591521.62 & 124866.6 & \\
\hline 11615 & 592021.62 & 122366.6 & \\
\hline 11616 & 592021.62 & 122616.6 & \\
\hline 11617 & 592021.62 & 122866.6 & \\
\hline 11618 & 592021.62 & 123116.6 & \\
\hline 11619 & 592021.62 & 123366.6 & \\
\hline 11620 & 592021.62 & 123616.6 & \\
\hline 11621 & 592021.62 & 123866.6 & \\
\hline 11622 & 592271.62 & 122366.6 & \\
\hline 11623 & 592021.62 & 124116.6 & \\
\hline 11624 & 591521.62 & 125116.6 & \\
\hline 11625 & 591021.62 & 126116.6 & \\
\hline 11626 & 590521.62 & 127116.6 & \\
\hline 11627 & 590021.62 & 128116.6 & \\
\hline 11628 & 585521.62 & 135616.59 & \\
\hline 11629 & 585771.62 & 135616.59 & \\
\hline 11630 & 586021.62 & 135616.59 & \\
\hline 11631 & 592521.62 & 121366.6 & \\
\hline 11632 & 592521.62 & 121616.6 & \\
\hline 11633 & 592521.62 & 121866.6 & \\
\hline 11634 & 592771.62 & 121366.6 & \\
\hline 11635 & 592521.62 & 122116.6 & \\
\hline 11636 & 593021.62 & 120366.6 & \\
\hline 11637 & 593021.62 & 120616.6 & \\
\hline 11638 & 593021.62 & 120866.6 & \\
\hline 11639 & 593271.62 & 120366.6 & \\
\hline 11640 & 593021.62 & 121116.6 & \\
\hline 11641 & 593521.62 & 119366.6 & \\
\hline 11642 & 593521.62 & 119616.6 & \\
\hline 11643 & 593521.62 & 119866.6 & \\
\hline 11644 & 593771.62 & 119366.6 & \\
\hline 11645 & 593521.62 & 120116.6 & \\
\hline 11646 & 594021.62 & 118366.6 & \\
\hline 11647 & 594021.62 & 118616.6 & \\
\hline 11648 & 594021.62 & 118866.6 & \\
\hline 11649 & 594159.25 & 118365.97 & \\
\hline 11650 & 594021.62 & 119116.6 & \\
\hline 11651 & 594119.12 & 117367.09 & \\
\hline 11652 & 594097.75 & 117613 & \\
\hline 11653 & 594164.12 & 117863.78 & \\
\hline 11654 & 594315.0014 & 117402.861 & \\
\hline 11655 & 594230.5 & 118114.55 & \\
\hline
\end{tabular}




\begin{tabular}{|c|c|c|}
\hline node & X_coord & Y_coord \\
\hline 11656 & 594769.3472 & 116321.3457 \\
\hline 11657 & 594756.8058 & 116564.0543 \\
\hline 11658 & 594775.12 & 116791.3 \\
\hline 11659 & 594816.81 & 117054.7 \\
\hline 11660 & 594858.44 & 117318.1 \\
\hline 11661 & 594296.88 & 118365.34 \\
\hline 11662 & 594021.62 & 119366.6 \\
\hline 11663 & 593521.62 & 120366.6 \\
\hline 11664 & 593021.62 & 121366.6 \\
\hline 11665 & 592521.62 & 122366.6 \\
\hline 11666 & 585114.69 & 136621.7 \\
\hline 11667 & 583537.62 & 138007.3 \\
\hline 11668 & 583709.803 & 137952.9589 \\
\hline 11669 & 584024.3744 & 137760.7817 \\
\hline 11670 & 584185.6018 & 137892.1517 \\
\hline 11671 & 583919.5088 & 137859.5733 \\
\hline 11672 & 583763.44 & 138060.856 \\
\hline 11673 & 579278.31 & 139838.28 \\
\hline 11674 & 579651.06 & 139729.09 \\
\hline 11675 & 579581.81 & 139786.61 \\
\hline 11676 & 579512.56 & 139844.11 \\
\hline 11677 & 591113.69 & 105700.8 \\
\hline 11678 & 591756.62 & 105412.1 \\
\hline 11679 & 592521.62 & 105616.6 \\
\hline 11680 & 593271.62 & 105616.6 \\
\hline 11681 & 594021.62 & 105616.6 \\
\hline 11682 & 594707.4957 & 105719.1567 \\
\hline 11683 & 595122.5 & 105856.5 \\
\hline 11684 & 571021.62 & 147866.59 \\
\hline 11685 & 571021.62 & 148116.59 \\
\hline 11686 & 571021.62 & 148366.59 \\
\hline 11687 & 571030.62 & 148630.64 \\
\hline 11688 & 571039.56 & 148894.69 \\
\hline 11689 & 571048.56 & 149158.73 \\
\hline 11690 & 570307.5057 & 149031.3029 \\
\hline 11691 & 570425.1971 & 149182.1757 \\
\hline 11692 & 570550.62 & 149340.8 \\
\hline 11693 & 570883.8806 & 149302.3741 \\
\hline 11694 & 571089.0715 & 149309.2344 \\
\hline 11695 & 570654.88 & 149470.86 \\
\hline 11696 & 571271.62 & 147866.59 \\
\hline 11697 & 571521.62 & 147866.59 \\
\hline 11698 & 571771.62 & 147866.59 \\
\hline 11699 & 572021.62 & 147866.59 \\
\hline 11700 & 572271.62 & 147866.59 \\
\hline 11701 & 572521.62 & 147866.59 \\
\hline 11702 & 572771.62 & 147866.59 \\
\hline 11703 & 573021.62 & 147866.59 \\
\hline 11704 & 573271.62 & 147866.59 \\
\hline 11705 & 573521.62 & 147866.59 \\
\hline 11706 & 573771.62 & 147866.59 \\
\hline 11707 & 574021.62 & 147866.59 \\
\hline 11708 & 574271.62 & 147866.59 \\
\hline 11709 & 574521.62 & 147866.59 \\
\hline 11710 & 574771.62 & 147866.59 \\
\hline 11711 & 575021.62 & 147866.59 \\
\hline
\end{tabular}

note: from sac04d created July 1, 2004 


\begin{tabular}{|c|c|c|c|}
\hline node & X_coord & Y_coord & note: from sac04d created July 1, 2004 \\
\hline 11712 & $5 \overline{7} 5271.62$ & $1 \overline{4} 7866.59$ & \\
\hline 11713 & 575521.62 & 147866.59 & \\
\hline 11714 & 575771.62 & 147866.59 & \\
\hline 11715 & 576021.62 & 147866.59 & \\
\hline 11716 & 576271.62 & 147866.59 & \\
\hline 11717 & 576521.62 & 147866.59 & \\
\hline 11718 & 576771.62 & 147866.59 & \\
\hline 11719 & 577021.62 & 147866.59 & \\
\hline 11720 & 577271.62 & 147866.59 & \\
\hline 11721 & 577521.62 & 147866.59 & \\
\hline 11722 & 577590.19 & 142655.77 & \\
\hline 11723 & 577752.25 & 142758.53 & \\
\hline 11724 & 577818.12 & 142684.77 & \\
\hline 11725 & 577758.69 & 142877.89 & \\
\hline 11726 & 577765.19 & 142997.23 & \\
\hline 11727 & 577771.62 & 143116.59 & \\
\hline 11728 & 577771.62 & 143366.59 & \\
\hline 11729 & 577771.62 & 143616.59 & \\
\hline 11730 & 577771.62 & 143866.59 & \\
\hline 11731 & 577771.62 & 144116.59 & \\
\hline 11732 & 577771.62 & 144366.59 & \\
\hline 11733 & 577771.62 & 144616.59 & \\
\hline 11734 & 577771.62 & 144866.59 & \\
\hline 11735 & 577771.62 & 145116.59 & \\
\hline 11736 & 577771.62 & 145366.59 & \\
\hline 11737 & 577771.62 & 145616.59 & \\
\hline 11738 & 577771.62 & 145866.59 & \\
\hline 11739 & 577771.62 & 146116.59 & \\
\hline 11740 & 577771.62 & 146366.59 & \\
\hline 11741 & 577771.62 & 146616.59 & \\
\hline 11742 & 577771.62 & 146866.59 & \\
\hline 11743 & 577771.62 & 147116.59 & \\
\hline 11744 & 577771.62 & 147366.59 & \\
\hline 11745 & 577771.62 & 147616.59 & \\
\hline 11746 & 577771.62 & 147866.59 & \\
\hline 11747 & 579229.25 & 139913.97 & \\
\hline 11748 & 583327.94 & 138224.91 & \\
\hline 11749 & 583356.12 & 138404.06 & \\
\hline 11750 & 583553.62 & 138148 & \\
\hline 11751 & 580511.5 & 139647.3 & \\
\hline 11752 & 580316.25 & 139688.62 & \\
\hline 11753 & 580656.12 & 139619.73 & \\
\hline 11754 & 580120.94 & 139729.97 & \\
\hline 11755 & 580800.75 & 139592.16 & \\
\hline 11756 & 579925.69 & 139771.3 & \\
\hline 11757 & 580945.38 & 139564.59 & \\
\hline 11758 & 584968.31 & 137006.8 & \\
\hline 11759 & 585066.62 & 137326.91 & \\
\hline 11760 & 585207.81 & 136876.8 & \\
\hline 11761 & 585271.62 & 135866.59 & \\
\hline 11762 & 585271.62 & 136116.59 & \\
\hline 11763 & 585271.62 & 136366.59 & \\
\hline 11764 & 585521.62 & 135866.59 & \\
\hline 11765 & 585383.19 & 136601.86 & \\
\hline 11766 & 587271.62 & 134116.59 & \\
\hline 11767 & 587271.62 & 134366.59 & \\
\hline
\end{tabular}




\begin{tabular}{|c|c|c|c|}
\hline node & X_coord & Y_coord & note: from sac04d created July 1, 2004 \\
\hline 11768 & $5 \overline{8} 7271.62$ & $1 \overline{3} 4616.59$ & \\
\hline 11769 & 587521.62 & 134116.59 & \\
\hline 11770 & 587271.62 & 134866.59 & \\
\hline 11771 & 587771.62 & 133116.59 & \\
\hline 11772 & 587771.62 & 133366.59 & \\
\hline 11773 & 587771.62 & 133616.59 & \\
\hline 11774 & 588021.62 & 133116.59 & \\
\hline 11775 & 587771.62 & 133866.59 & \\
\hline 11776 & 588271.62 & 132116.59 & \\
\hline 11777 & 588271.62 & 132366.59 & \\
\hline 11778 & 588271.62 & 132616.59 & \\
\hline 11779 & 588521.62 & 132116.59 & \\
\hline 11780 & 588271.62 & 132866.59 & \\
\hline 11781 & 588771.62 & 131116.59 & \\
\hline 11782 & 588771.62 & 131366.59 & \\
\hline 11783 & 588771.62 & 131616.59 & \\
\hline 11784 & 589021.62 & 131116.59 & \\
\hline 11785 & 588771.62 & 131866.59 & \\
\hline 11786 & 589271.62 & 130116.6 & \\
\hline 11787 & 589271.62 & 130366.6 & \\
\hline 11788 & 589271.62 & 130616.6 & \\
\hline 11789 & 589521.62 & 130116.6 & \\
\hline 11790 & 589271.62 & 130866.59 & \\
\hline 11791 & 589771.62 & 128366.6 & \\
\hline 11792 & 589771.62 & 128616.6 & \\
\hline 11793 & 589771.62 & 128866.6 & \\
\hline 11794 & 589771.62 & 129116.6 & \\
\hline 11795 & 589771.62 & 129366.6 & \\
\hline 11796 & 589771.62 & 129616.6 & \\
\hline 11797 & 589771.62 & 129866.6 & \\
\hline 11798 & 590021.62 & 128366.6 & \\
\hline 11799 & 589771.62 & 130116.6 & \\
\hline 11800 & 589271.62 & 131116.59 & \\
\hline 11801 & 588771.62 & 132116.59 & \\
\hline 11802 & 588271.62 & 133116.59 & \\
\hline 11803 & 587771.62 & 134116.59 & \\
\hline 11804 & 586271.62 & 135616.59 & \\
\hline 11805 & 586521.62 & 135616.59 & \\
\hline 11806 & 586771.62 & 135116.59 & \\
\hline 11807 & 587021.62 & 135116.59 & \\
\hline 11808 & 586771.62 & 135366.59 & \\
\hline 11809 & 587271.62 & 135116.59 & \\
\hline 11810 & 586771.62 & 135616.59 & \\
\hline 11811 & 590271.62 & 127366.6 & \\
\hline 11812 & 590271.62 & 127616.6 & \\
\hline 11813 & 590271.62 & 127866.6 & \\
\hline 11814 & 590521.62 & 127366.6 & \\
\hline 11815 & 590271.62 & 128116.6 & \\
\hline 11816 & 590771.62 & 126366.6 & \\
\hline 11817 & 590771.62 & 126616.6 & \\
\hline 11818 & 590771.62 & 126866.6 & \\
\hline 11819 & 591021.62 & 126366.6 & \\
\hline 11820 & 590771.62 & 127116.6 & \\
\hline 11821 & 591271.62 & 125366.6 & \\
\hline 11822 & 591271.62 & 125616.6 & \\
\hline 11823 & 591271.62 & 125866.6 & \\
\hline
\end{tabular}




\begin{tabular}{|c|c|c|c|}
\hline node & X_coord & Y_coord & note: from sac04d created July 1, 2004 \\
\hline 11824 & $5 \overline{9} 1521.62$ & $1 \overline{2} 5366.6$ & \\
\hline 11825 & 591271.62 & 126116.6 & \\
\hline 11826 & 591771.62 & 124366.6 & \\
\hline 11827 & 591771.62 & 124616.6 & \\
\hline 11828 & 591771.62 & 124866.6 & \\
\hline 11829 & 592021.62 & 124366.6 & \\
\hline 11830 & 591771.62 & 125116.6 & \\
\hline 11831 & 592271.62 & 122616.6 & \\
\hline 11832 & 592271.62 & 122866.6 & \\
\hline 11833 & 592271.62 & 123116.6 & \\
\hline 11834 & 592271.62 & 123366.6 & \\
\hline 11835 & 592271.62 & 123616.6 & \\
\hline 11836 & 592271.62 & 123866.6 & \\
\hline 11837 & 592271.62 & 124116.6 & \\
\hline 11838 & 592521.62 & 122616.6 & \\
\hline 11839 & 592271.62 & 124366.6 & \\
\hline 11840 & 591771.62 & 125366.6 & \\
\hline 11841 & 591271.62 & 126366.6 & \\
\hline 11842 & 590771.62 & 127366.6 & \\
\hline 11843 & 590271.62 & 128366.6 & \\
\hline 11844 & 585771.62 & 135866.59 & \\
\hline 11845 & 586021.62 & 135866.59 & \\
\hline 11846 & 586271.62 & 135866.59 & \\
\hline 11847 & 592771.62 & 121616.6 & \\
\hline 11848 & 592771.62 & 121866.6 & \\
\hline 11849 & 592771.62 & 122116.6 & \\
\hline 11850 & 593021.62 & 121616.6 & \\
\hline 11851 & 592771.62 & 122366.6 & \\
\hline 11852 & 593271.62 & 120616.6 & \\
\hline 11853 & 593271.62 & 120866.6 & \\
\hline 11854 & 593271.62 & 121116.6 & \\
\hline 11855 & 593521.62 & 120616.6 & \\
\hline 11856 & 593271.62 & 121366.6 & \\
\hline 11857 & 593771.62 & 119616.6 & \\
\hline 11858 & 593771.62 & 119866.6 & \\
\hline 11859 & 593771.62 & 120116.6 & \\
\hline 11860 & 594021.62 & 119616.6 & \\
\hline 11861 & 593771.62 & 120366.6 & \\
\hline 11862 & 594171.31 & 118615.49 & \\
\hline 11863 & 594183.31 & 118865.01 & \\
\hline 11864 & 594195.38 & 119114.53 & \\
\hline 11865 & 594320.94 & 118614.38 & \\
\hline 11866 & 594211.38 & 119364.05 & \\
\hline 11867 & 594314.8751 & 117680.0499 & \\
\hline 11868 & 594353.5586 & 117917.9348 & \\
\hline 11869 & 594397.6286 & 118135.8759 & \\
\hline 11870 & 594900.12 & 117581.5 & \\
\hline 11871 & 594434.5 & 118364.7 & \\
\hline 11872 & 594472.4322 & 118624.143 & \\
\hline 11873 & 594227.44 & 119613.58 & \\
\hline 11874 & 593771.62 & 120616.6 & \\
\hline 11875 & 593271.62 & 121616.6 & \\
\hline 11876 & 592771.62 & 122616.6 & \\
\hline 11877 & 585494.81 & 136837.14 & \\
\hline 11880 & 584054.0547 & 137956.5733 & \\
\hline 11883 & 579443.31 & 139901.62 & \\
\hline
\end{tabular}




\begin{tabular}{|c|c|c|}
\hline node & X_coord & Y_coord \\
\hline 11884 & $5 \overline{7} 9836.25$ & $1 \overline{3} 9810.62$ \\
\hline 11885 & 579746.81 & 139849.97 \\
\hline 11886 & 579657.38 & 139889.3 \\
\hline 11887 & 591245.62 & 105177 \\
\hline 11888 & 591579.31 & 104711.5 \\
\hline 11889 & 592521.62 & 104866.6 \\
\hline 11890 & 593240 & 104653.2 \\
\hline 11891 & 594021.62 & 104866.6 \\
\hline 11892 & 594973.4359 & 105016.1325 \\
\hline 11893 & 595408.62 & 105217.6 \\
\hline 11894 & 571271.62 & 148116.59 \\
\hline 11895 & 571271.62 & 148366.59 \\
\hline 11896 & 571276.12 & 148623.61 \\
\hline 11897 & 571280.56 & 148880.64 \\
\hline 11898 & 571285.06 & 149137.66 \\
\hline 11899 & 571342.2513 & 149332.9958 \\
\hline 11900 & 570970.3184 & 149437.6633 \\
\hline 11902 & 570759.06 & 149600.94 \\
\hline 11903 & 571363.3527 & 149662.3228 \\
\hline 11904 & 571521.62 & 148116.59 \\
\hline 11905 & 571771.62 & 148116.59 \\
\hline 11906 & 572021.62 & 148116.59 \\
\hline 11907 & 572271.62 & 148116.59 \\
\hline 11908 & 572521.62 & 148116.59 \\
\hline 11909 & 572771.62 & 148116.59 \\
\hline 11910 & 573021.62 & 148116.59 \\
\hline 11911 & 573271.62 & 148116.59 \\
\hline 11912 & 573521.62 & 148116.59 \\
\hline 11913 & 573771.62 & 148116.59 \\
\hline 11914 & 574021.62 & 148116.59 \\
\hline 11915 & 574271.62 & 148116.59 \\
\hline 11916 & 574521.62 & 148116.59 \\
\hline 11917 & 574771.62 & 148116.59 \\
\hline 11918 & 575021.62 & 148116.59 \\
\hline 11919 & 575271.62 & 148116.59 \\
\hline 11920 & 575521.62 & 148116.59 \\
\hline 11921 & 575771.62 & 148116.59 \\
\hline 11922 & 576021.62 & 148116.59 \\
\hline 11923 & 576271.62 & 148116.59 \\
\hline 11924 & 576521.62 & 148116.59 \\
\hline 11925 & 576771.62 & 148116.59 \\
\hline 11926 & 577021.62 & 148116.59 \\
\hline 11927 & 577271.62 & 148116.59 \\
\hline 11928 & 577521.62 & 148116.59 \\
\hline 11929 & 577771.62 & 148116.59 \\
\hline 11930 & 577685.06 & 142592.53 \\
\hline 11931 & 577884 & 142611 \\
\hline 11932 & 578009.12 & 142798.06 \\
\hline 11933 & 578046 & 142713.77 \\
\hline 11934 & 578013.31 & 142904.23 \\
\hline 11935 & 578082.94 & 142629.45 \\
\hline 11936 & 578017.44 & 143010.42 \\
\hline 11937 & 578021.62 & 143116.59 \\
\hline 11938 & 578021.62 & 143366.59 \\
\hline 11939 & 578021.62 & 143616.59 \\
\hline 11940 & 578021.62 & 143866.59 \\
\hline
\end{tabular}

note: from sac04d created July 1, 2004 


\begin{tabular}{|c|c|c|c|}
\hline node & X_coord & Y_coord & note: from sac04d created July 1, 2004 \\
\hline 11941 & $5 \overline{7} 8021.62$ & $1 \overline{4} 4116.59$ & \\
\hline 11942 & 578021.62 & 144366.59 & \\
\hline 11943 & 578021.62 & 144616.59 & \\
\hline 11944 & 578021.62 & 144866.59 & \\
\hline 11945 & 578021.62 & 145116.59 & \\
\hline 11946 & 578021.62 & 145366.59 & \\
\hline 11947 & 578021.62 & 145616.59 & \\
\hline 11948 & 578021.62 & 145866.59 & \\
\hline 11949 & 578021.62 & 146116.59 & \\
\hline 11950 & 578021.62 & 146366.59 & \\
\hline 11951 & 578021.62 & 146616.59 & \\
\hline 11952 & 578021.62 & 146866.59 & \\
\hline 11953 & 578021.62 & 147116.59 & \\
\hline 11954 & 578021.62 & 147366.59 & \\
\hline 11955 & 578021.62 & 147616.59 & \\
\hline 11956 & 578021.62 & 147866.59 & \\
\hline 11957 & 578021.62 & 148116.59 & \\
\hline 11958 & 583569.62 & 138288.7 & \\
\hline 11959 & 583791.3056 & 138194.5346 & \\
\hline 11960 & 585300.88 & 137131.91 & \\
\hline 11961 & 585606.38 & 137072.41 & \\
\hline 11962 & 585521.62 & 136116.59 & \\
\hline 11963 & 585521.62 & 136366.59 & \\
\hline 11964 & 585651.69 & 136582.03 & \\
\hline 11965 & 585771.62 & 136116.59 & \\
\hline 11966 & 585781.75 & 136797.47 & \\
\hline 11967 & 587521.62 & 134366.59 & \\
\hline 11968 & 587521.62 & 134616.59 & \\
\hline 11969 & 587521.62 & 134866.59 & \\
\hline 11970 & 587771.62 & 134366.59 & \\
\hline 11971 & 587521.62 & 135116.59 & \\
\hline 11972 & 588021.62 & 133366.59 & \\
\hline 11973 & 588021.62 & 133616.59 & \\
\hline 11974 & 588021.62 & 133866.59 & \\
\hline 11975 & 588271.62 & 133366.59 & \\
\hline 11976 & 588021.62 & 134116.59 & \\
\hline 11977 & 588521.62 & 132366.59 & \\
\hline 11978 & 588521.62 & 132616.59 & \\
\hline 11979 & 588521.62 & 132866.59 & \\
\hline 11980 & 588771.62 & 132366.59 & \\
\hline 11981 & 588521.62 & 133116.59 & \\
\hline 11982 & 589021.62 & 131366.59 & \\
\hline 11983 & 589021.62 & 131616.59 & \\
\hline 11984 & 589021.62 & 131866.59 & \\
\hline 11985 & 589271.62 & 131366.59 & \\
\hline 11986 & 589021.62 & 132116.59 & \\
\hline 11987 & 589521.62 & 130366.6 & \\
\hline 11988 & 589521.62 & 130616.6 & \\
\hline 11989 & 589521.62 & 130866.59 & \\
\hline 11990 & 589771.62 & 130366.6 & \\
\hline 11991 & 589521.62 & 131116.59 & \\
\hline 11992 & 590021.62 & 128616.6 & \\
\hline 11993 & 590021.62 & 128866.6 & \\
\hline 11994 & 590021.62 & 129116.6 & \\
\hline 11995 & 590021.62 & 129366.6 & \\
\hline 11996 & 590021.62 & 129616.6 & \\
\hline
\end{tabular}




\begin{tabular}{|c|c|c|c|}
\hline node & X_coord & Y_coord & note: from sac04d created July 1, 2004 \\
\hline 11997 & $5 \overline{9} 0021.62$ & $1 \overline{2} 9866.6$ & \\
\hline 11998 & 590021.62 & 130116.6 & \\
\hline 11999 & 590271.62 & 128616.6 & \\
\hline 12000 & 590021.62 & 130366.6 & \\
\hline 12001 & 589521.62 & 131366.59 & \\
\hline 12002 & 589021.62 & 132366.59 & \\
\hline 12003 & 588521.62 & 133366.59 & \\
\hline 12004 & 588021.62 & 134366.59 & \\
\hline 12005 & 586521.62 & 135866.59 & \\
\hline 12006 & 586771.62 & 135866.59 & \\
\hline 12007 & 587021.62 & 135366.59 & \\
\hline 12008 & 587271.62 & 135366.59 & \\
\hline 12009 & 587021.62 & 135616.59 & \\
\hline 12010 & 587521.62 & 135366.59 & \\
\hline 12011 & 587021.62 & 135866.59 & \\
\hline 12012 & 590521.62 & 127616.6 & \\
\hline 12013 & 590521.62 & 127866.6 & \\
\hline 12014 & 590521.62 & 128116.6 & \\
\hline 12015 & 590771.62 & 127616.6 & \\
\hline 12016 & 590521.62 & 128366.6 & \\
\hline 12017 & 591021.62 & 126616.6 & \\
\hline 12018 & 591021.62 & 126866.6 & \\
\hline 12019 & 591021.62 & 127116.6 & \\
\hline 12020 & 591271.62 & 126616.6 & \\
\hline 12021 & 591021.62 & 127366.6 & \\
\hline 12022 & 591521.62 & 125616.6 & \\
\hline 12023 & 591521.62 & 125866.6 & \\
\hline 12024 & 591521.62 & 126116.6 & \\
\hline 12025 & 591771.62 & 125616.6 & \\
\hline 12026 & 591521.62 & 126366.6 & \\
\hline 12027 & 592021.62 & 124616.6 & \\
\hline 12028 & 592021.62 & 124866.6 & \\
\hline 12029 & 592021.62 & 125116.6 & \\
\hline 12030 & 592271.62 & 124616.6 & \\
\hline 12031 & 592021.62 & 125366.6 & \\
\hline 12032 & 592521.62 & 122866.6 & \\
\hline 12033 & 592521.62 & 123116.6 & \\
\hline 12034 & 592521.62 & 123366.6 & \\
\hline 12035 & 592521.62 & 123616.6 & \\
\hline 12036 & 592521.62 & 123866.6 & \\
\hline 12037 & 592521.62 & 124116.6 & \\
\hline 12038 & 592521.62 & 124366.6 & \\
\hline 12039 & 592771.62 & 122866.6 & \\
\hline 12040 & 592521.62 & 124616.6 & \\
\hline 12041 & 592021.62 & 125616.6 & \\
\hline 12042 & 591521.62 & 126616.6 & \\
\hline 12043 & 591021.62 & 127616.6 & \\
\hline 12044 & 590521.62 & 128616.6 & \\
\hline 12045 & 586021.62 & 136116.59 & \\
\hline 12046 & 586271.62 & 136116.59 & \\
\hline 12047 & 586521.62 & 136116.59 & \\
\hline 12048 & 593021.62 & 121866.6 & \\
\hline 12049 & 593021.62 & 122116.6 & \\
\hline 12050 & 593021.62 & 122366.6 & \\
\hline 12051 & 593271.62 & 121866.6 & \\
\hline 12052 & 593021.62 & 122616.6 & \\
\hline
\end{tabular}




\begin{tabular}{|c|c|c|c|}
\hline node & X_coord & Y_coord & note: from sac04d created July 1, 2004 \\
\hline 12053 & $5 \overline{9} 3521.62$ & $1 \overline{2} 0866.6$ & \\
\hline 12054 & 593521.62 & 121116.6 & \\
\hline 12055 & 593521.62 & 121366.6 & \\
\hline 12056 & 593771.62 & 120866.6 & \\
\hline 12057 & 593521.62 & 121616.6 & \\
\hline 12058 & 594021.62 & 119866.6 & \\
\hline 12059 & 594021.62 & 120116.6 & \\
\hline 12060 & 594021.62 & 120366.6 & \\
\hline 12061 & 594243.44 & 119863.1 & \\
\hline 12062 & 594021.62 & 120616.6 & \\
\hline 12063 & 594345 & 118863.42 & \\
\hline 12064 & 594369.06 & 119112.47 & \\
\hline 12065 & 594401.12 & 119361.52 & \\
\hline 12066 & 594512.1265 & 118883.5859 & \\
\hline 12067 & 594433.25 & 119610.55 & \\
\hline 12068 & 594941.4856 & 117859.63 & \\
\hline 12069 & 594959.5971 & 118135.1929 & \\
\hline 12070 & 594931.38 & 118415.9 & \\
\hline 12071 & 594905.44 & 118667.2 & \\
\hline 12072 & 594879.44 & 118918.5 & \\
\hline 12073 & 594465.31 & 119859.6 & \\
\hline 12074 & 594021.62 & 120866.6 & \\
\hline 12075 & 593521.62 & 121866.6 & \\
\hline 12076 & 593021.62 & 122866.6 & \\
\hline 12077 & 585911.81 & 137012.91 & \\
\hline 12084 & 591951.69 & 104191.6 & \\
\hline 12085 & 592521.62 & 104116.6 & \\
\hline 12086 & 593061.19 & 103881.3 & \\
\hline 12087 & 594021.62 & 104116.6 & \\
\hline 12088 & 594771.62 & 104116.6 & \\
\hline 12089 & 595401.6846 & 104682.8136 & \\
\hline 12090 & 595420.81 & 103997.5 & \\
\hline 12091 & 595572.12 & 104852.5 & \\
\hline 12092 & 571521.62 & 148366.59 & \\
\hline 12093 & 571521.62 & 148616.59 & \\
\hline 12094 & 571521.62 & 148866.59 & \\
\hline 12095 & 571521.62 & 149116.59 & \\
\hline 12096 & 571497.56 & 149426.33 & \\
\hline 12097 & 571473.56 & 149736.06 & \\
\hline 12098 & 571069.7725 & 149578.9334 & \\
\hline 12099 & 571175.5698 & 149737.1862 & \\
\hline 12100 & 570863.31 & 149731 & \\
\hline 12101 & 571305.8207 & 149907.5898 & \\
\hline 12102 & 571449.5 & 150045.8 & \\
\hline 12103 & 571771.62 & 148366.59 & \\
\hline 12104 & 572021.62 & 148366.59 & \\
\hline 12105 & 572271.62 & 148366.59 & \\
\hline 12106 & 572521.62 & 148366.59 & \\
\hline 12107 & 572771.62 & 148366.59 & \\
\hline 12108 & 573021.62 & 148366.59 & \\
\hline 12109 & 573271.62 & 148366.59 & \\
\hline 12110 & 573521.62 & 148366.59 & \\
\hline 12111 & 573771.62 & 148366.59 & \\
\hline 12112 & 574021.62 & 148366.59 & \\
\hline 12113 & 574271.62 & 148366.59 & \\
\hline 12114 & 574521.62 & 148366.59 & \\
\hline
\end{tabular}




\begin{tabular}{|c|c|c|c|}
\hline node & X_coord & Y_coord & note: from sac04d created July 1, 2004 \\
\hline 12115 & $5 \overline{7} 4771.62$ & $1 \overline{4} 8366.59$ & \\
\hline 12116 & 575021.62 & 148366.59 & \\
\hline 12117 & 575271.62 & 148366.59 & \\
\hline 12118 & 575521.62 & 148366.59 & \\
\hline 12119 & 575771.62 & 148366.59 & \\
\hline 12120 & 576021.62 & 148366.59 & \\
\hline 12121 & 576271.62 & 148366.59 & \\
\hline 12122 & 576521.62 & 148366.59 & \\
\hline 12123 & 576771.62 & 148366.59 & \\
\hline 12124 & 577021.62 & 148366.59 & \\
\hline 12125 & 577271.62 & 148366.59 & \\
\hline 12126 & 577521.62 & 148366.59 & \\
\hline 12127 & 577771.62 & 148366.59 & \\
\hline 12128 & 578021.62 & 148366.59 & \\
\hline 12129 & 577779.88 & 142529.3 & \\
\hline 12130 & 577949.88 & 142537.23 & \\
\hline 12131 & 578119.81 & 142545.16 & \\
\hline 12132 & 578266 & 142837.59 & \\
\hline 12133 & 578273.94 & 142742.77 & \\
\hline 12134 & 578267.88 & 142930.59 & \\
\hline 12135 & 578281.88 & 142647.92 & \\
\hline 12136 & 578269.75 & 143023.59 & \\
\hline 12137 & 578289.81 & 142553.09 & \\
\hline 12138 & 578271.62 & 143116.59 & \\
\hline 12139 & 578271.62 & 143366.59 & \\
\hline 12140 & 578271.62 & 143616.59 & \\
\hline 12141 & 578271.62 & 143866.59 & \\
\hline 12142 & 578271.62 & 144116.59 & \\
\hline 12143 & 578271.62 & 144366.59 & \\
\hline 12144 & 578271.62 & 144616.59 & \\
\hline 12145 & 578271.62 & 144866.59 & \\
\hline 12146 & 578271.62 & 145116.59 & \\
\hline 12147 & 578271.62 & 145366.59 & \\
\hline 12148 & 578271.62 & 145616.59 & \\
\hline 12149 & 578271.62 & 145866.59 & \\
\hline 12150 & 578271.62 & 146116.59 & \\
\hline 12151 & 578271.62 & 146366.59 & \\
\hline 12152 & 578271.62 & 146616.59 & \\
\hline 12153 & 578271.62 & 146866.59 & \\
\hline 12154 & 578271.62 & 147116.59 & \\
\hline 12155 & 578271.62 & 147366.59 & \\
\hline 12156 & 578271.62 & 147616.59 & \\
\hline 12157 & 578271.62 & 147866.59 & \\
\hline 12158 & 578271.62 & 148116.59 & \\
\hline 12159 & 578271.62 & 148366.59 & \\
\hline 12163 & 585771.62 & 136366.59 & \\
\hline 12164 & 585920.19 & 136562.2 & \\
\hline 12165 & 586068.75 & 136757.8 & \\
\hline 12166 & 586021.62 & 136366.59 & \\
\hline 12167 & 586217.31 & 136953.41 & \\
\hline 12168 & 587771.62 & 134616.59 & \\
\hline 12169 & 587771.62 & 134866.59 & \\
\hline 12170 & 587771.62 & 135116.59 & \\
\hline 12171 & 588021.62 & 134616.59 & \\
\hline 12172 & 587771.62 & 135366.59 & \\
\hline 12173 & 588271.62 & 133616.59 & \\
\hline
\end{tabular}




\begin{tabular}{|c|c|c|c|}
\hline node & X_coord & Y_coord & note: from sac04d created July 1, 2004 \\
\hline 12174 & $5 \overline{8} 8271.62$ & $1 \overline{3} 3866.59$ & \\
\hline 12175 & 588271.62 & 134116.59 & \\
\hline 12176 & 588521.62 & 133616.59 & \\
\hline 12177 & 588271.62 & 134366.59 & \\
\hline 12178 & 588771.62 & 132616.59 & \\
\hline 12179 & 588771.62 & 132866.59 & \\
\hline 12180 & 588771.62 & 133116.59 & \\
\hline 12181 & 589021.62 & 132616.59 & \\
\hline 12182 & 588771.62 & 133366.59 & \\
\hline 12183 & 589271.62 & 131616.59 & \\
\hline 12184 & 589271.62 & 131866.59 & \\
\hline 12185 & 589271.62 & 132116.59 & \\
\hline 12186 & 589521.62 & 131616.59 & \\
\hline 12187 & 589271.62 & 132366.59 & \\
\hline 12188 & 589771.62 & 130616.6 & \\
\hline 12189 & 589771.62 & 130866.59 & \\
\hline 12190 & 589771.62 & 131116.59 & \\
\hline 12191 & 590021.62 & 130616.6 & \\
\hline 12192 & 589771.62 & 131366.59 & \\
\hline 12193 & 590271.62 & 128866.6 & \\
\hline 12194 & 590271.62 & 129116.6 & \\
\hline 12195 & 590271.62 & 129366.6 & \\
\hline 12196 & 590271.62 & 129616.6 & \\
\hline 12197 & 590271.62 & 129866.6 & \\
\hline 12198 & 590271.62 & 130116.6 & \\
\hline 12199 & 590271.62 & 130366.6 & \\
\hline 12200 & 590521.62 & 128866.6 & \\
\hline 12201 & 590271.62 & 130616.6 & \\
\hline 12202 & 589771.62 & 131616.59 & \\
\hline 12203 & 589271.62 & 132616.59 & \\
\hline 12204 & 588771.62 & 133616.59 & \\
\hline 12205 & 588271.62 & 134616.59 & \\
\hline 12206 & 586771.62 & 136116.59 & \\
\hline 12207 & 587021.62 & 136116.59 & \\
\hline 12208 & 587271.62 & 135616.59 & \\
\hline 12209 & 587521.62 & 135616.59 & \\
\hline 12210 & 587271.62 & 135866.59 & \\
\hline 12211 & 587771.62 & 135616.59 & \\
\hline 12212 & 587271.62 & 136116.59 & \\
\hline 12213 & 590771.62 & 127866.6 & \\
\hline 12214 & 590771.62 & 128116.6 & \\
\hline 12215 & 590771.62 & 128366.6 & \\
\hline 12216 & 591021.62 & 127866.6 & \\
\hline 12217 & 590771.62 & 128616.6 & \\
\hline 12218 & 591271.62 & 126866.6 & \\
\hline 12219 & 591271.62 & 127116.6 & \\
\hline 12220 & 591271.62 & 127366.6 & \\
\hline 12221 & 591521.62 & 126866.6 & \\
\hline 12222 & 591271.62 & 127616.6 & \\
\hline 12223 & 591771.62 & 125866.6 & \\
\hline 12224 & 591771.62 & 126116.6 & \\
\hline 12225 & 591771.62 & 126366.6 & \\
\hline 12226 & 592021.62 & 125866.6 & \\
\hline 12227 & 591771.62 & 126616.6 & \\
\hline 12228 & 592271.62 & 124866.6 & \\
\hline 12229 & 592271.62 & 125116.6 & \\
\hline
\end{tabular}




\begin{tabular}{|c|c|c|c|}
\hline node & X_coord & Y_coord & note: from sac04d created July 1, 2004 \\
\hline 12230 & $5 \overline{9} 2271.62$ & $1 \overline{2} 5366.6$ & \\
\hline 12231 & 592521.62 & 124866.6 & \\
\hline 12232 & 592271.62 & 125616.6 & \\
\hline 12233 & 592771.62 & 123116.6 & \\
\hline 12234 & 592771.62 & 123366.6 & \\
\hline 12235 & 592771.62 & 123616.6 & \\
\hline 12236 & 592771.62 & 123866.6 & \\
\hline 12237 & 592771.62 & 124116.6 & \\
\hline 12238 & 592771.62 & 124366.6 & \\
\hline 12239 & 592771.62 & 124616.6 & \\
\hline 12240 & 593021.62 & 123116.6 & \\
\hline 12241 & 592771.62 & 124866.6 & \\
\hline 12242 & 592271.62 & 125866.6 & \\
\hline 12243 & 591771.62 & 126866.6 & \\
\hline 12244 & 591271.62 & 127866.6 & \\
\hline 12245 & 590771.62 & 128866.6 & \\
\hline 12246 & 586271.62 & 136366.59 & \\
\hline 12247 & 586521.62 & 136366.59 & \\
\hline 12248 & 586771.62 & 136366.59 & \\
\hline 12249 & 593271.62 & 122116.6 & \\
\hline 12250 & 593271.62 & 122366.6 & \\
\hline 12251 & 593271.62 & 122616.6 & \\
\hline 12252 & 593521.62 & 122116.6 & \\
\hline 12253 & 593271.62 & 122866.6 & \\
\hline 12254 & 593771.62 & 121116.6 & \\
\hline 12255 & 593771.62 & 121366.6 & \\
\hline 12256 & 593771.62 & 121616.6 & \\
\hline 12257 & 594021.62 & 121116.6 & \\
\hline 12258 & 593771.62 & 121866.6 & \\
\hline 12259 & 594242.12 & 120113.97 & \\
\hline 12260 & 594240.75 & 120364.84 & \\
\hline 12261 & 594239.44 & 120615.7 & \\
\hline 12262 & 594462.62 & 120111.34 & \\
\hline 12263 & 594226.06 & 120865.23 & \\
\hline 12264 & 594544.6222 & 119135.7702 & \\
\hline 12265 & 594596.3765 & 119400.6497 & \\
\hline 12266 & 594644.4365 & 119665.5191 & \\
\hline 12267 & 594853.5 & 119169.8 & \\
\hline 12268 & 594679.8714 & 119894.1554 & \\
\hline 12269 & 594683.12 & 120119.573 & \\
\hline 12270 & 594212.75 & 121114.74 & \\
\hline 12271 & 593771.62 & 122116.6 & \\
\hline 12272 & 593271.62 & 123116.6 & \\
\hline 12274 & 584677.9769 & 138741.4257 & \\
\hline 12277 & 584769.9271 & 138560.6598 & \\
\hline 12278 & 584893.3168 & 138691.4654 & \\
\hline 12279 & 584852.3856 & 138827.1971 & \\
\hline 12280 & 593410.38 & 103439 & \\
\hline 12281 & 594021.62 & 103366.6 & \\
\hline 12282 & 594771.62 & 103366.6 & \\
\hline 12283 & 595521.62 & 103366.6 & \\
\hline 12284 & 595951.4934 & 104523.3189 & \\
\hline 12285 & 596433.3909 & 104231.6189 & \\
\hline 12286 & 595992.12 & 104614.8 & \\
\hline 12287 & 596287.5 & 103694.7 & \\
\hline 12288 & 571771.62 & 148616.59 & \\
\hline
\end{tabular}




\begin{tabular}{|c|c|c|c|}
\hline node & X_coord & Y_coord & note: from sac04d created July 1, 2004 \\
\hline 12289 & $5 \overline{7} 1771.62$ & $1 \overline{4} 8866.59$ & \\
\hline 12290 & 571771.62 & 149116.59 & \\
\hline 12291 & 571755.62 & 149406.42 & \\
\hline 12292 & 571739.56 & 149696.23 & \\
\hline 12293 & 571723.56 & 149986.06 & \\
\hline 12294 & 570988.38 & 149887.03 & \\
\hline 12295 & 571113.44 & 150043.06 & \\
\hline 12296 & 571238.5 & 150199.09 & \\
\hline 12297 & 571524.2535 & 150154.8114 & \\
\hline 12298 & 571777 & 150146.91 & \\
\hline 12299 & 571312.81 & 150309.77 & \\
\hline 12300 & 572021.62 & 148616.59 & \\
\hline 12301 & 572271.62 & 148616.59 & \\
\hline 12302 & 572521.62 & 148616.59 & \\
\hline 12303 & 572771.62 & 148616.59 & \\
\hline 12304 & 573021.62 & 148616.59 & \\
\hline 12305 & 573271.62 & 148616.59 & \\
\hline 12306 & 573521.62 & 148616.59 & \\
\hline 12307 & 573771.62 & 148616.59 & \\
\hline 12308 & 574021.62 & 148616.59 & \\
\hline 12309 & 574271.62 & 148616.59 & \\
\hline 12310 & 574521.62 & 148616.59 & \\
\hline 12311 & 574771.62 & 148616.59 & \\
\hline 12312 & 575021.62 & 148616.59 & \\
\hline 12313 & 575271.62 & 148616.59 & \\
\hline 12314 & 575521.62 & 148616.59 & \\
\hline 12315 & 575771.62 & 148616.59 & \\
\hline 12316 & 576021.62 & 148616.59 & \\
\hline 12317 & 576271.62 & 148616.59 & \\
\hline 12318 & 576521.62 & 148616.59 & \\
\hline 12319 & 576771.62 & 148616.59 & \\
\hline 12320 & 577021.62 & 148616.59 & \\
\hline 12321 & 577271.62 & 148616.59 & \\
\hline 12322 & 577521.62 & 148616.59 & \\
\hline 12323 & 577771.62 & 148616.59 & \\
\hline 12324 & 578021.62 & 148616.59 & \\
\hline 12325 & 578271.62 & 148616.59 & \\
\hline 12326 & 578515.75 & 142805.77 & \\
\hline 12327 & 578523.44 & 142708.36 & \\
\hline 12328 & 578517.69 & 142909.38 & \\
\hline 12329 & 578531.06 & 142610.97 & \\
\hline 12330 & 578519.69 & 143012.98 & \\
\hline 12331 & 578538.75 & 142513.56 & \\
\hline 12332 & 578521.62 & 143116.59 & \\
\hline 12333 & 578521.62 & 143366.59 & \\
\hline 12334 & 578521.62 & 143616.59 & \\
\hline 12335 & 578521.62 & 143866.59 & \\
\hline 12336 & 578521.62 & 144116.59 & \\
\hline 12337 & 578521.62 & 144366.59 & \\
\hline 12338 & 578521.62 & 144616.59 & \\
\hline 12339 & 578521.62 & 144866.59 & \\
\hline 12340 & 578521.62 & 145116.59 & \\
\hline 12341 & 578521.62 & 145366.59 & \\
\hline 12342 & 578521.62 & 145616.59 & \\
\hline 12343 & 578521.62 & 145866.59 & \\
\hline 12344 & 578521.62 & 146116.59 & \\
\hline
\end{tabular}




\begin{tabular}{|c|c|c|c|}
\hline node & X_coord & Y_coord & note: from sac04d created July 1, 2004 \\
\hline 12345 & $5 \overline{7} 8521.62$ & $1 \overline{4} 6366.59$ & \\
\hline 12346 & 578521.62 & 146616.59 & \\
\hline 12347 & 578521.62 & 146866.59 & \\
\hline 12348 & 578521.62 & 147116.59 & \\
\hline 12349 & 578521.62 & 147366.59 & \\
\hline 12350 & 578521.62 & 147616.59 & \\
\hline 12351 & 578521.62 & 147866.59 & \\
\hline 12352 & 578521.62 & 148116.59 & \\
\hline 12353 & 578521.62 & 148366.59 & \\
\hline 12354 & 578521.62 & 148616.59 & \\
\hline 12357 & 584481.8797 & 138912.8815 & \\
\hline 12358 & 584633.414 & 139031.9084 & \\
\hline 12359 & 586120.69 & 136580.33 & \\
\hline 12360 & 586219.69 & 136794.06 & \\
\hline 12361 & 586318.75 & 137007.8 & \\
\hline 12362 & 586321.12 & 136598.47 & \\
\hline 12363 & 586087.31 & 137188.03 & \\
\hline 12364 & 586232.12 & 137247.55 & \\
\hline 12365 & 588021.62 & 134866.59 & \\
\hline 12366 & 588021.62 & 135116.59 & \\
\hline 12367 & 588021.62 & 135366.59 & \\
\hline 12368 & 588271.62 & 134866.59 & \\
\hline 12369 & 588021.62 & 135616.59 & \\
\hline 12370 & 588521.62 & 133866.59 & \\
\hline 12371 & 588521.62 & 134116.59 & \\
\hline 12372 & 588521.62 & 134366.59 & \\
\hline 12373 & 588771.62 & 133866.59 & \\
\hline 12374 & 588521.62 & 134616.59 & \\
\hline 12375 & 589021.62 & 132866.59 & \\
\hline 12376 & 589021.62 & 133116.59 & \\
\hline 12377 & 589021.62 & 133366.59 & \\
\hline 12378 & 589271.62 & 132866.59 & \\
\hline 12379 & 589021.62 & 133616.59 & \\
\hline 12380 & 589521.62 & 131866.59 & \\
\hline 12381 & 589521.62 & 132116.59 & \\
\hline 12382 & 589521.62 & 132366.59 & \\
\hline 12383 & 589771.62 & 131866.59 & \\
\hline 12384 & 589521.62 & 132616.59 & \\
\hline 12385 & 590021.62 & 130866.59 & \\
\hline 12386 & 590021.62 & 131116.59 & \\
\hline 12387 & 590021.62 & 131366.59 & \\
\hline 12388 & 590271.62 & 130866.59 & \\
\hline 12389 & 590021.62 & 131616.59 & \\
\hline 12390 & 590521.62 & 129116.6 & \\
\hline 12391 & 590521.62 & 129366.6 & \\
\hline 12392 & 590521.62 & 129616.6 & \\
\hline 12393 & 590521.62 & 129866.6 & \\
\hline 12394 & 590521.62 & 130116.6 & \\
\hline 12395 & 590521.62 & 130366.6 & \\
\hline 12396 & 590521.62 & 130616.6 & \\
\hline 12397 & 590771.62 & 129116.6 & \\
\hline 12398 & 590521.62 & 130866.59 & \\
\hline 12399 & 590021.62 & 131866.59 & \\
\hline 12400 & 589521.62 & 132866.59 & \\
\hline 12401 & 589021.62 & 133866.59 & \\
\hline 12402 & 588521.62 & 134866.59 & \\
\hline
\end{tabular}




\begin{tabular}{|c|c|c|c|}
\hline node & X_coord & Y_coord & note: from sac04d created July 1, 2004 \\
\hline 12403 & $5 \overline{8} 7021.62$ & $1 \overline{3} 6366.59$ & \\
\hline 12404 & 587271.62 & 136366.59 & \\
\hline 12405 & 587521.62 & 135866.59 & \\
\hline 12406 & 587771.62 & 135866.59 & \\
\hline 12407 & 587521.62 & 136116.59 & \\
\hline 12408 & 588021.62 & 135866.59 & \\
\hline 12409 & 587521.62 & 136366.59 & \\
\hline 12410 & 591021.62 & 128116.6 & \\
\hline 12411 & 591021.62 & 128366.6 & \\
\hline 12412 & 591021.62 & 128616.6 & \\
\hline 12413 & 591271.62 & 128116.6 & \\
\hline 12414 & 591021.62 & 128866.6 & \\
\hline 12415 & 591521.62 & 127116.6 & \\
\hline 12416 & 591521.62 & 127366.6 & \\
\hline 12417 & 591521.62 & 127616.6 & \\
\hline 12418 & 591771.62 & 127116.6 & \\
\hline 12419 & 591521.62 & 127866.6 & \\
\hline 12420 & 592021.62 & 126116.6 & \\
\hline 12421 & 592021.62 & 126366.6 & \\
\hline 12422 & 592021.62 & 126616.6 & \\
\hline 12423 & 592271.62 & 126116.6 & \\
\hline 12424 & 592021.62 & 126866.6 & \\
\hline 12425 & 592521.62 & 125116.6 & \\
\hline 12426 & 592521.62 & 125366.6 & \\
\hline 12427 & 592521.62 & 125616.6 & \\
\hline 12428 & 592771.62 & 125116.6 & \\
\hline 12429 & 592521.62 & 125866.6 & \\
\hline 12430 & 593021.62 & 123366.6 & \\
\hline 12431 & 593021.62 & 123616.6 & \\
\hline 12432 & 593021.62 & 123866.6 & \\
\hline 12433 & 593021.62 & 124116.6 & \\
\hline 12434 & 593021.62 & 124366.6 & \\
\hline 12435 & 593021.62 & 124616.6 & \\
\hline 12436 & 593021.62 & 124866.6 & \\
\hline 12437 & 593271.62 & 123366.6 & \\
\hline 12438 & 593021.62 & 125116.6 & \\
\hline 12439 & 592521.62 & 126116.6 & \\
\hline 12440 & 592021.62 & 127116.6 & \\
\hline 12441 & 591521.62 & 128116.6 & \\
\hline 12442 & 591021.62 & 129116.6 & \\
\hline 12443 & 586521.62 & 136616.59 & \\
\hline 12444 & 586771.62 & 136616.59 & \\
\hline 12445 & 587021.62 & 136616.59 & \\
\hline 12446 & 593521.62 & 122366.6 & \\
\hline 12447 & 593521.62 & 122616.6 & \\
\hline 12448 & 593521.62 & 122866.6 & \\
\hline 12449 & 593771.62 & 122366.6 & \\
\hline 12450 & 593521.62 & 123116.6 & \\
\hline 12451 & 594021.62 & 121366.6 & \\
\hline 12452 & 594021.62 & 121616.6 & \\
\hline 12453 & 594021.62 & 121866.6 & \\
\hline 12454 & 594199.38 & 121364.27 & \\
\hline 12455 & 594021.62 & 122116.6 & \\
\hline 12456 & 594460 & 120363.06 & \\
\hline 12457 & 594457.31 & 120614.8 & \\
\hline 12458 & 594430.56 & 120863.84 & \\
\hline
\end{tabular}




\begin{tabular}{|c|c|c|c|}
\hline node & X_coord & Y_coord & note: from sac04d created July 1, 2004 \\
\hline 12459 & $5 \overline{9} 4680.9322$ & $1 \overline{2} 0372.173$ & \\
\hline 12460 & 594403.81 & 121112.89 & \\
\hline 12461 & 594826.0329 & 119398.2929 & \\
\hline 12462 & 594850.1686 & 119629.3529 & \\
\hline 12463 & 594887.12 & 119863 & \\
\hline 12464 & 594924.5 & 120093.34 & \\
\hline 12465 & 594961.94 & 120323.66 & \\
\hline 12466 & 594377.06 & 121361.94 & \\
\hline 12467 & 594021.62 & 122366.6 & \\
\hline 12468 & 593521.62 & 123366.6 & \\
\hline 12469 & 584735.3498 & 139030.9314 & \\
\hline 12470 & 584878.5199 & 139076.3428 & \\
\hline 12471 & 584981.9602 & 138341.4342 & \\
\hline 12472 & 585084.5442 & 138405.67 & \\
\hline 12473 & 585032.44 & 138511.12 & \\
\hline 12474 & 585021.62 & 138616.59 & \\
\hline 12475 & 585021.62 & 138866.59 & \\
\hline 12476 & 585021.62 & 139116.59 & \\
\hline 12477 & 593658.69 & 102989 & \\
\hline 12478 & 594031.12 & 102705.7 & \\
\hline 12479 & 594768.19 & 102659.2 & \\
\hline 12480 & 595557.88 & 102900.8 & \\
\hline 12481 & 596180.31 & 103190.5 & \\
\hline 12482 & 596534.31 & 104370.7 & \\
\hline 12483 & 597243.6037 & 103714.0056 & \\
\hline 12484 & 597073.6932 & 103182.5083 & \\
\hline 12485 & 597371.19 & 103823.5 & \\
\hline 12486 & 596917.5 & 102624.3 & \\
\hline 12487 & 572021.62 & 148866.59 & \\
\hline 12488 & 572021.62 & 149116.59 & \\
\hline 12489 & 572013.62 & 149386.5 & \\
\hline 12490 & 572005.56 & 149656.42 & \\
\hline 12491 & 571997.56 & 149926.33 & \\
\hline 12492 & 572024.31 & 150131.75 & \\
\hline 12493 & 571606.1857 & 150272.8935 & \\
\hline 12494 & 571830.44 & 150307.75 & \\
\hline 12495 & 571387.19 & 150420.42 & \\
\hline 12496 & 572051 & 150337.17 & \\
\hline 12497 & 572271.62 & 148866.59 & \\
\hline 12498 & 572521.62 & 148866.59 & \\
\hline 12499 & 572771.62 & 148866.59 & \\
\hline 12500 & 573021.62 & 148866.59 & \\
\hline 12501 & 573271.62 & 148866.59 & \\
\hline 12502 & 573521.62 & 148866.59 & \\
\hline 12503 & 573771.62 & 148866.59 & \\
\hline 12504 & 574021.62 & 148866.59 & \\
\hline 12505 & 574271.62 & 148866.59 & \\
\hline 12506 & 574521.62 & 148866.59 & \\
\hline 12507 & 574771.62 & 148866.59 & \\
\hline 12508 & 575021.62 & 148866.59 & \\
\hline 12509 & 575271.62 & 148866.59 & \\
\hline 12510 & 575521.62 & 148866.59 & \\
\hline 12511 & 575771.62 & 148866.59 & \\
\hline 12512 & 576021.62 & 148866.59 & \\
\hline 12513 & 576271.62 & 148866.59 & \\
\hline 12514 & 576521.62 & 148866.59 & \\
\hline
\end{tabular}




\begin{tabular}{|c|c|c|c|}
\hline node & X_coord & Y_coord & note: from sac04d created July 1,2004 \\
\hline 12515 & $5 \overline{7} 6771.62$ & $1 \overline{4} 8866.59$ & \\
\hline 12516 & 577021.62 & 148866.59 & \\
\hline 12517 & 577271.62 & 148866.59 & \\
\hline 12518 & 577521.62 & 148866.59 & \\
\hline 12519 & 577771.62 & 148866.59 & \\
\hline 12520 & 578021.62 & 148866.59 & \\
\hline 12521 & 578271.62 & 148866.59 & \\
\hline 12522 & 578521.62 & 148866.59 & \\
\hline 12523 & 578765.44 & 142773.92 & \\
\hline 12524 & 578772.88 & 142673.95 & \\
\hline 12525 & 578767.5 & 142888.14 & \\
\hline 12526 & 578780.25 & 142574 & \\
\hline 12527 & 578769.56 & 143002.38 & \\
\hline 12528 & 578787.69 & 142474.03 & \\
\hline 12529 & 578771.62 & 143116.59 & \\
\hline 12530 & 578771.62 & 143366.59 & \\
\hline 12531 & 578771.62 & 143616.59 & \\
\hline 12532 & 578771.62 & 143866.59 & \\
\hline 12533 & 578771.62 & 144116.59 & \\
\hline 12534 & 578771.62 & 144366.59 & \\
\hline 12535 & 578771.62 & 144616.59 & \\
\hline 12536 & 578771.62 & 144866.59 & \\
\hline 12537 & 578771.62 & 145116.59 & \\
\hline 12538 & 578771.62 & 145366.59 & \\
\hline 12539 & 578771.62 & 145616.59 & \\
\hline 12540 & 578771.62 & 145866.59 & \\
\hline 12541 & 578771.62 & 146116.59 & \\
\hline 12542 & 578771.62 & 146366.59 & \\
\hline 12543 & 578771.62 & 146616.59 & \\
\hline 12544 & 578771.62 & 146866.59 & \\
\hline 12545 & 578771.62 & 147116.59 & \\
\hline 12546 & 578771.62 & 147366.59 & \\
\hline 12547 & 578771.62 & 147616.59 & \\
\hline 12548 & 578771.62 & 147866.59 & \\
\hline 12549 & 578771.62 & 148116.59 & \\
\hline 12550 & 578771.62 & 148366.59 & \\
\hline 12551 & 578771.62 & 148616.59 & \\
\hline 12552 & 578771.62 & 148866.59 & \\
\hline 12553 & 584318.5799 & 139094.6944 & \\
\hline 12554 & 584360.3015 & 139209.4856 & \\
\hline 12555 & 584530.81 & 139195.44 & \\
\hline 12556 & 584655 & 139212.3 & \\
\hline 12557 & 584777.19 & 139263.73 & \\
\hline 12558 & 586370.69 & 136830.33 & \\
\hline 12559 & 586420.19 & 137062.2 & \\
\hline 12560 & 586376.88 & 137307.08 & \\
\hline 12561 & 586521.62 & 136866.59 & \\
\hline 12562 & 585957.38 & 137422.67 & \\
\hline 12563 & 586145.44 & 137487.31 & \\
\hline 12564 & 586333.5 & 137551.95 & \\
\hline 12565 & 588271.62 & 135116.59 & \\
\hline 12566 & 588271.62 & 135366.59 & \\
\hline 12567 & 588271.62 & 135616.59 & \\
\hline 12568 & 588521.62 & 135116.59 & \\
\hline 12569 & 588271.62 & 135866.59 & \\
\hline 12570 & 588771.62 & 134116.59 & \\
\hline
\end{tabular}




\begin{tabular}{|c|c|c|c|}
\hline node & X_coord & Y_coord & note: from sac04d created July 1, 2004 \\
\hline 12571 & $5 \overline{8} 8771.62$ & $1 \overline{3} 4366.59$ & \\
\hline 12572 & 588771.62 & 134616.59 & \\
\hline 12573 & 589021.62 & 134116.59 & \\
\hline 12574 & 588771.62 & 134866.59 & \\
\hline 12575 & 589271.62 & 133116.59 & \\
\hline 12576 & 589271.62 & 133366.59 & \\
\hline 12577 & 589271.62 & 133616.59 & \\
\hline 12578 & 589521.62 & 133116.59 & \\
\hline 12579 & 589271.62 & 133866.59 & \\
\hline 12580 & 589771.62 & 132116.59 & \\
\hline 12581 & 589771.62 & 132366.59 & \\
\hline 12582 & 589771.62 & 132616.59 & \\
\hline 12583 & 590021.62 & 132116.59 & \\
\hline 12584 & 589771.62 & 132866.59 & \\
\hline 12585 & 590271.62 & 131116.59 & \\
\hline 12586 & 590271.62 & 131366.59 & \\
\hline 12587 & 590271.62 & 131616.59 & \\
\hline 12588 & 590521.62 & 131116.59 & \\
\hline 12589 & 590271.62 & 131866.59 & \\
\hline 12590 & 590771.62 & 129366.6 & \\
\hline 12591 & 590771.62 & 129616.6 & \\
\hline 12592 & 590771.62 & 129866.6 & \\
\hline 12593 & 590771.62 & 130116.6 & \\
\hline 12594 & 590771.62 & 130366.6 & \\
\hline 12595 & 590771.62 & 130616.6 & \\
\hline 12596 & 590771.62 & 130866.59 & \\
\hline 12597 & 591021.62 & 129366.6 & \\
\hline 12598 & 590771.62 & 131116.59 & \\
\hline 12599 & 590271.62 & 132116.59 & \\
\hline 12600 & 589771.62 & 133116.59 & \\
\hline 12601 & 589271.62 & 134116.59 & \\
\hline 12602 & 588771.62 & 135116.59 & \\
\hline 12603 & 587271.62 & 136616.59 & \\
\hline 12604 & 587521.62 & 136616.59 & \\
\hline 12605 & 587771.62 & 136116.59 & \\
\hline 12606 & 588021.62 & 136116.59 & \\
\hline 12607 & 587771.62 & 136366.59 & \\
\hline 12608 & 588271.62 & 136116.59 & \\
\hline 12609 & 587771.62 & 136616.59 & \\
\hline 12610 & 591271.62 & 128366.6 & \\
\hline 12611 & 591271.62 & 128616.6 & \\
\hline 12612 & 591271.62 & 128866.6 & \\
\hline 12613 & 591521.62 & 128366.6 & \\
\hline 12614 & 591271.62 & 129116.6 & \\
\hline 12615 & 591771.62 & 127366.6 & \\
\hline 12616 & 591771.62 & 127616.6 & \\
\hline 12617 & 591771.62 & 127866.6 & \\
\hline 12618 & 592021.62 & 127366.6 & \\
\hline 12619 & 591771.62 & 128116.6 & \\
\hline 12620 & 592271.62 & 126366.6 & \\
\hline 12621 & 592271.62 & 126616.6 & \\
\hline 12622 & 592271.62 & 126866.6 & \\
\hline 12623 & 592521.62 & 126366.6 & \\
\hline 12624 & 592271.62 & 127116.6 & \\
\hline 12625 & 592771.62 & 125366.6 & \\
\hline 12626 & 592771.62 & 125616.6 & \\
\hline
\end{tabular}




\begin{tabular}{|c|c|c|c|}
\hline node & X_coord & Y_coord & note: from sac04d created July 1, 2004 \\
\hline 12627 & $5 \overline{9} 2771.62$ & $1 \overline{2} 5866.6$ & \\
\hline 12628 & 593021.62 & 125366.6 & \\
\hline 12629 & 592771.62 & 126116.6 & \\
\hline 12630 & 593271.62 & 123616.6 & \\
\hline 12631 & 593271.62 & 123866.6 & \\
\hline 12632 & 593271.62 & 124116.6 & \\
\hline 12633 & 593271.62 & 124366.6 & \\
\hline 12634 & 593271.62 & 124616.6 & \\
\hline 12635 & 593271.62 & 124866.6 & \\
\hline 12636 & 593271.62 & 125116.6 & \\
\hline 12637 & 593521.62 & 123616.6 & \\
\hline 12638 & 593271.62 & 125366.6 & \\
\hline 12639 & 592771.62 & 126366.6 & \\
\hline 12640 & 592271.62 & 127366.6 & \\
\hline 12641 & 591771.62 & 128366.6 & \\
\hline 12642 & 591271.62 & 129366.6 & \\
\hline 12643 & 586771.62 & 136866.59 & \\
\hline 12644 & 587021.62 & 136866.59 & \\
\hline 12645 & 587271.62 & 136866.59 & \\
\hline 12646 & 593771.62 & 122616.6 & \\
\hline 12647 & 593771.62 & 122866.6 & \\
\hline 12648 & 593771.62 & 123116.6 & \\
\hline 12649 & 594021.62 & 122616.6 & \\
\hline 12650 & 593771.62 & 123366.6 & \\
\hline 12651 & 594192.69 & 121613.79 & \\
\hline 12652 & 594186 & 121863.31 & \\
\hline 12653 & 594179.31 & 122112.84 & \\
\hline 12654 & 594363.69 & 121610.98 & \\
\hline 12655 & 594175.31 & 122365.04 & \\
\hline 12656 & 594676.9322 & 120608.4635 & \\
\hline 12657 & 594627.7514 & 120891.4646 & \\
\hline 12658 & 594580.4427 & 121156.334 & \\
\hline 12659 & 594999.31 & 120554 & \\
\hline 12660 & 594543.937 & 121430.2742 & \\
\hline 12661 & 594534.75 & 121706.0167 & \\
\hline 12662 & 594171.31 & 122617.23 & \\
\hline 12663 & 593771.62 & 123616.6 & \\
\hline 12664 & 584899.44 & 139315.16 & \\
\hline 12665 & 585021.62 & 139366.59 & \\
\hline 12666 & 585311.88 & 138085.91 & \\
\hline 12667 & 585298.44 & 138262.8 & \\
\hline 12668 & 585285.06 & 138439.7 & \\
\hline 12669 & 585271.62 & 138616.59 & \\
\hline 12670 & 585271.62 & 138866.59 & \\
\hline 12671 & 585271.62 & 139116.59 & \\
\hline 12672 & 585271.62 & 139366.59 & \\
\hline 12673 & 597792.88 & 103352 & \\
\hline 12674 & 598324.5 & 102709.3 & \\
\hline 12675 & 572271.62 & 149116.59 & \\
\hline 12676 & 572271.62 & 149366.59 & \\
\hline 12677 & 572271.62 & 149616.59 & \\
\hline 12678 & 572271.62 & 149866.59 & \\
\hline 12679 & 572271.62 & 150116.59 & \\
\hline 12680 & 572271.62 & 150366.59 & \\
\hline 12681 & 571684.5635 & 150383.717 & \\
\hline 12682 & 571907.0742 & 150473.7443 & \\
\hline
\end{tabular}




\begin{tabular}{|c|c|c|c|}
\hline node & X_coord & Y_coord & note: from sac04d created July 1, 2004 \\
\hline 12683 & $5 \overline{7} 1461.5$ & $1 \overline{50531.09}$ & \\
\hline 12684 & 572137.0242 & 150535.2597 & \\
\hline 12685 & 572325.3388 & 150576.8041 & \\
\hline 12686 & 572521.62 & 149116.59 & \\
\hline 12687 & 572771.62 & 149116.59 & \\
\hline 12688 & 573021.62 & 149116.59 & \\
\hline 12689 & 573271.62 & 149116.59 & \\
\hline 12690 & 573521.62 & 149116.59 & \\
\hline 12691 & 573771.62 & 149116.59 & \\
\hline 12692 & 574021.62 & 149116.59 & \\
\hline 12693 & 574271.62 & 149116.59 & \\
\hline 12694 & 574521.62 & 149116.59 & \\
\hline 12695 & 574771.62 & 149116.59 & \\
\hline 12696 & 575021.62 & 149116.59 & \\
\hline 12697 & 575271.62 & 149116.59 & \\
\hline 12698 & 575521.62 & 149116.59 & \\
\hline 12699 & 575771.62 & 149116.59 & \\
\hline 12700 & 576021.62 & 149116.59 & \\
\hline 12701 & 576271.62 & 149116.59 & \\
\hline 12702 & 576521.62 & 149116.59 & \\
\hline 12703 & 576771.62 & 149116.59 & \\
\hline 12704 & 577021.62 & 149116.59 & \\
\hline 12705 & 577271.62 & 149116.59 & \\
\hline 12706 & 577521.62 & 149116.59 & \\
\hline 12707 & 577771.62 & 149116.59 & \\
\hline 12708 & 578021.62 & 149116.59 & \\
\hline 12709 & 578271.62 & 149116.59 & \\
\hline 12710 & 578521.62 & 149116.59 & \\
\hline 12711 & 578771.62 & 149116.59 & \\
\hline 12712 & 579015.19 & 142742.09 & \\
\hline 12713 & 579022.31 & 142639.56 & \\
\hline 12714 & 579017.31 & 142866.92 & \\
\hline 12715 & 579029.5 & 142537.03 & \\
\hline 12716 & 579019.5 & 142991.77 & \\
\hline 12717 & 579036.62 & 142434.5 & \\
\hline 12718 & 579021.62 & 143116.59 & \\
\hline 12719 & 579021.62 & 143366.59 & \\
\hline 12720 & 579021.62 & 143616.59 & \\
\hline 12721 & 579021.62 & 143866.59 & \\
\hline 12722 & 579021.62 & 144116.59 & \\
\hline 12723 & 579021.62 & 144366.59 & \\
\hline 12724 & 579021.62 & 144616.59 & \\
\hline 12725 & 579021.62 & 144866.59 & \\
\hline 12726 & 579021.62 & 145116.59 & \\
\hline 12727 & 579021.62 & 145366.59 & \\
\hline 12728 & 579021.62 & 145616.59 & \\
\hline 12729 & 579021.62 & 145866.59 & \\
\hline 12730 & 579021.62 & 146116.59 & \\
\hline 12731 & 579021.62 & 146366.59 & \\
\hline 12732 & 579021.62 & 146616.59 & \\
\hline 12733 & 579021.62 & 146866.59 & \\
\hline 12734 & 579021.62 & 147116.59 & \\
\hline 12735 & 579021.62 & 147366.59 & \\
\hline 12736 & 579021.62 & 147616.59 & \\
\hline 12737 & 579021.62 & 147866.59 & \\
\hline 12738 & 579021.62 & 148116.59 & \\
\hline
\end{tabular}




\begin{tabular}{|c|c|c|c|}
\hline node & X_coord & Y_coord & note: from sac04d created July 1, 2004 \\
\hline 12739 & $5 \overline{7} 9021.62$ & $1 \overline{4} 8366.59$ & \\
\hline 12740 & 579021.62 & 148616.59 & \\
\hline 12741 & 579021.62 & 148866.59 & \\
\hline 12742 & 579021.62 & 149116.59 & \\
\hline 12743 & 584007.88 & 139353.61 & \\
\hline 12744 & 584181 & 139406.97 & \\
\hline 12745 & 584354.06 & 139460.36 & \\
\hline 12746 & 584527.19 & 139513.73 & \\
\hline 12747 & 584692 & 139548.02 & \\
\hline 12748 & 584856.81 & 139582.3 & \\
\hline 12749 & 586521.62 & 137116.59 & \\
\hline 12750 & 586521.62 & 137366.59 & \\
\hline 12751 & 586521.62 & 137616.59 & \\
\hline 12752 & 586771.62 & 137116.59 & \\
\hline 12753 & 585827.38 & 137657.3 & \\
\hline 12754 & 586058.81 & 137727.06 & \\
\hline 12755 & 586290.19 & 137796.83 & \\
\hline 12756 & 586521.62 & 137866.59 & \\
\hline 12757 & 588521.62 & 135366.59 & \\
\hline 12758 & 588521.62 & 135616.59 & \\
\hline 12759 & 588521.62 & 135866.59 & \\
\hline 12760 & 588771.62 & 135366.59 & \\
\hline 12761 & 588521.62 & 136116.59 & \\
\hline 12762 & 589021.62 & 134366.59 & \\
\hline 12763 & 589021.62 & 134616.59 & \\
\hline 12764 & 589021.62 & 134866.59 & \\
\hline 12765 & 589271.62 & 134366.59 & \\
\hline 12766 & 589021.62 & 135116.59 & \\
\hline 12767 & 589521.62 & 133366.59 & \\
\hline 12768 & 589521.62 & 133616.59 & \\
\hline 12769 & 589521.62 & 133866.59 & \\
\hline 12770 & 589771.62 & 133366.59 & \\
\hline 12771 & 589521.62 & 134116.59 & \\
\hline 12772 & 590021.62 & 132366.59 & \\
\hline 12773 & 590021.62 & 132616.59 & \\
\hline 12774 & 590021.62 & 132866.59 & \\
\hline 12775 & 590271.62 & 132366.59 & \\
\hline 12776 & 590021.62 & 133116.59 & \\
\hline 12777 & 590521.62 & 131366.59 & \\
\hline 12778 & 590521.62 & 131616.59 & \\
\hline 12779 & 590521.62 & 131866.59 & \\
\hline 12780 & 590771.62 & 131366.59 & \\
\hline 12781 & 590521.62 & 132116.59 & \\
\hline 12782 & 591021.62 & 129616.6 & \\
\hline 12783 & 591021.62 & 129866.6 & \\
\hline 12784 & 591021.62 & 130116.6 & \\
\hline 12785 & 591021.62 & 130366.6 & \\
\hline 12786 & 591021.62 & 130616.6 & \\
\hline 12787 & 591021.62 & 130866.59 & \\
\hline 12788 & 591021.62 & 131116.59 & \\
\hline 12789 & 591271.62 & 129616.6 & \\
\hline 12790 & 591021.62 & 131366.59 & \\
\hline 12791 & 590521.62 & 132366.59 & \\
\hline 12792 & 590021.62 & 133366.59 & \\
\hline 12793 & 589521.62 & 134366.59 & \\
\hline 12794 & 589021.62 & 135366.59 & \\
\hline
\end{tabular}




\begin{tabular}{|c|c|c|c|}
\hline node & X_coord & Y_coord & note: from sac04d created July 1, 2004 \\
\hline 12795 & $5 \overline{8} 7521.62$ & $1 \overline{3} 6866.59$ & \\
\hline 12796 & 587771.62 & 136866.59 & \\
\hline 12797 & 588021.62 & 136366.59 & \\
\hline 12798 & 588271.62 & 136366.59 & \\
\hline 12799 & 588021.62 & 136616.59 & \\
\hline 12800 & 588521.62 & 136366.59 & \\
\hline 12801 & 588021.62 & 136866.59 & \\
\hline 12802 & 591521.62 & 128616.6 & \\
\hline 12803 & 591521.62 & 128866.6 & \\
\hline 12804 & 591521.62 & 129116.6 & \\
\hline 12805 & 591771.62 & 128616.6 & \\
\hline 12806 & 591521.62 & 129366.6 & \\
\hline 12807 & 592021.62 & 127616.6 & \\
\hline 12808 & 592021.62 & 127866.6 & \\
\hline 12809 & 592021.62 & 128116.6 & \\
\hline 12810 & 592271.62 & 127616.6 & \\
\hline 12811 & 592021.62 & 128366.6 & \\
\hline 12812 & 592521.62 & 126616.6 & \\
\hline 12813 & 592521.62 & 126866.6 & \\
\hline 12814 & 592521.62 & 127116.6 & \\
\hline 12815 & 592771.62 & 126616.6 & \\
\hline 12816 & 592521.62 & 127366.6 & \\
\hline 12817 & 593021.62 & 125616.6 & \\
\hline 12818 & 593021.62 & 125866.6 & \\
\hline 12819 & 593021.62 & 126116.6 & \\
\hline 12820 & 593271.62 & 125616.6 & \\
\hline 12821 & 593021.62 & 126366.6 & \\
\hline 12822 & 593521.62 & 123866.6 & \\
\hline 12823 & 593521.62 & 124116.6 & \\
\hline 12824 & 593521.62 & 124366.6 & \\
\hline 12825 & 593521.62 & 124616.6 & \\
\hline 12826 & 593521.62 & 124866.6 & \\
\hline 12827 & 593521.62 & 125116.6 & \\
\hline 12828 & 593521.62 & 125366.6 & \\
\hline 12829 & 593771.62 & 123866.6 & \\
\hline 12830 & 593521.62 & 125616.6 & \\
\hline 12831 & 593021.62 & 126616.6 & \\
\hline 12832 & 592521.62 & 127616.6 & \\
\hline 12833 & 592021.62 & 128616.6 & \\
\hline 12834 & 591521.62 & 129616.6 & \\
\hline 12835 & 587021.62 & 137116.59 & \\
\hline 12836 & 587271.62 & 137116.59 & \\
\hline 12837 & 587521.62 & 137116.59 & \\
\hline 12838 & 594021.62 & 122866.6 & \\
\hline 12839 & 594021.62 & 123116.6 & \\
\hline 12840 & 594021.62 & 123366.6 & \\
\hline 12841 & 594167.31 & 122869.44 & \\
\hline 12842 & 594021.62 & 123616.6 & \\
\hline 12843 & 594350.31 & 121860.02 & \\
\hline 12844 & 594336.94 & 122109.06 & \\
\hline 12845 & 594328.94 & 122363.46 & \\
\hline 12846 & 594509.2535 & 121974.5204 & \\
\hline 12847 & 594320.94 & 122617.87 & \\
\hline 12848 & 595040.12 & 120817.53 & \\
\hline 12849 & 595081 & 121081.07 & \\
\hline 12850 & 595121.81 & 121344.6 & \\
\hline
\end{tabular}




\begin{tabular}{|c|c|c|c|}
\hline node & X_coord & Y_coord & note: from sac04d created July 1, 2004 \\
\hline 12851 & $5 \overline{9} 5161.31$ & $1 \overline{2} 1608.3$ & \\
\hline 12852 & 595200.88 & 121872 & \\
\hline 12853 & 594312.94 & 122872.27 & \\
\hline 12854 & 594021.62 & 123866.6 & \\
\hline 12855 & 585021.62 & 139616.59 & \\
\hline 12856 & 585258.56 & 139615.97 & \\
\hline 12857 & 585569.62 & 137871.59 & \\
\hline 12858 & 585553.62 & 138119.92 & \\
\hline 12859 & 585537.62 & 138368.27 & \\
\hline 12860 & 585521.62 & 138616.59 & \\
\hline 12861 & 585521.62 & 138866.59 & \\
\hline 12862 & 585521.62 & 139116.59 & \\
\hline 12863 & 585521.62 & 139366.59 & \\
\hline 12864 & 585495.56 & 139615.33 & \\
\hline 12865 & 572521.62 & 149366.59 & \\
\hline 12866 & 572521.62 & 149616.59 & \\
\hline 12867 & 572521.62 & 149866.59 & \\
\hline 12868 & 572521.62 & 150116.59 & \\
\hline 12869 & 572521.62 & 150366.59 & \\
\hline 12870 & 572521.62 & 150616.59 & \\
\hline 12871 & 571782.25 & 150562.2186 & \\
\hline 12872 & 571571.88 & 150697.86 & \\
\hline 12873 & 571970.92 & 150604.3929 & \\
\hline 12874 & 572215.9358 & 150690.8713 & \\
\hline 12875 & 572345.956 & 150754.8016 & \\
\hline 12876 & 572536.69 & 150835.02 & \\
\hline 12877 & 572771.62 & 149366.59 & \\
\hline 12878 & 573021.62 & 149366.59 & \\
\hline 12879 & 573271.62 & 149366.59 & \\
\hline 12880 & 573521.62 & 149366.59 & \\
\hline 12881 & 573771.62 & 149366.59 & \\
\hline 12882 & 574021.62 & 149366.59 & \\
\hline 12883 & 574271.62 & 149366.59 & \\
\hline 12884 & 574521.62 & 149366.59 & \\
\hline 12885 & 574771.62 & 149366.59 & \\
\hline 12886 & 575021.62 & 149366.59 & \\
\hline 12887 & 575271.62 & 149366.59 & \\
\hline 12888 & 575521.62 & 149366.59 & \\
\hline 12889 & 575771.62 & 149366.59 & \\
\hline 12890 & 576021.62 & 149366.59 & \\
\hline 12891 & 576271.62 & 149366.59 & \\
\hline 12892 & 576521.62 & 149366.59 & \\
\hline 12893 & 576771.62 & 149366.59 & \\
\hline 12894 & 577021.62 & 149366.59 & \\
\hline 12895 & 577271.62 & 149366.59 & \\
\hline 12896 & 577521.62 & 149366.59 & \\
\hline 12897 & 577771.62 & 149366.59 & \\
\hline 12898 & 578021.62 & 149366.59 & \\
\hline 12899 & 578271.62 & 149366.59 & \\
\hline 12900 & 578494.12 & 149366.47 & \\
\hline 12901 & 578716.69 & 149366.33 & \\
\hline 12902 & 578939.19 & 149366.2 & \\
\hline 12903 & 579271.31 & 142667.23 & \\
\hline 12904 & 579276.06 & 142559.36 & \\
\hline 12905 & 579271.44 & 142817.02 & \\
\hline 12906 & 579280.81 & 142451.47 & \\
\hline
\end{tabular}




\begin{tabular}{|c|c|c|c|}
\hline node & X_coord & Y_coord & note: from sac04d created July 1,2004 \\
\hline 12907 & $5 \overline{7} 9271.5$ & $1 \overline{4} 2966.81$ & \\
\hline 12908 & 579285.56 & 142343.59 & \\
\hline 12909 & 579271.62 & 143116.59 & \\
\hline 12910 & 579271.62 & 143366.59 & \\
\hline 12911 & 579271.62 & 143616.59 & \\
\hline 12912 & 579271.62 & 143866.59 & \\
\hline 12913 & 579271.62 & 144116.59 & \\
\hline 12914 & 579271.62 & 144366.59 & \\
\hline 12915 & 579271.62 & 144616.59 & \\
\hline 12916 & 579271.62 & 144866.59 & \\
\hline 12917 & 579271.62 & 145116.59 & \\
\hline 12918 & 579271.62 & 145366.59 & \\
\hline 12919 & 579271.62 & 145616.59 & \\
\hline 12920 & 579271.62 & 145866.59 & \\
\hline 12921 & 579271.62 & 146116.59 & \\
\hline 12922 & 579271.62 & 146366.59 & \\
\hline 12923 & 579271.62 & 146616.59 & \\
\hline 12924 & 579271.62 & 146866.59 & \\
\hline 12925 & 579271.62 & 147116.59 & \\
\hline 12926 & 579271.62 & 147366.59 & \\
\hline 12927 & 579271.62 & 147616.59 & \\
\hline 12928 & 579271.62 & 147866.59 & \\
\hline 12929 & 579271.62 & 148116.59 & \\
\hline 12930 & 579271.62 & 148366.59 & \\
\hline 12931 & 579271.62 & 148616.59 & \\
\hline 12932 & 579271.62 & 148866.59 & \\
\hline 12933 & 579271.62 & 149116.59 & \\
\hline 12934 & 579176.69 & 149366.2 & \\
\hline 12935 & 583733.31 & 139545.5 & \\
\hline 12936 & 583955.38 & 139635.39 & \\
\hline 12937 & 584177.38 & 139725.28 & \\
\hline 12938 & 584399.44 & 139815.16 & \\
\hline 12939 & 584606.81 & 139832.31 & \\
\hline 12940 & 584814.25 & 139849.45 & \\
\hline 12941 & 585021.62 & 139866.59 & \\
\hline 12942 & 586771.62 & 137366.59 & \\
\hline 12943 & 586771.62 & 137616.59 & \\
\hline 12944 & 586771.62 & 137866.59 & \\
\hline 12945 & 587021.62 & 137366.59 & \\
\hline 12946 & 585808.81 & 137977.06 & \\
\hline 12947 & 586046.44 & 138023.58 & \\
\hline 12948 & 586284 & 138070.08 & \\
\hline 12949 & 586521.62 & 138116.59 & \\
\hline 12950 & 586773.69 & 138128.94 & \\
\hline 12951 & 588771.62 & 135616.59 & \\
\hline 12952 & 588771.62 & 135866.59 & \\
\hline 12953 & 588771.62 & 136116.59 & \\
\hline 12954 & 589021.62 & 135616.59 & \\
\hline 12955 & 588771.62 & 136366.59 & \\
\hline 12956 & 589271.62 & 134616.59 & \\
\hline 12957 & 589271.62 & 134866.59 & \\
\hline 12958 & 589271.62 & 135116.59 & \\
\hline 12959 & 589521.62 & 134616.59 & \\
\hline 12960 & 589271.62 & 135366.59 & \\
\hline 12961 & 589771.62 & 133616.59 & \\
\hline 12962 & 589771.62 & 133866.59 & \\
\hline
\end{tabular}




\begin{tabular}{|c|c|c|c|}
\hline node & X_coord & Y_coord & note: from sac04d created July 1, 2004 \\
\hline 12963 & 589771.62 & 134116.59 & \\
\hline 12964 & 590021.62 & 133616.59 & \\
\hline 12965 & 589771.62 & 134366.59 & \\
\hline 12966 & 590271.62 & 132616.59 & \\
\hline 12967 & 590271.62 & 132866.59 & \\
\hline 12968 & 590271.62 & 133116.59 & \\
\hline 12969 & 590521.62 & 132616.59 & \\
\hline 12970 & 590271.62 & 133366.59 & \\
\hline 12971 & 590771.62 & 131616.59 & \\
\hline 12972 & 590771.62 & 131866.59 & \\
\hline 12973 & 590771.62 & 132116.59 & \\
\hline 12974 & 591021.62 & 131616.59 & \\
\hline 12975 & 590771.62 & 132366.59 & \\
\hline 12976 & 591271.62 & 129866.6 & \\
\hline 12977 & 591271.62 & 130116.6 & \\
\hline 12978 & 591271.62 & 130366.6 & \\
\hline 12979 & 591271.62 & 130616.6 & \\
\hline 12980 & 591271.62 & 130866.59 & \\
\hline 12981 & 591271.62 & 131116.59 & \\
\hline 12982 & 591271.62 & 131366.59 & \\
\hline 12983 & 591521.62 & 129866.6 & \\
\hline 12984 & 591271.62 & 131616.59 & \\
\hline 12985 & 590771.62 & 132616.59 & \\
\hline 12986 & 590271.62 & 133616.59 & \\
\hline 12987 & 589771.62 & 134616.59 & \\
\hline 12988 & 589271.62 & 135616.59 & \\
\hline 12989 & 587771.62 & 137116.59 & \\
\hline 12990 & 588021.62 & 137116.59 & \\
\hline 12991 & 588271.62 & 136616.59 & \\
\hline 12992 & 588521.62 & 136616.59 & \\
\hline 12993 & 588271.62 & 136866.59 & \\
\hline 12994 & 588771.62 & 136616.59 & \\
\hline 12995 & 588271.62 & 137116.59 & \\
\hline 12996 & 591771.62 & 128866.6 & \\
\hline 12997 & 591771.62 & 129116.6 & \\
\hline 12998 & 591771.62 & 129366.6 & \\
\hline 12999 & 592021.62 & 128866.6 & \\
\hline 13000 & 591771.62 & 129616.6 & \\
\hline 13001 & 592271.62 & 127866.6 & \\
\hline 13002 & 592271.62 & 128116.6 & \\
\hline 13003 & 592271.62 & 128366.6 & \\
\hline 13004 & 592521.62 & 127866.6 & \\
\hline 13005 & 592271.62 & 128616.6 & \\
\hline 13006 & 592771.62 & 126866.6 & \\
\hline 13007 & 592771.62 & 127116.6 & \\
\hline 13008 & 592771.62 & 127366.6 & \\
\hline 13009 & 593021.62 & 126866.6 & \\
\hline 13010 & 592771.62 & 127616.6 & \\
\hline 13011 & 593271.62 & 125866.6 & \\
\hline 13012 & 593271.62 & 126116.6 & \\
\hline 13013 & 593271.62 & 126366.6 & \\
\hline 13014 & 593521.62 & 125866.6 & \\
\hline 13015 & 593271.62 & 126616.6 & \\
\hline 13016 & 593771.62 & 124116.6 & \\
\hline 13017 & 593771.62 & 124366.6 & \\
\hline 13018 & 593771.62 & 124616.6 & \\
\hline
\end{tabular}




\begin{tabular}{|c|c|c|}
\hline node & X_coord & Y_coord \\
\hline 13019 & 593771.62 & 124866.6 \\
\hline 13020 & 593771.62 & 125116.6 \\
\hline 13021 & 593771.62 & 125366.6 \\
\hline 13022 & 593771.62 & 125616.6 \\
\hline 13023 & 594021.62 & 124116.6 \\
\hline 13024 & 593771.62 & 125866.6 \\
\hline 13025 & 593271.62 & 126866.6 \\
\hline 13026 & 592771.62 & 127866.6 \\
\hline 13027 & 592271.62 & 128866.6 \\
\hline 13028 & 591771.62 & 129866.6 \\
\hline 13029 & 587271.62 & 137366.59 \\
\hline 13030 & 587539.25 & 137392.78 \\
\hline 13031 & 587806.88 & 137418.97 \\
\hline 13032 & 594168.62 & 123119.62 \\
\hline 13033 & 594170 & 123369.81 \\
\hline 13034 & 594171.31 & 123620 \\
\hline 13035 & 594315.62 & 123122.64 \\
\hline 13036 & 594172.62 & 123868.19 \\
\hline 13037 & 594494.62 & 122203.1567 \\
\hline 13038 & 594486.2443 & 122378.2094 \\
\hline 13039 & 594468.8078 & 122575.0082 \\
\hline 13040 & 595240.38 & 122135.7 \\
\hline 13041 & 594458.62 & 122798.9893 \\
\hline 13042 & 594455.3714 & 123074.9195 \\
\hline 13043 & 594174 & 124116.38 \\
\hline 13044 & 585245.56 & 139865.33 \\
\hline 13045 & 585469.5 & 139864.06 \\
\hline 13046 & 585790.19 & 138296.83 \\
\hline 13047 & 585771.62 & 138616.59 \\
\hline 13048 & 585771.62 & 138866.59 \\
\hline 13049 & 585771.62 & 139116.59 \\
\hline 13050 & 585771.62 & 139366.59 \\
\hline 13051 & 585732.5 & 139614.7 \\
\hline 13052 & 585693.44 & 139862.8 \\
\hline 13053 & 572771.62 & 149616.59 \\
\hline 13054 & 572771.62 & 149866.59 \\
\hline 13055 & 572771.62 & 150116.59 \\
\hline 13056 & 572771.62 & 150366.59 \\
\hline 13057 & 572771.62 & 150616.59 \\
\hline 13058 & 572779.19 & 150850.81 \\
\hline 13059 & 571890.185 & 150729.3445 \\
\hline 13060 & 571682.25 & 150864.64 \\
\hline 13062 & 572262.3802 & 150953.2744 \\
\hline 13063 & 572381.3084 & 151029.5914 \\
\hline 13064 & 572551.81 & 151053.44 \\
\hline 13065 & 572786.69 & 151085.02 \\
\hline 13066 & 573021.62 & 149616.59 \\
\hline 13067 & 573271.62 & 149616.59 \\
\hline 13068 & 573521.62 & 149616.59 \\
\hline 13069 & 573771.62 & 149616.59 \\
\hline 13070 & 574021.62 & 149616.59 \\
\hline 13071 & 574271.62 & 149616.59 \\
\hline 13072 & 574521.62 & 149616.59 \\
\hline 13073 & 574771.62 & 149616.59 \\
\hline 13074 & 575021.62 & 149616.59 \\
\hline 13075 & 575271.62 & 149616.59 \\
\hline
\end{tabular}

note: from sac04d created July 1, 2004 


\begin{tabular}{|c|c|c|c|}
\hline node & X_coord & Y_coord & note: from sac04d created July 1,2004 \\
\hline 13076 & $5 \overline{7} 5521.62$ & $1 \overline{49616.59}$ & \\
\hline 13077 & 575771.62 & 149616.59 & \\
\hline 13078 & 576021.62 & 149616.59 & \\
\hline 13079 & 576271.62 & 149616.59 & \\
\hline 13080 & 576521.62 & 149616.59 & \\
\hline 13081 & 576771.62 & 149616.59 & \\
\hline 13082 & 577021.62 & 149616.59 & \\
\hline 13083 & 577271.62 & 149616.59 & \\
\hline 13084 & 577521.62 & 149616.59 & \\
\hline 13085 & 577771.62 & 149616.59 & \\
\hline 13086 & 578021.62 & 149616.59 & \\
\hline 13087 & 578271.62 & 149616.59 & \\
\hline 13088 & 578466.69 & 149616.33 & \\
\hline 13089 & 578661.75 & 149616.06 & \\
\hline 13090 & 578856.81 & 149615.8 & \\
\hline 13091 & 579081.81 & 149615.8 & \\
\hline 13092 & 579527.38 & 142592.36 & \\
\hline 13093 & 579529.75 & 142479.14 & \\
\hline 13094 & 579525.44 & 142767.11 & \\
\hline 13095 & 579532.19 & 142365.92 & \\
\hline 13096 & 579523.56 & 142941.84 & \\
\hline 13097 & 579534.56 & 142252.7 & \\
\hline 13098 & 579521.62 & 143116.59 & \\
\hline 13099 & 579521.62 & 143366.59 & \\
\hline 13100 & 579521.62 & 143616.59 & \\
\hline 13101 & 579521.62 & 143866.59 & \\
\hline 13102 & 579521.62 & 144116.59 & \\
\hline 13103 & 579521.62 & 144366.59 & \\
\hline 13104 & 579521.62 & 144616.59 & \\
\hline 13105 & 579521.62 & 144866.59 & \\
\hline 13106 & 579521.62 & 145116.59 & \\
\hline 13107 & 579521.62 & 145366.59 & \\
\hline 13108 & 579521.62 & 145616.59 & \\
\hline 13109 & 579521.62 & 145866.59 & \\
\hline 13110 & 579521.62 & 146116.59 & \\
\hline 13111 & 579521.62 & 146366.59 & \\
\hline 13112 & 579521.62 & 146616.59 & \\
\hline 13113 & 579521.62 & 146866.59 & \\
\hline 13114 & 579521.62 & 147116.59 & \\
\hline 13115 & 579521.62 & 147366.59 & \\
\hline 13116 & 579521.62 & 147616.59 & \\
\hline 13117 & 579521.62 & 147866.59 & \\
\hline 13118 & 579521.62 & 148116.59 & \\
\hline 13119 & 579521.62 & 148366.59 & \\
\hline 13120 & 579521.62 & 148616.59 & \\
\hline 13121 & 579521.62 & 148866.59 & \\
\hline 13122 & 579521.62 & 149116.59 & \\
\hline 13123 & 579414.19 & 149366.2 & \\
\hline 13124 & 579306.81 & 149615.8 & \\
\hline 13125 & 583458.69 & 139737.41 & \\
\hline 13126 & 583729.69 & 139863.8 & \\
\hline 13127 & 584000.62 & 139990.2 & \\
\hline 13128 & 584271.62 & 140116.59 & \\
\hline 13129 & 584521.62 & 140116.59 & \\
\hline 13130 & 584771.62 & 140116.59 & \\
\hline 13131 & 585021.62 & 140116.59 & \\
\hline
\end{tabular}




\begin{tabular}{|c|c|c|c|}
\hline node & X_coord & Y_coord & note: from sac04d created July 1, 2004 \\
\hline 13132 & $5 \overline{8} 5232.5$ & $1 \overline{4} 0114.7$ & \\
\hline 13133 & 587021.62 & 137616.59 & \\
\hline 13134 & 587021.62 & 137866.59 & \\
\hline 13135 & 587025.69 & 138141.28 & \\
\hline 13136 & 587271.62 & 137616.59 & \\
\hline 13137 & 586034 & 138320.08 & \\
\hline 13138 & 586277.81 & 138343.34 & \\
\hline 13139 & 586521.62 & 138366.59 & \\
\hline 13140 & 586775.69 & 138391.28 & \\
\hline 13141 & 587029.81 & 138415.98 & \\
\hline 13142 & 589021.62 & 135866.59 & \\
\hline 13143 & 589021.62 & 136116.59 & \\
\hline 13144 & 589021.62 & 136366.59 & \\
\hline 13145 & 589271.62 & 135866.59 & \\
\hline 13146 & 589036.94 & 136625.2 & \\
\hline 13147 & 589521.62 & 134866.59 & \\
\hline 13148 & 589521.62 & 135116.59 & \\
\hline 13149 & 589521.62 & 135366.59 & \\
\hline 13150 & 589771.62 & 134866.59 & \\
\hline 13151 & 589521.62 & 135616.59 & \\
\hline 13152 & 590021.62 & 133866.59 & \\
\hline 13153 & 590021.62 & 134116.59 & \\
\hline 13154 & 590021.62 & 134366.59 & \\
\hline 13155 & 590271.62 & 133866.59 & \\
\hline 13156 & 590021.62 & 134616.59 & \\
\hline 13157 & 590521.62 & 132866.59 & \\
\hline 13158 & 590521.62 & 133116.59 & \\
\hline 13159 & 590521.62 & 133366.59 & \\
\hline 13160 & 590771.62 & 132866.59 & \\
\hline 13161 & 590521.62 & 133616.59 & \\
\hline 13162 & 591021.62 & 131866.59 & \\
\hline 13163 & 591021.62 & 132116.59 & \\
\hline 13164 & 591021.62 & 132366.59 & \\
\hline 13165 & 591271.62 & 131866.59 & \\
\hline 13166 & 591021.62 & 132616.59 & \\
\hline 13167 & 591521.62 & 130116.6 & \\
\hline 13168 & 591521.62 & 130366.6 & \\
\hline 13169 & 591521.62 & 130616.6 & \\
\hline 13170 & 591521.62 & 130866.59 & \\
\hline 13171 & 591521.62 & 131116.59 & \\
\hline 13172 & 591521.62 & 131366.59 & \\
\hline 13173 & 591521.62 & 131616.59 & \\
\hline 13174 & 591771.62 & 130116.6 & \\
\hline 13175 & 591521.62 & 131866.59 & \\
\hline 13176 & 591021.62 & 132866.59 & \\
\hline 13177 & 590521.62 & 133866.59 & \\
\hline 13178 & 590021.62 & 134866.59 & \\
\hline 13179 & 589521.62 & 135866.59 & \\
\hline 13180 & 588074.44 & 137445.16 & \\
\hline 13181 & 588295.94 & 137413.08 & \\
\hline 13182 & 588521.62 & 136866.59 & \\
\hline 13183 & 588771.62 & 136866.59 & \\
\hline 13184 & 588521.62 & 137116.59 & \\
\hline 13185 & 589052.25 & 136883.81 & \\
\hline 13186 & 588517.38 & 137381 & \\
\hline 13187 & 592021.62 & 129116.6 & \\
\hline
\end{tabular}




\begin{tabular}{|c|c|c|c|}
\hline node & X_coord & Y_coord & note: from sac04d created July 1, 2004 \\
\hline 13188 & $5 \overline{9} 2021.62$ & $1 \overline{2} 9366.6$ & \\
\hline 13189 & 592021.62 & 129616.6 & \\
\hline 13190 & 592271.62 & 129116.6 & \\
\hline 13191 & 592021.62 & 129866.6 & \\
\hline 13192 & 592521.62 & 128116.6 & \\
\hline 13193 & 592521.62 & 128366.6 & \\
\hline 13194 & 592521.62 & 128616.6 & \\
\hline 13195 & 592771.62 & 128116.6 & \\
\hline 13196 & 592521.62 & 128866.6 & \\
\hline 13197 & 593021.62 & 127116.6 & \\
\hline 13198 & 593021.62 & 127366.6 & \\
\hline 13199 & 593021.62 & 127616.6 & \\
\hline 13200 & 593271.62 & 127116.6 & \\
\hline 13201 & 593021.62 & 127866.6 & \\
\hline 13202 & 593521.62 & 126116.6 & \\
\hline 13203 & 593521.62 & 126366.6 & \\
\hline 13204 & 593521.62 & 126616.6 & \\
\hline 13205 & 593771.62 & 126116.6 & \\
\hline 13206 & 593521.62 & 126866.6 & \\
\hline 13207 & 594021.62 & 124366.6 & \\
\hline 13208 & 594021.62 & 124616.6 & \\
\hline 13209 & 594021.62 & 124866.6 & \\
\hline 13210 & 594021.62 & 125116.6 & \\
\hline 13211 & 594021.62 & 125366.6 & \\
\hline 13212 & 594021.62 & 125616.6 & \\
\hline 13213 & 594021.62 & 125866.6 & \\
\hline 13214 & 594175.31 & 124364.57 & \\
\hline 13215 & 594021.62 & 126116.6 & \\
\hline 13216 & 593521.62 & 127116.6 & \\
\hline 13217 & 593021.62 & 128116.6 & \\
\hline 13218 & 592521.62 & 129116.6 & \\
\hline 13219 & 592021.62 & 130116.6 & \\
\hline 13220 & 587556.81 & 137668.97 & \\
\hline 13221 & 587842.06 & 137721.36 & \\
\hline 13222 & 588127.31 & 137773.73 & \\
\hline 13223 & 594318.25 & 123373.02 & \\
\hline 13224 & 594320.94 & 123623.4 & \\
\hline 13225 & 594323.62 & 123869.77 & \\
\hline 13226 & 594464.8078 & 123350.8598 & \\
\hline 13227 & 594326.25 & 124116.16 & \\
\hline 13228 & 595259.16 & 122368.3 & \\
\hline 13229 & 595257.3428 & 122598.3229 & \\
\hline 13230 & 595242.62 & 122833.5 & \\
\hline 13231 & 595231.88 & 123099.93 & \\
\hline 13232 & 595221.12 & 123366.37 & \\
\hline 13233 & 594328.94 & 124362.53 & \\
\hline 13234 & 585443.44 & 140112.8 & \\
\hline 13235 & 585679.6802 & 140101.8492 & \\
\hline 13236 & 586021.62 & 138616.59 & \\
\hline 13237 & 586021.62 & 138866.59 & \\
\hline 13238 & 586021.62 & 139116.59 & \\
\hline 13239 & 586021.62 & 139366.59 & \\
\hline 13240 & 585928.6862 & 139540.0825 & \\
\hline 13241 & 585837.5646 & 139798.7465 & \\
\hline 13242 & 585833.4267 & 139986.7362 & \\
\hline 13243 & 573021.62 & 149866.59 & \\
\hline
\end{tabular}




\begin{tabular}{|c|c|c|c|}
\hline node & X_coord & Y_coord & note: from sac04d created July 1, 2004 \\
\hline 13244 & $5 \overline{7} 3021.62$ & $1 \overline{50} 0116.59$ & \\
\hline 13245 & 573021.62 & 150366.59 & \\
\hline 13246 & 573021.62 & 150616.59 & \\
\hline 13247 & 573021.62 & 150866.59 & \\
\hline 13248 & 573021.62 & 151116.59 & \\
\hline 13249 & 572010.3008 & 150881.7825 & \\
\hline 13250 & 571792.62 & 151031.41 & \\
\hline 13251 & 572109.0616 & 151017.3402 & \\
\hline 13252 & 572215.1311 & 151156.7945 & \\
\hline 13253 & 572314.4936 & 151264.2859 & \\
\hline 13254 & 572566.88 & 151233.2029 & \\
\hline 13255 & 572848.3699 & 151326.9614 & \\
\hline 13256 & 573021.62 & 151366.59 & \\
\hline 13257 & 573271.62 & 149866.59 & \\
\hline 13258 & 573521.62 & 149866.59 & \\
\hline 13259 & 573771.62 & 149866.59 & \\
\hline 13260 & 574021.62 & 149866.59 & \\
\hline 13261 & 574271.62 & 149866.59 & \\
\hline 13262 & 574521.62 & 149866.59 & \\
\hline 13263 & 574771.62 & 149866.59 & \\
\hline 13264 & 575021.62 & 149866.59 & \\
\hline 13265 & 575271.62 & 149866.59 & \\
\hline 13266 & 575521.62 & 149866.59 & \\
\hline 13267 & 575771.62 & 149866.59 & \\
\hline 13268 & 576021.62 & 149866.59 & \\
\hline 13269 & 576271.62 & 149866.59 & \\
\hline 13270 & 576521.62 & 149866.59 & \\
\hline 13271 & 576771.62 & 149866.59 & \\
\hline 13272 & 577021.62 & 149866.59 & \\
\hline 13273 & 577271.62 & 149866.59 & \\
\hline 13274 & 577521.62 & 149866.59 & \\
\hline 13275 & 577771.62 & 149866.59 & \\
\hline 13276 & 578021.62 & 149866.59 & \\
\hline 13277 & 578271.62 & 149866.59 & \\
\hline 13278 & 578439.19 & 149866.2 & \\
\hline 13279 & 578606.81 & 149865.8 & \\
\hline 13280 & 578774.38 & 149865.41 & \\
\hline 13281 & 578986.88 & 149865.41 & \\
\hline 13282 & 579199.38 & 149865.41 & \\
\hline 13283 & 579783.5 & 142517.5 & \\
\hline 13284 & 579783.5 & 142398.94 & \\
\hline 13285 & 579779.56 & 142717.2 & \\
\hline 13286 & 579783.5 & 142280.36 & \\
\hline 13287 & 579775.56 & 142916.89 & \\
\hline 13288 & 579783.5 & 142161.8 & \\
\hline 13289 & 579771.62 & 143116.59 & \\
\hline 13290 & 579771.62 & 143366.59 & \\
\hline 13291 & 579771.62 & 143616.59 & \\
\hline 13292 & 579771.62 & 143866.59 & \\
\hline 13293 & 579771.62 & 144116.59 & \\
\hline 13294 & 579771.62 & 144366.59 & \\
\hline 13295 & 579771.62 & 144616.59 & \\
\hline 13296 & 579771.62 & 144866.59 & \\
\hline 13297 & 579771.62 & 145116.59 & \\
\hline 13298 & 579771.62 & 145366.59 & \\
\hline 13299 & 579771.62 & 145616.59 & \\
\hline
\end{tabular}




\begin{tabular}{|c|c|c|c|}
\hline node & X_coord & Y_coord & note: from sac04d created July 1, 2004 \\
\hline 13300 & $5 \overline{7} 9771.62$ & $1 \overline{4} 5866.59$ & \\
\hline 13301 & 579771.62 & 146116.59 & \\
\hline 13302 & 579771.62 & 146366.59 & \\
\hline 13303 & 579771.62 & 146616.59 & \\
\hline 13304 & 579771.62 & 146866.59 & \\
\hline 13305 & 579771.62 & 147116.59 & \\
\hline 13306 & 579771.62 & 147366.59 & \\
\hline 13307 & 579771.62 & 147616.59 & \\
\hline 13308 & 579771.62 & 147866.59 & \\
\hline 13309 & 579771.62 & 148116.59 & \\
\hline 13310 & 579771.62 & 148366.59 & \\
\hline 13311 & 579761.3115 & 148593.3958 & \\
\hline 13312 & 579758.7343 & 148840.8186 & \\
\hline 13313 & 579771.62 & 149116.59 & \\
\hline 13314 & 579633.5684 & 149409.6918 & \\
\hline 13315 & 579472.0087 & 149807.889 & \\
\hline 13316 & 579323.0842 & 150229.6542 & \\
\hline 13317 & 583479.69 & 140113.8 & \\
\hline 13318 & 583284.81 & 139907.34 & \\
\hline 13319 & 583264.56 & 140205.69 & \\
\hline 13320 & 583743.69 & 140198.06 & \\
\hline 13321 & 584007.62 & 140282.33 & \\
\hline 13322 & 584271.62 & 140366.59 & \\
\hline 13323 & 584515.75 & 140360.14 & \\
\hline 13324 & 584759.88 & 140353.69 & \\
\hline 13325 & 585004 & 140347.23 & \\
\hline 13326 & 585144.3203 & 140264.0074 & \\
\hline 13327 & 585400.6789 & 140220.6722 & \\
\hline 13328 & 587271.62 & 137866.59 & \\
\hline 13329 & 587277.75 & 138153.62 & \\
\hline 13330 & 587283.88 & 138440.67 & \\
\hline 13331 & 587574.44 & 137945.16 & \\
\hline 13332 & 586271.62 & 138616.59 & \\
\hline 13333 & 586521.62 & 138616.59 & \\
\hline 13334 & 586777.75 & 138653.62 & \\
\hline 13335 & 587033.88 & 138690.67 & \\
\hline 13336 & 587312.5925 & 138775.3362 & \\
\hline 13337 & 589271.62 & 136116.59 & \\
\hline 13338 & 589271.62 & 136366.59 & \\
\hline 13339 & 589302.25 & 136633.81 & \\
\hline 13340 & 589521.62 & 136116.59 & \\
\hline 13341 & 589332.94 & 136901.05 & \\
\hline 13342 & 589771.62 & 135116.59 & \\
\hline 13343 & 589771.62 & 135366.59 & \\
\hline 13344 & 589771.62 & 135616.59 & \\
\hline 13345 & 590021.62 & 135116.59 & \\
\hline 13346 & 589786.44 & 135869 & \\
\hline 13347 & 590271.62 & 134116.59 & \\
\hline 13348 & 590271.62 & 134366.59 & \\
\hline 13349 & 590271.62 & 134616.59 & \\
\hline 13350 & 590521.62 & 134116.59 & \\
\hline 13351 & 590271.62 & 134866.59 & \\
\hline 13352 & 590771.62 & 133116.59 & \\
\hline 13353 & 590771.62 & 133366.59 & \\
\hline 13354 & 590771.62 & 133616.59 & \\
\hline 13355 & 591021.62 & 133116.59 & \\
\hline
\end{tabular}




\begin{tabular}{|c|c|c|c|}
\hline node & X_coord & Y_coord & note: from sac04d created July 1, 2004 \\
\hline 13356 & $5 \overline{9} 0771.62$ & $1 \overline{3} 3866.59$ & \\
\hline 13357 & 591271.62 & 132116.59 & \\
\hline 13358 & 591271.62 & 132366.59 & \\
\hline 13359 & 591271.62 & 132616.59 & \\
\hline 13360 & 591521.62 & 132116.59 & \\
\hline 13361 & 591271.62 & 132866.59 & \\
\hline 13362 & 591771.62 & 130366.6 & \\
\hline 13363 & 591771.62 & 130616.6 & \\
\hline 13364 & 591771.62 & 130866.59 & \\
\hline 13365 & 591771.62 & 131116.59 & \\
\hline 13366 & 591771.62 & 131366.59 & \\
\hline 13367 & 591771.62 & 131616.59 & \\
\hline 13368 & 591771.62 & 131866.59 & \\
\hline 13369 & 592021.62 & 130366.6 & \\
\hline 13370 & 591771.62 & 132116.59 & \\
\hline 13371 & 591271.62 & 133116.59 & \\
\hline 13372 & 590771.62 & 134116.59 & \\
\hline 13373 & 590271.62 & 135116.59 & \\
\hline 13374 & 589801.31 & 136121.42 & \\
\hline 13375 & 588320.19 & 137709.58 & \\
\hline 13376 & 588513.19 & 137645.42 & \\
\hline 13377 & 588771.62 & 137116.59 & \\
\hline 13378 & 589065.7478 & 137107.989 & \\
\hline 13379 & 588742.5043 & 137327.1741 & \\
\hline 13380 & 589365.3722 & 137112.093 & \\
\hline 13381 & 588706.06 & 137581.27 & \\
\hline 13382 & 592271.62 & 129366.6 & \\
\hline 13383 & 592271.62 & 129616.6 & \\
\hline 13384 & 592271.62 & 129866.6 & \\
\hline 13385 & 592521.62 & 129366.6 & \\
\hline 13386 & 592271.62 & 130116.6 & \\
\hline 13387 & 592771.62 & 128366.6 & \\
\hline 13388 & 592771.62 & 128616.6 & \\
\hline 13389 & 592771.62 & 128866.6 & \\
\hline 13390 & 593021.62 & 128366.6 & \\
\hline 13391 & 592771.62 & 129116.6 & \\
\hline 13392 & 593271.62 & 127366.6 & \\
\hline 13393 & 593271.62 & 127616.6 & \\
\hline 13394 & 593271.62 & 127866.6 & \\
\hline 13395 & 593521.62 & 127366.6 & \\
\hline 13396 & 593271.62 & 128116.6 & \\
\hline 13397 & 593771.62 & 126366.6 & \\
\hline 13398 & 593771.62 & 126616.6 & \\
\hline 13399 & 593771.62 & 126866.6 & \\
\hline 13400 & 594021.62 & 126366.6 & \\
\hline 13401 & 593771.62 & 127116.6 & \\
\hline 13402 & 594200.69 & 124614.1 & \\
\hline 13403 & 594226.06 & 124863.63 & \\
\hline 13404 & 594251.44 & 125113.16 & \\
\hline 13405 & 594263.5 & 125365.35 & \\
\hline 13406 & 594275.5 & 125617.55 & \\
\hline 13407 & 594287.56 & 125869.73 & \\
\hline 13408 & 594300.94 & 126117.92 & \\
\hline 13409 & 594379.75 & 124611.6 & \\
\hline 13410 & 594314.25 & 126366.12 & \\
\hline 13411 & 593771.62 & 127366.6 & \\
\hline
\end{tabular}




\begin{tabular}{|c|c|c|}
\hline node & X_coord & Y_coord \\
\hline 13412 & 593271.62 & 128366.6 \\
\hline 13413 & 592771.62 & 129366.6 \\
\hline 13414 & 592271.62 & 130366.6 \\
\hline 13415 & 587877.31 & 138023.73 \\
\hline 13416 & 588180.12 & 138102.3 \\
\hline 13417 & 588362.54 & 138006.06 \\
\hline 13418 & 594468.8078 & 123606.8662 \\
\hline 13419 & 594470.9957 & 123798.8836 \\
\hline 13420 & 594482.2443 & 124036.195 \\
\hline 13421 & 595210.38 & 123632.8 \\
\hline 13422 & 594480.8078 & 124266.2677 \\
\hline 13423 & 594533.4398 & 124518.492 \\
\hline 13424 & 585582.6789 & 140255.23 \\
\hline 13425 & 586000.8072 & 140347.7286 \\
\hline 13426 & 586100.0329 & 140224.0229 \\
\hline 13427 & 585898.5158 & 140490.1129 \\
\hline 13428 & 586271.62 & 138866.59 \\
\hline 13429 & 586271.62 & 139116.59 \\
\hline 13430 & 586271.62 & 139366.59 \\
\hline 13431 & 586217.3026 & 139467.2771 \\
\hline 13433 & 585990.8675 & 139875.2576 \\
\hline 13434 & 586227.5372 & 140102.8843 \\
\hline 13435 & 573271.62 & 150116.59 \\
\hline 13436 & 573271.62 & 150366.59 \\
\hline 13437 & 573271.62 & 150616.59 \\
\hline 13438 & 573271.62 & 150866.59 \\
\hline 13439 & 573271.62 & 151116.59 \\
\hline 13440 & 573271.62 & 151366.59 \\
\hline 13441 & 571884.56 & 151170.41 \\
\hline 13442 & 571976.56 & 151309.41 \\
\hline 13443 & 572068.5 & 151448.41 \\
\hline 13444 & 572432.6765 & 151400.9779 \\
\hline 13445 & 572187.4943 & 151610.8857 \\
\hline 13446 & 572653.7485 & 151418.8215 \\
\hline 13447 & 572889.5785 & 151490.6044 \\
\hline 13448 & 573060.92 & 151541.7401 \\
\hline 13449 & 573285.75 & 151602.78 \\
\hline 13450 & 573521.62 & 150116.59 \\
\hline 13451 & 573771.62 & 150116.59 \\
\hline 13452 & 574021.62 & 150116.59 \\
\hline 13453 & 574271.62 & 150116.59 \\
\hline 13454 & 574521.62 & 150116.59 \\
\hline 13455 & 574771.62 & 150116.59 \\
\hline 13456 & 575021.62 & 150116.59 \\
\hline 13457 & 575271.62 & 150116.59 \\
\hline 13458 & 575521.62 & 150116.59 \\
\hline 13459 & 575771.62 & 150116.59 \\
\hline 13460 & 576021.62 & 150116.59 \\
\hline 13461 & 576271.62 & 150116.59 \\
\hline 13462 & 576521.62 & 150116.59 \\
\hline 13463 & 576771.62 & 150116.59 \\
\hline 13464 & 577021.62 & 150116.59 \\
\hline 13465 & 577271.62 & 150116.59 \\
\hline 13466 & 577521.62 & 150116.59 \\
\hline 13467 & 577771.62 & 150116.59 \\
\hline 13468 & 578021.62 & 150116.59 \\
\hline
\end{tabular}

note: from sac04d created July 1, 2004 


\begin{tabular}{|c|c|c|c|}
\hline node & X_coord & Y_coord & note: from sac04d created July 1, 2004 \\
\hline 13469 & $5 \overline{7} 8271.62$ & $1 \overline{5} 0116.59$ & \\
\hline 13470 & 578435.19 & 150117.06 & \\
\hline 13471 & 578598.81 & 150117.5 & \\
\hline 13472 & 578762.38 & 150117.97 & \\
\hline 13473 & 578961.5 & 150117.97 & \\
\hline 13474 & 579160.62 & 150117.97 & \\
\hline 13475 & 579309.0095 & 150418.7886 & \\
\hline 13476 & 580029.56 & 142467.2 & \\
\hline 13477 & 580030.5 & 142346.95 & \\
\hline 13478 & 580026.94 & 142683.67 & \\
\hline 13479 & 580031.5 & 142226.72 & \\
\hline 13480 & 580024.25 & 142900.12 & \\
\hline 13481 & 580032.44 & 142106.47 & \\
\hline 13482 & 580021.62 & 143116.59 & \\
\hline 13483 & 580021.62 & 143366.59 & \\
\hline 13484 & 580021.62 & 143616.59 & \\
\hline 13485 & 580021.62 & 143866.59 & \\
\hline 13486 & 580021.62 & 144116.59 & \\
\hline 13487 & 580021.62 & 144366.59 & \\
\hline 13488 & 580021.62 & 144616.59 & \\
\hline 13489 & 580021.62 & 144866.59 & \\
\hline 13490 & 580021.62 & 145116.59 & \\
\hline 13491 & 580021.62 & 145366.59 & \\
\hline 13492 & 580021.62 & 145616.59 & \\
\hline 13493 & 580021.62 & 145866.59 & \\
\hline 13494 & 580021.62 & 146116.59 & \\
\hline 13495 & 580021.62 & 146366.59 & \\
\hline 13496 & 580021.62 & 146616.59 & \\
\hline 13497 & 580021.62 & 146866.59 & \\
\hline 13498 & 580021.62 & 147116.59 & \\
\hline 13499 & 580021.62 & 147366.59 & \\
\hline 13500 & 580021.62 & 147616.59 & \\
\hline 13501 & 580029.31 & 147870.08 & \\
\hline 13502 & 580036.94 & 148123.58 & \\
\hline 13503 & 580047.1971 & 148320.363 & \\
\hline 13504 & 579964.4201 & 148497.6302 & \\
\hline 13505 & 579920.3601 & 148759.9329 & \\
\hline 13506 & 579943.1167 & 148991.2384 & \\
\hline 13507 & 579961.3949 & 149238.2147 & \\
\hline 13508 & 579876.0549 & 149484.1889 & \\
\hline 13509 & 580085.9462 & 149125.9175 & \\
\hline 13510 & 579832.019 & 149722.4216 & \\
\hline 13511 & 579934.81 & 149991.59 & \\
\hline 13512 & 580029.2941 & 150226.9628 & \\
\hline 13513 & 583500.62 & 140490.2 & \\
\hline 13514 & 583244.25 & 140504.05 & \\
\hline 13515 & 583757.62 & 140532.33 & \\
\hline 13516 & 583111 & 140077.27 & \\
\hline 13517 & 583049.5 & 140297.58 & \\
\hline 13518 & 582987.94 & 140517.89 & \\
\hline 13519 & 584014.62 & 140574.47 & \\
\hline 13520 & 584271.62 & 140616.59 & \\
\hline 13521 & 584509.88 & 140603.69 & \\
\hline 13522 & 584748.06 & 140590.77 & \\
\hline 13523 & 584986.31 & 140577.86 & \\
\hline 13524 & 585139.5 & 140518.44 & \\
\hline
\end{tabular}




\begin{tabular}{|c|c|c|c|}
\hline node & X_coord & Y_coord & note: from sac04d created July 1, 2004 \\
\hline 13526 & $5 \overline{8} 5453.1286$ & 140361.5246 & \\
\hline 13527 & 587527.6235 & 138154.8641 & \\
\hline 13528 & 587484.5014 & 138404.4257 & \\
\hline 13529 & 587478.0452 & 138670.4256 & \\
\hline 13530 & 587804.7494 & 138179.6562 & \\
\hline 13531 & 586521.62 & 138866.59 & \\
\hline 13532 & 586697.8225 & 138809.6395 & \\
\hline 13533 & 586919.259 & 138816.1346 & \\
\hline 13534 & 587142.4487 & 138869.7532 & \\
\hline 13535 & 587441.31 & 138962 & \\
\hline 13536 & 587606.69 & 138849.5 & \\
\hline 13537 & 587310.2686 & 139060.8143 & \\
\hline 13538 & 589521.62 & 136366.59 & \\
\hline 13539 & 589567.56 & 136642.42 & \\
\hline 13540 & 589613.56 & 136918.27 & \\
\hline 13541 & 589816.12 & 136373.83 & \\
\hline 13542 & 589648.7087 & 137234.277 & \\
\hline 13543 & 590021.62 & 135366.59 & \\
\hline 13544 & 590021.62 & 135616.59 & \\
\hline 13545 & 590051.31 & 135871.42 & \\
\hline 13546 & 590271.62 & 135366.59 & \\
\hline 13547 & 590081 & 136126.23 & \\
\hline 13548 & 590502.56 & 134363.27 & \\
\hline 13549 & 590483.56 & 134609.95 & \\
\hline 13550 & 590464.5 & 134856.62 & \\
\hline 13551 & 590733.56 & 134359.95 & \\
\hline 13552 & 590483.56 & 135109.95 & \\
\hline 13553 & 591021.62 & 133366.59 & \\
\hline 13554 & 591021.62 & 133616.59 & \\
\hline 13555 & 591021.62 & 133866.59 & \\
\hline 13556 & 591271.62 & 133366.59 & \\
\hline 13557 & 591021.62 & 134116.59 & \\
\hline 13558 & 591521.62 & 132366.59 & \\
\hline 13559 & 591521.62 & 132616.59 & \\
\hline 13560 & 591521.62 & 132866.59 & \\
\hline 13561 & 591771.62 & 132366.59 & \\
\hline 13562 & 591521.62 & 133116.59 & \\
\hline 13563 & 592021.62 & 130616.6 & \\
\hline 13564 & 592021.62 & 130866.59 & \\
\hline 13565 & 592021.62 & 131116.59 & \\
\hline 13566 & 592021.62 & 131366.59 & \\
\hline 13567 & 592021.62 & 131616.59 & \\
\hline 13568 & 592021.62 & 131866.59 & \\
\hline 13569 & 592021.62 & 132116.59 & \\
\hline 13570 & 592271.62 & 130616.6 & \\
\hline 13571 & 592021.62 & 132366.59 & \\
\hline 13572 & 591521.62 & 133366.59 & \\
\hline 13573 & 590964.5 & 134356.62 & \\
\hline 13574 & 590502.56 & 135363.27 & \\
\hline 13575 & 590094.3806 & 136382.8722 & \\
\hline 13576 & 588534.7114 & 137907.2529 & \\
\hline 13577 & 588719.6985 & 137818.7443 & \\
\hline 13578 & 588972.6919 & 137296.4003 & \\
\hline 13579 & 589306.3026 & 137252.9514 & \\
\hline 13580 & 588850.7014 & 137546.4151 & \\
\hline 13581 & 589516.9087 & 137337.7721 & \\
\hline
\end{tabular}




\begin{tabular}{|c|c|c|}
\hline node & X_coord & Y_coord \\
\hline 13582 & $5 \overline{8} 8892.3471$ & $1 \overline{3} 7724.2357$ \\
\hline 13583 & 592521.62 & 129616.6 \\
\hline 13584 & 592521.62 & 129866.6 \\
\hline 13585 & 592521.62 & 130116.6 \\
\hline 13586 & 592771.62 & 129616.6 \\
\hline 13587 & 592521.62 & 130366.6 \\
\hline 13588 & 593021.62 & 128616.6 \\
\hline 13589 & 593021.62 & 128866.6 \\
\hline 13590 & 593021.62 & 129116.6 \\
\hline 13591 & 593271.62 & 128616.6 \\
\hline 13592 & 593021.62 & 129366.6 \\
\hline 13593 & 593521.62 & 127616.6 \\
\hline 13594 & 593521.62 & 127866.6 \\
\hline 13595 & 593521.62 & 128116.6 \\
\hline 13596 & 593771.62 & 127616.6 \\
\hline 13597 & 593521.62 & 128366.6 \\
\hline 13598 & 594021.62 & 126616.6 \\
\hline 13599 & 594021.62 & 126866.6 \\
\hline 13600 & 594021.62 & 127116.6 \\
\hline 13601 & 594327.62 & 126614.3 \\
\hline 13602 & 594021.62 & 127366.6 \\
\hline 13603 & 594430.5 & 124860.66 \\
\hline 13604 & 594481.31 & 125109.73 \\
\hline 13605 & 594505.38 & 125364.11 \\
\hline 13606 & 594529.38 & 125618.49 \\
\hline 13607 & 594553.44 & 125872.87 \\
\hline 13608 & 594580.19 & 126119.24 \\
\hline 13609 & 594606.94 & 126365.62 \\
\hline 13610 & 594618.6306 & 124806.9595 \\
\hline 13611 & 594633.69 & 126612 \\
\hline 13612 & 594021.62 & 127616.6 \\
\hline 13613 & 593521.62 & 128616.6 \\
\hline 13614 & 593021.62 & 129616.6 \\
\hline 13615 & 592521.62 & 130616.6 \\
\hline 13616 & 588056.4951 & 138213.4992 \\
\hline 13617 & 588350.81 & 138343.3 \\
\hline 13618 & 588213 & 138437.03 \\
\hline 13619 & 588516.06 & 138230.62 \\
\hline 13620 & 588681.38 & 138117.97 \\
\hline 13621 & 595186.5 & 123864.8 \\
\hline 13622 & 595162.69 & 124096.8 \\
\hline 13623 & 595138.81 & 124328.8 \\
\hline 13624 & 595107.31 & 124593.6 \\
\hline 13625 & 595075.81 & 124858.4 \\
\hline 13626 & 585793.6473 & 140622.1986 \\
\hline 13627 & 586503.4984 & 139089.4076 \\
\hline 13628 & 586568.7362 & 139352.0927 \\
\hline 13629 & 586417.1232 & 139488.7241 \\
\hline 13630 & 586278.1154 & 139634.3962 \\
\hline 13631 & 586126.4924 & 139761.9568 \\
\hline 13632 & 586347.38 & 139986.91 \\
\hline 13633 & 573521.62 & 150366.59 \\
\hline 13634 & 573521.62 & 150616.59 \\
\hline 13635 & 573521.62 & 150866.59 \\
\hline 13636 & 573521.62 & 151116.59 \\
\hline 13637 & 573521.62 & 151366.59 \\
\hline
\end{tabular}

note: from sac04d created July 1, 2004 


\begin{tabular}{|c|c|c|c|}
\hline node & X_coord & Y_coord & note: from sac04d created July 1, 2004 \\
\hline 13638 & $5 \overline{7} 3528.69$ & $1 \overline{15} 1609.69$ & \\
\hline 13639 & 572551.6843 & 151541.1038 & \\
\hline 13640 & 572324.5786 & 151752.7643 & \\
\hline 13642 & 572930.7171 & 151734.1185 & \\
\hline 13643 & 573089.8314 & 151819.9857 & \\
\hline 13644 & 573299.94 & 151838.95 & \\
\hline 13645 & 573535.81 & 151852.77 & \\
\hline 13646 & 573771.62 & 150366.59 & \\
\hline 13647 & 574021.62 & 150366.59 & \\
\hline 13648 & 574271.62 & 150366.59 & \\
\hline 13649 & 574521.62 & 150366.59 & \\
\hline 13650 & 574771.62 & 150366.59 & \\
\hline 13651 & 575021.62 & 150366.59 & \\
\hline 13652 & 575271.62 & 150366.59 & \\
\hline 13653 & 575521.62 & 150366.59 & \\
\hline 13654 & 575771.62 & 150366.59 & \\
\hline 13655 & 576021.62 & 150366.59 & \\
\hline 13656 & 576271.62 & 150366.59 & \\
\hline 13657 & 576521.62 & 150366.59 & \\
\hline 13658 & 576771.62 & 150366.59 & \\
\hline 13659 & 577021.62 & 150366.59 & \\
\hline 13660 & 577271.62 & 150366.59 & \\
\hline 13661 & 577521.62 & 150366.59 & \\
\hline 13662 & 577771.62 & 150366.59 & \\
\hline 13663 & 578021.62 & 150366.59 & \\
\hline 13664 & 578271.62 & 150366.59 & \\
\hline 13665 & 578431.19 & 150367.91 & \\
\hline 13666 & 578590.75 & 150369.22 & \\
\hline 13667 & 578750.31 & 150370.53 & \\
\hline 13668 & 578936.06 & 150370.53 & \\
\hline 13669 & 579121.88 & 150370.53 & \\
\hline 13670 & 579273.189 & 150549.9339 & \\
\hline 13671 & 580121.131 & 150446.8528 & \\
\hline 13672 & 580275.56 & 142416.89 & \\
\hline 13673 & 580277.5 & 142294.97 & \\
\hline 13674 & 580274.25 & 142650.12 & \\
\hline 13675 & 580279.5 & 142173.05 & \\
\hline 13676 & 580272.94 & 142883.36 & \\
\hline 13677 & 580281.44 & 142051.12 & \\
\hline 13678 & 580271.62 & 143116.59 & \\
\hline 13679 & 580271.62 & 143366.59 & \\
\hline 13680 & 580271.62 & 143616.59 & \\
\hline 13681 & 580271.62 & 143866.59 & \\
\hline 13682 & 580271.62 & 144116.59 & \\
\hline 13683 & 580271.62 & 144366.59 & \\
\hline 13684 & 580271.62 & 144616.59 & \\
\hline 13685 & 580271.62 & 144866.59 & \\
\hline 13686 & 580271.62 & 145116.59 & \\
\hline 13687 & 580271.62 & 145366.59 & \\
\hline 13688 & 580271.62 & 145616.59 & \\
\hline 13689 & 580271.62 & 145866.59 & \\
\hline 13690 & 580271.62 & 146116.59 & \\
\hline 13691 & 580271.62 & 146366.59 & \\
\hline 13692 & 580271.62 & 146616.59 & \\
\hline 13693 & 580271.62 & 146866.59 & \\
\hline 13694 & 580271.62 & 147116.59 & \\
\hline
\end{tabular}




\begin{tabular}{|c|c|c|c|}
\hline node & X_coord & Y_coord & note: from sac04d created July 1, 2004 \\
\hline 13695 & $5 \overline{80} 271.62$ & $1 \overline{4} 7366.59$ & \\
\hline 13696 & 580271.62 & 147616.59 & \\
\hline 13697 & 580286.94 & 147873.58 & \\
\hline 13698 & 580351.2756 & 148153.7442 & \\
\hline 13699 & 580325.3514 & 148320.5244 & \\
\hline 13700 & 580255.1514 & 148474.0145 & \\
\hline 13702 & 580080.204 & 148869.3206 & \\
\hline 13703 & 580205.4233 & 149000.7246 & \\
\hline 13704 & 583521.62 & 140866.59 & \\
\hline 13705 & 583224 & 140802.39 & \\
\hline 13706 & 583771.62 & 140866.59 & \\
\hline 13707 & 582926.44 & 140738.2 & \\
\hline 13708 & 584021.62 & 140866.59 & \\
\hline 13709 & 582937.12 & 140247.2 & \\
\hline 13710 & 582834.38 & 140389.47 & \\
\hline 13711 & 582731.56 & 140531.73 & \\
\hline 13712 & 582628.81 & 140674 & \\
\hline 13713 & 584271.62 & 140866.59 & \\
\hline 13714 & 584489.5027 & 140839.9814 & \\
\hline 13715 & 584736.31 & 140827.86 & \\
\hline 13716 & 585061.1102 & 140777.6933 & \\
\hline 13717 & 585172.735 & 140691.3054 & \\
\hline 13718 & 585273.487 & 140594.0546 & \\
\hline 13719 & 585354.3051 & 140489.5452 & \\
\hline 13720 & 585696.5001 & 140754.2744 & \\
\hline 13722 & 587636.8036 & 138545.7819 & \\
\hline 13723 & 587772 & 138737 & \\
\hline 13724 & 587926.5271 & 138323.9434 & \\
\hline 13725 & 586632.3222 & 139039.9576 & \\
\hline 13727 & 586989.5198 & 138973.986 & \\
\hline 13728 & 587194.69 & 139185.39 & \\
\hline 13729 & 589805.38 & 136611.17 & \\
\hline 13730 & 589794.56 & 136848.52 & \\
\hline 13731 & 589804.4271 & 137116.7856 & \\
\hline 13732 & 590053.993 & 136579.92 & \\
\hline 13733 & 589751.81 & 137380.3 & \\
\hline 13734 & 589920.2485 & 137268.0614 & \\
\hline 13735 & 589614.62 & 137475 & \\
\hline 13736 & 590271.62 & 135616.59 & \\
\hline 13737 & 590316.12 & 135873.83 & \\
\hline 13738 & 590349.817 & 136134.6843 & \\
\hline 13739 & 590521.62 & 135616.59 & \\
\hline 13740 & 590390.6927 & 136417.2946 & \\
\hline 13741 & 590695.5 & 134603.31 & \\
\hline 13742 & 590657.44 & 134846.67 & \\
\hline 13743 & 590695.5 & 135103.31 & \\
\hline 13744 & 590907.44 & 134596.67 & \\
\hline 13745 & 590729.9357 & 135334.5798 & \\
\hline 13746 & 591250.75 & 133596.38 & \\
\hline 13747 & 591229.94 & 133826.14 & \\
\hline 13748 & 591209.06 & 134055.92 & \\
\hline 13749 & 591479.88 & 133576.16 & \\
\hline 13750 & 591145.62 & 134312.17 & \\
\hline 13751 & 591771.62 & 132616.59 & \\
\hline 13752 & 591771.62 & 132866.59 & \\
\hline 13753 & 591771.62 & 133116.59 & \\
\hline
\end{tabular}




\begin{tabular}{|c|c|c|c|}
\hline node & X_coord & Y_coord & note: from sac04d created July 1,2004 \\
\hline 13754 & $5 \overline{9} 2021.62$ & $1 \overline{3} 2616.59$ & \\
\hline 13755 & 591771.62 & 133366.59 & \\
\hline 13756 & 592271.62 & 130866.59 & \\
\hline 13757 & 592271.62 & 131116.59 & \\
\hline 13758 & 592271.62 & 131366.59 & \\
\hline 13759 & 592271.62 & 131616.59 & \\
\hline 13760 & 592271.62 & 131866.59 & \\
\hline 13761 & 592271.62 & 132116.59 & \\
\hline 13762 & 592271.62 & 132366.59 & \\
\hline 13763 & 592521.62 & 130866.59 & \\
\hline 13764 & 592271.62 & 132616.59 & \\
\hline 13765 & 591709.06 & 133555.92 & \\
\hline 13766 & 591082.12 & 134568.42 & \\
\hline 13767 & 590771.62 & 135616.59 & \\
\hline 13768 & 590268.2549 & 136574.0402 & \\
\hline 13769 & 588846.62 & 138005.3 & \\
\hline 13770 & 589011.19 & 137891.67 & \\
\hline 13772 & 589377.3073 & 137431.4514 & \\
\hline 13773 & 589069.1527 & 137625.8307 & \\
\hline 13774 & 589477.5 & 137569.7 & \\
\hline 13775 & 589175.75 & 137778.03 & \\
\hline 13776 & 592771.62 & 129866.6 & \\
\hline 13777 & 592771.62 & 130116.6 & \\
\hline 13778 & 592771.62 & 130366.6 & \\
\hline 13779 & 593021.62 & 129866.6 & \\
\hline 13780 & 592771.62 & 130616.6 & \\
\hline 13781 & 593271.62 & 128866.6 & \\
\hline 13782 & 593271.62 & 129116.6 & \\
\hline 13783 & 593271.62 & 129366.6 & \\
\hline 13784 & 593521.62 & 128866.6 & \\
\hline 13785 & 593271.62 & 129616.6 & \\
\hline 13786 & 593771.62 & 127866.6 & \\
\hline 13787 & 593771.62 & 128116.6 & \\
\hline 13788 & 593771.62 & 128366.6 & \\
\hline 13789 & 594021.62 & 127866.6 & \\
\hline 13790 & 593771.62 & 128616.6 & \\
\hline 13791 & 594314.25 & 126865.17 & \\
\hline 13792 & 594300.94 & 127116.03 & \\
\hline 13793 & 594287.56 & 127366.9 & \\
\hline 13794 & 594606.94 & 126863.73 & \\
\hline 13795 & 594275.5 & 127616.42 & \\
\hline 13796 & 594711.12 & 125086.3662 & \\
\hline 13797 & 594745.3778 & 125341.1241 & \\
\hline 13798 & 594783.31 & 125592.2476 & \\
\hline 13799 & 594812.1314 & 125837.9446 & \\
\hline 13800 & 594857.6878 & 126095.1998 & \\
\hline 13801 & 594899.56 & 126361.5057 & \\
\hline 13802 & 594936.0657 & 126620.573 & \\
\hline 13803 & 595044.31 & 125123.2 & \\
\hline 13804 & 594903.1843 & 126894.9189 & \\
\hline 13805 & 594263.5 & 127865.95 & \\
\hline 13806 & 593771.62 & 128866.6 & \\
\hline 13807 & 593271.62 & 129866.6 & \\
\hline 13808 & 592771.62 & 130866.59 & \\
\hline 13809 & 588075.19 & 138530.77 & \\
\hline 13810 & 586668.4546 & 139271.5134 & \\
\hline
\end{tabular}




\begin{tabular}{|c|c|c|}
\hline node & X_coord & Y_coord \\
\hline 13811 & $5 \overline{8} 6781.81$ & $1 \overline{3} 9573$ \\
\hline 13812 & 586878.31 & 139481.03 \\
\hline 13813 & 586637 & 139710.97 \\
\hline 13814 & 586492.19 & 139848.94 \\
\hline 13815 & 573771.62 & 150616.59 \\
\hline 13816 & 573771.62 & 150866.59 \\
\hline 13817 & 573771.62 & 151116.59 \\
\hline 13818 & 573771.62 & 151366.59 \\
\hline 13819 & 573771.62 & 151616.59 \\
\hline 13820 & 573771.62 & 151866.59 \\
\hline 13821 & 572679.8935 & 151689.0326 \\
\hline 13822 & 572464.19 & 151897.2 \\
\hline 13823 & 572802.0565 & 151808.673 \\
\hline 13824 & 572922.8784 & 151920.6735 \\
\hline 13825 & 573050.879 & 152030.8519 \\
\hline 13826 & 573326.9457 & 152021.0201 \\
\hline 13827 & 573648.5426 & 152049.4715 \\
\hline 13828 & 573869.5512 & 152106.2815 \\
\hline 13829 & 574021.62 & 150616.59 \\
\hline 13830 & 574271.62 & 150616.59 \\
\hline 13831 & 574521.62 & 150616.59 \\
\hline 13832 & 574771.62 & 150616.59 \\
\hline 13833 & 575021.62 & 150616.59 \\
\hline 13834 & 575271.62 & 150616.59 \\
\hline 13835 & 575521.62 & 150616.59 \\
\hline 13836 & 575771.62 & 150616.59 \\
\hline 13837 & 576021.62 & 150616.59 \\
\hline 13838 & 576271.62 & 150616.59 \\
\hline 13839 & 576521.62 & 150616.59 \\
\hline 13840 & 576771.62 & 150616.59 \\
\hline 13841 & 577021.62 & 150616.59 \\
\hline 13842 & 577271.62 & 150616.59 \\
\hline 13843 & 577521.62 & 150616.59 \\
\hline 13844 & 577771.62 & 150616.59 \\
\hline 13845 & 578021.62 & 150616.59 \\
\hline 13846 & 578271.62 & 150616.59 \\
\hline 13847 & 578427.19 & 150618.77 \\
\hline 13848 & 578582.75 & 150620.92 \\
\hline 13849 & 578738.31 & 150623.09 \\
\hline 13850 & 578910.69 & 150623.09 \\
\hline 13851 & 579083.12 & 150623.09 \\
\hline 13852 & 579221.069 & 150715.5102 \\
\hline 13853 & 580148.5995 & 150664.1857 \\
\hline 13854 & 580521.62 & 142366.59 \\
\hline 13855 & 580524.56 & 142243 \\
\hline 13856 & 580521.62 & 142616.59 \\
\hline 13857 & 580527.44 & 142119.39 \\
\hline 13858 & 580521.62 & 142866.59 \\
\hline 13859 & 580530.38 & 141995.8 \\
\hline 13860 & 580521.62 & 143116.59 \\
\hline 13861 & 580521.62 & 143366.59 \\
\hline 13862 & 580521.62 & 143616.59 \\
\hline 13863 & 580521.62 & 143866.59 \\
\hline 13864 & 580521.62 & 144116.59 \\
\hline 13865 & 580521.62 & 144366.59 \\
\hline 13866 & 580521.62 & 144616.59 \\
\hline
\end{tabular}




\begin{tabular}{|c|c|c|c|}
\hline node & X_coord & Y_coord & note: from sac04d created July 1, 2004 \\
\hline 13867 & $5 \overline{80} 521.62$ & $1 \overline{4} 4866.59$ & \\
\hline 13868 & 580521.62 & 145116.59 & \\
\hline 13869 & 580521.62 & 145366.59 & \\
\hline 13870 & 580521.62 & 145616.59 & \\
\hline 13871 & 580521.62 & 145866.59 & \\
\hline 13872 & 580521.62 & 146116.59 & \\
\hline 13873 & 580521.62 & 146366.59 & \\
\hline 13874 & 580521.62 & 146616.59 & \\
\hline 13875 & 580521.62 & 146866.59 & \\
\hline 13876 & 580521.62 & 147116.59 & \\
\hline 13877 & 580521.62 & 147366.59 & \\
\hline 13878 & 580521.62 & 147616.59 & \\
\hline 13879 & 580539.4657 & 147840.9801 & \\
\hline 13880 & 580567.62 & 148114.3358 & \\
\hline 13881 & 580614.1781 & 148401.6243 & \\
\hline 13882 & 580478.2438 & 148517.6149 & \\
\hline 13883 & 580346.4382 & 148624.9185 & \\
\hline 13884 & 580198.4548 & 148750.0515 & \\
\hline 13885 & 580319.6761 & 148883.2731 & \\
\hline 13886 & 583521.62 & 141116.59 & \\
\hline 13887 & 583239.88 & 141073.8 & \\
\hline 13888 & 583771.62 & 141116.59 & \\
\hline 13889 & 582958.19 & 141031 & \\
\hline 13890 & 584021.62 & 141116.59 & \\
\hline 13891 & 582676.44 & 140988.2 & \\
\hline 13892 & 584271.62 & 141116.59 & \\
\hline 13893 & 582451 & 140760.94 & \\
\hline 13894 & 582474.56 & 141046.16 & \\
\hline 13895 & 584471.4378 & 141019.0917 & \\
\hline 13896 & 584683.9408 & 140970.5117 & \\
\hline 13897 & 584952.6107 & 140920.1195 & \\
\hline 13898 & 585448.883 & 141070.7787 & \\
\hline 13899 & 585534.8816 & 140966.1429 & \\
\hline 13900 & 585349.513 & 141209.1729 & \\
\hline 13901 & 585615.6658 & 140858.9201 & \\
\hline 13902 & 587791.3732 & 138416.9394 & \\
\hline 13903 & 587937.38 & 138624.5 & \\
\hline 13904 & 586756.1829 & 139178.259 & \\
\hline 13905 & 586860.3279 & 139084.0663 & \\
\hline 13906 & 587071.38 & 139297.09 & \\
\hline 13908 & 589962.1799 & 137011.1428 & \\
\hline 13909 & 590078.3085 & 137155.8428 & \\
\hline 13910 & 590171.1173 & 136745.2732 & \\
\hline 13911 & 590497.6262 & 135821.9127 & \\
\hline 13912 & 590484.5054 & 136067.093 & \\
\hline 13913 & 590509.44 & 136288.7151 & \\
\hline 13914 & 590722.5643 & 135782.6706 & \\
\hline 13915 & 590557.38 & 136520.09 & \\
\hline 13916 & 590649.38 & 136381.12 & \\
\hline 13917 & 590446.94 & 136686.86 & \\
\hline 13918 & 590850.31 & 134836.7 & \\
\hline 13919 & 590836.7658 & 135074.9241 & \\
\hline 13920 & 590855.7704 & 135311.316 & \\
\hline 13921 & 591018.69 & 134824.67 & \\
\hline 13922 & 591016.1835 & 135627.463 & \\
\hline 13923 & 591438.19 & 133785.7 & \\
\hline
\end{tabular}




\begin{tabular}{|c|c|c|c|}
\hline node & X_coord & Y_coord & note: from sac04d created July 1, 2004 \\
\hline 13924 & $5 \overline{9} 1396.44$ & $1 \overline{3} 3995.27$ & \\
\hline 13925 & 591326.62 & 134267.72 & \\
\hline 13926 & 591646.44 & 133745.27 & \\
\hline 13927 & 591256.81 & 134540.17 & \\
\hline 13928 & 592021.62 & 132866.59 & \\
\hline 13929 & 592021.62 & 133116.59 & \\
\hline 13930 & 592021.62 & 133366.59 & \\
\hline 13931 & 592271.62 & 132866.59 & \\
\hline 13932 & 591970.62 & 133566.61 & \\
\hline 13933 & 592521.62 & 131116.59 & \\
\hline 13934 & 592521.62 & 131366.59 & \\
\hline 13935 & 592521.62 & 131616.59 & \\
\hline 13936 & 592521.62 & 131866.59 & \\
\hline 13937 & 592521.62 & 132116.59 & \\
\hline 13938 & 592521.62 & 132366.59 & \\
\hline 13939 & 592521.62 & 132616.59 & \\
\hline 13940 & 592771.62 & 131116.59 & \\
\hline 13941 & 592521.62 & 132866.59 & \\
\hline 13942 & 591919.56 & 133766.64 & \\
\hline 13943 & 591185.1878 & 134828.9294 & \\
\hline 13944 & 590920.38 & 135761.56 & \\
\hline 13945 & 590336.56 & 136853.64 & \\
\hline 13946 & 589236.8476 & 137516.2604 & \\
\hline 13947 & 589340.31 & 137664.41 & \\
\hline 13948 & 593021.62 & 130116.6 & \\
\hline 13949 & 593021.62 & 130366.6 & \\
\hline 13950 & 593021.62 & 130616.6 & \\
\hline 13951 & 593271.62 & 130116.6 & \\
\hline 13952 & 593021.62 & 130866.59 & \\
\hline 13953 & 593521.62 & 129116.6 & \\
\hline 13954 & 593521.62 & 129366.6 & \\
\hline 13955 & 593521.62 & 129616.6 & \\
\hline 13956 & 593771.62 & 129116.6 & \\
\hline 13957 & 593521.62 & 129866.6 & \\
\hline 13958 & 594021.62 & 128116.6 & \\
\hline 13959 & 594021.62 & 128366.6 & \\
\hline 13960 & 594021.62 & 128616.6 & \\
\hline 13961 & 594251.44 & 128115.47 & \\
\hline 13962 & 594021.62 & 128866.6 & \\
\hline 13963 & 594580.19 & 127115.47 & \\
\hline 13964 & 594553.44 & 127367.2 & \\
\hline 13965 & 594529.38 & 127616.25 & \\
\hline 13966 & 594863.1243 & 127142.0824 & \\
\hline 13967 & 594505.38 & 127865.29 & \\
\hline 13968 & 595016.2886 & 125355.6 & \\
\hline 13969 & 595021.84 & 125585.4229 & \\
\hline 13970 & 595037.62 & 125820.4 & \\
\hline 13971 & 595054.88 & 126086.5 & \\
\hline 13972 & 595072.06 & 126352.6 & \\
\hline 13973 & 595089.31 & 126618.7 & \\
\hline 13974 & 595109.3428 & 126887.5171 & \\
\hline 13975 & 595116.48 & 127153.7371 & \\
\hline 13976 & 594481.31 & 128114.34 & \\
\hline 13977 & 594021.62 & 129116.6 & \\
\hline 13978 & 593521.62 & 130116.6 & \\
\hline 13979 & 593021.62 & 131116.59 & \\
\hline
\end{tabular}




\begin{tabular}{|c|c|c|c|}
\hline node & X_coord & Y_coord & note: from sac04d created July 1, 2004 \\
\hline 13980 & $5 \overline{8} 6974.88$ & $1 \overline{3} 9389.06$ & \\
\hline 13981 & 574021.62 & 150866.59 & \\
\hline 13982 & 574021.62 & 151116.59 & \\
\hline 13983 & 574021.62 & 151366.59 & \\
\hline 13984 & 574021.62 & 151616.59 & \\
\hline 13985 & 574021.62 & 151866.59 & \\
\hline 13986 & 574021.62 & 152116.59 & \\
\hline 13987 & 572579.31 & 152017.73 & \\
\hline 13988 & 572694.5 & 152138.27 & \\
\hline 13989 & 572809.62 & 152258.8 & \\
\hline 13990 & 573223.4984 & 152174.7962 & \\
\hline 13991 & 572959.44 & 152415.67 & \\
\hline 13992 & 573469.5571 & 152204.8487 & \\
\hline 13993 & 573749.0869 & 152258.7687 & \\
\hline 13994 & 573940.8741 & 152310.1115 & \\
\hline 13995 & 574108.7114 & 152365.0143 & \\
\hline 13996 & 574271.62 & 150866.59 & \\
\hline 13997 & 574521.62 & 150866.59 & \\
\hline 13998 & 574771.62 & 150866.59 & \\
\hline 13999 & 575021.62 & 150866.59 & \\
\hline 14000 & 575271.62 & 150866.59 & \\
\hline 14001 & 575521.62 & 150866.59 & \\
\hline 14002 & 575771.62 & 150866.59 & \\
\hline 14003 & 576021.62 & 150866.59 & \\
\hline 14004 & 576271.62 & 150866.59 & \\
\hline 14005 & 576521.62 & 150866.59 & \\
\hline 14006 & 576771.62 & 150866.59 & \\
\hline 14007 & 577021.62 & 150866.59 & \\
\hline 14008 & 577271.62 & 150866.59 & \\
\hline 14009 & 577521.62 & 150866.59 & \\
\hline 14010 & 577771.62 & 150866.59 & \\
\hline 14011 & 578021.62 & 150866.59 & \\
\hline 14012 & 578271.62 & 150866.59 & \\
\hline 14013 & 578445.5 & 150885.48 & \\
\hline 14014 & 578596.1858 & 150878.6086 & \\
\hline 14015 & 578749.4387 & 150833.0702 & \\
\hline 14016 & 578871.5358 & 150822.9715 & \\
\hline 14017 & 579070.9571 & 150748.4644 & \\
\hline 14018 & 579185.9462 & 150841.295 & \\
\hline 14019 & 580160.8052 & 150833.4328 & \\
\hline 14020 & 580771.62 & 142366.59 & \\
\hline 14021 & 580774.19 & 142205.47 & \\
\hline 14022 & 580771.62 & 142616.59 & \\
\hline 14023 & 580776.81 & 142044.33 & \\
\hline 14024 & 580771.62 & 142866.59 & \\
\hline 14025 & 580779.38 & 141883.2 & \\
\hline 14026 & 580771.62 & 143116.59 & \\
\hline 14027 & 580771.62 & 143366.59 & \\
\hline 14028 & 580771.62 & 143616.59 & \\
\hline 14029 & 580771.62 & 143866.59 & \\
\hline 14030 & 580771.62 & 144116.59 & \\
\hline 14031 & 580771.62 & 144366.59 & \\
\hline 14032 & 580771.62 & 144616.59 & \\
\hline 14033 & 580771.62 & 144866.59 & \\
\hline 14034 & 580771.62 & 145116.59 & \\
\hline 14035 & 580771.62 & 145366.59 & \\
\hline
\end{tabular}




\begin{tabular}{|c|c|c|}
\hline node & X_coord & Y_coord \\
\hline 14036 & $5 \overline{80} 0771.62$ & $1 \overline{4} 5616.59$ \\
\hline 14037 & 580771.62 & 145866.59 \\
\hline 14038 & 580771.62 & 146116.59 \\
\hline 14039 & 580771.62 & 146366.59 \\
\hline 14040 & 580771.62 & 146616.59 \\
\hline 14041 & 580771.62 & 146866.59 \\
\hline 14042 & 580797.5 & 147127.23 \\
\hline 14043 & 580823.44 & 147387.89 \\
\hline 14044 & 580851.8871 & 147584.1016 \\
\hline 14045 & 580816.7257 & 147744.9688 \\
\hline 14046 & 580750.6287 & 148026.9415 \\
\hline 14047 & 580797.8067 & 148287.5422 \\
\hline 14048 & 580721.38 & 148571.3 \\
\hline 14049 & 580902.69 & 148474.47 \\
\hline 14050 & 580602.0758 & 148668.4187 \\
\hline 14051 & 580467.3188 & 148775.8459 \\
\hline 14052 & 583521.62 & 141366.59 \\
\hline 14053 & 583255.75 & 141345.19 \\
\hline 14054 & 583771.62 & 141366.59 \\
\hline 14055 & 582989.88 & 141323.8 \\
\hline 14056 & 584021.62 & 141366.59 \\
\hline 14057 & 582724 & 141302.39 \\
\hline 14058 & 584271.62 & 141366.59 \\
\hline 14059 & 582498.06 & 141331.38 \\
\hline 14060 & 584446.1843 & 141232.633 \\
\hline 14061 & 582273.12 & 140847.86 \\
\hline 14062 & 582272.62 & 141104.11 \\
\hline 14063 & 582272.12 & 141360.34 \\
\hline 14065 & 584874.918 & 141055.3071 \\
\hline 14066 & 585244.9887 & 141342.4029 \\
\hline 14067 & 590095.7612 & 136913.7857 \\
\hline 14068 & 590226.12 & 137020.41 \\
\hline 14070 & 590620.8686 & 136160.1457 \\
\hline 14071 & 590741.38 & 136242.17 \\
\hline 14072 & 590824.5565 & 135897.4692 \\
\hline 14073 & 590969.1979 & 135077.3689 \\
\hline 14074 & 590954.0869 & 135295.6467 \\
\hline 14075 & 591082.1865 & 135495.793 \\
\hline 14076 & 591134.189 & 135007.3373 \\
\hline 14077 & 591109.5 & 135686.3 \\
\hline 14078 & 591177.5972 & 135574.9386 \\
\hline 14079 & 591017.44 & 135825.27 \\
\hline 14080 & 591583.88 & 133934.59 \\
\hline 14081 & 591507.69 & 134223.27 \\
\hline 14082 & 591431.56 & 134511.92 \\
\hline 14083 & 591854.0627 & 133975.7208 \\
\hline 14084 & 591351.7557 & 134836.8332 \\
\hline 14085 & 592271.62 & 133116.59 \\
\hline 14086 & 592271.62 & 133366.59 \\
\hline 14087 & 592232.12 & 133577.31 \\
\hline 14088 & 592521.62 & 133116.59 \\
\hline 14089 & 592192.69 & 133788.02 \\
\hline 14090 & 592771.62 & 131366.59 \\
\hline 14091 & 592771.62 & 131616.59 \\
\hline 14092 & 592771.62 & 131866.59 \\
\hline 14093 & 592771.62 & 132116.59 \\
\hline
\end{tabular}

note: from sac04d created July 1, 2004 


\begin{tabular}{|c|c|c|}
\hline node & X_coord & Y_coord \\
\hline 14094 & 592771.62 & 132366.59 \\
\hline 14095 & 592771.62 & 132616.59 \\
\hline 14096 & 592777.88 & 132872.23 \\
\hline 14097 & 593021.62 & 131366.59 \\
\hline 14098 & 592784.12 & 133127.89 \\
\hline 14099 & 592153.19 & 133998.73 \\
\hline 14100 & 591297.4378 & 134968.1024 \\
\hline 14101 & 590925.44 & 135964.23 \\
\hline 14102 & 593271.62 & 130366.6 \\
\hline 14103 & 593271.62 & 130616.6 \\
\hline 14104 & 593271.62 & 130866.59 \\
\hline 14105 & 593521.62 & 130366.6 \\
\hline 14106 & 593271.62 & 131116.59 \\
\hline 14107 & 593771.62 & 129366.6 \\
\hline 14108 & 593771.62 & 129616.6 \\
\hline 14109 & 593771.62 & 129866.6 \\
\hline 14110 & 594021.62 & 129366.6 \\
\hline 14111 & 593771.62 & 130116.6 \\
\hline 14112 & 594231.44 & 128365.66 \\
\hline 14113 & 594211.38 & 128615.84 \\
\hline 14114 & 594191.38 & 128866.03 \\
\hline 14115 & 594441.25 & 128364.71 \\
\hline 14116 & 594188.69 & 129115.55 \\
\hline 14117 & 594812.1314 & 127403.7432 \\
\hline 14118 & 594783.31 & 127637.8159 \\
\hline 14119 & 594747.19 & 127864.63 \\
\hline 14120 & 595103 & 127417.4 \\
\hline 14121 & 594712.9322 & 128102.327 \\
\hline 14122 & 594651 & 128363.77 \\
\hline 14123 & 594186 & 129365.08 \\
\hline 14124 & 593771.62 & 130366.6 \\
\hline 14125 & 593271.62 & 131366.59 \\
\hline 14126 & 574271.62 & 151116.59 \\
\hline 14127 & 574271.62 & 151366.59 \\
\hline 14128 & 574271.62 & 151616.59 \\
\hline 14129 & 574271.62 & 151866.59 \\
\hline 14130 & 574271.62 & 152116.59 \\
\hline 14131 & 574302.25 & 152363.23 \\
\hline 14132 & 573374.4419 & 152320.5827 \\
\hline 14133 & 573109.31 & 152572.53 \\
\hline 14135 & 573872.7755 & 152517.0114 \\
\hline 14136 & 574038.0284 & 152580.9272 \\
\hline 14137 & 574180.3299 & 152605.6971 \\
\hline 14138 & 574332.94 & 152609.86 \\
\hline 14139 & 574521.62 & 151116.59 \\
\hline 14140 & 574771.62 & 151116.59 \\
\hline 14141 & 575021.62 & 151116.59 \\
\hline 14142 & 575271.62 & 151116.59 \\
\hline 14143 & 575521.62 & 151116.59 \\
\hline 14144 & 575771.62 & 151116.59 \\
\hline 14145 & 576021.62 & 151116.59 \\
\hline 14146 & 576271.62 & 151116.59 \\
\hline 14147 & 576521.62 & 151116.59 \\
\hline 14148 & 576771.62 & 151116.59 \\
\hline 14149 & 577021.62 & 151116.59 \\
\hline 14150 & 577271.62 & 151116.59 \\
\hline
\end{tabular}

note: from sac04d created July 1, 2004 


\begin{tabular}{|c|c|c|c|}
\hline node & X_coord & Y_coord & note: from sac04d created July 1, 2004 \\
\hline 14151 & $5 \overline{7} 7521.62$ & $1 \overline{5} 1116.59$ & \\
\hline 14152 & 577771.62 & 151116.59 & \\
\hline 14153 & 578021.62 & 151116.59 & \\
\hline 14154 & 578271.62 & 151116.59 & \\
\hline 14155 & 578463.81 & 151152.2 & \\
\hline 14156 & 578656.06 & 151187.81 & \\
\hline 14157 & 578819.9015 & 151177.0315 & \\
\hline 14158 & 578932.84 & 151120.7743 & \\
\hline 14160 & 579183.4324 & 150907.2786 & \\
\hline 14161 & 580178.0952 & 151000.0828 & \\
\hline 14162 & 581021.62 & 142366.59 & \\
\hline 14163 & 581023.88 & 142167.92 & \\
\hline 14164 & 581021.62 & 142616.59 & \\
\hline 14165 & 581026.06 & 141969.27 & \\
\hline 14166 & 581021.62 & 142866.59 & \\
\hline 14167 & 581028.31 & 141770.59 & \\
\hline 14168 & 581021.62 & 143116.59 & \\
\hline 14169 & 581021.62 & 143366.59 & \\
\hline 14170 & 581021.62 & 143616.59 & \\
\hline 14171 & 581021.62 & 143866.59 & \\
\hline 14172 & 581021.62 & 144116.59 & \\
\hline 14173 & 581021.62 & 144366.59 & \\
\hline 14174 & 581021.62 & 144616.59 & \\
\hline 14175 & 581021.62 & 144866.59 & \\
\hline 14176 & 581021.62 & 145116.59 & \\
\hline 14177 & 581021.62 & 145366.59 & \\
\hline 14178 & 581021.62 & 145616.59 & \\
\hline 14179 & 581021.62 & 145866.59 & \\
\hline 14180 & 581021.62 & 146116.59 & \\
\hline 14181 & 581021.62 & 146366.59 & \\
\hline 14182 & 581021.62 & 146616.59 & \\
\hline 14183 & 581021.62 & 146866.59 & \\
\hline 14184 & 581073.44 & 147137.89 & \\
\hline 14185 & 581125.19 & 147409.17 & \\
\hline 14186 & 581174.4229 & 147598.0016 & \\
\hline 14187 & 581142.9313 & 147759.7545 & \\
\hline 14189 & 580956.9717 & 148169.5635 & \\
\hline 14190 & 581084.06 & 148377.62 & \\
\hline 14191 & 583521.62 & 141616.59 & \\
\hline 14192 & 583271.62 & 141616.59 & \\
\hline 14193 & 583771.62 & 141616.59 & \\
\hline 14194 & 583021.62 & 141616.59 & \\
\hline 14195 & 584021.62 & 141616.59 & \\
\hline 14196 & 582771.62 & 141616.59 & \\
\hline 14197 & 584387.5983 & 141612.9657 & \\
\hline 14198 & 582521.62 & 141616.59 & \\
\hline 14199 & 584524.1639 & 141469.7225 & \\
\hline 14200 & 582271.62 & 141616.59 & \\
\hline 14201 & 584657.0453 & 141337.3522 & \\
\hline 14202 & 582095.31 & 140934.8 & \\
\hline 14203 & 582070.75 & 141162.06 & \\
\hline 14204 & 582046.19 & 141389.33 & \\
\hline 14205 & 582021.62 & 141616.59 & \\
\hline 14206 & 584768.2307 & 141195.9212 & \\
\hline 14207 & 585135.3002 & 141491.1058 & \\
\hline 14208 & 590728.753 & 136035.1906 & \\
\hline
\end{tabular}




\begin{tabular}{|c|c|c|c|}
\hline node & X_coord & Y_coord & note: from sac04d created July 1,2004 \\
\hline 14209 & $5 \overline{9} 0833.38$ & $1 \overline{3} 6103.2$ & \\
\hline 14211 & 591151.8138 & 135365.9551 & \\
\hline 14212 & 591263.6743 & 135473.8757 & \\
\hline 14213 & 591250.3686 & 135101.2038 & \\
\hline 14214 & 591739.4419 & 134165.1646 & \\
\hline 14215 & 591590.3901 & 134439.77 & \\
\hline 14216 & 591531.9462 & 134692.6394 & \\
\hline 14217 & 592054.4932 & 134126.993 & \\
\hline 14218 & 591621.5 & 135072.59 & \\
\hline 14219 & 591774 & 134896 & \\
\hline 14220 & 591534.38 & 135173.53 & \\
\hline 14221 & 592521.62 & 133366.59 & \\
\hline 14222 & 592493.69 & 133588 & \\
\hline 14223 & 592465.81 & 133809.39 & \\
\hline 14224 & 592790.38 & 133383.53 & \\
\hline 14225 & 592443.3165 & 134027.1757 & \\
\hline 14226 & 593021.62 & 131616.59 & \\
\hline 14227 & 593021.62 & 131866.59 & \\
\hline 14228 & 593021.62 & 132116.59 & \\
\hline 14229 & 593021.62 & 132366.59 & \\
\hline 14230 & 593021.62 & 132616.59 & \\
\hline 14231 & 593034.12 & 132877.89 & \\
\hline 14232 & 593046.62 & 133139.17 & \\
\hline 14233 & 593271.62 & 131616.59 & \\
\hline 14234 & 593059.12 & 133400.47 & \\
\hline 14236 & 591447.25 & 135274.47 & \\
\hline 14237 & 593502 & 130632.37 & \\
\hline 14238 & 593482.44 & 130898.12 & \\
\hline 14239 & 593462.81 & 131124.0225 & \\
\hline 14240 & 593732.38 & 130648.13 & \\
\hline 14241 & 593475.6314 & 131380.0395 & \\
\hline 14242 & 594021.62 & 129616.6 & \\
\hline 14243 & 594021.62 & 129866.6 & \\
\hline 14244 & 594021.62 & 130116.6 & \\
\hline 14245 & 594183.31 & 129614.6 & \\
\hline 14246 & 594021.62 & 130366.6 & \\
\hline 14247 & 594401.12 & 128615.09 & \\
\hline 14248 & 594361.06 & 128865.47 & \\
\hline 14249 & 594355.69 & 129114.52 & \\
\hline 14250 & 594592.7522 & 128646.9589 & \\
\hline 14251 & 594350.38 & 129363.55 & \\
\hline 14252 & 595092.06 & 127650.47 & \\
\hline 14253 & 595081.12 & 127883.53 & \\
\hline 14254 & 595070.19 & 128116.6 & \\
\hline 14255 & 595056.6915 & 128380.3929 & \\
\hline 14256 & 595050.9943 & 128651.9171 & \\
\hline 14257 & 594345 & 129612.6 & \\
\hline 14258 & 593962.81 & 130663.9 & \\
\hline 14259 & 593495.6314 & 131636.0566 & \\
\hline 14260 & 574521.62 & 151366.59 & \\
\hline 14261 & 574521.62 & 151616.59 & \\
\hline 14262 & 574521.62 & 151866.59 & \\
\hline 14263 & 574521.62 & 152116.59 & \\
\hline 14264 & 574521.62 & 152366.59 & \\
\hline 14265 & 574521.62 & 152616.59 & \\
\hline 14266 & 573579.1531 & 152478.4326 & \\
\hline
\end{tabular}




\begin{tabular}{|c|c|c|}
\hline node & X_coord & Y_coord \\
\hline 14267 & $5 \overline{7} 3259.12$ & 152729.41 \\
\hline 14268 & 573743.0131 & 152620.3869 \\
\hline 14269 & 573901.2416 & 152755.8675 \\
\hline 14270 & 574004.4536 & 152908.6231 \\
\hline 14271 & 574213.2914 & 152846.39 \\
\hline 14272 & 574363.56 & 152856.5 \\
\hline 14273 & 574521.62 & 152866.59 \\
\hline 14274 & 574771.62 & 151366.59 \\
\hline 14275 & 575021.62 & 151366.59 \\
\hline 14276 & 575271.62 & 151366.59 \\
\hline 14277 & 575521.62 & 151366.59 \\
\hline 14278 & 575771.62 & 151366.59 \\
\hline 14279 & 576021.62 & 151366.59 \\
\hline 14280 & 576271.62 & 151366.59 \\
\hline 14281 & 576521.62 & 151366.59 \\
\hline 14282 & 576771.62 & 151366.59 \\
\hline 14283 & 577021.62 & 151366.59 \\
\hline 14284 & 577271.62 & 151366.59 \\
\hline 14285 & 577521.62 & 151366.59 \\
\hline 14286 & 577771.62 & 151366.59 \\
\hline 14287 & 578021.62 & 151366.59 \\
\hline 14288 & 578271.62 & 151366.59 \\
\hline 14289 & 578482.12 & 151418.92 \\
\hline 14290 & 578692.69 & 151471.27 \\
\hline 14291 & 578948.494 & 151463.7887 \\
\hline 14292 & 579110.5363 & 151169.801 \\
\hline 14293 & 579200.0923 & 151028.0448 \\
\hline 14294 & 579208.101 & 150971.4501 \\
\hline 14295 & 580094.9368 & 151174.4942 \\
\hline 14296 & 581271.62 & 142366.59 \\
\hline 14297 & 581273.5 & 142130.39 \\
\hline 14298 & 581271.62 & 142616.59 \\
\hline 14299 & 581275.44 & 141894.2 \\
\hline 14300 & 581271.62 & 142866.59 \\
\hline 14301 & 581277.31 & 141658 \\
\hline 14302 & 581271.62 & 143116.59 \\
\hline 14303 & 581271.62 & 143366.59 \\
\hline 14304 & 581271.62 & 143616.59 \\
\hline 14305 & 581271.62 & 143866.59 \\
\hline 14306 & 581271.62 & 144116.59 \\
\hline 14307 & 581271.62 & 144366.59 \\
\hline 14308 & 581271.62 & 144616.59 \\
\hline 14309 & 581271.62 & 144866.59 \\
\hline 14310 & 581271.62 & 145116.59 \\
\hline 14311 & 581271.62 & 145366.59 \\
\hline 14312 & 581271.62 & 145616.59 \\
\hline 14313 & 581271.62 & 145866.59 \\
\hline 14314 & 581271.62 & 146116.59 \\
\hline 14315 & 581271.62 & 146366.59 \\
\hline 14316 & 581271.62 & 146616.59 \\
\hline 14317 & 581271.62 & 146866.59 \\
\hline 14318 & 581349.31 & 147148.53 \\
\hline 14319 & 581427 & 147430.47 \\
\hline 14320 & 581524.6238 & 147708.7857 \\
\hline 14321 & 581398.1259 & 147821.4214 \\
\hline 14322 & 581271.6781 & 147941.3157 \\
\hline
\end{tabular}




\begin{tabular}{|c|c|c|c|}
\hline node & X_coord & Y_coord & note: from sac04d created July 1,2004 \\
\hline 14323 & $5 \overline{8} 1134.1067$ & $1 \overline{4} 8036.758$ & \\
\hline 14324 & 581265.38 & 148280.8 & \\
\hline 14325 & 583521.62 & 141866.59 & \\
\hline 14326 & 583271.62 & 141866.59 & \\
\hline 14327 & 583747.5 & 141847.83 & \\
\hline 14328 & 583021.62 & 141866.59 & \\
\hline 14329 & 583973.38 & 141829.06 & \\
\hline 14330 & 582771.62 & 141866.59 & \\
\hline 14331 & 584242.8018 & 141803.0514 & \\
\hline 14332 & 582521.62 & 141866.59 & \\
\hline 14333 & 584764.9201 & 141917.6829 & \\
\hline 14334 & 584893.5344 & 141771.1986 & \\
\hline 14335 & 584620.4172 & 142092.8915 & \\
\hline 14336 & 582271.62 & 141866.59 & \\
\hline 14337 & 585019.5716 & 141622.1172 & \\
\hline 14338 & 582021.62 & 141866.59 & \\
\hline 14339 & 581905.62 & 141084.97 & \\
\hline 14340 & 581861.56 & 141266.78 & \\
\hline 14341 & 581817.56 & 141448.58 & \\
\hline 14342 & 581773.5 & 141630.39 & \\
\hline 14343 & 581772.88 & 141875.8 & \\
\hline 14344 & 591201.4973 & 135234.2751 & \\
\hline 14345 & 591360.12 & 135375.41 & \\
\hline 14347 & 591748.31 & 134562.933 & \\
\hline 14348 & 591926.5 & 134719.39 & \\
\hline 14349 & 592109.19 & 134295.47 & \\
\hline 14350 & 592710.9349 & 133556.2506 & \\
\hline 14351 & 592617.0725 & 133768.8386 & \\
\hline 14352 & 592590.19 & 133950.62 & \\
\hline 14353 & 592959.0565 & 133528.1454 & \\
\hline 14354 & 592516 & 134140.3 & \\
\hline 14355 & 592656.06 & 134049.89 & \\
\hline 14356 & 592274.6344 & 134164.8736 & \\
\hline 14357 & 592347.1158 & 134248.6986 & \\
\hline 14358 & 593271.62 & 131866.59 & \\
\hline 14359 & 593271.62 & 132116.59 & \\
\hline 14360 & 593271.62 & 132366.59 & \\
\hline 14361 & 593271.62 & 132616.59 & \\
\hline 14362 & 593246.8882 & 132854.5354 & \\
\hline 14363 & 593254.7552 & 133117.8511 & \\
\hline 14364 & 593349.6259 & 133402.9127 & \\
\hline 14365 & 593522.94 & 131964.56 & \\
\hline 14366 & 593198.0573 & 133541.7 & \\
\hline 14367 & 593693.19 & 130929.67 & \\
\hline 14368 & 593657.5643 & 131153.2109 & \\
\hline 14369 & 593666.8776 & 131388.0625 & \\
\hline 14370 & 593903.94 & 130961.2 & \\
\hline 14371 & 593728.7535 & 131735.2582 & \\
\hline 14372 & 594179.31 & 129865.47 & \\
\hline 14373 & 594175.31 & 130116.34 & \\
\hline 14374 & 594171.31 & 130367.2 & \\
\hline 14375 & 594337 & 129864.34 & \\
\hline 14376 & 594118.69 & 130652.27 & \\
\hline 14377 & 594536.2465 & 128937.3864 & \\
\hline 14378 & 594526.3743 & 129151.5254 & \\
\hline 14379 & 594518.3743 & 129343.9084 & \\
\hline
\end{tabular}




\begin{tabular}{|c|c|c|}
\hline node & X_coord & Y_coord \\
\hline 14380 & $5 \overline{95060.69}$ & $1 \overline{2} 8915.7$ \\
\hline 14381 & 594517.563 & 129552.6109 \\
\hline 14382 & 594494.69 & 129848.7027 \\
\hline 14383 & 594066.12 & 130937.34 \\
\hline 14384 & 593774.31 & 132062.53 \\
\hline 14385 & 574771.62 & 151616.59 \\
\hline 14386 & 574771.62 & 151866.59 \\
\hline 14387 & 574771.62 & 152116.59 \\
\hline 14388 & 574771.62 & 152366.59 \\
\hline 14389 & 574771.62 & 152616.59 \\
\hline 14390 & 574771.62 & 152866.59 \\
\hline 14391 & 573357 & 152884.11 \\
\hline 14392 & 573454.94 & 153038.8 \\
\hline 14393 & 573552.81 & 153193.5 \\
\hline 14394 & 574084.9965 & 153053.6946 \\
\hline 14395 & 573641.94 & 153334.33 \\
\hline 14396 & 574233.06 & 153038.11 \\
\hline 14397 & 574386.5 & 153051.55 \\
\hline 14398 & 574540 & 153064.97 \\
\hline 14399 & 574783.88 & 153082.17 \\
\hline 14400 & 575021.62 & 151616.59 \\
\hline 14401 & 575271.62 & 151616.59 \\
\hline 14402 & 575521.62 & 151616.59 \\
\hline 14403 & 575771.62 & 151616.59 \\
\hline 14404 & 576021.62 & 151616.59 \\
\hline 14405 & 576271.62 & 151616.59 \\
\hline 14406 & 576521.62 & 151616.59 \\
\hline 14407 & 576771.62 & 151616.59 \\
\hline 14408 & 577021.62 & 151616.59 \\
\hline 14409 & 577271.62 & 151616.59 \\
\hline 14410 & 577521.62 & 151616.59 \\
\hline 14411 & 577747.31 & 151615.7 \\
\hline 14412 & 577973 & 151614.81 \\
\hline 14413 & 578198.62 & 151613.92 \\
\hline 14414 & 578403.12 & 151647.47 \\
\hline 14415 & 578607.69 & 151681.02 \\
\hline 14416 & 578824.8751 & 151703.687 \\
\hline 14417 & 579393.12 & 151920.2 \\
\hline 14418 & 579626.1799 & 151694.8356 \\
\hline 14419 & 579223.38 & 152080.33 \\
\hline 14420 & 579887.6483 & 151448.8242 \\
\hline 14421 & 581521.62 & 142366.59 \\
\hline 14422 & 581522.88 & 142125.8 \\
\hline 14423 & 581521.62 & 142616.59 \\
\hline 14424 & 581524.19 & 141885 \\
\hline 14425 & 581521.62 & 142866.59 \\
\hline 14426 & 581525.44 & 141644.2 \\
\hline 14427 & 581521.62 & 143116.59 \\
\hline 14428 & 581360.31 & 141567.09 \\
\hline 14429 & 581588.94 & 141507.84 \\
\hline 14430 & 581521.62 & 143366.59 \\
\hline 14431 & 581521.62 & 143616.59 \\
\hline 14432 & 581521.62 & 143866.59 \\
\hline 14433 & 581521.62 & 144116.59 \\
\hline 14434 & 581521.62 & 144366.59 \\
\hline 14435 & 581521.62 & 144616.59 \\
\hline
\end{tabular}

note: from sac04d created July 1, 2004 


\begin{tabular}{|c|c|c|c|}
\hline node & X_coord & Y_coord & note: from sac04d created July 1,2004 \\
\hline 14436 & $5 \overline{8} 1521.62$ & $1 \overline{4} 4866.59$ & \\
\hline 14437 & 581521.62 & 145116.59 & \\
\hline 14438 & 581521.62 & 145366.59 & \\
\hline 14439 & 581531 & 145631.53 & \\
\hline 14440 & 581540.44 & 145896.45 & \\
\hline 14441 & 581549.81 & 146161.39 & \\
\hline 14442 & 581528.44 & 146396.89 & \\
\hline 14443 & 581507 & 146632.39 & \\
\hline 14444 & 581539.7399 & 146849.85 & \\
\hline 14445 & 581618.6213 & 147081.0444 & \\
\hline 14446 & 581664.06 & 147356.06 & \\
\hline 14447 & 581762.3108 & 147627.3224 & \\
\hline 14448 & 581706.38 & 148045.3 & \\
\hline 14449 & 581935.8871 & 147921.0828 & \\
\hline 14450 & 581559.38 & 148123.8 & \\
\hline 14451 & 581412.38 & 148202.3 & \\
\hline 14452 & 583490.6944 & 142065.0473 & \\
\hline 14453 & 583248.4258 & 142101.1272 & \\
\hline 14454 & 583731.1714 & 142032.6715 & \\
\hline 14455 & 583021.62 & 142116.59 & \\
\hline 14456 & 583930.3443 & 142005.4501 & \\
\hline 14457 & 582771.62 & 142116.59 & \\
\hline 14458 & 584152.3102 & 141996.7514 & \\
\hline 14459 & 582521.62 & 142116.59 & \\
\hline 14460 & 584470.81 & 142268.09 & \\
\hline 14461 & 582271.62 & 142116.59 & \\
\hline 14462 & 582021.62 & 142116.59 & \\
\hline 14463 & 581772.25 & 142121.19 & \\
\hline 14464 & 581716 & 141235.12 & \\
\hline 14465 & 581652.5 & 141371.48 & \\
\hline 14466 & 591933.937 & 134418.7392 & \\
\hline 14467 & 592079 & 134542.8 & \\
\hline 14468 & 592211.8043 & 134393.1572 & \\
\hline 14470 & 592731.687 & 133866.8457 & \\
\hline 14471 & 592796.06 & 133959.5 & \\
\hline 14472 & 593041.0022 & 133669.6243 & \\
\hline 14473 & 593496.19 & 132182.02 & \\
\hline 14474 & 593469.5 & 132399.47 & \\
\hline 14475 & 593442.75 & 132616.92 & \\
\hline 14476 & 593408.0076 & 132811.6098 & \\
\hline 14477 & 593404.1319 & 133075.1716 & \\
\hline 14478 & 593465.424 & 133231.806 & \\
\hline 14479 & 593440.19 & 133543.7 & \\
\hline 14480 & 593613.1756 & 133426.4928 & \\
\hline 14481 & 593272.19 & 133652.17 & \\
\hline 14482 & 593720.81 & 132247.44 & \\
\hline 14483 & 593104.12 & 133760.62 & \\
\hline 14484 & 593846.9322 & 131178.765 & \\
\hline 14485 & 593843.6966 & 131410.5729 & \\
\hline 14486 & 593874.832 & 131743.8517 & \\
\hline 14487 & 594013.5 & 131178.9182 & \\
\hline 14488 & 594023.8078 & 132185.8702 & \\
\hline 14489 & 594328.94 & 130116.06 & \\
\hline 14490 & 594320.94 & 130367.8 & \\
\hline 14491 & 594274.62 & 130640.63 & \\
\hline 14492 & 594482.62 & 130061.4352 & \\
\hline
\end{tabular}




\begin{tabular}{|c|c|c|c|}
\hline node & X_coord & Y_coord & note: from sac04d created July 1, 2004 \\
\hline 14493 & $5 \overline{9} 4228.25$ & $1 \overline{3} 0913.46$ & \\
\hline 14494 & 595070.75 & 129115.44 & \\
\hline 14495 & 595080.75 & 129315.16 & \\
\hline 14496 & 595090.81 & 129514.9 & \\
\hline 14497 & 595102.5985 & 129810.56 & \\
\hline 14498 & 595119.6013 & 130103.6529 & \\
\hline 14499 & 594181.94 & 131186.3 & \\
\hline 14500 & 593936.3792 & 132340.0424 & \\
\hline 14501 & 575021.62 & 151866.59 & \\
\hline 14502 & 575021.62 & 152116.59 & \\
\hline 14503 & 575021.62 & 152366.59 & \\
\hline 14504 & 575021.62 & 152616.59 & \\
\hline 14505 & 575021.62 & 152866.59 & \\
\hline 14506 & 575027.75 & 153099.39 & \\
\hline 14507 & 574111.62 & 153227.5873 & \\
\hline 14508 & 573731 & 153475.17 & \\
\hline 14509 & 574260.5 & 153229.84 & \\
\hline 14510 & 574409.44 & 153246.59 & \\
\hline 14511 & 574558.31 & 153263.33 & \\
\hline 14512 & 574796.06 & 153297.75 & \\
\hline 14513 & 575033.88 & 153332.17 & \\
\hline 14514 & 575271.62 & 151866.59 & \\
\hline 14515 & 575521.62 & 151866.59 & \\
\hline 14516 & 575771.62 & 151866.59 & \\
\hline 14517 & 576021.62 & 151866.59 & \\
\hline 14518 & 576271.62 & 151866.59 & \\
\hline 14519 & 576521.62 & 151866.59 & \\
\hline 14520 & 576771.62 & 151866.59 & \\
\hline 14521 & 577021.62 & 151866.59 & \\
\hline 14522 & 577271.62 & 151866.59 & \\
\hline 14523 & 577521.62 & 151866.59 & \\
\hline 14524 & 577722.94 & 151864.81 & \\
\hline 14525 & 577924.31 & 151863.05 & \\
\hline 14526 & 578125.69 & 151861.27 & \\
\hline 14527 & 578324.19 & 151876.02 & \\
\hline 14528 & 578522.62 & 151890.78 & \\
\hline 14529 & 578719.3078 & 151916.403 & \\
\hline 14530 & 579053.62 & 152240.47 & \\
\hline 14531 & 581771.62 & 142366.59 & \\
\hline 14532 & 581771.62 & 142616.59 & \\
\hline 14533 & 581771.62 & 142866.59 & \\
\hline 14534 & 581771.62 & 143116.59 & \\
\hline 14535 & 581771.62 & 143366.59 & \\
\hline 14536 & 581443.31 & 141476.2 & \\
\hline 14537 & 581771.62 & 143616.59 & \\
\hline 14538 & 581771.62 & 143866.59 & \\
\hline 14539 & 581771.62 & 144116.59 & \\
\hline 14540 & 581771.62 & 144366.59 & \\
\hline 14541 & 581771.62 & 144616.59 & \\
\hline 14542 & 581771.62 & 144866.59 & \\
\hline 14543 & 581771.62 & 145116.59 & \\
\hline 14544 & 581771.62 & 145366.59 & \\
\hline 14545 & 581790.38 & 145646.47 & \\
\hline 14546 & 581809.19 & 145926.33 & \\
\hline 14547 & 581830.5171 & 146141.7716 & \\
\hline 14548 & 581813.5385 & 146316.3831 & \\
\hline
\end{tabular}




\begin{tabular}{|c|c|c|}
\hline node & X_coord & Y_coord \\
\hline 14549 & 581781.0371 & 146552.8459 \\
\hline 14550 & 581800.1284 & 146791.8859 \\
\hline 14551 & 581900.8884 & 146946.5631 \\
\hline 14553 & 581978.2519 & 147513.2302 \\
\hline 14554 & 582165.4043 & 147776.2785 \\
\hline 14555 & 583449.4602 & 142235.156 \\
\hline 14556 & 583191.7287 & 142333.0872 \\
\hline 14557 & 583660.6529 & 142194.3288 \\
\hline 14558 & 583021.62 & 142366.59 \\
\hline 14559 & 583871.7857 & 142181.8402 \\
\hline 14560 & 582771.62 & 142366.59 \\
\hline 14561 & 584063.6808 & 142221.2581 \\
\hline 14562 & 582521.62 & 142366.59 \\
\hline 14563 & 584313.4214 & 142445.8857 \\
\hline 14564 & 582271.62 & 142366.59 \\
\hline 14565 & 582021.62 & 142366.59 \\
\hline 14566 & 581526.31 & 141385.3 \\
\hline 14567 & 592880.3827 & 133781.2392 \\
\hline 14568 & 592936.12 & 133869.09 \\
\hline 14569 & 593667.38 & 132432.36 \\
\hline 14570 & 593613.88 & 132617.27 \\
\hline 14571 & 593585.4965 & 132741.5117 \\
\hline 14573 & 593544.9989 & 133122.3027 \\
\hline 14574 & 593778.3699 & 133298.9971 \\
\hline 14575 & 593850.6927 & 132490.6002 \\
\hline 14576 & 593985.443 & 131419.1787 \\
\hline 14577 & 593989.955 & 131724.687 \\
\hline 14578 & 594095.9978 & 132019.3224 \\
\hline 14579 & 594177.94 & 131398.78 \\
\hline 14580 & 594299.19 & 132356.59 \\
\hline 14581 & 594395.38 & 132181.27 \\
\hline 14582 & 594219 & 132502.73 \\
\hline 14583 & 594486.9294 & 130246.9853 \\
\hline 14584 & 594450.4338 & 130545.6406 \\
\hline 14585 & 594403.1251 & 130835.2352 \\
\hline 14586 & 595041.19 & 130401.9 \\
\hline 14587 & 594357.5586 & 131126.6419 \\
\hline 14588 & 594325.123 & 131331.2951 \\
\hline 14589 & 594138.88 & 132648.86 \\
\hline 14590 & 575271.62 & 152116.59 \\
\hline 14591 & 575271.62 & 152366.59 \\
\hline 14592 & 575271.62 & 152616.59 \\
\hline 14593 & 575271.62 & 152866.59 \\
\hline 14594 & 575271.62 & 153116.59 \\
\hline 14595 & 575271.62 & 153366.59 \\
\hline 14596 & 574147.3143 & 153408.7486 \\
\hline 14597 & 573820.12 & 153616 \\
\hline 14598 & 574334.3885 & 153431.8685 \\
\hline 14599 & 574514.8484 & 153490.6056 \\
\hline 14600 & 574664.3127 & 153502.9342 \\
\hline 14601 & 574808.31 & 153513.33 \\
\hline 14602 & 575040 & 153564.97 \\
\hline 14603 & 575271.62 & 153616.59 \\
\hline 14604 & 575521.62 & 152116.59 \\
\hline 14605 & 575771.62 & 152116.59 \\
\hline 14606 & 576021.62 & 152116.59 \\
\hline
\end{tabular}




\begin{tabular}{|c|c|c|}
\hline node & X_coord & Y_coord \\
\hline 14607 & $5 \overline{7} 6271.62$ & $1 \overline{5} 2116.59$ \\
\hline 14608 & 576521.62 & 152116.59 \\
\hline 14609 & 576771.62 & 152116.59 \\
\hline 14610 & 577021.62 & 152116.59 \\
\hline 14611 & 577271.62 & 152116.59 \\
\hline 14612 & 577521.62 & 152116.59 \\
\hline 14613 & 577698.62 & 152113.92 \\
\hline 14614 & 577875.69 & 152111.27 \\
\hline 14615 & 578052.69 & 152108.59 \\
\hline 14616 & 578245.19 & 152104.56 \\
\hline 14617 & 578437.62 & 152100.53 \\
\hline 14618 & 578619.247 & 152121.8702 \\
\hline 14619 & 578883.88 & 152400.59 \\
\hline 14620 & 582021.62 & 142616.59 \\
\hline 14621 & 582021.62 & 142866.59 \\
\hline 14622 & 582021.62 & 143116.59 \\
\hline 14623 & 582021.62 & 143366.59 \\
\hline 14624 & 582021.62 & 143616.59 \\
\hline 14625 & 582021.62 & 143866.59 \\
\hline 14626 & 582021.62 & 144116.59 \\
\hline 14627 & 582021.62 & 144366.59 \\
\hline 14628 & 582021.62 & 144616.59 \\
\hline 14629 & 582021.62 & 144866.59 \\
\hline 14630 & 582021.62 & 145116.59 \\
\hline 14631 & 582021.62 & 145366.59 \\
\hline 14632 & 582049.81 & 145661.39 \\
\hline 14633 & 582093.5661 & 145872.6028 \\
\hline 14634 & 582325.3914 & 146038.9773 \\
\hline 14635 & 582219.5317 & 146201.9854 \\
\hline 14636 & 582135.4679 & 146381.303 \\
\hline 14637 & 582189.0683 & 146544.3112 \\
\hline 14638 & 582241.5271 & 146707.2347 \\
\hline 14639 & 582272.2199 & 146917.2844 \\
\hline 14640 & 582279.3746 & 147377.4022 \\
\hline 14641 & 582433.5785 & 147597.9515 \\
\hline 14642 & 583374.7232 & 142503.196 \\
\hline 14643 & 583189.1516 & 142575.3558 \\
\hline 14644 & 583547.6603 & 142449.2816 \\
\hline 14645 & 583021.62 & 142616.59 \\
\hline 14646 & 583769.493 & 142369.5959 \\
\hline 14647 & 582771.62 & 142616.59 \\
\hline 14648 & 583958.7512 & 142369.6725 \\
\hline 14649 & 582521.62 & 142616.59 \\
\hline 14650 & 584232.31 & 142541.23 \\
\hline 14651 & 582271.62 & 142616.59 \\
\hline 14652 & 593779.5635 & 132639.3359 \\
\hline 14653 & 593717.6314 & 132758.3873 \\
\hline 14654 & 593662.9378 & 132881.073 \\
\hline 14655 & 593620.9294 & 133007.373 \\
\hline 14656 & 593866.31 & 133145.7 \\
\hline 14657 & 594058.69 & 132795 \\
\hline 14659 & 594169.94 & 131823.77 \\
\hline 14660 & 594491.62 & 132005.92 \\
\hline 14661 & 594287.2508 & 131532.304 \\
\hline 14662 & 594952.44 & 130688.46 \\
\hline 14663 & 594863.75 & 130975.03 \\
\hline
\end{tabular}

note: from sac04d created July 1, 2004 


\begin{tabular}{|c|c|c|c|}
\hline node & X_coord & Y_coord & note: from sac04d created July 1, 2004 \\
\hline 14664 & $5 \overline{9} 4775$ & $1 \overline{13} 1261.59$ & \\
\hline 14665 & 594712.62 & 131451.27 & \\
\hline 14666 & 594663.0757 & 131643.4971 & \\
\hline 14667 & 575521.62 & 152366.59 & \\
\hline 14668 & 575521.62 & 152616.59 & \\
\hline 14669 & 575521.62 & 152866.59 & \\
\hline 14670 & 575521.62 & 153116.59 & \\
\hline 14671 & 575521.62 & 153366.59 & \\
\hline 14672 & 575521.62 & 153616.59 & \\
\hline 14673 & 574206.3327 & 153577.0543 & \\
\hline 14674 & 573909.25 & 153756.83 & \\
\hline 14675 & 574360.2756 & 153591.033 & \\
\hline 14676 & 574550.7812 & 153684.9129 & \\
\hline 14677 & 574674.2812 & 153747.8672 & \\
\hline 14678 & 574798.9571 & 153777.8744 & \\
\hline 14679 & 575034.5 & 153854.27 & \\
\hline 14680 & 575272.5 & 153899.73 & \\
\hline 14681 & 575522.25 & 153888.69 & \\
\hline 14682 & 575771.62 & 152366.59 & \\
\hline 14683 & 576021.62 & 152366.59 & \\
\hline 14684 & 576271.62 & 152366.59 & \\
\hline 14685 & 576521.62 & 152366.59 & \\
\hline 14686 & 576771.62 & 152366.59 & \\
\hline 14687 & 577021.62 & 152366.59 & \\
\hline 14688 & 577271.62 & 152366.59 & \\
\hline 14689 & 577521.62 & 152366.59 & \\
\hline 14690 & 577712 & 152356.75 & \\
\hline 14691 & 577902.44 & 152346.94 & \\
\hline 14692 & 578043.8444 & 152337.09 & \\
\hline 14693 & 578205.6473 & 152233.8087 & \\
\hline 14694 & 578411.3115 & 152225.8515 & \\
\hline 14695 & 578582.3757 & 152227.2673 & \\
\hline 14696 & 578808.0786 & 152463.1615 & \\
\hline 14697 & 582271.62 & 142866.59 & \\
\hline 14698 & 582271.62 & 143116.59 & \\
\hline 14699 & 582271.62 & 143366.59 & \\
\hline 14700 & 582271.62 & 143616.59 & \\
\hline 14701 & 582271.62 & 143866.59 & \\
\hline 14702 & 582297.88 & 144117.78 & \\
\hline 14703 & 582324.19 & 144368.97 & \\
\hline 14704 & 582350.44 & 144620.16 & \\
\hline 14705 & 582324.19 & 144868.97 & \\
\hline 14706 & 582300.4571 & 145073.9687 & \\
\hline 14707 & 582274.1971 & 145248.0417 & \\
\hline 14708 & 582238.6858 & 145490.8246 & \\
\hline 14709 & 582275.3842 & 145782.573 & \\
\hline 14710 & 582476.2087 & 145906.9567 & \\
\hline 14711 & 583454.31 & 146327.5 & \\
\hline 14712 & 583495.69 & 146166.06 & \\
\hline 14713 & 583404.56 & 146521.23 & \\
\hline 14714 & 583354.88 & 146714.97 & \\
\hline 14715 & 583305.12 & 146908.7 & \\
\hline 14716 & 583122.8226 & 147145.3329 & \\
\hline 14717 & 582775.6584 & 147369.05 & \\
\hline 14718 & 583441.7287 & 142861.4357 & \\
\hline 14719 & 583271.62 & 142866.59 & \\
\hline
\end{tabular}




\begin{tabular}{|c|c|c|c|}
\hline node & X_coord & Y_coord & note: from sac04d created July 1, 2004 \\
\hline 14720 & $5 \overline{8} 3550.5688$ & 142750.6229 & \\
\hline 14721 & 583021.62 & 142866.59 & \\
\hline 14723 & 582771.62 & 142866.59 & \\
\hline 14724 & 583862.2863 & 142524.9917 & \\
\hline 14725 & 582521.62 & 142866.59 & \\
\hline 14726 & 584174.4628 & 142657.2014 & \\
\hline 14727 & 593994.56 & 132911.91 & \\
\hline 14728 & 593930.44 & 133028.8 & \\
\hline 14729 & 594258.4294 & 131669.9073 & \\
\hline 14730 & 594587.81 & 131830.59 & \\
\hline 14731 & 575771.62 & 152616.59 & \\
\hline 14732 & 575771.62 & 152866.59 & \\
\hline 14733 & 575771.62 & 153116.59 & \\
\hline 14734 & 575771.62 & 153366.59 & \\
\hline 14735 & 575771.62 & 153616.59 & \\
\hline 14736 & 575771.94 & 153877.64 & \\
\hline 14737 & 574234.6577 & 153749.6476 & \\
\hline 14738 & 573998.38 & 153897.67 & \\
\hline 14740 & 574519.7784 & 153966.8629 & \\
\hline 14741 & 574655.9712 & 154064.97 & \\
\hline 14742 & 574784.44 & 154104.27 & \\
\hline 14743 & 575028.94 & 154143.56 & \\
\hline 14744 & 575273.44 & 154182.86 & \\
\hline 14745 & 575522.81 & 154160.77 & \\
\hline 14746 & 575772.19 & 154138.69 & \\
\hline 14747 & 576021.62 & 152616.59 & \\
\hline 14748 & 576271.62 & 152616.59 & \\
\hline 14749 & 576521.62 & 152616.59 & \\
\hline 14750 & 576771.62 & 152616.59 & \\
\hline 14751 & 577021.62 & 152616.59 & \\
\hline 14752 & 577271.62 & 152616.59 & \\
\hline 14753 & 577521.62 & 152616.59 & \\
\hline 14754 & 577725.38 & 152599.59 & \\
\hline 14755 & 577929.12 & 152582.59 & \\
\hline 14756 & 578091.6458 & 152593.9385 & \\
\hline 14757 & 578233.1701 & 152497.0385 & \\
\hline 14759 & 578538.3157 & 152354.4002 & \\
\hline 14760 & 578739.9586 & 152538.5986 & \\
\hline 14761 & 582521.62 & 143116.59 & \\
\hline 14762 & 582521.62 & 143366.59 & \\
\hline 14763 & 582521.62 & 143616.59 & \\
\hline 14764 & 582521.62 & 143866.59 & \\
\hline 14765 & 582592.23 & 144178.2442 & \\
\hline 14766 & 582647.3671 & 144453.8284 & \\
\hline 14767 & 582679.31 & 144623.73 & \\
\hline 14768 & 582626.75 & 144871.36 & \\
\hline 14769 & 582584.4985 & 145059.6958 & \\
\hline 14770 & 582549.9685 & 145224.8475 & \\
\hline 14771 & 582510.0799 & 145366.6376 & \\
\hline 14773 & 582645.0775 & 145773.114 & \\
\hline 14774 & 583537.12 & 146004.64 & \\
\hline 14775 & 583554.2389 & 143076.7225 & \\
\hline 14776 & 583297.3914 & 143108.8586 & \\
\hline 14777 & 583631.9802 & 142920.9412 & \\
\hline 14778 & 583021.62 & 143116.59 & \\
\hline 14779 & 583720.2751 & 142769.1855 & \\
\hline
\end{tabular}




\begin{tabular}{|c|c|c|}
\hline node & X_coord & Y_coord \\
\hline 14780 & 582771.62 & 143116.59 \\
\hline 14781 & 583802.7696 & 142628.8671 \\
\hline 14782 & 584129.4313 & 142768.0085 \\
\hline 14783 & 576021.62 & 152866.59 \\
\hline 14784 & 576021.62 & 153116.59 \\
\hline 14785 & 576021.62 & 153366.59 \\
\hline 14786 & 576021.62 & 153616.59 \\
\hline 14787 & 576021.62 & 153866.59 \\
\hline 14788 & 576021.62 & 154116.59 \\
\hline 14789 & 574270.4819 & 153921.0132 \\
\hline 14790 & 574087.5 & 154038.5 \\
\hline 14791 & 574328.8854 & 154067.4411 \\
\hline 14792 & 574410.7554 & 154200.7111 \\
\hline 14793 & 574510.747 & 154335.7833 \\
\hline 14794 & 574765.2514 & 154551.9515 \\
\hline 14795 & 575239.0871 & 154574.2085 \\
\hline 14796 & 575332.2991 & 154567.481 \\
\hline 14797 & 575407.4617 & 154550.6504 \\
\hline 14798 & 575526.0462 & 154512.0839 \\
\hline 14799 & 575827.7189 & 154431.8278 \\
\hline 14800 & 576271.62 & 152866.59 \\
\hline 14801 & 576521.62 & 152866.59 \\
\hline 14802 & 576771.62 & 152866.59 \\
\hline 14803 & 577021.62 & 152866.59 \\
\hline 14804 & 577271.62 & 152866.59 \\
\hline 14805 & 577521.62 & 152866.59 \\
\hline 14806 & 577738.75 & 152842.42 \\
\hline 14807 & 577963.6114 & 152800.23 \\
\hline 14808 & 578147.6298 & 152835.7697 \\
\hline 14809 & 578263.1284 & 152712.261 \\
\hline 14810 & 578375.0627 & 152592.3667 \\
\hline 14811 & 578485.6893 & 152452.6303 \\
\hline 14812 & 578679.62 & 152619.2 \\
\hline 14813 & 582771.62 & 143366.59 \\
\hline 14814 & 582771.62 & 143616.59 \\
\hline 14815 & 582727.8087 & 143858.8586 \\
\hline 14816 & 582731.8917 & 144153.6628 \\
\hline 14817 & 582774.6818 & 144422.6956 \\
\hline 14818 & 583000.8714 & 144750.5269 \\
\hline 14819 & 582920.2492 & 144960.7137 \\
\hline 14820 & 582872.1859 & 145149.1546 \\
\hline 14821 & 582826.4676 & 145310.8585 \\
\hline 14822 & 582807.4747 & 145411.579 \\
\hline 14823 & 582792.649 & 145502.5554 \\
\hline 14824 & 582736.4474 & 145616.2876 \\
\hline 14825 & 583578.5 & 145843.2 \\
\hline 14826 & 583933.5371 & 143235.2628 \\
\hline 14827 & 583999.6742 & 143086.3871 \\
\hline 14828 & 583448.7416 & 143356.3114 \\
\hline 14829 & 583211 & 143364.58 \\
\hline 14830 & 583827.6142 & 143500.71 \\
\hline 14831 & 582991.31 & 143365.58 \\
\hline 14832 & 584063.2942 & 142922.0385 \\
\hline 14833 & 576257.62 & 153112.08 \\
\hline 14834 & 576243.56 & 153357.58 \\
\hline 14835 & 576229.56 & 153603.06 \\
\hline
\end{tabular}

note: from sac04d created July 1, 2004 


\begin{tabular}{|c|c|c|c|}
\hline node & X_coord & Y_coord & note: from sac04d created July 1, 2004 \\
\hline 14836 & $5 \overline{7} 6217.56$ & $1 \overline{5} 3832.55$ & \\
\hline 14837 & 576205.5 & 154062.02 & \\
\hline 14838 & 576088.3947 & 154344.0526 & \\
\hline 14839 & 574184.2086 & 154173.2143 & \\
\hline 14840 & 574293.8029 & 154300.2171 & \\
\hline 14841 & 574400.81 & 154427.2 & \\
\hline 14842 & 574617.5 & 154680.47 & \\
\hline 14843 & 574834.12 & 154933.73 & \\
\hline 14844 & 575050.81 & 155187 & \\
\hline 14845 & 575349.0386 & 155271.3954 & \\
\hline 14846 & 575701.3871 & 155165.0727 & \\
\hline 14847 & 576022.81 & 155076.8 & \\
\hline 14848 & 576290.5343 & 155000.9027 & \\
\hline 14849 & 576493.56 & 153107.58 & \\
\hline 14850 & 576729.56 & 153103.06 & \\
\hline 14851 & 576984.44 & 153100.39 & \\
\hline 14852 & 577239.31 & 153097.7 & \\
\hline 14853 & 577458.1101 & 153076.99 & \\
\hline 14854 & 577662.4958 & 153037.6757 & \\
\hline 14855 & 577882.4043 & 152959.6944 & \\
\hline 14856 & 578056.0649 & 152976.4754 & \\
\hline 14857 & 578370.31 & 153012 & \\
\hline 14858 & 578473.44 & 152881.06 & \\
\hline 14859 & 578267.19 & 153142.94 & \\
\hline 14860 & 578576.5 & 152750.14 & \\
\hline 14861 & 582960.94 & 143614.58 & \\
\hline 14862 & 582904.8486 & 143868.7143 & \\
\hline 14863 & 582868.2602 & 144078.2357 & \\
\hline 14864 & 582914.2002 & 144388.2755 & \\
\hline 14865 & 583064.6857 & 144613.668 & \\
\hline 14866 & 583644.6228 & 144759.2443 & \\
\hline 14867 & 583644.9242 & 144628.7314 & \\
\hline 14868 & 583645.5042 & 144956.3771 & \\
\hline 14869 & 583648.9028 & 145153.5 & \\
\hline 14870 & 583649.7743 & 145368.6628 & \\
\hline 14871 & 583658.6399 & 145513.9529 & \\
\hline 14872 & 583618.6 & 145679.88 & \\
\hline 14873 & 583361.4359 & 143617.7786 & \\
\hline 14874 & 583150.31 & 143612.55 & \\
\hline 14875 & 583719.1142 & 143766.1471 & \\
\hline 14876 & 576465.5 & 153348.55 & \\
\hline 14877 & 576437.44 & 153589.53 & \\
\hline 14878 & 576413.38 & 153798.48 & \\
\hline 14879 & 576335.2601 & 154028.0571 & \\
\hline 14880 & 576291.0114 & 154294.3129 & \\
\hline 14881 & 576578.8656 & 154919.8712 & \\
\hline 14882 & 576687.44 & 153339.53 & \\
\hline 14883 & 576947.19 & 153334.17 & \\
\hline 14884 & 577207 & 153328.83 & \\
\hline 14885 & 577404.8987 & 153331.2014 & \\
\hline 14886 & 577557.953 & 153287.0413 & \\
\hline 14888 & 577953.687 & 153109.9524 & \\
\hline 14889 & 578164 & 153273.86 & \\
\hline 14890 & 583089.69 & 143860.53 & \\
\hline 14891 & 583055.7488 & 144028.1789 & \\
\hline 14893 & 583121.1914 & 144484.0678 & \\
\hline
\end{tabular}




\begin{tabular}{|c|c|c|c|}
\hline node & X_coord & Y_coord & note: from sac04d created July 1, 2004 \\
\hline 14894 & $5 \overline{8} 3640.0613$ & $1 \overline{4} 4493.0443$ & \\
\hline 14895 & 583274.0602 & 143964.4175 & \\
\hline 14896 & 583628.6542 & 144021.2957 & \\
\hline 14897 & 576645.38 & 153576 & \\
\hline 14898 & 576611.8871 & 153718.0515 & \\
\hline 14899 & 576547.4786 & 153906.4715 & \\
\hline 14900 & 576432.0847 & 154257.2783 & \\
\hline 14901 & 576810.5 & 154694.5 & \\
\hline 14902 & 576899.6915 & 153537.0444 & \\
\hline 14903 & 577205.6156 & 153508.3973 & \\
\hline 14904 & 577401.2546 & 153588.1532 & \\
\hline 14905 & 577539.7525 & 153476.2589 & \\
\hline 14906 & 577690.8049 & 153368.7439 & \\
\hline 14907 & 577844.565 & 153239.2924 & \\
\hline 14908 & 578060.88 & 153404.8 & \\
\hline 14909 & 583244.9994 & 144114.9653 & \\
\hline 14910 & 583215.8686 & 144231.0921 & \\
\hline 14911 & 583176.3804 & 144355.0219 & \\
\hline 14912 & 583640.3527 & 144367.6857 & \\
\hline 14913 & 583640.3084 & 144141.92 & \\
\hline 14914 & 576798.9972 & 153664.0873 & \\
\hline 14915 & 576690.5716 & 153876.1958 & \\
\hline 14916 & 576594.1406 & 154164.7588 & \\
\hline 14917 & 576955.19 & 154556.47 & \\
\hline 14918 & 577081.5214 & 153674.5715 & \\
\hline 14919 & 577246.6033 & 153695.4459 & \\
\hline 14920 & 577678.81 & 153866.3 & \\
\hline 14921 & 577811.3443 & 153720.2014 & \\
\hline 14922 & 577534.06 & 154004.33 & \\
\hline 14923 & 577936.0771 & 153566.3514 & \\
\hline 14924 & 583639.007 & 144252.2157 & \\
\hline 14926 & 576768.5505 & 154055.5588 & \\
\hline 14927 & 577099.94 & 154418.44 & \\
\hline 14928 & 577080.0219 & 153838.7912 & \\
\hline 14929 & 577389.38 & 154142.38 & \\
\hline 14930 & 576938.4195 & 153958.1673 & \\
\hline 14931 & 577244.62 & 154280.41 & \\
\hline 14932 & 566546.625 & 145629.6549 & \\
\hline 14933 & 566742.8886 & 145747.3193 & \\
\hline 14934 & 566708.9847 & 145639.644 & \\
\hline 14935 & 566601.1461 & 145729.7621 & \\
\hline 14936 & 568189.9547 & 146411.8196 & \\
\hline 14937 & 568048.2121 & 146414.3967 & \\
\hline 14938 & 568213.1489 & 146532.945 & \\
\hline 14939 & 568068.8292 & 146517.4822 & \\
\hline 14940 & 569037.8328 & 147076.721 & \\
\hline 14941 & 568932.1702 & 147084.4524 & \\
\hline 14942 & 569055.8728 & 147205.5778 & \\
\hline 14943 & 568968.2501 & 147200.4236 & \\
\hline 14944 & 569769.7398 & 147860.1707 & \\
\hline 14945 & 569653.7686 & 147860.1707 & \\
\hline 14946 & 569785.2026 & 147981.2961 & \\
\hline 14947 & 569671.8086 & 147970.9876 & \\
\hline 14948 & 570509.6976 & 148602.3862 & \\
\hline 14949 & 570403.7155 & 148586.9234 & \\
\hline 14950 & 570529.3492 & 148709.0144 & \\
\hline
\end{tabular}




\begin{tabular}{|c|c|c|c|}
\hline node & X_coord & Y_coord & note: from sac04d created July 1, 2004 \\
\hline 14951 & $5 \overline{7} 0425.7809$ & $1 \overline{4} 8659.4843$ & \\
\hline 14952 & 571238.708 & 149429.6472 & \\
\hline 14953 & 571119.0308 & 149432.7071 & \\
\hline 14954 & 571224.2107 & 149563.0939 & \\
\hline 14955 & 571133.0454 & 149537.887 & \\
\hline 14956 & 572135.5517 & 150743.9872 & \\
\hline 14957 & 572036.0906 & 150744.0688 & \\
\hline 14958 & 572149.0835 & 150878.5627 & \\
\hline 14959 & 572062.9908 & 150851.7442 & \\
\hline 14960 & 572826.2245 & 151555.7854 & \\
\hline 14961 & 572710.2533 & 151542.8997 & \\
\hline 14962 & 572823.6474 & 151658.8709 & \\
\hline 14963 & 572728.2933 & 151651.1395 & \\
\hline 14964 & 573697.2969 & 152336.658 & \\
\hline 14965 & 573576.1714 & 152339.2351 & \\
\hline 14966 & 573725.6454 & 152465.5148 & \\
\hline 14967 & 573622.5599 & 152439.7435 & \\
\hline 14968 & 574444.6667 & 153769.5463 & \\
\hline 14969 & 574346.7354 & 153738.6206 & \\
\hline 14970 & 574439.5124 & 153913.8659 & \\
\hline 14972 & 574344.1583 & 153867.4775 & \\
\hline 14973 & 576864.5985 & 153787.5862 & \\
\hline 14974 & 576823.3643 & 153882.9403 & \\
\hline 14975 & 576975.4154 & 153808.2033 & \\
\hline 14976 & 576903.2555 & 153885.5174 & \\
\hline 14977 & 577735.6709 & 153102.0677 & \\
\hline 14978 & 577691.8595 & 153215.4618 & \\
\hline 14979 & 577831.0249 & 153104.6449 & \\
\hline 14980 & 577812.985 & 153207.7304 & \\
\hline 14981 & 578318.1039 & 152321.1952 & \\
\hline 14982 & 578336.1438 & 152429.4349 & \\
\hline 14983 & 578416.0351 & 152321.1952 & \\
\hline 14984 & 578434.075 & 152411.395 & \\
\hline 14985 & 579065.4736 & 150841.9184 & \\
\hline 14986 & 578972.6967 & 150883.1526 & \\
\hline 14987 & 579024.2395 & 150981.0838 & \\
\hline 14988 & 579083.5136 & 150937.2725 & \\
\hline 14989 & 580181.3741 & 148574.0377 & \\
\hline 14990 & 580044.7858 & 148581.7691 & \\
\hline 14991 & 580037.0544 & 148697.7403 & \\
\hline 14992 & 580145.2941 & 148679.7003 & \\
\hline 14993 & 580933.8981 & 147857.5935 & \\
\hline 14994 & 580939.0524 & 147999.3361 & \\
\hline 14995 & 581101.412 & 147883.3649 & \\
\hline 14996 & 581062.755 & 147983.8733 & \\
\hline 14997 & 581804.9705 & 147164.3436 & \\
\hline 14998 & 581877.1303 & 147311.2404 & \\
\hline 14999 & 582000.8329 & 147089.6067 & \\
\hline 15000 & 582083.3013 & 147249.3892 & \\
\hline 15001 & 582426.0606 & 145545.9015 & \\
\hline 15002 & 582477.6033 & 145674.7583 & \\
\hline 15003 & 582567.8031 & 145491.7816 & \\
\hline 15004 & 582606.4602 & 145581.9814 & \\
\hline 15005 & 583003.3393 & 144208.3673 & \\
\hline 15006 & 583016.225 & 144321.7613 & \\
\hline 15007 & 583111.579 & 144198.0587 & \\
\hline
\end{tabular}




\begin{tabular}{|c|c|c|c|}
\hline node & X_coord & Y_coord & note: from sac04d created July 1, 2004 \\
\hline 15008 & $5 \overline{8} 3090.9619$ & $1 \overline{4} 4298.5671$ & \\
\hline 15009 & 583740.4005 & 142489.4168 & \\
\hline 15010 & 583621.8522 & 142515.1881 & \\
\hline 15011 & 583645.0464 & 142628.5822 & \\
\hline 15012 & 583745.5548 & 142600.2337 & \\
\hline 15013 & 584705.7883 & 141071.9233 & \\
\hline 15014 & 584598.8708 & 141111.7909 & \\
\hline 15015 & 584582.5614 & 141220.5205 & \\
\hline 15016 & 584694.9153 & 141169.78 & \\
\hline 15017 & 585336.42 & 140348.8714 & \\
\hline 15018 & 585240.3755 & 140348.8714 & \\
\hline 15019 & 585234.9391 & 140457.601 & \\
\hline 15020 & 585318.2984 & 140437.6673 & \\
\hline 15021 & 585976.1126 & 139613.1344 & \\
\hline 15022 & 585983.3612 & 139716.4275 & \\
\hline 15023 & 586102.9638 & 139622.1952 & \\
\hline 15024 & 586068.5328 & 139705.5546 & \\
\hline 15025 & 586769.8387 & 138922.7013 & \\
\hline 15026 & 586728.1591 & 139022.3702 & \\
\hline 15027 & 586858.6346 & 138920.8892 & \\
\hline 15028 & 586818.7671 & 139016.9337 & \\
\hline 15029 & 587636.0513 & 138261.2629 & \\
\hline 15030 & 587590.7473 & 138380.8655 & \\
\hline 15031 & 587777.3998 & 138250.3899 & \\
\hline 15032 & 587723.035 & 138360.9317 & \\
\hline 15033 & 589080.343 & 137366.0557 & \\
\hline 15034 & 589035.039 & 137496.5313 & \\
\hline 15035 & 589238.0009 & 137353.3706 & \\
\hline 15036 & 589183.6361 & 137465.7246 & \\
\hline 15037 & 589926.6218 & 136713.6781 & \\
\hline 15038 & 589922.9975 & 136835.0928 & \\
\hline 15039 & 590040.7879 & 136720.9267 & \\
\hline 15040 & 590020.8541 & 136824.2198 & \\
\hline 15041 & 590593.4968 & 135907.2668 & \\
\hline 15042 & 590591.6846 & 136014.1842 & \\
\hline 15043 & 590694.9777 & 135898.206 & \\
\hline 15044 & 590676.8561 & 135999.687 & \\
\hline 15045 & 591050.1611 & 135131.6622 & \\
\hline 15046 & 591064.6584 & 135240.3918 & \\
\hline 15047 & 591140.7691 & 135095.419 & \\
\hline 15048 & 591133.5205 & 135191.4635 & \\
\hline 15049 & 591811.2684 & 134252.7645 & \\
\hline 15050 & 591727.909 & 134372.3671 & \\
\hline 15051 & 591947.1804 & 134247.328 & \\
\hline 15052 & 591869.2575 & 134352.4333 & \\
\hline 15053 & 592798.8957 & 133652.9395 & \\
\hline 15054 & 592746.3431 & 133745.3597 & \\
\hline 15055 & 592905.8132 & 133636.6301 & \\
\hline 15056 & 592847.824 & 133734.4867 & \\
\hline 15057 & 593482.0801 & 132891.8322 & \\
\hline 15058 & 593489.3288 & 133016.8713 & \\
\hline 15059 & 593578.1246 & 132877.3349 & \\
\hline 15060 & 593563.6273 & 132980.6281 & \\
\hline 15061 & 594096.4024 & 131578.0161 & \\
\hline 15062 & 594110.8997 & 131675.8727 & \\
\hline 15063 & 594174.3253 & 131539.9607 & \\
\hline
\end{tabular}




$\begin{array}{lll}\text { node } & \text { X_coord } & \text { Y_coord } \\ 15064 & 594185.1983 & 131637.8174 \\ 15065 & 594362.79 & 113744.5476 \\ 15066 & 594406.2818 & 114259.2011 \\ 15067 & 594638.2383 & 113759.0449 \\ 15068 & 594623.741 & 114172.2174 \\ 15069 & 559721.5357 & 145094.919 \\ 15070 & 559301.1145 & 145142.0351 \\ 15071 & 559670.7952 & 145489.9699 \\ 15072 & 559333.7334 & 145471.8483 \\ 15073 & 562921.8106 & 145254.3891\end{array}$

note: from sac04d created July 1, 2004 
element_K_CA 
Element: 1 \# of layers: 1

Kx Ky Kz Ss Por

4.16721e+01 4.16721e+01 4.16722e+00 1.00000e-09 7.00000e-02

Element: 2 \# of layers: 1

Kx Ky Kz Ss Por

3.82087e+01 3.82087e+01 3.82087e+00 1.00000e-09 7.00000e-02

Element: 3 \# of layers: 1

Kx Ky Kz Ss Por

$2.93645 \mathrm{e}+012.93645 \mathrm{e}+012.93645 \mathrm{e}+00$ 1.00000e-09 7.00000e-02

Element: 4 \# of layers: 1

Kx Ky Kz Ss Por

$1.69388 \mathrm{e}+011.69388 \mathrm{e}+011.69388 \mathrm{e}+00$ 1.00000e-09 7.00000e-02

Element: 5 \# of layers: 1

Kx Ky Kz Ss Por

$1.31168 \mathrm{e}+011.31168 \mathrm{e}+011.31168 \mathrm{e}+00$ 1.00000e-09 7.00000e-02

Element: 6 \# of layers: 1

Kx Ky Kz Ss Por

$1.24248 \mathrm{e}+011.24248 \mathrm{e}+011.24248 \mathrm{e}+00$ 1.00000e-09 7.00000e-02

Element: 7 \# of layers: 1

Kx Ky Kz Ss Por

5.23607e+01 5.23607e+01 5.23607e+00 1.00000e-09 7.00000e-02

Element: 8 \# of layers: 1

Kx Ky Kz Ss Por

3.86196e+01 3.86196e+01 3.86196e+00 1.00000e-09 7.00000e-02

Element: 9 \# of layers: 1

Kx Ky Kz Ss Por

$2.36431 \mathrm{e}+012.36431 \mathrm{e}+012.36431 \mathrm{e}+00$ 1.00000e-09 7.00000e-02

Element: 10 \# of layers: 1

Kx Ky Kz Ss Por

$1.36222 \mathrm{e}+011.36222 \mathrm{e}+011.36222 \mathrm{e}+00$ 1.00000e-09 7.00000e-02

Element: 11 \# of layers: 1

Kx Ky Kz Ss Por

$1.04408 \mathrm{e}+011.04408 \mathrm{e}+01$ 1.04408e+00 1.00000e-09 7.00000e-02

Element: 12 \# of layers: 1

Kx Ky Kz Ss Por

$1.03047 \mathrm{e}+011.03047 \mathrm{e}+011.03047 \mathrm{e}+00$ 1.00000e-09 7.00000e-02

Element: 13 \# of layers: 3

Kx Ky Kz Ss Por

$1.06579 \mathrm{e}+02$ 1.06579e+02 1.06579e+01 1.00000e-09 7.00000e-02 $1.00000 \mathrm{e}-02$ 1.00000e-02 1.00000e-03 1.00000e-09 1.00000e-01

$1.00000 \mathrm{e}+001.00000 \mathrm{e}+001.00000 \mathrm{e}-011.00000 \mathrm{e}-091.00000 \mathrm{e}-01$

Element: 14 \# of layers: 3

Kx Ky Kz Ss Por

$8.78574 \mathrm{e}+01$ 8.78574e+01 8.78574e+00 1.00000e-09 7.00000e-02

$1.00000 \mathrm{e}-021.00000 \mathrm{e}-02$ 1.00000e-03 1.00000e-09 1.00000e-01

$1.00000 \mathrm{e}+001.00000 \mathrm{e}+001.00000 \mathrm{e}-011.00000 \mathrm{e}-091.00000 \mathrm{e}-01$ 
Element: 15 \# of layers: 3

Kx Ky Kz Ss Por

$1.13346 \mathrm{e}+02$ 1.13346e+02 1.13346e+01 1.00000e-09 7.00000e-02

$1.00000 \mathrm{e}-021.00000 \mathrm{e}-02$ 1.00000e-03 1.00000e-09 1.00000e-01

$1.00000 \mathrm{e}+001.00000 \mathrm{e}+001.00000 \mathrm{e}-011.00000 \mathrm{e}-091.00000 \mathrm{e}-01$

Element: 16 \# of layers: 3

Kx Ky Kz Ss Por

$6.37872 \mathrm{e}+01$ 6.37872e+01 6.37872e+00 1.00000e-09 7.00000e-02

$1.00000 \mathrm{e}-02$ 1.00000e-02 1.00000e-03 1.00000e-09 1.00000e-01

$1.00000 \mathrm{e}+001.00000 \mathrm{e}+001.00000 \mathrm{e}-011.00000 \mathrm{e}-091.00000 \mathrm{e}-01$

Element: 17 \# of layers: 3

Kx Ky Kz Ss Por

$2.63768 \mathrm{e}+012.63768 \mathrm{e}+012.63768 \mathrm{e}+00$ 1.00000e-09 7.00000e-02

$1.00000 \mathrm{e}-02$ 1.00000e-02 1.00000e-03 1.00000e-09 1.00000e-01

$1.00000 \mathrm{e}+001.00000 \mathrm{e}+001.00000 \mathrm{e}-011.00000 \mathrm{e}-091.00000 \mathrm{e}-01$

Element: 18 \# of layers: 3

Kx Ky Kz Ss Por

$1.45836 \mathrm{e}+011.45836 \mathrm{e}+011.45836 \mathrm{e}+00$ 1.00000e-09 7.00000e-02

$1.00000 \mathrm{e}-021.00000 \mathrm{e}-02$ 1.00000e-03 1.00000e-09 1.00000e-01

$1.00000 \mathrm{e}+001.00000 \mathrm{e}+001.00000 \mathrm{e}-011.00000 \mathrm{e}-091.00000 \mathrm{e}-01$

Element: 19 \# of layers: 3

Kx Ky Kz Ss Por

$1.57360 \mathrm{e}+011.57360 \mathrm{e}+011.57360 \mathrm{e}+00$ 1.00000e-09 7.00000e-02

$1.00000 \mathrm{e}-021.00000 \mathrm{e}-02$ 1.00000e-03 1.00000e-09 1.00000e-01

$1.00000 \mathrm{e}+001.00000 \mathrm{e}+001.00000 \mathrm{e}-011.00000 \mathrm{e}-091.00000 \mathrm{e}-01$

Element: 20 \# of layers: 1

Kx Ky Kz Ss Por

$1.13814 \mathrm{e}+011.13814 \mathrm{e}+011.13814 \mathrm{e}+00$ 1.00000e-09 7.00000e-02

Element: 21 \# of layers: 1

Kx Ky Kz Ss Por

9.81910e+00 9.81910e+00 9.81910e-01 1.00000e-09 7.00000e-02

Element: 22 \# of layers: 3

Kx Ky Kz Ss Por

$1.32843 \mathrm{e}+02$ 1.32843e+02 1.32843e+01 1.00000e-09 7.00000e-02

$1.00000 \mathrm{e}-021.00000 \mathrm{e}-02$ 1.00000e-03 1.00000e-09 1.00000e-01

$1.00000 \mathrm{e}+001.00000 \mathrm{e}+001.00000 \mathrm{e}-011.00000 \mathrm{e}-091.00000 \mathrm{e}-01$

Element: 23 \# of layers: 3

Kx Ky Kz Ss Por

9.83171e+01 9.83171e+01 9.83171e+00 1.00000e-09 7.00000e-02

$1.00000 \mathrm{e}-02$ 1.00000e-02 1.00000e-03 1.00000e-09 1.00000e-01

$1.00000 \mathrm{e}+001.00000 \mathrm{e}+001.00000 \mathrm{e}-011.00000 \mathrm{e}-091.00000 \mathrm{e}-01$

Element: 24 \# of layers: 3

Kx Ky Kz Ss Por

$9.66953 \mathrm{e}+01$ 9.66953e+01 9.66953e+00 1.00000e-09 7.00000e-02

$1.00000 \mathrm{e}-021.00000 \mathrm{e}-02$ 1.00000e-03 1.00000e-09 1.00000e-01

$1.00000 \mathrm{e}+001.00000 \mathrm{e}+001.00000 \mathrm{e}-011.00000 \mathrm{e}-091.00000 \mathrm{e}-01$ 
Element: 25 \# of layers: 3

$\mathrm{Kx} \mathrm{Ky} \mathrm{Kz}$ Ss Por

1.76857e+02 1.76857e+02 1.76857e+01 1.00000e-09 7.00000e-02

$1.00000 \mathrm{e}-02$ 1.00000e-02 1.00000e-03 1.00000e-09 1.00000e-01

$1.00000 \mathrm{e}+001.00000 \mathrm{e}+001.00000 \mathrm{e}-011.00000 \mathrm{e}-091.00000 \mathrm{e}-01$

Element: 26 \# of layers: 3

$\mathrm{Kx} \mathrm{Ky} \mathrm{Kz}$ Ss Por

1.10372e+02 1.10372e+02 1.10372e+01 1.00000e-09 7.00000e-02

$1.00000 \mathrm{e}-021.00000 \mathrm{e}-021.00000 \mathrm{e}-031.00000 \mathrm{e}-091.00000 \mathrm{e}-01$

$1.00000 \mathrm{e}+001.00000 \mathrm{e}+001.00000 \mathrm{e}-01$ 1.00000e-09 1.00000e-01

Element: 27 \# of layers: 3

$\mathrm{Kx} \mathrm{Ky} \mathrm{Kz}$ Ss Por

3.90088e+01 3.90088e+01 3.90088e+00 1.00000e-09 7.00000e-02

1.00000e-02 1.00000e-02 1.00000e-03 1.00000e-09 1.00000e-01

$1.00000 \mathrm{e}+001.00000 \mathrm{e}+001.00000 \mathrm{e}-011.00000 \mathrm{e}-091.00000 \mathrm{e}-01$

Element: 28 \# of layers: 3

$\mathrm{Kx} \mathrm{Ky} \mathrm{Kz}$ Ss Por

$2.34945 \mathrm{e}+012.34945 \mathrm{e}+012.34945 \mathrm{e}+00$ 1.00000e-09 7.00000e-02

$1.00000 \mathrm{e}-02$ 1.00000e-02 1.00000e-03 1.00000e-09 1.00000e-01

$1.00000 \mathrm{e}+001.00000 \mathrm{e}+001.00000 \mathrm{e}-011.00000 \mathrm{e}-091.00000 \mathrm{e}-01$

Element: 29 \# of layers: 4

$\mathrm{Kx} \mathrm{Ky} \mathrm{Kz}$ Ss Por

1.06687e+02 1.06687e+02 1.06687e+01 1.00000e-09 7.00000e-02

$4.26272 \mathrm{e}+004.26272 \mathrm{e}+004.26272 \mathrm{e}-01$ 1.00000e-09 2.12000e-01

$1.00000 \mathrm{e}-021.00000 \mathrm{e}-02$ 1.00000e-03 1.00000e-09 1.00000e-01

$1.00000 \mathrm{e}+001.00000 \mathrm{e}+001.00000 \mathrm{e}-01$ 1.00000e-09 1.00000e-01

Element: 30 \# of layers: 4

$\mathrm{Kx} \mathrm{Ky} \mathrm{Kz}$ Ss Por

$8.58824 \mathrm{e}+018.58824 \mathrm{e}+018.58824 \mathrm{e}+001.00000 \mathrm{e}-097.00000 \mathrm{e}-02$

$3.43155 \mathrm{e}+003.43155 \mathrm{e}+00$ 3.43155e-01 1.00000e-09 2.12000e-01

$1.00000 \mathrm{e}-02$ 1.00000e-02 1.00000e-03 1.00000e-09 1.00000e-01

$1.00000 \mathrm{e}+001.00000 \mathrm{e}+001.00000 \mathrm{e}-01$ 1.00000e-09 1.00000e-01

Element: 31 \# of layers: 4

$\mathrm{Kx} \mathrm{Ky} \mathrm{Kz}$ Ss Por

9.60826e+01 9.60826e+01 9.60826e+00 1.00000e-09 7.00000e-02

$3.83926 \mathrm{e}+003.83926 \mathrm{e}+003.83926 \mathrm{e}-01$ 1.00000e-09 2.12000e-01

$1.00000 \mathrm{e}-02$ 1.00000e-02 1.00000e-03 1.00000e-09 1.00000e-01

$1.00000 \mathrm{e}+001.00000 \mathrm{e}+001.00000 \mathrm{e}-011.00000 \mathrm{e}-091.00000 \mathrm{e}-01$

Element: 32 \# of layers: 4

$\mathrm{Kx} \mathrm{Ky} \mathrm{Kz}$ Ss Por

1.36420e+02 1.36420e+02 1.36420e+01 1.00000e-09 7.00000e-02

$5.45074 \mathrm{e}+005.45074 \mathrm{e}+00$ 5.45074e-01 1.00000e-09 2.12000e-01

$1.00000 \mathrm{e}-021.00000 \mathrm{e}-021.00000 \mathrm{e}-031.00000 \mathrm{e}-091.00000 \mathrm{e}-01$

$1.00000 \mathrm{e}+001.00000 \mathrm{e}+001.00000 \mathrm{e}-011.00000 \mathrm{e}-091.00000 \mathrm{e}-01$

Element: 33 \# of layers: 4

Kx Ky Kz Ss Por 
$1.05570 \mathrm{e}+02$ 1.05570e+02 1.05570e+01 1.00000e-09 7.00000e-02 $4.21816 \mathrm{e}+004.21816 \mathrm{e}+00$ 4.21816e-01 1.00000e-09 2.12000e-01 $1.00000 \mathrm{e}-02$ 1.00000e-02 1.00000e-03 1.00000e-09 1.00000e-01 $1.00000 \mathrm{e}+001.00000 \mathrm{e}+001.00000 \mathrm{e}-011.00000 \mathrm{e}-091.00000 \mathrm{e}-01$ Element: 34 \# of layers: 4

$\mathrm{Kx} \mathrm{Ky} \mathrm{Kz}$ Ss Por

4.64889e+01 4.64889e+01 4.64889e+00 1.00000e-09 7.00000e-02 $1.85755 \mathrm{e}+001.85755 \mathrm{e}+001.85755 \mathrm{e}-01$ 1.00000e-09 2.12000e-01 $1.00000 \mathrm{e}-02$ 1.00000e-02 1.00000e-03 1.00000e-09 1.00000e-01 $1.00000 \mathrm{e}+001.00000 \mathrm{e}+00$ 1.00000e-01 1.00000e-09 1.00000e-01 Element: 35 \# of layers: 3

$\mathrm{Kx} \mathrm{Ky} \mathrm{Kz}$ Ss Por

7.84726e+01 7.84726e+01 7.84726e+00 1.00000e-09 7.00000e-02 $1.00000 \mathrm{e}-02$ 1.00000e-02 1.00000e-03 1.00000e-09 1.00000e-01 $1.00000 \mathrm{e}+001.00000 \mathrm{e}+001.00000 \mathrm{e}-01$ 1.00000e-09 1.00000e-01 Element: 36 \# of layers: 4

$\mathrm{Kx} \mathrm{Ky} \mathrm{Kz}$ Ss Por

8.11017e+01 8.11017e+01 8.11017e+00 1.00000e-09 7.00000e-02 3.24052e+00 3.24052e+00 3.24052e-01 1.00000e-09 2.12000e-01 $1.00000 \mathrm{e}-021.00000 \mathrm{e}-02$ 1.00000e-03 1.00000e-09 1.00000e-01 $1.00000 \mathrm{e}+001.00000 \mathrm{e}+001.00000 \mathrm{e}-011.00000 \mathrm{e}-091.00000 \mathrm{e}-01$ Element: 37 \# of layers: 4

$\mathrm{Kx} \mathrm{Ky} \mathrm{Kz}$ Ss Por

8.25109e+01 8.25109e+01 8.25109e+00 1.00000e-09 7.00000e-02 $3.29677 \mathrm{e}+00$ 3.29677e+00 3.29677e-01 1.00000e-09 2.12000e-01 $1.00000 \mathrm{e}-02$ 1.00000e-02 1.00000e-03 1.00000e-09 1.00000e-01 $1.00000 \mathrm{e}+001.00000 \mathrm{e}+001.00000 \mathrm{e}-01$ 1.00000e-09 1.00000e-01 Element: 38 \# of layers: 4

$\mathrm{Kx} \mathrm{Ky} \mathrm{Kz}$ Ss Por

9.21903e+01 9.21903e+01 9.21903e+00 1.00000e-09 7.00000e-02 $3.68355 \mathrm{e}+003.68355 \mathrm{e}+003.68355 \mathrm{e}-01$ 1.00000e-09 2.12000e-01 $1.00000 \mathrm{e}-02$ 1.00000e-02 1.00000e-03 1.00000e-09 1.00000e-01 $1.00000 \mathrm{e}+001.00000 \mathrm{e}+001.00000 \mathrm{e}-011.00000 \mathrm{e}-091.00000 \mathrm{e}-01$ Element: 39 \# of layers: 4

$\mathrm{Kx} \mathrm{Ky} \mathrm{Kz}$ Ss Por

7.54470e+01 7.54470e+01 7.54470e+00 1.00000e-09 7.00000e-02 $3.01461 \mathrm{e}+003.01461 \mathrm{e}+00$ 3.01461e-01 1.00000e-09 2.12000e-01 $1.00000 \mathrm{e}-02$ 1.00000e-02 1.00000e-03 1.00000e-09 1.00000e-01 $1.00000 \mathrm{e}+001.00000 \mathrm{e}+001.00000 \mathrm{e}-01$ 1.00000e-09 1.00000e-01 Element: 40 \# of layers: 4

$\mathrm{Kx} \mathrm{Ky} \mathrm{Kz}$ Ss Por 5.09885e+01 5.09885e+01 5.09885e+00 1.00000e-09 7.00000e-02 $2.03733 \mathrm{e}+00$ 2.03733e+00 2.03733e-01 1.00000e-09 2.12000e-01 $1.00000 \mathrm{e}-02$ 1.00000e-02 1.00000e-03 1.00000e-09 1.00000e-01 $1.00000 \mathrm{e}+001.00000 \mathrm{e}+001.00000 \mathrm{e}-01$ 1.00000e-09 1.00000e-01 Element: 41 \# of layers: 4 
Kx Ky Kz Ss Por

3.13872e+01 3.13872e+01 3.13872e+00 1.00000e-09 7.00000e-02

$1.25411 \mathrm{e}+001.25411 \mathrm{e}+001.25411 \mathrm{e}-011.00000 \mathrm{e}-09$ 2.12000e-01

$1.00000 \mathrm{e}-02$ 1.00000e-02 1.00000e-03 1.00000e-09 1.00000e-01

$1.00000 \mathrm{e}+001.00000 \mathrm{e}+001.00000 \mathrm{e}-011.00000 \mathrm{e}-091.00000 \mathrm{e}-01$

Element: 42 \# of layers: 4

$\mathrm{Kx} \mathrm{Ky} \mathrm{Kz}$ Ss Por

9.56682e+01 9.56682e+01 9.56682e+00 1.00000e-09 7.00000e-02

$3.82261 \mathrm{e}+003.82261 \mathrm{e}+00$ 3.82261e-01 1.00000e-09 2.12000e-01

$1.00000 \mathrm{e}-02$ 1.00000e-02 1.00000e-03 1.00000e-09 1.00000e-01

$1.00000 \mathrm{e}+001.00000 \mathrm{e}+001.00000 \mathrm{e}-011.00000 \mathrm{e}-091.00000 \mathrm{e}-01$

Element: 43 \# of layers: 4

$\mathrm{Kx} \mathrm{Ky} \mathrm{Kz}$ Ss Por

6.63722e+01 6.63722e+01 6.63722e+00 1.00000e-09 7.00000e-02

$2.65191 \mathrm{e}+002.65191 \mathrm{e}+002.65191 \mathrm{e}-01$ 1.00000e-09 2.12000e-01

$1.00000 \mathrm{e}-02$ 1.00000e-02 1.00000e-03 1.00000e-09 1.00000e-01

$1.00000 \mathrm{e}+001.00000 \mathrm{e}+001.00000 \mathrm{e}-01$ 1.00000e-09 1.00000e-01

Element: 44 \# of layers: 4

$\mathrm{Kx} \mathrm{Ky} \mathrm{Kz}$ Ss Por

7.46019e+01 7.46019e+01 7.46019e+00 1.00000e-09 7.00000e-02

$2.98086 \mathrm{e}+002.98086 \mathrm{e}+00$ 2.98086e-01 1.00000e-09 2.12000e-01

$1.00000 \mathrm{e}-02$ 1.00000e-02 1.00000e-03 1.00000e-09 1.00000e-01

$1.00000 \mathrm{e}+001.00000 \mathrm{e}+001.00000 \mathrm{e}-01$ 1.00000e-09 1.00000e-01

Element: 45 \# of layers: 4

$\mathrm{Kx} \mathrm{Ky} \mathrm{Kz}$ Ss Por

7.59363e+01 7.59363e+01 7.59363e+00 1.00000e-09 7.00000e-02

$3.03419 \mathrm{e}+00$ 3.03419e+00 3.03419e-01 1.00000e-09 2.12000e-01

$1.00000 \mathrm{e}-02$ 1.00000e-02 1.00000e-03 1.00000e-09 1.00000e-01

$1.00000 \mathrm{e}+001.00000 \mathrm{e}+001.00000 \mathrm{e}-011.00000 \mathrm{e}-091.00000 \mathrm{e}-01$

Element: 46 \# of layers: 4

$\mathrm{Kx} \mathrm{Ky} \mathrm{Kz}$ Ss Por

5.84911e+01 5.84911e+01 5.84911e+00 1.00000e-09 7.00000e-02

$2.33713 \mathrm{e}+002.33713 \mathrm{e}+00$ 2.33713e-01 1.00000e-09 2.12000e-01

$1.00000 \mathrm{e}-02$ 1.00000e-02 1.00000e-03 1.00000e-09 1.00000e-01

$1.00000 \mathrm{e}+001.00000 \mathrm{e}+001.00000 \mathrm{e}-01$ 1.00000e-09 1.00000e-01

Element: 47 \# of layers: 4

$\mathrm{Kx} \mathrm{Ky} \mathrm{Kz}$ Ss Por

3.87070e+01 3.87070e+01 3.87070e+00 1.00000e-09 7.00000e-02

$1.54659 \mathrm{e}+001.54659 \mathrm{e}+00$ 1.54659e-01 1.00000e-09 2.12000e-01

$1.00000 \mathrm{e}-02$ 1.00000e-02 1.00000e-03 1.00000e-09 1.00000e-01

$1.00000 \mathrm{e}+001.00000 \mathrm{e}+001.00000 \mathrm{e}-011.00000 \mathrm{e}-091.00000 \mathrm{e}-01$

Element: 48 \# of layers: 4

$\mathrm{Kx} \mathrm{Ky} \mathrm{Kz}$ Ss Por

2.53343e+01 2.53343e+01 2.53343e+00 1.00000e-09 7.00000e-02

$1.01225 \mathrm{e}+001.01225 \mathrm{e}+001.01225 \mathrm{e}-011.00000 \mathrm{e}-092.12000 \mathrm{e}-01$

$1.00000 \mathrm{e}-02$ 1.00000e-02 1.00000e-03 1.00000e-09 1.00000e-01 
$1.00000 \mathrm{e}+001.00000 \mathrm{e}+001.00000 \mathrm{e}-011.00000 \mathrm{e}-091.00000 \mathrm{e}-01$

Element: 49 \# of layers: 4

Kx Ky Kz Ss Por

$9.17128 \mathrm{e}+019.17128 \mathrm{e}+019.17128 \mathrm{e}+001.00000 \mathrm{e}-09$ 7.00000e-02

$3.66443 \mathrm{e}+003.66443 \mathrm{e}+003.66443 \mathrm{e}-01$ 1.00000e-09 2.12000e-01

$1.00000 \mathrm{e}-021.00000 \mathrm{e}-02$ 1.00000e-03 1.00000e-09 1.00000e-01

$1.00000 \mathrm{e}+001.00000 \mathrm{e}+001.00000 \mathrm{e}-011.00000 \mathrm{e}-091.00000 \mathrm{e}-01$

Element: 50 \# of layers: 4

Kx Ky Kz Ss Por

$1.01173 \mathrm{e}+02$ 1.01173e+02 1.01173e+01 1.00000e-09 7.00000e-02

$4.04244 \mathrm{e}+00 \quad 4.04244 \mathrm{e}+00 \quad 4.04244 \mathrm{e}-011.00000 \mathrm{e}-09$ 2.12000e-01

$1.00000 \mathrm{e}-021.00000 \mathrm{e}-02$ 1.00000e-03 1.00000e-09 1.00000e-01

$1.00000 \mathrm{e}+001.00000 \mathrm{e}+001.00000 \mathrm{e}-011.00000 \mathrm{e}-091.00000 \mathrm{e}-01$

Element: 51 \# of layers: 4

Kx Ky Kz Ss Por

$1.14364 \mathrm{e}+02$ 1.14364e+02 1.14364e+01 1.00000e-09 7.00000e-02

4.56962e+00 4.56962e+00 4.56962e-01 1.00000e-09 2.12000e-01

$1.00000 \mathrm{e}-02$ 1.00000e-02 1.00000e-03 1.00000e-09 1.00000e-01

$1.00000 \mathrm{e}+001.00000 \mathrm{e}+001.00000 \mathrm{e}-011.00000 \mathrm{e}-091.00000 \mathrm{e}-01$

Element: 52 \# of layers: 4

Kx Ky Kz Ss Por

$1.12625 \mathrm{e}+021.12625 \mathrm{e}+021.12625 \mathrm{e}+01$ 1.00000e-09 7.00000e-02

4.49987e+00 4.49987e+00 4.49987e-01 1.00000e-09 2.12000e-01

$1.00000 \mathrm{e}-02$ 1.00000e-02 1.00000e-03 1.00000e-09 1.00000e-01

$1.00000 \mathrm{e}+001.00000 \mathrm{e}+001.00000 \mathrm{e}-011.00000 \mathrm{e}-091.00000 \mathrm{e}-01$

Element: 53 \# of layers: 4

Kx Ky Kz Ss Por

$6.34313 \mathrm{e}+016.34313 \mathrm{e}+016.34313 \mathrm{e}+00$ 1.00000e-09 7.00000e-02

$2.53445 \mathrm{e}+002.53445 \mathrm{e}+002.53445 \mathrm{e}-011.00000 \mathrm{e}-092.12000 \mathrm{e}-01$

$1.00000 \mathrm{e}-021.00000 \mathrm{e}-02$ 1.00000e-03 1.00000e-09 1.00000e-01

$1.00000 \mathrm{e}+001.00000 \mathrm{e}+001.00000 \mathrm{e}-011.00000 \mathrm{e}-091.00000 \mathrm{e}-01$

Element: 54 \# of layers: 4

Kx Ky Kz Ss Por

4.44869e+01 4.44869e+01 4.44869e+00 1.00000e-09 7.00000e-02

$1.77754 \mathrm{e}+001.77754 \mathrm{e}+00 \quad 1.77754 \mathrm{e}-011.00000 \mathrm{e}-092.12000 \mathrm{e}-01$

$1.00000 \mathrm{e}-02$ 1.00000e-02 1.00000e-03 1.00000e-09 1.00000e-01

$1.00000 \mathrm{e}+001.00000 \mathrm{e}+001.00000 \mathrm{e}-011.00000 \mathrm{e}-091.00000 \mathrm{e}-01$

Element: 55 \# of layers: 4

Kx Ky Kz Ss Por

$3.42867 \mathrm{e}+013.42867 \mathrm{e}+013.42867 \mathrm{e}+00$ 1.00000e-09 7.00000e-02

$1.36999 \mathrm{e}+001.36999 \mathrm{e}+00$ 1.36999e-01 1.00000e-09 2.12000e-01

$1.00000 \mathrm{e}-02$ 1.00000e-02 1.00000e-03 1.00000e-09 1.00000e-01

$1.00000 \mathrm{e}+001.00000 \mathrm{e}+001.00000 \mathrm{e}-011.00000 \mathrm{e}-091.00000 \mathrm{e}-01$

Element: 56 \# of layers: 4

Kx Ky Kz Ss Por

$2.53253 \mathrm{e}+012.53253 \mathrm{e}+012.53253 \mathrm{e}+00$ 1.00000e-09 7.00000e-02 
$1.01194 \mathrm{e}+00$ 1.01194e+00 1.01194e-01 1.00000e-09 2.12000e-01 $1.00000 \mathrm{e}-02$ 1.00000e-02 1.00000e-03 1.00000e-09 1.00000e-01

$1.00000 \mathrm{e}+001.00000 \mathrm{e}+001.00000 \mathrm{e}-01$ 1.00000e-09 1.00000e-01

Element: 57 \# of layers: 4

$\mathrm{Kx} \mathrm{Ky} \mathrm{Kz}$ Ss Por

2.44639e+01 2.44639e+01 2.44639e+00 1.00000e-09 7.00000e-02

9.77488e-01 9.77488e-01 9.77488e-02 1.00000e-09 2.12000e-01

$1.00000 \mathrm{e}-02$ 1.00000e-02 1.00000e-03 1.00000e-09 1.00000e-01

$1.00000 \mathrm{e}+001.00000 \mathrm{e}+001.00000 \mathrm{e}-011.00000 \mathrm{e}-091.00000 \mathrm{e}-01$

Element: 58 \# of layers: 4

$\mathrm{Kx} \mathrm{Ky} \mathrm{Kz}$ Ss Por

7.91078e+01 7.91078e+01 7.91078e+00 1.00000e-09 7.00000e-02

3.16087e+00 3.16087e+00 3.16087e-01 1.00000e-09 2.12000e-01

$1.00000 \mathrm{e}-02$ 1.00000e-02 1.00000e-03 1.00000e-09 1.00000e-01

$1.00000 \mathrm{e}+001.00000 \mathrm{e}+001.00000 \mathrm{e}-01$ 1.00000e-09 1.00000e-01

Element: 59 \# of layers: 4

$\mathrm{Kx} \mathrm{Ky} \mathrm{Kz}$ Ss Por

9.50645e+01 9.50645e+01 9.50645e+00 1.00000e-09 7.00000e-02

3.79853e+00 3.79853e+00 3.79853e-01 1.00000e-09 2.12000e-01

$1.00000 \mathrm{e}-02$ 1.00000e-02 1.00000e-03 1.00000e-09 1.00000e-01

$1.00000 \mathrm{e}+001.00000 \mathrm{e}+001.00000 \mathrm{e}-011.00000 \mathrm{e}-091.00000 \mathrm{e}-01$

Element: 60 \# of layers: 4

$\mathrm{Kx} \mathrm{Ky} \mathrm{Kz}$ Ss Por

1.26266e+02 1.26266e+02 1.26266e+01 1.00000e-09 7.00000e-02

$5.04528 \mathrm{e}+00$ 5.04528e+00 5.04528e-01 1.00000e-09 2.12000e-01

$1.00000 \mathrm{e}-021.00000 \mathrm{e}-021.00000 \mathrm{e}-031.00000 \mathrm{e}-091.00000 \mathrm{e}-01$

$1.00000 \mathrm{e}+001.00000 \mathrm{e}+001.00000 \mathrm{e}-011.00000 \mathrm{e}-091.00000 \mathrm{e}-01$

Element: 61 \# of layers: 4

$\mathrm{Kx} \mathrm{Ky} \mathrm{Kz}$ Ss Por

$1.46989 \mathrm{e}+02$ 1.46989e+02 1.46989e+01 1.00000e-09 7.00000e-02

5.87308e+00 5.87308e+00 5.87308e-01 1.00000e-09 2.12000e-01

$1.00000 \mathrm{e}-02$ 1.00000e-02 1.00000e-03 1.00000e-09 1.00000e-01

$1.00000 \mathrm{e}+001.00000 \mathrm{e}+001.00000 \mathrm{e}-011.00000 \mathrm{e}-091.00000 \mathrm{e}-01$

Element: 62 \# of layers: 4

$\mathrm{Kx} \mathrm{Ky} \mathrm{Kz}$ Ss Por

$1.23914 \mathrm{e}+02$ 1.23914e+02 1.23914e+01 1.00000e-09 7.00000e-02

$4.95123 \mathrm{e}+00$ 4.95123e+00 4.95123e-01 1.00000e-09 2.12000e-01

$1.00000 \mathrm{e}-02$ 1.00000e-02 1.00000e-03 1.00000e-09 1.00000e-01

$1.00000 \mathrm{e}+001.00000 \mathrm{e}+001.00000 \mathrm{e}-01$ 1.00000e-09 1.00000e-01

Element: 63 \# of layers: 4

$\mathrm{Kx} \mathrm{Ky} \mathrm{Kz}$ Ss Por

7.37505e+01 7.37505e+01 7.37505e+00 1.00000e-09 7.00000e-02

$2.94689 \mathrm{e}+00$ 2.94689e+00 2.94689e-01 1.00000e-09 2.12000e-01

$1.00000 \mathrm{e}-02$ 1.00000e-02 1.00000e-03 1.00000e-09 1.00000e-01

$1.00000 \mathrm{e}+001.00000 \mathrm{e}+001.00000 \mathrm{e}-011.00000 \mathrm{e}-091.00000 \mathrm{e}-01$

Element: 64 \# of layers: 4 
Kx Ky Kz Ss Por

$5.00884 \mathrm{e}+015.00884 \mathrm{e}+015.00884 \mathrm{e}+00$ 1.00000e-09 7.00000e-02

$2.00135 \mathrm{e}+002.00135 \mathrm{e}+002.00135 \mathrm{e}-01$ 1.00000e-09 2.12000e-01

$1.00000 \mathrm{e}-02$ 1.00000e-02 1.00000e-03 1.00000e-09 1.00000e-01

$1.00000 \mathrm{e}+001.00000 \mathrm{e}+001.00000 \mathrm{e}-01$ 1.00000e-09 1.00000e-01

Element: 65 \# of layers: 4

Kx Ky Kz Ss Por

2.87446e+01 2.87446e+01 2.87446e+00 1.00000e-09 7.00000e-02

$1.14854 \mathrm{e}+001.14854 \mathrm{e}+00 \quad 1.14854 \mathrm{e}-011.00000 \mathrm{e}-092.12000 \mathrm{e}-01$

$1.00000 \mathrm{e}-02$ 1.00000e-02 1.00000e-03 1.00000e-09 1.00000e-01

$1.00000 \mathrm{e}+001.00000 \mathrm{e}+001.00000 \mathrm{e}-011.00000 \mathrm{e}-091.00000 \mathrm{e}-01$

Element: 66 \# of layers: 4

$\mathrm{Kx} \mathrm{Ky} \mathrm{Kz}$ Ss Por

4.99451e+01 4.99451e+01 4.99451e+00 1.00000e-09 7.00000e-02

$1.99564 \mathrm{e}+001.99564 \mathrm{e}+001.99564 \mathrm{e}-01$ 1.00000e-09 2.12000e-01

$1.00000 \mathrm{e}-02$ 1.00000e-02 1.00000e-03 1.00000e-09 1.00000e-01

$1.00000 \mathrm{e}+001.00000 \mathrm{e}+001.00000 \mathrm{e}-01$ 1.00000e-09 1.00000e-01

Element: 67 \# of layers: 4

$\mathrm{Kx} \mathrm{Ky} \mathrm{Kz}$ Ss Por

7.18944e+01 7.18944e+01 7.18944e+00 1.00000e-09 7.00000e-02

$2.87264 \mathrm{e}+002.87264 \mathrm{e}+002.87264 \mathrm{e}-01$ 1.00000e-09 2.12000e-01

$1.00000 \mathrm{e}-02$ 1.00000e-02 1.00000e-03 1.00000e-09 1.00000e-01

$1.00000 \mathrm{e}+001.00000 \mathrm{e}+001.00000 \mathrm{e}-01$ 1.00000e-09 1.00000e-01

Element: 68 \# of layers: 4

Kx Ky Kz Ss Por

9.07938e+01 9.07938e+01 9.07938e+00 1.00000e-09 7.00000e-02

$3.62775 \mathrm{e}+003.62775 \mathrm{e}+003.62775 \mathrm{e}-01$ 1.00000e-09 2.12000e-01

$1.00000 \mathrm{e}-02$ 1.00000e-02 1.00000e-03 1.00000e-09 1.00000e-01

$1.00000 \mathrm{e}+001.00000 \mathrm{e}+001.00000 \mathrm{e}-011.00000 \mathrm{e}-091.00000 \mathrm{e}-01$

Element: 69 \# of layers: 4

$\mathrm{Kx} \mathrm{Ky} \mathrm{Kz}$ Ss Por

1.24041e+02 1.24041e+02 1.24041e+01 1.00000e-09 7.00000e-02

$4.95641 \mathrm{e}+004.95641 \mathrm{e}+004.95641 \mathrm{e}-01$ 1.00000e-09 2.12000e-01

$1.00000 \mathrm{e}-02$ 1.00000e-02 1.00000e-03 1.00000e-09 1.00000e-01

$1.00000 \mathrm{e}+001.00000 \mathrm{e}+001.00000 \mathrm{e}-01$ 1.00000e-09 1.00000e-01

Element: 70 \# of layers: 4

$\mathrm{Kx} \mathrm{Ky} \mathrm{Kz}$ Ss Por

1.79110e+02 1.79110e+02 1.79110e+01 1.00000e-09 7.00000e-02

$7.15650 \mathrm{e}+00$ 7.15650e+00 7.15650e-01 1.00000e-09 2.12000e-01

$1.00000 \mathrm{e}-021.00000 \mathrm{e}-021.00000 \mathrm{e}-031.00000 \mathrm{e}-091.00000 \mathrm{e}-01$

$1.00000 \mathrm{e}+001.00000 \mathrm{e}+001.00000 \mathrm{e}-011.00000 \mathrm{e}-091.00000 \mathrm{e}-01$

Element: 71 \# of layers: 4

$\mathrm{Kx} \mathrm{Ky} \mathrm{Kz}$ Ss Por

2.20015e+02 2.20015e+02 2.20015e+01 1.00000e-09 7.00000e-02

$8.79116 \mathrm{e}+008.79116 \mathrm{e}+00$ 8.79116e-01 1.00000e-09 2.12000e-01

$1.00000 \mathrm{e}-02$ 1.00000e-02 1.00000e-03 1.00000e-09 1.00000e-01 
$1.00000 \mathrm{e}+001.00000 \mathrm{e}+00$ 1.00000e-01 1.00000e-09 1.00000e-01

Element: 72 \# of layers: 4

Kx Ky Kz Ss Por

$1.05354 \mathrm{e}+02 \quad 1.05354 \mathrm{e}+02 \quad 1.05354 \mathrm{e}+01$ 1.00000e-09 7.00000e-02

4.20939e+00 4.20939e+00 4.20939e-01 1.00000e-09 2.12000e-01

$1.00000 \mathrm{e}-02$ 1.00000e-02 1.00000e-03 1.00000e-09 1.00000e-01

$1.00000 \mathrm{e}+001.00000 \mathrm{e}+001.00000 \mathrm{e}-011.00000 \mathrm{e}-091.00000 \mathrm{e}-01$

Element: 73 \# of layers: 4

Kx Ky Kz Ss Por

$6.40034 \mathrm{e}+016.40034 \mathrm{e}+016.40034 \mathrm{e}+00$ 1.00000e-09 7.00000e-02

$2.55740 \mathrm{e}+002.55740 \mathrm{e}+002.55741 \mathrm{e}-011.00000 \mathrm{e}-092.12000 \mathrm{e}-01$

$1.00000 \mathrm{e}-021.00000 \mathrm{e}-02$ 1.00000e-03 1.00000e-09 1.00000e-01

$1.00000 \mathrm{e}+001.00000 \mathrm{e}+001.00000 \mathrm{e}-011.00000 \mathrm{e}-091.00000 \mathrm{e}-01$

Element: 74 \# of layers: 4

Kx Ky Kz Ss Por

$3.30946 \mathrm{e}+013.30946 \mathrm{e}+013.30946 \mathrm{e}+00$ 1.00000e-09 7.00000e-02

$1.32235 \mathrm{e}+001.32235 \mathrm{e}+00$ 1.32235e-01 1.00000e-09 2.12000e-01

$1.00000 \mathrm{e}-021.00000 \mathrm{e}-02$ 1.00000e-03 1.00000e-09 1.00000e-01

$1.00000 \mathrm{e}+001.00000 \mathrm{e}+001.00000 \mathrm{e}-011.00000 \mathrm{e}-091.00000 \mathrm{e}-01$

Element: 75 \# of layers: 3

Kx Ky Kz Ss Por

$3.64635 \mathrm{e}+013.64635 \mathrm{e}+013.64635 \mathrm{e}+00$ 1.00000e-09 7.00000e-02

$1.45693 \mathrm{e}+001.45693 \mathrm{e}+00$ 1.45693e-01 1.00000e-09 2.12000e-01

$1.00000 \mathrm{e}+001.00000 \mathrm{e}+001.00000 \mathrm{e}-011.00000 \mathrm{e}-091.00000 \mathrm{e}-01$

Element: 76 \# of layers: 4

Kx Ky Kz Ss Por

6.50792e+01 6.50792e+01 6.50792e+00 1.00000e-09 7.00000e-02

$2.60038 \mathrm{e}+002.60038 \mathrm{e}+00$ 2.60038e-01 1.00000e-09 2.12000e-01

$1.00000 \mathrm{e}-021.00000 \mathrm{e}-02$ 1.00000e-03 1.00000e-09 1.00000e-01

$1.00000 \mathrm{e}+001.00000 \mathrm{e}+001.00000 \mathrm{e}-011.00000 \mathrm{e}-091.00000 \mathrm{e}-01$

Element: 77 \# of layers: 4

Kx Ky Kz Ss Por

7.59967e+01 7.59967e+01 7.59967e+00 1.00000e-09 7.00000e-02

$3.03666 \mathrm{e}+003.03666 \mathrm{e}+00$ 3.03667e-01 1.00000e-09 2.12000e-01

$1.00000 \mathrm{e}-021.00000 \mathrm{e}-02$ 1.00000e-03 1.00000e-09 1.00000e-01

$1.00000 \mathrm{e}+001.00000 \mathrm{e}+001.00000 \mathrm{e}-011.00000 \mathrm{e}-091.00000 \mathrm{e}-01$

Element: 78 \# of layers: 4

Kx Ky Kz Ss Por

$1.12012 \mathrm{e}+02$ 1.12012e+02 1.12012e+01 1.00000e-09 7.00000e-02

$4.47557 \mathrm{e}+00 \quad 4.47557 \mathrm{e}+00$ 4.47557e-01 1.00000e-09 2.12000e-01

$1.00000 \mathrm{e}-021.00000 \mathrm{e}-02$ 1.00000e-03 1.00000e-09 1.00000e-01

$1.00000 \mathrm{e}+001.00000 \mathrm{e}+001.00000 \mathrm{e}-011.00000 \mathrm{e}-091.00000 \mathrm{e}-01$

Element: 79 \# of layers: 4

Kx Ky Kz Ss Por

$1.79389 \mathrm{e}+02$ 1.79389e+02 1.79389e+01 1.00000e-09 7.00000e-02

$7.16775 \mathrm{e}+007.16775 \mathrm{e}+00$ 7.16775e-01 1.00000e-09 2.12000e-01 
$1.00000 \mathrm{e}-02$ 1.00000e-02 1.00000e-03 1.00000e-09 1.00000e-01 $1.00000 \mathrm{e}+001.00000 \mathrm{e}+001.00000 \mathrm{e}-01$ 1.00000e-09 1.00000e-01 Element: 80 \# of layers: 4

Kx Ky Kz Ss Por

1.93913e+02 1.93913e+02 1.93913e+01 1.00000e-09 7.00000e-02 $7.74804 \mathrm{e}+00$ 7.74804e+00 7.74804e-01 1.00000e-09 2.12000e-01 $1.00000 \mathrm{e}-02$ 1.00000e-02 1.00000e-03 1.00000e-09 1.00000e-01 $1.00000 \mathrm{e}+001.00000 \mathrm{e}+001.00000 \mathrm{e}-01$ 1.00000e-09 1.00000e-01 Element: 81 \# of layers: 4

$\mathrm{Kx} \mathrm{Ky} \mathrm{Kz}$ Ss Por

8.70835e+01 8.70835e+01 8.70835e+00 1.00000e-09 7.00000e-02 $3.47947 \mathrm{e}+003.47947 \mathrm{e}+00$ 3.47947e-01 1.00000e-09 2.12000e-01 $1.00000 \mathrm{e}-02$ 1.00000e-02 1.00000e-03 1.00000e-09 1.00000e-01 $1.00000 \mathrm{e}+001.00000 \mathrm{e}+001.00000 \mathrm{e}-011.00000 \mathrm{e}-091.00000 \mathrm{e}-01$ Element: 82 \# of layers: 4

$\mathrm{Kx} \mathrm{Ky} \mathrm{Kz}$ Ss Por

6.22708e+01 6.22708e+01 6.22708e+00 1.00000e-09 7.00000e-02 $2.48810 \mathrm{e}+002.48810 \mathrm{e}+002.48810 \mathrm{e}-01$ 1.00000e-09 2.12000e-01 $1.00000 \mathrm{e}-02$ 1.00000e-02 1.00000e-03 1.00000e-09 1.00000e-01 $1.00000 \mathrm{e}+001.00000 \mathrm{e}+001.00000 \mathrm{e}-011.00000 \mathrm{e}-091.00000 \mathrm{e}-01$ Element: 83 \# of layers: 4

$\mathrm{Kx} \mathrm{Ky} \mathrm{Kz}$ Ss Por

3.99125e+01 3.99125e+01 3.99125e+00 1.00000e-09 7.00000e-02 $1.59474 \mathrm{e}+001.59474 \mathrm{e}+00 \quad 1.59474 \mathrm{e}-011.00000 \mathrm{e}-092.12000 \mathrm{e}-01$ $1.00000 \mathrm{e}-021.00000 \mathrm{e}-02$ 1.00000e-03 1.00000e-09 1.00000e-01 $1.00000 \mathrm{e}+001.00000 \mathrm{e}+001.00000 \mathrm{e}-01$ 1.00000e-09 1.00000e-01 Element: 84 \# of layers: 3

$\mathrm{Kx} \mathrm{Ky} \mathrm{Kz}$ Ss Por

$2.53803 e+012.53803 e+012.53803 e+001.00000 e-09$ 7.00000e-02 $1.01412 \mathrm{e}+001.01412 \mathrm{e}+001.01412 \mathrm{e}-011.00000 \mathrm{e}-092.12000 \mathrm{e}-01$ $1.00000 \mathrm{e}+001.00000 \mathrm{e}+001.00000 \mathrm{e}-01$ 1.00000e-09 1.00000e-01 Element: 85 \# of layers: 3

$\mathrm{Kx} \mathrm{Ky} \mathrm{Kz}$ Ss Por

4.07162e+01 4.07162e+01 4.07162e+00 1.00000e-09 7.00000e-02 $1.62688 \mathrm{e}+001.62688 \mathrm{e}+00$ 1.62688e-01 1.00000e-09 2.12000e-01 $1.00000 \mathrm{e}+001.00000 \mathrm{e}+001.00000 \mathrm{e}-011.00000 \mathrm{e}-091.00000 \mathrm{e}-01$ Element: 86 \# of layers: 3

$\mathrm{Kx} \mathrm{Ky} \mathrm{Kz}$ Ss Por

5.63494e+01 5.63494e+01 5.63494e+00 1.00000e-09 7.00000e-02 $2.25162 \mathrm{e}+002.25162 \mathrm{e}+002.25162 \mathrm{e}-01$ 1.00000e-09 2.12000e-01 $1.00000 \mathrm{e}+001.00000 \mathrm{e}+001.00000 \mathrm{e}-011.00000 \mathrm{e}-091.00000 \mathrm{e}-01$ Element: 87 \# of layers: 4

$\mathrm{Kx} \mathrm{Ky} \mathrm{Kz}$ Ss Por

5.87470e+01 5.87470e+01 5.87470e+00 1.00000e-09 7.00000e-02 $2.34725 \mathrm{e}+002.34725 \mathrm{e}+002.34725 \mathrm{e}-01$ 1.00000e-09 2.12000e-01 $1.00000 \mathrm{e}-02$ 1.00000e-02 1.00000e-03 1.00000e-09 1.00000e-01 
$1.00000 \mathrm{e}+001.00000 \mathrm{e}+00$ 1.00000e-01 1.00000e-09 1.00000e-01

Element: 88 \# of layers: 4

Kx Ky Kz Ss Por

$6.77912 \mathrm{e}+016.77912 \mathrm{e}+016.77912 \mathrm{e}+00$ 1.00000e-09 7.00000e-02

$2.70861 \mathrm{e}+002.70861 \mathrm{e}+002.70861 \mathrm{e}-01$ 1.00000e-09 2.12000e-01

$1.00000 \mathrm{e}-021.00000 \mathrm{e}-02$ 1.00000e-03 1.00000e-09 1.00000e-01

$1.00000 \mathrm{e}+001.00000 \mathrm{e}+001.00000 \mathrm{e}-011.00000 \mathrm{e}-091.00000 \mathrm{e}-01$

Element: 89 \# of layers: 4

Kx Ky Kz Ss Por

$1.11832 \mathrm{e}+02$ 1.11832e+02 1.11832e+01 1.00000e-09 7.00000e-02

$4.46814 \mathrm{e}+00 \quad 4.46814 \mathrm{e}+00 \quad 4.46814 \mathrm{e}-011.00000 \mathrm{e}-09$ 2.12000e-01

$1.00000 \mathrm{e}-02$ 1.00000e-02 1.00000e-03 1.00000e-09 1.00000e-01

$1.00000 \mathrm{e}+001.00000 \mathrm{e}+001.00000 \mathrm{e}-011.00000 \mathrm{e}-091.00000 \mathrm{e}-01$

Element: 90 \# of layers: 4

Kx Ky Kz Ss Por

$2.16916 \mathrm{e}+022.16916 \mathrm{e}+022.16916 \mathrm{e}+01$ 1.00000e-09 7.00000e-02

$8.66718 \mathrm{e}+008.66718 \mathrm{e}+00$ 8.66718e-01 1.00000e-09 2.12000e-01

$1.00000 \mathrm{e}-021.00000 \mathrm{e}-02$ 1.00000e-03 1.00000e-09 1.00000e-01

$1.00000 \mathrm{e}+001.00000 \mathrm{e}+001.00000 \mathrm{e}-011.00000 \mathrm{e}-091.00000 \mathrm{e}-01$

Element: 91 \# of layers: 4

Kx Ky Kz Ss Por

$2.83896 \mathrm{e}+022.83896 \mathrm{e}+022.83896 \mathrm{e}+01$ 1.00000e-09 7.00000e-02

$1.13434 \mathrm{e}+011.13434 \mathrm{e}+011.13434 \mathrm{e}+001.00000 \mathrm{e}-092.12000 \mathrm{e}-01$

$1.00000 \mathrm{e}-021.00000 \mathrm{e}-02$ 1.00000e-03 1.00000e-09 1.00000e-01

$1.00000 \mathrm{e}+001.00000 \mathrm{e}+001.00000 \mathrm{e}-011.00000 \mathrm{e}-091.00000 \mathrm{e}-01$

Element: 92 \# of layers: 4

Kx Ky Kz Ss Por

$1.54422 \mathrm{e}+02$ 1.54422e+02 1.54422e+01 1.00000e-09 7.00000e-02

$6.17008 \mathrm{e}+006.17008 \mathrm{e}+00$ 6.17008e-01 1.00000e-09 2.12000e-01

$1.00000 \mathrm{e}-02$ 1.00000e-02 1.00000e-03 1.00000e-09 1.00000e-01

$1.00000 \mathrm{e}+001.00000 \mathrm{e}+001.00000 \mathrm{e}-011.00000 \mathrm{e}-091.00000 \mathrm{e}-01$

Element: 93 \# of layers: 4

Kx Ky Kz Ss Por

$1.06219 \mathrm{e}+021.06219 \mathrm{e}+02$ 1.06219e+01 1.00000e-09 7.00000e-02

$4.24404 \mathrm{e}+00 \quad 4.24404 \mathrm{e}+00 \quad 4.24404 \mathrm{e}-01$ 1.00000e-09 2.12000e-01

$1.00000 \mathrm{e}-021.00000 \mathrm{e}-02$ 1.00000e-03 1.00000e-09 1.00000e-01

$1.00000 \mathrm{e}+001.00000 \mathrm{e}+001.00000 \mathrm{e}-011.00000 \mathrm{e}-091.00000 \mathrm{e}-01$

Element: 94 \# of layers: 4

Kx Ky Kz Ss Por

8.68258e+01 8.68258e+01 8.68258e+00 1.00000e-09 7.00000e-02

$3.46935 \mathrm{e}+003.46935 \mathrm{e}+003.46935 \mathrm{e}-011.00000 \mathrm{e}-09$ 2.12000e-01

$1.00000 \mathrm{e}-02$ 1.00000e-02 1.00000e-03 1.00000e-09 1.00000e-01

$1.00000 \mathrm{e}+001.00000 \mathrm{e}+001.00000 \mathrm{e}-011.00000 \mathrm{e}-091.00000 \mathrm{e}-01$

Element: 95 \# of layers: 3

Kx Ky Kz Ss Por

$1.36871 \mathrm{e}+021.36871 \mathrm{e}+02$ 1.36871e+01 1.00000e-09 7.00000e-02 
5.46897e+00 5.46897e+00 5.46897e-01 1.00000e-09 2.12000e-01 $1.00000 \mathrm{e}+001.00000 \mathrm{e}+001.00000 \mathrm{e}-011.00000 \mathrm{e}-091.00000 \mathrm{e}-01$ Element: 96 \# of layers: 3

Kx Ky Kz Ss Por

$1.23671 \mathrm{e}+021.23671 \mathrm{e}+02$ 1.23671e+01 1.00000e-09 7.00000e-02 $4.94156 \mathrm{e}+004.94156 \mathrm{e}+004.94156 \mathrm{e}-011.00000 \mathrm{e}-092.12000 \mathrm{e}-01$ $1.00000 \mathrm{e}+001.00000 \mathrm{e}+00$ 1.00000e-01 1.00000e-09 1.00000e-01

Element: 97 \# of layers: 3

$\mathrm{Kx} \mathrm{Ky} \mathrm{Kz}$ Ss Por

7.75959e+01 7.75959e+01 7.75959e+00 1.00000e-09 7.00000e-02 $3.10057 \mathrm{e}+003.10057 \mathrm{e}+00$ 3.10057e-01 1.00000e-09 2.12000e-01 $1.00000 \mathrm{e}+001.00000 \mathrm{e}+00$ 1.00000e-01 1.00000e-09 1.00000e-01 Element: 98 \# of layers: 3

Kx Ky Kz Ss Por

6.44693e+01 6.44693e+01 6.44693e+00 1.00000e-09 7.00000e-02

$2.57586 \mathrm{e}+002.57586 \mathrm{e}+002.57586 \mathrm{e}-011.00000 \mathrm{e}-092.12000 \mathrm{e}-01$ $1.00000 \mathrm{e}+001.00000 \mathrm{e}+001.00000 \mathrm{e}-011.00000 \mathrm{e}-091.00000 \mathrm{e}-01$

Element: 99 \# of layers: 4

Kx Ky Kz Ss Por

$6.98807 \mathrm{e}+016.98807 \mathrm{e}+016.98807 \mathrm{e}+00$ 1.00000e-09 7.00000e-02

$2.79208 \mathrm{e}+002.79208 \mathrm{e}+002.79208 \mathrm{e}-01$ 1.00000e-09 2.12000e-01

$1.00000 \mathrm{e}-02$ 1.00000e-02 1.00000e-03 1.00000e-09 1.00000e-01

$1.00000 \mathrm{e}+001.00000 \mathrm{e}+001.00000 \mathrm{e}-011.00000 \mathrm{e}-091.00000 \mathrm{e}-01$

Element: 100 \# of layers: 4

Kx Ky Kz Ss Por

$1.32231 \mathrm{e}+021.32231 \mathrm{e}+02$ 1.32231e+01 1.00000e-09 7.00000e-02

$5.28334 \mathrm{e}+005.28334 \mathrm{e}+00$ 5.28334e-01 1.00000e-09 2.12000e-01

$1.00000 \mathrm{e}-021.00000 \mathrm{e}-02$ 1.00000e-03 1.00000e-09 1.00000e-01

$1.00000 \mathrm{e}+001.00000 \mathrm{e}+001.00000 \mathrm{e}-011.00000 \mathrm{e}-091.00000 \mathrm{e}-01$

Element: 101 \# of layers: 4

Kx Ky Kz Ss Por

$3.30460 \mathrm{e}+023.30460 \mathrm{e}+023.30460 \mathrm{e}+01$ 1.00000e-09 7.00000e-02

$1.32042 \mathrm{e}+011.32042 \mathrm{e}+011.32042 \mathrm{e}+001.00000 \mathrm{e}-092.12000 \mathrm{e}-01$

$1.00000 \mathrm{e}-02$ 1.00000e-02 1.00000e-03 1.00000e-09 1.00000e-01

$1.00000 \mathrm{e}+001.00000 \mathrm{e}+001.00000 \mathrm{e}-011.00000 \mathrm{e}-091.00000 \mathrm{e}-01$

Element: 102 \# of layers: 4

Kx Ky Kz Ss Por

$4.62330 \mathrm{e}+02$ 4.62330e+02 4.62330e+01 1.00000e-09 7.00000e-02 $1.84731 \mathrm{e}+011.84731 \mathrm{e}+011.84731 \mathrm{e}+001.00000 \mathrm{e}-092.12000 \mathrm{e}-01$ $1.00000 \mathrm{e}-021.00000 \mathrm{e}-02$ 1.00000e-03 1.00000e-09 1.00000e-01 $1.00000 \mathrm{e}+001.00000 \mathrm{e}+001.00000 \mathrm{e}-011.00000 \mathrm{e}-091.00000 \mathrm{e}-01$

Element: 103 \# of layers: 4

Kx Ky Kz Ss Por

$3.56345 \mathrm{e}+023.56345 \mathrm{e}+023.56345 \mathrm{e}+01$ 1.00000e-09 7.00000e-02 $1.42381 \mathrm{e}+011.42381 \mathrm{e}+011.42381 \mathrm{e}+001.00000 \mathrm{e}-092.12000 \mathrm{e}-01$ $1.00000 \mathrm{e}-021.00000 \mathrm{e}-02$ 1.00000e-03 1.00000e-09 1.00000e-01 
$1.00000 \mathrm{e}+001.00000 \mathrm{e}+00$ 1.00000e-01 1.00000e-09 1.00000e-01

Element: 104 \# of layers: 4

$\mathrm{Kx} \mathrm{Ky} \mathrm{Kz}$ Ss Por

2.07915e+02 2.07915e+02 2.07915e+01 1.00000e-09 7.00000e-02

8.30763e+00 8.30763e+00 8.30763e-01 1.00000e-09 2.12000e-01

$1.00000 \mathrm{e}-02$ 1.00000e-02 1.00000e-03 1.00000e-09 1.00000e-01

$1.00000 \mathrm{e}+001.00000 \mathrm{e}+001.00000 \mathrm{e}-01$ 1.00000e-09 1.00000e-01

Element: 105 \# of layers: 4

$\mathrm{Kx} \mathrm{Ky} \mathrm{Kz}$ Ss Por

1.35988e+02 1.35988e+02 1.35988e+01 1.00000e-09 7.00000e-02

$5.43342 \mathrm{e}+00$ 5.43342e+00 5.43342e-01 1.00000e-09 2.12000e-01

$1.00000 \mathrm{e}-02$ 1.00000e-02 1.00000e-03 1.00000e-09 1.00000e-01

$1.00000 \mathrm{e}+001.00000 \mathrm{e}+001.00000 \mathrm{e}-011.00000 \mathrm{e}-091.00000 \mathrm{e}-01$

Element: 106 \# of layers: 1

$\mathrm{Kx} \mathrm{Ky} \mathrm{Kz}$ Ss Por

2.65123e+01 2.65123e+01 2.65123e+00 1.00000e-09 2.12000e-01

Element: 107 \# of layers: 2

$\mathrm{Kx} \mathrm{Ky} \mathrm{Kz}$ Ss Por

$1.94262 \mathrm{e}+01$ 1.94262e+01 1.94262e+00 1.00000e-09 2.12000e-01

$1.00000 \mathrm{e}+001.00000 \mathrm{e}+001.00000 \mathrm{e}-01$ 1.00000e-09 1.00000e-01

Element: 108 \# of layers: 3

$\mathrm{Kx} \mathrm{Ky} \mathrm{Kz}$ Ss Por

2.31179e+02 2.31179e+02 2.31179e+01 1.00000e-09 7.00000e-02

$9.23712 \mathrm{e}+00$ 9.23712e+00 9.23712e-01 1.00000e-09 2.12000e-01

$1.00000 \mathrm{e}+001.00000 \mathrm{e}+001.00000 \mathrm{e}-01$ 1.00000e-09 1.00000e-01

Element: 109 \# of layers: 3

$\mathrm{Kx} \mathrm{Ky} \mathrm{Kz}$ Ss Por

8.69087e+01 8.69087e+01 8.69087e+00 1.00000e-09 7.00000e-02

$3.47250 \mathrm{e}+003.47250 \mathrm{e}+003.47250 \mathrm{e}-01$ 1.00000e-09 2.12000e-01

$1.00000 \mathrm{e}+001.00000 \mathrm{e}+001.00000 \mathrm{e}-011.00000 \mathrm{e}-091.00000 \mathrm{e}-01$

Element: 110 \# of layers: 3

$\mathrm{Kx} \mathrm{Ky} \mathrm{Kz}$ Ss Por

6.52252e+01 6.52252e+01 6.52252e+00 1.00000e-09 7.00000e-02

$2.60623 \mathrm{e}+00$ 2.60623e+00 2.60623e-01 1.00000e-09 2.12000e-01

$1.00000 \mathrm{e}+001.00000 \mathrm{e}+001.00000 \mathrm{e}-01$ 1.00000e-09 1.00000e-01

Element: 111 \# of layers: 4

Kx Ky Kz Ss Por

7.79572e+01 7.79572e+01 7.79572e+00 1.00000e-09 7.00000e-02

3.11497e+00 3.11497e+00 3.11497e-01 1.00000e-09 2.12000e-01

$1.00000 \mathrm{e}-02$ 1.00000e-02 1.00000e-03 1.00000e-09 1.00000e-01

$1.00000 \mathrm{e}+001.00000 \mathrm{e}+001.00000 \mathrm{e}-011.00000 \mathrm{e}-091.00000 \mathrm{e}-01$

Element: 112 \# of layers: 4

$\mathrm{Kx} \mathrm{Ky} \mathrm{Kz}$ Ss Por

1.09643e+02 1.09643e+02 1.09643e+01 1.00000e-09 7.00000e-02

$4.38084 \mathrm{e}+004.38084 \mathrm{e}+004.38084 \mathrm{e}-01$ 1.00000e-09 2.12000e-01

$1.00000 \mathrm{e}-02$ 1.00000e-02 1.00000e-03 1.00000e-09 1.00000e-01 
$1.00000 \mathrm{e}+001.00000 \mathrm{e}+00$ 1.00000e-01 1.00000e-09 1.00000e-01

Element: 113 \# of layers: 4

Kx Ky Kz Ss Por

$1.65045 \mathrm{e}+02$ 1.65045e+02 1.65045e+01 1.00000e-09 7.00000e-02

6.59467e+00 6.59467e+00 6.59467e-01 1.00000e-09 2.12000e-01

$1.00000 \mathrm{e}-02$ 1.00000e-02 1.00000e-03 1.00000e-09 1.00000e-01

$1.00000 \mathrm{e}+001.00000 \mathrm{e}+001.00000 \mathrm{e}-01$ 1.00000e-09 1.00000e-01

Element: 114 \# of layers: 4

$\mathrm{Kx} \mathrm{Ky} \mathrm{Kz}$ Ss Por

2.28106e+02 2.28106e+02 2.28106e+01 1.00000e-09 7.00000e-02

$9.11404 \mathrm{e}+009.11404 \mathrm{e}+00$ 9.11404e-01 1.00000e-09 2.12000e-01

$1.00000 \mathrm{e}-02$ 1.00000e-02 1.00000e-03 1.00000e-09 1.00000e-01

$1.00000 \mathrm{e}+001.00000 \mathrm{e}+001.00000 \mathrm{e}-011.00000 \mathrm{e}-091.00000 \mathrm{e}-01$

Element: 115 \# of layers: 4

Kx Ky Kz Ss Por

2.11203e+02 2.11203e+02 2.11203e+01 1.00000e-09 7.00000e-02

8.43903e+00 8.43903e+00 8.43903e-01 1.00000e-09 2.12000e-01

$1.00000 \mathrm{e}-02$ 1.00000e-02 1.00000e-03 1.00000e-09 1.00000e-01

$1.00000 \mathrm{e}+001.00000 \mathrm{e}+001.00000 \mathrm{e}-01$ 1.00000e-09 1.00000e-01

Element: 116 \# of layers: 4

$\mathrm{Kx} \mathrm{Ky} \mathrm{Kz}$ Ss Por

1.55657e+02 1.55657e+02 1.55657e+01 1.00000e-09 7.00000e-02

6.21958e+00 6.21958e+00 6.21958e-01 1.00000e-09 2.12000e-01

$1.00000 \mathrm{e}-02$ 1.00000e-02 1.00000e-03 1.00000e-09 1.00000e-01

$1.00000 \mathrm{e}+001.00000 \mathrm{e}+001.00000 \mathrm{e}-011.00000 \mathrm{e}-091.00000 \mathrm{e}-01$

Element: 117 \# of layers: 4

$\mathrm{Kx} \mathrm{Ky} \mathrm{Kz}$ Ss Por

9.64520e+01 9.64520e+01 9.64521e+00 1.00000e-09 7.00000e-02

$3.85411 \mathrm{e}+003.85411 \mathrm{e}+003.85411 \mathrm{e}-01$ 1.00000e-09 2.12000e-01

$1.00000 \mathrm{e}-02$ 1.00000e-02 1.00000e-03 1.00000e-09 1.00000e-01

$1.00000 \mathrm{e}+001.00000 \mathrm{e}+001.00000 \mathrm{e}-011.00000 \mathrm{e}-091.00000 \mathrm{e}-01$

Element: 118 \# of layers: 1

$\mathrm{Kx} \mathrm{Ky} \mathrm{Kz}$ Ss Por

4.23077e+01 4.23077e+01 4.23077e+00 1.00000e-09 2.12000e-01

Element: 119 \# of layers: 1

Kx Ky Kz Ss Por

3.75938e+01 3.75938e+01 3.75938e+00 1.00000e-09 2.12000e-01

Element: 120 \# of layers: 2

$\mathrm{Kx} \mathrm{Ky} \mathrm{Kz}$ Ss Por

4.27082e+01 4.27082e+01 4.27082e+00 1.00000e-09 2.12000e-01

$1.00000 \mathrm{e}+001.00000 \mathrm{e}+001.00000 \mathrm{e}-011.00000 \mathrm{e}-091.00000 \mathrm{e}-01$

Element: 121 \# of layers: 3

$\mathrm{Kx} \mathrm{Ky} \mathrm{Kz}$ Ss Por

2.31242e+02 2.31242e+02 2.31242e+01 1.00000e-09 7.00000e-02

$9.23960 \mathrm{e}+00$ 9.23960e+00 9.23960e-01 1.00000e-09 2.12000e-01

$1.00000 \mathrm{e}+001.00000 \mathrm{e}+001.00000 \mathrm{e}-011.00000 \mathrm{e}-091.00000 \mathrm{e}-01$ 
Element: 122 \# of layers: 3

Kx Ky Kz Ss Por

8.38399e+01 8.38399e+01 8.38399e+00 1.00000e-09 7.00000e-02

$3.34987 \mathrm{e}+003.34987 \mathrm{e}+00$ 3.34987e-01 1.00000e-09 2.12000e-01

$1.00000 \mathrm{e}+001.00000 \mathrm{e}+001.00000 \mathrm{e}-011.00000 \mathrm{e}-091.00000 \mathrm{e}-01$

Element: 123 \# of layers: 3

Kx Ky Kz Ss Por

$6.65830 \mathrm{e}+016.65830 \mathrm{e}+016.65830 \mathrm{e}+00$ 1.00000e-09 7.00000e-02

$2.66046 \mathrm{e}+002.66046 \mathrm{e}+002.66046 \mathrm{e}-011.00000 \mathrm{e}-092.12000 \mathrm{e}-01$

$1.00000 \mathrm{e}+001.00000 \mathrm{e}+001.00000 \mathrm{e}-011.00000 \mathrm{e}-091.00000 \mathrm{e}-01$

Element: 124 \# of layers: 4

Kx Ky Kz Ss Por

7.92943e+01 7.92943e+01 7.92943e+00 1.00000e-09 7.00000e-02

$3.16829 \mathrm{e}+003.16829 \mathrm{e}+003.16829 \mathrm{e}-01$ 1.00000e-09 2.12000e-01

$1.00000 \mathrm{e}-02$ 1.00000e-02 1.00000e-03 1.00000e-09 1.00000e-01

$1.00000 \mathrm{e}+001.00000 \mathrm{e}+001.00000 \mathrm{e}-011.00000 \mathrm{e}-091.00000 \mathrm{e}-01$

Element: 125 \# of layers: 4

Kx Ky Kz Ss Por

$1.15760 \mathrm{e}+021.15760 \mathrm{e}+021.15760 \mathrm{e}+01$ 1.00000e-09 7.00000e-02

$4.62542 \mathrm{e}+004.62542 \mathrm{e}+00 \quad 4.62542 \mathrm{e}-011.00000 \mathrm{e}-09$ 2.12000e-01

$1.00000 \mathrm{e}-021.00000 \mathrm{e}-02$ 1.00000e-03 1.00000e-09 1.00000e-01

$1.00000 \mathrm{e}+001.00000 \mathrm{e}+001.00000 \mathrm{e}-011.00000 \mathrm{e}-091.00000 \mathrm{e}-01$

Element: 126 \# of layers: 4

Kx Ky Kz Ss Por

$1.88237 \mathrm{e}+021.88237 \mathrm{e}+021.88237 \mathrm{e}+01$ 1.00000e-09 7.00000e-02

$7.52146 \mathrm{e}+00$ 7.52146e+00 7.52146e-01 1.00000e-09 2.12000e-01

$1.00000 \mathrm{e}-02$ 1.00000e-02 1.00000e-03 1.00000e-09 1.00000e-01

$1.00000 \mathrm{e}+001.00000 \mathrm{e}+001.00000 \mathrm{e}-011.00000 \mathrm{e}-091.00000 \mathrm{e}-01$

Element: 127 \# of layers: 4

Kx Ky Kz Ss Por

$2.77283 \mathrm{e}+022.77283 \mathrm{e}+022.77283 \mathrm{e}+01$ 1.00000e-09 7.00000e-02

$1.10795 \mathrm{e}+011.10795 \mathrm{e}+011.10795 \mathrm{e}+001.00000 \mathrm{e}-092.12000 \mathrm{e}-01$

$1.00000 \mathrm{e}-021.00000 \mathrm{e}-02$ 1.00000e-03 1.00000e-09 1.00000e-01

$1.00000 \mathrm{e}+001.00000 \mathrm{e}+001.00000 \mathrm{e}-011.00000 \mathrm{e}-091.00000 \mathrm{e}-01$

Element: 130 \# of layers: 4

Kx Ky Kz Ss Por

$1.12508 \mathrm{e}+02$ 1.12508e+02 1.12508e+01 1.00000e-09 7.00000e-02

$4.49537 \mathrm{e}+00 \quad 4.49537 \mathrm{e}+00$ 4.49537e-01 1.00000e-09 2.12000e-01

$1.00000 \mathrm{e}-02$ 1.00000e-02 1.00000e-03 1.00000e-09 1.00000e-01

$1.00000 \mathrm{e}+001.00000 \mathrm{e}+001.00000 \mathrm{e}-011.00000 \mathrm{e}-091.00000 \mathrm{e}-01$

Element: 131 \# of layers: 1

Kx Ky Kz Ss Por

$1.23548 \mathrm{e}+02$ 1.23548e+02 1.23548e+01 1.00000e-09 2.12000e-01

Element: 132 \# of layers: 1

Kx Ky Kz Ss Por

9.32307e+01 9.32307e+01 9.32307e+00 1.00000e-09 2.12000e-01 
Element: 133 \# of layers: 2

$\mathrm{Kx} \mathrm{Ky} \mathrm{Kz}$ Ss Por

7.98339e+01 7.98339e+01 7.98339e+00 1.00000e-09 2.12000e-01

$1.00000 \mathrm{e}+001.00000 \mathrm{e}+001.00000 \mathrm{e}-011.00000 \mathrm{e}-091.00000 \mathrm{e}-01$

Element: 134 \# of layers: 3

$\mathrm{Kx} \mathrm{Ky} \mathrm{Kz}$ Ss Por

$2.21808 \mathrm{e}+02$ 2.21808e+02 2.21808e+01 1.00000e-09 7.00000e-02

$8.86271 \mathrm{e}+008.86271 \mathrm{e}+008.86271 \mathrm{e}-01$ 1.00000e-09 2.12000e-01

$1.00000 \mathrm{e}+001.00000 \mathrm{e}+001.00000 \mathrm{e}-011.00000 \mathrm{e}-091.00000 \mathrm{e}-01$

Element: 135 \# of layers: 3

$\mathrm{Kx} \mathrm{Ky} \mathrm{Kz}$ Ss Por

7.91682e+01 7.91682e+01 7.91682e+00 1.00000e-09 7.00000e-02

$3.16334 \mathrm{e}+003.16334 \mathrm{e}+003.16334 \mathrm{e}-01$ 1.00000e-09 2.12000e-01

$1.00000 \mathrm{e}+001.00000 \mathrm{e}+001.00000 \mathrm{e}-01$ 1.00000e-09 1.00000e-01

Element: 136 \# of layers: 3

$\mathrm{Kx} \mathrm{Ky} \mathrm{Kz}$ Ss Por

6.51531e+01 6.51531e+01 6.51531e+00 1.00000e-09 7.00000e-02

$2.60331 \mathrm{e}+002.60331 \mathrm{e}+002.60331 \mathrm{e}-01$ 1.00000e-09 2.12000e-01

$1.00000 \mathrm{e}+001.00000 \mathrm{e}+001.00000 \mathrm{e}-01$ 1.00000e-09 1.00000e-01

Element: 137 \# of layers: 3

$\mathrm{Kx} \mathrm{Ky} \mathrm{Kz}$ Ss Por

8.53869e+01 8.53869e+01 8.53869e+00 1.00000e-09 7.00000e-02

$3.41175 \mathrm{e}+003.41175 \mathrm{e}+00$ 3.41175e-01 1.00000e-09 2.12000e-01

$1.00000 \mathrm{e}+001.00000 \mathrm{e}+001.00000 \mathrm{e}-01$ 1.00000e-09 1.00000e-01

Element: 138 \# of layers: 4

$\mathrm{Kx} \mathrm{Ky} \mathrm{Kz}$ Ss Por

1.41853e+02 1.41853e+02 1.41853e+01 1.00000e-09 7.00000e-02

5.66787e+00 5.66787e+00 5.66787e-01 1.00000e-09 2.12000e-01

$1.00000 \mathrm{e}-02$ 1.00000e-02 1.00000e-03 1.00000e-09 1.00000e-01

$1.00000 \mathrm{e}+001.00000 \mathrm{e}+001.00000 \mathrm{e}-011.00000 \mathrm{e}-091.00000 \mathrm{e}-01$

Element: 139 \# of layers: 4

Kx Ky Kz Ss Por

2.80175e+02 2.80175e+02 2.80175e+01 1.00000e-09 7.00000e-02

$1.11947 \mathrm{e}+01$ 1.11947e+01 1.11947e+00 1.00000e-09 2.12000e-01

$1.00000 \mathrm{e}-02$ 1.00000e-02 1.00000e-03 1.00000e-09 1.00000e-01

$1.00000 \mathrm{e}+001.00000 \mathrm{e}+001.00000 \mathrm{e}-011.00000 \mathrm{e}-091.00000 \mathrm{e}-01$

Element: 140 \# of layers: 6

Kx Ky Kz Ss Por

4.06027e+02 4.06027e+02 4.06027e+01 1.00000e-09 7.00000e-02 4.06027e+02 4.06027e+02 4.06027e+01 1.00000e-09 7.00000e-02

$1.62233 \mathrm{e}+01$ 1.62233e+01 1.62233e+00 1.00000e-09 2.12000e-01

$1.62233 \mathrm{e}+01$ 1.62233e+01 1.62233e+00 1.00000e-09 2.12000e-01 $1.00000 \mathrm{e}-02$ 1.00000e-02 1.00000e-03 1.00000e-09 1.00000e-01

$1.00000 \mathrm{e}+001.00000 \mathrm{e}+001.00000 \mathrm{e}-01$ 1.00000e-09 1.00000e-01

Element: 143 \# of layers: 3

Kx Ky Kz Ss Por 
1.37240e+02 1.37240e+02 1.37240e+01 1.00000e-09 7.00000e-02

5.48359e+00 5.48359e+00 5.48359e-01 1.00000e-09 2.12000e-01

1.00000e-02 1.00000e-02 1.00000e-03 1.00000e-09 1.00000e-01

Element: 144 \# of layers: 1

$\mathrm{Kx} \mathrm{Ky} \mathrm{Kz}$ Ss Por

1.04582e+02 1.04582e+02 1.04582e+01 1.00000e-09 2.12000e-01

Element: 145 \# of layers: 1

$\mathrm{Kx} \mathrm{Ky} \mathrm{Kz} \mathrm{Ss} \mathrm{Por}$

7.88484e+01 7.88484e+01 7.88484e+00 1.00000e-09 2.12000e-01

Element: 146 \# of layers: 2

$\mathrm{Kx} \mathrm{Ky} \mathrm{Kz}$ Ss Por

7.34033e+01 7.34033e+01 7.34033e+00 1.00000e-09 2.12000e-01 $1.00000 \mathrm{e}+001.00000 \mathrm{e}+00$ 1.00000e-01 1.00000e-09 1.00000e-01

Element: 147 \# of layers: 3

$\mathrm{Kx} \mathrm{Ky} \mathrm{Kz}$ Ss Por

$2.61885 \mathrm{e}+02$ 2.61885e+02 2.61885e+01 1.00000e-09 7.00000e-02

$1.04641 \mathrm{e}+011.04641 \mathrm{e}+011.04641 \mathrm{e}+001.00000 \mathrm{e}-092.12000 \mathrm{e}-01$

$1.00000 \mathrm{e}+001.00000 \mathrm{e}+001.00000 \mathrm{e}-01$ 1.00000e-09 1.00000e-01

Element: 148 \# of layers: 3

$\mathrm{Kx} \mathrm{Ky} \mathrm{Kz}$ Ss Por

9.71188e+01 9.71188e+01 9.71188e+00 1.00000e-09 7.00000e-02

3.88066e $+003.88066 \mathrm{e}+00$ 3.88066e-01 1.00000e-09 2.12000e-01

$1.00000 \mathrm{e}+001.00000 \mathrm{e}+001.00000 \mathrm{e}-01$ 1.00000e-09 1.00000e-01

Element: 149 \# of layers: 3

Kx Ky Kz Ss Por

$1.03534 \mathrm{e}+021.03534 \mathrm{e}+02$ 1.03534e+01 1.00000e-09 7.00000e-02

$4.13694 \mathrm{e}+004.13694 \mathrm{e}+004.13694 \mathrm{e}-01$ 1.00000e-09 2.12000e-01

$1.00000 \mathrm{e}+001.00000 \mathrm{e}+001.00000 \mathrm{e}-011.00000 \mathrm{e}-091.00000 \mathrm{e}-01$

Element: 150 \# of layers: 3

$\mathrm{Kx} \mathrm{Ky} \mathrm{Kz}$ Ss Por

1.45746e+02 1.45746e+02 1.45746e+01 1.00000e-09 7.00000e-02

$5.82358 \mathrm{e}+00$ 5.82358e+00 5.82358e-01 1.00000e-09 2.12000e-01

$1.00000 \mathrm{e}+001.00000 \mathrm{e}+001.00000 \mathrm{e}-011.00000 \mathrm{e}-091.00000 \mathrm{e}-01$

Element: 151 \# of layers: 4

$\mathrm{Kx} \mathrm{Ky} \mathrm{Kz}$ Ss Por

3.08791e+02 3.08791e+02 3.08791e+01 1.00000e-09 7.00000e-02

$1.23381 \mathrm{e}+011.23381 \mathrm{e}+011.23381 \mathrm{e}+001.00000 \mathrm{e}-092.12000 \mathrm{e}-01$

$1.00000 \mathrm{e}-02$ 1.00000e-02 1.00000e-03 1.00000e-09 1.00000e-01

$1.00000 \mathrm{e}+001.00000 \mathrm{e}+001.00000 \mathrm{e}-011.00000 \mathrm{e}-091.00000 \mathrm{e}-01$

Element: 152 \# of layers: 6

$\mathrm{Kx} \mathrm{Ky} \mathrm{Kz}$ Ss Por

8.64969e+02 8.64969e+02 8.64969e+01 1.00000e-09 7.00000e-02

8.64969e+02 8.64969e+02 8.64969e+01 1.00000e-09 7.00000e-02

3.45607e+01 3.45607e+01 3.45607e+00 1.00000e-09 2.12000e-01

$3.45607 \mathrm{e}+013.45607 \mathrm{e}+013.45607 \mathrm{e}+00$ 1.00000e-09 2.12000e-01

$1.00000 \mathrm{e}-02$ 1.00000e-02 1.00000e-03 1.00000e-09 1.00000e-01 
$1.00000 \mathrm{e}+001.00000 \mathrm{e}+00$ 1.00000e-01 1.00000e-09 1.00000e-01

Element: 153 \# of layers: 1

$\mathrm{Kx} \mathrm{Ky} \mathrm{Kz}$ Ss Por

1.34420e+02 1.34420e+02 1.34420e+01 1.00000e-09 2.12000e-01

Element: 154 \# of layers: 1

$\mathrm{Kx} \mathrm{Ky} \mathrm{Kz}$ Ss Por

8.33035e+01 8.33035e+01 8.33035e+00 1.00000e-09 2.12000e-01

Element: 155 \# of layers: 2

$\mathrm{Kx} \mathrm{Ky} \mathrm{Kz}$ Ss Por

6.86917e+01 6.86917e+01 6.86917e+00 1.00000e-09 2.12000e-01

$1.00000 \mathrm{e}+001.00000 \mathrm{e}+001.00000 \mathrm{e}-01$ 1.00000e-09 1.00000e-01

Element: 156 \# of layers: 2

$\mathrm{Kx} \mathrm{Ky} \mathrm{Kz}$ Ss Por

7.03027e+01 7.03027e+01 7.03028e+00 1.00000e-09 2.12000e-01 $1.00000 \mathrm{e}+001.00000 \mathrm{e}+001.00000 \mathrm{e}-01$ 1.00000e-09 1.00000e-01

Element: 157 \# of layers: 3

$\mathrm{Kx} \mathrm{Ky} \mathrm{Kz}$ Ss Por

4.05297e+02 4.05297e+02 4.05297e+01 1.00000e-09 7.00000e-02 $1.61943 \mathrm{e}+01$ 1.61943e+01 1.61943e+00 1.00000e-09 2.12000e-01

$1.00000 \mathrm{e}+001.00000 \mathrm{e}+001.00000 \mathrm{e}-011.00000 \mathrm{e}-091.00000 \mathrm{e}-01$

Element: 158 \# of layers: 3

$\mathrm{Kx} \mathrm{Ky} \mathrm{Kz}$ Ss Por

1.59810e+02 1.59810e+02 1.59810e+01 1.00000e-09 7.00000e-02

6.38541e+00 6.38541e+00 6.38541e-01 1.00000e-09 2.12000e-01

$1.00000 \mathrm{e}+001.00000 \mathrm{e}+001.00000 \mathrm{e}-011.00000 \mathrm{e}-091.00000 \mathrm{e}-01$

Element: 159 \# of layers: 3

$\mathrm{Kx} \mathrm{Ky} \mathrm{Kz}$ Ss Por

$1.60342 \mathrm{e}+02$ 1.60342e+02 1.60342e+01 1.00000e-09 7.00000e-02

6.40679e+00 6.40679e+00 6.40679e-01 1.00000e-09 2.12000e-01

$1.00000 \mathrm{e}+001.00000 \mathrm{e}+001.00000 \mathrm{e}-011.00000 \mathrm{e}-091.00000 \mathrm{e}-01$

Element: 160 \# of layers: 3

$\mathrm{Kx} \mathrm{Ky} \mathrm{Kz}$ Ss Por

2.15051e+02 2.15051e+02 2.15051e+01 1.00000e-09 7.00000e-02

$8.59248 \mathrm{e}+00$ 8.59248e+00 8.59248e-01 1.00000e-09 2.12000e-01

$1.00000 \mathrm{e}+001.00000 \mathrm{e}+001.00000 \mathrm{e}-01$ 1.00000e-09 1.00000e-01

Element: 161 \# of layers: 5

Kx Ky Kz Ss Por

5.63945e+02 5.63945e+02 5.63945e+01 1.00000e-09 7.00000e-02

$2.25342 \mathrm{e}+012.25342 \mathrm{e}+012.25342 \mathrm{e}+00$ 1.00000e-09 2.12000e-01

$2.25342 \mathrm{e}+012.25342 \mathrm{e}+012.25342 \mathrm{e}+00$ 1.00000e-09 2.12000e-01

$1.00000 \mathrm{e}-02$ 1.00000e-02 1.00000e-03 1.00000e-09 1.00000e-01

$1.00000 \mathrm{e}+001.00000 \mathrm{e}+001.00000 \mathrm{e}-011.00000 \mathrm{e}-091.00000 \mathrm{e}-01$

Element: 162 \# of layers: 1

$\mathrm{Kx} \mathrm{Ky} \mathrm{Kz}$ Ss Por

2.21803e+02 2.21803e+02 2.21803e+01 1.00000e-09 2.12000e-01

Element: 163 \# of layers: 1 
$\mathrm{Kx} \mathrm{Ky} \mathrm{Kz}$ Ss Por

$1.22882 \mathrm{e}+02$ 1.22882e+02 1.22882e+01 1.00000e-09 2.12000e-01

Element: 164 \# of layers: 2

$\mathrm{Kx} \mathrm{Ky} \mathrm{Kz}$ Ss Por

7.69291e+01 7.69291e+01 7.69291e+00 1.00000e-09 2.12000e-01

$1.00000 \mathrm{e}+001.00000 \mathrm{e}+001.00000 \mathrm{e}-011.00000 \mathrm{e}-091.00000 \mathrm{e}-01$

Element: 165 \# of layers: 2

$\mathrm{Kx} \mathrm{Ky} \mathrm{Kz}$ Ss Por

$7.56129 \mathrm{e}+01$ 7.56129e+01 7.56129e+00 1.00000e-09 2.12000e-01

$1.00000 \mathrm{e}+001.00000 \mathrm{e}+001.00000 \mathrm{e}-01$ 1.00000e-09 1.00000e-01

Element: 166 \# of layers: 2

$\mathrm{Kx} \mathrm{Ky} \mathrm{Kz}$ Ss Por

7.63554e+01 7.63554e+01 7.63554e+00 1.00000e-09 2.12000e-01 $1.00000 \mathrm{e}+001.00000 \mathrm{e}+001.00000 \mathrm{e}-01$ 1.00000e-09 1.00000e-01

Element: 167 \# of layers: 3

Kx Ky Kz Ss Por

8.44525e+02 8.44525e+02 8.44525e+01 1.00000e-09 7.00000e-02

$3.37440 \mathrm{e}+013.37440 \mathrm{e}+013.37440 \mathrm{e}+001.00000 \mathrm{e}-092.12000 \mathrm{e}-01$

$1.00000 \mathrm{e}+001.00000 \mathrm{e}+001.00000 \mathrm{e}-01$ 1.00000e-09 1.00000e-01

Element: 168 \# of layers: 3

$\mathrm{Kx} \mathrm{Ky} \mathrm{Kz}$ Ss Por

3.61571e+02 3.61571e+02 3.61571e+01 1.00000e-09 7.00000e-02 $1.44471 \mathrm{e}+011.44471 \mathrm{e}+011.44471 \mathrm{e}+001.00000 \mathrm{e}-092.12000 \mathrm{e}-01$

$1.00000 \mathrm{e}+001.00000 \mathrm{e}+001.00000 \mathrm{e}-011.00000 \mathrm{e}-091.00000 \mathrm{e}-01$

Element: 169 \# of layers: 3

$\mathrm{Kx} \mathrm{Ky} \mathrm{Kz}$ Ss Por

2.79860e+02 2.79860e+02 2.79860e+01 1.00000e-09 7.00000e-02

$1.11823 \mathrm{e}+01$ 1.11823e+01 1.11823e+00 1.00000e-09 2.12000e-01

$1.00000 \mathrm{e}+001.00000 \mathrm{e}+001.00000 \mathrm{e}-011.00000 \mathrm{e}-091.00000 \mathrm{e}-01$

Element: 170 \# of layers: 6

$\mathrm{Kx} \mathrm{Ky} \mathrm{Kz}$ Ss Por

3.33118e+02 3.33118e+02 3.33118e+01 1.00000e-09 7.00000e-02

$3.33118 \mathrm{e}+02$ 3.33118e+02 3.33118e+01 1.00000e-09 7.00000e-02

$1.33102 \mathrm{e}+01$ 1.33102e+01 1.33102e+00 1.00000e-09 2.12000e-01

$1.33102 \mathrm{e}+011.33102 \mathrm{e}+01$ 1.33102e+00 1.00000e-09 2.12000e-01

$1.33102 \mathrm{e}+011.33102 \mathrm{e}+01$ 1.33102e+00 1.00000e-09 2.12000e-01

$1.00000 \mathrm{e}+001.00000 \mathrm{e}+001.00000 \mathrm{e}-01$ 1.00000e-09 1.00000e-01

Element: 171 \# of layers: 1

$\mathrm{Kx} \mathrm{Ky} \mathrm{Kz}$ Ss Por

1.13447e+02 1.13447e+02 1.13447e+01 1.00000e-09 2.12000e-01

Element: 172 \# of layers: 2

$\mathrm{Kx} \mathrm{Ky} \mathrm{Kz}$ Ss Por

$8.24800 \mathrm{e}+018.24800 \mathrm{e}+018.24800 \mathrm{e}+001.00000 \mathrm{e}-092.12000 \mathrm{e}-01$ $1.00000 \mathrm{e}+001.00000 \mathrm{e}+001.00000 \mathrm{e}-01$ 1.00000e-09 1.00000e-01

Element: 173 \# of layers: 2

Kx Ky Kz Ss Por 
7.84074e+01 7.84074e+01 7.84074e+00 1.00000e-09 2.12000e-01 $1.00000 \mathrm{e}+001.00000 \mathrm{e}+001.00000 \mathrm{e}-01$ 1.00000e-09 1.00000e-01

Element: 174 \# of layers: 2

$\mathrm{Kx} \mathrm{Ky} \mathrm{Kz}$ Ss Por

7.57299e+01 7.57299e+01 7.57299e+00 1.00000e-09 2.12000e-01 $1.00000 \mathrm{e}+001.00000 \mathrm{e}+001.00000 \mathrm{e}-01$ 1.00000e-09 1.00000e-01

Element: 175 \# of layers: 2

Kx Ky Kz Ss Por

7.56309e+01 7.56309e+01 7.56309e+00 1.00000e-09 2.12000e-01 $1.00000 \mathrm{e}+001.00000 \mathrm{e}+001.00000 \mathrm{e}-011.00000 \mathrm{e}-091.00000 \mathrm{e}-01$

Element: 176 \# of layers: 2

Kx Ky Kz Ss Por

7.85267e+01 7.85267e+01 7.85267e+00 1.00000e-09 2.12000e-01 $1.00000 \mathrm{e}+001.00000 \mathrm{e}+001.00000 \mathrm{e}-01$ 1.00000e-09 1.00000e-01

Element: 177 \# of layers: 3

Kx Ky Kz Ss Por

9.02171e+02 9.02171e+02 9.02171e+01 1.00000e-09 7.00000e-02 $3.60458 \mathrm{e}+013.60458 \mathrm{e}+013.60458 \mathrm{e}+00$ 1.00000e-09 2.12000e-01 $1.00000 \mathrm{e}+001.00000 \mathrm{e}+001.00000 \mathrm{e}-01$ 1.00000e-09 1.00000e-01

Element: 178 \# of layers: 6

$\mathrm{Kx} \mathrm{Ky} \mathrm{Kz}$ Ss Por

4.83522e+02 4.83522e+02 4.83522e+01 1.00000e-09 7.00000e-02 $1.93198 \mathrm{e}+01$ 1.93198e+01 1.93198e+00 1.00000e-09 2.12000e-01 $1.93198 \mathrm{e}+01$ 1.93198e+01 1.93198e+00 1.00000e-09 2.12000e-01 $1.93198 \mathrm{e}+01$ 1.93198e+01 1.93198e+00 1.00000e-09 2.12000e-01 $1.93198 \mathrm{e}+01$ 1.93198e+01 1.93198e+00 1.00000e-09 2.12000e-01 $1.00000 \mathrm{e}+001.00000 \mathrm{e}+001.00000 \mathrm{e}-01$ 1.00000e-09 1.00000e-01 Element: 179 \# of layers: 1

$\mathrm{Kx} \mathrm{Ky} \mathrm{Kz}$ Ss Por 1.06472e+02 1.06472e+02 1.06472e+01 1.00000e-09 2.12000e-01 Element: 180 \# of layers: 2

$\mathrm{Kx} \mathrm{Ky} \mathrm{Kz}$ Ss Por

$1.47302 \mathrm{e}+02$ 1.47302e+02 1.47302e+01 1.00000e-09 2.12000e-01 $1.00000 \mathrm{e}+001.00000 \mathrm{e}+001.00000 \mathrm{e}-011.00000 \mathrm{e}-091.00000 \mathrm{e}-01$

Element: 181 \# of layers: 2

Kx Ky Kz Ss Por

$1.11121 \mathrm{e}+021.11121 \mathrm{e}+021.11121 \mathrm{e}+01$ 1.00000e-09 2.12000e-01 $1.00000 \mathrm{e}+001.00000 \mathrm{e}+00$ 1.00000e-01 1.00000e-09 1.00000e-01

Element: 182 \# of layers: 2

$\mathrm{Kx} \mathrm{Ky} \mathrm{Kz}$ Ss Por

7.13243e+01 7.13243e+01 7.13243e+00 1.00000e-09 2.12000e-01 $1.00000 \mathrm{e}+001.00000 \mathrm{e}+001.00000 \mathrm{e}-011.00000 \mathrm{e}-091.00000 \mathrm{e}-01$ Element: 183 \# of layers: 2

$\mathrm{Kx} \mathrm{Ky} \mathrm{Kz}$ Ss Por

7.84299e+01 7.84299e+01 7.84299e+00 1.00000e-09 2.12000e-01 $1.00000 \mathrm{e}+001.00000 \mathrm{e}+001.00000 \mathrm{e}-011.00000 \mathrm{e}-091.00000 \mathrm{e}-01$ 
Element: 184 \# of layers: 2

$\mathrm{Kx} \mathrm{Ky} \mathrm{Kz}$ Ss Por

7.73724e+01 7.73724e+01 7.73724e+00 1.00000e-09 2.12000e-01

$1.00000 \mathrm{e}+001.00000 \mathrm{e}+001.00000 \mathrm{e}-011.00000 \mathrm{e}-091.00000 \mathrm{e}-01$

Element: 185 \# of layers: 6

$\mathrm{Kx} \mathrm{Ky} \mathrm{Kz}$ Ss Por

4.81870e+01 4.81870e+01 4.81870e+00 1.00000e-09 2.12000e-01

$4.81870 \mathrm{e}+01$ 4.81870e+01 4.81870e+00 1.00000e-09 2.12000e-01

4.81870e+01 4.81870e+01 4.81870e+00 1.00000e-09 2.12000e-01

$4.81870 \mathrm{e}+014.81870 \mathrm{e}+014.81870 \mathrm{e}+00$ 1.00000e-09 2.12000e-01

$1.00000 \mathrm{e}-02$ 1.00000e-02 1.00000e-03 1.00000e-09 1.00000e-01

$1.00000 \mathrm{e}+001.00000 \mathrm{e}+001.00000 \mathrm{e}-011.00000 \mathrm{e}-091.00000 \mathrm{e}-01$

Element: 186 \# of layers: 2

$\mathrm{Kx} \mathrm{Ky} \mathrm{Kz}$ Ss Por

$2.65686 \mathrm{e}+02$ 2.65686e+02 2.65686e+01 1.00000e-09 2.12000e-01

$1.00000 \mathrm{e}+001.00000 \mathrm{e}+001.00000 \mathrm{e}-01$ 1.00000e-09 1.00000e-01

Element: 187 \# of layers: 2

$\mathrm{Kx} \mathrm{Ky} \mathrm{Kz}$ Ss Por

$2.45660 \mathrm{e}+02$ 2.45660e+02 2.45660e+01 1.00000e-09 2.12000e-01

$1.00000 \mathrm{e}+001.00000 \mathrm{e}+001.00000 \mathrm{e}-01$ 1.00000e-09 1.00000e-01

Element: 188 \# of layers: 2

$\mathrm{Kx} \mathrm{Ky} \mathrm{Kz}$ Ss Por

1.12167e+02 1.12167e+02 1.12167e+01 1.00000e-09 2.12000e-01

$1.00000 \mathrm{e}+001.00000 \mathrm{e}+001.00000 \mathrm{e}-01$ 1.00000e-09 1.00000e-01

Element: 189 \# of layers: 2

$\mathrm{Kx} \mathrm{Ky} \mathrm{Kz}$ Ss Por

$6.50061 \mathrm{e}+016.50061 \mathrm{e}+016.50061 \mathrm{e}+00$ 1.00000e-09 2.12000e-01

$1.00000 \mathrm{e}+001.00000 \mathrm{e}+001.00000 \mathrm{e}-011.00000 \mathrm{e}-09$ 1.00000e-01

Element: 190 \# of layers: 3

$\mathrm{Kx} \mathrm{Ky} \mathrm{Kz}$ Ss Por

6.70582e+01 6.70582e+01 6.70582e+00 1.00000e-09 2.12000e-01

$1.00000 \mathrm{e}-02$ 1.00000e-02 1.00000e-03 1.00000e-09 1.00000e-01

$1.00000 \mathrm{e}+001.00000 \mathrm{e}+001.00000 \mathrm{e}-011.00000 \mathrm{e}-091.00000 \mathrm{e}-01$

Element: 191 \# of layers: 3

$\mathrm{Kx} \mathrm{Ky} \mathrm{Kz}$ Ss Por

6.29181e+01 6.29181e+01 6.29181e+00 1.00000e-09 2.12000e-01

$1.00000 \mathrm{e}-02$ 1.00000e-02 1.00000e-03 1.00000e-09 1.00000e-01

$1.00000 \mathrm{e}+001.00000 \mathrm{e}+001.00000 \mathrm{e}-011.00000 \mathrm{e}-091.00000 \mathrm{e}-01$

Element: 192 \# of layers: 2

$\mathrm{Kx} \mathrm{Ky} \mathrm{Kz}$ Ss Por

$1.53048 \mathrm{e}+02$ 1.53048e+02 1.53048e+01 1.00000e-09 2.12000e-01 $1.00000 \mathrm{e}+001.00000 \mathrm{e}+001.00000 \mathrm{e}-011.00000 \mathrm{e}-091.00000 \mathrm{e}-01$

Element: 193 \# of layers: 2

$\mathrm{Kx} \mathrm{Ky} \mathrm{Kz}$ Ss Por

$1.52306 \mathrm{e}+02$ 1.52306e+02 1.52306e+01 1.00000e-09 2.12000e-01

$1.00000 \mathrm{e}+001.00000 \mathrm{e}+001.00000 \mathrm{e}-011.00000 \mathrm{e}-091.00000 \mathrm{e}-01$ 
Element: 194 \# of layers: 2

$\mathrm{Kx} \mathrm{Ky} \mathrm{Kz}$ Ss Por

$1.37345 \mathrm{e}+02$ 1.37345e+02 1.37345e+01 1.00000e-09 2.12000e-01

$1.00000 \mathrm{e}+001.00000 \mathrm{e}+001.00000 \mathrm{e}-011.00000 \mathrm{e}-091.00000 \mathrm{e}-01$

Element: 195 \# of layers: 3

$\mathrm{Kx} \mathrm{Ky} \mathrm{Kz}$ Ss Por

7.23278e+01 7.23278e+01 7.23278e+00 1.00000e-09 2.12000e-01

$1.00000 \mathrm{e}-02$ 1.00000e-02 1.00000e-03 1.00000e-09 1.00000e-01

$1.00000 \mathrm{e}+001.00000 \mathrm{e}+001.00000 \mathrm{e}-011.00000 \mathrm{e}-091.00000 \mathrm{e}-01$

Element: 196 \# of layers: 3

$\mathrm{Kx} \mathrm{Ky} \mathrm{Kz}$ Ss Por

5.78757e+01 5.78757e+01 5.78757e+00 1.00000e-09 2.12000e-01

$1.00000 \mathrm{e}-021.00000 \mathrm{e}-021.00000 \mathrm{e}-031.00000 \mathrm{e}-091.00000 \mathrm{e}-01$

$1.00000 \mathrm{e}+001.00000 \mathrm{e}+001.00000 \mathrm{e}-01$ 1.00000e-09 1.00000e-01

Element: 197 \# of layers: 3

Kx Ky Kz Ss Por

6.54426e+01 6.54426e+01 6.54426e+00 1.00000e-09 2.12000e-01 $1.00000 \mathrm{e}-02$ 1.00000e-02 1.00000e-03 1.00000e-09 1.00000e-01

$1.00000 \mathrm{e}+001.00000 \mathrm{e}+001.00000 \mathrm{e}-011.00000 \mathrm{e}-091.00000 \mathrm{e}-01$

Element: 198 \# of layers: 2

$\mathrm{Kx} \mathrm{Ky} \mathrm{Kz}$ Ss Por

7.57272e+00 7.57272e+00 7.57272e-01 1.00000e-09 7.00000e-02

$1.00000 \mathrm{e}+001.00000 \mathrm{e}+001.00000 \mathrm{e}-01$ 1.00000e-09 1.00000e-01

Element: 199 \# of layers: 3

$\mathrm{Kx} \mathrm{Ky} \mathrm{Kz}$ Ss Por

8.87809e+00 8.87809e+00 8.87809e-01 1.00000e-09 7.00000e-02

3.54743e-01 3.54743e-01 3.54743e-02 1.00000e-09 2.12000e-01

$1.00000 \mathrm{e}+001.00000 \mathrm{e}+001.00000 \mathrm{e}-01$ 1.00000e-09 1.00000e-01

Element: 200 \# of layers: 3

$\mathrm{Kx} \mathrm{Ky} \mathrm{Kz}$ Ss Por

7.76887e+01 7.76887e+01 7.76887e+00 1.00000e-09 7.00000e-02

$3.10417 \mathrm{e}+003.10417 \mathrm{e}+00$ 3.10417e-01 1.00000e-09 2.12000e-01

$1.00000 \mathrm{e}+001.00000 \mathrm{e}+001.00000 \mathrm{e}-01$ 1.00000e-09 1.00000e-01

Element: 201 \# of layers: 3

$\mathrm{Kx} \mathrm{Ky} \mathrm{Kz}$ Ss Por

2.29683e+02 2.29683e+02 2.29683e+01 1.00000e-09 7.00000e-02

$9.17727 \mathrm{e}+00$ 9.17727e+00 9.17727e-01 1.00000e-09 2.12000e-01

$1.00000 \mathrm{e}+001.00000 \mathrm{e}+001.00000 \mathrm{e}-01$ 1.00000e-09 1.00000e-01

Element: 202 \# of layers: 3

$\mathrm{Kx} \mathrm{Ky} \mathrm{Kz}$ Ss Por

9.99569e+02 9.99569e+02 9.99569e+01 1.00000e-09 7.00000e-02

$3.99406 \mathrm{e}+013.99406 \mathrm{e}+013.99406 \mathrm{e}+001.00000 \mathrm{e}-092.12000 \mathrm{e}-01$

$1.00000 \mathrm{e}+001.00000 \mathrm{e}+001.00000 \mathrm{e}-01$ 1.00000e-09 1.00000e-01

Element: 203 \# of layers: 3

$\mathrm{Kx} \mathrm{Ky} \mathrm{Kz} \mathrm{Ss} \mathrm{Por}$

$1.15070 \mathrm{e}+02$ 1.15070e+02 1.15070e+01 1.00000e-09 2.12000e-01 
$1.00000 \mathrm{e}-02$ 1.00000e-02 1.00000e-03 1.00000e-09 1.00000e-01 $1.00000 \mathrm{e}+001.00000 \mathrm{e}+001.00000 \mathrm{e}-01$ 1.00000e-09 1.00000e-01

Element: 204 \# of layers: 3

$\mathrm{Kx} \mathrm{Ky} \mathrm{Kz}$ Ss Por

8.78914e+01 8.78914e+01 8.78914e+00 1.00000e-09 2.12000e-01

$1.00000 \mathrm{e}-02$ 1.00000e-02 1.00000e-03 1.00000e-09 1.00000e-01

$1.00000 \mathrm{e}+001.00000 \mathrm{e}+001.00000 \mathrm{e}-01$ 1.00000e-09 1.00000e-01

Element: 205 \# of layers: 3

$\mathrm{Kx} \mathrm{Ky} \mathrm{Kz}$ Ss Por

8.91627e+01 8.91627e+01 8.91627e+00 1.00000e-09 2.12000e-01

$1.00000 \mathrm{e}-02$ 1.00000e-02 1.00000e-03 1.00000e-09 1.00000e-01

$1.00000 \mathrm{e}+001.00000 \mathrm{e}+001.00000 \mathrm{e}-011.00000 \mathrm{e}-091.00000 \mathrm{e}-01$

Element: 206 \# of layers: 3

$\mathrm{Kx} \mathrm{Ky} \mathrm{Kz}$ Ss Por

8.08127e+01 8.08127e+01 8.08127e+00 1.00000e-09 2.12000e-01

$1.00000 \mathrm{e}-02$ 1.00000e-02 1.00000e-03 1.00000e-09 1.00000e-01

$1.00000 \mathrm{e}+001.00000 \mathrm{e}+001.00000 \mathrm{e}-011.00000 \mathrm{e}-091.00000 \mathrm{e}-01$

Element: 207 \# of layers: 3

$\mathrm{Kx} \mathrm{Ky} \mathrm{Kz}$ Ss Por

6.10753e+01 6.10753e+01 6.10753e+00 1.00000e-09 2.12000e-01

$1.00000 \mathrm{e}-02$ 1.00000e-02 1.00000e-03 1.00000e-09 1.00000e-01

$1.00000 \mathrm{e}+001.00000 \mathrm{e}+001.00000 \mathrm{e}-01$ 1.00000e-09 1.00000e-01

Element: 208 \# of layers: 6

$\mathrm{Kx} \mathrm{Ky} \mathrm{Kz}$ Ss Por

6.14016e+01 6.14016e+01 6.14016e+00 1.00000e-09 2.12000e-01

6.14016e+01 6.14016e+01 6.14016e+00 1.00000e-09 2.12000e-01

6.14016e+01 6.14016e+01 6.14016e+00 1.00000e-09 2.12000e-01

$6.14016 \mathrm{e}+016.14016 \mathrm{e}+016.14016 \mathrm{e}+001.00000 \mathrm{e}-09$ 2.12000e-01

$1.00000 \mathrm{e}-02$ 1.00000e-02 1.00000e-03 1.00000e-09 1.00000e-01

$1.00000 \mathrm{e}+001.00000 \mathrm{e}+001.00000 \mathrm{e}-011.00000 \mathrm{e}-091.00000 \mathrm{e}-01$

Element: 209 \# of layers: 2

$\mathrm{Kx} \mathrm{Ky} \mathrm{Kz}$ Ss Por

$1.00083 \mathrm{e}+011.00083 \mathrm{e}+01$ 1.00083e+00 1.00000e-09 7.00000e-02

$1.00000 \mathrm{e}+001.00000 \mathrm{e}+001.00000 \mathrm{e}-011.00000 \mathrm{e}-091.00000 \mathrm{e}-01$

Element: 210 \# of layers: 3

Kx Ky Kz Ss Por

6.75227e+00 6.75227e+00 6.75228e-01 1.00000e-09 7.00000e-02

2.69803e-01 2.69803e-01 2.69803e-02 1.00000e-09 2.12000e-01

$1.00000 \mathrm{e}+001.00000 \mathrm{e}+001.00000 \mathrm{e}-01$ 1.00000e-09 1.00000e-01

Element: 211 \# of layers: 3

$\mathrm{Kx} \mathrm{Ky} \mathrm{Kz}$ Ss Por

$2.55614 \mathrm{e}+012.55614 \mathrm{e}+012.55614 \mathrm{e}+001.00000 \mathrm{e}-09$ 7.00000e-02

$1.02136 \mathrm{e}+001.02136 \mathrm{e}+00$ 1.02136e-01 1.00000e-09 2.12000e-01

$1.00000 \mathrm{e}+001.00000 \mathrm{e}+001.00000 \mathrm{e}-01$ 1.00000e-09 1.00000e-01

Element: 212 \# of layers: 4

Kx Ky Kz Ss Por 
$1.29780 \mathrm{e}+021.29780 \mathrm{e}+02$ 1.29780e+01 1.00000e-09 7.00000e-02

$5.18546 \mathrm{e}+00$ 5.18546e+00 5.18546e-01 1.00000e-09 2.12000e-01

$1.00000 \mathrm{e}-02$ 1.00000e-02 1.00000e-03 1.00000e-09 1.00000e-01

$1.00000 \mathrm{e}+001.00000 \mathrm{e}+001.00000 \mathrm{e}-011.00000 \mathrm{e}-091.00000 \mathrm{e}-01$

Element: 213 \# of layers: 4

$\mathrm{Kx} \mathrm{Ky} \mathrm{Kz}$ Ss Por

3.44290e+02 3.44290e+02 3.44290e+01 1.00000e-09 7.00000e-02

$1.37566 \mathrm{e}+011.37566 \mathrm{e}+011.37566 \mathrm{e}+001.00000 \mathrm{e}-092.12000 \mathrm{e}-01$

$1.00000 \mathrm{e}-02$ 1.00000e-02 1.00000e-03 1.00000e-09 1.00000e-01

$1.00000 \mathrm{e}+001.00000 \mathrm{e}+00$ 1.00000e-01 1.00000e-09 1.00000e-01

Element: 214 \# of layers: 4

$\mathrm{Kx} \mathrm{Ky} \mathrm{Kz}$ Ss Por

$1.30429 \mathrm{e}+03$ 1.30429e+03 1.30429e+02 1.00000e-09 7.00000e-02

$5.21134 \mathrm{e}+015.21134 \mathrm{e}+015.21134 \mathrm{e}+001.00000 \mathrm{e}-092.12000 \mathrm{e}-01$

$1.00000 \mathrm{e}-02$ 1.00000e-02 1.00000e-03 1.00000e-09 1.00000e-01

$1.00000 \mathrm{e}+001.00000 \mathrm{e}+001.00000 \mathrm{e}-011.00000 \mathrm{e}-091.00000 \mathrm{e}-01$

Element: 215 \# of layers: 3

$\mathrm{Kx} \mathrm{Ky} \mathrm{Kz}$ Ss Por

9.33725e+01 9.33725e+01 9.33725e+00 1.00000e-09 2.12000e-01

$1.00000 \mathrm{e}-021.00000 \mathrm{e}-02$ 1.00000e-03 1.00000e-09 1.00000e-01

$1.00000 \mathrm{e}+001.00000 \mathrm{e}+001.00000 \mathrm{e}-011.00000 \mathrm{e}-091.00000 \mathrm{e}-01$

Element: 216 \# of layers: 5

$\mathrm{Kx} \mathrm{Ky} \mathrm{Kz}$ Ss Por

9.18785e+01 9.18785e+01 9.18785e+00 1.00000e-09 2.12000e-01

$1.00000 \mathrm{e}-02$ 1.00000e-02 1.00000e-03 1.00000e-09 1.00000e-01

$1.00000 \mathrm{e}+001.00000 \mathrm{e}+001.00000 \mathrm{e}-011.00000 \mathrm{e}-091.00000 \mathrm{e}-01$

$1.00000 \mathrm{e}-05$ 1.00000e-05 1.00000e-06 1.00000e-09 1.00000e-01

$1.00000 \mathrm{e}+001.00000 \mathrm{e}+001.00000 \mathrm{e}-011.00000 \mathrm{e}-091.00000 \mathrm{e}-01$

Element: 217 \# of layers: 6

$\mathrm{Kx} \mathrm{Ky} \mathrm{Kz}$ Ss Por

1.33258e+03 1.33258e+03 1.33258e+02 1.00000e-09 7.00000e-02

$5.32451 \mathrm{e}+015.32451 \mathrm{e}+015.32451 \mathrm{e}+00$ 1.00000e-09 2.12000e-01

$1.00000 \mathrm{e}-021.00000 \mathrm{e}-02$ 1.00000e-03 1.00000e-09 1.00000e-01

$1.00000 \mathrm{e}+001.00000 \mathrm{e}+001.00000 \mathrm{e}-011.00000 \mathrm{e}-091.00000 \mathrm{e}-01$

$1.00000 \mathrm{e}-05$ 1.00000e-05 1.00000e-06 1.00000e-09 1.00000e-01

$1.00000 \mathrm{e}+001.00000 \mathrm{e}+001.00000 \mathrm{e}-01$ 1.00000e-09 1.00000e-01

Element: 218 \# of layers: 6

$\mathrm{Kx} \mathrm{Ky} \mathrm{Kz}$ Ss Por

8.80295e+02 8.80295e+02 8.80295e+01 1.00000e-09 7.00000e-02

$3.51727 \mathrm{e}+013.51727 \mathrm{e}+013.51727 \mathrm{e}+001.00000 \mathrm{e}-092.12000 \mathrm{e}-01$

1.00000e-02 1.00000e-02 1.00000e-03 1.00000e-09 1.00000e-01

$1.00000 \mathrm{e}+001.00000 \mathrm{e}+001.00000 \mathrm{e}-011.00000 \mathrm{e}-091.00000 \mathrm{e}-01$

$1.00000 \mathrm{e}-051.00000 \mathrm{e}-051.00000 \mathrm{e}-061.00000 \mathrm{e}-091.00000 \mathrm{e}-01$

$1.00000 \mathrm{e}+001.00000 \mathrm{e}+001.00000 \mathrm{e}-011.00000 \mathrm{e}-091.00000 \mathrm{e}-01$

Element: 219 \# of layers: 10

Kx Ky Kz Ss Por 
5.05065e+02 5.05065e+02 5.05065e+01 1.00000e-09 7.00000e-02 $2.01805 \mathrm{e}+012.01805 \mathrm{e}+012.01805 \mathrm{e}+001.00000 \mathrm{e}-092.12000 \mathrm{e}-01$ $2.01805 \mathrm{e}+012.01805 \mathrm{e}+012.01805 \mathrm{e}+001.00000 \mathrm{e}-092.12000 \mathrm{e}-01$ $2.01805 \mathrm{e}+012.01805 \mathrm{e}+012.01805 \mathrm{e}+001.00000 \mathrm{e}-092.12000 \mathrm{e}-01$ $2.01805 \mathrm{e}+012.01805 \mathrm{e}+012.01805 \mathrm{e}+001.00000 \mathrm{e}-092.12000 \mathrm{e}-01$ $2.01805 \mathrm{e}+012.01805 \mathrm{e}+012.01805 \mathrm{e}+001.00000 \mathrm{e}-092.12000 \mathrm{e}-01$ $1.00000 \mathrm{e}-02$ 1.00000e-02 1.00000e-03 1.00000e-09 1.00000e-01 $1.00000 \mathrm{e}+001.00000 \mathrm{e}+001.00000 \mathrm{e}-011.00000 \mathrm{e}-091.00000 \mathrm{e}-01$ $1.00000 \mathrm{e}-05$ 1.00000e-05 1.00000e-06 1.00000e-09 1.00000e-01 $1.00000 \mathrm{e}+001.00000 \mathrm{e}+001.00000 \mathrm{e}-011.00000 \mathrm{e}-091.00000 \mathrm{e}-01$ Element: 220 \# of layers: 3

$\mathrm{Kx} \mathrm{Ky} \mathrm{Kz}$ Ss Por

8.81259e+00 8.81259e+00 8.81259e-01 1.00000e-09 7.00000e-02 3.52110e-01 3.52110e-01 3.52110e-02 1.00000e-09 2.12000e-01 $1.00000 \mathrm{e}+001.00000 \mathrm{e}+001.00000 \mathrm{e}-011.00000 \mathrm{e}-091.00000 \mathrm{e}-01$ Element: 221 \# of layers: 4

$\mathrm{Kx} \mathrm{Ky} \mathrm{Kz}$ Ss Por

3.98287e+01 3.98287e+01 3.98287e+00 1.00000e-09 7.00000e-02 $1.59141 \mathrm{e}+001.59141 \mathrm{e}+001.59141 \mathrm{e}-01$ 1.00000e-09 2.12000e-01 $1.00000 \mathrm{e}+001.00000 \mathrm{e}+001.00000 \mathrm{e}-011.00000 \mathrm{e}-091.00000 \mathrm{e}-01$ $1.00000 \mathrm{e}-05$ 1.00000e-05 1.00000e-06 1.00000e-09 1.00000e-01 Element: 222 \# of layers: 5

$\mathrm{Kx} \mathrm{Ky} \mathrm{Kz}$ Ss Por

3.06196e+01 3.06196e+01 3.06196e+00 1.00000e-09 7.00000e-02 $1.22346 \mathrm{e}+001.22346 \mathrm{e}+00 \quad 1.22346 \mathrm{e}-011.00000 \mathrm{e}-092.12000 \mathrm{e}-01$ $1.00000 \mathrm{e}+001.00000 \mathrm{e}+001.00000 \mathrm{e}-011.00000 \mathrm{e}-091.00000 \mathrm{e}-01$ $1.00000 \mathrm{e}-05$ 1.00000e-05 1.00000e-06 1.00000e-09 1.00000e-01 $1.00000 \mathrm{e}+001.00000 \mathrm{e}+001.00000 \mathrm{e}-011.00000 \mathrm{e}-091.00000 \mathrm{e}-01$ Element: 223 \# of layers: 6

$\mathrm{Kx} \mathrm{Ky} \mathrm{Kz}$ Ss Por

8.93603e+01 8.93603e+01 8.93603e+00 1.00000e-09 7.00000e-02 $3.57060 \mathrm{e}+003.57060 \mathrm{e}+003.57060 \mathrm{e}-01$ 1.00000e-09 2.12000e-01 $1.00000 \mathrm{e}-021.00000 \mathrm{e}-02$ 1.00000e-03 1.00000e-09 1.00000e-01 $1.00000 \mathrm{e}+001.00000 \mathrm{e}+001.00000 \mathrm{e}-011.00000 \mathrm{e}-091.00000 \mathrm{e}-01$ $1.00000 \mathrm{e}-05$ 1.00000e-05 1.00000e-06 1.00000e-09 1.00000e-01 $1.00000 \mathrm{e}+001.00000 \mathrm{e}+001.00000 \mathrm{e}-011.00000 \mathrm{e}-091.00000 \mathrm{e}-01$ Element: 224 \# of layers: 6

$\mathrm{Kx} \mathrm{Ky} \mathrm{Kz}$ Ss Por

2.39729e+02 2.39729e+02 2.39729e+01 1.00000e-09 7.00000e-02 $9.57868 \mathrm{e}+00$ 9.57868e+00 9.57868e-01 1.00000e-09 2.12000e-01 1.00000e-02 1.00000e-02 1.00000e-03 1.00000e-09 1.00000e-01 $1.00000 \mathrm{e}+001.00000 \mathrm{e}+001.00000 \mathrm{e}-011.00000 \mathrm{e}-091.00000 \mathrm{e}-01$ 1.00000e-05 1.00000e-05 1.00000e-06 1.00000e-09 1.00000e-01 $1.00000 \mathrm{e}+001.00000 \mathrm{e}+001.00000 \mathrm{e}-01$ 1.00000e-09 1.00000e-01 Element: 225 \# of layers: 6

Kx Ky Kz Ss Por 
6.29961e+02 6.29961e+02 6.29961e+01 1.00000e-09 7.00000e-02 $2.51713 \mathrm{e}+012.51713 \mathrm{e}+012.51713 \mathrm{e}+00$ 1.00000e-09 2.12000e-01 $1.00000 \mathrm{e}-02$ 1.00000e-02 1.00000e-03 1.00000e-09 1.00000e-01 $1.00000 \mathrm{e}+001.00000 \mathrm{e}+001.00000 \mathrm{e}-011.00000 \mathrm{e}-091.00000 \mathrm{e}-01$ $1.00000 \mathrm{e}-05$ 1.00000e-05 1.00000e-06 1.00000e-09 1.00000e-01 $1.00000 \mathrm{e}+001.00000 \mathrm{e}+001.00000 \mathrm{e}-011.00000 \mathrm{e}-091.00000 \mathrm{e}-01$ Element: 226 \# of layers: 6

$\mathrm{Kx} \mathrm{Ky} \mathrm{Kz}$ Ss Por

$2.44216 \mathrm{e}+032.44216 \mathrm{e}+032.44216 \mathrm{e}+02$ 1.00000e-09 7.00000e-02 $9.75801 \mathrm{e}+019.75801 \mathrm{e}+019.75801 \mathrm{e}+001.00000 \mathrm{e}-092.12000 \mathrm{e}-01$ $1.00000 \mathrm{e}-02$ 1.00000e-02 1.00000e-03 1.00000e-09 1.00000e-01 $1.00000 \mathrm{e}+001.00000 \mathrm{e}+001.00000 \mathrm{e}-011.00000 \mathrm{e}-091.00000 \mathrm{e}-01$ $1.00000 \mathrm{e}-05$ 1.00000e-05 1.00000e-06 1.00000e-09 1.00000e-01 $1.00000 \mathrm{e}+001.00000 \mathrm{e}+001.00000 \mathrm{e}-011.00000 \mathrm{e}-091.00000 \mathrm{e}-01$ Element: 227 \# of layers: 5

Kx Ky Kz Ss Por $1.45823 \mathrm{e}+02$ 1.45823e+02 1.45823e+01 1.00000e-09 2.12000e-01 $1.00000 \mathrm{e}-02$ 1.00000e-02 1.00000e-03 1.00000e-09 1.00000e-01 $1.00000 \mathrm{e}+001.00000 \mathrm{e}+001.00000 \mathrm{e}-011.00000 \mathrm{e}-091.00000 \mathrm{e}-01$ $1.00000 \mathrm{e}-05$ 1.00000e-05 1.00000e-06 1.00000e-09 1.00000e-01 $1.00000 \mathrm{e}+001.00000 \mathrm{e}+001.00000 \mathrm{e}-011.00000 \mathrm{e}-091.00000 \mathrm{e}-01$ Element: 228 \# of layers: 6

$\mathrm{Kx} \mathrm{Ky} \mathrm{Kz}$ Ss Por

2.12591e+03 2.12591e+03 2.12591e+02 1.00000e-09 7.00000e-02 $8.49438 \mathrm{e}+01$ 8.49438e+01 8.49438e+00 1.00000e-09 2.12000e-01 $1.00000 \mathrm{e}-02$ 1.00000e-02 1.00000e-03 1.00000e-09 1.00000e-01 $1.00000 \mathrm{e}+001.00000 \mathrm{e}+001.00000 \mathrm{e}-011.00000 \mathrm{e}-091.00000 \mathrm{e}-01$ $1.00000 \mathrm{e}-05$ 1.00000e-05 1.00000e-06 1.00000e-09 1.00000e-01 $1.00000 \mathrm{e}+001.00000 \mathrm{e}+001.00000 \mathrm{e}-011.00000 \mathrm{e}-091.00000 \mathrm{e}-01$ Element: 229 \# of layers: 6

$\mathrm{Kx} \mathrm{Ky} \mathrm{Kz}$ Ss Por

5.70054e+02 5.70054e+02 5.70054e+01 1.00000e-09 7.00000e-02 $2.27772 \mathrm{e}+012.27772 \mathrm{e}+012.27772 \mathrm{e}+00$ 1.00000e-09 2.12000e-01 $1.00000 \mathrm{e}-02$ 1.00000e-02 1.00000e-03 1.00000e-09 1.00000e-01 $1.00000 \mathrm{e}+001.00000 \mathrm{e}+001.00000 \mathrm{e}-011.00000 \mathrm{e}-091.00000 \mathrm{e}-01$ $1.00000 \mathrm{e}-05$ 1.00000e-05 1.00000e-06 1.00000e-09 1.00000e-01 $1.00000 \mathrm{e}+001.00000 \mathrm{e}+001.00000 \mathrm{e}-011.00000 \mathrm{e}-091.00000 \mathrm{e}-01$ Element: 230 \# of layers: 11

$\mathrm{Kx} \mathrm{Ky} \mathrm{Kz}$ Ss Por

3.17161e+02 3.17161e+02 3.17161e+01 1.00000e-09 7.00000e-02 $3.17161 \mathrm{e}+02$ 3.17161e+02 3.17161e+01 1.00000e-09 7.00000e-02 $1.26727 \mathrm{e}+01$ 1.26727e+01 1.26727e+00 1.00000e-09 2.12000e-01 $1.26727 \mathrm{e}+01$ 1.26727e+01 1.26727e+00 1.00000e-09 2.12000e-01 $1.26727 \mathrm{e}+01$ 1.26727e+01 1.26727e+00 1.00000e-09 2.12000e-01 $1.26727 \mathrm{e}+011.26727 \mathrm{e}+01$ 1.26727e+00 1.00000e-09 2.12000e-01 $1.26727 \mathrm{e}+01$ 1.26727e+01 1.26727e+00 1.00000e-09 2.12000e-01 
$1.00000 \mathrm{e}-01$ 1.00000e-01 1.00000e-02 1.00000e-09 1.00000e-01 $1.00000 \mathrm{e}+001.00000 \mathrm{e}+001.00000 \mathrm{e}-011.00000 \mathrm{e}-091.00000 \mathrm{e}-01$ $1.00000 \mathrm{e}-05$ 1.00000e-05 1.00000e-06 1.00000e-09 1.00000e-01 $1.00000 \mathrm{e}+001.00000 \mathrm{e}+001.00000 \mathrm{e}-011.00000 \mathrm{e}-091.00000 \mathrm{e}-01$ Element: 231 \# of layers: 2

$\mathrm{Kx} \mathrm{Ky} \mathrm{Kz}$ Ss Por

7.42730e+00 7.42730e+00 7.42730e-01 1.00000e-09 7.00000e-02 $1.00000 \mathrm{e}+001.00000 \mathrm{e}+001.00000 \mathrm{e}-01$ 1.00000e-09 1.00000e-01 Element: 232 \# of layers: 5

$\mathrm{Kx} \mathrm{Ky} \mathrm{Kz}$ Ss Por

$1.99166 \mathrm{e}+01$ 1.99166e+01 1.99166e+00 1.00000e-09 7.00000e-02 7.95797e-01 7.95797e-01 7.95797e-02 1.00000e-09 2.12000e-01 $1.00000 \mathrm{e}+001.00000 \mathrm{e}+001.00000 \mathrm{e}-011.00000 \mathrm{e}-091.00000 \mathrm{e}-01$ $1.00000 \mathrm{e}-05$ 1.00000e-05 1.00000e-06 1.00000e-09 1.00000e-01 $1.00000 \mathrm{e}+001.00000 \mathrm{e}+001.00000 \mathrm{e}-01$ 1.00000e-09 1.00000e-01 Element: 233 \# of layers: 5

$\mathrm{Kx} \mathrm{Ky} \mathrm{Kz}$ Ss Por

$1.02128 \mathrm{e}+02$ 1.02128e+02 1.02128e+01 1.00000e-09 7.00000e-02 $4.08069 \mathrm{e}+004.08069 \mathrm{e}+004.08069 \mathrm{e}-01$ 1.00000e-09 2.12000e-01 $1.00000 \mathrm{e}+001.00000 \mathrm{e}+001.00000 \mathrm{e}-011.00000 \mathrm{e}-091.00000 \mathrm{e}-01$ $1.00000 \mathrm{e}-05$ 1.00000e-05 1.00000e-06 1.00000e-09 1.00000e-01 $1.00000 \mathrm{e}+001.00000 \mathrm{e}+001.00000 \mathrm{e}-011.00000 \mathrm{e}-091.00000 \mathrm{e}-01$ Element: 234 \# of layers: 6

Kx Ky Kz Ss Por

$1.04615 \mathrm{e}+02$ 1.04615e+02 1.04615e+01 1.00000e-09 7.00000e-02 $4.18014 \mathrm{e}+004.18014 \mathrm{e}+004.18014 \mathrm{e}-01$ 1.00000e-09 2.12000e-01 $1.00000 \mathrm{e}-02$ 1.00000e-02 1.00000e-03 1.00000e-09 1.00000e-01 $1.00000 \mathrm{e}+001.00000 \mathrm{e}+001.00000 \mathrm{e}-01$ 1.00000e-09 1.00000e-01 $1.00000 \mathrm{e}-05$ 1.00000e-05 1.00000e-06 1.00000e-09 1.00000e-01 $1.00000 \mathrm{e}+001.00000 \mathrm{e}+001.00000 \mathrm{e}-011.00000 \mathrm{e}-091.00000 \mathrm{e}-01$ Element: 235 \# of layers: 6

$\mathrm{Kx} \mathrm{Ky} \mathrm{Kz}$ Ss Por

$2.49604 \mathrm{e}+02$ 2.49604e+02 2.49604e+01 1.00000e-09 7.00000e-02 $9.97334 \mathrm{e}+00$ 9.97334e+00 9.97334e-01 1.00000e-09 2.12000e-01 $1.00000 \mathrm{e}-02$ 1.00000e-02 1.00000e-03 1.00000e-09 1.00000e-01 $1.00000 \mathrm{e}+001.00000 \mathrm{e}+001.00000 \mathrm{e}-011.00000 \mathrm{e}-091.00000 \mathrm{e}-01$ $1.00000 \mathrm{e}-05$ 1.00000e-05 1.00000e-06 1.00000e-09 1.00000e-01 $1.00000 \mathrm{e}+001.00000 \mathrm{e}+001.00000 \mathrm{e}-011.00000 \mathrm{e}-091.00000 \mathrm{e}-01$ Element: 236 \# of layers: 6

$\mathrm{Kx} \mathrm{Ky} \mathrm{Kz}$ Ss Por

7.68895e+02 7.68895e+02 7.68895e+01 1.00000e-09 7.00000e-02 $3.07222 \mathrm{e}+013.07222 \mathrm{e}+013.07222 \mathrm{e}+00$ 1.00000e-09 2.12000e-01 $1.00000 \mathrm{e}-02$ 1.00000e-02 1.00000e-03 1.00000e-09 1.00000e-01 $1.00000 \mathrm{e}+001.00000 \mathrm{e}+001.00000 \mathrm{e}-011.00000 \mathrm{e}-091.00000 \mathrm{e}-01$ $1.00000 \mathrm{e}-05$ 1.00000e-05 1.00000e-06 1.00000e-09 1.00000e-01 $1.00000 \mathrm{e}+001.00000 \mathrm{e}+001.00000 \mathrm{e}-011.00000 \mathrm{e}-091.00000 \mathrm{e}-01$ 
Element: 237 \# of layers: 6

Kx Ky Kz Ss Por

$2.18429 \mathrm{e}+032.18429 \mathrm{e}+032.18429 \mathrm{e}+02$ 1.00000e-09 7.00000e-02

$8.72749 \mathrm{e}+01$ 8.72749e+01 8.72749e+00 1.00000e-09 2.12000e-01

$1.00000 \mathrm{e}-02$ 1.00000e-02 1.00000e-03 1.00000e-09 1.00000e-01

$1.00000 \mathrm{e}+001.00000 \mathrm{e}+001.00000 \mathrm{e}-011.00000 \mathrm{e}-091.00000 \mathrm{e}-01$

$1.00000 \mathrm{e}-051.00000 \mathrm{e}-05$ 1.00000e-06 1.00000e-09 1.00000e-01

$1.00000 \mathrm{e}+001.00000 \mathrm{e}+001.00000 \mathrm{e}-011.00000 \mathrm{e}-091.00000 \mathrm{e}-01$

Element: 238 \# of layers: 5

Kx Ky Kz Ss Por

$1.62309 \mathrm{e}+02$ 1.62309e+02 1.62309e+01 1.00000e-09 2.12000e-01

$1.00000 \mathrm{e}-021.00000 \mathrm{e}-02$ 1.00000e-03 1.00000e-09 1.00000e-01

$1.00000 \mathrm{e}+001.00000 \mathrm{e}+001.00000 \mathrm{e}-011.00000 \mathrm{e}-091.00000 \mathrm{e}-01$

$1.00000 \mathrm{e}-05$ 1.00000e-05 1.00000e-06 1.00000e-09 1.00000e-01

$1.00000 \mathrm{e}+001.00000 \mathrm{e}+001.00000 \mathrm{e}-011.00000 \mathrm{e}-091.00000 \mathrm{e}-01$

Element: 239 \# of layers: 5

Kx Ky Kz Ss Por

$1.83680 \mathrm{e}+021.83680 \mathrm{e}+021.83680 \mathrm{e}+01$ 1.00000e-09 2.12000e-01

$1.00000 \mathrm{e}-02$ 1.00000e-02 1.00000e-03 1.00000e-09 1.00000e-01

$1.00000 \mathrm{e}+001.00000 \mathrm{e}+001.00000 \mathrm{e}-011.00000 \mathrm{e}-091.00000 \mathrm{e}-01$

$1.00000 \mathrm{e}-05$ 1.00000e-05 1.00000e-06 1.00000e-09 1.00000e-01

$1.00000 \mathrm{e}+001.00000 \mathrm{e}+001.00000 \mathrm{e}-011.00000 \mathrm{e}-091.00000 \mathrm{e}-01$

Element: 240 \# of layers: 6

Kx Ky Kz Ss Por

$1.94256 \mathrm{e}+031.94256 \mathrm{e}+031.94256 \mathrm{e}+02$ 1.00000e-09 7.00000e-02

$7.76154 \mathrm{e}+01$ 7.76154e+01 7.76154e+00 1.00000e-09 2.12000e-01

$1.00000 \mathrm{e}-02$ 1.00000e-02 1.00000e-03 1.00000e-09 1.00000e-01

$1.00000 \mathrm{e}+001.00000 \mathrm{e}+001.00000 \mathrm{e}-011.00000 \mathrm{e}-091.00000 \mathrm{e}-01$

$1.00000 \mathrm{e}-05$ 1.00000e-05 1.00000e-06 1.00000e-09 1.00000e-01

$1.00000 \mathrm{e}+001.00000 \mathrm{e}+001.00000 \mathrm{e}-011.00000 \mathrm{e}-091.00000 \mathrm{e}-01$

Element: 241 \# of layers: 11

Kx Ky Kz Ss Por

$4.33192 \mathrm{e}+02$ 4.33192e+02 4.33192e+01 1.00000e-09 7.00000e-02

$4.33192 \mathrm{e}+024.33192 \mathrm{e}+024.33192 \mathrm{e}+01$ 1.00000e-09 7.00000e-02

$1.73087 \mathrm{e}+011.73087 \mathrm{e}+011.73087 \mathrm{e}+001.00000 \mathrm{e}-092.12000 \mathrm{e}-01$

$1.73087 \mathrm{e}+011.73087 \mathrm{e}+011.73087 \mathrm{e}+001.00000 \mathrm{e}-092.12000 \mathrm{e}-01$

$1.73087 \mathrm{e}+011.73087 \mathrm{e}+011.73087 \mathrm{e}+001.00000 \mathrm{e}-092.12000 \mathrm{e}-01$

$1.73087 \mathrm{e}+011.73087 \mathrm{e}+011.73087 \mathrm{e}+001.00000 \mathrm{e}-092.12000 \mathrm{e}-01$

$1.73087 \mathrm{e}+011.73087 \mathrm{e}+011.73087 \mathrm{e}+00$ 1.00000e-09 2.12000e-01

$1.00000 \mathrm{e}-011.00000 \mathrm{e}-011.00000 \mathrm{e}-021.00000 \mathrm{e}-091.00000 \mathrm{e}-01$

$1.00000 \mathrm{e}+001.00000 \mathrm{e}+001.00000 \mathrm{e}-011.00000 \mathrm{e}-091.00000 \mathrm{e}-01$

$1.00000 \mathrm{e}-05$ 1.00000e-05 1.00000e-06 1.00000e-09 1.00000e-01

$1.00000 \mathrm{e}+001.00000 \mathrm{e}+001.00000 \mathrm{e}-011.00000 \mathrm{e}-091.00000 \mathrm{e}-01$

Element: 242 \# of layers: 3

Kx Ky Kz Ss Por

8.17712e+00 8.17712e+00 8.17712e-01 1.00000e-09 7.00000e-02 
3.26730e-01 3.26730e-01 3.26730e-02 1.00000e-09 2.12000e-01 $1.00000 \mathrm{e}+001.00000 \mathrm{e}+001.00000 \mathrm{e}-01$ 1.00000e-09 1.00000e-01 Element: 243 \# of layers: 5

$\mathrm{Kx} \mathrm{Ky} \mathrm{Kz}$ Ss Por

8.92855e+00 8.92855e+00 8.92855e-01 1.00000e-09 7.00000e-02

3.56745e-01 3.56745e-01 3.56745e-02 1.00000e-09 2.12000e-01

$1.00000 \mathrm{e}+001.00000 \mathrm{e}+001.00000 \mathrm{e}-011.00000 \mathrm{e}-091.00000 \mathrm{e}-01$

$1.00000 \mathrm{e}-05$ 1.00000e-05 1.00000e-06 1.00000e-09 1.00000e-01

$1.00000 \mathrm{e}+001.00000 \mathrm{e}+001.00000 \mathrm{e}-011.00000 \mathrm{e}-091.00000 \mathrm{e}-01$

Element: 244 \# of layers: 5

Kx Ky Kz Ss Por

5.30121e+01 5.30121e+01 5.30121e+00 1.00000e-09 7.00000e-02

$2.11820 \mathrm{e}+002.11820 \mathrm{e}+00$ 2.11820e-01 1.00000e-09 2.12000e-01

$1.00000 \mathrm{e}+001.00000 \mathrm{e}+001.00000 \mathrm{e}-011.00000 \mathrm{e}-091.00000 \mathrm{e}-01$

$1.00000 \mathrm{e}-05$ 1.00000e-05 1.00000e-06 1.00000e-09 1.00000e-01

$1.00000 \mathrm{e}+001.00000 \mathrm{e}+001.00000 \mathrm{e}-011.00000 \mathrm{e}-091.00000 \mathrm{e}-01$

Element: 245 \# of layers: 6

$\mathrm{Kx} \mathrm{Ky} \mathrm{Kz}$ Ss Por

3.41578e+02 3.41578e+02 3.41578e+01 1.00000e-09 7.00000e-02

$1.36483 \mathrm{e}+01$ 1.36483e+01 1.36483e+00 1.00000e-09 2.12000e-01

$1.00000 \mathrm{e}-02$ 1.00000e-02 1.00000e-03 1.00000e-09 1.00000e-01

$1.00000 \mathrm{e}+001.00000 \mathrm{e}+001.00000 \mathrm{e}-011.00000 \mathrm{e}-091.00000 \mathrm{e}-01$

$1.00000 \mathrm{e}-05$ 1.00000e-05 1.00000e-06 1.00000e-09 1.00000e-01

$1.00000 \mathrm{e}+001.00000 \mathrm{e}+001.00000 \mathrm{e}-011.00000 \mathrm{e}-091.00000 \mathrm{e}-01$

Element: 246 \# of layers: 5

$\mathrm{Kx} \mathrm{Ky} \mathrm{Kz}$ Ss Por

$2.36210 \mathrm{e}+012.36210 \mathrm{e}+012.36210 \mathrm{e}+001.00000 \mathrm{e}-092.12000 \mathrm{e}-01$

$1.00000 \mathrm{e}-02$ 1.00000e-02 1.00000e-03 1.00000e-09 1.00000e-01

$1.00000 \mathrm{e}+001.00000 \mathrm{e}+001.00000 \mathrm{e}-011.00000 \mathrm{e}-091.00000 \mathrm{e}-01$

$1.00000 \mathrm{e}-05$ 1.00000e-05 1.00000e-06 1.00000e-09 1.00000e-01

$1.00000 \mathrm{e}+001.00000 \mathrm{e}+001.00000 \mathrm{e}-011.00000 \mathrm{e}-091.00000 \mathrm{e}-01$

Element: 247 \# of layers: 5

$\mathrm{Kx} \mathrm{Ky} \mathrm{Kz}$ Ss Por

$2.04113 \mathrm{e}+012.04113 \mathrm{e}+012.04113 \mathrm{e}+00$ 1.00000e-09 2.12000e-01

$1.00000 \mathrm{e}-02$ 1.00000e-02 1.00000e-03 1.00000e-09 1.00000e-01

$1.00000 \mathrm{e}+001.00000 \mathrm{e}+001.00000 \mathrm{e}-011.00000 \mathrm{e}-091.00000 \mathrm{e}-01$

$1.00000 \mathrm{e}-05$ 1.00000e-05 1.00000e-06 1.00000e-09 1.00000e-01

$1.00000 \mathrm{e}+001.00000 \mathrm{e}+001.00000 \mathrm{e}-011.00000 \mathrm{e}-091.00000 \mathrm{e}-01$

Element: 248 \# of layers: 5

$\mathrm{Kx} \mathrm{Ky} \mathrm{Kz}$ Ss Por

$2.12400 \mathrm{e}+012.12400 \mathrm{e}+012.12400 \mathrm{e}+00$ 1.00000e-09 2.12000e-01

$1.00000 \mathrm{e}-02$ 1.00000e-02 1.00000e-03 1.00000e-09 1.00000e-01

$1.00000 \mathrm{e}+001.00000 \mathrm{e}+001.00000 \mathrm{e}-011.00000 \mathrm{e}-091.00000 \mathrm{e}-01$

$1.00000 \mathrm{e}-05$ 1.00000e-05 1.00000e-06 1.00000e-09 1.00000e-01

$1.00000 \mathrm{e}+001.00000 \mathrm{e}+001.00000 \mathrm{e}-01$ 1.00000e-09 1.00000e-01

Element: 249 \# of layers: 5 
$\mathrm{Kx} \mathrm{Ky} \mathrm{Kz}$ Ss Por

1.13783e+02 1.13783e+02 1.13783e+01 1.00000e-09 2.12000e-01

$1.00000 \mathrm{e}-02$ 1.00000e-02 1.00000e-03 1.00000e-09 1.00000e-01

$1.00000 \mathrm{e}+001.00000 \mathrm{e}+001.00000 \mathrm{e}-011.00000 \mathrm{e}-091.00000 \mathrm{e}-01$

$1.00000 \mathrm{e}-05$ 1.00000e-05 1.00000e-06 1.00000e-09 1.00000e-01

$1.00000 \mathrm{e}+001.00000 \mathrm{e}+001.00000 \mathrm{e}-011.00000 \mathrm{e}-091.00000 \mathrm{e}-01$

Element: 250 \# of layers: 5

$\mathrm{Kx} \mathrm{Ky} \mathrm{Kz}$ Ss Por

$1.60361 \mathrm{e}+021.60361 \mathrm{e}+02$ 1.60361e+01 1.00000e-09 2.12000e-01

$1.00000 \mathrm{e}-02$ 1.00000e-02 1.00000e-03 1.00000e-09 1.00000e-01

$1.00000 \mathrm{e}+001.00000 \mathrm{e}+001.00000 \mathrm{e}-011.00000 \mathrm{e}-091.00000 \mathrm{e}-01$

$1.00000 \mathrm{e}-05$ 1.00000e-05 1.00000e-06 1.00000e-09 1.00000e-01

$1.00000 \mathrm{e}+001.00000 \mathrm{e}+001.00000 \mathrm{e}-01$ 1.00000e-09 1.00000e-01

Element: 251 \# of layers: 5

$\mathrm{Kx} \mathrm{Ky} \mathrm{Kz}$ Ss Por

2.21931e+02 2.21931e+02 2.21931e+01 1.00000e-09 2.12000e-01

1.00000e-02 1.00000e-02 1.00000e-03 1.00000e-09 1.00000e-01

$1.00000 \mathrm{e}+001.00000 \mathrm{e}+001.00000 \mathrm{e}-011.00000 \mathrm{e}-091.00000 \mathrm{e}-01$

$1.00000 \mathrm{e}-051.00000 \mathrm{e}-051.00000 \mathrm{e}-061.00000 \mathrm{e}-091.00000 \mathrm{e}-01$

$1.00000 \mathrm{e}+001.00000 \mathrm{e}+001.00000 \mathrm{e}-011.00000 \mathrm{e}-091.00000 \mathrm{e}-01$

Element: 252 \# of layers: 6

$\mathrm{Kx} \mathrm{Ky} \mathrm{Kz}$ Ss Por

1.89706e+03 1.89706e+03 1.89706e+02 1.00000e-09 7.00000e-02

7.57996e+01 7.57996e+01 7.57996e+00 1.00000e-09 2.12000e-01

$1.00000 \mathrm{e}-02$ 1.00000e-02 1.00000e-03 1.00000e-09 1.00000e-01

$1.00000 \mathrm{e}+001.00000 \mathrm{e}+001.00000 \mathrm{e}-011.00000 \mathrm{e}-091.00000 \mathrm{e}-01$

$1.00000 \mathrm{e}-05$ 1.00000e-05 1.00000e-06 1.00000e-09 1.00000e-01

$1.00000 \mathrm{e}+001.00000 \mathrm{e}+001.00000 \mathrm{e}-011.00000 \mathrm{e}-09$ 1.00000e-01

Element: 253 \# of layers: 3

$\mathrm{Kx} \mathrm{Ky} \mathrm{Kz}$ Ss Por

9.36860e+00 9.36860e+00 9.36860e-01 1.00000e-09 7.00000e-02

3.74341e-01 3.74341e-01 3.74341e-02 1.00000e-09 2.12000e-01

$1.00000 \mathrm{e}+001.00000 \mathrm{e}+001.00000 \mathrm{e}-011.00000 \mathrm{e}-091.00000 \mathrm{e}-01$

Element: 254 \# of layers: 5

$\mathrm{Kx} \mathrm{Ky} \mathrm{Kz}$ Ss Por

$1.24843 \mathrm{e}+01$ 1.24843e+01 1.24843e+00 1.00000e-09 7.00000e-02

4.98836e-01 4.98836e-01 4.98836e-02 1.00000e-09 2.12000e-01

$1.00000 \mathrm{e}+001.00000 \mathrm{e}+001.00000 \mathrm{e}-011.00000 \mathrm{e}-091.00000 \mathrm{e}-01$

$1.00000 \mathrm{e}-05$ 1.00000e-05 1.00000e-06 1.00000e-09 1.00000e-01

$1.00000 \mathrm{e}+001.00000 \mathrm{e}+001.00000 \mathrm{e}-01$ 1.00000e-09 1.00000e-01

Element: 255 \# of layers: 6

$\mathrm{Kx} \mathrm{Ky} \mathrm{Kz}$ Ss Por

4.08342e+01 4.08342e+01 4.08342e+00 1.00000e-09 7.00000e-02

$1.63158 \mathrm{e}+001.63158 \mathrm{e}+00$ 1.63158e-01 1.00000e-09 2.12000e-01

$1.00000 \mathrm{e}-02$ 1.00000e-02 1.00000e-03 1.00000e-09 1.00000e-01

$1.00000 \mathrm{e}+001.00000 \mathrm{e}+001.00000 \mathrm{e}-011.00000 \mathrm{e}-091.00000 \mathrm{e}-01$ 
$1.00000 \mathrm{e}-05$ 1.00000e-05 1.00000e-06 1.00000e-09 1.00000e-01 $1.00000 \mathrm{e}+001.00000 \mathrm{e}+001.00000 \mathrm{e}-01$ 1.00000e-09 1.00000e-01

Element: 256 \# of layers: 6

$\mathrm{Kx} \mathrm{Ky} \mathrm{Kz}$ Ss Por

1.37646e+02 1.37646e+02 1.37646e+01 1.00000e-09 7.00000e-02

5.49979e+00 5.49979e+00 5.49979e-01 1.00000e-09 2.12000e-01

$1.00000 \mathrm{e}-02$ 1.00000e-02 1.00000e-03 1.00000e-09 1.00000e-01

$1.00000 \mathrm{e}+001.00000 \mathrm{e}+001.00000 \mathrm{e}-011.00000 \mathrm{e}-091.00000 \mathrm{e}-01$

$1.00000 \mathrm{e}-05$ 1.00000e-05 1.00000e-06 1.00000e-09 1.00000e-01

$1.00000 \mathrm{e}+001.00000 \mathrm{e}+001.00000 \mathrm{e}-011.00000 \mathrm{e}-091.00000 \mathrm{e}-01$

Element: 257 \# of layers: 5

Kx Ky Kz Ss Por

3.14039e+01 3.14039e+01 3.14039e+00 1.00000e-09 2.12000e-01

$1.00000 \mathrm{e}-02$ 1.00000e-02 1.00000e-03 1.00000e-09 1.00000e-01

$1.00000 \mathrm{e}+001.00000 \mathrm{e}+001.00000 \mathrm{e}-011.00000 \mathrm{e}-091.00000 \mathrm{e}-01$

$1.00000 \mathrm{e}-05$ 1.00000e-05 1.00000e-06 1.00000e-09 1.00000e-01

$1.00000 \mathrm{e}+001.00000 \mathrm{e}+001.00000 \mathrm{e}-011.00000 \mathrm{e}-091.00000 \mathrm{e}-01$

Element: 258 \# of layers: 5

$\mathrm{Kx} \mathrm{Ky} \mathrm{Kz}$ Ss Por

$2.69308 \mathrm{e}+012.69308 \mathrm{e}+012.69308 \mathrm{e}+00$ 1.00000e-09 2.12000e-01

$1.00000 \mathrm{e}-02$ 1.00000e-02 1.00000e-03 1.00000e-09 1.00000e-01

$1.00000 \mathrm{e}+001.00000 \mathrm{e}+001.00000 \mathrm{e}-011.00000 \mathrm{e}-091.00000 \mathrm{e}-01$

$1.00000 \mathrm{e}-05$ 1.00000e-05 1.00000e-06 1.00000e-09 1.00000e-01

$1.00000 \mathrm{e}+001.00000 \mathrm{e}+001.00000 \mathrm{e}-011.00000 \mathrm{e}-091.00000 \mathrm{e}-01$

Element: 259 \# of layers: 5

$\mathrm{Kx} \mathrm{Ky} \mathrm{Kz}$ Ss Por

8.87216e+01 8.87216e+01 8.87216e+00 1.00000e-09 2.12000e-01

$1.00000 \mathrm{e}-02$ 1.00000e-02 1.00000e-03 1.00000e-09 1.00000e-01

$1.00000 \mathrm{e}+001.00000 \mathrm{e}+001.00000 \mathrm{e}-011.00000 \mathrm{e}-091.00000 \mathrm{e}-01$

$1.00000 \mathrm{e}-051.00000 \mathrm{e}-051.00000 \mathrm{e}-061.00000 \mathrm{e}-091.00000 \mathrm{e}-01$

$1.00000 \mathrm{e}+001.00000 \mathrm{e}+00$ 1.00000e-01 1.00000e-09 1.00000e-01

Element: 260 \# of layers: 5

$\mathrm{Kx} \mathrm{Ky} \mathrm{Kz}$ Ss Por

8.36680e+01 8.36680e+01 8.36680e+00 1.00000e-09 2.12000e-01

$1.00000 \mathrm{e}-02$ 1.00000e-02 1.00000e-03 1.00000e-09 1.00000e-01

$1.00000 \mathrm{e}+001.00000 \mathrm{e}+001.00000 \mathrm{e}-011.00000 \mathrm{e}-091.00000 \mathrm{e}-01$

$1.00000 \mathrm{e}-05$ 1.00000e-05 1.00000e-06 1.00000e-09 1.00000e-01

$1.00000 \mathrm{e}+001.00000 \mathrm{e}+001.00000 \mathrm{e}-011.00000 \mathrm{e}-091.00000 \mathrm{e}-01$

Element: 261 \# of layers: 5

$\mathrm{Kx} \mathrm{Ky} \mathrm{Kz}$ Ss Por

1.42907e+02 1.42907e+02 1.42907e+01 1.00000e-09 2.12000e-01

$1.00000 \mathrm{e}-02$ 1.00000e-02 1.00000e-03 1.00000e-09 1.00000e-01

$1.00000 \mathrm{e}+001.00000 \mathrm{e}+001.00000 \mathrm{e}-011.00000 \mathrm{e}-091.00000 \mathrm{e}-01$

$1.00000 \mathrm{e}-05$ 1.00000e-05 1.00000e-06 1.00000e-09 1.00000e-01

$1.00000 \mathrm{e}+001.00000 \mathrm{e}+001.00000 \mathrm{e}-011.00000 \mathrm{e}-091.00000 \mathrm{e}-01$

Element: 262 \# of layers: 6 
$\mathrm{Kx} \mathrm{Ky} \mathrm{Kz}$ Ss Por

5.00000e-04 5.00000e-04 5.00000e-05 1.00000e-09 1.00000e-01

$1.25429 \mathrm{e}+02$ 1.25429e+02 1.25429e+01 1.00000e-09 2.12000e-01

$1.00000 \mathrm{e}-02$ 1.00000e-02 1.00000e-03 1.00000e-09 1.00000e-01

$1.00000 \mathrm{e}+001.00000 \mathrm{e}+001.00000 \mathrm{e}-011.00000 \mathrm{e}-091.00000 \mathrm{e}-01$

$1.00000 \mathrm{e}-05$ 1.00000e-05 1.00000e-06 1.00000e-09 1.00000e-01

$1.00000 \mathrm{e}+001.00000 \mathrm{e}+001.00000 \mathrm{e}-01$ 1.00000e-09 1.00000e-01

Element: 263 \# of layers: 7

$\mathrm{Kx} \mathrm{Ky} \mathrm{Kz}$ Ss Por

2.03698e+03 2.03698e+03 2.03698e+02 1.00000e-09 7.00000e-02

5.00000e-04 5.00000e-04 5.00000e-05 1.00000e-09 1.00000e-01

$8.13910 \mathrm{e}+018.13910 \mathrm{e}+018.13910 \mathrm{e}+001.00000 \mathrm{e}-092.12000 \mathrm{e}-01$

$1.00000 \mathrm{e}-02$ 1.00000e-02 1.00000e-03 1.00000e-09 1.00000e-01

$1.00000 \mathrm{e}+001.00000 \mathrm{e}+001.00000 \mathrm{e}-011.00000 \mathrm{e}-091.00000 \mathrm{e}-01$

$1.00000 \mathrm{e}-05$ 1.00000e-05 1.00000e-06 1.00000e-09 1.00000e-01

$1.00000 \mathrm{e}+001.00000 \mathrm{e}+001.00000 \mathrm{e}-011.00000 \mathrm{e}-091.00000 \mathrm{e}-01$

Element: 264 \# of layers: 1

$\mathrm{Kx} \mathrm{Ky} \mathrm{Kz}$ Ss Por

3.88944e+00 3.88944e+00 3.88944e-01 1.00000e-09 7.00000e-02

Element: 265 \# of layers: 3

$\mathrm{Kx} \mathrm{Ky} \mathrm{Kz}$ Ss Por

4.01891e+00 4.01891e+00 4.01891e-01 1.00000e-09 7.00000e-02

$1.60581 \mathrm{e}-01$ 1.60581e-01 1.60581e-02 1.00000e-09 2.12000e-01

$1.00000 \mathrm{e}+001.00000 \mathrm{e}+001.00000 \mathrm{e}-011.00000 \mathrm{e}-091.00000 \mathrm{e}-01$

Element: 266 \# of layers: 6

$\mathrm{Kx} \mathrm{Ky} \mathrm{Kz}$ Ss Por

9.41725e+00 9.41725e+00 9.41725e-01 1.00000e-09 7.00000e-02

3.76253e-01 3.76253e-01 3.76253e-02 1.00000e-09 2.12000e-01

$1.00000 \mathrm{e}-02$ 1.00000e-02 1.00000e-03 1.00000e-09 1.00000e-01

$1.00000 \mathrm{e}+001.00000 \mathrm{e}+001.00000 \mathrm{e}-011.00000 \mathrm{e}-091.00000 \mathrm{e}-01$

$1.00000 \mathrm{e}-05$ 1.00000e-05 1.00000e-06 1.00000e-09 1.00000e-01

$1.00000 \mathrm{e}+001.00000 \mathrm{e}+001.00000 \mathrm{e}-01$ 1.00000e-09 1.00000e-01

Element: 267 \# of layers: 6

$\mathrm{Kx} \mathrm{Ky} \mathrm{Kz}$ Ss Por

6.60667e+01 6.60667e+01 6.60667e+00 1.00000e-09 7.00000e-02

$2.63976 \mathrm{e}+002.63976 \mathrm{e}+00$ 2.63976e-01 1.00000e-09 2.12000e-01

$1.00000 \mathrm{e}-02$ 1.00000e-02 1.00000e-03 1.00000e-09 1.00000e-01

$1.00000 \mathrm{e}+001.00000 \mathrm{e}+001.00000 \mathrm{e}-011.00000 \mathrm{e}-091.00000 \mathrm{e}-01$

$1.00000 \mathrm{e}-05$ 1.00000e-05 1.00000e-06 1.00000e-09 1.00000e-01

$1.00000 \mathrm{e}+001.00000 \mathrm{e}+001.00000 \mathrm{e}-01$ 1.00000e-09 1.00000e-01

Element: 268 \# of layers: 6

$\mathrm{Kx} \mathrm{Ky} \mathrm{Kz}$ Ss Por

2.39819e+02 2.39819e+02 2.39819e+01 1.00000e-09 7.00000e-02

9.58228e+00 9.58228e+00 9.58228e-01 1.00000e-09 2.12000e-01

$1.00000 \mathrm{e}-02$ 1.00000e-02 1.00000e-03 1.00000e-09 1.00000e-01

$1.00000 \mathrm{e}+001.00000 \mathrm{e}+001.00000 \mathrm{e}-011.00000 \mathrm{e}-091.00000 \mathrm{e}-01$ 
$1.00000 \mathrm{e}-05$ 1.00000e-05 1.00000e-06 1.00000e-09 1.00000e-01 $1.00000 \mathrm{e}+001.00000 \mathrm{e}+001.00000 \mathrm{e}-01$ 1.00000e-09 1.00000e-01 Element: 269 \# of layers: 5

$\mathrm{Kx} \mathrm{Ky} \mathrm{Kz}$ Ss Por

$2.91201 \mathrm{e}+012.91201 \mathrm{e}+012.91201 \mathrm{e}+001.00000 \mathrm{e}-092.12000 \mathrm{e}-01$ $1.00000 \mathrm{e}-02$ 1.00000e-02 1.00000e-03 1.00000e-09 1.00000e-01 $1.00000 \mathrm{e}+001.00000 \mathrm{e}+001.00000 \mathrm{e}-011.00000 \mathrm{e}-091.00000 \mathrm{e}-01$ $1.00000 \mathrm{e}-05$ 1.00000e-05 1.00000e-06 1.00000e-09 1.00000e-01 $1.00000 \mathrm{e}+001.00000 \mathrm{e}+001.00000 \mathrm{e}-011.00000 \mathrm{e}-091.00000 \mathrm{e}-01$ Element: 270 \# of layers: 6

$\mathrm{Kx} \mathrm{Ky} \mathrm{Kz}$ Ss Por

3.91484e+02 3.91484e+02 3.91485e+01 1.00000e-09 7.00000e-02 $1.56426 \mathrm{e}+011.56426 \mathrm{e}+011.56426 \mathrm{e}+001.00000 \mathrm{e}-092.12000 \mathrm{e}-01$ $1.00000 \mathrm{e}-02$ 1.00000e-02 1.00000e-03 1.00000e-09 1.00000e-01 $1.00000 \mathrm{e}+001.00000 \mathrm{e}+001.00000 \mathrm{e}-011.00000 \mathrm{e}-091.00000 \mathrm{e}-01$ $1.00000 \mathrm{e}-05$ 1.00000e-05 1.00000e-06 1.00000e-09 1.00000e-01 $1.00000 \mathrm{e}+001.00000 \mathrm{e}+001.00000 \mathrm{e}-01$ 1.00000e-09 1.00000e-01 Element: 271 \# of layers: 6

$\mathrm{Kx} \mathrm{Ky} \mathrm{Kz}$ Ss Por

1.10661e+02 1.10661e+02 1.10661e+01 1.00000e-09 7.00000e-02 4.42157e+00 4.42157e+00 4.42157e-01 1.00000e-09 2.12000e-01 $1.00000 \mathrm{e}-02$ 1.00000e-02 1.00000e-03 1.00000e-09 1.00000e-01 $1.00000 \mathrm{e}+001.00000 \mathrm{e}+001.00000 \mathrm{e}-011.00000 \mathrm{e}-091.00000 \mathrm{e}-01$ $1.00000 \mathrm{e}-05$ 1.00000e-05 1.00000e-06 1.00000e-09 1.00000e-01 $1.00000 \mathrm{e}+001.00000 \mathrm{e}+001.00000 \mathrm{e}-011.00000 \mathrm{e}-091.00000 \mathrm{e}-01$ Element: 272 \# of layers: 6

$\mathrm{Kx} \mathrm{Ky} \mathrm{Kz}$ Ss Por

4.04603e+02 4.04603e+02 4.04603e+01 1.00000e-09 7.00000e-02 $1.61666 \mathrm{e}+011.61666 \mathrm{e}+011.61666 \mathrm{e}+001.00000 \mathrm{e}-092.12000 \mathrm{e}-01$ $1.00000 \mathrm{e}-02$ 1.00000e-02 1.00000e-03 1.00000e-09 1.00000e-01 $1.00000 \mathrm{e}+001.00000 \mathrm{e}+001.00000 \mathrm{e}-011.00000 \mathrm{e}-091.00000 \mathrm{e}-01$ $1.00000 \mathrm{e}-05$ 1.00000e-05 1.00000e-06 1.00000e-09 1.00000e-01 $1.00000 \mathrm{e}+001.00000 \mathrm{e}+001.00000 \mathrm{e}-011.00000 \mathrm{e}-091.00000 \mathrm{e}-01$ Element: 273 \# of layers: 7

$\mathrm{Kx} \mathrm{Ky} \mathrm{Kz}$ Ss Por

5.04560e+02 5.04560e+02 5.04560e+01 1.00000e-09 7.00000e-02 5.00000e-04 5.00000e-04 5.00000e-05 1.00000e-09 1.00000e-01 $2.01607 \mathrm{e}+012.01607 \mathrm{e}+012.01607 \mathrm{e}+001.00000 \mathrm{e}-092.12000 \mathrm{e}-01$ $1.00000 \mathrm{e}-02$ 1.00000e-02 1.00000e-03 1.00000e-09 1.00000e-01 $1.00000 \mathrm{e}+001.00000 \mathrm{e}+001.00000 \mathrm{e}-011.00000 \mathrm{e}-091.00000 \mathrm{e}-01$ $1.00000 \mathrm{e}-05$ 1.00000e-05 1.00000e-06 1.00000e-09 1.00000e-01 $1.00000 \mathrm{e}+001.00000 \mathrm{e}+001.00000 \mathrm{e}-011.00000 \mathrm{e}-091.00000 \mathrm{e}-01$ Element: 274 \# of layers: 7

$\mathrm{Kx} \mathrm{Ky} \mathrm{Kz}$ Ss Por $1.73920 \mathrm{e}+03$ 1.73920e+03 1.73920e+02 1.00000e-09 7.00000e-02 5.00000e-04 5.00000e-04 5.00000e-05 1.00000e-09 1.00000e-01 
$6.94950 \mathrm{e}+01$ 6.94950e+01 6.94950e+00 1.00000e-09 2.12000e-01 $1.00000 \mathrm{e}-02$ 1.00000e-02 1.00000e-03 1.00000e-09 1.00000e-01 $1.00000 \mathrm{e}+001.00000 \mathrm{e}+001.00000 \mathrm{e}-011.00000 \mathrm{e}-091.00000 \mathrm{e}-01$ $1.00000 \mathrm{e}-05$ 1.00000e-05 1.00000e-06 1.00000e-09 1.00000e-01 $1.00000 \mathrm{e}+001.00000 \mathrm{e}+001.00000 \mathrm{e}-01$ 1.00000e-09 1.00000e-01 Element: 275 \# of layers: 7

$\mathrm{Kx} \mathrm{Ky} \mathrm{Kz}$ Ss Por

$1.82786 \mathrm{e}+03$ 1.82786e+03 1.82786e+02 1.00000e-09 7.00000e-02 5.00000e-04 5.00000e-04 5.00000e-05 1.00000e-09 1.00000e-01

$7.30343 \mathrm{e}+01$ 7.30343e+01 7.30343e+00 1.00000e-09 2.12000e-01 $1.00000 \mathrm{e}-02$ 1.00000e-02 1.00000e-03 1.00000e-09 1.00000e-01 $1.00000 \mathrm{e}+001.00000 \mathrm{e}+001.00000 \mathrm{e}-011.00000 \mathrm{e}-091.00000 \mathrm{e}-01$ $1.00000 \mathrm{e}-05$ 1.00000e-05 1.00000e-06 1.00000e-09 1.00000e-01 $1.00000 \mathrm{e}+001.00000 \mathrm{e}+001.00000 \mathrm{e}-011.00000 \mathrm{e}-09$ 1.00000e-01 Element: 276 \# of layers: 12

Kx Ky Kz Ss Por

$1.33213 \mathrm{e}+03$ 1.33213e+03 1.33213e+02 1.00000e-09 7.00000e-02 $1.33213 \mathrm{e}+03$ 1.33213e+03 1.33213e+02 1.00000e-09 7.00000e-02 5.00000e-04 5.00000e-04 5.00000e-05 1.00000e-09 1.00000e-01 $5.32271 \mathrm{e}+015.32271 \mathrm{e}+015.32271 \mathrm{e}+00$ 1.00000e-09 2.12000e-01 $5.32271 \mathrm{e}+015.32271 \mathrm{e}+015.32271 \mathrm{e}+001.00000 \mathrm{e}-09$ 2.12000e-01 $5.32271 \mathrm{e}+015.32271 \mathrm{e}+015.32271 \mathrm{e}+00$ 1.00000e-09 2.12000e-01 $5.32271 \mathrm{e}+015.32271 \mathrm{e}+015.32271 \mathrm{e}+00$ 1.00000e-09 2.12000e-01 $5.32271 \mathrm{e}+015.32271 \mathrm{e}+015.32271 \mathrm{e}+001.00000 \mathrm{e}-092.12000 \mathrm{e}-01$ $1.00000 \mathrm{e}-02$ 1.00000e-02 1.00000e-03 1.00000e-09 1.00000e-01 $1.00000 \mathrm{e}+001.00000 \mathrm{e}+001.00000 \mathrm{e}-011.00000 \mathrm{e}-091.00000 \mathrm{e}-01$ $1.00000 \mathrm{e}-05$ 1.00000e-05 1.00000e-06 1.00000e-09 1.00000e-01 $1.00000 \mathrm{e}+001.00000 \mathrm{e}+001.00000 \mathrm{e}-011.00000 \mathrm{e}-09$ 1.00000e-01 Element: 277 \# of layers: 3

$\mathrm{Kx} \mathrm{Ky} \mathrm{Kz}$ Ss Por

5.50817e+00 5.50817e+00 5.50817e-01 1.00000e-09 7.00000e-02 2.20086e-01 2.20086e-01 2.20086e-02 1.00000e-09 2.12000e-01 $1.00000 \mathrm{e}+001.00000 \mathrm{e}+001.00000 \mathrm{e}-011.00000 \mathrm{e}-091.00000 \mathrm{e}-01$ Element: 278 \# of layers: 5

$\mathrm{Kx} \mathrm{Ky} \mathrm{Kz}$ Ss Por

3.66644e+00 3.66644e+00 3.66644e-01 1.00000e-09 7.00000e-02 1.46498e-01 1.46498e-01 1.46498e-02 1.00000e-09 2.12000e-01 $1.00000 \mathrm{e}+001.00000 \mathrm{e}+001.00000 \mathrm{e}-011.00000 \mathrm{e}-091.00000 \mathrm{e}-01$ $1.00000 \mathrm{e}-05$ 1.00000e-05 1.00000e-06 1.00000e-09 1.00000e-01 $1.00000 \mathrm{e}+001.00000 \mathrm{e}+001.00000 \mathrm{e}-01$ 1.00000e-09 1.00000e-01 Element: 279 \# of layers: 5

$\mathrm{Kx} \mathrm{Ky} \mathrm{Kz}$ Ss Por

4.55852e+00 4.55852e+00 4.55852e-01 1.00000e-09 7.00000e-02 $1.82144 \mathrm{e}-01$ 1.82144e-01 1.82144e-02 1.00000e-09 2.12000e-01 $1.00000 \mathrm{e}+001.00000 \mathrm{e}+001.00000 \mathrm{e}-011.00000 \mathrm{e}-091.00000 \mathrm{e}-01$ $1.00000 \mathrm{e}-05$ 1.00000e-05 1.00000e-06 1.00000e-09 1.00000e-01 
$1.00000 \mathrm{e}+001.00000 \mathrm{e}+00$ 1.00000e-01 1.00000e-09 1.00000e-01

Element: 280 \# of layers: 6

$\mathrm{Kx} \mathrm{Ky} \mathrm{Kz}$ Ss Por

$1.45286 \mathrm{e}+011.45286 \mathrm{e}+011.45286 \mathrm{e}+001.00000 \mathrm{e}-09$ 7.00000e-02

5.80512e-01 5.80512e-01 5.80512e-02 1.00000e-09 2.12000e-01

$1.00000 \mathrm{e}-02$ 1.00000e-02 1.00000e-03 1.00000e-09 1.00000e-01

$1.00000 \mathrm{e}+001.00000 \mathrm{e}+001.00000 \mathrm{e}-011.00000 \mathrm{e}-091.00000 \mathrm{e}-01$

$1.00000 \mathrm{e}-05$ 1.00000e-05 1.00000e-06 1.00000e-09 1.00000e-01

$1.00000 \mathrm{e}+001.00000 \mathrm{e}+001.00000 \mathrm{e}-011.00000 \mathrm{e}-091.00000 \mathrm{e}-01$

Element: 281 \# of layers: 6

$\mathrm{Kx} \mathrm{Ky} \mathrm{Kz}$ Ss Por

$1.38853 \mathrm{e}+02$ 1.38853e+02 1.38853e+01 1.00000e-09 7.00000e-02

5.54817e+00 5.54817e+00 5.54817e-01 1.00000e-09 2.12000e-01

$1.00000 \mathrm{e}-02$ 1.00000e-02 1.00000e-03 1.00000e-09 1.00000e-01

$1.00000 \mathrm{e}+001.00000 \mathrm{e}+001.00000 \mathrm{e}-011.00000 \mathrm{e}-091.00000 \mathrm{e}-01$

$1.00000 \mathrm{e}-05$ 1.00000e-05 1.00000e-06 1.00000e-09 1.00000e-01

$1.00000 \mathrm{e}+001.00000 \mathrm{e}+001.00000 \mathrm{e}-011.00000 \mathrm{e}-091.00000 \mathrm{e}-01$

Element: 282 \# of layers: 5

$\mathrm{Kx} \mathrm{Ky} \mathrm{Kz}$ Ss Por

$2.41858 \mathrm{e}+012.41858 \mathrm{e}+012.41858 \mathrm{e}+00$ 1.00000e-09 2.12000e-01

$1.00000 \mathrm{e}-02$ 1.00000e-02 1.00000e-03 1.00000e-09 1.00000e-01

$1.00000 \mathrm{e}+001.00000 \mathrm{e}+001.00000 \mathrm{e}-011.00000 \mathrm{e}-091.00000 \mathrm{e}-01$

$1.00000 \mathrm{e}-051.00000 \mathrm{e}-05$ 1.00000e-06 1.00000e-09 1.00000e-01

$1.00000 \mathrm{e}+001.00000 \mathrm{e}+001.00000 \mathrm{e}-011.00000 \mathrm{e}-091.00000 \mathrm{e}-01$

Element: 283 \# of layers: 6

$\mathrm{Kx} \mathrm{Ky} \mathrm{Kz}$ Ss Por

2.14573e+02 2.14573e+02 2.14573e+01 1.00000e-09 7.00000e-02

$8.57358 \mathrm{e}+00$ 8.57358e+00 8.57358e-01 1.00000e-09 2.12000e-01

$1.00000 \mathrm{e}-02$ 1.00000e-02 1.00000e-03 1.00000e-09 1.00000e-01

$1.00000 \mathrm{e}+001.00000 \mathrm{e}+001.00000 \mathrm{e}-011.00000 \mathrm{e}-091.00000 \mathrm{e}-01$

$1.00000 \mathrm{e}-05$ 1.00000e-05 1.00000e-06 1.00000e-09 1.00000e-01

$1.00000 \mathrm{e}+001.00000 \mathrm{e}+001.00000 \mathrm{e}-011.00000 \mathrm{e}-091.00000 \mathrm{e}-01$

Element: 284 \# of layers: 6

$\mathrm{Kx} \mathrm{Ky} \mathrm{Kz}$ Ss Por

6.77066e+01 6.77066e+01 6.77066e+00 1.00000e-09 7.00000e-02

$2.70523 \mathrm{e}+002.70523 \mathrm{e}+00$ 2.70523e-01 1.00000e-09 2.12000e-01

1.00000e-02 1.00000e-02 1.00000e-03 1.00000e-09 1.00000e-01

$1.00000 \mathrm{e}+001.00000 \mathrm{e}+001.00000 \mathrm{e}-011.00000 \mathrm{e}-091.00000 \mathrm{e}-01$

$1.00000 \mathrm{e}-05$ 1.00000e-05 1.00000e-06 1.00000e-09 1.00000e-01

$1.00000 \mathrm{e}+001.00000 \mathrm{e}+001.00000 \mathrm{e}-01$ 1.00000e-09 1.00000e-01

Element: 285 \# of layers: 7

$\mathrm{Kx} \mathrm{Ky} \mathrm{Kz}$ Ss Por

4.12892e+01 4.12892e+01 4.12892e+00 1.00000e-09 7.00000e-02

5.00000e-04 5.00000e-04 5.00000e-05 1.00000e-09 1.00000e-01

$1.64976 \mathrm{e}+001.64976 \mathrm{e}+001.64976 \mathrm{e}-01$ 1.00000e-09 2.12000e-01

$1.00000 \mathrm{e}-02$ 1.00000e-02 1.00000e-03 1.00000e-09 1.00000e-01 
$1.00000 \mathrm{e}+001.00000 \mathrm{e}+001.00000 \mathrm{e}-011.00000 \mathrm{e}-091.00000 \mathrm{e}-01$ $1.00000 \mathrm{e}-05$ 1.00000e-05 1.00000e-06 1.00000e-09 1.00000e-01 $1.00000 \mathrm{e}+001.00000 \mathrm{e}+001.00000 \mathrm{e}-011.00000 \mathrm{e}-091.00000 \mathrm{e}-01$ Element: 286 \# of layers: 7

$\mathrm{Kx} \mathrm{Ky} \mathrm{Kz}$ Ss Por

4.98803e+02 4.98803e+02 4.98803e+01 1.00000e-09 7.00000e-02 5.00000e-04 5.00000e-04 5.00000e-05 1.00000e-09 1.00000e-01 $1.99303 \mathrm{e}+01$ 1.99303e+01 1.99303e+00 1.00000e-09 2.12000e-01 $1.00000 \mathrm{e}-02$ 1.00000e-02 1.00000e-03 1.00000e-09 1.00000e-01 $1.00000 \mathrm{e}+001.00000 \mathrm{e}+001.00000 \mathrm{e}-011.00000 \mathrm{e}-091.00000 \mathrm{e}-01$ $1.00000 \mathrm{e}-05$ 1.00000e-05 1.00000e-06 1.00000e-09 1.00000e-01 $1.00000 \mathrm{e}+001.00000 \mathrm{e}+001.00000 \mathrm{e}-011.00000 \mathrm{e}-091.00000 \mathrm{e}-01$ Element: 287 \# of layers: 7

$\mathrm{Kx} \mathrm{Ky} \mathrm{Kz}$ Ss Por

4.85468e+02 4.85468e+02 4.85468e+01 1.00000e-09 7.00000e-02 5.00000e-04 5.00000e-04 5.00000e-05 1.00000e-09 1.00000e-01 $1.93974 \mathrm{e}+011.93974 \mathrm{e}+011.93974 \mathrm{e}+001.00000 \mathrm{e}-092.12000 \mathrm{e}-01$ $1.00000 \mathrm{e}-02$ 1.00000e-02 1.00000e-03 1.00000e-09 1.00000e-01 $1.00000 \mathrm{e}+001.00000 \mathrm{e}+001.00000 \mathrm{e}-011.00000 \mathrm{e}-091.00000 \mathrm{e}-01$ $1.00000 \mathrm{e}-05$ 1.00000e-05 1.00000e-06 1.00000e-09 1.00000e-01 $1.00000 \mathrm{e}+001.00000 \mathrm{e}+001.00000 \mathrm{e}-01$ 1.00000e-09 1.00000e-01 Element: 288 \# of layers: 7

$\mathrm{Kx} \mathrm{Ky} \mathrm{Kz}$ Ss Por 6.46026e+02 6.46026e+02 6.46026e+01 1.00000e-09 7.00000e-02 5.00000e-04 5.00000e-04 5.00000e-05 1.00000e-09 1.00000e-01 $2.58125 \mathrm{e}+012.58125 \mathrm{e}+012.58125 \mathrm{e}+001.00000 \mathrm{e}-092.12000 \mathrm{e}-01$ $1.00000 \mathrm{e}-02$ 1.00000e-02 1.00000e-03 1.00000e-09 1.00000e-01 $1.00000 \mathrm{e}+001.00000 \mathrm{e}+001.00000 \mathrm{e}-01$ 1.00000e-09 1.00000e-01 $1.00000 \mathrm{e}-05$ 1.00000e-05 1.00000e-06 1.00000e-09 1.00000e-01 $1.00000 \mathrm{e}+001.00000 \mathrm{e}+001.00000 \mathrm{e}-011.00000 \mathrm{e}-091.00000 \mathrm{e}-01$ Element: 289 \# of layers: 13

$\mathrm{Kx} \mathrm{Ky} \mathrm{Kz}$ Ss Por

6.31961e+02 6.31961e+02 6.31961e+01 1.00000e-09 7.00000e-02 6.31961e+02 6.31961e+02 6.31961e+01 1.00000e-09 7.00000e-02 5.00000e-04 5.00000e-04 5.00000e-05 1.00000e-09 1.00000e-01 5.00000e-04 5.00000e-04 5.00000e-05 1.00000e-09 1.00000e-01 $2.52500 \mathrm{e}+012.52500 \mathrm{e}+012.52500 \mathrm{e}+001.00000 \mathrm{e}-092.12000 \mathrm{e}-01$ $2.52500 \mathrm{e}+012.52500 \mathrm{e}+012.52500 \mathrm{e}+001.00000 \mathrm{e}-092.12000 \mathrm{e}-01$ $2.52500 \mathrm{e}+012.52500 \mathrm{e}+012.52500 \mathrm{e}+001.00000 \mathrm{e}-092.12000 \mathrm{e}-01$ $2.52500 \mathrm{e}+012.52500 \mathrm{e}+012.52500 \mathrm{e}+001.00000 \mathrm{e}-092.12000 \mathrm{e}-01$ $2.52500 \mathrm{e}+012.52500 \mathrm{e}+012.52500 \mathrm{e}+001.00000 \mathrm{e}-092.12000 \mathrm{e}-01$ $1.00000 \mathrm{e}-02$ 1.00000e-02 1.00000e-03 1.00000e-09 1.00000e-01 $1.00000 \mathrm{e}+001.00000 \mathrm{e}+001.00000 \mathrm{e}-011.00000 \mathrm{e}-091.00000 \mathrm{e}-01$ $1.00000 \mathrm{e}-05$ 1.00000e-05 1.00000e-06 1.00000e-09 1.00000e-01 $1.00000 \mathrm{e}+001.00000 \mathrm{e}+001.00000 \mathrm{e}-011.00000 \mathrm{e}-091.00000 \mathrm{e}-01$ Element: 290 \# of layers: 3 
Kx Ky Kz Ss Por

$1.21815 \mathrm{e}+011.21815 \mathrm{e}+01$ 1.21815e+00 1.00000e-09 7.00000e-02

4.86708e-01 4.86708e-01 4.86708e-02 1.00000e-09 2.12000e-01

$1.00000 \mathrm{e}+001.00000 \mathrm{e}+001.00000 \mathrm{e}-011.00000 \mathrm{e}-091.00000 \mathrm{e}-01$

Element: 291 \# of layers: 6

$\mathrm{Kx} \mathrm{Ky} \mathrm{Kz}$ Ss Por

2.05482e+01 2.05482e+01 2.05482e+00 1.00000e-09 7.00000e-02

8.21020e-01 8.21020e-01 8.21020e-02 1.00000e-09 2.12000e-01

$1.00000 \mathrm{e}-02$ 1.00000e-02 1.00000e-03 1.00000e-09 1.00000e-01

$1.00000 \mathrm{e}+001.00000 \mathrm{e}+001.00000 \mathrm{e}-011.00000 \mathrm{e}-091.00000 \mathrm{e}-01$

$1.00000 \mathrm{e}-05$ 1.00000e-05 1.00000e-06 1.00000e-09 1.00000e-01

$1.00000 \mathrm{e}+001.00000 \mathrm{e}+001.00000 \mathrm{e}-011.00000 \mathrm{e}-091.00000 \mathrm{e}-01$

Element: 292 \# of layers: 6

Kx Ky Kz Ss Por

$1.07868 \mathrm{e}+01$ 1.07868e+01 1.07868e+00 1.00000e-09 7.00000e-02

4.30997e-01 4.30997e-01 4.30997e-02 1.00000e-09 2.12000e-01

$1.00000 \mathrm{e}-02$ 1.00000e-02 1.00000e-03 1.00000e-09 1.00000e-01

$1.00000 \mathrm{e}+001.00000 \mathrm{e}+001.00000 \mathrm{e}-011.00000 \mathrm{e}-091.00000 \mathrm{e}-01$

$1.00000 \mathrm{e}-05$ 1.00000e-05 1.00000e-06 1.00000e-09 1.00000e-01

$1.00000 \mathrm{e}+001.00000 \mathrm{e}+001.00000 \mathrm{e}-01$ 1.00000e-09 1.00000e-01

Element: 293 \# of layers: 5

$\mathrm{Kx} \mathrm{Ky} \mathrm{Kz}$ Ss Por

8.57076e+00 8.57076e+00 8.57076e-01 1.00000e-09 7.00000e-02 3.42457e-01 3.42457e-01 3.42457e-02 1.00000e-09 2.12000e-01

$1.00000 \mathrm{e}+001.00000 \mathrm{e}+001.00000 \mathrm{e}-011.00000 \mathrm{e}-091.00000 \mathrm{e}-01$

$1.00000 \mathrm{e}-05$ 1.00000e-05 1.00000e-06 1.00000e-09 1.00000e-01

$1.00000 \mathrm{e}+001.00000 \mathrm{e}+001.00000 \mathrm{e}-011.00000 \mathrm{e}-091.00000 \mathrm{e}-01$

Element: 294 \# of layers: 5

$\mathrm{Kx} \mathrm{Ky} \mathrm{Kz}$ Ss Por

$1.21446 \mathrm{e}+01$ 1.21446e+01 1.21446e+00 1.00000e-09 7.00000e-02

4.85245e-01 4.85245e-01 4.85245e-02 1.00000e-09 2.12000e-01

$1.00000 \mathrm{e}+001.00000 \mathrm{e}+001.00000 \mathrm{e}-011.00000 \mathrm{e}-091.00000 \mathrm{e}-01$

$1.00000 \mathrm{e}-05$ 1.00000e-05 1.00000e-06 1.00000e-09 1.00000e-01

$1.00000 \mathrm{e}+001.00000 \mathrm{e}+001.00000 \mathrm{e}-011.00000 \mathrm{e}-091.00000 \mathrm{e}-01$

Element: 295 \# of layers: 6

Kx Ky Kz Ss Por

5.50808e+01 5.50808e+01 5.50808e+00 1.00000e-09 7.00000e-02

$2.20082 \mathrm{e}+002.20082 \mathrm{e}+00$ 2.20082e-01 1.00000e-09 2.12000e-01

$1.00000 \mathrm{e}-02$ 1.00000e-02 1.00000e-03 1.00000e-09 1.00000e-01

$1.00000 \mathrm{e}+001.00000 \mathrm{e}+001.00000 \mathrm{e}-011.00000 \mathrm{e}-091.00000 \mathrm{e}-01$

$1.00000 \mathrm{e}-05$ 1.00000e-05 1.00000e-06 1.00000e-09 1.00000e-01

$1.00000 \mathrm{e}+001.00000 \mathrm{e}+001.00000 \mathrm{e}-011.00000 \mathrm{e}-091.00000 \mathrm{e}-01$

Element: 296 \# of layers: 6

$\mathrm{Kx} \mathrm{Ky} \mathrm{Kz}$ Ss Por

4.97622e+01 4.97622e+01 4.97622e+00 1.00000e-09 7.00000e-02

$1.98832 \mathrm{e}+001.98832 \mathrm{e}+00$ 1.98832e-01 1.00000e-09 2.12000e-01 
$1.00000 \mathrm{e}-02$ 1.00000e-02 1.00000e-03 1.00000e-09 1.00000e-01 $1.00000 \mathrm{e}+001.00000 \mathrm{e}+001.00000 \mathrm{e}-011.00000 \mathrm{e}-091.00000 \mathrm{e}-01$ $1.00000 \mathrm{e}-05$ 1.00000e-05 1.00000e-06 1.00000e-09 1.00000e-01 $1.00000 \mathrm{e}+001.00000 \mathrm{e}+001.00000 \mathrm{e}-011.00000 \mathrm{e}-091.00000 \mathrm{e}-01$ Element: 297 \# of layers: 6

$\mathrm{Kx} \mathrm{Ky} \mathrm{Kz}$ Ss Por

3.76996e+01 3.76996e+01 3.76996e+00 1.00000e-09 7.00000e-02

$1.50634 \mathrm{e}+001.50634 \mathrm{e}+00 \quad 1.50634 \mathrm{e}-011.00000 \mathrm{e}-092.12000 \mathrm{e}-01$ $1.00000 \mathrm{e}-02$ 1.00000e-02 1.00000e-03 1.00000e-09 1.00000e-01 $1.00000 \mathrm{e}+001.00000 \mathrm{e}+001.00000 \mathrm{e}-01$ 1.00000e-09 1.00000e-01 $1.00000 \mathrm{e}-05$ 1.00000e-05 1.00000e-06 1.00000e-09 1.00000e-01 $1.00000 \mathrm{e}+001.00000 \mathrm{e}+001.00000 \mathrm{e}-011.00000 \mathrm{e}-091.00000 \mathrm{e}-01$ Element: 298 \# of layers: 7

$\mathrm{Kx} \mathrm{Ky} \mathrm{Kz}$ Ss Por

$2.54569 \mathrm{e}+012.54569 \mathrm{e}+012.54569 \mathrm{e}+00$ 1.00000e-09 7.00000e-02 5.00000e-04 5.00000e-04 5.00000e-05 1.00000e-09 1.00000e-01

$1.01718 \mathrm{e}+001.01718 \mathrm{e}+00$ 1.01718e-01 1.00000e-09 2.12000e-01 $1.00000 \mathrm{e}-02$ 1.00000e-02 1.00000e-03 1.00000e-09 1.00000e-01 $1.00000 \mathrm{e}+001.00000 \mathrm{e}+001.00000 \mathrm{e}-011.00000 \mathrm{e}-091.00000 \mathrm{e}-01$ $1.00000 \mathrm{e}-05$ 1.00000e-05 1.00000e-06 1.00000e-09 1.00000e-01 $1.00000 \mathrm{e}+001.00000 \mathrm{e}+001.00000 \mathrm{e}-011.00000 \mathrm{e}-091.00000 \mathrm{e}-01$ Element: 299 \# of layers: 7

$\mathrm{Kx} \mathrm{Ky} \mathrm{Kz}$ Ss Por 4.61898e+01 4.61898e+01 4.61898e+00 1.00000e-09 7.00000e-02 5.00000e-04 5.00000e-04 5.00000e-05 1.00000e-09 1.00000e-01 $1.84558 \mathrm{e}+001.84558 \mathrm{e}+00$ 1.84558e-01 1.00000e-09 2.12000e-01 $1.00000 \mathrm{e}-02$ 1.00000e-02 1.00000e-03 1.00000e-09 1.00000e-01 $1.00000 \mathrm{e}+001.00000 \mathrm{e}+001.00000 \mathrm{e}-01$ 1.00000e-09 1.00000e-01 $1.00000 \mathrm{e}-05$ 1.00000e-05 1.00000e-06 1.00000e-09 1.00000e-01 $1.00000 \mathrm{e}+001.00000 \mathrm{e}+001.00000 \mathrm{e}-011.00000 \mathrm{e}-091.00000 \mathrm{e}-01$ Element: 300 \# of layers: 7

$\mathrm{Kx} \mathrm{Ky} \mathrm{Kz}$ Ss Por 1.20022e+02 1.20022e+02 1.20022e+01 1.00000e-09 7.00000e-02 5.00000e-04 5.00000e-04 5.00000e-05 1.00000e-09 1.00000e-01 $4.79575 \mathrm{e}+00$ 4.79575e+00 4.79575e-01 1.00000e-09 2.12000e-01 $1.00000 \mathrm{e}-02$ 1.00000e-02 1.00000e-03 1.00000e-09 1.00000e-01 $1.00000 \mathrm{e}+001.00000 \mathrm{e}+001.00000 \mathrm{e}-011.00000 \mathrm{e}-091.00000 \mathrm{e}-01$ $1.00000 \mathrm{e}-05$ 1.00000e-05 1.00000e-06 1.00000e-09 1.00000e-01 $1.00000 \mathrm{e}+001.00000 \mathrm{e}+001.00000 \mathrm{e}-011.00000 \mathrm{e}-091.00000 \mathrm{e}-01$ Element: 301 \# of layers: 7

$\mathrm{Kx} \mathrm{Ky} \mathrm{Kz}$ Ss Por 4.05612e+02 4.05612e+02 4.05612e+01 1.00000e-09 7.00000e-02 5.00000e-04 5.00000e-04 5.00000e-05 1.00000e-09 1.00000e-01 $1.62066 \mathrm{e}+01$ 1.62066e+01 1.62067e+00 1.00000e-09 2.12000e-01 $1.00000 \mathrm{e}-02$ 1.00000e-02 1.00000e-03 1.00000e-09 1.00000e-01 $1.00000 \mathrm{e}+001.00000 \mathrm{e}+001.00000 \mathrm{e}-01$ 1.00000e-09 1.00000e-01 
$1.00000 \mathrm{e}-05$ 1.00000e-05 1.00000e-06 1.00000e-09 1.00000e-01 $1.00000 \mathrm{e}+001.00000 \mathrm{e}+001.00000 \mathrm{e}-01$ 1.00000e-09 1.00000e-01 Element: 302 \# of layers: 7

$\mathrm{Kx} \mathrm{Ky} \mathrm{Kz}$ Ss Por

4.04576e+02 4.04576e+02 4.04576e+01 1.00000e-09 7.00000e-02 5.00000e-04 5.00000e-04 5.00000e-05 1.00000e-09 1.00000e-01

$1.61655 \mathrm{e}+011.61655 \mathrm{e}+011.61655 \mathrm{e}+001.00000 \mathrm{e}-092.12000 \mathrm{e}-01$ $1.00000 \mathrm{e}-02$ 1.00000e-02 1.00000e-03 1.00000e-09 1.00000e-01 $1.00000 \mathrm{e}+001.00000 \mathrm{e}+001.00000 \mathrm{e}-011.00000 \mathrm{e}-091.00000 \mathrm{e}-01$ $1.00000 \mathrm{e}-05$ 1.00000e-05 1.00000e-06 1.00000e-09 1.00000e-01 $1.00000 \mathrm{e}+001.00000 \mathrm{e}+001.00000 \mathrm{e}-01$ 1.00000e-09 1.00000e-01 Element: 303 \# of layers: 14

$\mathrm{Kx} \mathrm{Ky} \mathrm{Kz}$ Ss Por

3.82393e+02 3.82393e+02 3.82393e+01 1.00000e-09 7.00000e-02 $3.82393 \mathrm{e}+02$ 3.82393e+02 3.82393e+01 1.00000e-09 7.00000e-02 $3.82393 \mathrm{e}+023.82393 \mathrm{e}+02$ 3.82393e+01 1.00000e-09 7.00000e-02 5.00000e-04 5.00000e-04 5.00000e-05 1.00000e-09 1.00000e-01 5.00000e-04 5.00000e-04 5.00000e-05 1.00000e-09 1.00000e-01 $1.52789 \mathrm{e}+01$ 1.52789e+01 1.52789e+00 1.00000e-09 2.12000e-01 $1.52789 \mathrm{e}+01$ 1.52789e+01 1.52789e+00 1.00000e-09 2.12000e-01 $1.52789 \mathrm{e}+011.52789 \mathrm{e}+011.52789 \mathrm{e}+001.00000 \mathrm{e}-092.12000 \mathrm{e}-01$ $1.52789 \mathrm{e}+01$ 1.52789e+01 1.52789e+00 1.00000e-09 2.12000e-01 $1.52789 \mathrm{e}+01$ 1.52789e+01 1.52789e+00 1.00000e-09 2.12000e-01 $1.00000 \mathrm{e}-02$ 1.00000e-02 1.00000e-03 1.00000e-09 1.00000e-01 $1.00000 \mathrm{e}+001.00000 \mathrm{e}+001.00000 \mathrm{e}-011.00000 \mathrm{e}-091.00000 \mathrm{e}-01$ $1.00000 \mathrm{e}-05$ 1.00000e-05 1.00000e-06 1.00000e-09 1.00000e-01 $1.00000 \mathrm{e}+001.00000 \mathrm{e}+001.00000 \mathrm{e}-011.00000 \mathrm{e}-091.00000 \mathrm{e}-01$ Element: 304 \# of layers: 6

$\mathrm{Kx} \mathrm{Ky} \mathrm{Kz}$ Ss Por

3.50000e+02 3.50000e+02 3.50000e+01 1.00000e-09 1.00000e-01 $1.13839 \mathrm{e}+00$ 1.13839e+00 1.13839e-01 1.00000e-09 2.12000e-01 $1.00000 \mathrm{e}-02$ 1.00000e-02 1.00000e-03 1.00000e-09 1.00000e-01 $1.00000 \mathrm{e}+001.00000 \mathrm{e}+001.00000 \mathrm{e}-011.00000 \mathrm{e}-091.00000 \mathrm{e}-01$ $1.00000 \mathrm{e}-05$ 1.00000e-05 1.00000e-06 1.00000e-09 1.00000e-01 $1.00000 \mathrm{e}+001.00000 \mathrm{e}+001.00000 \mathrm{e}-011.00000 \mathrm{e}-091.00000 \mathrm{e}-01$ Element: 305 \# of layers: 6

Kx Ky Kz Ss Por

$1.96535 \mathrm{e}+01$ 1.96535e+01 1.96535e+00 1.00000e-09 7.00000e-02 $3.50000 \mathrm{e}+023.50000 \mathrm{e}+023.50000 \mathrm{e}+01$ 1.00000e-09 1.00000e-01 7.85289e-01 7.85289e-01 7.85289e-02 1.00000e-09 2.12000e-01 $1.00000 \mathrm{e}+001.00000 \mathrm{e}+001.00000 \mathrm{e}-011.00000 \mathrm{e}-091.00000 \mathrm{e}-01$ $1.00000 \mathrm{e}-05$ 1.00000e-05 1.00000e-06 1.00000e-09 1.00000e-01 $1.00000 \mathrm{e}+001.00000 \mathrm{e}+001.00000 \mathrm{e}-011.00000 \mathrm{e}-091.00000 \mathrm{e}-01$ Element: 306 \# of layers: 5

$\mathrm{Kx} \mathrm{Ky} \mathrm{Kz}$ Ss Por

$2.94330 \mathrm{e}+012.94330 \mathrm{e}+012.94330 \mathrm{e}+001.00000 \mathrm{e}-09$ 7.00000e-02 
$1.17603 \mathrm{e}+001.17603 \mathrm{e}+00$ 1.17603e-01 1.00000e-09 2.12000e-01 $1.00000 \mathrm{e}+001.00000 \mathrm{e}+001.00000 \mathrm{e}-011.00000 \mathrm{e}-091.00000 \mathrm{e}-01$ $1.00000 \mathrm{e}-05$ 1.00000e-05 1.00000e-06 1.00000e-09 1.00000e-01 $1.00000 \mathrm{e}+001.00000 \mathrm{e}+001.00000 \mathrm{e}-011.00000 \mathrm{e}-091.00000 \mathrm{e}-01$ Element: 307 \# of layers: 5

Kx Ky Kz Ss Por

$1.05896 \mathrm{e}+011.05896 \mathrm{e}+011.05896 \mathrm{e}+00$ 1.00000e-09 2.12000e-01 $1.00000 \mathrm{e}-021.00000 \mathrm{e}-02$ 1.00000e-03 1.00000e-09 1.00000e-01 $1.00000 \mathrm{e}+001.00000 \mathrm{e}+001.00000 \mathrm{e}-011.00000 \mathrm{e}-091.00000 \mathrm{e}-01$ $1.00000 \mathrm{e}-051.00000 \mathrm{e}-05$ 1.00000e-06 1.00000e-09 1.00000e-01 $1.00000 \mathrm{e}+001.00000 \mathrm{e}+001.00000 \mathrm{e}-011.00000 \mathrm{e}-091.00000 \mathrm{e}-01$ Element: 308 \# of layers: 6

Kx Ky Kz Ss Por $1.07643 \mathrm{e}+02$ 1.07643e+02 1.07643e+01 1.00000e-09 7.00000e-02 $4.30119 \mathrm{e}+00$ 4.30119e+00 4.30119e-01 1.00000e-09 2.12000e-01 $1.00000 \mathrm{e}-02$ 1.00000e-02 1.00000e-03 1.00000e-09 1.00000e-01 $1.00000 \mathrm{e}+001.00000 \mathrm{e}+001.00000 \mathrm{e}-011.00000 \mathrm{e}-091.00000 \mathrm{e}-01$ $1.00000 \mathrm{e}-05$ 1.00000e-05 1.00000e-06 1.00000e-09 1.00000e-01 $1.00000 \mathrm{e}+001.00000 \mathrm{e}+001.00000 \mathrm{e}-011.00000 \mathrm{e}-091.00000 \mathrm{e}-01$ Element: 309 \# of layers: 5

Kx Ky Kz Ss Por

7.58624e+01 7.58624e+01 7.58624e+00 1.00000e-09 7.00000e-02 $3.03127 \mathrm{e}+003.03127 \mathrm{e}+00$ 3.03127e-01 1.00000e-09 2.12000e-01 $1.00000 \mathrm{e}+001.00000 \mathrm{e}+001.00000 \mathrm{e}-011.00000 \mathrm{e}-091.00000 \mathrm{e}-01$ $1.00000 \mathrm{e}-05$ 1.00000e-05 1.00000e-06 1.00000e-09 1.00000e-01 $1.00000 \mathrm{e}+001.00000 \mathrm{e}+001.00000 \mathrm{e}-011.00000 \mathrm{e}-091.00000 \mathrm{e}-01$ Element: 310 \# of layers: 5

Kx Ky Kz Ss Por

$6.87535 \mathrm{e}+016.87535 \mathrm{e}+016.87535 \mathrm{e}+00$ 1.00000e-09 7.00000e-02 $2.74708 \mathrm{e}+002.74708 \mathrm{e}+002.74708 \mathrm{e}-01$ 1.00000e-09 2.12000e-01 $1.00000 \mathrm{e}+001.00000 \mathrm{e}+001.00000 \mathrm{e}-011.00000 \mathrm{e}-091.00000 \mathrm{e}-01$ $1.00000 \mathrm{e}-05$ 1.00000e-05 1.00000e-06 1.00000e-09 1.00000e-01 $1.00000 \mathrm{e}+001.00000 \mathrm{e}+001.00000 \mathrm{e}-011.00000 \mathrm{e}-091.00000 \mathrm{e}-01$ Element: 311 \# of layers: 6

Kx Ky Kz Ss Por

$2.42792 \mathrm{e}+012.42792 \mathrm{e}+012.42792 \mathrm{e}+00$ 1.00000e-09 7.00000e-02 9.70108e-01 9.70108e-01 9.70108e-02 1.00000e-09 2.12000e-01 $1.00000 \mathrm{e}-02$ 1.00000e-02 1.00000e-03 1.00000e-09 1.00000e-01 $1.00000 \mathrm{e}+001.00000 \mathrm{e}+001.00000 \mathrm{e}-011.00000 \mathrm{e}-091.00000 \mathrm{e}-01$ $1.00000 \mathrm{e}-05$ 1.00000e-05 1.00000e-06 1.00000e-09 1.00000e-01 $1.00000 \mathrm{e}+001.00000 \mathrm{e}+001.00000 \mathrm{e}-011.00000 \mathrm{e}-091.00000 \mathrm{e}-01$ Element: 312 \# of layers: 6

Kx Ky Kz Ss Por

$1.83245 \mathrm{e}+011.83245 \mathrm{e}+011.83245 \mathrm{e}+00$ 1.00000e-09 7.00000e-02 7.32188e-01 7.32188e-01 7.32188e-02 1.00000e-09 2.12000e-01 $1.00000 \mathrm{e}-021.00000 \mathrm{e}-02$ 1.00000e-03 1.00000e-09 1.00000e-01 
$1.00000 \mathrm{e}+001.00000 \mathrm{e}+001.00000 \mathrm{e}-011.00000 \mathrm{e}-091.00000 \mathrm{e}-01$ $1.00000 \mathrm{e}-05$ 1.00000e-05 1.00000e-06 1.00000e-09 1.00000e-01 $1.00000 \mathrm{e}+001.00000 \mathrm{e}+001.00000 \mathrm{e}-01$ 1.00000e-09 1.00000e-01 Element: 313 \# of layers: 7

$\mathrm{Kx} \mathrm{Ky} \mathrm{Kz}$ Ss Por

$1.31420 \mathrm{e}+011.31420 \mathrm{e}+011.31420 \mathrm{e}+001.00000 \mathrm{e}-097.00000 \mathrm{e}-02$ 5.00000e-04 5.00000e-04 5.00000e-05 1.00000e-09 1.00000e-01

5.25094e-01 5.25094e-01 5.25094e-02 1.00000e-09 2.12000e-01

$1.00000 \mathrm{e}-02$ 1.00000e-02 1.00000e-03 1.00000e-09 1.00000e-01

$1.00000 \mathrm{e}+001.00000 \mathrm{e}+001.00000 \mathrm{e}-01$ 1.00000e-09 1.00000e-01

$1.00000 \mathrm{e}-05$ 1.00000e-05 1.00000e-06 1.00000e-09 1.00000e-01

$1.00000 \mathrm{e}+001.00000 \mathrm{e}+001.00000 \mathrm{e}-011.00000 \mathrm{e}-091.00000 \mathrm{e}-01$

Element: 314 \# of layers: 7

$\mathrm{Kx} \mathrm{Ky} \mathrm{Kz}$ Ss Por

3.64563e+01 3.64563e+01 3.64563e+00 1.00000e-09 7.00000e-02 5.00000e-04 5.00000e-04 5.00000e-05 1.00000e-09 1.00000e-01

$1.45666 \mathrm{e}+001.45666 \mathrm{e}+001.45666 \mathrm{e}-01$ 1.00000e-09 2.12000e-01 $1.00000 \mathrm{e}-02$ 1.00000e-02 1.00000e-03 1.00000e-09 1.00000e-01

$1.00000 \mathrm{e}+001.00000 \mathrm{e}+001.00000 \mathrm{e}-011.00000 \mathrm{e}-091.00000 \mathrm{e}-01$ $1.00000 \mathrm{e}-05$ 1.00000e-05 1.00000e-06 1.00000e-09 1.00000e-01 $1.00000 \mathrm{e}+001.00000 \mathrm{e}+001.00000 \mathrm{e}-011.00000 \mathrm{e}-091.00000 \mathrm{e}-01$ Element: 315 \# of layers: 7

$\mathrm{Kx} \mathrm{Ky} \mathrm{Kz}$ Ss Por

3.72203e+01 3.72203e+01 3.72203e+00 1.00000e-09 7.00000e-02 5.00000e-04 5.00000e-04 5.00000e-05 1.00000e-09 1.00000e-01 $1.48719 \mathrm{e}+001.48719 \mathrm{e}+00$ 1.48719e-01 1.00000e-09 2.12000e-01 $1.00000 \mathrm{e}-021.00000 \mathrm{e}-021.00000 \mathrm{e}-031.00000 \mathrm{e}-091.00000 \mathrm{e}-01$ $1.00000 \mathrm{e}+001.00000 \mathrm{e}+001.00000 \mathrm{e}-011.00000 \mathrm{e}-091.00000 \mathrm{e}-01$ $1.00000 \mathrm{e}-05$ 1.00000e-05 1.00000e-06 1.00000e-09 1.00000e-01 $1.00000 \mathrm{e}+001.00000 \mathrm{e}+001.00000 \mathrm{e}-011.00000 \mathrm{e}-091.00000 \mathrm{e}-01$ Element: 316 \# of layers: 7

$\mathrm{Kx} \mathrm{Ky} \mathrm{Kz}$ Ss Por

$1.83705 \mathrm{e}+02$ 1.83705e+02 1.83705e+01 1.00000e-09 7.00000e-02 5.00000e-04 5.00000e-04 5.00000e-05 1.00000e-09 1.00000e-01

7.34033e+00 7.34033e+00 7.34033e-01 1.00000e-09 2.12000e-01 1.00000e-02 1.00000e-02 1.00000e-03 1.00000e-09 1.00000e-01 $1.00000 \mathrm{e}+001.00000 \mathrm{e}+001.00000 \mathrm{e}-011.00000 \mathrm{e}-091.00000 \mathrm{e}-01$ $1.00000 \mathrm{e}-05$ 1.00000e-05 1.00000e-06 1.00000e-09 1.00000e-01 $1.00000 \mathrm{e}+001.00000 \mathrm{e}+001.00000 \mathrm{e}-011.00000 \mathrm{e}-091.00000 \mathrm{e}-01$ Element: 317 \# of layers: 16

$\mathrm{Kx} \mathrm{Ky} \mathrm{Kz}$ Ss Por

3.15846e+02 3.15846e+02 3.15846e+01 1.00000e-09 7.00000e-02 $3.15846 \mathrm{e}+02$ 3.15846e+02 3.15846e+01 1.00000e-09 7.00000e-02 3.15846e+02 3.15846e+02 3.15846e+01 1.00000e-09 7.00000e-02 3.15846e+02 3.15846e+02 3.15846e+01 1.00000e-09 7.00000e-02 $3.15846 \mathrm{e}+02$ 3.15846e+02 3.15846e+01 1.00000e-09 7.00000e-02 
5.00000e-04 5.00000e-04 5.00000e-05 1.00000e-09 1.00000e-01 5.00000e-04 5.00000e-04 5.00000e-05 1.00000e-09 1.00000e-01 $1.26201 \mathrm{e}+011.26201 \mathrm{e}+011.26201 \mathrm{e}+001.00000 \mathrm{e}-092.12000 \mathrm{e}-01$ $1.26201 \mathrm{e}+011.26201 \mathrm{e}+011.26201 \mathrm{e}+001.00000 \mathrm{e}-092.12000 \mathrm{e}-01$ $1.26201 \mathrm{e}+011.26201 \mathrm{e}+011.26201 \mathrm{e}+001.00000 \mathrm{e}-092.12000 \mathrm{e}-01$ $1.26201 \mathrm{e}+011.26201 \mathrm{e}+011.26201 \mathrm{e}+001.00000 \mathrm{e}-092.12000 \mathrm{e}-01$ $1.26201 \mathrm{e}+011.26201 \mathrm{e}+011.26201 \mathrm{e}+001.00000 \mathrm{e}-092.12000 \mathrm{e}-01$ $1.00000 \mathrm{e}-02$ 1.00000e-02 1.00000e-03 1.00000e-09 1.00000e-01 $1.00000 \mathrm{e}+001.00000 \mathrm{e}+001.00000 \mathrm{e}-011.00000 \mathrm{e}-091.00000 \mathrm{e}-01$ $1.00000 \mathrm{e}-05$ 1.00000e-05 1.00000e-06 1.00000e-09 1.00000e-01 $1.00000 \mathrm{e}+001.00000 \mathrm{e}+001.00000 \mathrm{e}-011.00000 \mathrm{e}-091.00000 \mathrm{e}-01$ Element: 318 \# of layers: 16

$\mathrm{Kx} \mathrm{Ky} \mathrm{Kz}$ Ss Por

3.20288e+02 3.20288e+02 3.20288e+01 1.00000e-09 7.00000e-02 $3.20288 \mathrm{e}+02$ 3.20288e+02 3.20288e+01 1.00000e-09 7.00000e-02 $3.20288 \mathrm{e}+02$ 3.20288e+02 3.20288e+01 1.00000e-09 7.00000e-02 $3.20288 \mathrm{e}+02$ 3.20288e+02 3.20288e+01 1.00000e-09 7.00000e-02 $3.20288 \mathrm{e}+02$ 3.20288e+02 3.20288e+01 1.00000e-09 7.00000e-02 5.00000e-04 5.00000e-04 5.00000e-05 1.00000e-09 1.00000e-01 5.00000e-04 5.00000e-04 5.00000e-05 1.00000e-09 1.00000e-01 $1.27976 \mathrm{e}+011.27976 \mathrm{e}+011.27976 \mathrm{e}+001.00000 \mathrm{e}-092.12000 \mathrm{e}-01$ $1.27976 \mathrm{e}+01$ 1.27976e+01 1.27976e+00 1.00000e-09 2.12000e-01 $1.27976 \mathrm{e}+01$ 1.27976e+01 1.27976e+00 1.00000e-09 2.12000e-01 $1.27976 \mathrm{e}+011.27976 \mathrm{e}+011.27976 \mathrm{e}+001.00000 \mathrm{e}-092.12000 \mathrm{e}-01$ $1.27976 \mathrm{e}+011.27976 \mathrm{e}+011.27976 \mathrm{e}+001.00000 \mathrm{e}-092.12000 \mathrm{e}-01$ $1.00000 \mathrm{e}-02$ 1.00000e-02 1.00000e-03 1.00000e-09 1.00000e-01 $1.00000 \mathrm{e}+001.00000 \mathrm{e}+001.00000 \mathrm{e}-011.00000 \mathrm{e}-091.00000 \mathrm{e}-01$ $1.00000 \mathrm{e}-05$ 1.00000e-05 1.00000e-06 1.00000e-09 1.00000e-01 $1.00000 \mathrm{e}+001.00000 \mathrm{e}+001.00000 \mathrm{e}-011.00000 \mathrm{e}-091.00000 \mathrm{e}-01$ Element: 319 \# of layers: 6

$\mathrm{Kx} \mathrm{Ky} \mathrm{Kz}$ Ss Por

3.50000e+02 3.50000e+02 3.50000e+01 1.00000e-09 1.00000e-01 $3.34155 \mathrm{e}+003.34155 \mathrm{e}+003.34155 \mathrm{e}-01$ 1.00000e-09 2.12000e-01 $1.00000 \mathrm{e}-021.00000 \mathrm{e}-021.00000 \mathrm{e}-031.00000 \mathrm{e}-091.00000 \mathrm{e}-01$ $1.00000 \mathrm{e}+001.00000 \mathrm{e}+001.00000 \mathrm{e}-011.00000 \mathrm{e}-091.00000 \mathrm{e}-01$ $1.00000 \mathrm{e}-05$ 1.00000e-05 1.00000e-06 1.00000e-09 1.00000e-01 $1.00000 \mathrm{e}+001.00000 \mathrm{e}+001.00000 \mathrm{e}-011.00000 \mathrm{e}-091.00000 \mathrm{e}-01$ Element: 320 \# of layers: 5

$\mathrm{Kx} \mathrm{Ky} \mathrm{Kz}$ Ss Por

3.50000e+02 3.50000e+02 3.50000e+01 1.00000e-09 1.00000e-01 4.76133e+00 4.76133e+00 4.76133e-01 1.00000e-09 2.12000e-01 $1.00000 \mathrm{e}+001.00000 \mathrm{e}+001.00000 \mathrm{e}-011.00000 \mathrm{e}-091.00000 \mathrm{e}-01$ $1.00000 \mathrm{e}-05$ 1.00000e-05 1.00000e-06 1.00000e-09 1.00000e-01 $1.00000 \mathrm{e}+001.00000 \mathrm{e}+001.00000 \mathrm{e}-01$ 1.00000e-09 1.00000e-01 Element: 321 \# of layers: 4

Kx Ky Kz Ss Por 
$1.10945 \mathrm{e}+01$ 1.10945e+01 1.10945e+00 1.00000e-09 2.12000e-01 $1.00000 \mathrm{e}+001.00000 \mathrm{e}+001.00000 \mathrm{e}-011.00000 \mathrm{e}-091.00000 \mathrm{e}-01$ $1.00000 \mathrm{e}-05$ 1.00000e-05 1.00000e-06 1.00000e-09 1.00000e-01 $1.00000 \mathrm{e}+001.00000 \mathrm{e}+001.00000 \mathrm{e}-011.00000 \mathrm{e}-091.00000 \mathrm{e}-01$ Element: 322 \# of layers: 4

$\mathrm{Kx} \mathrm{Ky} \mathrm{Kz}$ Ss Por

9.47090e+00 9.47090e+00 9.47090e-01 1.00000e-09 2.12000e-01

$1.00000 \mathrm{e}+001.00000 \mathrm{e}+001.00000 \mathrm{e}-011.00000 \mathrm{e}-091.00000 \mathrm{e}-01$

$1.00000 \mathrm{e}-05$ 1.00000e-05 1.00000e-06 1.00000e-09 1.00000e-01

$1.00000 \mathrm{e}+001.00000 \mathrm{e}+001.00000 \mathrm{e}-01$ 1.00000e-09 1.00000e-01

Element: 323 \# of layers: 4

Kx Ky Kz Ss Por

7.40873e+00 7.40873e+00 7.40873e-01 1.00000e-09 2.12000e-01 $1.00000 \mathrm{e}+001.00000 \mathrm{e}+001.00000 \mathrm{e}-011.00000 \mathrm{e}-091.00000 \mathrm{e}-01$ $1.00000 \mathrm{e}-05$ 1.00000e-05 1.00000e-06 1.00000e-09 1.00000e-01 $1.00000 \mathrm{e}+001.00000 \mathrm{e}+001.00000 \mathrm{e}-011.00000 \mathrm{e}-091.00000 \mathrm{e}-01$ Element: 324 \# of layers: 5

$\mathrm{Kx} \mathrm{Ky} \mathrm{Kz}$ Ss Por

1.10493e+01 1.10493e+01 1.10493e+00 1.00000e-09 2.12000e-01 $1.00000 \mathrm{e}-02$ 1.00000e-02 1.00000e-03 1.00000e-09 1.00000e-01

$1.00000 \mathrm{e}+001.00000 \mathrm{e}+001.00000 \mathrm{e}-011.00000 \mathrm{e}-091.00000 \mathrm{e}-01$ $1.00000 \mathrm{e}-05$ 1.00000e-05 1.00000e-06 1.00000e-09 1.00000e-01

$1.00000 \mathrm{e}+001.00000 \mathrm{e}+001.00000 \mathrm{e}-01$ 1.00000e-09 1.00000e-01 Element: 325 \# of layers: 6

$\mathrm{Kx} \mathrm{Ky} \mathrm{Kz}$ Ss Por

$3.68608 \mathrm{e}+013.68608 \mathrm{e}+013.68608 \mathrm{e}+001.00000 \mathrm{e}-09$ 7.00000e-02 $1.47281 \mathrm{e}+001.47281 \mathrm{e}+001.47281 \mathrm{e}-011.00000 \mathrm{e}-092.12000 \mathrm{e}-01$ $1.00000 \mathrm{e}-02$ 1.00000e-02 1.00000e-03 1.00000e-09 1.00000e-01

$1.00000 \mathrm{e}+001.00000 \mathrm{e}+001.00000 \mathrm{e}-011.00000 \mathrm{e}-091.00000 \mathrm{e}-01$ $1.00000 \mathrm{e}-05$ 1.00000e-05 1.00000e-06 1.00000e-09 1.00000e-01 $1.00000 \mathrm{e}+001.00000 \mathrm{e}+001.00000 \mathrm{e}-011.00000 \mathrm{e}-091.00000 \mathrm{e}-01$ Element: 326 \# of layers: 6

$\mathrm{Kx} \mathrm{Ky} \mathrm{Kz}$ Ss Por

$1.70848 \mathrm{e}+01$ 1.70848e+01 1.70848e+00 1.00000e-09 7.00000e-02 6.82642e-01 6.82642e-01 6.82642e-02 1.00000e-09 2.12000e-01 $1.00000 \mathrm{e}-02$ 1.00000e-02 1.00000e-03 1.00000e-09 1.00000e-01 $1.00000 \mathrm{e}+001.00000 \mathrm{e}+001.00000 \mathrm{e}-011.00000 \mathrm{e}-091.00000 \mathrm{e}-01$ $1.00000 \mathrm{e}-05$ 1.00000e-05 1.00000e-06 1.00000e-09 1.00000e-01 $1.00000 \mathrm{e}+001.00000 \mathrm{e}+001.00000 \mathrm{e}-011.00000 \mathrm{e}-091.00000 \mathrm{e}-01$ Element: 327 \# of layers: 7

$\mathrm{Kx} \mathrm{Ky} \mathrm{Kz}$ Ss Por $1.00128 \mathrm{e}+01$ 1.00128e+01 1.00128e+00 1.00000e-09 7.00000e-02 5.00000e-04 5.00000e-04 5.00000e-05 1.00000e-09 1.00000e-01 4.00081e-01 4.00081e-01 4.00081e-02 1.00000e-09 2.12000e-01 $1.00000 \mathrm{e}-02$ 1.00000e-02 1.00000e-03 1.00000e-09 1.00000e-01 $1.00000 \mathrm{e}+001.00000 \mathrm{e}+001.00000 \mathrm{e}-011.00000 \mathrm{e}-091.00000 \mathrm{e}-01$ 
$1.00000 \mathrm{e}-05$ 1.00000e-05 1.00000e-06 1.00000e-09 1.00000e-01 $1.00000 \mathrm{e}+001.00000 \mathrm{e}+001.00000 \mathrm{e}-01$ 1.00000e-09 1.00000e-01 Element: 328 \# of layers: 7

Kx Ky Kz Ss Por

3.45272e+01 3.45272e+01 3.45272e+00 1.00000e-09 7.00000e-02 5.00000e-04 5.00000e-04 5.00000e-05 1.00000e-09 1.00000e-01 $1.37959 \mathrm{e}+00$ 1.37959e+00 1.37959e-01 1.00000e-09 2.12000e-01 1.00000e-02 1.00000e-02 1.00000e-03 1.00000e-09 1.00000e-01 $1.00000 \mathrm{e}+001.00000 \mathrm{e}+001.00000 \mathrm{e}-011.00000 \mathrm{e}-091.00000 \mathrm{e}-01$ $1.00000 \mathrm{e}-05$ 1.00000e-05 1.00000e-06 1.00000e-09 1.00000e-01 $1.00000 \mathrm{e}+001.00000 \mathrm{e}+001.00000 \mathrm{e}-011.00000 \mathrm{e}-091.00000 \mathrm{e}-01$ Element: 329 \# of layers: 7

$\mathrm{Kx} \mathrm{Ky} \mathrm{Kz}$ Ss Por

$5.23769 \mathrm{e}+015.23769 \mathrm{e}+015.23769 \mathrm{e}+001.00000 \mathrm{e}-09$ 7.00000e-02 5.00000e-04 5.00000e-04 5.00000e-05 1.00000e-09 1.00000e-01 $2.09281 \mathrm{e}+002.09281 \mathrm{e}+002.09281 \mathrm{e}-01$ 1.00000e-09 2.12000e-01 $1.00000 \mathrm{e}-02$ 1.00000e-02 1.00000e-03 1.00000e-09 1.00000e-01 $1.00000 \mathrm{e}+001.00000 \mathrm{e}+001.00000 \mathrm{e}-011.00000 \mathrm{e}-091.00000 \mathrm{e}-01$ $1.00000 \mathrm{e}-051.00000 \mathrm{e}-05$ 1.00000e-06 1.00000e-09 1.00000e-01 $1.00000 \mathrm{e}+001.00000 \mathrm{e}+001.00000 \mathrm{e}-011.00000 \mathrm{e}-091.00000 \mathrm{e}-01$ Element: 330 \# of layers: 7

$\mathrm{Kx} \mathrm{Ky} \mathrm{Kz}$ Ss Por

4.87585e+01 4.87585e+01 4.87585e+00 1.00000e-09 7.00000e-02 5.00000e-04 5.00000e-04 5.00000e-05 1.00000e-09 1.00000e-01

$1.94823 \mathrm{e}+001.94823 \mathrm{e}+001.94823 \mathrm{e}-011.00000 \mathrm{e}-092.12000 \mathrm{e}-01$ $1.00000 \mathrm{e}-02$ 1.00000e-02 1.00000e-03 1.00000e-09 1.00000e-01 $1.00000 \mathrm{e}+001.00000 \mathrm{e}+001.00000 \mathrm{e}-011.00000 \mathrm{e}-091.00000 \mathrm{e}-01$ $1.00000 \mathrm{e}-05$ 1.00000e-05 1.00000e-06 1.00000e-09 1.00000e-01 $1.00000 \mathrm{e}+001.00000 \mathrm{e}+001.00000 \mathrm{e}-011.00000 \mathrm{e}-091.00000 \mathrm{e}-01$ Element: 331 \# of layers: 16

$\mathrm{Kx} \mathrm{Ky} \mathrm{Kz}$ Ss Por

$1.26708 \mathrm{e}+02$ 1.26708e+02 1.26708e+01 1.00000e-09 7.00000e-02 $1.26708 \mathrm{e}+021.26708 \mathrm{e}+02 \quad 1.26708 \mathrm{e}+01$ 1.00000e-09 7.00000e-02 $1.26708 \mathrm{e}+02$ 1.26708e+02 1.26708e+01 1.00000e-09 7.00000e-02 $1.26708 \mathrm{e}+02$ 1.26708e+02 1.26708e+01 1.00000e-09 7.00000e-02 $1.26708 \mathrm{e}+021.26708 \mathrm{e}+02$ 1.26708e+01 1.00000e-09 7.00000e-02 5.00000e-04 5.00000e-04 5.00000e-05 1.00000e-09 1.00000e-01 5.00000e-04 5.00000e-04 5.00000e-05 1.00000e-09 1.00000e-01 $5.06283 \mathrm{e}+00$ 5.06283e+00 5.06283e-01 1.00000e-09 2.12000e-01 5.06283e+00 5.06283e+00 5.06283e-01 1.00000e-09 2.12000e-01 $5.06283 \mathrm{e}+00$ 5.06283e+00 5.06283e-01 1.00000e-09 2.12000e-01 $5.06283 \mathrm{e}+00$ 5.06283e+00 5.06283e-01 1.00000e-09 2.12000e-01 5.06283e+00 5.06283e+00 5.06283e-01 1.00000e-09 2.12000e-01 $1.00000 \mathrm{e}-02$ 1.00000e-02 1.00000e-03 1.00000e-09 1.00000e-01 $1.00000 \mathrm{e}+001.00000 \mathrm{e}+001.00000 \mathrm{e}-011.00000 \mathrm{e}-091.00000 \mathrm{e}-01$ $1.00000 \mathrm{e}-05$ 1.00000e-05 1.00000e-06 1.00000e-09 1.00000e-01 
$1.00000 \mathrm{e}+001.00000 \mathrm{e}+00$ 1.00000e-01 1.00000e-09 1.00000e-01

Element: 332 \# of layers: 16

$\mathrm{Kx} \mathrm{Ky} \mathrm{Kz}$ Ss Por

1.15112e+02 1.15112e+02 1.15112e+01 1.00000e-09 7.00000e-02

$1.15112 \mathrm{e}+02$ 1.15112e+02 1.15112e+01 1.00000e-09 7.00000e-02

$1.15112 \mathrm{e}+02$ 1.15112e+02 1.15112e+01 1.00000e-09 7.00000e-02

$1.15112 \mathrm{e}+02$ 1.15112e+02 1.15112e+01 1.00000e-09 7.00000e-02

$1.15112 \mathrm{e}+021.15112 \mathrm{e}+021.15112 \mathrm{e}+01$ 1.00000e-09 7.00000e-02

5.00000e-04 5.00000e-04 5.00000e-05 1.00000e-09 1.00000e-01

5.00000e-04 5.00000e-04 5.00000e-05 1.00000e-09 1.00000e-01

$4.59955 \mathrm{e}+00$ 4.59955e+00 4.59955e-01 1.00000e-09 2.12000e-01

$4.59955 \mathrm{e}+00$ 4.59955e+00 4.59955e-01 1.00000e-09 2.12000e-01

$4.59955 \mathrm{e}+00$ 4.59955e+00 4.59955e-01 1.00000e-09 2.12000e-01

$4.59955 \mathrm{e}+004.59955 \mathrm{e}+00$ 4.59955e-01 1.00000e-09 2.12000e-01

$4.59955 \mathrm{e}+00$ 4.59955e+00 4.59955e-01 1.00000e-09 2.12000e-01

$1.00000 \mathrm{e}-02$ 1.00000e-02 1.00000e-03 1.00000e-09 1.00000e-01

$1.00000 \mathrm{e}+001.00000 \mathrm{e}+001.00000 \mathrm{e}-011.00000 \mathrm{e}-091.00000 \mathrm{e}-01$

$1.00000 \mathrm{e}-05$ 1.00000e-05 1.00000e-06 1.00000e-09 1.00000e-01

$1.00000 \mathrm{e}+001.00000 \mathrm{e}+001.00000 \mathrm{e}-011.00000 \mathrm{e}-091.00000 \mathrm{e}-01$

Element: 333 \# of layers: 5

$\mathrm{Kx} \mathrm{Ky} \mathrm{Kz}$ Ss Por

$1.23703 \mathrm{e}+01$ 1.23703e+01 1.23703e+00 1.00000e-09 2.12000e-01

$1.00000 \mathrm{e}-02$ 1.00000e-02 1.00000e-03 1.00000e-09 1.00000e-01

$1.00000 \mathrm{e}+001.00000 \mathrm{e}+001.00000 \mathrm{e}-011.00000 \mathrm{e}-091.00000 \mathrm{e}-01$

$1.00000 \mathrm{e}-05$ 1.00000e-05 1.00000e-06 1.00000e-09 1.00000e-01

$1.00000 \mathrm{e}+001.00000 \mathrm{e}+001.00000 \mathrm{e}-011.00000 \mathrm{e}-091.00000 \mathrm{e}-01$

Element: 334 \# of layers: 2

$\mathrm{Kx} \mathrm{Ky} \mathrm{Kz}$ Ss Por

$1.28325 \mathrm{e}+01$ 1.28325e+01 1.28325e+00 1.00000e-09 2.12000e-01

$1.00000 \mathrm{e}+001.00000 \mathrm{e}+001.00000 \mathrm{e}-01$ 1.00000e-09 1.00000e-01

Element: 335 \# of layers: 1

$\mathrm{Kx} \mathrm{Ky} \mathrm{Kz}$ Ss Por

$1.39044 \mathrm{e}+01$ 1.39044e+01 1.39044e+00 1.00000e-09 2.12000e-01

Element: 336 \# of layers: 4

$\mathrm{Kx} \mathrm{Ky} \mathrm{Kz}$ Ss Por

$1.60557 \mathrm{e}+01$ 1.60557e+01 1.60557e+00 1.00000e-09 2.12000e-01

$1.00000 \mathrm{e}-02$ 1.00000e-02 1.00000e-03 1.00000e-09 1.00000e-01

1.00000e-05 1.00000e-05 1.00000e-06 1.00000e-09 1.00000e-01

$1.00000 \mathrm{e}+001.00000 \mathrm{e}+001.00000 \mathrm{e}-01$ 1.00000e-09 1.00000e-01

Element: 337 \# of layers: 5

$\mathrm{Kx} \mathrm{Ky} \mathrm{Kz}$ Ss Por

1.25852e+01 1.25852e+01 1.25852e+00 1.00000e-09 2.12000e-01 $1.00000 \mathrm{e}-02$ 1.00000e-02 1.00000e-03 1.00000e-09 1.00000e-01

$1.00000 \mathrm{e}+001.00000 \mathrm{e}+001.00000 \mathrm{e}-011.00000 \mathrm{e}-091.00000 \mathrm{e}-01$ $1.00000 \mathrm{e}-05$ 1.00000e-05 1.00000e-06 1.00000e-09 1.00000e-01

$1.00000 \mathrm{e}+001.00000 \mathrm{e}+001.00000 \mathrm{e}-011.00000 \mathrm{e}-091.00000 \mathrm{e}-01$ 
Element: 338 \# of layers: 6

$\mathrm{Kx} \mathrm{Ky} \mathrm{Kz}$ Ss Por

7.83861e+01 7.83861e+01 7.83861e+00 1.00000e-09 7.00000e-02

3.13207e+00 3.13207e+00 3.13207e-01 1.00000e-09 2.12000e-01

$1.00000 \mathrm{e}-02$ 1.00000e-02 1.00000e-03 1.00000e-09 1.00000e-01

$1.00000 \mathrm{e}+001.00000 \mathrm{e}+001.00000 \mathrm{e}-011.00000 \mathrm{e}-091.00000 \mathrm{e}-01$

$1.00000 \mathrm{e}-05$ 1.00000e-05 1.00000e-06 1.00000e-09 1.00000e-01

$1.00000 \mathrm{e}+001.00000 \mathrm{e}+001.00000 \mathrm{e}-01$ 1.00000e-09 1.00000e-01

Element: 339 \# of layers: 6

$\mathrm{Kx} \mathrm{Ky} \mathrm{Kz}$ Ss Por

2.39873e+01 2.39873e+01 2.39873e+00 1.00000e-09 7.00000e-02

9.58453e-01 9.58453e-01 9.58453e-02 1.00000e-09 2.12000e-01

$1.00000 \mathrm{e}-02$ 1.00000e-02 1.00000e-03 1.00000e-09 1.00000e-01

$1.00000 \mathrm{e}+001.00000 \mathrm{e}+001.00000 \mathrm{e}-011.00000 \mathrm{e}-091.00000 \mathrm{e}-01$

$1.00000 \mathrm{e}-05$ 1.00000e-05 1.00000e-06 1.00000e-09 1.00000e-01

$1.00000 \mathrm{e}+001.00000 \mathrm{e}+001.00000 \mathrm{e}-011.00000 \mathrm{e}-091.00000 \mathrm{e}-01$

Element: 340 \# of layers: 7

$\mathrm{Kx} \mathrm{Ky} \mathrm{Kz}$ Ss Por

$1.11661 \mathrm{e}+011.11661 \mathrm{e}+01$ 1.11661e+00 1.00000e-09 7.00000e-02

5.00000e-04 5.00000e-04 5.00000e-05 1.00000e-09 1.00000e-01

4.46162e-01 4.46162e-01 4.46162e-02 1.00000e-09 2.12000e-01

$1.00000 \mathrm{e}-02$ 1.00000e-02 1.00000e-03 1.00000e-09 1.00000e-01

$1.00000 \mathrm{e}+001.00000 \mathrm{e}+001.00000 \mathrm{e}-011.00000 \mathrm{e}-091.00000 \mathrm{e}-01$

$1.00000 \mathrm{e}-05$ 1.00000e-05 1.00000e-06 1.00000e-09 1.00000e-01

$1.00000 \mathrm{e}+001.00000 \mathrm{e}+001.00000 \mathrm{e}-011.00000 \mathrm{e}-091.00000 \mathrm{e}-01$

Element: 341 \# of layers: 7

$\mathrm{Kx} \mathrm{Ky} \mathrm{Kz}$ Ss Por

4.65322e+01 4.65322e+01 4.65322e+00 1.00000e-09 7.00000e-02

5.00000e-04 5.00000e-04 5.00000e-05 1.00000e-09 1.00000e-01

$1.85928 \mathrm{e}+001.85928 \mathrm{e}+00$ 1.85928e-01 1.00000e-09 2.12000e-01

$1.00000 \mathrm{e}-02$ 1.00000e-02 1.00000e-03 1.00000e-09 1.00000e-01

$1.00000 \mathrm{e}+001.00000 \mathrm{e}+001.00000 \mathrm{e}-011.00000 \mathrm{e}-091.00000 \mathrm{e}-01$

$1.00000 \mathrm{e}-05$ 1.00000e-05 1.00000e-06 1.00000e-09 1.00000e-01

$1.00000 \mathrm{e}+001.00000 \mathrm{e}+001.00000 \mathrm{e}-011.00000 \mathrm{e}-091.00000 \mathrm{e}-01$

Element: 342 \# of layers: 16

$\mathrm{Kx} \mathrm{Ky} \mathrm{Kz}$ Ss Por

5.45438e+01 5.45438e+01 5.45438e+00 1.00000e-09 7.00000e-02

$5.45438 \mathrm{e}+015.45438 \mathrm{e}+015.45438 \mathrm{e}+001.00000 \mathrm{e}-09$ 7.00000e-02

$5.45438 \mathrm{e}+015.45438 \mathrm{e}+015.45438 \mathrm{e}+001.00000 \mathrm{e}-09$ 7.00000e-02

$5.45438 \mathrm{e}+015.45438 \mathrm{e}+015.45438 \mathrm{e}+001.00000 \mathrm{e}-09$ 7.00000e-02

5.45438e+01 5.45438e+01 5.45438e+00 1.00000e-09 7.00000e-02

5.00000e-04 5.00000e-04 5.00000e-05 1.00000e-09 1.00000e-01

5.00000e-04 5.00000e-04 5.00000e-05 1.00000e-09 1.00000e-01

$2.17937 \mathrm{e}+00$ 2.17937e+00 2.17937e-01 1.00000e-09 2.12000e-01

2.17937e+00 2.17937e+00 2.17937e-01 1.00000e-09 2.12000e-01

2.17937e+00 2.17937e+00 2.17937e-01 1.00000e-09 2.12000e-01 
$2.17937 \mathrm{e}+002.17937 \mathrm{e}+00$ 2.17937e-01 1.00000e-09 2.12000e-01 $2.17937 \mathrm{e}+002.17937 \mathrm{e}+00$ 2.17937e-01 1.00000e-09 2.12000e-01 $1.00000 \mathrm{e}-011.00000 \mathrm{e}-011.00000 \mathrm{e}-021.00000 \mathrm{e}-091.00000 \mathrm{e}-01$ $1.00000 \mathrm{e}+001.00000 \mathrm{e}+001.00000 \mathrm{e}-011.00000 \mathrm{e}-091.00000 \mathrm{e}-01$ $1.00000 \mathrm{e}-05$ 1.00000e-05 1.00000e-06 1.00000e-09 1.00000e-01 $1.00000 \mathrm{e}+001.00000 \mathrm{e}+001.00000 \mathrm{e}-011.00000 \mathrm{e}-091.00000 \mathrm{e}-01$ Element: 343 \# of layers: 16

Kx Ky Kz Ss Por

$1.78542 \mathrm{e}+02$ 1.78542e+02 1.78542e+01 1.00000e-09 7.00000e-02

$1.78542 \mathrm{e}+021.78542 \mathrm{e}+021.78542 \mathrm{e}+011.00000 \mathrm{e}-09$ 7.00000e-02

$1.78542 \mathrm{e}+021.78542 \mathrm{e}+021.78542 \mathrm{e}+011.00000 \mathrm{e}-097.00000 \mathrm{e}-02$

$1.78542 \mathrm{e}+021.78542 \mathrm{e}+021.78542 \mathrm{e}+011.00000 \mathrm{e}-097.00000 \mathrm{e}-02$

$1.78542 \mathrm{e}+021.78542 \mathrm{e}+021.78542 \mathrm{e}+011.00000 \mathrm{e}-097.00000 \mathrm{e}-02$

5.00000e-04 5.00000e-04 5.00000e-05 1.00000e-09 1.00000e-01

5.00000e-04 5.00000e-04 5.00000e-05 1.00000e-09 1.00000e-01

$7.13378 \mathrm{e}+00$ 7.13378e+00 7.13378e-01 1.00000e-09 2.12000e-01

$7.13378 \mathrm{e}+007.13378 \mathrm{e}+00$ 7.13378e-01 1.00000e-09 2.12000e-01

$7.13378 \mathrm{e}+00$ 7.13378e+00 7.13378e-01 1.00000e-09 2.12000e-01

$7.13378 \mathrm{e}+00$ 7.13378e+00 7.13378e-01 1.00000e-09 2.12000e-01

$7.13378 \mathrm{e}+00$ 7.13378e+00 7.13378e-01 1.00000e-09 2.12000e-01

$1.00000 \mathrm{e}-011.00000 \mathrm{e}-011.00000 \mathrm{e}-021.00000 \mathrm{e}-091.00000 \mathrm{e}-01$

$1.00000 \mathrm{e}+001.00000 \mathrm{e}+001.00000 \mathrm{e}-011.00000 \mathrm{e}-091.00000 \mathrm{e}-01$

$1.00000 \mathrm{e}-05$ 1.00000e-05 1.00000e-06 1.00000e-09 1.00000e-01

$1.00000 \mathrm{e}+001.00000 \mathrm{e}+001.00000 \mathrm{e}-011.00000 \mathrm{e}-091.00000 \mathrm{e}-01$

Element: 344 \# of layers: 16

Kx Ky Kz Ss Por

$2.34503 \mathrm{e}+022.34503 \mathrm{e}+022.34503 \mathrm{e}+01$ 1.00000e-09 7.00000e-02 $2.34503 \mathrm{e}+022.34503 \mathrm{e}+022.34503 \mathrm{e}+01$ 1.00000e-09 7.00000e-02 $2.34503 \mathrm{e}+022.34503 \mathrm{e}+022.34503 \mathrm{e}+01$ 1.00000e-09 7.00000e-02 $2.34503 \mathrm{e}+022.34503 \mathrm{e}+022.34503 \mathrm{e}+01$ 1.00000e-09 7.00000e-02 $2.34503 \mathrm{e}+022.34503 \mathrm{e}+022.34503 \mathrm{e}+01$ 1.00000e-09 7.00000e-02 5.00000e-04 5.00000e-04 5.00000e-05 1.00000e-09 1.00000e-01 5.00000e-04 5.00000e-04 5.00000e-05 1.00000e-09 1.00000e-01

$9.36987 \mathrm{e}+009.36987 \mathrm{e}+00$ 9.36988e-01 1.00000e-09 2.12000e-01

$9.36987 \mathrm{e}+00$ 9.36987e+00 9.36988e-01 1.00000e-09 2.12000e-01

$9.36987 \mathrm{e}+00$ 9.36987e+00 9.36988e-01 1.00000e-09 2.12000e-01

$9.36987 \mathrm{e}+009.36987 \mathrm{e}+00$ 9.36988e-01 1.00000e-09 2.12000e-01

$9.36987 \mathrm{e}+00$ 9.36987e+00 9.36988e-01 1.00000e-09 2.12000e-01

$1.00000 \mathrm{e}-02$ 1.00000e-02 1.00000e-03 1.00000e-09 1.00000e-01

$1.00000 \mathrm{e}+001.00000 \mathrm{e}+001.00000 \mathrm{e}-011.00000 \mathrm{e}-091.00000 \mathrm{e}-01$ $1.00000 \mathrm{e}-05$ 1.00000e-05 1.00000e-06 1.00000e-09 1.00000e-01 $1.00000 \mathrm{e}+001.00000 \mathrm{e}+001.00000 \mathrm{e}-011.00000 \mathrm{e}-091.00000 \mathrm{e}-01$ Element: 345 \# of layers: 16

Kx Ky Kz Ss Por

$2.34900 \mathrm{e}+022.34900 \mathrm{e}+022.34900 \mathrm{e}+01$ 1.00000e-09 7.00000e-02 $2.34900 \mathrm{e}+022.34900 \mathrm{e}+02$ 2.34900e+01 1.00000e-09 7.00000e-02 
2.34900e+02 2.34900e+02 2.34900e+01 1.00000e-09 7.00000e-02 $2.34900 \mathrm{e}+02$ 2.34900e+02 2.34900e+01 1.00000e-09 7.00000e-02 $2.34900 \mathrm{e}+02$ 2.34900e+02 2.34900e+01 1.00000e-09 7.00000e-02 5.00000e-04 5.00000e-04 5.00000e-05 1.00000e-09 1.00000e-01 5.00000e-04 5.00000e-04 5.00000e-05 1.00000e-09 1.00000e-01 9.38562e+00 9.38562e+00 9.38563e-01 1.00000e-09 2.12000e-01 9.38562e+00 9.38562e+00 9.38563e-01 1.00000e-09 2.12000e-01 $9.38562 \mathrm{e}+00$ 9.38562e+00 9.38563e-01 1.00000e-09 2.12000e-01 9.38562e+00 9.38562e+00 9.38563e-01 1.00000e-09 2.12000e-01 9.38562e+00 9.38562e+00 9.38563e-01 1.00000e-09 2.12000e-01 $1.00000 \mathrm{e}-02$ 1.00000e-02 1.00000e-03 1.00000e-09 1.00000e-01 $1.00000 \mathrm{e}+001.00000 \mathrm{e}+001.00000 \mathrm{e}-011.00000 \mathrm{e}-091.00000 \mathrm{e}-01$ 1.00000e-05 1.00000e-05 1.00000e-06 1.00000e-09 1.00000e-01 $1.00000 \mathrm{e}+001.00000 \mathrm{e}+001.00000 \mathrm{e}-01$ 1.00000e-09 1.00000e-01 Element: 346 \# of layers: 5

Kx Ky Kz Ss Por $1.99912 \mathrm{e}+01$ 1.99912e+01 1.99912e+00 1.00000e-09 2.12000e-01 $1.00000 \mathrm{e}-02$ 1.00000e-02 1.00000e-03 1.00000e-09 1.00000e-01 $1.00000 \mathrm{e}+001.00000 \mathrm{e}+001.00000 \mathrm{e}-011.00000 \mathrm{e}-091.00000 \mathrm{e}-01$ $1.00000 \mathrm{e}-05$ 1.00000e-05 1.00000e-06 1.00000e-09 1.00000e-01 $1.00000 \mathrm{e}+001.00000 \mathrm{e}+001.00000 \mathrm{e}-011.00000 \mathrm{e}-091.00000 \mathrm{e}-01$ Element: 347 \# of layers: 5

$\mathrm{Kx} \mathrm{Ky} \mathrm{Kz}$ Ss Por

$1.97374 \mathrm{e}+011.97374 \mathrm{e}+011.97374 \mathrm{e}+001.00000 \mathrm{e}-092.12000 \mathrm{e}-01$ $1.00000 \mathrm{e}-02$ 1.00000e-02 1.00000e-03 1.00000e-09 1.00000e-01 $1.00000 \mathrm{e}+001.00000 \mathrm{e}+001.00000 \mathrm{e}-011.00000 \mathrm{e}-091.00000 \mathrm{e}-01$ $1.00000 \mathrm{e}-05$ 1.00000e-05 1.00000e-06 1.00000e-09 1.00000e-01 $1.00000 \mathrm{e}+001.00000 \mathrm{e}+001.00000 \mathrm{e}-011.00000 \mathrm{e}-09$ 1.00000e-01 Element: 348 \# of layers: 5

$\mathrm{Kx} \mathrm{Ky} \mathrm{Kz}$ Ss Por

$1.55865 \mathrm{e}+01$ 1.55865e+01 1.55865e+00 1.00000e-09 2.12000e-01 $1.00000 \mathrm{e}-02$ 1.00000e-02 1.00000e-03 1.00000e-09 1.00000e-01 $1.00000 \mathrm{e}+001.00000 \mathrm{e}+001.00000 \mathrm{e}-011.00000 \mathrm{e}-091.00000 \mathrm{e}-01$ $1.00000 \mathrm{e}-05$ 1.00000e-05 1.00000e-06 1.00000e-09 1.00000e-01 $1.00000 \mathrm{e}+001.00000 \mathrm{e}+001.00000 \mathrm{e}-01$ 1.00000e-09 1.00000e-01 Element: 349 \# of layers: 5

Kx Ky Kz Ss Por

$1.08774 \mathrm{e}+011.08774 \mathrm{e}+01$ 1.08774e+00 1.00000e-09 2.12000e-01 $1.00000 \mathrm{e}-02$ 1.00000e-02 1.00000e-03 1.00000e-09 1.00000e-01 $1.00000 \mathrm{e}+001.00000 \mathrm{e}+001.00000 \mathrm{e}-011.00000 \mathrm{e}-091.00000 \mathrm{e}-01$ $1.00000 \mathrm{e}-05$ 1.00000e-05 1.00000e-06 1.00000e-09 1.00000e-01 $1.00000 \mathrm{e}+001.00000 \mathrm{e}+001.00000 \mathrm{e}-011.00000 \mathrm{e}-091.00000 \mathrm{e}-01$ Element: 350 \# of layers: 7

$\mathrm{Kx} \mathrm{Ky} \mathrm{Kz}$ Ss Por 6.40575e+01 6.40575e+01 6.40575e+00 1.00000e-09 7.00000e-02 5.00000e-04 5.00000e-04 5.00000e-05 1.00000e-09 1.00000e-01 
$2.55943 \mathrm{e}+002.55943 \mathrm{e}+00$ 2.55943e-01 1.00000e-09 2.12000e-01 $1.00000 \mathrm{e}-021.00000 \mathrm{e}-02$ 1.00000e-03 1.00000e-09 1.00000e-01 $1.00000 \mathrm{e}+001.00000 \mathrm{e}+001.00000 \mathrm{e}-011.00000 \mathrm{e}-091.00000 \mathrm{e}-01$ $1.00000 \mathrm{e}-05$ 1.00000e-05 1.00000e-06 1.00000e-09 1.00000e-01 $1.00000 \mathrm{e}+001.00000 \mathrm{e}+001.00000 \mathrm{e}-011.00000 \mathrm{e}-091.00000 \mathrm{e}-01$ Element: 351 \# of layers: 7

Kx Ky Kz Ss Por

$8.19820 \mathrm{e}+008.19820 \mathrm{e}+00$ 8.19820e-01 1.00000e-09 7.00000e-02 5.00000e-04 5.00000e-04 5.00000e-05 1.00000e-09 1.00000e-01 3.27562e-01 3.27562e-01 3.27562e-02 1.00000e-09 2.12000e-01 $1.00000 \mathrm{e}-021.00000 \mathrm{e}-02$ 1.00000e-03 1.00000e-09 1.00000e-01 $1.00000 \mathrm{e}+001.00000 \mathrm{e}+001.00000 \mathrm{e}-011.00000 \mathrm{e}-091.00000 \mathrm{e}-01$ $1.00000 \mathrm{e}-05$ 1.00000e-05 1.00000e-06 1.00000e-09 1.00000e-01 $1.00000 \mathrm{e}+001.00000 \mathrm{e}+001.00000 \mathrm{e}-011.00000 \mathrm{e}-091.00000 \mathrm{e}-01$ Element: 352 \# of layers: 7

Kx Ky Kz Ss Por

$1.98716 \mathrm{e}+011.98716 \mathrm{e}+011.98716 \mathrm{e}+001.00000 \mathrm{e}-09$ 7.00000e-02 5.00000e-04 5.00000e-04 5.00000e-05 1.00000e-09 1.00000e-01 7.93997e-01 7.93997e-01 7.93997e-02 1.00000e-09 2.12000e-01 $1.00000 \mathrm{e}-02$ 1.00000e-02 $1.00000 \mathrm{e}-031.00000 \mathrm{e}-091.00000 \mathrm{e}-01$ $1.00000 \mathrm{e}+001.00000 \mathrm{e}+001.00000 \mathrm{e}-011.00000 \mathrm{e}-091.00000 \mathrm{e}-01$ $1.00000 \mathrm{e}-05$ 1.00000e-05 1.00000e-06 1.00000e-09 1.00000e-01 $1.00000 \mathrm{e}+001.00000 \mathrm{e}+001.00000 \mathrm{e}-011.00000 \mathrm{e}-091.00000 \mathrm{e}-01$ Element: 353 \# of layers: 7

Kx Ky Kz Ss Por 5.39933e+01 5.39933e+01 5.39933e+00 1.00000e-09 7.00000e-02 5.00000e-04 5.00000e-04 5.00000e-05 1.00000e-09 1.00000e-01 $2.15739 \mathrm{e}+002.15739 \mathrm{e}+002.15739 \mathrm{e}-01$ 1.00000e-09 2.12000e-01 $1.00000 \mathrm{e}-011.00000 \mathrm{e}-011.00000 \mathrm{e}-021.00000 \mathrm{e}-091.00000 \mathrm{e}-01$ $1.00000 \mathrm{e}+001.00000 \mathrm{e}+001.00000 \mathrm{e}-011.00000 \mathrm{e}-091.00000 \mathrm{e}-01$ $1.00000 \mathrm{e}-05$ 1.00000e-05 1.00000e-06 1.00000e-09 1.00000e-01 $1.00000 \mathrm{e}+001.00000 \mathrm{e}+001.00000 \mathrm{e}-011.00000 \mathrm{e}-091.00000 \mathrm{e}-01$ Element: 354 \# of layers: 5

Kx Ky Kz Ss Por

$1.81784 \mathrm{e}+011.81784 \mathrm{e}+011.81784 \mathrm{e}+001.00000 \mathrm{e}-092.12000 \mathrm{e}-01$ $1.00000 \mathrm{e}-021.00000 \mathrm{e}-02$ 1.00000e-03 1.00000e-09 1.00000e-01 $1.00000 \mathrm{e}+001.00000 \mathrm{e}+001.00000 \mathrm{e}-011.00000 \mathrm{e}-091.00000 \mathrm{e}-01$ $1.00000 \mathrm{e}-05$ 1.00000e-05 1.00000e-06 1.00000e-09 1.00000e-01 $1.00000 \mathrm{e}+001.00000 \mathrm{e}+001.00000 \mathrm{e}-011.00000 \mathrm{e}-091.00000 \mathrm{e}-01$ Element: 355 \# of layers: 5

Kx Ky Kz Ss Por

$2.39518 \mathrm{e}+012.39518 \mathrm{e}+012.39518 \mathrm{e}+00$ 1.00000e-09 2.12000e-01 $1.00000 \mathrm{e}-02$ 1.00000e-02 1.00000e-03 1.00000e-09 1.00000e-01 $1.00000 \mathrm{e}+001.00000 \mathrm{e}+001.00000 \mathrm{e}-011.00000 \mathrm{e}-091.00000 \mathrm{e}-01$ $1.00000 \mathrm{e}-05$ 1.00000e-05 1.00000e-06 1.00000e-09 1.00000e-01 $1.00000 \mathrm{e}+001.00000 \mathrm{e}+001.00000 \mathrm{e}-011.00000 \mathrm{e}-091.00000 \mathrm{e}-01$ 
Element: 356 \# of layers: 5

$\mathrm{Kx} \mathrm{Ky} \mathrm{Kz}$ Ss Por

$1.99158 \mathrm{e}+01$ 1.99158e+01 1.99158e+00 1.00000e-09 2.12000e-01

$1.00000 \mathrm{e}-02$ 1.00000e-02 1.00000e-03 1.00000e-09 1.00000e-01

$1.00000 \mathrm{e}+001.00000 \mathrm{e}+001.00000 \mathrm{e}-011.00000 \mathrm{e}-091.00000 \mathrm{e}-01$

$1.00000 \mathrm{e}-05$ 1.00000e-05 1.00000e-06 1.00000e-09 1.00000e-01

$1.00000 \mathrm{e}+001.00000 \mathrm{e}+001.00000 \mathrm{e}-01$ 1.00000e-09 1.00000e-01

Element: 357 \# of layers: 5

$\mathrm{Kx} \mathrm{Ky} \mathrm{Kz}$ Ss Por

$1.53530 \mathrm{e}+01$ 1.53530e+01 1.53530e+00 1.00000e-09 2.12000e-01 $1.00000 \mathrm{e}-02$ 1.00000e-02 1.00000e-03 1.00000e-09 1.00000e-01

$1.00000 \mathrm{e}+001.00000 \mathrm{e}+001.00000 \mathrm{e}-011.00000 \mathrm{e}-091.00000 \mathrm{e}-01$

$1.00000 \mathrm{e}-05$ 1.00000e-05 1.00000e-06 1.00000e-09 1.00000e-01

$1.00000 \mathrm{e}+001.00000 \mathrm{e}+001.00000 \mathrm{e}-011.00000 \mathrm{e}-091.00000 \mathrm{e}-01$

Element: 358 \# of layers: 5

Kx Ky Kz Ss Por

7.86819e+00 7.86819e+00 7.86819e-01 1.00000e-09 2.12000e-01

$1.00000 \mathrm{e}-02$ 1.00000e-02 1.00000e-03 1.00000e-09 1.00000e-01

$1.00000 \mathrm{e}+001.00000 \mathrm{e}+001.00000 \mathrm{e}-011.00000 \mathrm{e}-091.00000 \mathrm{e}-01$

$1.00000 \mathrm{e}-05$ 1.00000e-05 1.00000e-06 1.00000e-09 1.00000e-01

$1.00000 \mathrm{e}+001.00000 \mathrm{e}+001.00000 \mathrm{e}-011.00000 \mathrm{e}-091.00000 \mathrm{e}-01$

Element: 359 \# of layers: 5

$\mathrm{Kx} \mathrm{Ky} \mathrm{Kz}$ Ss Por

6.81427e+00 6.81427e+00 6.81427e-01 1.00000e-09 2.12000e-01

$1.00000 \mathrm{e}-021.00000 \mathrm{e}-02$ 1.00000e-03 1.00000e-09 1.00000e-01

$1.00000 \mathrm{e}+001.00000 \mathrm{e}+001.00000 \mathrm{e}-011.00000 \mathrm{e}-091.00000 \mathrm{e}-01$

$1.00000 \mathrm{e}-05$ 1.00000e-05 1.00000e-06 1.00000e-09 1.00000e-01

$1.00000 \mathrm{e}+001.00000 \mathrm{e}+001.00000 \mathrm{e}-011.00000 \mathrm{e}-09$ 1.00000e-01

Element: 360 \# of layers: 7

$\mathrm{Kx} \mathrm{Ky} \mathrm{Kz}$ Ss Por

4.17235e+01 4.17235e+01 4.17235e+00 1.00000e-09 7.00000e-02

5.00000e-04 5.00000e-04 5.00000e-05 1.00000e-09 1.00000e-01

$1.66713 \mathrm{e}+001.66713 \mathrm{e}+001.66713 \mathrm{e}-01$ 1.00000e-09 2.12000e-01

$1.00000 \mathrm{e}-02$ 1.00000e-02 1.00000e-03 1.00000e-09 1.00000e-01

$1.00000 \mathrm{e}+001.00000 \mathrm{e}+001.00000 \mathrm{e}-011.00000 \mathrm{e}-091.00000 \mathrm{e}-01$

$1.00000 \mathrm{e}-05$ 1.00000e-05 1.00000e-06 1.00000e-09 1.00000e-01

$1.00000 \mathrm{e}+001.00000 \mathrm{e}+001.00000 \mathrm{e}-011.00000 \mathrm{e}-091.00000 \mathrm{e}-01$

Element: 361 \# of layers: 7

$\mathrm{Kx} \mathrm{Ky} \mathrm{Kz}$ Ss Por

$1.26221 \mathrm{e}+011.26221 \mathrm{e}+011.26221 \mathrm{e}+001.00000 \mathrm{e}-09$ 7.00000e-02

5.00000e-04 5.00000e-04 5.00000e-05 1.00000e-09 1.00000e-01

5.04348e-01 5.04348e-01 5.04348e-02 1.00000e-09 2.12000e-01

$1.00000 \mathrm{e}-02$ 1.00000e-02 1.00000e-03 1.00000e-09 1.00000e-01

$1.00000 \mathrm{e}+001.00000 \mathrm{e}+001.00000 \mathrm{e}-011.00000 \mathrm{e}-091.00000 \mathrm{e}-01$

$1.00000 \mathrm{e}-05$ 1.00000e-05 1.00000e-06 1.00000e-09 1.00000e-01

$1.00000 \mathrm{e}+001.00000 \mathrm{e}+001.00000 \mathrm{e}-011.00000 \mathrm{e}-091.00000 \mathrm{e}-01$ 
Element: 362 \# of layers: 7

$\mathrm{Kx} \mathrm{Ky} \mathrm{Kz}$ Ss Por

1.38835e+02 1.38835e+02 1.38835e+01 1.00000e-09 7.00000e-02

5.00000e-04 5.00000e-04 5.00000e-05 1.00000e-09 1.00000e-01

5.54727e+00 5.54727e+00 5.54727e-01 1.00000e-09 2.12000e-01

$1.00000 \mathrm{e}-02$ 1.00000e-02 1.00000e-03 1.00000e-09 1.00000e-01

$1.00000 \mathrm{e}+001.00000 \mathrm{e}+001.00000 \mathrm{e}-011.00000 \mathrm{e}-091.00000 \mathrm{e}-01$

$1.00000 \mathrm{e}-05$ 1.00000e-05 1.00000e-06 1.00000e-09 1.00000e-01

$1.00000 \mathrm{e}+001.00000 \mathrm{e}+001.00000 \mathrm{e}-011.00000 \mathrm{e}-091.00000 \mathrm{e}-01$

Element: 363 \# of layers: 3

$\mathrm{Kx} \mathrm{Ky} \mathrm{Kz}$ Ss Por

$1.47203 \mathrm{e}+01$ 1.47203e+01 1.47203e+00 1.00000e-09 2.12000e-01

$1.00000 \mathrm{e}-05$ 1.00000e-05 1.00000e-06 1.00000e-09 1.00000e-01

$1.00000 \mathrm{e}+001.00000 \mathrm{e}+001.00000 \mathrm{e}-01$ 1.00000e-09 1.00000e-01

Element: 364 \# of layers: 5

$\mathrm{Kx} \mathrm{Ky} \mathrm{Kz}$ Ss Por

$1.57184 \mathrm{e}+011.57184 \mathrm{e}+01$ 1.57184e+00 1.00000e-09 2.12000e-01

$1.00000 \mathrm{e}-02$ 1.00000e-02 1.00000e-03 1.00000e-09 1.00000e-01

$1.00000 \mathrm{e}+001.00000 \mathrm{e}+001.00000 \mathrm{e}-011.00000 \mathrm{e}-091.00000 \mathrm{e}-01$

$1.00000 \mathrm{e}-05$ 1.00000e-05 1.00000e-06 1.00000e-09 1.00000e-01

$1.00000 \mathrm{e}+001.00000 \mathrm{e}+001.00000 \mathrm{e}-011.00000 \mathrm{e}-091.00000 \mathrm{e}-01$

Element: 365 \# of layers: 5

$\mathrm{Kx} \mathrm{Ky} \mathrm{Kz}$ Ss Por

3.06052e+01 3.06052e+01 3.06052e+00 1.00000e-09 2.12000e-01

$1.00000 \mathrm{e}-021.00000 \mathrm{e}-02$ 1.00000e-03 1.00000e-09 1.00000e-01

$1.00000 \mathrm{e}+001.00000 \mathrm{e}+001.00000 \mathrm{e}-011.00000 \mathrm{e}-091.00000 \mathrm{e}-01$

$1.00000 \mathrm{e}-05$ 1.00000e-05 1.00000e-06 1.00000e-09 1.00000e-01

$1.00000 \mathrm{e}+001.00000 \mathrm{e}+001.00000 \mathrm{e}-011.00000 \mathrm{e}-09$ 1.00000e-01

Element: 366 \# of layers: 5

$\mathrm{Kx} \mathrm{Ky} \mathrm{Kz}$ Ss Por

$1.89965 \mathrm{e}+01$ 1.89965e+01 1.89965e+00 1.00000e-09 2.12000e-01

$1.00000 \mathrm{e}-02$ 1.00000e-02 1.00000e-03 1.00000e-09 1.00000e-01

$1.00000 \mathrm{e}+001.00000 \mathrm{e}+001.00000 \mathrm{e}-011.00000 \mathrm{e}-091.00000 \mathrm{e}-01$

$1.00000 \mathrm{e}-05$ 1.00000e-05 1.00000e-06 1.00000e-09 1.00000e-01

$1.00000 \mathrm{e}+001.00000 \mathrm{e}+001.00000 \mathrm{e}-011.00000 \mathrm{e}-091.00000 \mathrm{e}-01$

Element: 367 \# of layers: 5

Kx Ky Kz Ss Por

$1.54540 \mathrm{e}+01$ 1.54540e+01 1.54540e+00 1.00000e-09 2.12000e-01

$1.00000 \mathrm{e}-02$ 1.00000e-02 1.00000e-03 1.00000e-09 1.00000e-01

$1.00000 \mathrm{e}+001.00000 \mathrm{e}+001.00000 \mathrm{e}-011.00000 \mathrm{e}-091.00000 \mathrm{e}-01$

$1.00000 \mathrm{e}-05$ 1.00000e-05 1.00000e-06 1.00000e-09 1.00000e-01

$1.00000 \mathrm{e}+001.00000 \mathrm{e}+001.00000 \mathrm{e}-011.00000 \mathrm{e}-091.00000 \mathrm{e}-01$

Element: 368 \# of layers: 5

$\mathrm{Kx} \mathrm{Ky} \mathrm{Kz}$ Ss Por

$1.17885 \mathrm{e}+01$ 1.17885e+01 1.17885e+00 1.00000e-09 2.12000e-01

$1.00000 \mathrm{e}-02$ 1.00000e-02 1.00000e-03 1.00000e-09 1.00000e-01 
$1.00000 \mathrm{e}+001.00000 \mathrm{e}+001.00000 \mathrm{e}-011.00000 \mathrm{e}-091.00000 \mathrm{e}-01$ $1.00000 \mathrm{e}-05$ 1.00000e-05 1.00000e-06 1.00000e-09 1.00000e-01

$1.00000 \mathrm{e}+001.00000 \mathrm{e}+001.00000 \mathrm{e}-01$ 1.00000e-09 1.00000e-01

Element: 369 \# of layers: 5

$\mathrm{Kx} \mathrm{Ky} \mathrm{Kz}$ Ss Por

4.76043e+00 4.76043e+00 4.76043e-01 1.00000e-09 2.12000e-01

$1.00000 \mathrm{e}-02$ 1.00000e-02 1.00000e-03 1.00000e-09 1.00000e-01

$1.00000 \mathrm{e}+001.00000 \mathrm{e}+001.00000 \mathrm{e}-011.00000 \mathrm{e}-091.00000 \mathrm{e}-01$

$1.00000 \mathrm{e}-05$ 1.00000e-05 1.00000e-06 1.00000e-09 1.00000e-01

$1.00000 \mathrm{e}+001.00000 \mathrm{e}+001.00000 \mathrm{e}-011.00000 \mathrm{e}-091.00000 \mathrm{e}-01$

Element: 370 \# of layers: 5

$\mathrm{Kx} \mathrm{Ky} \mathrm{Kz}$ Ss Por

$1.50296 \mathrm{e}+01$ 1.50296e+01 1.50296e+00 1.00000e-09 2.12000e-01

$1.00000 \mathrm{e}-02$ 1.00000e-02 1.00000e-03 1.00000e-09 1.00000e-01

$1.00000 \mathrm{e}+001.00000 \mathrm{e}+001.00000 \mathrm{e}-011.00000 \mathrm{e}-091.00000 \mathrm{e}-01$

$1.00000 \mathrm{e}-05$ 1.00000e-05 1.00000e-06 1.00000e-09 1.00000e-01

$1.00000 \mathrm{e}+001.00000 \mathrm{e}+001.00000 \mathrm{e}-011.00000 \mathrm{e}-091.00000 \mathrm{e}-01$

Element: 371 \# of layers: 9

$\mathrm{Kx} \mathrm{Ky} \mathrm{Kz}$ Ss Por

$3.01866 \mathrm{e}+013.01866 \mathrm{e}+013.01866 \mathrm{e}+001.00000 \mathrm{e}-092.12000 \mathrm{e}-01$

$3.01866 \mathrm{e}+013.01866 \mathrm{e}+013.01866 \mathrm{e}+001.00000 \mathrm{e}-092.12000 \mathrm{e}-01$

$3.01866 \mathrm{e}+013.01866 \mathrm{e}+013.01866 \mathrm{e}+001.00000 \mathrm{e}-092.12000 \mathrm{e}-01$

$3.01866 \mathrm{e}+013.01866 \mathrm{e}+013.01866 \mathrm{e}+001.00000 \mathrm{e}-092.12000 \mathrm{e}-01$

$3.01866 \mathrm{e}+013.01866 \mathrm{e}+013.01866 \mathrm{e}+001.00000 \mathrm{e}-092.12000 \mathrm{e}-01$

$1.00000 \mathrm{e}-021.00000 \mathrm{e}-02$ 1.00000e-03 1.00000e-09 1.00000e-01

$1.00000 \mathrm{e}+001.00000 \mathrm{e}+001.00000 \mathrm{e}-011.00000 \mathrm{e}-091.00000 \mathrm{e}-01$

$1.00000 \mathrm{e}-05$ 1.00000e-05 1.00000e-06 1.00000e-09 1.00000e-01

$1.00000 \mathrm{e}+001.00000 \mathrm{e}+001.00000 \mathrm{e}-011.00000 \mathrm{e}-091.00000 \mathrm{e}-01$

Element: 372 \# of layers: 3

$\mathrm{Kx} \mathrm{Ky} \mathrm{Kz}$ Ss Por

5.15936e+00 5.15936e+00 5.15936e-01 1.00000e-09 2.12000e-01

1.00000e-05 1.00000e-05 1.00000e-06 1.00000e-09 1.00000e-01

$1.00000 \mathrm{e}+001.00000 \mathrm{e}+001.00000 \mathrm{e}-011.00000 \mathrm{e}-091.00000 \mathrm{e}-01$

Element: 373 \# of layers: 3

$\mathrm{Kx} \mathrm{Ky} \mathrm{Kz}$ Ss Por

4.30637e+00 4.30637e+00 4.30637e-01 1.00000e-09 2.12000e-01

$1.00000 \mathrm{e}-05$ 1.00000e-05 1.00000e-06 1.00000e-09 1.00000e-01

$1.00000 \mathrm{e}+001.00000 \mathrm{e}+001.00000 \mathrm{e}-011.00000 \mathrm{e}-091.00000 \mathrm{e}-01$

Element: 374 \# of layers: 3

$\mathrm{Kx} \mathrm{Ky} \mathrm{Kz}$ Ss Por

4.25169e+00 4.25169e+00 4.25169e-01 1.00000e-09 2.12000e-01

$1.00000 \mathrm{e}-05$ 1.00000e-05 1.00000e-06 1.00000e-09 1.00000e-01

$1.00000 \mathrm{e}+001.00000 \mathrm{e}+001.00000 \mathrm{e}-01$ 1.00000e-09 1.00000e-01

Element: 375 \# of layers: 3

$\mathrm{Kx} \mathrm{Ky} \mathrm{Kz} \mathrm{Ss} \mathrm{Por}$

5.73830e+00 5.73830e+00 5.73830e-01 1.00000e-09 2.12000e-01 
$1.00000 \mathrm{e}-05$ 1.00000e-05 1.00000e-06 1.00000e-09 1.00000e-01 $1.00000 \mathrm{e}+001.00000 \mathrm{e}+001.00000 \mathrm{e}-01$ 1.00000e-09 1.00000e-01 Element: 376 \# of layers: 3

$\mathrm{Kx} \mathrm{Ky} \mathrm{Kz}$ Ss Por

6.47744e+00 6.47744e+00 6.47744e-01 1.00000e-09 2.12000e-01 $1.00000 \mathrm{e}-05$ 1.00000e-05 1.00000e-06 1.00000e-09 1.00000e-01 $1.00000 \mathrm{e}+001.00000 \mathrm{e}+001.00000 \mathrm{e}-01$ 1.00000e-09 1.00000e-01 Element: 377 \# of layers: 3

$\mathrm{Kx} \mathrm{Ky} \mathrm{Kz}$ Ss Por

6.52131e+00 6.52131e+00 6.52131e-01 1.00000e-09 2.12000e-01 $1.00000 \mathrm{e}-05$ 1.00000e-05 1.00000e-06 1.00000e-09 1.00000e-01

$1.00000 \mathrm{e}+001.00000 \mathrm{e}+001.00000 \mathrm{e}-011.00000 \mathrm{e}-091.00000 \mathrm{e}-01$

Element: 378 \# of layers: 3

$\mathrm{Kx} \mathrm{Ky} \mathrm{Kz}$ Ss Por

6.92227e+00 6.92227e+00 6.92227e-01 1.00000e-09 2.12000e-01 $1.00000 \mathrm{e}-05$ 1.00000e-05 1.00000e-06 1.00000e-09 1.00000e-01 $1.00000 \mathrm{e}+001.00000 \mathrm{e}+001.00000 \mathrm{e}-01$ 1.00000e-09 1.00000e-01 Element: 379 \# of layers: 3

$\mathrm{Kx} \mathrm{Ky} \mathrm{Kz}$ Ss Por

8.86384e+00 8.86384e+00 8.86384e-01 1.00000e-09 2.12000e-01 $1.00000 \mathrm{e}-05$ 1.00000e-05 1.00000e-06 1.00000e-09 1.00000e-01 $1.00000 \mathrm{e}+001.00000 \mathrm{e}+001.00000 \mathrm{e}-011.00000 \mathrm{e}-091.00000 \mathrm{e}-01$ Element: 380 \# of layers: 3

$\mathrm{Kx} \mathrm{Ky} \mathrm{Kz}$ Ss Por 8.43813e+00 8.43813e+00 8.43813e-01 1.00000e-09 2.12000e-01 $1.00000 \mathrm{e}-05$ 1.00000e-05 1.00000e-06 1.00000e-09 1.00000e-01 $1.00000 \mathrm{e}+001.00000 \mathrm{e}+001.00000 \mathrm{e}-011.00000 \mathrm{e}-091.00000 \mathrm{e}-01$ Element: 381 \# of layers: 3

$\mathrm{Kx} \mathrm{Ky} \mathrm{Kz}$ Ss Por 6.14623e+00 6.14623e+00 6.14623e-01 1.00000e-09 2.12000e-01 $1.00000 \mathrm{e}-05$ 1.00000e-05 1.00000e-06 1.00000e-09 1.00000e-01 $1.00000 \mathrm{e}+001.00000 \mathrm{e}+001.00000 \mathrm{e}-011.00000 \mathrm{e}-091.00000 \mathrm{e}-01$ Element: 382 \# of layers: 5

$\mathrm{Kx} \mathrm{Ky} \mathrm{Kz}$ Ss Por

$1.70245 \mathrm{e}+01$ 1.70245e+01 1.70245e+00 1.00000e-09 2.12000e-01 $1.00000 \mathrm{e}-021.00000 \mathrm{e}-021.00000 \mathrm{e}-031.00000 \mathrm{e}-091.00000 \mathrm{e}-01$ $1.00000 \mathrm{e}+001.00000 \mathrm{e}+001.00000 \mathrm{e}-011.00000 \mathrm{e}-091.00000 \mathrm{e}-01$ $1.00000 \mathrm{e}-05$ 1.00000e-05 1.00000e-06 1.00000e-09 1.00000e-01 $1.00000 \mathrm{e}+001.00000 \mathrm{e}+001.00000 \mathrm{e}-011.00000 \mathrm{e}-09$ 1.00000e-01 Element: 383 \# of layers: 5

$\mathrm{Kx} \mathrm{Ky} \mathrm{Kz}$ Ss Por $2.13611 \mathrm{e}+012.13611 \mathrm{e}+012.13611 \mathrm{e}+00$ 1.00000e-09 2.12000e-01 $1.00000 \mathrm{e}-02$ 1.00000e-02 1.00000e-03 1.00000e-09 1.00000e-01 $1.00000 \mathrm{e}+001.00000 \mathrm{e}+001.00000 \mathrm{e}-011.00000 \mathrm{e}-091.00000 \mathrm{e}-01$ $1.00000 \mathrm{e}-051.00000 \mathrm{e}-051.00000 \mathrm{e}-061.00000 \mathrm{e}-091.00000 \mathrm{e}-01$ $1.00000 \mathrm{e}+001.00000 \mathrm{e}+001.00000 \mathrm{e}-011.00000 \mathrm{e}-091.00000 \mathrm{e}-01$ 
Element: 384 \# of layers: 5

$\mathrm{Kx} \mathrm{Ky} \mathrm{Kz}$ Ss Por

5.59902e+00 5.59902e+00 5.59902e-01 1.00000e-09 2.12000e-01

$1.00000 \mathrm{e}-021.00000 \mathrm{e}-02$ 1.00000e-03 1.00000e-09 1.00000e-01

$1.00000 \mathrm{e}+001.00000 \mathrm{e}+001.00000 \mathrm{e}-011.00000 \mathrm{e}-091.00000 \mathrm{e}-01$

$1.00000 \mathrm{e}-05$ 1.00000e-05 1.00000e-06 1.00000e-09 1.00000e-01

$1.00000 \mathrm{e}+001.00000 \mathrm{e}+001.00000 \mathrm{e}-011.00000 \mathrm{e}-091.00000 \mathrm{e}-01$

Element: 385 \# of layers: 5

$\mathrm{Kx} \mathrm{Ky} \mathrm{Kz}$ Ss Por

9.39778e+00 9.39778e+00 9.39778e-01 1.00000e-09 2.12000e-01

$1.00000 \mathrm{e}-02$ 1.00000e-02 1.00000e-03 1.00000e-09 1.00000e-01

$1.00000 \mathrm{e}+001.00000 \mathrm{e}+001.00000 \mathrm{e}-011.00000 \mathrm{e}-091.00000 \mathrm{e}-01$

$1.00000 \mathrm{e}-05$ 1.00000e-05 1.00000e-06 1.00000e-09 1.00000e-01

$1.00000 \mathrm{e}+001.00000 \mathrm{e}+001.00000 \mathrm{e}-011.00000 \mathrm{e}-091.00000 \mathrm{e}-01$

Element: 386 \# of layers: 5

$\mathrm{Kx} \mathrm{Ky} \mathrm{Kz}$ Ss Por

6.07918e+00 6.07918e+00 6.07918e-01 1.00000e-09 2.12000e-01

$1.00000 \mathrm{e}-02$ 1.00000e-02 1.00000e-03 1.00000e-09 1.00000e-01

$1.00000 \mathrm{e}+001.00000 \mathrm{e}+001.00000 \mathrm{e}-011.00000 \mathrm{e}-091.00000 \mathrm{e}-01$

$1.00000 \mathrm{e}-05$ 1.00000e-05 1.00000e-06 1.00000e-09 1.00000e-01

$1.00000 \mathrm{e}+001.00000 \mathrm{e}+001.00000 \mathrm{e}-011.00000 \mathrm{e}-091.00000 \mathrm{e}-01$

Element: 387 \# of layers: 5

$\mathrm{Kx} \mathrm{Ky} \mathrm{Kz}$ Ss Por

4.76335e+00 4.76335e+00 4.76335e-01 1.00000e-09 2.12000e-01

$1.00000 \mathrm{e}-02$ 1.00000e-02 1.00000e-03 1.00000e-09 1.00000e-01

$1.00000 \mathrm{e}+001.00000 \mathrm{e}+001.00000 \mathrm{e}-011.00000 \mathrm{e}-091.00000 \mathrm{e}-01$

$1.00000 \mathrm{e}-05$ 1.00000e-05 1.00000e-06 1.00000e-09 1.00000e-01

$1.00000 \mathrm{e}+001.00000 \mathrm{e}+001.00000 \mathrm{e}-011.00000 \mathrm{e}-091.00000 \mathrm{e}-01$

Element: 388 \# of layers: 5

$\mathrm{Kx} \mathrm{Ky} \mathrm{Kz}$ Ss Por

$2.95724 \mathrm{e}+012.95724 \mathrm{e}+012.95724 \mathrm{e}+001.00000 \mathrm{e}-092.12000 \mathrm{e}-01$

$1.00000 \mathrm{e}-02$ 1.00000e-02 1.00000e-03 1.00000e-09 1.00000e-01

$1.00000 \mathrm{e}+001.00000 \mathrm{e}+001.00000 \mathrm{e}-011.00000 \mathrm{e}-091.00000 \mathrm{e}-01$

$1.00000 \mathrm{e}-05$ 1.00000e-05 1.00000e-06 1.00000e-09 1.00000e-01

$1.00000 \mathrm{e}+001.00000 \mathrm{e}+001.00000 \mathrm{e}-011.00000 \mathrm{e}-091.00000 \mathrm{e}-01$

Element: 389 \# of layers: 5

$\mathrm{Kx} \mathrm{Ky} \mathrm{Kz}$ Ss Por

2.98446e+01 2.98446e+01 2.98446e+00 1.00000e-09 2.12000e-01

$1.00000 \mathrm{e}-02$ 1.00000e-02 1.00000e-03 1.00000e-09 1.00000e-01

$1.00000 \mathrm{e}+001.00000 \mathrm{e}+001.00000 \mathrm{e}-011.00000 \mathrm{e}-091.00000 \mathrm{e}-01$

$1.00000 \mathrm{e}-05$ 1.00000e-05 1.00000e-06 1.00000e-09 1.00000e-01

$1.00000 \mathrm{e}+001.00000 \mathrm{e}+001.00000 \mathrm{e}-011.00000 \mathrm{e}-091.00000 \mathrm{e}-01$

Element: 390 \# of layers: 10

$\mathrm{Kx} \mathrm{Ky} \mathrm{Kz}$ Ss Por

5.00000e-04 5.00000e-04 5.00000e-05 1.00000e-09 1.00000e-01

$7.96742 \mathrm{e}+017.96742 \mathrm{e}+017.96742 \mathrm{e}+001.00000 \mathrm{e}-092.12000 \mathrm{e}-01$ 
7.96742e+01 7.96742e+01 7.96742e+00 1.00000e-09 2.12000e-01 7.96742e+01 7.96742e+01 7.96742e+00 1.00000e-09 2.12000e-01 7.96742e+01 7.96742e+01 7.96742e+00 1.00000e-09 2.12000e-01 $7.96742 \mathrm{e}+01$ 7.96742e+01 7.96742e+00 1.00000e-09 2.12000e-01 $1.00000 \mathrm{e}-02$ 1.00000e-02 1.00000e-03 1.00000e-09 1.00000e-01 $1.00000 \mathrm{e}+001.00000 \mathrm{e}+001.00000 \mathrm{e}-011.00000 \mathrm{e}-091.00000 \mathrm{e}-01$ $1.00000 \mathrm{e}-05$ 1.00000e-05 1.00000e-06 1.00000e-09 1.00000e-01 $1.00000 \mathrm{e}+001.00000 \mathrm{e}+001.00000 \mathrm{e}-01$ 1.00000e-09 1.00000e-01 Element: 391 \# of layers: 3

$\mathrm{Kx} \mathrm{Ky} \mathrm{Kz}$ Ss Por

3.76793e+00 3.76793e+00 3.76793e-01 1.00000e-09 2.12000e-01 $1.00000 \mathrm{e}-05$ 1.00000e-05 1.00000e-06 1.00000e-09 1.00000e-01 $1.00000 \mathrm{e}+001.00000 \mathrm{e}+001.00000 \mathrm{e}-01$ 1.00000e-09 1.00000e-01 Element: 392 \# of layers: 3

$\mathrm{Kx} \mathrm{Ky} \mathrm{Kz}$ Ss Por 3.29992e+00 3.29992e+00 3.29992e-01 1.00000e-09 2.12000e-01 $1.00000 \mathrm{e}-05$ 1.00000e-05 1.00000e-06 1.00000e-09 1.00000e-01 $1.00000 \mathrm{e}+001.00000 \mathrm{e}+001.00000 \mathrm{e}-01$ 1.00000e-09 1.00000e-01 Element: 393 \# of layers: 3

$\mathrm{Kx} \mathrm{Ky} \mathrm{Kz}$ Ss Por

3.42480e+00 3.42480e+00 3.42480e-01 1.00000e-09 2.12000e-01 $1.00000 \mathrm{e}-05$ 1.00000e-05 1.00000e-06 1.00000e-09 1.00000e-01

$1.00000 \mathrm{e}+001.00000 \mathrm{e}+001.00000 \mathrm{e}-01$ 1.00000e-09 1.00000e-01 Element: 394 \# of layers: 3

$\mathrm{Kx} \mathrm{Ky} \mathrm{Kz}$ Ss Por

5.45254e+00 5.45254e+00 5.45254e-01 1.00000e-09 2.12000e-01 $1.00000 \mathrm{e}-05$ 1.00000e-05 1.00000e-06 1.00000e-09 1.00000e-01 $1.00000 \mathrm{e}+001.00000 \mathrm{e}+001.00000 \mathrm{e}-011.00000 \mathrm{e}-09$ 1.00000e-01 Element: 395 \# of layers: 3

$\mathrm{Kx} \mathrm{Ky} \mathrm{Kz}$ Ss Por

$1.04272 \mathrm{e}+01$ 1.04272e+01 1.04272e+00 1.00000e-09 2.12000e-01 $1.00000 \mathrm{e}-05$ 1.00000e-05 1.00000e-06 1.00000e-09 1.00000e-01 $1.00000 \mathrm{e}+001.00000 \mathrm{e}+001.00000 \mathrm{e}-011.00000 \mathrm{e}-091.00000 \mathrm{e}-01$ Element: 396 \# of layers: 3

$\mathrm{Kx} \mathrm{Ky} \mathrm{Kz}$ Ss Por

$1.39199 \mathrm{e}+01$ 1.39199e+01 1.39199e+00 1.00000e-09 2.12000e-01 $1.00000 \mathrm{e}-05$ 1.00000e-05 1.00000e-06 1.00000e-09 1.00000e-01 $1.00000 \mathrm{e}+001.00000 \mathrm{e}+001.00000 \mathrm{e}-011.00000 \mathrm{e}-091.00000 \mathrm{e}-01$ Element: 397 \# of layers: 3

$\mathrm{Kx} \mathrm{Ky} \mathrm{Kz}$ Ss Por 6.89055e+00 6.89055e+00 6.89055e-01 1.00000e-09 2.12000e-01 $1.00000 \mathrm{e}-05$ 1.00000e-05 1.00000e-06 1.00000e-09 1.00000e-01 $1.00000 \mathrm{e}+001.00000 \mathrm{e}+001.00000 \mathrm{e}-01$ 1.00000e-09 1.00000e-01 Element: 398 \# of layers: 3

$\mathrm{Kx} \mathrm{Ky} \mathrm{Kz} \mathrm{Ss} \mathrm{Por}$

7.50008e+00 7.50008e+00 7.50008e-01 1.00000e-09 2.12000e-01 
$1.00000 \mathrm{e}-05$ 1.00000e-05 1.00000e-06 1.00000e-09 1.00000e-01 $1.00000 \mathrm{e}+001.00000 \mathrm{e}+001.00000 \mathrm{e}-01$ 1.00000e-09 1.00000e-01 Element: 399 \# of layers: 3

$\mathrm{Kx} \mathrm{Ky} \mathrm{Kz}$ Ss Por

7.97979e+00 7.97979e+00 7.97980e-01 1.00000e-09 2.12000e-01 $1.00000 \mathrm{e}-05$ 1.00000e-05 1.00000e-06 1.00000e-09 1.00000e-01 $1.00000 \mathrm{e}+001.00000 \mathrm{e}+001.00000 \mathrm{e}-01$ 1.00000e-09 1.00000e-01 Element: 400 \# of layers: 3

$\mathrm{Kx} \mathrm{Ky} \mathrm{Kz}$ Ss Por

$1.42459 \mathrm{e}+01$ 1.42459e+01 1.42459e+00 1.00000e-09 2.12000e-01 $1.00000 \mathrm{e}-05$ 1.00000e-05 1.00000e-06 1.00000e-09 1.00000e-01

$1.00000 \mathrm{e}+001.00000 \mathrm{e}+001.00000 \mathrm{e}-011.00000 \mathrm{e}-091.00000 \mathrm{e}-01$ Element: 401 \# of layers: 9

$\mathrm{Kx} \mathrm{Ky} \mathrm{Kz}$ Ss Por

$1.36519 \mathrm{e}+01$ 1.36519e+01 1.36519e+00 1.00000e-09 2.12000e-01 $1.36519 \mathrm{e}+011.36519 \mathrm{e}+011.36519 \mathrm{e}+001.00000 \mathrm{e}-092.12000 \mathrm{e}-01$ $1.36519 \mathrm{e}+011.36519 \mathrm{e}+01$ 1.36519e+00 1.00000e-09 2.12000e-01 $1.36519 \mathrm{e}+01$ 1.36519e+01 1.36519e+00 1.00000e-09 2.12000e-01 $1.36519 \mathrm{e}+01$ 1.36519e+01 1.36519e+00 1.00000e-09 2.12000e-01 $1.00000 \mathrm{e}-02$ 1.00000e-02 1.00000e-03 1.00000e-09 1.00000e-01 $1.00000 \mathrm{e}+001.00000 \mathrm{e}+001.00000 \mathrm{e}-011.00000 \mathrm{e}-091.00000 \mathrm{e}-01$ $1.00000 \mathrm{e}-05$ 1.00000e-05 1.00000e-06 1.00000e-09 1.00000e-01 $1.00000 \mathrm{e}+001.00000 \mathrm{e}+001.00000 \mathrm{e}-01$ 1.00000e-09 1.00000e-01 Element: 402 \# of layers: 3

$\mathrm{Kx} \mathrm{Ky} \mathrm{Kz}$ Ss Por

8.35758e+00 8.35758e+00 8.35758e-01 1.00000e-09 2.12000e-01 $1.00000 \mathrm{e}-05$ 1.00000e-05 1.00000e-06 1.00000e-09 1.00000e-01 $1.00000 \mathrm{e}+001.00000 \mathrm{e}+001.00000 \mathrm{e}-011.00000 \mathrm{e}-091.00000 \mathrm{e}-01$ Element: 403 \# of layers: 3

$\mathrm{Kx} \mathrm{Ky} \mathrm{Kz}$ Ss Por

4.88418e+00 4.88418e+00 4.88418e-01 1.00000e-09 2.12000e-01 $1.00000 \mathrm{e}-05$ 1.00000e-05 1.00000e-06 1.00000e-09 1.00000e-01 $1.00000 \mathrm{e}+001.00000 \mathrm{e}+001.00000 \mathrm{e}-011.00000 \mathrm{e}-091.00000 \mathrm{e}-01$ Element: 404 \# of layers: 3

$\mathrm{Kx} \mathrm{Ky} \mathrm{Kz}$ Ss Por 3.38947e+00 3.38947e+00 3.38947e-01 1.00000e-09 2.12000e-01 $1.00000 \mathrm{e}-05$ 1.00000e-05 1.00000e-06 1.00000e-09 1.00000e-01 $1.00000 \mathrm{e}+001.00000 \mathrm{e}+001.00000 \mathrm{e}-011.00000 \mathrm{e}-091.00000 \mathrm{e}-01$ Element: 405 \# of layers: 3

$\mathrm{Kx} \mathrm{Ky} \mathrm{Kz}$ Ss Por 5.23384e+00 5.23384e+00 5.23384e-01 1.00000e-09 2.12000e-01 $1.00000 \mathrm{e}-05$ 1.00000e-05 1.00000e-06 1.00000e-09 1.00000e-01 $1.00000 \mathrm{e}+001.00000 \mathrm{e}+001.00000 \mathrm{e}-01$ 1.00000e-09 1.00000e-01 Element: 406 \# of layers: 3

$\mathrm{Kx} \mathrm{Ky} \mathrm{Kz}$ Ss Por $1.95968 \mathrm{e}+011.95968 \mathrm{e}+011.95968 \mathrm{e}+001.00000 \mathrm{e}-092.12000 \mathrm{e}-01$ 
$1.00000 \mathrm{e}-05$ 1.00000e-05 1.00000e-06 1.00000e-09 1.00000e-01 $1.00000 \mathrm{e}+001.00000 \mathrm{e}+001.00000 \mathrm{e}-01$ 1.00000e-09 1.00000e-01 Element: 407 \# of layers: 7

Kx Ky Kz Ss Por

$1.91155 \mathrm{e}+01$ 1.91155e+01 1.91155e+00 1.00000e-09 2.12000e-01 $1.91155 \mathrm{e}+01$ 1.91155e+01 1.91155e+00 1.00000e-09 2.12000e-01 $1.91155 \mathrm{e}+01$ 1.91155e+01 1.91155e+00 1.00000e-09 2.12000e-01 $1.91155 \mathrm{e}+011.91155 \mathrm{e}+011.91155 \mathrm{e}+001.00000 \mathrm{e}-092.12000 \mathrm{e}-01$ $1.91155 \mathrm{e}+01$ 1.91155e+01 1.91155e+00 1.00000e-09 2.12000e-01 $1.00000 \mathrm{e}-05$ 1.00000e-05 1.00000e-06 1.00000e-09 1.00000e-01 $1.00000 \mathrm{e}+001.00000 \mathrm{e}+001.00000 \mathrm{e}-011.00000 \mathrm{e}-091.00000 \mathrm{e}-01$ Element: 408 \# of layers: 3

$\mathrm{Kx} \mathrm{Ky} \mathrm{Kz}$ Ss Por

7.91207e+00 7.91207e+00 7.91207e-01 1.00000e-09 2.12000e-01 $1.00000 \mathrm{e}-05$ 1.00000e-05 1.00000e-06 1.00000e-09 1.00000e-01 $1.00000 \mathrm{e}+001.00000 \mathrm{e}+001.00000 \mathrm{e}-011.00000 \mathrm{e}-091.00000 \mathrm{e}-01$ Element: 409 \# of layers: 3

$\mathrm{Kx} \mathrm{Ky} \mathrm{Kz}$ Ss Por

6.66419e+00 6.66419e+00 6.66419e-01 1.00000e-09 2.12000e-01 $1.00000 \mathrm{e}-05$ 1.00000e-05 1.00000e-06 1.00000e-09 1.00000e-01 $1.00000 \mathrm{e}+001.00000 \mathrm{e}+001.00000 \mathrm{e}-011.00000 \mathrm{e}-091.00000 \mathrm{e}-01$ Element: 410 \# of layers: 3

$\mathrm{Kx} \mathrm{Ky} \mathrm{Kz}$ Ss Por

6.21598e+00 6.21598e+00 6.21598e-01 1.00000e-09 2.12000e-01 $1.00000 \mathrm{e}-05$ 1.00000e-05 1.00000e-06 1.00000e-09 1.00000e-01 $1.00000 \mathrm{e}+001.00000 \mathrm{e}+001.00000 \mathrm{e}-011.00000 \mathrm{e}-091.00000 \mathrm{e}-01$ Element: 411 \# of layers: 3

$\mathrm{Kx} \mathrm{Ky} \mathrm{Kz}$ Ss Por

7.14705e+00 7.14705e+00 7.14705e-01 1.00000e-09 2.12000e-01 $1.00000 \mathrm{e}-05$ 1.00000e-05 1.00000e-06 1.00000e-09 1.00000e-01 $1.00000 \mathrm{e}+001.00000 \mathrm{e}+001.00000 \mathrm{e}-011.00000 \mathrm{e}-091.00000 \mathrm{e}-01$ Element: 412 \# of layers: 7

$\mathrm{Kx} \mathrm{Ky} \mathrm{Kz}$ Ss Por $1.50922 \mathrm{e}+01$ 1.50922e+01 1.50922e+00 1.00000e-09 2.12000e-01 $1.50922 \mathrm{e}+01$ 1.50922e+01 1.50922e+00 1.00000e-09 2.12000e-01 $1.50922 \mathrm{e}+01$ 1.50922e+01 1.50922e+00 1.00000e-09 2.12000e-01 $1.50922 \mathrm{e}+011.50922 \mathrm{e}+01$ 1.50922e+00 1.00000e-09 2.12000e-01 $1.50922 \mathrm{e}+01$ 1.50922e+01 1.50922e+00 1.00000e-09 2.12000e-01 $1.00000 \mathrm{e}-05$ 1.00000e-05 1.00000e-06 1.00000e-09 1.00000e-01 $1.00000 \mathrm{e}+001.00000 \mathrm{e}+001.00000 \mathrm{e}-01$ 1.00000e-09 1.00000e-01 Element: 413 \# of layers: 3

$\mathrm{Kx} \mathrm{Ky} \mathrm{Kz}$ Ss Por

$1.22115 \mathrm{e}+011.22115 \mathrm{e}+01$ 1.22115e+00 1.00000e-09 2.12000e-01 $1.00000 \mathrm{e}-05$ 1.00000e-05 1.00000e-06 1.00000e-09 1.00000e-01 $1.00000 \mathrm{e}+001.00000 \mathrm{e}+001.00000 \mathrm{e}-011.00000 \mathrm{e}-091.00000 \mathrm{e}-01$ Element: 414 \# of layers: 3 
Kx Ky Kz Ss Por

7.64746e+00 7.64746e+00 7.64746e-01 1.00000e-09 2.12000e-01

$1.00000 \mathrm{e}-05$ 1.00000e-05 1.00000e-06 1.00000e-09 1.00000e-01

$1.00000 \mathrm{e}+001.00000 \mathrm{e}+001.00000 \mathrm{e}-011.00000 \mathrm{e}-091.00000 \mathrm{e}-01$

Element: 415 \# of layers: 3

$\mathrm{Kx} \mathrm{Ky} \mathrm{Kz}$ Ss Por

7.10003e+00 7.10003e+00 7.10003e-01 1.00000e-09 2.12000e-01

$1.00000 \mathrm{e}-05$ 1.00000e-05 1.00000e-06 1.00000e-09 1.00000e-01

$1.00000 \mathrm{e}+001.00000 \mathrm{e}+001.00000 \mathrm{e}-011.00000 \mathrm{e}-091.00000 \mathrm{e}-01$

Element: 416 \# of layers: 3

$\mathrm{Kx} \mathrm{Ky} \mathrm{Kz}$ Ss Por

6.75014e+00 6.75014e+00 6.75014e-01 1.00000e-09 2.12000e-01

$1.00000 \mathrm{e}-05$ 1.00000e-05 1.00000e-06 1.00000e-09 1.00000e-01

$1.00000 \mathrm{e}+001.00000 \mathrm{e}+001.00000 \mathrm{e}-01$ 1.00000e-09 1.00000e-01

Element: 417 \# of layers: 7

Kx Ky Kz Ss Por

6.87390e+00 6.87390e+00 6.87390e-01 1.00000e-09 2.12000e-01

$6.87390 \mathrm{e}+006.87390 \mathrm{e}+00$ 6.87390e-01 1.00000e-09 2.12000e-01

$6.87390 \mathrm{e}+006.87390 \mathrm{e}+00$ 6.87390e-01 1.00000e-09 2.12000e-01

$6.87390 \mathrm{e}+006.87390 \mathrm{e}+00$ 6.87390e-01 1.00000e-09 2.12000e-01

$6.87390 \mathrm{e}+006.87390 \mathrm{e}+00$ 6.87390e-01 1.00000e-09 2.12000e-01

$1.00000 \mathrm{e}-05$ 1.00000e-05 1.00000e-06 1.00000e-09 1.00000e-01

$1.00000 \mathrm{e}+001.00000 \mathrm{e}+001.00000 \mathrm{e}-01$ 1.00000e-09 1.00000e-01

Element: 418 \# of layers: 3

$\mathrm{Kx} \mathrm{Ky} \mathrm{Kz}$ Ss Por

$1.35984 \mathrm{e}+01$ 1.35984e+01 1.35984e+00 1.00000e-09 2.12000e-01

$1.00000 \mathrm{e}-05$ 1.00000e-05 1.00000e-06 1.00000e-09 1.00000e-01

$1.00000 \mathrm{e}+001.00000 \mathrm{e}+001.00000 \mathrm{e}-011.00000 \mathrm{e}-09$ 1.00000e-01

Element: 419 \# of layers: 3

$\mathrm{Kx} \mathrm{Ky} \mathrm{Kz}$ Ss Por

$1.04501 \mathrm{e}+011.04501 \mathrm{e}+011.04501 \mathrm{e}+001.00000 \mathrm{e}-092.12000 \mathrm{e}-01$

$1.00000 \mathrm{e}-05$ 1.00000e-05 1.00000e-06 1.00000e-09 1.00000e-01

$1.00000 \mathrm{e}+001.00000 \mathrm{e}+001.00000 \mathrm{e}-011.00000 \mathrm{e}-091.00000 \mathrm{e}-01$

Element: 420 \# of layers: 3

$\mathrm{Kx} \mathrm{Ky} \mathrm{Kz}$ Ss Por

6.96547e+00 6.96547e+00 6.96547e-01 1.00000e-09 2.12000e-01

$1.00000 \mathrm{e}-05$ 1.00000e-05 1.00000e-06 1.00000e-09 1.00000e-01

$1.00000 \mathrm{e}+001.00000 \mathrm{e}+001.00000 \mathrm{e}-011.00000 \mathrm{e}-091.00000 \mathrm{e}-01$

Element: 421 \# of layers: 3

$\mathrm{Kx} \mathrm{Ky} \mathrm{Kz}$ Ss Por

6.54877e+00 6.54877e+00 6.54877e-01 1.00000e-09 2.12000e-01

$1.00000 \mathrm{e}-05$ 1.00000e-05 1.00000e-06 1.00000e-09 1.00000e-01

$1.00000 \mathrm{e}+001.00000 \mathrm{e}+001.00000 \mathrm{e}-01$ 1.00000e-09 1.00000e-01

Element: 422 \# of layers: 7

Kx Ky Kz Ss Por

6.77017e+00 6.77017e+00 6.77017e-01 1.00000e-09 2.12000e-01 
$6.77017 \mathrm{e}+00$ 6.77017e+00 6.77017e-01 1.00000e-09 2.12000e-01

$6.77017 \mathrm{e}+006.77017 \mathrm{e}+00$ 6.77017e-01 1.00000e-09 2.12000e-01

$6.77017 \mathrm{e}+006.77017 \mathrm{e}+00$ 6.77017e-01 1.00000e-09 2.12000e-01

$6.77017 \mathrm{e}+006.77017 \mathrm{e}+006.77017 \mathrm{e}-011.00000 \mathrm{e}-09$ 2.12000e-01

$1.00000 \mathrm{e}-05$ 1.00000e-05 1.00000e-06 1.00000e-09 1.00000e-01

$1.00000 \mathrm{e}+001.00000 \mathrm{e}+001.00000 \mathrm{e}-011.00000 \mathrm{e}-091.00000 \mathrm{e}-01$

Element: 423 \# of layers: 3

Kx Ky Kz Ss Por

$2.89266 \mathrm{e}+012.89266 \mathrm{e}+012.89266 \mathrm{e}+001.00000 \mathrm{e}-092.12000 \mathrm{e}-01$

$1.00000 \mathrm{e}-05$ 1.00000e-05 1.00000e-06 1.00000e-09 1.00000e-01

$1.00000 \mathrm{e}+001.00000 \mathrm{e}+001.00000 \mathrm{e}-011.00000 \mathrm{e}-091.00000 \mathrm{e}-01$

Element: 424 \# of layers: 3

Kx Ky Kz Ss Por

$1.59801 \mathrm{e}+011.59801 \mathrm{e}+011.59801 \mathrm{e}+001.00000 \mathrm{e}-092.12000 \mathrm{e}-01$

$1.00000 \mathrm{e}-05$ 1.00000e-05 1.00000e-06 1.00000e-09 1.00000e-01

$1.00000 \mathrm{e}+001.00000 \mathrm{e}+001.00000 \mathrm{e}-011.00000 \mathrm{e}-091.00000 \mathrm{e}-01$

Element: 425 \# of layers: 3

Kx Ky Kz Ss Por

$1.04776 \mathrm{e}+011.04776 \mathrm{e}+011.04776 \mathrm{e}+00$ 1.00000e-09 2.12000e-01 $1.00000 \mathrm{e}-05$ 1.00000e-05 1.00000e-06 1.00000e-09 1.00000e-01

$1.00000 \mathrm{e}+001.00000 \mathrm{e}+001.00000 \mathrm{e}-011.00000 \mathrm{e}-091.00000 \mathrm{e}-01$

Element: 426 \# of layers: 3

Kx Ky Kz Ss Por

6.64507e+00 6.64507e+00 6.64507e-01 1.00000e-09 2.12000e-01

$1.00000 \mathrm{e}-05$ 1.00000e-05 1.00000e-06 1.00000e-09 1.00000e-01

$1.00000 \mathrm{e}+001.00000 \mathrm{e}+001.00000 \mathrm{e}-011.00000 \mathrm{e}-091.00000 \mathrm{e}-01$

Element: 427 \# of layers: 3

Kx Ky Kz Ss Por

7.01407e+00 7.01407e+00 7.01407e-01 1.00000e-09 2.12000e-01

$1.00000 \mathrm{e}-05$ 1.00000e-05 1.00000e-06 1.00000e-09 1.00000e-01

$1.00000 \mathrm{e}+001.00000 \mathrm{e}+001.00000 \mathrm{e}-011.00000 \mathrm{e}-091.00000 \mathrm{e}-01$

Element: 428 \# of layers: 7

Kx Ky Kz Ss Por

$7.38601 \mathrm{e}+007.38601 \mathrm{e}+00$ 7.38601e-01 1.00000e-09 2.12000e-01

$7.38601 \mathrm{e}+007.38601 \mathrm{e}+007.38601 \mathrm{e}-011.00000 \mathrm{e}-092.12000 \mathrm{e}-01$

$7.38601 \mathrm{e}+007.38601 \mathrm{e}+007.38601 \mathrm{e}-011.00000 \mathrm{e}-092.12000 \mathrm{e}-01$

$7.38601 \mathrm{e}+007.38601 \mathrm{e}+007.38601 \mathrm{e}-011.00000 \mathrm{e}-092.12000 \mathrm{e}-01$

$7.38601 \mathrm{e}+007.38601 \mathrm{e}+00$ 7.38601e-01 1.00000e-09 2.12000e-01

$1.00000 \mathrm{e}-05$ 1.00000e-05 1.00000e-06 1.00000e-09 1.00000e-01

$1.00000 \mathrm{e}+001.00000 \mathrm{e}+001.00000 \mathrm{e}-011.00000 \mathrm{e}-091.00000 \mathrm{e}-01$

Element: 429 \# of layers: 3

Kx Ky Kz Ss Por

$2.77138 \mathrm{e}+012.77138 \mathrm{e}+012.77138 \mathrm{e}+00$ 1.00000e-09 2.12000e-01

$1.00000 \mathrm{e}-05$ 1.00000e-05 1.00000e-06 1.00000e-09 1.00000e-01

$1.00000 \mathrm{e}+001.00000 \mathrm{e}+001.00000 \mathrm{e}-011.00000 \mathrm{e}-091.00000 \mathrm{e}-01$

Element: 430 \# of layers: 3 
$\mathrm{Kx} \mathrm{Ky} \mathrm{Kz}$ Ss Por

$2.28807 \mathrm{e}+012.28807 \mathrm{e}+012.28807 \mathrm{e}+00$ 1.00000e-09 2.12000e-01

$1.00000 \mathrm{e}-05$ 1.00000e-05 1.00000e-06 1.00000e-09 1.00000e-01

$1.00000 \mathrm{e}+001.00000 \mathrm{e}+001.00000 \mathrm{e}-011.00000 \mathrm{e}-091.00000 \mathrm{e}-01$

Element: 431 \# of layers: 3

$\mathrm{Kx} \mathrm{Ky} \mathrm{Kz}$ Ss Por

$1.56354 \mathrm{e}+011.56354 \mathrm{e}+011.56354 \mathrm{e}+001.00000 \mathrm{e}-092.12000 \mathrm{e}-01$

$1.00000 \mathrm{e}-05$ 1.00000e-05 1.00000e-06 1.00000e-09 1.00000e-01

$1.00000 \mathrm{e}+001.00000 \mathrm{e}+001.00000 \mathrm{e}-011.00000 \mathrm{e}-091.00000 \mathrm{e}-01$

Element: 432 \# of layers: 3

$\mathrm{Kx} \mathrm{Ky} \mathrm{Kz}$ Ss Por

$1.42502 \mathrm{e}+01$ 1.42502e+01 1.42502e+00 1.00000e-09 2.12000e-01

$1.00000 \mathrm{e}-051.00000 \mathrm{e}-051.00000 \mathrm{e}-061.00000 \mathrm{e}-091.00000 \mathrm{e}-01$

$1.00000 \mathrm{e}+001.00000 \mathrm{e}+001.00000 \mathrm{e}-011.00000 \mathrm{e}-09$ 1.00000e-01

Element: 433 \# of layers: 3

$\mathrm{Kx} \mathrm{Ky} \mathrm{Kz}$ Ss Por

8.10940e+00 8.10940e+00 8.10940e-01 1.00000e-09 2.12000e-01 $1.00000 \mathrm{e}-05$ 1.00000e-05 1.00000e-06 1.00000e-09 1.00000e-01

$1.00000 \mathrm{e}+001.00000 \mathrm{e}+001.00000 \mathrm{e}-01$ 1.00000e-09 1.00000e-01

Element: 434 \# of layers: 3

$\mathrm{Kx} \mathrm{Ky} \mathrm{Kz}$ Ss Por

7.84367e+00 7.84367e+00 7.84367e-01 1.00000e-09 2.12000e-01

$1.00000 \mathrm{e}-051.00000 \mathrm{e}-051.00000 \mathrm{e}-061.00000 \mathrm{e}-091.00000 \mathrm{e}-01$

$1.00000 \mathrm{e}+001.00000 \mathrm{e}+001.00000 \mathrm{e}-011.00000 \mathrm{e}-091.00000 \mathrm{e}-01$

Element: 435 \# of layers: 7

$\mathrm{Kx} \mathrm{Ky} \mathrm{Kz}$ Ss Por

7.81509e+00 7.81509e+00 7.81509e-01 1.00000e-09 2.12000e-01

$7.81509 \mathrm{e}+007.81509 \mathrm{e}+00$ 7.81509e-01 1.00000e-09 2.12000e-01

$7.81509 \mathrm{e}+007.81509 \mathrm{e}+007.81509 \mathrm{e}-01$ 1.00000e-09 2.12000e-01

$7.81509 \mathrm{e}+00$ 7.81509e+00 7.81509e-01 1.00000e-09 2.12000e-01

7.81509e+00 7.81509e+00 7.81509e-01 1.00000e-09 2.12000e-01

$1.00000 \mathrm{e}-05$ 1.00000e-05 1.00000e-06 1.00000e-09 1.00000e-01

$1.00000 \mathrm{e}+001.00000 \mathrm{e}+001.00000 \mathrm{e}-011.00000 \mathrm{e}-091.00000 \mathrm{e}-01$

Element: 436 \# of layers: 3

$\mathrm{Kx} \mathrm{Ky} \mathrm{Kz}$ Ss Por

$2.16286 \mathrm{e}+012.16286 \mathrm{e}+012.16286 \mathrm{e}+00$ 1.00000e-09 2.12000e-01 $1.00000 \mathrm{e}-05$ 1.00000e-05 1.00000e-06 1.00000e-09 1.00000e-01

$1.00000 \mathrm{e}+001.00000 \mathrm{e}+001.00000 \mathrm{e}-011.00000 \mathrm{e}-091.00000 \mathrm{e}-01$

Element: 437 \# of layers: 3

$\mathrm{Kx} \mathrm{Ky} \mathrm{Kz}$ Ss Por

2.05357e+01 2.05357e+01 2.05357e+00 1.00000e-09 2.12000e-01

$1.00000 \mathrm{e}-05$ 1.00000e-05 1.00000e-06 1.00000e-09 1.00000e-01

$1.00000 \mathrm{e}+001.00000 \mathrm{e}+001.00000 \mathrm{e}-01$ 1.00000e-09 1.00000e-01

Element: 438 \# of layers: 3

$\mathrm{Kx} \mathrm{Ky} \mathrm{Kz}$ Ss Por

$1.62667 e+01$ 1.62667e+01 1.62667e+00 1.00000e-09 2.12000e-01 
$1.00000 \mathrm{e}-05$ 1.00000e-05 1.00000e-06 1.00000e-09 1.00000e-01 $1.00000 \mathrm{e}+001.00000 \mathrm{e}+001.00000 \mathrm{e}-01$ 1.00000e-09 1.00000e-01 Element: 439 \# of layers: 3

$\mathrm{Kx} \mathrm{Ky} \mathrm{Kz}$ Ss Por

$1.23240 \mathrm{e}+011.23240 \mathrm{e}+011.23240 \mathrm{e}+001.00000 \mathrm{e}-092.12000 \mathrm{e}-01$ $1.00000 \mathrm{e}-05$ 1.00000e-05 1.00000e-06 1.00000e-09 1.00000e-01 $1.00000 \mathrm{e}+001.00000 \mathrm{e}+001.00000 \mathrm{e}-01$ 1.00000e-09 1.00000e-01 Element: 440 \# of layers: 3

$\mathrm{Kx} \mathrm{Ky} \mathrm{Kz}$ Ss Por

2.70006e+00 2.70006e+00 2.70006e-01 1.00000e-09 2.12000e-01 $1.00000 \mathrm{e}-05$ 1.00000e-05 1.00000e-06 1.00000e-09 1.00000e-01 $1.00000 \mathrm{e}+001.00000 \mathrm{e}+001.00000 \mathrm{e}-011.00000 \mathrm{e}-091.00000 \mathrm{e}-01$ Element: 441 \# of layers: 3

$\mathrm{Kx} \mathrm{Ky} \mathrm{Kz}$ Ss Por

5.56819e+00 5.56819e+00 5.56819e-01 1.00000e-09 2.12000e-01 $1.00000 \mathrm{e}-05$ 1.00000e-05 1.00000e-06 1.00000e-09 1.00000e-01 $1.00000 \mathrm{e}+001.00000 \mathrm{e}+001.00000 \mathrm{e}-011.00000 \mathrm{e}-091.00000 \mathrm{e}-01$ Element: 442 \# of layers: 7

$\mathrm{Kx} \mathrm{Ky} \mathrm{Kz}$ Ss Por

8.44893e+00 8.44893e+00 8.44893e-01 1.00000e-09 2.12000e-01 $8.44893 \mathrm{e}+00$ 8.44893e+00 8.44893e-01 1.00000e-09 2.12000e-01 8.44893e+00 8.44893e+00 8.44893e-01 1.00000e-09 2.12000e-01 8.44893e+00 8.44893e+00 8.44893e-01 1.00000e-09 2.12000e-01 $8.44893 \mathrm{e}+00$ 8.44893e+00 8.44893e-01 1.00000e-09 2.12000e-01 $1.00000 \mathrm{e}-051.00000 \mathrm{e}-05$ 1.00000e-06 1.00000e-09 1.00000e-01 $1.00000 \mathrm{e}+001.00000 \mathrm{e}+001.00000 \mathrm{e}-01$ 1.00000e-09 1.00000e-01 Element: 443 \# of layers: 3

$\mathrm{Kx} \mathrm{Ky} \mathrm{Kz}$ Ss Por

$2.11111 \mathrm{e}+012.11111 \mathrm{e}+012.11111 \mathrm{e}+001.00000 \mathrm{e}-092.12000 \mathrm{e}-01$ $1.00000 \mathrm{e}-05$ 1.00000e-05 1.00000e-06 1.00000e-09 1.00000e-01 $1.00000 \mathrm{e}+001.00000 \mathrm{e}+001.00000 \mathrm{e}-011.00000 \mathrm{e}-091.00000 \mathrm{e}-01$ Element: 444 \# of layers: 3

Kx Ky Kz Ss Por $1.81403 \mathrm{e}+01$ 1.81403e+01 1.81403e+00 1.00000e-09 2.12000e-01 $1.00000 \mathrm{e}-05$ 1.00000e-05 1.00000e-06 1.00000e-09 1.00000e-01 $1.00000 \mathrm{e}+001.00000 \mathrm{e}+001.00000 \mathrm{e}-011.00000 \mathrm{e}-091.00000 \mathrm{e}-01$ Element: 445 \# of layers: 3

$\mathrm{Kx} \mathrm{Ky} \mathrm{Kz}$ Ss Por

1.46552e+01 1.46552e+01 1.46552e+00 1.00000e-09 2.12000e-01 $1.00000 \mathrm{e}-05$ 1.00000e-05 1.00000e-06 1.00000e-09 1.00000e-01 $1.00000 \mathrm{e}+001.00000 \mathrm{e}+001.00000 \mathrm{e}-011.00000 \mathrm{e}-091.00000 \mathrm{e}-01$ Element: 446 \# of layers: 3

$\mathrm{Kx} \mathrm{Ky} \mathrm{Kz}$ Ss Por

7.74354e+00 7.74354e+00 7.74354e-01 1.00000e-09 2.12000e-01 $1.00000 \mathrm{e}-05$ 1.00000e-05 1.00000e-06 1.00000e-09 1.00000e-01 $1.00000 \mathrm{e}+001.00000 \mathrm{e}+001.00000 \mathrm{e}-011.00000 \mathrm{e}-091.00000 \mathrm{e}-01$ 
Element: 447 \# of layers: 3

Kx Ky Kz Ss Por

2.97479e+00 2.97479e+00 2.97479e-01 1.00000e-09 2.12000e-01

$1.00000 \mathrm{e}-05$ 1.00000e-05 1.00000e-06 1.00000e-09 1.00000e-01

$1.00000 \mathrm{e}+001.00000 \mathrm{e}+001.00000 \mathrm{e}-011.00000 \mathrm{e}-091.00000 \mathrm{e}-01$

Element: 448 \# of layers: 7

Kx Ky Kz Ss Por

4.50977e+00 4.50977e+00 4.50977e-01 1.00000e-09 2.12000e-01

$4.50977 \mathrm{e}+004.50977 \mathrm{e}+004.50977 \mathrm{e}-011.00000 \mathrm{e}-092.12000 \mathrm{e}-01$

$4.50977 \mathrm{e}+004.50977 \mathrm{e}+004.50977 \mathrm{e}-011.00000 \mathrm{e}-092.12000 \mathrm{e}-01$

$4.50977 \mathrm{e}+004.50977 \mathrm{e}+004.50977 \mathrm{e}-01$ 1.00000e-09 2.12000e-01

$4.50977 \mathrm{e}+004.50977 \mathrm{e}+00$ 4.50977e-01 1.00000e-09 2.12000e-01

$1.00000 \mathrm{e}-05$ 1.00000e-05 1.00000e-06 1.00000e-09 1.00000e-01

$1.00000 \mathrm{e}+001.00000 \mathrm{e}+001.00000 \mathrm{e}-011.00000 \mathrm{e}-091.00000 \mathrm{e}-01$

Element: 449 \# of layers: 3

Kx Ky Kz Ss Por

$2.07724 \mathrm{e}+012.07724 \mathrm{e}+012.07724 \mathrm{e}+00$ 1.00000e-09 2.12000e-01

$1.00000 \mathrm{e}-05$ 1.00000e-05 1.00000e-06 1.00000e-09 1.00000e-01

$1.00000 \mathrm{e}+001.00000 \mathrm{e}+001.00000 \mathrm{e}-011.00000 \mathrm{e}-091.00000 \mathrm{e}-01$

Element: 450 \# of layers: 3

Kx Ky Kz Ss Por

$1.72282 \mathrm{e}+011.72282 \mathrm{e}+011.72282 \mathrm{e}+00$ 1.00000e-09 2.12000e-01

$1.00000 \mathrm{e}-05$ 1.00000e-05 1.00000e-06 1.00000e-09 1.00000e-01

$1.00000 \mathrm{e}+001.00000 \mathrm{e}+001.00000 \mathrm{e}-011.00000 \mathrm{e}-091.00000 \mathrm{e}-01$

Element: 451 \# of layers: 3

Kx Ky Kz Ss Por

$1.37876 \mathrm{e}+01$ 1.37876e+01 1.37876e+00 1.00000e-09 2.12000e-01

$1.00000 \mathrm{e}-05$ 1.00000e-05 1.00000e-06 1.00000e-09 1.00000e-01

$1.00000 \mathrm{e}+001.00000 \mathrm{e}+001.00000 \mathrm{e}-011.00000 \mathrm{e}-091.00000 \mathrm{e}-01$

Element: 452 \# of layers: 3

Kx Ky Kz Ss Por

$1.59411 \mathrm{e}+011.59411 \mathrm{e}+011.59411 \mathrm{e}+00$ 1.00000e-09 2.12000e-01

$1.00000 \mathrm{e}-05$ 1.00000e-05 1.00000e-06 1.00000e-09 1.00000e-01

$1.00000 \mathrm{e}+001.00000 \mathrm{e}+001.00000 \mathrm{e}-011.00000 \mathrm{e}-091.00000 \mathrm{e}-01$

Element: 453 \# of layers: 3

Kx Ky Kz Ss Por

$1.73083 \mathrm{e}+01$ 1.73083e+01 1.73083e+00 1.00000e-09 2.12000e-01

$1.00000 \mathrm{e}-05$ 1.00000e-05 1.00000e-06 1.00000e-09 1.00000e-01

$1.00000 \mathrm{e}+001.00000 \mathrm{e}+001.00000 \mathrm{e}-011.00000 \mathrm{e}-091.00000 \mathrm{e}-01$

Element: 454 \# of layers: 3

Kx Ky Kz Ss Por

9.57778e+00 9.57778e+00 9.57778e-01 1.00000e-09 2.12000e-01 $1.00000 \mathrm{e}-05$ 1.00000e-05 1.00000e-06 1.00000e-09 1.00000e-01

$1.00000 \mathrm{e}+001.00000 \mathrm{e}+001.00000 \mathrm{e}-011.00000 \mathrm{e}-091.00000 \mathrm{e}-01$

Element: 455 \# of layers: 7

Kx Ky Kz Ss Por 
$3.28124 \mathrm{e}+003.28124 \mathrm{e}+003.28125 \mathrm{e}-011.00000 \mathrm{e}-092.12000 \mathrm{e}-01$ $3.28124 \mathrm{e}+003.28124 \mathrm{e}+003.28125 \mathrm{e}-011.00000 \mathrm{e}-092.12000 \mathrm{e}-01$ $3.28124 \mathrm{e}+003.28124 \mathrm{e}+003.28125 \mathrm{e}-01$ 1.00000e-09 2.12000e-01 $3.28124 \mathrm{e}+003.28124 \mathrm{e}+003.28125 \mathrm{e}-011.00000 \mathrm{e}-09$ 2.12000e-01 $3.28124 \mathrm{e}+003.28124 \mathrm{e}+003.28125 \mathrm{e}-011.00000 \mathrm{e}-092.12000 \mathrm{e}-01$ $1.00000 \mathrm{e}-05$ 1.00000e-05 1.00000e-06 1.00000e-09 1.00000e-01 $1.00000 \mathrm{e}+001.00000 \mathrm{e}+001.00000 \mathrm{e}-011.00000 \mathrm{e}-091.00000 \mathrm{e}-01$ Element: 456 \# of layers: 4

$\mathrm{Kx} \mathrm{Ky} \mathrm{Kz}$ Ss Por

$2.14180 \mathrm{e}+012.14180 \mathrm{e}+012.14180 \mathrm{e}+00$ 1.00000e-09 2.12000e-01 $1.00000 \mathrm{e}-05$ 1.00000e-05 1.00000e-06 1.00000e-09 1.00000e-01 $1.00000 \mathrm{e}+001.00000 \mathrm{e}+001.00000 \mathrm{e}-011.00000 \mathrm{e}-091.00000 \mathrm{e}-01$ 1.00000e-06 1.00000e-06 1.00000e-06 1.00000e-09 5.00000e-02 Element: 457 \# of layers: 4

$\mathrm{Kx} \mathrm{Ky} \mathrm{Kz}$ Ss Por $1.87926 \mathrm{e}+01$ 1.87926e+01 1.87926e+00 1.00000e-09 2.12000e-01 $1.00000 \mathrm{e}-05$ 1.00000e-05 1.00000e-06 1.00000e-09 1.00000e-01 $1.00000 \mathrm{e}+001.00000 \mathrm{e}+001.00000 \mathrm{e}-011.00000 \mathrm{e}-091.00000 \mathrm{e}-01$ $1.00000 \mathrm{e}-06$ 1.00000e-06 1.00000e-06 1.00000e-09 5.00000e-02 Element: 458 \# of layers: 4

Kx Ky Kz Ss Por $1.65849 \mathrm{e}+011.65849 \mathrm{e}+011.65849 \mathrm{e}+00$ 1.00000e-09 2.12000e-01 $1.00000 \mathrm{e}-05$ 1.00000e-05 1.00000e-06 1.00000e-09 1.00000e-01 $1.00000 \mathrm{e}+001.00000 \mathrm{e}+001.00000 \mathrm{e}-011.00000 \mathrm{e}-091.00000 \mathrm{e}-01$ $1.00000 \mathrm{e}-06$ 1.00000e-06 1.00000e-06 1.00000e-09 5.00000e-02 Element: 459 \# of layers: 3

Kx Ky Kz Ss Por $1.61029 \mathrm{e}+011.61029 \mathrm{e}+011.61029 \mathrm{e}+001.00000 \mathrm{e}-092.12000 \mathrm{e}-01$ $1.00000 \mathrm{e}-05$ 1.00000e-05 1.00000e-06 1.00000e-09 1.00000e-01 $1.00000 \mathrm{e}+001.00000 \mathrm{e}+001.00000 \mathrm{e}-011.00000 \mathrm{e}-091.00000 \mathrm{e}-01$ Element: 460 \# of layers: 3

Kx Ky Kz Ss Por $1.99069 \mathrm{e}+011.99069 \mathrm{e}+011.99069 \mathrm{e}+00$ 1.00000e-09 2.12000e-01 $1.00000 \mathrm{e}-05$ 1.00000e-05 1.00000e-06 1.00000e-09 1.00000e-01 $1.00000 \mathrm{e}+001.00000 \mathrm{e}+001.00000 \mathrm{e}-011.00000 \mathrm{e}-091.00000 \mathrm{e}-01$ Element: 461 \# of layers: 3

Kx Ky Kz Ss Por

$2.19566 \mathrm{e}+012.19566 \mathrm{e}+012.19566 \mathrm{e}+00$ 1.00000e-09 2.12000e-01 $1.00000 \mathrm{e}-05$ 1.00000e-05 1.00000e-06 1.00000e-09 1.00000e-01 $1.00000 \mathrm{e}+001.00000 \mathrm{e}+001.00000 \mathrm{e}-011.00000 \mathrm{e}-091.00000 \mathrm{e}-01$ Element: 462 \# of layers: 7

$\mathrm{Kx} \mathrm{Ky} \mathrm{Kz}$ Ss Por

$1.17322 \mathrm{e}+01$ 1.17322e+01 1.17322e+00 1.00000e-09 2.12000e-01 1.17322e+01 1.17322e+01 1.17322e+00 1.00000e-09 2.12000e-01 $1.17322 \mathrm{e}+011.17322 \mathrm{e}+01$ 1.17322e+00 1.00000e-09 2.12000e-01 $1.17322 \mathrm{e}+01$ 1.17322e+01 1.17322e+00 1.00000e-09 2.12000e-01 
$1.17322 \mathrm{e}+01$ 1.17322e+01 1.17322e+00 1.00000e-09 2.12000e-01 $1.00000 \mathrm{e}-05$ 1.00000e-05 1.00000e-06 1.00000e-09 1.00000e-01

$1.00000 \mathrm{e}+001.00000 \mathrm{e}+001.00000 \mathrm{e}-011.00000 \mathrm{e}-091.00000 \mathrm{e}-01$

Element: 463 \# of layers: 5

$\mathrm{Kx} \mathrm{Ky} \mathrm{Kz}$ Ss Por

9.01631e+01 9.01631e+01 9.01631e+00 1.00000e-09 7.00000e-02

$3.60255 \mathrm{e}+003.60255 \mathrm{e}+00$ 3.60255e-01 1.00000e-09 2.12000e-01

$1.00000 \mathrm{e}-05$ 1.00000e-05 1.00000e-06 1.00000e-09 1.00000e-01

$1.00000 \mathrm{e}+001.00000 \mathrm{e}+001.00000 \mathrm{e}-011.00000 \mathrm{e}-091.00000 \mathrm{e}-01$

1.00000e-06 1.00000e-06 1.00000e-06 1.00000e-09 5.00000e-02

Element: 464 \# of layers: 5

Kx Ky Kz Ss Por

9.65512e+01 9.65512e+01 9.65512e+00 1.00000e-09 7.00000e-02

$3.85793 \mathrm{e}+003.85793 \mathrm{e}+00$ 3.85793e-01 1.00000e-09 2.12000e-01

$1.00000 \mathrm{e}-05$ 1.00000e-05 1.00000e-06 1.00000e-09 1.00000e-01

$1.00000 \mathrm{e}+001.00000 \mathrm{e}+001.00000 \mathrm{e}-011.00000 \mathrm{e}-091.00000 \mathrm{e}-01$

1.00000e-06 1.00000e-06 1.00000e-06 1.00000e-09 5.00000e-02

Element: 465 \# of layers: 4

$\mathrm{Kx} \mathrm{Ky} \mathrm{Kz}$ Ss Por

$2.82358 \mathrm{e}+012.82358 \mathrm{e}+012.82358 \mathrm{e}+00$ 1.00000e-09 2.12000e-01

$1.00000 \mathrm{e}-05$ 1.00000e-05 1.00000e-06 1.00000e-09 1.00000e-01

$1.00000 \mathrm{e}+001.00000 \mathrm{e}+001.00000 \mathrm{e}-011.00000 \mathrm{e}-091.00000 \mathrm{e}-01$

$1.00000 \mathrm{e}-06$ 1.00000e-06 1.00000e-06 1.00000e-09 5.00000e-02

Element: 466 \# of layers: 3

$\mathrm{Kx} \mathrm{Ky} \mathrm{Kz}$ Ss Por

$2.66248 \mathrm{e}+012.66248 \mathrm{e}+012.66248 \mathrm{e}+00$ 1.00000e-09 2.12000e-01

$1.00000 \mathrm{e}-05$ 1.00000e-05 1.00000e-06 1.00000e-09 1.00000e-01

$1.00000 \mathrm{e}+001.00000 \mathrm{e}+001.00000 \mathrm{e}-011.00000 \mathrm{e}-09$ 1.00000e-01

Element: 467 \# of layers: 3

$\mathrm{Kx} \mathrm{Ky} \mathrm{Kz}$ Ss Por

$2.12999 \mathrm{e}+012.12999 \mathrm{e}+012.12999 \mathrm{e}+00$ 1.00000e-09 2.12000e-01

$1.00000 \mathrm{e}-05$ 1.00000e-05 1.00000e-06 1.00000e-09 1.00000e-01

$1.00000 \mathrm{e}+001.00000 \mathrm{e}+001.00000 \mathrm{e}-011.00000 \mathrm{e}-091.00000 \mathrm{e}-01$

Element: 468 \# of layers: 4

$\mathrm{Kx} \mathrm{Ky} \mathrm{Kz}$ Ss Por

$1.11733 \mathrm{e}+02$ 1.11733e+02 1.11733e+01 1.00000e-09 7.00000e-02

$4.46454 \mathrm{e}+004.46454 \mathrm{e}+004.46454 \mathrm{e}-01$ 1.00000e-09 2.12000e-01

$1.00000 \mathrm{e}-05$ 1.00000e-05 1.00000e-06 1.00000e-09 1.00000e-01

$1.00000 \mathrm{e}+001.00000 \mathrm{e}+001.00000 \mathrm{e}-011.00000 \mathrm{e}-091.00000 \mathrm{e}-01$

Element: 469 \# of layers: 4

$\mathrm{Kx} \mathrm{Ky} \mathrm{Kz}$ Ss Por

4.77881e+01 4.77881e+01 4.77881e+00 1.00000e-09 7.00000e-02

$1.90946 \mathrm{e}+001.90946 \mathrm{e}+00$ 1.90946e-01 1.00000e-09 2.12000e-01

$1.00000 \mathrm{e}-051.00000 \mathrm{e}-051.00000 \mathrm{e}-061.00000 \mathrm{e}-091.00000 \mathrm{e}-01$

$1.00000 \mathrm{e}+001.00000 \mathrm{e}+001.00000 \mathrm{e}-011.00000 \mathrm{e}-09$ 1.00000e-01

Element: 470 \# of layers: 4 
$\mathrm{Kx} \mathrm{Ky} \mathrm{Kz}$ Ss Por

$1.03309 \mathrm{e}+01$ 1.03309e+01 1.03309e+00 1.00000e-09 7.00000e-02

4.12771e-01 4.12771e-01 4.12771e-02 1.00000e-09 2.12000e-01

$1.00000 \mathrm{e}-05$ 1.00000e-05 1.00000e-06 1.00000e-09 1.00000e-01

$1.00000 \mathrm{e}+001.00000 \mathrm{e}+001.00000 \mathrm{e}-01$ 1.00000e-09 1.00000e-01

Element: 471 \# of layers: 4

Kx Ky Kz Ss Por

5.24193e+00 5.24193e+00 5.24193e-01 1.00000e-09 7.00000e-02

2.09450e-01 2.09450e-01 2.09450e-02 1.00000e-09 2.12000e-01

$1.00000 \mathrm{e}-05$ 1.00000e-05 1.00000e-06 1.00000e-09 1.00000e-01

$1.00000 \mathrm{e}+001.00000 \mathrm{e}+001.00000 \mathrm{e}-011.00000 \mathrm{e}-091.00000 \mathrm{e}-01$

Element: 472 \# of layers: 2

$\mathrm{Kx} \mathrm{Ky} \mathrm{Kz}$ Ss Por

3.31721e+00 3.31721e+00 3.31721e-01 1.00000e-09 7.00000e-02

1.32544e-01 1.32544e-01 1.32544e-02 1.00000e-09 2.12000e-01

Element: 473 \# of layers: 2

$\mathrm{Kx} \mathrm{Ky} \mathrm{Kz}$ Ss Por

2.49793e+01 2.49793e+01 2.49793e+00 1.00000e-09 7.00000e-02

9.98076e-01 9.98076e-01 9.98076e-02 1.00000e-09 2.12000e-01

Element: 474 \# of layers: 3

$\mathrm{Kx} \mathrm{Ky} \mathrm{Kz}$ Ss Por

1.71893e+00 1.71893e+00 1.71893e-01 1.00000e-09 7.00000e-02

6.86827e-02 6.86827e-02 6.86827e-03 1.00000e-09 2.12000e-01

1.00000e-06 1.00000e-06 1.00000e-06 1.00000e-09 5.00000e-02

Element: 475 \# of layers: 2

$\mathrm{Kx} \mathrm{Ky} \mathrm{Kz}$ Ss Por

$1.50007 \mathrm{e}+001.50007 \mathrm{e}+00$ 1.50008e-01 1.00000e-09 7.00000e-02

1.00000e-06 1.00000e-06 1.00000e-06 1.00000e-09 5.00000e-02

Element: 476 \# of layers: 2

$\mathrm{Kx} \mathrm{Ky} \mathrm{Kz}$ Ss Por

3.41605e+00 3.41605e+00 3.41605e-01 1.00000e-09 7.00000e-02

1.00000e-06 1.00000e-06 1.00000e-06 1.00000e-09 5.00000e-02

Element: 477 \# of layers: 3

$\mathrm{Kx} \mathrm{Ky} \mathrm{Kz}$ Ss Por

4.72908e+01 4.72908e+01 4.72908e+00 1.00000e-09 7.00000e-02

$1.88959 \mathrm{e}+001.88959 \mathrm{e}+00$ 1.88959e-01 1.00000e-09 2.12000e-01

1.00000e-06 1.00000e-06 1.00000e-06 1.00000e-09 5.00000e-02

Element: 478 \# of layers: 3

$\mathrm{Kx} \mathrm{Ky} \mathrm{Kz}$ Ss Por

6.83859e+01 6.83859e+01 6.83859e+00 1.00000e-09 7.00000e-02

$2.73246 \mathrm{e}+002.73246 \mathrm{e}+00$ 2.73246e-01 1.00000e-09 2.12000e-01

1.00000e-06 1.00000e-06 1.00000e-06 1.00000e-09 5.00000e-02

Element: 479 \# of layers: 5

$\mathrm{Kx} \mathrm{Ky} \mathrm{Kz}$ Ss Por

4.12919e+01 4.12919e+01 4.12919e+00 1.00000e-09 7.00000e-02

$1.64987 \mathrm{e}+001.64987 \mathrm{e}+00$ 1.64987e-01 1.00000e-09 2.12000e-01 
$1.00000 \mathrm{e}-05$ 1.00000e-05 1.00000e-06 1.00000e-09 1.00000e-01 $1.00000 \mathrm{e}+001.00000 \mathrm{e}+001.00000 \mathrm{e}-01$ 1.00000e-09 1.00000e-01 1.00000e-06 1.00000e-06 1.00000e-06 1.00000e-09 5.00000e-02

Element: 480 \# of layers: 4

$\mathrm{Kx} \mathrm{Ky} \mathrm{Kz}$ Ss Por

3.16260e+01 3.16260e+01 3.16260e+00 1.00000e-09 7.00000e-02 $1.26367 \mathrm{e}+00$ 1.26367e+00 1.26367e-01 1.00000e-09 2.12000e-01 $1.00000 \mathrm{e}-05$ 1.00000e-05 1.00000e-06 1.00000e-09 1.00000e-01 $1.00000 \mathrm{e}+001.00000 \mathrm{e}+001.00000 \mathrm{e}-011.00000 \mathrm{e}-091.00000 \mathrm{e}-01$ Element: 481 \# of layers: 4

$\mathrm{Kx} \mathrm{Ky} \mathrm{Kz}$ Ss Por

$2.86536 \mathrm{e}+012.86536 \mathrm{e}+012.86536 \mathrm{e}+00$ 1.00000e-09 7.00000e-02

$1.14489 \mathrm{e}+001.14489 \mathrm{e}+001.14489 \mathrm{e}-01$ 1.00000e-09 2.12000e-01 $1.00000 \mathrm{e}-05$ 1.00000e-05 1.00000e-06 1.00000e-09 1.00000e-01 $1.00000 \mathrm{e}+001.00000 \mathrm{e}+001.00000 \mathrm{e}-01$ 1.00000e-09 1.00000e-01 Element: 482 \# of layers: 4

$\mathrm{Kx} \mathrm{Ky} \mathrm{Kz}$ Ss Por

$1.39259 \mathrm{e}+01$ 1.39259e+01 1.39259e+00 1.00000e-09 7.00000e-02 5.56437e-01 5.56437e-01 5.56437e-02 1.00000e-09 2.12000e-01 $1.00000 \mathrm{e}-05$ 1.00000e-05 1.00000e-06 1.00000e-09 1.00000e-01 $1.00000 \mathrm{e}+001.00000 \mathrm{e}+001.00000 \mathrm{e}-011.00000 \mathrm{e}-091.00000 \mathrm{e}-01$ Element: 483 \# of layers: 3

$\mathrm{Kx} \mathrm{Ky} \mathrm{Kz}$ Ss Por

6.26420e+00 6.26420e+00 6.26420e-01 1.00000e-09 7.00000e-02 $1.00000 \mathrm{e}-051.00000 \mathrm{e}-05$ 1.00000e-06 1.00000e-09 1.00000e-01 $1.00000 \mathrm{e}+001.00000 \mathrm{e}+001.00000 \mathrm{e}-011.00000 \mathrm{e}-091.00000 \mathrm{e}-01$ Element: 484 \# of layers: 1

$\mathrm{Kx} \mathrm{Ky} \mathrm{Kz}$ Ss Por

3.15449e+00 3.15449e+00 3.15449e-01 1.00000e-09 7.00000e-02 Element: 485 \# of layers: 1

$\mathrm{Kx} \mathrm{Ky} \mathrm{Kz}$ Ss Por

3.13179e+00 3.13179e+00 3.13179e-01 1.00000e-09 7.00000e-02

Element: 486 \# of layers: 1

$\mathrm{Kx} \mathrm{Ky} \mathrm{Kz}$ Ss Por

4.11424e+00 4.11424e+00 4.11424e-01 1.00000e-09 7.00000e-02

Element: 487 \# of layers: 2

Kx Ky Kz Ss Por

$2.06536 \mathrm{e}+012.06536 \mathrm{e}+012.06536 \mathrm{e}+001.00000 \mathrm{e}-09$ 7.00000e-02 1.00000e-06 1.00000e-06 1.00000e-06 1.00000e-09 5.00000e-02

Element: 488 \# of layers: 5

$\mathrm{Kx} \mathrm{Ky} \mathrm{Kz}$ Ss Por

$2.92275 \mathrm{e}+012.92275 \mathrm{e}+012.92275 \mathrm{e}+00$ 1.00000e-09 7.00000e-02 $1.16784 \mathrm{e}+001.16784 \mathrm{e}+001.16784 \mathrm{e}-01$ 1.00000e-09 2.12000e-01 $1.00000 \mathrm{e}-05$ 1.00000e-05 1.00000e-06 1.00000e-09 1.00000e-01 $1.00000 \mathrm{e}+001.00000 \mathrm{e}+001.00000 \mathrm{e}-011.00000 \mathrm{e}-091.00000 \mathrm{e}-01$ $1.00000 \mathrm{e}-06$ 1.00000e-06 1.00000e-06 1.00000e-09 5.00000e-02 
Element: 489 \# of layers: 5

Kx Ky Kz Ss Por

$4.10595 \mathrm{e}+014.10595 \mathrm{e}+014.10595 \mathrm{e}+00$ 1.00000e-09 7.00000e-02

$1.64060 \mathrm{e}+001.64060 \mathrm{e}+001.64060 \mathrm{e}-011.00000 \mathrm{e}-092.12000 \mathrm{e}-01$

$1.00000 \mathrm{e}-05$ 1.00000e-05 1.00000e-06 1.00000e-09 1.00000e-01

$1.00000 \mathrm{e}+001.00000 \mathrm{e}+001.00000 \mathrm{e}-011.00000 \mathrm{e}-091.00000 \mathrm{e}-01$

$1.00000 \mathrm{e}-06$ 1.00000e-06 1.00000e-06 1.00000e-09 5.00000e-02

Element: 490 \# of layers: 5

Kx Ky Kz Ss Por

3.03727e+01 3.03727e+01 3.03727e+00 1.00000e-09 7.00000e-02

$1.21356 \mathrm{e}+001.21356 \mathrm{e}+001.21356 \mathrm{e}-011.00000 \mathrm{e}-09$ 2.12000e-01

$1.00000 \mathrm{e}-05$ 1.00000e-05 1.00000e-06 1.00000e-09 1.00000e-01

$1.00000 \mathrm{e}+001.00000 \mathrm{e}+001.00000 \mathrm{e}-011.00000 \mathrm{e}-091.00000 \mathrm{e}-01$

$1.00000 \mathrm{e}-06$ 1.00000e-06 1.00000e-06 1.00000e-09 5.00000e-02

Element: 491 \# of layers: 1

Kx Ky Kz Ss Por

$1.74956 \mathrm{e}+011.74956 \mathrm{e}+011.74956 \mathrm{e}+00$ 1.00000e-09 7.00000e-02

Element: 492 \# of layers: 1

Kx Ky Kz Ss Por

5.46736e+00 5.46736e+00 5.46736e-01 1.00000e-09 7.00000e-02

Element: 493 \# of layers: 1

Kx Ky Kz Ss Por

4.30074e+00 4.30074e+00 4.30074e-01 1.00000e-09 7.00000e-02

Element: 494 \# of layers: 2

Kx Ky Kz Ss Por

$6.02823 \mathrm{e}+026.02823 \mathrm{e}+026.02823 \mathrm{e}+01$ 1.00000e-09 7.00000e-02

$1.00000 \mathrm{e}-06$ 1.00000e-06 1.00000e-06 1.00000e-09 5.00000e-02

Element: 495 \# of layers: 2

Kx Ky Kz Ss Por

$6.98879 \mathrm{e}+026.98879 \mathrm{e}+026.98879 \mathrm{e}+01$ 1.00000e-09 7.00000e-02

1.00000e-06 1.00000e-06 1.00000e-06 1.00000e-09 5.00000e-02

Element: 496 \# of layers: 2

Kx Ky Kz Ss Por

$1.02417 \mathrm{e}+03$ 1.02417e+03 1.02417e+02 1.00000e-09 7.00000e-02

$1.00000 \mathrm{e}-06$ 1.00000e-06 1.00000e-06 1.00000e-09 5.00000e-02

Element: 497 \# of layers: 2

Kx Ky Kz Ss Por

$5.62170 \mathrm{e}+02$ 5.62170e+02 5.62170e+01 1.00000e-09 7.00000e-02 $1.00000 \mathrm{e}-06$ 1.00000e-06 1.00000e-06 1.00000e-09 5.00000e-02

Element: 498 \# of layers: 2

Kx Ky Kz Ss Por

$1.95310 \mathrm{e}+021.95310 \mathrm{e}+021.95310 \mathrm{e}+011.00000 \mathrm{e}-097.00000 \mathrm{e}-02$ $1.00000 \mathrm{e}-06$ 1.00000e-06 1.00000e-06 1.00000e-09 5.00000e-02

Element: 499 \# of layers: 3

Kx Ky Kz Ss Por

$1.29834 \mathrm{e}+02$ 1.29834e+02 1.29834e+01 1.00000e-09 7.00000e-02 
5.18749e+00 5.18749e+00 5.18749e-01 1.00000e-09 2.12000e-01 $1.00000 \mathrm{e}-06$ 1.00000e-06 1.00000e-06 1.00000e-09 5.00000e-02

Element: 500 \# of layers: 3

Kx Ky Kz Ss Por

$1.41493 \mathrm{e}+021.41493 \mathrm{e}+021.41493 \mathrm{e}+01$ 1.00000e-09 7.00000e-02

$5.65370 \mathrm{e}+00$ 5.65370e+00 5.65370e-01 1.00000e-09 2.12000e-01

$1.00000 \mathrm{e}-06$ 1.00000e-06 1.00000e-06 1.00000e-09 5.00000e-02

Element: 501 \# of layers: 2

Kx Ky Kz Ss Por

$3.68860 \mathrm{e}+023.68860 \mathrm{e}+023.68860 \mathrm{e}+01$ 1.00000e-09 7.00000e-02

$1.00000 \mathrm{e}+001.00000 \mathrm{e}+001.00000 \mathrm{e}-011.00000 \mathrm{e}-091.00000 \mathrm{e}-01$

Element: 502 \# of layers: 2

Kx Ky Kz Ss Por

$3.86214 \mathrm{e}+023.86214 \mathrm{e}+023.86214 \mathrm{e}+01$ 1.00000e-09 7.00000e-02

$1.00000 \mathrm{e}+001.00000 \mathrm{e}+001.00000 \mathrm{e}-011.00000 \mathrm{e}-091.00000 \mathrm{e}-01$

Element: 503 \# of layers: 3

Kx Ky Kz Ss Por

4.44193e+02 4.44193e+02 4.44193e+01 1.00000e-09 7.00000e-02 $1.00000 \mathrm{e}+001.00000 \mathrm{e}+001.00000 \mathrm{e}-011.00000 \mathrm{e}-091.00000 \mathrm{e}-01$

$1.00000 \mathrm{e}-06$ 1.00000e-06 1.00000e-06 1.00000e-09 5.00000e-02

Element: 504 \# of layers: 3

Kx Ky Kz Ss Por

6.01147e+02 6.01147e+02 6.01147e+01 1.00000e-09 7.00000e-02

$1.00000 \mathrm{e}+001.00000 \mathrm{e}+001.00000 \mathrm{e}-011.00000 \mathrm{e}-091.00000 \mathrm{e}-01$

$1.00000 \mathrm{e}-06$ 1.00000e-06 1.00000e-06 1.00000e-09 5.00000e-02

Element: 505 \# of layers: 2

Kx Ky Kz Ss Por

$6.33358 \mathrm{e}+026.33358 \mathrm{e}+026.33358 \mathrm{e}+01$ 1.00000e-09 7.00000e-02

$1.00000 \mathrm{e}-06$ 1.00000e-06 1.00000e-06 1.00000e-09 5.00000e-02

Element: 506 \# of layers: 2

Kx Ky Kz Ss Por

$4.53158 \mathrm{e}+02$ 4.53158e+02 4.53158e+01 1.00000e-09 7.00000e-02

$1.00000 \mathrm{e}-06$ 1.00000e-06 1.00000e-06 1.00000e-09 5.00000e-02

Element: 507 \# of layers: 3

Kx Ky Kz Ss Por

$4.29975 \mathrm{e}+02$ 4.29975e+02 4.29975e+01 1.00000e-09 7.00000e-02

$1.00000 \mathrm{e}-02$ 1.00000e-02 1.00000e-03 1.00000e-09 1.00000e-01

$1.00000 \mathrm{e}-06$ 1.00000e-06 1.00000e-06 1.00000e-09 5.00000e-02

Element: 508 \# of layers: 7

Kx Ky Kz Ss Por

$3.72437 \mathrm{e}+02$ 3.72437e+02 3.72437e+01 1.00000e-09 7.00000e-02

$3.72437 \mathrm{e}+023.72437 \mathrm{e}+023.72437 \mathrm{e}+01$ 1.00000e-09 7.00000e-02

$3.72437 \mathrm{e}+023.72437 \mathrm{e}+023.72437 \mathrm{e}+01$ 1.00000e-09 7.00000e-02

$1.48814 \mathrm{e}+011.48814 \mathrm{e}+011.48814 \mathrm{e}+001.00000 \mathrm{e}-092.12000 \mathrm{e}-01$

$1.48814 \mathrm{e}+011.48814 \mathrm{e}+011.48814 \mathrm{e}+001.00000 \mathrm{e}-092.12000 \mathrm{e}-01$

$1.00000 \mathrm{e}-021.00000 \mathrm{e}-02$ 1.00000e-03 1.00000e-09 1.00000e-01 
1.00000e-06 1.00000e-06 1.00000e-06 1.00000e-09 5.00000e-02

Element: 509 \# of layers: 4

$\mathrm{Kx} \mathrm{Ky} \mathrm{Kz}$ Ss Por

$2.99619 \mathrm{e}+02$ 2.99619e+02 2.99619e+01 1.00000e-09 7.00000e-02

$1.19718 \mathrm{e}+011.19718 \mathrm{e}+01$ 1.19718e+00 1.00000e-09 2.12000e-01

$1.00000 \mathrm{e}-02$ 1.00000e-02 1.00000e-03 1.00000e-09 1.00000e-01

$1.00000 \mathrm{e}+001.00000 \mathrm{e}+001.00000 \mathrm{e}-01$ 1.00000e-09 1.00000e-01

Element: 510 \# of layers: 4

$\mathrm{Kx} \mathrm{Ky} \mathrm{Kz}$ Ss Por

3.22522e+02 3.22522e+02 3.22522e+01 1.00000e-09 7.00000e-02

$1.28867 \mathrm{e}+01$ 1.28867e+01 1.28867e+00 1.00000e-09 2.12000e-01

$1.00000 \mathrm{e}-02$ 1.00000e-02 1.00000e-03 1.00000e-09 1.00000e-01

$1.00000 \mathrm{e}+001.00000 \mathrm{e}+001.00000 \mathrm{e}-011.00000 \mathrm{e}-091.00000 \mathrm{e}-01$

Element: 511 \# of layers: 5

$\mathrm{Kx} \mathrm{Ky} \mathrm{Kz}$ Ss Por

3.60112e+02 3.60112e+02 3.60112e+01 1.00000e-09 7.00000e-02

$1.43888 \mathrm{e}+01$ 1.43888e+01 1.43888e+00 1.00000e-09 2.12000e-01

$1.00000 \mathrm{e}-02$ 1.00000e-02 1.00000e-03 1.00000e-09 1.00000e-01

$1.00000 \mathrm{e}+001.00000 \mathrm{e}+001.00000 \mathrm{e}-011.00000 \mathrm{e}-091.00000 \mathrm{e}-01$

1.00000e-06 1.00000e-06 1.00000e-06 1.00000e-09 5.00000e-02

Element: 512 \# of layers: 5

$\mathrm{Kx} \mathrm{Ky} \mathrm{Kz}$ Ss Por

3.99161e+02 3.99161e+02 3.99161e+01 1.00000e-09 7.00000e-02

$1.59490 \mathrm{e}+011.59490 \mathrm{e}+011.59490 \mathrm{e}+001.00000 \mathrm{e}-092.12000 \mathrm{e}-01$

$1.00000 \mathrm{e}-02$ 1.00000e-02 1.00000e-03 1.00000e-09 1.00000e-01

$1.00000 \mathrm{e}+001.00000 \mathrm{e}+001.00000 \mathrm{e}-011.00000 \mathrm{e}-091.00000 \mathrm{e}-01$

1.00000e-06 1.00000e-06 1.00000e-06 1.00000e-09 5.00000e-02

Element: 513 \# of layers: 5

$\mathrm{Kx} \mathrm{Ky} \mathrm{Kz}$ Ss Por

$2.75021 \mathrm{e}+02$ 2.75021e+02 2.75021e+01 1.00000e-09 7.00000e-02

$1.09890 \mathrm{e}+011.09890 \mathrm{e}+011.09890 \mathrm{e}+001.00000 \mathrm{e}-092.12000 \mathrm{e}-01$

$1.00000 \mathrm{e}-02$ 1.00000e-02 1.00000e-03 1.00000e-09 1.00000e-01

$1.00000 \mathrm{e}+001.00000 \mathrm{e}+001.00000 \mathrm{e}-011.00000 \mathrm{e}-091.00000 \mathrm{e}-01$

$1.00000 \mathrm{e}-061.00000 \mathrm{e}-06$ 1.00000e-06 1.00000e-09 5.00000e-02

Element: 514 \# of layers: 5

$\mathrm{Kx} \mathrm{Ky} \mathrm{Kz}$ Ss Por

3.52823e+02 3.52823e+02 3.52823e+01 1.00000e-09 7.00000e-02

$1.40975 \mathrm{e}+011.40975 \mathrm{e}+011.40975 \mathrm{e}+001.00000 \mathrm{e}-092.12000 \mathrm{e}-01$

$1.00000 \mathrm{e}-02$ 1.00000e-02 1.00000e-03 1.00000e-09 1.00000e-01

$1.00000 \mathrm{e}+001.00000 \mathrm{e}+001.00000 \mathrm{e}-011.00000 \mathrm{e}-091.00000 \mathrm{e}-01$

1.00000e-06 1.00000e-06 1.00000e-06 1.00000e-09 5.00000e-02

Element: 515 \# of layers: 4

$\mathrm{Kx} \mathrm{Ky} \mathrm{Kz}$ Ss Por

2.94348e+02 2.94348e+02 2.94348e+01 1.00000e-09 7.00000e-02

$1.17612 \mathrm{e}+01$ 1.17612e+01 1.17612e+00 1.00000e-09 2.12000e-01

$1.00000 \mathrm{e}-02$ 1.00000e-02 1.00000e-03 1.00000e-09 1.00000e-01 
$1.00000 \mathrm{e}+001.00000 \mathrm{e}+00$ 1.00000e-01 1.00000e-09 1.00000e-01

Element: 516 \# of layers: 4

$\mathrm{Kx} \mathrm{Ky} \mathrm{Kz}$ Ss Por

3.11827e+02 3.11827e+02 3.11827e+01 1.00000e-09 7.00000e-02

$1.24594 \mathrm{e}+011.24594 \mathrm{e}+011.24594 \mathrm{e}+001.00000 \mathrm{e}-092.12000 \mathrm{e}-01$

$1.00000 \mathrm{e}-02$ 1.00000e-02 1.00000e-03 1.00000e-09 1.00000e-01

$1.00000 \mathrm{e}+001.00000 \mathrm{e}+001.00000 \mathrm{e}-01$ 1.00000e-09 1.00000e-01

Element: 517 \# of layers: 4

$\mathrm{Kx} \mathrm{Ky} \mathrm{Kz}$ Ss Por

$2.96663 \mathrm{e}+02$ 2.96663e+02 2.96663e+01 1.00000e-09 7.00000e-02

$1.18535 \mathrm{e}+011.18535 \mathrm{e}+011.18535 \mathrm{e}+00$ 1.00000e-09 2.12000e-01

$1.00000 \mathrm{e}-02$ 1.00000e-02 1.00000e-03 1.00000e-09 1.00000e-01

$1.00000 \mathrm{e}+001.00000 \mathrm{e}+001.00000 \mathrm{e}-011.00000 \mathrm{e}-091.00000 \mathrm{e}-01$

Element: 518 \# of layers: 4

$\mathrm{Kx} \mathrm{Ky} \mathrm{Kz}$ Ss Por

2.85968e+02 2.85968e+02 2.85968e+01 1.00000e-09 7.00000e-02

$1.14262 \mathrm{e}+011.14262 \mathrm{e}+01$ 1.14262e+00 1.00000e-09 2.12000e-01

$1.00000 \mathrm{e}-02$ 1.00000e-02 1.00000e-03 1.00000e-09 1.00000e-01

$1.00000 \mathrm{e}+001.00000 \mathrm{e}+001.00000 \mathrm{e}-01$ 1.00000e-09 1.00000e-01

Element: 521 \# of layers: 5

$\mathrm{Kx} \mathrm{Ky} \mathrm{Kz}$ Ss Por

$2.61200 \mathrm{e}+022.61200 \mathrm{e}+02$ 2.61200e+01 1.00000e-09 7.00000e-02

$1.04368 \mathrm{e}+01$ 1.04368e+01 1.04368e+00 1.00000e-09 2.12000e-01

$1.00000 \mathrm{e}-02$ 1.00000e-02 1.00000e-03 1.00000e-09 1.00000e-01

$1.00000 \mathrm{e}+001.00000 \mathrm{e}+001.00000 \mathrm{e}-011.00000 \mathrm{e}-091.00000 \mathrm{e}-01$

1.00000e-06 1.00000e-06 1.00000e-06 1.00000e-09 5.00000e-02

Element: 522 \# of layers: 5

$\mathrm{Kx} \mathrm{Ky} \mathrm{Kz}$ Ss Por

3.28739e+02 3.28739e+02 3.28739e+01 1.00000e-09 7.00000e-02

$1.31353 \mathrm{e}+01$ 1.31353e+01 1.31353e+00 1.00000e-09 2.12000e-01

$1.00000 \mathrm{e}-021.00000 \mathrm{e}-021.00000 \mathrm{e}-031.00000 \mathrm{e}-091.00000 \mathrm{e}-01$

$1.00000 \mathrm{e}+001.00000 \mathrm{e}+001.00000 \mathrm{e}-011.00000 \mathrm{e}-091.00000 \mathrm{e}-01$

1.00000e-06 1.00000e-06 1.00000e-06 1.00000e-09 5.00000e-02

Element: 523 \# of layers: 5

$\mathrm{Kx} \mathrm{Ky} \mathrm{Kz}$ Ss Por

3.86430e+02 3.86430e+02 3.86430e+01 1.00000e-09 7.00000e-02

$1.54405 \mathrm{e}+011.54405 \mathrm{e}+011.54405 \mathrm{e}+001.00000 \mathrm{e}-092.12000 \mathrm{e}-01$

$1.00000 \mathrm{e}-02$ 1.00000e-02 1.00000e-03 1.00000e-09 1.00000e-01

$1.00000 \mathrm{e}+001.00000 \mathrm{e}+001.00000 \mathrm{e}-011.00000 \mathrm{e}-091.00000 \mathrm{e}-01$

1.00000e-06 1.00000e-06 1.00000e-06 1.00000e-09 5.00000e-02

Element: 525 \# of layers: 4

$\mathrm{Kx} \mathrm{Ky} \mathrm{Kz}$ Ss Por

$2.98366 \mathrm{e}+02$ 2.98366e+02 2.98366e+01 1.00000e-09 7.00000e-02

$1.19216 \mathrm{e}+01$ 1.19216e+01 1.19217e+00 1.00000e-09 2.12000e-01

$1.00000 \mathrm{e}-02$ 1.00000e-02 1.00000e-03 1.00000e-09 1.00000e-01

$1.00000 \mathrm{e}+001.00000 \mathrm{e}+001.00000 \mathrm{e}-011.00000 \mathrm{e}-091.00000 \mathrm{e}-01$ 
Element: 528 \# of layers: 5

Kx Ky Kz Ss Por

$2.30188 \mathrm{e}+022.30188 \mathrm{e}+022.30188 \mathrm{e}+01$ 1.00000e-09 7.00000e-02

9.19752e+00 9.19752e+00 9.19752e-01 1.00000e-09 2.12000e-01

$1.00000 \mathrm{e}-02$ 1.00000e-02 1.00000e-03 1.00000e-09 1.00000e-01

$1.00000 \mathrm{e}+001.00000 \mathrm{e}+001.00000 \mathrm{e}-011.00000 \mathrm{e}-091.00000 \mathrm{e}-01$

$1.00000 \mathrm{e}-06$ 1.00000e-06 1.00000e-06 1.00000e-09 5.00000e-02

Element: 529 \# of layers: 5

Kx Ky Kz Ss Por

$2.49685 \mathrm{e}+022.49685 \mathrm{e}+022.49685 \mathrm{e}+01$ 1.00000e-09 7.00000e-02

$9.97649 \mathrm{e}+00$ 9.97649e+00 9.97649e-01 1.00000e-09 2.12000e-01

$1.00000 \mathrm{e}-021.00000 \mathrm{e}-02$ 1.00000e-03 1.00000e-09 1.00000e-01

$1.00000 \mathrm{e}+001.00000 \mathrm{e}+001.00000 \mathrm{e}-011.00000 \mathrm{e}-091.00000 \mathrm{e}-01$

1.00000e-06 1.00000e-06 1.00000e-06 1.00000e-09 5.00000e-02

Element: 532 \# of layers: 4

Kx Ky Kz Ss Por

3.00727e+02 3.00727e+02 3.00727e+01 1.00000e-09 7.00000e-02

$1.20162 \mathrm{e}+011.20162 \mathrm{e}+011.20162 \mathrm{e}+001.00000 \mathrm{e}-092.12000 \mathrm{e}-01$

$1.00000 \mathrm{e}-021.00000 \mathrm{e}-021.00000 \mathrm{e}-031.00000 \mathrm{e}-091.00000 \mathrm{e}-01$

$1.00000 \mathrm{e}+001.00000 \mathrm{e}+001.00000 \mathrm{e}-011.00000 \mathrm{e}-091.00000 \mathrm{e}-01$

Element: 533 \# of layers: 4

Kx Ky Kz Ss Por

$2.95501 \mathrm{e}+022.95501 \mathrm{e}+022.95501 \mathrm{e}+01$ 1.00000e-09 7.00000e-02

$1.18071 \mathrm{e}+011.18071 \mathrm{e}+011.18071 \mathrm{e}+001.00000 \mathrm{e}-092.12000 \mathrm{e}-01$

$1.00000 \mathrm{e}-021.00000 \mathrm{e}-02$ 1.00000e-03 1.00000e-09 1.00000e-01

$1.00000 \mathrm{e}+001.00000 \mathrm{e}+001.00000 \mathrm{e}-011.00000 \mathrm{e}-091.00000 \mathrm{e}-01$

Element: 534 \# of layers: 4

Kx Ky Kz Ss Por

$2.21979 \mathrm{e}+022.21979 \mathrm{e}+02$ 2.21979e+01 1.00000e-09 7.00000e-02

$8.86946 \mathrm{e}+00$ 8.86946e+00 8.86946e-01 1.00000e-09 2.12000e-01

$1.00000 \mathrm{e}-021.00000 \mathrm{e}-02$ 1.00000e-03 1.00000e-09 1.00000e-01

$1.00000 \mathrm{e}+001.00000 \mathrm{e}+001.00000 \mathrm{e}-011.00000 \mathrm{e}-091.00000 \mathrm{e}-01$

Element: 535 \# of layers: 4

Kx Ky Kz Ss Por

2.39459e+02 2.39459e+02 2.39459e+01 1.00000e-09 7.00000e-02

$9.56788 \mathrm{e}+00$ 9.56788e+00 9.56788e-01 1.00000e-09 2.12000e-01

$1.00000 \mathrm{e}-02$ 1.00000e-02 1.00000e-03 1.00000e-09 1.00000e-01

$1.00000 \mathrm{e}+001.00000 \mathrm{e}+001.00000 \mathrm{e}-011.00000 \mathrm{e}-091.00000 \mathrm{e}-01$

Element: 536 \# of layers: 4

Kx Ky Kz Ss Por

$2.96177 \mathrm{e}+022.96177 \mathrm{e}+022.96177 \mathrm{e}+01$ 1.00000e-09 7.00000e-02

$1.18341 \mathrm{e}+011.18341 \mathrm{e}+011.18341 \mathrm{e}+001.00000 \mathrm{e}-092.12000 \mathrm{e}-01$

$1.00000 \mathrm{e}-02$ 1.00000e-02 $1.00000 \mathrm{e}-031.00000 \mathrm{e}-091.00000 \mathrm{e}-01$

$1.00000 \mathrm{e}+001.00000 \mathrm{e}+001.00000 \mathrm{e}-011.00000 \mathrm{e}-091.00000 \mathrm{e}-01$

Element: 537 \# of layers: 4

Kx Ky Kz Ss Por 
$1.96526 \mathrm{e}+02$ 1.96526e+02 1.96526e+01 1.00000e-09 7.00000e-02 $7.85244 \mathrm{e}+007.85244 \mathrm{e}+007.85244 \mathrm{e}-01$ 1.00000e-09 2.12000e-01 $1.00000 \mathrm{e}-02$ 1.00000e-02 1.00000e-03 1.00000e-09 1.00000e-01 $1.00000 \mathrm{e}+001.00000 \mathrm{e}+001.00000 \mathrm{e}-011.00000 \mathrm{e}-091.00000 \mathrm{e}-01$ Element: 538 \# of layers: 4

$\mathrm{Kx} \mathrm{Ky} \mathrm{Kz}$ Ss Por

3.35118e+02 3.35118e+02 3.35118e+01 1.00000e-09 7.00000e-02 $1.33903 \mathrm{e}+01$ 1.33903e+01 1.33903e+00 1.00000e-09 2.12000e-01 $1.00000 \mathrm{e}-02$ 1.00000e-02 1.00000e-03 1.00000e-09 1.00000e-01 $1.00000 \mathrm{e}+001.00000 \mathrm{e}+001.00000 \mathrm{e}-011.00000 \mathrm{e}-091.00000 \mathrm{e}-01$ Element: 539 \# of layers: 5

$\mathrm{Kx} \mathrm{Ky} \mathrm{Kz}$ Ss Por $2.26809 \mathrm{e}+02$ 2.26809e+02 2.26809e+01 1.00000e-09 7.00000e-02 $2.26809 \mathrm{e}+02$ 2.26809e+02 2.26809e+01 1.00000e-09 7.00000e-02 $9.06229 \mathrm{e}+00$ 9.06229e+00 9.06229e-01 1.00000e-09 2.12000e-01 $9.06229 \mathrm{e}+00$ 9.06229e+00 9.06229e-01 1.00000e-09 2.12000e-01 9.06229e+00 9.06229e+00 9.06229e-01 1.00000e-09 2.12000e-01

Element: 540 \# of layers: 6

$\mathrm{Kx} \mathrm{Ky} \mathrm{Kz}$ Ss Por 8.83539e+02 8.83539e+02 8.83539e+01 1.00000e-09 7.00000e-02 $8.83539 \mathrm{e}+02$ 8.83539e+02 8.83539e+01 1.00000e-09 7.00000e-02 $3.53032 \mathrm{e}+013.53032 \mathrm{e}+01$ 3.53032e+00 1.00000e-09 2.12000e-01 $3.53032 \mathrm{e}+013.53032 \mathrm{e}+013.53032 \mathrm{e}+00$ 1.00000e-09 2.12000e-01 $1.00000 \mathrm{e}-02$ 1.00000e-02 1.00000e-03 1.00000e-09 1.00000e-01 $1.00000 \mathrm{e}+001.00000 \mathrm{e}+001.00000 \mathrm{e}-011.00000 \mathrm{e}-091.00000 \mathrm{e}-01$ Element: 541 \# of layers: 5

$\mathrm{Kx} \mathrm{Ky} \mathrm{Kz}$ Ss Por

8.83539e+02 8.83539e+02 8.83539e+01 1.00000e-09 7.00000e-02 $3.53032 \mathrm{e}+013.53032 \mathrm{e}+013.53032 \mathrm{e}+001.00000 \mathrm{e}-092.12000 \mathrm{e}-01$ $3.53032 \mathrm{e}+013.53032 \mathrm{e}+013.53032 \mathrm{e}+001.00000 \mathrm{e}-092.12000 \mathrm{e}-01$ 1.00000e-02 1.00000e-02 1.00000e-03 1.00000e-09 1.00000e-01 $1.00000 \mathrm{e}+001.00000 \mathrm{e}+001.00000 \mathrm{e}-011.00000 \mathrm{e}-091.00000 \mathrm{e}-01$ Element: 542 \# of layers: 5

$\mathrm{Kx} \mathrm{Ky} \mathrm{Kz}$ Ss Por

8.83539e+02 8.83539e+02 8.83539e+01 1.00000e-09 7.00000e-02 $3.53032 \mathrm{e}+013.53032 \mathrm{e}+013.53032 \mathrm{e}+00$ 1.00000e-09 2.12000e-01 $3.53032 \mathrm{e}+013.53032 \mathrm{e}+013.53032 \mathrm{e}+00$ 1.00000e-09 2.12000e-01 $1.00000 \mathrm{e}-02$ 1.00000e-02 1.00000e-03 1.00000e-09 1.00000e-01 $1.00000 \mathrm{e}+001.00000 \mathrm{e}+001.00000 \mathrm{e}-011.00000 \mathrm{e}-091.00000 \mathrm{e}-01$ Element: 543 \# of layers: 5

$\mathrm{Kx} \mathrm{Ky} \mathrm{Kz}$ Ss Por 8.83539e+02 8.83539e+02 8.83539e+01 1.00000e-09 7.00000e-02 $3.53032 \mathrm{e}+013.53032 \mathrm{e}+013.53032 \mathrm{e}+001.00000 \mathrm{e}-092.12000 \mathrm{e}-01$ $3.53032 \mathrm{e}+013.53032 \mathrm{e}+013.53032 \mathrm{e}+001.00000 \mathrm{e}-092.12000 \mathrm{e}-01$ $1.00000 \mathrm{e}-02$ 1.00000e-02 1.00000e-03 1.00000e-09 1.00000e-01 $1.00000 \mathrm{e}+001.00000 \mathrm{e}+001.00000 \mathrm{e}-011.00000 \mathrm{e}-091.00000 \mathrm{e}-01$ 
Element: 544 \# of layers: 6

Kx Ky Kz Ss Por

$8.83539 \mathrm{e}+02$ 8.83539e+02 8.83539e+01 1.00000e-09 7.00000e-02

$8.83539 \mathrm{e}+028.83539 \mathrm{e}+028.83539 \mathrm{e}+01$ 1.00000e-09 7.00000e-02

$3.53032 \mathrm{e}+013.53032 \mathrm{e}+013.53032 \mathrm{e}+001.00000 \mathrm{e}-092.12000 \mathrm{e}-01$

$3.53032 \mathrm{e}+013.53032 \mathrm{e}+013.53032 \mathrm{e}+001.00000 \mathrm{e}-092.12000 \mathrm{e}-01$

$1.00000 \mathrm{e}-021.00000 \mathrm{e}-02$ 1.00000e-03 1.00000e-09 1.00000e-01

$1.00000 \mathrm{e}+001.00000 \mathrm{e}+001.00000 \mathrm{e}-011.00000 \mathrm{e}-091.00000 \mathrm{e}-01$

Element: 545 \# of layers: 4

Kx Ky Kz Ss Por

$6.47828 \mathrm{e}+026.47828 \mathrm{e}+026.47828 \mathrm{e}+01$ 1.00000e-09 7.00000e-02

$2.58846 \mathrm{e}+012.58846 \mathrm{e}+012.58846 \mathrm{e}+001.00000 \mathrm{e}-092.12000 \mathrm{e}-01$

$2.58846 \mathrm{e}+012.58846 \mathrm{e}+012.58846 \mathrm{e}+001.00000 \mathrm{e}-092.12000 \mathrm{e}-01$

$2.58846 \mathrm{e}+012.58846 \mathrm{e}+012.58846 \mathrm{e}+001.00000 \mathrm{e}-092.12000 \mathrm{e}-01$

Element: 546 \# of layers: 5

Kx Ky Kz Ss Por

$6.47828 \mathrm{e}+026.47828 \mathrm{e}+026.47828 \mathrm{e}+01$ 1.00000e-09 7.00000e-02

$2.58846 \mathrm{e}+012.58846 \mathrm{e}+012.58846 \mathrm{e}+001.00000 \mathrm{e}-092.12000 \mathrm{e}-01$

$2.58846 \mathrm{e}+012.58846 \mathrm{e}+012.58846 \mathrm{e}+00$ 1.00000e-09 2.12000e-01

$1.00000 \mathrm{e}-021.00000 \mathrm{e}-02$ 1.00000e-03 1.00000e-09 1.00000e-01

$1.00000 \mathrm{e}+001.00000 \mathrm{e}+001.00000 \mathrm{e}-011.00000 \mathrm{e}-091.00000 \mathrm{e}-01$

Element: 547 \# of layers: 5

Kx Ky Kz Ss Por

$6.47828 \mathrm{e}+026.47828 \mathrm{e}+026.47828 \mathrm{e}+01$ 1.00000e-09 7.00000e-02

$2.58846 \mathrm{e}+012.58846 \mathrm{e}+012.58846 \mathrm{e}+001.00000 \mathrm{e}-092.12000 \mathrm{e}-01$

$2.58846 \mathrm{e}+012.58846 \mathrm{e}+012.58846 \mathrm{e}+001.00000 \mathrm{e}-092.12000 \mathrm{e}-01$

$1.00000 \mathrm{e}-021.00000 \mathrm{e}-02$ 1.00000e-03 1.00000e-09 1.00000e-01

$1.00000 \mathrm{e}+001.00000 \mathrm{e}+001.00000 \mathrm{e}-011.00000 \mathrm{e}-091.00000 \mathrm{e}-01$

Element: 548 \# of layers: 5

Kx Ky Kz Ss Por

$6.47828 \mathrm{e}+026.47828 \mathrm{e}+026.47828 \mathrm{e}+01$ 1.00000e-09 7.00000e-02

$2.58846 \mathrm{e}+012.58846 \mathrm{e}+012.58846 \mathrm{e}+001.00000 \mathrm{e}-092.12000 \mathrm{e}-01$

$2.58846 \mathrm{e}+012.58846 \mathrm{e}+012.58846 \mathrm{e}+001.00000 \mathrm{e}-092.12000 \mathrm{e}-01$

$1.00000 \mathrm{e}-021.00000 \mathrm{e}-02$ 1.00000e-03 1.00000e-09 1.00000e-01

$1.00000 \mathrm{e}+001.00000 \mathrm{e}+001.00000 \mathrm{e}-011.00000 \mathrm{e}-091.00000 \mathrm{e}-01$

Element: 549 \# of layers: 6

Kx Ky Kz Ss Por

$6.47828 \mathrm{e}+026.47828 \mathrm{e}+026.47828 \mathrm{e}+01$ 1.00000e-09 7.00000e-02

$2.58846 \mathrm{e}+012.58846 \mathrm{e}+012.58846 \mathrm{e}+001.00000 \mathrm{e}-092.12000 \mathrm{e}-01$

$2.58846 \mathrm{e}+012.58846 \mathrm{e}+012.58846 \mathrm{e}+001.00000 \mathrm{e}-092.12000 \mathrm{e}-01$

$2.58846 \mathrm{e}+012.58846 \mathrm{e}+012.58846 \mathrm{e}+001.00000 \mathrm{e}-092.12000 \mathrm{e}-01$

$1.00000 \mathrm{e}-021.00000 \mathrm{e}-02$ 1.00000e-03 1.00000e-09 1.00000e-01

$1.00000 \mathrm{e}+001.00000 \mathrm{e}+001.00000 \mathrm{e}-011.00000 \mathrm{e}-091.00000 \mathrm{e}-01$

Element: 550 \# of layers: 6

Kx Ky Kz Ss Por

6.47828e+02 6.47828e+02 6.47828e+01 1.00000e-09 7.00000e-02 
$2.58846 \mathrm{e}+012.58846 \mathrm{e}+012.58846 \mathrm{e}+00$ 1.00000e-09 2.12000e-01 $2.58846 \mathrm{e}+012.58846 \mathrm{e}+012.58846 \mathrm{e}+001.00000 \mathrm{e}-092.12000 \mathrm{e}-01$ $2.58846 \mathrm{e}+012.58846 \mathrm{e}+012.58846 \mathrm{e}+001.00000 \mathrm{e}-092.12000 \mathrm{e}-01$ $1.00000 \mathrm{e}-02$ 1.00000e-02 1.00000e-03 1.00000e-09 1.00000e-01 $1.00000 \mathrm{e}+001.00000 \mathrm{e}+001.00000 \mathrm{e}-01$ 1.00000e-09 1.00000e-01 Element: 551 \# of layers: 4

$\mathrm{Kx} \mathrm{Ky} \mathrm{Kz}$ Ss Por

6.47828e+02 6.47828e+02 6.47828e+01 1.00000e-09 7.00000e-02 $2.58846 \mathrm{e}+012.58846 \mathrm{e}+012.58846 \mathrm{e}+001.00000 \mathrm{e}-092.12000 \mathrm{e}-01$

$2.58846 \mathrm{e}+012.58846 \mathrm{e}+012.58846 \mathrm{e}+001.00000 \mathrm{e}-092.12000 \mathrm{e}-01$ $2.58846 \mathrm{e}+012.58846 \mathrm{e}+012.58846 \mathrm{e}+00$ 1.00000e-09 2.12000e-01 Element: 552 \# of layers: 5

$\mathrm{Kx} \mathrm{Ky} \mathrm{Kz}$ Ss Por

6.47828e+02 6.47828e+02 6.47828e+01 1.00000e-09 7.00000e-02 $2.58846 \mathrm{e}+012.58846 \mathrm{e}+012.58846 \mathrm{e}+001.00000 \mathrm{e}-092.12000 \mathrm{e}-01$

$2.58846 \mathrm{e}+012.58846 \mathrm{e}+012.58846 \mathrm{e}+001.00000 \mathrm{e}-092.12000 \mathrm{e}-01$ $1.00000 \mathrm{e}-02$ 1.00000e-02 1.00000e-03 1.00000e-09 1.00000e-01 $1.00000 \mathrm{e}+001.00000 \mathrm{e}+001.00000 \mathrm{e}-01$ 1.00000e-09 1.00000e-01 Element: 553 \# of layers: 4

$\mathrm{Kx} \mathrm{Ky} \mathrm{Kz}$ Ss Por

4.14055e+02 4.14055e+02 4.14055e+01 1.00000e-09 7.00000e-02 $1.65441 \mathrm{e}+011.65441 \mathrm{e}+011.65441 \mathrm{e}+001.00000 \mathrm{e}-092.12000 \mathrm{e}-01$ $1.65441 \mathrm{e}+011.65441 \mathrm{e}+011.65441 \mathrm{e}+001.00000 \mathrm{e}-092.12000 \mathrm{e}-01$ $1.65441 \mathrm{e}+011.65441 \mathrm{e}+01$ 1.65441e+00 1.00000e-09 2.12000e-01 Element: 554 \# of layers: 4

$\mathrm{Kx} \mathrm{Ky} \mathrm{Kz}$ Ss Por

4.14055e+02 4.14055e+02 4.14055e+01 1.00000e-09 7.00000e-02 $1.65441 \mathrm{e}+011.65441 \mathrm{e}+011.65441 \mathrm{e}+001.00000 \mathrm{e}-092.12000 \mathrm{e}-01$ $1.65441 \mathrm{e}+011.65441 \mathrm{e}+011.65441 \mathrm{e}+001.00000 \mathrm{e}-092.12000 \mathrm{e}-01$ $1.65441 \mathrm{e}+011.65441 \mathrm{e}+011.65441 \mathrm{e}+001.00000 \mathrm{e}-092.12000 \mathrm{e}-01$ Element: 555 \# of layers: 4

$\mathrm{Kx} \mathrm{Ky} \mathrm{Kz}$ Ss Por

4.14055e+02 4.14055e+02 4.14055e+01 1.00000e-09 7.00000e-02 $1.65441 \mathrm{e}+011.65441 \mathrm{e}+011.65441 \mathrm{e}+001.00000 \mathrm{e}-092.12000 \mathrm{e}-01$ $1.65441 \mathrm{e}+011.65441 \mathrm{e}+011.65441 \mathrm{e}+001.00000 \mathrm{e}-092.12000 \mathrm{e}-01$ $1.65441 \mathrm{e}+011.65441 \mathrm{e}+01$ 1.65441e+00 1.00000e-09 2.12000e-01 Element: 556 \# of layers: 5

$\mathrm{Kx} \mathrm{Ky} \mathrm{Kz}$ Ss Por

$1.69289 \mathrm{e}+03$ 1.69289e+03 1.69289e+02 1.00000e-09 7.00000e-02 $6.76410 \mathrm{e}+016.76410 \mathrm{e}+016.76410 \mathrm{e}+001.00000 \mathrm{e}-092.12000 \mathrm{e}-01$ $6.76410 \mathrm{e}+016.76410 \mathrm{e}+016.76410 \mathrm{e}+001.00000 \mathrm{e}-092.12000 \mathrm{e}-01$ $1.00000 \mathrm{e}-02$ 1.00000e-02 1.00000e-03 1.00000e-09 1.00000e-01 $1.00000 \mathrm{e}+001.00000 \mathrm{e}+001.00000 \mathrm{e}-011.00000 \mathrm{e}-091.00000 \mathrm{e}-01$ Element: 557 \# of layers: 4

$\mathrm{Kx} \mathrm{Ky} \mathrm{Kz}$ Ss Por $1.69289 e+03$ 1.69289e+03 1.69289e+02 1.00000e-09 7.00000e-02 
6.76410e+01 6.76410e+01 6.76410e+00 1.00000e-09 2.12000e-01 $1.00000 \mathrm{e}-021.00000 \mathrm{e}-02$ 1.00000e-03 1.00000e-09 1.00000e-01

$1.00000 \mathrm{e}+001.00000 \mathrm{e}+001.00000 \mathrm{e}-011.00000 \mathrm{e}-091.00000 \mathrm{e}-01$

Element: 558 \# of layers: 4

Kx Ky Kz Ss Por

$1.69289 \mathrm{e}+03$ 1.69289e+03 1.69289e+02 1.00000e-09 7.00000e-02

$6.76410 \mathrm{e}+016.76410 \mathrm{e}+016.76410 \mathrm{e}+001.00000 \mathrm{e}-092.12000 \mathrm{e}-01$

$1.00000 \mathrm{e}-011.00000 \mathrm{e}-011.00000 \mathrm{e}-021.00000 \mathrm{e}-09$ 1.00000e-01

$1.00000 \mathrm{e}+001.00000 \mathrm{e}+001.00000 \mathrm{e}-011.00000 \mathrm{e}-091.00000 \mathrm{e}-01$

Element: 559 \# of layers: 4

Kx Ky Kz Ss Por

$1.69289 \mathrm{e}+03$ 1.69289e+03 1.69289e+02 1.00000e-09 7.00000e-02

$6.76410 \mathrm{e}+016.76410 \mathrm{e}+016.76410 \mathrm{e}+001.00000 \mathrm{e}-092.12000 \mathrm{e}-01$

$1.00000 \mathrm{e}-011.00000 \mathrm{e}-011.00000 \mathrm{e}-021.00000 \mathrm{e}-091.00000 \mathrm{e}-01$

$1.00000 \mathrm{e}+001.00000 \mathrm{e}+001.00000 \mathrm{e}-011.00000 \mathrm{e}-091.00000 \mathrm{e}-01$

Element: 560 \# of layers: 5

Kx Ky Kz Ss Por

$1.69289 \mathrm{e}+03$ 1.69289e+03 1.69289e+02 1.00000e-09 7.00000e-02

$6.76410 \mathrm{e}+016.76410 \mathrm{e}+016.76410 \mathrm{e}+001.00000 \mathrm{e}-092.12000 \mathrm{e}-01$

$6.76410 \mathrm{e}+016.76410 \mathrm{e}+016.76410 \mathrm{e}+001.00000 \mathrm{e}-092.12000 \mathrm{e}-01$

$1.00000 \mathrm{e}-021.00000 \mathrm{e}-02$ 1.00000e-03 1.00000e-09 1.00000e-01

$1.00000 \mathrm{e}+001.00000 \mathrm{e}+001.00000 \mathrm{e}-011.00000 \mathrm{e}-091.00000 \mathrm{e}-01$

Element: 561 \# of layers: 4

Kx Ky Kz Ss Por

$1.07489 \mathrm{e}+03$ 1.07489e+03 1.07489e+02 1.00000e-09 7.00000e-02

$4.29489 \mathrm{e}+014.29489 \mathrm{e}+01 \quad 4.29489 \mathrm{e}+00$ 1.00000e-09 2.12000e-01

$1.00000 \mathrm{e}-02$ 1.00000e-02 1.00000e-03 1.00000e-09 1.00000e-01

$1.00000 \mathrm{e}+001.00000 \mathrm{e}+001.00000 \mathrm{e}-011.00000 \mathrm{e}-091.00000 \mathrm{e}-01$

Element: 562 \# of layers: 4

Kx Ky Kz Ss Por

$1.07489 \mathrm{e}+03$ 1.07489e+03 1.07489e+02 1.00000e-09 7.00000e-02

$4.29489 \mathrm{e}+01 \quad 4.29489 \mathrm{e}+01 \quad 4.29489 \mathrm{e}+00$ 1.00000e-09 2.12000e-01

$1.00000 \mathrm{e}-021.00000 \mathrm{e}-02$ 1.00000e-03 1.00000e-09 1.00000e-01

$1.00000 \mathrm{e}+001.00000 \mathrm{e}+001.00000 \mathrm{e}-011.00000 \mathrm{e}-091.00000 \mathrm{e}-01$

Element: 563 \# of layers: 5

Kx Ky Kz Ss Por

$1.07489 \mathrm{e}+03$ 1.07489e+03 1.07489e+02 1.00000e-09 7.00000e-02

$4.29489 \mathrm{e}+01$ 4.29489e+01 4.29489e+00 1.00000e-09 2.12000e-01

$4.29489 \mathrm{e}+014.29489 \mathrm{e}+014.29489 \mathrm{e}+00$ 1.00000e-09 2.12000e-01

$1.00000 \mathrm{e}-02$ 1.00000e-02 1.00000e-03 1.00000e-09 1.00000e-01

$1.00000 \mathrm{e}+001.00000 \mathrm{e}+001.00000 \mathrm{e}-011.00000 \mathrm{e}-091.00000 \mathrm{e}-01$

Element: 564 \# of layers: 6

Kx Ky Kz Ss Por

$1.07489 \mathrm{e}+03$ 1.07489e+03 1.07489e+02 1.00000e-09 7.00000e-02

$1.07489 \mathrm{e}+03$ 1.07489e+03 1.07489e+02 1.00000e-09 7.00000e-02

$4.29489 \mathrm{e}+01$ 4.29489e+01 4.29489e+00 1.00000e-09 2.12000e-01 
4.29489e+01 4.29489e+01 4.29489e+00 1.00000e-09 2.12000e-01 $1.00000 \mathrm{e}-02$ 1.00000e-02 1.00000e-03 1.00000e-09 1.00000e-01 $1.00000 \mathrm{e}+001.00000 \mathrm{e}+001.00000 \mathrm{e}-01$ 1.00000e-09 1.00000e-01

Element: 565 \# of layers: 5

$\mathrm{Kx} \mathrm{Ky} \mathrm{Kz}$ Ss Por

1.07489e+03 1.07489e+03 1.07489e+02 1.00000e-09 7.00000e-02 4.29489e+01 4.29489e+01 4.29489e+00 1.00000e-09 2.12000e-01 $4.29489 \mathrm{e}+01$ 4.29489e+01 4.29489e+00 1.00000e-09 2.12000e-01 $1.00000 \mathrm{e}-021.00000 \mathrm{e}-021.00000 \mathrm{e}-031.00000 \mathrm{e}-091.00000 \mathrm{e}-01$ $1.00000 \mathrm{e}+001.00000 \mathrm{e}+001.00000 \mathrm{e}-011.00000 \mathrm{e}-091.00000 \mathrm{e}-01$ Element: 566 \# of layers: 6

$\mathrm{Kx} \mathrm{Ky} \mathrm{Kz}$ Ss Por

$1.07489 \mathrm{e}+03$ 1.07489e+03 1.07489e+02 1.00000e-09 7.00000e-02 $1.07489 \mathrm{e}+03$ 1.07489e+03 1.07489e+02 1.00000e-09 7.00000e-02 $4.29489 \mathrm{e}+014.29489 \mathrm{e}+01$ 4.29489e+00 1.00000e-09 2.12000e-01 $4.29489 \mathrm{e}+014.29489 \mathrm{e}+014.29489 \mathrm{e}+00$ 1.00000e-09 2.12000e-01 $1.00000 \mathrm{e}-02$ 1.00000e-02 1.00000e-03 1.00000e-09 1.00000e-01 $1.00000 \mathrm{e}+001.00000 \mathrm{e}+001.00000 \mathrm{e}-01$ 1.00000e-09 1.00000e-01 Element: 567 \# of layers: 4

$\mathrm{Kx} \mathrm{Ky} \mathrm{Kz}$ Ss Por

$1.07489 \mathrm{e}+03$ 1.07489e+03 1.07489e+02 1.00000e-09 7.00000e-02 4.29489e+01 4.29489e+01 4.29489e+00 1.00000e-09 2.12000e-01 $1.00000 \mathrm{e}-011.00000 \mathrm{e}-011.00000 \mathrm{e}-021.00000 \mathrm{e}-091.00000 \mathrm{e}-01$ $1.00000 \mathrm{e}+001.00000 \mathrm{e}+001.00000 \mathrm{e}-011.00000 \mathrm{e}-091.00000 \mathrm{e}-01$

Element: 568 \# of layers: 4

$\mathrm{Kx} \mathrm{Ky} \mathrm{Kz}$ Ss Por

$1.07489 \mathrm{e}+03$ 1.07489e+03 1.07489e+02 1.00000e-09 7.00000e-02 $4.29489 \mathrm{e}+014.29489 \mathrm{e}+01$ 4.29489e+00 1.00000e-09 2.12000e-01 $1.00000 \mathrm{e}-02$ 1.00000e-02 1.00000e-03 1.00000e-09 1.00000e-01 $1.00000 \mathrm{e}+001.00000 \mathrm{e}+001.00000 \mathrm{e}-011.00000 \mathrm{e}-091.00000 \mathrm{e}-01$ Element: 569 \# of layers: 6

$\mathrm{Kx} \mathrm{Ky} \mathrm{Kz}$ Ss Por

$1.07489 \mathrm{e}+03$ 1.07489e+03 1.07489e+02 1.00000e-09 7.00000e-02 $1.07489 \mathrm{e}+03$ 1.07489e+03 1.07489e+02 1.00000e-09 7.00000e-02 4.29489e+01 4.29489e+01 4.29489e+00 1.00000e-09 2.12000e-01 $4.29489 \mathrm{e}+014.29489 \mathrm{e}+014.29489 \mathrm{e}+00$ 1.00000e-09 2.12000e-01 $1.00000 \mathrm{e}-02$ 1.00000e-02 1.00000e-03 1.00000e-09 1.00000e-01 $1.00000 \mathrm{e}+001.00000 \mathrm{e}+001.00000 \mathrm{e}-011.00000 \mathrm{e}-091.00000 \mathrm{e}-01$ Element: 570 \# of layers: 5

$\mathrm{Kx} \mathrm{Ky} \mathrm{Kz}$ Ss Por

4.23191e+02 4.23191e+02 4.23191e+01 1.00000e-09 7.00000e-02 $1.69091 \mathrm{e}+011.69091 \mathrm{e}+011.69091 \mathrm{e}+001.00000 \mathrm{e}-092.12000 \mathrm{e}-01$ $1.69091 \mathrm{e}+011.69091 \mathrm{e}+01$ 1.69091e+00 1.00000e-09 2.12000e-01 $1.00000 \mathrm{e}-021.00000 \mathrm{e}-021.00000 \mathrm{e}-031.00000 \mathrm{e}-091.00000 \mathrm{e}-01$ $1.00000 \mathrm{e}+001.00000 \mathrm{e}+001.00000 \mathrm{e}-01$ 1.00000e-09 1.00000e-01 Element: 571 \# of layers: 5 
$\mathrm{Kx} \mathrm{Ky} \mathrm{Kz}$ Ss Por

4.23191e+02 4.23191e+02 4.23191e+01 1.00000e-09 7.00000e-02

$1.69091 \mathrm{e}+011.69091 \mathrm{e}+011.69091 \mathrm{e}+001.00000 \mathrm{e}-092.12000 \mathrm{e}-01$

$1.69091 \mathrm{e}+011.69091 \mathrm{e}+011.69091 \mathrm{e}+001.00000 \mathrm{e}-092.12000 \mathrm{e}-01$

$1.00000 \mathrm{e}-02$ 1.00000e-02 1.00000e-03 1.00000e-09 1.00000e-01

$1.00000 \mathrm{e}+001.00000 \mathrm{e}+001.00000 \mathrm{e}-011.00000 \mathrm{e}-091.00000 \mathrm{e}-01$

Element: 572 \# of layers: 5

$\mathrm{Kx} \mathrm{Ky} \mathrm{Kz}$ Ss Por

4.23191e+02 4.23191e+02 4.23191e+01 1.00000e-09 7.00000e-02

$1.69091 \mathrm{e}+011.69091 \mathrm{e}+01$ 1.69091e+00 1.00000e-09 2.12000e-01

$1.69091 \mathrm{e}+011.69091 \mathrm{e}+011.69091 \mathrm{e}+001.00000 \mathrm{e}-092.12000 \mathrm{e}-01$

$1.69091 \mathrm{e}+011.69091 \mathrm{e}+011.69091 \mathrm{e}+001.00000 \mathrm{e}-092.12000 \mathrm{e}-01$

$1.00000 \mathrm{e}+001.00000 \mathrm{e}+00$ 1.00000e-01 1.00000e-09 1.00000e-01

Element: 573 \# of layers: 6

$\mathrm{Kx} \mathrm{Ky} \mathrm{Kz}$ Ss Por

4.23191e+02 4.23191e+02 4.23191e+01 1.00000e-09 7.00000e-02

4.23191e+02 4.23191e+02 4.23191e+01 1.00000e-09 7.00000e-02

$1.69091 \mathrm{e}+011.69091 \mathrm{e}+011.69091 \mathrm{e}+001.00000 \mathrm{e}-092.12000 \mathrm{e}-01$

$1.69091 \mathrm{e}+011.69091 \mathrm{e}+011.69091 \mathrm{e}+001.00000 \mathrm{e}-092.12000 \mathrm{e}-01$

$1.69091 \mathrm{e}+011.69091 \mathrm{e}+011.69091 \mathrm{e}+001.00000 \mathrm{e}-092.12000 \mathrm{e}-01$

$1.00000 \mathrm{e}+001.00000 \mathrm{e}+001.00000 \mathrm{e}-011.00000 \mathrm{e}-091.00000 \mathrm{e}-01$

Element: 574 \# of layers: 4

$\mathrm{Kx} \mathrm{Ky} \mathrm{Kz}$ Ss Por

4.23191e+02 4.23191e+02 4.23191e+01 1.00000e-09 7.00000e-02

$1.69091 \mathrm{e}+011.69091 \mathrm{e}+011.69091 \mathrm{e}+001.00000 \mathrm{e}-092.12000 \mathrm{e}-01$

$1.69091 \mathrm{e}+011.69091 \mathrm{e}+011.69091 \mathrm{e}+001.00000 \mathrm{e}-092.12000 \mathrm{e}-01$

$1.69091 \mathrm{e}+011.69091 \mathrm{e}+011.69091 \mathrm{e}+001.00000 \mathrm{e}-092.12000 \mathrm{e}-01$

Element: 575 \# of layers: 4

$\mathrm{Kx} \mathrm{Ky} \mathrm{Kz}$ Ss Por

4.23191e+02 4.23191e+02 4.23191e+01 1.00000e-09 7.00000e-02

$1.69091 \mathrm{e}+011.69091 \mathrm{e}+011.69091 \mathrm{e}+001.00000 \mathrm{e}-092.12000 \mathrm{e}-01$

$1.69091 \mathrm{e}+011.69091 \mathrm{e}+011.69091 \mathrm{e}+001.00000 \mathrm{e}-092.12000 \mathrm{e}-01$

$1.00000 \mathrm{e}+001.00000 \mathrm{e}+001.00000 \mathrm{e}-01$ 1.00000e-09 1.00000e-01

Element: 576 \# of layers: 5

$\mathrm{Kx} \mathrm{Ky} \mathrm{Kz}$ Ss Por

4.23191e+02 4.23191e+02 4.23191e+01 1.00000e-09 7.00000e-02

$1.69091 \mathrm{e}+011.69091 \mathrm{e}+011.69091 \mathrm{e}+001.00000 \mathrm{e}-092.12000 \mathrm{e}-01$

$1.69091 \mathrm{e}+011.69091 \mathrm{e}+011.69091 \mathrm{e}+001.00000 \mathrm{e}-092.12000 \mathrm{e}-01$

$1.00000 \mathrm{e}-02$ 1.00000e-02 1.00000e-03 1.00000e-09 1.00000e-01

$1.00000 \mathrm{e}+001.00000 \mathrm{e}+001.00000 \mathrm{e}-01$ 1.00000e-09 1.00000e-01

Element: 577 \# of layers: 6

$\mathrm{Kx} \mathrm{Ky} \mathrm{Kz}$ Ss Por

4.23191e+02 4.23191e+02 4.23191e+01 1.00000e-09 7.00000e-02 4.23191e+02 4.23191e+02 4.23191e+01 1.00000e-09 7.00000e-02

$1.69091 \mathrm{e}+011.69091 \mathrm{e}+011.69091 \mathrm{e}+001.00000 \mathrm{e}-092.12000 \mathrm{e}-01$

$1.69091 \mathrm{e}+011.69091 \mathrm{e}+011.69091 \mathrm{e}+001.00000 \mathrm{e}-092.12000 \mathrm{e}-01$ 
$1.00000 \mathrm{e}-02$ 1.00000e-02 1.00000e-03 1.00000e-09 1.00000e-01 $1.00000 \mathrm{e}+001.00000 \mathrm{e}+001.00000 \mathrm{e}-01$ 1.00000e-09 1.00000e-01 Element: 578 \# of layers: 6

Kx Ky Kz Ss Por

4.23191e+02 4.23191e+02 4.23191e+01 1.00000e-09 7.00000e-02 4.23191e+02 4.23191e+02 4.23191e+01 1.00000e-09 7.00000e-02 $1.69091 \mathrm{e}+011.69091 \mathrm{e}+011.69091 \mathrm{e}+001.00000 \mathrm{e}-092.12000 \mathrm{e}-01$ $1.69091 \mathrm{e}+011.69091 \mathrm{e}+011.69091 \mathrm{e}+001.00000 \mathrm{e}-092.12000 \mathrm{e}-01$ $1.00000 \mathrm{e}-021.00000 \mathrm{e}-021.00000 \mathrm{e}-031.00000 \mathrm{e}-091.00000 \mathrm{e}-01$ $1.00000 \mathrm{e}+001.00000 \mathrm{e}+001.00000 \mathrm{e}-01$ 1.00000e-09 1.00000e-01 Element: 579 \# of layers: 4

$\mathrm{Kx} \mathrm{Ky} \mathrm{Kz}$ Ss Por

$2.40540 \mathrm{e}+02$ 2.40540e+02 2.40540e+01 1.00000e-09 7.00000e-02 $9.61108 \mathrm{e}+009.61108 \mathrm{e}+00$ 9.61108e-01 1.00000e-09 2.12000e-01 9.61108e+00 9.61108e+00 9.61108e-01 1.00000e-09 2.12000e-01 9.61108e+00 9.61108e+00 9.61108e-01 1.00000e-09 2.12000e-01 Element: 580 \# of layers: 5

$\mathrm{Kx} \mathrm{Ky} \mathrm{Kz}$ Ss Por

$2.40540 \mathrm{e}+02$ 2.40540e+02 2.40540e+01 1.00000e-09 7.00000e-02 $2.40540 \mathrm{e}+02$ 2.40540e+02 2.40540e+01 1.00000e-09 7.00000e-02 $9.61108 \mathrm{e}+009.61108 \mathrm{e}+00$ 9.61108e-01 1.00000e-09 2.12000e-01 9.61108e+00 9.61108e+00 9.61108e-01 1.00000e-09 2.12000e-01 9.61108e+00 9.61108e+00 9.61108e-01 1.00000e-09 2.12000e-01 Element: 581 \# of layers: 5

$\mathrm{Kx} \mathrm{Ky} \mathrm{Kz}$ Ss Por

$2.40540 \mathrm{e}+02$ 2.40540e+02 2.40540e+01 1.00000e-09 7.00000e-02 $2.40540 \mathrm{e}+022.40540 \mathrm{e}+022.40540 \mathrm{e}+01$ 1.00000e-09 7.00000e-02 $9.61108 \mathrm{e}+00$ 9.61108e+00 9.61108e-01 1.00000e-09 2.12000e-01 $9.61108 \mathrm{e}+009.61108 \mathrm{e}+00$ 9.61108e-01 1.00000e-09 2.12000e-01 9.61108e+00 9.61108e+00 9.61108e-01 1.00000e-09 2.12000e-01 Element: 582 \# of layers: 7

$\mathrm{Kx} \mathrm{Ky} \mathrm{Kz}$ Ss Por 8.02485e+02 8.02485e+02 8.02485e+01 1.00000e-09 7.00000e-02 8.02485e+02 8.02485e+02 8.02485e+01 1.00000e-09 7.00000e-02 $3.20654 \mathrm{e}+013.20654 \mathrm{e}+013.20654 \mathrm{e}+00$ 1.00000e-09 2.12000e-01 $3.20654 \mathrm{e}+013.20654 \mathrm{e}+013.20654 \mathrm{e}+00$ 1.00000e-09 2.12000e-01 $3.20654 \mathrm{e}+013.20654 \mathrm{e}+013.20654 \mathrm{e}+001.00000 \mathrm{e}-092.12000 \mathrm{e}-01$ $1.00000 \mathrm{e}-01$ 1.00000e-01 1.00000e-02 1.00000e-09 1.00000e-01 $1.00000 \mathrm{e}+001.00000 \mathrm{e}+001.00000 \mathrm{e}-011.00000 \mathrm{e}-091.00000 \mathrm{e}-01$ Element: 583 \# of layers: 6

$\mathrm{Kx} \mathrm{Ky} \mathrm{Kz}$ Ss Por 8.02485e+02 8.02485e+02 8.02485e+01 1.00000e-09 7.00000e-02 $3.20654 \mathrm{e}+013.20654 \mathrm{e}+013.20654 \mathrm{e}+001.00000 \mathrm{e}-092.12000 \mathrm{e}-01$ 3.20654e+01 3.20654e+01 3.20654e+00 1.00000e-09 2.12000e-01 $3.20654 \mathrm{e}+013.20654 \mathrm{e}+013.20654 \mathrm{e}+001.00000 \mathrm{e}-092.12000 \mathrm{e}-01$ $1.00000 \mathrm{e}-01$ 1.00000e-01 1.00000e-02 1.00000e-09 1.00000e-01 
$1.00000 \mathrm{e}+001.00000 \mathrm{e}+00$ 1.00000e-01 1.00000e-09 1.00000e-01

Element: 584 \# of layers: 5

$\mathrm{Kx} \mathrm{Ky} \mathrm{Kz}$ Ss Por

8.02485e+02 8.02485e+02 8.02485e+01 1.00000e-09 7.00000e-02

$3.20654 \mathrm{e}+013.20654 \mathrm{e}+013.20654 \mathrm{e}+001.00000 \mathrm{e}-092.12000 \mathrm{e}-01$

$3.20654 \mathrm{e}+013.20654 \mathrm{e}+013.20654 \mathrm{e}+001.00000 \mathrm{e}-092.12000 \mathrm{e}-01$

$1.00000 \mathrm{e}-01$ 1.00000e-01 1.00000e-02 1.00000e-09 1.00000e-01

$1.00000 \mathrm{e}+001.00000 \mathrm{e}+001.00000 \mathrm{e}-01$ 1.00000e-09 1.00000e-01

Element: 585 \# of layers: 6

$\mathrm{Kx} \mathrm{Ky} \mathrm{Kz}$ Ss Por

8.02485e+02 8.02485e+02 8.02485e+01 1.00000e-09 7.00000e-02

$3.20654 \mathrm{e}+013.20654 \mathrm{e}+013.20654 \mathrm{e}+001.00000 \mathrm{e}-092.12000 \mathrm{e}-01$

$3.20654 \mathrm{e}+013.20654 \mathrm{e}+013.20654 \mathrm{e}+001.00000 \mathrm{e}-092.12000 \mathrm{e}-01$

$3.20654 \mathrm{e}+013.20654 \mathrm{e}+013.20654 \mathrm{e}+001.00000 \mathrm{e}-092.12000 \mathrm{e}-01$

$1.00000 \mathrm{e}-01$ 1.00000e-01 1.00000e-02 1.00000e-09 1.00000e-01

$1.00000 \mathrm{e}+001.00000 \mathrm{e}+001.00000 \mathrm{e}-011.00000 \mathrm{e}-091.00000 \mathrm{e}-01$

Element: 586 \# of layers: 7

$\mathrm{Kx} \mathrm{Ky} \mathrm{Kz}$ Ss Por

8.02485e+02 8.02485e+02 8.02485e+01 1.00000e-09 7.00000e-02

8.02485e+02 8.02485e+02 8.02485e+01 1.00000e-09 7.00000e-02

$3.20654 \mathrm{e}+013.20654 \mathrm{e}+013.20654 \mathrm{e}+001.00000 \mathrm{e}-092.12000 \mathrm{e}-01$

$3.20654 \mathrm{e}+013.20654 \mathrm{e}+013.20654 \mathrm{e}+00$ 1.00000e-09 2.12000e-01

$3.20654 \mathrm{e}+013.20654 \mathrm{e}+013.20654 \mathrm{e}+00$ 1.00000e-09 2.12000e-01

$1.00000 \mathrm{e}-01$ 1.00000e-01 1.00000e-02 1.00000e-09 1.00000e-01

$1.00000 \mathrm{e}+001.00000 \mathrm{e}+001.00000 \mathrm{e}-011.00000 \mathrm{e}-091.00000 \mathrm{e}-01$

Element: 587 \# of layers: 4

$\mathrm{Kx} \mathrm{Ky} \mathrm{Kz}$ Ss Por

6.37281e+01 6.37281e+01 6.37281e+00 1.00000e-09 2.12000e-01

$6.37281 \mathrm{e}+016.37281 \mathrm{e}+016.37281 \mathrm{e}+001.00000 \mathrm{e}-092.12000 \mathrm{e}-01$

$1.00000 \mathrm{e}-011.00000 \mathrm{e}-011.00000 \mathrm{e}-021.00000 \mathrm{e}-091.00000 \mathrm{e}-01$

$1.00000 \mathrm{e}+001.00000 \mathrm{e}+00$ 1.00000e-01 1.00000e-09 1.00000e-01

Element: 588 \# of layers: 3

$\mathrm{Kx} \mathrm{Ky} \mathrm{Kz}$ Ss Por

6.37281e+01 6.37281e+01 6.37281e+00 1.00000e-09 2.12000e-01

$1.00000 \mathrm{e}-011.00000 \mathrm{e}-01$ 1.00000e-02 1.00000e-09 1.00000e-01

$1.00000 \mathrm{e}+001.00000 \mathrm{e}+001.00000 \mathrm{e}-01$ 1.00000e-09 1.00000e-01

Element: 589 \# of layers: 4

Kx Ky Kz Ss Por

$1.59495 \mathrm{e}+03$ 1.59495e+03 1.59495e+02 1.00000e-09 7.00000e-02

$6.37281 \mathrm{e}+016.37281 \mathrm{e}+016.37281 \mathrm{e}+00$ 1.00000e-09 2.12000e-01

1.00000e-01 1.00000e-01 1.00000e-02 1.00000e-09 1.00000e-01

$1.00000 \mathrm{e}+001.00000 \mathrm{e}+001.00000 \mathrm{e}-011.00000 \mathrm{e}-091.00000 \mathrm{e}-01$

Element: 590 \# of layers: 4

$\mathrm{Kx} \mathrm{Ky} \mathrm{Kz}$ Ss Por

$1.59495 \mathrm{e}+03$ 1.59495e+03 1.59495e+02 1.00000e-09 7.00000e-02

$6.37281 \mathrm{e}+016.37281 \mathrm{e}+016.37281 \mathrm{e}+001.00000 \mathrm{e}-092.12000 \mathrm{e}-01$ 
$1.00000 \mathrm{e}-01$ 1.00000e-01 1.00000e-02 1.00000e-09 1.00000e-01 $1.00000 \mathrm{e}+001.00000 \mathrm{e}+001.00000 \mathrm{e}-01$ 1.00000e-09 1.00000e-01

Element: 591 \# of layers: 4

$\mathrm{Kx} \mathrm{Ky} \mathrm{Kz}$ Ss Por

$1.59495 \mathrm{e}+031.59495 \mathrm{e}+03$ 1.59495e+02 1.00000e-09 7.00000e-02

$6.37281 \mathrm{e}+016.37281 \mathrm{e}+016.37281 \mathrm{e}+00$ 1.00000e-09 2.12000e-01

$1.00000 \mathrm{e}-02$ 1.00000e-02 1.00000e-03 1.00000e-09 1.00000e-01

$1.00000 \mathrm{e}+001.00000 \mathrm{e}+001.00000 \mathrm{e}-01$ 1.00000e-09 1.00000e-01

Element: 592 \# of layers: 4

$\mathrm{Kx} \mathrm{Ky} \mathrm{Kz}$ Ss Por

$1.59495 \mathrm{e}+03$ 1.59495e+03 1.59495e+02 1.00000e-09 7.00000e-02

$6.37281 \mathrm{e}+016.37281 \mathrm{e}+016.37281 \mathrm{e}+001.00000 \mathrm{e}-092.12000 \mathrm{e}-01$

$1.00000 \mathrm{e}-02$ 1.00000e-02 1.00000e-03 1.00000e-09 1.00000e-01

$1.00000 \mathrm{e}+001.00000 \mathrm{e}+001.00000 \mathrm{e}-011.00000 \mathrm{e}-091.00000 \mathrm{e}-01$

Element: 593 \# of layers: 5

Kx Ky Kz Ss Por

$1.59495 \mathrm{e}+03$ 1.59495e+03 1.59495e+02 1.00000e-09 7.00000e-02

$6.37281 \mathrm{e}+016.37281 \mathrm{e}+016.37281 \mathrm{e}+00$ 1.00000e-09 2.12000e-01

$6.37281 \mathrm{e}+016.37281 \mathrm{e}+016.37281 \mathrm{e}+00$ 1.00000e-09 2.12000e-01

$1.00000 \mathrm{e}-01$ 1.00000e-01 1.00000e-02 1.00000e-09 1.00000e-01

$1.00000 \mathrm{e}+001.00000 \mathrm{e}+001.00000 \mathrm{e}-011.00000 \mathrm{e}-091.00000 \mathrm{e}-01$

Element: 594 \# of layers: 4

$\mathrm{Kx} \mathrm{Ky} \mathrm{Kz}$ Ss Por

6.37281e+01 6.37281e+01 6.37281e+00 1.00000e-09 2.12000e-01

$6.37281 \mathrm{e}+016.37281 \mathrm{e}+016.37281 \mathrm{e}+001.00000 \mathrm{e}-092.12000 \mathrm{e}-01$

$1.00000 \mathrm{e}-01$ 1.00000e-01 1.00000e-02 1.00000e-09 1.00000e-01

$1.00000 \mathrm{e}+001.00000 \mathrm{e}+001.00000 \mathrm{e}-011.00000 \mathrm{e}-091.00000 \mathrm{e}-01$

Element: 595 \# of layers: 3

$\mathrm{Kx} \mathrm{Ky} \mathrm{Kz}$ Ss Por

6.37281e+01 6.37281e+01 6.37281e+00 1.00000e-09 2.12000e-01

$1.00000 \mathrm{e}-011.00000 \mathrm{e}-01$ 1.00000e-02 1.00000e-09 1.00000e-01

$1.00000 \mathrm{e}+001.00000 \mathrm{e}+001.00000 \mathrm{e}-011.00000 \mathrm{e}-091.00000 \mathrm{e}-01$

Element: 596 \# of layers: 4

$\mathrm{Kx} \mathrm{Ky} \mathrm{Kz}$ Ss Por

$1.30924 \mathrm{e}+03$ 1.30924e+03 1.30924e+02 1.00000e-09 7.00000e-02

$5.23136 \mathrm{e}+015.23136 \mathrm{e}+015.23136 \mathrm{e}+00$ 1.00000e-09 2.12000e-01

1.00000e-01 1.00000e-01 1.00000e-02 1.00000e-09 1.00000e-01

$1.00000 \mathrm{e}+001.00000 \mathrm{e}+001.00000 \mathrm{e}-011.00000 \mathrm{e}-091.00000 \mathrm{e}-01$

Element: 597 \# of layers: 6

$\mathrm{Kx} \mathrm{Ky} \mathrm{Kz}$ Ss Por

$1.30924 \mathrm{e}+03$ 1.30924e+03 1.30924e+02 1.00000e-09 7.00000e-02

$1.30924 \mathrm{e}+031.30924 \mathrm{e}+031.30924 \mathrm{e}+02$ 1.00000e-09 7.00000e-02

$5.23136 \mathrm{e}+015.23136 \mathrm{e}+015.23136 \mathrm{e}+001.00000 \mathrm{e}-092.12000 \mathrm{e}-01$

5.23136e+01 5.23136e+01 5.23136e+00 1.00000e-09 2.12000e-01

$1.00000 \mathrm{e}-02$ 1.00000e-02 1.00000e-03 1.00000e-09 1.00000e-01

$1.00000 \mathrm{e}+001.00000 \mathrm{e}+001.00000 \mathrm{e}-011.00000 \mathrm{e}-091.00000 \mathrm{e}-01$ 
Element: 598 \# of layers: 6

Kx Ky Kz Ss Por

$1.30924 \mathrm{e}+03$ 1.30924e+03 1.30924e+02 1.00000e-09 7.00000e-02

$1.30924 \mathrm{e}+031.30924 \mathrm{e}+03 \quad 1.30924 \mathrm{e}+021.00000 \mathrm{e}-097.00000 \mathrm{e}-02$

$5.23136 \mathrm{e}+015.23136 \mathrm{e}+015.23136 \mathrm{e}+001.00000 \mathrm{e}-092.12000 \mathrm{e}-01$

$5.23136 \mathrm{e}+015.23136 \mathrm{e}+015.23136 \mathrm{e}+001.00000 \mathrm{e}-092.12000 \mathrm{e}-01$

$1.00000 \mathrm{e}-021.00000 \mathrm{e}-02$ 1.00000e-03 1.00000e-09 1.00000e-01

$1.00000 \mathrm{e}+001.00000 \mathrm{e}+001.00000 \mathrm{e}-011.00000 \mathrm{e}-091.00000 \mathrm{e}-01$

Element: 599 \# of layers: 5

Kx Ky Kz Ss Por

$1.30924 \mathrm{e}+031.30924 \mathrm{e}+03 \quad 1.30924 \mathrm{e}+02$ 1.00000e-09 7.00000e-02

$5.23136 \mathrm{e}+015.23136 \mathrm{e}+015.23136 \mathrm{e}+00$ 1.00000e-09 2.12000e-01

$5.23136 \mathrm{e}+015.23136 \mathrm{e}+015.23136 \mathrm{e}+001.00000 \mathrm{e}-092.12000 \mathrm{e}-01$

$1.00000 \mathrm{e}-021.00000 \mathrm{e}-02$ 1.00000e-03 1.00000e-09 1.00000e-01

$1.00000 \mathrm{e}+001.00000 \mathrm{e}+001.00000 \mathrm{e}-011.00000 \mathrm{e}-091.00000 \mathrm{e}-01$

Element: 600 \# of layers: 6

Kx Ky Kz Ss Por

$1.30924 \mathrm{e}+03$ 1.30924e+03 1.30924e+02 1.00000e-09 7.00000e-02

$1.30924 \mathrm{e}+031.30924 \mathrm{e}+031.30924 \mathrm{e}+021.00000 \mathrm{e}-097.00000 \mathrm{e}-02$

$5.23136 \mathrm{e}+015.23136 \mathrm{e}+015.23136 \mathrm{e}+001.00000 \mathrm{e}-092.12000 \mathrm{e}-01$

$5.23136 \mathrm{e}+015.23136 \mathrm{e}+015.23136 \mathrm{e}+001.00000 \mathrm{e}-092.12000 \mathrm{e}-01$

$1.00000 \mathrm{e}-021.00000 \mathrm{e}-02$ 1.00000e-03 1.00000e-09 1.00000e-01

$1.00000 \mathrm{e}+001.00000 \mathrm{e}+001.00000 \mathrm{e}-011.00000 \mathrm{e}-091.00000 \mathrm{e}-01$

Element: 601 \# of layers: 5

Kx Ky Kz Ss Por

$1.30924 \mathrm{e}+031.30924 \mathrm{e}+03$ 1.30924e+02 1.00000e-09 7.00000e-02

$5.23136 \mathrm{e}+015.23136 \mathrm{e}+015.23136 \mathrm{e}+001.00000 \mathrm{e}-092.12000 \mathrm{e}-01$

$5.23136 \mathrm{e}+015.23136 \mathrm{e}+015.23136 \mathrm{e}+001.00000 \mathrm{e}-092.12000 \mathrm{e}-01$

$1.00000 \mathrm{e}-021.00000 \mathrm{e}-02$ 1.00000e-03 1.00000e-09 1.00000e-01

$1.00000 \mathrm{e}+001.00000 \mathrm{e}+001.00000 \mathrm{e}-011.00000 \mathrm{e}-091.00000 \mathrm{e}-01$

Element: 602 \# of layers: 5

Kx Ky Kz Ss Por

$1.30924 \mathrm{e}+031.30924 \mathrm{e}+03$ 1.30924e+02 1.00000e-09 7.00000e-02

$5.23136 \mathrm{e}+015.23136 \mathrm{e}+015.23136 \mathrm{e}+00$ 1.00000e-09 2.12000e-01

$5.23136 \mathrm{e}+015.23136 \mathrm{e}+015.23136 \mathrm{e}+001.00000 \mathrm{e}-092.12000 \mathrm{e}-01$

$1.00000 \mathrm{e}-021.00000 \mathrm{e}-02$ 1.00000e-03 1.00000e-09 1.00000e-01

$1.00000 \mathrm{e}+001.00000 \mathrm{e}+001.00000 \mathrm{e}-011.00000 \mathrm{e}-091.00000 \mathrm{e}-01$

Element: 603 \# of layers: 4

Kx Ky Kz Ss Por

$1.30924 \mathrm{e}+03$ 1.30924e+03 1.30924e+02 1.00000e-09 7.00000e-02

$5.23136 \mathrm{e}+015.23136 \mathrm{e}+015.23136 \mathrm{e}+001.00000 \mathrm{e}-092.12000 \mathrm{e}-01$

$1.00000 \mathrm{e}-02$ 1.00000e-02 1.00000e-03 1.00000e-09 1.00000e-01

$1.00000 \mathrm{e}+001.00000 \mathrm{e}+001.00000 \mathrm{e}-011.00000 \mathrm{e}-091.00000 \mathrm{e}-01$

Element: 604 \# of layers: 5

Kx Ky Kz Ss Por

$1.30924 \mathrm{e}+03$ 1.30924e+03 1.30924e+02 1.00000e-09 7.00000e-02 
$5.23136 \mathrm{e}+015.23136 \mathrm{e}+015.23136 \mathrm{e}+00$ 1.00000e-09 2.12000e-01 $5.23136 \mathrm{e}+015.23136 \mathrm{e}+015.23136 \mathrm{e}+00$ 1.00000e-09 2.12000e-01 $1.00000 \mathrm{e}-02$ 1.00000e-02 1.00000e-03 1.00000e-09 1.00000e-01 $1.00000 \mathrm{e}+001.00000 \mathrm{e}+001.00000 \mathrm{e}-011.00000 \mathrm{e}-091.00000 \mathrm{e}-01$ Element: 605 \# of layers: 4

Kx Ky Kz Ss Por

$8.94206 \mathrm{e}+028.94206 \mathrm{e}+028.94206 \mathrm{e}+01$ 1.00000e-09 7.00000e-02 $3.57285 \mathrm{e}+013.57285 \mathrm{e}+013.57285 \mathrm{e}+001.00000 \mathrm{e}-092.12000 \mathrm{e}-01$ $3.57285 \mathrm{e}+013.57285 \mathrm{e}+013.57285 \mathrm{e}+00$ 1.00000e-09 2.12000e-01 $1.00000 \mathrm{e}+001.00000 \mathrm{e}+001.00000 \mathrm{e}-011.00000 \mathrm{e}-091.00000 \mathrm{e}-01$ Element: 606 \# of layers: 3

Kx Ky Kz Ss Por

$8.94206 \mathrm{e}+028.94206 \mathrm{e}+028.94206 \mathrm{e}+01$ 1.00000e-09 7.00000e-02 $3.57285 \mathrm{e}+013.57285 \mathrm{e}+013.57285 \mathrm{e}+001.00000 \mathrm{e}-092.12000 \mathrm{e}-01$ $3.57285 \mathrm{e}+013.57285 \mathrm{e}+013.57285 \mathrm{e}+00$ 1.00000e-09 2.12000e-01 Element: 607 \# of layers: 3

Kx Ky Kz Ss Por

$8.94206 \mathrm{e}+028.94206 \mathrm{e}+028.94206 \mathrm{e}+01$ 1.00000e-09 7.00000e-02 $3.57285 \mathrm{e}+013.57285 \mathrm{e}+013.57285 \mathrm{e}+001.00000 \mathrm{e}-092.12000 \mathrm{e}-01$ $3.57285 \mathrm{e}+013.57285 \mathrm{e}+013.57285 \mathrm{e}+00$ 1.00000e-09 2.12000e-01 Element: 608 \# of layers: 3

Kx Ky Kz Ss Por

$8.94206 \mathrm{e}+028.94206 \mathrm{e}+028.94206 \mathrm{e}+01$ 1.00000e-09 7.00000e-02 $3.57285 \mathrm{e}+013.57285 \mathrm{e}+013.57285 \mathrm{e}+001.00000 \mathrm{e}-092.12000 \mathrm{e}-01$ $3.57285 \mathrm{e}+013.57285 \mathrm{e}+013.57285 \mathrm{e}+001.00000 \mathrm{e}-092.12000 \mathrm{e}-01$ Element: 609 \# of layers: 3

Kx Ky Kz Ss Por

$8.94206 \mathrm{e}+028.94206 \mathrm{e}+028.94206 \mathrm{e}+01$ 1.00000e-09 7.00000e-02 $3.57285 \mathrm{e}+013.57285 \mathrm{e}+013.57285 \mathrm{e}+001.00000 \mathrm{e}-092.12000 \mathrm{e}-01$ $3.57285 \mathrm{e}+013.57285 \mathrm{e}+013.57285 \mathrm{e}+001.00000 \mathrm{e}-092.12000 \mathrm{e}-01$ Element: 610 \# of layers: 2

Kx Ky Kz Ss Por

$3.57285 \mathrm{e}+013.57285 \mathrm{e}+013.57285 \mathrm{e}+00$ 1.00000e-09 2.12000e-01

$3.57285 \mathrm{e}+013.57285 \mathrm{e}+013.57285 \mathrm{e}+00$ 1.00000e-09 2.12000e-01

Element: 611 \# of layers: 3

Kx Ky Kz Ss Por

$8.94206 \mathrm{e}+028.94206 \mathrm{e}+028.94206 \mathrm{e}+01$ 1.00000e-09 7.00000e-02 $3.57285 \mathrm{e}+013.57285 \mathrm{e}+013.57285 \mathrm{e}+001.00000 \mathrm{e}-092.12000 \mathrm{e}-01$ $3.57285 \mathrm{e}+013.57285 \mathrm{e}+013.57285 \mathrm{e}+00$ 1.00000e-09 2.12000e-01 Element: 612 \# of layers: 2

Kx Ky Kz Ss Por

$3.57285 \mathrm{e}+013.57285 \mathrm{e}+013.57285 \mathrm{e}+00$ 1.00000e-09 2.12000e-01

$3.57285 \mathrm{e}+013.57285 \mathrm{e}+013.57285 \mathrm{e}+00$ 1.00000e-09 2.12000e-01

Element: 613 \# of layers: 3

Kx Ky Kz Ss Por

8.94206e+02 8.94206e+02 8.94206e+01 1.00000e-09 7.00000e-02 
$3.57285 \mathrm{e}+013.57285 \mathrm{e}+013.57285 \mathrm{e}+00$ 1.00000e-09 2.12000e-01 $3.57285 \mathrm{e}+013.57285 \mathrm{e}+013.57285 \mathrm{e}+00$ 1.00000e-09 2.12000e-01 Element: 614 \# of layers: 5

Kx Ky Kz Ss Por

$4.19488 \mathrm{e}+02$ 4.19488e+02 4.19488e+01 1.00000e-09 7.00000e-02 $4.19488 \mathrm{e}+024.19488 \mathrm{e}+024.19488 \mathrm{e}+01$ 1.00000e-09 7.00000e-02 $1.67611 \mathrm{e}+011.67611 \mathrm{e}+011.67611 \mathrm{e}+001.00000 \mathrm{e}-092.12000 \mathrm{e}-01$ $1.67611 \mathrm{e}+011.67611 \mathrm{e}+011.67611 \mathrm{e}+001.00000 \mathrm{e}-092.12000 \mathrm{e}-01$ $1.67611 \mathrm{e}+011.67611 \mathrm{e}+011.67611 \mathrm{e}+001.00000 \mathrm{e}-092.12000 \mathrm{e}-01$ Element: 615 \# of layers: 5

Kx Ky Kz Ss Por

$4.19488 \mathrm{e}+02$ 4.19488e+02 4.19488e+01 1.00000e-09 7.00000e-02

$4.19488 \mathrm{e}+024.19488 \mathrm{e}+024.19488 \mathrm{e}+01$ 1.00000e-09 7.00000e-02 $1.67611 \mathrm{e}+011.67611 \mathrm{e}+011.67611 \mathrm{e}+001.00000 \mathrm{e}-092.12000 \mathrm{e}-01$ $1.67611 \mathrm{e}+011.67611 \mathrm{e}+011.67611 \mathrm{e}+001.00000 \mathrm{e}-092.12000 \mathrm{e}-01$ $1.67611 \mathrm{e}+011.67611 \mathrm{e}+011.67611 \mathrm{e}+001.00000 \mathrm{e}-092.12000 \mathrm{e}-01$ Element: 616 \# of layers: 5

Kx Ky Kz Ss Por

$4.19488 \mathrm{e}+02$ 4.19488e+02 4.19488e+01 1.00000e-09 7.00000e-02 $4.19488 \mathrm{e}+024.19488 \mathrm{e}+024.19488 \mathrm{e}+01$ 1.00000e-09 7.00000e-02 $1.67611 \mathrm{e}+011.67611 \mathrm{e}+011.67611 \mathrm{e}+001.00000 \mathrm{e}-092.12000 \mathrm{e}-01$ $1.67611 \mathrm{e}+011.67611 \mathrm{e}+011.67611 \mathrm{e}+001.00000 \mathrm{e}-092.12000 \mathrm{e}-01$ $1.67611 \mathrm{e}+011.67611 \mathrm{e}+011.67611 \mathrm{e}+001.00000 \mathrm{e}-092.12000 \mathrm{e}-01$ Element: 617 \# of layers: 8

Kx Ky Kz Ss Por

$5.30392 \mathrm{e}+02$ 5.30392e+02 5.30392e+01 1.00000e-09 7.00000e-02 $5.30392 \mathrm{e}+025.30392 \mathrm{e}+025.30392 \mathrm{e}+011.00000 \mathrm{e}-09$ 7.00000e-02 $2.11925 \mathrm{e}+012.11925 \mathrm{e}+012.11925 \mathrm{e}+00$ 1.00000e-09 2.12000e-01 $2.11925 \mathrm{e}+012.11925 \mathrm{e}+012.11925 \mathrm{e}+001.00000 \mathrm{e}-092.12000 \mathrm{e}-01$ $2.11925 \mathrm{e}+012.11925 \mathrm{e}+012.11925 \mathrm{e}+00$ 1.00000e-09 2.12000e-01 $2.11925 \mathrm{e}+012.11925 \mathrm{e}+012.11925 \mathrm{e}+001.00000 \mathrm{e}-092.12000 \mathrm{e}-01$ $1.00000 \mathrm{e}-011.00000 \mathrm{e}-011.00000 \mathrm{e}-021.00000 \mathrm{e}-09$ 1.00000e-01 $1.00000 \mathrm{e}+001.00000 \mathrm{e}+001.00000 \mathrm{e}-011.00000 \mathrm{e}-091.00000 \mathrm{e}-01$ Element: 618 \# of layers: 7

Kx Ky Kz Ss Por

$5.30392 \mathrm{e}+025.30392 \mathrm{e}+025.30392 \mathrm{e}+01$ 1.00000e-09 7.00000e-02 $2.11925 \mathrm{e}+012.11925 \mathrm{e}+012.11925 \mathrm{e}+00$ 1.00000e-09 2.12000e-01 $2.11925 \mathrm{e}+012.11925 \mathrm{e}+012.11925 \mathrm{e}+00$ 1.00000e-09 2.12000e-01 $2.11925 \mathrm{e}+012.11925 \mathrm{e}+012.11925 \mathrm{e}+00$ 1.00000e-09 2.12000e-01 $2.11925 \mathrm{e}+012.11925 \mathrm{e}+012.11925 \mathrm{e}+00$ 1.00000e-09 2.12000e-01 $1.00000 \mathrm{e}-011.00000 \mathrm{e}-011.00000 \mathrm{e}-021.00000 \mathrm{e}-091.00000 \mathrm{e}-01$ $1.00000 \mathrm{e}+001.00000 \mathrm{e}+001.00000 \mathrm{e}-011.00000 \mathrm{e}-091.00000 \mathrm{e}-01$ Element: 619 \# of layers: 6

Kx Ky Kz Ss Por 5.30392e+02 5.30392e+02 5.30392e+01 1.00000e-09 7.00000e-02 $2.11925 \mathrm{e}+012.11925 \mathrm{e}+012.11925 \mathrm{e}+001.00000 \mathrm{e}-092.12000 \mathrm{e}-01$ 
$2.11925 \mathrm{e}+012.11925 \mathrm{e}+012.11925 \mathrm{e}+00$ 1.00000e-09 2.12000e-01 $2.11925 \mathrm{e}+012.11925 \mathrm{e}+012.11925 \mathrm{e}+00$ 1.00000e-09 2.12000e-01 $1.00000 \mathrm{e}-011.00000 \mathrm{e}-011.00000 \mathrm{e}-021.00000 \mathrm{e}-091.00000 \mathrm{e}-01$ $1.00000 \mathrm{e}+001.00000 \mathrm{e}+001.00000 \mathrm{e}-011.00000 \mathrm{e}-091.00000 \mathrm{e}-01$ Element: 620 \# of layers: 7

Kx Ky Kz Ss Por

5.30392e+02 5.30392e+02 5.30392e+01 1.00000e-09 7.00000e-02 $2.11925 \mathrm{e}+012.11925 \mathrm{e}+012.11925 \mathrm{e}+001.00000 \mathrm{e}-092.12000 \mathrm{e}-01$ $2.11925 \mathrm{e}+012.11925 \mathrm{e}+012.11925 \mathrm{e}+00$ 1.00000e-09 2.12000e-01 $2.11925 \mathrm{e}+012.11925 \mathrm{e}+012.11925 \mathrm{e}+001.00000 \mathrm{e}-092.12000 \mathrm{e}-01$ $2.11925 \mathrm{e}+012.11925 \mathrm{e}+012.11925 \mathrm{e}+001.00000 \mathrm{e}-092.12000 \mathrm{e}-01$ $1.00000 \mathrm{e}-011.00000 \mathrm{e}-011.00000 \mathrm{e}-021.00000 \mathrm{e}-091.00000 \mathrm{e}-01$ $1.00000 \mathrm{e}+001.00000 \mathrm{e}+001.00000 \mathrm{e}-011.00000 \mathrm{e}-091.00000 \mathrm{e}-01$ Element: 621 \# of layers: 7

Kx Ky Kz Ss Por

$5.30392 \mathrm{e}+02$ 5.30392e+02 5.30392e+01 1.00000e-09 7.00000e-02 $5.30392 \mathrm{e}+02$ 5.30392e+02 5.30392e+01 1.00000e-09 7.00000e-02 $2.11925 \mathrm{e}+012.11925 \mathrm{e}+012.11925 \mathrm{e}+00$ 1.00000e-09 2.12000e-01 $2.11925 \mathrm{e}+012.11925 \mathrm{e}+012.11925 \mathrm{e}+00$ 1.00000e-09 2.12000e-01 $2.11925 \mathrm{e}+012.11925 \mathrm{e}+012.11925 \mathrm{e}+00$ 1.00000e-09 2.12000e-01 $2.11925 \mathrm{e}+012.11925 \mathrm{e}+012.11925 \mathrm{e}+001.00000 \mathrm{e}-092.12000 \mathrm{e}-01$ $1.00000 \mathrm{e}+001.00000 \mathrm{e}+001.00000 \mathrm{e}-011.00000 \mathrm{e}-091.00000 \mathrm{e}-01$

Element: 622 \# of layers: 6

Kx Ky Kz Ss Por

$2.16465 \mathrm{e}+032.16465 \mathrm{e}+032.16465 \mathrm{e}+02$ 1.00000e-09 7.00000e-02 $8.64941 \mathrm{e}+018.64941 \mathrm{e}+018.64941 \mathrm{e}+001.00000 \mathrm{e}-092.12000 \mathrm{e}-01$ $8.64941 \mathrm{e}+018.64941 \mathrm{e}+018.64941 \mathrm{e}+001.00000 \mathrm{e}-092.12000 \mathrm{e}-01$ $8.64941 \mathrm{e}+018.64941 \mathrm{e}+018.64941 \mathrm{e}+00$ 1.00000e-09 2.12000e-01 $1.00000 \mathrm{e}-011.00000 \mathrm{e}-011.00000 \mathrm{e}-021.00000 \mathrm{e}-091.00000 \mathrm{e}-01$ $1.00000 \mathrm{e}+001.00000 \mathrm{e}+001.00000 \mathrm{e}-011.00000 \mathrm{e}-091.00000 \mathrm{e}-01$ Element: 623 \# of layers: 6

Kx Ky Kz Ss Por

$2.16465 \mathrm{e}+032.16465 \mathrm{e}+032.16465 \mathrm{e}+02$ 1.00000e-09 7.00000e-02 $8.64941 \mathrm{e}+018.64941 \mathrm{e}+018.64941 \mathrm{e}+001.00000 \mathrm{e}-092.12000 \mathrm{e}-01$ $8.64941 \mathrm{e}+018.64941 \mathrm{e}+018.64941 \mathrm{e}+001.00000 \mathrm{e}-092.12000 \mathrm{e}-01$ $8.64941 \mathrm{e}+018.64941 \mathrm{e}+018.64941 \mathrm{e}+001.00000 \mathrm{e}-092.12000 \mathrm{e}-01$ $1.00000 \mathrm{e}-011.00000 \mathrm{e}-011.00000 \mathrm{e}-021.00000 \mathrm{e}-091.00000 \mathrm{e}-01$ $1.00000 \mathrm{e}+001.00000 \mathrm{e}+001.00000 \mathrm{e}-011.00000 \mathrm{e}-091.00000 \mathrm{e}-01$ Element: 624 \# of layers: 5

Kx Ky Kz Ss Por

$2.16465 \mathrm{e}+032.16465 \mathrm{e}+032.16465 \mathrm{e}+02$ 1.00000e-09 7.00000e-02 $8.64941 \mathrm{e}+018.64941 \mathrm{e}+018.64941 \mathrm{e}+001.00000 \mathrm{e}-092.12000 \mathrm{e}-01$ $8.64941 \mathrm{e}+018.64941 \mathrm{e}+018.64941 \mathrm{e}+00$ 1.00000e-09 2.12000e-01 $1.00000 \mathrm{e}-011.00000 \mathrm{e}-011.00000 \mathrm{e}-021.00000 \mathrm{e}-091.00000 \mathrm{e}-01$ $1.00000 \mathrm{e}+001.00000 \mathrm{e}+001.00000 \mathrm{e}-011.00000 \mathrm{e}-091.00000 \mathrm{e}-01$ Element: 625 \# of layers: 6 
$\mathrm{Kx} \mathrm{Ky} \mathrm{Kz} \mathrm{Ss} \mathrm{Por}$

2.16465e+03 2.16465e+03 2.16465e+02 1.00000e-09 7.00000e-02

8.64941e+01 8.64941e+01 8.64941e+00 1.00000e-09 2.12000e-01

$8.64941 \mathrm{e}+018.64941 \mathrm{e}+018.64941 \mathrm{e}+001.00000 \mathrm{e}-092.12000 \mathrm{e}-01$

$8.64941 \mathrm{e}+018.64941 \mathrm{e}+018.64941 \mathrm{e}+001.00000 \mathrm{e}-092.12000 \mathrm{e}-01$

$1.00000 \mathrm{e}-011.00000 \mathrm{e}-01$ 1.00000e-02 1.00000e-09 1.00000e-01

$1.00000 \mathrm{e}+001.00000 \mathrm{e}+001.00000 \mathrm{e}-01$ 1.00000e-09 1.00000e-01

Element: 626 \# of layers: 6

$\mathrm{Kx} \mathrm{Ky} \mathrm{Kz}$ Ss Por

2.16465e+03 2.16465e+03 2.16465e+02 1.00000e-09 7.00000e-02

8.64941e+01 8.64941e+01 8.64941e+00 1.00000e-09 2.12000e-01

$8.64941 \mathrm{e}+018.64941 \mathrm{e}+018.64941 \mathrm{e}+001.00000 \mathrm{e}-092.12000 \mathrm{e}-01$

$8.64941 \mathrm{e}+018.64941 \mathrm{e}+018.64941 \mathrm{e}+001.00000 \mathrm{e}-09$ 2.12000e-01

$1.00000 \mathrm{e}-011.00000 \mathrm{e}-01$ 1.00000e-02 1.00000e-09 1.00000e-01

$1.00000 \mathrm{e}+001.00000 \mathrm{e}+001.00000 \mathrm{e}-01$ 1.00000e-09 1.00000e-01

Element: 627 \# of layers: 6

$\mathrm{Kx} \mathrm{Ky} \mathrm{Kz}$ Ss Por

$2.16465 \mathrm{e}+032.16465 \mathrm{e}+032.16465 \mathrm{e}+02$ 1.00000e-09 7.00000e-02

$8.64941 \mathrm{e}+018.64941 \mathrm{e}+018.64941 \mathrm{e}+00$ 1.00000e-09 2.12000e-01

$8.64941 \mathrm{e}+018.64941 \mathrm{e}+018.64941 \mathrm{e}+001.00000 \mathrm{e}-092.12000 \mathrm{e}-01$

$8.64941 \mathrm{e}+018.64941 \mathrm{e}+018.64941 \mathrm{e}+001.00000 \mathrm{e}-092.12000 \mathrm{e}-01$

$1.00000 \mathrm{e}-011.00000 \mathrm{e}-011.00000 \mathrm{e}-021.00000 \mathrm{e}-091.00000 \mathrm{e}-01$

$1.00000 \mathrm{e}+001.00000 \mathrm{e}+001.00000 \mathrm{e}-01$ 1.00000e-09 1.00000e-01

Element: 628 \# of layers: 6

$\mathrm{Kx} \mathrm{Ky} \mathrm{Kz}$ Ss Por

$2.16465 \mathrm{e}+032.16465 \mathrm{e}+032.16465 \mathrm{e}+02$ 1.00000e-09 7.00000e-02

$8.64941 \mathrm{e}+018.64941 \mathrm{e}+018.64941 \mathrm{e}+001.00000 \mathrm{e}-092.12000 \mathrm{e}-01$

8.64941e+01 8.64941e+01 8.64941e+00 1.00000e-09 2.12000e-01

$8.64941 \mathrm{e}+018.64941 \mathrm{e}+018.64941 \mathrm{e}+001.00000 \mathrm{e}-092.12000 \mathrm{e}-01$

1.00000e-01 1.00000e-01 1.00000e-02 1.00000e-09 1.00000e-01

$1.00000 \mathrm{e}+001.00000 \mathrm{e}+001.00000 \mathrm{e}-011.00000 \mathrm{e}-091.00000 \mathrm{e}-01$

Element: 629 \# of layers: 6

$\mathrm{Kx} \mathrm{Ky} \mathrm{Kz}$ Ss Por

2.16465e+03 2.16465e+03 2.16465e+02 1.00000e-09 7.00000e-02

$8.64941 \mathrm{e}+018.64941 \mathrm{e}+018.64941 \mathrm{e}+00$ 1.00000e-09 2.12000e-01

$8.64941 \mathrm{e}+018.64941 \mathrm{e}+018.64941 \mathrm{e}+00$ 1.00000e-09 2.12000e-01

$8.64941 \mathrm{e}+018.64941 \mathrm{e}+018.64941 \mathrm{e}+001.00000 \mathrm{e}-092.12000 \mathrm{e}-01$

$1.00000 \mathrm{e}-01$ 1.00000e-01 1.00000e-02 1.00000e-09 1.00000e-01

$1.00000 \mathrm{e}+001.00000 \mathrm{e}+001.00000 \mathrm{e}-011.00000 \mathrm{e}-091.00000 \mathrm{e}-01$

Element: 630 \# of layers: 6

$\mathrm{Kx} \mathrm{Ky} \mathrm{Kz}$ Ss Por

2.16465e+03 2.16465e+03 2.16465e+02 1.00000e-09 7.00000e-02

$8.64941 \mathrm{e}+018.64941 \mathrm{e}+018.64941 \mathrm{e}+001.00000 \mathrm{e}-092.12000 \mathrm{e}-01$

8.64941e+01 8.64941e+01 8.64941e+00 1.00000e-09 2.12000e-01

$8.64941 \mathrm{e}+018.64941 \mathrm{e}+018.64941 \mathrm{e}+00$ 1.00000e-09 2.12000e-01

$1.00000 \mathrm{e}-01$ 1.00000e-01 1.00000e-02 1.00000e-09 1.00000e-01 
$1.00000 \mathrm{e}+001.00000 \mathrm{e}+00$ 1.00000e-01 1.00000e-09 1.00000e-01

Element: 631 \# of layers: 5

$\mathrm{Kx} \mathrm{Ky} \mathrm{Kz}$ Ss Por

$2.08113 e+03$ 2.08113e+03 2.08113e+02 1.00000e-09 7.00000e-02

$8.31550 \mathrm{e}+018.31550 \mathrm{e}+018.31550 \mathrm{e}+001.00000 \mathrm{e}-092.12000 \mathrm{e}-01$

$8.31550 \mathrm{e}+018.31550 \mathrm{e}+018.31550 \mathrm{e}+001.00000 \mathrm{e}-092.12000 \mathrm{e}-01$

$1.00000 \mathrm{e}-01$ 1.00000e-01 1.00000e-02 1.00000e-09 1.00000e-01

$1.00000 \mathrm{e}+001.00000 \mathrm{e}+001.00000 \mathrm{e}-01$ 1.00000e-09 1.00000e-01

Element: 632 \# of layers: 5

$\mathrm{Kx} \mathrm{Ky} \mathrm{Kz}$ Ss Por

2.08113e+03 2.08113e+03 2.08113e+02 1.00000e-09 7.00000e-02

$8.31550 \mathrm{e}+018.31550 \mathrm{e}+018.31550 \mathrm{e}+00$ 1.00000e-09 2.12000e-01

$8.31550 \mathrm{e}+018.31550 \mathrm{e}+018.31550 \mathrm{e}+001.00000 \mathrm{e}-092.12000 \mathrm{e}-01$

$1.00000 \mathrm{e}-02$ 1.00000e-02 1.00000e-03 1.00000e-09 1.00000e-01

$1.00000 \mathrm{e}+001.00000 \mathrm{e}+001.00000 \mathrm{e}-011.00000 \mathrm{e}-091.00000 \mathrm{e}-01$

Element: 633 \# of layers: 5

$\mathrm{Kx} \mathrm{Ky} \mathrm{Kz}$ Ss Por

2.08113e+03 2.08113e+03 2.08113e+02 1.00000e-09 7.00000e-02

$8.31550 \mathrm{e}+018.31550 \mathrm{e}+018.31550 \mathrm{e}+001.00000 \mathrm{e}-092.12000 \mathrm{e}-01$

$8.31550 \mathrm{e}+018.31550 \mathrm{e}+018.31550 \mathrm{e}+00$ 1.00000e-09 2.12000e-01

$1.00000 \mathrm{e}-02$ 1.00000e-02 1.00000e-03 1.00000e-09 1.00000e-01

$1.00000 \mathrm{e}+001.00000 \mathrm{e}+001.00000 \mathrm{e}-011.00000 \mathrm{e}-091.00000 \mathrm{e}-01$

Element: 634 \# of layers: 5

Kx Ky Kz Ss Por

$2.08113 e+032.08113 e+032.08113 e+021.00000 e-09$ 7.00000e-02

$8.31550 \mathrm{e}+018.31550 \mathrm{e}+018.31550 \mathrm{e}+001.00000 \mathrm{e}-092.12000 \mathrm{e}-01$

$8.31550 \mathrm{e}+018.31550 \mathrm{e}+018.31550 \mathrm{e}+001.00000 \mathrm{e}-092.12000 \mathrm{e}-01$

1.00000e-02 1.00000e-02 1.00000e-03 1.00000e-09 1.00000e-01

$1.00000 \mathrm{e}+001.00000 \mathrm{e}+001.00000 \mathrm{e}-011.00000 \mathrm{e}-091.00000 \mathrm{e}-01$

Element: 635 \# of layers: 6

$\mathrm{Kx} \mathrm{Ky} \mathrm{Kz}$ Ss Por

2.08113e+03 2.08113e+03 2.08113e+02 1.00000e-09 7.00000e-02

$8.31550 \mathrm{e}+018.31550 \mathrm{e}+018.31550 \mathrm{e}+00$ 1.00000e-09 2.12000e-01

$8.31550 \mathrm{e}+018.31550 \mathrm{e}+018.31550 \mathrm{e}+001.00000 \mathrm{e}-09$ 2.12000e-01

$8.31550 \mathrm{e}+018.31550 \mathrm{e}+018.31550 \mathrm{e}+00$ 1.00000e-09 2.12000e-01

$1.00000 \mathrm{e}-02$ 1.00000e-02 1.00000e-03 1.00000e-09 1.00000e-01

$1.00000 \mathrm{e}+001.00000 \mathrm{e}+001.00000 \mathrm{e}-011.00000 \mathrm{e}-091.00000 \mathrm{e}-01$

Element: 636 \# of layers: 6

$\mathrm{Kx} \mathrm{Ky} \mathrm{Kz}$ Ss Por

2.08113e+03 2.08113e+03 2.08113e+02 1.00000e-09 7.00000e-02

$8.31550 \mathrm{e}+018.31550 \mathrm{e}+018.31550 \mathrm{e}+001.00000 \mathrm{e}-092.12000 \mathrm{e}-01$

$8.31550 \mathrm{e}+018.31550 \mathrm{e}+018.31550 \mathrm{e}+001.00000 \mathrm{e}-092.12000 \mathrm{e}-01$

$8.31550 \mathrm{e}+018.31550 \mathrm{e}+018.31550 \mathrm{e}+00$ 1.00000e-09 2.12000e-01

$1.00000 \mathrm{e}-02$ 1.00000e-02 1.00000e-03 1.00000e-09 1.00000e-01

$1.00000 \mathrm{e}+001.00000 \mathrm{e}+001.00000 \mathrm{e}-011.00000 \mathrm{e}-09$ 1.00000e-01

Element: 637 \# of layers: 6 
Kx Ky Kz Ss Por

2.08113e+03 2.08113e+03 2.08113e+02 1.00000e-09 7.00000e-02

$8.31550 \mathrm{e}+018.31550 \mathrm{e}+018.31550 \mathrm{e}+001.00000 \mathrm{e}-092.12000 \mathrm{e}-01$

$8.31550 \mathrm{e}+018.31550 \mathrm{e}+018.31550 \mathrm{e}+001.00000 \mathrm{e}-092.12000 \mathrm{e}-01$

$8.31550 \mathrm{e}+018.31550 \mathrm{e}+018.31550 \mathrm{e}+001.00000 \mathrm{e}-092.12000 \mathrm{e}-01$ $1.00000 \mathrm{e}-02$ 1.00000e-02 1.00000e-03 1.00000e-09 1.00000e-01

$1.00000 \mathrm{e}+001.00000 \mathrm{e}+001.00000 \mathrm{e}-01$ 1.00000e-09 1.00000e-01

Element: 638 \# of layers: 5

$\mathrm{Kx} \mathrm{Ky} \mathrm{Kz}$ Ss Por

2.08113e+03 2.08113e+03 2.08113e+02 1.00000e-09 7.00000e-02

$8.31550 \mathrm{e}+018.31550 \mathrm{e}+018.31550 \mathrm{e}+001.00000 \mathrm{e}-09$ 2.12000e-01

$8.31550 \mathrm{e}+018.31550 \mathrm{e}+018.31550 \mathrm{e}+001.00000 \mathrm{e}-092.12000 \mathrm{e}-01$

$1.00000 \mathrm{e}-021.00000 \mathrm{e}-021.00000 \mathrm{e}-031.00000 \mathrm{e}-091.00000 \mathrm{e}-01$

$1.00000 \mathrm{e}+001.00000 \mathrm{e}+001.00000 \mathrm{e}-011.00000 \mathrm{e}-091.00000 \mathrm{e}-01$

Element: 639 \# of layers: 5

$\mathrm{Kx} \mathrm{Ky} \mathrm{Kz}$ Ss Por

2.08113e+03 2.08113e+03 2.08113e+02 1.00000e-09 7.00000e-02

$8.31550 \mathrm{e}+018.31550 \mathrm{e}+018.31550 \mathrm{e}+001.00000 \mathrm{e}-092.12000 \mathrm{e}-01$

$8.31550 \mathrm{e}+018.31550 \mathrm{e}+018.31550 \mathrm{e}+00$ 1.00000e-09 2.12000e-01

$1.00000 \mathrm{e}-021.00000 \mathrm{e}-021.00000 \mathrm{e}-031.00000 \mathrm{e}-091.00000 \mathrm{e}-01$

$1.00000 \mathrm{e}+001.00000 \mathrm{e}+001.00000 \mathrm{e}-011.00000 \mathrm{e}-091.00000 \mathrm{e}-01$

Element: 640 \# of layers: 5

$\mathrm{Kx} \mathrm{Ky} \mathrm{Kz}$ Ss Por

$1.63099 \mathrm{e}+03$ 1.63099e+03 1.63099e+02 1.00000e-09 7.00000e-02

$6.51681 \mathrm{e}+016.51681 \mathrm{e}+016.51681 \mathrm{e}+001.00000 \mathrm{e}-092.12000 \mathrm{e}-01$

$6.51681 \mathrm{e}+016.51681 \mathrm{e}+016.51681 \mathrm{e}+001.00000 \mathrm{e}-092.12000 \mathrm{e}-01$

$1.00000 \mathrm{e}-02$ 1.00000e-02 1.00000e-03 1.00000e-09 1.00000e-01

$1.00000 \mathrm{e}+001.00000 \mathrm{e}+001.00000 \mathrm{e}-011.00000 \mathrm{e}-09$ 1.00000e-01

Element: 641 \# of layers: 5

$\mathrm{Kx} \mathrm{Ky} \mathrm{Kz}$ Ss Por

$1.63099 \mathrm{e}+03$ 1.63099e+03 1.63099e+02 1.00000e-09 7.00000e-02

$6.51681 \mathrm{e}+016.51681 \mathrm{e}+016.51681 \mathrm{e}+00$ 1.00000e-09 2.12000e-01

$6.51681 \mathrm{e}+016.51681 \mathrm{e}+016.51681 \mathrm{e}+001.00000 \mathrm{e}-092.12000 \mathrm{e}-01$

$1.00000 \mathrm{e}-02$ 1.00000e-02 1.00000e-03 1.00000e-09 1.00000e-01

$1.00000 \mathrm{e}+001.00000 \mathrm{e}+001.00000 \mathrm{e}-01$ 1.00000e-09 1.00000e-01

Element: 642 \# of layers: 6

Kx Ky Kz Ss Por

$1.63099 \mathrm{e}+03$ 1.63099e+03 1.63099e+02 1.00000e-09 7.00000e-02

$1.63099 \mathrm{e}+031.63099 \mathrm{e}+03$ 1.63099e+02 1.00000e-09 7.00000e-02

$6.51681 \mathrm{e}+016.51681 \mathrm{e}+016.51681 \mathrm{e}+001.00000 \mathrm{e}-092.12000 \mathrm{e}-01$

$6.51681 \mathrm{e}+016.51681 \mathrm{e}+016.51681 \mathrm{e}+001.00000 \mathrm{e}-092.12000 \mathrm{e}-01$

$1.00000 \mathrm{e}-02$ 1.00000e-02 1.00000e-03 1.00000e-09 1.00000e-01

$1.00000 \mathrm{e}+001.00000 \mathrm{e}+001.00000 \mathrm{e}-011.00000 \mathrm{e}-091.00000 \mathrm{e}-01$

Element: 643 \# of layers: 3

$\mathrm{Kx} \mathrm{Ky} \mathrm{Kz}$ Ss Por

$1.63099 \mathrm{e}+03$ 1.63099e+03 1.63099e+02 1.00000e-09 7.00000e-02 
$6.51681 \mathrm{e}+016.51681 \mathrm{e}+016.51681 \mathrm{e}+00$ 1.00000e-09 2.12000e-01 6.51681e+01 6.51681e+01 6.51681e+00 1.00000e-09 2.12000e-01

Element: 644 \# of layers: 6

$\mathrm{Kx} \mathrm{Ky} \mathrm{Kz}$ Ss Por

$1.63099 \mathrm{e}+031.63099 \mathrm{e}+03$ 1.63099e+02 1.00000e-09 7.00000e-02

$6.51681 \mathrm{e}+016.51681 \mathrm{e}+016.51681 \mathrm{e}+001.00000 \mathrm{e}-092.12000 \mathrm{e}-01$

$6.51681 \mathrm{e}+016.51681 \mathrm{e}+016.51681 \mathrm{e}+001.00000 \mathrm{e}-092.12000 \mathrm{e}-01$

$6.51681 \mathrm{e}+016.51681 \mathrm{e}+016.51681 \mathrm{e}+001.00000 \mathrm{e}-092.12000 \mathrm{e}-01$

$1.00000 \mathrm{e}-02$ 1.00000e-02 1.00000e-03 1.00000e-09 1.00000e-01

$1.00000 \mathrm{e}+001.00000 \mathrm{e}+001.00000 \mathrm{e}-011.00000 \mathrm{e}-091.00000 \mathrm{e}-01$

Element: 645 \# of layers: 6

$\mathrm{Kx} \mathrm{Ky} \mathrm{Kz}$ Ss Por

$1.63099 \mathrm{e}+03$ 1.63099e+03 1.63099e+02 1.00000e-09 7.00000e-02

$6.51681 \mathrm{e}+016.51681 \mathrm{e}+016.51681 \mathrm{e}+001.00000 \mathrm{e}-092.12000 \mathrm{e}-01$

$6.51681 \mathrm{e}+016.51681 \mathrm{e}+016.51681 \mathrm{e}+001.00000 \mathrm{e}-092.12000 \mathrm{e}-01$

$6.51681 \mathrm{e}+016.51681 \mathrm{e}+016.51681 \mathrm{e}+001.00000 \mathrm{e}-092.12000 \mathrm{e}-01$

$1.00000 \mathrm{e}-02$ 1.00000e-02 1.00000e-03 1.00000e-09 1.00000e-01

$1.00000 \mathrm{e}+001.00000 \mathrm{e}+001.00000 \mathrm{e}-011.00000 \mathrm{e}-091.00000 \mathrm{e}-01$

Element: 646 \# of layers: 6

$\mathrm{Kx} \mathrm{Ky} \mathrm{Kz}$ Ss Por

$1.63099 \mathrm{e}+03$ 1.63099e+03 1.63099e+02 1.00000e-09 7.00000e-02

$6.51681 \mathrm{e}+016.51681 \mathrm{e}+016.51681 \mathrm{e}+00$ 1.00000e-09 2.12000e-01

$6.51681 \mathrm{e}+016.51681 \mathrm{e}+016.51681 \mathrm{e}+001.00000 \mathrm{e}-092.12000 \mathrm{e}-01$

$6.51681 \mathrm{e}+016.51681 \mathrm{e}+016.51681 \mathrm{e}+001.00000 \mathrm{e}-092.12000 \mathrm{e}-01$

$1.00000 \mathrm{e}-021.00000 \mathrm{e}-02$ 1.00000e-03 1.00000e-09 1.00000e-01

$1.00000 \mathrm{e}+001.00000 \mathrm{e}+001.00000 \mathrm{e}-011.00000 \mathrm{e}-091.00000 \mathrm{e}-01$

Element: 647 \# of layers: 5

$\mathrm{Kx} \mathrm{Ky} \mathrm{Kz}$ Ss Por

$1.63099 \mathrm{e}+03$ 1.63099e+03 1.63099e+02 1.00000e-09 7.00000e-02

$6.51681 \mathrm{e}+016.51681 \mathrm{e}+016.51681 \mathrm{e}+00$ 1.00000e-09 2.12000e-01

$6.51681 \mathrm{e}+016.51681 \mathrm{e}+016.51681 \mathrm{e}+001.00000 \mathrm{e}-092.12000 \mathrm{e}-01$

$1.00000 \mathrm{e}-02$ 1.00000e-02 1.00000e-03 1.00000e-09 1.00000e-01

$1.00000 \mathrm{e}+001.00000 \mathrm{e}+001.00000 \mathrm{e}-011.00000 \mathrm{e}-091.00000 \mathrm{e}-01$

Element: 648 \# of layers: 5

$\mathrm{Kx} \mathrm{Ky} \mathrm{Kz}$ Ss Por

$1.63099 \mathrm{e}+03$ 1.63099e+03 1.63099e+02 1.00000e-09 7.00000e-02

$6.51681 \mathrm{e}+016.51681 \mathrm{e}+016.51681 \mathrm{e}+001.00000 \mathrm{e}-092.12000 \mathrm{e}-01$

$6.51681 \mathrm{e}+016.51681 \mathrm{e}+016.51681 \mathrm{e}+001.00000 \mathrm{e}-092.12000 \mathrm{e}-01$

$1.00000 \mathrm{e}-02$ 1.00000e-02 1.00000e-03 1.00000e-09 1.00000e-01

$1.00000 \mathrm{e}+001.00000 \mathrm{e}+001.00000 \mathrm{e}-01$ 1.00000e-09 1.00000e-01

Element: 649 \# of layers: 4

$\mathrm{Kx} \mathrm{Ky} \mathrm{Kz}$ Ss Por

$1.34826 \mathrm{e}+03$ 1.34826e+03 1.34826e+02 1.00000e-09 7.00000e-02

1.34826e+03 1.34826e+03 1.34826e+02 1.00000e-09 7.00000e-02

$5.38707 \mathrm{e}+015.38707 \mathrm{e}+01$ 5.38707e+00 1.00000e-09 2.12000e-01

$5.38707 e+015.38707 e+015.38707 e+001.00000 e-092.12000 e-01$ 
Element: 650 \# of layers: 3

$\mathrm{Kx} \mathrm{Ky} \mathrm{Kz}$ Ss Por

$1.34826 \mathrm{e}+03$ 1.34826e+03 1.34826e+02 1.00000e-09 7.00000e-02

$5.38707 e+01$ 5.38707e+01 5.38707e+00 1.00000e-09 2.12000e-01

5.38707e+01 5.38707e+01 5.38707e+00 1.00000e-09 2.12000e-01

Element: 651 \# of layers: 4

$\mathrm{Kx} \mathrm{Ky} \mathrm{Kz}$ Ss Por

1.34826e+03 1.34826e+03 1.34826e+02 1.00000e-09 7.00000e-02

$1.34826 \mathrm{e}+03$ 1.34826e+03 1.34826e+02 1.00000e-09 7.00000e-02

$5.38707 \mathrm{e}+015.38707 \mathrm{e}+01$ 5.38707e+00 1.00000e-09 2.12000e-01

$5.38707 \mathrm{e}+015.38707 \mathrm{e}+01$ 5.38707e+00 1.00000e-09 2.12000e-01

Element: 652 \# of layers: 3

$\mathrm{Kx} \mathrm{Ky} \mathrm{Kz}$ Ss Por

1.34826e+03 1.34826e+03 1.34826e+02 1.00000e-09 7.00000e-02

$5.38707 \mathrm{e}+015.38707 \mathrm{e}+015.38707 \mathrm{e}+00$ 1.00000e-09 2.12000e-01

$5.38707 \mathrm{e}+015.38707 \mathrm{e}+01$ 5.38707e+00 1.00000e-09 2.12000e-01

Element: 653 \# of layers: 4

$\mathrm{Kx} \mathrm{Ky} \mathrm{Kz}$ Ss Por

1.34826e+03 1.34826e+03 1.34826e+02 1.00000e-09 7.00000e-02

$5.38707 \mathrm{e}+015.38707 \mathrm{e}+015.38707 \mathrm{e}+00$ 1.00000e-09 2.12000e-01

5.38707e+01 5.38707e+01 5.38707e+00 1.00000e-09 2.12000e-01

5.38707e+01 5.38707e+01 5.38707e+00 1.00000e-09 2.12000e-01

Element: 654 \# of layers: 4

$\mathrm{Kx} \mathrm{Ky} \mathrm{Kz}$ Ss Por

$1.34826 \mathrm{e}+03$ 1.34826e+03 1.34826e+02 1.00000e-09 7.00000e-02

5.38707e+01 5.38707e+01 5.38707e+00 1.00000e-09 2.12000e-01

$5.38707 \mathrm{e}+015.38707 \mathrm{e}+01$ 5.38707e+00 1.00000e-09 2.12000e-01

5.38707e+01 5.38707e+01 5.38707e+00 1.00000e-09 2.12000e-01

Element: 655 \# of layers: 4

$\mathrm{Kx} \mathrm{Ky} \mathrm{Kz}$ Ss Por

$1.34826 \mathrm{e}+03$ 1.34826e+03 1.34826e+02 1.00000e-09 7.00000e-02

5.38707e+01 5.38707e+01 5.38707e+00 1.00000e-09 2.12000e-01

$5.38707 \mathrm{e}+015.38707 \mathrm{e}+015.38707 \mathrm{e}+00$ 1.00000e-09 2.12000e-01

$5.38707 \mathrm{e}+015.38707 \mathrm{e}+01$ 5.38707e+00 1.00000e-09 2.12000e-01

Element: 656 \# of layers: 3

$\mathrm{Kx} \mathrm{Ky} \mathrm{Kz}$ Ss Por

1.34826e+03 1.34826e+03 1.34826e+02 1.00000e-09 7.00000e-02

$5.38707 \mathrm{e}+015.38707 \mathrm{e}+01$ 5.38707e+00 1.00000e-09 2.12000e-01

5.38707e+01 5.38707e+01 5.38707e+00 1.00000e-09 2.12000e-01

Element: 657 \# of layers: 3

$\mathrm{Kx} \mathrm{Ky} \mathrm{Kz}$ Ss Por

$1.34826 \mathrm{e}+03$ 1.34826e+03 1.34826e+02 1.00000e-09 7.00000e-02

5.38707e+01 5.38707e+01 5.38707e+00 1.00000e-09 2.12000e-01

5.38707e+01 5.38707e+01 5.38707e+00 1.00000e-09 2.12000e-01

Element: 658 \# of layers: 5

Kx Ky Kz Ss Por 
$6.33529 \mathrm{e}+026.33529 \mathrm{e}+026.33529 \mathrm{e}+01$ 1.00000e-09 7.00000e-02 $6.33529 \mathrm{e}+026.33529 \mathrm{e}+026.33529 \mathrm{e}+01$ 1.00000e-09 7.00000e-02 $2.53130 \mathrm{e}+012.53130 \mathrm{e}+012.53130 \mathrm{e}+001.00000 \mathrm{e}-092.12000 \mathrm{e}-01$ $2.53130 \mathrm{e}+012.53130 \mathrm{e}+012.53130 \mathrm{e}+001.00000 \mathrm{e}-092.12000 \mathrm{e}-01$ $2.53130 \mathrm{e}+012.53130 \mathrm{e}+012.53130 \mathrm{e}+001.00000 \mathrm{e}-092.12000 \mathrm{e}-01$ Element: 659 \# of layers: 5

Kx Ky Kz Ss Por

$6.33529 \mathrm{e}+026.33529 \mathrm{e}+026.33529 \mathrm{e}+01$ 1.00000e-09 7.00000e-02 $6.33529 \mathrm{e}+026.33529 \mathrm{e}+026.33529 \mathrm{e}+01$ 1.00000e-09 7.00000e-02 $2.53130 \mathrm{e}+012.53130 \mathrm{e}+012.53130 \mathrm{e}+001.00000 \mathrm{e}-092.12000 \mathrm{e}-01$ $2.53130 \mathrm{e}+012.53130 \mathrm{e}+012.53130 \mathrm{e}+001.00000 \mathrm{e}-092.12000 \mathrm{e}-01$ $2.53130 \mathrm{e}+012.53130 \mathrm{e}+012.53130 \mathrm{e}+001.00000 \mathrm{e}-092.12000 \mathrm{e}-01$ Element: 660 \# of layers: 5

Kx Ky Kz Ss Por

$6.33529 \mathrm{e}+026.33529 \mathrm{e}+026.33529 \mathrm{e}+01$ 1.00000e-09 7.00000e-02 $6.33529 \mathrm{e}+026.33529 \mathrm{e}+026.33529 \mathrm{e}+01$ 1.00000e-09 7.00000e-02 $2.53130 \mathrm{e}+012.53130 \mathrm{e}+012.53130 \mathrm{e}+001.00000 \mathrm{e}-092.12000 \mathrm{e}-01$

$2.53130 \mathrm{e}+012.53130 \mathrm{e}+012.53130 \mathrm{e}+001.00000 \mathrm{e}-092.12000 \mathrm{e}-01$ $2.53130 \mathrm{e}+012.53130 \mathrm{e}+012.53130 \mathrm{e}+00$ 1.00000e-09 2.12000e-01 Element: 661 \# of layers: 6

Kx Ky Kz Ss Por 7.00690e+02 7.00690e+02 7.00690e+01 1.00000e-09 7.00000e-02 $2.79974 \mathrm{e}+012.79974 \mathrm{e}+012.79974 \mathrm{e}+001.00000 \mathrm{e}-092.12000 \mathrm{e}-01$ $2.79974 \mathrm{e}+012.79974 \mathrm{e}+012.79974 \mathrm{e}+001.00000 \mathrm{e}-092.12000 \mathrm{e}-01$ $2.79974 \mathrm{e}+012.79974 \mathrm{e}+012.79974 \mathrm{e}+001.00000 \mathrm{e}-092.12000 \mathrm{e}-01$ $2.79974 \mathrm{e}+012.79974 \mathrm{e}+012.79974 \mathrm{e}+001.00000 \mathrm{e}-092.12000 \mathrm{e}-01$ $1.00000 \mathrm{e}+001.00000 \mathrm{e}+001.00000 \mathrm{e}-011.00000 \mathrm{e}-091.00000 \mathrm{e}-01$ Element: 662 \# of layers: 6

Kx Ky Kz Ss Por

$2.79974 \mathrm{e}+012.79974 \mathrm{e}+012.79974 \mathrm{e}+00$ 1.00000e-09 2.12000e-01 $2.79974 \mathrm{e}+012.79974 \mathrm{e}+012.79974 \mathrm{e}+001.00000 \mathrm{e}-092.12000 \mathrm{e}-01$ $2.79974 \mathrm{e}+012.79974 \mathrm{e}+012.79974 \mathrm{e}+001.00000 \mathrm{e}-092.12000 \mathrm{e}-01$ $2.79974 \mathrm{e}+012.79974 \mathrm{e}+012.79974 \mathrm{e}+001.00000 \mathrm{e}-092.12000 \mathrm{e}-01$ $1.00000 \mathrm{e}-02$ 1.00000e-02 1.00000e-03 1.00000e-09 1.00000e-01 $1.00000 \mathrm{e}+001.00000 \mathrm{e}+001.00000 \mathrm{e}-011.00000 \mathrm{e}-091.00000 \mathrm{e}-01$ Element: 663 \# of layers: 7

Kx Ky Kz Ss Por $7.00690 \mathrm{e}+02$ 7.00690e+02 7.00690e+01 1.00000e-09 7.00000e-02 $2.79974 \mathrm{e}+012.79974 \mathrm{e}+012.79974 \mathrm{e}+001.00000 \mathrm{e}-092.12000 \mathrm{e}-01$ $2.79974 \mathrm{e}+012.79974 \mathrm{e}+012.79974 \mathrm{e}+001.00000 \mathrm{e}-092.12000 \mathrm{e}-01$ $2.79974 \mathrm{e}+012.79974 \mathrm{e}+012.79974 \mathrm{e}+001.00000 \mathrm{e}-092.12000 \mathrm{e}-01$ $2.79974 \mathrm{e}+012.79974 \mathrm{e}+012.79974 \mathrm{e}+001.00000 \mathrm{e}-092.12000 \mathrm{e}-01$ $1.00000 \mathrm{e}-021.00000 \mathrm{e}-02$ 1.00000e-03 1.00000e-09 1.00000e-01 $1.00000 \mathrm{e}+001.00000 \mathrm{e}+001.00000 \mathrm{e}-011.00000 \mathrm{e}-091.00000 \mathrm{e}-01$ Element: 664 \# of layers: 6

Kx Ky Kz Ss Por 
$2.79974 \mathrm{e}+012.79974 \mathrm{e}+012.79974 \mathrm{e}+00$ 1.00000e-09 2.12000e-01 $2.79974 \mathrm{e}+012.79974 \mathrm{e}+012.79974 \mathrm{e}+001.00000 \mathrm{e}-092.12000 \mathrm{e}-01$ $2.79974 \mathrm{e}+012.79974 \mathrm{e}+012.79974 \mathrm{e}+001.00000 \mathrm{e}-092.12000 \mathrm{e}-01$ $2.79974 \mathrm{e}+012.79974 \mathrm{e}+012.79974 \mathrm{e}+001.00000 \mathrm{e}-092.12000 \mathrm{e}-01$ $1.00000 \mathrm{e}-02$ 1.00000e-02 1.00000e-03 1.00000e-09 1.00000e-01 $1.00000 \mathrm{e}+001.00000 \mathrm{e}+001.00000 \mathrm{e}-011.00000 \mathrm{e}-091.00000 \mathrm{e}-01$ Element: 665 \# of layers: 6

Kx Ky Kz Ss Por

$2.79974 \mathrm{e}+012.79974 \mathrm{e}+012.79974 \mathrm{e}+00$ 1.00000e-09 2.12000e-01 $2.79974 \mathrm{e}+012.79974 \mathrm{e}+012.79974 \mathrm{e}+001.00000 \mathrm{e}-092.12000 \mathrm{e}-01$ $2.79974 \mathrm{e}+012.79974 \mathrm{e}+012.79974 \mathrm{e}+001.00000 \mathrm{e}-092.12000 \mathrm{e}-01$ $2.79974 \mathrm{e}+012.79974 \mathrm{e}+012.79974 \mathrm{e}+001.00000 \mathrm{e}-092.12000 \mathrm{e}-01$ $1.00000 \mathrm{e}-021.00000 \mathrm{e}-02$ 1.00000e-03 1.00000e-09 1.00000e-01 $1.00000 \mathrm{e}+001.00000 \mathrm{e}+001.00000 \mathrm{e}-011.00000 \mathrm{e}-091.00000 \mathrm{e}-01$ Element: 666 \# of layers: 7

Kx Ky Kz Ss Por $1.22401 \mathrm{e}+031.22401 \mathrm{e}+03$ 1.22401e+02 1.00000e-09 7.00000e-02 $1.22401 \mathrm{e}+031.22401 \mathrm{e}+031.22401 \mathrm{e}+021.00000 \mathrm{e}-097.00000 \mathrm{e}-02$ $4.89048 \mathrm{e}+014.89048 \mathrm{e}+014.89048 \mathrm{e}+001.00000 \mathrm{e}-092.12000 \mathrm{e}-01$ $4.89048 \mathrm{e}+014.89048 \mathrm{e}+014.89048 \mathrm{e}+001.00000 \mathrm{e}-092.12000 \mathrm{e}-01$ $4.89048 \mathrm{e}+014.89048 \mathrm{e}+014.89048 \mathrm{e}+001.00000 \mathrm{e}-092.12000 \mathrm{e}-01$ $4.89048 \mathrm{e}+014.89048 \mathrm{e}+014.89048 \mathrm{e}+001.00000 \mathrm{e}-092.12000 \mathrm{e}-01$ $1.00000 \mathrm{e}+001.00000 \mathrm{e}+001.00000 \mathrm{e}-011.00000 \mathrm{e}-091.00000 \mathrm{e}-01$ Element: 667 \# of layers: 7

Kx Ky Kz Ss Por $1.22401 \mathrm{e}+031.22401 \mathrm{e}+031.22401 \mathrm{e}+02$ 1.00000e-09 7.00000e-02 $4.89048 \mathrm{e}+014.89048 \mathrm{e}+014.89048 \mathrm{e}+001.00000 \mathrm{e}-092.12000 \mathrm{e}-01$ $4.89048 \mathrm{e}+014.89048 \mathrm{e}+014.89048 \mathrm{e}+001.00000 \mathrm{e}-092.12000 \mathrm{e}-01$ $4.89048 \mathrm{e}+014.89048 \mathrm{e}+014.89048 \mathrm{e}+001.00000 \mathrm{e}-092.12000 \mathrm{e}-01$ $4.89048 \mathrm{e}+014.89048 \mathrm{e}+014.89048 \mathrm{e}+001.00000 \mathrm{e}-092.12000 \mathrm{e}-01$ $1.00000 \mathrm{e}-011.00000 \mathrm{e}-011.00000 \mathrm{e}-021.00000 \mathrm{e}-091.00000 \mathrm{e}-01$ $1.00000 \mathrm{e}+001.00000 \mathrm{e}+001.00000 \mathrm{e}-011.00000 \mathrm{e}-091.00000 \mathrm{e}-01$ Element: 668 \# of layers: 6

Kx Ky Kz Ss Por

$1.22401 \mathrm{e}+031.22401 \mathrm{e}+03$ 1.22401e+02 1.00000e-09 7.00000e-02 $4.89048 \mathrm{e}+014.89048 \mathrm{e}+014.89048 \mathrm{e}+001.00000 \mathrm{e}-092.12000 \mathrm{e}-01$ $4.89048 \mathrm{e}+014.89048 \mathrm{e}+014.89048 \mathrm{e}+001.00000 \mathrm{e}-092.12000 \mathrm{e}-01$ $4.89048 \mathrm{e}+014.89048 \mathrm{e}+014.89048 \mathrm{e}+00$ 1.00000e-09 2.12000e-01 $1.00000 \mathrm{e}-011.00000 \mathrm{e}-011.00000 \mathrm{e}-021.00000 \mathrm{e}-091.00000 \mathrm{e}-01$ $1.00000 \mathrm{e}+001.00000 \mathrm{e}+001.00000 \mathrm{e}-011.00000 \mathrm{e}-091.00000 \mathrm{e}-01$ Element: 669 \# of layers: 6

Kx Ky Kz Ss Por $1.22401 \mathrm{e}+031.22401 \mathrm{e}+03$ 1.22401e+02 1.00000e-09 7.00000e-02 $4.89048 \mathrm{e}+014.89048 \mathrm{e}+014.89048 \mathrm{e}+001.00000 \mathrm{e}-092.12000 \mathrm{e}-01$ $4.89048 \mathrm{e}+014.89048 \mathrm{e}+014.89048 \mathrm{e}+001.00000 \mathrm{e}-092.12000 \mathrm{e}-01$ $4.89048 \mathrm{e}+014.89048 \mathrm{e}+014.89048 \mathrm{e}+001.00000 \mathrm{e}-092.12000 \mathrm{e}-01$ 
$1.00000 \mathrm{e}-011.00000 \mathrm{e}-011.00000 \mathrm{e}-021.00000 \mathrm{e}-091.00000 \mathrm{e}-01$ $1.00000 \mathrm{e}+001.00000 \mathrm{e}+001.00000 \mathrm{e}-01$ 1.00000e-09 1.00000e-01 Element: 670 \# of layers: 6

$\mathrm{Kx} \mathrm{Ky} \mathrm{Kz}$ Ss Por

$1.22401 \mathrm{e}+031.22401 \mathrm{e}+031.22401 \mathrm{e}+02$ 1.00000e-09 7.00000e-02 $4.89048 \mathrm{e}+014.89048 \mathrm{e}+014.89048 \mathrm{e}+00$ 1.00000e-09 2.12000e-01 $4.89048 \mathrm{e}+014.89048 \mathrm{e}+014.89048 \mathrm{e}+00$ 1.00000e-09 2.12000e-01 $4.89048 \mathrm{e}+014.89048 \mathrm{e}+014.89048 \mathrm{e}+00$ 1.00000e-09 2.12000e-01 $1.00000 \mathrm{e}-02$ 1.00000e-02 1.00000e-03 1.00000e-09 1.00000e-01 $1.00000 \mathrm{e}+001.00000 \mathrm{e}+001.00000 \mathrm{e}-011.00000 \mathrm{e}-091.00000 \mathrm{e}-01$ Element: 671 \# of layers: 8

$\mathrm{Kx} \mathrm{Ky} \mathrm{Kz}$ Ss Por

$1.22401 \mathrm{e}+03$ 1.22401e+03 1.22401e+02 1.00000e-09 7.00000e-02 $1.22401 \mathrm{e}+031.22401 \mathrm{e}+031.22401 \mathrm{e}+02$ 1.00000e-09 7.00000e-02 $4.89048 \mathrm{e}+014.89048 \mathrm{e}+01$ 4.89048e+00 1.00000e-09 2.12000e-01 $4.89048 \mathrm{e}+014.89048 \mathrm{e}+014.89048 \mathrm{e}+00$ 1.00000e-09 2.12000e-01 $4.89048 \mathrm{e}+014.89048 \mathrm{e}+014.89048 \mathrm{e}+001.00000 \mathrm{e}-092.12000 \mathrm{e}-01$ $4.89048 \mathrm{e}+014.89048 \mathrm{e}+014.89048 \mathrm{e}+00$ 1.00000e-09 2.12000e-01 $1.00000 \mathrm{e}-02$ 1.00000e-02 1.00000e-03 1.00000e-09 1.00000e-01 $1.00000 \mathrm{e}+001.00000 \mathrm{e}+001.00000 \mathrm{e}-011.00000 \mathrm{e}-091.00000 \mathrm{e}-01$ Element: 672 \# of layers: 7

$\mathrm{Kx} \mathrm{Ky} \mathrm{Kz}$ Ss Por

$1.22401 \mathrm{e}+031.22401 \mathrm{e}+03$ 1.22401e+02 1.00000e-09 7.00000e-02 4.89048e+01 4.89048e+01 4.89048e+00 1.00000e-09 2.12000e-01 $4.89048 \mathrm{e}+014.89048 \mathrm{e}+014.89048 \mathrm{e}+001.00000 \mathrm{e}-092.12000 \mathrm{e}-01$ $4.89048 \mathrm{e}+014.89048 \mathrm{e}+014.89048 \mathrm{e}+001.00000 \mathrm{e}-092.12000 \mathrm{e}-01$ $4.89048 \mathrm{e}+014.89048 \mathrm{e}+014.89048 \mathrm{e}+00$ 1.00000e-09 2.12000e-01 $1.00000 \mathrm{e}-02$ 1.00000e-02 1.00000e-03 1.00000e-09 1.00000e-01 $1.00000 \mathrm{e}+001.00000 \mathrm{e}+001.00000 \mathrm{e}-011.00000 \mathrm{e}-091.00000 \mathrm{e}-01$ Element: 673 \# of layers: 8

$\mathrm{Kx} \mathrm{Ky} \mathrm{Kz}$ Ss Por

$1.22401 \mathrm{e}+031.22401 \mathrm{e}+03$ 1.22401e+02 1.00000e-09 7.00000e-02 $1.22401 \mathrm{e}+031.22401 \mathrm{e}+031.22401 \mathrm{e}+02$ 1.00000e-09 7.00000e-02 $4.89048 \mathrm{e}+01$ 4.89048e+01 4.89048e+00 1.00000e-09 2.12000e-01 $4.89048 \mathrm{e}+014.89048 \mathrm{e}+01$ 4.89048e+00 1.00000e-09 2.12000e-01 $4.89048 \mathrm{e}+014.89048 \mathrm{e}+01$ 4.89048e+00 1.00000e-09 2.12000e-01 $4.89048 \mathrm{e}+014.89048 \mathrm{e}+014.89048 \mathrm{e}+001.00000 \mathrm{e}-092.12000 \mathrm{e}-01$ $1.00000 \mathrm{e}-02$ 1.00000e-02 1.00000e-03 1.00000e-09 1.00000e-01 $1.00000 \mathrm{e}+001.00000 \mathrm{e}+001.00000 \mathrm{e}-011.00000 \mathrm{e}-091.00000 \mathrm{e}-01$ Element: 674 \# of layers: 8

$\mathrm{Kx} \mathrm{Ky} \mathrm{Kz}$ Ss Por $1.22401 \mathrm{e}+03$ 1.22401e+03 1.22401e+02 1.00000e-09 7.00000e-02 $1.22401 \mathrm{e}+031.22401 \mathrm{e}+031.22401 \mathrm{e}+02$ 1.00000e-09 7.00000e-02 4.89048e+01 4.89048e+01 4.89048e+00 1.00000e-09 2.12000e-01 $4.89048 \mathrm{e}+014.89048 \mathrm{e}+01$ 4.89048e+00 1.00000e-09 2.12000e-01 $4.89048 \mathrm{e}+014.89048 \mathrm{e}+014.89048 \mathrm{e}+00$ 1.00000e-09 2.12000e-01 
4.89048e+01 4.89048e+01 4.89048e+00 1.00000e-09 2.12000e-01 $1.00000 \mathrm{e}-02$ 1.00000e-02 1.00000e-03 1.00000e-09 1.00000e-01 $1.00000 \mathrm{e}+001.00000 \mathrm{e}+001.00000 \mathrm{e}-011.00000 \mathrm{e}-091.00000 \mathrm{e}-01$

Element: 675 \# of layers: 6

$\mathrm{Kx} \mathrm{Ky} \mathrm{Kz}$ Ss Por

1.33492e+03 1.33492e+03 1.33492e+02 1.00000e-09 7.00000e-02

$5.33396 \mathrm{e}+015.33396 \mathrm{e}+015.33396 \mathrm{e}+001.00000 \mathrm{e}-09$ 2.12000e-01

$5.33396 \mathrm{e}+015.33396 \mathrm{e}+015.33396 \mathrm{e}+001.00000 \mathrm{e}-092.12000 \mathrm{e}-01$

5.33396e+01 5.33396e+01 5.33396e+00 1.00000e-09 2.12000e-01

1.00000e-01 1.00000e-01 1.00000e-02 1.00000e-09 1.00000e-01

$1.00000 \mathrm{e}+001.00000 \mathrm{e}+001.00000 \mathrm{e}-011.00000 \mathrm{e}-091.00000 \mathrm{e}-01$

Element: 676 \# of layers: 6

$\mathrm{Kx} \mathrm{Ky} \mathrm{Kz}$ Ss Por

1.33492e+03 1.33492e+03 1.33492e+02 1.00000e-09 7.00000e-02

$5.33396 \mathrm{e}+015.33396 \mathrm{e}+015.33396 \mathrm{e}+001.00000 \mathrm{e}-092.12000 \mathrm{e}-01$

$5.33396 \mathrm{e}+015.33396 \mathrm{e}+015.33396 \mathrm{e}+001.00000 \mathrm{e}-092.12000 \mathrm{e}-01$

$5.33396 \mathrm{e}+015.33396 \mathrm{e}+015.33396 \mathrm{e}+001.00000 \mathrm{e}-092.12000 \mathrm{e}-01$

$1.00000 \mathrm{e}-011.00000 \mathrm{e}-01$ 1.00000e-02 1.00000e-09 1.00000e-01

$1.00000 \mathrm{e}+001.00000 \mathrm{e}+001.00000 \mathrm{e}-01$ 1.00000e-09 1.00000e-01

Element: 677 \# of layers: 5

$\mathrm{Kx} \mathrm{Ky} \mathrm{Kz}$ Ss Por

1.33492e+03 1.33492e+03 1.33492e+02 1.00000e-09 7.00000e-02

$5.33396 \mathrm{e}+015.33396 \mathrm{e}+015.33396 \mathrm{e}+001.00000 \mathrm{e}-092.12000 \mathrm{e}-01$

$5.33396 \mathrm{e}+015.33396 \mathrm{e}+015.33396 \mathrm{e}+001.00000 \mathrm{e}-092.12000 \mathrm{e}-01$

$1.00000 \mathrm{e}-021.00000 \mathrm{e}-02$ 1.00000e-03 1.00000e-09 1.00000e-01

$1.00000 \mathrm{e}+001.00000 \mathrm{e}+001.00000 \mathrm{e}-011.00000 \mathrm{e}-091.00000 \mathrm{e}-01$

Element: 678 \# of layers: 6

$\mathrm{Kx} \mathrm{Ky} \mathrm{Kz}$ Ss Por

1.33492e+03 1.33492e+03 1.33492e+02 1.00000e-09 7.00000e-02

$5.33396 \mathrm{e}+01$ 5.33396e+01 5.33396e+00 1.00000e-09 2.12000e-01

$5.33396 \mathrm{e}+015.33396 \mathrm{e}+015.33396 \mathrm{e}+001.00000 \mathrm{e}-092.12000 \mathrm{e}-01$

$5.33396 \mathrm{e}+015.33396 \mathrm{e}+015.33396 \mathrm{e}+00$ 1.00000e-09 2.12000e-01

$1.00000 \mathrm{e}-02$ 1.00000e-02 1.00000e-03 1.00000e-09 1.00000e-01

$1.00000 \mathrm{e}+001.00000 \mathrm{e}+001.00000 \mathrm{e}-011.00000 \mathrm{e}-091.00000 \mathrm{e}-01$

Element: 679 \# of layers: 5

$\mathrm{Kx} \mathrm{Ky} \mathrm{Kz}$ Ss Por

1.33492e+03 1.33492e+03 1.33492e+02 1.00000e-09 7.00000e-02

$5.33396 \mathrm{e}+015.33396 \mathrm{e}+015.33396 \mathrm{e}+001.00000 \mathrm{e}-092.12000 \mathrm{e}-01$

$5.33396 \mathrm{e}+015.33396 \mathrm{e}+015.33396 \mathrm{e}+001.00000 \mathrm{e}-09$ 2.12000e-01

$1.00000 \mathrm{e}-02$ 1.00000e-02 1.00000e-03 1.00000e-09 1.00000e-01

$1.00000 \mathrm{e}+001.00000 \mathrm{e}+001.00000 \mathrm{e}-011.00000 \mathrm{e}-091.00000 \mathrm{e}-01$

Element: 680 \# of layers: 5

$\mathrm{Kx} \mathrm{Ky} \mathrm{Kz}$ Ss Por

1.33492e+03 1.33492e+03 1.33492e+02 1.00000e-09 7.00000e-02

$5.33396 \mathrm{e}+015.33396 \mathrm{e}+015.33396 \mathrm{e}+00$ 1.00000e-09 2.12000e-01

$5.33396 \mathrm{e}+015.33396 \mathrm{e}+015.33396 \mathrm{e}+001.00000 \mathrm{e}-092.12000 \mathrm{e}-01$ 
$1.00000 \mathrm{e}-02$ 1.00000e-02 1.00000e-03 1.00000e-09 1.00000e-01 $1.00000 \mathrm{e}+001.00000 \mathrm{e}+001.00000 \mathrm{e}-01$ 1.00000e-09 1.00000e-01 Element: 681 \# of layers: 6

$\mathrm{Kx} \mathrm{Ky} \mathrm{Kz}$ Ss Por

1.33492e+03 1.33492e+03 1.33492e+02 1.00000e-09 7.00000e-02

$5.33396 \mathrm{e}+015.33396 \mathrm{e}+015.33396 \mathrm{e}+00$ 1.00000e-09 2.12000e-01

$5.33396 \mathrm{e}+015.33396 \mathrm{e}+015.33396 \mathrm{e}+00$ 1.00000e-09 2.12000e-01

$5.33396 \mathrm{e}+015.33396 \mathrm{e}+015.33396 \mathrm{e}+001.00000 \mathrm{e}-092.12000 \mathrm{e}-01$

$1.00000 \mathrm{e}-02$ 1.00000e-02 1.00000e-03 1.00000e-09 1.00000e-01

$1.00000 \mathrm{e}+001.00000 \mathrm{e}+001.00000 \mathrm{e}-011.00000 \mathrm{e}-091.00000 \mathrm{e}-01$

Element: 682 \# of layers: 6

$\mathrm{Kx} \mathrm{Ky} \mathrm{Kz}$ Ss Por

1.33492e+03 1.33492e+03 1.33492e+02 1.00000e-09 7.00000e-02

$5.33396 \mathrm{e}+015.33396 \mathrm{e}+015.33396 \mathrm{e}+00$ 1.00000e-09 2.12000e-01

$5.33396 \mathrm{e}+015.33396 \mathrm{e}+015.33396 \mathrm{e}+001.00000 \mathrm{e}-092.12000 \mathrm{e}-01$

$5.33396 \mathrm{e}+015.33396 \mathrm{e}+015.33396 \mathrm{e}+001.00000 \mathrm{e}-092.12000 \mathrm{e}-01$

$1.00000 \mathrm{e}-01$ 1.00000e-01 1.00000e-02 1.00000e-09 1.00000e-01

$1.00000 \mathrm{e}+001.00000 \mathrm{e}+001.00000 \mathrm{e}-01$ 1.00000e-09 1.00000e-01

Element: 683 \# of layers: 6

$\mathrm{Kx} \mathrm{Ky} \mathrm{Kz}$ Ss Por

$1.33492 \mathrm{e}+03$ 1.33492e+03 1.33492e+02 1.00000e-09 7.00000e-02

$5.33396 \mathrm{e}+015.33396 \mathrm{e}+015.33396 \mathrm{e}+00$ 1.00000e-09 2.12000e-01

$5.33396 \mathrm{e}+015.33396 \mathrm{e}+015.33396 \mathrm{e}+001.00000 \mathrm{e}-092.12000 \mathrm{e}-01$

$5.33396 \mathrm{e}+015.33396 \mathrm{e}+015.33396 \mathrm{e}+001.00000 \mathrm{e}-092.12000 \mathrm{e}-01$

$1.00000 \mathrm{e}-021.00000 \mathrm{e}-02$ 1.00000e-03 1.00000e-09 1.00000e-01

$1.00000 \mathrm{e}+001.00000 \mathrm{e}+001.00000 \mathrm{e}-011.00000 \mathrm{e}-091.00000 \mathrm{e}-01$

Element: 684 \# of layers: 5

$\mathrm{Kx} \mathrm{Ky} \mathrm{Kz}$ Ss Por

8.87215e+02 8.87215e+02 8.87215e+01 1.00000e-09 7.00000e-02

$3.54495 \mathrm{e}+013.54495 \mathrm{e}+013.54495 \mathrm{e}+00$ 1.00000e-09 2.12000e-01

$3.54495 \mathrm{e}+013.54495 \mathrm{e}+013.54495 \mathrm{e}+00$ 1.00000e-09 2.12000e-01

$1.00000 \mathrm{e}-02$ 1.00000e-02 1.00000e-03 1.00000e-09 1.00000e-01

$1.00000 \mathrm{e}+001.00000 \mathrm{e}+001.00000 \mathrm{e}-011.00000 \mathrm{e}-091.00000 \mathrm{e}-01$

Element: 685 \# of layers: 5

$\mathrm{Kx} \mathrm{Ky} \mathrm{Kz}$ Ss Por

8.87215e+02 8.87215e+02 8.87215e+01 1.00000e-09 7.00000e-02

$3.54495 \mathrm{e}+013.54495 \mathrm{e}+013.54495 \mathrm{e}+001.00000 \mathrm{e}-092.12000 \mathrm{e}-01$

$3.54495 \mathrm{e}+013.54495 \mathrm{e}+013.54495 \mathrm{e}+00$ 1.00000e-09 2.12000e-01

$1.00000 \mathrm{e}-02$ 1.00000e-02 1.00000e-03 1.00000e-09 1.00000e-01

$1.00000 \mathrm{e}+001.00000 \mathrm{e}+001.00000 \mathrm{e}-011.00000 \mathrm{e}-091.00000 \mathrm{e}-01$

Element: 686 \# of layers: 5

$\mathrm{Kx} \mathrm{Ky} \mathrm{Kz}$ Ss Por

8.87215e+02 8.87215e+02 8.87215e+01 1.00000e-09 7.00000e-02

$3.54495 \mathrm{e}+013.54495 \mathrm{e}+01$ 3.54495e+00 1.00000e-09 2.12000e-01

$3.54495 \mathrm{e}+013.54495 \mathrm{e}+013.54495 \mathrm{e}+001.00000 \mathrm{e}-092.12000 \mathrm{e}-01$

$1.00000 \mathrm{e}-02$ 1.00000e-02 1.00000e-03 1.00000e-09 1.00000e-01 
$1.00000 \mathrm{e}+001.00000 \mathrm{e}+00$ 1.00000e-01 1.00000e-09 1.00000e-01

Element: 687 \# of layers: 6

$\mathrm{Kx} \mathrm{Ky} \mathrm{Kz}$ Ss Por

8.87215e+02 8.87215e+02 8.87215e+01 1.00000e-09 7.00000e-02

$3.54495 \mathrm{e}+013.54495 \mathrm{e}+013.54495 \mathrm{e}+001.00000 \mathrm{e}-092.12000 \mathrm{e}-01$

$3.54495 \mathrm{e}+013.54495 \mathrm{e}+013.54495 \mathrm{e}+00$ 1.00000e-09 2.12000e-01

$3.54495 \mathrm{e}+013.54495 \mathrm{e}+013.54495 \mathrm{e}+00$ 1.00000e-09 2.12000e-01

$1.00000 \mathrm{e}-02$ 1.00000e-02 1.00000e-03 1.00000e-09 1.00000e-01

$1.00000 \mathrm{e}+001.00000 \mathrm{e}+001.00000 \mathrm{e}-011.00000 \mathrm{e}-091.00000 \mathrm{e}-01$

Element: 688 \# of layers: 5

$\mathrm{Kx} \mathrm{Ky} \mathrm{Kz}$ Ss Por

8.87215e+02 8.87215e+02 8.87215e+01 1.00000e-09 7.00000e-02

$3.54495 \mathrm{e}+013.54495 \mathrm{e}+013.54495 \mathrm{e}+001.00000 \mathrm{e}-092.12000 \mathrm{e}-01$

$3.54495 \mathrm{e}+013.54495 \mathrm{e}+013.54495 \mathrm{e}+00$ 1.00000e-09 2.12000e-01

$1.00000 \mathrm{e}-02$ 1.00000e-02 1.00000e-03 1.00000e-09 1.00000e-01

$1.00000 \mathrm{e}+001.00000 \mathrm{e}+001.00000 \mathrm{e}-011.00000 \mathrm{e}-091.00000 \mathrm{e}-01$

Element: 689 \# of layers: 5

$\mathrm{Kx} \mathrm{Ky} \mathrm{Kz}$ Ss Por

8.87215e+02 8.87215e+02 8.87215e+01 1.00000e-09 7.00000e-02

$3.54495 \mathrm{e}+013.54495 \mathrm{e}+013.54495 \mathrm{e}+001.00000 \mathrm{e}-092.12000 \mathrm{e}-01$

$3.54495 \mathrm{e}+013.54495 \mathrm{e}+013.54495 \mathrm{e}+00$ 1.00000e-09 2.12000e-01

$1.00000 \mathrm{e}-02$ 1.00000e-02 1.00000e-03 1.00000e-09 1.00000e-01

$1.00000 \mathrm{e}+001.00000 \mathrm{e}+001.00000 \mathrm{e}-01$ 1.00000e-09 1.00000e-01

Element: 690 \# of layers: 5

$\mathrm{Kx} \mathrm{Ky} \mathrm{Kz}$ Ss Por

8.87215e+02 8.87215e+02 8.87215e+01 1.00000e-09 7.00000e-02

$3.54495 \mathrm{e}+013.54495 \mathrm{e}+013.54495 \mathrm{e}+001.00000 \mathrm{e}-092.12000 \mathrm{e}-01$

$3.54495 \mathrm{e}+013.54495 \mathrm{e}+013.54495 \mathrm{e}+001.00000 \mathrm{e}-092.12000 \mathrm{e}-01$

$1.00000 \mathrm{e}-02$ 1.00000e-02 1.00000e-03 1.00000e-09 1.00000e-01

$1.00000 \mathrm{e}+001.00000 \mathrm{e}+001.00000 \mathrm{e}-011.00000 \mathrm{e}-091.00000 \mathrm{e}-01$

Element: 691 \# of layers: 6

$\mathrm{Kx} \mathrm{Ky} \mathrm{Kz}$ Ss Por

8.87215e+02 8.87215e+02 8.87215e+01 1.00000e-09 7.00000e-02

$3.54495 \mathrm{e}+013.54495 \mathrm{e}+013.54495 \mathrm{e}+001.00000 \mathrm{e}-092.12000 \mathrm{e}-01$

$3.54495 \mathrm{e}+013.54495 \mathrm{e}+013.54495 \mathrm{e}+00$ 1.00000e-09 2.12000e-01

$3.54495 \mathrm{e}+013.54495 \mathrm{e}+013.54495 \mathrm{e}+00$ 1.00000e-09 2.12000e-01

$1.00000 \mathrm{e}-02$ 1.00000e-02 1.00000e-03 1.00000e-09 1.00000e-01

$1.00000 \mathrm{e}+001.00000 \mathrm{e}+001.00000 \mathrm{e}-011.00000 \mathrm{e}-091.00000 \mathrm{e}-01$

Element: 692 \# of layers: 6

$\mathrm{Kx} \mathrm{Ky} \mathrm{Kz}$ Ss Por

8.87215e+02 8.87215e+02 8.87215e+01 1.00000e-09 7.00000e-02

$3.54495 \mathrm{e}+013.54495 \mathrm{e}+013.54495 \mathrm{e}+001.00000 \mathrm{e}-092.12000 \mathrm{e}-01$

$3.54495 \mathrm{e}+013.54495 \mathrm{e}+013.54495 \mathrm{e}+00$ 1.00000e-09 2.12000e-01

$3.54495 \mathrm{e}+013.54495 \mathrm{e}+01$ 3.54495e+00 1.00000e-09 2.12000e-01

$1.00000 \mathrm{e}-021.00000 \mathrm{e}-021.00000 \mathrm{e}-031.00000 \mathrm{e}-091.00000 \mathrm{e}-01$

$1.00000 \mathrm{e}+001.00000 \mathrm{e}+001.00000 \mathrm{e}-011.00000 \mathrm{e}-091.00000 \mathrm{e}-01$ 
Element: 693 \# of layers: 6

Kx Ky Kz Ss Por

6.31069e+02 6.31069e+02 6.31069e+01 1.00000e-09 7.00000e-02

$2.52163 \mathrm{e}+012.52163 \mathrm{e}+012.52163 \mathrm{e}+001.00000 \mathrm{e}-092.12000 \mathrm{e}-01$

$2.52163 \mathrm{e}+012.52163 \mathrm{e}+012.52163 \mathrm{e}+001.00000 \mathrm{e}-092.12000 \mathrm{e}-01$

$2.52163 \mathrm{e}+012.52163 \mathrm{e}+012.52163 \mathrm{e}+001.00000 \mathrm{e}-092.12000 \mathrm{e}-01$

$1.00000 \mathrm{e}-021.00000 \mathrm{e}-02$ 1.00000e-03 1.00000e-09 1.00000e-01

$1.00000 \mathrm{e}+001.00000 \mathrm{e}+001.00000 \mathrm{e}-011.00000 \mathrm{e}-091.00000 \mathrm{e}-01$

Element: 694 \# of layers: 6

Kx Ky Kz Ss Por

$6.31069 \mathrm{e}+026.31069 \mathrm{e}+026.31069 \mathrm{e}+01$ 1.00000e-09 7.00000e-02

$2.52163 \mathrm{e}+012.52163 \mathrm{e}+012.52163 \mathrm{e}+001.00000 \mathrm{e}-092.12000 \mathrm{e}-01$

$2.52163 \mathrm{e}+012.52163 \mathrm{e}+012.52163 \mathrm{e}+001.00000 \mathrm{e}-092.12000 \mathrm{e}-01$

$2.52163 \mathrm{e}+012.52163 \mathrm{e}+012.52163 \mathrm{e}+001.00000 \mathrm{e}-092.12000 \mathrm{e}-01$

$1.00000 \mathrm{e}-021.00000 \mathrm{e}-02$ 1.00000e-03 1.00000e-09 1.00000e-01

$1.00000 \mathrm{e}+001.00000 \mathrm{e}+001.00000 \mathrm{e}-011.00000 \mathrm{e}-091.00000 \mathrm{e}-01$

Element: 695 \# of layers: 6

Kx Ky Kz Ss Por

$6.31069 \mathrm{e}+026.31069 \mathrm{e}+026.31069 \mathrm{e}+01$ 1.00000e-09 7.00000e-02

$2.52163 \mathrm{e}+012.52163 \mathrm{e}+012.52163 \mathrm{e}+001.00000 \mathrm{e}-092.12000 \mathrm{e}-01$

$2.52163 \mathrm{e}+012.52163 \mathrm{e}+012.52163 \mathrm{e}+001.00000 \mathrm{e}-092.12000 \mathrm{e}-01$

$2.52163 \mathrm{e}+012.52163 \mathrm{e}+012.52163 \mathrm{e}+00$ 1.00000e-09 2.12000e-01

$1.00000 \mathrm{e}-02$ 1.00000e-02 1.00000e-03 1.00000e-09 1.00000e-01

$1.00000 \mathrm{e}+001.00000 \mathrm{e}+001.00000 \mathrm{e}-011.00000 \mathrm{e}-091.00000 \mathrm{e}-01$

Element: 696 \# of layers: 5

Kx Ky Kz Ss Por

6.31069e+02 6.31069e+02 6.31069e+01 1.00000e-09 7.00000e-02

$2.52163 \mathrm{e}+012.52163 \mathrm{e}+012.52163 \mathrm{e}+001.00000 \mathrm{e}-092.12000 \mathrm{e}-01$

$2.52163 \mathrm{e}+012.52163 \mathrm{e}+012.52163 \mathrm{e}+001.00000 \mathrm{e}-092.12000 \mathrm{e}-01$

$2.52163 \mathrm{e}+012.52163 \mathrm{e}+012.52163 \mathrm{e}+001.00000 \mathrm{e}-092.12000 \mathrm{e}-01$

$1.00000 \mathrm{e}-021.00000 \mathrm{e}-02$ 1.00000e-03 1.00000e-09 1.00000e-01

Element: 697 \# of layers: 5

Kx Ky Kz Ss Por

$6.31069 \mathrm{e}+026.31069 \mathrm{e}+026.31069 \mathrm{e}+01$ 1.00000e-09 7.00000e-02

$6.31069 \mathrm{e}+026.31069 \mathrm{e}+026.31069 \mathrm{e}+01$ 1.00000e-09 7.00000e-02

$2.52163 \mathrm{e}+012.52163 \mathrm{e}+012.52163 \mathrm{e}+001.00000 \mathrm{e}-092.12000 \mathrm{e}-01$

$2.52163 \mathrm{e}+012.52163 \mathrm{e}+012.52163 \mathrm{e}+00$ 1.00000e-09 2.12000e-01

$1.00000 \mathrm{e}-02$ 1.00000e-02 1.00000e-03 1.00000e-09 1.00000e-01

Element: 698 \# of layers: 5

Kx Ky Kz Ss Por

$6.31069 \mathrm{e}+026.31069 \mathrm{e}+026.31069 \mathrm{e}+01$ 1.00000e-09 7.00000e-02

$2.52163 \mathrm{e}+012.52163 \mathrm{e}+012.52163 \mathrm{e}+001.00000 \mathrm{e}-092.12000 \mathrm{e}-01$

$2.52163 \mathrm{e}+012.52163 \mathrm{e}+012.52163 \mathrm{e}+00$ 1.00000e-09 2.12000e-01

$1.00000 \mathrm{e}-02$ 1.00000e-02 1.00000e-03 1.00000e-09 1.00000e-01

$1.00000 \mathrm{e}+001.00000 \mathrm{e}+001.00000 \mathrm{e}-011.00000 \mathrm{e}-091.00000 \mathrm{e}-01$

Element: 699 \# of layers: 5 
$\mathrm{Kx} \mathrm{Ky} \mathrm{Kz}$ Ss Por

6.31069e+02 6.31069e+02 6.31069e+01 1.00000e-09 7.00000e-02

$2.52163 \mathrm{e}+012.52163 \mathrm{e}+012.52163 \mathrm{e}+00$ 1.00000e-09 2.12000e-01

$2.52163 \mathrm{e}+012.52163 \mathrm{e}+012.52163 \mathrm{e}+001.00000 \mathrm{e}-092.12000 \mathrm{e}-01$

$1.00000 \mathrm{e}-02$ 1.00000e-02 1.00000e-03 1.00000e-09 1.00000e-01

$1.00000 \mathrm{e}+001.00000 \mathrm{e}+001.00000 \mathrm{e}-011.00000 \mathrm{e}-091.00000 \mathrm{e}-01$

Element: 700 \# of layers: 6

$\mathrm{Kx} \mathrm{Ky} \mathrm{Kz}$ Ss Por

6.31069e+02 6.31069e+02 6.31069e+01 1.00000e-09 7.00000e-02

$2.52163 \mathrm{e}+012.52163 \mathrm{e}+012.52163 \mathrm{e}+00$ 1.00000e-09 2.12000e-01

$2.52163 \mathrm{e}+012.52163 \mathrm{e}+012.52163 \mathrm{e}+00$ 1.00000e-09 2.12000e-01

$2.52163 \mathrm{e}+012.52163 \mathrm{e}+012.52163 \mathrm{e}+001.00000 \mathrm{e}-092.12000 \mathrm{e}-01$

$1.00000 \mathrm{e}-02$ 1.00000e-02 1.00000e-03 1.00000e-09 1.00000e-01

$1.00000 \mathrm{e}+001.00000 \mathrm{e}+001.00000 \mathrm{e}-01$ 1.00000e-09 1.00000e-01

Element: 701 \# of layers: 6

Kx Ky Kz Ss Por

6.31069e+02 6.31069e+02 6.31069e+01 1.00000e-09 7.00000e-02

$2.52163 \mathrm{e}+012.52163 \mathrm{e}+012.52163 \mathrm{e}+00$ 1.00000e-09 2.12000e-01

$2.52163 \mathrm{e}+012.52163 \mathrm{e}+012.52163 \mathrm{e}+00$ 1.00000e-09 2.12000e-01

$2.52163 \mathrm{e}+012.52163 \mathrm{e}+012.52163 \mathrm{e}+001.00000 \mathrm{e}-092.12000 \mathrm{e}-01$

$1.00000 \mathrm{e}-02$ 1.00000e-02 1.00000e-03 1.00000e-09 1.00000e-01

$1.00000 \mathrm{e}+001.00000 \mathrm{e}+001.00000 \mathrm{e}-011.00000 \mathrm{e}-091.00000 \mathrm{e}-01$

Element: 702 \# of layers: 4

$\mathrm{Kx} \mathrm{Ky} \mathrm{Kz}$ Ss Por

4.59924e+02 4.59924e+02 4.59924e+01 1.00000e-09 7.00000e-02

$1.83768 \mathrm{e}+01$ 1.83768e+01 1.83768e+00 1.00000e-09 2.12000e-01

$1.83768 \mathrm{e}+01$ 1.83768e+01 1.83768e+00 1.00000e-09 2.12000e-01

$1.83768 \mathrm{e}+011.83768 \mathrm{e}+01$ 1.83768e+00 1.00000e-09 2.12000e-01

Element: 703 \# of layers: 4

$\mathrm{Kx} \mathrm{Ky} \mathrm{Kz}$ Ss Por

4.59924e+02 4.59924e+02 4.59924e+01 1.00000e-09 7.00000e-02

$1.83768 \mathrm{e}+01$ 1.83768e+01 1.83768e+00 1.00000e-09 2.12000e-01

$1.83768 \mathrm{e}+011.83768 \mathrm{e}+01$ 1.83768e+00 1.00000e-09 2.12000e-01

$1.83768 \mathrm{e}+01$ 1.83768e+01 1.83768e+00 1.00000e-09 2.12000e-01

Element: 704 \# of layers: 4

$\mathrm{Kx} \mathrm{Ky} \mathrm{Kz}$ Ss Por

4.59924e+02 4.59924e+02 4.59924e+01 1.00000e-09 7.00000e-02

$1.83768 \mathrm{e}+011.83768 \mathrm{e}+01$ 1.83768e+00 1.00000e-09 2.12000e-01

$1.83768 \mathrm{e}+01$ 1.83768e+01 1.83768e+00 1.00000e-09 2.12000e-01

$1.83768 \mathrm{e}+01$ 1.83768e+01 1.83768e+00 1.00000e-09 2.12000e-01

Element: 705 \# of layers: 5

$\mathrm{Kx} \mathrm{Ky} \mathrm{Kz}$ Ss Por

4.59924e+02 4.59924e+02 4.59924e+01 1.00000e-09 7.00000e-02 4.59924e+02 4.59924e+02 4.59924e+01 1.00000e-09 7.00000e-02 $1.83768 \mathrm{e}+011.83768 \mathrm{e}+011.83768 \mathrm{e}+001.00000 \mathrm{e}-092.12000 \mathrm{e}-01$ $1.83768 \mathrm{e}+011.83768 \mathrm{e}+011.83768 \mathrm{e}+001.00000 \mathrm{e}-092.12000 \mathrm{e}-01$ 
$1.83768 \mathrm{e}+011.83768 \mathrm{e}+011.83768 \mathrm{e}+00$ 1.00000e-09 2.12000e-01 Element: 706 \# of layers: 4

Kx Ky Kz Ss Por

$4.59924 \mathrm{e}+024.59924 \mathrm{e}+024.59924 \mathrm{e}+01$ 1.00000e-09 7.00000e-02

$4.59924 \mathrm{e}+024.59924 \mathrm{e}+024.59924 \mathrm{e}+011.00000 \mathrm{e}-097.00000 \mathrm{e}-02$

$1.83768 \mathrm{e}+011.83768 \mathrm{e}+011.83768 \mathrm{e}+001.00000 \mathrm{e}-092.12000 \mathrm{e}-01$

$1.83768 \mathrm{e}+011.83768 \mathrm{e}+011.83768 \mathrm{e}+00$ 1.00000e-09 2.12000e-01

Element: 707 \# of layers: 4

Kx Ky Kz Ss Por

$4.59924 \mathrm{e}+024.59924 \mathrm{e}+024.59924 \mathrm{e}+01$ 1.00000e-09 7.00000e-02

$4.59924 \mathrm{e}+024.59924 \mathrm{e}+024.59924 \mathrm{e}+01$ 1.00000e-09 7.00000e-02

$1.83768 \mathrm{e}+011.83768 \mathrm{e}+011.83768 \mathrm{e}+001.00000 \mathrm{e}-092.12000 \mathrm{e}-01$

$1.83768 \mathrm{e}+011.83768 \mathrm{e}+011.83768 \mathrm{e}+00$ 1.00000e-09 2.12000e-01

Element: 708 \# of layers: 4

Kx Ky Kz Ss Por

$4.59924 \mathrm{e}+02$ 4.59924e+02 4.59924e+01 1.00000e-09 7.00000e-02

$4.59924 \mathrm{e}+024.59924 \mathrm{e}+024.59924 \mathrm{e}+01$ 1.00000e-09 7.00000e-02

$1.83768 \mathrm{e}+011.83768 \mathrm{e}+011.83768 \mathrm{e}+001.00000 \mathrm{e}-092.12000 \mathrm{e}-01$

$1.83768 \mathrm{e}+011.83768 \mathrm{e}+011.83768 \mathrm{e}+001.00000 \mathrm{e}-092.12000 \mathrm{e}-01$

Element: 709 \# of layers: 4

Kx Ky Kz Ss Por

4.59924e+02 4.59924e+02 4.59924e+01 1.00000e-09 7.00000e-02

$1.83768 \mathrm{e}+011.83768 \mathrm{e}+011.83768 \mathrm{e}+001.00000 \mathrm{e}-092.12000 \mathrm{e}-01$

$1.83768 \mathrm{e}+011.83768 \mathrm{e}+011.83768 \mathrm{e}+001.00000 \mathrm{e}-092.12000 \mathrm{e}-01$

$1.83768 \mathrm{e}+011.83768 \mathrm{e}+011.83768 \mathrm{e}+001.00000 \mathrm{e}-092.12000 \mathrm{e}-01$

Element: 710 \# of layers: 5

Kx Ky Kz Ss Por

$4.59924 \mathrm{e}+024.59924 \mathrm{e}+024.59924 \mathrm{e}+01$ 1.00000e-09 7.00000e-02

$4.59924 \mathrm{e}+024.59924 \mathrm{e}+024.59924 \mathrm{e}+01$ 1.00000e-09 7.00000e-02

$1.83768 \mathrm{e}+011.83768 \mathrm{e}+011.83768 \mathrm{e}+001.00000 \mathrm{e}-092.12000 \mathrm{e}-01$

$1.83768 \mathrm{e}+011.83768 \mathrm{e}+011.83768 \mathrm{e}+001.00000 \mathrm{e}-092.12000 \mathrm{e}-01$

$1.83768 \mathrm{e}+011.83768 \mathrm{e}+011.83768 \mathrm{e}+00$ 1.00000e-09 2.12000e-01

Element: 711 \# of layers: 5

Kx Ky Kz Ss Por

$3.10944 \mathrm{e}+023.10944 \mathrm{e}+023.10944 \mathrm{e}+01$ 1.00000e-09 7.00000e-02

$3.10944 \mathrm{e}+023.10944 \mathrm{e}+023.10944 \mathrm{e}+01$ 1.00000e-09 7.00000e-02

$1.24241 \mathrm{e}+011.24241 \mathrm{e}+011.24241 \mathrm{e}+001.00000 \mathrm{e}-092.12000 \mathrm{e}-01$

$1.24241 \mathrm{e}+011.24241 \mathrm{e}+011.24241 \mathrm{e}+001.00000 \mathrm{e}-092.12000 \mathrm{e}-01$

$1.24241 \mathrm{e}+011.24241 \mathrm{e}+011.24241 \mathrm{e}+001.00000 \mathrm{e}-092.12000 \mathrm{e}-01$

Element: 712 \# of layers: 5

Kx Ky Kz Ss Por

$3.10944 \mathrm{e}+02$ 3.10944e+02 3.10944e+01 1.00000e-09 7.00000e-02

$3.10944 \mathrm{e}+023.10944 \mathrm{e}+023.10944 \mathrm{e}+01$ 1.00000e-09 7.00000e-02

$1.24241 \mathrm{e}+011.24241 \mathrm{e}+011.24241 \mathrm{e}+001.00000 \mathrm{e}-092.12000 \mathrm{e}-01$

$1.24241 \mathrm{e}+011.24241 \mathrm{e}+011.24241 \mathrm{e}+001.00000 \mathrm{e}-092.12000 \mathrm{e}-01$

$1.24241 \mathrm{e}+011.24241 \mathrm{e}+011.24241 \mathrm{e}+001.00000 \mathrm{e}-092.12000 \mathrm{e}-01$ 
Element: 713 \# of layers: 4

Kx Ky Kz Ss Por

$3.10944 \mathrm{e}+02$ 3.10944e+02 3.10944e+01 1.00000e-09 7.00000e-02

$3.10944 \mathrm{e}+023.10944 \mathrm{e}+023.10944 \mathrm{e}+01$ 1.00000e-09 7.00000e-02

$1.24241 \mathrm{e}+011.24241 \mathrm{e}+011.24241 \mathrm{e}+001.00000 \mathrm{e}-092.12000 \mathrm{e}-01$

$1.24241 \mathrm{e}+011.24241 \mathrm{e}+011.24241 \mathrm{e}+001.00000 \mathrm{e}-092.12000 \mathrm{e}-01$

Element: 714 \# of layers: 6

Kx Ky Kz Ss Por

$3.89056 \mathrm{e}+013.89056 \mathrm{e}+013.89056 \mathrm{e}+00$ 1.00000e-09 2.12000e-01

$3.89056 \mathrm{e}+013.89056 \mathrm{e}+013.89056 \mathrm{e}+001.00000 \mathrm{e}-092.12000 \mathrm{e}-01$

$3.89056 \mathrm{e}+013.89056 \mathrm{e}+013.89056 \mathrm{e}+001.00000 \mathrm{e}-092.12000 \mathrm{e}-01$

$3.89056 \mathrm{e}+013.89056 \mathrm{e}+013.89056 \mathrm{e}+001.00000 \mathrm{e}-092.12000 \mathrm{e}-01$

$1.00000 \mathrm{e}-021.00000 \mathrm{e}-02$ 1.00000e-03 1.00000e-09 1.00000e-01

$1.00000 \mathrm{e}+001.00000 \mathrm{e}+001.00000 \mathrm{e}-011.00000 \mathrm{e}-091.00000 \mathrm{e}-01$

Element: 715 \# of layers: 6

Kx Ky Kz Ss Por

$3.89056 \mathrm{e}+013.89056 \mathrm{e}+013.89056 \mathrm{e}+00$ 1.00000e-09 2.12000e-01

$3.89056 \mathrm{e}+013.89056 \mathrm{e}+013.89056 \mathrm{e}+001.00000 \mathrm{e}-092.12000 \mathrm{e}-01$

$3.89056 \mathrm{e}+013.89056 \mathrm{e}+013.89056 \mathrm{e}+001.00000 \mathrm{e}-092.12000 \mathrm{e}-01$

$3.89056 \mathrm{e}+013.89056 \mathrm{e}+013.89056 \mathrm{e}+001.00000 \mathrm{e}-092.12000 \mathrm{e}-01$

$1.00000 \mathrm{e}-021.00000 \mathrm{e}-02$ 1.00000e-03 1.00000e-09 1.00000e-01

$1.00000 \mathrm{e}+001.00000 \mathrm{e}+001.00000 \mathrm{e}-011.00000 \mathrm{e}-091.00000 \mathrm{e}-01$

Element: 716 \# of layers: 5

Kx Ky Kz Ss Por

$3.89056 \mathrm{e}+013.89056 \mathrm{e}+013.89056 \mathrm{e}+00$ 1.00000e-09 2.12000e-01

$3.89056 \mathrm{e}+013.89056 \mathrm{e}+013.89056 \mathrm{e}+001.00000 \mathrm{e}-092.12000 \mathrm{e}-01$

$3.89056 \mathrm{e}+013.89056 \mathrm{e}+013.89056 \mathrm{e}+001.00000 \mathrm{e}-092.12000 \mathrm{e}-01$

$1.00000 \mathrm{e}-02$ 1.00000e-02 1.00000e-03 1.00000e-09 1.00000e-01

$1.00000 \mathrm{e}+001.00000 \mathrm{e}+001.00000 \mathrm{e}-011.00000 \mathrm{e}-091.00000 \mathrm{e}-01$

Element: 717 \# of layers: 6

Kx Ky Kz Ss Por

$3.89056 \mathrm{e}+013.89056 \mathrm{e}+013.89056 \mathrm{e}+00$ 1.00000e-09 2.12000e-01

$3.89056 \mathrm{e}+013.89056 \mathrm{e}+013.89056 \mathrm{e}+00$ 1.00000e-09 2.12000e-01

$3.89056 \mathrm{e}+013.89056 \mathrm{e}+013.89056 \mathrm{e}+001.00000 \mathrm{e}-092.12000 \mathrm{e}-01$

$3.89056 \mathrm{e}+013.89056 \mathrm{e}+013.89056 \mathrm{e}+001.00000 \mathrm{e}-092.12000 \mathrm{e}-01$

$1.00000 \mathrm{e}-021.00000 \mathrm{e}-02$ 1.00000e-03 1.00000e-09 1.00000e-01

$1.00000 \mathrm{e}+001.00000 \mathrm{e}+001.00000 \mathrm{e}-011.00000 \mathrm{e}-091.00000 \mathrm{e}-01$

Element: 718 \# of layers: 6

Kx Ky Kz Ss Por

$3.89056 \mathrm{e}+013.89056 \mathrm{e}+013.89056 \mathrm{e}+00$ 1.00000e-09 2.12000e-01

$3.89056 \mathrm{e}+013.89056 \mathrm{e}+013.89056 \mathrm{e}+001.00000 \mathrm{e}-092.12000 \mathrm{e}-01$

$3.89056 \mathrm{e}+013.89056 \mathrm{e}+013.89056 \mathrm{e}+001.00000 \mathrm{e}-092.12000 \mathrm{e}-01$

$3.89056 \mathrm{e}+013.89056 \mathrm{e}+013.89056 \mathrm{e}+00$ 1.00000e-09 2.12000e-01

$1.00000 \mathrm{e}-021.00000 \mathrm{e}-02$ 1.00000e-03 1.00000e-09 1.00000e-01

$1.00000 \mathrm{e}+001.00000 \mathrm{e}+001.00000 \mathrm{e}-011.00000 \mathrm{e}-091.00000 \mathrm{e}-01$

Element: 719 \# of layers: 6 
$\mathrm{Kx} \mathrm{Ky} \mathrm{Kz}$ Ss Por

$1.69908 \mathrm{e}+01$ 1.69908e+01 1.69908e+00 1.00000e-09 2.12000e-01

$1.69908 \mathrm{e}+011.69908 \mathrm{e}+011.69908 \mathrm{e}+001.00000 \mathrm{e}-092.12000 \mathrm{e}-01$

$1.69908 \mathrm{e}+011.69908 \mathrm{e}+011.69908 \mathrm{e}+001.00000 \mathrm{e}-092.12000 \mathrm{e}-01$

$1.69908 \mathrm{e}+011.69908 \mathrm{e}+01$ 1.69908e+00 1.00000e-09 2.12000e-01

$1.00000 \mathrm{e}-02$ 1.00000e-02 1.00000e-03 1.00000e-09 1.00000e-01

$1.00000 \mathrm{e}+001.00000 \mathrm{e}+001.00000 \mathrm{e}-01$ 1.00000e-09 1.00000e-01

Element: 720 \# of layers: 6

$\mathrm{Kx} \mathrm{Ky} \mathrm{Kz}$ Ss Por

$1.69908 \mathrm{e}+011.69908 \mathrm{e}+011.69908 \mathrm{e}+001.00000 \mathrm{e}-092.12000 \mathrm{e}-01$

$1.69908 \mathrm{e}+011.69908 \mathrm{e}+01$ 1.69908e+00 1.00000e-09 2.12000e-01

$1.69908 \mathrm{e}+011.69908 \mathrm{e}+011.69908 \mathrm{e}+001.00000 \mathrm{e}-092.12000 \mathrm{e}-01$

$1.69908 \mathrm{e}+01$ 1.69908e+01 1.69908e+00 1.00000e-09 2.12000e-01

$1.00000 \mathrm{e}-02$ 1.00000e-02 1.00000e-03 1.00000e-09 1.00000e-01

$1.00000 \mathrm{e}+001.00000 \mathrm{e}+001.00000 \mathrm{e}-01$ 1.00000e-09 1.00000e-01

Element: 721 \# of layers: 7

$\mathrm{Kx} \mathrm{Ky} \mathrm{Kz}$ Ss Por

4.25236e+02 4.25236e+02 4.25236e+01 1.00000e-09 7.00000e-02

$1.69908 \mathrm{e}+01$ 1.69908e+01 1.69908e+00 1.00000e-09 2.12000e-01

$1.69908 \mathrm{e}+01$ 1.69908e+01 1.69908e+00 1.00000e-09 2.12000e-01

$1.69908 \mathrm{e}+011.69908 \mathrm{e}+011.69908 \mathrm{e}+001.00000 \mathrm{e}-092.12000 \mathrm{e}-01$

$1.69908 \mathrm{e}+01$ 1.69908e+01 1.69908e+00 1.00000e-09 2.12000e-01

$1.00000 \mathrm{e}-02$ 1.00000e-02 1.00000e-03 1.00000e-09 1.00000e-01

$1.00000 \mathrm{e}+001.00000 \mathrm{e}+001.00000 \mathrm{e}-011.00000 \mathrm{e}-091.00000 \mathrm{e}-01$

Element: 722 \# of layers: 6

$\mathrm{Kx} \mathrm{Ky} \mathrm{Kz}$ Ss Por

4.25236e+02 4.25236e+02 4.25236e+01 1.00000e-09 7.00000e-02

$1.69908 \mathrm{e}+011.69908 \mathrm{e}+01$ 1.69908e+00 1.00000e-09 2.12000e-01

$1.69908 \mathrm{e}+011.69908 \mathrm{e}+011.69908 \mathrm{e}+001.00000 \mathrm{e}-092.12000 \mathrm{e}-01$

$1.69908 \mathrm{e}+01$ 1.69908e+01 1.69908e+00 1.00000e-09 2.12000e-01

$1.00000 \mathrm{e}-02$ 1.00000e-02 1.00000e-03 1.00000e-09 1.00000e-01

$1.00000 \mathrm{e}+001.00000 \mathrm{e}+001.00000 \mathrm{e}-011.00000 \mathrm{e}-091.00000 \mathrm{e}-01$

Element: 723 \# of layers: 6

$\mathrm{Kx} \mathrm{Ky} \mathrm{Kz}$ Ss Por

4.25236e+02 4.25236e+02 4.25236e+01 1.00000e-09 7.00000e-02

$1.69908 \mathrm{e}+011.69908 \mathrm{e}+011.69908 \mathrm{e}+001.00000 \mathrm{e}-092.12000 \mathrm{e}-01$

$1.69908 \mathrm{e}+011.69908 \mathrm{e}+011.69908 \mathrm{e}+001.00000 \mathrm{e}-092.12000 \mathrm{e}-01$

$1.69908 \mathrm{e}+011.69908 \mathrm{e}+01$ 1.69908e+00 1.00000e-09 2.12000e-01

$1.00000 \mathrm{e}-021.00000 \mathrm{e}-02$ 1.00000e-03 1.00000e-09 1.00000e-01

$1.00000 \mathrm{e}+001.00000 \mathrm{e}+001.00000 \mathrm{e}-01$ 1.00000e-09 1.00000e-01

Element: 724 \# of layers: 5

$\mathrm{Kx} \mathrm{Ky} \mathrm{Kz}$ Ss Por

$1.69908 \mathrm{e}+01$ 1.69908e+01 1.69908e+00 1.00000e-09 2.12000e-01

$1.69908 \mathrm{e}+01$ 1.69908e+01 1.69908e+00 1.00000e-09 2.12000e-01

$1.69908 \mathrm{e}+011.69908 \mathrm{e}+01$ 1.69908e+00 1.00000e-09 2.12000e-01

$1.00000 \mathrm{e}-02$ 1.00000e-02 1.00000e-03 1.00000e-09 1.00000e-01 
$1.00000 \mathrm{e}+001.00000 \mathrm{e}+00$ 1.00000e-01 1.00000e-09 1.00000e-01

Element: 725 \# of layers: 5

$\mathrm{Kx} \mathrm{Ky} \mathrm{Kz}$ Ss Por

$1.69908 \mathrm{e}+01$ 1.69908e+01 1.69908e+00 1.00000e-09 2.12000e-01

$1.69908 \mathrm{e}+011.69908 \mathrm{e}+01$ 1.69908e+00 1.00000e-09 2.12000e-01

$1.69908 \mathrm{e}+011.69908 \mathrm{e}+01$ 1.69908e+00 1.00000e-09 2.12000e-01

$1.00000 \mathrm{e}-02$ 1.00000e-02 1.00000e-03 1.00000e-09 1.00000e-01

$1.00000 \mathrm{e}+001.00000 \mathrm{e}+001.00000 \mathrm{e}-01$ 1.00000e-09 1.00000e-01

Element: 726 \# of layers: 6

$\mathrm{Kx} \mathrm{Ky} \mathrm{Kz}$ Ss Por

$1.69908 \mathrm{e}+01$ 1.69908e+01 1.69908e+00 1.00000e-09 2.12000e-01

$1.69908 \mathrm{e}+011.69908 \mathrm{e}+011.69908 \mathrm{e}+001.00000 \mathrm{e}-092.12000 \mathrm{e}-01$

$1.69908 \mathrm{e}+011.69908 \mathrm{e}+011.69908 \mathrm{e}+001.00000 \mathrm{e}-092.12000 \mathrm{e}-01$

$1.69908 \mathrm{e}+01$ 1.69908e+01 1.69908e+00 1.00000e-09 2.12000e-01

$1.00000 \mathrm{e}-02$ 1.00000e-02 1.00000e-03 1.00000e-09 1.00000e-01

$1.00000 \mathrm{e}+001.00000 \mathrm{e}+001.00000 \mathrm{e}-011.00000 \mathrm{e}-091.00000 \mathrm{e}-01$

Element: 727 \# of layers: 6

$\mathrm{Kx} \mathrm{Ky} \mathrm{Kz}$ Ss Por

$1.69908 \mathrm{e}+01$ 1.69908e+01 1.69908e+00 1.00000e-09 2.12000e-01

$1.69908 \mathrm{e}+01$ 1.69908e+01 1.69908e+00 1.00000e-09 2.12000e-01

$1.69908 \mathrm{e}+011.69908 \mathrm{e}+011.69908 \mathrm{e}+001.00000 \mathrm{e}-092.12000 \mathrm{e}-01$

$1.69908 \mathrm{e}+01$ 1.69908e+01 1.69908e+00 1.00000e-09 2.12000e-01

$1.00000 \mathrm{e}-021.00000 \mathrm{e}-021.00000 \mathrm{e}-031.00000 \mathrm{e}-091.00000 \mathrm{e}-01$

$1.00000 \mathrm{e}+001.00000 \mathrm{e}+001.00000 \mathrm{e}-011.00000 \mathrm{e}-091.00000 \mathrm{e}-01$

Element: 728 \# of layers: 8

$\mathrm{Kx} \mathrm{Ky} \mathrm{Kz}$ Ss Por

$2.72264 \mathrm{e}+02$ 2.72264e+02 2.72264e+01 1.00000e-09 7.00000e-02

$2.72264 \mathrm{e}+022.72264 \mathrm{e}+02 \quad 2.72264 \mathrm{e}+01$ 1.00000e-09 7.00000e-02

$1.08788 \mathrm{e}+011.08788 \mathrm{e}+011.08788 \mathrm{e}+001.00000 \mathrm{e}-092.12000 \mathrm{e}-01$

$1.08788 \mathrm{e}+011.08788 \mathrm{e}+01$ 1.08788e+00 1.00000e-09 2.12000e-01

$1.08788 \mathrm{e}+011.08788 \mathrm{e}+01$ 1.08788e+00 1.00000e-09 2.12000e-01

$1.08788 \mathrm{e}+01$ 1.08788e+01 1.08788e+00 1.00000e-09 2.12000e-01

$1.00000 \mathrm{e}-02$ 1.00000e-02 1.00000e-03 1.00000e-09 1.00000e-01

$1.00000 \mathrm{e}+001.00000 \mathrm{e}+001.00000 \mathrm{e}-011.00000 \mathrm{e}-091.00000 \mathrm{e}-01$

Element: 729 \# of layers: 8

$\mathrm{Kx} \mathrm{Ky} \mathrm{Kz}$ Ss Por

$2.72264 \mathrm{e}+02$ 2.72264e+02 2.72264e+01 1.00000e-09 7.00000e-02

$2.72264 \mathrm{e}+022.72264 \mathrm{e}+02$ 2.72264e+01 1.00000e-09 7.00000e-02

$1.08788 \mathrm{e}+011.08788 \mathrm{e}+01$ 1.08788e+00 1.00000e-09 2.12000e-01

$1.08788 \mathrm{e}+01$ 1.08788e+01 1.08788e+00 1.00000e-09 2.12000e-01

$1.08788 \mathrm{e}+011.08788 \mathrm{e}+01$ 1.08788e+00 1.00000e-09 2.12000e-01

$1.08788 \mathrm{e}+01$ 1.08788e+01 1.08788e+00 1.00000e-09 2.12000e-01

$1.00000 \mathrm{e}-02$ 1.00000e-02 1.00000e-03 1.00000e-09 1.00000e-01

$1.00000 \mathrm{e}+001.00000 \mathrm{e}+001.00000 \mathrm{e}-01$ 1.00000e-09 1.00000e-01

Element: 730 \# of layers: 6

Kx Ky Kz Ss Por 
2.72264e+02 2.72264e+02 2.72264e+01 1.00000e-09 7.00000e-02 $1.08788 \mathrm{e}+01$ 1.08788e+01 1.08788e+00 1.00000e-09 2.12000e-01 $1.08788 \mathrm{e}+011.08788 \mathrm{e}+011.08788 \mathrm{e}+001.00000 \mathrm{e}-092.12000 \mathrm{e}-01$ $1.08788 \mathrm{e}+011.08788 \mathrm{e}+011.08788 \mathrm{e}+001.00000 \mathrm{e}-092.12000 \mathrm{e}-01$ $1.00000 \mathrm{e}-02$ 1.00000e-02 1.00000e-03 1.00000e-09 1.00000e-01 $1.00000 \mathrm{e}+001.00000 \mathrm{e}+001.00000 \mathrm{e}-011.00000 \mathrm{e}-091.00000 \mathrm{e}-01$ Element: 731 \# of layers: 6

$\mathrm{Kx} \mathrm{Ky} \mathrm{Kz}$ Ss Por

$2.72264 \mathrm{e}+02$ 2.72264e+02 2.72264e+01 1.00000e-09 7.00000e-02 $1.08788 \mathrm{e}+01$ 1.08788e+01 1.08788e+00 1.00000e-09 2.12000e-01 $1.08788 \mathrm{e}+01$ 1.08788e+01 1.08788e+00 1.00000e-09 2.12000e-01 $1.08788 \mathrm{e}+011.08788 \mathrm{e}+011.08788 \mathrm{e}+001.00000 \mathrm{e}-092.12000 \mathrm{e}-01$ $1.00000 \mathrm{e}-02$ 1.00000e-02 1.00000e-03 1.00000e-09 1.00000e-01 $1.00000 \mathrm{e}+001.00000 \mathrm{e}+001.00000 \mathrm{e}-011.00000 \mathrm{e}-091.00000 \mathrm{e}-01$ Element: 732 \# of layers: 5

Kx Ky Kz Ss Por

$2.72264 \mathrm{e}+02$ 2.72264e+02 2.72264e+01 1.00000e-09 7.00000e-02 $1.08788 \mathrm{e}+01$ 1.08788e+01 1.08788e+00 1.00000e-09 2.12000e-01 $1.08788 \mathrm{e}+01$ 1.08788e+01 1.08788e+00 1.00000e-09 2.12000e-01 $1.00000 \mathrm{e}-02$ 1.00000e-02 1.00000e-03 1.00000e-09 1.00000e-01 $1.00000 \mathrm{e}+001.00000 \mathrm{e}+001.00000 \mathrm{e}-011.00000 \mathrm{e}-091.00000 \mathrm{e}-01$ Element: 733 \# of layers: 6

$\mathrm{Kx} \mathrm{Ky} \mathrm{Kz}$ Ss Por

$2.72264 \mathrm{e}+02$ 2.72264e+02 2.72264e+01 1.00000e-09 7.00000e-02 $1.08788 \mathrm{e}+011.08788 \mathrm{e}+011.08788 \mathrm{e}+001.00000 \mathrm{e}-092.12000 \mathrm{e}-01$ $1.08788 \mathrm{e}+011.08788 \mathrm{e}+01$ 1.08788e+00 1.00000e-09 2.12000e-01 $1.08788 \mathrm{e}+011.08788 \mathrm{e}+01$ 1.08788e+00 1.00000e-09 2.12000e-01 $1.00000 \mathrm{e}-02$ 1.00000e-02 1.00000e-03 1.00000e-09 1.00000e-01 $1.00000 \mathrm{e}+001.00000 \mathrm{e}+001.00000 \mathrm{e}-011.00000 \mathrm{e}-091.00000 \mathrm{e}-01$ Element: 734 \# of layers: 7

$\mathrm{Kx} \mathrm{Ky} \mathrm{Kz}$ Ss Por

$2.72264 \mathrm{e}+02$ 2.72264e+02 2.72264e+01 1.00000e-09 7.00000e-02 $2.72264 \mathrm{e}+022.72264 \mathrm{e}+02 \quad 2.72264 \mathrm{e}+01$ 1.00000e-09 7.00000e-02 $1.08788 \mathrm{e}+011.08788 \mathrm{e}+01$ 1.08788e+00 1.00000e-09 2.12000e-01 $1.08788 \mathrm{e}+011.08788 \mathrm{e}+011.08788 \mathrm{e}+001.00000 \mathrm{e}-092.12000 \mathrm{e}-01$ $1.08788 \mathrm{e}+01$ 1.08788e+01 1.08788e+00 1.00000e-09 2.12000e-01 $1.00000 \mathrm{e}-02$ 1.00000e-02 1.00000e-03 1.00000e-09 1.00000e-01 $1.00000 \mathrm{e}+001.00000 \mathrm{e}+001.00000 \mathrm{e}-011.00000 \mathrm{e}-091.00000 \mathrm{e}-01$ Element: 735 \# of layers: 7

$\mathrm{Kx} \mathrm{Ky} \mathrm{Kz}$ Ss Por

$2.72264 \mathrm{e}+02$ 2.72264e+02 2.72264e+01 1.00000e-09 7.00000e-02 $2.72264 \mathrm{e}+022.72264 \mathrm{e}+022.72264 \mathrm{e}+01$ 1.00000e-09 7.00000e-02 $1.08788 \mathrm{e}+011.08788 \mathrm{e}+011.08788 \mathrm{e}+001.00000 \mathrm{e}-092.12000 \mathrm{e}-01$ $1.08788 \mathrm{e}+01$ 1.08788e+01 1.08788e+00 1.00000e-09 2.12000e-01 $1.08788 \mathrm{e}+011.08788 \mathrm{e}+01$ 1.08788e+00 1.00000e-09 2.12000e-01 $1.00000 \mathrm{e}-02$ 1.00000e-02 1.00000e-03 1.00000e-09 1.00000e-01 
$1.00000 \mathrm{e}+001.00000 \mathrm{e}+00$ 1.00000e-01 1.00000e-09 1.00000e-01

Element: 736 \# of layers: 7

$\mathrm{Kx} \mathrm{Ky} \mathrm{Kz}$ Ss Por

$2.72264 \mathrm{e}+02$ 2.72264e+02 2.72264e+01 1.00000e-09 7.00000e-02

$1.08788 \mathrm{e}+011.08788 \mathrm{e}+01$ 1.08788e+00 1.00000e-09 2.12000e-01

$1.08788 \mathrm{e}+011.08788 \mathrm{e}+011.08788 \mathrm{e}+001.00000 \mathrm{e}-092.12000 \mathrm{e}-01$

$1.08788 \mathrm{e}+011.08788 \mathrm{e}+011.08788 \mathrm{e}+001.00000 \mathrm{e}-092.12000 \mathrm{e}-01$

$1.08788 \mathrm{e}+011.08788 \mathrm{e}+011.08788 \mathrm{e}+001.00000 \mathrm{e}-092.12000 \mathrm{e}-01$

$1.00000 \mathrm{e}-02$ 1.00000e-02 1.00000e-03 1.00000e-09 1.00000e-01

$1.00000 \mathrm{e}+001.00000 \mathrm{e}+001.00000 \mathrm{e}-011.00000 \mathrm{e}-091.00000 \mathrm{e}-01$

Element: 737 \# of layers: 6

$\mathrm{Kx} \mathrm{Ky} \mathrm{Kz}$ Ss Por

7.66129e+02 7.66129e+02 7.66129e+01 1.00000e-09 7.00000e-02

$3.06119 \mathrm{e}+013.06119 \mathrm{e}+013.06119 \mathrm{e}+00$ 1.00000e-09 2.12000e-01

$3.06119 \mathrm{e}+013.06119 \mathrm{e}+013.06119 \mathrm{e}+001.00000 \mathrm{e}-092.12000 \mathrm{e}-01$

$3.06119 \mathrm{e}+013.06119 \mathrm{e}+013.06119 \mathrm{e}+001.00000 \mathrm{e}-092.12000 \mathrm{e}-01$

$1.00000 \mathrm{e}-02$ 1.00000e-02 1.00000e-03 1.00000e-09 1.00000e-01

$1.00000 \mathrm{e}+001.00000 \mathrm{e}+001.00000 \mathrm{e}-011.00000 \mathrm{e}-091.00000 \mathrm{e}-01$

Element: 738 \# of layers: 5

$\mathrm{Kx} \mathrm{Ky} \mathrm{Kz}$ Ss Por

7.66129e+02 7.66129e+02 7.66129e+01 1.00000e-09 7.00000e-02

$3.06119 \mathrm{e}+013.06119 \mathrm{e}+013.06119 \mathrm{e}+001.00000 \mathrm{e}-092.12000 \mathrm{e}-01$

$3.06119 \mathrm{e}+013.06119 \mathrm{e}+013.06119 \mathrm{e}+00$ 1.00000e-09 2.12000e-01

$1.00000 \mathrm{e}-02$ 1.00000e-02 1.00000e-03 1.00000e-09 1.00000e-01

$1.00000 \mathrm{e}+001.00000 \mathrm{e}+001.00000 \mathrm{e}-011.00000 \mathrm{e}-091.00000 \mathrm{e}-01$

Element: 739 \# of layers: 5

$\mathrm{Kx} \mathrm{Ky} \mathrm{Kz}$ Ss Por

7.66129e+02 7.66129e+02 7.66129e+01 1.00000e-09 7.00000e-02

$3.06119 \mathrm{e}+013.06119 \mathrm{e}+013.06119 \mathrm{e}+001.00000 \mathrm{e}-092.12000 \mathrm{e}-01$

$3.06119 \mathrm{e}+013.06119 \mathrm{e}+013.06119 \mathrm{e}+00$ 1.00000e-09 2.12000e-01

$1.00000 \mathrm{e}-02$ 1.00000e-02 1.00000e-03 1.00000e-09 1.00000e-01

$1.00000 \mathrm{e}+001.00000 \mathrm{e}+001.00000 \mathrm{e}-011.00000 \mathrm{e}-091.00000 \mathrm{e}-01$

Element: 740 \# of layers: 5

$\mathrm{Kx} \mathrm{Ky} \mathrm{Kz}$ Ss Por

7.66129e+02 7.66129e+02 7.66129e+01 1.00000e-09 7.00000e-02

$3.06119 \mathrm{e}+013.06119 \mathrm{e}+013.06119 \mathrm{e}+00$ 1.00000e-09 2.12000e-01

$3.06119 \mathrm{e}+013.06119 \mathrm{e}+013.06119 \mathrm{e}+001.00000 \mathrm{e}-092.12000 \mathrm{e}-01$

$1.00000 \mathrm{e}-02$ 1.00000e-02 1.00000e-03 1.00000e-09 1.00000e-01

$1.00000 \mathrm{e}+001.00000 \mathrm{e}+001.00000 \mathrm{e}-011.00000 \mathrm{e}-091.00000 \mathrm{e}-01$

Element: 741 \# of layers: 5

$\mathrm{Kx} \mathrm{Ky} \mathrm{Kz}$ Ss Por

7.66129e+02 7.66129e+02 7.66129e+01 1.00000e-09 7.00000e-02

$3.06119 \mathrm{e}+013.06119 \mathrm{e}+013.06119 \mathrm{e}+001.00000 \mathrm{e}-092.12000 \mathrm{e}-01$

$3.06119 \mathrm{e}+013.06119 \mathrm{e}+013.06119 \mathrm{e}+00$ 1.00000e-09 2.12000e-01

$1.00000 \mathrm{e}-02$ 1.00000e-02 1.00000e-03 1.00000e-09 1.00000e-01

$1.00000 \mathrm{e}+001.00000 \mathrm{e}+001.00000 \mathrm{e}-011.00000 \mathrm{e}-091.00000 \mathrm{e}-01$ 
Element: 742 \# of layers: 5

$\mathrm{Kx} \mathrm{Ky} \mathrm{Kz}$ Ss Por

7.66129e+02 7.66129e+02 7.66129e+01 1.00000e-09 7.00000e-02

$3.06119 \mathrm{e}+013.06119 \mathrm{e}+013.06119 \mathrm{e}+001.00000 \mathrm{e}-09$ 2.12000e-01

$3.06119 \mathrm{e}+013.06119 \mathrm{e}+013.06119 \mathrm{e}+001.00000 \mathrm{e}-092.12000 \mathrm{e}-01$

$1.00000 \mathrm{e}-02$ 1.00000e-02 1.00000e-03 1.00000e-09 1.00000e-01

$1.00000 \mathrm{e}+001.00000 \mathrm{e}+001.00000 \mathrm{e}-01$ 1.00000e-09 1.00000e-01

Element: 743 \# of layers: 6

$\mathrm{Kx} \mathrm{Ky} \mathrm{Kz}$ Ss Por

7.66129e+02 7.66129e+02 7.66129e+01 1.00000e-09 7.00000e-02

$3.06119 \mathrm{e}+013.06119 \mathrm{e}+013.06119 \mathrm{e}+00$ 1.00000e-09 2.12000e-01

$3.06119 \mathrm{e}+013.06119 \mathrm{e}+013.06119 \mathrm{e}+001.00000 \mathrm{e}-092.12000 \mathrm{e}-01$

$3.06119 \mathrm{e}+013.06119 \mathrm{e}+013.06119 \mathrm{e}+00$ 1.00000e-09 2.12000e-01

$1.00000 \mathrm{e}-02$ 1.00000e-02 1.00000e-03 1.00000e-09 1.00000e-01

$1.00000 \mathrm{e}+001.00000 \mathrm{e}+001.00000 \mathrm{e}-01$ 1.00000e-09 1.00000e-01

Element: 744 \# of layers: 6

$\mathrm{Kx} \mathrm{Ky} \mathrm{Kz}$ Ss Por

7.66129e+02 7.66129e+02 7.66129e+01 1.00000e-09 7.00000e-02 $3.06119 \mathrm{e}+013.06119 \mathrm{e}+013.06119 \mathrm{e}+001.00000 \mathrm{e}-092.12000 \mathrm{e}-01$ $3.06119 \mathrm{e}+013.06119 \mathrm{e}+013.06119 \mathrm{e}+00$ 1.00000e-09 2.12000e-01 $3.06119 \mathrm{e}+013.06119 \mathrm{e}+013.06119 \mathrm{e}+001.00000 \mathrm{e}-092.12000 \mathrm{e}-01$ $1.00000 \mathrm{e}-021.00000 \mathrm{e}-02$ 1.00000e-03 1.00000e-09 1.00000e-01

$1.00000 \mathrm{e}+001.00000 \mathrm{e}+001.00000 \mathrm{e}-011.00000 \mathrm{e}-091.00000 \mathrm{e}-01$

Element: 745 \# of layers: 5

$\mathrm{Kx} \mathrm{Ky} \mathrm{Kz}$ Ss Por

7.66129e+02 7.66129e+02 7.66129e+01 1.00000e-09 7.00000e-02 $3.06119 \mathrm{e}+013.06119 \mathrm{e}+013.06119 \mathrm{e}+001.00000 \mathrm{e}-092.12000 \mathrm{e}-01$ $3.06119 \mathrm{e}+013.06119 \mathrm{e}+013.06119 \mathrm{e}+001.00000 \mathrm{e}-09$ 2.12000e-01 $1.00000 \mathrm{e}-02$ 1.00000e-02 1.00000e-03 1.00000e-09 1.00000e-01 $1.00000 \mathrm{e}+001.00000 \mathrm{e}+001.00000 \mathrm{e}-011.00000 \mathrm{e}-091.00000 \mathrm{e}-01$

Element: 746 \# of layers: 5

$\mathrm{Kx} \mathrm{Ky} \mathrm{Kz}$ Ss Por

4.98397e+02 4.98397e+02 4.98397e+01 1.00000e-09 7.00000e-02 $1.99140 \mathrm{e}+011.99140 \mathrm{e}+011.99140 \mathrm{e}+001.00000 \mathrm{e}-092.12000 \mathrm{e}-01$ $1.99140 \mathrm{e}+011.99140 \mathrm{e}+011.99140 \mathrm{e}+001.00000 \mathrm{e}-092.12000 \mathrm{e}-01$ 1.00000e-02 1.00000e-02 1.00000e-03 1.00000e-09 1.00000e-01

$1.00000 \mathrm{e}+001.00000 \mathrm{e}+001.00000 \mathrm{e}-011.00000 \mathrm{e}-091.00000 \mathrm{e}-01$

Element: 747 \# of layers: 5

$\mathrm{Kx} \mathrm{Ky} \mathrm{Kz}$ Ss Por

4.98397e+02 4.98397e+02 4.98397e+01 1.00000e-09 7.00000e-02 $1.99140 \mathrm{e}+011.99140 \mathrm{e}+011.99140 \mathrm{e}+001.00000 \mathrm{e}-092.12000 \mathrm{e}-01$ $1.99140 \mathrm{e}+011.99140 \mathrm{e}+011.99140 \mathrm{e}+001.00000 \mathrm{e}-092.12000 \mathrm{e}-01$ $1.00000 \mathrm{e}-02$ 1.00000e-02 1.00000e-03 1.00000e-09 1.00000e-01 $1.00000 \mathrm{e}+001.00000 \mathrm{e}+001.00000 \mathrm{e}-01$ 1.00000e-09 1.00000e-01 Element: 748 \# of layers: 5

Kx Ky Kz Ss Por 
4.98397e+02 4.98397e+02 4.98397e+01 1.00000e-09 7.00000e-02 $1.99140 \mathrm{e}+011.99140 \mathrm{e}+011.99140 \mathrm{e}+001.00000 \mathrm{e}-092.12000 \mathrm{e}-01$ $1.99140 \mathrm{e}+011.99140 \mathrm{e}+011.99140 \mathrm{e}+001.00000 \mathrm{e}-092.12000 \mathrm{e}-01$ $1.00000 \mathrm{e}-02$ 1.00000e-02 1.00000e-03 1.00000e-09 1.00000e-01 $1.00000 \mathrm{e}+001.00000 \mathrm{e}+001.00000 \mathrm{e}-01$ 1.00000e-09 1.00000e-01

Element: 749 \# of layers: 5

$\mathrm{Kx} \mathrm{Ky} \mathrm{Kz}$ Ss Por

4.98397e+02 4.98397e+02 4.98397e+01 1.00000e-09 7.00000e-02 $1.99140 \mathrm{e}+011.99140 \mathrm{e}+011.99140 \mathrm{e}+001.00000 \mathrm{e}-092.12000 \mathrm{e}-01$ $1.99140 \mathrm{e}+011.99140 \mathrm{e}+011.99140 \mathrm{e}+001.00000 \mathrm{e}-092.12000 \mathrm{e}-01$ $1.00000 \mathrm{e}-02$ 1.00000e-02 1.00000e-03 1.00000e-09 1.00000e-01 $1.00000 \mathrm{e}+001.00000 \mathrm{e}+001.00000 \mathrm{e}-011.00000 \mathrm{e}-091.00000 \mathrm{e}-01$ Element: 750 \# of layers: 5

$\mathrm{Kx} \mathrm{Ky} \mathrm{Kz}$ Ss Por

4.98397e+02 4.98397e+02 4.98397e+01 1.00000e-09 7.00000e-02 4.98397e+02 4.98397e+02 4.98397e+01 1.00000e-09 7.00000e-02 $1.99140 \mathrm{e}+011.99140 \mathrm{e}+011.99140 \mathrm{e}+001.00000 \mathrm{e}-092.12000 \mathrm{e}-01$ $1.00000 \mathrm{e}-02$ 1.00000e-02 1.00000e-03 1.00000e-09 1.00000e-01 $1.00000 \mathrm{e}+001.00000 \mathrm{e}+001.00000 \mathrm{e}-01$ 1.00000e-09 1.00000e-01 Element: 751 \# of layers: 4

$\mathrm{Kx} \mathrm{Ky} \mathrm{Kz}$ Ss Por

4.98397e+02 4.98397e+02 4.98397e+01 1.00000e-09 7.00000e-02 $1.99140 \mathrm{e}+011.99140 \mathrm{e}+011.99140 \mathrm{e}+001.00000 \mathrm{e}-092.12000 \mathrm{e}-01$ $1.00000 \mathrm{e}-02$ 1.00000e-02 1.00000e-03 1.00000e-09 1.00000e-01 $1.00000 \mathrm{e}+001.00000 \mathrm{e}+001.00000 \mathrm{e}-011.00000 \mathrm{e}-091.00000 \mathrm{e}-01$ Element: 752 \# of layers: 4

$\mathrm{Kx} \mathrm{Ky} \mathrm{Kz}$ Ss Por 4.98397e+02 4.98397e+02 4.98397e+01 1.00000e-09 7.00000e-02 $1.99140 \mathrm{e}+011.99140 \mathrm{e}+011.99140 \mathrm{e}+001.00000 \mathrm{e}-092.12000 \mathrm{e}-01$ $1.00000 \mathrm{e}-02$ 1.00000e-02 1.00000e-03 1.00000e-09 1.00000e-01 $1.00000 \mathrm{e}+001.00000 \mathrm{e}+001.00000 \mathrm{e}-011.00000 \mathrm{e}-091.00000 \mathrm{e}-01$ Element: 753 \# of layers: 5

$\mathrm{Kx} \mathrm{Ky} \mathrm{Kz}$ Ss Por

4.98397e+02 4.98397e+02 4.98397e+01 1.00000e-09 7.00000e-02 $1.99140 \mathrm{e}+011.99140 \mathrm{e}+011.99140 \mathrm{e}+001.00000 \mathrm{e}-092.12000 \mathrm{e}-01$ $1.99140 \mathrm{e}+011.99140 \mathrm{e}+011.99140 \mathrm{e}+001.00000 \mathrm{e}-092.12000 \mathrm{e}-01$ 1.00000e-02 1.00000e-02 1.00000e-03 1.00000e-09 1.00000e-01 $1.00000 \mathrm{e}+001.00000 \mathrm{e}+001.00000 \mathrm{e}-011.00000 \mathrm{e}-091.00000 \mathrm{e}-01$ Element: 754 \# of layers: 5

$\mathrm{Kx} \mathrm{Ky} \mathrm{Kz}$ Ss Por 4.98397e+02 4.98397e+02 4.98397e+01 1.00000e-09 7.00000e-02 $1.99140 \mathrm{e}+011.99140 \mathrm{e}+011.99140 \mathrm{e}+001.00000 \mathrm{e}-092.12000 \mathrm{e}-01$ $1.99140 \mathrm{e}+011.99140 \mathrm{e}+011.99140 \mathrm{e}+001.00000 \mathrm{e}-092.12000 \mathrm{e}-01$ $1.00000 \mathrm{e}-021.00000 \mathrm{e}-021.00000 \mathrm{e}-031.00000 \mathrm{e}-091.00000 \mathrm{e}-01$ $1.00000 \mathrm{e}+001.00000 \mathrm{e}+001.00000 \mathrm{e}-01$ 1.00000e-09 1.00000e-01 Element: 755 \# of layers: 5 
$\mathrm{Kx} \mathrm{Ky} \mathrm{Kz}$ Ss Por

3.39668e+02 3.39668e+02 3.39668e+01 1.00000e-09 7.00000e-02

$1.35721 \mathrm{e}+011.35721 \mathrm{e}+011.35721 \mathrm{e}+001.00000 \mathrm{e}-092.12000 \mathrm{e}-01$

$1.35721 \mathrm{e}+011.35721 \mathrm{e}+011.35721 \mathrm{e}+001.00000 \mathrm{e}-092.12000 \mathrm{e}-01$

$1.00000 \mathrm{e}-02$ 1.00000e-02 1.00000e-03 1.00000e-09 1.00000e-01

$1.00000 \mathrm{e}+001.00000 \mathrm{e}+001.00000 \mathrm{e}-011.00000 \mathrm{e}-091.00000 \mathrm{e}-01$

Element: 756 \# of layers: 6

$\mathrm{Kx} \mathrm{Ky} \mathrm{Kz}$ Ss Por

3.39668e+02 3.39668e+02 3.39668e+01 1.00000e-09 7.00000e-02

$3.39668 \mathrm{e}+02$ 3.39668e+02 3.39668e+01 1.00000e-09 7.00000e-02

$1.35721 \mathrm{e}+011.35721 \mathrm{e}+011.35721 \mathrm{e}+001.00000 \mathrm{e}-092.12000 \mathrm{e}-01$

$1.35721 \mathrm{e}+011.35721 \mathrm{e}+011.35721 \mathrm{e}+001.00000 \mathrm{e}-092.12000 \mathrm{e}-01$

$1.00000 \mathrm{e}-02$ 1.00000e-02 1.00000e-03 1.00000e-09 1.00000e-01

$1.00000 \mathrm{e}+001.00000 \mathrm{e}+001.00000 \mathrm{e}-011.00000 \mathrm{e}-091.00000 \mathrm{e}-01$

Element: 757 \# of layers: 7

Kx Ky Kz Ss Por

3.39668e+02 3.39668e+02 3.39668e+01 1.00000e-09 7.00000e-02

$3.39668 \mathrm{e}+02$ 3.39668e+02 3.39668e+01 1.00000e-09 7.00000e-02

$3.39668 \mathrm{e}+02$ 3.39668e+02 3.39668e+01 1.00000e-09 7.00000e-02

$1.35721 \mathrm{e}+011.35721 \mathrm{e}+011.35721 \mathrm{e}+001.00000 \mathrm{e}-092.12000 \mathrm{e}-01$

$1.35721 \mathrm{e}+011.35721 \mathrm{e}+011.35721 \mathrm{e}+001.00000 \mathrm{e}-092.12000 \mathrm{e}-01$

$1.00000 \mathrm{e}-021.00000 \mathrm{e}-021.00000 \mathrm{e}-031.00000 \mathrm{e}-091.00000 \mathrm{e}-01$

$1.00000 \mathrm{e}+001.00000 \mathrm{e}+001.00000 \mathrm{e}-01$ 1.00000e-09 1.00000e-01

Element: 758 \# of layers: 6

$\mathrm{Kx} \mathrm{Ky} \mathrm{Kz}$ Ss Por

3.39668e+02 3.39668e+02 3.39668e+01 1.00000e-09 7.00000e-02

$3.39668 \mathrm{e}+02$ 3.39668e+02 3.39668e+01 1.00000e-09 7.00000e-02

$1.35721 \mathrm{e}+011.35721 \mathrm{e}+01$ 1.35721e+00 1.00000e-09 2.12000e-01

$1.35721 \mathrm{e}+011.35721 \mathrm{e}+011.35721 \mathrm{e}+001.00000 \mathrm{e}-092.12000 \mathrm{e}-01$

$1.00000 \mathrm{e}-02$ 1.00000e-02 1.00000e-03 1.00000e-09 1.00000e-01

$1.00000 \mathrm{e}+001.00000 \mathrm{e}+001.00000 \mathrm{e}-011.00000 \mathrm{e}-091.00000 \mathrm{e}-01$

Element: 759 \# of layers: 6

$\mathrm{Kx} \mathrm{Ky} \mathrm{Kz}$ Ss Por

3.39668e+02 3.39668e+02 3.39668e+01 1.00000e-09 7.00000e-02

3.39668e+02 3.39668e+02 3.39668e+01 1.00000e-09 7.00000e-02

$1.35721 \mathrm{e}+011.35721 \mathrm{e}+011.35721 \mathrm{e}+001.00000 \mathrm{e}-092.12000 \mathrm{e}-01$

$1.35721 \mathrm{e}+011.35721 \mathrm{e}+011.35721 \mathrm{e}+001.00000 \mathrm{e}-092.12000 \mathrm{e}-01$

$1.00000 \mathrm{e}-02$ 1.00000e-02 1.00000e-03 1.00000e-09 1.00000e-01

$1.00000 \mathrm{e}+001.00000 \mathrm{e}+001.00000 \mathrm{e}-011.00000 \mathrm{e}-091.00000 \mathrm{e}-01$

Element: 760 \# of layers: 7

$\mathrm{Kx} \mathrm{Ky} \mathrm{Kz}$ Ss Por

3.39668e+02 3.39668e+02 3.39668e+01 1.00000e-09 7.00000e-02

$3.39668 \mathrm{e}+02$ 3.39668e+02 3.39668e+01 1.00000e-09 7.00000e-02

3.39668e+02 3.39668e+02 3.39668e+01 1.00000e-09 7.00000e-02

$1.35721 \mathrm{e}+011.35721 \mathrm{e}+011.35721 \mathrm{e}+001.00000 \mathrm{e}-092.12000 \mathrm{e}-01$

$1.35721 \mathrm{e}+011.35721 \mathrm{e}+011.35721 \mathrm{e}+001.00000 \mathrm{e}-092.12000 \mathrm{e}-01$ 
$1.00000 \mathrm{e}-02$ 1.00000e-02 1.00000e-03 1.00000e-09 1.00000e-01 $1.00000 \mathrm{e}+001.00000 \mathrm{e}+001.00000 \mathrm{e}-01$ 1.00000e-09 1.00000e-01 Element: 761 \# of layers: 5

$\mathrm{Kx} \mathrm{Ky} \mathrm{Kz}$ Ss Por

3.39668e+02 3.39668e+02 3.39668e+01 1.00000e-09 7.00000e-02 $3.39668 \mathrm{e}+02$ 3.39668e+02 3.39668e+01 1.00000e-09 7.00000e-02 $1.35721 \mathrm{e}+011.35721 \mathrm{e}+011.35721 \mathrm{e}+001.00000 \mathrm{e}-09$ 2.12000e-01 $1.00000 \mathrm{e}-02$ 1.00000e-02 1.00000e-03 1.00000e-09 1.00000e-01 $1.00000 \mathrm{e}+001.00000 \mathrm{e}+001.00000 \mathrm{e}-011.00000 \mathrm{e}-091.00000 \mathrm{e}-01$ Element: 762 \# of layers: 6

$\mathrm{Kx} \mathrm{Ky} \mathrm{Kz}$ Ss Por

3.39668e+02 3.39668e+02 3.39668e+01 1.00000e-09 7.00000e-02 $3.39668 \mathrm{e}+02$ 3.39668e+02 3.39668e+01 1.00000e-09 7.00000e-02 $1.35721 \mathrm{e}+011.35721 \mathrm{e}+011.35721 \mathrm{e}+001.00000 \mathrm{e}-092.12000 \mathrm{e}-01$ $1.35721 \mathrm{e}+011.35721 \mathrm{e}+011.35721 \mathrm{e}+001.00000 \mathrm{e}-092.12000 \mathrm{e}-01$ $1.00000 \mathrm{e}-02$ 1.00000e-02 1.00000e-03 1.00000e-09 1.00000e-01 $1.00000 \mathrm{e}+001.00000 \mathrm{e}+001.00000 \mathrm{e}-01$ 1.00000e-09 1.00000e-01 Element: 763 \# of layers: 7

$\mathrm{Kx} \mathrm{Ky} \mathrm{Kz}$ Ss Por

3.39668e+02 3.39668e+02 3.39668e+01 1.00000e-09 7.00000e-02 $3.39668 \mathrm{e}+02$ 3.39668e+02 3.39668e+01 1.00000e-09 7.00000e-02 $3.39668 \mathrm{e}+02$ 3.39668e+02 3.39668e+01 1.00000e-09 7.00000e-02 $1.35721 \mathrm{e}+011.35721 \mathrm{e}+011.35721 \mathrm{e}+001.00000 \mathrm{e}-092.12000 \mathrm{e}-01$ $1.35721 \mathrm{e}+011.35721 \mathrm{e}+011.35721 \mathrm{e}+001.00000 \mathrm{e}-092.12000 \mathrm{e}-01$ $1.00000 \mathrm{e}-021.00000 \mathrm{e}-02$ 1.00000e-03 1.00000e-09 1.00000e-01 $1.00000 \mathrm{e}+001.00000 \mathrm{e}+001.00000 \mathrm{e}-011.00000 \mathrm{e}-091.00000 \mathrm{e}-01$ Element: 764 \# of layers: 6

$\mathrm{Kx} \mathrm{Ky} \mathrm{Kz} \mathrm{Ss} \mathrm{Por}$

$2.63191 \mathrm{e}+02$ 2.63191e+02 2.63191e+01 1.00000e-09 7.00000e-02

$2.63191 \mathrm{e}+02$ 2.63191e+02 2.63191e+01 1.00000e-09 7.00000e-02

$2.63191 \mathrm{e}+02$ 2.63191e+02 2.63191e+01 1.00000e-09 7.00000e-02 $1.05161 \mathrm{e}+011.05161 \mathrm{e}+011.05161 \mathrm{e}+001.00000 \mathrm{e}-092.12000 \mathrm{e}-01$ $1.05161 \mathrm{e}+011.05161 \mathrm{e}+011.05161 \mathrm{e}+001.00000 \mathrm{e}-092.12000 \mathrm{e}-01$ $1.00000 \mathrm{e}-02$ 1.00000e-02 1.00000e-03 1.00000e-09 1.00000e-01

Element: 765 \# of layers: 6

Kx Ky Kz Ss Por

$2.63191 \mathrm{e}+02$ 2.63191e+02 2.63191e+01 1.00000e-09 7.00000e-02 $2.63191 \mathrm{e}+022.63191 \mathrm{e}+022.63191 \mathrm{e}+01$ 1.00000e-09 7.00000e-02 $2.63191 \mathrm{e}+02$ 2.63191e+02 2.63191e+01 1.00000e-09 7.00000e-02 $1.05161 \mathrm{e}+011.05161 \mathrm{e}+011.05161 \mathrm{e}+001.00000 \mathrm{e}-092.12000 \mathrm{e}-01$ $1.05161 \mathrm{e}+011.05161 \mathrm{e}+011.05161 \mathrm{e}+001.00000 \mathrm{e}-092.12000 \mathrm{e}-01$ 1.00000e-02 1.00000e-02 1.00000e-03 1.00000e-09 1.00000e-01

Element: 766 \# of layers: 5

$\mathrm{Kx} \mathrm{Ky} \mathrm{Kz}$ Ss Por

$2.63191 \mathrm{e}+02$ 2.63191e+02 2.63191e+01 1.00000e-09 7.00000e-02 $2.63191 \mathrm{e}+022.63191 \mathrm{e}+02$ 2.63191e+01 1.00000e-09 7.00000e-02 
$2.63191 \mathrm{e}+022.63191 \mathrm{e}+02$ 2.63191e+01 1.00000e-09 7.00000e-02 $1.05161 \mathrm{e}+011.05161 \mathrm{e}+011.05161 \mathrm{e}+001.00000 \mathrm{e}-092.12000 \mathrm{e}-01$ $1.05161 \mathrm{e}+011.05161 \mathrm{e}+011.05161 \mathrm{e}+001.00000 \mathrm{e}-092.12000 \mathrm{e}-01$

Element: 767 \# of layers: 5

$\mathrm{Kx} \mathrm{Ky} \mathrm{Kz}$ Ss Por

$2.63191 \mathrm{e}+02$ 2.63191e+02 2.63191e+01 1.00000e-09 7.00000e-02

$2.63191 \mathrm{e}+02$ 2.63191e+02 2.63191e+01 1.00000e-09 7.00000e-02

$1.05161 \mathrm{e}+011.05161 \mathrm{e}+011.05161 \mathrm{e}+001.00000 \mathrm{e}-092.12000 \mathrm{e}-01$

$1.05161 \mathrm{e}+011.05161 \mathrm{e}+011.05161 \mathrm{e}+001.00000 \mathrm{e}-092.12000 \mathrm{e}-01$

$1.00000 \mathrm{e}-02$ 1.00000e-02 1.00000e-03 1.00000e-09 1.00000e-01

Element: 768 \# of layers: 6

$\mathrm{Kx} \mathrm{Ky} \mathrm{Kz}$ Ss Por

$2.63191 \mathrm{e}+02$ 2.63191e+02 2.63191e+01 1.00000e-09 7.00000e-02

$2.63191 \mathrm{e}+02$ 2.63191e+02 2.63191e+01 1.00000e-09 7.00000e-02

$1.05161 \mathrm{e}+011.05161 \mathrm{e}+011.05161 \mathrm{e}+001.00000 \mathrm{e}-092.12000 \mathrm{e}-01$

$1.05161 \mathrm{e}+011.05161 \mathrm{e}+011.05161 \mathrm{e}+001.00000 \mathrm{e}-092.12000 \mathrm{e}-01$

$1.00000 \mathrm{e}-021.00000 \mathrm{e}-02$ 1.00000e-03 1.00000e-09 1.00000e-01

$1.00000 \mathrm{e}+001.00000 \mathrm{e}+001.00000 \mathrm{e}-011.00000 \mathrm{e}-091.00000 \mathrm{e}-01$

Element: 769 \# of layers: 6

$\mathrm{Kx} \mathrm{Ky} \mathrm{Kz}$ Ss Por

$2.63191 \mathrm{e}+02$ 2.63191e+02 2.63191e+01 1.00000e-09 7.00000e-02

$2.63191 \mathrm{e}+02$ 2.63191e+02 2.63191e+01 1.00000e-09 7.00000e-02

$1.05161 \mathrm{e}+011.05161 \mathrm{e}+011.05161 \mathrm{e}+001.00000 \mathrm{e}-092.12000 \mathrm{e}-01$

$1.05161 \mathrm{e}+011.05161 \mathrm{e}+011.05161 \mathrm{e}+001.00000 \mathrm{e}-092.12000 \mathrm{e}-01$

$1.00000 \mathrm{e}-02$ 1.00000e-02 1.00000e-03 1.00000e-09 1.00000e-01

$1.00000 \mathrm{e}+001.00000 \mathrm{e}+001.00000 \mathrm{e}-011.00000 \mathrm{e}-091.00000 \mathrm{e}-01$

Element: 770 \# of layers: 6

$\mathrm{Kx} \mathrm{Ky} \mathrm{Kz} \mathrm{Ss} \mathrm{Por}$

$2.63191 \mathrm{e}+02$ 2.63191e+02 2.63191e+01 1.00000e-09 7.00000e-02

$2.63191 \mathrm{e}+022.63191 \mathrm{e}+02$ 2.63191e+01 1.00000e-09 7.00000e-02

$1.05161 \mathrm{e}+011.05161 \mathrm{e}+011.05161 \mathrm{e}+001.00000 \mathrm{e}-092.12000 \mathrm{e}-01$

$1.05161 \mathrm{e}+011.05161 \mathrm{e}+011.05161 \mathrm{e}+001.00000 \mathrm{e}-092.12000 \mathrm{e}-01$

$1.00000 \mathrm{e}-02$ 1.00000e-02 1.00000e-03 1.00000e-09 1.00000e-01

$1.00000 \mathrm{e}+001.00000 \mathrm{e}+001.00000 \mathrm{e}-011.00000 \mathrm{e}-091.00000 \mathrm{e}-01$

Element: 771 \# of layers: 6

Kx Ky Kz Ss Por

$2.63191 \mathrm{e}+02$ 2.63191e+02 2.63191e+01 1.00000e-09 7.00000e-02

$2.63191 \mathrm{e}+022.63191 \mathrm{e}+02$ 2.63191e+01 1.00000e-09 7.00000e-02

$1.05161 \mathrm{e}+011.05161 \mathrm{e}+011.05161 \mathrm{e}+001.00000 \mathrm{e}-092.12000 \mathrm{e}-01$

$1.05161 \mathrm{e}+011.05161 \mathrm{e}+011.05161 \mathrm{e}+001.00000 \mathrm{e}-092.12000 \mathrm{e}-01$

$1.00000 \mathrm{e}-02$ 1.00000e-02 1.00000e-03 1.00000e-09 1.00000e-01

$1.00000 \mathrm{e}+001.00000 \mathrm{e}+001.00000 \mathrm{e}-011.00000 \mathrm{e}-091.00000 \mathrm{e}-01$

Element: 772 \# of layers: 6

$\mathrm{Kx} \mathrm{Ky} \mathrm{Kz}$ Ss Por

$2.63191 \mathrm{e}+02$ 2.63191e+02 2.63191e+01 1.00000e-09 7.00000e-02

$2.63191 \mathrm{e}+02$ 2.63191e+02 2.63191e+01 1.00000e-09 7.00000e-02 
$1.05161 \mathrm{e}+011.05161 \mathrm{e}+011.05161 \mathrm{e}+001.00000 \mathrm{e}-092.12000 \mathrm{e}-01$ $1.05161 \mathrm{e}+011.05161 \mathrm{e}+011.05161 \mathrm{e}+001.00000 \mathrm{e}-092.12000 \mathrm{e}-01$ $1.00000 \mathrm{e}-02$ 1.00000e-02 1.00000e-03 1.00000e-09 1.00000e-01

$1.00000 \mathrm{e}+001.00000 \mathrm{e}+001.00000 \mathrm{e}-011.00000 \mathrm{e}-091.00000 \mathrm{e}-01$

Element: 773 \# of layers: 5

$\mathrm{Kx} \mathrm{Ky} \mathrm{Kz}$ Ss Por

2.34440e+02 2.34440e+02 2.34440e+01 1.00000e-09 7.00000e-02

$2.34440 \mathrm{e}+02$ 2.34440e+02 2.34440e+01 1.00000e-09 7.00000e-02

$2.34440 \mathrm{e}+02$ 2.34440e+02 2.34440e+01 1.00000e-09 7.00000e-02

9.36763e+00 9.36763e+00 9.36763e-01 1.00000e-09 2.12000e-01

9.36763e+00 9.36763e+00 9.36763e-01 1.00000e-09 2.12000e-01

Element: 774 \# of layers: 5

$\mathrm{Kx} \mathrm{Ky} \mathrm{Kz}$ Ss Por

2.34440e+02 2.34440e+02 2.34440e+01 1.00000e-09 7.00000e-02 $2.34440 \mathrm{e}+022.34440 \mathrm{e}+02$ 2.34440e+01 1.00000e-09 7.00000e-02

$2.34440 \mathrm{e}+02$ 2.34440e+02 2.34440e+01 1.00000e-09 7.00000e-02

$9.36763 e+00$ 9.36763e+00 9.36763e-01 1.00000e-09 2.12000e-01

9.36763e+00 9.36763e+00 9.36763e-01 1.00000e-09 2.12000e-01

Element: 775 \# of layers: 7

$\mathrm{Kx} \mathrm{Ky} \mathrm{Kz}$ Ss Por

2.34440e+02 2.34440e+02 2.34440e+01 1.00000e-09 7.00000e-02

$2.34440 \mathrm{e}+02$ 2.34440e+02 2.34440e+01 1.00000e-09 7.00000e-02

$2.34440 \mathrm{e}+02$ 2.34440e+02 2.34440e+01 1.00000e-09 7.00000e-02

9.36763e+00 9.36763e+00 9.36763e-01 1.00000e-09 2.12000e-01

$9.36763 e+009.36763 e+00$ 9.36763e-01 1.00000e-09 2.12000e-01

1.00000e-02 1.00000e-02 1.00000e-03 1.00000e-09 1.00000e-01

$1.00000 \mathrm{e}+001.00000 \mathrm{e}+001.00000 \mathrm{e}-011.00000 \mathrm{e}-091.00000 \mathrm{e}-01$

Element: 776 \# of layers: 6

Kx Ky Kz Ss Por

7.67874e+01 7.67874e+01 7.67874e+00 1.00000e-09 2.12000e-01

$7.67874 \mathrm{e}+017.67874 \mathrm{e}+017.67874 \mathrm{e}+001.00000 \mathrm{e}-092.12000 \mathrm{e}-01$

$7.67874 \mathrm{e}+017.67874 \mathrm{e}+017.67874 \mathrm{e}+001.00000 \mathrm{e}-092.12000 \mathrm{e}-01$

$7.67874 \mathrm{e}+017.67874 \mathrm{e}+017.67874 \mathrm{e}+001.00000 \mathrm{e}-092.12000 \mathrm{e}-01$

$1.00000 \mathrm{e}-02$ 1.00000e-02 1.00000e-03 1.00000e-09 1.00000e-01

$1.00000 \mathrm{e}+001.00000 \mathrm{e}+001.00000 \mathrm{e}-011.00000 \mathrm{e}-091.00000 \mathrm{e}-01$

Element: 777 \# of layers: 6

Kx Ky Kz Ss Por

7.67874e+01 7.67874e+01 7.67874e+00 1.00000e-09 2.12000e-01

$7.67874 \mathrm{e}+01$ 7.67874e+01 7.67874e+00 1.00000e-09 2.12000e-01

$7.67874 \mathrm{e}+017.67874 \mathrm{e}+017.67874 \mathrm{e}+001.00000 \mathrm{e}-092.12000 \mathrm{e}-01$

$7.67874 \mathrm{e}+017.67874 \mathrm{e}+017.67874 \mathrm{e}+001.00000 \mathrm{e}-092.12000 \mathrm{e}-01$

$1.00000 \mathrm{e}-02$ 1.00000e-02 1.00000e-03 1.00000e-09 1.00000e-01

$1.00000 \mathrm{e}+001.00000 \mathrm{e}+001.00000 \mathrm{e}-011.00000 \mathrm{e}-091.00000 \mathrm{e}-01$

Element: 778 \# of layers: 4

$\mathrm{Kx} \mathrm{Ky} \mathrm{Kz}$ Ss Por

7.67874e+01 7.67874e+01 7.67874e+00 1.00000e-09 2.12000e-01 
7.67874e+01 7.67874e+01 7.67874e+00 1.00000e-09 2.12000e-01 $1.00000 \mathrm{e}-02$ 1.00000e-02 1.00000e-03 1.00000e-09 1.00000e-01 $1.00000 \mathrm{e}+001.00000 \mathrm{e}+001.00000 \mathrm{e}-011.00000 \mathrm{e}-09$ 1.00000e-01

Element: 779 \# of layers: 5

$\mathrm{Kx} \mathrm{Ky} \mathrm{Kz}$ Ss Por

7.67874e+01 7.67874e+01 7.67874e+00 1.00000e-09 2.12000e-01 $7.67874 \mathrm{e}+017.67874 \mathrm{e}+01$ 7.67874e+00 1.00000e-09 2.12000e-01 $7.67874 \mathrm{e}+017.67874 \mathrm{e}+017.67874 \mathrm{e}+001.00000 \mathrm{e}-092.12000 \mathrm{e}-01$ $1.00000 \mathrm{e}-02$ 1.00000e-02 1.00000e-03 1.00000e-09 1.00000e-01 $1.00000 \mathrm{e}+001.00000 \mathrm{e}+001.00000 \mathrm{e}-011.00000 \mathrm{e}-091.00000 \mathrm{e}-01$ Element: 780 \# of layers: 5

$\mathrm{Kx} \mathrm{Ky} \mathrm{Kz}$ Ss Por

7.67874e+01 7.67874e+01 7.67874e+00 1.00000e-09 2.12000e-01 $7.67874 \mathrm{e}+017.67874 \mathrm{e}+017.67874 \mathrm{e}+001.00000 \mathrm{e}-092.12000 \mathrm{e}-01$ $7.67874 \mathrm{e}+017.67874 \mathrm{e}+017.67874 \mathrm{e}+001.00000 \mathrm{e}-092.12000 \mathrm{e}-01$ $1.00000 \mathrm{e}-02$ 1.00000e-02 1.00000e-03 1.00000e-09 1.00000e-01 $1.00000 \mathrm{e}+001.00000 \mathrm{e}+001.00000 \mathrm{e}-011.00000 \mathrm{e}-091.00000 \mathrm{e}-01$ Element: 781 \# of layers: 6

$\mathrm{Kx} \mathrm{Ky} \mathrm{Kz}$ Ss Por 6.01933e+01 6.01933e+01 6.01933e+00 1.00000e-09 2.12000e-01 $6.01933 \mathrm{e}+016.01933 \mathrm{e}+016.01933 \mathrm{e}+001.00000 \mathrm{e}-09$ 2.12000e-01 6.01933e+01 6.01933e+01 6.01933e+00 1.00000e-09 2.12000e-01 6.01933e+01 6.01933e+01 6.01933e+00 1.00000e-09 2.12000e-01 $1.00000 \mathrm{e}-02$ 1.00000e-02 1.00000e-03 1.00000e-09 1.00000e-01 $1.00000 \mathrm{e}+001.00000 \mathrm{e}+001.00000 \mathrm{e}-011.00000 \mathrm{e}-091.00000 \mathrm{e}-01$ Element: 782 \# of layers: 5

$\mathrm{Kx} \mathrm{Ky} \mathrm{Kz}$ Ss Por 6.01933e+01 6.01933e+01 6.01933e+00 1.00000e-09 2.12000e-01 $6.01933 \mathrm{e}+016.01933 \mathrm{e}+016.01933 \mathrm{e}+001.00000 \mathrm{e}-092.12000 \mathrm{e}-01$ 6.01933e+01 6.01933e+01 6.01933e+00 1.00000e-09 2.12000e-01 $1.00000 \mathrm{e}-02$ 1.00000e-02 1.00000e-03 1.00000e-09 1.00000e-01 $1.00000 \mathrm{e}+001.00000 \mathrm{e}+001.00000 \mathrm{e}-011.00000 \mathrm{e}-091.00000 \mathrm{e}-01$ Element: 783 \# of layers: 5

$\mathrm{Kx} \mathrm{Ky} \mathrm{Kz}$ Ss Por 6.01933e+01 6.01933e+01 6.01933e+00 1.00000e-09 2.12000e-01 $6.01933 \mathrm{e}+016.01933 \mathrm{e}+01$ 6.01933e+00 1.00000e-09 2.12000e-01 $6.01933 \mathrm{e}+016.01933 \mathrm{e}+016.01933 \mathrm{e}+00$ 1.00000e-09 2.12000e-01 $1.00000 \mathrm{e}-02$ 1.00000e-02 1.00000e-03 1.00000e-09 1.00000e-01 $1.00000 \mathrm{e}+001.00000 \mathrm{e}+001.00000 \mathrm{e}-011.00000 \mathrm{e}-091.00000 \mathrm{e}-01$ Element: 784 \# of layers: 5

$\mathrm{Kx} \mathrm{Ky} \mathrm{Kz}$ Ss Por 6.01933e+01 6.01933e+01 6.01933e+00 1.00000e-09 2.12000e-01 6.01933e+01 6.01933e+01 6.01933e+00 1.00000e-09 2.12000e-01 6.01933e+01 6.01933e+01 6.01933e+00 1.00000e-09 2.12000e-01 $1.00000 \mathrm{e}-02$ 1.00000e-02 1.00000e-03 1.00000e-09 1.00000e-01 $1.00000 \mathrm{e}+001.00000 \mathrm{e}+001.00000 \mathrm{e}-011.00000 \mathrm{e}-091.00000 \mathrm{e}-01$ 
Element: 785 \# of layers: 5

Kx Ky Kz Ss Por

6.01933e+01 6.01933e+01 6.01933e+00 1.00000e-09 2.12000e-01

$6.01933 \mathrm{e}+016.01933 \mathrm{e}+016.01933 \mathrm{e}+00$ 1.00000e-09 2.12000e-01

$6.01933 \mathrm{e}+016.01933 \mathrm{e}+016.01933 \mathrm{e}+00$ 1.00000e-09 2.12000e-01

$1.00000 \mathrm{e}-021.00000 \mathrm{e}-02$ 1.00000e-03 1.00000e-09 1.00000e-01

$1.00000 \mathrm{e}+001.00000 \mathrm{e}+001.00000 \mathrm{e}-011.00000 \mathrm{e}-091.00000 \mathrm{e}-01$

Element: 786 \# of layers: 5

Kx Ky Kz Ss Por

$6.01933 \mathrm{e}+016.01933 \mathrm{e}+016.01933 \mathrm{e}+00$ 1.00000e-09 2.12000e-01

$6.01933 \mathrm{e}+016.01933 \mathrm{e}+016.01933 \mathrm{e}+00$ 1.00000e-09 2.12000e-01

$6.01933 \mathrm{e}+016.01933 \mathrm{e}+016.01933 \mathrm{e}+001.00000 \mathrm{e}-092.12000 \mathrm{e}-01$

$1.00000 \mathrm{e}-02$ 1.00000e-02 1.00000e-03 1.00000e-09 1.00000e-01

$1.00000 \mathrm{e}+001.00000 \mathrm{e}+001.00000 \mathrm{e}-011.00000 \mathrm{e}-091.00000 \mathrm{e}-01$

Element: 787 \# of layers: 5

Kx Ky Kz Ss Por

$6.01933 \mathrm{e}+016.01933 \mathrm{e}+01$ 6.01933e+00 1.00000e-09 2.12000e-01

$6.01933 \mathrm{e}+016.01933 \mathrm{e}+016.01933 \mathrm{e}+00$ 1.00000e-09 2.12000e-01

$6.01933 \mathrm{e}+016.01933 \mathrm{e}+016.01933 \mathrm{e}+00$ 1.00000e-09 2.12000e-01

$1.00000 \mathrm{e}-021.00000 \mathrm{e}-02$ 1.00000e-03 1.00000e-09 1.00000e-01

$1.00000 \mathrm{e}+001.00000 \mathrm{e}+001.00000 \mathrm{e}-011.00000 \mathrm{e}-091.00000 \mathrm{e}-01$

Element: 788 \# of layers: 5

Kx Ky Kz Ss Por

$6.01933 \mathrm{e}+016.01933 \mathrm{e}+01$ 6.01933e+00 1.00000e-09 2.12000e-01

$6.01933 \mathrm{e}+016.01933 \mathrm{e}+016.01933 \mathrm{e}+001.00000 \mathrm{e}-092.12000 \mathrm{e}-01$

$6.01933 \mathrm{e}+016.01933 \mathrm{e}+016.01933 \mathrm{e}+00$ 1.00000e-09 2.12000e-01

$1.00000 \mathrm{e}-02$ 1.00000e-02 1.00000e-03 1.00000e-09 1.00000e-01

$1.00000 \mathrm{e}+001.00000 \mathrm{e}+001.00000 \mathrm{e}-011.00000 \mathrm{e}-091.00000 \mathrm{e}-01$

Element: 789 \# of layers: 5

Kx Ky Kz Ss Por

$6.01933 \mathrm{e}+016.01933 \mathrm{e}+016.01933 \mathrm{e}+00$ 1.00000e-09 2.12000e-01

$6.01933 \mathrm{e}+016.01933 \mathrm{e}+016.01933 \mathrm{e}+00$ 1.00000e-09 2.12000e-01

$6.01933 \mathrm{e}+016.01933 \mathrm{e}+016.01933 \mathrm{e}+00$ 1.00000e-09 2.12000e-01

$1.00000 \mathrm{e}-021.00000 \mathrm{e}-02$ 1.00000e-03 1.00000e-09 1.00000e-01

$1.00000 \mathrm{e}+001.00000 \mathrm{e}+001.00000 \mathrm{e}-011.00000 \mathrm{e}-091.00000 \mathrm{e}-01$

Element: 790 \# of layers: 5

Kx Ky Kz Ss Por

$2.14580 \mathrm{e}+012.14580 \mathrm{e}+012.14580 \mathrm{e}+00$ 1.00000e-09 2.12000e-01

$2.14580 \mathrm{e}+012.14580 \mathrm{e}+012.14580 \mathrm{e}+00$ 1.00000e-09 2.12000e-01

$2.14580 \mathrm{e}+012.14580 \mathrm{e}+012.14580 \mathrm{e}+00$ 1.00000e-09 2.12000e-01

$1.00000 \mathrm{e}-021.00000 \mathrm{e}-02$ 1.00000e-03 1.00000e-09 1.00000e-01

$1.00000 \mathrm{e}+001.00000 \mathrm{e}+001.00000 \mathrm{e}-011.00000 \mathrm{e}-091.00000 \mathrm{e}-01$

Element: 791 \# of layers: 6

Kx Ky Kz Ss Por

$5.37041 \mathrm{e}+025.37041 \mathrm{e}+025.37041 \mathrm{e}+01$ 1.00000e-09 7.00000e-02

$2.14580 \mathrm{e}+012.14580 \mathrm{e}+012.14580 \mathrm{e}+001.00000 \mathrm{e}-092.12000 \mathrm{e}-01$ 
$2.14580 \mathrm{e}+012.14580 \mathrm{e}+012.14580 \mathrm{e}+00$ 1.00000e-09 2.12000e-01 $2.14580 \mathrm{e}+012.14580 \mathrm{e}+012.14580 \mathrm{e}+00$ 1.00000e-09 2.12000e-01 $1.00000 \mathrm{e}-021.00000 \mathrm{e}-02$ 1.00000e-03 1.00000e-09 1.00000e-01 $1.00000 \mathrm{e}+001.00000 \mathrm{e}+001.00000 \mathrm{e}-011.00000 \mathrm{e}-091.00000 \mathrm{e}-01$ Element: 792 \# of layers: 6

Kx Ky Kz Ss Por

$5.37041 \mathrm{e}+02$ 5.37041e+02 5.37041e+01 1.00000e-09 7.00000e-02 $2.14580 \mathrm{e}+012.14580 \mathrm{e}+012.14580 \mathrm{e}+001.00000 \mathrm{e}-092.12000 \mathrm{e}-01$ $2.14580 \mathrm{e}+012.14580 \mathrm{e}+012.14580 \mathrm{e}+001.00000 \mathrm{e}-092.12000 \mathrm{e}-01$ $2.14580 \mathrm{e}+012.14580 \mathrm{e}+012.14580 \mathrm{e}+001.00000 \mathrm{e}-092.12000 \mathrm{e}-01$ $1.00000 \mathrm{e}-021.00000 \mathrm{e}-02$ 1.00000e-03 1.00000e-09 1.00000e-01 $1.00000 \mathrm{e}+001.00000 \mathrm{e}+001.00000 \mathrm{e}-011.00000 \mathrm{e}-091.00000 \mathrm{e}-01$ Element: 793 \# of layers: 6

Kx Ky Kz Ss Por

$5.37041 \mathrm{e}+02$ 5.37041e+02 5.37041e+01 1.00000e-09 7.00000e-02 $2.14580 \mathrm{e}+012.14580 \mathrm{e}+012.14580 \mathrm{e}+001.00000 \mathrm{e}-092.12000 \mathrm{e}-01$ $2.14580 \mathrm{e}+012.14580 \mathrm{e}+012.14580 \mathrm{e}+00$ 1.00000e-09 2.12000e-01 $2.14580 \mathrm{e}+012.14580 \mathrm{e}+012.14580 \mathrm{e}+00$ 1.00000e-09 2.12000e-01 $1.00000 \mathrm{e}-021.00000 \mathrm{e}-02$ 1.00000e-03 1.00000e-09 1.00000e-01 $1.00000 \mathrm{e}+001.00000 \mathrm{e}+001.00000 \mathrm{e}-011.00000 \mathrm{e}-091.00000 \mathrm{e}-01$ Element: 794 \# of layers: 6

Kx Ky Kz Ss Por

$5.37041 \mathrm{e}+02$ 5.37041e+02 5.37041e+01 1.00000e-09 7.00000e-02 $2.14580 \mathrm{e}+012.14580 \mathrm{e}+012.14580 \mathrm{e}+001.00000 \mathrm{e}-092.12000 \mathrm{e}-01$ $2.14580 \mathrm{e}+012.14580 \mathrm{e}+012.14580 \mathrm{e}+00$ 1.00000e-09 2.12000e-01 $2.14580 \mathrm{e}+012.14580 \mathrm{e}+012.14580 \mathrm{e}+001.00000 \mathrm{e}-092.12000 \mathrm{e}-01$ $1.00000 \mathrm{e}-021.00000 \mathrm{e}-02$ 1.00000e-03 1.00000e-09 1.00000e-01 $1.00000 \mathrm{e}+001.00000 \mathrm{e}+001.00000 \mathrm{e}-011.00000 \mathrm{e}-091.00000 \mathrm{e}-01$ Element: 795 \# of layers: 6

Kx Ky Kz Ss Por

$5.37041 \mathrm{e}+025.37041 \mathrm{e}+025.37041 \mathrm{e}+01$ 1.00000e-09 7.00000e-02 $2.14580 \mathrm{e}+012.14580 \mathrm{e}+012.14580 \mathrm{e}+001.00000 \mathrm{e}-092.12000 \mathrm{e}-01$ $2.14580 \mathrm{e}+012.14580 \mathrm{e}+012.14580 \mathrm{e}+00$ 1.00000e-09 2.12000e-01 $2.14580 \mathrm{e}+012.14580 \mathrm{e}+012.14580 \mathrm{e}+00$ 1.00000e-09 2.12000e-01 $1.00000 \mathrm{e}-021.00000 \mathrm{e}-02$ 1.00000e-03 1.00000e-09 1.00000e-01 $1.00000 \mathrm{e}+001.00000 \mathrm{e}+001.00000 \mathrm{e}-011.00000 \mathrm{e}-091.00000 \mathrm{e}-01$ Element: 796 \# of layers: 6

Kx Ky Kz Ss Por

$5.37041 \mathrm{e}+02$ 5.37041e+02 5.37041e+01 1.00000e-09 7.00000e-02 $2.14580 \mathrm{e}+012.14580 \mathrm{e}+012.14580 \mathrm{e}+001.00000 \mathrm{e}-092.12000 \mathrm{e}-01$ $2.14580 \mathrm{e}+012.14580 \mathrm{e}+012.14580 \mathrm{e}+00$ 1.00000e-09 2.12000e-01 $2.14580 \mathrm{e}+012.14580 \mathrm{e}+012.14580 \mathrm{e}+001.00000 \mathrm{e}-092.12000 \mathrm{e}-01$ $1.00000 \mathrm{e}-02$ 1.00000e-02 1.00000e-03 1.00000e-09 1.00000e-01 $1.00000 \mathrm{e}+001.00000 \mathrm{e}+001.00000 \mathrm{e}-011.00000 \mathrm{e}-091.00000 \mathrm{e}-01$ Element: 797 \# of layers: 5

Kx Ky Kz Ss Por 
$2.14580 \mathrm{e}+012.14580 \mathrm{e}+012.14580 \mathrm{e}+00$ 1.00000e-09 2.12000e-01 $2.14580 \mathrm{e}+012.14580 \mathrm{e}+012.14580 \mathrm{e}+00$ 1.00000e-09 2.12000e-01 $2.14580 \mathrm{e}+012.14580 \mathrm{e}+012.14580 \mathrm{e}+00$ 1.00000e-09 2.12000e-01 $1.00000 \mathrm{e}-021.00000 \mathrm{e}-02$ 1.00000e-03 1.00000e-09 1.00000e-01 $1.00000 \mathrm{e}+001.00000 \mathrm{e}+001.00000 \mathrm{e}-011.00000 \mathrm{e}-091.00000 \mathrm{e}-01$ Element: 798 \# of layers: 6

Kx Ky Kz Ss Por

$5.37041 \mathrm{e}+025.37041 \mathrm{e}+025.37041 \mathrm{e}+01$ 1.00000e-09 7.00000e-02

$2.14580 \mathrm{e}+012.14580 \mathrm{e}+012.14580 \mathrm{e}+001.00000 \mathrm{e}-092.12000 \mathrm{e}-01$

$2.14580 \mathrm{e}+012.14580 \mathrm{e}+012.14580 \mathrm{e}+00$ 1.00000e-09 2.12000e-01

$2.14580 \mathrm{e}+012.14580 \mathrm{e}+012.14580 \mathrm{e}+00$ 1.00000e-09 2.12000e-01 $1.00000 \mathrm{e}-021.00000 \mathrm{e}-02$ 1.00000e-03 1.00000e-09 1.00000e-01 $1.00000 \mathrm{e}+001.00000 \mathrm{e}+001.00000 \mathrm{e}-011.00000 \mathrm{e}-091.00000 \mathrm{e}-01$ Element: 799 \# of layers: 7

Kx Ky Kz Ss Por

$2.50190 \mathrm{e}+022.50190 \mathrm{e}+022.50190 \mathrm{e}+01$ 1.00000e-09 7.00000e-02

$2.50190 \mathrm{e}+022.50190 \mathrm{e}+022.50190 \mathrm{e}+011.00000 \mathrm{e}-097.00000 \mathrm{e}-02$

$9.99651 \mathrm{e}+009.99651 \mathrm{e}+00$ 9.99651e-01 1.00000e-09 2.12000e-01

$9.99651 \mathrm{e}+009.99651 \mathrm{e}+00$ 9.99651e-01 1.00000e-09 2.12000e-01

$9.99651 \mathrm{e}+009.99651 \mathrm{e}+00$ 9.99651e-01 1.00000e-09 2.12000e-01

$1.00000 \mathrm{e}-021.00000 \mathrm{e}-02$ 1.00000e-03 1.00000e-09 1.00000e-01

$1.00000 \mathrm{e}+001.00000 \mathrm{e}+001.00000 \mathrm{e}-011.00000 \mathrm{e}-091.00000 \mathrm{e}-01$

Element: 800 \# of layers: 5

Kx Ky Kz Ss Por

$2.50190 \mathrm{e}+022.50190 \mathrm{e}+022.50190 \mathrm{e}+01$ 1.00000e-09 7.00000e-02

$9.99651 \mathrm{e}+009.99651 \mathrm{e}+00$ 9.99651e-01 1.00000e-09 2.12000e-01

$9.99651 \mathrm{e}+00$ 9.99651e+00 9.99651e-01 1.00000e-09 2.12000e-01

$1.00000 \mathrm{e}-02$ 1.00000e-02 1.00000e-03 1.00000e-09 1.00000e-01

$1.00000 \mathrm{e}+001.00000 \mathrm{e}+001.00000 \mathrm{e}-011.00000 \mathrm{e}-091.00000 \mathrm{e}-01$

Element: 801 \# of layers: 5

Kx Ky Kz Ss Por

$2.50190 \mathrm{e}+022.50190 \mathrm{e}+022.50190 \mathrm{e}+01$ 1.00000e-09 7.00000e-02

$9.99651 \mathrm{e}+009.99651 \mathrm{e}+00$ 9.99651e-01 1.00000e-09 2.12000e-01

$9.99651 \mathrm{e}+009.99651 \mathrm{e}+00$ 9.99651e-01 1.00000e-09 2.12000e-01

$1.00000 \mathrm{e}-021.00000 \mathrm{e}-02$ 1.00000e-03 1.00000e-09 1.00000e-01

$1.00000 \mathrm{e}+001.00000 \mathrm{e}+001.00000 \mathrm{e}-011.00000 \mathrm{e}-091.00000 \mathrm{e}-01$

Element: 802 \# of layers: 5

Kx Ky Kz Ss Por

$2.50190 \mathrm{e}+022.50190 \mathrm{e}+022.50190 \mathrm{e}+01$ 1.00000e-09 7.00000e-02

$9.99651 \mathrm{e}+009.99651 \mathrm{e}+00$ 9.99651e-01 1.00000e-09 2.12000e-01

$9.99651 \mathrm{e}+009.99651 \mathrm{e}+00$ 9.99651e-01 1.00000e-09 2.12000e-01

$1.00000 \mathrm{e}-021.00000 \mathrm{e}-02$ 1.00000e-03 1.00000e-09 1.00000e-01

$1.00000 \mathrm{e}+001.00000 \mathrm{e}+001.00000 \mathrm{e}-011.00000 \mathrm{e}-091.00000 \mathrm{e}-01$

Element: 803 \# of layers: 5

Kx Ky Kz Ss Por

$2.50190 \mathrm{e}+022.50190 \mathrm{e}+02$ 2.50190e+01 1.00000e-09 7.00000e-02 
$9.99651 \mathrm{e}+009.99651 \mathrm{e}+00$ 9.99651e-01 1.00000e-09 2.12000e-01 $9.99651 \mathrm{e}+009.99651 \mathrm{e}+00$ 9.99651e-01 1.00000e-09 2.12000e-01 $1.00000 \mathrm{e}-021.00000 \mathrm{e}-02$ 1.00000e-03 1.00000e-09 1.00000e-01 $1.00000 \mathrm{e}+001.00000 \mathrm{e}+001.00000 \mathrm{e}-011.00000 \mathrm{e}-091.00000 \mathrm{e}-01$ Element: 804 \# of layers: 5

Kx Ky Kz Ss Por

$2.50190 \mathrm{e}+022.50190 \mathrm{e}+022.50190 \mathrm{e}+01$ 1.00000e-09 7.00000e-02 $9.99651 \mathrm{e}+009.99651 \mathrm{e}+00$ 9.99651e-01 1.00000e-09 2.12000e-01 $9.99651 \mathrm{e}+009.99651 \mathrm{e}+00$ 9.99651e-01 1.00000e-09 2.12000e-01 $1.00000 \mathrm{e}-021.00000 \mathrm{e}-02$ 1.00000e-03 1.00000e-09 1.00000e-01 $1.00000 \mathrm{e}+001.00000 \mathrm{e}+001.00000 \mathrm{e}-011.00000 \mathrm{e}-091.00000 \mathrm{e}-01$ Element: 805 \# of layers: 7

Kx Ky Kz Ss Por

$2.50190 \mathrm{e}+022.50190 \mathrm{e}+022.50190 \mathrm{e}+01$ 1.00000e-09 7.00000e-02 $2.50190 \mathrm{e}+022.50190 \mathrm{e}+022.50190 \mathrm{e}+011.00000 \mathrm{e}-097.00000 \mathrm{e}-02$ $9.99651 \mathrm{e}+009.99651 \mathrm{e}+00$ 9.99651e-01 1.00000e-09 2.12000e-01 $9.99651 \mathrm{e}+009.99651 \mathrm{e}+00$ 9.99651e-01 1.00000e-09 2.12000e-01 $9.99651 \mathrm{e}+009.99651 \mathrm{e}+00$ 9.99651e-01 1.00000e-09 2.12000e-01 $1.00000 \mathrm{e}-02$ 1.00000e-02 1.00000e-03 1.00000e-09 1.00000e-01 $1.00000 \mathrm{e}+001.00000 \mathrm{e}+001.00000 \mathrm{e}-011.00000 \mathrm{e}-091.00000 \mathrm{e}-01$ Element: 806 \# of layers: 7

Kx Ky Kz Ss Por

$2.50190 \mathrm{e}+022.50190 \mathrm{e}+022.50190 \mathrm{e}+01$ 1.00000e-09 7.00000e-02 $2.50190 \mathrm{e}+022.50190 \mathrm{e}+022.50190 \mathrm{e}+01$ 1.00000e-09 7.00000e-02 $9.99651 \mathrm{e}+009.99651 \mathrm{e}+00$ 9.99651e-01 1.00000e-09 2.12000e-01 $9.99651 \mathrm{e}+009.99651 \mathrm{e}+00$ 9.99651e-01 1.00000e-09 2.12000e-01 $9.99651 \mathrm{e}+009.99651 \mathrm{e}+00$ 9.99651e-01 1.00000e-09 2.12000e-01 $1.00000 \mathrm{e}-021.00000 \mathrm{e}-02$ 1.00000e-03 1.00000e-09 1.00000e-01 $1.00000 \mathrm{e}+001.00000 \mathrm{e}+001.00000 \mathrm{e}-011.00000 \mathrm{e}-091.00000 \mathrm{e}-01$ Element: 807 \# of layers: 5

Kx Ky Kz Ss Por

$2.50190 \mathrm{e}+022.50190 \mathrm{e}+022.50190 \mathrm{e}+01$ 1.00000e-09 7.00000e-02 $9.99651 \mathrm{e}+009.99651 \mathrm{e}+00$ 9.99651e-01 1.00000e-09 2.12000e-01 $9.99651 \mathrm{e}+009.99651 \mathrm{e}+00$ 9.99651e-01 1.00000e-09 2.12000e-01 $1.00000 \mathrm{e}-021.00000 \mathrm{e}-02$ 1.00000e-03 1.00000e-09 1.00000e-01 $1.00000 \mathrm{e}+001.00000 \mathrm{e}+001.00000 \mathrm{e}-011.00000 \mathrm{e}-091.00000 \mathrm{e}-01$ Element: 808 \# of layers: 6

Kx Ky Kz Ss Por

$2.47207 \mathrm{e}+022.47207 \mathrm{e}+022.47207 \mathrm{e}+01$ 1.00000e-09 7.00000e-02 $9.87749 \mathrm{e}+00$ 9.87749e+00 9.87749e-01 1.00000e-09 2.12000e-01 $9.87749 \mathrm{e}+009.87749 \mathrm{e}+00$ 9.87749e-01 1.00000e-09 2.12000e-01 $9.87749 \mathrm{e}+00$ 9.87749e+00 9.87749e-01 1.00000e-09 2.12000e-01 $1.00000 \mathrm{e}-02$ 1.00000e-02 1.00000e-03 1.00000e-09 1.00000e-01 $1.00000 \mathrm{e}+001.00000 \mathrm{e}+001.00000 \mathrm{e}-011.00000 \mathrm{e}-091.00000 \mathrm{e}-01$ Element: 809 \# of layers: 5

Kx Ky Kz Ss Por 
$2.47207 \mathrm{e}+022.47207 \mathrm{e}+022.47207 \mathrm{e}+01$ 1.00000e-09 7.00000e-02 $9.87749 \mathrm{e}+009.87749 \mathrm{e}+00$ 9.87749e-01 1.00000e-09 2.12000e-01 $9.87749 \mathrm{e}+00$ 9.87749e+00 9.87749e-01 1.00000e-09 2.12000e-01 $1.00000 \mathrm{e}-021.00000 \mathrm{e}-02$ 1.00000e-03 1.00000e-09 1.00000e-01 $1.00000 \mathrm{e}+001.00000 \mathrm{e}+001.00000 \mathrm{e}-011.00000 \mathrm{e}-091.00000 \mathrm{e}-01$ Element: 810 \# of layers: 5

Kx Ky Kz Ss Por

$2.47207 \mathrm{e}+022.47207 \mathrm{e}+022.47207 \mathrm{e}+01$ 1.00000e-09 7.00000e-02

$9.87749 \mathrm{e}+009.87749 \mathrm{e}+00$ 9.87749e-01 1.00000e-09 2.12000e-01

$9.87749 \mathrm{e}+00$ 9.87749e+00 9.87749e-01 1.00000e-09 2.12000e-01

$1.00000 \mathrm{e}-021.00000 \mathrm{e}-02$ 1.00000e-03 1.00000e-09 1.00000e-01

$1.00000 \mathrm{e}+001.00000 \mathrm{e}+001.00000 \mathrm{e}-011.00000 \mathrm{e}-091.00000 \mathrm{e}-01$

Element: 811 \# of layers: 5

Kx Ky Kz Ss Por

$2.47207 \mathrm{e}+022.47207 \mathrm{e}+022.47207 \mathrm{e}+01$ 1.00000e-09 7.00000e-02 $9.87749 \mathrm{e}+009.87749 \mathrm{e}+00$ 9.87749e-01 1.00000e-09 2.12000e-01 $9.87749 \mathrm{e}+00$ 9.87749e+00 9.87749e-01 1.00000e-09 2.12000e-01 $1.00000 \mathrm{e}-02$ 1.00000e-02 1.00000e-03 1.00000e-09 1.00000e-01 $1.00000 \mathrm{e}+001.00000 \mathrm{e}+001.00000 \mathrm{e}-011.00000 \mathrm{e}-091.00000 \mathrm{e}-01$ Element: 812 \# of layers: 5

Kx Ky Kz Ss Por

$2.47207 \mathrm{e}+022.47207 \mathrm{e}+022.47207 \mathrm{e}+01$ 1.00000e-09 7.00000e-02 $9.87749 \mathrm{e}+009.87749 \mathrm{e}+00$ 9.87749e-01 1.00000e-09 2.12000e-01 $9.87749 \mathrm{e}+00$ 9.87749e+00 9.87749e-01 1.00000e-09 2.12000e-01 $1.00000 \mathrm{e}-021.00000 \mathrm{e}-02$ 1.00000e-03 1.00000e-09 1.00000e-01 $1.00000 \mathrm{e}+001.00000 \mathrm{e}+001.00000 \mathrm{e}-011.00000 \mathrm{e}-091.00000 \mathrm{e}-01$ Element: 813 \# of layers: 5

Kx Ky Kz Ss Por

$2.47207 \mathrm{e}+022.47207 \mathrm{e}+022.47207 \mathrm{e}+01$ 1.00000e-09 7.00000e-02 $9.87749 \mathrm{e}+009.87749 \mathrm{e}+00$ 9.87749e-01 1.00000e-09 2.12000e-01 $9.87749 \mathrm{e}+00$ 9.87749e+00 9.87749e-01 1.00000e-09 2.12000e-01 $1.00000 \mathrm{e}-02$ 1.00000e-02 1.00000e-03 1.00000e-09 1.00000e-01 $1.00000 \mathrm{e}+001.00000 \mathrm{e}+001.00000 \mathrm{e}-011.00000 \mathrm{e}-091.00000 \mathrm{e}-01$ Element: 814 \# of layers: 6

Kx Ky Kz Ss Por

$2.47207 \mathrm{e}+022.47207 \mathrm{e}+022.47207 \mathrm{e}+01$ 1.00000e-09 7.00000e-02 $9.87749 \mathrm{e}+009.87749 \mathrm{e}+00$ 9.87749e-01 1.00000e-09 2.12000e-01 $9.87749 \mathrm{e}+009.87749 \mathrm{e}+00$ 9.87749e-01 1.00000e-09 2.12000e-01 $9.87749 \mathrm{e}+009.87749 \mathrm{e}+00$ 9.87749e-01 1.00000e-09 2.12000e-01 $1.00000 \mathrm{e}-02$ 1.00000e-02 1.00000e-03 1.00000e-09 1.00000e-01 $1.00000 \mathrm{e}+001.00000 \mathrm{e}+001.00000 \mathrm{e}-011.00000 \mathrm{e}-091.00000 \mathrm{e}-01$ Element: 815 \# of layers: 6

Kx Ky Kz Ss Por

$2.47207 \mathrm{e}+022.47207 \mathrm{e}+022.47207 \mathrm{e}+01$ 1.00000e-09 7.00000e-02 $9.87749 \mathrm{e}+009.87749 \mathrm{e}+00$ 9.87749e-01 1.00000e-09 2.12000e-01 $9.87749 \mathrm{e}+00$ 9.87749e+00 9.87749e-01 1.00000e-09 2.12000e-01 
9.87749e+00 9.87749e+00 9.87749e-01 1.00000e-09 2.12000e-01 $1.00000 \mathrm{e}-02$ 1.00000e-02 1.00000e-03 1.00000e-09 1.00000e-01 $1.00000 \mathrm{e}+001.00000 \mathrm{e}+001.00000 \mathrm{e}-01$ 1.00000e-09 1.00000e-01 Element: 816 \# of layers: 5

$\mathrm{Kx} \mathrm{Ky} \mathrm{Kz}$ Ss Por

2.47207e+02 2.47207e+02 2.47207e+01 1.00000e-09 7.00000e-02 9.87749e+00 9.87749e+00 9.87749e-01 1.00000e-09 2.12000e-01 $9.87749 \mathrm{e}+00$ 9.87749e+00 9.87749e-01 1.00000e-09 2.12000e-01 $1.00000 \mathrm{e}-02$ 1.00000e-02 1.00000e-03 1.00000e-09 1.00000e-01 $1.00000 \mathrm{e}+001.00000 \mathrm{e}+001.00000 \mathrm{e}-011.00000 \mathrm{e}-091.00000 \mathrm{e}-01$ Element: 817 \# of layers: 4

$\mathrm{Kx} \mathrm{Ky} \mathrm{Kz}$ Ss Por

3.20792e+02 3.20792e+02 3.20792e+01 1.00000e-09 7.00000e-02 $1.28179 \mathrm{e}+011.28179 \mathrm{e}+011.28179 \mathrm{e}+001.00000 \mathrm{e}-092.12000 \mathrm{e}-01$ $1.00000 \mathrm{e}-02$ 1.00000e-02 1.00000e-03 1.00000e-09 1.00000e-01 $1.00000 \mathrm{e}+001.00000 \mathrm{e}+001.00000 \mathrm{e}-011.00000 \mathrm{e}-091.00000 \mathrm{e}-01$ Element: 818 \# of layers: 4

$\mathrm{Kx} \mathrm{Ky} \mathrm{Kz}$ Ss Por

3.20792e+02 3.20792e+02 3.20792e+01 1.00000e-09 7.00000e-02 $1.28179 \mathrm{e}+01$ 1.28179e+01 1.28179e+00 1.00000e-09 2.12000e-01 $1.00000 \mathrm{e}-02$ 1.00000e-02 1.00000e-03 1.00000e-09 1.00000e-01 $1.00000 \mathrm{e}+001.00000 \mathrm{e}+001.00000 \mathrm{e}-01$ 1.00000e-09 1.00000e-01 Element: 819 \# of layers: 5

$\mathrm{Kx} \mathrm{Ky} \mathrm{Kz}$ Ss Por

3.20792e+02 3.20792e+02 3.20792e+01 1.00000e-09 7.00000e-02 3.20792e+02 3.20792e+02 3.20792e+01 1.00000e-09 7.00000e-02 $1.28179 \mathrm{e}+01$ 1.28179e+01 1.28179e+00 1.00000e-09 2.12000e-01 $1.00000 \mathrm{e}-02$ 1.00000e-02 1.00000e-03 1.00000e-09 1.00000e-01 $1.00000 \mathrm{e}+001.00000 \mathrm{e}+001.00000 \mathrm{e}-011.00000 \mathrm{e}-091.00000 \mathrm{e}-01$ Element: 820 \# of layers: 5

$\mathrm{Kx} \mathrm{Ky} \mathrm{Kz}$ Ss Por

3.20792e+02 3.20792e+02 3.20792e+01 1.00000e-09 7.00000e-02 3.20792e+02 3.20792e+02 3.20792e+01 1.00000e-09 7.00000e-02 $1.28179 \mathrm{e}+01$ 1.28179e+01 1.28179e+00 1.00000e-09 2.12000e-01 $1.00000 \mathrm{e}-02$ 1.00000e-02 1.00000e-03 1.00000e-09 1.00000e-01 $1.00000 \mathrm{e}+001.00000 \mathrm{e}+001.00000 \mathrm{e}-011.00000 \mathrm{e}-091.00000 \mathrm{e}-01$ Element: 821 \# of layers: 6

$\mathrm{Kx} \mathrm{Ky} \mathrm{Kz}$ Ss Por

3.20792e+02 3.20792e+02 3.20792e+01 1.00000e-09 7.00000e-02 3.20792e+02 3.20792e+02 3.20792e+01 1.00000e-09 7.00000e-02 $1.28179 \mathrm{e}+01$ 1.28179e+01 1.28179e+00 1.00000e-09 2.12000e-01 $1.28179 \mathrm{e}+01$ 1.28179e+01 1.28179e+00 1.00000e-09 2.12000e-01 $1.00000 \mathrm{e}-021.00000 \mathrm{e}-021.00000 \mathrm{e}-031.00000 \mathrm{e}-091.00000 \mathrm{e}-01$ $1.00000 \mathrm{e}+001.00000 \mathrm{e}+001.00000 \mathrm{e}-011.00000 \mathrm{e}-091.00000 \mathrm{e}-01$ Element: 822 \# of layers: 6

Kx Ky Kz Ss Por 
$3.20792 \mathrm{e}+02$ 3.20792e $+023.20792 \mathrm{e}+01$ 1.00000e-09 7.00000e-02 $3.20792 \mathrm{e}+023.20792 \mathrm{e}+023.20792 \mathrm{e}+01$ 1.00000e-09 7.00000e-02 $1.28179 \mathrm{e}+011.28179 \mathrm{e}+011.28179 \mathrm{e}+001.00000 \mathrm{e}-092.12000 \mathrm{e}-01$ $1.28179 \mathrm{e}+011.28179 \mathrm{e}+011.28179 \mathrm{e}+001.00000 \mathrm{e}-092.12000 \mathrm{e}-01$ $1.00000 \mathrm{e}-02$ 1.00000e-02 1.00000e-03 1.00000e-09 1.00000e-01 $1.00000 \mathrm{e}+001.00000 \mathrm{e}+001.00000 \mathrm{e}-011.00000 \mathrm{e}-091.00000 \mathrm{e}-01$ Element: 823 \# of layers: 5

Kx Ky Kz Ss Por

$3.20792 \mathrm{e}+02$ 3.20792e+02 3.20792e+01 1.00000e-09 7.00000e-02 $1.28179 \mathrm{e}+011.28179 \mathrm{e}+011.28179 \mathrm{e}+001.00000 \mathrm{e}-092.12000 \mathrm{e}-01$ $1.28179 \mathrm{e}+011.28179 \mathrm{e}+011.28179 \mathrm{e}+001.00000 \mathrm{e}-092.12000 \mathrm{e}-01$ $1.00000 \mathrm{e}-021.00000 \mathrm{e}-02$ 1.00000e-03 1.00000e-09 1.00000e-01 $1.00000 \mathrm{e}+001.00000 \mathrm{e}+001.00000 \mathrm{e}-011.00000 \mathrm{e}-091.00000 \mathrm{e}-01$ Element: 824 \# of layers: 5

Kx Ky Kz Ss Por

$3.20792 \mathrm{e}+02$ 3.20792e+02 3.20792e+01 1.00000e-09 7.00000e-02 $1.28179 \mathrm{e}+011.28179 \mathrm{e}+011.28179 \mathrm{e}+001.00000 \mathrm{e}-092.12000 \mathrm{e}-01$ $1.28179 \mathrm{e}+011.28179 \mathrm{e}+011.28179 \mathrm{e}+00$ 1.00000e-09 2.12000e-01 $1.00000 \mathrm{e}-02$ 1.00000e-02 1.00000e-03 1.00000e-09 1.00000e-01 $1.00000 \mathrm{e}+001.00000 \mathrm{e}+001.00000 \mathrm{e}-011.00000 \mathrm{e}-091.00000 \mathrm{e}-01$ Element: 825 \# of layers: 5

Kx Ky Kz Ss Por

$3.20792 \mathrm{e}+02$ 3.20792e+02 3.20792e+01 1.00000e-09 7.00000e-02 $3.20792 \mathrm{e}+023.20792 \mathrm{e}+023.20792 \mathrm{e}+01$ 1.00000e-09 7.00000e-02 $1.28179 \mathrm{e}+011.28179 \mathrm{e}+01$ 1.28179e+00 1.00000e-09 2.12000e-01 $1.00000 \mathrm{e}-02$ 1.00000e-02 1.00000e-03 1.00000e-09 1.00000e-01 $1.00000 \mathrm{e}+001.00000 \mathrm{e}+001.00000 \mathrm{e}-011.00000 \mathrm{e}-091.00000 \mathrm{e}-01$ Element: 826 \# of layers: 5

Kx Ky Kz Ss Por

$1.75416 \mathrm{e}+021.75416 \mathrm{e}+021.75416 \mathrm{e}+01$ 1.00000e-09 7.00000e-02 $1.75416 \mathrm{e}+021.75416 \mathrm{e}+021.75416 \mathrm{e}+011.00000 \mathrm{e}-097.00000 \mathrm{e}-02$ $7.00890 \mathrm{e}+007.00890 \mathrm{e}+00$ 7.00890e-01 1.00000e-09 2.12000e-01 $1.00000 \mathrm{e}-021.00000 \mathrm{e}-02$ 1.00000e-03 1.00000e-09 1.00000e-01 $1.00000 \mathrm{e}+001.00000 \mathrm{e}+001.00000 \mathrm{e}-011.00000 \mathrm{e}-091.00000 \mathrm{e}-01$ Element: 827 \# of layers: 6

Kx Ky Kz Ss Por

$1.75416 \mathrm{e}+02$ 1.75416e+02 1.75416e+01 1.00000e-09 7.00000e-02 $1.75416 \mathrm{e}+021.75416 \mathrm{e}+021.75416 \mathrm{e}+011.00000 \mathrm{e}-097.00000 \mathrm{e}-02$ $1.75416 \mathrm{e}+021.75416 \mathrm{e}+021.75416 \mathrm{e}+011.00000 \mathrm{e}-097.00000 \mathrm{e}-02$ $7.00890 \mathrm{e}+007.00890 \mathrm{e}+00$ 7.00890e-01 1.00000e-09 2.12000e-01 $1.00000 \mathrm{e}-02$ 1.00000e-02 1.00000e-03 1.00000e-09 1.00000e-01 $1.00000 \mathrm{e}+001.00000 \mathrm{e}+001.00000 \mathrm{e}-011.00000 \mathrm{e}-091.00000 \mathrm{e}-01$ Element: 828 \# of layers: 6

$\mathrm{Kx} \mathrm{Ky} \mathrm{Kz}$ Ss Por

$1.75416 \mathrm{e}+02$ 1.75416e+02 1.75416e+01 1.00000e-09 7.00000e-02 $1.75416 \mathrm{e}+021.75416 \mathrm{e}+021.75416 \mathrm{e}+011.00000 \mathrm{e}-09$ 7.00000e-02 
$7.00890 \mathrm{e}+007.00890 \mathrm{e}+00$ 7.00890e-01 1.00000e-09 2.12000e-01 $7.00890 \mathrm{e}+00$ 7.00890e+00 7.00890e-01 1.00000e-09 2.12000e-01 $1.00000 \mathrm{e}-02$ 1.00000e-02 1.00000e-03 1.00000e-09 1.00000e-01 $1.00000 \mathrm{e}+001.00000 \mathrm{e}+001.00000 \mathrm{e}-011.00000 \mathrm{e}-091.00000 \mathrm{e}-01$ Element: 829 \# of layers: 6

Kx Ky Kz Ss Por

$1.75416 \mathrm{e}+021.75416 \mathrm{e}+021.75416 \mathrm{e}+01$ 1.00000e-09 7.00000e-02 $1.75416 \mathrm{e}+021.75416 \mathrm{e}+021.75416 \mathrm{e}+011.00000 \mathrm{e}-097.00000 \mathrm{e}-02$ $7.00890 \mathrm{e}+007.00890 \mathrm{e}+00$ 7.00890e-01 1.00000e-09 2.12000e-01 $7.00890 \mathrm{e}+007.00890 \mathrm{e}+00$ 7.00890e-01 1.00000e-09 2.12000e-01 $1.00000 \mathrm{e}-021.00000 \mathrm{e}-02$ 1.00000e-03 1.00000e-09 1.00000e-01 $1.00000 \mathrm{e}+001.00000 \mathrm{e}+001.00000 \mathrm{e}-011.00000 \mathrm{e}-091.00000 \mathrm{e}-01$ Element: 830 \# of layers: 6

Kx Ky Kz Ss Por

$1.75416 \mathrm{e}+021.75416 \mathrm{e}+021.75416 \mathrm{e}+01$ 1.00000e-09 7.00000e-02 $1.75416 \mathrm{e}+021.75416 \mathrm{e}+021.75416 \mathrm{e}+011.00000 \mathrm{e}-097.00000 \mathrm{e}-02$ $7.00890 \mathrm{e}+007.00890 \mathrm{e}+00$ 7.00890e-01 1.00000e-09 2.12000e-01 $7.00890 \mathrm{e}+007.00890 \mathrm{e}+00$ 7.00890e-01 1.00000e-09 2.12000e-01 $1.00000 \mathrm{e}-021.00000 \mathrm{e}-02$ 1.00000e-03 1.00000e-09 1.00000e-01 $1.00000 \mathrm{e}+001.00000 \mathrm{e}+001.00000 \mathrm{e}-011.00000 \mathrm{e}-091.00000 \mathrm{e}-01$ Element: 831 \# of layers: 7

Kx Ky Kz Ss Por

$1.75416 \mathrm{e}+021.75416 \mathrm{e}+021.75416 \mathrm{e}+01$ 1.00000e-09 7.00000e-02 $1.75416 \mathrm{e}+021.75416 \mathrm{e}+021.75416 \mathrm{e}+011.00000 \mathrm{e}-097.00000 \mathrm{e}-02$ $1.75416 \mathrm{e}+021.75416 \mathrm{e}+021.75416 \mathrm{e}+011.00000 \mathrm{e}-097.00000 \mathrm{e}-02$ $7.00890 \mathrm{e}+007.00890 \mathrm{e}+00$ 7.00890e-01 1.00000e-09 2.12000e-01 $7.00890 \mathrm{e}+007.00890 \mathrm{e}+007.00890 \mathrm{e}-011.00000 \mathrm{e}-092.12000 \mathrm{e}-01$ $1.00000 \mathrm{e}-021.00000 \mathrm{e}-02$ 1.00000e-03 1.00000e-09 1.00000e-01 $1.00000 \mathrm{e}+001.00000 \mathrm{e}+001.00000 \mathrm{e}-011.00000 \mathrm{e}-091.00000 \mathrm{e}-01$ Element: 832 \# of layers: 6

Kx Ky Kz Ss Por

$1.75416 \mathrm{e}+021.75416 \mathrm{e}+021.75416 \mathrm{e}+01$ 1.00000e-09 7.00000e-02 $1.75416 \mathrm{e}+021.75416 \mathrm{e}+021.75416 \mathrm{e}+011.00000 \mathrm{e}-097.00000 \mathrm{e}-02$ $7.00890 \mathrm{e}+007.00890 \mathrm{e}+00$ 7.00890e-01 1.00000e-09 2.12000e-01 $7.00890 \mathrm{e}+007.00890 \mathrm{e}+00$ 7.00890e-01 1.00000e-09 2.12000e-01 $1.00000 \mathrm{e}-02$ 1.00000e-02 1.00000e-03 1.00000e-09 1.00000e-01 $1.00000 \mathrm{e}+001.00000 \mathrm{e}+001.00000 \mathrm{e}-011.00000 \mathrm{e}-091.00000 \mathrm{e}-01$ Element: 833 \# of layers: 5

Kx Ky Kz Ss Por

$1.75416 \mathrm{e}+02$ 1.75416e+02 1.75416e+01 1.00000e-09 7.00000e-02 $1.75416 \mathrm{e}+021.75416 \mathrm{e}+021.75416 \mathrm{e}+011.00000 \mathrm{e}-097.00000 \mathrm{e}-02$ $7.00890 \mathrm{e}+007.00890 \mathrm{e}+00$ 7.00890e-01 1.00000e-09 2.12000e-01 $1.00000 \mathrm{e}-021.00000 \mathrm{e}-02$ 1.00000e-03 1.00000e-09 1.00000e-01 $1.00000 \mathrm{e}+001.00000 \mathrm{e}+001.00000 \mathrm{e}-011.00000 \mathrm{e}-091.00000 \mathrm{e}-01$ Element: 834 \# of layers: 7

Kx Ky Kz Ss Por 
1.75416e+02 1.75416e+02 1.75416e+01 1.00000e-09 7.00000e-02 $1.75416 \mathrm{e}+02$ 1.75416e+02 1.75416e+01 1.00000e-09 7.00000e-02 $1.75416 \mathrm{e}+021.75416 \mathrm{e}+02$ 1.75416e+01 1.00000e-09 7.00000e-02 $7.00890 \mathrm{e}+007.00890 \mathrm{e}+00$ 7.00890e-01 1.00000e-09 2.12000e-01 $7.00890 \mathrm{e}+007.00890 \mathrm{e}+007.00890 \mathrm{e}-01$ 1.00000e-09 2.12000e-01 $1.00000 \mathrm{e}-02$ 1.00000e-02 1.00000e-03 1.00000e-09 1.00000e-01 $1.00000 \mathrm{e}+001.00000 \mathrm{e}+001.00000 \mathrm{e}-01$ 1.00000e-09 1.00000e-01 Element: 835 \# of layers: 6

$\mathrm{Kx} \mathrm{Ky} \mathrm{Kz}$ Ss Por

8.67249e+01 8.67249e+01 8.67249e+00 1.00000e-09 7.00000e-02 8.67249e+01 8.67249e+01 8.67249e+00 1.00000e-09 7.00000e-02 $3.46530 \mathrm{e}+003.46530 \mathrm{e}+003.46530 \mathrm{e}-01$ 1.00000e-09 2.12000e-01 $3.46530 \mathrm{e}+003.46530 \mathrm{e}+003.46530 \mathrm{e}-01$ 1.00000e-09 2.12000e-01 $1.00000 \mathrm{e}-02$ 1.00000e-02 1.00000e-03 1.00000e-09 1.00000e-01 $1.00000 \mathrm{e}+001.00000 \mathrm{e}+001.00000 \mathrm{e}-011.00000 \mathrm{e}-091.00000 \mathrm{e}-01$ Element: 836 \# of layers: 6

$\mathrm{Kx} \mathrm{Ky} \mathrm{Kz}$ Ss Por

8.67249e+01 8.67249e+01 8.67249e+00 1.00000e-09 7.00000e-02 $8.67249 \mathrm{e}+018.67249 \mathrm{e}+018.67249 \mathrm{e}+001.00000 \mathrm{e}-09$ 7.00000e-02 $3.46530 \mathrm{e}+003.46530 \mathrm{e}+003.46530 \mathrm{e}-01$ 1.00000e-09 2.12000e-01 $3.46530 \mathrm{e}+003.46530 \mathrm{e}+003.46530 \mathrm{e}-01$ 1.00000e-09 2.12000e-01 $1.00000 \mathrm{e}-02$ 1.00000e-02 1.00000e-03 1.00000e-09 1.00000e-01 $1.00000 \mathrm{e}+001.00000 \mathrm{e}+001.00000 \mathrm{e}-01$ 1.00000e-09 1.00000e-01 Element: 837 \# of layers: 6

$\mathrm{Kx} \mathrm{Ky} \mathrm{Kz}$ Ss Por

8.67249e+01 8.67249e+01 8.67249e+00 1.00000e-09 7.00000e-02 8.67249e+01 8.67249e+01 8.67249e+00 1.00000e-09 7.00000e-02 $3.46530 \mathrm{e}+003.46530 \mathrm{e}+00$ 3.46530e-01 1.00000e-09 2.12000e-01 $3.46530 \mathrm{e}+003.46530 \mathrm{e}+003.46530 \mathrm{e}-01$ 1.00000e-09 2.12000e-01 $1.00000 \mathrm{e}-02$ 1.00000e-02 1.00000e-03 1.00000e-09 1.00000e-01 $1.00000 \mathrm{e}+001.00000 \mathrm{e}+00$ 1.00000e-01 1.00000e-09 1.00000e-01 Element: 838 \# of layers: 7

$\mathrm{Kx} \mathrm{Ky} \mathrm{Kz}$ Ss Por

8.67249e+01 8.67249e+01 8.67249e+00 1.00000e-09 7.00000e-02 8.67249e+01 8.67249e+01 8.67249e+00 1.00000e-09 7.00000e-02 8.67249e+01 8.67249e+01 8.67249e+00 1.00000e-09 7.00000e-02 $3.46530 \mathrm{e}+003.46530 \mathrm{e}+003.46530 \mathrm{e}-01$ 1.00000e-09 2.12000e-01 $3.46530 \mathrm{e}+003.46530 \mathrm{e}+00$ 3.46530e-01 1.00000e-09 2.12000e-01 $1.00000 \mathrm{e}-02$ 1.00000e-02 1.00000e-03 1.00000e-09 1.00000e-01 $1.00000 \mathrm{e}+001.00000 \mathrm{e}+001.00000 \mathrm{e}-01$ 1.00000e-09 1.00000e-01 Element: 839 \# of layers: 7

$\mathrm{Kx} \mathrm{Ky} \mathrm{Kz}$ Ss Por

8.67249e+01 8.67249e+01 8.67249e+00 1.00000e-09 7.00000e-02 8.67249e+01 8.67249e+01 8.67249e+00 1.00000e-09 7.00000e-02 8.67249e+01 8.67249e+01 8.67249e+00 1.00000e-09 7.00000e-02 $3.46530 \mathrm{e}+003.46530 \mathrm{e}+003.46530 \mathrm{e}-01$ 1.00000e-09 2.12000e-01 
$3.46530 \mathrm{e}+003.46530 \mathrm{e}+00$ 3.46530e-01 1.00000e-09 2.12000e-01 $1.00000 \mathrm{e}-02$ 1.00000e-02 1.00000e-03 1.00000e-09 1.00000e-01 $1.00000 \mathrm{e}+001.00000 \mathrm{e}+001.00000 \mathrm{e}-01$ 1.00000e-09 1.00000e-01 Element: 840 \# of layers: 6

$\mathrm{Kx} \mathrm{Ky} \mathrm{Kz}$ Ss Por

8.67249e+01 8.67249e+01 8.67249e+00 1.00000e-09 7.00000e-02

8.67249e+01 8.67249e+01 8.67249e+00 1.00000e-09 7.00000e-02

$3.46530 \mathrm{e}+003.46530 \mathrm{e}+00 \quad 3.46530 \mathrm{e}-01$ 1.00000e-09 2.12000e-01

$3.46530 \mathrm{e}+003.46530 \mathrm{e}+00$ 3.46530e-01 1.00000e-09 2.12000e-01

$1.00000 \mathrm{e}-02$ 1.00000e-02 1.00000e-03 1.00000e-09 1.00000e-01

$1.00000 \mathrm{e}+001.00000 \mathrm{e}+001.00000 \mathrm{e}-01$ 1.00000e-09 1.00000e-01

Element: 841 \# of layers: 6

$\mathrm{Kx} \mathrm{Ky} \mathrm{Kz}$ Ss Por

8.67249e+01 8.67249e+01 8.67249e+00 1.00000e-09 7.00000e-02

$8.67249 \mathrm{e}+018.67249 \mathrm{e}+018.67249 \mathrm{e}+001.00000 \mathrm{e}-09$ 7.00000e-02

$3.46530 \mathrm{e}+003.46530 \mathrm{e}+003.46530 \mathrm{e}-01$ 1.00000e-09 2.12000e-01

$3.46530 \mathrm{e}+003.46530 \mathrm{e}+003.46530 \mathrm{e}-01$ 1.00000e-09 2.12000e-01

$1.00000 \mathrm{e}-02$ 1.00000e-02 1.00000e-03 1.00000e-09 1.00000e-01

$1.00000 \mathrm{e}+001.00000 \mathrm{e}+001.00000 \mathrm{e}-011.00000 \mathrm{e}-091.00000 \mathrm{e}-01$

Element: 842 \# of layers: 6

$\mathrm{Kx} \mathrm{Ky} \mathrm{Kz}$ Ss Por

8.67249e+01 8.67249e+01 8.67249e+00 1.00000e-09 7.00000e-02

8.67249e+01 8.67249e+01 8.67249e+00 1.00000e-09 7.00000e-02

$3.46530 \mathrm{e}+003.46530 \mathrm{e}+003.46530 \mathrm{e}-01$ 1.00000e-09 2.12000e-01

$3.46530 \mathrm{e}+003.46530 \mathrm{e}+003.46530 \mathrm{e}-01$ 1.00000e-09 2.12000e-01

$1.00000 \mathrm{e}-02$ 1.00000e-02 1.00000e-03 1.00000e-09 1.00000e-01

$1.00000 \mathrm{e}+001.00000 \mathrm{e}+001.00000 \mathrm{e}-011.00000 \mathrm{e}-091.00000 \mathrm{e}-01$

Element: 843 \# of layers: 6

$\mathrm{Kx} \mathrm{Ky} \mathrm{Kz}$ Ss Por

8.67249e+01 8.67249e+01 8.67249e+00 1.00000e-09 7.00000e-02

8.67249e+01 8.67249e+01 8.67249e+00 1.00000e-09 7.00000e-02

$3.46530 \mathrm{e}+003.46530 \mathrm{e}+00$ 3.46530e-01 1.00000e-09 2.12000e-01

$3.46530 \mathrm{e}+003.46530 \mathrm{e}+003.46530 \mathrm{e}-01$ 1.00000e-09 2.12000e-01

1.00000e-02 1.00000e-02 1.00000e-03 1.00000e-09 1.00000e-01

$1.00000 \mathrm{e}+001.00000 \mathrm{e}+001.00000 \mathrm{e}-01$ 1.00000e-09 1.00000e-01

Element: 844 \# of layers: 7

Kx Ky Kz Ss Por

5.31878e+01 5.31878e+01 5.31878e+00 1.00000e-09 7.00000e-02

$5.31878 \mathrm{e}+015.31878 \mathrm{e}+015.31878 \mathrm{e}+00$ 1.00000e-09 7.00000e-02

$5.31878 \mathrm{e}+015.31878 \mathrm{e}+015.31878 \mathrm{e}+00$ 1.00000e-09 7.00000e-02

$2.12522 \mathrm{e}+002.12522 \mathrm{e}+00$ 2.12522e-01 1.00000e-09 2.12000e-01

$2.12522 \mathrm{e}+002.12522 \mathrm{e}+002.12522 \mathrm{e}-01$ 1.00000e-09 2.12000e-01

$1.00000 \mathrm{e}-021.00000 \mathrm{e}-021.00000 \mathrm{e}-031.00000 \mathrm{e}-091.00000 \mathrm{e}-01$

$1.00000 \mathrm{e}+001.00000 \mathrm{e}+001.00000 \mathrm{e}-01$ 1.00000e-09 1.00000e-01

Element: 845 \# of layers: 7

Kx Ky Kz Ss Por 
$5.31878 \mathrm{e}+015.31878 \mathrm{e}+01$ 5.31878e+00 1.00000e-09 7.00000e-02 $5.31878 \mathrm{e}+015.31878 \mathrm{e}+015.31878 \mathrm{e}+001.00000 \mathrm{e}-09$ 7.00000e-02 $5.31878 \mathrm{e}+015.31878 \mathrm{e}+015.31878 \mathrm{e}+001.00000 \mathrm{e}-09$ 7.00000e-02 $2.12522 \mathrm{e}+002.12522 \mathrm{e}+002.12522 \mathrm{e}-011.00000 \mathrm{e}-092.12000 \mathrm{e}-01$ $2.12522 \mathrm{e}+002.12522 \mathrm{e}+002.12522 \mathrm{e}-01$ 1.00000e-09 2.12000e-01 $1.00000 \mathrm{e}-021.00000 \mathrm{e}-02$ 1.00000e-03 1.00000e-09 1.00000e-01 $1.00000 \mathrm{e}+001.00000 \mathrm{e}+001.00000 \mathrm{e}-011.00000 \mathrm{e}-091.00000 \mathrm{e}-01$ Element: 846 \# of layers: 7

Kx Ky Kz Ss Por

$5.31878 \mathrm{e}+015.31878 \mathrm{e}+015.31878 \mathrm{e}+00$ 1.00000e-09 7.00000e-02 $5.31878 \mathrm{e}+015.31878 \mathrm{e}+015.31878 \mathrm{e}+001.00000 \mathrm{e}-09$ 7.00000e-02 $5.31878 \mathrm{e}+015.31878 \mathrm{e}+015.31878 \mathrm{e}+001.00000 \mathrm{e}-09$ 7.00000e-02 $2.12522 \mathrm{e}+002.12522 \mathrm{e}+002.12522 \mathrm{e}-01$ 1.00000e-09 2.12000e-01 $2.12522 \mathrm{e}+002.12522 \mathrm{e}+002.12522 \mathrm{e}-011.00000 \mathrm{e}-092.12000 \mathrm{e}-01$ $1.00000 \mathrm{e}-021.00000 \mathrm{e}-02$ 1.00000e-03 1.00000e-09 1.00000e-01 $1.00000 \mathrm{e}+001.00000 \mathrm{e}+001.00000 \mathrm{e}-011.00000 \mathrm{e}-091.00000 \mathrm{e}-01$ Element: 847 \# of layers: 5

Kx Ky Kz Ss Por

$3.31837 \mathrm{e}+013.31837 \mathrm{e}+013.31837 \mathrm{e}+00$ 1.00000e-09 2.12000e-01 $3.31837 \mathrm{e}+013.31837 \mathrm{e}+013.31837 \mathrm{e}+00$ 1.00000e-09 2.12000e-01 $3.31837 \mathrm{e}+013.31837 \mathrm{e}+013.31837 \mathrm{e}+001.00000 \mathrm{e}-092.12000 \mathrm{e}-01$ $1.00000 \mathrm{e}-02$ 1.00000e-02 1.00000e-03 1.00000e-09 1.00000e-01 $1.00000 \mathrm{e}+001.00000 \mathrm{e}+001.00000 \mathrm{e}-011.00000 \mathrm{e}-091.00000 \mathrm{e}-01$ Element: 848 \# of layers: 5

Kx Ky Kz Ss Por

$3.31837 \mathrm{e}+013.31837 \mathrm{e}+013.31837 \mathrm{e}+00$ 1.00000e-09 2.12000e-01 $3.31837 \mathrm{e}+013.31837 \mathrm{e}+013.31837 \mathrm{e}+001.00000 \mathrm{e}-092.12000 \mathrm{e}-01$ $3.31837 \mathrm{e}+013.31837 \mathrm{e}+013.31837 \mathrm{e}+001.00000 \mathrm{e}-092.12000 \mathrm{e}-01$ $1.00000 \mathrm{e}-021.00000 \mathrm{e}-02$ 1.00000e-03 1.00000e-09 1.00000e-01 $1.00000 \mathrm{e}+001.00000 \mathrm{e}+001.00000 \mathrm{e}-011.00000 \mathrm{e}-091.00000 \mathrm{e}-01$ Element: 849 \# of layers: 6

Kx Ky Kz Ss Por $3.31837 \mathrm{e}+013.31837 \mathrm{e}+013.31837 \mathrm{e}+00$ 1.00000e-09 2.12000e-01 $3.31837 \mathrm{e}+013.31837 \mathrm{e}+013.31837 \mathrm{e}+00$ 1.00000e-09 2.12000e-01 $3.31837 \mathrm{e}+013.31837 \mathrm{e}+013.31837 \mathrm{e}+00$ 1.00000e-09 2.12000e-01 $3.31837 \mathrm{e}+013.31837 \mathrm{e}+013.31837 \mathrm{e}+00$ 1.00000e-09 2.12000e-01 $1.00000 \mathrm{e}-021.00000 \mathrm{e}-02$ 1.00000e-03 1.00000e-09 1.00000e-01 $1.00000 \mathrm{e}+001.00000 \mathrm{e}+001.00000 \mathrm{e}-011.00000 \mathrm{e}-091.00000 \mathrm{e}-01$ Element: 850 \# of layers: 6

Kx Ky Kz Ss Por $3.31837 \mathrm{e}+013.31837 \mathrm{e}+013.31837 \mathrm{e}+00$ 1.00000e-09 2.12000e-01 $3.31837 \mathrm{e}+013.31837 \mathrm{e}+013.31837 \mathrm{e}+00$ 1.00000e-09 2.12000e-01 $3.31837 \mathrm{e}+013.31837 \mathrm{e}+013.31837 \mathrm{e}+00$ 1.00000e-09 2.12000e-01 $3.31837 \mathrm{e}+013.31837 \mathrm{e}+013.31837 \mathrm{e}+00$ 1.00000e-09 2.12000e-01 $1.00000 \mathrm{e}-021.00000 \mathrm{e}-02$ 1.00000e-03 1.00000e-09 1.00000e-01 $1.00000 \mathrm{e}+001.00000 \mathrm{e}+001.00000 \mathrm{e}-011.00000 \mathrm{e}-091.00000 \mathrm{e}-01$ 
Element: 851 \# of layers: 6

Kx Ky Kz Ss Por

3.31837e+01 3.31837e+01 3.31837e+00 1.00000e-09 2.12000e-01

$3.31837 \mathrm{e}+013.31837 \mathrm{e}+013.31837 \mathrm{e}+00$ 1.00000e-09 2.12000e-01

$3.31837 \mathrm{e}+013.31837 \mathrm{e}+013.31837 \mathrm{e}+00$ 1.00000e-09 2.12000e-01

$3.31837 \mathrm{e}+013.31837 \mathrm{e}+013.31837 \mathrm{e}+00$ 1.00000e-09 2.12000e-01

$1.00000 \mathrm{e}-021.00000 \mathrm{e}-02$ 1.00000e-03 1.00000e-09 1.00000e-01

$1.00000 \mathrm{e}+001.00000 \mathrm{e}+001.00000 \mathrm{e}-011.00000 \mathrm{e}-091.00000 \mathrm{e}-01$

Element: 852 \# of layers: 6

Kx Ky Kz Ss Por

$3.31837 \mathrm{e}+013.31837 \mathrm{e}+013.31837 \mathrm{e}+00$ 1.00000e-09 2.12000e-01

$3.31837 \mathrm{e}+013.31837 \mathrm{e}+013.31837 \mathrm{e}+00$ 1.00000e-09 2.12000e-01

$3.31837 \mathrm{e}+013.31837 \mathrm{e}+013.31837 \mathrm{e}+00$ 1.00000e-09 2.12000e-01

$3.31837 \mathrm{e}+013.31837 \mathrm{e}+013.31837 \mathrm{e}+00$ 1.00000e-09 2.12000e-01

$1.00000 \mathrm{e}-021.00000 \mathrm{e}-02$ 1.00000e-03 1.00000e-09 1.00000e-01

$1.00000 \mathrm{e}+001.00000 \mathrm{e}+001.00000 \mathrm{e}-011.00000 \mathrm{e}-091.00000 \mathrm{e}-01$

Element: 853 \# of layers: 5

Kx Ky Kz Ss Por

3.31837e+01 3.31837e+01 3.31837e+00 1.00000e-09 2.12000e-01

$3.31837 \mathrm{e}+013.31837 \mathrm{e}+013.31837 \mathrm{e}+00$ 1.00000e-09 2.12000e-01

$3.31837 \mathrm{e}+013.31837 \mathrm{e}+013.31837 \mathrm{e}+00$ 1.00000e-09 2.12000e-01

$1.00000 \mathrm{e}-02$ 1.00000e-02 1.00000e-03 1.00000e-09 1.00000e-01

$1.00000 \mathrm{e}+001.00000 \mathrm{e}+001.00000 \mathrm{e}-011.00000 \mathrm{e}-091.00000 \mathrm{e}-01$

Element: 854 \# of layers: 5

Kx Ky Kz Ss Por

$3.31837 \mathrm{e}+013.31837 \mathrm{e}+013.31837 \mathrm{e}+00$ 1.00000e-09 2.12000e-01

$3.31837 \mathrm{e}+013.31837 \mathrm{e}+013.31837 \mathrm{e}+00$ 1.00000e-09 2.12000e-01

$3.31837 \mathrm{e}+013.31837 \mathrm{e}+013.31837 \mathrm{e}+00$ 1.00000e-09 2.12000e-01

$1.00000 \mathrm{e}-021.00000 \mathrm{e}-02$ 1.00000e-03 1.00000e-09 1.00000e-01

$1.00000 \mathrm{e}+001.00000 \mathrm{e}+001.00000 \mathrm{e}-011.00000 \mathrm{e}-091.00000 \mathrm{e}-01$

Element: 855 \# of layers: 5

Kx Ky Kz Ss Por

$1.34564 \mathrm{e}+011.34564 \mathrm{e}+011.34564 \mathrm{e}+00$ 1.00000e-09 2.12000e-01

$1.34564 \mathrm{e}+011.34564 \mathrm{e}+011.34564 \mathrm{e}+001.00000 \mathrm{e}-092.12000 \mathrm{e}-01$

$1.34564 \mathrm{e}+011.34564 \mathrm{e}+011.34564 \mathrm{e}+001.00000 \mathrm{e}-092.12000 \mathrm{e}-01$

$1.00000 \mathrm{e}-021.00000 \mathrm{e}-02$ 1.00000e-03 1.00000e-09 1.00000e-01

$1.00000 \mathrm{e}+001.00000 \mathrm{e}+001.00000 \mathrm{e}-011.00000 \mathrm{e}-091.00000 \mathrm{e}-01$

Element: 856 \# of layers: 5

Kx Ky Kz Ss Por

$1.34564 \mathrm{e}+011.34564 \mathrm{e}+011.34564 \mathrm{e}+00$ 1.00000e-09 2.12000e-01

$1.34564 \mathrm{e}+011.34564 \mathrm{e}+011.34564 \mathrm{e}+001.00000 \mathrm{e}-092.12000 \mathrm{e}-01$

$1.34564 \mathrm{e}+011.34564 \mathrm{e}+011.34564 \mathrm{e}+001.00000 \mathrm{e}-092.12000 \mathrm{e}-01$

$1.00000 \mathrm{e}-021.00000 \mathrm{e}-02$ 1.00000e-03 1.00000e-09 1.00000e-01

$1.00000 \mathrm{e}+001.00000 \mathrm{e}+001.00000 \mathrm{e}-011.00000 \mathrm{e}-091.00000 \mathrm{e}-01$

Element: 857 \# of layers: 5

Kx Ky Kz Ss Por 
$1.34564 \mathrm{e}+011.34564 \mathrm{e}+01$ 1.34564e+00 1.00000e-09 2.12000e-01 $1.34564 \mathrm{e}+011.34564 \mathrm{e}+01$ 1.34564e+00 1.00000e-09 2.12000e-01 $1.34564 \mathrm{e}+011.34564 \mathrm{e}+011.34564 \mathrm{e}+001.00000 \mathrm{e}-092.12000 \mathrm{e}-01$ $1.00000 \mathrm{e}-02$ 1.00000e-02 1.00000e-03 1.00000e-09 1.00000e-01 $1.00000 \mathrm{e}+001.00000 \mathrm{e}+001.00000 \mathrm{e}-011.00000 \mathrm{e}-091.00000 \mathrm{e}-01$ Element: 858 \# of layers: 6

$\mathrm{Kx} \mathrm{Ky} \mathrm{Kz}$ Ss Por

3.36776e+02 3.36776e+02 3.36776e+01 1.00000e-09 7.00000e-02 $1.34564 \mathrm{e}+011.34564 \mathrm{e}+01$ 1.34564e+00 1.00000e-09 2.12000e-01

$1.34564 \mathrm{e}+011.34564 \mathrm{e}+011.34564 \mathrm{e}+001.00000 \mathrm{e}-092.12000 \mathrm{e}-01$ $1.34564 \mathrm{e}+011.34564 \mathrm{e}+011.34564 \mathrm{e}+001.00000 \mathrm{e}-092.12000 \mathrm{e}-01$ $1.00000 \mathrm{e}-02$ 1.00000e-02 1.00000e-03 1.00000e-09 1.00000e-01 $1.00000 \mathrm{e}+001.00000 \mathrm{e}+001.00000 \mathrm{e}-011.00000 \mathrm{e}-091.00000 \mathrm{e}-01$ Element: 859 \# of layers: 7

$\mathrm{Kx} \mathrm{Ky} \mathrm{Kz}$ Ss Por

3.36776e+02 3.36776e+02 3.36776e+01 1.00000e-09 7.00000e-02 $1.34564 \mathrm{e}+011.34564 \mathrm{e}+011.34564 \mathrm{e}+001.00000 \mathrm{e}-092.12000 \mathrm{e}-01$ $1.34564 \mathrm{e}+011.34564 \mathrm{e}+011.34564 \mathrm{e}+001.00000 \mathrm{e}-092.12000 \mathrm{e}-01$ $1.34564 \mathrm{e}+01$ 1.34564e+01 1.34564e+00 1.00000e-09 2.12000e-01 $1.34564 \mathrm{e}+011.34564 \mathrm{e}+01$ 1.34564e+00 1.00000e-09 2.12000e-01 $1.00000 \mathrm{e}-02$ 1.00000e-02 1.00000e-03 1.00000e-09 1.00000e-01 $1.00000 \mathrm{e}+001.00000 \mathrm{e}+001.00000 \mathrm{e}-011.00000 \mathrm{e}-091.00000 \mathrm{e}-01$ Element: 860 \# of layers: 7

$\mathrm{Kx} \mathrm{Ky} \mathrm{Kz}$ Ss Por

3.36776e+02 3.36776e+02 3.36776e+01 1.00000e-09 7.00000e-02 $1.34564 \mathrm{e}+011.34564 \mathrm{e}+011.34564 \mathrm{e}+001.00000 \mathrm{e}-092.12000 \mathrm{e}-01$ $1.34564 \mathrm{e}+011.34564 \mathrm{e}+011.34564 \mathrm{e}+001.00000 \mathrm{e}-092.12000 \mathrm{e}-01$ $1.34564 \mathrm{e}+011.34564 \mathrm{e}+011.34564 \mathrm{e}+001.00000 \mathrm{e}-092.12000 \mathrm{e}-01$ $1.34564 \mathrm{e}+011.34564 \mathrm{e}+011.34564 \mathrm{e}+001.00000 \mathrm{e}-092.12000 \mathrm{e}-01$ $1.00000 \mathrm{e}-02$ 1.00000e-02 1.00000e-03 1.00000e-09 1.00000e-01 $1.00000 \mathrm{e}+001.00000 \mathrm{e}+001.00000 \mathrm{e}-011.00000 \mathrm{e}-091.00000 \mathrm{e}-01$ Element: 861 \# of layers: 6

$\mathrm{Kx} \mathrm{Ky} \mathrm{Kz}$ Ss Por

$1.34564 \mathrm{e}+011.34564 \mathrm{e}+011.34564 \mathrm{e}+001.00000 \mathrm{e}-092.12000 \mathrm{e}-01$ $1.34564 \mathrm{e}+011.34564 \mathrm{e}+011.34564 \mathrm{e}+001.00000 \mathrm{e}-092.12000 \mathrm{e}-01$ $1.34564 \mathrm{e}+011.34564 \mathrm{e}+011.34564 \mathrm{e}+001.00000 \mathrm{e}-092.12000 \mathrm{e}-01$ $1.34564 \mathrm{e}+011.34564 \mathrm{e}+011.34564 \mathrm{e}+001.00000 \mathrm{e}-092.12000 \mathrm{e}-01$ $1.00000 \mathrm{e}-02$ 1.00000e-02 1.00000e-03 1.00000e-09 1.00000e-01 $1.00000 \mathrm{e}+001.00000 \mathrm{e}+001.00000 \mathrm{e}-011.00000 \mathrm{e}-091.00000 \mathrm{e}-01$ Element: 862 \# of layers: 5

$\mathrm{Kx} \mathrm{Ky} \mathrm{Kz}$ Ss Por

$1.34564 \mathrm{e}+01$ 1.34564e+01 1.34564e+00 1.00000e-09 2.12000e-01 $1.34564 \mathrm{e}+011.34564 \mathrm{e}+011.34564 \mathrm{e}+001.00000 \mathrm{e}-092.12000 \mathrm{e}-01$ $1.34564 \mathrm{e}+01$ 1.34564e+01 1.34564e+00 1.00000e-09 2.12000e-01 $1.00000 \mathrm{e}-02$ 1.00000e-02 1.00000e-03 1.00000e-09 1.00000e-01 $1.00000 \mathrm{e}+001.00000 \mathrm{e}+001.00000 \mathrm{e}-011.00000 \mathrm{e}-091.00000 \mathrm{e}-01$ 
Element: 863 \# of layers: 5

$\mathrm{Kx} \mathrm{Ky} \mathrm{Kz}$ Ss Por

$1.34564 \mathrm{e}+01$ 1.34564e+01 1.34564e+00 1.00000e-09 2.12000e-01

$1.34564 \mathrm{e}+011.34564 \mathrm{e}+011.34564 \mathrm{e}+001.00000 \mathrm{e}-092.12000 \mathrm{e}-01$

$1.34564 \mathrm{e}+011.34564 \mathrm{e}+01$ 1.34564e+00 1.00000e-09 2.12000e-01

$1.00000 \mathrm{e}-02$ 1.00000e-02 1.00000e-03 1.00000e-09 1.00000e-01

$1.00000 \mathrm{e}+001.00000 \mathrm{e}+001.00000 \mathrm{e}-01$ 1.00000e-09 1.00000e-01

Element: 864 \# of layers: 6

$\mathrm{Kx} \mathrm{Ky} \mathrm{Kz}$ Ss Por

2.24709e+02 2.24709e+02 2.24709e+01 1.00000e-09 7.00000e-02

8.97859e+00 8.97859e+00 8.97859e-01 1.00000e-09 2.12000e-01

$8.97859 \mathrm{e}+008.97859 \mathrm{e}+00$ 8.97859e-01 1.00000e-09 2.12000e-01

$8.97859 \mathrm{e}+00$ 8.97859e+00 8.97859e-01 1.00000e-09 2.12000e-01

1.00000e-02 1.00000e-02 1.00000e-03 1.00000e-09 1.00000e-01

$1.00000 \mathrm{e}+001.00000 \mathrm{e}+001.00000 \mathrm{e}-011.00000 \mathrm{e}-091.00000 \mathrm{e}-01$

Element: 865 \# of layers: 6

$\mathrm{Kx} \mathrm{Ky} \mathrm{Kz}$ Ss Por

2.24709e+02 2.24709e+02 2.24709e+01 1.00000e-09 7.00000e-02

8.97859e+00 8.97859e+00 8.97859e-01 1.00000e-09 2.12000e-01

$8.97859 \mathrm{e}+00$ 8.97859e+00 8.97859e-01 1.00000e-09 2.12000e-01

$8.97859 \mathrm{e}+00$ 8.97859e+00 8.97859e-01 1.00000e-09 2.12000e-01

$1.00000 \mathrm{e}-02$ 1.00000e-02 1.00000e-03 1.00000e-09 1.00000e-01

$1.00000 \mathrm{e}+001.00000 \mathrm{e}+001.00000 \mathrm{e}-01$ 1.00000e-09 1.00000e-01

Element: 866 \# of layers: 6

$\mathrm{Kx} \mathrm{Ky} \mathrm{Kz}$ Ss Por

$2.24709 \mathrm{e}+02$ 2.24709e+02 2.24709e+01 1.00000e-09 7.00000e-02

8.97859e+00 8.97859e+00 8.97859e-01 1.00000e-09 2.12000e-01

$8.97859 \mathrm{e}+00$ 8.97859e+00 8.97859e-01 1.00000e-09 2.12000e-01

$8.97859 \mathrm{e}+00$ 8.97859e+00 8.97859e-01 1.00000e-09 2.12000e-01

$1.00000 \mathrm{e}-02$ 1.00000e-02 1.00000e-03 1.00000e-09 1.00000e-01

$1.00000 \mathrm{e}+001.00000 \mathrm{e}+001.00000 \mathrm{e}-011.00000 \mathrm{e}-091.00000 \mathrm{e}-01$

Element: 867 \# of layers: 7

$\mathrm{Kx} \mathrm{Ky} \mathrm{Kz}$ Ss Por

$2.24709 \mathrm{e}+02$ 2.24709e+02 2.24709e+01 1.00000e-09 7.00000e-02

2.24709e+02 2.24709e+02 2.24709e+01 1.00000e-09 7.00000e-02

8.97859e+00 8.97859e+00 8.97859e-01 1.00000e-09 2.12000e-01

$8.97859 \mathrm{e}+008.97859 \mathrm{e}+00$ 8.97859e-01 1.00000e-09 2.12000e-01

$8.97859 \mathrm{e}+00$ 8.97859e+00 8.97859e-01 1.00000e-09 2.12000e-01

$1.00000 \mathrm{e}-02$ 1.00000e-02 1.00000e-03 1.00000e-09 1.00000e-01

$1.00000 \mathrm{e}+001.00000 \mathrm{e}+001.00000 \mathrm{e}-01$ 1.00000e-09 1.00000e-01

Element: 868 \# of layers: 8

$\mathrm{Kx} \mathrm{Ky} \mathrm{Kz}$ Ss Por

$2.24709 \mathrm{e}+02$ 2.24709e+02 2.24709e+01 1.00000e-09 7.00000e-02

2.24709e+02 2.24709e+02 2.24709e+01 1.00000e-09 7.00000e-02

$8.97859 \mathrm{e}+00$ 8.97859e+00 8.97859e-01 1.00000e-09 2.12000e-01

$8.97859 \mathrm{e}+008.97859 \mathrm{e}+00$ 8.97859e-01 1.00000e-09 2.12000e-01 
$8.97859 \mathrm{e}+008.97859 \mathrm{e}+00$ 8.97859e-01 1.00000e-09 2.12000e-01 $8.97859 \mathrm{e}+008.97859 \mathrm{e}+00$ 8.97859e-01 1.00000e-09 2.12000e-01 $1.00000 \mathrm{e}-021.00000 \mathrm{e}-02$ 1.00000e-03 $1.00000 \mathrm{e}-091.00000 \mathrm{e}-01$ $1.00000 \mathrm{e}+001.00000 \mathrm{e}+001.00000 \mathrm{e}-011.00000 \mathrm{e}-091.00000 \mathrm{e}-01$ Element: 869 \# of layers: 7

Kx Ky Kz Ss Por

$2.24709 \mathrm{e}+022.24709 \mathrm{e}+022.24709 \mathrm{e}+01$ 1.00000e-09 7.00000e-02 $8.97859 \mathrm{e}+008.97859 \mathrm{e}+00$ 8.97859e-01 1.00000e-09 2.12000e-01 $8.97859 \mathrm{e}+00$ 8.97859e+00 8.97859e-01 1.00000e-09 2.12000e-01 $8.97859 \mathrm{e}+008.97859 \mathrm{e}+00$ 8.97859e-01 1.00000e-09 2.12000e-01 $8.97859 \mathrm{e}+008.97859 \mathrm{e}+00$ 8.97859e-01 1.00000e-09 2.12000e-01 $1.00000 \mathrm{e}-021.00000 \mathrm{e}-02$ 1.00000e-03 1.00000e-09 1.00000e-01 $1.00000 \mathrm{e}+001.00000 \mathrm{e}+001.00000 \mathrm{e}-011.00000 \mathrm{e}-091.00000 \mathrm{e}-01$ Element: 870 \# of layers: 7

Kx Ky Kz Ss Por

$2.24709 \mathrm{e}+022.24709 \mathrm{e}+022.24709 \mathrm{e}+01$ 1.00000e-09 7.00000e-02 $8.97859 \mathrm{e}+008.97859 \mathrm{e}+00$ 8.97859e-01 1.00000e-09 2.12000e-01 $8.97859 \mathrm{e}+008.97859 \mathrm{e}+008.97859 \mathrm{e}-01$ 1.00000e-09 2.12000e-01 $8.97859 \mathrm{e}+008.97859 \mathrm{e}+00$ 8.97859e-01 1.00000e-09 2.12000e-01 $8.97859 \mathrm{e}+008.97859 \mathrm{e}+00$ 8.97859e-01 1.00000e-09 2.12000e-01 $1.00000 \mathrm{e}-021.00000 \mathrm{e}-02$ 1.00000e-03 1.00000e-09 1.00000e-01 $1.00000 \mathrm{e}+001.00000 \mathrm{e}+001.00000 \mathrm{e}-011.00000 \mathrm{e}-091.00000 \mathrm{e}-01$ Element: 871 \# of layers: 6

Kx Ky Kz Ss Por

$2.24709 \mathrm{e}+022.24709 \mathrm{e}+02$ 2.24709e+01 1.00000e-09 7.00000e-02 $8.97859 \mathrm{e}+008.97859 \mathrm{e}+00$ 8.97859e-01 1.00000e-09 2.12000e-01 $8.97859 \mathrm{e}+008.97859 \mathrm{e}+008.97859 \mathrm{e}-011.00000 \mathrm{e}-092.12000 \mathrm{e}-01$ $8.97859 \mathrm{e}+008.97859 \mathrm{e}+00$ 8.97859e-01 1.00000e-09 2.12000e-01 $1.00000 \mathrm{e}-021.00000 \mathrm{e}-02$ 1.00000e-03 1.00000e-09 1.00000e-01 $1.00000 \mathrm{e}+001.00000 \mathrm{e}+001.00000 \mathrm{e}-011.00000 \mathrm{e}-091.00000 \mathrm{e}-01$ Element: 872 \# of layers: 6

Kx Ky Kz Ss Por

$2.24709 \mathrm{e}+022.24709 \mathrm{e}+022.24709 \mathrm{e}+01$ 1.00000e-09 7.00000e-02 $8.97859 \mathrm{e}+00$ 8.97859e+00 8.97859e-01 1.00000e-09 2.12000e-01 $8.97859 \mathrm{e}+008.97859 \mathrm{e}+00$ 8.97859e-01 1.00000e-09 2.12000e-01 $8.97859 \mathrm{e}+008.97859 \mathrm{e}+00$ 8.97859e-01 1.00000e-09 2.12000e-01 $1.00000 \mathrm{e}-021.00000 \mathrm{e}-02$ 1.00000e-03 1.00000e-09 1.00000e-01 $1.00000 \mathrm{e}+001.00000 \mathrm{e}+001.00000 \mathrm{e}-011.00000 \mathrm{e}-091.00000 \mathrm{e}-01$ Element: 873 \# of layers: 7

Kx Ky Kz Ss Por

$1.70983 \mathrm{e}+02$ 1.70983e+02 1.70983e+01 1.00000e-09 7.00000e-02 $1.70983 \mathrm{e}+02$ 1.70983e+02 1.70983e+01 1.00000e-09 7.00000e-02 $6.83182 \mathrm{e}+006.83182 \mathrm{e}+00$ 6.83182e-01 1.00000e-09 2.12000e-01 $6.83182 \mathrm{e}+006.83182 \mathrm{e}+00$ 6.83182e-01 1.00000e-09 2.12000e-01 $6.83182 \mathrm{e}+006.83182 \mathrm{e}+00$ 6.83182e-01 1.00000e-09 2.12000e-01 $1.00000 \mathrm{e}-021.00000 \mathrm{e}-02$ 1.00000e-03 1.00000e-09 1.00000e-01 
$1.00000 \mathrm{e}+001.00000 \mathrm{e}+00$ 1.00000e-01 1.00000e-09 1.00000e-01

Element: 874 \# of layers: 7

Kx Ky Kz Ss Por

$1.70983 e+02$ 1.70983e+02 1.70983e+01 1.00000e-09 7.00000e-02

6.83182e+00 6.83182e+00 6.83182e-01 1.00000e-09 2.12000e-01

$6.83182 \mathrm{e}+006.83182 \mathrm{e}+00$ 6.83182e-01 1.00000e-09 2.12000e-01

6.83182e+00 6.83182e+00 6.83182e-01 1.00000e-09 2.12000e-01

$6.83182 \mathrm{e}+00$ 6.83182e+00 6.83182e-01 1.00000e-09 2.12000e-01

$1.00000 \mathrm{e}-02$ 1.00000e-02 1.00000e-03 1.00000e-09 1.00000e-01

$1.00000 \mathrm{e}+001.00000 \mathrm{e}+001.00000 \mathrm{e}-011.00000 \mathrm{e}-091.00000 \mathrm{e}-01$

Element: 875 \# of layers: 6

$\mathrm{Kx} \mathrm{Ky} \mathrm{Kz}$ Ss Por

1.70983e+02 1.70983e+02 1.70983e+01 1.00000e-09 7.00000e-02

$6.83182 \mathrm{e}+00$ 6.83182e+00 6.83182e-01 1.00000e-09 2.12000e-01

6.83182e+00 6.83182e+00 6.83182e-01 1.00000e-09 2.12000e-01

6.83182e+00 6.83182e+00 6.83182e-01 1.00000e-09 2.12000e-01

$1.00000 \mathrm{e}-02$ 1.00000e-02 1.00000e-03 1.00000e-09 1.00000e-01

$1.00000 \mathrm{e}+001.00000 \mathrm{e}+001.00000 \mathrm{e}-011.00000 \mathrm{e}-091.00000 \mathrm{e}-01$

Element: 876 \# of layers: 6

$\mathrm{Kx} \mathrm{Ky} \mathrm{Kz}$ Ss Por

$1.70983 \mathrm{e}+02$ 1.70983e+02 1.70983e+01 1.00000e-09 7.00000e-02

6.83182e+00 6.83182e+00 6.83182e-01 1.00000e-09 2.12000e-01

$6.83182 \mathrm{e}+00$ 6.83182e+00 6.83182e-01 1.00000e-09 2.12000e-01

6.83182e+00 6.83182e+00 6.83182e-01 1.00000e-09 2.12000e-01

$1.00000 \mathrm{e}-021.00000 \mathrm{e}-02$ 1.00000e-03 1.00000e-09 1.00000e-01

$1.00000 \mathrm{e}+001.00000 \mathrm{e}+001.00000 \mathrm{e}-011.00000 \mathrm{e}-091.00000 \mathrm{e}-01$

Element: 877 \# of layers: 6

$\mathrm{Kx} \mathrm{Ky} \mathrm{Kz}$ Ss Por

$1.70983 e+02$ 1.70983e+02 1.70983e+01 1.00000e-09 7.00000e-02

6.83182e+00 6.83182e+00 6.83182e-01 1.00000e-09 2.12000e-01

6.83182e+00 6.83182e+00 6.83182e-01 1.00000e-09 2.12000e-01

$6.83182 \mathrm{e}+006.83182 \mathrm{e}+00$ 6.83182e-01 1.00000e-09 2.12000e-01

$1.00000 \mathrm{e}-02$ 1.00000e-02 1.00000e-03 1.00000e-09 1.00000e-01

$1.00000 \mathrm{e}+001.00000 \mathrm{e}+001.00000 \mathrm{e}-011.00000 \mathrm{e}-091.00000 \mathrm{e}-01$

Element: 878 \# of layers: 7

$\mathrm{Kx} \mathrm{Ky} \mathrm{Kz}$ Ss Por

1.70983e+02 1.70983e+02 1.70983e+01 1.00000e-09 7.00000e-02

$6.83182 \mathrm{e}+006.83182 \mathrm{e}+00$ 6.83182e-01 1.00000e-09 2.12000e-01

$6.83182 \mathrm{e}+006.83182 \mathrm{e}+00$ 6.83182e-01 1.00000e-09 2.12000e-01

6.83182e+00 6.83182e+00 6.83182e-01 1.00000e-09 2.12000e-01

$6.83182 \mathrm{e}+006.83182 \mathrm{e}+00$ 6.83182e-01 1.00000e-09 2.12000e-01

$1.00000 \mathrm{e}-02$ 1.00000e-02 1.00000e-03 1.00000e-09 1.00000e-01

$1.00000 \mathrm{e}+001.00000 \mathrm{e}+001.00000 \mathrm{e}-01$ 1.00000e-09 1.00000e-01

Element: 879 \# of layers: 7

$\mathrm{Kx} \mathrm{Ky} \mathrm{Kz}$ Ss Por

1.70983e+02 1.70983e+02 1.70983e+01 1.00000e-09 7.00000e-02 
$6.83182 \mathrm{e}+006.83182 \mathrm{e}+00$ 6.83182e-01 1.00000e-09 2.12000e-01 $6.83182 \mathrm{e}+006.83182 \mathrm{e}+00$ 6.83182e-01 1.00000e-09 2.12000e-01 $6.83182 \mathrm{e}+006.83182 \mathrm{e}+00$ 6.83182e-01 1.00000e-09 2.12000e-01 $6.83182 \mathrm{e}+006.83182 \mathrm{e}+00$ 6.83182e-01 1.00000e-09 2.12000e-01 $1.00000 \mathrm{e}-021.00000 \mathrm{e}-021.00000 \mathrm{e}-031.00000 \mathrm{e}-091.00000 \mathrm{e}-01$ $1.00000 \mathrm{e}+001.00000 \mathrm{e}+001.00000 \mathrm{e}-011.00000 \mathrm{e}-091.00000 \mathrm{e}-01$ Element: 880 \# of layers: 7

Kx Ky Kz Ss Por

$1.70983 \mathrm{e}+02$ 1.70983e+02 1.70983e+01 1.00000e-09 7.00000e-02 $1.70983 \mathrm{e}+02$ 1.70983e+02 1.70983e+01 1.00000e-09 7.00000e-02 $6.83182 \mathrm{e}+006.83182 \mathrm{e}+00$ 6.83182e-01 1.00000e-09 2.12000e-01 $6.83182 \mathrm{e}+006.83182 \mathrm{e}+00$ 6.83182e-01 1.00000e-09 2.12000e-01 $6.83182 \mathrm{e}+006.83182 \mathrm{e}+00$ 6.83182e-01 1.00000e-09 2.12000e-01 $1.00000 \mathrm{e}-021.00000 \mathrm{e}-02$ 1.00000e-03 1.00000e-09 1.00000e-01 $1.00000 \mathrm{e}+001.00000 \mathrm{e}+001.00000 \mathrm{e}-011.00000 \mathrm{e}-091.00000 \mathrm{e}-01$ Element: 881 \# of layers: 7

Kx Ky Kz Ss Por

$1.70983 \mathrm{e}+02$ 1.70983e+02 1.70983e+01 1.00000e-09 7.00000e-02 6.83182e+00 6.83182e+00 6.83182e-01 1.00000e-09 2.12000e-01 $6.83182 \mathrm{e}+006.83182 \mathrm{e}+00$ 6.83182e-01 1.00000e-09 2.12000e-01 $6.83182 \mathrm{e}+006.83182 \mathrm{e}+006.83182 \mathrm{e}-011.00000 \mathrm{e}-092.12000 \mathrm{e}-01$ $6.83182 \mathrm{e}+006.83182 \mathrm{e}+00$ 6.83182e-01 1.00000e-09 2.12000e-01 $1.00000 \mathrm{e}-021.00000 \mathrm{e}-02$ 1.00000e-03 1.00000e-09 1.00000e-01 $1.00000 \mathrm{e}+001.00000 \mathrm{e}+001.00000 \mathrm{e}-011.00000 \mathrm{e}-091.00000 \mathrm{e}-01$ Element: 882 \# of layers: 6

Kx Ky Kz Ss Por

$6.61397 \mathrm{e}+016.61397 \mathrm{e}+016.61397 \mathrm{e}+00$ 1.00000e-09 7.00000e-02 $2.64268 \mathrm{e}+002.64268 \mathrm{e}+002.64268 \mathrm{e}-011.00000 \mathrm{e}-092.12000 \mathrm{e}-01$ $2.64268 \mathrm{e}+002.64268 \mathrm{e}+002.64268 \mathrm{e}-011.00000 \mathrm{e}-092.12000 \mathrm{e}-01$ $2.64268 \mathrm{e}+002.64268 \mathrm{e}+002.64268 \mathrm{e}-01$ 1.00000e-09 2.12000e-01 $1.00000 \mathrm{e}-021.00000 \mathrm{e}-02$ 1.00000e-03 1.00000e-09 1.00000e-01 $1.00000 \mathrm{e}+001.00000 \mathrm{e}+001.00000 \mathrm{e}-011.00000 \mathrm{e}-091.00000 \mathrm{e}-01$ Element: 883 \# of layers: 5

Kx Ky Kz Ss Por

$6.61397 \mathrm{e}+016.61397 \mathrm{e}+016.61397 \mathrm{e}+00$ 1.00000e-09 7.00000e-02 $2.64268 \mathrm{e}+002.64268 \mathrm{e}+002.64268 \mathrm{e}-011.00000 \mathrm{e}-092.12000 \mathrm{e}-01$ $2.64268 \mathrm{e}+002.64268 \mathrm{e}+002.64268 \mathrm{e}-01$ 1.00000e-09 2.12000e-01 $1.00000 \mathrm{e}-02$ 1.00000e-02 1.00000e-03 1.00000e-09 1.00000e-01 $1.00000 \mathrm{e}+001.00000 \mathrm{e}+001.00000 \mathrm{e}-011.00000 \mathrm{e}-091.00000 \mathrm{e}-01$ Element: 884 \# of layers: 5

Kx Ky Kz Ss Por $6.61397 \mathrm{e}+016.61397 \mathrm{e}+016.61397 \mathrm{e}+00$ 1.00000e-09 7.00000e-02 $2.64268 \mathrm{e}+002.64268 \mathrm{e}+002.64268 \mathrm{e}-01$ 1.00000e-09 2.12000e-01 $2.64268 \mathrm{e}+002.64268 \mathrm{e}+002.64268 \mathrm{e}-01$ 1.00000e-09 2.12000e-01 $1.00000 \mathrm{e}-021.00000 \mathrm{e}-02$ 1.00000e-03 1.00000e-09 1.00000e-01 $1.00000 \mathrm{e}+001.00000 \mathrm{e}+001.00000 \mathrm{e}-011.00000 \mathrm{e}-091.00000 \mathrm{e}-01$ 
Element: 885 \# of layers: 6

Kx Ky Kz Ss Por

$6.61397 \mathrm{e}+01$ 6.61397e+01 6.61397e+00 1.00000e-09 7.00000e-02

$2.64268 \mathrm{e}+002.64268 \mathrm{e}+002.64268 \mathrm{e}-011.00000 \mathrm{e}-092.12000 \mathrm{e}-01$

$2.64268 \mathrm{e}+002.64268 \mathrm{e}+002.64268 \mathrm{e}-01$ 1.00000e-09 2.12000e-01

$2.64268 \mathrm{e}+002.64268 \mathrm{e}+002.64268 \mathrm{e}-011.00000 \mathrm{e}-092.12000 \mathrm{e}-01$

$1.00000 \mathrm{e}-021.00000 \mathrm{e}-02$ 1.00000e-03 1.00000e-09 1.00000e-01

$1.00000 \mathrm{e}+001.00000 \mathrm{e}+001.00000 \mathrm{e}-011.00000 \mathrm{e}-091.00000 \mathrm{e}-01$

Element: 886 \# of layers: 6

Kx Ky Kz Ss Por

$6.61397 \mathrm{e}+01$ 6.61397e+01 6.61397e+00 1.00000e-09 7.00000e-02

$2.64268 \mathrm{e}+002.64268 \mathrm{e}+002.64268 \mathrm{e}-011.00000 \mathrm{e}-092.12000 \mathrm{e}-01$

$2.64268 \mathrm{e}+002.64268 \mathrm{e}+002.64268 \mathrm{e}-011.00000 \mathrm{e}-092.12000 \mathrm{e}-01$

$2.64268 \mathrm{e}+002.64268 \mathrm{e}+002.64268 \mathrm{e}-011.00000 \mathrm{e}-092.12000 \mathrm{e}-01$

$1.00000 \mathrm{e}-02$ 1.00000e-02 1.00000e-03 1.00000e-09 1.00000e-01

$1.00000 \mathrm{e}+001.00000 \mathrm{e}+001.00000 \mathrm{e}-011.00000 \mathrm{e}-091.00000 \mathrm{e}-01$

Element: 887 \# of layers: 6

Kx Ky Kz Ss Por

$6.61397 \mathrm{e}+016.61397 \mathrm{e}+016.61397 \mathrm{e}+00$ 1.00000e-09 7.00000e-02

$2.64268 \mathrm{e}+002.64268 \mathrm{e}+002.64268 \mathrm{e}-011.00000 \mathrm{e}-092.12000 \mathrm{e}-01$

$2.64268 \mathrm{e}+002.64268 \mathrm{e}+002.64268 \mathrm{e}-011.00000 \mathrm{e}-092.12000 \mathrm{e}-01$

$2.64268 \mathrm{e}+002.64268 \mathrm{e}+002.64268 \mathrm{e}-011.00000 \mathrm{e}-092.12000 \mathrm{e}-01$

$1.00000 \mathrm{e}-02$ 1.00000e-02 1.00000e-03 1.00000e-09 1.00000e-01

$1.00000 \mathrm{e}+001.00000 \mathrm{e}+001.00000 \mathrm{e}-011.00000 \mathrm{e}-091.00000 \mathrm{e}-01$

Element: 888 \# of layers: 6

Kx Ky Kz Ss Por

$6.61397 \mathrm{e}+01$ 6.61397e+01 6.61397e+00 1.00000e-09 7.00000e-02

$2.64268 \mathrm{e}+002.64268 \mathrm{e}+002.64268 \mathrm{e}-011.00000 \mathrm{e}-092.12000 \mathrm{e}-01$

$2.64268 \mathrm{e}+002.64268 \mathrm{e}+002.64268 \mathrm{e}-011.00000 \mathrm{e}-092.12000 \mathrm{e}-01$

$2.64268 \mathrm{e}+002.64268 \mathrm{e}+002.64268 \mathrm{e}-011.00000 \mathrm{e}-092.12000 \mathrm{e}-01$

$1.00000 \mathrm{e}-021.00000 \mathrm{e}-02$ 1.00000e-03 1.00000e-09 1.00000e-01

$1.00000 \mathrm{e}+001.00000 \mathrm{e}+001.00000 \mathrm{e}-011.00000 \mathrm{e}-091.00000 \mathrm{e}-01$

Element: 889 \# of layers: 6

Kx Ky Kz Ss Por

$6.61397 \mathrm{e}+016.61397 \mathrm{e}+016.61397 \mathrm{e}+00$ 1.00000e-09 7.00000e-02

$2.64268 \mathrm{e}+002.64268 \mathrm{e}+002.64268 \mathrm{e}-011.00000 \mathrm{e}-092.12000 \mathrm{e}-01$

$2.64268 \mathrm{e}+002.64268 \mathrm{e}+002.64268 \mathrm{e}-011.00000 \mathrm{e}-092.12000 \mathrm{e}-01$

$2.64268 \mathrm{e}+002.64268 \mathrm{e}+002.64268 \mathrm{e}-01$ 1.00000e-09 2.12000e-01

$1.00000 \mathrm{e}-02$ 1.00000e-02 1.00000e-03 1.00000e-09 1.00000e-01

$1.00000 \mathrm{e}+001.00000 \mathrm{e}+001.00000 \mathrm{e}-011.00000 \mathrm{e}-091.00000 \mathrm{e}-01$

Element: 890 \# of layers: 6

Kx Ky Kz Ss Por

$6.61397 \mathrm{e}+016.61397 \mathrm{e}+016.61397 \mathrm{e}+00$ 1.00000e-09 7.00000e-02

$2.64268 \mathrm{e}+002.64268 \mathrm{e}+002.64268 \mathrm{e}-011.00000 \mathrm{e}-092.12000 \mathrm{e}-01$

$2.64268 \mathrm{e}+002.64268 \mathrm{e}+002.64268 \mathrm{e}-011.00000 \mathrm{e}-092.12000 \mathrm{e}-01$

$2.64268 \mathrm{e}+002.64268 \mathrm{e}+002.64268 \mathrm{e}-01$ 1.00000e-09 2.12000e-01 
$1.00000 \mathrm{e}-02$ 1.00000e-02 1.00000e-03 1.00000e-09 1.00000e-01 $1.00000 \mathrm{e}+001.00000 \mathrm{e}+001.00000 \mathrm{e}-01$ 1.00000e-09 1.00000e-01 Element: 891 \# of layers: 5

$\mathrm{Kx} \mathrm{Ky} \mathrm{Kz}$ Ss Por

5.32122e+01 5.32122e+01 5.32122e+00 1.00000e-09 7.00000e-02 $2.12618 \mathrm{e}+002.12618 \mathrm{e}+00$ 2.12618e-01 1.00000e-09 2.12000e-01

$2.12618 \mathrm{e}+002.12618 \mathrm{e}+00$ 2.12618e-01 1.00000e-09 2.12000e-01 $1.00000 \mathrm{e}-02$ 1.00000e-02 1.00000e-03 1.00000e-09 1.00000e-01 $1.00000 \mathrm{e}+001.00000 \mathrm{e}+001.00000 \mathrm{e}-011.00000 \mathrm{e}-091.00000 \mathrm{e}-01$ Element: 892 \# of layers: 6

$\mathrm{Kx} \mathrm{Ky} \mathrm{Kz}$ Ss Por

5.32122e+01 5.32122e+01 5.32122e+00 1.00000e-09 7.00000e-02

$5.32122 \mathrm{e}+015.32122 \mathrm{e}+015.32122 \mathrm{e}+001.00000 \mathrm{e}-09$ 7.00000e-02

$2.12618 \mathrm{e}+002.12618 \mathrm{e}+00$ 2.12618e-01 1.00000e-09 2.12000e-01

$2.12618 \mathrm{e}+002.12618 \mathrm{e}+00$ 2.12618e-01 1.00000e-09 2.12000e-01 1.00000e-02 1.00000e-02 1.00000e-03 1.00000e-09 1.00000e-01 $1.00000 \mathrm{e}+001.00000 \mathrm{e}+001.00000 \mathrm{e}-011.00000 \mathrm{e}-091.00000 \mathrm{e}-01$ Element: 893 \# of layers: 6

$\mathrm{Kx} \mathrm{Ky} \mathrm{Kz}$ Ss Por

5.32122e+01 5.32122e+01 5.32122e+00 1.00000e-09 7.00000e-02 $5.32122 \mathrm{e}+015.32122 \mathrm{e}+015.32122 \mathrm{e}+00$ 1.00000e-09 7.00000e-02 $2.12618 \mathrm{e}+002.12618 \mathrm{e}+00$ 2.12618e-01 1.00000e-09 2.12000e-01 $2.12618 \mathrm{e}+002.12618 \mathrm{e}+00$ 2.12618e-01 1.00000e-09 2.12000e-01 1.00000e-02 1.00000e-02 1.00000e-03 1.00000e-09 1.00000e-01 $1.00000 \mathrm{e}+001.00000 \mathrm{e}+001.00000 \mathrm{e}-011.00000 \mathrm{e}-091.00000 \mathrm{e}-01$ Element: 894 \# of layers: 7

$\mathrm{Kx} \mathrm{Ky} \mathrm{Kz}$ Ss Por

5.32122e+01 5.32122e+01 5.32122e+00 1.00000e-09 7.00000e-02 $5.32122 \mathrm{e}+015.32122 \mathrm{e}+015.32122 \mathrm{e}+00$ 1.00000e-09 7.00000e-02 $2.12618 \mathrm{e}+002.12618 \mathrm{e}+00$ 2.12618e-01 1.00000e-09 2.12000e-01 $2.12618 \mathrm{e}+002.12618 \mathrm{e}+00$ 2.12618e-01 1.00000e-09 2.12000e-01 $2.12618 \mathrm{e}+002.12618 \mathrm{e}+002.12618 \mathrm{e}-01$ 1.00000e-09 2.12000e-01 $1.00000 \mathrm{e}-02$ 1.00000e-02 1.00000e-03 1.00000e-09 1.00000e-01 $1.00000 \mathrm{e}+001.00000 \mathrm{e}+001.00000 \mathrm{e}-011.00000 \mathrm{e}-091.00000 \mathrm{e}-01$ Element: 895 \# of layers: 7

$\mathrm{Kx} \mathrm{Ky} \mathrm{Kz}$ Ss Por

5.32122e+01 5.32122e+01 5.32122e+00 1.00000e-09 7.00000e-02 $5.32122 \mathrm{e}+015.32122 \mathrm{e}+015.32122 \mathrm{e}+001.00000 \mathrm{e}-09$ 7.00000e-02 $2.12618 \mathrm{e}+002.12618 \mathrm{e}+00$ 2.12618e-01 1.00000e-09 2.12000e-01 $2.12618 \mathrm{e}+002.12618 \mathrm{e}+00$ 2.12618e-01 1.00000e-09 2.12000e-01 $2.12618 \mathrm{e}+002.12618 \mathrm{e}+00$ 2.12618e-01 1.00000e-09 2.12000e-01 $1.00000 \mathrm{e}-02$ 1.00000e-02 1.00000e-03 1.00000e-09 1.00000e-01 $1.00000 \mathrm{e}+001.00000 \mathrm{e}+001.00000 \mathrm{e}-011.00000 \mathrm{e}-091.00000 \mathrm{e}-01$ Element: 896 \# of layers: 6

$\mathrm{Kx} \mathrm{Ky} \mathrm{Kz}$ Ss Por

5.32122e+01 5.32122e+01 5.32122e+00 1.00000e-09 7.00000e-02 
$2.12618 \mathrm{e}+002.12618 \mathrm{e}+00$ 2.12618e-01 1.00000e-09 2.12000e-01 $2.12618 \mathrm{e}+002.12618 \mathrm{e}+00$ 2.12618e-01 1.00000e-09 2.12000e-01 $2.12618 \mathrm{e}+002.12618 \mathrm{e}+00$ 2.12618e-01 1.00000e-09 2.12000e-01 $1.00000 \mathrm{e}-021.00000 \mathrm{e}-02$ 1.00000e-03 1.00000e-09 1.00000e-01 $1.00000 \mathrm{e}+001.00000 \mathrm{e}+001.00000 \mathrm{e}-011.00000 \mathrm{e}-091.00000 \mathrm{e}-01$ Element: 897 \# of layers: 6

Kx Ky Kz Ss Por

5.32122e+01 5.32122e+01 5.32122e+00 1.00000e-09 7.00000e-02

$2.12618 \mathrm{e}+002.12618 \mathrm{e}+002.12618 \mathrm{e}-011.00000 \mathrm{e}-092.12000 \mathrm{e}-01$

$2.12618 \mathrm{e}+002.12618 \mathrm{e}+002.12618 \mathrm{e}-011.00000 \mathrm{e}-092.12000 \mathrm{e}-01$

$2.12618 \mathrm{e}+002.12618 \mathrm{e}+002.12618 \mathrm{e}-01$ 1.00000e-09 2.12000e-01 $1.00000 \mathrm{e}-021.00000 \mathrm{e}-02$ 1.00000e-03 1.00000e-09 1.00000e-01 $1.00000 \mathrm{e}+001.00000 \mathrm{e}+001.00000 \mathrm{e}-011.00000 \mathrm{e}-091.00000 \mathrm{e}-01$ Element: 898 \# of layers: 6

Kx Ky Kz Ss Por

5.32122e+01 5.32122e+01 5.32122e+00 1.00000e-09 7.00000e-02

$2.12618 \mathrm{e}+002.12618 \mathrm{e}+002.12618 \mathrm{e}-011.00000 \mathrm{e}-09$ 2.12000e-01

$2.12618 \mathrm{e}+002.12618 \mathrm{e}+002.12618 \mathrm{e}-011.00000 \mathrm{e}-092.12000 \mathrm{e}-01$

$2.12618 \mathrm{e}+002.12618 \mathrm{e}+00$ 2.12618e-01 1.00000e-09 2.12000e-01 $1.00000 \mathrm{e}-021.00000 \mathrm{e}-02$ 1.00000e-03 1.00000e-09 1.00000e-01 $1.00000 \mathrm{e}+001.00000 \mathrm{e}+001.00000 \mathrm{e}-011.00000 \mathrm{e}-091.00000 \mathrm{e}-01$ Element: 899 \# of layers: 7

Kx Ky Kz Ss Por

$5.32122 \mathrm{e}+015.32122 \mathrm{e}+015.32122 \mathrm{e}+00$ 1.00000e-09 7.00000e-02 $5.32122 \mathrm{e}+015.32122 \mathrm{e}+015.32122 \mathrm{e}+001.00000 \mathrm{e}-09$ 7.00000e-02 $2.12618 \mathrm{e}+002.12618 \mathrm{e}+002.12618 \mathrm{e}-01$ 1.00000e-09 2.12000e-01 $2.12618 \mathrm{e}+002.12618 \mathrm{e}+002.12618 \mathrm{e}-011.00000 \mathrm{e}-092.12000 \mathrm{e}-01$ $2.12618 \mathrm{e}+002.12618 \mathrm{e}+00$ 2.12618e-01 1.00000e-09 2.12000e-01 $1.00000 \mathrm{e}-021.00000 \mathrm{e}-02$ 1.00000e-03 1.00000e-09 1.00000e-01 $1.00000 \mathrm{e}+001.00000 \mathrm{e}+001.00000 \mathrm{e}-011.00000 \mathrm{e}-091.00000 \mathrm{e}-01$ Element: 900 \# of layers: 6

Kx Ky Kz Ss Por

$5.51115 \mathrm{e}+015.51115 \mathrm{e}+015.51115 \mathrm{e}+00$ 1.00000e-09 7.00000e-02 $5.51115 \mathrm{e}+015.51115 \mathrm{e}+015.51115 \mathrm{e}+001.00000 \mathrm{e}-097.00000 \mathrm{e}-02$ $2.20205 \mathrm{e}+002.20205 \mathrm{e}+002.20206 \mathrm{e}-011.00000 \mathrm{e}-092.12000 \mathrm{e}-01$ $2.20205 \mathrm{e}+002.20205 \mathrm{e}+00$ 2.20206e-01 1.00000e-09 2.12000e-01 $1.00000 \mathrm{e}-02$ 1.00000e-02 1.00000e-03 1.00000e-09 1.00000e-01 $1.00000 \mathrm{e}+001.00000 \mathrm{e}+001.00000 \mathrm{e}-011.00000 \mathrm{e}-091.00000 \mathrm{e}-01$ Element: 901 \# of layers: 7

Kx Ky Kz Ss Por

$5.51115 \mathrm{e}+015.51115 \mathrm{e}+01$ 5.51115e+00 1.00000e-09 7.00000e-02 $5.51115 \mathrm{e}+015.51115 \mathrm{e}+015.51115 \mathrm{e}+001.00000 \mathrm{e}-097.00000 \mathrm{e}-02$ $5.51115 \mathrm{e}+015.51115 \mathrm{e}+015.51115 \mathrm{e}+001.00000 \mathrm{e}-09$ 7.00000e-02 $2.20205 \mathrm{e}+002.20205 \mathrm{e}+002.20206 \mathrm{e}-011.00000 \mathrm{e}-092.12000 \mathrm{e}-01$ $2.20205 \mathrm{e}+002.20205 \mathrm{e}+002.20206 \mathrm{e}-01$ 1.00000e-09 2.12000e-01 $1.00000 \mathrm{e}-021.00000 \mathrm{e}-02$ 1.00000e-03 1.00000e-09 1.00000e-01 
$1.00000 \mathrm{e}+001.00000 \mathrm{e}+00$ 1.00000e-01 1.00000e-09 1.00000e-01

Element: 902 \# of layers: 6

$\mathrm{Kx} \mathrm{Ky} \mathrm{Kz}$ Ss Por

5.51115e+01 5.51115e+01 5.51115e+00 1.00000e-09 7.00000e-02

$5.51115 \mathrm{e}+015.51115 \mathrm{e}+015.51115 \mathrm{e}+001.00000 \mathrm{e}-09$ 7.00000e-02

$2.20205 \mathrm{e}+002.20205 \mathrm{e}+00$ 2.20206e-01 1.00000e-09 2.12000e-01

$2.20205 \mathrm{e}+002.20205 \mathrm{e}+00$ 2.20206e-01 1.00000e-09 2.12000e-01

$1.00000 \mathrm{e}-02$ 1.00000e-02 1.00000e-03 1.00000e-09 1.00000e-01

$1.00000 \mathrm{e}+001.00000 \mathrm{e}+001.00000 \mathrm{e}-011.00000 \mathrm{e}-091.00000 \mathrm{e}-01$

Element: 903 \# of layers: 7

$\mathrm{Kx} \mathrm{Ky} \mathrm{Kz}$ Ss Por

5.51115e+01 5.51115e+01 5.51115e+00 1.00000e-09 7.00000e-02

$5.51115 \mathrm{e}+015.51115 \mathrm{e}+015.51115 \mathrm{e}+001.00000 \mathrm{e}-09$ 7.00000e-02

$2.20205 \mathrm{e}+002.20205 \mathrm{e}+002.20206 \mathrm{e}-01$ 1.00000e-09 2.12000e-01

$2.20205 \mathrm{e}+002.20205 \mathrm{e}+002.20206 \mathrm{e}-01$ 1.00000e-09 2.12000e-01

$2.20205 \mathrm{e}+002.20205 \mathrm{e}+00$ 2.20206e-01 1.00000e-09 2.12000e-01

$1.00000 \mathrm{e}-02$ 1.00000e-02 1.00000e-03 1.00000e-09 1.00000e-01

$1.00000 \mathrm{e}+001.00000 \mathrm{e}+001.00000 \mathrm{e}-011.00000 \mathrm{e}-091.00000 \mathrm{e}-01$

Element: 904 \# of layers: 8

$\mathrm{Kx} \mathrm{Ky} \mathrm{Kz}$ Ss Por

5.51115e+01 5.51115e+01 5.51115e+00 1.00000e-09 7.00000e-02

$5.51115 \mathrm{e}+015.51115 \mathrm{e}+015.51115 \mathrm{e}+001.00000 \mathrm{e}-09$ 7.00000e-02

$5.51115 \mathrm{e}+015.51115 \mathrm{e}+015.51115 \mathrm{e}+001.00000 \mathrm{e}-09$ 7.00000e-02

$2.20205 \mathrm{e}+002.20205 \mathrm{e}+00$ 2.20206e-01 1.00000e-09 2.12000e-01

$2.20205 \mathrm{e}+002.20205 \mathrm{e}+00$ 2.20206e-01 1.00000e-09 2.12000e-01

$2.20205 \mathrm{e}+002.20205 \mathrm{e}+00$ 2.20206e-01 1.00000e-09 2.12000e-01

$1.00000 \mathrm{e}-02$ 1.00000e-02 1.00000e-03 1.00000e-09 1.00000e-01

$1.00000 \mathrm{e}+001.00000 \mathrm{e}+001.00000 \mathrm{e}-011.00000 \mathrm{e}-091.00000 \mathrm{e}-01$

Element: 905 \# of layers: 8

$\mathrm{Kx} \mathrm{Ky} \mathrm{Kz}$ Ss Por

5.51115e+01 5.51115e+01 5.51115e+00 1.00000e-09 7.00000e-02

$5.51115 \mathrm{e}+015.51115 \mathrm{e}+015.51115 \mathrm{e}+001.00000 \mathrm{e}-09$ 7.00000e-02

$5.51115 \mathrm{e}+015.51115 \mathrm{e}+015.51115 \mathrm{e}+001.00000 \mathrm{e}-09$ 7.00000e-02

$2.20205 \mathrm{e}+00$ 2.20205e+00 2.20206e-01 1.00000e-09 2.12000e-01

$2.20205 \mathrm{e}+002.20205 \mathrm{e}+00$ 2.20206e-01 1.00000e-09 2.12000e-01

$2.20205 \mathrm{e}+002.20205 \mathrm{e}+00$ 2.20206e-01 1.00000e-09 2.12000e-01

$1.00000 \mathrm{e}-02$ 1.00000e-02 1.00000e-03 1.00000e-09 1.00000e-01

$1.00000 \mathrm{e}+001.00000 \mathrm{e}+001.00000 \mathrm{e}-011.00000 \mathrm{e}-091.00000 \mathrm{e}-01$

Element: 906 \# of layers: 7

$\mathrm{Kx} \mathrm{Ky} \mathrm{Kz}$ Ss Por

5.51115e+01 5.51115e+01 5.51115e+00 1.00000e-09 7.00000e-02

$5.51115 \mathrm{e}+015.51115 \mathrm{e}+015.51115 \mathrm{e}+001.00000 \mathrm{e}-09$ 7.00000e-02

$2.20205 \mathrm{e}+00$ 2.20205e+00 2.20206e-01 1.00000e-09 2.12000e-01

$2.20205 \mathrm{e}+002.20205 \mathrm{e}+00$ 2.20206e-01 1.00000e-09 2.12000e-01

$2.20205 \mathrm{e}+002.20205 \mathrm{e}+002.20206 \mathrm{e}-01$ 1.00000e-09 2.12000e-01

$1.00000 \mathrm{e}-02$ 1.00000e-02 1.00000e-03 1.00000e-09 1.00000e-01 
$1.00000 \mathrm{e}+001.00000 \mathrm{e}+00$ 1.00000e-01 1.00000e-09 1.00000e-01

Element: 907 \# of layers: 7

$\mathrm{Kx} \mathrm{Ky} \mathrm{Kz}$ Ss Por

5.51115e+01 5.51115e+01 5.51115e+00 1.00000e-09 7.00000e-02

$5.51115 \mathrm{e}+015.51115 \mathrm{e}+015.51115 \mathrm{e}+001.00000 \mathrm{e}-09$ 7.00000e-02

$2.20205 \mathrm{e}+002.20205 \mathrm{e}+00$ 2.20206e-01 1.00000e-09 2.12000e-01

$2.20205 \mathrm{e}+00$ 2.20205e+00 2.20206e-01 1.00000e-09 2.12000e-01

$2.20205 \mathrm{e}+002.20205 \mathrm{e}+00$ 2.20206e-01 1.00000e-09 2.12000e-01

$1.00000 \mathrm{e}-02$ 1.00000e-02 1.00000e-03 1.00000e-09 1.00000e-01

$1.00000 \mathrm{e}+001.00000 \mathrm{e}+001.00000 \mathrm{e}-011.00000 \mathrm{e}-091.00000 \mathrm{e}-01$

Element: 908 \# of layers: 8

Kx Ky Kz Ss Por

5.51115e+01 5.51115e+01 5.51115e+00 1.00000e-09 7.00000e-02

$5.51115 \mathrm{e}+015.51115 \mathrm{e}+015.51115 \mathrm{e}+001.00000 \mathrm{e}-09$ 7.00000e-02

$5.51115 \mathrm{e}+015.51115 \mathrm{e}+015.51115 \mathrm{e}+001.00000 \mathrm{e}-09$ 7.00000e-02

$2.20205 \mathrm{e}+002.20205 \mathrm{e}+00$ 2.20206e-01 1.00000e-09 2.12000e-01

$2.20205 \mathrm{e}+002.20205 \mathrm{e}+00$ 2.20206e-01 1.00000e-09 2.12000e-01

$2.20205 \mathrm{e}+002.20205 \mathrm{e}+00$ 2.20206e-01 1.00000e-09 2.12000e-01

$1.00000 \mathrm{e}-02$ 1.00000e-02 1.00000e-03 1.00000e-09 1.00000e-01

$1.00000 \mathrm{e}+001.00000 \mathrm{e}+001.00000 \mathrm{e}-011.00000 \mathrm{e}-091.00000 \mathrm{e}-01$

Element: 909 \# of layers: 6

$\mathrm{Kx} \mathrm{Ky} \mathrm{Kz}$ Ss Por

4.69628e+01 4.69628e+01 4.69628e+00 1.00000e-09 7.00000e-02

$4.69628 \mathrm{e}+014.69628 \mathrm{e}+014.69628 \mathrm{e}+001.00000 \mathrm{e}-09$ 7.00000e-02

$1.87645 \mathrm{e}+001.87645 \mathrm{e}+00$ 1.87645e-01 1.00000e-09 2.12000e-01

$1.87645 \mathrm{e}+001.87645 \mathrm{e}+001.87645 \mathrm{e}-01$ 1.00000e-09 2.12000e-01

$1.00000 \mathrm{e}-02$ 1.00000e-02 1.00000e-03 1.00000e-09 1.00000e-01

$1.00000 \mathrm{e}+001.00000 \mathrm{e}+001.00000 \mathrm{e}-011.00000 \mathrm{e}-091.00000 \mathrm{e}-01$

Element: 910 \# of layers: 6

$\mathrm{Kx} \mathrm{Ky} \mathrm{Kz}$ Ss Por

4.69628e+01 4.69628e+01 4.69628e+00 1.00000e-09 7.00000e-02

$4.69628 \mathrm{e}+014.69628 \mathrm{e}+014.69628 \mathrm{e}+00$ 1.00000e-09 7.00000e-02

$1.87645 \mathrm{e}+001.87645 \mathrm{e}+001.87645 \mathrm{e}-01$ 1.00000e-09 2.12000e-01

$1.87645 \mathrm{e}+001.87645 \mathrm{e}+00$ 1.87645e-01 1.00000e-09 2.12000e-01

$1.00000 \mathrm{e}-02$ 1.00000e-02 1.00000e-03 1.00000e-09 1.00000e-01

$1.00000 \mathrm{e}+001.00000 \mathrm{e}+001.00000 \mathrm{e}-011.00000 \mathrm{e}-091.00000 \mathrm{e}-01$

Element: 911 \# of layers: 7

$\mathrm{Kx} \mathrm{Ky} \mathrm{Kz}$ Ss Por

4.69628e+01 4.69628e+01 4.69628e+00 1.00000e-09 7.00000e-02

$4.69628 \mathrm{e}+014.69628 \mathrm{e}+014.69628 \mathrm{e}+001.00000 \mathrm{e}-09$ 7.00000e-02

$4.69628 \mathrm{e}+014.69628 \mathrm{e}+014.69628 \mathrm{e}+001.00000 \mathrm{e}-09$ 7.00000e-02

$1.87645 \mathrm{e}+001.87645 \mathrm{e}+00$ 1.87645e-01 1.00000e-09 2.12000e-01

$1.87645 \mathrm{e}+001.87645 \mathrm{e}+00$ 1.87645e-01 1.00000e-09 2.12000e-01

$1.00000 \mathrm{e}-02$ 1.00000e-02 1.00000e-03 1.00000e-09 1.00000e-01

$1.00000 \mathrm{e}+001.00000 \mathrm{e}+001.00000 \mathrm{e}-011.00000 \mathrm{e}-091.00000 \mathrm{e}-01$

Element: 912 \# of layers: 7 
$\mathrm{Kx} \mathrm{Ky} \mathrm{Kz}$ Ss Por

4.69628e+01 4.69628e+01 4.69628e+00 1.00000e-09 7.00000e-02 $4.69628 \mathrm{e}+014.69628 \mathrm{e}+014.69628 \mathrm{e}+001.00000 \mathrm{e}-09$ 7.00000e-02 $1.87645 \mathrm{e}+001.87645 \mathrm{e}+00$ 1.87645e-01 1.00000e-09 2.12000e-01 $1.87645 \mathrm{e}+001.87645 \mathrm{e}+001.87645 \mathrm{e}-01$ 1.00000e-09 2.12000e-01 $1.87645 \mathrm{e}+001.87645 \mathrm{e}+001.87645 \mathrm{e}-01$ 1.00000e-09 2.12000e-01 $1.00000 \mathrm{e}-02$ 1.00000e-02 1.00000e-03 1.00000e-09 1.00000e-01 $1.00000 \mathrm{e}+001.00000 \mathrm{e}+001.00000 \mathrm{e}-011.00000 \mathrm{e}-091.00000 \mathrm{e}-01$ Element: 913 \# of layers: 8

$\mathrm{Kx} \mathrm{Ky} \mathrm{Kz}$ Ss Por

4.69628e+01 4.69628e+01 4.69628e+00 1.00000e-09 7.00000e-02 $4.69628 \mathrm{e}+014.69628 \mathrm{e}+014.69628 \mathrm{e}+001.00000 \mathrm{e}-09$ 7.00000e-02 $4.69628 \mathrm{e}+014.69628 \mathrm{e}+014.69628 \mathrm{e}+001.00000 \mathrm{e}-09$ 7.00000e-02 $1.87645 \mathrm{e}+001.87645 \mathrm{e}+00$ 1.87645e-01 1.00000e-09 2.12000e-01 $1.87645 \mathrm{e}+001.87645 \mathrm{e}+00$ 1.87645e-01 1.00000e-09 2.12000e-01 $1.87645 \mathrm{e}+001.87645 \mathrm{e}+001.87645 \mathrm{e}-011.00000 \mathrm{e}-092.12000 \mathrm{e}-01$ $1.00000 \mathrm{e}-02$ 1.00000e-02 1.00000e-03 1.00000e-09 1.00000e-01 $1.00000 \mathrm{e}+001.00000 \mathrm{e}+001.00000 \mathrm{e}-011.00000 \mathrm{e}-091.00000 \mathrm{e}-01$ Element: 914 \# of layers: 8

$\mathrm{Kx} \mathrm{Ky} \mathrm{Kz}$ Ss Por

4.69628e+01 4.69628e+01 4.69628e+00 1.00000e-09 7.00000e-02 $4.69628 \mathrm{e}+014.69628 \mathrm{e}+01$ 4.69628e+00 1.00000e-09 7.00000e-02 $4.69628 \mathrm{e}+014.69628 \mathrm{e}+01$ 4.69628e+00 1.00000e-09 7.00000e-02 $1.87645 \mathrm{e}+001.87645 \mathrm{e}+001.87645 \mathrm{e}-01$ 1.00000e-09 2.12000e-01 $1.87645 \mathrm{e}+001.87645 \mathrm{e}+00$ 1.87645e-01 1.00000e-09 2.12000e-01 $1.87645 \mathrm{e}+001.87645 \mathrm{e}+001.87645 \mathrm{e}-01$ 1.00000e-09 2.12000e-01 $1.00000 \mathrm{e}-02$ 1.00000e-02 1.00000e-03 1.00000e-09 1.00000e-01 $1.00000 \mathrm{e}+001.00000 \mathrm{e}+001.00000 \mathrm{e}-011.00000 \mathrm{e}-091.00000 \mathrm{e}-01$ Element: 915 \# of layers: 8

$\mathrm{Kx} \mathrm{Ky} \mathrm{Kz}$ Ss Por

4.69628e+01 4.69628e+01 4.69628e+00 1.00000e-09 7.00000e-02 $4.69628 \mathrm{e}+014.69628 \mathrm{e}+014.69628 \mathrm{e}+00$ 1.00000e-09 7.00000e-02 $4.69628 \mathrm{e}+014.69628 \mathrm{e}+014.69628 \mathrm{e}+001.00000 \mathrm{e}-09$ 7.00000e-02 $1.87645 \mathrm{e}+001.87645 \mathrm{e}+00$ 1.87645e-01 1.00000e-09 2.12000e-01 $1.87645 \mathrm{e}+001.87645 \mathrm{e}+00$ 1.87645e-01 1.00000e-09 2.12000e-01 $1.87645 \mathrm{e}+001.87645 \mathrm{e}+001.87645 \mathrm{e}-01$ 1.00000e-09 2.12000e-01 $1.00000 \mathrm{e}-02$ 1.00000e-02 1.00000e-03 1.00000e-09 1.00000e-01 $1.00000 \mathrm{e}+001.00000 \mathrm{e}+001.00000 \mathrm{e}-011.00000 \mathrm{e}-091.00000 \mathrm{e}-01$ Element: 916 \# of layers: 7

$\mathrm{Kx} \mathrm{Ky} \mathrm{Kz}$ Ss Por $4.69628 \mathrm{e}+014.69628 \mathrm{e}+01$ 4.69628e+00 1.00000e-09 7.00000e-02 $4.69628 \mathrm{e}+014.69628 \mathrm{e}+014.69628 \mathrm{e}+001.00000 \mathrm{e}-09$ 7.00000e-02 $1.87645 \mathrm{e}+001.87645 \mathrm{e}+00$ 1.87645e-01 1.00000e-09 2.12000e-01 $1.87645 \mathrm{e}+001.87645 \mathrm{e}+00$ 1.87645e-01 1.00000e-09 2.12000e-01 $1.87645 \mathrm{e}+001.87645 \mathrm{e}+001.87645 \mathrm{e}-01$ 1.00000e-09 2.12000e-01 $1.00000 \mathrm{e}-02$ 1.00000e-02 1.00000e-03 1.00000e-09 1.00000e-01 
$1.00000 \mathrm{e}+001.00000 \mathrm{e}+00$ 1.00000e-01 1.00000e-09 1.00000e-01

Element: 917 \# of layers: 7

Kx Ky Kz Ss Por

4.69628e+01 4.69628e+01 4.69628e+00 1.00000e-09 7.00000e-02

$4.69628 \mathrm{e}+014.69628 \mathrm{e}+014.69628 \mathrm{e}+001.00000 \mathrm{e}-09$ 7.00000e-02

$1.87645 \mathrm{e}+001.87645 \mathrm{e}+00$ 1.87645e-01 1.00000e-09 2.12000e-01

$1.87645 \mathrm{e}+001.87645 \mathrm{e}+00$ 1.87645e-01 1.00000e-09 2.12000e-01

$1.87645 \mathrm{e}+001.87645 \mathrm{e}+001.87645 \mathrm{e}-01$ 1.00000e-09 2.12000e-01

$1.00000 \mathrm{e}-02$ 1.00000e-02 1.00000e-03 1.00000e-09 1.00000e-01

$1.00000 \mathrm{e}+001.00000 \mathrm{e}+001.00000 \mathrm{e}-011.00000 \mathrm{e}-091.00000 \mathrm{e}-01$

Element: 918 \# of layers: 7

$\mathrm{Kx} \mathrm{Ky} \mathrm{Kz}$ Ss Por

4.00413e+01 4.00413e+01 4.00413e+00 1.00000e-09 7.00000e-02

$4.00413 \mathrm{e}+014.00413 \mathrm{e}+014.00413 \mathrm{e}+00$ 1.00000e-09 7.00000e-02

4.00413e+01 4.00413e+01 4.00413e+00 1.00000e-09 7.00000e-02

$1.59990 \mathrm{e}+001.59990 \mathrm{e}+00$ 1.59990e-01 1.00000e-09 2.12000e-01

$1.59990 \mathrm{e}+001.59990 \mathrm{e}+001.59990 \mathrm{e}-01 \quad 1.00000 \mathrm{e}-092.12000 \mathrm{e}-01$

$1.00000 \mathrm{e}-02$ 1.00000e-02 1.00000e-03 1.00000e-09 1.00000e-01

$1.00000 \mathrm{e}+001.00000 \mathrm{e}+001.00000 \mathrm{e}-01$ 1.00000e-09 1.00000e-01

Element: 919 \# of layers: 8

$\mathrm{Kx} \mathrm{Ky} \mathrm{Kz}$ Ss Por

4.00413e+01 4.00413e+01 4.00413e+00 1.00000e-09 7.00000e-02 4.00413e+01 4.00413e+01 4.00413e+00 1.00000e-09 7.00000e-02 4.00413e+01 4.00413e+01 4.00413e+00 1.00000e-09 7.00000e-02

$1.59990 \mathrm{e}+001.59990 \mathrm{e}+001.59990 \mathrm{e}-011.00000 \mathrm{e}-092.12000 \mathrm{e}-01$

$1.59990 \mathrm{e}+001.59990 \mathrm{e}+00$ 1.59990e-01 1.00000e-09 2.12000e-01

$1.59990 \mathrm{e}+001.59990 \mathrm{e}+001.59990 \mathrm{e}-011.00000 \mathrm{e}-092.12000 \mathrm{e}-01$

$1.00000 \mathrm{e}-02$ 1.00000e-02 1.00000e-03 1.00000e-09 1.00000e-01

$1.00000 \mathrm{e}+001.00000 \mathrm{e}+001.00000 \mathrm{e}-011.00000 \mathrm{e}-091.00000 \mathrm{e}-01$

Element: 920 \# of layers: 8

$\mathrm{Kx} \mathrm{Ky} \mathrm{Kz}$ Ss Por

4.00413e+01 4.00413e+01 4.00413e+00 1.00000e-09 7.00000e-02 $4.00413 \mathrm{e}+014.00413 \mathrm{e}+014.00413 \mathrm{e}+00$ 1.00000e-09 7.00000e-02 4.00413e+01 4.00413e+01 4.00413e+00 1.00000e-09 7.00000e-02 $1.59990 \mathrm{e}+001.59990 \mathrm{e}+001.59990 \mathrm{e}-01$ 1.00000e-09 2.12000e-01 $1.59990 \mathrm{e}+001.59990 \mathrm{e}+001.59990 \mathrm{e}-01$ 1.00000e-09 2.12000e-01 $1.59990 \mathrm{e}+001.59990 \mathrm{e}+001.59990 \mathrm{e}-01$ 1.00000e-09 2.12000e-01 $1.00000 \mathrm{e}-02$ 1.00000e-02 1.00000e-03 1.00000e-09 1.00000e-01 $1.00000 \mathrm{e}+001.00000 \mathrm{e}+001.00000 \mathrm{e}-01$ 1.00000e-09 1.00000e-01 Element: 921 \# of layers: 6

$\mathrm{Kx} \mathrm{Ky} \mathrm{Kz}$ Ss Por

2.07362e+01 2.07362e+01 2.07362e+00 1.00000e-09 2.12000e-01 $2.07362 \mathrm{e}+012.07362 \mathrm{e}+012.07362 \mathrm{e}+001.00000 \mathrm{e}-092.12000 \mathrm{e}-01$ $2.07362 \mathrm{e}+012.07362 \mathrm{e}+012.07362 \mathrm{e}+00$ 1.00000e-09 2.12000e-01 $2.07362 \mathrm{e}+012.07362 \mathrm{e}+012.07362 \mathrm{e}+001.00000 \mathrm{e}-092.12000 \mathrm{e}-01$ $1.00000 \mathrm{e}-02$ 1.00000e-02 1.00000e-03 1.00000e-09 1.00000e-01 
$1.00000 \mathrm{e}+001.00000 \mathrm{e}+001.00000 \mathrm{e}-011.00000 \mathrm{e}-091.00000 \mathrm{e}-01$

Element: 922 \# of layers: 7

Kx Ky Kz Ss Por

$2.07362 \mathrm{e}+012.07362 \mathrm{e}+012.07362 \mathrm{e}+00$ 1.00000e-09 2.12000e-01

$2.07362 \mathrm{e}+012.07362 \mathrm{e}+012.07362 \mathrm{e}+001.00000 \mathrm{e}-092.12000 \mathrm{e}-01$

$2.07362 \mathrm{e}+012.07362 \mathrm{e}+012.07362 \mathrm{e}+001.00000 \mathrm{e}-092.12000 \mathrm{e}-01$

$2.07362 \mathrm{e}+012.07362 \mathrm{e}+012.07362 \mathrm{e}+001.00000 \mathrm{e}-092.12000 \mathrm{e}-01$

$2.07362 \mathrm{e}+012.07362 \mathrm{e}+012.07362 \mathrm{e}+00$ 1.00000e-09 2.12000e-01

$1.00000 \mathrm{e}-02$ 1.00000e-02 1.00000e-03 1.00000e-09 1.00000e-01

$1.00000 \mathrm{e}+001.00000 \mathrm{e}+001.00000 \mathrm{e}-011.00000 \mathrm{e}-091.00000 \mathrm{e}-01$

Element: 923 \# of layers: 8

Kx Ky Kz Ss Por

5.18976e+02 5.18976e+02 5.18976e+01 1.00000e-09 7.00000e-02

$2.07362 \mathrm{e}+012.07362 \mathrm{e}+012.07362 \mathrm{e}+00$ 1.00000e-09 2.12000e-01

$2.07362 \mathrm{e}+012.07362 \mathrm{e}+012.07362 \mathrm{e}+001.00000 \mathrm{e}-092.12000 \mathrm{e}-01$

$2.07362 \mathrm{e}+012.07362 \mathrm{e}+012.07362 \mathrm{e}+00$ 1.00000e-09 2.12000e-01

$2.07362 \mathrm{e}+012.07362 \mathrm{e}+012.07362 \mathrm{e}+00$ 1.00000e-09 2.12000e-01

$2.07362 \mathrm{e}+012.07362 \mathrm{e}+012.07362 \mathrm{e}+001.00000 \mathrm{e}-092.12000 \mathrm{e}-01$

$1.00000 \mathrm{e}-02$ 1.00000e-02 1.00000e-03 1.00000e-09 1.00000e-01

$1.00000 \mathrm{e}+001.00000 \mathrm{e}+001.00000 \mathrm{e}-011.00000 \mathrm{e}-091.00000 \mathrm{e}-01$

Element: 924 \# of layers: 8

$\mathrm{Kx} \mathrm{Ky} \mathrm{Kz}$ Ss Por

5.18976e+02 5.18976e+02 5.18976e+01 1.00000e-09 7.00000e-02

$2.07362 \mathrm{e}+012.07362 \mathrm{e}+012.07362 \mathrm{e}+001.00000 \mathrm{e}-092.12000 \mathrm{e}-01$

$2.07362 \mathrm{e}+012.07362 \mathrm{e}+012.07362 \mathrm{e}+001.00000 \mathrm{e}-092.12000 \mathrm{e}-01$

$2.07362 \mathrm{e}+012.07362 \mathrm{e}+012.07362 \mathrm{e}+001.00000 \mathrm{e}-092.12000 \mathrm{e}-01$

$2.07362 \mathrm{e}+012.07362 \mathrm{e}+012.07362 \mathrm{e}+001.00000 \mathrm{e}-092.12000 \mathrm{e}-01$

$2.07362 \mathrm{e}+012.07362 \mathrm{e}+012.07362 \mathrm{e}+001.00000 \mathrm{e}-092.12000 \mathrm{e}-01$

$1.00000 \mathrm{e}-02$ 1.00000e-02 1.00000e-03 1.00000e-09 1.00000e-01

$1.00000 \mathrm{e}+001.00000 \mathrm{e}+001.00000 \mathrm{e}-011.00000 \mathrm{e}-091.00000 \mathrm{e}-01$

Element: 925 \# of layers: 8

Kx Ky Kz Ss Por

5.18976e+02 5.18976e+02 5.18976e+01 1.00000e-09 7.00000e-02

$2.07362 \mathrm{e}+012.07362 \mathrm{e}+012.07362 \mathrm{e}+001.00000 \mathrm{e}-092.12000 \mathrm{e}-01$

$2.07362 \mathrm{e}+012.07362 \mathrm{e}+012.07362 \mathrm{e}+001.00000 \mathrm{e}-092.12000 \mathrm{e}-01$

$2.07362 \mathrm{e}+012.07362 \mathrm{e}+012.07362 \mathrm{e}+001.00000 \mathrm{e}-092.12000 \mathrm{e}-01$

$2.07362 \mathrm{e}+012.07362 \mathrm{e}+012.07362 \mathrm{e}+001.00000 \mathrm{e}-092.12000 \mathrm{e}-01$

$2.07362 \mathrm{e}+012.07362 \mathrm{e}+012.07362 \mathrm{e}+00$ 1.00000e-09 2.12000e-01

$1.00000 \mathrm{e}-02$ 1.00000e-02 1.00000e-03 1.00000e-09 1.00000e-01

$1.00000 \mathrm{e}+001.00000 \mathrm{e}+001.00000 \mathrm{e}-01$ 1.00000e-09 1.00000e-01

Element: 926 \# of layers: 6

$\mathrm{Kx} \mathrm{Ky} \mathrm{Kz}$ Ss Por

$1.45841 \mathrm{e}+011.45841 \mathrm{e}+011.45841 \mathrm{e}+001.00000 \mathrm{e}-092.12000 \mathrm{e}-01$

$1.45841 \mathrm{e}+011.45841 \mathrm{e}+01$ 1.45841e+00 1.00000e-09 2.12000e-01

$1.45841 \mathrm{e}+011.45841 \mathrm{e}+011.45841 \mathrm{e}+001.00000 \mathrm{e}-092.12000 \mathrm{e}-01$

$1.45841 \mathrm{e}+011.45841 \mathrm{e}+011.45841 \mathrm{e}+001.00000 \mathrm{e}-092.12000 \mathrm{e}-01$ 
$1.00000 \mathrm{e}-02$ 1.00000e-02 1.00000e-03 1.00000e-09 1.00000e-01 $1.00000 \mathrm{e}+001.00000 \mathrm{e}+001.00000 \mathrm{e}-01$ 1.00000e-09 1.00000e-01 Element: 927 \# of layers: 6

$\mathrm{Kx} \mathrm{Ky} \mathrm{Kz}$ Ss Por

$1.45841 \mathrm{e}+011.45841 \mathrm{e}+011.45841 \mathrm{e}+001.00000 \mathrm{e}-092.12000 \mathrm{e}-01$ $1.45841 \mathrm{e}+011.45841 \mathrm{e}+011.45841 \mathrm{e}+001.00000 \mathrm{e}-092.12000 \mathrm{e}-01$ $1.45841 \mathrm{e}+011.45841 \mathrm{e}+011.45841 \mathrm{e}+001.00000 \mathrm{e}-092.12000 \mathrm{e}-01$ $1.45841 \mathrm{e}+011.45841 \mathrm{e}+011.45841 \mathrm{e}+001.00000 \mathrm{e}-092.12000 \mathrm{e}-01$ $1.00000 \mathrm{e}-02$ 1.00000e-02 1.00000e-03 1.00000e-09 1.00000e-01 $1.00000 \mathrm{e}+001.00000 \mathrm{e}+001.00000 \mathrm{e}-011.00000 \mathrm{e}-091.00000 \mathrm{e}-01$ Element: 928 \# of layers: 6

$\mathrm{Kx} \mathrm{Ky} \mathrm{Kz}$ Ss Por

$1.45841 \mathrm{e}+01$ 1.45841e+01 1.45841e+00 1.00000e-09 2.12000e-01 $1.45841 \mathrm{e}+011.45841 \mathrm{e}+011.45841 \mathrm{e}+001.00000 \mathrm{e}-092.12000 \mathrm{e}-01$ $1.45841 \mathrm{e}+011.45841 \mathrm{e}+011.45841 \mathrm{e}+001.00000 \mathrm{e}-092.12000 \mathrm{e}-01$ $1.45841 \mathrm{e}+011.45841 \mathrm{e}+011.45841 \mathrm{e}+001.00000 \mathrm{e}-092.12000 \mathrm{e}-01$ $1.00000 \mathrm{e}-02$ 1.00000e-02 1.00000e-03 1.00000e-09 1.00000e-01 $1.00000 \mathrm{e}+001.00000 \mathrm{e}+001.00000 \mathrm{e}-011.00000 \mathrm{e}-091.00000 \mathrm{e}-01$ Element: 929 \# of layers: 8

$\mathrm{Kx} \mathrm{Ky} \mathrm{Kz}$ Ss Por

3.64995e+02 3.64995e+02 3.64995e+01 1.00000e-09 7.00000e-02 $1.45841 \mathrm{e}+011.45841 \mathrm{e}+011.45841 \mathrm{e}+001.00000 \mathrm{e}-092.12000 \mathrm{e}-01$ $1.45841 \mathrm{e}+011.45841 \mathrm{e}+011.45841 \mathrm{e}+001.00000 \mathrm{e}-092.12000 \mathrm{e}-01$ $1.45841 \mathrm{e}+011.45841 \mathrm{e}+011.45841 \mathrm{e}+001.00000 \mathrm{e}-092.12000 \mathrm{e}-01$ $1.45841 \mathrm{e}+011.45841 \mathrm{e}+011.45841 \mathrm{e}+001.00000 \mathrm{e}-092.12000 \mathrm{e}-01$ $1.45841 \mathrm{e}+011.45841 \mathrm{e}+011.45841 \mathrm{e}+001.00000 \mathrm{e}-092.12000 \mathrm{e}-01$ $1.00000 \mathrm{e}-02$ 1.00000e-02 1.00000e-03 1.00000e-09 1.00000e-01 $1.00000 \mathrm{e}+001.00000 \mathrm{e}+001.00000 \mathrm{e}-011.00000 \mathrm{e}-091.00000 \mathrm{e}-01$ Element: 930 \# of layers: 8

$\mathrm{Kx} \mathrm{Ky} \mathrm{Kz}$ Ss Por

3.64995e+02 3.64995e+02 3.64995e+01 1.00000e-09 7.00000e-02 $1.45841 \mathrm{e}+011.45841 \mathrm{e}+011.45841 \mathrm{e}+001.00000 \mathrm{e}-092.12000 \mathrm{e}-01$ $1.45841 \mathrm{e}+011.45841 \mathrm{e}+011.45841 \mathrm{e}+001.00000 \mathrm{e}-092.12000 \mathrm{e}-01$ $1.45841 \mathrm{e}+011.45841 \mathrm{e}+011.45841 \mathrm{e}+001.00000 \mathrm{e}-092.12000 \mathrm{e}-01$ $1.45841 \mathrm{e}+011.45841 \mathrm{e}+011.45841 \mathrm{e}+001.00000 \mathrm{e}-092.12000 \mathrm{e}-01$ $1.45841 \mathrm{e}+011.45841 \mathrm{e}+011.45841 \mathrm{e}+001.00000 \mathrm{e}-092.12000 \mathrm{e}-01$ $1.00000 \mathrm{e}-02$ 1.00000e-02 1.00000e-03 1.00000e-09 1.00000e-01 $1.00000 \mathrm{e}+001.00000 \mathrm{e}+001.00000 \mathrm{e}-011.00000 \mathrm{e}-091.00000 \mathrm{e}-01$ Element: 931 \# of layers: 8

$\mathrm{Kx} \mathrm{Ky} \mathrm{Kz}$ Ss Por

3.64995e+02 3.64995e+02 3.64995e+01 1.00000e-09 7.00000e-02 $1.45841 \mathrm{e}+011.45841 \mathrm{e}+011.45841 \mathrm{e}+001.00000 \mathrm{e}-092.12000 \mathrm{e}-01$ $1.45841 \mathrm{e}+011.45841 \mathrm{e}+011.45841 \mathrm{e}+001.00000 \mathrm{e}-092.12000 \mathrm{e}-01$ $1.45841 \mathrm{e}+011.45841 \mathrm{e}+01$ 1.45841e+00 1.00000e-09 2.12000e-01 $1.45841 \mathrm{e}+011.45841 \mathrm{e}+011.45841 \mathrm{e}+001.00000 \mathrm{e}-092.12000 \mathrm{e}-01$ $1.45841 \mathrm{e}+011.45841 \mathrm{e}+011.45841 \mathrm{e}+001.00000 \mathrm{e}-092.12000 \mathrm{e}-01$ 
$1.00000 \mathrm{e}-02$ 1.00000e-02 1.00000e-03 1.00000e-09 1.00000e-01 $1.00000 \mathrm{e}+001.00000 \mathrm{e}+001.00000 \mathrm{e}-01$ 1.00000e-09 1.00000e-01 Element: 932 \# of layers: 8

$\mathrm{Kx} \mathrm{Ky} \mathrm{Kz}$ Ss Por

3.64995e+02 3.64995e+02 3.64995e+01 1.00000e-09 7.00000e-02 $1.45841 \mathrm{e}+011.45841 \mathrm{e}+011.45841 \mathrm{e}+001.00000 \mathrm{e}-092.12000 \mathrm{e}-01$ $1.45841 \mathrm{e}+011.45841 \mathrm{e}+011.45841 \mathrm{e}+001.00000 \mathrm{e}-092.12000 \mathrm{e}-01$ $1.45841 \mathrm{e}+011.45841 \mathrm{e}+011.45841 \mathrm{e}+001.00000 \mathrm{e}-092.12000 \mathrm{e}-01$ $1.45841 \mathrm{e}+011.45841 \mathrm{e}+01$ 1.45841e+00 1.00000e-09 2.12000e-01 $1.45841 \mathrm{e}+011.45841 \mathrm{e}+011.45841 \mathrm{e}+001.00000 \mathrm{e}-092.12000 \mathrm{e}-01$ $1.00000 \mathrm{e}-02$ 1.00000e-02 1.00000e-03 1.00000e-09 1.00000e-01 $1.00000 \mathrm{e}+001.00000 \mathrm{e}+001.00000 \mathrm{e}-011.00000 \mathrm{e}-091.00000 \mathrm{e}-01$ Element: 933 \# of layers: 7

$\mathrm{Kx} \mathrm{Ky} \mathrm{Kz}$ Ss Por

$1.45841 \mathrm{e}+011.45841 \mathrm{e}+01$ 1.45841e+00 1.00000e-09 2.12000e-01 $1.45841 \mathrm{e}+011.45841 \mathrm{e}+011.45841 \mathrm{e}+001.00000 \mathrm{e}-092.12000 \mathrm{e}-01$ $1.45841 \mathrm{e}+011.45841 \mathrm{e}+011.45841 \mathrm{e}+001.00000 \mathrm{e}-092.12000 \mathrm{e}-01$ $1.45841 \mathrm{e}+011.45841 \mathrm{e}+011.45841 \mathrm{e}+001.00000 \mathrm{e}-092.12000 \mathrm{e}-01$ $1.45841 \mathrm{e}+011.45841 \mathrm{e}+011.45841 \mathrm{e}+001.00000 \mathrm{e}-092.12000 \mathrm{e}-01$ $1.00000 \mathrm{e}-02$ 1.00000e-02 1.00000e-03 1.00000e-09 1.00000e-01 $1.00000 \mathrm{e}+001.00000 \mathrm{e}+001.00000 \mathrm{e}-011.00000 \mathrm{e}-091.00000 \mathrm{e}-01$ Element: 934 \# of layers: 8

$\mathrm{Kx} \mathrm{Ky} \mathrm{Kz}$ Ss Por

3.64995e+02 3.64995e+02 3.64995e+01 1.00000e-09 7.00000e-02 $1.45841 \mathrm{e}+011.45841 \mathrm{e}+011.45841 \mathrm{e}+001.00000 \mathrm{e}-092.12000 \mathrm{e}-01$ $1.45841 \mathrm{e}+011.45841 \mathrm{e}+011.45841 \mathrm{e}+001.00000 \mathrm{e}-092.12000 \mathrm{e}-01$ $1.45841 \mathrm{e}+011.45841 \mathrm{e}+011.45841 \mathrm{e}+001.00000 \mathrm{e}-092.12000 \mathrm{e}-01$ $1.45841 \mathrm{e}+011.45841 \mathrm{e}+011.45841 \mathrm{e}+001.00000 \mathrm{e}-092.12000 \mathrm{e}-01$ $1.45841 \mathrm{e}+011.45841 \mathrm{e}+011.45841 \mathrm{e}+001.00000 \mathrm{e}-092.12000 \mathrm{e}-01$ $1.00000 \mathrm{e}-02$ 1.00000e-02 1.00000e-03 1.00000e-09 1.00000e-01 $1.00000 \mathrm{e}+001.00000 \mathrm{e}+001.00000 \mathrm{e}-011.00000 \mathrm{e}-091.00000 \mathrm{e}-01$ Element: 935 \# of layers: 7

$\mathrm{Kx} \mathrm{Ky} \mathrm{Kz}$ Ss Por

$1.27005 \mathrm{e}+02$ 1.27005e+02 1.27005e+01 1.00000e-09 7.00000e-02 5.07453e+00 5.07453e+00 5.07453e-01 1.00000e-09 2.12000e-01 5.07453e+00 5.07453e+00 5.07453e-01 1.00000e-09 2.12000e-01 5.07453e+00 5.07453e+00 5.07453e-01 1.00000e-09 2.12000e-01 5.07453e+00 5.07453e+00 5.07453e-01 1.00000e-09 2.12000e-01 $1.00000 \mathrm{e}-02$ 1.00000e-02 1.00000e-03 1.00000e-09 1.00000e-01 $1.00000 \mathrm{e}+001.00000 \mathrm{e}+001.00000 \mathrm{e}-01$ 1.00000e-09 1.00000e-01 Element: 936 \# of layers: 7

$\mathrm{Kx} \mathrm{Ky} \mathrm{Kz}$ Ss Por

$1.27005 \mathrm{e}+021.27005 \mathrm{e}+02$ 1.27005e+01 1.00000e-09 7.00000e-02 5.07453e+00 5.07453e+00 5.07453e-01 1.00000e-09 2.12000e-01 5.07453e+00 5.07453e+00 5.07453e-01 1.00000e-09 2.12000e-01 $5.07453 \mathrm{e}+00$ 5.07453e+00 5.07453e-01 1.00000e-09 2.12000e-01 
5.07453e+00 5.07453e+00 5.07453e-01 1.00000e-09 2.12000e-01 $1.00000 \mathrm{e}-02$ 1.00000e-02 1.00000e-03 1.00000e-09 1.00000e-01 $1.00000 \mathrm{e}+001.00000 \mathrm{e}+001.00000 \mathrm{e}-01$ 1.00000e-09 1.00000e-01 Element: 937 \# of layers: 7

$\mathrm{Kx} \mathrm{Ky} \mathrm{Kz}$ Ss Por

$1.27005 \mathrm{e}+02$ 1.27005e+02 1.27005e+01 1.00000e-09 7.00000e-02 5.07453e+00 5.07453e+00 5.07453e-01 1.00000e-09 2.12000e-01 $5.07453 \mathrm{e}+00$ 5.07453e+00 5.07453e-01 1.00000e-09 2.12000e-01 5.07453e+00 5.07453e+00 5.07453e-01 1.00000e-09 2.12000e-01 5.07453e+00 5.07453e+00 5.07453e-01 1.00000e-09 2.12000e-01 $1.00000 \mathrm{e}-02$ 1.00000e-02 1.00000e-03 1.00000e-09 1.00000e-01 $1.00000 \mathrm{e}+001.00000 \mathrm{e}+001.00000 \mathrm{e}-011.00000 \mathrm{e}-091.00000 \mathrm{e}-01$ Element: 938 \# of layers: 8

$\mathrm{Kx} \mathrm{Ky} \mathrm{Kz}$ Ss Por

$1.27005 \mathrm{e}+02$ 1.27005e+02 1.27005e+01 1.00000e-09 7.00000e-02 5.07453e+00 5.07453e+00 5.07453e-01 1.00000e-09 2.12000e-01 5.07453e+00 5.07453e+00 5.07453e-01 1.00000e-09 2.12000e-01 5.07453e+00 5.07453e+00 5.07453e-01 1.00000e-09 2.12000e-01 5.07453e+00 5.07453e+00 5.07453e-01 1.00000e-09 2.12000e-01 5.07453e+00 5.07453e+00 5.07453e-01 1.00000e-09 2.12000e-01 $1.00000 \mathrm{e}-02$ 1.00000e-02 1.00000e-03 1.00000e-09 1.00000e-01 $1.00000 \mathrm{e}+001.00000 \mathrm{e}+001.00000 \mathrm{e}-011.00000 \mathrm{e}-091.00000 \mathrm{e}-01$ Element: 939 \# of layers: 9

$\mathrm{Kx} \mathrm{Ky} \mathrm{Kz}$ Ss Por

$1.27005 \mathrm{e}+02$ 1.27005e+02 1.27005e+01 1.00000e-09 7.00000e-02 $1.27005 \mathrm{e}+021.27005 \mathrm{e}+02$ 1.27005e+01 1.00000e-09 7.00000e-02 5.07453e+00 5.07453e+00 5.07453e-01 1.00000e-09 2.12000e-01 5.07453e+00 5.07453e+00 5.07453e-01 1.00000e-09 2.12000e-01 $5.07453 \mathrm{e}+00$ 5.07453e+00 5.07453e-01 1.00000e-09 2.12000e-01 $5.07453 \mathrm{e}+00$ 5.07453e+00 5.07453e-01 1.00000e-09 2.12000e-01 $5.07453 \mathrm{e}+00$ 5.07453e+00 5.07453e-01 1.00000e-09 2.12000e-01 1.00000e-02 1.00000e-02 1.00000e-03 1.00000e-09 1.00000e-01 $1.00000 \mathrm{e}+001.00000 \mathrm{e}+001.00000 \mathrm{e}-011.00000 \mathrm{e}-091.00000 \mathrm{e}-01$ Element: 940 \# of layers: 8

$\mathrm{Kx} \mathrm{Ky} \mathrm{Kz}$ Ss Por

$1.27005 \mathrm{e}+02$ 1.27005e+02 1.27005e+01 1.00000e-09 7.00000e-02 5.07453e+00 5.07453e+00 5.07453e-01 1.00000e-09 2.12000e-01 5.07453e+00 5.07453e+00 5.07453e-01 1.00000e-09 2.12000e-01 5.07453e+00 5.07453e+00 5.07453e-01 1.00000e-09 2.12000e-01 5.07453e+00 5.07453e+00 5.07453e-01 1.00000e-09 2.12000e-01 5.07453e+00 5.07453e+00 5.07453e-01 1.00000e-09 2.12000e-01 $1.00000 \mathrm{e}-02$ 1.00000e-02 1.00000e-03 1.00000e-09 1.00000e-01 $1.00000 \mathrm{e}+001.00000 \mathrm{e}+001.00000 \mathrm{e}-011.00000 \mathrm{e}-091.00000 \mathrm{e}-01$ Element: 941 \# of layers: 8

$\mathrm{Kx} \mathrm{Ky} \mathrm{Kz}$ Ss Por

$1.27005 \mathrm{e}+02$ 1.27005e+02 1.27005e+01 1.00000e-09 7.00000e-02 
5.07453e+00 5.07453e+00 5.07453e-01 1.00000e-09 2.12000e-01 5.07453e+00 5.07453e+00 5.07453e-01 1.00000e-09 2.12000e-01 5.07453e+00 5.07453e+00 5.07453e-01 1.00000e-09 2.12000e-01 $5.07453 \mathrm{e}+00$ 5.07453e+00 5.07453e-01 1.00000e-09 2.12000e-01 5.07453e+00 5.07453e+00 5.07453e-01 1.00000e-09 2.12000e-01 $1.00000 \mathrm{e}-02$ 1.00000e-02 1.00000e-03 1.00000e-09 1.00000e-01 $1.00000 \mathrm{e}+001.00000 \mathrm{e}+001.00000 \mathrm{e}-011.00000 \mathrm{e}-091.00000 \mathrm{e}-01$ Element: 942 \# of layers: 8

$\mathrm{Kx} \mathrm{Ky} \mathrm{Kz}$ Ss Por

$1.27005 \mathrm{e}+02$ 1.27005e+02 1.27005e+01 1.00000e-09 7.00000e-02 5.07453e+00 5.07453e+00 5.07453e-01 1.00000e-09 2.12000e-01 $5.07453 \mathrm{e}+00$ 5.07453e+00 5.07453e-01 1.00000e-09 2.12000e-01 5.07453e+00 5.07453e+00 5.07453e-01 1.00000e-09 2.12000e-01 5.07453e+00 5.07453e+00 5.07453e-01 1.00000e-09 2.12000e-01 5.07453e+00 5.07453e+00 5.07453e-01 1.00000e-09 2.12000e-01 $1.00000 \mathrm{e}-02$ 1.00000e-02 1.00000e-03 1.00000e-09 1.00000e-01 $1.00000 \mathrm{e}+001.00000 \mathrm{e}+001.00000 \mathrm{e}-011.00000 \mathrm{e}-091.00000 \mathrm{e}-01$ Element: 943 \# of layers: 8

$\mathrm{Kx} \mathrm{Ky} \mathrm{Kz}$ Ss Por

$1.27005 \mathrm{e}+02$ 1.27005e+02 1.27005e+01 1.00000e-09 7.00000e-02 5.07453e+00 5.07453e+00 5.07453e-01 1.00000e-09 2.12000e-01 5.07453e+00 5.07453e+00 5.07453e-01 1.00000e-09 2.12000e-01 $5.07453 \mathrm{e}+00$ 5.07453e+00 5.07453e-01 1.00000e-09 2.12000e-01 5.07453e+00 5.07453e+00 5.07453e-01 1.00000e-09 2.12000e-01 5.07453e+00 5.07453e+00 5.07453e-01 1.00000e-09 2.12000e-01 $1.00000 \mathrm{e}-02$ 1.00000e-02 1.00000e-03 1.00000e-09 1.00000e-01 $1.00000 \mathrm{e}+001.00000 \mathrm{e}+001.00000 \mathrm{e}-011.00000 \mathrm{e}-091.00000 \mathrm{e}-01$ Element: 944 \# of layers: 7

$\mathrm{Kx} \mathrm{Ky} \mathrm{Kz}$ Ss Por

6.78516e+01 6.78516e+01 6.78516e+00 1.00000e-09 7.00000e-02

$2.71108 \mathrm{e}+002.71108 \mathrm{e}+002.71108 \mathrm{e}-01$ 1.00000e-09 2.12000e-01

$2.71108 \mathrm{e}+002.71108 \mathrm{e}+002.71108 \mathrm{e}-01$ 1.00000e-09 2.12000e-01

$2.71108 \mathrm{e}+002.71108 \mathrm{e}+002.71108 \mathrm{e}-01$ 1.00000e-09 2.12000e-01

$2.71108 \mathrm{e}+002.71108 \mathrm{e}+00$ 2.71108e-01 1.00000e-09 2.12000e-01 $1.00000 \mathrm{e}-02$ 1.00000e-02 1.00000e-03 1.00000e-09 1.00000e-01 $1.00000 \mathrm{e}+001.00000 \mathrm{e}+001.00000 \mathrm{e}-011.00000 \mathrm{e}-091.00000 \mathrm{e}-01$ Element: 945 \# of layers: 8

$\mathrm{Kx} \mathrm{Ky} \mathrm{Kz}$ Ss Por

6.78516e+01 6.78516e+01 6.78516e+00 1.00000e-09 7.00000e-02 $6.78516 \mathrm{e}+016.78516 \mathrm{e}+016.78516 \mathrm{e}+001.00000 \mathrm{e}-09$ 7.00000e-02 $2.71108 \mathrm{e}+002.71108 \mathrm{e}+00$ 2.71108e-01 1.00000e-09 2.12000e-01 $2.71108 \mathrm{e}+002.71108 \mathrm{e}+00$ 2.71108e-01 1.00000e-09 2.12000e-01 $2.71108 \mathrm{e}+002.71108 \mathrm{e}+00$ 2.71108e-01 1.00000e-09 2.12000e-01 $2.71108 \mathrm{e}+002.71108 \mathrm{e}+00$ 2.71108e-01 1.00000e-09 2.12000e-01 $1.00000 \mathrm{e}-02$ 1.00000e-02 1.00000e-03 1.00000e-09 1.00000e-01 $1.00000 \mathrm{e}+001.00000 \mathrm{e}+001.00000 \mathrm{e}-011.00000 \mathrm{e}-091.00000 \mathrm{e}-01$ 
Element: 946 \# of layers: 8

$\mathrm{Kx} \mathrm{Ky} \mathrm{Kz}$ Ss Por

6.78516e+01 6.78516e+01 6.78516e+00 1.00000e-09 7.00000e-02

6.78516e+01 6.78516e+01 6.78516e+00 1.00000e-09 7.00000e-02

$2.71108 \mathrm{e}+002.71108 \mathrm{e}+00$ 2.71108e-01 1.00000e-09 2.12000e-01

$2.71108 \mathrm{e}+002.71108 \mathrm{e}+00$ 2.71108e-01 1.00000e-09 2.12000e-01

$2.71108 \mathrm{e}+002.71108 \mathrm{e}+00$ 2.71108e-01 1.00000e-09 2.12000e-01

$2.71108 \mathrm{e}+002.71108 \mathrm{e}+00$ 2.71108e-01 1.00000e-09 2.12000e-01

$1.00000 \mathrm{e}-021.00000 \mathrm{e}-021.00000 \mathrm{e}-031.00000 \mathrm{e}-091.00000 \mathrm{e}-01$

$1.00000 \mathrm{e}+001.00000 \mathrm{e}+001.00000 \mathrm{e}-011.00000 \mathrm{e}-091.00000 \mathrm{e}-01$

Element: 947 \# of layers: 8

$\mathrm{Kx} \mathrm{Ky} \mathrm{Kz}$ Ss Por

6.78516e+01 6.78516e+01 6.78516e+00 1.00000e-09 7.00000e-02

$2.71108 \mathrm{e}+002.71108 \mathrm{e}+002.71108 \mathrm{e}-01$ 1.00000e-09 2.12000e-01

$2.71108 \mathrm{e}+002.71108 \mathrm{e}+002.71108 \mathrm{e}-01$ 1.00000e-09 2.12000e-01

$2.71108 \mathrm{e}+002.71108 \mathrm{e}+002.71108 \mathrm{e}-01$ 1.00000e-09 2.12000e-01

$2.71108 \mathrm{e}+002.71108 \mathrm{e}+00$ 2.71108e-01 1.00000e-09 2.12000e-01

$2.71108 \mathrm{e}+002.71108 \mathrm{e}+002.71108 \mathrm{e}-01$ 1.00000e-09 2.12000e-01

$1.00000 \mathrm{e}-02$ 1.00000e-02 1.00000e-03 1.00000e-09 1.00000e-01

$1.00000 \mathrm{e}+001.00000 \mathrm{e}+001.00000 \mathrm{e}-011.00000 \mathrm{e}-091.00000 \mathrm{e}-01$

Element: 948 \# of layers: 8

$\mathrm{Kx} \mathrm{Ky} \mathrm{Kz}$ Ss Por

6.78516e+01 6.78516e+01 6.78516e+00 1.00000e-09 7.00000e-02

$2.71108 \mathrm{e}+002.71108 \mathrm{e}+002.71108 \mathrm{e}-01$ 1.00000e-09 2.12000e-01

$2.71108 \mathrm{e}+002.71108 \mathrm{e}+00$ 2.71108e-01 1.00000e-09 2.12000e-01

$2.71108 \mathrm{e}+002.71108 \mathrm{e}+00$ 2.71108e-01 1.00000e-09 2.12000e-01

$2.71108 \mathrm{e}+002.71108 \mathrm{e}+002.71108 \mathrm{e}-01$ 1.00000e-09 2.12000e-01

$2.71108 \mathrm{e}+002.71108 \mathrm{e}+00$ 2.71108e-01 1.00000e-09 2.12000e-01

$1.00000 \mathrm{e}-02$ 1.00000e-02 1.00000e-03 1.00000e-09 1.00000e-01

$1.00000 \mathrm{e}+001.00000 \mathrm{e}+001.00000 \mathrm{e}-011.00000 \mathrm{e}-091.00000 \mathrm{e}-01$

Element: 949 \# of layers: 8

$\mathrm{Kx} \mathrm{Ky} \mathrm{Kz}$ Ss Por

6.78516e+01 6.78516e+01 6.78516e+00 1.00000e-09 7.00000e-02

$2.71108 \mathrm{e}+00$ 2.71108e+00 2.71108e-01 1.00000e-09 2.12000e-01

$2.71108 \mathrm{e}+002.71108 \mathrm{e}+002.71108 \mathrm{e}-01$ 1.00000e-09 2.12000e-01

$2.71108 \mathrm{e}+002.71108 \mathrm{e}+00$ 2.71108e-01 1.00000e-09 2.12000e-01

$2.71108 \mathrm{e}+002.71108 \mathrm{e}+00$ 2.71108e-01 1.00000e-09 2.12000e-01

$2.71108 \mathrm{e}+002.71108 \mathrm{e}+00$ 2.71108e-01 1.00000e-09 2.12000e-01

$1.00000 \mathrm{e}-02$ 1.00000e-02 1.00000e-03 1.00000e-09 1.00000e-01

$1.00000 \mathrm{e}+001.00000 \mathrm{e}+001.00000 \mathrm{e}-01$ 1.00000e-09 1.00000e-01

Element: 950 \# of layers: 9

$\mathrm{Kx} \mathrm{Ky} \mathrm{Kz}$ Ss Por

6.78516e+01 6.78516e+01 6.78516e+00 1.00000e-09 7.00000e-02

6.78516e+01 6.78516e+01 6.78516e+00 1.00000e-09 7.00000e-02

$2.71108 \mathrm{e}+002.71108 \mathrm{e}+002.71108 \mathrm{e}-01$ 1.00000e-09 2.12000e-01

$2.71108 \mathrm{e}+002.71108 \mathrm{e}+00$ 2.71108e-01 1.00000e-09 2.12000e-01 
$2.71108 \mathrm{e}+002.71108 \mathrm{e}+002.71108 \mathrm{e}-011.00000 \mathrm{e}-092.12000 \mathrm{e}-01$ $2.71108 \mathrm{e}+002.71108 \mathrm{e}+002.71108 \mathrm{e}-01$ 1.00000e-09 2.12000e-01 $2.71108 \mathrm{e}+002.71108 \mathrm{e}+002.71108 \mathrm{e}-011.00000 \mathrm{e}-092.12000 \mathrm{e}-01$ $1.00000 \mathrm{e}-021.00000 \mathrm{e}-02$ 1.00000e-03 1.00000e-09 1.00000e-01 $1.00000 \mathrm{e}+001.00000 \mathrm{e}+001.00000 \mathrm{e}-011.00000 \mathrm{e}-091.00000 \mathrm{e}-01$ Element: 951 \# of layers: 9

Kx Ky Kz Ss Por

$6.78516 \mathrm{e}+016.78516 \mathrm{e}+016.78516 \mathrm{e}+00$ 1.00000e-09 7.00000e-02

$6.78516 \mathrm{e}+016.78516 \mathrm{e}+016.78516 \mathrm{e}+001.00000 \mathrm{e}-09$ 7.00000e-02

$2.71108 \mathrm{e}+002.71108 \mathrm{e}+002.71108 \mathrm{e}-011.00000 \mathrm{e}-092.12000 \mathrm{e}-01$

$2.71108 \mathrm{e}+002.71108 \mathrm{e}+002.71108 \mathrm{e}-01$ 1.00000e-09 2.12000e-01

$2.71108 \mathrm{e}+002.71108 \mathrm{e}+002.71108 \mathrm{e}-01$ 1.00000e-09 2.12000e-01

$2.71108 \mathrm{e}+002.71108 \mathrm{e}+002.71108 \mathrm{e}-01$ 1.00000e-09 2.12000e-01

$2.71108 \mathrm{e}+002.71108 \mathrm{e}+002.71108 \mathrm{e}-01$ 1.00000e-09 2.12000e-01

$1.00000 \mathrm{e}-02$ 1.00000e-02 1.00000e-03 1.00000e-09 1.00000e-01

$1.00000 \mathrm{e}+001.00000 \mathrm{e}+001.00000 \mathrm{e}-011.00000 \mathrm{e}-091.00000 \mathrm{e}-01$

Element: 952 \# of layers: 9

Kx Ky Kz Ss Por

$6.78516 \mathrm{e}+016.78516 \mathrm{e}+016.78516 \mathrm{e}+00$ 1.00000e-09 7.00000e-02

$6.78516 \mathrm{e}+016.78516 \mathrm{e}+016.78516 \mathrm{e}+001.00000 \mathrm{e}-097.00000 \mathrm{e}-02$

$2.71108 \mathrm{e}+002.71108 \mathrm{e}+002.71108 \mathrm{e}-011.00000 \mathrm{e}-092.12000 \mathrm{e}-01$

$2.71108 \mathrm{e}+002.71108 \mathrm{e}+002.71108 \mathrm{e}-011.00000 \mathrm{e}-092.12000 \mathrm{e}-01$

$2.71108 \mathrm{e}+002.71108 \mathrm{e}+002.71108 \mathrm{e}-011.00000 \mathrm{e}-092.12000 \mathrm{e}-01$

$2.71108 \mathrm{e}+002.71108 \mathrm{e}+002.71108 \mathrm{e}-01$ 1.00000e-09 2.12000e-01

$2.71108 \mathrm{e}+002.71108 \mathrm{e}+002.71108 \mathrm{e}-011.00000 \mathrm{e}-092.12000 \mathrm{e}-01$

$1.00000 \mathrm{e}-02$ 1.00000e-02 1.00000e-03 1.00000e-09 1.00000e-01

$1.00000 \mathrm{e}+001.00000 \mathrm{e}+001.00000 \mathrm{e}-011.00000 \mathrm{e}-091.00000 \mathrm{e}-01$

Element: 953 \# of layers: 7

Kx Ky Kz Ss Por

3.53832e+01 3.53832e+01 3.53832e+00 1.00000e-09 7.00000e-02

$1.41379 \mathrm{e}+001.41379 \mathrm{e}+001.41380 \mathrm{e}-011.00000 \mathrm{e}-09$ 2.12000e-01

$1.41379 \mathrm{e}+001.41379 \mathrm{e}+001.41380 \mathrm{e}-011.00000 \mathrm{e}-092.12000 \mathrm{e}-01$

$1.41379 \mathrm{e}+001.41379 \mathrm{e}+00$ 1.41380e-01 1.00000e-09 2.12000e-01

$1.41379 \mathrm{e}+001.41379 \mathrm{e}+00$ 1.41380e-01 1.00000e-09 2.12000e-01

$1.00000 \mathrm{e}-021.00000 \mathrm{e}-02$ 1.00000e-03 1.00000e-09 1.00000e-01

$1.00000 \mathrm{e}+001.00000 \mathrm{e}+001.00000 \mathrm{e}-011.00000 \mathrm{e}-091.00000 \mathrm{e}-01$

Element: 954 \# of layers: 7

Kx Ky Kz Ss Por

3.53832e+01 3.53832e+01 3.53832e+00 1.00000e-09 7.00000e-02

$1.41379 \mathrm{e}+001.41379 \mathrm{e}+001.41380 \mathrm{e}-011.00000 \mathrm{e}-09$ 2.12000e-01

$1.41379 \mathrm{e}+001.41379 \mathrm{e}+001.41380 \mathrm{e}-011.00000 \mathrm{e}-092.12000 \mathrm{e}-01$

$1.41379 \mathrm{e}+001.41379 \mathrm{e}+00$ 1.41380e-01 1.00000e-09 2.12000e-01

$1.41379 \mathrm{e}+001.41379 \mathrm{e}+001.41380 \mathrm{e}-011.00000 \mathrm{e}-09$ 2.12000e-01

$1.00000 \mathrm{e}-02$ 1.00000e-02 1.00000e-03 1.00000e-09 1.00000e-01

$1.00000 \mathrm{e}+001.00000 \mathrm{e}+001.00000 \mathrm{e}-011.00000 \mathrm{e}-091.00000 \mathrm{e}-01$

Element: 955 \# of layers: 6 
$\mathrm{Kx} \mathrm{Ky} \mathrm{Kz}$ Ss Por

3.53832e+01 3.53832e+01 3.53832e+00 1.00000e-09 7.00000e-02 $1.41379 \mathrm{e}+001.41379 \mathrm{e}+00$ 1.41380e-01 1.00000e-09 2.12000e-01 $1.41379 \mathrm{e}+001.41379 \mathrm{e}+00$ 1.41380e-01 1.00000e-09 2.12000e-01 $1.41379 \mathrm{e}+001.41379 \mathrm{e}+001.41380 \mathrm{e}-01$ 1.00000e-09 2.12000e-01 $1.00000 \mathrm{e}-02$ 1.00000e-02 1.00000e-03 1.00000e-09 1.00000e-01 $1.00000 \mathrm{e}+001.00000 \mathrm{e}+001.00000 \mathrm{e}-01$ 1.00000e-09 1.00000e-01 Element: 956 \# of layers: 8

$\mathrm{Kx} \mathrm{Ky} \mathrm{Kz}$ Ss Por

3.53832e+01 3.53832e+01 3.53832e+00 1.00000e-09 7.00000e-02 $1.41379 \mathrm{e}+001.41379 \mathrm{e}+00$ 1.41380e-01 1.00000e-09 2.12000e-01 $1.41379 \mathrm{e}+001.41379 \mathrm{e}+001.41380 \mathrm{e}-011.00000 \mathrm{e}-092.12000 \mathrm{e}-01$ $1.41379 \mathrm{e}+001.41379 \mathrm{e}+001.41380 \mathrm{e}-011.00000 \mathrm{e}-092.12000 \mathrm{e}-01$ $1.41379 \mathrm{e}+001.41379 \mathrm{e}+00$ 1.41380e-01 1.00000e-09 2.12000e-01 $1.41379 \mathrm{e}+001.41379 \mathrm{e}+001.41380 \mathrm{e}-01$ 1.00000e-09 2.12000e-01 $1.00000 \mathrm{e}-02$ 1.00000e-02 1.00000e-03 1.00000e-09 1.00000e-01 $1.00000 \mathrm{e}+001.00000 \mathrm{e}+001.00000 \mathrm{e}-01$ 1.00000e-09 1.00000e-01 Element: 957 \# of layers: 7

$\mathrm{Kx} \mathrm{Ky} \mathrm{Kz}$ Ss Por

3.53832e+01 3.53832e+01 3.53832e+00 1.00000e-09 7.00000e-02 $1.41379 \mathrm{e}+001.41379 \mathrm{e}+001.41380 \mathrm{e}-01$ 1.00000e-09 2.12000e-01 $1.41379 \mathrm{e}+00$ 1.41379e+00 1.41380e-01 1.00000e-09 2.12000e-01 $1.41379 \mathrm{e}+001.41379 \mathrm{e}+00$ 1.41380e-01 1.00000e-09 2.12000e-01 $1.41379 \mathrm{e}+001.41379 \mathrm{e}+001.41380 \mathrm{e}-01$ 1.00000e-09 2.12000e-01 $1.00000 \mathrm{e}-02$ 1.00000e-02 1.00000e-03 1.00000e-09 1.00000e-01 $1.00000 \mathrm{e}+001.00000 \mathrm{e}+001.00000 \mathrm{e}-011.00000 \mathrm{e}-091.00000 \mathrm{e}-01$ Element: 958 \# of layers: 8

$\mathrm{Kx} \mathrm{Ky} \mathrm{Kz} \mathrm{Ss} \mathrm{Por}$

3.53832e+01 3.53832e+01 3.53832e+00 1.00000e-09 7.00000e-02 $1.41379 \mathrm{e}+001.41379 \mathrm{e}+00$ 1.41380e-01 1.00000e-09 2.12000e-01 $1.41379 \mathrm{e}+001.41379 \mathrm{e}+00$ 1.41380e-01 1.00000e-09 2.12000e-01 $1.41379 \mathrm{e}+001.41379 \mathrm{e}+00$ 1.41380e-01 1.00000e-09 2.12000e-01 $1.41379 \mathrm{e}+001.41379 \mathrm{e}+001.41380 \mathrm{e}-01$ 1.00000e-09 2.12000e-01 $1.41379 \mathrm{e}+001.41379 \mathrm{e}+001.41380 \mathrm{e}-01$ 1.00000e-09 2.12000e-01 $1.00000 \mathrm{e}-021.00000 \mathrm{e}-021.00000 \mathrm{e}-031.00000 \mathrm{e}-091.00000 \mathrm{e}-01$ $1.00000 \mathrm{e}+001.00000 \mathrm{e}+001.00000 \mathrm{e}-011.00000 \mathrm{e}-091.00000 \mathrm{e}-01$ Element: 959 \# of layers: 8

Kx Ky Kz Ss Por

3.53832e+01 3.53832e+01 3.53832e+00 1.00000e-09 7.00000e-02 $1.41379 \mathrm{e}+001.41379 \mathrm{e}+00$ 1.41380e-01 1.00000e-09 2.12000e-01 $1.41379 \mathrm{e}+001.41379 \mathrm{e}+001.41380 \mathrm{e}-01$ 1.00000e-09 2.12000e-01 $1.41379 \mathrm{e}+001.41379 \mathrm{e}+00$ 1.41380e-01 1.00000e-09 2.12000e-01 $1.41379 \mathrm{e}+001.41379 \mathrm{e}+001.41380 \mathrm{e}-01$ 1.00000e-09 2.12000e-01 $1.41379 \mathrm{e}+001.41379 \mathrm{e}+001.41380 \mathrm{e}-01$ 1.00000e-09 2.12000e-01 1.00000e-02 1.00000e-02 1.00000e-03 1.00000e-09 1.00000e-01 $1.00000 \mathrm{e}+001.00000 \mathrm{e}+001.00000 \mathrm{e}-011.00000 \mathrm{e}-091.00000 \mathrm{e}-01$ 
Element: 960 \# of layers: 8

$\mathrm{Kx} \mathrm{Ky} \mathrm{Kz}$ Ss Por

3.53832e+01 3.53832e+01 3.53832e+00 1.00000e-09 7.00000e-02

$1.41379 \mathrm{e}+001.41379 \mathrm{e}+00$ 1.41380e-01 1.00000e-09 2.12000e-01

$1.41379 \mathrm{e}+001.41379 \mathrm{e}+00$ 1.41380e-01 1.00000e-09 2.12000e-01

$1.41379 \mathrm{e}+001.41379 \mathrm{e}+001.41380 \mathrm{e}-01$ 1.00000e-09 2.12000e-01

$1.41379 \mathrm{e}+001.41379 \mathrm{e}+00$ 1.41380e-01 1.00000e-09 2.12000e-01

$1.41379 \mathrm{e}+001.41379 \mathrm{e}+001.41380 \mathrm{e}-01$ 1.00000e-09 2.12000e-01

$1.00000 \mathrm{e}-02$ 1.00000e-02 1.00000e-03 1.00000e-09 1.00000e-01

$1.00000 \mathrm{e}+001.00000 \mathrm{e}+001.00000 \mathrm{e}-011.00000 \mathrm{e}-091.00000 \mathrm{e}-01$

Element: 961 \# of layers: 8

Kx Ky Kz Ss Por

3.53832e+01 3.53832e+01 3.53832e+00 1.00000e-09 7.00000e-02

$1.41379 \mathrm{e}+001.41379 \mathrm{e}+00$ 1.41380e-01 1.00000e-09 2.12000e-01

$1.41379 \mathrm{e}+00$ 1.41379e+00 1.41380e-01 1.00000e-09 2.12000e-01

$1.41379 \mathrm{e}+001.41379 \mathrm{e}+001.41380 \mathrm{e}-01$ 1.00000e-09 2.12000e-01

$1.41379 \mathrm{e}+001.41379 \mathrm{e}+00$ 1.41380e-01 1.00000e-09 2.12000e-01

$1.41379 \mathrm{e}+001.41379 \mathrm{e}+001.41380 \mathrm{e}-01$ 1.00000e-09 2.12000e-01

$1.00000 \mathrm{e}-02$ 1.00000e-02 1.00000e-03 1.00000e-09 1.00000e-01

$1.00000 \mathrm{e}+001.00000 \mathrm{e}+001.00000 \mathrm{e}-01$ 1.00000e-09 1.00000e-01

Element: 962 \# of layers: 6

$\mathrm{Kx} \mathrm{Ky} \mathrm{Kz}$ Ss Por

2.54433e+01 2.54433e+01 2.54433e+00 1.00000e-09 7.00000e-02

$1.01662 \mathrm{e}+001.01662 \mathrm{e}+001.01662 \mathrm{e}-01$ 1.00000e-09 2.12000e-01

$1.01662 \mathrm{e}+001.01662 \mathrm{e}+001.01662 \mathrm{e}-011.00000 \mathrm{e}-092.12000 \mathrm{e}-01$

$1.01662 \mathrm{e}+001.01662 \mathrm{e}+001.01662 \mathrm{e}-01$ 1.00000e-09 2.12000e-01

$1.00000 \mathrm{e}-02$ 1.00000e-02 1.00000e-03 1.00000e-09 1.00000e-01

$1.00000 \mathrm{e}+001.00000 \mathrm{e}+001.00000 \mathrm{e}-011.00000 \mathrm{e}-09$ 1.00000e-01

Element: 963 \# of layers: 6

$\mathrm{Kx} \mathrm{Ky} \mathrm{Kz}$ Ss Por

2.54433e+01 2.54433e+01 2.54433e+00 1.00000e-09 7.00000e-02

$1.01662 \mathrm{e}+001.01662 \mathrm{e}+00$ 1.01662e-01 1.00000e-09 2.12000e-01

$1.01662 \mathrm{e}+001.01662 \mathrm{e}+00$ 1.01662e-01 1.00000e-09 2.12000e-01

$1.01662 \mathrm{e}+00$ 1.01662e+00 1.01662e-01 1.00000e-09 2.12000e-01

$1.00000 \mathrm{e}-02$ 1.00000e-02 1.00000e-03 1.00000e-09 1.00000e-01

$1.00000 \mathrm{e}+001.00000 \mathrm{e}+001.00000 \mathrm{e}-011.00000 \mathrm{e}-091.00000 \mathrm{e}-01$

Element: 964 \# of layers: 6

$\mathrm{Kx} \mathrm{Ky} \mathrm{Kz}$ Ss Por

$2.54433 \mathrm{e}+012.54433 \mathrm{e}+012.54433 \mathrm{e}+00$ 1.00000e-09 7.00000e-02

$1.01662 \mathrm{e}+001.01662 \mathrm{e}+00$ 1.01662e-01 1.00000e-09 2.12000e-01

$1.01662 \mathrm{e}+001.01662 \mathrm{e}+001.01662 \mathrm{e}-01$ 1.00000e-09 2.12000e-01

$1.01662 \mathrm{e}+001.01662 \mathrm{e}+001.01662 \mathrm{e}-01$ 1.00000e-09 2.12000e-01

$1.00000 \mathrm{e}-021.00000 \mathrm{e}-021.00000 \mathrm{e}-031.00000 \mathrm{e}-091.00000 \mathrm{e}-01$

$1.00000 \mathrm{e}+001.00000 \mathrm{e}+001.00000 \mathrm{e}-01$ 1.00000e-09 1.00000e-01

Element: 965 \# of layers: 7

Kx Ky Kz Ss Por 
$2.54433 \mathrm{e}+012.54433 \mathrm{e}+012.54433 \mathrm{e}+00$ 1.00000e-09 7.00000e-02 $1.01662 \mathrm{e}+001.01662 \mathrm{e}+00$ 1.01662e-01 1.00000e-09 2.12000e-01 $1.01662 \mathrm{e}+001.01662 \mathrm{e}+001.01662 \mathrm{e}-01$ 1.00000e-09 2.12000e-01 $1.01662 \mathrm{e}+001.01662 \mathrm{e}+00$ 1.01662e-01 1.00000e-09 2.12000e-01 $1.01662 \mathrm{e}+001.01662 \mathrm{e}+001.01662 \mathrm{e}-01$ 1.00000e-09 2.12000e-01 $1.00000 \mathrm{e}-02$ 1.00000e-02 1.00000e-03 1.00000e-09 1.00000e-01 $1.00000 \mathrm{e}+001.00000 \mathrm{e}+001.00000 \mathrm{e}-011.00000 \mathrm{e}-091.00000 \mathrm{e}-01$ Element: 966 \# of layers: 7

$\mathrm{Kx} \mathrm{Ky} \mathrm{Kz}$ Ss Por

$2.54433 \mathrm{e}+012.54433 \mathrm{e}+012.54433 \mathrm{e}+00$ 1.00000e-09 7.00000e-02 $1.01662 \mathrm{e}+001.01662 \mathrm{e}+00$ 1.01662e-01 1.00000e-09 2.12000e-01 $1.01662 \mathrm{e}+001.01662 \mathrm{e}+001.01662 \mathrm{e}-01$ 1.00000e-09 2.12000e-01 $1.01662 \mathrm{e}+001.01662 \mathrm{e}+001.01662 \mathrm{e}-01$ 1.00000e-09 2.12000e-01 $1.01662 \mathrm{e}+001.01662 \mathrm{e}+00$ 1.01662e-01 1.00000e-09 2.12000e-01 $1.00000 \mathrm{e}-02$ 1.00000e-02 1.00000e-03 1.00000e-09 1.00000e-01 $1.00000 \mathrm{e}+001.00000 \mathrm{e}+001.00000 \mathrm{e}-011.00000 \mathrm{e}-091.00000 \mathrm{e}-01$ Element: 967 \# of layers: 8

$\mathrm{Kx} \mathrm{Ky} \mathrm{Kz}$ Ss Por

$2.54433 \mathrm{e}+012.54433 \mathrm{e}+012.54433 \mathrm{e}+00$ 1.00000e-09 7.00000e-02 $1.01662 \mathrm{e}+001.01662 \mathrm{e}+001.01662 \mathrm{e}-01$ 1.00000e-09 2.12000e-01 $1.01662 \mathrm{e}+001.01662 \mathrm{e}+00$ 1.01662e-01 1.00000e-09 2.12000e-01 $1.01662 \mathrm{e}+001.01662 \mathrm{e}+00$ 1.01662e-01 1.00000e-09 2.12000e-01 $1.01662 \mathrm{e}+001.01662 \mathrm{e}+00$ 1.01662e-01 1.00000e-09 2.12000e-01 $1.01662 \mathrm{e}+00$ 1.01662e+00 1.01662e-01 1.00000e-09 2.12000e-01 $1.00000 \mathrm{e}-02$ 1.00000e-02 1.00000e-03 1.00000e-09 1.00000e-01 $1.00000 \mathrm{e}+001.00000 \mathrm{e}+001.00000 \mathrm{e}-011.00000 \mathrm{e}-091.00000 \mathrm{e}-01$ Element: 968 \# of layers: 7

$\mathrm{Kx} \mathrm{Ky} \mathrm{Kz}$ Ss Por

$2.54433 \mathrm{e}+012.54433 \mathrm{e}+012.54433 \mathrm{e}+00$ 1.00000e-09 7.00000e-02 $1.01662 \mathrm{e}+001.01662 \mathrm{e}+001.01662 \mathrm{e}-011.00000 \mathrm{e}-092.12000 \mathrm{e}-01$ $1.01662 \mathrm{e}+001.01662 \mathrm{e}+00$ 1.01662e-01 1.00000e-09 2.12000e-01 $1.01662 \mathrm{e}+001.01662 \mathrm{e}+00$ 1.01662e-01 1.00000e-09 2.12000e-01 $1.01662 \mathrm{e}+001.01662 \mathrm{e}+00$ 1.01662e-01 1.00000e-09 2.12000e-01 $1.00000 \mathrm{e}-02$ 1.00000e-02 1.00000e-03 1.00000e-09 1.00000e-01 $1.00000 \mathrm{e}+001.00000 \mathrm{e}+001.00000 \mathrm{e}-01$ 1.00000e-09 1.00000e-01 Element: 969 \# of layers: 8

Kx Ky Kz Ss Por

$2.54433 \mathrm{e}+012.54433 \mathrm{e}+012.54433 \mathrm{e}+00$ 1.00000e-09 7.00000e-02 $1.01662 \mathrm{e}+001.01662 \mathrm{e}+00$ 1.01662e-01 1.00000e-09 2.12000e-01 $1.01662 \mathrm{e}+001.01662 \mathrm{e}+00$ 1.01662e-01 1.00000e-09 2.12000e-01 $1.01662 \mathrm{e}+001.01662 \mathrm{e}+001.01662 \mathrm{e}-01$ 1.00000e-09 2.12000e-01 $1.01662 \mathrm{e}+001.01662 \mathrm{e}+001.01662 \mathrm{e}-01$ 1.00000e-09 2.12000e-01 $1.01662 \mathrm{e}+001.01662 \mathrm{e}+00$ 1.01662e-01 1.00000e-09 2.12000e-01 $1.00000 \mathrm{e}-021.00000 \mathrm{e}-021.00000 \mathrm{e}-031.00000 \mathrm{e}-091.00000 \mathrm{e}-01$ $1.00000 \mathrm{e}+001.00000 \mathrm{e}+001.00000 \mathrm{e}-011.00000 \mathrm{e}-091.00000 \mathrm{e}-01$ Element: 970 \# of layers: 8 
$\mathrm{Kx} \mathrm{Ky} \mathrm{Kz}$ Ss Por

$2.54433 \mathrm{e}+012.54433 \mathrm{e}+012.54433 \mathrm{e}+00$ 1.00000e-09 7.00000e-02 $1.01662 \mathrm{e}+001.01662 \mathrm{e}+001.01662 \mathrm{e}-01$ 1.00000e-09 2.12000e-01 $1.01662 \mathrm{e}+001.01662 \mathrm{e}+00$ 1.01662e-01 1.00000e-09 2.12000e-01 $1.01662 \mathrm{e}+001.01662 \mathrm{e}+00$ 1.01662e-01 1.00000e-09 2.12000e-01 $1.01662 \mathrm{e}+001.01662 \mathrm{e}+001.01662 \mathrm{e}-01$ 1.00000e-09 2.12000e-01 $1.01662 \mathrm{e}+00$ 1.01662e+00 1.01662e-01 1.00000e-09 2.12000e-01 $1.00000 \mathrm{e}-02$ 1.00000e-02 1.00000e-03 1.00000e-09 1.00000e-01 $1.00000 \mathrm{e}+001.00000 \mathrm{e}+001.00000 \mathrm{e}-011.00000 \mathrm{e}-091.00000 \mathrm{e}-01$ Element: 971 \# of layers: 6

$\mathrm{Kx} \mathrm{Ky} \mathrm{Kz}$ Ss Por

5.78956e+01 5.78956e+01 5.78956e+00 1.00000e-09 7.00000e-02 $2.31327 \mathrm{e}+002.31327 \mathrm{e}+00$ 2.31327e-01 1.00000e-09 2.12000e-01 2.31327e+00 2.31327e+00 2.31327e-01 1.00000e-09 2.12000e-01 2.31327e+00 2.31327e+00 2.31327e-01 1.00000e-09 2.12000e-01 1.00000e-02 1.00000e-02 1.00000e-03 1.00000e-09 1.00000e-01 $1.00000 \mathrm{e}+001.00000 \mathrm{e}+001.00000 \mathrm{e}-01$ 1.00000e-09 1.00000e-01 Element: 972 \# of layers: 6

$\mathrm{Kx} \mathrm{Ky} \mathrm{Kz}$ Ss Por

5.78956e+01 5.78956e+01 5.78956e+00 1.00000e-09 7.00000e-02 $2.31327 \mathrm{e}+00$ 2.31327e+00 2.31327e-01 1.00000e-09 2.12000e-01 2.31327e+00 2.31327e+00 2.31327e-01 1.00000e-09 2.12000e-01 2.31327e+00 2.31327e+00 2.31327e-01 1.00000e-09 2.12000e-01 $1.00000 \mathrm{e}-02$ 1.00000e-02 1.00000e-03 1.00000e-09 1.00000e-01 $1.00000 \mathrm{e}+001.00000 \mathrm{e}+001.00000 \mathrm{e}-011.00000 \mathrm{e}-091.00000 \mathrm{e}-01$ Element: 973 \# of layers: 6

$\mathrm{Kx} \mathrm{Ky} \mathrm{Kz}$ Ss Por

5.78956e+01 5.78956e+01 5.78956e+00 1.00000e-09 7.00000e-02 $2.31327 \mathrm{e}+002.31327 \mathrm{e}+00$ 2.31327e-01 1.00000e-09 2.12000e-01 $2.31327 \mathrm{e}+00$ 2.31327e+00 2.31327e-01 1.00000e-09 2.12000e-01 $2.31327 \mathrm{e}+00$ 2.31327e+00 2.31327e-01 1.00000e-09 2.12000e-01 1.00000e-02 1.00000e-02 1.00000e-03 1.00000e-09 1.00000e-01 $1.00000 \mathrm{e}+001.00000 \mathrm{e}+001.00000 \mathrm{e}-011.00000 \mathrm{e}-091.00000 \mathrm{e}-01$ Element: 974 \# of layers: 7

$\mathrm{Kx} \mathrm{Ky} \mathrm{Kz}$ Ss Por

5.78956e+01 5.78956e+01 5.78956e+00 1.00000e-09 7.00000e-02 $2.31327 \mathrm{e}+002.31327 \mathrm{e}+00$ 2.31327e-01 1.00000e-09 2.12000e-01 2.31327e+00 2.31327e+00 2.31327e-01 1.00000e-09 2.12000e-01 2.31327e+00 2.31327e+00 2.31327e-01 1.00000e-09 2.12000e-01 2.31327e+00 2.31327e+00 2.31327e-01 1.00000e-09 2.12000e-01 1.00000e-02 1.00000e-02 1.00000e-03 1.00000e-09 1.00000e-01 $1.00000 \mathrm{e}+001.00000 \mathrm{e}+001.00000 \mathrm{e}-011.00000 \mathrm{e}-091.00000 \mathrm{e}-01$ Element: 975 \# of layers: 7

$\mathrm{Kx} \mathrm{Ky} \mathrm{Kz}$ Ss Por

5.78956e+01 5.78956e+01 5.78956e+00 1.00000e-09 7.00000e-02 $2.31327 \mathrm{e}+00$ 2.31327e+00 2.31327e-01 1.00000e-09 2.12000e-01 
$2.31327 \mathrm{e}+002.31327 \mathrm{e}+002.31327 \mathrm{e}-01$ 1.00000e-09 2.12000e-01 $2.31327 \mathrm{e}+002.31327 \mathrm{e}+002.31327 \mathrm{e}-011.00000 \mathrm{e}-092.12000 \mathrm{e}-01$ $2.31327 \mathrm{e}+002.31327 \mathrm{e}+00$ 2.31327e-01 1.00000e-09 2.12000e-01 $1.00000 \mathrm{e}-021.00000 \mathrm{e}-02$ 1.00000e-03 1.00000e-09 1.00000e-01 $1.00000 \mathrm{e}+001.00000 \mathrm{e}+001.00000 \mathrm{e}-011.00000 \mathrm{e}-091.00000 \mathrm{e}-01$ Element: 976 \# of layers: 7

Kx Ky Kz Ss Por

$5.78956 \mathrm{e}+015.78956 \mathrm{e}+015.78956 \mathrm{e}+00$ 1.00000e-09 7.00000e-02 $2.31327 \mathrm{e}+002.31327 \mathrm{e}+00$ 2.31327e-01 1.00000e-09 2.12000e-01 $2.31327 \mathrm{e}+002.31327 \mathrm{e}+002.31327 \mathrm{e}-011.00000 \mathrm{e}-092.12000 \mathrm{e}-01$ $2.31327 \mathrm{e}+002.31327 \mathrm{e}+002.31327 \mathrm{e}-01$ 1.00000e-09 2.12000e-01 $2.31327 \mathrm{e}+002.31327 \mathrm{e}+002.31327 \mathrm{e}-01$ 1.00000e-09 2.12000e-01 $1.00000 \mathrm{e}-02$ 1.00000e-02 1.00000e-03 1.00000e-09 1.00000e-01 $1.00000 \mathrm{e}+001.00000 \mathrm{e}+001.00000 \mathrm{e}-011.00000 \mathrm{e}-091.00000 \mathrm{e}-01$ Element: 977 \# of layers: 7

Kx Ky Kz Ss Por

$5.78956 \mathrm{e}+015.78956 \mathrm{e}+01$ 5.78956e+00 1.00000e-09 7.00000e-02 $2.31327 \mathrm{e}+002.31327 \mathrm{e}+002.31327 \mathrm{e}-011.00000 \mathrm{e}-092.12000 \mathrm{e}-01$ $2.31327 \mathrm{e}+002.31327 \mathrm{e}+002.31327 \mathrm{e}-01$ 1.00000e-09 2.12000e-01 $2.31327 \mathrm{e}+002.31327 \mathrm{e}+002.31327 \mathrm{e}-011.00000 \mathrm{e}-092.12000 \mathrm{e}-01$ $2.31327 \mathrm{e}+002.31327 \mathrm{e}+002.31327 \mathrm{e}-011.00000 \mathrm{e}-092.12000 \mathrm{e}-01$ $1.00000 \mathrm{e}-02$ 1.00000e-02 1.00000e-03 1.00000e-09 1.00000e-01 $1.00000 \mathrm{e}+001.00000 \mathrm{e}+001.00000 \mathrm{e}-011.00000 \mathrm{e}-091.00000 \mathrm{e}-01$ Element: 978 \# of layers: 7

Kx Ky Kz Ss Por

$5.78956 \mathrm{e}+015.78956 \mathrm{e}+015.78956 \mathrm{e}+00$ 1.00000e-09 7.00000e-02 $2.31327 \mathrm{e}+002.31327 \mathrm{e}+002.31327 \mathrm{e}-011.00000 \mathrm{e}-092.12000 \mathrm{e}-01$ $2.31327 \mathrm{e}+002.31327 \mathrm{e}+00$ 2.31327e-01 1.00000e-09 2.12000e-01 $2.31327 \mathrm{e}+002.31327 \mathrm{e}+002.31327 \mathrm{e}-011.00000 \mathrm{e}-092.12000 \mathrm{e}-01$ $2.31327 \mathrm{e}+002.31327 \mathrm{e}+00$ 2.31327e-01 1.00000e-09 2.12000e-01 $1.00000 \mathrm{e}-021.00000 \mathrm{e}-02$ 1.00000e-03 1.00000e-09 1.00000e-01 $1.00000 \mathrm{e}+001.00000 \mathrm{e}+001.00000 \mathrm{e}-011.00000 \mathrm{e}-091.00000 \mathrm{e}-01$ Element: 979 \# of layers: 7

Kx Ky Kz Ss Por

$5.78956 \mathrm{e}+015.78956 \mathrm{e}+015.78956 \mathrm{e}+00$ 1.00000e-09 7.00000e-02 $2.31327 \mathrm{e}+002.31327 \mathrm{e}+002.31327 \mathrm{e}-01$ 1.00000e-09 2.12000e-01 $2.31327 \mathrm{e}+002.31327 \mathrm{e}+002.31327 \mathrm{e}-011.00000 \mathrm{e}-092.12000 \mathrm{e}-01$ $2.31327 \mathrm{e}+002.31327 \mathrm{e}+002.31327 \mathrm{e}-01$ 1.00000e-09 2.12000e-01 $2.31327 \mathrm{e}+002.31327 \mathrm{e}+00$ 2.31327e-01 1.00000e-09 2.12000e-01 $1.00000 \mathrm{e}-02$ 1.00000e-02 1.00000e-03 1.00000e-09 1.00000e-01 $1.00000 \mathrm{e}+001.00000 \mathrm{e}+001.00000 \mathrm{e}-011.00000 \mathrm{e}-091.00000 \mathrm{e}-01$ Element: 980 \# of layers: 7

Kx Ky Kz Ss Por

7.58858e+01 7.58858e+01 7.58858e+00 1.00000e-09 7.00000e-02 $7.58858 \mathrm{e}+017.58858 \mathrm{e}+017.58858 \mathrm{e}+001.00000 \mathrm{e}-097.00000 \mathrm{e}-02$ $3.03217 \mathrm{e}+003.03217 \mathrm{e}+003.03217 \mathrm{e}-01$ 1.00000e-09 2.12000e-01 
$3.03217 \mathrm{e}+003.03217 \mathrm{e}+00$ 3.03217e-01 1.00000e-09 2.12000e-01 $3.03217 \mathrm{e}+003.03217 \mathrm{e}+003.03217 \mathrm{e}-01$ 1.00000e-09 2.12000e-01 $1.00000 \mathrm{e}-02$ 1.00000e-02 1.00000e-03 1.00000e-09 1.00000e-01 $1.00000 \mathrm{e}+001.00000 \mathrm{e}+001.00000 \mathrm{e}-011.00000 \mathrm{e}-091.00000 \mathrm{e}-01$ Element: 981 \# of layers: 7

Kx Ky Kz Ss Por

$7.58858 \mathrm{e}+017.58858 \mathrm{e}+01$ 7.58858e+00 1.00000e-09 7.00000e-02

$7.58858 \mathrm{e}+017.58858 \mathrm{e}+017.58858 \mathrm{e}+001.00000 \mathrm{e}-09$ 7.00000e-02 $3.03217 \mathrm{e}+003.03217 \mathrm{e}+003.03217 \mathrm{e}-011.00000 \mathrm{e}-092.12000 \mathrm{e}-01$ $3.03217 \mathrm{e}+003.03217 \mathrm{e}+003.03217 \mathrm{e}-011.00000 \mathrm{e}-092.12000 \mathrm{e}-01$ $3.03217 \mathrm{e}+003.03217 \mathrm{e}+003.03217 \mathrm{e}-01$ 1.00000e-09 2.12000e-01 $1.00000 \mathrm{e}-021.00000 \mathrm{e}-02$ 1.00000e-03 1.00000e-09 1.00000e-01 $1.00000 \mathrm{e}+001.00000 \mathrm{e}+001.00000 \mathrm{e}-011.00000 \mathrm{e}-091.00000 \mathrm{e}-01$ Element: 982 \# of layers: 7

Kx Ky Kz Ss Por

$7.58858 \mathrm{e}+01$ 7.58858e+01 7.58858e+00 1.00000e-09 7.00000e-02 $7.58858 \mathrm{e}+017.58858 \mathrm{e}+017.58858 \mathrm{e}+001.00000 \mathrm{e}-09$ 7.00000e-02 $3.03217 \mathrm{e}+003.03217 \mathrm{e}+003.03217 \mathrm{e}-011.00000 \mathrm{e}-092.12000 \mathrm{e}-01$ $3.03217 \mathrm{e}+003.03217 \mathrm{e}+003.03217 \mathrm{e}-01$ 1.00000e-09 2.12000e-01 $3.03217 \mathrm{e}+003.03217 \mathrm{e}+00$ 3.03217e-01 1.00000e-09 2.12000e-01 $1.00000 \mathrm{e}-021.00000 \mathrm{e}-02$ 1.00000e-03 1.00000e-09 1.00000e-01 $1.00000 \mathrm{e}+001.00000 \mathrm{e}+001.00000 \mathrm{e}-011.00000 \mathrm{e}-091.00000 \mathrm{e}-01$ Element: 983 \# of layers: 7

Kx Ky Kz Ss Por

$7.58858 \mathrm{e}+017.58858 \mathrm{e}+017.58858 \mathrm{e}+001.00000 \mathrm{e}-09$ 7.00000e-02 $3.03217 \mathrm{e}+003.03217 \mathrm{e}+003.03217 \mathrm{e}-011.00000 \mathrm{e}-09$ 2.12000e-01 $3.03217 \mathrm{e}+003.03217 \mathrm{e}+003.03217 \mathrm{e}-011.00000 \mathrm{e}-092.12000 \mathrm{e}-01$ $3.03217 \mathrm{e}+003.03217 \mathrm{e}+003.03217 \mathrm{e}-011.00000 \mathrm{e}-092.12000 \mathrm{e}-01$ $3.03217 \mathrm{e}+003.03217 \mathrm{e}+003.03217 \mathrm{e}-011.00000 \mathrm{e}-09$ 2.12000e-01 $1.00000 \mathrm{e}-02$ 1.00000e-02 1.00000e-03 1.00000e-09 1.00000e-01 $1.00000 \mathrm{e}+001.00000 \mathrm{e}+001.00000 \mathrm{e}-011.00000 \mathrm{e}-091.00000 \mathrm{e}-01$ Element: 984 \# of layers: 7

Kx Ky Kz Ss Por

$7.58858 \mathrm{e}+017.58858 \mathrm{e}+017.58858 \mathrm{e}+00$ 1.00000e-09 7.00000e-02 $3.03217 \mathrm{e}+003.03217 \mathrm{e}+003.03217 \mathrm{e}-011.00000 \mathrm{e}-092.12000 \mathrm{e}-01$ $3.03217 \mathrm{e}+003.03217 \mathrm{e}+003.03217 \mathrm{e}-01$ 1.00000e-09 2.12000e-01 $3.03217 \mathrm{e}+003.03217 \mathrm{e}+003.03217 \mathrm{e}-01$ 1.00000e-09 2.12000e-01 $3.03217 \mathrm{e}+003.03217 \mathrm{e}+00$ 3.03217e-01 1.00000e-09 2.12000e-01 $1.00000 \mathrm{e}-02$ 1.00000e-02 1.00000e-03 1.00000e-09 1.00000e-01 $1.00000 \mathrm{e}+001.00000 \mathrm{e}+001.00000 \mathrm{e}-011.00000 \mathrm{e}-091.00000 \mathrm{e}-01$ Element: 985 \# of layers: 7

Kx Ky Kz Ss Por

7.58858e+01 7.58858e+01 7.58858e+00 1.00000e-09 7.00000e-02 $3.03217 \mathrm{e}+003.03217 \mathrm{e}+003.03217 \mathrm{e}-011.00000 \mathrm{e}-092.12000 \mathrm{e}-01$ $3.03217 \mathrm{e}+003.03217 \mathrm{e}+003.03217 \mathrm{e}-011.00000 \mathrm{e}-092.12000 \mathrm{e}-01$ $3.03217 \mathrm{e}+003.03217 \mathrm{e}+003.03217 \mathrm{e}-01$ 1.00000e-09 2.12000e-01 
3.03217e+00 3.03217e+00 3.03217e-01 1.00000e-09 2.12000e-01 $1.00000 \mathrm{e}-02$ 1.00000e-02 1.00000e-03 1.00000e-09 1.00000e-01 $1.00000 \mathrm{e}+001.00000 \mathrm{e}+001.00000 \mathrm{e}-01$ 1.00000e-09 1.00000e-01 Element: 986 \# of layers: 7

$\mathrm{Kx} \mathrm{Ky} \mathrm{Kz}$ Ss Por

7.58858e+01 7.58858e+01 7.58858e+00 1.00000e-09 7.00000e-02 $3.03217 \mathrm{e}+00$ 3.03217e+00 3.03217e-01 1.00000e-09 2.12000e-01 $3.03217 \mathrm{e}+003.03217 \mathrm{e}+00$ 3.03217e-01 1.00000e-09 2.12000e-01 $3.03217 \mathrm{e}+003.03217 \mathrm{e}+00$ 3.03217e-01 1.00000e-09 2.12000e-01 $3.03217 \mathrm{e}+003.03217 \mathrm{e}+00$ 3.03217e-01 1.00000e-09 2.12000e-01 $1.00000 \mathrm{e}-02$ 1.00000e-02 1.00000e-03 1.00000e-09 1.00000e-01 $1.00000 \mathrm{e}+001.00000 \mathrm{e}+001.00000 \mathrm{e}-011.00000 \mathrm{e}-091.00000 \mathrm{e}-01$ Element: 987 \# of layers: 7

$\mathrm{Kx} \mathrm{Ky} \mathrm{Kz}$ Ss Por

7.58858e+01 7.58858e+01 7.58858e+00 1.00000e-09 7.00000e-02 $3.03217 \mathrm{e}+003.03217 \mathrm{e}+00$ 3.03217e-01 1.00000e-09 2.12000e-01 3.03217e+00 3.03217e+00 3.03217e-01 1.00000e-09 2.12000e-01 3.03217e+00 3.03217e+00 3.03217e-01 1.00000e-09 2.12000e-01 $3.03217 \mathrm{e}+003.03217 \mathrm{e}+00$ 3.03217e-01 1.00000e-09 2.12000e-01 $1.00000 \mathrm{e}-02$ 1.00000e-02 1.00000e-03 1.00000e-09 1.00000e-01 $1.00000 \mathrm{e}+001.00000 \mathrm{e}+001.00000 \mathrm{e}-011.00000 \mathrm{e}-091.00000 \mathrm{e}-01$ Element: 988 \# of layers: 7

$\mathrm{Kx} \mathrm{Ky} \mathrm{Kz}$ Ss Por

7.58858e+01 7.58858e+01 7.58858e+00 1.00000e-09 7.00000e-02 $3.03217 \mathrm{e}+003.03217 \mathrm{e}+00$ 3.03217e-01 1.00000e-09 2.12000e-01 $3.03217 \mathrm{e}+003.03217 \mathrm{e}+00$ 3.03217e-01 1.00000e-09 2.12000e-01 $3.03217 \mathrm{e}+003.03217 \mathrm{e}+00$ 3.03217e-01 1.00000e-09 2.12000e-01 $3.03217 \mathrm{e}+00$ 3.03217e+00 3.03217e-01 1.00000e-09 2.12000e-01 $1.00000 \mathrm{e}-02$ 1.00000e-02 1.00000e-03 1.00000e-09 1.00000e-01 $1.00000 \mathrm{e}+001.00000 \mathrm{e}+001.00000 \mathrm{e}-011.00000 \mathrm{e}-091.00000 \mathrm{e}-01$ Element: 989 \# of layers: 7

$\mathrm{Kx} \mathrm{Ky} \mathrm{Kz}$ Ss Por

7.46199e+01 7.46199e+01 7.46199e+00 1.00000e-09 7.00000e-02 $7.46199 \mathrm{e}+01$ 7.46199e+01 7.46199e+00 1.00000e-09 7.00000e-02 $2.98154 \mathrm{e}+002.98154 \mathrm{e}+002.98154 \mathrm{e}-01$ 1.00000e-09 2.12000e-01 $2.98154 \mathrm{e}+002.98154 \mathrm{e}+002.98154 \mathrm{e}-01$ 1.00000e-09 2.12000e-01 $2.98154 \mathrm{e}+002.98154 \mathrm{e}+002.98154 \mathrm{e}-01$ 1.00000e-09 2.12000e-01 $1.00000 \mathrm{e}-02$ 1.00000e-02 1.00000e-03 1.00000e-09 1.00000e-01 $1.00000 \mathrm{e}+001.00000 \mathrm{e}+001.00000 \mathrm{e}-011.00000 \mathrm{e}-091.00000 \mathrm{e}-01$ Element: 990 \# of layers: 7

$\mathrm{Kx} \mathrm{Ky} \mathrm{Kz}$ Ss Por

7.46199e+01 7.46199e+01 7.46199e+00 1.00000e-09 7.00000e-02 7.46199e+01 7.46199e+01 7.46199e+00 1.00000e-09 7.00000e-02 $2.98154 \mathrm{e}+002.98154 \mathrm{e}+002.98154 \mathrm{e}-01$ 1.00000e-09 2.12000e-01 $2.98154 \mathrm{e}+002.98154 \mathrm{e}+002.98154 \mathrm{e}-01$ 1.00000e-09 2.12000e-01 $2.98154 \mathrm{e}+002.98154 \mathrm{e}+002.98154 \mathrm{e}-011.00000 \mathrm{e}-092.12000 \mathrm{e}-01$ 
$1.00000 \mathrm{e}-02$ 1.00000e-02 1.00000e-03 1.00000e-09 1.00000e-01 $1.00000 \mathrm{e}+001.00000 \mathrm{e}+001.00000 \mathrm{e}-01$ 1.00000e-09 1.00000e-01 Element: 991 \# of layers: 7

Kx Ky Kz Ss Por

7.46199e+01 7.46199e+01 7.46199e+00 1.00000e-09 7.00000e-02

7.46199e+01 7.46199e+01 7.46199e+00 1.00000e-09 7.00000e-02 $2.98154 \mathrm{e}+002.98154 \mathrm{e}+002.98154 \mathrm{e}-01$ 1.00000e-09 2.12000e-01 $2.98154 \mathrm{e}+002.98154 \mathrm{e}+002.98154 \mathrm{e}-01$ 1.00000e-09 2.12000e-01 $2.98154 \mathrm{e}+002.98154 \mathrm{e}+002.98154 \mathrm{e}-01$ 1.00000e-09 2.12000e-01 $1.00000 \mathrm{e}-02$ 1.00000e-02 1.00000e-03 1.00000e-09 1.00000e-01 $1.00000 \mathrm{e}+001.00000 \mathrm{e}+001.00000 \mathrm{e}-011.00000 \mathrm{e}-091.00000 \mathrm{e}-01$ Element: 992 \# of layers: 7

$\mathrm{Kx} \mathrm{Ky} \mathrm{Kz}$ Ss Por

7.46199e+01 7.46199e+01 7.46199e+00 1.00000e-09 7.00000e-02 $7.46199 \mathrm{e}+01$ 7.46199e+01 7.46199e+00 1.00000e-09 7.00000e-02 $2.98154 \mathrm{e}+002.98154 \mathrm{e}+002.98154 \mathrm{e}-01$ 1.00000e-09 2.12000e-01 $2.98154 \mathrm{e}+002.98154 \mathrm{e}+002.98154 \mathrm{e}-01$ 1.00000e-09 2.12000e-01 $2.98154 \mathrm{e}+002.98154 \mathrm{e}+002.98154 \mathrm{e}-01$ 1.00000e-09 2.12000e-01 $1.00000 \mathrm{e}-02$ 1.00000e-02 1.00000e-03 1.00000e-09 1.00000e-01 $1.00000 \mathrm{e}+001.00000 \mathrm{e}+001.00000 \mathrm{e}-011.00000 \mathrm{e}-091.00000 \mathrm{e}-01$ Element: 993 \# of layers: 6

$\mathrm{Kx} \mathrm{Ky} \mathrm{Kz}$ Ss Por

7.46199e+01 7.46199e+01 7.46199e+00 1.00000e-09 7.00000e-02 $2.98154 \mathrm{e}+002.98154 \mathrm{e}+002.98154 \mathrm{e}-01$ 1.00000e-09 2.12000e-01 $2.98154 \mathrm{e}+002.98154 \mathrm{e}+00 \quad 2.98154 \mathrm{e}-011.00000 \mathrm{e}-092.12000 \mathrm{e}-01$ $2.98154 \mathrm{e}+002.98154 \mathrm{e}+002.98154 \mathrm{e}-01$ 1.00000e-09 2.12000e-01 $1.00000 \mathrm{e}-02$ 1.00000e-02 1.00000e-03 1.00000e-09 1.00000e-01 $1.00000 \mathrm{e}+001.00000 \mathrm{e}+001.00000 \mathrm{e}-011.00000 \mathrm{e}-091.00000 \mathrm{e}-01$ Element: 994 \# of layers: 7

$\mathrm{Kx} \mathrm{Ky} \mathrm{Kz}$ Ss Por

7.46199e+01 7.46199e+01 7.46199e+00 1.00000e-09 7.00000e-02 $2.98154 \mathrm{e}+002.98154 \mathrm{e}+002.98154 \mathrm{e}-01$ 1.00000e-09 2.12000e-01 $2.98154 \mathrm{e}+002.98154 \mathrm{e}+002.98154 \mathrm{e}-01$ 1.00000e-09 2.12000e-01 $2.98154 \mathrm{e}+002.98154 \mathrm{e}+002.98154 \mathrm{e}-01$ 1.00000e-09 2.12000e-01 $2.98154 \mathrm{e}+002.98154 \mathrm{e}+002.98154 \mathrm{e}-01$ 1.00000e-09 2.12000e-01 1.00000e-02 1.00000e-02 1.00000e-03 1.00000e-09 1.00000e-01 $1.00000 \mathrm{e}+001.00000 \mathrm{e}+001.00000 \mathrm{e}-011.00000 \mathrm{e}-091.00000 \mathrm{e}-01$ Element: 995 \# of layers: 7

$\mathrm{Kx} \mathrm{Ky} \mathrm{Kz}$ Ss Por

7.46199e+01 7.46199e+01 7.46199e+00 1.00000e-09 7.00000e-02 $2.98154 \mathrm{e}+002.98154 \mathrm{e}+002.98154 \mathrm{e}-01$ 1.00000e-09 2.12000e-01 $2.98154 \mathrm{e}+002.98154 \mathrm{e}+002.98154 \mathrm{e}-01$ 1.00000e-09 2.12000e-01 $2.98154 \mathrm{e}+002.98154 \mathrm{e}+002.98154 \mathrm{e}-01$ 1.00000e-09 2.12000e-01 $2.98154 \mathrm{e}+002.98154 \mathrm{e}+00$ 2.98154e-01 1.00000e-09 2.12000e-01 $1.00000 \mathrm{e}-02$ 1.00000e-02 1.00000e-03 1.00000e-09 1.00000e-01 $1.00000 \mathrm{e}+001.00000 \mathrm{e}+001.00000 \mathrm{e}-011.00000 \mathrm{e}-091.00000 \mathrm{e}-01$ 
Element: 996 \# of layers: 7

$\mathrm{Kx} \mathrm{Ky} \mathrm{Kz}$ Ss Por

7.46199e+01 7.46199e+01 7.46199e+00 1.00000e-09 7.00000e-02

$2.98154 \mathrm{e}+002.98154 \mathrm{e}+002.98154 \mathrm{e}-01$ 1.00000e-09 2.12000e-01

$2.98154 \mathrm{e}+002.98154 \mathrm{e}+002.98154 \mathrm{e}-01$ 1.00000e-09 2.12000e-01

$2.98154 \mathrm{e}+002.98154 \mathrm{e}+002.98154 \mathrm{e}-01$ 1.00000e-09 2.12000e-01

$2.98154 \mathrm{e}+002.98154 \mathrm{e}+002.98154 \mathrm{e}-01$ 1.00000e-09 2.12000e-01

$1.00000 \mathrm{e}-02$ 1.00000e-02 1.00000e-03 1.00000e-09 1.00000e-01

$1.00000 \mathrm{e}+001.00000 \mathrm{e}+001.00000 \mathrm{e}-011.00000 \mathrm{e}-091.00000 \mathrm{e}-01$

Element: 997 \# of layers: 8

$\mathrm{Kx} \mathrm{Ky} \mathrm{Kz}$ Ss Por

7.46199e+01 7.46199e+01 7.46199e+00 1.00000e-09 7.00000e-02

$7.46199 \mathrm{e}+01$ 7.46199e+01 7.46199e+00 1.00000e-09 7.00000e-02

$2.98154 \mathrm{e}+002.98154 \mathrm{e}+002.98154 \mathrm{e}-01$ 1.00000e-09 2.12000e-01

$2.98154 \mathrm{e}+002.98154 \mathrm{e}+002.98154 \mathrm{e}-01$ 1.00000e-09 2.12000e-01

$2.98154 \mathrm{e}+002.98154 \mathrm{e}+002.98154 \mathrm{e}-01$ 1.00000e-09 2.12000e-01

$2.98154 \mathrm{e}+002.98154 \mathrm{e}+002.98154 \mathrm{e}-01$ 1.00000e-09 2.12000e-01

$1.00000 \mathrm{e}-02$ 1.00000e-02 1.00000e-03 1.00000e-09 1.00000e-01

$1.00000 \mathrm{e}+001.00000 \mathrm{e}+001.00000 \mathrm{e}-011.00000 \mathrm{e}-091.00000 \mathrm{e}-01$

Element: 998 \# of layers: 7

$\mathrm{Kx} \mathrm{Ky} \mathrm{Kz}$ Ss Por

5.52295e+01 5.52295e+01 5.52295e+00 1.00000e-09 7.00000e-02

$5.52295 \mathrm{e}+015.52295 \mathrm{e}+015.52295 \mathrm{e}+001.00000 \mathrm{e}-09$ 7.00000e-02

$2.20676 \mathrm{e}+00$ 2.20676e+00 2.20676e-01 1.00000e-09 2.12000e-01

$2.20676 \mathrm{e}+002.20676 \mathrm{e}+00$ 2.20676e-01 1.00000e-09 2.12000e-01

$2.20676 \mathrm{e}+002.20676 \mathrm{e}+00$ 2.20676e-01 1.00000e-09 2.12000e-01

$1.00000 \mathrm{e}-02$ 1.00000e-02 1.00000e-03 1.00000e-09 1.00000e-01

$1.00000 \mathrm{e}+001.00000 \mathrm{e}+001.00000 \mathrm{e}-011.00000 \mathrm{e}-091.00000 \mathrm{e}-01$

Element: 999 \# of layers: 7

$\mathrm{Kx} \mathrm{Ky} \mathrm{Kz}$ Ss Por

5.52295e+01 5.52295e+01 5.52295e+00 1.00000e-09 7.00000e-02

5.52295e+01 5.52295e+01 5.52295e+00 1.00000e-09 7.00000e-02

$2.20676 \mathrm{e}+002.20676 \mathrm{e}+002.20676 \mathrm{e}-01$ 1.00000e-09 2.12000e-01

2.20676e+00 2.20676e+00 2.20676e-01 1.00000e-09 2.12000e-01

$2.20676 \mathrm{e}+002.20676 \mathrm{e}+00$ 2.20676e-01 1.00000e-09 2.12000e-01

$1.00000 \mathrm{e}-02$ 1.00000e-02 1.00000e-03 1.00000e-09 1.00000e-01

$1.00000 \mathrm{e}+001.00000 \mathrm{e}+001.00000 \mathrm{e}-011.00000 \mathrm{e}-091.00000 \mathrm{e}-01$

Element: 1000 \# of layers: 7

$\mathrm{Kx} \mathrm{Ky} \mathrm{Kz}$ Ss Por

5.52295e+01 5.52295e+01 5.52295e+00 1.00000e-09 7.00000e-02

$5.52295 \mathrm{e}+015.52295 \mathrm{e}+015.52295 \mathrm{e}+001.00000 \mathrm{e}-09$ 7.00000e-02

$2.20676 \mathrm{e}+002.20676 \mathrm{e}+00$ 2.20676e-01 1.00000e-09 2.12000e-01

2.20676e+00 2.20676e+00 2.20676e-01 1.00000e-09 2.12000e-01

$2.20676 \mathrm{e}+00$ 2.20676e+00 2.20676e-01 1.00000e-09 2.12000e-01

$1.00000 \mathrm{e}-02$ 1.00000e-02 1.00000e-03 1.00000e-09 1.00000e-01

$1.00000 \mathrm{e}+001.00000 \mathrm{e}+001.00000 \mathrm{e}-011.00000 \mathrm{e}-091.00000 \mathrm{e}-01$ 
Element: 1001 \# of layers: 11

$\mathrm{Kx} \mathrm{Ky} \mathrm{Kz}$ Ss Por

$2.18574 \mathrm{e}+02$ 2.18574e+02 2.18574e+01 1.00000e-09 7.00000e-02

$2.18574 \mathrm{e}+02$ 2.18574e+02 2.18574e+01 1.00000e-09 7.00000e-02

8.73356e+00 8.73356e+00 8.73356e-01 1.00000e-09 2.12000e-01

$8.73356 \mathrm{e}+00$ 8.73356e+00 8.73356e-01 1.00000e-09 2.12000e-01

8.73356e+00 8.73356e+00 8.73356e-01 1.00000e-09 2.12000e-01

$8.73356 \mathrm{e}+00$ 8.73356e+00 8.73356e-01 1.00000e-09 2.12000e-01

8.73356e+00 8.73356e+00 8.73356e-01 1.00000e-09 2.12000e-01

$1.00000 \mathrm{e}-02$ 1.00000e-02 1.00000e-03 1.00000e-09 1.00000e-01

$1.00000 \mathrm{e}+001.00000 \mathrm{e}+001.00000 \mathrm{e}-011.00000 \mathrm{e}-091.00000 \mathrm{e}-01$

$1.00000 \mathrm{e}-05$ 1.00000e-05 1.00000e-06 1.00000e-09 1.00000e-01

$1.00000 \mathrm{e}+001.00000 \mathrm{e}+001.00000 \mathrm{e}-01$ 1.00000e-09 1.00000e-01

Element: 1002 \# of layers: 10

$\mathrm{Kx} \mathrm{Ky} \mathrm{Kz}$ Ss Por

2.18574e+02 2.18574e+02 2.18574e+01 1.00000e-09 7.00000e-02

8.73356e+00 8.73356e+00 8.73356e-01 1.00000e-09 2.12000e-01

8.73356e+00 8.73356e+00 8.73356e-01 1.00000e-09 2.12000e-01

8.73356e+00 8.73356e+00 8.73356e-01 1.00000e-09 2.12000e-01

$8.73356 \mathrm{e}+00$ 8.73356e+00 8.73356e-01 1.00000e-09 2.12000e-01

$8.73356 \mathrm{e}+00$ 8.73356e+00 8.73356e-01 1.00000e-09 2.12000e-01

$1.00000 \mathrm{e}-02$ 1.00000e-02 1.00000e-03 1.00000e-09 1.00000e-01

$1.00000 \mathrm{e}+001.00000 \mathrm{e}+001.00000 \mathrm{e}-011.00000 \mathrm{e}-091.00000 \mathrm{e}-01$

$1.00000 \mathrm{e}-05$ 1.00000e-05 1.00000e-06 1.00000e-09 1.00000e-01

$1.00000 \mathrm{e}+001.00000 \mathrm{e}+001.00000 \mathrm{e}-01$ 1.00000e-09 1.00000e-01

Element: 1003 \# of layers: 10

$\mathrm{Kx} \mathrm{Ky} \mathrm{Kz}$ Ss Por

2.18574e+02 2.18574e+02 2.18574e+01 1.00000e-09 7.00000e-02

$8.73356 \mathrm{e}+00$ 8.73356e+00 8.73356e-01 1.00000e-09 2.12000e-01

8.73356e+00 8.73356e+00 8.73356e-01 1.00000e-09 2.12000e-01

$8.73356 \mathrm{e}+00$ 8.73356e+00 8.73356e-01 1.00000e-09 2.12000e-01

$8.73356 \mathrm{e}+00$ 8.73356e+00 8.73356e-01 1.00000e-09 2.12000e-01

$8.73356 \mathrm{e}+008.73356 \mathrm{e}+00$ 8.73356e-01 1.00000e-09 2.12000e-01

$1.00000 \mathrm{e}-02$ 1.00000e-02 1.00000e-03 1.00000e-09 1.00000e-01

$1.00000 \mathrm{e}+001.00000 \mathrm{e}+001.00000 \mathrm{e}-011.00000 \mathrm{e}-091.00000 \mathrm{e}-01$

$1.00000 \mathrm{e}-05$ 1.00000e-05 1.00000e-06 1.00000e-09 1.00000e-01

$1.00000 \mathrm{e}+001.00000 \mathrm{e}+001.00000 \mathrm{e}-011.00000 \mathrm{e}-091.00000 \mathrm{e}-01$

Element: 1004 \# of layers: 10

$\mathrm{Kx} \mathrm{Ky} \mathrm{Kz}$ Ss Por

2.18574e+02 2.18574e+02 2.18574e+01 1.00000e-09 7.00000e-02

8.73356e+00 8.73356e+00 8.73356e-01 1.00000e-09 2.12000e-01

$8.73356 \mathrm{e}+00$ 8.73356e+00 8.73356e-01 1.00000e-09 2.12000e-01

8.73356e+00 8.73356e+00 8.73356e-01 1.00000e-09 2.12000e-01

8.73356e+00 8.73356e+00 8.73356e-01 1.00000e-09 2.12000e-01

8.73356e+00 8.73356e+00 8.73356e-01 1.00000e-09 2.12000e-01

$1.00000 \mathrm{e}-02$ 1.00000e-02 1.00000e-03 1.00000e-09 1.00000e-01 
$1.00000 \mathrm{e}+001.00000 \mathrm{e}+001.00000 \mathrm{e}-011.00000 \mathrm{e}-091.00000 \mathrm{e}-01$ $1.00000 \mathrm{e}-05$ 1.00000e-05 1.00000e-06 1.00000e-09 1.00000e-01 $1.00000 \mathrm{e}+001.00000 \mathrm{e}+001.00000 \mathrm{e}-011.00000 \mathrm{e}-09$ 1.00000e-01 Element: 1005 \# of layers: 11

$\mathrm{Kx} \mathrm{Ky} \mathrm{Kz}$ Ss Por

$2.18574 \mathrm{e}+02$ 2.18574e+02 2.18574e+01 1.00000e-09 7.00000e-02 $2.18574 \mathrm{e}+02$ 2.18574e+02 2.18574e+01 1.00000e-09 7.00000e-02 8.73356e+00 8.73356e+00 8.73356e-01 1.00000e-09 2.12000e-01 8.73356e+00 8.73356e+00 8.73356e-01 1.00000e-09 2.12000e-01 8.73356e+00 8.73356e+00 8.73356e-01 1.00000e-09 2.12000e-01 8.73356e+00 8.73356e+00 8.73356e-01 1.00000e-09 2.12000e-01 $8.73356 \mathrm{e}+008.73356 \mathrm{e}+00$ 8.73356e-01 1.00000e-09 2.12000e-01 $1.00000 \mathrm{e}-02$ 1.00000e-02 1.00000e-03 1.00000e-09 1.00000e-01 $1.00000 \mathrm{e}+001.00000 \mathrm{e}+001.00000 \mathrm{e}-011.00000 \mathrm{e}-091.00000 \mathrm{e}-01$ $1.00000 \mathrm{e}-051.00000 \mathrm{e}-051.00000 \mathrm{e}-061.00000 \mathrm{e}-091.00000 \mathrm{e}-01$ $1.00000 \mathrm{e}+001.00000 \mathrm{e}+001.00000 \mathrm{e}-011.00000 \mathrm{e}-091.00000 \mathrm{e}-01$ Element: 1006 \# of layers: 11

$\mathrm{Kx} \mathrm{Ky} \mathrm{Kz}$ Ss Por

1.90949e+02 1.90949e+02 1.90949e+01 1.00000e-09 7.00000e-02 $1.90949 \mathrm{e}+02$ 1.90949e+02 1.90949e+01 1.00000e-09 7.00000e-02 $7.62969 \mathrm{e}+00$ 7.62969e+00 7.62969e-01 1.00000e-09 2.12000e-01 7.62969e+00 7.62969e+00 7.62969e-01 1.00000e-09 2.12000e-01 $7.62969 \mathrm{e}+00$ 7.62969e+00 7.62969e-01 1.00000e-09 2.12000e-01 $7.62969 \mathrm{e}+00$ 7.62969e+00 7.62969e-01 1.00000e-09 2.12000e-01 $7.62969 \mathrm{e}+007.62969 \mathrm{e}+00$ 7.62969e-01 1.00000e-09 2.12000e-01 $1.00000 \mathrm{e}-02$ 1.00000e-02 1.00000e-03 1.00000e-09 1.00000e-01 $1.00000 \mathrm{e}+001.00000 \mathrm{e}+001.00000 \mathrm{e}-011.00000 \mathrm{e}-091.00000 \mathrm{e}-01$ $1.00000 \mathrm{e}-05$ 1.00000e-05 1.00000e-06 1.00000e-09 1.00000e-01 $1.00000 \mathrm{e}+001.00000 \mathrm{e}+001.00000 \mathrm{e}-011.00000 \mathrm{e}-091.00000 \mathrm{e}-01$ Element: 1007 \# of layers: 10

$\mathrm{Kx} \mathrm{Ky} \mathrm{Kz}$ Ss Por

1.90949e+02 1.90949e+02 1.90949e+01 1.00000e-09 7.00000e-02 $7.62969 \mathrm{e}+00$ 7.62969e+00 7.62969e-01 1.00000e-09 2.12000e-01 $7.62969 \mathrm{e}+00$ 7.62969e+00 7.62969e-01 1.00000e-09 2.12000e-01 $7.62969 \mathrm{e}+00$ 7.62969e+00 7.62969e-01 1.00000e-09 2.12000e-01 $7.62969 \mathrm{e}+00$ 7.62969e+00 7.62969e-01 1.00000e-09 2.12000e-01 $7.62969 \mathrm{e}+00$ 7.62969e+00 7.62969e-01 1.00000e-09 2.12000e-01 $1.00000 \mathrm{e}-02$ 1.00000e-02 1.00000e-03 1.00000e-09 1.00000e-01 $1.00000 \mathrm{e}+001.00000 \mathrm{e}+001.00000 \mathrm{e}-011.00000 \mathrm{e}-091.00000 \mathrm{e}-01$ $1.00000 \mathrm{e}-05$ 1.00000e-05 1.00000e-06 1.00000e-09 1.00000e-01 $1.00000 \mathrm{e}+001.00000 \mathrm{e}+001.00000 \mathrm{e}-011.00000 \mathrm{e}-091.00000 \mathrm{e}-01$ Element: 1008 \# of layers: 10

$\mathrm{Kx} \mathrm{Ky} \mathrm{Kz}$ Ss Por 1.90949e+02 1.90949e+02 1.90949e+01 1.00000e-09 7.00000e-02 $7.62969 \mathrm{e}+00$ 7.62969e+00 7.62969e-01 1.00000e-09 2.12000e-01 $7.62969 \mathrm{e}+00$ 7.62969e+00 7.62969e-01 1.00000e-09 2.12000e-01 
7.62969e+00 7.62969e+00 7.62969e-01 1.00000e-09 2.12000e-01 $7.62969 \mathrm{e}+00$ 7.62969e+00 7.62969e-01 1.00000e-09 2.12000e-01 $7.62969 \mathrm{e}+00$ 7.62969e+00 7.62969e-01 1.00000e-09 2.12000e-01 $1.00000 \mathrm{e}-02$ 1.00000e-02 1.00000e-03 1.00000e-09 1.00000e-01 $1.00000 \mathrm{e}+001.00000 \mathrm{e}+001.00000 \mathrm{e}-011.00000 \mathrm{e}-091.00000 \mathrm{e}-01$ $1.00000 \mathrm{e}-05$ 1.00000e-05 1.00000e-06 1.00000e-09 1.00000e-01 $1.00000 \mathrm{e}+001.00000 \mathrm{e}+001.00000 \mathrm{e}-011.00000 \mathrm{e}-091.00000 \mathrm{e}-01$ Element: 1009 \# of layers: 11

$\mathrm{Kx} \mathrm{Ky} \mathrm{Kz}$ Ss Por

$1.90949 \mathrm{e}+02$ 1.90949e+02 1.90949e+01 1.00000e-09 7.00000e-02 $1.90949 \mathrm{e}+02$ 1.90949e+02 1.90949e+01 1.00000e-09 7.00000e-02 $7.62969 \mathrm{e}+00$ 7.62969e+00 7.62969e-01 1.00000e-09 2.12000e-01 $7.62969 \mathrm{e}+00$ 7.62969e+00 7.62969e-01 1.00000e-09 2.12000e-01 7.62969e+00 7.62969e+00 7.62969e-01 1.00000e-09 2.12000e-01 7.62969e+00 7.62969e+00 7.62969e-01 1.00000e-09 2.12000e-01 $7.62969 \mathrm{e}+00$ 7.62969e+00 7.62969e-01 1.00000e-09 2.12000e-01 $1.00000 \mathrm{e}-02$ 1.00000e-02 1.00000e-03 1.00000e-09 1.00000e-01 $1.00000 \mathrm{e}+001.00000 \mathrm{e}+001.00000 \mathrm{e}-011.00000 \mathrm{e}-091.00000 \mathrm{e}-01$ $1.00000 \mathrm{e}-051.00000 \mathrm{e}-051.00000 \mathrm{e}-061.00000 \mathrm{e}-091.00000 \mathrm{e}-01$ $1.00000 \mathrm{e}+001.00000 \mathrm{e}+001.00000 \mathrm{e}-011.00000 \mathrm{e}-091.00000 \mathrm{e}-01$ Element: 1010 \# of layers: 10

$\mathrm{Kx} \mathrm{Ky} \mathrm{Kz}$ Ss Por

1.90949e+02 1.90949e+02 1.90949e+01 1.00000e-09 7.00000e-02 $7.62969 \mathrm{e}+00$ 7.62969e+00 7.62969e-01 1.00000e-09 2.12000e-01 $7.62969 \mathrm{e}+007.62969 \mathrm{e}+00$ 7.62969e-01 1.00000e-09 2.12000e-01 7.62969e+00 7.62969e+00 7.62969e-01 1.00000e-09 2.12000e-01 $7.62969 \mathrm{e}+00$ 7.62969e+00 7.62969e-01 1.00000e-09 2.12000e-01 $7.62969 \mathrm{e}+00$ 7.62969e+00 7.62969e-01 1.00000e-09 2.12000e-01 $1.00000 \mathrm{e}-02$ 1.00000e-02 1.00000e-03 1.00000e-09 1.00000e-01 $1.00000 \mathrm{e}+001.00000 \mathrm{e}+001.00000 \mathrm{e}-011.00000 \mathrm{e}-091.00000 \mathrm{e}-01$ $1.00000 \mathrm{e}-05$ 1.00000e-05 1.00000e-06 1.00000e-09 1.00000e-01 $1.00000 \mathrm{e}+001.00000 \mathrm{e}+001.00000 \mathrm{e}-01$ 1.00000e-09 1.00000e-01 Element: 1011 \# of layers: 10

$\mathrm{Kx} \mathrm{Ky} \mathrm{Kz}$ Ss Por

$1.90949 \mathrm{e}+02$ 1.90949e+02 1.90949e+01 1.00000e-09 7.00000e-02 7.62969e+00 7.62969e+00 7.62969e-01 1.00000e-09 2.12000e-01 $7.62969 \mathrm{e}+00$ 7.62969e+00 7.62969e-01 1.00000e-09 2.12000e-01 $7.62969 \mathrm{e}+00$ 7.62969e+00 7.62969e-01 1.00000e-09 2.12000e-01 $7.62969 \mathrm{e}+00$ 7.62969e+00 7.62969e-01 1.00000e-09 2.12000e-01 $7.62969 \mathrm{e}+00$ 7.62969e+00 7.62969e-01 1.00000e-09 2.12000e-01 $1.00000 \mathrm{e}-02$ 1.00000e-02 1.00000e-03 1.00000e-09 1.00000e-01 $1.00000 \mathrm{e}+001.00000 \mathrm{e}+001.00000 \mathrm{e}-011.00000 \mathrm{e}-091.00000 \mathrm{e}-01$ $1.00000 \mathrm{e}-051.00000 \mathrm{e}-051.00000 \mathrm{e}-061.00000 \mathrm{e}-091.00000 \mathrm{e}-01$ $1.00000 \mathrm{e}+001.00000 \mathrm{e}+001.00000 \mathrm{e}-011.00000 \mathrm{e}-091.00000 \mathrm{e}-01$ Element: 1012 \# of layers: 10

Kx Ky Kz Ss Por 
$1.90949 \mathrm{e}+02$ 1.90949e+02 1.90949e+01 1.00000e-09 7.00000e-02 $7.62969 \mathrm{e}+00$ 7.62969e+00 7.62969e-01 1.00000e-09 2.12000e-01 $7.62969 \mathrm{e}+00$ 7.62969e+00 7.62969e-01 1.00000e-09 2.12000e-01 $7.62969 \mathrm{e}+00$ 7.62969e+00 7.62969e-01 1.00000e-09 2.12000e-01 7.62969e+00 7.62969e+00 7.62969e-01 1.00000e-09 2.12000e-01 $7.62969 \mathrm{e}+00$ 7.62969e+00 7.62969e-01 1.00000e-09 2.12000e-01 $1.00000 \mathrm{e}-02$ 1.00000e-02 1.00000e-03 1.00000e-09 1.00000e-01 $1.00000 \mathrm{e}+001.00000 \mathrm{e}+001.00000 \mathrm{e}-011.00000 \mathrm{e}-091.00000 \mathrm{e}-01$ $1.00000 \mathrm{e}-05$ 1.00000e-05 1.00000e-06 1.00000e-09 1.00000e-01 $1.00000 \mathrm{e}+001.00000 \mathrm{e}+001.00000 \mathrm{e}-011.00000 \mathrm{e}-091.00000 \mathrm{e}-01$ Element: 1013 \# of layers: 11

$\mathrm{Kx} \mathrm{Ky} \mathrm{Kz}$ Ss Por

1.90949e+02 1.90949e+02 1.90949e+01 1.00000e-09 7.00000e-02 $1.90949 \mathrm{e}+02$ 1.90949e+02 1.90949e+01 1.00000e-09 7.00000e-02 $7.62969 \mathrm{e}+00$ 7.62969e+00 7.62969e-01 1.00000e-09 2.12000e-01 $7.62969 \mathrm{e}+00$ 7.62969e+00 7.62969e-01 1.00000e-09 2.12000e-01 $7.62969 \mathrm{e}+00$ 7.62969e+00 7.62969e-01 1.00000e-09 2.12000e-01 $7.62969 \mathrm{e}+00$ 7.62969e+00 7.62969e-01 1.00000e-09 2.12000e-01 $7.62969 \mathrm{e}+00$ 7.62969e+00 7.62969e-01 1.00000e-09 2.12000e-01 $1.00000 \mathrm{e}-02$ 1.00000e-02 1.00000e-03 1.00000e-09 1.00000e-01 $1.00000 \mathrm{e}+001.00000 \mathrm{e}+001.00000 \mathrm{e}-011.00000 \mathrm{e}-091.00000 \mathrm{e}-01$ $1.00000 \mathrm{e}-05$ 1.00000e-05 1.00000e-06 1.00000e-09 1.00000e-01 $1.00000 \mathrm{e}+001.00000 \mathrm{e}+001.00000 \mathrm{e}-01$ 1.00000e-09 1.00000e-01 Element: 1014 \# of layers: 11

$\mathrm{Kx} \mathrm{Ky} \mathrm{Kz}$ Ss Por

$1.90949 \mathrm{e}+02$ 1.90949e+02 1.90949e+01 1.00000e-09 7.00000e-02 $1.90949 \mathrm{e}+02$ 1.90949e+02 1.90949e+01 1.00000e-09 7.00000e-02 7.62969e+00 7.62969e+00 7.62969e-01 1.00000e-09 2.12000e-01 $7.62969 \mathrm{e}+00$ 7.62969e+00 7.62969e-01 1.00000e-09 2.12000e-01 $7.62969 \mathrm{e}+00$ 7.62969e+00 7.62969e-01 1.00000e-09 2.12000e-01 $7.62969 \mathrm{e}+00$ 7.62969e+00 7.62969e-01 1.00000e-09 2.12000e-01 $7.62969 \mathrm{e}+00$ 7.62969e+00 7.62969e-01 1.00000e-09 2.12000e-01 $1.00000 \mathrm{e}-02$ 1.00000e-02 1.00000e-03 1.00000e-09 1.00000e-01 $1.00000 \mathrm{e}+001.00000 \mathrm{e}+001.00000 \mathrm{e}-011.00000 \mathrm{e}-091.00000 \mathrm{e}-01$ $1.00000 \mathrm{e}-05$ 1.00000e-05 1.00000e-06 1.00000e-09 1.00000e-01 $1.00000 \mathrm{e}+001.00000 \mathrm{e}+001.00000 \mathrm{e}-01$ 1.00000e-09 1.00000e-01 Element: 1015 \# of layers: 10

$\mathrm{Kx} \mathrm{Ky} \mathrm{Kz}$ Ss Por $2.04815 \mathrm{e}+02$ 2.04815e+02 2.04815e+01 1.00000e-09 7.00000e-02 8.18388e+00 8.18388e+00 8.18388e-01 1.00000e-09 2.12000e-01 8.18388e+00 8.18388e+00 8.18388e-01 1.00000e-09 2.12000e-01 8.18388e+00 8.18388e+00 8.18388e-01 1.00000e-09 2.12000e-01 8.18388e+00 8.18388e+00 8.18388e-01 1.00000e-09 2.12000e-01 8.18388e+00 8.18388e+00 8.18388e-01 1.00000e-09 2.12000e-01 $1.00000 \mathrm{e}-02$ 1.00000e-02 1.00000e-03 1.00000e-09 1.00000e-01 $1.00000 \mathrm{e}+001.00000 \mathrm{e}+001.00000 \mathrm{e}-011.00000 \mathrm{e}-091.00000 \mathrm{e}-01$ 
$1.00000 \mathrm{e}-05$ 1.00000e-05 1.00000e-06 1.00000e-09 1.00000e-01 $1.00000 \mathrm{e}+001.00000 \mathrm{e}+001.00000 \mathrm{e}-01$ 1.00000e-09 1.00000e-01 Element: 1016 \# of layers: 10

Kx Ky Kz Ss Por

2.04815e+02 2.04815e+02 2.04815e+01 1.00000e-09 7.00000e-02

8.18388e+00 8.18388e+00 8.18388e-01 1.00000e-09 2.12000e-01

8.18388e+00 8.18388e+00 8.18388e-01 1.00000e-09 2.12000e-01

8.18388e+00 8.18388e+00 8.18388e-01 1.00000e-09 2.12000e-01

8.18388e+00 8.18388e+00 8.18388e-01 1.00000e-09 2.12000e-01

8.18388e+00 8.18388e+00 8.18388e-01 1.00000e-09 2.12000e-01

$1.00000 \mathrm{e}-02$ 1.00000e-02 1.00000e-03 1.00000e-09 1.00000e-01

$1.00000 \mathrm{e}+001.00000 \mathrm{e}+001.00000 \mathrm{e}-011.00000 \mathrm{e}-091.00000 \mathrm{e}-01$

$1.00000 \mathrm{e}-051.00000 \mathrm{e}-05$ 1.00000e-06 1.00000e-09 1.00000e-01

$1.00000 \mathrm{e}+001.00000 \mathrm{e}+001.00000 \mathrm{e}-011.00000 \mathrm{e}-091.00000 \mathrm{e}-01$

Element: 1017 \# of layers: 11

Kx Ky Kz Ss Por

2.04815e+02 2.04815e+02 2.04815e+01 1.00000e-09 7.00000e-02

$2.04815 \mathrm{e}+02$ 2.04815e+02 2.04815e+01 1.00000e-09 7.00000e-02

8.18388e+00 8.18388e+00 8.18388e-01 1.00000e-09 2.12000e-01

8.18388e+00 8.18388e+00 8.18388e-01 1.00000e-09 2.12000e-01

$8.18388 \mathrm{e}+00$ 8.18388e+00 8.18388e-01 1.00000e-09 2.12000e-01

8.18388e+00 8.18388e+00 8.18388e-01 1.00000e-09 2.12000e-01

8.18388e+00 8.18388e+00 8.18388e-01 1.00000e-09 2.12000e-01

1.00000e-02 1.00000e-02 1.00000e-03 1.00000e-09 1.00000e-01

$1.00000 \mathrm{e}+001.00000 \mathrm{e}+001.00000 \mathrm{e}-011.00000 \mathrm{e}-091.00000 \mathrm{e}-01$

$1.00000 \mathrm{e}-05$ 1.00000e-05 1.00000e-06 1.00000e-09 1.00000e-01

$1.00000 \mathrm{e}+001.00000 \mathrm{e}+001.00000 \mathrm{e}-011.00000 \mathrm{e}-091.00000 \mathrm{e}-01$

Element: 1018 \# of layers: 11

$\mathrm{Kx} \mathrm{Ky} \mathrm{Kz}$ Ss Por

$2.04815 \mathrm{e}+02$ 2.04815e+02 2.04815e+01 1.00000e-09 7.00000e-02

$2.04815 \mathrm{e}+02$ 2.04815e+02 2.04815e+01 1.00000e-09 7.00000e-02

8.18388e+00 8.18388e+00 8.18388e-01 1.00000e-09 2.12000e-01

8.18388e+00 8.18388e+00 8.18388e-01 1.00000e-09 2.12000e-01

8.18388e+00 8.18388e+00 8.18388e-01 1.00000e-09 2.12000e-01

8.18388e+00 8.18388e+00 8.18388e-01 1.00000e-09 2.12000e-01

8.18388e+00 8.18388e+00 8.18388e-01 1.00000e-09 2.12000e-01

1.00000e-02 1.00000e-02 1.00000e-03 1.00000e-09 1.00000e-01

$1.00000 \mathrm{e}+001.00000 \mathrm{e}+001.00000 \mathrm{e}-011.00000 \mathrm{e}-091.00000 \mathrm{e}-01$

$1.00000 \mathrm{e}-05$ 1.00000e-05 1.00000e-06 1.00000e-09 1.00000e-01

$1.00000 \mathrm{e}+001.00000 \mathrm{e}+001.00000 \mathrm{e}-01$ 1.00000e-09 1.00000e-01

Element: 1019 \# of layers: 10

$\mathrm{Kx} \mathrm{Ky} \mathrm{Kz}$ Ss Por

2.04815e+02 2.04815e+02 2.04815e+01 1.00000e-09 7.00000e-02

8.18388e+00 8.18388e+00 8.18388e-01 1.00000e-09 2.12000e-01

8.18388e+00 8.18388e+00 8.18388e-01 1.00000e-09 2.12000e-01

$8.18388 \mathrm{e}+00$ 8.18388e+00 8.18388e-01 1.00000e-09 2.12000e-01 
$8.18388 \mathrm{e}+00$ 8.18388e+00 8.18388e-01 1.00000e-09 2.12000e-01 8.18388e+00 8.18388e+00 8.18388e-01 1.00000e-09 2.12000e-01 $1.00000 \mathrm{e}-021.00000 \mathrm{e}-02$ 1.00000e-03 1.00000e-09 1.00000e-01 $1.00000 \mathrm{e}+001.00000 \mathrm{e}+001.00000 \mathrm{e}-011.00000 \mathrm{e}-091.00000 \mathrm{e}-01$ $1.00000 \mathrm{e}-05$ 1.00000e-05 1.00000e-06 1.00000e-09 1.00000e-01 $1.00000 \mathrm{e}+001.00000 \mathrm{e}+001.00000 \mathrm{e}-011.00000 \mathrm{e}-091.00000 \mathrm{e}-01$ Element: 1020 \# of layers: 10

Kx Ky Kz Ss Por

$2.04815 \mathrm{e}+022.04815 \mathrm{e}+022.04815 \mathrm{e}+01$ 1.00000e-09 7.00000e-02

$8.18388 \mathrm{e}+00$ 8.18388e+00 8.18388e-01 1.00000e-09 2.12000e-01

$8.18388 \mathrm{e}+008.18388 \mathrm{e}+00$ 8.18388e-01 1.00000e-09 2.12000e-01

$8.18388 \mathrm{e}+008.18388 \mathrm{e}+00$ 8.18388e-01 1.00000e-09 2.12000e-01

$8.18388 \mathrm{e}+008.18388 \mathrm{e}+00$ 8.18388e-01 1.00000e-09 2.12000e-01

$8.18388 \mathrm{e}+00$ 8.18388e+00 8.18388e-01 1.00000e-09 2.12000e-01 $1.00000 \mathrm{e}-02$ 1.00000e-02 1.00000e-03 1.00000e-09 1.00000e-01 $1.00000 \mathrm{e}+001.00000 \mathrm{e}+001.00000 \mathrm{e}-011.00000 \mathrm{e}-091.00000 \mathrm{e}-01$ $1.00000 \mathrm{e}-05$ 1.00000e-05 1.00000e-06 1.00000e-09 1.00000e-01 $1.00000 \mathrm{e}+001.00000 \mathrm{e}+001.00000 \mathrm{e}-011.00000 \mathrm{e}-091.00000 \mathrm{e}-01$ Element: 1021 \# of layers: 10

Kx Ky Kz Ss Por

$2.04815 \mathrm{e}+022.04815 \mathrm{e}+022.04815 \mathrm{e}+01$ 1.00000e-09 7.00000e-02

$8.18388 \mathrm{e}+008.18388 \mathrm{e}+00$ 8.18388e-01 1.00000e-09 2.12000e-01

$8.18388 \mathrm{e}+00$ 8.18388e+00 8.18388e-01 1.00000e-09 2.12000e-01

$8.18388 \mathrm{e}+008.18388 \mathrm{e}+00$ 8.18388e-01 1.00000e-09 2.12000e-01

$8.18388 \mathrm{e}+00$ 8.18388e+00 8.18388e-01 1.00000e-09 2.12000e-01

$8.18388 \mathrm{e}+00$ 8.18388e+00 8.18388e-01 1.00000e-09 2.12000e-01

$1.00000 \mathrm{e}-02$ 1.00000e-02 1.00000e-03 1.00000e-09 1.00000e-01

$1.00000 \mathrm{e}+001.00000 \mathrm{e}+001.00000 \mathrm{e}-011.00000 \mathrm{e}-091.00000 \mathrm{e}-01$

$1.00000 \mathrm{e}-051.00000 \mathrm{e}-05$ 1.00000e-06 1.00000e-09 1.00000e-01

$1.00000 \mathrm{e}+001.00000 \mathrm{e}+001.00000 \mathrm{e}-011.00000 \mathrm{e}-091.00000 \mathrm{e}-01$

Element: 1022 \# of layers: 11

Kx Ky Kz Ss Por

$2.04815 \mathrm{e}+022.04815 \mathrm{e}+022.04815 \mathrm{e}+01$ 1.00000e-09 7.00000e-02

$2.04815 \mathrm{e}+022.04815 \mathrm{e}+022.04815 \mathrm{e}+01$ 1.00000e-09 7.00000e-02

$8.18388 \mathrm{e}+00$ 8.18388e+00 8.18388e-01 1.00000e-09 2.12000e-01

$8.18388 \mathrm{e}+008.18388 \mathrm{e}+00$ 8.18388e-01 1.00000e-09 2.12000e-01

$8.18388 \mathrm{e}+008.18388 \mathrm{e}+00$ 8.18388e-01 1.00000e-09 2.12000e-01

$8.18388 \mathrm{e}+00$ 8.18388e+00 8.18388e-01 1.00000e-09 2.12000e-01

$8.18388 \mathrm{e}+00$ 8.18388e+00 8.18388e-01 1.00000e-09 2.12000e-01

$1.00000 \mathrm{e}-02$ 1.00000e-02 1.00000e-03 1.00000e-09 1.00000e-01

$1.00000 \mathrm{e}+001.00000 \mathrm{e}+001.00000 \mathrm{e}-011.00000 \mathrm{e}-091.00000 \mathrm{e}-01$

$1.00000 \mathrm{e}-05$ 1.00000e-05 1.00000e-06 1.00000e-09 1.00000e-01

$1.00000 \mathrm{e}+001.00000 \mathrm{e}+001.00000 \mathrm{e}-011.00000 \mathrm{e}-091.00000 \mathrm{e}-01$

Element: 1023 \# of layers: 11

Kx Ky Kz Ss Por

$2.04815 \mathrm{e}+022.04815 \mathrm{e}+02$ 2.04815e+01 1.00000e-09 7.00000e-02 
2.04815e+02 2.04815e+02 2.04815e+01 1.00000e-09 7.00000e-02 8.18388e+00 8.18388e+00 8.18388e-01 1.00000e-09 2.12000e-01 8.18388e+00 8.18388e+00 8.18388e-01 1.00000e-09 2.12000e-01 8.18388e+00 8.18388e+00 8.18388e-01 1.00000e-09 2.12000e-01 8.18388e+00 8.18388e+00 8.18388e-01 1.00000e-09 2.12000e-01 $8.18388 \mathrm{e}+00$ 8.18388e+00 8.18388e-01 1.00000e-09 2.12000e-01 $1.00000 \mathrm{e}-02$ 1.00000e-02 1.00000e-03 1.00000e-09 1.00000e-01 $1.00000 \mathrm{e}+001.00000 \mathrm{e}+001.00000 \mathrm{e}-011.00000 \mathrm{e}-091.00000 \mathrm{e}-01$ $1.00000 \mathrm{e}-05$ 1.00000e-05 1.00000e-06 1.00000e-09 1.00000e-01 $1.00000 \mathrm{e}+001.00000 \mathrm{e}+001.00000 \mathrm{e}-011.00000 \mathrm{e}-091.00000 \mathrm{e}-01$ Element: 1024 \# of layers: 9

$\mathrm{Kx} \mathrm{Ky} \mathrm{Kz}$ Ss Por

7.95069e+01 7.95069e+01 7.95069e+00 1.00000e-09 7.00000e-02 $7.95069 \mathrm{e}+017.95069 \mathrm{e}+017.95069 \mathrm{e}+001.00000 \mathrm{e}-09$ 7.00000e-02 $3.17684 \mathrm{e}+003.17684 \mathrm{e}+003.17684 \mathrm{e}-01$ 1.00000e-09 2.12000e-01 $3.17684 \mathrm{e}+003.17684 \mathrm{e}+003.17684 \mathrm{e}-01$ 1.00000e-09 2.12000e-01 $3.17684 \mathrm{e}+003.17684 \mathrm{e}+00 \quad 3.17684 \mathrm{e}-01$ 1.00000e-09 2.12000e-01 $3.17684 \mathrm{e}+003.17684 \mathrm{e}+003.17684 \mathrm{e}-01$ 1.00000e-09 2.12000e-01 $3.17684 \mathrm{e}+003.17684 \mathrm{e}+003.17684 \mathrm{e}-01$ 1.00000e-09 2.12000e-01 $1.00000 \mathrm{e}-02$ 1.00000e-02 1.00000e-03 1.00000e-09 1.00000e-01 $1.00000 \mathrm{e}+001.00000 \mathrm{e}+001.00000 \mathrm{e}-011.00000 \mathrm{e}-091.00000 \mathrm{e}-01$ Element: 1025 \# of layers: 9

$\mathrm{Kx} \mathrm{Ky} \mathrm{Kz}$ Ss Por

7.95069e+01 7.95069e+01 7.95069e+00 1.00000e-09 7.00000e-02 $7.95069 \mathrm{e}+01$ 7.95069e+01 7.95069e+00 1.00000e-09 7.00000e-02 $3.17684 \mathrm{e}+003.17684 \mathrm{e}+003.17684 \mathrm{e}-01$ 1.00000e-09 2.12000e-01 $3.17684 \mathrm{e}+003.17684 \mathrm{e}+003.17684 \mathrm{e}-01$ 1.00000e-09 2.12000e-01 $3.17684 \mathrm{e}+003.17684 \mathrm{e}+003.17684 \mathrm{e}-01$ 1.00000e-09 2.12000e-01 $3.17684 \mathrm{e}+003.17684 \mathrm{e}+003.17684 \mathrm{e}-01$ 1.00000e-09 2.12000e-01 $3.17684 \mathrm{e}+003.17684 \mathrm{e}+003.17684 \mathrm{e}-01$ 1.00000e-09 2.12000e-01 $1.00000 \mathrm{e}-02$ 1.00000e-02 1.00000e-03 1.00000e-09 1.00000e-01 $1.00000 \mathrm{e}+001.00000 \mathrm{e}+001.00000 \mathrm{e}-01$ 1.00000e-09 1.00000e-01 Element: 1026 \# of layers: 9

$\mathrm{Kx} \mathrm{Ky} \mathrm{Kz}$ Ss Por

7.95069e+01 7.95069e+01 7.95069e+00 1.00000e-09 7.00000e-02 $7.95069 \mathrm{e}+017.95069 \mathrm{e}+017.95069 \mathrm{e}+001.00000 \mathrm{e}-09$ 7.00000e-02 $3.17684 \mathrm{e}+003.17684 \mathrm{e}+003.17684 \mathrm{e}-01$ 1.00000e-09 2.12000e-01 $3.17684 \mathrm{e}+003.17684 \mathrm{e}+003.17684 \mathrm{e}-01$ 1.00000e-09 2.12000e-01 $3.17684 \mathrm{e}+003.17684 \mathrm{e}+003.17684 \mathrm{e}-01$ 1.00000e-09 2.12000e-01 $3.17684 \mathrm{e}+003.17684 \mathrm{e}+003.17684 \mathrm{e}-01$ 1.00000e-09 2.12000e-01 $3.17684 \mathrm{e}+003.17684 \mathrm{e}+003.17684 \mathrm{e}-01$ 1.00000e-09 2.12000e-01 $1.00000 \mathrm{e}-02$ 1.00000e-02 1.00000e-03 1.00000e-09 1.00000e-01 $1.00000 \mathrm{e}+001.00000 \mathrm{e}+001.00000 \mathrm{e}-01$ 1.00000e-09 1.00000e-01 Element: 1027 \# of layers: 10

$\mathrm{Kx} \mathrm{Ky} \mathrm{Kz}$ Ss Por

7.95069e+01 7.95069e+01 7.95069e+00 1.00000e-09 7.00000e-02 
$3.17684 \mathrm{e}+003.17684 \mathrm{e}+003.17684 \mathrm{e}-01$ 1.00000e-09 2.12000e-01 $3.17684 \mathrm{e}+003.17684 \mathrm{e}+003.17684 \mathrm{e}-011.00000 \mathrm{e}-092.12000 \mathrm{e}-01$ $3.17684 \mathrm{e}+003.17684 \mathrm{e}+003.17684 \mathrm{e}-01$ 1.00000e-09 2.12000e-01 $3.17684 \mathrm{e}+003.17684 \mathrm{e}+003.17684 \mathrm{e}-011.00000 \mathrm{e}-092.12000 \mathrm{e}-01$ $3.17684 \mathrm{e}+003.17684 \mathrm{e}+003.17684 \mathrm{e}-01$ 1.00000e-09 2.12000e-01 $1.00000 \mathrm{e}-021.00000 \mathrm{e}-02$ 1.00000e-03 1.00000e-09 1.00000e-01 $1.00000 \mathrm{e}+001.00000 \mathrm{e}+001.00000 \mathrm{e}-011.00000 \mathrm{e}-091.00000 \mathrm{e}-01$ $1.00000 \mathrm{e}-05$ 1.00000e-05 1.00000e-06 1.00000e-09 1.00000e-01 $1.00000 \mathrm{e}+001.00000 \mathrm{e}+001.00000 \mathrm{e}-011.00000 \mathrm{e}-091.00000 \mathrm{e}-01$ Element: 1028 \# of layers: 10

Kx Ky Kz Ss Por

7.95069e+01 7.95069e+01 7.95069e+00 1.00000e-09 7.00000e-02 $3.17684 \mathrm{e}+003.17684 \mathrm{e}+003.17684 \mathrm{e}-01$ 1.00000e-09 2.12000e-01 $3.17684 \mathrm{e}+003.17684 \mathrm{e}+003.17684 \mathrm{e}-011.00000 \mathrm{e}-092.12000 \mathrm{e}-01$ $3.17684 \mathrm{e}+003.17684 \mathrm{e}+003.17684 \mathrm{e}-01$ 1.00000e-09 2.12000e-01 $3.17684 \mathrm{e}+003.17684 \mathrm{e}+003.17684 \mathrm{e}-01$ 1.00000e-09 2.12000e-01 $3.17684 \mathrm{e}+003.17684 \mathrm{e}+003.17684 \mathrm{e}-01$ 1.00000e-09 2.12000e-01 $1.00000 \mathrm{e}-02$ 1.00000e-02 1.00000e-03 1.00000e-09 1.00000e-01 $1.00000 \mathrm{e}+001.00000 \mathrm{e}+001.00000 \mathrm{e}-011.00000 \mathrm{e}-091.00000 \mathrm{e}-01$ $1.00000 \mathrm{e}-05$ 1.00000e-05 1.00000e-06 1.00000e-09 1.00000e-01 $1.00000 \mathrm{e}+001.00000 \mathrm{e}+001.00000 \mathrm{e}-011.00000 \mathrm{e}-091.00000 \mathrm{e}-01$ Element: 1029 \# of layers: 10

Kx Ky Kz Ss Por

7.95069e+01 7.95069e+01 7.95069e+00 1.00000e-09 7.00000e-02

$3.17684 \mathrm{e}+003.17684 \mathrm{e}+003.17684 \mathrm{e}-011.00000 \mathrm{e}-092.12000 \mathrm{e}-01$

$3.17684 \mathrm{e}+003.17684 \mathrm{e}+003.17684 \mathrm{e}-01$ 1.00000e-09 2.12000e-01

$3.17684 \mathrm{e}+003.17684 \mathrm{e}+003.17684 \mathrm{e}-01$ 1.00000e-09 2.12000e-01

$3.17684 \mathrm{e}+003.17684 \mathrm{e}+003.17684 \mathrm{e}-011.00000 \mathrm{e}-092.12000 \mathrm{e}-01$

$3.17684 \mathrm{e}+003.17684 \mathrm{e}+003.17684 \mathrm{e}-01$ 1.00000e-09 2.12000e-01 $1.00000 \mathrm{e}-02$ 1.00000e-02 1.00000e-03 1.00000e-09 1.00000e-01 $1.00000 \mathrm{e}+001.00000 \mathrm{e}+001.00000 \mathrm{e}-011.00000 \mathrm{e}-091.00000 \mathrm{e}-01$ $1.00000 \mathrm{e}-05$ 1.00000e-05 1.00000e-06 1.00000e-09 1.00000e-01 $1.00000 \mathrm{e}+001.00000 \mathrm{e}+001.00000 \mathrm{e}-011.00000 \mathrm{e}-091.00000 \mathrm{e}-01$ Element: 1030 \# of layers: 10

Kx Ky Kz Ss Por

$7.95069 \mathrm{e}+01$ 7.95069e+01 7.95069e+00 1.00000e-09 7.00000e-02 $3.17684 \mathrm{e}+003.17684 \mathrm{e}+003.17684 \mathrm{e}-011.00000 \mathrm{e}-092.12000 \mathrm{e}-01$ $3.17684 \mathrm{e}+003.17684 \mathrm{e}+003.17684 \mathrm{e}-011.00000 \mathrm{e}-092.12000 \mathrm{e}-01$ $3.17684 \mathrm{e}+003.17684 \mathrm{e}+003.17684 \mathrm{e}-011.00000 \mathrm{e}-092.12000 \mathrm{e}-01$ $3.17684 \mathrm{e}+003.17684 \mathrm{e}+003.17684 \mathrm{e}-01$ 1.00000e-09 2.12000e-01 $3.17684 \mathrm{e}+003.17684 \mathrm{e}+003.17684 \mathrm{e}-01$ 1.00000e-09 2.12000e-01 $1.00000 \mathrm{e}-021.00000 \mathrm{e}-02$ 1.00000e-03 1.00000e-09 1.00000e-01 $1.00000 \mathrm{e}+001.00000 \mathrm{e}+001.00000 \mathrm{e}-011.00000 \mathrm{e}-091.00000 \mathrm{e}-01$ $1.00000 \mathrm{e}-05$ 1.00000e-05 1.00000e-06 1.00000e-09 1.00000e-01 $1.00000 \mathrm{e}+001.00000 \mathrm{e}+001.00000 \mathrm{e}-011.00000 \mathrm{e}-091.00000 \mathrm{e}-01$ Element: 1031 \# of layers: 10 
$\mathrm{Kx} \mathrm{Ky} \mathrm{Kz}$ Ss Por

7.95069e+01 7.95069e+01 7.95069e+00 1.00000e-09 7.00000e-02

$3.17684 \mathrm{e}+003.17684 \mathrm{e}+003.17684 \mathrm{e}-01$ 1.00000e-09 2.12000e-01

$3.17684 \mathrm{e}+003.17684 \mathrm{e}+003.17684 \mathrm{e}-01$ 1.00000e-09 2.12000e-01

$3.17684 \mathrm{e}+003.17684 \mathrm{e}+003.17684 \mathrm{e}-01$ 1.00000e-09 2.12000e-01

$3.17684 \mathrm{e}+003.17684 \mathrm{e}+003.17684 \mathrm{e}-01$ 1.00000e-09 2.12000e-01

$3.17684 \mathrm{e}+003.17684 \mathrm{e}+003.17684 \mathrm{e}-01$ 1.00000e-09 2.12000e-01

$1.00000 \mathrm{e}-02$ 1.00000e-02 1.00000e-03 1.00000e-09 1.00000e-01

$1.00000 \mathrm{e}+001.00000 \mathrm{e}+001.00000 \mathrm{e}-011.00000 \mathrm{e}-091.00000 \mathrm{e}-01$

$1.00000 \mathrm{e}-05$ 1.00000e-05 1.00000e-06 1.00000e-09 1.00000e-01

$1.00000 \mathrm{e}+001.00000 \mathrm{e}+001.00000 \mathrm{e}-011.00000 \mathrm{e}-091.00000 \mathrm{e}-01$

Element: 1032 \# of layers: 10

Kx Ky Kz Ss Por

7.95069e+01 7.95069e+01 7.95069e+00 1.00000e-09 7.00000e-02

$3.17684 \mathrm{e}+003.17684 \mathrm{e}+003.17684 \mathrm{e}-01$ 1.00000e-09 2.12000e-01

$3.17684 \mathrm{e}+003.17684 \mathrm{e}+003.17684 \mathrm{e}-01$ 1.00000e-09 2.12000e-01

$3.17684 \mathrm{e}+003.17684 \mathrm{e}+003.17684 \mathrm{e}-01$ 1.00000e-09 2.12000e-01

$3.17684 \mathrm{e}+003.17684 \mathrm{e}+003.17684 \mathrm{e}-01$ 1.00000e-09 2.12000e-01

$3.17684 \mathrm{e}+003.17684 \mathrm{e}+003.17684 \mathrm{e}-01$ 1.00000e-09 2.12000e-01

$1.00000 \mathrm{e}-02$ 1.00000e-02 1.00000e-03 1.00000e-09 1.00000e-01

$1.00000 \mathrm{e}+001.00000 \mathrm{e}+001.00000 \mathrm{e}-011.00000 \mathrm{e}-091.00000 \mathrm{e}-01$

$1.00000 \mathrm{e}-05$ 1.00000e-05 1.00000e-06 1.00000e-09 1.00000e-01

$1.00000 \mathrm{e}+001.00000 \mathrm{e}+001.00000 \mathrm{e}-01$ 1.00000e-09 1.00000e-01

Element: 1033 \# of layers: 8

$\mathrm{Kx} \mathrm{Ky} \mathrm{Kz}$ Ss Por

$5.20228 \mathrm{e}+015.20228 \mathrm{e}+015.20228 \mathrm{e}+001.00000 \mathrm{e}-09$ 7.00000e-02

$2.07864 \mathrm{e}+002.07864 \mathrm{e}+002.07864 \mathrm{e}-01$ 1.00000e-09 2.12000e-01

$2.07864 \mathrm{e}+002.07864 \mathrm{e}+002.07864 \mathrm{e}-01$ 1.00000e-09 2.12000e-01

$2.07864 \mathrm{e}+002.07864 \mathrm{e}+002.07864 \mathrm{e}-01 \quad 1.00000 \mathrm{e}-092.12000 \mathrm{e}-01$

$2.07864 \mathrm{e}+002.07864 \mathrm{e}+002.07864 \mathrm{e}-01$ 1.00000e-09 2.12000e-01

$2.07864 \mathrm{e}+002.07864 \mathrm{e}+002.07864 \mathrm{e}-01 \quad 1.00000 \mathrm{e}-092.12000 \mathrm{e}-01$

$1.00000 \mathrm{e}-02$ 1.00000e-02 1.00000e-03 1.00000e-09 1.00000e-01

$1.00000 \mathrm{e}+001.00000 \mathrm{e}+001.00000 \mathrm{e}-011.00000 \mathrm{e}-091.00000 \mathrm{e}-01$

Element: 1034 \# of layers: 8

$\mathrm{Kx} \mathrm{Ky} \mathrm{Kz}$ Ss Por

5.20228e+01 5.20228e+01 5.20228e+00 1.00000e-09 7.00000e-02

$2.07864 \mathrm{e}+002.07864 \mathrm{e}+002.07864 \mathrm{e}-01$ 1.00000e-09 2.12000e-01

$2.07864 \mathrm{e}+002.07864 \mathrm{e}+002.07864 \mathrm{e}-01$ 1.00000e-09 2.12000e-01

$2.07864 \mathrm{e}+002.07864 \mathrm{e}+002.07864 \mathrm{e}-01$ 1.00000e-09 2.12000e-01

$2.07864 \mathrm{e}+002.07864 \mathrm{e}+002.07864 \mathrm{e}-01$ 1.00000e-09 2.12000e-01

$2.07864 \mathrm{e}+002.07864 \mathrm{e}+002.07864 \mathrm{e}-01$ 1.00000e-09 2.12000e-01

$1.00000 \mathrm{e}-02$ 1.00000e-02 1.00000e-03 1.00000e-09 1.00000e-01

$1.00000 \mathrm{e}+001.00000 \mathrm{e}+001.00000 \mathrm{e}-011.00000 \mathrm{e}-091.00000 \mathrm{e}-01$

Element: 1035 \# of layers: 8

$\mathrm{Kx} \mathrm{Ky} \mathrm{Kz}$ Ss Por

5.20228e+01 5.20228e+01 5.20228e+00 1.00000e-09 7.00000e-02 
$2.07864 \mathrm{e}+002.07864 \mathrm{e}+002.07864 \mathrm{e}-01$ 1.00000e-09 2.12000e-01 $2.07864 \mathrm{e}+002.07864 \mathrm{e}+002.07864 \mathrm{e}-01$ 1.00000e-09 2.12000e-01 $2.07864 \mathrm{e}+002.07864 \mathrm{e}+002.07864 \mathrm{e}-01$ 1.00000e-09 2.12000e-01 $2.07864 \mathrm{e}+002.07864 \mathrm{e}+002.07864 \mathrm{e}-011.00000 \mathrm{e}-092.12000 \mathrm{e}-01$ $2.07864 \mathrm{e}+002.07864 \mathrm{e}+002.07864 \mathrm{e}-01$ 1.00000e-09 2.12000e-01 $1.00000 \mathrm{e}-02$ 1.00000e-02 1.00000e-03 1.00000e-09 1.00000e-01 $1.00000 \mathrm{e}+001.00000 \mathrm{e}+001.00000 \mathrm{e}-011.00000 \mathrm{e}-091.00000 \mathrm{e}-01$ Element: 1036 \# of layers: 8

$\mathrm{Kx} \mathrm{Ky} \mathrm{Kz}$ Ss Por

5.20228e+01 5.20228e+01 5.20228e+00 1.00000e-09 7.00000e-02 $2.07864 \mathrm{e}+002.07864 \mathrm{e}+002.07864 \mathrm{e}-01$ 1.00000e-09 2.12000e-01 $2.07864 \mathrm{e}+002.07864 \mathrm{e}+002.07864 \mathrm{e}-01$ 1.00000e-09 2.12000e-01 $2.07864 \mathrm{e}+002.07864 \mathrm{e}+002.07864 \mathrm{e}-01$ 1.00000e-09 2.12000e-01 $2.07864 \mathrm{e}+002.07864 \mathrm{e}+002.07864 \mathrm{e}-01$ 1.00000e-09 2.12000e-01 $2.07864 \mathrm{e}+002.07864 \mathrm{e}+002.07864 \mathrm{e}-01$ 1.00000e-09 2.12000e-01 $1.00000 \mathrm{e}-02$ 1.00000e-02 1.00000e-03 1.00000e-09 1.00000e-01 $1.00000 \mathrm{e}+001.00000 \mathrm{e}+001.00000 \mathrm{e}-011.00000 \mathrm{e}-091.00000 \mathrm{e}-01$ Element: 1037 \# of layers: 8

$\mathrm{Kx} \mathrm{Ky} \mathrm{Kz}$ Ss Por

5.20228e+01 5.20228e+01 5.20228e+00 1.00000e-09 7.00000e-02 $2.07864 \mathrm{e}+002.07864 \mathrm{e}+00 \quad 2.07864 \mathrm{e}-011.00000 \mathrm{e}-092.12000 \mathrm{e}-01$ $2.07864 \mathrm{e}+002.07864 \mathrm{e}+002.07864 \mathrm{e}-01$ 1.00000e-09 2.12000e-01 $2.07864 \mathrm{e}+002.07864 \mathrm{e}+002.07864 \mathrm{e}-01$ 1.00000e-09 2.12000e-01 $2.07864 \mathrm{e}+002.07864 \mathrm{e}+002.07864 \mathrm{e}-01$ 1.00000e-09 2.12000e-01 $2.07864 \mathrm{e}+002.07864 \mathrm{e}+00 \quad 2.07864 \mathrm{e}-011.00000 \mathrm{e}-092.12000 \mathrm{e}-01$ $1.00000 \mathrm{e}-02$ 1.00000e-02 1.00000e-03 1.00000e-09 1.00000e-01 $1.00000 \mathrm{e}+001.00000 \mathrm{e}+001.00000 \mathrm{e}-011.00000 \mathrm{e}-091.00000 \mathrm{e}-01$ Element: 1038 \# of layers: 10

$\mathrm{Kx} \mathrm{Ky} \mathrm{Kz}$ Ss Por

$5.20228 \mathrm{e}+015.20228 \mathrm{e}+015.20228 \mathrm{e}+00$ 1.00000e-09 7.00000e-02 $2.07864 \mathrm{e}+002.07864 \mathrm{e}+002.07864 \mathrm{e}-01$ 1.00000e-09 2.12000e-01 $2.07864 \mathrm{e}+002.07864 \mathrm{e}+002.07864 \mathrm{e}-01$ 1.00000e-09 2.12000e-01 $2.07864 \mathrm{e}+002.07864 \mathrm{e}+002.07864 \mathrm{e}-01 \quad 1.00000 \mathrm{e}-092.12000 \mathrm{e}-01$ $2.07864 \mathrm{e}+002.07864 \mathrm{e}+002.07864 \mathrm{e}-01$ 1.00000e-09 2.12000e-01 $2.07864 \mathrm{e}+002.07864 \mathrm{e}+002.07864 \mathrm{e}-01$ 1.00000e-09 2.12000e-01 1.00000e-02 1.00000e-02 1.00000e-03 1.00000e-09 1.00000e-01 $1.00000 \mathrm{e}+001.00000 \mathrm{e}+001.00000 \mathrm{e}-011.00000 \mathrm{e}-091.00000 \mathrm{e}-01$ $1.00000 \mathrm{e}-05$ 1.00000e-05 1.00000e-06 1.00000e-09 1.00000e-01 $1.00000 \mathrm{e}+001.00000 \mathrm{e}+001.00000 \mathrm{e}-011.00000 \mathrm{e}-091.00000 \mathrm{e}-01$ Element: 1039 \# of layers: 10

$\mathrm{Kx} \mathrm{Ky} \mathrm{Kz}$ Ss Por

5.20228e+01 5.20228e+01 5.20228e+00 1.00000e-09 7.00000e-02 $2.07864 \mathrm{e}+002.07864 \mathrm{e}+00$ 2.07864e-01 1.00000e-09 2.12000e-01 $2.07864 \mathrm{e}+002.07864 \mathrm{e}+00$ 2.07864e-01 1.00000e-09 2.12000e-01 $2.07864 \mathrm{e}+002.07864 \mathrm{e}+002.07864 \mathrm{e}-01$ 1.00000e-09 2.12000e-01 $2.07864 \mathrm{e}+002.07864 \mathrm{e}+002.07864 \mathrm{e}-01$ 1.00000e-09 2.12000e-01 
$2.07864 \mathrm{e}+002.07864 \mathrm{e}+00$ 2.07864e-01 1.00000e-09 2.12000e-01 $1.00000 \mathrm{e}-02$ 1.00000e-02 1.00000e-03 1.00000e-09 1.00000e-01 $1.00000 \mathrm{e}+001.00000 \mathrm{e}+001.00000 \mathrm{e}-011.00000 \mathrm{e}-091.00000 \mathrm{e}-01$ $1.00000 \mathrm{e}-05$ 1.00000e-05 1.00000e-06 1.00000e-09 1.00000e-01 $1.00000 \mathrm{e}+001.00000 \mathrm{e}+001.00000 \mathrm{e}-011.00000 \mathrm{e}-091.00000 \mathrm{e}-01$ Element: 1040 \# of layers: 8

$\mathrm{Kx} \mathrm{Ky} \mathrm{Kz}$ Ss Por

5.20228e+01 5.20228e+01 5.20228e+00 1.00000e-09 7.00000e-02 $2.07864 \mathrm{e}+002.07864 \mathrm{e}+002.07864 \mathrm{e}-01$ 1.00000e-09 2.12000e-01 $2.07864 \mathrm{e}+002.07864 \mathrm{e}+002.07864 \mathrm{e}-01$ 1.00000e-09 2.12000e-01 $2.07864 \mathrm{e}+002.07864 \mathrm{e}+002.07864 \mathrm{e}-01$ 1.00000e-09 2.12000e-01 $2.07864 \mathrm{e}+002.07864 \mathrm{e}+002.07864 \mathrm{e}-01$ 1.00000e-09 2.12000e-01 $2.07864 \mathrm{e}+002.07864 \mathrm{e}+002.07864 \mathrm{e}-01$ 1.00000e-09 2.12000e-01 $1.00000 \mathrm{e}-02$ 1.00000e-02 1.00000e-03 1.00000e-09 1.00000e-01 $1.00000 \mathrm{e}+001.00000 \mathrm{e}+001.00000 \mathrm{e}-01$ 1.00000e-09 1.00000e-01 Element: 1041 \# of layers: 8

$\mathrm{Kx} \mathrm{Ky} \mathrm{Kz}$ Ss Por

$5.20228 \mathrm{e}+01$ 5.20228e+01 5.20228e+00 1.00000e-09 7.00000e-02 $2.07864 \mathrm{e}+002.07864 \mathrm{e}+002.07864 \mathrm{e}-01$ 1.00000e-09 2.12000e-01 $2.07864 \mathrm{e}+002.07864 \mathrm{e}+002.07864 \mathrm{e}-01$ 1.00000e-09 2.12000e-01 $2.07864 \mathrm{e}+002.07864 \mathrm{e}+002.07864 \mathrm{e}-011.00000 \mathrm{e}-092.12000 \mathrm{e}-01$ $2.07864 \mathrm{e}+002.07864 \mathrm{e}+00$ 2.07864e-01 1.00000e-09 2.12000e-01 $2.07864 \mathrm{e}+002.07864 \mathrm{e}+002.07864 \mathrm{e}-01$ 1.00000e-09 2.12000e-01 $1.00000 \mathrm{e}-02$ 1.00000e-02 1.00000e-03 1.00000e-09 1.00000e-01 $1.00000 \mathrm{e}+001.00000 \mathrm{e}+001.00000 \mathrm{e}-011.00000 \mathrm{e}-09$ 1.00000e-01 Element: 1042 \# of layers: 8

$\mathrm{Kx} \mathrm{Ky} \mathrm{Kz}$ Ss Por

3.13287e+01 3.13287e+01 3.13287e+00 1.00000e-09 7.00000e-02 $1.25179 \mathrm{e}+00$ 1.25179e+00 1.25179e-01 1.00000e-09 2.12000e-01 $1.25179 \mathrm{e}+001.25179 \mathrm{e}+00$ 1.25179e-01 1.00000e-09 2.12000e-01 $1.25179 \mathrm{e}+001.25179 \mathrm{e}+001.25179 \mathrm{e}-01$ 1.00000e-09 2.12000e-01 $1.25179 \mathrm{e}+001.25179 \mathrm{e}+00$ 1.25179e-01 1.00000e-09 2.12000e-01 $1.25179 \mathrm{e}+001.25179 \mathrm{e}+001.25179 \mathrm{e}-01$ 1.00000e-09 2.12000e-01 $1.00000 \mathrm{e}-02$ 1.00000e-02 1.00000e-03 1.00000e-09 1.00000e-01 $1.00000 \mathrm{e}+001.00000 \mathrm{e}+001.00000 \mathrm{e}-01$ 1.00000e-09 1.00000e-01 Element: 1043 \# of layers: 8

Kx Ky Kz Ss Por

3.13287e+01 3.13287e+01 3.13287e+00 1.00000e-09 7.00000e-02 $1.25179 \mathrm{e}+001.25179 \mathrm{e}+00$ 1.25179e-01 1.00000e-09 2.12000e-01 $1.25179 \mathrm{e}+001.25179 \mathrm{e}+001.25179 \mathrm{e}-01$ 1.00000e-09 2.12000e-01 $1.25179 \mathrm{e}+001.25179 \mathrm{e}+00$ 1.25179e-01 1.00000e-09 2.12000e-01 $1.25179 \mathrm{e}+001.25179 \mathrm{e}+00$ 1.25179e-01 1.00000e-09 2.12000e-01 $1.25179 \mathrm{e}+001.25179 \mathrm{e}+00$ 1.25179e-01 1.00000e-09 2.12000e-01 $1.00000 \mathrm{e}-02$ 1.00000e-02 1.00000e-03 1.00000e-09 1.00000e-01 $1.00000 \mathrm{e}+001.00000 \mathrm{e}+001.00000 \mathrm{e}-011.00000 \mathrm{e}-091.00000 \mathrm{e}-01$ Element: 1044 \# of layers: 8 
$\mathrm{Kx} \mathrm{Ky} \mathrm{Kz}$ Ss Por

3.13287e+01 3.13287e+01 3.13287e+00 1.00000e-09 7.00000e-02

$1.25179 \mathrm{e}+001.25179 \mathrm{e}+00$ 1.25179e-01 1.00000e-09 2.12000e-01

$1.25179 \mathrm{e}+001.25179 \mathrm{e}+00$ 1.25179e-01 1.00000e-09 2.12000e-01

$1.25179 \mathrm{e}+00$ 1.25179e+00 1.25179e-01 1.00000e-09 2.12000e-01

$1.25179 \mathrm{e}+001.25179 \mathrm{e}+00$ 1.25179e-01 1.00000e-09 2.12000e-01

$1.25179 \mathrm{e}+001.25179 \mathrm{e}+00$ 1.25179e-01 1.00000e-09 2.12000e-01

$1.00000 \mathrm{e}-02$ 1.00000e-02 1.00000e-03 1.00000e-09 1.00000e-01

$1.00000 \mathrm{e}+001.00000 \mathrm{e}+001.00000 \mathrm{e}-011.00000 \mathrm{e}-091.00000 \mathrm{e}-01$

Element: 1045 \# of layers: 8

$\mathrm{Kx} \mathrm{Ky} \mathrm{Kz}$ Ss Por

3.13287e+01 3.13287e+01 3.13287e+00 1.00000e-09 7.00000e-02

$1.25179 \mathrm{e}+001.25179 \mathrm{e}+001.25179 \mathrm{e}-01$ 1.00000e-09 2.12000e-01

$1.25179 \mathrm{e}+001.25179 \mathrm{e}+001.25179 \mathrm{e}-01$ 1.00000e-09 2.12000e-01

$1.25179 \mathrm{e}+001.25179 \mathrm{e}+00$ 1.25179e-01 1.00000e-09 2.12000e-01

$1.25179 \mathrm{e}+001.25179 \mathrm{e}+00$ 1.25179e-01 1.00000e-09 2.12000e-01

$1.25179 \mathrm{e}+001.25179 \mathrm{e}+00$ 1.25179e-01 1.00000e-09 2.12000e-01

$1.00000 \mathrm{e}-02$ 1.00000e-02 1.00000e-03 1.00000e-09 1.00000e-01

$1.00000 \mathrm{e}+001.00000 \mathrm{e}+001.00000 \mathrm{e}-011.00000 \mathrm{e}-091.00000 \mathrm{e}-01$

Element: 1046 \# of layers: 8

$\mathrm{Kx} \mathrm{Ky} \mathrm{Kz}$ Ss Por

3.13287e+01 3.13287e+01 3.13287e+00 1.00000e-09 7.00000e-02

$1.25179 \mathrm{e}+001.25179 \mathrm{e}+00$ 1.25179e-01 1.00000e-09 2.12000e-01

$1.25179 \mathrm{e}+001.25179 \mathrm{e}+00$ 1.25179e-01 1.00000e-09 2.12000e-01

$1.25179 \mathrm{e}+001.25179 \mathrm{e}+00$ 1.25179e-01 1.00000e-09 2.12000e-01

$1.25179 \mathrm{e}+001.25179 \mathrm{e}+00$ 1.25179e-01 1.00000e-09 2.12000e-01

$1.25179 \mathrm{e}+001.25179 \mathrm{e}+001.25179 \mathrm{e}-01$ 1.00000e-09 2.12000e-01

$1.00000 \mathrm{e}-02$ 1.00000e-02 1.00000e-03 1.00000e-09 1.00000e-01

$1.00000 \mathrm{e}+001.00000 \mathrm{e}+001.00000 \mathrm{e}-011.00000 \mathrm{e}-091.00000 \mathrm{e}-01$

Element: 1047 \# of layers: 8

$\mathrm{Kx} \mathrm{Ky} \mathrm{Kz}$ Ss Por

3.13287e+01 3.13287e+01 3.13287e+00 1.00000e-09 7.00000e-02

$1.25179 \mathrm{e}+001.25179 \mathrm{e}+001.25179 \mathrm{e}-01$ 1.00000e-09 2.12000e-01

$1.25179 \mathrm{e}+001.25179 \mathrm{e}+00$ 1.25179e-01 1.00000e-09 2.12000e-01

$1.25179 \mathrm{e}+001.25179 \mathrm{e}+001.25179 \mathrm{e}-01$ 1.00000e-09 2.12000e-01

$1.25179 \mathrm{e}+001.25179 \mathrm{e}+00$ 1.25179e-01 1.00000e-09 2.12000e-01

$1.25179 \mathrm{e}+001.25179 \mathrm{e}+001.25179 \mathrm{e}-01$ 1.00000e-09 2.12000e-01

$1.00000 \mathrm{e}-02$ 1.00000e-02 1.00000e-03 1.00000e-09 1.00000e-01

$1.00000 \mathrm{e}+001.00000 \mathrm{e}+001.00000 \mathrm{e}-011.00000 \mathrm{e}-091.00000 \mathrm{e}-01$

Element: 1048 \# of layers: 8

$\mathrm{Kx} \mathrm{Ky} \mathrm{Kz}$ Ss Por

3.13287e+01 3.13287e+01 3.13287e+00 1.00000e-09 7.00000e-02

$1.25179 \mathrm{e}+001.25179 \mathrm{e}+00$ 1.25179e-01 1.00000e-09 2.12000e-01

$1.25179 \mathrm{e}+001.25179 \mathrm{e}+001.25179 \mathrm{e}-01$ 1.00000e-09 2.12000e-01

$1.25179 \mathrm{e}+001.25179 \mathrm{e}+00$ 1.25179e-01 1.00000e-09 2.12000e-01

$1.25179 \mathrm{e}+001.25179 \mathrm{e}+00$ 1.25179e-01 1.00000e-09 2.12000e-01 
$1.25179 \mathrm{e}+00$ 1.25179e+00 1.25179e-01 1.00000e-09 2.12000e-01 $1.00000 \mathrm{e}-02$ 1.00000e-02 1.00000e-03 1.00000e-09 1.00000e-01 $1.00000 \mathrm{e}+001.00000 \mathrm{e}+001.00000 \mathrm{e}-011.00000 \mathrm{e}-091.00000 \mathrm{e}-01$ Element: 1049 \# of layers: 8

$\mathrm{Kx} \mathrm{Ky} \mathrm{Kz}$ Ss Por

3.13287e+01 3.13287e+01 3.13287e+00 1.00000e-09 7.00000e-02

$1.25179 \mathrm{e}+001.25179 \mathrm{e}+00$ 1.25179e-01 1.00000e-09 2.12000e-01

$1.25179 \mathrm{e}+001.25179 \mathrm{e}+001.25179 \mathrm{e}-01$ 1.00000e-09 2.12000e-01

$1.25179 \mathrm{e}+001.25179 \mathrm{e}+001.25179 \mathrm{e}-01$ 1.00000e-09 2.12000e-01

$1.25179 \mathrm{e}+00$ 1.25179e+00 1.25179e-01 1.00000e-09 2.12000e-01

$1.25179 \mathrm{e}+001.25179 \mathrm{e}+00$ 1.25179e-01 1.00000e-09 2.12000e-01

$1.00000 \mathrm{e}-02$ 1.00000e-02 1.00000e-03 1.00000e-09 1.00000e-01

$1.00000 \mathrm{e}+001.00000 \mathrm{e}+001.00000 \mathrm{e}-011.00000 \mathrm{e}-091.00000 \mathrm{e}-01$

Element: 1050 \# of layers: 8

$\mathrm{Kx} \mathrm{Ky} \mathrm{Kz}$ Ss Por

3.13287e+01 3.13287e+01 3.13287e+00 1.00000e-09 7.00000e-02 $1.25179 \mathrm{e}+00$ 1.25179e+00 1.25179e-01 1.00000e-09 2.12000e-01 $1.25179 \mathrm{e}+00$ 1.25179e+00 1.25179e-01 1.00000e-09 2.12000e-01 $1.25179 \mathrm{e}+001.25179 \mathrm{e}+00$ 1.25179e-01 1.00000e-09 2.12000e-01 $1.25179 \mathrm{e}+001.25179 \mathrm{e}+00$ 1.25179e-01 1.00000e-09 2.12000e-01 $1.25179 \mathrm{e}+001.25179 \mathrm{e}+00 \quad 1.25179 \mathrm{e}-01$ 1.00000e-09 2.12000e-01 $1.00000 \mathrm{e}-02$ 1.00000e-02 1.00000e-03 1.00000e-09 1.00000e-01 $1.00000 \mathrm{e}+001.00000 \mathrm{e}+001.00000 \mathrm{e}-01$ 1.00000e-09 1.00000e-01 Element: 1051 \# of layers: 8

$\mathrm{Kx} \mathrm{Ky} \mathrm{Kz}$ Ss Por

2.49262e+01 2.49262e+01 2.49262e+00 1.00000e-09 7.00000e-02 9.95984e-01 9.95984e-01 9.95984e-02 1.00000e-09 2.12000e-01 9.95984e-01 9.95984e-01 9.95984e-02 1.00000e-09 2.12000e-01 9.95984e-01 9.95984e-01 9.95984e-02 1.00000e-09 2.12000e-01 9.95984e-01 9.95984e-01 9.95984e-02 1.00000e-09 2.12000e-01 9.95984e-01 9.95984e-01 9.95984e-02 1.00000e-09 2.12000e-01 $1.00000 \mathrm{e}-02$ 1.00000e-02 1.00000e-03 1.00000e-09 1.00000e-01 $1.00000 \mathrm{e}+001.00000 \mathrm{e}+001.00000 \mathrm{e}-011.00000 \mathrm{e}-091.00000 \mathrm{e}-01$ Element: 1052 \# of layers: 8

$\mathrm{Kx} \mathrm{Ky} \mathrm{Kz}$ Ss Por

2.49262e+01 2.49262e+01 2.49262e+00 1.00000e-09 7.00000e-02 9.95984e-01 9.95984e-01 9.95984e-02 1.00000e-09 2.12000e-01 9.95984e-01 9.95984e-01 9.95984e-02 1.00000e-09 2.12000e-01 9.95984e-01 9.95984e-01 9.95984e-02 1.00000e-09 2.12000e-01 9.95984e-01 9.95984e-01 9.95984e-02 1.00000e-09 2.12000e-01 9.95984e-01 9.95984e-01 9.95984e-02 1.00000e-09 2.12000e-01 $1.00000 \mathrm{e}-02$ 1.00000e-02 1.00000e-03 1.00000e-09 1.00000e-01 $1.00000 \mathrm{e}+001.00000 \mathrm{e}+001.00000 \mathrm{e}-011.00000 \mathrm{e}-091.00000 \mathrm{e}-01$ Element: 1053 \# of layers: 7

$\mathrm{Kx} \mathrm{Ky} \mathrm{Kz}$ Ss Por

2.49262e+01 2.49262e+01 2.49262e+00 1.00000e-09 7.00000e-02 
9.95984e-01 9.95984e-01 9.95984e-02 1.00000e-09 2.12000e-01 9.95984e-01 9.95984e-01 9.95984e-02 1.00000e-09 2.12000e-01 9.95984e-01 9.95984e-01 9.95984e-02 1.00000e-09 2.12000e-01 9.95984e-01 9.95984e-01 9.95984e-02 1.00000e-09 2.12000e-01 $1.00000 \mathrm{e}-02$ 1.00000e-02 1.00000e-03 1.00000e-09 1.00000e-01 $1.00000 \mathrm{e}+001.00000 \mathrm{e}+001.00000 \mathrm{e}-011.00000 \mathrm{e}-091.00000 \mathrm{e}-01$ Element: 1054 \# of layers: 8

$\mathrm{Kx} \mathrm{Ky} \mathrm{Kz}$ Ss Por

$2.49262 \mathrm{e}+012.49262 \mathrm{e}+012.49262 \mathrm{e}+001.00000 \mathrm{e}-09$ 7.00000e-02

9.95984e-01 9.95984e-01 9.95984e-02 1.00000e-09 2.12000e-01

9.95984e-01 9.95984e-01 9.95984e-02 1.00000e-09 2.12000e-01 9.95984e-01 9.95984e-01 9.95984e-02 1.00000e-09 2.12000e-01 9.95984e-01 9.95984e-01 9.95984e-02 1.00000e-09 2.12000e-01 9.95984e-01 9.95984e-01 9.95984e-02 1.00000e-09 2.12000e-01 $1.00000 \mathrm{e}-02$ 1.00000e-02 1.00000e-03 1.00000e-09 1.00000e-01 $1.00000 \mathrm{e}+001.00000 \mathrm{e}+001.00000 \mathrm{e}-011.00000 \mathrm{e}-091.00000 \mathrm{e}-01$ Element: 1055 \# of layers: 7

$\mathrm{Kx} \mathrm{Ky} \mathrm{Kz}$ Ss Por

2.49262e+01 2.49262e+01 2.49262e+00 1.00000e-09 7.00000e-02 9.95984e-01 9.95984e-01 9.95984e-02 1.00000e-09 2.12000e-01 9.95984e-01 9.95984e-01 9.95984e-02 1.00000e-09 2.12000e-01 9.95984e-01 9.95984e-01 9.95984e-02 1.00000e-09 2.12000e-01 9.95984e-01 9.95984e-01 9.95984e-02 1.00000e-09 2.12000e-01 $1.00000 \mathrm{e}-02$ 1.00000e-02 1.00000e-03 1.00000e-09 1.00000e-01 $1.00000 \mathrm{e}+001.00000 \mathrm{e}+001.00000 \mathrm{e}-011.00000 \mathrm{e}-091.00000 \mathrm{e}-01$ Element: 1056 \# of layers: 8

$\mathrm{Kx} \mathrm{Ky} \mathrm{Kz}$ Ss Por

$2.49262 \mathrm{e}+012.49262 \mathrm{e}+012.49262 \mathrm{e}+00$ 1.00000e-09 7.00000e-02 9.95984e-01 9.95984e-01 9.95984e-02 1.00000e-09 2.12000e-01 9.95984e-01 9.95984e-01 9.95984e-02 1.00000e-09 2.12000e-01 9.95984e-01 9.95984e-01 9.95984e-02 1.00000e-09 2.12000e-01 9.95984e-01 9.95984e-01 9.95984e-02 1.00000e-09 2.12000e-01 9.95984e-01 9.95984e-01 9.95984e-02 1.00000e-09 2.12000e-01 $1.00000 \mathrm{e}-02$ 1.00000e-02 1.00000e-03 1.00000e-09 1.00000e-01 $1.00000 \mathrm{e}+001.00000 \mathrm{e}+001.00000 \mathrm{e}-011.00000 \mathrm{e}-091.00000 \mathrm{e}-01$ Element: 1057 \# of layers: 8

Kx Ky Kz Ss Por

2.49262e+01 2.49262e+01 2.49262e+00 1.00000e-09 7.00000e-02 9.95984e-01 9.95984e-01 9.95984e-02 1.00000e-09 2.12000e-01 9.95984e-01 9.95984e-01 9.95984e-02 1.00000e-09 2.12000e-01 9.95984e-01 9.95984e-01 9.95984e-02 1.00000e-09 2.12000e-01 9.95984e-01 9.95984e-01 9.95984e-02 1.00000e-09 2.12000e-01 9.95984e-01 9.95984e-01 9.95984e-02 1.00000e-09 2.12000e-01 $1.00000 \mathrm{e}-02$ 1.00000e-02 1.00000e-03 1.00000e-09 1.00000e-01 $1.00000 \mathrm{e}+001.00000 \mathrm{e}+001.00000 \mathrm{e}-011.00000 \mathrm{e}-091.00000 \mathrm{e}-01$ Element: 1058 \# of layers: 8 
Kx Ky Kz Ss Por

$2.49262 \mathrm{e}+012.49262 \mathrm{e}+012.49262 \mathrm{e}+00$ 1.00000e-09 7.00000e-02

9.95984e-01 9.95984e-01 9.95984e-02 1.00000e-09 2.12000e-01

9.95984e-01 9.95984e-01 9.95984e-02 1.00000e-09 2.12000e-01

9.95984e-01 9.95984e-01 9.95984e-02 1.00000e-09 2.12000e-01

9.95984e-01 9.95984e-01 9.95984e-02 1.00000e-09 2.12000e-01

9.95984e-01 9.95984e-01 9.95984e-02 1.00000e-09 2.12000e-01

$1.00000 \mathrm{e}-021.00000 \mathrm{e}-02$ 1.00000e-03 1.00000e-09 1.00000e-01

$1.00000 \mathrm{e}+001.00000 \mathrm{e}+001.00000 \mathrm{e}-011.00000 \mathrm{e}-091.00000 \mathrm{e}-01$

Element: 1059 \# of layers: 8

Kx Ky Kz Ss Por

$2.49262 \mathrm{e}+012.49262 \mathrm{e}+012.49262 \mathrm{e}+001.00000 \mathrm{e}-09$ 7.00000e-02

9.95984e-01 9.95984e-01 9.95984e-02 1.00000e-09 2.12000e-01

9.95984e-01 9.95984e-01 9.95984e-02 1.00000e-09 2.12000e-01

9.95984e-01 9.95984e-01 9.95984e-02 1.00000e-09 2.12000e-01

9.95984e-01 9.95984e-01 9.95984e-02 1.00000e-09 2.12000e-01

9.95984e-01 9.95984e-01 9.95984e-02 1.00000e-09 2.12000e-01

$1.00000 \mathrm{e}-02$ 1.00000e-02 1.00000e-03 1.00000e-09 1.00000e-01

$1.00000 \mathrm{e}+001.00000 \mathrm{e}+001.00000 \mathrm{e}-011.00000 \mathrm{e}-091.00000 \mathrm{e}-01$

Element: 1060 \# of layers: 7

Kx Ky Kz Ss Por

$7.26990 \mathrm{e}+017.26990 \mathrm{e}+01$ 7.26990e+00 1.00000e-09 7.00000e-02

$2.90481 \mathrm{e}+002.90481 \mathrm{e}+002.90481 \mathrm{e}-011.00000 \mathrm{e}-092.12000 \mathrm{e}-01$

$2.90481 \mathrm{e}+002.90481 \mathrm{e}+002.90481 \mathrm{e}-011.00000 \mathrm{e}-092.12000 \mathrm{e}-01$

$2.90481 \mathrm{e}+002.90481 \mathrm{e}+002.90481 \mathrm{e}-01$ 1.00000e-09 2.12000e-01

$2.90481 \mathrm{e}+002.90481 \mathrm{e}+002.90481 \mathrm{e}-011.00000 \mathrm{e}-092.12000 \mathrm{e}-01$

$1.00000 \mathrm{e}-02$ 1.00000e-02 1.00000e-03 1.00000e-09 1.00000e-01

$1.00000 \mathrm{e}+001.00000 \mathrm{e}+001.00000 \mathrm{e}-011.00000 \mathrm{e}-091.00000 \mathrm{e}-01$

Element: 1061 \# of layers: 7

Kx Ky Kz Ss Por

7.26990e+01 7.26990e+01 7.26990e+00 1.00000e-09 7.00000e-02

$2.90481 \mathrm{e}+002.90481 \mathrm{e}+002.90481 \mathrm{e}-01$ 1.00000e-09 2.12000e-01

$2.90481 \mathrm{e}+002.90481 \mathrm{e}+002.90481 \mathrm{e}-01$ 1.00000e-09 2.12000e-01

$2.90481 \mathrm{e}+002.90481 \mathrm{e}+002.90481 \mathrm{e}-011.00000 \mathrm{e}-092.12000 \mathrm{e}-01$

$2.90481 \mathrm{e}+002.90481 \mathrm{e}+002.90481 \mathrm{e}-011.00000 \mathrm{e}-092.12000 \mathrm{e}-01$

$1.00000 \mathrm{e}-021.00000 \mathrm{e}-02$ 1.00000e-03 1.00000e-09 1.00000e-01

$1.00000 \mathrm{e}+001.00000 \mathrm{e}+001.00000 \mathrm{e}-011.00000 \mathrm{e}-091.00000 \mathrm{e}-01$

Element: 1062 \# of layers: 7

Kx Ky Kz Ss Por

7.26990e+01 7.26990e+01 7.26990e+00 1.00000e-09 7.00000e-02

$2.90481 \mathrm{e}+002.90481 \mathrm{e}+002.90481 \mathrm{e}-011.00000 \mathrm{e}-092.12000 \mathrm{e}-01$

$2.90481 \mathrm{e}+002.90481 \mathrm{e}+002.90481 \mathrm{e}-011.00000 \mathrm{e}-092.12000 \mathrm{e}-01$

$2.90481 \mathrm{e}+002.90481 \mathrm{e}+002.90481 \mathrm{e}-011.00000 \mathrm{e}-092.12000 \mathrm{e}-01$

$2.90481 \mathrm{e}+002.90481 \mathrm{e}+002.90481 \mathrm{e}-011.00000 \mathrm{e}-092.12000 \mathrm{e}-01$

$1.00000 \mathrm{e}-021.00000 \mathrm{e}-021.00000 \mathrm{e}-031.00000 \mathrm{e}-091.00000 \mathrm{e}-01$

$1.00000 \mathrm{e}+001.00000 \mathrm{e}+001.00000 \mathrm{e}-011.00000 \mathrm{e}-091.00000 \mathrm{e}-01$ 
Element: 1063 \# of layers: 7

$\mathrm{Kx} \mathrm{Ky} \mathrm{Kz}$ Ss Por

7.26990e+01 7.26990e+01 7.26990e+00 1.00000e-09 7.00000e-02

$2.90481 \mathrm{e}+002.90481 \mathrm{e}+002.90481 \mathrm{e}-01$ 1.00000e-09 2.12000e-01

$2.90481 \mathrm{e}+002.90481 \mathrm{e}+002.90481 \mathrm{e}-01$ 1.00000e-09 2.12000e-01

$2.90481 \mathrm{e}+002.90481 \mathrm{e}+00$ 2.90481e-01 1.00000e-09 2.12000e-01

$2.90481 \mathrm{e}+002.90481 \mathrm{e}+00$ 2.90481e-01 1.00000e-09 2.12000e-01

$1.00000 \mathrm{e}-02$ 1.00000e-02 1.00000e-03 1.00000e-09 1.00000e-01

$1.00000 \mathrm{e}+001.00000 \mathrm{e}+001.00000 \mathrm{e}-01$ 1.00000e-09 1.00000e-01

Element: 1064 \# of layers: 7

$\mathrm{Kx} \mathrm{Ky} \mathrm{Kz}$ Ss Por

7.26990e+01 7.26990e+01 7.26990e+00 1.00000e-09 7.00000e-02

$2.90481 \mathrm{e}+002.90481 \mathrm{e}+002.90481 \mathrm{e}-01$ 1.00000e-09 2.12000e-01

$2.90481 \mathrm{e}+002.90481 \mathrm{e}+00$ 2.90481e-01 1.00000e-09 2.12000e-01

$2.90481 \mathrm{e}+002.90481 \mathrm{e}+00$ 2.90481e-01 1.00000e-09 2.12000e-01

$2.90481 \mathrm{e}+002.90481 \mathrm{e}+002.90481 \mathrm{e}-01$ 1.00000e-09 2.12000e-01

$1.00000 \mathrm{e}-02$ 1.00000e-02 1.00000e-03 1.00000e-09 1.00000e-01

$1.00000 \mathrm{e}+001.00000 \mathrm{e}+001.00000 \mathrm{e}-011.00000 \mathrm{e}-091.00000 \mathrm{e}-01$

Element: 1065 \# of layers: 8

$\mathrm{Kx} \mathrm{Ky} \mathrm{Kz}$ Ss Por

7.26990e+01 7.26990e+01 7.26990e+00 1.00000e-09 7.00000e-02

$2.90481 \mathrm{e}+002.90481 \mathrm{e}+00$ 2.90481e-01 1.00000e-09 2.12000e-01

$2.90481 \mathrm{e}+002.90481 \mathrm{e}+00$ 2.90481e-01 1.00000e-09 2.12000e-01

$2.90481 \mathrm{e}+002.90481 \mathrm{e}+002.90481 \mathrm{e}-01$ 1.00000e-09 2.12000e-01

$2.90481 \mathrm{e}+002.90481 \mathrm{e}+002.90481 \mathrm{e}-01$ 1.00000e-09 2.12000e-01

$2.90481 \mathrm{e}+002.90481 \mathrm{e}+002.90481 \mathrm{e}-01$ 1.00000e-09 2.12000e-01

$1.00000 \mathrm{e}-02$ 1.00000e-02 1.00000e-03 1.00000e-09 1.00000e-01

$1.00000 \mathrm{e}+001.00000 \mathrm{e}+001.00000 \mathrm{e}-011.00000 \mathrm{e}-091.00000 \mathrm{e}-01$

Element: 1066 \# of layers: 7

$\mathrm{Kx} \mathrm{Ky} \mathrm{Kz}$ Ss Por

7.26990e+01 7.26990e+01 7.26990e+00 1.00000e-09 7.00000e-02

$2.90481 \mathrm{e}+002.90481 \mathrm{e}+00$ 2.90481e-01 1.00000e-09 2.12000e-01

$2.90481 \mathrm{e}+002.90481 \mathrm{e}+002.90481 \mathrm{e}-01$ 1.00000e-09 2.12000e-01

$2.90481 \mathrm{e}+00$ 2.90481e+00 2.90481e-01 1.00000e-09 2.12000e-01

$2.90481 \mathrm{e}+002.90481 \mathrm{e}+002.90481 \mathrm{e}-01$ 1.00000e-09 2.12000e-01

$1.00000 \mathrm{e}-02$ 1.00000e-02 1.00000e-03 1.00000e-09 1.00000e-01

$1.00000 \mathrm{e}+001.00000 \mathrm{e}+001.00000 \mathrm{e}-011.00000 \mathrm{e}-091.00000 \mathrm{e}-01$

Element: 1067 \# of layers: 8

$\mathrm{Kx} \mathrm{Ky} \mathrm{Kz}$ Ss Por

7.26990e+01 7.26990e+01 7.26990e+00 1.00000e-09 7.00000e-02

$2.90481 \mathrm{e}+002.90481 \mathrm{e}+002.90481 \mathrm{e}-01$ 1.00000e-09 2.12000e-01

$2.90481 \mathrm{e}+002.90481 \mathrm{e}+002.90481 \mathrm{e}-01$ 1.00000e-09 2.12000e-01

$2.90481 \mathrm{e}+002.90481 \mathrm{e}+002.90481 \mathrm{e}-01$ 1.00000e-09 2.12000e-01

2.90481e+00 2.90481e+00 2.90481e-01 1.00000e-09 2.12000e-01

$2.90481 \mathrm{e}+002.90481 \mathrm{e}+002.90481 \mathrm{e}-01$ 1.00000e-09 2.12000e-01

$1.00000 \mathrm{e}-02$ 1.00000e-02 1.00000e-03 1.00000e-09 1.00000e-01 
$1.00000 \mathrm{e}+001.00000 \mathrm{e}+00$ 1.00000e-01 1.00000e-09 1.00000e-01

Element: 1068 \# of layers: 8

$\mathrm{Kx} \mathrm{Ky} \mathrm{Kz}$ Ss Por

7.26990e+01 7.26990e+01 7.26990e+00 1.00000e-09 7.00000e-02

$2.90481 \mathrm{e}+002.90481 \mathrm{e}+002.90481 \mathrm{e}-01$ 1.00000e-09 2.12000e-01

$2.90481 \mathrm{e}+002.90481 \mathrm{e}+00$ 2.90481e-01 1.00000e-09 2.12000e-01

$2.90481 \mathrm{e}+002.90481 \mathrm{e}+00$ 2.90481e-01 1.00000e-09 2.12000e-01

$2.90481 \mathrm{e}+002.90481 \mathrm{e}+002.90481 \mathrm{e}-01$ 1.00000e-09 2.12000e-01

$2.90481 \mathrm{e}+002.90481 \mathrm{e}+00$ 2.90481e-01 1.00000e-09 2.12000e-01

$1.00000 \mathrm{e}-02$ 1.00000e-02 1.00000e-03 1.00000e-09 1.00000e-01

$1.00000 \mathrm{e}+001.00000 \mathrm{e}+001.00000 \mathrm{e}-011.00000 \mathrm{e}-091.00000 \mathrm{e}-01$

Element: 1069 \# of layers: 7

$\mathrm{Kx} \mathrm{Ky} \mathrm{Kz}$ Ss Por

9.61547e+01 9.61547e+01 9.61547e+00 1.00000e-09 7.00000e-02

$3.84196 \mathrm{e}+003.84196 \mathrm{e}+00$ 3.84196e-01 1.00000e-09 2.12000e-01

$3.84196 \mathrm{e}+003.84196 \mathrm{e}+003.84196 \mathrm{e}-01$ 1.00000e-09 2.12000e-01

$3.84196 \mathrm{e}+003.84196 \mathrm{e}+00$ 3.84196e-01 1.00000e-09 2.12000e-01

$3.84196 \mathrm{e}+00$ 3.84196e+00 3.84196e-01 1.00000e-09 2.12000e-01

$1.00000 \mathrm{e}-02$ 1.00000e-02 1.00000e-03 1.00000e-09 1.00000e-01

$1.00000 \mathrm{e}+001.00000 \mathrm{e}+001.00000 \mathrm{e}-011.00000 \mathrm{e}-091.00000 \mathrm{e}-01$

Element: 1070 \# of layers: 7

$\mathrm{Kx} \mathrm{Ky} \mathrm{Kz}$ Ss Por

9.61547e+01 9.61547e+01 9.61547e+00 1.00000e-09 7.00000e-02

$3.84196 \mathrm{e}+003.84196 \mathrm{e}+00$ 3.84196e-01 1.00000e-09 2.12000e-01

$3.84196 \mathrm{e}+003.84196 \mathrm{e}+00$ 3.84196e-01 1.00000e-09 2.12000e-01

$3.84196 \mathrm{e}+003.84196 \mathrm{e}+003.84196 \mathrm{e}-01$ 1.00000e-09 2.12000e-01

$3.84196 \mathrm{e}+003.84196 \mathrm{e}+003.84196 \mathrm{e}-01$ 1.00000e-09 2.12000e-01

$1.00000 \mathrm{e}-02$ 1.00000e-02 1.00000e-03 1.00000e-09 1.00000e-01

$1.00000 \mathrm{e}+001.00000 \mathrm{e}+001.00000 \mathrm{e}-011.00000 \mathrm{e}-091.00000 \mathrm{e}-01$

Element: 1071 \# of layers: 7

$\mathrm{Kx} \mathrm{Ky} \mathrm{Kz}$ Ss Por

9.61547e+01 9.61547e+01 9.61547e+00 1.00000e-09 7.00000e-02

$3.84196 \mathrm{e}+003.84196 \mathrm{e}+003.84196 \mathrm{e}-01$ 1.00000e-09 2.12000e-01

$3.84196 \mathrm{e}+003.84196 \mathrm{e}+003.84196 \mathrm{e}-01$ 1.00000e-09 2.12000e-01

$3.84196 \mathrm{e}+003.84196 \mathrm{e}+003.84196 \mathrm{e}-01$ 1.00000e-09 2.12000e-01

$3.84196 \mathrm{e}+003.84196 \mathrm{e}+00$ 3.84196e-01 1.00000e-09 2.12000e-01

1.00000e-02 1.00000e-02 1.00000e-03 1.00000e-09 1.00000e-01

$1.00000 \mathrm{e}+001.00000 \mathrm{e}+001.00000 \mathrm{e}-011.00000 \mathrm{e}-09$ 1.00000e-01

Element: 1072 \# of layers: 7

$\mathrm{Kx} \mathrm{Ky} \mathrm{Kz}$ Ss Por

9.61547e+01 9.61547e+01 9.61547e+00 1.00000e-09 7.00000e-02

$3.84196 \mathrm{e}+003.84196 \mathrm{e}+00$ 3.84196e-01 1.00000e-09 2.12000e-01

$3.84196 \mathrm{e}+00$ 3.84196e+00 3.84196e-01 1.00000e-09 2.12000e-01

3.84196e $+003.84196 \mathrm{e}+00$ 3.84196e-01 1.00000e-09 2.12000e-01

$3.84196 \mathrm{e}+003.84196 \mathrm{e}+003.84196 \mathrm{e}-01$ 1.00000e-09 2.12000e-01

$1.00000 \mathrm{e}-02$ 1.00000e-02 1.00000e-03 1.00000e-09 1.00000e-01 
$1.00000 \mathrm{e}+001.00000 \mathrm{e}+00$ 1.00000e-01 1.00000e-09 1.00000e-01

Element: 1073 \# of layers: 6

Kx Ky Kz Ss Por

9.61547e+01 9.61547e+01 9.61547e+00 1.00000e-09 7.00000e-02

$3.84196 \mathrm{e}+003.84196 \mathrm{e}+003.84196 \mathrm{e}-01$ 1.00000e-09 2.12000e-01

$3.84196 \mathrm{e}+003.84196 \mathrm{e}+00$ 3.84196e-01 1.00000e-09 2.12000e-01

$3.84196 \mathrm{e}+00$ 3.84196e+00 3.84196e-01 1.00000e-09 2.12000e-01

$1.00000 \mathrm{e}-02$ 1.00000e-02 1.00000e-03 1.00000e-09 1.00000e-01

$1.00000 \mathrm{e}+001.00000 \mathrm{e}+001.00000 \mathrm{e}-011.00000 \mathrm{e}-091.00000 \mathrm{e}-01$

Element: 1074 \# of layers: 7

Kx Ky Kz Ss Por

9.61547e+01 9.61547e+01 9.61547e+00 1.00000e-09 7.00000e-02

$3.84196 \mathrm{e}+003.84196 \mathrm{e}+003.84196 \mathrm{e}-01$ 1.00000e-09 2.12000e-01

$3.84196 \mathrm{e}+003.84196 \mathrm{e}+003.84196 \mathrm{e}-01$ 1.00000e-09 2.12000e-01

$3.84196 \mathrm{e}+003.84196 \mathrm{e}+003.84196 \mathrm{e}-01$ 1.00000e-09 2.12000e-01

$3.84196 \mathrm{e}+003.84196 \mathrm{e}+003.84196 \mathrm{e}-01$ 1.00000e-09 2.12000e-01

$1.00000 \mathrm{e}-02$ 1.00000e-02 1.00000e-03 1.00000e-09 1.00000e-01

$1.00000 \mathrm{e}+001.00000 \mathrm{e}+001.00000 \mathrm{e}-01$ 1.00000e-09 1.00000e-01

Element: 1075 \# of layers: 7

$\mathrm{Kx} \mathrm{Ky} \mathrm{Kz}$ Ss Por

9.61547e+01 9.61547e+01 9.61547e+00 1.00000e-09 7.00000e-02

$3.84196 \mathrm{e}+003.84196 \mathrm{e}+00$ 3.84196e-01 1.00000e-09 2.12000e-01

$3.84196 \mathrm{e}+003.84196 \mathrm{e}+003.84196 \mathrm{e}-01$ 1.00000e-09 2.12000e-01

$3.84196 \mathrm{e}+003.84196 \mathrm{e}+00$ 3.84196e-01 1.00000e-09 2.12000e-01

$3.84196 \mathrm{e}+003.84196 \mathrm{e}+003.84196 \mathrm{e}-01$ 1.00000e-09 2.12000e-01

$1.00000 \mathrm{e}-02$ 1.00000e-02 1.00000e-03 1.00000e-09 1.00000e-01

$1.00000 \mathrm{e}+001.00000 \mathrm{e}+001.00000 \mathrm{e}-011.00000 \mathrm{e}-09$ 1.00000e-01

Element: 1076 \# of layers: 7

Kx Ky Kz Ss Por

9.61547e+01 9.61547e+01 9.61547e+00 1.00000e-09 7.00000e-02

$3.84196 \mathrm{e}+003.84196 \mathrm{e}+003.84196 \mathrm{e}-01$ 1.00000e-09 2.12000e-01

$3.84196 \mathrm{e}+00$ 3.84196e+00 3.84196e-01 1.00000e-09 2.12000e-01

$3.84196 \mathrm{e}+003.84196 \mathrm{e}+003.84196 \mathrm{e}-01$ 1.00000e-09 2.12000e-01

$3.84196 \mathrm{e}+003.84196 \mathrm{e}+003.84196 \mathrm{e}-01$ 1.00000e-09 2.12000e-01

$1.00000 \mathrm{e}-02$ 1.00000e-02 1.00000e-03 1.00000e-09 1.00000e-01

$1.00000 \mathrm{e}+001.00000 \mathrm{e}+001.00000 \mathrm{e}-011.00000 \mathrm{e}-091.00000 \mathrm{e}-01$

Element: 1077 \# of layers: 7

$\mathrm{Kx} \mathrm{Ky} \mathrm{Kz}$ Ss Por

9.61547e+01 9.61547e+01 9.61547e+00 1.00000e-09 7.00000e-02

$3.84196 \mathrm{e}+003.84196 \mathrm{e}+00$ 3.84196e-01 1.00000e-09 2.12000e-01

$3.84196 \mathrm{e}+003.84196 \mathrm{e}+00$ 3.84196e-01 1.00000e-09 2.12000e-01

$3.84196 \mathrm{e}+003.84196 \mathrm{e}+00$ 3.84196e-01 1.00000e-09 2.12000e-01

$3.84196 \mathrm{e}+00$ 3.84196e+00 3.84196e-01 1.00000e-09 2.12000e-01

$1.00000 \mathrm{e}-02$ 1.00000e-02 1.00000e-03 1.00000e-09 1.00000e-01

$1.00000 \mathrm{e}+001.00000 \mathrm{e}+001.00000 \mathrm{e}-011.00000 \mathrm{e}-091.00000 \mathrm{e}-01$

Element: 1078 \# of layers: 7 
$\mathrm{Kx} \mathrm{Ky} \mathrm{Kz}$ Ss Por

1.28248e+02 1.28248e+02 1.28248e+01 1.00000e-09 7.00000e-02

5.12426e+00 5.12426e+00 5.12426e-01 1.00000e-09 2.12000e-01

$5.12426 \mathrm{e}+00$ 5.12426e+00 5.12426e-01 1.00000e-09 2.12000e-01

$5.12426 \mathrm{e}+00$ 5.12426e+00 5.12426e-01 1.00000e-09 2.12000e-01

$5.12426 \mathrm{e}+00$ 5.12426e+00 5.12426e-01 1.00000e-09 2.12000e-01

$1.00000 \mathrm{e}-02$ 1.00000e-02 1.00000e-03 1.00000e-09 1.00000e-01

$1.00000 \mathrm{e}+001.00000 \mathrm{e}+001.00000 \mathrm{e}-011.00000 \mathrm{e}-091.00000 \mathrm{e}-01$

Element: 1079 \# of layers: 7

$\mathrm{Kx} \mathrm{Ky} \mathrm{Kz}$ Ss Por

1.28248e+02 1.28248e+02 1.28248e+01 1.00000e-09 7.00000e-02

$5.12426 \mathrm{e}+005.12426 \mathrm{e}+00$ 5.12426e-01 1.00000e-09 2.12000e-01

$5.12426 \mathrm{e}+00$ 5.12426e+00 5.12426e-01 1.00000e-09 2.12000e-01

$5.12426 \mathrm{e}+005.12426 \mathrm{e}+00$ 5.12426e-01 1.00000e-09 2.12000e-01

$5.12426 \mathrm{e}+00$ 5.12426e+00 5.12426e-01 1.00000e-09 2.12000e-01

$1.00000 \mathrm{e}-02$ 1.00000e-02 1.00000e-03 1.00000e-09 1.00000e-01

$1.00000 \mathrm{e}+001.00000 \mathrm{e}+001.00000 \mathrm{e}-01$ 1.00000e-09 1.00000e-01

Element: 1080 \# of layers: 6

$\mathrm{Kx} \mathrm{Ky} \mathrm{Kz}$ Ss Por

1.28248e+02 1.28248e+02 1.28248e+01 1.00000e-09 7.00000e-02

$5.12426 \mathrm{e}+005.12426 \mathrm{e}+00$ 5.12426e-01 1.00000e-09 2.12000e-01

5.12426e+00 5.12426e+00 5.12426e-01 1.00000e-09 2.12000e-01

5.12426e+00 5.12426e+00 5.12426e-01 1.00000e-09 2.12000e-01

$1.00000 \mathrm{e}-02$ 1.00000e-02 1.00000e-03 1.00000e-09 1.00000e-01

$1.00000 \mathrm{e}+001.00000 \mathrm{e}+001.00000 \mathrm{e}-011.00000 \mathrm{e}-091.00000 \mathrm{e}-01$

Element: 1081 \# of layers: 6

$\mathrm{Kx} \mathrm{Ky} \mathrm{Kz}$ Ss Por

$1.28248 \mathrm{e}+02$ 1.28248e+02 1.28248e+01 1.00000e-09 7.00000e-02

$5.12426 \mathrm{e}+00$ 5.12426e+00 5.12426e-01 1.00000e-09 2.12000e-01

$5.12426 \mathrm{e}+005.12426 \mathrm{e}+00$ 5.12426e-01 1.00000e-09 2.12000e-01

$5.12426 \mathrm{e}+005.12426 \mathrm{e}+00$ 5.12426e-01 1.00000e-09 2.12000e-01

$1.00000 \mathrm{e}-02$ 1.00000e-02 1.00000e-03 1.00000e-09 1.00000e-01

$1.00000 \mathrm{e}+001.00000 \mathrm{e}+001.00000 \mathrm{e}-011.00000 \mathrm{e}-091.00000 \mathrm{e}-01$

Element: 1082 \# of layers: 6

$\mathrm{Kx} \mathrm{Ky} \mathrm{Kz}$ Ss Por

$1.28248 \mathrm{e}+02$ 1.28248e+02 1.28248e+01 1.00000e-09 7.00000e-02

$5.12426 \mathrm{e}+005.12426 \mathrm{e}+00$ 5.12426e-01 1.00000e-09 2.12000e-01

5.12426e+00 5.12426e+00 5.12426e-01 1.00000e-09 2.12000e-01

$5.12426 \mathrm{e}+00$ 5.12426e+00 5.12426e-01 1.00000e-09 2.12000e-01

$1.00000 \mathrm{e}-02$ 1.00000e-02 1.00000e-03 1.00000e-09 1.00000e-01

$1.00000 \mathrm{e}+001.00000 \mathrm{e}+001.00000 \mathrm{e}-011.00000 \mathrm{e}-091.00000 \mathrm{e}-01$

Element: 1083 \# of layers: 7

$\mathrm{Kx} \mathrm{Ky} \mathrm{Kz}$ Ss Por

1.28248e+02 1.28248e+02 1.28248e+01 1.00000e-09 7.00000e-02

$5.12426 \mathrm{e}+005.12426 \mathrm{e}+00$ 5.12426e-01 1.00000e-09 2.12000e-01

$5.12426 \mathrm{e}+00$ 5.12426e+00 5.12426e-01 1.00000e-09 2.12000e-01 
$5.12426 \mathrm{e}+00$ 5.12426e+00 5.12426e-01 1.00000e-09 2.12000e-01 $5.12426 \mathrm{e}+005.12426 \mathrm{e}+00$ 5.12426e-01 1.00000e-09 2.12000e-01 $1.00000 \mathrm{e}-021.00000 \mathrm{e}-02$ 1.00000e-03 1.00000e-09 1.00000e-01 $1.00000 \mathrm{e}+001.00000 \mathrm{e}+001.00000 \mathrm{e}-011.00000 \mathrm{e}-091.00000 \mathrm{e}-01$ Element: 1084 \# of layers: 6

Kx Ky Kz Ss Por

$1.28248 \mathrm{e}+021.28248 \mathrm{e}+021.28248 \mathrm{e}+01$ 1.00000e-09 7.00000e-02 $5.12426 \mathrm{e}+005.12426 \mathrm{e}+00$ 5.12426e-01 1.00000e-09 2.12000e-01 $5.12426 \mathrm{e}+005.12426 \mathrm{e}+00$ 5.12426e-01 1.00000e-09 2.12000e-01 $5.12426 \mathrm{e}+00$ 5.12426e+00 5.12426e-01 1.00000e-09 2.12000e-01 $1.00000 \mathrm{e}-02$ 1.00000e-02 1.00000e-03 1.00000e-09 1.00000e-01 $1.00000 \mathrm{e}+001.00000 \mathrm{e}+001.00000 \mathrm{e}-011.00000 \mathrm{e}-091.00000 \mathrm{e}-01$ Element: 1085 \# of layers: 7

Kx Ky Kz Ss Por

$1.28248 \mathrm{e}+021.28248 \mathrm{e}+021.28248 \mathrm{e}+01$ 1.00000e-09 7.00000e-02 $5.12426 \mathrm{e}+005.12426 \mathrm{e}+00$ 5.12426e-01 1.00000e-09 2.12000e-01 $5.12426 \mathrm{e}+005.12426 \mathrm{e}+00$ 5.12426e-01 1.00000e-09 2.12000e-01 $5.12426 \mathrm{e}+005.12426 \mathrm{e}+005.12426 \mathrm{e}-011.00000 \mathrm{e}-092.12000 \mathrm{e}-01$ $5.12426 \mathrm{e}+005.12426 \mathrm{e}+00$ 5.12426e-01 1.00000e-09 2.12000e-01 $1.00000 \mathrm{e}-021.00000 \mathrm{e}-02$ 1.00000e-03 1.00000e-09 1.00000e-01 $1.00000 \mathrm{e}+001.00000 \mathrm{e}+001.00000 \mathrm{e}-011.00000 \mathrm{e}-091.00000 \mathrm{e}-01$ Element: 1086 \# of layers: 7

Kx Ky Kz Ss Por

$1.28248 \mathrm{e}+021.28248 \mathrm{e}+02$ 1.28248e+01 1.00000e-09 7.00000e-02

$5.12426 \mathrm{e}+005.12426 \mathrm{e}+00$ 5.12426e-01 1.00000e-09 2.12000e-01

$5.12426 \mathrm{e}+005.12426 \mathrm{e}+00$ 5.12426e-01 1.00000e-09 2.12000e-01

$5.12426 \mathrm{e}+005.12426 \mathrm{e}+005.12426 \mathrm{e}-011.00000 \mathrm{e}-092.12000 \mathrm{e}-01$

$5.12426 \mathrm{e}+005.12426 \mathrm{e}+00$ 5.12426e-01 1.00000e-09 2.12000e-01

$1.00000 \mathrm{e}-021.00000 \mathrm{e}-02$ 1.00000e-03 1.00000e-09 1.00000e-01

$1.00000 \mathrm{e}+001.00000 \mathrm{e}+001.00000 \mathrm{e}-011.00000 \mathrm{e}-091.00000 \mathrm{e}-01$

Element: 1087 \# of layers: 7

Kx Ky Kz Ss Por

8.10792e+01 8.10792e+01 8.10792e+00 1.00000e-09 7.00000e-02

$8.10792 \mathrm{e}+018.10792 \mathrm{e}+018.10792 \mathrm{e}+00$ 1.00000e-09 7.00000e-02

$3.23962 \mathrm{e}+003.23962 \mathrm{e}+003.23962 \mathrm{e}-011.00000 \mathrm{e}-09$ 2.12000e-01

$3.23962 \mathrm{e}+003.23962 \mathrm{e}+003.23962 \mathrm{e}-01$ 1.00000e-09 2.12000e-01

$3.23962 \mathrm{e}+003.23962 \mathrm{e}+003.23962 \mathrm{e}-01$ 1.00000e-09 2.12000e-01

$1.00000 \mathrm{e}-02$ 1.00000e-02 1.00000e-03 1.00000e-09 1.00000e-01

$1.00000 \mathrm{e}+001.00000 \mathrm{e}+001.00000 \mathrm{e}-011.00000 \mathrm{e}-091.00000 \mathrm{e}-01$

Element: 1088 \# of layers: 7

Kx Ky Kz Ss Por

8.10792e+01 8.10792e+01 8.10792e+00 1.00000e-09 7.00000e-02

$8.10792 \mathrm{e}+018.10792 \mathrm{e}+018.10792 \mathrm{e}+00$ 1.00000e-09 7.00000e-02

$3.23962 \mathrm{e}+003.23962 \mathrm{e}+003.23962 \mathrm{e}-01$ 1.00000e-09 2.12000e-01

$3.23962 \mathrm{e}+003.23962 \mathrm{e}+003.23962 \mathrm{e}-01$ 1.00000e-09 2.12000e-01

$3.23962 \mathrm{e}+003.23962 \mathrm{e}+003.23962 \mathrm{e}-01$ 1.00000e-09 2.12000e-01 
$1.00000 \mathrm{e}-02$ 1.00000e-02 1.00000e-03 1.00000e-09 1.00000e-01 $1.00000 \mathrm{e}+001.00000 \mathrm{e}+001.00000 \mathrm{e}-01$ 1.00000e-09 1.00000e-01 Element: 1089 \# of layers: 7

Kx Ky Kz Ss Por

8.10792e+01 8.10792e+01 8.10792e+00 1.00000e-09 7.00000e-02 8.10792e+01 8.10792e+01 8.10792e+00 1.00000e-09 7.00000e-02 $3.23962 \mathrm{e}+003.23962 \mathrm{e}+00$ 3.23962e-01 1.00000e-09 2.12000e-01 $3.23962 \mathrm{e}+003.23962 \mathrm{e}+00$ 3.23962e-01 1.00000e-09 2.12000e-01 $3.23962 \mathrm{e}+00$ 3.23962e+00 3.23962e-01 1.00000e-09 2.12000e-01 $1.00000 \mathrm{e}-02$ 1.00000e-02 1.00000e-03 1.00000e-09 1.00000e-01 $1.00000 \mathrm{e}+001.00000 \mathrm{e}+001.00000 \mathrm{e}-01$ 1.00000e-09 1.00000e-01 Element: 1090 \# of layers: 11

$\mathrm{Kx} \mathrm{Ky} \mathrm{Kz}$ Ss Por

$1.73956 \mathrm{e}+02$ 1.73956e+02 1.73956e+01 1.00000e-09 7.00000e-02 $1.73956 \mathrm{e}+02$ 1.73956e+02 1.73956e+01 1.00000e-09 7.00000e-02 6.95062e+00 6.95062e+00 6.95062e-01 1.00000e-09 2.12000e-01 $6.95062 \mathrm{e}+006.95062 \mathrm{e}+00$ 6.95062e-01 1.00000e-09 2.12000e-01 6.95062e+00 6.95062e+00 6.95062e-01 1.00000e-09 2.12000e-01 $6.95062 \mathrm{e}+006.95062 \mathrm{e}+006.95062 \mathrm{e}-01$ 1.00000e-09 2.12000e-01 6.95062e+00 6.95062e+00 6.95062e-01 1.00000e-09 2.12000e-01 $1.00000 \mathrm{e}-011.00000 \mathrm{e}-011.00000 \mathrm{e}-021.00000 \mathrm{e}-091.00000 \mathrm{e}-01$ $1.00000 \mathrm{e}+001.00000 \mathrm{e}+001.00000 \mathrm{e}-011.00000 \mathrm{e}-091.00000 \mathrm{e}-01$ $1.00000 \mathrm{e}-05$ 1.00000e-05 1.00000e-06 1.00000e-09 1.00000e-01 $1.00000 \mathrm{e}+001.00000 \mathrm{e}+001.00000 \mathrm{e}-011.00000 \mathrm{e}-09$ 1.00000e-01 Element: 1091 \# of layers: 11

$\mathrm{Kx} \mathrm{Ky} \mathrm{Kz}$ Ss Por

$1.73956 \mathrm{e}+02$ 1.73956e+02 1.73956e+01 1.00000e-09 7.00000e-02 $1.73956 \mathrm{e}+02$ 1.73956e+02 1.73956e+01 1.00000e-09 7.00000e-02 6.95062e+00 6.95062e+00 6.95062e-01 1.00000e-09 2.12000e-01 $6.95062 \mathrm{e}+006.95062 \mathrm{e}+00$ 6.95062e-01 1.00000e-09 2.12000e-01 $6.95062 \mathrm{e}+006.95062 \mathrm{e}+00$ 6.95062e-01 1.00000e-09 2.12000e-01 6.95062e+00 6.95062e+00 6.95062e-01 1.00000e-09 2.12000e-01 $6.95062 \mathrm{e}+006.95062 \mathrm{e}+006.95062 \mathrm{e}-01$ 1.00000e-09 2.12000e-01 1.00000e-01 1.00000e-01 1.00000e-02 1.00000e-09 1.00000e-01 $1.00000 \mathrm{e}+001.00000 \mathrm{e}+001.00000 \mathrm{e}-011.00000 \mathrm{e}-091.00000 \mathrm{e}-01$ $1.00000 \mathrm{e}-05$ 1.00000e-05 1.00000e-06 1.00000e-09 1.00000e-01 $1.00000 \mathrm{e}+001.00000 \mathrm{e}+001.00000 \mathrm{e}-011.00000 \mathrm{e}-091.00000 \mathrm{e}-01$ Element: 1092 \# of layers: 9

$\mathrm{Kx} \mathrm{Ky} \mathrm{Kz}$ Ss Por

$1.73956 \mathrm{e}+02$ 1.73956e+02 1.73956e+01 1.00000e-09 7.00000e-02 6.95062e+00 6.95062e+00 6.95062e-01 1.00000e-09 2.12000e-01 $6.95062 \mathrm{e}+006.95062 \mathrm{e}+00$ 6.95062e-01 1.00000e-09 2.12000e-01 6.95062e+00 6.95062e+00 6.95062e-01 1.00000e-09 2.12000e-01 $6.95062 \mathrm{e}+006.95062 \mathrm{e}+006.95062 \mathrm{e}-01$ 1.00000e-09 2.12000e-01 $1.00000 \mathrm{e}-011.00000 \mathrm{e}-011.00000 \mathrm{e}-021.00000 \mathrm{e}-091.00000 \mathrm{e}-01$ $1.00000 \mathrm{e}+001.00000 \mathrm{e}+001.00000 \mathrm{e}-011.00000 \mathrm{e}-091.00000 \mathrm{e}-01$ 
$1.00000 \mathrm{e}-05$ 1.00000e-05 1.00000e-06 1.00000e-09 1.00000e-01 $1.00000 \mathrm{e}+001.00000 \mathrm{e}+001.00000 \mathrm{e}-01$ 1.00000e-09 1.00000e-01 Element: 1093 \# of layers: 11

Kx Ky Kz Ss Por

1.73956e+02 1.73956e+02 1.73956e+01 1.00000e-09 7.00000e-02 $1.73956 \mathrm{e}+02$ 1.73956e+02 1.73956e+01 1.00000e-09 7.00000e-02 $6.95062 \mathrm{e}+006.95062 \mathrm{e}+00$ 6.95062e-01 1.00000e-09 2.12000e-01 $6.95062 \mathrm{e}+00$ 6.95062e+00 6.95062e-01 1.00000e-09 2.12000e-01 $6.95062 \mathrm{e}+006.95062 \mathrm{e}+00$ 6.95062e-01 1.00000e-09 2.12000e-01 $6.95062 \mathrm{e}+006.95062 \mathrm{e}+00$ 6.95062e-01 1.00000e-09 2.12000e-01 6.95062e+00 6.95062e+00 6.95062e-01 1.00000e-09 2.12000e-01 $1.00000 \mathrm{e}-01$ 1.00000e-01 1.00000e-02 1.00000e-09 1.00000e-01 $1.00000 \mathrm{e}+001.00000 \mathrm{e}+001.00000 \mathrm{e}-011.00000 \mathrm{e}-091.00000 \mathrm{e}-01$ $1.00000 \mathrm{e}-05$ 1.00000e-05 1.00000e-06 1.00000e-09 1.00000e-01 $1.00000 \mathrm{e}+001.00000 \mathrm{e}+001.00000 \mathrm{e}-01$ 1.00000e-09 1.00000e-01 Element: 1094 \# of layers: 11

$\mathrm{Kx} \mathrm{Ky} \mathrm{Kz}$ Ss Por

$1.73956 \mathrm{e}+02$ 1.73956e+02 1.73956e+01 1.00000e-09 7.00000e-02 $1.73956 \mathrm{e}+02$ 1.73956e+02 1.73956e+01 1.00000e-09 7.00000e-02 6.95062e+00 6.95062e+00 6.95062e-01 1.00000e-09 2.12000e-01 $6.95062 \mathrm{e}+006.95062 \mathrm{e}+00$ 6.95062e-01 1.00000e-09 2.12000e-01 6.95062e+00 6.95062e+00 6.95062e-01 1.00000e-09 2.12000e-01 6.95062e+00 6.95062e+00 6.95062e-01 1.00000e-09 2.12000e-01 $6.95062 \mathrm{e}+006.95062 \mathrm{e}+006.95062 \mathrm{e}-01$ 1.00000e-09 2.12000e-01 $1.00000 \mathrm{e}-011.00000 \mathrm{e}-011.00000 \mathrm{e}-021.00000 \mathrm{e}-091.00000 \mathrm{e}-01$ $1.00000 \mathrm{e}+001.00000 \mathrm{e}+001.00000 \mathrm{e}-011.00000 \mathrm{e}-091.00000 \mathrm{e}-01$ $1.00000 \mathrm{e}-05$ 1.00000e-05 1.00000e-06 1.00000e-09 1.00000e-01 $1.00000 \mathrm{e}+001.00000 \mathrm{e}+001.00000 \mathrm{e}-011.00000 \mathrm{e}-091.00000 \mathrm{e}-01$ Element: 1095 \# of layers: 9

$\mathrm{Kx} \mathrm{Ky} \mathrm{Kz}$ Ss Por

1.53972e+02 1.53972e+02 1.53972e+01 1.00000e-09 7.00000e-02 6.15208e+00 6.15208e+00 6.15208e-01 1.00000e-09 2.12000e-01 6.15208e+00 6.15208e+00 6.15208e-01 1.00000e-09 2.12000e-01 $6.15208 \mathrm{e}+006.15208 \mathrm{e}+00$ 6.15208e-01 1.00000e-09 2.12000e-01 6.15208e+00 6.15208e+00 6.15208e-01 1.00000e-09 2.12000e-01 1.00000e-01 1.00000e-01 1.00000e-02 1.00000e-09 1.00000e-01 $1.00000 \mathrm{e}+001.00000 \mathrm{e}+001.00000 \mathrm{e}-011.00000 \mathrm{e}-091.00000 \mathrm{e}-01$ $1.00000 \mathrm{e}-05$ 1.00000e-05 1.00000e-06 1.00000e-09 1.00000e-01 $1.00000 \mathrm{e}+001.00000 \mathrm{e}+001.00000 \mathrm{e}-011.00000 \mathrm{e}-091.00000 \mathrm{e}-01$ Element: 1096 \# of layers: 10

$\mathrm{Kx} \mathrm{Ky} \mathrm{Kz}$ Ss Por

1.53972e+02 1.53972e+02 1.53972e+01 1.00000e-09 7.00000e-02 6.15208e+00 6.15208e+00 6.15208e-01 1.00000e-09 2.12000e-01 $6.15208 \mathrm{e}+00$ 6.15208e+00 6.15208e-01 1.00000e-09 2.12000e-01 6.15208e+00 6.15208e+00 6.15208e-01 1.00000e-09 2.12000e-01 $6.15208 \mathrm{e}+006.15208 \mathrm{e}+00$ 6.15208e-01 1.00000e-09 2.12000e-01 
$6.15208 \mathrm{e}+006.15208 \mathrm{e}+00$ 6.15208e-01 1.00000e-09 2.12000e-01 $1.00000 \mathrm{e}-02$ 1.00000e-02 1.00000e-03 1.00000e-09 1.00000e-01 $1.00000 \mathrm{e}+001.00000 \mathrm{e}+001.00000 \mathrm{e}-011.00000 \mathrm{e}-091.00000 \mathrm{e}-01$ $1.00000 \mathrm{e}-05$ 1.00000e-05 1.00000e-06 1.00000e-09 1.00000e-01 $1.00000 \mathrm{e}+001.00000 \mathrm{e}+001.00000 \mathrm{e}-011.00000 \mathrm{e}-091.00000 \mathrm{e}-01$ Element: 1097 \# of layers: 10

Kx Ky Kz Ss Por

$1.53972 \mathrm{e}+02$ 1.53972e+02 1.53972e+01 1.00000e-09 7.00000e-02 $6.15208 \mathrm{e}+006.15208 \mathrm{e}+00$ 6.15208e-01 1.00000e-09 2.12000e-01 $6.15208 \mathrm{e}+006.15208 \mathrm{e}+00$ 6.15208e-01 1.00000e-09 2.12000e-01 $6.15208 \mathrm{e}+006.15208 \mathrm{e}+006.15208 \mathrm{e}-01$ 1.00000e-09 2.12000e-01 $6.15208 \mathrm{e}+006.15208 \mathrm{e}+006.15208 \mathrm{e}-011.00000 \mathrm{e}-092.12000 \mathrm{e}-01$ $6.15208 \mathrm{e}+006.15208 \mathrm{e}+00$ 6.15208e-01 1.00000e-09 2.12000e-01 $1.00000 \mathrm{e}-02$ 1.00000e-02 1.00000e-03 1.00000e-09 1.00000e-01 $1.00000 \mathrm{e}+001.00000 \mathrm{e}+001.00000 \mathrm{e}-011.00000 \mathrm{e}-091.00000 \mathrm{e}-01$ $1.00000 \mathrm{e}-05$ 1.00000e-05 1.00000e-06 1.00000e-09 1.00000e-01 $1.00000 \mathrm{e}+001.00000 \mathrm{e}+001.00000 \mathrm{e}-011.00000 \mathrm{e}-091.00000 \mathrm{e}-01$ Element: 1098 \# of layers: 10

Kx Ky Kz Ss Por

$1.53972 \mathrm{e}+02$ 1.53972e+02 1.53972e+01 1.00000e-09 7.00000e-02 $6.15208 \mathrm{e}+006.15208 \mathrm{e}+00$ 6.15208e-01 1.00000e-09 2.12000e-01 $6.15208 \mathrm{e}+006.15208 \mathrm{e}+00$ 6.15208e-01 1.00000e-09 2.12000e-01 $6.15208 \mathrm{e}+006.15208 \mathrm{e}+00$ 6.15208e-01 1.00000e-09 2.12000e-01 $6.15208 \mathrm{e}+006.15208 \mathrm{e}+00$ 6.15208e-01 1.00000e-09 2.12000e-01 $6.15208 \mathrm{e}+006.15208 \mathrm{e}+00$ 6.15208e-01 1.00000e-09 2.12000e-01 $1.00000 \mathrm{e}-02$ 1.00000e-02 1.00000e-03 1.00000e-09 1.00000e-01 $1.00000 \mathrm{e}+001.00000 \mathrm{e}+001.00000 \mathrm{e}-011.00000 \mathrm{e}-091.00000 \mathrm{e}-01$ $1.00000 \mathrm{e}-05$ 1.00000e-05 1.00000e-06 1.00000e-09 1.00000e-01 $1.00000 \mathrm{e}+001.00000 \mathrm{e}+001.00000 \mathrm{e}-011.00000 \mathrm{e}-091.00000 \mathrm{e}-01$ Element: 1099 \# of layers: 10

Kx Ky Kz Ss Por

$1.53972 \mathrm{e}+02$ 1.53972e+02 1.53972e+01 1.00000e-09 7.00000e-02 $6.15208 \mathrm{e}+006.15208 \mathrm{e}+00$ 6.15208e-01 1.00000e-09 2.12000e-01 $6.15208 \mathrm{e}+006.15208 \mathrm{e}+006.15208 \mathrm{e}-011.00000 \mathrm{e}-092.12000 \mathrm{e}-01$ $6.15208 \mathrm{e}+006.15208 \mathrm{e}+00$ 6.15208e-01 1.00000e-09 2.12000e-01 $6.15208 \mathrm{e}+006.15208 \mathrm{e}+006.15208 \mathrm{e}-01$ 1.00000e-09 2.12000e-01 $6.15208 \mathrm{e}+006.15208 \mathrm{e}+006.15208 \mathrm{e}-01$ 1.00000e-09 2.12000e-01 $1.00000 \mathrm{e}-02$ 1.00000e-02 1.00000e-03 1.00000e-09 1.00000e-01 $1.00000 \mathrm{e}+001.00000 \mathrm{e}+001.00000 \mathrm{e}-011.00000 \mathrm{e}-091.00000 \mathrm{e}-01$ $1.00000 \mathrm{e}-05$ 1.00000e-05 1.00000e-06 1.00000e-09 1.00000e-01 $1.00000 \mathrm{e}+001.00000 \mathrm{e}+001.00000 \mathrm{e}-011.00000 \mathrm{e}-091.00000 \mathrm{e}-01$ Element: 1100 \# of layers: 10

Kx Ky Kz Ss Por

$1.53972 \mathrm{e}+02$ 1.53972e+02 1.53972e+01 1.00000e-09 7.00000e-02 $6.15208 \mathrm{e}+006.15208 \mathrm{e}+00$ 6.15208e-01 1.00000e-09 2.12000e-01 $6.15208 \mathrm{e}+006.15208 \mathrm{e}+00$ 6.15208e-01 1.00000e-09 2.12000e-01 
$6.15208 \mathrm{e}+006.15208 \mathrm{e}+00$ 6.15208e-01 1.00000e-09 2.12000e-01 $6.15208 \mathrm{e}+006.15208 \mathrm{e}+006.15208 \mathrm{e}-01$ 1.00000e-09 2.12000e-01 $6.15208 \mathrm{e}+006.15208 \mathrm{e}+00$ 6.15208e-01 1.00000e-09 2.12000e-01 $1.00000 \mathrm{e}-011.00000 \mathrm{e}-011.00000 \mathrm{e}-021.00000 \mathrm{e}-091.00000 \mathrm{e}-01$ $1.00000 \mathrm{e}+001.00000 \mathrm{e}+001.00000 \mathrm{e}-011.00000 \mathrm{e}-091.00000 \mathrm{e}-01$ $1.00000 \mathrm{e}-05$ 1.00000e-05 1.00000e-06 1.00000e-09 1.00000e-01 $1.00000 \mathrm{e}+001.00000 \mathrm{e}+001.00000 \mathrm{e}-011.00000 \mathrm{e}-091.00000 \mathrm{e}-01$ Element: 1101 \# of layers: 9

$\mathrm{Kx} \mathrm{Ky} \mathrm{Kz}$ Ss Por

1.53972e+02 1.53972e+02 1.53972e+01 1.00000e-09 7.00000e-02 6.15208e+00 6.15208e+00 6.15208e-01 1.00000e-09 2.12000e-01 6.15208e+00 6.15208e+00 6.15208e-01 1.00000e-09 2.12000e-01 $6.15208 \mathrm{e}+006.15208 \mathrm{e}+006.15208 \mathrm{e}-011.00000 \mathrm{e}-092.12000 \mathrm{e}-01$ $6.15208 \mathrm{e}+006.15208 \mathrm{e}+00$ 6.15208e-01 1.00000e-09 2.12000e-01 $1.00000 \mathrm{e}-011.00000 \mathrm{e}-011.00000 \mathrm{e}-021.00000 \mathrm{e}-091.00000 \mathrm{e}-01$ $1.00000 \mathrm{e}+001.00000 \mathrm{e}+001.00000 \mathrm{e}-011.00000 \mathrm{e}-091.00000 \mathrm{e}-01$ $1.00000 \mathrm{e}-05$ 1.00000e-05 1.00000e-06 1.00000e-09 1.00000e-01 $1.00000 \mathrm{e}+001.00000 \mathrm{e}+001.00000 \mathrm{e}-011.00000 \mathrm{e}-091.00000 \mathrm{e}-01$ Element: 1102 \# of layers: 9

Kx Ky Kz Ss Por

$1.53972 \mathrm{e}+02$ 1.53972e+02 1.53972e+01 1.00000e-09 7.00000e-02 $6.15208 \mathrm{e}+006.15208 \mathrm{e}+00$ 6.15208e-01 1.00000e-09 2.12000e-01 $6.15208 \mathrm{e}+006.15208 \mathrm{e}+00$ 6.15208e-01 1.00000e-09 2.12000e-01 $6.15208 \mathrm{e}+006.15208 \mathrm{e}+00$ 6.15208e-01 1.00000e-09 2.12000e-01 $6.15208 \mathrm{e}+006.15208 \mathrm{e}+00$ 6.15208e-01 1.00000e-09 2.12000e-01 $1.00000 \mathrm{e}-011.00000 \mathrm{e}-011.00000 \mathrm{e}-021.00000 \mathrm{e}-091.00000 \mathrm{e}-01$ $1.00000 \mathrm{e}+001.00000 \mathrm{e}+001.00000 \mathrm{e}-011.00000 \mathrm{e}-091.00000 \mathrm{e}-01$ $1.00000 \mathrm{e}-051.00000 \mathrm{e}-05$ 1.00000e-06 1.00000e-09 1.00000e-01 $1.00000 \mathrm{e}+001.00000 \mathrm{e}+001.00000 \mathrm{e}-011.00000 \mathrm{e}-091.00000 \mathrm{e}-01$ Element: 1103 \# of layers: 10

Kx Ky Kz Ss Por

$1.53972 \mathrm{e}+02$ 1.53972e+02 1.53972e+01 1.00000e-09 7.00000e-02 $6.15208 \mathrm{e}+006.15208 \mathrm{e}+00$ 6.15208e-01 1.00000e-09 2.12000e-01 $6.15208 \mathrm{e}+006.15208 \mathrm{e}+006.15208 \mathrm{e}-011.00000 \mathrm{e}-092.12000 \mathrm{e}-01$ $6.15208 \mathrm{e}+006.15208 \mathrm{e}+006.15208 \mathrm{e}-01$ 1.00000e-09 2.12000e-01 $6.15208 \mathrm{e}+006.15208 \mathrm{e}+00$ 6.15208e-01 1.00000e-09 2.12000e-01 $6.15208 \mathrm{e}+006.15208 \mathrm{e}+00$ 6.15208e-01 1.00000e-09 2.12000e-01 $1.00000 \mathrm{e}-02$ 1.00000e-02 1.00000e-03 1.00000e-09 1.00000e-01 $1.00000 \mathrm{e}+001.00000 \mathrm{e}+001.00000 \mathrm{e}-011.00000 \mathrm{e}-091.00000 \mathrm{e}-01$ $1.00000 \mathrm{e}-05$ 1.00000e-05 1.00000e-06 1.00000e-09 1.00000e-01 $1.00000 \mathrm{e}+001.00000 \mathrm{e}+001.00000 \mathrm{e}-011.00000 \mathrm{e}-091.00000 \mathrm{e}-01$ Element: 1104 \# of layers: 10

Kx Ky Kz Ss Por

$1.28122 \mathrm{e}+02$ 1.28122e+02 1.28122e+01 1.00000e-09 7.00000e-02 $5.11931 \mathrm{e}+005.11931 \mathrm{e}+00$ 5.11931e-01 1.00000e-09 2.12000e-01 $5.11931 \mathrm{e}+00$ 5.11931e+00 5.11931e-01 1.00000e-09 2.12000e-01 
$5.11931 \mathrm{e}+00$ 5.11931e+00 5.11931e-01 1.00000e-09 2.12000e-01 $5.11931 \mathrm{e}+005.11931 \mathrm{e}+00$ 5.11931e-01 1.00000e-09 2.12000e-01 $5.11931 \mathrm{e}+00$ 5.11931e+00 5.11931e-01 1.00000e-09 2.12000e-01 $1.00000 \mathrm{e}-02$ 1.00000e-02 1.00000e-03 1.00000e-09 1.00000e-01 $1.00000 \mathrm{e}+001.00000 \mathrm{e}+001.00000 \mathrm{e}-011.00000 \mathrm{e}-091.00000 \mathrm{e}-01$ $1.00000 \mathrm{e}-05$ 1.00000e-05 1.00000e-06 1.00000e-09 1.00000e-01 $1.00000 \mathrm{e}+001.00000 \mathrm{e}+001.00000 \mathrm{e}-011.00000 \mathrm{e}-091.00000 \mathrm{e}-01$ Element: 1105 \# of layers: 10

Kx Ky Kz Ss Por

$1.28122 \mathrm{e}+02$ 1.28122e+02 1.28122e+01 1.00000e-09 7.00000e-02 $5.11931 \mathrm{e}+00$ 5.11931e+00 5.11931e-01 1.00000e-09 2.12000e-01 $5.11931 \mathrm{e}+005.11931 \mathrm{e}+00$ 5.11931e-01 1.00000e-09 2.12000e-01 $5.11931 \mathrm{e}+005.11931 \mathrm{e}+00$ 5.11931e-01 1.00000e-09 2.12000e-01 $5.11931 \mathrm{e}+00$ 5.11931e+00 5.11931e-01 1.00000e-09 2.12000e-01 $5.11931 \mathrm{e}+00$ 5.11931e+00 5.11931e-01 1.00000e-09 2.12000e-01 $1.00000 \mathrm{e}-021.00000 \mathrm{e}-02$ 1.00000e-03 1.00000e-09 1.00000e-01 $1.00000 \mathrm{e}+001.00000 \mathrm{e}+001.00000 \mathrm{e}-011.00000 \mathrm{e}-091.00000 \mathrm{e}-01$ $1.00000 \mathrm{e}-05$ 1.00000e-05 1.00000e-06 1.00000e-09 1.00000e-01 $1.00000 \mathrm{e}+001.00000 \mathrm{e}+001.00000 \mathrm{e}-011.00000 \mathrm{e}-091.00000 \mathrm{e}-01$ Element: 1106 \# of layers: 10

Kx Ky Kz Ss Por

$1.28122 \mathrm{e}+021.28122 \mathrm{e}+02$ 1.28122e+01 1.00000e-09 7.00000e-02 $5.11931 \mathrm{e}+005.11931 \mathrm{e}+00$ 5.11931e-01 1.00000e-09 2.12000e-01 $5.11931 \mathrm{e}+00$ 5.11931e+00 5.11931e-01 1.00000e-09 2.12000e-01 $5.11931 \mathrm{e}+00$ 5.11931e+00 5.11931e-01 1.00000e-09 2.12000e-01 $5.11931 \mathrm{e}+005.11931 \mathrm{e}+00$ 5.11931e-01 1.00000e-09 2.12000e-01 $5.11931 \mathrm{e}+00$ 5.11931e+00 5.11931e-01 1.00000e-09 2.12000e-01 $1.00000 \mathrm{e}-021.00000 \mathrm{e}-02$ 1.00000e-03 1.00000e-09 1.00000e-01 $1.00000 \mathrm{e}+001.00000 \mathrm{e}+001.00000 \mathrm{e}-011.00000 \mathrm{e}-091.00000 \mathrm{e}-01$ $1.00000 \mathrm{e}-05$ 1.00000e-05 1.00000e-06 1.00000e-09 1.00000e-01 $1.00000 \mathrm{e}+001.00000 \mathrm{e}+001.00000 \mathrm{e}-011.00000 \mathrm{e}-091.00000 \mathrm{e}-01$ Element: 1107 \# of layers: 10

Kx Ky Kz Ss Por

$1.28122 \mathrm{e}+021.28122 \mathrm{e}+02$ 1.28122e+01 1.00000e-09 7.00000e-02 $5.11931 \mathrm{e}+005.11931 \mathrm{e}+00$ 5.11931e-01 1.00000e-09 2.12000e-01 $5.11931 \mathrm{e}+00$ 5.11931e+00 5.11931e-01 1.00000e-09 2.12000e-01 $5.11931 \mathrm{e}+00$ 5.11931e+00 5.11931e-01 1.00000e-09 2.12000e-01 $5.11931 \mathrm{e}+005.11931 \mathrm{e}+00$ 5.11931e-01 1.00000e-09 2.12000e-01 $5.11931 \mathrm{e}+00$ 5.11931e+00 5.11931e-01 1.00000e-09 2.12000e-01 $1.00000 \mathrm{e}-02$ 1.00000e-02 1.00000e-03 1.00000e-09 1.00000e-01 $1.00000 \mathrm{e}+001.00000 \mathrm{e}+001.00000 \mathrm{e}-011.00000 \mathrm{e}-091.00000 \mathrm{e}-01$ $1.00000 \mathrm{e}-05$ 1.00000e-05 1.00000e-06 1.00000e-09 1.00000e-01 $1.00000 \mathrm{e}+001.00000 \mathrm{e}+001.00000 \mathrm{e}-011.00000 \mathrm{e}-091.00000 \mathrm{e}-01$ Element: 1108 \# of layers: 10

Kx Ky Kz Ss Por

$1.28122 \mathrm{e}+02$ 1.28122e+02 1.28122e+01 1.00000e-09 7.00000e-02 
$5.11931 \mathrm{e}+00$ 5.11931e+00 5.11931e-01 1.00000e-09 2.12000e-01 $5.11931 \mathrm{e}+00$ 5.11931e+00 5.11931e-01 1.00000e-09 2.12000e-01 $5.11931 \mathrm{e}+005.11931 \mathrm{e}+00$ 5.11931e-01 1.00000e-09 2.12000e-01 $5.11931 \mathrm{e}+00$ 5.11931e+00 5.11931e-01 1.00000e-09 2.12000e-01 $5.11931 \mathrm{e}+00$ 5.11931e+00 5.11931e-01 1.00000e-09 2.12000e-01 $1.00000 \mathrm{e}-021.00000 \mathrm{e}-02$ 1.00000e-03 1.00000e-09 1.00000e-01 $1.00000 \mathrm{e}+001.00000 \mathrm{e}+001.00000 \mathrm{e}-011.00000 \mathrm{e}-091.00000 \mathrm{e}-01$ $1.00000 \mathrm{e}-05$ 1.00000e-05 1.00000e-06 1.00000e-09 1.00000e-01 $1.00000 \mathrm{e}+001.00000 \mathrm{e}+001.00000 \mathrm{e}-011.00000 \mathrm{e}-091.00000 \mathrm{e}-01$ Element: 1109 \# of layers: 10

Kx Ky Kz Ss Por

$1.28122 \mathrm{e}+02$ 1.28122e+02 1.28122e+01 1.00000e-09 7.00000e-02 $5.11931 \mathrm{e}+005.11931 \mathrm{e}+00$ 5.11931e-01 1.00000e-09 2.12000e-01 $5.11931 \mathrm{e}+00$ 5.11931e+00 5.11931e-01 1.00000e-09 2.12000e-01 $5.11931 \mathrm{e}+00$ 5.11931e+00 5.11931e-01 1.00000e-09 2.12000e-01 $5.11931 \mathrm{e}+005.11931 \mathrm{e}+00$ 5.11931e-01 1.00000e-09 2.12000e-01 $5.11931 \mathrm{e}+005.11931 \mathrm{e}+00$ 5.11931e-01 1.00000e-09 2.12000e-01 $1.00000 \mathrm{e}-02$ 1.00000e-02 1.00000e-03 1.00000e-09 1.00000e-01 $1.00000 \mathrm{e}+001.00000 \mathrm{e}+001.00000 \mathrm{e}-011.00000 \mathrm{e}-091.00000 \mathrm{e}-01$ $1.00000 \mathrm{e}-05$ 1.00000e-05 1.00000e-06 1.00000e-09 1.00000e-01 $1.00000 \mathrm{e}+001.00000 \mathrm{e}+001.00000 \mathrm{e}-011.00000 \mathrm{e}-091.00000 \mathrm{e}-01$ Element: 1110 \# of layers: 10

$\mathrm{Kx} \mathrm{Ky} \mathrm{Kz}$ Ss Por

1.28122e+02 1.28122e+02 1.28122e+01 1.00000e-09 7.00000e-02 $5.11931 \mathrm{e}+005.11931 \mathrm{e}+00$ 5.11931e-01 1.00000e-09 2.12000e-01 $5.11931 \mathrm{e}+005.11931 \mathrm{e}+00$ 5.11931e-01 1.00000e-09 2.12000e-01 $5.11931 \mathrm{e}+00$ 5.11931e+00 5.11931e-01 1.00000e-09 2.12000e-01 $5.11931 \mathrm{e}+00$ 5.11931e+00 5.11931e-01 1.00000e-09 2.12000e-01 $5.11931 \mathrm{e}+00$ 5.11931e+00 5.11931e-01 1.00000e-09 2.12000e-01 $1.00000 \mathrm{e}-02$ 1.00000e-02 1.00000e-03 1.00000e-09 1.00000e-01 $1.00000 \mathrm{e}+001.00000 \mathrm{e}+001.00000 \mathrm{e}-011.00000 \mathrm{e}-091.00000 \mathrm{e}-01$ $1.00000 \mathrm{e}-05$ 1.00000e-05 1.00000e-06 1.00000e-09 1.00000e-01 $1.00000 \mathrm{e}+001.00000 \mathrm{e}+001.00000 \mathrm{e}-011.00000 \mathrm{e}-091.00000 \mathrm{e}-01$ Element: 1111 \# of layers: 10

Kx Ky Kz Ss Por

$1.28122 \mathrm{e}+02$ 1.28122e+02 1.28122e+01 1.00000e-09 7.00000e-02 $5.11931 \mathrm{e}+005.11931 \mathrm{e}+00$ 5.11931e-01 1.00000e-09 2.12000e-01 $5.11931 \mathrm{e}+005.11931 \mathrm{e}+00$ 5.11931e-01 1.00000e-09 2.12000e-01 $5.11931 \mathrm{e}+005.11931 \mathrm{e}+005.11931 \mathrm{e}-011.00000 \mathrm{e}-092.12000 \mathrm{e}-01$ $5.11931 \mathrm{e}+00$ 5.11931e+00 5.11931e-01 1.00000e-09 2.12000e-01 $5.11931 \mathrm{e}+005.11931 \mathrm{e}+00$ 5.11931e-01 1.00000e-09 2.12000e-01 $1.00000 \mathrm{e}-021.00000 \mathrm{e}-02$ 1.00000e-03 1.00000e-09 1.00000e-01 $1.00000 \mathrm{e}+001.00000 \mathrm{e}+001.00000 \mathrm{e}-011.00000 \mathrm{e}-091.00000 \mathrm{e}-01$ $1.00000 \mathrm{e}-05$ 1.00000e-05 1.00000e-06 1.00000e-09 1.00000e-01 $1.00000 \mathrm{e}+001.00000 \mathrm{e}+001.00000 \mathrm{e}-011.00000 \mathrm{e}-091.00000 \mathrm{e}-01$ Element: 1112 \# of layers: 10 
$\mathrm{Kx} \mathrm{Ky} \mathrm{Kz}$ Ss Por

1.28122e+02 1.28122e+02 1.28122e+01 1.00000e-09 7.00000e-02

5.11931e+00 5.11931e+00 5.11931e-01 1.00000e-09 2.12000e-01

$5.11931 \mathrm{e}+00$ 5.11931e+00 5.11931e-01 1.00000e-09 2.12000e-01

5.11931e+00 5.11931e+00 5.11931e-01 1.00000e-09 2.12000e-01

5.11931e+00 5.11931e+00 5.11931e-01 1.00000e-09 2.12000e-01

5.11931e+00 5.11931e+00 5.11931e-01 1.00000e-09 2.12000e-01

$1.00000 \mathrm{e}-02$ 1.00000e-02 1.00000e-03 1.00000e-09 1.00000e-01

$1.00000 \mathrm{e}+001.00000 \mathrm{e}+001.00000 \mathrm{e}-011.00000 \mathrm{e}-091.00000 \mathrm{e}-01$

$1.00000 \mathrm{e}-05$ 1.00000e-05 1.00000e-06 1.00000e-09 1.00000e-01

$1.00000 \mathrm{e}+001.00000 \mathrm{e}+001.00000 \mathrm{e}-011.00000 \mathrm{e}-091.00000 \mathrm{e}-01$

Element: 1113 \# of layers: 10

$\mathrm{Kx} \mathrm{Ky} \mathrm{Kz}$ Ss Por

1.45538e+02 1.45538e+02 1.45539e+01 1.00000e-09 7.00000e-02

5.81502e+00 5.81502e+00 5.81502e-01 1.00000e-09 2.12000e-01

$5.81502 \mathrm{e}+005.81502 \mathrm{e}+00$ 5.81502e-01 1.00000e-09 2.12000e-01

5.81502e+00 5.81502e+00 5.81502e-01 1.00000e-09 2.12000e-01

5.81502e+00 5.81502e+00 5.81502e-01 1.00000e-09 2.12000e-01

$5.81502 \mathrm{e}+00$ 5.81502e+00 5.81502e-01 1.00000e-09 2.12000e-01 $1.00000 \mathrm{e}-02$ 1.00000e-02 1.00000e-03 1.00000e-09 1.00000e-01

$1.00000 \mathrm{e}+001.00000 \mathrm{e}+001.00000 \mathrm{e}-011.00000 \mathrm{e}-091.00000 \mathrm{e}-01$ $1.00000 \mathrm{e}-05$ 1.00000e-05 1.00000e-06 1.00000e-09 1.00000e-01

$1.00000 \mathrm{e}+001.00000 \mathrm{e}+001.00000 \mathrm{e}-01$ 1.00000e-09 1.00000e-01

Element: 1114 \# of layers: 10

Kx Ky Kz Ss Por

$1.45538 \mathrm{e}+02$ 1.45538e+02 1.45539e+01 1.00000e-09 7.00000e-02

5.81502e+00 5.81502e+00 5.81502e-01 1.00000e-09 2.12000e-01

5.81502e+00 5.81502e+00 5.81502e-01 1.00000e-09 2.12000e-01

$5.81502 \mathrm{e}+005.81502 \mathrm{e}+00$ 5.81502e-01 1.00000e-09 2.12000e-01

5.81502e+00 5.81502e+00 5.81502e-01 1.00000e-09 2.12000e-01

5.81502e+00 5.81502e+00 5.81502e-01 1.00000e-09 2.12000e-01

1.00000e-02 1.00000e-02 1.00000e-03 1.00000e-09 1.00000e-01

$1.00000 \mathrm{e}+001.00000 \mathrm{e}+001.00000 \mathrm{e}-011.00000 \mathrm{e}-091.00000 \mathrm{e}-01$

$1.00000 \mathrm{e}-05$ 1.00000e-05 1.00000e-06 1.00000e-09 1.00000e-01

$1.00000 \mathrm{e}+001.00000 \mathrm{e}+001.00000 \mathrm{e}-011.00000 \mathrm{e}-091.00000 \mathrm{e}-01$

Element: 1115 \# of layers: 10

Kx Ky Kz Ss Por

1.45538e+02 1.45538e+02 1.45539e+01 1.00000e-09 7.00000e-02

$5.81502 \mathrm{e}+00$ 5.81502e+00 5.81502e-01 1.00000e-09 2.12000e-01

$5.81502 \mathrm{e}+00$ 5.81502e+00 5.81502e-01 1.00000e-09 2.12000e-01

$5.81502 \mathrm{e}+00$ 5.81502e+00 5.81502e-01 1.00000e-09 2.12000e-01

$5.81502 \mathrm{e}+00$ 5.81502e+00 5.81502e-01 1.00000e-09 2.12000e-01

5.81502e+00 5.81502e+00 5.81502e-01 1.00000e-09 2.12000e-01

$1.00000 \mathrm{e}-02$ 1.00000e-02 1.00000e-03 1.00000e-09 1.00000e-01

$1.00000 \mathrm{e}+001.00000 \mathrm{e}+001.00000 \mathrm{e}-011.00000 \mathrm{e}-091.00000 \mathrm{e}-01$

$1.00000 \mathrm{e}-05$ 1.00000e-05 1.00000e-06 1.00000e-09 1.00000e-01 
$1.00000 \mathrm{e}+001.00000 \mathrm{e}+00$ 1.00000e-01 1.00000e-09 1.00000e-01

Element: 1116 \# of layers: 10

Kx Ky Kz Ss Por

$1.45538 \mathrm{e}+02$ 1.45538e+02 1.45539e+01 1.00000e-09 7.00000e-02

5.81502e+00 5.81502e+00 5.81502e-01 1.00000e-09 2.12000e-01

$5.81502 \mathrm{e}+005.81502 \mathrm{e}+00$ 5.81502e-01 1.00000e-09 2.12000e-01

$5.81502 \mathrm{e}+00$ 5.81502e+00 5.81502e-01 1.00000e-09 2.12000e-01

$5.81502 \mathrm{e}+00$ 5.81502e+00 5.81502e-01 1.00000e-09 2.12000e-01

5.81502e+00 5.81502e+00 5.81502e-01 1.00000e-09 2.12000e-01

$1.00000 \mathrm{e}-02$ 1.00000e-02 1.00000e-03 1.00000e-09 1.00000e-01

$1.00000 \mathrm{e}+001.00000 \mathrm{e}+001.00000 \mathrm{e}-011.00000 \mathrm{e}-091.00000 \mathrm{e}-01$

$1.00000 \mathrm{e}-05$ 1.00000e-05 1.00000e-06 1.00000e-09 1.00000e-01

$1.00000 \mathrm{e}+001.00000 \mathrm{e}+001.00000 \mathrm{e}-01$ 1.00000e-09 1.00000e-01

Element: 1117 \# of layers: 10

Kx Ky Kz Ss Por

1.45538e+02 1.45538e+02 1.45539e+01 1.00000e-09 7.00000e-02

5.81502e+00 5.81502e+00 5.81502e-01 1.00000e-09 2.12000e-01

$5.81502 \mathrm{e}+00$ 5.81502e+00 5.81502e-01 1.00000e-09 2.12000e-01

5.81502e+00 5.81502e+00 5.81502e-01 1.00000e-09 2.12000e-01

$5.81502 \mathrm{e}+00$ 5.81502e+00 5.81502e-01 1.00000e-09 2.12000e-01

$5.81502 \mathrm{e}+00$ 5.81502e+00 5.81502e-01 1.00000e-09 2.12000e-01

$1.00000 \mathrm{e}-02$ 1.00000e-02 1.00000e-03 1.00000e-09 1.00000e-01

$1.00000 \mathrm{e}+001.00000 \mathrm{e}+001.00000 \mathrm{e}-011.00000 \mathrm{e}-091.00000 \mathrm{e}-01$

$1.00000 \mathrm{e}-05$ 1.00000e-05 1.00000e-06 1.00000e-09 1.00000e-01

$1.00000 \mathrm{e}+001.00000 \mathrm{e}+001.00000 \mathrm{e}-011.00000 \mathrm{e}-09$ 1.00000e-01

Element: 1118 \# of layers: 10

$\mathrm{Kx} \mathrm{Ky} \mathrm{Kz}$ Ss Por

1.45538e+02 1.45538e+02 1.45539e+01 1.00000e-09 7.00000e-02

$5.81502 \mathrm{e}+00$ 5.81502e+00 5.81502e-01 1.00000e-09 2.12000e-01

5.81502e+00 5.81502e+00 5.81502e-01 1.00000e-09 2.12000e-01

5.81502e+00 5.81502e+00 5.81502e-01 1.00000e-09 2.12000e-01

$5.81502 \mathrm{e}+00$ 5.81502e+00 5.81502e-01 1.00000e-09 2.12000e-01

$5.81502 \mathrm{e}+00$ 5.81502e+00 5.81502e-01 1.00000e-09 2.12000e-01

$1.00000 \mathrm{e}-02$ 1.00000e-02 1.00000e-03 1.00000e-09 1.00000e-01

$1.00000 \mathrm{e}+001.00000 \mathrm{e}+001.00000 \mathrm{e}-011.00000 \mathrm{e}-091.00000 \mathrm{e}-01$

$1.00000 \mathrm{e}-05$ 1.00000e-05 1.00000e-06 1.00000e-09 1.00000e-01

$1.00000 \mathrm{e}+001.00000 \mathrm{e}+001.00000 \mathrm{e}-011.00000 \mathrm{e}-091.00000 \mathrm{e}-01$

Element: 1119 \# of layers: 10

$\mathrm{Kx} \mathrm{Ky} \mathrm{Kz}$ Ss Por

$1.45538 \mathrm{e}+02$ 1.45538e+02 1.45539e+01 1.00000e-09 7.00000e-02

5.81502e+00 5.81502e+00 5.81502e-01 1.00000e-09 2.12000e-01

$5.81502 \mathrm{e}+00$ 5.81502e+00 5.81502e-01 1.00000e-09 2.12000e-01

5.81502e+00 5.81502e+00 5.81502e-01 1.00000e-09 2.12000e-01

5.81502e+00 5.81502e+00 5.81502e-01 1.00000e-09 2.12000e-01

5.81502e+00 5.81502e+00 5.81502e-01 1.00000e-09 2.12000e-01

$1.00000 \mathrm{e}-02$ 1.00000e-02 1.00000e-03 1.00000e-09 1.00000e-01 
$1.00000 \mathrm{e}+001.00000 \mathrm{e}+001.00000 \mathrm{e}-011.00000 \mathrm{e}-091.00000 \mathrm{e}-01$ $1.00000 \mathrm{e}-05$ 1.00000e-05 1.00000e-06 1.00000e-09 1.00000e-01 $1.00000 \mathrm{e}+001.00000 \mathrm{e}+001.00000 \mathrm{e}-011.00000 \mathrm{e}-091.00000 \mathrm{e}-01$ Element: 1120 \# of layers: 10

$\mathrm{Kx} \mathrm{Ky} \mathrm{Kz}$ Ss Por

1.45538e+02 1.45538e+02 1.45539e+01 1.00000e-09 7.00000e-02 5.81502e+00 5.81502e+00 5.81502e-01 1.00000e-09 2.12000e-01 $5.81502 \mathrm{e}+005.81502 \mathrm{e}+00$ 5.81502e-01 1.00000e-09 2.12000e-01 5.81502e+00 5.81502e+00 5.81502e-01 1.00000e-09 2.12000e-01 5.81502e+00 5.81502e+00 5.81502e-01 1.00000e-09 2.12000e-01 $5.81502 \mathrm{e}+00$ 5.81502e+00 5.81502e-01 1.00000e-09 2.12000e-01 $1.00000 \mathrm{e}-02$ 1.00000e-02 1.00000e-03 1.00000e-09 1.00000e-01 $1.00000 \mathrm{e}+001.00000 \mathrm{e}+001.00000 \mathrm{e}-011.00000 \mathrm{e}-091.00000 \mathrm{e}-01$ $1.00000 \mathrm{e}-05$ 1.00000e-05 1.00000e-06 1.00000e-09 1.00000e-01 $1.00000 \mathrm{e}+001.00000 \mathrm{e}+001.00000 \mathrm{e}-01$ 1.00000e-09 1.00000e-01 Element: 1121 \# of layers: 10

$\mathrm{Kx} \mathrm{Ky} \mathrm{Kz}$ Ss Por

1.45538e+02 1.45538e+02 1.45539e+01 1.00000e-09 7.00000e-02 $5.81502 \mathrm{e}+005.81502 \mathrm{e}+00$ 5.81502e-01 1.00000e-09 2.12000e-01 $5.81502 \mathrm{e}+005.81502 \mathrm{e}+00$ 5.81502e-01 1.00000e-09 2.12000e-01 $5.81502 \mathrm{e}+00$ 5.81502e+00 5.81502e-01 1.00000e-09 2.12000e-01 $5.81502 \mathrm{e}+005.81502 \mathrm{e}+00$ 5.81502e-01 1.00000e-09 2.12000e-01 5.81502e+00 5.81502e+00 5.81502e-01 1.00000e-09 2.12000e-01 $1.00000 \mathrm{e}-02$ 1.00000e-02 1.00000e-03 1.00000e-09 1.00000e-01 $1.00000 \mathrm{e}+001.00000 \mathrm{e}+001.00000 \mathrm{e}-011.00000 \mathrm{e}-091.00000 \mathrm{e}-01$ $1.00000 \mathrm{e}-05$ 1.00000e-05 1.00000e-06 1.00000e-09 1.00000e-01 $1.00000 \mathrm{e}+001.00000 \mathrm{e}+001.00000 \mathrm{e}-01$ 1.00000e-09 1.00000e-01 Element: 1122 \# of layers: 10

$\mathrm{Kx} \mathrm{Ky} \mathrm{Kz}$ Ss Por

$1.00065 \mathrm{e}+021.00065 \mathrm{e}+02$ 1.00065e+01 1.00000e-09 7.00000e-02 $3.99833 \mathrm{e}+003.99833 \mathrm{e}+00$ 3.99833e-01 1.00000e-09 2.12000e-01 3.99833e+00 3.99833e+00 3.99833e-01 1.00000e-09 2.12000e-01 $3.99833 \mathrm{e}+003.99833 \mathrm{e}+00$ 3.99833e-01 1.00000e-09 2.12000e-01 $3.99833 \mathrm{e}+00$ 3.99833e+00 3.99833e-01 1.00000e-09 2.12000e-01 $3.99833 \mathrm{e}+003.99833 \mathrm{e}+00$ 3.99833e-01 1.00000e-09 2.12000e-01 1.00000e-02 1.00000e-02 1.00000e-03 1.00000e-09 1.00000e-01 $1.00000 \mathrm{e}+001.00000 \mathrm{e}+001.00000 \mathrm{e}-011.00000 \mathrm{e}-091.00000 \mathrm{e}-01$ $1.00000 \mathrm{e}-05$ 1.00000e-05 1.00000e-06 1.00000e-09 1.00000e-01 $1.00000 \mathrm{e}+001.00000 \mathrm{e}+001.00000 \mathrm{e}-01$ 1.00000e-09 1.00000e-01 Element: 1123 \# of layers: 10

$\mathrm{Kx} \mathrm{Ky} \mathrm{Kz}$ Ss Por 1.00065e+02 1.00065e+02 1.00065e+01 1.00000e-09 7.00000e-02 $3.99833 \mathrm{e}+003.99833 \mathrm{e}+00$ 3.99833e-01 1.00000e-09 2.12000e-01 $3.99833 \mathrm{e}+00$ 3.99833e+00 3.99833e-01 1.00000e-09 2.12000e-01 $3.99833 \mathrm{e}+00$ 3.99833e+00 3.99833e-01 1.00000e-09 2.12000e-01 $3.99833 \mathrm{e}+003.99833 \mathrm{e}+00$ 3.99833e-01 1.00000e-09 2.12000e-01 
3.99833e+00 3.99833e+00 3.99833e-01 1.00000e-09 2.12000e-01 $1.00000 \mathrm{e}-02$ 1.00000e-02 1.00000e-03 1.00000e-09 1.00000e-01 $1.00000 \mathrm{e}+001.00000 \mathrm{e}+001.00000 \mathrm{e}-011.00000 \mathrm{e}-091.00000 \mathrm{e}-01$ $1.00000 \mathrm{e}-05$ 1.00000e-05 1.00000e-06 1.00000e-09 1.00000e-01 $1.00000 \mathrm{e}+001.00000 \mathrm{e}+001.00000 \mathrm{e}-01$ 1.00000e-09 1.00000e-01 Element: 1124 \# of layers: 10

$\mathrm{Kx} \mathrm{Ky} \mathrm{Kz}$ Ss Por

$1.00065 \mathrm{e}+02$ 1.00065e+02 1.00065e+01 1.00000e-09 7.00000e-02 $3.99833 \mathrm{e}+003.99833 \mathrm{e}+00$ 3.99833e-01 1.00000e-09 2.12000e-01 $3.99833 \mathrm{e}+003.99833 \mathrm{e}+00$ 3.99833e-01 1.00000e-09 2.12000e-01 3.99833e+00 3.99833e+00 3.99833e-01 1.00000e-09 2.12000e-01 $3.99833 \mathrm{e}+003.99833 \mathrm{e}+003.99833 \mathrm{e}-01$ 1.00000e-09 2.12000e-01 $3.99833 \mathrm{e}+00$ 3.99833e+00 3.99833e-01 1.00000e-09 2.12000e-01 $1.00000 \mathrm{e}-02$ 1.00000e-02 1.00000e-03 1.00000e-09 1.00000e-01 $1.00000 \mathrm{e}+001.00000 \mathrm{e}+001.00000 \mathrm{e}-011.00000 \mathrm{e}-091.00000 \mathrm{e}-01$ $1.00000 \mathrm{e}-05$ 1.00000e-05 1.00000e-06 1.00000e-09 1.00000e-01 $1.00000 \mathrm{e}+001.00000 \mathrm{e}+001.00000 \mathrm{e}-011.00000 \mathrm{e}-091.00000 \mathrm{e}-01$ Element: 1125 \# of layers: 10

$\mathrm{Kx} \mathrm{Ky} \mathrm{Kz}$ Ss Por $1.00065 \mathrm{e}+02$ 1.00065e+02 1.00065e+01 1.00000e-09 7.00000e-02 $3.99833 \mathrm{e}+003.99833 \mathrm{e}+00$ 3.99833e-01 1.00000e-09 2.12000e-01 3.99833e+00 3.99833e+00 3.99833e-01 1.00000e-09 2.12000e-01 $3.99833 \mathrm{e}+003.99833 \mathrm{e}+00$ 3.99833e-01 1.00000e-09 2.12000e-01 $3.99833 \mathrm{e}+003.99833 \mathrm{e}+00$ 3.99833e-01 1.00000e-09 2.12000e-01 $3.99833 \mathrm{e}+003.99833 \mathrm{e}+003.99833 \mathrm{e}-01$ 1.00000e-09 2.12000e-01 $1.00000 \mathrm{e}-02$ 1.00000e-02 1.00000e-03 1.00000e-09 1.00000e-01 $1.00000 \mathrm{e}+001.00000 \mathrm{e}+001.00000 \mathrm{e}-011.00000 \mathrm{e}-091.00000 \mathrm{e}-01$ $1.00000 \mathrm{e}-05$ 1.00000e-05 1.00000e-06 1.00000e-09 1.00000e-01 $1.00000 \mathrm{e}+001.00000 \mathrm{e}+001.00000 \mathrm{e}-011.00000 \mathrm{e}-091.00000 \mathrm{e}-01$ Element: 1126 \# of layers: 10

$\mathrm{Kx} \mathrm{Ky} \mathrm{Kz}$ Ss Por

$1.00065 \mathrm{e}+02$ 1.00065e+02 1.00065e+01 1.00000e-09 7.00000e-02 $3.99833 \mathrm{e}+00$ 3.99833e+00 3.99833e-01 1.00000e-09 2.12000e-01 $3.99833 \mathrm{e}+00$ 3.99833e+00 3.99833e-01 1.00000e-09 2.12000e-01 3.99833e+00 3.99833e+00 3.99833e-01 1.00000e-09 2.12000e-01 3.99833e+00 3.99833e+00 3.99833e-01 1.00000e-09 2.12000e-01 $3.99833 \mathrm{e}+003.99833 \mathrm{e}+00$ 3.99833e-01 1.00000e-09 2.12000e-01 $1.00000 \mathrm{e}-02$ 1.00000e-02 1.00000e-03 1.00000e-09 1.00000e-01 $1.00000 \mathrm{e}+001.00000 \mathrm{e}+001.00000 \mathrm{e}-011.00000 \mathrm{e}-091.00000 \mathrm{e}-01$ $1.00000 \mathrm{e}-05$ 1.00000e-05 1.00000e-06 1.00000e-09 1.00000e-01 $1.00000 \mathrm{e}+001.00000 \mathrm{e}+001.00000 \mathrm{e}-011.00000 \mathrm{e}-091.00000 \mathrm{e}-01$ Element: 1127 \# of layers: 10

$\mathrm{Kx} \mathrm{Ky} \mathrm{Kz}$ Ss Por $1.00065 \mathrm{e}+02$ 1.00065e+02 1.00065e+01 1.00000e-09 7.00000e-02 $3.99833 \mathrm{e}+003.99833 \mathrm{e}+00$ 3.99833e-01 1.00000e-09 2.12000e-01 $3.99833 \mathrm{e}+003.99833 \mathrm{e}+00$ 3.99833e-01 1.00000e-09 2.12000e-01 
$3.99833 \mathrm{e}+00$ 3.99833e+00 3.99833e-01 1.00000e-09 2.12000e-01 $3.99833 \mathrm{e}+003.99833 \mathrm{e}+00$ 3.99833e-01 1.00000e-09 2.12000e-01 $3.99833 \mathrm{e}+003.99833 \mathrm{e}+00$ 3.99833e-01 1.00000e-09 2.12000e-01 $1.00000 \mathrm{e}-021.00000 \mathrm{e}-02$ 1.00000e-03 1.00000e-09 1.00000e-01 $1.00000 \mathrm{e}+001.00000 \mathrm{e}+001.00000 \mathrm{e}-011.00000 \mathrm{e}-091.00000 \mathrm{e}-01$ $1.00000 \mathrm{e}-05$ 1.00000e-05 1.00000e-06 1.00000e-09 1.00000e-01 $1.00000 \mathrm{e}+001.00000 \mathrm{e}+001.00000 \mathrm{e}-011.00000 \mathrm{e}-091.00000 \mathrm{e}-01$ Element: 1128 \# of layers: 10

Kx Ky Kz Ss Por

$1.00065 \mathrm{e}+021.00065 \mathrm{e}+021.00065 \mathrm{e}+011.00000 \mathrm{e}-097.00000 \mathrm{e}-02$ $3.99833 \mathrm{e}+003.99833 \mathrm{e}+003.99833 \mathrm{e}-01$ 1.00000e-09 2.12000e-01 $3.99833 \mathrm{e}+003.99833 \mathrm{e}+003.99833 \mathrm{e}-01$ 1.00000e-09 2.12000e-01 $3.99833 \mathrm{e}+003.99833 \mathrm{e}+00$ 3.99833e-01 1.00000e-09 2.12000e-01 $3.99833 \mathrm{e}+003.99833 \mathrm{e}+003.99833 \mathrm{e}-01$ 1.00000e-09 2.12000e-01 $3.99833 \mathrm{e}+003.99833 \mathrm{e}+00$ 3.99833e-01 1.00000e-09 2.12000e-01 $1.00000 \mathrm{e}-02$ 1.00000e-02 1.00000e-03 1.00000e-09 1.00000e-01 $1.00000 \mathrm{e}+001.00000 \mathrm{e}+001.00000 \mathrm{e}-011.00000 \mathrm{e}-091.00000 \mathrm{e}-01$ $1.00000 \mathrm{e}-05$ 1.00000e-05 1.00000e-06 1.00000e-09 1.00000e-01 $1.00000 \mathrm{e}+001.00000 \mathrm{e}+001.00000 \mathrm{e}-011.00000 \mathrm{e}-091.00000 \mathrm{e}-01$ Element: 1129 \# of layers: 10

Kx Ky Kz Ss Por $1.00065 \mathrm{e}+021.00065 \mathrm{e}+021.00065 \mathrm{e}+011.00000 \mathrm{e}-097.00000 \mathrm{e}-02$ $3.99833 \mathrm{e}+003.99833 \mathrm{e}+003.99833 \mathrm{e}-01$ 1.00000e-09 2.12000e-01 $3.99833 \mathrm{e}+003.99833 \mathrm{e}+003.99833 \mathrm{e}-01$ 1.00000e-09 2.12000e-01 $3.99833 \mathrm{e}+003.99833 \mathrm{e}+003.99833 \mathrm{e}-01$ 1.00000e-09 2.12000e-01 $3.99833 \mathrm{e}+003.99833 \mathrm{e}+00$ 3.99833e-01 1.00000e-09 2.12000e-01 $3.99833 \mathrm{e}+003.99833 \mathrm{e}+003.99833 \mathrm{e}-01$ 1.00000e-09 2.12000e-01 $1.00000 \mathrm{e}-021.00000 \mathrm{e}-02$ 1.00000e-03 1.00000e-09 1.00000e-01 $1.00000 \mathrm{e}+001.00000 \mathrm{e}+001.00000 \mathrm{e}-011.00000 \mathrm{e}-091.00000 \mathrm{e}-01$ $1.00000 \mathrm{e}-05$ 1.00000e-05 1.00000e-06 1.00000e-09 1.00000e-01 $1.00000 \mathrm{e}+001.00000 \mathrm{e}+001.00000 \mathrm{e}-011.00000 \mathrm{e}-091.00000 \mathrm{e}-01$ Element: 1130 \# of layers: 10

Kx Ky Kz Ss Por $1.00065 \mathrm{e}+021.00065 \mathrm{e}+021.00065 \mathrm{e}+011.00000 \mathrm{e}-097.00000 \mathrm{e}-02$ $3.99833 \mathrm{e}+003.99833 \mathrm{e}+00$ 3.99833e-01 1.00000e-09 2.12000e-01 $3.99833 \mathrm{e}+003.99833 \mathrm{e}+003.99833 \mathrm{e}-01$ 1.00000e-09 2.12000e-01 $3.99833 \mathrm{e}+003.99833 \mathrm{e}+003.99833 \mathrm{e}-01$ 1.00000e-09 2.12000e-01 $3.99833 \mathrm{e}+003.99833 \mathrm{e}+00$ 3.99833e-01 1.00000e-09 2.12000e-01 $3.99833 \mathrm{e}+003.99833 \mathrm{e}+00$ 3.99833e-01 1.00000e-09 2.12000e-01 $1.00000 \mathrm{e}-02$ 1.00000e-02 1.00000e-03 1.00000e-09 1.00000e-01 $1.00000 \mathrm{e}+001.00000 \mathrm{e}+001.00000 \mathrm{e}-011.00000 \mathrm{e}-091.00000 \mathrm{e}-01$ $1.00000 \mathrm{e}-05$ 1.00000e-05 1.00000e-06 1.00000e-09 1.00000e-01 $1.00000 \mathrm{e}+001.00000 \mathrm{e}+001.00000 \mathrm{e}-011.00000 \mathrm{e}-091.00000 \mathrm{e}-01$ Element: 1131 \# of layers: 10

Kx Ky Kz Ss Por

5.99715e+01 5.99715e+01 5.99715e+00 1.00000e-09 7.00000e-02 
$2.39630 \mathrm{e}+002.39630 \mathrm{e}+002.39630 \mathrm{e}-011.00000 \mathrm{e}-092.12000 \mathrm{e}-01$ $2.39630 \mathrm{e}+002.39630 \mathrm{e}+002.39630 \mathrm{e}-011.00000 \mathrm{e}-092.12000 \mathrm{e}-01$ $2.39630 \mathrm{e}+002.39630 \mathrm{e}+002.39630 \mathrm{e}-01$ 1.00000e-09 2.12000e-01 $2.39630 \mathrm{e}+002.39630 \mathrm{e}+002.39630 \mathrm{e}-011.00000 \mathrm{e}-092.12000 \mathrm{e}-01$ $2.39630 \mathrm{e}+002.39630 \mathrm{e}+002.39630 \mathrm{e}-011.00000 \mathrm{e}-092.12000 \mathrm{e}-01$ $1.00000 \mathrm{e}-021.00000 \mathrm{e}-02$ 1.00000e-03 1.00000e-09 1.00000e-01 $1.00000 \mathrm{e}+001.00000 \mathrm{e}+001.00000 \mathrm{e}-011.00000 \mathrm{e}-091.00000 \mathrm{e}-01$ $1.00000 \mathrm{e}-05$ 1.00000e-05 1.00000e-06 1.00000e-09 1.00000e-01 $1.00000 \mathrm{e}+001.00000 \mathrm{e}+001.00000 \mathrm{e}-011.00000 \mathrm{e}-091.00000 \mathrm{e}-01$ Element: 1132 \# of layers: 10

Kx Ky Kz Ss Por

$5.99715 \mathrm{e}+015.99715 \mathrm{e}+015.99715 \mathrm{e}+001.00000 \mathrm{e}-09$ 7.00000e-02 $2.39630 \mathrm{e}+002.39630 \mathrm{e}+002.39630 \mathrm{e}-01$ 1.00000e-09 2.12000e-01

$2.39630 \mathrm{e}+002.39630 \mathrm{e}+002.39630 \mathrm{e}-011.00000 \mathrm{e}-092.12000 \mathrm{e}-01$ $2.39630 \mathrm{e}+002.39630 \mathrm{e}+002.39630 \mathrm{e}-011.00000 \mathrm{e}-092.12000 \mathrm{e}-01$ $2.39630 \mathrm{e}+002.39630 \mathrm{e}+002.39630 \mathrm{e}-01$ 1.00000e-09 2.12000e-01 $2.39630 \mathrm{e}+002.39630 \mathrm{e}+002.39630 \mathrm{e}-011.00000 \mathrm{e}-092.12000 \mathrm{e}-01$ $1.00000 \mathrm{e}-02$ 1.00000e-02 1.00000e-03 1.00000e-09 1.00000e-01 $1.00000 \mathrm{e}+001.00000 \mathrm{e}+001.00000 \mathrm{e}-011.00000 \mathrm{e}-091.00000 \mathrm{e}-01$ $1.00000 \mathrm{e}-05$ 1.00000e-05 1.00000e-06 1.00000e-09 1.00000e-01 $1.00000 \mathrm{e}+001.00000 \mathrm{e}+001.00000 \mathrm{e}-011.00000 \mathrm{e}-091.00000 \mathrm{e}-01$ Element: 1133 \# of layers: 10

Kx Ky Kz Ss Por

$5.99715 \mathrm{e}+015.99715 \mathrm{e}+015.99715 \mathrm{e}+00$ 1.00000e-09 7.00000e-02 $2.39630 \mathrm{e}+002.39630 \mathrm{e}+002.39630 \mathrm{e}-011.00000 \mathrm{e}-092.12000 \mathrm{e}-01$ $2.39630 \mathrm{e}+002.39630 \mathrm{e}+002.39630 \mathrm{e}-01$ 1.00000e-09 2.12000e-01 $2.39630 \mathrm{e}+002.39630 \mathrm{e}+002.39630 \mathrm{e}-011.00000 \mathrm{e}-092.12000 \mathrm{e}-01$ $2.39630 \mathrm{e}+002.39630 \mathrm{e}+002.39630 \mathrm{e}-011.00000 \mathrm{e}-092.12000 \mathrm{e}-01$ $2.39630 \mathrm{e}+002.39630 \mathrm{e}+002.39630 \mathrm{e}-011.00000 \mathrm{e}-092.12000 \mathrm{e}-01$ $1.00000 \mathrm{e}-02$ 1.00000e-02 1.00000e-03 1.00000e-09 1.00000e-01 $1.00000 \mathrm{e}+001.00000 \mathrm{e}+001.00000 \mathrm{e}-011.00000 \mathrm{e}-091.00000 \mathrm{e}-01$ $1.00000 \mathrm{e}-05$ 1.00000e-05 1.00000e-06 1.00000e-09 1.00000e-01 $1.00000 \mathrm{e}+001.00000 \mathrm{e}+001.00000 \mathrm{e}-011.00000 \mathrm{e}-091.00000 \mathrm{e}-01$ Element: 1134 \# of layers: 10

Kx Ky Kz Ss Por

$5.99715 \mathrm{e}+015.99715 \mathrm{e}+015.99715 \mathrm{e}+00$ 1.00000e-09 7.00000e-02 $2.39630 \mathrm{e}+002.39630 \mathrm{e}+002.39630 \mathrm{e}-011.00000 \mathrm{e}-092.12000 \mathrm{e}-01$ $2.39630 \mathrm{e}+002.39630 \mathrm{e}+002.39630 \mathrm{e}-011.00000 \mathrm{e}-092.12000 \mathrm{e}-01$ $2.39630 \mathrm{e}+002.39630 \mathrm{e}+002.39630 \mathrm{e}-01$ 1.00000e-09 2.12000e-01 $2.39630 \mathrm{e}+002.39630 \mathrm{e}+002.39630 \mathrm{e}-01$ 1.00000e-09 2.12000e-01 $2.39630 \mathrm{e}+002.39630 \mathrm{e}+002.39630 \mathrm{e}-01$ 1.00000e-09 2.12000e-01 $1.00000 \mathrm{e}-021.00000 \mathrm{e}-02$ 1.00000e-03 1.00000e-09 1.00000e-01 $1.00000 \mathrm{e}+001.00000 \mathrm{e}+001.00000 \mathrm{e}-011.00000 \mathrm{e}-091.00000 \mathrm{e}-01$ $1.00000 \mathrm{e}-05$ 1.00000e-05 1.00000e-06 1.00000e-09 1.00000e-01 $1.00000 \mathrm{e}+001.00000 \mathrm{e}+001.00000 \mathrm{e}-011.00000 \mathrm{e}-091.00000 \mathrm{e}-01$ Element: 1135 \# of layers: 10 
Kx Ky Kz Ss Por

5.99715e+01 5.99715e+01 5.99715e+00 1.00000e-09 7.00000e-02 $2.39630 \mathrm{e}+002.39630 \mathrm{e}+002.39630 \mathrm{e}-01$ 1.00000e-09 2.12000e-01 $2.39630 \mathrm{e}+002.39630 \mathrm{e}+00$ 2.39630e-01 1.00000e-09 2.12000e-01 $2.39630 \mathrm{e}+002.39630 \mathrm{e}+002.39630 \mathrm{e}-01$ 1.00000e-09 2.12000e-01 $2.39630 \mathrm{e}+002.39630 \mathrm{e}+00$ 2.39630e-01 1.00000e-09 2.12000e-01 $2.39630 \mathrm{e}+002.39630 \mathrm{e}+00$ 2.39630e-01 1.00000e-09 2.12000e-01 $1.00000 \mathrm{e}-02$ 1.00000e-02 1.00000e-03 1.00000e-09 1.00000e-01 $1.00000 \mathrm{e}+001.00000 \mathrm{e}+001.00000 \mathrm{e}-011.00000 \mathrm{e}-091.00000 \mathrm{e}-01$ $1.00000 \mathrm{e}-05$ 1.00000e-05 1.00000e-06 1.00000e-09 1.00000e-01 $1.00000 \mathrm{e}+001.00000 \mathrm{e}+001.00000 \mathrm{e}-011.00000 \mathrm{e}-091.00000 \mathrm{e}-01$ Element: 1136 \# of layers: 10

$\mathrm{Kx} \mathrm{Ky} \mathrm{Kz}$ Ss Por

5.99715e+01 5.99715e+01 5.99715e+00 1.00000e-09 7.00000e-02 $2.39630 \mathrm{e}+002.39630 \mathrm{e}+002.39630 \mathrm{e}-01$ 1.00000e-09 2.12000e-01 $2.39630 \mathrm{e}+002.39630 \mathrm{e}+002.39630 \mathrm{e}-01$ 1.00000e-09 2.12000e-01 $2.39630 \mathrm{e}+002.39630 \mathrm{e}+002.39630 \mathrm{e}-01$ 1.00000e-09 2.12000e-01 $2.39630 \mathrm{e}+002.39630 \mathrm{e}+00$ 2.39630e-01 1.00000e-09 2.12000e-01 $2.39630 \mathrm{e}+002.39630 \mathrm{e}+00$ 2.39630e-01 1.00000e-09 2.12000e-01 $1.00000 \mathrm{e}-02$ 1.00000e-02 1.00000e-03 1.00000e-09 1.00000e-01 $1.00000 \mathrm{e}+001.00000 \mathrm{e}+001.00000 \mathrm{e}-011.00000 \mathrm{e}-091.00000 \mathrm{e}-01$ $1.00000 \mathrm{e}-05$ 1.00000e-05 1.00000e-06 1.00000e-09 1.00000e-01 $1.00000 \mathrm{e}+001.00000 \mathrm{e}+001.00000 \mathrm{e}-01$ 1.00000e-09 1.00000e-01 Element: 1137 \# of layers: 10

Kx Ky Kz Ss Por

5.99715e+01 5.99715e+01 5.99715e+00 1.00000e-09 7.00000e-02 $2.39630 \mathrm{e}+002.39630 \mathrm{e}+00$ 2.39630e-01 1.00000e-09 2.12000e-01 $2.39630 \mathrm{e}+002.39630 \mathrm{e}+002.39630 \mathrm{e}-01$ 1.00000e-09 2.12000e-01 $2.39630 \mathrm{e}+002.39630 \mathrm{e}+002.39630 \mathrm{e}-01$ 1.00000e-09 2.12000e-01 $2.39630 \mathrm{e}+002.39630 \mathrm{e}+00$ 2.39630e-01 1.00000e-09 2.12000e-01 $2.39630 \mathrm{e}+002.39630 \mathrm{e}+00$ 2.39630e-01 1.00000e-09 2.12000e-01 $1.00000 \mathrm{e}-02$ 1.00000e-02 1.00000e-03 1.00000e-09 1.00000e-01 $1.00000 \mathrm{e}+001.00000 \mathrm{e}+001.00000 \mathrm{e}-011.00000 \mathrm{e}-091.00000 \mathrm{e}-01$ $1.00000 \mathrm{e}-05$ 1.00000e-05 1.00000e-06 1.00000e-09 1.00000e-01 $1.00000 \mathrm{e}+001.00000 \mathrm{e}+001.00000 \mathrm{e}-01$ 1.00000e-09 1.00000e-01 Element: 1138 \# of layers: 10

Kx Ky Kz Ss Por

5.99715e+01 5.99715e+01 5.99715e+00 1.00000e-09 7.00000e-02 $2.39630 \mathrm{e}+002.39630 \mathrm{e}+002.39630 \mathrm{e}-01$ 1.00000e-09 2.12000e-01 $2.39630 \mathrm{e}+002.39630 \mathrm{e}+00$ 2.39630e-01 1.00000e-09 2.12000e-01 $2.39630 \mathrm{e}+002.39630 \mathrm{e}+00$ 2.39630e-01 1.00000e-09 2.12000e-01 $2.39630 \mathrm{e}+002.39630 \mathrm{e}+002.39630 \mathrm{e}-01$ 1.00000e-09 2.12000e-01 $2.39630 \mathrm{e}+002.39630 \mathrm{e}+00$ 2.39630e-01 1.00000e-09 2.12000e-01 $1.00000 \mathrm{e}-02$ 1.00000e-02 1.00000e-03 1.00000e-09 1.00000e-01 $1.00000 \mathrm{e}+001.00000 \mathrm{e}+001.00000 \mathrm{e}-011.00000 \mathrm{e}-091.00000 \mathrm{e}-01$ $1.00000 \mathrm{e}-05$ 1.00000e-05 1.00000e-06 1.00000e-09 1.00000e-01 
$1.00000 \mathrm{e}+001.00000 \mathrm{e}+00$ 1.00000e-01 1.00000e-09 1.00000e-01

Element: 1139 \# of layers: 10

Kx Ky Kz Ss Por

5.99715e+01 5.99715e+01 5.99715e+00 1.00000e-09 7.00000e-02

$2.39630 \mathrm{e}+002.39630 \mathrm{e}+002.39630 \mathrm{e}-01$ 1.00000e-09 2.12000e-01

$2.39630 \mathrm{e}+002.39630 \mathrm{e}+00$ 2.39630e-01 1.00000e-09 2.12000e-01

$2.39630 \mathrm{e}+002.39630 \mathrm{e}+00$ 2.39630e-01 1.00000e-09 2.12000e-01

$2.39630 \mathrm{e}+002.39630 \mathrm{e}+00$ 2.39630e-01 1.00000e-09 2.12000e-01

$2.39630 \mathrm{e}+002.39630 \mathrm{e}+002.39630 \mathrm{e}-01$ 1.00000e-09 2.12000e-01

$1.00000 \mathrm{e}-02$ 1.00000e-02 1.00000e-03 1.00000e-09 1.00000e-01

$1.00000 \mathrm{e}+001.00000 \mathrm{e}+001.00000 \mathrm{e}-011.00000 \mathrm{e}-091.00000 \mathrm{e}-01$

$1.00000 \mathrm{e}-05$ 1.00000e-05 1.00000e-06 1.00000e-09 1.00000e-01

$1.00000 \mathrm{e}+001.00000 \mathrm{e}+001.00000 \mathrm{e}-01$ 1.00000e-09 1.00000e-01

Element: 1140 \# of layers: 10

$\mathrm{Kx} \mathrm{Ky} \mathrm{Kz}$ Ss Por

4.22884e+01 4.22884e+01 4.22884e+00 1.00000e-09 7.00000e-02

$1.68972 \mathrm{e}+00$ 1.68972e+00 1.68972e-01 1.00000e-09 2.12000e-01

$1.68972 \mathrm{e}+00$ 1.68972e+00 1.68972e-01 1.00000e-09 2.12000e-01

$1.68972 \mathrm{e}+001.68972 \mathrm{e}+00$ 1.68972e-01 1.00000e-09 2.12000e-01

$1.68972 \mathrm{e}+001.68972 \mathrm{e}+00$ 1.68972e-01 1.00000e-09 2.12000e-01

$1.68972 \mathrm{e}+001.68972 \mathrm{e}+00$ 1.68972e-01 1.00000e-09 2.12000e-01

$1.00000 \mathrm{e}-021.00000 \mathrm{e}-021.00000 \mathrm{e}-031.00000 \mathrm{e}-091.00000 \mathrm{e}-01$

$1.00000 \mathrm{e}+001.00000 \mathrm{e}+001.00000 \mathrm{e}-011.00000 \mathrm{e}-091.00000 \mathrm{e}-01$

$1.00000 \mathrm{e}-051.00000 \mathrm{e}-05$ 1.00000e-06 1.00000e-09 1.00000e-01

$1.00000 \mathrm{e}+001.00000 \mathrm{e}+001.00000 \mathrm{e}-011.00000 \mathrm{e}-09$ 1.00000e-01

Element: 1141 \# of layers: 10

$\mathrm{Kx} \mathrm{Ky} \mathrm{Kz}$ Ss Por

4.22884e+01 4.22884e+01 4.22884e+00 1.00000e-09 7.00000e-02

$1.68972 \mathrm{e}+001.68972 \mathrm{e}+00$ 1.68972e-01 1.00000e-09 2.12000e-01

$1.68972 \mathrm{e}+00$ 1.68972e+00 1.68972e-01 1.00000e-09 2.12000e-01

$1.68972 \mathrm{e}+001.68972 \mathrm{e}+00$ 1.68972e-01 1.00000e-09 2.12000e-01

$1.68972 \mathrm{e}+001.68972 \mathrm{e}+00$ 1.68972e-01 1.00000e-09 2.12000e-01

$1.68972 \mathrm{e}+001.68972 \mathrm{e}+00$ 1.68972e-01 1.00000e-09 2.12000e-01

$1.00000 \mathrm{e}-02$ 1.00000e-02 1.00000e-03 1.00000e-09 1.00000e-01

$1.00000 \mathrm{e}+001.00000 \mathrm{e}+001.00000 \mathrm{e}-011.00000 \mathrm{e}-091.00000 \mathrm{e}-01$

$1.00000 \mathrm{e}-05$ 1.00000e-05 1.00000e-06 1.00000e-09 1.00000e-01

$1.00000 \mathrm{e}+001.00000 \mathrm{e}+001.00000 \mathrm{e}-011.00000 \mathrm{e}-091.00000 \mathrm{e}-01$

Element: 1142 \# of layers: 10

$\mathrm{Kx} \mathrm{Ky} \mathrm{Kz}$ Ss Por

4.22884e+01 4.22884e+01 4.22884e+00 1.00000e-09 7.00000e-02

$1.68972 \mathrm{e}+00$ 1.68972e+00 1.68972e-01 1.00000e-09 2.12000e-01

$1.68972 \mathrm{e}+001.68972 \mathrm{e}+00$ 1.68972e-01 1.00000e-09 2.12000e-01

$1.68972 \mathrm{e}+001.68972 \mathrm{e}+00$ 1.68972e-01 1.00000e-09 2.12000e-01

$1.68972 \mathrm{e}+00$ 1.68972e+00 1.68972e-01 1.00000e-09 2.12000e-01

$1.68972 \mathrm{e}+001.68972 \mathrm{e}+001.68972 \mathrm{e}-01$ 1.00000e-09 2.12000e-01

$1.00000 \mathrm{e}-02$ 1.00000e-02 1.00000e-03 1.00000e-09 1.00000e-01 
$1.00000 \mathrm{e}+001.00000 \mathrm{e}+001.00000 \mathrm{e}-011.00000 \mathrm{e}-091.00000 \mathrm{e}-01$ $1.00000 \mathrm{e}-05$ 1.00000e-05 1.00000e-06 1.00000e-09 1.00000e-01 $1.00000 \mathrm{e}+001.00000 \mathrm{e}+001.00000 \mathrm{e}-01$ 1.00000e-09 1.00000e-01

Element: 1143 \# of layers: 10

$\mathrm{Kx} \mathrm{Ky} \mathrm{Kz}$ Ss Por

4.22884e+01 4.22884e+01 4.22884e+00 1.00000e-09 7.00000e-02 $1.68972 \mathrm{e}+001.68972 \mathrm{e}+00$ 1.68972e-01 1.00000e-09 2.12000e-01 $1.68972 \mathrm{e}+001.68972 \mathrm{e}+001.68972 \mathrm{e}-011.00000 \mathrm{e}-092.12000 \mathrm{e}-01$ $1.68972 \mathrm{e}+001.68972 \mathrm{e}+00$ 1.68972e-01 1.00000e-09 2.12000e-01 $1.68972 \mathrm{e}+001.68972 \mathrm{e}+00$ 1.68972e-01 1.00000e-09 2.12000e-01 $1.68972 \mathrm{e}+001.68972 \mathrm{e}+00$ 1.68972e-01 1.00000e-09 2.12000e-01 $1.00000 \mathrm{e}-02$ 1.00000e-02 1.00000e-03 1.00000e-09 1.00000e-01 $1.00000 \mathrm{e}+001.00000 \mathrm{e}+001.00000 \mathrm{e}-011.00000 \mathrm{e}-091.00000 \mathrm{e}-01$ $1.00000 \mathrm{e}-05$ 1.00000e-05 1.00000e-06 1.00000e-09 1.00000e-01 $1.00000 \mathrm{e}+001.00000 \mathrm{e}+001.00000 \mathrm{e}-01$ 1.00000e-09 1.00000e-01 Element: 1144 \# of layers: 10

$\mathrm{Kx} \mathrm{Ky} \mathrm{Kz}$ Ss Por

4.22884e+01 4.22884e+01 4.22884e+00 1.00000e-09 7.00000e-02 $1.68972 \mathrm{e}+001.68972 \mathrm{e}+00$ 1.68972e-01 1.00000e-09 2.12000e-01 $1.68972 \mathrm{e}+001.68972 \mathrm{e}+00$ 1.68972e-01 1.00000e-09 2.12000e-01 $1.68972 \mathrm{e}+001.68972 \mathrm{e}+001.68972 \mathrm{e}-011.00000 \mathrm{e}-092.12000 \mathrm{e}-01$ $1.68972 \mathrm{e}+001.68972 \mathrm{e}+00$ 1.68972e-01 1.00000e-09 2.12000e-01 $1.68972 \mathrm{e}+001.68972 \mathrm{e}+00$ 1.68972e-01 1.00000e-09 2.12000e-01 $1.00000 \mathrm{e}-02$ 1.00000e-02 1.00000e-03 1.00000e-09 1.00000e-01 $1.00000 \mathrm{e}+001.00000 \mathrm{e}+001.00000 \mathrm{e}-011.00000 \mathrm{e}-091.00000 \mathrm{e}-01$ $1.00000 \mathrm{e}-051.00000 \mathrm{e}-05$ 1.00000e-06 1.00000e-09 1.00000e-01 $1.00000 \mathrm{e}+001.00000 \mathrm{e}+001.00000 \mathrm{e}-011.00000 \mathrm{e}-091.00000 \mathrm{e}-01$ Element: 1145 \# of layers: 10

$\mathrm{Kx} \mathrm{Ky} \mathrm{Kz} \mathrm{Ss} \mathrm{Por}$

4.22884e+01 4.22884e+01 4.22884e+00 1.00000e-09 7.00000e-02 $1.68972 \mathrm{e}+001.68972 \mathrm{e}+00$ 1.68972e-01 1.00000e-09 2.12000e-01 $1.68972 \mathrm{e}+001.68972 \mathrm{e}+00$ 1.68972e-01 1.00000e-09 2.12000e-01 $1.68972 \mathrm{e}+001.68972 \mathrm{e}+001.68972 \mathrm{e}-011.00000 \mathrm{e}-092.12000 \mathrm{e}-01$ $1.68972 \mathrm{e}+001.68972 \mathrm{e}+00$ 1.68972e-01 1.00000e-09 2.12000e-01 $1.68972 \mathrm{e}+001.68972 \mathrm{e}+00$ 1.68972e-01 1.00000e-09 2.12000e-01 1.00000e-02 1.00000e-02 1.00000e-03 1.00000e-09 1.00000e-01 $1.00000 \mathrm{e}+001.00000 \mathrm{e}+001.00000 \mathrm{e}-011.00000 \mathrm{e}-091.00000 \mathrm{e}-01$ $1.00000 \mathrm{e}-051.00000 \mathrm{e}-05$ 1.00000e-06 1.00000e-09 1.00000e-01 $1.00000 \mathrm{e}+001.00000 \mathrm{e}+001.00000 \mathrm{e}-011.00000 \mathrm{e}-091.00000 \mathrm{e}-01$ Element: 1146 \# of layers: 10

$\mathrm{Kx} \mathrm{Ky} \mathrm{Kz}$ Ss Por

4.22884e+01 4.22884e+01 4.22884e+00 1.00000e-09 7.00000e-02 $1.68972 \mathrm{e}+001.68972 \mathrm{e}+00$ 1.68972e-01 1.00000e-09 2.12000e-01 $1.68972 \mathrm{e}+001.68972 \mathrm{e}+00$ 1.68972e-01 1.00000e-09 2.12000e-01 $1.68972 \mathrm{e}+001.68972 \mathrm{e}+001.68972 \mathrm{e}-01$ 1.00000e-09 2.12000e-01 $1.68972 \mathrm{e}+001.68972 \mathrm{e}+00$ 1.68972e-01 1.00000e-09 2.12000e-01 
$1.68972 \mathrm{e}+00$ 1.68972e+00 1.68972e-01 1.00000e-09 2.12000e-01 $1.00000 \mathrm{e}-02$ 1.00000e-02 1.00000e-03 1.00000e-09 1.00000e-01 $1.00000 \mathrm{e}+001.00000 \mathrm{e}+001.00000 \mathrm{e}-011.00000 \mathrm{e}-091.00000 \mathrm{e}-01$ $1.00000 \mathrm{e}-05$ 1.00000e-05 1.00000e-06 1.00000e-09 1.00000e-01 $1.00000 \mathrm{e}+001.00000 \mathrm{e}+001.00000 \mathrm{e}-011.00000 \mathrm{e}-091.00000 \mathrm{e}-01$ Element: 1147 \# of layers: 10

$\mathrm{Kx} \mathrm{Ky} \mathrm{Kz}$ Ss Por

4.22884e+01 4.22884e+01 4.22884e+00 1.00000e-09 7.00000e-02 $1.68972 \mathrm{e}+001.68972 \mathrm{e}+00$ 1.68972e-01 1.00000e-09 2.12000e-01 $1.68972 \mathrm{e}+001.68972 \mathrm{e}+00$ 1.68972e-01 1.00000e-09 2.12000e-01 $1.68972 \mathrm{e}+001.68972 \mathrm{e}+00$ 1.68972e-01 1.00000e-09 2.12000e-01 $1.68972 \mathrm{e}+001.68972 \mathrm{e}+001.68972 \mathrm{e}-01$ 1.00000e-09 2.12000e-01 $1.68972 \mathrm{e}+00$ 1.68972e+00 1.68972e-01 1.00000e-09 2.12000e-01 $1.00000 \mathrm{e}-02$ 1.00000e-02 1.00000e-03 1.00000e-09 1.00000e-01 $1.00000 \mathrm{e}+001.00000 \mathrm{e}+001.00000 \mathrm{e}-011.00000 \mathrm{e}-091.00000 \mathrm{e}-01$ $1.00000 \mathrm{e}-05$ 1.00000e-05 1.00000e-06 1.00000e-09 1.00000e-01 $1.00000 \mathrm{e}+001.00000 \mathrm{e}+001.00000 \mathrm{e}-011.00000 \mathrm{e}-091.00000 \mathrm{e}-01$ Element: 1148 \# of layers: 10

$\mathrm{Kx} \mathrm{Ky} \mathrm{Kz}$ Ss Por

4.22884e+01 4.22884e+01 4.22884e+00 1.00000e-09 7.00000e-02 $1.68972 \mathrm{e}+001.68972 \mathrm{e}+00$ 1.68972e-01 1.00000e-09 2.12000e-01 $1.68972 \mathrm{e}+001.68972 \mathrm{e}+00$ 1.68972e-01 1.00000e-09 2.12000e-01 $1.68972 \mathrm{e}+001.68972 \mathrm{e}+00$ 1.68972e-01 1.00000e-09 2.12000e-01 $1.68972 \mathrm{e}+001.68972 \mathrm{e}+001.68972 \mathrm{e}-01$ 1.00000e-09 2.12000e-01 $1.68972 \mathrm{e}+001.68972 \mathrm{e}+001.68972 \mathrm{e}-01$ 1.00000e-09 2.12000e-01 $1.00000 \mathrm{e}-021.00000 \mathrm{e}-021.00000 \mathrm{e}-031.00000 \mathrm{e}-091.00000 \mathrm{e}-01$ $1.00000 \mathrm{e}+001.00000 \mathrm{e}+001.00000 \mathrm{e}-011.00000 \mathrm{e}-091.00000 \mathrm{e}-01$ $1.00000 \mathrm{e}-05$ 1.00000e-05 1.00000e-06 1.00000e-09 1.00000e-01 $1.00000 \mathrm{e}+001.00000 \mathrm{e}+001.00000 \mathrm{e}-011.00000 \mathrm{e}-091.00000 \mathrm{e}-01$ Element: 1149 \# of layers: 8

$\mathrm{Kx} \mathrm{Ky} \mathrm{Kz}$ Ss Por

3.56436e+01 3.56436e+01 3.56436e+00 1.00000e-09 7.00000e-02 $1.42419 \mathrm{e}+00$ 1.42419e+00 1.42419e-01 1.00000e-09 2.12000e-01 $1.42419 \mathrm{e}+001.42419 \mathrm{e}+00$ 1.42419e-01 1.00000e-09 2.12000e-01 $1.42419 \mathrm{e}+001.42419 \mathrm{e}+00$ 1.42419e-01 1.00000e-09 2.12000e-01 $1.42419 \mathrm{e}+001.42419 \mathrm{e}+00$ 1.42419e-01 1.00000e-09 2.12000e-01 $1.42419 \mathrm{e}+00$ 1.42419e+00 1.42419e-01 1.00000e-09 2.12000e-01 1.00000e-02 1.00000e-02 1.00000e-03 1.00000e-09 1.00000e-01 $1.00000 \mathrm{e}+001.00000 \mathrm{e}+001.00000 \mathrm{e}-011.00000 \mathrm{e}-091.00000 \mathrm{e}-01$ Element: 1150 \# of layers: 8

$\mathrm{Kx} \mathrm{Ky} \mathrm{Kz}$ Ss Por

3.56436e+01 3.56436e+01 3.56436e+00 1.00000e-09 7.00000e-02 $1.42419 \mathrm{e}+00$ 1.42419e+00 1.42419e-01 1.00000e-09 2.12000e-01 $1.42419 \mathrm{e}+001.42419 \mathrm{e}+00$ 1.42419e-01 1.00000e-09 2.12000e-01 $1.42419 \mathrm{e}+00$ 1.42419e+00 1.42419e-01 1.00000e-09 2.12000e-01 $1.42419 \mathrm{e}+001.42419 \mathrm{e}+00$ 1.42419e-01 1.00000e-09 2.12000e-01 
$1.42419 \mathrm{e}+00$ 1.42419e+00 1.42419e-01 1.00000e-09 2.12000e-01 $1.00000 \mathrm{e}-02$ 1.00000e-02 1.00000e-03 1.00000e-09 1.00000e-01 $1.00000 \mathrm{e}+001.00000 \mathrm{e}+001.00000 \mathrm{e}-011.00000 \mathrm{e}-091.00000 \mathrm{e}-01$ Element: 1151 \# of layers: 8

$\mathrm{Kx} \mathrm{Ky} \mathrm{Kz}$ Ss Por

3.56436e+01 3.56436e+01 3.56436e+00 1.00000e-09 7.00000e-02 $1.42419 \mathrm{e}+001.42419 \mathrm{e}+00$ 1.42419e-01 1.00000e-09 2.12000e-01 $1.42419 \mathrm{e}+001.42419 \mathrm{e}+00$ 1.42419e-01 1.00000e-09 2.12000e-01 $1.42419 \mathrm{e}+00$ 1.42419e+00 1.42419e-01 1.00000e-09 2.12000e-01 $1.42419 \mathrm{e}+00$ 1.42419e+00 1.42419e-01 1.00000e-09 2.12000e-01 $1.42419 \mathrm{e}+00$ 1.42419e+00 1.42419e-01 1.00000e-09 2.12000e-01 $1.00000 \mathrm{e}-02$ 1.00000e-02 1.00000e-03 1.00000e-09 1.00000e-01 $1.00000 \mathrm{e}+001.00000 \mathrm{e}+001.00000 \mathrm{e}-011.00000 \mathrm{e}-091.00000 \mathrm{e}-01$ Element: 1152 \# of layers: 8

$\mathrm{Kx} \mathrm{Ky} \mathrm{Kz}$ Ss Por

3.56436e+01 3.56436e+01 3.56436e+00 1.00000e-09 7.00000e-02 $1.42419 \mathrm{e}+001.42419 \mathrm{e}+00$ 1.42419e-01 1.00000e-09 2.12000e-01 $1.42419 \mathrm{e}+001.42419 \mathrm{e}+00$ 1.42419e-01 1.00000e-09 2.12000e-01 $1.42419 \mathrm{e}+00$ 1.42419e+00 1.42419e-01 1.00000e-09 2.12000e-01 $1.42419 \mathrm{e}+001.42419 \mathrm{e}+00$ 1.42419e-01 1.00000e-09 2.12000e-01 $1.42419 \mathrm{e}+001.42419 \mathrm{e}+00$ 1.42419e-01 1.00000e-09 2.12000e-01 $1.00000 \mathrm{e}-02$ 1.00000e-02 1.00000e-03 1.00000e-09 1.00000e-01 $1.00000 \mathrm{e}+001.00000 \mathrm{e}+001.00000 \mathrm{e}-01$ 1.00000e-09 1.00000e-01 Element: 1153 \# of layers: 10

Kx Ky Kz Ss Por

3.56436e+01 3.56436e+01 3.56436e+00 1.00000e-09 7.00000e-02 $1.42419 \mathrm{e}+001.42419 \mathrm{e}+00$ 1.42419e-01 1.00000e-09 2.12000e-01 $1.42419 \mathrm{e}+001.42419 \mathrm{e}+00$ 1.42419e-01 1.00000e-09 2.12000e-01 $1.42419 \mathrm{e}+001.42419 \mathrm{e}+00$ 1.42419e-01 1.00000e-09 2.12000e-01 $1.42419 \mathrm{e}+00$ 1.42419e+00 1.42419e-01 1.00000e-09 2.12000e-01 $1.42419 \mathrm{e}+001.42419 \mathrm{e}+00$ 1.42419e-01 1.00000e-09 2.12000e-01 $1.00000 \mathrm{e}-02$ 1.00000e-02 1.00000e-03 1.00000e-09 1.00000e-01 $1.00000 \mathrm{e}+001.00000 \mathrm{e}+001.00000 \mathrm{e}-011.00000 \mathrm{e}-091.00000 \mathrm{e}-01$ $1.00000 \mathrm{e}-05$ 1.00000e-05 1.00000e-06 1.00000e-09 1.00000e-01 $1.00000 \mathrm{e}+001.00000 \mathrm{e}+001.00000 \mathrm{e}-011.00000 \mathrm{e}-091.00000 \mathrm{e}-01$ Element: 1154 \# of layers: 10

Kx Ky Kz Ss Por

3.56436e+01 3.56436e+01 3.56436e+00 1.00000e-09 7.00000e-02 $1.42419 \mathrm{e}+001.42419 \mathrm{e}+00$ 1.42419e-01 1.00000e-09 2.12000e-01 $1.42419 \mathrm{e}+00$ 1.42419e+00 1.42419e-01 1.00000e-09 2.12000e-01 $1.42419 \mathrm{e}+001.42419 \mathrm{e}+00$ 1.42419e-01 1.00000e-09 2.12000e-01 $1.42419 \mathrm{e}+001.42419 \mathrm{e}+00$ 1.42419e-01 1.00000e-09 2.12000e-01 $1.42419 \mathrm{e}+001.42419 \mathrm{e}+00$ 1.42419e-01 1.00000e-09 2.12000e-01 $1.00000 \mathrm{e}-02$ 1.00000e-02 1.00000e-03 1.00000e-09 1.00000e-01 $1.00000 \mathrm{e}+001.00000 \mathrm{e}+001.00000 \mathrm{e}-011.00000 \mathrm{e}-091.00000 \mathrm{e}-01$ $1.00000 \mathrm{e}-05$ 1.00000e-05 1.00000e-06 1.00000e-09 1.00000e-01 
$1.00000 \mathrm{e}+001.00000 \mathrm{e}+00$ 1.00000e-01 1.00000e-09 1.00000e-01

Element: 1155 \# of layers: 10

Kx Ky Kz Ss Por

3.56436e+01 3.56436e+01 3.56436e+00 1.00000e-09 7.00000e-02 $1.42419 \mathrm{e}+001.42419 \mathrm{e}+00$ 1.42419e-01 1.00000e-09 2.12000e-01

$1.42419 \mathrm{e}+001.42419 \mathrm{e}+001.42419 \mathrm{e}-01$ 1.00000e-09 2.12000e-01 $1.42419 \mathrm{e}+00$ 1.42419e+00 1.42419e-01 1.00000e-09 2.12000e-01 $1.42419 \mathrm{e}+001.42419 \mathrm{e}+00$ 1.42419e-01 1.00000e-09 2.12000e-01 $1.42419 \mathrm{e}+00$ 1.42419e+00 1.42419e-01 1.00000e-09 2.12000e-01 $1.00000 \mathrm{e}-02$ 1.00000e-02 1.00000e-03 1.00000e-09 1.00000e-01 $1.00000 \mathrm{e}+001.00000 \mathrm{e}+001.00000 \mathrm{e}-011.00000 \mathrm{e}-091.00000 \mathrm{e}-01$ $1.00000 \mathrm{e}-05$ 1.00000e-05 1.00000e-06 1.00000e-09 1.00000e-01 $1.00000 \mathrm{e}+001.00000 \mathrm{e}+001.00000 \mathrm{e}-011.00000 \mathrm{e}-09$ 1.00000e-01 Element: 1156 \# of layers: 10

$\mathrm{Kx} \mathrm{Ky} \mathrm{Kz}$ Ss Por

3.56436e+01 3.56436e+01 3.56436e+00 1.00000e-09 7.00000e-02 $1.42419 \mathrm{e}+001.42419 \mathrm{e}+00$ 1.42419e-01 1.00000e-09 2.12000e-01 $1.42419 \mathrm{e}+00$ 1.42419e+00 1.42419e-01 1.00000e-09 2.12000e-01 $1.42419 \mathrm{e}+001.42419 \mathrm{e}+00$ 1.42419e-01 1.00000e-09 2.12000e-01 $1.42419 \mathrm{e}+001.42419 \mathrm{e}+00$ 1.42419e-01 1.00000e-09 2.12000e-01 $1.42419 \mathrm{e}+001.42419 \mathrm{e}+00$ 1.42419e-01 1.00000e-09 2.12000e-01 $1.00000 \mathrm{e}-02$ 1.00000e-02 1.00000e-03 1.00000e-09 1.00000e-01 $1.00000 \mathrm{e}+001.00000 \mathrm{e}+001.00000 \mathrm{e}-011.00000 \mathrm{e}-091.00000 \mathrm{e}-01$ $1.00000 \mathrm{e}-05$ 1.00000e-05 1.00000e-06 1.00000e-09 1.00000e-01 $1.00000 \mathrm{e}+001.00000 \mathrm{e}+001.00000 \mathrm{e}-011.00000 \mathrm{e}-09$ 1.00000e-01 Element: 1157 \# of layers: 10

$\mathrm{Kx} \mathrm{Ky} \mathrm{Kz}$ Ss Por

3.56436e+01 3.56436e+01 3.56436e+00 1.00000e-09 7.00000e-02 $1.42419 \mathrm{e}+001.42419 \mathrm{e}+00$ 1.42419e-01 1.00000e-09 2.12000e-01 $1.42419 \mathrm{e}+00$ 1.42419e+00 1.42419e-01 1.00000e-09 2.12000e-01 $1.42419 \mathrm{e}+001.42419 \mathrm{e}+00$ 1.42419e-01 1.00000e-09 2.12000e-01 $1.42419 \mathrm{e}+00$ 1.42419e+00 1.42419e-01 1.00000e-09 2.12000e-01 $1.42419 \mathrm{e}+001.42419 \mathrm{e}+00$ 1.42419e-01 1.00000e-09 2.12000e-01 $1.00000 \mathrm{e}-021.00000 \mathrm{e}-021.00000 \mathrm{e}-031.00000 \mathrm{e}-091.00000 \mathrm{e}-01$ $1.00000 \mathrm{e}+001.00000 \mathrm{e}+001.00000 \mathrm{e}-011.00000 \mathrm{e}-091.00000 \mathrm{e}-01$ $1.00000 \mathrm{e}-05$ 1.00000e-05 1.00000e-06 1.00000e-09 1.00000e-01 $1.00000 \mathrm{e}+001.00000 \mathrm{e}+001.00000 \mathrm{e}-011.00000 \mathrm{e}-091.00000 \mathrm{e}-01$ Element: 1158 \# of layers: 7

$\mathrm{Kx} \mathrm{Ky} \mathrm{Kz}$ Ss Por

5.55926e+01 5.55926e+01 5.55926e+00 1.00000e-09 7.00000e-02 $2.22127 \mathrm{e}+002.22127 \mathrm{e}+00$ 2.22127e-01 1.00000e-09 2.12000e-01 $2.22127 \mathrm{e}+002.22127 \mathrm{e}+00$ 2.22127e-01 1.00000e-09 2.12000e-01 2.22127e+00 2.22127e+00 2.22127e-01 1.00000e-09 2.12000e-01 2.22127e+00 2.22127e+00 2.22127e-01 1.00000e-09 2.12000e-01 $1.00000 \mathrm{e}-021.00000 \mathrm{e}-021.00000 \mathrm{e}-031.00000 \mathrm{e}-091.00000 \mathrm{e}-01$ $1.00000 \mathrm{e}+001.00000 \mathrm{e}+001.00000 \mathrm{e}-011.00000 \mathrm{e}-091.00000 \mathrm{e}-01$ 
Element: 1159 \# of layers: 8

$\mathrm{Kx} \mathrm{Ky} \mathrm{Kz}$ Ss Por

5.55926e+01 5.55926e+01 5.55926e+00 1.00000e-09 7.00000e-02

$2.22127 \mathrm{e}+00$ 2.22127e+00 2.22127e-01 1.00000e-09 2.12000e-01

$2.22127 \mathrm{e}+00$ 2.22127e+00 2.22127e-01 1.00000e-09 2.12000e-01

$2.22127 \mathrm{e}+002.22127 \mathrm{e}+00$ 2.22127e-01 1.00000e-09 2.12000e-01

$2.22127 \mathrm{e}+00$ 2.22127e+00 2.22127e-01 1.00000e-09 2.12000e-01

$2.22127 \mathrm{e}+002.22127 \mathrm{e}+00$ 2.22127e-01 1.00000e-09 2.12000e-01

$1.00000 \mathrm{e}-02$ 1.00000e-02 1.00000e-03 1.00000e-09 1.00000e-01

$1.00000 \mathrm{e}+001.00000 \mathrm{e}+001.00000 \mathrm{e}-011.00000 \mathrm{e}-091.00000 \mathrm{e}-01$

Element: 1160 \# of layers: 7

Kx Ky Kz Ss Por

5.55926e+01 5.55926e+01 5.55926e+00 1.00000e-09 7.00000e-02

$2.22127 \mathrm{e}+002.22127 \mathrm{e}+00$ 2.22127e-01 1.00000e-09 2.12000e-01

$2.22127 \mathrm{e}+002.22127 \mathrm{e}+00$ 2.22127e-01 1.00000e-09 2.12000e-01

$2.22127 \mathrm{e}+002.22127 \mathrm{e}+00$ 2.22127e-01 1.00000e-09 2.12000e-01

$2.22127 \mathrm{e}+002.22127 \mathrm{e}+00$ 2.22127e-01 1.00000e-09 2.12000e-01

$1.00000 \mathrm{e}-021.00000 \mathrm{e}-021.00000 \mathrm{e}-031.00000 \mathrm{e}-091.00000 \mathrm{e}-01$

$1.00000 \mathrm{e}+001.00000 \mathrm{e}+001.00000 \mathrm{e}-01$ 1.00000e-09 1.00000e-01

Element: 1161 \# of layers: 7

$\mathrm{Kx} \mathrm{Ky} \mathrm{Kz}$ Ss Por

5.55926e+01 5.55926e+01 5.55926e+00 1.00000e-09 7.00000e-02

$2.22127 \mathrm{e}+00$ 2.22127e+00 2.22127e-01 1.00000e-09 2.12000e-01

$2.22127 \mathrm{e}+002.22127 \mathrm{e}+00$ 2.22127e-01 1.00000e-09 2.12000e-01

$2.22127 \mathrm{e}+002.22127 \mathrm{e}+00$ 2.22127e-01 1.00000e-09 2.12000e-01

$2.22127 \mathrm{e}+002.22127 \mathrm{e}+00$ 2.22127e-01 1.00000e-09 2.12000e-01

$1.00000 \mathrm{e}-02$ 1.00000e-02 1.00000e-03 1.00000e-09 1.00000e-01

$1.00000 \mathrm{e}+001.00000 \mathrm{e}+001.00000 \mathrm{e}-011.00000 \mathrm{e}-09$ 1.00000e-01

Element: 1162 \# of layers: 7

$\mathrm{Kx} \mathrm{Ky} \mathrm{Kz}$ Ss Por

$5.55926 \mathrm{e}+015.55926 \mathrm{e}+015.55926 \mathrm{e}+00$ 1.00000e-09 7.00000e-02 $2.22127 \mathrm{e}+00$ 2.22127e+00 2.22127e-01 1.00000e-09 2.12000e-01

$2.22127 \mathrm{e}+002.22127 \mathrm{e}+00$ 2.22127e-01 1.00000e-09 2.12000e-01

2.22127e+00 2.22127e+00 2.22127e-01 1.00000e-09 2.12000e-01

$2.22127 \mathrm{e}+002.22127 \mathrm{e}+002.22127 \mathrm{e}-01$ 1.00000e-09 2.12000e-01

$1.00000 \mathrm{e}-02$ 1.00000e-02 1.00000e-03 1.00000e-09 1.00000e-01

$1.00000 \mathrm{e}+001.00000 \mathrm{e}+001.00000 \mathrm{e}-011.00000 \mathrm{e}-091.00000 \mathrm{e}-01$

Element: 1163 \# of layers: 8

$\mathrm{Kx} \mathrm{Ky} \mathrm{Kz}$ Ss Por

$5.55926 \mathrm{e}+015.55926 \mathrm{e}+015.55926 \mathrm{e}+001.00000 \mathrm{e}-09$ 7.00000e-02 $2.22127 \mathrm{e}+002.22127 \mathrm{e}+00$ 2.22127e-01 1.00000e-09 2.12000e-01 $2.22127 \mathrm{e}+002.22127 \mathrm{e}+00$ 2.22127e-01 1.00000e-09 2.12000e-01 $2.22127 \mathrm{e}+00$ 2.22127e+00 2.22127e-01 1.00000e-09 2.12000e-01 2.22127e+00 2.22127e+00 2.22127e-01 1.00000e-09 2.12000e-01 $2.22127 \mathrm{e}+002.22127 \mathrm{e}+002.22127 \mathrm{e}-01$ 1.00000e-09 2.12000e-01 $1.00000 \mathrm{e}-02$ 1.00000e-02 1.00000e-03 1.00000e-09 1.00000e-01 
$1.00000 \mathrm{e}+001.00000 \mathrm{e}+001.00000 \mathrm{e}-01$ 1.00000e-09 1.00000e-01

Element: 1164 \# of layers: 7

Kx Ky Kz Ss Por

$5.55926 \mathrm{e}+015.55926 \mathrm{e}+015.55926 \mathrm{e}+001.00000 \mathrm{e}-09$ 7.00000e-02

$2.22127 \mathrm{e}+00$ 2.22127e+00 2.22127e-01 1.00000e-09 2.12000e-01

$2.22127 \mathrm{e}+002.22127 \mathrm{e}+00$ 2.22127e-01 1.00000e-09 2.12000e-01

$2.22127 \mathrm{e}+00$ 2.22127e+00 2.22127e-01 1.00000e-09 2.12000e-01

$2.22127 \mathrm{e}+002.22127 \mathrm{e}+002.22127 \mathrm{e}-01$ 1.00000e-09 2.12000e-01

$1.00000 \mathrm{e}-02$ 1.00000e-02 1.00000e-03 1.00000e-09 1.00000e-01

$1.00000 \mathrm{e}+001.00000 \mathrm{e}+001.00000 \mathrm{e}-011.00000 \mathrm{e}-091.00000 \mathrm{e}-01$

Element: 1165 \# of layers: 7

Kx Ky Kz Ss Por

5.55926e+01 5.55926e+01 5.55926e+00 1.00000e-09 7.00000e-02

$2.22127 \mathrm{e}+002.22127 \mathrm{e}+00$ 2.22127e-01 1.00000e-09 2.12000e-01

$2.22127 \mathrm{e}+002.22127 \mathrm{e}+00$ 2.22127e-01 1.00000e-09 2.12000e-01

$2.22127 \mathrm{e}+002.22127 \mathrm{e}+00$ 2.22127e-01 1.00000e-09 2.12000e-01

$2.22127 \mathrm{e}+002.22127 \mathrm{e}+00$ 2.22127e-01 1.00000e-09 2.12000e-01

$1.00000 \mathrm{e}-02$ 1.00000e-02 1.00000e-03 1.00000e-09 1.00000e-01

$1.00000 \mathrm{e}+001.00000 \mathrm{e}+001.00000 \mathrm{e}-01$ 1.00000e-09 1.00000e-01

Element: 1166 \# of layers: 8

$\mathrm{Kx} \mathrm{Ky} \mathrm{Kz}$ Ss Por

5.55926e+01 5.55926e+01 5.55926e+00 1.00000e-09 7.00000e-02

$2.22127 \mathrm{e}+00$ 2.22127e+00 2.22127e-01 1.00000e-09 2.12000e-01

$2.22127 \mathrm{e}+002.22127 \mathrm{e}+00$ 2.22127e-01 1.00000e-09 2.12000e-01

$2.22127 \mathrm{e}+002.22127 \mathrm{e}+00$ 2.22127e-01 1.00000e-09 2.12000e-01

$2.22127 \mathrm{e}+00$ 2.22127e+00 2.22127e-01 1.00000e-09 2.12000e-01

$2.22127 \mathrm{e}+002.22127 \mathrm{e}+00$ 2.22127e-01 1.00000e-09 2.12000e-01

1.00000e-02 1.00000e-02 1.00000e-03 1.00000e-09 1.00000e-01

$1.00000 \mathrm{e}+001.00000 \mathrm{e}+001.00000 \mathrm{e}-011.00000 \mathrm{e}-091.00000 \mathrm{e}-01$

Element: 1167 \# of layers: 7

$\mathrm{Kx} \mathrm{Ky} \mathrm{Kz}$ Ss Por

5.72135e+01 5.72135e+01 5.72135e+00 1.00000e-09 7.00000e-02

$2.28605 \mathrm{e}+002.28605 \mathrm{e}+002.28605 \mathrm{e}-01$ 1.00000e-09 2.12000e-01

$2.28605 \mathrm{e}+002.28605 \mathrm{e}+00$ 2.28605e-01 1.00000e-09 2.12000e-01

$2.28605 \mathrm{e}+002.28605 \mathrm{e}+00$ 2.28605e-01 1.00000e-09 2.12000e-01

$2.28605 \mathrm{e}+002.28605 \mathrm{e}+00$ 2.28605e-01 1.00000e-09 2.12000e-01

$1.00000 \mathrm{e}-02$ 1.00000e-02 1.00000e-03 1.00000e-09 1.00000e-01

$1.00000 \mathrm{e}+001.00000 \mathrm{e}+001.00000 \mathrm{e}-011.00000 \mathrm{e}-091.00000 \mathrm{e}-01$

Element: 1168 \# of layers: 6

$\mathrm{Kx} \mathrm{Ky} \mathrm{Kz}$ Ss Por

5.72135e+01 5.72135e+01 5.72135e+00 1.00000e-09 7.00000e-02

$2.28605 \mathrm{e}+002.28605 \mathrm{e}+00$ 2.28605e-01 1.00000e-09 2.12000e-01

$2.28605 \mathrm{e}+00$ 2.28605e+00 2.28605e-01 1.00000e-09 2.12000e-01

$2.28605 \mathrm{e}+00$ 2.28605e+00 2.28605e-01 1.00000e-09 2.12000e-01

$1.00000 \mathrm{e}-02$ 1.00000e-02 1.00000e-03 1.00000e-09 1.00000e-01

$1.00000 \mathrm{e}+001.00000 \mathrm{e}+001.00000 \mathrm{e}-011.00000 \mathrm{e}-091.00000 \mathrm{e}-01$ 
Element: 1169 \# of layers: 6

$\mathrm{Kx} \mathrm{Ky} \mathrm{Kz}$ Ss Por

5.72135e+01 5.72135e+01 5.72135e+00 1.00000e-09 7.00000e-02

$2.28605 \mathrm{e}+002.28605 \mathrm{e}+00$ 2.28605e-01 1.00000e-09 2.12000e-01

$2.28605 \mathrm{e}+002.28605 \mathrm{e}+00$ 2.28605e-01 1.00000e-09 2.12000e-01

$2.28605 \mathrm{e}+002.28605 \mathrm{e}+00$ 2.28605e-01 1.00000e-09 2.12000e-01

$1.00000 \mathrm{e}-02$ 1.00000e-02 1.00000e-03 1.00000e-09 1.00000e-01

$1.00000 \mathrm{e}+001.00000 \mathrm{e}+001.00000 \mathrm{e}-01$ 1.00000e-09 1.00000e-01

Element: 1170 \# of layers: 6

$\mathrm{Kx} \mathrm{Ky} \mathrm{Kz}$ Ss Por

5.72135e+01 5.72135e+01 5.72135e+00 1.00000e-09 7.00000e-02

$2.28605 \mathrm{e}+002.28605 \mathrm{e}+00$ 2.28605e-01 1.00000e-09 2.12000e-01

$2.28605 \mathrm{e}+002.28605 \mathrm{e}+00$ 2.28605e-01 1.00000e-09 2.12000e-01

$2.28605 \mathrm{e}+002.28605 \mathrm{e}+00$ 2.28605e-01 1.00000e-09 2.12000e-01

$1.00000 \mathrm{e}-02$ 1.00000e-02 1.00000e-03 1.00000e-09 1.00000e-01

$1.00000 \mathrm{e}+001.00000 \mathrm{e}+001.00000 \mathrm{e}-011.00000 \mathrm{e}-091.00000 \mathrm{e}-01$

Element: 1171 \# of layers: 6

Kx Ky Kz Ss Por

5.72135e+01 5.72135e+01 5.72135e+00 1.00000e-09 7.00000e-02

$2.28605 \mathrm{e}+002.28605 \mathrm{e}+00$ 2.28605e-01 1.00000e-09 2.12000e-01

$2.28605 \mathrm{e}+002.28605 \mathrm{e}+00$ 2.28605e-01 1.00000e-09 2.12000e-01

$2.28605 \mathrm{e}+00$ 2.28605e+00 2.28605e-01 1.00000e-09 2.12000e-01

$1.00000 \mathrm{e}-02$ 1.00000e-02 1.00000e-03 1.00000e-09 1.00000e-01

$1.00000 \mathrm{e}+001.00000 \mathrm{e}+001.00000 \mathrm{e}-011.00000 \mathrm{e}-091.00000 \mathrm{e}-01$

Element: 1172 \# of layers: 6

$\mathrm{Kx} \mathrm{Ky} \mathrm{Kz}$ Ss Por

5.72135e+01 5.72135e+01 5.72135e+00 1.00000e-09 7.00000e-02

$2.28605 \mathrm{e}+002.28605 \mathrm{e}+00$ 2.28605e-01 1.00000e-09 2.12000e-01

$2.28605 \mathrm{e}+002.28605 \mathrm{e}+002.28605 \mathrm{e}-01$ 1.00000e-09 2.12000e-01

$2.28605 \mathrm{e}+00$ 2.28605e+00 2.28605e-01 1.00000e-09 2.12000e-01

$1.00000 \mathrm{e}-02$ 1.00000e-02 1.00000e-03 1.00000e-09 1.00000e-01

$1.00000 \mathrm{e}+001.00000 \mathrm{e}+001.00000 \mathrm{e}-01$ 1.00000e-09 1.00000e-01

Element: 1173 \# of layers: 7

$\mathrm{Kx} \mathrm{Ky} \mathrm{Kz}$ Ss Por

5.72135e+01 5.72135e+01 5.72135e+00 1.00000e-09 7.00000e-02

$2.28605 \mathrm{e}+002.28605 \mathrm{e}+00$ 2.28605e-01 1.00000e-09 2.12000e-01

$2.28605 \mathrm{e}+002.28605 \mathrm{e}+00$ 2.28605e-01 1.00000e-09 2.12000e-01

$2.28605 \mathrm{e}+002.28605 \mathrm{e}+00$ 2.28605e-01 1.00000e-09 2.12000e-01

$2.28605 \mathrm{e}+002.28605 \mathrm{e}+00$ 2.28605e-01 1.00000e-09 2.12000e-01

$1.00000 \mathrm{e}-02$ 1.00000e-02 1.00000e-03 1.00000e-09 1.00000e-01

$1.00000 \mathrm{e}+001.00000 \mathrm{e}+001.00000 \mathrm{e}-011.00000 \mathrm{e}-091.00000 \mathrm{e}-01$

Element: 1174 \# of layers: 6

$\mathrm{Kx} \mathrm{Ky} \mathrm{Kz}$ Ss Por

5.72135e+01 5.72135e+01 5.72135e+00 1.00000e-09 7.00000e-02

$2.28605 \mathrm{e}+002.28605 \mathrm{e}+00$ 2.28605e-01 1.00000e-09 2.12000e-01

$2.28605 \mathrm{e}+002.28605 \mathrm{e}+00$ 2.28605e-01 1.00000e-09 2.12000e-01 
$2.28605 \mathrm{e}+002.28605 \mathrm{e}+002.28605 \mathrm{e}-01$ 1.00000e-09 2.12000e-01 $1.00000 \mathrm{e}-021.00000 \mathrm{e}-02$ 1.00000e-03 1.00000e-09 1.00000e-01 $1.00000 \mathrm{e}+001.00000 \mathrm{e}+001.00000 \mathrm{e}-011.00000 \mathrm{e}-091.00000 \mathrm{e}-01$ Element: 1175 \# of layers: 6

Kx Ky Kz Ss Por

$5.72135 \mathrm{e}+015.72135 \mathrm{e}+015.72135 \mathrm{e}+00$ 1.00000e-09 7.00000e-02 $2.28605 \mathrm{e}+002.28605 \mathrm{e}+002.28605 \mathrm{e}-011.00000 \mathrm{e}-092.12000 \mathrm{e}-01$ $2.28605 \mathrm{e}+002.28605 \mathrm{e}+002.28605 \mathrm{e}-011.00000 \mathrm{e}-092.12000 \mathrm{e}-01$ $2.28605 \mathrm{e}+002.28605 \mathrm{e}+002.28605 \mathrm{e}-01$ 1.00000e-09 2.12000e-01 $1.00000 \mathrm{e}-021.00000 \mathrm{e}-02$ 1.00000e-03 1.00000e-09 1.00000e-01 $1.00000 \mathrm{e}+001.00000 \mathrm{e}+001.00000 \mathrm{e}-011.00000 \mathrm{e}-091.00000 \mathrm{e}-01$ Element: 1176 \# of layers: 6

Kx Ky Kz Ss Por

7.17565e+01 7.17565e+01 7.17565e+00 1.00000e-09 7.00000e-02 $2.86724 \mathrm{e}+002.86724 \mathrm{e}+002.86724 \mathrm{e}-011.00000 \mathrm{e}-092.12000 \mathrm{e}-01$ $2.86724 \mathrm{e}+002.86724 \mathrm{e}+002.86724 \mathrm{e}-011.00000 \mathrm{e}-092.12000 \mathrm{e}-01$ $2.86724 \mathrm{e}+002.86724 \mathrm{e}+002.86724 \mathrm{e}-011.00000 \mathrm{e}-092.12000 \mathrm{e}-01$ $1.00000 \mathrm{e}-02$ 1.00000e-02 1.00000e-03 1.00000e-09 1.00000e-01 $1.00000 \mathrm{e}+001.00000 \mathrm{e}+001.00000 \mathrm{e}-011.00000 \mathrm{e}-091.00000 \mathrm{e}-01$ Element: 1177 \# of layers: 7

Kx Ky Kz Ss Por

7.17565e+01 7.17565e+01 7.17565e+00 1.00000e-09 7.00000e-02 $2.86724 \mathrm{e}+002.86724 \mathrm{e}+002.86724 \mathrm{e}-011.00000 \mathrm{e}-092.12000 \mathrm{e}-01$ $2.86724 \mathrm{e}+002.86724 \mathrm{e}+002.86724 \mathrm{e}-011.00000 \mathrm{e}-092.12000 \mathrm{e}-01$ $2.86724 \mathrm{e}+002.86724 \mathrm{e}+002.86724 \mathrm{e}-011.00000 \mathrm{e}-092.12000 \mathrm{e}-01$ $2.86724 \mathrm{e}+002.86724 \mathrm{e}+002.86724 \mathrm{e}-011.00000 \mathrm{e}-092.12000 \mathrm{e}-01$ $1.00000 \mathrm{e}-02$ 1.00000e-02 1.00000e-03 1.00000e-09 1.00000e-01 $1.00000 \mathrm{e}+001.00000 \mathrm{e}+001.00000 \mathrm{e}-011.00000 \mathrm{e}-091.00000 \mathrm{e}-01$ Element: 1178 \# of layers: 6

Kx Ky Kz Ss Por

7.17565e+01 7.17565e+01 7.17565e+00 1.00000e-09 7.00000e-02 $2.86724 \mathrm{e}+002.86724 \mathrm{e}+002.86724 \mathrm{e}-011.00000 \mathrm{e}-092.12000 \mathrm{e}-01$ $2.86724 \mathrm{e}+002.86724 \mathrm{e}+002.86724 \mathrm{e}-011.00000 \mathrm{e}-092.12000 \mathrm{e}-01$ $2.86724 \mathrm{e}+002.86724 \mathrm{e}+002.86724 \mathrm{e}-011.00000 \mathrm{e}-092.12000 \mathrm{e}-01$ $1.00000 \mathrm{e}-021.00000 \mathrm{e}-02$ 1.00000e-03 1.00000e-09 1.00000e-01 $1.00000 \mathrm{e}+001.00000 \mathrm{e}+001.00000 \mathrm{e}-011.00000 \mathrm{e}-091.00000 \mathrm{e}-01$ Element: 1179 \# of layers: 6

Kx Ky Kz Ss Por

$7.17565 \mathrm{e}+017.17565 \mathrm{e}+01$ 7.17565e+00 1.00000e-09 7.00000e-02 $2.86724 \mathrm{e}+002.86724 \mathrm{e}+002.86724 \mathrm{e}-011.00000 \mathrm{e}-092.12000 \mathrm{e}-01$ $2.86724 \mathrm{e}+002.86724 \mathrm{e}+002.86724 \mathrm{e}-011.00000 \mathrm{e}-092.12000 \mathrm{e}-01$ $2.86724 \mathrm{e}+002.86724 \mathrm{e}+002.86724 \mathrm{e}-011.00000 \mathrm{e}-092.12000 \mathrm{e}-01$ $1.00000 \mathrm{e}-02$ 1.00000e-02 1.00000e-03 1.00000e-09 1.00000e-01 $1.00000 \mathrm{e}+001.00000 \mathrm{e}+001.00000 \mathrm{e}-011.00000 \mathrm{e}-091.00000 \mathrm{e}-01$ Element: 1180 \# of layers: 6

Kx Ky Kz Ss Por 
$7.17565 \mathrm{e}+017.17565 \mathrm{e}+01$ 7.17565e+00 1.00000e-09 7.00000e-02 $2.86724 \mathrm{e}+002.86724 \mathrm{e}+002.86724 \mathrm{e}-011.00000 \mathrm{e}-092.12000 \mathrm{e}-01$ $2.86724 \mathrm{e}+002.86724 \mathrm{e}+002.86724 \mathrm{e}-011.00000 \mathrm{e}-092.12000 \mathrm{e}-01$ $2.86724 \mathrm{e}+002.86724 \mathrm{e}+002.86724 \mathrm{e}-011.00000 \mathrm{e}-092.12000 \mathrm{e}-01$ $1.00000 \mathrm{e}-02$ 1.00000e-02 1.00000e-03 1.00000e-09 1.00000e-01 $1.00000 \mathrm{e}+001.00000 \mathrm{e}+001.00000 \mathrm{e}-011.00000 \mathrm{e}-091.00000 \mathrm{e}-01$ Element: 1181 \# of layers: 7

Kx Ky Kz Ss Por

$7.17565 \mathrm{e}+017.17565 \mathrm{e}+017.17565 \mathrm{e}+00$ 1.00000e-09 7.00000e-02 $2.86724 \mathrm{e}+002.86724 \mathrm{e}+002.86724 \mathrm{e}-011.00000 \mathrm{e}-092.12000 \mathrm{e}-01$ $2.86724 \mathrm{e}+002.86724 \mathrm{e}+002.86724 \mathrm{e}-011.00000 \mathrm{e}-092.12000 \mathrm{e}-01$ $2.86724 \mathrm{e}+002.86724 \mathrm{e}+002.86724 \mathrm{e}-011.00000 \mathrm{e}-092.12000 \mathrm{e}-01$ $2.86724 \mathrm{e}+002.86724 \mathrm{e}+002.86724 \mathrm{e}-011.00000 \mathrm{e}-092.12000 \mathrm{e}-01$ $1.00000 \mathrm{e}-021.00000 \mathrm{e}-02$ 1.00000e-03 1.00000e-09 1.00000e-01 $1.00000 \mathrm{e}+001.00000 \mathrm{e}+001.00000 \mathrm{e}-011.00000 \mathrm{e}-091.00000 \mathrm{e}-01$ Element: 1182 \# of layers: 6

Kx Ky Kz Ss Por

$7.17565 \mathrm{e}+017.17565 \mathrm{e}+01$ 7.17565e+00 1.00000e-09 7.00000e-02 $2.86724 \mathrm{e}+002.86724 \mathrm{e}+002.86724 \mathrm{e}-011.00000 \mathrm{e}-092.12000 \mathrm{e}-01$ $2.86724 \mathrm{e}+002.86724 \mathrm{e}+002.86724 \mathrm{e}-011.00000 \mathrm{e}-092.12000 \mathrm{e}-01$ $2.86724 \mathrm{e}+002.86724 \mathrm{e}+002.86724 \mathrm{e}-011.00000 \mathrm{e}-092.12000 \mathrm{e}-01$ $1.00000 \mathrm{e}-02$ 1.00000e-02 1.00000e-03 1.00000e-09 1.00000e-01 $1.00000 \mathrm{e}+001.00000 \mathrm{e}+001.00000 \mathrm{e}-011.00000 \mathrm{e}-091.00000 \mathrm{e}-01$ Element: 1183 \# of layers: 6

Kx Ky Kz Ss Por

$7.17565 \mathrm{e}+017.17565 \mathrm{e}+017.17565 \mathrm{e}+001.00000 \mathrm{e}-097.00000 \mathrm{e}-02$ $2.86724 \mathrm{e}+002.86724 \mathrm{e}+002.86724 \mathrm{e}-011.00000 \mathrm{e}-092.12000 \mathrm{e}-01$ $2.86724 \mathrm{e}+002.86724 \mathrm{e}+002.86724 \mathrm{e}-011.00000 \mathrm{e}-092.12000 \mathrm{e}-01$ $2.86724 \mathrm{e}+002.86724 \mathrm{e}+002.86724 \mathrm{e}-011.00000 \mathrm{e}-092.12000 \mathrm{e}-01$ $1.00000 \mathrm{e}-021.00000 \mathrm{e}-02$ 1.00000e-03 1.00000e-09 1.00000e-01 $1.00000 \mathrm{e}+001.00000 \mathrm{e}+001.00000 \mathrm{e}-011.00000 \mathrm{e}-091.00000 \mathrm{e}-01$ Element: 1184 \# of layers: 7

Kx Ky Kz Ss Por

7.17565e+01 7.17565e+01 7.17565e+00 1.00000e-09 7.00000e-02 $2.86724 \mathrm{e}+002.86724 \mathrm{e}+002.86724 \mathrm{e}-01$ 1.00000e-09 2.12000e-01 $2.86724 \mathrm{e}+002.86724 \mathrm{e}+002.86724 \mathrm{e}-011.00000 \mathrm{e}-092.12000 \mathrm{e}-01$ $2.86724 \mathrm{e}+002.86724 \mathrm{e}+002.86724 \mathrm{e}-011.00000 \mathrm{e}-092.12000 \mathrm{e}-01$ $2.86724 \mathrm{e}+002.86724 \mathrm{e}+002.86724 \mathrm{e}-011.00000 \mathrm{e}-092.12000 \mathrm{e}-01$ $1.00000 \mathrm{e}-02$ 1.00000e-02 1.00000e-03 1.00000e-09 1.00000e-01 $1.00000 \mathrm{e}+001.00000 \mathrm{e}+001.00000 \mathrm{e}-011.00000 \mathrm{e}-091.00000 \mathrm{e}-01$ Element: 1185 \# of layers: 7

Kx Ky Kz Ss Por $5.30581 \mathrm{e}+015.30581 \mathrm{e}+015.30581 \mathrm{e}+00$ 1.00000e-09 7.00000e-02 $5.30581 \mathrm{e}+015.30581 \mathrm{e}+015.30581 \mathrm{e}+001.00000 \mathrm{e}-09$ 7.00000e-02 $2.12002 \mathrm{e}+002.12002 \mathrm{e}+002.12002 \mathrm{e}-011.00000 \mathrm{e}-092.12000 \mathrm{e}-01$ $2.12002 \mathrm{e}+002.12002 \mathrm{e}+002.12002 \mathrm{e}-01$ 1.00000e-09 2.12000e-01 
$2.12002 \mathrm{e}+002.12002 \mathrm{e}+00$ 2.12002e-01 1.00000e-09 2.12000e-01 $1.00000 \mathrm{e}-02$ 1.00000e-02 1.00000e-03 1.00000e-09 1.00000e-01 $1.00000 \mathrm{e}+001.00000 \mathrm{e}+001.00000 \mathrm{e}-011.00000 \mathrm{e}-091.00000 \mathrm{e}-01$ Element: 1186 \# of layers: 7

Kx Ky Kz Ss Por

$5.30581 \mathrm{e}+015.30581 \mathrm{e}+015.30581 \mathrm{e}+00$ 1.00000e-09 7.00000e-02 $5.30581 \mathrm{e}+015.30581 \mathrm{e}+015.30581 \mathrm{e}+001.00000 \mathrm{e}-09$ 7.00000e-02 $2.12002 \mathrm{e}+002.12002 \mathrm{e}+002.12002 \mathrm{e}-01$ 1.00000e-09 2.12000e-01 $2.12002 \mathrm{e}+002.12002 \mathrm{e}+002.12002 \mathrm{e}-011.00000 \mathrm{e}-092.12000 \mathrm{e}-01$ $2.12002 \mathrm{e}+002.12002 \mathrm{e}+002.12002 \mathrm{e}-01$ 1.00000e-09 2.12000e-01 $1.00000 \mathrm{e}-021.00000 \mathrm{e}-02$ 1.00000e-03 1.00000e-09 1.00000e-01 $1.00000 \mathrm{e}+001.00000 \mathrm{e}+001.00000 \mathrm{e}-011.00000 \mathrm{e}-091.00000 \mathrm{e}-01$ Element: 1187 \# of layers: 7

Kx Ky Kz Ss Por

$5.30581 \mathrm{e}+015.30581 \mathrm{e}+015.30581 \mathrm{e}+00$ 1.00000e-09 7.00000e-02 $5.30581 \mathrm{e}+015.30581 \mathrm{e}+015.30581 \mathrm{e}+001.00000 \mathrm{e}-09$ 7.00000e-02 $2.12002 \mathrm{e}+002.12002 \mathrm{e}+002.12002 \mathrm{e}-011.00000 \mathrm{e}-092.12000 \mathrm{e}-01$ $2.12002 \mathrm{e}+002.12002 \mathrm{e}+002.12002 \mathrm{e}-01$ 1.00000e-09 2.12000e-01 $2.12002 \mathrm{e}+002.12002 \mathrm{e}+002.12002 \mathrm{e}-01$ 1.00000e-09 2.12000e-01 $1.00000 \mathrm{e}-021.00000 \mathrm{e}-02$ 1.00000e-03 1.00000e-09 1.00000e-01 $1.00000 \mathrm{e}+001.00000 \mathrm{e}+001.00000 \mathrm{e}-011.00000 \mathrm{e}-091.00000 \mathrm{e}-01$ Element: 1188 \# of layers: 11

Kx Ky Kz Ss Por

$5.58052 \mathrm{e}+025.58052 \mathrm{e}+025.58052 \mathrm{e}+01$ 1.00000e-09 7.00000e-02 $5.58052 \mathrm{e}+025.58052 \mathrm{e}+025.58052 \mathrm{e}+01$ 1.00000e-09 7.00000e-02 $2.22978 \mathrm{e}+012.22978 \mathrm{e}+012.22978 \mathrm{e}+001.00000 \mathrm{e}-092.12000 \mathrm{e}-01$ $2.22978 \mathrm{e}+012.22978 \mathrm{e}+012.22978 \mathrm{e}+001.00000 \mathrm{e}-092.12000 \mathrm{e}-01$ $2.22978 \mathrm{e}+012.22978 \mathrm{e}+012.22978 \mathrm{e}+001.00000 \mathrm{e}-092.12000 \mathrm{e}-01$ $2.22978 \mathrm{e}+012.22978 \mathrm{e}+012.22978 \mathrm{e}+001.00000 \mathrm{e}-092.12000 \mathrm{e}-01$ $2.22978 \mathrm{e}+012.22978 \mathrm{e}+012.22978 \mathrm{e}+00$ 1.00000e-09 2.12000e-01 $1.00000 \mathrm{e}-011.00000 \mathrm{e}-011.00000 \mathrm{e}-021.00000 \mathrm{e}-091.00000 \mathrm{e}-01$ $1.00000 \mathrm{e}+001.00000 \mathrm{e}+001.00000 \mathrm{e}-011.00000 \mathrm{e}-091.00000 \mathrm{e}-01$ $1.00000 \mathrm{e}-05$ 1.00000e-05 1.00000e-06 1.00000e-09 1.00000e-01 $1.00000 \mathrm{e}+001.00000 \mathrm{e}+001.00000 \mathrm{e}-011.00000 \mathrm{e}-091.00000 \mathrm{e}-01$ Element: 1189 \# of layers: 11

Kx Ky Kz Ss Por $5.58052 \mathrm{e}+025.58052 \mathrm{e}+025.58052 \mathrm{e}+01$ 1.00000e-09 7.00000e-02 $5.58052 \mathrm{e}+025.58052 \mathrm{e}+025.58052 \mathrm{e}+01$ 1.00000e-09 7.00000e-02 $2.22978 \mathrm{e}+012.22978 \mathrm{e}+012.22978 \mathrm{e}+00$ 1.00000e-09 2.12000e-01 $2.22978 \mathrm{e}+012.22978 \mathrm{e}+012.22978 \mathrm{e}+001.00000 \mathrm{e}-092.12000 \mathrm{e}-01$ $2.22978 \mathrm{e}+012.22978 \mathrm{e}+012.22978 \mathrm{e}+001.00000 \mathrm{e}-092.12000 \mathrm{e}-01$ $2.22978 \mathrm{e}+012.22978 \mathrm{e}+012.22978 \mathrm{e}+001.00000 \mathrm{e}-092.12000 \mathrm{e}-01$ $2.22978 \mathrm{e}+012.22978 \mathrm{e}+012.22978 \mathrm{e}+00$ 1.00000e-09 2.12000e-01 $1.00000 \mathrm{e}-011.00000 \mathrm{e}-011.00000 \mathrm{e}-021.00000 \mathrm{e}-091.00000 \mathrm{e}-01$ $1.00000 \mathrm{e}+001.00000 \mathrm{e}+001.00000 \mathrm{e}-011.00000 \mathrm{e}-091.00000 \mathrm{e}-01$ $1.00000 \mathrm{e}-05$ 1.00000e-05 1.00000e-06 1.00000e-09 1.00000e-01 
$1.00000 \mathrm{e}+001.00000 \mathrm{e}+00$ 1.00000e-01 1.00000e-09 1.00000e-01

Element: 1190 \# of layers: 10

Kx Ky Kz Ss Por

5.58052e+02 5.58052e+02 5.58052e+01 1.00000e-09 7.00000e-02

$2.22978 \mathrm{e}+012.22978 \mathrm{e}+012.22978 \mathrm{e}+00$ 1.00000e-09 2.12000e-01

$2.22978 \mathrm{e}+012.22978 \mathrm{e}+012.22978 \mathrm{e}+00$ 1.00000e-09 2.12000e-01

$2.22978 \mathrm{e}+012.22978 \mathrm{e}+012.22978 \mathrm{e}+00$ 1.00000e-09 2.12000e-01

$2.22978 \mathrm{e}+012.22978 \mathrm{e}+012.22978 \mathrm{e}+00$ 1.00000e-09 2.12000e-01

$2.22978 \mathrm{e}+012.22978 \mathrm{e}+012.22978 \mathrm{e}+00$ 1.00000e-09 2.12000e-01

$1.00000 \mathrm{e}-02$ 1.00000e-02 1.00000e-03 1.00000e-09 1.00000e-01

$1.00000 \mathrm{e}+001.00000 \mathrm{e}+001.00000 \mathrm{e}-011.00000 \mathrm{e}-091.00000 \mathrm{e}-01$

$1.00000 \mathrm{e}-05$ 1.00000e-05 1.00000e-06 1.00000e-09 1.00000e-01

$1.00000 \mathrm{e}+001.00000 \mathrm{e}+001.00000 \mathrm{e}-011.00000 \mathrm{e}-091.00000 \mathrm{e}-01$

Element: 1191 \# of layers: 11

$\mathrm{Kx} \mathrm{Ky} \mathrm{Kz}$ Ss Por

5.58052e+02 5.58052e+02 5.58052e+01 1.00000e-09 7.00000e-02

$5.58052 \mathrm{e}+02$ 5.58052e+02 5.58052e+01 1.00000e-09 7.00000e-02

$2.22978 \mathrm{e}+012.22978 \mathrm{e}+012.22978 \mathrm{e}+00$ 1.00000e-09 2.12000e-01

$2.22978 \mathrm{e}+012.22978 \mathrm{e}+012.22978 \mathrm{e}+00$ 1.00000e-09 2.12000e-01

$2.22978 \mathrm{e}+012.22978 \mathrm{e}+012.22978 \mathrm{e}+00$ 1.00000e-09 2.12000e-01

$2.22978 \mathrm{e}+012.22978 \mathrm{e}+012.22978 \mathrm{e}+00$ 1.00000e-09 2.12000e-01

$2.22978 \mathrm{e}+012.22978 \mathrm{e}+012.22978 \mathrm{e}+00$ 1.00000e-09 2.12000e-01

$1.00000 \mathrm{e}-02$ 1.00000e-02 1.00000e-03 1.00000e-09 1.00000e-01

$1.00000 \mathrm{e}+001.00000 \mathrm{e}+001.00000 \mathrm{e}-011.00000 \mathrm{e}-091.00000 \mathrm{e}-01$

$1.00000 \mathrm{e}-05$ 1.00000e-05 1.00000e-06 1.00000e-09 1.00000e-01

$1.00000 \mathrm{e}+001.00000 \mathrm{e}+001.00000 \mathrm{e}-01$ 1.00000e-09 1.00000e-01

Element: 1192 \# of layers: 11

$\mathrm{Kx} \mathrm{Ky} \mathrm{Kz}$ Ss Por

5.58052e+02 5.58052e+02 5.58052e+01 1.00000e-09 7.00000e-02

5.58052e+02 5.58052e+02 5.58052e+01 1.00000e-09 7.00000e-02

$2.22978 \mathrm{e}+012.22978 \mathrm{e}+012.22978 \mathrm{e}+00$ 1.00000e-09 2.12000e-01

$2.22978 \mathrm{e}+012.22978 \mathrm{e}+012.22978 \mathrm{e}+001.00000 \mathrm{e}-092.12000 \mathrm{e}-01$

$2.22978 \mathrm{e}+012.22978 \mathrm{e}+012.22978 \mathrm{e}+00$ 1.00000e-09 2.12000e-01

$2.22978 \mathrm{e}+012.22978 \mathrm{e}+012.22978 \mathrm{e}+00$ 1.00000e-09 2.12000e-01

$2.22978 \mathrm{e}+012.22978 \mathrm{e}+012.22978 \mathrm{e}+00$ 1.00000e-09 2.12000e-01

$1.00000 \mathrm{e}-02$ 1.00000e-02 1.00000e-03 1.00000e-09 1.00000e-01

$1.00000 \mathrm{e}+001.00000 \mathrm{e}+001.00000 \mathrm{e}-011.00000 \mathrm{e}-091.00000 \mathrm{e}-01$

$1.00000 \mathrm{e}-05$ 1.00000e-05 1.00000e-06 1.00000e-09 1.00000e-01

$1.00000 \mathrm{e}+001.00000 \mathrm{e}+001.00000 \mathrm{e}-011.00000 \mathrm{e}-091.00000 \mathrm{e}-01$

Element: 1193 \# of layers: 9

$\mathrm{Kx} \mathrm{Ky} \mathrm{Kz}$ Ss Por

$1.39204 \mathrm{e}+02$ 1.39204e+02 1.39205e+01 1.00000e-09 7.00000e-02

$5.56212 \mathrm{e}+00$ 5.56212e+00 5.56212e-01 1.00000e-09 2.12000e-01

$5.56212 \mathrm{e}+005.56212 \mathrm{e}+00$ 5.56212e-01 1.00000e-09 2.12000e-01

$5.56212 \mathrm{e}+005.56212 \mathrm{e}+005.56212 \mathrm{e}-01$ 1.00000e-09 2.12000e-01

$5.56212 \mathrm{e}+00$ 5.56212e+00 5.56212e-01 1.00000e-09 2.12000e-01 
$1.00000 \mathrm{e}-01$ 1.00000e-01 1.00000e-02 1.00000e-09 1.00000e-01 $1.00000 \mathrm{e}+001.00000 \mathrm{e}+001.00000 \mathrm{e}-011.00000 \mathrm{e}-091.00000 \mathrm{e}-01$ $1.00000 \mathrm{e}-05$ 1.00000e-05 1.00000e-06 1.00000e-09 1.00000e-01 $1.00000 \mathrm{e}+001.00000 \mathrm{e}+001.00000 \mathrm{e}-011.00000 \mathrm{e}-091.00000 \mathrm{e}-01$ Element: 1194 \# of layers: 9

Kx Ky Kz Ss Por

$1.39204 \mathrm{e}+02$ 1.39204e+02 1.39205e+01 1.00000e-09 7.00000e-02 $5.56212 \mathrm{e}+005.56212 \mathrm{e}+00$ 5.56212e-01 1.00000e-09 2.12000e-01 $5.56212 \mathrm{e}+005.56212 \mathrm{e}+005.56212 \mathrm{e}-011.00000 \mathrm{e}-092.12000 \mathrm{e}-01$ $5.56212 \mathrm{e}+005.56212 \mathrm{e}+005.56212 \mathrm{e}-011.00000 \mathrm{e}-092.12000 \mathrm{e}-01$ $5.56212 \mathrm{e}+005.56212 \mathrm{e}+00$ 5.56212e-01 1.00000e-09 2.12000e-01 $1.00000 \mathrm{e}-011.00000 \mathrm{e}-011.00000 \mathrm{e}-021.00000 \mathrm{e}-091.00000 \mathrm{e}-01$ $1.00000 \mathrm{e}+001.00000 \mathrm{e}+001.00000 \mathrm{e}-011.00000 \mathrm{e}-091.00000 \mathrm{e}-01$ $1.00000 \mathrm{e}-05$ 1.00000e-05 1.00000e-06 1.00000e-09 1.00000e-01 $1.00000 \mathrm{e}+001.00000 \mathrm{e}+001.00000 \mathrm{e}-011.00000 \mathrm{e}-091.00000 \mathrm{e}-01$ Element: 1195 \# of layers: 10

Kx Ky Kz Ss Por

$1.39204 \mathrm{e}+021.39204 \mathrm{e}+021.39205 \mathrm{e}+01$ 1.00000e-09 7.00000e-02 $5.56212 \mathrm{e}+005.56212 \mathrm{e}+00$ 5.56212e-01 1.00000e-09 2.12000e-01 $5.56212 \mathrm{e}+005.56212 \mathrm{e}+005.56212 \mathrm{e}-011.00000 \mathrm{e}-092.12000 \mathrm{e}-01$ $5.56212 \mathrm{e}+005.56212 \mathrm{e}+005.56212 \mathrm{e}-011.00000 \mathrm{e}-092.12000 \mathrm{e}-01$ $5.56212 \mathrm{e}+005.56212 \mathrm{e}+005.56212 \mathrm{e}-011.00000 \mathrm{e}-092.12000 \mathrm{e}-01$ $5.56212 \mathrm{e}+00$ 5.56212e+00 5.56212e-01 1.00000e-09 2.12000e-01 $1.00000 \mathrm{e}-011.00000 \mathrm{e}-011.00000 \mathrm{e}-021.00000 \mathrm{e}-091.00000 \mathrm{e}-01$ $1.00000 \mathrm{e}+001.00000 \mathrm{e}+001.00000 \mathrm{e}-011.00000 \mathrm{e}-091.00000 \mathrm{e}-01$ $1.00000 \mathrm{e}-05$ 1.00000e-05 1.00000e-06 1.00000e-09 1.00000e-01 $1.00000 \mathrm{e}+001.00000 \mathrm{e}+001.00000 \mathrm{e}-011.00000 \mathrm{e}-091.00000 \mathrm{e}-01$ Element: 1196 \# of layers: 10

$\mathrm{Kx} \mathrm{Ky} \mathrm{Kz}$ Ss Por

$1.39204 \mathrm{e}+02$ 1.39204e+02 1.39205e+01 1.00000e-09 7.00000e-02

$5.56212 \mathrm{e}+00$ 5.56212e+00 5.56212e-01 1.00000e-09 2.12000e-01 $5.56212 \mathrm{e}+005.56212 \mathrm{e}+00$ 5.56212e-01 1.00000e-09 2.12000e-01 $5.56212 \mathrm{e}+005.56212 \mathrm{e}+00$ 5.56212e-01 1.00000e-09 2.12000e-01 5.56212e+00 5.56212e+00 5.56212e-01 1.00000e-09 2.12000e-01 $5.56212 \mathrm{e}+005.56212 \mathrm{e}+005.56212 \mathrm{e}-01$ 1.00000e-09 2.12000e-01 1.00000e-01 1.00000e-01 1.00000e-02 1.00000e-09 1.00000e-01 $1.00000 \mathrm{e}+001.00000 \mathrm{e}+001.00000 \mathrm{e}-011.00000 \mathrm{e}-091.00000 \mathrm{e}-01$ $1.00000 \mathrm{e}-05$ 1.00000e-05 1.00000e-06 1.00000e-09 1.00000e-01 $1.00000 \mathrm{e}+001.00000 \mathrm{e}+001.00000 \mathrm{e}-011.00000 \mathrm{e}-091.00000 \mathrm{e}-01$ Element: 1197 \# of layers: 10

$\mathrm{Kx} \mathrm{Ky} \mathrm{Kz}$ Ss Por

$1.39204 \mathrm{e}+02$ 1.39204e+02 1.39205e+01 1.00000e-09 7.00000e-02 $5.56212 \mathrm{e}+00$ 5.56212e+00 5.56212e-01 1.00000e-09 2.12000e-01 $5.56212 \mathrm{e}+005.56212 \mathrm{e}+00$ 5.56212e-01 1.00000e-09 2.12000e-01 $5.56212 \mathrm{e}+005.56212 \mathrm{e}+005.56212 \mathrm{e}-01$ 1.00000e-09 2.12000e-01 $5.56212 \mathrm{e}+005.56212 \mathrm{e}+00$ 5.56212e-01 1.00000e-09 2.12000e-01 
$5.56212 \mathrm{e}+00$ 5.56212e+00 5.56212e-01 1.00000e-09 2.12000e-01 $1.00000 \mathrm{e}-011.00000 \mathrm{e}-011.00000 \mathrm{e}-021.00000 \mathrm{e}-091.00000 \mathrm{e}-01$ $1.00000 \mathrm{e}+001.00000 \mathrm{e}+001.00000 \mathrm{e}-011.00000 \mathrm{e}-091.00000 \mathrm{e}-01$ $1.00000 \mathrm{e}-05$ 1.00000e-05 1.00000e-06 1.00000e-09 1.00000e-01 $1.00000 \mathrm{e}+001.00000 \mathrm{e}+001.00000 \mathrm{e}-011.00000 \mathrm{e}-091.00000 \mathrm{e}-01$ Element: 1198 \# of layers: 10

Kx Ky Kz Ss Por

$1.39204 \mathrm{e}+021.39204 \mathrm{e}+021.39205 \mathrm{e}+01$ 1.00000e-09 7.00000e-02 $5.56212 \mathrm{e}+005.56212 \mathrm{e}+00$ 5.56212e-01 1.00000e-09 2.12000e-01

$5.56212 \mathrm{e}+005.56212 \mathrm{e}+00$ 5.56212e-01 1.00000e-09 2.12000e-01 $5.56212 \mathrm{e}+005.56212 \mathrm{e}+005.56212 \mathrm{e}-011.00000 \mathrm{e}-092.12000 \mathrm{e}-01$ $5.56212 \mathrm{e}+005.56212 \mathrm{e}+005.56212 \mathrm{e}-011.00000 \mathrm{e}-092.12000 \mathrm{e}-01$ $5.56212 \mathrm{e}+005.56212 \mathrm{e}+00$ 5.56212e-01 1.00000e-09 2.12000e-01 $1.00000 \mathrm{e}-01$ 1.00000e-01 1.00000e-02 1.00000e-09 1.00000e-01 $1.00000 \mathrm{e}+001.00000 \mathrm{e}+001.00000 \mathrm{e}-011.00000 \mathrm{e}-091.00000 \mathrm{e}-01$ $1.00000 \mathrm{e}-051.00000 \mathrm{e}-05$ 1.00000e-06 1.00000e-09 1.00000e-01 $1.00000 \mathrm{e}+001.00000 \mathrm{e}+001.00000 \mathrm{e}-011.00000 \mathrm{e}-091.00000 \mathrm{e}-01$ Element: 1199 \# of layers: 10

Kx Ky Kz Ss Por

$1.39204 \mathrm{e}+021.39204 \mathrm{e}+021.39205 \mathrm{e}+01$ 1.00000e-09 7.00000e-02 $5.56212 \mathrm{e}+00$ 5.56212e+00 5.56212e-01 1.00000e-09 2.12000e-01 $5.56212 \mathrm{e}+005.56212 \mathrm{e}+005.56212 \mathrm{e}-011.00000 \mathrm{e}-092.12000 \mathrm{e}-01$ $5.56212 \mathrm{e}+005.56212 \mathrm{e}+005.56212 \mathrm{e}-011.00000 \mathrm{e}-092.12000 \mathrm{e}-01$ $5.56212 \mathrm{e}+005.56212 \mathrm{e}+00$ 5.56212e-01 1.00000e-09 2.12000e-01 $5.56212 \mathrm{e}+00$ 5.56212e+00 5.56212e-01 1.00000e-09 2.12000e-01 $1.00000 \mathrm{e}-021.00000 \mathrm{e}-02$ 1.00000e-03 1.00000e-09 1.00000e-01 $1.00000 \mathrm{e}+001.00000 \mathrm{e}+001.00000 \mathrm{e}-011.00000 \mathrm{e}-091.00000 \mathrm{e}-01$ $1.00000 \mathrm{e}-05$ 1.00000e-05 1.00000e-06 1.00000e-09 1.00000e-01 $1.00000 \mathrm{e}+001.00000 \mathrm{e}+001.00000 \mathrm{e}-011.00000 \mathrm{e}-091.00000 \mathrm{e}-01$ Element: 1200 \# of layers: 10

Kx Ky Kz Ss Por

$1.39204 \mathrm{e}+021.39204 \mathrm{e}+021.39205 \mathrm{e}+01$ 1.00000e-09 7.00000e-02 $5.56212 \mathrm{e}+00$ 5.56212e+00 5.56212e-01 1.00000e-09 2.12000e-01 $5.56212 \mathrm{e}+005.56212 \mathrm{e}+005.56212 \mathrm{e}-011.00000 \mathrm{e}-092.12000 \mathrm{e}-01$ $5.56212 \mathrm{e}+005.56212 \mathrm{e}+005.56212 \mathrm{e}-011.00000 \mathrm{e}-092.12000 \mathrm{e}-01$ $5.56212 \mathrm{e}+005.56212 \mathrm{e}+005.56212 \mathrm{e}-011.00000 \mathrm{e}-092.12000 \mathrm{e}-01$ $5.56212 \mathrm{e}+00$ 5.56212e+00 5.56212e-01 1.00000e-09 2.12000e-01 $1.00000 \mathrm{e}-011.00000 \mathrm{e}-011.00000 \mathrm{e}-021.00000 \mathrm{e}-091.00000 \mathrm{e}-01$ $1.00000 \mathrm{e}+001.00000 \mathrm{e}+001.00000 \mathrm{e}-011.00000 \mathrm{e}-091.00000 \mathrm{e}-01$ $1.00000 \mathrm{e}-05$ 1.00000e-05 1.00000e-06 1.00000e-09 1.00000e-01 $1.00000 \mathrm{e}+001.00000 \mathrm{e}+001.00000 \mathrm{e}-011.00000 \mathrm{e}-091.00000 \mathrm{e}-01$ Element: 1201 \# of layers: 10

Kx Ky Kz Ss Por

$1.39204 \mathrm{e}+021.39204 \mathrm{e}+021.39205 \mathrm{e}+01$ 1.00000e-09 7.00000e-02 $5.56212 \mathrm{e}+00$ 5.56212e+00 5.56212e-01 1.00000e-09 2.12000e-01 $5.56212 \mathrm{e}+00$ 5.56212e+00 5.56212e-01 1.00000e-09 2.12000e-01 
$5.56212 \mathrm{e}+00$ 5.56212e+00 5.56212e-01 1.00000e-09 2.12000e-01 $5.56212 \mathrm{e}+005.56212 \mathrm{e}+005.56212 \mathrm{e}-011.00000 \mathrm{e}-092.12000 \mathrm{e}-01$ $5.56212 \mathrm{e}+005.56212 \mathrm{e}+00$ 5.56212e-01 1.00000e-09 2.12000e-01 $1.00000 \mathrm{e}-011.00000 \mathrm{e}-011.00000 \mathrm{e}-021.00000 \mathrm{e}-091.00000 \mathrm{e}-01$ $1.00000 \mathrm{e}+001.00000 \mathrm{e}+001.00000 \mathrm{e}-011.00000 \mathrm{e}-091.00000 \mathrm{e}-01$ $1.00000 \mathrm{e}-05$ 1.00000e-05 1.00000e-06 1.00000e-09 1.00000e-01 $1.00000 \mathrm{e}+001.00000 \mathrm{e}+001.00000 \mathrm{e}-011.00000 \mathrm{e}-091.00000 \mathrm{e}-01$ Element: 1202 \# of layers: 10

Kx Ky Kz Ss Por

$2.35720 \mathrm{e}+022.35720 \mathrm{e}+022.35720 \mathrm{e}+01$ 1.00000e-09 7.00000e-02 $9.41870 \mathrm{e}+009.41870 \mathrm{e}+00$ 9.41870e-01 1.00000e-09 2.12000e-01 $9.41870 \mathrm{e}+009.41870 \mathrm{e}+00$ 9.41870e-01 1.00000e-09 2.12000e-01 $9.41870 \mathrm{e}+009.41870 \mathrm{e}+00$ 9.41870e-01 1.00000e-09 2.12000e-01 $9.41870 \mathrm{e}+009.41870 \mathrm{e}+00$ 9.41870e-01 1.00000e-09 2.12000e-01 $9.41870 \mathrm{e}+00$ 9.41870e+00 9.41870e-01 1.00000e-09 2.12000e-01 $1.00000 \mathrm{e}-011.00000 \mathrm{e}-011.00000 \mathrm{e}-021.00000 \mathrm{e}-091.00000 \mathrm{e}-01$ $1.00000 \mathrm{e}+001.00000 \mathrm{e}+001.00000 \mathrm{e}-011.00000 \mathrm{e}-091.00000 \mathrm{e}-01$ $1.00000 \mathrm{e}-05$ 1.00000e-05 1.00000e-06 1.00000e-09 1.00000e-01 $1.00000 \mathrm{e}+001.00000 \mathrm{e}+001.00000 \mathrm{e}-011.00000 \mathrm{e}-091.00000 \mathrm{e}-01$ Element: 1203 \# of layers: 10

Kx Ky Kz Ss Por

$2.35720 \mathrm{e}+022.35720 \mathrm{e}+022.35720 \mathrm{e}+01$ 1.00000e-09 7.00000e-02 $9.41870 \mathrm{e}+009.41870 \mathrm{e}+00$ 9.41870e-01 1.00000e-09 2.12000e-01 $9.41870 \mathrm{e}+009.41870 \mathrm{e}+00$ 9.41870e-01 1.00000e-09 2.12000e-01 $9.41870 \mathrm{e}+009.41870 \mathrm{e}+00$ 9.41870e-01 1.00000e-09 2.12000e-01 $9.41870 \mathrm{e}+009.41870 \mathrm{e}+009.41870 \mathrm{e}-011.00000 \mathrm{e}-092.12000 \mathrm{e}-01$ $9.41870 \mathrm{e}+00$ 9.41870e+00 9.41870e-01 1.00000e-09 2.12000e-01 $1.00000 \mathrm{e}-011.00000 \mathrm{e}-011.00000 \mathrm{e}-021.00000 \mathrm{e}-091.00000 \mathrm{e}-01$ $1.00000 \mathrm{e}+001.00000 \mathrm{e}+001.00000 \mathrm{e}-011.00000 \mathrm{e}-091.00000 \mathrm{e}-01$ $1.00000 \mathrm{e}-05$ 1.00000e-05 1.00000e-06 1.00000e-09 1.00000e-01 $1.00000 \mathrm{e}+001.00000 \mathrm{e}+001.00000 \mathrm{e}-011.00000 \mathrm{e}-091.00000 \mathrm{e}-01$ Element: 1204 \# of layers: 10

Kx Ky Kz Ss Por

$2.35720 \mathrm{e}+022.35720 \mathrm{e}+022.35720 \mathrm{e}+01$ 1.00000e-09 7.00000e-02 $9.41870 \mathrm{e}+009.41870 \mathrm{e}+00$ 9.41870e-01 1.00000e-09 2.12000e-01 $9.41870 \mathrm{e}+009.41870 \mathrm{e}+009.41870 \mathrm{e}-011.00000 \mathrm{e}-09$ 2.12000e-01 $9.41870 \mathrm{e}+009.41870 \mathrm{e}+009.41870 \mathrm{e}-011.00000 \mathrm{e}-092.12000 \mathrm{e}-01$ $9.41870 \mathrm{e}+009.41870 \mathrm{e}+009.41870 \mathrm{e}-011.00000 \mathrm{e}-09$ 2.12000e-01 $9.41870 \mathrm{e}+009.41870 \mathrm{e}+00$ 9.41870e-01 1.00000e-09 2.12000e-01 $1.00000 \mathrm{e}-02$ 1.00000e-02 1.00000e-03 1.00000e-09 1.00000e-01 $1.00000 \mathrm{e}+001.00000 \mathrm{e}+001.00000 \mathrm{e}-011.00000 \mathrm{e}-091.00000 \mathrm{e}-01$ $1.00000 \mathrm{e}-05$ 1.00000e-05 1.00000e-06 1.00000e-09 1.00000e-01 $1.00000 \mathrm{e}+001.00000 \mathrm{e}+001.00000 \mathrm{e}-011.00000 \mathrm{e}-091.00000 \mathrm{e}-01$ Element: 1205 \# of layers: 10

Kx Ky Kz Ss Por

$2.35720 \mathrm{e}+022.35720 \mathrm{e}+02$ 2.35720e+01 1.00000e-09 7.00000e-02 
9.41870e+00 9.41870e+00 9.41870e-01 1.00000e-09 2.12000e-01 9.41870e+00 9.41870e+00 9.41870e-01 1.00000e-09 2.12000e-01 9.41870e+00 9.41870e+00 9.41870e-01 1.00000e-09 2.12000e-01 $9.41870 \mathrm{e}+00$ 9.41870e+00 9.41870e-01 1.00000e-09 2.12000e-01 $9.41870 \mathrm{e}+00$ 9.41870e+00 9.41870e-01 1.00000e-09 2.12000e-01 $1.00000 \mathrm{e}-02$ 1.00000e-02 1.00000e-03 1.00000e-09 1.00000e-01 $1.00000 \mathrm{e}+001.00000 \mathrm{e}+001.00000 \mathrm{e}-011.00000 \mathrm{e}-091.00000 \mathrm{e}-01$ $1.00000 \mathrm{e}-05$ 1.00000e-05 1.00000e-06 1.00000e-09 1.00000e-01 $1.00000 \mathrm{e}+001.00000 \mathrm{e}+001.00000 \mathrm{e}-011.00000 \mathrm{e}-091.00000 \mathrm{e}-01$ Element: 1206 \# of layers: 10

$\mathrm{Kx} \mathrm{Ky} \mathrm{Kz}$ Ss Por

2.35720e+02 2.35720e+02 2.35720e+01 1.00000e-09 7.00000e-02 9.41870e+00 9.41870e+00 9.41870e-01 1.00000e-09 2.12000e-01 9.41870e+00 9.41870e+00 9.41870e-01 1.00000e-09 2.12000e-01 9.41870e+00 9.41870e+00 9.41870e-01 1.00000e-09 2.12000e-01 $9.41870 \mathrm{e}+009.41870 \mathrm{e}+00$ 9.41870e-01 1.00000e-09 2.12000e-01 $9.41870 \mathrm{e}+00$ 9.41870e+00 9.41870e-01 1.00000e-09 2.12000e-01 $1.00000 \mathrm{e}-02$ 1.00000e-02 1.00000e-03 1.00000e-09 1.00000e-01 $1.00000 \mathrm{e}+001.00000 \mathrm{e}+001.00000 \mathrm{e}-011.00000 \mathrm{e}-091.00000 \mathrm{e}-01$ $1.00000 \mathrm{e}-05$ 1.00000e-05 1.00000e-06 1.00000e-09 1.00000e-01 $1.00000 \mathrm{e}+001.00000 \mathrm{e}+001.00000 \mathrm{e}-011.00000 \mathrm{e}-091.00000 \mathrm{e}-01$ Element: 1207 \# of layers: 10

$\mathrm{Kx} \mathrm{Ky} \mathrm{Kz}$ Ss Por

2.35720e+02 2.35720e+02 2.35720e+01 1.00000e-09 7.00000e-02 $9.41870 \mathrm{e}+009.41870 \mathrm{e}+00$ 9.41870e-01 1.00000e-09 2.12000e-01 $9.41870 \mathrm{e}+00$ 9.41870e+00 9.41870e-01 1.00000e-09 2.12000e-01 9.41870e+00 9.41870e+00 9.41870e-01 1.00000e-09 2.12000e-01 9.41870e+00 9.41870e+00 9.41870e-01 1.00000e-09 2.12000e-01 $9.41870 \mathrm{e}+009.41870 \mathrm{e}+00$ 9.41870e-01 1.00000e-09 2.12000e-01 $1.00000 \mathrm{e}-02$ 1.00000e-02 1.00000e-03 1.00000e-09 1.00000e-01 $1.00000 \mathrm{e}+001.00000 \mathrm{e}+001.00000 \mathrm{e}-01$ 1.00000e-09 1.00000e-01 $1.00000 \mathrm{e}-05$ 1.00000e-05 1.00000e-06 1.00000e-09 1.00000e-01 $1.00000 \mathrm{e}+001.00000 \mathrm{e}+001.00000 \mathrm{e}-011.00000 \mathrm{e}-091.00000 \mathrm{e}-01$ Element: 1208 \# of layers: 10

$\mathrm{Kx} \mathrm{Ky} \mathrm{Kz}$ Ss Por

$2.35720 \mathrm{e}+02$ 2.35720e+02 2.35720e+01 1.00000e-09 7.00000e-02 $9.41870 \mathrm{e}+009.41870 \mathrm{e}+00$ 9.41870e-01 1.00000e-09 2.12000e-01 9.41870e+00 9.41870e+00 9.41870e-01 1.00000e-09 2.12000e-01 $9.41870 \mathrm{e}+00$ 9.41870e+00 9.41870e-01 1.00000e-09 2.12000e-01 9.41870e+00 9.41870e+00 9.41870e-01 1.00000e-09 2.12000e-01 9.41870e+00 9.41870e+00 9.41870e-01 1.00000e-09 2.12000e-01 $1.00000 \mathrm{e}-02$ 1.00000e-02 1.00000e-03 1.00000e-09 1.00000e-01 $1.00000 \mathrm{e}+001.00000 \mathrm{e}+001.00000 \mathrm{e}-011.00000 \mathrm{e}-091.00000 \mathrm{e}-01$ $1.00000 \mathrm{e}-05$ 1.00000e-05 1.00000e-06 1.00000e-09 1.00000e-01 $1.00000 \mathrm{e}+001.00000 \mathrm{e}+001.00000 \mathrm{e}-011.00000 \mathrm{e}-09$ 1.00000e-01 Element: 1209 \# of layers: 10 
$\mathrm{Kx} \mathrm{Ky} \mathrm{Kz}$ Ss Por

2.35720e+02 2.35720e+02 2.35720e+01 1.00000e-09 7.00000e-02 9.41870e+00 9.41870e+00 9.41870e-01 1.00000e-09 2.12000e-01 $9.41870 \mathrm{e}+00$ 9.41870e+00 9.41870e-01 1.00000e-09 2.12000e-01 $9.41870 \mathrm{e}+00$ 9.41870e+00 9.41870e-01 1.00000e-09 2.12000e-01 9.41870e+00 9.41870e+00 9.41870e-01 1.00000e-09 2.12000e-01 9.41870e+00 9.41870e+00 9.41870e-01 1.00000e-09 2.12000e-01 $1.00000 \mathrm{e}-01$ 1.00000e-01 1.00000e-02 1.00000e-09 1.00000e-01 $1.00000 \mathrm{e}+001.00000 \mathrm{e}+001.00000 \mathrm{e}-011.00000 \mathrm{e}-091.00000 \mathrm{e}-01$ $1.00000 \mathrm{e}-05$ 1.00000e-05 1.00000e-06 1.00000e-09 1.00000e-01 $1.00000 \mathrm{e}+001.00000 \mathrm{e}+001.00000 \mathrm{e}-011.00000 \mathrm{e}-091.00000 \mathrm{e}-01$ Element: 1210 \# of layers: 10

$\mathrm{Kx} \mathrm{Ky} \mathrm{Kz}$ Ss Por

$2.35720 \mathrm{e}+02$ 2.35720e+02 2.35720e+01 1.00000e-09 7.00000e-02 9.41870e+00 9.41870e+00 9.41870e-01 1.00000e-09 2.12000e-01 $9.41870 \mathrm{e}+009.41870 \mathrm{e}+00$ 9.41870e-01 1.00000e-09 2.12000e-01 $9.41870 \mathrm{e}+00$ 9.41870e+00 9.41870e-01 1.00000e-09 2.12000e-01 9.41870e+00 9.41870e+00 9.41870e-01 1.00000e-09 2.12000e-01 9.41870e+00 9.41870e+00 9.41870e-01 1.00000e-09 2.12000e-01 $1.00000 \mathrm{e}-01$ 1.00000e-01 1.00000e-02 1.00000e-09 1.00000e-01 $1.00000 \mathrm{e}+001.00000 \mathrm{e}+001.00000 \mathrm{e}-011.00000 \mathrm{e}-091.00000 \mathrm{e}-01$ $1.00000 \mathrm{e}-05$ 1.00000e-05 1.00000e-06 1.00000e-09 1.00000e-01 $1.00000 \mathrm{e}+001.00000 \mathrm{e}+001.00000 \mathrm{e}-01$ 1.00000e-09 1.00000e-01 Element: 1211 \# of layers: 10

Kx Ky Kz Ss Por

3.76032e+02 3.76032e+02 3.76032e+01 1.00000e-09 7.00000e-02 $1.50247 \mathrm{e}+01$ 1.50247e+01 1.50247e+00 1.00000e-09 2.12000e-01 $1.50247 \mathrm{e}+01$ 1.50247e+01 1.50247e+00 1.00000e-09 2.12000e-01 $1.50247 \mathrm{e}+011.50247 \mathrm{e}+01$ 1.50247e+00 1.00000e-09 2.12000e-01 $1.50247 \mathrm{e}+01$ 1.50247e+01 1.50247e+00 1.00000e-09 2.12000e-01 $1.50247 \mathrm{e}+01$ 1.50247e+01 1.50247e+00 1.00000e-09 2.12000e-01 $1.00000 \mathrm{e}-02$ 1.00000e-02 1.00000e-03 1.00000e-09 1.00000e-01 $1.00000 \mathrm{e}+001.00000 \mathrm{e}+001.00000 \mathrm{e}-011.00000 \mathrm{e}-091.00000 \mathrm{e}-01$ $1.00000 \mathrm{e}-05$ 1.00000e-05 1.00000e-06 1.00000e-09 1.00000e-01 $1.00000 \mathrm{e}+001.00000 \mathrm{e}+001.00000 \mathrm{e}-011.00000 \mathrm{e}-091.00000 \mathrm{e}-01$ Element: 1212 \# of layers: 10

$\mathrm{Kx} \mathrm{Ky} \mathrm{Kz}$ Ss Por

3.76032e+02 3.76032e+02 3.76032e+01 1.00000e-09 7.00000e-02 $1.50247 \mathrm{e}+01$ 1.50247e+01 1.50247e+00 1.00000e-09 2.12000e-01 $1.50247 \mathrm{e}+011.50247 \mathrm{e}+01$ 1.50247e+00 1.00000e-09 2.12000e-01 $1.50247 \mathrm{e}+01$ 1.50247e+01 1.50247e+00 1.00000e-09 2.12000e-01 $1.50247 \mathrm{e}+01$ 1.50247e+01 1.50247e+00 1.00000e-09 2.12000e-01 $1.50247 \mathrm{e}+01$ 1.50247e+01 1.50247e+00 1.00000e-09 2.12000e-01 $1.00000 \mathrm{e}-02$ 1.00000e-02 1.00000e-03 1.00000e-09 1.00000e-01 $1.00000 \mathrm{e}+001.00000 \mathrm{e}+001.00000 \mathrm{e}-011.00000 \mathrm{e}-091.00000 \mathrm{e}-01$ $1.00000 \mathrm{e}-05$ 1.00000e-05 1.00000e-06 1.00000e-09 1.00000e-01 
$1.00000 \mathrm{e}+001.00000 \mathrm{e}+00$ 1.00000e-01 1.00000e-09 1.00000e-01

Element: 1213 \# of layers: 10

Kx Ky Kz Ss Por

3.76032e+02 3.76032e+02 3.76032e+01 1.00000e-09 7.00000e-02

$1.50247 \mathrm{e}+01$ 1.50247e+01 1.50247e+00 1.00000e-09 2.12000e-01

$1.50247 \mathrm{e}+011.50247 \mathrm{e}+01$ 1.50247e+00 1.00000e-09 2.12000e-01

$1.50247 \mathrm{e}+011.50247 \mathrm{e}+01$ 1.50247e+00 1.00000e-09 2.12000e-01

$1.50247 \mathrm{e}+011.50247 \mathrm{e}+01$ 1.50247e+00 1.00000e-09 2.12000e-01

$1.50247 \mathrm{e}+01$ 1.50247e+01 1.50247e+00 1.00000e-09 2.12000e-01

$1.00000 \mathrm{e}-02$ 1.00000e-02 1.00000e-03 1.00000e-09 1.00000e-01

$1.00000 \mathrm{e}+001.00000 \mathrm{e}+001.00000 \mathrm{e}-011.00000 \mathrm{e}-091.00000 \mathrm{e}-01$

$1.00000 \mathrm{e}-05$ 1.00000e-05 1.00000e-06 1.00000e-09 1.00000e-01

$1.00000 \mathrm{e}+001.00000 \mathrm{e}+001.00000 \mathrm{e}-011.00000 \mathrm{e}-091.00000 \mathrm{e}-01$

Element: 1214 \# of layers: 10

$\mathrm{Kx} \mathrm{Ky} \mathrm{Kz}$ Ss Por

3.76032e+02 3.76032e+02 3.76032e+01 1.00000e-09 7.00000e-02

$1.50247 \mathrm{e}+01$ 1.50247e+01 1.50247e+00 1.00000e-09 2.12000e-01

$1.50247 \mathrm{e}+01$ 1.50247e+01 1.50247e+00 1.00000e-09 2.12000e-01

$1.50247 \mathrm{e}+01$ 1.50247e+01 1.50247e+00 1.00000e-09 2.12000e-01

$1.50247 \mathrm{e}+01$ 1.50247e+01 1.50247e+00 1.00000e-09 2.12000e-01

$1.50247 \mathrm{e}+01$ 1.50247e+01 1.50247e+00 1.00000e-09 2.12000e-01

$1.00000 \mathrm{e}-02$ 1.00000e-02 1.00000e-03 1.00000e-09 1.00000e-01

$1.00000 \mathrm{e}+001.00000 \mathrm{e}+001.00000 \mathrm{e}-011.00000 \mathrm{e}-091.00000 \mathrm{e}-01$

$1.00000 \mathrm{e}-05$ 1.00000e-05 1.00000e-06 1.00000e-09 1.00000e-01

$1.00000 \mathrm{e}+001.00000 \mathrm{e}+001.00000 \mathrm{e}-011.00000 \mathrm{e}-091.00000 \mathrm{e}-01$

Element: 1215 \# of layers: 10

$\mathrm{Kx} \mathrm{Ky} \mathrm{Kz}$ Ss Por

3.76032e+02 3.76032e+02 3.76032e+01 1.00000e-09 7.00000e-02

$1.50247 \mathrm{e}+01$ 1.50247e+01 1.50247e+00 1.00000e-09 2.12000e-01

$1.50247 \mathrm{e}+01$ 1.50247e+01 1.50247e+00 1.00000e-09 2.12000e-01

$1.50247 \mathrm{e}+01$ 1.50247e+01 1.50247e+00 1.00000e-09 2.12000e-01

$1.50247 \mathrm{e}+01$ 1.50247e+01 1.50247e+00 1.00000e-09 2.12000e-01

$1.50247 \mathrm{e}+011.50247 \mathrm{e}+01$ 1.50247e+00 1.00000e-09 2.12000e-01

$1.00000 \mathrm{e}-02$ 1.00000e-02 1.00000e-03 1.00000e-09 1.00000e-01

$1.00000 \mathrm{e}+001.00000 \mathrm{e}+001.00000 \mathrm{e}-011.00000 \mathrm{e}-091.00000 \mathrm{e}-01$

$1.00000 \mathrm{e}-05$ 1.00000e-05 1.00000e-06 1.00000e-09 1.00000e-01

$1.00000 \mathrm{e}+001.00000 \mathrm{e}+001.00000 \mathrm{e}-011.00000 \mathrm{e}-091.00000 \mathrm{e}-01$

Element: 1216 \# of layers: 10

$\mathrm{Kx} \mathrm{Ky} \mathrm{Kz}$ Ss Por

3.76032e+02 3.76032e+02 3.76032e+01 1.00000e-09 7.00000e-02

$1.50247 \mathrm{e}+01$ 1.50247e+01 1.50247e+00 1.00000e-09 2.12000e-01

$1.50247 \mathrm{e}+01$ 1.50247e+01 1.50247e+00 1.00000e-09 2.12000e-01

$1.50247 \mathrm{e}+01$ 1.50247e+01 1.50247e+00 1.00000e-09 2.12000e-01

1.50247e+01 1.50247e+01 1.50247e+00 1.00000e-09 2.12000e-01

$1.50247 \mathrm{e}+01$ 1.50247e+01 1.50247e+00 1.00000e-09 2.12000e-01

$1.00000 \mathrm{e}-02$ 1.00000e-02 1.00000e-03 1.00000e-09 1.00000e-01 
$1.00000 \mathrm{e}+001.00000 \mathrm{e}+001.00000 \mathrm{e}-011.00000 \mathrm{e}-091.00000 \mathrm{e}-01$ $1.00000 \mathrm{e}-05$ 1.00000e-05 1.00000e-06 1.00000e-09 1.00000e-01 $1.00000 \mathrm{e}+001.00000 \mathrm{e}+001.00000 \mathrm{e}-011.00000 \mathrm{e}-09$ 1.00000e-01 Element: 1217 \# of layers: 10

$\mathrm{Kx} \mathrm{Ky} \mathrm{Kz}$ Ss Por

3.76032e+02 3.76032e+02 3.76032e+01 1.00000e-09 7.00000e-02 $1.50247 \mathrm{e}+011.50247 \mathrm{e}+01$ 1.50247e+00 1.00000e-09 2.12000e-01 $1.50247 \mathrm{e}+011.50247 \mathrm{e}+01$ 1.50247e+00 1.00000e-09 2.12000e-01 $1.50247 \mathrm{e}+01$ 1.50247e+01 1.50247e+00 1.00000e-09 2.12000e-01 $1.50247 \mathrm{e}+01$ 1.50247e+01 1.50247e+00 1.00000e-09 2.12000e-01 $1.50247 \mathrm{e}+01$ 1.50247e+01 1.50247e+00 1.00000e-09 2.12000e-01 $1.00000 \mathrm{e}-02$ 1.00000e-02 1.00000e-03 1.00000e-09 1.00000e-01 $1.00000 \mathrm{e}+001.00000 \mathrm{e}+001.00000 \mathrm{e}-011.00000 \mathrm{e}-091.00000 \mathrm{e}-01$ $1.00000 \mathrm{e}-05$ 1.00000e-05 1.00000e-06 1.00000e-09 1.00000e-01 $1.00000 \mathrm{e}+001.00000 \mathrm{e}+001.00000 \mathrm{e}-01$ 1.00000e-09 1.00000e-01 Element: 1218 \# of layers: 10

$\mathrm{Kx} \mathrm{Ky} \mathrm{Kz}$ Ss Por

3.76032e+02 3.76032e+02 3.76032e+01 1.00000e-09 7.00000e-02 $1.50247 \mathrm{e}+01$ 1.50247e+01 1.50247e+00 1.00000e-09 2.12000e-01 $1.50247 \mathrm{e}+01$ 1.50247e+01 1.50247e+00 1.00000e-09 2.12000e-01 $1.50247 \mathrm{e}+01$ 1.50247e+01 1.50247e+00 1.00000e-09 2.12000e-01 $1.50247 \mathrm{e}+01$ 1.50247e+01 1.50247e+00 1.00000e-09 2.12000e-01 $1.50247 \mathrm{e}+01$ 1.50247e+01 1.50247e+00 1.00000e-09 2.12000e-01 $1.00000 \mathrm{e}-02$ 1.00000e-02 1.00000e-03 1.00000e-09 1.00000e-01 $1.00000 \mathrm{e}+001.00000 \mathrm{e}+001.00000 \mathrm{e}-011.00000 \mathrm{e}-091.00000 \mathrm{e}-01$ $1.00000 \mathrm{e}-05$ 1.00000e-05 1.00000e-06 1.00000e-09 1.00000e-01 $1.00000 \mathrm{e}+001.00000 \mathrm{e}+001.00000 \mathrm{e}-011.00000 \mathrm{e}-091.00000 \mathrm{e}-01$ Element: 1219 \# of layers: 10

Kx Ky Kz Ss Por

3.76032e+02 3.76032e+02 3.76032e+01 1.00000e-09 7.00000e-02 $1.50247 \mathrm{e}+01$ 1.50247e+01 1.50247e+00 1.00000e-09 2.12000e-01 $1.50247 \mathrm{e}+01$ 1.50247e+01 1.50247e+00 1.00000e-09 2.12000e-01 $1.50247 \mathrm{e}+011.50247 \mathrm{e}+01$ 1.50247e+00 1.00000e-09 2.12000e-01 $1.50247 \mathrm{e}+01$ 1.50247e+01 1.50247e+00 1.00000e-09 2.12000e-01 $1.50247 \mathrm{e}+011.50247 \mathrm{e}+01$ 1.50247e+00 1.00000e-09 2.12000e-01 $1.00000 \mathrm{e}-02$ 1.00000e-02 1.00000e-03 1.00000e-09 1.00000e-01 $1.00000 \mathrm{e}+001.00000 \mathrm{e}+001.00000 \mathrm{e}-011.00000 \mathrm{e}-091.00000 \mathrm{e}-01$ $1.00000 \mathrm{e}-05$ 1.00000e-05 1.00000e-06 1.00000e-09 1.00000e-01 $1.00000 \mathrm{e}+001.00000 \mathrm{e}+001.00000 \mathrm{e}-01$ 1.00000e-09 1.00000e-01 Element: 1220 \# of layers: 10

$\mathrm{Kx} \mathrm{Ky} \mathrm{Kz}$ Ss Por

2.14970e+02 2.14970e+02 2.14970e+01 1.00000e-09 7.00000e-02 8.58933e+00 8.58933e+00 8.58933e-01 1.00000e-09 2.12000e-01 8.58933e+00 8.58933e+00 8.58933e-01 1.00000e-09 2.12000e-01 $8.58933 \mathrm{e}+00$ 8.58933e+00 8.58933e-01 1.00000e-09 2.12000e-01 $8.58933 e+00$ 8.58933e+00 8.58933e-01 1.00000e-09 2.12000e-01 
8.58933e+00 8.58933e+00 8.58933e-01 1.00000e-09 2.12000e-01 $1.00000 \mathrm{e}-02$ 1.00000e-02 1.00000e-03 1.00000e-09 1.00000e-01 $1.00000 \mathrm{e}+001.00000 \mathrm{e}+001.00000 \mathrm{e}-011.00000 \mathrm{e}-091.00000 \mathrm{e}-01$ $1.00000 \mathrm{e}-05$ 1.00000e-05 1.00000e-06 1.00000e-09 1.00000e-01 $1.00000 \mathrm{e}+001.00000 \mathrm{e}+001.00000 \mathrm{e}-01$ 1.00000e-09 1.00000e-01 Element: 1221 \# of layers: 10

$\mathrm{Kx} \mathrm{Ky} \mathrm{Kz}$ Ss Por

2.14970e+02 2.14970e+02 2.14970e+01 1.00000e-09 7.00000e-02 8.58933e+00 8.58933e+00 8.58933e-01 1.00000e-09 2.12000e-01 $8.58933 \mathrm{e}+00$ 8.58933e+00 8.58933e-01 1.00000e-09 2.12000e-01 8.58933e+00 8.58933e+00 8.58933e-01 1.00000e-09 2.12000e-01 8.58933e+00 8.58933e+00 8.58933e-01 1.00000e-09 2.12000e-01 8.58933e+00 8.58933e+00 8.58933e-01 1.00000e-09 2.12000e-01 $1.00000 \mathrm{e}-02$ 1.00000e-02 1.00000e-03 1.00000e-09 1.00000e-01 $1.00000 \mathrm{e}+001.00000 \mathrm{e}+001.00000 \mathrm{e}-011.00000 \mathrm{e}-091.00000 \mathrm{e}-01$ $1.00000 \mathrm{e}-05$ 1.00000e-05 1.00000e-06 1.00000e-09 1.00000e-01 $1.00000 \mathrm{e}+001.00000 \mathrm{e}+001.00000 \mathrm{e}-011.00000 \mathrm{e}-091.00000 \mathrm{e}-01$ Element: 1222 \# of layers: 10

$\mathrm{Kx} \mathrm{Ky} \mathrm{Kz}$ Ss Por

2.14970e+02 2.14970e+02 2.14970e+01 1.00000e-09 7.00000e-02 8.58933e+00 8.58933e+00 8.58933e-01 1.00000e-09 2.12000e-01 8.58933e+00 8.58933e+00 8.58933e-01 1.00000e-09 2.12000e-01 8.58933e+00 8.58933e+00 8.58933e-01 1.00000e-09 2.12000e-01 $8.58933 \mathrm{e}+00$ 8.58933e+00 8.58933e-01 1.00000e-09 2.12000e-01 $8.58933 \mathrm{e}+00$ 8.58933e+00 8.58933e-01 1.00000e-09 2.12000e-01 $1.00000 \mathrm{e}-021.00000 \mathrm{e}-021.00000 \mathrm{e}-031.00000 \mathrm{e}-091.00000 \mathrm{e}-01$ $1.00000 \mathrm{e}+001.00000 \mathrm{e}+001.00000 \mathrm{e}-011.00000 \mathrm{e}-091.00000 \mathrm{e}-01$ $1.00000 \mathrm{e}-05$ 1.00000e-05 1.00000e-06 1.00000e-09 1.00000e-01 $1.00000 \mathrm{e}+001.00000 \mathrm{e}+001.00000 \mathrm{e}-011.00000 \mathrm{e}-091.00000 \mathrm{e}-01$ Element: 1223 \# of layers: 10

$\mathrm{Kx} \mathrm{Ky} \mathrm{Kz}$ Ss Por

2.14970e+02 2.14970e+02 2.14970e+01 1.00000e-09 7.00000e-02 8.58933e+00 8.58933e+00 8.58933e-01 1.00000e-09 2.12000e-01 8.58933e+00 8.58933e+00 8.58933e-01 1.00000e-09 2.12000e-01 8.58933e+00 8.58933e+00 8.58933e-01 1.00000e-09 2.12000e-01 8.58933e+00 8.58933e+00 8.58933e-01 1.00000e-09 2.12000e-01 $8.58933 \mathrm{e}+00$ 8.58933e+00 8.58933e-01 1.00000e-09 2.12000e-01 $1.00000 \mathrm{e}-02$ 1.00000e-02 1.00000e-03 1.00000e-09 1.00000e-01 $1.00000 \mathrm{e}+001.00000 \mathrm{e}+001.00000 \mathrm{e}-011.00000 \mathrm{e}-091.00000 \mathrm{e}-01$ $1.00000 \mathrm{e}-05$ 1.00000e-05 1.00000e-06 1.00000e-09 1.00000e-01 $1.00000 \mathrm{e}+001.00000 \mathrm{e}+001.00000 \mathrm{e}-011.00000 \mathrm{e}-091.00000 \mathrm{e}-01$ Element: 1224 \# of layers: 10

$\mathrm{Kx} \mathrm{Ky} \mathrm{Kz}$ Ss Por

2.14970e+02 2.14970e+02 2.14970e+01 1.00000e-09 7.00000e-02 $8.58933 \mathrm{e}+00$ 8.58933e+00 8.58933e-01 1.00000e-09 2.12000e-01 $8.58933 \mathrm{e}+00$ 8.58933e+00 8.58933e-01 1.00000e-09 2.12000e-01 
8.58933e+00 8.58933e+00 8.58933e-01 1.00000e-09 2.12000e-01 $8.58933 \mathrm{e}+00$ 8.58933e+00 8.58933e-01 1.00000e-09 2.12000e-01 $8.58933 \mathrm{e}+00$ 8.58933e+00 8.58933e-01 1.00000e-09 2.12000e-01 $1.00000 \mathrm{e}-02$ 1.00000e-02 1.00000e-03 1.00000e-09 1.00000e-01 $1.00000 \mathrm{e}+001.00000 \mathrm{e}+001.00000 \mathrm{e}-011.00000 \mathrm{e}-091.00000 \mathrm{e}-01$ $1.00000 \mathrm{e}-05$ 1.00000e-05 1.00000e-06 1.00000e-09 1.00000e-01 $1.00000 \mathrm{e}+001.00000 \mathrm{e}+001.00000 \mathrm{e}-011.00000 \mathrm{e}-091.00000 \mathrm{e}-01$ Element: 1225 \# of layers: 10

$\mathrm{Kx} \mathrm{Ky} \mathrm{Kz}$ Ss Por

2.14970e+02 2.14970e+02 2.14970e+01 1.00000e-09 7.00000e-02 $8.58933 \mathrm{e}+00$ 8.58933e+00 8.58933e-01 1.00000e-09 2.12000e-01 $8.58933 \mathrm{e}+00$ 8.58933e+00 8.58933e-01 1.00000e-09 2.12000e-01 8.58933e+00 8.58933e+00 8.58933e-01 1.00000e-09 2.12000e-01 8.58933e+00 8.58933e+00 8.58933e-01 1.00000e-09 2.12000e-01 8.58933e+00 8.58933e+00 8.58933e-01 1.00000e-09 2.12000e-01 $1.00000 \mathrm{e}-02$ 1.00000e-02 1.00000e-03 1.00000e-09 1.00000e-01 $1.00000 \mathrm{e}+001.00000 \mathrm{e}+001.00000 \mathrm{e}-011.00000 \mathrm{e}-091.00000 \mathrm{e}-01$ $1.00000 \mathrm{e}-05$ 1.00000e-05 1.00000e-06 1.00000e-09 1.00000e-01 $1.00000 \mathrm{e}+001.00000 \mathrm{e}+001.00000 \mathrm{e}-011.00000 \mathrm{e}-091.00000 \mathrm{e}-01$ Element: 1226 \# of layers: 10

$\mathrm{Kx} \mathrm{Ky} \mathrm{Kz}$ Ss Por

2.14970e+02 2.14970e+02 2.14970e+01 1.00000e-09 7.00000e-02 8.58933e+00 8.58933e+00 8.58933e-01 1.00000e-09 2.12000e-01 $8.58933 \mathrm{e}+00$ 8.58933e+00 8.58933e-01 1.00000e-09 2.12000e-01 $8.58933 \mathrm{e}+00$ 8.58933e+00 8.58933e-01 1.00000e-09 2.12000e-01 8.58933e+00 8.58933e+00 8.58933e-01 1.00000e-09 2.12000e-01 $8.58933 \mathrm{e}+00$ 8.58933e+00 8.58933e-01 1.00000e-09 2.12000e-01 $1.00000 \mathrm{e}-02$ 1.00000e-02 1.00000e-03 1.00000e-09 1.00000e-01 $1.00000 \mathrm{e}+001.00000 \mathrm{e}+001.00000 \mathrm{e}-011.00000 \mathrm{e}-091.00000 \mathrm{e}-01$ $1.00000 \mathrm{e}-05$ 1.00000e-05 1.00000e-06 1.00000e-09 1.00000e-01 $1.00000 \mathrm{e}+001.00000 \mathrm{e}+001.00000 \mathrm{e}-011.00000 \mathrm{e}-091.00000 \mathrm{e}-01$ Element: 1227 \# of layers: 10

Kx Ky Kz Ss Por

2.14970e+02 2.14970e+02 2.14970e+01 1.00000e-09 7.00000e-02 8.58933e+00 8.58933e+00 8.58933e-01 1.00000e-09 2.12000e-01 8.58933e+00 8.58933e+00 8.58933e-01 1.00000e-09 2.12000e-01 $8.58933 \mathrm{e}+00$ 8.58933e+00 8.58933e-01 1.00000e-09 2.12000e-01 8.58933e+00 8.58933e+00 8.58933e-01 1.00000e-09 2.12000e-01 8.58933e+00 8.58933e+00 8.58933e-01 1.00000e-09 2.12000e-01 $1.00000 \mathrm{e}-02$ 1.00000e-02 1.00000e-03 1.00000e-09 1.00000e-01 $1.00000 \mathrm{e}+001.00000 \mathrm{e}+001.00000 \mathrm{e}-011.00000 \mathrm{e}-091.00000 \mathrm{e}-01$ $1.00000 \mathrm{e}-05$ 1.00000e-05 1.00000e-06 1.00000e-09 1.00000e-01 $1.00000 \mathrm{e}+001.00000 \mathrm{e}+001.00000 \mathrm{e}-01$ 1.00000e-09 1.00000e-01 Element: 1228 \# of layers: 10

$\mathrm{Kx} \mathrm{Ky} \mathrm{Kz}$ Ss Por

2.14970e+02 2.14970e+02 2.14970e+01 1.00000e-09 7.00000e-02 
8.58933e+00 8.58933e+00 8.58933e-01 1.00000e-09 2.12000e-01 $8.58933 \mathrm{e}+00$ 8.58933e+00 8.58933e-01 1.00000e-09 2.12000e-01 8.58933e+00 8.58933e+00 8.58933e-01 1.00000e-09 2.12000e-01 $8.58933 \mathrm{e}+00$ 8.58933e+00 8.58933e-01 1.00000e-09 2.12000e-01 8.58933e+00 8.58933e+00 8.58933e-01 1.00000e-09 2.12000e-01 $1.00000 \mathrm{e}-02$ 1.00000e-02 1.00000e-03 1.00000e-09 1.00000e-01 $1.00000 \mathrm{e}+001.00000 \mathrm{e}+001.00000 \mathrm{e}-011.00000 \mathrm{e}-091.00000 \mathrm{e}-01$ $1.00000 \mathrm{e}-05$ 1.00000e-05 1.00000e-06 1.00000e-09 1.00000e-01 $1.00000 \mathrm{e}+001.00000 \mathrm{e}+00$ 1.00000e-01 1.00000e-09 1.00000e-01 Element: 1229 \# of layers: 10

$\mathrm{Kx} \mathrm{Ky} \mathrm{Kz}$ Ss Por

$1.58765 \mathrm{e}+02$ 1.58765e+02 1.58765e+01 1.00000e-09 7.00000e-02 $6.34378 \mathrm{e}+00$ 6.34378e+00 6.34378e-01 1.00000e-09 2.12000e-01 $6.34378 \mathrm{e}+006.34378 \mathrm{e}+00$ 6.34378e-01 1.00000e-09 2.12000e-01 $6.34378 \mathrm{e}+00$ 6.34378e+00 6.34378e-01 1.00000e-09 2.12000e-01 $6.34378 \mathrm{e}+006.34378 \mathrm{e}+00$ 6.34378e-01 1.00000e-09 2.12000e-01 $6.34378 \mathrm{e}+00$ 6.34378e+00 6.34378e-01 1.00000e-09 2.12000e-01 $1.00000 \mathrm{e}-02$ 1.00000e-02 1.00000e-03 1.00000e-09 1.00000e-01 $1.00000 \mathrm{e}+001.00000 \mathrm{e}+001.00000 \mathrm{e}-011.00000 \mathrm{e}-091.00000 \mathrm{e}-01$ $1.00000 \mathrm{e}-05$ 1.00000e-05 1.00000e-06 1.00000e-09 1.00000e-01 $1.00000 \mathrm{e}+001.00000 \mathrm{e}+001.00000 \mathrm{e}-011.00000 \mathrm{e}-091.00000 \mathrm{e}-01$ Element: 1230 \# of layers: 10

$\mathrm{Kx} \mathrm{Ky} \mathrm{Kz}$ Ss Por

$1.58765 \mathrm{e}+02$ 1.58765e+02 1.58765e+01 1.00000e-09 7.00000e-02 $6.34378 \mathrm{e}+00$ 6.34378e+00 6.34378e-01 1.00000e-09 2.12000e-01 6.34378e+00 6.34378e+00 6.34378e-01 1.00000e-09 2.12000e-01 6.34378e+00 6.34378e+00 6.34378e-01 1.00000e-09 2.12000e-01 6.34378e+00 6.34378e+00 6.34378e-01 1.00000e-09 2.12000e-01 6.34378e+00 6.34378e+00 6.34378e-01 1.00000e-09 2.12000e-01 $1.00000 \mathrm{e}-021.00000 \mathrm{e}-021.00000 \mathrm{e}-031.00000 \mathrm{e}-091.00000 \mathrm{e}-01$ $1.00000 \mathrm{e}+001.00000 \mathrm{e}+001.00000 \mathrm{e}-01$ 1.00000e-09 1.00000e-01 $1.00000 \mathrm{e}-05$ 1.00000e-05 1.00000e-06 1.00000e-09 1.00000e-01 $1.00000 \mathrm{e}+001.00000 \mathrm{e}+001.00000 \mathrm{e}-01$ 1.00000e-09 1.00000e-01 Element: 1231 \# of layers: 10

$\mathrm{Kx} \mathrm{Ky} \mathrm{Kz}$ Ss Por

$1.58765 \mathrm{e}+02$ 1.58765e+02 1.58765e+01 1.00000e-09 7.00000e-02 $6.34378 \mathrm{e}+006.34378 \mathrm{e}+00$ 6.34378e-01 1.00000e-09 2.12000e-01 $6.34378 \mathrm{e}+00$ 6.34378e+00 6.34378e-01 1.00000e-09 2.12000e-01 6.34378e+00 6.34378e+00 6.34378e-01 1.00000e-09 2.12000e-01 6.34378e+00 6.34378e+00 6.34378e-01 1.00000e-09 2.12000e-01 $6.34378 \mathrm{e}+00$ 6.34378e+00 6.34378e-01 1.00000e-09 2.12000e-01 $1.00000 \mathrm{e}-02$ 1.00000e-02 1.00000e-03 1.00000e-09 1.00000e-01 $1.00000 \mathrm{e}+001.00000 \mathrm{e}+001.00000 \mathrm{e}-011.00000 \mathrm{e}-091.00000 \mathrm{e}-01$ $1.00000 \mathrm{e}-05$ 1.00000e-05 1.00000e-06 1.00000e-09 1.00000e-01 $1.00000 \mathrm{e}+001.00000 \mathrm{e}+001.00000 \mathrm{e}-011.00000 \mathrm{e}-09$ 1.00000e-01 Element: 1232 \# of layers: 10 
Kx Ky Kz Ss Por

$1.58765 \mathrm{e}+02$ 1.58765e+02 1.58765e+01 1.00000e-09 7.00000e-02 6.34378e+00 6.34378e+00 6.34378e-01 1.00000e-09 2.12000e-01 $6.34378 \mathrm{e}+00$ 6.34378e+00 6.34378e-01 1.00000e-09 2.12000e-01 6.34378e+00 6.34378e+00 6.34378e-01 1.00000e-09 2.12000e-01 6.34378e+00 6.34378e+00 6.34378e-01 1.00000e-09 2.12000e-01 $6.34378 \mathrm{e}+00$ 6.34378e+00 6.34378e-01 1.00000e-09 2.12000e-01 $1.00000 \mathrm{e}-02$ 1.00000e-02 1.00000e-03 1.00000e-09 1.00000e-01 $1.00000 \mathrm{e}+001.00000 \mathrm{e}+001.00000 \mathrm{e}-011.00000 \mathrm{e}-091.00000 \mathrm{e}-01$ $1.00000 \mathrm{e}-05$ 1.00000e-05 1.00000e-06 1.00000e-09 1.00000e-01 $1.00000 \mathrm{e}+001.00000 \mathrm{e}+001.00000 \mathrm{e}-011.00000 \mathrm{e}-091.00000 \mathrm{e}-01$ Element: 1233 \# of layers: 10

$\mathrm{Kx} \mathrm{Ky} \mathrm{Kz}$ Ss Por

$1.58765 \mathrm{e}+02$ 1.58765e+02 1.58765e+01 1.00000e-09 7.00000e-02 6.34378e+00 6.34378e+00 6.34378e-01 1.00000e-09 2.12000e-01 $6.34378 \mathrm{e}+006.34378 \mathrm{e}+00$ 6.34378e-01 1.00000e-09 2.12000e-01 $6.34378 \mathrm{e}+006.34378 \mathrm{e}+00$ 6.34378e-01 1.00000e-09 2.12000e-01 $6.34378 \mathrm{e}+00$ 6.34378e+00 6.34378e-01 1.00000e-09 2.12000e-01 6.34378e+00 6.34378e+00 6.34378e-01 1.00000e-09 2.12000e-01 $1.00000 \mathrm{e}-02$ 1.00000e-02 1.00000e-03 1.00000e-09 1.00000e-01 $1.00000 \mathrm{e}+001.00000 \mathrm{e}+001.00000 \mathrm{e}-011.00000 \mathrm{e}-091.00000 \mathrm{e}-01$ $1.00000 \mathrm{e}-05$ 1.00000e-05 1.00000e-06 1.00000e-09 1.00000e-01 $1.00000 \mathrm{e}+001.00000 \mathrm{e}+001.00000 \mathrm{e}-01$ 1.00000e-09 1.00000e-01 Element: 1234 \# of layers: 10

Kx Ky Kz Ss Por

$1.58765 \mathrm{e}+02$ 1.58765e+02 1.58765e+01 1.00000e-09 7.00000e-02 6.34378e+00 6.34378e+00 6.34378e-01 1.00000e-09 2.12000e-01 6.34378e+00 6.34378e+00 6.34378e-01 1.00000e-09 2.12000e-01 6.34378e+00 6.34378e+00 6.34378e-01 1.00000e-09 2.12000e-01 6.34378e+00 6.34378e+00 6.34378e-01 1.00000e-09 2.12000e-01 $6.34378 \mathrm{e}+00$ 6.34378e+00 6.34378e-01 1.00000e-09 2.12000e-01 $1.00000 \mathrm{e}-02$ 1.00000e-02 1.00000e-03 1.00000e-09 1.00000e-01 $1.00000 \mathrm{e}+001.00000 \mathrm{e}+001.00000 \mathrm{e}-011.00000 \mathrm{e}-091.00000 \mathrm{e}-01$ $1.00000 \mathrm{e}-05$ 1.00000e-05 1.00000e-06 1.00000e-09 1.00000e-01 $1.00000 \mathrm{e}+001.00000 \mathrm{e}+001.00000 \mathrm{e}-01$ 1.00000e-09 1.00000e-01 Element: 1235 \# of layers: 10

Kx Ky Kz Ss Por

$1.58765 \mathrm{e}+021.58765 \mathrm{e}+02$ 1.58765e+01 1.00000e-09 7.00000e-02 $6.34378 \mathrm{e}+00$ 6.34378e+00 6.34378e-01 1.00000e-09 2.12000e-01 $6.34378 \mathrm{e}+006.34378 \mathrm{e}+00$ 6.34378e-01 1.00000e-09 2.12000e-01 $6.34378 \mathrm{e}+00$ 6.34378e+00 6.34378e-01 1.00000e-09 2.12000e-01 $6.34378 \mathrm{e}+00$ 6.34378e+00 6.34378e-01 1.00000e-09 2.12000e-01 6.34378e+00 6.34378e+00 6.34378e-01 1.00000e-09 2.12000e-01 $1.00000 \mathrm{e}-02$ 1.00000e-02 1.00000e-03 1.00000e-09 1.00000e-01 $1.00000 \mathrm{e}+001.00000 \mathrm{e}+001.00000 \mathrm{e}-011.00000 \mathrm{e}-091.00000 \mathrm{e}-01$ $1.00000 \mathrm{e}-05$ 1.00000e-05 1.00000e-06 1.00000e-09 1.00000e-01 
$1.00000 \mathrm{e}+001.00000 \mathrm{e}+00$ 1.00000e-01 1.00000e-09 1.00000e-01

Element: 1236 \# of layers: 10

Kx Ky Kz Ss Por

$1.58765 \mathrm{e}+02$ 1.58765e+02 1.58765e+01 1.00000e-09 7.00000e-02

6.34378e+00 6.34378e+00 6.34378e-01 1.00000e-09 2.12000e-01

$6.34378 \mathrm{e}+006.34378 \mathrm{e}+00$ 6.34378e-01 1.00000e-09 2.12000e-01

6.34378e+00 6.34378e+00 6.34378e-01 1.00000e-09 2.12000e-01

$6.34378 \mathrm{e}+00$ 6.34378e+00 6.34378e-01 1.00000e-09 2.12000e-01

$6.34378 \mathrm{e}+00$ 6.34378e+00 6.34378e-01 1.00000e-09 2.12000e-01

$1.00000 \mathrm{e}-02$ 1.00000e-02 1.00000e-03 1.00000e-09 1.00000e-01

$1.00000 \mathrm{e}+001.00000 \mathrm{e}+001.00000 \mathrm{e}-011.00000 \mathrm{e}-091.00000 \mathrm{e}-01$

$1.00000 \mathrm{e}-05$ 1.00000e-05 1.00000e-06 1.00000e-09 1.00000e-01

$1.00000 \mathrm{e}+001.00000 \mathrm{e}+001.00000 \mathrm{e}-011.00000 \mathrm{e}-09$ 1.00000e-01

Element: 1237 \# of layers: 10

$\mathrm{Kx} \mathrm{Ky} \mathrm{Kz}$ Ss Por

$1.58765 \mathrm{e}+02$ 1.58765e+02 1.58765e+01 1.00000e-09 7.00000e-02

6.34378e+00 6.34378e+00 6.34378e-01 1.00000e-09 2.12000e-01

6.34378e+00 6.34378e+00 6.34378e-01 1.00000e-09 2.12000e-01

6.34378e+00 6.34378e+00 6.34378e-01 1.00000e-09 2.12000e-01

$6.34378 \mathrm{e}+00$ 6.34378e+00 6.34378e-01 1.00000e-09 2.12000e-01

$6.34378 \mathrm{e}+006.34378 \mathrm{e}+00$ 6.34378e-01 1.00000e-09 2.12000e-01

$1.00000 \mathrm{e}-02$ 1.00000e-02 1.00000e-03 1.00000e-09 1.00000e-01

$1.00000 \mathrm{e}+001.00000 \mathrm{e}+001.00000 \mathrm{e}-011.00000 \mathrm{e}-091.00000 \mathrm{e}-01$

$1.00000 \mathrm{e}-05$ 1.00000e-05 1.00000e-06 1.00000e-09 1.00000e-01

$1.00000 \mathrm{e}+001.00000 \mathrm{e}+001.00000 \mathrm{e}-011.00000 \mathrm{e}-091.00000 \mathrm{e}-01$

Element: 1238 \# of layers: 10

$\mathrm{Kx} \mathrm{Ky} \mathrm{Kz}$ Ss Por

9.15146e+01 9.15146e+01 9.15146e+00 1.00000e-09 7.00000e-02

$3.65655 \mathrm{e}+003.65655 \mathrm{e}+003.65655 \mathrm{e}-01$ 1.00000e-09 2.12000e-01

$3.65655 \mathrm{e}+003.65655 \mathrm{e}+003.65655 \mathrm{e}-01$ 1.00000e-09 2.12000e-01

$3.65655 \mathrm{e}+003.65655 \mathrm{e}+00$ 3.65655e-01 1.00000e-09 2.12000e-01

$3.65655 \mathrm{e}+003.65655 \mathrm{e}+00$ 3.65655e-01 1.00000e-09 2.12000e-01

$3.65655 \mathrm{e}+003.65655 \mathrm{e}+003.65655 \mathrm{e}-01$ 1.00000e-09 2.12000e-01

$1.00000 \mathrm{e}-02$ 1.00000e-02 1.00000e-03 1.00000e-09 1.00000e-01

$1.00000 \mathrm{e}+001.00000 \mathrm{e}+001.00000 \mathrm{e}-011.00000 \mathrm{e}-091.00000 \mathrm{e}-01$

$1.00000 \mathrm{e}-05$ 1.00000e-05 1.00000e-06 1.00000e-09 1.00000e-01

$1.00000 \mathrm{e}+001.00000 \mathrm{e}+001.00000 \mathrm{e}-011.00000 \mathrm{e}-091.00000 \mathrm{e}-01$

Element: 1239 \# of layers: 10

$\mathrm{Kx} \mathrm{Ky} \mathrm{Kz}$ Ss Por

9.15146e+01 9.15146e+01 9.15146e+00 1.00000e-09 7.00000e-02

$3.65655 \mathrm{e}+003.65655 \mathrm{e}+00$ 3.65655e-01 1.00000e-09 2.12000e-01

$3.65655 \mathrm{e}+003.65655 \mathrm{e}+00$ 3.65655e-01 1.00000e-09 2.12000e-01

$3.65655 \mathrm{e}+003.65655 \mathrm{e}+00$ 3.65655e-01 1.00000e-09 2.12000e-01

$3.65655 \mathrm{e}+003.65655 \mathrm{e}+00$ 3.65655e-01 1.00000e-09 2.12000e-01

$3.65655 \mathrm{e}+003.65655 \mathrm{e}+003.65655 \mathrm{e}-01$ 1.00000e-09 2.12000e-01

$1.00000 \mathrm{e}-02$ 1.00000e-02 1.00000e-03 1.00000e-09 1.00000e-01 
$1.00000 \mathrm{e}+001.00000 \mathrm{e}+001.00000 \mathrm{e}-011.00000 \mathrm{e}-091.00000 \mathrm{e}-01$ $1.00000 \mathrm{e}-05$ 1.00000e-05 1.00000e-06 1.00000e-09 1.00000e-01 $1.00000 \mathrm{e}+001.00000 \mathrm{e}+001.00000 \mathrm{e}-01$ 1.00000e-09 1.00000e-01 Element: 1240 \# of layers: 10

$\mathrm{Kx} \mathrm{Ky} \mathrm{Kz}$ Ss Por

9.15146e+01 9.15146e+01 9.15146e+00 1.00000e-09 7.00000e-02 $3.65655 \mathrm{e}+003.65655 \mathrm{e}+00$ 3.65655e-01 1.00000e-09 2.12000e-01 $3.65655 \mathrm{e}+003.65655 \mathrm{e}+003.65655 \mathrm{e}-01$ 1.00000e-09 2.12000e-01 $3.65655 \mathrm{e}+003.65655 \mathrm{e}+003.65655 \mathrm{e}-01$ 1.00000e-09 2.12000e-01 $3.65655 \mathrm{e}+003.65655 \mathrm{e}+00$ 3.65655e-01 1.00000e-09 2.12000e-01 $3.65655 \mathrm{e}+003.65655 \mathrm{e}+003.65655 \mathrm{e}-01$ 1.00000e-09 2.12000e-01 $1.00000 \mathrm{e}-02$ 1.00000e-02 1.00000e-03 1.00000e-09 1.00000e-01 $1.00000 \mathrm{e}+001.00000 \mathrm{e}+001.00000 \mathrm{e}-011.00000 \mathrm{e}-091.00000 \mathrm{e}-01$ $1.00000 \mathrm{e}-05$ 1.00000e-05 1.00000e-06 1.00000e-09 1.00000e-01 $1.00000 \mathrm{e}+001.00000 \mathrm{e}+001.00000 \mathrm{e}-01$ 1.00000e-09 1.00000e-01 Element: 1241 \# of layers: 10

$\mathrm{Kx} \mathrm{Ky} \mathrm{Kz}$ Ss Por

9.15146e+01 9.15146e+01 9.15146e+00 1.00000e-09 7.00000e-02 $3.65655 \mathrm{e}+003.65655 \mathrm{e}+00$ 3.65655e-01 1.00000e-09 2.12000e-01 $3.65655 \mathrm{e}+003.65655 \mathrm{e}+003.65655 \mathrm{e}-01$ 1.00000e-09 2.12000e-01 $3.65655 \mathrm{e}+003.65655 \mathrm{e}+003.65655 \mathrm{e}-01$ 1.00000e-09 2.12000e-01 $3.65655 \mathrm{e}+003.65655 \mathrm{e}+00$ 3.65655e-01 1.00000e-09 2.12000e-01 $3.65655 \mathrm{e}+003.65655 \mathrm{e}+003.65655 \mathrm{e}-01$ 1.00000e-09 2.12000e-01 $1.00000 \mathrm{e}-02$ 1.00000e-02 1.00000e-03 1.00000e-09 1.00000e-01 $1.00000 \mathrm{e}+001.00000 \mathrm{e}+001.00000 \mathrm{e}-011.00000 \mathrm{e}-091.00000 \mathrm{e}-01$ $1.00000 \mathrm{e}-05$ 1.00000e-05 1.00000e-06 1.00000e-09 1.00000e-01 $1.00000 \mathrm{e}+001.00000 \mathrm{e}+001.00000 \mathrm{e}-011.00000 \mathrm{e}-091.00000 \mathrm{e}-01$ Element: 1242 \# of layers: 10

Kx Ky Kz Ss Por

9.15146e+01 9.15146e+01 9.15146e+00 1.00000e-09 7.00000e-02 $3.65655 \mathrm{e}+003.65655 \mathrm{e}+003.65655 \mathrm{e}-01$ 1.00000e-09 2.12000e-01 $3.65655 \mathrm{e}+003.65655 \mathrm{e}+00$ 3.65655e-01 1.00000e-09 2.12000e-01 $3.65655 \mathrm{e}+003.65655 \mathrm{e}+003.65655 \mathrm{e}-01$ 1.00000e-09 2.12000e-01 $3.65655 \mathrm{e}+003.65655 \mathrm{e}+003.65655 \mathrm{e}-01$ 1.00000e-09 2.12000e-01 $3.65655 \mathrm{e}+003.65655 \mathrm{e}+00$ 3.65655e-01 1.00000e-09 2.12000e-01 1.00000e-02 1.00000e-02 1.00000e-03 1.00000e-09 1.00000e-01 $1.00000 \mathrm{e}+001.00000 \mathrm{e}+001.00000 \mathrm{e}-011.00000 \mathrm{e}-091.00000 \mathrm{e}-01$ $1.00000 \mathrm{e}-05$ 1.00000e-05 1.00000e-06 1.00000e-09 1.00000e-01 $1.00000 \mathrm{e}+001.00000 \mathrm{e}+001.00000 \mathrm{e}-011.00000 \mathrm{e}-091.00000 \mathrm{e}-01$ Element: 1243 \# of layers: 10

Kx Ky Kz Ss Por

9.15146e+01 9.15146e+01 9.15146e+00 1.00000e-09 7.00000e-02 3.65655e+00 3.65655e+00 3.65655e-01 1.00000e-09 2.12000e-01 $3.65655 \mathrm{e}+003.65655 \mathrm{e}+003.65655 \mathrm{e}-01$ 1.00000e-09 2.12000e-01 $3.65655 \mathrm{e}+003.65655 \mathrm{e}+00$ 3.65655e-01 1.00000e-09 2.12000e-01 $3.65655 \mathrm{e}+003.65655 \mathrm{e}+003.65655 \mathrm{e}-01$ 1.00000e-09 2.12000e-01 
$3.65655 \mathrm{e}+00$ 3.65655e+00 3.65655e-01 1.00000e-09 2.12000e-01 $1.00000 \mathrm{e}-02$ 1.00000e-02 1.00000e-03 1.00000e-09 1.00000e-01 $1.00000 \mathrm{e}+001.00000 \mathrm{e}+001.00000 \mathrm{e}-011.00000 \mathrm{e}-091.00000 \mathrm{e}-01$ $1.00000 \mathrm{e}-05$ 1.00000e-05 1.00000e-06 1.00000e-09 1.00000e-01 $1.00000 \mathrm{e}+001.00000 \mathrm{e}+001.00000 \mathrm{e}-01$ 1.00000e-09 1.00000e-01 Element: 1244 \# of layers: 10

$\mathrm{Kx} \mathrm{Ky} \mathrm{Kz}$ Ss Por

9.15146e+01 9.15146e+01 9.15146e+00 1.00000e-09 7.00000e-02 $3.65655 \mathrm{e}+003.65655 \mathrm{e}+00$ 3.65655e-01 1.00000e-09 2.12000e-01 $3.65655 \mathrm{e}+003.65655 \mathrm{e}+00$ 3.65655e-01 1.00000e-09 2.12000e-01 $3.65655 \mathrm{e}+003.65655 \mathrm{e}+00$ 3.65655e-01 1.00000e-09 2.12000e-01 $3.65655 \mathrm{e}+003.65655 \mathrm{e}+003.65655 \mathrm{e}-01$ 1.00000e-09 2.12000e-01 $3.65655 \mathrm{e}+003.65655 \mathrm{e}+003.65655 \mathrm{e}-01$ 1.00000e-09 2.12000e-01 $1.00000 \mathrm{e}-02$ 1.00000e-02 1.00000e-03 1.00000e-09 1.00000e-01 $1.00000 \mathrm{e}+001.00000 \mathrm{e}+001.00000 \mathrm{e}-011.00000 \mathrm{e}-091.00000 \mathrm{e}-01$ $1.00000 \mathrm{e}-05$ 1.00000e-05 1.00000e-06 1.00000e-09 1.00000e-01 $1.00000 \mathrm{e}+001.00000 \mathrm{e}+001.00000 \mathrm{e}-011.00000 \mathrm{e}-091.00000 \mathrm{e}-01$ Element: 1245 \# of layers: 10

$\mathrm{Kx} \mathrm{Ky} \mathrm{Kz}$ Ss Por

9.15146e+01 9.15146e+01 9.15146e+00 1.00000e-09 7.00000e-02 $3.65655 \mathrm{e}+003.65655 \mathrm{e}+00$ 3.65655e-01 1.00000e-09 2.12000e-01 $3.65655 \mathrm{e}+003.65655 \mathrm{e}+00$ 3.65655e-01 1.00000e-09 2.12000e-01 $3.65655 \mathrm{e}+003.65655 \mathrm{e}+003.65655 \mathrm{e}-01$ 1.00000e-09 2.12000e-01 $3.65655 \mathrm{e}+003.65655 \mathrm{e}+003.65655 \mathrm{e}-01$ 1.00000e-09 2.12000e-01 $3.65655 \mathrm{e}+003.65655 \mathrm{e}+003.65655 \mathrm{e}-01$ 1.00000e-09 2.12000e-01 $1.00000 \mathrm{e}-021.00000 \mathrm{e}-02$ 1.00000e-03 1.00000e-09 1.00000e-01 $1.00000 \mathrm{e}+001.00000 \mathrm{e}+001.00000 \mathrm{e}-011.00000 \mathrm{e}-091.00000 \mathrm{e}-01$ $1.00000 \mathrm{e}-05$ 1.00000e-05 1.00000e-06 1.00000e-09 1.00000e-01 $1.00000 \mathrm{e}+001.00000 \mathrm{e}+001.00000 \mathrm{e}-011.00000 \mathrm{e}-091.00000 \mathrm{e}-01$ Element: 1246 \# of layers: 10

$\mathrm{Kx} \mathrm{Ky} \mathrm{Kz}$ Ss Por

9.15146e+01 9.15146e+01 9.15146e+00 1.00000e-09 7.00000e-02 $3.65655 \mathrm{e}+003.65655 \mathrm{e}+003.65655 \mathrm{e}-01$ 1.00000e-09 2.12000e-01 $3.65655 \mathrm{e}+003.65655 \mathrm{e}+003.65655 \mathrm{e}-01$ 1.00000e-09 2.12000e-01 $3.65655 \mathrm{e}+003.65655 \mathrm{e}+003.65655 \mathrm{e}-01$ 1.00000e-09 2.12000e-01 $3.65655 \mathrm{e}+003.65655 \mathrm{e}+00$ 3.65655e-01 1.00000e-09 2.12000e-01 $3.65655 \mathrm{e}+003.65655 \mathrm{e}+003.65655 \mathrm{e}-01$ 1.00000e-09 2.12000e-01 $1.00000 \mathrm{e}-02$ 1.00000e-02 1.00000e-03 1.00000e-09 1.00000e-01 $1.00000 \mathrm{e}+001.00000 \mathrm{e}+001.00000 \mathrm{e}-011.00000 \mathrm{e}-091.00000 \mathrm{e}-01$ $1.00000 \mathrm{e}-05$ 1.00000e-05 1.00000e-06 1.00000e-09 1.00000e-01 $1.00000 \mathrm{e}+001.00000 \mathrm{e}+001.00000 \mathrm{e}-011.00000 \mathrm{e}-091.00000 \mathrm{e}-01$ Element: 1247 \# of layers: 10

$\mathrm{Kx} \mathrm{Ky} \mathrm{Kz}$ Ss Por

5.57854e+01 5.57854e+01 5.57854e+00 1.00000e-09 7.00000e-02 $2.22899 \mathrm{e}+002.22899 \mathrm{e}+00$ 2.22899e-01 1.00000e-09 2.12000e-01 $2.22899 \mathrm{e}+002.22899 \mathrm{e}+00$ 2.22899e-01 1.00000e-09 2.12000e-01 
$2.22899 \mathrm{e}+002.22899 \mathrm{e}+00$ 2.22899e-01 1.00000e-09 2.12000e-01 $2.22899 \mathrm{e}+002.22899 \mathrm{e}+002.22899 \mathrm{e}-01$ 1.00000e-09 2.12000e-01 $2.22899 \mathrm{e}+002.22899 \mathrm{e}+002.22899 \mathrm{e}-011.00000 \mathrm{e}-092.12000 \mathrm{e}-01$ $1.00000 \mathrm{e}-021.00000 \mathrm{e}-02$ 1.00000e-03 1.00000e-09 1.00000e-01 $1.00000 \mathrm{e}+001.00000 \mathrm{e}+001.00000 \mathrm{e}-011.00000 \mathrm{e}-091.00000 \mathrm{e}-01$ $1.00000 \mathrm{e}-05$ 1.00000e-05 1.00000e-06 1.00000e-09 1.00000e-01 $1.00000 \mathrm{e}+001.00000 \mathrm{e}+001.00000 \mathrm{e}-011.00000 \mathrm{e}-091.00000 \mathrm{e}-01$ Element: 1248 \# of layers: 10

Kx Ky Kz Ss Por

$5.57854 \mathrm{e}+015.57854 \mathrm{e}+015.57854 \mathrm{e}+00$ 1.00000e-09 7.00000e-02 $2.22899 \mathrm{e}+002.22899 \mathrm{e}+002.22899 \mathrm{e}-01$ 1.00000e-09 2.12000e-01 $2.22899 \mathrm{e}+002.22899 \mathrm{e}+002.22899 \mathrm{e}-01$ 1.00000e-09 2.12000e-01 $2.22899 \mathrm{e}+002.22899 \mathrm{e}+002.22899 \mathrm{e}-011.00000 \mathrm{e}-092.12000 \mathrm{e}-01$ $2.22899 \mathrm{e}+002.22899 \mathrm{e}+002.22899 \mathrm{e}-01$ 1.00000e-09 2.12000e-01 $2.22899 \mathrm{e}+002.22899 \mathrm{e}+002.22899 \mathrm{e}-01$ 1.00000e-09 2.12000e-01 $1.00000 \mathrm{e}-02$ 1.00000e-02 1.00000e-03 1.00000e-09 1.00000e-01 $1.00000 \mathrm{e}+001.00000 \mathrm{e}+001.00000 \mathrm{e}-011.00000 \mathrm{e}-091.00000 \mathrm{e}-01$ $1.00000 \mathrm{e}-05$ 1.00000e-05 1.00000e-06 1.00000e-09 1.00000e-01 $1.00000 \mathrm{e}+001.00000 \mathrm{e}+001.00000 \mathrm{e}-011.00000 \mathrm{e}-091.00000 \mathrm{e}-01$ Element: 1249 \# of layers: 10

Kx Ky Kz Ss Por

$5.57854 \mathrm{e}+015.57854 \mathrm{e}+015.57854 \mathrm{e}+00$ 1.00000e-09 7.00000e-02 $2.22899 \mathrm{e}+002.22899 \mathrm{e}+002.22899 \mathrm{e}-011.00000 \mathrm{e}-09$ 2.12000e-01 $2.22899 \mathrm{e}+002.22899 \mathrm{e}+002.22899 \mathrm{e}-011.00000 \mathrm{e}-092.12000 \mathrm{e}-01$ $2.22899 \mathrm{e}+002.22899 \mathrm{e}+002.22899 \mathrm{e}-011.00000 \mathrm{e}-092.12000 \mathrm{e}-01$ $2.22899 \mathrm{e}+002.22899 \mathrm{e}+002.22899 \mathrm{e}-01$ 1.00000e-09 2.12000e-01 $2.22899 \mathrm{e}+002.22899 \mathrm{e}+002.22899 \mathrm{e}-01$ 1.00000e-09 2.12000e-01 $1.00000 \mathrm{e}-021.00000 \mathrm{e}-02$ 1.00000e-03 1.00000e-09 1.00000e-01 $1.00000 \mathrm{e}+001.00000 \mathrm{e}+001.00000 \mathrm{e}-011.00000 \mathrm{e}-091.00000 \mathrm{e}-01$ $1.00000 \mathrm{e}-05$ 1.00000e-05 1.00000e-06 1.00000e-09 1.00000e-01 $1.00000 \mathrm{e}+001.00000 \mathrm{e}+001.00000 \mathrm{e}-011.00000 \mathrm{e}-091.00000 \mathrm{e}-01$ Element: 1250 \# of layers: 10

Kx Ky Kz Ss Por

$5.57854 \mathrm{e}+015.57854 \mathrm{e}+015.57854 \mathrm{e}+001.00000 \mathrm{e}-097.00000 \mathrm{e}-02$ $2.22899 \mathrm{e}+002.22899 \mathrm{e}+002.22899 \mathrm{e}-01$ 1.00000e-09 2.12000e-01 $2.22899 \mathrm{e}+002.22899 \mathrm{e}+002.22899 \mathrm{e}-01$ 1.00000e-09 2.12000e-01 $2.22899 \mathrm{e}+002.22899 \mathrm{e}+002.22899 \mathrm{e}-011.00000 \mathrm{e}-092.12000 \mathrm{e}-01$ $2.22899 \mathrm{e}+002.22899 \mathrm{e}+002.22899 \mathrm{e}-01$ 1.00000e-09 2.12000e-01 $2.22899 \mathrm{e}+002.22899 \mathrm{e}+00$ 2.22899e-01 1.00000e-09 2.12000e-01 $1.00000 \mathrm{e}-02$ 1.00000e-02 1.00000e-03 1.00000e-09 1.00000e-01 $1.00000 \mathrm{e}+001.00000 \mathrm{e}+001.00000 \mathrm{e}-011.00000 \mathrm{e}-091.00000 \mathrm{e}-01$ $1.00000 \mathrm{e}-05$ 1.00000e-05 1.00000e-06 1.00000e-09 1.00000e-01 $1.00000 \mathrm{e}+001.00000 \mathrm{e}+001.00000 \mathrm{e}-011.00000 \mathrm{e}-091.00000 \mathrm{e}-01$ Element: 1251 \# of layers: 10

Kx Ky Kz Ss Por

$5.57854 \mathrm{e}+01$ 5.57854e+01 5.57854e+00 1.00000e-09 7.00000e-02 
$2.22899 \mathrm{e}+002.22899 \mathrm{e}+00$ 2.22899e-01 1.00000e-09 2.12000e-01 $2.22899 \mathrm{e}+002.22899 \mathrm{e}+002.22899 \mathrm{e}-01$ 1.00000e-09 2.12000e-01 $2.22899 \mathrm{e}+002.22899 \mathrm{e}+00$ 2.22899e-01 1.00000e-09 2.12000e-01 $2.22899 \mathrm{e}+002.22899 \mathrm{e}+002.22899 \mathrm{e}-011.00000 \mathrm{e}-092.12000 \mathrm{e}-01$ $2.22899 \mathrm{e}+002.22899 \mathrm{e}+002.22899 \mathrm{e}-01$ 1.00000e-09 2.12000e-01 $1.00000 \mathrm{e}-021.00000 \mathrm{e}-02$ 1.00000e-03 1.00000e-09 1.00000e-01 $1.00000 \mathrm{e}+001.00000 \mathrm{e}+001.00000 \mathrm{e}-011.00000 \mathrm{e}-091.00000 \mathrm{e}-01$ $1.00000 \mathrm{e}-05$ 1.00000e-05 1.00000e-06 1.00000e-09 1.00000e-01 $1.00000 \mathrm{e}+001.00000 \mathrm{e}+001.00000 \mathrm{e}-011.00000 \mathrm{e}-091.00000 \mathrm{e}-01$ Element: 1252 \# of layers: 10

Kx Ky Kz Ss Por

$5.57854 \mathrm{e}+015.57854 \mathrm{e}+015.57854 \mathrm{e}+001.00000 \mathrm{e}-09$ 7.00000e-02 $2.22899 \mathrm{e}+002.22899 \mathrm{e}+002.22899 \mathrm{e}-01$ 1.00000e-09 2.12000e-01

$2.22899 \mathrm{e}+002.22899 \mathrm{e}+00$ 2.22899e-01 1.00000e-09 2.12000e-01 $2.22899 \mathrm{e}+002.22899 \mathrm{e}+002.22899 \mathrm{e}-01$ 1.00000e-09 2.12000e-01 $2.22899 \mathrm{e}+002.22899 \mathrm{e}+002.22899 \mathrm{e}-01$ 1.00000e-09 2.12000e-01 $2.22899 \mathrm{e}+002.22899 \mathrm{e}+002.22899 \mathrm{e}-011.00000 \mathrm{e}-092.12000 \mathrm{e}-01$ $1.00000 \mathrm{e}-02$ 1.00000e-02 1.00000e-03 1.00000e-09 1.00000e-01 $1.00000 \mathrm{e}+001.00000 \mathrm{e}+001.00000 \mathrm{e}-011.00000 \mathrm{e}-091.00000 \mathrm{e}-01$ $1.00000 \mathrm{e}-05$ 1.00000e-05 1.00000e-06 1.00000e-09 1.00000e-01 $1.00000 \mathrm{e}+001.00000 \mathrm{e}+001.00000 \mathrm{e}-011.00000 \mathrm{e}-091.00000 \mathrm{e}-01$ Element: 1253 \# of layers: 10

Kx Ky Kz Ss Por

$5.57854 \mathrm{e}+015.57854 \mathrm{e}+015.57854 \mathrm{e}+00$ 1.00000e-09 7.00000e-02 $2.22899 \mathrm{e}+002.22899 \mathrm{e}+002.22899 \mathrm{e}-011.00000 \mathrm{e}-092.12000 \mathrm{e}-01$ $2.22899 \mathrm{e}+002.22899 \mathrm{e}+00$ 2.22899e-01 1.00000e-09 2.12000e-01 $2.22899 \mathrm{e}+002.22899 \mathrm{e}+002.22899 \mathrm{e}-01$ 1.00000e-09 2.12000e-01 $2.22899 \mathrm{e}+002.22899 \mathrm{e}+002.22899 \mathrm{e}-01$ 1.00000e-09 2.12000e-01 $2.22899 \mathrm{e}+002.22899 \mathrm{e}+002.22899 \mathrm{e}-01$ 1.00000e-09 2.12000e-01 $1.00000 \mathrm{e}-02$ 1.00000e-02 1.00000e-03 1.00000e-09 1.00000e-01 $1.00000 \mathrm{e}+001.00000 \mathrm{e}+001.00000 \mathrm{e}-011.00000 \mathrm{e}-091.00000 \mathrm{e}-01$ $1.00000 \mathrm{e}-05$ 1.00000e-05 1.00000e-06 1.00000e-09 1.00000e-01 $1.00000 \mathrm{e}+001.00000 \mathrm{e}+001.00000 \mathrm{e}-011.00000 \mathrm{e}-091.00000 \mathrm{e}-01$ Element: 1254 \# of layers: 10

Kx Ky Kz Ss Por

$5.57854 \mathrm{e}+015.57854 \mathrm{e}+015.57854 \mathrm{e}+001.00000 \mathrm{e}-097.00000 \mathrm{e}-02$ $2.22899 \mathrm{e}+002.22899 \mathrm{e}+002.22899 \mathrm{e}-011.00000 \mathrm{e}-092.12000 \mathrm{e}-01$ $2.22899 \mathrm{e}+002.22899 \mathrm{e}+00$ 2.22899e-01 1.00000e-09 2.12000e-01 $2.22899 \mathrm{e}+002.22899 \mathrm{e}+00$ 2.22899e-01 1.00000e-09 2.12000e-01 $2.22899 \mathrm{e}+002.22899 \mathrm{e}+002.22899 \mathrm{e}-01$ 1.00000e-09 2.12000e-01 $2.22899 \mathrm{e}+002.22899 \mathrm{e}+002.22899 \mathrm{e}-01$ 1.00000e-09 2.12000e-01 $1.00000 \mathrm{e}-021.00000 \mathrm{e}-02$ 1.00000e-03 1.00000e-09 1.00000e-01 $1.00000 \mathrm{e}+001.00000 \mathrm{e}+001.00000 \mathrm{e}-011.00000 \mathrm{e}-091.00000 \mathrm{e}-01$ $1.00000 \mathrm{e}-05$ 1.00000e-05 1.00000e-06 1.00000e-09 1.00000e-01 $1.00000 \mathrm{e}+001.00000 \mathrm{e}+001.00000 \mathrm{e}-011.00000 \mathrm{e}-091.00000 \mathrm{e}-01$ Element: 1255 \# of layers: 10 
$\mathrm{Kx} \mathrm{Ky} \mathrm{Kz} \mathrm{Ss} \mathrm{Por}$

5.57854e+01 5.57854e+01 5.57854e+00 1.00000e-09 7.00000e-02 $2.22899 \mathrm{e}+00$ 2.22899e+00 2.22899e-01 1.00000e-09 2.12000e-01 $2.22899 \mathrm{e}+002.22899 \mathrm{e}+00$ 2.22899e-01 1.00000e-09 2.12000e-01 $2.22899 \mathrm{e}+00$ 2.22899e+00 2.22899e-01 1.00000e-09 2.12000e-01 $2.22899 \mathrm{e}+00$ 2.22899e+00 2.22899e-01 1.00000e-09 2.12000e-01 $2.22899 \mathrm{e}+00$ 2.22899e+00 2.22899e-01 1.00000e-09 2.12000e-01 $1.00000 \mathrm{e}-02$ 1.00000e-02 1.00000e-03 1.00000e-09 1.00000e-01 $1.00000 \mathrm{e}+001.00000 \mathrm{e}+001.00000 \mathrm{e}-011.00000 \mathrm{e}-091.00000 \mathrm{e}-01$ $1.00000 \mathrm{e}-05$ 1.00000e-05 1.00000e-06 1.00000e-09 1.00000e-01 $1.00000 \mathrm{e}+001.00000 \mathrm{e}+001.00000 \mathrm{e}-011.00000 \mathrm{e}-091.00000 \mathrm{e}-01$ Element: 1256 \# of layers: 10

$\mathrm{Kx} \mathrm{Ky} \mathrm{Kz}$ Ss Por

4.88513e+01 4.88513e+01 4.88513e+00 1.00000e-09 7.00000e-02 1.95192e+00 1.95192e+00 1.95192e-01 1.00000e-09 2.12000e-01 $1.95192 \mathrm{e}+001.95192 \mathrm{e}+00$ 1.95192e-01 1.00000e-09 2.12000e-01 $1.95192 \mathrm{e}+001.95192 \mathrm{e}+00$ 1.95192e-01 1.00000e-09 2.12000e-01 $1.95192 \mathrm{e}+00$ 1.95192e+00 1.95192e-01 1.00000e-09 2.12000e-01 $1.95192 \mathrm{e}+00$ 1.95192e+00 1.95192e-01 1.00000e-09 2.12000e-01 1.00000e-02 1.00000e-02 1.00000e-03 1.00000e-09 1.00000e-01 $1.00000 \mathrm{e}+001.00000 \mathrm{e}+001.00000 \mathrm{e}-011.00000 \mathrm{e}-091.00000 \mathrm{e}-01$ $1.00000 \mathrm{e}-05$ 1.00000e-05 1.00000e-06 1.00000e-09 1.00000e-01 $1.00000 \mathrm{e}+001.00000 \mathrm{e}+001.00000 \mathrm{e}-01$ 1.00000e-09 1.00000e-01 Element: 1257 \# of layers: 10

$\mathrm{Kx} \mathrm{Ky} \mathrm{Kz}$ Ss Por

4.88513e+01 4.88513e+01 4.88513e+00 1.00000e-09 7.00000e-02 $1.95192 \mathrm{e}+001.95192 \mathrm{e}+00$ 1.95192e-01 1.00000e-09 2.12000e-01 $1.95192 \mathrm{e}+001.95192 \mathrm{e}+001.95192 \mathrm{e}-01$ 1.00000e-09 2.12000e-01 $1.95192 \mathrm{e}+001.95192 \mathrm{e}+00$ 1.95192e-01 1.00000e-09 2.12000e-01 $1.95192 \mathrm{e}+001.95192 \mathrm{e}+00$ 1.95192e-01 1.00000e-09 2.12000e-01 $1.95192 \mathrm{e}+00$ 1.95192e+00 1.95192e-01 1.00000e-09 2.12000e-01 1.00000e-02 1.00000e-02 1.00000e-03 1.00000e-09 1.00000e-01 $1.00000 \mathrm{e}+001.00000 \mathrm{e}+001.00000 \mathrm{e}-011.00000 \mathrm{e}-091.00000 \mathrm{e}-01$ $1.00000 \mathrm{e}-05$ 1.00000e-05 1.00000e-06 1.00000e-09 1.00000e-01 $1.00000 \mathrm{e}+001.00000 \mathrm{e}+001.00000 \mathrm{e}-011.00000 \mathrm{e}-091.00000 \mathrm{e}-01$ Element: 1258 \# of layers: 10

$\mathrm{Kx} \mathrm{Ky} \mathrm{Kz}$ Ss Por

4.88513e+01 4.88513e+01 4.88513e+00 1.00000e-09 7.00000e-02 $1.95192 \mathrm{e}+001.95192 \mathrm{e}+00$ 1.95192e-01 1.00000e-09 2.12000e-01 $1.95192 \mathrm{e}+00$ 1.95192e+00 1.95192e-01 1.00000e-09 2.12000e-01 $1.95192 \mathrm{e}+001.95192 \mathrm{e}+00$ 1.95192e-01 1.00000e-09 2.12000e-01 $1.95192 \mathrm{e}+001.95192 \mathrm{e}+00$ 1.95192e-01 1.00000e-09 2.12000e-01 $1.95192 \mathrm{e}+00$ 1.95192e+00 1.95192e-01 1.00000e-09 2.12000e-01 $1.00000 \mathrm{e}-02$ 1.00000e-02 1.00000e-03 1.00000e-09 1.00000e-01 $1.00000 \mathrm{e}+001.00000 \mathrm{e}+001.00000 \mathrm{e}-011.00000 \mathrm{e}-091.00000 \mathrm{e}-01$ $1.00000 \mathrm{e}-05$ 1.00000e-05 1.00000e-06 1.00000e-09 1.00000e-01 
$1.00000 \mathrm{e}+001.00000 \mathrm{e}+00$ 1.00000e-01 1.00000e-09 1.00000e-01

Element: 1259 \# of layers: 10

$\mathrm{Kx} \mathrm{Ky} \mathrm{Kz}$ Ss Por

4.88513e+01 4.88513e+01 4.88513e+00 1.00000e-09 7.00000e-02

$1.95192 \mathrm{e}+001.95192 \mathrm{e}+00$ 1.95192e-01 1.00000e-09 2.12000e-01

$1.95192 \mathrm{e}+001.95192 \mathrm{e}+00$ 1.95192e-01 1.00000e-09 2.12000e-01

1.95192e+00 1.95192e+00 1.95192e-01 1.00000e-09 2.12000e-01

$1.95192 \mathrm{e}+00$ 1.95192e+00 1.95192e-01 1.00000e-09 2.12000e-01

1.95192e+00 1.95192e+00 1.95192e-01 1.00000e-09 2.12000e-01

$1.00000 \mathrm{e}-02$ 1.00000e-02 1.00000e-03 1.00000e-09 1.00000e-01

$1.00000 \mathrm{e}+001.00000 \mathrm{e}+001.00000 \mathrm{e}-011.00000 \mathrm{e}-091.00000 \mathrm{e}-01$

$1.00000 \mathrm{e}-05$ 1.00000e-05 1.00000e-06 1.00000e-09 1.00000e-01

$1.00000 \mathrm{e}+001.00000 \mathrm{e}+001.00000 \mathrm{e}-011.00000 \mathrm{e}-09$ 1.00000e-01

Element: 1260 \# of layers: 10

$\mathrm{Kx} \mathrm{Ky} \mathrm{Kz}$ Ss Por

4.88513e+01 4.88513e+01 4.88513e+00 1.00000e-09 7.00000e-02

$1.95192 \mathrm{e}+00$ 1.95192e+00 1.95192e-01 1.00000e-09 2.12000e-01

$1.95192 \mathrm{e}+00$ 1.95192e+00 1.95192e-01 1.00000e-09 2.12000e-01

1.95192e+00 1.95192e+00 1.95192e-01 1.00000e-09 2.12000e-01

$1.95192 \mathrm{e}+00$ 1.95192e+00 1.95192e-01 1.00000e-09 2.12000e-01

$1.95192 \mathrm{e}+001.95192 \mathrm{e}+001.95192 \mathrm{e}-011.00000 \mathrm{e}-092.12000 \mathrm{e}-01$

$1.00000 \mathrm{e}-021.00000 \mathrm{e}-021.00000 \mathrm{e}-031.00000 \mathrm{e}-091.00000 \mathrm{e}-01$

$1.00000 \mathrm{e}+001.00000 \mathrm{e}+001.00000 \mathrm{e}-011.00000 \mathrm{e}-091.00000 \mathrm{e}-01$

$1.00000 \mathrm{e}-05$ 1.00000e-05 1.00000e-06 1.00000e-09 1.00000e-01

$1.00000 \mathrm{e}+001.00000 \mathrm{e}+001.00000 \mathrm{e}-011.00000 \mathrm{e}-091.00000 \mathrm{e}-01$

Element: 1261 \# of layers: 10

$\mathrm{Kx} \mathrm{Ky} \mathrm{Kz}$ Ss Por

4.88513e+01 4.88513e+01 4.88513e+00 1.00000e-09 7.00000e-02

$1.95192 \mathrm{e}+00$ 1.95192e+00 1.95192e-01 1.00000e-09 2.12000e-01

$1.95192 \mathrm{e}+00$ 1.95192e+00 1.95192e-01 1.00000e-09 2.12000e-01

1.95192e+00 1.95192e+00 1.95192e-01 1.00000e-09 2.12000e-01

1.95192e+00 1.95192e+00 1.95192e-01 1.00000e-09 2.12000e-01

$1.95192 \mathrm{e}+001.95192 \mathrm{e}+00$ 1.95192e-01 1.00000e-09 2.12000e-01

$1.00000 \mathrm{e}-02$ 1.00000e-02 1.00000e-03 1.00000e-09 1.00000e-01

$1.00000 \mathrm{e}+001.00000 \mathrm{e}+001.00000 \mathrm{e}-011.00000 \mathrm{e}-091.00000 \mathrm{e}-01$

$1.00000 \mathrm{e}-05$ 1.00000e-05 1.00000e-06 1.00000e-09 1.00000e-01

$1.00000 \mathrm{e}+001.00000 \mathrm{e}+001.00000 \mathrm{e}-011.00000 \mathrm{e}-091.00000 \mathrm{e}-01$

Element: 1262 \# of layers: 10

$\mathrm{Kx} \mathrm{Ky} \mathrm{Kz}$ Ss Por

4.88513e+01 4.88513e+01 4.88513e+00 1.00000e-09 7.00000e-02

$1.95192 \mathrm{e}+00$ 1.95192e+00 1.95192e-01 1.00000e-09 2.12000e-01

$1.95192 \mathrm{e}+001.95192 \mathrm{e}+00$ 1.95192e-01 1.00000e-09 2.12000e-01

1.95192e+00 1.95192e+00 1.95192e-01 1.00000e-09 2.12000e-01

$1.95192 \mathrm{e}+001.95192 \mathrm{e}+00$ 1.95192e-01 1.00000e-09 2.12000e-01

$1.95192 \mathrm{e}+001.95192 \mathrm{e}+001.95192 \mathrm{e}-01$ 1.00000e-09 2.12000e-01

$1.00000 \mathrm{e}-02$ 1.00000e-02 1.00000e-03 1.00000e-09 1.00000e-01 
$1.00000 \mathrm{e}+001.00000 \mathrm{e}+001.00000 \mathrm{e}-011.00000 \mathrm{e}-091.00000 \mathrm{e}-01$ $1.00000 \mathrm{e}-05$ 1.00000e-05 1.00000e-06 1.00000e-09 1.00000e-01 $1.00000 \mathrm{e}+001.00000 \mathrm{e}+001.00000 \mathrm{e}-01$ 1.00000e-09 1.00000e-01 Element: 1263 \# of layers: 10

$\mathrm{Kx} \mathrm{Ky} \mathrm{Kz}$ Ss Por

4.88513e+01 4.88513e+01 4.88513e+00 1.00000e-09 7.00000e-02 1.95192e+00 1.95192e+00 1.95192e-01 1.00000e-09 2.12000e-01 $1.95192 \mathrm{e}+001.95192 \mathrm{e}+001.95192 \mathrm{e}-01$ 1.00000e-09 2.12000e-01 $1.95192 \mathrm{e}+00$ 1.95192e+00 1.95192e-01 1.00000e-09 2.12000e-01 $1.95192 \mathrm{e}+001.95192 \mathrm{e}+00$ 1.95192e-01 1.00000e-09 2.12000e-01 $1.95192 \mathrm{e}+001.95192 \mathrm{e}+00$ 1.95192e-01 1.00000e-09 2.12000e-01 1.00000e-02 1.00000e-02 1.00000e-03 1.00000e-09 1.00000e-01 $1.00000 \mathrm{e}+001.00000 \mathrm{e}+001.00000 \mathrm{e}-011.00000 \mathrm{e}-091.00000 \mathrm{e}-01$ $1.00000 \mathrm{e}-05$ 1.00000e-05 1.00000e-06 1.00000e-09 1.00000e-01 $1.00000 \mathrm{e}+001.00000 \mathrm{e}+001.00000 \mathrm{e}-011.00000 \mathrm{e}-091.00000 \mathrm{e}-01$ Element: 1264 \# of layers: 10

$\mathrm{Kx} \mathrm{Ky} \mathrm{Kz}$ Ss Por

4.88513e+01 4.88513e+01 4.88513e+00 1.00000e-09 7.00000e-02 $1.95192 \mathrm{e}+001.95192 \mathrm{e}+00$ 1.95192e-01 1.00000e-09 2.12000e-01 $1.95192 \mathrm{e}+001.95192 \mathrm{e}+00$ 1.95192e-01 1.00000e-09 2.12000e-01 $1.95192 \mathrm{e}+001.95192 \mathrm{e}+001.95192 \mathrm{e}-01$ 1.00000e-09 2.12000e-01 1.95192e+00 1.95192e+00 1.95192e-01 1.00000e-09 2.12000e-01 $1.95192 \mathrm{e}+001.95192 \mathrm{e}+00$ 1.95192e-01 1.00000e-09 2.12000e-01 $1.00000 \mathrm{e}-02$ 1.00000e-02 1.00000e-03 1.00000e-09 1.00000e-01 $1.00000 \mathrm{e}+001.00000 \mathrm{e}+001.00000 \mathrm{e}-011.00000 \mathrm{e}-091.00000 \mathrm{e}-01$ $1.00000 \mathrm{e}-051.00000 \mathrm{e}-05$ 1.00000e-06 1.00000e-09 1.00000e-01 $1.00000 \mathrm{e}+001.00000 \mathrm{e}+001.00000 \mathrm{e}-01$ 1.00000e-09 1.00000e-01 Element: 1265 \# of layers: 10

$\mathrm{Kx} \mathrm{Ky} \mathrm{Kz} \mathrm{Ss} \mathrm{Por}$

5.23886e+01 5.23886e+01 5.23886e+00 1.00000e-09 7.00000e-02 $2.09327 \mathrm{e}+002.09327 \mathrm{e}+00$ 2.09327e-01 1.00000e-09 2.12000e-01 $2.09327 \mathrm{e}+002.09327 \mathrm{e}+00$ 2.09327e-01 1.00000e-09 2.12000e-01 $2.09327 \mathrm{e}+002.09327 \mathrm{e}+002.09327 \mathrm{e}-01$ 1.00000e-09 2.12000e-01 $2.09327 \mathrm{e}+002.09327 \mathrm{e}+00$ 2.09327e-01 1.00000e-09 2.12000e-01 $2.09327 \mathrm{e}+00$ 2.09327e+00 2.09327e-01 1.00000e-09 2.12000e-01 $1.00000 \mathrm{e}-02$ 1.00000e-02 1.00000e-03 1.00000e-09 1.00000e-01 $1.00000 \mathrm{e}+001.00000 \mathrm{e}+001.00000 \mathrm{e}-011.00000 \mathrm{e}-091.00000 \mathrm{e}-01$ $1.00000 \mathrm{e}-051.00000 \mathrm{e}-05$ 1.00000e-06 1.00000e-09 1.00000e-01 $1.00000 \mathrm{e}+001.00000 \mathrm{e}+001.00000 \mathrm{e}-011.00000 \mathrm{e}-091.00000 \mathrm{e}-01$ Element: 1266 \# of layers: 10

$\mathrm{Kx} \mathrm{Ky} \mathrm{Kz}$ Ss Por

5.23886e+01 5.23886e+01 5.23886e+00 1.00000e-09 7.00000e-02 2.09327e+00 2.09327e+00 2.09327e-01 1.00000e-09 2.12000e-01 $2.09327 \mathrm{e}+002.09327 \mathrm{e}+002.09327 \mathrm{e}-01$ 1.00000e-09 2.12000e-01 $2.09327 \mathrm{e}+002.09327 \mathrm{e}+00$ 2.09327e-01 1.00000e-09 2.12000e-01 $2.09327 \mathrm{e}+002.09327 \mathrm{e}+00$ 2.09327e-01 1.00000e-09 2.12000e-01 
2.09327e+00 2.09327e+00 2.09327e-01 1.00000e-09 2.12000e-01 $1.00000 \mathrm{e}-02$ 1.00000e-02 1.00000e-03 1.00000e-09 1.00000e-01 $1.00000 \mathrm{e}+001.00000 \mathrm{e}+001.00000 \mathrm{e}-011.00000 \mathrm{e}-091.00000 \mathrm{e}-01$ $1.00000 \mathrm{e}-05$ 1.00000e-05 1.00000e-06 1.00000e-09 1.00000e-01 $1.00000 \mathrm{e}+001.00000 \mathrm{e}+001.00000 \mathrm{e}-011.00000 \mathrm{e}-091.00000 \mathrm{e}-01$ Element: 1267 \# of layers: 9

$\mathrm{Kx} \mathrm{Ky} \mathrm{Kz}$ Ss Por

5.23886e+01 5.23886e+01 5.23886e+00 1.00000e-09 7.00000e-02 $2.09327 \mathrm{e}+00$ 2.09327e+00 2.09327e-01 1.00000e-09 2.12000e-01 $2.09327 \mathrm{e}+002.09327 \mathrm{e}+00$ 2.09327e-01 1.00000e-09 2.12000e-01 $2.09327 \mathrm{e}+002.09327 \mathrm{e}+00$ 2.09327e-01 1.00000e-09 2.12000e-01 $2.09327 \mathrm{e}+002.09327 \mathrm{e}+002.09327 \mathrm{e}-01$ 1.00000e-09 2.12000e-01 1.00000e-02 1.00000e-02 1.00000e-03 1.00000e-09 1.00000e-01 $1.00000 \mathrm{e}+001.00000 \mathrm{e}+001.00000 \mathrm{e}-011.00000 \mathrm{e}-091.00000 \mathrm{e}-01$ $1.00000 \mathrm{e}-051.00000 \mathrm{e}-051.00000 \mathrm{e}-061.00000 \mathrm{e}-091.00000 \mathrm{e}-01$ $1.00000 \mathrm{e}+001.00000 \mathrm{e}+001.00000 \mathrm{e}-011.00000 \mathrm{e}-091.00000 \mathrm{e}-01$ Element: 1268 \# of layers: 9

$\mathrm{Kx} \mathrm{Ky} \mathrm{Kz}$ Ss Por

5.23886e+01 5.23886e+01 5.23886e+00 1.00000e-09 7.00000e-02 $2.09327 \mathrm{e}+002.09327 \mathrm{e}+00$ 2.09327e-01 1.00000e-09 2.12000e-01 $2.09327 \mathrm{e}+002.09327 \mathrm{e}+00$ 2.09327e-01 1.00000e-09 2.12000e-01 2.09327e+00 2.09327e+00 2.09327e-01 1.00000e-09 2.12000e-01 $2.09327 \mathrm{e}+002.09327 \mathrm{e}+00$ 2.09327e-01 1.00000e-09 2.12000e-01 $1.00000 \mathrm{e}-02$ 1.00000e-02 1.00000e-03 1.00000e-09 1.00000e-01 $1.00000 \mathrm{e}+001.00000 \mathrm{e}+001.00000 \mathrm{e}-011.00000 \mathrm{e}-091.00000 \mathrm{e}-01$ $1.00000 \mathrm{e}-051.00000 \mathrm{e}-05$ 1.00000e-06 1.00000e-09 1.00000e-01 $1.00000 \mathrm{e}+001.00000 \mathrm{e}+001.00000 \mathrm{e}-01$ 1.00000e-09 1.00000e-01 Element: 1269 \# of layers: 9

Kx Ky Kz Ss Por

5.23886e+01 5.23886e+01 5.23886e+00 1.00000e-09 7.00000e-02 $2.09327 \mathrm{e}+002.09327 \mathrm{e}+00$ 2.09327e-01 1.00000e-09 2.12000e-01 $2.09327 \mathrm{e}+00$ 2.09327e+00 2.09327e-01 1.00000e-09 2.12000e-01 $2.09327 \mathrm{e}+002.09327 \mathrm{e}+00$ 2.09327e-01 1.00000e-09 2.12000e-01 $2.09327 \mathrm{e}+002.09327 \mathrm{e}+002.09327 \mathrm{e}-01$ 1.00000e-09 2.12000e-01 $1.00000 \mathrm{e}-02$ 1.00000e-02 1.00000e-03 1.00000e-09 1.00000e-01 $1.00000 \mathrm{e}+001.00000 \mathrm{e}+001.00000 \mathrm{e}-011.00000 \mathrm{e}-091.00000 \mathrm{e}-01$ $1.00000 \mathrm{e}-05$ 1.00000e-05 1.00000e-06 1.00000e-09 1.00000e-01 $1.00000 \mathrm{e}+001.00000 \mathrm{e}+001.00000 \mathrm{e}-01$ 1.00000e-09 1.00000e-01 Element: 1270 \# of layers: 10

$\mathrm{Kx} \mathrm{Ky} \mathrm{Kz}$ Ss Por

5.23886e+01 5.23886e+01 5.23886e+00 1.00000e-09 7.00000e-02 $2.09327 \mathrm{e}+002.09327 \mathrm{e}+00$ 2.09327e-01 1.00000e-09 2.12000e-01 $2.09327 \mathrm{e}+002.09327 \mathrm{e}+00$ 2.09327e-01 1.00000e-09 2.12000e-01 2.09327e+00 2.09327e+00 2.09327e-01 1.00000e-09 2.12000e-01 $2.09327 \mathrm{e}+002.09327 \mathrm{e}+00$ 2.09327e-01 1.00000e-09 2.12000e-01 $2.09327 \mathrm{e}+002.09327 \mathrm{e}+00$ 2.09327e-01 1.00000e-09 2.12000e-01 
$1.00000 \mathrm{e}-02$ 1.00000e-02 1.00000e-03 1.00000e-09 1.00000e-01 $1.00000 \mathrm{e}+001.00000 \mathrm{e}+001.00000 \mathrm{e}-011.00000 \mathrm{e}-091.00000 \mathrm{e}-01$ $1.00000 \mathrm{e}-05$ 1.00000e-05 1.00000e-06 1.00000e-09 1.00000e-01 $1.00000 \mathrm{e}+001.00000 \mathrm{e}+001.00000 \mathrm{e}-011.00000 \mathrm{e}-091.00000 \mathrm{e}-01$ Element: 1271 \# of layers: 10

Kx Ky Kz Ss Por

$5.23886 \mathrm{e}+015.23886 \mathrm{e}+015.23886 \mathrm{e}+00$ 1.00000e-09 7.00000e-02 $2.09327 \mathrm{e}+002.09327 \mathrm{e}+00$ 2.09327e-01 1.00000e-09 2.12000e-01 $2.09327 \mathrm{e}+002.09327 \mathrm{e}+002.09327 \mathrm{e}-01$ 1.00000e-09 2.12000e-01 $2.09327 \mathrm{e}+002.09327 \mathrm{e}+002.09327 \mathrm{e}-011.00000 \mathrm{e}-092.12000 \mathrm{e}-01$ $2.09327 \mathrm{e}+002.09327 \mathrm{e}+002.09327 \mathrm{e}-01$ 1.00000e-09 2.12000e-01 $2.09327 \mathrm{e}+002.09327 \mathrm{e}+002.09327 \mathrm{e}-01$ 1.00000e-09 2.12000e-01 $1.00000 \mathrm{e}-021.00000 \mathrm{e}-021.00000 \mathrm{e}-031.00000 \mathrm{e}-091.00000 \mathrm{e}-01$ $1.00000 \mathrm{e}+001.00000 \mathrm{e}+001.00000 \mathrm{e}-011.00000 \mathrm{e}-091.00000 \mathrm{e}-01$ $1.00000 \mathrm{e}-05$ 1.00000e-05 1.00000e-06 1.00000e-09 1.00000e-01 $1.00000 \mathrm{e}+001.00000 \mathrm{e}+001.00000 \mathrm{e}-011.00000 \mathrm{e}-091.00000 \mathrm{e}-01$ Element: 1272 \# of layers: 10

Kx Ky Kz Ss Por

$5.23886 \mathrm{e}+015.23886 \mathrm{e}+01$ 5.23886e+00 1.00000e-09 7.00000e-02 $2.09327 \mathrm{e}+002.09327 \mathrm{e}+00$ 2.09327e-01 1.00000e-09 2.12000e-01 $2.09327 \mathrm{e}+002.09327 \mathrm{e}+002.09327 \mathrm{e}-011.00000 \mathrm{e}-092.12000 \mathrm{e}-01$ $2.09327 \mathrm{e}+002.09327 \mathrm{e}+002.09327 \mathrm{e}-011.00000 \mathrm{e}-092.12000 \mathrm{e}-01$ $2.09327 \mathrm{e}+002.09327 \mathrm{e}+002.09327 \mathrm{e}-01$ 1.00000e-09 2.12000e-01 $2.09327 \mathrm{e}+002.09327 \mathrm{e}+00$ 2.09327e-01 1.00000e-09 2.12000e-01 $1.00000 \mathrm{e}-021.00000 \mathrm{e}-02$ 1.00000e-03 1.00000e-09 1.00000e-01 $1.00000 \mathrm{e}+001.00000 \mathrm{e}+001.00000 \mathrm{e}-011.00000 \mathrm{e}-091.00000 \mathrm{e}-01$ $1.00000 \mathrm{e}-05$ 1.00000e-05 1.00000e-06 1.00000e-09 1.00000e-01 $1.00000 \mathrm{e}+001.00000 \mathrm{e}+001.00000 \mathrm{e}-011.00000 \mathrm{e}-091.00000 \mathrm{e}-01$ Element: 1273 \# of layers: 10

Kx Ky Kz Ss Por

$5.23886 \mathrm{e}+015.23886 \mathrm{e}+015.23886 \mathrm{e}+00$ 1.00000e-09 7.00000e-02 $2.09327 \mathrm{e}+002.09327 \mathrm{e}+002.09327 \mathrm{e}-01$ 1.00000e-09 2.12000e-01 $2.09327 \mathrm{e}+002.09327 \mathrm{e}+002.09327 \mathrm{e}-01$ 1.00000e-09 2.12000e-01 $2.09327 \mathrm{e}+002.09327 \mathrm{e}+002.09327 \mathrm{e}-011.00000 \mathrm{e}-092.12000 \mathrm{e}-01$ $2.09327 \mathrm{e}+002.09327 \mathrm{e}+002.09327 \mathrm{e}-01$ 1.00000e-09 2.12000e-01 $2.09327 \mathrm{e}+002.09327 \mathrm{e}+00$ 2.09327e-01 1.00000e-09 2.12000e-01 $1.00000 \mathrm{e}-02$ 1.00000e-02 1.00000e-03 1.00000e-09 1.00000e-01 $1.00000 \mathrm{e}+001.00000 \mathrm{e}+001.00000 \mathrm{e}-011.00000 \mathrm{e}-091.00000 \mathrm{e}-01$ $1.00000 \mathrm{e}-05$ 1.00000e-05 1.00000e-06 1.00000e-09 1.00000e-01 $1.00000 \mathrm{e}+001.00000 \mathrm{e}+001.00000 \mathrm{e}-011.00000 \mathrm{e}-091.00000 \mathrm{e}-01$ Element: 1274 \# of layers: 7

Kx Ky Kz Ss Por

4.67583e+01 4.67583e+01 4.67583e+00 1.00000e-09 7.00000e-02 $1.86828 \mathrm{e}+001.86828 \mathrm{e}+001.86828 \mathrm{e}-011.00000 \mathrm{e}-092.12000 \mathrm{e}-01$ $1.86828 \mathrm{e}+001.86828 \mathrm{e}+001.86828 \mathrm{e}-011.00000 \mathrm{e}-092.12000 \mathrm{e}-01$ $1.86828 \mathrm{e}+001.86828 \mathrm{e}+001.86828 \mathrm{e}-011.00000 \mathrm{e}-092.12000 \mathrm{e}-01$ 
$1.86828 \mathrm{e}+00$ 1.86828e+00 1.86828e-01 1.00000e-09 2.12000e-01 $1.00000 \mathrm{e}-02$ 1.00000e-02 1.00000e-03 1.00000e-09 1.00000e-01 $1.00000 \mathrm{e}+001.00000 \mathrm{e}+001.00000 \mathrm{e}-01$ 1.00000e-09 1.00000e-01 Element: 1275 \# of layers: 6

$\mathrm{Kx} \mathrm{Ky} \mathrm{Kz}$ Ss Por

4.67583e+01 4.67583e+01 4.67583e+00 1.00000e-09 7.00000e-02 $1.86828 \mathrm{e}+001.86828 \mathrm{e}+00$ 1.86828e-01 1.00000e-09 2.12000e-01 $1.86828 \mathrm{e}+001.86828 \mathrm{e}+001.86828 \mathrm{e}-01$ 1.00000e-09 2.12000e-01 $1.86828 \mathrm{e}+001.86828 \mathrm{e}+00$ 1.86828e-01 1.00000e-09 2.12000e-01 $1.00000 \mathrm{e}-02$ 1.00000e-02 1.00000e-03 1.00000e-09 1.00000e-01 $1.00000 \mathrm{e}+001.00000 \mathrm{e}+001.00000 \mathrm{e}-01$ 1.00000e-09 1.00000e-01 Element: 1276 \# of layers: 6

$\mathrm{Kx} \mathrm{Ky} \mathrm{Kz}$ Ss Por

4.67583e+01 4.67583e+01 4.67583e+00 1.00000e-09 7.00000e-02 $1.86828 \mathrm{e}+001.86828 \mathrm{e}+00$ 1.86828e-01 1.00000e-09 2.12000e-01 $1.86828 \mathrm{e}+001.86828 \mathrm{e}+00$ 1.86828e-01 1.00000e-09 2.12000e-01 $1.86828 \mathrm{e}+001.86828 \mathrm{e}+00$ 1.86828e-01 1.00000e-09 2.12000e-01 $1.00000 \mathrm{e}-02$ 1.00000e-02 1.00000e-03 1.00000e-09 1.00000e-01 $1.00000 \mathrm{e}+001.00000 \mathrm{e}+001.00000 \mathrm{e}-01$ 1.00000e-09 1.00000e-01 Element: 1277 \# of layers: 6

$\mathrm{Kx} \mathrm{Ky} \mathrm{Kz}$ Ss Por

4.67583e+01 4.67583e+01 4.67583e+00 1.00000e-09 7.00000e-02 $1.86828 \mathrm{e}+001.86828 \mathrm{e}+00$ 1.86828e-01 1.00000e-09 2.12000e-01 $1.86828 \mathrm{e}+001.86828 \mathrm{e}+00$ 1.86828e-01 1.00000e-09 2.12000e-01 $1.86828 \mathrm{e}+001.86828 \mathrm{e}+001.86828 \mathrm{e}-01$ 1.00000e-09 2.12000e-01 $1.00000 \mathrm{e}-021.00000 \mathrm{e}-021.00000 \mathrm{e}-031.00000 \mathrm{e}-091.00000 \mathrm{e}-01$ $1.00000 \mathrm{e}+001.00000 \mathrm{e}+001.00000 \mathrm{e}-01$ 1.00000e-09 1.00000e-01 Element: 1278 \# of layers: 8

Kx Ky Kz Ss Por

4.67583e+01 4.67583e+01 4.67583e+00 1.00000e-09 7.00000e-02 $1.86828 \mathrm{e}+001.86828 \mathrm{e}+00$ 1.86828e-01 1.00000e-09 2.12000e-01 $1.86828 \mathrm{e}+001.86828 \mathrm{e}+00$ 1.86828e-01 1.00000e-09 2.12000e-01 $1.86828 \mathrm{e}+001.86828 \mathrm{e}+001.86828 \mathrm{e}-01$ 1.00000e-09 2.12000e-01 $1.00000 \mathrm{e}-021.00000 \mathrm{e}-021.00000 \mathrm{e}-031.00000 \mathrm{e}-091.00000 \mathrm{e}-01$ $1.00000 \mathrm{e}+001.00000 \mathrm{e}+001.00000 \mathrm{e}-011.00000 \mathrm{e}-091.00000 \mathrm{e}-01$ $1.00000 \mathrm{e}-05$ 1.00000e-05 1.00000e-06 1.00000e-09 1.00000e-01 $1.00000 \mathrm{e}+001.00000 \mathrm{e}+001.00000 \mathrm{e}-011.00000 \mathrm{e}-091.00000 \mathrm{e}-01$ Element: 1279 \# of layers: 9

$\mathrm{Kx} \mathrm{Ky} \mathrm{Kz}$ Ss Por

4.67583e+01 4.67583e+01 4.67583e+00 1.00000e-09 7.00000e-02 $1.86828 \mathrm{e}+001.86828 \mathrm{e}+00$ 1.86828e-01 1.00000e-09 2.12000e-01 $1.86828 \mathrm{e}+001.86828 \mathrm{e}+00$ 1.86828e-01 1.00000e-09 2.12000e-01 $1.86828 \mathrm{e}+001.86828 \mathrm{e}+00$ 1.86828e-01 1.00000e-09 2.12000e-01 $1.86828 \mathrm{e}+001.86828 \mathrm{e}+00$ 1.86828e-01 1.00000e-09 2.12000e-01 $1.00000 \mathrm{e}-02$ 1.00000e-02 1.00000e-03 1.00000e-09 1.00000e-01 $1.00000 \mathrm{e}+001.00000 \mathrm{e}+001.00000 \mathrm{e}-011.00000 \mathrm{e}-091.00000 \mathrm{e}-01$ 
$1.00000 \mathrm{e}-05$ 1.00000e-05 1.00000e-06 1.00000e-09 1.00000e-01 $1.00000 \mathrm{e}+001.00000 \mathrm{e}+001.00000 \mathrm{e}-011.00000 \mathrm{e}-091.00000 \mathrm{e}-01$ Element: 1280 \# of layers: 9

Kx Ky Kz Ss Por

4.67583e+01 4.67583e+01 4.67583e+00 1.00000e-09 7.00000e-02 $1.86828 \mathrm{e}+001.86828 \mathrm{e}+00$ 1.86828e-01 1.00000e-09 2.12000e-01 $1.86828 \mathrm{e}+001.86828 \mathrm{e}+00$ 1.86828e-01 1.00000e-09 2.12000e-01 $1.86828 \mathrm{e}+001.86828 \mathrm{e}+00$ 1.86828e-01 1.00000e-09 2.12000e-01 $1.86828 \mathrm{e}+001.86828 \mathrm{e}+00$ 1.86828e-01 1.00000e-09 2.12000e-01 $1.00000 \mathrm{e}-02$ 1.00000e-02 1.00000e-03 1.00000e-09 1.00000e-01 $1.00000 \mathrm{e}+001.00000 \mathrm{e}+001.00000 \mathrm{e}-011.00000 \mathrm{e}-091.00000 \mathrm{e}-01$ $1.00000 \mathrm{e}-05$ 1.00000e-05 1.00000e-06 1.00000e-09 1.00000e-01 $1.00000 \mathrm{e}+001.00000 \mathrm{e}+001.00000 \mathrm{e}-011.00000 \mathrm{e}-091.00000 \mathrm{e}-01$ Element: 1281 \# of layers: 9

$\mathrm{Kx} \mathrm{Ky} \mathrm{Kz}$ Ss Por

4.67583e+01 4.67583e+01 4.67583e+00 1.00000e-09 7.00000e-02 $1.86828 \mathrm{e}+001.86828 \mathrm{e}+00$ 1.86828e-01 1.00000e-09 2.12000e-01 $1.86828 \mathrm{e}+001.86828 \mathrm{e}+00$ 1.86828e-01 1.00000e-09 2.12000e-01 $1.86828 \mathrm{e}+001.86828 \mathrm{e}+00$ 1.86828e-01 1.00000e-09 2.12000e-01 $1.86828 \mathrm{e}+001.86828 \mathrm{e}+001.86828 \mathrm{e}-01$ 1.00000e-09 2.12000e-01 $1.00000 \mathrm{e}-02$ 1.00000e-02 1.00000e-03 1.00000e-09 1.00000e-01 $1.00000 \mathrm{e}+001.00000 \mathrm{e}+001.00000 \mathrm{e}-011.00000 \mathrm{e}-091.00000 \mathrm{e}-01$ $1.00000 \mathrm{e}-05$ 1.00000e-05 1.00000e-06 1.00000e-09 1.00000e-01 $1.00000 \mathrm{e}+001.00000 \mathrm{e}+001.00000 \mathrm{e}-011.00000 \mathrm{e}-091.00000 \mathrm{e}-01$ Element: 1282 \# of layers: 8

$\mathrm{Kx} \mathrm{Ky} \mathrm{Kz}$ Ss Por

4.67583e+01 4.67583e+01 4.67583e+00 1.00000e-09 7.00000e-02 $1.86828 \mathrm{e}+001.86828 \mathrm{e}+00$ 1.86828e-01 1.00000e-09 2.12000e-01 $1.86828 \mathrm{e}+001.86828 \mathrm{e}+00$ 1.86828e-01 1.00000e-09 2.12000e-01 $1.86828 \mathrm{e}+001.86828 \mathrm{e}+001.86828 \mathrm{e}-01$ 1.00000e-09 2.12000e-01 $1.00000 \mathrm{e}-02$ 1.00000e-02 1.00000e-03 1.00000e-09 1.00000e-01 $1.00000 \mathrm{e}+001.00000 \mathrm{e}+001.00000 \mathrm{e}-011.00000 \mathrm{e}-091.00000 \mathrm{e}-01$ $1.00000 \mathrm{e}-05$ 1.00000e-05 1.00000e-06 1.00000e-09 1.00000e-01 $1.00000 \mathrm{e}+001.00000 \mathrm{e}+001.00000 \mathrm{e}-011.00000 \mathrm{e}-091.00000 \mathrm{e}-01$ Element: 1283 \# of layers: 6

$\mathrm{Kx} \mathrm{Ky} \mathrm{Kz}$ Ss Por 4.99965e+01 4.99965e+01 4.99965e+00 1.00000e-09 7.00000e-02 $1.99768 \mathrm{e}+001.99768 \mathrm{e}+00$ 1.99768e-01 1.00000e-09 2.12000e-01 $1.99768 \mathrm{e}+001.99768 \mathrm{e}+00$ 1.99768e-01 1.00000e-09 2.12000e-01 $1.99768 \mathrm{e}+001.99768 \mathrm{e}+00$ 1.99768e-01 1.00000e-09 2.12000e-01 $1.00000 \mathrm{e}-02$ 1.00000e-02 1.00000e-03 1.00000e-09 1.00000e-01 $1.00000 \mathrm{e}+001.00000 \mathrm{e}+001.00000 \mathrm{e}-011.00000 \mathrm{e}-091.00000 \mathrm{e}-01$ Element: 1284 \# of layers: 7

$\mathrm{Kx} \mathrm{Ky} \mathrm{Kz}$ Ss Por 4.99965e+01 4.99965e+01 4.99965e+00 1.00000e-09 7.00000e-02 $1.99768 \mathrm{e}+001.99768 \mathrm{e}+001.99768 \mathrm{e}-01$ 1.00000e-09 2.12000e-01 
$1.99768 \mathrm{e}+001.99768 \mathrm{e}+00$ 1.99768e-01 1.00000e-09 2.12000e-01 $1.99768 \mathrm{e}+001.99768 \mathrm{e}+001.99768 \mathrm{e}-011.00000 \mathrm{e}-092.12000 \mathrm{e}-01$ $1.99768 \mathrm{e}+001.99768 \mathrm{e}+00$ 1.99768e-01 1.00000e-09 2.12000e-01 $1.00000 \mathrm{e}-021.00000 \mathrm{e}-02$ 1.00000e-03 1.00000e-09 1.00000e-01 $1.00000 \mathrm{e}+001.00000 \mathrm{e}+001.00000 \mathrm{e}-011.00000 \mathrm{e}-091.00000 \mathrm{e}-01$ Element: 1285 \# of layers: 6

Kx Ky Kz Ss Por

4.99965e+01 4.99965e+01 4.99965e+00 1.00000e-09 7.00000e-02 $1.99768 \mathrm{e}+001.99768 \mathrm{e}+001.99768 \mathrm{e}-011.00000 \mathrm{e}-092.12000 \mathrm{e}-01$ $1.99768 \mathrm{e}+001.99768 \mathrm{e}+001.99768 \mathrm{e}-011.00000 \mathrm{e}-092.12000 \mathrm{e}-01$ $1.99768 \mathrm{e}+001.99768 \mathrm{e}+001.99768 \mathrm{e}-011.00000 \mathrm{e}-09$ 2.12000e-01 $1.00000 \mathrm{e}-021.00000 \mathrm{e}-02$ 1.00000e-03 1.00000e-09 1.00000e-01 $1.00000 \mathrm{e}+001.00000 \mathrm{e}+001.00000 \mathrm{e}-011.00000 \mathrm{e}-091.00000 \mathrm{e}-01$ Element: 1286 \# of layers: 6

Kx Ky Kz Ss Por $4.99965 \mathrm{e}+014.99965 \mathrm{e}+014.99965 \mathrm{e}+00$ 1.00000e-09 7.00000e-02 $1.99768 \mathrm{e}+001.99768 \mathrm{e}+00$ 1.99768e-01 1.00000e-09 2.12000e-01 $1.99768 \mathrm{e}+001.99768 \mathrm{e}+001.99768 \mathrm{e}-011.00000 \mathrm{e}-092.12000 \mathrm{e}-01$ $1.99768 \mathrm{e}+001.99768 \mathrm{e}+001.99768 \mathrm{e}-011.00000 \mathrm{e}-092.12000 \mathrm{e}-01$ $1.00000 \mathrm{e}-02$ 1.00000e-02 1.00000e-03 1.00000e-09 1.00000e-01 $1.00000 \mathrm{e}+001.00000 \mathrm{e}+001.00000 \mathrm{e}-011.00000 \mathrm{e}-091.00000 \mathrm{e}-01$ Element: 1287 \# of layers: 6

Kx Ky Kz Ss Por $4.99965 \mathrm{e}+014.99965 \mathrm{e}+014.99965 \mathrm{e}+00$ 1.00000e-09 7.00000e-02 $1.99768 \mathrm{e}+001.99768 \mathrm{e}+001.99768 \mathrm{e}-011.00000 \mathrm{e}-092.12000 \mathrm{e}-01$ $1.99768 \mathrm{e}+001.99768 \mathrm{e}+001.99768 \mathrm{e}-011.00000 \mathrm{e}-092.12000 \mathrm{e}-01$ $1.99768 \mathrm{e}+001.99768 \mathrm{e}+001.99768 \mathrm{e}-011.00000 \mathrm{e}-092.12000 \mathrm{e}-01$ $1.00000 \mathrm{e}-011.00000 \mathrm{e}-011.00000 \mathrm{e}-021.00000 \mathrm{e}-091.00000 \mathrm{e}-01$ $1.00000 \mathrm{e}+001.00000 \mathrm{e}+001.00000 \mathrm{e}-011.00000 \mathrm{e}-091.00000 \mathrm{e}-01$ Element: 1288 \# of layers: 7

Kx Ky Kz Ss Por

$4.99965 \mathrm{e}+014.99965 \mathrm{e}+014.99965 \mathrm{e}+00$ 1.00000e-09 7.00000e-02 $1.99768 \mathrm{e}+001.99768 \mathrm{e}+00$ 1.99768e-01 1.00000e-09 2.12000e-01 $1.99768 \mathrm{e}+001.99768 \mathrm{e}+001.99768 \mathrm{e}-011.00000 \mathrm{e}-092.12000 \mathrm{e}-01$ $1.99768 \mathrm{e}+001.99768 \mathrm{e}+001.99768 \mathrm{e}-011.00000 \mathrm{e}-092.12000 \mathrm{e}-01$ $1.99768 \mathrm{e}+001.99768 \mathrm{e}+001.99768 \mathrm{e}-011.00000 \mathrm{e}-09$ 2.12000e-01 $1.00000 \mathrm{e}-011.00000 \mathrm{e}-011.00000 \mathrm{e}-021.00000 \mathrm{e}-091.00000 \mathrm{e}-01$ $1.00000 \mathrm{e}+001.00000 \mathrm{e}+001.00000 \mathrm{e}-011.00000 \mathrm{e}-091.00000 \mathrm{e}-01$ Element: 1289 \# of layers: 6

Kx Ky Kz Ss Por $4.99965 \mathrm{e}+014.99965 \mathrm{e}+014.99965 \mathrm{e}+00$ 1.00000e-09 7.00000e-02 $1.99768 \mathrm{e}+001.99768 \mathrm{e}+00$ 1.99768e-01 1.00000e-09 2.12000e-01 $1.99768 \mathrm{e}+001.99768 \mathrm{e}+001.99768 \mathrm{e}-011.00000 \mathrm{e}-092.12000 \mathrm{e}-01$ $1.99768 \mathrm{e}+001.99768 \mathrm{e}+001.99768 \mathrm{e}-011.00000 \mathrm{e}-092.12000 \mathrm{e}-01$ $1.00000 \mathrm{e}-011.00000 \mathrm{e}-011.00000 \mathrm{e}-021.00000 \mathrm{e}-091.00000 \mathrm{e}-01$ $1.00000 \mathrm{e}+001.00000 \mathrm{e}+001.00000 \mathrm{e}-011.00000 \mathrm{e}-091.00000 \mathrm{e}-01$ 
Element: 1290 \# of layers: 6

Kx Ky Kz Ss Por

$4.99965 \mathrm{e}+014.99965 \mathrm{e}+014.99965 \mathrm{e}+00$ 1.00000e-09 7.00000e-02

$1.99768 \mathrm{e}+001.99768 \mathrm{e}+001.99768 \mathrm{e}-011.00000 \mathrm{e}-092.12000 \mathrm{e}-01$

$1.99768 \mathrm{e}+001.99768 \mathrm{e}+001.99768 \mathrm{e}-011.00000 \mathrm{e}-092.12000 \mathrm{e}-01$

$1.99768 \mathrm{e}+001.99768 \mathrm{e}+001.99768 \mathrm{e}-011.00000 \mathrm{e}-092.12000 \mathrm{e}-01$

$1.00000 \mathrm{e}-021.00000 \mathrm{e}-02$ 1.00000e-03 1.00000e-09 1.00000e-01

$1.00000 \mathrm{e}+001.00000 \mathrm{e}+001.00000 \mathrm{e}-011.00000 \mathrm{e}-091.00000 \mathrm{e}-01$

Element: 1291 \# of layers: 7

Kx Ky Kz Ss Por

$4.99965 \mathrm{e}+014.99965 \mathrm{e}+014.99965 \mathrm{e}+00$ 1.00000e-09 7.00000e-02

$1.99768 \mathrm{e}+001.99768 \mathrm{e}+00$ 1.99768e-01 1.00000e-09 2.12000e-01

$1.99768 \mathrm{e}+001.99768 \mathrm{e}+001.99768 \mathrm{e}-011.00000 \mathrm{e}-092.12000 \mathrm{e}-01$

$1.99768 \mathrm{e}+001.99768 \mathrm{e}+001.99768 \mathrm{e}-01$ 1.00000e-09 2.12000e-01

$1.99768 \mathrm{e}+001.99768 \mathrm{e}+001.99768 \mathrm{e}-011.00000 \mathrm{e}-092.12000 \mathrm{e}-01$

$1.00000 \mathrm{e}-021.00000 \mathrm{e}-02$ 1.00000e-03 1.00000e-09 1.00000e-01

$1.00000 \mathrm{e}+001.00000 \mathrm{e}+001.00000 \mathrm{e}-011.00000 \mathrm{e}-091.00000 \mathrm{e}-01$

Element: 1292 \# of layers: 7

Kx Ky Kz Ss Por

$4.18623 \mathrm{e}+014.18623 \mathrm{e}+014.18623 \mathrm{e}+00$ 1.00000e-09 7.00000e-02

$4.18623 \mathrm{e}+014.18623 \mathrm{e}+014.18623 \mathrm{e}+001.00000 \mathrm{e}-09$ 7.00000e-02

$1.67266 \mathrm{e}+001.67266 \mathrm{e}+001.67266 \mathrm{e}-011.00000 \mathrm{e}-092.12000 \mathrm{e}-01$

$1.67266 \mathrm{e}+001.67266 \mathrm{e}+001.67266 \mathrm{e}-011.00000 \mathrm{e}-092.12000 \mathrm{e}-01$

$1.67266 \mathrm{e}+001.67266 \mathrm{e}+001.67266 \mathrm{e}-011.00000 \mathrm{e}-092.12000 \mathrm{e}-01$

$1.00000 \mathrm{e}-021.00000 \mathrm{e}-02$ 1.00000e-03 1.00000e-09 1.00000e-01

$1.00000 \mathrm{e}+001.00000 \mathrm{e}+001.00000 \mathrm{e}-011.00000 \mathrm{e}-091.00000 \mathrm{e}-01$

Element: 1293 \# of layers: 7

Kx Ky Kz Ss Por

4.18623e+01 4.18623e+01 4.18623e+00 1.00000e-09 7.00000e-02

$4.18623 \mathrm{e}+014.18623 \mathrm{e}+014.18623 \mathrm{e}+001.00000 \mathrm{e}-09$ 7.00000e-02

$1.67266 \mathrm{e}+001.67266 \mathrm{e}+001.67266 \mathrm{e}-011.00000 \mathrm{e}-092.12000 \mathrm{e}-01$

$1.67266 \mathrm{e}+001.67266 \mathrm{e}+001.67266 \mathrm{e}-011.00000 \mathrm{e}-092.12000 \mathrm{e}-01$

$1.67266 \mathrm{e}+001.67266 \mathrm{e}+001.67266 \mathrm{e}-011.00000 \mathrm{e}-092.12000 \mathrm{e}-01$

$1.00000 \mathrm{e}-011.00000 \mathrm{e}-011.00000 \mathrm{e}-021.00000 \mathrm{e}-091.00000 \mathrm{e}-01$

$1.00000 \mathrm{e}+001.00000 \mathrm{e}+001.00000 \mathrm{e}-011.00000 \mathrm{e}-091.00000 \mathrm{e}-01$

Element: 1294 \# of layers: 7

Kx Ky Kz Ss Por

$4.18623 \mathrm{e}+014.18623 \mathrm{e}+014.18623 \mathrm{e}+00$ 1.00000e-09 7.00000e-02

$4.18623 \mathrm{e}+014.18623 \mathrm{e}+014.18623 \mathrm{e}+00$ 1.00000e-09 7.00000e-02

$1.67266 \mathrm{e}+001.67266 \mathrm{e}+001.67266 \mathrm{e}-011.00000 \mathrm{e}-092.12000 \mathrm{e}-01$

$1.67266 \mathrm{e}+001.67266 \mathrm{e}+001.67266 \mathrm{e}-011.00000 \mathrm{e}-092.12000 \mathrm{e}-01$

$1.67266 \mathrm{e}+001.67266 \mathrm{e}+001.67266 \mathrm{e}-011.00000 \mathrm{e}-09$ 2.12000e-01

$1.00000 \mathrm{e}-011.00000 \mathrm{e}-011.00000 \mathrm{e}-021.00000 \mathrm{e}-091.00000 \mathrm{e}-01$

$1.00000 \mathrm{e}+001.00000 \mathrm{e}+001.00000 \mathrm{e}-011.00000 \mathrm{e}-091.00000 \mathrm{e}-01$

Element: 1295 \# of layers: 11

Kx Ky Kz Ss Por 
$1.06786 \mathrm{e}+031.06786 \mathrm{e}+03$ 1.06787e+02 1.00000e-09 7.00000e-02 $1.06786 \mathrm{e}+03$ 1.06786e+03 1.06787e+02 1.00000e-09 7.00000e-02 $4.26699 \mathrm{e}+014.26699 \mathrm{e}+01$ 4.26699e+00 1.00000e-09 2.12000e-01 $4.26699 \mathrm{e}+014.26699 \mathrm{e}+014.26699 \mathrm{e}+001.00000 \mathrm{e}-09$ 2.12000e-01 $4.26699 \mathrm{e}+014.26699 \mathrm{e}+014.26699 \mathrm{e}+001.00000 \mathrm{e}-092.12000 \mathrm{e}-01$ $4.26699 \mathrm{e}+014.26699 \mathrm{e}+014.26699 \mathrm{e}+00$ 1.00000e-09 2.12000e-01 $4.26699 \mathrm{e}+014.26699 \mathrm{e}+014.26699 \mathrm{e}+00$ 1.00000e-09 2.12000e-01 $1.00000 \mathrm{e}-02$ 1.00000e-02 1.00000e-03 1.00000e-09 1.00000e-01 $1.00000 \mathrm{e}+001.00000 \mathrm{e}+001.00000 \mathrm{e}-011.00000 \mathrm{e}-091.00000 \mathrm{e}-01$ $1.00000 \mathrm{e}-05$ 1.00000e-05 1.00000e-06 1.00000e-09 1.00000e-01 $1.00000 \mathrm{e}+001.00000 \mathrm{e}+001.00000 \mathrm{e}-011.00000 \mathrm{e}-091.00000 \mathrm{e}-01$ Element: 1296 \# of layers: 11

$\mathrm{Kx} \mathrm{Ky} \mathrm{Kz}$ Ss Por

$1.06786 \mathrm{e}+031.06786 \mathrm{e}+03$ 1.06787e+02 1.00000e-09 7.00000e-02 $1.06786 \mathrm{e}+031.06786 \mathrm{e}+03$ 1.06787e+02 1.00000e-09 7.00000e-02 $4.26699 \mathrm{e}+014.26699 \mathrm{e}+014.26699 \mathrm{e}+001.00000 \mathrm{e}-092.12000 \mathrm{e}-01$ $4.26699 \mathrm{e}+014.26699 \mathrm{e}+014.26699 \mathrm{e}+00$ 1.00000e-09 2.12000e-01 $4.26699 \mathrm{e}+014.26699 \mathrm{e}+014.26699 \mathrm{e}+00$ 1.00000e-09 2.12000e-01 4.26699e+01 4.26699e+01 4.26699e+00 1.00000e-09 2.12000e-01 $4.26699 \mathrm{e}+014.26699 \mathrm{e}+014.26699 \mathrm{e}+00$ 1.00000e-09 2.12000e-01 $1.00000 \mathrm{e}-02$ 1.00000e-02 1.00000e-03 1.00000e-09 1.00000e-01 $1.00000 \mathrm{e}+001.00000 \mathrm{e}+001.00000 \mathrm{e}-011.00000 \mathrm{e}-091.00000 \mathrm{e}-01$ $1.00000 \mathrm{e}-051.00000 \mathrm{e}-05$ 1.00000e-06 1.00000e-09 1.00000e-01 $1.00000 \mathrm{e}+001.00000 \mathrm{e}+001.00000 \mathrm{e}-011.00000 \mathrm{e}-09$ 1.00000e-01 Element: 1297 \# of layers: 12

$\mathrm{Kx} \mathrm{Ky} \mathrm{Kz}$ Ss Por

$1.06786 \mathrm{e}+03$ 1.06786e+03 1.06787e+02 1.00000e-09 7.00000e-02 $1.06786 \mathrm{e}+031.06786 \mathrm{e}+03$ 1.06787e+02 1.00000e-09 7.00000e-02 5.00000e-04 5.00000e-04 5.00000e-05 1.00000e-09 1.00000e-01 $4.26699 \mathrm{e}+01$ 4.26699e+01 4.26699e+00 1.00000e-09 2.12000e-01 $4.26699 \mathrm{e}+014.26699 \mathrm{e}+014.26699 \mathrm{e}+00$ 1.00000e-09 2.12000e-01 4.26699e+01 4.26699e+01 4.26699e+00 1.00000e-09 2.12000e-01 $4.26699 \mathrm{e}+01$ 4.26699e+01 4.26699e+00 1.00000e-09 2.12000e-01 $4.26699 \mathrm{e}+014.26699 \mathrm{e}+014.26699 \mathrm{e}+00$ 1.00000e-09 2.12000e-01 $1.00000 \mathrm{e}-02$ 1.00000e-02 1.00000e-03 1.00000e-09 1.00000e-01 $1.00000 \mathrm{e}+001.00000 \mathrm{e}+001.00000 \mathrm{e}-011.00000 \mathrm{e}-091.00000 \mathrm{e}-01$ $1.00000 \mathrm{e}-05$ 1.00000e-05 1.00000e-06 1.00000e-09 1.00000e-01 $1.00000 \mathrm{e}+001.00000 \mathrm{e}+001.00000 \mathrm{e}-011.00000 \mathrm{e}-091.00000 \mathrm{e}-01$ Element: 1298 \# of layers: 12

$\mathrm{Kx} \mathrm{Ky} \mathrm{Kz}$ Ss Por $1.06786 \mathrm{e}+03$ 1.06786e+03 1.06787e+02 1.00000e-09 7.00000e-02 $1.06786 \mathrm{e}+03$ 1.06786e+03 1.06787e+02 1.00000e-09 7.00000e-02 5.00000e-04 5.00000e-04 5.00000e-05 1.00000e-09 1.00000e-01 4.26699e+01 4.26699e+01 4.26699e+00 1.00000e-09 2.12000e-01 4.26699e+01 4.26699e+01 4.26699e+00 1.00000e-09 2.12000e-01 $4.26699 \mathrm{e}+014.26699 \mathrm{e}+014.26699 \mathrm{e}+001.00000 \mathrm{e}-09$ 2.12000e-01 
4.26699e+01 4.26699e+01 4.26699e+00 1.00000e-09 2.12000e-01 4.26699e+01 4.26699e+01 4.26699e+00 1.00000e-09 2.12000e-01 $1.00000 \mathrm{e}-02$ 1.00000e-02 1.00000e-03 1.00000e-09 1.00000e-01 $1.00000 \mathrm{e}+001.00000 \mathrm{e}+001.00000 \mathrm{e}-011.00000 \mathrm{e}-091.00000 \mathrm{e}-01$ $1.00000 \mathrm{e}-05$ 1.00000e-05 1.00000e-06 1.00000e-09 1.00000e-01 $1.00000 \mathrm{e}+001.00000 \mathrm{e}+001.00000 \mathrm{e}-011.00000 \mathrm{e}-091.00000 \mathrm{e}-01$ Element: 1299 \# of layers: 12

Kx Ky Kz Ss Por

$1.06786 \mathrm{e}+03$ 1.06786e+03 1.06787e+02 1.00000e-09 7.00000e-02 $1.06786 \mathrm{e}+031.06786 \mathrm{e}+03$ 1.06787e+02 1.00000e-09 7.00000e-02 5.00000e-04 5.00000e-04 5.00000e-05 1.00000e-09 1.00000e-01 $4.26699 \mathrm{e}+01$ 4.26699e+01 4.26699e+00 1.00000e-09 2.12000e-01 4.26699e+01 4.26699e+01 4.26699e+00 1.00000e-09 2.12000e-01 $4.26699 \mathrm{e}+014.26699 \mathrm{e}+014.26699 \mathrm{e}+00$ 1.00000e-09 2.12000e-01 $4.26699 \mathrm{e}+014.26699 \mathrm{e}+014.26699 \mathrm{e}+00$ 1.00000e-09 2.12000e-01 $4.26699 \mathrm{e}+014.26699 \mathrm{e}+014.26699 \mathrm{e}+00$ 1.00000e-09 2.12000e-01 $1.00000 \mathrm{e}-02$ 1.00000e-02 1.00000e-03 1.00000e-09 1.00000e-01 $1.00000 \mathrm{e}+001.00000 \mathrm{e}+001.00000 \mathrm{e}-011.00000 \mathrm{e}-091.00000 \mathrm{e}-01$ $1.00000 \mathrm{e}-05$ 1.00000e-05 1.00000e-06 1.00000e-09 1.00000e-01 $1.00000 \mathrm{e}+001.00000 \mathrm{e}+001.00000 \mathrm{e}-011.00000 \mathrm{e}-091.00000 \mathrm{e}-01$ Element: 1300 \# of layers: 11

$\mathrm{Kx} \mathrm{Ky} \mathrm{Kz}$ Ss Por

7.31603e+02 7.31603e+02 7.31603e+01 1.00000e-09 7.00000e-02 7.31603e+02 7.31603e+02 7.31603e+01 1.00000e-09 7.00000e-02 $2.92326 \mathrm{e}+012.92326 \mathrm{e}+012.92326 \mathrm{e}+001.00000 \mathrm{e}-092.12000 \mathrm{e}-01$ $2.92326 \mathrm{e}+012.92326 \mathrm{e}+012.92326 \mathrm{e}+001.00000 \mathrm{e}-092.12000 \mathrm{e}-01$ $2.92326 \mathrm{e}+012.92326 \mathrm{e}+012.92326 \mathrm{e}+00$ 1.00000e-09 2.12000e-01 $2.92326 \mathrm{e}+012.92326 \mathrm{e}+012.92326 \mathrm{e}+00$ 1.00000e-09 2.12000e-01 $2.92326 \mathrm{e}+012.92326 \mathrm{e}+012.92326 \mathrm{e}+001.00000 \mathrm{e}-092.12000 \mathrm{e}-01$ $1.00000 \mathrm{e}-02$ 1.00000e-02 1.00000e-03 1.00000e-09 1.00000e-01 $1.00000 \mathrm{e}+001.00000 \mathrm{e}+001.00000 \mathrm{e}-011.00000 \mathrm{e}-091.00000 \mathrm{e}-01$ $1.00000 \mathrm{e}-05$ 1.00000e-05 1.00000e-06 1.00000e-09 1.00000e-01 $1.00000 \mathrm{e}+001.00000 \mathrm{e}+001.00000 \mathrm{e}-011.00000 \mathrm{e}-091.00000 \mathrm{e}-01$ Element: 1301 \# of layers: 10

$\mathrm{Kx} \mathrm{Ky} \mathrm{Kz}$ Ss Por

7.31603e+02 7.31603e+02 7.31603e+01 1.00000e-09 7.00000e-02 $2.92326 \mathrm{e}+012.92326 \mathrm{e}+012.92326 \mathrm{e}+001.00000 \mathrm{e}-092.12000 \mathrm{e}-01$ $2.92326 \mathrm{e}+012.92326 \mathrm{e}+012.92326 \mathrm{e}+001.00000 \mathrm{e}-092.12000 \mathrm{e}-01$ $2.92326 \mathrm{e}+012.92326 \mathrm{e}+012.92326 \mathrm{e}+001.00000 \mathrm{e}-092.12000 \mathrm{e}-01$ $2.92326 \mathrm{e}+012.92326 \mathrm{e}+012.92326 \mathrm{e}+001.00000 \mathrm{e}-092.12000 \mathrm{e}-01$ $2.92326 \mathrm{e}+012.92326 \mathrm{e}+012.92326 \mathrm{e}+001.00000 \mathrm{e}-092.12000 \mathrm{e}-01$ $1.00000 \mathrm{e}-021.00000 \mathrm{e}-02$ 1.00000e-03 1.00000e-09 1.00000e-01 $1.00000 \mathrm{e}+001.00000 \mathrm{e}+001.00000 \mathrm{e}-011.00000 \mathrm{e}-091.00000 \mathrm{e}-01$ $1.00000 \mathrm{e}-051.00000 \mathrm{e}-051.00000 \mathrm{e}-061.00000 \mathrm{e}-091.00000 \mathrm{e}-01$ $1.00000 \mathrm{e}+001.00000 \mathrm{e}+001.00000 \mathrm{e}-01$ 1.00000e-09 1.00000e-01 Element: 1302 \# of layers: 10 
$\mathrm{Kx} \mathrm{Ky} \mathrm{Kz}$ Ss Por

7.31603e+02 7.31603e+02 7.31603e+01 1.00000e-09 7.00000e-02 $2.92326 \mathrm{e}+012.92326 \mathrm{e}+012.92326 \mathrm{e}+00$ 1.00000e-09 2.12000e-01 $2.92326 \mathrm{e}+012.92326 \mathrm{e}+012.92326 \mathrm{e}+001.00000 \mathrm{e}-092.12000 \mathrm{e}-01$ $2.92326 \mathrm{e}+012.92326 \mathrm{e}+012.92326 \mathrm{e}+001.00000 \mathrm{e}-092.12000 \mathrm{e}-01$ $2.92326 \mathrm{e}+012.92326 \mathrm{e}+012.92326 \mathrm{e}+001.00000 \mathrm{e}-092.12000 \mathrm{e}-01$ $2.92326 \mathrm{e}+012.92326 \mathrm{e}+012.92326 \mathrm{e}+001.00000 \mathrm{e}-092.12000 \mathrm{e}-01$ $1.00000 \mathrm{e}-02$ 1.00000e-02 1.00000e-03 1.00000e-09 1.00000e-01 $1.00000 \mathrm{e}+001.00000 \mathrm{e}+001.00000 \mathrm{e}-011.00000 \mathrm{e}-091.00000 \mathrm{e}-01$ $1.00000 \mathrm{e}-05$ 1.00000e-05 1.00000e-06 1.00000e-09 1.00000e-01 $1.00000 \mathrm{e}+001.00000 \mathrm{e}+001.00000 \mathrm{e}-011.00000 \mathrm{e}-091.00000 \mathrm{e}-01$ Element: 1303 \# of layers: 10

$\mathrm{Kx} \mathrm{Ky} \mathrm{Kz}$ Ss Por

7.31603e+02 7.31603e+02 7.31603e+01 1.00000e-09 7.00000e-02 $2.92326 \mathrm{e}+012.92326 \mathrm{e}+012.92326 \mathrm{e}+001.00000 \mathrm{e}-092.12000 \mathrm{e}-01$ $2.92326 \mathrm{e}+012.92326 \mathrm{e}+012.92326 \mathrm{e}+001.00000 \mathrm{e}-092.12000 \mathrm{e}-01$ $2.92326 \mathrm{e}+012.92326 \mathrm{e}+012.92326 \mathrm{e}+00$ 1.00000e-09 2.12000e-01 $2.92326 \mathrm{e}+012.92326 \mathrm{e}+012.92326 \mathrm{e}+00$ 1.00000e-09 2.12000e-01 $2.92326 \mathrm{e}+012.92326 \mathrm{e}+012.92326 \mathrm{e}+00$ 1.00000e-09 2.12000e-01 $1.00000 \mathrm{e}-02$ 1.00000e-02 1.00000e-03 1.00000e-09 1.00000e-01 $1.00000 \mathrm{e}+001.00000 \mathrm{e}+001.00000 \mathrm{e}-011.00000 \mathrm{e}-091.00000 \mathrm{e}-01$ $1.00000 \mathrm{e}-05$ 1.00000e-05 1.00000e-06 1.00000e-09 1.00000e-01 $1.00000 \mathrm{e}+001.00000 \mathrm{e}+001.00000 \mathrm{e}-01$ 1.00000e-09 1.00000e-01 Element: 1304 \# of layers: 11

Kx Ky Kz Ss Por

7.31603e+02 7.31603e+02 7.31603e+01 1.00000e-09 7.00000e-02 7.31603e+02 7.31603e+02 7.31603e+01 1.00000e-09 7.00000e-02 $2.92326 \mathrm{e}+012.92326 \mathrm{e}+012.92326 \mathrm{e}+001.00000 \mathrm{e}-092.12000 \mathrm{e}-01$ $2.92326 \mathrm{e}+012.92326 \mathrm{e}+012.92326 \mathrm{e}+001.00000 \mathrm{e}-092.12000 \mathrm{e}-01$ $2.92326 \mathrm{e}+012.92326 \mathrm{e}+012.92326 \mathrm{e}+001.00000 \mathrm{e}-092.12000 \mathrm{e}-01$ $2.92326 \mathrm{e}+012.92326 \mathrm{e}+012.92326 \mathrm{e}+001.00000 \mathrm{e}-092.12000 \mathrm{e}-01$ $2.92326 \mathrm{e}+012.92326 \mathrm{e}+012.92326 \mathrm{e}+00$ 1.00000e-09 2.12000e-01 1.00000e-02 1.00000e-02 1.00000e-03 1.00000e-09 1.00000e-01 $1.00000 \mathrm{e}+001.00000 \mathrm{e}+001.00000 \mathrm{e}-011.00000 \mathrm{e}-091.00000 \mathrm{e}-01$ $1.00000 \mathrm{e}-05$ 1.00000e-05 1.00000e-06 1.00000e-09 1.00000e-01 $1.00000 \mathrm{e}+001.00000 \mathrm{e}+001.00000 \mathrm{e}-011.00000 \mathrm{e}-091.00000 \mathrm{e}-01$ Element: 1305 \# of layers: 12

Kx Ky Kz Ss Por

7.31603e+02 7.31603e+02 7.31603e+01 1.00000e-09 7.00000e-02 $7.31603 \mathrm{e}+02$ 7.31603e+02 7.31603e+01 1.00000e-09 7.00000e-02 5.00000e-04 5.00000e-04 5.00000e-05 1.00000e-09 1.00000e-01 $2.92326 \mathrm{e}+012.92326 \mathrm{e}+012.92326 \mathrm{e}+001.00000 \mathrm{e}-092.12000 \mathrm{e}-01$ $2.92326 \mathrm{e}+012.92326 \mathrm{e}+012.92326 \mathrm{e}+00$ 1.00000e-09 2.12000e-01 $2.92326 \mathrm{e}+012.92326 \mathrm{e}+012.92326 \mathrm{e}+001.00000 \mathrm{e}-092.12000 \mathrm{e}-01$ $2.92326 \mathrm{e}+012.92326 \mathrm{e}+012.92326 \mathrm{e}+00$ 1.00000e-09 2.12000e-01 $2.92326 \mathrm{e}+012.92326 \mathrm{e}+012.92326 \mathrm{e}+001.00000 \mathrm{e}-092.12000 \mathrm{e}-01$ 
$1.00000 \mathrm{e}-02$ 1.00000e-02 1.00000e-03 1.00000e-09 1.00000e-01 $1.00000 \mathrm{e}+001.00000 \mathrm{e}+001.00000 \mathrm{e}-011.00000 \mathrm{e}-091.00000 \mathrm{e}-01$ $1.00000 \mathrm{e}-05$ 1.00000e-05 1.00000e-06 1.00000e-09 1.00000e-01 $1.00000 \mathrm{e}+001.00000 \mathrm{e}+001.00000 \mathrm{e}-011.00000 \mathrm{e}-091.00000 \mathrm{e}-01$ Element: 1306 \# of layers: 12

Kx Ky Kz Ss Por

7.31603e+02 7.31603e+02 7.31603e+01 1.00000e-09 7.00000e-02 $7.31603 \mathrm{e}+02$ 7.31603e+02 7.31603e+01 1.00000e-09 7.00000e-02 5.00000e-04 5.00000e-04 5.00000e-05 1.00000e-09 1.00000e-01 $2.92326 \mathrm{e}+012.92326 \mathrm{e}+012.92326 \mathrm{e}+001.00000 \mathrm{e}-092.12000 \mathrm{e}-01$ $2.92326 \mathrm{e}+012.92326 \mathrm{e}+012.92326 \mathrm{e}+001.00000 \mathrm{e}-092.12000 \mathrm{e}-01$ $2.92326 \mathrm{e}+012.92326 \mathrm{e}+012.92326 \mathrm{e}+001.00000 \mathrm{e}-092.12000 \mathrm{e}-01$ $2.92326 \mathrm{e}+012.92326 \mathrm{e}+012.92326 \mathrm{e}+001.00000 \mathrm{e}-092.12000 \mathrm{e}-01$ $2.92326 \mathrm{e}+012.92326 \mathrm{e}+012.92326 \mathrm{e}+001.00000 \mathrm{e}-092.12000 \mathrm{e}-01$ $1.00000 \mathrm{e}-021.00000 \mathrm{e}-02$ 1.00000e-03 1.00000e-09 1.00000e-01 $1.00000 \mathrm{e}+001.00000 \mathrm{e}+001.00000 \mathrm{e}-011.00000 \mathrm{e}-091.00000 \mathrm{e}-01$ $1.00000 \mathrm{e}-05$ 1.00000e-05 1.00000e-06 1.00000e-09 1.00000e-01 $1.00000 \mathrm{e}+001.00000 \mathrm{e}+001.00000 \mathrm{e}-011.00000 \mathrm{e}-091.00000 \mathrm{e}-01$ Element: 1307 \# of layers: 10

Kx Ky Kz Ss Por

$7.31603 \mathrm{e}+02$ 7.31603e+02 7.31603e+01 1.00000e-09 7.00000e-02 $2.92326 \mathrm{e}+012.92326 \mathrm{e}+012.92326 \mathrm{e}+001.00000 \mathrm{e}-092.12000 \mathrm{e}-01$ $2.92326 \mathrm{e}+012.92326 \mathrm{e}+012.92326 \mathrm{e}+001.00000 \mathrm{e}-092.12000 \mathrm{e}-01$ $2.92326 \mathrm{e}+012.92326 \mathrm{e}+012.92326 \mathrm{e}+001.00000 \mathrm{e}-092.12000 \mathrm{e}-01$ $2.92326 \mathrm{e}+012.92326 \mathrm{e}+012.92326 \mathrm{e}+001.00000 \mathrm{e}-092.12000 \mathrm{e}-01$ $2.92326 \mathrm{e}+012.92326 \mathrm{e}+012.92326 \mathrm{e}+001.00000 \mathrm{e}-092.12000 \mathrm{e}-01$ $1.00000 \mathrm{e}-02$ 1.00000e-02 1.00000e-03 1.00000e-09 1.00000e-01 $1.00000 \mathrm{e}+001.00000 \mathrm{e}+001.00000 \mathrm{e}-011.00000 \mathrm{e}-091.00000 \mathrm{e}-01$ $1.00000 \mathrm{e}-05$ 1.00000e-05 1.00000e-06 1.00000e-09 1.00000e-01 $1.00000 \mathrm{e}+001.00000 \mathrm{e}+001.00000 \mathrm{e}-011.00000 \mathrm{e}-091.00000 \mathrm{e}-01$ Element: 1308 \# of layers: 10

Kx Ky Kz Ss Por

$7.31603 \mathrm{e}+02$ 7.31603e+02 7.31603e+01 1.00000e-09 7.00000e-02 $2.92326 \mathrm{e}+012.92326 \mathrm{e}+012.92326 \mathrm{e}+001.00000 \mathrm{e}-092.12000 \mathrm{e}-01$ $2.92326 \mathrm{e}+012.92326 \mathrm{e}+012.92326 \mathrm{e}+001.00000 \mathrm{e}-092.12000 \mathrm{e}-01$ $2.92326 \mathrm{e}+012.92326 \mathrm{e}+012.92326 \mathrm{e}+001.00000 \mathrm{e}-092.12000 \mathrm{e}-01$ $2.92326 \mathrm{e}+012.92326 \mathrm{e}+012.92326 \mathrm{e}+001.00000 \mathrm{e}-092.12000 \mathrm{e}-01$ $2.92326 \mathrm{e}+012.92326 \mathrm{e}+012.92326 \mathrm{e}+001.00000 \mathrm{e}-092.12000 \mathrm{e}-01$ $1.00000 \mathrm{e}-02$ 1.00000e-02 1.00000e-03 1.00000e-09 1.00000e-01 $1.00000 \mathrm{e}+001.00000 \mathrm{e}+001.00000 \mathrm{e}-011.00000 \mathrm{e}-091.00000 \mathrm{e}-01$ $1.00000 \mathrm{e}-05$ 1.00000e-05 1.00000e-06 1.00000e-09 1.00000e-01 $1.00000 \mathrm{e}+001.00000 \mathrm{e}+001.00000 \mathrm{e}-011.00000 \mathrm{e}-091.00000 \mathrm{e}-01$ Element: 1309 \# of layers: 10

Kx Ky Kz Ss Por

4.45409e+02 4.45409e+02 4.45409e+01 1.00000e-09 7.00000e-02 $1.77967 \mathrm{e}+011.77967 \mathrm{e}+01$ 1.77967e+00 1.00000e-09 2.12000e-01 
1.77967e+01 1.77967e+01 1.77967e+00 1.00000e-09 2.12000e-01 $1.77967 \mathrm{e}+01$ 1.77967e+01 1.77967e+00 1.00000e-09 2.12000e-01 $1.77967 \mathrm{e}+01$ 1.77967e+01 1.77967e+00 1.00000e-09 2.12000e-01 $1.77967 \mathrm{e}+01$ 1.77967e+01 1.77967e+00 1.00000e-09 2.12000e-01 $1.00000 \mathrm{e}-02$ 1.00000e-02 1.00000e-03 1.00000e-09 1.00000e-01 $1.00000 \mathrm{e}+001.00000 \mathrm{e}+001.00000 \mathrm{e}-011.00000 \mathrm{e}-091.00000 \mathrm{e}-01$ $1.00000 \mathrm{e}-05$ 1.00000e-05 1.00000e-06 1.00000e-09 1.00000e-01 $1.00000 \mathrm{e}+001.00000 \mathrm{e}+001.00000 \mathrm{e}-011.00000 \mathrm{e}-091.00000 \mathrm{e}-01$ Element: 1310 \# of layers: 10

$\mathrm{Kx} \mathrm{Ky} \mathrm{Kz}$ Ss Por

4.45409e+02 4.45409e+02 4.45409e+01 1.00000e-09 7.00000e-02 $1.77967 \mathrm{e}+01$ 1.77967e+01 1.77967e+00 1.00000e-09 2.12000e-01 $1.77967 \mathrm{e}+01$ 1.77967e+01 1.77967e+00 1.00000e-09 2.12000e-01 $1.77967 \mathrm{e}+01$ 1.77967e+01 1.77967e+00 1.00000e-09 2.12000e-01 $1.77967 \mathrm{e}+01$ 1.77967e+01 1.77967e+00 1.00000e-09 2.12000e-01 $1.77967 \mathrm{e}+01$ 1.77967e+01 1.77967e+00 1.00000e-09 2.12000e-01 $1.00000 \mathrm{e}-02$ 1.00000e-02 1.00000e-03 1.00000e-09 1.00000e-01 $1.00000 \mathrm{e}+001.00000 \mathrm{e}+001.00000 \mathrm{e}-011.00000 \mathrm{e}-091.00000 \mathrm{e}-01$ $1.00000 \mathrm{e}-05$ 1.00000e-05 1.00000e-06 1.00000e-09 1.00000e-01 $1.00000 \mathrm{e}+001.00000 \mathrm{e}+001.00000 \mathrm{e}-01$ 1.00000e-09 1.00000e-01 Element: 1311 \# of layers: 10

$\mathrm{Kx} \mathrm{Ky} \mathrm{Kz}$ Ss Por

4.45409e+02 4.45409e+02 4.45409e+01 1.00000e-09 7.00000e-02 $1.77967 \mathrm{e}+011.77967 \mathrm{e}+01$ 1.77967e+00 1.00000e-09 2.12000e-01 $1.77967 \mathrm{e}+01$ 1.77967e+01 1.77967e+00 1.00000e-09 2.12000e-01 $1.77967 \mathrm{e}+01$ 1.77967e+01 1.77967e+00 1.00000e-09 2.12000e-01 $1.77967 \mathrm{e}+01$ 1.77967e+01 1.77967e+00 1.00000e-09 2.12000e-01 $1.77967 \mathrm{e}+01$ 1.77967e+01 1.77967e+00 1.00000e-09 2.12000e-01 $1.00000 \mathrm{e}-02$ 1.00000e-02 1.00000e-03 1.00000e-09 1.00000e-01 $1.00000 \mathrm{e}+001.00000 \mathrm{e}+001.00000 \mathrm{e}-011.00000 \mathrm{e}-091.00000 \mathrm{e}-01$ $1.00000 \mathrm{e}-05$ 1.00000e-05 1.00000e-06 1.00000e-09 1.00000e-01 $1.00000 \mathrm{e}+001.00000 \mathrm{e}+001.00000 \mathrm{e}-011.00000 \mathrm{e}-091.00000 \mathrm{e}-01$ Element: 1312 \# of layers: 10

$\mathrm{Kx} \mathrm{Ky} \mathrm{Kz}$ Ss Por

4.45409e+02 4.45409e+02 4.45409e+01 1.00000e-09 7.00000e-02 $1.77967 \mathrm{e}+011.77967 \mathrm{e}+01$ 1.77967e+00 1.00000e-09 2.12000e-01 $1.77967 \mathrm{e}+01$ 1.77967e+01 1.77967e+00 1.00000e-09 2.12000e-01 $1.77967 \mathrm{e}+01$ 1.77967e+01 1.77967e+00 1.00000e-09 2.12000e-01 $1.77967 \mathrm{e}+01$ 1.77967e+01 1.77967e+00 1.00000e-09 2.12000e-01 $1.77967 \mathrm{e}+01$ 1.77967e+01 1.77967e+00 1.00000e-09 2.12000e-01 $1.00000 \mathrm{e}-02$ 1.00000e-02 1.00000e-03 1.00000e-09 1.00000e-01 $1.00000 \mathrm{e}+001.00000 \mathrm{e}+001.00000 \mathrm{e}-011.00000 \mathrm{e}-091.00000 \mathrm{e}-01$ $1.00000 \mathrm{e}-05$ 1.00000e-05 1.00000e-06 1.00000e-09 1.00000e-01 $1.00000 \mathrm{e}+001.00000 \mathrm{e}+001.00000 \mathrm{e}-01$ 1.00000e-09 1.00000e-01 Element: 1313 \# of layers: 10

Kx Ky Kz Ss Por 
4.45409e+02 4.45409e+02 4.45409e+01 1.00000e-09 7.00000e-02 $1.77967 \mathrm{e}+01$ 1.77967e+01 1.77967e+00 1.00000e-09 2.12000e-01 $1.77967 \mathrm{e}+01$ 1.77967e+01 1.77967e+00 1.00000e-09 2.12000e-01 $1.77967 e+011.77967 e+01$ 1.77967e+00 1.00000e-09 2.12000e-01 $1.77967 \mathrm{e}+01$ 1.77967e+01 1.77967e+00 1.00000e-09 2.12000e-01 $1.77967 \mathrm{e}+01$ 1.77967e+01 1.77967e+00 1.00000e-09 2.12000e-01 $1.00000 \mathrm{e}-02$ 1.00000e-02 1.00000e-03 1.00000e-09 1.00000e-01 $1.00000 \mathrm{e}+001.00000 \mathrm{e}+001.00000 \mathrm{e}-011.00000 \mathrm{e}-091.00000 \mathrm{e}-01$ $1.00000 \mathrm{e}-05$ 1.00000e-05 1.00000e-06 1.00000e-09 1.00000e-01 $1.00000 \mathrm{e}+001.00000 \mathrm{e}+001.00000 \mathrm{e}-011.00000 \mathrm{e}-091.00000 \mathrm{e}-01$ Element: 1314 \# of layers: 10

Kx Ky Kz Ss Por

4.45409e+02 4.45409e+02 4.45409e+01 1.00000e-09 7.00000e-02 $1.77967 \mathrm{e}+01$ 1.77967e+01 1.77967e+00 1.00000e-09 2.12000e-01 $1.77967 \mathrm{e}+01$ 1.77967e+01 1.77967e+00 1.00000e-09 2.12000e-01 $1.77967 \mathrm{e}+01$ 1.77967e+01 1.77967e+00 1.00000e-09 2.12000e-01 $1.77967 \mathrm{e}+01$ 1.77967e+01 1.77967e+00 1.00000e-09 2.12000e-01 $1.77967 \mathrm{e}+01$ 1.77967e+01 1.77967e+00 1.00000e-09 2.12000e-01 $1.00000 \mathrm{e}-02$ 1.00000e-02 1.00000e-03 1.00000e-09 1.00000e-01 $1.00000 \mathrm{e}+001.00000 \mathrm{e}+001.00000 \mathrm{e}-011.00000 \mathrm{e}-091.00000 \mathrm{e}-01$ $1.00000 \mathrm{e}-05$ 1.00000e-05 1.00000e-06 1.00000e-09 1.00000e-01 $1.00000 \mathrm{e}+001.00000 \mathrm{e}+001.00000 \mathrm{e}-01$ 1.00000e-09 1.00000e-01 Element: 1315 \# of layers: 11

$\mathrm{Kx} \mathrm{Ky} \mathrm{Kz}$ Ss Por

4.45409e+02 4.45409e+02 4.45409e+01 1.00000e-09 7.00000e-02 4.45409e+02 4.45409e+02 4.45409e+01 1.00000e-09 7.00000e-02 $1.77967 \mathrm{e}+01$ 1.77967e+01 1.77967e+00 1.00000e-09 2.12000e-01 $1.77967 \mathrm{e}+01$ 1.77967e+01 1.77967e+00 1.00000e-09 2.12000e-01 $1.77967 \mathrm{e}+01$ 1.77967e+01 1.77967e+00 1.00000e-09 2.12000e-01 $1.77967 \mathrm{e}+01$ 1.77967e+01 1.77967e+00 1.00000e-09 2.12000e-01 $1.77967 \mathrm{e}+01$ 1.77967e+01 1.77967e+00 1.00000e-09 2.12000e-01 $1.00000 \mathrm{e}-02$ 1.00000e-02 1.00000e-03 1.00000e-09 1.00000e-01 $1.00000 \mathrm{e}+001.00000 \mathrm{e}+001.00000 \mathrm{e}-011.00000 \mathrm{e}-091.00000 \mathrm{e}-01$ $1.00000 \mathrm{e}-05$ 1.00000e-05 1.00000e-06 1.00000e-09 1.00000e-01 $1.00000 \mathrm{e}+001.00000 \mathrm{e}+001.00000 \mathrm{e}-01$ 1.00000e-09 1.00000e-01 Element: 1316 \# of layers: 10

Kx Ky Kz Ss Por

4.45409e+02 4.45409e+02 4.45409e+01 1.00000e-09 7.00000e-02 $1.77967 \mathrm{e}+01$ 1.77967e+01 1.77967e+00 1.00000e-09 2.12000e-01 $1.77967 \mathrm{e}+01$ 1.77967e+01 1.77967e+00 1.00000e-09 2.12000e-01 $1.77967 \mathrm{e}+01$ 1.77967e+01 1.77967e+00 1.00000e-09 2.12000e-01 $1.77967 \mathrm{e}+01$ 1.77967e+01 1.77967e+00 1.00000e-09 2.12000e-01 $1.77967 \mathrm{e}+01$ 1.77967e+01 1.77967e+00 1.00000e-09 2.12000e-01 $1.00000 \mathrm{e}-02$ 1.00000e-02 1.00000e-03 1.00000e-09 1.00000e-01 $1.00000 \mathrm{e}+001.00000 \mathrm{e}+001.00000 \mathrm{e}-011.00000 \mathrm{e}-091.00000 \mathrm{e}-01$ $1.00000 \mathrm{e}-05$ 1.00000e-05 1.00000e-06 1.00000e-09 1.00000e-01 
$1.00000 \mathrm{e}+001.00000 \mathrm{e}+00$ 1.00000e-01 1.00000e-09 1.00000e-01

Element: 1317 \# of layers: 10

Kx Ky Kz Ss Por

4.45409e+02 4.45409e+02 4.45409e+01 1.00000e-09 7.00000e-02

$1.77967 \mathrm{e}+01$ 1.77967e+01 1.77967e+00 1.00000e-09 2.12000e-01

$1.77967 \mathrm{e}+011.77967 \mathrm{e}+01$ 1.77967e+00 1.00000e-09 2.12000e-01

$1.77967 \mathrm{e}+01$ 1.77967e+01 1.77967e+00 1.00000e-09 2.12000e-01

$1.77967 \mathrm{e}+01$ 1.77967e+01 1.77967e+00 1.00000e-09 2.12000e-01

$1.77967 \mathrm{e}+01$ 1.77967e+01 1.77967e+00 1.00000e-09 2.12000e-01

$1.00000 \mathrm{e}-02$ 1.00000e-02 1.00000e-03 1.00000e-09 1.00000e-01

$1.00000 \mathrm{e}+001.00000 \mathrm{e}+001.00000 \mathrm{e}-011.00000 \mathrm{e}-091.00000 \mathrm{e}-01$

$1.00000 \mathrm{e}-05$ 1.00000e-05 1.00000e-06 1.00000e-09 1.00000e-01

$1.00000 \mathrm{e}+001.00000 \mathrm{e}+001.00000 \mathrm{e}-011.00000 \mathrm{e}-091.00000 \mathrm{e}-01$

Element: 1318 \# of layers: 10

Kx Ky Kz Ss Por

7.17791e+02 7.17791e+02 7.17791e+01 1.00000e-09 7.00000e-02

$2.86814 \mathrm{e}+012.86814 \mathrm{e}+012.86814 \mathrm{e}+001.00000 \mathrm{e}-092.12000 \mathrm{e}-01$

$2.86814 \mathrm{e}+012.86814 \mathrm{e}+012.86814 \mathrm{e}+001.00000 \mathrm{e}-092.12000 \mathrm{e}-01$

$2.86814 \mathrm{e}+012.86814 \mathrm{e}+012.86814 \mathrm{e}+001.00000 \mathrm{e}-092.12000 \mathrm{e}-01$

$2.86814 \mathrm{e}+012.86814 \mathrm{e}+012.86814 \mathrm{e}+001.00000 \mathrm{e}-092.12000 \mathrm{e}-01$

$2.86814 \mathrm{e}+012.86814 \mathrm{e}+012.86814 \mathrm{e}+001.00000 \mathrm{e}-092.12000 \mathrm{e}-01$

$1.00000 \mathrm{e}-02$ 1.00000e-02 1.00000e-03 1.00000e-09 1.00000e-01

$1.00000 \mathrm{e}+001.00000 \mathrm{e}+001.00000 \mathrm{e}-011.00000 \mathrm{e}-091.00000 \mathrm{e}-01$

$1.00000 \mathrm{e}-05$ 1.00000e-05 1.00000e-06 1.00000e-09 1.00000e-01

$1.00000 \mathrm{e}+001.00000 \mathrm{e}+001.00000 \mathrm{e}-011.00000 \mathrm{e}-091.00000 \mathrm{e}-01$

Element: 1319 \# of layers: 10

Kx Ky Kz Ss Por

7.17791e+02 7.17791e+02 7.17791e+01 1.00000e-09 7.00000e-02

$2.86814 \mathrm{e}+012.86814 \mathrm{e}+012.86814 \mathrm{e}+001.00000 \mathrm{e}-092.12000 \mathrm{e}-01$

$2.86814 \mathrm{e}+012.86814 \mathrm{e}+012.86814 \mathrm{e}+001.00000 \mathrm{e}-092.12000 \mathrm{e}-01$

$2.86814 \mathrm{e}+012.86814 \mathrm{e}+012.86814 \mathrm{e}+001.00000 \mathrm{e}-092.12000 \mathrm{e}-01$

$2.86814 \mathrm{e}+012.86814 \mathrm{e}+012.86814 \mathrm{e}+001.00000 \mathrm{e}-092.12000 \mathrm{e}-01$

$2.86814 \mathrm{e}+012.86814 \mathrm{e}+012.86814 \mathrm{e}+001.00000 \mathrm{e}-092.12000 \mathrm{e}-01$

$1.00000 \mathrm{e}-02$ 1.00000e-02 1.00000e-03 1.00000e-09 1.00000e-01

$1.00000 \mathrm{e}+001.00000 \mathrm{e}+001.00000 \mathrm{e}-011.00000 \mathrm{e}-091.00000 \mathrm{e}-01$

$1.00000 \mathrm{e}-05$ 1.00000e-05 1.00000e-06 1.00000e-09 1.00000e-01

$1.00000 \mathrm{e}+001.00000 \mathrm{e}+001.00000 \mathrm{e}-011.00000 \mathrm{e}-091.00000 \mathrm{e}-01$

Element: 1320 \# of layers: 11

$\mathrm{Kx} \mathrm{Ky} \mathrm{Kz}$ Ss Por

7.17791e+02 7.17791e+02 7.17791e+01 1.00000e-09 7.00000e-02

7.17791e+02 7.17791e+02 7.17791e+01 1.00000e-09 7.00000e-02

$2.86814 \mathrm{e}+012.86814 \mathrm{e}+012.86814 \mathrm{e}+001.00000 \mathrm{e}-092.12000 \mathrm{e}-01$

$2.86814 \mathrm{e}+012.86814 \mathrm{e}+012.86814 \mathrm{e}+001.00000 \mathrm{e}-092.12000 \mathrm{e}-01$

$2.86814 \mathrm{e}+012.86814 \mathrm{e}+012.86814 \mathrm{e}+00$ 1.00000e-09 2.12000e-01

$2.86814 \mathrm{e}+012.86814 \mathrm{e}+012.86814 \mathrm{e}+001.00000 \mathrm{e}-092.12000 \mathrm{e}-01$

$2.86814 \mathrm{e}+012.86814 \mathrm{e}+012.86814 \mathrm{e}+001.00000 \mathrm{e}-092.12000 \mathrm{e}-01$ 
$1.00000 \mathrm{e}-02$ 1.00000e-02 1.00000e-03 1.00000e-09 1.00000e-01 $1.00000 \mathrm{e}+001.00000 \mathrm{e}+001.00000 \mathrm{e}-011.00000 \mathrm{e}-091.00000 \mathrm{e}-01$ $1.00000 \mathrm{e}-051.00000 \mathrm{e}-05$ 1.00000e-06 1.00000e-09 1.00000e-01 $1.00000 \mathrm{e}+001.00000 \mathrm{e}+001.00000 \mathrm{e}-011.00000 \mathrm{e}-091.00000 \mathrm{e}-01$ Element: 1321 \# of layers: 11

Kx Ky Kz Ss Por

$7.17791 \mathrm{e}+02$ 7.17791e+02 7.17791e+01 1.00000e-09 7.00000e-02 $7.17791 \mathrm{e}+02$ 7.17791e+02 7.17791e+01 1.00000e-09 7.00000e-02 $2.86814 \mathrm{e}+012.86814 \mathrm{e}+012.86814 \mathrm{e}+001.00000 \mathrm{e}-092.12000 \mathrm{e}-01$ $2.86814 \mathrm{e}+012.86814 \mathrm{e}+012.86814 \mathrm{e}+001.00000 \mathrm{e}-092.12000 \mathrm{e}-01$ $2.86814 \mathrm{e}+012.86814 \mathrm{e}+012.86814 \mathrm{e}+001.00000 \mathrm{e}-092.12000 \mathrm{e}-01$ $2.86814 \mathrm{e}+012.86814 \mathrm{e}+012.86814 \mathrm{e}+001.00000 \mathrm{e}-092.12000 \mathrm{e}-01$ $2.86814 \mathrm{e}+012.86814 \mathrm{e}+012.86814 \mathrm{e}+001.00000 \mathrm{e}-092.12000 \mathrm{e}-01$ $1.00000 \mathrm{e}-021.00000 \mathrm{e}-02$ 1.00000e-03 1.00000e-09 1.00000e-01 $1.00000 \mathrm{e}+001.00000 \mathrm{e}+001.00000 \mathrm{e}-011.00000 \mathrm{e}-091.00000 \mathrm{e}-01$ $1.00000 \mathrm{e}-05$ 1.00000e-05 1.00000e-06 1.00000e-09 1.00000e-01 $1.00000 \mathrm{e}+001.00000 \mathrm{e}+001.00000 \mathrm{e}-011.00000 \mathrm{e}-091.00000 \mathrm{e}-01$ Element: 1322 \# of layers: 11

Kx Ky Kz Ss Por

$7.17791 \mathrm{e}+02$ 7.17791e+02 7.17791e+01 1.00000e-09 7.00000e-02 $7.17791 \mathrm{e}+02$ 7.17791e+02 7.17791e+01 1.00000e-09 7.00000e-02 $2.86814 \mathrm{e}+012.86814 \mathrm{e}+012.86814 \mathrm{e}+001.00000 \mathrm{e}-092.12000 \mathrm{e}-01$ $2.86814 \mathrm{e}+012.86814 \mathrm{e}+012.86814 \mathrm{e}+001.00000 \mathrm{e}-092.12000 \mathrm{e}-01$ $2.86814 \mathrm{e}+012.86814 \mathrm{e}+012.86814 \mathrm{e}+001.00000 \mathrm{e}-092.12000 \mathrm{e}-01$ $2.86814 \mathrm{e}+012.86814 \mathrm{e}+012.86814 \mathrm{e}+00 \quad 1.00000 \mathrm{e}-092.12000 \mathrm{e}-01$ $2.86814 \mathrm{e}+012.86814 \mathrm{e}+012.86814 \mathrm{e}+001.00000 \mathrm{e}-092.12000 \mathrm{e}-01$ $1.00000 \mathrm{e}-02$ 1.00000e-02 1.00000e-03 1.00000e-09 1.00000e-01 $1.00000 \mathrm{e}+001.00000 \mathrm{e}+001.00000 \mathrm{e}-011.00000 \mathrm{e}-091.00000 \mathrm{e}-01$ $1.00000 \mathrm{e}-051.00000 \mathrm{e}-05$ 1.00000e-06 1.00000e-09 1.00000e-01 $1.00000 \mathrm{e}+001.00000 \mathrm{e}+001.00000 \mathrm{e}-011.00000 \mathrm{e}-091.00000 \mathrm{e}-01$ Element: 1323 \# of layers: 10

Kx Ky Kz Ss Por

$7.17791 \mathrm{e}+02$ 7.17791e+02 7.17791e+01 1.00000e-09 7.00000e-02 $2.86814 \mathrm{e}+012.86814 \mathrm{e}+012.86814 \mathrm{e}+001.00000 \mathrm{e}-092.12000 \mathrm{e}-01$

$2.86814 \mathrm{e}+012.86814 \mathrm{e}+012.86814 \mathrm{e}+001.00000 \mathrm{e}-092.12000 \mathrm{e}-01$ $2.86814 \mathrm{e}+012.86814 \mathrm{e}+012.86814 \mathrm{e}+001.00000 \mathrm{e}-092.12000 \mathrm{e}-01$ $2.86814 \mathrm{e}+012.86814 \mathrm{e}+012.86814 \mathrm{e}+001.00000 \mathrm{e}-092.12000 \mathrm{e}-01$ $2.86814 \mathrm{e}+012.86814 \mathrm{e}+012.86814 \mathrm{e}+001.00000 \mathrm{e}-092.12000 \mathrm{e}-01$ $1.00000 \mathrm{e}-02$ 1.00000e-02 1.00000e-03 1.00000e-09 1.00000e-01 $1.00000 \mathrm{e}+001.00000 \mathrm{e}+001.00000 \mathrm{e}-011.00000 \mathrm{e}-091.00000 \mathrm{e}-01$ $1.00000 \mathrm{e}-05$ 1.00000e-05 1.00000e-06 1.00000e-09 1.00000e-01 $1.00000 \mathrm{e}+001.00000 \mathrm{e}+001.00000 \mathrm{e}-011.00000 \mathrm{e}-091.00000 \mathrm{e}-01$ Element: 1324 \# of layers: 10

Kx Ky Kz Ss Por

$7.17791 \mathrm{e}+02$ 7.17791e+02 7.17791e+01 1.00000e-09 7.00000e-02 $2.86814 \mathrm{e}+012.86814 \mathrm{e}+012.86814 \mathrm{e}+001.00000 \mathrm{e}-092.12000 \mathrm{e}-01$ 
$2.86814 \mathrm{e}+012.86814 \mathrm{e}+012.86814 \mathrm{e}+001.00000 \mathrm{e}-092.12000 \mathrm{e}-01$ $2.86814 \mathrm{e}+012.86814 \mathrm{e}+012.86814 \mathrm{e}+001.00000 \mathrm{e}-092.12000 \mathrm{e}-01$ $2.86814 \mathrm{e}+012.86814 \mathrm{e}+012.86814 \mathrm{e}+001.00000 \mathrm{e}-092.12000 \mathrm{e}-01$ $2.86814 \mathrm{e}+012.86814 \mathrm{e}+012.86814 \mathrm{e}+001.00000 \mathrm{e}-092.12000 \mathrm{e}-01$ $1.00000 \mathrm{e}-02$ 1.00000e-02 1.00000e-03 1.00000e-09 1.00000e-01 $1.00000 \mathrm{e}+001.00000 \mathrm{e}+001.00000 \mathrm{e}-011.00000 \mathrm{e}-091.00000 \mathrm{e}-01$ $1.00000 \mathrm{e}-05$ 1.00000e-05 1.00000e-06 1.00000e-09 1.00000e-01 $1.00000 \mathrm{e}+001.00000 \mathrm{e}+001.00000 \mathrm{e}-011.00000 \mathrm{e}-091.00000 \mathrm{e}-01$ Element: 1325 \# of layers: 10

$\mathrm{Kx} \mathrm{Ky} \mathrm{Kz}$ Ss Por

7.17791e+02 7.17791e+02 7.17791e+01 1.00000e-09 7.00000e-02 $2.86814 \mathrm{e}+012.86814 \mathrm{e}+012.86814 \mathrm{e}+001.00000 \mathrm{e}-092.12000 \mathrm{e}-01$ $2.86814 \mathrm{e}+012.86814 \mathrm{e}+012.86814 \mathrm{e}+001.00000 \mathrm{e}-092.12000 \mathrm{e}-01$ $2.86814 \mathrm{e}+012.86814 \mathrm{e}+012.86814 \mathrm{e}+001.00000 \mathrm{e}-092.12000 \mathrm{e}-01$ $2.86814 \mathrm{e}+012.86814 \mathrm{e}+012.86814 \mathrm{e}+001.00000 \mathrm{e}-092.12000 \mathrm{e}-01$ $2.86814 \mathrm{e}+012.86814 \mathrm{e}+012.86814 \mathrm{e}+001.00000 \mathrm{e}-092.12000 \mathrm{e}-01$ $1.00000 \mathrm{e}-02$ 1.00000e-02 1.00000e-03 1.00000e-09 1.00000e-01 $1.00000 \mathrm{e}+001.00000 \mathrm{e}+001.00000 \mathrm{e}-011.00000 \mathrm{e}-091.00000 \mathrm{e}-01$ $1.00000 \mathrm{e}-05$ 1.00000e-05 1.00000e-06 1.00000e-09 1.00000e-01 $1.00000 \mathrm{e}+001.00000 \mathrm{e}+001.00000 \mathrm{e}-011.00000 \mathrm{e}-091.00000 \mathrm{e}-01$ Element: 1326 \# of layers: 10

$\mathrm{Kx} \mathrm{Ky} \mathrm{Kz}$ Ss Por

7.17791e+02 7.17791e+02 7.17791e+01 1.00000e-09 7.00000e-02 $2.86814 \mathrm{e}+012.86814 \mathrm{e}+012.86814 \mathrm{e}+001.00000 \mathrm{e}-092.12000 \mathrm{e}-01$ $2.86814 \mathrm{e}+012.86814 \mathrm{e}+012.86814 \mathrm{e}+001.00000 \mathrm{e}-092.12000 \mathrm{e}-01$ $2.86814 \mathrm{e}+012.86814 \mathrm{e}+012.86814 \mathrm{e}+001.00000 \mathrm{e}-092.12000 \mathrm{e}-01$ $2.86814 \mathrm{e}+012.86814 \mathrm{e}+012.86814 \mathrm{e}+001.00000 \mathrm{e}-092.12000 \mathrm{e}-01$ $2.86814 \mathrm{e}+012.86814 \mathrm{e}+012.86814 \mathrm{e}+001.00000 \mathrm{e}-092.12000 \mathrm{e}-01$ $1.00000 \mathrm{e}-02$ 1.00000e-02 1.00000e-03 1.00000e-09 1.00000e-01 $1.00000 \mathrm{e}+001.00000 \mathrm{e}+001.00000 \mathrm{e}-011.00000 \mathrm{e}-091.00000 \mathrm{e}-01$ $1.00000 \mathrm{e}-05$ 1.00000e-05 1.00000e-06 1.00000e-09 1.00000e-01 $1.00000 \mathrm{e}+001.00000 \mathrm{e}+001.00000 \mathrm{e}-01$ 1.00000e-09 1.00000e-01 Element: 1327 \# of layers: 11

$\mathrm{Kx} \mathrm{Ky} \mathrm{Kz}$ Ss Por

6.31448e+02 6.31448e+02 6.31448e+01 1.00000e-09 7.00000e-02 6.31448e+02 6.31448e+02 6.31448e+01 1.00000e-09 7.00000e-02 $2.52298 \mathrm{e}+012.52298 \mathrm{e}+012.52298 \mathrm{e}+001.00000 \mathrm{e}-092.12000 \mathrm{e}-01$ $2.52298 \mathrm{e}+012.52298 \mathrm{e}+012.52298 \mathrm{e}+00$ 1.00000e-09 2.12000e-01 $2.52298 \mathrm{e}+012.52298 \mathrm{e}+012.52298 \mathrm{e}+00$ 1.00000e-09 2.12000e-01 $2.52298 \mathrm{e}+012.52298 \mathrm{e}+012.52298 \mathrm{e}+00$ 1.00000e-09 2.12000e-01 $2.52298 \mathrm{e}+012.52298 \mathrm{e}+012.52298 \mathrm{e}+00$ 1.00000e-09 2.12000e-01 $1.00000 \mathrm{e}-02$ 1.00000e-02 1.00000e-03 1.00000e-09 1.00000e-01 $1.00000 \mathrm{e}+001.00000 \mathrm{e}+001.00000 \mathrm{e}-011.00000 \mathrm{e}-091.00000 \mathrm{e}-01$ $1.00000 \mathrm{e}-05$ 1.00000e-05 1.00000e-06 1.00000e-09 1.00000e-01 $1.00000 \mathrm{e}+001.00000 \mathrm{e}+001.00000 \mathrm{e}-011.00000 \mathrm{e}-091.00000 \mathrm{e}-01$ Element: 1328 \# of layers: 11 
$\mathrm{Kx} \mathrm{Ky} \mathrm{Kz}$ Ss Por

6.31448e+02 6.31448e+02 6.31448e+01 1.00000e-09 7.00000e-02

6.31448e+02 6.31448e+02 6.31448e+01 1.00000e-09 7.00000e-02

$2.52298 \mathrm{e}+012.52298 \mathrm{e}+012.52298 \mathrm{e}+001.00000 \mathrm{e}-092.12000 \mathrm{e}-01$

$2.52298 \mathrm{e}+012.52298 \mathrm{e}+012.52298 \mathrm{e}+001.00000 \mathrm{e}-092.12000 \mathrm{e}-01$

$2.52298 \mathrm{e}+012.52298 \mathrm{e}+012.52298 \mathrm{e}+00$ 1.00000e-09 2.12000e-01

$2.52298 \mathrm{e}+012.52298 \mathrm{e}+012.52298 \mathrm{e}+00$ 1.00000e-09 2.12000e-01

$2.52298 \mathrm{e}+012.52298 \mathrm{e}+012.52298 \mathrm{e}+001.00000 \mathrm{e}-092.12000 \mathrm{e}-01$

$1.00000 \mathrm{e}-02$ 1.00000e-02 1.00000e-03 1.00000e-09 1.00000e-01

$1.00000 \mathrm{e}+001.00000 \mathrm{e}+001.00000 \mathrm{e}-011.00000 \mathrm{e}-091.00000 \mathrm{e}-01$

$1.00000 \mathrm{e}-05$ 1.00000e-05 1.00000e-06 1.00000e-09 1.00000e-01

$1.00000 \mathrm{e}+001.00000 \mathrm{e}+001.00000 \mathrm{e}-011.00000 \mathrm{e}-091.00000 \mathrm{e}-01$

Element: 1329 \# of layers: 11

$\mathrm{Kx} \mathrm{Ky} \mathrm{Kz}$ Ss Por

6.31448e+02 6.31448e+02 6.31448e+01 1.00000e-09 7.00000e-02

$6.31448 \mathrm{e}+026.31448 \mathrm{e}+02$ 6.31448e+01 1.00000e-09 7.00000e-02

$2.52298 \mathrm{e}+012.52298 \mathrm{e}+012.52298 \mathrm{e}+00$ 1.00000e-09 2.12000e-01

$2.52298 \mathrm{e}+012.52298 \mathrm{e}+012.52298 \mathrm{e}+00$ 1.00000e-09 2.12000e-01

$2.52298 \mathrm{e}+012.52298 \mathrm{e}+012.52298 \mathrm{e}+00$ 1.00000e-09 2.12000e-01

$2.52298 \mathrm{e}+012.52298 \mathrm{e}+012.52298 \mathrm{e}+00$ 1.00000e-09 2.12000e-01

$2.52298 \mathrm{e}+012.52298 \mathrm{e}+012.52298 \mathrm{e}+00$ 1.00000e-09 2.12000e-01

$1.00000 \mathrm{e}-02$ 1.00000e-02 1.00000e-03 1.00000e-09 1.00000e-01

$1.00000 \mathrm{e}+001.00000 \mathrm{e}+001.00000 \mathrm{e}-011.00000 \mathrm{e}-091.00000 \mathrm{e}-01$

$1.00000 \mathrm{e}-05$ 1.00000e-05 1.00000e-06 1.00000e-09 1.00000e-01

$1.00000 \mathrm{e}+001.00000 \mathrm{e}+001.00000 \mathrm{e}-011.00000 \mathrm{e}-091.00000 \mathrm{e}-01$

Element: 1330 \# of layers: 10

$\mathrm{Kx} \mathrm{Ky} \mathrm{Kz}$ Ss Por

6.31448e+02 6.31448e+02 6.31448e+01 1.00000e-09 7.00000e-02

$2.52298 \mathrm{e}+012.52298 \mathrm{e}+012.52298 \mathrm{e}+001.00000 \mathrm{e}-092.12000 \mathrm{e}-01$

$2.52298 \mathrm{e}+012.52298 \mathrm{e}+012.52298 \mathrm{e}+001.00000 \mathrm{e}-092.12000 \mathrm{e}-01$

$2.52298 \mathrm{e}+012.52298 \mathrm{e}+012.52298 \mathrm{e}+00$ 1.00000e-09 2.12000e-01

$2.52298 \mathrm{e}+012.52298 \mathrm{e}+012.52298 \mathrm{e}+001.00000 \mathrm{e}-092.12000 \mathrm{e}-01$

$2.52298 \mathrm{e}+012.52298 \mathrm{e}+012.52298 \mathrm{e}+00$ 1.00000e-09 2.12000e-01

$1.00000 \mathrm{e}-021.00000 \mathrm{e}-021.00000 \mathrm{e}-031.00000 \mathrm{e}-091.00000 \mathrm{e}-01$

$1.00000 \mathrm{e}+001.00000 \mathrm{e}+001.00000 \mathrm{e}-011.00000 \mathrm{e}-091.00000 \mathrm{e}-01$

$1.00000 \mathrm{e}-05$ 1.00000e-05 1.00000e-06 1.00000e-09 1.00000e-01

$1.00000 \mathrm{e}+001.00000 \mathrm{e}+001.00000 \mathrm{e}-011.00000 \mathrm{e}-091.00000 \mathrm{e}-01$

Element: 1331 \# of layers: 10

$\mathrm{Kx} \mathrm{Ky} \mathrm{Kz}$ Ss Por

6.31448e+02 6.31448e+02 6.31448e+01 1.00000e-09 7.00000e-02

$2.52298 \mathrm{e}+012.52298 \mathrm{e}+012.52298 \mathrm{e}+001.00000 \mathrm{e}-092.12000 \mathrm{e}-01$

$2.52298 \mathrm{e}+012.52298 \mathrm{e}+012.52298 \mathrm{e}+00$ 1.00000e-09 2.12000e-01

$2.52298 \mathrm{e}+012.52298 \mathrm{e}+012.52298 \mathrm{e}+00$ 1.00000e-09 2.12000e-01

$2.52298 \mathrm{e}+012.52298 \mathrm{e}+01$ 2.52298e+00 1.00000e-09 2.12000e-01

$2.52298 \mathrm{e}+012.52298 \mathrm{e}+012.52298 \mathrm{e}+001.00000 \mathrm{e}-092.12000 \mathrm{e}-01$

$1.00000 \mathrm{e}-02$ 1.00000e-02 1.00000e-03 1.00000e-09 1.00000e-01 
$1.00000 \mathrm{e}+001.00000 \mathrm{e}+001.00000 \mathrm{e}-011.00000 \mathrm{e}-091.00000 \mathrm{e}-01$ $1.00000 \mathrm{e}-05$ 1.00000e-05 1.00000e-06 1.00000e-09 1.00000e-01 $1.00000 \mathrm{e}+001.00000 \mathrm{e}+001.00000 \mathrm{e}-011.00000 \mathrm{e}-09$ 1.00000e-01 Element: 1332 \# of layers: 10

$\mathrm{Kx} \mathrm{Ky} \mathrm{Kz}$ Ss Por

6.31448e+02 6.31448e+02 6.31448e+01 1.00000e-09 7.00000e-02 $2.52298 \mathrm{e}+012.52298 \mathrm{e}+012.52298 \mathrm{e}+00$ 1.00000e-09 2.12000e-01 $2.52298 \mathrm{e}+012.52298 \mathrm{e}+012.52298 \mathrm{e}+001.00000 \mathrm{e}-092.12000 \mathrm{e}-01$ $2.52298 \mathrm{e}+012.52298 \mathrm{e}+012.52298 \mathrm{e}+00$ 1.00000e-09 2.12000e-01 $2.52298 \mathrm{e}+012.52298 \mathrm{e}+012.52298 \mathrm{e}+00$ 1.00000e-09 2.12000e-01 $2.52298 \mathrm{e}+012.52298 \mathrm{e}+012.52298 \mathrm{e}+00$ 1.00000e-09 2.12000e-01 $1.00000 \mathrm{e}-02$ 1.00000e-02 1.00000e-03 1.00000e-09 1.00000e-01 $1.00000 \mathrm{e}+001.00000 \mathrm{e}+001.00000 \mathrm{e}-011.00000 \mathrm{e}-091.00000 \mathrm{e}-01$ $1.00000 \mathrm{e}-05$ 1.00000e-05 1.00000e-06 1.00000e-09 1.00000e-01 $1.00000 \mathrm{e}+001.00000 \mathrm{e}+001.00000 \mathrm{e}-01$ 1.00000e-09 1.00000e-01 Element: 1333 \# of layers: 11

$\mathrm{Kx} \mathrm{Ky} \mathrm{Kz}$ Ss Por

6.31448e+02 6.31448e+02 6.31448e+01 1.00000e-09 7.00000e-02 6.31448e+02 6.31448e+02 6.31448e+01 1.00000e-09 7.00000e-02 $2.52298 \mathrm{e}+012.52298 \mathrm{e}+012.52298 \mathrm{e}+00$ 1.00000e-09 2.12000e-01 $2.52298 \mathrm{e}+012.52298 \mathrm{e}+012.52298 \mathrm{e}+001.00000 \mathrm{e}-092.12000 \mathrm{e}-01$ $2.52298 \mathrm{e}+012.52298 \mathrm{e}+012.52298 \mathrm{e}+00$ 1.00000e-09 2.12000e-01 $2.52298 \mathrm{e}+012.52298 \mathrm{e}+012.52298 \mathrm{e}+00$ 1.00000e-09 2.12000e-01 $2.52298 \mathrm{e}+012.52298 \mathrm{e}+012.52298 \mathrm{e}+00$ 1.00000e-09 2.12000e-01 $1.00000 \mathrm{e}-02$ 1.00000e-02 1.00000e-03 1.00000e-09 1.00000e-01 $1.00000 \mathrm{e}+001.00000 \mathrm{e}+001.00000 \mathrm{e}-011.00000 \mathrm{e}-091.00000 \mathrm{e}-01$ $1.00000 \mathrm{e}-05$ 1.00000e-05 1.00000e-06 1.00000e-09 1.00000e-01 $1.00000 \mathrm{e}+001.00000 \mathrm{e}+001.00000 \mathrm{e}-011.00000 \mathrm{e}-091.00000 \mathrm{e}-01$ Element: 1334 \# of layers: 10

$\mathrm{Kx} \mathrm{Ky} \mathrm{Kz}$ Ss Por

6.31448e+02 6.31448e+02 6.31448e+01 1.00000e-09 7.00000e-02 $2.52298 \mathrm{e}+012.52298 \mathrm{e}+012.52298 \mathrm{e}+001.00000 \mathrm{e}-092.12000 \mathrm{e}-01$ $2.52298 \mathrm{e}+012.52298 \mathrm{e}+012.52298 \mathrm{e}+00$ 1.00000e-09 2.12000e-01 $2.52298 \mathrm{e}+012.52298 \mathrm{e}+012.52298 \mathrm{e}+00$ 1.00000e-09 2.12000e-01 $2.52298 \mathrm{e}+012.52298 \mathrm{e}+012.52298 \mathrm{e}+00$ 1.00000e-09 2.12000e-01 $2.52298 \mathrm{e}+012.52298 \mathrm{e}+012.52298 \mathrm{e}+00$ 1.00000e-09 2.12000e-01 $1.00000 \mathrm{e}-02$ 1.00000e-02 1.00000e-03 1.00000e-09 1.00000e-01 $1.00000 \mathrm{e}+001.00000 \mathrm{e}+001.00000 \mathrm{e}-011.00000 \mathrm{e}-091.00000 \mathrm{e}-01$ $1.00000 \mathrm{e}-05$ 1.00000e-05 1.00000e-06 1.00000e-09 1.00000e-01 $1.00000 \mathrm{e}+001.00000 \mathrm{e}+001.00000 \mathrm{e}-01$ 1.00000e-09 1.00000e-01 Element: 1335 \# of layers: 10

$\mathrm{Kx} \mathrm{Ky} \mathrm{Kz}$ Ss Por 6.31448e+02 6.31448e+02 6.31448e+01 1.00000e-09 7.00000e-02 $2.52298 \mathrm{e}+012.52298 \mathrm{e}+012.52298 \mathrm{e}+00$ 1.00000e-09 2.12000e-01 $2.52298 \mathrm{e}+012.52298 \mathrm{e}+012.52298 \mathrm{e}+00$ 1.00000e-09 2.12000e-01 $2.52298 \mathrm{e}+012.52298 \mathrm{e}+012.52298 \mathrm{e}+001.00000 \mathrm{e}-092.12000 \mathrm{e}-01$ 
$2.52298 \mathrm{e}+012.52298 \mathrm{e}+012.52298 \mathrm{e}+00$ 1.00000e-09 2.12000e-01 $2.52298 \mathrm{e}+012.52298 \mathrm{e}+012.52298 \mathrm{e}+00$ 1.00000e-09 2.12000e-01 $1.00000 \mathrm{e}-02$ 1.00000e-02 1.00000e-03 1.00000e-09 1.00000e-01 $1.00000 \mathrm{e}+001.00000 \mathrm{e}+001.00000 \mathrm{e}-011.00000 \mathrm{e}-091.00000 \mathrm{e}-01$ $1.00000 \mathrm{e}-05$ 1.00000e-05 1.00000e-06 1.00000e-09 1.00000e-01 $1.00000 \mathrm{e}+001.00000 \mathrm{e}+001.00000 \mathrm{e}-011.00000 \mathrm{e}-091.00000 \mathrm{e}-01$ Element: 1336 \# of layers: 11

$\mathrm{Kx} \mathrm{Ky} \mathrm{Kz}$ Ss Por

3.40425e+02 3.40425e+02 3.40425e+01 1.00000e-09 7.00000e-02 $3.40425 \mathrm{e}+02$ 3.40425e+02 3.40425e+01 1.00000e-09 7.00000e-02 $1.36022 \mathrm{e}+01$ 1.36022e+01 1.36022e+00 1.00000e-09 2.12000e-01 $1.36022 \mathrm{e}+01$ 1.36022 $+011.36022 \mathrm{e}+001.00000 \mathrm{e}-092.12000 \mathrm{e}-01$ $1.36022 \mathrm{e}+011.36022 \mathrm{e}+01$ 1.36022e+00 1.00000e-09 2.12000e-01 $1.36022 \mathrm{e}+01$ 1.36022e+01 1.36022e+00 1.00000e-09 2.12000e-01 $1.36022 \mathrm{e}+01$ 1.36022e+01 1.36022e+00 1.00000e-09 2.12000e-01 $1.00000 \mathrm{e}-02$ 1.00000e-02 1.00000e-03 1.00000e-09 1.00000e-01 $1.00000 \mathrm{e}+001.00000 \mathrm{e}+001.00000 \mathrm{e}-011.00000 \mathrm{e}-091.00000 \mathrm{e}-01$ $1.00000 \mathrm{e}-05$ 1.00000e-05 1.00000e-06 1.00000e-09 1.00000e-01 $1.00000 \mathrm{e}+001.00000 \mathrm{e}+001.00000 \mathrm{e}-011.00000 \mathrm{e}-091.00000 \mathrm{e}-01$ Element: 1337 \# of layers: 11

$\mathrm{Kx} \mathrm{Ky} \mathrm{Kz}$ Ss Por

3.40425e+02 3.40425e+02 3.40425e+01 1.00000e-09 7.00000e-02 $3.40425 \mathrm{e}+023.40425 \mathrm{e}+02$ 3.40425e+01 1.00000e-09 7.00000e-02 $1.36022 \mathrm{e}+011.36022 \mathrm{e}+01$ 1.36022e+00 1.00000e-09 2.12000e-01 $1.36022 \mathrm{e}+01$ 1.36022e+01 1.36022e+00 1.00000e-09 2.12000e-01 $1.36022 \mathrm{e}+01$ 1.36022e+01 1.36022e+00 1.00000e-09 2.12000e-01 $1.36022 \mathrm{e}+011.36022 \mathrm{e}+011.36022 \mathrm{e}+001.00000 \mathrm{e}-092.12000 \mathrm{e}-01$ $1.36022 \mathrm{e}+01$ 1.36022e+01 1.36022e+00 1.00000e-09 2.12000e-01 $1.00000 \mathrm{e}-02$ 1.00000e-02 1.00000e-03 1.00000e-09 1.00000e-01 $1.00000 \mathrm{e}+001.00000 \mathrm{e}+001.00000 \mathrm{e}-011.00000 \mathrm{e}-091.00000 \mathrm{e}-01$ $1.00000 \mathrm{e}-05$ 1.00000e-05 1.00000e-06 1.00000e-09 1.00000e-01 $1.00000 \mathrm{e}+001.00000 \mathrm{e}+001.00000 \mathrm{e}-01$ 1.00000e-09 1.00000e-01 Element: 1338 \# of layers: 11

$\mathrm{Kx} \mathrm{Ky} \mathrm{Kz}$ Ss Por

3.40425e+02 3.40425e+02 3.40425e+01 1.00000e-09 7.00000e-02 $3.40425 \mathrm{e}+02$ 3.40425e+02 3.40425e+01 1.00000e-09 7.00000e-02 $1.36022 \mathrm{e}+011.36022 \mathrm{e}+011.36022 \mathrm{e}+001.00000 \mathrm{e}-092.12000 \mathrm{e}-01$ $1.36022 \mathrm{e}+011.36022 \mathrm{e}+01$ 1.36022e+00 1.00000e-09 2.12000e-01 $1.36022 \mathrm{e}+01$ 1.36022e+01 1.36022e+00 1.00000e-09 2.12000e-01 $1.36022 \mathrm{e}+01$ 1.36022e+01 1.36022e+00 1.00000e-09 2.12000e-01 $1.36022 \mathrm{e}+01$ 1.36022e+01 1.36022e+00 1.00000e-09 2.12000e-01 $1.00000 \mathrm{e}-02$ 1.00000e-02 1.00000e-03 1.00000e-09 1.00000e-01 $1.00000 \mathrm{e}+001.00000 \mathrm{e}+001.00000 \mathrm{e}-011.00000 \mathrm{e}-091.00000 \mathrm{e}-01$ $1.00000 \mathrm{e}-05$ 1.00000e-05 1.00000e-06 1.00000e-09 1.00000e-01 $1.00000 \mathrm{e}+001.00000 \mathrm{e}+001.00000 \mathrm{e}-011.00000 \mathrm{e}-09$ 1.00000e-01 Element: 1339 \# of layers: 10 
Kx Ky Kz Ss Por

3.40425e+02 3.40425e+02 3.40425e+01 1.00000e-09 7.00000e-02 $1.36022 \mathrm{e}+011.36022 \mathrm{e}+01$ 1.36022e+00 1.00000e-09 2.12000e-01 $1.36022 \mathrm{e}+01$ 1.36022e+01 1.36022e+00 1.00000e-09 2.12000e-01 $1.36022 \mathrm{e}+011.36022 \mathrm{e}+011.36022 \mathrm{e}+001.00000 \mathrm{e}-092.12000 \mathrm{e}-01$ $1.36022 \mathrm{e}+01$ 1.36022e+01 1.36022e+00 1.00000e-09 2.12000e-01 $1.36022 \mathrm{e}+01$ 1.36022e+01 1.36022e+00 1.00000e-09 2.12000e-01 $1.00000 \mathrm{e}-02$ 1.00000e-02 1.00000e-03 1.00000e-09 1.00000e-01 $1.00000 \mathrm{e}+001.00000 \mathrm{e}+001.00000 \mathrm{e}-011.00000 \mathrm{e}-091.00000 \mathrm{e}-01$ $1.00000 \mathrm{e}-05$ 1.00000e-05 1.00000e-06 1.00000e-09 1.00000e-01 $1.00000 \mathrm{e}+001.00000 \mathrm{e}+001.00000 \mathrm{e}-011.00000 \mathrm{e}-091.00000 \mathrm{e}-01$ Element: 1340 \# of layers: 10

$\mathrm{Kx} \mathrm{Ky} \mathrm{Kz}$ Ss Por

3.40425e+02 3.40425e+02 3.40425e+01 1.00000e-09 7.00000e-02 $1.36022 \mathrm{e}+01$ 1.36022e+01 1.36022e+00 1.00000e-09 2.12000e-01 $1.36022 \mathrm{e}+01$ 1.36022e+01 1.36022e+00 1.00000e-09 2.12000e-01 $1.36022 \mathrm{e}+01$ 1.36022e+01 1.36022e+00 1.00000e-09 2.12000e-01 $1.36022 \mathrm{e}+01$ 1.36022e+01 1.36022e+00 1.00000e-09 2.12000e-01 $1.36022 \mathrm{e}+01$ 1.36022e+01 1.36022e+00 1.00000e-09 2.12000e-01 $1.00000 \mathrm{e}-02$ 1.00000e-02 1.00000e-03 1.00000e-09 1.00000e-01 $1.00000 \mathrm{e}+001.00000 \mathrm{e}+001.00000 \mathrm{e}-011.00000 \mathrm{e}-091.00000 \mathrm{e}-01$ $1.00000 \mathrm{e}-05$ 1.00000e-05 1.00000e-06 1.00000e-09 1.00000e-01 $1.00000 \mathrm{e}+001.00000 \mathrm{e}+001.00000 \mathrm{e}-011.00000 \mathrm{e}-091.00000 \mathrm{e}-01$ Element: 1341 \# of layers: 10

Kx Ky Kz Ss Por 3.40425e+02 3.40425e+02 3.40425e+01 1.00000e-09 7.00000e-02 $1.36022 \mathrm{e}+01$ 1.36022e+01 1.36022e+00 1.00000e-09 2.12000e-01 $1.36022 \mathrm{e}+01$ 1.36022e+01 1.36022e+00 1.00000e-09 2.12000e-01 $1.36022 \mathrm{e}+01$ 1.36022e+01 1.36022e+00 1.00000e-09 2.12000e-01 $1.36022 \mathrm{e}+01$ 1.36022e+01 1.36022e+00 1.00000e-09 2.12000e-01 $1.36022 \mathrm{e}+01$ 1.36022e+01 1.36022e+00 1.00000e-09 2.12000e-01 $1.00000 \mathrm{e}-02$ 1.00000e-02 1.00000e-03 1.00000e-09 1.00000e-01 $1.00000 \mathrm{e}+001.00000 \mathrm{e}+001.00000 \mathrm{e}-011.00000 \mathrm{e}-091.00000 \mathrm{e}-01$ $1.00000 \mathrm{e}-05$ 1.00000e-05 1.00000e-06 1.00000e-09 1.00000e-01 $1.00000 \mathrm{e}+001.00000 \mathrm{e}+001.00000 \mathrm{e}-01$ 1.00000e-09 1.00000e-01 Element: 1342 \# of layers: 10

Kx Ky Kz Ss Por

3.40425e+02 3.40425e+02 3.40425e+01 1.00000e-09 7.00000e-02 $1.36022 \mathrm{e}+01$ 1.36022e+01 1.36022e+00 1.00000e-09 2.12000e-01 $1.36022 \mathrm{e}+01$ 1.36022e+01 1.36022e+00 1.00000e-09 2.12000e-01 $1.36022 \mathrm{e}+01$ 1.36022e+01 1.36022e+00 1.00000e-09 2.12000e-01 $1.36022 \mathrm{e}+01$ 1.36022e+01 1.36022e+00 1.00000e-09 2.12000e-01 $1.36022 \mathrm{e}+01$ 1.36022e+01 1.36022e+00 1.00000e-09 2.12000e-01 $1.00000 \mathrm{e}-02$ 1.00000e-02 1.00000e-03 1.00000e-09 1.00000e-01 $1.00000 \mathrm{e}+001.00000 \mathrm{e}+001.00000 \mathrm{e}-011.00000 \mathrm{e}-091.00000 \mathrm{e}-01$ $1.00000 \mathrm{e}-05$ 1.00000e-05 1.00000e-06 1.00000e-09 1.00000e-01 
$1.00000 \mathrm{e}+001.00000 \mathrm{e}+00$ 1.00000e-01 1.00000e-09 1.00000e-01

Element: 1343 \# of layers: 10

Kx Ky Kz Ss Por

3.40425e+02 3.40425e+02 3.40425e+01 1.00000e-09 7.00000e-02

$1.36022 \mathrm{e}+011.36022 \mathrm{e}+01$ 1.36022e+00 1.00000e-09 2.12000e-01

$1.36022 \mathrm{e}+01$ 1.36022e+01 1.36022e+00 1.00000e-09 2.12000e-01

$1.36022 \mathrm{e}+01$ 1.36022e+01 1.36022e+00 1.00000e-09 2.12000e-01

$1.36022 \mathrm{e}+01$ 1.36022e+01 1.36022e+00 1.00000e-09 2.12000e-01

$1.36022 \mathrm{e}+01$ 1.36022e+01 1.36022e+00 1.00000e-09 2.12000e-01

$1.00000 \mathrm{e}-02$ 1.00000e-02 1.00000e-03 1.00000e-09 1.00000e-01

$1.00000 \mathrm{e}+001.00000 \mathrm{e}+001.00000 \mathrm{e}-011.00000 \mathrm{e}-091.00000 \mathrm{e}-01$

$1.00000 \mathrm{e}-05$ 1.00000e-05 1.00000e-06 1.00000e-09 1.00000e-01

$1.00000 \mathrm{e}+001.00000 \mathrm{e}+001.00000 \mathrm{e}-01$ 1.00000e-09 1.00000e-01

Element: 1344 \# of layers: 10

$\mathrm{Kx} \mathrm{Ky} \mathrm{Kz}$ Ss Por

3.40425e+02 3.40425e+02 3.40425e+01 1.00000e-09 7.00000e-02

$1.36022 \mathrm{e}+01$ 1.36022e+01 1.36022e+00 1.00000e-09 2.12000e-01

$1.36022 \mathrm{e}+01$ 1.36022e+01 1.36022e+00 1.00000e-09 2.12000e-01

$1.36022 \mathrm{e}+01$ 1.36022e+01 1.36022e+00 1.00000e-09 2.12000e-01

$1.36022 \mathrm{e}+011.36022 \mathrm{e}+01$ 1.36022e+00 1.00000e-09 2.12000e-01

$1.36022 \mathrm{e}+01$ 1.36022e+01 1.36022e+00 1.00000e-09 2.12000e-01

$1.00000 \mathrm{e}-021.00000 \mathrm{e}-021.00000 \mathrm{e}-031.00000 \mathrm{e}-091.00000 \mathrm{e}-01$

$1.00000 \mathrm{e}+001.00000 \mathrm{e}+001.00000 \mathrm{e}-011.00000 \mathrm{e}-091.00000 \mathrm{e}-01$

$1.00000 \mathrm{e}-05$ 1.00000e-05 1.00000e-06 1.00000e-09 1.00000e-01

$1.00000 \mathrm{e}+001.00000 \mathrm{e}+001.00000 \mathrm{e}-011.00000 \mathrm{e}-09$ 1.00000e-01

Element: 1345 \# of layers: 11

$\mathrm{Kx} \mathrm{Ky} \mathrm{Kz}$ Ss Por

$1.80533 \mathrm{e}+02$ 1.80533e+02 1.80533e+01 1.00000e-09 7.00000e-02

$1.80533 \mathrm{e}+02$ 1.80533e+02 1.80533e+01 1.00000e-09 7.00000e-02

7.21343e+00 7.21343e+00 7.21343e-01 1.00000e-09 2.12000e-01

$7.21343 \mathrm{e}+00$ 7.21343e+00 7.21343e-01 1.00000e-09 2.12000e-01

7.21343e+00 7.21343e+00 7.21343e-01 1.00000e-09 2.12000e-01

$7.21343 \mathrm{e}+00$ 7.21343e+00 7.21343e-01 1.00000e-09 2.12000e-01

$7.21343 \mathrm{e}+00$ 7.21343e+00 7.21343e-01 1.00000e-09 2.12000e-01

$1.00000 \mathrm{e}-02$ 1.00000e-02 1.00000e-03 1.00000e-09 1.00000e-01

$1.00000 \mathrm{e}+001.00000 \mathrm{e}+001.00000 \mathrm{e}-011.00000 \mathrm{e}-091.00000 \mathrm{e}-01$

$1.00000 \mathrm{e}-05$ 1.00000e-05 1.00000e-06 1.00000e-09 1.00000e-01

$1.00000 \mathrm{e}+001.00000 \mathrm{e}+001.00000 \mathrm{e}-01$ 1.00000e-09 1.00000e-01

Element: 1346 \# of layers: 11

$\mathrm{Kx} \mathrm{Ky} \mathrm{Kz}$ Ss Por

$1.80533 \mathrm{e}+02$ 1.80533e+02 1.80533e+01 1.00000e-09 7.00000e-02

$1.80533 \mathrm{e}+02$ 1.80533e+02 1.80533e+01 1.00000e-09 7.00000e-02

7.21343e+00 7.21343e+00 7.21343e-01 1.00000e-09 2.12000e-01

$7.21343 \mathrm{e}+00$ 7.21343e+00 7.21343e-01 1.00000e-09 2.12000e-01

$7.21343 \mathrm{e}+00$ 7.21343e+00 7.21343e-01 1.00000e-09 2.12000e-01

$7.21343 \mathrm{e}+00$ 7.21343e+00 7.21343e-01 1.00000e-09 2.12000e-01 
7.21343e+00 7.21343e+00 7.21343e-01 1.00000e-09 2.12000e-01 $1.00000 \mathrm{e}-02$ 1.00000e-02 1.00000e-03 1.00000e-09 1.00000e-01 $1.00000 \mathrm{e}+001.00000 \mathrm{e}+001.00000 \mathrm{e}-011.00000 \mathrm{e}-091.00000 \mathrm{e}-01$ $1.00000 \mathrm{e}-05$ 1.00000e-05 1.00000e-06 1.00000e-09 1.00000e-01 $1.00000 \mathrm{e}+001.00000 \mathrm{e}+001.00000 \mathrm{e}-011.00000 \mathrm{e}-091.00000 \mathrm{e}-01$ Element: 1347 \# of layers: 11

Kx Ky Kz Ss Por

$1.80533 \mathrm{e}+02$ 1.80533e+02 1.80533e+01 1.00000e-09 7.00000e-02 $1.80533 \mathrm{e}+021.80533 \mathrm{e}+021.80533 \mathrm{e}+01$ 1.00000e-09 7.00000e-02 $7.21343 \mathrm{e}+00$ 7.21343e+00 7.21343e-01 1.00000e-09 2.12000e-01 $7.21343 \mathrm{e}+00$ 7.21343e+00 7.21343e-01 1.00000e-09 2.12000e-01 $7.21343 \mathrm{e}+00$ 7.21343e+00 7.21343e-01 1.00000e-09 2.12000e-01 $7.21343 \mathrm{e}+00$ 7.21343e+00 7.21343e-01 1.00000e-09 2.12000e-01 $7.21343 \mathrm{e}+00$ 7.21343e+00 7.21343e-01 1.00000e-09 2.12000e-01 $1.00000 \mathrm{e}-02$ 1.00000e-02 1.00000e-03 1.00000e-09 1.00000e-01 $1.00000 \mathrm{e}+001.00000 \mathrm{e}+001.00000 \mathrm{e}-011.00000 \mathrm{e}-091.00000 \mathrm{e}-01$ $1.00000 \mathrm{e}-05$ 1.00000e-05 1.00000e-06 1.00000e-09 1.00000e-01 $1.00000 \mathrm{e}+001.00000 \mathrm{e}+001.00000 \mathrm{e}-011.00000 \mathrm{e}-091.00000 \mathrm{e}-01$ Element: 1348 \# of layers: 10

Kx Ky Kz Ss Por

$1.80533 \mathrm{e}+02$ 1.80533e+02 1.80533e+01 1.00000e-09 7.00000e-02 $7.21343 \mathrm{e}+00$ 7.21343e+00 7.21343e-01 1.00000e-09 2.12000e-01 $7.21343 \mathrm{e}+00$ 7.21343e+00 7.21343e-01 1.00000e-09 2.12000e-01 $7.21343 \mathrm{e}+00$ 7.21343e+00 7.21343e-01 1.00000e-09 2.12000e-01 $7.21343 \mathrm{e}+007.21343 \mathrm{e}+00$ 7.21343e-01 1.00000e-09 2.12000e-01 $7.21343 \mathrm{e}+007.21343 \mathrm{e}+00$ 7.21343e-01 1.00000e-09 2.12000e-01 $1.00000 \mathrm{e}-02$ 1.00000e-02 1.00000e-03 1.00000e-09 1.00000e-01 $1.00000 \mathrm{e}+001.00000 \mathrm{e}+001.00000 \mathrm{e}-011.00000 \mathrm{e}-091.00000 \mathrm{e}-01$ $1.00000 \mathrm{e}-051.00000 \mathrm{e}-05$ 1.00000e-06 1.00000e-09 1.00000e-01 $1.00000 \mathrm{e}+001.00000 \mathrm{e}+001.00000 \mathrm{e}-011.00000 \mathrm{e}-091.00000 \mathrm{e}-01$ Element: 1349 \# of layers: 10

Kx Ky Kz Ss Por

$1.80533 \mathrm{e}+02$ 1.80533e+02 1.80533e+01 1.00000e-09 7.00000e-02 $7.21343 \mathrm{e}+00$ 7.21343e+00 7.21343e-01 1.00000e-09 2.12000e-01 $7.21343 \mathrm{e}+00$ 7.21343e+00 7.21343e-01 1.00000e-09 2.12000e-01 $7.21343 \mathrm{e}+00$ 7.21343e+00 7.21343e-01 1.00000e-09 2.12000e-01 $7.21343 \mathrm{e}+00$ 7.21343e+00 7.21343e-01 1.00000e-09 2.12000e-01 $7.21343 \mathrm{e}+00$ 7.21343e+00 7.21343e-01 1.00000e-09 2.12000e-01 $1.00000 \mathrm{e}-02$ 1.00000e-02 1.00000e-03 1.00000e-09 1.00000e-01 $1.00000 \mathrm{e}+001.00000 \mathrm{e}+001.00000 \mathrm{e}-011.00000 \mathrm{e}-091.00000 \mathrm{e}-01$ $1.00000 \mathrm{e}-05$ 1.00000e-05 1.00000e-06 1.00000e-09 1.00000e-01 $1.00000 \mathrm{e}+001.00000 \mathrm{e}+001.00000 \mathrm{e}-011.00000 \mathrm{e}-091.00000 \mathrm{e}-01$ Element: 1350 \# of layers: 10

Kx Ky Kz Ss Por

$1.80533 \mathrm{e}+02$ 1.80533e+02 1.80533e+01 1.00000e-09 7.00000e-02 $7.21343 \mathrm{e}+00$ 7.21343e+00 7.21343e-01 1.00000e-09 2.12000e-01 
7.21343e+00 7.21343e+00 7.21343e-01 1.00000e-09 2.12000e-01 $7.21343 \mathrm{e}+00$ 7.21343e+00 7.21343e-01 1.00000e-09 2.12000e-01 $7.21343 \mathrm{e}+00$ 7.21343e+00 7.21343e-01 1.00000e-09 2.12000e-01 $7.21343 \mathrm{e}+007.21343 \mathrm{e}+00$ 7.21343e-01 1.00000e-09 2.12000e-01 $1.00000 \mathrm{e}-02$ 1.00000e-02 1.00000e-03 1.00000e-09 1.00000e-01 $1.00000 \mathrm{e}+001.00000 \mathrm{e}+001.00000 \mathrm{e}-011.00000 \mathrm{e}-091.00000 \mathrm{e}-01$ $1.00000 \mathrm{e}-051.00000 \mathrm{e}-05$ 1.00000e-06 1.00000e-09 1.00000e-01 $1.00000 \mathrm{e}+001.00000 \mathrm{e}+001.00000 \mathrm{e}-011.00000 \mathrm{e}-091.00000 \mathrm{e}-01$ Element: 1351 \# of layers: 10

Kx Ky Kz Ss Por

$1.80533 \mathrm{e}+02$ 1.80533e+02 1.80533e+01 1.00000e-09 7.00000e-02 $7.21343 \mathrm{e}+00$ 7.21343e+00 7.21343e-01 1.00000e-09 2.12000e-01 $7.21343 \mathrm{e}+00$ 7.21343e+00 7.21343e-01 1.00000e-09 2.12000e-01 $7.21343 \mathrm{e}+007.21343 \mathrm{e}+00$ 7.21343e-01 1.00000e-09 2.12000e-01 $7.21343 \mathrm{e}+00$ 7.21343e+00 7.21343e-01 1.00000e-09 2.12000e-01 $7.21343 \mathrm{e}+00$ 7.21343e+00 7.21343e-01 1.00000e-09 2.12000e-01 $1.00000 \mathrm{e}-021.00000 \mathrm{e}-02$ 1.00000e-03 1.00000e-09 1.00000e-01 $1.00000 \mathrm{e}+001.00000 \mathrm{e}+001.00000 \mathrm{e}-011.00000 \mathrm{e}-091.00000 \mathrm{e}-01$ $1.00000 \mathrm{e}-05$ 1.00000e-05 1.00000e-06 1.00000e-09 1.00000e-01 $1.00000 \mathrm{e}+001.00000 \mathrm{e}+001.00000 \mathrm{e}-011.00000 \mathrm{e}-091.00000 \mathrm{e}-01$ Element: 1352 \# of layers: 10

Kx Ky Kz Ss Por

$1.80533 \mathrm{e}+02$ 1.80533e+02 1.80533e+01 1.00000e-09 7.00000e-02 $7.21343 \mathrm{e}+00$ 7.21343e+00 7.21343e-01 1.00000e-09 2.12000e-01 $7.21343 \mathrm{e}+00$ 7.21343e+00 7.21343e-01 1.00000e-09 2.12000e-01 $7.21343 \mathrm{e}+00$ 7.21343e+00 7.21343e-01 1.00000e-09 2.12000e-01 $7.21343 \mathrm{e}+007.21343 \mathrm{e}+00$ 7.21343e-01 1.00000e-09 2.12000e-01 $7.21343 \mathrm{e}+00$ 7.21343e+00 7.21343e-01 1.00000e-09 2.12000e-01 $1.00000 \mathrm{e}-021.00000 \mathrm{e}-02$ 1.00000e-03 1.00000e-09 1.00000e-01 $1.00000 \mathrm{e}+001.00000 \mathrm{e}+001.00000 \mathrm{e}-011.00000 \mathrm{e}-091.00000 \mathrm{e}-01$ $1.00000 \mathrm{e}-05$ 1.00000e-05 1.00000e-06 1.00000e-09 1.00000e-01 $1.00000 \mathrm{e}+001.00000 \mathrm{e}+001.00000 \mathrm{e}-011.00000 \mathrm{e}-091.00000 \mathrm{e}-01$ Element: 1353 \# of layers: 10

Kx Ky Kz Ss Por

$1.80533 \mathrm{e}+02$ 1.80533e+02 1.80533e+01 1.00000e-09 7.00000e-02 $7.21343 \mathrm{e}+00$ 7.21343e+00 7.21343e-01 1.00000e-09 2.12000e-01 $7.21343 \mathrm{e}+007.21343 \mathrm{e}+00$ 7.21343e-01 1.00000e-09 2.12000e-01 $7.21343 \mathrm{e}+00$ 7.21343e+00 7.21343e-01 1.00000e-09 2.12000e-01 $7.21343 \mathrm{e}+00$ 7.21343e+00 7.21343e-01 1.00000e-09 2.12000e-01 $7.21343 \mathrm{e}+00$ 7.21343e+00 7.21343e-01 1.00000e-09 2.12000e-01 $1.00000 \mathrm{e}-021.00000 \mathrm{e}-02$ 1.00000e-03 1.00000e-09 1.00000e-01 $1.00000 \mathrm{e}+001.00000 \mathrm{e}+001.00000 \mathrm{e}-011.00000 \mathrm{e}-091.00000 \mathrm{e}-01$ $1.00000 \mathrm{e}-05$ 1.00000e-05 1.00000e-06 1.00000e-09 1.00000e-01 $1.00000 \mathrm{e}+001.00000 \mathrm{e}+001.00000 \mathrm{e}-011.00000 \mathrm{e}-091.00000 \mathrm{e}-01$ Element: 1354 \# of layers: 11

Kx Ky Kz Ss Por 
1.43872e+02 1.43872e+02 1.43872e+01 1.00000e-09 7.00000e-02 1.43872e+02 1.43872e+02 1.43872e+01 1.00000e-09 7.00000e-02 5.74842e+00 5.74842e+00 5.74842e-01 1.00000e-09 2.12000e-01 $5.74842 \mathrm{e}+00$ 5.74842e+00 5.74842e-01 1.00000e-09 2.12000e-01 5.74842e+00 5.74842e+00 5.74842e-01 1.00000e-09 2.12000e-01 5.74842e+00 5.74842e+00 5.74842e-01 1.00000e-09 2.12000e-01 $5.74842 \mathrm{e}+00$ 5.74842e+00 5.74842e-01 1.00000e-09 2.12000e-01 $1.00000 \mathrm{e}-02$ 1.00000e-02 1.00000e-03 1.00000e-09 1.00000e-01 $1.00000 \mathrm{e}+001.00000 \mathrm{e}+001.00000 \mathrm{e}-011.00000 \mathrm{e}-091.00000 \mathrm{e}-01$ $1.00000 \mathrm{e}-05$ 1.00000e-05 1.00000e-06 1.00000e-09 1.00000e-01 $1.00000 \mathrm{e}+001.00000 \mathrm{e}+001.00000 \mathrm{e}-011.00000 \mathrm{e}-091.00000 \mathrm{e}-01$ Element: 1355 \# of layers: 11

$\mathrm{Kx} \mathrm{Ky} \mathrm{Kz}$ Ss Por

1.43872e+02 1.43872e+02 1.43872e+01 1.00000e-09 7.00000e-02 1.43872e+02 1.43872e+02 1.43872e+01 1.00000e-09 7.00000e-02 $5.74842 \mathrm{e}+00$ 5.74842e+00 5.74842e-01 1.00000e-09 2.12000e-01 $5.74842 \mathrm{e}+00$ 5.74842e+00 5.74842e-01 1.00000e-09 2.12000e-01 5.74842e+00 5.74842e+00 5.74842e-01 1.00000e-09 2.12000e-01 5.74842e+00 5.74842e+00 5.74842e-01 1.00000e-09 2.12000e-01 5.74842e+00 5.74842e+00 5.74842e-01 1.00000e-09 2.12000e-01 $1.00000 \mathrm{e}-02$ 1.00000e-02 1.00000e-03 1.00000e-09 1.00000e-01 $1.00000 \mathrm{e}+001.00000 \mathrm{e}+001.00000 \mathrm{e}-011.00000 \mathrm{e}-091.00000 \mathrm{e}-01$ $1.00000 \mathrm{e}-05$ 1.00000e-05 1.00000e-06 1.00000e-09 1.00000e-01 $1.00000 \mathrm{e}+001.00000 \mathrm{e}+001.00000 \mathrm{e}-011.00000 \mathrm{e}-091.00000 \mathrm{e}-01$ Element: 1356 \# of layers: 11

$\mathrm{Kx} \mathrm{Ky} \mathrm{Kz}$ Ss Por

1.43872e+02 1.43872e+02 1.43872e+01 1.00000e-09 7.00000e-02 1.43872e+02 1.43872e+02 1.43872e+01 1.00000e-09 7.00000e-02 $5.74842 \mathrm{e}+00$ 5.74842e+00 5.74842e-01 1.00000e-09 2.12000e-01 5.74842e+00 5.74842e+00 5.74842e-01 1.00000e-09 2.12000e-01 $5.74842 \mathrm{e}+00$ 5.74842e+00 5.74842e-01 1.00000e-09 2.12000e-01 5.74842e+00 5.74842e+00 5.74842e-01 1.00000e-09 2.12000e-01 $5.74842 \mathrm{e}+00$ 5.74842e+00 5.74842e-01 1.00000e-09 2.12000e-01 $1.00000 \mathrm{e}-02$ 1.00000e-02 1.00000e-03 1.00000e-09 1.00000e-01 $1.00000 \mathrm{e}+001.00000 \mathrm{e}+001.00000 \mathrm{e}-011.00000 \mathrm{e}-091.00000 \mathrm{e}-01$ $1.00000 \mathrm{e}-05$ 1.00000e-05 1.00000e-06 1.00000e-09 1.00000e-01 $1.00000 \mathrm{e}+001.00000 \mathrm{e}+001.00000 \mathrm{e}-011.00000 \mathrm{e}-091.00000 \mathrm{e}-01$ Element: 1357 \# of layers: 10

$\mathrm{Kx} \mathrm{Ky} \mathrm{Kz}$ Ss Por

1.43872e+02 1.43872e+02 1.43872e+01 1.00000e-09 7.00000e-02 $5.74842 \mathrm{e}+00$ 5.74842e+00 5.74842e-01 1.00000e-09 2.12000e-01 $5.74842 \mathrm{e}+00$ 5.74842e+00 5.74842e-01 1.00000e-09 2.12000e-01 5.74842e+00 5.74842e+00 5.74842e-01 1.00000e-09 2.12000e-01 5.74842e+00 5.74842e+00 5.74842e-01 1.00000e-09 2.12000e-01 5.74842e+00 5.74842e+00 5.74842e-01 1.00000e-09 2.12000e-01 $1.00000 \mathrm{e}-02$ 1.00000e-02 1.00000e-03 1.00000e-09 1.00000e-01 
$1.00000 \mathrm{e}+001.00000 \mathrm{e}+001.00000 \mathrm{e}-011.00000 \mathrm{e}-091.00000 \mathrm{e}-01$ $1.00000 \mathrm{e}-05$ 1.00000e-05 1.00000e-06 1.00000e-09 1.00000e-01 $1.00000 \mathrm{e}+001.00000 \mathrm{e}+001.00000 \mathrm{e}-01$ 1.00000e-09 1.00000e-01 Element: 1358 \# of layers: 10

$\mathrm{Kx} \mathrm{Ky} \mathrm{Kz}$ Ss Por

1.43872e+02 1.43872e+02 1.43872e+01 1.00000e-09 7.00000e-02 5.74842e+00 5.74842e+00 5.74842e-01 1.00000e-09 2.12000e-01 $5.74842 \mathrm{e}+00$ 5.74842e+00 5.74842e-01 1.00000e-09 2.12000e-01 5.74842e+00 5.74842e+00 5.74842e-01 1.00000e-09 2.12000e-01 $5.74842 \mathrm{e}+00$ 5.74842e+00 5.74842e-01 1.00000e-09 2.12000e-01 $5.74842 \mathrm{e}+00$ 5.74842e+00 5.74842e-01 1.00000e-09 2.12000e-01 $1.00000 \mathrm{e}-021.00000 \mathrm{e}-02$ 1.00000e-03 1.00000e-09 1.00000e-01 $1.00000 \mathrm{e}+001.00000 \mathrm{e}+001.00000 \mathrm{e}-011.00000 \mathrm{e}-091.00000 \mathrm{e}-01$ $1.00000 \mathrm{e}-05$ 1.00000e-05 1.00000e-06 1.00000e-09 1.00000e-01 $1.00000 \mathrm{e}+001.00000 \mathrm{e}+001.00000 \mathrm{e}-011.00000 \mathrm{e}-091.00000 \mathrm{e}-01$ Element: 1359 \# of layers: 10

$\mathrm{Kx} \mathrm{Ky} \mathrm{Kz}$ Ss Por

1.43872e+02 1.43872e+02 1.43872e+01 1.00000e-09 7.00000e-02 $5.74842 \mathrm{e}+00$ 5.74842e+00 5.74842e-01 1.00000e-09 2.12000e-01 $5.74842 \mathrm{e}+00$ 5.74842e+00 5.74842e-01 1.00000e-09 2.12000e-01 $5.74842 \mathrm{e}+00$ 5.74842e+00 5.74842e-01 1.00000e-09 2.12000e-01 5.74842e+00 5.74842e+00 5.74842e-01 1.00000e-09 2.12000e-01 $5.74842 \mathrm{e}+00$ 5.74842e+00 5.74842e-01 1.00000e-09 2.12000e-01 $1.00000 \mathrm{e}-02$ 1.00000e-02 1.00000e-03 1.00000e-09 1.00000e-01 $1.00000 \mathrm{e}+001.00000 \mathrm{e}+001.00000 \mathrm{e}-011.00000 \mathrm{e}-091.00000 \mathrm{e}-01$ $1.00000 \mathrm{e}-05$ 1.00000e-05 1.00000e-06 1.00000e-09 1.00000e-01 $1.00000 \mathrm{e}+001.00000 \mathrm{e}+001.00000 \mathrm{e}-01$ 1.00000e-09 1.00000e-01 Element: 1360 \# of layers: 10

$\mathrm{Kx} \mathrm{Ky} \mathrm{Kz} \mathrm{Ss} \mathrm{Por}$

1.43872e+02 1.43872e+02 1.43872e+01 1.00000e-09 7.00000e-02 $5.74842 \mathrm{e}+00$ 5.74842e+00 5.74842e-01 1.00000e-09 2.12000e-01 $5.74842 \mathrm{e}+00$ 5.74842e+00 5.74842e-01 1.00000e-09 2.12000e-01 $5.74842 \mathrm{e}+00$ 5.74842e+00 5.74842e-01 1.00000e-09 2.12000e-01 $5.74842 \mathrm{e}+00$ 5.74842e+00 5.74842e-01 1.00000e-09 2.12000e-01 5.74842e+00 5.74842e+00 5.74842e-01 1.00000e-09 2.12000e-01 $1.00000 \mathrm{e}-02$ 1.00000e-02 1.00000e-03 1.00000e-09 1.00000e-01 $1.00000 \mathrm{e}+001.00000 \mathrm{e}+001.00000 \mathrm{e}-011.00000 \mathrm{e}-091.00000 \mathrm{e}-01$ 1.00000e-05 1.00000e-05 1.00000e-06 1.00000e-09 1.00000e-01 $1.00000 \mathrm{e}+001.00000 \mathrm{e}+001.00000 \mathrm{e}-011.00000 \mathrm{e}-091.00000 \mathrm{e}-01$ Element: 1361 \# of layers: 10

$\mathrm{Kx} \mathrm{Ky} \mathrm{Kz}$ Ss Por 1.43872e+02 1.43872e+02 1.43872e+01 1.00000e-09 7.00000e-02 5.74842e+00 5.74842e+00 5.74842e-01 1.00000e-09 2.12000e-01 $5.74842 \mathrm{e}+00$ 5.74842e+00 5.74842e-01 1.00000e-09 2.12000e-01 $5.74842 \mathrm{e}+00$ 5.74842e+00 5.74842e-01 1.00000e-09 2.12000e-01 $5.74842 \mathrm{e}+00$ 5.74842e+00 5.74842e-01 1.00000e-09 2.12000e-01 
$5.74842 \mathrm{e}+00$ 5.74842e+00 5.74842e-01 1.00000e-09 2.12000e-01 $1.00000 \mathrm{e}-021.00000 \mathrm{e}-02$ 1.00000e-03 1.00000e-09 1.00000e-01 $1.00000 \mathrm{e}+001.00000 \mathrm{e}+001.00000 \mathrm{e}-011.00000 \mathrm{e}-091.00000 \mathrm{e}-01$ $1.00000 \mathrm{e}-05$ 1.00000e-05 1.00000e-06 1.00000e-09 1.00000e-01 $1.00000 \mathrm{e}+001.00000 \mathrm{e}+001.00000 \mathrm{e}-011.00000 \mathrm{e}-091.00000 \mathrm{e}-01$ Element: 1362 \# of layers: 10

Kx Ky Kz Ss Por

$1.43872 \mathrm{e}+02$ 1.43872e+02 1.43872e+01 1.00000e-09 7.00000e-02 $5.74842 \mathrm{e}+005.74842 \mathrm{e}+00$ 5.74842e-01 1.00000e-09 2.12000e-01 $5.74842 \mathrm{e}+005.74842 \mathrm{e}+00$ 5.74842e-01 1.00000e-09 2.12000e-01 $5.74842 \mathrm{e}+005.74842 \mathrm{e}+00$ 5.74842e-01 1.00000e-09 2.12000e-01 $5.74842 \mathrm{e}+005.74842 \mathrm{e}+00$ 5.74842e-01 1.00000e-09 2.12000e-01 $5.74842 \mathrm{e}+005.74842 \mathrm{e}+00$ 5.74842e-01 1.00000e-09 2.12000e-01 $1.00000 \mathrm{e}-02$ 1.00000e-02 1.00000e-03 1.00000e-09 1.00000e-01 $1.00000 \mathrm{e}+001.00000 \mathrm{e}+001.00000 \mathrm{e}-011.00000 \mathrm{e}-091.00000 \mathrm{e}-01$ $1.00000 \mathrm{e}-051.00000 \mathrm{e}-05$ 1.00000e-06 1.00000e-09 1.00000e-01 $1.00000 \mathrm{e}+001.00000 \mathrm{e}+001.00000 \mathrm{e}-011.00000 \mathrm{e}-091.00000 \mathrm{e}-01$ Element: 1363 \# of layers: 11

Kx Ky Kz Ss Por

$9.12623 \mathrm{e}+019.12623 \mathrm{e}+019.12623 \mathrm{e}+00$ 1.00000e-09 7.00000e-02

$9.12623 \mathrm{e}+019.12623 \mathrm{e}+019.12623 \mathrm{e}+001.00000 \mathrm{e}-09$ 7.00000e-02

$3.64643 \mathrm{e}+003.64643 \mathrm{e}+00$ 3.64643e-01 1.00000e-09 2.12000e-01

$3.64643 \mathrm{e}+003.64643 \mathrm{e}+003.64643 \mathrm{e}-01$ 1.00000e-09 2.12000e-01

$3.64643 \mathrm{e}+003.64643 \mathrm{e}+003.64643 \mathrm{e}-011.00000 \mathrm{e}-092.12000 \mathrm{e}-01$

$3.64643 \mathrm{e}+003.64643 \mathrm{e}+003.64643 \mathrm{e}-011.00000 \mathrm{e}-092.12000 \mathrm{e}-01$

$3.64643 \mathrm{e}+003.64643 \mathrm{e}+003.64643 \mathrm{e}-011.00000 \mathrm{e}-092.12000 \mathrm{e}-01$

$1.00000 \mathrm{e}-02$ 1.00000e-02 1.00000e-03 1.00000e-09 1.00000e-01

$1.00000 \mathrm{e}+001.00000 \mathrm{e}+001.00000 \mathrm{e}-011.00000 \mathrm{e}-091.00000 \mathrm{e}-01$

$1.00000 \mathrm{e}-051.00000 \mathrm{e}-05$ 1.00000e-06 1.00000e-09 1.00000e-01

$1.00000 \mathrm{e}+001.00000 \mathrm{e}+001.00000 \mathrm{e}-011.00000 \mathrm{e}-091.00000 \mathrm{e}-01$

Element: 1364 \# of layers: 11

Kx Ky Kz Ss Por

$9.12623 \mathrm{e}+01$ 9.12623e+01 9.12623e+00 1.00000e-09 7.00000e-02

$9.12623 \mathrm{e}+019.12623 \mathrm{e}+019.12623 \mathrm{e}+001.00000 \mathrm{e}-09$ 7.00000e-02

$3.64643 \mathrm{e}+003.64643 \mathrm{e}+003.64643 \mathrm{e}-01$ 1.00000e-09 2.12000e-01

$3.64643 \mathrm{e}+003.64643 \mathrm{e}+003.64643 \mathrm{e}-01$ 1.00000e-09 2.12000e-01

$3.64643 \mathrm{e}+003.64643 \mathrm{e}+003.64643 \mathrm{e}-011.00000 \mathrm{e}-092.12000 \mathrm{e}-01$

$3.64643 \mathrm{e}+003.64643 \mathrm{e}+003.64643 \mathrm{e}-011.00000 \mathrm{e}-092.12000 \mathrm{e}-01$

$3.64643 \mathrm{e}+003.64643 \mathrm{e}+003.64643 \mathrm{e}-01$ 1.00000e-09 2.12000e-01

$1.00000 \mathrm{e}-02$ 1.00000e-02 1.00000e-03 1.00000e-09 1.00000e-01

$1.00000 \mathrm{e}+001.00000 \mathrm{e}+001.00000 \mathrm{e}-011.00000 \mathrm{e}-091.00000 \mathrm{e}-01$

$1.00000 \mathrm{e}-05$ 1.00000e-05 1.00000e-06 1.00000e-09 1.00000e-01

$1.00000 \mathrm{e}+001.00000 \mathrm{e}+001.00000 \mathrm{e}-011.00000 \mathrm{e}-091.00000 \mathrm{e}-01$

Element: 1365 \# of layers: 11

Kx Ky Kz Ss Por

9.12623e+01 9.12623e+01 9.12623e+00 1.00000e-09 7.00000e-02 
9.12623e+01 9.12623e+01 9.12623e+00 1.00000e-09 7.00000e-02 3.64643e+00 3.64643e+00 3.64643e-01 1.00000e-09 2.12000e-01 $3.64643 \mathrm{e}+003.64643 \mathrm{e}+00$ 3.64643e-01 1.00000e-09 2.12000e-01 $3.64643 \mathrm{e}+003.64643 \mathrm{e}+00$ 3.64643e-01 1.00000e-09 2.12000e-01 $3.64643 \mathrm{e}+003.64643 \mathrm{e}+00$ 3.64643e-01 1.00000e-09 2.12000e-01 $3.64643 \mathrm{e}+003.64643 \mathrm{e}+00$ 3.64643e-01 1.00000e-09 2.12000e-01 $1.00000 \mathrm{e}-02$ 1.00000e-02 1.00000e-03 1.00000e-09 1.00000e-01 $1.00000 \mathrm{e}+001.00000 \mathrm{e}+001.00000 \mathrm{e}-011.00000 \mathrm{e}-091.00000 \mathrm{e}-01$ $1.00000 \mathrm{e}-05$ 1.00000e-05 1.00000e-06 1.00000e-09 1.00000e-01 $1.00000 \mathrm{e}+001.00000 \mathrm{e}+001.00000 \mathrm{e}-011.00000 \mathrm{e}-091.00000 \mathrm{e}-01$ Element: 1366 \# of layers: 10

Kx Ky Kz Ss Por

9.12623e+01 9.12623e+01 9.12623e+00 1.00000e-09 7.00000e-02 3.64643e+00 3.64643e+00 3.64643e-01 1.00000e-09 2.12000e-01 $3.64643 \mathrm{e}+003.64643 \mathrm{e}+00$ 3.64643e-01 1.00000e-09 2.12000e-01 $3.64643 \mathrm{e}+003.64643 \mathrm{e}+00$ 3.64643e-01 1.00000e-09 2.12000e-01 $3.64643 \mathrm{e}+00$ 3.64643e+00 3.64643e-01 1.00000e-09 2.12000e-01 $3.64643 \mathrm{e}+003.64643 \mathrm{e}+00$ 3.64643e-01 1.00000e-09 2.12000e-01 $1.00000 \mathrm{e}-02$ 1.00000e-02 1.00000e-03 1.00000e-09 1.00000e-01 $1.00000 \mathrm{e}+001.00000 \mathrm{e}+001.00000 \mathrm{e}-011.00000 \mathrm{e}-091.00000 \mathrm{e}-01$ $1.00000 \mathrm{e}-05$ 1.00000e-05 1.00000e-06 1.00000e-09 1.00000e-01 $1.00000 \mathrm{e}+001.00000 \mathrm{e}+001.00000 \mathrm{e}-01$ 1.00000e-09 1.00000e-01 Element: 1367 \# of layers: 10

Kx Ky Kz Ss Por

9.12623e+01 9.12623e+01 9.12623e+00 1.00000e-09 7.00000e-02 $3.64643 \mathrm{e}+00$ 3.64643e+00 3.64643e-01 1.00000e-09 2.12000e-01 3.64643e+00 3.64643e+00 3.64643e-01 1.00000e-09 2.12000e-01 $3.64643 \mathrm{e}+00$ 3.64643e+00 3.64643e-01 1.00000e-09 2.12000e-01 $3.64643 \mathrm{e}+003.64643 \mathrm{e}+00$ 3.64643e-01 1.00000e-09 2.12000e-01 $3.64643 \mathrm{e}+00$ 3.64643e+00 3.64643e-01 1.00000e-09 2.12000e-01 $1.00000 \mathrm{e}-02$ 1.00000e-02 1.00000e-03 1.00000e-09 1.00000e-01 $1.00000 \mathrm{e}+001.00000 \mathrm{e}+001.00000 \mathrm{e}-011.00000 \mathrm{e}-091.00000 \mathrm{e}-01$ $1.00000 \mathrm{e}-05$ 1.00000e-05 1.00000e-06 1.00000e-09 1.00000e-01 $1.00000 \mathrm{e}+001.00000 \mathrm{e}+001.00000 \mathrm{e}-011.00000 \mathrm{e}-091.00000 \mathrm{e}-01$ Element: 1368 \# of layers: 10

$\mathrm{Kx} \mathrm{Ky} \mathrm{Kz}$ Ss Por

9.12623e+01 9.12623e+01 9.12623e+00 1.00000e-09 7.00000e-02 $3.64643 \mathrm{e}+00$ 3.64643e+00 3.64643e-01 1.00000e-09 2.12000e-01 $3.64643 \mathrm{e}+003.64643 \mathrm{e}+00$ 3.64643e-01 1.00000e-09 2.12000e-01 3.64643e+00 3.64643e+00 3.64643e-01 1.00000e-09 2.12000e-01 $3.64643 \mathrm{e}+003.64643 \mathrm{e}+00$ 3.64643e-01 1.00000e-09 2.12000e-01 3.64643e+00 3.64643e+00 3.64643e-01 1.00000e-09 2.12000e-01 $1.00000 \mathrm{e}-02$ 1.00000e-02 1.00000e-03 1.00000e-09 1.00000e-01 $1.00000 \mathrm{e}+001.00000 \mathrm{e}+001.00000 \mathrm{e}-011.00000 \mathrm{e}-091.00000 \mathrm{e}-01$ $1.00000 \mathrm{e}-05$ 1.00000e-05 1.00000e-06 1.00000e-09 1.00000e-01 $1.00000 \mathrm{e}+001.00000 \mathrm{e}+001.00000 \mathrm{e}-011.00000 \mathrm{e}-091.00000 \mathrm{e}-01$ 
Element: 1369 \# of layers: 10

$\mathrm{Kx} \mathrm{Ky} \mathrm{Kz}$ Ss Por

9.12623e+01 9.12623e+01 9.12623e+00 1.00000e-09 7.00000e-02

$3.64643 \mathrm{e}+003.64643 \mathrm{e}+00$ 3.64643e-01 1.00000e-09 2.12000e-01

$3.64643 \mathrm{e}+003.64643 \mathrm{e}+00$ 3.64643e-01 1.00000e-09 2.12000e-01

$3.64643 \mathrm{e}+003.64643 \mathrm{e}+00$ 3.64643e-01 1.00000e-09 2.12000e-01

$3.64643 \mathrm{e}+003.64643 \mathrm{e}+00$ 3.64643e-01 1.00000e-09 2.12000e-01

$3.64643 \mathrm{e}+00$ 3.64643e+00 3.64643e-01 1.00000e-09 2.12000e-01

$1.00000 \mathrm{e}-02$ 1.00000e-02 1.00000e-03 1.00000e-09 1.00000e-01

$1.00000 \mathrm{e}+001.00000 \mathrm{e}+001.00000 \mathrm{e}-011.00000 \mathrm{e}-091.00000 \mathrm{e}-01$

$1.00000 \mathrm{e}-05$ 1.00000e-05 1.00000e-06 1.00000e-09 1.00000e-01

$1.00000 \mathrm{e}+001.00000 \mathrm{e}+001.00000 \mathrm{e}-01$ 1.00000e-09 1.00000e-01

Element: 1370 \# of layers: 10

$\mathrm{Kx} \mathrm{Ky} \mathrm{Kz}$ Ss Por

9.12623e+01 9.12623e+01 9.12623e+00 1.00000e-09 7.00000e-02

$3.64643 \mathrm{e}+003.64643 \mathrm{e}+00$ 3.64643e-01 1.00000e-09 2.12000e-01

$3.64643 \mathrm{e}+00$ 3.64643e+00 3.64643e-01 1.00000e-09 2.12000e-01

$3.64643 \mathrm{e}+003.64643 \mathrm{e}+00$ 3.64643e-01 1.00000e-09 2.12000e-01

$3.64643 \mathrm{e}+003.64643 \mathrm{e}+00$ 3.64643e-01 1.00000e-09 2.12000e-01

$3.64643 \mathrm{e}+00$ 3.64643e+00 3.64643e-01 1.00000e-09 2.12000e-01

$1.00000 \mathrm{e}-02$ 1.00000e-02 1.00000e-03 1.00000e-09 1.00000e-01

$1.00000 \mathrm{e}+001.00000 \mathrm{e}+001.00000 \mathrm{e}-011.00000 \mathrm{e}-091.00000 \mathrm{e}-01$

$1.00000 \mathrm{e}-05$ 1.00000e-05 1.00000e-06 1.00000e-09 1.00000e-01

$1.00000 \mathrm{e}+001.00000 \mathrm{e}+001.00000 \mathrm{e}-011.00000 \mathrm{e}-09$ 1.00000e-01

Element: 1371 \# of layers: 10

$\mathrm{Kx} \mathrm{Ky} \mathrm{Kz}$ Ss Por

9.12623e+01 9.12623e+01 9.12623e+00 1.00000e-09 7.00000e-02

$3.64643 \mathrm{e}+00$ 3.64643e+00 3.64643e-01 1.00000e-09 2.12000e-01

$3.64643 \mathrm{e}+003.64643 \mathrm{e}+00$ 3.64643e-01 1.00000e-09 2.12000e-01

$3.64643 \mathrm{e}+00$ 3.64643e+00 3.64643e-01 1.00000e-09 2.12000e-01

$3.64643 \mathrm{e}+003.64643 \mathrm{e}+00$ 3.64643e-01 1.00000e-09 2.12000e-01

$3.64643 \mathrm{e}+003.64643 \mathrm{e}+00$ 3.64643e-01 1.00000e-09 2.12000e-01

$1.00000 \mathrm{e}-02$ 1.00000e-02 1.00000e-03 1.00000e-09 1.00000e-01

$1.00000 \mathrm{e}+001.00000 \mathrm{e}+001.00000 \mathrm{e}-011.00000 \mathrm{e}-091.00000 \mathrm{e}-01$

$1.00000 \mathrm{e}-05$ 1.00000e-05 1.00000e-06 1.00000e-09 1.00000e-01

$1.00000 \mathrm{e}+001.00000 \mathrm{e}+001.00000 \mathrm{e}-011.00000 \mathrm{e}-091.00000 \mathrm{e}-01$

Element: 1372 \# of layers: 11

$\mathrm{Kx} \mathrm{Ky} \mathrm{Kz}$ Ss Por

8.65122e+01 8.65122e+01 8.65122e+00 1.00000e-09 7.00000e-02

8.65122e+01 8.65122e+01 8.65122e+00 1.00000e-09 7.00000e-02

$3.45675 \mathrm{e}+003.45675 \mathrm{e}+003.45675 \mathrm{e}-01$ 1.00000e-09 2.12000e-01

$3.45675 \mathrm{e}+003.45675 \mathrm{e}+00$ 3.45675e-01 1.00000e-09 2.12000e-01

$3.45675 \mathrm{e}+003.45675 \mathrm{e}+00$ 3.45675e-01 1.00000e-09 2.12000e-01

$3.45675 \mathrm{e}+003.45675 \mathrm{e}+003.45675 \mathrm{e}-01$ 1.00000e-09 2.12000e-01

$3.45675 \mathrm{e}+003.45675 \mathrm{e}+003.45675 \mathrm{e}-01$ 1.00000e-09 2.12000e-01

$1.00000 \mathrm{e}-02$ 1.00000e-02 1.00000e-03 1.00000e-09 1.00000e-01 
$1.00000 \mathrm{e}+001.00000 \mathrm{e}+001.00000 \mathrm{e}-011.00000 \mathrm{e}-091.00000 \mathrm{e}-01$ $1.00000 \mathrm{e}-05$ 1.00000e-05 1.00000e-06 1.00000e-09 1.00000e-01 $1.00000 \mathrm{e}+001.00000 \mathrm{e}+001.00000 \mathrm{e}-01$ 1.00000e-09 1.00000e-01 Element: 1373 \# of layers: 11

$\mathrm{Kx} \mathrm{Ky} \mathrm{Kz}$ Ss Por

8.65122e+01 8.65122e+01 8.65122e+00 1.00000e-09 7.00000e-02 8.65122e+01 8.65122e+01 8.65122e+00 1.00000e-09 7.00000e-02 $3.45675 \mathrm{e}+003.45675 \mathrm{e}+003.45675 \mathrm{e}-01$ 1.00000e-09 2.12000e-01 $3.45675 \mathrm{e}+003.45675 \mathrm{e}+003.45675 \mathrm{e}-01$ 1.00000e-09 2.12000e-01 $3.45675 \mathrm{e}+003.45675 \mathrm{e}+00$ 3.45675e-01 1.00000e-09 2.12000e-01 $3.45675 \mathrm{e}+003.45675 \mathrm{e}+003.45675 \mathrm{e}-01$ 1.00000e-09 2.12000e-01 $3.45675 \mathrm{e}+003.45675 \mathrm{e}+003.45675 \mathrm{e}-01$ 1.00000e-09 2.12000e-01 $1.00000 \mathrm{e}-02$ 1.00000e-02 1.00000e-03 1.00000e-09 1.00000e-01 $1.00000 \mathrm{e}+001.00000 \mathrm{e}+001.00000 \mathrm{e}-011.00000 \mathrm{e}-091.00000 \mathrm{e}-01$ $1.00000 \mathrm{e}-051.00000 \mathrm{e}-051.00000 \mathrm{e}-061.00000 \mathrm{e}-091.00000 \mathrm{e}-01$ $1.00000 \mathrm{e}+001.00000 \mathrm{e}+001.00000 \mathrm{e}-011.00000 \mathrm{e}-091.00000 \mathrm{e}-01$ Element: 1374 \# of layers: 10

$\mathrm{Kx} \mathrm{Ky} \mathrm{Kz}$ Ss Por

8.65122e+01 8.65122e+01 8.65122e+00 1.00000e-09 7.00000e-02 $3.45675 \mathrm{e}+003.45675 \mathrm{e}+003.45675 \mathrm{e}-01$ 1.00000e-09 2.12000e-01 $3.45675 \mathrm{e}+003.45675 \mathrm{e}+003.45675 \mathrm{e}-01$ 1.00000e-09 2.12000e-01 $3.45675 \mathrm{e}+003.45675 \mathrm{e}+003.45675 \mathrm{e}-01$ 1.00000e-09 2.12000e-01 $3.45675 \mathrm{e}+003.45675 \mathrm{e}+003.45675 \mathrm{e}-01$ 1.00000e-09 2.12000e-01 $3.45675 \mathrm{e}+003.45675 \mathrm{e}+003.45675 \mathrm{e}-01$ 1.00000e-09 2.12000e-01 $1.00000 \mathrm{e}-021.00000 \mathrm{e}-02$ 1.00000e-03 1.00000e-09 1.00000e-01 $1.00000 \mathrm{e}+001.00000 \mathrm{e}+001.00000 \mathrm{e}-011.00000 \mathrm{e}-091.00000 \mathrm{e}-01$ $1.00000 \mathrm{e}-05$ 1.00000e-05 1.00000e-06 1.00000e-09 1.00000e-01 $1.00000 \mathrm{e}+001.00000 \mathrm{e}+001.00000 \mathrm{e}-011.00000 \mathrm{e}-091.00000 \mathrm{e}-01$ Element: 1375 \# of layers: 11

$\mathrm{Kx} \mathrm{Ky} \mathrm{Kz}$ Ss Por

8.65122e+01 8.65122e+01 8.65122e+00 1.00000e-09 7.00000e-02 8.65122e+01 8.65122e+01 8.65122e+00 1.00000e-09 7.00000e-02 $3.45675 \mathrm{e}+003.45675 \mathrm{e}+003.45675 \mathrm{e}-01$ 1.00000e-09 2.12000e-01 $3.45675 \mathrm{e}+003.45675 \mathrm{e}+003.45675 \mathrm{e}-01$ 1.00000e-09 2.12000e-01 $3.45675 \mathrm{e}+003.45675 \mathrm{e}+003.45675 \mathrm{e}-01$ 1.00000e-09 2.12000e-01 $3.45675 \mathrm{e}+003.45675 \mathrm{e}+003.45675 \mathrm{e}-01$ 1.00000e-09 2.12000e-01 $3.45675 \mathrm{e}+003.45675 \mathrm{e}+003.45675 \mathrm{e}-01$ 1.00000e-09 2.12000e-01 $1.00000 \mathrm{e}-02$ 1.00000e-02 1.00000e-03 1.00000e-09 1.00000e-01 $1.00000 \mathrm{e}+001.00000 \mathrm{e}+001.00000 \mathrm{e}-011.00000 \mathrm{e}-091.00000 \mathrm{e}-01$ $1.00000 \mathrm{e}-05$ 1.00000e-05 1.00000e-06 1.00000e-09 1.00000e-01 $1.00000 \mathrm{e}+001.00000 \mathrm{e}+001.00000 \mathrm{e}-011.00000 \mathrm{e}-091.00000 \mathrm{e}-01$ Element: 1376 \# of layers: 10

$\mathrm{Kx} \mathrm{Ky} \mathrm{Kz}$ Ss Por

8.65122e+01 8.65122e+01 8.65122e+00 1.00000e-09 7.00000e-02 $3.45675 \mathrm{e}+003.45675 \mathrm{e}+003.45675 \mathrm{e}-01$ 1.00000e-09 2.12000e-01 $3.45675 \mathrm{e}+003.45675 \mathrm{e}+003.45675 \mathrm{e}-01$ 1.00000e-09 2.12000e-01 
$3.45675 \mathrm{e}+003.45675 \mathrm{e}+003.45675 \mathrm{e}-011.00000 \mathrm{e}-092.12000 \mathrm{e}-01$ $3.45675 \mathrm{e}+003.45675 \mathrm{e}+003.45675 \mathrm{e}-01$ 1.00000e-09 2.12000e-01 $3.45675 \mathrm{e}+003.45675 \mathrm{e}+003.45675 \mathrm{e}-01$ 1.00000e-09 2.12000e-01 $1.00000 \mathrm{e}-021.00000 \mathrm{e}-02$ 1.00000e-03 1.00000e-09 1.00000e-01 $1.00000 \mathrm{e}+001.00000 \mathrm{e}+001.00000 \mathrm{e}-011.00000 \mathrm{e}-091.00000 \mathrm{e}-01$ $1.00000 \mathrm{e}-05$ 1.00000e-05 1.00000e-06 1.00000e-09 1.00000e-01 $1.00000 \mathrm{e}+001.00000 \mathrm{e}+001.00000 \mathrm{e}-011.00000 \mathrm{e}-091.00000 \mathrm{e}-01$ Element: 1377 \# of layers: 10

Kx Ky Kz Ss Por

8.65122e+01 8.65122e+01 8.65122e+00 1.00000e-09 7.00000e-02 $3.45675 \mathrm{e}+003.45675 \mathrm{e}+003.45675 \mathrm{e}-011.00000 \mathrm{e}-092.12000 \mathrm{e}-01$ $3.45675 \mathrm{e}+003.45675 \mathrm{e}+003.45675 \mathrm{e}-01$ 1.00000e-09 2.12000e-01 $3.45675 \mathrm{e}+003.45675 \mathrm{e}+003.45675 \mathrm{e}-011.00000 \mathrm{e}-092.12000 \mathrm{e}-01$ $3.45675 \mathrm{e}+003.45675 \mathrm{e}+003.45675 \mathrm{e}-011.00000 \mathrm{e}-092.12000 \mathrm{e}-01$ $3.45675 \mathrm{e}+003.45675 \mathrm{e}+003.45675 \mathrm{e}-011.00000 \mathrm{e}-092.12000 \mathrm{e}-01$ $1.00000 \mathrm{e}-021.00000 \mathrm{e}-02$ 1.00000e-03 1.00000e-09 1.00000e-01 $1.00000 \mathrm{e}+001.00000 \mathrm{e}+001.00000 \mathrm{e}-011.00000 \mathrm{e}-091.00000 \mathrm{e}-01$ $1.00000 \mathrm{e}-05$ 1.00000e-05 1.00000e-06 1.00000e-09 1.00000e-01 $1.00000 \mathrm{e}+001.00000 \mathrm{e}+001.00000 \mathrm{e}-011.00000 \mathrm{e}-091.00000 \mathrm{e}-01$ Element: 1378 \# of layers: 10

Kx Ky Kz Ss Por

8.65122e+01 8.65122e+01 8.65122e+00 1.00000e-09 7.00000e-02 $3.45675 \mathrm{e}+003.45675 \mathrm{e}+003.45675 \mathrm{e}-011.00000 \mathrm{e}-092.12000 \mathrm{e}-01$ $3.45675 \mathrm{e}+003.45675 \mathrm{e}+003.45675 \mathrm{e}-011.00000 \mathrm{e}-092.12000 \mathrm{e}-01$ $3.45675 \mathrm{e}+003.45675 \mathrm{e}+003.45675 \mathrm{e}-011.00000 \mathrm{e}-092.12000 \mathrm{e}-01$ $3.45675 \mathrm{e}+003.45675 \mathrm{e}+003.45675 \mathrm{e}-01$ 1.00000e-09 2.12000e-01 $3.45675 \mathrm{e}+003.45675 \mathrm{e}+003.45675 \mathrm{e}-011.00000 \mathrm{e}-092.12000 \mathrm{e}-01$ $1.00000 \mathrm{e}-021.00000 \mathrm{e}-02$ 1.00000e-03 1.00000e-09 1.00000e-01 $1.00000 \mathrm{e}+001.00000 \mathrm{e}+001.00000 \mathrm{e}-011.00000 \mathrm{e}-091.00000 \mathrm{e}-01$ $1.00000 \mathrm{e}-05$ 1.00000e-05 1.00000e-06 1.00000e-09 1.00000e-01 $1.00000 \mathrm{e}+001.00000 \mathrm{e}+001.00000 \mathrm{e}-011.00000 \mathrm{e}-091.00000 \mathrm{e}-01$ Element: 1379 \# of layers: 10

Kx Ky Kz Ss Por

8.65122e+01 8.65122e+01 8.65122e+00 1.00000e-09 7.00000e-02 $3.45675 \mathrm{e}+003.45675 \mathrm{e}+003.45675 \mathrm{e}-011.00000 \mathrm{e}-092.12000 \mathrm{e}-01$ $3.45675 \mathrm{e}+003.45675 \mathrm{e}+003.45675 \mathrm{e}-011.00000 \mathrm{e}-092.12000 \mathrm{e}-01$ $3.45675 \mathrm{e}+003.45675 \mathrm{e}+003.45675 \mathrm{e}-011.00000 \mathrm{e}-092.12000 \mathrm{e}-01$ $3.45675 \mathrm{e}+003.45675 \mathrm{e}+003.45675 \mathrm{e}-01$ 1.00000e-09 2.12000e-01 $3.45675 \mathrm{e}+003.45675 \mathrm{e}+003.45675 \mathrm{e}-01$ 1.00000e-09 2.12000e-01 $1.00000 \mathrm{e}-02$ 1.00000e-02 1.00000e-03 1.00000e-09 1.00000e-01 $1.00000 \mathrm{e}+001.00000 \mathrm{e}+001.00000 \mathrm{e}-011.00000 \mathrm{e}-091.00000 \mathrm{e}-01$ $1.00000 \mathrm{e}-05$ 1.00000e-05 1.00000e-06 1.00000e-09 1.00000e-01 $1.00000 \mathrm{e}+001.00000 \mathrm{e}+001.00000 \mathrm{e}-011.00000 \mathrm{e}-091.00000 \mathrm{e}-01$ Element: 1380 \# of layers: 11

Kx Ky Kz Ss Por

8.65122e+01 8.65122e+01 8.65122e+00 1.00000e-09 7.00000e-02 
8.65122e+01 8.65122e+01 8.65122e+00 1.00000e-09 7.00000e-02 $3.45675 \mathrm{e}+003.45675 \mathrm{e}+003.45675 \mathrm{e}-01$ 1.00000e-09 2.12000e-01 $3.45675 \mathrm{e}+003.45675 \mathrm{e}+003.45675 \mathrm{e}-01$ 1.00000e-09 2.12000e-01 $3.45675 \mathrm{e}+003.45675 \mathrm{e}+003.45675 \mathrm{e}-01$ 1.00000e-09 2.12000e-01 $3.45675 \mathrm{e}+003.45675 \mathrm{e}+003.45675 \mathrm{e}-01$ 1.00000e-09 2.12000e-01 $3.45675 \mathrm{e}+003.45675 \mathrm{e}+003.45675 \mathrm{e}-01$ 1.00000e-09 2.12000e-01 $1.00000 \mathrm{e}-02$ 1.00000e-02 1.00000e-03 1.00000e-09 1.00000e-01 $1.00000 \mathrm{e}+001.00000 \mathrm{e}+001.00000 \mathrm{e}-011.00000 \mathrm{e}-091.00000 \mathrm{e}-01$ $1.00000 \mathrm{e}-051.00000 \mathrm{e}-051.00000 \mathrm{e}-061.00000 \mathrm{e}-091.00000 \mathrm{e}-01$ $1.00000 \mathrm{e}+001.00000 \mathrm{e}+001.00000 \mathrm{e}-011.00000 \mathrm{e}-091.00000 \mathrm{e}-01$ Element: 1381 \# of layers: 10

$\mathrm{Kx} \mathrm{Ky} \mathrm{Kz}$ Ss Por

8.27235e+01 8.27235e+01 8.27235e+00 1.00000e-09 7.00000e-02 $3.30532 \mathrm{e}+00$ 3.30532e+00 3.30532e-01 1.00000e-09 2.12000e-01 3.30532e+00 3.30532e+00 3.30532e-01 1.00000e-09 2.12000e-01 $3.30532 \mathrm{e}+003.30532 \mathrm{e}+00$ 3.30532e-01 1.00000e-09 2.12000e-01 3.30532e+00 3.30532e+00 3.30532e-01 1.00000e-09 2.12000e-01 3.30532e+00 3.30532e+00 3.30532e-01 1.00000e-09 2.12000e-01 $1.00000 \mathrm{e}-02$ 1.00000e-02 1.00000e-03 1.00000e-09 1.00000e-01 $1.00000 \mathrm{e}+001.00000 \mathrm{e}+001.00000 \mathrm{e}-011.00000 \mathrm{e}-091.00000 \mathrm{e}-01$ $1.00000 \mathrm{e}-051.00000 \mathrm{e}-05$ 1.00000e-06 1.00000e-09 1.00000e-01 $1.00000 \mathrm{e}+001.00000 \mathrm{e}+001.00000 \mathrm{e}-01$ 1.00000e-09 1.00000e-01 Element: 1382 \# of layers: 10

Kx Ky Kz Ss Por

8.27235e+01 8.27235e+01 8.27235e+00 1.00000e-09 7.00000e-02 3.30532e+00 3.30532e+00 3.30532e-01 1.00000e-09 2.12000e-01 3.30532e+00 3.30532e+00 3.30532e-01 1.00000e-09 2.12000e-01 3.30532e+00 3.30532e+00 3.30532e-01 1.00000e-09 2.12000e-01 $3.30532 \mathrm{e}+00$ 3.30532e+00 3.30532e-01 1.00000e-09 2.12000e-01 $3.30532 \mathrm{e}+00$ 3.30532e+00 3.30532e-01 1.00000e-09 2.12000e-01 $1.00000 \mathrm{e}-02$ 1.00000e-02 1.00000e-03 1.00000e-09 1.00000e-01 $1.00000 \mathrm{e}+001.00000 \mathrm{e}+001.00000 \mathrm{e}-011.00000 \mathrm{e}-091.00000 \mathrm{e}-01$ $1.00000 \mathrm{e}-05$ 1.00000e-05 1.00000e-06 1.00000e-09 1.00000e-01 $1.00000 \mathrm{e}+001.00000 \mathrm{e}+001.00000 \mathrm{e}-011.00000 \mathrm{e}-091.00000 \mathrm{e}-01$ Element: 1383 \# of layers: 9

$\mathrm{Kx} \mathrm{Ky} \mathrm{Kz}$ Ss Por

8.27235e+01 8.27235e+01 8.27235e+00 1.00000e-09 7.00000e-02 $3.30532 \mathrm{e}+00$ 3.30532e+00 3.30532e-01 1.00000e-09 2.12000e-01 3.30532e+00 3.30532e+00 3.30532e-01 1.00000e-09 2.12000e-01 3.30532e+00 3.30532e+00 3.30532e-01 1.00000e-09 2.12000e-01 $3.30532 \mathrm{e}+00$ 3.30532e+00 3.30532e-01 1.00000e-09 2.12000e-01 $1.00000 \mathrm{e}-02$ 1.00000e-02 1.00000e-03 1.00000e-09 1.00000e-01 $1.00000 \mathrm{e}+001.00000 \mathrm{e}+001.00000 \mathrm{e}-011.00000 \mathrm{e}-091.00000 \mathrm{e}-01$ $1.00000 \mathrm{e}-05$ 1.00000e-05 1.00000e-06 1.00000e-09 1.00000e-01 $1.00000 \mathrm{e}+001.00000 \mathrm{e}+001.00000 \mathrm{e}-011.00000 \mathrm{e}-09$ 1.00000e-01 Element: 1384 \# of layers: 10 
$\mathrm{Kx} \mathrm{Ky} \mathrm{Kz}$ Ss Por

8.27235e+01 8.27235e+01 8.27235e+00 1.00000e-09 7.00000e-02

8.27235e+01 8.27235e+01 8.27235e+00 1.00000e-09 7.00000e-02

$3.30532 \mathrm{e}+00$ 3.30532e+00 3.30532e-01 1.00000e-09 2.12000e-01

$3.30532 \mathrm{e}+00$ 3.30532e+00 3.30532e-01 1.00000e-09 2.12000e-01

$3.30532 \mathrm{e}+003.30532 \mathrm{e}+00$ 3.30532e-01 1.00000e-09 2.12000e-01

3.30532e+00 3.30532e+00 3.30532e-01 1.00000e-09 2.12000e-01

$1.00000 \mathrm{e}-02$ 1.00000e-02 1.00000e-03 1.00000e-09 1.00000e-01

$1.00000 \mathrm{e}+001.00000 \mathrm{e}+001.00000 \mathrm{e}-011.00000 \mathrm{e}-091.00000 \mathrm{e}-01$

$1.00000 \mathrm{e}-05$ 1.00000e-05 1.00000e-06 1.00000e-09 1.00000e-01

$1.00000 \mathrm{e}+001.00000 \mathrm{e}+001.00000 \mathrm{e}-011.00000 \mathrm{e}-091.00000 \mathrm{e}-01$

Element: 1385 \# of layers: 9

$\mathrm{Kx} \mathrm{Ky} \mathrm{Kz}$ Ss Por

8.27235e+01 8.27235e+01 8.27235e+00 1.00000e-09 7.00000e-02

3.30532e+00 3.30532e+00 3.30532e-01 1.00000e-09 2.12000e-01

$3.30532 \mathrm{e}+003.30532 \mathrm{e}+00$ 3.30532e-01 1.00000e-09 2.12000e-01

3.30532e+00 3.30532e+00 3.30532e-01 1.00000e-09 2.12000e-01

3.30532e+00 3.30532e+00 3.30532e-01 1.00000e-09 2.12000e-01

$1.00000 \mathrm{e}-02$ 1.00000e-02 1.00000e-03 1.00000e-09 1.00000e-01

$1.00000 \mathrm{e}+001.00000 \mathrm{e}+001.00000 \mathrm{e}-011.00000 \mathrm{e}-091.00000 \mathrm{e}-01$

$1.00000 \mathrm{e}-05$ 1.00000e-05 1.00000e-06 1.00000e-09 1.00000e-01

$1.00000 \mathrm{e}+001.00000 \mathrm{e}+001.00000 \mathrm{e}-011.00000 \mathrm{e}-091.00000 \mathrm{e}-01$

Element: 1386 \# of layers: 10

Kx Ky Kz Ss Por

8.27235e+01 8.27235e+01 8.27235e+00 1.00000e-09 7.00000e-02

3.30532e+00 3.30532e+00 3.30532e-01 1.00000e-09 2.12000e-01

$3.30532 \mathrm{e}+00$ 3.30532e+00 3.30532e-01 1.00000e-09 2.12000e-01

3.30532e+00 3.30532e+00 3.30532e-01 1.00000e-09 2.12000e-01

$3.30532 \mathrm{e}+00$ 3.30532e+00 3.30532e-01 1.00000e-09 2.12000e-01

$3.30532 \mathrm{e}+00$ 3.30532e+00 3.30532e-01 1.00000e-09 2.12000e-01

$1.00000 \mathrm{e}-02$ 1.00000e-02 1.00000e-03 1.00000e-09 1.00000e-01

$1.00000 \mathrm{e}+001.00000 \mathrm{e}+001.00000 \mathrm{e}-011.00000 \mathrm{e}-091.00000 \mathrm{e}-01$

1.00000e-05 1.00000e-05 1.00000e-06 1.00000e-09 1.00000e-01

$1.00000 \mathrm{e}+001.00000 \mathrm{e}+001.00000 \mathrm{e}-011.00000 \mathrm{e}-091.00000 \mathrm{e}-01$

Element: 1387 \# of layers: 10

Kx Ky Kz Ss Por

8.27235e+01 8.27235e+01 8.27235e+00 1.00000e-09 7.00000e-02

3.30532e+00 3.30532e+00 3.30532e-01 1.00000e-09 2.12000e-01

3.30532e+00 3.30532e+00 3.30532e-01 1.00000e-09 2.12000e-01

3.30532e+00 3.30532e+00 3.30532e-01 1.00000e-09 2.12000e-01

$3.30532 \mathrm{e}+00$ 3.30532e+00 3.30532e-01 1.00000e-09 2.12000e-01

$3.30532 \mathrm{e}+003.30532 \mathrm{e}+00$ 3.30532e-01 1.00000e-09 2.12000e-01

$1.00000 \mathrm{e}-02$ 1.00000e-02 1.00000e-03 1.00000e-09 1.00000e-01

$1.00000 \mathrm{e}+001.00000 \mathrm{e}+001.00000 \mathrm{e}-011.00000 \mathrm{e}-091.00000 \mathrm{e}-01$

$1.00000 \mathrm{e}-05$ 1.00000e-05 1.00000e-06 1.00000e-09 1.00000e-01

$1.00000 \mathrm{e}+001.00000 \mathrm{e}+001.00000 \mathrm{e}-011.00000 \mathrm{e}-091.00000 \mathrm{e}-01$ 
Element: 1388 \# of layers: 11

$\mathrm{Kx} \mathrm{Ky} \mathrm{Kz}$ Ss Por

8.27235e+01 8.27235e+01 8.27235e+00 1.00000e-09 7.00000e-02

$8.27235 \mathrm{e}+018.27235 \mathrm{e}+018.27235 \mathrm{e}+00$ 1.00000e-09 7.00000e-02

3.30532e+00 3.30532e+00 3.30532e-01 1.00000e-09 2.12000e-01

$3.30532 \mathrm{e}+003.30532 \mathrm{e}+00$ 3.30532e-01 1.00000e-09 2.12000e-01

3.30532e+00 3.30532e+00 3.30532e-01 1.00000e-09 2.12000e-01

$3.30532 \mathrm{e}+00$ 3.30532e+00 3.30532e-01 1.00000e-09 2.12000e-01

3.30532e+00 3.30532e+00 3.30532e-01 1.00000e-09 2.12000e-01

$1.00000 \mathrm{e}-02$ 1.00000e-02 1.00000e-03 1.00000e-09 1.00000e-01

$1.00000 \mathrm{e}+001.00000 \mathrm{e}+001.00000 \mathrm{e}-011.00000 \mathrm{e}-091.00000 \mathrm{e}-01$

$1.00000 \mathrm{e}-05$ 1.00000e-05 1.00000e-06 1.00000e-09 1.00000e-01

$1.00000 \mathrm{e}+001.00000 \mathrm{e}+001.00000 \mathrm{e}-01$ 1.00000e-09 1.00000e-01

Element: 1389 \# of layers: 11

$\mathrm{Kx} \mathrm{Ky} \mathrm{Kz}$ Ss Por

8.27235e+01 8.27235e+01 8.27235e+00 1.00000e-09 7.00000e-02

$8.27235 \mathrm{e}+018.27235 \mathrm{e}+018.27235 \mathrm{e}+00$ 1.00000e-09 7.00000e-02

3.30532e+00 3.30532e+00 3.30532e-01 1.00000e-09 2.12000e-01

3.30532e+00 3.30532e+00 3.30532e-01 1.00000e-09 2.12000e-01

$3.30532 \mathrm{e}+00$ 3.30532e+00 3.30532e-01 1.00000e-09 2.12000e-01

$3.30532 \mathrm{e}+00$ 3.30532e+00 3.30532e-01 1.00000e-09 2.12000e-01

3.30532e+00 3.30532e+00 3.30532e-01 1.00000e-09 2.12000e-01

$1.00000 \mathrm{e}-02$ 1.00000e-02 1.00000e-03 1.00000e-09 1.00000e-01

$1.00000 \mathrm{e}+001.00000 \mathrm{e}+001.00000 \mathrm{e}-011.00000 \mathrm{e}-091.00000 \mathrm{e}-01$

$1.00000 \mathrm{e}-05$ 1.00000e-05 1.00000e-06 1.00000e-09 1.00000e-01

$1.00000 \mathrm{e}+001.00000 \mathrm{e}+001.00000 \mathrm{e}-011.00000 \mathrm{e}-091.00000 \mathrm{e}-01$

Element: 1390 \# of layers: 9

$\mathrm{Kx} \mathrm{Ky} \mathrm{Kz}$ Ss Por

6.23060e+01 6.23060e+01 6.23060e+00 1.00000e-09 7.00000e-02

$2.48945 \mathrm{e}+002.48945 \mathrm{e}+00$ 2.48945e-01 1.00000e-09 2.12000e-01

$2.48945 \mathrm{e}+002.48945 \mathrm{e}+002.48945 \mathrm{e}-01$ 1.00000e-09 2.12000e-01

$2.48945 \mathrm{e}+002.48945 \mathrm{e}+00$ 2.48945e-01 1.00000e-09 2.12000e-01

$2.48945 \mathrm{e}+002.48945 \mathrm{e}+002.48945 \mathrm{e}-01$ 1.00000e-09 2.12000e-01

$1.00000 \mathrm{e}-02$ 1.00000e-02 1.00000e-03 1.00000e-09 1.00000e-01

$1.00000 \mathrm{e}+001.00000 \mathrm{e}+001.00000 \mathrm{e}-011.00000 \mathrm{e}-091.00000 \mathrm{e}-01$

$1.00000 \mathrm{e}-05$ 1.00000e-05 1.00000e-06 1.00000e-09 1.00000e-01

$1.00000 \mathrm{e}+001.00000 \mathrm{e}+001.00000 \mathrm{e}-011.00000 \mathrm{e}-091.00000 \mathrm{e}-01$

Element: 1391 \# of layers: 9

$\mathrm{Kx} \mathrm{Ky} \mathrm{Kz}$ Ss Por

6.23060e+01 6.23060e+01 6.23060e+00 1.00000e-09 7.00000e-02

$2.48945 \mathrm{e}+002.48945 \mathrm{e}+002.48945 \mathrm{e}-01$ 1.00000e-09 2.12000e-01

$2.48945 \mathrm{e}+002.48945 \mathrm{e}+002.48945 \mathrm{e}-01$ 1.00000e-09 2.12000e-01

$2.48945 \mathrm{e}+002.48945 \mathrm{e}+002.48945 \mathrm{e}-01$ 1.00000e-09 2.12000e-01

$2.48945 \mathrm{e}+002.48945 \mathrm{e}+002.48945 \mathrm{e}-01$ 1.00000e-09 2.12000e-01

$1.00000 \mathrm{e}-01$ 1.00000e-01 1.00000e-02 1.00000e-09 1.00000e-01

$1.00000 \mathrm{e}+001.00000 \mathrm{e}+001.00000 \mathrm{e}-011.00000 \mathrm{e}-091.00000 \mathrm{e}-01$ 
$1.00000 \mathrm{e}-05$ 1.00000e-05 1.00000e-06 1.00000e-09 1.00000e-01 $1.00000 \mathrm{e}+001.00000 \mathrm{e}+001.00000 \mathrm{e}-01$ 1.00000e-09 1.00000e-01 Element: 1392 \# of layers: 9

Kx Ky Kz Ss Por

6.23060e+01 6.23060e+01 6.23060e+00 1.00000e-09 7.00000e-02

$2.48945 \mathrm{e}+002.48945 \mathrm{e}+00$ 2.48945e-01 1.00000e-09 2.12000e-01

$2.48945 \mathrm{e}+002.48945 \mathrm{e}+00$ 2.48945e-01 1.00000e-09 2.12000e-01

$2.48945 \mathrm{e}+002.48945 \mathrm{e}+002.48945 \mathrm{e}-01$ 1.00000e-09 2.12000e-01

$2.48945 \mathrm{e}+002.48945 \mathrm{e}+002.48945 \mathrm{e}-01$ 1.00000e-09 2.12000e-01

$1.00000 \mathrm{e}-011.00000 \mathrm{e}-01$ 1.00000e-02 1.00000e-09 1.00000e-01

$1.00000 \mathrm{e}+001.00000 \mathrm{e}+001.00000 \mathrm{e}-011.00000 \mathrm{e}-091.00000 \mathrm{e}-01$

$1.00000 \mathrm{e}-05$ 1.00000e-05 1.00000e-06 1.00000e-09 1.00000e-01

$1.00000 \mathrm{e}+001.00000 \mathrm{e}+001.00000 \mathrm{e}-01$ 1.00000e-09 1.00000e-01

Element: 1393 \# of layers: 9

$\mathrm{Kx} \mathrm{Ky} \mathrm{Kz}$ Ss Por

6.23060e+01 6.23060e+01 6.23060e+00 1.00000e-09 7.00000e-02

$2.48945 \mathrm{e}+002.48945 \mathrm{e}+002.48945 \mathrm{e}-01$ 1.00000e-09 2.12000e-01

$2.48945 \mathrm{e}+002.48945 \mathrm{e}+00$ 2.48945e-01 1.00000e-09 2.12000e-01

$2.48945 \mathrm{e}+002.48945 \mathrm{e}+002.48945 \mathrm{e}-01$ 1.00000e-09 2.12000e-01

$2.48945 \mathrm{e}+002.48945 \mathrm{e}+002.48945 \mathrm{e}-01$ 1.00000e-09 2.12000e-01

$1.00000 \mathrm{e}-011.00000 \mathrm{e}-011.00000 \mathrm{e}-021.00000 \mathrm{e}-091.00000 \mathrm{e}-01$

$1.00000 \mathrm{e}+001.00000 \mathrm{e}+001.00000 \mathrm{e}-011.00000 \mathrm{e}-091.00000 \mathrm{e}-01$

$1.00000 \mathrm{e}-05$ 1.00000e-05 1.00000e-06 1.00000e-09 1.00000e-01

$1.00000 \mathrm{e}+001.00000 \mathrm{e}+00$ 1.00000e-01 1.00000e-09 1.00000e-01

Element: 1394 \# of layers: 9

$\mathrm{Kx} \mathrm{Ky} \mathrm{Kz}$ Ss Por

6.23060e+01 6.23060e+01 6.23060e+00 1.00000e-09 7.00000e-02

$2.48945 \mathrm{e}+002.48945 \mathrm{e}+00$ 2.48945e-01 1.00000e-09 2.12000e-01

$2.48945 \mathrm{e}+002.48945 \mathrm{e}+002.48945 \mathrm{e}-01$ 1.00000e-09 2.12000e-01

$2.48945 \mathrm{e}+002.48945 \mathrm{e}+002.48945 \mathrm{e}-01$ 1.00000e-09 2.12000e-01

$2.48945 \mathrm{e}+002.48945 \mathrm{e}+002.48945 \mathrm{e}-01$ 1.00000e-09 2.12000e-01

$1.00000 \mathrm{e}-01$ 1.00000e-01 1.00000e-02 1.00000e-09 1.00000e-01

$1.00000 \mathrm{e}+001.00000 \mathrm{e}+001.00000 \mathrm{e}-011.00000 \mathrm{e}-091.00000 \mathrm{e}-01$

$1.00000 \mathrm{e}-05$ 1.00000e-05 1.00000e-06 1.00000e-09 1.00000e-01

$1.00000 \mathrm{e}+001.00000 \mathrm{e}+001.00000 \mathrm{e}-011.00000 \mathrm{e}-091.00000 \mathrm{e}-01$

Element: 1395 \# of layers: 10

Kx Ky Kz Ss Por

6.23060e+01 6.23060e+01 6.23060e+00 1.00000e-09 7.00000e-02

$6.23060 \mathrm{e}+016.23060 \mathrm{e}+016.23060 \mathrm{e}+001.00000 \mathrm{e}-09$ 7.00000e-02

$2.48945 \mathrm{e}+002.48945 \mathrm{e}+00$ 2.48945e-01 1.00000e-09 2.12000e-01

$2.48945 \mathrm{e}+002.48945 \mathrm{e}+002.48945 \mathrm{e}-01$ 1.00000e-09 2.12000e-01

$2.48945 \mathrm{e}+002.48945 \mathrm{e}+002.48945 \mathrm{e}-01$ 1.00000e-09 2.12000e-01

$2.48945 \mathrm{e}+002.48945 \mathrm{e}+002.48945 \mathrm{e}-01$ 1.00000e-09 2.12000e-01

$1.00000 \mathrm{e}-011.00000 \mathrm{e}-011.00000 \mathrm{e}-021.00000 \mathrm{e}-091.00000 \mathrm{e}-01$

$1.00000 \mathrm{e}+001.00000 \mathrm{e}+001.00000 \mathrm{e}-011.00000 \mathrm{e}-091.00000 \mathrm{e}-01$

$1.00000 \mathrm{e}-05$ 1.00000e-05 1.00000e-06 1.00000e-09 1.00000e-01 
$1.00000 \mathrm{e}+001.00000 \mathrm{e}+00$ 1.00000e-01 1.00000e-09 1.00000e-01

Element: 1396 \# of layers: 9

$\mathrm{Kx} \mathrm{Ky} \mathrm{Kz}$ Ss Por

6.23060e+01 6.23060e+01 6.23060e+00 1.00000e-09 7.00000e-02

$2.48945 \mathrm{e}+002.48945 \mathrm{e}+00$ 2.48945e-01 1.00000e-09 2.12000e-01

$2.48945 \mathrm{e}+002.48945 \mathrm{e}+00$ 2.48945e-01 1.00000e-09 2.12000e-01

$2.48945 \mathrm{e}+002.48945 \mathrm{e}+00$ 2.48945e-01 1.00000e-09 2.12000e-01

$2.48945 \mathrm{e}+002.48945 \mathrm{e}+002.48945 \mathrm{e}-01$ 1.00000e-09 2.12000e-01

$1.00000 \mathrm{e}-02$ 1.00000e-02 1.00000e-03 1.00000e-09 1.00000e-01

$1.00000 \mathrm{e}+001.00000 \mathrm{e}+001.00000 \mathrm{e}-011.00000 \mathrm{e}-091.00000 \mathrm{e}-01$

$1.00000 \mathrm{e}-05$ 1.00000e-05 1.00000e-06 1.00000e-09 1.00000e-01

$1.00000 \mathrm{e}+001.00000 \mathrm{e}+001.00000 \mathrm{e}-01$ 1.00000e-09 1.00000e-01

Element: 1397 \# of layers: 10

$\mathrm{Kx} \mathrm{Ky} \mathrm{Kz}$ Ss Por

6.23060e+01 6.23060e+01 6.23060e+00 1.00000e-09 7.00000e-02

$6.23060 \mathrm{e}+016.23060 \mathrm{e}+016.23060 \mathrm{e}+001.00000 \mathrm{e}-09$ 7.00000e-02

$2.48945 \mathrm{e}+002.48945 \mathrm{e}+00$ 2.48945e-01 1.00000e-09 2.12000e-01

$2.48945 \mathrm{e}+002.48945 \mathrm{e}+00$ 2.48945e-01 1.00000e-09 2.12000e-01

$2.48945 \mathrm{e}+002.48945 \mathrm{e}+002.48945 \mathrm{e}-01$ 1.00000e-09 2.12000e-01

$2.48945 \mathrm{e}+002.48945 \mathrm{e}+002.48945 \mathrm{e}-01$ 1.00000e-09 2.12000e-01

$1.00000 \mathrm{e}-02$ 1.00000e-02 1.00000e-03 1.00000e-09 1.00000e-01

$1.00000 \mathrm{e}+001.00000 \mathrm{e}+001.00000 \mathrm{e}-011.00000 \mathrm{e}-091.00000 \mathrm{e}-01$

$1.00000 \mathrm{e}-05$ 1.00000e-05 1.00000e-06 1.00000e-09 1.00000e-01

$1.00000 \mathrm{e}+001.00000 \mathrm{e}+001.00000 \mathrm{e}-011.00000 \mathrm{e}-09$ 1.00000e-01

Element: 1398 \# of layers: 10

$\mathrm{Kx} \mathrm{Ky} \mathrm{Kz}$ Ss Por

6.23060e+01 6.23060e+01 6.23060e+00 1.00000e-09 7.00000e-02

6.23060e+01 6.23060e+01 6.23060e+00 1.00000e-09 7.00000e-02

$2.48945 \mathrm{e}+002.48945 \mathrm{e}+002.48945 \mathrm{e}-01$ 1.00000e-09 2.12000e-01

$2.48945 \mathrm{e}+002.48945 \mathrm{e}+002.48945 \mathrm{e}-01$ 1.00000e-09 2.12000e-01

$2.48945 \mathrm{e}+002.48945 \mathrm{e}+00$ 2.48945e-01 1.00000e-09 2.12000e-01

$2.48945 \mathrm{e}+002.48945 \mathrm{e}+00$ 2.48945e-01 1.00000e-09 2.12000e-01

$1.00000 \mathrm{e}-01$ 1.00000e-01 1.00000e-02 1.00000e-09 1.00000e-01

$1.00000 \mathrm{e}+001.00000 \mathrm{e}+001.00000 \mathrm{e}-011.00000 \mathrm{e}-091.00000 \mathrm{e}-01$

$1.00000 \mathrm{e}-05$ 1.00000e-05 1.00000e-06 1.00000e-09 1.00000e-01

$1.00000 \mathrm{e}+001.00000 \mathrm{e}+001.00000 \mathrm{e}-011.00000 \mathrm{e}-091.00000 \mathrm{e}-01$

Element: 1399 \# of layers: 8

$\mathrm{Kx} \mathrm{Ky} \mathrm{Kz}$ Ss Por

5.72225e+01 5.72225e+01 5.72225e+00 1.00000e-09 7.00000e-02

$2.28650 \mathrm{e}+002.28650 \mathrm{e}+00$ 2.28650e-01 1.00000e-09 2.12000e-01

$2.28650 \mathrm{e}+002.28650 \mathrm{e}+002.28650 \mathrm{e}-01$ 1.00000e-09 2.12000e-01

$2.28650 \mathrm{e}+002.28650 \mathrm{e}+00$ 2.28650e-01 1.00000e-09 2.12000e-01

$1.00000 \mathrm{e}-01$ 1.00000e-01 1.00000e-02 1.00000e-09 1.00000e-01

$1.00000 \mathrm{e}+001.00000 \mathrm{e}+001.00000 \mathrm{e}-011.00000 \mathrm{e}-091.00000 \mathrm{e}-01$

$1.00000 \mathrm{e}-05$ 1.00000e-05 1.00000e-06 1.00000e-09 1.00000e-01

$1.00000 \mathrm{e}+001.00000 \mathrm{e}+001.00000 \mathrm{e}-011.00000 \mathrm{e}-091.00000 \mathrm{e}-01$ 
Element: 1400 \# of layers: 9

$\mathrm{Kx} \mathrm{Ky} \mathrm{Kz}$ Ss Por

5.72225e+01 5.72225e+01 5.72225e+00 1.00000e-09 7.00000e-02

$2.28650 \mathrm{e}+002.28650 \mathrm{e}+002.28650 \mathrm{e}-01$ 1.00000e-09 2.12000e-01

$2.28650 \mathrm{e}+002.28650 \mathrm{e}+002.28650 \mathrm{e}-01$ 1.00000e-09 2.12000e-01

$2.28650 \mathrm{e}+002.28650 \mathrm{e}+002.28650 \mathrm{e}-01$ 1.00000e-09 2.12000e-01

$2.28650 \mathrm{e}+002.28650 \mathrm{e}+00$ 2.28650e-01 1.00000e-09 2.12000e-01

1.00000e-01 1.00000e-01 1.00000e-02 1.00000e-09 1.00000e-01

$1.00000 \mathrm{e}+001.00000 \mathrm{e}+001.00000 \mathrm{e}-011.00000 \mathrm{e}-091.00000 \mathrm{e}-01$

$1.00000 \mathrm{e}-05$ 1.00000e-05 1.00000e-06 1.00000e-09 1.00000e-01

$1.00000 \mathrm{e}+001.00000 \mathrm{e}+001.00000 \mathrm{e}-011.00000 \mathrm{e}-091.00000 \mathrm{e}-01$

Element: 1401 \# of layers: 7

$\mathrm{Kx} \mathrm{Ky} \mathrm{Kz}$ Ss Por

5.72225e+01 5.72225e+01 5.72225e+00 1.00000e-09 7.00000e-02

$5.72225 \mathrm{e}+015.72225 \mathrm{e}+015.72225 \mathrm{e}+001.00000 \mathrm{e}-09$ 7.00000e-02

$2.28650 \mathrm{e}+002.28650 \mathrm{e}+002.28650 \mathrm{e}-01$ 1.00000e-09 2.12000e-01

$2.28650 \mathrm{e}+002.28650 \mathrm{e}+002.28650 \mathrm{e}-01$ 1.00000e-09 2.12000e-01

$2.28650 \mathrm{e}+002.28650 \mathrm{e}+002.28650 \mathrm{e}-01$ 1.00000e-09 2.12000e-01

$1.00000 \mathrm{e}-011.00000 \mathrm{e}-011.00000 \mathrm{e}-021.00000 \mathrm{e}-091.00000 \mathrm{e}-01$

$1.00000 \mathrm{e}+001.00000 \mathrm{e}+001.00000 \mathrm{e}-011.00000 \mathrm{e}-091.00000 \mathrm{e}-01$

Element: 1402 \# of layers: 9

$\mathrm{Kx} \mathrm{Ky} \mathrm{Kz}$ Ss Por

5.72225e+01 5.72225e+01 5.72225e+00 1.00000e-09 7.00000e-02

$5.72225 \mathrm{e}+015.72225 \mathrm{e}+015.72225 \mathrm{e}+001.00000 \mathrm{e}-09$ 7.00000e-02

$2.28650 \mathrm{e}+002.28650 \mathrm{e}+00 \quad 2.28650 \mathrm{e}-01$ 1.00000e-09 2.12000e-01

$2.28650 \mathrm{e}+002.28650 \mathrm{e}+002.28650 \mathrm{e}-01$ 1.00000e-09 2.12000e-01

$2.28650 \mathrm{e}+002.28650 \mathrm{e}+002.28650 \mathrm{e}-01$ 1.00000e-09 2.12000e-01

$1.00000 \mathrm{e}-01$ 1.00000e-01 1.00000e-02 1.00000e-09 1.00000e-01

$1.00000 \mathrm{e}+001.00000 \mathrm{e}+001.00000 \mathrm{e}-011.00000 \mathrm{e}-091.00000 \mathrm{e}-01$

$1.00000 \mathrm{e}-05$ 1.00000e-05 1.00000e-06 1.00000e-09 1.00000e-01

$1.00000 \mathrm{e}+001.00000 \mathrm{e}+001.00000 \mathrm{e}-011.00000 \mathrm{e}-091.00000 \mathrm{e}-01$

Element: 1403 \# of layers: 9

Kx Ky Kz Ss Por

$5.72225 \mathrm{e}+015.72225 \mathrm{e}+015.72225 \mathrm{e}+001.00000 \mathrm{e}-09$ 7.00000e-02

$5.72225 \mathrm{e}+015.72225 \mathrm{e}+015.72225 \mathrm{e}+00$ 1.00000e-09 7.00000e-02

$2.28650 \mathrm{e}+002.28650 \mathrm{e}+002.28650 \mathrm{e}-01$ 1.00000e-09 2.12000e-01

$2.28650 \mathrm{e}+002.28650 \mathrm{e}+002.28650 \mathrm{e}-01$ 1.00000e-09 2.12000e-01

$2.28650 \mathrm{e}+002.28650 \mathrm{e}+002.28650 \mathrm{e}-01$ 1.00000e-09 2.12000e-01

$1.00000 \mathrm{e}-011.00000 \mathrm{e}-011.00000 \mathrm{e}-021.00000 \mathrm{e}-091.00000 \mathrm{e}-01$

$1.00000 \mathrm{e}+001.00000 \mathrm{e}+001.00000 \mathrm{e}-011.00000 \mathrm{e}-091.00000 \mathrm{e}-01$

$1.00000 \mathrm{e}-05$ 1.00000e-05 1.00000e-06 1.00000e-09 1.00000e-01

$1.00000 \mathrm{e}+001.00000 \mathrm{e}+001.00000 \mathrm{e}-011.00000 \mathrm{e}-091.00000 \mathrm{e}-01$

Element: 1404 \# of layers: 9

$\mathrm{Kx} \mathrm{Ky} \mathrm{Kz}$ Ss Por

5.72225e+01 5.72225e+01 5.72225e+00 1.00000e-09 7.00000e-02

$2.28650 \mathrm{e}+002.28650 \mathrm{e}+00$ 2.28650e-01 1.00000e-09 2.12000e-01 
$2.28650 \mathrm{e}+002.28650 \mathrm{e}+002.28650 \mathrm{e}-011.00000 \mathrm{e}-092.12000 \mathrm{e}-01$ $2.28650 \mathrm{e}+002.28650 \mathrm{e}+002.28650 \mathrm{e}-011.00000 \mathrm{e}-092.12000 \mathrm{e}-01$ $2.28650 \mathrm{e}+002.28650 \mathrm{e}+002.28650 \mathrm{e}-011.00000 \mathrm{e}-092.12000 \mathrm{e}-01$ $1.00000 \mathrm{e}-011.00000 \mathrm{e}-011.00000 \mathrm{e}-021.00000 \mathrm{e}-091.00000 \mathrm{e}-01$ $1.00000 \mathrm{e}+001.00000 \mathrm{e}+001.00000 \mathrm{e}-011.00000 \mathrm{e}-091.00000 \mathrm{e}-01$ $1.00000 \mathrm{e}-05$ 1.00000e-05 1.00000e-06 1.00000e-09 1.00000e-01 $1.00000 \mathrm{e}+001.00000 \mathrm{e}+001.00000 \mathrm{e}-011.00000 \mathrm{e}-091.00000 \mathrm{e}-01$ Element: 1405 \# of layers: 8

Kx Ky Kz Ss Por

$5.72225 \mathrm{e}+015.72225 \mathrm{e}+015.72225 \mathrm{e}+00$ 1.00000e-09 7.00000e-02 $2.28650 \mathrm{e}+002.28650 \mathrm{e}+002.28650 \mathrm{e}-011.00000 \mathrm{e}-092.12000 \mathrm{e}-01$ $2.28650 \mathrm{e}+002.28650 \mathrm{e}+002.28650 \mathrm{e}-01$ 1.00000e-09 2.12000e-01 $2.28650 \mathrm{e}+002.28650 \mathrm{e}+002.28650 \mathrm{e}-011.00000 \mathrm{e}-092.12000 \mathrm{e}-01$ $1.00000 \mathrm{e}-01$ 1.00000e-01 1.00000e-02 1.00000e-09 1.00000e-01 $1.00000 \mathrm{e}+001.00000 \mathrm{e}+001.00000 \mathrm{e}-011.00000 \mathrm{e}-091.00000 \mathrm{e}-01$ $1.00000 \mathrm{e}-051.00000 \mathrm{e}-05$ 1.00000e-06 1.00000e-09 1.00000e-01 $1.00000 \mathrm{e}+001.00000 \mathrm{e}+001.00000 \mathrm{e}-011.00000 \mathrm{e}-091.00000 \mathrm{e}-01$ Element: 1406 \# of layers: 8

Kx Ky Kz Ss Por

$5.72225 \mathrm{e}+015.72225 \mathrm{e}+015.72225 \mathrm{e}+00$ 1.00000e-09 7.00000e-02 $2.28650 \mathrm{e}+002.28650 \mathrm{e}+002.28650 \mathrm{e}-011.00000 \mathrm{e}-092.12000 \mathrm{e}-01$ $2.28650 \mathrm{e}+002.28650 \mathrm{e}+002.28650 \mathrm{e}-011.00000 \mathrm{e}-092.12000 \mathrm{e}-01$ $2.28650 \mathrm{e}+002.28650 \mathrm{e}+002.28650 \mathrm{e}-01$ 1.00000e-09 2.12000e-01 $1.00000 \mathrm{e}-011.00000 \mathrm{e}-011.00000 \mathrm{e}-021.00000 \mathrm{e}-091.00000 \mathrm{e}-01$ $1.00000 \mathrm{e}+001.00000 \mathrm{e}+001.00000 \mathrm{e}-011.00000 \mathrm{e}-091.00000 \mathrm{e}-01$ $1.00000 \mathrm{e}-051.00000 \mathrm{e}-05$ 1.00000e-06 1.00000e-09 1.00000e-01 $1.00000 \mathrm{e}+001.00000 \mathrm{e}+00$ 1.00000e-01 1.00000e-09 1.00000e-01 Element: 1407 \# of layers: 9

Kx Ky Kz Ss Por

$5.72225 \mathrm{e}+015.72225 \mathrm{e}+015.72225 \mathrm{e}+00$ 1.00000e-09 7.00000e-02 $2.28650 \mathrm{e}+002.28650 \mathrm{e}+002.28650 \mathrm{e}-011.00000 \mathrm{e}-092.12000 \mathrm{e}-01$ $2.28650 \mathrm{e}+002.28650 \mathrm{e}+002.28650 \mathrm{e}-011.00000 \mathrm{e}-092.12000 \mathrm{e}-01$ $2.28650 \mathrm{e}+002.28650 \mathrm{e}+002.28650 \mathrm{e}-011.00000 \mathrm{e}-092.12000 \mathrm{e}-01$ $2.28650 \mathrm{e}+002.28650 \mathrm{e}+002.28650 \mathrm{e}-011.00000 \mathrm{e}-092.12000 \mathrm{e}-01$ $1.00000 \mathrm{e}-011.00000 \mathrm{e}-011.00000 \mathrm{e}-021.00000 \mathrm{e}-091.00000 \mathrm{e}-01$ $1.00000 \mathrm{e}+001.00000 \mathrm{e}+001.00000 \mathrm{e}-011.00000 \mathrm{e}-091.00000 \mathrm{e}-01$ $1.00000 \mathrm{e}-05$ 1.00000e-05 1.00000e-06 1.00000e-09 1.00000e-01 $1.00000 \mathrm{e}+001.00000 \mathrm{e}+001.00000 \mathrm{e}-011.00000 \mathrm{e}-091.00000 \mathrm{e}-01$ Element: 1408 \# of layers: 7

Kx Ky Kz Ss Por $4.50662 \mathrm{e}+014.50662 \mathrm{e}+014.50662 \mathrm{e}+001.00000 \mathrm{e}-09$ 7.00000e-02 $4.50662 \mathrm{e}+014.50662 \mathrm{e}+014.50662 \mathrm{e}+001.00000 \mathrm{e}-09$ 7.00000e-02 $1.80067 \mathrm{e}+001.80067 \mathrm{e}+00$ 1.80067e-01 1.00000e-09 2.12000e-01 $1.80067 \mathrm{e}+001.80067 \mathrm{e}+001.80067 \mathrm{e}-011.00000 \mathrm{e}-092.12000 \mathrm{e}-01$ $1.80067 \mathrm{e}+001.80067 \mathrm{e}+001.80067 \mathrm{e}-011.00000 \mathrm{e}-092.12000 \mathrm{e}-01$ $1.00000 \mathrm{e}-011.00000 \mathrm{e}-011.00000 \mathrm{e}-021.00000 \mathrm{e}-091.00000 \mathrm{e}-01$ 
$1.00000 \mathrm{e}+001.00000 \mathrm{e}+00$ 1.00000e-01 1.00000e-09 1.00000e-01 Element: 1409 \# of layers: 7

Kx Ky Kz Ss Por

4.50662e+01 4.50662e+01 4.50662e+00 1.00000e-09 7.00000e-02

$4.50662 \mathrm{e}+014.50662 \mathrm{e}+014.50662 \mathrm{e}+001.00000 \mathrm{e}-09$ 7.00000e-02

$1.80067 \mathrm{e}+001.80067 \mathrm{e}+00$ 1.80067e-01 1.00000e-09 2.12000e-01

$1.80067 \mathrm{e}+001.80067 \mathrm{e}+00$ 1.80067e-01 1.00000e-09 2.12000e-01

$1.80067 \mathrm{e}+001.80067 \mathrm{e}+00$ 1.80067e-01 1.00000e-09 2.12000e-01

$1.00000 \mathrm{e}-011.00000 \mathrm{e}-011.00000 \mathrm{e}-021.00000 \mathrm{e}-091.00000 \mathrm{e}-01$

$1.00000 \mathrm{e}+001.00000 \mathrm{e}+001.00000 \mathrm{e}-011.00000 \mathrm{e}-091.00000 \mathrm{e}-01$

Element: 1410 \# of layers: 7

$\mathrm{Kx} \mathrm{Ky} \mathrm{Kz}$ Ss Por

4.50662e+01 4.50662e+01 4.50662e+00 1.00000e-09 7.00000e-02

$4.50662 \mathrm{e}+014.50662 \mathrm{e}+014.50662 \mathrm{e}+00$ 1.00000e-09 7.00000e-02

$1.80067 \mathrm{e}+00$ 1.80067e+00 1.80067e-01 1.00000e-09 2.12000e-01

$1.80067 \mathrm{e}+001.80067 \mathrm{e}+00$ 1.80067e-01 1.00000e-09 2.12000e-01

$1.80067 \mathrm{e}+00$ 1.80067e+00 1.80067e-01 1.00000e-09 2.12000e-01

$1.00000 \mathrm{e}-011.00000 \mathrm{e}-011.00000 \mathrm{e}-021.00000 \mathrm{e}-091.00000 \mathrm{e}-01$

$1.00000 \mathrm{e}+001.00000 \mathrm{e}+001.00000 \mathrm{e}-01$ 1.00000e-09 1.00000e-01

Element: 1411 \# of layers: 12

$\mathrm{Kx} \mathrm{Ky} \mathrm{Kz}$ Ss Por

8.99549e+02 8.99549e+02 8.99549e+01 1.00000e-09 7.00000e-02

8.99549e+02 8.99549e+02 8.99549e+01 1.00000e-09 7.00000e-02

5.00000e-04 5.00000e-04 5.00000e-05 1.00000e-09 1.00000e-01

$3.59423 \mathrm{e}+013.59423 \mathrm{e}+013.59423 \mathrm{e}+001.00000 \mathrm{e}-092.12000 \mathrm{e}-01$

$3.59423 \mathrm{e}+013.59423 \mathrm{e}+013.59423 \mathrm{e}+00$ 1.00000e-09 2.12000e-01

$3.59423 \mathrm{e}+013.59423 \mathrm{e}+013.59423 \mathrm{e}+001.00000 \mathrm{e}-092.12000 \mathrm{e}-01$

$3.59423 \mathrm{e}+013.59423 \mathrm{e}+01$ 3.59423e+00 1.00000e-09 2.12000e-01

$3.59423 \mathrm{e}+013.59423 \mathrm{e}+013.59423 \mathrm{e}+001.00000 \mathrm{e}-092.12000 \mathrm{e}-01$

$1.00000 \mathrm{e}-02$ 1.00000e-02 1.00000e-03 1.00000e-09 1.00000e-01

$1.00000 \mathrm{e}+001.00000 \mathrm{e}+001.00000 \mathrm{e}-01$ 1.00000e-09 1.00000e-01

$1.00000 \mathrm{e}-05$ 1.00000e-05 1.00000e-06 1.00000e-09 1.00000e-01

$1.00000 \mathrm{e}+001.00000 \mathrm{e}+001.00000 \mathrm{e}-011.00000 \mathrm{e}-091.00000 \mathrm{e}-01$

Element: 1412 \# of layers: 13

$\mathrm{Kx} \mathrm{Ky} \mathrm{Kz}$ Ss Por

8.99549e+02 8.99549e+02 8.99549e+01 1.00000e-09 7.00000e-02

$8.99549 \mathrm{e}+02$ 8.99549e+02 8.99549e+01 1.00000e-09 7.00000e-02

5.00000e-04 5.00000e-04 5.00000e-05 1.00000e-09 1.00000e-01

5.00000e-04 5.00000e-04 5.00000e-05 1.00000e-09 1.00000e-01

$3.59423 \mathrm{e}+013.59423 \mathrm{e}+013.59423 \mathrm{e}+001.00000 \mathrm{e}-092.12000 \mathrm{e}-01$

$3.59423 \mathrm{e}+013.59423 \mathrm{e}+01$ 3.59423e+00 1.00000e-09 2.12000e-01

$3.59423 \mathrm{e}+013.59423 \mathrm{e}+013.59423 \mathrm{e}+00$ 1.00000e-09 2.12000e-01

$3.59423 \mathrm{e}+013.59423 \mathrm{e}+013.59423 \mathrm{e}+00$ 1.00000e-09 2.12000e-01

3.59423e+01 3.59423e+01 3.59423e+00 1.00000e-09 2.12000e-01

$1.00000 \mathrm{e}-02$ 1.00000e-02 1.00000e-03 1.00000e-09 1.00000e-01

$1.00000 \mathrm{e}+001.00000 \mathrm{e}+001.00000 \mathrm{e}-011.00000 \mathrm{e}-091.00000 \mathrm{e}-01$ 
$1.00000 \mathrm{e}-05$ 1.00000e-05 1.00000e-06 1.00000e-09 1.00000e-01 $1.00000 \mathrm{e}+001.00000 \mathrm{e}+001.00000 \mathrm{e}-01$ 1.00000e-09 1.00000e-01 Element: 1413 \# of layers: 13

Kx Ky Kz Ss Por

8.99549e+02 8.99549e+02 8.99549e+01 1.00000e-09 7.00000e-02 8.99549e+02 8.99549e+02 8.99549e+01 1.00000e-09 7.00000e-02 5.00000e-04 5.00000e-04 5.00000e-05 1.00000e-09 1.00000e-01 5.00000e-04 5.00000e-04 5.00000e-05 1.00000e-09 1.00000e-01 $3.59423 \mathrm{e}+013.59423 \mathrm{e}+013.59423 \mathrm{e}+001.00000 \mathrm{e}-092.12000 \mathrm{e}-01$ $3.59423 \mathrm{e}+013.59423 \mathrm{e}+013.59423 \mathrm{e}+00$ 1.00000e-09 2.12000e-01 $3.59423 \mathrm{e}+013.59423 \mathrm{e}+013.59423 \mathrm{e}+00$ 1.00000e-09 2.12000e-01 $3.59423 \mathrm{e}+013.59423 \mathrm{e}+013.59423 \mathrm{e}+001.00000 \mathrm{e}-092.12000 \mathrm{e}-01$ $3.59423 \mathrm{e}+013.59423 \mathrm{e}+01$ 3.59423e+00 1.00000e-09 2.12000e-01 $1.00000 \mathrm{e}-02$ 1.00000e-02 1.00000e-03 1.00000e-09 1.00000e-01 $1.00000 \mathrm{e}+001.00000 \mathrm{e}+001.00000 \mathrm{e}-011.00000 \mathrm{e}-091.00000 \mathrm{e}-01$ $1.00000 \mathrm{e}-05$ 1.00000e-05 1.00000e-06 1.00000e-09 1.00000e-01 $1.00000 \mathrm{e}+001.00000 \mathrm{e}+001.00000 \mathrm{e}-011.00000 \mathrm{e}-091.00000 \mathrm{e}-01$ Element: 1414 \# of layers: 13

$\mathrm{Kx} \mathrm{Ky} \mathrm{Kz}$ Ss Por 8.99549e+02 8.99549e+02 8.99549e+01 1.00000e-09 7.00000e-02 8.99549e+02 8.99549e+02 8.99549e+01 1.00000e-09 7.00000e-02 5.00000e-04 5.00000e-04 5.00000e-05 1.00000e-09 1.00000e-01 5.00000e-04 5.00000e-04 5.00000e-05 1.00000e-09 1.00000e-01 $3.59423 \mathrm{e}+013.59423 \mathrm{e}+013.59423 \mathrm{e}+001.00000 \mathrm{e}-092.12000 \mathrm{e}-01$ $3.59423 \mathrm{e}+013.59423 \mathrm{e}+013.59423 \mathrm{e}+001.00000 \mathrm{e}-092.12000 \mathrm{e}-01$ $3.59423 \mathrm{e}+013.59423 \mathrm{e}+013.59423 \mathrm{e}+001.00000 \mathrm{e}-092.12000 \mathrm{e}-01$ $3.59423 \mathrm{e}+013.59423 \mathrm{e}+01$ 3.59423e+00 1.00000e-09 2.12000e-01 $3.59423 \mathrm{e}+013.59423 \mathrm{e}+013.59423 \mathrm{e}+001.00000 \mathrm{e}-092.12000 \mathrm{e}-01$ $1.00000 \mathrm{e}-02$ 1.00000e-02 1.00000e-03 1.00000e-09 1.00000e-01 $1.00000 \mathrm{e}+001.00000 \mathrm{e}+001.00000 \mathrm{e}-011.00000 \mathrm{e}-091.00000 \mathrm{e}-01$ $1.00000 \mathrm{e}-05$ 1.00000e-05 1.00000e-06 1.00000e-09 1.00000e-01 $1.00000 \mathrm{e}+001.00000 \mathrm{e}+001.00000 \mathrm{e}-01$ 1.00000e-09 1.00000e-01 Element: 1415 \# of layers: 12

$\mathrm{Kx} \mathrm{Ky} \mathrm{Kz}$ Ss Por

8.99549e+02 8.99549e+02 8.99549e+01 1.00000e-09 7.00000e-02 8.99549e+02 8.99549e+02 8.99549e+01 1.00000e-09 7.00000e-02 5.00000e-04 5.00000e-04 5.00000e-05 1.00000e-09 1.00000e-01

$3.59423 \mathrm{e}+013.59423 \mathrm{e}+013.59423 \mathrm{e}+00$ 1.00000e-09 2.12000e-01 $3.59423 \mathrm{e}+013.59423 \mathrm{e}+013.59423 \mathrm{e}+001.00000 \mathrm{e}-092.12000 \mathrm{e}-01$ $3.59423 \mathrm{e}+013.59423 \mathrm{e}+013.59423 \mathrm{e}+001.00000 \mathrm{e}-092.12000 \mathrm{e}-01$ $3.59423 \mathrm{e}+013.59423 \mathrm{e}+01$ 3.59423e+00 1.00000e-09 2.12000e-01 $3.59423 \mathrm{e}+013.59423 \mathrm{e}+013.59423 \mathrm{e}+001.00000 \mathrm{e}-092.12000 \mathrm{e}-01$ $1.00000 \mathrm{e}-02$ 1.00000e-02 1.00000e-03 1.00000e-09 1.00000e-01 $1.00000 \mathrm{e}+001.00000 \mathrm{e}+001.00000 \mathrm{e}-011.00000 \mathrm{e}-091.00000 \mathrm{e}-01$ $1.00000 \mathrm{e}-05$ 1.00000e-05 1.00000e-06 1.00000e-09 1.00000e-01 $1.00000 \mathrm{e}+001.00000 \mathrm{e}+001.00000 \mathrm{e}-011.00000 \mathrm{e}-091.00000 \mathrm{e}-01$ 
Element: 1416 \# of layers: 12

$\mathrm{Kx} \mathrm{Ky} \mathrm{Kz}$ Ss Por

8.99549e+02 8.99549e+02 8.99549e+01 1.00000e-09 7.00000e-02

$8.99549 \mathrm{e}+02$ 8.99549e+02 8.99549e+01 1.00000e-09 7.00000e-02

5.00000e-04 5.00000e-04 5.00000e-05 1.00000e-09 1.00000e-01

$3.59423 \mathrm{e}+013.59423 \mathrm{e}+013.59423 \mathrm{e}+00$ 1.00000e-09 2.12000e-01

$3.59423 \mathrm{e}+013.59423 \mathrm{e}+013.59423 \mathrm{e}+00$ 1.00000e-09 2.12000e-01

$3.59423 \mathrm{e}+013.59423 \mathrm{e}+01$ 3.59423e+00 1.00000e-09 2.12000e-01

$3.59423 \mathrm{e}+013.59423 \mathrm{e}+013.59423 \mathrm{e}+001.00000 \mathrm{e}-092.12000 \mathrm{e}-01$

$3.59423 \mathrm{e}+013.59423 \mathrm{e}+013.59423 \mathrm{e}+001.00000 \mathrm{e}-092.12000 \mathrm{e}-01$

$1.00000 \mathrm{e}-02$ 1.00000e-02 1.00000e-03 1.00000e-09 1.00000e-01

$1.00000 \mathrm{e}+001.00000 \mathrm{e}+001.00000 \mathrm{e}-011.00000 \mathrm{e}-091.00000 \mathrm{e}-01$

$1.00000 \mathrm{e}-05$ 1.00000e-05 1.00000e-06 1.00000e-09 1.00000e-01

$1.00000 \mathrm{e}+001.00000 \mathrm{e}+001.00000 \mathrm{e}-011.00000 \mathrm{e}-091.00000 \mathrm{e}-01$

Element: 1417 \# of layers: 12

Kx Ky Kz Ss Por

8.99549e+02 8.99549e+02 8.99549e+01 1.00000e-09 7.00000e-02

8.99549e+02 8.99549e+02 8.99549e+01 1.00000e-09 7.00000e-02

5.00000e-04 5.00000e-04 5.00000e-05 1.00000e-09 1.00000e-01

$3.59423 \mathrm{e}+013.59423 \mathrm{e}+013.59423 \mathrm{e}+001.00000 \mathrm{e}-092.12000 \mathrm{e}-01$

$3.59423 \mathrm{e}+013.59423 \mathrm{e}+013.59423 \mathrm{e}+001.00000 \mathrm{e}-092.12000 \mathrm{e}-01$

$3.59423 \mathrm{e}+013.59423 \mathrm{e}+01$ 3.59423e+00 1.00000e-09 2.12000e-01

$3.59423 \mathrm{e}+013.59423 \mathrm{e}+01$ 3.59423e+00 1.00000e-09 2.12000e-01

$3.59423 \mathrm{e}+013.59423 \mathrm{e}+013.59423 \mathrm{e}+00$ 1.00000e-09 2.12000e-01

$1.00000 \mathrm{e}-021.00000 \mathrm{e}-02$ 1.00000e-03 1.00000e-09 1.00000e-01

$1.00000 \mathrm{e}+001.00000 \mathrm{e}+001.00000 \mathrm{e}-011.00000 \mathrm{e}-091.00000 \mathrm{e}-01$

$1.00000 \mathrm{e}-05$ 1.00000e-05 1.00000e-06 1.00000e-09 1.00000e-01

$1.00000 \mathrm{e}+001.00000 \mathrm{e}+001.00000 \mathrm{e}-011.00000 \mathrm{e}-091.00000 \mathrm{e}-01$

Element: 1418 \# of layers: 13

$\mathrm{Kx} \mathrm{Ky} \mathrm{Kz}$ Ss Por

8.99549e+02 8.99549e+02 8.99549e+01 1.00000e-09 7.00000e-02

8.99549e+02 8.99549e+02 8.99549e+01 1.00000e-09 7.00000e-02

5.00000e-04 5.00000e-04 5.00000e-05 1.00000e-09 1.00000e-01

5.00000e-04 5.00000e-04 5.00000e-05 1.00000e-09 1.00000e-01

$3.59423 \mathrm{e}+013.59423 \mathrm{e}+013.59423 \mathrm{e}+00$ 1.00000e-09 2.12000e-01

$3.59423 \mathrm{e}+013.59423 \mathrm{e}+013.59423 \mathrm{e}+00$ 1.00000e-09 2.12000e-01

$3.59423 \mathrm{e}+013.59423 \mathrm{e}+013.59423 \mathrm{e}+00$ 1.00000e-09 2.12000e-01

$3.59423 \mathrm{e}+013.59423 \mathrm{e}+01$ 3.59423e+00 1.00000e-09 2.12000e-01

$3.59423 \mathrm{e}+013.59423 \mathrm{e}+013.59423 \mathrm{e}+00$ 1.00000e-09 2.12000e-01

$1.00000 \mathrm{e}-02$ 1.00000e-02 1.00000e-03 1.00000e-09 1.00000e-01

$1.00000 \mathrm{e}+001.00000 \mathrm{e}+001.00000 \mathrm{e}-011.00000 \mathrm{e}-091.00000 \mathrm{e}-01$

$1.00000 \mathrm{e}-05$ 1.00000e-05 1.00000e-06 1.00000e-09 1.00000e-01

$1.00000 \mathrm{e}+001.00000 \mathrm{e}+001.00000 \mathrm{e}-01$ 1.00000e-09 1.00000e-01

Element: 1419 \# of layers: 12

$\mathrm{Kx} \mathrm{Ky} \mathrm{Kz}$ Ss Por

5.30626e+02 5.30626e+02 5.30626e+01 1.00000e-09 7.00000e-02 
5.30626e+02 5.30626e+02 5.30626e+01 1.00000e-09 7.00000e-02 5.00000e-04 5.00000e-04 5.00000e-05 1.00000e-09 1.00000e-01

$2.12020 \mathrm{e}+012.12020 \mathrm{e}+012.12020 \mathrm{e}+001.00000 \mathrm{e}-092.12000 \mathrm{e}-01$ $2.12020 \mathrm{e}+012.12020 \mathrm{e}+012.12020 \mathrm{e}+00$ 1.00000e-09 2.12000e-01 $2.12020 \mathrm{e}+012.12020 \mathrm{e}+012.12020 \mathrm{e}+001.00000 \mathrm{e}-092.12000 \mathrm{e}-01$ $2.12020 \mathrm{e}+012.12020 \mathrm{e}+012.12020 \mathrm{e}+00$ 1.00000e-09 2.12000e-01 $2.12020 \mathrm{e}+012.12020 \mathrm{e}+012.12020 \mathrm{e}+00$ 1.00000e-09 2.12000e-01 $1.00000 \mathrm{e}-02$ 1.00000e-02 1.00000e-03 1.00000e-09 1.00000e-01 $1.00000 \mathrm{e}+001.00000 \mathrm{e}+001.00000 \mathrm{e}-011.00000 \mathrm{e}-091.00000 \mathrm{e}-01$ $1.00000 \mathrm{e}-05$ 1.00000e-05 1.00000e-06 1.00000e-09 1.00000e-01 $1.00000 \mathrm{e}+001.00000 \mathrm{e}+00$ 1.00000e-01 1.00000e-09 1.00000e-01 Element: 1420 \# of layers: 12

$\mathrm{Kx} \mathrm{Ky} \mathrm{Kz}$ Ss Por

$5.30626 \mathrm{e}+025.30626 \mathrm{e}+025.30626 \mathrm{e}+01$ 1.00000e-09 7.00000e-02 $5.30626 \mathrm{e}+025.30626 \mathrm{e}+025.30626 \mathrm{e}+01$ 1.00000e-09 7.00000e-02 5.00000e-04 5.00000e-04 5.00000e-05 1.00000e-09 1.00000e-01

$2.12020 \mathrm{e}+012.12020 \mathrm{e}+012.12020 \mathrm{e}+001.00000 \mathrm{e}-092.12000 \mathrm{e}-01$ $2.12020 \mathrm{e}+012.12020 \mathrm{e}+012.12020 \mathrm{e}+00$ 1.00000e-09 2.12000e-01 $2.12020 \mathrm{e}+012.12020 \mathrm{e}+012.12020 \mathrm{e}+00$ 1.00000e-09 2.12000e-01 $2.12020 \mathrm{e}+012.12020 \mathrm{e}+012.12020 \mathrm{e}+00$ 1.00000e-09 2.12000e-01 $2.12020 \mathrm{e}+012.12020 \mathrm{e}+012.12020 \mathrm{e}+001.00000 \mathrm{e}-092.12000 \mathrm{e}-01$ $1.00000 \mathrm{e}-02$ 1.00000e-02 1.00000e-03 1.00000e-09 1.00000e-01 $1.00000 \mathrm{e}+001.00000 \mathrm{e}+001.00000 \mathrm{e}-011.00000 \mathrm{e}-091.00000 \mathrm{e}-01$ $1.00000 \mathrm{e}-05$ 1.00000e-05 1.00000e-06 1.00000e-09 1.00000e-01 $1.00000 \mathrm{e}+001.00000 \mathrm{e}+001.00000 \mathrm{e}-011.00000 \mathrm{e}-091.00000 \mathrm{e}-01$ Element: 1421 \# of layers: 12

$\mathrm{Kx} \mathrm{Ky} \mathrm{Kz}$ Ss Por

5.30626e+02 5.30626e+02 5.30626e+01 1.00000e-09 7.00000e-02 $5.30626 \mathrm{e}+025.30626 \mathrm{e}+025.30626 \mathrm{e}+011.00000 \mathrm{e}-097.00000 \mathrm{e}-02$ 5.00000e-04 5.00000e-04 5.00000e-05 1.00000e-09 1.00000e-01

$2.12020 \mathrm{e}+012.12020 \mathrm{e}+012.12020 \mathrm{e}+00$ 1.00000e-09 2.12000e-01 $2.12020 \mathrm{e}+012.12020 \mathrm{e}+012.12020 \mathrm{e}+00$ 1.00000e-09 2.12000e-01 $2.12020 \mathrm{e}+012.12020 \mathrm{e}+012.12020 \mathrm{e}+001.00000 \mathrm{e}-092.12000 \mathrm{e}-01$ $2.12020 \mathrm{e}+012.12020 \mathrm{e}+012.12020 \mathrm{e}+00$ 1.00000e-09 2.12000e-01 $2.12020 \mathrm{e}+012.12020 \mathrm{e}+012.12020 \mathrm{e}+00$ 1.00000e-09 2.12000e-01 $1.00000 \mathrm{e}-02$ 1.00000e-02 1.00000e-03 1.00000e-09 1.00000e-01 $1.00000 \mathrm{e}+001.00000 \mathrm{e}+001.00000 \mathrm{e}-011.00000 \mathrm{e}-091.00000 \mathrm{e}-01$ 1.00000e-05 1.00000e-05 1.00000e-06 1.00000e-09 1.00000e-01 $1.00000 \mathrm{e}+001.00000 \mathrm{e}+001.00000 \mathrm{e}-011.00000 \mathrm{e}-091.00000 \mathrm{e}-01$ Element: 1422 \# of layers: 13

$\mathrm{Kx} \mathrm{Ky} \mathrm{Kz}$ Ss Por

5.30626e+02 5.30626e+02 5.30626e+01 1.00000e-09 7.00000e-02 $5.30626 \mathrm{e}+025.30626 \mathrm{e}+025.30626 \mathrm{e}+01$ 1.00000e-09 7.00000e-02 5.00000e-04 5.00000e-04 5.00000e-05 1.00000e-09 1.00000e-01 5.00000e-04 5.00000e-04 5.00000e-05 1.00000e-09 1.00000e-01 $2.12020 \mathrm{e}+012.12020 \mathrm{e}+012.12020 \mathrm{e}+00$ 1.00000e-09 2.12000e-01 
$2.12020 \mathrm{e}+012.12020 \mathrm{e}+012.12020 \mathrm{e}+00$ 1.00000e-09 2.12000e-01 $2.12020 \mathrm{e}+012.12020 \mathrm{e}+012.12020 \mathrm{e}+00$ 1.00000e-09 2.12000e-01 $2.12020 \mathrm{e}+012.12020 \mathrm{e}+012.12020 \mathrm{e}+00$ 1.00000e-09 2.12000e-01 $2.12020 \mathrm{e}+012.12020 \mathrm{e}+012.12020 \mathrm{e}+001.00000 \mathrm{e}-092.12000 \mathrm{e}-01$ $1.00000 \mathrm{e}-02$ 1.00000e-02 1.00000e-03 1.00000e-09 1.00000e-01 $1.00000 \mathrm{e}+001.00000 \mathrm{e}+001.00000 \mathrm{e}-011.00000 \mathrm{e}-091.00000 \mathrm{e}-01$ $1.00000 \mathrm{e}-051.00000 \mathrm{e}-05$ 1.00000e-06 1.00000e-09 1.00000e-01 $1.00000 \mathrm{e}+001.00000 \mathrm{e}+001.00000 \mathrm{e}-011.00000 \mathrm{e}-091.00000 \mathrm{e}-01$ Element: 1423 \# of layers: 13

Kx Ky Kz Ss Por

$5.30626 \mathrm{e}+025.30626 \mathrm{e}+025.30626 \mathrm{e}+01$ 1.00000e-09 7.00000e-02 $5.30626 \mathrm{e}+025.30626 \mathrm{e}+025.30626 \mathrm{e}+011.00000 \mathrm{e}-09$ 7.00000e-02 5.00000e-04 5.00000e-04 5.00000e-05 1.00000e-09 1.00000e-01 5.00000e-04 5.00000e-04 5.00000e-05 1.00000e-09 1.00000e-01 $2.12020 \mathrm{e}+012.12020 \mathrm{e}+012.12020 \mathrm{e}+001.00000 \mathrm{e}-092.12000 \mathrm{e}-01$ $2.12020 \mathrm{e}+012.12020 \mathrm{e}+012.12020 \mathrm{e}+00$ 1.00000e-09 2.12000e-01 $2.12020 \mathrm{e}+012.12020 \mathrm{e}+012.12020 \mathrm{e}+00$ 1.00000e-09 2.12000e-01 $2.12020 \mathrm{e}+012.12020 \mathrm{e}+012.12020 \mathrm{e}+00$ 1.00000e-09 2.12000e-01 $2.12020 \mathrm{e}+012.12020 \mathrm{e}+012.12020 \mathrm{e}+00$ 1.00000e-09 2.12000e-01 $1.00000 \mathrm{e}-021.00000 \mathrm{e}-02$ 1.00000e-03 1.00000e-09 1.00000e-01 $1.00000 \mathrm{e}+001.00000 \mathrm{e}+001.00000 \mathrm{e}-011.00000 \mathrm{e}-091.00000 \mathrm{e}-01$ $1.00000 \mathrm{e}-05$ 1.00000e-05 1.00000e-06 1.00000e-09 1.00000e-01 $1.00000 \mathrm{e}+001.00000 \mathrm{e}+001.00000 \mathrm{e}-011.00000 \mathrm{e}-091.00000 \mathrm{e}-01$ Element: 1424 \# of layers: 13

Kx Ky Kz Ss Por $5.30626 \mathrm{e}+025.30626 \mathrm{e}+025.30626 \mathrm{e}+01$ 1.00000e-09 7.00000e-02 $5.30626 \mathrm{e}+025.30626 \mathrm{e}+025.30626 \mathrm{e}+011.00000 \mathrm{e}-097.00000 \mathrm{e}-02$ 5.00000e-04 5.00000e-04 5.00000e-05 1.00000e-09 1.00000e-01 5.00000e-04 5.00000e-04 5.00000e-05 1.00000e-09 1.00000e-01 $2.12020 \mathrm{e}+012.12020 \mathrm{e}+012.12020 \mathrm{e}+001.00000 \mathrm{e}-092.12000 \mathrm{e}-01$ $2.12020 \mathrm{e}+012.12020 \mathrm{e}+012.12020 \mathrm{e}+001.00000 \mathrm{e}-092.12000 \mathrm{e}-01$ $2.12020 \mathrm{e}+012.12020 \mathrm{e}+012.12020 \mathrm{e}+00$ 1.00000e-09 2.12000e-01 $2.12020 \mathrm{e}+012.12020 \mathrm{e}+012.12020 \mathrm{e}+00$ 1.00000e-09 2.12000e-01 $2.12020 \mathrm{e}+012.12020 \mathrm{e}+012.12020 \mathrm{e}+00$ 1.00000e-09 2.12000e-01 $1.00000 \mathrm{e}-021.00000 \mathrm{e}-02$ 1.00000e-03 1.00000e-09 1.00000e-01 $1.00000 \mathrm{e}+001.00000 \mathrm{e}+001.00000 \mathrm{e}-011.00000 \mathrm{e}-091.00000 \mathrm{e}-01$ $1.00000 \mathrm{e}-05$ 1.00000e-05 1.00000e-06 1.00000e-09 1.00000e-01 $1.00000 \mathrm{e}+001.00000 \mathrm{e}+001.00000 \mathrm{e}-011.00000 \mathrm{e}-091.00000 \mathrm{e}-01$ Element: 1425 \# of layers: 13

Kx Ky Kz Ss Por

$5.30626 \mathrm{e}+025.30626 \mathrm{e}+025.30626 \mathrm{e}+01$ 1.00000e-09 7.00000e-02 $5.30626 \mathrm{e}+025.30626 \mathrm{e}+025.30626 \mathrm{e}+011.00000 \mathrm{e}-097.00000 \mathrm{e}-02$ $5.00000 \mathrm{e}-04$ 5.00000e-04 5.00000e-05 1.00000e-09 1.00000e-01 $5.00000 \mathrm{e}-04$ 5.00000e-04 5.00000e-05 1.00000e-09 1.00000e-01 $2.12020 \mathrm{e}+012.12020 \mathrm{e}+012.12020 \mathrm{e}+001.00000 \mathrm{e}-092.12000 \mathrm{e}-01$ $2.12020 \mathrm{e}+012.12020 \mathrm{e}+012.12020 \mathrm{e}+00$ 1.00000e-09 2.12000e-01 
$2.12020 \mathrm{e}+012.12020 \mathrm{e}+012.12020 \mathrm{e}+00$ 1.00000e-09 2.12000e-01 $2.12020 \mathrm{e}+012.12020 \mathrm{e}+012.12020 \mathrm{e}+00$ 1.00000e-09 2.12000e-01

$2.12020 \mathrm{e}+012.12020 \mathrm{e}+012.12020 \mathrm{e}+00$ 1.00000e-09 2.12000e-01 $1.00000 \mathrm{e}-021.00000 \mathrm{e}-02$ 1.00000e-03 1.00000e-09 1.00000e-01 $1.00000 \mathrm{e}+001.00000 \mathrm{e}+001.00000 \mathrm{e}-011.00000 \mathrm{e}-091.00000 \mathrm{e}-01$ $1.00000 \mathrm{e}-05$ 1.00000e-05 1.00000e-06 1.00000e-09 1.00000e-01 $1.00000 \mathrm{e}+001.00000 \mathrm{e}+001.00000 \mathrm{e}-011.00000 \mathrm{e}-091.00000 \mathrm{e}-01$ Element: 1426 \# of layers: 13

Kx Ky Kz Ss Por

$5.30626 \mathrm{e}+025.30626 \mathrm{e}+025.30626 \mathrm{e}+01$ 1.00000e-09 7.00000e-02 $5.30626 \mathrm{e}+025.30626 \mathrm{e}+025.30626 \mathrm{e}+011.00000 \mathrm{e}-097.00000 \mathrm{e}-02$ 5.00000e-04 5.00000e-04 5.00000e-05 1.00000e-09 1.00000e-01 5.00000e-04 5.00000e-04 5.00000e-05 1.00000e-09 1.00000e-01 $2.12020 \mathrm{e}+012.12020 \mathrm{e}+012.12020 \mathrm{e}+001.00000 \mathrm{e}-092.12000 \mathrm{e}-01$ $2.12020 \mathrm{e}+012.12020 \mathrm{e}+012.12020 \mathrm{e}+00$ 1.00000e-09 2.12000e-01 $2.12020 \mathrm{e}+012.12020 \mathrm{e}+012.12020 \mathrm{e}+001.00000 \mathrm{e}-092.12000 \mathrm{e}-01$ $2.12020 \mathrm{e}+012.12020 \mathrm{e}+012.12020 \mathrm{e}+001.00000 \mathrm{e}-092.12000 \mathrm{e}-01$ $2.12020 \mathrm{e}+012.12020 \mathrm{e}+012.12020 \mathrm{e}+00$ 1.00000e-09 2.12000e-01 $1.00000 \mathrm{e}-02$ 1.00000e-02 1.00000e-03 1.00000e-09 1.00000e-01 $1.00000 \mathrm{e}+001.00000 \mathrm{e}+001.00000 \mathrm{e}-011.00000 \mathrm{e}-091.00000 \mathrm{e}-01$ $1.00000 \mathrm{e}-05$ 1.00000e-05 1.00000e-06 1.00000e-09 1.00000e-01 $1.00000 \mathrm{e}+001.00000 \mathrm{e}+001.00000 \mathrm{e}-011.00000 \mathrm{e}-091.00000 \mathrm{e}-01$ Element: 1427 \# of layers: 13

Kx Ky Kz Ss Por

$5.30626 \mathrm{e}+025.30626 \mathrm{e}+025.30626 \mathrm{e}+01$ 1.00000e-09 7.00000e-02 $5.30626 \mathrm{e}+025.30626 \mathrm{e}+025.30626 \mathrm{e}+011.00000 \mathrm{e}-097.00000 \mathrm{e}-02$ 5.00000e-04 5.00000e-04 5.00000e-05 1.00000e-09 1.00000e-01 5.00000e-04 5.00000e-04 5.00000e-05 1.00000e-09 1.00000e-01 $2.12020 \mathrm{e}+012.12020 \mathrm{e}+012.12020 \mathrm{e}+001.00000 \mathrm{e}-092.12000 \mathrm{e}-01$ $2.12020 \mathrm{e}+012.12020 \mathrm{e}+012.12020 \mathrm{e}+00$ 1.00000e-09 2.12000e-01 $2.12020 \mathrm{e}+012.12020 \mathrm{e}+012.12020 \mathrm{e}+001.00000 \mathrm{e}-092.12000 \mathrm{e}-01$ $2.12020 \mathrm{e}+012.12020 \mathrm{e}+012.12020 \mathrm{e}+00$ 1.00000e-09 2.12000e-01 $2.12020 \mathrm{e}+012.12020 \mathrm{e}+012.12020 \mathrm{e}+00$ 1.00000e-09 2.12000e-01 $1.00000 \mathrm{e}-021.00000 \mathrm{e}-02$ 1.00000e-03 1.00000e-09 1.00000e-01 $1.00000 \mathrm{e}+001.00000 \mathrm{e}+001.00000 \mathrm{e}-011.00000 \mathrm{e}-091.00000 \mathrm{e}-01$ $1.00000 \mathrm{e}-05$ 1.00000e-05 1.00000e-06 1.00000e-09 1.00000e-01 $1.00000 \mathrm{e}+001.00000 \mathrm{e}+001.00000 \mathrm{e}-011.00000 \mathrm{e}-091.00000 \mathrm{e}-01$ Element: 1428 \# of layers: 12

Kx Ky Kz Ss Por 3.59922e+02 3.59922e+02 3.59922e+01 1.00000e-09 7.00000e-02 $3.59922 \mathrm{e}+023.59922 \mathrm{e}+023.59922 \mathrm{e}+01$ 1.00000e-09 7.00000e-02 5.00000e-04 5.00000e-04 5.00000e-05 1.00000e-09 1.00000e-01 $1.43812 \mathrm{e}+011.43812 \mathrm{e}+011.43812 \mathrm{e}+001.00000 \mathrm{e}-092.12000 \mathrm{e}-01$ $1.43812 \mathrm{e}+011.43812 \mathrm{e}+011.43812 \mathrm{e}+001.00000 \mathrm{e}-092.12000 \mathrm{e}-01$ $1.43812 \mathrm{e}+011.43812 \mathrm{e}+011.43812 \mathrm{e}+001.00000 \mathrm{e}-092.12000 \mathrm{e}-01$ $1.43812 \mathrm{e}+011.43812 \mathrm{e}+011.43812 \mathrm{e}+001.00000 \mathrm{e}-092.12000 \mathrm{e}-01$ 
$1.43812 \mathrm{e}+01$ 1.43812e+01 1.43812e+00 1.00000e-09 2.12000e-01 $1.00000 \mathrm{e}-02$ 1.00000e-02 1.00000e-03 1.00000e-09 1.00000e-01 $1.00000 \mathrm{e}+001.00000 \mathrm{e}+001.00000 \mathrm{e}-011.00000 \mathrm{e}-091.00000 \mathrm{e}-01$ $1.00000 \mathrm{e}-05$ 1.00000e-05 1.00000e-06 1.00000e-09 1.00000e-01 $1.00000 \mathrm{e}+001.00000 \mathrm{e}+001.00000 \mathrm{e}-01$ 1.00000e-09 1.00000e-01 Element: 1429 \# of layers: 11

$\mathrm{Kx} \mathrm{Ky} \mathrm{Kz}$ Ss Por

3.59922e+02 3.59922e+02 3.59922e+01 1.00000e-09 7.00000e-02 5.00000e-04 5.00000e-04 5.00000e-05 1.00000e-09 1.00000e-01

$1.43812 \mathrm{e}+01$ 1.43812e+01 1.43812e+00 1.00000e-09 2.12000e-01 $1.43812 \mathrm{e}+01$ 1.43812e+01 1.43812e+00 1.00000e-09 2.12000e-01 $1.43812 \mathrm{e}+011.43812 \mathrm{e}+011.43812 \mathrm{e}+001.00000 \mathrm{e}-092.12000 \mathrm{e}-01$ $1.43812 \mathrm{e}+011.43812 \mathrm{e}+011.43812 \mathrm{e}+001.00000 \mathrm{e}-092.12000 \mathrm{e}-01$ $1.43812 \mathrm{e}+011.43812 \mathrm{e}+011.43812 \mathrm{e}+001.00000 \mathrm{e}-092.12000 \mathrm{e}-01$ $1.00000 \mathrm{e}-02$ 1.00000e-02 1.00000e-03 1.00000e-09 1.00000e-01 $1.00000 \mathrm{e}+001.00000 \mathrm{e}+001.00000 \mathrm{e}-011.00000 \mathrm{e}-091.00000 \mathrm{e}-01$ $1.00000 \mathrm{e}-05$ 1.00000e-05 1.00000e-06 1.00000e-09 1.00000e-01 $1.00000 \mathrm{e}+001.00000 \mathrm{e}+001.00000 \mathrm{e}-01$ 1.00000e-09 1.00000e-01 Element: 1430 \# of layers: 11

$\mathrm{Kx} \mathrm{Ky} \mathrm{Kz}$ Ss Por

3.59922e+02 3.59922e+02 3.59922e+01 1.00000e-09 7.00000e-02 5.00000e-04 5.00000e-04 5.00000e-05 1.00000e-09 1.00000e-01

$1.43812 \mathrm{e}+01$ 1.43812e+01 1.43812e+00 1.00000e-09 2.12000e-01 $1.43812 \mathrm{e}+011.43812 \mathrm{e}+011.43812 \mathrm{e}+001.00000 \mathrm{e}-092.12000 \mathrm{e}-01$ $1.43812 \mathrm{e}+011.43812 \mathrm{e}+011.43812 \mathrm{e}+001.00000 \mathrm{e}-092.12000 \mathrm{e}-01$ $1.43812 \mathrm{e}+01$ 1.43812e+01 1.43812e+00 1.00000e-09 2.12000e-01 $1.43812 \mathrm{e}+011.43812 \mathrm{e}+011.43812 \mathrm{e}+001.00000 \mathrm{e}-092.12000 \mathrm{e}-01$ $1.00000 \mathrm{e}-02$ 1.00000e-02 1.00000e-03 1.00000e-09 1.00000e-01 $1.00000 \mathrm{e}+001.00000 \mathrm{e}+001.00000 \mathrm{e}-011.00000 \mathrm{e}-091.00000 \mathrm{e}-01$ $1.00000 \mathrm{e}-05$ 1.00000e-05 1.00000e-06 1.00000e-09 1.00000e-01 $1.00000 \mathrm{e}+001.00000 \mathrm{e}+001.00000 \mathrm{e}-011.00000 \mathrm{e}-091.00000 \mathrm{e}-01$ Element: 1431 \# of layers: 11

$\mathrm{Kx} \mathrm{Ky} \mathrm{Kz}$ Ss Por

3.59922e+02 3.59922e+02 3.59922e+01 1.00000e-09 7.00000e-02 5.00000e-04 5.00000e-04 5.00000e-05 1.00000e-09 1.00000e-01 $1.43812 \mathrm{e}+01$ 1.43812e+01 1.43812e+00 1.00000e-09 2.12000e-01 $1.43812 \mathrm{e}+011.43812 \mathrm{e}+011.43812 \mathrm{e}+001.00000 \mathrm{e}-092.12000 \mathrm{e}-01$ $1.43812 \mathrm{e}+011.43812 \mathrm{e}+011.43812 \mathrm{e}+001.00000 \mathrm{e}-092.12000 \mathrm{e}-01$ $1.43812 \mathrm{e}+011.43812 \mathrm{e}+011.43812 \mathrm{e}+001.00000 \mathrm{e}-092.12000 \mathrm{e}-01$ $1.43812 \mathrm{e}+011.43812 \mathrm{e}+01$ 1.43812e+00 1.00000e-09 2.12000e-01 $1.00000 \mathrm{e}-02$ 1.00000e-02 1.00000e-03 1.00000e-09 1.00000e-01 $1.00000 \mathrm{e}+001.00000 \mathrm{e}+001.00000 \mathrm{e}-011.00000 \mathrm{e}-091.00000 \mathrm{e}-01$ $1.00000 \mathrm{e}-05$ 1.00000e-05 1.00000e-06 1.00000e-09 1.00000e-01 $1.00000 \mathrm{e}+001.00000 \mathrm{e}+001.00000 \mathrm{e}-011.00000 \mathrm{e}-091.00000 \mathrm{e}-01$ Element: 1432 \# of layers: 11

Kx Ky Kz Ss Por 
3.59922e+02 3.59922e+02 3.59922e+01 1.00000e-09 7.00000e-02 5.00000e-04 5.00000e-04 5.00000e-05 1.00000e-09 1.00000e-01 $1.43812 \mathrm{e}+011.43812 \mathrm{e}+011.43812 \mathrm{e}+001.00000 \mathrm{e}-092.12000 \mathrm{e}-01$ $1.43812 \mathrm{e}+011.43812 \mathrm{e}+011.43812 \mathrm{e}+001.00000 \mathrm{e}-092.12000 \mathrm{e}-01$ $1.43812 \mathrm{e}+011.43812 \mathrm{e}+011.43812 \mathrm{e}+001.00000 \mathrm{e}-092.12000 \mathrm{e}-01$ $1.43812 \mathrm{e}+01$ 1.43812e+01 1.43812e+00 1.00000e-09 2.12000e-01 $1.43812 \mathrm{e}+011.43812 \mathrm{e}+011.43812 \mathrm{e}+001.00000 \mathrm{e}-092.12000 \mathrm{e}-01$ $1.00000 \mathrm{e}-02$ 1.00000e-02 1.00000e-03 1.00000e-09 1.00000e-01 $1.00000 \mathrm{e}+001.00000 \mathrm{e}+001.00000 \mathrm{e}-01$ 1.00000e-09 1.00000e-01 $1.00000 \mathrm{e}-05$ 1.00000e-05 1.00000e-06 1.00000e-09 1.00000e-01 $1.00000 \mathrm{e}+001.00000 \mathrm{e}+00$ 1.00000e-01 1.00000e-09 1.00000e-01 Element: 1433 \# of layers: 12

$\mathrm{Kx} \mathrm{Ky} \mathrm{Kz}$ Ss Por

3.59922e+02 3.59922e+02 3.59922e+01 1.00000e-09 7.00000e-02 5.00000e-04 5.00000e-04 5.00000e-05 1.00000e-09 1.00000e-01 5.00000e-04 5.00000e-04 5.00000e-05 1.00000e-09 1.00000e-01 $1.43812 \mathrm{e}+011.43812 \mathrm{e}+011.43812 \mathrm{e}+001.00000 \mathrm{e}-092.12000 \mathrm{e}-01$ $1.43812 \mathrm{e}+01$ 1.43812e+01 1.43812e+00 1.00000e-09 2.12000e-01 $1.43812 \mathrm{e}+01$ 1.43812e+01 1.43812e+00 1.00000e-09 2.12000e-01 $1.43812 \mathrm{e}+011.43812 \mathrm{e}+011.43812 \mathrm{e}+001.00000 \mathrm{e}-092.12000 \mathrm{e}-01$ $1.43812 \mathrm{e}+011.43812 \mathrm{e}+011.43812 \mathrm{e}+001.00000 \mathrm{e}-092.12000 \mathrm{e}-01$ $1.00000 \mathrm{e}-021.00000 \mathrm{e}-021.00000 \mathrm{e}-031.00000 \mathrm{e}-091.00000 \mathrm{e}-01$ $1.00000 \mathrm{e}+001.00000 \mathrm{e}+001.00000 \mathrm{e}-011.00000 \mathrm{e}-091.00000 \mathrm{e}-01$ $1.00000 \mathrm{e}-05$ 1.00000e-05 1.00000e-06 1.00000e-09 1.00000e-01 $1.00000 \mathrm{e}+001.00000 \mathrm{e}+001.00000 \mathrm{e}-011.00000 \mathrm{e}-09$ 1.00000e-01 Element: 1434 \# of layers: 13

$\mathrm{Kx} \mathrm{Ky} \mathrm{Kz}$ Ss Por

3.59922e+02 3.59922e+02 3.59922e+01 1.00000e-09 7.00000e-02 $3.59922 \mathrm{e}+02$ 3.59922e+02 3.59922e+01 1.00000e-09 7.00000e-02 5.00000e-04 5.00000e-04 5.00000e-05 1.00000e-09 1.00000e-01 $5.00000 \mathrm{e}-04$ 5.00000e-04 5.00000e-05 1.00000e-09 1.00000e-01 $1.43812 \mathrm{e}+01$ 1.43812e+01 1.43812e+00 1.00000e-09 2.12000e-01 $1.43812 \mathrm{e}+01$ 1.43812e+01 1.43812e+00 1.00000e-09 2.12000e-01 $1.43812 \mathrm{e}+011.43812 \mathrm{e}+011.43812 \mathrm{e}+001.00000 \mathrm{e}-092.12000 \mathrm{e}-01$ $1.43812 \mathrm{e}+01$ 1.43812e+01 1.43812e+00 1.00000e-09 2.12000e-01 $1.43812 \mathrm{e}+011.43812 \mathrm{e}+011.43812 \mathrm{e}+001.00000 \mathrm{e}-092.12000 \mathrm{e}-01$ $1.00000 \mathrm{e}-02$ 1.00000e-02 1.00000e-03 1.00000e-09 1.00000e-01 $1.00000 \mathrm{e}+001.00000 \mathrm{e}+001.00000 \mathrm{e}-011.00000 \mathrm{e}-091.00000 \mathrm{e}-01$ $1.00000 \mathrm{e}-05$ 1.00000e-05 1.00000e-06 1.00000e-09 1.00000e-01 $1.00000 \mathrm{e}+001.00000 \mathrm{e}+001.00000 \mathrm{e}-011.00000 \mathrm{e}-091.00000 \mathrm{e}-01$ Element: 1435 \# of layers: 13

$\mathrm{Kx} \mathrm{Ky} \mathrm{Kz}$ Ss Por 3.59922e+02 3.59922e+02 3.59922e+01 1.00000e-09 7.00000e-02 3.59922e+02 3.59922e+02 3.59922e+01 1.00000e-09 7.00000e-02 5.00000e-04 5.00000e-04 5.00000e-05 1.00000e-09 1.00000e-01 5.00000e-04 5.00000e-04 5.00000e-05 1.00000e-09 1.00000e-01 
$1.43812 \mathrm{e}+01$ 1.43812e+01 1.43812e+00 1.00000e-09 2.12000e-01 $1.43812 \mathrm{e}+01$ 1.43812e+01 1.43812e+00 1.00000e-09 2.12000e-01 $1.43812 \mathrm{e}+011.43812 \mathrm{e}+011.43812 \mathrm{e}+001.00000 \mathrm{e}-092.12000 \mathrm{e}-01$ $1.43812 \mathrm{e}+01$ 1.43812e+01 1.43812e+00 1.00000e-09 2.12000e-01 $1.43812 \mathrm{e}+01$ 1.43812e+01 1.43812e+00 1.00000e-09 2.12000e-01 $1.00000 \mathrm{e}-02$ 1.00000e-02 1.00000e-03 1.00000e-09 1.00000e-01 $1.00000 \mathrm{e}+001.00000 \mathrm{e}+001.00000 \mathrm{e}-011.00000 \mathrm{e}-091.00000 \mathrm{e}-01$ $1.00000 \mathrm{e}-05$ 1.00000e-05 1.00000e-06 1.00000e-09 1.00000e-01 $1.00000 \mathrm{e}+001.00000 \mathrm{e}+001.00000 \mathrm{e}-011.00000 \mathrm{e}-091.00000 \mathrm{e}-01$ Element: 1436 \# of layers: 12

$\mathrm{Kx} \mathrm{Ky} \mathrm{Kz}$ Ss Por

3.59922e+02 3.59922e+02 3.59922e+01 1.00000e-09 7.00000e-02 5.00000e-04 5.00000e-04 5.00000e-05 1.00000e-09 1.00000e-01 5.00000e-04 5.00000e-04 5.00000e-05 1.00000e-09 1.00000e-01 $1.43812 \mathrm{e}+01$ 1.43812e+01 1.43812e+00 1.00000e-09 2.12000e-01 $1.43812 \mathrm{e}+011.43812 \mathrm{e}+011.43812 \mathrm{e}+001.00000 \mathrm{e}-092.12000 \mathrm{e}-01$ $1.43812 \mathrm{e}+011.43812 \mathrm{e}+011.43812 \mathrm{e}+001.00000 \mathrm{e}-092.12000 \mathrm{e}-01$ $1.43812 \mathrm{e}+011.43812 \mathrm{e}+011.43812 \mathrm{e}+001.00000 \mathrm{e}-092.12000 \mathrm{e}-01$ $1.43812 \mathrm{e}+01$ 1.43812e+01 1.43812e+00 1.00000e-09 2.12000e-01 $1.00000 \mathrm{e}-02$ 1.00000e-02 1.00000e-03 1.00000e-09 1.00000e-01 $1.00000 \mathrm{e}+001.00000 \mathrm{e}+001.00000 \mathrm{e}-011.00000 \mathrm{e}-091.00000 \mathrm{e}-01$ $1.00000 \mathrm{e}-05$ 1.00000e-05 1.00000e-06 1.00000e-09 1.00000e-01 $1.00000 \mathrm{e}+001.00000 \mathrm{e}+001.00000 \mathrm{e}-01$ 1.00000e-09 1.00000e-01 Element: 1437 \# of layers: 11

Kx Ky Kz Ss Por

5.36798e+02 5.36798e+02 5.36798e+01 1.00000e-09 7.00000e-02 5.00000e-04 5.00000e-04 5.00000e-05 1.00000e-09 1.00000e-01 $2.14486 \mathrm{e}+012.14486 \mathrm{e}+012.14486 \mathrm{e}+00$ 1.00000e-09 2.12000e-01 $2.14486 \mathrm{e}+012.14486 \mathrm{e}+012.14486 \mathrm{e}+001.00000 \mathrm{e}-092.12000 \mathrm{e}-01$ $2.14486 \mathrm{e}+012.14486 \mathrm{e}+012.14486 \mathrm{e}+001.00000 \mathrm{e}-092.12000 \mathrm{e}-01$ $2.14486 \mathrm{e}+012.14486 \mathrm{e}+012.14486 \mathrm{e}+00$ 1.00000e-09 2.12000e-01 $2.14486 \mathrm{e}+012.14486 \mathrm{e}+012.14486 \mathrm{e}+00$ 1.00000e-09 2.12000e-01 $1.00000 \mathrm{e}-02$ 1.00000e-02 1.00000e-03 1.00000e-09 1.00000e-01 $1.00000 \mathrm{e}+001.00000 \mathrm{e}+001.00000 \mathrm{e}-011.00000 \mathrm{e}-091.00000 \mathrm{e}-01$ $1.00000 \mathrm{e}-05$ 1.00000e-05 1.00000e-06 1.00000e-09 1.00000e-01 $1.00000 \mathrm{e}+001.00000 \mathrm{e}+001.00000 \mathrm{e}-01$ 1.00000e-09 1.00000e-01 Element: 1438 \# of layers: 11

Kx Ky Kz Ss Por

5.36798e+02 5.36798e+02 5.36798e+01 1.00000e-09 7.00000e-02 5.00000e-04 5.00000e-04 5.00000e-05 1.00000e-09 1.00000e-01 $2.14486 \mathrm{e}+012.14486 \mathrm{e}+012.14486 \mathrm{e}+00$ 1.00000e-09 2.12000e-01 $2.14486 \mathrm{e}+012.14486 \mathrm{e}+012.14486 \mathrm{e}+001.00000 \mathrm{e}-092.12000 \mathrm{e}-01$ $2.14486 \mathrm{e}+012.14486 \mathrm{e}+012.14486 \mathrm{e}+001.00000 \mathrm{e}-092.12000 \mathrm{e}-01$ 2.14486e+01 2.14486e+01 2.14486e+00 1.00000e-09 2.12000e-01 $2.14486 \mathrm{e}+012.14486 \mathrm{e}+012.14486 \mathrm{e}+001.00000 \mathrm{e}-092.12000 \mathrm{e}-01$ $1.00000 \mathrm{e}-02$ 1.00000e-02 1.00000e-03 1.00000e-09 1.00000e-01 
$1.00000 \mathrm{e}+001.00000 \mathrm{e}+001.00000 \mathrm{e}-011.00000 \mathrm{e}-091.00000 \mathrm{e}-01$ $1.00000 \mathrm{e}-05$ 1.00000e-05 1.00000e-06 1.00000e-09 1.00000e-01 $1.00000 \mathrm{e}+001.00000 \mathrm{e}+001.00000 \mathrm{e}-011.00000 \mathrm{e}-09$ 1.00000e-01

Element: 1439 \# of layers: 10

$\mathrm{Kx} \mathrm{Ky} \mathrm{Kz}$ Ss Por

5.36798e+02 5.36798e+02 5.36798e+01 1.00000e-09 7.00000e-02

$2.14486 \mathrm{e}+012.14486 \mathrm{e}+012.14486 \mathrm{e}+001.00000 \mathrm{e}-09$ 2.12000e-01

$2.14486 \mathrm{e}+012.14486 \mathrm{e}+012.14486 \mathrm{e}+00$ 1.00000e-09 2.12000e-01

$2.14486 \mathrm{e}+012.14486 \mathrm{e}+012.14486 \mathrm{e}+00 \quad 1.00000 \mathrm{e}-092.12000 \mathrm{e}-01$

$2.14486 \mathrm{e}+012.14486 \mathrm{e}+012.14486 \mathrm{e}+00$ 1.00000e-09 2.12000e-01

$2.14486 \mathrm{e}+012.14486 \mathrm{e}+012.14486 \mathrm{e}+00$ 1.00000e-09 2.12000e-01 $1.00000 \mathrm{e}-02$ 1.00000e-02 1.00000e-03 1.00000e-09 1.00000e-01

$1.00000 \mathrm{e}+001.00000 \mathrm{e}+001.00000 \mathrm{e}-011.00000 \mathrm{e}-091.00000 \mathrm{e}-01$ $1.00000 \mathrm{e}-05$ 1.00000e-05 1.00000e-06 1.00000e-09 1.00000e-01

$1.00000 \mathrm{e}+001.00000 \mathrm{e}+001.00000 \mathrm{e}-01$ 1.00000e-09 1.00000e-01

Element: 1440 \# of layers: 11

$\mathrm{Kx} \mathrm{Ky} \mathrm{Kz}$ Ss Por

5.36798e+02 5.36798e+02 5.36798e+01 1.00000e-09 7.00000e-02 5.00000e-04 5.00000e-04 5.00000e-05 1.00000e-09 1.00000e-01

$2.14486 \mathrm{e}+012.14486 \mathrm{e}+012.14486 \mathrm{e}+00$ 1.00000e-09 2.12000e-01 $2.14486 \mathrm{e}+012.14486 \mathrm{e}+012.14486 \mathrm{e}+001.00000 \mathrm{e}-092.12000 \mathrm{e}-01$

$2.14486 \mathrm{e}+012.14486 \mathrm{e}+012.14486 \mathrm{e}+00$ 1.00000e-09 2.12000e-01

$2.14486 \mathrm{e}+012.14486 \mathrm{e}+012.14486 \mathrm{e}+00$ 1.00000e-09 2.12000e-01

$2.14486 \mathrm{e}+012.14486 \mathrm{e}+012.14486 \mathrm{e}+001.00000 \mathrm{e}-092.12000 \mathrm{e}-01$ $1.00000 \mathrm{e}-02$ 1.00000e-02 1.00000e-03 1.00000e-09 1.00000e-01 $1.00000 \mathrm{e}+001.00000 \mathrm{e}+001.00000 \mathrm{e}-011.00000 \mathrm{e}-091.00000 \mathrm{e}-01$ $1.00000 \mathrm{e}-05$ 1.00000e-05 1.00000e-06 1.00000e-09 1.00000e-01 $1.00000 \mathrm{e}+001.00000 \mathrm{e}+001.00000 \mathrm{e}-011.00000 \mathrm{e}-09$ 1.00000e-01

Element: 1441 \# of layers: 11

$\mathrm{Kx} \mathrm{Ky} \mathrm{Kz}$ Ss Por

5.36798e+02 5.36798e+02 5.36798e+01 1.00000e-09 7.00000e-02 5.00000e-04 5.00000e-04 5.00000e-05 1.00000e-09 1.00000e-01

$2.14486 \mathrm{e}+012.14486 \mathrm{e}+012.14486 \mathrm{e}+001.00000 \mathrm{e}-092.12000 \mathrm{e}-01$

$2.14486 \mathrm{e}+012.14486 \mathrm{e}+012.14486 \mathrm{e}+001.00000 \mathrm{e}-092.12000 \mathrm{e}-01$

$2.14486 \mathrm{e}+012.14486 \mathrm{e}+012.14486 \mathrm{e}+001.00000 \mathrm{e}-092.12000 \mathrm{e}-01$

$2.14486 \mathrm{e}+012.14486 \mathrm{e}+012.14486 \mathrm{e}+00$ 1.00000e-09 2.12000e-01

$2.14486 \mathrm{e}+012.14486 \mathrm{e}+012.14486 \mathrm{e}+001.00000 \mathrm{e}-092.12000 \mathrm{e}-01$ $1.00000 \mathrm{e}-02$ 1.00000e-02 1.00000e-03 1.00000e-09 1.00000e-01 $1.00000 \mathrm{e}+001.00000 \mathrm{e}+001.00000 \mathrm{e}-011.00000 \mathrm{e}-091.00000 \mathrm{e}-01$ $1.00000 \mathrm{e}-05$ 1.00000e-05 1.00000e-06 1.00000e-09 1.00000e-01 $1.00000 \mathrm{e}+001.00000 \mathrm{e}+001.00000 \mathrm{e}-011.00000 \mathrm{e}-091.00000 \mathrm{e}-01$ Element: 1442 \# of layers: 11

$\mathrm{Kx} \mathrm{Ky} \mathrm{Kz}$ Ss Por

5.36798e+02 5.36798e+02 5.36798e+01 1.00000e-09 7.00000e-02 5.00000e-04 5.00000e-04 5.00000e-05 1.00000e-09 1.00000e-01

$2.14486 \mathrm{e}+012.14486 \mathrm{e}+012.14486 \mathrm{e}+001.00000 \mathrm{e}-092.12000 \mathrm{e}-01$ 
2.14486e+01 2.14486e+01 2.14486e+00 1.00000e-09 2.12000e-01 $2.14486 \mathrm{e}+012.14486 \mathrm{e}+012.14486 \mathrm{e}+00$ 1.00000e-09 2.12000e-01 $2.14486 \mathrm{e}+012.14486 \mathrm{e}+012.14486 \mathrm{e}+00$ 1.00000e-09 2.12000e-01 $2.14486 \mathrm{e}+012.14486 \mathrm{e}+012.14486 \mathrm{e}+001.00000 \mathrm{e}-092.12000 \mathrm{e}-01$ $1.00000 \mathrm{e}-02$ 1.00000e-02 1.00000e-03 1.00000e-09 1.00000e-01 $1.00000 \mathrm{e}+001.00000 \mathrm{e}+001.00000 \mathrm{e}-011.00000 \mathrm{e}-091.00000 \mathrm{e}-01$ 1.00000e-05 1.00000e-05 1.00000e-06 1.00000e-09 1.00000e-01 $1.00000 \mathrm{e}+001.00000 \mathrm{e}+001.00000 \mathrm{e}-011.00000 \mathrm{e}-091.00000 \mathrm{e}-01$ Element: 1443 \# of layers: 11

$\mathrm{Kx} \mathrm{Ky} \mathrm{Kz}$ Ss Por

5.36798e+02 5.36798e+02 5.36798e+01 1.00000e-09 7.00000e-02 5.00000e-04 5.00000e-04 5.00000e-05 1.00000e-09 1.00000e-01

$2.14486 \mathrm{e}+012.14486 \mathrm{e}+012.14486 \mathrm{e}+001.00000 \mathrm{e}-092.12000 \mathrm{e}-01$ $2.14486 \mathrm{e}+012.14486 \mathrm{e}+012.14486 \mathrm{e}+001.00000 \mathrm{e}-092.12000 \mathrm{e}-01$ $2.14486 \mathrm{e}+012.14486 \mathrm{e}+012.14486 \mathrm{e}+001.00000 \mathrm{e}-092.12000 \mathrm{e}-01$ $2.14486 \mathrm{e}+012.14486 \mathrm{e}+012.14486 \mathrm{e}+001.00000 \mathrm{e}-092.12000 \mathrm{e}-01$ $2.14486 \mathrm{e}+012.14486 \mathrm{e}+012.14486 \mathrm{e}+001.00000 \mathrm{e}-092.12000 \mathrm{e}-01$ $1.00000 \mathrm{e}-02$ 1.00000e-02 1.00000e-03 1.00000e-09 1.00000e-01 $1.00000 \mathrm{e}+001.00000 \mathrm{e}+001.00000 \mathrm{e}-011.00000 \mathrm{e}-091.00000 \mathrm{e}-01$ $1.00000 \mathrm{e}-05$ 1.00000e-05 1.00000e-06 1.00000e-09 1.00000e-01 $1.00000 \mathrm{e}+001.00000 \mathrm{e}+001.00000 \mathrm{e}-011.00000 \mathrm{e}-091.00000 \mathrm{e}-01$ Element: 1444 \# of layers: 11

$\mathrm{Kx} \mathrm{Ky} \mathrm{Kz}$ Ss Por

5.36798e+02 5.36798e+02 5.36798e+01 1.00000e-09 7.00000e-02 5.00000e-04 5.00000e-04 5.00000e-05 1.00000e-09 1.00000e-01

$2.14486 \mathrm{e}+012.14486 \mathrm{e}+012.14486 \mathrm{e}+001.00000 \mathrm{e}-092.12000 \mathrm{e}-01$ $2.14486 \mathrm{e}+012.14486 \mathrm{e}+012.14486 \mathrm{e}+001.00000 \mathrm{e}-092.12000 \mathrm{e}-01$ $2.14486 \mathrm{e}+012.14486 \mathrm{e}+012.14486 \mathrm{e}+001.00000 \mathrm{e}-092.12000 \mathrm{e}-01$ $2.14486 \mathrm{e}+012.14486 \mathrm{e}+012.14486 \mathrm{e}+001.00000 \mathrm{e}-092.12000 \mathrm{e}-01$ $2.14486 \mathrm{e}+012.14486 \mathrm{e}+012.14486 \mathrm{e}+001.00000 \mathrm{e}-092.12000 \mathrm{e}-01$ $1.00000 \mathrm{e}-02$ 1.00000e-02 1.00000e-03 1.00000e-09 1.00000e-01 $1.00000 \mathrm{e}+001.00000 \mathrm{e}+001.00000 \mathrm{e}-011.00000 \mathrm{e}-091.00000 \mathrm{e}-01$ $1.00000 \mathrm{e}-05$ 1.00000e-05 1.00000e-06 1.00000e-09 1.00000e-01 $1.00000 \mathrm{e}+001.00000 \mathrm{e}+001.00000 \mathrm{e}-011.00000 \mathrm{e}-091.00000 \mathrm{e}-01$ Element: 1445 \# of layers: 11

$\mathrm{Kx} \mathrm{Ky} \mathrm{Kz}$ Ss Por

5.36798e+02 5.36798e+02 5.36798e+01 1.00000e-09 7.00000e-02 5.00000e-04 5.00000e-04 5.00000e-05 1.00000e-09 1.00000e-01

$2.14486 \mathrm{e}+012.14486 \mathrm{e}+012.14486 \mathrm{e}+00$ 1.00000e-09 2.12000e-01 $2.14486 \mathrm{e}+012.14486 \mathrm{e}+012.14486 \mathrm{e}+00$ 1.00000e-09 2.12000e-01 $2.14486 \mathrm{e}+012.14486 \mathrm{e}+012.14486 \mathrm{e}+001.00000 \mathrm{e}-092.12000 \mathrm{e}-01$ $2.14486 \mathrm{e}+012.14486 \mathrm{e}+012.14486 \mathrm{e}+001.00000 \mathrm{e}-092.12000 \mathrm{e}-01$ $2.14486 \mathrm{e}+012.14486 \mathrm{e}+012.14486 \mathrm{e}+00$ 1.00000e-09 2.12000e-01 $1.00000 \mathrm{e}-02$ 1.00000e-02 1.00000e-03 1.00000e-09 1.00000e-01 $1.00000 \mathrm{e}+001.00000 \mathrm{e}+001.00000 \mathrm{e}-011.00000 \mathrm{e}-091.00000 \mathrm{e}-01$ $1.00000 \mathrm{e}-05$ 1.00000e-05 1.00000e-06 1.00000e-09 1.00000e-01 
$1.00000 \mathrm{e}+001.00000 \mathrm{e}+00$ 1.00000e-01 1.00000e-09 1.00000e-01

Element: 1446 \# of layers: 11

Kx Ky Kz Ss Por

5.17372e+02 5.17372e+02 5.17372e+01 1.00000e-09 7.00000e-02

5.17372e+02 5.17372e+02 5.17372e+01 1.00000e-09 7.00000e-02

$2.06725 \mathrm{e}+012.06725 \mathrm{e}+012.06725 \mathrm{e}+001.00000 \mathrm{e}-092.12000 \mathrm{e}-01$

$2.06725 \mathrm{e}+012.06725 \mathrm{e}+012.06725 \mathrm{e}+001.00000 \mathrm{e}-092.12000 \mathrm{e}-01$

$2.06725 \mathrm{e}+012.06725 \mathrm{e}+012.06725 \mathrm{e}+00$ 1.00000e-09 2.12000e-01

$2.06725 \mathrm{e}+012.06725 \mathrm{e}+012.06725 \mathrm{e}+001.00000 \mathrm{e}-092.12000 \mathrm{e}-01$

$2.06725 \mathrm{e}+012.06725 \mathrm{e}+012.06725 \mathrm{e}+001.00000 \mathrm{e}-092.12000 \mathrm{e}-01$

$1.00000 \mathrm{e}-02$ 1.00000e-02 1.00000e-03 1.00000e-09 1.00000e-01

$1.00000 \mathrm{e}+001.00000 \mathrm{e}+001.00000 \mathrm{e}-011.00000 \mathrm{e}-091.00000 \mathrm{e}-01$

$1.00000 \mathrm{e}-05$ 1.00000e-05 1.00000e-06 1.00000e-09 1.00000e-01

$1.00000 \mathrm{e}+001.00000 \mathrm{e}+001.00000 \mathrm{e}-011.00000 \mathrm{e}-09$ 1.00000e-01

Element: 1447 \# of layers: 10

Kx Ky Kz Ss Por

5.17372e+02 5.17372e+02 5.17372e+01 1.00000e-09 7.00000e-02 $2.06725 \mathrm{e}+012.06725 \mathrm{e}+012.06725 \mathrm{e}+001.00000 \mathrm{e}-092.12000 \mathrm{e}-01$

$2.06725 \mathrm{e}+012.06725 \mathrm{e}+012.06725 \mathrm{e}+001.00000 \mathrm{e}-092.12000 \mathrm{e}-01$

$2.06725 \mathrm{e}+012.06725 \mathrm{e}+012.06725 \mathrm{e}+001.00000 \mathrm{e}-092.12000 \mathrm{e}-01$

$2.06725 \mathrm{e}+012.06725 \mathrm{e}+012.06725 \mathrm{e}+001.00000 \mathrm{e}-092.12000 \mathrm{e}-01$

$2.06725 \mathrm{e}+012.06725 \mathrm{e}+012.06725 \mathrm{e}+00$ 1.00000e-09 2.12000e-01

$1.00000 \mathrm{e}-02$ 1.00000e-02 1.00000e-03 1.00000e-09 1.00000e-01

$1.00000 \mathrm{e}+001.00000 \mathrm{e}+001.00000 \mathrm{e}-011.00000 \mathrm{e}-091.00000 \mathrm{e}-01$

$1.00000 \mathrm{e}-05$ 1.00000e-05 1.00000e-06 1.00000e-09 1.00000e-01

$1.00000 \mathrm{e}+001.00000 \mathrm{e}+001.00000 \mathrm{e}-01$ 1.00000e-09 1.00000e-01

Element: 1448 \# of layers: 10

$\mathrm{Kx} \mathrm{Ky} \mathrm{Kz} \mathrm{Ss} \mathrm{Por}$

5.17372e+02 5.17372e+02 5.17372e+01 1.00000e-09 7.00000e-02

$2.06725 \mathrm{e}+012.06725 \mathrm{e}+012.06725 \mathrm{e}+001.00000 \mathrm{e}-092.12000 \mathrm{e}-01$

$2.06725 \mathrm{e}+012.06725 \mathrm{e}+012.06725 \mathrm{e}+001.00000 \mathrm{e}-092.12000 \mathrm{e}-01$

$2.06725 \mathrm{e}+012.06725 \mathrm{e}+012.06725 \mathrm{e}+00$ 1.00000e-09 2.12000e-01

$2.06725 \mathrm{e}+012.06725 \mathrm{e}+012.06725 \mathrm{e}+001.00000 \mathrm{e}-092.12000 \mathrm{e}-01$

$2.06725 \mathrm{e}+012.06725 \mathrm{e}+012.06725 \mathrm{e}+001.00000 \mathrm{e}-092.12000 \mathrm{e}-01$

$1.00000 \mathrm{e}-021.00000 \mathrm{e}-02$ 1.00000e-03 1.00000e-09 1.00000e-01

$1.00000 \mathrm{e}+001.00000 \mathrm{e}+001.00000 \mathrm{e}-011.00000 \mathrm{e}-091.00000 \mathrm{e}-01$

1.00000e-05 1.00000e-05 1.00000e-06 1.00000e-09 1.00000e-01

$1.00000 \mathrm{e}+001.00000 \mathrm{e}+001.00000 \mathrm{e}-011.00000 \mathrm{e}-091.00000 \mathrm{e}-01$

Element: 1449 \# of layers: 10

$\mathrm{Kx} \mathrm{Ky} \mathrm{Kz}$ Ss Por

5.17372e+02 5.17372e+02 5.17372e+01 1.00000e-09 7.00000e-02

$2.06725 \mathrm{e}+012.06725 \mathrm{e}+012.06725 \mathrm{e}+00$ 1.00000e-09 2.12000e-01

$2.06725 \mathrm{e}+012.06725 \mathrm{e}+012.06725 \mathrm{e}+001.00000 \mathrm{e}-092.12000 \mathrm{e}-01$

$2.06725 \mathrm{e}+012.06725 \mathrm{e}+012.06725 \mathrm{e}+00$ 1.00000e-09 2.12000e-01

$2.06725 \mathrm{e}+012.06725 \mathrm{e}+012.06725 \mathrm{e}+001.00000 \mathrm{e}-092.12000 \mathrm{e}-01$

$2.06725 \mathrm{e}+012.06725 \mathrm{e}+012.06725 \mathrm{e}+001.00000 \mathrm{e}-092.12000 \mathrm{e}-01$ 
$1.00000 \mathrm{e}-02$ 1.00000e-02 1.00000e-03 1.00000e-09 1.00000e-01 $1.00000 \mathrm{e}+001.00000 \mathrm{e}+001.00000 \mathrm{e}-011.00000 \mathrm{e}-091.00000 \mathrm{e}-01$ $1.00000 \mathrm{e}-051.00000 \mathrm{e}-05$ 1.00000e-06 1.00000e-09 1.00000e-01 $1.00000 \mathrm{e}+001.00000 \mathrm{e}+001.00000 \mathrm{e}-011.00000 \mathrm{e}-091.00000 \mathrm{e}-01$ Element: 1450 \# of layers: 11

Kx Ky Kz Ss Por

5.17372e+02 5.17372e+02 5.17372e+01 1.00000e-09 7.00000e-02 $5.17372 \mathrm{e}+025.17372 \mathrm{e}+025.17372 \mathrm{e}+01$ 1.00000e-09 7.00000e-02 $2.06725 \mathrm{e}+012.06725 \mathrm{e}+012.06725 \mathrm{e}+001.00000 \mathrm{e}-092.12000 \mathrm{e}-01$ $2.06725 \mathrm{e}+012.06725 \mathrm{e}+012.06725 \mathrm{e}+001.00000 \mathrm{e}-092.12000 \mathrm{e}-01$ $2.06725 \mathrm{e}+012.06725 \mathrm{e}+012.06725 \mathrm{e}+001.00000 \mathrm{e}-092.12000 \mathrm{e}-01$ $2.06725 \mathrm{e}+012.06725 \mathrm{e}+012.06725 \mathrm{e}+001.00000 \mathrm{e}-092.12000 \mathrm{e}-01$ $2.06725 \mathrm{e}+012.06725 \mathrm{e}+012.06725 \mathrm{e}+001.00000 \mathrm{e}-092.12000 \mathrm{e}-01$ $1.00000 \mathrm{e}-02$ 1.00000e-02 1.00000e-03 1.00000e-09 1.00000e-01 $1.00000 \mathrm{e}+001.00000 \mathrm{e}+001.00000 \mathrm{e}-011.00000 \mathrm{e}-091.00000 \mathrm{e}-01$ $1.00000 \mathrm{e}-05$ 1.00000e-05 1.00000e-06 1.00000e-09 1.00000e-01 $1.00000 \mathrm{e}+001.00000 \mathrm{e}+001.00000 \mathrm{e}-011.00000 \mathrm{e}-091.00000 \mathrm{e}-01$ Element: 1451 \# of layers: 12

Kx Ky Kz Ss Por

5.17372e+02 5.17372e+02 5.17372e+01 1.00000e-09 7.00000e-02 $5.17372 \mathrm{e}+025.17372 \mathrm{e}+025.17372 \mathrm{e}+01$ 1.00000e-09 7.00000e-02 $5.00000 \mathrm{e}-04$ 5.00000e-04 5.00000e-05 1.00000e-09 1.00000e-01 $2.06725 \mathrm{e}+012.06725 \mathrm{e}+012.06725 \mathrm{e}+001.00000 \mathrm{e}-092.12000 \mathrm{e}-01$ $2.06725 \mathrm{e}+012.06725 \mathrm{e}+012.06725 \mathrm{e}+001.00000 \mathrm{e}-092.12000 \mathrm{e}-01$ $2.06725 \mathrm{e}+012.06725 \mathrm{e}+012.06725 \mathrm{e}+001.00000 \mathrm{e}-092.12000 \mathrm{e}-01$ $2.06725 \mathrm{e}+012.06725 \mathrm{e}+012.06725 \mathrm{e}+001.00000 \mathrm{e}-092.12000 \mathrm{e}-01$ $2.06725 \mathrm{e}+012.06725 \mathrm{e}+012.06725 \mathrm{e}+001.00000 \mathrm{e}-092.12000 \mathrm{e}-01$ $1.00000 \mathrm{e}-021.00000 \mathrm{e}-02$ 1.00000e-03 1.00000e-09 1.00000e-01 $1.00000 \mathrm{e}+001.00000 \mathrm{e}+001.00000 \mathrm{e}-011.00000 \mathrm{e}-091.00000 \mathrm{e}-01$ $1.00000 \mathrm{e}-05$ 1.00000e-05 1.00000e-06 1.00000e-09 1.00000e-01 $1.00000 \mathrm{e}+001.00000 \mathrm{e}+001.00000 \mathrm{e}-011.00000 \mathrm{e}-091.00000 \mathrm{e}-01$ Element: 1452 \# of layers: 12

Kx Ky Kz Ss Por

5.17372e+02 5.17372e+02 5.17372e+01 1.00000e-09 7.00000e-02 $5.17372 \mathrm{e}+025.17372 \mathrm{e}+025.17372 \mathrm{e}+01$ 1.00000e-09 7.00000e-02 5.00000e-04 5.00000e-04 5.00000e-05 1.00000e-09 1.00000e-01 $2.06725 \mathrm{e}+012.06725 \mathrm{e}+012.06725 \mathrm{e}+001.00000 \mathrm{e}-092.12000 \mathrm{e}-01$ $2.06725 \mathrm{e}+012.06725 \mathrm{e}+012.06725 \mathrm{e}+001.00000 \mathrm{e}-092.12000 \mathrm{e}-01$ $2.06725 \mathrm{e}+012.06725 \mathrm{e}+012.06725 \mathrm{e}+001.00000 \mathrm{e}-092.12000 \mathrm{e}-01$ $2.06725 \mathrm{e}+012.06725 \mathrm{e}+012.06725 \mathrm{e}+001.00000 \mathrm{e}-092.12000 \mathrm{e}-01$ $2.06725 \mathrm{e}+012.06725 \mathrm{e}+012.06725 \mathrm{e}+001.00000 \mathrm{e}-092.12000 \mathrm{e}-01$ $1.00000 \mathrm{e}-021.00000 \mathrm{e}-02$ 1.00000e-03 1.00000e-09 1.00000e-01 $1.00000 \mathrm{e}+001.00000 \mathrm{e}+001.00000 \mathrm{e}-011.00000 \mathrm{e}-091.00000 \mathrm{e}-01$ $1.00000 \mathrm{e}-05$ 1.00000e-05 1.00000e-06 1.00000e-09 1.00000e-01 $1.00000 \mathrm{e}+001.00000 \mathrm{e}+001.00000 \mathrm{e}-011.00000 \mathrm{e}-091.00000 \mathrm{e}-01$ Element: 1453 \# of layers: 12 
$\mathrm{Kx} \mathrm{Ky} \mathrm{Kz} \mathrm{Ss} \mathrm{Por}$

5.17372e+02 5.17372e+02 5.17372e+01 1.00000e-09 7.00000e-02

5.17372e+02 5.17372e+02 5.17372e+01 1.00000e-09 7.00000e-02

5.00000e-04 5.00000e-04 5.00000e-05 1.00000e-09 1.00000e-01

$2.06725 \mathrm{e}+012.06725 \mathrm{e}+012.06725 \mathrm{e}+001.00000 \mathrm{e}-092.12000 \mathrm{e}-01$

$2.06725 \mathrm{e}+012.06725 \mathrm{e}+012.06725 \mathrm{e}+001.00000 \mathrm{e}-092.12000 \mathrm{e}-01$

$2.06725 \mathrm{e}+012.06725 \mathrm{e}+012.06725 \mathrm{e}+001.00000 \mathrm{e}-092.12000 \mathrm{e}-01$

$2.06725 \mathrm{e}+012.06725 \mathrm{e}+012.06725 \mathrm{e}+00$ 1.00000e-09 2.12000e-01

$2.06725 \mathrm{e}+012.06725 \mathrm{e}+012.06725 \mathrm{e}+001.00000 \mathrm{e}-092.12000 \mathrm{e}-01$

$1.00000 \mathrm{e}-02$ 1.00000e-02 1.00000e-03 1.00000e-09 1.00000e-01

$1.00000 \mathrm{e}+001.00000 \mathrm{e}+001.00000 \mathrm{e}-011.00000 \mathrm{e}-091.00000 \mathrm{e}-01$

$1.00000 \mathrm{e}-05$ 1.00000e-05 1.00000e-06 1.00000e-09 1.00000e-01

$1.00000 \mathrm{e}+001.00000 \mathrm{e}+001.00000 \mathrm{e}-011.00000 \mathrm{e}-091.00000 \mathrm{e}-01$

Element: 1454 \# of layers: 10

Kx Ky Kz Ss Por

5.17372e+02 5.17372e+02 5.17372e+01 1.00000e-09 7.00000e-02

$2.06725 \mathrm{e}+012.06725 \mathrm{e}+012.06725 \mathrm{e}+00$ 1.00000e-09 2.12000e-01

$2.06725 \mathrm{e}+012.06725 \mathrm{e}+012.06725 \mathrm{e}+001.00000 \mathrm{e}-092.12000 \mathrm{e}-01$

$2.06725 \mathrm{e}+012.06725 \mathrm{e}+012.06725 \mathrm{e}+001.00000 \mathrm{e}-092.12000 \mathrm{e}-01$

$2.06725 \mathrm{e}+012.06725 \mathrm{e}+012.06725 \mathrm{e}+001.00000 \mathrm{e}-092.12000 \mathrm{e}-01$

$2.06725 \mathrm{e}+012.06725 \mathrm{e}+012.06725 \mathrm{e}+001.00000 \mathrm{e}-092.12000 \mathrm{e}-01$

$1.00000 \mathrm{e}-02$ 1.00000e-02 1.00000e-03 1.00000e-09 1.00000e-01

$1.00000 \mathrm{e}+001.00000 \mathrm{e}+001.00000 \mathrm{e}-011.00000 \mathrm{e}-091.00000 \mathrm{e}-01$

$1.00000 \mathrm{e}-05$ 1.00000e-05 1.00000e-06 1.00000e-09 1.00000e-01

$1.00000 \mathrm{e}+001.00000 \mathrm{e}+001.00000 \mathrm{e}-011.00000 \mathrm{e}-091.00000 \mathrm{e}-01$

Element: 1455 \# of layers: 10

$\mathrm{Kx} \mathrm{Ky} \mathrm{Kz}$ Ss Por

5.56674e+02 5.56674e+02 5.56674e+01 1.00000e-09 7.00000e-02

$2.22426 \mathrm{e}+012.22426 \mathrm{e}+012.22426 \mathrm{e}+00$ 1.00000e-09 2.12000e-01

$2.22426 \mathrm{e}+012.22426 \mathrm{e}+012.22426 \mathrm{e}+001.00000 \mathrm{e}-092.12000 \mathrm{e}-01$

$2.22426 \mathrm{e}+012.22426 \mathrm{e}+012.22426 \mathrm{e}+001.00000 \mathrm{e}-092.12000 \mathrm{e}-01$

$2.22426 \mathrm{e}+012.22426 \mathrm{e}+012.22426 \mathrm{e}+001.00000 \mathrm{e}-092.12000 \mathrm{e}-01$

$2.22426 \mathrm{e}+012.22426 \mathrm{e}+012.22426 \mathrm{e}+00$ 1.00000e-09 2.12000e-01

$1.00000 \mathrm{e}-02$ 1.00000e-02 1.00000e-03 1.00000e-09 1.00000e-01

$1.00000 \mathrm{e}+001.00000 \mathrm{e}+001.00000 \mathrm{e}-011.00000 \mathrm{e}-091.00000 \mathrm{e}-01$

1.00000e-05 1.00000e-05 1.00000e-06 1.00000e-09 1.00000e-01

$1.00000 \mathrm{e}+001.00000 \mathrm{e}+001.00000 \mathrm{e}-011.00000 \mathrm{e}-091.00000 \mathrm{e}-01$

Element: 1456 \# of layers: 10

$\mathrm{Kx} \mathrm{Ky} \mathrm{Kz}$ Ss Por

$5.56674 \mathrm{e}+02$ 5.56674e+02 5.56674e+01 1.00000e-09 7.00000e-02

$2.22426 \mathrm{e}+012.22426 \mathrm{e}+012.22426 \mathrm{e}+001.00000 \mathrm{e}-092.12000 \mathrm{e}-01$

$2.22426 \mathrm{e}+012.22426 \mathrm{e}+012.22426 \mathrm{e}+001.00000 \mathrm{e}-092.12000 \mathrm{e}-01$

$2.22426 \mathrm{e}+012.22426 \mathrm{e}+012.22426 \mathrm{e}+00$ 1.00000e-09 2.12000e-01

$2.22426 \mathrm{e}+012.22426 \mathrm{e}+01$ 2.22426e+00 1.00000e-09 2.12000e-01

$2.22426 \mathrm{e}+012.22426 \mathrm{e}+012.22426 \mathrm{e}+001.00000 \mathrm{e}-092.12000 \mathrm{e}-01$

$1.00000 \mathrm{e}-02$ 1.00000e-02 1.00000e-03 1.00000e-09 1.00000e-01 
$1.00000 \mathrm{e}+001.00000 \mathrm{e}+001.00000 \mathrm{e}-011.00000 \mathrm{e}-091.00000 \mathrm{e}-01$ $1.00000 \mathrm{e}-05$ 1.00000e-05 1.00000e-06 1.00000e-09 1.00000e-01 $1.00000 \mathrm{e}+001.00000 \mathrm{e}+001.00000 \mathrm{e}-011.00000 \mathrm{e}-09$ 1.00000e-01 Element: 1457 \# of layers: 10

$\mathrm{Kx} \mathrm{Ky} \mathrm{Kz}$ Ss Por

5.56674e+02 5.56674e+02 5.56674e+01 1.00000e-09 7.00000e-02 $2.22426 \mathrm{e}+012.22426 \mathrm{e}+012.22426 \mathrm{e}+001.00000 \mathrm{e}-092.12000 \mathrm{e}-01$ $2.22426 \mathrm{e}+012.22426 \mathrm{e}+012.22426 \mathrm{e}+00$ 1.00000e-09 2.12000e-01 $2.22426 \mathrm{e}+012.22426 \mathrm{e}+012.22426 \mathrm{e}+00$ 1.00000e-09 2.12000e-01 $2.22426 \mathrm{e}+012.22426 \mathrm{e}+012.22426 \mathrm{e}+00$ 1.00000e-09 2.12000e-01 $2.22426 \mathrm{e}+012.22426 \mathrm{e}+012.22426 \mathrm{e}+00$ 1.00000e-09 2.12000e-01 $1.00000 \mathrm{e}-02$ 1.00000e-02 1.00000e-03 1.00000e-09 1.00000e-01 $1.00000 \mathrm{e}+001.00000 \mathrm{e}+001.00000 \mathrm{e}-011.00000 \mathrm{e}-091.00000 \mathrm{e}-01$ $1.00000 \mathrm{e}-05$ 1.00000e-05 1.00000e-06 1.00000e-09 1.00000e-01 $1.00000 \mathrm{e}+001.00000 \mathrm{e}+001.00000 \mathrm{e}-01$ 1.00000e-09 1.00000e-01 Element: 1458 \# of layers: 9

$\mathrm{Kx} \mathrm{Ky} \mathrm{Kz}$ Ss Por

$2.22426 \mathrm{e}+012.22426 \mathrm{e}+012.22426 \mathrm{e}+00$ 1.00000e-09 2.12000e-01 $2.22426 \mathrm{e}+012.22426 \mathrm{e}+012.22426 \mathrm{e}+00$ 1.00000e-09 2.12000e-01 $2.22426 \mathrm{e}+012.22426 \mathrm{e}+012.22426 \mathrm{e}+00$ 1.00000e-09 2.12000e-01 $2.22426 \mathrm{e}+012.22426 \mathrm{e}+012.22426 \mathrm{e}+001.00000 \mathrm{e}-092.12000 \mathrm{e}-01$ $2.22426 \mathrm{e}+012.22426 \mathrm{e}+012.22426 \mathrm{e}+00$ 1.00000e-09 2.12000e-01 $1.00000 \mathrm{e}-021.00000 \mathrm{e}-021.00000 \mathrm{e}-031.00000 \mathrm{e}-091.00000 \mathrm{e}-01$ $1.00000 \mathrm{e}+001.00000 \mathrm{e}+001.00000 \mathrm{e}-011.00000 \mathrm{e}-091.00000 \mathrm{e}-01$ $1.00000 \mathrm{e}-05$ 1.00000e-05 1.00000e-06 1.00000e-09 1.00000e-01 $1.00000 \mathrm{e}+001.00000 \mathrm{e}+001.00000 \mathrm{e}-011.00000 \mathrm{e}-091.00000 \mathrm{e}-01$ Element: 1459 \# of layers: 9

$\mathrm{Kx} \mathrm{Ky} \mathrm{Kz}$ Ss Por

$2.22426 \mathrm{e}+012.22426 \mathrm{e}+012.22426 \mathrm{e}+00$ 1.00000e-09 2.12000e-01 $2.22426 \mathrm{e}+012.22426 \mathrm{e}+012.22426 \mathrm{e}+001.00000 \mathrm{e}-092.12000 \mathrm{e}-01$ $2.22426 \mathrm{e}+012.22426 \mathrm{e}+012.22426 \mathrm{e}+00$ 1.00000e-09 2.12000e-01 $2.22426 \mathrm{e}+012.22426 \mathrm{e}+012.22426 \mathrm{e}+001.00000 \mathrm{e}-092.12000 \mathrm{e}-01$ $2.22426 \mathrm{e}+012.22426 \mathrm{e}+012.22426 \mathrm{e}+001.00000 \mathrm{e}-092.12000 \mathrm{e}-01$ $1.00000 \mathrm{e}-02$ 1.00000e-02 1.00000e-03 1.00000e-09 1.00000e-01 $1.00000 \mathrm{e}+001.00000 \mathrm{e}+001.00000 \mathrm{e}-011.00000 \mathrm{e}-091.00000 \mathrm{e}-01$ 1.00000e-05 1.00000e-05 1.00000e-06 1.00000e-09 1.00000e-01 $1.00000 \mathrm{e}+001.00000 \mathrm{e}+001.00000 \mathrm{e}-011.00000 \mathrm{e}-091.00000 \mathrm{e}-01$ Element: 1460 \# of layers: 9

$\mathrm{Kx} \mathrm{Ky} \mathrm{Kz}$ Ss Por

$2.22426 \mathrm{e}+012.22426 \mathrm{e}+012.22426 \mathrm{e}+00$ 1.00000e-09 2.12000e-01 $2.22426 \mathrm{e}+012.22426 \mathrm{e}+012.22426 \mathrm{e}+001.00000 \mathrm{e}-092.12000 \mathrm{e}-01$ $2.22426 \mathrm{e}+012.22426 \mathrm{e}+012.22426 \mathrm{e}+001.00000 \mathrm{e}-092.12000 \mathrm{e}-01$ $2.22426 \mathrm{e}+012.22426 \mathrm{e}+012.22426 \mathrm{e}+00$ 1.00000e-09 2.12000e-01 $2.22426 \mathrm{e}+012.22426 \mathrm{e}+012.22426 \mathrm{e}+00$ 1.00000e-09 2.12000e-01 $1.00000 \mathrm{e}-02$ 1.00000e-02 1.00000e-03 1.00000e-09 1.00000e-01 $1.00000 \mathrm{e}+001.00000 \mathrm{e}+001.00000 \mathrm{e}-011.00000 \mathrm{e}-091.00000 \mathrm{e}-01$ 
$1.00000 \mathrm{e}-05$ 1.00000e-05 1.00000e-06 1.00000e-09 1.00000e-01 $1.00000 \mathrm{e}+001.00000 \mathrm{e}+001.00000 \mathrm{e}-01$ 1.00000e-09 1.00000e-01 Element: 1461 \# of layers: 9

Kx Ky Kz Ss Por

$2.22426 \mathrm{e}+012.22426 \mathrm{e}+012.22426 \mathrm{e}+00$ 1.00000e-09 2.12000e-01 $2.22426 \mathrm{e}+012.22426 \mathrm{e}+012.22426 \mathrm{e}+00$ 1.00000e-09 2.12000e-01 $2.22426 \mathrm{e}+012.22426 \mathrm{e}+012.22426 \mathrm{e}+001.00000 \mathrm{e}-092.12000 \mathrm{e}-01$ $2.22426 \mathrm{e}+012.22426 \mathrm{e}+012.22426 \mathrm{e}+00$ 1.00000e-09 2.12000e-01 $2.22426 \mathrm{e}+012.22426 \mathrm{e}+012.22426 \mathrm{e}+001.00000 \mathrm{e}-092.12000 \mathrm{e}-01$ $1.00000 \mathrm{e}-02$ 1.00000e-02 1.00000e-03 1.00000e-09 1.00000e-01 $1.00000 \mathrm{e}+001.00000 \mathrm{e}+001.00000 \mathrm{e}-011.00000 \mathrm{e}-091.00000 \mathrm{e}-01$ $1.00000 \mathrm{e}-05$ 1.00000e-05 1.00000e-06 1.00000e-09 1.00000e-01 $1.00000 \mathrm{e}+001.00000 \mathrm{e}+001.00000 \mathrm{e}-01$ 1.00000e-09 1.00000e-01 Element: 1462 \# of layers: 10

$\mathrm{Kx} \mathrm{Ky} \mathrm{Kz}$ Ss Por

5.56674e+02 5.56674e+02 5.56674e+01 1.00000e-09 7.00000e-02 $2.22426 \mathrm{e}+012.22426 \mathrm{e}+012.22426 \mathrm{e}+00$ 1.00000e-09 2.12000e-01

$2.22426 \mathrm{e}+012.22426 \mathrm{e}+012.22426 \mathrm{e}+00$ 1.00000e-09 2.12000e-01 $2.22426 \mathrm{e}+012.22426 \mathrm{e}+012.22426 \mathrm{e}+00$ 1.00000e-09 2.12000e-01 $2.22426 \mathrm{e}+012.22426 \mathrm{e}+012.22426 \mathrm{e}+00$ 1.00000e-09 2.12000e-01 $2.22426 \mathrm{e}+012.22426 \mathrm{e}+012.22426 \mathrm{e}+001.00000 \mathrm{e}-092.12000 \mathrm{e}-01$ $1.00000 \mathrm{e}-02$ 1.00000e-02 1.00000e-03 1.00000e-09 1.00000e-01 $1.00000 \mathrm{e}+001.00000 \mathrm{e}+001.00000 \mathrm{e}-011.00000 \mathrm{e}-091.00000 \mathrm{e}-01$ $1.00000 \mathrm{e}-05$ 1.00000e-05 1.00000e-06 1.00000e-09 1.00000e-01 $1.00000 \mathrm{e}+001.00000 \mathrm{e}+001.00000 \mathrm{e}-011.00000 \mathrm{e}-091.00000 \mathrm{e}-01$ Element: 1463 \# of layers: 9

$\mathrm{Kx} \mathrm{Ky} \mathrm{Kz}$ Ss Por

$2.22426 \mathrm{e}+012.22426 \mathrm{e}+012.22426 \mathrm{e}+00$ 1.00000e-09 2.12000e-01 $2.22426 \mathrm{e}+012.22426 \mathrm{e}+012.22426 \mathrm{e}+001.00000 \mathrm{e}-092.12000 \mathrm{e}-01$ $2.22426 \mathrm{e}+012.22426 \mathrm{e}+012.22426 \mathrm{e}+001.00000 \mathrm{e}-092.12000 \mathrm{e}-01$ $2.22426 \mathrm{e}+012.22426 \mathrm{e}+012.22426 \mathrm{e}+00$ 1.00000e-09 2.12000e-01 $2.22426 \mathrm{e}+012.22426 \mathrm{e}+012.22426 \mathrm{e}+00$ 1.00000e-09 2.12000e-01 $1.00000 \mathrm{e}-02$ 1.00000e-02 1.00000e-03 1.00000e-09 1.00000e-01 $1.00000 \mathrm{e}+001.00000 \mathrm{e}+001.00000 \mathrm{e}-011.00000 \mathrm{e}-091.00000 \mathrm{e}-01$ $1.00000 \mathrm{e}-05$ 1.00000e-05 1.00000e-06 1.00000e-09 1.00000e-01 $1.00000 \mathrm{e}+001.00000 \mathrm{e}+001.00000 \mathrm{e}-01$ 1.00000e-09 1.00000e-01 Element: 1464 \# of layers: 10

$\mathrm{Kx} \mathrm{Ky} \mathrm{Kz}$ Ss Por

2.98402e+02 2.98402e+02 2.98402e+01 1.00000e-09 7.00000e-02 $1.19230 \mathrm{e}+01$ 1.19230e+01 1.19230e+00 1.00000e-09 2.12000e-01 $1.19230 \mathrm{e}+01$ 1.19230e+01 1.19230e+00 1.00000e-09 2.12000e-01 $1.19230 \mathrm{e}+01$ 1.19230e+01 1.19230e+00 1.00000e-09 2.12000e-01 $1.19230 \mathrm{e}+01$ 1.19230e+01 1.19230e+00 1.00000e-09 2.12000e-01 $1.19230 \mathrm{e}+01$ 1.19230e+01 1.19230e+00 1.00000e-09 2.12000e-01 $1.00000 \mathrm{e}-02$ 1.00000e-02 1.00000e-03 1.00000e-09 1.00000e-01 $1.00000 \mathrm{e}+001.00000 \mathrm{e}+001.00000 \mathrm{e}-011.00000 \mathrm{e}-091.00000 \mathrm{e}-01$ 
$1.00000 \mathrm{e}-05$ 1.00000e-05 1.00000e-06 1.00000e-09 1.00000e-01 $1.00000 \mathrm{e}+001.00000 \mathrm{e}+001.00000 \mathrm{e}-01$ 1.00000e-09 1.00000e-01 Element: 1465 \# of layers: 10

Kx Ky Kz Ss Por

2.98402e+02 2.98402e+02 2.98402e+01 1.00000e-09 7.00000e-02 $1.19230 \mathrm{e}+01$ 1.19230e+01 1.19230e+00 1.00000e-09 2.12000e-01 $1.19230 \mathrm{e}+01$ 1.19230e+01 1.19230e+00 1.00000e-09 2.12000e-01 $1.19230 \mathrm{e}+01$ 1.19230e+01 1.19230e+00 1.00000e-09 2.12000e-01 $1.19230 \mathrm{e}+011.19230 \mathrm{e}+011.19230 \mathrm{e}+001.00000 \mathrm{e}-092.12000 \mathrm{e}-01$ $1.19230 \mathrm{e}+011.19230 \mathrm{e}+011.19230 \mathrm{e}+001.00000 \mathrm{e}-092.12000 \mathrm{e}-01$ 1.00000e-02 1.00000e-02 1.00000e-03 1.00000e-09 1.00000e-01 $1.00000 \mathrm{e}+001.00000 \mathrm{e}+001.00000 \mathrm{e}-011.00000 \mathrm{e}-091.00000 \mathrm{e}-01$ $1.00000 \mathrm{e}-05$ 1.00000e-05 1.00000e-06 1.00000e-09 1.00000e-01 $1.00000 \mathrm{e}+001.00000 \mathrm{e}+001.00000 \mathrm{e}-011.00000 \mathrm{e}-09$ 1.00000e-01 Element: 1466 \# of layers: 10

$\mathrm{Kx} \mathrm{Ky} \mathrm{Kz}$ Ss Por

2.98402e+02 2.98402e+02 2.98402e+01 1.00000e-09 7.00000e-02 $1.19230 \mathrm{e}+011.19230 \mathrm{e}+011.19230 \mathrm{e}+001.00000 \mathrm{e}-09$ 2.12000e-01 $1.19230 \mathrm{e}+01$ 1.19230e+01 1.19230e+00 1.00000e-09 2.12000e-01 $1.19230 \mathrm{e}+01$ 1.19230e+01 1.19230e+00 1.00000e-09 2.12000e-01 $1.19230 \mathrm{e}+011.19230 \mathrm{e}+011.19230 \mathrm{e}+001.00000 \mathrm{e}-092.12000 \mathrm{e}-01$ $1.19230 \mathrm{e}+011.19230 \mathrm{e}+01$ 1.19230e+00 1.00000e-09 2.12000e-01 $1.00000 \mathrm{e}-02$ 1.00000e-02 1.00000e-03 1.00000e-09 1.00000e-01 $1.00000 \mathrm{e}+001.00000 \mathrm{e}+001.00000 \mathrm{e}-011.00000 \mathrm{e}-091.00000 \mathrm{e}-01$ $1.00000 \mathrm{e}-05$ 1.00000e-05 1.00000e-06 1.00000e-09 1.00000e-01 $1.00000 \mathrm{e}+001.00000 \mathrm{e}+001.00000 \mathrm{e}-01$ 1.00000e-09 1.00000e-01 Element: 1467 \# of layers: 9

$\mathrm{Kx} \mathrm{Ky} \mathrm{Kz}$ Ss Por

$1.19230 \mathrm{e}+01$ 1.19230e+01 1.19230e+00 1.00000e-09 2.12000e-01 $1.19230 \mathrm{e}+011.19230 \mathrm{e}+011.19230 \mathrm{e}+001.00000 \mathrm{e}-092.12000 \mathrm{e}-01$ $1.19230 \mathrm{e}+01$ 1.19230e+01 1.19230e+00 1.00000e-09 2.12000e-01 $1.19230 \mathrm{e}+011.19230 \mathrm{e}+01$ 1.19230e+00 1.00000e-09 2.12000e-01 $1.19230 \mathrm{e}+011.19230 \mathrm{e}+011.19230 \mathrm{e}+001.00000 \mathrm{e}-092.12000 \mathrm{e}-01$ $1.00000 \mathrm{e}-02$ 1.00000e-02 1.00000e-03 1.00000e-09 1.00000e-01 $1.00000 \mathrm{e}+001.00000 \mathrm{e}+001.00000 \mathrm{e}-011.00000 \mathrm{e}-091.00000 \mathrm{e}-01$ $1.00000 \mathrm{e}-05$ 1.00000e-05 1.00000e-06 1.00000e-09 1.00000e-01 $1.00000 \mathrm{e}+001.00000 \mathrm{e}+001.00000 \mathrm{e}-011.00000 \mathrm{e}-091.00000 \mathrm{e}-01$ Element: 1468 \# of layers: 9

$\mathrm{Kx} \mathrm{Ky} \mathrm{Kz}$ Ss Por

$1.19230 \mathrm{e}+01$ 1.19230e+01 1.19230e+00 1.00000e-09 2.12000e-01 $1.19230 \mathrm{e}+011.19230 \mathrm{e}+011.19230 \mathrm{e}+001.00000 \mathrm{e}-092.12000 \mathrm{e}-01$ $1.19230 \mathrm{e}+011.19230 \mathrm{e}+011.19230 \mathrm{e}+001.00000 \mathrm{e}-092.12000 \mathrm{e}-01$ $1.19230 \mathrm{e}+011.19230 \mathrm{e}+011.19230 \mathrm{e}+001.00000 \mathrm{e}-092.12000 \mathrm{e}-01$ $1.19230 \mathrm{e}+01$ 1.19230e+01 1.19230e+00 1.00000e-09 2.12000e-01 1.00000e-02 1.00000e-02 1.00000e-03 1.00000e-09 1.00000e-01 $1.00000 \mathrm{e}+001.00000 \mathrm{e}+001.00000 \mathrm{e}-011.00000 \mathrm{e}-091.00000 \mathrm{e}-01$ 
$1.00000 \mathrm{e}-05$ 1.00000e-05 1.00000e-06 1.00000e-09 1.00000e-01 $1.00000 \mathrm{e}+001.00000 \mathrm{e}+001.00000 \mathrm{e}-01$ 1.00000e-09 1.00000e-01 Element: 1469 \# of layers: 9

Kx Ky Kz Ss Por

$1.19230 \mathrm{e}+01$ 1.19230e+01 1.19230e+00 1.00000e-09 2.12000e-01 $1.19230 \mathrm{e}+01$ 1.19230e+01 1.19230e+00 1.00000e-09 2.12000e-01 $1.19230 \mathrm{e}+01$ 1.19230e+01 1.19230e+00 1.00000e-09 2.12000e-01 $1.19230 \mathrm{e}+011.19230 \mathrm{e}+011.19230 \mathrm{e}+001.00000 \mathrm{e}-092.12000 \mathrm{e}-01$ $1.19230 \mathrm{e}+011.19230 \mathrm{e}+011.19230 \mathrm{e}+001.00000 \mathrm{e}-092.12000 \mathrm{e}-01$ $1.00000 \mathrm{e}-02$ 1.00000e-02 1.00000e-03 1.00000e-09 1.00000e-01 $1.00000 \mathrm{e}+001.00000 \mathrm{e}+001.00000 \mathrm{e}-011.00000 \mathrm{e}-091.00000 \mathrm{e}-01$ $1.00000 \mathrm{e}-05$ 1.00000e-05 1.00000e-06 1.00000e-09 1.00000e-01 $1.00000 \mathrm{e}+001.00000 \mathrm{e}+001.00000 \mathrm{e}-011.00000 \mathrm{e}-091.00000 \mathrm{e}-01$ Element: 1470 \# of layers: 9

$\mathrm{Kx} \mathrm{Ky} \mathrm{Kz}$ Ss Por

$1.19230 \mathrm{e}+01$ 1.19230e+01 1.19230e+00 1.00000e-09 2.12000e-01 $1.19230 \mathrm{e}+011.19230 \mathrm{e}+011.19230 \mathrm{e}+001.00000 \mathrm{e}-092.12000 \mathrm{e}-01$ $1.19230 \mathrm{e}+01$ 1.19230e+01 1.19230e+00 1.00000e-09 2.12000e-01 $1.19230 \mathrm{e}+01$ 1.19230e+01 1.19230e+00 1.00000e-09 2.12000e-01 $1.19230 \mathrm{e}+011.19230 \mathrm{e}+01 \quad 1.19230 \mathrm{e}+001.00000 \mathrm{e}-092.12000 \mathrm{e}-01$ $1.00000 \mathrm{e}-02$ 1.00000e-02 1.00000e-03 1.00000e-09 1.00000e-01 $1.00000 \mathrm{e}+001.00000 \mathrm{e}+001.00000 \mathrm{e}-011.00000 \mathrm{e}-091.00000 \mathrm{e}-01$ $1.00000 \mathrm{e}-05$ 1.00000e-05 1.00000e-06 1.00000e-09 1.00000e-01 $1.00000 \mathrm{e}+001.00000 \mathrm{e}+001.00000 \mathrm{e}-011.00000 \mathrm{e}-091.00000 \mathrm{e}-01$ Element: 1471 \# of layers: 9

$\mathrm{Kx} \mathrm{Ky} \mathrm{Kz}$ Ss Por

$1.19230 \mathrm{e}+01$ 1.19230e+01 1.19230e+00 1.00000e-09 2.12000e-01 $1.19230 \mathrm{e}+011.19230 \mathrm{e}+011.19230 \mathrm{e}+001.00000 \mathrm{e}-092.12000 \mathrm{e}-01$ $1.19230 \mathrm{e}+01$ 1.19230e+01 1.19230e+00 1.00000e-09 2.12000e-01 $1.19230 \mathrm{e}+011.19230 \mathrm{e}+011.19230 \mathrm{e}+001.00000 \mathrm{e}-092.12000 \mathrm{e}-01$ $1.19230 \mathrm{e}+011.19230 \mathrm{e}+01 \quad 1.19230 \mathrm{e}+001.00000 \mathrm{e}-092.12000 \mathrm{e}-01$ $1.00000 \mathrm{e}-02$ 1.00000e-02 1.00000e-03 1.00000e-09 1.00000e-01 $1.00000 \mathrm{e}+001.00000 \mathrm{e}+001.00000 \mathrm{e}-011.00000 \mathrm{e}-091.00000 \mathrm{e}-01$ $1.00000 \mathrm{e}-05$ 1.00000e-05 1.00000e-06 1.00000e-09 1.00000e-01 $1.00000 \mathrm{e}+001.00000 \mathrm{e}+001.00000 \mathrm{e}-011.00000 \mathrm{e}-091.00000 \mathrm{e}-01$ Element: 1472 \# of layers: 9

Kx Ky Kz Ss Por

$1.19230 \mathrm{e}+01$ 1.19230e+01 1.19230e+00 1.00000e-09 2.12000e-01 $1.19230 \mathrm{e}+01$ 1.19230e+01 1.19230e+00 1.00000e-09 2.12000e-01 $1.19230 \mathrm{e}+01$ 1.19230e+01 1.19230e+00 1.00000e-09 2.12000e-01 $1.19230 \mathrm{e}+01$ 1.19230e+01 1.19230e+00 1.00000e-09 2.12000e-01 $1.19230 \mathrm{e}+011.19230 \mathrm{e}+011.19230 \mathrm{e}+001.00000 \mathrm{e}-092.12000 \mathrm{e}-01$ $1.00000 \mathrm{e}-02$ 1.00000e-02 1.00000e-03 1.00000e-09 1.00000e-01 $1.00000 \mathrm{e}+001.00000 \mathrm{e}+001.00000 \mathrm{e}-011.00000 \mathrm{e}-091.00000 \mathrm{e}-01$ $1.00000 \mathrm{e}-05$ 1.00000e-05 1.00000e-06 1.00000e-09 1.00000e-01 $1.00000 \mathrm{e}+001.00000 \mathrm{e}+001.00000 \mathrm{e}-011.00000 \mathrm{e}-091.00000 \mathrm{e}-01$ 
Element: 1473 \# of layers: 10

Kx Ky Kz Ss Por

$2.76805 \mathrm{e}+022.76805 \mathrm{e}+022.76805 \mathrm{e}+01$ 1.00000e-09 7.00000e-02

$1.10601 \mathrm{e}+011.10601 \mathrm{e}+011.10601 \mathrm{e}+001.00000 \mathrm{e}-092.12000 \mathrm{e}-01$

$1.10601 \mathrm{e}+011.10601 \mathrm{e}+011.10601 \mathrm{e}+001.00000 \mathrm{e}-092.12000 \mathrm{e}-01$

$1.10601 \mathrm{e}+011.10601 \mathrm{e}+011.10601 \mathrm{e}+001.00000 \mathrm{e}-092.12000 \mathrm{e}-01$

$1.10601 \mathrm{e}+011.10601 \mathrm{e}+011.10601 \mathrm{e}+001.00000 \mathrm{e}-092.12000 \mathrm{e}-01$

$1.10601 \mathrm{e}+011.10601 \mathrm{e}+011.10601 \mathrm{e}+001.00000 \mathrm{e}-092.12000 \mathrm{e}-01$

$1.00000 \mathrm{e}-02$ 1.00000e-02 1.00000e-03 1.00000e-09 1.00000e-01

$1.00000 \mathrm{e}+001.00000 \mathrm{e}+001.00000 \mathrm{e}-011.00000 \mathrm{e}-091.00000 \mathrm{e}-01$

$1.00000 \mathrm{e}-05$ 1.00000e-05 1.00000e-06 1.00000e-09 1.00000e-01

$1.00000 \mathrm{e}+001.00000 \mathrm{e}+001.00000 \mathrm{e}-011.00000 \mathrm{e}-091.00000 \mathrm{e}-01$

Element: 1474 \# of layers: 10

Kx Ky Kz Ss Por

$2.76805 \mathrm{e}+022.76805 \mathrm{e}+022.76805 \mathrm{e}+01$ 1.00000e-09 7.00000e-02

$1.10601 \mathrm{e}+011.10601 \mathrm{e}+011.10601 \mathrm{e}+001.00000 \mathrm{e}-092.12000 \mathrm{e}-01$

$1.10601 \mathrm{e}+011.10601 \mathrm{e}+011.10601 \mathrm{e}+001.00000 \mathrm{e}-092.12000 \mathrm{e}-01$

$1.10601 \mathrm{e}+011.10601 \mathrm{e}+011.10601 \mathrm{e}+001.00000 \mathrm{e}-092.12000 \mathrm{e}-01$

$1.10601 \mathrm{e}+011.10601 \mathrm{e}+011.10601 \mathrm{e}+001.00000 \mathrm{e}-092.12000 \mathrm{e}-01$

$1.10601 \mathrm{e}+011.10601 \mathrm{e}+011.10601 \mathrm{e}+001.00000 \mathrm{e}-092.12000 \mathrm{e}-01$

$1.00000 \mathrm{e}-021.00000 \mathrm{e}-02$ 1.00000e-03 1.00000e-09 1.00000e-01

$1.00000 \mathrm{e}+001.00000 \mathrm{e}+001.00000 \mathrm{e}-011.00000 \mathrm{e}-091.00000 \mathrm{e}-01$

$1.00000 \mathrm{e}-05$ 1.00000e-05 1.00000e-06 1.00000e-09 1.00000e-01

$1.00000 \mathrm{e}+001.00000 \mathrm{e}+001.00000 \mathrm{e}-011.00000 \mathrm{e}-091.00000 \mathrm{e}-01$

Element: 1475 \# of layers: 10

Kx Ky Kz Ss Por

$2.76805 \mathrm{e}+02$ 2.76805e+02 2.76805e+01 1.00000e-09 7.00000e-02

$1.10601 \mathrm{e}+011.10601 \mathrm{e}+011.10601 \mathrm{e}+001.00000 \mathrm{e}-092.12000 \mathrm{e}-01$

$1.10601 \mathrm{e}+011.10601 \mathrm{e}+011.10601 \mathrm{e}+001.00000 \mathrm{e}-092.12000 \mathrm{e}-01$

$1.10601 \mathrm{e}+011.10601 \mathrm{e}+011.10601 \mathrm{e}+001.00000 \mathrm{e}-092.12000 \mathrm{e}-01$

$1.10601 \mathrm{e}+011.10601 \mathrm{e}+011.10601 \mathrm{e}+001.00000 \mathrm{e}-092.12000 \mathrm{e}-01$

$1.10601 \mathrm{e}+011.10601 \mathrm{e}+011.10601 \mathrm{e}+001.00000 \mathrm{e}-092.12000 \mathrm{e}-01$

$1.00000 \mathrm{e}-021.00000 \mathrm{e}-02$ 1.00000e-03 1.00000e-09 1.00000e-01

$1.00000 \mathrm{e}+001.00000 \mathrm{e}+001.00000 \mathrm{e}-011.00000 \mathrm{e}-091.00000 \mathrm{e}-01$

$1.00000 \mathrm{e}-05$ 1.00000e-05 1.00000e-06 1.00000e-09 1.00000e-01

$1.00000 \mathrm{e}+001.00000 \mathrm{e}+001.00000 \mathrm{e}-011.00000 \mathrm{e}-091.00000 \mathrm{e}-01$

Element: 1476 \# of layers: 9

Kx Ky Kz Ss Por

$1.10601 \mathrm{e}+011.10601 \mathrm{e}+011.10601 \mathrm{e}+00$ 1.00000e-09 2.12000e-01

$1.10601 \mathrm{e}+011.10601 \mathrm{e}+011.10601 \mathrm{e}+001.00000 \mathrm{e}-092.12000 \mathrm{e}-01$

$1.10601 \mathrm{e}+011.10601 \mathrm{e}+011.10601 \mathrm{e}+001.00000 \mathrm{e}-092.12000 \mathrm{e}-01$

$1.10601 \mathrm{e}+011.10601 \mathrm{e}+011.10601 \mathrm{e}+001.00000 \mathrm{e}-092.12000 \mathrm{e}-01$

$1.10601 \mathrm{e}+011.10601 \mathrm{e}+011.10601 \mathrm{e}+001.00000 \mathrm{e}-092.12000 \mathrm{e}-01$

$1.00000 \mathrm{e}-021.00000 \mathrm{e}-02$ 1.00000e-03 1.00000e-09 1.00000e-01

$1.00000 \mathrm{e}+001.00000 \mathrm{e}+001.00000 \mathrm{e}-011.00000 \mathrm{e}-091.00000 \mathrm{e}-01$

$1.00000 \mathrm{e}-05$ 1.00000e-05 1.00000e-06 1.00000e-09 1.00000e-01 
$1.00000 \mathrm{e}+001.00000 \mathrm{e}+00$ 1.00000e-01 1.00000e-09 1.00000e-01

Element: 1477 \# of layers: 9

$\mathrm{Kx} \mathrm{Ky} \mathrm{Kz}$ Ss Por

$1.10601 \mathrm{e}+011.10601 \mathrm{e}+01$ 1.10601e+00 1.00000e-09 2.12000e-01

$1.10601 \mathrm{e}+011.10601 \mathrm{e}+011.10601 \mathrm{e}+001.00000 \mathrm{e}-092.12000 \mathrm{e}-01$

$1.10601 \mathrm{e}+011.10601 \mathrm{e}+011.10601 \mathrm{e}+001.00000 \mathrm{e}-092.12000 \mathrm{e}-01$

$1.10601 \mathrm{e}+011.10601 \mathrm{e}+011.10601 \mathrm{e}+001.00000 \mathrm{e}-092.12000 \mathrm{e}-01$

$1.10601 \mathrm{e}+011.10601 \mathrm{e}+011.10601 \mathrm{e}+001.00000 \mathrm{e}-092.12000 \mathrm{e}-01$

$1.00000 \mathrm{e}-021.00000 \mathrm{e}-021.00000 \mathrm{e}-031.00000 \mathrm{e}-091.00000 \mathrm{e}-01$

$1.00000 \mathrm{e}+001.00000 \mathrm{e}+001.00000 \mathrm{e}-011.00000 \mathrm{e}-091.00000 \mathrm{e}-01$

$1.00000 \mathrm{e}-05$ 1.00000e-05 1.00000e-06 1.00000e-09 1.00000e-01

$1.00000 \mathrm{e}+001.00000 \mathrm{e}+001.00000 \mathrm{e}-011.00000 \mathrm{e}-091.00000 \mathrm{e}-01$

Element: 1478 \# of layers: 9

$\mathrm{Kx} \mathrm{Ky} \mathrm{Kz}$ Ss Por

$1.10601 \mathrm{e}+011.10601 \mathrm{e}+01$ 1.10601e+00 1.00000e-09 2.12000e-01

$1.10601 \mathrm{e}+011.10601 \mathrm{e}+011.10601 \mathrm{e}+001.00000 \mathrm{e}-092.12000 \mathrm{e}-01$

$1.10601 \mathrm{e}+011.10601 \mathrm{e}+011.10601 \mathrm{e}+001.00000 \mathrm{e}-092.12000 \mathrm{e}-01$

$1.10601 \mathrm{e}+011.10601 \mathrm{e}+011.10601 \mathrm{e}+001.00000 \mathrm{e}-092.12000 \mathrm{e}-01$

$1.10601 \mathrm{e}+011.10601 \mathrm{e}+011.10601 \mathrm{e}+001.00000 \mathrm{e}-092.12000 \mathrm{e}-01$

$1.00000 \mathrm{e}-02$ 1.00000e-02 1.00000e-03 1.00000e-09 1.00000e-01

$1.00000 \mathrm{e}+001.00000 \mathrm{e}+001.00000 \mathrm{e}-011.00000 \mathrm{e}-091.00000 \mathrm{e}-01$

$1.00000 \mathrm{e}-05$ 1.00000e-05 1.00000e-06 1.00000e-09 1.00000e-01

$1.00000 \mathrm{e}+001.00000 \mathrm{e}+001.00000 \mathrm{e}-01$ 1.00000e-09 1.00000e-01

Element: 1479 \# of layers: 9

Kx Ky Kz Ss Por

$1.10601 \mathrm{e}+011.10601 \mathrm{e}+011.10601 \mathrm{e}+001.00000 \mathrm{e}-092.12000 \mathrm{e}-01$

$1.10601 \mathrm{e}+011.10601 \mathrm{e}+011.10601 \mathrm{e}+001.00000 \mathrm{e}-092.12000 \mathrm{e}-01$

$1.10601 \mathrm{e}+011.10601 \mathrm{e}+011.10601 \mathrm{e}+001.00000 \mathrm{e}-092.12000 \mathrm{e}-01$

$1.10601 \mathrm{e}+011.10601 \mathrm{e}+011.10601 \mathrm{e}+001.00000 \mathrm{e}-092.12000 \mathrm{e}-01$

$1.10601 \mathrm{e}+011.10601 \mathrm{e}+01$ 1.10601e+00 1.00000e-09 2.12000e-01

$1.00000 \mathrm{e}-02$ 1.00000e-02 1.00000e-03 1.00000e-09 1.00000e-01

$1.00000 \mathrm{e}+001.00000 \mathrm{e}+001.00000 \mathrm{e}-011.00000 \mathrm{e}-091.00000 \mathrm{e}-01$

$1.00000 \mathrm{e}-05$ 1.00000e-05 1.00000e-06 1.00000e-09 1.00000e-01

$1.00000 \mathrm{e}+001.00000 \mathrm{e}+001.00000 \mathrm{e}-011.00000 \mathrm{e}-091.00000 \mathrm{e}-01$

Element: 1480 \# of layers: 9

Kx Ky Kz Ss Por

$1.10601 \mathrm{e}+011.10601 \mathrm{e}+011.10601 \mathrm{e}+001.00000 \mathrm{e}-092.12000 \mathrm{e}-01$

$1.10601 \mathrm{e}+011.10601 \mathrm{e}+011.10601 \mathrm{e}+001.00000 \mathrm{e}-092.12000 \mathrm{e}-01$

$1.10601 \mathrm{e}+011.10601 \mathrm{e}+011.10601 \mathrm{e}+001.00000 \mathrm{e}-092.12000 \mathrm{e}-01$

$1.10601 \mathrm{e}+011.10601 \mathrm{e}+011.10601 \mathrm{e}+001.00000 \mathrm{e}-092.12000 \mathrm{e}-01$

$1.10601 \mathrm{e}+011.10601 \mathrm{e}+011.10601 \mathrm{e}+001.00000 \mathrm{e}-092.12000 \mathrm{e}-01$

$1.00000 \mathrm{e}-02$ 1.00000e-02 1.00000e-03 1.00000e-09 1.00000e-01

$1.00000 \mathrm{e}+001.00000 \mathrm{e}+001.00000 \mathrm{e}-011.00000 \mathrm{e}-091.00000 \mathrm{e}-01$

$1.00000 \mathrm{e}-05$ 1.00000e-05 1.00000e-06 1.00000e-09 1.00000e-01

$1.00000 \mathrm{e}+001.00000 \mathrm{e}+001.00000 \mathrm{e}-01$ 1.00000e-09 1.00000e-01

Element: 1481 \# of layers: 9 
$\mathrm{Kx} \mathrm{Ky} \mathrm{Kz}$ Ss Por

$1.10601 \mathrm{e}+011.10601 \mathrm{e}+01$ 1.10601e+00 1.00000e-09 2.12000e-01

$1.10601 \mathrm{e}+011.10601 \mathrm{e}+011.10601 \mathrm{e}+001.00000 \mathrm{e}-092.12000 \mathrm{e}-01$

$1.10601 \mathrm{e}+011.10601 \mathrm{e}+011.10601 \mathrm{e}+001.00000 \mathrm{e}-092.12000 \mathrm{e}-01$

$1.10601 \mathrm{e}+011.10601 \mathrm{e}+011.10601 \mathrm{e}+001.00000 \mathrm{e}-092.12000 \mathrm{e}-01$

$1.10601 \mathrm{e}+011.10601 \mathrm{e}+011.10601 \mathrm{e}+001.00000 \mathrm{e}-092.12000 \mathrm{e}-01$

$1.00000 \mathrm{e}-02$ 1.00000e-02 1.00000e-03 1.00000e-09 1.00000e-01

$1.00000 \mathrm{e}+001.00000 \mathrm{e}+001.00000 \mathrm{e}-011.00000 \mathrm{e}-091.00000 \mathrm{e}-01$

$1.00000 \mathrm{e}-051.00000 \mathrm{e}-051.00000 \mathrm{e}-061.00000 \mathrm{e}-091.00000 \mathrm{e}-01$

$1.00000 \mathrm{e}+001.00000 \mathrm{e}+001.00000 \mathrm{e}-011.00000 \mathrm{e}-091.00000 \mathrm{e}-01$

Element: 1482 \# of layers: 10

$\mathrm{Kx} \mathrm{Ky} \mathrm{Kz}$ Ss Por

2.16564e+02 2.16564e+02 2.16564e+01 1.00000e-09 7.00000e-02

$8.65301 \mathrm{e}+008.65301 \mathrm{e}+00$ 8.65301e-01 1.00000e-09 2.12000e-01

8.65301e+00 8.65301e+00 8.65301e-01 1.00000e-09 2.12000e-01

$8.65301 \mathrm{e}+008.65301 \mathrm{e}+008.65301 \mathrm{e}-01$ 1.00000e-09 2.12000e-01

$8.65301 \mathrm{e}+00$ 8.65301e+00 8.65301e-01 1.00000e-09 2.12000e-01

8.65301e+00 8.65301e+00 8.65301e-01 1.00000e-09 2.12000e-01

$1.00000 \mathrm{e}-02$ 1.00000e-02 1.00000e-03 1.00000e-09 1.00000e-01

$1.00000 \mathrm{e}+001.00000 \mathrm{e}+001.00000 \mathrm{e}-011.00000 \mathrm{e}-091.00000 \mathrm{e}-01$

$1.00000 \mathrm{e}-05$ 1.00000e-05 1.00000e-06 1.00000e-09 1.00000e-01

$1.00000 \mathrm{e}+001.00000 \mathrm{e}+001.00000 \mathrm{e}-01$ 1.00000e-09 1.00000e-01

Element: 1483 \# of layers: 10

$\mathrm{Kx} \mathrm{Ky} \mathrm{Kz}$ Ss Por

$2.16564 \mathrm{e}+02$ 2.16564e+02 2.16564e+01 1.00000e-09 7.00000e-02

$8.65301 \mathrm{e}+008.65301 \mathrm{e}+008.65301 \mathrm{e}-01$ 1.00000e-09 2.12000e-01

$8.65301 \mathrm{e}+008.65301 \mathrm{e}+008.65301 \mathrm{e}-01$ 1.00000e-09 2.12000e-01

$8.65301 \mathrm{e}+008.65301 \mathrm{e}+00$ 8.65301e-01 1.00000e-09 2.12000e-01

$8.65301 \mathrm{e}+008.65301 \mathrm{e}+008.65301 \mathrm{e}-01$ 1.00000e-09 2.12000e-01

$8.65301 \mathrm{e}+008.65301 \mathrm{e}+00$ 8.65301e-01 1.00000e-09 2.12000e-01

$1.00000 \mathrm{e}-02$ 1.00000e-02 1.00000e-03 1.00000e-09 1.00000e-01

$1.00000 \mathrm{e}+001.00000 \mathrm{e}+001.00000 \mathrm{e}-011.00000 \mathrm{e}-091.00000 \mathrm{e}-01$

$1.00000 \mathrm{e}-051.00000 \mathrm{e}-05$ 1.00000e-06 1.00000e-09 1.00000e-01

$1.00000 \mathrm{e}+001.00000 \mathrm{e}+001.00000 \mathrm{e}-011.00000 \mathrm{e}-091.00000 \mathrm{e}-01$

Element: 1484 \# of layers: 10

$\mathrm{Kx} \mathrm{Ky} \mathrm{Kz}$ Ss Por

2.16564e+02 2.16564e+02 2.16564e+01 1.00000e-09 7.00000e-02

$8.65301 \mathrm{e}+00$ 8.65301e+00 8.65301e-01 1.00000e-09 2.12000e-01

$8.65301 \mathrm{e}+008.65301 \mathrm{e}+00$ 8.65301e-01 1.00000e-09 2.12000e-01

$8.65301 \mathrm{e}+00$ 8.65301e+00 8.65301e-01 1.00000e-09 2.12000e-01

$8.65301 \mathrm{e}+008.65301 \mathrm{e}+00$ 8.65301e-01 1.00000e-09 2.12000e-01

$8.65301 \mathrm{e}+008.65301 \mathrm{e}+00$ 8.65301e-01 1.00000e-09 2.12000e-01

$1.00000 \mathrm{e}-021.00000 \mathrm{e}-021.00000 \mathrm{e}-031.00000 \mathrm{e}-091.00000 \mathrm{e}-01$

$1.00000 \mathrm{e}+001.00000 \mathrm{e}+001.00000 \mathrm{e}-011.00000 \mathrm{e}-091.00000 \mathrm{e}-01$

$1.00000 \mathrm{e}-05$ 1.00000e-05 1.00000e-06 1.00000e-09 1.00000e-01

$1.00000 \mathrm{e}+001.00000 \mathrm{e}+001.00000 \mathrm{e}-011.00000 \mathrm{e}-091.00000 \mathrm{e}-01$ 
Element: 1485 \# of layers: 10

$\mathrm{Kx} \mathrm{Ky} \mathrm{Kz}$ Ss Por

$2.16564 \mathrm{e}+02$ 2.16564e+02 2.16564e+01 1.00000e-09 7.00000e-02

$8.65301 \mathrm{e}+008.65301 \mathrm{e}+008.65301 \mathrm{e}-01$ 1.00000e-09 2.12000e-01

$8.65301 \mathrm{e}+008.65301 \mathrm{e}+00$ 8.65301e-01 1.00000e-09 2.12000e-01

$8.65301 \mathrm{e}+008.65301 \mathrm{e}+00$ 8.65301e-01 1.00000e-09 2.12000e-01

$8.65301 \mathrm{e}+008.65301 \mathrm{e}+00$ 8.65301e-01 1.00000e-09 2.12000e-01

$8.65301 \mathrm{e}+008.65301 \mathrm{e}+008.65301 \mathrm{e}-01$ 1.00000e-09 2.12000e-01

$1.00000 \mathrm{e}-021.00000 \mathrm{e}-021.00000 \mathrm{e}-031.00000 \mathrm{e}-091.00000 \mathrm{e}-01$

$1.00000 \mathrm{e}+001.00000 \mathrm{e}+001.00000 \mathrm{e}-011.00000 \mathrm{e}-091.00000 \mathrm{e}-01$

$1.00000 \mathrm{e}-05$ 1.00000e-05 1.00000e-06 1.00000e-09 1.00000e-01

$1.00000 \mathrm{e}+001.00000 \mathrm{e}+001.00000 \mathrm{e}-011.00000 \mathrm{e}-091.00000 \mathrm{e}-01$

Element: 1486 \# of layers: 9

$\mathrm{Kx} \mathrm{Ky} \mathrm{Kz}$ Ss Por

8.65301e+00 8.65301e+00 8.65301e-01 1.00000e-09 2.12000e-01

$8.65301 \mathrm{e}+008.65301 \mathrm{e}+008.65301 \mathrm{e}-01$ 1.00000e-09 2.12000e-01

$8.65301 \mathrm{e}+008.65301 \mathrm{e}+00$ 8.65301e-01 1.00000e-09 2.12000e-01

8.65301e+00 8.65301e+00 8.65301e-01 1.00000e-09 2.12000e-01

$8.65301 \mathrm{e}+00$ 8.65301e+00 8.65301e-01 1.00000e-09 2.12000e-01 $1.00000 \mathrm{e}-02$ 1.00000e-02 1.00000e-03 1.00000e-09 1.00000e-01

$1.00000 \mathrm{e}+001.00000 \mathrm{e}+001.00000 \mathrm{e}-011.00000 \mathrm{e}-091.00000 \mathrm{e}-01$ $1.00000 \mathrm{e}-05$ 1.00000e-05 1.00000e-06 1.00000e-09 1.00000e-01

$1.00000 \mathrm{e}+001.00000 \mathrm{e}+001.00000 \mathrm{e}-01$ 1.00000e-09 1.00000e-01 Element: 1487 \# of layers: 9

Kx Ky Kz Ss Por

8.65301e+00 8.65301e+00 8.65301e-01 1.00000e-09 2.12000e-01

$8.65301 \mathrm{e}+008.65301 \mathrm{e}+008.65301 \mathrm{e}-01$ 1.00000e-09 2.12000e-01

$8.65301 \mathrm{e}+00$ 8.65301e+00 8.65301e-01 1.00000e-09 2.12000e-01

$8.65301 \mathrm{e}+008.65301 \mathrm{e}+008.65301 \mathrm{e}-01$ 1.00000e-09 2.12000e-01

$8.65301 \mathrm{e}+00$ 8.65301e+00 8.65301e-01 1.00000e-09 2.12000e-01

$1.00000 \mathrm{e}-02$ 1.00000e-02 1.00000e-03 1.00000e-09 1.00000e-01

$1.00000 \mathrm{e}+001.00000 \mathrm{e}+001.00000 \mathrm{e}-011.00000 \mathrm{e}-091.00000 \mathrm{e}-01$

$1.00000 \mathrm{e}-05$ 1.00000e-05 1.00000e-06 1.00000e-09 1.00000e-01

$1.00000 \mathrm{e}+001.00000 \mathrm{e}+001.00000 \mathrm{e}-011.00000 \mathrm{e}-091.00000 \mathrm{e}-01$

Element: 1488 \# of layers: 9

$\mathrm{Kx} \mathrm{Ky} \mathrm{Kz}$ Ss Por

8.65301e+00 8.65301e+00 8.65301e-01 1.00000e-09 2.12000e-01

$8.65301 \mathrm{e}+008.65301 \mathrm{e}+00$ 8.65301e-01 1.00000e-09 2.12000e-01

$8.65301 \mathrm{e}+008.65301 \mathrm{e}+00$ 8.65301e-01 1.00000e-09 2.12000e-01

$8.65301 \mathrm{e}+00$ 8.65301e+00 8.65301e-01 1.00000e-09 2.12000e-01

$8.65301 \mathrm{e}+008.65301 \mathrm{e}+008.65301 \mathrm{e}-01$ 1.00000e-09 2.12000e-01

$1.00000 \mathrm{e}-02$ 1.00000e-02 1.00000e-03 1.00000e-09 1.00000e-01

$1.00000 \mathrm{e}+001.00000 \mathrm{e}+001.00000 \mathrm{e}-011.00000 \mathrm{e}-091.00000 \mathrm{e}-01$

$1.00000 \mathrm{e}-051.00000 \mathrm{e}-051.00000 \mathrm{e}-061.00000 \mathrm{e}-091.00000 \mathrm{e}-01$

$1.00000 \mathrm{e}+001.00000 \mathrm{e}+001.00000 \mathrm{e}-011.00000 \mathrm{e}-09$ 1.00000e-01

Element: 1489 \# of layers: 9 
$\mathrm{Kx} \mathrm{Ky} \mathrm{Kz} \mathrm{Ss} \mathrm{Por}$

8.65301e+00 8.65301e+00 8.65301e-01 1.00000e-09 2.12000e-01

$8.65301 \mathrm{e}+008.65301 \mathrm{e}+008.65301 \mathrm{e}-01$ 1.00000e-09 2.12000e-01

$8.65301 \mathrm{e}+008.65301 \mathrm{e}+008.65301 \mathrm{e}-011.00000 \mathrm{e}-092.12000 \mathrm{e}-01$

$8.65301 \mathrm{e}+00$ 8.65301e+00 8.65301e-01 1.00000e-09 2.12000e-01

$8.65301 \mathrm{e}+008.65301 \mathrm{e}+00$ 8.65301e-01 1.00000e-09 2.12000e-01

$1.00000 \mathrm{e}-02$ 1.00000e-02 1.00000e-03 1.00000e-09 1.00000e-01

$1.00000 \mathrm{e}+001.00000 \mathrm{e}+001.00000 \mathrm{e}-011.00000 \mathrm{e}-091.00000 \mathrm{e}-01$

$1.00000 \mathrm{e}-051.00000 \mathrm{e}-051.00000 \mathrm{e}-061.00000 \mathrm{e}-091.00000 \mathrm{e}-01$

$1.00000 \mathrm{e}+001.00000 \mathrm{e}+001.00000 \mathrm{e}-011.00000 \mathrm{e}-091.00000 \mathrm{e}-01$

Element: 1490 \# of layers: 9

$\mathrm{Kx} \mathrm{Ky} \mathrm{Kz}$ Ss Por

8.65301e+00 8.65301e+00 8.65301e-01 1.00000e-09 2.12000e-01

$8.65301 \mathrm{e}+008.65301 \mathrm{e}+00$ 8.65301e-01 1.00000e-09 2.12000e-01

$8.65301 \mathrm{e}+008.65301 \mathrm{e}+008.65301 \mathrm{e}-01$ 1.00000e-09 2.12000e-01

$8.65301 \mathrm{e}+008.65301 \mathrm{e}+008.65301 \mathrm{e}-01$ 1.00000e-09 2.12000e-01

$8.65301 \mathrm{e}+00$ 8.65301e+00 8.65301e-01 1.00000e-09 2.12000e-01

$1.00000 \mathrm{e}-02$ 1.00000e-02 1.00000e-03 1.00000e-09 1.00000e-01

$1.00000 \mathrm{e}+001.00000 \mathrm{e}+001.00000 \mathrm{e}-011.00000 \mathrm{e}-091.00000 \mathrm{e}-01$

$1.00000 \mathrm{e}-05$ 1.00000e-05 1.00000e-06 1.00000e-09 1.00000e-01

$1.00000 \mathrm{e}+001.00000 \mathrm{e}+001.00000 \mathrm{e}-011.00000 \mathrm{e}-091.00000 \mathrm{e}-01$

Element: 1491 \# of layers: 10

$\mathrm{Kx} \mathrm{Ky} \mathrm{Kz}$ Ss Por

2.32188e+02 2.32188e+02 2.32188e+01 1.00000e-09 7.00000e-02

$9.27740 \mathrm{e}+009.27740 \mathrm{e}+00$ 9.27740e-01 1.00000e-09 2.12000e-01

$9.27740 \mathrm{e}+009.27740 \mathrm{e}+00$ 9.27740e-01 1.00000e-09 2.12000e-01

9.27740e+00 9.27740e+00 9.27740e-01 1.00000e-09 2.12000e-01

$9.27740 \mathrm{e}+00$ 9.27740e+00 9.27740e-01 1.00000e-09 2.12000e-01

$9.27740 \mathrm{e}+00 \quad 9.27740 \mathrm{e}+00$ 9.27740e-01 1.00000e-09 2.12000e-01

$1.00000 \mathrm{e}-02$ 1.00000e-02 1.00000e-03 1.00000e-09 1.00000e-01

$1.00000 \mathrm{e}+001.00000 \mathrm{e}+001.00000 \mathrm{e}-011.00000 \mathrm{e}-091.00000 \mathrm{e}-01$

1.00000e-05 1.00000e-05 1.00000e-06 1.00000e-09 1.00000e-01

$1.00000 \mathrm{e}+001.00000 \mathrm{e}+001.00000 \mathrm{e}-011.00000 \mathrm{e}-091.00000 \mathrm{e}-01$

Element: 1492 \# of layers: 10

$\mathrm{Kx} \mathrm{Ky} \mathrm{Kz}$ Ss Por

2.32188e+02 2.32188e+02 2.32188e+01 1.00000e-09 7.00000e-02

$9.27740 \mathrm{e}+009.27740 \mathrm{e}+00$ 9.27740e-01 1.00000e-09 2.12000e-01

9.27740e+00 9.27740e+00 9.27740e-01 1.00000e-09 2.12000e-01

$9.27740 \mathrm{e}+009.27740 \mathrm{e}+009.27740 \mathrm{e}-01$ 1.00000e-09 2.12000e-01

$9.27740 \mathrm{e}+009.27740 \mathrm{e}+00$ 9.27740e-01 1.00000e-09 2.12000e-01

$9.27740 \mathrm{e}+00$ 9.27740e+00 9.27740e-01 1.00000e-09 2.12000e-01

$1.00000 \mathrm{e}-02$ 1.00000e-02 1.00000e-03 1.00000e-09 1.00000e-01

$1.00000 \mathrm{e}+001.00000 \mathrm{e}+001.00000 \mathrm{e}-011.00000 \mathrm{e}-091.00000 \mathrm{e}-01$

$1.00000 \mathrm{e}-05$ 1.00000e-05 1.00000e-06 1.00000e-09 1.00000e-01

$1.00000 \mathrm{e}+001.00000 \mathrm{e}+001.00000 \mathrm{e}-011.00000 \mathrm{e}-09$ 1.00000e-01

Element: 1493 \# of layers: 10 
$\mathrm{Kx} \mathrm{Ky} \mathrm{Kz}$ Ss Por

2.32188e+02 2.32188e+02 2.32188e+01 1.00000e-09 7.00000e-02 9.27740e+00 9.27740e+00 9.27740e-01 1.00000e-09 2.12000e-01 $9.27740 \mathrm{e}+00$ 9.27740e+00 9.27740e-01 1.00000e-09 2.12000e-01 9.27740e+00 9.27740e+00 9.27740e-01 1.00000e-09 2.12000e-01 $9.27740 \mathrm{e}+00$ 9.27740e+00 9.27740e-01 1.00000e-09 2.12000e-01 $9.27740 \mathrm{e}+00$ 9.27740e+00 9.27740e-01 1.00000e-09 2.12000e-01 $1.00000 \mathrm{e}-02$ 1.00000e-02 1.00000e-03 1.00000e-09 1.00000e-01 $1.00000 \mathrm{e}+001.00000 \mathrm{e}+001.00000 \mathrm{e}-011.00000 \mathrm{e}-091.00000 \mathrm{e}-01$ $1.00000 \mathrm{e}-05$ 1.00000e-05 1.00000e-06 1.00000e-09 1.00000e-01 $1.00000 \mathrm{e}+001.00000 \mathrm{e}+001.00000 \mathrm{e}-011.00000 \mathrm{e}-091.00000 \mathrm{e}-01$ Element: 1494 \# of layers: 10

$\mathrm{Kx} \mathrm{Ky} \mathrm{Kz}$ Ss Por

2.32188e+02 2.32188e+02 2.32188e+01 1.00000e-09 7.00000e-02 9.27740e+00 9.27740e+00 9.27740e-01 1.00000e-09 2.12000e-01 $9.27740 \mathrm{e}+009.27740 \mathrm{e}+00$ 9.27740e-01 1.00000e-09 2.12000e-01 $9.27740 \mathrm{e}+00$ 9.27740e+00 9.27740e-01 1.00000e-09 2.12000e-01 $9.27740 \mathrm{e}+009.27740 \mathrm{e}+00$ 9.27740e-01 1.00000e-09 2.12000e-01 $9.27740 \mathrm{e}+00$ 9.27740e+00 9.27740e-01 1.00000e-09 2.12000e-01 $1.00000 \mathrm{e}-02$ 1.00000e-02 1.00000e-03 1.00000e-09 1.00000e-01 $1.00000 \mathrm{e}+001.00000 \mathrm{e}+001.00000 \mathrm{e}-011.00000 \mathrm{e}-091.00000 \mathrm{e}-01$ $1.00000 \mathrm{e}-05$ 1.00000e-05 1.00000e-06 1.00000e-09 1.00000e-01 $1.00000 \mathrm{e}+001.00000 \mathrm{e}+001.00000 \mathrm{e}-01$ 1.00000e-09 1.00000e-01 Element: 1495 \# of layers: 10

$\mathrm{Kx} \mathrm{Ky} \mathrm{Kz}$ Ss Por

2.32188e+02 2.32188e+02 2.32188e+01 1.00000e-09 7.00000e-02 9.27740e+00 9.27740e+00 9.27740e-01 1.00000e-09 2.12000e-01 $9.27740 \mathrm{e}+00$ 9.27740e+00 9.27740e-01 1.00000e-09 2.12000e-01 $9.27740 \mathrm{e}+00$ 9.27740e+00 9.27740e-01 1.00000e-09 2.12000e-01 $9.27740 \mathrm{e}+009.27740 \mathrm{e}+009.27740 \mathrm{e}-01$ 1.00000e-09 2.12000e-01 $9.27740 \mathrm{e}+00$ 9.27740e+00 9.27740e-01 1.00000e-09 2.12000e-01 $1.00000 \mathrm{e}-02$ 1.00000e-02 1.00000e-03 1.00000e-09 1.00000e-01 $1.00000 \mathrm{e}+001.00000 \mathrm{e}+001.00000 \mathrm{e}-011.00000 \mathrm{e}-091.00000 \mathrm{e}-01$ $1.00000 \mathrm{e}-05$ 1.00000e-05 1.00000e-06 1.00000e-09 1.00000e-01 $1.00000 \mathrm{e}+001.00000 \mathrm{e}+001.00000 \mathrm{e}-01$ 1.00000e-09 1.00000e-01 Element: 1496 \# of layers: 9

Kx Ky Kz Ss Por

9.27740e+00 9.27740e+00 9.27740e-01 1.00000e-09 2.12000e-01 $9.27740 \mathrm{e}+009.27740 \mathrm{e}+009.27740 \mathrm{e}-01$ 1.00000e-09 2.12000e-01 $9.27740 \mathrm{e}+00$ 9.27740e+00 9.27740e-01 1.00000e-09 2.12000e-01 $9.27740 \mathrm{e}+00$ 9.27740e+00 9.27740e-01 1.00000e-09 2.12000e-01 $9.27740 \mathrm{e}+00$ 9.27740e+00 9.27740e-01 1.00000e-09 2.12000e-01 $1.00000 \mathrm{e}-021.00000 \mathrm{e}-021.00000 \mathrm{e}-031.00000 \mathrm{e}-091.00000 \mathrm{e}-01$ $1.00000 \mathrm{e}+001.00000 \mathrm{e}+001.00000 \mathrm{e}-011.00000 \mathrm{e}-091.00000 \mathrm{e}-01$ $1.00000 \mathrm{e}-05$ 1.00000e-05 1.00000e-06 1.00000e-09 1.00000e-01 $1.00000 \mathrm{e}+001.00000 \mathrm{e}+001.00000 \mathrm{e}-011.00000 \mathrm{e}-091.00000 \mathrm{e}-01$ 
Element: 1497 \# of layers: 9

$\mathrm{Kx} \mathrm{Ky} \mathrm{Kz}$ Ss Por

9.27740e+00 9.27740e+00 9.27740e-01 1.00000e-09 2.12000e-01

$9.27740 \mathrm{e}+00$ 9.27740e+00 9.27740e-01 1.00000e-09 2.12000e-01

$9.27740 \mathrm{e}+00$ 9.27740e+00 9.27740e-01 1.00000e-09 2.12000e-01

$9.27740 \mathrm{e}+00$ 9.27740e+00 9.27740e-01 1.00000e-09 2.12000e-01

$9.27740 \mathrm{e}+00$ 9.27740e+00 9.27740e-01 1.00000e-09 2.12000e-01

$1.00000 \mathrm{e}-02$ 1.00000e-02 1.00000e-03 1.00000e-09 1.00000e-01

$1.00000 \mathrm{e}+001.00000 \mathrm{e}+001.00000 \mathrm{e}-011.00000 \mathrm{e}-091.00000 \mathrm{e}-01$

$1.00000 \mathrm{e}-05$ 1.00000e-05 1.00000e-06 1.00000e-09 1.00000e-01

$1.00000 \mathrm{e}+001.00000 \mathrm{e}+001.00000 \mathrm{e}-011.00000 \mathrm{e}-091.00000 \mathrm{e}-01$

Element: 1498 \# of layers: 10

$\mathrm{Kx} \mathrm{Ky} \mathrm{Kz}$ Ss Por

2.32188e+02 2.32188e+02 2.32188e+01 1.00000e-09 7.00000e-02

$9.27740 \mathrm{e}+00$ 9.27740e+00 9.27740e-01 1.00000e-09 2.12000e-01

$9.27740 \mathrm{e}+009.27740 \mathrm{e}+00$ 9.27740e-01 1.00000e-09 2.12000e-01

$9.27740 \mathrm{e}+00$ 9.27740e+00 9.27740e-01 1.00000e-09 2.12000e-01

$9.27740 \mathrm{e}+009.27740 \mathrm{e}+00$ 9.27740e-01 1.00000e-09 2.12000e-01

$9.27740 \mathrm{e}+00$ 9.27740e+00 9.27740e-01 1.00000e-09 2.12000e-01

$1.00000 \mathrm{e}-02$ 1.00000e-02 1.00000e-03 1.00000e-09 1.00000e-01

$1.00000 \mathrm{e}+001.00000 \mathrm{e}+001.00000 \mathrm{e}-011.00000 \mathrm{e}-091.00000 \mathrm{e}-01$

$1.00000 \mathrm{e}-05$ 1.00000e-05 1.00000e-06 1.00000e-09 1.00000e-01

$1.00000 \mathrm{e}+001.00000 \mathrm{e}+001.00000 \mathrm{e}-01$ 1.00000e-09 1.00000e-01

Element: 1499 \# of layers: 10

$\mathrm{Kx} \mathrm{Ky} \mathrm{Kz}$ Ss Por

2.32188e+02 2.32188e+02 2.32188e+01 1.00000e-09 7.00000e-02

$9.27740 \mathrm{e}+00$ 9.27740e+00 9.27740e-01 1.00000e-09 2.12000e-01

$9.27740 \mathrm{e}+00$ 9.27740e+00 9.27740e-01 1.00000e-09 2.12000e-01

$9.27740 \mathrm{e}+00$ 9.27740e+00 9.27740e-01 1.00000e-09 2.12000e-01

$9.27740 \mathrm{e}+00$ 9.27740e+00 9.27740e-01 1.00000e-09 2.12000e-01

$9.27740 \mathrm{e}+00$ 9.27740e+00 9.27740e-01 1.00000e-09 2.12000e-01

$1.00000 \mathrm{e}-02$ 1.00000e-02 1.00000e-03 1.00000e-09 1.00000e-01

$1.00000 \mathrm{e}+001.00000 \mathrm{e}+001.00000 \mathrm{e}-011.00000 \mathrm{e}-091.00000 \mathrm{e}-01$

$1.00000 \mathrm{e}-05$ 1.00000e-05 1.00000e-06 1.00000e-09 1.00000e-01

$1.00000 \mathrm{e}+001.00000 \mathrm{e}+001.00000 \mathrm{e}-011.00000 \mathrm{e}-091.00000 \mathrm{e}-01$

Element: 1500 \# of layers: 10

$\mathrm{Kx} \mathrm{Ky} \mathrm{Kz}$ Ss Por

1.99121e+02 1.99121e+02 1.99121e+01 1.00000e-09 7.00000e-02

$7.95640 \mathrm{e}+00$ 7.95640e+00 7.95640e-01 1.00000e-09 2.12000e-01

$7.95640 \mathrm{e}+00$ 7.95640e+00 7.95640e-01 1.00000e-09 2.12000e-01

$7.95640 \mathrm{e}+007.95640 \mathrm{e}+007.95640 \mathrm{e}-01$ 1.00000e-09 2.12000e-01

7.95640e+00 7.95640e+00 7.95640e-01 1.00000e-09 2.12000e-01

7.95640e+00 7.95640e+00 7.95640e-01 1.00000e-09 2.12000e-01

$1.00000 \mathrm{e}-02$ 1.00000e-02 1.00000e-03 1.00000e-09 1.00000e-01

$1.00000 \mathrm{e}+001.00000 \mathrm{e}+001.00000 \mathrm{e}-011.00000 \mathrm{e}-091.00000 \mathrm{e}-01$

$1.00000 \mathrm{e}-05$ 1.00000e-05 1.00000e-06 1.00000e-09 1.00000e-01 
$1.00000 \mathrm{e}+001.00000 \mathrm{e}+00$ 1.00000e-01 1.00000e-09 1.00000e-01

Element: 1501 \# of layers: 10

Kx Ky Kz Ss Por

$1.99121 \mathrm{e}+02$ 1.99121e+02 1.99121e+01 1.00000e-09 7.00000e-02

$7.95640 \mathrm{e}+00$ 7.95640e+00 7.95640e-01 1.00000e-09 2.12000e-01

$7.95640 \mathrm{e}+007.95640 \mathrm{e}+00$ 7.95640e-01 1.00000e-09 2.12000e-01

$7.95640 \mathrm{e}+00$ 7.95640e+00 7.95640e-01 1.00000e-09 2.12000e-01

$7.95640 \mathrm{e}+00$ 7.95640e+00 7.95640e-01 1.00000e-09 2.12000e-01

$7.95640 \mathrm{e}+007.95640 \mathrm{e}+00$ 7.95640e-01 1.00000e-09 2.12000e-01

$1.00000 \mathrm{e}-02$ 1.00000e-02 1.00000e-03 1.00000e-09 1.00000e-01

$1.00000 \mathrm{e}+001.00000 \mathrm{e}+001.00000 \mathrm{e}-011.00000 \mathrm{e}-091.00000 \mathrm{e}-01$

$1.00000 \mathrm{e}-05$ 1.00000e-05 1.00000e-06 1.00000e-09 1.00000e-01

$1.00000 \mathrm{e}+001.00000 \mathrm{e}+001.00000 \mathrm{e}-011.00000 \mathrm{e}-091.00000 \mathrm{e}-01$

Element: 1502 \# of layers: 9

$\mathrm{Kx} \mathrm{Ky} \mathrm{Kz}$ Ss Por

1.99121e+02 1.99121e+02 1.99121e+01 1.00000e-09 7.00000e-02

7.95640e+00 7.95640e+00 7.95640e-01 1.00000e-09 2.12000e-01

$7.95640 \mathrm{e}+00$ 7.95640e+00 7.95640e-01 1.00000e-09 2.12000e-01

$7.95640 \mathrm{e}+00$ 7.95640e+00 7.95640e-01 1.00000e-09 2.12000e-01

$7.95640 \mathrm{e}+007.95640 \mathrm{e}+007.95640 \mathrm{e}-01$ 1.00000e-09 2.12000e-01

$1.00000 \mathrm{e}-02$ 1.00000e-02 1.00000e-03 1.00000e-09 1.00000e-01

$1.00000 \mathrm{e}+001.00000 \mathrm{e}+001.00000 \mathrm{e}-011.00000 \mathrm{e}-091.00000 \mathrm{e}-01$

$1.00000 \mathrm{e}-05$ 1.00000e-05 1.00000e-06 1.00000e-09 1.00000e-01

$1.00000 \mathrm{e}+001.00000 \mathrm{e}+001.00000 \mathrm{e}-011.00000 \mathrm{e}-091.00000 \mathrm{e}-01$

Element: 1503 \# of layers: 9

$\mathrm{Kx} \mathrm{Ky} \mathrm{Kz}$ Ss Por

1.99121e+02 1.99121e+02 1.99121e+01 1.00000e-09 7.00000e-02

7.95640e+00 7.95640e+00 7.95640e-01 1.00000e-09 2.12000e-01

$7.95640 \mathrm{e}+007.95640 \mathrm{e}+007.95640 \mathrm{e}-01$ 1.00000e-09 2.12000e-01

7.95640e+00 7.95640e+00 7.95640e-01 1.00000e-09 2.12000e-01

$7.95640 \mathrm{e}+00$ 7.95640e+00 7.95640e-01 1.00000e-09 2.12000e-01

$1.00000 \mathrm{e}-02$ 1.00000e-02 1.00000e-03 1.00000e-09 1.00000e-01

$1.00000 \mathrm{e}+001.00000 \mathrm{e}+001.00000 \mathrm{e}-011.00000 \mathrm{e}-091.00000 \mathrm{e}-01$

$1.00000 \mathrm{e}-051.00000 \mathrm{e}-051.00000 \mathrm{e}-061.00000 \mathrm{e}-091.00000 \mathrm{e}-01$

$1.00000 \mathrm{e}+001.00000 \mathrm{e}+001.00000 \mathrm{e}-011.00000 \mathrm{e}-091.00000 \mathrm{e}-01$

Element: 1504 \# of layers: 8

Kx Ky Kz Ss Por

$1.99121 \mathrm{e}+02$ 1.99121e+02 1.99121e+01 1.00000e-09 7.00000e-02

$7.95640 \mathrm{e}+007.95640 \mathrm{e}+00$ 7.95640e-01 1.00000e-09 2.12000e-01

$7.95640 \mathrm{e}+00$ 7.95640e+00 7.95640e-01 1.00000e-09 2.12000e-01

$7.95640 \mathrm{e}+00$ 7.95640e+00 7.95640e-01 1.00000e-09 2.12000e-01

$1.00000 \mathrm{e}-02$ 1.00000e-02 1.00000e-03 1.00000e-09 1.00000e-01

$1.00000 \mathrm{e}+001.00000 \mathrm{e}+001.00000 \mathrm{e}-011.00000 \mathrm{e}-091.00000 \mathrm{e}-01$

$1.00000 \mathrm{e}-05$ 1.00000e-05 1.00000e-06 1.00000e-09 1.00000e-01

$1.00000 \mathrm{e}+001.00000 \mathrm{e}+001.00000 \mathrm{e}-011.00000 \mathrm{e}-09$ 1.00000e-01

Element: 1505 \# of layers: 9 
$\mathrm{Kx} \mathrm{Ky} \mathrm{Kz}$ Ss Por

1.99121e+02 1.99121e+02 1.99121e+01 1.00000e-09 7.00000e-02

7.95640e+00 7.95640e+00 7.95640e-01 1.00000e-09 2.12000e-01

$7.95640 \mathrm{e}+007.95640 \mathrm{e}+007.95640 \mathrm{e}-01$ 1.00000e-09 2.12000e-01

7.95640e+00 7.95640e+00 7.95640e-01 1.00000e-09 2.12000e-01

$7.95640 \mathrm{e}+00$ 7.95640e+00 7.95640e-01 1.00000e-09 2.12000e-01

$1.00000 \mathrm{e}-02$ 1.00000e-02 1.00000e-03 1.00000e-09 1.00000e-01

$1.00000 \mathrm{e}+001.00000 \mathrm{e}+001.00000 \mathrm{e}-011.00000 \mathrm{e}-091.00000 \mathrm{e}-01$

$1.00000 \mathrm{e}-05$ 1.00000e-05 1.00000e-06 1.00000e-09 1.00000e-01

$1.00000 \mathrm{e}+001.00000 \mathrm{e}+001.00000 \mathrm{e}-011.00000 \mathrm{e}-091.00000 \mathrm{e}-01$

Element: 1506 \# of layers: 9

$\mathrm{Kx} \mathrm{Ky} \mathrm{Kz}$ Ss Por

$1.99121 \mathrm{e}+021.99121 \mathrm{e}+021.99121 \mathrm{e}+01$ 1.00000e-09 7.00000e-02

$7.95640 \mathrm{e}+00$ 7.95640e+00 7.95640e-01 1.00000e-09 2.12000e-01

$7.95640 \mathrm{e}+007.95640 \mathrm{e}+00$ 7.95640e-01 1.00000e-09 2.12000e-01

$7.95640 \mathrm{e}+007.95640 \mathrm{e}+00$ 7.95640e-01 1.00000e-09 2.12000e-01

$7.95640 \mathrm{e}+007.95640 \mathrm{e}+00$ 7.95640e-01 1.00000e-09 2.12000e-01

$1.00000 \mathrm{e}-02$ 1.00000e-02 1.00000e-03 1.00000e-09 1.00000e-01

$1.00000 \mathrm{e}+001.00000 \mathrm{e}+001.00000 \mathrm{e}-011.00000 \mathrm{e}-091.00000 \mathrm{e}-01$

$1.00000 \mathrm{e}-051.00000 \mathrm{e}-05$ 1.00000e-06 1.00000e-09 1.00000e-01

$1.00000 \mathrm{e}+001.00000 \mathrm{e}+001.00000 \mathrm{e}-011.00000 \mathrm{e}-091.00000 \mathrm{e}-01$

Element: 1507 \# of layers: 10

$\mathrm{Kx} \mathrm{Ky} \mathrm{Kz}$ Ss Por

$1.99121 \mathrm{e}+02$ 1.99121e+02 1.99121e+01 1.00000e-09 7.00000e-02

$7.95640 \mathrm{e}+007.95640 \mathrm{e}+00$ 7.95640e-01 1.00000e-09 2.12000e-01

$7.95640 \mathrm{e}+00$ 7.95640e+00 7.95640e-01 1.00000e-09 2.12000e-01

$7.95640 \mathrm{e}+007.95640 \mathrm{e}+00$ 7.95640e-01 1.00000e-09 2.12000e-01

$7.95640 \mathrm{e}+007.95640 \mathrm{e}+00$ 7.95640e-01 1.00000e-09 2.12000e-01

$7.95640 \mathrm{e}+007.95640 \mathrm{e}+007.95640 \mathrm{e}-01$ 1.00000e-09 2.12000e-01

$1.00000 \mathrm{e}-02$ 1.00000e-02 1.00000e-03 1.00000e-09 1.00000e-01

$1.00000 \mathrm{e}+001.00000 \mathrm{e}+001.00000 \mathrm{e}-011.00000 \mathrm{e}-091.00000 \mathrm{e}-01$

1.00000e-05 1.00000e-05 1.00000e-06 1.00000e-09 1.00000e-01

$1.00000 \mathrm{e}+001.00000 \mathrm{e}+001.00000 \mathrm{e}-011.00000 \mathrm{e}-091.00000 \mathrm{e}-01$

Element: 1508 \# of layers: 10

$\mathrm{Kx} \mathrm{Ky} \mathrm{Kz}$ Ss Por

$1.99121 \mathrm{e}+021.99121 \mathrm{e}+02$ 1.99121e+01 1.00000e-09 7.00000e-02

$7.95640 \mathrm{e}+00$ 7.95640e+00 7.95640e-01 1.00000e-09 2.12000e-01

$7.95640 \mathrm{e}+00$ 7.95640e+00 7.95640e-01 1.00000e-09 2.12000e-01

$7.95640 \mathrm{e}+007.95640 \mathrm{e}+00$ 7.95640e-01 1.00000e-09 2.12000e-01

$7.95640 \mathrm{e}+007.95640 \mathrm{e}+00$ 7.95640e-01 1.00000e-09 2.12000e-01

$7.95640 \mathrm{e}+007.95640 \mathrm{e}+00$ 7.95640e-01 1.00000e-09 2.12000e-01

$1.00000 \mathrm{e}-02$ 1.00000e-02 1.00000e-03 1.00000e-09 1.00000e-01

$1.00000 \mathrm{e}+001.00000 \mathrm{e}+001.00000 \mathrm{e}-011.00000 \mathrm{e}-091.00000 \mathrm{e}-01$

$1.00000 \mathrm{e}-051.00000 \mathrm{e}-051.00000 \mathrm{e}-061.00000 \mathrm{e}-091.00000 \mathrm{e}-01$

$1.00000 \mathrm{e}+001.00000 \mathrm{e}+001.00000 \mathrm{e}-011.00000 \mathrm{e}-09$ 1.00000e-01

Element: 1509 \# of layers: 9 
$\mathrm{Kx} \mathrm{Ky} \mathrm{Kz} \mathrm{Ss} \mathrm{Por}$

$1.05651 \mathrm{e}+02$ 1.05651e+02 1.05651e+01 1.00000e-09 7.00000e-02 $4.22154 \mathrm{e}+004.22154 \mathrm{e}+004.22154 \mathrm{e}-01$ 1.00000e-09 2.12000e-01 $4.22154 \mathrm{e}+00$ 4.22154e+00 4.22154e-01 1.00000e-09 2.12000e-01 $4.22154 \mathrm{e}+004.22154 \mathrm{e}+004.22154 \mathrm{e}-01$ 1.00000e-09 2.12000e-01 $4.22154 \mathrm{e}+004.22154 \mathrm{e}+004.22154 \mathrm{e}-01$ 1.00000e-09 2.12000e-01 $1.00000 \mathrm{e}-01$ 1.00000e-01 1.00000e-02 1.00000e-09 1.00000e-01 $1.00000 \mathrm{e}+001.00000 \mathrm{e}+001.00000 \mathrm{e}-011.00000 \mathrm{e}-091.00000 \mathrm{e}-01$ $1.00000 \mathrm{e}-05$ 1.00000e-05 1.00000e-06 1.00000e-09 1.00000e-01 $1.00000 \mathrm{e}+001.00000 \mathrm{e}+001.00000 \mathrm{e}-011.00000 \mathrm{e}-091.00000 \mathrm{e}-01$ Element: 1510 \# of layers: 10

$\mathrm{Kx} \mathrm{Ky} \mathrm{Kz}$ Ss Por

1.05651e+02 1.05651e+02 1.05651e+01 1.00000e-09 7.00000e-02 $1.05651 \mathrm{e}+021.05651 \mathrm{e}+02$ 1.05651e+01 1.00000e-09 7.00000e-02 4.22154e+00 4.22154e+00 4.22154e-01 1.00000e-09 2.12000e-01 $4.22154 \mathrm{e}+004.22154 \mathrm{e}+004.22154 \mathrm{e}-01$ 1.00000e-09 2.12000e-01 $4.22154 \mathrm{e}+004.22154 \mathrm{e}+004.22154 \mathrm{e}-01$ 1.00000e-09 2.12000e-01 $4.22154 \mathrm{e}+004.22154 \mathrm{e}+004.22154 \mathrm{e}-01$ 1.00000e-09 2.12000e-01 $1.00000 \mathrm{e}-011.00000 \mathrm{e}-011.00000 \mathrm{e}-021.00000 \mathrm{e}-091.00000 \mathrm{e}-01$ $1.00000 \mathrm{e}+001.00000 \mathrm{e}+001.00000 \mathrm{e}-011.00000 \mathrm{e}-091.00000 \mathrm{e}-01$ $1.00000 \mathrm{e}-05$ 1.00000e-05 1.00000e-06 1.00000e-09 1.00000e-01 $1.00000 \mathrm{e}+001.00000 \mathrm{e}+001.00000 \mathrm{e}-01$ 1.00000e-09 1.00000e-01 Element: 1511 \# of layers: 8

Kx Ky Kz Ss Por

$1.05651 \mathrm{e}+02$ 1.05651e+02 1.05651e+01 1.00000e-09 7.00000e-02 $4.22154 \mathrm{e}+004.22154 \mathrm{e}+004.22154 \mathrm{e}-01$ 1.00000e-09 2.12000e-01 4.22154e+00 4.22154e+00 4.22154e-01 1.00000e-09 2.12000e-01 $4.22154 \mathrm{e}+004.22154 \mathrm{e}+004.22154 \mathrm{e}-01$ 1.00000e-09 2.12000e-01 $1.00000 \mathrm{e}-011.00000 \mathrm{e}-01$ 1.00000e-02 1.00000e-09 1.00000e-01 $1.00000 \mathrm{e}+001.00000 \mathrm{e}+001.00000 \mathrm{e}-011.00000 \mathrm{e}-091.00000 \mathrm{e}-01$ $1.00000 \mathrm{e}-05$ 1.00000e-05 1.00000e-06 1.00000e-09 1.00000e-01 $1.00000 \mathrm{e}+001.00000 \mathrm{e}+001.00000 \mathrm{e}-011.00000 \mathrm{e}-091.00000 \mathrm{e}-01$ Element: 1512 \# of layers: 9

$\mathrm{Kx} \mathrm{Ky} \mathrm{Kz}$ Ss Por

$1.05651 \mathrm{e}+02$ 1.05651e+02 1.05651e+01 1.00000e-09 7.00000e-02 $4.22154 \mathrm{e}+004.22154 \mathrm{e}+00$ 4.22154e-01 1.00000e-09 2.12000e-01 $4.22154 \mathrm{e}+004.22154 \mathrm{e}+004.22154 \mathrm{e}-01$ 1.00000e-09 2.12000e-01 $4.22154 \mathrm{e}+004.22154 \mathrm{e}+004.22154 \mathrm{e}-01$ 1.00000e-09 2.12000e-01 $4.22154 \mathrm{e}+004.22154 \mathrm{e}+004.22154 \mathrm{e}-01$ 1.00000e-09 2.12000e-01 $1.00000 \mathrm{e}-01$ 1.00000e-01 1.00000e-02 1.00000e-09 1.00000e-01 $1.00000 \mathrm{e}+001.00000 \mathrm{e}+001.00000 \mathrm{e}-011.00000 \mathrm{e}-091.00000 \mathrm{e}-01$ $1.00000 \mathrm{e}-05$ 1.00000e-05 1.00000e-06 1.00000e-09 1.00000e-01 $1.00000 \mathrm{e}+001.00000 \mathrm{e}+001.00000 \mathrm{e}-01$ 1.00000e-09 1.00000e-01 Element: 1513 \# of layers: 7

$\mathrm{Kx} \mathrm{Ky} \mathrm{Kz} \mathrm{Ss} \mathrm{Por}$

$1.05651 \mathrm{e}+02$ 1.05651e+02 1.05651e+01 1.00000e-09 7.00000e-02 
$4.22154 \mathrm{e}+004.22154 \mathrm{e}+00$ 4.22154e-01 1.00000e-09 2.12000e-01 $4.22154 \mathrm{e}+004.22154 \mathrm{e}+00 \quad 4.22154 \mathrm{e}-011.00000 \mathrm{e}-09$ 2.12000e-01 $1.00000 \mathrm{e}-011.00000 \mathrm{e}-011.00000 \mathrm{e}-021.00000 \mathrm{e}-091.00000 \mathrm{e}-01$ $1.00000 \mathrm{e}+001.00000 \mathrm{e}+001.00000 \mathrm{e}-011.00000 \mathrm{e}-091.00000 \mathrm{e}-01$ $1.00000 \mathrm{e}-05$ 1.00000e-05 1.00000e-06 1.00000e-09 1.00000e-01 $1.00000 \mathrm{e}+001.00000 \mathrm{e}+001.00000 \mathrm{e}-011.00000 \mathrm{e}-091.00000 \mathrm{e}-01$ Element: 1514 \# of layers: 9

Kx Ky Kz Ss Por

$1.05651 \mathrm{e}+021.05651 \mathrm{e}+021.05651 \mathrm{e}+011.00000 \mathrm{e}-097.00000 \mathrm{e}-02$ $1.05651 \mathrm{e}+021.05651 \mathrm{e}+021.05651 \mathrm{e}+011.00000 \mathrm{e}-097.00000 \mathrm{e}-02$ $4.22154 \mathrm{e}+004.22154 \mathrm{e}+00 \quad 4.22154 \mathrm{e}-011.00000 \mathrm{e}-09$ 2.12000e-01 $4.22154 \mathrm{e}+004.22154 \mathrm{e}+004.22154 \mathrm{e}-011.00000 \mathrm{e}-09$ 2.12000e-01 $4.22154 \mathrm{e}+004.22154 \mathrm{e}+00 \quad 4.22154 \mathrm{e}-011.00000 \mathrm{e}-09$ 2.12000e-01 $1.00000 \mathrm{e}-01$ 1.00000e-01 1.00000e-02 1.00000e-09 1.00000e-01 $1.00000 \mathrm{e}+001.00000 \mathrm{e}+001.00000 \mathrm{e}-011.00000 \mathrm{e}-091.00000 \mathrm{e}-01$ $1.00000 \mathrm{e}-051.00000 \mathrm{e}-05$ 1.00000e-06 1.00000e-09 1.00000e-01 $1.00000 \mathrm{e}+001.00000 \mathrm{e}+001.00000 \mathrm{e}-011.00000 \mathrm{e}-091.00000 \mathrm{e}-01$ Element: 1515 \# of layers: 8

Kx Ky Kz Ss Por

$1.05651 \mathrm{e}+021.05651 \mathrm{e}+021.05651 \mathrm{e}+01$ 1.00000e-09 7.00000e-02 $4.22154 \mathrm{e}+00 \quad 4.22154 \mathrm{e}+004.22154 \mathrm{e}-011.00000 \mathrm{e}-092.12000 \mathrm{e}-01$ $4.22154 \mathrm{e}+004.22154 \mathrm{e}+004.22154 \mathrm{e}-011.00000 \mathrm{e}-092.12000 \mathrm{e}-01$ $4.22154 \mathrm{e}+004.22154 \mathrm{e}+00 \quad 4.22154 \mathrm{e}-011.00000 \mathrm{e}-09$ 2.12000e-01 $1.00000 \mathrm{e}-02$ 1.00000e-02 1.00000e-03 1.00000e-09 1.00000e-01 $1.00000 \mathrm{e}+001.00000 \mathrm{e}+001.00000 \mathrm{e}-011.00000 \mathrm{e}-091.00000 \mathrm{e}-01$ $1.00000 \mathrm{e}-05$ 1.00000e-05 1.00000e-06 1.00000e-09 1.00000e-01 $1.00000 \mathrm{e}+001.00000 \mathrm{e}+001.00000 \mathrm{e}-011.00000 \mathrm{e}-091.00000 \mathrm{e}-01$ Element: 1516 \# of layers: 9

Kx Ky Kz Ss Por

$1.05651 \mathrm{e}+021.05651 \mathrm{e}+021.05651 \mathrm{e}+011.00000 \mathrm{e}-097.00000 \mathrm{e}-02$ $4.22154 \mathrm{e}+004.22154 \mathrm{e}+00 \quad 4.22154 \mathrm{e}-011.00000 \mathrm{e}-09$ 2.12000e-01 $4.22154 \mathrm{e}+004.22154 \mathrm{e}+004.22154 \mathrm{e}-011.00000 \mathrm{e}-09$ 2.12000e-01 $4.22154 \mathrm{e}+004.22154 \mathrm{e}+004.22154 \mathrm{e}-011.00000 \mathrm{e}-092.12000 \mathrm{e}-01$ $4.22154 \mathrm{e}+004.22154 \mathrm{e}+00 \quad 4.22154 \mathrm{e}-01$ 1.00000e-09 2.12000e-01 $1.00000 \mathrm{e}-02$ 1.00000e-02 1.00000e-03 1.00000e-09 1.00000e-01 $1.00000 \mathrm{e}+001.00000 \mathrm{e}+001.00000 \mathrm{e}-011.00000 \mathrm{e}-091.00000 \mathrm{e}-01$ $1.00000 \mathrm{e}-05$ 1.00000e-05 1.00000e-06 1.00000e-09 1.00000e-01 $1.00000 \mathrm{e}+001.00000 \mathrm{e}+001.00000 \mathrm{e}-011.00000 \mathrm{e}-091.00000 \mathrm{e}-01$ Element: 1517 \# of layers: 10

Kx Ky Kz Ss Por $1.05651 \mathrm{e}+021.05651 \mathrm{e}+021.05651 \mathrm{e}+01$ 1.00000e-09 7.00000e-02 $1.05651 \mathrm{e}+021.05651 \mathrm{e}+021.05651 \mathrm{e}+011.00000 \mathrm{e}-097.00000 \mathrm{e}-02$ $4.22154 \mathrm{e}+004.22154 \mathrm{e}+004.22154 \mathrm{e}-011.00000 \mathrm{e}-092.12000 \mathrm{e}-01$ $4.22154 \mathrm{e}+004.22154 \mathrm{e}+004.22154 \mathrm{e}-01$ 1.00000e-09 2.12000e-01 $4.22154 \mathrm{e}+004.22154 \mathrm{e}+004.22154 \mathrm{e}-011.00000 \mathrm{e}-092.12000 \mathrm{e}-01$ $4.22154 \mathrm{e}+004.22154 \mathrm{e}+004.22154 \mathrm{e}-011.00000 \mathrm{e}-092.12000 \mathrm{e}-01$ 
$1.00000 \mathrm{e}-01$ 1.00000e-01 1.00000e-02 1.00000e-09 1.00000e-01 $1.00000 \mathrm{e}+001.00000 \mathrm{e}+001.00000 \mathrm{e}-011.00000 \mathrm{e}-091.00000 \mathrm{e}-01$ $1.00000 \mathrm{e}-05$ 1.00000e-05 1.00000e-06 1.00000e-09 1.00000e-01 $1.00000 \mathrm{e}+001.00000 \mathrm{e}+001.00000 \mathrm{e}-011.00000 \mathrm{e}-091.00000 \mathrm{e}-01$ Element: 1518 \# of layers: 8

$\mathrm{Kx} \mathrm{Ky} \mathrm{Kz}$ Ss Por

7.36775e+01 7.36775e+01 7.36775e+00 1.00000e-09 7.00000e-02 $2.94396 \mathrm{e}+002.94396 \mathrm{e}+00$ 2.94396e-01 1.00000e-09 2.12000e-01 $2.94396 \mathrm{e}+002.94396 \mathrm{e}+00$ 2.94396e-01 1.00000e-09 2.12000e-01 $2.94396 \mathrm{e}+002.94396 \mathrm{e}+00$ 2.94396e-01 1.00000e-09 2.12000e-01 1.00000e-01 1.00000e-01 1.00000e-02 1.00000e-09 1.00000e-01 $1.00000 \mathrm{e}+001.00000 \mathrm{e}+001.00000 \mathrm{e}-011.00000 \mathrm{e}-091.00000 \mathrm{e}-01$ $1.00000 \mathrm{e}-05$ 1.00000e-05 1.00000e-06 1.00000e-09 1.00000e-01 $1.00000 \mathrm{e}+001.00000 \mathrm{e}+001.00000 \mathrm{e}-01$ 1.00000e-09 1.00000e-01 Element: 1519 \# of layers: 9

Kx Ky Kz Ss Por

7.36775e+01 7.36775e+01 7.36775e+00 1.00000e-09 7.00000e-02 $2.94396 \mathrm{e}+002.94396 \mathrm{e}+00$ 2.94396e-01 1.00000e-09 2.12000e-01 $2.94396 \mathrm{e}+00$ 2.94396e+00 2.94396e-01 1.00000e-09 2.12000e-01 $2.94396 \mathrm{e}+002.94396 \mathrm{e}+00$ 2.94396e-01 1.00000e-09 2.12000e-01 $2.94396 \mathrm{e}+002.94396 \mathrm{e}+00 \quad 2.94396 \mathrm{e}-01$ 1.00000e-09 2.12000e-01 $1.00000 \mathrm{e}-01$ 1.00000e-01 1.00000e-02 1.00000e-09 1.00000e-01 $1.00000 \mathrm{e}+001.00000 \mathrm{e}+001.00000 \mathrm{e}-011.00000 \mathrm{e}-091.00000 \mathrm{e}-01$ $1.00000 \mathrm{e}-05$ 1.00000e-05 1.00000e-06 1.00000e-09 1.00000e-01 $1.00000 \mathrm{e}+001.00000 \mathrm{e}+001.00000 \mathrm{e}-011.00000 \mathrm{e}-091.00000 \mathrm{e}-01$ Element: 1520 \# of layers: 9

$\mathrm{Kx} \mathrm{Ky} \mathrm{Kz}$ Ss Por

7.36775e+01 7.36775e+01 7.36775e+00 1.00000e-09 7.00000e-02

$7.36775 \mathrm{e}+01$ 7.36775e+01 7.36775e+00 1.00000e-09 7.00000e-02 $2.94396 \mathrm{e}+002.94396 \mathrm{e}+00$ 2.94396e-01 1.00000e-09 2.12000e-01 $2.94396 \mathrm{e}+002.94396 \mathrm{e}+00$ 2.94396e-01 1.00000e-09 2.12000e-01 $2.94396 \mathrm{e}+002.94396 \mathrm{e}+00$ 2.94396e-01 1.00000e-09 2.12000e-01 1.00000e-01 1.00000e-01 1.00000e-02 1.00000e-09 1.00000e-01 $1.00000 \mathrm{e}+001.00000 \mathrm{e}+001.00000 \mathrm{e}-011.00000 \mathrm{e}-091.00000 \mathrm{e}-01$ $1.00000 \mathrm{e}-05$ 1.00000e-05 1.00000e-06 1.00000e-09 1.00000e-01 $1.00000 \mathrm{e}+001.00000 \mathrm{e}+001.00000 \mathrm{e}-01$ 1.00000e-09 1.00000e-01 Element: 1521 \# of layers: 9

$\mathrm{Kx} \mathrm{Ky} \mathrm{Kz}$ Ss Por

7.36775e+01 7.36775e+01 7.36775e+00 1.00000e-09 7.00000e-02 7.36775e+01 7.36775e+01 7.36775e+00 1.00000e-09 7.00000e-02 $2.94396 \mathrm{e}+002.94396 \mathrm{e}+00$ 2.94396e-01 1.00000e-09 2.12000e-01 $2.94396 \mathrm{e}+002.94396 \mathrm{e}+00$ 2.94396e-01 1.00000e-09 2.12000e-01 2.94396e+00 2.94396e+00 2.94396e-01 1.00000e-09 2.12000e-01 $1.00000 \mathrm{e}-011.00000 \mathrm{e}-011.00000 \mathrm{e}-021.00000 \mathrm{e}-091.00000 \mathrm{e}-01$ $1.00000 \mathrm{e}+001.00000 \mathrm{e}+001.00000 \mathrm{e}-011.00000 \mathrm{e}-091.00000 \mathrm{e}-01$ $1.00000 \mathrm{e}-05$ 1.00000e-05 1.00000e-06 1.00000e-09 1.00000e-01 
$1.00000 \mathrm{e}+001.00000 \mathrm{e}+00$ 1.00000e-01 1.00000e-09 1.00000e-01

Element: 1522 \# of layers: 9

Kx Ky Kz Ss Por

7.36775e+01 7.36775e+01 7.36775e+00 1.00000e-09 7.00000e-02

7.36775e+01 7.36775e+01 7.36775e+00 1.00000e-09 7.00000e-02

$2.94396 \mathrm{e}+002.94396 \mathrm{e}+00$ 2.94396e-01 1.00000e-09 2.12000e-01

$2.94396 \mathrm{e}+00$ 2.94396e+00 2.94396e-01 1.00000e-09 2.12000e-01

$2.94396 \mathrm{e}+002.94396 \mathrm{e}+00$ 2.94396e-01 1.00000e-09 2.12000e-01

$1.00000 \mathrm{e}-01$ 1.00000e-01 1.00000e-02 1.00000e-09 1.00000e-01

$1.00000 \mathrm{e}+001.00000 \mathrm{e}+001.00000 \mathrm{e}-011.00000 \mathrm{e}-091.00000 \mathrm{e}-01$

$1.00000 \mathrm{e}-05$ 1.00000e-05 1.00000e-06 1.00000e-09 1.00000e-01

$1.00000 \mathrm{e}+001.00000 \mathrm{e}+001.00000 \mathrm{e}-011.00000 \mathrm{e}-091.00000 \mathrm{e}-01$

Element: 1523 \# of layers: 8

$\mathrm{Kx} \mathrm{Ky} \mathrm{Kz}$ Ss Por

7.36775e+01 7.36775e+01 7.36775e+00 1.00000e-09 7.00000e-02

$7.36775 \mathrm{e}+017.36775 \mathrm{e}+01$ 7.36775e+00 1.00000e-09 7.00000e-02

$2.94396 \mathrm{e}+00$ 2.94396e+00 2.94396e-01 1.00000e-09 2.12000e-01

$2.94396 \mathrm{e}+00$ 2.94396e+00 2.94396e-01 1.00000e-09 2.12000e-01

$1.00000 \mathrm{e}-011.00000 \mathrm{e}-011.00000 \mathrm{e}-021.00000 \mathrm{e}-091.00000 \mathrm{e}-01$

$1.00000 \mathrm{e}+001.00000 \mathrm{e}+001.00000 \mathrm{e}-011.00000 \mathrm{e}-091.00000 \mathrm{e}-01$

$1.00000 \mathrm{e}-05$ 1.00000e-05 1.00000e-06 1.00000e-09 1.00000e-01

$1.00000 \mathrm{e}+001.00000 \mathrm{e}+001.00000 \mathrm{e}-01$ 1.00000e-09 1.00000e-01

Element: 1524 \# of layers: 7

Kx Ky Kz Ss Por

7.36775e+01 7.36775e+01 7.36775e+00 1.00000e-09 7.00000e-02

$2.94396 \mathrm{e}+00$ 2.94396e+00 2.94396e-01 1.00000e-09 2.12000e-01

$2.94396 \mathrm{e}+002.94396 \mathrm{e}+00$ 2.94396e-01 1.00000e-09 2.12000e-01

$1.00000 \mathrm{e}-01$ 1.00000e-01 1.00000e-02 1.00000e-09 1.00000e-01

$1.00000 \mathrm{e}+001.00000 \mathrm{e}+001.00000 \mathrm{e}-011.00000 \mathrm{e}-091.00000 \mathrm{e}-01$

$1.00000 \mathrm{e}-05$ 1.00000e-05 1.00000e-06 1.00000e-09 1.00000e-01

$1.00000 \mathrm{e}+001.00000 \mathrm{e}+001.00000 \mathrm{e}-011.00000 \mathrm{e}-091.00000 \mathrm{e}-01$

Element: 1525 \# of layers: 9

Kx Ky Kz Ss Por

7.36775e+01 7.36775e+01 7.36775e+00 1.00000e-09 7.00000e-02

$2.94396 \mathrm{e}+002.94396 \mathrm{e}+00$ 2.94396e-01 1.00000e-09 2.12000e-01

$2.94396 \mathrm{e}+002.94396 \mathrm{e}+00$ 2.94396e-01 1.00000e-09 2.12000e-01

$2.94396 \mathrm{e}+002.94396 \mathrm{e}+00$ 2.94396e-01 1.00000e-09 2.12000e-01

$2.94396 \mathrm{e}+002.94396 \mathrm{e}+00$ 2.94396e-01 1.00000e-09 2.12000e-01

$1.00000 \mathrm{e}-011.00000 \mathrm{e}-011.00000 \mathrm{e}-021.00000 \mathrm{e}-091.00000 \mathrm{e}-01$

$1.00000 \mathrm{e}+001.00000 \mathrm{e}+001.00000 \mathrm{e}-011.00000 \mathrm{e}-091.00000 \mathrm{e}-01$

$1.00000 \mathrm{e}-05$ 1.00000e-05 1.00000e-06 1.00000e-09 1.00000e-01

$1.00000 \mathrm{e}+001.00000 \mathrm{e}+001.00000 \mathrm{e}-011.00000 \mathrm{e}-091.00000 \mathrm{e}-01$

Element: 1526 \# of layers: 9

$\mathrm{Kx} \mathrm{Ky} \mathrm{Kz}$ Ss Por

7.36775e+01 7.36775e+01 7.36775e+00 1.00000e-09 7.00000e-02

$2.94396 \mathrm{e}+002.94396 \mathrm{e}+00$ 2.94396e-01 1.00000e-09 2.12000e-01 
$2.94396 \mathrm{e}+002.94396 \mathrm{e}+002.94396 \mathrm{e}-011.00000 \mathrm{e}-092.12000 \mathrm{e}-01$ $2.94396 \mathrm{e}+002.94396 \mathrm{e}+002.94396 \mathrm{e}-01$ 1.00000e-09 2.12000e-01 $2.94396 \mathrm{e}+002.94396 \mathrm{e}+002.94396 \mathrm{e}-01$ 1.00000e-09 2.12000e-01 $1.00000 \mathrm{e}-011.00000 \mathrm{e}-011.00000 \mathrm{e}-021.00000 \mathrm{e}-091.00000 \mathrm{e}-01$ $1.00000 \mathrm{e}+001.00000 \mathrm{e}+001.00000 \mathrm{e}-011.00000 \mathrm{e}-091.00000 \mathrm{e}-01$ $1.00000 \mathrm{e}-05$ 1.00000e-05 1.00000e-06 1.00000e-09 1.00000e-01 $1.00000 \mathrm{e}+001.00000 \mathrm{e}+001.00000 \mathrm{e}-011.00000 \mathrm{e}-091.00000 \mathrm{e}-01$ Element: 1527 \# of layers: 7

Kx Ky Kz Ss Por

$5.49051 \mathrm{e}+015.49051 \mathrm{e}+015.49051 \mathrm{e}+00$ 1.00000e-09 7.00000e-02 $5.49051 \mathrm{e}+015.49051 \mathrm{e}+015.49051 \mathrm{e}+001.00000 \mathrm{e}-097.00000 \mathrm{e}-02$ $2.19382 \mathrm{e}+002.19382 \mathrm{e}+002.19382 \mathrm{e}-01$ 1.00000e-09 2.12000e-01 $2.19382 \mathrm{e}+002.19382 \mathrm{e}+00$ 2.19382e-01 1.00000e-09 2.12000e-01 $2.19382 \mathrm{e}+002.19382 \mathrm{e}+002.19382 \mathrm{e}-01$ 1.00000e-09 2.12000e-01 $1.00000 \mathrm{e}-011.00000 \mathrm{e}-011.00000 \mathrm{e}-021.00000 \mathrm{e}-091.00000 \mathrm{e}-01$ $1.00000 \mathrm{e}+001.00000 \mathrm{e}+001.00000 \mathrm{e}-011.00000 \mathrm{e}-091.00000 \mathrm{e}-01$ Element: 1528 \# of layers: 7

Kx Ky Kz Ss Por

$5.49051 \mathrm{e}+015.49051 \mathrm{e}+015.49051 \mathrm{e}+00$ 1.00000e-09 7.00000e-02 $5.49051 \mathrm{e}+015.49051 \mathrm{e}+015.49051 \mathrm{e}+001.00000 \mathrm{e}-097.00000 \mathrm{e}-02$ $2.19382 \mathrm{e}+002.19382 \mathrm{e}+002.19382 \mathrm{e}-01$ 1.00000e-09 2.12000e-01 $2.19382 \mathrm{e}+002.19382 \mathrm{e}+00$ 2.19382e-01 1.00000e-09 2.12000e-01 $2.19382 \mathrm{e}+002.19382 \mathrm{e}+002.19382 \mathrm{e}-01$ 1.00000e-09 2.12000e-01 $1.00000 \mathrm{e}-011.00000 \mathrm{e}-011.00000 \mathrm{e}-021.00000 \mathrm{e}-091.00000 \mathrm{e}-01$ $1.00000 \mathrm{e}+001.00000 \mathrm{e}+001.00000 \mathrm{e}-011.00000 \mathrm{e}-091.00000 \mathrm{e}-01$ Element: 1529 \# of layers: 7

Kx Ky Kz Ss Por

$5.49051 \mathrm{e}+015.49051 \mathrm{e}+015.49051 \mathrm{e}+00$ 1.00000e-09 7.00000e-02 $5.49051 \mathrm{e}+015.49051 \mathrm{e}+015.49051 \mathrm{e}+001.00000 \mathrm{e}-09$ 7.00000e-02 $2.19382 \mathrm{e}+002.19382 \mathrm{e}+002.19382 \mathrm{e}-01$ 1.00000e-09 2.12000e-01 $2.19382 \mathrm{e}+002.19382 \mathrm{e}+002.19382 \mathrm{e}-01$ 1.00000e-09 2.12000e-01 $2.19382 \mathrm{e}+002.19382 \mathrm{e}+002.19382 \mathrm{e}-01$ 1.00000e-09 2.12000e-01 $1.00000 \mathrm{e}-011.00000 \mathrm{e}-011.00000 \mathrm{e}-021.00000 \mathrm{e}-091.00000 \mathrm{e}-01$ $1.00000 \mathrm{e}+001.00000 \mathrm{e}+001.00000 \mathrm{e}-011.00000 \mathrm{e}-091.00000 \mathrm{e}-01$ Element: 1530 \# of layers: 12

Kx Ky Kz Ss Por

$5.65315 \mathrm{e}+025.65315 \mathrm{e}+025.65315 \mathrm{e}+01$ 1.00000e-09 7.00000e-02 $5.65315 \mathrm{e}+025.65315 \mathrm{e}+025.65315 \mathrm{e}+011.00000 \mathrm{e}-097.00000 \mathrm{e}-02$ $5.00000 \mathrm{e}-04$ 5.00000e-04 5.00000e-05 1.00000e-09 1.00000e-01 $2.25882 \mathrm{e}+012.25882 \mathrm{e}+012.25882 \mathrm{e}+001.00000 \mathrm{e}-092.12000 \mathrm{e}-01$ $2.25882 \mathrm{e}+012.25882 \mathrm{e}+012.25882 \mathrm{e}+001.00000 \mathrm{e}-092.12000 \mathrm{e}-01$ $2.25882 \mathrm{e}+012.25882 \mathrm{e}+012.25882 \mathrm{e}+00 \quad 1.00000 \mathrm{e}-092.12000 \mathrm{e}-01$ $2.25882 \mathrm{e}+012.25882 \mathrm{e}+012.25882 \mathrm{e}+001.00000 \mathrm{e}-092.12000 \mathrm{e}-01$ $2.25882 \mathrm{e}+012.25882 \mathrm{e}+012.25882 \mathrm{e}+00$ 1.00000e-09 2.12000e-01 $1.00000 \mathrm{e}-021.00000 \mathrm{e}-02$ 1.00000e-03 1.00000e-09 1.00000e-01 $1.00000 \mathrm{e}+001.00000 \mathrm{e}+001.00000 \mathrm{e}-011.00000 \mathrm{e}-091.00000 \mathrm{e}-01$ 
$1.00000 \mathrm{e}-05$ 1.00000e-05 1.00000e-06 1.00000e-09 1.00000e-01 $1.00000 \mathrm{e}+001.00000 \mathrm{e}+001.00000 \mathrm{e}-01$ 1.00000e-09 1.00000e-01 Element: 1531 \# of layers: 13

Kx Ky Kz Ss Por

5.65315e+02 5.65315e+02 5.65315e+01 1.00000e-09 7.00000e-02

$5.65315 \mathrm{e}+025.65315 \mathrm{e}+025.65315 \mathrm{e}+01$ 1.00000e-09 7.00000e-02

5.00000e-04 5.00000e-04 5.00000e-05 1.00000e-09 1.00000e-01

5.00000e-04 5.00000e-04 5.00000e-05 1.00000e-09 1.00000e-01

$2.25882 \mathrm{e}+012.25882 \mathrm{e}+012.25882 \mathrm{e}+00$ 1.00000e-09 2.12000e-01

$2.25882 \mathrm{e}+012.25882 \mathrm{e}+012.25882 \mathrm{e}+00$ 1.00000e-09 2.12000e-01

$2.25882 \mathrm{e}+012.25882 \mathrm{e}+012.25882 \mathrm{e}+00$ 1.00000e-09 2.12000e-01

$2.25882 \mathrm{e}+012.25882 \mathrm{e}+012.25882 \mathrm{e}+001.00000 \mathrm{e}-092.12000 \mathrm{e}-01$

$2.25882 \mathrm{e}+012.25882 \mathrm{e}+012.25882 \mathrm{e}+00$ 1.00000e-09 2.12000e-01

$1.00000 \mathrm{e}-02$ 1.00000e-02 1.00000e-03 1.00000e-09 1.00000e-01

$1.00000 \mathrm{e}+001.00000 \mathrm{e}+001.00000 \mathrm{e}-011.00000 \mathrm{e}-091.00000 \mathrm{e}-01$ $1.00000 \mathrm{e}-05$ 1.00000e-05 1.00000e-06 1.00000e-09 1.00000e-01

$1.00000 \mathrm{e}+001.00000 \mathrm{e}+001.00000 \mathrm{e}-011.00000 \mathrm{e}-091.00000 \mathrm{e}-01$

Element: 1532 \# of layers: 13

$\mathrm{Kx} \mathrm{Ky} \mathrm{Kz}$ Ss Por

5.65315e+02 5.65315e+02 5.65315e+01 1.00000e-09 7.00000e-02

$5.65315 \mathrm{e}+025.65315 \mathrm{e}+025.65315 \mathrm{e}+011.00000 \mathrm{e}-097.00000 \mathrm{e}-02$

5.00000e-04 5.00000e-04 5.00000e-05 1.00000e-09 1.00000e-01

5.00000e-04 5.00000e-04 5.00000e-05 1.00000e-09 1.00000e-01

$2.25882 \mathrm{e}+012.25882 \mathrm{e}+012.25882 \mathrm{e}+00$ 1.00000e-09 2.12000e-01

$2.25882 \mathrm{e}+012.25882 \mathrm{e}+012.25882 \mathrm{e}+00$ 1.00000e-09 2.12000e-01

$2.25882 \mathrm{e}+012.25882 \mathrm{e}+012.25882 \mathrm{e}+00$ 1.00000e-09 2.12000e-01

$2.25882 \mathrm{e}+012.25882 \mathrm{e}+012.25882 \mathrm{e}+00$ 1.00000e-09 2.12000e-01

$2.25882 \mathrm{e}+012.25882 \mathrm{e}+012.25882 \mathrm{e}+00$ 1.00000e-09 2.12000e-01

$1.00000 \mathrm{e}-02$ 1.00000e-02 1.00000e-03 1.00000e-09 1.00000e-01

$1.00000 \mathrm{e}+001.00000 \mathrm{e}+001.00000 \mathrm{e}-011.00000 \mathrm{e}-091.00000 \mathrm{e}-01$

$1.00000 \mathrm{e}-05$ 1.00000e-05 1.00000e-06 1.00000e-09 1.00000e-01

$1.00000 \mathrm{e}+001.00000 \mathrm{e}+001.00000 \mathrm{e}-01$ 1.00000e-09 1.00000e-01

Element: 1533 \# of layers: 13

$\mathrm{Kx} \mathrm{Ky} \mathrm{Kz}$ Ss Por

5.65315e+02 5.65315e+02 5.65315e+01 1.00000e-09 7.00000e-02

$5.65315 \mathrm{e}+025.65315 \mathrm{e}+025.65315 \mathrm{e}+01$ 1.00000e-09 7.00000e-02

5.00000e-04 5.00000e-04 5.00000e-05 1.00000e-09 1.00000e-01

5.00000e-04 5.00000e-04 5.00000e-05 1.00000e-09 1.00000e-01

$2.25882 \mathrm{e}+012.25882 \mathrm{e}+012.25882 \mathrm{e}+00$ 1.00000e-09 2.12000e-01

$2.25882 \mathrm{e}+012.25882 \mathrm{e}+012.25882 \mathrm{e}+00$ 1.00000e-09 2.12000e-01

$2.25882 \mathrm{e}+012.25882 \mathrm{e}+012.25882 \mathrm{e}+00$ 1.00000e-09 2.12000e-01

$2.25882 \mathrm{e}+012.25882 \mathrm{e}+012.25882 \mathrm{e}+00$ 1.00000e-09 2.12000e-01

$2.25882 \mathrm{e}+012.25882 \mathrm{e}+012.25882 \mathrm{e}+00$ 1.00000e-09 2.12000e-01

$1.00000 \mathrm{e}-02$ 1.00000e-02 1.00000e-03 1.00000e-09 1.00000e-01

$1.00000 \mathrm{e}+001.00000 \mathrm{e}+001.00000 \mathrm{e}-011.00000 \mathrm{e}-091.00000 \mathrm{e}-01$

$1.00000 \mathrm{e}-05$ 1.00000e-05 1.00000e-06 1.00000e-09 1.00000e-01 
$1.00000 \mathrm{e}+001.00000 \mathrm{e}+00$ 1.00000e-01 1.00000e-09 1.00000e-01

Element: 1534 \# of layers: 13

Kx Ky Kz Ss Por

5.65315e+02 5.65315e+02 5.65315e+01 1.00000e-09 7.00000e-02

$5.65315 \mathrm{e}+025.65315 \mathrm{e}+025.65315 \mathrm{e}+01$ 1.00000e-09 7.00000e-02

5.00000e-04 5.00000e-04 5.00000e-05 1.00000e-09 1.00000e-01

5.00000e-04 5.00000e-04 5.00000e-05 1.00000e-09 1.00000e-01

$2.25882 \mathrm{e}+012.25882 \mathrm{e}+012.25882 \mathrm{e}+00$ 1.00000e-09 2.12000e-01

$2.25882 \mathrm{e}+012.25882 \mathrm{e}+012.25882 \mathrm{e}+00$ 1.00000e-09 2.12000e-01

$2.25882 \mathrm{e}+012.25882 \mathrm{e}+012.25882 \mathrm{e}+00$ 1.00000e-09 2.12000e-01

$2.25882 \mathrm{e}+012.25882 \mathrm{e}+012.25882 \mathrm{e}+001.00000 \mathrm{e}-092.12000 \mathrm{e}-01$

$2.25882 \mathrm{e}+012.25882 \mathrm{e}+012.25882 \mathrm{e}+001.00000 \mathrm{e}-092.12000 \mathrm{e}-01$

$1.00000 \mathrm{e}-02$ 1.00000e-02 1.00000e-03 1.00000e-09 1.00000e-01

$1.00000 \mathrm{e}+001.00000 \mathrm{e}+001.00000 \mathrm{e}-011.00000 \mathrm{e}-091.00000 \mathrm{e}-01$

$1.00000 \mathrm{e}-05$ 1.00000e-05 1.00000e-06 1.00000e-09 1.00000e-01

$1.00000 \mathrm{e}+001.00000 \mathrm{e}+001.00000 \mathrm{e}-011.00000 \mathrm{e}-091.00000 \mathrm{e}-01$

Element: 1535 \# of layers: 13

$\mathrm{Kx} \mathrm{Ky} \mathrm{Kz}$ Ss Por

5.13138e+02 5.13138e+02 5.13138e+01 1.00000e-09 7.00000e-02

5.13138e+02 5.13138e+02 5.13138e+01 1.00000e-09 7.00000e-02

5.00000e-04 5.00000e-04 5.00000e-05 1.00000e-09 1.00000e-01

5.00000e-04 5.00000e-04 5.00000e-05 1.00000e-09 1.00000e-01

$2.05031 \mathrm{e}+012.05031 \mathrm{e}+012.05031 \mathrm{e}+001.00000 \mathrm{e}-092.12000 \mathrm{e}-01$

$2.05031 \mathrm{e}+012.05031 \mathrm{e}+012.05031 \mathrm{e}+001.00000 \mathrm{e}-092.12000 \mathrm{e}-01$

$2.05031 \mathrm{e}+012.05031 \mathrm{e}+012.05031 \mathrm{e}+001.00000 \mathrm{e}-092.12000 \mathrm{e}-01$

$2.05031 \mathrm{e}+012.05031 \mathrm{e}+012.05031 \mathrm{e}+001.00000 \mathrm{e}-092.12000 \mathrm{e}-01$

$2.05031 \mathrm{e}+012.05031 \mathrm{e}+012.05031 \mathrm{e}+001.00000 \mathrm{e}-092.12000 \mathrm{e}-01$

$1.00000 \mathrm{e}-02$ 1.00000e-02 1.00000e-03 1.00000e-09 1.00000e-01

$1.00000 \mathrm{e}+001.00000 \mathrm{e}+001.00000 \mathrm{e}-011.00000 \mathrm{e}-091.00000 \mathrm{e}-01$

$1.00000 \mathrm{e}-05$ 1.00000e-05 1.00000e-06 1.00000e-09 1.00000e-01

$1.00000 \mathrm{e}+001.00000 \mathrm{e}+001.00000 \mathrm{e}-011.00000 \mathrm{e}-091.00000 \mathrm{e}-01$

Element: 1536 \# of layers: 13

Kx Ky Kz Ss Por

5.13138e+02 5.13138e+02 5.13138e+01 1.00000e-09 7.00000e-02

$5.13138 \mathrm{e}+025.13138 \mathrm{e}+025.13138 \mathrm{e}+01$ 1.00000e-09 7.00000e-02

5.00000e-04 5.00000e-04 5.00000e-05 1.00000e-09 1.00000e-01

5.00000e-04 5.00000e-04 5.00000e-05 1.00000e-09 1.00000e-01

$2.05031 \mathrm{e}+012.05031 \mathrm{e}+012.05031 \mathrm{e}+001.00000 \mathrm{e}-092.12000 \mathrm{e}-01$

$2.05031 \mathrm{e}+012.05031 \mathrm{e}+012.05031 \mathrm{e}+001.00000 \mathrm{e}-092.12000 \mathrm{e}-01$

$2.05031 \mathrm{e}+012.05031 \mathrm{e}+012.05031 \mathrm{e}+001.00000 \mathrm{e}-092.12000 \mathrm{e}-01$

$2.05031 \mathrm{e}+012.05031 \mathrm{e}+012.05031 \mathrm{e}+001.00000 \mathrm{e}-092.12000 \mathrm{e}-01$

$2.05031 \mathrm{e}+012.05031 \mathrm{e}+012.05031 \mathrm{e}+001.00000 \mathrm{e}-092.12000 \mathrm{e}-01$

$1.00000 \mathrm{e}-02$ 1.00000e-02 1.00000e-03 1.00000e-09 1.00000e-01

$1.00000 \mathrm{e}+001.00000 \mathrm{e}+001.00000 \mathrm{e}-011.00000 \mathrm{e}-091.00000 \mathrm{e}-01$

$1.00000 \mathrm{e}-05$ 1.00000e-05 1.00000e-06 1.00000e-09 1.00000e-01

$1.00000 \mathrm{e}+001.00000 \mathrm{e}+001.00000 \mathrm{e}-011.00000 \mathrm{e}-091.00000 \mathrm{e}-01$ 
Element: 1537 \# of layers: 13

$\mathrm{Kx} \mathrm{Ky} \mathrm{Kz}$ Ss Por

5.13138e+02 5.13138e+02 5.13138e+01 1.00000e-09 7.00000e-02

5.13138e+02 5.13138e+02 5.13138e+01 1.00000e-09 7.00000e-02

5.00000e-04 5.00000e-04 5.00000e-05 1.00000e-09 1.00000e-01

5.00000e-04 5.00000e-04 5.00000e-05 1.00000e-09 1.00000e-01

$2.05031 \mathrm{e}+012.05031 \mathrm{e}+012.05031 \mathrm{e}+001.00000 \mathrm{e}-092.12000 \mathrm{e}-01$

$2.05031 \mathrm{e}+012.05031 \mathrm{e}+012.05031 \mathrm{e}+001.00000 \mathrm{e}-092.12000 \mathrm{e}-01$

$2.05031 \mathrm{e}+012.05031 \mathrm{e}+012.05031 \mathrm{e}+001.00000 \mathrm{e}-092.12000 \mathrm{e}-01$

$2.05031 \mathrm{e}+012.05031 \mathrm{e}+012.05031 \mathrm{e}+001.00000 \mathrm{e}-092.12000 \mathrm{e}-01$

$2.05031 \mathrm{e}+012.05031 \mathrm{e}+012.05031 \mathrm{e}+001.00000 \mathrm{e}-092.12000 \mathrm{e}-01$

$1.00000 \mathrm{e}-02$ 1.00000e-02 1.00000e-03 1.00000e-09 1.00000e-01

$1.00000 \mathrm{e}+001.00000 \mathrm{e}+001.00000 \mathrm{e}-011.00000 \mathrm{e}-091.00000 \mathrm{e}-01$

$1.00000 \mathrm{e}-05$ 1.00000e-05 1.00000e-06 1.00000e-09 1.00000e-01

$1.00000 \mathrm{e}+001.00000 \mathrm{e}+001.00000 \mathrm{e}-01$ 1.00000e-09 1.00000e-01

Element: 1538 \# of layers: 13

$\mathrm{Kx} \mathrm{Ky} \mathrm{Kz}$ Ss Por

5.13138e+02 5.13138e+02 5.13138e+01 1.00000e-09 7.00000e-02

$5.13138 \mathrm{e}+02$ 5.13138e+02 5.13138e+01 1.00000e-09 7.00000e-02

5.00000e-04 5.00000e-04 5.00000e-05 1.00000e-09 1.00000e-01

5.00000e-04 5.00000e-04 5.00000e-05 1.00000e-09 1.00000e-01

$2.05031 \mathrm{e}+012.05031 \mathrm{e}+012.05031 \mathrm{e}+001.00000 \mathrm{e}-092.12000 \mathrm{e}-01$

$2.05031 \mathrm{e}+012.05031 \mathrm{e}+012.05031 \mathrm{e}+001.00000 \mathrm{e}-092.12000 \mathrm{e}-01$

$2.05031 \mathrm{e}+012.05031 \mathrm{e}+012.05031 \mathrm{e}+001.00000 \mathrm{e}-092.12000 \mathrm{e}-01$

$2.05031 \mathrm{e}+012.05031 \mathrm{e}+012.05031 \mathrm{e}+001.00000 \mathrm{e}-092.12000 \mathrm{e}-01$

$2.05031 \mathrm{e}+012.05031 \mathrm{e}+012.05031 \mathrm{e}+001.00000 \mathrm{e}-092.12000 \mathrm{e}-01$

$1.00000 \mathrm{e}-02$ 1.00000e-02 1.00000e-03 1.00000e-09 1.00000e-01

$1.00000 \mathrm{e}+001.00000 \mathrm{e}+001.00000 \mathrm{e}-011.00000 \mathrm{e}-091.00000 \mathrm{e}-01$

$1.00000 \mathrm{e}-05$ 1.00000e-05 1.00000e-06 1.00000e-09 1.00000e-01

$1.00000 \mathrm{e}+001.00000 \mathrm{e}+001.00000 \mathrm{e}-011.00000 \mathrm{e}-091.00000 \mathrm{e}-01$

Element: 1539 \# of layers: 13

$\mathrm{Kx} \mathrm{Ky} \mathrm{Kz}$ Ss Por

5.13138e+02 5.13138e+02 5.13138e+01 1.00000e-09 7.00000e-02

$5.13138 \mathrm{e}+02$ 5.13138e+02 5.13138e+01 1.00000e-09 7.00000e-02

5.00000e-04 5.00000e-04 5.00000e-05 1.00000e-09 1.00000e-01

5.00000e-04 5.00000e-04 5.00000e-05 1.00000e-09 1.00000e-01

$2.05031 \mathrm{e}+012.05031 \mathrm{e}+012.05031 \mathrm{e}+001.00000 \mathrm{e}-092.12000 \mathrm{e}-01$

$2.05031 \mathrm{e}+012.05031 \mathrm{e}+012.05031 \mathrm{e}+001.00000 \mathrm{e}-092.12000 \mathrm{e}-01$

$2.05031 \mathrm{e}+012.05031 \mathrm{e}+012.05031 \mathrm{e}+001.00000 \mathrm{e}-092.12000 \mathrm{e}-01$

$2.05031 \mathrm{e}+012.05031 \mathrm{e}+012.05031 \mathrm{e}+00$ 1.00000e-09 2.12000e-01

$2.05031 \mathrm{e}+012.05031 \mathrm{e}+012.05031 \mathrm{e}+001.00000 \mathrm{e}-092.12000 \mathrm{e}-01$

$1.00000 \mathrm{e}-02$ 1.00000e-02 1.00000e-03 1.00000e-09 1.00000e-01

$1.00000 \mathrm{e}+001.00000 \mathrm{e}+001.00000 \mathrm{e}-011.00000 \mathrm{e}-091.00000 \mathrm{e}-01$

$1.00000 \mathrm{e}-05$ 1.00000e-05 1.00000e-06 1.00000e-09 1.00000e-01

$1.00000 \mathrm{e}+001.00000 \mathrm{e}+001.00000 \mathrm{e}-011.00000 \mathrm{e}-09$ 1.00000e-01

Element: 1540 \# of layers: 13 
$\mathrm{Kx} \mathrm{Ky} \mathrm{Kz}$ Ss Por

5.13138e+02 5.13138e+02 5.13138e+01 1.00000e-09 7.00000e-02

5.13138e+02 5.13138e+02 5.13138e+01 1.00000e-09 7.00000e-02

5.00000e-04 5.00000e-04 5.00000e-05 1.00000e-09 1.00000e-01

5.00000e-04 5.00000e-04 5.00000e-05 1.00000e-09 1.00000e-01

$2.05031 \mathrm{e}+012.05031 \mathrm{e}+012.05031 \mathrm{e}+001.00000 \mathrm{e}-092.12000 \mathrm{e}-01$

$2.05031 \mathrm{e}+012.05031 \mathrm{e}+012.05031 \mathrm{e}+001.00000 \mathrm{e}-092.12000 \mathrm{e}-01$

$2.05031 \mathrm{e}+012.05031 \mathrm{e}+012.05031 \mathrm{e}+001.00000 \mathrm{e}-092.12000 \mathrm{e}-01$

$2.05031 \mathrm{e}+012.05031 \mathrm{e}+012.05031 \mathrm{e}+001.00000 \mathrm{e}-092.12000 \mathrm{e}-01$

$2.05031 \mathrm{e}+012.05031 \mathrm{e}+012.05031 \mathrm{e}+001.00000 \mathrm{e}-092.12000 \mathrm{e}-01$

1.00000e-02 1.00000e-02 1.00000e-03 1.00000e-09 1.00000e-01

$1.00000 \mathrm{e}+001.00000 \mathrm{e}+001.00000 \mathrm{e}-011.00000 \mathrm{e}-091.00000 \mathrm{e}-01$

$1.00000 \mathrm{e}-05$ 1.00000e-05 1.00000e-06 1.00000e-09 1.00000e-01

$1.00000 \mathrm{e}+001.00000 \mathrm{e}+001.00000 \mathrm{e}-011.00000 \mathrm{e}-09$ 1.00000e-01

Element: 1541 \# of layers: 13

Kx Ky Kz Ss Por

5.13138e+02 5.13138e+02 5.13138e+01 1.00000e-09 7.00000e-02

$5.13138 \mathrm{e}+025.13138 \mathrm{e}+02$ 5.13138e+01 1.00000e-09 7.00000e-02

5.00000e-04 5.00000e-04 5.00000e-05 1.00000e-09 1.00000e-01

5.00000e-04 5.00000e-04 5.00000e-05 1.00000e-09 1.00000e-01

$2.05031 \mathrm{e}+012.05031 \mathrm{e}+012.05031 \mathrm{e}+001.00000 \mathrm{e}-092.12000 \mathrm{e}-01$

$2.05031 \mathrm{e}+012.05031 \mathrm{e}+012.05031 \mathrm{e}+00$ 1.00000e-09 2.12000e-01

$2.05031 \mathrm{e}+012.05031 \mathrm{e}+012.05031 \mathrm{e}+001.00000 \mathrm{e}-092.12000 \mathrm{e}-01$

$2.05031 \mathrm{e}+012.05031 \mathrm{e}+012.05031 \mathrm{e}+001.00000 \mathrm{e}-092.12000 \mathrm{e}-01$

$2.05031 \mathrm{e}+012.05031 \mathrm{e}+012.05031 \mathrm{e}+001.00000 \mathrm{e}-092.12000 \mathrm{e}-01$

$1.00000 \mathrm{e}-02$ 1.00000e-02 1.00000e-03 1.00000e-09 1.00000e-01

$1.00000 \mathrm{e}+001.00000 \mathrm{e}+001.00000 \mathrm{e}-011.00000 \mathrm{e}-091.00000 \mathrm{e}-01$

$1.00000 \mathrm{e}-05$ 1.00000e-05 1.00000e-06 1.00000e-09 1.00000e-01

$1.00000 \mathrm{e}+001.00000 \mathrm{e}+001.00000 \mathrm{e}-011.00000 \mathrm{e}-091.00000 \mathrm{e}-01$

Element: 1542 \# of layers: 13

$\mathrm{Kx} \mathrm{Ky} \mathrm{Kz}$ Ss Por

5.13138e+02 5.13138e+02 5.13138e+01 1.00000e-09 7.00000e-02

$5.13138 \mathrm{e}+025.13138 \mathrm{e}+025.13138 \mathrm{e}+01$ 1.00000e-09 7.00000e-02

5.00000e-04 5.00000e-04 5.00000e-05 1.00000e-09 1.00000e-01

5.00000e-04 5.00000e-04 5.00000e-05 1.00000e-09 1.00000e-01

$2.05031 \mathrm{e}+012.05031 \mathrm{e}+012.05031 \mathrm{e}+001.00000 \mathrm{e}-092.12000 \mathrm{e}-01$

$2.05031 \mathrm{e}+012.05031 \mathrm{e}+012.05031 \mathrm{e}+001.00000 \mathrm{e}-092.12000 \mathrm{e}-01$

$2.05031 \mathrm{e}+012.05031 \mathrm{e}+012.05031 \mathrm{e}+001.00000 \mathrm{e}-092.12000 \mathrm{e}-01$

$2.05031 \mathrm{e}+012.05031 \mathrm{e}+012.05031 \mathrm{e}+001.00000 \mathrm{e}-092.12000 \mathrm{e}-01$

$2.05031 \mathrm{e}+012.05031 \mathrm{e}+012.05031 \mathrm{e}+001.00000 \mathrm{e}-092.12000 \mathrm{e}-01$

$1.00000 \mathrm{e}-02$ 1.00000e-02 1.00000e-03 1.00000e-09 1.00000e-01

$1.00000 \mathrm{e}+001.00000 \mathrm{e}+001.00000 \mathrm{e}-011.00000 \mathrm{e}-091.00000 \mathrm{e}-01$

$1.00000 \mathrm{e}-05$ 1.00000e-05 1.00000e-06 1.00000e-09 1.00000e-01

$1.00000 \mathrm{e}+001.00000 \mathrm{e}+001.00000 \mathrm{e}-01$ 1.00000e-09 1.00000e-01

Element: 1543 \# of layers: 13

Kx Ky Kz Ss Por 
5.13138e+02 5.13138e+02 5.13138e+01 1.00000e-09 7.00000e-02 $5.13138 \mathrm{e}+025.13138 \mathrm{e}+02$ 5.13138e+01 1.00000e-09 7.00000e-02 5.00000e-04 5.00000e-04 5.00000e-05 1.00000e-09 1.00000e-01 5.00000e-04 5.00000e-04 5.00000e-05 1.00000e-09 1.00000e-01 $2.05031 \mathrm{e}+012.05031 \mathrm{e}+012.05031 \mathrm{e}+001.00000 \mathrm{e}-092.12000 \mathrm{e}-01$ $2.05031 \mathrm{e}+012.05031 \mathrm{e}+012.05031 \mathrm{e}+001.00000 \mathrm{e}-092.12000 \mathrm{e}-01$ $2.05031 \mathrm{e}+012.05031 \mathrm{e}+012.05031 \mathrm{e}+001.00000 \mathrm{e}-092.12000 \mathrm{e}-01$ $2.05031 \mathrm{e}+012.05031 \mathrm{e}+012.05031 \mathrm{e}+001.00000 \mathrm{e}-092.12000 \mathrm{e}-01$ $2.05031 \mathrm{e}+012.05031 \mathrm{e}+012.05031 \mathrm{e}+001.00000 \mathrm{e}-092.12000 \mathrm{e}-01$ $1.00000 \mathrm{e}-02$ 1.00000e-02 1.00000e-03 1.00000e-09 1.00000e-01 $1.00000 \mathrm{e}+001.00000 \mathrm{e}+001.00000 \mathrm{e}-011.00000 \mathrm{e}-091.00000 \mathrm{e}-01$ $1.00000 \mathrm{e}-05$ 1.00000e-05 1.00000e-06 1.00000e-09 1.00000e-01 $1.00000 \mathrm{e}+001.00000 \mathrm{e}+001.00000 \mathrm{e}-011.00000 \mathrm{e}-091.00000 \mathrm{e}-01$ Element: 1544 \# of layers: 13

$\mathrm{Kx} \mathrm{Ky} \mathrm{Kz}$ Ss Por

$1.29140 \mathrm{e}+02$ 1.29140e+02 1.29140e+01 1.00000e-09 7.00000e-02 $1.29140 \mathrm{e}+021.29140 \mathrm{e}+021.29140 \mathrm{e}+01$ 1.00000e-09 7.00000e-02 5.00000e-04 5.00000e-04 5.00000e-05 1.00000e-09 1.00000e-01 5.00000e-04 5.00000e-04 5.00000e-05 1.00000e-09 1.00000e-01 $5.16004 \mathrm{e}+005.16004 \mathrm{e}+00$ 5.16004e-01 1.00000e-09 2.12000e-01 $5.16004 \mathrm{e}+005.16004 \mathrm{e}+005.16004 \mathrm{e}-01$ 1.00000e-09 2.12000e-01 $5.16004 \mathrm{e}+00$ 5.16004e+00 5.16004e-01 1.00000e-09 2.12000e-01 $5.16004 \mathrm{e}+005.16004 \mathrm{e}+00$ 5.16004e-01 1.00000e-09 2.12000e-01 $5.16004 \mathrm{e}+00$ 5.16004e+00 5.16004e-01 1.00000e-09 2.12000e-01 $1.00000 \mathrm{e}-02$ 1.00000e-02 1.00000e-03 1.00000e-09 1.00000e-01 $1.00000 \mathrm{e}+001.00000 \mathrm{e}+001.00000 \mathrm{e}-011.00000 \mathrm{e}-091.00000 \mathrm{e}-01$ $1.00000 \mathrm{e}-05$ 1.00000e-05 1.00000e-06 1.00000e-09 1.00000e-01 $1.00000 \mathrm{e}+001.00000 \mathrm{e}+001.00000 \mathrm{e}-011.00000 \mathrm{e}-09$ 1.00000e-01 Element: 1545 \# of layers: 13

$\mathrm{Kx} \mathrm{Ky} \mathrm{Kz}$ Ss Por

$1.29140 \mathrm{e}+021.29140 \mathrm{e}+021.29140 \mathrm{e}+01$ 1.00000e-09 7.00000e-02 $1.29140 \mathrm{e}+021.29140 \mathrm{e}+021.29140 \mathrm{e}+01$ 1.00000e-09 7.00000e-02 5.00000e-04 5.00000e-04 5.00000e-05 1.00000e-09 1.00000e-01 5.00000e-04 5.00000e-04 5.00000e-05 1.00000e-09 1.00000e-01

$5.16004 \mathrm{e}+005.16004 \mathrm{e}+00$ 5.16004e-01 1.00000e-09 2.12000e-01 5.16004e+00 5.16004e+00 5.16004e-01 1.00000e-09 2.12000e-01 $5.16004 \mathrm{e}+005.16004 \mathrm{e}+00$ 5.16004e-01 1.00000e-09 2.12000e-01 $5.16004 \mathrm{e}+005.16004 \mathrm{e}+005.16004 \mathrm{e}-01$ 1.00000e-09 2.12000e-01 $5.16004 \mathrm{e}+005.16004 \mathrm{e}+00$ 5.16004e-01 1.00000e-09 2.12000e-01 $1.00000 \mathrm{e}-02$ 1.00000e-02 1.00000e-03 1.00000e-09 1.00000e-01 $1.00000 \mathrm{e}+001.00000 \mathrm{e}+001.00000 \mathrm{e}-011.00000 \mathrm{e}-091.00000 \mathrm{e}-01$ $1.00000 \mathrm{e}-05$ 1.00000e-05 1.00000e-06 1.00000e-09 1.00000e-01 $1.00000 \mathrm{e}+001.00000 \mathrm{e}+001.00000 \mathrm{e}-011.00000 \mathrm{e}-091.00000 \mathrm{e}-01$ Element: 1546 \# of layers: 13

$\mathrm{Kx} \mathrm{Ky} \mathrm{Kz}$ Ss Por

$1.29140 \mathrm{e}+02$ 1.29140e+02 1.29140e+01 1.00000e-09 7.00000e-02 
$1.29140 \mathrm{e}+021.29140 \mathrm{e}+021.29140 \mathrm{e}+01$ 1.00000e-09 7.00000e-02 5.00000e-04 5.00000e-04 5.00000e-05 1.00000e-09 1.00000e-01 5.00000e-04 5.00000e-04 5.00000e-05 1.00000e-09 1.00000e-01

$5.16004 \mathrm{e}+005.16004 \mathrm{e}+00$ 5.16004e-01 1.00000e-09 2.12000e-01 $5.16004 \mathrm{e}+005.16004 \mathrm{e}+00$ 5.16004e-01 1.00000e-09 2.12000e-01 $5.16004 \mathrm{e}+005.16004 \mathrm{e}+005.16004 \mathrm{e}-011.00000 \mathrm{e}-092.12000 \mathrm{e}-01$ $5.16004 \mathrm{e}+005.16004 \mathrm{e}+00$ 5.16004e-01 1.00000e-09 2.12000e-01 $5.16004 \mathrm{e}+005.16004 \mathrm{e}+00$ 5.16004e-01 1.00000e-09 2.12000e-01 $1.00000 \mathrm{e}-02$ 1.00000e-02 1.00000e-03 1.00000e-09 1.00000e-01 $1.00000 \mathrm{e}+001.00000 \mathrm{e}+001.00000 \mathrm{e}-011.00000 \mathrm{e}-091.00000 \mathrm{e}-01$ $1.00000 \mathrm{e}-05$ 1.00000e-05 1.00000e-06 1.00000e-09 1.00000e-01 $1.00000 \mathrm{e}+001.00000 \mathrm{e}+001.00000 \mathrm{e}-011.00000 \mathrm{e}-091.00000 \mathrm{e}-01$ Element: 1547 \# of layers: 13

$\mathrm{Kx} \mathrm{Ky} \mathrm{Kz}$ Ss Por

$1.29140 \mathrm{e}+02$ 1.29140e+02 1.29140e+01 1.00000e-09 7.00000e-02 $1.29140 \mathrm{e}+021.29140 \mathrm{e}+021.29140 \mathrm{e}+01$ 1.00000e-09 7.00000e-02 5.00000e-04 5.00000e-04 5.00000e-05 1.00000e-09 1.00000e-01 5.00000e-04 5.00000e-04 5.00000e-05 1.00000e-09 1.00000e-01 $5.16004 \mathrm{e}+005.16004 \mathrm{e}+005.16004 \mathrm{e}-01$ 1.00000e-09 2.12000e-01 $5.16004 \mathrm{e}+005.16004 \mathrm{e}+005.16004 \mathrm{e}-011.00000 \mathrm{e}-092.12000 \mathrm{e}-01$ $5.16004 \mathrm{e}+005.16004 \mathrm{e}+005.16004 \mathrm{e}-01$ 1.00000e-09 2.12000e-01 5.16004e+00 5.16004e+00 5.16004e-01 1.00000e-09 2.12000e-01 5.16004e+00 5.16004e+00 5.16004e-01 1.00000e-09 2.12000e-01 $1.00000 \mathrm{e}-02$ 1.00000e-02 1.00000e-03 1.00000e-09 1.00000e-01 $1.00000 \mathrm{e}+001.00000 \mathrm{e}+001.00000 \mathrm{e}-011.00000 \mathrm{e}-091.00000 \mathrm{e}-01$ $1.00000 \mathrm{e}-05$ 1.00000e-05 1.00000e-06 1.00000e-09 1.00000e-01 $1.00000 \mathrm{e}+001.00000 \mathrm{e}+001.00000 \mathrm{e}-011.00000 \mathrm{e}-091.00000 \mathrm{e}-01$ Element: 1548 \# of layers: 13

$\mathrm{Kx} \mathrm{Ky} \mathrm{Kz}$ Ss Por

$1.29140 \mathrm{e}+021.29140 \mathrm{e}+02$ 1.29140e+01 1.00000e-09 7.00000e-02 $1.29140 \mathrm{e}+021.29140 \mathrm{e}+02 \quad 1.29140 \mathrm{e}+01$ 1.00000e-09 7.00000e-02 5.00000e-04 5.00000e-04 5.00000e-05 1.00000e-09 1.00000e-01 5.00000e-04 5.00000e-04 5.00000e-05 1.00000e-09 1.00000e-01 $5.16004 \mathrm{e}+005.16004 \mathrm{e}+005.16004 \mathrm{e}-01$ 1.00000e-09 2.12000e-01 $5.16004 \mathrm{e}+005.16004 \mathrm{e}+005.16004 \mathrm{e}-01$ 1.00000e-09 2.12000e-01 $5.16004 \mathrm{e}+005.16004 \mathrm{e}+005.16004 \mathrm{e}-01$ 1.00000e-09 2.12000e-01 $5.16004 \mathrm{e}+005.16004 \mathrm{e}+00$ 5.16004e-01 1.00000e-09 2.12000e-01 $5.16004 \mathrm{e}+005.16004 \mathrm{e}+005.16004 \mathrm{e}-01$ 1.00000e-09 2.12000e-01 $1.00000 \mathrm{e}-02$ 1.00000e-02 1.00000e-03 1.00000e-09 1.00000e-01 $1.00000 \mathrm{e}+001.00000 \mathrm{e}+001.00000 \mathrm{e}-011.00000 \mathrm{e}-091.00000 \mathrm{e}-01$ $1.00000 \mathrm{e}-05$ 1.00000e-05 1.00000e-06 1.00000e-09 1.00000e-01 $1.00000 \mathrm{e}+001.00000 \mathrm{e}+001.00000 \mathrm{e}-011.00000 \mathrm{e}-091.00000 \mathrm{e}-01$ Element: 1549 \# of layers: 13

$\mathrm{Kx} \mathrm{Ky} \mathrm{Kz}$ Ss Por

$1.29140 \mathrm{e}+02$ 1.29140e+02 1.29140e+01 1.00000e-09 7.00000e-02 $1.29140 \mathrm{e}+021.29140 \mathrm{e}+021.29140 \mathrm{e}+01$ 1.00000e-09 7.00000e-02 
5.00000e-04 5.00000e-04 5.00000e-05 1.00000e-09 1.00000e-01 5.00000e-04 5.00000e-04 5.00000e-05 1.00000e-09 1.00000e-01 $5.16004 \mathrm{e}+005.16004 \mathrm{e}+005.16004 \mathrm{e}-01$ 1.00000e-09 2.12000e-01 $5.16004 \mathrm{e}+00$ 5.16004e+00 5.16004e-01 1.00000e-09 2.12000e-01 $5.16004 \mathrm{e}+005.16004 \mathrm{e}+00$ 5.16004e-01 1.00000e-09 2.12000e-01 $5.16004 \mathrm{e}+005.16004 \mathrm{e}+00$ 5.16004e-01 1.00000e-09 2.12000e-01 $5.16004 \mathrm{e}+005.16004 \mathrm{e}+00$ 5.16004e-01 1.00000e-09 2.12000e-01 $1.00000 \mathrm{e}-02$ 1.00000e-02 1.00000e-03 1.00000e-09 1.00000e-01 $1.00000 \mathrm{e}+001.00000 \mathrm{e}+001.00000 \mathrm{e}-011.00000 \mathrm{e}-091.00000 \mathrm{e}-01$ $1.00000 \mathrm{e}-05$ 1.00000e-05 1.00000e-06 1.00000e-09 1.00000e-01 $1.00000 \mathrm{e}+001.00000 \mathrm{e}+001.00000 \mathrm{e}-01$ 1.00000e-09 1.00000e-01 Element: 1550 \# of layers: 13

$\mathrm{Kx} \mathrm{Ky} \mathrm{Kz}$ Ss Por

$1.29140 \mathrm{e}+02$ 1.29140e+02 1.29140e+01 1.00000e-09 7.00000e-02 $1.29140 \mathrm{e}+021.29140 \mathrm{e}+021.29140 \mathrm{e}+01$ 1.00000e-09 7.00000e-02 5.00000e-04 5.00000e-04 5.00000e-05 1.00000e-09 1.00000e-01 5.00000e-04 5.00000e-04 5.00000e-05 1.00000e-09 1.00000e-01

$5.16004 \mathrm{e}+005.16004 \mathrm{e}+005.16004 \mathrm{e}-01$ 1.00000e-09 2.12000e-01 $5.16004 \mathrm{e}+005.16004 \mathrm{e}+00$ 5.16004e-01 1.00000e-09 2.12000e-01 $5.16004 \mathrm{e}+005.16004 \mathrm{e}+005.16004 \mathrm{e}-01$ 1.00000e-09 2.12000e-01 $5.16004 \mathrm{e}+005.16004 \mathrm{e}+00$ 5.16004e-01 1.00000e-09 2.12000e-01 $5.16004 \mathrm{e}+005.16004 \mathrm{e}+00$ 5.16004e-01 1.00000e-09 2.12000e-01 $1.00000 \mathrm{e}-02$ 1.00000e-02 1.00000e-03 1.00000e-09 1.00000e-01 $1.00000 \mathrm{e}+001.00000 \mathrm{e}+001.00000 \mathrm{e}-011.00000 \mathrm{e}-091.00000 \mathrm{e}-01$ $1.00000 \mathrm{e}-05$ 1.00000e-05 1.00000e-06 1.00000e-09 1.00000e-01 $1.00000 \mathrm{e}+001.00000 \mathrm{e}+001.00000 \mathrm{e}-01$ 1.00000e-09 1.00000e-01 Element: 1551 \# of layers: 13

$\mathrm{Kx} \mathrm{Ky} \mathrm{Kz}$ Ss Por

$1.29140 \mathrm{e}+02$ 1.29140e+02 1.29140e+01 1.00000e-09 7.00000e-02 $1.29140 \mathrm{e}+02 \quad 1.29140 \mathrm{e}+02 \quad 1.29140 \mathrm{e}+01$ 1.00000e-09 7.00000e-02 5.00000e-04 5.00000e-04 5.00000e-05 1.00000e-09 1.00000e-01 5.00000e-04 5.00000e-04 5.00000e-05 1.00000e-09 1.00000e-01 $5.16004 \mathrm{e}+005.16004 \mathrm{e}+005.16004 \mathrm{e}-011.00000 \mathrm{e}-092.12000 \mathrm{e}-01$ $5.16004 \mathrm{e}+005.16004 \mathrm{e}+005.16004 \mathrm{e}-01$ 1.00000e-09 2.12000e-01 $5.16004 \mathrm{e}+005.16004 \mathrm{e}+005.16004 \mathrm{e}-01$ 1.00000e-09 2.12000e-01 $5.16004 \mathrm{e}+005.16004 \mathrm{e}+00$ 5.16004e-01 1.00000e-09 2.12000e-01 $5.16004 \mathrm{e}+005.16004 \mathrm{e}+00$ 5.16004e-01 1.00000e-09 2.12000e-01 $1.00000 \mathrm{e}-02$ 1.00000e-02 1.00000e-03 1.00000e-09 1.00000e-01 $1.00000 \mathrm{e}+001.00000 \mathrm{e}+001.00000 \mathrm{e}-011.00000 \mathrm{e}-091.00000 \mathrm{e}-01$ $1.00000 \mathrm{e}-05$ 1.00000e-05 1.00000e-06 1.00000e-09 1.00000e-01 $1.00000 \mathrm{e}+001.00000 \mathrm{e}+001.00000 \mathrm{e}-011.00000 \mathrm{e}-091.00000 \mathrm{e}-01$ Element: 1552 \# of layers: 13

$\mathrm{Kx} \mathrm{Ky} \mathrm{Kz}$ Ss Por

$1.29140 \mathrm{e}+02$ 1.29140e+02 1.29140e+01 1.00000e-09 7.00000e-02 $1.29140 \mathrm{e}+021.29140 \mathrm{e}+02$ 1.29140e+01 1.00000e-09 7.00000e-02 5.00000e-04 5.00000e-04 5.00000e-05 1.00000e-09 1.00000e-01 
5.00000e-04 5.00000e-04 5.00000e-05 1.00000e-09 1.00000e-01

5.16004e+00 5.16004e+00 5.16004e-01 1.00000e-09 2.12000e-01

$5.16004 \mathrm{e}+00$ 5.16004e+00 5.16004e-01 1.00000e-09 2.12000e-01

$5.16004 \mathrm{e}+00$ 5.16004e+00 5.16004e-01 1.00000e-09 2.12000e-01

$5.16004 \mathrm{e}+005.16004 \mathrm{e}+00$ 5.16004e-01 1.00000e-09 2.12000e-01

$5.16004 \mathrm{e}+005.16004 \mathrm{e}+00$ 5.16004e-01 1.00000e-09 2.12000e-01

$1.00000 \mathrm{e}-02$ 1.00000e-02 1.00000e-03 1.00000e-09 1.00000e-01

$1.00000 \mathrm{e}+001.00000 \mathrm{e}+001.00000 \mathrm{e}-011.00000 \mathrm{e}-091.00000 \mathrm{e}-01$

$1.00000 \mathrm{e}-05$ 1.00000e-05 1.00000e-06 1.00000e-09 1.00000e-01

$1.00000 \mathrm{e}+001.00000 \mathrm{e}+001.00000 \mathrm{e}-011.00000 \mathrm{e}-091.00000 \mathrm{e}-01$

Element: 1553 \# of layers: 13

Kx Ky Kz Ss Por

$1.07994 \mathrm{e}+02$ 1.07994e+02 1.07994e+01 1.00000e-09 7.00000e-02

$1.07994 \mathrm{e}+021.07994 \mathrm{e}+02$ 1.07994e+01 1.00000e-09 7.00000e-02

5.00000e-04 5.00000e-04 5.00000e-05 1.00000e-09 1.00000e-01

5.00000e-04 5.00000e-04 5.00000e-05 1.00000e-09 1.00000e-01

$4.31492 \mathrm{e}+00$ 4.31492e+00 4.31492e-01 1.00000e-09 2.12000e-01

4.31492e+00 4.31492e+00 4.31492e-01 1.00000e-09 2.12000e-01

4.31492e+00 4.31492e+00 4.31492e-01 1.00000e-09 2.12000e-01

4.31492e+00 4.31492e+00 4.31492e-01 1.00000e-09 2.12000e-01

$4.31492 \mathrm{e}+004.31492 \mathrm{e}+00$ 4.31492e-01 1.00000e-09 2.12000e-01

$1.00000 \mathrm{e}-021.00000 \mathrm{e}-021.00000 \mathrm{e}-031.00000 \mathrm{e}-091.00000 \mathrm{e}-01$

$1.00000 \mathrm{e}+001.00000 \mathrm{e}+001.00000 \mathrm{e}-011.00000 \mathrm{e}-091.00000 \mathrm{e}-01$

$1.00000 \mathrm{e}-05$ 1.00000e-05 1.00000e-06 1.00000e-09 1.00000e-01

$1.00000 \mathrm{e}+001.00000 \mathrm{e}+001.00000 \mathrm{e}-011.00000 \mathrm{e}-091.00000 \mathrm{e}-01$

Element: 1554 \# of layers: 12

$\mathrm{Kx} \mathrm{Ky} \mathrm{Kz}$ Ss Por

$1.07994 \mathrm{e}+02$ 1.07994e+02 1.07994e+01 1.00000e-09 7.00000e-02

5.00000e-04 5.00000e-04 5.00000e-05 1.00000e-09 1.00000e-01

5.00000e-04 5.00000e-04 5.00000e-05 1.00000e-09 1.00000e-01

4.31492e+00 4.31492e+00 4.31492e-01 1.00000e-09 2.12000e-01

4.31492e+00 4.31492e+00 4.31492e-01 1.00000e-09 2.12000e-01

4.31492e+00 4.31492e+00 4.31492e-01 1.00000e-09 2.12000e-01

$4.31492 \mathrm{e}+00$ 4.31492e+00 4.31492e-01 1.00000e-09 2.12000e-01

4.31492e+00 4.31492e+00 4.31492e-01 1.00000e-09 2.12000e-01

1.00000e-02 1.00000e-02 1.00000e-03 1.00000e-09 1.00000e-01

$1.00000 \mathrm{e}+001.00000 \mathrm{e}+001.00000 \mathrm{e}-011.00000 \mathrm{e}-091.00000 \mathrm{e}-01$

$1.00000 \mathrm{e}-05$ 1.00000e-05 1.00000e-06 1.00000e-09 1.00000e-01

$1.00000 \mathrm{e}+001.00000 \mathrm{e}+001.00000 \mathrm{e}-011.00000 \mathrm{e}-091.00000 \mathrm{e}-01$

Element: 1555 \# of layers: 11

Kx Ky Kz Ss Por

$1.07994 \mathrm{e}+02$ 1.07994e+02 1.07994e+01 1.00000e-09 7.00000e-02

5.00000e-04 5.00000e-04 5.00000e-05 1.00000e-09 1.00000e-01

4.31492e+00 4.31492e+00 4.31492e-01 1.00000e-09 2.12000e-01

4.31492e+00 4.31492e+00 4.31492e-01 1.00000e-09 2.12000e-01

$4.31492 \mathrm{e}+00$ 4.31492e+00 4.31492e-01 1.00000e-09 2.12000e-01 
$4.31492 \mathrm{e}+004.31492 \mathrm{e}+00$ 4.31492e-01 1.00000e-09 2.12000e-01 4.31492e+00 4.31492e+00 4.31492e-01 1.00000e-09 2.12000e-01 $1.00000 \mathrm{e}-021.00000 \mathrm{e}-02$ 1.00000e-03 1.00000e-09 1.00000e-01 $1.00000 \mathrm{e}+001.00000 \mathrm{e}+001.00000 \mathrm{e}-011.00000 \mathrm{e}-091.00000 \mathrm{e}-01$ $1.00000 \mathrm{e}-05$ 1.00000e-05 1.00000e-06 1.00000e-09 1.00000e-01 $1.00000 \mathrm{e}+001.00000 \mathrm{e}+001.00000 \mathrm{e}-011.00000 \mathrm{e}-091.00000 \mathrm{e}-01$ Element: 1556 \# of layers: 11

Kx Ky Kz Ss Por

$1.07994 \mathrm{e}+021.07994 \mathrm{e}+021.07994 \mathrm{e}+01$ 1.00000e-09 7.00000e-02 5.00000e-04 5.00000e-04 5.00000e-05 1.00000e-09 1.00000e-01 $4.31492 \mathrm{e}+004.31492 \mathrm{e}+00$ 4.31492e-01 1.00000e-09 2.12000e-01 $4.31492 \mathrm{e}+004.31492 \mathrm{e}+004.31492 \mathrm{e}-011.00000 \mathrm{e}-09$ 2.12000e-01 $4.31492 \mathrm{e}+004.31492 \mathrm{e}+004.31492 \mathrm{e}-011.00000 \mathrm{e}-09$ 2.12000e-01 $4.31492 \mathrm{e}+004.31492 \mathrm{e}+004.31492 \mathrm{e}-011.00000 \mathrm{e}-09$ 2.12000e-01 $4.31492 \mathrm{e}+00$ 4.31492e+00 4.31492e-01 1.00000e-09 2.12000e-01 $1.00000 \mathrm{e}-02$ 1.00000e-02 1.00000e-03 1.00000e-09 1.00000e-01 $1.00000 \mathrm{e}+001.00000 \mathrm{e}+001.00000 \mathrm{e}-011.00000 \mathrm{e}-091.00000 \mathrm{e}-01$ $1.00000 \mathrm{e}-05$ 1.00000e-05 1.00000e-06 1.00000e-09 1.00000e-01 $1.00000 \mathrm{e}+001.00000 \mathrm{e}+001.00000 \mathrm{e}-011.00000 \mathrm{e}-091.00000 \mathrm{e}-01$ Element: 1557 \# of layers: 12

Kx Ky Kz Ss Por $1.07994 \mathrm{e}+021.07994 \mathrm{e}+021.07994 \mathrm{e}+011.00000 \mathrm{e}-097.00000 \mathrm{e}-02$ 5.00000e-04 5.00000e-04 5.00000e-05 1.00000e-09 1.00000e-01 5.00000e-04 5.00000e-04 5.00000e-05 1.00000e-09 1.00000e-01 $4.31492 \mathrm{e}+004.31492 \mathrm{e}+004.31492 \mathrm{e}-011.00000 \mathrm{e}-09$ 2.12000e-01 $4.31492 \mathrm{e}+004.31492 \mathrm{e}+004.31492 \mathrm{e}-011.00000 \mathrm{e}-092.12000 \mathrm{e}-01$ $4.31492 \mathrm{e}+004.31492 \mathrm{e}+004.31492 \mathrm{e}-01$ 1.00000e-09 2.12000e-01 $4.31492 \mathrm{e}+004.31492 \mathrm{e}+004.31492 \mathrm{e}-011.00000 \mathrm{e}-092.12000 \mathrm{e}-01$ $4.31492 \mathrm{e}+00$ 4.31492e+00 4.31492e-01 1.00000e-09 2.12000e-01 $1.00000 \mathrm{e}-02$ 1.00000e-02 1.00000e-03 1.00000e-09 1.00000e-01 $1.00000 \mathrm{e}+001.00000 \mathrm{e}+001.00000 \mathrm{e}-011.00000 \mathrm{e}-091.00000 \mathrm{e}-01$ $1.00000 \mathrm{e}-05$ 1.00000e-05 1.00000e-06 1.00000e-09 1.00000e-01 $1.00000 \mathrm{e}+001.00000 \mathrm{e}+001.00000 \mathrm{e}-011.00000 \mathrm{e}-091.00000 \mathrm{e}-01$ Element: 1558 \# of layers: 13

Kx Ky Kz Ss Por $1.07994 \mathrm{e}+02$ 1.07994e+02 1.07994e+01 1.00000e-09 7.00000e-02 $1.07994 \mathrm{e}+021.07994 \mathrm{e}+021.07994 \mathrm{e}+011.00000 \mathrm{e}-097.00000 \mathrm{e}-02$ 5.00000e-04 5.00000e-04 5.00000e-05 1.00000e-09 1.00000e-01 5.00000e-04 5.00000e-04 5.00000e-05 1.00000e-09 1.00000e-01 $4.31492 \mathrm{e}+004.31492 \mathrm{e}+00$ 4.31492e-01 1.00000e-09 2.12000e-01 $4.31492 \mathrm{e}+00$ 4.31492e+00 4.31492e-01 1.00000e-09 2.12000e-01 $4.31492 \mathrm{e}+00$ 4.31492e+00 4.31492e-01 1.00000e-09 2.12000e-01 $4.31492 \mathrm{e}+004.31492 \mathrm{e}+004.31492 \mathrm{e}-011.00000 \mathrm{e}-092.12000 \mathrm{e}-01$ 4.31492e+00 4.31492e+00 4.31492e-01 1.00000e-09 2.12000e-01 $1.00000 \mathrm{e}-021.00000 \mathrm{e}-02$ 1.00000e-03 1.00000e-09 1.00000e-01 $1.00000 \mathrm{e}+001.00000 \mathrm{e}+001.00000 \mathrm{e}-011.00000 \mathrm{e}-091.00000 \mathrm{e}-01$ 
$1.00000 \mathrm{e}-05$ 1.00000e-05 1.00000e-06 1.00000e-09 1.00000e-01 $1.00000 \mathrm{e}+001.00000 \mathrm{e}+001.00000 \mathrm{e}-01$ 1.00000e-09 1.00000e-01 Element: 1559 \# of layers: 13

$\mathrm{Kx} \mathrm{Ky} \mathrm{Kz}$ Ss Por

$1.07994 \mathrm{e}+021.07994 \mathrm{e}+02$ 1.07994e+01 1.00000e-09 7.00000e-02 $1.07994 \mathrm{e}+021.07994 \mathrm{e}+02$ 1.07994e+01 1.00000e-09 7.00000e-02 5.00000e-04 5.00000e-04 5.00000e-05 1.00000e-09 1.00000e-01 5.00000e-04 5.00000e-04 5.00000e-05 1.00000e-09 1.00000e-01 4.31492e+00 4.31492e+00 4.31492e-01 1.00000e-09 2.12000e-01 4.31492e+00 4.31492e+00 4.31492e-01 1.00000e-09 2.12000e-01 4.31492e+00 4.31492e+00 4.31492e-01 1.00000e-09 2.12000e-01 $4.31492 \mathrm{e}+004.31492 \mathrm{e}+00$ 4.31492e-01 1.00000e-09 2.12000e-01 4.31492e+00 4.31492e+00 4.31492e-01 1.00000e-09 2.12000e-01 $1.00000 \mathrm{e}-02$ 1.00000e-02 1.00000e-03 1.00000e-09 1.00000e-01 $1.00000 \mathrm{e}+001.00000 \mathrm{e}+001.00000 \mathrm{e}-011.00000 \mathrm{e}-091.00000 \mathrm{e}-01$ $1.00000 \mathrm{e}-05$ 1.00000e-05 1.00000e-06 1.00000e-09 1.00000e-01 $1.00000 \mathrm{e}+001.00000 \mathrm{e}+001.00000 \mathrm{e}-01$ 1.00000e-09 1.00000e-01 Element: 1560 \# of layers: 13

$\mathrm{Kx} \mathrm{Ky} \mathrm{Kz}$ Ss Por

1.07994e+02 1.07994e+02 1.07994e+01 1.00000e-09 7.00000e-02 $1.07994 \mathrm{e}+021.07994 \mathrm{e}+02$ 1.07994e+01 1.00000e-09 7.00000e-02 5.00000e-04 5.00000e-04 5.00000e-05 1.00000e-09 1.00000e-01 5.00000e-04 5.00000e-04 5.00000e-05 1.00000e-09 1.00000e-01 $4.31492 \mathrm{e}+004.31492 \mathrm{e}+00$ 4.31492e-01 1.00000e-09 2.12000e-01 $4.31492 \mathrm{e}+004.31492 \mathrm{e}+00$ 4.31492e-01 1.00000e-09 2.12000e-01 4.31492e+00 4.31492e+00 4.31492e-01 1.00000e-09 2.12000e-01 4.31492e+00 4.31492e+00 4.31492e-01 1.00000e-09 2.12000e-01 4.31492e+00 4.31492e+00 4.31492e-01 1.00000e-09 2.12000e-01 1.00000e-02 1.00000e-02 1.00000e-03 1.00000e-09 1.00000e-01 $1.00000 \mathrm{e}+001.00000 \mathrm{e}+001.00000 \mathrm{e}-011.00000 \mathrm{e}-091.00000 \mathrm{e}-01$ $1.00000 \mathrm{e}-05$ 1.00000e-05 1.00000e-06 1.00000e-09 1.00000e-01 $1.00000 \mathrm{e}+001.00000 \mathrm{e}+001.00000 \mathrm{e}-01$ 1.00000e-09 1.00000e-01 Element: 1561 \# of layers: 13

$\mathrm{Kx} \mathrm{Ky} \mathrm{Kz}$ Ss Por

$1.07994 \mathrm{e}+02$ 1.07994e+02 1.07994e+01 1.00000e-09 7.00000e-02 $1.07994 \mathrm{e}+021.07994 \mathrm{e}+02$ 1.07994e+01 1.00000e-09 7.00000e-02 5.00000e-04 5.00000e-04 5.00000e-05 1.00000e-09 1.00000e-01 5.00000e-04 5.00000e-04 5.00000e-05 1.00000e-09 1.00000e-01 4.31492e+00 4.31492e+00 4.31492e-01 1.00000e-09 2.12000e-01 4.31492e+00 4.31492e+00 4.31492e-01 1.00000e-09 2.12000e-01 4.31492e+00 4.31492e+00 4.31492e-01 1.00000e-09 2.12000e-01 4.31492e+00 4.31492e+00 4.31492e-01 1.00000e-09 2.12000e-01 4.31492e+00 4.31492e+00 4.31492e-01 1.00000e-09 2.12000e-01 $1.00000 \mathrm{e}-02$ 1.00000e-02 1.00000e-03 1.00000e-09 1.00000e-01 $1.00000 \mathrm{e}+001.00000 \mathrm{e}+001.00000 \mathrm{e}-011.00000 \mathrm{e}-091.00000 \mathrm{e}-01$ $1.00000 \mathrm{e}-05$ 1.00000e-05 1.00000e-06 1.00000e-09 1.00000e-01 
$1.00000 \mathrm{e}+001.00000 \mathrm{e}+00$ 1.00000e-01 1.00000e-09 1.00000e-01

Element: 1562 \# of layers: 11

$\mathrm{Kx} \mathrm{Ky} \mathrm{Kz}$ Ss Por

$1.96895 \mathrm{e}+02$ 1.96895e+02 1.96895e+01 1.00000e-09 7.00000e-02

5.00000e-04 5.00000e-04 5.00000e-05 1.00000e-09 1.00000e-01

$7.86729 \mathrm{e}+00$ 7.86729e+00 7.86729e-01 1.00000e-09 2.12000e-01

$7.86729 \mathrm{e}+00$ 7.86729e+00 7.86729e-01 1.00000e-09 2.12000e-01

$7.86729 \mathrm{e}+00$ 7.86729e+00 7.86729e-01 1.00000e-09 2.12000e-01

7.86729e+00 7.86729e+00 7.86729e-01 1.00000e-09 2.12000e-01

$7.86729 \mathrm{e}+00$ 7.86729e+00 7.86729e-01 1.00000e-09 2.12000e-01

$1.00000 \mathrm{e}-02$ 1.00000e-02 1.00000e-03 1.00000e-09 1.00000e-01

$1.00000 \mathrm{e}+001.00000 \mathrm{e}+001.00000 \mathrm{e}-011.00000 \mathrm{e}-091.00000 \mathrm{e}-01$

$1.00000 \mathrm{e}-05$ 1.00000e-05 1.00000e-06 1.00000e-09 1.00000e-01

$1.00000 \mathrm{e}+001.00000 \mathrm{e}+001.00000 \mathrm{e}-011.00000 \mathrm{e}-09$ 1.00000e-01

Element: 1563 \# of layers: 11

Kx Ky Kz Ss Por

$1.96895 \mathrm{e}+02$ 1.96895e+02 1.96895e+01 1.00000e-09 7.00000e-02

5.00000e-04 5.00000e-04 5.00000e-05 1.00000e-09 1.00000e-01

$7.86729 \mathrm{e}+00$ 7.86729e+00 7.86729e-01 1.00000e-09 2.12000e-01

$7.86729 \mathrm{e}+00$ 7.86729e+00 7.86729e-01 1.00000e-09 2.12000e-01

$7.86729 \mathrm{e}+007.86729 \mathrm{e}+00$ 7.86729e-01 1.00000e-09 2.12000e-01

7.86729e+00 7.86729e+00 7.86729e-01 1.00000e-09 2.12000e-01

$7.86729 \mathrm{e}+00$ 7.86729e+00 7.86729e-01 1.00000e-09 2.12000e-01

$1.00000 \mathrm{e}-02$ 1.00000e-02 1.00000e-03 1.00000e-09 1.00000e-01

$1.00000 \mathrm{e}+001.00000 \mathrm{e}+001.00000 \mathrm{e}-011.00000 \mathrm{e}-091.00000 \mathrm{e}-01$

$1.00000 \mathrm{e}-051.00000 \mathrm{e}-051.00000 \mathrm{e}-061.00000 \mathrm{e}-091.00000 \mathrm{e}-01$

$1.00000 \mathrm{e}+001.00000 \mathrm{e}+001.00000 \mathrm{e}-011.00000 \mathrm{e}-091.00000 \mathrm{e}-01$

Element: 1564 \# of layers: 12

$\mathrm{Kx} \mathrm{Ky} \mathrm{Kz}$ Ss Por

$1.96895 \mathrm{e}+021.96895 \mathrm{e}+02$ 1.96895e+01 1.00000e-09 7.00000e-02

5.00000e-04 5.00000e-04 5.00000e-05 1.00000e-09 1.00000e-01

5.00000e-04 5.00000e-04 5.00000e-05 1.00000e-09 1.00000e-01

$7.86729 \mathrm{e}+007.86729 \mathrm{e}+00$ 7.86729e-01 1.00000e-09 2.12000e-01

$7.86729 \mathrm{e}+00$ 7.86729e+00 7.86729e-01 1.00000e-09 2.12000e-01

$7.86729 \mathrm{e}+00$ 7.86729e+00 7.86729e-01 1.00000e-09 2.12000e-01

$7.86729 \mathrm{e}+00$ 7.86729e+00 7.86729e-01 1.00000e-09 2.12000e-01

$7.86729 \mathrm{e}+007.86729 \mathrm{e}+007.86729 \mathrm{e}-01$ 1.00000e-09 2.12000e-01

$1.00000 \mathrm{e}-02$ 1.00000e-02 1.00000e-03 1.00000e-09 1.00000e-01

$1.00000 \mathrm{e}+001.00000 \mathrm{e}+001.00000 \mathrm{e}-011.00000 \mathrm{e}-091.00000 \mathrm{e}-01$

$1.00000 \mathrm{e}-05$ 1.00000e-05 1.00000e-06 1.00000e-09 1.00000e-01

$1.00000 \mathrm{e}+001.00000 \mathrm{e}+001.00000 \mathrm{e}-011.00000 \mathrm{e}-091.00000 \mathrm{e}-01$

Element: 1565 \# of layers: 12

$\mathrm{Kx} \mathrm{Ky} \mathrm{Kz}$ Ss Por

1.96895e+02 1.96895e+02 1.96895e+01 1.00000e-09 7.00000e-02 5.00000e-04 5.00000e-04 5.00000e-05 1.00000e-09 1.00000e-01

5.00000e-04 5.00000e-04 5.00000e-05 1.00000e-09 1.00000e-01 
$7.86729 \mathrm{e}+00$ 7.86729e+00 7.86729e-01 1.00000e-09 2.12000e-01 $7.86729 \mathrm{e}+007.86729 \mathrm{e}+00$ 7.86729e-01 1.00000e-09 2.12000e-01 $7.86729 \mathrm{e}+007.86729 \mathrm{e}+00$ 7.86729e-01 1.00000e-09 2.12000e-01 $7.86729 \mathrm{e}+007.86729 \mathrm{e}+007.86729 \mathrm{e}-011.00000 \mathrm{e}-092.12000 \mathrm{e}-01$ $7.86729 \mathrm{e}+007.86729 \mathrm{e}+00$ 7.86729e-01 1.00000e-09 2.12000e-01 $1.00000 \mathrm{e}-021.00000 \mathrm{e}-02$ 1.00000e-03 1.00000e-09 1.00000e-01 $1.00000 \mathrm{e}+001.00000 \mathrm{e}+001.00000 \mathrm{e}-011.00000 \mathrm{e}-091.00000 \mathrm{e}-01$ $1.00000 \mathrm{e}-05$ 1.00000e-05 1.00000e-06 1.00000e-09 1.00000e-01 $1.00000 \mathrm{e}+001.00000 \mathrm{e}+001.00000 \mathrm{e}-011.00000 \mathrm{e}-091.00000 \mathrm{e}-01$ Element: 1566 \# of layers: 12

Kx Ky Kz Ss Por

$1.96895 \mathrm{e}+021.96895 \mathrm{e}+021.96895 \mathrm{e}+01$ 1.00000e-09 7.00000e-02 5.00000e-04 5.00000e-04 5.00000e-05 1.00000e-09 1.00000e-01 5.00000e-04 5.00000e-04 5.00000e-05 1.00000e-09 1.00000e-01 $7.86729 \mathrm{e}+007.86729 \mathrm{e}+00$ 7.86729e-01 1.00000e-09 2.12000e-01 $7.86729 \mathrm{e}+007.86729 \mathrm{e}+00$ 7.86729e-01 1.00000e-09 2.12000e-01 $7.86729 \mathrm{e}+007.86729 \mathrm{e}+00$ 7.86729e-01 1.00000e-09 2.12000e-01 $7.86729 \mathrm{e}+007.86729 \mathrm{e}+00$ 7.86729e-01 1.00000e-09 2.12000e-01 $7.86729 \mathrm{e}+007.86729 \mathrm{e}+00$ 7.86729e-01 1.00000e-09 2.12000e-01 $1.00000 \mathrm{e}-021.00000 \mathrm{e}-02$ 1.00000e-03 1.00000e-09 1.00000e-01 $1.00000 \mathrm{e}+001.00000 \mathrm{e}+001.00000 \mathrm{e}-011.00000 \mathrm{e}-091.00000 \mathrm{e}-01$ $1.00000 \mathrm{e}-05$ 1.00000e-05 1.00000e-06 1.00000e-09 1.00000e-01 $1.00000 \mathrm{e}+001.00000 \mathrm{e}+001.00000 \mathrm{e}-011.00000 \mathrm{e}-091.00000 \mathrm{e}-01$ Element: 1567 \# of layers: 12

Kx Ky Kz Ss Por

$1.96895 \mathrm{e}+021.96895 \mathrm{e}+021.96895 \mathrm{e}+011.00000 \mathrm{e}-097.00000 \mathrm{e}-02$ 5.00000e-04 5.00000e-04 5.00000e-05 1.00000e-09 1.00000e-01 5.00000e-04 5.00000e-04 5.00000e-05 1.00000e-09 1.00000e-01 $7.86729 \mathrm{e}+007.86729 \mathrm{e}+007.86729 \mathrm{e}-011.00000 \mathrm{e}-09$ 2.12000e-01 $7.86729 \mathrm{e}+00$ 7.86729e+00 7.86729e-01 1.00000e-09 2.12000e-01 $7.86729 \mathrm{e}+007.86729 \mathrm{e}+007.86729 \mathrm{e}-01$ 1.00000e-09 2.12000e-01 $7.86729 \mathrm{e}+007.86729 \mathrm{e}+007.86729 \mathrm{e}-011.00000 \mathrm{e}-092.12000 \mathrm{e}-01$ $7.86729 \mathrm{e}+00$ 7.86729e+00 7.86729e-01 1.00000e-09 2.12000e-01 $1.00000 \mathrm{e}-021.00000 \mathrm{e}-02$ 1.00000e-03 1.00000e-09 1.00000e-01 $1.00000 \mathrm{e}+001.00000 \mathrm{e}+001.00000 \mathrm{e}-011.00000 \mathrm{e}-091.00000 \mathrm{e}-01$ $1.00000 \mathrm{e}-05$ 1.00000e-05 1.00000e-06 1.00000e-09 1.00000e-01 $1.00000 \mathrm{e}+001.00000 \mathrm{e}+001.00000 \mathrm{e}-011.00000 \mathrm{e}-091.00000 \mathrm{e}-01$ Element: 1568 \# of layers: 12

Kx Ky Kz Ss Por

$1.96895 \mathrm{e}+02$ 1.96895e+02 1.96895e+01 1.00000e-09 7.00000e-02 5.00000e-04 5.00000e-04 5.00000e-05 1.00000e-09 1.00000e-01 5.00000e-04 5.00000e-04 5.00000e-05 1.00000e-09 1.00000e-01 $7.86729 \mathrm{e}+007.86729 \mathrm{e}+00$ 7.86729e-01 1.00000e-09 2.12000e-01 $7.86729 \mathrm{e}+007.86729 \mathrm{e}+007.86729 \mathrm{e}-01$ 1.00000e-09 2.12000e-01 $7.86729 \mathrm{e}+007.86729 \mathrm{e}+007.86729 \mathrm{e}-011.00000 \mathrm{e}-092.12000 \mathrm{e}-01$ $7.86729 \mathrm{e}+007.86729 \mathrm{e}+00$ 7.86729e-01 1.00000e-09 2.12000e-01 
7.86729e+00 7.86729e+00 7.86729e-01 1.00000e-09 2.12000e-01 $1.00000 \mathrm{e}-02$ 1.00000e-02 1.00000e-03 1.00000e-09 1.00000e-01 $1.00000 \mathrm{e}+001.00000 \mathrm{e}+001.00000 \mathrm{e}-011.00000 \mathrm{e}-091.00000 \mathrm{e}-01$ $1.00000 \mathrm{e}-05$ 1.00000e-05 1.00000e-06 1.00000e-09 1.00000e-01 $1.00000 \mathrm{e}+001.00000 \mathrm{e}+001.00000 \mathrm{e}-01$ 1.00000e-09 1.00000e-01 Element: 1569 \# of layers: 11

$\mathrm{Kx} \mathrm{Ky} \mathrm{Kz}$ Ss Por

$1.96895 \mathrm{e}+02$ 1.96895e+02 1.96895e+01 1.00000e-09 7.00000e-02 5.00000e-04 5.00000e-04 5.00000e-05 1.00000e-09 1.00000e-01

7.86729e+00 7.86729e+00 7.86729e-01 1.00000e-09 2.12000e-01 $7.86729 \mathrm{e}+00$ 7.86729e+00 7.86729e-01 1.00000e-09 2.12000e-01 $7.86729 \mathrm{e}+00$ 7.86729e+00 7.86729e-01 1.00000e-09 2.12000e-01 $7.86729 \mathrm{e}+00$ 7.86729e+00 7.86729e-01 1.00000e-09 2.12000e-01 $7.86729 \mathrm{e}+00$ 7.86729e+00 7.86729e-01 1.00000e-09 2.12000e-01 $1.00000 \mathrm{e}-02$ 1.00000e-02 1.00000e-03 1.00000e-09 1.00000e-01 $1.00000 \mathrm{e}+001.00000 \mathrm{e}+001.00000 \mathrm{e}-011.00000 \mathrm{e}-091.00000 \mathrm{e}-01$ $1.00000 \mathrm{e}-05$ 1.00000e-05 1.00000e-06 1.00000e-09 1.00000e-01 $1.00000 \mathrm{e}+001.00000 \mathrm{e}+001.00000 \mathrm{e}-011.00000 \mathrm{e}-091.00000 \mathrm{e}-01$ Element: 1570 \# of layers: 11

$\mathrm{Kx} \mathrm{Ky} \mathrm{Kz}$ Ss Por

$1.96895 \mathrm{e}+02$ 1.96895e+02 1.96895e+01 1.00000e-09 7.00000e-02 5.00000e-04 5.00000e-04 5.00000e-05 1.00000e-09 1.00000e-01

$7.86729 \mathrm{e}+00$ 7.86729e+00 7.86729e-01 1.00000e-09 2.12000e-01 $7.86729 \mathrm{e}+00$ 7.86729e+00 7.86729e-01 1.00000e-09 2.12000e-01 $7.86729 \mathrm{e}+007.86729 \mathrm{e}+00$ 7.86729e-01 1.00000e-09 2.12000e-01 $7.86729 \mathrm{e}+00$ 7.86729e+00 7.86729e-01 1.00000e-09 2.12000e-01 $7.86729 \mathrm{e}+00$ 7.86729e+00 7.86729e-01 1.00000e-09 2.12000e-01 $1.00000 \mathrm{e}-02$ 1.00000e-02 1.00000e-03 1.00000e-09 1.00000e-01 $1.00000 \mathrm{e}+001.00000 \mathrm{e}+001.00000 \mathrm{e}-011.00000 \mathrm{e}-091.00000 \mathrm{e}-01$ $1.00000 \mathrm{e}-051.00000 \mathrm{e}-051.00000 \mathrm{e}-061.00000 \mathrm{e}-091.00000 \mathrm{e}-01$ $1.00000 \mathrm{e}+001.00000 \mathrm{e}+001.00000 \mathrm{e}-011.00000 \mathrm{e}-091.00000 \mathrm{e}-01$ Element: 1571 \# of layers: 12

Kx Ky Kz Ss Por

4.10793e+02 4.10793e+02 4.10793e+01 1.00000e-09 7.00000e-02 5.00000e-04 5.00000e-04 5.00000e-05 1.00000e-09 1.00000e-01 5.00000e-04 5.00000e-04 5.00000e-05 1.00000e-09 1.00000e-01 $1.64139 \mathrm{e}+011.64139 \mathrm{e}+01$ 1.64139e+00 1.00000e-09 2.12000e-01 $1.64139 \mathrm{e}+011.64139 \mathrm{e}+01$ 1.64139e+00 1.00000e-09 2.12000e-01 $1.64139 \mathrm{e}+01$ 1.64139e+01 1.64139e+00 1.00000e-09 2.12000e-01 $1.64139 \mathrm{e}+01$ 1.64139e+01 1.64139e+00 1.00000e-09 2.12000e-01 $1.64139 \mathrm{e}+01$ 1.64139e+01 1.64139e+00 1.00000e-09 2.12000e-01 $1.00000 \mathrm{e}-02$ 1.00000e-02 1.00000e-03 1.00000e-09 1.00000e-01 $1.00000 \mathrm{e}+001.00000 \mathrm{e}+001.00000 \mathrm{e}-011.00000 \mathrm{e}-091.00000 \mathrm{e}-01$ $1.00000 \mathrm{e}-05$ 1.00000e-05 1.00000e-06 1.00000e-09 1.00000e-01 $1.00000 \mathrm{e}+001.00000 \mathrm{e}+001.00000 \mathrm{e}-01$ 1.00000e-09 1.00000e-01 Element: 1572 \# of layers: 11 
$\mathrm{Kx} \mathrm{Ky} \mathrm{Kz}$ Ss Por

4.10793e+02 4.10793e+02 4.10793e+01 1.00000e-09 7.00000e-02 5.00000e-04 5.00000e-04 5.00000e-05 1.00000e-09 1.00000e-01

$1.64139 \mathrm{e}+011.64139 \mathrm{e}+01$ 1.64139e+00 1.00000e-09 2.12000e-01 $1.64139 \mathrm{e}+011.64139 \mathrm{e}+011.64139 \mathrm{e}+001.00000 \mathrm{e}-092.12000 \mathrm{e}-01$ $1.64139 \mathrm{e}+011.64139 \mathrm{e}+011.64139 \mathrm{e}+001.00000 \mathrm{e}-092.12000 \mathrm{e}-01$ $1.64139 \mathrm{e}+011.64139 \mathrm{e}+01$ 1.64139e+00 1.00000e-09 2.12000e-01 $1.64139 \mathrm{e}+01$ 1.64139e+01 1.64139e+00 1.00000e-09 2.12000e-01 $1.00000 \mathrm{e}-02$ 1.00000e-02 1.00000e-03 1.00000e-09 1.00000e-01 $1.00000 \mathrm{e}+001.00000 \mathrm{e}+001.00000 \mathrm{e}-011.00000 \mathrm{e}-091.00000 \mathrm{e}-01$ $1.00000 \mathrm{e}-05$ 1.00000e-05 1.00000e-06 1.00000e-09 1.00000e-01 $1.00000 \mathrm{e}+001.00000 \mathrm{e}+001.00000 \mathrm{e}-01$ 1.00000e-09 1.00000e-01 Element: 1573 \# of layers: 12

$\mathrm{Kx} \mathrm{Ky} \mathrm{Kz}$ Ss Por

4.10793e+02 4.10793e+02 4.10793e+01 1.00000e-09 7.00000e-02 4.10793e+02 4.10793e+02 4.10793e+01 1.00000e-09 7.00000e-02 5.00000e-04 5.00000e-04 5.00000e-05 1.00000e-09 1.00000e-01

$1.64139 \mathrm{e}+011.64139 \mathrm{e}+011.64139 \mathrm{e}+001.00000 \mathrm{e}-09$ 2.12000e-01 $1.64139 \mathrm{e}+01$ 1.64139e+01 1.64139e+00 1.00000e-09 2.12000e-01 $1.64139 \mathrm{e}+01$ 1.64139e+01 1.64139e+00 1.00000e-09 2.12000e-01 $1.64139 \mathrm{e}+01$ 1.64139e+01 1.64139e+00 1.00000e-09 2.12000e-01 $1.64139 \mathrm{e}+01$ 1.64139e+01 1.64139e+00 1.00000e-09 2.12000e-01 $1.00000 \mathrm{e}-02$ 1.00000e-02 1.00000e-03 1.00000e-09 1.00000e-01 $1.00000 \mathrm{e}+001.00000 \mathrm{e}+001.00000 \mathrm{e}-011.00000 \mathrm{e}-091.00000 \mathrm{e}-01$ $1.00000 \mathrm{e}-05$ 1.00000e-05 1.00000e-06 1.00000e-09 1.00000e-01 $1.00000 \mathrm{e}+001.00000 \mathrm{e}+001.00000 \mathrm{e}-01$ 1.00000e-09 1.00000e-01 Element: 1574 \# of layers: 12

$\mathrm{Kx} \mathrm{Ky} \mathrm{Kz}$ Ss Por

4.10793e+02 4.10793e+02 4.10793e+01 1.00000e-09 7.00000e-02 4.10793e+02 4.10793e+02 4.10793e+01 1.00000e-09 7.00000e-02 5.00000e-04 5.00000e-04 5.00000e-05 1.00000e-09 1.00000e-01 $1.64139 \mathrm{e}+01$ 1.64139e+01 1.64139e+00 1.00000e-09 2.12000e-01 $1.64139 \mathrm{e}+011.64139 \mathrm{e}+011.64139 \mathrm{e}+001.00000 \mathrm{e}-092.12000 \mathrm{e}-01$ $1.64139 \mathrm{e}+011.64139 \mathrm{e}+01$ 1.64139e+00 1.00000e-09 2.12000e-01 $1.64139 \mathrm{e}+01$ 1.64139e+01 1.64139e+00 1.00000e-09 2.12000e-01 $1.64139 \mathrm{e}+011.64139 \mathrm{e}+011.64139 \mathrm{e}+001.00000 \mathrm{e}-092.12000 \mathrm{e}-01$ $1.00000 \mathrm{e}-02$ 1.00000e-02 1.00000e-03 1.00000e-09 1.00000e-01 $1.00000 \mathrm{e}+001.00000 \mathrm{e}+001.00000 \mathrm{e}-011.00000 \mathrm{e}-091.00000 \mathrm{e}-01$ $1.00000 \mathrm{e}-05$ 1.00000e-05 1.00000e-06 1.00000e-09 1.00000e-01 $1.00000 \mathrm{e}+001.00000 \mathrm{e}+001.00000 \mathrm{e}-01$ 1.00000e-09 1.00000e-01 Element: 1575 \# of layers: 12

$\mathrm{Kx} \mathrm{Ky} \mathrm{Kz}$ Ss Por

4.10793e+02 4.10793e+02 4.10793e+01 1.00000e-09 7.00000e-02 5.00000e-04 5.00000e-04 5.00000e-05 1.00000e-09 1.00000e-01 5.00000e-04 5.00000e-04 5.00000e-05 1.00000e-09 1.00000e-01 $1.64139 \mathrm{e}+011.64139 \mathrm{e}+011.64139 \mathrm{e}+001.00000 \mathrm{e}-092.12000 \mathrm{e}-01$ 
$1.64139 \mathrm{e}+01$ 1.64139e+01 1.64139e+00 1.00000e-09 2.12000e-01 $1.64139 \mathrm{e}+01$ 1.64139e+01 1.64139e+00 1.00000e-09 2.12000e-01 $1.64139 \mathrm{e}+01$ 1.64139e+01 1.64139e+00 1.00000e-09 2.12000e-01 $1.64139 \mathrm{e}+01$ 1.64139e+01 1.64139e+00 1.00000e-09 2.12000e-01 $1.00000 \mathrm{e}-02$ 1.00000e-02 1.00000e-03 1.00000e-09 1.00000e-01 $1.00000 \mathrm{e}+001.00000 \mathrm{e}+001.00000 \mathrm{e}-011.00000 \mathrm{e}-091.00000 \mathrm{e}-01$ $1.00000 \mathrm{e}-05$ 1.00000e-05 1.00000e-06 1.00000e-09 1.00000e-01 $1.00000 \mathrm{e}+001.00000 \mathrm{e}+001.00000 \mathrm{e}-011.00000 \mathrm{e}-091.00000 \mathrm{e}-01$ Element: 1576 \# of layers: 12

$\mathrm{Kx} \mathrm{Ky} \mathrm{Kz}$ Ss Por

4.10793e+02 4.10793e+02 4.10793e+01 1.00000e-09 7.00000e-02 5.00000e-04 5.00000e-04 5.00000e-05 1.00000e-09 1.00000e-01 5.00000e-04 5.00000e-04 5.00000e-05 1.00000e-09 1.00000e-01 $1.64139 \mathrm{e}+011.64139 \mathrm{e}+01$ 1.64139e+00 1.00000e-09 2.12000e-01 $1.64139 \mathrm{e}+01$ 1.64139e+01 1.64139e+00 1.00000e-09 2.12000e-01 $1.64139 \mathrm{e}+011.64139 \mathrm{e}+011.64139 \mathrm{e}+001.00000 \mathrm{e}-092.12000 \mathrm{e}-01$ $1.64139 \mathrm{e}+011.64139 \mathrm{e}+01$ 1.64139e+00 1.00000e-09 2.12000e-01 $1.64139 \mathrm{e}+011.64139 \mathrm{e}+01$ 1.64139e+00 1.00000e-09 2.12000e-01 $1.00000 \mathrm{e}-02$ 1.00000e-02 1.00000e-03 1.00000e-09 1.00000e-01 $1.00000 \mathrm{e}+001.00000 \mathrm{e}+001.00000 \mathrm{e}-011.00000 \mathrm{e}-091.00000 \mathrm{e}-01$ $1.00000 \mathrm{e}-05$ 1.00000e-05 1.00000e-06 1.00000e-09 1.00000e-01 $1.00000 \mathrm{e}+001.00000 \mathrm{e}+001.00000 \mathrm{e}-011.00000 \mathrm{e}-09$ 1.00000e-01 Element: 1577 \# of layers: 12

Kx Ky Kz Ss Por

4.10793e+02 4.10793e+02 4.10793e+01 1.00000e-09 7.00000e-02 $5.00000 \mathrm{e}-04$ 5.00000e-04 5.00000e-05 1.00000e-09 1.00000e-01 $5.00000 \mathrm{e}-04$ 5.00000e-04 5.00000e-05 1.00000e-09 1.00000e-01 $1.64139 \mathrm{e}+011.64139 \mathrm{e}+01$ 1.64139e+00 1.00000e-09 2.12000e-01 $1.64139 \mathrm{e}+011.64139 \mathrm{e}+011.64139 \mathrm{e}+001.00000 \mathrm{e}-092.12000 \mathrm{e}-01$ $1.64139 \mathrm{e}+01$ 1.64139e+01 1.64139e+00 1.00000e-09 2.12000e-01 $1.64139 \mathrm{e}+01$ 1.64139e+01 1.64139e+00 1.00000e-09 2.12000e-01 $1.64139 \mathrm{e}+01$ 1.64139e+01 1.64139e+00 1.00000e-09 2.12000e-01 $1.00000 \mathrm{e}-02$ 1.00000e-02 1.00000e-03 1.00000e-09 1.00000e-01 $1.00000 \mathrm{e}+001.00000 \mathrm{e}+001.00000 \mathrm{e}-011.00000 \mathrm{e}-091.00000 \mathrm{e}-01$ $1.00000 \mathrm{e}-05$ 1.00000e-05 1.00000e-06 1.00000e-09 1.00000e-01 $1.00000 \mathrm{e}+001.00000 \mathrm{e}+001.00000 \mathrm{e}-011.00000 \mathrm{e}-091.00000 \mathrm{e}-01$ Element: 1578 \# of layers: 12

Kx Ky Kz Ss Por

4.10793e+02 4.10793e+02 4.10793e+01 1.00000e-09 7.00000e-02 5.00000e-04 5.00000e-04 5.00000e-05 1.00000e-09 1.00000e-01 5.00000e-04 5.00000e-04 5.00000e-05 1.00000e-09 1.00000e-01 $1.64139 \mathrm{e}+011.64139 \mathrm{e}+011.64139 \mathrm{e}+001.00000 \mathrm{e}-092.12000 \mathrm{e}-01$ $1.64139 \mathrm{e}+01$ 1.64139e+01 1.64139e+00 1.00000e-09 2.12000e-01 $1.64139 \mathrm{e}+01$ 1.64139e+01 1.64139e+00 1.00000e-09 2.12000e-01 $1.64139 \mathrm{e}+01$ 1.64139e+01 1.64139e+00 1.00000e-09 2.12000e-01 $1.64139 \mathrm{e}+011.64139 \mathrm{e}+011.64139 \mathrm{e}+001.00000 \mathrm{e}-092.12000 \mathrm{e}-01$ 
$1.00000 \mathrm{e}-02$ 1.00000e-02 1.00000e-03 1.00000e-09 1.00000e-01 $1.00000 \mathrm{e}+001.00000 \mathrm{e}+001.00000 \mathrm{e}-011.00000 \mathrm{e}-091.00000 \mathrm{e}-01$ $1.00000 \mathrm{e}-051.00000 \mathrm{e}-05$ 1.00000e-06 1.00000e-09 1.00000e-01 $1.00000 \mathrm{e}+001.00000 \mathrm{e}+001.00000 \mathrm{e}-011.00000 \mathrm{e}-091.00000 \mathrm{e}-01$ Element: 1579 \# of layers: 11

Kx Ky Kz Ss Por

4.10793e+02 4.10793e+02 4.10793e+01 1.00000e-09 7.00000e-02 5.00000e-04 5.00000e-04 5.00000e-05 1.00000e-09 1.00000e-01

$1.64139 \mathrm{e}+011.64139 \mathrm{e}+011.64139 \mathrm{e}+001.00000 \mathrm{e}-092.12000 \mathrm{e}-01$ $1.64139 \mathrm{e}+011.64139 \mathrm{e}+011.64139 \mathrm{e}+001.00000 \mathrm{e}-092.12000 \mathrm{e}-01$ $1.64139 \mathrm{e}+011.64139 \mathrm{e}+011.64139 \mathrm{e}+001.00000 \mathrm{e}-092.12000 \mathrm{e}-01$ $1.64139 \mathrm{e}+011.64139 \mathrm{e}+011.64139 \mathrm{e}+001.00000 \mathrm{e}-092.12000 \mathrm{e}-01$ $1.64139 \mathrm{e}+011.64139 \mathrm{e}+011.64139 \mathrm{e}+001.00000 \mathrm{e}-092.12000 \mathrm{e}-01$ $1.00000 \mathrm{e}-021.00000 \mathrm{e}-02$ 1.00000e-03 1.00000e-09 1.00000e-01 $1.00000 \mathrm{e}+001.00000 \mathrm{e}+001.00000 \mathrm{e}-011.00000 \mathrm{e}-091.00000 \mathrm{e}-01$ $1.00000 \mathrm{e}-05$ 1.00000e-05 1.00000e-06 1.00000e-09 1.00000e-01 $1.00000 \mathrm{e}+001.00000 \mathrm{e}+001.00000 \mathrm{e}-011.00000 \mathrm{e}-091.00000 \mathrm{e}-01$ Element: 1580 \# of layers: 10

Kx Ky Kz Ss Por

$5.25752 \mathrm{e}+025.25752 \mathrm{e}+025.25752 \mathrm{e}+01$ 1.00000e-09 7.00000e-02 $2.10071 \mathrm{e}+012.10071 \mathrm{e}+012.10071 \mathrm{e}+001.00000 \mathrm{e}-092.12000 \mathrm{e}-01$ $2.10071 \mathrm{e}+012.10071 \mathrm{e}+012.10071 \mathrm{e}+00$ 1.00000e-09 2.12000e-01 $2.10071 \mathrm{e}+012.10071 \mathrm{e}+012.10071 \mathrm{e}+00$ 1.00000e-09 2.12000e-01 $2.10071 \mathrm{e}+012.10071 \mathrm{e}+012.10071 \mathrm{e}+001.00000 \mathrm{e}-092.12000 \mathrm{e}-01$ $2.10071 \mathrm{e}+012.10071 \mathrm{e}+012.10071 \mathrm{e}+001.00000 \mathrm{e}-092.12000 \mathrm{e}-01$ $1.00000 \mathrm{e}-02$ 1.00000e-02 1.00000e-03 1.00000e-09 1.00000e-01 $1.00000 \mathrm{e}+001.00000 \mathrm{e}+001.00000 \mathrm{e}-011.00000 \mathrm{e}-091.00000 \mathrm{e}-01$ $1.00000 \mathrm{e}-051.00000 \mathrm{e}-05$ 1.00000e-06 1.00000e-09 1.00000e-01 $1.00000 \mathrm{e}+001.00000 \mathrm{e}+001.00000 \mathrm{e}-011.00000 \mathrm{e}-091.00000 \mathrm{e}-01$ Element: 1581 \# of layers: 9

Kx Ky Kz Ss Por

$2.10071 \mathrm{e}+012.10071 \mathrm{e}+012.10071 \mathrm{e}+00$ 1.00000e-09 2.12000e-01 $2.10071 \mathrm{e}+012.10071 \mathrm{e}+012.10071 \mathrm{e}+00$ 1.00000e-09 2.12000e-01 $2.10071 \mathrm{e}+012.10071 \mathrm{e}+012.10071 \mathrm{e}+001.00000 \mathrm{e}-092.12000 \mathrm{e}-01$ $2.10071 \mathrm{e}+012.10071 \mathrm{e}+012.10071 \mathrm{e}+001.00000 \mathrm{e}-092.12000 \mathrm{e}-01$ $2.10071 \mathrm{e}+012.10071 \mathrm{e}+012.10071 \mathrm{e}+00$ 1.00000e-09 2.12000e-01 $1.00000 \mathrm{e}-021.00000 \mathrm{e}-02$ 1.00000e-03 1.00000e-09 1.00000e-01 $1.00000 \mathrm{e}+001.00000 \mathrm{e}+001.00000 \mathrm{e}-011.00000 \mathrm{e}-091.00000 \mathrm{e}-01$ $1.00000 \mathrm{e}-05$ 1.00000e-05 1.00000e-06 1.00000e-09 1.00000e-01 $1.00000 \mathrm{e}+001.00000 \mathrm{e}+001.00000 \mathrm{e}-011.00000 \mathrm{e}-091.00000 \mathrm{e}-01$ Element: 1582 \# of layers: 9

Kx Ky Kz Ss Por

$2.10071 \mathrm{e}+012.10071 \mathrm{e}+012.10071 \mathrm{e}+00$ 1.00000e-09 2.12000e-01 $2.10071 \mathrm{e}+012.10071 \mathrm{e}+012.10071 \mathrm{e}+00$ 1.00000e-09 2.12000e-01 $2.10071 \mathrm{e}+012.10071 \mathrm{e}+012.10071 \mathrm{e}+00$ 1.00000e-09 2.12000e-01 $2.10071 \mathrm{e}+012.10071 \mathrm{e}+012.10071 \mathrm{e}+00$ 1.00000e-09 2.12000e-01 
$2.10071 \mathrm{e}+012.10071 \mathrm{e}+012.10071 \mathrm{e}+00$ 1.00000e-09 2.12000e-01 $1.00000 \mathrm{e}-02$ 1.00000e-02 1.00000e-03 1.00000e-09 1.00000e-01 $1.00000 \mathrm{e}+001.00000 \mathrm{e}+001.00000 \mathrm{e}-011.00000 \mathrm{e}-091.00000 \mathrm{e}-01$ $1.00000 \mathrm{e}-05$ 1.00000e-05 1.00000e-06 1.00000e-09 1.00000e-01 $1.00000 \mathrm{e}+001.00000 \mathrm{e}+001.00000 \mathrm{e}-011.00000 \mathrm{e}-091.00000 \mathrm{e}-01$ Element: 1583 \# of layers: 9

$\mathrm{Kx} \mathrm{Ky} \mathrm{Kz}$ Ss Por

$2.10071 \mathrm{e}+012.10071 \mathrm{e}+012.10071 \mathrm{e}+00$ 1.00000e-09 2.12000e-01 $2.10071 \mathrm{e}+012.10071 \mathrm{e}+012.10071 \mathrm{e}+00$ 1.00000e-09 2.12000e-01 $2.10071 \mathrm{e}+012.10071 \mathrm{e}+012.10071 \mathrm{e}+00$ 1.00000e-09 2.12000e-01 $2.10071 \mathrm{e}+012.10071 \mathrm{e}+012.10071 \mathrm{e}+00$ 1.00000e-09 2.12000e-01 $2.10071 \mathrm{e}+012.10071 \mathrm{e}+012.10071 \mathrm{e}+001.00000 \mathrm{e}-092.12000 \mathrm{e}-01$ $1.00000 \mathrm{e}-02$ 1.00000e-02 1.00000e-03 1.00000e-09 1.00000e-01 $1.00000 \mathrm{e}+001.00000 \mathrm{e}+001.00000 \mathrm{e}-011.00000 \mathrm{e}-091.00000 \mathrm{e}-01$ $1.00000 \mathrm{e}-05$ 1.00000e-05 1.00000e-06 1.00000e-09 1.00000e-01 $1.00000 \mathrm{e}+001.00000 \mathrm{e}+001.00000 \mathrm{e}-011.00000 \mathrm{e}-091.00000 \mathrm{e}-01$ Element: 1584 \# of layers: 9

$\mathrm{Kx} \mathrm{Ky} \mathrm{Kz}$ Ss Por

$2.10071 \mathrm{e}+012.10071 \mathrm{e}+012.10071 \mathrm{e}+00$ 1.00000e-09 2.12000e-01 $2.10071 \mathrm{e}+012.10071 \mathrm{e}+012.10071 \mathrm{e}+00$ 1.00000e-09 2.12000e-01 $2.10071 \mathrm{e}+012.10071 \mathrm{e}+012.10071 \mathrm{e}+001.00000 \mathrm{e}-092.12000 \mathrm{e}-01$ $2.10071 \mathrm{e}+012.10071 \mathrm{e}+012.10071 \mathrm{e}+00$ 1.00000e-09 2.12000e-01 $2.10071 \mathrm{e}+012.10071 \mathrm{e}+012.10071 \mathrm{e}+00$ 1.00000e-09 2.12000e-01 $1.00000 \mathrm{e}-02$ 1.00000e-02 1.00000e-03 1.00000e-09 1.00000e-01 $1.00000 \mathrm{e}+001.00000 \mathrm{e}+001.00000 \mathrm{e}-011.00000 \mathrm{e}-091.00000 \mathrm{e}-01$ $1.00000 \mathrm{e}-05$ 1.00000e-05 1.00000e-06 1.00000e-09 1.00000e-01 $1.00000 \mathrm{e}+001.00000 \mathrm{e}+001.00000 \mathrm{e}-011.00000 \mathrm{e}-091.00000 \mathrm{e}-01$ Element: 1585 \# of layers: 10

$\mathrm{Kx} \mathrm{Ky} \mathrm{Kz}$ Ss Por

5.25752e+02 5.25752e+02 5.25752e+01 1.00000e-09 7.00000e-02 $2.10071 \mathrm{e}+012.10071 \mathrm{e}+012.10071 \mathrm{e}+00$ 1.00000e-09 2.12000e-01 $2.10071 \mathrm{e}+012.10071 \mathrm{e}+012.10071 \mathrm{e}+00$ 1.00000e-09 2.12000e-01 $2.10071 \mathrm{e}+012.10071 \mathrm{e}+012.10071 \mathrm{e}+00$ 1.00000e-09 2.12000e-01 $2.10071 \mathrm{e}+012.10071 \mathrm{e}+012.10071 \mathrm{e}+00$ 1.00000e-09 2.12000e-01 $2.10071 \mathrm{e}+012.10071 \mathrm{e}+012.10071 \mathrm{e}+00$ 1.00000e-09 2.12000e-01 1.00000e-02 1.00000e-02 1.00000e-03 1.00000e-09 1.00000e-01 $1.00000 \mathrm{e}+001.00000 \mathrm{e}+001.00000 \mathrm{e}-011.00000 \mathrm{e}-091.00000 \mathrm{e}-01$ $1.00000 \mathrm{e}-05$ 1.00000e-05 1.00000e-06 1.00000e-09 1.00000e-01 $1.00000 \mathrm{e}+001.00000 \mathrm{e}+001.00000 \mathrm{e}-011.00000 \mathrm{e}-091.00000 \mathrm{e}-01$ Element: 1586 \# of layers: 12

$\mathrm{Kx} \mathrm{Ky} \mathrm{Kz}$ Ss Por

5.25752e+02 5.25752e+02 5.25752e+01 1.00000e-09 7.00000e-02 $5.00000 \mathrm{e}-04$ 5.00000e-04 5.00000e-05 1.00000e-09 1.00000e-01 5.00000e-04 5.00000e-04 5.00000e-05 1.00000e-09 1.00000e-01 $2.10071 \mathrm{e}+012.10071 \mathrm{e}+012.10071 \mathrm{e}+00$ 1.00000e-09 2.12000e-01 $2.10071 \mathrm{e}+012.10071 \mathrm{e}+012.10071 \mathrm{e}+00$ 1.00000e-09 2.12000e-01 
$2.10071 \mathrm{e}+012.10071 \mathrm{e}+012.10071 \mathrm{e}+00$ 1.00000e-09 2.12000e-01 $2.10071 \mathrm{e}+012.10071 \mathrm{e}+012.10071 \mathrm{e}+00$ 1.00000e-09 2.12000e-01 $2.10071 \mathrm{e}+012.10071 \mathrm{e}+012.10071 \mathrm{e}+00$ 1.00000e-09 2.12000e-01 $1.00000 \mathrm{e}-021.00000 \mathrm{e}-02$ 1.00000e-03 1.00000e-09 1.00000e-01 $1.00000 \mathrm{e}+001.00000 \mathrm{e}+001.00000 \mathrm{e}-011.00000 \mathrm{e}-091.00000 \mathrm{e}-01$ $1.00000 \mathrm{e}-05$ 1.00000e-05 1.00000e-06 1.00000e-09 1.00000e-01 $1.00000 \mathrm{e}+001.00000 \mathrm{e}+001.00000 \mathrm{e}-011.00000 \mathrm{e}-091.00000 \mathrm{e}-01$ Element: 1587 \# of layers: 11

$\mathrm{Kx} \mathrm{Ky} \mathrm{Kz}$ Ss Por

5.25752e+02 5.25752e+02 5.25752e+01 1.00000e-09 7.00000e-02 $5.25752 \mathrm{e}+025.25752 \mathrm{e}+02$ 5.25752e+01 1.00000e-09 7.00000e-02 $2.10071 \mathrm{e}+012.10071 \mathrm{e}+012.10071 \mathrm{e}+001.00000 \mathrm{e}-092.12000 \mathrm{e}-01$ $2.10071 \mathrm{e}+012.10071 \mathrm{e}+012.10071 \mathrm{e}+00$ 1.00000e-09 2.12000e-01 $2.10071 \mathrm{e}+012.10071 \mathrm{e}+012.10071 \mathrm{e}+00$ 1.00000e-09 2.12000e-01 $2.10071 \mathrm{e}+012.10071 \mathrm{e}+012.10071 \mathrm{e}+00$ 1.00000e-09 2.12000e-01 $2.10071 \mathrm{e}+012.10071 \mathrm{e}+012.10071 \mathrm{e}+001.00000 \mathrm{e}-092.12000 \mathrm{e}-01$ $1.00000 \mathrm{e}-021.00000 \mathrm{e}-02$ 1.00000e-03 1.00000e-09 1.00000e-01 $1.00000 \mathrm{e}+001.00000 \mathrm{e}+001.00000 \mathrm{e}-011.00000 \mathrm{e}-091.00000 \mathrm{e}-01$ $1.00000 \mathrm{e}-05$ 1.00000e-05 1.00000e-06 1.00000e-09 1.00000e-01 $1.00000 \mathrm{e}+001.00000 \mathrm{e}+001.00000 \mathrm{e}-011.00000 \mathrm{e}-091.00000 \mathrm{e}-01$ Element: 1588 \# of layers: 9

Kx Ky Kz Ss Por

$2.10071 \mathrm{e}+012.10071 \mathrm{e}+012.10071 \mathrm{e}+00$ 1.00000e-09 2.12000e-01 $2.10071 \mathrm{e}+012.10071 \mathrm{e}+012.10071 \mathrm{e}+00$ 1.00000e-09 2.12000e-01 $2.10071 \mathrm{e}+012.10071 \mathrm{e}+012.10071 \mathrm{e}+001.00000 \mathrm{e}-092.12000 \mathrm{e}-01$ $2.10071 \mathrm{e}+012.10071 \mathrm{e}+012.10071 \mathrm{e}+00$ 1.00000e-09 2.12000e-01 $2.10071 \mathrm{e}+012.10071 \mathrm{e}+012.10071 \mathrm{e}+001.00000 \mathrm{e}-092.12000 \mathrm{e}-01$ $1.00000 \mathrm{e}-021.00000 \mathrm{e}-02$ 1.00000e-03 1.00000e-09 1.00000e-01 $1.00000 \mathrm{e}+001.00000 \mathrm{e}+001.00000 \mathrm{e}-011.00000 \mathrm{e}-091.00000 \mathrm{e}-01$ $1.00000 \mathrm{e}-05$ 1.00000e-05 1.00000e-06 1.00000e-09 1.00000e-01 $1.00000 \mathrm{e}+001.00000 \mathrm{e}+001.00000 \mathrm{e}-011.00000 \mathrm{e}-091.00000 \mathrm{e}-01$ Element: 1589 \# of layers: 9

Kx Ky Kz Ss Por

$1.42750 \mathrm{e}+011.42750 \mathrm{e}+011.42750 \mathrm{e}+00$ 1.00000e-09 2.12000e-01 $1.42750 \mathrm{e}+011.42750 \mathrm{e}+011.42750 \mathrm{e}+001.00000 \mathrm{e}-092.12000 \mathrm{e}-01$ $1.42750 \mathrm{e}+011.42750 \mathrm{e}+011.42750 \mathrm{e}+001.00000 \mathrm{e}-092.12000 \mathrm{e}-01$ $1.42750 \mathrm{e}+011.42750 \mathrm{e}+011.42750 \mathrm{e}+001.00000 \mathrm{e}-092.12000 \mathrm{e}-01$ $1.42750 \mathrm{e}+011.42750 \mathrm{e}+011.42750 \mathrm{e}+001.00000 \mathrm{e}-092.12000 \mathrm{e}-01$ $1.00000 \mathrm{e}-021.00000 \mathrm{e}-02$ 1.00000e-03 1.00000e-09 1.00000e-01 $1.00000 \mathrm{e}+001.00000 \mathrm{e}+001.00000 \mathrm{e}-011.00000 \mathrm{e}-091.00000 \mathrm{e}-01$ $1.00000 \mathrm{e}-05$ 1.00000e-05 1.00000e-06 1.00000e-09 1.00000e-01 $1.00000 \mathrm{e}+001.00000 \mathrm{e}+001.00000 \mathrm{e}-011.00000 \mathrm{e}-091.00000 \mathrm{e}-01$ Element: 1590 \# of layers: 9

Kx Ky Kz Ss Por

$1.42750 \mathrm{e}+011.42750 \mathrm{e}+011.42750 \mathrm{e}+00$ 1.00000e-09 2.12000e-01 $1.42750 \mathrm{e}+011.42750 \mathrm{e}+011.42750 \mathrm{e}+001.00000 \mathrm{e}-092.12000 \mathrm{e}-01$ 
$1.42750 \mathrm{e}+011.42750 \mathrm{e}+011.42750 \mathrm{e}+001.00000 \mathrm{e}-092.12000 \mathrm{e}-01$ $1.42750 \mathrm{e}+011.42750 \mathrm{e}+011.42750 \mathrm{e}+001.00000 \mathrm{e}-092.12000 \mathrm{e}-01$ $1.42750 \mathrm{e}+011.42750 \mathrm{e}+011.42750 \mathrm{e}+001.00000 \mathrm{e}-092.12000 \mathrm{e}-01$ $1.00000 \mathrm{e}-02$ 1.00000e-02 1.00000e-03 1.00000e-09 1.00000e-01 $1.00000 \mathrm{e}+001.00000 \mathrm{e}+001.00000 \mathrm{e}-011.00000 \mathrm{e}-091.00000 \mathrm{e}-01$ $1.00000 \mathrm{e}-05$ 1.00000e-05 1.00000e-06 1.00000e-09 1.00000e-01 $1.00000 \mathrm{e}+001.00000 \mathrm{e}+001.00000 \mathrm{e}-01$ 1.00000e-09 1.00000e-01 Element: 1591 \# of layers: 9

$\mathrm{Kx} \mathrm{Ky} \mathrm{Kz}$ Ss Por

$1.42750 \mathrm{e}+011.42750 \mathrm{e}+011.42750 \mathrm{e}+001.00000 \mathrm{e}-092.12000 \mathrm{e}-01$ $1.42750 \mathrm{e}+011.42750 \mathrm{e}+011.42750 \mathrm{e}+001.00000 \mathrm{e}-092.12000 \mathrm{e}-01$ $1.42750 \mathrm{e}+011.42750 \mathrm{e}+011.42750 \mathrm{e}+001.00000 \mathrm{e}-092.12000 \mathrm{e}-01$ $1.42750 \mathrm{e}+011.42750 \mathrm{e}+011.42750 \mathrm{e}+001.00000 \mathrm{e}-092.12000 \mathrm{e}-01$ $1.42750 \mathrm{e}+011.42750 \mathrm{e}+011.42750 \mathrm{e}+001.00000 \mathrm{e}-092.12000 \mathrm{e}-01$ $1.00000 \mathrm{e}-02$ 1.00000e-02 1.00000e-03 1.00000e-09 1.00000e-01 $1.00000 \mathrm{e}+001.00000 \mathrm{e}+001.00000 \mathrm{e}-011.00000 \mathrm{e}-091.00000 \mathrm{e}-01$ $1.00000 \mathrm{e}-05$ 1.00000e-05 1.00000e-06 1.00000e-09 1.00000e-01 $1.00000 \mathrm{e}+001.00000 \mathrm{e}+001.00000 \mathrm{e}-01$ 1.00000e-09 1.00000e-01 Element: 1592 \# of layers: 9

$\mathrm{Kx} \mathrm{Ky} \mathrm{Kz}$ Ss Por

$1.42750 \mathrm{e}+01$ 1.42750e+01 1.42750e+00 1.00000e-09 2.12000e-01 $1.42750 \mathrm{e}+011.42750 \mathrm{e}+011.42750 \mathrm{e}+001.00000 \mathrm{e}-092.12000 \mathrm{e}-01$ $1.42750 \mathrm{e}+011.42750 \mathrm{e}+011.42750 \mathrm{e}+001.00000 \mathrm{e}-092.12000 \mathrm{e}-01$ $1.42750 \mathrm{e}+011.42750 \mathrm{e}+011.42750 \mathrm{e}+001.00000 \mathrm{e}-092.12000 \mathrm{e}-01$ $1.42750 \mathrm{e}+011.42750 \mathrm{e}+011.42750 \mathrm{e}+001.00000 \mathrm{e}-092.12000 \mathrm{e}-01$ $1.00000 \mathrm{e}-02$ 1.00000e-02 1.00000e-03 1.00000e-09 1.00000e-01 $1.00000 \mathrm{e}+001.00000 \mathrm{e}+001.00000 \mathrm{e}-011.00000 \mathrm{e}-091.00000 \mathrm{e}-01$ $1.00000 \mathrm{e}-05$ 1.00000e-05 1.00000e-06 1.00000e-09 1.00000e-01 $1.00000 \mathrm{e}+001.00000 \mathrm{e}+001.00000 \mathrm{e}-011.00000 \mathrm{e}-091.00000 \mathrm{e}-01$ Element: 1593 \# of layers: 10

$\mathrm{Kx} \mathrm{Ky} \mathrm{Kz}$ Ss Por

3.57264e+02 3.57264e+02 3.57265e+01 1.00000e-09 7.00000e-02 $1.42750 \mathrm{e}+011.42750 \mathrm{e}+011.42750 \mathrm{e}+001.00000 \mathrm{e}-092.12000 \mathrm{e}-01$ $1.42750 \mathrm{e}+011.42750 \mathrm{e}+011.42750 \mathrm{e}+001.00000 \mathrm{e}-092.12000 \mathrm{e}-01$ $1.42750 \mathrm{e}+011.42750 \mathrm{e}+011.42750 \mathrm{e}+001.00000 \mathrm{e}-092.12000 \mathrm{e}-01$ $1.42750 \mathrm{e}+011.42750 \mathrm{e}+011.42750 \mathrm{e}+001.00000 \mathrm{e}-092.12000 \mathrm{e}-01$ $1.42750 \mathrm{e}+011.42750 \mathrm{e}+011.42750 \mathrm{e}+001.00000 \mathrm{e}-092.12000 \mathrm{e}-01$ $1.00000 \mathrm{e}-02$ 1.00000e-02 1.00000e-03 1.00000e-09 1.00000e-01 $1.00000 \mathrm{e}+001.00000 \mathrm{e}+001.00000 \mathrm{e}-011.00000 \mathrm{e}-091.00000 \mathrm{e}-01$ $1.00000 \mathrm{e}-05$ 1.00000e-05 1.00000e-06 1.00000e-09 1.00000e-01 $1.00000 \mathrm{e}+001.00000 \mathrm{e}+001.00000 \mathrm{e}-011.00000 \mathrm{e}-091.00000 \mathrm{e}-01$ Element: 1594 \# of layers: 9

$\mathrm{Kx} \mathrm{Ky} \mathrm{Kz}$ Ss Por

$1.42750 \mathrm{e}+011.42750 \mathrm{e}+011.42750 \mathrm{e}+001.00000 \mathrm{e}-092.12000 \mathrm{e}-01$ $1.42750 \mathrm{e}+011.42750 \mathrm{e}+011.42750 \mathrm{e}+001.00000 \mathrm{e}-092.12000 \mathrm{e}-01$ $1.42750 \mathrm{e}+011.42750 \mathrm{e}+01$ 1.42750e+00 1.00000e-09 2.12000e-01 
$1.42750 \mathrm{e}+011.42750 \mathrm{e}+011.42750 \mathrm{e}+001.00000 \mathrm{e}-092.12000 \mathrm{e}-01$ $1.42750 \mathrm{e}+011.42750 \mathrm{e}+011.42750 \mathrm{e}+001.00000 \mathrm{e}-092.12000 \mathrm{e}-01$ $1.00000 \mathrm{e}-02$ 1.00000e-02 1.00000e-03 1.00000e-09 1.00000e-01 $1.00000 \mathrm{e}+001.00000 \mathrm{e}+001.00000 \mathrm{e}-011.00000 \mathrm{e}-091.00000 \mathrm{e}-01$ $1.00000 \mathrm{e}-051.00000 \mathrm{e}-05$ 1.00000e-06 1.00000e-09 1.00000e-01 $1.00000 \mathrm{e}+001.00000 \mathrm{e}+001.00000 \mathrm{e}-011.00000 \mathrm{e}-091.00000 \mathrm{e}-01$ Element: 1595 \# of layers: 9

Kx Ky Kz Ss Por

$1.42750 \mathrm{e}+011.42750 \mathrm{e}+011.42750 \mathrm{e}+001.00000 \mathrm{e}-092.12000 \mathrm{e}-01$ $1.42750 \mathrm{e}+011.42750 \mathrm{e}+011.42750 \mathrm{e}+001.00000 \mathrm{e}-092.12000 \mathrm{e}-01$ $1.42750 \mathrm{e}+011.42750 \mathrm{e}+011.42750 \mathrm{e}+001.00000 \mathrm{e}-092.12000 \mathrm{e}-01$ $1.42750 \mathrm{e}+011.42750 \mathrm{e}+011.42750 \mathrm{e}+001.00000 \mathrm{e}-092.12000 \mathrm{e}-01$ $1.42750 \mathrm{e}+011.42750 \mathrm{e}+011.42750 \mathrm{e}+001.00000 \mathrm{e}-092.12000 \mathrm{e}-01$ $1.00000 \mathrm{e}-02$ 1.00000e-02 1.00000e-03 1.00000e-09 1.00000e-01 $1.00000 \mathrm{e}+001.00000 \mathrm{e}+001.00000 \mathrm{e}-011.00000 \mathrm{e}-091.00000 \mathrm{e}-01$ $1.00000 \mathrm{e}-051.00000 \mathrm{e}-05$ 1.00000e-06 1.00000e-09 1.00000e-01 $1.00000 \mathrm{e}+001.00000 \mathrm{e}+001.00000 \mathrm{e}-011.00000 \mathrm{e}-091.00000 \mathrm{e}-01$ Element: 1596 \# of layers: 9

$\mathrm{Kx} \mathrm{Ky} \mathrm{Kz}$ Ss Por

$1.42750 \mathrm{e}+01$ 1.42750e+01 1.42750e+00 1.00000e-09 2.12000e-01 $1.42750 \mathrm{e}+011.42750 \mathrm{e}+011.42750 \mathrm{e}+001.00000 \mathrm{e}-092.12000 \mathrm{e}-01$ $1.42750 \mathrm{e}+011.42750 \mathrm{e}+01$ 1.42750e+00 1.00000e-09 2.12000e-01 $1.42750 \mathrm{e}+011.42750 \mathrm{e}+011.42750 \mathrm{e}+001.00000 \mathrm{e}-092.12000 \mathrm{e}-01$ $1.42750 \mathrm{e}+011.42750 \mathrm{e}+01 \quad 1.42750 \mathrm{e}+001.00000 \mathrm{e}-092.12000 \mathrm{e}-01$ $1.00000 \mathrm{e}-021.00000 \mathrm{e}-02$ 1.00000e-03 1.00000e-09 1.00000e-01 $1.00000 \mathrm{e}+001.00000 \mathrm{e}+001.00000 \mathrm{e}-011.00000 \mathrm{e}-091.00000 \mathrm{e}-01$ $1.00000 \mathrm{e}-05$ 1.00000e-05 1.00000e-06 1.00000e-09 1.00000e-01 $1.00000 \mathrm{e}+001.00000 \mathrm{e}+001.00000 \mathrm{e}-011.00000 \mathrm{e}-091.00000 \mathrm{e}-01$ Element: 1597 \# of layers: 9

$\mathrm{Kx} \mathrm{Ky} \mathrm{Kz}$ Ss Por

$1.42750 \mathrm{e}+01$ 1.42750e+01 1.42750e+00 1.00000e-09 2.12000e-01 $1.42750 \mathrm{e}+011.42750 \mathrm{e}+011.42750 \mathrm{e}+001.00000 \mathrm{e}-092.12000 \mathrm{e}-01$ $1.42750 \mathrm{e}+011.42750 \mathrm{e}+011.42750 \mathrm{e}+001.00000 \mathrm{e}-092.12000 \mathrm{e}-01$ $1.42750 \mathrm{e}+011.42750 \mathrm{e}+011.42750 \mathrm{e}+001.00000 \mathrm{e}-092.12000 \mathrm{e}-01$ $1.42750 \mathrm{e}+011.42750 \mathrm{e}+011.42750 \mathrm{e}+001.00000 \mathrm{e}-092.12000 \mathrm{e}-01$ 1.00000e-02 1.00000e-02 1.00000e-03 1.00000e-09 1.00000e-01 $1.00000 \mathrm{e}+001.00000 \mathrm{e}+001.00000 \mathrm{e}-011.00000 \mathrm{e}-091.00000 \mathrm{e}-01$ $1.00000 \mathrm{e}-05$ 1.00000e-05 1.00000e-06 1.00000e-09 1.00000e-01 $1.00000 \mathrm{e}+001.00000 \mathrm{e}+001.00000 \mathrm{e}-011.00000 \mathrm{e}-091.00000 \mathrm{e}-01$ Element: 1598 \# of layers: 9

Kx Ky Kz Ss Por

$1.35610 \mathrm{e}+01$ 1.35610e+01 1.35610e+00 1.00000e-09 2.12000e-01 $1.35610 \mathrm{e}+01$ 1.35610e+01 1.35610e+00 1.00000e-09 2.12000e-01 $1.35610 \mathrm{e}+01$ 1.35610e+01 1.35610e+00 1.00000e-09 2.12000e-01 $1.35610 \mathrm{e}+011.35610 \mathrm{e}+011.35610 \mathrm{e}+001.00000 \mathrm{e}-092.12000 \mathrm{e}-01$ $1.35610 \mathrm{e}+011.35610 \mathrm{e}+011.35610 \mathrm{e}+001.00000 \mathrm{e}-092.12000 \mathrm{e}-01$ 
$1.00000 \mathrm{e}-02$ 1.00000e-02 1.00000e-03 1.00000e-09 1.00000e-01 $1.00000 \mathrm{e}+001.00000 \mathrm{e}+001.00000 \mathrm{e}-011.00000 \mathrm{e}-091.00000 \mathrm{e}-01$ $1.00000 \mathrm{e}-051.00000 \mathrm{e}-05$ 1.00000e-06 1.00000e-09 1.00000e-01 $1.00000 \mathrm{e}+001.00000 \mathrm{e}+001.00000 \mathrm{e}-011.00000 \mathrm{e}-091.00000 \mathrm{e}-01$ Element: 1599 \# of layers: 9

Kx Ky Kz Ss Por

$1.35610 \mathrm{e}+011.35610 \mathrm{e}+011.35610 \mathrm{e}+00$ 1.00000e-09 2.12000e-01 $1.35610 \mathrm{e}+011.35610 \mathrm{e}+011.35610 \mathrm{e}+001.00000 \mathrm{e}-092.12000 \mathrm{e}-01$ $1.35610 \mathrm{e}+011.35610 \mathrm{e}+011.35610 \mathrm{e}+001.00000 \mathrm{e}-092.12000 \mathrm{e}-01$ $1.35610 \mathrm{e}+011.35610 \mathrm{e}+011.35610 \mathrm{e}+001.00000 \mathrm{e}-092.12000 \mathrm{e}-01$ $1.35610 \mathrm{e}+011.35610 \mathrm{e}+011.35610 \mathrm{e}+001.00000 \mathrm{e}-092.12000 \mathrm{e}-01$ $1.00000 \mathrm{e}-021.00000 \mathrm{e}-02$ 1.00000e-03 1.00000e-09 1.00000e-01 $1.00000 \mathrm{e}+001.00000 \mathrm{e}+001.00000 \mathrm{e}-011.00000 \mathrm{e}-091.00000 \mathrm{e}-01$ $1.00000 \mathrm{e}-05$ 1.00000e-05 1.00000e-06 1.00000e-09 1.00000e-01 $1.00000 \mathrm{e}+001.00000 \mathrm{e}+001.00000 \mathrm{e}-011.00000 \mathrm{e}-091.00000 \mathrm{e}-01$ Element: 1600 \# of layers: 9

Kx Ky Kz Ss Por

$1.35610 \mathrm{e}+011.35610 \mathrm{e}+011.35610 \mathrm{e}+00$ 1.00000e-09 2.12000e-01 $1.35610 \mathrm{e}+011.35610 \mathrm{e}+011.35610 \mathrm{e}+001.00000 \mathrm{e}-092.12000 \mathrm{e}-01$ $1.35610 \mathrm{e}+011.35610 \mathrm{e}+011.35610 \mathrm{e}+001.00000 \mathrm{e}-092.12000 \mathrm{e}-01$ $1.35610 \mathrm{e}+011.35610 \mathrm{e}+011.35610 \mathrm{e}+001.00000 \mathrm{e}-092.12000 \mathrm{e}-01$ $1.35610 \mathrm{e}+011.35610 \mathrm{e}+011.35610 \mathrm{e}+001.00000 \mathrm{e}-092.12000 \mathrm{e}-01$ $1.00000 \mathrm{e}-021.00000 \mathrm{e}-02$ 1.00000e-03 1.00000e-09 1.00000e-01 $1.00000 \mathrm{e}+001.00000 \mathrm{e}+001.00000 \mathrm{e}-011.00000 \mathrm{e}-091.00000 \mathrm{e}-01$ $1.00000 \mathrm{e}-05$ 1.00000e-05 1.00000e-06 1.00000e-09 1.00000e-01 $1.00000 \mathrm{e}+001.00000 \mathrm{e}+001.00000 \mathrm{e}-011.00000 \mathrm{e}-091.00000 \mathrm{e}-01$ Element: 1601 \# of layers: 9

Kx Ky Kz Ss Por

$1.35610 \mathrm{e}+011.35610 \mathrm{e}+011.35610 \mathrm{e}+001.00000 \mathrm{e}-092.12000 \mathrm{e}-01$ $1.35610 \mathrm{e}+011.35610 \mathrm{e}+011.35610 \mathrm{e}+001.00000 \mathrm{e}-092.12000 \mathrm{e}-01$ $1.35610 \mathrm{e}+011.35610 \mathrm{e}+011.35610 \mathrm{e}+001.00000 \mathrm{e}-092.12000 \mathrm{e}-01$ $1.35610 \mathrm{e}+011.35610 \mathrm{e}+011.35610 \mathrm{e}+001.00000 \mathrm{e}-092.12000 \mathrm{e}-01$ $1.35610 \mathrm{e}+011.35610 \mathrm{e}+011.35610 \mathrm{e}+001.00000 \mathrm{e}-092.12000 \mathrm{e}-01$ $1.00000 \mathrm{e}-021.00000 \mathrm{e}-02$ 1.00000e-03 1.00000e-09 1.00000e-01 $1.00000 \mathrm{e}+001.00000 \mathrm{e}+001.00000 \mathrm{e}-011.00000 \mathrm{e}-091.00000 \mathrm{e}-01$ $1.00000 \mathrm{e}-05$ 1.00000e-05 1.00000e-06 1.00000e-09 1.00000e-01 $1.00000 \mathrm{e}+001.00000 \mathrm{e}+001.00000 \mathrm{e}-011.00000 \mathrm{e}-091.00000 \mathrm{e}-01$ Element: 1602 \# of layers: 9

Kx Ky Kz Ss Por

$1.35610 \mathrm{e}+011.35610 \mathrm{e}+011.35610 \mathrm{e}+00$ 1.00000e-09 2.12000e-01 $1.35610 \mathrm{e}+011.35610 \mathrm{e}+011.35610 \mathrm{e}+001.00000 \mathrm{e}-092.12000 \mathrm{e}-01$ $1.35610 \mathrm{e}+011.35610 \mathrm{e}+011.35610 \mathrm{e}+001.00000 \mathrm{e}-092.12000 \mathrm{e}-01$ $1.35610 \mathrm{e}+011.35610 \mathrm{e}+011.35610 \mathrm{e}+001.00000 \mathrm{e}-092.12000 \mathrm{e}-01$ $1.35610 \mathrm{e}+011.35610 \mathrm{e}+011.35610 \mathrm{e}+001.00000 \mathrm{e}-092.12000 \mathrm{e}-01$ $1.00000 \mathrm{e}-011.00000 \mathrm{e}-011.00000 \mathrm{e}-021.00000 \mathrm{e}-091.00000 \mathrm{e}-01$ $1.00000 \mathrm{e}+001.00000 \mathrm{e}+001.00000 \mathrm{e}-011.00000 \mathrm{e}-091.00000 \mathrm{e}-01$ 
$1.00000 \mathrm{e}-05$ 1.00000e-05 1.00000e-06 1.00000e-09 1.00000e-01 $1.00000 \mathrm{e}+001.00000 \mathrm{e}+001.00000 \mathrm{e}-01$ 1.00000e-09 1.00000e-01 Element: 1603 \# of layers: 10

Kx Ky Kz Ss Por

3.39398e+02 3.39398e+02 3.39398e+01 1.00000e-09 7.00000e-02

$1.35610 \mathrm{e}+01$ 1.35610e+01 1.35610e+00 1.00000e-09 2.12000e-01

$1.35610 \mathrm{e}+01$ 1.35610e+01 1.35610e+00 1.00000e-09 2.12000e-01

$1.35610 \mathrm{e}+011.35610 \mathrm{e}+011.35610 \mathrm{e}+001.00000 \mathrm{e}-092.12000 \mathrm{e}-01$

$1.35610 \mathrm{e}+011.35610 \mathrm{e}+011.35610 \mathrm{e}+001.00000 \mathrm{e}-092.12000 \mathrm{e}-01$

$1.35610 \mathrm{e}+011.35610 \mathrm{e}+011.35610 \mathrm{e}+001.00000 \mathrm{e}-092.12000 \mathrm{e}-01$

$1.00000 \mathrm{e}-01$ 1.00000e-01 1.00000e-02 1.00000e-09 1.00000e-01

$1.00000 \mathrm{e}+001.00000 \mathrm{e}+001.00000 \mathrm{e}-011.00000 \mathrm{e}-091.00000 \mathrm{e}-01$

$1.00000 \mathrm{e}-05$ 1.00000e-05 1.00000e-06 1.00000e-09 1.00000e-01

$1.00000 \mathrm{e}+001.00000 \mathrm{e}+001.00000 \mathrm{e}-011.00000 \mathrm{e}-09$ 1.00000e-01

Element: 1604 \# of layers: 10

Kx Ky Kz Ss Por

3.39398e+02 3.39398e+02 3.39398e+01 1.00000e-09 7.00000e-02

$1.35610 \mathrm{e}+011.35610 \mathrm{e}+011.35610 \mathrm{e}+001.00000 \mathrm{e}-092.12000 \mathrm{e}-01$

$1.35610 \mathrm{e}+01$ 1.35610e+01 1.35610e+00 1.00000e-09 2.12000e-01

$1.35610 \mathrm{e}+011.35610 \mathrm{e}+011.35610 \mathrm{e}+001.00000 \mathrm{e}-092.12000 \mathrm{e}-01$

$1.35610 \mathrm{e}+011.35610 \mathrm{e}+011.35610 \mathrm{e}+001.00000 \mathrm{e}-092.12000 \mathrm{e}-01$

$1.35610 \mathrm{e}+011.35610 \mathrm{e}+011.35610 \mathrm{e}+001.00000 \mathrm{e}-092.12000 \mathrm{e}-01$

$1.00000 \mathrm{e}-011.00000 \mathrm{e}-011.00000 \mathrm{e}-021.00000 \mathrm{e}-091.00000 \mathrm{e}-01$

$1.00000 \mathrm{e}+001.00000 \mathrm{e}+001.00000 \mathrm{e}-011.00000 \mathrm{e}-091.00000 \mathrm{e}-01$

$1.00000 \mathrm{e}-05$ 1.00000e-05 1.00000e-06 1.00000e-09 1.00000e-01

$1.00000 \mathrm{e}+001.00000 \mathrm{e}+001.00000 \mathrm{e}-01$ 1.00000e-09 1.00000e-01

Element: 1605 \# of layers: 9

$\mathrm{Kx} \mathrm{Ky} \mathrm{Kz}$ Ss Por

$1.35610 \mathrm{e}+01$ 1.35610e+01 1.35610e+00 1.00000e-09 2.12000e-01

$1.35610 \mathrm{e}+011.35610 \mathrm{e}+011.35610 \mathrm{e}+001.00000 \mathrm{e}-092.12000 \mathrm{e}-01$

$1.35610 \mathrm{e}+01$ 1.35610e+01 1.35610e+00 1.00000e-09 2.12000e-01

$1.35610 \mathrm{e}+01$ 1.35610e+01 1.35610e+00 1.00000e-09 2.12000e-01

$1.35610 \mathrm{e}+011.35610 \mathrm{e}+011.35610 \mathrm{e}+001.00000 \mathrm{e}-092.12000 \mathrm{e}-01$

$1.00000 \mathrm{e}-02$ 1.00000e-02 1.00000e-03 1.00000e-09 1.00000e-01

$1.00000 \mathrm{e}+001.00000 \mathrm{e}+001.00000 \mathrm{e}-011.00000 \mathrm{e}-091.00000 \mathrm{e}-01$

1.00000e-05 1.00000e-05 1.00000e-06 1.00000e-09 1.00000e-01

$1.00000 \mathrm{e}+001.00000 \mathrm{e}+001.00000 \mathrm{e}-011.00000 \mathrm{e}-091.00000 \mathrm{e}-01$

Element: 1606 \# of layers: 9

$\mathrm{Kx} \mathrm{Ky} \mathrm{Kz}$ Ss Por

$1.35610 \mathrm{e}+01$ 1.35610e+01 1.35610e+00 1.00000e-09 2.12000e-01

$1.35610 \mathrm{e}+011.35610 \mathrm{e}+01$ 1.35610e+00 1.00000e-09 2.12000e-01

$1.35610 \mathrm{e}+011.35610 \mathrm{e}+011.35610 \mathrm{e}+001.00000 \mathrm{e}-092.12000 \mathrm{e}-01$

$1.35610 \mathrm{e}+01$ 1.35610e+01 1.35610e+00 1.00000e-09 2.12000e-01

$1.35610 \mathrm{e}+01$ 1.35610e+01 1.35610e+00 1.00000e-09 2.12000e-01 1.00000e-02 1.00000e-02 1.00000e-03 1.00000e-09 1.00000e-01

$1.00000 \mathrm{e}+001.00000 \mathrm{e}+001.00000 \mathrm{e}-011.00000 \mathrm{e}-091.00000 \mathrm{e}-01$ 
$1.00000 \mathrm{e}-05$ 1.00000e-05 1.00000e-06 1.00000e-09 1.00000e-01 $1.00000 \mathrm{e}+001.00000 \mathrm{e}+001.00000 \mathrm{e}-01$ 1.00000e-09 1.00000e-01 Element: 1607 \# of layers: 9

Kx Ky Kz Ss Por

$1.59918 \mathrm{e}+01$ 1.59918e+01 1.59918e+00 1.00000e-09 2.12000e-01 $1.59918 \mathrm{e}+01$ 1.59918e+01 1.59918e+00 1.00000e-09 2.12000e-01 $1.59918 \mathrm{e}+01$ 1.59918e+01 1.59918e+00 1.00000e-09 2.12000e-01 $1.59918 \mathrm{e}+011.59918 \mathrm{e}+011.59918 \mathrm{e}+001.00000 \mathrm{e}-092.12000 \mathrm{e}-01$ $1.59918 \mathrm{e}+01$ 1.59918e+01 1.59918e+00 1.00000e-09 2.12000e-01 $1.00000 \mathrm{e}-02$ 1.00000e-02 1.00000e-03 1.00000e-09 1.00000e-01 $1.00000 \mathrm{e}+001.00000 \mathrm{e}+001.00000 \mathrm{e}-011.00000 \mathrm{e}-091.00000 \mathrm{e}-01$ $1.00000 \mathrm{e}-05$ 1.00000e-05 1.00000e-06 1.00000e-09 1.00000e-01 $1.00000 \mathrm{e}+001.00000 \mathrm{e}+001.00000 \mathrm{e}-011.00000 \mathrm{e}-091.00000 \mathrm{e}-01$ Element: 1608 \# of layers: 9

$\mathrm{Kx} \mathrm{Ky} \mathrm{Kz}$ Ss Por

$1.59918 \mathrm{e}+01$ 1.59918e+01 1.59918e+00 1.00000e-09 2.12000e-01 $1.59918 \mathrm{e}+011.59918 \mathrm{e}+011.59918 \mathrm{e}+001.00000 \mathrm{e}-092.12000 \mathrm{e}-01$ $1.59918 \mathrm{e}+01$ 1.59918e+01 1.59918e+00 1.00000e-09 2.12000e-01 $1.59918 \mathrm{e}+01$ 1.59918e+01 1.59918e+00 1.00000e-09 2.12000e-01 $1.59918 \mathrm{e}+011.59918 \mathrm{e}+01 \quad 1.59918 \mathrm{e}+001.00000 \mathrm{e}-092.12000 \mathrm{e}-01$ $1.00000 \mathrm{e}-02$ 1.00000e-02 1.00000e-03 1.00000e-09 1.00000e-01 $1.00000 \mathrm{e}+001.00000 \mathrm{e}+001.00000 \mathrm{e}-011.00000 \mathrm{e}-091.00000 \mathrm{e}-01$ $1.00000 \mathrm{e}-05$ 1.00000e-05 1.00000e-06 1.00000e-09 1.00000e-01 $1.00000 \mathrm{e}+001.00000 \mathrm{e}+001.00000 \mathrm{e}-011.00000 \mathrm{e}-091.00000 \mathrm{e}-01$ Element: 1609 \# of layers: 9

$\mathrm{Kx} \mathrm{Ky} \mathrm{Kz}$ Ss Por

$1.59918 \mathrm{e}+01$ 1.59918e+01 1.59918e+00 1.00000e-09 2.12000e-01 $1.59918 \mathrm{e}+011.59918 \mathrm{e}+01$ 1.59918e+00 1.00000e-09 2.12000e-01 $1.59918 \mathrm{e}+01$ 1.59918e+01 1.59918e+00 1.00000e-09 2.12000e-01 $1.59918 \mathrm{e}+01$ 1.59918e+01 1.59918e+00 1.00000e-09 2.12000e-01 $1.59918 \mathrm{e}+011.59918 \mathrm{e}+01 \quad 1.59918 \mathrm{e}+001.00000 \mathrm{e}-092.12000 \mathrm{e}-01$ $1.00000 \mathrm{e}-02$ 1.00000e-02 1.00000e-03 1.00000e-09 1.00000e-01 $1.00000 \mathrm{e}+001.00000 \mathrm{e}+001.00000 \mathrm{e}-011.00000 \mathrm{e}-091.00000 \mathrm{e}-01$ $1.00000 \mathrm{e}-05$ 1.00000e-05 1.00000e-06 1.00000e-09 1.00000e-01 $1.00000 \mathrm{e}+001.00000 \mathrm{e}+001.00000 \mathrm{e}-011.00000 \mathrm{e}-091.00000 \mathrm{e}-01$ Element: 1610 \# of layers: 9

Kx Ky Kz Ss Por

$1.59918 \mathrm{e}+01$ 1.59918e+01 1.59918e+00 1.00000e-09 2.12000e-01 $1.59918 \mathrm{e}+01$ 1.59918e+01 1.59918e+00 1.00000e-09 2.12000e-01 $1.59918 \mathrm{e}+01$ 1.59918e+01 1.59918e+00 1.00000e-09 2.12000e-01 $1.59918 \mathrm{e}+01$ 1.59918e+01 1.59918e+00 1.00000e-09 2.12000e-01 $1.59918 \mathrm{e}+011.59918 \mathrm{e}+011.59918 \mathrm{e}+001.00000 \mathrm{e}-092.12000 \mathrm{e}-01$ $1.00000 \mathrm{e}-02$ 1.00000e-02 1.00000e-03 1.00000e-09 1.00000e-01 $1.00000 \mathrm{e}+001.00000 \mathrm{e}+001.00000 \mathrm{e}-011.00000 \mathrm{e}-091.00000 \mathrm{e}-01$ $1.00000 \mathrm{e}-05$ 1.00000e-05 1.00000e-06 1.00000e-09 1.00000e-01 $1.00000 \mathrm{e}+001.00000 \mathrm{e}+001.00000 \mathrm{e}-011.00000 \mathrm{e}-091.00000 \mathrm{e}-01$ 
Element: 1611 \# of layers: 9

$\mathrm{Kx} \mathrm{Ky} \mathrm{Kz}$ Ss Por

$1.59918 \mathrm{e}+01$ 1.59918e+01 1.59918e+00 1.00000e-09 2.12000e-01

$1.59918 \mathrm{e}+01$ 1.59918e+01 1.59918e+00 1.00000e-09 2.12000e-01

$1.59918 \mathrm{e}+01$ 1.59918e+01 1.59918e+00 1.00000e-09 2.12000e-01

$1.59918 \mathrm{e}+01$ 1.59918e+01 1.59918e+00 1.00000e-09 2.12000e-01

$1.59918 \mathrm{e}+011.59918 \mathrm{e}+01$ 1.59918e+00 1.00000e-09 2.12000e-01

$1.00000 \mathrm{e}-02$ 1.00000e-02 1.00000e-03 1.00000e-09 1.00000e-01

$1.00000 \mathrm{e}+001.00000 \mathrm{e}+001.00000 \mathrm{e}-011.00000 \mathrm{e}-091.00000 \mathrm{e}-01$

$1.00000 \mathrm{e}-05$ 1.00000e-05 1.00000e-06 1.00000e-09 1.00000e-01

$1.00000 \mathrm{e}+001.00000 \mathrm{e}+001.00000 \mathrm{e}-011.00000 \mathrm{e}-091.00000 \mathrm{e}-01$

Element: 1612 \# of layers: 9

$\mathrm{Kx} \mathrm{Ky} \mathrm{Kz}$ Ss Por

$1.59918 \mathrm{e}+01$ 1.59918e+01 1.59918e+00 1.00000e-09 2.12000e-01

$1.59918 \mathrm{e}+01$ 1.59918e+01 1.59918e+00 1.00000e-09 2.12000e-01

$1.59918 \mathrm{e}+01$ 1.59918e+01 1.59918e+00 1.00000e-09 2.12000e-01

$1.59918 \mathrm{e}+011.59918 \mathrm{e}+01$ 1.59918e+00 1.00000e-09 2.12000e-01

$1.59918 \mathrm{e}+01$ 1.59918e+01 1.59918e+00 1.00000e-09 2.12000e-01

$1.00000 \mathrm{e}-02$ 1.00000e-02 1.00000e-03 1.00000e-09 1.00000e-01

$1.00000 \mathrm{e}+001.00000 \mathrm{e}+001.00000 \mathrm{e}-011.00000 \mathrm{e}-091.00000 \mathrm{e}-01$

$1.00000 \mathrm{e}-05$ 1.00000e-05 1.00000e-06 1.00000e-09 1.00000e-01

$1.00000 \mathrm{e}+001.00000 \mathrm{e}+001.00000 \mathrm{e}-01$ 1.00000e-09 1.00000e-01

Element: 1613 \# of layers: 9

Kx Ky Kz Ss Por

$1.59918 \mathrm{e}+01$ 1.59918e+01 1.59918e+00 1.00000e-09 2.12000e-01

$1.59918 \mathrm{e}+01$ 1.59918e+01 1.59918e+00 1.00000e-09 2.12000e-01

$1.59918 \mathrm{e}+01$ 1.59918e+01 1.59918e+00 1.00000e-09 2.12000e-01

$1.59918 \mathrm{e}+01$ 1.59918e+01 1.59918e+00 1.00000e-09 2.12000e-01

$1.59918 \mathrm{e}+01$ 1.59918e+01 1.59918e+00 1.00000e-09 2.12000e-01

$1.00000 \mathrm{e}-02$ 1.00000e-02 1.00000e-03 1.00000e-09 1.00000e-01

$1.00000 \mathrm{e}+001.00000 \mathrm{e}+001.00000 \mathrm{e}-011.00000 \mathrm{e}-091.00000 \mathrm{e}-01$

$1.00000 \mathrm{e}-05$ 1.00000e-05 1.00000e-06 1.00000e-09 1.00000e-01

$1.00000 \mathrm{e}+001.00000 \mathrm{e}+001.00000 \mathrm{e}-011.00000 \mathrm{e}-091.00000 \mathrm{e}-01$

Element: 1614 \# of layers: 9

Kx Ky Kz Ss Por

$1.59918 \mathrm{e}+01$ 1.59918e+01 1.59918e+00 1.00000e-09 2.12000e-01

$1.59918 \mathrm{e}+01$ 1.59918e+01 1.59918e+00 1.00000e-09 2.12000e-01

$1.59918 \mathrm{e}+011.59918 \mathrm{e}+01$ 1.59918e+00 1.00000e-09 2.12000e-01

$1.59918 \mathrm{e}+01$ 1.59918e+01 1.59918e+00 1.00000e-09 2.12000e-01

$1.59918 \mathrm{e}+011.59918 \mathrm{e}+01$ 1.59918e+00 1.00000e-09 2.12000e-01 $1.00000 \mathrm{e}-02$ 1.00000e-02 1.00000e-03 1.00000e-09 1.00000e-01

$1.00000 \mathrm{e}+001.00000 \mathrm{e}+001.00000 \mathrm{e}-011.00000 \mathrm{e}-091.00000 \mathrm{e}-01$ $1.00000 \mathrm{e}-05$ 1.00000e-05 1.00000e-06 1.00000e-09 1.00000e-01

$1.00000 \mathrm{e}+001.00000 \mathrm{e}+001.00000 \mathrm{e}-01$ 1.00000e-09 1.00000e-01

Element: 1615 \# of layers: 9

Kx Ky Kz Ss Por 
$1.59918 \mathrm{e}+01$ 1.59918e+01 1.59918e+00 1.00000e-09 2.12000e-01 $1.59918 \mathrm{e}+01$ 1.59918e+01 1.59918e+00 1.00000e-09 2.12000e-01 $1.59918 \mathrm{e}+011.59918 \mathrm{e}+01$ 1.59918e+00 1.00000e-09 2.12000e-01 $1.59918 \mathrm{e}+01$ 1.59918e+01 1.59918e+00 1.00000e-09 2.12000e-01 $1.59918 \mathrm{e}+011.59918 \mathrm{e}+01$ 1.59918e+00 1.00000e-09 2.12000e-01 $1.00000 \mathrm{e}-02$ 1.00000e-02 1.00000e-03 1.00000e-09 1.00000e-01 $1.00000 \mathrm{e}+001.00000 \mathrm{e}+001.00000 \mathrm{e}-011.00000 \mathrm{e}-091.00000 \mathrm{e}-01$ $1.00000 \mathrm{e}-05$ 1.00000e-05 1.00000e-06 1.00000e-09 1.00000e-01 $1.00000 \mathrm{e}+001.00000 \mathrm{e}+001.00000 \mathrm{e}-011.00000 \mathrm{e}-091.00000 \mathrm{e}-01$ Element: 1616 \# of layers: 9

$\mathrm{Kx} \mathrm{Ky} \mathrm{Kz}$ Ss Por

$2.22642 \mathrm{e}+012.22642 \mathrm{e}+012.22642 \mathrm{e}+00$ 1.00000e-09 2.12000e-01 $2.22642 \mathrm{e}+012.22642 \mathrm{e}+012.22642 \mathrm{e}+00$ 1.00000e-09 2.12000e-01 $2.22642 \mathrm{e}+012.22642 \mathrm{e}+012.22642 \mathrm{e}+00$ 1.00000e-09 2.12000e-01 $2.22642 \mathrm{e}+012.22642 \mathrm{e}+012.22642 \mathrm{e}+00$ 1.00000e-09 2.12000e-01 $2.22642 \mathrm{e}+012.22642 \mathrm{e}+012.22642 \mathrm{e}+00$ 1.00000e-09 2.12000e-01 $1.00000 \mathrm{e}-02$ 1.00000e-02 1.00000e-03 1.00000e-09 1.00000e-01 $1.00000 \mathrm{e}+001.00000 \mathrm{e}+001.00000 \mathrm{e}-011.00000 \mathrm{e}-091.00000 \mathrm{e}-01$ $1.00000 \mathrm{e}-05$ 1.00000e-05 1.00000e-06 1.00000e-09 1.00000e-01 $1.00000 \mathrm{e}+001.00000 \mathrm{e}+001.00000 \mathrm{e}-011.00000 \mathrm{e}-091.00000 \mathrm{e}-01$ Element: 1617 \# of layers: 9

$\mathrm{Kx} \mathrm{Ky} \mathrm{Kz}$ Ss Por

2.22642e+01 2.22642e+01 2.22642e+00 1.00000e-09 2.12000e-01 $2.22642 \mathrm{e}+012.22642 \mathrm{e}+012.22642 \mathrm{e}+00$ 1.00000e-09 2.12000e-01 $2.22642 \mathrm{e}+012.22642 \mathrm{e}+012.22642 \mathrm{e}+001.00000 \mathrm{e}-092.12000 \mathrm{e}-01$ $2.22642 \mathrm{e}+012.22642 \mathrm{e}+012.22642 \mathrm{e}+00$ 1.00000e-09 2.12000e-01 $2.22642 \mathrm{e}+012.22642 \mathrm{e}+012.22642 \mathrm{e}+00$ 1.00000e-09 2.12000e-01 $1.00000 \mathrm{e}-02$ 1.00000e-02 1.00000e-03 1.00000e-09 1.00000e-01 $1.00000 \mathrm{e}+001.00000 \mathrm{e}+001.00000 \mathrm{e}-011.00000 \mathrm{e}-091.00000 \mathrm{e}-01$ $1.00000 \mathrm{e}-05$ 1.00000e-05 1.00000e-06 1.00000e-09 1.00000e-01 $1.00000 \mathrm{e}+001.00000 \mathrm{e}+001.00000 \mathrm{e}-011.00000 \mathrm{e}-091.00000 \mathrm{e}-01$ Element: 1618 \# of layers: 9

$\mathrm{Kx} \mathrm{Ky} \mathrm{Kz}$ Ss Por

$2.22642 \mathrm{e}+012.22642 \mathrm{e}+012.22642 \mathrm{e}+00$ 1.00000e-09 2.12000e-01 $2.22642 \mathrm{e}+012.22642 \mathrm{e}+012.22642 \mathrm{e}+00$ 1.00000e-09 2.12000e-01 $2.22642 \mathrm{e}+012.22642 \mathrm{e}+012.22642 \mathrm{e}+00$ 1.00000e-09 2.12000e-01 $2.22642 \mathrm{e}+012.22642 \mathrm{e}+012.22642 \mathrm{e}+00$ 1.00000e-09 2.12000e-01 $2.22642 \mathrm{e}+012.22642 \mathrm{e}+012.22642 \mathrm{e}+00$ 1.00000e-09 2.12000e-01 $1.00000 \mathrm{e}-02$ 1.00000e-02 1.00000e-03 1.00000e-09 1.00000e-01 $1.00000 \mathrm{e}+001.00000 \mathrm{e}+001.00000 \mathrm{e}-011.00000 \mathrm{e}-091.00000 \mathrm{e}-01$ $1.00000 \mathrm{e}-05$ 1.00000e-05 1.00000e-06 1.00000e-09 1.00000e-01 $1.00000 \mathrm{e}+001.00000 \mathrm{e}+001.00000 \mathrm{e}-011.00000 \mathrm{e}-091.00000 \mathrm{e}-01$ Element: 1619 \# of layers: 8

$\mathrm{Kx} \mathrm{Ky} \mathrm{Kz}$ Ss Por

$2.22642 \mathrm{e}+012.22642 \mathrm{e}+012.22642 \mathrm{e}+00$ 1.00000e-09 2.12000e-01 $2.22642 \mathrm{e}+012.22642 \mathrm{e}+012.22642 \mathrm{e}+001.00000 \mathrm{e}-092.12000 \mathrm{e}-01$ 
$2.22642 \mathrm{e}+012.22642 \mathrm{e}+012.22642 \mathrm{e}+00$ 1.00000e-09 2.12000e-01 $2.22642 \mathrm{e}+012.22642 \mathrm{e}+012.22642 \mathrm{e}+00$ 1.00000e-09 2.12000e-01 $1.00000 \mathrm{e}-021.00000 \mathrm{e}-02$ 1.00000e-03 1.00000e-09 1.00000e-01 $1.00000 \mathrm{e}+001.00000 \mathrm{e}+001.00000 \mathrm{e}-011.00000 \mathrm{e}-091.00000 \mathrm{e}-01$ $1.00000 \mathrm{e}-05$ 1.00000e-05 1.00000e-06 1.00000e-09 1.00000e-01 $1.00000 \mathrm{e}+001.00000 \mathrm{e}+001.00000 \mathrm{e}-011.00000 \mathrm{e}-091.00000 \mathrm{e}-01$ Element: 1620 \# of layers: 8

Kx Ky Kz Ss Por

$2.22642 \mathrm{e}+012.22642 \mathrm{e}+012.22642 \mathrm{e}+00$ 1.00000e-09 2.12000e-01 $2.22642 \mathrm{e}+012.22642 \mathrm{e}+012.22642 \mathrm{e}+001.00000 \mathrm{e}-092.12000 \mathrm{e}-01$ $2.22642 \mathrm{e}+012.22642 \mathrm{e}+012.22642 \mathrm{e}+001.00000 \mathrm{e}-092.12000 \mathrm{e}-01$ $2.22642 \mathrm{e}+012.22642 \mathrm{e}+012.22642 \mathrm{e}+001.00000 \mathrm{e}-092.12000 \mathrm{e}-01$ $1.00000 \mathrm{e}-021.00000 \mathrm{e}-02$ 1.00000e-03 1.00000e-09 1.00000e-01 $1.00000 \mathrm{e}+001.00000 \mathrm{e}+001.00000 \mathrm{e}-011.00000 \mathrm{e}-091.00000 \mathrm{e}-01$ $1.00000 \mathrm{e}-05$ 1.00000e-05 1.00000e-06 1.00000e-09 1.00000e-01 $1.00000 \mathrm{e}+001.00000 \mathrm{e}+001.00000 \mathrm{e}-011.00000 \mathrm{e}-091.00000 \mathrm{e}-01$ Element: 1621 \# of layers: 9

Kx Ky Kz Ss Por

$2.22642 \mathrm{e}+012.22642 \mathrm{e}+012.22642 \mathrm{e}+00$ 1.00000e-09 2.12000e-01 $2.22642 \mathrm{e}+012.22642 \mathrm{e}+012.22642 \mathrm{e}+00$ 1.00000e-09 2.12000e-01 $2.22642 \mathrm{e}+012.22642 \mathrm{e}+012.22642 \mathrm{e}+001.00000 \mathrm{e}-092.12000 \mathrm{e}-01$ $2.22642 \mathrm{e}+012.22642 \mathrm{e}+012.22642 \mathrm{e}+00$ 1.00000e-09 2.12000e-01 $2.22642 \mathrm{e}+012.22642 \mathrm{e}+012.22642 \mathrm{e}+00$ 1.00000e-09 2.12000e-01 $1.00000 \mathrm{e}-021.00000 \mathrm{e}-02$ 1.00000e-03 1.00000e-09 1.00000e-01 $1.00000 \mathrm{e}+001.00000 \mathrm{e}+001.00000 \mathrm{e}-011.00000 \mathrm{e}-091.00000 \mathrm{e}-01$ $1.00000 \mathrm{e}-05$ 1.00000e-05 1.00000e-06 1.00000e-09 1.00000e-01 $1.00000 \mathrm{e}+001.00000 \mathrm{e}+001.00000 \mathrm{e}-011.00000 \mathrm{e}-091.00000 \mathrm{e}-01$ Element: 1622 \# of layers: 9

Kx Ky Kz Ss Por

$2.22642 \mathrm{e}+012.22642 \mathrm{e}+012.22642 \mathrm{e}+00$ 1.00000e-09 2.12000e-01 $2.22642 \mathrm{e}+012.22642 \mathrm{e}+012.22642 \mathrm{e}+00$ 1.00000e-09 2.12000e-01 $2.22642 \mathrm{e}+012.22642 \mathrm{e}+012.22642 \mathrm{e}+00$ 1.00000e-09 2.12000e-01 $2.22642 \mathrm{e}+012.22642 \mathrm{e}+012.22642 \mathrm{e}+00$ 1.00000e-09 2.12000e-01 $2.22642 \mathrm{e}+012.22642 \mathrm{e}+012.22642 \mathrm{e}+00$ 1.00000e-09 2.12000e-01 $1.00000 \mathrm{e}-021.00000 \mathrm{e}-02$ 1.00000e-03 1.00000e-09 1.00000e-01 $1.00000 \mathrm{e}+001.00000 \mathrm{e}+001.00000 \mathrm{e}-011.00000 \mathrm{e}-091.00000 \mathrm{e}-01$ $1.00000 \mathrm{e}-05$ 1.00000e-05 1.00000e-06 1.00000e-09 1.00000e-01 $1.00000 \mathrm{e}+001.00000 \mathrm{e}+001.00000 \mathrm{e}-011.00000 \mathrm{e}-091.00000 \mathrm{e}-01$ Element: 1623 \# of layers: 9

Kx Ky Kz Ss Por

$2.22642 \mathrm{e}+012.22642 \mathrm{e}+012.22642 \mathrm{e}+00$ 1.00000e-09 2.12000e-01 $2.22642 \mathrm{e}+012.22642 \mathrm{e}+012.22642 \mathrm{e}+00 \quad 1.00000 \mathrm{e}-092.12000 \mathrm{e}-01$ $2.22642 \mathrm{e}+012.22642 \mathrm{e}+012.22642 \mathrm{e}+00$ 1.00000e-09 2.12000e-01 $2.22642 \mathrm{e}+012.22642 \mathrm{e}+012.22642 \mathrm{e}+001.00000 \mathrm{e}-092.12000 \mathrm{e}-01$ $2.22642 \mathrm{e}+012.22642 \mathrm{e}+012.22642 \mathrm{e}+00$ 1.00000e-09 2.12000e-01 $1.00000 \mathrm{e}-021.00000 \mathrm{e}-02$ 1.00000e-03 1.00000e-09 1.00000e-01 
$1.00000 \mathrm{e}+001.00000 \mathrm{e}+001.00000 \mathrm{e}-011.00000 \mathrm{e}-091.00000 \mathrm{e}-01$ $1.00000 \mathrm{e}-05$ 1.00000e-05 1.00000e-06 1.00000e-09 1.00000e-01 $1.00000 \mathrm{e}+001.00000 \mathrm{e}+001.00000 \mathrm{e}-01$ 1.00000e-09 1.00000e-01 Element: 1624 \# of layers: 9

$\mathrm{Kx} \mathrm{Ky} \mathrm{Kz}$ Ss Por

$2.22642 \mathrm{e}+012.22642 \mathrm{e}+01$ 2.22642e+00 1.00000e-09 2.12000e-01 $2.22642 \mathrm{e}+012.22642 \mathrm{e}+012.22642 \mathrm{e}+00$ 1.00000e-09 2.12000e-01 $2.22642 \mathrm{e}+012.22642 \mathrm{e}+012.22642 \mathrm{e}+00$ 1.00000e-09 2.12000e-01 $2.22642 \mathrm{e}+012.22642 \mathrm{e}+012.22642 \mathrm{e}+001.00000 \mathrm{e}-092.12000 \mathrm{e}-01$ $2.22642 \mathrm{e}+012.22642 \mathrm{e}+012.22642 \mathrm{e}+00$ 1.00000e-09 2.12000e-01 $1.00000 \mathrm{e}-02$ 1.00000e-02 1.00000e-03 1.00000e-09 1.00000e-01 $1.00000 \mathrm{e}+001.00000 \mathrm{e}+001.00000 \mathrm{e}-011.00000 \mathrm{e}-091.00000 \mathrm{e}-01$ $1.00000 \mathrm{e}-051.00000 \mathrm{e}-05$ 1.00000e-06 1.00000e-09 1.00000e-01 $1.00000 \mathrm{e}+001.00000 \mathrm{e}+001.00000 \mathrm{e}-011.00000 \mathrm{e}-091.00000 \mathrm{e}-01$ Element: 1625 \# of layers: 8

$\mathrm{Kx} \mathrm{Ky} \mathrm{Kz}$ Ss Por

$1.80699 \mathrm{e}+01$ 1.80699e+01 1.80699e+00 1.00000e-09 2.12000e-01 $1.80699 \mathrm{e}+01$ 1.80699e+01 1.80699e+00 1.00000e-09 2.12000e-01 $1.80699 \mathrm{e}+01$ 1.80699e+01 1.80699e+00 1.00000e-09 2.12000e-01 $1.80699 \mathrm{e}+01$ 1.80699e+01 1.80699e+00 1.00000e-09 2.12000e-01 $1.00000 \mathrm{e}-02$ 1.00000e-02 1.00000e-03 1.00000e-09 1.00000e-01 $1.00000 \mathrm{e}+001.00000 \mathrm{e}+001.00000 \mathrm{e}-011.00000 \mathrm{e}-091.00000 \mathrm{e}-01$ $1.00000 \mathrm{e}-05$ 1.00000e-05 1.00000e-06 1.00000e-09 1.00000e-01 $1.00000 \mathrm{e}+001.00000 \mathrm{e}+001.00000 \mathrm{e}-011.00000 \mathrm{e}-09$ 1.00000e-01 Element: 1626 \# of layers: 9

$\mathrm{Kx} \mathrm{Ky} \mathrm{Kz}$ Ss Por

4.52239e+02 4.52239e+02 4.52239e+01 1.00000e-09 7.00000e-02 $1.80699 \mathrm{e}+01$ 1.80699e+01 1.80699e+00 1.00000e-09 2.12000e-01 $1.80699 \mathrm{e}+01$ 1.80699e+01 1.80699e+00 1.00000e-09 2.12000e-01 $1.80699 \mathrm{e}+011.80699 \mathrm{e}+01$ 1.80699e+00 1.00000e-09 2.12000e-01 $1.80699 \mathrm{e}+01$ 1.80699e+01 1.80699e+00 1.00000e-09 2.12000e-01 $1.00000 \mathrm{e}-02$ 1.00000e-02 1.00000e-03 1.00000e-09 1.00000e-01 $1.00000 \mathrm{e}+001.00000 \mathrm{e}+001.00000 \mathrm{e}-011.00000 \mathrm{e}-091.00000 \mathrm{e}-01$ $1.00000 \mathrm{e}-05$ 1.00000e-05 1.00000e-06 1.00000e-09 1.00000e-01 $1.00000 \mathrm{e}+001.00000 \mathrm{e}+001.00000 \mathrm{e}-01$ 1.00000e-09 1.00000e-01 Element: 1627 \# of layers: 8

Kx Ky Kz Ss Por

4.52239e+02 4.52239e+02 4.52239e+01 1.00000e-09 7.00000e-02 $1.80699 \mathrm{e}+01$ 1.80699e+01 1.80699e+00 1.00000e-09 2.12000e-01 $1.80699 \mathrm{e}+01$ 1.80699e+01 1.80699e+00 1.00000e-09 2.12000e-01 $1.80699 \mathrm{e}+01$ 1.80699e+01 1.80699e+00 1.00000e-09 2.12000e-01 $1.00000 \mathrm{e}-02$ 1.00000e-02 1.00000e-03 1.00000e-09 1.00000e-01 $1.00000 \mathrm{e}+001.00000 \mathrm{e}+001.00000 \mathrm{e}-011.00000 \mathrm{e}-091.00000 \mathrm{e}-01$ $1.00000 \mathrm{e}-05$ 1.00000e-05 1.00000e-06 1.00000e-09 1.00000e-01 $1.00000 \mathrm{e}+001.00000 \mathrm{e}+001.00000 \mathrm{e}-011.00000 \mathrm{e}-091.00000 \mathrm{e}-01$ Element: 1628 \# of layers: 8 
$\mathrm{Kx} \mathrm{Ky} \mathrm{Kz}$ Ss Por

4.52239e+02 4.52239e+02 4.52239e+01 1.00000e-09 7.00000e-02

$1.80699 \mathrm{e}+01$ 1.80699e+01 1.80699e+00 1.00000e-09 2.12000e-01

$1.80699 \mathrm{e}+011.80699 \mathrm{e}+011.80699 \mathrm{e}+001.00000 \mathrm{e}-092.12000 \mathrm{e}-01$

$1.80699 \mathrm{e}+011.80699 \mathrm{e}+011.80699 \mathrm{e}+001.00000 \mathrm{e}-092.12000 \mathrm{e}-01$

$1.00000 \mathrm{e}-02$ 1.00000e-02 1.00000e-03 1.00000e-09 1.00000e-01

$1.00000 \mathrm{e}+001.00000 \mathrm{e}+001.00000 \mathrm{e}-011.00000 \mathrm{e}-091.00000 \mathrm{e}-01$

$1.00000 \mathrm{e}-05$ 1.00000e-05 1.00000e-06 1.00000e-09 1.00000e-01

$1.00000 \mathrm{e}+001.00000 \mathrm{e}+001.00000 \mathrm{e}-011.00000 \mathrm{e}-091.00000 \mathrm{e}-01$

Element: 1629 \# of layers: 8

$\mathrm{Kx} \mathrm{Ky} \mathrm{Kz}$ Ss Por

4.52239e+02 4.52239e+02 4.52239e+01 1.00000e-09 7.00000e-02

$1.80699 \mathrm{e}+01$ 1.80699e+01 1.80699e+00 1.00000e-09 2.12000e-01

$1.80699 \mathrm{e}+01$ 1.80699e+01 1.80699e+00 1.00000e-09 2.12000e-01

$1.80699 \mathrm{e}+01$ 1.80699e+01 1.80699e+00 1.00000e-09 2.12000e-01

$1.00000 \mathrm{e}-02$ 1.00000e-02 1.00000e-03 1.00000e-09 1.00000e-01

$1.00000 \mathrm{e}+001.00000 \mathrm{e}+001.00000 \mathrm{e}-011.00000 \mathrm{e}-091.00000 \mathrm{e}-01$

$1.00000 \mathrm{e}-05$ 1.00000e-05 1.00000e-06 1.00000e-09 1.00000e-01

$1.00000 \mathrm{e}+001.00000 \mathrm{e}+001.00000 \mathrm{e}-011.00000 \mathrm{e}-091.00000 \mathrm{e}-01$

Element: 1630 \# of layers: 8

$\mathrm{Kx} \mathrm{Ky} \mathrm{Kz}$ Ss Por

$1.80699 \mathrm{e}+01$ 1.80699e+01 1.80699e+00 1.00000e-09 2.12000e-01

$1.80699 \mathrm{e}+01$ 1.80699e+01 1.80699e+00 1.00000e-09 2.12000e-01

$1.80699 \mathrm{e}+01$ 1.80699e+01 1.80699e+00 1.00000e-09 2.12000e-01

$1.80699 \mathrm{e}+011.80699 \mathrm{e}+011.80699 \mathrm{e}+001.00000 \mathrm{e}-092.12000 \mathrm{e}-01$

$1.00000 \mathrm{e}-02$ 1.00000e-02 1.00000e-03 1.00000e-09 1.00000e-01

$1.00000 \mathrm{e}+001.00000 \mathrm{e}+001.00000 \mathrm{e}-011.00000 \mathrm{e}-091.00000 \mathrm{e}-01$

$1.00000 \mathrm{e}-05$ 1.00000e-05 1.00000e-06 1.00000e-09 1.00000e-01

$1.00000 \mathrm{e}+001.00000 \mathrm{e}+001.00000 \mathrm{e}-011.00000 \mathrm{e}-091.00000 \mathrm{e}-01$

Element: 1631 \# of layers: 8

$\mathrm{Kx} \mathrm{Ky} \mathrm{Kz}$ Ss Por

$1.80699 \mathrm{e}+01$ 1.80699e+01 1.80699e+00 1.00000e-09 2.12000e-01

$1.80699 \mathrm{e}+011.80699 \mathrm{e}+011.80699 \mathrm{e}+001.00000 \mathrm{e}-092.12000 \mathrm{e}-01$

$1.80699 \mathrm{e}+011.80699 \mathrm{e}+01$ 1.80699e+00 1.00000e-09 2.12000e-01

$1.80699 \mathrm{e}+01$ 1.80699e+01 1.80699e+00 1.00000e-09 2.12000e-01

1.00000e-02 1.00000e-02 1.00000e-03 1.00000e-09 1.00000e-01

$1.00000 \mathrm{e}+001.00000 \mathrm{e}+001.00000 \mathrm{e}-011.00000 \mathrm{e}-091.00000 \mathrm{e}-01$

$1.00000 \mathrm{e}-05$ 1.00000e-05 1.00000e-06 1.00000e-09 1.00000e-01

$1.00000 \mathrm{e}+001.00000 \mathrm{e}+001.00000 \mathrm{e}-011.00000 \mathrm{e}-09$ 1.00000e-01

Element: 1632 \# of layers: 8

$\mathrm{Kx} \mathrm{Ky} \mathrm{Kz}$ Ss Por

$1.80699 \mathrm{e}+01$ 1.80699e+01 1.80699e+00 1.00000e-09 2.12000e-01

$1.80699 \mathrm{e}+011.80699 \mathrm{e}+01$ 1.80699e+00 1.00000e-09 2.12000e-01

$1.80699 \mathrm{e}+01$ 1.80699e+01 1.80699e+00 1.00000e-09 2.12000e-01

$1.80699 \mathrm{e}+011.80699 \mathrm{e}+01$ 1.80699e+00 1.00000e-09 2.12000e-01

$1.00000 \mathrm{e}-02$ 1.00000e-02 1.00000e-03 1.00000e-09 1.00000e-01 
$1.00000 \mathrm{e}+001.00000 \mathrm{e}+001.00000 \mathrm{e}-011.00000 \mathrm{e}-091.00000 \mathrm{e}-01$ $1.00000 \mathrm{e}-05$ 1.00000e-05 1.00000e-06 1.00000e-09 1.00000e-01 $1.00000 \mathrm{e}+001.00000 \mathrm{e}+001.00000 \mathrm{e}-01$ 1.00000e-09 1.00000e-01 Element: 1633 \# of layers: 9

$\mathrm{Kx} \mathrm{Ky} \mathrm{Kz}$ Ss Por

4.52239e+02 4.52239e+02 4.52239e+01 1.00000e-09 7.00000e-02 $1.80699 \mathrm{e}+01$ 1.80699e+01 1.80699e+00 1.00000e-09 2.12000e-01 $1.80699 \mathrm{e}+01$ 1.80699e+01 1.80699e+00 1.00000e-09 2.12000e-01 $1.80699 \mathrm{e}+01$ 1.80699e+01 1.80699e+00 1.00000e-09 2.12000e-01 $1.80699 \mathrm{e}+01$ 1.80699e+01 1.80699e+00 1.00000e-09 2.12000e-01 $1.00000 \mathrm{e}-02$ 1.00000e-02 1.00000e-03 1.00000e-09 1.00000e-01 $1.00000 \mathrm{e}+001.00000 \mathrm{e}+001.00000 \mathrm{e}-011.00000 \mathrm{e}-091.00000 \mathrm{e}-01$ 1.00000e-05 1.00000e-05 1.00000e-06 1.00000e-09 1.00000e-01 $1.00000 \mathrm{e}+001.00000 \mathrm{e}+001.00000 \mathrm{e}-01$ 1.00000e-09 1.00000e-01 Element: 1634 \# of layers: 8

Kx Ky Kz Ss Por

$1.42160 \mathrm{e}+02$ 1.42160e+02 1.42160e+01 1.00000e-09 7.00000e-02

5.68002e+00 5.68002e+00 5.68002e-01 1.00000e-09 2.12000e-01

5.68002e+00 5.68002e+00 5.68002e-01 1.00000e-09 2.12000e-01

$5.68002 \mathrm{e}+005.68002 \mathrm{e}+00$ 5.68002e-01 1.00000e-09 2.12000e-01

$1.00000 \mathrm{e}-02$ 1.00000e-02 1.00000e-03 1.00000e-09 1.00000e-01

$1.00000 \mathrm{e}+001.00000 \mathrm{e}+001.00000 \mathrm{e}-011.00000 \mathrm{e}-091.00000 \mathrm{e}-01$

$1.00000 \mathrm{e}-05$ 1.00000e-05 1.00000e-06 1.00000e-09 1.00000e-01

$1.00000 \mathrm{e}+001.00000 \mathrm{e}+001.00000 \mathrm{e}-011.00000 \mathrm{e}-09$ 1.00000e-01

Element: 1635 \# of layers: 9

$\mathrm{Kx} \mathrm{Ky} \mathrm{Kz}$ Ss Por

$1.42160 \mathrm{e}+02$ 1.42160e+02 1.42160e+01 1.00000e-09 7.00000e-02 $1.42160 \mathrm{e}+021.42160 \mathrm{e}+02 \quad 1.42160 \mathrm{e}+01$ 1.00000e-09 7.00000e-02 $5.68002 \mathrm{e}+00$ 5.68002e+00 5.68002e-01 1.00000e-09 2.12000e-01 $5.68002 \mathrm{e}+00$ 5.68002e+00 5.68002e-01 1.00000e-09 2.12000e-01 $5.68002 \mathrm{e}+005.68002 \mathrm{e}+00$ 5.68002e-01 1.00000e-09 2.12000e-01 1.00000e-01 1.00000e-01 1.00000e-02 1.00000e-09 1.00000e-01 $1.00000 \mathrm{e}+001.00000 \mathrm{e}+001.00000 \mathrm{e}-011.00000 \mathrm{e}-091.00000 \mathrm{e}-01$ $1.00000 \mathrm{e}-051.00000 \mathrm{e}-051.00000 \mathrm{e}-061.00000 \mathrm{e}-091.00000 \mathrm{e}-01$ $1.00000 \mathrm{e}+001.00000 \mathrm{e}+001.00000 \mathrm{e}-01$ 1.00000e-09 1.00000e-01 Element: 1636 \# of layers: 7

Kx Ky Kz Ss Por

$1.42160 \mathrm{e}+02$ 1.42160e+02 1.42160e+01 1.00000e-09 7.00000e-02

$5.68002 \mathrm{e}+005.68002 \mathrm{e}+00$ 5.68002e-01 1.00000e-09 2.12000e-01

5.68002e+00 5.68002e+00 5.68002e-01 1.00000e-09 2.12000e-01 1.00000e-01 1.00000e-01 1.00000e-02 1.00000e-09 1.00000e-01 $1.00000 \mathrm{e}+001.00000 \mathrm{e}+001.00000 \mathrm{e}-011.00000 \mathrm{e}-091.00000 \mathrm{e}-01$ $1.00000 \mathrm{e}-05$ 1.00000e-05 1.00000e-06 1.00000e-09 1.00000e-01 $1.00000 \mathrm{e}+001.00000 \mathrm{e}+001.00000 \mathrm{e}-01$ 1.00000e-09 1.00000e-01 Element: 1637 \# of layers: 7

Kx Ky Kz Ss Por 
$1.42160 \mathrm{e}+021.42160 \mathrm{e}+02$ 1.42160e+01 1.00000e-09 7.00000e-02 $5.68002 \mathrm{e}+00$ 5.68002e+00 5.68002e-01 1.00000e-09 2.12000e-01 5.68002e+00 5.68002e+00 5.68002e-01 1.00000e-09 2.12000e-01 $1.00000 \mathrm{e}-011.00000 \mathrm{e}-01$ 1.00000e-02 1.00000e-09 1.00000e-01 $1.00000 \mathrm{e}+001.00000 \mathrm{e}+001.00000 \mathrm{e}-011.00000 \mathrm{e}-091.00000 \mathrm{e}-01$ $1.00000 \mathrm{e}-05$ 1.00000e-05 1.00000e-06 1.00000e-09 1.00000e-01 $1.00000 \mathrm{e}+001.00000 \mathrm{e}+001.00000 \mathrm{e}-011.00000 \mathrm{e}-091.00000 \mathrm{e}-01$ Element: 1638 \# of layers: 7

$\mathrm{Kx} \mathrm{Ky} \mathrm{Kz}$ Ss Por

$1.42160 \mathrm{e}+021.42160 \mathrm{e}+02$ 1.42160e+01 1.00000e-09 7.00000e-02 $5.68002 \mathrm{e}+005.68002 \mathrm{e}+00$ 5.68002e-01 1.00000e-09 2.12000e-01

$5.68002 \mathrm{e}+00$ 5.68002e+00 5.68002e-01 1.00000e-09 2.12000e-01 $1.00000 \mathrm{e}-01$ 1.00000e-01 1.00000e-02 1.00000e-09 1.00000e-01 $1.00000 \mathrm{e}+001.00000 \mathrm{e}+001.00000 \mathrm{e}-011.00000 \mathrm{e}-091.00000 \mathrm{e}-01$ $1.00000 \mathrm{e}-05$ 1.00000e-05 1.00000e-06 1.00000e-09 1.00000e-01 $1.00000 \mathrm{e}+001.00000 \mathrm{e}+001.00000 \mathrm{e}-011.00000 \mathrm{e}-091.00000 \mathrm{e}-01$ Element: 1639 \# of layers: 9

$\mathrm{Kx} \mathrm{Ky} \mathrm{Kz}$ Ss Por

1.42160e+02 1.42160e+02 1.42160e+01 1.00000e-09 7.00000e-02 $1.42160 \mathrm{e}+02 \quad 1.42160 \mathrm{e}+02 \quad 1.42160 \mathrm{e}+01$ 1.00000e-09 7.00000e-02 $5.68002 \mathrm{e}+00$ 5.68002e+00 5.68002e-01 1.00000e-09 2.12000e-01 5.68002e+00 5.68002e+00 5.68002e-01 1.00000e-09 2.12000e-01 5.68002e+00 5.68002e+00 5.68002e-01 1.00000e-09 2.12000e-01 $1.00000 \mathrm{e}-011.00000 \mathrm{e}-01$ 1.00000e-02 1.00000e-09 1.00000e-01 $1.00000 \mathrm{e}+001.00000 \mathrm{e}+001.00000 \mathrm{e}-011.00000 \mathrm{e}-091.00000 \mathrm{e}-01$ $1.00000 \mathrm{e}-05$ 1.00000e-05 1.00000e-06 1.00000e-09 1.00000e-01 $1.00000 \mathrm{e}+001.00000 \mathrm{e}+001.00000 \mathrm{e}-011.00000 \mathrm{e}-091.00000 \mathrm{e}-01$ Element: 1640 \# of layers: 8

$\mathrm{Kx} \mathrm{Ky} \mathrm{Kz}$ Ss Por

$1.42160 \mathrm{e}+021.42160 \mathrm{e}+021.42160 \mathrm{e}+01$ 1.00000e-09 7.00000e-02

$5.68002 \mathrm{e}+005.68002 \mathrm{e}+00$ 5.68002e-01 1.00000e-09 2.12000e-01

$5.68002 \mathrm{e}+005.68002 \mathrm{e}+00$ 5.68002e-01 1.00000e-09 2.12000e-01

$5.68002 \mathrm{e}+00$ 5.68002e+00 5.68002e-01 1.00000e-09 2.12000e-01

$1.00000 \mathrm{e}-02$ 1.00000e-02 1.00000e-03 1.00000e-09 1.00000e-01

$1.00000 \mathrm{e}+001.00000 \mathrm{e}+001.00000 \mathrm{e}-011.00000 \mathrm{e}-091.00000 \mathrm{e}-01$ $1.00000 \mathrm{e}-05$ 1.00000e-05 1.00000e-06 1.00000e-09 1.00000e-01 $1.00000 \mathrm{e}+001.00000 \mathrm{e}+001.00000 \mathrm{e}-011.00000 \mathrm{e}-091.00000 \mathrm{e}-01$ Element: 1641 \# of layers: 8

$\mathrm{Kx} \mathrm{Ky} \mathrm{Kz}$ Ss Por

$1.42160 \mathrm{e}+02$ 1.42160e+02 1.42160e+01 1.00000e-09 7.00000e-02 $5.68002 \mathrm{e}+00$ 5.68002e+00 5.68002e-01 1.00000e-09 2.12000e-01 $5.68002 \mathrm{e}+00$ 5.68002e+00 5.68002e-01 1.00000e-09 2.12000e-01 5.68002e+00 5.68002e+00 5.68002e-01 1.00000e-09 2.12000e-01 $1.00000 \mathrm{e}-021.00000 \mathrm{e}-021.00000 \mathrm{e}-031.00000 \mathrm{e}-091.00000 \mathrm{e}-01$ $1.00000 \mathrm{e}+001.00000 \mathrm{e}+001.00000 \mathrm{e}-011.00000 \mathrm{e}-091.00000 \mathrm{e}-01$ $1.00000 \mathrm{e}-05$ 1.00000e-05 1.00000e-06 1.00000e-09 1.00000e-01 
$1.00000 \mathrm{e}+001.00000 \mathrm{e}+00$ 1.00000e-01 1.00000e-09 1.00000e-01

Element: 1642 \# of layers: 9

Kx Ky Kz Ss Por

$1.42160 \mathrm{e}+02$ 1.42160e+02 1.42160e+01 1.00000e-09 7.00000e-02

$1.42160 \mathrm{e}+021.42160 \mathrm{e}+021.42160 \mathrm{e}+01$ 1.00000e-09 7.00000e-02

$5.68002 \mathrm{e}+00$ 5.68002e+00 5.68002e-01 1.00000e-09 2.12000e-01

$5.68002 \mathrm{e}+005.68002 \mathrm{e}+00$ 5.68002e-01 1.00000e-09 2.12000e-01

$5.68002 \mathrm{e}+00$ 5.68002e+00 5.68002e-01 1.00000e-09 2.12000e-01

$1.00000 \mathrm{e}-01$ 1.00000e-01 1.00000e-02 1.00000e-09 1.00000e-01

$1.00000 \mathrm{e}+001.00000 \mathrm{e}+001.00000 \mathrm{e}-011.00000 \mathrm{e}-091.00000 \mathrm{e}-01$

$1.00000 \mathrm{e}-05$ 1.00000e-05 1.00000e-06 1.00000e-09 1.00000e-01

$1.00000 \mathrm{e}+001.00000 \mathrm{e}+001.00000 \mathrm{e}-011.00000 \mathrm{e}-091.00000 \mathrm{e}-01$

Element: 1643 \# of layers: 7

$\mathrm{Kx} \mathrm{Ky} \mathrm{Kz}$ Ss Por

7.32234e+01 7.32234e+01 7.32234e+00 1.00000e-09 7.00000e-02

$2.92574 \mathrm{e}+002.92574 \mathrm{e}+002.92574 \mathrm{e}-01$ 1.00000e-09 2.12000e-01

$2.92574 \mathrm{e}+002.92574 \mathrm{e}+002.92574 \mathrm{e}-01$ 1.00000e-09 2.12000e-01

$1.00000 \mathrm{e}-011.00000 \mathrm{e}-01$ 1.00000e-02 1.00000e-09 1.00000e-01

$1.00000 \mathrm{e}+001.00000 \mathrm{e}+001.00000 \mathrm{e}-011.00000 \mathrm{e}-091.00000 \mathrm{e}-01$

$1.00000 \mathrm{e}-05$ 1.00000e-05 1.00000e-06 1.00000e-09 1.00000e-01

$1.00000 \mathrm{e}+001.00000 \mathrm{e}+001.00000 \mathrm{e}-011.00000 \mathrm{e}-091.00000 \mathrm{e}-01$

Element: 1644 \# of layers: 8

$\mathrm{Kx} \mathrm{Ky} \mathrm{Kz}$ Ss Por

7.32234e+01 7.32234e+01 7.32234e+00 1.00000e-09 7.00000e-02

$7.32234 \mathrm{e}+017.32234 \mathrm{e}+017.32234 \mathrm{e}+001.00000 \mathrm{e}-097.00000 \mathrm{e}-02$

$2.92574 \mathrm{e}+002.92574 \mathrm{e}+002.92574 \mathrm{e}-01$ 1.00000e-09 2.12000e-01

$2.92574 \mathrm{e}+002.92574 \mathrm{e}+002.92574 \mathrm{e}-01$ 1.00000e-09 2.12000e-01

1.00000e-01 1.00000e-01 1.00000e-02 1.00000e-09 1.00000e-01

$1.00000 \mathrm{e}+001.00000 \mathrm{e}+001.00000 \mathrm{e}-011.00000 \mathrm{e}-091.00000 \mathrm{e}-01$

$1.00000 \mathrm{e}-05$ 1.00000e-05 1.00000e-06 1.00000e-09 1.00000e-01

$1.00000 \mathrm{e}+001.00000 \mathrm{e}+001.00000 \mathrm{e}-011.00000 \mathrm{e}-091.00000 \mathrm{e}-01$

Element: 1645 \# of layers: 6

Kx Ky Kz Ss Por

7.32234e+01 7.32234e+01 7.32234e+00 1.00000e-09 7.00000e-02

$7.32234 \mathrm{e}+017.32234 \mathrm{e}+017.32234 \mathrm{e}+001.00000 \mathrm{e}-09$ 7.00000e-02

$2.92574 \mathrm{e}+002.92574 \mathrm{e}+002.92574 \mathrm{e}-01$ 1.00000e-09 2.12000e-01

$2.92574 \mathrm{e}+002.92574 \mathrm{e}+002.92574 \mathrm{e}-01$ 1.00000e-09 2.12000e-01

1.00000e-01 1.00000e-01 1.00000e-02 1.00000e-09 1.00000e-01

$1.00000 \mathrm{e}+001.00000 \mathrm{e}+001.00000 \mathrm{e}-011.00000 \mathrm{e}-091.00000 \mathrm{e}-01$

Element: 1646 \# of layers: 6

$\mathrm{Kx} \mathrm{Ky} \mathrm{Kz}$ Ss Por

7.32234e+01 7.32234e+01 7.32234e+00 1.00000e-09 7.00000e-02

$7.32234 \mathrm{e}+01$ 7.32234e+01 7.32234e+00 1.00000e-09 7.00000e-02

$2.92574 \mathrm{e}+002.92574 \mathrm{e}+002.92574 \mathrm{e}-01$ 1.00000e-09 2.12000e-01

$2.92574 \mathrm{e}+002.92574 \mathrm{e}+002.92574 \mathrm{e}-01$ 1.00000e-09 2.12000e-01

$1.00000 \mathrm{e}-01$ 1.00000e-01 1.00000e-02 1.00000e-09 1.00000e-01 
$1.00000 \mathrm{e}+001.00000 \mathrm{e}+00$ 1.00000e-01 1.00000e-09 1.00000e-01

Element: 1647 \# of layers: 6

$\mathrm{Kx} \mathrm{Ky} \mathrm{Kz}$ Ss Por

7.32234e+01 7.32234e+01 7.32234e+00 1.00000e-09 7.00000e-02

$7.32234 \mathrm{e}+017.32234 \mathrm{e}+01$ 7.32234e+00 1.00000e-09 7.00000e-02

$2.92574 \mathrm{e}+002.92574 \mathrm{e}+002.92574 \mathrm{e}-01$ 1.00000e-09 2.12000e-01

$2.92574 \mathrm{e}+002.92574 \mathrm{e}+002.92574 \mathrm{e}-01$ 1.00000e-09 2.12000e-01

1.00000e-01 1.00000e-01 1.00000e-02 1.00000e-09 1.00000e-01

$1.00000 \mathrm{e}+001.00000 \mathrm{e}+001.00000 \mathrm{e}-011.00000 \mathrm{e}-091.00000 \mathrm{e}-01$

Element: 1648 \# of layers: 6

$\mathrm{Kx} \mathrm{Ky} \mathrm{Kz}$ Ss Por

7.32234e+01 7.32234e+01 7.32234e+00 1.00000e-09 7.00000e-02

$7.32234 \mathrm{e}+017.32234 \mathrm{e}+01$ 7.32234e+00 1.00000e-09 7.00000e-02

$2.92574 \mathrm{e}+002.92574 \mathrm{e}+002.92574 \mathrm{e}-01$ 1.00000e-09 2.12000e-01

$2.92574 \mathrm{e}+002.92574 \mathrm{e}+002.92574 \mathrm{e}-01$ 1.00000e-09 2.12000e-01

$1.00000 \mathrm{e}-01$ 1.00000e-01 1.00000e-02 1.00000e-09 1.00000e-01

$1.00000 \mathrm{e}+001.00000 \mathrm{e}+001.00000 \mathrm{e}-01$ 1.00000e-09 1.00000e-01

Element: 1649 \# of layers: 7

$\mathrm{Kx} \mathrm{Ky} \mathrm{Kz}$ Ss Por

7.32234e+01 7.32234e+01 7.32234e+00 1.00000e-09 7.00000e-02

$2.92574 \mathrm{e}+002.92574 \mathrm{e}+002.92574 \mathrm{e}-01$ 1.00000e-09 2.12000e-01

$2.92574 \mathrm{e}+002.92574 \mathrm{e}+002.92574 \mathrm{e}-01$ 1.00000e-09 2.12000e-01

$1.00000 \mathrm{e}-011.00000 \mathrm{e}-011.00000 \mathrm{e}-021.00000 \mathrm{e}-091.00000 \mathrm{e}-01$

$1.00000 \mathrm{e}+001.00000 \mathrm{e}+001.00000 \mathrm{e}-011.00000 \mathrm{e}-091.00000 \mathrm{e}-01$

$1.00000 \mathrm{e}-05$ 1.00000e-05 1.00000e-06 1.00000e-09 1.00000e-01

$1.00000 \mathrm{e}+001.00000 \mathrm{e}+001.00000 \mathrm{e}-01$ 1.00000e-09 1.00000e-01

Element: 1650 \# of layers: 7

$\mathrm{Kx} \mathrm{Ky} \mathrm{Kz}$ Ss Por

7.32234e+01 7.32234e+01 7.32234e+00 1.00000e-09 7.00000e-02

$2.92574 \mathrm{e}+002.92574 \mathrm{e}+002.92574 \mathrm{e}-01$ 1.00000e-09 2.12000e-01

$2.92574 \mathrm{e}+002.92574 \mathrm{e}+002.92574 \mathrm{e}-01$ 1.00000e-09 2.12000e-01

1.00000e-01 1.00000e-01 1.00000e-02 1.00000e-09 1.00000e-01

$1.00000 \mathrm{e}+001.00000 \mathrm{e}+001.00000 \mathrm{e}-011.00000 \mathrm{e}-091.00000 \mathrm{e}-01$

$1.00000 \mathrm{e}-05$ 1.00000e-05 1.00000e-06 1.00000e-09 1.00000e-01

$1.00000 \mathrm{e}+001.00000 \mathrm{e}+001.00000 \mathrm{e}-011.00000 \mathrm{e}-091.00000 \mathrm{e}-01$

Element: 1651 \# of layers: 8

Kx Ky Kz Ss Por

7.32234e+01 7.32234e+01 7.32234e+00 1.00000e-09 7.00000e-02

$7.32234 \mathrm{e}+01$ 7.32234e+01 7.32234e+00 1.00000e-09 7.00000e-02

$2.92574 \mathrm{e}+002.92574 \mathrm{e}+002.92574 \mathrm{e}-01$ 1.00000e-09 2.12000e-01

$2.92574 \mathrm{e}+002.92574 \mathrm{e}+002.92574 \mathrm{e}-01$ 1.00000e-09 2.12000e-01

$1.00000 \mathrm{e}-01$ 1.00000e-01 1.00000e-02 1.00000e-09 1.00000e-01

$1.00000 \mathrm{e}+001.00000 \mathrm{e}+001.00000 \mathrm{e}-011.00000 \mathrm{e}-091.00000 \mathrm{e}-01$

$1.00000 \mathrm{e}-05$ 1.00000e-05 1.00000e-06 1.00000e-09 1.00000e-01

$1.00000 \mathrm{e}+001.00000 \mathrm{e}+001.00000 \mathrm{e}-011.00000 \mathrm{e}-09$ 1.00000e-01

Element: 1652 \# of layers: 6 
$\mathrm{Kx} \mathrm{Ky} \mathrm{Kz}$ Ss Por

5.30932e+01 5.30932e+01 5.30932e+00 1.00000e-09 7.00000e-02

5.30932e+01 5.30932e+01 5.30932e+00 1.00000e-09 7.00000e-02

$2.12141 \mathrm{e}+002.12141 \mathrm{e}+002.12141 \mathrm{e}-01$ 1.00000e-09 2.12000e-01

$2.12141 \mathrm{e}+002.12141 \mathrm{e}+002.12141 \mathrm{e}-01$ 1.00000e-09 2.12000e-01

$1.00000 \mathrm{e}-011.00000 \mathrm{e}-01$ 1.00000e-02 1.00000e-09 1.00000e-01

$1.00000 \mathrm{e}+001.00000 \mathrm{e}+001.00000 \mathrm{e}-01$ 1.00000e-09 1.00000e-01

Element: 1653 \# of layers: 6

$\mathrm{Kx} \mathrm{Ky} \mathrm{Kz}$ Ss Por

5.30932e+01 5.30932e+01 5.30932e+00 1.00000e-09 7.00000e-02

$5.30932 \mathrm{e}+015.30932 \mathrm{e}+015.30932 \mathrm{e}+00$ 1.00000e-09 7.00000e-02

$2.12141 \mathrm{e}+002.12141 \mathrm{e}+00$ 2.12141e-01 1.00000e-09 2.12000e-01

$2.12141 \mathrm{e}+002.12141 \mathrm{e}+002.12141 \mathrm{e}-01$ 1.00000e-09 2.12000e-01

$1.00000 \mathrm{e}-01$ 1.00000e-01 1.00000e-02 1.00000e-09 1.00000e-01

$1.00000 \mathrm{e}+001.00000 \mathrm{e}+001.00000 \mathrm{e}-01$ 1.00000e-09 1.00000e-01

Element: 1654 \# of layers: 5

$\mathrm{Kx} \mathrm{Ky} \mathrm{Kz}$ Ss Por

5.30932e+01 5.30932e+01 5.30932e+00 1.00000e-09 7.00000e-02

5.30932e+01 5.30932e+01 5.30932e+00 1.00000e-09 7.00000e-02

$2.12141 \mathrm{e}+002.12141 \mathrm{e}+002.12141 \mathrm{e}-01$ 1.00000e-09 2.12000e-01

$1.00000 \mathrm{e}-011.00000 \mathrm{e}-01$ 1.00000e-02 1.00000e-09 1.00000e-01

$1.00000 \mathrm{e}+001.00000 \mathrm{e}+001.00000 \mathrm{e}-011.00000 \mathrm{e}-09$ 1.00000e-01

Element: 1655 \# of layers: 14

$\mathrm{Kx} \mathrm{Ky} \mathrm{Kz}$ Ss Por

3.08268e+02 3.08268e+02 3.08268e+01 1.00000e-09 7.00000e-02

$3.08268 \mathrm{e}+023.08268 \mathrm{e}+023.08268 \mathrm{e}+01$ 1.00000e-09 7.00000e-02

$3.08268 \mathrm{e}+023.08268 \mathrm{e}+023.08268 \mathrm{e}+01$ 1.00000e-09 7.00000e-02

5.00000e-04 5.00000e-04 5.00000e-05 1.00000e-09 1.00000e-01

5.00000e-04 5.00000e-04 5.00000e-05 1.00000e-09 1.00000e-01

$1.23172 \mathrm{e}+01$ 1.23172e+01 1.23172e+00 1.00000e-09 2.12000e-01

$1.23172 \mathrm{e}+01$ 1.23172e+01 1.23172e+00 1.00000e-09 2.12000e-01

$1.23172 \mathrm{e}+011.23172 \mathrm{e}+011.23172 \mathrm{e}+001.00000 \mathrm{e}-092.12000 \mathrm{e}-01$

$1.23172 \mathrm{e}+011.23172 \mathrm{e}+011.23172 \mathrm{e}+001.00000 \mathrm{e}-092.12000 \mathrm{e}-01$

$1.23172 \mathrm{e}+01$ 1.23172e+01 1.23172e+00 1.00000e-09 2.12000e-01

$1.00000 \mathrm{e}-02$ 1.00000e-02 1.00000e-03 1.00000e-09 1.00000e-01

$1.00000 \mathrm{e}+001.00000 \mathrm{e}+001.00000 \mathrm{e}-011.00000 \mathrm{e}-091.00000 \mathrm{e}-01$

$1.00000 \mathrm{e}-05$ 1.00000e-05 1.00000e-06 1.00000e-09 1.00000e-01

$1.00000 \mathrm{e}+001.00000 \mathrm{e}+001.00000 \mathrm{e}-01$ 1.00000e-09 1.00000e-01

Element: 1656 \# of layers: 14

$\mathrm{Kx} \mathrm{Ky} \mathrm{Kz}$ Ss Por

3.08268e+02 3.08268e+02 3.08268e+01 1.00000e-09 7.00000e-02

$3.08268 \mathrm{e}+023.08268 \mathrm{e}+023.08268 \mathrm{e}+01$ 1.00000e-09 7.00000e-02

$3.08268 \mathrm{e}+02$ 3.08268e+02 3.08268e+01 1.00000e-09 7.00000e-02

$5.00000 \mathrm{e}-04$ 5.00000e-04 5.00000e-05 1.00000e-09 1.00000e-01

5.00000e-04 5.00000e-04 5.00000e-05 1.00000e-09 1.00000e-01

$1.23172 \mathrm{e}+011.23172 \mathrm{e}+011.23172 \mathrm{e}+001.00000 \mathrm{e}-092.12000 \mathrm{e}-01$ 
1.23172e+01 1.23172e+01 1.23172e+00 1.00000e-09 2.12000e-01 $1.23172 \mathrm{e}+01$ 1.23172e+01 1.23172e+00 1.00000e-09 2.12000e-01 $1.23172 \mathrm{e}+011.23172 \mathrm{e}+011.23172 \mathrm{e}+001.00000 \mathrm{e}-092.12000 \mathrm{e}-01$ $1.23172 \mathrm{e}+01$ 1.23172e+01 1.23172e+00 1.00000e-09 2.12000e-01 $1.00000 \mathrm{e}-02$ 1.00000e-02 1.00000e-03 1.00000e-09 1.00000e-01 $1.00000 \mathrm{e}+001.00000 \mathrm{e}+001.00000 \mathrm{e}-011.00000 \mathrm{e}-091.00000 \mathrm{e}-01$ $1.00000 \mathrm{e}-05$ 1.00000e-05 1.00000e-06 1.00000e-09 1.00000e-01 $1.00000 \mathrm{e}+001.00000 \mathrm{e}+001.00000 \mathrm{e}-011.00000 \mathrm{e}-091.00000 \mathrm{e}-01$ Element: 1657 \# of layers: 14

$\mathrm{Kx} \mathrm{Ky} \mathrm{Kz}$ Ss Por

3.08268e+02 3.08268e+02 3.08268e+01 1.00000e-09 7.00000e-02 $3.08268 \mathrm{e}+023.08268 \mathrm{e}+023.08268 \mathrm{e}+01$ 1.00000e-09 7.00000e-02 $3.08268 \mathrm{e}+02$ 3.08268e+02 3.08268e+01 1.00000e-09 7.00000e-02 5.00000e-04 5.00000e-04 5.00000e-05 1.00000e-09 1.00000e-01 5.00000e-04 5.00000e-04 5.00000e-05 1.00000e-09 1.00000e-01 $1.23172 \mathrm{e}+011.23172 \mathrm{e}+011.23172 \mathrm{e}+001.00000 \mathrm{e}-092.12000 \mathrm{e}-01$ $1.23172 \mathrm{e}+01$ 1.23172e+01 1.23172e+00 1.00000e-09 2.12000e-01 $1.23172 \mathrm{e}+011.23172 \mathrm{e}+01$ 1.23172e+00 1.00000e-09 2.12000e-01 $1.23172 \mathrm{e}+01$ 1.23172e+01 1.23172e+00 1.00000e-09 2.12000e-01 $1.23172 \mathrm{e}+01$ 1.23172e+01 1.23172e+00 1.00000e-09 2.12000e-01 $1.00000 \mathrm{e}-02$ 1.00000e-02 1.00000e-03 1.00000e-09 1.00000e-01 $1.00000 \mathrm{e}+001.00000 \mathrm{e}+001.00000 \mathrm{e}-011.00000 \mathrm{e}-091.00000 \mathrm{e}-01$ $1.00000 \mathrm{e}-05$ 1.00000e-05 1.00000e-06 1.00000e-09 1.00000e-01 $1.00000 \mathrm{e}+001.00000 \mathrm{e}+001.00000 \mathrm{e}-011.00000 \mathrm{e}-09$ 1.00000e-01 Element: 1658 \# of layers: 14

$\mathrm{Kx} \mathrm{Ky} \mathrm{Kz}$ Ss Por

3.08268e+02 3.08268e+02 3.08268e+01 1.00000e-09 7.00000e-02 $3.08268 \mathrm{e}+02$ 3.08268e+02 3.08268e+01 1.00000e-09 7.00000e-02 $3.08268 \mathrm{e}+02$ 3.08268e+02 3.08268e+01 1.00000e-09 7.00000e-02 5.00000e-04 5.00000e-04 5.00000e-05 1.00000e-09 1.00000e-01 5.00000e-04 5.00000e-04 5.00000e-05 1.00000e-09 1.00000e-01 $1.23172 \mathrm{e}+01$ 1.23172e+01 1.23172e+00 1.00000e-09 2.12000e-01 $1.23172 \mathrm{e}+011.23172 \mathrm{e}+011.23172 \mathrm{e}+001.00000 \mathrm{e}-092.12000 \mathrm{e}-01$ $1.23172 \mathrm{e}+011.23172 \mathrm{e}+01$ 1.23172e+00 1.00000e-09 2.12000e-01 $1.23172 \mathrm{e}+01$ 1.23172e+01 1.23172e+00 1.00000e-09 2.12000e-01 $1.23172 \mathrm{e}+011.23172 \mathrm{e}+011.23172 \mathrm{e}+001.00000 \mathrm{e}-092.12000 \mathrm{e}-01$ $1.00000 \mathrm{e}-02$ 1.00000e-02 1.00000e-03 1.00000e-09 1.00000e-01 $1.00000 \mathrm{e}+001.00000 \mathrm{e}+001.00000 \mathrm{e}-011.00000 \mathrm{e}-091.00000 \mathrm{e}-01$ $1.00000 \mathrm{e}-05$ 1.00000e-05 1.00000e-06 1.00000e-09 1.00000e-01 $1.00000 \mathrm{e}+001.00000 \mathrm{e}+001.00000 \mathrm{e}-01$ 1.00000e-09 1.00000e-01 Element: 1659 \# of layers: 14

$\mathrm{Kx} \mathrm{Ky} \mathrm{Kz}$ Ss Por 3.08268e+02 3.08268e+02 3.08268e+01 1.00000e-09 7.00000e-02 3.08268e+02 3.08268e+02 3.08268e+01 1.00000e-09 7.00000e-02 $3.08268 \mathrm{e}+02$ 3.08268e+02 3.08268e+01 1.00000e-09 7.00000e-02 5.00000e-04 5.00000e-04 5.00000e-05 1.00000e-09 1.00000e-01 
5.00000e-04 5.00000e-04 5.00000e-05 1.00000e-09 1.00000e-01 $1.23172 \mathrm{e}+011.23172 \mathrm{e}+01$ 1.23172e+00 1.00000e-09 2.12000e-01 $1.23172 \mathrm{e}+011.23172 \mathrm{e}+011.23172 \mathrm{e}+001.00000 \mathrm{e}-092.12000 \mathrm{e}-01$ $1.23172 \mathrm{e}+01$ 1.23172e+01 1.23172e+00 1.00000e-09 2.12000e-01 $1.23172 \mathrm{e}+011.23172 \mathrm{e}+01$ 1.23172e+00 1.00000e-09 2.12000e-01 $1.23172 \mathrm{e}+01$ 1.23172e+01 1.23172e+00 1.00000e-09 2.12000e-01 $1.00000 \mathrm{e}-02$ 1.00000e-02 1.00000e-03 1.00000e-09 1.00000e-01 $1.00000 \mathrm{e}+001.00000 \mathrm{e}+001.00000 \mathrm{e}-011.00000 \mathrm{e}-091.00000 \mathrm{e}-01$ $1.00000 \mathrm{e}-05$ 1.00000e-05 1.00000e-06 1.00000e-09 1.00000e-01 $1.00000 \mathrm{e}+001.00000 \mathrm{e}+001.00000 \mathrm{e}-011.00000 \mathrm{e}-091.00000 \mathrm{e}-01$ Element: 1660 \# of layers: 14

$\mathrm{Kx} \mathrm{Ky} \mathrm{Kz}$ Ss Por

2.98645e+02 2.98645e+02 2.98645e+01 1.00000e-09 7.00000e-02 $2.98645 \mathrm{e}+02$ 2.98645e+02 2.98645e+01 1.00000e-09 7.00000e-02 $2.98645 \mathrm{e}+022.98645 \mathrm{e}+02$ 2.98645e+01 1.00000e-09 7.00000e-02 5.00000e-04 5.00000e-04 5.00000e-05 1.00000e-09 1.00000e-01 5.00000e-04 5.00000e-04 5.00000e-05 1.00000e-09 1.00000e-01 $1.19327 \mathrm{e}+01$ 1.19327e+01 1.19327e+00 1.00000e-09 2.12000e-01 $1.19327 \mathrm{e}+01$ 1.19327e+01 1.19327e+00 1.00000e-09 2.12000e-01 $1.19327 \mathrm{e}+01$ 1.19327e+01 1.19327e+00 1.00000e-09 2.12000e-01 $1.19327 \mathrm{e}+01$ 1.19327e+01 1.19327e+00 1.00000e-09 2.12000e-01 $1.19327 \mathrm{e}+01$ 1.19327e+01 1.19327e+00 1.00000e-09 2.12000e-01 $1.00000 \mathrm{e}-02$ 1.00000e-02 1.00000e-03 1.00000e-09 1.00000e-01 $1.00000 \mathrm{e}+001.00000 \mathrm{e}+001.00000 \mathrm{e}-011.00000 \mathrm{e}-091.00000 \mathrm{e}-01$ $1.00000 \mathrm{e}-05$ 1.00000e-05 1.00000e-06 1.00000e-09 1.00000e-01 $1.00000 \mathrm{e}+001.00000 \mathrm{e}+001.00000 \mathrm{e}-011.00000 \mathrm{e}-091.00000 \mathrm{e}-01$ Element: 1661 \# of layers: 14

$\mathrm{Kx} \mathrm{Ky} \mathrm{Kz}$ Ss Por

$2.98645 \mathrm{e}+02$ 2.98645e+02 2.98645e+01 1.00000e-09 7.00000e-02 $2.98645 \mathrm{e}+02$ 2.98645e+02 2.98645e+01 1.00000e-09 7.00000e-02 $2.98645 \mathrm{e}+022.98645 \mathrm{e}+022.98645 \mathrm{e}+01$ 1.00000e-09 7.00000e-02 5.00000e-04 5.00000e-04 5.00000e-05 1.00000e-09 1.00000e-01 5.00000e-04 5.00000e-04 5.00000e-05 1.00000e-09 1.00000e-01 $1.19327 \mathrm{e}+01$ 1.19327e+01 1.19327e+00 1.00000e-09 2.12000e-01 $1.19327 \mathrm{e}+01$ 1.19327e+01 1.19327e+00 1.00000e-09 2.12000e-01 $1.19327 \mathrm{e}+01$ 1.19327e+01 1.19327e+00 1.00000e-09 2.12000e-01 $1.19327 \mathrm{e}+01$ 1.19327e+01 1.19327e+00 1.00000e-09 2.12000e-01 $1.19327 \mathrm{e}+01$ 1.19327e+01 1.19327e+00 1.00000e-09 2.12000e-01 $1.00000 \mathrm{e}-02$ 1.00000e-02 1.00000e-03 1.00000e-09 1.00000e-01 $1.00000 \mathrm{e}+001.00000 \mathrm{e}+001.00000 \mathrm{e}-011.00000 \mathrm{e}-091.00000 \mathrm{e}-01$ $1.00000 \mathrm{e}-05$ 1.00000e-05 1.00000e-06 1.00000e-09 1.00000e-01 $1.00000 \mathrm{e}+001.00000 \mathrm{e}+001.00000 \mathrm{e}-011.00000 \mathrm{e}-091.00000 \mathrm{e}-01$ Element: 1662 \# of layers: 14

$\mathrm{Kx} \mathrm{Ky} \mathrm{Kz}$ Ss Por $2.98645 \mathrm{e}+02$ 2.98645e+02 2.98645e+01 1.00000e-09 7.00000e-02 $2.98645 \mathrm{e}+022.98645 \mathrm{e}+022.98645 \mathrm{e}+01$ 1.00000e-09 7.00000e-02 
$2.98645 \mathrm{e}+02$ 2.98645e+02 2.98645e+01 1.00000e-09 7.00000e-02 5.00000e-04 5.00000e-04 5.00000e-05 1.00000e-09 1.00000e-01 5.00000e-04 5.00000e-04 5.00000e-05 1.00000e-09 1.00000e-01 $1.19327 \mathrm{e}+01$ 1.19327e+01 1.19327e+00 1.00000e-09 2.12000e-01 $1.19327 \mathrm{e}+01$ 1.19327e+01 1.19327e+00 1.00000e-09 2.12000e-01 $1.19327 \mathrm{e}+01$ 1.19327e+01 1.19327e+00 1.00000e-09 2.12000e-01 $1.19327 \mathrm{e}+01$ 1.19327e+01 1.19327e+00 1.00000e-09 2.12000e-01 $1.19327 \mathrm{e}+01$ 1.19327e+01 1.19327e+00 1.00000e-09 2.12000e-01 1.00000e-02 1.00000e-02 1.00000e-03 1.00000e-09 1.00000e-01 $1.00000 \mathrm{e}+001.00000 \mathrm{e}+001.00000 \mathrm{e}-011.00000 \mathrm{e}-091.00000 \mathrm{e}-01$ $1.00000 \mathrm{e}-05$ 1.00000e-05 1.00000e-06 1.00000e-09 1.00000e-01 $1.00000 \mathrm{e}+001.00000 \mathrm{e}+001.00000 \mathrm{e}-011.00000 \mathrm{e}-091.00000 \mathrm{e}-01$ Element: 1663 \# of layers: 14

$\mathrm{Kx} \mathrm{Ky} \mathrm{Kz}$ Ss Por

$2.98645 \mathrm{e}+02$ 2.98645e+02 2.98645e+01 1.00000e-09 7.00000e-02 $2.98645 \mathrm{e}+022.98645 \mathrm{e}+022.98645 \mathrm{e}+01$ 1.00000e-09 7.00000e-02 $2.98645 \mathrm{e}+02$ 2.98645e+02 2.98645e+01 1.00000e-09 7.00000e-02 5.00000e-04 5.00000e-04 5.00000e-05 1.00000e-09 1.00000e-01 5.00000e-04 5.00000e-04 5.00000e-05 1.00000e-09 1.00000e-01 $1.19327 \mathrm{e}+01$ 1.19327e+01 1.19327e+00 1.00000e-09 2.12000e-01 $1.19327 \mathrm{e}+01$ 1.19327e+01 1.19327e+00 1.00000e-09 2.12000e-01 $1.19327 \mathrm{e}+01$ 1.19327e+01 1.19327e+00 1.00000e-09 2.12000e-01 $1.19327 \mathrm{e}+01$ 1.19327e+01 1.19327e+00 1.00000e-09 2.12000e-01 $1.19327 \mathrm{e}+011.19327 \mathrm{e}+01$ 1.19327e+00 1.00000e-09 2.12000e-01 $1.00000 \mathrm{e}-021.00000 \mathrm{e}-02$ 1.00000e-03 1.00000e-09 1.00000e-01 $1.00000 \mathrm{e}+001.00000 \mathrm{e}+001.00000 \mathrm{e}-011.00000 \mathrm{e}-091.00000 \mathrm{e}-01$ $1.00000 \mathrm{e}-05$ 1.00000e-05 1.00000e-06 1.00000e-09 1.00000e-01 $1.00000 \mathrm{e}+001.00000 \mathrm{e}+001.00000 \mathrm{e}-011.00000 \mathrm{e}-09$ 1.00000e-01 Element: 1664 \# of layers: 14

$\mathrm{Kx} \mathrm{Ky} \mathrm{Kz}$ Ss Por

$2.98645 \mathrm{e}+02$ 2.98645e+02 2.98645e+01 1.00000e-09 7.00000e-02 $2.98645 \mathrm{e}+02$ 2.98645e+02 2.98645e+01 1.00000e-09 7.00000e-02 $2.98645 \mathrm{e}+022.98645 \mathrm{e}+02$ 2.98645e+01 1.00000e-09 7.00000e-02 5.00000e-04 5.00000e-04 5.00000e-05 1.00000e-09 1.00000e-01 5.00000e-04 5.00000e-04 5.00000e-05 1.00000e-09 1.00000e-01 $1.19327 \mathrm{e}+01$ 1.19327e+01 1.19327e+00 1.00000e-09 2.12000e-01 $1.19327 \mathrm{e}+01$ 1.19327e+01 1.19327e+00 1.00000e-09 2.12000e-01 $1.19327 \mathrm{e}+01$ 1.19327e+01 1.19327e+00 1.00000e-09 2.12000e-01 $1.19327 \mathrm{e}+01$ 1.19327e+01 1.19327e+00 1.00000e-09 2.12000e-01 $1.19327 \mathrm{e}+01$ 1.19327e+01 1.19327e+00 1.00000e-09 2.12000e-01 $1.00000 \mathrm{e}-02$ 1.00000e-02 1.00000e-03 1.00000e-09 1.00000e-01 $1.00000 \mathrm{e}+001.00000 \mathrm{e}+001.00000 \mathrm{e}-011.00000 \mathrm{e}-091.00000 \mathrm{e}-01$ $1.00000 \mathrm{e}-05$ 1.00000e-05 1.00000e-06 1.00000e-09 1.00000e-01 $1.00000 \mathrm{e}+001.00000 \mathrm{e}+001.00000 \mathrm{e}-01$ 1.00000e-09 1.00000e-01 Element: 1665 \# of layers: 14

Kx Ky Kz Ss Por 
2.98645e+02 2.98645e+02 2.98645e+01 1.00000e-09 7.00000e-02 $2.98645 \mathrm{e}+02$ 2.98645e+02 2.98645e+01 1.00000e-09 7.00000e-02 $2.98645 \mathrm{e}+022.98645 \mathrm{e}+022.98645 \mathrm{e}+01$ 1.00000e-09 7.00000e-02 5.00000e-04 5.00000e-04 5.00000e-05 1.00000e-09 1.00000e-01 5.00000e-04 5.00000e-04 5.00000e-05 1.00000e-09 1.00000e-01 $1.19327 \mathrm{e}+01$ 1.19327e+01 1.19327e+00 1.00000e-09 2.12000e-01 $1.19327 \mathrm{e}+01$ 1.19327e+01 1.19327e+00 1.00000e-09 2.12000e-01 $1.19327 \mathrm{e}+01$ 1.19327e+01 1.19327e+00 1.00000e-09 2.12000e-01 $1.19327 \mathrm{e}+01$ 1.19327e+01 1.19327e+00 1.00000e-09 2.12000e-01 $1.19327 \mathrm{e}+01$ 1.19327e+01 1.19327e+00 1.00000e-09 2.12000e-01 $1.00000 \mathrm{e}-02$ 1.00000e-02 1.00000e-03 1.00000e-09 1.00000e-01 $1.00000 \mathrm{e}+001.00000 \mathrm{e}+001.00000 \mathrm{e}-011.00000 \mathrm{e}-091.00000 \mathrm{e}-01$ $1.00000 \mathrm{e}-05$ 1.00000e-05 1.00000e-06 1.00000e-09 1.00000e-01 $1.00000 \mathrm{e}+001.00000 \mathrm{e}+001.00000 \mathrm{e}-011.00000 \mathrm{e}-09$ 1.00000e-01 Element: 1666 \# of layers: 14

$\mathrm{Kx} \mathrm{Ky} \mathrm{Kz}$ Ss Por

$2.98645 \mathrm{e}+02$ 2.98645e+02 2.98645e+01 1.00000e-09 7.00000e-02 $2.98645 \mathrm{e}+022.98645 \mathrm{e}+02$ 2.98645e+01 1.00000e-09 7.00000e-02 $2.98645 \mathrm{e}+02$ 2.98645e+02 2.98645e+01 1.00000e-09 7.00000e-02 5.00000e-04 5.00000e-04 5.00000e-05 1.00000e-09 1.00000e-01 5.00000e-04 5.00000e-04 5.00000e-05 1.00000e-09 1.00000e-01 $1.19327 \mathrm{e}+01$ 1.19327e+01 1.19327e+00 1.00000e-09 2.12000e-01 $1.19327 \mathrm{e}+01$ 1.19327e+01 1.19327e+00 1.00000e-09 2.12000e-01 $1.19327 \mathrm{e}+01$ 1.19327e+01 1.19327e+00 1.00000e-09 2.12000e-01 $1.19327 \mathrm{e}+01$ 1.19327e+01 1.19327e+00 1.00000e-09 2.12000e-01 $1.19327 \mathrm{e}+01$ 1.19327e+01 1.19327e+00 1.00000e-09 2.12000e-01 $1.00000 \mathrm{e}-02$ 1.00000e-02 1.00000e-03 1.00000e-09 1.00000e-01 $1.00000 \mathrm{e}+001.00000 \mathrm{e}+001.00000 \mathrm{e}-011.00000 \mathrm{e}-091.00000 \mathrm{e}-01$ $1.00000 \mathrm{e}-05$ 1.00000e-05 1.00000e-06 1.00000e-09 1.00000e-01 $1.00000 \mathrm{e}+001.00000 \mathrm{e}+001.00000 \mathrm{e}-011.00000 \mathrm{e}-091.00000 \mathrm{e}-01$ Element: 1667 \# of layers: 14

$\mathrm{Kx} \mathrm{Ky} \mathrm{Kz}$ Ss Por

$2.98645 \mathrm{e}+02$ 2.98645e+02 2.98645e+01 1.00000e-09 7.00000e-02 $2.98645 \mathrm{e}+02$ 2.98645e+02 2.98645e+01 1.00000e-09 7.00000e-02 $2.98645 \mathrm{e}+022.98645 \mathrm{e}+022.98645 \mathrm{e}+01$ 1.00000e-09 7.00000e-02 5.00000e-04 5.00000e-04 5.00000e-05 1.00000e-09 1.00000e-01 5.00000e-04 5.00000e-04 5.00000e-05 1.00000e-09 1.00000e-01 $1.19327 \mathrm{e}+011.19327 \mathrm{e}+011.19327 \mathrm{e}+001.00000 \mathrm{e}-092.12000 \mathrm{e}-01$ $1.19327 \mathrm{e}+01$ 1.19327e+01 1.19327e+00 1.00000e-09 2.12000e-01 $1.19327 \mathrm{e}+01$ 1.19327e+01 1.19327e+00 1.00000e-09 2.12000e-01 $1.19327 \mathrm{e}+01$ 1.19327e+01 1.19327e+00 1.00000e-09 2.12000e-01 $1.19327 \mathrm{e}+01$ 1.19327e+01 1.19327e+00 1.00000e-09 2.12000e-01 $1.00000 \mathrm{e}-021.00000 \mathrm{e}-021.00000 \mathrm{e}-031.00000 \mathrm{e}-091.00000 \mathrm{e}-01$ $1.00000 \mathrm{e}+001.00000 \mathrm{e}+001.00000 \mathrm{e}-011.00000 \mathrm{e}-091.00000 \mathrm{e}-01$ $1.00000 \mathrm{e}-05$ 1.00000e-05 1.00000e-06 1.00000e-09 1.00000e-01 $1.00000 \mathrm{e}+001.00000 \mathrm{e}+001.00000 \mathrm{e}-011.00000 \mathrm{e}-091.00000 \mathrm{e}-01$ 
Element: 1668 \# of layers: 14

$\mathrm{Kx} \mathrm{Ky} \mathrm{Kz}$ Ss Por

2.98645e+02 2.98645e+02 2.98645e+01 1.00000e-09 7.00000e-02

$2.98645 \mathrm{e}+02$ 2.98645e+02 2.98645e+01 1.00000e-09 7.00000e-02

$2.98645 \mathrm{e}+022.98645 \mathrm{e}+022.98645 \mathrm{e}+01$ 1.00000e-09 7.00000e-02

5.00000e-04 5.00000e-04 5.00000e-05 1.00000e-09 1.00000e-01

5.00000e-04 5.00000e-04 5.00000e-05 1.00000e-09 1.00000e-01

$1.19327 \mathrm{e}+01$ 1.19327e+01 1.19327e+00 1.00000e-09 2.12000e-01

$1.19327 \mathrm{e}+01$ 1.19327e+01 1.19327e+00 1.00000e-09 2.12000e-01

$1.19327 \mathrm{e}+01$ 1.19327e+01 1.19327e+00 1.00000e-09 2.12000e-01

$1.19327 \mathrm{e}+01$ 1.19327e+01 1.19327e+00 1.00000e-09 2.12000e-01

$1.19327 \mathrm{e}+01$ 1.19327e+01 1.19327e+00 1.00000e-09 2.12000e-01

$1.00000 \mathrm{e}-02$ 1.00000e-02 1.00000e-03 1.00000e-09 1.00000e-01

$1.00000 \mathrm{e}+001.00000 \mathrm{e}+001.00000 \mathrm{e}-011.00000 \mathrm{e}-091.00000 \mathrm{e}-01$

$1.00000 \mathrm{e}-05$ 1.00000e-05 1.00000e-06 1.00000e-09 1.00000e-01

$1.00000 \mathrm{e}+001.00000 \mathrm{e}+001.00000 \mathrm{e}-011.00000 \mathrm{e}-091.00000 \mathrm{e}-01$

Element: 1669 \# of layers: 14

$\mathrm{Kx} \mathrm{Ky} \mathrm{Kz}$ Ss Por

$2.56091 \mathrm{e}+02$ 2.56091e+02 2.56091e+01 1.00000e-09 7.00000e-02

$2.56091 \mathrm{e}+022.56091 \mathrm{e}+022.56091 \mathrm{e}+01$ 1.00000e-09 7.00000e-02

$2.56091 \mathrm{e}+022.56091 \mathrm{e}+022.56091 \mathrm{e}+01$ 1.00000e-09 7.00000e-02

5.00000e-04 5.00000e-04 5.00000e-05 1.00000e-09 1.00000e-01

5.00000e-04 5.00000e-04 5.00000e-05 1.00000e-09 1.00000e-01

$1.02325 \mathrm{e}+011.02325 \mathrm{e}+011.02325 \mathrm{e}+001.00000 \mathrm{e}-092.12000 \mathrm{e}-01$

$1.02325 \mathrm{e}+011.02325 \mathrm{e}+011.02325 \mathrm{e}+001.00000 \mathrm{e}-092.12000 \mathrm{e}-01$

$1.02325 \mathrm{e}+011.02325 \mathrm{e}+011.02325 \mathrm{e}+001.00000 \mathrm{e}-092.12000 \mathrm{e}-01$

$1.02325 \mathrm{e}+011.02325 \mathrm{e}+011.02325 \mathrm{e}+001.00000 \mathrm{e}-092.12000 \mathrm{e}-01$

$1.02325 \mathrm{e}+011.02325 \mathrm{e}+011.02325 \mathrm{e}+001.00000 \mathrm{e}-092.12000 \mathrm{e}-01$

$1.00000 \mathrm{e}-02$ 1.00000e-02 1.00000e-03 1.00000e-09 1.00000e-01

$1.00000 \mathrm{e}+001.00000 \mathrm{e}+001.00000 \mathrm{e}-011.00000 \mathrm{e}-091.00000 \mathrm{e}-01$

$1.00000 \mathrm{e}-05$ 1.00000e-05 1.00000e-06 1.00000e-09 1.00000e-01

$1.00000 \mathrm{e}+001.00000 \mathrm{e}+001.00000 \mathrm{e}-01$ 1.00000e-09 1.00000e-01

Element: 1670 \# of layers: 14

$\mathrm{Kx} \mathrm{Ky} \mathrm{Kz}$ Ss Por

$2.56091 \mathrm{e}+02$ 2.56091e+02 2.56091e+01 1.00000e-09 7.00000e-02

$2.56091 \mathrm{e}+022.56091 \mathrm{e}+022.56091 \mathrm{e}+01$ 1.00000e-09 7.00000e-02

$2.56091 \mathrm{e}+022.56091 \mathrm{e}+022.56091 \mathrm{e}+01$ 1.00000e-09 7.00000e-02

5.00000e-04 5.00000e-04 5.00000e-05 1.00000e-09 1.00000e-01

5.00000e-04 5.00000e-04 5.00000e-05 1.00000e-09 1.00000e-01

$1.02325 \mathrm{e}+011.02325 \mathrm{e}+011.02325 \mathrm{e}+001.00000 \mathrm{e}-092.12000 \mathrm{e}-01$

$1.02325 \mathrm{e}+011.02325 \mathrm{e}+01 \quad 1.02325 \mathrm{e}+001.00000 \mathrm{e}-092.12000 \mathrm{e}-01$

$1.02325 \mathrm{e}+011.02325 \mathrm{e}+011.02325 \mathrm{e}+001.00000 \mathrm{e}-092.12000 \mathrm{e}-01$

$1.02325 \mathrm{e}+011.02325 \mathrm{e}+01$ 1.02325e+00 1.00000e-09 2.12000e-01

$1.02325 \mathrm{e}+01$ 1.02325e+01 1.02325e+00 1.00000e-09 2.12000e-01

$1.00000 \mathrm{e}-02$ 1.00000e-02 1.00000e-03 1.00000e-09 1.00000e-01

$1.00000 \mathrm{e}+001.00000 \mathrm{e}+001.00000 \mathrm{e}-011.00000 \mathrm{e}-091.00000 \mathrm{e}-01$ 
$1.00000 \mathrm{e}-05$ 1.00000e-05 1.00000e-06 1.00000e-09 1.00000e-01 $1.00000 \mathrm{e}+001.00000 \mathrm{e}+001.00000 \mathrm{e}-01$ 1.00000e-09 1.00000e-01 Element: 1671 \# of layers: 14

$\mathrm{Kx} \mathrm{Ky} \mathrm{Kz}$ Ss Por

$2.56091 \mathrm{e}+02$ 2.56091e+02 2.56091e+01 1.00000e-09 7.00000e-02

$2.56091 \mathrm{e}+022.56091 \mathrm{e}+022.56091 \mathrm{e}+01$ 1.00000e-09 7.00000e-02

$2.56091 \mathrm{e}+022.56091 \mathrm{e}+022.56091 \mathrm{e}+01$ 1.00000e-09 7.00000e-02

5.00000e-04 5.00000e-04 5.00000e-05 1.00000e-09 1.00000e-01

5.00000e-04 5.00000e-04 5.00000e-05 1.00000e-09 1.00000e-01

$1.02325 \mathrm{e}+011.02325 \mathrm{e}+011.02325 \mathrm{e}+001.00000 \mathrm{e}-092.12000 \mathrm{e}-01$

$1.02325 \mathrm{e}+011.02325 \mathrm{e}+011.02325 \mathrm{e}+00$ 1.00000e-09 2.12000e-01

$1.02325 \mathrm{e}+011.02325 \mathrm{e}+011.02325 \mathrm{e}+001.00000 \mathrm{e}-092.12000 \mathrm{e}-01$

$1.02325 \mathrm{e}+011.02325 \mathrm{e}+011.02325 \mathrm{e}+001.00000 \mathrm{e}-092.12000 \mathrm{e}-01$

$1.02325 \mathrm{e}+011.02325 \mathrm{e}+01 \quad 1.02325 \mathrm{e}+001.00000 \mathrm{e}-092.12000 \mathrm{e}-01$

$1.00000 \mathrm{e}-02$ 1.00000e-02 1.00000e-03 1.00000e-09 1.00000e-01

$1.00000 \mathrm{e}+001.00000 \mathrm{e}+001.00000 \mathrm{e}-011.00000 \mathrm{e}-091.00000 \mathrm{e}-01$

$1.00000 \mathrm{e}-051.00000 \mathrm{e}-05$ 1.00000e-06 1.00000e-09 1.00000e-01

$1.00000 \mathrm{e}+001.00000 \mathrm{e}+001.00000 \mathrm{e}-01$ 1.00000e-09 1.00000e-01

Element: 1672 \# of layers: 14

$\mathrm{Kx} \mathrm{Ky} \mathrm{Kz}$ Ss Por

$2.56091 \mathrm{e}+02$ 2.56091e+02 2.56091e+01 1.00000e-09 7.00000e-02

$2.56091 \mathrm{e}+02$ 2.56091e+02 2.56091e+01 1.00000e-09 7.00000e-02

$2.56091 \mathrm{e}+022.56091 \mathrm{e}+02$ 2.56091e+01 1.00000e-09 7.00000e-02

5.00000e-04 5.00000e-04 5.00000e-05 1.00000e-09 1.00000e-01

$5.00000 \mathrm{e}-04$ 5.00000e-04 5.00000e-05 1.00000e-09 1.00000e-01

$1.02325 \mathrm{e}+011.02325 \mathrm{e}+011.02325 \mathrm{e}+001.00000 \mathrm{e}-092.12000 \mathrm{e}-01$

$1.02325 \mathrm{e}+011.02325 \mathrm{e}+011.02325 \mathrm{e}+001.00000 \mathrm{e}-092.12000 \mathrm{e}-01$

$1.02325 \mathrm{e}+011.02325 \mathrm{e}+011.02325 \mathrm{e}+001.00000 \mathrm{e}-092.12000 \mathrm{e}-01$

$1.02325 \mathrm{e}+011.02325 \mathrm{e}+011.02325 \mathrm{e}+001.00000 \mathrm{e}-092.12000 \mathrm{e}-01$

$1.02325 \mathrm{e}+011.02325 \mathrm{e}+01 \quad 1.02325 \mathrm{e}+001.00000 \mathrm{e}-092.12000 \mathrm{e}-01$

$1.00000 \mathrm{e}-02$ 1.00000e-02 1.00000e-03 1.00000e-09 1.00000e-01

$1.00000 \mathrm{e}+001.00000 \mathrm{e}+001.00000 \mathrm{e}-011.00000 \mathrm{e}-091.00000 \mathrm{e}-01$

1.00000e-05 1.00000e-05 1.00000e-06 1.00000e-09 1.00000e-01

$1.00000 \mathrm{e}+001.00000 \mathrm{e}+001.00000 \mathrm{e}-011.00000 \mathrm{e}-091.00000 \mathrm{e}-01$

Element: 1673 \# of layers: 14

$\mathrm{Kx} \mathrm{Ky} \mathrm{Kz}$ Ss Por

$2.56091 \mathrm{e}+02$ 2.56091e+02 2.56091e+01 1.00000e-09 7.00000e-02

$2.56091 \mathrm{e}+022.56091 \mathrm{e}+022.56091 \mathrm{e}+01$ 1.00000e-09 7.00000e-02

$2.56091 \mathrm{e}+022.56091 \mathrm{e}+022.56091 \mathrm{e}+01$ 1.00000e-09 7.00000e-02

5.00000e-04 5.00000e-04 5.00000e-05 1.00000e-09 1.00000e-01

5.00000e-04 5.00000e-04 5.00000e-05 1.00000e-09 1.00000e-01

$1.02325 \mathrm{e}+011.02325 \mathrm{e}+011.02325 \mathrm{e}+001.00000 \mathrm{e}-092.12000 \mathrm{e}-01$

$1.02325 \mathrm{e}+011.02325 \mathrm{e}+011.02325 \mathrm{e}+001.00000 \mathrm{e}-092.12000 \mathrm{e}-01$

$1.02325 \mathrm{e}+01$ 1.02325e+01 1.02325e+00 1.00000e-09 2.12000e-01

$1.02325 \mathrm{e}+011.02325 \mathrm{e}+01 \quad 1.02325 \mathrm{e}+001.00000 \mathrm{e}-092.12000 \mathrm{e}-01$

$1.02325 \mathrm{e}+011.02325 \mathrm{e}+011.02325 \mathrm{e}+001.00000 \mathrm{e}-092.12000 \mathrm{e}-01$ 
$1.00000 \mathrm{e}-02$ 1.00000e-02 1.00000e-03 1.00000e-09 1.00000e-01 $1.00000 \mathrm{e}+001.00000 \mathrm{e}+001.00000 \mathrm{e}-011.00000 \mathrm{e}-091.00000 \mathrm{e}-01$ $1.00000 \mathrm{e}-051.00000 \mathrm{e}-05$ 1.00000e-06 1.00000e-09 1.00000e-01 $1.00000 \mathrm{e}+001.00000 \mathrm{e}+001.00000 \mathrm{e}-011.00000 \mathrm{e}-091.00000 \mathrm{e}-01$ Element: 1674 \# of layers: 14

Kx Ky Kz Ss Por

$2.56091 \mathrm{e}+022.56091 \mathrm{e}+022.56091 \mathrm{e}+01$ 1.00000e-09 7.00000e-02 $2.56091 \mathrm{e}+022.56091 \mathrm{e}+022.56091 \mathrm{e}+011.00000 \mathrm{e}-097.00000 \mathrm{e}-02$ $2.56091 \mathrm{e}+022.56091 \mathrm{e}+022.56091 \mathrm{e}+011.00000 \mathrm{e}-097.00000 \mathrm{e}-02$ 5.00000e-04 5.00000e-04 5.00000e-05 1.00000e-09 1.00000e-01 5.00000e-04 5.00000e-04 5.00000e-05 1.00000e-09 1.00000e-01 $1.02325 \mathrm{e}+011.02325 \mathrm{e}+011.02325 \mathrm{e}+001.00000 \mathrm{e}-092.12000 \mathrm{e}-01$ $1.02325 \mathrm{e}+011.02325 \mathrm{e}+011.02325 \mathrm{e}+001.00000 \mathrm{e}-092.12000 \mathrm{e}-01$ $1.02325 \mathrm{e}+011.02325 \mathrm{e}+011.02325 \mathrm{e}+001.00000 \mathrm{e}-092.12000 \mathrm{e}-01$ $1.02325 \mathrm{e}+011.02325 \mathrm{e}+011.02325 \mathrm{e}+001.00000 \mathrm{e}-092.12000 \mathrm{e}-01$ $1.02325 \mathrm{e}+011.02325 \mathrm{e}+011.02325 \mathrm{e}+001.00000 \mathrm{e}-092.12000 \mathrm{e}-01$ $1.00000 \mathrm{e}-021.00000 \mathrm{e}-02$ 1.00000e-03 1.00000e-09 1.00000e-01 $1.00000 \mathrm{e}+001.00000 \mathrm{e}+001.00000 \mathrm{e}-011.00000 \mathrm{e}-091.00000 \mathrm{e}-01$ $1.00000 \mathrm{e}-05$ 1.00000e-05 1.00000e-06 1.00000e-09 1.00000e-01 $1.00000 \mathrm{e}+001.00000 \mathrm{e}+001.00000 \mathrm{e}-011.00000 \mathrm{e}-091.00000 \mathrm{e}-01$ Element: 1675 \# of layers: 14

Kx Ky Kz Ss Por

$2.56091 \mathrm{e}+022.56091 \mathrm{e}+022.56091 \mathrm{e}+01$ 1.00000e-09 7.00000e-02 $2.56091 \mathrm{e}+022.56091 \mathrm{e}+022.56091 \mathrm{e}+01$ 1.00000e-09 7.00000e-02 $2.56091 \mathrm{e}+022.56091 \mathrm{e}+022.56091 \mathrm{e}+011.00000 \mathrm{e}-097.00000 \mathrm{e}-02$ $5.00000 \mathrm{e}-04$ 5.00000e-04 5.00000e-05 1.00000e-09 1.00000e-01 5.00000e-04 5.00000e-04 5.00000e-05 1.00000e-09 1.00000e-01 $1.02325 \mathrm{e}+011.02325 \mathrm{e}+011.02325 \mathrm{e}+001.00000 \mathrm{e}-092.12000 \mathrm{e}-01$ $1.02325 \mathrm{e}+011.02325 \mathrm{e}+011.02325 \mathrm{e}+001.00000 \mathrm{e}-092.12000 \mathrm{e}-01$ $1.02325 \mathrm{e}+011.02325 \mathrm{e}+011.02325 \mathrm{e}+001.00000 \mathrm{e}-092.12000 \mathrm{e}-01$ $1.02325 \mathrm{e}+011.02325 \mathrm{e}+011.02325 \mathrm{e}+001.00000 \mathrm{e}-092.12000 \mathrm{e}-01$ $1.02325 \mathrm{e}+011.02325 \mathrm{e}+011.02325 \mathrm{e}+001.00000 \mathrm{e}-092.12000 \mathrm{e}-01$ $1.00000 \mathrm{e}-021.00000 \mathrm{e}-02$ 1.00000e-03 1.00000e-09 1.00000e-01 $1.00000 \mathrm{e}+001.00000 \mathrm{e}+001.00000 \mathrm{e}-011.00000 \mathrm{e}-091.00000 \mathrm{e}-01$ $1.00000 \mathrm{e}-05$ 1.00000e-05 1.00000e-06 1.00000e-09 1.00000e-01 $1.00000 \mathrm{e}+001.00000 \mathrm{e}+001.00000 \mathrm{e}-011.00000 \mathrm{e}-091.00000 \mathrm{e}-01$ Element: 1676 \# of layers: 14

Kx Ky Kz Ss Por

$2.56091 \mathrm{e}+022.56091 \mathrm{e}+022.56091 \mathrm{e}+01$ 1.00000e-09 7.00000e-02 $2.56091 \mathrm{e}+022.56091 \mathrm{e}+022.56091 \mathrm{e}+011.00000 \mathrm{e}-097.00000 \mathrm{e}-02$ $2.56091 \mathrm{e}+022.56091 \mathrm{e}+022.56091 \mathrm{e}+01$ 1.00000e-09 7.00000e-02 5.00000e-04 5.00000e-04 5.00000e-05 1.00000e-09 1.00000e-01 $5.00000 \mathrm{e}-04$ 5.00000e-04 5.00000e-05 1.00000e-09 1.00000e-01 $1.02325 \mathrm{e}+011.02325 \mathrm{e}+011.02325 \mathrm{e}+001.00000 \mathrm{e}-092.12000 \mathrm{e}-01$ $1.02325 \mathrm{e}+011.02325 \mathrm{e}+011.02325 \mathrm{e}+001.00000 \mathrm{e}-092.12000 \mathrm{e}-01$ $1.02325 \mathrm{e}+011.02325 \mathrm{e}+011.02325 \mathrm{e}+001.00000 \mathrm{e}-092.12000 \mathrm{e}-01$ 
$1.02325 \mathrm{e}+011.02325 \mathrm{e}+01$ 1.02325e+00 1.00000e-09 2.12000e-01 $1.02325 \mathrm{e}+011.02325 \mathrm{e}+011.02325 \mathrm{e}+001.00000 \mathrm{e}-092.12000 \mathrm{e}-01$ $1.00000 \mathrm{e}-02$ 1.00000e-02 1.00000e-03 1.00000e-09 1.00000e-01 $1.00000 \mathrm{e}+001.00000 \mathrm{e}+001.00000 \mathrm{e}-011.00000 \mathrm{e}-091.00000 \mathrm{e}-01$ $1.00000 \mathrm{e}-05$ 1.00000e-05 1.00000e-06 1.00000e-09 1.00000e-01 $1.00000 \mathrm{e}+001.00000 \mathrm{e}+001.00000 \mathrm{e}-011.00000 \mathrm{e}-091.00000 \mathrm{e}-01$ Element: 1677 \# of layers: 14

$\mathrm{Kx} \mathrm{Ky} \mathrm{Kz}$ Ss Por

$2.56091 \mathrm{e}+022.56091 \mathrm{e}+02$ 2.56091e+01 1.00000e-09 7.00000e-02

$2.56091 \mathrm{e}+022.56091 \mathrm{e}+022.56091 \mathrm{e}+01$ 1.00000e-09 7.00000e-02

$2.56091 \mathrm{e}+022.56091 \mathrm{e}+022.56091 \mathrm{e}+01$ 1.00000e-09 7.00000e-02 5.00000e-04 5.00000e-04 5.00000e-05 1.00000e-09 1.00000e-01 5.00000e-04 5.00000e-04 5.00000e-05 1.00000e-09 1.00000e-01 $1.02325 \mathrm{e}+011.02325 \mathrm{e}+011.02325 \mathrm{e}+001.00000 \mathrm{e}-092.12000 \mathrm{e}-01$ $1.02325 \mathrm{e}+011.02325 \mathrm{e}+011.02325 \mathrm{e}+001.00000 \mathrm{e}-092.12000 \mathrm{e}-01$ $1.02325 \mathrm{e}+011.02325 \mathrm{e}+011.02325 \mathrm{e}+001.00000 \mathrm{e}-092.12000 \mathrm{e}-01$ $1.02325 \mathrm{e}+011.02325 \mathrm{e}+011.02325 \mathrm{e}+001.00000 \mathrm{e}-092.12000 \mathrm{e}-01$ $1.02325 \mathrm{e}+011.02325 \mathrm{e}+011.02325 \mathrm{e}+001.00000 \mathrm{e}-092.12000 \mathrm{e}-01$ $1.00000 \mathrm{e}-02$ 1.00000e-02 1.00000e-03 1.00000e-09 1.00000e-01 $1.00000 \mathrm{e}+001.00000 \mathrm{e}+001.00000 \mathrm{e}-011.00000 \mathrm{e}-091.00000 \mathrm{e}-01$ $1.00000 \mathrm{e}-05$ 1.00000e-05 1.00000e-06 1.00000e-09 1.00000e-01 $1.00000 \mathrm{e}+001.00000 \mathrm{e}+001.00000 \mathrm{e}-011.00000 \mathrm{e}-091.00000 \mathrm{e}-01$ Element: 1678 \# of layers: 14

Kx Ky Kz Ss Por

5.92804e+01 5.92804e+01 5.92804e+00 1.00000e-09 7.00000e-02 $5.92804 \mathrm{e}+015.92804 \mathrm{e}+015.92804 \mathrm{e}+001.00000 \mathrm{e}-09$ 7.00000e-02 $5.92804 \mathrm{e}+015.92804 \mathrm{e}+015.92804 \mathrm{e}+001.00000 \mathrm{e}-09$ 7.00000e-02 5.00000e-04 5.00000e-04 5.00000e-05 1.00000e-09 1.00000e-01 5.00000e-04 5.00000e-04 5.00000e-05 1.00000e-09 1.00000e-01 $2.36863 \mathrm{e}+002.36863 \mathrm{e}+00$ 2.36863e-01 1.00000e-09 2.12000e-01 $2.36863 \mathrm{e}+00$ 2.36863e+00 2.36863e-01 1.00000e-09 2.12000e-01 $2.36863 \mathrm{e}+00$ 2.36863e+00 2.36863e-01 1.00000e-09 2.12000e-01 $2.36863 \mathrm{e}+002.36863 \mathrm{e}+00$ 2.36863e-01 1.00000e-09 2.12000e-01 $2.36863 \mathrm{e}+002.36863 \mathrm{e}+00$ 2.36863e-01 1.00000e-09 2.12000e-01 $1.00000 \mathrm{e}-02$ 1.00000e-02 1.00000e-03 1.00000e-09 1.00000e-01 $1.00000 \mathrm{e}+001.00000 \mathrm{e}+001.00000 \mathrm{e}-011.00000 \mathrm{e}-091.00000 \mathrm{e}-01$ $1.00000 \mathrm{e}-05$ 1.00000e-05 1.00000e-06 1.00000e-09 1.00000e-01 $1.00000 \mathrm{e}+001.00000 \mathrm{e}+001.00000 \mathrm{e}-011.00000 \mathrm{e}-091.00000 \mathrm{e}-01$ Element: 1679 \# of layers: 14

$\mathrm{Kx} \mathrm{Ky} \mathrm{Kz}$ Ss Por 5.92804e+01 5.92804e+01 5.92804e+00 1.00000e-09 7.00000e-02 $5.92804 \mathrm{e}+015.92804 \mathrm{e}+015.92804 \mathrm{e}+001.00000 \mathrm{e}-09$ 7.00000e-02 $5.92804 \mathrm{e}+015.92804 \mathrm{e}+015.92804 \mathrm{e}+001.00000 \mathrm{e}-09$ 7.00000e-02 5.00000e-04 5.00000e-04 5.00000e-05 1.00000e-09 1.00000e-01 5.00000e-04 5.00000e-04 5.00000e-05 1.00000e-09 1.00000e-01 $2.36863 \mathrm{e}+002.36863 \mathrm{e}+00$ 2.36863e-01 1.00000e-09 2.12000e-01 
$2.36863 \mathrm{e}+002.36863 \mathrm{e}+00$ 2.36863e-01 1.00000e-09 2.12000e-01

$2.36863 \mathrm{e}+002.36863 \mathrm{e}+002.36863 \mathrm{e}-011.00000 \mathrm{e}-092.12000 \mathrm{e}-01$

$2.36863 \mathrm{e}+002.36863 \mathrm{e}+002.36863 \mathrm{e}-01$ 1.00000e-09 2.12000e-01

$2.36863 \mathrm{e}+002.36863 \mathrm{e}+002.36863 \mathrm{e}-01$ 1.00000e-09 2.12000e-01

$1.00000 \mathrm{e}-02$ 1.00000e-02 1.00000e-03 1.00000e-09 1.00000e-01

$1.00000 \mathrm{e}+001.00000 \mathrm{e}+001.00000 \mathrm{e}-011.00000 \mathrm{e}-091.00000 \mathrm{e}-01$

$1.00000 \mathrm{e}-05$ 1.00000e-05 1.00000e-06 1.00000e-09 1.00000e-01

$1.00000 \mathrm{e}+001.00000 \mathrm{e}+001.00000 \mathrm{e}-011.00000 \mathrm{e}-091.00000 \mathrm{e}-01$

Element: 1680 \# of layers: 13

Kx Ky Kz Ss Por

$5.92804 \mathrm{e}+015.92804 \mathrm{e}+015.92804 \mathrm{e}+00$ 1.00000e-09 7.00000e-02

$5.92804 \mathrm{e}+015.92804 \mathrm{e}+015.92804 \mathrm{e}+001.00000 \mathrm{e}-09$ 7.00000e-02

$5.92804 \mathrm{e}+015.92804 \mathrm{e}+015.92804 \mathrm{e}+001.00000 \mathrm{e}-097.00000 \mathrm{e}-02$

5.00000e-04 5.00000e-04 5.00000e-05 1.00000e-09 1.00000e-01

$2.36863 \mathrm{e}+002.36863 \mathrm{e}+002.36863 \mathrm{e}-01$ 1.00000e-09 2.12000e-01

$2.36863 \mathrm{e}+002.36863 \mathrm{e}+002.36863 \mathrm{e}-01$ 1.00000e-09 2.12000e-01

$2.36863 \mathrm{e}+002.36863 \mathrm{e}+002.36863 \mathrm{e}-01$ 1.00000e-09 2.12000e-01

$2.36863 \mathrm{e}+002.36863 \mathrm{e}+002.36863 \mathrm{e}-011.00000 \mathrm{e}-092.12000 \mathrm{e}-01$

$2.36863 \mathrm{e}+002.36863 \mathrm{e}+002.36863 \mathrm{e}-01$ 1.00000e-09 2.12000e-01

$1.00000 \mathrm{e}-021.00000 \mathrm{e}-02$ 1.00000e-03 1.00000e-09 1.00000e-01

$1.00000 \mathrm{e}+001.00000 \mathrm{e}+001.00000 \mathrm{e}-011.00000 \mathrm{e}-091.00000 \mathrm{e}-01$

$1.00000 \mathrm{e}-05$ 1.00000e-05 1.00000e-06 1.00000e-09 1.00000e-01

$1.00000 \mathrm{e}+001.00000 \mathrm{e}+001.00000 \mathrm{e}-011.00000 \mathrm{e}-091.00000 \mathrm{e}-01$

Element: 1681 \# of layers: 12

Kx Ky Kz Ss Por

$5.92804 \mathrm{e}+015.92804 \mathrm{e}+015.92804 \mathrm{e}+001.00000 \mathrm{e}-097.00000 \mathrm{e}-02$

$5.92804 \mathrm{e}+015.92804 \mathrm{e}+015.92804 \mathrm{e}+001.00000 \mathrm{e}-097.00000 \mathrm{e}-02$

5.00000e-04 5.00000e-04 5.00000e-05 1.00000e-09 1.00000e-01

$2.36863 \mathrm{e}+002.36863 \mathrm{e}+002.36863 \mathrm{e}-01$ 1.00000e-09 2.12000e-01

$2.36863 \mathrm{e}+002.36863 \mathrm{e}+002.36863 \mathrm{e}-01$ 1.00000e-09 2.12000e-01

$2.36863 \mathrm{e}+002.36863 \mathrm{e}+002.36863 \mathrm{e}-011.00000 \mathrm{e}-092.12000 \mathrm{e}-01$

$2.36863 \mathrm{e}+002.36863 \mathrm{e}+002.36863 \mathrm{e}-01$ 1.00000e-09 2.12000e-01

$2.36863 \mathrm{e}+002.36863 \mathrm{e}+002.36863 \mathrm{e}-01$ 1.00000e-09 2.12000e-01

$1.00000 \mathrm{e}-021.00000 \mathrm{e}-02$ 1.00000e-03 1.00000e-09 1.00000e-01

$1.00000 \mathrm{e}+001.00000 \mathrm{e}+001.00000 \mathrm{e}-011.00000 \mathrm{e}-091.00000 \mathrm{e}-01$

$1.00000 \mathrm{e}-05$ 1.00000e-05 1.00000e-06 1.00000e-09 1.00000e-01

$1.00000 \mathrm{e}+001.00000 \mathrm{e}+001.00000 \mathrm{e}-011.00000 \mathrm{e}-09$ 1.00000e-01

Element: 1682 \# of layers: 14

Kx Ky Kz Ss Por

$5.92804 \mathrm{e}+015.92804 \mathrm{e}+015.92804 \mathrm{e}+00$ 1.00000e-09 7.00000e-02

$5.92804 \mathrm{e}+015.92804 \mathrm{e}+015.92804 \mathrm{e}+001.00000 \mathrm{e}-097.00000 \mathrm{e}-02$

$5.92804 \mathrm{e}+015.92804 \mathrm{e}+015.92804 \mathrm{e}+001.00000 \mathrm{e}-097.00000 \mathrm{e}-02$

$5.00000 \mathrm{e}-04$ 5.00000e-04 5.00000e-05 1.00000e-09 1.00000e-01

5.00000e-04 5.00000e-04 5.00000e-05 1.00000e-09 1.00000e-01

$2.36863 \mathrm{e}+002.36863 \mathrm{e}+002.36863 \mathrm{e}-011.00000 \mathrm{e}-092.12000 \mathrm{e}-01$

$2.36863 \mathrm{e}+002.36863 \mathrm{e}+002.36863 \mathrm{e}-01$ 1.00000e-09 2.12000e-01 
$2.36863 \mathrm{e}+002.36863 \mathrm{e}+00$ 2.36863e-01 1.00000e-09 2.12000e-01

$2.36863 \mathrm{e}+002.36863 \mathrm{e}+002.36863 \mathrm{e}-011.00000 \mathrm{e}-092.12000 \mathrm{e}-01$

$2.36863 \mathrm{e}+002.36863 \mathrm{e}+002.36863 \mathrm{e}-011.00000 \mathrm{e}-092.12000 \mathrm{e}-01$

$1.00000 \mathrm{e}-021.00000 \mathrm{e}-02$ 1.00000e-03 1.00000e-09 1.00000e-01

$1.00000 \mathrm{e}+001.00000 \mathrm{e}+001.00000 \mathrm{e}-011.00000 \mathrm{e}-091.00000 \mathrm{e}-01$

$1.00000 \mathrm{e}-05$ 1.00000e-05 1.00000e-06 1.00000e-09 1.00000e-01

$1.00000 \mathrm{e}+001.00000 \mathrm{e}+001.00000 \mathrm{e}-011.00000 \mathrm{e}-091.00000 \mathrm{e}-01$

Element: 1683 \# of layers: 14

Kx Ky Kz Ss Por

$5.92804 \mathrm{e}+015.92804 \mathrm{e}+015.92804 \mathrm{e}+001.00000 \mathrm{e}-09$ 7.00000e-02 $5.92804 \mathrm{e}+015.92804 \mathrm{e}+015.92804 \mathrm{e}+001.00000 \mathrm{e}-097.00000 \mathrm{e}-02$ $5.92804 \mathrm{e}+015.92804 \mathrm{e}+015.92804 \mathrm{e}+001.00000 \mathrm{e}-097.00000 \mathrm{e}-02$ 5.00000e-04 5.00000e-04 5.00000e-05 1.00000e-09 1.00000e-01 5.00000e-04 5.00000e-04 5.00000e-05 1.00000e-09 1.00000e-01 $2.36863 \mathrm{e}+002.36863 \mathrm{e}+002.36863 \mathrm{e}-01$ 1.00000e-09 2.12000e-01 $2.36863 \mathrm{e}+002.36863 \mathrm{e}+002.36863 \mathrm{e}-011.00000 \mathrm{e}-092.12000 \mathrm{e}-01$ $2.36863 \mathrm{e}+002.36863 \mathrm{e}+002.36863 \mathrm{e}-01$ 1.00000e-09 2.12000e-01 $2.36863 \mathrm{e}+002.36863 \mathrm{e}+002.36863 \mathrm{e}-01$ 1.00000e-09 2.12000e-01 $2.36863 \mathrm{e}+002.36863 \mathrm{e}+002.36863 \mathrm{e}-01$ 1.00000e-09 2.12000e-01 $1.00000 \mathrm{e}-021.00000 \mathrm{e}-02$ 1.00000e-03 1.00000e-09 1.00000e-01 $1.00000 \mathrm{e}+001.00000 \mathrm{e}+001.00000 \mathrm{e}-011.00000 \mathrm{e}-091.00000 \mathrm{e}-01$ $1.00000 \mathrm{e}-05$ 1.00000e-05 1.00000e-06 1.00000e-09 1.00000e-01 $1.00000 \mathrm{e}+001.00000 \mathrm{e}+001.00000 \mathrm{e}-011.00000 \mathrm{e}-091.00000 \mathrm{e}-01$ Element: 1684 \# of layers: 14

Kx Ky Kz Ss Por $5.92804 \mathrm{e}+015.92804 \mathrm{e}+015.92804 \mathrm{e}+001.00000 \mathrm{e}-097.00000 \mathrm{e}-02$ $5.92804 \mathrm{e}+015.92804 \mathrm{e}+015.92804 \mathrm{e}+001.00000 \mathrm{e}-097.00000 \mathrm{e}-02$ $5.92804 \mathrm{e}+015.92804 \mathrm{e}+015.92804 \mathrm{e}+001.00000 \mathrm{e}-097.00000 \mathrm{e}-02$ 5.00000e-04 5.00000e-04 5.00000e-05 1.00000e-09 1.00000e-01 $5.00000 \mathrm{e}-04$ 5.00000e-04 5.00000e-05 1.00000e-09 1.00000e-01 $2.36863 \mathrm{e}+002.36863 \mathrm{e}+002.36863 \mathrm{e}-011.00000 \mathrm{e}-092.12000 \mathrm{e}-01$ $2.36863 \mathrm{e}+002.36863 \mathrm{e}+002.36863 \mathrm{e}-01$ 1.00000e-09 2.12000e-01 $2.36863 \mathrm{e}+002.36863 \mathrm{e}+002.36863 \mathrm{e}-011.00000 \mathrm{e}-092.12000 \mathrm{e}-01$ $2.36863 \mathrm{e}+002.36863 \mathrm{e}+002.36863 \mathrm{e}-01$ 1.00000e-09 2.12000e-01 $2.36863 \mathrm{e}+002.36863 \mathrm{e}+002.36863 \mathrm{e}-01$ 1.00000e-09 2.12000e-01 $1.00000 \mathrm{e}-021.00000 \mathrm{e}-02$ 1.00000e-03 1.00000e-09 1.00000e-01 $1.00000 \mathrm{e}+001.00000 \mathrm{e}+001.00000 \mathrm{e}-011.00000 \mathrm{e}-091.00000 \mathrm{e}-01$ $1.00000 \mathrm{e}-05$ 1.00000e-05 1.00000e-06 1.00000e-09 1.00000e-01 $1.00000 \mathrm{e}+001.00000 \mathrm{e}+001.00000 \mathrm{e}-011.00000 \mathrm{e}-091.00000 \mathrm{e}-01$ Element: 1685 \# of layers: 14

Kx Ky Kz Ss Por $5.92804 \mathrm{e}+015.92804 \mathrm{e}+015.92804 \mathrm{e}+00$ 1.00000e-09 7.00000e-02 $5.92804 \mathrm{e}+015.92804 \mathrm{e}+015.92804 \mathrm{e}+001.00000 \mathrm{e}-097.00000 \mathrm{e}-02$ $5.92804 \mathrm{e}+015.92804 \mathrm{e}+015.92804 \mathrm{e}+001.00000 \mathrm{e}-09$ 7.00000e-02 5.00000e-04 5.00000e-04 5.00000e-05 1.00000e-09 1.00000e-01 5.00000e-04 5.00000e-04 5.00000e-05 1.00000e-09 1.00000e-01 
$2.36863 \mathrm{e}+002.36863 \mathrm{e}+00$ 2.36863e-01 1.00000e-09 2.12000e-01 $2.36863 \mathrm{e}+002.36863 \mathrm{e}+002.36863 \mathrm{e}-01$ 1.00000e-09 2.12000e-01 $2.36863 \mathrm{e}+002.36863 \mathrm{e}+002.36863 \mathrm{e}-01$ 1.00000e-09 2.12000e-01 $2.36863 \mathrm{e}+002.36863 \mathrm{e}+002.36863 \mathrm{e}-01$ 1.00000e-09 2.12000e-01 $2.36863 \mathrm{e}+002.36863 \mathrm{e}+002.36863 \mathrm{e}-01$ 1.00000e-09 2.12000e-01 $1.00000 \mathrm{e}-021.00000 \mathrm{e}-02$ 1.00000e-03 1.00000e-09 1.00000e-01 $1.00000 \mathrm{e}+001.00000 \mathrm{e}+001.00000 \mathrm{e}-011.00000 \mathrm{e}-091.00000 \mathrm{e}-01$ $1.00000 \mathrm{e}-05$ 1.00000e-05 1.00000e-06 1.00000e-09 1.00000e-01 $1.00000 \mathrm{e}+001.00000 \mathrm{e}+001.00000 \mathrm{e}-011.00000 \mathrm{e}-091.00000 \mathrm{e}-01$ Element: 1686 \# of layers: 14

Kx Ky Kz Ss Por

$5.92804 \mathrm{e}+015.92804 \mathrm{e}+015.92804 \mathrm{e}+00$ 1.00000e-09 7.00000e-02 $5.92804 \mathrm{e}+015.92804 \mathrm{e}+015.92804 \mathrm{e}+001.00000 \mathrm{e}-097.00000 \mathrm{e}-02$ $5.92804 \mathrm{e}+015.92804 \mathrm{e}+015.92804 \mathrm{e}+001.00000 \mathrm{e}-097.00000 \mathrm{e}-02$ 5.00000e-04 5.00000e-04 5.00000e-05 1.00000e-09 1.00000e-01 5.00000e-04 5.00000e-04 5.00000e-05 1.00000e-09 1.00000e-01 $2.36863 \mathrm{e}+002.36863 \mathrm{e}+002.36863 \mathrm{e}-01$ 1.00000e-09 2.12000e-01 $2.36863 \mathrm{e}+002.36863 \mathrm{e}+002.36863 \mathrm{e}-01$ 1.00000e-09 2.12000e-01 $2.36863 \mathrm{e}+002.36863 \mathrm{e}+002.36863 \mathrm{e}-011.00000 \mathrm{e}-092.12000 \mathrm{e}-01$ $2.36863 \mathrm{e}+002.36863 \mathrm{e}+002.36863 \mathrm{e}-011.00000 \mathrm{e}-092.12000 \mathrm{e}-01$ $2.36863 \mathrm{e}+002.36863 \mathrm{e}+002.36863 \mathrm{e}-011.00000 \mathrm{e}-092.12000 \mathrm{e}-01$ $1.00000 \mathrm{e}-02$ 1.00000e-02 1.00000e-03 1.00000e-09 1.00000e-01 $1.00000 \mathrm{e}+001.00000 \mathrm{e}+001.00000 \mathrm{e}-011.00000 \mathrm{e}-091.00000 \mathrm{e}-01$ $1.00000 \mathrm{e}-051.00000 \mathrm{e}-05$ 1.00000e-06 1.00000e-09 1.00000e-01 $1.00000 \mathrm{e}+001.00000 \mathrm{e}+001.00000 \mathrm{e}-011.00000 \mathrm{e}-091.00000 \mathrm{e}-01$ Element: 1687 \# of layers: 14

Kx Ky Kz Ss Por

$8.64311 \mathrm{e}+018.64311 \mathrm{e}+018.64311 \mathrm{e}+00$ 1.00000e-09 7.00000e-02 $8.64311 \mathrm{e}+018.64311 \mathrm{e}+018.64311 \mathrm{e}+001.00000 \mathrm{e}-09$ 7.00000e-02 $8.64311 \mathrm{e}+018.64311 \mathrm{e}+018.64311 \mathrm{e}+001.00000 \mathrm{e}-097.00000 \mathrm{e}-02$ $5.00000 \mathrm{e}-04$ 5.00000e-04 5.00000e-05 1.00000e-09 1.00000e-01 5.00000e-04 5.00000e-04 5.00000e-05 1.00000e-09 1.00000e-01 $3.45337 \mathrm{e}+003.45337 \mathrm{e}+003.45337 \mathrm{e}-01$ 1.00000e-09 2.12000e-01 $3.45337 \mathrm{e}+003.45337 \mathrm{e}+003.45337 \mathrm{e}-01$ 1.00000e-09 2.12000e-01 $3.45337 \mathrm{e}+003.45337 \mathrm{e}+003.45337 \mathrm{e}-011.00000 \mathrm{e}-092.12000 \mathrm{e}-01$ $3.45337 \mathrm{e}+003.45337 \mathrm{e}+003.45337 \mathrm{e}-01$ 1.00000e-09 2.12000e-01 $3.45337 \mathrm{e}+003.45337 \mathrm{e}+003.45337 \mathrm{e}-011.00000 \mathrm{e}-09$ 2.12000e-01 $1.00000 \mathrm{e}-021.00000 \mathrm{e}-02$ 1.00000e-03 1.00000e-09 1.00000e-01 $1.00000 \mathrm{e}+001.00000 \mathrm{e}+001.00000 \mathrm{e}-011.00000 \mathrm{e}-091.00000 \mathrm{e}-01$ $1.00000 \mathrm{e}-05$ 1.00000e-05 1.00000e-06 1.00000e-09 1.00000e-01 $1.00000 \mathrm{e}+001.00000 \mathrm{e}+001.00000 \mathrm{e}-011.00000 \mathrm{e}-091.00000 \mathrm{e}-01$ Element: 1688 \# of layers: 14

Kx Ky Kz Ss Por

$8.64311 \mathrm{e}+018.64311 \mathrm{e}+018.64311 \mathrm{e}+00$ 1.00000e-09 7.00000e-02 $8.64311 \mathrm{e}+018.64311 \mathrm{e}+018.64311 \mathrm{e}+001.00000 \mathrm{e}-097.00000 \mathrm{e}-02$ $8.64311 \mathrm{e}+018.64311 \mathrm{e}+018.64311 \mathrm{e}+001.00000 \mathrm{e}-09$ 7.00000e-02 
5.00000e-04 5.00000e-04 5.00000e-05 1.00000e-09 1.00000e-01 5.00000e-04 5.00000e-04 5.00000e-05 1.00000e-09 1.00000e-01 3.45337e+00 3.45337e+00 3.45337e-01 1.00000e-09 2.12000e-01 $3.45337 \mathrm{e}+00$ 3.45337e+00 3.45337e-01 1.00000e-09 2.12000e-01 $3.45337 \mathrm{e}+003.45337 \mathrm{e}+00$ 3.45337e-01 1.00000e-09 2.12000e-01 $3.45337 \mathrm{e}+003.45337 \mathrm{e}+00$ 3.45337e-01 1.00000e-09 2.12000e-01 $3.45337 \mathrm{e}+003.45337 \mathrm{e}+00$ 3.45337e-01 1.00000e-09 2.12000e-01 $1.00000 \mathrm{e}-02$ 1.00000e-02 1.00000e-03 1.00000e-09 1.00000e-01 $1.00000 \mathrm{e}+001.00000 \mathrm{e}+001.00000 \mathrm{e}-011.00000 \mathrm{e}-091.00000 \mathrm{e}-01$ $1.00000 \mathrm{e}-05$ 1.00000e-05 1.00000e-06 1.00000e-09 1.00000e-01 $1.00000 \mathrm{e}+001.00000 \mathrm{e}+001.00000 \mathrm{e}-011.00000 \mathrm{e}-091.00000 \mathrm{e}-01$ Element: 1689 \# of layers: 13

Kx Ky Kz Ss Por

8.64311e+01 8.64311e+01 8.64311e+00 1.00000e-09 7.00000e-02 $8.64311 \mathrm{e}+018.64311 \mathrm{e}+018.64311 \mathrm{e}+001.00000 \mathrm{e}-09$ 7.00000e-02 5.00000e-04 5.00000e-04 5.00000e-05 1.00000e-09 1.00000e-01 5.00000e-04 5.00000e-04 5.00000e-05 1.00000e-09 1.00000e-01

$3.45337 \mathrm{e}+003.45337 \mathrm{e}+00$ 3.45337e-01 1.00000e-09 2.12000e-01 3.45337e+00 3.45337e+00 3.45337e-01 1.00000e-09 2.12000e-01 $3.45337 \mathrm{e}+003.45337 \mathrm{e}+00$ 3.45337e-01 1.00000e-09 2.12000e-01 $3.45337 \mathrm{e}+00$ 3.45337e+00 3.45337e-01 1.00000e-09 2.12000e-01 3.45337e+00 3.45337e+00 3.45337e-01 1.00000e-09 2.12000e-01 $1.00000 \mathrm{e}-02$ 1.00000e-02 1.00000e-03 1.00000e-09 1.00000e-01 $1.00000 \mathrm{e}+001.00000 \mathrm{e}+001.00000 \mathrm{e}-011.00000 \mathrm{e}-091.00000 \mathrm{e}-01$ $1.00000 \mathrm{e}-05$ 1.00000e-05 1.00000e-06 1.00000e-09 1.00000e-01 $1.00000 \mathrm{e}+001.00000 \mathrm{e}+001.00000 \mathrm{e}-011.00000 \mathrm{e}-091.00000 \mathrm{e}-01$ Element: 1690 \# of layers: 13

$\mathrm{Kx} \mathrm{Ky} \mathrm{Kz}$ Ss Por

8.64311e+01 8.64311e+01 8.64311e+00 1.00000e-09 7.00000e-02 $8.64311 \mathrm{e}+018.64311 \mathrm{e}+018.64311 \mathrm{e}+001.00000 \mathrm{e}-097.00000 \mathrm{e}-02$ 5.00000e-04 5.00000e-04 5.00000e-05 1.00000e-09 1.00000e-01 5.00000e-04 5.00000e-04 5.00000e-05 1.00000e-09 1.00000e-01 $3.45337 \mathrm{e}+003.45337 \mathrm{e}+00$ 3.45337e-01 1.00000e-09 2.12000e-01 $3.45337 \mathrm{e}+003.45337 \mathrm{e}+003.45337 \mathrm{e}-01$ 1.00000e-09 2.12000e-01 $3.45337 \mathrm{e}+003.45337 \mathrm{e}+00$ 3.45337e-01 1.00000e-09 2.12000e-01 3.45337e+00 3.45337e+00 3.45337e-01 1.00000e-09 2.12000e-01 $3.45337 \mathrm{e}+003.45337 \mathrm{e}+00$ 3.45337e-01 1.00000e-09 2.12000e-01 $1.00000 \mathrm{e}-02$ 1.00000e-02 1.00000e-03 1.00000e-09 1.00000e-01 $1.00000 \mathrm{e}+001.00000 \mathrm{e}+001.00000 \mathrm{e}-011.00000 \mathrm{e}-091.00000 \mathrm{e}-01$ $1.00000 \mathrm{e}-05$ 1.00000e-05 1.00000e-06 1.00000e-09 1.00000e-01 $1.00000 \mathrm{e}+001.00000 \mathrm{e}+001.00000 \mathrm{e}-011.00000 \mathrm{e}-091.00000 \mathrm{e}-01$ Element: 1691 \# of layers: 13

$\mathrm{Kx} \mathrm{Ky} \mathrm{Kz}$ Ss Por

8.64311e+01 8.64311e+01 8.64311e+00 1.00000e-09 7.00000e-02 $8.64311 \mathrm{e}+018.64311 \mathrm{e}+018.64311 \mathrm{e}+001.00000 \mathrm{e}-09$ 7.00000e-02 5.00000e-04 5.00000e-04 5.00000e-05 1.00000e-09 1.00000e-01 
5.00000e-04 5.00000e-04 5.00000e-05 1.00000e-09 1.00000e-01 3.45337e+00 3.45337e+00 3.45337e-01 1.00000e-09 2.12000e-01 3.45337e+00 3.45337e+00 3.45337e-01 1.00000e-09 2.12000e-01 $3.45337 \mathrm{e}+003.45337 \mathrm{e}+00$ 3.45337e-01 1.00000e-09 2.12000e-01 $3.45337 \mathrm{e}+003.45337 \mathrm{e}+00$ 3.45337e-01 1.00000e-09 2.12000e-01 $3.45337 \mathrm{e}+003.45337 \mathrm{e}+00$ 3.45337e-01 1.00000e-09 2.12000e-01 $1.00000 \mathrm{e}-02$ 1.00000e-02 1.00000e-03 1.00000e-09 1.00000e-01 $1.00000 \mathrm{e}+001.00000 \mathrm{e}+001.00000 \mathrm{e}-011.00000 \mathrm{e}-091.00000 \mathrm{e}-01$ $1.00000 \mathrm{e}-05$ 1.00000e-05 1.00000e-06 1.00000e-09 1.00000e-01 $1.00000 \mathrm{e}+001.00000 \mathrm{e}+001.00000 \mathrm{e}-011.00000 \mathrm{e}-091.00000 \mathrm{e}-01$ Element: 1692 \# of layers: 14

$\mathrm{Kx} \mathrm{Ky} \mathrm{Kz}$ Ss Por

8.64311e+01 8.64311e+01 8.64311e+00 1.00000e-09 7.00000e-02 $8.64311 \mathrm{e}+018.64311 \mathrm{e}+018.64311 \mathrm{e}+001.00000 \mathrm{e}-09$ 7.00000e-02 $8.64311 \mathrm{e}+018.64311 \mathrm{e}+018.64311 \mathrm{e}+001.00000 \mathrm{e}-097.00000 \mathrm{e}-02$ 5.00000e-04 5.00000e-04 5.00000e-05 1.00000e-09 1.00000e-01 5.00000e-04 5.00000e-04 5.00000e-05 1.00000e-09 1.00000e-01 3.45337e+00 3.45337e+00 3.45337e-01 1.00000e-09 2.12000e-01 3.45337e+00 3.45337e+00 3.45337e-01 1.00000e-09 2.12000e-01 $3.45337 \mathrm{e}+003.45337 \mathrm{e}+00$ 3.45337e-01 1.00000e-09 2.12000e-01 $3.45337 \mathrm{e}+00$ 3.45337e+00 3.45337e-01 1.00000e-09 2.12000e-01 3.45337e+00 3.45337e+00 3.45337e-01 1.00000e-09 2.12000e-01 $1.00000 \mathrm{e}-02$ 1.00000e-02 1.00000e-03 1.00000e-09 1.00000e-01 $1.00000 \mathrm{e}+001.00000 \mathrm{e}+001.00000 \mathrm{e}-011.00000 \mathrm{e}-091.00000 \mathrm{e}-01$ $1.00000 \mathrm{e}-05$ 1.00000e-05 1.00000e-06 1.00000e-09 1.00000e-01 $1.00000 \mathrm{e}+001.00000 \mathrm{e}+001.00000 \mathrm{e}-011.00000 \mathrm{e}-091.00000 \mathrm{e}-01$ Element: 1693 \# of layers: 13

$\mathrm{Kx} \mathrm{Ky} \mathrm{Kz}$ Ss Por

8.64311e+01 8.64311e+01 8.64311e+00 1.00000e-09 7.00000e-02 $8.64311 \mathrm{e}+018.64311 \mathrm{e}+018.64311 \mathrm{e}+001.00000 \mathrm{e}-09$ 7.00000e-02 $5.00000 \mathrm{e}-04$ 5.00000e-04 5.00000e-05 1.00000e-09 1.00000e-01 5.00000e-04 5.00000e-04 5.00000e-05 1.00000e-09 1.00000e-01 $3.45337 \mathrm{e}+003.45337 \mathrm{e}+00$ 3.45337e-01 1.00000e-09 2.12000e-01 $3.45337 \mathrm{e}+003.45337 \mathrm{e}+00$ 3.45337e-01 1.00000e-09 2.12000e-01 3.45337e+00 3.45337e+00 3.45337e-01 1.00000e-09 2.12000e-01 3.45337e+00 3.45337e+00 3.45337e-01 1.00000e-09 2.12000e-01 $3.45337 \mathrm{e}+003.45337 \mathrm{e}+00$ 3.45337e-01 1.00000e-09 2.12000e-01 $1.00000 \mathrm{e}-02$ 1.00000e-02 1.00000e-03 1.00000e-09 1.00000e-01 $1.00000 \mathrm{e}+001.00000 \mathrm{e}+001.00000 \mathrm{e}-011.00000 \mathrm{e}-091.00000 \mathrm{e}-01$ $1.00000 \mathrm{e}-05$ 1.00000e-05 1.00000e-06 1.00000e-09 1.00000e-01 $1.00000 \mathrm{e}+001.00000 \mathrm{e}+001.00000 \mathrm{e}-011.00000 \mathrm{e}-091.00000 \mathrm{e}-01$ Element: 1694 \# of layers: 13

$\mathrm{Kx} \mathrm{Ky} \mathrm{Kz}$ Ss Por

8.64311e+01 8.64311e+01 8.64311e+00 1.00000e-09 7.00000e-02 $8.64311 \mathrm{e}+018.64311 \mathrm{e}+018.64311 \mathrm{e}+001.00000 \mathrm{e}-09$ 7.00000e-02 5.00000e-04 5.00000e-04 5.00000e-05 1.00000e-09 1.00000e-01 
5.00000e-04 5.00000e-04 5.00000e-05 1.00000e-09 1.00000e-01 3.45337e+00 3.45337e+00 3.45337e-01 1.00000e-09 2.12000e-01 3.45337e+00 3.45337e+00 3.45337e-01 1.00000e-09 2.12000e-01 $3.45337 \mathrm{e}+003.45337 \mathrm{e}+00$ 3.45337e-01 1.00000e-09 2.12000e-01 $3.45337 \mathrm{e}+003.45337 \mathrm{e}+00$ 3.45337e-01 1.00000e-09 2.12000e-01 $3.45337 \mathrm{e}+003.45337 \mathrm{e}+00$ 3.45337e-01 1.00000e-09 2.12000e-01 $1.00000 \mathrm{e}-02$ 1.00000e-02 1.00000e-03 1.00000e-09 1.00000e-01 $1.00000 \mathrm{e}+001.00000 \mathrm{e}+001.00000 \mathrm{e}-011.00000 \mathrm{e}-091.00000 \mathrm{e}-01$ $1.00000 \mathrm{e}-05$ 1.00000e-05 1.00000e-06 1.00000e-09 1.00000e-01 $1.00000 \mathrm{e}+001.00000 \mathrm{e}+001.00000 \mathrm{e}-011.00000 \mathrm{e}-091.00000 \mathrm{e}-01$ Element: 1695 \# of layers: 14

Kx Ky Kz Ss Por

8.64311e+01 8.64311e+01 8.64311e+00 1.00000e-09 7.00000e-02 $8.64311 \mathrm{e}+018.64311 \mathrm{e}+018.64311 \mathrm{e}+001.00000 \mathrm{e}-09$ 7.00000e-02 $8.64311 \mathrm{e}+018.64311 \mathrm{e}+018.64311 \mathrm{e}+001.00000 \mathrm{e}-097.00000 \mathrm{e}-02$ 5.00000e-04 5.00000e-04 5.00000e-05 1.00000e-09 1.00000e-01 5.00000e-04 5.00000e-04 5.00000e-05 1.00000e-09 1.00000e-01 3.45337e+00 3.45337e+00 3.45337e-01 1.00000e-09 2.12000e-01 3.45337e+00 3.45337e+00 3.45337e-01 1.00000e-09 2.12000e-01 $3.45337 \mathrm{e}+003.45337 \mathrm{e}+00$ 3.45337e-01 1.00000e-09 2.12000e-01 $3.45337 \mathrm{e}+00$ 3.45337e+00 3.45337e-01 1.00000e-09 2.12000e-01 3.45337e+00 3.45337e+00 3.45337e-01 1.00000e-09 2.12000e-01 $1.00000 \mathrm{e}-02$ 1.00000e-02 1.00000e-03 1.00000e-09 1.00000e-01 $1.00000 \mathrm{e}+001.00000 \mathrm{e}+001.00000 \mathrm{e}-011.00000 \mathrm{e}-091.00000 \mathrm{e}-01$ $1.00000 \mathrm{e}-05$ 1.00000e-05 1.00000e-06 1.00000e-09 1.00000e-01 $1.00000 \mathrm{e}+001.00000 \mathrm{e}+001.00000 \mathrm{e}-011.00000 \mathrm{e}-091.00000 \mathrm{e}-01$ Element: 1696 \# of layers: 12

$\mathrm{Kx} \mathrm{Ky} \mathrm{Kz}$ Ss Por

$1.18193 \mathrm{e}+02$ 1.18193e+02 1.18193e+01 1.00000e-09 7.00000e-02 5.00000e-04 5.00000e-04 5.00000e-05 1.00000e-09 1.00000e-01 5.00000e-04 5.00000e-04 5.00000e-05 1.00000e-09 1.00000e-01 4.72263e+00 4.72263e+00 4.72263e-01 1.00000e-09 2.12000e-01 $4.72263 \mathrm{e}+00$ 4.72263e+00 4.72263e-01 1.00000e-09 2.12000e-01 4.72263e+00 4.72263e+00 4.72263e-01 1.00000e-09 2.12000e-01 4.72263e+00 4.72263e+00 4.72263e-01 1.00000e-09 2.12000e-01 4.72263e+00 4.72263e+00 4.72263e-01 1.00000e-09 2.12000e-01 $1.00000 \mathrm{e}-021.00000 \mathrm{e}-02$ 1.00000e-03 1.00000e-09 1.00000e-01 $1.00000 \mathrm{e}+001.00000 \mathrm{e}+001.00000 \mathrm{e}-011.00000 \mathrm{e}-091.00000 \mathrm{e}-01$ $1.00000 \mathrm{e}-05$ 1.00000e-05 1.00000e-06 1.00000e-09 1.00000e-01 $1.00000 \mathrm{e}+001.00000 \mathrm{e}+001.00000 \mathrm{e}-011.00000 \mathrm{e}-091.00000 \mathrm{e}-01$ Element: 1697 \# of layers: 12

$\mathrm{Kx} \mathrm{Ky} \mathrm{Kz}$ Ss Por

1.18193e+02 1.18193e+02 1.18193e+01 1.00000e-09 7.00000e-02 5.00000e-04 5.00000e-04 5.00000e-05 1.00000e-09 1.00000e-01 5.00000e-04 5.00000e-04 5.00000e-05 1.00000e-09 1.00000e-01 $4.72263 \mathrm{e}+004.72263 \mathrm{e}+00$ 4.72263e-01 1.00000e-09 2.12000e-01 
$4.72263 \mathrm{e}+00$ 4.72263e+00 4.72263e-01 1.00000e-09 2.12000e-01 $4.72263 \mathrm{e}+004.72263 \mathrm{e}+00$ 4.72263e-01 1.00000e-09 2.12000e-01 $4.72263 \mathrm{e}+004.72263 \mathrm{e}+00$ 4.72263e-01 1.00000e-09 2.12000e-01 $4.72263 \mathrm{e}+004.72263 \mathrm{e}+00$ 4.72263e-01 1.00000e-09 2.12000e-01 $1.00000 \mathrm{e}-02$ 1.00000e-02 1.00000e-03 1.00000e-09 1.00000e-01 $1.00000 \mathrm{e}+001.00000 \mathrm{e}+001.00000 \mathrm{e}-011.00000 \mathrm{e}-091.00000 \mathrm{e}-01$ $1.00000 \mathrm{e}-051.00000 \mathrm{e}-05$ 1.00000e-06 1.00000e-09 1.00000e-01 $1.00000 \mathrm{e}+001.00000 \mathrm{e}+001.00000 \mathrm{e}-011.00000 \mathrm{e}-091.00000 \mathrm{e}-01$ Element: 1698 \# of layers: 12

Kx Ky Kz Ss Por

$1.18193 \mathrm{e}+02$ 1.18193e+02 1.18193e+01 1.00000e-09 7.00000e-02 5.00000e-04 5.00000e-04 5.00000e-05 1.00000e-09 1.00000e-01 5.00000e-04 5.00000e-04 5.00000e-05 1.00000e-09 1.00000e-01 $4.72263 \mathrm{e}+004.72263 \mathrm{e}+00$ 4.72263e-01 1.00000e-09 2.12000e-01 $4.72263 \mathrm{e}+004.72263 \mathrm{e}+00$ 4.72263e-01 1.00000e-09 2.12000e-01 $4.72263 \mathrm{e}+004.72263 \mathrm{e}+00$ 4.72263e-01 1.00000e-09 2.12000e-01 $4.72263 \mathrm{e}+004.72263 \mathrm{e}+00$ 4.72263e-01 1.00000e-09 2.12000e-01 $4.72263 \mathrm{e}+004.72263 \mathrm{e}+00$ 4.72263e-01 1.00000e-09 2.12000e-01 $1.00000 \mathrm{e}-021.00000 \mathrm{e}-02$ 1.00000e-03 1.00000e-09 1.00000e-01 $1.00000 \mathrm{e}+001.00000 \mathrm{e}+001.00000 \mathrm{e}-011.00000 \mathrm{e}-091.00000 \mathrm{e}-01$ $1.00000 \mathrm{e}-05$ 1.00000e-05 1.00000e-06 1.00000e-09 1.00000e-01 $1.00000 \mathrm{e}+001.00000 \mathrm{e}+001.00000 \mathrm{e}-011.00000 \mathrm{e}-091.00000 \mathrm{e}-01$ Element: 1699 \# of layers: 12

Kx Ky Kz Ss Por

$1.18193 \mathrm{e}+02$ 1.18193e+02 1.18193e+01 1.00000e-09 7.00000e-02 $5.00000 \mathrm{e}-04$ 5.00000e-04 5.00000e-05 1.00000e-09 1.00000e-01 $5.00000 \mathrm{e}-04$ 5.00000e-04 5.00000e-05 1.00000e-09 1.00000e-01 $4.72263 \mathrm{e}+004.72263 \mathrm{e}+004.72263 \mathrm{e}-01$ 1.00000e-09 2.12000e-01 $4.72263 \mathrm{e}+004.72263 \mathrm{e}+00$ 4.72263e-01 1.00000e-09 2.12000e-01 $4.72263 \mathrm{e}+004.72263 \mathrm{e}+00$ 4.72263e-01 1.00000e-09 2.12000e-01 $4.72263 \mathrm{e}+004.72263 \mathrm{e}+00$ 4.72263e-01 1.00000e-09 2.12000e-01 $4.72263 \mathrm{e}+004.72263 \mathrm{e}+00$ 4.72263e-01 1.00000e-09 2.12000e-01 $1.00000 \mathrm{e}-021.00000 \mathrm{e}-02$ 1.00000e-03 1.00000e-09 1.00000e-01 $1.00000 \mathrm{e}+001.00000 \mathrm{e}+001.00000 \mathrm{e}-011.00000 \mathrm{e}-091.00000 \mathrm{e}-01$ $1.00000 \mathrm{e}-05$ 1.00000e-05 1.00000e-06 1.00000e-09 1.00000e-01 $1.00000 \mathrm{e}+001.00000 \mathrm{e}+001.00000 \mathrm{e}-011.00000 \mathrm{e}-091.00000 \mathrm{e}-01$ Element: 1700 \# of layers: 12

Kx Ky Kz Ss Por $1.18193 \mathrm{e}+02$ 1.18193e+02 1.18193e+01 1.00000e-09 7.00000e-02 5.00000e-04 5.00000e-04 5.00000e-05 1.00000e-09 1.00000e-01 5.00000e-04 5.00000e-04 5.00000e-05 1.00000e-09 1.00000e-01 $4.72263 \mathrm{e}+004.72263 \mathrm{e}+00$ 4.72263e-01 1.00000e-09 2.12000e-01 $4.72263 \mathrm{e}+004.72263 \mathrm{e}+00$ 4.72263e-01 1.00000e-09 2.12000e-01 $4.72263 \mathrm{e}+004.72263 \mathrm{e}+00$ 4.72263e-01 1.00000e-09 2.12000e-01 $4.72263 \mathrm{e}+004.72263 \mathrm{e}+004.72263 \mathrm{e}-011.00000 \mathrm{e}-09$ 2.12000e-01 $4.72263 \mathrm{e}+004.72263 \mathrm{e}+004.72263 \mathrm{e}-01$ 1.00000e-09 2.12000e-01 
$1.00000 \mathrm{e}-02$ 1.00000e-02 1.00000e-03 1.00000e-09 1.00000e-01 $1.00000 \mathrm{e}+001.00000 \mathrm{e}+001.00000 \mathrm{e}-011.00000 \mathrm{e}-091.00000 \mathrm{e}-01$ $1.00000 \mathrm{e}-051.00000 \mathrm{e}-05$ 1.00000e-06 1.00000e-09 1.00000e-01 $1.00000 \mathrm{e}+001.00000 \mathrm{e}+001.00000 \mathrm{e}-011.00000 \mathrm{e}-091.00000 \mathrm{e}-01$ Element: 1701 \# of layers: 12

Kx Ky Kz Ss Por

$1.18193 \mathrm{e}+02$ 1.18193e+02 1.18193e+01 1.00000e-09 7.00000e-02 5.00000e-04 5.00000e-04 5.00000e-05 1.00000e-09 1.00000e-01 5.00000e-04 5.00000e-04 5.00000e-05 1.00000e-09 1.00000e-01 $4.72263 \mathrm{e}+004.72263 \mathrm{e}+00$ 4.72263e-01 1.00000e-09 2.12000e-01 $4.72263 \mathrm{e}+004.72263 \mathrm{e}+00$ 4.72263e-01 1.00000e-09 2.12000e-01 $4.72263 \mathrm{e}+004.72263 \mathrm{e}+00$ 4.72263e-01 1.00000e-09 2.12000e-01 $4.72263 \mathrm{e}+004.72263 \mathrm{e}+00$ 4.72263e-01 1.00000e-09 2.12000e-01 $4.72263 \mathrm{e}+004.72263 \mathrm{e}+00$ 4.72263e-01 1.00000e-09 2.12000e-01 $1.00000 \mathrm{e}-02$ 1.00000e-02 1.00000e-03 1.00000e-09 1.00000e-01 $1.00000 \mathrm{e}+001.00000 \mathrm{e}+001.00000 \mathrm{e}-011.00000 \mathrm{e}-091.00000 \mathrm{e}-01$ $1.00000 \mathrm{e}-05$ 1.00000e-05 1.00000e-06 1.00000e-09 1.00000e-01 $1.00000 \mathrm{e}+001.00000 \mathrm{e}+001.00000 \mathrm{e}-011.00000 \mathrm{e}-091.00000 \mathrm{e}-01$ Element: 1702 \# of layers: 13

Kx Ky Kz Ss Por

$1.18193 \mathrm{e}+02$ 1.18193e+02 1.18193e+01 1.00000e-09 7.00000e-02 $1.18193 \mathrm{e}+021.18193 \mathrm{e}+021.18193 \mathrm{e}+011.00000 \mathrm{e}-09$ 7.00000e-02 5.00000e-04 5.00000e-04 5.00000e-05 1.00000e-09 1.00000e-01 5.00000e-04 5.00000e-04 5.00000e-05 1.00000e-09 1.00000e-01

$4.72263 \mathrm{e}+004.72263 \mathrm{e}+00$ 4.72263e-01 1.00000e-09 2.12000e-01 $4.72263 \mathrm{e}+004.72263 \mathrm{e}+00$ 4.72263e-01 1.00000e-09 2.12000e-01 $4.72263 \mathrm{e}+004.72263 \mathrm{e}+004.72263 \mathrm{e}-011.00000 \mathrm{e}-092.12000 \mathrm{e}-01$ $4.72263 \mathrm{e}+004.72263 \mathrm{e}+004.72263 \mathrm{e}-01$ 1.00000e-09 2.12000e-01 $4.72263 \mathrm{e}+004.72263 \mathrm{e}+00$ 4.72263e-01 1.00000e-09 2.12000e-01 $1.00000 \mathrm{e}-021.00000 \mathrm{e}-02$ 1.00000e-03 1.00000e-09 1.00000e-01 $1.00000 \mathrm{e}+001.00000 \mathrm{e}+001.00000 \mathrm{e}-011.00000 \mathrm{e}-091.00000 \mathrm{e}-01$ $1.00000 \mathrm{e}-05$ 1.00000e-05 1.00000e-06 1.00000e-09 1.00000e-01 $1.00000 \mathrm{e}+001.00000 \mathrm{e}+001.00000 \mathrm{e}-011.00000 \mathrm{e}-091.00000 \mathrm{e}-01$ Element: 1703 \# of layers: 12

Kx Ky Kz Ss Por

$1.18193 \mathrm{e}+02$ 1.18193e+02 1.18193e+01 1.00000e-09 7.00000e-02 5.00000e-04 5.00000e-04 5.00000e-05 1.00000e-09 1.00000e-01 5.00000e-04 5.00000e-04 5.00000e-05 1.00000e-09 1.00000e-01 $4.72263 \mathrm{e}+004.72263 \mathrm{e}+00$ 4.72263e-01 1.00000e-09 2.12000e-01 $4.72263 \mathrm{e}+004.72263 \mathrm{e}+00$ 4.72263e-01 1.00000e-09 2.12000e-01 $4.72263 \mathrm{e}+004.72263 \mathrm{e}+00$ 4.72263e-01 1.00000e-09 2.12000e-01 $4.72263 \mathrm{e}+004.72263 \mathrm{e}+00$ 4.72263e-01 1.00000e-09 2.12000e-01 $4.72263 \mathrm{e}+004.72263 \mathrm{e}+00$ 4.72263e-01 1.00000e-09 2.12000e-01 $1.00000 \mathrm{e}-02$ 1.00000e-02 1.00000e-03 1.00000e-09 1.00000e-01 $1.00000 \mathrm{e}+001.00000 \mathrm{e}+001.00000 \mathrm{e}-011.00000 \mathrm{e}-091.00000 \mathrm{e}-01$ $1.00000 \mathrm{e}-05$ 1.00000e-05 1.00000e-06 1.00000e-09 1.00000e-01 
$1.00000 \mathrm{e}+001.00000 \mathrm{e}+00$ 1.00000e-01 1.00000e-09 1.00000e-01

Element: 1704 \# of layers: 12

Kx Ky Kz Ss Por

$1.18193 \mathrm{e}+02$ 1.18193e+02 1.18193e+01 1.00000e-09 7.00000e-02

5.00000e-04 5.00000e-04 5.00000e-05 1.00000e-09 1.00000e-01

5.00000e-04 5.00000e-04 5.00000e-05 1.00000e-09 1.00000e-01

$4.72263 \mathrm{e}+00$ 4.72263e+00 4.72263e-01 1.00000e-09 2.12000e-01

$4.72263 \mathrm{e}+00$ 4.72263e+00 4.72263e-01 1.00000e-09 2.12000e-01

4.72263e+00 4.72263e+00 4.72263e-01 1.00000e-09 2.12000e-01

4.72263e+00 4.72263e+00 4.72263e-01 1.00000e-09 2.12000e-01

4.72263e+00 4.72263e+00 4.72263e-01 1.00000e-09 2.12000e-01

$1.00000 \mathrm{e}-02$ 1.00000e-02 1.00000e-03 1.00000e-09 1.00000e-01

$1.00000 \mathrm{e}+001.00000 \mathrm{e}+001.00000 \mathrm{e}-011.00000 \mathrm{e}-091.00000 \mathrm{e}-01$

$1.00000 \mathrm{e}-05$ 1.00000e-05 1.00000e-06 1.00000e-09 1.00000e-01

$1.00000 \mathrm{e}+001.00000 \mathrm{e}+001.00000 \mathrm{e}-01$ 1.00000e-09 1.00000e-01

Element: 1705 \# of layers: 12

$\mathrm{Kx} \mathrm{Ky} \mathrm{Kz}$ Ss Por

$1.97094 \mathrm{e}+021.97094 \mathrm{e}+02$ 1.97094e+01 1.00000e-09 7.00000e-02

5.00000e-04 5.00000e-04 5.00000e-05 1.00000e-09 1.00000e-01

5.00000e-04 5.00000e-04 5.00000e-05 1.00000e-09 1.00000e-01

$7.87539 \mathrm{e}+007.87539 \mathrm{e}+00$ 7.87539e-01 1.00000e-09 2.12000e-01

7.87539e+00 7.87539e+00 7.87539e-01 1.00000e-09 2.12000e-01

7.87539e+00 7.87539e+00 7.87539e-01 1.00000e-09 2.12000e-01

$7.87539 \mathrm{e}+00$ 7.87539e+00 7.87539e-01 1.00000e-09 2.12000e-01

$7.87539 \mathrm{e}+007.87539 \mathrm{e}+007.87539 \mathrm{e}-01$ 1.00000e-09 2.12000e-01

$1.00000 \mathrm{e}-021.00000 \mathrm{e}-021.00000 \mathrm{e}-031.00000 \mathrm{e}-091.00000 \mathrm{e}-01$

$1.00000 \mathrm{e}+001.00000 \mathrm{e}+001.00000 \mathrm{e}-011.00000 \mathrm{e}-091.00000 \mathrm{e}-01$

$1.00000 \mathrm{e}-05$ 1.00000e-05 1.00000e-06 1.00000e-09 1.00000e-01

$1.00000 \mathrm{e}+001.00000 \mathrm{e}+001.00000 \mathrm{e}-011.00000 \mathrm{e}-091.00000 \mathrm{e}-01$

Element: 1706 \# of layers: 12

$\mathrm{Kx} \mathrm{Ky} \mathrm{Kz}$ Ss Por

$1.97094 \mathrm{e}+02$ 1.97094e+02 1.97094e+01 1.00000e-09 7.00000e-02

5.00000e-04 5.00000e-04 5.00000e-05 1.00000e-09 1.00000e-01

5.00000e-04 5.00000e-04 5.00000e-05 1.00000e-09 1.00000e-01

$7.87539 \mathrm{e}+00$ 7.87539e+00 7.87539e-01 1.00000e-09 2.12000e-01

7.87539e+00 7.87539e+00 7.87539e-01 1.00000e-09 2.12000e-01

$7.87539 \mathrm{e}+007.87539 \mathrm{e}+00$ 7.87539e-01 1.00000e-09 2.12000e-01

$7.87539 \mathrm{e}+007.87539 \mathrm{e}+00$ 7.87539e-01 1.00000e-09 2.12000e-01

$7.87539 \mathrm{e}+00$ 7.87539e+00 7.87539e-01 1.00000e-09 2.12000e-01

$1.00000 \mathrm{e}-021.00000 \mathrm{e}-02$ 1.00000e-03 1.00000e-09 1.00000e-01

$1.00000 \mathrm{e}+001.00000 \mathrm{e}+001.00000 \mathrm{e}-011.00000 \mathrm{e}-091.00000 \mathrm{e}-01$

$1.00000 \mathrm{e}-05$ 1.00000e-05 1.00000e-06 1.00000e-09 1.00000e-01

$1.00000 \mathrm{e}+001.00000 \mathrm{e}+001.00000 \mathrm{e}-011.00000 \mathrm{e}-091.00000 \mathrm{e}-01$

Element: 1707 \# of layers: 12

$\mathrm{Kx} \mathrm{Ky} \mathrm{Kz}$ Ss Por

$1.97094 \mathrm{e}+02$ 1.97094e+02 1.97094e+01 1.00000e-09 7.00000e-02 
5.00000e-04 5.00000e-04 5.00000e-05 1.00000e-09 1.00000e-01 5.00000e-04 5.00000e-04 5.00000e-05 1.00000e-09 1.00000e-01 $7.87539 \mathrm{e}+00$ 7.87539e+00 7.87539e-01 1.00000e-09 2.12000e-01 $7.87539 \mathrm{e}+00$ 7.87539e+00 7.87539e-01 1.00000e-09 2.12000e-01 7.87539e+00 7.87539e+00 7.87539e-01 1.00000e-09 2.12000e-01 7.87539e+00 7.87539e+00 7.87539e-01 1.00000e-09 2.12000e-01 $7.87539 \mathrm{e}+00$ 7.87539e+00 7.87539e-01 1.00000e-09 2.12000e-01 $1.00000 \mathrm{e}-02$ 1.00000e-02 1.00000e-03 1.00000e-09 1.00000e-01 $1.00000 \mathrm{e}+001.00000 \mathrm{e}+001.00000 \mathrm{e}-011.00000 \mathrm{e}-091.00000 \mathrm{e}-01$ $1.00000 \mathrm{e}-05$ 1.00000e-05 1.00000e-06 1.00000e-09 1.00000e-01 $1.00000 \mathrm{e}+001.00000 \mathrm{e}+001.00000 \mathrm{e}-011.00000 \mathrm{e}-091.00000 \mathrm{e}-01$ Element: 1708 \# of layers: 12

$\mathrm{Kx} \mathrm{Ky} \mathrm{Kz}$ Ss Por

$1.97094 \mathrm{e}+021.97094 \mathrm{e}+02$ 1.97094e+01 1.00000e-09 7.00000e-02 5.00000e-04 5.00000e-04 5.00000e-05 1.00000e-09 1.00000e-01 5.00000e-04 5.00000e-04 5.00000e-05 1.00000e-09 1.00000e-01 7.87539e+00 7.87539e+00 7.87539e-01 1.00000e-09 2.12000e-01 $7.87539 \mathrm{e}+00$ 7.87539e+00 7.87539e-01 1.00000e-09 2.12000e-01 7.87539e+00 7.87539e+00 7.87539e-01 1.00000e-09 2.12000e-01 $7.87539 \mathrm{e}+00$ 7.87539e+00 7.87539e-01 1.00000e-09 2.12000e-01 $7.87539 \mathrm{e}+007.87539 \mathrm{e}+00$ 7.87539e-01 1.00000e-09 2.12000e-01 $1.00000 \mathrm{e}-021.00000 \mathrm{e}-021.00000 \mathrm{e}-031.00000 \mathrm{e}-091.00000 \mathrm{e}-01$ $1.00000 \mathrm{e}+001.00000 \mathrm{e}+001.00000 \mathrm{e}-011.00000 \mathrm{e}-091.00000 \mathrm{e}-01$ $1.00000 \mathrm{e}-05$ 1.00000e-05 1.00000e-06 1.00000e-09 1.00000e-01 $1.00000 \mathrm{e}+001.00000 \mathrm{e}+001.00000 \mathrm{e}-011.00000 \mathrm{e}-091.00000 \mathrm{e}-01$ Element: 1709 \# of layers: 12

$\mathrm{Kx} \mathrm{Ky} \mathrm{Kz}$ Ss Por

$1.97094 \mathrm{e}+02$ 1.97094e+02 1.97094e+01 1.00000e-09 7.00000e-02 5.00000e-04 5.00000e-04 5.00000e-05 1.00000e-09 1.00000e-01 5.00000e-04 5.00000e-04 5.00000e-05 1.00000e-09 1.00000e-01 7.87539e+00 7.87539e+00 7.87539e-01 1.00000e-09 2.12000e-01 7.87539e+00 7.87539e+00 7.87539e-01 1.00000e-09 2.12000e-01 $7.87539 \mathrm{e}+007.87539 \mathrm{e}+00$ 7.87539e-01 1.00000e-09 2.12000e-01 $7.87539 \mathrm{e}+00$ 7.87539e+00 7.87539e-01 1.00000e-09 2.12000e-01 $7.87539 \mathrm{e}+00$ 7.87539e+00 7.87539e-01 1.00000e-09 2.12000e-01 $1.00000 \mathrm{e}-02$ 1.00000e-02 1.00000e-03 1.00000e-09 1.00000e-01 $1.00000 \mathrm{e}+001.00000 \mathrm{e}+001.00000 \mathrm{e}-011.00000 \mathrm{e}-091.00000 \mathrm{e}-01$ 1.00000e-05 1.00000e-05 1.00000e-06 1.00000e-09 1.00000e-01 $1.00000 \mathrm{e}+001.00000 \mathrm{e}+001.00000 \mathrm{e}-011.00000 \mathrm{e}-091.00000 \mathrm{e}-01$ Element: 1710 \# of layers: 12

$\mathrm{Kx} \mathrm{Ky} \mathrm{Kz}$ Ss Por $1.97094 \mathrm{e}+02$ 1.97094e+02 1.97094e+01 1.00000e-09 7.00000e-02 5.00000e-04 5.00000e-04 5.00000e-05 1.00000e-09 1.00000e-01 5.00000e-04 5.00000e-04 5.00000e-05 1.00000e-09 1.00000e-01 $7.87539 \mathrm{e}+00$ 7.87539e+00 7.87539e-01 1.00000e-09 2.12000e-01 $7.87539 \mathrm{e}+00$ 7.87539e+00 7.87539e-01 1.00000e-09 2.12000e-01 
7.87539e+00 7.87539e+00 7.87539e-01 1.00000e-09 2.12000e-01 $7.87539 \mathrm{e}+007.87539 \mathrm{e}+00$ 7.87539e-01 1.00000e-09 2.12000e-01 $7.87539 \mathrm{e}+00$ 7.87539e+00 7.87539e-01 1.00000e-09 2.12000e-01 $1.00000 \mathrm{e}-021.00000 \mathrm{e}-02$ 1.00000e-03 1.00000e-09 1.00000e-01 $1.00000 \mathrm{e}+001.00000 \mathrm{e}+001.00000 \mathrm{e}-011.00000 \mathrm{e}-091.00000 \mathrm{e}-01$ $1.00000 \mathrm{e}-05$ 1.00000e-05 1.00000e-06 1.00000e-09 1.00000e-01 $1.00000 \mathrm{e}+001.00000 \mathrm{e}+001.00000 \mathrm{e}-011.00000 \mathrm{e}-091.00000 \mathrm{e}-01$ Element: 1711 \# of layers: 12

Kx Ky Kz Ss Por

$1.97094 \mathrm{e}+021.97094 \mathrm{e}+02 \quad 1.97094 \mathrm{e}+01$ 1.00000e-09 7.00000e-02 5.00000e-04 5.00000e-04 5.00000e-05 1.00000e-09 1.00000e-01 5.00000e-04 5.00000e-04 5.00000e-05 1.00000e-09 1.00000e-01 $7.87539 \mathrm{e}+007.87539 \mathrm{e}+00$ 7.87539e-01 1.00000e-09 2.12000e-01 $7.87539 \mathrm{e}+007.87539 \mathrm{e}+00$ 7.87539e-01 1.00000e-09 2.12000e-01 $7.87539 \mathrm{e}+007.87539 \mathrm{e}+00$ 7.87539e-01 1.00000e-09 2.12000e-01 $7.87539 \mathrm{e}+007.87539 \mathrm{e}+007.87539 \mathrm{e}-011.00000 \mathrm{e}-092.12000 \mathrm{e}-01$ $7.87539 \mathrm{e}+007.87539 \mathrm{e}+00$ 7.87539e-01 1.00000e-09 2.12000e-01 $1.00000 \mathrm{e}-02$ 1.00000e-02 1.00000e-03 1.00000e-09 1.00000e-01 $1.00000 \mathrm{e}+001.00000 \mathrm{e}+001.00000 \mathrm{e}-011.00000 \mathrm{e}-091.00000 \mathrm{e}-01$ $1.00000 \mathrm{e}-051.00000 \mathrm{e}-05$ 1.00000e-06 1.00000e-09 1.00000e-01 $1.00000 \mathrm{e}+001.00000 \mathrm{e}+001.00000 \mathrm{e}-011.00000 \mathrm{e}-091.00000 \mathrm{e}-01$ Element: 1712 \# of layers: 12

Kx Ky Kz Ss Por

$1.97094 \mathrm{e}+02$ 1.97094e+02 1.97094e+01 1.00000e-09 7.00000e-02 5.00000e-04 5.00000e-04 5.00000e-05 1.00000e-09 1.00000e-01 $5.00000 \mathrm{e}-04$ 5.00000e-04 5.00000e-05 1.00000e-09 1.00000e-01 $7.87539 \mathrm{e}+00$ 7.87539e+00 7.87539e-01 1.00000e-09 2.12000e-01 $7.87539 \mathrm{e}+007.87539 \mathrm{e}+007.87539 \mathrm{e}-011.00000 \mathrm{e}-092.12000 \mathrm{e}-01$ $7.87539 \mathrm{e}+007.87539 \mathrm{e}+007.87539 \mathrm{e}-011.00000 \mathrm{e}-092.12000 \mathrm{e}-01$ $7.87539 \mathrm{e}+007.87539 \mathrm{e}+00$ 7.87539e-01 1.00000e-09 2.12000e-01 $7.87539 \mathrm{e}+007.87539 \mathrm{e}+00$ 7.87539e-01 1.00000e-09 2.12000e-01 $1.00000 \mathrm{e}-02$ 1.00000e-02 1.00000e-03 1.00000e-09 1.00000e-01 $1.00000 \mathrm{e}+001.00000 \mathrm{e}+001.00000 \mathrm{e}-011.00000 \mathrm{e}-091.00000 \mathrm{e}-01$ $1.00000 \mathrm{e}-05$ 1.00000e-05 1.00000e-06 1.00000e-09 1.00000e-01 $1.00000 \mathrm{e}+001.00000 \mathrm{e}+001.00000 \mathrm{e}-011.00000 \mathrm{e}-091.00000 \mathrm{e}-01$ Element: 1713 \# of layers: 12

Kx Ky Kz Ss Por

$1.97094 \mathrm{e}+02$ 1.97094e+02 1.97094e+01 1.00000e-09 7.00000e-02 5.00000e-04 5.00000e-04 5.00000e-05 1.00000e-09 1.00000e-01 5.00000e-04 5.00000e-04 5.00000e-05 1.00000e-09 1.00000e-01 $7.87539 \mathrm{e}+00$ 7.87539e+00 7.87539e-01 1.00000e-09 2.12000e-01 $7.87539 \mathrm{e}+007.87539 \mathrm{e}+00$ 7.87539e-01 1.00000e-09 2.12000e-01 $7.87539 \mathrm{e}+00$ 7.87539e+00 7.87539e-01 1.00000e-09 2.12000e-01 $7.87539 \mathrm{e}+00$ 7.87539e+00 7.87539e-01 1.00000e-09 2.12000e-01 $7.87539 \mathrm{e}+007.87539 \mathrm{e}+00$ 7.87539e-01 1.00000e-09 2.12000e-01 $1.00000 \mathrm{e}-021.00000 \mathrm{e}-02$ 1.00000e-03 1.00000e-09 1.00000e-01 
$1.00000 \mathrm{e}+001.00000 \mathrm{e}+001.00000 \mathrm{e}-011.00000 \mathrm{e}-091.00000 \mathrm{e}-01$ $1.00000 \mathrm{e}-05$ 1.00000e-05 1.00000e-06 1.00000e-09 1.00000e-01 $1.00000 \mathrm{e}+001.00000 \mathrm{e}+001.00000 \mathrm{e}-01$ 1.00000e-09 1.00000e-01 Element: 1714 \# of layers: 12

$\mathrm{Kx} \mathrm{Ky} \mathrm{Kz}$ Ss Por

$2.66219 \mathrm{e}+02$ 2.66219e+02 2.66219e+01 1.00000e-09 7.00000e-02 5.00000e-04 5.00000e-04 5.00000e-05 1.00000e-09 1.00000e-01 5.00000e-04 5.00000e-04 5.00000e-05 1.00000e-09 1.00000e-01 $1.06371 \mathrm{e}+011.06371 \mathrm{e}+011.06371 \mathrm{e}+001.00000 \mathrm{e}-092.12000 \mathrm{e}-01$ $1.06371 \mathrm{e}+011.06371 \mathrm{e}+011.06371 \mathrm{e}+001.00000 \mathrm{e}-092.12000 \mathrm{e}-01$ $1.06371 \mathrm{e}+011.06371 \mathrm{e}+011.06371 \mathrm{e}+001.00000 \mathrm{e}-092.12000 \mathrm{e}-01$ $1.06371 \mathrm{e}+011.06371 \mathrm{e}+011.06371 \mathrm{e}+001.00000 \mathrm{e}-092.12000 \mathrm{e}-01$ $1.06371 \mathrm{e}+011.06371 \mathrm{e}+011.06371 \mathrm{e}+001.00000 \mathrm{e}-092.12000 \mathrm{e}-01$ $1.00000 \mathrm{e}-02$ 1.00000e-02 1.00000e-03 1.00000e-09 1.00000e-01 $1.00000 \mathrm{e}+001.00000 \mathrm{e}+001.00000 \mathrm{e}-011.00000 \mathrm{e}-091.00000 \mathrm{e}-01$ $1.00000 \mathrm{e}-05$ 1.00000e-05 1.00000e-06 1.00000e-09 1.00000e-01 $1.00000 \mathrm{e}+001.00000 \mathrm{e}+001.00000 \mathrm{e}-011.00000 \mathrm{e}-091.00000 \mathrm{e}-01$ Element: 1715 \# of layers: 10

$\mathrm{Kx} \mathrm{Ky} \mathrm{Kz}$ Ss Por

$2.66219 \mathrm{e}+02$ 2.66219e+02 2.66219e+01 1.00000e-09 7.00000e-02 $1.06371 \mathrm{e}+011.06371 \mathrm{e}+011.06371 \mathrm{e}+001.00000 \mathrm{e}-092.12000 \mathrm{e}-01$ $1.06371 \mathrm{e}+011.06371 \mathrm{e}+011.06371 \mathrm{e}+001.00000 \mathrm{e}-092.12000 \mathrm{e}-01$ $1.06371 \mathrm{e}+011.06371 \mathrm{e}+011.06371 \mathrm{e}+001.00000 \mathrm{e}-092.12000 \mathrm{e}-01$ $1.06371 \mathrm{e}+011.06371 \mathrm{e}+011.06371 \mathrm{e}+001.00000 \mathrm{e}-092.12000 \mathrm{e}-01$ $1.06371 \mathrm{e}+011.06371 \mathrm{e}+011.06371 \mathrm{e}+001.00000 \mathrm{e}-092.12000 \mathrm{e}-01$ $1.00000 \mathrm{e}-02$ 1.00000e-02 1.00000e-03 1.00000e-09 1.00000e-01 $1.00000 \mathrm{e}+001.00000 \mathrm{e}+001.00000 \mathrm{e}-011.00000 \mathrm{e}-091.00000 \mathrm{e}-01$ $1.00000 \mathrm{e}-05$ 1.00000e-05 1.00000e-06 1.00000e-09 1.00000e-01 $1.00000 \mathrm{e}+001.00000 \mathrm{e}+001.00000 \mathrm{e}-011.00000 \mathrm{e}-091.00000 \mathrm{e}-01$ Element: 1716 \# of layers: 10

$\mathrm{Kx} \mathrm{Ky} \mathrm{Kz}$ Ss Por

$2.66219 \mathrm{e}+02$ 2.66219e+02 2.66219e+01 1.00000e-09 7.00000e-02 $1.06371 \mathrm{e}+011.06371 \mathrm{e}+011.06371 \mathrm{e}+001.00000 \mathrm{e}-092.12000 \mathrm{e}-01$ $1.06371 \mathrm{e}+011.06371 \mathrm{e}+011.06371 \mathrm{e}+001.00000 \mathrm{e}-092.12000 \mathrm{e}-01$ $1.06371 \mathrm{e}+011.06371 \mathrm{e}+011.06371 \mathrm{e}+001.00000 \mathrm{e}-092.12000 \mathrm{e}-01$ $1.06371 \mathrm{e}+011.06371 \mathrm{e}+011.06371 \mathrm{e}+001.00000 \mathrm{e}-092.12000 \mathrm{e}-01$ $1.06371 \mathrm{e}+011.06371 \mathrm{e}+011.06371 \mathrm{e}+001.00000 \mathrm{e}-092.12000 \mathrm{e}-01$ $1.00000 \mathrm{e}-02$ 1.00000e-02 1.00000e-03 1.00000e-09 1.00000e-01 $1.00000 \mathrm{e}+001.00000 \mathrm{e}+001.00000 \mathrm{e}-011.00000 \mathrm{e}-091.00000 \mathrm{e}-01$ $1.00000 \mathrm{e}-05$ 1.00000e-05 1.00000e-06 1.00000e-09 1.00000e-01 $1.00000 \mathrm{e}+001.00000 \mathrm{e}+001.00000 \mathrm{e}-011.00000 \mathrm{e}-091.00000 \mathrm{e}-01$ Element: 1717 \# of layers: 10

$\mathrm{Kx} \mathrm{Ky} \mathrm{Kz}$ Ss Por

2.66219e+02 2.66219e+02 2.66219e+01 1.00000e-09 7.00000e-02 $1.06371 \mathrm{e}+011.06371 \mathrm{e}+011.06371 \mathrm{e}+001.00000 \mathrm{e}-092.12000 \mathrm{e}-01$ $1.06371 \mathrm{e}+011.06371 \mathrm{e}+011.06371 \mathrm{e}+001.00000 \mathrm{e}-092.12000 \mathrm{e}-01$ 
$1.06371 \mathrm{e}+011.06371 \mathrm{e}+011.06371 \mathrm{e}+001.00000 \mathrm{e}-092.12000 \mathrm{e}-01$ $1.06371 \mathrm{e}+011.06371 \mathrm{e}+011.06371 \mathrm{e}+001.00000 \mathrm{e}-092.12000 \mathrm{e}-01$ $1.06371 \mathrm{e}+011.06371 \mathrm{e}+011.06371 \mathrm{e}+001.00000 \mathrm{e}-092.12000 \mathrm{e}-01$ $1.00000 \mathrm{e}-02$ 1.00000e-02 1.00000e-03 1.00000e-09 1.00000e-01 $1.00000 \mathrm{e}+001.00000 \mathrm{e}+001.00000 \mathrm{e}-011.00000 \mathrm{e}-091.00000 \mathrm{e}-01$ $1.00000 \mathrm{e}-05$ 1.00000e-05 1.00000e-06 1.00000e-09 1.00000e-01 $1.00000 \mathrm{e}+001.00000 \mathrm{e}+001.00000 \mathrm{e}-011.00000 \mathrm{e}-091.00000 \mathrm{e}-01$ Element: 1718 \# of layers: 10

$\mathrm{Kx} \mathrm{Ky} \mathrm{Kz}$ Ss Por

$2.66219 \mathrm{e}+02$ 2.66219e+02 2.66219e+01 1.00000e-09 7.00000e-02 $1.06371 \mathrm{e}+011.06371 \mathrm{e}+011.06371 \mathrm{e}+001.00000 \mathrm{e}-092.12000 \mathrm{e}-01$ $1.06371 \mathrm{e}+011.06371 \mathrm{e}+011.06371 \mathrm{e}+001.00000 \mathrm{e}-092.12000 \mathrm{e}-01$ $1.06371 \mathrm{e}+011.06371 \mathrm{e}+011.06371 \mathrm{e}+001.00000 \mathrm{e}-092.12000 \mathrm{e}-01$ $1.06371 \mathrm{e}+011.06371 \mathrm{e}+011.06371 \mathrm{e}+001.00000 \mathrm{e}-092.12000 \mathrm{e}-01$ $1.06371 \mathrm{e}+011.06371 \mathrm{e}+011.06371 \mathrm{e}+001.00000 \mathrm{e}-092.12000 \mathrm{e}-01$ $1.00000 \mathrm{e}-02$ 1.00000e-02 1.00000e-03 1.00000e-09 1.00000e-01 $1.00000 \mathrm{e}+001.00000 \mathrm{e}+001.00000 \mathrm{e}-011.00000 \mathrm{e}-091.00000 \mathrm{e}-01$ $1.00000 \mathrm{e}-05$ 1.00000e-05 1.00000e-06 1.00000e-09 1.00000e-01 $1.00000 \mathrm{e}+001.00000 \mathrm{e}+001.00000 \mathrm{e}-011.00000 \mathrm{e}-091.00000 \mathrm{e}-01$ Element: 1719 \# of layers: 11

$\mathrm{Kx} \mathrm{Ky} \mathrm{Kz}$ Ss Por

$2.66219 \mathrm{e}+02$ 2.66219e+02 2.66219e+01 1.00000e-09 7.00000e-02 5.00000e-04 5.00000e-04 5.00000e-05 1.00000e-09 1.00000e-01 $1.06371 \mathrm{e}+011.06371 \mathrm{e}+011.06371 \mathrm{e}+001.00000 \mathrm{e}-092.12000 \mathrm{e}-01$ $1.06371 \mathrm{e}+011.06371 \mathrm{e}+011.06371 \mathrm{e}+001.00000 \mathrm{e}-092.12000 \mathrm{e}-01$ $1.06371 \mathrm{e}+011.06371 \mathrm{e}+011.06371 \mathrm{e}+001.00000 \mathrm{e}-092.12000 \mathrm{e}-01$ $1.06371 \mathrm{e}+011.06371 \mathrm{e}+011.06371 \mathrm{e}+001.00000 \mathrm{e}-092.12000 \mathrm{e}-01$ $1.06371 \mathrm{e}+011.06371 \mathrm{e}+011.06371 \mathrm{e}+001.00000 \mathrm{e}-092.12000 \mathrm{e}-01$ $1.00000 \mathrm{e}-02$ 1.00000e-02 1.00000e-03 1.00000e-09 1.00000e-01 $1.00000 \mathrm{e}+001.00000 \mathrm{e}+001.00000 \mathrm{e}-011.00000 \mathrm{e}-091.00000 \mathrm{e}-01$ $1.00000 \mathrm{e}-05$ 1.00000e-05 1.00000e-06 1.00000e-09 1.00000e-01 $1.00000 \mathrm{e}+001.00000 \mathrm{e}+001.00000 \mathrm{e}-01$ 1.00000e-09 1.00000e-01 Element: 1720 \# of layers: 12

$\mathrm{Kx} \mathrm{Ky} \mathrm{Kz}$ Ss Por

$2.66219 \mathrm{e}+02$ 2.66219e+02 2.66219e+01 1.00000e-09 7.00000e-02 5.00000e-04 5.00000e-04 5.00000e-05 1.00000e-09 1.00000e-01 5.00000e-04 5.00000e-04 5.00000e-05 1.00000e-09 1.00000e-01 $1.06371 \mathrm{e}+011.06371 \mathrm{e}+011.06371 \mathrm{e}+001.00000 \mathrm{e}-092.12000 \mathrm{e}-01$ $1.06371 \mathrm{e}+011.06371 \mathrm{e}+011.06371 \mathrm{e}+001.00000 \mathrm{e}-092.12000 \mathrm{e}-01$ $1.06371 \mathrm{e}+011.06371 \mathrm{e}+011.06371 \mathrm{e}+001.00000 \mathrm{e}-092.12000 \mathrm{e}-01$ $1.06371 \mathrm{e}+011.06371 \mathrm{e}+011.06371 \mathrm{e}+001.00000 \mathrm{e}-092.12000 \mathrm{e}-01$ $1.06371 \mathrm{e}+011.06371 \mathrm{e}+011.06371 \mathrm{e}+001.00000 \mathrm{e}-092.12000 \mathrm{e}-01$ $1.00000 \mathrm{e}-02$ 1.00000e-02 1.00000e-03 1.00000e-09 1.00000e-01 $1.00000 \mathrm{e}+001.00000 \mathrm{e}+001.00000 \mathrm{e}-011.00000 \mathrm{e}-091.00000 \mathrm{e}-01$ $1.00000 \mathrm{e}-05$ 1.00000e-05 1.00000e-06 1.00000e-09 1.00000e-01 $1.00000 \mathrm{e}+001.00000 \mathrm{e}+001.00000 \mathrm{e}-011.00000 \mathrm{e}-091.00000 \mathrm{e}-01$ 
Element: 1721 \# of layers: 12

$\mathrm{Kx} \mathrm{Ky} \mathrm{Kz}$ Ss Por

2.66219e+02 2.66219e+02 2.66219e+01 1.00000e-09 7.00000e-02

5.00000e-04 5.00000e-04 5.00000e-05 1.00000e-09 1.00000e-01

5.00000e-04 5.00000e-04 5.00000e-05 1.00000e-09 1.00000e-01

$1.06371 \mathrm{e}+011.06371 \mathrm{e}+011.06371 \mathrm{e}+001.00000 \mathrm{e}-092.12000 \mathrm{e}-01$

$1.06371 \mathrm{e}+011.06371 \mathrm{e}+011.06371 \mathrm{e}+001.00000 \mathrm{e}-092.12000 \mathrm{e}-01$

$1.06371 \mathrm{e}+011.06371 \mathrm{e}+011.06371 \mathrm{e}+001.00000 \mathrm{e}-092.12000 \mathrm{e}-01$

$1.06371 \mathrm{e}+011.06371 \mathrm{e}+011.06371 \mathrm{e}+001.00000 \mathrm{e}-092.12000 \mathrm{e}-01$

$1.06371 \mathrm{e}+011.06371 \mathrm{e}+011.06371 \mathrm{e}+001.00000 \mathrm{e}-092.12000 \mathrm{e}-01$

$1.00000 \mathrm{e}-02$ 1.00000e-02 1.00000e-03 1.00000e-09 1.00000e-01

$1.00000 \mathrm{e}+001.00000 \mathrm{e}+001.00000 \mathrm{e}-011.00000 \mathrm{e}-091.00000 \mathrm{e}-01$

$1.00000 \mathrm{e}-05$ 1.00000e-05 1.00000e-06 1.00000e-09 1.00000e-01

$1.00000 \mathrm{e}+001.00000 \mathrm{e}+001.00000 \mathrm{e}-01$ 1.00000e-09 1.00000e-01

Element: 1722 \# of layers: 11

Kx Ky Kz Ss Por

2.66219e+02 2.66219e+02 2.66219e+01 1.00000e-09 7.00000e-02

5.00000e-04 5.00000e-04 5.00000e-05 1.00000e-09 1.00000e-01

$1.06371 \mathrm{e}+011.06371 \mathrm{e}+011.06371 \mathrm{e}+001.00000 \mathrm{e}-092.12000 \mathrm{e}-01$

$1.06371 \mathrm{e}+011.06371 \mathrm{e}+011.06371 \mathrm{e}+001.00000 \mathrm{e}-092.12000 \mathrm{e}-01$

$1.06371 \mathrm{e}+011.06371 \mathrm{e}+011.06371 \mathrm{e}+001.00000 \mathrm{e}-092.12000 \mathrm{e}-01$

$1.06371 \mathrm{e}+011.06371 \mathrm{e}+011.06371 \mathrm{e}+001.00000 \mathrm{e}-092.12000 \mathrm{e}-01$

$1.06371 \mathrm{e}+011.06371 \mathrm{e}+011.06371 \mathrm{e}+001.00000 \mathrm{e}-092.12000 \mathrm{e}-01$

$1.00000 \mathrm{e}-02$ 1.00000e-02 1.00000e-03 1.00000e-09 1.00000e-01

$1.00000 \mathrm{e}+001.00000 \mathrm{e}+001.00000 \mathrm{e}-011.00000 \mathrm{e}-091.00000 \mathrm{e}-01$

$1.00000 \mathrm{e}-051.00000 \mathrm{e}-051.00000 \mathrm{e}-061.00000 \mathrm{e}-091.00000 \mathrm{e}-01$

$1.00000 \mathrm{e}+001.00000 \mathrm{e}+001.00000 \mathrm{e}-01$ 1.00000e-09 1.00000e-01

Element: 1723 \# of layers: 9

Kx Ky Kz Ss Por

$1.35151 \mathrm{e}+011.35151 \mathrm{e}+011.35151 \mathrm{e}+00$ 1.00000e-09 2.12000e-01

$1.35151 \mathrm{e}+011.35151 \mathrm{e}+011.35151 \mathrm{e}+001.00000 \mathrm{e}-092.12000 \mathrm{e}-01$

$1.35151 \mathrm{e}+011.35151 \mathrm{e}+011.35151 \mathrm{e}+001.00000 \mathrm{e}-092.12000 \mathrm{e}-01$

$1.35151 \mathrm{e}+011.35151 \mathrm{e}+011.35151 \mathrm{e}+001.00000 \mathrm{e}-092.12000 \mathrm{e}-01$

$1.35151 \mathrm{e}+011.35151 \mathrm{e}+01$ 1.35151e+00 1.00000e-09 2.12000e-01

$1.00000 \mathrm{e}-02$ 1.00000e-02 1.00000e-03 1.00000e-09 1.00000e-01

$1.00000 \mathrm{e}+001.00000 \mathrm{e}+001.00000 \mathrm{e}-011.00000 \mathrm{e}-091.00000 \mathrm{e}-01$

$1.00000 \mathrm{e}-05$ 1.00000e-05 1.00000e-06 1.00000e-09 1.00000e-01

$1.00000 \mathrm{e}+001.00000 \mathrm{e}+001.00000 \mathrm{e}-011.00000 \mathrm{e}-091.00000 \mathrm{e}-01$

Element: 1724 \# of layers: 9

$\mathrm{Kx} \mathrm{Ky} \mathrm{Kz}$ Ss Por

$1.35151 \mathrm{e}+011.35151 \mathrm{e}+01$ 1.35151e+00 1.00000e-09 2.12000e-01

$1.35151 \mathrm{e}+011.35151 \mathrm{e}+011.35151 \mathrm{e}+001.00000 \mathrm{e}-092.12000 \mathrm{e}-01$

$1.35151 \mathrm{e}+011.35151 \mathrm{e}+011.35151 \mathrm{e}+001.00000 \mathrm{e}-092.12000 \mathrm{e}-01$

$1.35151 \mathrm{e}+01$ 1.35151e+01 1.35151e+00 1.00000e-09 2.12000e-01

$1.35151 \mathrm{e}+011.35151 \mathrm{e}+011.35151 \mathrm{e}+001.00000 \mathrm{e}-092.12000 \mathrm{e}-01$

$1.00000 \mathrm{e}-02$ 1.00000e-02 1.00000e-03 1.00000e-09 1.00000e-01 
$1.00000 \mathrm{e}+001.00000 \mathrm{e}+001.00000 \mathrm{e}-011.00000 \mathrm{e}-091.00000 \mathrm{e}-01$ $1.00000 \mathrm{e}-05$ 1.00000e-05 1.00000e-06 1.00000e-09 1.00000e-01 $1.00000 \mathrm{e}+001.00000 \mathrm{e}+001.00000 \mathrm{e}-01$ 1.00000e-09 1.00000e-01

Element: 1725 \# of layers: 10

$\mathrm{Kx} \mathrm{Ky} \mathrm{Kz}$ Ss Por

3.38244e+02 3.38244e+02 3.38244e+01 1.00000e-09 7.00000e-02 $1.35151 \mathrm{e}+011.35151 \mathrm{e}+011.35151 \mathrm{e}+001.00000 \mathrm{e}-092.12000 \mathrm{e}-01$ $1.35151 \mathrm{e}+011.35151 \mathrm{e}+011.35151 \mathrm{e}+001.00000 \mathrm{e}-092.12000 \mathrm{e}-01$ $1.35151 \mathrm{e}+011.35151 \mathrm{e}+011.35151 \mathrm{e}+001.00000 \mathrm{e}-092.12000 \mathrm{e}-01$ $1.35151 \mathrm{e}+011.35151 \mathrm{e}+011.35151 \mathrm{e}+001.00000 \mathrm{e}-092.12000 \mathrm{e}-01$ $1.35151 \mathrm{e}+011.35151 \mathrm{e}+011.35151 \mathrm{e}+001.00000 \mathrm{e}-092.12000 \mathrm{e}-01$ $1.00000 \mathrm{e}-02$ 1.00000e-02 1.00000e-03 1.00000e-09 1.00000e-01 $1.00000 \mathrm{e}+001.00000 \mathrm{e}+001.00000 \mathrm{e}-011.00000 \mathrm{e}-091.00000 \mathrm{e}-01$ $1.00000 \mathrm{e}-05$ 1.00000e-05 1.00000e-06 1.00000e-09 1.00000e-01 $1.00000 \mathrm{e}+001.00000 \mathrm{e}+00$ 1.00000e-01 1.00000e-09 1.00000e-01 Element: 1726 \# of layers: 10

$\mathrm{Kx} \mathrm{Ky} \mathrm{Kz}$ Ss Por

3.38244e+02 3.38244e+02 3.38244e+01 1.00000e-09 7.00000e-02 $1.35151 \mathrm{e}+011.35151 \mathrm{e}+011.35151 \mathrm{e}+001.00000 \mathrm{e}-092.12000 \mathrm{e}-01$ $1.35151 \mathrm{e}+011.35151 \mathrm{e}+011.35151 \mathrm{e}+001.00000 \mathrm{e}-092.12000 \mathrm{e}-01$ $1.35151 \mathrm{e}+011.35151 \mathrm{e}+011.35151 \mathrm{e}+001.00000 \mathrm{e}-092.12000 \mathrm{e}-01$ $1.35151 \mathrm{e}+011.35151 \mathrm{e}+011.35151 \mathrm{e}+001.00000 \mathrm{e}-092.12000 \mathrm{e}-01$ $1.35151 \mathrm{e}+011.35151 \mathrm{e}+011.35151 \mathrm{e}+001.00000 \mathrm{e}-092.12000 \mathrm{e}-01$ $1.00000 \mathrm{e}-02$ 1.00000e-02 1.00000e-03 1.00000e-09 1.00000e-01 $1.00000 \mathrm{e}+001.00000 \mathrm{e}+001.00000 \mathrm{e}-011.00000 \mathrm{e}-091.00000 \mathrm{e}-01$ $1.00000 \mathrm{e}-051.00000 \mathrm{e}-05$ 1.00000e-06 1.00000e-09 1.00000e-01 $1.00000 \mathrm{e}+001.00000 \mathrm{e}+001.00000 \mathrm{e}-01$ 1.00000e-09 1.00000e-01 Element: 1727 \# of layers: 10

$\mathrm{Kx} \mathrm{Ky} \mathrm{Kz} \mathrm{Ss} \mathrm{Por}$

3.38244e+02 3.38244e+02 3.38244e+01 1.00000e-09 7.00000e-02 $1.35151 \mathrm{e}+011.35151 \mathrm{e}+011.35151 \mathrm{e}+001.00000 \mathrm{e}-092.12000 \mathrm{e}-01$ $1.35151 \mathrm{e}+011.35151 \mathrm{e}+011.35151 \mathrm{e}+001.00000 \mathrm{e}-092.12000 \mathrm{e}-01$ $1.35151 \mathrm{e}+011.35151 \mathrm{e}+011.35151 \mathrm{e}+001.00000 \mathrm{e}-092.12000 \mathrm{e}-01$ $1.35151 \mathrm{e}+011.35151 \mathrm{e}+011.35151 \mathrm{e}+001.00000 \mathrm{e}-092.12000 \mathrm{e}-01$ $1.35151 \mathrm{e}+011.35151 \mathrm{e}+011.35151 \mathrm{e}+001.00000 \mathrm{e}-092.12000 \mathrm{e}-01$ 1.00000e-02 1.00000e-02 1.00000e-03 1.00000e-09 1.00000e-01 $1.00000 \mathrm{e}+001.00000 \mathrm{e}+001.00000 \mathrm{e}-011.00000 \mathrm{e}-091.00000 \mathrm{e}-01$ $1.00000 \mathrm{e}-051.00000 \mathrm{e}-05$ 1.00000e-06 1.00000e-09 1.00000e-01 $1.00000 \mathrm{e}+001.00000 \mathrm{e}+001.00000 \mathrm{e}-011.00000 \mathrm{e}-091.00000 \mathrm{e}-01$ Element: 1728 \# of layers: 9

$\mathrm{Kx} \mathrm{Ky} \mathrm{Kz}$ Ss Por

$1.35151 \mathrm{e}+011.35151 \mathrm{e}+011.35151 \mathrm{e}+001.00000 \mathrm{e}-092.12000 \mathrm{e}-01$ $1.35151 \mathrm{e}+01$ 1.35151e+01 1.35151e+00 1.00000e-09 2.12000e-01 $1.35151 \mathrm{e}+01$ 1.35151e+01 1.35151e+00 1.00000e-09 2.12000e-01 $1.35151 \mathrm{e}+011.35151 \mathrm{e}+011.35151 \mathrm{e}+001.00000 \mathrm{e}-092.12000 \mathrm{e}-01$ $1.35151 \mathrm{e}+011.35151 \mathrm{e}+011.35151 \mathrm{e}+001.00000 \mathrm{e}-092.12000 \mathrm{e}-01$ 
$1.00000 \mathrm{e}-02$ 1.00000e-02 1.00000e-03 1.00000e-09 1.00000e-01 $1.00000 \mathrm{e}+001.00000 \mathrm{e}+001.00000 \mathrm{e}-011.00000 \mathrm{e}-091.00000 \mathrm{e}-01$ $1.00000 \mathrm{e}-051.00000 \mathrm{e}-05$ 1.00000e-06 1.00000e-09 1.00000e-01 $1.00000 \mathrm{e}+001.00000 \mathrm{e}+001.00000 \mathrm{e}-011.00000 \mathrm{e}-091.00000 \mathrm{e}-01$ Element: 1729 \# of layers: 10

$\mathrm{Kx} \mathrm{Ky} \mathrm{Kz}$ Ss Por

3.38244e+02 3.38244e+02 3.38244e+01 1.00000e-09 7.00000e-02 $1.35151 \mathrm{e}+011.35151 \mathrm{e}+011.35151 \mathrm{e}+001.00000 \mathrm{e}-092.12000 \mathrm{e}-01$ $1.35151 \mathrm{e}+011.35151 \mathrm{e}+01$ 1.35151e+00 1.00000e-09 2.12000e-01 $1.35151 \mathrm{e}+011.35151 \mathrm{e}+011.35151 \mathrm{e}+001.00000 \mathrm{e}-092.12000 \mathrm{e}-01$ $1.35151 \mathrm{e}+011.35151 \mathrm{e}+011.35151 \mathrm{e}+00$ 1.00000e-09 2.12000e-01 $1.35151 \mathrm{e}+011.35151 \mathrm{e}+011.35151 \mathrm{e}+001.00000 \mathrm{e}-092.12000 \mathrm{e}-01$ $1.00000 \mathrm{e}-02$ 1.00000e-02 1.00000e-03 1.00000e-09 1.00000e-01 $1.00000 \mathrm{e}+001.00000 \mathrm{e}+001.00000 \mathrm{e}-011.00000 \mathrm{e}-091.00000 \mathrm{e}-01$ $1.00000 \mathrm{e}-05$ 1.00000e-05 1.00000e-06 1.00000e-09 1.00000e-01 $1.00000 \mathrm{e}+001.00000 \mathrm{e}+001.00000 \mathrm{e}-011.00000 \mathrm{e}-091.00000 \mathrm{e}-01$ Element: 1730 \# of layers: 10

$\mathrm{Kx} \mathrm{Ky} \mathrm{Kz}$ Ss Por

3.38244e+02 3.38244e+02 3.38244e+01 1.00000e-09 7.00000e-02 $1.35151 \mathrm{e}+011.35151 \mathrm{e}+011.35151 \mathrm{e}+001.00000 \mathrm{e}-092.12000 \mathrm{e}-01$ $1.35151 \mathrm{e}+011.35151 \mathrm{e}+011.35151 \mathrm{e}+001.00000 \mathrm{e}-092.12000 \mathrm{e}-01$ $1.35151 \mathrm{e}+011.35151 \mathrm{e}+011.35151 \mathrm{e}+001.00000 \mathrm{e}-092.12000 \mathrm{e}-01$ $1.35151 \mathrm{e}+011.35151 \mathrm{e}+01$ 1.35151e+00 1.00000e-09 2.12000e-01 $1.35151 \mathrm{e}+011.35151 \mathrm{e}+011.35151 \mathrm{e}+001.00000 \mathrm{e}-092.12000 \mathrm{e}-01$ $1.00000 \mathrm{e}-02$ 1.00000e-02 1.00000e-03 1.00000e-09 1.00000e-01 $1.00000 \mathrm{e}+001.00000 \mathrm{e}+001.00000 \mathrm{e}-011.00000 \mathrm{e}-091.00000 \mathrm{e}-01$ $1.00000 \mathrm{e}-05$ 1.00000e-05 1.00000e-06 1.00000e-09 1.00000e-01 $1.00000 \mathrm{e}+001.00000 \mathrm{e}+001.00000 \mathrm{e}-011.00000 \mathrm{e}-09$ 1.00000e-01 Element: 1731 \# of layers: 9

$\mathrm{Kx} \mathrm{Ky} \mathrm{Kz}$ Ss Por

$1.35151 \mathrm{e}+011.35151 \mathrm{e}+01$ 1.35151e+00 1.00000e-09 2.12000e-01 $1.35151 \mathrm{e}+011.35151 \mathrm{e}+01$ 1.35151e+00 1.00000e-09 2.12000e-01 $1.35151 \mathrm{e}+011.35151 \mathrm{e}+011.35151 \mathrm{e}+001.00000 \mathrm{e}-092.12000 \mathrm{e}-01$ $1.35151 \mathrm{e}+011.35151 \mathrm{e}+011.35151 \mathrm{e}+001.00000 \mathrm{e}-092.12000 \mathrm{e}-01$ $1.35151 \mathrm{e}+011.35151 \mathrm{e}+011.35151 \mathrm{e}+001.00000 \mathrm{e}-092.12000 \mathrm{e}-01$ $1.00000 \mathrm{e}-02$ 1.00000e-02 1.00000e-03 1.00000e-09 1.00000e-01 $1.00000 \mathrm{e}+001.00000 \mathrm{e}+001.00000 \mathrm{e}-011.00000 \mathrm{e}-091.00000 \mathrm{e}-01$ $1.00000 \mathrm{e}-05$ 1.00000e-05 1.00000e-06 1.00000e-09 1.00000e-01 $1.00000 \mathrm{e}+001.00000 \mathrm{e}+001.00000 \mathrm{e}-01$ 1.00000e-09 1.00000e-01 Element: 1732 \# of layers: 10

$\mathrm{Kx} \mathrm{Ky} \mathrm{Kz}$ Ss Por 3.60905e+02 3.60905e+02 3.60905e+01 1.00000e-09 7.00000e-02 $1.44206 \mathrm{e}+011.44206 \mathrm{e}+011.44206 \mathrm{e}+001.00000 \mathrm{e}-092.12000 \mathrm{e}-01$ $1.44206 \mathrm{e}+01$ 1.44206e+01 1.44206e+00 1.00000e-09 2.12000e-01 $1.44206 \mathrm{e}+01$ 1.44206e+01 1.44206e+00 1.00000e-09 2.12000e-01 $1.44206 \mathrm{e}+011.44206 \mathrm{e}+011.44206 \mathrm{e}+001.00000 \mathrm{e}-092.12000 \mathrm{e}-01$ 
$1.44206 \mathrm{e}+01$ 1.44206e+01 1.44206e+00 1.00000e-09 2.12000e-01 $1.00000 \mathrm{e}-011.00000 \mathrm{e}-01$ 1.00000e-02 1.00000e-09 1.00000e-01 $1.00000 \mathrm{e}+001.00000 \mathrm{e}+001.00000 \mathrm{e}-011.00000 \mathrm{e}-091.00000 \mathrm{e}-01$ $1.00000 \mathrm{e}-05$ 1.00000e-05 1.00000e-06 1.00000e-09 1.00000e-01 $1.00000 \mathrm{e}+001.00000 \mathrm{e}+001.00000 \mathrm{e}-01$ 1.00000e-09 1.00000e-01 Element: 1733 \# of layers: 10

$\mathrm{Kx} \mathrm{Ky} \mathrm{Kz}$ Ss Por

3.60905e+02 3.60905e+02 3.60905e+01 1.00000e-09 7.00000e-02 $1.44206 \mathrm{e}+011.44206 \mathrm{e}+011.44206 \mathrm{e}+001.00000 \mathrm{e}-092.12000 \mathrm{e}-01$ $1.44206 \mathrm{e}+011.44206 \mathrm{e}+011.44206 \mathrm{e}+001.00000 \mathrm{e}-092.12000 \mathrm{e}-01$ $1.44206 \mathrm{e}+011.44206 \mathrm{e}+011.44206 \mathrm{e}+001.00000 \mathrm{e}-092.12000 \mathrm{e}-01$ $1.44206 \mathrm{e}+011.44206 \mathrm{e}+011.44206 \mathrm{e}+001.00000 \mathrm{e}-092.12000 \mathrm{e}-01$ $1.44206 \mathrm{e}+011.44206 \mathrm{e}+011.44206 \mathrm{e}+001.00000 \mathrm{e}-092.12000 \mathrm{e}-01$ $1.00000 \mathrm{e}-011.00000 \mathrm{e}-01$ 1.00000e-02 1.00000e-09 1.00000e-01 $1.00000 \mathrm{e}+001.00000 \mathrm{e}+001.00000 \mathrm{e}-011.00000 \mathrm{e}-091.00000 \mathrm{e}-01$ $1.00000 \mathrm{e}-05$ 1.00000e-05 1.00000e-06 1.00000e-09 1.00000e-01 $1.00000 \mathrm{e}+001.00000 \mathrm{e}+00$ 1.00000e-01 1.00000e-09 1.00000e-01 Element: 1734 \# of layers: 9

$\mathrm{Kx} \mathrm{Ky} \mathrm{Kz}$ Ss Por

$1.44206 \mathrm{e}+01$ 1.44206e+01 1.44206e+00 1.00000e-09 2.12000e-01 $1.44206 \mathrm{e}+011.44206 \mathrm{e}+011.44206 \mathrm{e}+001.00000 \mathrm{e}-092.12000 \mathrm{e}-01$ $1.44206 \mathrm{e}+01$ 1.44206e+01 1.44206e+00 1.00000e-09 2.12000e-01 $1.44206 \mathrm{e}+011.44206 \mathrm{e}+011.44206 \mathrm{e}+001.00000 \mathrm{e}-092.12000 \mathrm{e}-01$ $1.44206 \mathrm{e}+011.44206 \mathrm{e}+011.44206 \mathrm{e}+001.00000 \mathrm{e}-092.12000 \mathrm{e}-01$ $1.00000 \mathrm{e}-011.00000 \mathrm{e}-011.00000 \mathrm{e}-021.00000 \mathrm{e}-091.00000 \mathrm{e}-01$ $1.00000 \mathrm{e}+001.00000 \mathrm{e}+001.00000 \mathrm{e}-011.00000 \mathrm{e}-091.00000 \mathrm{e}-01$ $1.00000 \mathrm{e}-05$ 1.00000e-05 1.00000e-06 1.00000e-09 1.00000e-01 $1.00000 \mathrm{e}+001.00000 \mathrm{e}+001.00000 \mathrm{e}-011.00000 \mathrm{e}-091.00000 \mathrm{e}-01$ Element: 1735 \# of layers: 9

$\mathrm{Kx} \mathrm{Ky} \mathrm{Kz}$ Ss Por

$1.44206 \mathrm{e}+01$ 1.44206e+01 1.44206e+00 1.00000e-09 2.12000e-01 $1.44206 \mathrm{e}+011.44206 \mathrm{e}+011.44206 \mathrm{e}+001.00000 \mathrm{e}-092.12000 \mathrm{e}-01$ $1.44206 \mathrm{e}+011.44206 \mathrm{e}+011.44206 \mathrm{e}+001.00000 \mathrm{e}-092.12000 \mathrm{e}-01$ $1.44206 \mathrm{e}+011.44206 \mathrm{e}+011.44206 \mathrm{e}+001.00000 \mathrm{e}-092.12000 \mathrm{e}-01$ $1.44206 \mathrm{e}+011.44206 \mathrm{e}+011.44206 \mathrm{e}+001.00000 \mathrm{e}-092.12000 \mathrm{e}-01$ 1.00000e-01 1.00000e-01 1.00000e-02 1.00000e-09 1.00000e-01 $1.00000 \mathrm{e}+001.00000 \mathrm{e}+001.00000 \mathrm{e}-011.00000 \mathrm{e}-091.00000 \mathrm{e}-01$ 1.00000e-05 1.00000e-05 1.00000e-06 1.00000e-09 1.00000e-01 $1.00000 \mathrm{e}+001.00000 \mathrm{e}+001.00000 \mathrm{e}-011.00000 \mathrm{e}-091.00000 \mathrm{e}-01$ Element: 1736 \# of layers: 9

Kx Ky Kz Ss Por

$1.44206 \mathrm{e}+01$ 1.44206e+01 1.44206e+00 1.00000e-09 2.12000e-01 $1.44206 \mathrm{e}+01$ 1.44206e+01 1.44206e+00 1.00000e-09 2.12000e-01 $1.44206 \mathrm{e}+01$ 1.44206e+01 1.44206e+00 1.00000e-09 2.12000e-01 $1.44206 \mathrm{e}+011.44206 \mathrm{e}+011.44206 \mathrm{e}+001.00000 \mathrm{e}-092.12000 \mathrm{e}-01$ $1.44206 \mathrm{e}+011.44206 \mathrm{e}+011.44206 \mathrm{e}+00$ 1.00000e-09 2.12000e-01 
$1.00000 \mathrm{e}-02$ 1.00000e-02 1.00000e-03 1.00000e-09 1.00000e-01 $1.00000 \mathrm{e}+001.00000 \mathrm{e}+001.00000 \mathrm{e}-011.00000 \mathrm{e}-091.00000 \mathrm{e}-01$ $1.00000 \mathrm{e}-051.00000 \mathrm{e}-05$ 1.00000e-06 1.00000e-09 1.00000e-01 $1.00000 \mathrm{e}+001.00000 \mathrm{e}+001.00000 \mathrm{e}-011.00000 \mathrm{e}-091.00000 \mathrm{e}-01$ Element: 1737 \# of layers: 10

Kx Ky Kz Ss Por

$3.60905 \mathrm{e}+023.60905 \mathrm{e}+023.60905 \mathrm{e}+01$ 1.00000e-09 7.00000e-02 $1.44206 \mathrm{e}+011.44206 \mathrm{e}+011.44206 \mathrm{e}+001.00000 \mathrm{e}-092.12000 \mathrm{e}-01$ $1.44206 \mathrm{e}+011.44206 \mathrm{e}+011.44206 \mathrm{e}+001.00000 \mathrm{e}-092.12000 \mathrm{e}-01$ $1.44206 \mathrm{e}+011.44206 \mathrm{e}+011.44206 \mathrm{e}+001.00000 \mathrm{e}-092.12000 \mathrm{e}-01$ $1.44206 \mathrm{e}+011.44206 \mathrm{e}+011.44206 \mathrm{e}+001.00000 \mathrm{e}-092.12000 \mathrm{e}-01$ $1.44206 \mathrm{e}+011.44206 \mathrm{e}+011.44206 \mathrm{e}+001.00000 \mathrm{e}-092.12000 \mathrm{e}-01$ $1.00000 \mathrm{e}-02$ 1.00000e-02 1.00000e-03 1.00000e-09 1.00000e-01 $1.00000 \mathrm{e}+001.00000 \mathrm{e}+001.00000 \mathrm{e}-011.00000 \mathrm{e}-091.00000 \mathrm{e}-01$ $1.00000 \mathrm{e}-05$ 1.00000e-05 1.00000e-06 1.00000e-09 1.00000e-01 $1.00000 \mathrm{e}+001.00000 \mathrm{e}+001.00000 \mathrm{e}-011.00000 \mathrm{e}-091.00000 \mathrm{e}-01$ Element: 1738 \# of layers: 10

Kx Ky Kz Ss Por $3.60905 \mathrm{e}+023.60905 \mathrm{e}+023.60905 \mathrm{e}+01$ 1.00000e-09 7.00000e-02 $1.44206 \mathrm{e}+011.44206 \mathrm{e}+011.44206 \mathrm{e}+001.00000 \mathrm{e}-092.12000 \mathrm{e}-01$ $1.44206 \mathrm{e}+011.44206 \mathrm{e}+011.44206 \mathrm{e}+001.00000 \mathrm{e}-092.12000 \mathrm{e}-01$ $1.44206 \mathrm{e}+011.44206 \mathrm{e}+011.44206 \mathrm{e}+001.00000 \mathrm{e}-092.12000 \mathrm{e}-01$ $1.44206 \mathrm{e}+011.44206 \mathrm{e}+011.44206 \mathrm{e}+001.00000 \mathrm{e}-092.12000 \mathrm{e}-01$ $1.44206 \mathrm{e}+011.44206 \mathrm{e}+011.44206 \mathrm{e}+001.00000 \mathrm{e}-092.12000 \mathrm{e}-01$ $1.00000 \mathrm{e}-021.00000 \mathrm{e}-02$ 1.00000e-03 1.00000e-09 1.00000e-01 $1.00000 \mathrm{e}+001.00000 \mathrm{e}+001.00000 \mathrm{e}-011.00000 \mathrm{e}-091.00000 \mathrm{e}-01$ $1.00000 \mathrm{e}-05$ 1.00000e-05 1.00000e-06 1.00000e-09 1.00000e-01 $1.00000 \mathrm{e}+001.00000 \mathrm{e}+001.00000 \mathrm{e}-011.00000 \mathrm{e}-091.00000 \mathrm{e}-01$ Element: 1739 \# of layers: 10

Kx Ky Kz Ss Por

$3.60905 \mathrm{e}+023.60905 \mathrm{e}+023.60905 \mathrm{e}+01$ 1.00000e-09 7.00000e-02 $1.44206 \mathrm{e}+011.44206 \mathrm{e}+011.44206 \mathrm{e}+001.00000 \mathrm{e}-092.12000 \mathrm{e}-01$ $1.44206 \mathrm{e}+011.44206 \mathrm{e}+011.44206 \mathrm{e}+001.00000 \mathrm{e}-092.12000 \mathrm{e}-01$ $1.44206 \mathrm{e}+011.44206 \mathrm{e}+011.44206 \mathrm{e}+001.00000 \mathrm{e}-092.12000 \mathrm{e}-01$ $1.44206 \mathrm{e}+011.44206 \mathrm{e}+011.44206 \mathrm{e}+001.00000 \mathrm{e}-092.12000 \mathrm{e}-01$ $1.44206 \mathrm{e}+011.44206 \mathrm{e}+011.44206 \mathrm{e}+001.00000 \mathrm{e}-092.12000 \mathrm{e}-01$ $1.00000 \mathrm{e}-011.00000 \mathrm{e}-011.00000 \mathrm{e}-021.00000 \mathrm{e}-091.00000 \mathrm{e}-01$ $1.00000 \mathrm{e}+001.00000 \mathrm{e}+001.00000 \mathrm{e}-011.00000 \mathrm{e}-091.00000 \mathrm{e}-01$ $1.00000 \mathrm{e}-05$ 1.00000e-05 1.00000e-06 1.00000e-09 1.00000e-01 $1.00000 \mathrm{e}+001.00000 \mathrm{e}+001.00000 \mathrm{e}-011.00000 \mathrm{e}-091.00000 \mathrm{e}-01$ Element: 1740 \# of layers: 10

Kx Ky Kz Ss Por $3.60905 \mathrm{e}+023.60905 \mathrm{e}+023.60905 \mathrm{e}+01$ 1.00000e-09 7.00000e-02 $1.44206 \mathrm{e}+011.44206 \mathrm{e}+011.44206 \mathrm{e}+001.00000 \mathrm{e}-092.12000 \mathrm{e}-01$ $1.44206 \mathrm{e}+011.44206 \mathrm{e}+011.44206 \mathrm{e}+001.00000 \mathrm{e}-092.12000 \mathrm{e}-01$ $1.44206 \mathrm{e}+011.44206 \mathrm{e}+011.44206 \mathrm{e}+001.00000 \mathrm{e}-092.12000 \mathrm{e}-01$ 
$1.44206 \mathrm{e}+01$ 1.44206e+01 1.44206e+00 1.00000e-09 2.12000e-01 $1.44206 \mathrm{e}+011.44206 \mathrm{e}+011.44206 \mathrm{e}+001.00000 \mathrm{e}-092.12000 \mathrm{e}-01$ $1.00000 \mathrm{e}-01$ 1.00000e-01 1.00000e-02 1.00000e-09 1.00000e-01

$1.00000 \mathrm{e}+001.00000 \mathrm{e}+001.00000 \mathrm{e}-011.00000 \mathrm{e}-091.00000 \mathrm{e}-01$ $1.00000 \mathrm{e}-051.00000 \mathrm{e}-05$ 1.00000e-06 1.00000e-09 1.00000e-01

$1.00000 \mathrm{e}+001.00000 \mathrm{e}+001.00000 \mathrm{e}-011.00000 \mathrm{e}-091.00000 \mathrm{e}-01$ Element: 1741 \# of layers: 9

Kx Ky Kz Ss Por

$1.95664 \mathrm{e}+011.95664 \mathrm{e}+011.95664 \mathrm{e}+001.00000 \mathrm{e}-092.12000 \mathrm{e}-01$ $1.95664 \mathrm{e}+011.95664 \mathrm{e}+011.95664 \mathrm{e}+001.00000 \mathrm{e}-092.12000 \mathrm{e}-01$ $1.95664 \mathrm{e}+011.95664 \mathrm{e}+011.95664 \mathrm{e}+001.00000 \mathrm{e}-092.12000 \mathrm{e}-01$ $1.95664 \mathrm{e}+011.95664 \mathrm{e}+011.95664 \mathrm{e}+001.00000 \mathrm{e}-092.12000 \mathrm{e}-01$ $1.95664 \mathrm{e}+011.95664 \mathrm{e}+011.95664 \mathrm{e}+001.00000 \mathrm{e}-092.12000 \mathrm{e}-01$ $1.00000 \mathrm{e}-02$ 1.00000e-02 1.00000e-03 1.00000e-09 1.00000e-01 $1.00000 \mathrm{e}+001.00000 \mathrm{e}+001.00000 \mathrm{e}-011.00000 \mathrm{e}-091.00000 \mathrm{e}-01$ $1.00000 \mathrm{e}-05$ 1.00000e-05 1.00000e-06 1.00000e-09 1.00000e-01 $1.00000 \mathrm{e}+001.00000 \mathrm{e}+001.00000 \mathrm{e}-011.00000 \mathrm{e}-091.00000 \mathrm{e}-01$ Element: 1742 \# of layers: 9

$\mathrm{Kx} \mathrm{Ky} \mathrm{Kz}$ Ss Por

$1.95664 \mathrm{e}+01$ 1.95664e+01 1.95664e+00 1.00000e-09 2.12000e-01 $1.95664 \mathrm{e}+011.95664 \mathrm{e}+011.95664 \mathrm{e}+001.00000 \mathrm{e}-092.12000 \mathrm{e}-01$ $1.95664 \mathrm{e}+011.95664 \mathrm{e}+011.95664 \mathrm{e}+001.00000 \mathrm{e}-092.12000 \mathrm{e}-01$ $1.95664 \mathrm{e}+011.95664 \mathrm{e}+011.95664 \mathrm{e}+001.00000 \mathrm{e}-092.12000 \mathrm{e}-01$ $1.95664 \mathrm{e}+011.95664 \mathrm{e}+011.95664 \mathrm{e}+001.00000 \mathrm{e}-092.12000 \mathrm{e}-01$ $1.00000 \mathrm{e}-02$ 1.00000e-02 1.00000e-03 1.00000e-09 1.00000e-01 $1.00000 \mathrm{e}+001.00000 \mathrm{e}+001.00000 \mathrm{e}-011.00000 \mathrm{e}-091.00000 \mathrm{e}-01$ $1.00000 \mathrm{e}-05$ 1.00000e-05 1.00000e-06 1.00000e-09 1.00000e-01 $1.00000 \mathrm{e}+001.00000 \mathrm{e}+001.00000 \mathrm{e}-011.00000 \mathrm{e}-091.00000 \mathrm{e}-01$ Element: 1743 \# of layers: 9

$\mathrm{Kx} \mathrm{Ky} \mathrm{Kz}$ Ss Por

$1.95664 \mathrm{e}+011.95664 \mathrm{e}+011.95664 \mathrm{e}+001.00000 \mathrm{e}-092.12000 \mathrm{e}-01$ $1.95664 \mathrm{e}+011.95664 \mathrm{e}+011.95664 \mathrm{e}+001.00000 \mathrm{e}-092.12000 \mathrm{e}-01$ $1.95664 \mathrm{e}+011.95664 \mathrm{e}+011.95664 \mathrm{e}+001.00000 \mathrm{e}-092.12000 \mathrm{e}-01$ $1.95664 \mathrm{e}+011.95664 \mathrm{e}+011.95664 \mathrm{e}+001.00000 \mathrm{e}-092.12000 \mathrm{e}-01$ $1.95664 \mathrm{e}+011.95664 \mathrm{e}+011.95664 \mathrm{e}+001.00000 \mathrm{e}-092.12000 \mathrm{e}-01$ 1.00000e-02 1.00000e-02 1.00000e-03 1.00000e-09 1.00000e-01 $1.00000 \mathrm{e}+001.00000 \mathrm{e}+001.00000 \mathrm{e}-011.00000 \mathrm{e}-091.00000 \mathrm{e}-01$ $1.00000 \mathrm{e}-05$ 1.00000e-05 1.00000e-06 1.00000e-09 1.00000e-01 $1.00000 \mathrm{e}+001.00000 \mathrm{e}+001.00000 \mathrm{e}-011.00000 \mathrm{e}-091.00000 \mathrm{e}-01$ Element: 1744 \# of layers: 9

Kx Ky Kz Ss Por

$1.95664 \mathrm{e}+011.95664 \mathrm{e}+011.95664 \mathrm{e}+001.00000 \mathrm{e}-092.12000 \mathrm{e}-01$ $1.95664 \mathrm{e}+011.95664 \mathrm{e}+011.95664 \mathrm{e}+001.00000 \mathrm{e}-092.12000 \mathrm{e}-01$ $1.95664 \mathrm{e}+01$ 1.95664e+01 1.95664e+00 1.00000e-09 2.12000e-01 $1.95664 \mathrm{e}+011.95664 \mathrm{e}+011.95664 \mathrm{e}+001.00000 \mathrm{e}-092.12000 \mathrm{e}-01$ $1.95664 \mathrm{e}+011.95664 \mathrm{e}+011.95664 \mathrm{e}+001.00000 \mathrm{e}-092.12000 \mathrm{e}-01$ 
$1.00000 \mathrm{e}-02$ 1.00000e-02 1.00000e-03 1.00000e-09 1.00000e-01 $1.00000 \mathrm{e}+001.00000 \mathrm{e}+001.00000 \mathrm{e}-011.00000 \mathrm{e}-091.00000 \mathrm{e}-01$ $1.00000 \mathrm{e}-05$ 1.00000e-05 1.00000e-06 1.00000e-09 1.00000e-01 $1.00000 \mathrm{e}+001.00000 \mathrm{e}+001.00000 \mathrm{e}-011.00000 \mathrm{e}-091.00000 \mathrm{e}-01$ Element: 1745 \# of layers: 9

$\mathrm{Kx} \mathrm{Ky} \mathrm{Kz}$ Ss Por

$1.95664 \mathrm{e}+011.95664 \mathrm{e}+011.95664 \mathrm{e}+001.00000 \mathrm{e}-092.12000 \mathrm{e}-01$ $1.95664 \mathrm{e}+011.95664 \mathrm{e}+011.95664 \mathrm{e}+001.00000 \mathrm{e}-092.12000 \mathrm{e}-01$ $1.95664 \mathrm{e}+011.95664 \mathrm{e}+011.95664 \mathrm{e}+001.00000 \mathrm{e}-092.12000 \mathrm{e}-01$ $1.95664 \mathrm{e}+011.95664 \mathrm{e}+011.95664 \mathrm{e}+001.00000 \mathrm{e}-092.12000 \mathrm{e}-01$ $1.95664 \mathrm{e}+011.95664 \mathrm{e}+011.95664 \mathrm{e}+001.00000 \mathrm{e}-092.12000 \mathrm{e}-01$ $1.00000 \mathrm{e}-02$ 1.00000e-02 1.00000e-03 1.00000e-09 1.00000e-01 $1.00000 \mathrm{e}+001.00000 \mathrm{e}+001.00000 \mathrm{e}-011.00000 \mathrm{e}-091.00000 \mathrm{e}-01$ $1.00000 \mathrm{e}-05$ 1.00000e-05 1.00000e-06 1.00000e-09 1.00000e-01 $1.00000 \mathrm{e}+001.00000 \mathrm{e}+001.00000 \mathrm{e}-01$ 1.00000e-09 1.00000e-01 Element: 1746 \# of layers: 9

$\mathrm{Kx} \mathrm{Ky} \mathrm{Kz}$ Ss Por

$1.95664 \mathrm{e}+01$ 1.95664e+01 1.95664e+00 1.00000e-09 2.12000e-01 $1.95664 \mathrm{e}+011.95664 \mathrm{e}+011.95664 \mathrm{e}+001.00000 \mathrm{e}-092.12000 \mathrm{e}-01$ $1.95664 \mathrm{e}+011.95664 \mathrm{e}+011.95664 \mathrm{e}+001.00000 \mathrm{e}-092.12000 \mathrm{e}-01$ $1.95664 \mathrm{e}+011.95664 \mathrm{e}+011.95664 \mathrm{e}+001.00000 \mathrm{e}-092.12000 \mathrm{e}-01$ $1.95664 \mathrm{e}+011.95664 \mathrm{e}+011.95664 \mathrm{e}+001.00000 \mathrm{e}-092.12000 \mathrm{e}-01$ 1.00000e-02 1.00000e-02 1.00000e-03 1.00000e-09 1.00000e-01 $1.00000 \mathrm{e}+001.00000 \mathrm{e}+001.00000 \mathrm{e}-011.00000 \mathrm{e}-091.00000 \mathrm{e}-01$ $1.00000 \mathrm{e}-05$ 1.00000e-05 1.00000e-06 1.00000e-09 1.00000e-01 $1.00000 \mathrm{e}+001.00000 \mathrm{e}+001.00000 \mathrm{e}-011.00000 \mathrm{e}-091.00000 \mathrm{e}-01$ Element: 1747 \# of layers: 9

$\mathrm{Kx} \mathrm{Ky} \mathrm{Kz}$ Ss Por

$1.95664 \mathrm{e}+011.95664 \mathrm{e}+011.95664 \mathrm{e}+001.00000 \mathrm{e}-092.12000 \mathrm{e}-01$ $1.95664 \mathrm{e}+011.95664 \mathrm{e}+011.95664 \mathrm{e}+001.00000 \mathrm{e}-092.12000 \mathrm{e}-01$ $1.95664 \mathrm{e}+011.95664 \mathrm{e}+011.95664 \mathrm{e}+001.00000 \mathrm{e}-092.12000 \mathrm{e}-01$ $1.95664 \mathrm{e}+011.95664 \mathrm{e}+011.95664 \mathrm{e}+001.00000 \mathrm{e}-092.12000 \mathrm{e}-01$ $1.95664 \mathrm{e}+011.95664 \mathrm{e}+011.95664 \mathrm{e}+001.00000 \mathrm{e}-092.12000 \mathrm{e}-01$ 1.00000e-02 1.00000e-02 1.00000e-03 1.00000e-09 1.00000e-01 $1.00000 \mathrm{e}+001.00000 \mathrm{e}+001.00000 \mathrm{e}-011.00000 \mathrm{e}-091.00000 \mathrm{e}-01$ $1.00000 \mathrm{e}-05$ 1.00000e-05 1.00000e-06 1.00000e-09 1.00000e-01 $1.00000 \mathrm{e}+001.00000 \mathrm{e}+001.00000 \mathrm{e}-011.00000 \mathrm{e}-091.00000 \mathrm{e}-01$ Element: 1748 \# of layers: 9

$\mathrm{Kx} \mathrm{Ky} \mathrm{Kz}$ Ss Por

$1.95664 \mathrm{e}+011.95664 \mathrm{e}+011.95664 \mathrm{e}+001.00000 \mathrm{e}-092.12000 \mathrm{e}-01$ $1.95664 \mathrm{e}+011.95664 \mathrm{e}+011.95664 \mathrm{e}+001.00000 \mathrm{e}-092.12000 \mathrm{e}-01$ $1.95664 \mathrm{e}+011.95664 \mathrm{e}+011.95664 \mathrm{e}+001.00000 \mathrm{e}-092.12000 \mathrm{e}-01$ $1.95664 \mathrm{e}+011.95664 \mathrm{e}+011.95664 \mathrm{e}+001.00000 \mathrm{e}-092.12000 \mathrm{e}-01$ $1.95664 \mathrm{e}+01$ 1.95664e+01 1.95664e+00 1.00000e-09 2.12000e-01 $1.00000 \mathrm{e}-02$ 1.00000e-02 1.00000e-03 1.00000e-09 1.00000e-01 $1.00000 \mathrm{e}+001.00000 \mathrm{e}+001.00000 \mathrm{e}-011.00000 \mathrm{e}-091.00000 \mathrm{e}-01$ 
$1.00000 \mathrm{e}-05$ 1.00000e-05 1.00000e-06 1.00000e-09 1.00000e-01 $1.00000 \mathrm{e}+001.00000 \mathrm{e}+001.00000 \mathrm{e}-01$ 1.00000e-09 1.00000e-01 Element: 1749 \# of layers: 9

Kx Ky Kz Ss Por

$1.95664 \mathrm{e}+011.95664 \mathrm{e}+011.95664 \mathrm{e}+001.00000 \mathrm{e}-092.12000 \mathrm{e}-01$ $1.95664 \mathrm{e}+011.95664 \mathrm{e}+011.95664 \mathrm{e}+001.00000 \mathrm{e}-092.12000 \mathrm{e}-01$ $1.95664 \mathrm{e}+011.95664 \mathrm{e}+011.95664 \mathrm{e}+001.00000 \mathrm{e}-092.12000 \mathrm{e}-01$ $1.95664 \mathrm{e}+011.95664 \mathrm{e}+011.95664 \mathrm{e}+001.00000 \mathrm{e}-092.12000 \mathrm{e}-01$ $1.95664 \mathrm{e}+011.95664 \mathrm{e}+011.95664 \mathrm{e}+001.00000 \mathrm{e}-092.12000 \mathrm{e}-01$ $1.00000 \mathrm{e}-02$ 1.00000e-02 1.00000e-03 1.00000e-09 1.00000e-01 $1.00000 \mathrm{e}+001.00000 \mathrm{e}+001.00000 \mathrm{e}-011.00000 \mathrm{e}-091.00000 \mathrm{e}-01$ $1.00000 \mathrm{e}-05$ 1.00000e-05 1.00000e-06 1.00000e-09 1.00000e-01 $1.00000 \mathrm{e}+001.00000 \mathrm{e}+001.00000 \mathrm{e}-011.00000 \mathrm{e}-091.00000 \mathrm{e}-01$ Element: 1750 \# of layers: 9

$\mathrm{Kx} \mathrm{Ky} \mathrm{Kz}$ Ss Por

$2.42083 e+012.42083 e+012.42083 e+001.00000 e-092.12000 e-01$ $2.42083 \mathrm{e}+012.42083 \mathrm{e}+012.42083 \mathrm{e}+00$ 1.00000e-09 2.12000e-01 $2.42083 \mathrm{e}+012.42083 \mathrm{e}+012.42083 \mathrm{e}+001.00000 \mathrm{e}-092.12000 \mathrm{e}-01$ $2.42083 \mathrm{e}+012.42083 \mathrm{e}+012.42083 \mathrm{e}+00$ 1.00000e-09 2.12000e-01 $2.42083 \mathrm{e}+012.42083 \mathrm{e}+012.42083 \mathrm{e}+00$ 1.00000e-09 2.12000e-01 $1.00000 \mathrm{e}-02$ 1.00000e-02 1.00000e-03 1.00000e-09 1.00000e-01 $1.00000 \mathrm{e}+001.00000 \mathrm{e}+001.00000 \mathrm{e}-011.00000 \mathrm{e}-091.00000 \mathrm{e}-01$ $1.00000 \mathrm{e}-05$ 1.00000e-05 1.00000e-06 1.00000e-09 1.00000e-01 $1.00000 \mathrm{e}+001.00000 \mathrm{e}+001.00000 \mathrm{e}-011.00000 \mathrm{e}-091.00000 \mathrm{e}-01$ Element: 1751 \# of layers: 8

$\mathrm{Kx} \mathrm{Ky} \mathrm{Kz}$ Ss Por

$2.42083 \mathrm{e}+012.42083 \mathrm{e}+012.42083 \mathrm{e}+00$ 1.00000e-09 2.12000e-01 $2.42083 \mathrm{e}+012.42083 \mathrm{e}+012.42083 \mathrm{e}+00$ 1.00000e-09 2.12000e-01 $2.42083 \mathrm{e}+012.42083 \mathrm{e}+012.42083 \mathrm{e}+001.00000 \mathrm{e}-092.12000 \mathrm{e}-01$ $2.42083 \mathrm{e}+012.42083 \mathrm{e}+012.42083 \mathrm{e}+001.00000 \mathrm{e}-092.12000 \mathrm{e}-01$ $1.00000 \mathrm{e}-02$ 1.00000e-02 1.00000e-03 1.00000e-09 1.00000e-01 $1.00000 \mathrm{e}+001.00000 \mathrm{e}+001.00000 \mathrm{e}-011.00000 \mathrm{e}-091.00000 \mathrm{e}-01$ $1.00000 \mathrm{e}-05$ 1.00000e-05 1.00000e-06 1.00000e-09 1.00000e-01 $1.00000 \mathrm{e}+001.00000 \mathrm{e}+001.00000 \mathrm{e}-011.00000 \mathrm{e}-091.00000 \mathrm{e}-01$ Element: 1752 \# of layers: 8

$\mathrm{Kx} \mathrm{Ky} \mathrm{Kz}$ Ss Por

$2.42083 \mathrm{e}+012.42083 \mathrm{e}+012.42083 \mathrm{e}+00$ 1.00000e-09 2.12000e-01 $2.42083 \mathrm{e}+012.42083 \mathrm{e}+012.42083 \mathrm{e}+00$ 1.00000e-09 2.12000e-01 $2.42083 \mathrm{e}+012.42083 \mathrm{e}+012.42083 \mathrm{e}+001.00000 \mathrm{e}-092.12000 \mathrm{e}-01$ $2.42083 \mathrm{e}+012.42083 \mathrm{e}+012.42083 \mathrm{e}+00$ 1.00000e-09 2.12000e-01 1.00000e-02 1.00000e-02 1.00000e-03 1.00000e-09 1.00000e-01 $1.00000 \mathrm{e}+001.00000 \mathrm{e}+001.00000 \mathrm{e}-011.00000 \mathrm{e}-091.00000 \mathrm{e}-01$ $1.00000 \mathrm{e}-05$ 1.00000e-05 1.00000e-06 1.00000e-09 1.00000e-01 $1.00000 \mathrm{e}+001.00000 \mathrm{e}+001.00000 \mathrm{e}-011.00000 \mathrm{e}-091.00000 \mathrm{e}-01$ Element: 1753 \# of layers: 8

Kx Ky Kz Ss Por 
$2.42083 \mathrm{e}+012.42083 \mathrm{e}+012.42083 \mathrm{e}+00$ 1.00000e-09 2.12000e-01 $2.42083 \mathrm{e}+012.42083 \mathrm{e}+012.42083 \mathrm{e}+00$ 1.00000e-09 2.12000e-01 $2.42083 \mathrm{e}+012.42083 \mathrm{e}+012.42083 \mathrm{e}+00$ 1.00000e-09 2.12000e-01 $2.42083 \mathrm{e}+012.42083 \mathrm{e}+012.42083 \mathrm{e}+001.00000 \mathrm{e}-092.12000 \mathrm{e}-01$ $1.00000 \mathrm{e}-02$ 1.00000e-02 1.00000e-03 1.00000e-09 1.00000e-01 $1.00000 \mathrm{e}+001.00000 \mathrm{e}+001.00000 \mathrm{e}-011.00000 \mathrm{e}-091.00000 \mathrm{e}-01$ $1.00000 \mathrm{e}-051.00000 \mathrm{e}-05$ 1.00000e-06 1.00000e-09 1.00000e-01 $1.00000 \mathrm{e}+001.00000 \mathrm{e}+001.00000 \mathrm{e}-011.00000 \mathrm{e}-091.00000 \mathrm{e}-01$ Element: 1754 \# of layers: 8

Kx Ky Kz Ss Por

$2.42083 \mathrm{e}+012.42083 \mathrm{e}+012.42083 \mathrm{e}+00$ 1.00000e-09 2.12000e-01 $2.42083 \mathrm{e}+012.42083 \mathrm{e}+012.42083 \mathrm{e}+00$ 1.00000e-09 2.12000e-01 $2.42083 \mathrm{e}+012.42083 \mathrm{e}+012.42083 \mathrm{e}+00$ 1.00000e-09 2.12000e-01 $2.42083 \mathrm{e}+012.42083 \mathrm{e}+012.42083 \mathrm{e}+00$ 1.00000e-09 2.12000e-01 $1.00000 \mathrm{e}-02$ 1.00000e-02 1.00000e-03 1.00000e-09 1.00000e-01 $1.00000 \mathrm{e}+001.00000 \mathrm{e}+001.00000 \mathrm{e}-011.00000 \mathrm{e}-091.00000 \mathrm{e}-01$ $1.00000 \mathrm{e}-05$ 1.00000e-05 1.00000e-06 1.00000e-09 1.00000e-01 $1.00000 \mathrm{e}+001.00000 \mathrm{e}+001.00000 \mathrm{e}-011.00000 \mathrm{e}-091.00000 \mathrm{e}-01$ Element: 1755 \# of layers: 9

Kx Ky Kz Ss Por

$2.42083 \mathrm{e}+012.42083 \mathrm{e}+012.42083 \mathrm{e}+00$ 1.00000e-09 2.12000e-01 $2.42083 \mathrm{e}+012.42083 \mathrm{e}+012.42083 \mathrm{e}+00$ 1.00000e-09 2.12000e-01 $2.42083 \mathrm{e}+012.42083 \mathrm{e}+012.42083 \mathrm{e}+00$ 1.00000e-09 2.12000e-01 $2.42083 \mathrm{e}+012.42083 \mathrm{e}+012.42083 \mathrm{e}+00$ 1.00000e-09 2.12000e-01 $2.42083 \mathrm{e}+012.42083 \mathrm{e}+012.42083 \mathrm{e}+001.00000 \mathrm{e}-092.12000 \mathrm{e}-01$ $1.00000 \mathrm{e}-02$ 1.00000e-02 1.00000e-03 1.00000e-09 1.00000e-01 $1.00000 \mathrm{e}+001.00000 \mathrm{e}+001.00000 \mathrm{e}-011.00000 \mathrm{e}-091.00000 \mathrm{e}-01$ $1.00000 \mathrm{e}-051.00000 \mathrm{e}-05$ 1.00000e-06 1.00000e-09 1.00000e-01 $1.00000 \mathrm{e}+001.00000 \mathrm{e}+001.00000 \mathrm{e}-011.00000 \mathrm{e}-091.00000 \mathrm{e}-01$ Element: 1756 \# of layers: 9

Kx Ky Kz Ss Por

$2.42083 \mathrm{e}+012.42083 \mathrm{e}+012.42083 \mathrm{e}+00$ 1.00000e-09 2.12000e-01 $2.42083 \mathrm{e}+012.42083 \mathrm{e}+012.42083 \mathrm{e}+00$ 1.00000e-09 2.12000e-01 $2.42083 \mathrm{e}+012.42083 \mathrm{e}+012.42083 \mathrm{e}+00$ 1.00000e-09 2.12000e-01 $2.42083 \mathrm{e}+012.42083 \mathrm{e}+012.42083 \mathrm{e}+00$ 1.00000e-09 2.12000e-01 $2.42083 \mathrm{e}+012.42083 \mathrm{e}+012.42083 \mathrm{e}+00$ 1.00000e-09 2.12000e-01 $1.00000 \mathrm{e}-02$ 1.00000e-02 1.00000e-03 1.00000e-09 1.00000e-01 $1.00000 \mathrm{e}+001.00000 \mathrm{e}+001.00000 \mathrm{e}-011.00000 \mathrm{e}-091.00000 \mathrm{e}-01$ $1.00000 \mathrm{e}-05$ 1.00000e-05 1.00000e-06 1.00000e-09 1.00000e-01 $1.00000 \mathrm{e}+001.00000 \mathrm{e}+001.00000 \mathrm{e}-011.00000 \mathrm{e}-091.00000 \mathrm{e}-01$ Element: 1757 \# of layers: 9

Kx Ky Kz Ss Por $2.42083 \mathrm{e}+012.42083 \mathrm{e}+012.42083 \mathrm{e}+00$ 1.00000e-09 2.12000e-01 $2.42083 \mathrm{e}+012.42083 \mathrm{e}+012.42083 \mathrm{e}+001.00000 \mathrm{e}-092.12000 \mathrm{e}-01$ $2.42083 \mathrm{e}+012.42083 \mathrm{e}+012.42083 \mathrm{e}+00$ 1.00000e-09 2.12000e-01 $2.42083 \mathrm{e}+012.42083 \mathrm{e}+012.42083 \mathrm{e}+00$ 1.00000e-09 2.12000e-01 
$2.42083 \mathrm{e}+012.42083 \mathrm{e}+012.42083 \mathrm{e}+00$ 1.00000e-09 2.12000e-01 $1.00000 \mathrm{e}-02$ 1.00000e-02 1.00000e-03 1.00000e-09 1.00000e-01 $1.00000 \mathrm{e}+001.00000 \mathrm{e}+001.00000 \mathrm{e}-011.00000 \mathrm{e}-091.00000 \mathrm{e}-01$ $1.00000 \mathrm{e}-05$ 1.00000e-05 1.00000e-06 1.00000e-09 1.00000e-01 $1.00000 \mathrm{e}+001.00000 \mathrm{e}+001.00000 \mathrm{e}-01$ 1.00000e-09 1.00000e-01 Element: 1758 \# of layers: 9

$\mathrm{Kx} \mathrm{Ky} \mathrm{Kz}$ Ss Por

$2.42083 e+012.42083 e+012.42083 e+001.00000 e-092.12000 e-01$ $2.42083 \mathrm{e}+012.42083 \mathrm{e}+012.42083 \mathrm{e}+001.00000 \mathrm{e}-092.12000 \mathrm{e}-01$

$2.42083 \mathrm{e}+012.42083 \mathrm{e}+012.42083 \mathrm{e}+00$ 1.00000e-09 2.12000e-01

$2.42083 \mathrm{e}+012.42083 \mathrm{e}+012.42083 \mathrm{e}+00$ 1.00000e-09 2.12000e-01

$2.42083 \mathrm{e}+012.42083 \mathrm{e}+012.42083 \mathrm{e}+001.00000 \mathrm{e}-092.12000 \mathrm{e}-01$

$1.00000 \mathrm{e}-02$ 1.00000e-02 1.00000e-03 1.00000e-09 1.00000e-01

$1.00000 \mathrm{e}+001.00000 \mathrm{e}+001.00000 \mathrm{e}-011.00000 \mathrm{e}-091.00000 \mathrm{e}-01$

$1.00000 \mathrm{e}-05$ 1.00000e-05 1.00000e-06 1.00000e-09 1.00000e-01

$1.00000 \mathrm{e}+001.00000 \mathrm{e}+001.00000 \mathrm{e}-011.00000 \mathrm{e}-091.00000 \mathrm{e}-01$

Element: 1759 \# of layers: 8

$\mathrm{Kx} \mathrm{Ky} \mathrm{Kz}$ Ss Por

3.74948e+01 3.74948e+01 3.74948e+00 1.00000e-09 2.12000e-01

$3.74948 \mathrm{e}+013.74948 \mathrm{e}+013.74948 \mathrm{e}+00$ 1.00000e-09 2.12000e-01

$3.74948 \mathrm{e}+013.74948 \mathrm{e}+013.74948 \mathrm{e}+00$ 1.00000e-09 2.12000e-01

$3.74948 \mathrm{e}+013.74948 \mathrm{e}+013.74948 \mathrm{e}+00$ 1.00000e-09 2.12000e-01

$1.00000 \mathrm{e}-02$ 1.00000e-02 1.00000e-03 1.00000e-09 1.00000e-01

$1.00000 \mathrm{e}+001.00000 \mathrm{e}+001.00000 \mathrm{e}-011.00000 \mathrm{e}-091.00000 \mathrm{e}-01$

$1.00000 \mathrm{e}-05$ 1.00000e-05 1.00000e-06 1.00000e-09 1.00000e-01

$1.00000 \mathrm{e}+001.00000 \mathrm{e}+001.00000 \mathrm{e}-01$ 1.00000e-09 1.00000e-01

Element: 1760 \# of layers: 8

$\mathrm{Kx} \mathrm{Ky} \mathrm{Kz}$ Ss Por

3.74948e+01 3.74948e+01 3.74948e+00 1.00000e-09 2.12000e-01

$3.74948 \mathrm{e}+013.74948 \mathrm{e}+013.74948 \mathrm{e}+001.00000 \mathrm{e}-092.12000 \mathrm{e}-01$

$3.74948 \mathrm{e}+013.74948 \mathrm{e}+013.74948 \mathrm{e}+001.00000 \mathrm{e}-092.12000 \mathrm{e}-01$

$3.74948 \mathrm{e}+013.74948 \mathrm{e}+013.74948 \mathrm{e}+00$ 1.00000e-09 2.12000e-01

$1.00000 \mathrm{e}-02$ 1.00000e-02 1.00000e-03 1.00000e-09 1.00000e-01

$1.00000 \mathrm{e}+001.00000 \mathrm{e}+001.00000 \mathrm{e}-011.00000 \mathrm{e}-091.00000 \mathrm{e}-01$

$1.00000 \mathrm{e}-05$ 1.00000e-05 1.00000e-06 1.00000e-09 1.00000e-01

$1.00000 \mathrm{e}+001.00000 \mathrm{e}+001.00000 \mathrm{e}-011.00000 \mathrm{e}-091.00000 \mathrm{e}-01$

Element: 1761 \# of layers: 8

Kx Ky Kz Ss Por

9.38391e+02 9.38391e+02 9.38391e+01 1.00000e-09 7.00000e-02

$3.74948 \mathrm{e}+013.74948 \mathrm{e}+013.74948 \mathrm{e}+00$ 1.00000e-09 2.12000e-01

$3.74948 \mathrm{e}+013.74948 \mathrm{e}+013.74948 \mathrm{e}+00$ 1.00000e-09 2.12000e-01

$3.74948 \mathrm{e}+013.74948 \mathrm{e}+013.74948 \mathrm{e}+00$ 1.00000e-09 2.12000e-01

$1.00000 \mathrm{e}-02$ 1.00000e-02 1.00000e-03 1.00000e-09 1.00000e-01

$1.00000 \mathrm{e}+001.00000 \mathrm{e}+001.00000 \mathrm{e}-011.00000 \mathrm{e}-091.00000 \mathrm{e}-01$

$1.00000 \mathrm{e}-05$ 1.00000e-05 1.00000e-06 1.00000e-09 1.00000e-01

$1.00000 \mathrm{e}+001.00000 \mathrm{e}+001.00000 \mathrm{e}-011.00000 \mathrm{e}-091.00000 \mathrm{e}-01$ 
Element: 1762 \# of layers: 8

$\mathrm{Kx} \mathrm{Ky} \mathrm{Kz}$ Ss Por

9.38391e+02 9.38391e+02 9.38391e+01 1.00000e-09 7.00000e-02

$3.74948 \mathrm{e}+01$ 3.74948e+01 3.74948e+00 1.00000e-09 2.12000e-01

$3.74948 \mathrm{e}+013.74948 \mathrm{e}+013.74948 \mathrm{e}+00$ 1.00000e-09 2.12000e-01

$3.74948 \mathrm{e}+013.74948 \mathrm{e}+013.74948 \mathrm{e}+00$ 1.00000e-09 2.12000e-01

$1.00000 \mathrm{e}-02$ 1.00000e-02 1.00000e-03 1.00000e-09 1.00000e-01

$1.00000 \mathrm{e}+001.00000 \mathrm{e}+001.00000 \mathrm{e}-011.00000 \mathrm{e}-091.00000 \mathrm{e}-01$

$1.00000 \mathrm{e}-05$ 1.00000e-05 1.00000e-06 1.00000e-09 1.00000e-01

$1.00000 \mathrm{e}+001.00000 \mathrm{e}+001.00000 \mathrm{e}-011.00000 \mathrm{e}-091.00000 \mathrm{e}-01$

Element: 1763 \# of layers: 7

Kx Ky Kz Ss Por

3.74948e+01 3.74948e+01 3.74948e+00 1.00000e-09 2.12000e-01

$3.74948 \mathrm{e}+013.74948 \mathrm{e}+013.74948 \mathrm{e}+00$ 1.00000e-09 2.12000e-01

$3.74948 \mathrm{e}+013.74948 \mathrm{e}+013.74948 \mathrm{e}+00$ 1.00000e-09 2.12000e-01

$1.00000 \mathrm{e}-02$ 1.00000e-02 1.00000e-03 1.00000e-09 1.00000e-01

$1.00000 \mathrm{e}+001.00000 \mathrm{e}+001.00000 \mathrm{e}-011.00000 \mathrm{e}-091.00000 \mathrm{e}-01$

$1.00000 \mathrm{e}-05$ 1.00000e-05 1.00000e-06 1.00000e-09 1.00000e-01

$1.00000 \mathrm{e}+001.00000 \mathrm{e}+001.00000 \mathrm{e}-01$ 1.00000e-09 1.00000e-01

Element: 1764 \# of layers: 8

$\mathrm{Kx} \mathrm{Ky} \mathrm{Kz}$ Ss Por

3.74948e+01 3.74948e+01 3.74948e+00 1.00000e-09 2.12000e-01

$3.74948 \mathrm{e}+013.74948 \mathrm{e}+01$ 3.74948e+00 1.00000e-09 2.12000e-01

$3.74948 \mathrm{e}+013.74948 \mathrm{e}+01$ 3.74948e+00 1.00000e-09 2.12000e-01

$3.74948 \mathrm{e}+013.74948 \mathrm{e}+013.74948 \mathrm{e}+001.00000 \mathrm{e}-092.12000 \mathrm{e}-01$

$1.00000 \mathrm{e}-02$ 1.00000e-02 1.00000e-03 1.00000e-09 1.00000e-01

$1.00000 \mathrm{e}+001.00000 \mathrm{e}+001.00000 \mathrm{e}-011.00000 \mathrm{e}-091.00000 \mathrm{e}-01$

$1.00000 \mathrm{e}-05$ 1.00000e-05 1.00000e-06 1.00000e-09 1.00000e-01

$1.00000 \mathrm{e}+001.00000 \mathrm{e}+001.00000 \mathrm{e}-011.00000 \mathrm{e}-091.00000 \mathrm{e}-01$

Element: 1765 \# of layers: 8

$\mathrm{Kx} \mathrm{Ky} \mathrm{Kz}$ Ss Por

$3.74948 \mathrm{e}+013.74948 \mathrm{e}+01$ 3.74948e+00 1.00000e-09 2.12000e-01

$3.74948 \mathrm{e}+013.74948 \mathrm{e}+013.74948 \mathrm{e}+00$ 1.00000e-09 2.12000e-01

$3.74948 \mathrm{e}+013.74948 \mathrm{e}+01$ 3.74948e+00 1.00000e-09 2.12000e-01

$3.74948 \mathrm{e}+013.74948 \mathrm{e}+013.74948 \mathrm{e}+00$ 1.00000e-09 2.12000e-01

$1.00000 \mathrm{e}-02$ 1.00000e-02 1.00000e-03 1.00000e-09 1.00000e-01

$1.00000 \mathrm{e}+001.00000 \mathrm{e}+001.00000 \mathrm{e}-011.00000 \mathrm{e}-091.00000 \mathrm{e}-01$

$1.00000 \mathrm{e}-05$ 1.00000e-05 1.00000e-06 1.00000e-09 1.00000e-01

$1.00000 \mathrm{e}+001.00000 \mathrm{e}+001.00000 \mathrm{e}-011.00000 \mathrm{e}-091.00000 \mathrm{e}-01$

Element: 1766 \# of layers: 8

Kx Ky Kz Ss Por

3.74948e+01 3.74948e+01 3.74948e+00 1.00000e-09 2.12000e-01

$3.74948 \mathrm{e}+013.74948 \mathrm{e}+013.74948 \mathrm{e}+00$ 1.00000e-09 2.12000e-01

3.74948e+01 3.74948e+01 3.74948e+00 1.00000e-09 2.12000e-01

$3.74948 \mathrm{e}+013.74948 \mathrm{e}+013.74948 \mathrm{e}+00$ 1.00000e-09 2.12000e-01

$1.00000 \mathrm{e}-02$ 1.00000e-02 1.00000e-03 1.00000e-09 1.00000e-01 
$1.00000 \mathrm{e}+001.00000 \mathrm{e}+001.00000 \mathrm{e}-011.00000 \mathrm{e}-091.00000 \mathrm{e}-01$ $1.00000 \mathrm{e}-05$ 1.00000e-05 1.00000e-06 1.00000e-09 1.00000e-01

$1.00000 \mathrm{e}+001.00000 \mathrm{e}+001.00000 \mathrm{e}-011.00000 \mathrm{e}-091.00000 \mathrm{e}-01$

Element: 1767 \# of layers: 8

$\mathrm{Kx} \mathrm{Ky} \mathrm{Kz}$ Ss Por

3.74948e+01 3.74948e+01 3.74948e+00 1.00000e-09 2.12000e-01

$3.74948 \mathrm{e}+013.74948 \mathrm{e}+01$ 3.74948e+00 1.00000e-09 2.12000e-01

$3.74948 \mathrm{e}+013.74948 \mathrm{e}+013.74948 \mathrm{e}+00$ 1.00000e-09 2.12000e-01

$3.74948 \mathrm{e}+013.74948 \mathrm{e}+013.74948 \mathrm{e}+001.00000 \mathrm{e}-092.12000 \mathrm{e}-01$

1.00000e-02 1.00000e-02 1.00000e-03 1.00000e-09 1.00000e-01

$1.00000 \mathrm{e}+001.00000 \mathrm{e}+001.00000 \mathrm{e}-011.00000 \mathrm{e}-091.00000 \mathrm{e}-01$

$1.00000 \mathrm{e}-05$ 1.00000e-05 1.00000e-06 1.00000e-09 1.00000e-01

$1.00000 \mathrm{e}+001.00000 \mathrm{e}+001.00000 \mathrm{e}-011.00000 \mathrm{e}-091.00000 \mathrm{e}-01$

Element: 1768 \# of layers: 8

$\mathrm{Kx} \mathrm{Ky} \mathrm{Kz}$ Ss Por

1.87750e+02 1.87750e+02 1.87750e+01 1.00000e-09 7.00000e-02

7.50166e+00 7.50166e+00 7.50166e-01 1.00000e-09 2.12000e-01

$7.50166 \mathrm{e}+007.50166 \mathrm{e}+00$ 7.50166e-01 1.00000e-09 2.12000e-01

7.50166e+00 7.50166e+00 7.50166e-01 1.00000e-09 2.12000e-01

$1.00000 \mathrm{e}-02$ 1.00000e-02 1.00000e-03 1.00000e-09 1.00000e-01

$1.00000 \mathrm{e}+001.00000 \mathrm{e}+001.00000 \mathrm{e}-011.00000 \mathrm{e}-091.00000 \mathrm{e}-01$

$1.00000 \mathrm{e}-05$ 1.00000e-05 1.00000e-06 1.00000e-09 1.00000e-01

$1.00000 \mathrm{e}+001.00000 \mathrm{e}+001.00000 \mathrm{e}-01$ 1.00000e-09 1.00000e-01

Element: 1769 \# of layers: 9

Kx Ky Kz Ss Por

$1.87750 \mathrm{e}+021.87750 \mathrm{e}+021.87750 \mathrm{e}+01$ 1.00000e-09 7.00000e-02

$1.87750 \mathrm{e}+021.87750 \mathrm{e}+021.87750 \mathrm{e}+01$ 1.00000e-09 7.00000e-02

7.50166e+00 7.50166e+00 7.50166e-01 1.00000e-09 2.12000e-01

$7.50166 \mathrm{e}+007.50166 \mathrm{e}+007.50166 \mathrm{e}-01$ 1.00000e-09 2.12000e-01

7.50166e+00 7.50166e+00 7.50166e-01 1.00000e-09 2.12000e-01

$1.00000 \mathrm{e}-01$ 1.00000e-01 1.00000e-02 1.00000e-09 1.00000e-01

$1.00000 \mathrm{e}+001.00000 \mathrm{e}+001.00000 \mathrm{e}-011.00000 \mathrm{e}-091.00000 \mathrm{e}-01$

1.00000e-05 1.00000e-05 1.00000e-06 1.00000e-09 1.00000e-01

$1.00000 \mathrm{e}+001.00000 \mathrm{e}+001.00000 \mathrm{e}-011.00000 \mathrm{e}-091.00000 \mathrm{e}-01$

Element: 1770 \# of layers: 7

Kx Ky Kz Ss Por

$1.87750 \mathrm{e}+02$ 1.87750e+02 1.87750e+01 1.00000e-09 7.00000e-02

7.50166e+00 7.50166e+00 7.50166e-01 1.00000e-09 2.12000e-01

$7.50166 \mathrm{e}+00$ 7.50166e+00 7.50166e-01 1.00000e-09 2.12000e-01

$1.00000 \mathrm{e}-01$ 1.00000e-01 1.00000e-02 1.00000e-09 1.00000e-01

$1.00000 \mathrm{e}+001.00000 \mathrm{e}+001.00000 \mathrm{e}-011.00000 \mathrm{e}-091.00000 \mathrm{e}-01$

$1.00000 \mathrm{e}-05$ 1.00000e-05 1.00000e-06 1.00000e-09 1.00000e-01

$1.00000 \mathrm{e}+001.00000 \mathrm{e}+001.00000 \mathrm{e}-011.00000 \mathrm{e}-091.00000 \mathrm{e}-01$

Element: 1771 \# of layers: 7

Kx Ky Kz Ss Por

$1.87750 \mathrm{e}+02$ 1.87750e+02 1.87750e+01 1.00000e-09 7.00000e-02 
7.50166e+00 7.50166e+00 7.50166e-01 1.00000e-09 2.12000e-01 7.50166e+00 7.50166e+00 7.50166e-01 1.00000e-09 2.12000e-01 $1.00000 \mathrm{e}-011.00000 \mathrm{e}-011.00000 \mathrm{e}-021.00000 \mathrm{e}-091.00000 \mathrm{e}-01$ $1.00000 \mathrm{e}+001.00000 \mathrm{e}+001.00000 \mathrm{e}-011.00000 \mathrm{e}-091.00000 \mathrm{e}-01$ $1.00000 \mathrm{e}-05$ 1.00000e-05 1.00000e-06 1.00000e-09 1.00000e-01 $1.00000 \mathrm{e}+001.00000 \mathrm{e}+001.00000 \mathrm{e}-011.00000 \mathrm{e}-091.00000 \mathrm{e}-01$ Element: 1772 \# of layers: 7

Kx Ky Kz Ss Por

$1.87750 \mathrm{e}+021.87750 \mathrm{e}+021.87750 \mathrm{e}+011.00000 \mathrm{e}-097.00000 \mathrm{e}-02$

$7.50166 \mathrm{e}+007.50166 \mathrm{e}+007.50166 \mathrm{e}-011.00000 \mathrm{e}-092.12000 \mathrm{e}-01$ $7.50166 \mathrm{e}+007.50166 \mathrm{e}+00$ 7.50166e-01 1.00000e-09 2.12000e-01 $1.00000 \mathrm{e}-011.00000 \mathrm{e}-011.00000 \mathrm{e}-021.00000 \mathrm{e}-091.00000 \mathrm{e}-01$ $1.00000 \mathrm{e}+001.00000 \mathrm{e}+001.00000 \mathrm{e}-011.00000 \mathrm{e}-091.00000 \mathrm{e}-01$ $1.00000 \mathrm{e}-05$ 1.00000e-05 1.00000e-06 1.00000e-09 1.00000e-01 $1.00000 \mathrm{e}+001.00000 \mathrm{e}+001.00000 \mathrm{e}-011.00000 \mathrm{e}-091.00000 \mathrm{e}-01$ Element: 1773 \# of layers: 9

Kx Ky Kz Ss Por

$1.87750 \mathrm{e}+021.87750 \mathrm{e}+021.87750 \mathrm{e}+011.00000 \mathrm{e}-097.00000 \mathrm{e}-02$ $1.87750 \mathrm{e}+021.87750 \mathrm{e}+021.87750 \mathrm{e}+011.00000 \mathrm{e}-097.00000 \mathrm{e}-02$ $7.50166 \mathrm{e}+007.50166 \mathrm{e}+007.50166 \mathrm{e}-011.00000 \mathrm{e}-092.12000 \mathrm{e}-01$ $7.50166 \mathrm{e}+007.50166 \mathrm{e}+007.50166 \mathrm{e}-011.00000 \mathrm{e}-092.12000 \mathrm{e}-01$ 7.50166e+00 7.50166e+00 7.50166e-01 1.00000e-09 2.12000e-01 $1.00000 \mathrm{e}-011.00000 \mathrm{e}-011.00000 \mathrm{e}-021.00000 \mathrm{e}-091.00000 \mathrm{e}-01$ $1.00000 \mathrm{e}+001.00000 \mathrm{e}+001.00000 \mathrm{e}-011.00000 \mathrm{e}-091.00000 \mathrm{e}-01$ $1.00000 \mathrm{e}-051.00000 \mathrm{e}-05$ 1.00000e-06 1.00000e-09 1.00000e-01 $1.00000 \mathrm{e}+001.00000 \mathrm{e}+001.00000 \mathrm{e}-011.00000 \mathrm{e}-091.00000 \mathrm{e}-01$ Element: 1774 \# of layers: 8

Kx Ky Kz Ss Por

$1.87750 \mathrm{e}+021.87750 \mathrm{e}+021.87750 \mathrm{e}+01$ 1.00000e-09 7.00000e-02 $7.50166 \mathrm{e}+007.50166 \mathrm{e}+00$ 7.50166e-01 1.00000e-09 2.12000e-01 $7.50166 \mathrm{e}+007.50166 \mathrm{e}+007.50166 \mathrm{e}-011.00000 \mathrm{e}-092.12000 \mathrm{e}-01$ $7.50166 \mathrm{e}+007.50166 \mathrm{e}+00$ 7.50166e-01 1.00000e-09 2.12000e-01 $1.00000 \mathrm{e}-021.00000 \mathrm{e}-02$ 1.00000e-03 1.00000e-09 1.00000e-01 $1.00000 \mathrm{e}+001.00000 \mathrm{e}+001.00000 \mathrm{e}-011.00000 \mathrm{e}-091.00000 \mathrm{e}-01$ $1.00000 \mathrm{e}-05$ 1.00000e-05 1.00000e-06 1.00000e-09 1.00000e-01 $1.00000 \mathrm{e}+001.00000 \mathrm{e}+001.00000 \mathrm{e}-011.00000 \mathrm{e}-091.00000 \mathrm{e}-01$ Element: 1775 \# of layers: 8

Kx Ky Kz Ss Por

$1.87750 \mathrm{e}+021.87750 \mathrm{e}+021.87750 \mathrm{e}+011.00000 \mathrm{e}-097.00000 \mathrm{e}-02$ $7.50166 \mathrm{e}+007.50166 \mathrm{e}+00$ 7.50166e-01 1.00000e-09 2.12000e-01 $7.50166 \mathrm{e}+007.50166 \mathrm{e}+007.50166 \mathrm{e}-011.00000 \mathrm{e}-092.12000 \mathrm{e}-01$ $7.50166 \mathrm{e}+007.50166 \mathrm{e}+007.50166 \mathrm{e}-011.00000 \mathrm{e}-092.12000 \mathrm{e}-01$ $1.00000 \mathrm{e}-021.00000 \mathrm{e}-02$ 1.00000e-03 1.00000e-09 1.00000e-01 $1.00000 \mathrm{e}+001.00000 \mathrm{e}+001.00000 \mathrm{e}-011.00000 \mathrm{e}-091.00000 \mathrm{e}-01$ $1.00000 \mathrm{e}-05$ 1.00000e-05 1.00000e-06 1.00000e-09 1.00000e-01 $1.00000 \mathrm{e}+001.00000 \mathrm{e}+001.00000 \mathrm{e}-011.00000 \mathrm{e}-091.00000 \mathrm{e}-01$ 
Element: 1776 \# of layers: 9

$\mathrm{Kx} \mathrm{Ky} \mathrm{Kz}$ Ss Por

$1.87750 \mathrm{e}+02$ 1.87750e+02 1.87750e+01 1.00000e-09 7.00000e-02

$1.87750 \mathrm{e}+02$ 1.87750e+02 1.87750e+01 1.00000e-09 7.00000e-02

7.50166e+00 7.50166e+00 7.50166e-01 1.00000e-09 2.12000e-01

$7.50166 \mathrm{e}+007.50166 \mathrm{e}+00$ 7.50166e-01 1.00000e-09 2.12000e-01

$7.50166 \mathrm{e}+00$ 7.50166e+00 7.50166e-01 1.00000e-09 2.12000e-01

$1.00000 \mathrm{e}-011.00000 \mathrm{e}-01$ 1.00000e-02 1.00000e-09 1.00000e-01

$1.00000 \mathrm{e}+001.00000 \mathrm{e}+001.00000 \mathrm{e}-01$ 1.00000e-09 1.00000e-01

$1.00000 \mathrm{e}-05$ 1.00000e-05 1.00000e-06 1.00000e-09 1.00000e-01

$1.00000 \mathrm{e}+001.00000 \mathrm{e}+001.00000 \mathrm{e}-01$ 1.00000e-09 1.00000e-01

Element: 1777 \# of layers: 7

$\mathrm{Kx} \mathrm{Ky} \mathrm{Kz}$ Ss Por

7.64922e+01 7.64922e+01 7.64922e+00 1.00000e-09 7.00000e-02

$3.05646 \mathrm{e}+003.05646 \mathrm{e}+003.05646 \mathrm{e}-01$ 1.00000e-09 2.12000e-01

$3.05646 \mathrm{e}+003.05646 \mathrm{e}+003.05646 \mathrm{e}-01$ 1.00000e-09 2.12000e-01

$1.00000 \mathrm{e}-011.00000 \mathrm{e}-011.00000 \mathrm{e}-021.00000 \mathrm{e}-091.00000 \mathrm{e}-01$

$1.00000 \mathrm{e}+001.00000 \mathrm{e}+001.00000 \mathrm{e}-011.00000 \mathrm{e}-091.00000 \mathrm{e}-01$

$1.00000 \mathrm{e}-051.00000 \mathrm{e}-05$ 1.00000e-06 1.00000e-09 1.00000e-01

$1.00000 \mathrm{e}+001.00000 \mathrm{e}+001.00000 \mathrm{e}-011.00000 \mathrm{e}-091.00000 \mathrm{e}-01$

Element: 1778 \# of layers: 6

$\mathrm{Kx} \mathrm{Ky} \mathrm{Kz}$ Ss Por

7.64922e+01 7.64922e+01 7.64922e+00 1.00000e-09 7.00000e-02

7.64922e+01 7.64922e+01 7.64922e+00 1.00000e-09 7.00000e-02

$3.05646 \mathrm{e}+003.05646 \mathrm{e}+003.05646 \mathrm{e}-01$ 1.00000e-09 2.12000e-01

$3.05646 \mathrm{e}+003.05646 \mathrm{e}+00$ 3.05646e-01 1.00000e-09 2.12000e-01

$1.00000 \mathrm{e}-011.00000 \mathrm{e}-011.00000 \mathrm{e}-021.00000 \mathrm{e}-091.00000 \mathrm{e}-01$

$1.00000 \mathrm{e}+001.00000 \mathrm{e}+001.00000 \mathrm{e}-011.00000 \mathrm{e}-091.00000 \mathrm{e}-01$

Element: 1779 \# of layers: 5

$\mathrm{Kx} \mathrm{Ky} \mathrm{Kz}$ Ss Por

7.64922e+01 7.64922e+01 7.64922e+00 1.00000e-09 7.00000e-02

$7.64922 \mathrm{e}+017.64922 \mathrm{e}+01$ 7.64922e+00 1.00000e-09 7.00000e-02

$3.05646 \mathrm{e}+003.05646 \mathrm{e}+003.05646 \mathrm{e}-01$ 1.00000e-09 2.12000e-01

$1.00000 \mathrm{e}-011.00000 \mathrm{e}-011.00000 \mathrm{e}-021.00000 \mathrm{e}-091.00000 \mathrm{e}-01$

$1.00000 \mathrm{e}+001.00000 \mathrm{e}+001.00000 \mathrm{e}-011.00000 \mathrm{e}-091.00000 \mathrm{e}-01$

Element: 1780 \# of layers: 5

Kx Ky Kz Ss Por

7.64922e+01 7.64922e+01 7.64922e+00 1.00000e-09 7.00000e-02

$7.64922 \mathrm{e}+017.64922 \mathrm{e}+017.64922 \mathrm{e}+001.00000 \mathrm{e}-09$ 7.00000e-02

$3.05646 \mathrm{e}+003.05646 \mathrm{e}+003.05646 \mathrm{e}-01$ 1.00000e-09 2.12000e-01

1.00000e-01 1.00000e-01 1.00000e-02 1.00000e-09 1.00000e-01

$1.00000 \mathrm{e}+001.00000 \mathrm{e}+001.00000 \mathrm{e}-011.00000 \mathrm{e}-091.00000 \mathrm{e}-01$

Element: 1781 \# of layers: 5

$\mathrm{Kx} \mathrm{Ky} \mathrm{Kz}$ Ss Por

7.64922e+01 7.64922e+01 7.64922e+00 1.00000e-09 7.00000e-02

$7.64922 \mathrm{e}+017.64922 \mathrm{e}+01$ 7.64922e+00 1.00000e-09 7.00000e-02 
$3.05646 \mathrm{e}+003.05646 \mathrm{e}+00$ 3.05646e-01 1.00000e-09 2.12000e-01 $1.00000 \mathrm{e}-01$ 1.00000e-01 1.00000e-02 1.00000e-09 1.00000e-01 $1.00000 \mathrm{e}+001.00000 \mathrm{e}+001.00000 \mathrm{e}-011.00000 \mathrm{e}-091.00000 \mathrm{e}-01$ Element: 1782 \# of layers: 5

Kx Ky Kz Ss Por

7.64922e+01 7.64922e+01 7.64922e+00 1.00000e-09 7.00000e-02 $7.64922 \mathrm{e}+017.64922 \mathrm{e}+017.64922 \mathrm{e}+001.00000 \mathrm{e}-097.00000 \mathrm{e}-02$ $3.05646 \mathrm{e}+003.05646 \mathrm{e}+003.05646 \mathrm{e}-01$ 1.00000e-09 2.12000e-01 $1.00000 \mathrm{e}-011.00000 \mathrm{e}-011.00000 \mathrm{e}-021.00000 \mathrm{e}-091.00000 \mathrm{e}-01$ $1.00000 \mathrm{e}+001.00000 \mathrm{e}+001.00000 \mathrm{e}-011.00000 \mathrm{e}-091.00000 \mathrm{e}-01$ Element: 1783 \# of layers: 5

Kx Ky Kz Ss Por

7.64922e+01 7.64922e+01 7.64922e+00 1.00000e-09 7.00000e-02 $3.05646 \mathrm{e}+003.05646 \mathrm{e}+003.05646 \mathrm{e}-01$ 1.00000e-09 2.12000e-01 $3.05646 \mathrm{e}+003.05646 \mathrm{e}+003.05646 \mathrm{e}-01$ 1.00000e-09 2.12000e-01 $1.00000 \mathrm{e}-011.00000 \mathrm{e}-011.00000 \mathrm{e}-021.00000 \mathrm{e}-091.00000 \mathrm{e}-01$ $1.00000 \mathrm{e}+001.00000 \mathrm{e}+001.00000 \mathrm{e}-011.00000 \mathrm{e}-091.00000 \mathrm{e}-01$ Element: 1784 \# of layers: 7

Kx Ky Kz Ss Por

$7.64922 \mathrm{e}+01$ 7.64922e+01 7.64922e+00 1.00000e-09 7.00000e-02 $3.05646 \mathrm{e}+003.05646 \mathrm{e}+003.05646 \mathrm{e}-011.00000 \mathrm{e}-092.12000 \mathrm{e}-01$ $3.05646 \mathrm{e}+003.05646 \mathrm{e}+00$ 3.05646e-01 1.00000e-09 2.12000e-01 $1.00000 \mathrm{e}-011.00000 \mathrm{e}-011.00000 \mathrm{e}-021.00000 \mathrm{e}-091.00000 \mathrm{e}-01$ $1.00000 \mathrm{e}+001.00000 \mathrm{e}+001.00000 \mathrm{e}-011.00000 \mathrm{e}-091.00000 \mathrm{e}-01$ $1.00000 \mathrm{e}-051.00000 \mathrm{e}-05$ 1.00000e-06 1.00000e-09 1.00000e-01 $1.00000 \mathrm{e}+001.00000 \mathrm{e}+001.00000 \mathrm{e}-011.00000 \mathrm{e}-091.00000 \mathrm{e}-01$ Element: 1785 \# of layers: 6

Kx Ky Kz Ss Por

$7.64922 \mathrm{e}+01$ 7.64922e+01 7.64922e+00 1.00000e-09 7.00000e-02

$7.64922 \mathrm{e}+017.64922 \mathrm{e}+01$ 7.64922e+00 1.00000e-09 7.00000e-02 $3.05646 \mathrm{e}+003.05646 \mathrm{e}+003.05646 \mathrm{e}-011.00000 \mathrm{e}-092.12000 \mathrm{e}-01$ $3.05646 \mathrm{e}+003.05646 \mathrm{e}+003.05646 \mathrm{e}-01$ 1.00000e-09 2.12000e-01 $1.00000 \mathrm{e}-011.00000 \mathrm{e}-011.00000 \mathrm{e}-021.00000 \mathrm{e}-091.00000 \mathrm{e}-01$ $1.00000 \mathrm{e}+001.00000 \mathrm{e}+001.00000 \mathrm{e}-011.00000 \mathrm{e}-091.00000 \mathrm{e}-01$ Element: 1786 \# of layers: 5

Kx Ky Kz Ss Por

$5.45420 \mathrm{e}+015.45420 \mathrm{e}+015.45420 \mathrm{e}+00$ 1.00000e-09 7.00000e-02

$5.45420 \mathrm{e}+015.45420 \mathrm{e}+015.45420 \mathrm{e}+001.00000 \mathrm{e}-097.00000 \mathrm{e}-02$ $2.17931 \mathrm{e}+002.17931 \mathrm{e}+002.17931 \mathrm{e}-011.00000 \mathrm{e}-092.12000 \mathrm{e}-01$ $1.00000 \mathrm{e}-01$ 1.00000e-01 1.00000e-02 1.00000e-09 1.00000e-01 $1.00000 \mathrm{e}+001.00000 \mathrm{e}+001.00000 \mathrm{e}-011.00000 \mathrm{e}-091.00000 \mathrm{e}-01$ Element: 1787 \# of layers: 5

Kx Ky Kz Ss Por

$5.45420 \mathrm{e}+015.45420 \mathrm{e}+015.45420 \mathrm{e}+00$ 1.00000e-09 7.00000e-02 $5.45420 \mathrm{e}+015.45420 \mathrm{e}+015.45420 \mathrm{e}+001.00000 \mathrm{e}-097.00000 \mathrm{e}-02$ $2.17931 \mathrm{e}+002.17931 \mathrm{e}+002.17931 \mathrm{e}-01$ 1.00000e-09 2.12000e-01 
$1.00000 \mathrm{e}-011.00000 \mathrm{e}-011.00000 \mathrm{e}-021.00000 \mathrm{e}-091.00000 \mathrm{e}-01$ $1.00000 \mathrm{e}+001.00000 \mathrm{e}+001.00000 \mathrm{e}-011.00000 \mathrm{e}-09$ 1.00000e-01 Element: 1788 \# of layers: 5

Kx Ky Kz Ss Por

$5.45420 \mathrm{e}+015.45420 \mathrm{e}+015.45420 \mathrm{e}+001.00000 \mathrm{e}-097.00000 \mathrm{e}-02$

$5.45420 \mathrm{e}+015.45420 \mathrm{e}+015.45420 \mathrm{e}+001.00000 \mathrm{e}-09$ 7.00000e-02

$2.17931 \mathrm{e}+002.17931 \mathrm{e}+00$ 2.17931e-01 1.00000e-09 2.12000e-01

1.00000e-01 1.00000e-01 1.00000e-02 1.00000e-09 1.00000e-01

$1.00000 \mathrm{e}+001.00000 \mathrm{e}+001.00000 \mathrm{e}-011.00000 \mathrm{e}-09$ 1.00000e-01

Element: 1789 \# of layers: 16

$\mathrm{Kx} \mathrm{Ky} \mathrm{Kz}$ Ss Por

$2.91924 \mathrm{e}+02$ 2.91924e+02 2.91924e+01 1.00000e-09 7.00000e-02

$2.91924 \mathrm{e}+02$ 2.91924e+02 2.91924e+01 1.00000e-09 7.00000e-02

$2.91924 \mathrm{e}+022.91924 \mathrm{e}+02$ 2.91924e+01 1.00000e-09 7.00000e-02

$2.91924 \mathrm{e}+022.91924 \mathrm{e}+022.91924 \mathrm{e}+01$ 1.00000e-09 7.00000e-02

$2.91924 \mathrm{e}+022.91924 \mathrm{e}+022.91924 \mathrm{e}+01$ 1.00000e-09 7.00000e-02

5.00000e-04 5.00000e-04 5.00000e-05 1.00000e-09 1.00000e-01

5.00000e-04 5.00000e-04 5.00000e-05 1.00000e-09 1.00000e-01

$1.16645 \mathrm{e}+011.16645 \mathrm{e}+01$ 1.16645e+00 1.00000e-09 2.12000e-01

$1.16645 \mathrm{e}+011.16645 \mathrm{e}+011.16645 \mathrm{e}+001.00000 \mathrm{e}-092.12000 \mathrm{e}-01$

$1.16645 \mathrm{e}+011.16645 \mathrm{e}+011.16645 \mathrm{e}+001.00000 \mathrm{e}-092.12000 \mathrm{e}-01$

$1.16645 \mathrm{e}+011.16645 \mathrm{e}+01$ 1.16645e+00 1.00000e-09 2.12000e-01

$1.16645 \mathrm{e}+01$ 1.16645e+01 1.16645e+00 1.00000e-09 2.12000e-01 $1.00000 \mathrm{e}-02$ 1.00000e-02 1.00000e-03 1.00000e-09 1.00000e-01

$1.00000 \mathrm{e}+001.00000 \mathrm{e}+001.00000 \mathrm{e}-011.00000 \mathrm{e}-091.00000 \mathrm{e}-01$

$1.00000 \mathrm{e}-05$ 1.00000e-05 1.00000e-06 1.00000e-09 1.00000e-01

$1.00000 \mathrm{e}+001.00000 \mathrm{e}+001.00000 \mathrm{e}-011.00000 \mathrm{e}-091.00000 \mathrm{e}-01$

Element: 1790 \# of layers: 16

$\mathrm{Kx} \mathrm{Ky} \mathrm{Kz}$ Ss Por

$2.91924 \mathrm{e}+02$ 2.91924e+02 2.91924e+01 1.00000e-09 7.00000e-02

$2.91924 \mathrm{e}+02$ 2.91924e+02 2.91924e+01 1.00000e-09 7.00000e-02

$2.91924 \mathrm{e}+022.91924 \mathrm{e}+02$ 2.91924e+01 1.00000e-09 7.00000e-02

$2.91924 \mathrm{e}+02$ 2.91924e+02 2.91924e+01 1.00000e-09 7.00000e-02

$2.91924 \mathrm{e}+02$ 2.91924e+02 2.91924e+01 1.00000e-09 7.00000e-02

5.00000e-04 5.00000e-04 5.00000e-05 1.00000e-09 1.00000e-01

5.00000e-04 5.00000e-04 5.00000e-05 1.00000e-09 1.00000e-01

$1.16645 \mathrm{e}+011.16645 \mathrm{e}+011.16645 \mathrm{e}+001.00000 \mathrm{e}-092.12000 \mathrm{e}-01$

$1.16645 \mathrm{e}+011.16645 \mathrm{e}+011.16645 \mathrm{e}+001.00000 \mathrm{e}-092.12000 \mathrm{e}-01$

$1.16645 \mathrm{e}+011.16645 \mathrm{e}+011.16645 \mathrm{e}+001.00000 \mathrm{e}-092.12000 \mathrm{e}-01$

$1.16645 \mathrm{e}+011.16645 \mathrm{e}+011.16645 \mathrm{e}+001.00000 \mathrm{e}-092.12000 \mathrm{e}-01$

$1.16645 \mathrm{e}+011.16645 \mathrm{e}+01$ 1.16645e+00 1.00000e-09 2.12000e-01

$1.00000 \mathrm{e}-02$ 1.00000e-02 1.00000e-03 1.00000e-09 1.00000e-01

$1.00000 \mathrm{e}+001.00000 \mathrm{e}+001.00000 \mathrm{e}-011.00000 \mathrm{e}-091.00000 \mathrm{e}-01$

$1.00000 \mathrm{e}-05$ 1.00000e-05 1.00000e-06 1.00000e-09 1.00000e-01

$1.00000 \mathrm{e}+001.00000 \mathrm{e}+001.00000 \mathrm{e}-011.00000 \mathrm{e}-091.00000 \mathrm{e}-01$

Element: 1791 \# of layers: 16 
$\mathrm{Kx} \mathrm{Ky} \mathrm{Kz}$ Ss Por

$2.91924 \mathrm{e}+02$ 2.91924e+02 2.91924e+01 1.00000e-09 7.00000e-02 $2.91924 \mathrm{e}+022.91924 \mathrm{e}+02 \quad 2.91924 \mathrm{e}+01$ 1.00000e-09 7.00000e-02 $2.91924 \mathrm{e}+02$ 2.91924e+02 2.91924e+01 1.00000e-09 7.00000e-02 $2.91924 \mathrm{e}+022.91924 \mathrm{e}+022.91924 \mathrm{e}+01$ 1.00000e-09 7.00000e-02 $2.91924 \mathrm{e}+02$ 2.91924e+02 2.91924e+01 1.00000e-09 7.00000e-02 5.00000e-04 5.00000e-04 5.00000e-05 1.00000e-09 1.00000e-01 5.00000e-04 5.00000e-04 5.00000e-05 1.00000e-09 1.00000e-01 $1.16645 \mathrm{e}+011.16645 \mathrm{e}+01$ 1.16645e+00 1.00000e-09 2.12000e-01 $1.16645 \mathrm{e}+011.16645 \mathrm{e}+011.16645 \mathrm{e}+001.00000 \mathrm{e}-092.12000 \mathrm{e}-01$ $1.16645 \mathrm{e}+011.16645 \mathrm{e}+01$ 1.16645e+00 1.00000e-09 2.12000e-01 $1.16645 \mathrm{e}+011.16645 \mathrm{e}+011.16645 \mathrm{e}+001.00000 \mathrm{e}-092.12000 \mathrm{e}-01$ $1.16645 \mathrm{e}+011.16645 \mathrm{e}+011.16645 \mathrm{e}+001.00000 \mathrm{e}-092.12000 \mathrm{e}-01$ $1.00000 \mathrm{e}-02$ 1.00000e-02 1.00000e-03 1.00000e-09 1.00000e-01 $1.00000 \mathrm{e}+001.00000 \mathrm{e}+001.00000 \mathrm{e}-011.00000 \mathrm{e}-091.00000 \mathrm{e}-01$ $1.00000 \mathrm{e}-05$ 1.00000e-05 1.00000e-06 1.00000e-09 1.00000e-01 $1.00000 \mathrm{e}+001.00000 \mathrm{e}+001.00000 \mathrm{e}-01$ 1.00000e-09 1.00000e-01 Element: 1792 \# of layers: 15

$\mathrm{Kx} \mathrm{Ky} \mathrm{Kz}$ Ss Por

$2.91924 \mathrm{e}+02$ 2.91924e+02 2.91924e+01 1.00000e-09 7.00000e-02 $2.91924 \mathrm{e}+02$ 2.91924e+02 2.91924e+01 1.00000e-09 7.00000e-02 $2.91924 \mathrm{e}+02$ 2.91924e+02 2.91924e+01 1.00000e-09 7.00000e-02 $2.91924 \mathrm{e}+022.91924 \mathrm{e}+02$ 2.91924e+01 1.00000e-09 7.00000e-02 5.00000e-04 5.00000e-04 5.00000e-05 1.00000e-09 1.00000e-01 5.00000e-04 5.00000e-04 5.00000e-05 1.00000e-09 1.00000e-01 $1.16645 \mathrm{e}+011.16645 \mathrm{e}+011.16645 \mathrm{e}+001.00000 \mathrm{e}-092.12000 \mathrm{e}-01$ $1.16645 \mathrm{e}+011.16645 \mathrm{e}+011.16645 \mathrm{e}+001.00000 \mathrm{e}-092.12000 \mathrm{e}-01$ $1.16645 \mathrm{e}+011.16645 \mathrm{e}+011.16645 \mathrm{e}+001.00000 \mathrm{e}-092.12000 \mathrm{e}-01$ $1.16645 \mathrm{e}+011.16645 \mathrm{e}+011.16645 \mathrm{e}+001.00000 \mathrm{e}-092.12000 \mathrm{e}-01$ $1.16645 \mathrm{e}+011.16645 \mathrm{e}+011.16645 \mathrm{e}+001.00000 \mathrm{e}-092.12000 \mathrm{e}-01$ $1.00000 \mathrm{e}-02$ 1.00000e-02 1.00000e-03 1.00000e-09 1.00000e-01 $1.00000 \mathrm{e}+001.00000 \mathrm{e}+001.00000 \mathrm{e}-011.00000 \mathrm{e}-091.00000 \mathrm{e}-01$ $1.00000 \mathrm{e}-05$ 1.00000e-05 1.00000e-06 1.00000e-09 1.00000e-01 $1.00000 \mathrm{e}+001.00000 \mathrm{e}+001.00000 \mathrm{e}-011.00000 \mathrm{e}-091.00000 \mathrm{e}-01$ Element: 1793 \# of layers: 16

$\mathrm{Kx} \mathrm{Ky} \mathrm{Kz}$ Ss Por

$2.91924 \mathrm{e}+02$ 2.91924e+02 2.91924e+01 1.00000e-09 7.00000e-02 $2.91924 \mathrm{e}+022.91924 \mathrm{e}+022.91924 \mathrm{e}+01$ 1.00000e-09 7.00000e-02 $2.91924 \mathrm{e}+022.91924 \mathrm{e}+02$ 2.91924e+01 1.00000e-09 7.00000e-02 $2.91924 \mathrm{e}+022.91924 \mathrm{e}+02$ 2.91924e+01 1.00000e-09 7.00000e-02 $2.91924 \mathrm{e}+02$ 2.91924e+02 2.91924e+01 1.00000e-09 7.00000e-02 5.00000e-04 5.00000e-04 5.00000e-05 1.00000e-09 1.00000e-01 5.00000e-04 5.00000e-04 5.00000e-05 1.00000e-09 1.00000e-01 $1.16645 \mathrm{e}+011.16645 \mathrm{e}+01$ 1.16645e+00 1.00000e-09 2.12000e-01 $1.16645 \mathrm{e}+01$ 1.16645e+01 1.16645e+00 1.00000e-09 2.12000e-01 $1.16645 \mathrm{e}+01$ 1.16645e+01 1.16645e+00 1.00000e-09 2.12000e-01 
$1.16645 \mathrm{e}+011.16645 \mathrm{e}+01$ 1.16645e+00 1.00000e-09 2.12000e-01 $1.16645 \mathrm{e}+011.16645 \mathrm{e}+01$ 1.16645e+00 1.00000e-09 2.12000e-01 $1.00000 \mathrm{e}-02$ 1.00000e-02 1.00000e-03 1.00000e-09 1.00000e-01 $1.00000 \mathrm{e}+001.00000 \mathrm{e}+001.00000 \mathrm{e}-011.00000 \mathrm{e}-091.00000 \mathrm{e}-01$ $1.00000 \mathrm{e}-05$ 1.00000e-05 1.00000e-06 1.00000e-09 1.00000e-01 $1.00000 \mathrm{e}+001.00000 \mathrm{e}+001.00000 \mathrm{e}-011.00000 \mathrm{e}-091.00000 \mathrm{e}-01$ Element: 1794 \# of layers: 16

$\mathrm{Kx} \mathrm{Ky} \mathrm{Kz}$ Ss Por

1.35772e+02 1.35772e+02 1.35772e+01 1.00000e-09 7.00000e-02 1.35772e+02 1.35772e+02 1.35772e+01 1.00000e-09 7.00000e-02 $1.35772 \mathrm{e}+02$ 1.35772e+02 1.35772e+01 1.00000e-09 7.00000e-02 $1.35772 \mathrm{e}+02$ 1.35772e+02 1.35772e+01 1.00000e-09 7.00000e-02 $1.35772 \mathrm{e}+02$ 1.35772e+02 1.35772e+01 1.00000e-09 7.00000e-02 5.00000e-04 5.00000e-04 5.00000e-05 1.00000e-09 1.00000e-01 5.00000e-04 5.00000e-04 5.00000e-05 1.00000e-09 1.00000e-01 $5.42487 \mathrm{e}+00$ 5.42487e+00 5.42487e-01 1.00000e-09 2.12000e-01 5.42487e+00 5.42487e+00 5.42487e-01 1.00000e-09 2.12000e-01 5.42487e+00 5.42487e+00 5.42487e-01 1.00000e-09 2.12000e-01 5.42487e+00 5.42487e+00 5.42487e-01 1.00000e-09 2.12000e-01 5.42487e+00 5.42487e+00 5.42487e-01 1.00000e-09 2.12000e-01 $1.00000 \mathrm{e}-02$ 1.00000e-02 1.00000e-03 1.00000e-09 1.00000e-01 $1.00000 \mathrm{e}+001.00000 \mathrm{e}+001.00000 \mathrm{e}-011.00000 \mathrm{e}-091.00000 \mathrm{e}-01$ $1.00000 \mathrm{e}-05$ 1.00000e-05 1.00000e-06 1.00000e-09 1.00000e-01 $1.00000 \mathrm{e}+001.00000 \mathrm{e}+001.00000 \mathrm{e}-011.00000 \mathrm{e}-09$ 1.00000e-01 Element: 1795 \# of layers: 16

$\mathrm{Kx} \mathrm{Ky} \mathrm{Kz}$ Ss Por

1.35772e+02 1.35772e+02 1.35772e+01 1.00000e-09 7.00000e-02 1.35772e+02 1.35772e+02 1.35772e+01 1.00000e-09 7.00000e-02 $1.35772 \mathrm{e}+02$ 1.35772e+02 1.35772e+01 1.00000e-09 7.00000e-02 1.35772e+02 1.35772e+02 1.35772e+01 1.00000e-09 7.00000e-02 $1.35772 \mathrm{e}+02$ 1.35772e+02 1.35772e+01 1.00000e-09 7.00000e-02 5.00000e-04 5.00000e-04 5.00000e-05 1.00000e-09 1.00000e-01 5.00000e-04 5.00000e-04 5.00000e-05 1.00000e-09 1.00000e-01 $5.42487 \mathrm{e}+00$ 5.42487e+00 5.42487e-01 1.00000e-09 2.12000e-01 $5.42487 \mathrm{e}+00$ 5.42487e+00 5.42487e-01 1.00000e-09 2.12000e-01 5.42487e+00 5.42487e+00 5.42487e-01 1.00000e-09 2.12000e-01 $5.42487 \mathrm{e}+00$ 5.42487e+00 5.42487e-01 1.00000e-09 2.12000e-01 $5.42487 \mathrm{e}+00$ 5.42487e+00 5.42487e-01 1.00000e-09 2.12000e-01 $1.00000 \mathrm{e}-02$ 1.00000e-02 1.00000e-03 1.00000e-09 1.00000e-01 $1.00000 \mathrm{e}+001.00000 \mathrm{e}+001.00000 \mathrm{e}-011.00000 \mathrm{e}-091.00000 \mathrm{e}-01$ $1.00000 \mathrm{e}-05$ 1.00000e-05 1.00000e-06 1.00000e-09 1.00000e-01 $1.00000 \mathrm{e}+001.00000 \mathrm{e}+001.00000 \mathrm{e}-011.00000 \mathrm{e}-091.00000 \mathrm{e}-01$ Element: 1796 \# of layers: 16

$\mathrm{Kx} \mathrm{Ky} \mathrm{Kz}$ Ss Por

1.35772e+02 1.35772e+02 1.35772e+01 1.00000e-09 7.00000e-02 $1.35772 \mathrm{e}+02$ 1.35772e+02 1.35772e+01 1.00000e-09 7.00000e-02 
1.35772e+02 1.35772e+02 1.35772e+01 1.00000e-09 7.00000e-02 1.35772e+02 1.35772e+02 1.35772e+01 1.00000e-09 7.00000e-02 $1.35772 \mathrm{e}+02$ 1.35772e+02 1.35772e+01 1.00000e-09 7.00000e-02 5.00000e-04 5.00000e-04 5.00000e-05 1.00000e-09 1.00000e-01 5.00000e-04 5.00000e-04 5.00000e-05 1.00000e-09 1.00000e-01 5.42487e+00 5.42487e+00 5.42487e-01 1.00000e-09 2.12000e-01 5.42487e+00 5.42487e+00 5.42487e-01 1.00000e-09 2.12000e-01 $5.42487 \mathrm{e}+00$ 5.42487e+00 5.42487e-01 1.00000e-09 2.12000e-01 5.42487e+00 5.42487e+00 5.42487e-01 1.00000e-09 2.12000e-01 5.42487e+00 5.42487e+00 5.42487e-01 1.00000e-09 2.12000e-01 $1.00000 \mathrm{e}-02$ 1.00000e-02 1.00000e-03 1.00000e-09 1.00000e-01 $1.00000 \mathrm{e}+001.00000 \mathrm{e}+001.00000 \mathrm{e}-011.00000 \mathrm{e}-091.00000 \mathrm{e}-01$ $1.00000 \mathrm{e}-05$ 1.00000e-05 1.00000e-06 1.00000e-09 1.00000e-01 $1.00000 \mathrm{e}+001.00000 \mathrm{e}+001.00000 \mathrm{e}-011.00000 \mathrm{e}-09$ 1.00000e-01 Element: 1797 \# of layers: 16

Kx Ky Kz Ss Por

1.35772e+02 1.35772e+02 1.35772e+01 1.00000e-09 7.00000e-02 $1.35772 \mathrm{e}+02$ 1.35772e+02 1.35772e+01 1.00000e-09 7.00000e-02 1.35772e+02 1.35772e+02 1.35772e+01 1.00000e-09 7.00000e-02 $1.35772 \mathrm{e}+02$ 1.35772e+02 1.35772e+01 1.00000e-09 7.00000e-02 $1.35772 \mathrm{e}+02$ 1.35772e+02 1.35772e+01 1.00000e-09 7.00000e-02 5.00000e-04 5.00000e-04 5.00000e-05 1.00000e-09 1.00000e-01 5.00000e-04 5.00000e-04 5.00000e-05 1.00000e-09 1.00000e-01 $5.42487 \mathrm{e}+00$ 5.42487e+00 5.42487e-01 1.00000e-09 2.12000e-01 $5.42487 \mathrm{e}+00$ 5.42487e+00 5.42487e-01 1.00000e-09 2.12000e-01 5.42487e+00 5.42487e+00 5.42487e-01 1.00000e-09 2.12000e-01 5.42487e+00 5.42487e+00 5.42487e-01 1.00000e-09 2.12000e-01 5.42487e+00 5.42487e+00 5.42487e-01 1.00000e-09 2.12000e-01 $1.00000 \mathrm{e}-02$ 1.00000e-02 1.00000e-03 1.00000e-09 1.00000e-01 $1.00000 \mathrm{e}+001.00000 \mathrm{e}+001.00000 \mathrm{e}-011.00000 \mathrm{e}-091.00000 \mathrm{e}-01$ $1.00000 \mathrm{e}-05$ 1.00000e-05 1.00000e-06 1.00000e-09 1.00000e-01 $1.00000 \mathrm{e}+001.00000 \mathrm{e}+001.00000 \mathrm{e}-01$ 1.00000e-09 1.00000e-01 Element: 1798 \# of layers: 16

$\mathrm{Kx} \mathrm{Ky} \mathrm{Kz}$ Ss Por

1.35772e+02 1.35772e+02 1.35772e+01 1.00000e-09 7.00000e-02 1.35772e+02 1.35772e+02 1.35772e+01 1.00000e-09 7.00000e-02 $1.35772 \mathrm{e}+02$ 1.35772e+02 1.35772e+01 1.00000e-09 7.00000e-02 $1.35772 \mathrm{e}+02$ 1.35772e+02 1.35772e+01 1.00000e-09 7.00000e-02 1.35772e+02 1.35772e+02 1.35772e+01 1.00000e-09 7.00000e-02 5.00000e-04 5.00000e-04 5.00000e-05 1.00000e-09 1.00000e-01 5.00000e-04 5.00000e-04 5.00000e-05 1.00000e-09 1.00000e-01 5.42487e+00 5.42487e+00 5.42487e-01 1.00000e-09 2.12000e-01 $5.42487 \mathrm{e}+005.42487 \mathrm{e}+00$ 5.42487e-01 1.00000e-09 2.12000e-01 5.42487e+00 5.42487e+00 5.42487e-01 1.00000e-09 2.12000e-01 5.42487e+00 5.42487e+00 5.42487e-01 1.00000e-09 2.12000e-01 $5.42487 \mathrm{e}+00$ 5.42487e+00 5.42487e-01 1.00000e-09 2.12000e-01 
$1.00000 \mathrm{e}-02$ 1.00000e-02 1.00000e-03 1.00000e-09 1.00000e-01 $1.00000 \mathrm{e}+001.00000 \mathrm{e}+001.00000 \mathrm{e}-011.00000 \mathrm{e}-091.00000 \mathrm{e}-01$ $1.00000 \mathrm{e}-051.00000 \mathrm{e}-05$ 1.00000e-06 1.00000e-09 1.00000e-01 $1.00000 \mathrm{e}+001.00000 \mathrm{e}+001.00000 \mathrm{e}-011.00000 \mathrm{e}-091.00000 \mathrm{e}-01$ Element: 1799 \# of layers: 16

$\mathrm{Kx} \mathrm{Ky} \mathrm{Kz}$ Ss Por

1.35772e+02 1.35772e+02 1.35772e+01 1.00000e-09 7.00000e-02 $1.35772 \mathrm{e}+02$ 1.35772e+02 1.35772e+01 1.00000e-09 7.00000e-02 1.35772e+02 1.35772e+02 1.35772e+01 1.00000e-09 7.00000e-02 $1.35772 \mathrm{e}+02$ 1.35772e+02 1.35772e+01 1.00000e-09 7.00000e-02 $1.35772 \mathrm{e}+02$ 1.35772e+02 1.35772e+01 1.00000e-09 7.00000e-02 5.00000e-04 5.00000e-04 5.00000e-05 1.00000e-09 1.00000e-01 5.00000e-04 5.00000e-04 5.00000e-05 1.00000e-09 1.00000e-01 $5.42487 \mathrm{e}+005.42487 \mathrm{e}+005.42487 \mathrm{e}-011.00000 \mathrm{e}-092.12000 \mathrm{e}-01$ $5.42487 \mathrm{e}+005.42487 \mathrm{e}+005.42487 \mathrm{e}-011.00000 \mathrm{e}-092.12000 \mathrm{e}-01$ $5.42487 \mathrm{e}+005.42487 \mathrm{e}+00$ 5.42487e-01 1.00000e-09 2.12000e-01 $5.42487 \mathrm{e}+005.42487 \mathrm{e}+00$ 5.42487e-01 1.00000e-09 2.12000e-01 $5.42487 \mathrm{e}+00$ 5.42487e+00 5.42487e-01 1.00000e-09 2.12000e-01 $1.00000 \mathrm{e}-02$ 1.00000e-02 1.00000e-03 1.00000e-09 1.00000e-01 $1.00000 \mathrm{e}+001.00000 \mathrm{e}+001.00000 \mathrm{e}-011.00000 \mathrm{e}-091.00000 \mathrm{e}-01$ $1.00000 \mathrm{e}-05$ 1.00000e-05 1.00000e-06 1.00000e-09 1.00000e-01 $1.00000 \mathrm{e}+001.00000 \mathrm{e}+001.00000 \mathrm{e}-011.00000 \mathrm{e}-091.00000 \mathrm{e}-01$ Element: 1800 \# of layers: 16

Kx Ky Kz Ss Por

$1.35772 \mathrm{e}+02$ 1.35772e+02 1.35772e+01 1.00000e-09 7.00000e-02 $1.35772 \mathrm{e}+021.35772 \mathrm{e}+021.35772 \mathrm{e}+011.00000 \mathrm{e}-097.00000 \mathrm{e}-02$ $1.35772 \mathrm{e}+021.35772 \mathrm{e}+021.35772 \mathrm{e}+011.00000 \mathrm{e}-097.00000 \mathrm{e}-02$ $1.35772 \mathrm{e}+021.35772 \mathrm{e}+021.35772 \mathrm{e}+01$ 1.00000e-09 7.00000e-02 $1.35772 \mathrm{e}+021.35772 \mathrm{e}+021.35772 \mathrm{e}+011.00000 \mathrm{e}-097.00000 \mathrm{e}-02$ $5.00000 \mathrm{e}-04$ 5.00000e-04 5.00000e-05 1.00000e-09 1.00000e-01 $5.00000 \mathrm{e}-04$ 5.00000e-04 5.00000e-05 1.00000e-09 1.00000e-01 $5.42487 \mathrm{e}+005.42487 \mathrm{e}+00$ 5.42487e-01 1.00000e-09 2.12000e-01 $5.42487 \mathrm{e}+005.42487 \mathrm{e}+00$ 5.42487e-01 1.00000e-09 2.12000e-01 $5.42487 \mathrm{e}+005.42487 \mathrm{e}+005.42487 \mathrm{e}-011.00000 \mathrm{e}-092.12000 \mathrm{e}-01$ $5.42487 \mathrm{e}+005.42487 \mathrm{e}+005.42487 \mathrm{e}-011.00000 \mathrm{e}-092.12000 \mathrm{e}-01$ $5.42487 \mathrm{e}+00$ 5.42487e+00 5.42487e-01 1.00000e-09 2.12000e-01 $1.00000 \mathrm{e}-021.00000 \mathrm{e}-02$ 1.00000e-03 1.00000e-09 1.00000e-01 $1.00000 \mathrm{e}+001.00000 \mathrm{e}+001.00000 \mathrm{e}-011.00000 \mathrm{e}-091.00000 \mathrm{e}-01$ $1.00000 \mathrm{e}-05$ 1.00000e-05 1.00000e-06 1.00000e-09 1.00000e-01 $1.00000 \mathrm{e}+001.00000 \mathrm{e}+001.00000 \mathrm{e}-011.00000 \mathrm{e}-091.00000 \mathrm{e}-01$ Element: 1801 \# of layers: 16

Kx Ky Kz Ss Por

$1.35772 \mathrm{e}+02$ 1.35772e+02 1.35772e+01 1.00000e-09 7.00000e-02 $1.35772 \mathrm{e}+021.35772 \mathrm{e}+021.35772 \mathrm{e}+011.00000 \mathrm{e}-097.00000 \mathrm{e}-02$ $1.35772 \mathrm{e}+021.35772 \mathrm{e}+021.35772 \mathrm{e}+01$ 1.00000e-09 7.00000e-02 $1.35772 \mathrm{e}+02$ 1.35772e+02 1.35772e+01 1.00000e-09 7.00000e-02 
1.35772e+02 1.35772e+02 1.35772e+01 1.00000e-09 7.00000e-02 5.00000e-04 5.00000e-04 5.00000e-05 1.00000e-09 1.00000e-01 5.00000e-04 5.00000e-04 5.00000e-05 1.00000e-09 1.00000e-01 $5.42487 \mathrm{e}+00$ 5.42487e+00 5.42487e-01 1.00000e-09 2.12000e-01 5.42487e+00 5.42487e+00 5.42487e-01 1.00000e-09 2.12000e-01 5.42487e+00 5.42487e+00 5.42487e-01 1.00000e-09 2.12000e-01 5.42487e+00 5.42487e+00 5.42487e-01 1.00000e-09 2.12000e-01 $5.42487 \mathrm{e}+00$ 5.42487e+00 5.42487e-01 1.00000e-09 2.12000e-01 $1.00000 \mathrm{e}-02$ 1.00000e-02 1.00000e-03 1.00000e-09 1.00000e-01 $1.00000 \mathrm{e}+001.00000 \mathrm{e}+001.00000 \mathrm{e}-011.00000 \mathrm{e}-091.00000 \mathrm{e}-01$ $1.00000 \mathrm{e}-05$ 1.00000e-05 1.00000e-06 1.00000e-09 1.00000e-01 $1.00000 \mathrm{e}+001.00000 \mathrm{e}+001.00000 \mathrm{e}-011.00000 \mathrm{e}-091.00000 \mathrm{e}-01$ Element: 1802 \# of layers: 16

$\mathrm{Kx} \mathrm{Ky} \mathrm{Kz}$ Ss Por

1.35772e+02 1.35772e+02 1.35772e+01 1.00000e-09 7.00000e-02 $1.35772 \mathrm{e}+02$ 1.35772e+02 1.35772e+01 1.00000e-09 7.00000e-02 1.35772e+02 1.35772e+02 1.35772e+01 1.00000e-09 7.00000e-02 1.35772e+02 1.35772e+02 1.35772e+01 1.00000e-09 7.00000e-02 1.35772e+02 1.35772e+02 1.35772e+01 1.00000e-09 7.00000e-02 5.00000e-04 5.00000e-04 5.00000e-05 1.00000e-09 1.00000e-01 5.00000e-04 5.00000e-04 5.00000e-05 1.00000e-09 1.00000e-01 5.42487e+00 5.42487e+00 5.42487e-01 1.00000e-09 2.12000e-01 5.42487e+00 5.42487e+00 5.42487e-01 1.00000e-09 2.12000e-01 $5.42487 \mathrm{e}+005.42487 \mathrm{e}+00$ 5.42487e-01 1.00000e-09 2.12000e-01 $5.42487 \mathrm{e}+00$ 5.42487e+00 5.42487e-01 1.00000e-09 2.12000e-01 5.42487e+00 5.42487e+00 5.42487e-01 1.00000e-09 2.12000e-01 $1.00000 \mathrm{e}-02$ 1.00000e-02 1.00000e-03 1.00000e-09 1.00000e-01 $1.00000 \mathrm{e}+001.00000 \mathrm{e}+001.00000 \mathrm{e}-011.00000 \mathrm{e}-091.00000 \mathrm{e}-01$ $1.00000 \mathrm{e}-05$ 1.00000e-05 1.00000e-06 1.00000e-09 1.00000e-01 $1.00000 \mathrm{e}+001.00000 \mathrm{e}+001.00000 \mathrm{e}-011.00000 \mathrm{e}-091.00000 \mathrm{e}-01$ Element: 1803 \# of layers: 16

$\mathrm{Kx} \mathrm{Ky} \mathrm{Kz}$ Ss Por

9.16858e+01 9.16858e+01 9.16858e+00 1.00000e-09 7.00000e-02 9.16858e+01 9.16858e+01 9.16858e+00 1.00000e-09 7.00000e-02 9.16858e+01 9.16858e+01 9.16858e+00 1.00000e-09 7.00000e-02 9.16858e+01 9.16858e+01 9.16858e+00 1.00000e-09 7.00000e-02 $9.16858 \mathrm{e}+019.16858 \mathrm{e}+019.16858 \mathrm{e}+001.00000 \mathrm{e}-09$ 7.00000e-02 5.00000e-04 5.00000e-04 5.00000e-05 1.00000e-09 1.00000e-01 5.00000e-04 5.00000e-04 5.00000e-05 1.00000e-09 1.00000e-01 $3.66353 \mathrm{e}+003.66353 \mathrm{e}+00$ 3.66353e-01 1.00000e-09 2.12000e-01 $3.66353 \mathrm{e}+003.66353 \mathrm{e}+00$ 3.66353e-01 1.00000e-09 2.12000e-01 $3.66353 \mathrm{e}+003.66353 \mathrm{e}+00$ 3.66353e-01 1.00000e-09 2.12000e-01 $3.66353 \mathrm{e}+00$ 3.66353e+00 3.66353e-01 1.00000e-09 2.12000e-01 3.66353e+00 3.66353e+00 3.66353e-01 1.00000e-09 2.12000e-01 $1.00000 \mathrm{e}-02$ 1.00000e-02 1.00000e-03 1.00000e-09 1.00000e-01 $1.00000 \mathrm{e}+001.00000 \mathrm{e}+001.00000 \mathrm{e}-011.00000 \mathrm{e}-091.00000 \mathrm{e}-01$ 
$1.00000 \mathrm{e}-05$ 1.00000e-05 1.00000e-06 1.00000e-09 1.00000e-01 $1.00000 \mathrm{e}+001.00000 \mathrm{e}+001.00000 \mathrm{e}-01$ 1.00000e-09 1.00000e-01 Element: 1804 \# of layers: 16

Kx Ky Kz Ss Por

9.16858e+01 9.16858e+01 9.16858e+00 1.00000e-09 7.00000e-02

$9.16858 \mathrm{e}+019.16858 \mathrm{e}+01$ 9.16858e+00 1.00000e-09 7.00000e-02

$9.16858 \mathrm{e}+019.16858 \mathrm{e}+01$ 9.16858e+00 1.00000e-09 7.00000e-02

$9.16858 \mathrm{e}+019.16858 \mathrm{e}+019.16858 \mathrm{e}+001.00000 \mathrm{e}-09$ 7.00000e-02

$9.16858 \mathrm{e}+019.16858 \mathrm{e}+019.16858 \mathrm{e}+001.00000 \mathrm{e}-09$ 7.00000e-02

5.00000e-04 5.00000e-04 5.00000e-05 1.00000e-09 1.00000e-01

5.00000e-04 5.00000e-04 5.00000e-05 1.00000e-09 1.00000e-01

$3.66353 \mathrm{e}+003.66353 \mathrm{e}+003.66353 \mathrm{e}-01$ 1.00000e-09 2.12000e-01

$3.66353 \mathrm{e}+003.66353 \mathrm{e}+00$ 3.66353e-01 1.00000e-09 2.12000e-01

$3.66353 \mathrm{e}+00$ 3.66353e+00 3.66353e-01 1.00000e-09 2.12000e-01

$3.66353 \mathrm{e}+003.66353 \mathrm{e}+00$ 3.66353e-01 1.00000e-09 2.12000e-01

$3.66353 \mathrm{e}+003.66353 \mathrm{e}+00$ 3.66353e-01 1.00000e-09 2.12000e-01

$1.00000 \mathrm{e}-02$ 1.00000e-02 1.00000e-03 1.00000e-09 1.00000e-01

$1.00000 \mathrm{e}+001.00000 \mathrm{e}+001.00000 \mathrm{e}-011.00000 \mathrm{e}-091.00000 \mathrm{e}-01$

$1.00000 \mathrm{e}-05$ 1.00000e-05 1.00000e-06 1.00000e-09 1.00000e-01

$1.00000 \mathrm{e}+001.00000 \mathrm{e}+001.00000 \mathrm{e}-011.00000 \mathrm{e}-091.00000 \mathrm{e}-01$

Element: 1805 \# of layers: 16

$\mathrm{Kx} \mathrm{Ky} \mathrm{Kz}$ Ss Por

9.16858e+01 9.16858e+01 9.16858e+00 1.00000e-09 7.00000e-02

9.16858e+01 9.16858e+01 9.16858e+00 1.00000e-09 7.00000e-02

$9.16858 \mathrm{e}+019.16858 \mathrm{e}+019.16858 \mathrm{e}+001.00000 \mathrm{e}-09$ 7.00000e-02

$9.16858 \mathrm{e}+019.16858 \mathrm{e}+01$ 9.16858e+00 1.00000e-09 7.00000e-02

$9.16858 \mathrm{e}+019.16858 \mathrm{e}+01$ 9.16858e+00 1.00000e-09 7.00000e-02

5.00000e-04 5.00000e-04 5.00000e-05 1.00000e-09 1.00000e-01

5.00000e-04 5.00000e-04 5.00000e-05 1.00000e-09 1.00000e-01

$3.66353 \mathrm{e}+003.66353 \mathrm{e}+003.66353 \mathrm{e}-01$ 1.00000e-09 2.12000e-01

$3.66353 \mathrm{e}+003.66353 \mathrm{e}+00$ 3.66353e-01 1.00000e-09 2.12000e-01

$3.66353 \mathrm{e}+003.66353 \mathrm{e}+00$ 3.66353e-01 1.00000e-09 2.12000e-01

$3.66353 \mathrm{e}+003.66353 \mathrm{e}+00$ 3.66353e-01 1.00000e-09 2.12000e-01

$3.66353 \mathrm{e}+003.66353 \mathrm{e}+00$ 3.66353e-01 1.00000e-09 2.12000e-01

$1.00000 \mathrm{e}-02$ 1.00000e-02 1.00000e-03 1.00000e-09 1.00000e-01

$1.00000 \mathrm{e}+001.00000 \mathrm{e}+001.00000 \mathrm{e}-011.00000 \mathrm{e}-091.00000 \mathrm{e}-01$

$1.00000 \mathrm{e}-05$ 1.00000e-05 1.00000e-06 1.00000e-09 1.00000e-01

$1.00000 \mathrm{e}+001.00000 \mathrm{e}+001.00000 \mathrm{e}-011.00000 \mathrm{e}-091.00000 \mathrm{e}-01$

Element: 1806 \# of layers: 16

$\mathrm{Kx} \mathrm{Ky} \mathrm{Kz}$ Ss Por

9.16858e+01 9.16858e+01 9.16858e+00 1.00000e-09 7.00000e-02

9.16858e+01 9.16858e+01 9.16858e+00 1.00000e-09 7.00000e-02

9.16858e+01 9.16858e+01 9.16858e+00 1.00000e-09 7.00000e-02

$9.16858 \mathrm{e}+019.16858 \mathrm{e}+019.16858 \mathrm{e}+00$ 1.00000e-09 7.00000e-02

9.16858e+01 9.16858e+01 9.16858e+00 1.00000e-09 7.00000e-02

5.00000e-04 5.00000e-04 5.00000e-05 1.00000e-09 1.00000e-01 
5.00000e-04 5.00000e-04 5.00000e-05 1.00000e-09 1.00000e-01 $3.66353 \mathrm{e}+003.66353 \mathrm{e}+003.66353 \mathrm{e}-01$ 1.00000e-09 2.12000e-01 $3.66353 \mathrm{e}+003.66353 \mathrm{e}+00$ 3.66353e-01 1.00000e-09 2.12000e-01 $3.66353 \mathrm{e}+003.66353 \mathrm{e}+003.66353 \mathrm{e}-01$ 1.00000e-09 2.12000e-01 $3.66353 \mathrm{e}+003.66353 \mathrm{e}+00$ 3.66353e-01 1.00000e-09 2.12000e-01 $3.66353 \mathrm{e}+003.66353 \mathrm{e}+00$ 3.66353e-01 1.00000e-09 2.12000e-01 $1.00000 \mathrm{e}-02$ 1.00000e-02 1.00000e-03 1.00000e-09 1.00000e-01 $1.00000 \mathrm{e}+001.00000 \mathrm{e}+001.00000 \mathrm{e}-011.00000 \mathrm{e}-091.00000 \mathrm{e}-01$ $1.00000 \mathrm{e}-05$ 1.00000e-05 1.00000e-06 1.00000e-09 1.00000e-01 $1.00000 \mathrm{e}+001.00000 \mathrm{e}+001.00000 \mathrm{e}-011.00000 \mathrm{e}-091.00000 \mathrm{e}-01$ Element: 1807 \# of layers: 16

Kx Ky Kz Ss Por

9.16858e+01 9.16858e+01 9.16858e+00 1.00000e-09 7.00000e-02

9.16858e+01 9.16858e+01 9.16858e+00 1.00000e-09 7.00000e-02

9.16858e+01 9.16858e+01 9.16858e+00 1.00000e-09 7.00000e-02

$9.16858 \mathrm{e}+019.16858 \mathrm{e}+019.16858 \mathrm{e}+00$ 1.00000e-09 7.00000e-02

$9.16858 \mathrm{e}+019.16858 \mathrm{e}+019.16858 \mathrm{e}+001.00000 \mathrm{e}-09$ 7.00000e-02

5.00000e-04 5.00000e-04 5.00000e-05 1.00000e-09 1.00000e-01

5.00000e-04 5.00000e-04 5.00000e-05 1.00000e-09 1.00000e-01

$3.66353 \mathrm{e}+003.66353 \mathrm{e}+003.66353 \mathrm{e}-01$ 1.00000e-09 2.12000e-01

$3.66353 \mathrm{e}+003.66353 \mathrm{e}+00$ 3.66353e-01 1.00000e-09 2.12000e-01

3.66353e+00 3.66353e+00 3.66353e-01 1.00000e-09 2.12000e-01

$3.66353 \mathrm{e}+003.66353 \mathrm{e}+00$ 3.66353e-01 1.00000e-09 2.12000e-01

$3.66353 \mathrm{e}+00$ 3.66353e+00 3.66353e-01 1.00000e-09 2.12000e-01

$1.00000 \mathrm{e}-021.00000 \mathrm{e}-02$ 1.00000e-03 1.00000e-09 1.00000e-01

$1.00000 \mathrm{e}+001.00000 \mathrm{e}+001.00000 \mathrm{e}-011.00000 \mathrm{e}-091.00000 \mathrm{e}-01$

$1.00000 \mathrm{e}-05$ 1.00000e-05 1.00000e-06 1.00000e-09 1.00000e-01

$1.00000 \mathrm{e}+001.00000 \mathrm{e}+001.00000 \mathrm{e}-011.00000 \mathrm{e}-091.00000 \mathrm{e}-01$

Element: 1808 \# of layers: 16

$\mathrm{Kx} \mathrm{Ky} \mathrm{Kz}$ Ss Por

9.16858e+01 9.16858e+01 9.16858e+00 1.00000e-09 7.00000e-02

9.16858e+01 9.16858e+01 9.16858e+00 1.00000e-09 7.00000e-02

$9.16858 \mathrm{e}+019.16858 \mathrm{e}+019.16858 \mathrm{e}+00$ 1.00000e-09 7.00000e-02

9.16858e+01 9.16858e+01 9.16858e+00 1.00000e-09 7.00000e-02

$9.16858 \mathrm{e}+019.16858 \mathrm{e}+01$ 9.16858e+00 1.00000e-09 7.00000e-02

5.00000e-04 5.00000e-04 5.00000e-05 1.00000e-09 1.00000e-01

5.00000e-04 5.00000e-04 5.00000e-05 1.00000e-09 1.00000e-01

$3.66353 \mathrm{e}+003.66353 \mathrm{e}+00$ 3.66353e-01 1.00000e-09 2.12000e-01

3.66353e+00 3.66353e+00 3.66353e-01 1.00000e-09 2.12000e-01

$3.66353 \mathrm{e}+003.66353 \mathrm{e}+00$ 3.66353e-01 1.00000e-09 2.12000e-01

$3.66353 \mathrm{e}+00$ 3.66353e+00 3.66353e-01 1.00000e-09 2.12000e-01

3.66353e+00 3.66353e+00 3.66353e-01 1.00000e-09 2.12000e-01

1.00000e-02 1.00000e-02 1.00000e-03 1.00000e-09 1.00000e-01

$1.00000 \mathrm{e}+001.00000 \mathrm{e}+001.00000 \mathrm{e}-011.00000 \mathrm{e}-091.00000 \mathrm{e}-01$ $1.00000 \mathrm{e}-05$ 1.00000e-05 1.00000e-06 1.00000e-09 1.00000e-01

$1.00000 \mathrm{e}+001.00000 \mathrm{e}+001.00000 \mathrm{e}-011.00000 \mathrm{e}-091.00000 \mathrm{e}-01$ 
Element: 1809 \# of layers: 16

Kx Ky Kz Ss Por

$9.16858 \mathrm{e}+01$ 9.16858e+01 9.16858e+00 1.00000e-09 7.00000e-02

$9.16858 \mathrm{e}+019.16858 \mathrm{e}+019.16858 \mathrm{e}+001.00000 \mathrm{e}-09$ 7.00000e-02

$9.16858 \mathrm{e}+019.16858 \mathrm{e}+019.16858 \mathrm{e}+00$ 1.00000e-09 7.00000e-02

$9.16858 \mathrm{e}+019.16858 \mathrm{e}+019.16858 \mathrm{e}+001.00000 \mathrm{e}-09$ 7.00000e-02

$9.16858 \mathrm{e}+01$ 9.16858e+01 9.16858e+00 1.00000e-09 7.00000e-02

5.00000e-04 5.00000e-04 5.00000e-05 1.00000e-09 1.00000e-01

5.00000e-04 5.00000e-04 5.00000e-05 1.00000e-09 1.00000e-01

$3.66353 \mathrm{e}+003.66353 \mathrm{e}+003.66353 \mathrm{e}-011.00000 \mathrm{e}-09$ 2.12000e-01

$3.66353 \mathrm{e}+003.66353 \mathrm{e}+003.66353 \mathrm{e}-01$ 1.00000e-09 2.12000e-01

$3.66353 \mathrm{e}+003.66353 \mathrm{e}+003.66353 \mathrm{e}-01$ 1.00000e-09 2.12000e-01

$3.66353 \mathrm{e}+003.66353 \mathrm{e}+003.66353 \mathrm{e}-011.00000 \mathrm{e}-092.12000 \mathrm{e}-01$

$3.66353 \mathrm{e}+003.66353 \mathrm{e}+003.66353 \mathrm{e}-01$ 1.00000e-09 2.12000e-01

$1.00000 \mathrm{e}-02$ 1.00000e-02 1.00000e-03 1.00000e-09 1.00000e-01

$1.00000 \mathrm{e}+001.00000 \mathrm{e}+001.00000 \mathrm{e}-011.00000 \mathrm{e}-091.00000 \mathrm{e}-01$

$1.00000 \mathrm{e}-05$ 1.00000e-05 1.00000e-06 1.00000e-09 1.00000e-01

$1.00000 \mathrm{e}+001.00000 \mathrm{e}+001.00000 \mathrm{e}-011.00000 \mathrm{e}-091.00000 \mathrm{e}-01$

Element: 1810 \# of layers: 16

Kx Ky Kz Ss Por

9.16858e+01 9.16858e+01 9.16858e+00 1.00000e-09 7.00000e-02

$9.16858 \mathrm{e}+01$ 9.16858e+01 9.16858e+00 1.00000e-09 7.00000e-02

$9.16858 \mathrm{e}+019.16858 \mathrm{e}+019.16858 \mathrm{e}+001.00000 \mathrm{e}-09$ 7.00000e-02

$9.16858 \mathrm{e}+019.16858 \mathrm{e}+019.16858 \mathrm{e}+00$ 1.00000e-09 7.00000e-02

$9.16858 \mathrm{e}+01$ 9.16858e+01 9.16858e+00 1.00000e-09 7.00000e-02

$5.00000 \mathrm{e}-04$ 5.00000e-04 5.00000e-05 1.00000e-09 1.00000e-01

$5.00000 \mathrm{e}-04$ 5.00000e-04 5.00000e-05 1.00000e-09 1.00000e-01

$3.66353 \mathrm{e}+003.66353 \mathrm{e}+003.66353 \mathrm{e}-011.00000 \mathrm{e}-09$ 2.12000e-01

$3.66353 \mathrm{e}+003.66353 \mathrm{e}+003.66353 \mathrm{e}-01$ 1.00000e-09 2.12000e-01

$3.66353 \mathrm{e}+003.66353 \mathrm{e}+003.66353 \mathrm{e}-01$ 1.00000e-09 2.12000e-01

$3.66353 \mathrm{e}+003.66353 \mathrm{e}+003.66353 \mathrm{e}-011.00000 \mathrm{e}-092.12000 \mathrm{e}-01$

$3.66353 \mathrm{e}+003.66353 \mathrm{e}+003.66353 \mathrm{e}-01$ 1.00000e-09 2.12000e-01

$1.00000 \mathrm{e}-021.00000 \mathrm{e}-02$ 1.00000e-03 1.00000e-09 1.00000e-01

$1.00000 \mathrm{e}+001.00000 \mathrm{e}+001.00000 \mathrm{e}-011.00000 \mathrm{e}-091.00000 \mathrm{e}-01$

$1.00000 \mathrm{e}-05$ 1.00000e-05 1.00000e-06 1.00000e-09 1.00000e-01

$1.00000 \mathrm{e}+001.00000 \mathrm{e}+001.00000 \mathrm{e}-011.00000 \mathrm{e}-091.00000 \mathrm{e}-01$

Element: 1811 \# of layers: 16

Kx Ky Kz Ss Por

9.16858e+01 9.16858e+01 9.16858e+00 1.00000e-09 7.00000e-02

$9.16858 \mathrm{e}+019.16858 \mathrm{e}+019.16858 \mathrm{e}+00$ 1.00000e-09 7.00000e-02

$9.16858 \mathrm{e}+019.16858 \mathrm{e}+019.16858 \mathrm{e}+00$ 1.00000e-09 7.00000e-02

$9.16858 \mathrm{e}+019.16858 \mathrm{e}+019.16858 \mathrm{e}+001.00000 \mathrm{e}-09$ 7.00000e-02

$9.16858 \mathrm{e}+019.16858 \mathrm{e}+01$ 9.16858e+00 1.00000e-09 7.00000e-02

5.00000e-04 5.00000e-04 5.00000e-05 1.00000e-09 1.00000e-01

5.00000e-04 5.00000e-04 5.00000e-05 1.00000e-09 1.00000e-01

$3.66353 \mathrm{e}+003.66353 \mathrm{e}+003.66353 \mathrm{e}-01$ 1.00000e-09 2.12000e-01 
3.66353e+00 3.66353e+00 3.66353e-01 1.00000e-09 2.12000e-01 $3.66353 \mathrm{e}+003.66353 \mathrm{e}+003.66353 \mathrm{e}-01$ 1.00000e-09 2.12000e-01 $3.66353 \mathrm{e}+003.66353 \mathrm{e}+00$ 3.66353e-01 1.00000e-09 2.12000e-01 $3.66353 \mathrm{e}+003.66353 \mathrm{e}+00$ 3.66353e-01 1.00000e-09 2.12000e-01 $1.00000 \mathrm{e}-021.00000 \mathrm{e}-02$ 1.00000e-03 1.00000e-09 1.00000e-01 $1.00000 \mathrm{e}+001.00000 \mathrm{e}+001.00000 \mathrm{e}-011.00000 \mathrm{e}-091.00000 \mathrm{e}-01$ $1.00000 \mathrm{e}-05$ 1.00000e-05 1.00000e-06 1.00000e-09 1.00000e-01 $1.00000 \mathrm{e}+001.00000 \mathrm{e}+001.00000 \mathrm{e}-011.00000 \mathrm{e}-091.00000 \mathrm{e}-01$ Element: 1812 \# of layers: 16

$\mathrm{Kx} \mathrm{Ky} \mathrm{Kz}$ Ss Por

6.80138e+01 6.80138e+01 6.80138e+00 1.00000e-09 7.00000e-02 $6.80138 \mathrm{e}+016.80138 \mathrm{e}+016.80138 \mathrm{e}+00$ 1.00000e-09 7.00000e-02 $6.80138 \mathrm{e}+016.80138 \mathrm{e}+016.80138 \mathrm{e}+001.00000 \mathrm{e}-09$ 7.00000e-02 $6.80138 \mathrm{e}+016.80138 \mathrm{e}+016.80138 \mathrm{e}+00$ 1.00000e-09 7.00000e-02 $6.80138 \mathrm{e}+016.80138 \mathrm{e}+016.80138 \mathrm{e}+001.00000 \mathrm{e}-09$ 7.00000e-02 5.00000e-04 5.00000e-04 5.00000e-05 1.00000e-09 1.00000e-01 5.00000e-04 5.00000e-04 5.00000e-05 1.00000e-09 1.00000e-01

$2.71761 \mathrm{e}+002.71761 \mathrm{e}+002.71761 \mathrm{e}-01$ 1.00000e-09 2.12000e-01 $2.71761 \mathrm{e}+002.71761 \mathrm{e}+00$ 2.71761e-01 1.00000e-09 2.12000e-01 $2.71761 \mathrm{e}+002.71761 \mathrm{e}+00$ 2.71761e-01 1.00000e-09 2.12000e-01 $2.71761 \mathrm{e}+002.71761 \mathrm{e}+002.71761 \mathrm{e}-01$ 1.00000e-09 2.12000e-01 2.71761e+00 2.71761e+00 2.71761e-01 1.00000e-09 2.12000e-01 $1.00000 \mathrm{e}-02$ 1.00000e-02 1.00000e-03 1.00000e-09 1.00000e-01 $1.00000 \mathrm{e}+001.00000 \mathrm{e}+001.00000 \mathrm{e}-011.00000 \mathrm{e}-091.00000 \mathrm{e}-01$ $1.00000 \mathrm{e}-05$ 1.00000e-05 1.00000e-06 1.00000e-09 1.00000e-01 $1.00000 \mathrm{e}+001.00000 \mathrm{e}+001.00000 \mathrm{e}-01$ 1.00000e-09 1.00000e-01 Element: 1813 \# of layers: 16

$\mathrm{Kx} \mathrm{Ky} \mathrm{Kz}$ Ss Por

6.80138e+01 6.80138e+01 6.80138e+00 1.00000e-09 7.00000e-02 $6.80138 \mathrm{e}+016.80138 \mathrm{e}+016.80138 \mathrm{e}+00$ 1.00000e-09 7.00000e-02 $6.80138 \mathrm{e}+016.80138 \mathrm{e}+016.80138 \mathrm{e}+001.00000 \mathrm{e}-09$ 7.00000e-02 $6.80138 \mathrm{e}+016.80138 \mathrm{e}+016.80138 \mathrm{e}+00$ 1.00000e-09 7.00000e-02 $6.80138 \mathrm{e}+016.80138 \mathrm{e}+016.80138 \mathrm{e}+00$ 1.00000e-09 7.00000e-02 5.00000e-04 5.00000e-04 5.00000e-05 1.00000e-09 1.00000e-01 5.00000e-04 5.00000e-04 5.00000e-05 1.00000e-09 1.00000e-01 $2.71761 \mathrm{e}+002.71761 \mathrm{e}+002.71761 \mathrm{e}-01$ 1.00000e-09 2.12000e-01 $2.71761 \mathrm{e}+002.71761 \mathrm{e}+002.71761 \mathrm{e}-01$ 1.00000e-09 2.12000e-01 $2.71761 \mathrm{e}+002.71761 \mathrm{e}+002.71761 \mathrm{e}-01$ 1.00000e-09 2.12000e-01 $2.71761 \mathrm{e}+002.71761 \mathrm{e}+00$ 2.71761e-01 1.00000e-09 2.12000e-01 $2.71761 \mathrm{e}+002.71761 \mathrm{e}+00$ 2.71761e-01 1.00000e-09 2.12000e-01 $1.00000 \mathrm{e}-02$ 1.00000e-02 1.00000e-03 1.00000e-09 1.00000e-01 $1.00000 \mathrm{e}+001.00000 \mathrm{e}+001.00000 \mathrm{e}-011.00000 \mathrm{e}-091.00000 \mathrm{e}-01$ $1.00000 \mathrm{e}-05$ 1.00000e-05 1.00000e-06 1.00000e-09 1.00000e-01 $1.00000 \mathrm{e}+001.00000 \mathrm{e}+001.00000 \mathrm{e}-01$ 1.00000e-09 1.00000e-01 Element: 1814 \# of layers: 15

Kx Ky Kz Ss Por 
6.80138e+01 6.80138e+01 6.80138e+00 1.00000e-09 7.00000e-02 $6.80138 \mathrm{e}+016.80138 \mathrm{e}+016.80138 \mathrm{e}+00$ 1.00000e-09 7.00000e-02 $6.80138 \mathrm{e}+016.80138 \mathrm{e}+016.80138 \mathrm{e}+00$ 1.00000e-09 7.00000e-02 $6.80138 \mathrm{e}+016.80138 \mathrm{e}+016.80138 \mathrm{e}+001.00000 \mathrm{e}-09$ 7.00000e-02 5.00000e-04 5.00000e-04 5.00000e-05 1.00000e-09 1.00000e-01 5.00000e-04 5.00000e-04 5.00000e-05 1.00000e-09 1.00000e-01 $2.71761 \mathrm{e}+002.71761 \mathrm{e}+00$ 2.71761e-01 1.00000e-09 2.12000e-01 $2.71761 \mathrm{e}+002.71761 \mathrm{e}+002.71761 \mathrm{e}-01$ 1.00000e-09 2.12000e-01 $2.71761 \mathrm{e}+00$ 2.71761e+00 2.71761e-01 1.00000e-09 2.12000e-01 $2.71761 \mathrm{e}+002.71761 \mathrm{e}+00$ 2.71761e-01 1.00000e-09 2.12000e-01 $2.71761 \mathrm{e}+002.71761 \mathrm{e}+002.71761 \mathrm{e}-01$ 1.00000e-09 2.12000e-01 $1.00000 \mathrm{e}-02$ 1.00000e-02 1.00000e-03 1.00000e-09 1.00000e-01 $1.00000 \mathrm{e}+001.00000 \mathrm{e}+001.00000 \mathrm{e}-011.00000 \mathrm{e}-091.00000 \mathrm{e}-01$ $1.00000 \mathrm{e}-05$ 1.00000e-05 1.00000e-06 1.00000e-09 1.00000e-01 $1.00000 \mathrm{e}+001.00000 \mathrm{e}+001.00000 \mathrm{e}-01$ 1.00000e-09 1.00000e-01 Element: 1815 \# of layers: 15

$\mathrm{Kx} \mathrm{Ky} \mathrm{Kz}$ Ss Por

6.80138e+01 6.80138e+01 6.80138e+00 1.00000e-09 7.00000e-02 $6.80138 \mathrm{e}+016.80138 \mathrm{e}+016.80138 \mathrm{e}+00$ 1.00000e-09 7.00000e-02 $6.80138 \mathrm{e}+016.80138 \mathrm{e}+016.80138 \mathrm{e}+00$ 1.00000e-09 7.00000e-02 $6.80138 \mathrm{e}+016.80138 \mathrm{e}+016.80138 \mathrm{e}+00$ 1.00000e-09 7.00000e-02 $5.00000 \mathrm{e}-04$ 5.00000e-04 5.00000e-05 1.00000e-09 1.00000e-01 5.00000e-04 5.00000e-04 5.00000e-05 1.00000e-09 1.00000e-01 $2.71761 \mathrm{e}+002.71761 \mathrm{e}+002.71761 \mathrm{e}-01$ 1.00000e-09 2.12000e-01 $2.71761 \mathrm{e}+002.71761 \mathrm{e}+002.71761 \mathrm{e}-011.00000 \mathrm{e}-092.12000 \mathrm{e}-01$ $2.71761 \mathrm{e}+002.71761 \mathrm{e}+002.71761 \mathrm{e}-01$ 1.00000e-09 2.12000e-01 $2.71761 \mathrm{e}+002.71761 \mathrm{e}+00$ 2.71761e-01 1.00000e-09 2.12000e-01 $2.71761 \mathrm{e}+002.71761 \mathrm{e}+002.71761 \mathrm{e}-01$ 1.00000e-09 2.12000e-01 $1.00000 \mathrm{e}-02$ 1.00000e-02 1.00000e-03 1.00000e-09 1.00000e-01 $1.00000 \mathrm{e}+001.00000 \mathrm{e}+001.00000 \mathrm{e}-011.00000 \mathrm{e}-091.00000 \mathrm{e}-01$ $1.00000 \mathrm{e}-05$ 1.00000e-05 1.00000e-06 1.00000e-09 1.00000e-01 $1.00000 \mathrm{e}+001.00000 \mathrm{e}+001.00000 \mathrm{e}-01$ 1.00000e-09 1.00000e-01 Element: 1816 \# of layers: 15

$\mathrm{Kx} \mathrm{Ky} \mathrm{Kz}$ Ss Por

6.80138e+01 6.80138e+01 6.80138e+00 1.00000e-09 7.00000e-02 $6.80138 \mathrm{e}+016.80138 \mathrm{e}+016.80138 \mathrm{e}+001.00000 \mathrm{e}-09$ 7.00000e-02 $6.80138 \mathrm{e}+016.80138 \mathrm{e}+016.80138 \mathrm{e}+00$ 1.00000e-09 7.00000e-02 $6.80138 \mathrm{e}+016.80138 \mathrm{e}+016.80138 \mathrm{e}+00$ 1.00000e-09 7.00000e-02 5.00000e-04 5.00000e-04 5.00000e-05 1.00000e-09 1.00000e-01 5.00000e-04 5.00000e-04 5.00000e-05 1.00000e-09 1.00000e-01 $2.71761 \mathrm{e}+002.71761 \mathrm{e}+002.71761 \mathrm{e}-01$ 1.00000e-09 2.12000e-01 $2.71761 \mathrm{e}+002.71761 \mathrm{e}+00$ 2.71761e-01 1.00000e-09 2.12000e-01 $2.71761 \mathrm{e}+00$ 2.71761e+00 2.71761e-01 1.00000e-09 2.12000e-01 2.71761e+00 2.71761e+00 2.71761e-01 1.00000e-09 2.12000e-01 $2.71761 \mathrm{e}+002.71761 \mathrm{e}+002.71761 \mathrm{e}-01$ 1.00000e-09 2.12000e-01 $1.00000 \mathrm{e}-02$ 1.00000e-02 1.00000e-03 1.00000e-09 1.00000e-01 
$1.00000 \mathrm{e}+001.00000 \mathrm{e}+001.00000 \mathrm{e}-011.00000 \mathrm{e}-091.00000 \mathrm{e}-01$ $1.00000 \mathrm{e}-05$ 1.00000e-05 1.00000e-06 1.00000e-09 1.00000e-01 $1.00000 \mathrm{e}+001.00000 \mathrm{e}+001.00000 \mathrm{e}-011.00000 \mathrm{e}-09$ 1.00000e-01 Element: 1817 \# of layers: 16

$\mathrm{Kx} \mathrm{Ky} \mathrm{Kz}$ Ss Por

6.80138e+01 6.80138e+01 6.80138e+00 1.00000e-09 7.00000e-02 $6.80138 \mathrm{e}+016.80138 \mathrm{e}+016.80138 \mathrm{e}+00$ 1.00000e-09 7.00000e-02 $6.80138 \mathrm{e}+016.80138 \mathrm{e}+016.80138 \mathrm{e}+00$ 1.00000e-09 7.00000e-02 $6.80138 \mathrm{e}+016.80138 \mathrm{e}+016.80138 \mathrm{e}+00$ 1.00000e-09 7.00000e-02 $6.80138 \mathrm{e}+016.80138 \mathrm{e}+016.80138 \mathrm{e}+00$ 1.00000e-09 7.00000e-02 5.00000e-04 5.00000e-04 5.00000e-05 1.00000e-09 1.00000e-01 5.00000e-04 5.00000e-04 5.00000e-05 1.00000e-09 1.00000e-01

$2.71761 \mathrm{e}+002.71761 \mathrm{e}+002.71761 \mathrm{e}-01$ 1.00000e-09 2.12000e-01 $2.71761 \mathrm{e}+002.71761 \mathrm{e}+00$ 2.71761e-01 1.00000e-09 2.12000e-01 $2.71761 \mathrm{e}+002.71761 \mathrm{e}+002.71761 \mathrm{e}-01$ 1.00000e-09 2.12000e-01 $2.71761 \mathrm{e}+002.71761 \mathrm{e}+002.71761 \mathrm{e}-01$ 1.00000e-09 2.12000e-01 $2.71761 \mathrm{e}+002.71761 \mathrm{e}+002.71761 \mathrm{e}-011.00000 \mathrm{e}-092.12000 \mathrm{e}-01$ $1.00000 \mathrm{e}-02$ 1.00000e-02 1.00000e-03 1.00000e-09 1.00000e-01 $1.00000 \mathrm{e}+001.00000 \mathrm{e}+001.00000 \mathrm{e}-011.00000 \mathrm{e}-091.00000 \mathrm{e}-01$ $1.00000 \mathrm{e}-05$ 1.00000e-05 1.00000e-06 1.00000e-09 1.00000e-01 $1.00000 \mathrm{e}+001.00000 \mathrm{e}+001.00000 \mathrm{e}-011.00000 \mathrm{e}-091.00000 \mathrm{e}-01$ Element: 1818 \# of layers: 16

$\mathrm{Kx} \mathrm{Ky} \mathrm{Kz}$ Ss Por

6.80138e+01 6.80138e+01 6.80138e+00 1.00000e-09 7.00000e-02 $6.80138 \mathrm{e}+016.80138 \mathrm{e}+016.80138 \mathrm{e}+001.00000 \mathrm{e}-09$ 7.00000e-02 $6.80138 \mathrm{e}+016.80138 \mathrm{e}+016.80138 \mathrm{e}+00$ 1.00000e-09 7.00000e-02 $6.80138 \mathrm{e}+016.80138 \mathrm{e}+016.80138 \mathrm{e}+00$ 1.00000e-09 7.00000e-02 $6.80138 \mathrm{e}+016.80138 \mathrm{e}+016.80138 \mathrm{e}+00$ 1.00000e-09 7.00000e-02 5.00000e-04 5.00000e-04 5.00000e-05 1.00000e-09 1.00000e-01 5.00000e-04 5.00000e-04 5.00000e-05 1.00000e-09 1.00000e-01 $2.71761 \mathrm{e}+002.71761 \mathrm{e}+002.71761 \mathrm{e}-01$ 1.00000e-09 2.12000e-01 $2.71761 \mathrm{e}+002.71761 \mathrm{e}+002.71761 \mathrm{e}-01$ 1.00000e-09 2.12000e-01 $2.71761 \mathrm{e}+002.71761 \mathrm{e}+002.71761 \mathrm{e}-01$ 1.00000e-09 2.12000e-01 $2.71761 \mathrm{e}+002.71761 \mathrm{e}+002.71761 \mathrm{e}-01$ 1.00000e-09 2.12000e-01 $2.71761 \mathrm{e}+002.71761 \mathrm{e}+00$ 2.71761e-01 1.00000e-09 2.12000e-01 1.00000e-02 1.00000e-02 1.00000e-03 1.00000e-09 1.00000e-01 $1.00000 \mathrm{e}+001.00000 \mathrm{e}+001.00000 \mathrm{e}-011.00000 \mathrm{e}-091.00000 \mathrm{e}-01$ 1.00000e-05 1.00000e-05 1.00000e-06 1.00000e-09 1.00000e-01 $1.00000 \mathrm{e}+001.00000 \mathrm{e}+001.00000 \mathrm{e}-011.00000 \mathrm{e}-091.00000 \mathrm{e}-01$ Element: 1819 \# of layers: 15

Kx Ky Kz Ss Por

6.80138e+01 6.80138e+01 6.80138e+00 1.00000e-09 7.00000e-02 $6.80138 \mathrm{e}+016.80138 \mathrm{e}+01$ 6.80138e+00 1.00000e-09 7.00000e-02 $6.80138 \mathrm{e}+016.80138 \mathrm{e}+016.80138 \mathrm{e}+00$ 1.00000e-09 7.00000e-02 $6.80138 \mathrm{e}+016.80138 \mathrm{e}+016.80138 \mathrm{e}+00$ 1.00000e-09 7.00000e-02 5.00000e-04 5.00000e-04 5.00000e-05 1.00000e-09 1.00000e-01 
5.00000e-04 5.00000e-04 5.00000e-05 1.00000e-09 1.00000e-01 $2.71761 \mathrm{e}+002.71761 \mathrm{e}+002.71761 \mathrm{e}-01$ 1.00000e-09 2.12000e-01 $2.71761 \mathrm{e}+002.71761 \mathrm{e}+002.71761 \mathrm{e}-01$ 1.00000e-09 2.12000e-01 $2.71761 \mathrm{e}+002.71761 \mathrm{e}+002.71761 \mathrm{e}-011.00000 \mathrm{e}-092.12000 \mathrm{e}-01$ $2.71761 \mathrm{e}+002.71761 \mathrm{e}+002.71761 \mathrm{e}-011.00000 \mathrm{e}-092.12000 \mathrm{e}-01$ $2.71761 \mathrm{e}+002.71761 \mathrm{e}+002.71761 \mathrm{e}-011.00000 \mathrm{e}-092.12000 \mathrm{e}-01$ $1.00000 \mathrm{e}-021.00000 \mathrm{e}-02$ 1.00000e-03 1.00000e-09 1.00000e-01 $1.00000 \mathrm{e}+001.00000 \mathrm{e}+001.00000 \mathrm{e}-011.00000 \mathrm{e}-091.00000 \mathrm{e}-01$ $1.00000 \mathrm{e}-05$ 1.00000e-05 1.00000e-06 1.00000e-09 1.00000e-01 $1.00000 \mathrm{e}+001.00000 \mathrm{e}+001.00000 \mathrm{e}-011.00000 \mathrm{e}-091.00000 \mathrm{e}-01$ Element: 1820 \# of layers: 16

Kx Ky Kz Ss Por

$6.80138 \mathrm{e}+016.80138 \mathrm{e}+016.80138 \mathrm{e}+00$ 1.00000e-09 7.00000e-02 $6.80138 \mathrm{e}+016.80138 \mathrm{e}+016.80138 \mathrm{e}+001.00000 \mathrm{e}-09$ 7.00000e-02 $6.80138 \mathrm{e}+016.80138 \mathrm{e}+016.80138 \mathrm{e}+001.00000 \mathrm{e}-09$ 7.00000e-02 $6.80138 \mathrm{e}+016.80138 \mathrm{e}+016.80138 \mathrm{e}+001.00000 \mathrm{e}-09$ 7.00000e-02 $6.80138 \mathrm{e}+016.80138 \mathrm{e}+016.80138 \mathrm{e}+001.00000 \mathrm{e}-09$ 7.00000e-02 5.00000e-04 5.00000e-04 5.00000e-05 1.00000e-09 1.00000e-01 5.00000e-04 5.00000e-04 5.00000e-05 1.00000e-09 1.00000e-01 $2.71761 \mathrm{e}+002.71761 \mathrm{e}+002.71761 \mathrm{e}-011.00000 \mathrm{e}-092.12000 \mathrm{e}-01$ $2.71761 \mathrm{e}+002.71761 \mathrm{e}+002.71761 \mathrm{e}-011.00000 \mathrm{e}-092.12000 \mathrm{e}-01$ $2.71761 \mathrm{e}+002.71761 \mathrm{e}+002.71761 \mathrm{e}-011.00000 \mathrm{e}-092.12000 \mathrm{e}-01$ $2.71761 \mathrm{e}+002.71761 \mathrm{e}+002.71761 \mathrm{e}-011.00000 \mathrm{e}-092.12000 \mathrm{e}-01$ $2.71761 \mathrm{e}+002.71761 \mathrm{e}+002.71761 \mathrm{e}-011.00000 \mathrm{e}-092.12000 \mathrm{e}-01$ $1.00000 \mathrm{e}-021.00000 \mathrm{e}-02$ 1.00000e-03 1.00000e-09 1.00000e-01 $1.00000 \mathrm{e}+001.00000 \mathrm{e}+001.00000 \mathrm{e}-011.00000 \mathrm{e}-091.00000 \mathrm{e}-01$ $1.00000 \mathrm{e}-05$ 1.00000e-05 1.00000e-06 1.00000e-09 1.00000e-01 $1.00000 \mathrm{e}+001.00000 \mathrm{e}+001.00000 \mathrm{e}-011.00000 \mathrm{e}-091.00000 \mathrm{e}-01$ Element: 1821 \# of layers: 15

Kx Ky Kz Ss Por

$4.85891 \mathrm{e}+014.85891 \mathrm{e}+014.85891 \mathrm{e}+00$ 1.00000e-09 7.00000e-02 $4.85891 \mathrm{e}+014.85891 \mathrm{e}+014.85891 \mathrm{e}+001.00000 \mathrm{e}-097.00000 \mathrm{e}-02$ $4.85891 \mathrm{e}+014.85891 \mathrm{e}+014.85891 \mathrm{e}+001.00000 \mathrm{e}-09$ 7.00000e-02 $4.85891 \mathrm{e}+014.85891 \mathrm{e}+014.85891 \mathrm{e}+001.00000 \mathrm{e}-097.00000 \mathrm{e}-02$ 5.00000e-04 5.00000e-04 5.00000e-05 1.00000e-09 1.00000e-01 5.00000e-04 5.00000e-04 5.00000e-05 1.00000e-09 1.00000e-01 $1.94145 \mathrm{e}+001.94145 \mathrm{e}+001.94145 \mathrm{e}-011.00000 \mathrm{e}-092.12000 \mathrm{e}-01$ $1.94145 \mathrm{e}+001.94145 \mathrm{e}+001.94145 \mathrm{e}-011.00000 \mathrm{e}-092.12000 \mathrm{e}-01$ $1.94145 \mathrm{e}+001.94145 \mathrm{e}+001.94145 \mathrm{e}-011.00000 \mathrm{e}-092.12000 \mathrm{e}-01$ $1.94145 \mathrm{e}+001.94145 \mathrm{e}+001.94145 \mathrm{e}-011.00000 \mathrm{e}-092.12000 \mathrm{e}-01$ $1.94145 \mathrm{e}+001.94145 \mathrm{e}+001.94145 \mathrm{e}-011.00000 \mathrm{e}-09$ 2.12000e-01 $1.00000 \mathrm{e}-021.00000 \mathrm{e}-02$ 1.00000e-03 1.00000e-09 1.00000e-01 $1.00000 \mathrm{e}+001.00000 \mathrm{e}+001.00000 \mathrm{e}-011.00000 \mathrm{e}-091.00000 \mathrm{e}-01$ $1.00000 \mathrm{e}-05$ 1.00000e-05 1.00000e-06 1.00000e-09 1.00000e-01 $1.00000 \mathrm{e}+001.00000 \mathrm{e}+001.00000 \mathrm{e}-011.00000 \mathrm{e}-091.00000 \mathrm{e}-01$ Element: 1822 \# of layers: 15 
$\mathrm{Kx} \mathrm{Ky} \mathrm{Kz}$ Ss Por

4.85891e+01 4.85891e+01 4.85891e+00 1.00000e-09 7.00000e-02 4.85891e+01 4.85891e+01 4.85891e+00 1.00000e-09 7.00000e-02 $4.85891 \mathrm{e}+014.85891 \mathrm{e}+014.85891 \mathrm{e}+001.00000 \mathrm{e}-09$ 7.00000e-02 $4.85891 \mathrm{e}+014.85891 \mathrm{e}+014.85891 \mathrm{e}+001.00000 \mathrm{e}-09$ 7.00000e-02 5.00000e-04 5.00000e-04 5.00000e-05 1.00000e-09 1.00000e-01 5.00000e-04 5.00000e-04 5.00000e-05 1.00000e-09 1.00000e-01 $1.94145 \mathrm{e}+001.94145 \mathrm{e}+00$ 1.94145e-01 1.00000e-09 2.12000e-01 $1.94145 \mathrm{e}+001.94145 \mathrm{e}+00$ 1.94145e-01 1.00000e-09 2.12000e-01 $1.94145 \mathrm{e}+001.94145 \mathrm{e}+00$ 1.94145e-01 1.00000e-09 2.12000e-01 $1.94145 \mathrm{e}+001.94145 \mathrm{e}+00$ 1.94145e-01 1.00000e-09 2.12000e-01 $1.94145 \mathrm{e}+001.94145 \mathrm{e}+001.94145 \mathrm{e}-01$ 1.00000e-09 2.12000e-01 $1.00000 \mathrm{e}-02$ 1.00000e-02 1.00000e-03 1.00000e-09 1.00000e-01 $1.00000 \mathrm{e}+001.00000 \mathrm{e}+001.00000 \mathrm{e}-011.00000 \mathrm{e}-091.00000 \mathrm{e}-01$ $1.00000 \mathrm{e}-05$ 1.00000e-05 1.00000e-06 1.00000e-09 1.00000e-01 $1.00000 \mathrm{e}+001.00000 \mathrm{e}+001.00000 \mathrm{e}-011.00000 \mathrm{e}-091.00000 \mathrm{e}-01$ Element: 1823 \# of layers: 14

$\mathrm{Kx} \mathrm{Ky} \mathrm{Kz}$ Ss Por

4.85891e+01 4.85891e+01 4.85891e+00 1.00000e-09 7.00000e-02 $4.85891 \mathrm{e}+014.85891 \mathrm{e}+014.85891 \mathrm{e}+00$ 1.00000e-09 7.00000e-02 $4.85891 \mathrm{e}+014.85891 \mathrm{e}+014.85891 \mathrm{e}+00$ 1.00000e-09 7.00000e-02 5.00000e-04 5.00000e-04 5.00000e-05 1.00000e-09 1.00000e-01 $5.00000 \mathrm{e}-04$ 5.00000e-04 5.00000e-05 1.00000e-09 1.00000e-01 $1.94145 \mathrm{e}+001.94145 \mathrm{e}+001.94145 \mathrm{e}-011.00000 \mathrm{e}-092.12000 \mathrm{e}-01$ $1.94145 \mathrm{e}+001.94145 \mathrm{e}+001.94145 \mathrm{e}-011.00000 \mathrm{e}-092.12000 \mathrm{e}-01$ $1.94145 \mathrm{e}+001.94145 \mathrm{e}+00$ 1.94145e-01 1.00000e-09 2.12000e-01 $1.94145 \mathrm{e}+001.94145 \mathrm{e}+00$ 1.94145e-01 1.00000e-09 2.12000e-01 $1.94145 \mathrm{e}+001.94145 \mathrm{e}+001.94145 \mathrm{e}-01$ 1.00000e-09 2.12000e-01 $1.00000 \mathrm{e}-02$ 1.00000e-02 1.00000e-03 1.00000e-09 1.00000e-01 $1.00000 \mathrm{e}+001.00000 \mathrm{e}+001.00000 \mathrm{e}-011.00000 \mathrm{e}-091.00000 \mathrm{e}-01$ $1.00000 \mathrm{e}-05$ 1.00000e-05 1.00000e-06 1.00000e-09 1.00000e-01 $1.00000 \mathrm{e}+001.00000 \mathrm{e}+001.00000 \mathrm{e}-011.00000 \mathrm{e}-091.00000 \mathrm{e}-01$ Element: 1824 \# of layers: 14

$\mathrm{Kx} \mathrm{Ky} \mathrm{Kz}$ Ss Por

4.85891e+01 4.85891e+01 4.85891e+00 1.00000e-09 7.00000e-02 $4.85891 \mathrm{e}+014.85891 \mathrm{e}+014.85891 \mathrm{e}+001.00000 \mathrm{e}-09$ 7.00000e-02 $4.85891 \mathrm{e}+014.85891 \mathrm{e}+014.85891 \mathrm{e}+001.00000 \mathrm{e}-09$ 7.00000e-02 5.00000e-04 5.00000e-04 5.00000e-05 1.00000e-09 1.00000e-01 5.00000e-04 5.00000e-04 5.00000e-05 1.00000e-09 1.00000e-01 $1.94145 \mathrm{e}+001.94145 \mathrm{e}+001.94145 \mathrm{e}-01$ 1.00000e-09 2.12000e-01 $1.94145 \mathrm{e}+001.94145 \mathrm{e}+001.94145 \mathrm{e}-01$ 1.00000e-09 2.12000e-01 $1.94145 \mathrm{e}+001.94145 \mathrm{e}+00$ 1.94145e-01 1.00000e-09 2.12000e-01 $1.94145 \mathrm{e}+001.94145 \mathrm{e}+00$ 1.94145e-01 1.00000e-09 2.12000e-01 $1.94145 \mathrm{e}+001.94145 \mathrm{e}+00$ 1.94145e-01 1.00000e-09 2.12000e-01 $1.00000 \mathrm{e}-02$ 1.00000e-02 1.00000e-03 1.00000e-09 1.00000e-01 $1.00000 \mathrm{e}+001.00000 \mathrm{e}+001.00000 \mathrm{e}-011.00000 \mathrm{e}-091.00000 \mathrm{e}-01$ 
$1.00000 \mathrm{e}-05$ 1.00000e-05 1.00000e-06 1.00000e-09 1.00000e-01 $1.00000 \mathrm{e}+001.00000 \mathrm{e}+001.00000 \mathrm{e}-01$ 1.00000e-09 1.00000e-01 Element: 1825 \# of layers: 14

Kx Ky Kz Ss Por

4.85891e+01 4.85891e+01 4.85891e+00 1.00000e-09 7.00000e-02 $4.85891 \mathrm{e}+014.85891 \mathrm{e}+014.85891 \mathrm{e}+001.00000 \mathrm{e}-09$ 7.00000e-02 $4.85891 \mathrm{e}+014.85891 \mathrm{e}+014.85891 \mathrm{e}+00$ 1.00000e-09 7.00000e-02 5.00000e-04 5.00000e-04 5.00000e-05 1.00000e-09 1.00000e-01 5.00000e-04 5.00000e-04 5.00000e-05 1.00000e-09 1.00000e-01 $1.94145 \mathrm{e}+001.94145 \mathrm{e}+00$ 1.94145e-01 1.00000e-09 2.12000e-01 $1.94145 \mathrm{e}+001.94145 \mathrm{e}+00$ 1.94145e-01 1.00000e-09 2.12000e-01 $1.94145 \mathrm{e}+001.94145 \mathrm{e}+00$ 1.94145e-01 1.00000e-09 2.12000e-01 $1.94145 \mathrm{e}+001.94145 \mathrm{e}+001.94145 \mathrm{e}-01$ 1.00000e-09 2.12000e-01 $1.94145 \mathrm{e}+001.94145 \mathrm{e}+00$ 1.94145e-01 1.00000e-09 2.12000e-01 $1.00000 \mathrm{e}-02$ 1.00000e-02 1.00000e-03 1.00000e-09 1.00000e-01 $1.00000 \mathrm{e}+001.00000 \mathrm{e}+001.00000 \mathrm{e}-011.00000 \mathrm{e}-091.00000 \mathrm{e}-01$ $1.00000 \mathrm{e}-05$ 1.00000e-05 1.00000e-06 1.00000e-09 1.00000e-01 $1.00000 \mathrm{e}+001.00000 \mathrm{e}+001.00000 \mathrm{e}-01$ 1.00000e-09 1.00000e-01 Element: 1826 \# of layers: 15

$\mathrm{Kx} \mathrm{Ky} \mathrm{Kz}$ Ss Por

4.85891e+01 4.85891e+01 4.85891e+00 1.00000e-09 7.00000e-02 $4.85891 \mathrm{e}+014.85891 \mathrm{e}+014.85891 \mathrm{e}+00$ 1.00000e-09 7.00000e-02 4.85891e+01 4.85891e+01 4.85891e+00 1.00000e-09 7.00000e-02 4.85891e+01 4.85891e+01 4.85891e+00 1.00000e-09 7.00000e-02 $5.00000 \mathrm{e}-04$ 5.00000e-04 5.00000e-05 1.00000e-09 1.00000e-01 5.00000e-04 5.00000e-04 5.00000e-05 1.00000e-09 1.00000e-01 $1.94145 \mathrm{e}+001.94145 \mathrm{e}+001.94145 \mathrm{e}-01$ 1.00000e-09 2.12000e-01 $1.94145 \mathrm{e}+001.94145 \mathrm{e}+001.94145 \mathrm{e}-01$ 1.00000e-09 2.12000e-01 $1.94145 \mathrm{e}+001.94145 \mathrm{e}+00$ 1.94145e-01 1.00000e-09 2.12000e-01 $1.94145 \mathrm{e}+001.94145 \mathrm{e}+00$ 1.94145e-01 1.00000e-09 2.12000e-01 $1.94145 \mathrm{e}+001.94145 \mathrm{e}+001.94145 \mathrm{e}-01$ 1.00000e-09 2.12000e-01 1.00000e-02 1.00000e-02 1.00000e-03 1.00000e-09 1.00000e-01 $1.00000 \mathrm{e}+001.00000 \mathrm{e}+001.00000 \mathrm{e}-011.00000 \mathrm{e}-091.00000 \mathrm{e}-01$ $1.00000 \mathrm{e}-05$ 1.00000e-05 1.00000e-06 1.00000e-09 1.00000e-01 $1.00000 \mathrm{e}+001.00000 \mathrm{e}+001.00000 \mathrm{e}-01$ 1.00000e-09 1.00000e-01 Element: 1827 \# of layers: 15

Kx Ky Kz Ss Por

4.85891e+01 4.85891e+01 4.85891e+00 1.00000e-09 7.00000e-02 4.85891e+01 4.85891e+01 4.85891e+00 1.00000e-09 7.00000e-02 $4.85891 \mathrm{e}+014.85891 \mathrm{e}+014.85891 \mathrm{e}+00$ 1.00000e-09 7.00000e-02 $4.85891 \mathrm{e}+014.85891 \mathrm{e}+014.85891 \mathrm{e}+001.00000 \mathrm{e}-09$ 7.00000e-02 5.00000e-04 5.00000e-04 5.00000e-05 1.00000e-09 1.00000e-01 5.00000e-04 5.00000e-04 5.00000e-05 1.00000e-09 1.00000e-01 $1.94145 \mathrm{e}+001.94145 \mathrm{e}+00$ 1.94145e-01 1.00000e-09 2.12000e-01 $1.94145 \mathrm{e}+001.94145 \mathrm{e}+001.94145 \mathrm{e}-01$ 1.00000e-09 2.12000e-01 $1.94145 \mathrm{e}+001.94145 \mathrm{e}+00$ 1.94145e-01 1.00000e-09 2.12000e-01 
$1.94145 \mathrm{e}+001.94145 \mathrm{e}+00$ 1.94145e-01 1.00000e-09 2.12000e-01 $1.94145 \mathrm{e}+001.94145 \mathrm{e}+00$ 1.94145e-01 1.00000e-09 2.12000e-01 $1.00000 \mathrm{e}-02$ 1.00000e-02 1.00000e-03 1.00000e-09 1.00000e-01 $1.00000 \mathrm{e}+001.00000 \mathrm{e}+001.00000 \mathrm{e}-011.00000 \mathrm{e}-091.00000 \mathrm{e}-01$ $1.00000 \mathrm{e}-05$ 1.00000e-05 1.00000e-06 1.00000e-09 1.00000e-01 $1.00000 \mathrm{e}+001.00000 \mathrm{e}+001.00000 \mathrm{e}-011.00000 \mathrm{e}-091.00000 \mathrm{e}-01$ Element: 1828 \# of layers: 14

$\mathrm{Kx} \mathrm{Ky} \mathrm{Kz}$ Ss Por

4.85891e+01 4.85891e+01 4.85891e+00 1.00000e-09 7.00000e-02 $4.85891 \mathrm{e}+014.85891 \mathrm{e}+014.85891 \mathrm{e}+001.00000 \mathrm{e}-09$ 7.00000e-02 $4.85891 \mathrm{e}+014.85891 \mathrm{e}+014.85891 \mathrm{e}+001.00000 \mathrm{e}-09$ 7.00000e-02 5.00000e-04 5.00000e-04 5.00000e-05 1.00000e-09 1.00000e-01 5.00000e-04 5.00000e-04 5.00000e-05 1.00000e-09 1.00000e-01 $1.94145 \mathrm{e}+001.94145 \mathrm{e}+001.94145 \mathrm{e}-01$ 1.00000e-09 2.12000e-01 $1.94145 \mathrm{e}+001.94145 \mathrm{e}+00$ 1.94145e-01 1.00000e-09 2.12000e-01 $1.94145 \mathrm{e}+001.94145 \mathrm{e}+00$ 1.94145e-01 1.00000e-09 2.12000e-01 $1.94145 \mathrm{e}+001.94145 \mathrm{e}+001.94145 \mathrm{e}-01$ 1.00000e-09 2.12000e-01 $1.94145 \mathrm{e}+001.94145 \mathrm{e}+00$ 1.94145e-01 1.00000e-09 2.12000e-01 $1.00000 \mathrm{e}-02$ 1.00000e-02 1.00000e-03 1.00000e-09 1.00000e-01 $1.00000 \mathrm{e}+001.00000 \mathrm{e}+001.00000 \mathrm{e}-011.00000 \mathrm{e}-091.00000 \mathrm{e}-01$ $1.00000 \mathrm{e}-05$ 1.00000e-05 1.00000e-06 1.00000e-09 1.00000e-01 $1.00000 \mathrm{e}+001.00000 \mathrm{e}+001.00000 \mathrm{e}-01$ 1.00000e-09 1.00000e-01 Element: 1829 \# of layers: 15

$\mathrm{Kx} \mathrm{Ky} \mathrm{Kz}$ Ss Por

4.85891e+01 4.85891e+01 4.85891e+00 1.00000e-09 7.00000e-02 $4.85891 \mathrm{e}+014.85891 \mathrm{e}+014.85891 \mathrm{e}+001.00000 \mathrm{e}-09$ 7.00000e-02 $4.85891 \mathrm{e}+014.85891 \mathrm{e}+014.85891 \mathrm{e}+001.00000 \mathrm{e}-09$ 7.00000e-02 $4.85891 \mathrm{e}+014.85891 \mathrm{e}+014.85891 \mathrm{e}+001.00000 \mathrm{e}-09$ 7.00000e-02 5.00000e-04 5.00000e-04 5.00000e-05 1.00000e-09 1.00000e-01 5.00000e-04 5.00000e-04 5.00000e-05 1.00000e-09 1.00000e-01 $1.94145 \mathrm{e}+001.94145 \mathrm{e}+00$ 1.94145e-01 1.00000e-09 2.12000e-01 $1.94145 \mathrm{e}+00$ 1.94145e+00 1.94145e-01 1.00000e-09 2.12000e-01 $1.94145 \mathrm{e}+001.94145 \mathrm{e}+001.94145 \mathrm{e}-01$ 1.00000e-09 2.12000e-01 $1.94145 \mathrm{e}+001.94145 \mathrm{e}+00$ 1.94145e-01 1.00000e-09 2.12000e-01 $1.94145 \mathrm{e}+001.94145 \mathrm{e}+00$ 1.94145e-01 1.00000e-09 2.12000e-01 1.00000e-02 1.00000e-02 1.00000e-03 1.00000e-09 1.00000e-01 $1.00000 \mathrm{e}+001.00000 \mathrm{e}+001.00000 \mathrm{e}-011.00000 \mathrm{e}-091.00000 \mathrm{e}-01$ 1.00000e-05 1.00000e-05 1.00000e-06 1.00000e-09 1.00000e-01 $1.00000 \mathrm{e}+001.00000 \mathrm{e}+001.00000 \mathrm{e}-011.00000 \mathrm{e}-091.00000 \mathrm{e}-01$ Element: 1830 \# of layers: 13

$\mathrm{Kx} \mathrm{Ky} \mathrm{Kz}$ Ss Por

7.10015e+01 7.10015e+01 7.10015e+00 1.00000e-09 7.00000e-02 7.10015e+01 7.10015e+01 7.10015e+00 1.00000e-09 7.00000e-02 5.00000e-04 5.00000e-04 5.00000e-05 1.00000e-09 1.00000e-01 5.00000e-04 5.00000e-04 5.00000e-05 1.00000e-09 1.00000e-01 $2.83686 \mathrm{e}+002.83686 \mathrm{e}+002.83686 \mathrm{e}-01$ 1.00000e-09 2.12000e-01 
$2.83686 \mathrm{e}+002.83686 \mathrm{e}+002.83686 \mathrm{e}-011.00000 \mathrm{e}-092.12000 \mathrm{e}-01$ $2.83686 \mathrm{e}+002.83686 \mathrm{e}+002.83686 \mathrm{e}-011.00000 \mathrm{e}-092.12000 \mathrm{e}-01$ $2.83686 \mathrm{e}+002.83686 \mathrm{e}+002.83686 \mathrm{e}-01$ 1.00000e-09 2.12000e-01 $2.83686 \mathrm{e}+002.83686 \mathrm{e}+002.83686 \mathrm{e}-011.00000 \mathrm{e}-092.12000 \mathrm{e}-01$ $1.00000 \mathrm{e}-02$ 1.00000e-02 1.00000e-03 1.00000e-09 1.00000e-01 $1.00000 \mathrm{e}+001.00000 \mathrm{e}+001.00000 \mathrm{e}-011.00000 \mathrm{e}-091.00000 \mathrm{e}-01$ $1.00000 \mathrm{e}-051.00000 \mathrm{e}-05$ 1.00000e-06 1.00000e-09 1.00000e-01 $1.00000 \mathrm{e}+001.00000 \mathrm{e}+001.00000 \mathrm{e}-011.00000 \mathrm{e}-091.00000 \mathrm{e}-01$ Element: 1831 \# of layers: 14

Kx Ky Kz Ss Por

7.10015e+01 7.10015e+01 7.10015e+00 1.00000e-09 7.00000e-02 $7.10015 \mathrm{e}+01$ 7.10015e+01 7.10015e+00 1.00000e-09 7.00000e-02 $7.10015 \mathrm{e}+017.10015 \mathrm{e}+01$ 7.10015e+00 1.00000e-09 7.00000e-02 5.00000e-04 5.00000e-04 5.00000e-05 1.00000e-09 1.00000e-01 $5.00000 \mathrm{e}-04$ 5.00000e-04 5.00000e-05 1.00000e-09 1.00000e-01 $2.83686 \mathrm{e}+002.83686 \mathrm{e}+002.83686 \mathrm{e}-011.00000 \mathrm{e}-092.12000 \mathrm{e}-01$ $2.83686 \mathrm{e}+002.83686 \mathrm{e}+002.83686 \mathrm{e}-011.00000 \mathrm{e}-092.12000 \mathrm{e}-01$ $2.83686 \mathrm{e}+002.83686 \mathrm{e}+002.83686 \mathrm{e}-011.00000 \mathrm{e}-092.12000 \mathrm{e}-01$ $2.83686 \mathrm{e}+002.83686 \mathrm{e}+002.83686 \mathrm{e}-011.00000 \mathrm{e}-092.12000 \mathrm{e}-01$ $2.83686 \mathrm{e}+002.83686 \mathrm{e}+002.83686 \mathrm{e}-01$ 1.00000e-09 2.12000e-01 $1.00000 \mathrm{e}-021.00000 \mathrm{e}-02$ 1.00000e-03 1.00000e-09 1.00000e-01 $1.00000 \mathrm{e}+001.00000 \mathrm{e}+001.00000 \mathrm{e}-011.00000 \mathrm{e}-091.00000 \mathrm{e}-01$ $1.00000 \mathrm{e}-05$ 1.00000e-05 1.00000e-06 1.00000e-09 1.00000e-01 $1.00000 \mathrm{e}+001.00000 \mathrm{e}+001.00000 \mathrm{e}-011.00000 \mathrm{e}-091.00000 \mathrm{e}-01$ Element: 1832 \# of layers: 13

Kx Ky Kz Ss Por

7.10015e+01 7.10015e+01 7.10015e+00 1.00000e-09 7.00000e-02 $7.10015 \mathrm{e}+01$ 7.10015e+01 7.10015e+00 1.00000e-09 7.00000e-02 5.00000e-04 5.00000e-04 5.00000e-05 1.00000e-09 1.00000e-01 $5.00000 \mathrm{e}-04$ 5.00000e-04 5.00000e-05 1.00000e-09 1.00000e-01 $2.83686 \mathrm{e}+002.83686 \mathrm{e}+002.83686 \mathrm{e}-011.00000 \mathrm{e}-092.12000 \mathrm{e}-01$ $2.83686 \mathrm{e}+002.83686 \mathrm{e}+002.83686 \mathrm{e}-011.00000 \mathrm{e}-092.12000 \mathrm{e}-01$ $2.83686 \mathrm{e}+002.83686 \mathrm{e}+002.83686 \mathrm{e}-011.00000 \mathrm{e}-092.12000 \mathrm{e}-01$ $2.83686 \mathrm{e}+002.83686 \mathrm{e}+002.83686 \mathrm{e}-011.00000 \mathrm{e}-092.12000 \mathrm{e}-01$ $2.83686 \mathrm{e}+002.83686 \mathrm{e}+002.83686 \mathrm{e}-01$ 1.00000e-09 2.12000e-01 $1.00000 \mathrm{e}-021.00000 \mathrm{e}-02$ 1.00000e-03 1.00000e-09 1.00000e-01 $1.00000 \mathrm{e}+001.00000 \mathrm{e}+001.00000 \mathrm{e}-011.00000 \mathrm{e}-091.00000 \mathrm{e}-01$ $1.00000 \mathrm{e}-05$ 1.00000e-05 1.00000e-06 1.00000e-09 1.00000e-01 $1.00000 \mathrm{e}+001.00000 \mathrm{e}+001.00000 \mathrm{e}-011.00000 \mathrm{e}-091.00000 \mathrm{e}-01$ Element: 1833 \# of layers: 13

Kx Ky Kz Ss Por

7.10015e+01 7.10015e+01 7.10015e+00 1.00000e-09 7.00000e-02 $7.10015 \mathrm{e}+017.10015 \mathrm{e}+01$ 7.10015e+00 1.00000e-09 7.00000e-02 5.00000e-04 5.00000e-04 5.00000e-05 1.00000e-09 1.00000e-01 5.00000e-04 5.00000e-04 5.00000e-05 1.00000e-09 1.00000e-01 $2.83686 \mathrm{e}+002.83686 \mathrm{e}+002.83686 \mathrm{e}-01$ 1.00000e-09 2.12000e-01 
$2.83686 \mathrm{e}+002.83686 \mathrm{e}+002.83686 \mathrm{e}-011.00000 \mathrm{e}-092.12000 \mathrm{e}-01$ $2.83686 \mathrm{e}+002.83686 \mathrm{e}+002.83686 \mathrm{e}-011.00000 \mathrm{e}-092.12000 \mathrm{e}-01$ $2.83686 \mathrm{e}+002.83686 \mathrm{e}+002.83686 \mathrm{e}-01$ 1.00000e-09 2.12000e-01 $2.83686 \mathrm{e}+002.83686 \mathrm{e}+002.83686 \mathrm{e}-011.00000 \mathrm{e}-092.12000 \mathrm{e}-01$ $1.00000 \mathrm{e}-02$ 1.00000e-02 1.00000e-03 1.00000e-09 1.00000e-01 $1.00000 \mathrm{e}+001.00000 \mathrm{e}+001.00000 \mathrm{e}-011.00000 \mathrm{e}-091.00000 \mathrm{e}-01$ $1.00000 \mathrm{e}-051.00000 \mathrm{e}-05$ 1.00000e-06 1.00000e-09 1.00000e-01 $1.00000 \mathrm{e}+001.00000 \mathrm{e}+001.00000 \mathrm{e}-011.00000 \mathrm{e}-091.00000 \mathrm{e}-01$ Element: 1834 \# of layers: 13

Kx Ky Kz Ss Por

7.10015e+01 7.10015e+01 7.10015e+00 1.00000e-09 7.00000e-02 $7.10015 \mathrm{e}+01$ 7.10015e+01 7.10015e+00 1.00000e-09 7.00000e-02 5.00000e-04 5.00000e-04 5.00000e-05 1.00000e-09 1.00000e-01 5.00000e-04 5.00000e-04 5.00000e-05 1.00000e-09 1.00000e-01 $2.83686 \mathrm{e}+002.83686 \mathrm{e}+002.83686 \mathrm{e}-011.00000 \mathrm{e}-092.12000 \mathrm{e}-01$ $2.83686 \mathrm{e}+002.83686 \mathrm{e}+002.83686 \mathrm{e}-01$ 1.00000e-09 2.12000e-01 $2.83686 \mathrm{e}+002.83686 \mathrm{e}+002.83686 \mathrm{e}-011.00000 \mathrm{e}-092.12000 \mathrm{e}-01$ $2.83686 \mathrm{e}+002.83686 \mathrm{e}+002.83686 \mathrm{e}-011.00000 \mathrm{e}-092.12000 \mathrm{e}-01$ $2.83686 \mathrm{e}+002.83686 \mathrm{e}+002.83686 \mathrm{e}-01$ 1.00000e-09 2.12000e-01 $1.00000 \mathrm{e}-021.00000 \mathrm{e}-02$ 1.00000e-03 1.00000e-09 1.00000e-01 $1.00000 \mathrm{e}+001.00000 \mathrm{e}+001.00000 \mathrm{e}-011.00000 \mathrm{e}-091.00000 \mathrm{e}-01$ $1.00000 \mathrm{e}-05$ 1.00000e-05 1.00000e-06 1.00000e-09 1.00000e-01 $1.00000 \mathrm{e}+001.00000 \mathrm{e}+001.00000 \mathrm{e}-011.00000 \mathrm{e}-091.00000 \mathrm{e}-01$ Element: 1835 \# of layers: 14

Kx Ky Kz Ss Por 7.10015e+01 7.10015e+01 7.10015e+00 1.00000e-09 7.00000e-02 $7.10015 \mathrm{e}+017.10015 \mathrm{e}+01$ 7.10015e+00 1.00000e-09 7.00000e-02 $7.10015 \mathrm{e}+01$ 7.10015e+01 7.10015e+00 1.00000e-09 7.00000e-02 5.00000e-04 5.00000e-04 5.00000e-05 1.00000e-09 1.00000e-01 $5.00000 \mathrm{e}-04$ 5.00000e-04 5.00000e-05 1.00000e-09 1.00000e-01 $2.83686 \mathrm{e}+002.83686 \mathrm{e}+002.83686 \mathrm{e}-01$ 1.00000e-09 2.12000e-01 $2.83686 \mathrm{e}+002.83686 \mathrm{e}+002.83686 \mathrm{e}-011.00000 \mathrm{e}-092.12000 \mathrm{e}-01$ $2.83686 \mathrm{e}+002.83686 \mathrm{e}+002.83686 \mathrm{e}-011.00000 \mathrm{e}-092.12000 \mathrm{e}-01$ $2.83686 \mathrm{e}+002.83686 \mathrm{e}+002.83686 \mathrm{e}-011.00000 \mathrm{e}-092.12000 \mathrm{e}-01$ $2.83686 \mathrm{e}+002.83686 \mathrm{e}+002.83686 \mathrm{e}-01$ 1.00000e-09 2.12000e-01 $1.00000 \mathrm{e}-021.00000 \mathrm{e}-02$ 1.00000e-03 1.00000e-09 1.00000e-01 $1.00000 \mathrm{e}+001.00000 \mathrm{e}+001.00000 \mathrm{e}-011.00000 \mathrm{e}-091.00000 \mathrm{e}-01$ $1.00000 \mathrm{e}-05$ 1.00000e-05 1.00000e-06 1.00000e-09 1.00000e-01 $1.00000 \mathrm{e}+001.00000 \mathrm{e}+001.00000 \mathrm{e}-011.00000 \mathrm{e}-091.00000 \mathrm{e}-01$ Element: 1836 \# of layers: 14

Kx Ky Kz Ss Por

7.10015e+01 7.10015e+01 7.10015e+00 1.00000e-09 7.00000e-02 $7.10015 \mathrm{e}+01$ 7.10015e+01 7.10015e+00 1.00000e-09 7.00000e-02 $7.10015 \mathrm{e}+017.10015 \mathrm{e}+01$ 7.10015e+00 1.00000e-09 7.00000e-02 5.00000e-04 5.00000e-04 5.00000e-05 1.00000e-09 1.00000e-01 5.00000e-04 5.00000e-04 5.00000e-05 1.00000e-09 1.00000e-01 
$2.83686 \mathrm{e}+002.83686 \mathrm{e}+002.83686 \mathrm{e}-011.00000 \mathrm{e}-092.12000 \mathrm{e}-01$ $2.83686 \mathrm{e}+002.83686 \mathrm{e}+002.83686 \mathrm{e}-011.00000 \mathrm{e}-092.12000 \mathrm{e}-01$ $2.83686 \mathrm{e}+002.83686 \mathrm{e}+002.83686 \mathrm{e}-01$ 1.00000e-09 2.12000e-01 $2.83686 \mathrm{e}+002.83686 \mathrm{e}+002.83686 \mathrm{e}-011.00000 \mathrm{e}-092.12000 \mathrm{e}-01$ $2.83686 \mathrm{e}+002.83686 \mathrm{e}+002.83686 \mathrm{e}-011.00000 \mathrm{e}-092.12000 \mathrm{e}-01$ $1.00000 \mathrm{e}-021.00000 \mathrm{e}-02$ 1.00000e-03 1.00000e-09 1.00000e-01 $1.00000 \mathrm{e}+001.00000 \mathrm{e}+001.00000 \mathrm{e}-011.00000 \mathrm{e}-091.00000 \mathrm{e}-01$ $1.00000 \mathrm{e}-05$ 1.00000e-05 1.00000e-06 1.00000e-09 1.00000e-01 $1.00000 \mathrm{e}+001.00000 \mathrm{e}+001.00000 \mathrm{e}-011.00000 \mathrm{e}-091.00000 \mathrm{e}-01$ Element: 1837 \# of layers: 14

Kx Ky Kz Ss Por

$7.10015 \mathrm{e}+01$ 7.10015e+01 7.10015e+00 1.00000e-09 7.00000e-02 $7.10015 \mathrm{e}+01$ 7.10015e+01 7.10015e+00 1.00000e-09 7.00000e-02 $7.10015 \mathrm{e}+01$ 7.10015e+01 7.10015e+00 1.00000e-09 7.00000e-02 $5.00000 \mathrm{e}-04$ 5.00000e-04 5.00000e-05 1.00000e-09 1.00000e-01 $5.00000 \mathrm{e}-04$ 5.00000e-04 5.00000e-05 1.00000e-09 1.00000e-01 $2.83686 \mathrm{e}+002.83686 \mathrm{e}+002.83686 \mathrm{e}-011.00000 \mathrm{e}-092.12000 \mathrm{e}-01$ $2.83686 \mathrm{e}+002.83686 \mathrm{e}+002.83686 \mathrm{e}-01$ 1.00000e-09 2.12000e-01 $2.83686 \mathrm{e}+002.83686 \mathrm{e}+002.83686 \mathrm{e}-011.00000 \mathrm{e}-092.12000 \mathrm{e}-01$ $2.83686 \mathrm{e}+002.83686 \mathrm{e}+002.83686 \mathrm{e}-011.00000 \mathrm{e}-092.12000 \mathrm{e}-01$ $2.83686 \mathrm{e}+002.83686 \mathrm{e}+002.83686 \mathrm{e}-011.00000 \mathrm{e}-092.12000 \mathrm{e}-01$ $1.00000 \mathrm{e}-02$ 1.00000e-02 1.00000e-03 1.00000e-09 1.00000e-01 $1.00000 \mathrm{e}+001.00000 \mathrm{e}+001.00000 \mathrm{e}-011.00000 \mathrm{e}-091.00000 \mathrm{e}-01$ $1.00000 \mathrm{e}-051.00000 \mathrm{e}-05$ 1.00000e-06 1.00000e-09 1.00000e-01 $1.00000 \mathrm{e}+001.00000 \mathrm{e}+001.00000 \mathrm{e}-011.00000 \mathrm{e}-091.00000 \mathrm{e}-01$ Element: 1838 \# of layers: 14

Kx Ky Kz Ss Por

7.10015e+01 7.10015e+01 7.10015e+00 1.00000e-09 7.00000e-02 $7.10015 \mathrm{e}+01$ 7.10015e+01 7.10015e+00 1.00000e-09 7.00000e-02 $7.10015 \mathrm{e}+01$ 7.10015e+01 7.10015e+00 1.00000e-09 7.00000e-02 5.00000e-04 5.00000e-04 5.00000e-05 1.00000e-09 1.00000e-01 5.00000e-04 5.00000e-04 5.00000e-05 1.00000e-09 1.00000e-01 $2.83686 \mathrm{e}+002.83686 \mathrm{e}+002.83686 \mathrm{e}-01$ 1.00000e-09 2.12000e-01 $2.83686 \mathrm{e}+002.83686 \mathrm{e}+002.83686 \mathrm{e}-01$ 1.00000e-09 2.12000e-01 $2.83686 \mathrm{e}+002.83686 \mathrm{e}+002.83686 \mathrm{e}-011.00000 \mathrm{e}-092.12000 \mathrm{e}-01$ $2.83686 \mathrm{e}+002.83686 \mathrm{e}+002.83686 \mathrm{e}-011.00000 \mathrm{e}-092.12000 \mathrm{e}-01$ $2.83686 \mathrm{e}+002.83686 \mathrm{e}+002.83686 \mathrm{e}-011.00000 \mathrm{e}-092.12000 \mathrm{e}-01$ $1.00000 \mathrm{e}-021.00000 \mathrm{e}-02$ 1.00000e-03 1.00000e-09 1.00000e-01 $1.00000 \mathrm{e}+001.00000 \mathrm{e}+001.00000 \mathrm{e}-011.00000 \mathrm{e}-091.00000 \mathrm{e}-01$ $1.00000 \mathrm{e}-05$ 1.00000e-05 1.00000e-06 1.00000e-09 1.00000e-01 $1.00000 \mathrm{e}+001.00000 \mathrm{e}+001.00000 \mathrm{e}-011.00000 \mathrm{e}-091.00000 \mathrm{e}-01$ Element: 1839 \# of layers: 13

Kx Ky Kz Ss Por $8.98198 \mathrm{e}+018.98198 \mathrm{e}+01$ 8.98198e+00 1.00000e-09 7.00000e-02 $8.98198 \mathrm{e}+018.98198 \mathrm{e}+018.98198 \mathrm{e}+001.00000 \mathrm{e}-09$ 7.00000e-02 5.00000e-04 5.00000e-04 5.00000e-05 1.00000e-09 1.00000e-01 
5.00000e-04 5.00000e-04 5.00000e-05 1.00000e-09 1.00000e-01 3.58883e+00 3.58883e+00 3.58883e-01 1.00000e-09 2.12000e-01 $3.58883 \mathrm{e}+00$ 3.58883e+00 3.58883e-01 1.00000e-09 2.12000e-01 $3.58883 e+003.58883 e+003.58883 e-01$ 1.00000e-09 2.12000e-01 $3.58883 \mathrm{e}+003.58883 \mathrm{e}+00$ 3.58883e-01 1.00000e-09 2.12000e-01 $3.58883 \mathrm{e}+003.58883 \mathrm{e}+00$ 3.58883e-01 1.00000e-09 2.12000e-01 $1.00000 \mathrm{e}-02$ 1.00000e-02 1.00000e-03 1.00000e-09 1.00000e-01 $1.00000 \mathrm{e}+001.00000 \mathrm{e}+001.00000 \mathrm{e}-011.00000 \mathrm{e}-091.00000 \mathrm{e}-01$ $1.00000 \mathrm{e}-05$ 1.00000e-05 1.00000e-06 1.00000e-09 1.00000e-01 $1.00000 \mathrm{e}+001.00000 \mathrm{e}+001.00000 \mathrm{e}-011.00000 \mathrm{e}-091.00000 \mathrm{e}-01$ Element: 1840 \# of layers: 12

$\mathrm{Kx} \mathrm{Ky} \mathrm{Kz}$ Ss Por

8.98198e+01 8.98198e+01 8.98198e+00 1.00000e-09 7.00000e-02 5.00000e-04 5.00000e-04 5.00000e-05 1.00000e-09 1.00000e-01 5.00000e-04 5.00000e-04 5.00000e-05 1.00000e-09 1.00000e-01 $3.58883 \mathrm{e}+003.58883 \mathrm{e}+003.58883 \mathrm{e}-01$ 1.00000e-09 2.12000e-01 $3.58883 e+003.58883 e+003.58883 e-01$ 1.00000e-09 2.12000e-01 $3.58883 \mathrm{e}+00$ 3.58883e+00 3.58883e-01 1.00000e-09 2.12000e-01 $3.58883 \mathrm{e}+003.58883 \mathrm{e}+00$ 3.58883e-01 1.00000e-09 2.12000e-01 $3.58883 \mathrm{e}+003.58883 \mathrm{e}+00$ 3.58883e-01 1.00000e-09 2.12000e-01 $1.00000 \mathrm{e}-02$ 1.00000e-02 1.00000e-03 1.00000e-09 1.00000e-01 $1.00000 \mathrm{e}+001.00000 \mathrm{e}+001.00000 \mathrm{e}-011.00000 \mathrm{e}-091.00000 \mathrm{e}-01$ $1.00000 \mathrm{e}-05$ 1.00000e-05 1.00000e-06 1.00000e-09 1.00000e-01 $1.00000 \mathrm{e}+001.00000 \mathrm{e}+001.00000 \mathrm{e}-011.00000 \mathrm{e}-091.00000 \mathrm{e}-01$ Element: 1841 \# of layers: 12

$\mathrm{Kx} \mathrm{Ky} \mathrm{Kz}$ Ss Por

8.98198e+01 8.98198e+01 8.98198e+00 1.00000e-09 7.00000e-02 5.00000e-04 5.00000e-04 5.00000e-05 1.00000e-09 1.00000e-01 5.00000e-04 5.00000e-04 5.00000e-05 1.00000e-09 1.00000e-01 $3.58883 \mathrm{e}+00$ 3.58883e+00 3.58883e-01 1.00000e-09 2.12000e-01 $3.58883 \mathrm{e}+003.58883 \mathrm{e}+00$ 3.58883e-01 1.00000e-09 2.12000e-01 $3.58883 \mathrm{e}+00$ 3.58883e+00 3.58883e-01 1.00000e-09 2.12000e-01 $3.58883 \mathrm{e}+003.58883 \mathrm{e}+00$ 3.58883e-01 1.00000e-09 2.12000e-01 $3.58883 \mathrm{e}+00$ 3.58883e+00 3.58883e-01 1.00000e-09 2.12000e-01 $1.00000 \mathrm{e}-02$ 1.00000e-02 1.00000e-03 1.00000e-09 1.00000e-01 $1.00000 \mathrm{e}+001.00000 \mathrm{e}+001.00000 \mathrm{e}-011.00000 \mathrm{e}-091.00000 \mathrm{e}-01$ $1.00000 \mathrm{e}-05$ 1.00000e-05 1.00000e-06 1.00000e-09 1.00000e-01 $1.00000 \mathrm{e}+001.00000 \mathrm{e}+001.00000 \mathrm{e}-01$ 1.00000e-09 1.00000e-01 Element: 1842 \# of layers: 12

$\mathrm{Kx} \mathrm{Ky} \mathrm{Kz}$ Ss Por 8.98198e+01 8.98198e+01 8.98198e+00 1.00000e-09 7.00000e-02 $5.00000 \mathrm{e}-04$ 5.00000e-04 5.00000e-05 1.00000e-09 1.00000e-01 5.00000e-04 5.00000e-04 5.00000e-05 1.00000e-09 1.00000e-01 $3.58883 \mathrm{e}+00$ 3.58883e+00 3.58883e-01 1.00000e-09 2.12000e-01 $3.58883 \mathrm{e}+00$ 3.58883e+00 3.58883e-01 1.00000e-09 2.12000e-01 $3.58883 e+003.58883 e+003.58883 e-01$ 1.00000e-09 2.12000e-01 
3.58883e+00 3.58883e+00 3.58883e-01 1.00000e-09 2.12000e-01 $3.58883 \mathrm{e}+003.58883 \mathrm{e}+00$ 3.58883e-01 1.00000e-09 2.12000e-01 $1.00000 \mathrm{e}-02$ 1.00000e-02 1.00000e-03 1.00000e-09 1.00000e-01 $1.00000 \mathrm{e}+001.00000 \mathrm{e}+001.00000 \mathrm{e}-011.00000 \mathrm{e}-091.00000 \mathrm{e}-01$ $1.00000 \mathrm{e}-051.00000 \mathrm{e}-051.00000 \mathrm{e}-061.00000 \mathrm{e}-091.00000 \mathrm{e}-01$ $1.00000 \mathrm{e}+001.00000 \mathrm{e}+001.00000 \mathrm{e}-011.00000 \mathrm{e}-091.00000 \mathrm{e}-01$ Element: 1843 \# of layers: 12

Kx Ky Kz Ss Por

8.98198e+01 8.98198e+01 8.98198e+00 1.00000e-09 7.00000e-02 5.00000e-04 5.00000e-04 5.00000e-05 1.00000e-09 1.00000e-01 5.00000e-04 5.00000e-04 5.00000e-05 1.00000e-09 1.00000e-01 $3.58883 \mathrm{e}+003.58883 \mathrm{e}+00$ 3.58883e-01 1.00000e-09 2.12000e-01 $3.58883 \mathrm{e}+00$ 3.58883e+00 3.58883e-01 1.00000e-09 2.12000e-01 $3.58883 \mathrm{e}+003.58883 \mathrm{e}+00$ 3.58883e-01 1.00000e-09 2.12000e-01 $3.58883 \mathrm{e}+003.58883 \mathrm{e}+00$ 3.58883e-01 1.00000e-09 2.12000e-01 $3.58883 \mathrm{e}+003.58883 \mathrm{e}+00$ 3.58883e-01 1.00000e-09 2.12000e-01 $1.00000 \mathrm{e}-02$ 1.00000e-02 1.00000e-03 1.00000e-09 1.00000e-01 $1.00000 \mathrm{e}+001.00000 \mathrm{e}+001.00000 \mathrm{e}-011.00000 \mathrm{e}-091.00000 \mathrm{e}-01$ $1.00000 \mathrm{e}-051.00000 \mathrm{e}-05$ 1.00000e-06 1.00000e-09 1.00000e-01 $1.00000 \mathrm{e}+001.00000 \mathrm{e}+001.00000 \mathrm{e}-011.00000 \mathrm{e}-091.00000 \mathrm{e}-01$ Element: 1844 \# of layers: 13

$\mathrm{Kx} \mathrm{Ky} \mathrm{Kz}$ Ss Por

8.98198e+01 8.98198e+01 8.98198e+00 1.00000e-09 7.00000e-02 8.98198e+01 8.98198e+01 8.98198e+00 1.00000e-09 7.00000e-02 $5.00000 \mathrm{e}-04$ 5.00000e-04 5.00000e-05 1.00000e-09 1.00000e-01 $5.00000 \mathrm{e}-04$ 5.00000e-04 5.00000e-05 1.00000e-09 1.00000e-01 $3.58883 e+003.58883 e+003.58883 e-01$ 1.00000e-09 2.12000e-01 $3.58883 \mathrm{e}+003.58883 \mathrm{e}+00$ 3.58883e-01 1.00000e-09 2.12000e-01 $3.58883 \mathrm{e}+003.58883 \mathrm{e}+00$ 3.58883e-01 1.00000e-09 2.12000e-01 $3.58883 \mathrm{e}+003.58883 \mathrm{e}+00$ 3.58883e-01 1.00000e-09 2.12000e-01 $3.58883 \mathrm{e}+003.58883 \mathrm{e}+00$ 3.58883e-01 1.00000e-09 2.12000e-01 $1.00000 \mathrm{e}-02$ 1.00000e-02 1.00000e-03 1.00000e-09 1.00000e-01 $1.00000 \mathrm{e}+001.00000 \mathrm{e}+001.00000 \mathrm{e}-011.00000 \mathrm{e}-091.00000 \mathrm{e}-01$ $1.00000 \mathrm{e}-05$ 1.00000e-05 1.00000e-06 1.00000e-09 1.00000e-01 $1.00000 \mathrm{e}+001.00000 \mathrm{e}+001.00000 \mathrm{e}-01$ 1.00000e-09 1.00000e-01 Element: 1845 \# of layers: 13

Kx Ky Kz Ss Por

8.98198e+01 8.98198e+01 8.98198e+00 1.00000e-09 7.00000e-02 8.98198e+01 8.98198e+01 8.98198e+00 1.00000e-09 7.00000e-02 5.00000e-04 5.00000e-04 5.00000e-05 1.00000e-09 1.00000e-01 5.00000e-04 5.00000e-04 5.00000e-05 1.00000e-09 1.00000e-01 $3.58883 \mathrm{e}+003.58883 \mathrm{e}+00$ 3.58883e-01 1.00000e-09 2.12000e-01 3.58883e+00 3.58883e+00 3.58883e-01 1.00000e-09 2.12000e-01 $3.58883 \mathrm{e}+003.58883 \mathrm{e}+00$ 3.58883e-01 1.00000e-09 2.12000e-01 $3.58883 e+003.58883 e+003.58883 e-01$ 1.00000e-09 2.12000e-01 $3.58883 \mathrm{e}+003.58883 \mathrm{e}+00$ 3.58883e-01 1.00000e-09 2.12000e-01 
$1.00000 \mathrm{e}-02$ 1.00000e-02 1.00000e-03 1.00000e-09 1.00000e-01 $1.00000 \mathrm{e}+001.00000 \mathrm{e}+001.00000 \mathrm{e}-011.00000 \mathrm{e}-091.00000 \mathrm{e}-01$ $1.00000 \mathrm{e}-05$ 1.00000e-05 1.00000e-06 1.00000e-09 1.00000e-01 $1.00000 \mathrm{e}+001.00000 \mathrm{e}+001.00000 \mathrm{e}-011.00000 \mathrm{e}-091.00000 \mathrm{e}-01$ Element: 1846 \# of layers: 13

$\mathrm{Kx} \mathrm{Ky} \mathrm{Kz}$ Ss Por

8.98198e+01 8.98198e+01 8.98198e+00 1.00000e-09 7.00000e-02 $8.98198 \mathrm{e}+018.98198 \mathrm{e}+018.98198 \mathrm{e}+001.00000 \mathrm{e}-09$ 7.00000e-02 5.00000e-04 5.00000e-04 5.00000e-05 1.00000e-09 1.00000e-01 $5.00000 \mathrm{e}-04$ 5.00000e-04 5.00000e-05 1.00000e-09 1.00000e-01 $3.58883 \mathrm{e}+003.58883 \mathrm{e}+00$ 3.58883e-01 1.00000e-09 2.12000e-01 $3.58883 \mathrm{e}+003.58883 \mathrm{e}+00$ 3.58883e-01 1.00000e-09 2.12000e-01 $3.58883 \mathrm{e}+003.58883 \mathrm{e}+00$ 3.58883e-01 1.00000e-09 2.12000e-01 $3.58883 \mathrm{e}+003.58883 \mathrm{e}+00$ 3.58883e-01 1.00000e-09 2.12000e-01 3.58883e+00 3.58883e+00 3.58883e-01 1.00000e-09 2.12000e-01 $1.00000 \mathrm{e}-02$ 1.00000e-02 1.00000e-03 1.00000e-09 1.00000e-01 $1.00000 \mathrm{e}+001.00000 \mathrm{e}+001.00000 \mathrm{e}-011.00000 \mathrm{e}-091.00000 \mathrm{e}-01$ $1.00000 \mathrm{e}-05$ 1.00000e-05 1.00000e-06 1.00000e-09 1.00000e-01 $1.00000 \mathrm{e}+001.00000 \mathrm{e}+001.00000 \mathrm{e}-01$ 1.00000e-09 1.00000e-01 Element: 1847 \# of layers: 13

$\mathrm{Kx} \mathrm{Ky} \mathrm{Kz}$ Ss Por

8.98198e+01 8.98198e+01 8.98198e+00 1.00000e-09 7.00000e-02 8.98198e+01 8.98198e+01 8.98198e+00 1.00000e-09 7.00000e-02 5.00000e-04 5.00000e-04 5.00000e-05 1.00000e-09 1.00000e-01 $5.00000 \mathrm{e}-04$ 5.00000e-04 5.00000e-05 1.00000e-09 1.00000e-01 $3.58883 \mathrm{e}+003.58883 \mathrm{e}+00$ 3.58883e-01 1.00000e-09 2.12000e-01 $3.58883 \mathrm{e}+003.58883 \mathrm{e}+00$ 3.58883e-01 1.00000e-09 2.12000e-01 $3.58883 \mathrm{e}+003.58883 \mathrm{e}+00$ 3.58883e-01 1.00000e-09 2.12000e-01 $3.58883 e+003.58883 e+003.58883 e-01$ 1.00000e-09 2.12000e-01 $3.58883 \mathrm{e}+00$ 3.58883e+00 3.58883e-01 1.00000e-09 2.12000e-01 $1.00000 \mathrm{e}-02$ 1.00000e-02 1.00000e-03 1.00000e-09 1.00000e-01 $1.00000 \mathrm{e}+001.00000 \mathrm{e}+001.00000 \mathrm{e}-011.00000 \mathrm{e}-091.00000 \mathrm{e}-01$ $1.00000 \mathrm{e}-05$ 1.00000e-05 1.00000e-06 1.00000e-09 1.00000e-01 $1.00000 \mathrm{e}+001.00000 \mathrm{e}+001.00000 \mathrm{e}-011.00000 \mathrm{e}-091.00000 \mathrm{e}-01$ Element: 1848 \# of layers: 12

$\mathrm{Kx} \mathrm{Ky} \mathrm{Kz}$ Ss Por 1.18382e+02 1.18382e+02 1.18382e+01 1.00000e-09 7.00000e-02 5.00000e-04 5.00000e-04 5.00000e-05 1.00000e-09 1.00000e-01 5.00000e-04 5.00000e-04 5.00000e-05 1.00000e-09 1.00000e-01 $4.73028 \mathrm{e}+00$ 4.73028e+00 4.73028e-01 1.00000e-09 2.12000e-01 $4.73028 \mathrm{e}+00$ 4.73028e+00 4.73028e-01 1.00000e-09 2.12000e-01 $4.73028 \mathrm{e}+00$ 4.73028e+00 4.73028e-01 1.00000e-09 2.12000e-01 4.73028e+00 4.73028e+00 4.73028e-01 1.00000e-09 2.12000e-01 4.73028e+00 4.73028e+00 4.73028e-01 1.00000e-09 2.12000e-01 $1.00000 \mathrm{e}-02$ 1.00000e-02 1.00000e-03 1.00000e-09 1.00000e-01 $1.00000 \mathrm{e}+001.00000 \mathrm{e}+001.00000 \mathrm{e}-011.00000 \mathrm{e}-091.00000 \mathrm{e}-01$ 
$1.00000 \mathrm{e}-05$ 1.00000e-05 1.00000e-06 1.00000e-09 1.00000e-01 $1.00000 \mathrm{e}+001.00000 \mathrm{e}+001.00000 \mathrm{e}-01$ 1.00000e-09 1.00000e-01 Element: 1849 \# of layers: 12

Kx Ky Kz Ss Por

$1.18382 \mathrm{e}+021.18382 \mathrm{e}+02$ 1.18382e+01 1.00000e-09 7.00000e-02 5.00000e-04 5.00000e-04 5.00000e-05 1.00000e-09 1.00000e-01 5.00000e-04 5.00000e-04 5.00000e-05 1.00000e-09 1.00000e-01 $4.73028 \mathrm{e}+00$ 4.73028e+00 4.73028e-01 1.00000e-09 2.12000e-01 $4.73028 \mathrm{e}+00$ 4.73028e+00 4.73028e-01 1.00000e-09 2.12000e-01 $4.73028 \mathrm{e}+004.73028 \mathrm{e}+00$ 4.73028e-01 1.00000e-09 2.12000e-01 4.73028e+00 4.73028e+00 4.73028e-01 1.00000e-09 2.12000e-01 $4.73028 \mathrm{e}+00$ 4.73028e+00 4.73028e-01 1.00000e-09 2.12000e-01 $1.00000 \mathrm{e}-02$ 1.00000e-02 1.00000e-03 1.00000e-09 1.00000e-01 $1.00000 \mathrm{e}+001.00000 \mathrm{e}+001.00000 \mathrm{e}-011.00000 \mathrm{e}-091.00000 \mathrm{e}-01$ $1.00000 \mathrm{e}-05$ 1.00000e-05 1.00000e-06 1.00000e-09 1.00000e-01 $1.00000 \mathrm{e}+001.00000 \mathrm{e}+001.00000 \mathrm{e}-011.00000 \mathrm{e}-091.00000 \mathrm{e}-01$ Element: 1850 \# of layers: 12

$\mathrm{Kx} \mathrm{Ky} \mathrm{Kz}$ Ss Por

1.18382e+02 1.18382e+02 1.18382e+01 1.00000e-09 7.00000e-02 5.00000e-04 5.00000e-04 5.00000e-05 1.00000e-09 1.00000e-01 5.00000e-04 5.00000e-04 5.00000e-05 1.00000e-09 1.00000e-01

$4.73028 \mathrm{e}+00$ 4.73028e+00 4.73028e-01 1.00000e-09 2.12000e-01 $4.73028 \mathrm{e}+00$ 4.73028e+00 4.73028e-01 1.00000e-09 2.12000e-01 $4.73028 \mathrm{e}+00$ 4.73028e+00 4.73028e-01 1.00000e-09 2.12000e-01 $4.73028 \mathrm{e}+00$ 4.73028e+00 4.73028e-01 1.00000e-09 2.12000e-01 $4.73028 \mathrm{e}+00$ 4.73028e+00 4.73028e-01 1.00000e-09 2.12000e-01 $1.00000 \mathrm{e}-021.00000 \mathrm{e}-021.00000 \mathrm{e}-031.00000 \mathrm{e}-091.00000 \mathrm{e}-01$ $1.00000 \mathrm{e}+001.00000 \mathrm{e}+001.00000 \mathrm{e}-011.00000 \mathrm{e}-091.00000 \mathrm{e}-01$ $1.00000 \mathrm{e}-05$ 1.00000e-05 1.00000e-06 1.00000e-09 1.00000e-01 $1.00000 \mathrm{e}+001.00000 \mathrm{e}+001.00000 \mathrm{e}-011.00000 \mathrm{e}-091.00000 \mathrm{e}-01$ Element: 1851 \# of layers: 12

$\mathrm{Kx} \mathrm{Ky} \mathrm{Kz}$ Ss Por

1.18382e+02 1.18382e+02 1.18382e+01 1.00000e-09 7.00000e-02 $5.00000 \mathrm{e}-045.00000 \mathrm{e}-045.00000 \mathrm{e}-051.00000 \mathrm{e}-091.00000 \mathrm{e}-01$ 5.00000e-04 5.00000e-04 5.00000e-05 1.00000e-09 1.00000e-01 $4.73028 \mathrm{e}+004.73028 \mathrm{e}+00$ 4.73028e-01 1.00000e-09 2.12000e-01 $4.73028 \mathrm{e}+004.73028 \mathrm{e}+00$ 4.73028e-01 1.00000e-09 2.12000e-01 4.73028e+00 4.73028e+00 4.73028e-01 1.00000e-09 2.12000e-01 $4.73028 \mathrm{e}+00$ 4.73028e+00 4.73028e-01 1.00000e-09 2.12000e-01 $4.73028 \mathrm{e}+00$ 4.73028e+00 4.73028e-01 1.00000e-09 2.12000e-01 $1.00000 \mathrm{e}-02$ 1.00000e-02 1.00000e-03 1.00000e-09 1.00000e-01 $1.00000 \mathrm{e}+001.00000 \mathrm{e}+001.00000 \mathrm{e}-011.00000 \mathrm{e}-091.00000 \mathrm{e}-01$ $1.00000 \mathrm{e}-051.00000 \mathrm{e}-051.00000 \mathrm{e}-061.00000 \mathrm{e}-091.00000 \mathrm{e}-01$ $1.00000 \mathrm{e}+001.00000 \mathrm{e}+001.00000 \mathrm{e}-01$ 1.00000e-09 1.00000e-01 Element: 1852 \# of layers: 12

Kx Ky Kz Ss Por 
$1.18382 \mathrm{e}+02$ 1.18382e+02 1.18382e+01 1.00000e-09 7.00000e-02 5.00000e-04 5.00000e-04 5.00000e-05 1.00000e-09 1.00000e-01 5.00000e-04 5.00000e-04 5.00000e-05 1.00000e-09 1.00000e-01 $4.73028 \mathrm{e}+00$ 4.73028e+00 4.73028e-01 1.00000e-09 2.12000e-01 4.73028e+00 4.73028e+00 4.73028e-01 1.00000e-09 2.12000e-01 $4.73028 \mathrm{e}+00$ 4.73028e+00 4.73028e-01 1.00000e-09 2.12000e-01 $4.73028 \mathrm{e}+00$ 4.73028e+00 4.73028e-01 1.00000e-09 2.12000e-01 $4.73028 \mathrm{e}+00$ 4.73028e+00 4.73028e-01 1.00000e-09 2.12000e-01 $1.00000 \mathrm{e}-02$ 1.00000e-02 1.00000e-03 1.00000e-09 1.00000e-01 $1.00000 \mathrm{e}+001.00000 \mathrm{e}+001.00000 \mathrm{e}-011.00000 \mathrm{e}-091.00000 \mathrm{e}-01$ $1.00000 \mathrm{e}-05$ 1.00000e-05 1.00000e-06 1.00000e-09 1.00000e-01 $1.00000 \mathrm{e}+001.00000 \mathrm{e}+001.00000 \mathrm{e}-011.00000 \mathrm{e}-091.00000 \mathrm{e}-01$ Element: 1853 \# of layers: 12

$\mathrm{Kx} \mathrm{Ky} \mathrm{Kz}$ Ss Por

1.18382e+02 1.18382e+02 1.18382e+01 1.00000e-09 7.00000e-02 5.00000e-04 5.00000e-04 5.00000e-05 1.00000e-09 1.00000e-01 5.00000e-04 5.00000e-04 5.00000e-05 1.00000e-09 1.00000e-01 $4.73028 \mathrm{e}+00$ 4.73028e+00 4.73028e-01 1.00000e-09 2.12000e-01 4.73028e+00 4.73028e+00 4.73028e-01 1.00000e-09 2.12000e-01 $4.73028 \mathrm{e}+00$ 4.73028e+00 4.73028e-01 1.00000e-09 2.12000e-01 $4.73028 \mathrm{e}+00$ 4.73028e+00 4.73028e-01 1.00000e-09 2.12000e-01 4.73028e+00 4.73028e+00 4.73028e-01 1.00000e-09 2.12000e-01 $1.00000 \mathrm{e}-021.00000 \mathrm{e}-021.00000 \mathrm{e}-031.00000 \mathrm{e}-091.00000 \mathrm{e}-01$ $1.00000 \mathrm{e}+001.00000 \mathrm{e}+001.00000 \mathrm{e}-011.00000 \mathrm{e}-091.00000 \mathrm{e}-01$ $1.00000 \mathrm{e}-051.00000 \mathrm{e}-05$ 1.00000e-06 1.00000e-09 1.00000e-01 $1.00000 \mathrm{e}+001.00000 \mathrm{e}+001.00000 \mathrm{e}-011.00000 \mathrm{e}-091.00000 \mathrm{e}-01$ Element: 1854 \# of layers: 12

$\mathrm{Kx} \mathrm{Ky} \mathrm{Kz}$ Ss Por

1.18382e+02 1.18382e+02 1.18382e+01 1.00000e-09 7.00000e-02 5.00000e-04 5.00000e-04 5.00000e-05 1.00000e-09 1.00000e-01 5.00000e-04 5.00000e-04 5.00000e-05 1.00000e-09 1.00000e-01 $4.73028 \mathrm{e}+00$ 4.73028e+00 4.73028e-01 1.00000e-09 2.12000e-01 $4.73028 \mathrm{e}+00$ 4.73028e+00 4.73028e-01 1.00000e-09 2.12000e-01 4.73028e+00 4.73028e+00 4.73028e-01 1.00000e-09 2.12000e-01 $4.73028 \mathrm{e}+004.73028 \mathrm{e}+00$ 4.73028e-01 1.00000e-09 2.12000e-01 4.73028e+00 4.73028e+00 4.73028e-01 1.00000e-09 2.12000e-01 $1.00000 \mathrm{e}-02$ 1.00000e-02 1.00000e-03 1.00000e-09 1.00000e-01 $1.00000 \mathrm{e}+001.00000 \mathrm{e}+001.00000 \mathrm{e}-011.00000 \mathrm{e}-091.00000 \mathrm{e}-01$ $1.00000 \mathrm{e}-05$ 1.00000e-05 1.00000e-06 1.00000e-09 1.00000e-01 $1.00000 \mathrm{e}+001.00000 \mathrm{e}+001.00000 \mathrm{e}-011.00000 \mathrm{e}-091.00000 \mathrm{e}-01$ Element: 1855 \# of layers: 12

$\mathrm{Kx} \mathrm{Ky} \mathrm{Kz}$ Ss Por

1.18382e+02 1.18382e+02 1.18382e+01 1.00000e-09 7.00000e-02 5.00000e-04 5.00000e-04 5.00000e-05 1.00000e-09 1.00000e-01 5.00000e-04 5.00000e-04 5.00000e-05 1.00000e-09 1.00000e-01 $4.73028 \mathrm{e}+004.73028 \mathrm{e}+00$ 4.73028e-01 1.00000e-09 2.12000e-01 
$4.73028 \mathrm{e}+004.73028 \mathrm{e}+004.73028 \mathrm{e}-01$ 1.00000e-09 2.12000e-01 $4.73028 \mathrm{e}+004.73028 \mathrm{e}+004.73028 \mathrm{e}-011.00000 \mathrm{e}-092.12000 \mathrm{e}-01$ $4.73028 \mathrm{e}+004.73028 \mathrm{e}+00$ 4.73028e-01 1.00000e-09 2.12000e-01 $4.73028 \mathrm{e}+004.73028 \mathrm{e}+00$ 4.73028e-01 1.00000e-09 2.12000e-01 $1.00000 \mathrm{e}-02$ 1.00000e-02 1.00000e-03 1.00000e-09 1.00000e-01 $1.00000 \mathrm{e}+001.00000 \mathrm{e}+001.00000 \mathrm{e}-011.00000 \mathrm{e}-091.00000 \mathrm{e}-01$ $1.00000 \mathrm{e}-051.00000 \mathrm{e}-05$ 1.00000e-06 1.00000e-09 1.00000e-01 $1.00000 \mathrm{e}+001.00000 \mathrm{e}+001.00000 \mathrm{e}-011.00000 \mathrm{e}-091.00000 \mathrm{e}-01$ Element: 1856 \# of layers: 12

Kx Ky Kz Ss Por

$1.18382 \mathrm{e}+02$ 1.18382e+02 1.18382e+01 1.00000e-09 7.00000e-02 5.00000e-04 5.00000e-04 5.00000e-05 1.00000e-09 1.00000e-01 5.00000e-04 5.00000e-04 5.00000e-05 1.00000e-09 1.00000e-01 $4.73028 \mathrm{e}+004.73028 \mathrm{e}+00$ 4.73028e-01 1.00000e-09 2.12000e-01 $4.73028 \mathrm{e}+004.73028 \mathrm{e}+004.73028 \mathrm{e}-01$ 1.00000e-09 2.12000e-01 $4.73028 \mathrm{e}+004.73028 \mathrm{e}+00$ 4.73028e-01 1.00000e-09 2.12000e-01 $4.73028 \mathrm{e}+004.73028 \mathrm{e}+004.73028 \mathrm{e}-01$ 1.00000e-09 2.12000e-01 $4.73028 \mathrm{e}+004.73028 \mathrm{e}+00$ 4.73028e-01 1.00000e-09 2.12000e-01 $1.00000 \mathrm{e}-02$ 1.00000e-02 1.00000e-03 1.00000e-09 1.00000e-01 $1.00000 \mathrm{e}+001.00000 \mathrm{e}+001.00000 \mathrm{e}-011.00000 \mathrm{e}-091.00000 \mathrm{e}-01$ $1.00000 \mathrm{e}-05$ 1.00000e-05 1.00000e-06 1.00000e-09 1.00000e-01 $1.00000 \mathrm{e}+001.00000 \mathrm{e}+001.00000 \mathrm{e}-011.00000 \mathrm{e}-091.00000 \mathrm{e}-01$ Element: 1857 \# of layers: 12

Kx Ky Kz Ss Por

$1.72379 \mathrm{e}+02$ 1.72379e+02 1.72379e+01 1.00000e-09 7.00000e-02 $5.00000 \mathrm{e}-04$ 5.00000e-04 5.00000e-05 1.00000e-09 1.00000e-01 $5.00000 \mathrm{e}-04$ 5.00000e-04 5.00000e-05 1.00000e-09 1.00000e-01 $6.88762 \mathrm{e}+006.88762 \mathrm{e}+00$ 6.88762e-01 1.00000e-09 2.12000e-01 $6.88762 \mathrm{e}+006.88762 \mathrm{e}+00$ 6.88762e-01 1.00000e-09 2.12000e-01 $6.88762 \mathrm{e}+006.88762 \mathrm{e}+006.88762 \mathrm{e}-011.00000 \mathrm{e}-092.12000 \mathrm{e}-01$ $6.88762 \mathrm{e}+006.88762 \mathrm{e}+006.88762 \mathrm{e}-011.00000 \mathrm{e}-092.12000 \mathrm{e}-01$ $6.88762 \mathrm{e}+006.88762 \mathrm{e}+00$ 6.88762e-01 1.00000e-09 2.12000e-01 $1.00000 \mathrm{e}-021.00000 \mathrm{e}-02$ 1.00000e-03 1.00000e-09 1.00000e-01 $1.00000 \mathrm{e}+001.00000 \mathrm{e}+001.00000 \mathrm{e}-011.00000 \mathrm{e}-091.00000 \mathrm{e}-01$ $1.00000 \mathrm{e}-05$ 1.00000e-05 1.00000e-06 1.00000e-09 1.00000e-01 $1.00000 \mathrm{e}+001.00000 \mathrm{e}+001.00000 \mathrm{e}-011.00000 \mathrm{e}-091.00000 \mathrm{e}-01$ Element: 1858 \# of layers: 11

Kx Ky Kz Ss Por

$1.72379 \mathrm{e}+02$ 1.72379e+02 1.72379e+01 1.00000e-09 7.00000e-02 5.00000e-04 5.00000e-04 5.00000e-05 1.00000e-09 1.00000e-01 $6.88762 \mathrm{e}+006.88762 \mathrm{e}+00$ 6.88762e-01 1.00000e-09 2.12000e-01 $6.88762 \mathrm{e}+006.88762 \mathrm{e}+00$ 6.88762e-01 1.00000e-09 2.12000e-01 $6.88762 \mathrm{e}+006.88762 \mathrm{e}+006.88762 \mathrm{e}-011.00000 \mathrm{e}-092.12000 \mathrm{e}-01$ $6.88762 \mathrm{e}+006.88762 \mathrm{e}+00$ 6.88762e-01 1.00000e-09 2.12000e-01 $6.88762 \mathrm{e}+006.88762 \mathrm{e}+00$ 6.88762e-01 1.00000e-09 2.12000e-01 $1.00000 \mathrm{e}-021.00000 \mathrm{e}-02$ 1.00000e-03 1.00000e-09 1.00000e-01 
$1.00000 \mathrm{e}+001.00000 \mathrm{e}+001.00000 \mathrm{e}-011.00000 \mathrm{e}-091.00000 \mathrm{e}-01$ $1.00000 \mathrm{e}-05$ 1.00000e-05 1.00000e-06 1.00000e-09 1.00000e-01 $1.00000 \mathrm{e}+001.00000 \mathrm{e}+001.00000 \mathrm{e}-01$ 1.00000e-09 1.00000e-01 Element: 1859 \# of layers: 10

$\mathrm{Kx} \mathrm{Ky} \mathrm{Kz}$ Ss Por

1.72379e+02 1.72379e+02 1.72379e+01 1.00000e-09 7.00000e-02 $6.88762 \mathrm{e}+006.88762 \mathrm{e}+00$ 6.88762e-01 1.00000e-09 2.12000e-01 6.88762e+00 6.88762e+00 6.88762e-01 1.00000e-09 2.12000e-01 $6.88762 \mathrm{e}+006.88762 \mathrm{e}+00$ 6.88762e-01 1.00000e-09 2.12000e-01 $6.88762 \mathrm{e}+00$ 6.88762e+00 6.88762e-01 1.00000e-09 2.12000e-01 $6.88762 \mathrm{e}+006.88762 \mathrm{e}+00$ 6.88762e-01 1.00000e-09 2.12000e-01 $1.00000 \mathrm{e}-02$ 1.00000e-02 1.00000e-03 1.00000e-09 1.00000e-01 $1.00000 \mathrm{e}+001.00000 \mathrm{e}+001.00000 \mathrm{e}-011.00000 \mathrm{e}-091.00000 \mathrm{e}-01$ $1.00000 \mathrm{e}-05$ 1.00000e-05 1.00000e-06 1.00000e-09 1.00000e-01 $1.00000 \mathrm{e}+001.00000 \mathrm{e}+001.00000 \mathrm{e}-01$ 1.00000e-09 1.00000e-01 Element: 1860 \# of layers: 10

$\mathrm{Kx} \mathrm{Ky} \mathrm{Kz}$ Ss Por

1.72379e+02 1.72379e+02 1.72379e+01 1.00000e-09 7.00000e-02 $6.88762 \mathrm{e}+00$ 6.88762e+00 6.88762e-01 1.00000e-09 2.12000e-01 $6.88762 \mathrm{e}+006.88762 \mathrm{e}+00$ 6.88762e-01 1.00000e-09 2.12000e-01 6.88762e+00 6.88762e+00 6.88762e-01 1.00000e-09 2.12000e-01 6.88762e+00 6.88762e+00 6.88762e-01 1.00000e-09 2.12000e-01 $6.88762 \mathrm{e}+006.88762 \mathrm{e}+00$ 6.88762e-01 1.00000e-09 2.12000e-01 $1.00000 \mathrm{e}-02$ 1.00000e-02 1.00000e-03 1.00000e-09 1.00000e-01 $1.00000 \mathrm{e}+001.00000 \mathrm{e}+001.00000 \mathrm{e}-011.00000 \mathrm{e}-091.00000 \mathrm{e}-01$ $1.00000 \mathrm{e}-05$ 1.00000e-05 1.00000e-06 1.00000e-09 1.00000e-01 $1.00000 \mathrm{e}+001.00000 \mathrm{e}+001.00000 \mathrm{e}-01$ 1.00000e-09 1.00000e-01 Element: 1861 \# of layers: 11

$\mathrm{Kx} \mathrm{Ky} \mathrm{Kz}$ Ss Por

$1.72379 \mathrm{e}+02$ 1.72379e+02 1.72379e+01 1.00000e-09 7.00000e-02 5.00000e-04 5.00000e-04 5.00000e-05 1.00000e-09 1.00000e-01 $6.88762 \mathrm{e}+006.88762 \mathrm{e}+00$ 6.88762e-01 1.00000e-09 2.12000e-01 $6.88762 \mathrm{e}+00$ 6.88762e+00 6.88762e-01 1.00000e-09 2.12000e-01 $6.88762 \mathrm{e}+006.88762 \mathrm{e}+00$ 6.88762e-01 1.00000e-09 2.12000e-01 $6.88762 \mathrm{e}+00$ 6.88762e+00 6.88762e-01 1.00000e-09 2.12000e-01 6.88762e+00 6.88762e+00 6.88762e-01 1.00000e-09 2.12000e-01 $1.00000 \mathrm{e}-02$ 1.00000e-02 1.00000e-03 1.00000e-09 1.00000e-01 $1.00000 \mathrm{e}+001.00000 \mathrm{e}+001.00000 \mathrm{e}-011.00000 \mathrm{e}-091.00000 \mathrm{e}-01$ $1.00000 \mathrm{e}-05$ 1.00000e-05 1.00000e-06 1.00000e-09 1.00000e-01 $1.00000 \mathrm{e}+001.00000 \mathrm{e}+001.00000 \mathrm{e}-011.00000 \mathrm{e}-091.00000 \mathrm{e}-01$ Element: 1862 \# of layers: 11

$\mathrm{Kx} \mathrm{Ky} \mathrm{Kz}$ Ss Por

$1.72379 \mathrm{e}+02$ 1.72379e+02 1.72379e+01 1.00000e-09 7.00000e-02 5.00000e-04 5.00000e-04 5.00000e-05 1.00000e-09 1.00000e-01 $6.88762 \mathrm{e}+006.88762 \mathrm{e}+006.88762 \mathrm{e}-01$ 1.00000e-09 2.12000e-01 $6.88762 \mathrm{e}+006.88762 \mathrm{e}+006.88762 \mathrm{e}-01$ 1.00000e-09 2.12000e-01 
$6.88762 \mathrm{e}+006.88762 \mathrm{e}+00$ 6.88762e-01 1.00000e-09 2.12000e-01 $6.88762 \mathrm{e}+006.88762 \mathrm{e}+00$ 6.88762e-01 1.00000e-09 2.12000e-01 $6.88762 \mathrm{e}+006.88762 \mathrm{e}+00$ 6.88762e-01 1.00000e-09 2.12000e-01 $1.00000 \mathrm{e}-021.00000 \mathrm{e}-02$ 1.00000e-03 1.00000e-09 1.00000e-01 $1.00000 \mathrm{e}+001.00000 \mathrm{e}+001.00000 \mathrm{e}-011.00000 \mathrm{e}-091.00000 \mathrm{e}-01$ $1.00000 \mathrm{e}-05$ 1.00000e-05 1.00000e-06 1.00000e-09 1.00000e-01 $1.00000 \mathrm{e}+001.00000 \mathrm{e}+001.00000 \mathrm{e}-011.00000 \mathrm{e}-091.00000 \mathrm{e}-01$ Element: 1863 \# of layers: 12

Kx Ky Kz Ss Por

$1.72379 \mathrm{e}+02$ 1.72379e+02 1.72379e+01 1.00000e-09 7.00000e-02 5.00000e-04 5.00000e-04 5.00000e-05 1.00000e-09 1.00000e-01 5.00000e-04 5.00000e-04 5.00000e-05 1.00000e-09 1.00000e-01 $6.88762 \mathrm{e}+006.88762 \mathrm{e}+006.88762 \mathrm{e}-01$ 1.00000e-09 2.12000e-01 $6.88762 \mathrm{e}+006.88762 \mathrm{e}+00$ 6.88762e-01 1.00000e-09 2.12000e-01 $6.88762 \mathrm{e}+006.88762 \mathrm{e}+00$ 6.88762e-01 1.00000e-09 2.12000e-01 $6.88762 \mathrm{e}+006.88762 \mathrm{e}+00$ 6.88762e-01 1.00000e-09 2.12000e-01 $6.88762 \mathrm{e}+006.88762 \mathrm{e}+00$ 6.88762e-01 1.00000e-09 2.12000e-01 $1.00000 \mathrm{e}-02$ 1.00000e-02 1.00000e-03 1.00000e-09 1.00000e-01 $1.00000 \mathrm{e}+001.00000 \mathrm{e}+001.00000 \mathrm{e}-011.00000 \mathrm{e}-091.00000 \mathrm{e}-01$ $1.00000 \mathrm{e}-05$ 1.00000e-05 1.00000e-06 1.00000e-09 1.00000e-01 $1.00000 \mathrm{e}+001.00000 \mathrm{e}+001.00000 \mathrm{e}-011.00000 \mathrm{e}-091.00000 \mathrm{e}-01$ Element: 1864 \# of layers: 12

Kx Ky Kz Ss Por

$1.72379 \mathrm{e}+02$ 1.72379e+02 1.72379e+01 1.00000e-09 7.00000e-02 5.00000e-04 5.00000e-04 5.00000e-05 1.00000e-09 1.00000e-01 5.00000e-04 5.00000e-04 5.00000e-05 1.00000e-09 1.00000e-01 $6.88762 \mathrm{e}+006.88762 \mathrm{e}+00$ 6.88762e-01 1.00000e-09 2.12000e-01 $6.88762 \mathrm{e}+006.88762 \mathrm{e}+006.88762 \mathrm{e}-011.00000 \mathrm{e}-092.12000 \mathrm{e}-01$ $6.88762 \mathrm{e}+006.88762 \mathrm{e}+006.88762 \mathrm{e}-011.00000 \mathrm{e}-092.12000 \mathrm{e}-01$ $6.88762 \mathrm{e}+006.88762 \mathrm{e}+006.88762 \mathrm{e}-011.00000 \mathrm{e}-092.12000 \mathrm{e}-01$ $6.88762 \mathrm{e}+006.88762 \mathrm{e}+00$ 6.88762e-01 1.00000e-09 2.12000e-01 $1.00000 \mathrm{e}-021.00000 \mathrm{e}-02$ 1.00000e-03 1.00000e-09 1.00000e-01 $1.00000 \mathrm{e}+001.00000 \mathrm{e}+001.00000 \mathrm{e}-011.00000 \mathrm{e}-091.00000 \mathrm{e}-01$ $1.00000 \mathrm{e}-05$ 1.00000e-05 1.00000e-06 1.00000e-09 1.00000e-01 $1.00000 \mathrm{e}+001.00000 \mathrm{e}+001.00000 \mathrm{e}-011.00000 \mathrm{e}-091.00000 \mathrm{e}-01$ Element: 1865 \# of layers: 11

Kx Ky Kz Ss Por

$1.72379 \mathrm{e}+02$ 1.72379e+02 1.72379e+01 1.00000e-09 7.00000e-02 $5.00000 \mathrm{e}-04$ 5.00000e-04 5.00000e-05 1.00000e-09 1.00000e-01 $6.88762 \mathrm{e}+006.88762 \mathrm{e}+00$ 6.88762e-01 1.00000e-09 2.12000e-01 $6.88762 \mathrm{e}+006.88762 \mathrm{e}+00$ 6.88762e-01 1.00000e-09 2.12000e-01 $6.88762 \mathrm{e}+006.88762 \mathrm{e}+00$ 6.88762e-01 1.00000e-09 2.12000e-01 $6.88762 \mathrm{e}+006.88762 \mathrm{e}+006.88762 \mathrm{e}-011.00000 \mathrm{e}-092.12000 \mathrm{e}-01$ $6.88762 \mathrm{e}+006.88762 \mathrm{e}+00$ 6.88762e-01 1.00000e-09 2.12000e-01 $1.00000 \mathrm{e}-021.00000 \mathrm{e}-02$ 1.00000e-03 1.00000e-09 1.00000e-01 $1.00000 \mathrm{e}+001.00000 \mathrm{e}+001.00000 \mathrm{e}-011.00000 \mathrm{e}-091.00000 \mathrm{e}-01$ 
$1.00000 \mathrm{e}-05$ 1.00000e-05 1.00000e-06 1.00000e-09 1.00000e-01 $1.00000 \mathrm{e}+001.00000 \mathrm{e}+001.00000 \mathrm{e}-01$ 1.00000e-09 1.00000e-01 Element: 1866 \# of layers: 9

Kx Ky Kz Ss Por

$1.14827 \mathrm{e}+01$ 1.14827e+01 1.14827e+00 1.00000e-09 2.12000e-01 $1.14827 \mathrm{e}+011.14827 \mathrm{e}+01$ 1.14827e+00 1.00000e-09 2.12000e-01 $1.14827 \mathrm{e}+01$ 1.14827e+01 1.14827e+00 1.00000e-09 2.12000e-01 $1.14827 \mathrm{e}+01$ 1.14827e+01 1.14827e+00 1.00000e-09 2.12000e-01 $1.14827 \mathrm{e}+01$ 1.14827e+01 1.14827e+00 1.00000e-09 2.12000e-01 $1.00000 \mathrm{e}-02$ 1.00000e-02 1.00000e-03 1.00000e-09 1.00000e-01 $1.00000 \mathrm{e}+001.00000 \mathrm{e}+001.00000 \mathrm{e}-011.00000 \mathrm{e}-091.00000 \mathrm{e}-01$ $1.00000 \mathrm{e}-05$ 1.00000e-05 1.00000e-06 1.00000e-09 1.00000e-01 $1.00000 \mathrm{e}+001.00000 \mathrm{e}+001.00000 \mathrm{e}-011.00000 \mathrm{e}-091.00000 \mathrm{e}-01$ Element: 1867 \# of layers: 9

$\mathrm{Kx} \mathrm{Ky} \mathrm{Kz}$ Ss Por

$1.14827 \mathrm{e}+01$ 1.14827e+01 1.14827e+00 1.00000e-09 2.12000e-01 $1.14827 \mathrm{e}+01$ 1.14827e+01 1.14827e+00 1.00000e-09 2.12000e-01 $1.14827 \mathrm{e}+01$ 1.14827e+01 1.14827e+00 1.00000e-09 2.12000e-01 $1.14827 \mathrm{e}+01$ 1.14827e+01 1.14827e+00 1.00000e-09 2.12000e-01 $1.14827 \mathrm{e}+01$ 1.14827e+01 1.14827e+00 1.00000e-09 2.12000e-01 $1.00000 \mathrm{e}-02$ 1.00000e-02 1.00000e-03 1.00000e-09 1.00000e-01 $1.00000 \mathrm{e}+001.00000 \mathrm{e}+001.00000 \mathrm{e}-011.00000 \mathrm{e}-091.00000 \mathrm{e}-01$ $1.00000 \mathrm{e}-05$ 1.00000e-05 1.00000e-06 1.00000e-09 1.00000e-01 $1.00000 \mathrm{e}+001.00000 \mathrm{e}+001.00000 \mathrm{e}-011.00000 \mathrm{e}-091.00000 \mathrm{e}-01$ Element: 1868 \# of layers: 9

$\mathrm{Kx} \mathrm{Ky} \mathrm{Kz}$ Ss Por

1.14827e+01 1.14827e+01 1.14827e+00 1.00000e-09 2.12000e-01 $1.14827 \mathrm{e}+01$ 1.14827e+01 1.14827e+00 1.00000e-09 2.12000e-01 $1.14827 \mathrm{e}+01$ 1.14827e+01 1.14827e+00 1.00000e-09 2.12000e-01 $1.14827 \mathrm{e}+01$ 1.14827e+01 1.14827e+00 1.00000e-09 2.12000e-01 $1.14827 \mathrm{e}+01$ 1.14827e+01 1.14827e+00 1.00000e-09 2.12000e-01 $1.00000 \mathrm{e}-02$ 1.00000e-02 1.00000e-03 1.00000e-09 1.00000e-01 $1.00000 \mathrm{e}+001.00000 \mathrm{e}+001.00000 \mathrm{e}-011.00000 \mathrm{e}-091.00000 \mathrm{e}-01$ $1.00000 \mathrm{e}-05$ 1.00000e-05 1.00000e-06 1.00000e-09 1.00000e-01 $1.00000 \mathrm{e}+001.00000 \mathrm{e}+001.00000 \mathrm{e}-011.00000 \mathrm{e}-091.00000 \mathrm{e}-01$ Element: 1869 \# of layers: 9

Kx Ky Kz Ss Por

$1.14827 \mathrm{e}+01$ 1.14827e+01 1.14827e+00 1.00000e-09 2.12000e-01 $1.14827 \mathrm{e}+01$ 1.14827e+01 1.14827e+00 1.00000e-09 2.12000e-01 $1.14827 \mathrm{e}+01$ 1.14827e+01 1.14827e+00 1.00000e-09 2.12000e-01 $1.14827 \mathrm{e}+01$ 1.14827e+01 1.14827e+00 1.00000e-09 2.12000e-01 $1.14827 \mathrm{e}+011.14827 \mathrm{e}+011.14827 \mathrm{e}+001.00000 \mathrm{e}-092.12000 \mathrm{e}-01$ $1.00000 \mathrm{e}-02$ 1.00000e-02 1.00000e-03 1.00000e-09 1.00000e-01 $1.00000 \mathrm{e}+001.00000 \mathrm{e}+001.00000 \mathrm{e}-011.00000 \mathrm{e}-091.00000 \mathrm{e}-01$ $1.00000 \mathrm{e}-05$ 1.00000e-05 1.00000e-06 1.00000e-09 1.00000e-01 $1.00000 \mathrm{e}+001.00000 \mathrm{e}+001.00000 \mathrm{e}-011.00000 \mathrm{e}-091.00000 \mathrm{e}-01$ 
Element: 1870 \# of layers: 9

$\mathrm{Kx} \mathrm{Ky} \mathrm{Kz}$ Ss Por

1.14827e+01 1.14827e+01 1.14827e+00 1.00000e-09 2.12000e-01

$1.14827 \mathrm{e}+01$ 1.14827e+01 1.14827e+00 1.00000e-09 2.12000e-01

$1.14827 \mathrm{e}+01$ 1.14827e+01 1.14827e+00 1.00000e-09 2.12000e-01

$1.14827 \mathrm{e}+01$ 1.14827e+01 1.14827e+00 1.00000e-09 2.12000e-01

$1.14827 \mathrm{e}+011.14827 \mathrm{e}+01$ 1.14827e+00 1.00000e-09 2.12000e-01

$1.00000 \mathrm{e}-02$ 1.00000e-02 1.00000e-03 1.00000e-09 1.00000e-01

$1.00000 \mathrm{e}+001.00000 \mathrm{e}+001.00000 \mathrm{e}-011.00000 \mathrm{e}-091.00000 \mathrm{e}-01$

$1.00000 \mathrm{e}-05$ 1.00000e-05 1.00000e-06 1.00000e-09 1.00000e-01

$1.00000 \mathrm{e}+001.00000 \mathrm{e}+001.00000 \mathrm{e}-011.00000 \mathrm{e}-091.00000 \mathrm{e}-01$

Element: 1871 \# of layers: 9

$\mathrm{Kx} \mathrm{Ky} \mathrm{Kz}$ Ss Por

1.14827e+01 1.14827e+01 1.14827e+00 1.00000e-09 2.12000e-01

$1.14827 \mathrm{e}+01$ 1.14827e+01 1.14827e+00 1.00000e-09 2.12000e-01

$1.14827 \mathrm{e}+011.14827 \mathrm{e}+01$ 1.14827e+00 1.00000e-09 2.12000e-01

$1.14827 \mathrm{e}+01$ 1.14827e+01 1.14827e+00 1.00000e-09 2.12000e-01

$1.14827 \mathrm{e}+011.14827 \mathrm{e}+01$ 1.14827e+00 1.00000e-09 2.12000e-01

$1.00000 \mathrm{e}-02$ 1.00000e-02 1.00000e-03 1.00000e-09 1.00000e-01

$1.00000 \mathrm{e}+001.00000 \mathrm{e}+001.00000 \mathrm{e}-011.00000 \mathrm{e}-091.00000 \mathrm{e}-01$

$1.00000 \mathrm{e}-05$ 1.00000e-05 1.00000e-06 1.00000e-09 1.00000e-01

$1.00000 \mathrm{e}+001.00000 \mathrm{e}+001.00000 \mathrm{e}-011.00000 \mathrm{e}-091.00000 \mathrm{e}-01$

Element: 1872 \# of layers: 10

Kx Ky Kz Ss Por

$2.87383 e+02$ 2.87383e+02 2.87383e+01 1.00000e-09 7.00000e-02

$1.14827 \mathrm{e}+01$ 1.14827e+01 1.14827e+00 1.00000e-09 2.12000e-01

$1.14827 \mathrm{e}+01$ 1.14827e+01 1.14827e+00 1.00000e-09 2.12000e-01

$1.14827 \mathrm{e}+01$ 1.14827e+01 1.14827e+00 1.00000e-09 2.12000e-01

$1.14827 \mathrm{e}+01$ 1.14827e+01 1.14827e+00 1.00000e-09 2.12000e-01

$1.14827 \mathrm{e}+01$ 1.14827e+01 1.14827e+00 1.00000e-09 2.12000e-01

$1.00000 \mathrm{e}-021.00000 \mathrm{e}-021.00000 \mathrm{e}-031.00000 \mathrm{e}-091.00000 \mathrm{e}-01$

$1.00000 \mathrm{e}+001.00000 \mathrm{e}+001.00000 \mathrm{e}-011.00000 \mathrm{e}-091.00000 \mathrm{e}-01$

$1.00000 \mathrm{e}-05$ 1.00000e-05 1.00000e-06 1.00000e-09 1.00000e-01

$1.00000 \mathrm{e}+001.00000 \mathrm{e}+001.00000 \mathrm{e}-011.00000 \mathrm{e}-091.00000 \mathrm{e}-01$

Element: 1873 \# of layers: 9

Kx Ky Kz Ss Por

$1.14827 \mathrm{e}+01$ 1.14827e+01 1.14827e+00 1.00000e-09 2.12000e-01

$1.14827 \mathrm{e}+011.14827 \mathrm{e}+01$ 1.14827e+00 1.00000e-09 2.12000e-01

$1.14827 \mathrm{e}+01$ 1.14827e+01 1.14827e+00 1.00000e-09 2.12000e-01

$1.14827 \mathrm{e}+011.14827 \mathrm{e}+01$ 1.14827e+00 1.00000e-09 2.12000e-01

$1.14827 \mathrm{e}+01$ 1.14827e+01 1.14827e+00 1.00000e-09 2.12000e-01

$1.00000 \mathrm{e}-02$ 1.00000e-02 1.00000e-03 1.00000e-09 1.00000e-01

$1.00000 \mathrm{e}+001.00000 \mathrm{e}+001.00000 \mathrm{e}-011.00000 \mathrm{e}-091.00000 \mathrm{e}-01$

$1.00000 \mathrm{e}-05$ 1.00000e-05 1.00000e-06 1.00000e-09 1.00000e-01

$1.00000 \mathrm{e}+001.00000 \mathrm{e}+001.00000 \mathrm{e}-01$ 1.00000e-09 1.00000e-01

Element: 1874 \# of layers: 9 
$\mathrm{Kx} \mathrm{Ky} \mathrm{Kz} \mathrm{Ss} \mathrm{Por}$

1.14827e+01 1.14827e+01 1.14827e+00 1.00000e-09 2.12000e-01

$1.14827 \mathrm{e}+01$ 1.14827e+01 1.14827e+00 1.00000e-09 2.12000e-01

$1.14827 \mathrm{e}+01$ 1.14827e+01 1.14827e+00 1.00000e-09 2.12000e-01

$1.14827 \mathrm{e}+01$ 1.14827e+01 1.14827e+00 1.00000e-09 2.12000e-01

$1.14827 \mathrm{e}+01$ 1.14827e+01 1.14827e+00 1.00000e-09 2.12000e-01

$1.00000 \mathrm{e}-02$ 1.00000e-02 1.00000e-03 1.00000e-09 1.00000e-01

$1.00000 \mathrm{e}+001.00000 \mathrm{e}+001.00000 \mathrm{e}-011.00000 \mathrm{e}-091.00000 \mathrm{e}-01$

$1.00000 \mathrm{e}-05$ 1.00000e-05 1.00000e-06 1.00000e-09 1.00000e-01

$1.00000 \mathrm{e}+001.00000 \mathrm{e}+001.00000 \mathrm{e}-011.00000 \mathrm{e}-091.00000 \mathrm{e}-01$

Element: 1875 \# of layers: 9

Kx Ky Kz Ss Por

$1.63934 \mathrm{e}+01$ 1.63934e+01 1.63934e+00 1.00000e-09 2.12000e-01

$1.63934 \mathrm{e}+01$ 1.63934e+01 1.63934e+00 1.00000e-09 2.12000e-01

$1.63934 \mathrm{e}+011.63934 \mathrm{e}+011.63934 \mathrm{e}+001.00000 \mathrm{e}-092.12000 \mathrm{e}-01$

$1.63934 \mathrm{e}+011.63934 \mathrm{e}+011.63934 \mathrm{e}+001.00000 \mathrm{e}-092.12000 \mathrm{e}-01$

$1.63934 \mathrm{e}+011.63934 \mathrm{e}+011.63934 \mathrm{e}+001.00000 \mathrm{e}-092.12000 \mathrm{e}-01$

$1.00000 \mathrm{e}-02$ 1.00000e-02 1.00000e-03 1.00000e-09 1.00000e-01

$1.00000 \mathrm{e}+001.00000 \mathrm{e}+001.00000 \mathrm{e}-011.00000 \mathrm{e}-091.00000 \mathrm{e}-01$

$1.00000 \mathrm{e}-05$ 1.00000e-05 1.00000e-06 1.00000e-09 1.00000e-01

$1.00000 \mathrm{e}+001.00000 \mathrm{e}+001.00000 \mathrm{e}-011.00000 \mathrm{e}-091.00000 \mathrm{e}-01$

Element: 1876 \# of layers: 9

$\mathrm{Kx} \mathrm{Ky} \mathrm{Kz}$ Ss Por

$1.63934 \mathrm{e}+011.63934 \mathrm{e}+011.63934 \mathrm{e}+001.00000 \mathrm{e}-092.12000 \mathrm{e}-01$

$1.63934 \mathrm{e}+011.63934 \mathrm{e}+011.63934 \mathrm{e}+001.00000 \mathrm{e}-092.12000 \mathrm{e}-01$

$1.63934 \mathrm{e}+01$ 1.63934e+01 1.63934e+00 1.00000e-09 2.12000e-01

$1.63934 \mathrm{e}+011.63934 \mathrm{e}+01$ 1.63934e+00 1.00000e-09 2.12000e-01

$1.63934 \mathrm{e}+011.63934 \mathrm{e}+011.63934 \mathrm{e}+001.00000 \mathrm{e}-092.12000 \mathrm{e}-01$

$1.00000 \mathrm{e}-02$ 1.00000e-02 1.00000e-03 1.00000e-09 1.00000e-01

$1.00000 \mathrm{e}+001.00000 \mathrm{e}+001.00000 \mathrm{e}-011.00000 \mathrm{e}-091.00000 \mathrm{e}-01$

$1.00000 \mathrm{e}-05$ 1.00000e-05 1.00000e-06 1.00000e-09 1.00000e-01

$1.00000 \mathrm{e}+001.00000 \mathrm{e}+001.00000 \mathrm{e}-01$ 1.00000e-09 1.00000e-01

Element: 1877 \# of layers: 9

$\mathrm{Kx} \mathrm{Ky} \mathrm{Kz}$ Ss Por

$1.63934 \mathrm{e}+011.63934 \mathrm{e}+011.63934 \mathrm{e}+00$ 1.00000e-09 2.12000e-01

$1.63934 \mathrm{e}+011.63934 \mathrm{e}+011.63934 \mathrm{e}+001.00000 \mathrm{e}-092.12000 \mathrm{e}-01$

$1.63934 \mathrm{e}+011.63934 \mathrm{e}+011.63934 \mathrm{e}+001.00000 \mathrm{e}-092.12000 \mathrm{e}-01$

$1.63934 \mathrm{e}+011.63934 \mathrm{e}+011.63934 \mathrm{e}+001.00000 \mathrm{e}-092.12000 \mathrm{e}-01$

$1.63934 \mathrm{e}+011.63934 \mathrm{e}+01$ 1.63934e+00 1.00000e-09 2.12000e-01

$1.00000 \mathrm{e}-02$ 1.00000e-02 1.00000e-03 1.00000e-09 1.00000e-01

$1.00000 \mathrm{e}+001.00000 \mathrm{e}+001.00000 \mathrm{e}-011.00000 \mathrm{e}-091.00000 \mathrm{e}-01$

$1.00000 \mathrm{e}-05$ 1.00000e-05 1.00000e-06 1.00000e-09 1.00000e-01

$1.00000 \mathrm{e}+001.00000 \mathrm{e}+001.00000 \mathrm{e}-01$ 1.00000e-09 1.00000e-01

Element: 1878 \# of layers: 9

$\mathrm{Kx} \mathrm{Ky} \mathrm{Kz}$ Ss Por

$1.63934 \mathrm{e}+011.63934 \mathrm{e}+011.63934 \mathrm{e}+001.00000 \mathrm{e}-092.12000 \mathrm{e}-01$ 
$1.63934 \mathrm{e}+01$ 1.63934e+01 1.63934e+00 1.00000e-09 2.12000e-01 $1.63934 \mathrm{e}+011.63934 \mathrm{e}+011.63934 \mathrm{e}+001.00000 \mathrm{e}-092.12000 \mathrm{e}-01$ $1.63934 \mathrm{e}+011.63934 \mathrm{e}+011.63934 \mathrm{e}+001.00000 \mathrm{e}-092.12000 \mathrm{e}-01$ $1.63934 \mathrm{e}+011.63934 \mathrm{e}+011.63934 \mathrm{e}+001.00000 \mathrm{e}-092.12000 \mathrm{e}-01$ $1.00000 \mathrm{e}-02$ 1.00000e-02 1.00000e-03 1.00000e-09 1.00000e-01 $1.00000 \mathrm{e}+001.00000 \mathrm{e}+001.00000 \mathrm{e}-011.00000 \mathrm{e}-091.00000 \mathrm{e}-01$ 1.00000e-05 1.00000e-05 1.00000e-06 1.00000e-09 1.00000e-01 $1.00000 \mathrm{e}+001.00000 \mathrm{e}+001.00000 \mathrm{e}-011.00000 \mathrm{e}-091.00000 \mathrm{e}-01$ Element: 1879 \# of layers: 9

$\mathrm{Kx} \mathrm{Ky} \mathrm{Kz}$ Ss Por

$1.63934 \mathrm{e}+011.63934 \mathrm{e}+01$ 1.63934e+00 1.00000e-09 2.12000e-01 $1.63934 \mathrm{e}+011.63934 \mathrm{e}+011.63934 \mathrm{e}+001.00000 \mathrm{e}-092.12000 \mathrm{e}-01$ $1.63934 \mathrm{e}+011.63934 \mathrm{e}+011.63934 \mathrm{e}+001.00000 \mathrm{e}-092.12000 \mathrm{e}-01$ $1.63934 \mathrm{e}+011.63934 \mathrm{e}+011.63934 \mathrm{e}+001.00000 \mathrm{e}-092.12000 \mathrm{e}-01$ $1.63934 \mathrm{e}+011.63934 \mathrm{e}+011.63934 \mathrm{e}+001.00000 \mathrm{e}-092.12000 \mathrm{e}-01$ $1.00000 \mathrm{e}-02$ 1.00000e-02 1.00000e-03 1.00000e-09 1.00000e-01 $1.00000 \mathrm{e}+001.00000 \mathrm{e}+001.00000 \mathrm{e}-011.00000 \mathrm{e}-091.00000 \mathrm{e}-01$ $1.00000 \mathrm{e}-051.00000 \mathrm{e}-051.00000 \mathrm{e}-061.00000 \mathrm{e}-091.00000 \mathrm{e}-01$ $1.00000 \mathrm{e}+001.00000 \mathrm{e}+001.00000 \mathrm{e}-011.00000 \mathrm{e}-091.00000 \mathrm{e}-01$ Element: 1880 \# of layers: 9

$\mathrm{Kx} \mathrm{Ky} \mathrm{Kz}$ Ss Por

$1.63934 \mathrm{e}+01$ 1.63934e+01 1.63934e+00 1.00000e-09 2.12000e-01 $1.63934 \mathrm{e}+01$ 1.63934e+01 1.63934e+00 1.00000e-09 2.12000e-01 $1.63934 \mathrm{e}+011.63934 \mathrm{e}+011.63934 \mathrm{e}+001.00000 \mathrm{e}-092.12000 \mathrm{e}-01$ $1.63934 \mathrm{e}+011.63934 \mathrm{e}+011.63934 \mathrm{e}+001.00000 \mathrm{e}-092.12000 \mathrm{e}-01$ $1.63934 \mathrm{e}+011.63934 \mathrm{e}+011.63934 \mathrm{e}+001.00000 \mathrm{e}-092.12000 \mathrm{e}-01$ $1.00000 \mathrm{e}-02$ 1.00000e-02 1.00000e-03 1.00000e-09 1.00000e-01 $1.00000 \mathrm{e}+001.00000 \mathrm{e}+001.00000 \mathrm{e}-011.00000 \mathrm{e}-091.00000 \mathrm{e}-01$ $1.00000 \mathrm{e}-05$ 1.00000e-05 1.00000e-06 1.00000e-09 1.00000e-01 $1.00000 \mathrm{e}+001.00000 \mathrm{e}+001.00000 \mathrm{e}-011.00000 \mathrm{e}-091.00000 \mathrm{e}-01$ Element: 1881 \# of layers: 9

Kx Ky Kz Ss Por

$1.63934 \mathrm{e}+01$ 1.63934e+01 1.63934e+00 1.00000e-09 2.12000e-01 $1.63934 \mathrm{e}+011.63934 \mathrm{e}+011.63934 \mathrm{e}+001.00000 \mathrm{e}-092.12000 \mathrm{e}-01$ $1.63934 \mathrm{e}+011.63934 \mathrm{e}+011.63934 \mathrm{e}+001.00000 \mathrm{e}-092.12000 \mathrm{e}-01$ $1.63934 \mathrm{e}+011.63934 \mathrm{e}+011.63934 \mathrm{e}+001.00000 \mathrm{e}-092.12000 \mathrm{e}-01$ $1.63934 \mathrm{e}+011.63934 \mathrm{e}+011.63934 \mathrm{e}+001.00000 \mathrm{e}-092.12000 \mathrm{e}-01$ $1.00000 \mathrm{e}-02$ 1.00000e-02 1.00000e-03 1.00000e-09 1.00000e-01 $1.00000 \mathrm{e}+001.00000 \mathrm{e}+001.00000 \mathrm{e}-011.00000 \mathrm{e}-091.00000 \mathrm{e}-01$ $1.00000 \mathrm{e}-05$ 1.00000e-05 1.00000e-06 1.00000e-09 1.00000e-01 $1.00000 \mathrm{e}+001.00000 \mathrm{e}+001.00000 \mathrm{e}-011.00000 \mathrm{e}-091.00000 \mathrm{e}-01$ Element: 1882 \# of layers: 9

$\mathrm{Kx} \mathrm{Ky} \mathrm{Kz}$ Ss Por

1.63934e+01 1.63934e+01 1.63934e+00 1.00000e-09 2.12000e-01 $1.63934 \mathrm{e}+011.63934 \mathrm{e}+011.63934 \mathrm{e}+001.00000 \mathrm{e}-092.12000 \mathrm{e}-01$ $1.63934 \mathrm{e}+011.63934 \mathrm{e}+011.63934 \mathrm{e}+001.00000 \mathrm{e}-092.12000 \mathrm{e}-01$ 
$1.63934 \mathrm{e}+011.63934 \mathrm{e}+011.63934 \mathrm{e}+001.00000 \mathrm{e}-092.12000 \mathrm{e}-01$ $1.63934 \mathrm{e}+011.63934 \mathrm{e}+011.63934 \mathrm{e}+001.00000 \mathrm{e}-092.12000 \mathrm{e}-01$ $1.00000 \mathrm{e}-02$ 1.00000e-02 1.00000e-03 1.00000e-09 1.00000e-01

$1.00000 \mathrm{e}+001.00000 \mathrm{e}+001.00000 \mathrm{e}-011.00000 \mathrm{e}-091.00000 \mathrm{e}-01$ $1.00000 \mathrm{e}-05$ 1.00000e-05 1.00000e-06 1.00000e-09 1.00000e-01

$1.00000 \mathrm{e}+001.00000 \mathrm{e}+001.00000 \mathrm{e}-011.00000 \mathrm{e}-091.00000 \mathrm{e}-01$

Element: 1883 \# of layers: 9

$\mathrm{Kx} \mathrm{Ky} \mathrm{Kz}$ Ss Por

$1.63934 \mathrm{e}+011.63934 \mathrm{e}+011.63934 \mathrm{e}+001.00000 \mathrm{e}-092.12000 \mathrm{e}-01$

$1.63934 \mathrm{e}+011.63934 \mathrm{e}+011.63934 \mathrm{e}+001.00000 \mathrm{e}-092.12000 \mathrm{e}-01$

$1.63934 \mathrm{e}+011.63934 \mathrm{e}+01$ 1.63934e+00 1.00000e-09 2.12000e-01

$1.63934 \mathrm{e}+011.63934 \mathrm{e}+011.63934 \mathrm{e}+001.00000 \mathrm{e}-092.12000 \mathrm{e}-01$

$1.63934 \mathrm{e}+011.63934 \mathrm{e}+011.63934 \mathrm{e}+001.00000 \mathrm{e}-092.12000 \mathrm{e}-01$

$1.00000 \mathrm{e}-02$ 1.00000e-02 1.00000e-03 1.00000e-09 1.00000e-01

$1.00000 \mathrm{e}+001.00000 \mathrm{e}+001.00000 \mathrm{e}-011.00000 \mathrm{e}-091.00000 \mathrm{e}-01$

$1.00000 \mathrm{e}-05$ 1.00000e-05 1.00000e-06 1.00000e-09 1.00000e-01

$1.00000 \mathrm{e}+001.00000 \mathrm{e}+001.00000 \mathrm{e}-011.00000 \mathrm{e}-091.00000 \mathrm{e}-01$

Element: 1884 \# of layers: 9

$\mathrm{Kx} \mathrm{Ky} \mathrm{Kz}$ Ss Por

$1.84792 \mathrm{e}+01$ 1.84792e+01 1.84792e+00 1.00000e-09 2.12000e-01 $1.84792 \mathrm{e}+01$ 1.84792e+01 1.84792e+00 1.00000e-09 2.12000e-01

$1.84792 \mathrm{e}+01$ 1.84792e+01 1.84792e+00 1.00000e-09 2.12000e-01

$1.84792 \mathrm{e}+01$ 1.84792e+01 1.84792e+00 1.00000e-09 2.12000e-01

$1.84792 \mathrm{e}+011.84792 \mathrm{e}+01$ 1.84792e+00 1.00000e-09 2.12000e-01

$1.00000 \mathrm{e}-021.00000 \mathrm{e}-02$ 1.00000e-03 1.00000e-09 1.00000e-01

$1.00000 \mathrm{e}+001.00000 \mathrm{e}+001.00000 \mathrm{e}-011.00000 \mathrm{e}-091.00000 \mathrm{e}-01$

$1.00000 \mathrm{e}-05$ 1.00000e-05 1.00000e-06 1.00000e-09 1.00000e-01

$1.00000 \mathrm{e}+001.00000 \mathrm{e}+001.00000 \mathrm{e}-011.00000 \mathrm{e}-091.00000 \mathrm{e}-01$

Element: 1885 \# of layers: 9

$\mathrm{Kx} \mathrm{Ky} \mathrm{Kz}$ Ss Por

1.84792e+01 1.84792e+01 1.84792e+00 1.00000e-09 2.12000e-01

$1.84792 \mathrm{e}+01$ 1.84792e+01 1.84792e+00 1.00000e-09 2.12000e-01

$1.84792 \mathrm{e}+011.84792 \mathrm{e}+01$ 1.84792e+00 1.00000e-09 2.12000e-01

$1.84792 \mathrm{e}+01$ 1.84792e+01 1.84792e+00 1.00000e-09 2.12000e-01

$1.84792 \mathrm{e}+01$ 1.84792e+01 1.84792e+00 1.00000e-09 2.12000e-01

1.00000e-02 1.00000e-02 1.00000e-03 1.00000e-09 1.00000e-01

$1.00000 \mathrm{e}+001.00000 \mathrm{e}+001.00000 \mathrm{e}-011.00000 \mathrm{e}-091.00000 \mathrm{e}-01$

$1.00000 \mathrm{e}-05$ 1.00000e-05 1.00000e-06 1.00000e-09 1.00000e-01

$1.00000 \mathrm{e}+001.00000 \mathrm{e}+001.00000 \mathrm{e}-011.00000 \mathrm{e}-091.00000 \mathrm{e}-01$

Element: 1886 \# of layers: 9

$\mathrm{Kx} \mathrm{Ky} \mathrm{Kz}$ Ss Por

$1.84792 \mathrm{e}+01$ 1.84792e+01 1.84792e+00 1.00000e-09 2.12000e-01

$1.84792 \mathrm{e}+01$ 1.84792e+01 1.84792e+00 1.00000e-09 2.12000e-01

1.84792e+01 1.84792e+01 1.84792e+00 1.00000e-09 2.12000e-01

$1.84792 \mathrm{e}+011.84792 \mathrm{e}+01$ 1.84792e+00 1.00000e-09 2.12000e-01

$1.84792 \mathrm{e}+011.84792 \mathrm{e}+011.84792 \mathrm{e}+001.00000 \mathrm{e}-092.12000 \mathrm{e}-01$ 
$1.00000 \mathrm{e}-02$ 1.00000e-02 1.00000e-03 1.00000e-09 1.00000e-01 $1.00000 \mathrm{e}+001.00000 \mathrm{e}+001.00000 \mathrm{e}-011.00000 \mathrm{e}-091.00000 \mathrm{e}-01$ $1.00000 \mathrm{e}-051.00000 \mathrm{e}-05$ 1.00000e-06 1.00000e-09 1.00000e-01 $1.00000 \mathrm{e}+001.00000 \mathrm{e}+001.00000 \mathrm{e}-011.00000 \mathrm{e}-091.00000 \mathrm{e}-01$ Element: 1887 \# of layers: 9

Kx Ky Kz Ss Por

$1.84792 \mathrm{e}+011.84792 \mathrm{e}+011.84792 \mathrm{e}+00$ 1.00000e-09 2.12000e-01 $1.84792 \mathrm{e}+011.84792 \mathrm{e}+011.84792 \mathrm{e}+001.00000 \mathrm{e}-092.12000 \mathrm{e}-01$ $1.84792 \mathrm{e}+011.84792 \mathrm{e}+011.84792 \mathrm{e}+001.00000 \mathrm{e}-092.12000 \mathrm{e}-01$ $1.84792 \mathrm{e}+011.84792 \mathrm{e}+011.84792 \mathrm{e}+001.00000 \mathrm{e}-092.12000 \mathrm{e}-01$ $1.84792 \mathrm{e}+011.84792 \mathrm{e}+011.84792 \mathrm{e}+001.00000 \mathrm{e}-092.12000 \mathrm{e}-01$ $1.00000 \mathrm{e}-021.00000 \mathrm{e}-02$ 1.00000e-03 1.00000e-09 1.00000e-01 $1.00000 \mathrm{e}+001.00000 \mathrm{e}+001.00000 \mathrm{e}-011.00000 \mathrm{e}-091.00000 \mathrm{e}-01$ $1.00000 \mathrm{e}-05$ 1.00000e-05 1.00000e-06 1.00000e-09 1.00000e-01 $1.00000 \mathrm{e}+001.00000 \mathrm{e}+001.00000 \mathrm{e}-011.00000 \mathrm{e}-091.00000 \mathrm{e}-01$ Element: 1888 \# of layers: 9

Kx Ky Kz Ss Por

$1.84792 \mathrm{e}+011.84792 \mathrm{e}+01$ 1.84792e+00 1.00000e-09 2.12000e-01 $1.84792 \mathrm{e}+011.84792 \mathrm{e}+011.84792 \mathrm{e}+001.00000 \mathrm{e}-092.12000 \mathrm{e}-01$ $1.84792 \mathrm{e}+011.84792 \mathrm{e}+011.84792 \mathrm{e}+001.00000 \mathrm{e}-092.12000 \mathrm{e}-01$ $1.84792 \mathrm{e}+011.84792 \mathrm{e}+011.84792 \mathrm{e}+001.00000 \mathrm{e}-092.12000 \mathrm{e}-01$ $1.84792 \mathrm{e}+011.84792 \mathrm{e}+011.84792 \mathrm{e}+001.00000 \mathrm{e}-092.12000 \mathrm{e}-01$ $1.00000 \mathrm{e}-021.00000 \mathrm{e}-02$ 1.00000e-03 1.00000e-09 1.00000e-01 $1.00000 \mathrm{e}+001.00000 \mathrm{e}+001.00000 \mathrm{e}-011.00000 \mathrm{e}-091.00000 \mathrm{e}-01$ $1.00000 \mathrm{e}-05$ 1.00000e-05 1.00000e-06 1.00000e-09 1.00000e-01 $1.00000 \mathrm{e}+001.00000 \mathrm{e}+001.00000 \mathrm{e}-011.00000 \mathrm{e}-091.00000 \mathrm{e}-01$ Element: 1889 \# of layers: 9

Kx Ky Kz Ss Por

$1.84792 \mathrm{e}+011.84792 \mathrm{e}+011.84792 \mathrm{e}+00$ 1.00000e-09 2.12000e-01 $1.84792 \mathrm{e}+011.84792 \mathrm{e}+011.84792 \mathrm{e}+001.00000 \mathrm{e}-092.12000 \mathrm{e}-01$ $1.84792 \mathrm{e}+011.84792 \mathrm{e}+011.84792 \mathrm{e}+001.00000 \mathrm{e}-092.12000 \mathrm{e}-01$ $1.84792 \mathrm{e}+011.84792 \mathrm{e}+011.84792 \mathrm{e}+001.00000 \mathrm{e}-092.12000 \mathrm{e}-01$ $1.84792 \mathrm{e}+011.84792 \mathrm{e}+011.84792 \mathrm{e}+001.00000 \mathrm{e}-092.12000 \mathrm{e}-01$ $1.00000 \mathrm{e}-021.00000 \mathrm{e}-02$ 1.00000e-03 1.00000e-09 1.00000e-01 $1.00000 \mathrm{e}+001.00000 \mathrm{e}+001.00000 \mathrm{e}-011.00000 \mathrm{e}-091.00000 \mathrm{e}-01$ $1.00000 \mathrm{e}-05$ 1.00000e-05 1.00000e-06 1.00000e-09 1.00000e-01 $1.00000 \mathrm{e}+001.00000 \mathrm{e}+001.00000 \mathrm{e}-011.00000 \mathrm{e}-091.00000 \mathrm{e}-01$ Element: 1890 \# of layers: 9

Kx Ky Kz Ss Por

$1.84792 \mathrm{e}+011.84792 \mathrm{e}+011.84792 \mathrm{e}+00$ 1.00000e-09 2.12000e-01 $1.84792 \mathrm{e}+011.84792 \mathrm{e}+011.84792 \mathrm{e}+001.00000 \mathrm{e}-092.12000 \mathrm{e}-01$ $1.84792 \mathrm{e}+011.84792 \mathrm{e}+011.84792 \mathrm{e}+001.00000 \mathrm{e}-092.12000 \mathrm{e}-01$ $1.84792 \mathrm{e}+011.84792 \mathrm{e}+011.84792 \mathrm{e}+001.00000 \mathrm{e}-092.12000 \mathrm{e}-01$ $1.84792 \mathrm{e}+011.84792 \mathrm{e}+011.84792 \mathrm{e}+001.00000 \mathrm{e}-092.12000 \mathrm{e}-01$ $1.00000 \mathrm{e}-021.00000 \mathrm{e}-02$ 1.00000e-03 1.00000e-09 1.00000e-01 $1.00000 \mathrm{e}+001.00000 \mathrm{e}+001.00000 \mathrm{e}-011.00000 \mathrm{e}-091.00000 \mathrm{e}-01$ 
$1.00000 \mathrm{e}-05$ 1.00000e-05 1.00000e-06 1.00000e-09 1.00000e-01 $1.00000 \mathrm{e}+001.00000 \mathrm{e}+001.00000 \mathrm{e}-01$ 1.00000e-09 1.00000e-01 Element: 1891 \# of layers: 9

Kx Ky Kz Ss Por

$1.84792 \mathrm{e}+011.84792 \mathrm{e}+01$ 1.84792e+00 1.00000e-09 2.12000e-01 $1.84792 \mathrm{e}+01$ 1.84792e+01 1.84792e+00 1.00000e-09 2.12000e-01 $1.84792 \mathrm{e}+01$ 1.84792e+01 1.84792e+00 1.00000e-09 2.12000e-01 $1.84792 \mathrm{e}+01$ 1.84792e+01 1.84792e+00 1.00000e-09 2.12000e-01 $1.84792 \mathrm{e}+01$ 1.84792e+01 1.84792e+00 1.00000e-09 2.12000e-01 $1.00000 \mathrm{e}-02$ 1.00000e-02 1.00000e-03 1.00000e-09 1.00000e-01 $1.00000 \mathrm{e}+001.00000 \mathrm{e}+001.00000 \mathrm{e}-011.00000 \mathrm{e}-091.00000 \mathrm{e}-01$ $1.00000 \mathrm{e}-05$ 1.00000e-05 1.00000e-06 1.00000e-09 1.00000e-01 $1.00000 \mathrm{e}+001.00000 \mathrm{e}+001.00000 \mathrm{e}-011.00000 \mathrm{e}-091.00000 \mathrm{e}-01$ Element: 1892 \# of layers: 9

$\mathrm{Kx} \mathrm{Ky} \mathrm{Kz}$ Ss Por

$1.84792 \mathrm{e}+01$ 1.84792e+01 1.84792e+00 1.00000e-09 2.12000e-01 $1.84792 \mathrm{e}+01$ 1.84792e+01 1.84792e+00 1.00000e-09 2.12000e-01 $1.84792 \mathrm{e}+01$ 1.84792e+01 1.84792e+00 1.00000e-09 2.12000e-01 $1.84792 \mathrm{e}+01$ 1.84792e+01 1.84792e+00 1.00000e-09 2.12000e-01 $1.84792 \mathrm{e}+01$ 1.84792e+01 1.84792e+00 1.00000e-09 2.12000e-01 $1.00000 \mathrm{e}-02$ 1.00000e-02 1.00000e-03 1.00000e-09 1.00000e-01 $1.00000 \mathrm{e}+001.00000 \mathrm{e}+001.00000 \mathrm{e}-011.00000 \mathrm{e}-091.00000 \mathrm{e}-01$ $1.00000 \mathrm{e}-05$ 1.00000e-05 1.00000e-06 1.00000e-09 1.00000e-01 $1.00000 \mathrm{e}+001.00000 \mathrm{e}+001.00000 \mathrm{e}-011.00000 \mathrm{e}-09$ 1.00000e-01 Element: 1893 \# of layers: 9

$\mathrm{Kx} \mathrm{Ky} \mathrm{Kz}$ Ss Por

$2.15645 \mathrm{e}+012.15645 \mathrm{e}+012.15645 \mathrm{e}+00$ 1.00000e-09 2.12000e-01 $2.15645 \mathrm{e}+012.15645 \mathrm{e}+012.15645 \mathrm{e}+00$ 1.00000e-09 2.12000e-01 $2.15645 \mathrm{e}+012.15645 \mathrm{e}+012.15645 \mathrm{e}+001.00000 \mathrm{e}-092.12000 \mathrm{e}-01$ $2.15645 \mathrm{e}+012.15645 \mathrm{e}+012.15645 \mathrm{e}+00$ 1.00000e-09 2.12000e-01 $2.15645 \mathrm{e}+012.15645 \mathrm{e}+012.15645 \mathrm{e}+00$ 1.00000e-09 2.12000e-01 1.00000e-02 1.00000e-02 1.00000e-03 1.00000e-09 1.00000e-01 $1.00000 \mathrm{e}+001.00000 \mathrm{e}+001.00000 \mathrm{e}-011.00000 \mathrm{e}-091.00000 \mathrm{e}-01$ $1.00000 \mathrm{e}-05$ 1.00000e-05 1.00000e-06 1.00000e-09 1.00000e-01 $1.00000 \mathrm{e}+001.00000 \mathrm{e}+001.00000 \mathrm{e}-011.00000 \mathrm{e}-091.00000 \mathrm{e}-01$ Element: 1894 \# of layers: 9

Kx Ky Kz Ss Por

$2.15645 \mathrm{e}+012.15645 \mathrm{e}+012.15645 \mathrm{e}+00$ 1.00000e-09 2.12000e-01 $2.15645 \mathrm{e}+012.15645 \mathrm{e}+012.15645 \mathrm{e}+00$ 1.00000e-09 2.12000e-01 $2.15645 \mathrm{e}+012.15645 \mathrm{e}+012.15645 \mathrm{e}+00$ 1.00000e-09 2.12000e-01 $2.15645 \mathrm{e}+012.15645 \mathrm{e}+012.15645 \mathrm{e}+00$ 1.00000e-09 2.12000e-01 $2.15645 \mathrm{e}+012.15645 \mathrm{e}+012.15645 \mathrm{e}+001.00000 \mathrm{e}-092.12000 \mathrm{e}-01$ $1.00000 \mathrm{e}-02$ 1.00000e-02 1.00000e-03 1.00000e-09 1.00000e-01 $1.00000 \mathrm{e}+001.00000 \mathrm{e}+001.00000 \mathrm{e}-011.00000 \mathrm{e}-091.00000 \mathrm{e}-01$ $1.00000 \mathrm{e}-05$ 1.00000e-05 1.00000e-06 1.00000e-09 1.00000e-01 $1.00000 \mathrm{e}+001.00000 \mathrm{e}+001.00000 \mathrm{e}-011.00000 \mathrm{e}-091.00000 \mathrm{e}-01$ 
Element: 1895 \# of layers: 9

$\mathrm{Kx} \mathrm{Ky} \mathrm{Kz}$ Ss Por

$2.15645 \mathrm{e}+012.15645 \mathrm{e}+012.15645 \mathrm{e}+00$ 1.00000e-09 2.12000e-01

$2.15645 \mathrm{e}+012.15645 \mathrm{e}+012.15645 \mathrm{e}+001.00000 \mathrm{e}-092.12000 \mathrm{e}-01$

$2.15645 \mathrm{e}+012.15645 \mathrm{e}+012.15645 \mathrm{e}+00$ 1.00000e-09 2.12000e-01

$2.15645 \mathrm{e}+012.15645 \mathrm{e}+012.15645 \mathrm{e}+00$ 1.00000e-09 2.12000e-01

$2.15645 \mathrm{e}+012.15645 \mathrm{e}+012.15645 \mathrm{e}+00$ 1.00000e-09 2.12000e-01 $1.00000 \mathrm{e}-02$ 1.00000e-02 1.00000e-03 1.00000e-09 1.00000e-01

$1.00000 \mathrm{e}+001.00000 \mathrm{e}+001.00000 \mathrm{e}-011.00000 \mathrm{e}-091.00000 \mathrm{e}-01$

$1.00000 \mathrm{e}-05$ 1.00000e-05 1.00000e-06 1.00000e-09 1.00000e-01

$1.00000 \mathrm{e}+001.00000 \mathrm{e}+001.00000 \mathrm{e}-011.00000 \mathrm{e}-091.00000 \mathrm{e}-01$

Element: 1896 \# of layers: 9

$\mathrm{Kx} \mathrm{Ky} \mathrm{Kz}$ Ss Por

$2.15645 \mathrm{e}+012.15645 \mathrm{e}+012.15645 \mathrm{e}+00$ 1.00000e-09 2.12000e-01

$2.15645 \mathrm{e}+012.15645 \mathrm{e}+012.15645 \mathrm{e}+00$ 1.00000e-09 2.12000e-01

$2.15645 \mathrm{e}+012.15645 \mathrm{e}+012.15645 \mathrm{e}+001.00000 \mathrm{e}-092.12000 \mathrm{e}-01$

$2.15645 \mathrm{e}+012.15645 \mathrm{e}+012.15645 \mathrm{e}+00$ 1.00000e-09 2.12000e-01

$2.15645 \mathrm{e}+012.15645 \mathrm{e}+012.15645 \mathrm{e}+00$ 1.00000e-09 2.12000e-01

$1.00000 \mathrm{e}-02$ 1.00000e-02 1.00000e-03 1.00000e-09 1.00000e-01

$1.00000 \mathrm{e}+001.00000 \mathrm{e}+001.00000 \mathrm{e}-011.00000 \mathrm{e}-091.00000 \mathrm{e}-01$

$1.00000 \mathrm{e}-05$ 1.00000e-05 1.00000e-06 1.00000e-09 1.00000e-01

$1.00000 \mathrm{e}+001.00000 \mathrm{e}+001.00000 \mathrm{e}-01$ 1.00000e-09 1.00000e-01

Element: 1897 \# of layers: 9

Kx Ky Kz Ss Por

$2.15645 \mathrm{e}+012.15645 \mathrm{e}+012.15645 \mathrm{e}+00$ 1.00000e-09 2.12000e-01

$2.15645 \mathrm{e}+012.15645 \mathrm{e}+012.15645 \mathrm{e}+001.00000 \mathrm{e}-092.12000 \mathrm{e}-01$

$2.15645 \mathrm{e}+012.15645 \mathrm{e}+012.15645 \mathrm{e}+001.00000 \mathrm{e}-092.12000 \mathrm{e}-01$

$2.15645 \mathrm{e}+012.15645 \mathrm{e}+012.15645 \mathrm{e}+00$ 1.00000e-09 2.12000e-01

$2.15645 \mathrm{e}+012.15645 \mathrm{e}+012.15645 \mathrm{e}+001.00000 \mathrm{e}-092.12000 \mathrm{e}-01$

$1.00000 \mathrm{e}-02$ 1.00000e-02 1.00000e-03 1.00000e-09 1.00000e-01

$1.00000 \mathrm{e}+001.00000 \mathrm{e}+001.00000 \mathrm{e}-011.00000 \mathrm{e}-091.00000 \mathrm{e}-01$

1.00000e-05 1.00000e-05 1.00000e-06 1.00000e-09 1.00000e-01

$1.00000 \mathrm{e}+001.00000 \mathrm{e}+001.00000 \mathrm{e}-011.00000 \mathrm{e}-091.00000 \mathrm{e}-01$

Element: 1898 \# of layers: 9

$\mathrm{Kx} \mathrm{Ky} \mathrm{Kz}$ Ss Por

$2.15645 \mathrm{e}+012.15645 \mathrm{e}+012.15645 \mathrm{e}+00$ 1.00000e-09 2.12000e-01

$2.15645 \mathrm{e}+012.15645 \mathrm{e}+012.15645 \mathrm{e}+001.00000 \mathrm{e}-092.12000 \mathrm{e}-01$

$2.15645 \mathrm{e}+012.15645 \mathrm{e}+012.15645 \mathrm{e}+00$ 1.00000e-09 2.12000e-01

$2.15645 \mathrm{e}+012.15645 \mathrm{e}+012.15645 \mathrm{e}+00$ 1.00000e-09 2.12000e-01

$2.15645 \mathrm{e}+012.15645 \mathrm{e}+012.15645 \mathrm{e}+00$ 1.00000e-09 2.12000e-01 $1.00000 \mathrm{e}-02$ 1.00000e-02 1.00000e-03 1.00000e-09 1.00000e-01

$1.00000 \mathrm{e}+001.00000 \mathrm{e}+001.00000 \mathrm{e}-011.00000 \mathrm{e}-091.00000 \mathrm{e}-01$ $1.00000 \mathrm{e}-05$ 1.00000e-05 1.00000e-06 1.00000e-09 1.00000e-01

$1.00000 \mathrm{e}+001.00000 \mathrm{e}+001.00000 \mathrm{e}-011.00000 \mathrm{e}-091.00000 \mathrm{e}-01$

Element: 1899 \# of layers: 9

Kx Ky Kz Ss Por 
$2.15645 \mathrm{e}+012.15645 \mathrm{e}+012.15645 \mathrm{e}+00$ 1.00000e-09 2.12000e-01 $2.15645 \mathrm{e}+012.15645 \mathrm{e}+012.15645 \mathrm{e}+00$ 1.00000e-09 2.12000e-01 $2.15645 \mathrm{e}+012.15645 \mathrm{e}+012.15645 \mathrm{e}+00$ 1.00000e-09 2.12000e-01 $2.15645 \mathrm{e}+012.15645 \mathrm{e}+012.15645 \mathrm{e}+001.00000 \mathrm{e}-092.12000 \mathrm{e}-01$ $2.15645 \mathrm{e}+012.15645 \mathrm{e}+012.15645 \mathrm{e}+001.00000 \mathrm{e}-092.12000 \mathrm{e}-01$ $1.00000 \mathrm{e}-02$ 1.00000e-02 1.00000e-03 1.00000e-09 1.00000e-01 $1.00000 \mathrm{e}+001.00000 \mathrm{e}+001.00000 \mathrm{e}-011.00000 \mathrm{e}-091.00000 \mathrm{e}-01$ $1.00000 \mathrm{e}-05$ 1.00000e-05 1.00000e-06 1.00000e-09 1.00000e-01 $1.00000 \mathrm{e}+001.00000 \mathrm{e}+001.00000 \mathrm{e}-011.00000 \mathrm{e}-091.00000 \mathrm{e}-01$ Element: 1900 \# of layers: 9

$\mathrm{Kx} \mathrm{Ky} \mathrm{Kz}$ Ss Por

$2.15645 \mathrm{e}+012.15645 \mathrm{e}+012.15645 \mathrm{e}+00$ 1.00000e-09 2.12000e-01 $2.15645 \mathrm{e}+012.15645 \mathrm{e}+012.15645 \mathrm{e}+00$ 1.00000e-09 2.12000e-01 $2.15645 \mathrm{e}+012.15645 \mathrm{e}+012.15645 \mathrm{e}+00$ 1.00000e-09 2.12000e-01 $2.15645 \mathrm{e}+012.15645 \mathrm{e}+012.15645 \mathrm{e}+00$ 1.00000e-09 2.12000e-01 $2.15645 \mathrm{e}+012.15645 \mathrm{e}+012.15645 \mathrm{e}+001.00000 \mathrm{e}-092.12000 \mathrm{e}-01$ 1.00000e-02 1.00000e-02 1.00000e-03 1.00000e-09 1.00000e-01 $1.00000 \mathrm{e}+001.00000 \mathrm{e}+001.00000 \mathrm{e}-011.00000 \mathrm{e}-091.00000 \mathrm{e}-01$ $1.00000 \mathrm{e}-05$ 1.00000e-05 1.00000e-06 1.00000e-09 1.00000e-01 $1.00000 \mathrm{e}+001.00000 \mathrm{e}+001.00000 \mathrm{e}-011.00000 \mathrm{e}-091.00000 \mathrm{e}-01$ Element: 1901 \# of layers: 9

$\mathrm{Kx} \mathrm{Ky} \mathrm{Kz}$ Ss Por

$2.15645 \mathrm{e}+012.15645 \mathrm{e}+01$ 2.15645e+00 1.00000e-09 2.12000e-01 $2.15645 \mathrm{e}+012.15645 \mathrm{e}+012.15645 \mathrm{e}+00$ 1.00000e-09 2.12000e-01 $2.15645 \mathrm{e}+012.15645 \mathrm{e}+012.15645 \mathrm{e}+001.00000 \mathrm{e}-092.12000 \mathrm{e}-01$ $2.15645 \mathrm{e}+012.15645 \mathrm{e}+012.15645 \mathrm{e}+001.00000 \mathrm{e}-092.12000 \mathrm{e}-01$ $2.15645 \mathrm{e}+012.15645 \mathrm{e}+012.15645 \mathrm{e}+00$ 1.00000e-09 2.12000e-01 $1.00000 \mathrm{e}-02$ 1.00000e-02 1.00000e-03 1.00000e-09 1.00000e-01 $1.00000 \mathrm{e}+001.00000 \mathrm{e}+001.00000 \mathrm{e}-011.00000 \mathrm{e}-091.00000 \mathrm{e}-01$ $1.00000 \mathrm{e}-05$ 1.00000e-05 1.00000e-06 1.00000e-09 1.00000e-01 $1.00000 \mathrm{e}+001.00000 \mathrm{e}+001.00000 \mathrm{e}-01$ 1.00000e-09 1.00000e-01 Element: 1902 \# of layers: 8

Kx Ky Kz Ss Por 4.83108e+01 4.83108e+01 4.83108e+00 1.00000e-09 2.12000e-01 $4.83108 \mathrm{e}+014.83108 \mathrm{e}+014.83108 \mathrm{e}+00$ 1.00000e-09 2.12000e-01 $4.83108 \mathrm{e}+014.83108 \mathrm{e}+014.83108 \mathrm{e}+00$ 1.00000e-09 2.12000e-01 $4.83108 \mathrm{e}+014.83108 \mathrm{e}+014.83108 \mathrm{e}+001.00000 \mathrm{e}-092.12000 \mathrm{e}-01$ $1.00000 \mathrm{e}-02$ 1.00000e-02 1.00000e-03 1.00000e-09 1.00000e-01 $1.00000 \mathrm{e}+001.00000 \mathrm{e}+001.00000 \mathrm{e}-011.00000 \mathrm{e}-091.00000 \mathrm{e}-01$ $1.00000 \mathrm{e}-05$ 1.00000e-05 1.00000e-06 1.00000e-09 1.00000e-01 $1.00000 \mathrm{e}+001.00000 \mathrm{e}+001.00000 \mathrm{e}-011.00000 \mathrm{e}-091.00000 \mathrm{e}-01$ Element: 1903 \# of layers: 8

$\mathrm{Kx} \mathrm{Ky} \mathrm{Kz}$ Ss Por 4.83108e+01 4.83108e+01 4.83108e+00 1.00000e-09 2.12000e-01 $4.83108 \mathrm{e}+014.83108 \mathrm{e}+014.83108 \mathrm{e}+00$ 1.00000e-09 2.12000e-01 $4.83108 \mathrm{e}+014.83108 \mathrm{e}+014.83108 \mathrm{e}+00$ 1.00000e-09 2.12000e-01 
4.83108e+01 4.83108e+01 4.83108e+00 1.00000e-09 2.12000e-01 $1.00000 \mathrm{e}-02$ 1.00000e-02 1.00000e-03 1.00000e-09 1.00000e-01 $1.00000 \mathrm{e}+001.00000 \mathrm{e}+001.00000 \mathrm{e}-011.00000 \mathrm{e}-091.00000 \mathrm{e}-01$ $1.00000 \mathrm{e}-05$ 1.00000e-05 1.00000e-06 1.00000e-09 1.00000e-01 $1.00000 \mathrm{e}+001.00000 \mathrm{e}+001.00000 \mathrm{e}-011.00000 \mathrm{e}-091.00000 \mathrm{e}-01$ Element: 1904 \# of layers: 8

$\mathrm{Kx} \mathrm{Ky} \mathrm{Kz}$ Ss Por

4.83108e+01 4.83108e+01 4.83108e+00 1.00000e-09 2.12000e-01 $4.83108 \mathrm{e}+014.83108 \mathrm{e}+014.83108 \mathrm{e}+001.00000 \mathrm{e}-092.12000 \mathrm{e}-01$ $4.83108 \mathrm{e}+014.83108 \mathrm{e}+014.83108 \mathrm{e}+00$ 1.00000e-09 2.12000e-01 $4.83108 \mathrm{e}+014.83108 \mathrm{e}+014.83108 \mathrm{e}+00$ 1.00000e-09 2.12000e-01 $1.00000 \mathrm{e}-02$ 1.00000e-02 1.00000e-03 1.00000e-09 1.00000e-01 $1.00000 \mathrm{e}+001.00000 \mathrm{e}+001.00000 \mathrm{e}-011.00000 \mathrm{e}-091.00000 \mathrm{e}-01$ $1.00000 \mathrm{e}-05$ 1.00000e-05 1.00000e-06 1.00000e-09 1.00000e-01 $1.00000 \mathrm{e}+001.00000 \mathrm{e}+001.00000 \mathrm{e}-01$ 1.00000e-09 1.00000e-01 Element: 1905 \# of layers: 8

$\mathrm{Kx} \mathrm{Ky} \mathrm{Kz}$ Ss Por

4.83108e+01 4.83108e+01 4.83108e+00 1.00000e-09 2.12000e-01 $4.83108 \mathrm{e}+014.83108 \mathrm{e}+01$ 4.83108e+00 1.00000e-09 2.12000e-01 $4.83108 \mathrm{e}+014.83108 \mathrm{e}+014.83108 \mathrm{e}+00$ 1.00000e-09 2.12000e-01 $4.83108 \mathrm{e}+014.83108 \mathrm{e}+014.83108 \mathrm{e}+00$ 1.00000e-09 2.12000e-01 $1.00000 \mathrm{e}-02$ 1.00000e-02 1.00000e-03 1.00000e-09 1.00000e-01 $1.00000 \mathrm{e}+001.00000 \mathrm{e}+001.00000 \mathrm{e}-011.00000 \mathrm{e}-091.00000 \mathrm{e}-01$ $1.00000 \mathrm{e}-05$ 1.00000e-05 1.00000e-06 1.00000e-09 1.00000e-01 $1.00000 \mathrm{e}+001.00000 \mathrm{e}+001.00000 \mathrm{e}-011.00000 \mathrm{e}-091.00000 \mathrm{e}-01$ Element: 1906 \# of layers: 8

$\mathrm{Kx} \mathrm{Ky} \mathrm{Kz}$ Ss Por

$4.83108 \mathrm{e}+014.83108 \mathrm{e}+014.83108 \mathrm{e}+00$ 1.00000e-09 2.12000e-01 $4.83108 \mathrm{e}+014.83108 \mathrm{e}+014.83108 \mathrm{e}+001.00000 \mathrm{e}-092.12000 \mathrm{e}-01$ $4.83108 \mathrm{e}+014.83108 \mathrm{e}+014.83108 \mathrm{e}+001.00000 \mathrm{e}-092.12000 \mathrm{e}-01$ $4.83108 \mathrm{e}+014.83108 \mathrm{e}+014.83108 \mathrm{e}+00$ 1.00000e-09 2.12000e-01 $1.00000 \mathrm{e}-02$ 1.00000e-02 1.00000e-03 1.00000e-09 1.00000e-01 $1.00000 \mathrm{e}+001.00000 \mathrm{e}+001.00000 \mathrm{e}-011.00000 \mathrm{e}-091.00000 \mathrm{e}-01$ $1.00000 \mathrm{e}-05$ 1.00000e-05 1.00000e-06 1.00000e-09 1.00000e-01 $1.00000 \mathrm{e}+001.00000 \mathrm{e}+001.00000 \mathrm{e}-011.00000 \mathrm{e}-091.00000 \mathrm{e}-01$ Element: 1907 \# of layers: 8

Kx Ky Kz Ss Por

4.83108e+01 4.83108e+01 4.83108e+00 1.00000e-09 2.12000e-01 $4.83108 \mathrm{e}+014.83108 \mathrm{e}+014.83108 \mathrm{e}+00$ 1.00000e-09 2.12000e-01 $4.83108 \mathrm{e}+014.83108 \mathrm{e}+01$ 4.83108e+00 1.00000e-09 2.12000e-01 $4.83108 \mathrm{e}+014.83108 \mathrm{e}+014.83108 \mathrm{e}+00$ 1.00000e-09 2.12000e-01 $1.00000 \mathrm{e}-02$ 1.00000e-02 1.00000e-03 1.00000e-09 1.00000e-01 $1.00000 \mathrm{e}+001.00000 \mathrm{e}+001.00000 \mathrm{e}-011.00000 \mathrm{e}-091.00000 \mathrm{e}-01$ $1.00000 \mathrm{e}-05$ 1.00000e-05 1.00000e-06 1.00000e-09 1.00000e-01 $1.00000 \mathrm{e}+001.00000 \mathrm{e}+001.00000 \mathrm{e}-01$ 1.00000e-09 1.00000e-01 Element: 1908 \# of layers: 9 
$\mathrm{Kx} \mathrm{Ky} \mathrm{Kz}$ Ss Por

4.83108e+01 4.83108e+01 4.83108e+00 1.00000e-09 2.12000e-01

$4.83108 \mathrm{e}+014.83108 \mathrm{e}+014.83108 \mathrm{e}+00$ 1.00000e-09 2.12000e-01

$4.83108 \mathrm{e}+014.83108 \mathrm{e}+014.83108 \mathrm{e}+001.00000 \mathrm{e}-09$ 2.12000e-01

$4.83108 \mathrm{e}+014.83108 \mathrm{e}+014.83108 \mathrm{e}+001.00000 \mathrm{e}-092.12000 \mathrm{e}-01$

$4.83108 \mathrm{e}+014.83108 \mathrm{e}+014.83108 \mathrm{e}+00$ 1.00000e-09 2.12000e-01

$1.00000 \mathrm{e}-02$ 1.00000e-02 1.00000e-03 1.00000e-09 1.00000e-01

$1.00000 \mathrm{e}+001.00000 \mathrm{e}+001.00000 \mathrm{e}-011.00000 \mathrm{e}-091.00000 \mathrm{e}-01$

$1.00000 \mathrm{e}-05$ 1.00000e-05 1.00000e-06 1.00000e-09 1.00000e-01

$1.00000 \mathrm{e}+001.00000 \mathrm{e}+001.00000 \mathrm{e}-011.00000 \mathrm{e}-091.00000 \mathrm{e}-01$

Element: 1909 \# of layers: 9

Kx Ky Kz Ss Por

4.83108e+01 4.83108e+01 4.83108e+00 1.00000e-09 2.12000e-01

$4.83108 \mathrm{e}+014.83108 \mathrm{e}+014.83108 \mathrm{e}+00$ 1.00000e-09 2.12000e-01

$4.83108 \mathrm{e}+014.83108 \mathrm{e}+01$ 4.83108e+00 1.00000e-09 2.12000e-01

$4.83108 \mathrm{e}+014.83108 \mathrm{e}+014.83108 \mathrm{e}+00$ 1.00000e-09 2.12000e-01

$4.83108 \mathrm{e}+014.83108 \mathrm{e}+014.83108 \mathrm{e}+00$ 1.00000e-09 2.12000e-01

$1.00000 \mathrm{e}-02$ 1.00000e-02 1.00000e-03 1.00000e-09 1.00000e-01

$1.00000 \mathrm{e}+001.00000 \mathrm{e}+001.00000 \mathrm{e}-011.00000 \mathrm{e}-091.00000 \mathrm{e}-01$

$1.00000 \mathrm{e}-05$ 1.00000e-05 1.00000e-06 1.00000e-09 1.00000e-01

$1.00000 \mathrm{e}+001.00000 \mathrm{e}+001.00000 \mathrm{e}-011.00000 \mathrm{e}-091.00000 \mathrm{e}-01$

Element: 1910 \# of layers: 8

$\mathrm{Kx} \mathrm{Ky} \mathrm{Kz}$ Ss Por

4.83108e+01 4.83108e+01 4.83108e+00 1.00000e-09 2.12000e-01

$4.83108 \mathrm{e}+014.83108 \mathrm{e}+014.83108 \mathrm{e}+001.00000 \mathrm{e}-092.12000 \mathrm{e}-01$

$4.83108 \mathrm{e}+014.83108 \mathrm{e}+01$ 4.83108e+00 1.00000e-09 2.12000e-01

$4.83108 \mathrm{e}+014.83108 \mathrm{e}+014.83108 \mathrm{e}+00$ 1.00000e-09 2.12000e-01

$1.00000 \mathrm{e}-02$ 1.00000e-02 1.00000e-03 1.00000e-09 1.00000e-01

$1.00000 \mathrm{e}+001.00000 \mathrm{e}+001.00000 \mathrm{e}-011.00000 \mathrm{e}-091.00000 \mathrm{e}-01$

$1.00000 \mathrm{e}-05$ 1.00000e-05 1.00000e-06 1.00000e-09 1.00000e-01

$1.00000 \mathrm{e}+001.00000 \mathrm{e}+001.00000 \mathrm{e}-011.00000 \mathrm{e}-091.00000 \mathrm{e}-01$

Element: 1911 \# of layers: 8

Kx Ky Kz Ss Por

2.78193e+02 2.78193e+02 2.78193e+01 1.00000e-09 7.00000e-02

$1.11157 \mathrm{e}+01$ 1.11157e+01 1.11157e+00 1.00000e-09 2.12000e-01

$1.11157 \mathrm{e}+011.11157 \mathrm{e}+01$ 1.11157e+00 1.00000e-09 2.12000e-01

$1.11157 \mathrm{e}+011.11157 \mathrm{e}+01$ 1.11157e+00 1.00000e-09 2.12000e-01

$1.00000 \mathrm{e}-02$ 1.00000e-02 1.00000e-03 1.00000e-09 1.00000e-01

$1.00000 \mathrm{e}+001.00000 \mathrm{e}+001.00000 \mathrm{e}-011.00000 \mathrm{e}-091.00000 \mathrm{e}-01$

$1.00000 \mathrm{e}-05$ 1.00000e-05 1.00000e-06 1.00000e-09 1.00000e-01

$1.00000 \mathrm{e}+001.00000 \mathrm{e}+001.00000 \mathrm{e}-011.00000 \mathrm{e}-091.00000 \mathrm{e}-01$

Element: 1912 \# of layers: 9

$\mathrm{Kx} \mathrm{Ky} \mathrm{Kz}$ Ss Por

2.78193e+02 2.78193e+02 2.78193e+01 1.00000e-09 7.00000e-02

$2.78193 e+022.78193 e+02$ 2.78193e+01 1.00000e-09 7.00000e-02

$1.11157 \mathrm{e}+011.11157 \mathrm{e}+01$ 1.11157e+00 1.00000e-09 2.12000e-01 
$1.11157 \mathrm{e}+01$ 1.11157e+01 1.11157e+00 1.00000e-09 2.12000e-01 $1.11157 \mathrm{e}+01$ 1.11157e+01 1.11157e+00 1.00000e-09 2.12000e-01 $1.00000 \mathrm{e}-01$ 1.00000e-01 1.00000e-02 1.00000e-09 1.00000e-01 $1.00000 \mathrm{e}+001.00000 \mathrm{e}+001.00000 \mathrm{e}-011.00000 \mathrm{e}-091.00000 \mathrm{e}-01$ $1.00000 \mathrm{e}-051.00000 \mathrm{e}-05$ 1.00000e-06 1.00000e-09 1.00000e-01 $1.00000 \mathrm{e}+001.00000 \mathrm{e}+001.00000 \mathrm{e}-01$ 1.00000e-09 1.00000e-01 Element: 1913 \# of layers: 7

Kx Ky Kz Ss Por

2.78193e+02 2.78193e+02 2.78193e+01 1.00000e-09 7.00000e-02 $1.11157 \mathrm{e}+01$ 1.11157e+01 1.11157e+00 1.00000e-09 2.12000e-01 $1.11157 \mathrm{e}+01$ 1.11157e+01 1.11157e+00 1.00000e-09 2.12000e-01 $1.00000 \mathrm{e}-01$ 1.00000e-01 1.00000e-02 1.00000e-09 1.00000e-01 $1.00000 \mathrm{e}+001.00000 \mathrm{e}+001.00000 \mathrm{e}-011.00000 \mathrm{e}-091.00000 \mathrm{e}-01$ $1.00000 \mathrm{e}-05$ 1.00000e-05 1.00000e-06 1.00000e-09 1.00000e-01 $1.00000 \mathrm{e}+001.00000 \mathrm{e}+001.00000 \mathrm{e}-01$ 1.00000e-09 1.00000e-01 Element: 1914 \# of layers: 8

$\mathrm{Kx} \mathrm{Ky} \mathrm{Kz}$ Ss Por

2.78193e+02 2.78193e+02 2.78193e+01 1.00000e-09 7.00000e-02 5.00000e-04 5.00000e-04 5.00000e-05 1.00000e-09 1.00000e-01 $1.11157 \mathrm{e}+01$ 1.11157e+01 1.11157e+00 1.00000e-09 2.12000e-01 $1.11157 \mathrm{e}+011.11157 \mathrm{e}+011.11157 \mathrm{e}+001.00000 \mathrm{e}-092.12000 \mathrm{e}-01$ $1.00000 \mathrm{e}-011.00000 \mathrm{e}-011.00000 \mathrm{e}-021.00000 \mathrm{e}-091.00000 \mathrm{e}-01$ $1.00000 \mathrm{e}+001.00000 \mathrm{e}+001.00000 \mathrm{e}-011.00000 \mathrm{e}-091.00000 \mathrm{e}-01$ $1.00000 \mathrm{e}-05$ 1.00000e-05 1.00000e-06 1.00000e-09 1.00000e-01 $1.00000 \mathrm{e}+001.00000 \mathrm{e}+001.00000 \mathrm{e}-011.00000 \mathrm{e}-091.00000 \mathrm{e}-01$ Element: 1915 \# of layers: 8

Kx Ky Kz Ss Por

2.78193e+02 2.78193e+02 2.78193e+01 1.00000e-09 7.00000e-02 $2.78193 \mathrm{e}+02$ 2.78193e+02 2.78193e+01 1.00000e-09 7.00000e-02 5.00000e-04 5.00000e-04 5.00000e-05 1.00000e-09 1.00000e-01 5.00000e-04 5.00000e-04 5.00000e-05 1.00000e-09 1.00000e-01 $1.11157 \mathrm{e}+01$ 1.11157e+01 1.11157e+00 1.00000e-09 2.12000e-01 $1.11157 \mathrm{e}+011.11157 \mathrm{e}+011.11157 \mathrm{e}+001.00000 \mathrm{e}-092.12000 \mathrm{e}-01$ $1.00000 \mathrm{e}-01$ 1.00000e-01 1.00000e-02 1.00000e-09 1.00000e-01 $1.00000 \mathrm{e}+001.00000 \mathrm{e}+001.00000 \mathrm{e}-011.00000 \mathrm{e}-091.00000 \mathrm{e}-01$ Element: 1916 \# of layers: 10

Kx Ky Kz Ss Por

$2.78193 e+02$ 2.78193e+02 2.78193e+01 1.00000e-09 7.00000e-02

$2.78193 \mathrm{e}+02$ 2.78193e+02 2.78193e+01 1.00000e-09 7.00000e-02 5.00000e-04 5.00000e-04 5.00000e-05 1.00000e-09 1.00000e-01 $1.11157 \mathrm{e}+01$ 1.11157e+01 1.11157e+00 1.00000e-09 2.12000e-01 $1.11157 \mathrm{e}+01$ 1.11157e+01 1.11157e+00 1.00000e-09 2.12000e-01 $1.11157 \mathrm{e}+01$ 1.11157e+01 1.11157e+00 1.00000e-09 2.12000e-01 $1.00000 \mathrm{e}-011.00000 \mathrm{e}-011.00000 \mathrm{e}-021.00000 \mathrm{e}-091.00000 \mathrm{e}-01$ $1.00000 \mathrm{e}+001.00000 \mathrm{e}+001.00000 \mathrm{e}-011.00000 \mathrm{e}-091.00000 \mathrm{e}-01$ $1.00000 \mathrm{e}-05$ 1.00000e-05 1.00000e-06 1.00000e-09 1.00000e-01 
$1.00000 \mathrm{e}+001.00000 \mathrm{e}+00$ 1.00000e-01 1.00000e-09 1.00000e-01

Element: 1917 \# of layers: 9

Kx Ky Kz Ss Por

$2.78193 e+02$ 2.78193e+02 2.78193e+01 1.00000e-09 7.00000e-02

5.00000e-04 5.00000e-04 5.00000e-05 1.00000e-09 1.00000e-01

$1.11157 \mathrm{e}+01$ 1.11157e+01 1.11157e+00 1.00000e-09 2.12000e-01

$1.11157 \mathrm{e}+011.11157 \mathrm{e}+01$ 1.11157e+00 1.00000e-09 2.12000e-01

$1.11157 \mathrm{e}+011.11157 \mathrm{e}+01$ 1.11157e+00 1.00000e-09 2.12000e-01

$1.00000 \mathrm{e}-02$ 1.00000e-02 1.00000e-03 1.00000e-09 1.00000e-01

$1.00000 \mathrm{e}+001.00000 \mathrm{e}+001.00000 \mathrm{e}-011.00000 \mathrm{e}-091.00000 \mathrm{e}-01$

1.00000e-05 1.00000e-05 1.00000e-06 1.00000e-09 1.00000e-01

$1.00000 \mathrm{e}+001.00000 \mathrm{e}+001.00000 \mathrm{e}-011.00000 \mathrm{e}-091.00000 \mathrm{e}-01$

Element: 1918 \# of layers: 9

$\mathrm{Kx} \mathrm{Ky} \mathrm{Kz}$ Ss Por

$2.78193 \mathrm{e}+02$ 2.78193e+02 2.78193e+01 1.00000e-09 7.00000e-02

5.00000e-04 5.00000e-04 5.00000e-05 1.00000e-09 1.00000e-01

$1.11157 \mathrm{e}+01$ 1.11157e+01 1.11157e+00 1.00000e-09 2.12000e-01

$1.11157 \mathrm{e}+011.11157 \mathrm{e}+01$ 1.11157e+00 1.00000e-09 2.12000e-01

$1.11157 \mathrm{e}+01$ 1.11157e+01 1.11157e+00 1.00000e-09 2.12000e-01

$1.00000 \mathrm{e}-02$ 1.00000e-02 1.00000e-03 1.00000e-09 1.00000e-01

$1.00000 \mathrm{e}+001.00000 \mathrm{e}+001.00000 \mathrm{e}-011.00000 \mathrm{e}-091.00000 \mathrm{e}-01$

$1.00000 \mathrm{e}-05$ 1.00000e-05 1.00000e-06 1.00000e-09 1.00000e-01

$1.00000 \mathrm{e}+001.00000 \mathrm{e}+001.00000 \mathrm{e}-01$ 1.00000e-09 1.00000e-01

Element: 1919 \# of layers: 10

Kx Ky Kz Ss Por

2.78193e+02 2.78193e+02 2.78193e+01 1.00000e-09 7.00000e-02

$2.78193 \mathrm{e}+02$ 2.78193e+02 2.78193e+01 1.00000e-09 7.00000e-02

5.00000e-04 5.00000e-04 5.00000e-05 1.00000e-09 1.00000e-01

$1.11157 \mathrm{e}+01$ 1.11157e+01 1.11157e+00 1.00000e-09 2.12000e-01

$1.11157 \mathrm{e}+01$ 1.11157e+01 1.11157e+00 1.00000e-09 2.12000e-01

$1.11157 \mathrm{e}+01$ 1.11157e+01 1.11157e+00 1.00000e-09 2.12000e-01

$1.00000 \mathrm{e}-011.00000 \mathrm{e}-01$ 1.00000e-02 1.00000e-09 1.00000e-01

$1.00000 \mathrm{e}+001.00000 \mathrm{e}+001.00000 \mathrm{e}-011.00000 \mathrm{e}-091.00000 \mathrm{e}-01$

$1.00000 \mathrm{e}-05$ 1.00000e-05 1.00000e-06 1.00000e-09 1.00000e-01

$1.00000 \mathrm{e}+001.00000 \mathrm{e}+001.00000 \mathrm{e}-011.00000 \mathrm{e}-091.00000 \mathrm{e}-01$

Element: 1920 \# of layers: 5

Kx Ky Kz Ss Por

9.81099e+01 9.81099e+01 9.81099e+00 1.00000e-09 7.00000e-02

$3.92026 \mathrm{e}+003.92026 \mathrm{e}+003.92026 \mathrm{e}-01$ 1.00000e-09 2.12000e-01

$3.92026 \mathrm{e}+003.92026 \mathrm{e}+00$ 3.92026e-01 1.00000e-09 2.12000e-01

1.00000e-01 1.00000e-01 1.00000e-02 1.00000e-09 1.00000e-01

$1.00000 \mathrm{e}+001.00000 \mathrm{e}+001.00000 \mathrm{e}-011.00000 \mathrm{e}-091.00000 \mathrm{e}-01$

Element: 1921 \# of layers: 6

$\mathrm{Kx} \mathrm{Ky} \mathrm{Kz}$ Ss Por

9.81099e+01 9.81099e+01 9.81099e+00 1.00000e-09 7.00000e-02

$9.81099 \mathrm{e}+019.81099 \mathrm{e}+019.81099 \mathrm{e}+001.00000 \mathrm{e}-09$ 7.00000e-02 
$3.92026 \mathrm{e}+003.92026 \mathrm{e}+003.92026 \mathrm{e}-01$ 1.00000e-09 2.12000e-01 $3.92026 \mathrm{e}+003.92026 \mathrm{e}+003.92026 \mathrm{e}-01$ 1.00000e-09 2.12000e-01 $1.00000 \mathrm{e}-011.00000 \mathrm{e}-011.00000 \mathrm{e}-021.00000 \mathrm{e}-091.00000 \mathrm{e}-01$ $1.00000 \mathrm{e}+001.00000 \mathrm{e}+001.00000 \mathrm{e}-011.00000 \mathrm{e}-091.00000 \mathrm{e}-01$ Element: 1922 \# of layers: 5

Kx Ky Kz Ss Por

9.81099e+01 9.81099e+01 9.81099e+00 1.00000e-09 7.00000e-02 $9.81099 \mathrm{e}+019.81099 \mathrm{e}+019.81099 \mathrm{e}+00$ 1.00000e-09 7.00000e-02 $3.92026 \mathrm{e}+003.92026 \mathrm{e}+00$ 3.92026e-01 1.00000e-09 2.12000e-01 $1.00000 \mathrm{e}-011.00000 \mathrm{e}-011.00000 \mathrm{e}-021.00000 \mathrm{e}-091.00000 \mathrm{e}-01$ $1.00000 \mathrm{e}+001.00000 \mathrm{e}+001.00000 \mathrm{e}-011.00000 \mathrm{e}-091.00000 \mathrm{e}-01$ Element: 1923 \# of layers: 8

Kx Ky Kz Ss Por

$9.81099 \mathrm{e}+01$ 9.81099e+01 9.81099e+00 1.00000e-09 7.00000e-02 $9.81099 \mathrm{e}+01$ 9.81099e+01 9.81099e+00 1.00000e-09 7.00000e-02 5.00000e-04 5.00000e-04 5.00000e-05 1.00000e-09 1.00000e-01 5.00000e-04 5.00000e-04 5.00000e-05 1.00000e-09 1.00000e-01 $3.92026 \mathrm{e}+003.92026 \mathrm{e}+003.92026 \mathrm{e}-011.00000 \mathrm{e}-092.12000 \mathrm{e}-01$ $3.92026 \mathrm{e}+003.92026 \mathrm{e}+003.92026 \mathrm{e}-01$ 1.00000e-09 2.12000e-01 $1.00000 \mathrm{e}-011.00000 \mathrm{e}-011.00000 \mathrm{e}-021.00000 \mathrm{e}-091.00000 \mathrm{e}-01$ $1.00000 \mathrm{e}+001.00000 \mathrm{e}+001.00000 \mathrm{e}-011.00000 \mathrm{e}-091.00000 \mathrm{e}-01$ Element: 1924 \# of layers: 7

Kx Ky Kz Ss Por 9.81099e+01 9.81099e+01 9.81099e+00 1.00000e-09 7.00000e-02 5.00000e-04 5.00000e-04 5.00000e-05 1.00000e-09 1.00000e-01 5.00000e-04 5.00000e-04 5.00000e-05 1.00000e-09 1.00000e-01 $3.92026 \mathrm{e}+003.92026 \mathrm{e}+003.92026 \mathrm{e}-011.00000 \mathrm{e}-092.12000 \mathrm{e}-01$ $3.92026 \mathrm{e}+003.92026 \mathrm{e}+003.92026 \mathrm{e}-011.00000 \mathrm{e}-092.12000 \mathrm{e}-01$ $1.00000 \mathrm{e}-011.00000 \mathrm{e}-011.00000 \mathrm{e}-021.00000 \mathrm{e}-091.00000 \mathrm{e}-01$ $1.00000 \mathrm{e}+001.00000 \mathrm{e}+001.00000 \mathrm{e}-011.00000 \mathrm{e}-091.00000 \mathrm{e}-01$ Element: 1925 \# of layers: 8

Kx Ky Kz Ss Por $9.81099 \mathrm{e}+01$ 9.81099e+01 9.81099e+00 1.00000e-09 7.00000e-02 $9.81099 \mathrm{e}+01$ 9.81099e+01 9.81099e+00 1.00000e-09 7.00000e-02 5.00000e-04 5.00000e-04 5.00000e-05 1.00000e-09 1.00000e-01 5.00000e-04 5.00000e-04 5.00000e-05 1.00000e-09 1.00000e-01 $3.92026 \mathrm{e}+003.92026 \mathrm{e}+003.92026 \mathrm{e}-011.00000 \mathrm{e}-092.12000 \mathrm{e}-01$ $3.92026 \mathrm{e}+003.92026 \mathrm{e}+003.92026 \mathrm{e}-01$ 1.00000e-09 2.12000e-01 $1.00000 \mathrm{e}-011.00000 \mathrm{e}-011.00000 \mathrm{e}-021.00000 \mathrm{e}-091.00000 \mathrm{e}-01$ $1.00000 \mathrm{e}+001.00000 \mathrm{e}+001.00000 \mathrm{e}-011.00000 \mathrm{e}-091.00000 \mathrm{e}-01$ Element: 1926 \# of layers: 8

Kx Ky Kz Ss Por 9.81099e+01 9.81099e+01 9.81099e+00 1.00000e-09 7.00000e-02 $9.81099 \mathrm{e}+01$ 9.81099e+01 9.81099e+00 1.00000e-09 7.00000e-02 5.00000e-04 5.00000e-04 5.00000e-05 1.00000e-09 1.00000e-01 5.00000e-04 5.00000e-04 5.00000e-05 1.00000e-09 1.00000e-01 
$3.92026 \mathrm{e}+003.92026 \mathrm{e}+003.92026 \mathrm{e}-01$ 1.00000e-09 2.12000e-01 $3.92026 \mathrm{e}+003.92026 \mathrm{e}+003.92026 \mathrm{e}-01$ 1.00000e-09 2.12000e-01 $1.00000 \mathrm{e}-011.00000 \mathrm{e}-011.00000 \mathrm{e}-021.00000 \mathrm{e}-091.00000 \mathrm{e}-01$ $1.00000 \mathrm{e}+001.00000 \mathrm{e}+001.00000 \mathrm{e}-011.00000 \mathrm{e}-091.00000 \mathrm{e}-01$ Element: 1927 \# of layers: 6

Kx Ky Kz Ss Por

$9.81099 \mathrm{e}+01$ 9.81099e+01 9.81099e+00 1.00000e-09 7.00000e-02 5.00000e-04 5.00000e-04 5.00000e-05 1.00000e-09 1.00000e-01 $3.92026 \mathrm{e}+003.92026 \mathrm{e}+003.92026 \mathrm{e}-011.00000 \mathrm{e}-092.12000 \mathrm{e}-01$ $3.92026 \mathrm{e}+003.92026 \mathrm{e}+003.92026 \mathrm{e}-01$ 1.00000e-09 2.12000e-01 $1.00000 \mathrm{e}-011.00000 \mathrm{e}-011.00000 \mathrm{e}-021.00000 \mathrm{e}-091.00000 \mathrm{e}-01$ $1.00000 \mathrm{e}+001.00000 \mathrm{e}+001.00000 \mathrm{e}-011.00000 \mathrm{e}-091.00000 \mathrm{e}-01$ Element: 1928 \# of layers: 7

Kx Ky Kz Ss Por

9.81099e+01 9.81099e+01 9.81099e+00 1.00000e-09 7.00000e-02 5.00000e-04 5.00000e-04 5.00000e-05 1.00000e-09 1.00000e-01 $5.00000 \mathrm{e}-04$ 5.00000e-04 5.00000e-05 1.00000e-09 1.00000e-01 $3.92026 \mathrm{e}+003.92026 \mathrm{e}+003.92026 \mathrm{e}-011.00000 \mathrm{e}-092.12000 \mathrm{e}-01$ $3.92026 \mathrm{e}+003.92026 \mathrm{e}+003.92026 \mathrm{e}-01$ 1.00000e-09 2.12000e-01 $1.00000 \mathrm{e}-011.00000 \mathrm{e}-011.00000 \mathrm{e}-021.00000 \mathrm{e}-091.00000 \mathrm{e}-01$ $1.00000 \mathrm{e}+001.00000 \mathrm{e}+001.00000 \mathrm{e}-011.00000 \mathrm{e}-091.00000 \mathrm{e}-01$ Element: 1929 \# of layers: 7

Kx Ky Kz Ss Por 6.69957e+01 6.69957e+01 6.69957e+00 1.00000e-09 7.00000e-02 $6.69957 \mathrm{e}+016.69957 \mathrm{e}+016.69957 \mathrm{e}+001.00000 \mathrm{e}-09$ 7.00000e-02 5.00000e-04 5.00000e-04 5.00000e-05 1.00000e-09 1.00000e-01 5.00000e-04 5.00000e-04 5.00000e-05 1.00000e-09 1.00000e-01 $2.67688 \mathrm{e}+002.67688 \mathrm{e}+002.67688 \mathrm{e}-011.00000 \mathrm{e}-092.12000 \mathrm{e}-01$ $1.00000 \mathrm{e}-011.00000 \mathrm{e}-011.00000 \mathrm{e}-021.00000 \mathrm{e}-091.00000 \mathrm{e}-01$ $1.00000 \mathrm{e}+001.00000 \mathrm{e}+001.00000 \mathrm{e}-011.00000 \mathrm{e}-091.00000 \mathrm{e}-01$ Element: 1930 \# of layers: 8

Kx Ky Kz Ss Por $6.69957 \mathrm{e}+016.69957 \mathrm{e}+016.69957 \mathrm{e}+00$ 1.00000e-09 7.00000e-02 $6.69957 \mathrm{e}+016.69957 \mathrm{e}+016.69957 \mathrm{e}+001.00000 \mathrm{e}-09$ 7.00000e-02 5.00000e-04 5.00000e-04 5.00000e-05 1.00000e-09 1.00000e-01 $5.00000 \mathrm{e}-04$ 5.00000e-04 5.00000e-05 1.00000e-09 1.00000e-01 $2.67688 \mathrm{e}+002.67688 \mathrm{e}+002.67688 \mathrm{e}-01$ 1.00000e-09 2.12000e-01 $2.67688 \mathrm{e}+002.67688 \mathrm{e}+002.67688 \mathrm{e}-01$ 1.00000e-09 2.12000e-01 $1.00000 \mathrm{e}-011.00000 \mathrm{e}-011.00000 \mathrm{e}-021.00000 \mathrm{e}-091.00000 \mathrm{e}-01$ $1.00000 \mathrm{e}+001.00000 \mathrm{e}+001.00000 \mathrm{e}-011.00000 \mathrm{e}-091.00000 \mathrm{e}-01$ Element: 1931 \# of layers: 7

Kx Ky Kz Ss Por 6.69957e+01 6.69957e+01 6.69957e+00 1.00000e-09 7.00000e-02 $5.00000 \mathrm{e}-04$ 5.00000e-04 5.00000e-05 1.00000e-09 1.00000e-01 5.00000e-04 5.00000e-04 5.00000e-05 1.00000e-09 1.00000e-01 $2.67688 \mathrm{e}+002.67688 \mathrm{e}+002.67688 \mathrm{e}-01$ 1.00000e-09 2.12000e-01 
$2.67688 \mathrm{e}+00$ 2.67688e+00 2.67688e-01 1.00000e-09 2.12000e-01 $1.00000 \mathrm{e}-011.00000 \mathrm{e}-01$ 1.00000e-02 1.00000e-09 1.00000e-01 $1.00000 \mathrm{e}+001.00000 \mathrm{e}+001.00000 \mathrm{e}-01$ 1.00000e-09 1.00000e-01 Element: 1932 \# of layers: 15

$\mathrm{Kx} \mathrm{Ky} \mathrm{Kz}$ Ss Por

1.55648e+02 1.55648e+02 1.55648e+01 1.00000e-09 7.00000e-02 $1.55648 \mathrm{e}+021.55648 \mathrm{e}+02$ 1.55648e+01 1.00000e-09 7.00000e-02 $1.55648 \mathrm{e}+021.55648 \mathrm{e}+02 \quad 1.55648 \mathrm{e}+01$ 1.00000e-09 7.00000e-02 $1.55648 \mathrm{e}+021.55648 \mathrm{e}+02$ 1.55648e+01 1.00000e-09 7.00000e-02 5.00000e-04 5.00000e-04 5.00000e-05 1.00000e-09 1.00000e-01 5.00000e-04 5.00000e-04 5.00000e-05 1.00000e-09 1.00000e-01 $6.21913 \mathrm{e}+006.21913 \mathrm{e}+00$ 6.21913e-01 1.00000e-09 2.12000e-01 6.21913e+00 6.21913e+00 6.21913e-01 1.00000e-09 2.12000e-01 6.21913e+00 6.21913e+00 6.21913e-01 1.00000e-09 2.12000e-01 6.21913e+00 6.21913e+00 6.21913e-01 1.00000e-09 2.12000e-01 $6.21913 \mathrm{e}+00$ 6.21913e+00 6.21913e-01 1.00000e-09 2.12000e-01 $1.00000 \mathrm{e}-02$ 1.00000e-02 1.00000e-03 1.00000e-09 1.00000e-01 $1.00000 \mathrm{e}+001.00000 \mathrm{e}+001.00000 \mathrm{e}-011.00000 \mathrm{e}-091.00000 \mathrm{e}-01$ $1.00000 \mathrm{e}-05$ 1.00000e-05 1.00000e-06 1.00000e-09 1.00000e-01 $1.00000 \mathrm{e}+001.00000 \mathrm{e}+001.00000 \mathrm{e}-011.00000 \mathrm{e}-091.00000 \mathrm{e}-01$ Element: 1933 \# of layers: 15

$\mathrm{Kx} \mathrm{Ky} \mathrm{Kz}$ Ss Por

1.55648e+02 1.55648e+02 1.55648e+01 1.00000e-09 7.00000e-02 $1.55648 \mathrm{e}+02$ 1.55648e+02 1.55648e+01 1.00000e-09 7.00000e-02 $1.55648 \mathrm{e}+02$ 1.55648e+02 1.55648e+01 1.00000e-09 7.00000e-02 $1.55648 \mathrm{e}+021.55648 \mathrm{e}+02$ 1.55648e+01 1.00000e-09 7.00000e-02 5.00000e-04 5.00000e-04 5.00000e-05 1.00000e-09 1.00000e-01 5.00000e-04 5.00000e-04 5.00000e-05 1.00000e-09 1.00000e-01 $6.21913 \mathrm{e}+00$ 6.21913e+00 6.21913e-01 1.00000e-09 2.12000e-01 $6.21913 \mathrm{e}+00$ 6.21913e+00 6.21913e-01 1.00000e-09 2.12000e-01 6.21913e+00 6.21913e+00 6.21913e-01 1.00000e-09 2.12000e-01 $6.21913 \mathrm{e}+006.21913 \mathrm{e}+00$ 6.21913e-01 1.00000e-09 2.12000e-01 6.21913e+00 6.21913e+00 6.21913e-01 1.00000e-09 2.12000e-01 $1.00000 \mathrm{e}-02$ 1.00000e-02 1.00000e-03 1.00000e-09 1.00000e-01 $1.00000 \mathrm{e}+001.00000 \mathrm{e}+001.00000 \mathrm{e}-011.00000 \mathrm{e}-091.00000 \mathrm{e}-01$ $1.00000 \mathrm{e}-05$ 1.00000e-05 1.00000e-06 1.00000e-09 1.00000e-01 $1.00000 \mathrm{e}+001.00000 \mathrm{e}+001.00000 \mathrm{e}-011.00000 \mathrm{e}-091.00000 \mathrm{e}-01$ Element: 1934 \# of layers: 14

Kx Ky Kz Ss Por

1.55648e+02 1.55648e+02 1.55648e+01 1.00000e-09 7.00000e-02 $1.55648 \mathrm{e}+02$ 1.55648e+02 1.55648e+01 1.00000e-09 7.00000e-02 $1.55648 \mathrm{e}+02$ 1.55648e+02 1.55648e+01 1.00000e-09 7.00000e-02 $1.55648 \mathrm{e}+021.55648 \mathrm{e}+02$ 1.55648e+01 1.00000e-09 7.00000e-02 5.00000e-04 5.00000e-04 5.00000e-05 1.00000e-09 1.00000e-01 $6.21913 \mathrm{e}+006.21913 \mathrm{e}+00$ 6.21913e-01 1.00000e-09 2.12000e-01 $6.21913 \mathrm{e}+00$ 6.21913e+00 6.21913e-01 1.00000e-09 2.12000e-01 
6.21913e+00 6.21913e+00 6.21913e-01 1.00000e-09 2.12000e-01 $6.21913 \mathrm{e}+006.21913 \mathrm{e}+00$ 6.21913e-01 1.00000e-09 2.12000e-01 $6.21913 \mathrm{e}+006.21913 \mathrm{e}+00$ 6.21913e-01 1.00000e-09 2.12000e-01 $1.00000 \mathrm{e}-021.00000 \mathrm{e}-02$ 1.00000e-03 1.00000e-09 1.00000e-01 $1.00000 \mathrm{e}+001.00000 \mathrm{e}+001.00000 \mathrm{e}-011.00000 \mathrm{e}-091.00000 \mathrm{e}-01$ $1.00000 \mathrm{e}-05$ 1.00000e-05 1.00000e-06 1.00000e-09 1.00000e-01 $1.00000 \mathrm{e}+001.00000 \mathrm{e}+00$ 1.00000e-01 1.00000e-09 1.00000e-01 Element: 1935 \# of layers: 15

$\mathrm{Kx} \mathrm{Ky} \mathrm{Kz}$ Ss Por

1.55648e+02 1.55648e+02 1.55648e+01 1.00000e-09 7.00000e-02 $1.55648 \mathrm{e}+02$ 1.55648e+02 1.55648e+01 1.00000e-09 7.00000e-02 $1.55648 \mathrm{e}+02$ 1.55648e+02 1.55648e+01 1.00000e-09 7.00000e-02 $1.55648 \mathrm{e}+02$ 1.55648e+02 1.55648e+01 1.00000e-09 7.00000e-02 5.00000e-04 5.00000e-04 5.00000e-05 1.00000e-09 1.00000e-01 5.00000e-04 5.00000e-04 5.00000e-05 1.00000e-09 1.00000e-01 $6.21913 \mathrm{e}+006.21913 \mathrm{e}+00$ 6.21913e-01 1.00000e-09 2.12000e-01 $6.21913 \mathrm{e}+006.21913 \mathrm{e}+00$ 6.21913e-01 1.00000e-09 2.12000e-01 $6.21913 \mathrm{e}+006.21913 \mathrm{e}+00$ 6.21913e-01 1.00000e-09 2.12000e-01 $6.21913 \mathrm{e}+006.21913 \mathrm{e}+00$ 6.21913e-01 1.00000e-09 2.12000e-01 $6.21913 \mathrm{e}+006.21913 \mathrm{e}+00$ 6.21913e-01 1.00000e-09 2.12000e-01 $1.00000 \mathrm{e}-021.00000 \mathrm{e}-02$ 1.00000e-03 1.00000e-09 1.00000e-01 $1.00000 \mathrm{e}+001.00000 \mathrm{e}+001.00000 \mathrm{e}-011.00000 \mathrm{e}-091.00000 \mathrm{e}-01$ $1.00000 \mathrm{e}-05$ 1.00000e-05 1.00000e-06 1.00000e-09 1.00000e-01 $1.00000 \mathrm{e}+001.00000 \mathrm{e}+001.00000 \mathrm{e}-011.00000 \mathrm{e}-091.00000 \mathrm{e}-01$ Element: 1936 \# of layers: 15

$\mathrm{Kx} \mathrm{Ky} \mathrm{Kz}$ Ss Por

$1.55648 \mathrm{e}+02$ 1.55648e+02 1.55648e+01 1.00000e-09 7.00000e-02 $1.55648 \mathrm{e}+02$ 1.55648e+02 1.55648e+01 1.00000e-09 7.00000e-02 $1.55648 \mathrm{e}+02$ 1.55648e+02 1.55648e+01 1.00000e-09 7.00000e-02 $1.55648 \mathrm{e}+02$ 1.55648e+02 1.55648e+01 1.00000e-09 7.00000e-02 5.00000e-04 5.00000e-04 5.00000e-05 1.00000e-09 1.00000e-01 5.00000e-04 5.00000e-04 5.00000e-05 1.00000e-09 1.00000e-01 $6.21913 \mathrm{e}+00$ 6.21913e+00 6.21913e-01 1.00000e-09 2.12000e-01 $6.21913 \mathrm{e}+006.21913 \mathrm{e}+00$ 6.21913e-01 1.00000e-09 2.12000e-01 $6.21913 \mathrm{e}+006.21913 \mathrm{e}+00$ 6.21913e-01 1.00000e-09 2.12000e-01 6.21913e+00 6.21913e+00 6.21913e-01 1.00000e-09 2.12000e-01 $6.21913 \mathrm{e}+006.21913 \mathrm{e}+00$ 6.21913e-01 1.00000e-09 2.12000e-01 $1.00000 \mathrm{e}-02$ 1.00000e-02 1.00000e-03 1.00000e-09 1.00000e-01 $1.00000 \mathrm{e}+001.00000 \mathrm{e}+001.00000 \mathrm{e}-011.00000 \mathrm{e}-091.00000 \mathrm{e}-01$ $1.00000 \mathrm{e}-05$ 1.00000e-05 1.00000e-06 1.00000e-09 1.00000e-01 $1.00000 \mathrm{e}+001.00000 \mathrm{e}+00$ 1.00000e-01 1.00000e-09 1.00000e-01 Element: 1937 \# of layers: 15

Kx Ky Kz Ss Por $2.00328 \mathrm{e}+022.00328 \mathrm{e}+022.00328 \mathrm{e}+01$ 1.00000e-09 7.00000e-02 $2.00328 \mathrm{e}+022.00328 \mathrm{e}+022.00328 \mathrm{e}+011.00000 \mathrm{e}-097.00000 \mathrm{e}-02$ $2.00328 \mathrm{e}+022.00328 \mathrm{e}+022.00328 \mathrm{e}+01$ 1.00000e-09 7.00000e-02 
$2.00328 \mathrm{e}+02$ 2.00328e+02 2.00328e+01 1.00000e-09 7.00000e-02 5.00000e-04 5.00000e-04 5.00000e-05 1.00000e-09 1.00000e-01 $5.00000 \mathrm{e}-04$ 5.00000e-04 5.00000e-05 1.00000e-09 1.00000e-01 $8.00455 \mathrm{e}+008.00455 \mathrm{e}+00$ 8.00455e-01 1.00000e-09 2.12000e-01 $8.00455 \mathrm{e}+008.00455 \mathrm{e}+00$ 8.00455e-01 1.00000e-09 2.12000e-01 $8.00455 \mathrm{e}+008.00455 \mathrm{e}+00$ 8.00455e-01 1.00000e-09 2.12000e-01 8.00455e+00 8.00455e+00 8.00455e-01 1.00000e-09 2.12000e-01 $8.00455 \mathrm{e}+00$ 8.00455e+00 8.00455e-01 1.00000e-09 2.12000e-01 $1.00000 \mathrm{e}-02$ 1.00000e-02 1.00000e-03 1.00000e-09 1.00000e-01 $1.00000 \mathrm{e}+001.00000 \mathrm{e}+001.00000 \mathrm{e}-011.00000 \mathrm{e}-091.00000 \mathrm{e}-01$ $1.00000 \mathrm{e}-05$ 1.00000e-05 1.00000e-06 1.00000e-09 1.00000e-01 $1.00000 \mathrm{e}+001.00000 \mathrm{e}+001.00000 \mathrm{e}-011.00000 \mathrm{e}-091.00000 \mathrm{e}-01$ Element: 1938 \# of layers: 15

$\mathrm{Kx} \mathrm{Ky} \mathrm{Kz}$ Ss Por

$2.00328 \mathrm{e}+02$ 2.00328e+02 2.00328e+01 1.00000e-09 7.00000e-02 $2.00328 \mathrm{e}+022.00328 \mathrm{e}+022.00328 \mathrm{e}+01$ 1.00000e-09 7.00000e-02 $2.00328 \mathrm{e}+022.00328 \mathrm{e}+02 \quad 2.00328 \mathrm{e}+01$ 1.00000e-09 7.00000e-02 $2.00328 \mathrm{e}+022.00328 \mathrm{e}+022.00328 \mathrm{e}+01$ 1.00000e-09 7.00000e-02 $5.00000 \mathrm{e}-04$ 5.00000e-04 5.00000e-05 1.00000e-09 1.00000e-01 5.00000e-04 5.00000e-04 5.00000e-05 1.00000e-09 1.00000e-01 $8.00455 \mathrm{e}+00$ 8.00455e+00 8.00455e-01 1.00000e-09 2.12000e-01 $8.00455 \mathrm{e}+00$ 8.00455e+00 8.00455e-01 1.00000e-09 2.12000e-01 $8.00455 \mathrm{e}+00$ 8.00455e+00 8.00455e-01 1.00000e-09 2.12000e-01 $8.00455 \mathrm{e}+008.00455 \mathrm{e}+008.00455 \mathrm{e}-01$ 1.00000e-09 2.12000e-01 $8.00455 \mathrm{e}+00$ 8.00455e+00 8.00455e-01 1.00000e-09 2.12000e-01 $1.00000 \mathrm{e}-02$ 1.00000e-02 1.00000e-03 1.00000e-09 1.00000e-01 $1.00000 \mathrm{e}+001.00000 \mathrm{e}+001.00000 \mathrm{e}-011.00000 \mathrm{e}-091.00000 \mathrm{e}-01$ $1.00000 \mathrm{e}-05$ 1.00000e-05 1.00000e-06 1.00000e-09 1.00000e-01 $1.00000 \mathrm{e}+001.00000 \mathrm{e}+001.00000 \mathrm{e}-011.00000 \mathrm{e}-091.00000 \mathrm{e}-01$ Element: 1939 \# of layers: 16

$\mathrm{Kx} \mathrm{Ky} \mathrm{Kz}$ Ss Por

$2.00328 \mathrm{e}+02$ 2.00328e+02 2.00328e+01 1.00000e-09 7.00000e-02 $2.00328 \mathrm{e}+022.00328 \mathrm{e}+02 \quad 2.00328 \mathrm{e}+01$ 1.00000e-09 7.00000e-02 $2.00328 \mathrm{e}+022.00328 \mathrm{e}+022.00328 \mathrm{e}+01$ 1.00000e-09 7.00000e-02 $2.00328 \mathrm{e}+02$ 2.00328e+02 2.00328e+01 1.00000e-09 7.00000e-02 $2.00328 \mathrm{e}+022.00328 \mathrm{e}+022.00328 \mathrm{e}+01$ 1.00000e-09 7.00000e-02 5.00000e-04 5.00000e-04 5.00000e-05 1.00000e-09 1.00000e-01 5.00000e-04 5.00000e-04 5.00000e-05 1.00000e-09 1.00000e-01 $8.00455 \mathrm{e}+008.00455 \mathrm{e}+00$ 8.00455e-01 1.00000e-09 2.12000e-01 $8.00455 \mathrm{e}+00$ 8.00455e+00 8.00455e-01 1.00000e-09 2.12000e-01 $8.00455 \mathrm{e}+00$ 8.00455e+00 8.00455e-01 1.00000e-09 2.12000e-01 $8.00455 \mathrm{e}+00$ 8.00455e+00 8.00455e-01 1.00000e-09 2.12000e-01 $8.00455 \mathrm{e}+00$ 8.00455e+00 8.00455e-01 1.00000e-09 2.12000e-01 $1.00000 \mathrm{e}-02$ 1.00000e-02 1.00000e-03 1.00000e-09 1.00000e-01 $1.00000 \mathrm{e}+001.00000 \mathrm{e}+001.00000 \mathrm{e}-011.00000 \mathrm{e}-091.00000 \mathrm{e}-01$ $1.00000 \mathrm{e}-05$ 1.00000e-05 1.00000e-06 1.00000e-09 1.00000e-01 
$1.00000 \mathrm{e}+001.00000 \mathrm{e}+00$ 1.00000e-01 1.00000e-09 1.00000e-01

Element: 1940 \# of layers: 16

Kx Ky Kz Ss Por

$2.00328 \mathrm{e}+02$ 2.00328e+02 2.00328e+01 1.00000e-09 7.00000e-02

$2.00328 \mathrm{e}+022.00328 \mathrm{e}+022.00328 \mathrm{e}+01$ 1.00000e-09 7.00000e-02

$2.00328 \mathrm{e}+022.00328 \mathrm{e}+022.00328 \mathrm{e}+01$ 1.00000e-09 7.00000e-02

$2.00328 \mathrm{e}+022.00328 \mathrm{e}+022.00328 \mathrm{e}+01$ 1.00000e-09 7.00000e-02

$2.00328 \mathrm{e}+02$ 2.00328e+02 2.00328e+01 1.00000e-09 7.00000e-02

$5.00000 \mathrm{e}-04$ 5.00000e-04 5.00000e-05 1.00000e-09 1.00000e-01

5.00000e-04 5.00000e-04 5.00000e-05 1.00000e-09 1.00000e-01

$8.00455 \mathrm{e}+00$ 8.00455e+00 8.00455e-01 1.00000e-09 2.12000e-01

$8.00455 \mathrm{e}+008.00455 \mathrm{e}+008.00455 \mathrm{e}-01$ 1.00000e-09 2.12000e-01

$8.00455 \mathrm{e}+00$ 8.00455e+00 8.00455e-01 1.00000e-09 2.12000e-01

8.00455e+00 8.00455e+00 8.00455e-01 1.00000e-09 2.12000e-01

8.00455e+00 8.00455e+00 8.00455e-01 1.00000e-09 2.12000e-01

1.00000e-02 1.00000e-02 1.00000e-03 1.00000e-09 1.00000e-01

$1.00000 \mathrm{e}+001.00000 \mathrm{e}+001.00000 \mathrm{e}-011.00000 \mathrm{e}-091.00000 \mathrm{e}-01$

$1.00000 \mathrm{e}-05$ 1.00000e-05 1.00000e-06 1.00000e-09 1.00000e-01

$1.00000 \mathrm{e}+001.00000 \mathrm{e}+001.00000 \mathrm{e}-01$ 1.00000e-09 1.00000e-01

Element: 1941 \# of layers: 15

$\mathrm{Kx} \mathrm{Ky} \mathrm{Kz}$ Ss Por

$2.00328 \mathrm{e}+02$ 2.00328e+02 2.00328e+01 1.00000e-09 7.00000e-02

$2.00328 \mathrm{e}+02$ 2.00328e+02 2.00328e+01 1.00000e-09 7.00000e-02

$2.00328 \mathrm{e}+022.00328 \mathrm{e}+02$ 2.00328e+01 1.00000e-09 7.00000e-02

$2.00328 \mathrm{e}+02$ 2.00328e+02 2.00328e+01 1.00000e-09 7.00000e-02

$5.00000 \mathrm{e}-04$ 5.00000e-04 5.00000e-05 1.00000e-09 1.00000e-01

$5.00000 \mathrm{e}-04$ 5.00000e-04 5.00000e-05 1.00000e-09 1.00000e-01

$8.00455 \mathrm{e}+00$ 8.00455e+00 8.00455e-01 1.00000e-09 2.12000e-01

$8.00455 \mathrm{e}+008.00455 \mathrm{e}+00$ 8.00455e-01 1.00000e-09 2.12000e-01

$8.00455 \mathrm{e}+00$ 8.00455e+00 8.00455e-01 1.00000e-09 2.12000e-01

$8.00455 \mathrm{e}+00$ 8.00455e+00 8.00455e-01 1.00000e-09 2.12000e-01

8.00455e+00 8.00455e+00 8.00455e-01 1.00000e-09 2.12000e-01

$1.00000 \mathrm{e}-02$ 1.00000e-02 1.00000e-03 1.00000e-09 1.00000e-01

$1.00000 \mathrm{e}+001.00000 \mathrm{e}+001.00000 \mathrm{e}-011.00000 \mathrm{e}-091.00000 \mathrm{e}-01$

$1.00000 \mathrm{e}-05$ 1.00000e-05 1.00000e-06 1.00000e-09 1.00000e-01

$1.00000 \mathrm{e}+001.00000 \mathrm{e}+001.00000 \mathrm{e}-011.00000 \mathrm{e}-091.00000 \mathrm{e}-01$

Element: 1942 \# of layers: 15

Kx Ky Kz Ss Por

$2.00328 \mathrm{e}+02$ 2.00328e+02 2.00328e+01 1.00000e-09 7.00000e-02

$2.00328 \mathrm{e}+02$ 2.00328e+02 2.00328e+01 1.00000e-09 7.00000e-02

$2.00328 \mathrm{e}+022.00328 \mathrm{e}+02$ 2.00328e+01 1.00000e-09 7.00000e-02

$2.00328 \mathrm{e}+022.00328 \mathrm{e}+02$ 2.00328e+01 1.00000e-09 7.00000e-02

5.00000e-04 5.00000e-04 5.00000e-05 1.00000e-09 1.00000e-01

$5.00000 \mathrm{e}-04$ 5.00000e-04 5.00000e-05 1.00000e-09 1.00000e-01

$8.00455 \mathrm{e}+00$ 8.00455e+00 8.00455e-01 1.00000e-09 2.12000e-01

$8.00455 \mathrm{e}+008.00455 \mathrm{e}+00$ 8.00455e-01 1.00000e-09 2.12000e-01 
8.00455e+00 8.00455e+00 8.00455e-01 1.00000e-09 2.12000e-01 8.00455e+00 8.00455e+00 8.00455e-01 1.00000e-09 2.12000e-01 $8.00455 \mathrm{e}+00$ 8.00455e+00 8.00455e-01 1.00000e-09 2.12000e-01 $1.00000 \mathrm{e}-02$ 1.00000e-02 1.00000e-03 1.00000e-09 1.00000e-01 $1.00000 \mathrm{e}+001.00000 \mathrm{e}+001.00000 \mathrm{e}-011.00000 \mathrm{e}-091.00000 \mathrm{e}-01$ $1.00000 \mathrm{e}-05$ 1.00000e-05 1.00000e-06 1.00000e-09 1.00000e-01 $1.00000 \mathrm{e}+001.00000 \mathrm{e}+001.00000 \mathrm{e}-011.00000 \mathrm{e}-091.00000 \mathrm{e}-01$ Element: 1943 \# of layers: 14

$\mathrm{Kx} \mathrm{Ky} \mathrm{Kz}$ Ss Por

$2.00328 \mathrm{e}+02$ 2.00328e+02 2.00328e+01 1.00000e-09 7.00000e-02 $2.00328 \mathrm{e}+02$ 2.00328e+02 2.00328e+01 1.00000e-09 7.00000e-02 $2.00328 \mathrm{e}+022.00328 \mathrm{e}+02 \quad 2.00328 \mathrm{e}+01$ 1.00000e-09 7.00000e-02 $2.00328 \mathrm{e}+022.00328 \mathrm{e}+022.00328 \mathrm{e}+01$ 1.00000e-09 7.00000e-02 5.00000e-04 5.00000e-04 5.00000e-05 1.00000e-09 1.00000e-01 8.00455e+00 8.00455e+00 8.00455e-01 1.00000e-09 2.12000e-01 $8.00455 \mathrm{e}+00$ 8.00455e+00 8.00455e-01 1.00000e-09 2.12000e-01 $8.00455 \mathrm{e}+00$ 8.00455e+00 8.00455e-01 1.00000e-09 2.12000e-01 8.00455e+00 8.00455e+00 8.00455e-01 1.00000e-09 2.12000e-01 $8.00455 \mathrm{e}+00$ 8.00455e+00 8.00455e-01 1.00000e-09 2.12000e-01 $1.00000 \mathrm{e}-02$ 1.00000e-02 1.00000e-03 1.00000e-09 1.00000e-01 $1.00000 \mathrm{e}+001.00000 \mathrm{e}+001.00000 \mathrm{e}-011.00000 \mathrm{e}-091.00000 \mathrm{e}-01$ $1.00000 \mathrm{e}-05$ 1.00000e-05 1.00000e-06 1.00000e-09 1.00000e-01 $1.00000 \mathrm{e}+001.00000 \mathrm{e}+001.00000 \mathrm{e}-01$ 1.00000e-09 1.00000e-01 Element: 1944 \# of layers: 15

$\mathrm{Kx} \mathrm{Ky} \mathrm{Kz}$ Ss Por

$2.00328 \mathrm{e}+02$ 2.00328e+02 2.00328e+01 1.00000e-09 7.00000e-02 $2.00328 \mathrm{e}+022.00328 \mathrm{e}+02$ 2.00328e+01 1.00000e-09 7.00000e-02 $2.00328 \mathrm{e}+02$ 2.00328e+02 2.00328e+01 1.00000e-09 7.00000e-02 $2.00328 \mathrm{e}+022.00328 \mathrm{e}+022.00328 \mathrm{e}+01$ 1.00000e-09 7.00000e-02 $5.00000 \mathrm{e}-04$ 5.00000e-04 5.00000e-05 1.00000e-09 1.00000e-01 $5.00000 \mathrm{e}-04$ 5.00000e-04 5.00000e-05 1.00000e-09 1.00000e-01 $8.00455 \mathrm{e}+00$ 8.00455e+00 8.00455e-01 1.00000e-09 2.12000e-01 $8.00455 \mathrm{e}+008.00455 \mathrm{e}+00$ 8.00455e-01 1.00000e-09 2.12000e-01 $8.00455 \mathrm{e}+00$ 8.00455e+00 8.00455e-01 1.00000e-09 2.12000e-01 8.00455e+00 8.00455e+00 8.00455e-01 1.00000e-09 2.12000e-01 8.00455e+00 8.00455e+00 8.00455e-01 1.00000e-09 2.12000e-01 $1.00000 \mathrm{e}-02$ 1.00000e-02 1.00000e-03 1.00000e-09 1.00000e-01 $1.00000 \mathrm{e}+001.00000 \mathrm{e}+001.00000 \mathrm{e}-011.00000 \mathrm{e}-091.00000 \mathrm{e}-01$ $1.00000 \mathrm{e}-05$ 1.00000e-05 1.00000e-06 1.00000e-09 1.00000e-01 $1.00000 \mathrm{e}+001.00000 \mathrm{e}+001.00000 \mathrm{e}-011.00000 \mathrm{e}-091.00000 \mathrm{e}-01$ Element: 1945 \# of layers: 15

$\mathrm{Kx} \mathrm{Ky} \mathrm{Kz}$ Ss Por $2.00328 \mathrm{e}+02$ 2.00328e+02 2.00328e+01 1.00000e-09 7.00000e-02 $2.00328 \mathrm{e}+02$ 2.00328e+02 2.00328e+01 1.00000e-09 7.00000e-02 $2.00328 \mathrm{e}+022.00328 \mathrm{e}+022.00328 \mathrm{e}+01$ 1.00000e-09 7.00000e-02 $2.00328 \mathrm{e}+02$ 2.00328e+02 2.00328e+01 1.00000e-09 7.00000e-02 
5.00000e-04 5.00000e-04 5.00000e-05 1.00000e-09 1.00000e-01 5.00000e-04 5.00000e-04 5.00000e-05 1.00000e-09 1.00000e-01 $8.00455 \mathrm{e}+00$ 8.00455e+00 8.00455e-01 1.00000e-09 2.12000e-01 $8.00455 \mathrm{e}+008.00455 \mathrm{e}+00$ 8.00455e-01 1.00000e-09 2.12000e-01 $8.00455 \mathrm{e}+008.00455 \mathrm{e}+00$ 8.00455e-01 1.00000e-09 2.12000e-01 $8.00455 \mathrm{e}+00$ 8.00455e+00 8.00455e-01 1.00000e-09 2.12000e-01 $8.00455 \mathrm{e}+00$ 8.00455e+00 8.00455e-01 1.00000e-09 2.12000e-01 $1.00000 \mathrm{e}-02$ 1.00000e-02 1.00000e-03 1.00000e-09 1.00000e-01 $1.00000 \mathrm{e}+001.00000 \mathrm{e}+001.00000 \mathrm{e}-01$ 1.00000e-09 1.00000e-01 $1.00000 \mathrm{e}-05$ 1.00000e-05 1.00000e-06 1.00000e-09 1.00000e-01 $1.00000 \mathrm{e}+001.00000 \mathrm{e}+001.00000 \mathrm{e}-01$ 1.00000e-09 1.00000e-01 Element: 1946 \# of layers: 16

$\mathrm{Kx} \mathrm{Ky} \mathrm{Kz}$ Ss Por

1.34772e+02 1.34772e+02 1.34772e+01 1.00000e-09 7.00000e-02 1.34772e+02 1.34772e+02 1.34772e+01 1.00000e-09 7.00000e-02 $1.34772 \mathrm{e}+02$ 1.34772e+02 1.34772e+01 1.00000e-09 7.00000e-02 $1.34772 \mathrm{e}+02$ 1.34772e+02 1.34772e+01 1.00000e-09 7.00000e-02 $1.34772 \mathrm{e}+02$ 1.34772e+02 1.34772e+01 1.00000e-09 7.00000e-02 5.00000e-04 5.00000e-04 5.00000e-05 1.00000e-09 1.00000e-01 5.00000e-04 5.00000e-04 5.00000e-05 1.00000e-09 1.00000e-01 $5.38504 \mathrm{e}+005.38504 \mathrm{e}+00$ 5.38504e-01 1.00000e-09 2.12000e-01 5.38504e+00 5.38504e+00 5.38504e-01 1.00000e-09 2.12000e-01 $5.38504 \mathrm{e}+005.38504 \mathrm{e}+005.38504 \mathrm{e}-011.00000 \mathrm{e}-092.12000 \mathrm{e}-01$ $5.38504 \mathrm{e}+005.38504 \mathrm{e}+00$ 5.38504e-01 1.00000e-09 2.12000e-01 $5.38504 \mathrm{e}+005.38504 \mathrm{e}+005.38504 \mathrm{e}-01$ 1.00000e-09 2.12000e-01 $1.00000 \mathrm{e}-02$ 1.00000e-02 1.00000e-03 1.00000e-09 1.00000e-01 $1.00000 \mathrm{e}+001.00000 \mathrm{e}+001.00000 \mathrm{e}-011.00000 \mathrm{e}-091.00000 \mathrm{e}-01$ $1.00000 \mathrm{e}-05$ 1.00000e-05 1.00000e-06 1.00000e-09 1.00000e-01 $1.00000 \mathrm{e}+001.00000 \mathrm{e}+001.00000 \mathrm{e}-011.00000 \mathrm{e}-091.00000 \mathrm{e}-01$ Element: 1947 \# of layers: 16

$\mathrm{Kx} \mathrm{Ky} \mathrm{Kz}$ Ss Por

1.34772e+02 1.34772e+02 1.34772e+01 1.00000e-09 7.00000e-02 $1.34772 \mathrm{e}+02$ 1.34772e+02 1.34772e+01 1.00000e-09 7.00000e-02 1.34772e+02 1.34772e+02 1.34772e+01 1.00000e-09 7.00000e-02 1.34772e+02 1.34772e+02 1.34772e+01 1.00000e-09 7.00000e-02 $1.34772 \mathrm{e}+02$ 1.34772e+02 1.34772e+01 1.00000e-09 7.00000e-02 5.00000e-04 5.00000e-04 5.00000e-05 1.00000e-09 1.00000e-01 5.00000e-04 5.00000e-04 5.00000e-05 1.00000e-09 1.00000e-01 $5.38504 \mathrm{e}+005.38504 \mathrm{e}+00$ 5.38504e-01 1.00000e-09 2.12000e-01 $5.38504 \mathrm{e}+00$ 5.38504e+00 5.38504e-01 1.00000e-09 2.12000e-01 $5.38504 \mathrm{e}+005.38504 \mathrm{e}+005.38504 \mathrm{e}-011.00000 \mathrm{e}-092.12000 \mathrm{e}-01$ $5.38504 \mathrm{e}+005.38504 \mathrm{e}+005.38504 \mathrm{e}-011.00000 \mathrm{e}-092.12000 \mathrm{e}-01$ 5.38504e+00 5.38504e+00 5.38504e-01 1.00000e-09 2.12000e-01 $1.00000 \mathrm{e}-02$ 1.00000e-02 1.00000e-03 1.00000e-09 1.00000e-01 $1.00000 \mathrm{e}+001.00000 \mathrm{e}+001.00000 \mathrm{e}-011.00000 \mathrm{e}-091.00000 \mathrm{e}-01$ $1.00000 \mathrm{e}-05$ 1.00000e-05 1.00000e-06 1.00000e-09 1.00000e-01 
$1.00000 \mathrm{e}+001.00000 \mathrm{e}+00$ 1.00000e-01 1.00000e-09 1.00000e-01 Element: 1948 \# of layers: 16

Kx Ky Kz Ss Por

1.34772e+02 1.34772e+02 1.34772e+01 1.00000e-09 7.00000e-02 $1.34772 \mathrm{e}+02$ 1.34772e+02 1.34772e+01 1.00000e-09 7.00000e-02 $1.34772 \mathrm{e}+02$ 1.34772e+02 1.34772e+01 1.00000e-09 7.00000e-02 $1.34772 \mathrm{e}+02$ 1.34772e+02 1.34772e+01 1.00000e-09 7.00000e-02 $1.34772 \mathrm{e}+02$ 1.34772e+02 1.34772e+01 1.00000e-09 7.00000e-02 5.00000e-04 5.00000e-04 5.00000e-05 1.00000e-09 1.00000e-01 5.00000e-04 5.00000e-04 5.00000e-05 1.00000e-09 1.00000e-01 $5.38504 \mathrm{e}+005.38504 \mathrm{e}+00$ 5.38504e-01 1.00000e-09 2.12000e-01 $5.38504 \mathrm{e}+005.38504 \mathrm{e}+005.38504 \mathrm{e}-01$ 1.00000e-09 2.12000e-01 $5.38504 \mathrm{e}+005.38504 \mathrm{e}+00$ 5.38504e-01 1.00000e-09 2.12000e-01 $5.38504 \mathrm{e}+005.38504 \mathrm{e}+005.38504 \mathrm{e}-01$ 1.00000e-09 2.12000e-01 $5.38504 \mathrm{e}+005.38504 \mathrm{e}+00$ 5.38504e-01 1.00000e-09 2.12000e-01 $1.00000 \mathrm{e}-02$ 1.00000e-02 1.00000e-03 1.00000e-09 1.00000e-01 $1.00000 \mathrm{e}+001.00000 \mathrm{e}+001.00000 \mathrm{e}-011.00000 \mathrm{e}-091.00000 \mathrm{e}-01$ $1.00000 \mathrm{e}-051.00000 \mathrm{e}-051.00000 \mathrm{e}-061.00000 \mathrm{e}-091.00000 \mathrm{e}-01$ $1.00000 \mathrm{e}+001.00000 \mathrm{e}+001.00000 \mathrm{e}-011.00000 \mathrm{e}-091.00000 \mathrm{e}-01$ Element: 1949 \# of layers: 16

$\mathrm{Kx} \mathrm{Ky} \mathrm{Kz}$ Ss Por

1.34772e+02 1.34772e+02 1.34772e+01 1.00000e-09 7.00000e-02 1.34772e+02 1.34772e+02 1.34772e+01 1.00000e-09 7.00000e-02 $1.34772 \mathrm{e}+02$ 1.34772e+02 1.34772e+01 1.00000e-09 7.00000e-02 $1.34772 \mathrm{e}+02$ 1.34772e+02 1.34772e+01 1.00000e-09 7.00000e-02 $1.34772 \mathrm{e}+02$ 1.34772e+02 1.34772e+01 1.00000e-09 7.00000e-02 $5.00000 \mathrm{e}-04$ 5.00000e-04 5.00000e-05 1.00000e-09 1.00000e-01 5.00000e-04 5.00000e-04 5.00000e-05 1.00000e-09 1.00000e-01

$5.38504 \mathrm{e}+00$ 5.38504e+00 5.38504e-01 1.00000e-09 2.12000e-01 5.38504e+00 5.38504e+00 5.38504e-01 1.00000e-09 2.12000e-01 $5.38504 \mathrm{e}+005.38504 \mathrm{e}+005.38504 \mathrm{e}-01$ 1.00000e-09 2.12000e-01 $5.38504 \mathrm{e}+00$ 5.38504e+00 5.38504e-01 1.00000e-09 2.12000e-01 $5.38504 \mathrm{e}+005.38504 \mathrm{e}+00$ 5.38504e-01 1.00000e-09 2.12000e-01 $1.00000 \mathrm{e}-02$ 1.00000e-02 1.00000e-03 1.00000e-09 1.00000e-01 $1.00000 \mathrm{e}+001.00000 \mathrm{e}+001.00000 \mathrm{e}-011.00000 \mathrm{e}-091.00000 \mathrm{e}-01$ $1.00000 \mathrm{e}-05$ 1.00000e-05 1.00000e-06 1.00000e-09 1.00000e-01 $1.00000 \mathrm{e}+001.00000 \mathrm{e}+001.00000 \mathrm{e}-011.00000 \mathrm{e}-091.00000 \mathrm{e}-01$ Element: 1950 \# of layers: 16

$\mathrm{Kx} \mathrm{Ky} \mathrm{Kz}$ Ss Por

1.34772e+02 1.34772e+02 1.34772e+01 1.00000e-09 7.00000e-02 1.34772e+02 1.34772e+02 1.34772e+01 1.00000e-09 7.00000e-02 1.34772e+02 1.34772e+02 1.34772e+01 1.00000e-09 7.00000e-02 1.34772e+02 1.34772e+02 1.34772e+01 1.00000e-09 7.00000e-02 1.34772e+02 1.34772e+02 1.34772e+01 1.00000e-09 7.00000e-02 5.00000e-04 5.00000e-04 5.00000e-05 1.00000e-09 1.00000e-01 5.00000e-04 5.00000e-04 5.00000e-05 1.00000e-09 1.00000e-01 
$5.38504 \mathrm{e}+005.38504 \mathrm{e}+00$ 5.38504e-01 1.00000e-09 2.12000e-01 $5.38504 \mathrm{e}+005.38504 \mathrm{e}+005.38504 \mathrm{e}-011.00000 \mathrm{e}-092.12000 \mathrm{e}-01$ $5.38504 \mathrm{e}+005.38504 \mathrm{e}+00$ 5.38504e-01 1.00000e-09 2.12000e-01 $5.38504 \mathrm{e}+005.38504 \mathrm{e}+005.38504 \mathrm{e}-011.00000 \mathrm{e}-092.12000 \mathrm{e}-01$ $5.38504 \mathrm{e}+005.38504 \mathrm{e}+00$ 5.38504e-01 1.00000e-09 2.12000e-01 $1.00000 \mathrm{e}-021.00000 \mathrm{e}-02$ 1.00000e-03 1.00000e-09 1.00000e-01 $1.00000 \mathrm{e}+001.00000 \mathrm{e}+001.00000 \mathrm{e}-011.00000 \mathrm{e}-091.00000 \mathrm{e}-01$ $1.00000 \mathrm{e}-05$ 1.00000e-05 1.00000e-06 1.00000e-09 1.00000e-01 $1.00000 \mathrm{e}+001.00000 \mathrm{e}+001.00000 \mathrm{e}-011.00000 \mathrm{e}-091.00000 \mathrm{e}-01$ Element: 1951 \# of layers: 16

Kx Ky Kz Ss Por

$1.34772 \mathrm{e}+02$ 1.34772e+02 1.34772e+01 1.00000e-09 7.00000e-02 $1.34772 \mathrm{e}+021.34772 \mathrm{e}+021.34772 \mathrm{e}+01$ 1.00000e-09 7.00000e-02 $1.34772 \mathrm{e}+021.34772 \mathrm{e}+021.34772 \mathrm{e}+01$ 1.00000e-09 7.00000e-02 $1.34772 \mathrm{e}+021.34772 \mathrm{e}+021.34772 \mathrm{e}+011.00000 \mathrm{e}-097.00000 \mathrm{e}-02$ $1.34772 \mathrm{e}+021.34772 \mathrm{e}+021.34772 \mathrm{e}+01$ 1.00000e-09 7.00000e-02 5.00000e-04 5.00000e-04 5.00000e-05 1.00000e-09 1.00000e-01 5.00000e-04 5.00000e-04 5.00000e-05 1.00000e-09 1.00000e-01 $5.38504 \mathrm{e}+005.38504 \mathrm{e}+005.38504 \mathrm{e}-011.00000 \mathrm{e}-092.12000 \mathrm{e}-01$ $5.38504 \mathrm{e}+005.38504 \mathrm{e}+005.38504 \mathrm{e}-011.00000 \mathrm{e}-092.12000 \mathrm{e}-01$ $5.38504 \mathrm{e}+005.38504 \mathrm{e}+005.38504 \mathrm{e}-011.00000 \mathrm{e}-092.12000 \mathrm{e}-01$ $5.38504 \mathrm{e}+005.38504 \mathrm{e}+005.38504 \mathrm{e}-011.00000 \mathrm{e}-092.12000 \mathrm{e}-01$ $5.38504 \mathrm{e}+005.38504 \mathrm{e}+00$ 5.38504e-01 1.00000e-09 2.12000e-01 $1.00000 \mathrm{e}-02$ 1.00000e-02 1.00000e-03 1.00000e-09 1.00000e-01 $1.00000 \mathrm{e}+001.00000 \mathrm{e}+001.00000 \mathrm{e}-011.00000 \mathrm{e}-091.00000 \mathrm{e}-01$ $1.00000 \mathrm{e}-05$ 1.00000e-05 1.00000e-06 1.00000e-09 1.00000e-01 $1.00000 \mathrm{e}+001.00000 \mathrm{e}+00$ 1.00000e-01 1.00000e-09 1.00000e-01 Element: 1952 \# of layers: 16

Kx Ky Kz Ss Por

1.34772e+02 1.34772e+02 1.34772e+01 1.00000e-09 7.00000e-02 $1.34772 \mathrm{e}+02$ 1.34772e+02 1.34772e+01 1.00000e-09 7.00000e-02 $1.34772 \mathrm{e}+02$ 1.34772e+02 1.34772e+01 1.00000e-09 7.00000e-02 $1.34772 \mathrm{e}+02$ 1.34772e+02 1.34772e+01 1.00000e-09 7.00000e-02 1.34772e+02 1.34772e+02 1.34772e+01 1.00000e-09 7.00000e-02 5.00000e-04 5.00000e-04 5.00000e-05 1.00000e-09 1.00000e-01 5.00000e-04 5.00000e-04 5.00000e-05 1.00000e-09 1.00000e-01 $5.38504 \mathrm{e}+005.38504 \mathrm{e}+005.38504 \mathrm{e}-01$ 1.00000e-09 2.12000e-01 $5.38504 \mathrm{e}+005.38504 \mathrm{e}+00$ 5.38504e-01 1.00000e-09 2.12000e-01 $5.38504 \mathrm{e}+005.38504 \mathrm{e}+00$ 5.38504e-01 1.00000e-09 2.12000e-01 $5.38504 \mathrm{e}+005.38504 \mathrm{e}+005.38504 \mathrm{e}-011.00000 \mathrm{e}-092.12000 \mathrm{e}-01$ $5.38504 \mathrm{e}+005.38504 \mathrm{e}+00$ 5.38504e-01 1.00000e-09 2.12000e-01 $1.00000 \mathrm{e}-021.00000 \mathrm{e}-02$ 1.00000e-03 1.00000e-09 1.00000e-01 $1.00000 \mathrm{e}+001.00000 \mathrm{e}+001.00000 \mathrm{e}-011.00000 \mathrm{e}-091.00000 \mathrm{e}-01$ $1.00000 \mathrm{e}-05$ 1.00000e-05 1.00000e-06 1.00000e-09 1.00000e-01 $1.00000 \mathrm{e}+001.00000 \mathrm{e}+001.00000 \mathrm{e}-011.00000 \mathrm{e}-091.00000 \mathrm{e}-01$ Element: 1953 \# of layers: 16 
$\mathrm{Kx} \mathrm{Ky} \mathrm{Kz}$ Ss Por

1.34772e+02 1.34772e+02 1.34772e+01 1.00000e-09 7.00000e-02 1.34772e+02 1.34772e+02 1.34772e+01 1.00000e-09 7.00000e-02 $1.34772 \mathrm{e}+02$ 1.34772e+02 1.34772e+01 1.00000e-09 7.00000e-02 $1.34772 \mathrm{e}+02$ 1.34772e+02 1.34772e+01 1.00000e-09 7.00000e-02 $1.34772 \mathrm{e}+02$ 1.34772e+02 1.34772e+01 1.00000e-09 7.00000e-02 5.00000e-04 5.00000e-04 5.00000e-05 1.00000e-09 1.00000e-01 5.00000e-04 5.00000e-04 5.00000e-05 1.00000e-09 1.00000e-01 $5.38504 \mathrm{e}+00$ 5.38504e+00 5.38504e-01 1.00000e-09 2.12000e-01 $5.38504 \mathrm{e}+005.38504 \mathrm{e}+00$ 5.38504e-01 1.00000e-09 2.12000e-01 $5.38504 \mathrm{e}+00$ 5.38504e+00 5.38504e-01 1.00000e-09 2.12000e-01 $5.38504 \mathrm{e}+005.38504 \mathrm{e}+005.38504 \mathrm{e}-011.00000 \mathrm{e}-092.12000 \mathrm{e}-01$ $5.38504 \mathrm{e}+005.38504 \mathrm{e}+005.38504 \mathrm{e}-01$ 1.00000e-09 2.12000e-01 $1.00000 \mathrm{e}-02$ 1.00000e-02 1.00000e-03 1.00000e-09 1.00000e-01 $1.00000 \mathrm{e}+001.00000 \mathrm{e}+001.00000 \mathrm{e}-011.00000 \mathrm{e}-091.00000 \mathrm{e}-01$ $1.00000 \mathrm{e}-05$ 1.00000e-05 1.00000e-06 1.00000e-09 1.00000e-01 $1.00000 \mathrm{e}+001.00000 \mathrm{e}+001.00000 \mathrm{e}-011.00000 \mathrm{e}-091.00000 \mathrm{e}-01$ Element: 1954 \# of layers: 16

$\mathrm{Kx} \mathrm{Ky} \mathrm{Kz}$ Ss Por

1.34772e+02 1.34772e+02 1.34772e+01 1.00000e-09 7.00000e-02 $1.34772 \mathrm{e}+02$ 1.34772e+02 1.34772e+01 1.00000e-09 7.00000e-02 1.34772e+02 1.34772e+02 1.34772e+01 1.00000e-09 7.00000e-02 1.34772e+02 1.34772e+02 1.34772e+01 1.00000e-09 7.00000e-02 $1.34772 \mathrm{e}+02$ 1.34772e+02 1.34772e+01 1.00000e-09 7.00000e-02 $5.00000 \mathrm{e}-04$ 5.00000e-04 5.00000e-05 1.00000e-09 1.00000e-01 $5.00000 \mathrm{e}-04$ 5.00000e-04 5.00000e-05 1.00000e-09 1.00000e-01

$5.38504 \mathrm{e}+005.38504 \mathrm{e}+005.38504 \mathrm{e}-011.00000 \mathrm{e}-092.12000 \mathrm{e}-01$ $5.38504 \mathrm{e}+005.38504 \mathrm{e}+00$ 5.38504e-01 1.00000e-09 2.12000e-01 $5.38504 \mathrm{e}+005.38504 \mathrm{e}+00$ 5.38504e-01 1.00000e-09 2.12000e-01 $5.38504 \mathrm{e}+00$ 5.38504e+00 5.38504e-01 1.00000e-09 2.12000e-01 $5.38504 \mathrm{e}+005.38504 \mathrm{e}+005.38504 \mathrm{e}-01$ 1.00000e-09 2.12000e-01 $1.00000 \mathrm{e}-02$ 1.00000e-02 1.00000e-03 1.00000e-09 1.00000e-01 $1.00000 \mathrm{e}+001.00000 \mathrm{e}+001.00000 \mathrm{e}-011.00000 \mathrm{e}-091.00000 \mathrm{e}-01$ $1.00000 \mathrm{e}-05$ 1.00000e-05 1.00000e-06 1.00000e-09 1.00000e-01 $1.00000 \mathrm{e}+001.00000 \mathrm{e}+001.00000 \mathrm{e}-01$ 1.00000e-09 1.00000e-01 Element: 1955 \# of layers: 16

Kx Ky Kz Ss Por

5.24274e+01 5.24274e+01 5.24274e+00 1.00000e-09 7.00000e-02 $5.24274 \mathrm{e}+015.24274 \mathrm{e}+015.24274 \mathrm{e}+001.00000 \mathrm{e}-09$ 7.00000e-02 $5.24274 \mathrm{e}+015.24274 \mathrm{e}+015.24274 \mathrm{e}+001.00000 \mathrm{e}-09$ 7.00000e-02 $5.24274 \mathrm{e}+015.24274 \mathrm{e}+015.24274 \mathrm{e}+001.00000 \mathrm{e}-09$ 7.00000e-02 $5.24274 \mathrm{e}+015.24274 \mathrm{e}+015.24274 \mathrm{e}+001.00000 \mathrm{e}-097.00000 \mathrm{e}-02$ 5.00000e-04 5.00000e-04 5.00000e-05 1.00000e-09 1.00000e-01 $5.00000 \mathrm{e}-04$ 5.00000e-04 5.00000e-05 1.00000e-09 1.00000e-01 $2.09482 \mathrm{e}+002.09482 \mathrm{e}+00$ 2.09482e-01 1.00000e-09 2.12000e-01 $2.09482 \mathrm{e}+002.09482 \mathrm{e}+00$ 2.09482e-01 1.00000e-09 2.12000e-01 
$2.09482 \mathrm{e}+002.09482 \mathrm{e}+002.09482 \mathrm{e}-01$ 1.00000e-09 2.12000e-01 $2.09482 \mathrm{e}+002.09482 \mathrm{e}+002.09482 \mathrm{e}-01$ 1.00000e-09 2.12000e-01 $2.09482 \mathrm{e}+002.09482 \mathrm{e}+002.09482 \mathrm{e}-01$ 1.00000e-09 2.12000e-01 $1.00000 \mathrm{e}-021.00000 \mathrm{e}-02$ 1.00000e-03 1.00000e-09 1.00000e-01 $1.00000 \mathrm{e}+001.00000 \mathrm{e}+001.00000 \mathrm{e}-011.00000 \mathrm{e}-091.00000 \mathrm{e}-01$ $1.00000 \mathrm{e}-05$ 1.00000e-05 1.00000e-06 1.00000e-09 1.00000e-01 $1.00000 \mathrm{e}+001.00000 \mathrm{e}+001.00000 \mathrm{e}-011.00000 \mathrm{e}-091.00000 \mathrm{e}-01$ Element: 1956 \# of layers: 16

$\mathrm{Kx} \mathrm{Ky} \mathrm{Kz}$ Ss Por

5.24274e+01 5.24274e+01 5.24274e+00 1.00000e-09 7.00000e-02 $5.24274 \mathrm{e}+015.24274 \mathrm{e}+015.24274 \mathrm{e}+001.00000 \mathrm{e}-09$ 7.00000e-02 $5.24274 \mathrm{e}+015.24274 \mathrm{e}+015.24274 \mathrm{e}+001.00000 \mathrm{e}-09$ 7.00000e-02 $5.24274 \mathrm{e}+015.24274 \mathrm{e}+015.24274 \mathrm{e}+001.00000 \mathrm{e}-09$ 7.00000e-02 $5.24274 \mathrm{e}+015.24274 \mathrm{e}+015.24274 \mathrm{e}+001.00000 \mathrm{e}-097.00000 \mathrm{e}-02$ 5.00000e-04 5.00000e-04 5.00000e-05 1.00000e-09 1.00000e-01 5.00000e-04 5.00000e-04 5.00000e-05 1.00000e-09 1.00000e-01 $2.09482 \mathrm{e}+002.09482 \mathrm{e}+002.09482 \mathrm{e}-011.00000 \mathrm{e}-092.12000 \mathrm{e}-01$ $2.09482 \mathrm{e}+002.09482 \mathrm{e}+002.09482 \mathrm{e}-01$ 1.00000e-09 2.12000e-01 $2.09482 \mathrm{e}+002.09482 \mathrm{e}+002.09482 \mathrm{e}-011.00000 \mathrm{e}-092.12000 \mathrm{e}-01$ $2.09482 \mathrm{e}+002.09482 \mathrm{e}+002.09482 \mathrm{e}-01$ 1.00000e-09 2.12000e-01 $2.09482 \mathrm{e}+002.09482 \mathrm{e}+002.09482 \mathrm{e}-011.00000 \mathrm{e}-092.12000 \mathrm{e}-01$ $1.00000 \mathrm{e}-02$ 1.00000e-02 1.00000e-03 1.00000e-09 1.00000e-01 $1.00000 \mathrm{e}+001.00000 \mathrm{e}+001.00000 \mathrm{e}-011.00000 \mathrm{e}-091.00000 \mathrm{e}-01$ $1.00000 \mathrm{e}-051.00000 \mathrm{e}-05$ 1.00000e-06 1.00000e-09 1.00000e-01 $1.00000 \mathrm{e}+001.00000 \mathrm{e}+001.00000 \mathrm{e}-011.00000 \mathrm{e}-091.00000 \mathrm{e}-01$ Element: 1957 \# of layers: 16

Kx Ky Kz Ss Por

$5.24274 \mathrm{e}+015.24274 \mathrm{e}+015.24274 \mathrm{e}+00$ 1.00000e-09 7.00000e-02 $5.24274 \mathrm{e}+015.24274 \mathrm{e}+015.24274 \mathrm{e}+001.00000 \mathrm{e}-09$ 7.00000e-02 $5.24274 \mathrm{e}+015.24274 \mathrm{e}+015.24274 \mathrm{e}+001.00000 \mathrm{e}-09$ 7.00000e-02 $5.24274 \mathrm{e}+015.24274 \mathrm{e}+015.24274 \mathrm{e}+001.00000 \mathrm{e}-09$ 7.00000e-02 $5.24274 \mathrm{e}+015.24274 \mathrm{e}+015.24274 \mathrm{e}+001.00000 \mathrm{e}-097.00000 \mathrm{e}-02$ 5.00000e-04 5.00000e-04 5.00000e-05 1.00000e-09 1.00000e-01 $5.00000 \mathrm{e}-04$ 5.00000e-04 5.00000e-05 1.00000e-09 1.00000e-01 $2.09482 \mathrm{e}+002.09482 \mathrm{e}+002.09482 \mathrm{e}-01$ 1.00000e-09 2.12000e-01 $2.09482 \mathrm{e}+002.09482 \mathrm{e}+002.09482 \mathrm{e}-01$ 1.00000e-09 2.12000e-01 $2.09482 \mathrm{e}+002.09482 \mathrm{e}+002.09482 \mathrm{e}-011.00000 \mathrm{e}-092.12000 \mathrm{e}-01$ $2.09482 \mathrm{e}+002.09482 \mathrm{e}+002.09482 \mathrm{e}-011.00000 \mathrm{e}-092.12000 \mathrm{e}-01$ $2.09482 \mathrm{e}+002.09482 \mathrm{e}+002.09482 \mathrm{e}-01$ 1.00000e-09 2.12000e-01 $1.00000 \mathrm{e}-02$ 1.00000e-02 1.00000e-03 1.00000e-09 1.00000e-01 $1.00000 \mathrm{e}+001.00000 \mathrm{e}+001.00000 \mathrm{e}-011.00000 \mathrm{e}-091.00000 \mathrm{e}-01$ $1.00000 \mathrm{e}-05$ 1.00000e-05 1.00000e-06 1.00000e-09 1.00000e-01 $1.00000 \mathrm{e}+001.00000 \mathrm{e}+001.00000 \mathrm{e}-011.00000 \mathrm{e}-091.00000 \mathrm{e}-01$ Element: 1958 \# of layers: 16

Kx Ky Kz Ss Por

5.24274e+01 5.24274e+01 5.24274e+00 1.00000e-09 7.00000e-02 
$5.24274 \mathrm{e}+015.24274 \mathrm{e}+015.24274 \mathrm{e}+001.00000 \mathrm{e}-09$ 7.00000e-02 $5.24274 \mathrm{e}+015.24274 \mathrm{e}+015.24274 \mathrm{e}+001.00000 \mathrm{e}-097.00000 \mathrm{e}-02$ $5.24274 \mathrm{e}+015.24274 \mathrm{e}+015.24274 \mathrm{e}+001.00000 \mathrm{e}-09$ 7.00000e-02 $5.24274 \mathrm{e}+015.24274 \mathrm{e}+015.24274 \mathrm{e}+001.00000 \mathrm{e}-097.00000 \mathrm{e}-02$ $5.00000 \mathrm{e}-04$ 5.00000e-04 5.00000e-05 1.00000e-09 1.00000e-01 5.00000e-04 5.00000e-04 5.00000e-05 1.00000e-09 1.00000e-01 $2.09482 \mathrm{e}+002.09482 \mathrm{e}+00$ 2.09482e-01 1.00000e-09 2.12000e-01 $2.09482 \mathrm{e}+002.09482 \mathrm{e}+00$ 2.09482e-01 1.00000e-09 2.12000e-01 2.09482e+00 2.09482e+00 2.09482e-01 1.00000e-09 2.12000e-01 $2.09482 \mathrm{e}+002.09482 \mathrm{e}+00$ 2.09482e-01 1.00000e-09 2.12000e-01 $2.09482 \mathrm{e}+002.09482 \mathrm{e}+00$ 2.09482e-01 1.00000e-09 2.12000e-01 $1.00000 \mathrm{e}-02$ 1.00000e-02 1.00000e-03 1.00000e-09 1.00000e-01 $1.00000 \mathrm{e}+001.00000 \mathrm{e}+001.00000 \mathrm{e}-011.00000 \mathrm{e}-091.00000 \mathrm{e}-01$ $1.00000 \mathrm{e}-05$ 1.00000e-05 1.00000e-06 1.00000e-09 1.00000e-01 $1.00000 \mathrm{e}+001.00000 \mathrm{e}+001.00000 \mathrm{e}-01$ 1.00000e-09 1.00000e-01 Element: 1959 \# of layers: 16

$\mathrm{Kx} \mathrm{Ky} \mathrm{Kz}$ Ss Por

5.24274e+01 5.24274e+01 5.24274e+00 1.00000e-09 7.00000e-02 $5.24274 \mathrm{e}+015.24274 \mathrm{e}+015.24274 \mathrm{e}+001.00000 \mathrm{e}-097.00000 \mathrm{e}-02$ $5.24274 \mathrm{e}+015.24274 \mathrm{e}+015.24274 \mathrm{e}+001.00000 \mathrm{e}-09$ 7.00000e-02 $5.24274 \mathrm{e}+015.24274 \mathrm{e}+015.24274 \mathrm{e}+001.00000 \mathrm{e}-09$ 7.00000e-02 $5.24274 \mathrm{e}+015.24274 \mathrm{e}+015.24274 \mathrm{e}+001.00000 \mathrm{e}-09$ 7.00000e-02 5.00000e-04 5.00000e-04 5.00000e-05 1.00000e-09 1.00000e-01 5.00000e-04 5.00000e-04 5.00000e-05 1.00000e-09 1.00000e-01 $2.09482 \mathrm{e}+002.09482 \mathrm{e}+002.09482 \mathrm{e}-01$ 1.00000e-09 2.12000e-01 $2.09482 \mathrm{e}+002.09482 \mathrm{e}+00$ 2.09482e-01 1.00000e-09 2.12000e-01 $2.09482 \mathrm{e}+002.09482 \mathrm{e}+00$ 2.09482e-01 1.00000e-09 2.12000e-01 $2.09482 \mathrm{e}+002.09482 \mathrm{e}+00$ 2.09482e-01 1.00000e-09 2.12000e-01 $2.09482 \mathrm{e}+002.09482 \mathrm{e}+00$ 2.09482e-01 1.00000e-09 2.12000e-01 $1.00000 \mathrm{e}-02$ 1.00000e-02 1.00000e-03 1.00000e-09 1.00000e-01 $1.00000 \mathrm{e}+001.00000 \mathrm{e}+001.00000 \mathrm{e}-01$ 1.00000e-09 1.00000e-01 $1.00000 \mathrm{e}-05$ 1.00000e-05 1.00000e-06 1.00000e-09 1.00000e-01 $1.00000 \mathrm{e}+001.00000 \mathrm{e}+001.00000 \mathrm{e}-011.00000 \mathrm{e}-091.00000 \mathrm{e}-01$ Element: 1960 \# of layers: 16

$\mathrm{Kx} \mathrm{Ky} \mathrm{Kz}$ Ss Por

$5.24274 \mathrm{e}+015.24274 \mathrm{e}+015.24274 \mathrm{e}+00$ 1.00000e-09 7.00000e-02 $5.24274 \mathrm{e}+015.24274 \mathrm{e}+015.24274 \mathrm{e}+001.00000 \mathrm{e}-09$ 7.00000e-02 $5.24274 \mathrm{e}+015.24274 \mathrm{e}+015.24274 \mathrm{e}+001.00000 \mathrm{e}-09$ 7.00000e-02 $5.24274 \mathrm{e}+015.24274 \mathrm{e}+015.24274 \mathrm{e}+001.00000 \mathrm{e}-09$ 7.00000e-02 $5.24274 \mathrm{e}+015.24274 \mathrm{e}+015.24274 \mathrm{e}+001.00000 \mathrm{e}-097.00000 \mathrm{e}-02$ 5.00000e-04 5.00000e-04 5.00000e-05 1.00000e-09 1.00000e-01 5.00000e-04 5.00000e-04 5.00000e-05 1.00000e-09 1.00000e-01 $2.09482 \mathrm{e}+002.09482 \mathrm{e}+00$ 2.09482e-01 1.00000e-09 2.12000e-01 $2.09482 \mathrm{e}+002.09482 \mathrm{e}+00$ 2.09482e-01 1.00000e-09 2.12000e-01 $2.09482 \mathrm{e}+002.09482 \mathrm{e}+002.09482 \mathrm{e}-01$ 1.00000e-09 2.12000e-01 $2.09482 \mathrm{e}+002.09482 \mathrm{e}+00$ 2.09482e-01 1.00000e-09 2.12000e-01 
$2.09482 \mathrm{e}+00$ 2.09482e+00 2.09482e-01 1.00000e-09 2.12000e-01 $1.00000 \mathrm{e}-02$ 1.00000e-02 1.00000e-03 1.00000e-09 1.00000e-01 $1.00000 \mathrm{e}+001.00000 \mathrm{e}+001.00000 \mathrm{e}-011.00000 \mathrm{e}-091.00000 \mathrm{e}-01$ $1.00000 \mathrm{e}-05$ 1.00000e-05 1.00000e-06 1.00000e-09 1.00000e-01 $1.00000 \mathrm{e}+001.00000 \mathrm{e}+001.00000 \mathrm{e}-011.00000 \mathrm{e}-091.00000 \mathrm{e}-01$ Element: 1961 \# of layers: 16

$\mathrm{Kx} \mathrm{Ky} \mathrm{Kz}$ Ss Por

5.24274e+01 5.24274e+01 5.24274e+00 1.00000e-09 7.00000e-02 $5.24274 \mathrm{e}+015.24274 \mathrm{e}+015.24274 \mathrm{e}+001.00000 \mathrm{e}-09$ 7.00000e-02 $5.24274 \mathrm{e}+015.24274 \mathrm{e}+015.24274 \mathrm{e}+00$ 1.00000e-09 7.00000e-02 $5.24274 \mathrm{e}+015.24274 \mathrm{e}+015.24274 \mathrm{e}+001.00000 \mathrm{e}-09$ 7.00000e-02 $5.24274 \mathrm{e}+015.24274 \mathrm{e}+015.24274 \mathrm{e}+001.00000 \mathrm{e}-097.00000 \mathrm{e}-02$ 5.00000e-04 5.00000e-04 5.00000e-05 1.00000e-09 1.00000e-01 5.00000e-04 5.00000e-04 5.00000e-05 1.00000e-09 1.00000e-01 $2.09482 \mathrm{e}+002.09482 \mathrm{e}+002.09482 \mathrm{e}-01$ 1.00000e-09 2.12000e-01 $2.09482 \mathrm{e}+002.09482 \mathrm{e}+002.09482 \mathrm{e}-01$ 1.00000e-09 2.12000e-01 $2.09482 \mathrm{e}+002.09482 \mathrm{e}+00$ 2.09482e-01 1.00000e-09 2.12000e-01 $2.09482 \mathrm{e}+002.09482 \mathrm{e}+00$ 2.09482e-01 1.00000e-09 2.12000e-01 $2.09482 \mathrm{e}+002.09482 \mathrm{e}+00$ 2.09482e-01 1.00000e-09 2.12000e-01 $1.00000 \mathrm{e}-02$ 1.00000e-02 1.00000e-03 1.00000e-09 1.00000e-01 $1.00000 \mathrm{e}+001.00000 \mathrm{e}+001.00000 \mathrm{e}-011.00000 \mathrm{e}-091.00000 \mathrm{e}-01$ $1.00000 \mathrm{e}-05$ 1.00000e-05 1.00000e-06 1.00000e-09 1.00000e-01 $1.00000 \mathrm{e}+001.00000 \mathrm{e}+001.00000 \mathrm{e}-01$ 1.00000e-09 1.00000e-01 Element: 1962 \# of layers: 16

$\mathrm{Kx} \mathrm{Ky} \mathrm{Kz}$ Ss Por

5.24274e+01 5.24274e+01 5.24274e+00 1.00000e-09 7.00000e-02 $5.24274 \mathrm{e}+015.24274 \mathrm{e}+015.24274 \mathrm{e}+001.00000 \mathrm{e}-097.00000 \mathrm{e}-02$ $5.24274 \mathrm{e}+015.24274 \mathrm{e}+015.24274 \mathrm{e}+001.00000 \mathrm{e}-097.00000 \mathrm{e}-02$ $5.24274 \mathrm{e}+015.24274 \mathrm{e}+015.24274 \mathrm{e}+001.00000 \mathrm{e}-09$ 7.00000e-02 $5.24274 \mathrm{e}+015.24274 \mathrm{e}+015.24274 \mathrm{e}+001.00000 \mathrm{e}-09$ 7.00000e-02 5.00000e-04 5.00000e-04 5.00000e-05 1.00000e-09 1.00000e-01 5.00000e-04 5.00000e-04 5.00000e-05 1.00000e-09 1.00000e-01 $2.09482 \mathrm{e}+002.09482 \mathrm{e}+002.09482 \mathrm{e}-01$ 1.00000e-09 2.12000e-01 $2.09482 \mathrm{e}+002.09482 \mathrm{e}+002.09482 \mathrm{e}-01$ 1.00000e-09 2.12000e-01 $2.09482 \mathrm{e}+002.09482 \mathrm{e}+00$ 2.09482e-01 1.00000e-09 2.12000e-01 $2.09482 \mathrm{e}+002.09482 \mathrm{e}+00$ 2.09482e-01 1.00000e-09 2.12000e-01 $2.09482 \mathrm{e}+002.09482 \mathrm{e}+002.09482 \mathrm{e}-01$ 1.00000e-09 2.12000e-01 $1.00000 \mathrm{e}-02$ 1.00000e-02 1.00000e-03 1.00000e-09 1.00000e-01 $1.00000 \mathrm{e}+001.00000 \mathrm{e}+001.00000 \mathrm{e}-011.00000 \mathrm{e}-091.00000 \mathrm{e}-01$ $1.00000 \mathrm{e}-05$ 1.00000e-05 1.00000e-06 1.00000e-09 1.00000e-01 $1.00000 \mathrm{e}+001.00000 \mathrm{e}+001.00000 \mathrm{e}-011.00000 \mathrm{e}-091.00000 \mathrm{e}-01$ Element: 1963 \# of layers: 16

$\mathrm{Kx} \mathrm{Ky} \mathrm{Kz}$ Ss Por

5.24274e+01 5.24274e+01 5.24274e+00 1.00000e-09 7.00000e-02 $5.24274 \mathrm{e}+015.24274 \mathrm{e}+015.24274 \mathrm{e}+001.00000 \mathrm{e}-09$ 7.00000e-02 $5.24274 \mathrm{e}+015.24274 \mathrm{e}+015.24274 \mathrm{e}+001.00000 \mathrm{e}-097.00000 \mathrm{e}-02$ 
$5.24274 \mathrm{e}+015.24274 \mathrm{e}+015.24274 \mathrm{e}+001.00000 \mathrm{e}-09$ 7.00000e-02 $5.24274 \mathrm{e}+015.24274 \mathrm{e}+015.24274 \mathrm{e}+001.00000 \mathrm{e}-097.00000 \mathrm{e}-02$ 5.00000e-04 5.00000e-04 5.00000e-05 1.00000e-09 1.00000e-01 5.00000e-04 5.00000e-04 5.00000e-05 1.00000e-09 1.00000e-01 $2.09482 \mathrm{e}+002.09482 \mathrm{e}+00$ 2.09482e-01 1.00000e-09 2.12000e-01 $2.09482 \mathrm{e}+002.09482 \mathrm{e}+00$ 2.09482e-01 1.00000e-09 2.12000e-01 $2.09482 \mathrm{e}+002.09482 \mathrm{e}+00$ 2.09482e-01 1.00000e-09 2.12000e-01 $2.09482 \mathrm{e}+002.09482 \mathrm{e}+00$ 2.09482e-01 1.00000e-09 2.12000e-01 2.09482e+00 2.09482e+00 2.09482e-01 1.00000e-09 2.12000e-01 $1.00000 \mathrm{e}-02$ 1.00000e-02 1.00000e-03 1.00000e-09 1.00000e-01 $1.00000 \mathrm{e}+001.00000 \mathrm{e}+001.00000 \mathrm{e}-011.00000 \mathrm{e}-091.00000 \mathrm{e}-01$ $1.00000 \mathrm{e}-05$ 1.00000e-05 1.00000e-06 1.00000e-09 1.00000e-01 $1.00000 \mathrm{e}+001.00000 \mathrm{e}+001.00000 \mathrm{e}-011.00000 \mathrm{e}-091.00000 \mathrm{e}-01$ Element: 1964 \# of layers: 16

$\mathrm{Kx} \mathrm{Ky} \mathrm{Kz}$ Ss Por

$5.79424 \mathrm{e}+015.79424 \mathrm{e}+015.79424 \mathrm{e}+001.00000 \mathrm{e}-09$ 7.00000e-02 $5.79424 \mathrm{e}+015.79424 \mathrm{e}+015.79424 \mathrm{e}+001.00000 \mathrm{e}-09$ 7.00000e-02 $5.79424 \mathrm{e}+015.79424 \mathrm{e}+015.79424 \mathrm{e}+001.00000 \mathrm{e}-09$ 7.00000e-02 $5.79424 \mathrm{e}+015.79424 \mathrm{e}+015.79424 \mathrm{e}+001.00000 \mathrm{e}-097.00000 \mathrm{e}-02$ $5.79424 \mathrm{e}+015.79424 \mathrm{e}+015.79424 \mathrm{e}+001.00000 \mathrm{e}-09$ 7.00000e-02 5.00000e-04 5.00000e-04 5.00000e-05 1.00000e-09 1.00000e-01 5.00000e-04 5.00000e-04 5.00000e-05 1.00000e-09 1.00000e-01 $2.31530 \mathrm{e}+002.31530 \mathrm{e}+00$ 2.31530e-01 1.00000e-09 2.12000e-01 $2.31530 \mathrm{e}+002.31530 \mathrm{e}+002.31530 \mathrm{e}-01$ 1.00000e-09 2.12000e-01 $2.31530 \mathrm{e}+002.31530 \mathrm{e}+00$ 2.31530e-01 1.00000e-09 2.12000e-01 $2.31530 \mathrm{e}+002.31530 \mathrm{e}+00$ 2.31530e-01 1.00000e-09 2.12000e-01 $2.31530 \mathrm{e}+002.31530 \mathrm{e}+00$ 2.31530e-01 1.00000e-09 2.12000e-01 $1.00000 \mathrm{e}-02$ 1.00000e-02 1.00000e-03 1.00000e-09 1.00000e-01 $1.00000 \mathrm{e}+001.00000 \mathrm{e}+001.00000 \mathrm{e}-011.00000 \mathrm{e}-091.00000 \mathrm{e}-01$ $1.00000 \mathrm{e}-05$ 1.00000e-05 1.00000e-06 1.00000e-09 1.00000e-01 $1.00000 \mathrm{e}+001.00000 \mathrm{e}+001.00000 \mathrm{e}-011.00000 \mathrm{e}-091.00000 \mathrm{e}-01$ Element: 1965 \# of layers: 16

Kx Ky Kz Ss Por

$5.79424 \mathrm{e}+015.79424 \mathrm{e}+015.79424 \mathrm{e}+001.00000 \mathrm{e}-09$ 7.00000e-02 $5.79424 \mathrm{e}+015.79424 \mathrm{e}+015.79424 \mathrm{e}+001.00000 \mathrm{e}-09$ 7.00000e-02 $5.79424 \mathrm{e}+015.79424 \mathrm{e}+015.79424 \mathrm{e}+001.00000 \mathrm{e}-09$ 7.00000e-02 $5.79424 \mathrm{e}+015.79424 \mathrm{e}+015.79424 \mathrm{e}+001.00000 \mathrm{e}-09$ 7.00000e-02 $5.79424 \mathrm{e}+015.79424 \mathrm{e}+015.79424 \mathrm{e}+001.00000 \mathrm{e}-09$ 7.00000e-02 5.00000e-04 5.00000e-04 5.00000e-05 1.00000e-09 1.00000e-01 5.00000e-04 5.00000e-04 5.00000e-05 1.00000e-09 1.00000e-01 $2.31530 \mathrm{e}+002.31530 \mathrm{e}+002.31530 \mathrm{e}-01$ 1.00000e-09 2.12000e-01 $2.31530 \mathrm{e}+002.31530 \mathrm{e}+00$ 2.31530e-01 1.00000e-09 2.12000e-01 $2.31530 \mathrm{e}+002.31530 \mathrm{e}+00$ 2.31530e-01 1.00000e-09 2.12000e-01 $2.31530 \mathrm{e}+002.31530 \mathrm{e}+00$ 2.31530e-01 1.00000e-09 2.12000e-01 $2.31530 \mathrm{e}+002.31530 \mathrm{e}+002.31530 \mathrm{e}-01$ 1.00000e-09 2.12000e-01 $1.00000 \mathrm{e}-02$ 1.00000e-02 1.00000e-03 1.00000e-09 1.00000e-01 
$1.00000 \mathrm{e}+001.00000 \mathrm{e}+001.00000 \mathrm{e}-011.00000 \mathrm{e}-091.00000 \mathrm{e}-01$ $1.00000 \mathrm{e}-05$ 1.00000e-05 1.00000e-06 1.00000e-09 1.00000e-01 $1.00000 \mathrm{e}+001.00000 \mathrm{e}+001.00000 \mathrm{e}-011.00000 \mathrm{e}-091.00000 \mathrm{e}-01$ Element: 1966 \# of layers: 15

$\mathrm{Kx} \mathrm{Ky} \mathrm{Kz}$ Ss Por

$5.79424 \mathrm{e}+015.79424 \mathrm{e}+015.79424 \mathrm{e}+00$ 1.00000e-09 7.00000e-02 $5.79424 \mathrm{e}+015.79424 \mathrm{e}+015.79424 \mathrm{e}+001.00000 \mathrm{e}-097.00000 \mathrm{e}-02$ $5.79424 \mathrm{e}+015.79424 \mathrm{e}+015.79424 \mathrm{e}+001.00000 \mathrm{e}-097.00000 \mathrm{e}-02$ $5.79424 \mathrm{e}+015.79424 \mathrm{e}+015.79424 \mathrm{e}+001.00000 \mathrm{e}-097.00000 \mathrm{e}-02$ 5.00000e-04 5.00000e-04 5.00000e-05 1.00000e-09 1.00000e-01 5.00000e-04 5.00000e-04 5.00000e-05 1.00000e-09 1.00000e-01 $2.31530 \mathrm{e}+002.31530 \mathrm{e}+00$ 2.31530e-01 1.00000e-09 2.12000e-01 $2.31530 \mathrm{e}+002.31530 \mathrm{e}+00$ 2.31530e-01 1.00000e-09 2.12000e-01 $2.31530 \mathrm{e}+002.31530 \mathrm{e}+00$ 2.31530e-01 1.00000e-09 2.12000e-01 $2.31530 \mathrm{e}+00$ 2.31530e+00 2.31530e-01 1.00000e-09 2.12000e-01 $2.31530 \mathrm{e}+002.31530 \mathrm{e}+002.31530 \mathrm{e}-01$ 1.00000e-09 2.12000e-01 $1.00000 \mathrm{e}-02$ 1.00000e-02 1.00000e-03 1.00000e-09 1.00000e-01 $1.00000 \mathrm{e}+001.00000 \mathrm{e}+001.00000 \mathrm{e}-011.00000 \mathrm{e}-091.00000 \mathrm{e}-01$ $1.00000 \mathrm{e}-05$ 1.00000e-05 1.00000e-06 1.00000e-09 1.00000e-01 $1.00000 \mathrm{e}+001.00000 \mathrm{e}+001.00000 \mathrm{e}-011.00000 \mathrm{e}-091.00000 \mathrm{e}-01$ Element: 1967 \# of layers: 15

$\mathrm{Kx} \mathrm{Ky} \mathrm{Kz}$ Ss Por

5.79424e+01 5.79424e+01 5.79424e+00 1.00000e-09 7.00000e-02 $5.79424 \mathrm{e}+015.79424 \mathrm{e}+015.79424 \mathrm{e}+001.00000 \mathrm{e}-09$ 7.00000e-02 $5.79424 \mathrm{e}+015.79424 \mathrm{e}+015.79424 \mathrm{e}+001.00000 \mathrm{e}-097.00000 \mathrm{e}-02$ $5.79424 \mathrm{e}+015.79424 \mathrm{e}+015.79424 \mathrm{e}+001.00000 \mathrm{e}-09$ 7.00000e-02 5.00000e-04 5.00000e-04 5.00000e-05 1.00000e-09 1.00000e-01 5.00000e-04 5.00000e-04 5.00000e-05 1.00000e-09 1.00000e-01

$2.31530 \mathrm{e}+002.31530 \mathrm{e}+00$ 2.31530e-01 1.00000e-09 2.12000e-01 $2.31530 \mathrm{e}+002.31530 \mathrm{e}+00$ 2.31530e-01 1.00000e-09 2.12000e-01 $2.31530 \mathrm{e}+002.31530 \mathrm{e}+00$ 2.31530e-01 1.00000e-09 2.12000e-01 $2.31530 \mathrm{e}+00$ 2.31530e+00 2.31530e-01 1.00000e-09 2.12000e-01 $2.31530 \mathrm{e}+002.31530 \mathrm{e}+00$ 2.31530e-01 1.00000e-09 2.12000e-01 $1.00000 \mathrm{e}-02$ 1.00000e-02 1.00000e-03 1.00000e-09 1.00000e-01 $1.00000 \mathrm{e}+001.00000 \mathrm{e}+001.00000 \mathrm{e}-011.00000 \mathrm{e}-091.00000 \mathrm{e}-01$ $1.00000 \mathrm{e}-05$ 1.00000e-05 1.00000e-06 1.00000e-09 1.00000e-01 $1.00000 \mathrm{e}+001.00000 \mathrm{e}+001.00000 \mathrm{e}-011.00000 \mathrm{e}-091.00000 \mathrm{e}-01$ Element: 1968 \# of layers: 15

$\mathrm{Kx} \mathrm{Ky} \mathrm{Kz}$ Ss Por

$5.79424 \mathrm{e}+015.79424 \mathrm{e}+015.79424 \mathrm{e}+00$ 1.00000e-09 7.00000e-02 $5.79424 \mathrm{e}+015.79424 \mathrm{e}+015.79424 \mathrm{e}+001.00000 \mathrm{e}-09$ 7.00000e-02 $5.79424 \mathrm{e}+015.79424 \mathrm{e}+015.79424 \mathrm{e}+001.00000 \mathrm{e}-097.00000 \mathrm{e}-02$ $5.79424 \mathrm{e}+015.79424 \mathrm{e}+015.79424 \mathrm{e}+001.00000 \mathrm{e}-097.00000 \mathrm{e}-02$ 5.00000e-04 5.00000e-04 5.00000e-05 1.00000e-09 1.00000e-01 5.00000e-04 5.00000e-04 5.00000e-05 1.00000e-09 1.00000e-01 $2.31530 \mathrm{e}+002.31530 \mathrm{e}+00$ 2.31530e-01 1.00000e-09 2.12000e-01 
$2.31530 \mathrm{e}+002.31530 \mathrm{e}+002.31530 \mathrm{e}-011.00000 \mathrm{e}-092.12000 \mathrm{e}-01$ $2.31530 \mathrm{e}+002.31530 \mathrm{e}+002.31530 \mathrm{e}-011.00000 \mathrm{e}-092.12000 \mathrm{e}-01$ $2.31530 \mathrm{e}+002.31530 \mathrm{e}+002.31530 \mathrm{e}-01$ 1.00000e-09 2.12000e-01 $2.31530 \mathrm{e}+002.31530 \mathrm{e}+002.31530 \mathrm{e}-011.00000 \mathrm{e}-092.12000 \mathrm{e}-01$ $1.00000 \mathrm{e}-02$ 1.00000e-02 1.00000e-03 1.00000e-09 1.00000e-01 $1.00000 \mathrm{e}+001.00000 \mathrm{e}+001.00000 \mathrm{e}-011.00000 \mathrm{e}-091.00000 \mathrm{e}-01$ $1.00000 \mathrm{e}-051.00000 \mathrm{e}-05$ 1.00000e-06 1.00000e-09 1.00000e-01 $1.00000 \mathrm{e}+001.00000 \mathrm{e}+001.00000 \mathrm{e}-011.00000 \mathrm{e}-091.00000 \mathrm{e}-01$ Element: 1969 \# of layers: 16

Kx Ky Kz Ss Por

$5.79424 \mathrm{e}+015.79424 \mathrm{e}+015.79424 \mathrm{e}+00$ 1.00000e-09 7.00000e-02 $5.79424 \mathrm{e}+015.79424 \mathrm{e}+015.79424 \mathrm{e}+001.00000 \mathrm{e}-09$ 7.00000e-02 $5.79424 \mathrm{e}+015.79424 \mathrm{e}+015.79424 \mathrm{e}+001.00000 \mathrm{e}-097.00000 \mathrm{e}-02$ $5.79424 \mathrm{e}+015.79424 \mathrm{e}+015.79424 \mathrm{e}+001.00000 \mathrm{e}-097.00000 \mathrm{e}-02$ $5.79424 \mathrm{e}+015.79424 \mathrm{e}+015.79424 \mathrm{e}+001.00000 \mathrm{e}-097.00000 \mathrm{e}-02$ $5.00000 \mathrm{e}-04$ 5.00000e-04 5.00000e-05 1.00000e-09 1.00000e-01 5.00000e-04 5.00000e-04 5.00000e-05 1.00000e-09 1.00000e-01 $2.31530 \mathrm{e}+002.31530 \mathrm{e}+002.31530 \mathrm{e}-01$ 1.00000e-09 2.12000e-01 $2.31530 \mathrm{e}+002.31530 \mathrm{e}+002.31530 \mathrm{e}-01$ 1.00000e-09 2.12000e-01 $2.31530 \mathrm{e}+002.31530 \mathrm{e}+002.31530 \mathrm{e}-01$ 1.00000e-09 2.12000e-01 $2.31530 \mathrm{e}+002.31530 \mathrm{e}+002.31530 \mathrm{e}-011.00000 \mathrm{e}-092.12000 \mathrm{e}-01$ $2.31530 \mathrm{e}+002.31530 \mathrm{e}+002.31530 \mathrm{e}-011.00000 \mathrm{e}-092.12000 \mathrm{e}-01$ $1.00000 \mathrm{e}-02$ 1.00000e-02 1.00000e-03 1.00000e-09 1.00000e-01 $1.00000 \mathrm{e}+001.00000 \mathrm{e}+001.00000 \mathrm{e}-011.00000 \mathrm{e}-091.00000 \mathrm{e}-01$ $1.00000 \mathrm{e}-05$ 1.00000e-05 1.00000e-06 1.00000e-09 1.00000e-01 $1.00000 \mathrm{e}+001.00000 \mathrm{e}+001.00000 \mathrm{e}-011.00000 \mathrm{e}-091.00000 \mathrm{e}-01$ Element: 1970 \# of layers: 16

Kx Ky Kz Ss Por

$5.79424 \mathrm{e}+015.79424 \mathrm{e}+015.79424 \mathrm{e}+001.00000 \mathrm{e}-09$ 7.00000e-02 $5.79424 \mathrm{e}+015.79424 \mathrm{e}+015.79424 \mathrm{e}+001.00000 \mathrm{e}-097.00000 \mathrm{e}-02$ $5.79424 \mathrm{e}+015.79424 \mathrm{e}+015.79424 \mathrm{e}+001.00000 \mathrm{e}-097.00000 \mathrm{e}-02$ $5.79424 \mathrm{e}+015.79424 \mathrm{e}+015.79424 \mathrm{e}+001.00000 \mathrm{e}-097.00000 \mathrm{e}-02$ $5.79424 \mathrm{e}+015.79424 \mathrm{e}+015.79424 \mathrm{e}+001.00000 \mathrm{e}-09$ 7.00000e-02 5.00000e-04 5.00000e-04 5.00000e-05 1.00000e-09 1.00000e-01 5.00000e-04 5.00000e-04 5.00000e-05 1.00000e-09 1.00000e-01 $2.31530 \mathrm{e}+002.31530 \mathrm{e}+002.31530 \mathrm{e}-01$ 1.00000e-09 2.12000e-01 $2.31530 \mathrm{e}+002.31530 \mathrm{e}+002.31530 \mathrm{e}-011.00000 \mathrm{e}-092.12000 \mathrm{e}-01$ $2.31530 \mathrm{e}+002.31530 \mathrm{e}+002.31530 \mathrm{e}-011.00000 \mathrm{e}-092.12000 \mathrm{e}-01$ $2.31530 \mathrm{e}+002.31530 \mathrm{e}+002.31530 \mathrm{e}-011.00000 \mathrm{e}-092.12000 \mathrm{e}-01$ $2.31530 \mathrm{e}+002.31530 \mathrm{e}+002.31530 \mathrm{e}-01$ 1.00000e-09 2.12000e-01 $1.00000 \mathrm{e}-021.00000 \mathrm{e}-02$ 1.00000e-03 1.00000e-09 1.00000e-01 $1.00000 \mathrm{e}+001.00000 \mathrm{e}+001.00000 \mathrm{e}-011.00000 \mathrm{e}-091.00000 \mathrm{e}-01$ $1.00000 \mathrm{e}-05$ 1.00000e-05 1.00000e-06 1.00000e-09 1.00000e-01 $1.00000 \mathrm{e}+001.00000 \mathrm{e}+001.00000 \mathrm{e}-011.00000 \mathrm{e}-091.00000 \mathrm{e}-01$ Element: 1971 \# of layers: 16

Kx Ky Kz Ss Por 
$5.79424 \mathrm{e}+015.79424 \mathrm{e}+015.79424 \mathrm{e}+001.00000 \mathrm{e}-09$ 7.00000e-02 $5.79424 \mathrm{e}+015.79424 \mathrm{e}+015.79424 \mathrm{e}+001.00000 \mathrm{e}-097.00000 \mathrm{e}-02$ $5.79424 \mathrm{e}+015.79424 \mathrm{e}+015.79424 \mathrm{e}+001.00000 \mathrm{e}-09$ 7.00000e-02 $5.79424 \mathrm{e}+015.79424 \mathrm{e}+015.79424 \mathrm{e}+001.00000 \mathrm{e}-097.00000 \mathrm{e}-02$ $5.79424 \mathrm{e}+015.79424 \mathrm{e}+015.79424 \mathrm{e}+001.00000 \mathrm{e}-097.00000 \mathrm{e}-02$ 5.00000e-04 5.00000e-04 5.00000e-05 1.00000e-09 1.00000e-01 5.00000e-04 5.00000e-04 5.00000e-05 1.00000e-09 1.00000e-01 $2.31530 \mathrm{e}+002.31530 \mathrm{e}+00$ 2.31530e-01 1.00000e-09 2.12000e-01 2.31530e+00 2.31530e+00 2.31530e-01 1.00000e-09 2.12000e-01 $2.31530 \mathrm{e}+002.31530 \mathrm{e}+00$ 2.31530e-01 1.00000e-09 2.12000e-01 $2.31530 \mathrm{e}+002.31530 \mathrm{e}+00$ 2.31530e-01 1.00000e-09 2.12000e-01 $2.31530 \mathrm{e}+002.31530 \mathrm{e}+002.31530 \mathrm{e}-01$ 1.00000e-09 2.12000e-01 $1.00000 \mathrm{e}-02$ 1.00000e-02 1.00000e-03 1.00000e-09 1.00000e-01 $1.00000 \mathrm{e}+001.00000 \mathrm{e}+001.00000 \mathrm{e}-011.00000 \mathrm{e}-091.00000 \mathrm{e}-01$ $1.00000 \mathrm{e}-05$ 1.00000e-05 1.00000e-06 1.00000e-09 1.00000e-01 $1.00000 \mathrm{e}+001.00000 \mathrm{e}+001.00000 \mathrm{e}-011.00000 \mathrm{e}-091.00000 \mathrm{e}-01$ Element: 1972 \# of layers: 16

$\mathrm{Kx} \mathrm{Ky} \mathrm{Kz}$ Ss Por

5.79424e+01 5.79424e+01 5.79424e+00 1.00000e-09 7.00000e-02 $5.79424 \mathrm{e}+015.79424 \mathrm{e}+015.79424 \mathrm{e}+001.00000 \mathrm{e}-097.00000 \mathrm{e}-02$ $5.79424 \mathrm{e}+015.79424 \mathrm{e}+015.79424 \mathrm{e}+001.00000 \mathrm{e}-09$ 7.00000e-02 $5.79424 \mathrm{e}+015.79424 \mathrm{e}+015.79424 \mathrm{e}+001.00000 \mathrm{e}-097.00000 \mathrm{e}-02$ $5.79424 \mathrm{e}+015.79424 \mathrm{e}+015.79424 \mathrm{e}+001.00000 \mathrm{e}-097.00000 \mathrm{e}-02$ 5.00000e-04 5.00000e-04 5.00000e-05 1.00000e-09 1.00000e-01 5.00000e-04 5.00000e-04 5.00000e-05 1.00000e-09 1.00000e-01 $2.31530 \mathrm{e}+002.31530 \mathrm{e}+002.31530 \mathrm{e}-01$ 1.00000e-09 2.12000e-01 2.31530e+00 2.31530e+00 2.31530e-01 1.00000e-09 2.12000e-01 $2.31530 \mathrm{e}+002.31530 \mathrm{e}+00$ 2.31530e-01 1.00000e-09 2.12000e-01 $2.31530 \mathrm{e}+002.31530 \mathrm{e}+00$ 2.31530e-01 1.00000e-09 2.12000e-01 $2.31530 \mathrm{e}+002.31530 \mathrm{e}+00$ 2.31530e-01 1.00000e-09 2.12000e-01 $1.00000 \mathrm{e}-02$ 1.00000e-02 1.00000e-03 1.00000e-09 1.00000e-01 $1.00000 \mathrm{e}+001.00000 \mathrm{e}+001.00000 \mathrm{e}-011.00000 \mathrm{e}-091.00000 \mathrm{e}-01$ $1.00000 \mathrm{e}-05$ 1.00000e-05 1.00000e-06 1.00000e-09 1.00000e-01 $1.00000 \mathrm{e}+001.00000 \mathrm{e}+001.00000 \mathrm{e}-011.00000 \mathrm{e}-091.00000 \mathrm{e}-01$ Element: 1973 \# of layers: 15

$\mathrm{Kx} \mathrm{Ky} \mathrm{Kz}$ Ss Por

4.26092e+01 4.26092e+01 4.26092e+00 1.00000e-09 7.00000e-02 $4.26092 \mathrm{e}+014.26092 \mathrm{e}+014.26092 \mathrm{e}+00$ 1.00000e-09 7.00000e-02 4.26092e+01 4.26092e+01 4.26092e+00 1.00000e-09 7.00000e-02 4.26092e+01 4.26092e+01 4.26092e+00 1.00000e-09 7.00000e-02 5.00000e-04 5.00000e-04 5.00000e-05 1.00000e-09 1.00000e-01 5.00000e-04 5.00000e-04 5.00000e-05 1.00000e-09 1.00000e-01 $1.70250 \mathrm{e}+001.70250 \mathrm{e}+001.70250 \mathrm{e}-01$ 1.00000e-09 2.12000e-01 $1.70250 \mathrm{e}+001.70250 \mathrm{e}+00$ 1.70250e-01 1.00000e-09 2.12000e-01 $1.70250 \mathrm{e}+001.70250 \mathrm{e}+001.70250 \mathrm{e}-01$ 1.00000e-09 2.12000e-01 $1.70250 \mathrm{e}+001.70250 \mathrm{e}+001.70250 \mathrm{e}-011.00000 \mathrm{e}-092.12000 \mathrm{e}-01$ 
$1.70250 \mathrm{e}+00$ 1.70250e+00 1.70250e-01 1.00000e-09 2.12000e-01 $1.00000 \mathrm{e}-02$ 1.00000e-02 1.00000e-03 1.00000e-09 1.00000e-01 $1.00000 \mathrm{e}+001.00000 \mathrm{e}+001.00000 \mathrm{e}-011.00000 \mathrm{e}-091.00000 \mathrm{e}-01$ $1.00000 \mathrm{e}-05$ 1.00000e-05 1.00000e-06 1.00000e-09 1.00000e-01 $1.00000 \mathrm{e}+001.00000 \mathrm{e}+001.00000 \mathrm{e}-011.00000 \mathrm{e}-091.00000 \mathrm{e}-01$ Element: 1974 \# of layers: 15

$\mathrm{Kx} \mathrm{Ky} \mathrm{Kz}$ Ss Por

4.26092e+01 4.26092e+01 4.26092e+00 1.00000e-09 7.00000e-02 4.26092e+01 4.26092e+01 4.26092e+00 1.00000e-09 7.00000e-02 $4.26092 \mathrm{e}+014.26092 \mathrm{e}+014.26092 \mathrm{e}+00$ 1.00000e-09 7.00000e-02 4.26092e+01 4.26092e+01 4.26092e+00 1.00000e-09 7.00000e-02 5.00000e-04 5.00000e-04 5.00000e-05 1.00000e-09 1.00000e-01 5.00000e-04 5.00000e-04 5.00000e-05 1.00000e-09 1.00000e-01

$1.70250 \mathrm{e}+001.70250 \mathrm{e}+001.70250 \mathrm{e}-01$ 1.00000e-09 2.12000e-01 $1.70250 \mathrm{e}+001.70250 \mathrm{e}+00$ 1.70250e-01 1.00000e-09 2.12000e-01 $1.70250 \mathrm{e}+001.70250 \mathrm{e}+001.70250 \mathrm{e}-011.00000 \mathrm{e}-092.12000 \mathrm{e}-01$ $1.70250 \mathrm{e}+001.70250 \mathrm{e}+001.70250 \mathrm{e}-01$ 1.00000e-09 2.12000e-01 $1.70250 \mathrm{e}+001.70250 \mathrm{e}+001.70250 \mathrm{e}-01$ 1.00000e-09 2.12000e-01 $1.00000 \mathrm{e}-02$ 1.00000e-02 1.00000e-03 1.00000e-09 1.00000e-01 $1.00000 \mathrm{e}+001.00000 \mathrm{e}+001.00000 \mathrm{e}-011.00000 \mathrm{e}-091.00000 \mathrm{e}-01$ $1.00000 \mathrm{e}-05$ 1.00000e-05 1.00000e-06 1.00000e-09 1.00000e-01 $1.00000 \mathrm{e}+001.00000 \mathrm{e}+001.00000 \mathrm{e}-01$ 1.00000e-09 1.00000e-01 Element: 1975 \# of layers: 14

$\mathrm{Kx} \mathrm{Ky} \mathrm{Kz}$ Ss Por

4.26092e+01 4.26092e+01 4.26092e+00 1.00000e-09 7.00000e-02 4.26092e+01 4.26092e+01 4.26092e+00 1.00000e-09 7.00000e-02 $4.26092 \mathrm{e}+014.26092 \mathrm{e}+014.26092 \mathrm{e}+001.00000 \mathrm{e}-09$ 7.00000e-02 5.00000e-04 5.00000e-04 5.00000e-05 1.00000e-09 1.00000e-01 5.00000e-04 5.00000e-04 5.00000e-05 1.00000e-09 1.00000e-01 $1.70250 \mathrm{e}+001.70250 \mathrm{e}+001.70250 \mathrm{e}-01$ 1.00000e-09 2.12000e-01 $1.70250 \mathrm{e}+001.70250 \mathrm{e}+001.70250 \mathrm{e}-01$ 1.00000e-09 2.12000e-01 $1.70250 \mathrm{e}+001.70250 \mathrm{e}+001.70250 \mathrm{e}-011.00000 \mathrm{e}-092.12000 \mathrm{e}-01$ $1.70250 \mathrm{e}+001.70250 \mathrm{e}+001.70250 \mathrm{e}-011.00000 \mathrm{e}-092.12000 \mathrm{e}-01$ $1.70250 \mathrm{e}+001.70250 \mathrm{e}+001.70250 \mathrm{e}-01$ 1.00000e-09 2.12000e-01 $1.00000 \mathrm{e}-02$ 1.00000e-02 1.00000e-03 1.00000e-09 1.00000e-01 $1.00000 \mathrm{e}+001.00000 \mathrm{e}+001.00000 \mathrm{e}-011.00000 \mathrm{e}-091.00000 \mathrm{e}-01$ $1.00000 \mathrm{e}-05$ 1.00000e-05 1.00000e-06 1.00000e-09 1.00000e-01 $1.00000 \mathrm{e}+001.00000 \mathrm{e}+001.00000 \mathrm{e}-011.00000 \mathrm{e}-091.00000 \mathrm{e}-01$ Element: 1976 \# of layers: 14

$\mathrm{Kx} \mathrm{Ky} \mathrm{Kz}$ Ss Por 4.26092e+01 4.26092e+01 4.26092e+00 1.00000e-09 7.00000e-02 4.26092e+01 4.26092e+01 4.26092e+00 1.00000e-09 7.00000e-02 $4.26092 \mathrm{e}+014.26092 \mathrm{e}+014.26092 \mathrm{e}+001.00000 \mathrm{e}-09$ 7.00000e-02 5.00000e-04 5.00000e-04 5.00000e-05 1.00000e-09 1.00000e-01 5.00000e-04 5.00000e-04 5.00000e-05 1.00000e-09 1.00000e-01 $1.70250 \mathrm{e}+001.70250 \mathrm{e}+001.70250 \mathrm{e}-01$ 1.00000e-09 2.12000e-01 
$1.70250 \mathrm{e}+001.70250 \mathrm{e}+001.70250 \mathrm{e}-011.00000 \mathrm{e}-092.12000 \mathrm{e}-01$ $1.70250 \mathrm{e}+001.70250 \mathrm{e}+001.70250 \mathrm{e}-011.00000 \mathrm{e}-092.12000 \mathrm{e}-01$ $1.70250 \mathrm{e}+001.70250 \mathrm{e}+00$ 1.70250e-01 1.00000e-09 2.12000e-01 $1.70250 \mathrm{e}+001.70250 \mathrm{e}+001.70250 \mathrm{e}-011.00000 \mathrm{e}-092.12000 \mathrm{e}-01$ $1.00000 \mathrm{e}-02$ 1.00000e-02 1.00000e-03 1.00000e-09 1.00000e-01 $1.00000 \mathrm{e}+001.00000 \mathrm{e}+001.00000 \mathrm{e}-011.00000 \mathrm{e}-091.00000 \mathrm{e}-01$ $1.00000 \mathrm{e}-051.00000 \mathrm{e}-05$ 1.00000e-06 1.00000e-09 1.00000e-01 $1.00000 \mathrm{e}+001.00000 \mathrm{e}+001.00000 \mathrm{e}-011.00000 \mathrm{e}-091.00000 \mathrm{e}-01$ Element: 1977 \# of layers: 14

Kx Ky Kz Ss Por

$4.26092 \mathrm{e}+014.26092 \mathrm{e}+014.26092 \mathrm{e}+00$ 1.00000e-09 7.00000e-02 $4.26092 \mathrm{e}+014.26092 \mathrm{e}+014.26092 \mathrm{e}+001.00000 \mathrm{e}-09$ 7.00000e-02 $4.26092 \mathrm{e}+014.26092 \mathrm{e}+014.26092 \mathrm{e}+001.00000 \mathrm{e}-09$ 7.00000e-02 5.00000e-04 5.00000e-04 5.00000e-05 1.00000e-09 1.00000e-01 $5.00000 \mathrm{e}-04$ 5.00000e-04 5.00000e-05 1.00000e-09 1.00000e-01 $1.70250 \mathrm{e}+001.70250 \mathrm{e}+001.70250 \mathrm{e}-011.00000 \mathrm{e}-092.12000 \mathrm{e}-01$ $1.70250 \mathrm{e}+001.70250 \mathrm{e}+001.70250 \mathrm{e}-011.00000 \mathrm{e}-092.12000 \mathrm{e}-01$ $1.70250 \mathrm{e}+001.70250 \mathrm{e}+001.70250 \mathrm{e}-011.00000 \mathrm{e}-092.12000 \mathrm{e}-01$ $1.70250 \mathrm{e}+001.70250 \mathrm{e}+001.70250 \mathrm{e}-011.00000 \mathrm{e}-092.12000 \mathrm{e}-01$ $1.70250 \mathrm{e}+001.70250 \mathrm{e}+00$ 1.70250e-01 1.00000e-09 2.12000e-01 $1.00000 \mathrm{e}-021.00000 \mathrm{e}-02$ 1.00000e-03 1.00000e-09 1.00000e-01 $1.00000 \mathrm{e}+001.00000 \mathrm{e}+001.00000 \mathrm{e}-011.00000 \mathrm{e}-091.00000 \mathrm{e}-01$ $1.00000 \mathrm{e}-05$ 1.00000e-05 1.00000e-06 1.00000e-09 1.00000e-01 $1.00000 \mathrm{e}+001.00000 \mathrm{e}+001.00000 \mathrm{e}-011.00000 \mathrm{e}-091.00000 \mathrm{e}-01$ Element: 1978 \# of layers: 15

Kx Ky Kz Ss Por

4.26092e+01 4.26092e+01 4.26092e+00 1.00000e-09 7.00000e-02 $4.26092 \mathrm{e}+014.26092 \mathrm{e}+014.26092 \mathrm{e}+00$ 1.00000e-09 7.00000e-02 $4.26092 \mathrm{e}+014.26092 \mathrm{e}+014.26092 \mathrm{e}+001.00000 \mathrm{e}-09$ 7.00000e-02 $4.26092 \mathrm{e}+014.26092 \mathrm{e}+014.26092 \mathrm{e}+001.00000 \mathrm{e}-09$ 7.00000e-02 5.00000e-04 5.00000e-04 5.00000e-05 1.00000e-09 1.00000e-01 5.00000e-04 5.00000e-04 5.00000e-05 1.00000e-09 1.00000e-01 $1.70250 \mathrm{e}+001.70250 \mathrm{e}+001.70250 \mathrm{e}-011.00000 \mathrm{e}-092.12000 \mathrm{e}-01$ $1.70250 \mathrm{e}+001.70250 \mathrm{e}+001.70250 \mathrm{e}-011.00000 \mathrm{e}-092.12000 \mathrm{e}-01$ $1.70250 \mathrm{e}+001.70250 \mathrm{e}+001.70250 \mathrm{e}-011.00000 \mathrm{e}-092.12000 \mathrm{e}-01$ $1.70250 \mathrm{e}+001.70250 \mathrm{e}+00$ 1.70250e-01 1.00000e-09 2.12000e-01 $1.70250 \mathrm{e}+001.70250 \mathrm{e}+00$ 1.70250e-01 1.00000e-09 2.12000e-01 $1.00000 \mathrm{e}-021.00000 \mathrm{e}-02$ 1.00000e-03 1.00000e-09 1.00000e-01 $1.00000 \mathrm{e}+001.00000 \mathrm{e}+001.00000 \mathrm{e}-011.00000 \mathrm{e}-091.00000 \mathrm{e}-01$ $1.00000 \mathrm{e}-05$ 1.00000e-05 1.00000e-06 1.00000e-09 1.00000e-01 $1.00000 \mathrm{e}+001.00000 \mathrm{e}+001.00000 \mathrm{e}-011.00000 \mathrm{e}-091.00000 \mathrm{e}-01$ Element: 1979 \# of layers: 15

Kx Ky Kz Ss Por $4.26092 \mathrm{e}+014.26092 \mathrm{e}+014.26092 \mathrm{e}+00$ 1.00000e-09 7.00000e-02 $4.26092 \mathrm{e}+014.26092 \mathrm{e}+014.26092 \mathrm{e}+00$ 1.00000e-09 7.00000e-02 $4.26092 \mathrm{e}+014.26092 \mathrm{e}+014.26092 \mathrm{e}+001.00000 \mathrm{e}-09$ 7.00000e-02 
4.26092e+01 4.26092e+01 4.26092e+00 1.00000e-09 7.00000e-02 5.00000e-04 5.00000e-04 5.00000e-05 1.00000e-09 1.00000e-01 5.00000e-04 5.00000e-04 5.00000e-05 1.00000e-09 1.00000e-01

$1.70250 \mathrm{e}+001.70250 \mathrm{e}+001.70250 \mathrm{e}-011.00000 \mathrm{e}-092.12000 \mathrm{e}-01$ $1.70250 \mathrm{e}+001.70250 \mathrm{e}+001.70250 \mathrm{e}-01$ 1.00000e-09 2.12000e-01 $1.70250 \mathrm{e}+001.70250 \mathrm{e}+001.70250 \mathrm{e}-01$ 1.00000e-09 2.12000e-01 $1.70250 \mathrm{e}+001.70250 \mathrm{e}+001.70250 \mathrm{e}-01$ 1.00000e-09 2.12000e-01 $1.70250 \mathrm{e}+001.70250 \mathrm{e}+001.70250 \mathrm{e}-011.00000 \mathrm{e}-092.12000 \mathrm{e}-01$ $1.00000 \mathrm{e}-02$ 1.00000e-02 1.00000e-03 1.00000e-09 1.00000e-01 $1.00000 \mathrm{e}+001.00000 \mathrm{e}+001.00000 \mathrm{e}-011.00000 \mathrm{e}-091.00000 \mathrm{e}-01$ $1.00000 \mathrm{e}-05$ 1.00000e-05 1.00000e-06 1.00000e-09 1.00000e-01 $1.00000 \mathrm{e}+001.00000 \mathrm{e}+001.00000 \mathrm{e}-011.00000 \mathrm{e}-091.00000 \mathrm{e}-01$ Element: 1980 \# of layers: 15

$\mathrm{Kx} \mathrm{Ky} \mathrm{Kz}$ Ss Por

4.26092e+01 4.26092e+01 4.26092e+00 1.00000e-09 7.00000e-02 $4.26092 \mathrm{e}+014.26092 \mathrm{e}+014.26092 \mathrm{e}+00$ 1.00000e-09 7.00000e-02 $4.26092 \mathrm{e}+014.26092 \mathrm{e}+014.26092 \mathrm{e}+00$ 1.00000e-09 7.00000e-02 4.26092e+01 4.26092e+01 4.26092e+00 1.00000e-09 7.00000e-02 $5.00000 \mathrm{e}-04$ 5.00000e-04 5.00000e-05 1.00000e-09 1.00000e-01 5.00000e-04 5.00000e-04 5.00000e-05 1.00000e-09 1.00000e-01

$1.70250 \mathrm{e}+001.70250 \mathrm{e}+001.70250 \mathrm{e}-01$ 1.00000e-09 2.12000e-01 $1.70250 \mathrm{e}+001.70250 \mathrm{e}+00$ 1.70250e-01 1.00000e-09 2.12000e-01 $1.70250 \mathrm{e}+001.70250 \mathrm{e}+00$ 1.70250e-01 1.00000e-09 2.12000e-01 $1.70250 \mathrm{e}+001.70250 \mathrm{e}+001.70250 \mathrm{e}-01$ 1.00000e-09 2.12000e-01 $1.70250 \mathrm{e}+001.70250 \mathrm{e}+001.70250 \mathrm{e}-01$ 1.00000e-09 2.12000e-01 $1.00000 \mathrm{e}-02$ 1.00000e-02 1.00000e-03 1.00000e-09 1.00000e-01 $1.00000 \mathrm{e}+001.00000 \mathrm{e}+001.00000 \mathrm{e}-011.00000 \mathrm{e}-091.00000 \mathrm{e}-01$ $1.00000 \mathrm{e}-05$ 1.00000e-05 1.00000e-06 1.00000e-09 1.00000e-01 $1.00000 \mathrm{e}+001.00000 \mathrm{e}+001.00000 \mathrm{e}-011.00000 \mathrm{e}-091.00000 \mathrm{e}-01$ Element: 1981 \# of layers: 15

$\mathrm{Kx} \mathrm{Ky} \mathrm{Kz}$ Ss Por

4.26092e+01 4.26092e+01 4.26092e+00 1.00000e-09 7.00000e-02 4.26092e+01 4.26092e+01 4.26092e+00 1.00000e-09 7.00000e-02 4.26092e+01 4.26092e+01 4.26092e+00 1.00000e-09 7.00000e-02 4.26092e+01 4.26092e+01 4.26092e+00 1.00000e-09 7.00000e-02 5.00000e-04 5.00000e-04 5.00000e-05 1.00000e-09 1.00000e-01 5.00000e-04 5.00000e-04 5.00000e-05 1.00000e-09 1.00000e-01 $1.70250 \mathrm{e}+001.70250 \mathrm{e}+001.70250 \mathrm{e}-011.00000 \mathrm{e}-092.12000 \mathrm{e}-01$ $1.70250 \mathrm{e}+001.70250 \mathrm{e}+00$ 1.70250e-01 1.00000e-09 2.12000e-01 $1.70250 \mathrm{e}+001.70250 \mathrm{e}+00$ 1.70250e-01 1.00000e-09 2.12000e-01 $1.70250 \mathrm{e}+001.70250 \mathrm{e}+001.70250 \mathrm{e}-01$ 1.00000e-09 2.12000e-01 $1.70250 \mathrm{e}+001.70250 \mathrm{e}+001.70250 \mathrm{e}-011.00000 \mathrm{e}-092.12000 \mathrm{e}-01$ $1.00000 \mathrm{e}-021.00000 \mathrm{e}-021.00000 \mathrm{e}-031.00000 \mathrm{e}-091.00000 \mathrm{e}-01$ $1.00000 \mathrm{e}+001.00000 \mathrm{e}+001.00000 \mathrm{e}-011.00000 \mathrm{e}-091.00000 \mathrm{e}-01$ $1.00000 \mathrm{e}-05$ 1.00000e-05 1.00000e-06 1.00000e-09 1.00000e-01 $1.00000 \mathrm{e}+001.00000 \mathrm{e}+001.00000 \mathrm{e}-011.00000 \mathrm{e}-091.00000 \mathrm{e}-01$ 
Element: 1982 \# of layers: 14

Kx Ky Kz Ss Por

5.16958e +01 5.16958e+01 5.16958e+00 1.00000e-09 7.00000e-02

$5.16958 \mathrm{e}+015.16958 \mathrm{e}+015.16958 \mathrm{e}+001.00000 \mathrm{e}-09$ 7.00000e-02

$5.16958 \mathrm{e}+015.16958 \mathrm{e}+015.16958 \mathrm{e}+001.00000 \mathrm{e}-09$ 7.00000e-02

5.00000e-04 5.00000e-04 5.00000e-05 1.00000e-09 1.00000e-01

5.00000e-04 5.00000e-04 5.00000e-05 1.00000e-09 1.00000e-01

$2.06559 \mathrm{e}+002.06559 \mathrm{e}+002.06559 \mathrm{e}-01$ 1.00000e-09 2.12000e-01

$2.06559 \mathrm{e}+002.06559 \mathrm{e}+002.06559 \mathrm{e}-01$ 1.00000e-09 2.12000e-01

$2.06559 \mathrm{e}+002.06559 \mathrm{e}+002.06559 \mathrm{e}-011.00000 \mathrm{e}-092.12000 \mathrm{e}-01$

$2.06559 \mathrm{e}+002.06559 \mathrm{e}+002.06559 \mathrm{e}-01$ 1.00000e-09 2.12000e-01

$2.06559 \mathrm{e}+002.06559 \mathrm{e}+002.06559 \mathrm{e}-01$ 1.00000e-09 2.12000e-01

$1.00000 \mathrm{e}-02$ 1.00000e-02 1.00000e-03 1.00000e-09 1.00000e-01

$1.00000 \mathrm{e}+001.00000 \mathrm{e}+001.00000 \mathrm{e}-011.00000 \mathrm{e}-091.00000 \mathrm{e}-01$

$1.00000 \mathrm{e}-05$ 1.00000e-05 1.00000e-06 1.00000e-09 1.00000e-01

$1.00000 \mathrm{e}+001.00000 \mathrm{e}+001.00000 \mathrm{e}-011.00000 \mathrm{e}-091.00000 \mathrm{e}-01$

Element: 1983 \# of layers: 14

Kx Ky Kz Ss Por

5.16958e+01 5.16958e+01 5.16958e+00 1.00000e-09 7.00000e-02

$5.16958 \mathrm{e}+015.16958 \mathrm{e}+015.16958 \mathrm{e}+001.00000 \mathrm{e}-09$ 7.00000e-02

$5.16958 \mathrm{e}+015.16958 \mathrm{e}+015.16958 \mathrm{e}+001.00000 \mathrm{e}-09$ 7.00000e-02

5.00000e-04 5.00000e-04 5.00000e-05 1.00000e-09 1.00000e-01

5.00000e-04 5.00000e-04 5.00000e-05 1.00000e-09 1.00000e-01

$2.06559 \mathrm{e}+002.06559 \mathrm{e}+002.06559 \mathrm{e}-011.00000 \mathrm{e}-092.12000 \mathrm{e}-01$

$2.06559 \mathrm{e}+002.06559 \mathrm{e}+002.06559 \mathrm{e}-011.00000 \mathrm{e}-092.12000 \mathrm{e}-01$

$2.06559 \mathrm{e}+002.06559 \mathrm{e}+002.06559 \mathrm{e}-01$ 1.00000e-09 2.12000e-01

$2.06559 \mathrm{e}+002.06559 \mathrm{e}+002.06559 \mathrm{e}-01$ 1.00000e-09 2.12000e-01

$2.06559 \mathrm{e}+002.06559 \mathrm{e}+002.06559 \mathrm{e}-011.00000 \mathrm{e}-092.12000 \mathrm{e}-01$

$1.00000 \mathrm{e}-021.00000 \mathrm{e}-02$ 1.00000e-03 1.00000e-09 1.00000e-01

$1.00000 \mathrm{e}+001.00000 \mathrm{e}+001.00000 \mathrm{e}-011.00000 \mathrm{e}-091.00000 \mathrm{e}-01$

$1.00000 \mathrm{e}-05$ 1.00000e-05 1.00000e-06 1.00000e-09 1.00000e-01

$1.00000 \mathrm{e}+001.00000 \mathrm{e}+001.00000 \mathrm{e}-011.00000 \mathrm{e}-091.00000 \mathrm{e}-01$

Element: 1984 \# of layers: 13

Kx Ky Kz Ss Por

5.16958e+01 5.16958e+01 5.16958e+00 1.00000e-09 7.00000e-02

$5.16958 \mathrm{e}+015.16958 \mathrm{e}+01$ 5.16958e+00 1.00000e-09 7.00000e-02

5.00000e-04 5.00000e-04 5.00000e-05 1.00000e-09 1.00000e-01

5.00000e-04 5.00000e-04 5.00000e-05 1.00000e-09 1.00000e-01

$2.06559 \mathrm{e}+002.06559 \mathrm{e}+002.06559 \mathrm{e}-011.00000 \mathrm{e}-092.12000 \mathrm{e}-01$

$2.06559 \mathrm{e}+002.06559 \mathrm{e}+002.06559 \mathrm{e}-011.00000 \mathrm{e}-092.12000 \mathrm{e}-01$

$2.06559 \mathrm{e}+002.06559 \mathrm{e}+002.06559 \mathrm{e}-01$ 1.00000e-09 2.12000e-01

$2.06559 \mathrm{e}+002.06559 \mathrm{e}+002.06559 \mathrm{e}-01$ 1.00000e-09 2.12000e-01

$2.06559 \mathrm{e}+002.06559 \mathrm{e}+00$ 2.06559e-01 1.00000e-09 2.12000e-01

$1.00000 \mathrm{e}-021.00000 \mathrm{e}-02$ 1.00000e-03 1.00000e-09 1.00000e-01

$1.00000 \mathrm{e}+001.00000 \mathrm{e}+001.00000 \mathrm{e}-011.00000 \mathrm{e}-091.00000 \mathrm{e}-01$

$1.00000 \mathrm{e}-05$ 1.00000e-05 1.00000e-06 1.00000e-09 1.00000e-01 
$1.00000 \mathrm{e}+001.00000 \mathrm{e}+00$ 1.00000e-01 1.00000e-09 1.00000e-01 Element: 1985 \# of layers: 13

Kx Ky Kz Ss Por

5.16958e+01 5.16958e+01 5.16958e+00 1.00000e-09 7.00000e-02

$5.16958 \mathrm{e}+015.16958 \mathrm{e}+015.16958 \mathrm{e}+001.00000 \mathrm{e}-09$ 7.00000e-02

5.00000e-04 5.00000e-04 5.00000e-05 1.00000e-09 1.00000e-01

5.00000e-04 5.00000e-04 5.00000e-05 1.00000e-09 1.00000e-01

$2.06559 \mathrm{e}+002.06559 \mathrm{e}+00$ 2.06559e-01 1.00000e-09 2.12000e-01

$2.06559 \mathrm{e}+002.06559 \mathrm{e}+002.06559 \mathrm{e}-01$ 1.00000e-09 2.12000e-01

$2.06559 \mathrm{e}+002.06559 \mathrm{e}+00$ 2.06559e-01 1.00000e-09 2.12000e-01

$2.06559 \mathrm{e}+002.06559 \mathrm{e}+00$ 2.06559e-01 1.00000e-09 2.12000e-01

$2.06559 \mathrm{e}+002.06559 \mathrm{e}+00$ 2.06559e-01 1.00000e-09 2.12000e-01

$1.00000 \mathrm{e}-02$ 1.00000e-02 1.00000e-03 1.00000e-09 1.00000e-01

$1.00000 \mathrm{e}+001.00000 \mathrm{e}+001.00000 \mathrm{e}-011.00000 \mathrm{e}-091.00000 \mathrm{e}-01$

$1.00000 \mathrm{e}-05$ 1.00000e-05 1.00000e-06 1.00000e-09 1.00000e-01

$1.00000 \mathrm{e}+001.00000 \mathrm{e}+001.00000 \mathrm{e}-011.00000 \mathrm{e}-091.00000 \mathrm{e}-01$

Element: 1986 \# of layers: 14

$\mathrm{Kx} \mathrm{Ky} \mathrm{Kz}$ Ss Por

5.16958e+01 5.16958e+01 5.16958e+00 1.00000e-09 7.00000e-02

$5.16958 \mathrm{e}+015.16958 \mathrm{e}+015.16958 \mathrm{e}+001.00000 \mathrm{e}-09$ 7.00000e-02

$5.16958 \mathrm{e}+015.16958 \mathrm{e}+015.16958 \mathrm{e}+00$ 1.00000e-09 7.00000e-02

5.00000e-04 5.00000e-04 5.00000e-05 1.00000e-09 1.00000e-01

5.00000e-04 5.00000e-04 5.00000e-05 1.00000e-09 1.00000e-01

$2.06559 \mathrm{e}+002.06559 \mathrm{e}+002.06559 \mathrm{e}-01$ 1.00000e-09 2.12000e-01

$2.06559 \mathrm{e}+002.06559 \mathrm{e}+00$ 2.06559e-01 1.00000e-09 2.12000e-01

$2.06559 \mathrm{e}+002.06559 \mathrm{e}+00$ 2.06559e-01 1.00000e-09 2.12000e-01

$2.06559 \mathrm{e}+002.06559 \mathrm{e}+002.06559 \mathrm{e}-01$ 1.00000e-09 2.12000e-01

$2.06559 \mathrm{e}+002.06559 \mathrm{e}+00$ 2.06559e-01 1.00000e-09 2.12000e-01

$1.00000 \mathrm{e}-02$ 1.00000e-02 1.00000e-03 1.00000e-09 1.00000e-01

$1.00000 \mathrm{e}+001.00000 \mathrm{e}+001.00000 \mathrm{e}-011.00000 \mathrm{e}-091.00000 \mathrm{e}-01$

$1.00000 \mathrm{e}-05$ 1.00000e-05 1.00000e-06 1.00000e-09 1.00000e-01

$1.00000 \mathrm{e}+001.00000 \mathrm{e}+001.00000 \mathrm{e}-011.00000 \mathrm{e}-091.00000 \mathrm{e}-01$

Element: 1987 \# of layers: 14

$\mathrm{Kx} \mathrm{Ky} \mathrm{Kz}$ Ss Por

5.16958e+01 5.16958e+01 5.16958e+00 1.00000e-09 7.00000e-02

$5.16958 \mathrm{e}+015.16958 \mathrm{e}+015.16958 \mathrm{e}+00$ 1.00000e-09 7.00000e-02

$5.16958 \mathrm{e}+015.16958 \mathrm{e}+015.16958 \mathrm{e}+001.00000 \mathrm{e}-09$ 7.00000e-02

5.00000e-04 5.00000e-04 5.00000e-05 1.00000e-09 1.00000e-01

5.00000e-04 5.00000e-04 5.00000e-05 1.00000e-09 1.00000e-01

$2.06559 \mathrm{e}+002.06559 \mathrm{e}+00$ 2.06559e-01 1.00000e-09 2.12000e-01

$2.06559 \mathrm{e}+002.06559 \mathrm{e}+002.06559 \mathrm{e}-01$ 1.00000e-09 2.12000e-01

$2.06559 \mathrm{e}+002.06559 \mathrm{e}+002.06559 \mathrm{e}-01$ 1.00000e-09 2.12000e-01

$2.06559 \mathrm{e}+002.06559 \mathrm{e}+002.06559 \mathrm{e}-01$ 1.00000e-09 2.12000e-01

2.06559e+00 2.06559e+00 2.06559e-01 1.00000e-09 2.12000e-01

1.00000e-02 1.00000e-02 1.00000e-03 1.00000e-09 1.00000e-01

$1.00000 \mathrm{e}+001.00000 \mathrm{e}+001.00000 \mathrm{e}-011.00000 \mathrm{e}-091.00000 \mathrm{e}-01$ 
$1.00000 \mathrm{e}-05$ 1.00000e-05 1.00000e-06 1.00000e-09 1.00000e-01 $1.00000 \mathrm{e}+001.00000 \mathrm{e}+001.00000 \mathrm{e}-01$ 1.00000e-09 1.00000e-01 Element: 1988 \# of layers: 14

Kx Ky Kz Ss Por

5.16958e+01 5.16958e+01 5.16958e+00 1.00000e-09 7.00000e-02

$5.16958 \mathrm{e}+015.16958 \mathrm{e}+015.16958 \mathrm{e}+00$ 1.00000e-09 7.00000e-02

$5.16958 \mathrm{e}+015.16958 \mathrm{e}+015.16958 \mathrm{e}+00$ 1.00000e-09 7.00000e-02 5.00000e-04 5.00000e-04 5.00000e-05 1.00000e-09 1.00000e-01 5.00000e-04 5.00000e-04 5.00000e-05 1.00000e-09 1.00000e-01

$2.06559 \mathrm{e}+002.06559 \mathrm{e}+002.06559 \mathrm{e}-01$ 1.00000e-09 2.12000e-01 $2.06559 \mathrm{e}+002.06559 \mathrm{e}+00$ 2.06559e-01 1.00000e-09 2.12000e-01 $2.06559 \mathrm{e}+002.06559 \mathrm{e}+00$ 2.06559e-01 1.00000e-09 2.12000e-01 $2.06559 \mathrm{e}+002.06559 \mathrm{e}+002.06559 \mathrm{e}-01$ 1.00000e-09 2.12000e-01 $2.06559 \mathrm{e}+002.06559 \mathrm{e}+002.06559 \mathrm{e}-01$ 1.00000e-09 2.12000e-01 $1.00000 \mathrm{e}-02$ 1.00000e-02 1.00000e-03 1.00000e-09 1.00000e-01 $1.00000 \mathrm{e}+001.00000 \mathrm{e}+001.00000 \mathrm{e}-011.00000 \mathrm{e}-091.00000 \mathrm{e}-01$ $1.00000 \mathrm{e}-05$ 1.00000e-05 1.00000e-06 1.00000e-09 1.00000e-01 $1.00000 \mathrm{e}+001.00000 \mathrm{e}+001.00000 \mathrm{e}-01$ 1.00000e-09 1.00000e-01 Element: 1989 \# of layers: 14

Kx Ky Kz Ss Por

5.16958e+01 5.16958e+01 5.16958e+00 1.00000e-09 7.00000e-02 $5.16958 \mathrm{e}+015.16958 \mathrm{e}+015.16958 \mathrm{e}+001.00000 \mathrm{e}-09$ 7.00000e-02 $5.16958 \mathrm{e}+015.16958 \mathrm{e}+015.16958 \mathrm{e}+001.00000 \mathrm{e}-09$ 7.00000e-02 5.00000e-04 5.00000e-04 5.00000e-05 1.00000e-09 1.00000e-01 $5.00000 \mathrm{e}-04$ 5.00000e-04 5.00000e-05 1.00000e-09 1.00000e-01 $2.06559 \mathrm{e}+002.06559 \mathrm{e}+002.06559 \mathrm{e}-01$ 1.00000e-09 2.12000e-01 $2.06559 \mathrm{e}+002.06559 \mathrm{e}+002.06559 \mathrm{e}-01$ 1.00000e-09 2.12000e-01 $2.06559 \mathrm{e}+002.06559 \mathrm{e}+00$ 2.06559e-01 1.00000e-09 2.12000e-01 $2.06559 \mathrm{e}+002.06559 \mathrm{e}+002.06559 \mathrm{e}-01$ 1.00000e-09 2.12000e-01 $2.06559 \mathrm{e}+00$ 2.06559e+00 2.06559e-01 1.00000e-09 2.12000e-01 $1.00000 \mathrm{e}-02$ 1.00000e-02 1.00000e-03 1.00000e-09 1.00000e-01 $1.00000 \mathrm{e}+001.00000 \mathrm{e}+001.00000 \mathrm{e}-011.00000 \mathrm{e}-091.00000 \mathrm{e}-01$ $1.00000 \mathrm{e}-05$ 1.00000e-05 1.00000e-06 1.00000e-09 1.00000e-01 $1.00000 \mathrm{e}+001.00000 \mathrm{e}+001.00000 \mathrm{e}-011.00000 \mathrm{e}-091.00000 \mathrm{e}-01$ Element: 1990 \# of layers: 14

Kx Ky Kz Ss Por

5.16958e+01 5.16958e+01 5.16958e+00 1.00000e-09 7.00000e-02 $5.16958 \mathrm{e}+015.16958 \mathrm{e}+015.16958 \mathrm{e}+00$ 1.00000e-09 7.00000e-02 $5.16958 \mathrm{e}+015.16958 \mathrm{e}+015.16958 \mathrm{e}+001.00000 \mathrm{e}-09$ 7.00000e-02 5.00000e-04 5.00000e-04 5.00000e-05 1.00000e-09 1.00000e-01 5.00000e-04 5.00000e-04 5.00000e-05 1.00000e-09 1.00000e-01 $2.06559 \mathrm{e}+002.06559 \mathrm{e}+00$ 2.06559e-01 1.00000e-09 2.12000e-01 $2.06559 \mathrm{e}+002.06559 \mathrm{e}+002.06559 \mathrm{e}-01$ 1.00000e-09 2.12000e-01 $2.06559 \mathrm{e}+00$ 2.06559e+00 2.06559e-01 1.00000e-09 2.12000e-01 $2.06559 \mathrm{e}+002.06559 \mathrm{e}+002.06559 \mathrm{e}-01$ 1.00000e-09 2.12000e-01 $2.06559 \mathrm{e}+002.06559 \mathrm{e}+00$ 2.06559e-01 1.00000e-09 2.12000e-01 
$1.00000 \mathrm{e}-02$ 1.00000e-02 1.00000e-03 1.00000e-09 1.00000e-01 $1.00000 \mathrm{e}+001.00000 \mathrm{e}+001.00000 \mathrm{e}-011.00000 \mathrm{e}-091.00000 \mathrm{e}-01$ $1.00000 \mathrm{e}-05$ 1.00000e-05 1.00000e-06 1.00000e-09 1.00000e-01 $1.00000 \mathrm{e}+001.00000 \mathrm{e}+001.00000 \mathrm{e}-011.00000 \mathrm{e}-091.00000 \mathrm{e}-01$ Element: 1991 \# of layers: 13

$\mathrm{Kx} \mathrm{Ky} \mathrm{Kz}$ Ss Por

6.42107e+01 6.42107e+01 6.42107e+00 1.00000e-09 7.00000e-02 $6.42107 \mathrm{e}+016.42107 \mathrm{e}+016.42107 \mathrm{e}+001.00000 \mathrm{e}-09$ 7.00000e-02 5.00000e-04 5.00000e-04 5.00000e-05 1.00000e-09 1.00000e-01 5.00000e-04 5.00000e-04 5.00000e-05 1.00000e-09 1.00000e-01 $2.56573 \mathrm{e}+002.56573 \mathrm{e}+00$ 2.56573e-01 1.00000e-09 2.12000e-01 $2.56573 \mathrm{e}+002.56573 \mathrm{e}+00$ 2.56573e-01 1.00000e-09 2.12000e-01 $2.56573 \mathrm{e}+00$ 2.56573e+00 2.56573e-01 1.00000e-09 2.12000e-01 $2.56573 \mathrm{e}+002.56573 \mathrm{e}+00$ 2.56573e-01 1.00000e-09 2.12000e-01 $2.56573 \mathrm{e}+00$ 2.56573e+00 2.56573e-01 1.00000e-09 2.12000e-01 $1.00000 \mathrm{e}-02$ 1.00000e-02 1.00000e-03 1.00000e-09 1.00000e-01 $1.00000 \mathrm{e}+001.00000 \mathrm{e}+001.00000 \mathrm{e}-011.00000 \mathrm{e}-091.00000 \mathrm{e}-01$ $1.00000 \mathrm{e}-05$ 1.00000e-05 1.00000e-06 1.00000e-09 1.00000e-01 $1.00000 \mathrm{e}+001.00000 \mathrm{e}+001.00000 \mathrm{e}-011.00000 \mathrm{e}-091.00000 \mathrm{e}-01$ Element: 1992 \# of layers: 13

$\mathrm{Kx} \mathrm{Ky} \mathrm{Kz}$ Ss Por 6.42107e+01 6.42107e+01 6.42107e+00 1.00000e-09 7.00000e-02 6.42107e+01 6.42107e+01 6.42107e+00 1.00000e-09 7.00000e-02 5.00000e-04 5.00000e-04 5.00000e-05 1.00000e-09 1.00000e-01 5.00000e-04 5.00000e-04 5.00000e-05 1.00000e-09 1.00000e-01 $2.56573 \mathrm{e}+002.56573 \mathrm{e}+00$ 2.56573e-01 1.00000e-09 2.12000e-01 $2.56573 \mathrm{e}+002.56573 \mathrm{e}+00$ 2.56573e-01 1.00000e-09 2.12000e-01 $2.56573 \mathrm{e}+00$ 2.56573e+00 2.56573e-01 1.00000e-09 2.12000e-01 $2.56573 \mathrm{e}+002.56573 \mathrm{e}+00$ 2.56573e-01 1.00000e-09 2.12000e-01 2.56573e+00 2.56573e+00 2.56573e-01 1.00000e-09 2.12000e-01 $1.00000 \mathrm{e}-02$ 1.00000e-02 1.00000e-03 1.00000e-09 1.00000e-01 $1.00000 \mathrm{e}+001.00000 \mathrm{e}+001.00000 \mathrm{e}-011.00000 \mathrm{e}-091.00000 \mathrm{e}-01$ $1.00000 \mathrm{e}-05$ 1.00000e-05 1.00000e-06 1.00000e-09 1.00000e-01 $1.00000 \mathrm{e}+001.00000 \mathrm{e}+001.00000 \mathrm{e}-011.00000 \mathrm{e}-091.00000 \mathrm{e}-01$ Element: 1993 \# of layers: 12

$\mathrm{Kx} \mathrm{Ky} \mathrm{Kz}$ Ss Por 6.42107e+01 6.42107e+01 6.42107e+00 1.00000e-09 7.00000e-02 5.00000e-04 5.00000e-04 5.00000e-05 1.00000e-09 1.00000e-01 5.00000e-04 5.00000e-04 5.00000e-05 1.00000e-09 1.00000e-01 $2.56573 \mathrm{e}+002.56573 \mathrm{e}+00$ 2.56573e-01 1.00000e-09 2.12000e-01 $2.56573 \mathrm{e}+002.56573 \mathrm{e}+00$ 2.56573e-01 1.00000e-09 2.12000e-01 $2.56573 \mathrm{e}+002.56573 \mathrm{e}+00$ 2.56573e-01 1.00000e-09 2.12000e-01 2.56573e+00 2.56573e+00 2.56573e-01 1.00000e-09 2.12000e-01 2.56573e+00 2.56573e+00 2.56573e-01 1.00000e-09 2.12000e-01 $1.00000 \mathrm{e}-02$ 1.00000e-02 1.00000e-03 1.00000e-09 1.00000e-01 $1.00000 \mathrm{e}+001.00000 \mathrm{e}+001.00000 \mathrm{e}-011.00000 \mathrm{e}-091.00000 \mathrm{e}-01$ 
$1.00000 \mathrm{e}-05$ 1.00000e-05 1.00000e-06 1.00000e-09 1.00000e-01 $1.00000 \mathrm{e}+001.00000 \mathrm{e}+001.00000 \mathrm{e}-01$ 1.00000e-09 1.00000e-01 Element: 1994 \# of layers: 13

Kx Ky Kz Ss Por

6.42107e+01 6.42107e+01 6.42107e+00 1.00000e-09 7.00000e-02 $6.42107 \mathrm{e}+016.42107 \mathrm{e}+016.42107 \mathrm{e}+00$ 1.00000e-09 7.00000e-02 5.00000e-04 5.00000e-04 5.00000e-05 1.00000e-09 1.00000e-01 5.00000e-04 5.00000e-04 5.00000e-05 1.00000e-09 1.00000e-01 $2.56573 \mathrm{e}+002.56573 \mathrm{e}+00$ 2.56573e-01 1.00000e-09 2.12000e-01 $2.56573 \mathrm{e}+002.56573 \mathrm{e}+00$ 2.56573e-01 1.00000e-09 2.12000e-01 $2.56573 \mathrm{e}+002.56573 \mathrm{e}+00$ 2.56573e-01 1.00000e-09 2.12000e-01 $2.56573 \mathrm{e}+002.56573 \mathrm{e}+00$ 2.56573e-01 1.00000e-09 2.12000e-01 $2.56573 \mathrm{e}+002.56573 \mathrm{e}+002.56573 \mathrm{e}-01$ 1.00000e-09 2.12000e-01 $1.00000 \mathrm{e}-02$ 1.00000e-02 1.00000e-03 1.00000e-09 1.00000e-01 $1.00000 \mathrm{e}+001.00000 \mathrm{e}+001.00000 \mathrm{e}-011.00000 \mathrm{e}-091.00000 \mathrm{e}-01$ $1.00000 \mathrm{e}-05$ 1.00000e-05 1.00000e-06 1.00000e-09 1.00000e-01 $1.00000 \mathrm{e}+001.00000 \mathrm{e}+001.00000 \mathrm{e}-011.00000 \mathrm{e}-091.00000 \mathrm{e}-01$ Element: 1995 \# of layers: 13

$\mathrm{Kx} \mathrm{Ky} \mathrm{Kz}$ Ss Por 6.42107e+01 6.42107e+01 6.42107e+00 1.00000e-09 7.00000e-02 6.42107e+01 6.42107e+01 6.42107e+00 1.00000e-09 7.00000e-02 $5.00000 \mathrm{e}-04$ 5.00000e-04 5.00000e-05 1.00000e-09 1.00000e-01 5.00000e-04 5.00000e-04 5.00000e-05 1.00000e-09 1.00000e-01 $2.56573 \mathrm{e}+002.56573 \mathrm{e}+00$ 2.56573e-01 1.00000e-09 2.12000e-01 $2.56573 \mathrm{e}+002.56573 \mathrm{e}+00$ 2.56573e-01 1.00000e-09 2.12000e-01 $2.56573 \mathrm{e}+002.56573 \mathrm{e}+00$ 2.56573e-01 1.00000e-09 2.12000e-01 $2.56573 \mathrm{e}+002.56573 \mathrm{e}+00$ 2.56573e-01 1.00000e-09 2.12000e-01 $2.56573 \mathrm{e}+002.56573 \mathrm{e}+00$ 2.56573e-01 1.00000e-09 2.12000e-01 $1.00000 \mathrm{e}-02$ 1.00000e-02 1.00000e-03 1.00000e-09 1.00000e-01 $1.00000 \mathrm{e}+001.00000 \mathrm{e}+001.00000 \mathrm{e}-011.00000 \mathrm{e}-091.00000 \mathrm{e}-01$ $1.00000 \mathrm{e}-05$ 1.00000e-05 1.00000e-06 1.00000e-09 1.00000e-01 $1.00000 \mathrm{e}+001.00000 \mathrm{e}+001.00000 \mathrm{e}-01$ 1.00000e-09 1.00000e-01 Element: 1996 \# of layers: 14

$\mathrm{Kx} \mathrm{Ky} \mathrm{Kz}$ Ss Por

6.42107e+01 6.42107e+01 6.42107e+00 1.00000e-09 7.00000e-02 6.42107e+01 6.42107e+01 6.42107e+00 1.00000e-09 7.00000e-02 $6.42107 \mathrm{e}+016.42107 \mathrm{e}+016.42107 \mathrm{e}+00$ 1.00000e-09 7.00000e-02 5.00000e-04 5.00000e-04 5.00000e-05 1.00000e-09 1.00000e-01 5.00000e-04 5.00000e-04 5.00000e-05 1.00000e-09 1.00000e-01 $2.56573 \mathrm{e}+002.56573 \mathrm{e}+00$ 2.56573e-01 1.00000e-09 2.12000e-01 $2.56573 \mathrm{e}+002.56573 \mathrm{e}+00$ 2.56573e-01 1.00000e-09 2.12000e-01 $2.56573 \mathrm{e}+002.56573 \mathrm{e}+00$ 2.56573e-01 1.00000e-09 2.12000e-01 2.56573e+00 2.56573e+00 2.56573e-01 1.00000e-09 2.12000e-01 2.56573e+00 2.56573e+00 2.56573e-01 1.00000e-09 2.12000e-01 $1.00000 \mathrm{e}-02$ 1.00000e-02 1.00000e-03 1.00000e-09 1.00000e-01 $1.00000 \mathrm{e}+001.00000 \mathrm{e}+001.00000 \mathrm{e}-011.00000 \mathrm{e}-091.00000 \mathrm{e}-01$ 
$1.00000 \mathrm{e}-05$ 1.00000e-05 1.00000e-06 1.00000e-09 1.00000e-01 $1.00000 \mathrm{e}+001.00000 \mathrm{e}+001.00000 \mathrm{e}-01$ 1.00000e-09 1.00000e-01 Element: 1997 \# of layers: 14

Kx Ky Kz Ss Por

6.42107e+01 6.42107e+01 6.42107e+00 1.00000e-09 7.00000e-02 6.42107e+01 6.42107e+01 6.42107e+00 1.00000e-09 7.00000e-02 6.42107e+01 6.42107e+01 6.42107e+00 1.00000e-09 7.00000e-02 5.00000e-04 5.00000e-04 5.00000e-05 1.00000e-09 1.00000e-01 5.00000e-04 5.00000e-04 5.00000e-05 1.00000e-09 1.00000e-01 $2.56573 \mathrm{e}+002.56573 \mathrm{e}+00$ 2.56573e-01 1.00000e-09 2.12000e-01 $2.56573 \mathrm{e}+002.56573 \mathrm{e}+00$ 2.56573e-01 1.00000e-09 2.12000e-01 $2.56573 \mathrm{e}+002.56573 \mathrm{e}+00$ 2.56573e-01 1.00000e-09 2.12000e-01 $2.56573 \mathrm{e}+002.56573 \mathrm{e}+00$ 2.56573e-01 1.00000e-09 2.12000e-01 $2.56573 \mathrm{e}+002.56573 \mathrm{e}+00$ 2.56573e-01 1.00000e-09 2.12000e-01 $1.00000 \mathrm{e}-02$ 1.00000e-02 1.00000e-03 1.00000e-09 1.00000e-01 $1.00000 \mathrm{e}+001.00000 \mathrm{e}+001.00000 \mathrm{e}-011.00000 \mathrm{e}-091.00000 \mathrm{e}-01$ $1.00000 \mathrm{e}-05$ 1.00000e-05 1.00000e-06 1.00000e-09 1.00000e-01 $1.00000 \mathrm{e}+001.00000 \mathrm{e}+001.00000 \mathrm{e}-01$ 1.00000e-09 1.00000e-01 Element: 1998 \# of layers: 13

$\mathrm{Kx} \mathrm{Ky} \mathrm{Kz}$ Ss Por 6.42107e+01 6.42107e+01 6.42107e+00 1.00000e-09 7.00000e-02 6.42107e+01 6.42107e+01 6.42107e+00 1.00000e-09 7.00000e-02 5.00000e-04 5.00000e-04 5.00000e-05 1.00000e-09 1.00000e-01 5.00000e-04 5.00000e-04 5.00000e-05 1.00000e-09 1.00000e-01 $2.56573 \mathrm{e}+002.56573 \mathrm{e}+00$ 2.56573e-01 1.00000e-09 2.12000e-01 $2.56573 \mathrm{e}+002.56573 \mathrm{e}+00$ 2.56573e-01 1.00000e-09 2.12000e-01 $2.56573 \mathrm{e}+002.56573 \mathrm{e}+00$ 2.56573e-01 1.00000e-09 2.12000e-01 $2.56573 \mathrm{e}+00$ 2.56573e+00 2.56573e-01 1.00000e-09 2.12000e-01 $2.56573 \mathrm{e}+002.56573 \mathrm{e}+00$ 2.56573e-01 1.00000e-09 2.12000e-01 $1.00000 \mathrm{e}-02$ 1.00000e-02 1.00000e-03 1.00000e-09 1.00000e-01 $1.00000 \mathrm{e}+001.00000 \mathrm{e}+001.00000 \mathrm{e}-01$ 1.00000e-09 1.00000e-01 $1.00000 \mathrm{e}-05$ 1.00000e-05 1.00000e-06 1.00000e-09 1.00000e-01 $1.00000 \mathrm{e}+001.00000 \mathrm{e}+001.00000 \mathrm{e}-011.00000 \mathrm{e}-091.00000 \mathrm{e}-01$ Element: 1999 \# of layers: 13

$\mathrm{Kx} \mathrm{Ky} \mathrm{Kz}$ Ss Por 6.42107e+01 6.42107e+01 6.42107e+00 1.00000e-09 7.00000e-02 $6.42107 \mathrm{e}+016.42107 \mathrm{e}+016.42107 \mathrm{e}+00$ 1.00000e-09 7.00000e-02 5.00000e-04 5.00000e-04 5.00000e-05 1.00000e-09 1.00000e-01 5.00000e-04 5.00000e-04 5.00000e-05 1.00000e-09 1.00000e-01 $2.56573 \mathrm{e}+002.56573 \mathrm{e}+00$ 2.56573e-01 1.00000e-09 2.12000e-01 $2.56573 \mathrm{e}+002.56573 \mathrm{e}+00$ 2.56573e-01 1.00000e-09 2.12000e-01 $2.56573 \mathrm{e}+002.56573 \mathrm{e}+00$ 2.56573e-01 1.00000e-09 2.12000e-01 $2.56573 \mathrm{e}+002.56573 \mathrm{e}+00$ 2.56573e-01 1.00000e-09 2.12000e-01 2.56573e+00 2.56573e+00 2.56573e-01 1.00000e-09 2.12000e-01 1.00000e-02 1.00000e-02 1.00000e-03 1.00000e-09 1.00000e-01 $1.00000 \mathrm{e}+001.00000 \mathrm{e}+001.00000 \mathrm{e}-011.00000 \mathrm{e}-091.00000 \mathrm{e}-01$ 
$1.00000 \mathrm{e}-05$ 1.00000e-05 1.00000e-06 1.00000e-09 1.00000e-01 $1.00000 \mathrm{e}+001.00000 \mathrm{e}+001.00000 \mathrm{e}-01$ 1.00000e-09 1.00000e-01 Element: 2000 \# of layers: 12

$\mathrm{Kx} \mathrm{Ky} \mathrm{Kz}$ Ss Por

7.17241e+01 7.17241e+01 7.17241e+00 1.00000e-09 7.00000e-02 5.00000e-04 5.00000e-04 5.00000e-05 1.00000e-09 1.00000e-01 5.00000e-04 5.00000e-04 5.00000e-05 1.00000e-09 1.00000e-01 $2.86589 \mathrm{e}+002.86589 \mathrm{e}+00$ 2.86589e-01 1.00000e-09 2.12000e-01 $2.86589 \mathrm{e}+002.86589 \mathrm{e}+00$ 2.86589e-01 1.00000e-09 2.12000e-01 $2.86589 \mathrm{e}+002.86589 \mathrm{e}+00$ 2.86589e-01 1.00000e-09 2.12000e-01 $2.86589 \mathrm{e}+002.86589 \mathrm{e}+00$ 2.86589e-01 1.00000e-09 2.12000e-01 $2.86589 \mathrm{e}+002.86589 \mathrm{e}+002.86589 \mathrm{e}-01$ 1.00000e-09 2.12000e-01 $1.00000 \mathrm{e}-02$ 1.00000e-02 1.00000e-03 1.00000e-09 1.00000e-01 $1.00000 \mathrm{e}+001.00000 \mathrm{e}+001.00000 \mathrm{e}-011.00000 \mathrm{e}-091.00000 \mathrm{e}-01$ $1.00000 \mathrm{e}-051.00000 \mathrm{e}-051.00000 \mathrm{e}-061.00000 \mathrm{e}-091.00000 \mathrm{e}-01$ $1.00000 \mathrm{e}+001.00000 \mathrm{e}+001.00000 \mathrm{e}-011.00000 \mathrm{e}-091.00000 \mathrm{e}-01$ Element: 2001 \# of layers: 12

$\mathrm{Kx} \mathrm{Ky} \mathrm{Kz}$ Ss Por

7.17241e+01 7.17241e+01 7.17241e+00 1.00000e-09 7.00000e-02 5.00000e-04 5.00000e-04 5.00000e-05 1.00000e-09 1.00000e-01 5.00000e-04 5.00000e-04 5.00000e-05 1.00000e-09 1.00000e-01

$2.86589 \mathrm{e}+002.86589 \mathrm{e}+00$ 2.86589e-01 1.00000e-09 2.12000e-01 $2.86589 \mathrm{e}+002.86589 \mathrm{e}+00$ 2.86589e-01 1.00000e-09 2.12000e-01 $2.86589 \mathrm{e}+002.86589 \mathrm{e}+00$ 2.86589e-01 1.00000e-09 2.12000e-01 $2.86589 \mathrm{e}+002.86589 \mathrm{e}+00$ 2.86589e-01 1.00000e-09 2.12000e-01 $2.86589 \mathrm{e}+002.86589 \mathrm{e}+00$ 2.86589e-01 1.00000e-09 2.12000e-01 $1.00000 \mathrm{e}-02$ 1.00000e-02 1.00000e-03 1.00000e-09 1.00000e-01 $1.00000 \mathrm{e}+001.00000 \mathrm{e}+001.00000 \mathrm{e}-011.00000 \mathrm{e}-091.00000 \mathrm{e}-01$ $1.00000 \mathrm{e}-05$ 1.00000e-05 1.00000e-06 1.00000e-09 1.00000e-01 $1.00000 \mathrm{e}+001.00000 \mathrm{e}+001.00000 \mathrm{e}-011.00000 \mathrm{e}-091.00000 \mathrm{e}-01$ Element: 2002 \# of layers: 12

Kx Ky Kz Ss Por

7.17241e+01 7.17241e+01 7.17241e+00 1.00000e-09 7.00000e-02 $5.00000 \mathrm{e}-04$ 5.00000e-04 5.00000e-05 1.00000e-09 1.00000e-01 5.00000e-04 5.00000e-04 5.00000e-05 1.00000e-09 1.00000e-01 $2.86589 \mathrm{e}+002.86589 \mathrm{e}+00$ 2.86589e-01 1.00000e-09 2.12000e-01 $2.86589 \mathrm{e}+002.86589 \mathrm{e}+002.86589 \mathrm{e}-01$ 1.00000e-09 2.12000e-01 $2.86589 \mathrm{e}+002.86589 \mathrm{e}+002.86589 \mathrm{e}-01$ 1.00000e-09 2.12000e-01 $2.86589 \mathrm{e}+002.86589 \mathrm{e}+002.86589 \mathrm{e}-01$ 1.00000e-09 2.12000e-01 $2.86589 \mathrm{e}+002.86589 \mathrm{e}+00$ 2.86589e-01 1.00000e-09 2.12000e-01 $1.00000 \mathrm{e}-02$ 1.00000e-02 1.00000e-03 1.00000e-09 1.00000e-01 $1.00000 \mathrm{e}+001.00000 \mathrm{e}+001.00000 \mathrm{e}-011.00000 \mathrm{e}-091.00000 \mathrm{e}-01$ $1.00000 \mathrm{e}-05$ 1.00000e-05 1.00000e-06 1.00000e-09 1.00000e-01 $1.00000 \mathrm{e}+001.00000 \mathrm{e}+001.00000 \mathrm{e}-01$ 1.00000e-09 1.00000e-01 Element: 2003 \# of layers: 12

Kx Ky Kz Ss Por 
$7.17241 \mathrm{e}+017.17241 \mathrm{e}+01$ 7.17241e+00 1.00000e-09 7.00000e-02 5.00000e-04 5.00000e-04 5.00000e-05 1.00000e-09 1.00000e-01 5.00000e-04 5.00000e-04 5.00000e-05 1.00000e-09 1.00000e-01 $2.86589 \mathrm{e}+002.86589 \mathrm{e}+002.86589 \mathrm{e}-011.00000 \mathrm{e}-092.12000 \mathrm{e}-01$ $2.86589 \mathrm{e}+002.86589 \mathrm{e}+002.86589 \mathrm{e}-011.00000 \mathrm{e}-092.12000 \mathrm{e}-01$ $2.86589 \mathrm{e}+002.86589 \mathrm{e}+002.86589 \mathrm{e}-011.00000 \mathrm{e}-092.12000 \mathrm{e}-01$ $2.86589 \mathrm{e}+002.86589 \mathrm{e}+002.86589 \mathrm{e}-011.00000 \mathrm{e}-092.12000 \mathrm{e}-01$ $2.86589 \mathrm{e}+002.86589 \mathrm{e}+002.86589 \mathrm{e}-01$ 1.00000e-09 2.12000e-01 $1.00000 \mathrm{e}-02$ 1.00000e-02 1.00000e-03 1.00000e-09 1.00000e-01 $1.00000 \mathrm{e}+001.00000 \mathrm{e}+001.00000 \mathrm{e}-011.00000 \mathrm{e}-091.00000 \mathrm{e}-01$ $1.00000 \mathrm{e}-05$ 1.00000e-05 1.00000e-06 1.00000e-09 1.00000e-01 $1.00000 \mathrm{e}+001.00000 \mathrm{e}+001.00000 \mathrm{e}-011.00000 \mathrm{e}-091.00000 \mathrm{e}-01$ Element: 2004 \# of layers: 12

Kx Ky Kz Ss Por

7.17241e+01 7.17241e+01 7.17241e+00 1.00000e-09 7.00000e-02 5.00000e-04 5.00000e-04 5.00000e-05 1.00000e-09 1.00000e-01 5.00000e-04 5.00000e-04 5.00000e-05 1.00000e-09 1.00000e-01

$2.86589 \mathrm{e}+002.86589 \mathrm{e}+002.86589 \mathrm{e}-011.00000 \mathrm{e}-092.12000 \mathrm{e}-01$ $2.86589 \mathrm{e}+002.86589 \mathrm{e}+002.86589 \mathrm{e}-011.00000 \mathrm{e}-092.12000 \mathrm{e}-01$ $2.86589 \mathrm{e}+002.86589 \mathrm{e}+002.86589 \mathrm{e}-01$ 1.00000e-09 2.12000e-01 $2.86589 \mathrm{e}+002.86589 \mathrm{e}+002.86589 \mathrm{e}-011.00000 \mathrm{e}-092.12000 \mathrm{e}-01$ $2.86589 \mathrm{e}+002.86589 \mathrm{e}+00$ 2.86589e-01 1.00000e-09 2.12000e-01 $1.00000 \mathrm{e}-02$ 1.00000e-02 1.00000e-03 1.00000e-09 1.00000e-01 $1.00000 \mathrm{e}+001.00000 \mathrm{e}+001.00000 \mathrm{e}-011.00000 \mathrm{e}-091.00000 \mathrm{e}-01$ $1.00000 \mathrm{e}-05$ 1.00000e-05 1.00000e-06 1.00000e-09 1.00000e-01 $1.00000 \mathrm{e}+001.00000 \mathrm{e}+001.00000 \mathrm{e}-011.00000 \mathrm{e}-091.00000 \mathrm{e}-01$ Element: 2005 \# of layers: 12

Kx Ky Kz Ss Por

7.17241e+01 7.17241e+01 7.17241e+00 1.00000e-09 7.00000e-02 $5.00000 \mathrm{e}-04$ 5.00000e-04 5.00000e-05 1.00000e-09 1.00000e-01 $5.00000 \mathrm{e}-04$ 5.00000e-04 5.00000e-05 1.00000e-09 1.00000e-01 $2.86589 \mathrm{e}+002.86589 \mathrm{e}+002.86589 \mathrm{e}-01$ 1.00000e-09 2.12000e-01 $2.86589 \mathrm{e}+002.86589 \mathrm{e}+002.86589 \mathrm{e}-01$ 1.00000e-09 2.12000e-01 $2.86589 \mathrm{e}+002.86589 \mathrm{e}+002.86589 \mathrm{e}-011.00000 \mathrm{e}-092.12000 \mathrm{e}-01$ $2.86589 \mathrm{e}+002.86589 \mathrm{e}+002.86589 \mathrm{e}-01$ 1.00000e-09 2.12000e-01 $2.86589 \mathrm{e}+002.86589 \mathrm{e}+002.86589 \mathrm{e}-01$ 1.00000e-09 2.12000e-01 $1.00000 \mathrm{e}-02$ 1.00000e-02 1.00000e-03 1.00000e-09 1.00000e-01 $1.00000 \mathrm{e}+001.00000 \mathrm{e}+001.00000 \mathrm{e}-011.00000 \mathrm{e}-091.00000 \mathrm{e}-01$ $1.00000 \mathrm{e}-05$ 1.00000e-05 1.00000e-06 1.00000e-09 1.00000e-01 $1.00000 \mathrm{e}+001.00000 \mathrm{e}+001.00000 \mathrm{e}-011.00000 \mathrm{e}-091.00000 \mathrm{e}-01$ Element: 2006 \# of layers: 12

Kx Ky Kz Ss Por

7.17241e+01 7.17241e+01 7.17241e+00 1.00000e-09 7.00000e-02 5.00000e-04 5.00000e-04 5.00000e-05 1.00000e-09 1.00000e-01 5.00000e-04 5.00000e-04 5.00000e-05 1.00000e-09 1.00000e-01 $2.86589 \mathrm{e}+002.86589 \mathrm{e}+002.86589 \mathrm{e}-01$ 1.00000e-09 2.12000e-01 
$2.86589 \mathrm{e}+002.86589 \mathrm{e}+002.86589 \mathrm{e}-01$ 1.00000e-09 2.12000e-01

$2.86589 \mathrm{e}+002.86589 \mathrm{e}+002.86589 \mathrm{e}-011.00000 \mathrm{e}-092.12000 \mathrm{e}-01$

$2.86589 \mathrm{e}+002.86589 \mathrm{e}+002.86589 \mathrm{e}-01$ 1.00000e-09 2.12000e-01

$2.86589 \mathrm{e}+002.86589 \mathrm{e}+002.86589 \mathrm{e}-01$ 1.00000e-09 2.12000e-01

$1.00000 \mathrm{e}-02$ 1.00000e-02 1.00000e-03 1.00000e-09 1.00000e-01

$1.00000 \mathrm{e}+001.00000 \mathrm{e}+001.00000 \mathrm{e}-011.00000 \mathrm{e}-091.00000 \mathrm{e}-01$

$1.00000 \mathrm{e}-051.00000 \mathrm{e}-05$ 1.00000e-06 1.00000e-09 1.00000e-01

$1.00000 \mathrm{e}+001.00000 \mathrm{e}+001.00000 \mathrm{e}-011.00000 \mathrm{e}-091.00000 \mathrm{e}-01$

Element: 2007 \# of layers: 12

Kx Ky Kz Ss Por

7.17241e+01 7.17241e+01 7.17241e+00 1.00000e-09 7.00000e-02

5.00000e-04 5.00000e-04 5.00000e-05 1.00000e-09 1.00000e-01

5.00000e-04 5.00000e-04 5.00000e-05 1.00000e-09 1.00000e-01

$2.86589 \mathrm{e}+002.86589 \mathrm{e}+002.86589 \mathrm{e}-011.00000 \mathrm{e}-092.12000 \mathrm{e}-01$

$2.86589 \mathrm{e}+002.86589 \mathrm{e}+002.86589 \mathrm{e}-011.00000 \mathrm{e}-092.12000 \mathrm{e}-01$

$2.86589 \mathrm{e}+002.86589 \mathrm{e}+002.86589 \mathrm{e}-01$ 1.00000e-09 2.12000e-01

$2.86589 \mathrm{e}+002.86589 \mathrm{e}+002.86589 \mathrm{e}-011.00000 \mathrm{e}-092.12000 \mathrm{e}-01$

$2.86589 \mathrm{e}+002.86589 \mathrm{e}+002.86589 \mathrm{e}-01$ 1.00000e-09 2.12000e-01

$1.00000 \mathrm{e}-02$ 1.00000e-02 1.00000e-03 1.00000e-09 1.00000e-01

$1.00000 \mathrm{e}+001.00000 \mathrm{e}+001.00000 \mathrm{e}-011.00000 \mathrm{e}-091.00000 \mathrm{e}-01$

$1.00000 \mathrm{e}-05$ 1.00000e-05 1.00000e-06 1.00000e-09 1.00000e-01

$1.00000 \mathrm{e}+001.00000 \mathrm{e}+001.00000 \mathrm{e}-011.00000 \mathrm{e}-091.00000 \mathrm{e}-01$

Element: 2008 \# of layers: 12

Kx Ky Kz Ss Por

7.17241e+01 7.17241e+01 7.17241e+00 1.00000e-09 7.00000e-02

$5.00000 \mathrm{e}-04$ 5.00000e-04 5.00000e-05 1.00000e-09 1.00000e-01

$5.00000 \mathrm{e}-04$ 5.00000e-04 5.00000e-05 1.00000e-09 1.00000e-01

$2.86589 \mathrm{e}+002.86589 \mathrm{e}+002.86589 \mathrm{e}-011.00000 \mathrm{e}-092.12000 \mathrm{e}-01$

$2.86589 \mathrm{e}+002.86589 \mathrm{e}+002.86589 \mathrm{e}-01$ 1.00000e-09 2.12000e-01

$2.86589 \mathrm{e}+002.86589 \mathrm{e}+002.86589 \mathrm{e}-011.00000 \mathrm{e}-092.12000 \mathrm{e}-01$

$2.86589 \mathrm{e}+002.86589 \mathrm{e}+002.86589 \mathrm{e}-011.00000 \mathrm{e}-092.12000 \mathrm{e}-01$

$2.86589 \mathrm{e}+002.86589 \mathrm{e}+002.86589 \mathrm{e}-01$ 1.00000e-09 2.12000e-01

$1.00000 \mathrm{e}-021.00000 \mathrm{e}-02$ 1.00000e-03 1.00000e-09 1.00000e-01

$1.00000 \mathrm{e}+001.00000 \mathrm{e}+001.00000 \mathrm{e}-011.00000 \mathrm{e}-091.00000 \mathrm{e}-01$

$1.00000 \mathrm{e}-05$ 1.00000e-05 1.00000e-06 1.00000e-09 1.00000e-01

$1.00000 \mathrm{e}+001.00000 \mathrm{e}+001.00000 \mathrm{e}-011.00000 \mathrm{e}-091.00000 \mathrm{e}-01$

Element: 2009 \# of layers: 12

Kx Ky Kz Ss Por

$1.02272 \mathrm{e}+021.02272 \mathrm{e}+02$ 1.02273e+01 1.00000e-09 7.00000e-02

5.00000e-04 5.00000e-04 5.00000e-05 1.00000e-09 1.00000e-01

5.00000e-04 5.00000e-04 5.00000e-05 1.00000e-09 1.00000e-01

$4.08654 \mathrm{e}+00 \quad 4.08654 \mathrm{e}+004.08654 \mathrm{e}-011.00000 \mathrm{e}-092.12000 \mathrm{e}-01$

$4.08654 \mathrm{e}+004.08654 \mathrm{e}+004.08654 \mathrm{e}-011.00000 \mathrm{e}-092.12000 \mathrm{e}-01$

$4.08654 \mathrm{e}+004.08654 \mathrm{e}+004.08654 \mathrm{e}-011.00000 \mathrm{e}-092.12000 \mathrm{e}-01$

$4.08654 \mathrm{e}+004.08654 \mathrm{e}+004.08654 \mathrm{e}-011.00000 \mathrm{e}-092.12000 \mathrm{e}-01$

$4.08654 \mathrm{e}+004.08654 \mathrm{e}+004.08654 \mathrm{e}-011.00000 \mathrm{e}-092.12000 \mathrm{e}-01$ 
$1.00000 \mathrm{e}-02$ 1.00000e-02 1.00000e-03 1.00000e-09 1.00000e-01 $1.00000 \mathrm{e}+001.00000 \mathrm{e}+001.00000 \mathrm{e}-011.00000 \mathrm{e}-091.00000 \mathrm{e}-01$ $1.00000 \mathrm{e}-051.00000 \mathrm{e}-05$ 1.00000e-06 1.00000e-09 1.00000e-01 $1.00000 \mathrm{e}+001.00000 \mathrm{e}+001.00000 \mathrm{e}-011.00000 \mathrm{e}-091.00000 \mathrm{e}-01$ Element: 2010 \# of layers: 11

Kx Ky Kz Ss Por

$1.02272 \mathrm{e}+02$ 1.02272e+02 1.02273e+01 1.00000e-09 7.00000e-02 5.00000e-04 5.00000e-04 5.00000e-05 1.00000e-09 1.00000e-01 $4.08654 \mathrm{e}+00 \quad 4.08654 \mathrm{e}+004.08654 \mathrm{e}-011.00000 \mathrm{e}-092.12000 \mathrm{e}-01$ $4.08654 \mathrm{e}+004.08654 \mathrm{e}+004.08654 \mathrm{e}-011.00000 \mathrm{e}-092.12000 \mathrm{e}-01$ $4.08654 \mathrm{e}+004.08654 \mathrm{e}+004.08654 \mathrm{e}-011.00000 \mathrm{e}-092.12000 \mathrm{e}-01$ $4.08654 \mathrm{e}+004.08654 \mathrm{e}+004.08654 \mathrm{e}-011.00000 \mathrm{e}-092.12000 \mathrm{e}-01$ $4.08654 \mathrm{e}+004.08654 \mathrm{e}+00 \quad 4.08654 \mathrm{e}-011.00000 \mathrm{e}-09$ 2.12000e-01 $1.00000 \mathrm{e}-02$ 1.00000e-02 1.00000e-03 1.00000e-09 1.00000e-01 $1.00000 \mathrm{e}+001.00000 \mathrm{e}+001.00000 \mathrm{e}-011.00000 \mathrm{e}-091.00000 \mathrm{e}-01$ $1.00000 \mathrm{e}-05$ 1.00000e-05 1.00000e-06 1.00000e-09 1.00000e-01 $1.00000 \mathrm{e}+001.00000 \mathrm{e}+001.00000 \mathrm{e}-011.00000 \mathrm{e}-091.00000 \mathrm{e}-01$ Element: 2011 \# of layers: 11

Kx Ky Kz Ss Por $1.02272 \mathrm{e}+021.02272 \mathrm{e}+021.02273 \mathrm{e}+01$ 1.00000e-09 7.00000e-02 5.00000e-04 5.00000e-04 5.00000e-05 1.00000e-09 1.00000e-01 $4.08654 \mathrm{e}+004.08654 \mathrm{e}+004.08654 \mathrm{e}-011.00000 \mathrm{e}-092.12000 \mathrm{e}-01$ $4.08654 \mathrm{e}+004.08654 \mathrm{e}+00 \quad 4.08654 \mathrm{e}-011.00000 \mathrm{e}-092.12000 \mathrm{e}-01$ $4.08654 \mathrm{e}+004.08654 \mathrm{e}+004.08654 \mathrm{e}-011.00000 \mathrm{e}-092.12000 \mathrm{e}-01$ $4.08654 \mathrm{e}+00 \quad 4.08654 \mathrm{e}+004.08654 \mathrm{e}-011.00000 \mathrm{e}-092.12000 \mathrm{e}-01$ $4.08654 \mathrm{e}+004.08654 \mathrm{e}+00 \quad 4.08654 \mathrm{e}-011.00000 \mathrm{e}-09$ 2.12000e-01 $1.00000 \mathrm{e}-021.00000 \mathrm{e}-02$ 1.00000e-03 1.00000e-09 1.00000e-01 $1.00000 \mathrm{e}+001.00000 \mathrm{e}+001.00000 \mathrm{e}-011.00000 \mathrm{e}-091.00000 \mathrm{e}-01$ $1.00000 \mathrm{e}-051.00000 \mathrm{e}-05$ 1.00000e-06 1.00000e-09 1.00000e-01 $1.00000 \mathrm{e}+001.00000 \mathrm{e}+001.00000 \mathrm{e}-011.00000 \mathrm{e}-091.00000 \mathrm{e}-01$ Element: 2012 \# of layers: 11

Kx Ky Kz Ss Por $1.02272 \mathrm{e}+021.02272 \mathrm{e}+021.02273 \mathrm{e}+01$ 1.00000e-09 7.00000e-02 5.00000e-04 5.00000e-04 5.00000e-05 1.00000e-09 1.00000e-01 $4.08654 \mathrm{e}+00 \quad 4.08654 \mathrm{e}+00 \quad 4.08654 \mathrm{e}-011.00000 \mathrm{e}-092.12000 \mathrm{e}-01$ $4.08654 \mathrm{e}+004.08654 \mathrm{e}+004.08654 \mathrm{e}-011.00000 \mathrm{e}-092.12000 \mathrm{e}-01$ $4.08654 \mathrm{e}+004.08654 \mathrm{e}+004.08654 \mathrm{e}-011.00000 \mathrm{e}-092.12000 \mathrm{e}-01$ $4.08654 \mathrm{e}+004.08654 \mathrm{e}+004.08654 \mathrm{e}-011.00000 \mathrm{e}-092.12000 \mathrm{e}-01$ $4.08654 \mathrm{e}+004.08654 \mathrm{e}+00$ 4.08654e-01 1.00000e-09 2.12000e-01 $1.00000 \mathrm{e}-02$ 1.00000e-02 1.00000e-03 1.00000e-09 1.00000e-01 $1.00000 \mathrm{e}+001.00000 \mathrm{e}+001.00000 \mathrm{e}-011.00000 \mathrm{e}-091.00000 \mathrm{e}-01$ $1.00000 \mathrm{e}-05$ 1.00000e-05 1.00000e-06 1.00000e-09 1.00000e-01 $1.00000 \mathrm{e}+001.00000 \mathrm{e}+001.00000 \mathrm{e}-011.00000 \mathrm{e}-091.00000 \mathrm{e}-01$ Element: 2013 \# of layers: 12

Kx Ky Kz Ss Por

$1.02272 \mathrm{e}+02$ 1.02272e+02 1.02273e+01 1.00000e-09 7.00000e-02 
5.00000e-04 5.00000e-04 5.00000e-05 1.00000e-09 1.00000e-01 5.00000e-04 5.00000e-04 5.00000e-05 1.00000e-09 1.00000e-01 $4.08654 \mathrm{e}+004.08654 \mathrm{e}+004.08654 \mathrm{e}-01$ 1.00000e-09 2.12000e-01 $4.08654 \mathrm{e}+004.08654 \mathrm{e}+004.08654 \mathrm{e}-01$ 1.00000e-09 2.12000e-01 $4.08654 \mathrm{e}+004.08654 \mathrm{e}+004.08654 \mathrm{e}-01$ 1.00000e-09 2.12000e-01 $4.08654 \mathrm{e}+004.08654 \mathrm{e}+004.08654 \mathrm{e}-01$ 1.00000e-09 2.12000e-01 $4.08654 \mathrm{e}+004.08654 \mathrm{e}+004.08654 \mathrm{e}-01$ 1.00000e-09 2.12000e-01 $1.00000 \mathrm{e}-02$ 1.00000e-02 1.00000e-03 1.00000e-09 1.00000e-01 $1.00000 \mathrm{e}+001.00000 \mathrm{e}+001.00000 \mathrm{e}-011.00000 \mathrm{e}-091.00000 \mathrm{e}-01$ $1.00000 \mathrm{e}-05$ 1.00000e-05 1.00000e-06 1.00000e-09 1.00000e-01 $1.00000 \mathrm{e}+001.00000 \mathrm{e}+001.00000 \mathrm{e}-011.00000 \mathrm{e}-091.00000 \mathrm{e}-01$ Element: 2014 \# of layers: 12

$\mathrm{Kx} \mathrm{Ky} \mathrm{Kz}$ Ss Por

$1.02272 \mathrm{e}+02$ 1.02272e+02 1.02273e+01 1.00000e-09 7.00000e-02 5.00000e-04 5.00000e-04 5.00000e-05 1.00000e-09 1.00000e-01 5.00000e-04 5.00000e-04 5.00000e-05 1.00000e-09 1.00000e-01 $4.08654 \mathrm{e}+004.08654 \mathrm{e}+004.08654 \mathrm{e}-01$ 1.00000e-09 2.12000e-01 $4.08654 \mathrm{e}+004.08654 \mathrm{e}+004.08654 \mathrm{e}-01$ 1.00000e-09 2.12000e-01 $4.08654 \mathrm{e}+004.08654 \mathrm{e}+004.08654 \mathrm{e}-01$ 1.00000e-09 2.12000e-01 $4.08654 \mathrm{e}+004.08654 \mathrm{e}+004.08654 \mathrm{e}-01$ 1.00000e-09 2.12000e-01 $4.08654 \mathrm{e}+00 \quad 4.08654 \mathrm{e}+00 \quad 4.08654 \mathrm{e}-01$ 1.00000e-09 2.12000e-01 $1.00000 \mathrm{e}-02$ 1.00000e-02 1.00000e-03 1.00000e-09 1.00000e-01 $1.00000 \mathrm{e}+001.00000 \mathrm{e}+001.00000 \mathrm{e}-011.00000 \mathrm{e}-091.00000 \mathrm{e}-01$ $1.00000 \mathrm{e}-05$ 1.00000e-05 1.00000e-06 1.00000e-09 1.00000e-01 $1.00000 \mathrm{e}+001.00000 \mathrm{e}+001.00000 \mathrm{e}-011.00000 \mathrm{e}-091.00000 \mathrm{e}-01$ Element: 2015 \# of layers: 12

$\mathrm{Kx} \mathrm{Ky} \mathrm{Kz}$ Ss Por

$1.02272 \mathrm{e}+02$ 1.02272e+02 1.02273e+01 1.00000e-09 7.00000e-02 5.00000e-04 5.00000e-04 5.00000e-05 1.00000e-09 1.00000e-01 5.00000e-04 5.00000e-04 5.00000e-05 1.00000e-09 1.00000e-01 $4.08654 \mathrm{e}+004.08654 \mathrm{e}+004.08654 \mathrm{e}-01$ 1.00000e-09 2.12000e-01 $4.08654 \mathrm{e}+004.08654 \mathrm{e}+004.08654 \mathrm{e}-01$ 1.00000e-09 2.12000e-01 $4.08654 \mathrm{e}+004.08654 \mathrm{e}+004.08654 \mathrm{e}-01$ 1.00000e-09 2.12000e-01 $4.08654 \mathrm{e}+004.08654 \mathrm{e}+004.08654 \mathrm{e}-01$ 1.00000e-09 2.12000e-01 $4.08654 \mathrm{e}+004.08654 \mathrm{e}+004.08654 \mathrm{e}-01$ 1.00000e-09 2.12000e-01 1.00000e-02 1.00000e-02 1.00000e-03 1.00000e-09 1.00000e-01 $1.00000 \mathrm{e}+001.00000 \mathrm{e}+001.00000 \mathrm{e}-011.00000 \mathrm{e}-091.00000 \mathrm{e}-01$ $1.00000 \mathrm{e}-05$ 1.00000e-05 1.00000e-06 1.00000e-09 1.00000e-01 $1.00000 \mathrm{e}+001.00000 \mathrm{e}+001.00000 \mathrm{e}-011.00000 \mathrm{e}-091.00000 \mathrm{e}-01$ Element: 2016 \# of layers: 12

$\mathrm{Kx} \mathrm{Ky} \mathrm{Kz}$ Ss Por $1.02272 \mathrm{e}+02$ 1.02272e+02 1.02273e+01 1.00000e-09 7.00000e-02 5.00000e-04 5.00000e-04 5.00000e-05 1.00000e-09 1.00000e-01 5.00000e-04 5.00000e-04 5.00000e-05 1.00000e-09 1.00000e-01 $4.08654 \mathrm{e}+004.08654 \mathrm{e}+004.08654 \mathrm{e}-01$ 1.00000e-09 2.12000e-01 $4.08654 \mathrm{e}+004.08654 \mathrm{e}+004.08654 \mathrm{e}-01$ 1.00000e-09 2.12000e-01 
$4.08654 \mathrm{e}+004.08654 \mathrm{e}+004.08654 \mathrm{e}-01$ 1.00000e-09 2.12000e-01 $4.08654 \mathrm{e}+004.08654 \mathrm{e}+004.08654 \mathrm{e}-01$ 1.00000e-09 2.12000e-01 $4.08654 \mathrm{e}+004.08654 \mathrm{e}+004.08654 \mathrm{e}-01$ 1.00000e-09 2.12000e-01 $1.00000 \mathrm{e}-02$ 1.00000e-02 1.00000e-03 1.00000e-09 1.00000e-01 $1.00000 \mathrm{e}+001.00000 \mathrm{e}+001.00000 \mathrm{e}-011.00000 \mathrm{e}-091.00000 \mathrm{e}-01$ $1.00000 \mathrm{e}-05$ 1.00000e-05 1.00000e-06 1.00000e-09 1.00000e-01 $1.00000 \mathrm{e}+001.00000 \mathrm{e}+001.00000 \mathrm{e}-011.00000 \mathrm{e}-091.00000 \mathrm{e}-01$ Element: 2017 \# of layers: 11

$\mathrm{Kx} \mathrm{Ky} \mathrm{Kz}$ Ss Por

$1.02272 \mathrm{e}+021.02272 \mathrm{e}+02$ 1.02273e+01 1.00000e-09 7.00000e-02 5.00000e-04 5.00000e-04 5.00000e-05 1.00000e-09 1.00000e-01 $4.08654 \mathrm{e}+004.08654 \mathrm{e}+00 \quad 4.08654 \mathrm{e}-01$ 1.00000e-09 2.12000e-01 $4.08654 \mathrm{e}+004.08654 \mathrm{e}+004.08654 \mathrm{e}-01$ 1.00000e-09 2.12000e-01 $4.08654 \mathrm{e}+004.08654 \mathrm{e}+004.08654 \mathrm{e}-01$ 1.00000e-09 2.12000e-01 $4.08654 \mathrm{e}+004.08654 \mathrm{e}+004.08654 \mathrm{e}-01$ 1.00000e-09 2.12000e-01 $4.08654 \mathrm{e}+004.08654 \mathrm{e}+004.08654 \mathrm{e}-01$ 1.00000e-09 2.12000e-01 $1.00000 \mathrm{e}-02$ 1.00000e-02 1.00000e-03 1.00000e-09 1.00000e-01 $1.00000 \mathrm{e}+001.00000 \mathrm{e}+001.00000 \mathrm{e}-011.00000 \mathrm{e}-091.00000 \mathrm{e}-01$ $1.00000 \mathrm{e}-05$ 1.00000e-05 1.00000e-06 1.00000e-09 1.00000e-01 $1.00000 \mathrm{e}+001.00000 \mathrm{e}+001.00000 \mathrm{e}-011.00000 \mathrm{e}-091.00000 \mathrm{e}-01$ Element: 2018 \# of layers: 11

$\mathrm{Kx} \mathrm{Ky} \mathrm{Kz}$ Ss Por

1.52188e+02 1.52188e+02 1.52188e+01 1.00000e-09 7.00000e-02 $1.52188 \mathrm{e}+02$ 1.52188e+02 1.52188e+01 1.00000e-09 7.00000e-02 $6.08098 \mathrm{e}+00$ 6.08098e+00 6.08098e-01 1.00000e-09 2.12000e-01 $6.08098 \mathrm{e}+006.08098 \mathrm{e}+00$ 6.08098e-01 1.00000e-09 2.12000e-01 $6.08098 \mathrm{e}+006.08098 \mathrm{e}+00$ 6.08098e-01 1.00000e-09 2.12000e-01 $6.08098 \mathrm{e}+00$ 6.08098e+00 6.08098e-01 1.00000e-09 2.12000e-01 $6.08098 \mathrm{e}+00$ 6.08098e+00 6.08098e-01 1.00000e-09 2.12000e-01 $1.00000 \mathrm{e}-021.00000 \mathrm{e}-021.00000 \mathrm{e}-031.00000 \mathrm{e}-091.00000 \mathrm{e}-01$ $1.00000 \mathrm{e}+001.00000 \mathrm{e}+001.00000 \mathrm{e}-011.00000 \mathrm{e}-091.00000 \mathrm{e}-01$ $1.00000 \mathrm{e}-05$ 1.00000e-05 1.00000e-06 1.00000e-09 1.00000e-01 $1.00000 \mathrm{e}+001.00000 \mathrm{e}+001.00000 \mathrm{e}-011.00000 \mathrm{e}-09$ 1.00000e-01 Element: 2019 \# of layers: 10

$\mathrm{Kx} \mathrm{Ky} \mathrm{Kz}$ Ss Por

$1.52188 \mathrm{e}+02$ 1.52188e+02 1.52188e+01 1.00000e-09 7.00000e-02 $6.08098 \mathrm{e}+00$ 6.08098e+00 6.08098e-01 1.00000e-09 2.12000e-01 $6.08098 \mathrm{e}+00$ 6.08098e+00 6.08098e-01 1.00000e-09 2.12000e-01 $6.08098 \mathrm{e}+006.08098 \mathrm{e}+00$ 6.08098e-01 1.00000e-09 2.12000e-01 $6.08098 \mathrm{e}+00$ 6.08098e+00 6.08098e-01 1.00000e-09 2.12000e-01 $6.08098 \mathrm{e}+006.08098 \mathrm{e}+00$ 6.08098e-01 1.00000e-09 2.12000e-01 $1.00000 \mathrm{e}-02$ 1.00000e-02 1.00000e-03 1.00000e-09 1.00000e-01 $1.00000 \mathrm{e}+001.00000 \mathrm{e}+001.00000 \mathrm{e}-011.00000 \mathrm{e}-091.00000 \mathrm{e}-01$ $1.00000 \mathrm{e}-05$ 1.00000e-05 1.00000e-06 1.00000e-09 1.00000e-01 $1.00000 \mathrm{e}+001.00000 \mathrm{e}+001.00000 \mathrm{e}-01$ 1.00000e-09 1.00000e-01 Element: 2020 \# of layers: 9 
$\mathrm{Kx} \mathrm{Ky} \mathrm{Kz}$ Ss Por

6.08098e+00 6.08098e+00 6.08098e-01 1.00000e-09 2.12000e-01

6.08098e+00 6.08098e+00 6.08098e-01 1.00000e-09 2.12000e-01

$6.08098 \mathrm{e}+00$ 6.08098e+00 6.08098e-01 1.00000e-09 2.12000e-01

$6.08098 \mathrm{e}+00$ 6.08098e+00 6.08098e-01 1.00000e-09 2.12000e-01

$6.08098 \mathrm{e}+006.08098 \mathrm{e}+00$ 6.08098e-01 1.00000e-09 2.12000e-01

$1.00000 \mathrm{e}-02$ 1.00000e-02 1.00000e-03 1.00000e-09 1.00000e-01

$1.00000 \mathrm{e}+001.00000 \mathrm{e}+001.00000 \mathrm{e}-011.00000 \mathrm{e}-091.00000 \mathrm{e}-01$

$1.00000 \mathrm{e}-051.00000 \mathrm{e}-051.00000 \mathrm{e}-061.00000 \mathrm{e}-091.00000 \mathrm{e}-01$

$1.00000 \mathrm{e}+001.00000 \mathrm{e}+001.00000 \mathrm{e}-011.00000 \mathrm{e}-091.00000 \mathrm{e}-01$

Element: 2021 \# of layers: 10

$\mathrm{Kx} \mathrm{Ky} \mathrm{Kz}$ Ss Por

1.52188e+02 1.52188e+02 1.52188e+01 1.00000e-09 7.00000e-02

$6.08098 \mathrm{e}+00$ 6.08098e+00 6.08098e-01 1.00000e-09 2.12000e-01

$6.08098 \mathrm{e}+00$ 6.08098e+00 6.08098e-01 1.00000e-09 2.12000e-01

$6.08098 \mathrm{e}+006.08098 \mathrm{e}+00$ 6.08098e-01 1.00000e-09 2.12000e-01

$6.08098 \mathrm{e}+00$ 6.08098e+00 6.08098e-01 1.00000e-09 2.12000e-01

$6.08098 \mathrm{e}+006.08098 \mathrm{e}+00$ 6.08098e-01 1.00000e-09 2.12000e-01

$1.00000 \mathrm{e}-02$ 1.00000e-02 1.00000e-03 1.00000e-09 1.00000e-01

$1.00000 \mathrm{e}+001.00000 \mathrm{e}+001.00000 \mathrm{e}-011.00000 \mathrm{e}-091.00000 \mathrm{e}-01$

$1.00000 \mathrm{e}-05$ 1.00000e-05 1.00000e-06 1.00000e-09 1.00000e-01

$1.00000 \mathrm{e}+001.00000 \mathrm{e}+001.00000 \mathrm{e}-01$ 1.00000e-09 1.00000e-01

Element: 2022 \# of layers: 12

Kx Ky Kz Ss Por

$1.52188 \mathrm{e}+02$ 1.52188e+02 1.52188e+01 1.00000e-09 7.00000e-02

$1.52188 \mathrm{e}+021.52188 \mathrm{e}+02$ 1.52188e+01 1.00000e-09 7.00000e-02

5.00000e-04 5.00000e-04 5.00000e-05 1.00000e-09 1.00000e-01

$6.08098 \mathrm{e}+00$ 6.08098e+00 6.08098e-01 1.00000e-09 2.12000e-01

$6.08098 \mathrm{e}+00$ 6.08098e+00 6.08098e-01 1.00000e-09 2.12000e-01

6.08098e+00 6.08098e+00 6.08098e-01 1.00000e-09 2.12000e-01

$6.08098 \mathrm{e}+00$ 6.08098e+00 6.08098e-01 1.00000e-09 2.12000e-01

$6.08098 \mathrm{e}+006.08098 \mathrm{e}+00$ 6.08098e-01 1.00000e-09 2.12000e-01

$1.00000 \mathrm{e}-02$ 1.00000e-02 1.00000e-03 1.00000e-09 1.00000e-01

$1.00000 \mathrm{e}+001.00000 \mathrm{e}+001.00000 \mathrm{e}-011.00000 \mathrm{e}-091.00000 \mathrm{e}-01$

$1.00000 \mathrm{e}-05$ 1.00000e-05 1.00000e-06 1.00000e-09 1.00000e-01

$1.00000 \mathrm{e}+001.00000 \mathrm{e}+001.00000 \mathrm{e}-011.00000 \mathrm{e}-091.00000 \mathrm{e}-01$

Element: 2023 \# of layers: 13

$\mathrm{Kx} \mathrm{Ky} \mathrm{Kz}$ Ss Por

$1.52188 \mathrm{e}+02$ 1.52188e+02 1.52188e+01 1.00000e-09 7.00000e-02

$1.52188 \mathrm{e}+021.52188 \mathrm{e}+02$ 1.52188e+01 1.00000e-09 7.00000e-02

5.00000e-04 5.00000e-04 5.00000e-05 1.00000e-09 1.00000e-01

5.00000e-04 5.00000e-04 5.00000e-05 1.00000e-09 1.00000e-01

6.08098e+00 6.08098e+00 6.08098e-01 1.00000e-09 2.12000e-01

6.08098e+00 6.08098e+00 6.08098e-01 1.00000e-09 2.12000e-01

6.08098e+00 6.08098e+00 6.08098e-01 1.00000e-09 2.12000e-01

$6.08098 \mathrm{e}+00$ 6.08098e+00 6.08098e-01 1.00000e-09 2.12000e-01 
$6.08098 \mathrm{e}+006.08098 \mathrm{e}+00$ 6.08098e-01 1.00000e-09 2.12000e-01 $1.00000 \mathrm{e}-02$ 1.00000e-02 1.00000e-03 1.00000e-09 1.00000e-01 $1.00000 \mathrm{e}+001.00000 \mathrm{e}+001.00000 \mathrm{e}-011.00000 \mathrm{e}-091.00000 \mathrm{e}-01$ $1.00000 \mathrm{e}-05$ 1.00000e-05 1.00000e-06 1.00000e-09 1.00000e-01 $1.00000 \mathrm{e}+001.00000 \mathrm{e}+001.00000 \mathrm{e}-011.00000 \mathrm{e}-091.00000 \mathrm{e}-01$ Element: 2024 \# of layers: 13

Kx Ky Kz Ss Por

$1.52188 \mathrm{e}+02$ 1.52188e+02 1.52188e+01 1.00000e-09 7.00000e-02 $1.52188 \mathrm{e}+021.52188 \mathrm{e}+021.52188 \mathrm{e}+011.00000 \mathrm{e}-09$ 7.00000e-02 5.00000e-04 5.00000e-04 5.00000e-05 1.00000e-09 1.00000e-01 5.00000e-04 5.00000e-04 5.00000e-05 1.00000e-09 1.00000e-01 $6.08098 \mathrm{e}+006.08098 \mathrm{e}+00$ 6.08098e-01 1.00000e-09 2.12000e-01 $6.08098 \mathrm{e}+006.08098 \mathrm{e}+00$ 6.08098e-01 1.00000e-09 2.12000e-01 $6.08098 \mathrm{e}+006.08098 \mathrm{e}+00$ 6.08098e-01 1.00000e-09 2.12000e-01 $6.08098 \mathrm{e}+006.08098 \mathrm{e}+006.08098 \mathrm{e}-011.00000 \mathrm{e}-092.12000 \mathrm{e}-01$ $6.08098 \mathrm{e}+006.08098 \mathrm{e}+00$ 6.08098e-01 1.00000e-09 2.12000e-01 $1.00000 \mathrm{e}-021.00000 \mathrm{e}-02$ 1.00000e-03 1.00000e-09 1.00000e-01 $1.00000 \mathrm{e}+001.00000 \mathrm{e}+001.00000 \mathrm{e}-011.00000 \mathrm{e}-091.00000 \mathrm{e}-01$ $1.00000 \mathrm{e}-05$ 1.00000e-05 1.00000e-06 1.00000e-09 1.00000e-01 $1.00000 \mathrm{e}+001.00000 \mathrm{e}+001.00000 \mathrm{e}-011.00000 \mathrm{e}-091.00000 \mathrm{e}-01$ Element: 2025 \# of layers: 12

Kx Ky Kz Ss Por

$1.52188 \mathrm{e}+02$ 1.52188e+02 1.52188e+01 1.00000e-09 7.00000e-02 $1.52188 \mathrm{e}+021.52188 \mathrm{e}+021.52188 \mathrm{e}+011.00000 \mathrm{e}-097.00000 \mathrm{e}-02$ 5.00000e-04 5.00000e-04 5.00000e-05 1.00000e-09 1.00000e-01 $6.08098 \mathrm{e}+006.08098 \mathrm{e}+00$ 6.08098e-01 1.00000e-09 2.12000e-01 $6.08098 \mathrm{e}+006.08098 \mathrm{e}+00$ 6.08098e-01 1.00000e-09 2.12000e-01 $6.08098 \mathrm{e}+006.08098 \mathrm{e}+00$ 6.08098e-01 1.00000e-09 2.12000e-01 $6.08098 \mathrm{e}+006.08098 \mathrm{e}+00$ 6.08098e-01 1.00000e-09 2.12000e-01 $6.08098 \mathrm{e}+00$ 6.08098e+00 6.08098e-01 1.00000e-09 2.12000e-01 $1.00000 \mathrm{e}-021.00000 \mathrm{e}-02$ 1.00000e-03 1.00000e-09 1.00000e-01 $1.00000 \mathrm{e}+001.00000 \mathrm{e}+001.00000 \mathrm{e}-011.00000 \mathrm{e}-091.00000 \mathrm{e}-01$ $1.00000 \mathrm{e}-05$ 1.00000e-05 1.00000e-06 1.00000e-09 1.00000e-01 $1.00000 \mathrm{e}+001.00000 \mathrm{e}+001.00000 \mathrm{e}-011.00000 \mathrm{e}-091.00000 \mathrm{e}-01$ Element: 2026 \# of layers: 11

Kx Ky Kz Ss Por $1.52188 \mathrm{e}+02$ 1.52188e+02 1.52188e+01 1.00000e-09 7.00000e-02 5.00000e-04 5.00000e-04 5.00000e-05 1.00000e-09 1.00000e-01 $6.08098 \mathrm{e}+006.08098 \mathrm{e}+00$ 6.08098e-01 1.00000e-09 2.12000e-01 $6.08098 \mathrm{e}+006.08098 \mathrm{e}+00$ 6.08098e-01 1.00000e-09 2.12000e-01 $6.08098 \mathrm{e}+00$ 6.08098e+00 6.08098e-01 1.00000e-09 2.12000e-01 $6.08098 \mathrm{e}+00$ 6.08098e+00 6.08098e-01 1.00000e-09 2.12000e-01 $6.08098 \mathrm{e}+006.08098 \mathrm{e}+00$ 6.08098e-01 1.00000e-09 2.12000e-01 $1.00000 \mathrm{e}-021.00000 \mathrm{e}-02$ 1.00000e-03 1.00000e-09 1.00000e-01 $1.00000 \mathrm{e}+001.00000 \mathrm{e}+001.00000 \mathrm{e}-011.00000 \mathrm{e}-091.00000 \mathrm{e}-01$ $1.00000 \mathrm{e}-05$ 1.00000e-05 1.00000e-06 1.00000e-09 1.00000e-01 
$1.00000 \mathrm{e}+001.00000 \mathrm{e}+00$ 1.00000e-01 1.00000e-09 1.00000e-01

Element: 2027 \# of layers: 9

$\mathrm{Kx} \mathrm{Ky} \mathrm{Kz}$ Ss Por

$1.22783 e+01$ 1.22783e+01 1.22783e+00 1.00000e-09 2.12000e-01

$1.22783 \mathrm{e}+01$ 1.22783e+01 1.22783e+00 1.00000e-09 2.12000e-01

$1.22783 \mathrm{e}+011.22783 \mathrm{e}+011.22783 \mathrm{e}+001.00000 \mathrm{e}-092.12000 \mathrm{e}-01$

$1.22783 \mathrm{e}+01$ 1.22783e+01 1.22783e+00 1.00000e-09 2.12000e-01

$1.22783 \mathrm{e}+011.22783 \mathrm{e}+01 \quad 1.22783 \mathrm{e}+001.00000 \mathrm{e}-092.12000 \mathrm{e}-01$

$1.00000 \mathrm{e}-02$ 1.00000e-02 1.00000e-03 1.00000e-09 1.00000e-01

$1.00000 \mathrm{e}+001.00000 \mathrm{e}+001.00000 \mathrm{e}-011.00000 \mathrm{e}-091.00000 \mathrm{e}-01$

$1.00000 \mathrm{e}-05$ 1.00000e-05 1.00000e-06 1.00000e-09 1.00000e-01

$1.00000 \mathrm{e}+001.00000 \mathrm{e}+001.00000 \mathrm{e}-011.00000 \mathrm{e}-091.00000 \mathrm{e}-01$

Element: 2028 \# of layers: 9

$\mathrm{Kx} \mathrm{Ky} \mathrm{Kz}$ Ss Por

$1.22783 \mathrm{e}+01$ 1.22783e+01 1.22783e+00 1.00000e-09 2.12000e-01

$1.22783 \mathrm{e}+011.22783 \mathrm{e}+01$ 1.22783e+00 1.00000e-09 2.12000e-01

$1.22783 \mathrm{e}+011.22783 \mathrm{e}+01$ 1.22783e+00 1.00000e-09 2.12000e-01

$1.22783 \mathrm{e}+011.22783 \mathrm{e}+01$ 1.22783e+00 1.00000e-09 2.12000e-01

$1.22783 \mathrm{e}+01$ 1.22783e+01 1.22783e+00 1.00000e-09 2.12000e-01

$1.00000 \mathrm{e}-021.00000 \mathrm{e}-021.00000 \mathrm{e}-031.00000 \mathrm{e}-091.00000 \mathrm{e}-01$

$1.00000 \mathrm{e}+001.00000 \mathrm{e}+001.00000 \mathrm{e}-011.00000 \mathrm{e}-091.00000 \mathrm{e}-01$

$1.00000 \mathrm{e}-05$ 1.00000e-05 1.00000e-06 1.00000e-09 1.00000e-01

$1.00000 \mathrm{e}+001.00000 \mathrm{e}+001.00000 \mathrm{e}-011.00000 \mathrm{e}-091.00000 \mathrm{e}-01$

Element: 2029 \# of layers: 9

Kx Ky Kz Ss Por

$1.22783 \mathrm{e}+01$ 1.22783e+01 1.22783e+00 1.00000e-09 2.12000e-01

$1.22783 \mathrm{e}+01$ 1.22783e+01 1.22783e+00 1.00000e-09 2.12000e-01

$1.22783 \mathrm{e}+011.22783 \mathrm{e}+01$ 1.22783e+00 1.00000e-09 2.12000e-01

$1.22783 \mathrm{e}+011.22783 \mathrm{e}+011.22783 \mathrm{e}+001.00000 \mathrm{e}-092.12000 \mathrm{e}-01$

$1.22783 \mathrm{e}+01$ 1.22783e+01 1.22783e+00 1.00000e-09 2.12000e-01

$1.00000 \mathrm{e}-02$ 1.00000e-02 1.00000e-03 1.00000e-09 1.00000e-01

$1.00000 \mathrm{e}+001.00000 \mathrm{e}+001.00000 \mathrm{e}-011.00000 \mathrm{e}-091.00000 \mathrm{e}-01$

$1.00000 \mathrm{e}-05$ 1.00000e-05 1.00000e-06 1.00000e-09 1.00000e-01

$1.00000 \mathrm{e}+001.00000 \mathrm{e}+001.00000 \mathrm{e}-011.00000 \mathrm{e}-091.00000 \mathrm{e}-01$

Element: 2030 \# of layers: 9

$\mathrm{Kx} \mathrm{Ky} \mathrm{Kz}$ Ss Por

$1.22783 \mathrm{e}+01$ 1.22783e+01 1.22783e+00 1.00000e-09 2.12000e-01

$1.22783 \mathrm{e}+011.22783 \mathrm{e}+01$ 1.22783e+00 1.00000e-09 2.12000e-01

$1.22783 \mathrm{e}+011.22783 \mathrm{e}+01$ 1.22783e+00 1.00000e-09 2.12000e-01

$1.22783 \mathrm{e}+01$ 1.22783e+01 1.22783e+00 1.00000e-09 2.12000e-01

$1.22783 \mathrm{e}+01$ 1.22783e+01 1.22783e+00 1.00000e-09 2.12000e-01

$1.00000 \mathrm{e}-02$ 1.00000e-02 1.00000e-03 1.00000e-09 1.00000e-01

$1.00000 \mathrm{e}+001.00000 \mathrm{e}+001.00000 \mathrm{e}-011.00000 \mathrm{e}-091.00000 \mathrm{e}-01$

$1.00000 \mathrm{e}-051.00000 \mathrm{e}-051.00000 \mathrm{e}-061.00000 \mathrm{e}-091.00000 \mathrm{e}-01$

$1.00000 \mathrm{e}+001.00000 \mathrm{e}+001.00000 \mathrm{e}-01$ 1.00000e-09 1.00000e-01

Element: 2031 \# of layers: 9 
$\mathrm{Kx} \mathrm{Ky} \mathrm{Kz}$ Ss Por

$1.22783 \mathrm{e}+01$ 1.22783e+01 1.22783e+00 1.00000e-09 2.12000e-01

$1.22783 \mathrm{e}+011.22783 \mathrm{e}+01$ 1.22783e+00 1.00000e-09 2.12000e-01

$1.22783 \mathrm{e}+01$ 1.22783e+01 1.22783e+00 1.00000e-09 2.12000e-01

$1.22783 \mathrm{e}+011.22783 \mathrm{e}+01$ 1.22783e+00 1.00000e-09 2.12000e-01

$1.22783 \mathrm{e}+011.22783 \mathrm{e}+011.22783 \mathrm{e}+001.00000 \mathrm{e}-092.12000 \mathrm{e}-01$

$1.00000 \mathrm{e}-02$ 1.00000e-02 1.00000e-03 1.00000e-09 1.00000e-01

$1.00000 \mathrm{e}+001.00000 \mathrm{e}+001.00000 \mathrm{e}-011.00000 \mathrm{e}-091.00000 \mathrm{e}-01$

$1.00000 \mathrm{e}-05$ 1.00000e-05 1.00000e-06 1.00000e-09 1.00000e-01

$1.00000 \mathrm{e}+001.00000 \mathrm{e}+001.00000 \mathrm{e}-011.00000 \mathrm{e}-091.00000 \mathrm{e}-01$

Element: 2032 \# of layers: 10

Kx Ky Kz Ss Por

5.00000e-04 5.00000e-04 5.00000e-05 1.00000e-09 1.00000e-01

$1.22783 \mathrm{e}+01$ 1.22783e+01 1.22783e+00 1.00000e-09 2.12000e-01

$1.22783 \mathrm{e}+01$ 1.22783e+01 1.22783e+00 1.00000e-09 2.12000e-01

$1.22783 \mathrm{e}+011.22783 \mathrm{e}+01$ 1.22783e+00 1.00000e-09 2.12000e-01

$1.22783 \mathrm{e}+011.22783 \mathrm{e}+01 \quad 1.22783 \mathrm{e}+001.00000 \mathrm{e}-092.12000 \mathrm{e}-01$

$1.22783 \mathrm{e}+011.22783 \mathrm{e}+01$ 1.22783e+00 1.00000e-09 2.12000e-01

$1.00000 \mathrm{e}-02$ 1.00000e-02 1.00000e-03 1.00000e-09 1.00000e-01

$1.00000 \mathrm{e}+001.00000 \mathrm{e}+001.00000 \mathrm{e}-011.00000 \mathrm{e}-091.00000 \mathrm{e}-01$

$1.00000 \mathrm{e}-05$ 1.00000e-05 1.00000e-06 1.00000e-09 1.00000e-01

$1.00000 \mathrm{e}+001.00000 \mathrm{e}+001.00000 \mathrm{e}-011.00000 \mathrm{e}-09$ 1.00000e-01

Element: 2033 \# of layers: 11

Kx Ky Kz Ss Por

3.07295e+02 3.07295e+02 3.07295e+01 1.00000e-09 7.00000e-02

5.00000e-04 5.00000e-04 5.00000e-05 1.00000e-09 1.00000e-01

$1.22783 \mathrm{e}+01$ 1.22783e+01 1.22783e+00 1.00000e-09 2.12000e-01

$1.22783 \mathrm{e}+011.22783 \mathrm{e}+01$ 1.22783e+00 1.00000e-09 2.12000e-01

$1.22783 \mathrm{e}+011.22783 \mathrm{e}+011.22783 \mathrm{e}+001.00000 \mathrm{e}-092.12000 \mathrm{e}-01$

$1.22783 \mathrm{e}+01$ 1.22783e+01 1.22783e+00 1.00000e-09 2.12000e-01

$1.22783 \mathrm{e}+011.22783 \mathrm{e}+01$ 1.22783e+00 1.00000e-09 2.12000e-01

$1.00000 \mathrm{e}-02$ 1.00000e-02 1.00000e-03 1.00000e-09 1.00000e-01

$1.00000 \mathrm{e}+001.00000 \mathrm{e}+001.00000 \mathrm{e}-011.00000 \mathrm{e}-091.00000 \mathrm{e}-01$

$1.00000 \mathrm{e}-05$ 1.00000e-05 1.00000e-06 1.00000e-09 1.00000e-01

$1.00000 \mathrm{e}+001.00000 \mathrm{e}+001.00000 \mathrm{e}-01$ 1.00000e-09 1.00000e-01

Element: 2034 \# of layers: 9

Kx Ky Kz Ss Por

$1.22783 \mathrm{e}+01$ 1.22783e+01 1.22783e+00 1.00000e-09 2.12000e-01

$1.22783 \mathrm{e}+01$ 1.22783e+01 1.22783e+00 1.00000e-09 2.12000e-01

$1.22783 \mathrm{e}+01$ 1.22783e+01 1.22783e+00 1.00000e-09 2.12000e-01

$1.22783 \mathrm{e}+011.22783 \mathrm{e}+01 \quad 1.22783 \mathrm{e}+001.00000 \mathrm{e}-092.12000 \mathrm{e}-01$

$1.22783 \mathrm{e}+01$ 1.22783e+01 1.22783e+00 1.00000e-09 2.12000e-01

$1.00000 \mathrm{e}-021.00000 \mathrm{e}-021.00000 \mathrm{e}-031.00000 \mathrm{e}-091.00000 \mathrm{e}-01$

$1.00000 \mathrm{e}+001.00000 \mathrm{e}+001.00000 \mathrm{e}-011.00000 \mathrm{e}-091.00000 \mathrm{e}-01$

$1.00000 \mathrm{e}-05$ 1.00000e-05 1.00000e-06 1.00000e-09 1.00000e-01

$1.00000 \mathrm{e}+001.00000 \mathrm{e}+001.00000 \mathrm{e}-011.00000 \mathrm{e}-091.00000 \mathrm{e}-01$ 
Element: 2035 \# of layers: 9

$\mathrm{Kx} \mathrm{Ky} \mathrm{Kz}$ Ss Por

$1.22783 \mathrm{e}+01$ 1.22783e+01 1.22783e+00 1.00000e-09 2.12000e-01

$1.22783 \mathrm{e}+01$ 1.22783e+01 1.22783e+00 1.00000e-09 2.12000e-01

$1.22783 \mathrm{e}+01$ 1.22783e+01 1.22783e+00 1.00000e-09 2.12000e-01

$1.22783 \mathrm{e}+011.22783 \mathrm{e}+011.22783 \mathrm{e}+001.00000 \mathrm{e}-092.12000 \mathrm{e}-01$

$1.22783 \mathrm{e}+01$ 1.22783e+01 1.22783e+00 1.00000e-09 2.12000e-01

$1.00000 \mathrm{e}-02$ 1.00000e-02 1.00000e-03 1.00000e-09 1.00000e-01

$1.00000 \mathrm{e}+001.00000 \mathrm{e}+001.00000 \mathrm{e}-011.00000 \mathrm{e}-091.00000 \mathrm{e}-01$

$1.00000 \mathrm{e}-05$ 1.00000e-05 1.00000e-06 1.00000e-09 1.00000e-01

$1.00000 \mathrm{e}+001.00000 \mathrm{e}+001.00000 \mathrm{e}-011.00000 \mathrm{e}-091.00000 \mathrm{e}-01$

Element: 2036 \# of layers: 9

$\mathrm{Kx} \mathrm{Ky} \mathrm{Kz}$ Ss Por

$1.71046 \mathrm{e}+01$ 1.71046e+01 1.71046e+00 1.00000e-09 2.12000e-01

$1.71046 \mathrm{e}+01$ 1.71046e+01 1.71046e+00 1.00000e-09 2.12000e-01

$1.71046 \mathrm{e}+011.71046 \mathrm{e}+011.71046 \mathrm{e}+001.00000 \mathrm{e}-092.12000 \mathrm{e}-01$

$1.71046 \mathrm{e}+011.71046 \mathrm{e}+011.71046 \mathrm{e}+001.00000 \mathrm{e}-092.12000 \mathrm{e}-01$

$1.71046 \mathrm{e}+011.71046 \mathrm{e}+011.71046 \mathrm{e}+001.00000 \mathrm{e}-092.12000 \mathrm{e}-01$

$1.00000 \mathrm{e}-02$ 1.00000e-02 1.00000e-03 1.00000e-09 1.00000e-01

$1.00000 \mathrm{e}+001.00000 \mathrm{e}+001.00000 \mathrm{e}-011.00000 \mathrm{e}-091.00000 \mathrm{e}-01$

$1.00000 \mathrm{e}-05$ 1.00000e-05 1.00000e-06 1.00000e-09 1.00000e-01

$1.00000 \mathrm{e}+001.00000 \mathrm{e}+001.00000 \mathrm{e}-01$ 1.00000e-09 1.00000e-01

Element: 2037 \# of layers: 9

Kx Ky Kz Ss Por

$1.71046 \mathrm{e}+011.71046 \mathrm{e}+01$ 1.71046e+00 1.00000e-09 2.12000e-01

$1.71046 \mathrm{e}+011.71046 \mathrm{e}+011.71046 \mathrm{e}+001.00000 \mathrm{e}-092.12000 \mathrm{e}-01$

$1.71046 \mathrm{e}+011.71046 \mathrm{e}+011.71046 \mathrm{e}+001.00000 \mathrm{e}-092.12000 \mathrm{e}-01$

$1.71046 \mathrm{e}+011.71046 \mathrm{e}+011.71046 \mathrm{e}+001.00000 \mathrm{e}-092.12000 \mathrm{e}-01$

$1.71046 \mathrm{e}+011.71046 \mathrm{e}+011.71046 \mathrm{e}+001.00000 \mathrm{e}-092.12000 \mathrm{e}-01$

$1.00000 \mathrm{e}-02$ 1.00000e-02 1.00000e-03 1.00000e-09 1.00000e-01

$1.00000 \mathrm{e}+001.00000 \mathrm{e}+001.00000 \mathrm{e}-01$ 1.00000e-09 1.00000e-01

$1.00000 \mathrm{e}-05$ 1.00000e-05 1.00000e-06 1.00000e-09 1.00000e-01

$1.00000 \mathrm{e}+001.00000 \mathrm{e}+001.00000 \mathrm{e}-011.00000 \mathrm{e}-091.00000 \mathrm{e}-01$

Element: 2038 \# of layers: 9

$\mathrm{Kx} \mathrm{Ky} \mathrm{Kz}$ Ss Por

$1.71046 \mathrm{e}+011.71046 \mathrm{e}+01$ 1.71046e+00 1.00000e-09 2.12000e-01

$1.71046 \mathrm{e}+011.71046 \mathrm{e}+011.71046 \mathrm{e}+001.00000 \mathrm{e}-092.12000 \mathrm{e}-01$

$1.71046 \mathrm{e}+011.71046 \mathrm{e}+011.71046 \mathrm{e}+001.00000 \mathrm{e}-092.12000 \mathrm{e}-01$

$1.71046 \mathrm{e}+01$ 1.71046e+01 1.71046e+00 1.00000e-09 2.12000e-01

$1.71046 \mathrm{e}+011.71046 \mathrm{e}+01$ 1.71046e+00 1.00000e-09 2.12000e-01 $1.00000 \mathrm{e}-02$ 1.00000e-02 1.00000e-03 1.00000e-09 1.00000e-01

$1.00000 \mathrm{e}+001.00000 \mathrm{e}+001.00000 \mathrm{e}-011.00000 \mathrm{e}-091.00000 \mathrm{e}-01$ $1.00000 \mathrm{e}-051.00000 \mathrm{e}-051.00000 \mathrm{e}-061.00000 \mathrm{e}-091.00000 \mathrm{e}-01$

$1.00000 \mathrm{e}+001.00000 \mathrm{e}+001.00000 \mathrm{e}-01$ 1.00000e-09 1.00000e-01

Element: 2039 \# of layers: 9

$\mathrm{Kx} \mathrm{Ky} \mathrm{Kz}$ Ss Por 
$1.71046 \mathrm{e}+01$ 1.71046e+01 1.71046e+00 1.00000e-09 2.12000e-01 $1.71046 \mathrm{e}+01$ 1.71046e+01 1.71046e+00 1.00000e-09 2.12000e-01 $1.71046 \mathrm{e}+011.71046 \mathrm{e}+011.71046 \mathrm{e}+001.00000 \mathrm{e}-092.12000 \mathrm{e}-01$ $1.71046 \mathrm{e}+011.71046 \mathrm{e}+011.71046 \mathrm{e}+001.00000 \mathrm{e}-092.12000 \mathrm{e}-01$ $1.71046 \mathrm{e}+011.71046 \mathrm{e}+011.71046 \mathrm{e}+001.00000 \mathrm{e}-092.12000 \mathrm{e}-01$ $1.00000 \mathrm{e}-02$ 1.00000e-02 1.00000e-03 1.00000e-09 1.00000e-01 $1.00000 \mathrm{e}+001.00000 \mathrm{e}+001.00000 \mathrm{e}-011.00000 \mathrm{e}-091.00000 \mathrm{e}-01$ $1.00000 \mathrm{e}-05$ 1.00000e-05 1.00000e-06 1.00000e-09 1.00000e-01 $1.00000 \mathrm{e}+001.00000 \mathrm{e}+001.00000 \mathrm{e}-011.00000 \mathrm{e}-091.00000 \mathrm{e}-01$ Element: 2040 \# of layers: 9

$\mathrm{Kx} \mathrm{Ky} \mathrm{Kz}$ Ss Por

$1.71046 \mathrm{e}+01$ 1.71046e+01 1.71046e+00 1.00000e-09 2.12000e-01 $1.71046 \mathrm{e}+011.71046 \mathrm{e}+011.71046 \mathrm{e}+001.00000 \mathrm{e}-092.12000 \mathrm{e}-01$ $1.71046 \mathrm{e}+011.71046 \mathrm{e}+011.71046 \mathrm{e}+001.00000 \mathrm{e}-092.12000 \mathrm{e}-01$ $1.71046 \mathrm{e}+01$ 1.71046e+01 1.71046e+00 1.00000e-09 2.12000e-01 $1.71046 \mathrm{e}+011.71046 \mathrm{e}+011.71046 \mathrm{e}+001.00000 \mathrm{e}-092.12000 \mathrm{e}-01$ $1.00000 \mathrm{e}-02$ 1.00000e-02 1.00000e-03 1.00000e-09 1.00000e-01 $1.00000 \mathrm{e}+001.00000 \mathrm{e}+001.00000 \mathrm{e}-011.00000 \mathrm{e}-091.00000 \mathrm{e}-01$ $1.00000 \mathrm{e}-05$ 1.00000e-05 1.00000e-06 1.00000e-09 1.00000e-01 $1.00000 \mathrm{e}+001.00000 \mathrm{e}+001.00000 \mathrm{e}-011.00000 \mathrm{e}-091.00000 \mathrm{e}-01$ Element: 2041 \# of layers: 9

$\mathrm{Kx} \mathrm{Ky} \mathrm{Kz}$ Ss Por

$1.71046 \mathrm{e}+01$ 1.71046e+01 1.71046e+00 1.00000e-09 2.12000e-01 $1.71046 \mathrm{e}+011.71046 \mathrm{e}+011.71046 \mathrm{e}+001.00000 \mathrm{e}-092.12000 \mathrm{e}-01$ $1.71046 \mathrm{e}+011.71046 \mathrm{e}+011.71046 \mathrm{e}+001.00000 \mathrm{e}-092.12000 \mathrm{e}-01$ $1.71046 \mathrm{e}+011.71046 \mathrm{e}+011.71046 \mathrm{e}+001.00000 \mathrm{e}-092.12000 \mathrm{e}-01$ $1.71046 \mathrm{e}+011.71046 \mathrm{e}+011.71046 \mathrm{e}+001.00000 \mathrm{e}-092.12000 \mathrm{e}-01$ $1.00000 \mathrm{e}-02$ 1.00000e-02 1.00000e-03 1.00000e-09 1.00000e-01 $1.00000 \mathrm{e}+001.00000 \mathrm{e}+001.00000 \mathrm{e}-011.00000 \mathrm{e}-091.00000 \mathrm{e}-01$ $1.00000 \mathrm{e}-05$ 1.00000e-05 1.00000e-06 1.00000e-09 1.00000e-01 $1.00000 \mathrm{e}+001.00000 \mathrm{e}+001.00000 \mathrm{e}-011.00000 \mathrm{e}-091.00000 \mathrm{e}-01$ Element: 2042 \# of layers: 9

Kx Ky Kz Ss Por

$1.71046 \mathrm{e}+01$ 1.71046e+01 1.71046e+00 1.00000e-09 2.12000e-01 $1.71046 \mathrm{e}+01$ 1.71046e+01 1.71046e+00 1.00000e-09 2.12000e-01 $1.71046 \mathrm{e}+011.71046 \mathrm{e}+011.71046 \mathrm{e}+001.00000 \mathrm{e}-092.12000 \mathrm{e}-01$ $1.71046 \mathrm{e}+011.71046 \mathrm{e}+011.71046 \mathrm{e}+001.00000 \mathrm{e}-092.12000 \mathrm{e}-01$ $1.71046 \mathrm{e}+011.71046 \mathrm{e}+011.71046 \mathrm{e}+001.00000 \mathrm{e}-092.12000 \mathrm{e}-01$ $1.00000 \mathrm{e}-02$ 1.00000e-02 1.00000e-03 1.00000e-09 1.00000e-01 $1.00000 \mathrm{e}+001.00000 \mathrm{e}+001.00000 \mathrm{e}-011.00000 \mathrm{e}-091.00000 \mathrm{e}-01$ $1.00000 \mathrm{e}-05$ 1.00000e-05 1.00000e-06 1.00000e-09 1.00000e-01 $1.00000 \mathrm{e}+001.00000 \mathrm{e}+001.00000 \mathrm{e}-011.00000 \mathrm{e}-091.00000 \mathrm{e}-01$ Element: 2043 \# of layers: 9

$\mathrm{Kx} \mathrm{Ky} \mathrm{Kz}$ Ss Por

$1.71046 \mathrm{e}+011.71046 \mathrm{e}+01$ 1.71046e+00 1.00000e-09 2.12000e-01 $1.71046 \mathrm{e}+011.71046 \mathrm{e}+011.71046 \mathrm{e}+001.00000 \mathrm{e}-092.12000 \mathrm{e}-01$ 
$1.71046 \mathrm{e}+01$ 1.71046e+01 1.71046e+00 1.00000e-09 2.12000e-01 $1.71046 \mathrm{e}+01$ 1.71046e+01 1.71046e+00 1.00000e-09 2.12000e-01 $1.71046 \mathrm{e}+011.71046 \mathrm{e}+011.71046 \mathrm{e}+001.00000 \mathrm{e}-092.12000 \mathrm{e}-01$ $1.00000 \mathrm{e}-02$ 1.00000e-02 1.00000e-03 1.00000e-09 1.00000e-01 $1.00000 \mathrm{e}+001.00000 \mathrm{e}+001.00000 \mathrm{e}-011.00000 \mathrm{e}-091.00000 \mathrm{e}-01$ $1.00000 \mathrm{e}-05$ 1.00000e-05 1.00000e-06 1.00000e-09 1.00000e-01 $1.00000 \mathrm{e}+001.00000 \mathrm{e}+001.00000 \mathrm{e}-01$ 1.00000e-09 1.00000e-01 Element: 2044 \# of layers: 9

$\mathrm{Kx} \mathrm{Ky} \mathrm{Kz}$ Ss Por

$1.71046 \mathrm{e}+01$ 1.71046e+01 1.71046e+00 1.00000e-09 2.12000e-01 $1.71046 \mathrm{e}+011.71046 \mathrm{e}+011.71046 \mathrm{e}+001.00000 \mathrm{e}-092.12000 \mathrm{e}-01$ $1.71046 \mathrm{e}+011.71046 \mathrm{e}+011.71046 \mathrm{e}+001.00000 \mathrm{e}-092.12000 \mathrm{e}-01$ $1.71046 \mathrm{e}+011.71046 \mathrm{e}+011.71046 \mathrm{e}+001.00000 \mathrm{e}-092.12000 \mathrm{e}-01$ $1.71046 \mathrm{e}+011.71046 \mathrm{e}+011.71046 \mathrm{e}+001.00000 \mathrm{e}-092.12000 \mathrm{e}-01$ $1.00000 \mathrm{e}-02$ 1.00000e-02 1.00000e-03 1.00000e-09 1.00000e-01 $1.00000 \mathrm{e}+001.00000 \mathrm{e}+001.00000 \mathrm{e}-011.00000 \mathrm{e}-091.00000 \mathrm{e}-01$ $1.00000 \mathrm{e}-05$ 1.00000e-05 1.00000e-06 1.00000e-09 1.00000e-01 $1.00000 \mathrm{e}+001.00000 \mathrm{e}+001.00000 \mathrm{e}-01$ 1.00000e-09 1.00000e-01 Element: 2045 \# of layers: 9

$\mathrm{Kx} \mathrm{Ky} \mathrm{Kz}$ Ss Por

$1.68603 \mathrm{e}+011.68603 \mathrm{e}+011.68603 \mathrm{e}+00$ 1.00000e-09 2.12000e-01 $1.68603 \mathrm{e}+011.68603 \mathrm{e}+01$ 1.68603e+00 1.00000e-09 2.12000e-01 $1.68603 \mathrm{e}+01$ 1.68603e+01 1.68603e+00 1.00000e-09 2.12000e-01 $1.68603 \mathrm{e}+011.68603 \mathrm{e}+01$ 1.68603e+00 1.00000e-09 2.12000e-01 $1.68603 \mathrm{e}+011.68603 \mathrm{e}+011.68603 \mathrm{e}+001.00000 \mathrm{e}-092.12000 \mathrm{e}-01$ $1.00000 \mathrm{e}-02$ 1.00000e-02 1.00000e-03 1.00000e-09 1.00000e-01 $1.00000 \mathrm{e}+001.00000 \mathrm{e}+001.00000 \mathrm{e}-011.00000 \mathrm{e}-091.00000 \mathrm{e}-01$ $1.00000 \mathrm{e}-05$ 1.00000e-05 1.00000e-06 1.00000e-09 1.00000e-01 $1.00000 \mathrm{e}+001.00000 \mathrm{e}+001.00000 \mathrm{e}-011.00000 \mathrm{e}-091.00000 \mathrm{e}-01$ Element: 2046 \# of layers: 9

$\mathrm{Kx} \mathrm{Ky} \mathrm{Kz}$ Ss Por

$1.68603 \mathrm{e}+01$ 1.68603e+01 1.68603e+00 1.00000e-09 2.12000e-01 $1.68603 \mathrm{e}+011.68603 \mathrm{e}+011.68603 \mathrm{e}+001.00000 \mathrm{e}-092.12000 \mathrm{e}-01$ $1.68603 \mathrm{e}+011.68603 \mathrm{e}+01$ 1.68603e+00 1.00000e-09 2.12000e-01 $1.68603 \mathrm{e}+011.68603 \mathrm{e}+011.68603 \mathrm{e}+001.00000 \mathrm{e}-092.12000 \mathrm{e}-01$ $1.68603 \mathrm{e}+011.68603 \mathrm{e}+011.68603 \mathrm{e}+001.00000 \mathrm{e}-092.12000 \mathrm{e}-01$ 1.00000e-02 1.00000e-02 1.00000e-03 1.00000e-09 1.00000e-01 $1.00000 \mathrm{e}+001.00000 \mathrm{e}+001.00000 \mathrm{e}-011.00000 \mathrm{e}-091.00000 \mathrm{e}-01$ $1.00000 \mathrm{e}-05$ 1.00000e-05 1.00000e-06 1.00000e-09 1.00000e-01 $1.00000 \mathrm{e}+001.00000 \mathrm{e}+001.00000 \mathrm{e}-01$ 1.00000e-09 1.00000e-01 Element: 2047 \# of layers: 9

$\mathrm{Kx} \mathrm{Ky} \mathrm{Kz}$ Ss Por $1.68603 \mathrm{e}+01$ 1.68603e+01 1.68603e+00 1.00000e-09 2.12000e-01 $1.68603 \mathrm{e}+01$ 1.68603e+01 1.68603e+00 1.00000e-09 2.12000e-01 $1.68603 \mathrm{e}+011.68603 \mathrm{e}+011.68603 \mathrm{e}+001.00000 \mathrm{e}-092.12000 \mathrm{e}-01$ $1.68603 e+011.68603 e+011.68603 e+001.00000 e-092.12000 e-01$ 
$1.68603 \mathrm{e}+01$ 1.68603e+01 1.68603e+00 1.00000e-09 2.12000e-01 $1.00000 \mathrm{e}-02$ 1.00000e-02 1.00000e-03 1.00000e-09 1.00000e-01 $1.00000 \mathrm{e}+001.00000 \mathrm{e}+001.00000 \mathrm{e}-011.00000 \mathrm{e}-091.00000 \mathrm{e}-01$ $1.00000 \mathrm{e}-05$ 1.00000e-05 1.00000e-06 1.00000e-09 1.00000e-01 $1.00000 \mathrm{e}+001.00000 \mathrm{e}+001.00000 \mathrm{e}-011.00000 \mathrm{e}-091.00000 \mathrm{e}-01$ Element: 2048 \# of layers: 9

$\mathrm{Kx} \mathrm{Ky} \mathrm{Kz}$ Ss Por

$1.68603 e+011.68603 e+011.68603 e+001.00000 e-092.12000 e-01$ $1.68603 \mathrm{e}+011.68603 \mathrm{e}+011.68603 \mathrm{e}+001.00000 \mathrm{e}-092.12000 \mathrm{e}-01$ $1.68603 \mathrm{e}+011.68603 \mathrm{e}+011.68603 \mathrm{e}+001.00000 \mathrm{e}-092.12000 \mathrm{e}-01$ $1.68603 \mathrm{e}+011.68603 \mathrm{e}+011.68603 \mathrm{e}+001.00000 \mathrm{e}-092.12000 \mathrm{e}-01$ $1.68603 \mathrm{e}+011.68603 \mathrm{e}+011.68603 \mathrm{e}+001.00000 \mathrm{e}-092.12000 \mathrm{e}-01$ 1.00000e-02 1.00000e-02 1.00000e-03 1.00000e-09 1.00000e-01 $1.00000 \mathrm{e}+001.00000 \mathrm{e}+001.00000 \mathrm{e}-011.00000 \mathrm{e}-091.00000 \mathrm{e}-01$ $1.00000 \mathrm{e}-051.00000 \mathrm{e}-051.00000 \mathrm{e}-061.00000 \mathrm{e}-091.00000 \mathrm{e}-01$ $1.00000 \mathrm{e}+001.00000 \mathrm{e}+001.00000 \mathrm{e}-011.00000 \mathrm{e}-091.00000 \mathrm{e}-01$ Element: 2049 \# of layers: 9

$\mathrm{Kx} \mathrm{Ky} \mathrm{Kz}$ Ss Por

$1.68603 \mathrm{e}+01$ 1.68603e+01 1.68603e+00 1.00000e-09 2.12000e-01 $1.68603 \mathrm{e}+011.68603 \mathrm{e}+011.68603 \mathrm{e}+001.00000 \mathrm{e}-092.12000 \mathrm{e}-01$ $1.68603 \mathrm{e}+011.68603 \mathrm{e}+011.68603 \mathrm{e}+001.00000 \mathrm{e}-092.12000 \mathrm{e}-01$ $1.68603 \mathrm{e}+01$ 1.68603e+01 1.68603e+00 1.00000e-09 2.12000e-01 $1.68603 \mathrm{e}+011.68603 \mathrm{e}+011.68603 \mathrm{e}+001.00000 \mathrm{e}-092.12000 \mathrm{e}-01$ $1.00000 \mathrm{e}-02$ 1.00000e-02 1.00000e-03 1.00000e-09 1.00000e-01 $1.00000 \mathrm{e}+001.00000 \mathrm{e}+001.00000 \mathrm{e}-011.00000 \mathrm{e}-091.00000 \mathrm{e}-01$ $1.00000 \mathrm{e}-05$ 1.00000e-05 1.00000e-06 1.00000e-09 1.00000e-01 $1.00000 \mathrm{e}+001.00000 \mathrm{e}+001.00000 \mathrm{e}-011.00000 \mathrm{e}-091.00000 \mathrm{e}-01$ Element: 2050 \# of layers: 8

Kx Ky Kz Ss Por

$1.68603 \mathrm{e}+01$ 1.68603e+01 1.68603e+00 1.00000e-09 2.12000e-01 $1.68603 \mathrm{e}+011.68603 \mathrm{e}+011.68603 \mathrm{e}+001.00000 \mathrm{e}-092.12000 \mathrm{e}-01$ $1.68603 \mathrm{e}+011.68603 \mathrm{e}+011.68603 \mathrm{e}+001.00000 \mathrm{e}-092.12000 \mathrm{e}-01$ $1.68603 \mathrm{e}+011.68603 \mathrm{e}+011.68603 \mathrm{e}+001.00000 \mathrm{e}-092.12000 \mathrm{e}-01$ $1.68603 \mathrm{e}+011.68603 \mathrm{e}+011.68603 \mathrm{e}+001.00000 \mathrm{e}-092.12000 \mathrm{e}-01$ $1.00000 \mathrm{e}+001.00000 \mathrm{e}+001.00000 \mathrm{e}-011.00000 \mathrm{e}-091.00000 \mathrm{e}-01$ $1.00000 \mathrm{e}-05$ 1.00000e-05 1.00000e-06 1.00000e-09 1.00000e-01 $1.00000 \mathrm{e}+001.00000 \mathrm{e}+001.00000 \mathrm{e}-011.00000 \mathrm{e}-091.00000 \mathrm{e}-01$ Element: 2051 \# of layers: 9

$\mathrm{Kx} \mathrm{Ky} \mathrm{Kz}$ Ss Por $1.68603 \mathrm{e}+01$ 1.68603e+01 1.68603e+00 1.00000e-09 2.12000e-01 $1.68603 \mathrm{e}+011.68603 \mathrm{e}+011.68603 \mathrm{e}+001.00000 \mathrm{e}-092.12000 \mathrm{e}-01$ $1.68603 \mathrm{e}+011.68603 \mathrm{e}+011.68603 \mathrm{e}+001.00000 \mathrm{e}-092.12000 \mathrm{e}-01$ $1.68603 \mathrm{e}+01$ 1.68603e+01 1.68603e+00 1.00000e-09 2.12000e-01 $1.68603 \mathrm{e}+011.68603 \mathrm{e}+011.68603 \mathrm{e}+001.00000 \mathrm{e}-092.12000 \mathrm{e}-01$ $1.00000 \mathrm{e}-02$ 1.00000e-02 1.00000e-03 1.00000e-09 1.00000e-01 $1.00000 \mathrm{e}+001.00000 \mathrm{e}+001.00000 \mathrm{e}-011.00000 \mathrm{e}-091.00000 \mathrm{e}-01$ 
$1.00000 \mathrm{e}-05$ 1.00000e-05 1.00000e-06 1.00000e-09 1.00000e-01 $1.00000 \mathrm{e}+001.00000 \mathrm{e}+001.00000 \mathrm{e}-01$ 1.00000e-09 1.00000e-01 Element: 2052 \# of layers: 9

Kx Ky Kz Ss Por

$1.68603 \mathrm{e}+011.68603 \mathrm{e}+011.68603 \mathrm{e}+001.00000 \mathrm{e}-092.12000 \mathrm{e}-01$ $1.68603 \mathrm{e}+011.68603 \mathrm{e}+011.68603 \mathrm{e}+001.00000 \mathrm{e}-092.12000 \mathrm{e}-01$ $1.68603 \mathrm{e}+011.68603 \mathrm{e}+011.68603 \mathrm{e}+001.00000 \mathrm{e}-092.12000 \mathrm{e}-01$ $1.68603 \mathrm{e}+011.68603 \mathrm{e}+011.68603 \mathrm{e}+001.00000 \mathrm{e}-092.12000 \mathrm{e}-01$ $1.68603 \mathrm{e}+011.68603 \mathrm{e}+01$ 1.68603e+00 1.00000e-09 2.12000e-01 $1.00000 \mathrm{e}-02$ 1.00000e-02 1.00000e-03 1.00000e-09 1.00000e-01 $1.00000 \mathrm{e}+001.00000 \mathrm{e}+001.00000 \mathrm{e}-011.00000 \mathrm{e}-091.00000 \mathrm{e}-01$ $1.00000 \mathrm{e}-05$ 1.00000e-05 1.00000e-06 1.00000e-09 1.00000e-01 $1.00000 \mathrm{e}+001.00000 \mathrm{e}+001.00000 \mathrm{e}-01$ 1.00000e-09 1.00000e-01 Element: 2053 \# of layers: 9

$\mathrm{Kx} \mathrm{Ky} \mathrm{Kz}$ Ss Por

$1.68603 \mathrm{e}+01$ 1.68603e+01 1.68603e+00 1.00000e-09 2.12000e-01 $1.68603 \mathrm{e}+011.68603 \mathrm{e}+011.68603 \mathrm{e}+001.00000 \mathrm{e}-092.12000 \mathrm{e}-01$ $1.68603 \mathrm{e}+01$ 1.68603e+01 1.68603e+00 1.00000e-09 2.12000e-01 $1.68603 \mathrm{e}+01$ 1.68603e+01 1.68603e+00 1.00000e-09 2.12000e-01 $1.68603 \mathrm{e}+011.68603 \mathrm{e}+011.68603 \mathrm{e}+001.00000 \mathrm{e}-092.12000 \mathrm{e}-01$ $1.00000 \mathrm{e}-02$ 1.00000e-02 1.00000e-03 1.00000e-09 1.00000e-01 $1.00000 \mathrm{e}+001.00000 \mathrm{e}+001.00000 \mathrm{e}-011.00000 \mathrm{e}-091.00000 \mathrm{e}-01$ $1.00000 \mathrm{e}-05$ 1.00000e-05 1.00000e-06 1.00000e-09 1.00000e-01 $1.00000 \mathrm{e}+001.00000 \mathrm{e}+001.00000 \mathrm{e}-011.00000 \mathrm{e}-091.00000 \mathrm{e}-01$ Element: 2054 \# of layers: 9

$\mathrm{Kx} \mathrm{Ky} \mathrm{Kz}$ Ss Por

3.22522e+01 3.22522e+01 3.22522e+00 1.00000e-09 2.12000e-01 $3.22522 \mathrm{e}+013.22522 \mathrm{e}+013.22522 \mathrm{e}+00$ 1.00000e-09 2.12000e-01 $3.22522 \mathrm{e}+013.22522 \mathrm{e}+013.22522 \mathrm{e}+001.00000 \mathrm{e}-092.12000 \mathrm{e}-01$ $3.22522 \mathrm{e}+013.22522 \mathrm{e}+013.22522 \mathrm{e}+00$ 1.00000e-09 2.12000e-01 $3.22522 \mathrm{e}+013.22522 \mathrm{e}+013.22522 \mathrm{e}+00$ 1.00000e-09 2.12000e-01 $1.00000 \mathrm{e}-02$ 1.00000e-02 1.00000e-03 1.00000e-09 1.00000e-01 $1.00000 \mathrm{e}+001.00000 \mathrm{e}+001.00000 \mathrm{e}-011.00000 \mathrm{e}-091.00000 \mathrm{e}-01$ $1.00000 \mathrm{e}-05$ 1.00000e-05 1.00000e-06 1.00000e-09 1.00000e-01 $1.00000 \mathrm{e}+001.00000 \mathrm{e}+001.00000 \mathrm{e}-011.00000 \mathrm{e}-091.00000 \mathrm{e}-01$ Element: 2055 \# of layers: 8

$\mathrm{Kx} \mathrm{Ky} \mathrm{Kz}$ Ss Por

3.22522e+01 3.22522e+01 3.22522e+00 1.00000e-09 2.12000e-01 $3.22522 \mathrm{e}+013.22522 \mathrm{e}+01$ 3.22522e+00 1.00000e-09 2.12000e-01 $3.22522 \mathrm{e}+013.22522 \mathrm{e}+013.22522 \mathrm{e}+00$ 1.00000e-09 2.12000e-01 $3.22522 \mathrm{e}+013.22522 \mathrm{e}+013.22522 \mathrm{e}+00$ 1.00000e-09 2.12000e-01 $1.00000 \mathrm{e}-02$ 1.00000e-02 1.00000e-03 1.00000e-09 1.00000e-01 $1.00000 \mathrm{e}+001.00000 \mathrm{e}+001.00000 \mathrm{e}-011.00000 \mathrm{e}-091.00000 \mathrm{e}-01$ $1.00000 \mathrm{e}-05$ 1.00000e-05 1.00000e-06 1.00000e-09 1.00000e-01 $1.00000 \mathrm{e}+001.00000 \mathrm{e}+001.00000 \mathrm{e}-011.00000 \mathrm{e}-09$ 1.00000e-01 Element: 2056 \# of layers: 8 
$\mathrm{Kx} \mathrm{Ky} \mathrm{Kz}$ Ss Por

3.22522e+01 3.22522e+01 3.22522e+00 1.00000e-09 2.12000e-01

$3.22522 \mathrm{e}+013.22522 \mathrm{e}+013.22522 \mathrm{e}+00$ 1.00000e-09 2.12000e-01

$3.22522 \mathrm{e}+01$ 3.22522e+01 3.22522e+00 1.00000e-09 2.12000e-01

$3.22522 \mathrm{e}+013.22522 \mathrm{e}+013.22522 \mathrm{e}+00$ 1.00000e-09 2.12000e-01

$1.00000 \mathrm{e}-02$ 1.00000e-02 1.00000e-03 1.00000e-09 1.00000e-01

$1.00000 \mathrm{e}+001.00000 \mathrm{e}+001.00000 \mathrm{e}-011.00000 \mathrm{e}-091.00000 \mathrm{e}-01$

$1.00000 \mathrm{e}-05$ 1.00000e-05 1.00000e-06 1.00000e-09 1.00000e-01

$1.00000 \mathrm{e}+001.00000 \mathrm{e}+001.00000 \mathrm{e}-011.00000 \mathrm{e}-091.00000 \mathrm{e}-01$

Element: 2057 \# of layers: 9

$\mathrm{Kx} \mathrm{Ky} \mathrm{Kz}$ Ss Por

5.00000e-04 5.00000e-04 5.00000e-05 1.00000e-09 1.00000e-01

$3.22522 \mathrm{e}+01$ 3.22522e+01 3.22522e+00 1.00000e-09 2.12000e-01

$3.22522 \mathrm{e}+013.22522 \mathrm{e}+013.22522 \mathrm{e}+00$ 1.00000e-09 2.12000e-01

$3.22522 \mathrm{e}+013.22522 \mathrm{e}+013.22522 \mathrm{e}+00$ 1.00000e-09 2.12000e-01

$3.22522 \mathrm{e}+013.22522 \mathrm{e}+013.22522 \mathrm{e}+00$ 1.00000e-09 2.12000e-01

$1.00000 \mathrm{e}-02$ 1.00000e-02 1.00000e-03 1.00000e-09 1.00000e-01

$1.00000 \mathrm{e}+001.00000 \mathrm{e}+001.00000 \mathrm{e}-011.00000 \mathrm{e}-091.00000 \mathrm{e}-01$

$1.00000 \mathrm{e}-05$ 1.00000e-05 1.00000e-06 1.00000e-09 1.00000e-01

$1.00000 \mathrm{e}+001.00000 \mathrm{e}+001.00000 \mathrm{e}-011.00000 \mathrm{e}-091.00000 \mathrm{e}-01$

Element: 2058 \# of layers: 9

$\mathrm{Kx} \mathrm{Ky} \mathrm{Kz}$ Ss Por

5.00000e-04 5.00000e-04 5.00000e-05 1.00000e-09 1.00000e-01

$3.22522 \mathrm{e}+013.22522 \mathrm{e}+013.22522 \mathrm{e}+001.00000 \mathrm{e}-092.12000 \mathrm{e}-01$

$3.22522 \mathrm{e}+013.22522 \mathrm{e}+013.22522 \mathrm{e}+00$ 1.00000e-09 2.12000e-01

$3.22522 \mathrm{e}+013.22522 \mathrm{e}+013.22522 \mathrm{e}+00$ 1.00000e-09 2.12000e-01

$3.22522 \mathrm{e}+013.22522 \mathrm{e}+013.22522 \mathrm{e}+00$ 1.00000e-09 2.12000e-01

$1.00000 \mathrm{e}-02$ 1.00000e-02 1.00000e-03 1.00000e-09 1.00000e-01

$1.00000 \mathrm{e}+001.00000 \mathrm{e}+001.00000 \mathrm{e}-011.00000 \mathrm{e}-091.00000 \mathrm{e}-01$

$1.00000 \mathrm{e}-05$ 1.00000e-05 1.00000e-06 1.00000e-09 1.00000e-01

$1.00000 \mathrm{e}+001.00000 \mathrm{e}+001.00000 \mathrm{e}-011.00000 \mathrm{e}-091.00000 \mathrm{e}-01$

Element: 2059 \# of layers: 9

$\mathrm{Kx} \mathrm{Ky} \mathrm{Kz}$ Ss Por

5.00000e-04 5.00000e-04 5.00000e-05 1.00000e-09 1.00000e-01

$3.22522 \mathrm{e}+013.22522 \mathrm{e}+013.22522 \mathrm{e}+00$ 1.00000e-09 2.12000e-01

$3.22522 \mathrm{e}+013.22522 \mathrm{e}+013.22522 \mathrm{e}+00$ 1.00000e-09 2.12000e-01

$3.22522 \mathrm{e}+013.22522 \mathrm{e}+013.22522 \mathrm{e}+00$ 1.00000e-09 2.12000e-01

$3.22522 \mathrm{e}+013.22522 \mathrm{e}+013.22522 \mathrm{e}+00$ 1.00000e-09 2.12000e-01

$1.00000 \mathrm{e}-02$ 1.00000e-02 1.00000e-03 1.00000e-09 1.00000e-01

$1.00000 \mathrm{e}+001.00000 \mathrm{e}+001.00000 \mathrm{e}-011.00000 \mathrm{e}-091.00000 \mathrm{e}-01$

$1.00000 \mathrm{e}-05$ 1.00000e-05 1.00000e-06 1.00000e-09 1.00000e-01

$1.00000 \mathrm{e}+001.00000 \mathrm{e}+001.00000 \mathrm{e}-011.00000 \mathrm{e}-091.00000 \mathrm{e}-01$

Element: 2060 \# of layers: 9

$\mathrm{Kx} \mathrm{Ky} \mathrm{Kz}$ Ss Por

3.22522e+01 3.22522e+01 3.22522e+00 1.00000e-09 2.12000e-01

$3.22522 \mathrm{e}+013.22522 \mathrm{e}+013.22522 \mathrm{e}+00$ 1.00000e-09 2.12000e-01 
3.22522e+01 3.22522e+01 3.22522e+00 1.00000e-09 2.12000e-01 $3.22522 \mathrm{e}+013.22522 \mathrm{e}+013.22522 \mathrm{e}+00$ 1.00000e-09 2.12000e-01 $3.22522 \mathrm{e}+013.22522 \mathrm{e}+013.22522 \mathrm{e}+00$ 1.00000e-09 2.12000e-01 $1.00000 \mathrm{e}-02$ 1.00000e-02 1.00000e-03 1.00000e-09 1.00000e-01 $1.00000 \mathrm{e}+001.00000 \mathrm{e}+001.00000 \mathrm{e}-011.00000 \mathrm{e}-091.00000 \mathrm{e}-01$ $1.00000 \mathrm{e}-05$ 1.00000e-05 1.00000e-06 1.00000e-09 1.00000e-01 $1.00000 \mathrm{e}+001.00000 \mathrm{e}+001.00000 \mathrm{e}-01$ 1.00000e-09 1.00000e-01 Element: 2061 \# of layers: 9

$\mathrm{Kx} \mathrm{Ky} \mathrm{Kz}$ Ss Por

$3.22522 \mathrm{e}+013.22522 \mathrm{e}+01$ 3.22522e+00 1.00000e-09 2.12000e-01 $3.22522 \mathrm{e}+013.22522 \mathrm{e}+013.22522 \mathrm{e}+00$ 1.00000e-09 2.12000e-01 $3.22522 \mathrm{e}+013.22522 \mathrm{e}+013.22522 \mathrm{e}+00$ 1.00000e-09 2.12000e-01 $3.22522 \mathrm{e}+013.22522 \mathrm{e}+013.22522 \mathrm{e}+001.00000 \mathrm{e}-092.12000 \mathrm{e}-01$ $3.22522 \mathrm{e}+013.22522 \mathrm{e}+013.22522 \mathrm{e}+00$ 1.00000e-09 2.12000e-01 $1.00000 \mathrm{e}-02$ 1.00000e-02 1.00000e-03 1.00000e-09 1.00000e-01 $1.00000 \mathrm{e}+001.00000 \mathrm{e}+001.00000 \mathrm{e}-011.00000 \mathrm{e}-091.00000 \mathrm{e}-01$ $1.00000 \mathrm{e}-05$ 1.00000e-05 1.00000e-06 1.00000e-09 1.00000e-01 $1.00000 \mathrm{e}+001.00000 \mathrm{e}+001.00000 \mathrm{e}-01$ 1.00000e-09 1.00000e-01 Element: 2062 \# of layers: 8

$\mathrm{Kx} \mathrm{Ky} \mathrm{Kz}$ Ss Por

3.22522e+01 3.22522e+01 3.22522e+00 1.00000e-09 2.12000e-01

$3.22522 \mathrm{e}+013.22522 \mathrm{e}+01$ 3.22522e+00 1.00000e-09 2.12000e-01

$3.22522 \mathrm{e}+013.22522 \mathrm{e}+01$ 3.22522e+00 1.00000e-09 2.12000e-01

$3.22522 \mathrm{e}+013.22522 \mathrm{e}+013.22522 \mathrm{e}+00$ 1.00000e-09 2.12000e-01

$1.00000 \mathrm{e}-021.00000 \mathrm{e}-02$ 1.00000e-03 1.00000e-09 1.00000e-01

$1.00000 \mathrm{e}+001.00000 \mathrm{e}+001.00000 \mathrm{e}-011.00000 \mathrm{e}-091.00000 \mathrm{e}-01$

$1.00000 \mathrm{e}-05$ 1.00000e-05 1.00000e-06 1.00000e-09 1.00000e-01

$1.00000 \mathrm{e}+001.00000 \mathrm{e}+001.00000 \mathrm{e}-011.00000 \mathrm{e}-09$ 1.00000e-01

Element: 2063 \# of layers: 8

$\mathrm{Kx} \mathrm{Ky} \mathrm{Kz}$ Ss Por

5.00000e-04 5.00000e-04 5.00000e-05 1.00000e-09 1.00000e-01

$1.63398 \mathrm{e}+01$ 1.63398e+01 1.63398e+00 1.00000e-09 2.12000e-01

$1.63398 \mathrm{e}+011.63398 \mathrm{e}+01$ 1.63398e+00 1.00000e-09 2.12000e-01

$1.63398 \mathrm{e}+011.63398 \mathrm{e}+011.63398 \mathrm{e}+001.00000 \mathrm{e}-092.12000 \mathrm{e}-01$

$1.00000 \mathrm{e}-02$ 1.00000e-02 1.00000e-03 1.00000e-09 1.00000e-01

$1.00000 \mathrm{e}+001.00000 \mathrm{e}+001.00000 \mathrm{e}-011.00000 \mathrm{e}-091.00000 \mathrm{e}-01$

$1.00000 \mathrm{e}-05$ 1.00000e-05 1.00000e-06 1.00000e-09 1.00000e-01

$1.00000 \mathrm{e}+001.00000 \mathrm{e}+001.00000 \mathrm{e}-011.00000 \mathrm{e}-091.00000 \mathrm{e}-01$

Element: 2064 \# of layers: 9

$\mathrm{Kx} \mathrm{Ky} \mathrm{Kz}$ Ss Por

4.08937e+02 4.08937e+02 4.08937e+01 1.00000e-09 7.00000e-02 5.00000e-04 5.00000e-04 5.00000e-05 1.00000e-09 1.00000e-01

$1.63398 \mathrm{e}+01$ 1.63398e+01 1.63398e+00 1.00000e-09 2.12000e-01

$1.63398 \mathrm{e}+01$ 1.63398e+01 1.63398e+00 1.00000e-09 2.12000e-01

$1.63398 \mathrm{e}+01$ 1.63398e+01 1.63398e+00 1.00000e-09 2.12000e-01

$1.00000 \mathrm{e}-01$ 1.00000e-01 1.00000e-02 1.00000e-09 1.00000e-01 
$1.00000 \mathrm{e}+001.00000 \mathrm{e}+001.00000 \mathrm{e}-011.00000 \mathrm{e}-091.00000 \mathrm{e}-01$ $1.00000 \mathrm{e}-05$ 1.00000e-05 1.00000e-06 1.00000e-09 1.00000e-01 $1.00000 \mathrm{e}+001.00000 \mathrm{e}+001.00000 \mathrm{e}-01$ 1.00000e-09 1.00000e-01 Element: 2065 \# of layers: 8

$\mathrm{Kx} \mathrm{Ky} \mathrm{Kz}$ Ss Por

4.08937e+02 4.08937e+02 4.08937e+01 1.00000e-09 7.00000e-02 5.00000e-04 5.00000e-04 5.00000e-05 1.00000e-09 1.00000e-01

5.00000e-04 5.00000e-04 5.00000e-05 1.00000e-09 1.00000e-01

$1.63398 \mathrm{e}+01$ 1.63398e+01 1.63398e+00 1.00000e-09 2.12000e-01

$1.63398 \mathrm{e}+01$ 1.63398e+01 1.63398e+00 1.00000e-09 2.12000e-01

$1.63398 \mathrm{e}+01$ 1.63398e+01 1.63398e+00 1.00000e-09 2.12000e-01 $1.00000 \mathrm{e}-01$ 1.00000e-01 1.00000e-02 1.00000e-09 1.00000e-01 $1.00000 \mathrm{e}+001.00000 \mathrm{e}+001.00000 \mathrm{e}-01$ 1.00000e-09 1.00000e-01 Element: 2066 \# of layers: 7

$\mathrm{Kx} \mathrm{Ky} \mathrm{Kz}$ Ss Por 4.08937e+02 4.08937e+02 4.08937e+01 1.00000e-09 7.00000e-02 5.00000e-04 5.00000e-04 5.00000e-05 1.00000e-09 1.00000e-01 $1.63398 \mathrm{e}+01$ 1.63398e+01 1.63398e+00 1.00000e-09 2.12000e-01 $1.63398 \mathrm{e}+01$ 1.63398e+01 1.63398e+00 1.00000e-09 2.12000e-01 $1.63398 \mathrm{e}+01$ 1.63398e+01 1.63398e+00 1.00000e-09 2.12000e-01 $1.00000 \mathrm{e}-01$ 1.00000e-01 1.00000e-02 1.00000e-09 1.00000e-01 $1.00000 \mathrm{e}+001.00000 \mathrm{e}+001.00000 \mathrm{e}-01$ 1.00000e-09 1.00000e-01 Element: 2067 \# of layers: 8

$\mathrm{Kx} \mathrm{Ky} \mathrm{Kz}$ Ss Por

4.08937e+02 4.08937e+02 4.08937e+01 1.00000e-09 7.00000e-02 $5.00000 \mathrm{e}-04$ 5.00000e-04 5.00000e-05 1.00000e-09 1.00000e-01 5.00000e-04 5.00000e-04 5.00000e-05 1.00000e-09 1.00000e-01 $1.63398 \mathrm{e}+01$ 1.63398e+01 1.63398e+00 1.00000e-09 2.12000e-01 $1.63398 \mathrm{e}+01$ 1.63398e+01 1.63398e+00 1.00000e-09 2.12000e-01 $1.63398 \mathrm{e}+01$ 1.63398e+01 1.63398e+00 1.00000e-09 2.12000e-01 $1.00000 \mathrm{e}-011.00000 \mathrm{e}-01$ 1.00000e-02 1.00000e-09 1.00000e-01 $1.00000 \mathrm{e}+001.00000 \mathrm{e}+001.00000 \mathrm{e}-01$ 1.00000e-09 1.00000e-01 Element: 2068 \# of layers: 7

$\mathrm{Kx} \mathrm{Ky} \mathrm{Kz}$ Ss Por

4.08937e+02 4.08937e+02 4.08937e+01 1.00000e-09 7.00000e-02 5.00000e-04 5.00000e-04 5.00000e-05 1.00000e-09 1.00000e-01 $1.63398 \mathrm{e}+01$ 1.63398e+01 1.63398e+00 1.00000e-09 2.12000e-01 $1.63398 \mathrm{e}+011.63398 \mathrm{e}+01$ 1.63398e+00 1.00000e-09 2.12000e-01 $1.63398 \mathrm{e}+01$ 1.63398e+01 1.63398e+00 1.00000e-09 2.12000e-01 $1.00000 \mathrm{e}-01$ 1.00000e-01 1.00000e-02 1.00000e-09 1.00000e-01 $1.00000 \mathrm{e}+001.00000 \mathrm{e}+001.00000 \mathrm{e}-011.00000 \mathrm{e}-091.00000 \mathrm{e}-01$ Element: 2069 \# of layers: 6

$\mathrm{Kx} \mathrm{Ky} \mathrm{Kz}$ Ss Por 5.00000e-04 5.00000e-04 5.00000e-05 1.00000e-09 1.00000e-01 $1.63398 \mathrm{e}+011.63398 \mathrm{e}+01$ 1.63398e+00 1.00000e-09 2.12000e-01 $1.63398 \mathrm{e}+011.63398 \mathrm{e}+011.63398 \mathrm{e}+001.00000 \mathrm{e}-092.12000 \mathrm{e}-01$ 
$1.63398 \mathrm{e}+01$ 1.63398e+01 1.63398e+00 1.00000e-09 2.12000e-01 $1.00000 \mathrm{e}-01$ 1.00000e-01 1.00000e-02 1.00000e-09 1.00000e-01 $1.00000 \mathrm{e}+001.00000 \mathrm{e}+001.00000 \mathrm{e}-011.00000 \mathrm{e}-091.00000 \mathrm{e}-01$ Element: 2070 \# of layers: 8

$\mathrm{Kx} \mathrm{Ky} \mathrm{Kz}$ Ss Por

5.00000e-04 5.00000e-04 5.00000e-05 1.00000e-09 1.00000e-01

$1.63398 \mathrm{e}+011.63398 \mathrm{e}+01$ 1.63398e+00 1.00000e-09 2.12000e-01

$1.63398 \mathrm{e}+011.63398 \mathrm{e}+011.63398 \mathrm{e}+001.00000 \mathrm{e}-092.12000 \mathrm{e}-01$

$1.63398 \mathrm{e}+011.63398 \mathrm{e}+011.63398 \mathrm{e}+001.00000 \mathrm{e}-092.12000 \mathrm{e}-01$

$1.00000 \mathrm{e}-01$ 1.00000e-01 1.00000e-02 1.00000e-09 1.00000e-01

$1.00000 \mathrm{e}+001.00000 \mathrm{e}+001.00000 \mathrm{e}-011.00000 \mathrm{e}-091.00000 \mathrm{e}-01$

$1.00000 \mathrm{e}-05$ 1.00000e-05 1.00000e-06 1.00000e-09 1.00000e-01

$1.00000 \mathrm{e}+001.00000 \mathrm{e}+001.00000 \mathrm{e}-011.00000 \mathrm{e}-091.00000 \mathrm{e}-01$

Element: 2071 \# of layers: 9

$\mathrm{Kx} \mathrm{Ky} \mathrm{Kz}$ Ss Por

4.08937e+02 4.08937e+02 4.08937e+01 1.00000e-09 7.00000e-02

5.00000e-04 5.00000e-04 5.00000e-05 1.00000e-09 1.00000e-01

$1.63398 \mathrm{e}+01$ 1.63398e+01 1.63398e+00 1.00000e-09 2.12000e-01

$1.63398 \mathrm{e}+01$ 1.63398e+01 1.63398e+00 1.00000e-09 2.12000e-01

$1.63398 \mathrm{e}+01$ 1.63398e+01 1.63398e+00 1.00000e-09 2.12000e-01

$1.00000 \mathrm{e}-011.00000 \mathrm{e}-01$ 1.00000e-02 1.00000e-09 1.00000e-01

$1.00000 \mathrm{e}+001.00000 \mathrm{e}+001.00000 \mathrm{e}-011.00000 \mathrm{e}-091.00000 \mathrm{e}-01$

$1.00000 \mathrm{e}-05$ 1.00000e-05 1.00000e-06 1.00000e-09 1.00000e-01

$1.00000 \mathrm{e}+001.00000 \mathrm{e}+001.00000 \mathrm{e}-011.00000 \mathrm{e}-091.00000 \mathrm{e}-01$

Element: 2072 \# of layers: 8

$\mathrm{Kx} \mathrm{Ky} \mathrm{Kz}$ Ss Por

$1.84345 \mathrm{e}+021.84345 \mathrm{e}+021.84345 \mathrm{e}+01$ 1.00000e-09 7.00000e-02

5.00000e-04 5.00000e-04 5.00000e-05 1.00000e-09 1.00000e-01

5.00000e-04 5.00000e-04 5.00000e-05 1.00000e-09 1.00000e-01

$7.36598 \mathrm{e}+00$ 7.36598e+00 7.36598e-01 1.00000e-09 2.12000e-01

$7.36598 \mathrm{e}+00$ 7.36598e+00 7.36598e-01 1.00000e-09 2.12000e-01

7.36598e+00 7.36598e+00 7.36598e-01 1.00000e-09 2.12000e-01

1.00000e-01 1.00000e-01 1.00000e-02 1.00000e-09 1.00000e-01

$1.00000 \mathrm{e}+001.00000 \mathrm{e}+001.00000 \mathrm{e}-011.00000 \mathrm{e}-091.00000 \mathrm{e}-01$

Element: 2073 \# of layers: 8

Kx Ky Kz Ss Por

$1.84345 \mathrm{e}+02$ 1.84345e+02 1.84345e+01 1.00000e-09 7.00000e-02

$1.84345 \mathrm{e}+021.84345 \mathrm{e}+021.84345 \mathrm{e}+01$ 1.00000e-09 7.00000e-02

5.00000e-04 5.00000e-04 5.00000e-05 1.00000e-09 1.00000e-01

7.36598e+00 7.36598e+00 7.36598e-01 1.00000e-09 2.12000e-01

7.36598e+00 7.36598e+00 7.36598e-01 1.00000e-09 2.12000e-01

$7.36598 \mathrm{e}+00$ 7.36598e+00 7.36598e-01 1.00000e-09 2.12000e-01

$1.00000 \mathrm{e}-01$ 1.00000e-01 1.00000e-02 1.00000e-09 1.00000e-01

$1.00000 \mathrm{e}+001.00000 \mathrm{e}+001.00000 \mathrm{e}-01$ 1.00000e-09 1.00000e-01

Element: 2074 \# of layers: 7

Kx Ky Kz Ss Por 
$1.84345 \mathrm{e}+02$ 1.84345e+02 1.84345e+01 1.00000e-09 7.00000e-02 5.00000e-04 5.00000e-04 5.00000e-05 1.00000e-09 1.00000e-01 $7.36598 \mathrm{e}+00$ 7.36598e+00 7.36598e-01 1.00000e-09 2.12000e-01 $7.36598 \mathrm{e}+00$ 7.36598e+00 7.36598e-01 1.00000e-09 2.12000e-01 7.36598e+00 7.36598e+00 7.36598e-01 1.00000e-09 2.12000e-01 $1.00000 \mathrm{e}-01$ 1.00000e-01 1.00000e-02 1.00000e-09 1.00000e-01 $1.00000 \mathrm{e}+001.00000 \mathrm{e}+001.00000 \mathrm{e}-011.00000 \mathrm{e}-091.00000 \mathrm{e}-01$ Element: 2075 \# of layers: 8

$\mathrm{Kx} \mathrm{Ky} \mathrm{Kz}$ Ss Por

$1.84345 \mathrm{e}+02$ 1.84345e+02 1.84345e+01 1.00000e-09 7.00000e-02 5.00000e-04 5.00000e-04 5.00000e-05 1.00000e-09 1.00000e-01 5.00000e-04 5.00000e-04 5.00000e-05 1.00000e-09 1.00000e-01

7.36598e+00 7.36598e+00 7.36598e-01 1.00000e-09 2.12000e-01

7.36598e+00 7.36598e+00 7.36598e-01 1.00000e-09 2.12000e-01

7.36598e+00 7.36598e+00 7.36598e-01 1.00000e-09 2.12000e-01 $1.00000 \mathrm{e}-011.00000 \mathrm{e}-01$ 1.00000e-02 1.00000e-09 1.00000e-01 $1.00000 \mathrm{e}+001.00000 \mathrm{e}+001.00000 \mathrm{e}-011.00000 \mathrm{e}-091.00000 \mathrm{e}-01$ Element: 2076 \# of layers: 8

$\mathrm{Kx} \mathrm{Ky} \mathrm{Kz}$ Ss Por

$1.84345 \mathrm{e}+02$ 1.84345e+02 1.84345e+01 1.00000e-09 7.00000e-02 5.00000e-04 5.00000e-04 5.00000e-05 1.00000e-09 1.00000e-01 5.00000e-04 5.00000e-04 5.00000e-05 1.00000e-09 1.00000e-01 7.36598e+00 7.36598e+00 7.36598e-01 1.00000e-09 2.12000e-01 $7.36598 \mathrm{e}+00$ 7.36598e+00 7.36598e-01 1.00000e-09 2.12000e-01 $7.36598 \mathrm{e}+00$ 7.36598e+00 7.36598e-01 1.00000e-09 2.12000e-01 $1.00000 \mathrm{e}-011.00000 \mathrm{e}-011.00000 \mathrm{e}-021.00000 \mathrm{e}-091.00000 \mathrm{e}-01$ $1.00000 \mathrm{e}+001.00000 \mathrm{e}+001.00000 \mathrm{e}-01$ 1.00000e-09 1.00000e-01 Element: 2077 \# of layers: 9

Kx Ky Kz Ss Por

$1.84345 \mathrm{e}+02$ 1.84345e+02 1.84345e+01 1.00000e-09 7.00000e-02 $1.84345 \mathrm{e}+02$ 1.84345e+02 1.84345e+01 1.00000e-09 7.00000e-02 5.00000e-04 5.00000e-04 5.00000e-05 1.00000e-09 1.00000e-01 5.00000e-04 5.00000e-04 5.00000e-05 1.00000e-09 1.00000e-01 $7.36598 \mathrm{e}+00$ 7.36598e+00 7.36598e-01 1.00000e-09 2.12000e-01 7.36598e+00 7.36598e+00 7.36598e-01 1.00000e-09 2.12000e-01 7.36598e+00 7.36598e+00 7.36598e-01 1.00000e-09 2.12000e-01 $1.00000 \mathrm{e}-011.00000 \mathrm{e}-01$ 1.00000e-02 1.00000e-09 1.00000e-01 $1.00000 \mathrm{e}+001.00000 \mathrm{e}+001.00000 \mathrm{e}-011.00000 \mathrm{e}-091.00000 \mathrm{e}-01$ Element: 2078 \# of layers: 8

$\mathrm{Kx} \mathrm{Ky} \mathrm{Kz}$ Ss Por $1.84345 \mathrm{e}+02$ 1.84345e+02 1.84345e+01 1.00000e-09 7.00000e-02 5.00000e-04 5.00000e-04 5.00000e-05 1.00000e-09 1.00000e-01 5.00000e-04 5.00000e-04 5.00000e-05 1.00000e-09 1.00000e-01 7.36598e+00 7.36598e+00 7.36598e-01 1.00000e-09 2.12000e-01 $7.36598 \mathrm{e}+00$ 7.36598e+00 7.36598e-01 1.00000e-09 2.12000e-01 $7.36598 \mathrm{e}+00$ 7.36598e+00 7.36598e-01 1.00000e-09 2.12000e-01 
$1.00000 \mathrm{e}-01$ 1.00000e-01 1.00000e-02 1.00000e-09 1.00000e-01 $1.00000 \mathrm{e}+001.00000 \mathrm{e}+001.00000 \mathrm{e}-01$ 1.00000e-09 1.00000e-01 Element: 2079 \# of layers: 7

Kx Ky Kz Ss Por

$1.84345 \mathrm{e}+021.84345 \mathrm{e}+021.84345 \mathrm{e}+01$ 1.00000e-09 7.00000e-02 5.00000e-04 5.00000e-04 5.00000e-05 1.00000e-09 1.00000e-01 5.00000e-04 5.00000e-04 5.00000e-05 1.00000e-09 1.00000e-01 $7.36598 \mathrm{e}+00$ 7.36598e+00 7.36598e-01 1.00000e-09 2.12000e-01 7.36598e+00 7.36598e+00 7.36598e-01 1.00000e-09 2.12000e-01 $1.00000 \mathrm{e}-011.00000 \mathrm{e}-01$ 1.00000e-02 1.00000e-09 1.00000e-01 $1.00000 \mathrm{e}+001.00000 \mathrm{e}+001.00000 \mathrm{e}-011.00000 \mathrm{e}-091.00000 \mathrm{e}-01$ Element: 2080 \# of layers: 9

$\mathrm{Kx} \mathrm{Ky} \mathrm{Kz}$ Ss Por

$1.84345 \mathrm{e}+02$ 1.84345e+02 1.84345e+01 1.00000e-09 7.00000e-02 $1.84345 \mathrm{e}+021.84345 \mathrm{e}+021.84345 \mathrm{e}+01$ 1.00000e-09 7.00000e-02 5.00000e-04 5.00000e-04 5.00000e-05 1.00000e-09 1.00000e-01 5.00000e-04 5.00000e-04 5.00000e-05 1.00000e-09 1.00000e-01

7.36598e+00 7.36598e+00 7.36598e-01 1.00000e-09 2.12000e-01 7.36598e+00 7.36598e+00 7.36598e-01 1.00000e-09 2.12000e-01 $7.36598 \mathrm{e}+00$ 7.36598e+00 7.36598e-01 1.00000e-09 2.12000e-01 $1.00000 \mathrm{e}-011.00000 \mathrm{e}-01$ 1.00000e-02 1.00000e-09 1.00000e-01 $1.00000 \mathrm{e}+001.00000 \mathrm{e}+001.00000 \mathrm{e}-01$ 1.00000e-09 1.00000e-01 Element: 2081 \# of layers: 9

$\mathrm{Kx} \mathrm{Ky} \mathrm{Kz}$ Ss Por

1.19671e+02 1.19671e+02 1.19671e+01 1.00000e-09 7.00000e-02 $1.19671 \mathrm{e}+021.19671 \mathrm{e}+021.19671 \mathrm{e}+01$ 1.00000e-09 7.00000e-02 5.00000e-04 5.00000e-04 5.00000e-05 1.00000e-09 1.00000e-01 5.00000e-04 5.00000e-04 5.00000e-05 1.00000e-09 1.00000e-01 $4.78158 \mathrm{e}+00$ 4.78158e+00 4.78158e-01 1.00000e-09 2.12000e-01 $4.78158 \mathrm{e}+00$ 4.78158e+00 4.78158e-01 1.00000e-09 2.12000e-01 4.78158e+00 4.78158e+00 4.78158e-01 1.00000e-09 2.12000e-01 1.00000e-01 1.00000e-01 1.00000e-02 1.00000e-09 1.00000e-01 $1.00000 \mathrm{e}+001.00000 \mathrm{e}+001.00000 \mathrm{e}-011.00000 \mathrm{e}-091.00000 \mathrm{e}-01$ Element: 2082 \# of layers: 9

$\mathrm{Kx} \mathrm{Ky} \mathrm{Kz}$ Ss Por

1.19671e+02 1.19671e+02 1.19671e+01 1.00000e-09 7.00000e-02 $1.19671 \mathrm{e}+021.19671 \mathrm{e}+021.19671 \mathrm{e}+01$ 1.00000e-09 7.00000e-02 5.00000e-04 5.00000e-04 5.00000e-05 1.00000e-09 1.00000e-01 5.00000e-04 5.00000e-04 5.00000e-05 1.00000e-09 1.00000e-01 4.78158e+00 4.78158e+00 4.78158e-01 1.00000e-09 2.12000e-01 $4.78158 \mathrm{e}+00$ 4.78158e+00 4.78158e-01 1.00000e-09 2.12000e-01 $4.78158 \mathrm{e}+004.78158 \mathrm{e}+00$ 4.78158e-01 1.00000e-09 2.12000e-01 $1.00000 \mathrm{e}-011.00000 \mathrm{e}-011.00000 \mathrm{e}-021.00000 \mathrm{e}-091.00000 \mathrm{e}-01$ $1.00000 \mathrm{e}+001.00000 \mathrm{e}+001.00000 \mathrm{e}-01$ 1.00000e-09 1.00000e-01 Element: 2083 \# of layers: 9

Kx Ky Kz Ss Por 
1.19671e+02 1.19671e+02 1.19671e+01 1.00000e-09 7.00000e-02 $1.19671 \mathrm{e}+021.19671 \mathrm{e}+021.19671 \mathrm{e}+01$ 1.00000e-09 7.00000e-02 5.00000e-04 5.00000e-04 5.00000e-05 1.00000e-09 1.00000e-01 5.00000e-04 5.00000e-04 5.00000e-05 1.00000e-09 1.00000e-01 $4.78158 \mathrm{e}+00$ 4.78158e+00 4.78158e-01 1.00000e-09 2.12000e-01 $4.78158 \mathrm{e}+004.78158 \mathrm{e}+00$ 4.78158e-01 1.00000e-09 2.12000e-01 4.78158e+00 4.78158e+00 4.78158e-01 1.00000e-09 2.12000e-01 $1.00000 \mathrm{e}-011.00000 \mathrm{e}-01$ 1.00000e-02 1.00000e-09 1.00000e-01 $1.00000 \mathrm{e}+001.00000 \mathrm{e}+001.00000 \mathrm{e}-011.00000 \mathrm{e}-091.00000 \mathrm{e}-01$ Element: 2084 \# of layers: 16

$\mathrm{Kx} \mathrm{Ky} \mathrm{Kz}$ Ss Por

$2.44594 \mathrm{e}+02$ 2.44594e+02 2.44595e+01 1.00000e-09 7.00000e-02 $2.44594 \mathrm{e}+02$ 2.44594e+02 2.44595e+01 1.00000e-09 7.00000e-02

$2.44594 \mathrm{e}+022.44594 \mathrm{e}+02$ 2.44595e+01 1.00000e-09 7.00000e-02 $2.44594 \mathrm{e}+02$ 2.44594e+02 2.44595e+01 1.00000e-09 7.00000e-02 $2.44594 \mathrm{e}+022.44594 \mathrm{e}+022.44595 \mathrm{e}+01$ 1.00000e-09 7.00000e-02 5.00000e-04 5.00000e-04 5.00000e-05 1.00000e-09 1.00000e-01 5.00000e-04 5.00000e-04 5.00000e-05 1.00000e-09 1.00000e-01 $9.77308 \mathrm{e}+009.77308 \mathrm{e}+00$ 9.77308e-01 1.00000e-09 2.12000e-01 $9.77308 \mathrm{e}+009.77308 \mathrm{e}+00$ 9.77308e-01 1.00000e-09 2.12000e-01 $9.77308 \mathrm{e}+00$ 9.77308e+00 9.77308e-01 1.00000e-09 2.12000e-01 9.77308e+00 9.77308e+00 9.77308e-01 1.00000e-09 2.12000e-01 9.77308e+00 9.77308e+00 9.77308e-01 1.00000e-09 2.12000e-01 $1.00000 \mathrm{e}-02$ 1.00000e-02 1.00000e-03 1.00000e-09 1.00000e-01 $1.00000 \mathrm{e}+001.00000 \mathrm{e}+001.00000 \mathrm{e}-011.00000 \mathrm{e}-091.00000 \mathrm{e}-01$ $1.00000 \mathrm{e}-05$ 1.00000e-05 1.00000e-06 1.00000e-09 1.00000e-01 $1.00000 \mathrm{e}+001.00000 \mathrm{e}+001.00000 \mathrm{e}-011.00000 \mathrm{e}-091.00000 \mathrm{e}-01$ Element: 2085 \# of layers: 16

$\mathrm{Kx} \mathrm{Ky} \mathrm{Kz}$ Ss Por

2.44594e+02 2.44594e+02 2.44595e+01 1.00000e-09 7.00000e-02 $2.44594 \mathrm{e}+02$ 2.44594e+02 2.44595e+01 1.00000e-09 7.00000e-02 $2.44594 \mathrm{e}+022.44594 \mathrm{e}+02$ 2.44595e+01 1.00000e-09 7.00000e-02 $2.44594 \mathrm{e}+02$ 2.44594e+02 2.44595e+01 1.00000e-09 7.00000e-02 $2.44594 \mathrm{e}+02$ 2.44594e+02 2.44595e+01 1.00000e-09 7.00000e-02 5.00000e-04 5.00000e-04 5.00000e-05 1.00000e-09 1.00000e-01 5.00000e-04 5.00000e-04 5.00000e-05 1.00000e-09 1.00000e-01 $9.77308 \mathrm{e}+009.77308 \mathrm{e}+00$ 9.77308e-01 1.00000e-09 2.12000e-01 9.77308e+00 9.77308e+00 9.77308e-01 1.00000e-09 2.12000e-01 $9.77308 \mathrm{e}+00$ 9.77308e+00 9.77308e-01 1.00000e-09 2.12000e-01 9.77308e+00 9.77308e+00 9.77308e-01 1.00000e-09 2.12000e-01 $9.77308 \mathrm{e}+009.77308 \mathrm{e}+00$ 9.77308e-01 1.00000e-09 2.12000e-01 $1.00000 \mathrm{e}-02$ 1.00000e-02 1.00000e-03 1.00000e-09 1.00000e-01 $1.00000 \mathrm{e}+001.00000 \mathrm{e}+001.00000 \mathrm{e}-011.00000 \mathrm{e}-091.00000 \mathrm{e}-01$ $1.00000 \mathrm{e}-051.00000 \mathrm{e}-051.00000 \mathrm{e}-061.00000 \mathrm{e}-091.00000 \mathrm{e}-01$ $1.00000 \mathrm{e}+001.00000 \mathrm{e}+001.00000 \mathrm{e}-01$ 1.00000e-09 1.00000e-01 Element: 2086 \# of layers: 15 
$\mathrm{Kx} \mathrm{Ky} \mathrm{Kz}$ Ss Por

$2.44594 \mathrm{e}+02$ 2.44594e+02 2.44595e+01 1.00000e-09 7.00000e-02

$2.44594 \mathrm{e}+022.44594 \mathrm{e}+02$ 2.44595e+01 1.00000e-09 7.00000e-02

$2.44594 \mathrm{e}+02$ 2.44594e+02 2.44595e+01 1.00000e-09 7.00000e-02

$2.44594 \mathrm{e}+02$ 2.44594e+02 2.44595e+01 1.00000e-09 7.00000e-02

5.00000e-04 5.00000e-04 5.00000e-05 1.00000e-09 1.00000e-01

5.00000e-04 5.00000e-04 5.00000e-05 1.00000e-09 1.00000e-01

$9.77308 \mathrm{e}+00$ 9.77308e+00 9.77308e-01 1.00000e-09 2.12000e-01

$9.77308 \mathrm{e}+00$ 9.77308e+00 9.77308e-01 1.00000e-09 2.12000e-01

9.77308e+00 9.77308e+00 9.77308e-01 1.00000e-09 2.12000e-01

$9.77308 \mathrm{e}+00$ 9.77308e+00 9.77308e-01 1.00000e-09 2.12000e-01

$9.77308 \mathrm{e}+00$ 9.77308e+00 9.77308e-01 1.00000e-09 2.12000e-01

$1.00000 \mathrm{e}-02$ 1.00000e-02 1.00000e-03 1.00000e-09 1.00000e-01

$1.00000 \mathrm{e}+001.00000 \mathrm{e}+001.00000 \mathrm{e}-011.00000 \mathrm{e}-091.00000 \mathrm{e}-01$

$1.00000 \mathrm{e}-05$ 1.00000e-05 1.00000e-06 1.00000e-09 1.00000e-01

$1.00000 \mathrm{e}+001.00000 \mathrm{e}+001.00000 \mathrm{e}-011.00000 \mathrm{e}-091.00000 \mathrm{e}-01$

Element: 2087 \# of layers: 16

$\mathrm{Kx} \mathrm{Ky} \mathrm{Kz}$ Ss Por

2.44594e+02 2.44594e+02 2.44595e+01 1.00000e-09 7.00000e-02

$2.44594 \mathrm{e}+02$ 2.44594e+02 2.44595e+01 1.00000e-09 7.00000e-02

$2.44594 \mathrm{e}+02$ 2.44594e+02 2.44595e+01 1.00000e-09 7.00000e-02

$2.44594 \mathrm{e}+022.44594 \mathrm{e}+02$ 2.44595e+01 1.00000e-09 7.00000e-02

$2.44594 \mathrm{e}+02$ 2.44594e+02 2.44595e+01 1.00000e-09 7.00000e-02

5.00000e-04 5.00000e-04 5.00000e-05 1.00000e-09 1.00000e-01

5.00000e-04 5.00000e-04 5.00000e-05 1.00000e-09 1.00000e-01

$9.77308 \mathrm{e}+00$ 9.77308e+00 9.77308e-01 1.00000e-09 2.12000e-01

9.77308e+00 9.77308e+00 9.77308e-01 1.00000e-09 2.12000e-01

$9.77308 \mathrm{e}+00$ 9.77308e+00 9.77308e-01 1.00000e-09 2.12000e-01

$9.77308 \mathrm{e}+00$ 9.77308e+00 9.77308e-01 1.00000e-09 2.12000e-01

$9.77308 \mathrm{e}+00$ 9.77308e+00 9.77308e-01 1.00000e-09 2.12000e-01

$1.00000 \mathrm{e}-02$ 1.00000e-02 1.00000e-03 1.00000e-09 1.00000e-01

$1.00000 \mathrm{e}+001.00000 \mathrm{e}+001.00000 \mathrm{e}-011.00000 \mathrm{e}-091.00000 \mathrm{e}-01$

$1.00000 \mathrm{e}-05$ 1.00000e-05 1.00000e-06 1.00000e-09 1.00000e-01

$1.00000 \mathrm{e}+001.00000 \mathrm{e}+001.00000 \mathrm{e}-011.00000 \mathrm{e}-091.00000 \mathrm{e}-01$

Element: 2088 \# of layers: 16

$\mathrm{Kx} \mathrm{Ky} \mathrm{Kz}$ Ss Por

$2.44594 \mathrm{e}+02$ 2.44594e+02 2.44595e+01 1.00000e-09 7.00000e-02

$2.44594 \mathrm{e}+022.44594 \mathrm{e}+02$ 2.44595e+01 1.00000e-09 7.00000e-02

$2.44594 \mathrm{e}+022.44594 \mathrm{e}+02$ 2.44595e+01 1.00000e-09 7.00000e-02

$2.44594 \mathrm{e}+02$ 2.44594e+02 2.44595e+01 1.00000e-09 7.00000e-02

$2.44594 \mathrm{e}+02$ 2.44594e+02 2.44595e+01 1.00000e-09 7.00000e-02

5.00000e-04 5.00000e-04 5.00000e-05 1.00000e-09 1.00000e-01

5.00000e-04 5.00000e-04 5.00000e-05 1.00000e-09 1.00000e-01

9.77308e+00 9.77308e+00 9.77308e-01 1.00000e-09 2.12000e-01

9.77308e+00 9.77308e+00 9.77308e-01 1.00000e-09 2.12000e-01

$9.77308 \mathrm{e}+00$ 9.77308e+00 9.77308e-01 1.00000e-09 2.12000e-01 
$9.77308 \mathrm{e}+00$ 9.77308e+00 9.77308e-01 1.00000e-09 2.12000e-01 $9.77308 \mathrm{e}+00$ 9.77308e+00 9.77308e-01 1.00000e-09 2.12000e-01 $1.00000 \mathrm{e}-021.00000 \mathrm{e}-02$ 1.00000e-03 1.00000e-09 1.00000e-01 $1.00000 \mathrm{e}+001.00000 \mathrm{e}+001.00000 \mathrm{e}-011.00000 \mathrm{e}-091.00000 \mathrm{e}-01$ $1.00000 \mathrm{e}-05$ 1.00000e-05 1.00000e-06 1.00000e-09 1.00000e-01 $1.00000 \mathrm{e}+001.00000 \mathrm{e}+001.00000 \mathrm{e}-011.00000 \mathrm{e}-091.00000 \mathrm{e}-01$ Element: 2089 \# of layers: 15

Kx Ky Kz Ss Por

$2.25007 \mathrm{e}+022.25007 \mathrm{e}+022.25007 \mathrm{e}+01$ 1.00000e-09 7.00000e-02 $2.25007 \mathrm{e}+022.25007 \mathrm{e}+022.25007 \mathrm{e}+011.00000 \mathrm{e}-09$ 7.00000e-02 $2.25007 \mathrm{e}+022.25007 \mathrm{e}+022.25007 \mathrm{e}+011.00000 \mathrm{e}-097.00000 \mathrm{e}-02$ $2.25007 \mathrm{e}+022.25007 \mathrm{e}+022.25007 \mathrm{e}+01$ 1.00000e-09 7.00000e-02 5.00000e-04 5.00000e-04 5.00000e-05 1.00000e-09 1.00000e-01 5.00000e-04 5.00000e-04 5.00000e-05 1.00000e-09 1.00000e-01 $8.99052 \mathrm{e}+008.99052 \mathrm{e}+008.99052 \mathrm{e}-011.00000 \mathrm{e}-092.12000 \mathrm{e}-01$ $8.99052 \mathrm{e}+008.99052 \mathrm{e}+00$ 8.99052e-01 1.00000e-09 2.12000e-01 $8.99052 \mathrm{e}+008.99052 \mathrm{e}+00$ 8.99052e-01 1.00000e-09 2.12000e-01 $8.99052 \mathrm{e}+008.99052 \mathrm{e}+008.99052 \mathrm{e}-011.00000 \mathrm{e}-092.12000 \mathrm{e}-01$ $8.99052 \mathrm{e}+008.99052 \mathrm{e}+008.99052 \mathrm{e}-01$ 1.00000e-09 2.12000e-01 $1.00000 \mathrm{e}-021.00000 \mathrm{e}-02$ 1.00000e-03 1.00000e-09 1.00000e-01 $1.00000 \mathrm{e}+001.00000 \mathrm{e}+001.00000 \mathrm{e}-011.00000 \mathrm{e}-091.00000 \mathrm{e}-01$ $1.00000 \mathrm{e}-05$ 1.00000e-05 1.00000e-06 1.00000e-09 1.00000e-01 $1.00000 \mathrm{e}+001.00000 \mathrm{e}+001.00000 \mathrm{e}-011.00000 \mathrm{e}-091.00000 \mathrm{e}-01$ Element: 2090 \# of layers: 15

$\mathrm{Kx}$ Ky Kz Ss Por

$2.25007 \mathrm{e}+022.25007 \mathrm{e}+022.25007 \mathrm{e}+01$ 1.00000e-09 7.00000e-02 $2.25007 \mathrm{e}+022.25007 \mathrm{e}+02 \quad 2.25007 \mathrm{e}+01 \quad 1.00000 \mathrm{e}-09$ 7.00000e-02 $2.25007 \mathrm{e}+022.25007 \mathrm{e}+022.25007 \mathrm{e}+01$ 1.00000e-09 7.00000e-02 $2.25007 \mathrm{e}+022.25007 \mathrm{e}+022.25007 \mathrm{e}+01$ 1.00000e-09 7.00000e-02 5.00000e-04 5.00000e-04 5.00000e-05 1.00000e-09 1.00000e-01 $5.00000 \mathrm{e}-04$ 5.00000e-04 5.00000e-05 1.00000e-09 1.00000e-01 $8.99052 \mathrm{e}+008.99052 \mathrm{e}+008.99052 \mathrm{e}-01$ 1.00000e-09 2.12000e-01 $8.99052 \mathrm{e}+008.99052 \mathrm{e}+00$ 8.99052e-01 1.00000e-09 2.12000e-01 $8.99052 \mathrm{e}+008.99052 \mathrm{e}+008.99052 \mathrm{e}-011.00000 \mathrm{e}-092.12000 \mathrm{e}-01$ $8.99052 \mathrm{e}+008.99052 \mathrm{e}+008.99052 \mathrm{e}-01$ 1.00000e-09 2.12000e-01 $8.99052 \mathrm{e}+008.99052 \mathrm{e}+00$ 8.99052e-01 1.00000e-09 2.12000e-01 $1.00000 \mathrm{e}-021.00000 \mathrm{e}-02$ 1.00000e-03 1.00000e-09 1.00000e-01 $1.00000 \mathrm{e}+001.00000 \mathrm{e}+001.00000 \mathrm{e}-011.00000 \mathrm{e}-091.00000 \mathrm{e}-01$ $1.00000 \mathrm{e}-05$ 1.00000e-05 1.00000e-06 1.00000e-09 1.00000e-01 $1.00000 \mathrm{e}+001.00000 \mathrm{e}+001.00000 \mathrm{e}-011.00000 \mathrm{e}-091.00000 \mathrm{e}-01$ Element: 2091 \# of layers: 15

Kx Ky Kz Ss Por

$2.25007 \mathrm{e}+022.25007 \mathrm{e}+022.25007 \mathrm{e}+01$ 1.00000e-09 7.00000e-02 $2.25007 \mathrm{e}+022.25007 \mathrm{e}+022.25007 \mathrm{e}+011.00000 \mathrm{e}-09$ 7.00000e-02 $2.25007 \mathrm{e}+022.25007 \mathrm{e}+02 \quad 2.25007 \mathrm{e}+01 \quad 1.00000 \mathrm{e}-09$ 7.00000e-02 $2.25007 \mathrm{e}+022.25007 \mathrm{e}+02 \quad 2.25007 \mathrm{e}+01$ 1.00000e-09 7.00000e-02 
5.00000e-04 5.00000e-04 5.00000e-05 1.00000e-09 1.00000e-01 5.00000e-04 5.00000e-04 5.00000e-05 1.00000e-09 1.00000e-01 $8.99052 \mathrm{e}+008.99052 \mathrm{e}+00$ 8.99052e-01 1.00000e-09 2.12000e-01 $8.99052 \mathrm{e}+00$ 8.99052e+00 8.99052e-01 1.00000e-09 2.12000e-01 8.99052e+00 8.99052e+00 8.99052e-01 1.00000e-09 2.12000e-01 8.99052e+00 8.99052e+00 8.99052e-01 1.00000e-09 2.12000e-01 $8.99052 \mathrm{e}+00$ 8.99052e+00 8.99052e-01 1.00000e-09 2.12000e-01 $1.00000 \mathrm{e}-02$ 1.00000e-02 1.00000e-03 1.00000e-09 1.00000e-01 $1.00000 \mathrm{e}+001.00000 \mathrm{e}+001.00000 \mathrm{e}-01$ 1.00000e-09 1.00000e-01 $1.00000 \mathrm{e}-05$ 1.00000e-05 1.00000e-06 1.00000e-09 1.00000e-01 $1.00000 \mathrm{e}+001.00000 \mathrm{e}+001.00000 \mathrm{e}-01$ 1.00000e-09 1.00000e-01 Element: 2092 \# of layers: 15

$\mathrm{Kx} \mathrm{Ky} \mathrm{Kz}$ Ss Por

2.25007e+02 2.25007e+02 2.25007e+01 1.00000e-09 7.00000e-02 $2.25007 \mathrm{e}+02$ 2.25007e+02 2.25007e+01 1.00000e-09 7.00000e-02 $2.25007 \mathrm{e}+022.25007 \mathrm{e}+02$ 2.25007e+01 1.00000e-09 7.00000e-02 $2.25007 \mathrm{e}+022.25007 \mathrm{e}+02$ 2.25007e+01 1.00000e-09 7.00000e-02 5.00000e-04 5.00000e-04 5.00000e-05 1.00000e-09 1.00000e-01 $5.00000 \mathrm{e}-04$ 5.00000e-04 5.00000e-05 1.00000e-09 1.00000e-01 $8.99052 \mathrm{e}+008.99052 \mathrm{e}+00$ 8.99052e-01 1.00000e-09 2.12000e-01 $8.99052 \mathrm{e}+00$ 8.99052e+00 8.99052e-01 1.00000e-09 2.12000e-01 8.99052e+00 8.99052e+00 8.99052e-01 1.00000e-09 2.12000e-01 $8.99052 \mathrm{e}+00$ 8.99052e+00 8.99052e-01 1.00000e-09 2.12000e-01 $8.99052 \mathrm{e}+00$ 8.99052e+00 8.99052e-01 1.00000e-09 2.12000e-01 $1.00000 \mathrm{e}-02$ 1.00000e-02 1.00000e-03 1.00000e-09 1.00000e-01 $1.00000 \mathrm{e}+001.00000 \mathrm{e}+001.00000 \mathrm{e}-011.00000 \mathrm{e}-091.00000 \mathrm{e}-01$ $1.00000 \mathrm{e}-05$ 1.00000e-05 1.00000e-06 1.00000e-09 1.00000e-01 $1.00000 \mathrm{e}+001.00000 \mathrm{e}+001.00000 \mathrm{e}-011.00000 \mathrm{e}-091.00000 \mathrm{e}-01$ Element: 2093 \# of layers: 15

$\mathrm{Kx} \mathrm{Ky} \mathrm{Kz}$ Ss Por

$2.25007 \mathrm{e}+02$ 2.25007e+02 2.25007e+01 1.00000e-09 7.00000e-02 $2.25007 \mathrm{e}+022.25007 \mathrm{e}+02$ 2.25007e+01 1.00000e-09 7.00000e-02 $2.25007 \mathrm{e}+022.25007 \mathrm{e}+02$ 2.25007e+01 1.00000e-09 7.00000e-02 $2.25007 \mathrm{e}+022.25007 \mathrm{e}+02$ 2.25007e+01 1.00000e-09 7.00000e-02 5.00000e-04 5.00000e-04 5.00000e-05 1.00000e-09 1.00000e-01 5.00000e-04 5.00000e-04 5.00000e-05 1.00000e-09 1.00000e-01 $8.99052 \mathrm{e}+00$ 8.99052e+00 8.99052e-01 1.00000e-09 2.12000e-01 8.99052e+00 8.99052e+00 8.99052e-01 1.00000e-09 2.12000e-01 8.99052e+00 8.99052e+00 8.99052e-01 1.00000e-09 2.12000e-01 $8.99052 \mathrm{e}+008.99052 \mathrm{e}+00$ 8.99052e-01 1.00000e-09 2.12000e-01 $8.99052 \mathrm{e}+00$ 8.99052e+00 8.99052e-01 1.00000e-09 2.12000e-01 $1.00000 \mathrm{e}-02$ 1.00000e-02 1.00000e-03 1.00000e-09 1.00000e-01 $1.00000 \mathrm{e}+001.00000 \mathrm{e}+001.00000 \mathrm{e}-011.00000 \mathrm{e}-091.00000 \mathrm{e}-01$ $1.00000 \mathrm{e}-05$ 1.00000e-05 1.00000e-06 1.00000e-09 1.00000e-01 $1.00000 \mathrm{e}+001.00000 \mathrm{e}+00$ 1.00000e-01 1.00000e-09 1.00000e-01 Element: 2094 \# of layers: 15 
$\mathrm{Kx} \mathrm{Ky} \mathrm{Kz}$ Ss Por

$2.25007 \mathrm{e}+02$ 2.25007e+02 2.25007e+01 1.00000e-09 7.00000e-02 $2.25007 \mathrm{e}+02$ 2.25007e+02 2.25007e+01 1.00000e-09 7.00000e-02 $2.25007 \mathrm{e}+02$ 2.25007e+02 2.25007e+01 1.00000e-09 7.00000e-02 $2.25007 \mathrm{e}+022.25007 \mathrm{e}+02$ 2.25007e+01 1.00000e-09 7.00000e-02 5.00000e-04 5.00000e-04 5.00000e-05 1.00000e-09 1.00000e-01 5.00000e-04 5.00000e-04 5.00000e-05 1.00000e-09 1.00000e-01 $8.99052 \mathrm{e}+00$ 8.99052e+00 8.99052e-01 1.00000e-09 2.12000e-01 8.99052e+00 8.99052e+00 8.99052e-01 1.00000e-09 2.12000e-01 8.99052e+00 8.99052e+00 8.99052e-01 1.00000e-09 2.12000e-01 8.99052e+00 8.99052e+00 8.99052e-01 1.00000e-09 2.12000e-01 $8.99052 \mathrm{e}+008.99052 \mathrm{e}+00$ 8.99052e-01 1.00000e-09 2.12000e-01 $1.00000 \mathrm{e}-02$ 1.00000e-02 1.00000e-03 1.00000e-09 1.00000e-01 $1.00000 \mathrm{e}+001.00000 \mathrm{e}+001.00000 \mathrm{e}-011.00000 \mathrm{e}-091.00000 \mathrm{e}-01$ $1.00000 \mathrm{e}-05$ 1.00000e-05 1.00000e-06 1.00000e-09 1.00000e-01 $1.00000 \mathrm{e}+001.00000 \mathrm{e}+001.00000 \mathrm{e}-011.00000 \mathrm{e}-091.00000 \mathrm{e}-01$ Element: 2095 \# of layers: 15

$\mathrm{Kx} \mathrm{Ky} \mathrm{Kz}$ Ss Por

2.25007e+02 2.25007e+02 2.25007e+01 1.00000e-09 7.00000e-02 $2.25007 \mathrm{e}+02$ 2.25007e+02 2.25007e+01 1.00000e-09 7.00000e-02 $2.25007 \mathrm{e}+02$ 2.25007e+02 2.25007e+01 1.00000e-09 7.00000e-02 $2.25007 \mathrm{e}+02$ 2.25007e+02 2.25007e+01 1.00000e-09 7.00000e-02 5.00000e-04 5.00000e-04 5.00000e-05 1.00000e-09 1.00000e-01 5.00000e-04 5.00000e-04 5.00000e-05 1.00000e-09 1.00000e-01 $8.99052 \mathrm{e}+008.99052 \mathrm{e}+008.99052 \mathrm{e}-01$ 1.00000e-09 2.12000e-01 $8.99052 \mathrm{e}+008.99052 \mathrm{e}+00$ 8.99052e-01 1.00000e-09 2.12000e-01 $8.99052 \mathrm{e}+008.99052 \mathrm{e}+008.99052 \mathrm{e}-01$ 1.00000e-09 2.12000e-01 8.99052e+00 8.99052e+00 8.99052e-01 1.00000e-09 2.12000e-01 $8.99052 \mathrm{e}+008.99052 \mathrm{e}+00$ 8.99052e-01 1.00000e-09 2.12000e-01 $1.00000 \mathrm{e}-021.00000 \mathrm{e}-021.00000 \mathrm{e}-031.00000 \mathrm{e}-091.00000 \mathrm{e}-01$ $1.00000 \mathrm{e}+001.00000 \mathrm{e}+001.00000 \mathrm{e}-01$ 1.00000e-09 1.00000e-01 $1.00000 \mathrm{e}-05$ 1.00000e-05 1.00000e-06 1.00000e-09 1.00000e-01 $1.00000 \mathrm{e}+001.00000 \mathrm{e}+001.00000 \mathrm{e}-011.00000 \mathrm{e}-091.00000 \mathrm{e}-01$ Element: 2096 \# of layers: 15

$\mathrm{Kx} \mathrm{Ky} \mathrm{Kz}$ Ss Por

$2.25007 \mathrm{e}+02$ 2.25007e+02 2.25007e+01 1.00000e-09 7.00000e-02 $2.25007 \mathrm{e}+02$ 2.25007e+02 2.25007e+01 1.00000e-09 7.00000e-02 $2.25007 \mathrm{e}+02$ 2.25007e+02 2.25007e+01 1.00000e-09 7.00000e-02 $2.25007 \mathrm{e}+02$ 2.25007e+02 2.25007e+01 1.00000e-09 7.00000e-02 5.00000e-04 5.00000e-04 5.00000e-05 1.00000e-09 1.00000e-01 5.00000e-04 5.00000e-04 5.00000e-05 1.00000e-09 1.00000e-01 $8.99052 \mathrm{e}+008.99052 \mathrm{e}+00$ 8.99052e-01 1.00000e-09 2.12000e-01 $8.99052 \mathrm{e}+00$ 8.99052e+00 8.99052e-01 1.00000e-09 2.12000e-01 8.99052e+00 8.99052e+00 8.99052e-01 1.00000e-09 2.12000e-01 $8.99052 \mathrm{e}+00$ 8.99052e+00 8.99052e-01 1.00000e-09 2.12000e-01 $8.99052 \mathrm{e}+008.99052 \mathrm{e}+00$ 8.99052e-01 1.00000e-09 2.12000e-01 
$1.00000 \mathrm{e}-02$ 1.00000e-02 1.00000e-03 1.00000e-09 1.00000e-01 $1.00000 \mathrm{e}+001.00000 \mathrm{e}+001.00000 \mathrm{e}-011.00000 \mathrm{e}-091.00000 \mathrm{e}-01$ $1.00000 \mathrm{e}-051.00000 \mathrm{e}-05$ 1.00000e-06 1.00000e-09 1.00000e-01 $1.00000 \mathrm{e}+001.00000 \mathrm{e}+001.00000 \mathrm{e}-011.00000 \mathrm{e}-091.00000 \mathrm{e}-01$ Element: 2097 \# of layers: 15

Kx Ky Kz Ss Por

$2.25007 \mathrm{e}+022.25007 \mathrm{e}+022.25007 \mathrm{e}+01$ 1.00000e-09 7.00000e-02 $2.25007 \mathrm{e}+022.25007 \mathrm{e}+022.25007 \mathrm{e}+01$ 1.00000e-09 7.00000e-02 $2.25007 \mathrm{e}+022.25007 \mathrm{e}+022.25007 \mathrm{e}+011.00000 \mathrm{e}-09$ 7.00000e-02 $2.25007 \mathrm{e}+022.25007 \mathrm{e}+022.25007 \mathrm{e}+011.00000 \mathrm{e}-097.00000 \mathrm{e}-02$ 5.00000e-04 5.00000e-04 5.00000e-05 1.00000e-09 1.00000e-01 5.00000e-04 5.00000e-04 5.00000e-05 1.00000e-09 1.00000e-01 $8.99052 \mathrm{e}+008.99052 \mathrm{e}+008.99052 \mathrm{e}-01$ 1.00000e-09 2.12000e-01 $8.99052 \mathrm{e}+008.99052 \mathrm{e}+008.99052 \mathrm{e}-01$ 1.00000e-09 2.12000e-01 $8.99052 \mathrm{e}+008.99052 \mathrm{e}+008.99052 \mathrm{e}-01$ 1.00000e-09 2.12000e-01 $8.99052 \mathrm{e}+008.99052 \mathrm{e}+008.99052 \mathrm{e}-01$ 1.00000e-09 2.12000e-01 $8.99052 \mathrm{e}+008.99052 \mathrm{e}+00$ 8.99052e-01 1.00000e-09 2.12000e-01 $1.00000 \mathrm{e}-02$ 1.00000e-02 1.00000e-03 1.00000e-09 1.00000e-01 $1.00000 \mathrm{e}+001.00000 \mathrm{e}+001.00000 \mathrm{e}-011.00000 \mathrm{e}-091.00000 \mathrm{e}-01$ $1.00000 \mathrm{e}-051.00000 \mathrm{e}-05$ 1.00000e-06 1.00000e-09 1.00000e-01 $1.00000 \mathrm{e}+001.00000 \mathrm{e}+001.00000 \mathrm{e}-011.00000 \mathrm{e}-091.00000 \mathrm{e}-01$ Element: 2098 \# of layers: 15

Kx Ky Kz Ss Por

$1.16247 \mathrm{e}+02$ 1.16247e+02 1.16247e+01 1.00000e-09 7.00000e-02 $1.16247 \mathrm{e}+021.16247 \mathrm{e}+021.16247 \mathrm{e}+011.00000 \mathrm{e}-09$ 7.00000e-02 $1.16247 \mathrm{e}+021.16247 \mathrm{e}+021.16247 \mathrm{e}+011.00000 \mathrm{e}-09$ 7.00000e-02 $1.16247 \mathrm{e}+02$ 1.16247e+02 1.16247e+01 1.00000e-09 7.00000e-02 5.00000e-04 5.00000e-04 5.00000e-05 1.00000e-09 1.00000e-01 5.00000e-04 5.00000e-04 5.00000e-05 1.00000e-09 1.00000e-01 $4.64477 \mathrm{e}+004.64477 \mathrm{e}+00$ 4.64477e-01 1.00000e-09 2.12000e-01 $4.64477 \mathrm{e}+004.64477 \mathrm{e}+00$ 4.64477e-01 1.00000e-09 2.12000e-01 $4.64477 \mathrm{e}+004.64477 \mathrm{e}+00$ 4.64477e-01 1.00000e-09 2.12000e-01 $4.64477 \mathrm{e}+004.64477 \mathrm{e}+004.64477 \mathrm{e}-01$ 1.00000e-09 2.12000e-01 $4.64477 \mathrm{e}+004.64477 \mathrm{e}+00$ 4.64477e-01 1.00000e-09 2.12000e-01 $1.00000 \mathrm{e}-02$ 1.00000e-02 1.00000e-03 1.00000e-09 1.00000e-01 $1.00000 \mathrm{e}+001.00000 \mathrm{e}+001.00000 \mathrm{e}-011.00000 \mathrm{e}-091.00000 \mathrm{e}-01$ $1.00000 \mathrm{e}-05$ 1.00000e-05 1.00000e-06 1.00000e-09 1.00000e-01 $1.00000 \mathrm{e}+001.00000 \mathrm{e}+001.00000 \mathrm{e}-011.00000 \mathrm{e}-091.00000 \mathrm{e}-01$ Element: 2099 \# of layers: 15

Kx Ky Kz Ss Por

$1.16247 \mathrm{e}+02$ 1.16247e+02 1.16247e+01 1.00000e-09 7.00000e-02 $1.16247 \mathrm{e}+021.16247 \mathrm{e}+021.16247 \mathrm{e}+01$ 1.00000e-09 7.00000e-02 $1.16247 \mathrm{e}+021.16247 \mathrm{e}+021.16247 \mathrm{e}+011.00000 \mathrm{e}-097.00000 \mathrm{e}-02$ $1.16247 \mathrm{e}+021.16247 \mathrm{e}+021.16247 \mathrm{e}+01$ 1.00000e-09 7.00000e-02 5.00000e-04 5.00000e-04 5.00000e-05 1.00000e-09 1.00000e-01 5.00000e-04 5.00000e-04 5.00000e-05 1.00000e-09 1.00000e-01 
4.64477e+00 4.64477e+00 4.64477e-01 1.00000e-09 2.12000e-01 4.64477e+00 4.64477e+00 4.64477e-01 1.00000e-09 2.12000e-01 4.64477e+00 4.64477e+00 4.64477e-01 1.00000e-09 2.12000e-01 $4.64477 \mathrm{e}+00$ 4.64477e+00 4.64477e-01 1.00000e-09 2.12000e-01 4.64477e+00 4.64477e+00 4.64477e-01 1.00000e-09 2.12000e-01 $1.00000 \mathrm{e}-02$ 1.00000e-02 1.00000e-03 1.00000e-09 1.00000e-01 $1.00000 \mathrm{e}+001.00000 \mathrm{e}+001.00000 \mathrm{e}-011.00000 \mathrm{e}-091.00000 \mathrm{e}-01$ $1.00000 \mathrm{e}-05$ 1.00000e-05 1.00000e-06 1.00000e-09 1.00000e-01 $1.00000 \mathrm{e}+001.00000 \mathrm{e}+001.00000 \mathrm{e}-011.00000 \mathrm{e}-091.00000 \mathrm{e}-01$ Element: 2100 \# of layers: 15

$\mathrm{Kx} \mathrm{Ky} \mathrm{Kz}$ Ss Por

1.16247e+02 1.16247e+02 1.16247e+01 1.00000e-09 7.00000e-02 $1.16247 \mathrm{e}+02$ 1.16247e+02 1.16247e+01 1.00000e-09 7.00000e-02 $1.16247 \mathrm{e}+02$ 1.16247e+02 1.16247e+01 1.00000e-09 7.00000e-02 $1.16247 \mathrm{e}+02$ 1.16247e+02 1.16247e+01 1.00000e-09 7.00000e-02 5.00000e-04 5.00000e-04 5.00000e-05 1.00000e-09 1.00000e-01 5.00000e-04 5.00000e-04 5.00000e-05 1.00000e-09 1.00000e-01 4.64477e+00 4.64477e+00 4.64477e-01 1.00000e-09 2.12000e-01 4.64477e+00 4.64477e+00 4.64477e-01 1.00000e-09 2.12000e-01 4.64477e+00 4.64477e+00 4.64477e-01 1.00000e-09 2.12000e-01 $4.64477 \mathrm{e}+00$ 4.64477e+00 4.64477e-01 1.00000e-09 2.12000e-01 4.64477e+00 4.64477e+00 4.64477e-01 1.00000e-09 2.12000e-01 $1.00000 \mathrm{e}-02$ 1.00000e-02 1.00000e-03 1.00000e-09 1.00000e-01 $1.00000 \mathrm{e}+001.00000 \mathrm{e}+001.00000 \mathrm{e}-011.00000 \mathrm{e}-091.00000 \mathrm{e}-01$ $1.00000 \mathrm{e}-05$ 1.00000e-05 1.00000e-06 1.00000e-09 1.00000e-01 $1.00000 \mathrm{e}+001.00000 \mathrm{e}+001.00000 \mathrm{e}-01$ 1.00000e-09 1.00000e-01 Element: 2101 \# of layers: 15

$\mathrm{Kx} \mathrm{Ky} \mathrm{Kz}$ Ss Por

1.16247e+02 1.16247e+02 1.16247e+01 1.00000e-09 7.00000e-02 1.16247e+02 1.16247e+02 1.16247e+01 1.00000e-09 7.00000e-02 $1.16247 \mathrm{e}+02$ 1.16247e+02 1.16247e+01 1.00000e-09 7.00000e-02 $1.16247 \mathrm{e}+02$ 1.16247e+02 1.16247e+01 1.00000e-09 7.00000e-02 5.00000e-04 5.00000e-04 5.00000e-05 1.00000e-09 1.00000e-01 5.00000e-04 5.00000e-04 5.00000e-05 1.00000e-09 1.00000e-01 4.64477e+00 4.64477e+00 4.64477e-01 1.00000e-09 2.12000e-01 4.64477e+00 4.64477e+00 4.64477e-01 1.00000e-09 2.12000e-01 $4.64477 \mathrm{e}+004.64477 \mathrm{e}+00$ 4.64477e-01 1.00000e-09 2.12000e-01 4.64477e+00 4.64477e+00 4.64477e-01 1.00000e-09 2.12000e-01 4.64477e+00 4.64477e+00 4.64477e-01 1.00000e-09 2.12000e-01 $1.00000 \mathrm{e}-02$ 1.00000e-02 1.00000e-03 1.00000e-09 1.00000e-01 $1.00000 \mathrm{e}+001.00000 \mathrm{e}+001.00000 \mathrm{e}-011.00000 \mathrm{e}-091.00000 \mathrm{e}-01$ $1.00000 \mathrm{e}-051.00000 \mathrm{e}-051.00000 \mathrm{e}-061.00000 \mathrm{e}-091.00000 \mathrm{e}-01$ $1.00000 \mathrm{e}+001.00000 \mathrm{e}+001.00000 \mathrm{e}-011.00000 \mathrm{e}-091.00000 \mathrm{e}-01$ Element: 2102 \# of layers: 15

$\mathrm{Kx} \mathrm{Ky} \mathrm{Kz}$ Ss Por

1.16247e+02 1.16247e+02 1.16247e+01 1.00000e-09 7.00000e-02 
1.16247e+02 1.16247e+02 1.16247e+01 1.00000e-09 7.00000e-02 1.16247e+02 1.16247e+02 1.16247e+01 1.00000e-09 7.00000e-02 $1.16247 \mathrm{e}+02$ 1.16247e+02 1.16247e+01 1.00000e-09 7.00000e-02 5.00000e-04 5.00000e-04 5.00000e-05 1.00000e-09 1.00000e-01 5.00000e-04 5.00000e-04 5.00000e-05 1.00000e-09 1.00000e-01 4.64477e+00 4.64477e+00 4.64477e-01 1.00000e-09 2.12000e-01 4.64477e+00 4.64477e+00 4.64477e-01 1.00000e-09 2.12000e-01 $4.64477 \mathrm{e}+00$ 4.64477e+00 4.64477e-01 1.00000e-09 2.12000e-01 4.64477e+00 4.64477e+00 4.64477e-01 1.00000e-09 2.12000e-01 4.64477e+00 4.64477e+00 4.64477e-01 1.00000e-09 2.12000e-01 $1.00000 \mathrm{e}-02$ 1.00000e-02 1.00000e-03 1.00000e-09 1.00000e-01 $1.00000 \mathrm{e}+001.00000 \mathrm{e}+001.00000 \mathrm{e}-011.00000 \mathrm{e}-091.00000 \mathrm{e}-01$ $1.00000 \mathrm{e}-05$ 1.00000e-05 1.00000e-06 1.00000e-09 1.00000e-01 $1.00000 \mathrm{e}+001.00000 \mathrm{e}+001.00000 \mathrm{e}-011.00000 \mathrm{e}-09$ 1.00000e-01 Element: 2103 \# of layers: 15

Kx Ky Kz Ss Por

1.16247e+02 1.16247e+02 1.16247e+01 1.00000e-09 7.00000e-02 $1.16247 \mathrm{e}+02$ 1.16247e+02 1.16247e+01 1.00000e-09 7.00000e-02 1.16247e+02 1.16247e+02 1.16247e+01 1.00000e-09 7.00000e-02 1.16247e+02 1.16247e+02 1.16247e+01 1.00000e-09 7.00000e-02 5.00000e-04 5.00000e-04 5.00000e-05 1.00000e-09 1.00000e-01 5.00000e-04 5.00000e-04 5.00000e-05 1.00000e-09 1.00000e-01 4.64477e+00 4.64477e+00 4.64477e-01 1.00000e-09 2.12000e-01 $4.64477 \mathrm{e}+004.64477 \mathrm{e}+00$ 4.64477e-01 1.00000e-09 2.12000e-01 $4.64477 \mathrm{e}+00$ 4.64477e+00 4.64477e-01 1.00000e-09 2.12000e-01 4.64477e+00 4.64477e+00 4.64477e-01 1.00000e-09 2.12000e-01 4.64477e+00 4.64477e+00 4.64477e-01 1.00000e-09 2.12000e-01 $1.00000 \mathrm{e}-02$ 1.00000e-02 1.00000e-03 1.00000e-09 1.00000e-01 $1.00000 \mathrm{e}+001.00000 \mathrm{e}+001.00000 \mathrm{e}-011.00000 \mathrm{e}-091.00000 \mathrm{e}-01$ $1.00000 \mathrm{e}-05$ 1.00000e-05 1.00000e-06 1.00000e-09 1.00000e-01 $1.00000 \mathrm{e}+001.00000 \mathrm{e}+001.00000 \mathrm{e}-011.00000 \mathrm{e}-091.00000 \mathrm{e}-01$ Element: 2104 \# of layers: 15

$\mathrm{Kx} \mathrm{Ky} \mathrm{Kz}$ Ss Por

1.16247e+02 1.16247e+02 1.16247e+01 1.00000e-09 7.00000e-02 $1.16247 \mathrm{e}+02$ 1.16247e+02 1.16247e+01 1.00000e-09 7.00000e-02 $1.16247 \mathrm{e}+02$ 1.16247e+02 1.16247e+01 1.00000e-09 7.00000e-02 $1.16247 \mathrm{e}+021.16247 \mathrm{e}+02$ 1.16247e+01 1.00000e-09 7.00000e-02 5.00000e-04 5.00000e-04 5.00000e-05 1.00000e-09 1.00000e-01 5.00000e-04 5.00000e-04 5.00000e-05 1.00000e-09 1.00000e-01 4.64477e+00 4.64477e+00 4.64477e-01 1.00000e-09 2.12000e-01 $4.64477 \mathrm{e}+00$ 4.64477e+00 4.64477e-01 1.00000e-09 2.12000e-01 4.64477e+00 4.64477e+00 4.64477e-01 1.00000e-09 2.12000e-01 4.64477e+00 4.64477e+00 4.64477e-01 1.00000e-09 2.12000e-01 4.64477e+00 4.64477e+00 4.64477e-01 1.00000e-09 2.12000e-01 1.00000e-02 1.00000e-02 1.00000e-03 1.00000e-09 1.00000e-01 $1.00000 \mathrm{e}+001.00000 \mathrm{e}+001.00000 \mathrm{e}-011.00000 \mathrm{e}-091.00000 \mathrm{e}-01$ 
$1.00000 \mathrm{e}-05$ 1.00000e-05 1.00000e-06 1.00000e-09 1.00000e-01 $1.00000 \mathrm{e}+001.00000 \mathrm{e}+001.00000 \mathrm{e}-01$ 1.00000e-09 1.00000e-01 Element: 2105 \# of layers: 15

Kx Ky Kz Ss Por

1.16247e+02 1.16247e+02 1.16247e+01 1.00000e-09 7.00000e-02 $1.16247 \mathrm{e}+02$ 1.16247e+02 1.16247e+01 1.00000e-09 7.00000e-02 $1.16247 \mathrm{e}+02$ 1.16247e+02 1.16247e+01 1.00000e-09 7.00000e-02 $1.16247 \mathrm{e}+02$ 1.16247e+02 1.16247e+01 1.00000e-09 7.00000e-02 5.00000e-04 5.00000e-04 5.00000e-05 1.00000e-09 1.00000e-01 5.00000e-04 5.00000e-04 5.00000e-05 1.00000e-09 1.00000e-01 4.64477e+00 4.64477e+00 4.64477e-01 1.00000e-09 2.12000e-01 $4.64477 \mathrm{e}+00$ 4.64477e+00 4.64477e-01 1.00000e-09 2.12000e-01 4.64477e+00 4.64477e+00 4.64477e-01 1.00000e-09 2.12000e-01 4.64477e+00 4.64477e+00 4.64477e-01 1.00000e-09 2.12000e-01 4.64477e+00 4.64477e+00 4.64477e-01 1.00000e-09 2.12000e-01 $1.00000 \mathrm{e}-02$ 1.00000e-02 1.00000e-03 1.00000e-09 1.00000e-01 $1.00000 \mathrm{e}+001.00000 \mathrm{e}+001.00000 \mathrm{e}-011.00000 \mathrm{e}-091.00000 \mathrm{e}-01$ $1.00000 \mathrm{e}-05$ 1.00000e-05 1.00000e-06 1.00000e-09 1.00000e-01 $1.00000 \mathrm{e}+001.00000 \mathrm{e}+001.00000 \mathrm{e}-011.00000 \mathrm{e}-091.00000 \mathrm{e}-01$ Element: 2106 \# of layers: 15

$\mathrm{Kx} \mathrm{Ky} \mathrm{Kz}$ Ss Por

1.16247e+02 1.16247e+02 1.16247e+01 1.00000e-09 7.00000e-02 1.16247e+02 1.16247e+02 1.16247e+01 1.00000e-09 7.00000e-02 $1.16247 \mathrm{e}+02$ 1.16247e+02 1.16247e+01 1.00000e-09 7.00000e-02 $1.16247 \mathrm{e}+02$ 1.16247e+02 1.16247e+01 1.00000e-09 7.00000e-02 $5.00000 \mathrm{e}-04$ 5.00000e-04 5.00000e-05 1.00000e-09 1.00000e-01 5.00000e-04 5.00000e-04 5.00000e-05 1.00000e-09 1.00000e-01 4.64477e+00 4.64477e+00 4.64477e-01 1.00000e-09 2.12000e-01 $4.64477 \mathrm{e}+00$ 4.64477e+00 4.64477e-01 1.00000e-09 2.12000e-01 4.64477e+00 4.64477e+00 4.64477e-01 1.00000e-09 2.12000e-01 4.64477e+00 4.64477e+00 4.64477e-01 1.00000e-09 2.12000e-01 4.64477e+00 4.64477e+00 4.64477e-01 1.00000e-09 2.12000e-01 $1.00000 \mathrm{e}-02$ 1.00000e-02 1.00000e-03 1.00000e-09 1.00000e-01 $1.00000 \mathrm{e}+001.00000 \mathrm{e}+001.00000 \mathrm{e}-011.00000 \mathrm{e}-091.00000 \mathrm{e}-01$ $1.00000 \mathrm{e}-05$ 1.00000e-05 1.00000e-06 1.00000e-09 1.00000e-01 $1.00000 \mathrm{e}+001.00000 \mathrm{e}+001.00000 \mathrm{e}-011.00000 \mathrm{e}-091.00000 \mathrm{e}-01$ Element: 2107 \# of layers: 16

$\mathrm{Kx} \mathrm{Ky} \mathrm{Kz}$ Ss Por

1.10147e+02 1.10147e+02 1.10147e+01 1.00000e-09 7.00000e-02 1.10147e+02 1.10147e+02 1.10147e+01 1.00000e-09 7.00000e-02 1.10147e+02 1.10147e+02 1.10147e+01 1.00000e-09 7.00000e-02 $1.10147 \mathrm{e}+02$ 1.10147e+02 1.10147e+01 1.00000e-09 7.00000e-02 $1.10147 \mathrm{e}+02$ 1.10147e+02 1.10147e+01 1.00000e-09 7.00000e-02 5.00000e-04 5.00000e-04 5.00000e-05 1.00000e-09 1.00000e-01 5.00000e-04 5.00000e-04 5.00000e-05 1.00000e-09 1.00000e-01 $4.40087 \mathrm{e}+004.40087 \mathrm{e}+00$ 4.40087e-01 1.00000e-09 2.12000e-01 
4.40087e+00 4.40087e+00 4.40087e-01 1.00000e-09 2.12000e-01 4.40087e+00 4.40087e+00 4.40087e-01 1.00000e-09 2.12000e-01 4.40087e+00 4.40087e+00 4.40087e-01 1.00000e-09 2.12000e-01 $4.40087 \mathrm{e}+00$ 4.40087e+00 4.40087e-01 1.00000e-09 2.12000e-01 $1.00000 \mathrm{e}-021.00000 \mathrm{e}-021.00000 \mathrm{e}-031.00000 \mathrm{e}-091.00000 \mathrm{e}-01$ $1.00000 \mathrm{e}+001.00000 \mathrm{e}+001.00000 \mathrm{e}-011.00000 \mathrm{e}-091.00000 \mathrm{e}-01$ $1.00000 \mathrm{e}-05$ 1.00000e-05 1.00000e-06 1.00000e-09 1.00000e-01 $1.00000 \mathrm{e}+001.00000 \mathrm{e}+001.00000 \mathrm{e}-011.00000 \mathrm{e}-091.00000 \mathrm{e}-01$ Element: 2108 \# of layers: 16

$\mathrm{Kx} \mathrm{Ky} \mathrm{Kz}$ Ss Por

1.10147e+02 1.10147e+02 1.10147e+01 1.00000e-09 7.00000e-02 1.10147e+02 1.10147e+02 1.10147e+01 1.00000e-09 7.00000e-02 1.10147e+02 1.10147e+02 1.10147e+01 1.00000e-09 7.00000e-02 $1.10147 \mathrm{e}+02$ 1.10147e+02 1.10147e+01 1.00000e-09 7.00000e-02 $1.10147 \mathrm{e}+02$ 1.10147e+02 1.10147e+01 1.00000e-09 7.00000e-02 5.00000e-04 5.00000e-04 5.00000e-05 1.00000e-09 1.00000e-01 5.00000e-04 5.00000e-04 5.00000e-05 1.00000e-09 1.00000e-01 4.40087e+00 4.40087e+00 4.40087e-01 1.00000e-09 2.12000e-01 4.40087e+00 4.40087e+00 4.40087e-01 1.00000e-09 2.12000e-01 4.40087e+00 4.40087e+00 4.40087e-01 1.00000e-09 2.12000e-01 4.40087e+00 4.40087e+00 4.40087e-01 1.00000e-09 2.12000e-01 4.40087e+00 4.40087e+00 4.40087e-01 1.00000e-09 2.12000e-01 $1.00000 \mathrm{e}-021.00000 \mathrm{e}-021.00000 \mathrm{e}-031.00000 \mathrm{e}-091.00000 \mathrm{e}-01$ $1.00000 \mathrm{e}+001.00000 \mathrm{e}+001.00000 \mathrm{e}-011.00000 \mathrm{e}-091.00000 \mathrm{e}-01$ $1.00000 \mathrm{e}-051.00000 \mathrm{e}-05$ 1.00000e-06 1.00000e-09 1.00000e-01 $1.00000 \mathrm{e}+001.00000 \mathrm{e}+001.00000 \mathrm{e}-011.00000 \mathrm{e}-091.00000 \mathrm{e}-01$ Element: 2109 \# of layers: 16

$\mathrm{Kx} \mathrm{Ky} \mathrm{Kz}$ Ss Por

1.10147e+02 1.10147e+02 1.10147e+01 1.00000e-09 7.00000e-02 1.10147e+02 1.10147e+02 1.10147e+01 1.00000e-09 7.00000e-02 $1.10147 \mathrm{e}+02$ 1.10147e+02 1.10147e+01 1.00000e-09 7.00000e-02 1.10147e+02 1.10147e+02 1.10147e+01 1.00000e-09 7.00000e-02 $1.10147 \mathrm{e}+02$ 1.10147e+02 1.10147e+01 1.00000e-09 7.00000e-02 5.00000e-04 5.00000e-04 5.00000e-05 1.00000e-09 1.00000e-01 5.00000e-04 5.00000e-04 5.00000e-05 1.00000e-09 1.00000e-01 4.40087e+00 4.40087e+00 4.40087e-01 1.00000e-09 2.12000e-01 4.40087e+00 4.40087e+00 4.40087e-01 1.00000e-09 2.12000e-01 $4.40087 \mathrm{e}+004.40087 \mathrm{e}+00$ 4.40087e-01 1.00000e-09 2.12000e-01 4.40087e+00 4.40087e+00 4.40087e-01 1.00000e-09 2.12000e-01 4.40087e+00 4.40087e+00 4.40087e-01 1.00000e-09 2.12000e-01 $1.00000 \mathrm{e}-02$ 1.00000e-02 1.00000e-03 1.00000e-09 1.00000e-01 $1.00000 \mathrm{e}+001.00000 \mathrm{e}+001.00000 \mathrm{e}-011.00000 \mathrm{e}-091.00000 \mathrm{e}-01$ $1.00000 \mathrm{e}-05$ 1.00000e-05 1.00000e-06 1.00000e-09 1.00000e-01 $1.00000 \mathrm{e}+001.00000 \mathrm{e}+001.00000 \mathrm{e}-01$ 1.00000e-09 1.00000e-01 Element: 2110 \# of layers: 15

Kx Ky Kz Ss Por 
1.10147e+02 1.10147e+02 1.10147e+01 1.00000e-09 7.00000e-02 1.10147e+02 1.10147e+02 1.10147e+01 1.00000e-09 7.00000e-02 $1.10147 \mathrm{e}+02$ 1.10147e+02 1.10147e+01 1.00000e-09 7.00000e-02 $1.10147 \mathrm{e}+02$ 1.10147e+02 1.10147e+01 1.00000e-09 7.00000e-02 5.00000e-04 5.00000e-04 5.00000e-05 1.00000e-09 1.00000e-01 5.00000e-04 5.00000e-04 5.00000e-05 1.00000e-09 1.00000e-01 4.40087e+00 4.40087e+00 4.40087e-01 1.00000e-09 2.12000e-01 4.40087e+00 4.40087e+00 4.40087e-01 1.00000e-09 2.12000e-01 4.40087e+00 4.40087e+00 4.40087e-01 1.00000e-09 2.12000e-01 $4.40087 \mathrm{e}+004.40087 \mathrm{e}+00$ 4.40087e-01 1.00000e-09 2.12000e-01 4.40087e+00 4.40087e+00 4.40087e-01 1.00000e-09 2.12000e-01 $1.00000 \mathrm{e}-02$ 1.00000e-02 1.00000e-03 1.00000e-09 1.00000e-01 $1.00000 \mathrm{e}+001.00000 \mathrm{e}+001.00000 \mathrm{e}-011.00000 \mathrm{e}-091.00000 \mathrm{e}-01$ $1.00000 \mathrm{e}-05$ 1.00000e-05 1.00000e-06 1.00000e-09 1.00000e-01 $1.00000 \mathrm{e}+001.00000 \mathrm{e}+001.00000 \mathrm{e}-01$ 1.00000e-09 1.00000e-01 Element: 2111 \# of layers: 15

$\mathrm{Kx} \mathrm{Ky} \mathrm{Kz}$ Ss Por

1.10147e+02 1.10147e+02 1.10147e+01 1.00000e-09 7.00000e-02 1.10147e+02 1.10147e+02 1.10147e+01 1.00000e-09 7.00000e-02 1.10147e+02 1.10147e+02 1.10147e+01 1.00000e-09 7.00000e-02 $1.10147 \mathrm{e}+02$ 1.10147e+02 1.10147e+01 1.00000e-09 7.00000e-02 5.00000e-04 5.00000e-04 5.00000e-05 1.00000e-09 1.00000e-01 5.00000e-04 5.00000e-04 5.00000e-05 1.00000e-09 1.00000e-01 4.40087e+00 4.40087e+00 4.40087e-01 1.00000e-09 2.12000e-01 $4.40087 \mathrm{e}+00$ 4.40087e+00 4.40087e-01 1.00000e-09 2.12000e-01 4.40087e+00 4.40087e+00 4.40087e-01 1.00000e-09 2.12000e-01 4.40087e+00 4.40087e+00 4.40087e-01 1.00000e-09 2.12000e-01 4.40087e+00 4.40087e+00 4.40087e-01 1.00000e-09 2.12000e-01 $1.00000 \mathrm{e}-02$ 1.00000e-02 1.00000e-03 1.00000e-09 1.00000e-01 $1.00000 \mathrm{e}+001.00000 \mathrm{e}+001.00000 \mathrm{e}-011.00000 \mathrm{e}-091.00000 \mathrm{e}-01$ $1.00000 \mathrm{e}-05$ 1.00000e-05 1.00000e-06 1.00000e-09 1.00000e-01 $1.00000 \mathrm{e}+001.00000 \mathrm{e}+001.00000 \mathrm{e}-011.00000 \mathrm{e}-091.00000 \mathrm{e}-01$ Element: 2112 \# of layers: 15

$\mathrm{Kx} \mathrm{Ky} \mathrm{Kz}$ Ss Por

1.10147e+02 1.10147e+02 1.10147e+01 1.00000e-09 7.00000e-02 1.10147e+02 1.10147e+02 1.10147e+01 1.00000e-09 7.00000e-02 $1.10147 \mathrm{e}+02$ 1.10147e+02 1.10147e+01 1.00000e-09 7.00000e-02 $1.10147 \mathrm{e}+021.10147 \mathrm{e}+02$ 1.10147e+01 1.00000e-09 7.00000e-02 5.00000e-04 5.00000e-04 5.00000e-05 1.00000e-09 1.00000e-01 5.00000e-04 5.00000e-04 5.00000e-05 1.00000e-09 1.00000e-01 4.40087e+00 4.40087e+00 4.40087e-01 1.00000e-09 2.12000e-01 $4.40087 \mathrm{e}+00$ 4.40087e+00 4.40087e-01 1.00000e-09 2.12000e-01 $4.40087 \mathrm{e}+00$ 4.40087e+00 4.40087e-01 1.00000e-09 2.12000e-01 4.40087e+00 4.40087e+00 4.40087e-01 1.00000e-09 2.12000e-01 4.40087e+00 4.40087e+00 4.40087e-01 1.00000e-09 2.12000e-01 $1.00000 \mathrm{e}-02$ 1.00000e-02 1.00000e-03 1.00000e-09 1.00000e-01 
$1.00000 \mathrm{e}+001.00000 \mathrm{e}+001.00000 \mathrm{e}-011.00000 \mathrm{e}-091.00000 \mathrm{e}-01$ $1.00000 \mathrm{e}-05$ 1.00000e-05 1.00000e-06 1.00000e-09 1.00000e-01 $1.00000 \mathrm{e}+001.00000 \mathrm{e}+001.00000 \mathrm{e}-011.00000 \mathrm{e}-09$ 1.00000e-01 Element: 2113 \# of layers: 15

$\mathrm{Kx} \mathrm{Ky} \mathrm{Kz}$ Ss Por

1.10147e+02 1.10147e+02 1.10147e+01 1.00000e-09 7.00000e-02 $1.10147 \mathrm{e}+02$ 1.10147e+02 1.10147e+01 1.00000e-09 7.00000e-02 $1.10147 \mathrm{e}+02$ 1.10147e+02 1.10147e+01 1.00000e-09 7.00000e-02 $1.10147 \mathrm{e}+02$ 1.10147e+02 1.10147e+01 1.00000e-09 7.00000e-02 5.00000e-04 5.00000e-04 5.00000e-05 1.00000e-09 1.00000e-01 5.00000e-04 5.00000e-04 5.00000e-05 1.00000e-09 1.00000e-01 4.40087e+00 4.40087e+00 4.40087e-01 1.00000e-09 2.12000e-01 4.40087e+00 4.40087e+00 4.40087e-01 1.00000e-09 2.12000e-01 4.40087e+00 4.40087e+00 4.40087e-01 1.00000e-09 2.12000e-01 4.40087e+00 4.40087e+00 4.40087e-01 1.00000e-09 2.12000e-01 4.40087e+00 4.40087e+00 4.40087e-01 1.00000e-09 2.12000e-01 $1.00000 \mathrm{e}-02$ 1.00000e-02 1.00000e-03 1.00000e-09 1.00000e-01 $1.00000 \mathrm{e}+001.00000 \mathrm{e}+001.00000 \mathrm{e}-011.00000 \mathrm{e}-091.00000 \mathrm{e}-01$ $1.00000 \mathrm{e}-05$ 1.00000e-05 1.00000e-06 1.00000e-09 1.00000e-01 $1.00000 \mathrm{e}+001.00000 \mathrm{e}+001.00000 \mathrm{e}-011.00000 \mathrm{e}-091.00000 \mathrm{e}-01$ Element: 2114 \# of layers: 15

$\mathrm{Kx} \mathrm{Ky} \mathrm{Kz}$ Ss Por

1.10147e+02 1.10147e+02 1.10147e+01 1.00000e-09 7.00000e-02 $1.10147 \mathrm{e}+02$ 1.10147e+02 1.10147e+01 1.00000e-09 7.00000e-02 $1.10147 \mathrm{e}+02$ 1.10147e+02 1.10147e+01 1.00000e-09 7.00000e-02 $1.10147 \mathrm{e}+021.10147 \mathrm{e}+02$ 1.10147e+01 1.00000e-09 7.00000e-02 5.00000e-04 5.00000e-04 5.00000e-05 1.00000e-09 1.00000e-01 5.00000e-04 5.00000e-04 5.00000e-05 1.00000e-09 1.00000e-01 4.40087e+00 4.40087e+00 4.40087e-01 1.00000e-09 2.12000e-01 4.40087e+00 4.40087e+00 4.40087e-01 1.00000e-09 2.12000e-01 4.40087e+00 4.40087e+00 4.40087e-01 1.00000e-09 2.12000e-01 4.40087e+00 4.40087e+00 4.40087e-01 1.00000e-09 2.12000e-01 4.40087e+00 4.40087e+00 4.40087e-01 1.00000e-09 2.12000e-01 $1.00000 \mathrm{e}-02$ 1.00000e-02 1.00000e-03 1.00000e-09 1.00000e-01 $1.00000 \mathrm{e}+001.00000 \mathrm{e}+001.00000 \mathrm{e}-011.00000 \mathrm{e}-091.00000 \mathrm{e}-01$ $1.00000 \mathrm{e}-05$ 1.00000e-05 1.00000e-06 1.00000e-09 1.00000e-01 $1.00000 \mathrm{e}+001.00000 \mathrm{e}+001.00000 \mathrm{e}-011.00000 \mathrm{e}-091.00000 \mathrm{e}-01$ Element: 2115 \# of layers: 15

Kx Ky Kz Ss Por

1.10147e+02 1.10147e+02 1.10147e+01 1.00000e-09 7.00000e-02 1.10147e+02 1.10147e+02 1.10147e+01 1.00000e-09 7.00000e-02 1.10147e+02 1.10147e+02 1.10147e+01 1.00000e-09 7.00000e-02 1.10147e+02 1.10147e+02 1.10147e+01 1.00000e-09 7.00000e-02 5.00000e-04 5.00000e-04 5.00000e-05 1.00000e-09 1.00000e-01 5.00000e-04 5.00000e-04 5.00000e-05 1.00000e-09 1.00000e-01 $4.40087 \mathrm{e}+00$ 4.40087e+00 4.40087e-01 1.00000e-09 2.12000e-01 
4.40087e+00 4.40087e+00 4.40087e-01 1.00000e-09 2.12000e-01 4.40087e+00 4.40087e+00 4.40087e-01 1.00000e-09 2.12000e-01 4.40087e+00 4.40087e+00 4.40087e-01 1.00000e-09 2.12000e-01 $4.40087 \mathrm{e}+00$ 4.40087e+00 4.40087e-01 1.00000e-09 2.12000e-01 $1.00000 \mathrm{e}-021.00000 \mathrm{e}-021.00000 \mathrm{e}-031.00000 \mathrm{e}-091.00000 \mathrm{e}-01$ $1.00000 \mathrm{e}+001.00000 \mathrm{e}+001.00000 \mathrm{e}-011.00000 \mathrm{e}-091.00000 \mathrm{e}-01$ $1.00000 \mathrm{e}-05$ 1.00000e-05 1.00000e-06 1.00000e-09 1.00000e-01 $1.00000 \mathrm{e}+001.00000 \mathrm{e}+001.00000 \mathrm{e}-011.00000 \mathrm{e}-091.00000 \mathrm{e}-01$ Element: 2116 \# of layers: 16

$\mathrm{Kx} \mathrm{Ky} \mathrm{Kz}$ Ss Por

5.13273e+01 5.13273e+01 5.13273e+00 1.00000e-09 7.00000e-02 5.13273e+01 5.13273e+01 5.13273e+00 1.00000e-09 7.00000e-02 5.13273e+01 5.13273e+01 5.13273e+00 1.00000e-09 7.00000e-02 5.13273e+01 5.13273e+01 5.13273e+00 1.00000e-09 7.00000e-02 $5.13273 \mathrm{e}+015.13273 \mathrm{e}+015.13273 \mathrm{e}+001.00000 \mathrm{e}-09$ 7.00000e-02 5.00000e-04 5.00000e-04 5.00000e-05 1.00000e-09 1.00000e-01 5.00000e-04 5.00000e-04 5.00000e-05 1.00000e-09 1.00000e-01 $2.05083 \mathrm{e}+002.05083 \mathrm{e}+002.05083 \mathrm{e}-01$ 1.00000e-09 2.12000e-01 $2.05083 \mathrm{e}+00$ 2.05083e+00 2.05083e-01 1.00000e-09 2.12000e-01 $2.05083 \mathrm{e}+002.05083 \mathrm{e}+00$ 2.05083e-01 1.00000e-09 2.12000e-01 $2.05083 \mathrm{e}+002.05083 \mathrm{e}+00$ 2.05083e-01 1.00000e-09 2.12000e-01 $2.05083 \mathrm{e}+00$ 2.05083e+00 2.05083e-01 1.00000e-09 2.12000e-01 $1.00000 \mathrm{e}-02$ 1.00000e-02 1.00000e-03 1.00000e-09 1.00000e-01 $1.00000 \mathrm{e}+001.00000 \mathrm{e}+001.00000 \mathrm{e}-011.00000 \mathrm{e}-091.00000 \mathrm{e}-01$ $1.00000 \mathrm{e}-05$ 1.00000e-05 1.00000e-06 1.00000e-09 1.00000e-01 $1.00000 \mathrm{e}+001.00000 \mathrm{e}+001.00000 \mathrm{e}-01$ 1.00000e-09 1.00000e-01 Element: 2117 \# of layers: 16

$\mathrm{Kx} \mathrm{Ky} \mathrm{Kz}$ Ss Por

5.13273e+01 5.13273e+01 5.13273e+00 1.00000e-09 7.00000e-02 5.13273e+01 5.13273e+01 5.13273e+00 1.00000e-09 7.00000e-02 5.13273e+01 5.13273e+01 5.13273e+00 1.00000e-09 7.00000e-02 $5.13273 \mathrm{e}+015.13273 \mathrm{e}+01$ 5.13273e+00 1.00000e-09 7.00000e-02 $5.13273 \mathrm{e}+015.13273 \mathrm{e}+015.13273 \mathrm{e}+00$ 1.00000e-09 7.00000e-02 5.00000e-04 5.00000e-04 5.00000e-05 1.00000e-09 1.00000e-01 5.00000e-04 5.00000e-04 5.00000e-05 1.00000e-09 1.00000e-01 $2.05083 \mathrm{e}+002.05083 \mathrm{e}+00$ 2.05083e-01 1.00000e-09 2.12000e-01 $2.05083 \mathrm{e}+002.05083 \mathrm{e}+00$ 2.05083e-01 1.00000e-09 2.12000e-01 $2.05083 \mathrm{e}+002.05083 \mathrm{e}+00$ 2.05083e-01 1.00000e-09 2.12000e-01 $2.05083 \mathrm{e}+002.05083 \mathrm{e}+00$ 2.05083e-01 1.00000e-09 2.12000e-01 $2.05083 \mathrm{e}+002.05083 \mathrm{e}+00$ 2.05083e-01 1.00000e-09 2.12000e-01 $1.00000 \mathrm{e}-02$ 1.00000e-02 1.00000e-03 1.00000e-09 1.00000e-01 $1.00000 \mathrm{e}+001.00000 \mathrm{e}+001.00000 \mathrm{e}-011.00000 \mathrm{e}-091.00000 \mathrm{e}-01$ $1.00000 \mathrm{e}-05$ 1.00000e-05 1.00000e-06 1.00000e-09 1.00000e-01 $1.00000 \mathrm{e}+001.00000 \mathrm{e}+001.00000 \mathrm{e}-01$ 1.00000e-09 1.00000e-01 Element: 2118 \# of layers: 16

Kx Ky Kz Ss Por 
5.13273e+01 5.13273e+01 5.13273e+00 1.00000e-09 7.00000e-02 5.13273e+01 5.13273e+01 5.13273e+00 1.00000e-09 7.00000e-02 5.13273e+01 5.13273e+01 5.13273e+00 1.00000e-09 7.00000e-02 $5.13273 e+015.13273 e+015.13273 e+001.00000 e-09$ 7.00000e-02 $5.13273 \mathrm{e}+015.13273 \mathrm{e}+015.13273 \mathrm{e}+001.00000 \mathrm{e}-09$ 7.00000e-02 5.00000e-04 5.00000e-04 5.00000e-05 1.00000e-09 1.00000e-01 5.00000e-04 5.00000e-04 5.00000e-05 1.00000e-09 1.00000e-01 $2.05083 \mathrm{e}+002.05083 \mathrm{e}+00$ 2.05083e-01 1.00000e-09 2.12000e-01 $2.05083 \mathrm{e}+002.05083 \mathrm{e}+00$ 2.05083e-01 1.00000e-09 2.12000e-01 $2.05083 \mathrm{e}+002.05083 \mathrm{e}+00$ 2.05083e-01 1.00000e-09 2.12000e-01 $2.05083 \mathrm{e}+002.05083 \mathrm{e}+00$ 2.05083e-01 1.00000e-09 2.12000e-01 $2.05083 \mathrm{e}+002.05083 \mathrm{e}+002.05083 \mathrm{e}-01$ 1.00000e-09 2.12000e-01 $1.00000 \mathrm{e}-02$ 1.00000e-02 1.00000e-03 1.00000e-09 1.00000e-01 $1.00000 \mathrm{e}+001.00000 \mathrm{e}+001.00000 \mathrm{e}-011.00000 \mathrm{e}-091.00000 \mathrm{e}-01$ $1.00000 \mathrm{e}-05$ 1.00000e-05 1.00000e-06 1.00000e-09 1.00000e-01 $1.00000 \mathrm{e}+001.00000 \mathrm{e}+001.00000 \mathrm{e}-011.00000 \mathrm{e}-091.00000 \mathrm{e}-01$ Element: 2119 \# of layers: 16

$\mathrm{Kx} \mathrm{Ky} \mathrm{Kz} \mathrm{Ss} \mathrm{Por}$

5.13273e+01 5.13273e+01 5.13273e+00 1.00000e-09 7.00000e-02 5.13273e+01 5.13273e+01 5.13273e+00 1.00000e-09 7.00000e-02 5.13273e+01 5.13273e+01 5.13273e+00 1.00000e-09 7.00000e-02 5.13273e+01 5.13273e+01 5.13273e+00 1.00000e-09 7.00000e-02 5.13273e+01 5.13273e+01 5.13273e+00 1.00000e-09 7.00000e-02 5.00000e-04 5.00000e-04 5.00000e-05 1.00000e-09 1.00000e-01 $5.00000 \mathrm{e}-04$ 5.00000e-04 5.00000e-05 1.00000e-09 1.00000e-01 $2.05083 \mathrm{e}+002.05083 \mathrm{e}+00$ 2.05083e-01 1.00000e-09 2.12000e-01 $2.05083 \mathrm{e}+002.05083 \mathrm{e}+002.05083 \mathrm{e}-01$ 1.00000e-09 2.12000e-01 $2.05083 \mathrm{e}+002.05083 \mathrm{e}+00$ 2.05083e-01 1.00000e-09 2.12000e-01 $2.05083 \mathrm{e}+002.05083 \mathrm{e}+002.05083 \mathrm{e}-01$ 1.00000e-09 2.12000e-01 $2.05083 \mathrm{e}+002.05083 \mathrm{e}+002.05083 \mathrm{e}-01$ 1.00000e-09 2.12000e-01 $1.00000 \mathrm{e}-02$ 1.00000e-02 1.00000e-03 1.00000e-09 1.00000e-01 $1.00000 \mathrm{e}+001.00000 \mathrm{e}+001.00000 \mathrm{e}-011.00000 \mathrm{e}-091.00000 \mathrm{e}-01$ $1.00000 \mathrm{e}-05$ 1.00000e-05 1.00000e-06 1.00000e-09 1.00000e-01 $1.00000 \mathrm{e}+001.00000 \mathrm{e}+001.00000 \mathrm{e}-011.00000 \mathrm{e}-091.00000 \mathrm{e}-01$ Element: 2120 \# of layers: 15

$\mathrm{Kx} \mathrm{Ky} \mathrm{Kz}$ Ss Por

5.13273e+01 5.13273e+01 5.13273e+00 1.00000e-09 7.00000e-02 $5.13273 \mathrm{e}+015.13273 \mathrm{e}+015.13273 \mathrm{e}+00$ 1.00000e-09 7.00000e-02 5.13273e+01 5.13273e+01 5.13273e+00 1.00000e-09 7.00000e-02 $5.13273 \mathrm{e}+015.13273 \mathrm{e}+015.13273 \mathrm{e}+001.00000 \mathrm{e}-09$ 7.00000e-02 5.00000e-04 5.00000e-04 5.00000e-05 1.00000e-09 1.00000e-01 5.00000e-04 5.00000e-04 5.00000e-05 1.00000e-09 1.00000e-01 $2.05083 \mathrm{e}+002.05083 \mathrm{e}+002.05083 \mathrm{e}-01$ 1.00000e-09 2.12000e-01 2.05083e+00 2.05083e+00 2.05083e-01 1.00000e-09 2.12000e-01 $2.05083 \mathrm{e}+002.05083 \mathrm{e}+00$ 2.05083e-01 1.00000e-09 2.12000e-01 $2.05083 \mathrm{e}+002.05083 \mathrm{e}+00$ 2.05083e-01 1.00000e-09 2.12000e-01 
$2.05083 \mathrm{e}+00$ 2.05083e+00 2.05083e-01 1.00000e-09 2.12000e-01 $1.00000 \mathrm{e}-02$ 1.00000e-02 1.00000e-03 1.00000e-09 1.00000e-01 $1.00000 \mathrm{e}+001.00000 \mathrm{e}+001.00000 \mathrm{e}-011.00000 \mathrm{e}-091.00000 \mathrm{e}-01$ $1.00000 \mathrm{e}-05$ 1.00000e-05 1.00000e-06 1.00000e-09 1.00000e-01 $1.00000 \mathrm{e}+001.00000 \mathrm{e}+001.00000 \mathrm{e}-011.00000 \mathrm{e}-091.00000 \mathrm{e}-01$ Element: 2121 \# of layers: 16

$\mathrm{Kx} \mathrm{Ky} \mathrm{Kz}$ Ss Por

5.13273e+01 5.13273e+01 5.13273e+00 1.00000e-09 7.00000e-02 5.13273e+01 5.13273e+01 5.13273e+00 1.00000e-09 7.00000e-02 5.13273e+01 5.13273e+01 5.13273e+00 1.00000e-09 7.00000e-02 $5.13273 \mathrm{e}+015.13273 \mathrm{e}+01$ 5.13273e+00 1.00000e-09 7.00000e-02 $5.13273 \mathrm{e}+015.13273 \mathrm{e}+015.13273 \mathrm{e}+001.00000 \mathrm{e}-09$ 7.00000e-02 5.00000e-04 5.00000e-04 5.00000e-05 1.00000e-09 1.00000e-01 5.00000e-04 5.00000e-04 5.00000e-05 1.00000e-09 1.00000e-01 $2.05083 \mathrm{e}+002.05083 \mathrm{e}+00$ 2.05083e-01 1.00000e-09 2.12000e-01 $2.05083 \mathrm{e}+002.05083 \mathrm{e}+00$ 2.05083e-01 1.00000e-09 2.12000e-01 $2.05083 \mathrm{e}+002.05083 \mathrm{e}+00$ 2.05083e-01 1.00000e-09 2.12000e-01 $2.05083 \mathrm{e}+00$ 2.05083e+00 2.05083e-01 1.00000e-09 2.12000e-01 $2.05083 \mathrm{e}+002.05083 \mathrm{e}+00$ 2.05083e-01 1.00000e-09 2.12000e-01 $1.00000 \mathrm{e}-02$ 1.00000e-02 1.00000e-03 1.00000e-09 1.00000e-01 $1.00000 \mathrm{e}+001.00000 \mathrm{e}+001.00000 \mathrm{e}-011.00000 \mathrm{e}-091.00000 \mathrm{e}-01$ $1.00000 \mathrm{e}-05$ 1.00000e-05 1.00000e-06 1.00000e-09 1.00000e-01 $1.00000 \mathrm{e}+001.00000 \mathrm{e}+001.00000 \mathrm{e}-01$ 1.00000e-09 1.00000e-01 Element: 2122 \# of layers: 15

Kx Ky Kz Ss Por

5.13273e+01 5.13273e+01 5.13273e+00 1.00000e-09 7.00000e-02 5.13273e+01 5.13273e+01 5.13273e+00 1.00000e-09 7.00000e-02 $5.13273 \mathrm{e}+015.13273 \mathrm{e}+01$ 5.13273e+00 1.00000e-09 7.00000e-02 $5.13273 \mathrm{e}+015.13273 \mathrm{e}+015.13273 \mathrm{e}+001.00000 \mathrm{e}-09$ 7.00000e-02 5.00000e-04 5.00000e-04 5.00000e-05 1.00000e-09 1.00000e-01 5.00000e-04 5.00000e-04 5.00000e-05 1.00000e-09 1.00000e-01 $2.05083 \mathrm{e}+002.05083 \mathrm{e}+00$ 2.05083e-01 1.00000e-09 2.12000e-01 $2.05083 \mathrm{e}+002.05083 \mathrm{e}+00$ 2.05083e-01 1.00000e-09 2.12000e-01 $2.05083 \mathrm{e}+002.05083 \mathrm{e}+002.05083 \mathrm{e}-01$ 1.00000e-09 2.12000e-01 $2.05083 \mathrm{e}+002.05083 \mathrm{e}+00$ 2.05083e-01 1.00000e-09 2.12000e-01 $2.05083 \mathrm{e}+002.05083 \mathrm{e}+00$ 2.05083e-01 1.00000e-09 2.12000e-01 $1.00000 \mathrm{e}-02$ 1.00000e-02 1.00000e-03 1.00000e-09 1.00000e-01 $1.00000 \mathrm{e}+001.00000 \mathrm{e}+001.00000 \mathrm{e}-011.00000 \mathrm{e}-091.00000 \mathrm{e}-01$ $1.00000 \mathrm{e}-05$ 1.00000e-05 1.00000e-06 1.00000e-09 1.00000e-01 $1.00000 \mathrm{e}+001.00000 \mathrm{e}+001.00000 \mathrm{e}-011.00000 \mathrm{e}-091.00000 \mathrm{e}-01$ Element: 2123 \# of layers: 15

$\mathrm{Kx} \mathrm{Ky} \mathrm{Kz}$ Ss Por

5.13273e+01 5.13273e+01 5.13273e+00 1.00000e-09 7.00000e-02 5.13273e+01 5.13273e+01 5.13273e+00 1.00000e-09 7.00000e-02 5.13273e+01 5.13273e+01 5.13273e+00 1.00000e-09 7.00000e-02 $5.13273 e+015.13273 e+015.13273 e+001.00000 e-09$ 7.00000e-02 
5.00000e-04 5.00000e-04 5.00000e-05 1.00000e-09 1.00000e-01 5.00000e-04 5.00000e-04 5.00000e-05 1.00000e-09 1.00000e-01 $2.05083 \mathrm{e}+002.05083 \mathrm{e}+00$ 2.05083e-01 1.00000e-09 2.12000e-01 $2.05083 \mathrm{e}+002.05083 \mathrm{e}+002.05083 \mathrm{e}-01$ 1.00000e-09 2.12000e-01 $2.05083 \mathrm{e}+002.05083 \mathrm{e}+00$ 2.05083e-01 1.00000e-09 2.12000e-01 $2.05083 \mathrm{e}+002.05083 \mathrm{e}+00$ 2.05083e-01 1.00000e-09 2.12000e-01 $2.05083 \mathrm{e}+002.05083 \mathrm{e}+00$ 2.05083e-01 1.00000e-09 2.12000e-01 $1.00000 \mathrm{e}-02$ 1.00000e-02 1.00000e-03 1.00000e-09 1.00000e-01 $1.00000 \mathrm{e}+001.00000 \mathrm{e}+001.00000 \mathrm{e}-011.00000 \mathrm{e}-091.00000 \mathrm{e}-01$ $1.00000 \mathrm{e}-05$ 1.00000e-05 1.00000e-06 1.00000e-09 1.00000e-01 $1.00000 \mathrm{e}+001.00000 \mathrm{e}+001.00000 \mathrm{e}-011.00000 \mathrm{e}-091.00000 \mathrm{e}-01$ Element: 2124 \# of layers: 16

Kx Ky Kz Ss Por

5.13273e+01 5.13273e+01 5.13273e+00 1.00000e-09 7.00000e-02 5.13273e+01 5.13273e+01 5.13273e+00 1.00000e-09 7.00000e-02 $5.13273 \mathrm{e}+015.13273 \mathrm{e}+015.13273 \mathrm{e}+00$ 1.00000e-09 7.00000e-02 5.13273e+01 5.13273e+01 5.13273e+00 1.00000e-09 7.00000e-02 $5.13273 \mathrm{e}+015.13273 \mathrm{e}+015.13273 \mathrm{e}+00$ 1.00000e-09 7.00000e-02 5.00000e-04 5.00000e-04 5.00000e-05 1.00000e-09 1.00000e-01 5.00000e-04 5.00000e-04 5.00000e-05 1.00000e-09 1.00000e-01 $2.05083 \mathrm{e}+002.05083 \mathrm{e}+00$ 2.05083e-01 1.00000e-09 2.12000e-01 $2.05083 \mathrm{e}+002.05083 \mathrm{e}+00$ 2.05083e-01 1.00000e-09 2.12000e-01 $2.05083 \mathrm{e}+002.05083 \mathrm{e}+00$ 2.05083e-01 1.00000e-09 2.12000e-01 $2.05083 \mathrm{e}+002.05083 \mathrm{e}+002.05083 \mathrm{e}-01$ 1.00000e-09 2.12000e-01 $2.05083 \mathrm{e}+002.05083 \mathrm{e}+002.05083 \mathrm{e}-01$ 1.00000e-09 2.12000e-01 $1.00000 \mathrm{e}-021.00000 \mathrm{e}-02$ 1.00000e-03 1.00000e-09 1.00000e-01 $1.00000 \mathrm{e}+001.00000 \mathrm{e}+001.00000 \mathrm{e}-011.00000 \mathrm{e}-091.00000 \mathrm{e}-01$ $1.00000 \mathrm{e}-05$ 1.00000e-05 1.00000e-06 1.00000e-09 1.00000e-01 $1.00000 \mathrm{e}+001.00000 \mathrm{e}+001.00000 \mathrm{e}-011.00000 \mathrm{e}-091.00000 \mathrm{e}-01$ Element: 2125 \# of layers: 15

$\mathrm{Kx} \mathrm{Ky} \mathrm{Kz}$ Ss Por

4.06081e+01 4.06081e+01 4.06081e+00 1.00000e-09 7.00000e-02 $4.06081 \mathrm{e}+014.06081 \mathrm{e}+014.06081 \mathrm{e}+001.00000 \mathrm{e}-09$ 7.00000e-02 $4.06081 \mathrm{e}+014.06081 \mathrm{e}+014.06081 \mathrm{e}+001.00000 \mathrm{e}-09$ 7.00000e-02 $4.06081 \mathrm{e}+014.06081 \mathrm{e}+014.06081 \mathrm{e}+001.00000 \mathrm{e}-09$ 7.00000e-02 5.00000e-04 5.00000e-04 5.00000e-05 1.00000e-09 1.00000e-01 5.00000e-04 5.00000e-04 5.00000e-05 1.00000e-09 1.00000e-01 $1.62256 \mathrm{e}+001.62256 \mathrm{e}+001.62256 \mathrm{e}-011.00000 \mathrm{e}-092.12000 \mathrm{e}-01$ $1.62256 \mathrm{e}+001.62256 \mathrm{e}+00$ 1.62256e-01 1.00000e-09 2.12000e-01 $1.62256 \mathrm{e}+001.62256 \mathrm{e}+001.62256 \mathrm{e}-01$ 1.00000e-09 2.12000e-01 $1.62256 \mathrm{e}+001.62256 \mathrm{e}+001.62256 \mathrm{e}-011.00000 \mathrm{e}-092.12000 \mathrm{e}-01$ $1.62256 \mathrm{e}+001.62256 \mathrm{e}+001.62256 \mathrm{e}-011.00000 \mathrm{e}-092.12000 \mathrm{e}-01$ $1.00000 \mathrm{e}-02$ 1.00000e-02 1.00000e-03 1.00000e-09 1.00000e-01 $1.00000 \mathrm{e}+001.00000 \mathrm{e}+001.00000 \mathrm{e}-011.00000 \mathrm{e}-091.00000 \mathrm{e}-01$ $1.00000 \mathrm{e}-05$ 1.00000e-05 1.00000e-06 1.00000e-09 1.00000e-01 $1.00000 \mathrm{e}+001.00000 \mathrm{e}+001.00000 \mathrm{e}-011.00000 \mathrm{e}-091.00000 \mathrm{e}-01$ 
Element: 2126 \# of layers: 16

$\mathrm{Kx} \mathrm{Ky} \mathrm{Kz}$ Ss Por

4.06081e+01 4.06081e+01 4.06081e+00 1.00000e-09 7.00000e-02

$4.06081 \mathrm{e}+014.06081 \mathrm{e}+014.06081 \mathrm{e}+001.00000 \mathrm{e}-09$ 7.00000e-02

$4.06081 \mathrm{e}+014.06081 \mathrm{e}+014.06081 \mathrm{e}+001.00000 \mathrm{e}-097.00000 \mathrm{e}-02$

$4.06081 \mathrm{e}+014.06081 \mathrm{e}+014.06081 \mathrm{e}+001.00000 \mathrm{e}-09$ 7.00000e-02

$4.06081 \mathrm{e}+014.06081 \mathrm{e}+014.06081 \mathrm{e}+001.00000 \mathrm{e}-09$ 7.00000e-02

5.00000e-04 5.00000e-04 5.00000e-05 1.00000e-09 1.00000e-01

$5.00000 \mathrm{e}-04$ 5.00000e-04 5.00000e-05 1.00000e-09 1.00000e-01

$1.62256 \mathrm{e}+001.62256 \mathrm{e}+001.62256 \mathrm{e}-01$ 1.00000e-09 2.12000e-01

$1.62256 \mathrm{e}+001.62256 \mathrm{e}+001.62256 \mathrm{e}-01$ 1.00000e-09 2.12000e-01

$1.62256 \mathrm{e}+001.62256 \mathrm{e}+001.62256 \mathrm{e}-011.00000 \mathrm{e}-092.12000 \mathrm{e}-01$

$1.62256 \mathrm{e}+001.62256 \mathrm{e}+00$ 1.62256e-01 1.00000e-09 2.12000e-01

$1.62256 \mathrm{e}+001.62256 \mathrm{e}+001.62256 \mathrm{e}-01$ 1.00000e-09 2.12000e-01

$1.00000 \mathrm{e}-02$ 1.00000e-02 1.00000e-03 1.00000e-09 1.00000e-01

$1.00000 \mathrm{e}+001.00000 \mathrm{e}+001.00000 \mathrm{e}-011.00000 \mathrm{e}-091.00000 \mathrm{e}-01$

$1.00000 \mathrm{e}-05$ 1.00000e-05 1.00000e-06 1.00000e-09 1.00000e-01

$1.00000 \mathrm{e}+001.00000 \mathrm{e}+001.00000 \mathrm{e}-01$ 1.00000e-09 1.00000e-01

Element: 2127 \# of layers: 15

$\mathrm{Kx} \mathrm{Ky} \mathrm{Kz}$ Ss Por

4.06081e+01 4.06081e+01 4.06081e+00 1.00000e-09 7.00000e-02

$4.06081 \mathrm{e}+014.06081 \mathrm{e}+014.06081 \mathrm{e}+001.00000 \mathrm{e}-09$ 7.00000e-02

$4.06081 \mathrm{e}+014.06081 \mathrm{e}+014.06081 \mathrm{e}+001.00000 \mathrm{e}-09$ 7.00000e-02

$4.06081 \mathrm{e}+014.06081 \mathrm{e}+014.06081 \mathrm{e}+001.00000 \mathrm{e}-09$ 7.00000e-02

5.00000e-04 5.00000e-04 5.00000e-05 1.00000e-09 1.00000e-01

$5.00000 \mathrm{e}-04$ 5.00000e-04 5.00000e-05 1.00000e-09 1.00000e-01

$1.62256 \mathrm{e}+001.62256 \mathrm{e}+001.62256 \mathrm{e}-011.00000 \mathrm{e}-092.12000 \mathrm{e}-01$

$1.62256 \mathrm{e}+001.62256 \mathrm{e}+001.62256 \mathrm{e}-011.00000 \mathrm{e}-092.12000 \mathrm{e}-01$

$1.62256 \mathrm{e}+001.62256 \mathrm{e}+001.62256 \mathrm{e}-011.00000 \mathrm{e}-092.12000 \mathrm{e}-01$

$1.62256 \mathrm{e}+001.62256 \mathrm{e}+00$ 1.62256e-01 1.00000e-09 2.12000e-01

$1.62256 \mathrm{e}+001.62256 \mathrm{e}+00$ 1.62256e-01 1.00000e-09 2.12000e-01

1.00000e-02 1.00000e-02 1.00000e-03 1.00000e-09 1.00000e-01

$1.00000 \mathrm{e}+001.00000 \mathrm{e}+001.00000 \mathrm{e}-011.00000 \mathrm{e}-091.00000 \mathrm{e}-01$

$1.00000 \mathrm{e}-05$ 1.00000e-05 1.00000e-06 1.00000e-09 1.00000e-01

$1.00000 \mathrm{e}+001.00000 \mathrm{e}+001.00000 \mathrm{e}-011.00000 \mathrm{e}-091.00000 \mathrm{e}-01$

Element: 2128 \# of layers: 15

$\mathrm{Kx} \mathrm{Ky} \mathrm{Kz}$ Ss Por

4.06081e+01 4.06081e+01 4.06081e+00 1.00000e-09 7.00000e-02

$4.06081 \mathrm{e}+014.06081 \mathrm{e}+014.06081 \mathrm{e}+001.00000 \mathrm{e}-09$ 7.00000e-02

$4.06081 \mathrm{e}+014.06081 \mathrm{e}+014.06081 \mathrm{e}+001.00000 \mathrm{e}-09$ 7.00000e-02

$4.06081 \mathrm{e}+014.06081 \mathrm{e}+014.06081 \mathrm{e}+001.00000 \mathrm{e}-09$ 7.00000e-02

5.00000e-04 5.00000e-04 5.00000e-05 1.00000e-09 1.00000e-01

5.00000e-04 5.00000e-04 5.00000e-05 1.00000e-09 1.00000e-01

$1.62256 \mathrm{e}+001.62256 \mathrm{e}+00$ 1.62256e-01 1.00000e-09 2.12000e-01

$1.62256 \mathrm{e}+001.62256 \mathrm{e}+001.62256 \mathrm{e}-011.00000 \mathrm{e}-092.12000 \mathrm{e}-01$

$1.62256 \mathrm{e}+001.62256 \mathrm{e}+001.62256 \mathrm{e}-011.00000 \mathrm{e}-092.12000 \mathrm{e}-01$ 
$1.62256 \mathrm{e}+001.62256 \mathrm{e}+00$ 1.62256e-01 1.00000e-09 2.12000e-01 $1.62256 \mathrm{e}+001.62256 \mathrm{e}+001.62256 \mathrm{e}-01$ 1.00000e-09 2.12000e-01 $1.00000 \mathrm{e}-02$ 1.00000e-02 1.00000e-03 1.00000e-09 1.00000e-01 $1.00000 \mathrm{e}+001.00000 \mathrm{e}+001.00000 \mathrm{e}-011.00000 \mathrm{e}-091.00000 \mathrm{e}-01$ $1.00000 \mathrm{e}-05$ 1.00000e-05 1.00000e-06 1.00000e-09 1.00000e-01 $1.00000 \mathrm{e}+001.00000 \mathrm{e}+001.00000 \mathrm{e}-011.00000 \mathrm{e}-091.00000 \mathrm{e}-01$ Element: 2129 \# of layers: 15

$\mathrm{Kx} \mathrm{Ky} \mathrm{Kz}$ Ss Por 4.06081e+01 4.06081e+01 4.06081e+00 1.00000e-09 7.00000e-02 $4.06081 \mathrm{e}+014.06081 \mathrm{e}+014.06081 \mathrm{e}+001.00000 \mathrm{e}-09$ 7.00000e-02 $4.06081 \mathrm{e}+014.06081 \mathrm{e}+014.06081 \mathrm{e}+001.00000 \mathrm{e}-09$ 7.00000e-02 $4.06081 \mathrm{e}+014.06081 \mathrm{e}+014.06081 \mathrm{e}+001.00000 \mathrm{e}-097.00000 \mathrm{e}-02$ 5.00000e-04 5.00000e-04 5.00000e-05 1.00000e-09 1.00000e-01 5.00000e-04 5.00000e-04 5.00000e-05 1.00000e-09 1.00000e-01 $1.62256 \mathrm{e}+001.62256 \mathrm{e}+001.62256 \mathrm{e}-01$ 1.00000e-09 2.12000e-01 $1.62256 \mathrm{e}+001.62256 \mathrm{e}+001.62256 \mathrm{e}-011.00000 \mathrm{e}-092.12000 \mathrm{e}-01$ $1.62256 \mathrm{e}+001.62256 \mathrm{e}+001.62256 \mathrm{e}-011.00000 \mathrm{e}-092.12000 \mathrm{e}-01$ $1.62256 \mathrm{e}+001.62256 \mathrm{e}+001.62256 \mathrm{e}-01$ 1.00000e-09 2.12000e-01 $1.62256 \mathrm{e}+001.62256 \mathrm{e}+001.62256 \mathrm{e}-01$ 1.00000e-09 2.12000e-01 $1.00000 \mathrm{e}-02$ 1.00000e-02 1.00000e-03 1.00000e-09 1.00000e-01 $1.00000 \mathrm{e}+001.00000 \mathrm{e}+001.00000 \mathrm{e}-011.00000 \mathrm{e}-091.00000 \mathrm{e}-01$ $1.00000 \mathrm{e}-05$ 1.00000e-05 1.00000e-06 1.00000e-09 1.00000e-01 $1.00000 \mathrm{e}+001.00000 \mathrm{e}+001.00000 \mathrm{e}-01$ 1.00000e-09 1.00000e-01 Element: 2130 \# of layers: 15

$\mathrm{Kx} \mathrm{Ky} \mathrm{Kz}$ Ss Por 4.06081e+01 4.06081e+01 4.06081e+00 1.00000e-09 7.00000e-02 $4.06081 \mathrm{e}+014.06081 \mathrm{e}+014.06081 \mathrm{e}+001.00000 \mathrm{e}-09$ 7.00000e-02 $4.06081 \mathrm{e}+014.06081 \mathrm{e}+014.06081 \mathrm{e}+001.00000 \mathrm{e}-09$ 7.00000e-02 $4.06081 \mathrm{e}+014.06081 \mathrm{e}+014.06081 \mathrm{e}+001.00000 \mathrm{e}-09$ 7.00000e-02 5.00000e-04 5.00000e-04 5.00000e-05 1.00000e-09 1.00000e-01 5.00000e-04 5.00000e-04 5.00000e-05 1.00000e-09 1.00000e-01 $1.62256 \mathrm{e}+001.62256 \mathrm{e}+001.62256 \mathrm{e}-01$ 1.00000e-09 2.12000e-01 $1.62256 \mathrm{e}+001.62256 \mathrm{e}+001.62256 \mathrm{e}-011.00000 \mathrm{e}-092.12000 \mathrm{e}-01$ $1.62256 \mathrm{e}+001.62256 \mathrm{e}+001.62256 \mathrm{e}-011.00000 \mathrm{e}-092.12000 \mathrm{e}-01$ $1.62256 \mathrm{e}+001.62256 \mathrm{e}+001.62256 \mathrm{e}-01$ 1.00000e-09 2.12000e-01 $1.62256 \mathrm{e}+001.62256 \mathrm{e}+001.62256 \mathrm{e}-01$ 1.00000e-09 2.12000e-01 $1.00000 \mathrm{e}-02$ 1.00000e-02 1.00000e-03 1.00000e-09 1.00000e-01 $1.00000 \mathrm{e}+001.00000 \mathrm{e}+001.00000 \mathrm{e}-011.00000 \mathrm{e}-091.00000 \mathrm{e}-01$ $1.00000 \mathrm{e}-05$ 1.00000e-05 1.00000e-06 1.00000e-09 1.00000e-01 $1.00000 \mathrm{e}+001.00000 \mathrm{e}+001.00000 \mathrm{e}-011.00000 \mathrm{e}-091.00000 \mathrm{e}-01$ Element: 2131 \# of layers: 15

$\mathrm{Kx} \mathrm{Ky} \mathrm{Kz}$ Ss Por 4.06081e+01 4.06081e+01 4.06081e+00 1.00000e-09 7.00000e-02 $4.06081 \mathrm{e}+014.06081 \mathrm{e}+014.06081 \mathrm{e}+001.00000 \mathrm{e}-097.00000 \mathrm{e}-02$ $4.06081 \mathrm{e}+014.06081 \mathrm{e}+014.06081 \mathrm{e}+001.00000 \mathrm{e}-09$ 7.00000e-02 $4.06081 \mathrm{e}+014.06081 \mathrm{e}+014.06081 \mathrm{e}+001.00000 \mathrm{e}-09$ 7.00000e-02 
5.00000e-04 5.00000e-04 5.00000e-05 1.00000e-09 1.00000e-01 $5.00000 \mathrm{e}-04$ 5.00000e-04 5.00000e-05 1.00000e-09 1.00000e-01 $1.62256 \mathrm{e}+001.62256 \mathrm{e}+00$ 1.62256e-01 1.00000e-09 2.12000e-01 $1.62256 \mathrm{e}+001.62256 \mathrm{e}+001.62256 \mathrm{e}-011.00000 \mathrm{e}-092.12000 \mathrm{e}-01$ $1.62256 \mathrm{e}+001.62256 \mathrm{e}+001.62256 \mathrm{e}-01$ 1.00000e-09 2.12000e-01 $1.62256 \mathrm{e}+001.62256 \mathrm{e}+001.62256 \mathrm{e}-01 \quad 1.00000 \mathrm{e}-092.12000 \mathrm{e}-01$ $1.62256 \mathrm{e}+001.62256 \mathrm{e}+00$ 1.62256e-01 1.00000e-09 2.12000e-01 $1.00000 \mathrm{e}-02$ 1.00000e-02 1.00000e-03 1.00000e-09 1.00000e-01 $1.00000 \mathrm{e}+001.00000 \mathrm{e}+001.00000 \mathrm{e}-01$ 1.00000e-09 1.00000e-01 $1.00000 \mathrm{e}-05$ 1.00000e-05 1.00000e-06 1.00000e-09 1.00000e-01 $1.00000 \mathrm{e}+001.00000 \mathrm{e}+001.00000 \mathrm{e}-011.00000 \mathrm{e}-091.00000 \mathrm{e}-01$ Element: 2132 \# of layers: 16

$\mathrm{Kx} \mathrm{Ky} \mathrm{Kz}$ Ss Por

4.06081e+01 4.06081e+01 4.06081e+00 1.00000e-09 7.00000e-02 $4.06081 \mathrm{e}+014.06081 \mathrm{e}+014.06081 \mathrm{e}+001.00000 \mathrm{e}-09$ 7.00000e-02 $4.06081 \mathrm{e}+014.06081 \mathrm{e}+014.06081 \mathrm{e}+001.00000 \mathrm{e}-09$ 7.00000e-02 $4.06081 \mathrm{e}+014.06081 \mathrm{e}+014.06081 \mathrm{e}+001.00000 \mathrm{e}-09$ 7.00000e-02 $4.06081 \mathrm{e}+014.06081 \mathrm{e}+014.06081 \mathrm{e}+001.00000 \mathrm{e}-09$ 7.00000e-02 5.00000e-04 5.00000e-04 5.00000e-05 1.00000e-09 1.00000e-01 5.00000e-04 5.00000e-04 5.00000e-05 1.00000e-09 1.00000e-01

$1.62256 \mathrm{e}+001.62256 \mathrm{e}+001.62256 \mathrm{e}-011.00000 \mathrm{e}-092.12000 \mathrm{e}-01$ $1.62256 \mathrm{e}+001.62256 \mathrm{e}+00$ 1.62256e-01 1.00000e-09 2.12000e-01 $1.62256 \mathrm{e}+001.62256 \mathrm{e}+001.62256 \mathrm{e}-01$ 1.00000e-09 2.12000e-01 $1.62256 \mathrm{e}+001.62256 \mathrm{e}+001.62256 \mathrm{e}-011.00000 \mathrm{e}-092.12000 \mathrm{e}-01$ $1.62256 \mathrm{e}+001.62256 \mathrm{e}+001.62256 \mathrm{e}-011.00000 \mathrm{e}-092.12000 \mathrm{e}-01$ $1.00000 \mathrm{e}-02$ 1.00000e-02 1.00000e-03 1.00000e-09 1.00000e-01 $1.00000 \mathrm{e}+001.00000 \mathrm{e}+001.00000 \mathrm{e}-011.00000 \mathrm{e}-091.00000 \mathrm{e}-01$ $1.00000 \mathrm{e}-05$ 1.00000e-05 1.00000e-06 1.00000e-09 1.00000e-01 $1.00000 \mathrm{e}+001.00000 \mathrm{e}+001.00000 \mathrm{e}-011.00000 \mathrm{e}-091.00000 \mathrm{e}-01$ Element: 2133 \# of layers: 16

$\mathrm{Kx} \mathrm{Ky} \mathrm{Kz}$ Ss Por

4.06081e+01 4.06081e+01 4.06081e+00 1.00000e-09 7.00000e-02 $4.06081 \mathrm{e}+014.06081 \mathrm{e}+014.06081 \mathrm{e}+001.00000 \mathrm{e}-09$ 7.00000e-02 $4.06081 \mathrm{e}+014.06081 \mathrm{e}+014.06081 \mathrm{e}+001.00000 \mathrm{e}-09$ 7.00000e-02 $4.06081 \mathrm{e}+014.06081 \mathrm{e}+014.06081 \mathrm{e}+001.00000 \mathrm{e}-09$ 7.00000e-02 $4.06081 \mathrm{e}+014.06081 \mathrm{e}+014.06081 \mathrm{e}+001.00000 \mathrm{e}-09$ 7.00000e-02 5.00000e-04 5.00000e-04 5.00000e-05 1.00000e-09 1.00000e-01 5.00000e-04 5.00000e-04 5.00000e-05 1.00000e-09 1.00000e-01 $1.62256 \mathrm{e}+001.62256 \mathrm{e}+001.62256 \mathrm{e}-01$ 1.00000e-09 2.12000e-01 $1.62256 \mathrm{e}+001.62256 \mathrm{e}+001.62256 \mathrm{e}-01$ 1.00000e-09 2.12000e-01 $1.62256 \mathrm{e}+001.62256 \mathrm{e}+001.62256 \mathrm{e}-011.00000 \mathrm{e}-092.12000 \mathrm{e}-01$ $1.62256 \mathrm{e}+001.62256 \mathrm{e}+001.62256 \mathrm{e}-011.00000 \mathrm{e}-092.12000 \mathrm{e}-01$ $1.62256 \mathrm{e}+001.62256 \mathrm{e}+00$ 1.62256e-01 1.00000e-09 2.12000e-01 $1.00000 \mathrm{e}-021.00000 \mathrm{e}-02$ 1.00000e-03 1.00000e-09 1.00000e-01 $1.00000 \mathrm{e}+001.00000 \mathrm{e}+001.00000 \mathrm{e}-011.00000 \mathrm{e}-091.00000 \mathrm{e}-01$ $1.00000 \mathrm{e}-05$ 1.00000e-05 1.00000e-06 1.00000e-09 1.00000e-01 
$1.00000 \mathrm{e}+001.00000 \mathrm{e}+00$ 1.00000e-01 1.00000e-09 1.00000e-01

Element: 2134 \# of layers: 15

Kx Ky Kz Ss Por

4.02305e+01 4.02305e+01 4.02305e+00 1.00000e-09 7.00000e-02 $4.02305 \mathrm{e}+014.02305 \mathrm{e}+014.02305 \mathrm{e}+001.00000 \mathrm{e}-09$ 7.00000e-02 4.02305e+01 4.02305e+01 4.02305e+00 1.00000e-09 7.00000e-02 4.02305e+01 4.02305e+01 4.02305e+00 1.00000e-09 7.00000e-02 5.00000e-04 5.00000e-04 5.00000e-05 1.00000e-09 1.00000e-01 5.00000e-04 5.00000e-04 5.00000e-05 1.00000e-09 1.00000e-01

$1.60748 \mathrm{e}+001.60748 \mathrm{e}+00$ 1.60748e-01 1.00000e-09 2.12000e-01 $1.60748 \mathrm{e}+001.60748 \mathrm{e}+00$ 1.60748e-01 1.00000e-09 2.12000e-01 $1.60748 \mathrm{e}+001.60748 \mathrm{e}+00$ 1.60748e-01 1.00000e-09 2.12000e-01 $1.60748 \mathrm{e}+001.60748 \mathrm{e}+00$ 1.60748e-01 1.00000e-09 2.12000e-01 $1.60748 \mathrm{e}+001.60748 \mathrm{e}+00$ 1.60748e-01 1.00000e-09 2.12000e-01 $1.00000 \mathrm{e}-02$ 1.00000e-02 1.00000e-03 1.00000e-09 1.00000e-01 $1.00000 \mathrm{e}+001.00000 \mathrm{e}+001.00000 \mathrm{e}-011.00000 \mathrm{e}-091.00000 \mathrm{e}-01$ $1.00000 \mathrm{e}-05$ 1.00000e-05 1.00000e-06 1.00000e-09 1.00000e-01 $1.00000 \mathrm{e}+001.00000 \mathrm{e}+001.00000 \mathrm{e}-01$ 1.00000e-09 1.00000e-01 Element: 2135 \# of layers: 15

$\mathrm{Kx} \mathrm{Ky} \mathrm{Kz}$ Ss Por

4.02305e+01 4.02305e+01 4.02305e+00 1.00000e-09 7.00000e-02 4.02305e+01 4.02305e+01 4.02305e+00 1.00000e-09 7.00000e-02 4.02305e+01 4.02305e+01 4.02305e+00 1.00000e-09 7.00000e-02 4.02305e+01 4.02305e+01 4.02305e+00 1.00000e-09 7.00000e-02 5.00000e-04 5.00000e-04 5.00000e-05 1.00000e-09 1.00000e-01 $5.00000 \mathrm{e}-04$ 5.00000e-04 5.00000e-05 1.00000e-09 1.00000e-01

$1.60748 \mathrm{e}+001.60748 \mathrm{e}+00$ 1.60748e-01 1.00000e-09 2.12000e-01 $1.60748 \mathrm{e}+001.60748 \mathrm{e}+00$ 1.60748e-01 1.00000e-09 2.12000e-01 $1.60748 \mathrm{e}+001.60748 \mathrm{e}+00$ 1.60748e-01 1.00000e-09 2.12000e-01 $1.60748 \mathrm{e}+00$ 1.60748e+00 1.60748e-01 1.00000e-09 2.12000e-01 $1.60748 \mathrm{e}+001.60748 \mathrm{e}+00$ 1.60748e-01 1.00000e-09 2.12000e-01 1.00000e-02 1.00000e-02 1.00000e-03 1.00000e-09 1.00000e-01 $1.00000 \mathrm{e}+001.00000 \mathrm{e}+001.00000 \mathrm{e}-011.00000 \mathrm{e}-091.00000 \mathrm{e}-01$ $1.00000 \mathrm{e}-05$ 1.00000e-05 1.00000e-06 1.00000e-09 1.00000e-01 $1.00000 \mathrm{e}+001.00000 \mathrm{e}+001.00000 \mathrm{e}-011.00000 \mathrm{e}-091.00000 \mathrm{e}-01$ Element: 2136 \# of layers: 14

Kx Ky Kz Ss Por

4.02305e+01 4.02305e+01 4.02305e+00 1.00000e-09 7.00000e-02 4.02305e+01 4.02305e+01 4.02305e+00 1.00000e-09 7.00000e-02 $4.02305 \mathrm{e}+014.02305 \mathrm{e}+014.02305 \mathrm{e}+001.00000 \mathrm{e}-09$ 7.00000e-02 5.00000e-04 5.00000e-04 5.00000e-05 1.00000e-09 1.00000e-01 5.00000e-04 5.00000e-04 5.00000e-05 1.00000e-09 1.00000e-01 $1.60748 \mathrm{e}+00$ 1.60748e+00 1.60748e-01 1.00000e-09 2.12000e-01 $1.60748 \mathrm{e}+001.60748 \mathrm{e}+00$ 1.60748e-01 1.00000e-09 2.12000e-01 $1.60748 \mathrm{e}+001.60748 \mathrm{e}+00$ 1.60748e-01 1.00000e-09 2.12000e-01 $1.60748 \mathrm{e}+001.60748 \mathrm{e}+00$ 1.60748e-01 1.00000e-09 2.12000e-01 
$1.60748 \mathrm{e}+00$ 1.60748e+00 1.60748e-01 1.00000e-09 2.12000e-01 $1.00000 \mathrm{e}-02$ 1.00000e-02 1.00000e-03 1.00000e-09 1.00000e-01 $1.00000 \mathrm{e}+001.00000 \mathrm{e}+001.00000 \mathrm{e}-011.00000 \mathrm{e}-091.00000 \mathrm{e}-01$ $1.00000 \mathrm{e}-05$ 1.00000e-05 1.00000e-06 1.00000e-09 1.00000e-01 $1.00000 \mathrm{e}+001.00000 \mathrm{e}+001.00000 \mathrm{e}-011.00000 \mathrm{e}-091.00000 \mathrm{e}-01$ Element: 2137 \# of layers: 14

$\mathrm{Kx} \mathrm{Ky} \mathrm{Kz}$ Ss Por

4.02305e+01 4.02305e+01 4.02305e+00 1.00000e-09 7.00000e-02 $4.02305 \mathrm{e}+014.02305 \mathrm{e}+014.02305 \mathrm{e}+001.00000 \mathrm{e}-09$ 7.00000e-02 $4.02305 \mathrm{e}+014.02305 \mathrm{e}+014.02305 \mathrm{e}+001.00000 \mathrm{e}-09$ 7.00000e-02 5.00000e-04 5.00000e-04 5.00000e-05 1.00000e-09 1.00000e-01 5.00000e-04 5.00000e-04 5.00000e-05 1.00000e-09 1.00000e-01

$1.60748 \mathrm{e}+001.60748 \mathrm{e}+00$ 1.60748e-01 1.00000e-09 2.12000e-01 $1.60748 \mathrm{e}+001.60748 \mathrm{e}+00$ 1.60748e-01 1.00000e-09 2.12000e-01 $1.60748 \mathrm{e}+001.60748 \mathrm{e}+00$ 1.60748e-01 1.00000e-09 2.12000e-01 $1.60748 \mathrm{e}+001.60748 \mathrm{e}+00$ 1.60748e-01 1.00000e-09 2.12000e-01 $1.60748 \mathrm{e}+001.60748 \mathrm{e}+00$ 1.60748e-01 1.00000e-09 2.12000e-01 $1.00000 \mathrm{e}-02$ 1.00000e-02 1.00000e-03 1.00000e-09 1.00000e-01 $1.00000 \mathrm{e}+001.00000 \mathrm{e}+001.00000 \mathrm{e}-011.00000 \mathrm{e}-091.00000 \mathrm{e}-01$ $1.00000 \mathrm{e}-05$ 1.00000e-05 1.00000e-06 1.00000e-09 1.00000e-01 $1.00000 \mathrm{e}+001.00000 \mathrm{e}+001.00000 \mathrm{e}-011.00000 \mathrm{e}-091.00000 \mathrm{e}-01$ Element: 2138 \# of layers: 14

$\mathrm{Kx} \mathrm{Ky} \mathrm{Kz}$ Ss Por 4.02305e+01 4.02305e+01 4.02305e+00 1.00000e-09 7.00000e-02 $4.02305 \mathrm{e}+014.02305 \mathrm{e}+014.02305 \mathrm{e}+00$ 1.00000e-09 7.00000e-02 $4.02305 \mathrm{e}+014.02305 \mathrm{e}+014.02305 \mathrm{e}+001.00000 \mathrm{e}-09$ 7.00000e-02 $5.00000 \mathrm{e}-04$ 5.00000e-04 5.00000e-05 1.00000e-09 1.00000e-01 5.00000e-04 5.00000e-04 5.00000e-05 1.00000e-09 1.00000e-01

$1.60748 \mathrm{e}+001.60748 \mathrm{e}+00$ 1.60748e-01 1.00000e-09 2.12000e-01 $1.60748 \mathrm{e}+001.60748 \mathrm{e}+00$ 1.60748e-01 1.00000e-09 2.12000e-01 $1.60748 \mathrm{e}+001.60748 \mathrm{e}+00$ 1.60748e-01 1.00000e-09 2.12000e-01 $1.60748 \mathrm{e}+001.60748 \mathrm{e}+00$ 1.60748e-01 1.00000e-09 2.12000e-01 $1.60748 \mathrm{e}+001.60748 \mathrm{e}+00$ 1.60748e-01 1.00000e-09 2.12000e-01 $1.00000 \mathrm{e}-02$ 1.00000e-02 1.00000e-03 1.00000e-09 1.00000e-01 $1.00000 \mathrm{e}+001.00000 \mathrm{e}+001.00000 \mathrm{e}-011.00000 \mathrm{e}-091.00000 \mathrm{e}-01$ $1.00000 \mathrm{e}-05$ 1.00000e-05 1.00000e-06 1.00000e-09 1.00000e-01 $1.00000 \mathrm{e}+001.00000 \mathrm{e}+001.00000 \mathrm{e}-011.00000 \mathrm{e}-091.00000 \mathrm{e}-01$ Element: 2139 \# of layers: 15

$\mathrm{Kx} \mathrm{Ky} \mathrm{Kz}$ Ss Por 4.02305e+01 4.02305e+01 4.02305e+00 1.00000e-09 7.00000e-02 4.02305e+01 4.02305e+01 4.02305e+00 1.00000e-09 7.00000e-02 $4.02305 \mathrm{e}+014.02305 \mathrm{e}+014.02305 \mathrm{e}+001.00000 \mathrm{e}-09$ 7.00000e-02 $4.02305 \mathrm{e}+014.02305 \mathrm{e}+014.02305 \mathrm{e}+001.00000 \mathrm{e}-09$ 7.00000e-02 5.00000e-04 5.00000e-04 5.00000e-05 1.00000e-09 1.00000e-01 5.00000e-04 5.00000e-04 5.00000e-05 1.00000e-09 1.00000e-01 $1.60748 \mathrm{e}+001.60748 \mathrm{e}+00$ 1.60748e-01 1.00000e-09 2.12000e-01 
$1.60748 \mathrm{e}+001.60748 \mathrm{e}+00$ 1.60748e-01 1.00000e-09 2.12000e-01 $1.60748 \mathrm{e}+00$ 1.60748e+00 1.60748e-01 1.00000e-09 2.12000e-01 $1.60748 \mathrm{e}+001.60748 \mathrm{e}+00$ 1.60748e-01 1.00000e-09 2.12000e-01 $1.60748 \mathrm{e}+001.60748 \mathrm{e}+001.60748 \mathrm{e}-01$ 1.00000e-09 2.12000e-01 $1.00000 \mathrm{e}-02$ 1.00000e-02 1.00000e-03 1.00000e-09 1.00000e-01 $1.00000 \mathrm{e}+001.00000 \mathrm{e}+001.00000 \mathrm{e}-011.00000 \mathrm{e}-091.00000 \mathrm{e}-01$ $1.00000 \mathrm{e}-05$ 1.00000e-05 1.00000e-06 1.00000e-09 1.00000e-01 $1.00000 \mathrm{e}+001.00000 \mathrm{e}+001.00000 \mathrm{e}-011.00000 \mathrm{e}-091.00000 \mathrm{e}-01$ Element: 2140 \# of layers: 14

$\mathrm{Kx} \mathrm{Ky} \mathrm{Kz}$ Ss Por

4.02305e+01 4.02305e+01 4.02305e+00 1.00000e-09 7.00000e-02 $4.02305 \mathrm{e}+014.02305 \mathrm{e}+014.02305 \mathrm{e}+001.00000 \mathrm{e}-09$ 7.00000e-02 $4.02305 \mathrm{e}+014.02305 \mathrm{e}+014.02305 \mathrm{e}+001.00000 \mathrm{e}-09$ 7.00000e-02 5.00000e-04 5.00000e-04 5.00000e-05 1.00000e-09 1.00000e-01 5.00000e-04 5.00000e-04 5.00000e-05 1.00000e-09 1.00000e-01 $1.60748 \mathrm{e}+001.60748 \mathrm{e}+00$ 1.60748e-01 1.00000e-09 2.12000e-01 $1.60748 \mathrm{e}+001.60748 \mathrm{e}+00$ 1.60748e-01 1.00000e-09 2.12000e-01 $1.60748 \mathrm{e}+001.60748 \mathrm{e}+00$ 1.60748e-01 1.00000e-09 2.12000e-01 $1.60748 \mathrm{e}+001.60748 \mathrm{e}+00$ 1.60748e-01 1.00000e-09 2.12000e-01 $1.60748 \mathrm{e}+001.60748 \mathrm{e}+001.60748 \mathrm{e}-01$ 1.00000e-09 2.12000e-01 $1.00000 \mathrm{e}-02$ 1.00000e-02 1.00000e-03 1.00000e-09 1.00000e-01 $1.00000 \mathrm{e}+001.00000 \mathrm{e}+001.00000 \mathrm{e}-011.00000 \mathrm{e}-091.00000 \mathrm{e}-01$ $1.00000 \mathrm{e}-05$ 1.00000e-05 1.00000e-06 1.00000e-09 1.00000e-01 $1.00000 \mathrm{e}+001.00000 \mathrm{e}+001.00000 \mathrm{e}-011.00000 \mathrm{e}-091.00000 \mathrm{e}-01$ Element: 2141 \# of layers: 15

$\mathrm{Kx} \mathrm{Ky} \mathrm{Kz}$ Ss Por

4.02305e+01 4.02305e+01 4.02305e+00 1.00000e-09 7.00000e-02 4.02305e+01 4.02305e+01 4.02305e+00 1.00000e-09 7.00000e-02 $4.02305 \mathrm{e}+014.02305 \mathrm{e}+014.02305 \mathrm{e}+001.00000 \mathrm{e}-09$ 7.00000e-02 4.02305e+01 4.02305e+01 4.02305e+00 1.00000e-09 7.00000e-02 $5.00000 \mathrm{e}-04$ 5.00000e-04 5.00000e-05 1.00000e-09 1.00000e-01 5.00000e-04 5.00000e-04 5.00000e-05 1.00000e-09 1.00000e-01 $1.60748 \mathrm{e}+001.60748 \mathrm{e}+001.60748 \mathrm{e}-011.00000 \mathrm{e}-092.12000 \mathrm{e}-01$ $1.60748 \mathrm{e}+00$ 1.60748e+00 1.60748e-01 1.00000e-09 2.12000e-01 $1.60748 \mathrm{e}+001.60748 \mathrm{e}+00$ 1.60748e-01 1.00000e-09 2.12000e-01 $1.60748 \mathrm{e}+001.60748 \mathrm{e}+00$ 1.60748e-01 1.00000e-09 2.12000e-01 $1.60748 \mathrm{e}+001.60748 \mathrm{e}+00$ 1.60748e-01 1.00000e-09 2.12000e-01 $1.00000 \mathrm{e}-02$ 1.00000e-02 1.00000e-03 1.00000e-09 1.00000e-01 $1.00000 \mathrm{e}+001.00000 \mathrm{e}+001.00000 \mathrm{e}-011.00000 \mathrm{e}-091.00000 \mathrm{e}-01$ $1.00000 \mathrm{e}-05$ 1.00000e-05 1.00000e-06 1.00000e-09 1.00000e-01 $1.00000 \mathrm{e}+001.00000 \mathrm{e}+001.00000 \mathrm{e}-011.00000 \mathrm{e}-091.00000 \mathrm{e}-01$ Element: 2142 \# of layers: 15

$\mathrm{Kx} \mathrm{Ky} \mathrm{Kz}$ Ss Por 4.02305e+01 4.02305e+01 4.02305e+00 1.00000e-09 7.00000e-02 4.02305e+01 4.02305e+01 4.02305e+00 1.00000e-09 7.00000e-02 $4.02305 \mathrm{e}+014.02305 \mathrm{e}+014.02305 \mathrm{e}+001.00000 \mathrm{e}-09$ 7.00000e-02 
4.02305e+01 4.02305e+01 4.02305e+00 1.00000e-09 7.00000e-02 $5.00000 \mathrm{e}-04$ 5.00000e-04 5.00000e-05 1.00000e-09 1.00000e-01 5.00000e-04 5.00000e-04 5.00000e-05 1.00000e-09 1.00000e-01

$1.60748 \mathrm{e}+001.60748 \mathrm{e}+00$ 1.60748e-01 1.00000e-09 2.12000e-01 $1.60748 \mathrm{e}+001.60748 \mathrm{e}+00$ 1.60748e-01 1.00000e-09 2.12000e-01 $1.60748 \mathrm{e}+001.60748 \mathrm{e}+00$ 1.60748e-01 1.00000e-09 2.12000e-01 $1.60748 \mathrm{e}+001.60748 \mathrm{e}+00$ 1.60748e-01 1.00000e-09 2.12000e-01 $1.60748 \mathrm{e}+001.60748 \mathrm{e}+00$ 1.60748e-01 1.00000e-09 2.12000e-01 $1.00000 \mathrm{e}-02$ 1.00000e-02 1.00000e-03 1.00000e-09 1.00000e-01 $1.00000 \mathrm{e}+001.00000 \mathrm{e}+001.00000 \mathrm{e}-011.00000 \mathrm{e}-091.00000 \mathrm{e}-01$ $1.00000 \mathrm{e}-05$ 1.00000e-05 1.00000e-06 1.00000e-09 1.00000e-01 $1.00000 \mathrm{e}+001.00000 \mathrm{e}+001.00000 \mathrm{e}-011.00000 \mathrm{e}-091.00000 \mathrm{e}-01$ Element: 2143 \# of layers: 14

$\mathrm{Kx} \mathrm{Ky} \mathrm{Kz}$ Ss Por

3.96395e+01 3.96395e+01 3.96395e+00 1.00000e-09 7.00000e-02 $3.96395 \mathrm{e}+013.96395 \mathrm{e}+013.96395 \mathrm{e}+00$ 1.00000e-09 7.00000e-02 $3.96395 \mathrm{e}+013.96395 \mathrm{e}+013.96395 \mathrm{e}+001.00000 \mathrm{e}-09$ 7.00000e-02 5.00000e-04 5.00000e-04 5.00000e-05 1.00000e-09 1.00000e-01 $5.00000 \mathrm{e}-04$ 5.00000e-04 5.00000e-05 1.00000e-09 1.00000e-01 $1.58385 \mathrm{e}+001.58385 \mathrm{e}+001.58385 \mathrm{e}-011.00000 \mathrm{e}-092.12000 \mathrm{e}-01$ $1.58385 \mathrm{e}+001.58385 \mathrm{e}+00$ 1.58385e-01 1.00000e-09 2.12000e-01 $1.58385 \mathrm{e}+00$ 1.58385e+00 1.58385e-01 1.00000e-09 2.12000e-01 $1.58385 \mathrm{e}+001.58385 \mathrm{e}+00$ 1.58385e-01 1.00000e-09 2.12000e-01 $1.58385 \mathrm{e}+001.58385 \mathrm{e}+001.58385 \mathrm{e}-011.00000 \mathrm{e}-092.12000 \mathrm{e}-01$ $1.00000 \mathrm{e}-02$ 1.00000e-02 1.00000e-03 1.00000e-09 1.00000e-01 $1.00000 \mathrm{e}+001.00000 \mathrm{e}+001.00000 \mathrm{e}-011.00000 \mathrm{e}-091.00000 \mathrm{e}-01$ $1.00000 \mathrm{e}-05$ 1.00000e-05 1.00000e-06 1.00000e-09 1.00000e-01 $1.00000 \mathrm{e}+001.00000 \mathrm{e}+001.00000 \mathrm{e}-011.00000 \mathrm{e}-09$ 1.00000e-01 Element: 2144 \# of layers: 13

$\mathrm{Kx} \mathrm{Ky} \mathrm{Kz}$ Ss Por

3.96395e+01 3.96395e+01 3.96395e+00 1.00000e-09 7.00000e-02 $3.96395 \mathrm{e}+013.96395 \mathrm{e}+013.96395 \mathrm{e}+00$ 1.00000e-09 7.00000e-02 5.00000e-04 5.00000e-04 5.00000e-05 1.00000e-09 1.00000e-01 5.00000e-04 5.00000e-04 5.00000e-05 1.00000e-09 1.00000e-01 $1.58385 \mathrm{e}+001.58385 \mathrm{e}+001.58385 \mathrm{e}-01$ 1.00000e-09 2.12000e-01 $1.58385 \mathrm{e}+001.58385 \mathrm{e}+00$ 1.58385e-01 1.00000e-09 2.12000e-01 $1.58385 \mathrm{e}+001.58385 \mathrm{e}+00$ 1.58385e-01 1.00000e-09 2.12000e-01 $1.58385 \mathrm{e}+001.58385 \mathrm{e}+00$ 1.58385e-01 1.00000e-09 2.12000e-01 $1.58385 \mathrm{e}+001.58385 \mathrm{e}+00$ 1.58385e-01 1.00000e-09 2.12000e-01 $1.00000 \mathrm{e}-02$ 1.00000e-02 1.00000e-03 1.00000e-09 1.00000e-01 $1.00000 \mathrm{e}+001.00000 \mathrm{e}+001.00000 \mathrm{e}-011.00000 \mathrm{e}-091.00000 \mathrm{e}-01$ $1.00000 \mathrm{e}-05$ 1.00000e-05 1.00000e-06 1.00000e-09 1.00000e-01 $1.00000 \mathrm{e}+001.00000 \mathrm{e}+001.00000 \mathrm{e}-011.00000 \mathrm{e}-091.00000 \mathrm{e}-01$ Element: 2145 \# of layers: 13

$\mathrm{Kx} \mathrm{Ky} \mathrm{Kz}$ Ss Por

3.96395e+01 3.96395e+01 3.96395e+00 1.00000e-09 7.00000e-02 
$3.96395 \mathrm{e}+013.96395 \mathrm{e}+013.96395 \mathrm{e}+00$ 1.00000e-09 7.00000e-02 5.00000e-04 5.00000e-04 5.00000e-05 1.00000e-09 1.00000e-01 5.00000e-04 5.00000e-04 5.00000e-05 1.00000e-09 1.00000e-01

$1.58385 \mathrm{e}+001.58385 \mathrm{e}+001.58385 \mathrm{e}-011.00000 \mathrm{e}-092.12000 \mathrm{e}-01$ $1.58385 \mathrm{e}+001.58385 \mathrm{e}+00$ 1.58385e-01 1.00000e-09 2.12000e-01 $1.58385 \mathrm{e}+001.58385 \mathrm{e}+001.58385 \mathrm{e}-01$ 1.00000e-09 2.12000e-01 $1.58385 \mathrm{e}+001.58385 \mathrm{e}+001.58385 \mathrm{e}-01$ 1.00000e-09 2.12000e-01 $1.58385 \mathrm{e}+001.58385 \mathrm{e}+001.58385 \mathrm{e}-011.00000 \mathrm{e}-092.12000 \mathrm{e}-01$ $1.00000 \mathrm{e}-021.00000 \mathrm{e}-021.00000 \mathrm{e}-031.00000 \mathrm{e}-091.00000 \mathrm{e}-01$ $1.00000 \mathrm{e}+001.00000 \mathrm{e}+001.00000 \mathrm{e}-011.00000 \mathrm{e}-091.00000 \mathrm{e}-01$ $1.00000 \mathrm{e}-05$ 1.00000e-05 1.00000e-06 1.00000e-09 1.00000e-01 $1.00000 \mathrm{e}+001.00000 \mathrm{e}+001.00000 \mathrm{e}-011.00000 \mathrm{e}-091.00000 \mathrm{e}-01$ Element: 2146 \# of layers: 13

$\mathrm{Kx} \mathrm{Ky} \mathrm{Kz}$ Ss Por

3.96395e+01 3.96395e+01 3.96395e+00 1.00000e-09 7.00000e-02 $3.96395 \mathrm{e}+013.96395 \mathrm{e}+013.96395 \mathrm{e}+001.00000 \mathrm{e}-09$ 7.00000e-02 5.00000e-04 5.00000e-04 5.00000e-05 1.00000e-09 1.00000e-01 5.00000e-04 5.00000e-04 5.00000e-05 1.00000e-09 1.00000e-01 $1.58385 \mathrm{e}+001.58385 \mathrm{e}+00$ 1.58385e-01 1.00000e-09 2.12000e-01 $1.58385 \mathrm{e}+001.58385 \mathrm{e}+00$ 1.58385e-01 1.00000e-09 2.12000e-01 $1.58385 \mathrm{e}+001.58385 \mathrm{e}+00$ 1.58385e-01 1.00000e-09 2.12000e-01 $1.58385 \mathrm{e}+001.58385 \mathrm{e}+00$ 1.58385e-01 1.00000e-09 2.12000e-01 $1.58385 \mathrm{e}+001.58385 \mathrm{e}+00$ 1.58385e-01 1.00000e-09 2.12000e-01 $1.00000 \mathrm{e}-02$ 1.00000e-02 1.00000e-03 1.00000e-09 1.00000e-01 $1.00000 \mathrm{e}+001.00000 \mathrm{e}+001.00000 \mathrm{e}-011.00000 \mathrm{e}-091.00000 \mathrm{e}-01$ $1.00000 \mathrm{e}-05$ 1.00000e-05 1.00000e-06 1.00000e-09 1.00000e-01 $1.00000 \mathrm{e}+001.00000 \mathrm{e}+001.00000 \mathrm{e}-011.00000 \mathrm{e}-091.00000 \mathrm{e}-01$ Element: 2147 \# of layers: 13

$\mathrm{Kx} \mathrm{Ky} \mathrm{Kz}$ Ss Por

$3.96395 \mathrm{e}+013.96395 \mathrm{e}+013.96395 \mathrm{e}+001.00000 \mathrm{e}-09$ 7.00000e-02 $3.96395 \mathrm{e}+013.96395 \mathrm{e}+013.96395 \mathrm{e}+001.00000 \mathrm{e}-09$ 7.00000e-02 5.00000e-04 5.00000e-04 5.00000e-05 1.00000e-09 1.00000e-01 5.00000e-04 5.00000e-04 5.00000e-05 1.00000e-09 1.00000e-01 $1.58385 \mathrm{e}+001.58385 \mathrm{e}+001.58385 \mathrm{e}-01$ 1.00000e-09 2.12000e-01 $1.58385 \mathrm{e}+001.58385 \mathrm{e}+00$ 1.58385e-01 1.00000e-09 2.12000e-01 $1.58385 \mathrm{e}+001.58385 \mathrm{e}+001.58385 \mathrm{e}-01$ 1.00000e-09 2.12000e-01 $1.58385 \mathrm{e}+001.58385 \mathrm{e}+001.58385 \mathrm{e}-011.00000 \mathrm{e}-092.12000 \mathrm{e}-01$ $1.58385 \mathrm{e}+001.58385 \mathrm{e}+001.58385 \mathrm{e}-01$ 1.00000e-09 2.12000e-01 $1.00000 \mathrm{e}-02$ 1.00000e-02 1.00000e-03 1.00000e-09 1.00000e-01 $1.00000 \mathrm{e}+001.00000 \mathrm{e}+001.00000 \mathrm{e}-011.00000 \mathrm{e}-091.00000 \mathrm{e}-01$ $1.00000 \mathrm{e}-05$ 1.00000e-05 1.00000e-06 1.00000e-09 1.00000e-01 $1.00000 \mathrm{e}+001.00000 \mathrm{e}+001.00000 \mathrm{e}-011.00000 \mathrm{e}-091.00000 \mathrm{e}-01$ Element: 2148 \# of layers: 13

$\mathrm{Kx} \mathrm{Ky} \mathrm{Kz}$ Ss Por

3.96395e+01 3.96395e+01 3.96395e+00 1.00000e-09 7.00000e-02 $3.96395 \mathrm{e}+013.96395 \mathrm{e}+013.96395 \mathrm{e}+001.00000 \mathrm{e}-09$ 7.00000e-02 
5.00000e-04 5.00000e-04 5.00000e-05 1.00000e-09 1.00000e-01 5.00000e-04 5.00000e-04 5.00000e-05 1.00000e-09 1.00000e-01

$1.58385 \mathrm{e}+001.58385 \mathrm{e}+00$ 1.58385e-01 1.00000e-09 2.12000e-01 $1.58385 \mathrm{e}+001.58385 \mathrm{e}+001.58385 \mathrm{e}-011.00000 \mathrm{e}-092.12000 \mathrm{e}-01$ $1.58385 \mathrm{e}+001.58385 \mathrm{e}+00$ 1.58385e-01 1.00000e-09 2.12000e-01 $1.58385 \mathrm{e}+001.58385 \mathrm{e}+001.58385 \mathrm{e}-01$ 1.00000e-09 2.12000e-01 $1.58385 \mathrm{e}+001.58385 \mathrm{e}+00$ 1.58385e-01 1.00000e-09 2.12000e-01 $1.00000 \mathrm{e}-02$ 1.00000e-02 1.00000e-03 1.00000e-09 1.00000e-01 $1.00000 \mathrm{e}+001.00000 \mathrm{e}+001.00000 \mathrm{e}-01$ 1.00000e-09 1.00000e-01 $1.00000 \mathrm{e}-05$ 1.00000e-05 1.00000e-06 1.00000e-09 1.00000e-01 $1.00000 \mathrm{e}+001.00000 \mathrm{e}+001.00000 \mathrm{e}-01$ 1.00000e-09 1.00000e-01 Element: 2149 \# of layers: 14

$\mathrm{Kx} \mathrm{Ky} \mathrm{Kz}$ Ss Por

$3.96395 \mathrm{e}+013.96395 \mathrm{e}+013.96395 \mathrm{e}+001.00000 \mathrm{e}-09$ 7.00000e-02 $3.96395 \mathrm{e}+013.96395 \mathrm{e}+013.96395 \mathrm{e}+001.00000 \mathrm{e}-09$ 7.00000e-02 $3.96395 \mathrm{e}+013.96395 \mathrm{e}+013.96395 \mathrm{e}+001.00000 \mathrm{e}-09$ 7.00000e-02 5.00000e-04 5.00000e-04 5.00000e-05 1.00000e-09 1.00000e-01 5.00000e-04 5.00000e-04 5.00000e-05 1.00000e-09 1.00000e-01 $1.58385 \mathrm{e}+001.58385 \mathrm{e}+00$ 1.58385e-01 1.00000e-09 2.12000e-01 $1.58385 \mathrm{e}+001.58385 \mathrm{e}+00$ 1.58385e-01 1.00000e-09 2.12000e-01 $1.58385 \mathrm{e}+001.58385 \mathrm{e}+001.58385 \mathrm{e}-01$ 1.00000e-09 2.12000e-01 $1.58385 \mathrm{e}+001.58385 \mathrm{e}+00$ 1.58385e-01 1.00000e-09 2.12000e-01 $1.58385 \mathrm{e}+001.58385 \mathrm{e}+001.58385 \mathrm{e}-01$ 1.00000e-09 2.12000e-01 $1.00000 \mathrm{e}-02$ 1.00000e-02 1.00000e-03 1.00000e-09 1.00000e-01 $1.00000 \mathrm{e}+001.00000 \mathrm{e}+001.00000 \mathrm{e}-011.00000 \mathrm{e}-091.00000 \mathrm{e}-01$ $1.00000 \mathrm{e}-05$ 1.00000e-05 1.00000e-06 1.00000e-09 1.00000e-01 $1.00000 \mathrm{e}+001.00000 \mathrm{e}+001.00000 \mathrm{e}-01$ 1.00000e-09 1.00000e-01 Element: 2150 \# of layers: 14

$\mathrm{Kx} \mathrm{Ky} \mathrm{Kz}$ Ss Por

3.96395e+01 3.96395e+01 3.96395e+00 1.00000e-09 7.00000e-02 $3.96395 \mathrm{e}+013.96395 \mathrm{e}+013.96395 \mathrm{e}+00$ 1.00000e-09 7.00000e-02 $3.96395 \mathrm{e}+013.96395 \mathrm{e}+013.96395 \mathrm{e}+001.00000 \mathrm{e}-09$ 7.00000e-02 5.00000e-04 5.00000e-04 5.00000e-05 1.00000e-09 1.00000e-01 5.00000e-04 5.00000e-04 5.00000e-05 1.00000e-09 1.00000e-01 $1.58385 \mathrm{e}+001.58385 \mathrm{e}+00$ 1.58385e-01 1.00000e-09 2.12000e-01 $1.58385 \mathrm{e}+001.58385 \mathrm{e}+00$ 1.58385e-01 1.00000e-09 2.12000e-01 $1.58385 \mathrm{e}+001.58385 \mathrm{e}+001.58385 \mathrm{e}-011.00000 \mathrm{e}-092.12000 \mathrm{e}-01$ $1.58385 \mathrm{e}+001.58385 \mathrm{e}+00$ 1.58385e-01 1.00000e-09 2.12000e-01 $1.58385 \mathrm{e}+001.58385 \mathrm{e}+00$ 1.58385e-01 1.00000e-09 2.12000e-01 $1.00000 \mathrm{e}-02$ 1.00000e-02 1.00000e-03 1.00000e-09 1.00000e-01 $1.00000 \mathrm{e}+001.00000 \mathrm{e}+001.00000 \mathrm{e}-01$ 1.00000e-09 1.00000e-01 $1.00000 \mathrm{e}-05$ 1.00000e-05 1.00000e-06 1.00000e-09 1.00000e-01 $1.00000 \mathrm{e}+001.00000 \mathrm{e}+001.00000 \mathrm{e}-01$ 1.00000e-09 1.00000e-01 Element: 2151 \# of layers: 13

$\mathrm{Kx} \mathrm{Ky} \mathrm{Kz}$ Ss Por

3.96395e+01 3.96395e+01 3.96395e+00 1.00000e-09 7.00000e-02 
$3.96395 \mathrm{e}+013.96395 \mathrm{e}+013.96395 \mathrm{e}+00$ 1.00000e-09 7.00000e-02 5.00000e-04 5.00000e-04 5.00000e-05 1.00000e-09 1.00000e-01 5.00000e-04 5.00000e-04 5.00000e-05 1.00000e-09 1.00000e-01

$1.58385 \mathrm{e}+001.58385 \mathrm{e}+001.58385 \mathrm{e}-011.00000 \mathrm{e}-092.12000 \mathrm{e}-01$ $1.58385 \mathrm{e}+001.58385 \mathrm{e}+00$ 1.58385e-01 1.00000e-09 2.12000e-01 $1.58385 \mathrm{e}+001.58385 \mathrm{e}+001.58385 \mathrm{e}-01$ 1.00000e-09 2.12000e-01 $1.58385 \mathrm{e}+001.58385 \mathrm{e}+001.58385 \mathrm{e}-01$ 1.00000e-09 2.12000e-01 $1.58385 \mathrm{e}+001.58385 \mathrm{e}+001.58385 \mathrm{e}-011.00000 \mathrm{e}-092.12000 \mathrm{e}-01$ $1.00000 \mathrm{e}-021.00000 \mathrm{e}-021.00000 \mathrm{e}-031.00000 \mathrm{e}-091.00000 \mathrm{e}-01$ $1.00000 \mathrm{e}+001.00000 \mathrm{e}+001.00000 \mathrm{e}-011.00000 \mathrm{e}-091.00000 \mathrm{e}-01$ $1.00000 \mathrm{e}-05$ 1.00000e-05 1.00000e-06 1.00000e-09 1.00000e-01 $1.00000 \mathrm{e}+001.00000 \mathrm{e}+001.00000 \mathrm{e}-011.00000 \mathrm{e}-091.00000 \mathrm{e}-01$ Element: 2152 \# of layers: 13

$\mathrm{Kx} \mathrm{Ky} \mathrm{Kz}$ Ss Por

5.23841e+01 5.23841e+01 5.23841e+00 1.00000e-09 7.00000e-02 $5.23841 \mathrm{e}+015.23841 \mathrm{e}+015.23841 \mathrm{e}+001.00000 \mathrm{e}-09$ 7.00000e-02 5.00000e-04 5.00000e-04 5.00000e-05 1.00000e-09 1.00000e-01 5.00000e-04 5.00000e-04 5.00000e-05 1.00000e-09 1.00000e-01 $2.09309 \mathrm{e}+002.09309 \mathrm{e}+00$ 2.09309e-01 1.00000e-09 2.12000e-01 $2.09309 \mathrm{e}+002.09309 \mathrm{e}+002.09309 \mathrm{e}-01$ 1.00000e-09 2.12000e-01 $2.09309 \mathrm{e}+002.09309 \mathrm{e}+00$ 2.09309e-01 1.00000e-09 2.12000e-01 $2.09309 \mathrm{e}+002.09309 \mathrm{e}+00$ 2.09309e-01 1.00000e-09 2.12000e-01 $2.09309 \mathrm{e}+002.09309 \mathrm{e}+00$ 2.09309e-01 1.00000e-09 2.12000e-01 $1.00000 \mathrm{e}-02$ 1.00000e-02 1.00000e-03 1.00000e-09 1.00000e-01 $1.00000 \mathrm{e}+001.00000 \mathrm{e}+001.00000 \mathrm{e}-011.00000 \mathrm{e}-091.00000 \mathrm{e}-01$ $1.00000 \mathrm{e}-05$ 1.00000e-05 1.00000e-06 1.00000e-09 1.00000e-01 $1.00000 \mathrm{e}+001.00000 \mathrm{e}+001.00000 \mathrm{e}-011.00000 \mathrm{e}-091.00000 \mathrm{e}-01$ Element: 2153 \# of layers: 14

$\mathrm{Kx} \mathrm{Ky} \mathrm{Kz}$ Ss Por

5.23841e+01 5.23841e+01 5.23841e+00 1.00000e-09 7.00000e-02 $5.23841 \mathrm{e}+015.23841 \mathrm{e}+015.23841 \mathrm{e}+00$ 1.00000e-09 7.00000e-02 $5.23841 \mathrm{e}+015.23841 \mathrm{e}+015.23841 \mathrm{e}+001.00000 \mathrm{e}-09$ 7.00000e-02 5.00000e-04 5.00000e-04 5.00000e-05 1.00000e-09 1.00000e-01 $5.00000 \mathrm{e}-04$ 5.00000e-04 5.00000e-05 1.00000e-09 1.00000e-01 $2.09309 \mathrm{e}+002.09309 \mathrm{e}+002.09309 \mathrm{e}-01$ 1.00000e-09 2.12000e-01 $2.09309 \mathrm{e}+002.09309 \mathrm{e}+00$ 2.09309e-01 1.00000e-09 2.12000e-01 $2.09309 \mathrm{e}+002.09309 \mathrm{e}+002.09309 \mathrm{e}-01$ 1.00000e-09 2.12000e-01 $2.09309 \mathrm{e}+002.09309 \mathrm{e}+002.09309 \mathrm{e}-01$ 1.00000e-09 2.12000e-01 $2.09309 \mathrm{e}+002.09309 \mathrm{e}+002.09309 \mathrm{e}-01$ 1.00000e-09 2.12000e-01 $1.00000 \mathrm{e}-02$ 1.00000e-02 1.00000e-03 1.00000e-09 1.00000e-01 $1.00000 \mathrm{e}+001.00000 \mathrm{e}+001.00000 \mathrm{e}-011.00000 \mathrm{e}-091.00000 \mathrm{e}-01$ $1.00000 \mathrm{e}-05$ 1.00000e-05 1.00000e-06 1.00000e-09 1.00000e-01 $1.00000 \mathrm{e}+001.00000 \mathrm{e}+001.00000 \mathrm{e}-01$ 1.00000e-09 1.00000e-01 Element: 2154 \# of layers: 13

$\mathrm{Kx} \mathrm{Ky} \mathrm{Kz}$ Ss Por

5.23841e+01 5.23841e+01 5.23841e+00 1.00000e-09 7.00000e-02 
5.23841e+01 5.23841e+01 5.23841e+00 1.00000e-09 7.00000e-02 $5.00000 \mathrm{e}-04$ 5.00000e-04 5.00000e-05 1.00000e-09 1.00000e-01 5.00000e-04 5.00000e-04 5.00000e-05 1.00000e-09 1.00000e-01 $2.09309 \mathrm{e}+002.09309 \mathrm{e}+002.09309 \mathrm{e}-01$ 1.00000e-09 2.12000e-01 $2.09309 \mathrm{e}+00$ 2.09309e+00 2.09309e-01 1.00000e-09 2.12000e-01 $2.09309 \mathrm{e}+002.09309 \mathrm{e}+00$ 2.09309e-01 1.00000e-09 2.12000e-01 $2.09309 \mathrm{e}+002.09309 \mathrm{e}+00$ 2.09309e-01 1.00000e-09 2.12000e-01 $2.09309 \mathrm{e}+002.09309 \mathrm{e}+002.09309 \mathrm{e}-01$ 1.00000e-09 2.12000e-01 $1.00000 \mathrm{e}-02$ 1.00000e-02 1.00000e-03 1.00000e-09 1.00000e-01 $1.00000 \mathrm{e}+001.00000 \mathrm{e}+001.00000 \mathrm{e}-011.00000 \mathrm{e}-091.00000 \mathrm{e}-01$ $1.00000 \mathrm{e}-05$ 1.00000e-05 1.00000e-06 1.00000e-09 1.00000e-01 $1.00000 \mathrm{e}+001.00000 \mathrm{e}+001.00000 \mathrm{e}-011.00000 \mathrm{e}-091.00000 \mathrm{e}-01$ Element: 2155 \# of layers: 13

$\mathrm{Kx} \mathrm{Ky} \mathrm{Kz}$ Ss Por

5.23841e+01 5.23841e+01 5.23841e+00 1.00000e-09 7.00000e-02 $5.23841 \mathrm{e}+015.23841 \mathrm{e}+015.23841 \mathrm{e}+001.00000 \mathrm{e}-09$ 7.00000e-02 5.00000e-04 5.00000e-04 5.00000e-05 1.00000e-09 1.00000e-01 5.00000e-04 5.00000e-04 5.00000e-05 1.00000e-09 1.00000e-01 $2.09309 \mathrm{e}+002.09309 \mathrm{e}+00$ 2.09309e-01 1.00000e-09 2.12000e-01 $2.09309 \mathrm{e}+002.09309 \mathrm{e}+00$ 2.09309e-01 1.00000e-09 2.12000e-01 $2.09309 \mathrm{e}+002.09309 \mathrm{e}+00$ 2.09309e-01 1.00000e-09 2.12000e-01 $2.09309 \mathrm{e}+00$ 2.09309e+00 2.09309e-01 1.00000e-09 2.12000e-01 $2.09309 \mathrm{e}+002.09309 \mathrm{e}+00$ 2.09309e-01 1.00000e-09 2.12000e-01 $1.00000 \mathrm{e}-02$ 1.00000e-02 1.00000e-03 1.00000e-09 1.00000e-01 $1.00000 \mathrm{e}+001.00000 \mathrm{e}+001.00000 \mathrm{e}-011.00000 \mathrm{e}-091.00000 \mathrm{e}-01$ $1.00000 \mathrm{e}-05$ 1.00000e-05 1.00000e-06 1.00000e-09 1.00000e-01 $1.00000 \mathrm{e}+001.00000 \mathrm{e}+001.00000 \mathrm{e}-011.00000 \mathrm{e}-091.00000 \mathrm{e}-01$ Element: 2156 \# of layers: 13

$\mathrm{Kx} \mathrm{Ky} \mathrm{Kz}$ Ss Por

5.23841e+01 5.23841e+01 5.23841e+00 1.00000e-09 7.00000e-02 $5.23841 \mathrm{e}+015.23841 \mathrm{e}+015.23841 \mathrm{e}+001.00000 \mathrm{e}-09$ 7.00000e-02 5.00000e-04 5.00000e-04 5.00000e-05 1.00000e-09 1.00000e-01 5.00000e-04 5.00000e-04 5.00000e-05 1.00000e-09 1.00000e-01 $2.09309 \mathrm{e}+002.09309 \mathrm{e}+00$ 2.09309e-01 1.00000e-09 2.12000e-01 $2.09309 \mathrm{e}+002.09309 \mathrm{e}+002.09309 \mathrm{e}-01$ 1.00000e-09 2.12000e-01 $2.09309 \mathrm{e}+002.09309 \mathrm{e}+00$ 2.09309e-01 1.00000e-09 2.12000e-01 $2.09309 \mathrm{e}+002.09309 \mathrm{e}+002.09309 \mathrm{e}-01$ 1.00000e-09 2.12000e-01 $2.09309 \mathrm{e}+002.09309 \mathrm{e}+00$ 2.09309e-01 1.00000e-09 2.12000e-01 $1.00000 \mathrm{e}-02$ 1.00000e-02 1.00000e-03 1.00000e-09 1.00000e-01 $1.00000 \mathrm{e}+001.00000 \mathrm{e}+001.00000 \mathrm{e}-011.00000 \mathrm{e}-091.00000 \mathrm{e}-01$ $1.00000 \mathrm{e}-05$ 1.00000e-05 1.00000e-06 1.00000e-09 1.00000e-01 $1.00000 \mathrm{e}+001.00000 \mathrm{e}+001.00000 \mathrm{e}-011.00000 \mathrm{e}-091.00000 \mathrm{e}-01$ Element: 2157 \# of layers: 14

$\mathrm{Kx} \mathrm{Ky} \mathrm{Kz}$ Ss Por

5.23841e+01 5.23841e+01 5.23841e+00 1.00000e-09 7.00000e-02 $5.23841 \mathrm{e}+015.23841 \mathrm{e}+015.23841 \mathrm{e}+001.00000 \mathrm{e}-09$ 7.00000e-02 
5.23841e+01 5.23841e+01 5.23841e+00 1.00000e-09 7.00000e-02 $5.00000 \mathrm{e}-04$ 5.00000e-04 5.00000e-05 1.00000e-09 1.00000e-01 5.00000e-04 5.00000e-04 5.00000e-05 1.00000e-09 1.00000e-01 $2.09309 \mathrm{e}+002.09309 \mathrm{e}+002.09309 \mathrm{e}-01$ 1.00000e-09 2.12000e-01 $2.09309 \mathrm{e}+00$ 2.09309e+00 2.09309e-01 1.00000e-09 2.12000e-01 $2.09309 \mathrm{e}+002.09309 \mathrm{e}+00$ 2.09309e-01 1.00000e-09 2.12000e-01 $2.09309 \mathrm{e}+002.09309 \mathrm{e}+00$ 2.09309e-01 1.00000e-09 2.12000e-01 $2.09309 \mathrm{e}+002.09309 \mathrm{e}+00$ 2.09309e-01 1.00000e-09 2.12000e-01 $1.00000 \mathrm{e}-02$ 1.00000e-02 1.00000e-03 1.00000e-09 1.00000e-01 $1.00000 \mathrm{e}+001.00000 \mathrm{e}+001.00000 \mathrm{e}-011.00000 \mathrm{e}-091.00000 \mathrm{e}-01$ $1.00000 \mathrm{e}-05$ 1.00000e-05 1.00000e-06 1.00000e-09 1.00000e-01 $1.00000 \mathrm{e}+001.00000 \mathrm{e}+001.00000 \mathrm{e}-011.00000 \mathrm{e}-091.00000 \mathrm{e}-01$ Element: 2158 \# of layers: 13

$\mathrm{Kx} \mathrm{Ky} \mathrm{Kz}$ Ss Por

5.23841e+01 5.23841e+01 5.23841e+00 1.00000e-09 7.00000e-02 $5.23841 \mathrm{e}+015.23841 \mathrm{e}+015.23841 \mathrm{e}+001.00000 \mathrm{e}-09$ 7.00000e-02 5.00000e-04 5.00000e-04 5.00000e-05 1.00000e-09 1.00000e-01 5.00000e-04 5.00000e-04 5.00000e-05 1.00000e-09 1.00000e-01 $2.09309 \mathrm{e}+002.09309 \mathrm{e}+00$ 2.09309e-01 1.00000e-09 2.12000e-01 $2.09309 \mathrm{e}+002.09309 \mathrm{e}+00$ 2.09309e-01 1.00000e-09 2.12000e-01 $2.09309 \mathrm{e}+002.09309 \mathrm{e}+00$ 2.09309e-01 1.00000e-09 2.12000e-01 $2.09309 \mathrm{e}+00$ 2.09309e+00 2.09309e-01 1.00000e-09 2.12000e-01 $2.09309 \mathrm{e}+002.09309 \mathrm{e}+00$ 2.09309e-01 1.00000e-09 2.12000e-01 $1.00000 \mathrm{e}-02$ 1.00000e-02 1.00000e-03 1.00000e-09 1.00000e-01 $1.00000 \mathrm{e}+001.00000 \mathrm{e}+001.00000 \mathrm{e}-011.00000 \mathrm{e}-091.00000 \mathrm{e}-01$ $1.00000 \mathrm{e}-05$ 1.00000e-05 1.00000e-06 1.00000e-09 1.00000e-01 $1.00000 \mathrm{e}+001.00000 \mathrm{e}+001.00000 \mathrm{e}-011.00000 \mathrm{e}-091.00000 \mathrm{e}-01$ Element: 2159 \# of layers: 13

$\mathrm{Kx} \mathrm{Ky} \mathrm{Kz}$ Ss Por

5.23841e+01 5.23841e+01 5.23841e+00 1.00000e-09 7.00000e-02 $5.23841 \mathrm{e}+015.23841 \mathrm{e}+015.23841 \mathrm{e}+001.00000 \mathrm{e}-09$ 7.00000e-02 5.00000e-04 5.00000e-04 5.00000e-05 1.00000e-09 1.00000e-01 5.00000e-04 5.00000e-04 5.00000e-05 1.00000e-09 1.00000e-01 $2.09309 \mathrm{e}+002.09309 \mathrm{e}+00$ 2.09309e-01 1.00000e-09 2.12000e-01 $2.09309 \mathrm{e}+002.09309 \mathrm{e}+002.09309 \mathrm{e}-01$ 1.00000e-09 2.12000e-01 $2.09309 \mathrm{e}+002.09309 \mathrm{e}+00$ 2.09309e-01 1.00000e-09 2.12000e-01 $2.09309 \mathrm{e}+002.09309 \mathrm{e}+002.09309 \mathrm{e}-01$ 1.00000e-09 2.12000e-01 $2.09309 \mathrm{e}+002.09309 \mathrm{e}+00$ 2.09309e-01 1.00000e-09 2.12000e-01 $1.00000 \mathrm{e}-02$ 1.00000e-02 1.00000e-03 1.00000e-09 1.00000e-01 $1.00000 \mathrm{e}+001.00000 \mathrm{e}+001.00000 \mathrm{e}-011.00000 \mathrm{e}-091.00000 \mathrm{e}-01$ $1.00000 \mathrm{e}-05$ 1.00000e-05 1.00000e-06 1.00000e-09 1.00000e-01 $1.00000 \mathrm{e}+001.00000 \mathrm{e}+001.00000 \mathrm{e}-011.00000 \mathrm{e}-091.00000 \mathrm{e}-01$ Element: 2160 \# of layers: 14

$\mathrm{Kx} \mathrm{Ky} \mathrm{Kz}$ Ss Por

5.23841e+01 5.23841e+01 5.23841e+00 1.00000e-09 7.00000e-02 $5.23841 \mathrm{e}+015.23841 \mathrm{e}+015.23841 \mathrm{e}+001.00000 \mathrm{e}-09$ 7.00000e-02 
5.23841e+01 5.23841e+01 5.23841e+00 1.00000e-09 7.00000e-02 $5.00000 \mathrm{e}-04$ 5.00000e-04 5.00000e-05 1.00000e-09 1.00000e-01 5.00000e-04 5.00000e-04 5.00000e-05 1.00000e-09 1.00000e-01 $2.09309 \mathrm{e}+002.09309 \mathrm{e}+002.09309 \mathrm{e}-01$ 1.00000e-09 2.12000e-01 $2.09309 \mathrm{e}+00$ 2.09309e+00 2.09309e-01 1.00000e-09 2.12000e-01 $2.09309 \mathrm{e}+002.09309 \mathrm{e}+00$ 2.09309e-01 1.00000e-09 2.12000e-01 $2.09309 \mathrm{e}+002.09309 \mathrm{e}+00$ 2.09309e-01 1.00000e-09 2.12000e-01 $2.09309 \mathrm{e}+002.09309 \mathrm{e}+002.09309 \mathrm{e}-01$ 1.00000e-09 2.12000e-01 $1.00000 \mathrm{e}-02$ 1.00000e-02 1.00000e-03 1.00000e-09 1.00000e-01 $1.00000 \mathrm{e}+001.00000 \mathrm{e}+001.00000 \mathrm{e}-011.00000 \mathrm{e}-091.00000 \mathrm{e}-01$ $1.00000 \mathrm{e}-05$ 1.00000e-05 1.00000e-06 1.00000e-09 1.00000e-01 $1.00000 \mathrm{e}+001.00000 \mathrm{e}+001.00000 \mathrm{e}-011.00000 \mathrm{e}-091.00000 \mathrm{e}-01$ Element: 2161 \# of layers: 12

$\mathrm{Kx} \mathrm{Ky} \mathrm{Kz}$ Ss Por

4.43688e+01 4.43688e+01 4.43688e+00 1.00000e-09 7.00000e-02 5.00000e-04 5.00000e-04 5.00000e-05 1.00000e-09 1.00000e-01 5.00000e-04 5.00000e-04 5.00000e-05 1.00000e-09 1.00000e-01

$1.77281 \mathrm{e}+001.77281 \mathrm{e}+00$ 1.77281e-01 1.00000e-09 2.12000e-01 $1.77281 \mathrm{e}+001.77281 \mathrm{e}+00$ 1.77281e-01 1.00000e-09 2.12000e-01 $1.77281 \mathrm{e}+001.77281 \mathrm{e}+00$ 1.77281e-01 1.00000e-09 2.12000e-01 $1.77281 \mathrm{e}+001.77281 \mathrm{e}+001.77281 \mathrm{e}-011.00000 \mathrm{e}-092.12000 \mathrm{e}-01$ $1.77281 \mathrm{e}+001.77281 \mathrm{e}+00$ 1.77281e-01 1.00000e-09 2.12000e-01 $1.00000 \mathrm{e}-02$ 1.00000e-02 1.00000e-03 1.00000e-09 1.00000e-01 $1.00000 \mathrm{e}+001.00000 \mathrm{e}+001.00000 \mathrm{e}-011.00000 \mathrm{e}-091.00000 \mathrm{e}-01$ $1.00000 \mathrm{e}-05$ 1.00000e-05 1.00000e-06 1.00000e-09 1.00000e-01 $1.00000 \mathrm{e}+001.00000 \mathrm{e}+001.00000 \mathrm{e}-01$ 1.00000e-09 1.00000e-01 Element: 2162 \# of layers: 12

$\mathrm{Kx} \mathrm{Ky} \mathrm{Kz}$ Ss Por

4.43688e+01 4.43688e+01 4.43688e+00 1.00000e-09 7.00000e-02 5.00000e-04 5.00000e-04 5.00000e-05 1.00000e-09 1.00000e-01 5.00000e-04 5.00000e-04 5.00000e-05 1.00000e-09 1.00000e-01 $1.77281 \mathrm{e}+001.77281 \mathrm{e}+001.77281 \mathrm{e}-01$ 1.00000e-09 2.12000e-01 $1.77281 \mathrm{e}+001.77281 \mathrm{e}+001.77281 \mathrm{e}-011.00000 \mathrm{e}-092.12000 \mathrm{e}-01$ $1.77281 \mathrm{e}+001.77281 \mathrm{e}+001.77281 \mathrm{e}-011.00000 \mathrm{e}-092.12000 \mathrm{e}-01$ $1.77281 \mathrm{e}+001.77281 \mathrm{e}+00$ 1.77281e-01 1.00000e-09 2.12000e-01 $1.77281 \mathrm{e}+001.77281 \mathrm{e}+001.77281 \mathrm{e}-01$ 1.00000e-09 2.12000e-01 1.00000e-02 1.00000e-02 1.00000e-03 1.00000e-09 1.00000e-01 $1.00000 \mathrm{e}+001.00000 \mathrm{e}+001.00000 \mathrm{e}-011.00000 \mathrm{e}-091.00000 \mathrm{e}-01$ $1.00000 \mathrm{e}-05$ 1.00000e-05 1.00000e-06 1.00000e-09 1.00000e-01 $1.00000 \mathrm{e}+001.00000 \mathrm{e}+001.00000 \mathrm{e}-01$ 1.00000e-09 1.00000e-01 Element: 2163 \# of layers: 12

$\mathrm{Kx} \mathrm{Ky} \mathrm{Kz}$ Ss Por 4.43688e+01 4.43688e+01 4.43688e+00 1.00000e-09 7.00000e-02 $5.00000 \mathrm{e}-04$ 5.00000e-04 5.00000e-05 1.00000e-09 1.00000e-01 5.00000e-04 5.00000e-04 5.00000e-05 1.00000e-09 1.00000e-01 $1.77281 \mathrm{e}+001.77281 \mathrm{e}+001.77281 \mathrm{e}-011.00000 \mathrm{e}-092.12000 \mathrm{e}-01$ 
$1.77281 \mathrm{e}+001.77281 \mathrm{e}+00$ 1.77281e-01 1.00000e-09 2.12000e-01 $1.77281 \mathrm{e}+001.77281 \mathrm{e}+00$ 1.77281e-01 1.00000e-09 2.12000e-01 $1.77281 \mathrm{e}+001.77281 \mathrm{e}+001.77281 \mathrm{e}-01$ 1.00000e-09 2.12000e-01 $1.77281 \mathrm{e}+001.77281 \mathrm{e}+001.77281 \mathrm{e}-011.00000 \mathrm{e}-092.12000 \mathrm{e}-01$ $1.00000 \mathrm{e}-021.00000 \mathrm{e}-021.00000 \mathrm{e}-031.00000 \mathrm{e}-091.00000 \mathrm{e}-01$ $1.00000 \mathrm{e}+001.00000 \mathrm{e}+001.00000 \mathrm{e}-011.00000 \mathrm{e}-091.00000 \mathrm{e}-01$ $1.00000 \mathrm{e}-05$ 1.00000e-05 1.00000e-06 1.00000e-09 1.00000e-01 $1.00000 \mathrm{e}+001.00000 \mathrm{e}+001.00000 \mathrm{e}-011.00000 \mathrm{e}-091.00000 \mathrm{e}-01$ Element: 2164 \# of layers: 12

$\mathrm{Kx} \mathrm{Ky} \mathrm{Kz}$ Ss Por

4.43688e+01 4.43688e+01 4.43688e+00 1.00000e-09 7.00000e-02 5.00000e-04 5.00000e-04 5.00000e-05 1.00000e-09 1.00000e-01 5.00000e-04 5.00000e-04 5.00000e-05 1.00000e-09 1.00000e-01 $1.77281 \mathrm{e}+001.77281 \mathrm{e}+001.77281 \mathrm{e}-01$ 1.00000e-09 2.12000e-01 $1.77281 \mathrm{e}+001.77281 \mathrm{e}+001.77281 \mathrm{e}-01$ 1.00000e-09 2.12000e-01 $1.77281 \mathrm{e}+001.77281 \mathrm{e}+001.77281 \mathrm{e}-01$ 1.00000e-09 2.12000e-01 $1.77281 \mathrm{e}+001.77281 \mathrm{e}+001.77281 \mathrm{e}-01$ 1.00000e-09 2.12000e-01 $1.77281 \mathrm{e}+001.77281 \mathrm{e}+001.77281 \mathrm{e}-01$ 1.00000e-09 2.12000e-01 $1.00000 \mathrm{e}-02$ 1.00000e-02 1.00000e-03 1.00000e-09 1.00000e-01 $1.00000 \mathrm{e}+001.00000 \mathrm{e}+001.00000 \mathrm{e}-011.00000 \mathrm{e}-091.00000 \mathrm{e}-01$ $1.00000 \mathrm{e}-05$ 1.00000e-05 1.00000e-06 1.00000e-09 1.00000e-01 $1.00000 \mathrm{e}+001.00000 \mathrm{e}+001.00000 \mathrm{e}-01$ 1.00000e-09 1.00000e-01 Element: 2165 \# of layers: 12

Kx Ky Kz Ss Por

4.43688e+01 4.43688e+01 4.43688e+00 1.00000e-09 7.00000e-02 $5.00000 \mathrm{e}-04$ 5.00000e-04 5.00000e-05 1.00000e-09 1.00000e-01 5.00000e-04 5.00000e-04 5.00000e-05 1.00000e-09 1.00000e-01 $1.77281 \mathrm{e}+001.77281 \mathrm{e}+00$ 1.77281e-01 1.00000e-09 2.12000e-01 $1.77281 \mathrm{e}+001.77281 \mathrm{e}+001.77281 \mathrm{e}-011.00000 \mathrm{e}-092.12000 \mathrm{e}-01$ $1.77281 \mathrm{e}+001.77281 \mathrm{e}+00$ 1.77281e-01 1.00000e-09 2.12000e-01 $1.77281 \mathrm{e}+001.77281 \mathrm{e}+001.77281 \mathrm{e}-01$ 1.00000e-09 2.12000e-01 $1.77281 \mathrm{e}+001.77281 \mathrm{e}+001.77281 \mathrm{e}-01$ 1.00000e-09 2.12000e-01 $1.00000 \mathrm{e}-02$ 1.00000e-02 1.00000e-03 1.00000e-09 1.00000e-01 $1.00000 \mathrm{e}+001.00000 \mathrm{e}+001.00000 \mathrm{e}-011.00000 \mathrm{e}-091.00000 \mathrm{e}-01$ $1.00000 \mathrm{e}-05$ 1.00000e-05 1.00000e-06 1.00000e-09 1.00000e-01 $1.00000 \mathrm{e}+001.00000 \mathrm{e}+001.00000 \mathrm{e}-011.00000 \mathrm{e}-091.00000 \mathrm{e}-01$ Element: 2166 \# of layers: 11

$\mathrm{Kx} \mathrm{Ky} \mathrm{Kz}$ Ss Por

4.43688e+01 4.43688e+01 4.43688e+00 1.00000e-09 7.00000e-02 5.00000e-04 5.00000e-04 5.00000e-05 1.00000e-09 1.00000e-01 $1.77281 \mathrm{e}+001.77281 \mathrm{e}+001.77281 \mathrm{e}-01$ 1.00000e-09 2.12000e-01 $1.77281 \mathrm{e}+001.77281 \mathrm{e}+001.77281 \mathrm{e}-01$ 1.00000e-09 2.12000e-01 $1.77281 \mathrm{e}+001.77281 \mathrm{e}+00$ 1.77281e-01 1.00000e-09 2.12000e-01 $1.77281 \mathrm{e}+001.77281 \mathrm{e}+00$ 1.77281e-01 1.00000e-09 2.12000e-01 $1.77281 \mathrm{e}+001.77281 \mathrm{e}+001.77281 \mathrm{e}-01$ 1.00000e-09 2.12000e-01 $1.00000 \mathrm{e}-02$ 1.00000e-02 1.00000e-03 1.00000e-09 1.00000e-01 
$1.00000 \mathrm{e}+001.00000 \mathrm{e}+001.00000 \mathrm{e}-011.00000 \mathrm{e}-091.00000 \mathrm{e}-01$ $1.00000 \mathrm{e}-05$ 1.00000e-05 1.00000e-06 1.00000e-09 1.00000e-01 $1.00000 \mathrm{e}+001.00000 \mathrm{e}+001.00000 \mathrm{e}-01$ 1.00000e-09 1.00000e-01 Element: 2167 \# of layers: 13

$\mathrm{Kx} \mathrm{Ky} \mathrm{Kz}$ Ss Por

4.43688e+01 4.43688e+01 4.43688e+00 1.00000e-09 7.00000e-02 $4.43688 \mathrm{e}+014.43688 \mathrm{e}+014.43688 \mathrm{e}+00$ 1.00000e-09 7.00000e-02 5.00000e-04 5.00000e-04 5.00000e-05 1.00000e-09 1.00000e-01 5.00000e-04 5.00000e-04 5.00000e-05 1.00000e-09 1.00000e-01

$1.77281 \mathrm{e}+001.77281 \mathrm{e}+001.77281 \mathrm{e}-01$ 1.00000e-09 2.12000e-01 $1.77281 \mathrm{e}+001.77281 \mathrm{e}+001.77281 \mathrm{e}-01$ 1.00000e-09 2.12000e-01 $1.77281 \mathrm{e}+001.77281 \mathrm{e}+001.77281 \mathrm{e}-011.00000 \mathrm{e}-092.12000 \mathrm{e}-01$ $1.77281 \mathrm{e}+001.77281 \mathrm{e}+001.77281 \mathrm{e}-01$ 1.00000e-09 2.12000e-01 $1.77281 \mathrm{e}+001.77281 \mathrm{e}+001.77281 \mathrm{e}-01$ 1.00000e-09 2.12000e-01 $1.00000 \mathrm{e}-02$ 1.00000e-02 1.00000e-03 1.00000e-09 1.00000e-01 $1.00000 \mathrm{e}+001.00000 \mathrm{e}+001.00000 \mathrm{e}-011.00000 \mathrm{e}-091.00000 \mathrm{e}-01$ $1.00000 \mathrm{e}-05$ 1.00000e-05 1.00000e-06 1.00000e-09 1.00000e-01 $1.00000 \mathrm{e}+001.00000 \mathrm{e}+001.00000 \mathrm{e}-011.00000 \mathrm{e}-091.00000 \mathrm{e}-01$ Element: 2168 \# of layers: 13

$\mathrm{Kx} \mathrm{Ky} \mathrm{Kz}$ Ss Por

4.43688e+01 4.43688e+01 4.43688e+00 1.00000e-09 7.00000e-02 $4.43688 \mathrm{e}+014.43688 \mathrm{e}+014.43688 \mathrm{e}+001.00000 \mathrm{e}-09$ 7.00000e-02 5.00000e-04 5.00000e-04 5.00000e-05 1.00000e-09 1.00000e-01 5.00000e-04 5.00000e-04 5.00000e-05 1.00000e-09 1.00000e-01

$1.77281 \mathrm{e}+001.77281 \mathrm{e}+001.77281 \mathrm{e}-011.00000 \mathrm{e}-092.12000 \mathrm{e}-01$ $1.77281 \mathrm{e}+001.77281 \mathrm{e}+001.77281 \mathrm{e}-01$ 1.00000e-09 2.12000e-01 $1.77281 \mathrm{e}+001.77281 \mathrm{e}+001.77281 \mathrm{e}-01$ 1.00000e-09 2.12000e-01 $1.77281 \mathrm{e}+001.77281 \mathrm{e}+001.77281 \mathrm{e}-01$ 1.00000e-09 2.12000e-01 $1.77281 \mathrm{e}+001.77281 \mathrm{e}+001.77281 \mathrm{e}-01$ 1.00000e-09 2.12000e-01 $1.00000 \mathrm{e}-02$ 1.00000e-02 1.00000e-03 1.00000e-09 1.00000e-01 $1.00000 \mathrm{e}+001.00000 \mathrm{e}+001.00000 \mathrm{e}-011.00000 \mathrm{e}-091.00000 \mathrm{e}-01$ $1.00000 \mathrm{e}-05$ 1.00000e-05 1.00000e-06 1.00000e-09 1.00000e-01 $1.00000 \mathrm{e}+001.00000 \mathrm{e}+001.00000 \mathrm{e}-011.00000 \mathrm{e}-091.00000 \mathrm{e}-01$ Element: 2169 \# of layers: 12

$\mathrm{Kx} \mathrm{Ky} \mathrm{Kz}$ Ss Por

4.43688e+01 4.43688e+01 4.43688e+00 1.00000e-09 7.00000e-02 5.00000e-04 5.00000e-04 5.00000e-05 1.00000e-09 1.00000e-01 5.00000e-04 5.00000e-04 5.00000e-05 1.00000e-09 1.00000e-01 $1.77281 \mathrm{e}+001.77281 \mathrm{e}+001.77281 \mathrm{e}-01$ 1.00000e-09 2.12000e-01 $1.77281 \mathrm{e}+001.77281 \mathrm{e}+001.77281 \mathrm{e}-01$ 1.00000e-09 2.12000e-01 $1.77281 \mathrm{e}+001.77281 \mathrm{e}+001.77281 \mathrm{e}-01$ 1.00000e-09 2.12000e-01 $1.77281 \mathrm{e}+001.77281 \mathrm{e}+001.77281 \mathrm{e}-011.00000 \mathrm{e}-092.12000 \mathrm{e}-01$ $1.77281 \mathrm{e}+001.77281 \mathrm{e}+00$ 1.77281e-01 1.00000e-09 2.12000e-01 1.00000e-02 1.00000e-02 1.00000e-03 1.00000e-09 1.00000e-01 $1.00000 \mathrm{e}+001.00000 \mathrm{e}+001.00000 \mathrm{e}-011.00000 \mathrm{e}-091.00000 \mathrm{e}-01$ $1.00000 \mathrm{e}-05$ 1.00000e-05 1.00000e-06 1.00000e-09 1.00000e-01 
$1.00000 \mathrm{e}+001.00000 \mathrm{e}+00$ 1.00000e-01 1.00000e-09 1.00000e-01 Element: 2170 \# of layers: 12

Kx Ky Kz Ss Por

5.70342e+01 5.70342e+01 5.70342e+00 1.00000e-09 7.00000e-02

5.00000e-04 5.00000e-04 5.00000e-05 1.00000e-09 1.00000e-01

5.00000e-04 5.00000e-04 5.00000e-05 1.00000e-09 1.00000e-01

$2.27885 \mathrm{e}+002.27885 \mathrm{e}+00$ 2.27885e-01 1.00000e-09 2.12000e-01

$2.27885 \mathrm{e}+002.27885 \mathrm{e}+002.27885 \mathrm{e}-01$ 1.00000e-09 2.12000e-01

$2.27885 \mathrm{e}+002.27885 \mathrm{e}+00$ 2.27885e-01 1.00000e-09 2.12000e-01

$2.27885 \mathrm{e}+002.27885 \mathrm{e}+00$ 2.27885e-01 1.00000e-09 2.12000e-01

$2.27885 \mathrm{e}+002.27885 \mathrm{e}+002.27885 \mathrm{e}-01$ 1.00000e-09 2.12000e-01

1.00000e-02 1.00000e-02 1.00000e-03 1.00000e-09 1.00000e-01

$1.00000 \mathrm{e}+001.00000 \mathrm{e}+001.00000 \mathrm{e}-011.00000 \mathrm{e}-091.00000 \mathrm{e}-01$

$1.00000 \mathrm{e}-05$ 1.00000e-05 1.00000e-06 1.00000e-09 1.00000e-01

$1.00000 \mathrm{e}+001.00000 \mathrm{e}+001.00000 \mathrm{e}-01$ 1.00000e-09 1.00000e-01

Element: 2171 \# of layers: 12

$\mathrm{Kx} \mathrm{Ky} \mathrm{Kz}$ Ss Por

5.70342e+01 5.70342e+01 5.70342e+00 1.00000e-09 7.00000e-02 5.00000e-04 5.00000e-04 5.00000e-05 1.00000e-09 1.00000e-01 5.00000e-04 5.00000e-04 5.00000e-05 1.00000e-09 1.00000e-01

$2.27885 \mathrm{e}+002.27885 \mathrm{e}+00$ 2.27885e-01 1.00000e-09 2.12000e-01

$2.27885 \mathrm{e}+00$ 2.27885e+00 2.27885e-01 1.00000e-09 2.12000e-01

$2.27885 \mathrm{e}+00$ 2.27885e+00 2.27885e-01 1.00000e-09 2.12000e-01

$2.27885 \mathrm{e}+002.27885 \mathrm{e}+002.27885 \mathrm{e}-01$ 1.00000e-09 2.12000e-01

$2.27885 \mathrm{e}+002.27885 \mathrm{e}+00 \quad 2.27885 \mathrm{e}-01$ 1.00000e-09 2.12000e-01

$1.00000 \mathrm{e}-02$ 1.00000e-02 1.00000e-03 1.00000e-09 1.00000e-01

$1.00000 \mathrm{e}+001.00000 \mathrm{e}+001.00000 \mathrm{e}-011.00000 \mathrm{e}-091.00000 \mathrm{e}-01$

$1.00000 \mathrm{e}-05$ 1.00000e-05 1.00000e-06 1.00000e-09 1.00000e-01

$1.00000 \mathrm{e}+001.00000 \mathrm{e}+001.00000 \mathrm{e}-011.00000 \mathrm{e}-091.00000 \mathrm{e}-01$

Element: 2172 \# of layers: 12

$\mathrm{Kx} \mathrm{Ky} \mathrm{Kz}$ Ss Por

5.70342e+01 5.70342e+01 5.70342e+00 1.00000e-09 7.00000e-02

5.00000e-04 5.00000e-04 5.00000e-05 1.00000e-09 1.00000e-01

5.00000e-04 5.00000e-04 5.00000e-05 1.00000e-09 1.00000e-01

$2.27885 \mathrm{e}+002.27885 \mathrm{e}+00$ 2.27885e-01 1.00000e-09 2.12000e-01

$2.27885 \mathrm{e}+002.27885 \mathrm{e}+00$ 2.27885e-01 1.00000e-09 2.12000e-01

$2.27885 \mathrm{e}+002.27885 \mathrm{e}+002.27885 \mathrm{e}-01$ 1.00000e-09 2.12000e-01

$2.27885 \mathrm{e}+002.27885 \mathrm{e}+002.27885 \mathrm{e}-01$ 1.00000e-09 2.12000e-01

$2.27885 \mathrm{e}+002.27885 \mathrm{e}+002.27885 \mathrm{e}-01$ 1.00000e-09 2.12000e-01

$1.00000 \mathrm{e}-02$ 1.00000e-02 1.00000e-03 1.00000e-09 1.00000e-01

$1.00000 \mathrm{e}+001.00000 \mathrm{e}+001.00000 \mathrm{e}-011.00000 \mathrm{e}-091.00000 \mathrm{e}-01$

$1.00000 \mathrm{e}-05$ 1.00000e-05 1.00000e-06 1.00000e-09 1.00000e-01

$1.00000 \mathrm{e}+001.00000 \mathrm{e}+001.00000 \mathrm{e}-011.00000 \mathrm{e}-091.00000 \mathrm{e}-01$

Element: 2173 \# of layers: 12

$\mathrm{Kx} \mathrm{Ky} \mathrm{Kz}$ Ss Por

5.70342e+01 5.70342e+01 5.70342e+00 1.00000e-09 7.00000e-02 
5.00000e-04 5.00000e-04 5.00000e-05 1.00000e-09 1.00000e-01 5.00000e-04 5.00000e-04 5.00000e-05 1.00000e-09 1.00000e-01 $2.27885 \mathrm{e}+002.27885 \mathrm{e}+00$ 2.27885e-01 1.00000e-09 2.12000e-01 $2.27885 \mathrm{e}+002.27885 \mathrm{e}+00$ 2.27885e-01 1.00000e-09 2.12000e-01 $2.27885 \mathrm{e}+002.27885 \mathrm{e}+00$ 2.27885e-01 1.00000e-09 2.12000e-01 $2.27885 \mathrm{e}+002.27885 \mathrm{e}+00$ 2.27885e-01 1.00000e-09 2.12000e-01 $2.27885 \mathrm{e}+002.27885 \mathrm{e}+00$ 2.27885e-01 1.00000e-09 2.12000e-01 $1.00000 \mathrm{e}-02$ 1.00000e-02 1.00000e-03 1.00000e-09 1.00000e-01 $1.00000 \mathrm{e}+001.00000 \mathrm{e}+001.00000 \mathrm{e}-01$ 1.00000e-09 1.00000e-01 $1.00000 \mathrm{e}-05$ 1.00000e-05 1.00000e-06 1.00000e-09 1.00000e-01 $1.00000 \mathrm{e}+001.00000 \mathrm{e}+00$ 1.00000e-01 1.00000e-09 1.00000e-01 Element: 2174 \# of layers: 12

$\mathrm{Kx} \mathrm{Ky} \mathrm{Kz}$ Ss Por

5.70342e+01 5.70342e+01 5.70342e+00 1.00000e-09 7.00000e-02 5.00000e-04 5.00000e-04 5.00000e-05 1.00000e-09 1.00000e-01 5.00000e-04 5.00000e-04 5.00000e-05 1.00000e-09 1.00000e-01 $2.27885 \mathrm{e}+002.27885 \mathrm{e}+002.27885 \mathrm{e}-01$ 1.00000e-09 2.12000e-01 $2.27885 \mathrm{e}+002.27885 \mathrm{e}+00$ 2.27885e-01 1.00000e-09 2.12000e-01 $2.27885 \mathrm{e}+002.27885 \mathrm{e}+00$ 2.27885e-01 1.00000e-09 2.12000e-01 $2.27885 \mathrm{e}+002.27885 \mathrm{e}+00$ 2.27885e-01 1.00000e-09 2.12000e-01 $2.27885 \mathrm{e}+002.27885 \mathrm{e}+002.27885 \mathrm{e}-01$ 1.00000e-09 2.12000e-01 $1.00000 \mathrm{e}-02$ 1.00000e-02 1.00000e-03 1.00000e-09 1.00000e-01 $1.00000 \mathrm{e}+001.00000 \mathrm{e}+001.00000 \mathrm{e}-011.00000 \mathrm{e}-091.00000 \mathrm{e}-01$ $1.00000 \mathrm{e}-05$ 1.00000e-05 1.00000e-06 1.00000e-09 1.00000e-01 $1.00000 \mathrm{e}+001.00000 \mathrm{e}+001.00000 \mathrm{e}-011.00000 \mathrm{e}-09$ 1.00000e-01 Element: 2175 \# of layers: 12

$\mathrm{Kx} \mathrm{Ky} \mathrm{Kz}$ Ss Por

5.70342e+01 5.70342e+01 5.70342e+00 1.00000e-09 7.00000e-02 5.00000e-04 5.00000e-04 5.00000e-05 1.00000e-09 1.00000e-01 5.00000e-04 5.00000e-04 5.00000e-05 1.00000e-09 1.00000e-01 $2.27885 \mathrm{e}+002.27885 \mathrm{e}+002.27885 \mathrm{e}-01$ 1.00000e-09 2.12000e-01 $2.27885 \mathrm{e}+00$ 2.27885e+00 2.27885e-01 1.00000e-09 2.12000e-01 $2.27885 \mathrm{e}+002.27885 \mathrm{e}+002.27885 \mathrm{e}-01$ 1.00000e-09 2.12000e-01 $2.27885 \mathrm{e}+002.27885 \mathrm{e}+00$ 2.27885e-01 1.00000e-09 2.12000e-01 $2.27885 \mathrm{e}+002.27885 \mathrm{e}+00$ 2.27885e-01 1.00000e-09 2.12000e-01 $1.00000 \mathrm{e}-02$ 1.00000e-02 1.00000e-03 1.00000e-09 1.00000e-01 $1.00000 \mathrm{e}+001.00000 \mathrm{e}+001.00000 \mathrm{e}-011.00000 \mathrm{e}-091.00000 \mathrm{e}-01$ 1.00000e-05 1.00000e-05 1.00000e-06 1.00000e-09 1.00000e-01 $1.00000 \mathrm{e}+001.00000 \mathrm{e}+001.00000 \mathrm{e}-011.00000 \mathrm{e}-091.00000 \mathrm{e}-01$ Element: 2176 \# of layers: 12

$\mathrm{Kx} \mathrm{Ky} \mathrm{Kz}$ Ss Por 5.70342e+01 5.70342e+01 5.70342e+00 1.00000e-09 7.00000e-02 5.00000e-04 5.00000e-04 5.00000e-05 1.00000e-09 1.00000e-01 $5.00000 \mathrm{e}-04$ 5.00000e-04 5.00000e-05 1.00000e-09 1.00000e-01 $2.27885 \mathrm{e}+002.27885 \mathrm{e}+002.27885 \mathrm{e}-01$ 1.00000e-09 2.12000e-01 $2.27885 \mathrm{e}+002.27885 \mathrm{e}+00$ 2.27885e-01 1.00000e-09 2.12000e-01 
$2.27885 \mathrm{e}+002.27885 \mathrm{e}+002.27885 \mathrm{e}-011.00000 \mathrm{e}-092.12000 \mathrm{e}-01$ $2.27885 \mathrm{e}+002.27885 \mathrm{e}+002.27885 \mathrm{e}-011.00000 \mathrm{e}-092.12000 \mathrm{e}-01$ $2.27885 \mathrm{e}+002.27885 \mathrm{e}+002.27885 \mathrm{e}-011.00000 \mathrm{e}-092.12000 \mathrm{e}-01$ $1.00000 \mathrm{e}-021.00000 \mathrm{e}-02$ 1.00000e-03 1.00000e-09 1.00000e-01 $1.00000 \mathrm{e}+001.00000 \mathrm{e}+001.00000 \mathrm{e}-011.00000 \mathrm{e}-091.00000 \mathrm{e}-01$ $1.00000 \mathrm{e}-05$ 1.00000e-05 1.00000e-06 1.00000e-09 1.00000e-01 $1.00000 \mathrm{e}+001.00000 \mathrm{e}+001.00000 \mathrm{e}-011.00000 \mathrm{e}-091.00000 \mathrm{e}-01$ Element: 2177 \# of layers: 12

Kx Ky Kz Ss Por

5.70342e+01 5.70342e+01 5.70342e+00 1.00000e-09 7.00000e-02 $5.00000 \mathrm{e}-04$ 5.00000e-04 5.00000e-05 1.00000e-09 1.00000e-01 $5.00000 \mathrm{e}-04$ 5.00000e-04 5.00000e-05 1.00000e-09 1.00000e-01 $2.27885 \mathrm{e}+002.27885 \mathrm{e}+002.27885 \mathrm{e}-01$ 1.00000e-09 2.12000e-01 $2.27885 \mathrm{e}+002.27885 \mathrm{e}+002.27885 \mathrm{e}-011.00000 \mathrm{e}-092.12000 \mathrm{e}-01$ $2.27885 \mathrm{e}+002.27885 \mathrm{e}+002.27885 \mathrm{e}-011.00000 \mathrm{e}-092.12000 \mathrm{e}-01$ $2.27885 \mathrm{e}+002.27885 \mathrm{e}+002.27885 \mathrm{e}-011.00000 \mathrm{e}-092.12000 \mathrm{e}-01$ $2.27885 \mathrm{e}+002.27885 \mathrm{e}+002.27885 \mathrm{e}-011.00000 \mathrm{e}-092.12000 \mathrm{e}-01$ $1.00000 \mathrm{e}-02$ 1.00000e-02 1.00000e-03 1.00000e-09 1.00000e-01 $1.00000 \mathrm{e}+001.00000 \mathrm{e}+001.00000 \mathrm{e}-011.00000 \mathrm{e}-091.00000 \mathrm{e}-01$ $1.00000 \mathrm{e}-05$ 1.00000e-05 1.00000e-06 1.00000e-09 1.00000e-01 $1.00000 \mathrm{e}+001.00000 \mathrm{e}+001.00000 \mathrm{e}-011.00000 \mathrm{e}-091.00000 \mathrm{e}-01$ Element: 2178 \# of layers: 12

Kx Ky Kz Ss Por

$5.70342 \mathrm{e}+015.70342 \mathrm{e}+015.70342 \mathrm{e}+001.00000 \mathrm{e}-09$ 7.00000e-02 $5.00000 \mathrm{e}-04$ 5.00000e-04 5.00000e-05 1.00000e-09 1.00000e-01 $5.00000 \mathrm{e}-04$ 5.00000e-04 5.00000e-05 1.00000e-09 1.00000e-01 $2.27885 \mathrm{e}+002.27885 \mathrm{e}+002.27885 \mathrm{e}-011.00000 \mathrm{e}-092.12000 \mathrm{e}-01$ $2.27885 \mathrm{e}+002.27885 \mathrm{e}+002.27885 \mathrm{e}-011.00000 \mathrm{e}-092.12000 \mathrm{e}-01$ $2.27885 \mathrm{e}+002.27885 \mathrm{e}+002.27885 \mathrm{e}-011.00000 \mathrm{e}-092.12000 \mathrm{e}-01$ $2.27885 \mathrm{e}+002.27885 \mathrm{e}+002.27885 \mathrm{e}-01$ 1.00000e-09 2.12000e-01 $2.27885 \mathrm{e}+002.27885 \mathrm{e}+002.27885 \mathrm{e}-01$ 1.00000e-09 2.12000e-01 $1.00000 \mathrm{e}-02$ 1.00000e-02 1.00000e-03 1.00000e-09 1.00000e-01 $1.00000 \mathrm{e}+001.00000 \mathrm{e}+001.00000 \mathrm{e}-011.00000 \mathrm{e}-091.00000 \mathrm{e}-01$ $1.00000 \mathrm{e}-05$ 1.00000e-05 1.00000e-06 1.00000e-09 1.00000e-01 $1.00000 \mathrm{e}+001.00000 \mathrm{e}+001.00000 \mathrm{e}-011.00000 \mathrm{e}-091.00000 \mathrm{e}-01$ Element: 2179 \# of layers: 12

Kx Ky Kz Ss Por

6.78102e+01 6.78102e+01 6.78102e+00 1.00000e-09 7.00000e-02 5.00000e-04 5.00000e-04 5.00000e-05 1.00000e-09 1.00000e-01 5.00000e-04 5.00000e-04 5.00000e-05 1.00000e-09 1.00000e-01 $2.70951 \mathrm{e}+002.70951 \mathrm{e}+002.70951 \mathrm{e}-011.00000 \mathrm{e}-092.12000 \mathrm{e}-01$ $2.70951 \mathrm{e}+002.70951 \mathrm{e}+002.70951 \mathrm{e}-011.00000 \mathrm{e}-092.12000 \mathrm{e}-01$ $2.70951 \mathrm{e}+002.70951 \mathrm{e}+002.70951 \mathrm{e}-011.00000 \mathrm{e}-092.12000 \mathrm{e}-01$ $2.70951 \mathrm{e}+002.70951 \mathrm{e}+002.70951 \mathrm{e}-01$ 1.00000e-09 2.12000e-01 $2.70951 \mathrm{e}+002.70951 \mathrm{e}+002.70951 \mathrm{e}-011.00000 \mathrm{e}-092.12000 \mathrm{e}-01$ $1.00000 \mathrm{e}-021.00000 \mathrm{e}-02$ 1.00000e-03 1.00000e-09 1.00000e-01 
$1.00000 \mathrm{e}+001.00000 \mathrm{e}+001.00000 \mathrm{e}-011.00000 \mathrm{e}-091.00000 \mathrm{e}-01$ $1.00000 \mathrm{e}-05$ 1.00000e-05 1.00000e-06 1.00000e-09 1.00000e-01 $1.00000 \mathrm{e}+001.00000 \mathrm{e}+001.00000 \mathrm{e}-01$ 1.00000e-09 1.00000e-01 Element: 2180 \# of layers: 12

$\mathrm{Kx} \mathrm{Ky} \mathrm{Kz}$ Ss Por

6.78102e+01 6.78102e+01 6.78102e+00 1.00000e-09 7.00000e-02 $5.00000 \mathrm{e}-04$ 5.00000e-04 5.00000e-05 1.00000e-09 1.00000e-01 5.00000e-04 5.00000e-04 5.00000e-05 1.00000e-09 1.00000e-01

$2.70951 \mathrm{e}+002.70951 \mathrm{e}+002.70951 \mathrm{e}-01$ 1.00000e-09 2.12000e-01 $2.70951 \mathrm{e}+002.70951 \mathrm{e}+00$ 2.70951e-01 1.00000e-09 2.12000e-01 $2.70951 \mathrm{e}+002.70951 \mathrm{e}+002.70951 \mathrm{e}-01$ 1.00000e-09 2.12000e-01 $2.70951 \mathrm{e}+002.70951 \mathrm{e}+002.70951 \mathrm{e}-01$ 1.00000e-09 2.12000e-01 $2.70951 \mathrm{e}+002.70951 \mathrm{e}+002.70951 \mathrm{e}-01$ 1.00000e-09 2.12000e-01 $1.00000 \mathrm{e}-02$ 1.00000e-02 1.00000e-03 1.00000e-09 1.00000e-01 $1.00000 \mathrm{e}+001.00000 \mathrm{e}+001.00000 \mathrm{e}-011.00000 \mathrm{e}-091.00000 \mathrm{e}-01$ $1.00000 \mathrm{e}-05$ 1.00000e-05 1.00000e-06 1.00000e-09 1.00000e-01 $1.00000 \mathrm{e}+001.00000 \mathrm{e}+001.00000 \mathrm{e}-011.00000 \mathrm{e}-091.00000 \mathrm{e}-01$ Element: 2181 \# of layers: 12

$\mathrm{Kx} \mathrm{Ky} \mathrm{Kz}$ Ss Por

6.78102e+01 6.78102e+01 6.78102e+00 1.00000e-09 7.00000e-02 5.00000e-04 5.00000e-04 5.00000e-05 1.00000e-09 1.00000e-01 5.00000e-04 5.00000e-04 5.00000e-05 1.00000e-09 1.00000e-01 $2.70951 \mathrm{e}+002.70951 \mathrm{e}+00$ 2.70951e-01 1.00000e-09 2.12000e-01 $2.70951 \mathrm{e}+002.70951 \mathrm{e}+002.70951 \mathrm{e}-01$ 1.00000e-09 2.12000e-01 $2.70951 \mathrm{e}+002.70951 \mathrm{e}+002.70951 \mathrm{e}-01$ 1.00000e-09 2.12000e-01 $2.70951 \mathrm{e}+002.70951 \mathrm{e}+00$ 2.70951e-01 1.00000e-09 2.12000e-01 $2.70951 \mathrm{e}+002.70951 \mathrm{e}+002.70951 \mathrm{e}-01$ 1.00000e-09 2.12000e-01 $1.00000 \mathrm{e}-02$ 1.00000e-02 1.00000e-03 1.00000e-09 1.00000e-01 $1.00000 \mathrm{e}+001.00000 \mathrm{e}+001.00000 \mathrm{e}-011.00000 \mathrm{e}-091.00000 \mathrm{e}-01$ $1.00000 \mathrm{e}-05$ 1.00000e-05 1.00000e-06 1.00000e-09 1.00000e-01 $1.00000 \mathrm{e}+001.00000 \mathrm{e}+001.00000 \mathrm{e}-011.00000 \mathrm{e}-091.00000 \mathrm{e}-01$ Element: 2182 \# of layers: 12

Kx Ky Kz Ss Por

6.78102e+01 6.78102e+01 6.78102e+00 1.00000e-09 7.00000e-02 5.00000e-04 5.00000e-04 5.00000e-05 1.00000e-09 1.00000e-01 5.00000e-04 5.00000e-04 5.00000e-05 1.00000e-09 1.00000e-01 $2.70951 \mathrm{e}+002.70951 \mathrm{e}+002.70951 \mathrm{e}-01$ 1.00000e-09 2.12000e-01 $2.70951 \mathrm{e}+002.70951 \mathrm{e}+002.70951 \mathrm{e}-01$ 1.00000e-09 2.12000e-01 $2.70951 \mathrm{e}+002.70951 \mathrm{e}+00$ 2.70951e-01 1.00000e-09 2.12000e-01 $2.70951 \mathrm{e}+002.70951 \mathrm{e}+00$ 2.70951e-01 1.00000e-09 2.12000e-01 $2.70951 \mathrm{e}+002.70951 \mathrm{e}+002.70951 \mathrm{e}-01$ 1.00000e-09 2.12000e-01 $1.00000 \mathrm{e}-02$ 1.00000e-02 1.00000e-03 1.00000e-09 1.00000e-01 $1.00000 \mathrm{e}+001.00000 \mathrm{e}+001.00000 \mathrm{e}-011.00000 \mathrm{e}-091.00000 \mathrm{e}-01$ $1.00000 \mathrm{e}-05$ 1.00000e-05 1.00000e-06 1.00000e-09 1.00000e-01 $1.00000 \mathrm{e}+001.00000 \mathrm{e}+001.00000 \mathrm{e}-01$ 1.00000e-09 1.00000e-01 Element: 2183 \# of layers: 12 
$\mathrm{Kx} \mathrm{Ky} \mathrm{Kz}$ Ss Por

6.78102e+01 6.78102e+01 6.78102e+00 1.00000e-09 7.00000e-02 5.00000e-04 5.00000e-04 5.00000e-05 1.00000e-09 1.00000e-01 5.00000e-04 5.00000e-04 5.00000e-05 1.00000e-09 1.00000e-01 $2.70951 \mathrm{e}+002.70951 \mathrm{e}+002.70951 \mathrm{e}-01$ 1.00000e-09 2.12000e-01 $2.70951 \mathrm{e}+002.70951 \mathrm{e}+002.70951 \mathrm{e}-01$ 1.00000e-09 2.12000e-01 $2.70951 \mathrm{e}+002.70951 \mathrm{e}+00$ 2.70951e-01 1.00000e-09 2.12000e-01 $2.70951 \mathrm{e}+002.70951 \mathrm{e}+002.70951 \mathrm{e}-01$ 1.00000e-09 2.12000e-01 $2.70951 \mathrm{e}+00$ 2.70951e+00 2.70951e-01 1.00000e-09 2.12000e-01 $1.00000 \mathrm{e}-02$ 1.00000e-02 1.00000e-03 1.00000e-09 1.00000e-01 $1.00000 \mathrm{e}+001.00000 \mathrm{e}+001.00000 \mathrm{e}-011.00000 \mathrm{e}-091.00000 \mathrm{e}-01$ $1.00000 \mathrm{e}-05$ 1.00000e-05 1.00000e-06 1.00000e-09 1.00000e-01 $1.00000 \mathrm{e}+001.00000 \mathrm{e}+001.00000 \mathrm{e}-01$ 1.00000e-09 1.00000e-01 Element: 2184 \# of layers: 12

$\mathrm{Kx} \mathrm{Ky} \mathrm{Kz}$ Ss Por

6.78102e+01 6.78102e+01 6.78102e+00 1.00000e-09 7.00000e-02 5.00000e-04 5.00000e-04 5.00000e-05 1.00000e-09 1.00000e-01 5.00000e-04 5.00000e-04 5.00000e-05 1.00000e-09 1.00000e-01 $2.70951 \mathrm{e}+002.70951 \mathrm{e}+002.70951 \mathrm{e}-01$ 1.00000e-09 2.12000e-01 $2.70951 \mathrm{e}+002.70951 \mathrm{e}+002.70951 \mathrm{e}-01$ 1.00000e-09 2.12000e-01 $2.70951 \mathrm{e}+002.70951 \mathrm{e}+002.70951 \mathrm{e}-01$ 1.00000e-09 2.12000e-01 2.70951e+00 2.70951e+00 2.70951e-01 1.00000e-09 2.12000e-01 $2.70951 \mathrm{e}+002.70951 \mathrm{e}+00$ 2.70951e-01 1.00000e-09 2.12000e-01 $1.00000 \mathrm{e}-02$ 1.00000e-02 1.00000e-03 1.00000e-09 1.00000e-01 $1.00000 \mathrm{e}+001.00000 \mathrm{e}+001.00000 \mathrm{e}-011.00000 \mathrm{e}-091.00000 \mathrm{e}-01$ $1.00000 \mathrm{e}-05$ 1.00000e-05 1.00000e-06 1.00000e-09 1.00000e-01 $1.00000 \mathrm{e}+001.00000 \mathrm{e}+001.00000 \mathrm{e}-011.00000 \mathrm{e}-091.00000 \mathrm{e}-01$ Element: 2185 \# of layers: 12

$\mathrm{Kx} \mathrm{Ky} \mathrm{Kz}$ Ss Por

6.78102e+01 6.78102e+01 6.78102e+00 1.00000e-09 7.00000e-02 $5.00000 \mathrm{e}-04$ 5.00000e-04 5.00000e-05 1.00000e-09 1.00000e-01 5.00000e-04 5.00000e-04 5.00000e-05 1.00000e-09 1.00000e-01 $2.70951 \mathrm{e}+002.70951 \mathrm{e}+002.70951 \mathrm{e}-01$ 1.00000e-09 2.12000e-01 2.70951e+00 2.70951e+00 2.70951e-01 1.00000e-09 2.12000e-01 $2.70951 \mathrm{e}+002.70951 \mathrm{e}+002.70951 \mathrm{e}-01$ 1.00000e-09 2.12000e-01 $2.70951 \mathrm{e}+002.70951 \mathrm{e}+00$ 2.70951e-01 1.00000e-09 2.12000e-01 $2.70951 \mathrm{e}+002.70951 \mathrm{e}+00$ 2.70951e-01 1.00000e-09 2.12000e-01 $1.00000 \mathrm{e}-021.00000 \mathrm{e}-021.00000 \mathrm{e}-031.00000 \mathrm{e}-091.00000 \mathrm{e}-01$ $1.00000 \mathrm{e}+001.00000 \mathrm{e}+001.00000 \mathrm{e}-011.00000 \mathrm{e}-091.00000 \mathrm{e}-01$ $1.00000 \mathrm{e}-05$ 1.00000e-05 1.00000e-06 1.00000e-09 1.00000e-01 $1.00000 \mathrm{e}+001.00000 \mathrm{e}+001.00000 \mathrm{e}-011.00000 \mathrm{e}-091.00000 \mathrm{e}-01$ Element: 2186 \# of layers: 12

$\mathrm{Kx} \mathrm{Ky} \mathrm{Kz}$ Ss Por 6.78102e+01 6.78102e+01 6.78102e+00 1.00000e-09 7.00000e-02 5.00000e-04 5.00000e-04 5.00000e-05 1.00000e-09 1.00000e-01 5.00000e-04 5.00000e-04 5.00000e-05 1.00000e-09 1.00000e-01 
$2.70951 \mathrm{e}+002.70951 \mathrm{e}+002.70951 \mathrm{e}-01$ 1.00000e-09 2.12000e-01 $2.70951 \mathrm{e}+002.70951 \mathrm{e}+002.70951 \mathrm{e}-011.00000 \mathrm{e}-092.12000 \mathrm{e}-01$ $2.70951 \mathrm{e}+002.70951 \mathrm{e}+002.70951 \mathrm{e}-01$ 1.00000e-09 2.12000e-01 $2.70951 \mathrm{e}+002.70951 \mathrm{e}+002.70951 \mathrm{e}-011.00000 \mathrm{e}-092.12000 \mathrm{e}-01$ $2.70951 \mathrm{e}+002.70951 \mathrm{e}+002.70951 \mathrm{e}-01$ 1.00000e-09 2.12000e-01 $1.00000 \mathrm{e}-021.00000 \mathrm{e}-02$ 1.00000e-03 1.00000e-09 1.00000e-01 $1.00000 \mathrm{e}+001.00000 \mathrm{e}+001.00000 \mathrm{e}-011.00000 \mathrm{e}-091.00000 \mathrm{e}-01$ $1.00000 \mathrm{e}-05$ 1.00000e-05 1.00000e-06 1.00000e-09 1.00000e-01 $1.00000 \mathrm{e}+001.00000 \mathrm{e}+001.00000 \mathrm{e}-011.00000 \mathrm{e}-091.00000 \mathrm{e}-01$ Element: 2187 \# of layers: 12

Kx Ky Kz Ss Por $6.78102 \mathrm{e}+016.78102 \mathrm{e}+016.78102 \mathrm{e}+00$ 1.00000e-09 7.00000e-02 5.00000e-04 5.00000e-04 5.00000e-05 1.00000e-09 1.00000e-01 5.00000e-04 5.00000e-04 5.00000e-05 1.00000e-09 1.00000e-01 $2.70951 \mathrm{e}+002.70951 \mathrm{e}+002.70951 \mathrm{e}-01$ 1.00000e-09 2.12000e-01 $2.70951 \mathrm{e}+002.70951 \mathrm{e}+002.70951 \mathrm{e}-01$ 1.00000e-09 2.12000e-01 $2.70951 \mathrm{e}+002.70951 \mathrm{e}+002.70951 \mathrm{e}-01$ 1.00000e-09 2.12000e-01 $2.70951 \mathrm{e}+002.70951 \mathrm{e}+002.70951 \mathrm{e}-01$ 1.00000e-09 2.12000e-01 $2.70951 \mathrm{e}+002.70951 \mathrm{e}+002.70951 \mathrm{e}-011.00000 \mathrm{e}-092.12000 \mathrm{e}-01$ $1.00000 \mathrm{e}-021.00000 \mathrm{e}-02$ 1.00000e-03 1.00000e-09 1.00000e-01 $1.00000 \mathrm{e}+001.00000 \mathrm{e}+001.00000 \mathrm{e}-011.00000 \mathrm{e}-091.00000 \mathrm{e}-01$ $1.00000 \mathrm{e}-05$ 1.00000e-05 1.00000e-06 1.00000e-09 1.00000e-01 $1.00000 \mathrm{e}+001.00000 \mathrm{e}+001.00000 \mathrm{e}-011.00000 \mathrm{e}-091.00000 \mathrm{e}-01$ Element: 2188 \# of layers: 12

Kx Ky Kz Ss Por

$9.95515 \mathrm{e}+019.95515 \mathrm{e}+01$ 9.95515e+00 1.00000e-09 7.00000e-02 5.00000e-04 5.00000e-04 5.00000e-05 1.00000e-09 1.00000e-01 5.00000e-04 5.00000e-04 5.00000e-05 1.00000e-09 1.00000e-01 $3.97786 \mathrm{e}+003.97786 \mathrm{e}+003.97786 \mathrm{e}-011.00000 \mathrm{e}-092.12000 \mathrm{e}-01$ $3.97786 \mathrm{e}+003.97786 \mathrm{e}+003.97786 \mathrm{e}-011.00000 \mathrm{e}-092.12000 \mathrm{e}-01$ $3.97786 \mathrm{e}+003.97786 \mathrm{e}+003.97786 \mathrm{e}-011.00000 \mathrm{e}-092.12000 \mathrm{e}-01$ $3.97786 \mathrm{e}+003.97786 \mathrm{e}+003.97786 \mathrm{e}-01$ 1.00000e-09 2.12000e-01 $3.97786 \mathrm{e}+003.97786 \mathrm{e}+003.97786 \mathrm{e}-01$ 1.00000e-09 2.12000e-01 $1.00000 \mathrm{e}-021.00000 \mathrm{e}-02$ 1.00000e-03 1.00000e-09 1.00000e-01 $1.00000 \mathrm{e}+001.00000 \mathrm{e}+001.00000 \mathrm{e}-011.00000 \mathrm{e}-091.00000 \mathrm{e}-01$ $1.00000 \mathrm{e}-05$ 1.00000e-05 1.00000e-06 1.00000e-09 1.00000e-01 $1.00000 \mathrm{e}+001.00000 \mathrm{e}+001.00000 \mathrm{e}-011.00000 \mathrm{e}-091.00000 \mathrm{e}-01$ Element: 2189 \# of layers: 11

Kx Ky Kz Ss Por

$9.95515 \mathrm{e}+01$ 9.95515e+01 9.95515e+00 1.00000e-09 7.00000e-02 5.00000e-04 5.00000e-04 5.00000e-05 1.00000e-09 1.00000e-01 $3.97786 \mathrm{e}+003.97786 \mathrm{e}+003.97786 \mathrm{e}-01$ 1.00000e-09 2.12000e-01 $3.97786 \mathrm{e}+003.97786 \mathrm{e}+003.97786 \mathrm{e}-011.00000 \mathrm{e}-092.12000 \mathrm{e}-01$ $3.97786 \mathrm{e}+003.97786 \mathrm{e}+003.97786 \mathrm{e}-011.00000 \mathrm{e}-092.12000 \mathrm{e}-01$ $3.97786 \mathrm{e}+003.97786 \mathrm{e}+003.97786 \mathrm{e}-011.00000 \mathrm{e}-092.12000 \mathrm{e}-01$ $3.97786 \mathrm{e}+003.97786 \mathrm{e}+003.97786 \mathrm{e}-01$ 1.00000e-09 2.12000e-01 
$1.00000 \mathrm{e}-02$ 1.00000e-02 1.00000e-03 1.00000e-09 1.00000e-01 $1.00000 \mathrm{e}+001.00000 \mathrm{e}+001.00000 \mathrm{e}-011.00000 \mathrm{e}-091.00000 \mathrm{e}-01$ $1.00000 \mathrm{e}-051.00000 \mathrm{e}-05$ 1.00000e-06 1.00000e-09 1.00000e-01 $1.00000 \mathrm{e}+001.00000 \mathrm{e}+001.00000 \mathrm{e}-011.00000 \mathrm{e}-091.00000 \mathrm{e}-01$ Element: 2190 \# of layers: 11

Kx Ky Kz Ss Por

$9.95515 \mathrm{e}+019.95515 \mathrm{e}+019.95515 \mathrm{e}+001.00000 \mathrm{e}-09$ 7.00000e-02 5.00000e-04 5.00000e-04 5.00000e-05 1.00000e-09 1.00000e-01

$3.97786 \mathrm{e}+003.97786 \mathrm{e}+003.97786 \mathrm{e}-011.00000 \mathrm{e}-092.12000 \mathrm{e}-01$ $3.97786 \mathrm{e}+003.97786 \mathrm{e}+003.97786 \mathrm{e}-011.00000 \mathrm{e}-092.12000 \mathrm{e}-01$ $3.97786 \mathrm{e}+003.97786 \mathrm{e}+003.97786 \mathrm{e}-011.00000 \mathrm{e}-092.12000 \mathrm{e}-01$ $3.97786 \mathrm{e}+003.97786 \mathrm{e}+003.97786 \mathrm{e}-01$ 1.00000e-09 2.12000e-01 $3.97786 \mathrm{e}+003.97786 \mathrm{e}+003.97786 \mathrm{e}-01$ 1.00000e-09 2.12000e-01 $1.00000 \mathrm{e}-021.00000 \mathrm{e}-02$ 1.00000e-03 1.00000e-09 1.00000e-01 $1.00000 \mathrm{e}+001.00000 \mathrm{e}+001.00000 \mathrm{e}-011.00000 \mathrm{e}-091.00000 \mathrm{e}-01$ $1.00000 \mathrm{e}-05$ 1.00000e-05 1.00000e-06 1.00000e-09 1.00000e-01 $1.00000 \mathrm{e}+001.00000 \mathrm{e}+001.00000 \mathrm{e}-011.00000 \mathrm{e}-091.00000 \mathrm{e}-01$ Element: 2191 \# of layers: 11

Kx Ky Kz Ss Por $9.95515 \mathrm{e}+019.95515 \mathrm{e}+019.95515 \mathrm{e}+001.00000 \mathrm{e}-09$ 7.00000e-02 5.00000e-04 5.00000e-04 5.00000e-05 1.00000e-09 1.00000e-01 $3.97786 \mathrm{e}+003.97786 \mathrm{e}+003.97786 \mathrm{e}-011.00000 \mathrm{e}-092.12000 \mathrm{e}-01$ $3.97786 \mathrm{e}+003.97786 \mathrm{e}+003.97786 \mathrm{e}-011.00000 \mathrm{e}-092.12000 \mathrm{e}-01$ $3.97786 \mathrm{e}+003.97786 \mathrm{e}+003.97786 \mathrm{e}-011.00000 \mathrm{e}-092.12000 \mathrm{e}-01$ $3.97786 \mathrm{e}+003.97786 \mathrm{e}+003.97786 \mathrm{e}-011.00000 \mathrm{e}-092.12000 \mathrm{e}-01$ $3.97786 \mathrm{e}+003.97786 \mathrm{e}+003.97786 \mathrm{e}-011.00000 \mathrm{e}-092.12000 \mathrm{e}-01$ $1.00000 \mathrm{e}-02$ 1.00000e-02 1.00000e-03 1.00000e-09 1.00000e-01 $1.00000 \mathrm{e}+001.00000 \mathrm{e}+001.00000 \mathrm{e}-011.00000 \mathrm{e}-091.00000 \mathrm{e}-01$ $1.00000 \mathrm{e}-051.00000 \mathrm{e}-05$ 1.00000e-06 1.00000e-09 1.00000e-01 $1.00000 \mathrm{e}+001.00000 \mathrm{e}+001.00000 \mathrm{e}-011.00000 \mathrm{e}-091.00000 \mathrm{e}-01$ Element: 2192 \# of layers: 12

Kx Ky Kz Ss Por $9.95515 \mathrm{e}+019.95515 \mathrm{e}+019.95515 \mathrm{e}+00$ 1.00000e-09 7.00000e-02 5.00000e-04 5.00000e-04 5.00000e-05 1.00000e-09 1.00000e-01 5.00000e-04 5.00000e-04 5.00000e-05 1.00000e-09 1.00000e-01 $3.97786 \mathrm{e}+003.97786 \mathrm{e}+003.97786 \mathrm{e}-011.00000 \mathrm{e}-092.12000 \mathrm{e}-01$ $3.97786 \mathrm{e}+003.97786 \mathrm{e}+003.97786 \mathrm{e}-011.00000 \mathrm{e}-092.12000 \mathrm{e}-01$ $3.97786 \mathrm{e}+003.97786 \mathrm{e}+003.97786 \mathrm{e}-01$ 1.00000e-09 2.12000e-01 $3.97786 \mathrm{e}+003.97786 \mathrm{e}+003.97786 \mathrm{e}-01$ 1.00000e-09 2.12000e-01 $3.97786 \mathrm{e}+003.97786 \mathrm{e}+003.97786 \mathrm{e}-01$ 1.00000e-09 2.12000e-01 $1.00000 \mathrm{e}-021.00000 \mathrm{e}-02$ 1.00000e-03 1.00000e-09 1.00000e-01 $1.00000 \mathrm{e}+001.00000 \mathrm{e}+001.00000 \mathrm{e}-011.00000 \mathrm{e}-091.00000 \mathrm{e}-01$ $1.00000 \mathrm{e}-05$ 1.00000e-05 1.00000e-06 1.00000e-09 1.00000e-01 $1.00000 \mathrm{e}+001.00000 \mathrm{e}+001.00000 \mathrm{e}-011.00000 \mathrm{e}-091.00000 \mathrm{e}-01$ Element: 2193 \# of layers: 12

Kx Ky Kz Ss Por 
9.95515e+01 9.95515e+01 9.95515e+00 1.00000e-09 7.00000e-02 5.00000e-04 5.00000e-04 5.00000e-05 1.00000e-09 1.00000e-01 5.00000e-04 5.00000e-04 5.00000e-05 1.00000e-09 1.00000e-01 $3.97786 \mathrm{e}+003.97786 \mathrm{e}+003.97786 \mathrm{e}-01$ 1.00000e-09 2.12000e-01 $3.97786 \mathrm{e}+003.97786 \mathrm{e}+003.97786 \mathrm{e}-01$ 1.00000e-09 2.12000e-01 $3.97786 \mathrm{e}+003.97786 \mathrm{e}+003.97786 \mathrm{e}-01$ 1.00000e-09 2.12000e-01 $3.97786 \mathrm{e}+003.97786 \mathrm{e}+00$ 3.97786e-01 1.00000e-09 2.12000e-01 $3.97786 \mathrm{e}+003.97786 \mathrm{e}+003.97786 \mathrm{e}-01$ 1.00000e-09 2.12000e-01 $1.00000 \mathrm{e}-02$ 1.00000e-02 1.00000e-03 1.00000e-09 1.00000e-01 $1.00000 \mathrm{e}+001.00000 \mathrm{e}+001.00000 \mathrm{e}-011.00000 \mathrm{e}-091.00000 \mathrm{e}-01$ $1.00000 \mathrm{e}-05$ 1.00000e-05 1.00000e-06 1.00000e-09 1.00000e-01 $1.00000 \mathrm{e}+001.00000 \mathrm{e}+001.00000 \mathrm{e}-011.00000 \mathrm{e}-091.00000 \mathrm{e}-01$ Element: 2194 \# of layers: 12

$\mathrm{Kx} \mathrm{Ky} \mathrm{Kz}$ Ss Por

9.95515e+01 9.95515e+01 9.95515e+00 1.00000e-09 7.00000e-02 5.00000e-04 5.00000e-04 5.00000e-05 1.00000e-09 1.00000e-01 5.00000e-04 5.00000e-04 5.00000e-05 1.00000e-09 1.00000e-01 $3.97786 \mathrm{e}+003.97786 \mathrm{e}+00$ 3.97786e-01 1.00000e-09 2.12000e-01 3.97786e+00 3.97786e+00 3.97786e-01 1.00000e-09 2.12000e-01 $3.97786 \mathrm{e}+003.97786 \mathrm{e}+003.97786 \mathrm{e}-01$ 1.00000e-09 2.12000e-01 $3.97786 \mathrm{e}+003.97786 \mathrm{e}+00$ 3.97786e-01 1.00000e-09 2.12000e-01 $3.97786 \mathrm{e}+00$ 3.97786e+00 3.97786e-01 1.00000e-09 2.12000e-01 $1.00000 \mathrm{e}-02$ 1.00000e-02 1.00000e-03 1.00000e-09 1.00000e-01 $1.00000 \mathrm{e}+001.00000 \mathrm{e}+001.00000 \mathrm{e}-011.00000 \mathrm{e}-091.00000 \mathrm{e}-01$ $1.00000 \mathrm{e}-05$ 1.00000e-05 1.00000e-06 1.00000e-09 1.00000e-01 $1.00000 \mathrm{e}+001.00000 \mathrm{e}+001.00000 \mathrm{e}-011.00000 \mathrm{e}-091.00000 \mathrm{e}-01$ Element: 2195 \# of layers: 12

$\mathrm{Kx} \mathrm{Ky} \mathrm{Kz}$ Ss Por

9.95515e+01 9.95515e+01 9.95515e+00 1.00000e-09 7.00000e-02 5.00000e-04 5.00000e-04 5.00000e-05 1.00000e-09 1.00000e-01 5.00000e-04 5.00000e-04 5.00000e-05 1.00000e-09 1.00000e-01 $3.97786 \mathrm{e}+003.97786 \mathrm{e}+00$ 3.97786e-01 1.00000e-09 2.12000e-01 $3.97786 \mathrm{e}+003.97786 \mathrm{e}+003.97786 \mathrm{e}-01$ 1.00000e-09 2.12000e-01 $3.97786 \mathrm{e}+00$ 3.97786e+00 3.97786e-01 1.00000e-09 2.12000e-01 $3.97786 \mathrm{e}+003.97786 \mathrm{e}+003.97786 \mathrm{e}-01$ 1.00000e-09 2.12000e-01 $3.97786 \mathrm{e}+003.97786 \mathrm{e}+003.97786 \mathrm{e}-01$ 1.00000e-09 2.12000e-01 $1.00000 \mathrm{e}-02$ 1.00000e-02 1.00000e-03 1.00000e-09 1.00000e-01 $1.00000 \mathrm{e}+001.00000 \mathrm{e}+001.00000 \mathrm{e}-011.00000 \mathrm{e}-091.00000 \mathrm{e}-01$ $1.00000 \mathrm{e}-05$ 1.00000e-05 1.00000e-06 1.00000e-09 1.00000e-01 $1.00000 \mathrm{e}+001.00000 \mathrm{e}+001.00000 \mathrm{e}-01$ 1.00000e-09 1.00000e-01 Element: 2196 \# of layers: 11

$\mathrm{Kx} \mathrm{Ky} \mathrm{Kz}$ Ss Por

9.95515e+01 9.95515e+01 9.95515e+00 1.00000e-09 7.00000e-02 5.00000e-04 5.00000e-04 5.00000e-05 1.00000e-09 1.00000e-01 $3.97786 \mathrm{e}+003.97786 \mathrm{e}+003.97786 \mathrm{e}-01$ 1.00000e-09 2.12000e-01 $3.97786 \mathrm{e}+003.97786 \mathrm{e}+003.97786 \mathrm{e}-01$ 1.00000e-09 2.12000e-01 
3.97786e+00 3.97786e+00 3.97786e-01 1.00000e-09 2.12000e-01 3.97786e+00 3.97786e+00 3.97786e-01 1.00000e-09 2.12000e-01 $3.97786 \mathrm{e}+003.97786 \mathrm{e}+003.97786 \mathrm{e}-01$ 1.00000e-09 2.12000e-01 $1.00000 \mathrm{e}-02$ 1.00000e-02 1.00000e-03 1.00000e-09 1.00000e-01 $1.00000 \mathrm{e}+001.00000 \mathrm{e}+001.00000 \mathrm{e}-011.00000 \mathrm{e}-091.00000 \mathrm{e}-01$ $1.00000 \mathrm{e}-05$ 1.00000e-05 1.00000e-06 1.00000e-09 1.00000e-01 $1.00000 \mathrm{e}+001.00000 \mathrm{e}+001.00000 \mathrm{e}-01$ 1.00000e-09 1.00000e-01 Element: 2197 \# of layers: 8

$\mathrm{Kx} \mathrm{Ky} \mathrm{Kz}$ Ss Por

5.00000e-04 5.00000e-04 5.00000e-05 1.00000e-09 1.00000e-01 8.28288e+00 8.28288e+00 8.28288e-01 1.00000e-09 2.12000e-01 $8.28288 \mathrm{e}+00$ 8.28288e+00 8.28288e-01 1.00000e-09 2.12000e-01 $8.28288 \mathrm{e}+00$ 8.28288e+00 8.28288e-01 1.00000e-09 2.12000e-01 8.28288e+00 8.28288e+00 8.28288e-01 1.00000e-09 2.12000e-01 $8.28288 \mathrm{e}+00$ 8.28288e+00 8.28288e-01 1.00000e-09 2.12000e-01 $1.00000 \mathrm{e}-02$ 1.00000e-02 1.00000e-03 1.00000e-09 1.00000e-01 $1.00000 \mathrm{e}+001.00000 \mathrm{e}+001.00000 \mathrm{e}-011.00000 \mathrm{e}-091.00000 \mathrm{e}-01$ Element: 2198 \# of layers: 7

$\mathrm{Kx} \mathrm{Ky} \mathrm{Kz}$ Ss Por

8.28288e+00 8.28288e+00 8.28288e-01 1.00000e-09 2.12000e-01 $8.28288 \mathrm{e}+00$ 8.28288e+00 8.28288e-01 1.00000e-09 2.12000e-01 $8.28288 \mathrm{e}+00$ 8.28288e+00 8.28288e-01 1.00000e-09 2.12000e-01 8.28288e+00 8.28288e+00 8.28288e-01 1.00000e-09 2.12000e-01 $8.28288 \mathrm{e}+00$ 8.28288e+00 8.28288e-01 1.00000e-09 2.12000e-01 $1.00000 \mathrm{e}-021.00000 \mathrm{e}-02$ 1.00000e-03 1.00000e-09 1.00000e-01 $1.00000 \mathrm{e}+001.00000 \mathrm{e}+001.00000 \mathrm{e}-011.00000 \mathrm{e}-091.00000 \mathrm{e}-01$ Element: 2199 \# of layers: 5

$\mathrm{Kx} \mathrm{Ky} \mathrm{Kz}$ Ss Por

8.28288e+00 8.28288e+00 8.28288e-01 1.00000e-09 2.12000e-01 8.28288e+00 8.28288e+00 8.28288e-01 1.00000e-09 2.12000e-01 8.28288e+00 8.28288e+00 8.28288e-01 1.00000e-09 2.12000e-01 8.28288e+00 8.28288e+00 8.28288e-01 1.00000e-09 2.12000e-01 8.28288e+00 8.28288e+00 8.28288e-01 1.00000e-09 2.12000e-01 Element: 2200 \# of layers: 6

$\mathrm{Kx} \mathrm{Ky} \mathrm{Kz}$ Ss Por 5.00000e-04 5.00000e-04 5.00000e-05 1.00000e-09 1.00000e-01 $8.28288 \mathrm{e}+00$ 8.28288e+00 8.28288e-01 1.00000e-09 2.12000e-01 8.28288e+00 8.28288e+00 8.28288e-01 1.00000e-09 2.12000e-01 8.28288e+00 8.28288e+00 8.28288e-01 1.00000e-09 2.12000e-01 8.28288e+00 8.28288e+00 8.28288e-01 1.00000e-09 2.12000e-01 $8.28288 \mathrm{e}+00$ 8.28288e+00 8.28288e-01 1.00000e-09 2.12000e-01 Element: 2201 \# of layers: 8

$\mathrm{Kx} \mathrm{Ky} \mathrm{Kz}$ Ss Por

2.07293e+02 2.07293e+02 2.07293e+01 1.00000e-09 7.00000e-02 5.00000e-04 5.00000e-04 5.00000e-05 1.00000e-09 1.00000e-01 5.00000e-04 5.00000e-04 5.00000e-05 1.00000e-09 1.00000e-01 
8.28288e +00 8.28288e+00 8.28288e-01 1.00000e-09 2.12000e-01 8.28288e+00 8.28288e+00 8.28288e-01 1.00000e-09 2.12000e-01 $8.28288 \mathrm{e}+00$ 8.28288e+00 8.28288e-01 1.00000e-09 2.12000e-01 $8.28288 \mathrm{e}+00$ 8.28288e+00 8.28288e-01 1.00000e-09 2.12000e-01 8.28288e+00 8.28288e+00 8.28288e-01 1.00000e-09 2.12000e-01 Element: 2202 \# of layers: 8

$\mathrm{Kx} \mathrm{Ky} \mathrm{Kz}$ Ss Por

2.07293e+02 2.07293e+02 2.07293e+01 1.00000e-09 7.00000e-02 $5.00000 \mathrm{e}-04$ 5.00000e-04 5.00000e-05 1.00000e-09 1.00000e-01 5.00000e-04 5.00000e-04 5.00000e-05 1.00000e-09 1.00000e-01 $8.28288 \mathrm{e}+00$ 8.28288e+00 8.28288e-01 1.00000e-09 2.12000e-01 $8.28288 \mathrm{e}+008.28288 \mathrm{e}+00$ 8.28288e-01 1.00000e-09 2.12000e-01 $8.28288 \mathrm{e}+00$ 8.28288e+00 8.28288e-01 1.00000e-09 2.12000e-01 8.28288e+00 8.28288e+00 8.28288e-01 1.00000e-09 2.12000e-01 8.28288e+00 8.28288e+00 8.28288e-01 1.00000e-09 2.12000e-01 Element: 2203 \# of layers: 9

$\mathrm{Kx} \mathrm{Ky} \mathrm{Kz}$ Ss Por

$2.07293 \mathrm{e}+02$ 2.07293e+02 2.07293e+01 1.00000e-09 7.00000e-02 5.00000e-04 5.00000e-04 5.00000e-05 1.00000e-09 1.00000e-01 5.00000e-04 5.00000e-04 5.00000e-05 1.00000e-09 1.00000e-01 $8.28288 \mathrm{e}+00$ 8.28288e+00 8.28288e-01 1.00000e-09 2.12000e-01 $8.28288 \mathrm{e}+00$ 8.28288e+00 8.28288e-01 1.00000e-09 2.12000e-01 8.28288e+00 8.28288e+00 8.28288e-01 1.00000e-09 2.12000e-01 $8.28288 \mathrm{e}+00$ 8.28288e+00 8.28288e-01 1.00000e-09 2.12000e-01 $8.28288 \mathrm{e}+00$ 8.28288e+00 8.28288e-01 1.00000e-09 2.12000e-01 $1.00000 \mathrm{e}-02$ 1.00000e-02 1.00000e-03 1.00000e-09 1.00000e-01 Element: 2204 \# of layers: 8

$\mathrm{Kx} \mathrm{Ky} \mathrm{Kz} \mathrm{Ss} \mathrm{Por}$ $2.07293 \mathrm{e}+02$ 2.07293e+02 2.07293e+01 1.00000e-09 7.00000e-02 5.00000e-04 5.00000e-04 5.00000e-05 1.00000e-09 1.00000e-01 8.28288e+00 8.28288e+00 8.28288e-01 1.00000e-09 2.12000e-01 8.28288e+00 8.28288e+00 8.28288e-01 1.00000e-09 2.12000e-01 $8.28288 \mathrm{e}+008.28288 \mathrm{e}+00$ 8.28288e-01 1.00000e-09 2.12000e-01 8.28288e+00 8.28288e+00 8.28288e-01 1.00000e-09 2.12000e-01 8.28288e+00 8.28288e+00 8.28288e-01 1.00000e-09 2.12000e-01 1.00000e-02 1.00000e-02 1.00000e-03 1.00000e-09 1.00000e-01 Element: 2205 \# of layers: 6

$\mathrm{Kx} \mathrm{Ky} \mathrm{Kz}$ Ss Por 5.00000e-04 5.00000e-04 5.00000e-05 1.00000e-09 1.00000e-01 $8.28288 \mathrm{e}+00$ 8.28288e+00 8.28288e-01 1.00000e-09 2.12000e-01 $8.28288 \mathrm{e}+00$ 8.28288e+00 8.28288e-01 1.00000e-09 2.12000e-01 $8.28288 \mathrm{e}+00$ 8.28288e+00 8.28288e-01 1.00000e-09 2.12000e-01 8.28288e+00 8.28288e+00 8.28288e-01 1.00000e-09 2.12000e-01 8.28288e+00 8.28288e+00 8.28288e-01 1.00000e-09 2.12000e-01 Element: 2206 \# of layers: 5

Kx Ky Kz Ss Por 
$1.58061 \mathrm{e}+011.58061 \mathrm{e}+011.58061 \mathrm{e}+001.00000 \mathrm{e}-092.12000 \mathrm{e}-01$ $1.58061 \mathrm{e}+011.58061 \mathrm{e}+011.58061 \mathrm{e}+001.00000 \mathrm{e}-092.12000 \mathrm{e}-01$ $1.58061 \mathrm{e}+011.58061 \mathrm{e}+011.58061 \mathrm{e}+001.00000 \mathrm{e}-092.12000 \mathrm{e}-01$ $1.58061 \mathrm{e}+011.58061 \mathrm{e}+011.58061 \mathrm{e}+001.00000 \mathrm{e}-092.12000 \mathrm{e}-01$ $1.58061 \mathrm{e}+011.58061 \mathrm{e}+011.58061 \mathrm{e}+001.00000 \mathrm{e}-092.12000 \mathrm{e}-01$ Element: 2207 \# of layers: 5

$\mathrm{Kx} \mathrm{Ky} \mathrm{Kz}$ Ss Por

$1.58061 \mathrm{e}+011.58061 \mathrm{e}+011.58061 \mathrm{e}+001.00000 \mathrm{e}-092.12000 \mathrm{e}-01$

$1.58061 \mathrm{e}+011.58061 \mathrm{e}+01$ 1.58061e+00 1.00000e-09 2.12000e-01

$1.58061 \mathrm{e}+011.58061 \mathrm{e}+011.58061 \mathrm{e}+001.00000 \mathrm{e}-092.12000 \mathrm{e}-01$

$1.58061 \mathrm{e}+011.58061 \mathrm{e}+011.58061 \mathrm{e}+001.00000 \mathrm{e}-092.12000 \mathrm{e}-01$

$1.58061 \mathrm{e}+011.58061 \mathrm{e}+011.58061 \mathrm{e}+00$ 1.00000e-09 2.12000e-01

Element: 2208 \# of layers: 8

$\mathrm{Kx} \mathrm{Ky} \mathrm{Kz}$ Ss Por

$1.58061 \mathrm{e}+011.58061 \mathrm{e}+01$ 1.58061e+00 1.00000e-09 2.12000e-01

$1.58061 \mathrm{e}+011.58061 \mathrm{e}+011.58061 \mathrm{e}+001.00000 \mathrm{e}-092.12000 \mathrm{e}-01$

$1.58061 \mathrm{e}+011.58061 \mathrm{e}+011.58061 \mathrm{e}+001.00000 \mathrm{e}-092.12000 \mathrm{e}-01$

$1.58061 \mathrm{e}+011.58061 \mathrm{e}+011.58061 \mathrm{e}+001.00000 \mathrm{e}-092.12000 \mathrm{e}-01$

$1.58061 \mathrm{e}+011.58061 \mathrm{e}+011.58061 \mathrm{e}+001.00000 \mathrm{e}-092.12000 \mathrm{e}-01$

$1.00000 \mathrm{e}+001.00000 \mathrm{e}+001.00000 \mathrm{e}-011.00000 \mathrm{e}-091.00000 \mathrm{e}-01$

$1.00000 \mathrm{e}-05$ 1.00000e-05 1.00000e-06 1.00000e-09 1.00000e-01

$1.00000 \mathrm{e}+001.00000 \mathrm{e}+001.00000 \mathrm{e}-011.00000 \mathrm{e}-091.00000 \mathrm{e}-01$

Element: 2209 \# of layers: 6

Kx Ky Kz Ss Por

5.00000e-04 5.00000e-04 5.00000e-05 1.00000e-09 1.00000e-01

$1.58061 \mathrm{e}+011.58061 \mathrm{e}+011.58061 \mathrm{e}+001.00000 \mathrm{e}-092.12000 \mathrm{e}-01$

$1.58061 \mathrm{e}+011.58061 \mathrm{e}+011.58061 \mathrm{e}+001.00000 \mathrm{e}-092.12000 \mathrm{e}-01$

$1.58061 \mathrm{e}+011.58061 \mathrm{e}+011.58061 \mathrm{e}+001.00000 \mathrm{e}-092.12000 \mathrm{e}-01$

$1.58061 \mathrm{e}+011.58061 \mathrm{e}+011.58061 \mathrm{e}+001.00000 \mathrm{e}-092.12000 \mathrm{e}-01$

$1.58061 \mathrm{e}+011.58061 \mathrm{e}+011.58061 \mathrm{e}+001.00000 \mathrm{e}-092.12000 \mathrm{e}-01$

Element: 2210 \# of layers: 7

$\mathrm{Kx} \mathrm{Ky} \mathrm{Kz}$ Ss Por

5.00000e-04 5.00000e-04 5.00000e-05 1.00000e-09 1.00000e-01

5.00000e-04 5.00000e-04 5.00000e-05 1.00000e-09 1.00000e-01

$1.58061 \mathrm{e}+011.58061 \mathrm{e}+011.58061 \mathrm{e}+001.00000 \mathrm{e}-092.12000 \mathrm{e}-01$

$1.58061 \mathrm{e}+011.58061 \mathrm{e}+011.58061 \mathrm{e}+001.00000 \mathrm{e}-092.12000 \mathrm{e}-01$

$1.58061 \mathrm{e}+011.58061 \mathrm{e}+011.58061 \mathrm{e}+001.00000 \mathrm{e}-092.12000 \mathrm{e}-01$

$1.58061 \mathrm{e}+011.58061 \mathrm{e}+011.58061 \mathrm{e}+001.00000 \mathrm{e}-092.12000 \mathrm{e}-01$

$1.58061 \mathrm{e}+011.58061 \mathrm{e}+01$ 1.58061e+00 1.00000e-09 2.12000e-01

Element: 2211 \# of layers: 6

$\mathrm{Kx} \mathrm{Ky} \mathrm{Kz}$ Ss Por

5.00000e-04 5.00000e-04 5.00000e-05 1.00000e-09 1.00000e-01

$1.58061 \mathrm{e}+011.58061 \mathrm{e}+011.58061 \mathrm{e}+001.00000 \mathrm{e}-092.12000 \mathrm{e}-01$

$1.58061 \mathrm{e}+011.58061 \mathrm{e}+01$ 1.58061e+00 1.00000e-09 2.12000e-01

$1.58061 \mathrm{e}+011.58061 \mathrm{e}+011.58061 \mathrm{e}+001.00000 \mathrm{e}-092.12000 \mathrm{e}-01$

$1.58061 \mathrm{e}+011.58061 \mathrm{e}+011.58061 \mathrm{e}+00$ 1.00000e-09 2.12000e-01 
$1.58061 \mathrm{e}+011.58061 \mathrm{e}+011.58061 \mathrm{e}+001.00000 \mathrm{e}-092.12000 \mathrm{e}-01$

Element: 2212 \# of layers: 7

Kx Ky Kz Ss Por

5.00000e-04 5.00000e-04 5.00000e-05 1.00000e-09 1.00000e-01

5.00000e-04 5.00000e-04 5.00000e-05 1.00000e-09 1.00000e-01

$1.58061 \mathrm{e}+011.58061 \mathrm{e}+011.58061 \mathrm{e}+001.00000 \mathrm{e}-092.12000 \mathrm{e}-01$

$1.58061 \mathrm{e}+011.58061 \mathrm{e}+011.58061 \mathrm{e}+001.00000 \mathrm{e}-092.12000 \mathrm{e}-01$

$1.58061 \mathrm{e}+011.58061 \mathrm{e}+011.58061 \mathrm{e}+001.00000 \mathrm{e}-092.12000 \mathrm{e}-01$

$1.58061 \mathrm{e}+011.58061 \mathrm{e}+011.58061 \mathrm{e}+001.00000 \mathrm{e}-092.12000 \mathrm{e}-01$

$1.58061 \mathrm{e}+01$ 1.58061e+01 1.58061e+00 1.00000e-09 2.12000e-01

Element: 2213 \# of layers: 6

Kx Ky Kz Ss Por

5.00000e-04 5.00000e-04 5.00000e-05 1.00000e-09 1.00000e-01

$1.58061 \mathrm{e}+011.58061 \mathrm{e}+011.58061 \mathrm{e}+001.00000 \mathrm{e}-092.12000 \mathrm{e}-01$

$1.58061 \mathrm{e}+011.58061 \mathrm{e}+011.58061 \mathrm{e}+001.00000 \mathrm{e}-092.12000 \mathrm{e}-01$

$1.58061 \mathrm{e}+011.58061 \mathrm{e}+011.58061 \mathrm{e}+001.00000 \mathrm{e}-092.12000 \mathrm{e}-01$

$1.58061 \mathrm{e}+011.58061 \mathrm{e}+011.58061 \mathrm{e}+001.00000 \mathrm{e}-092.12000 \mathrm{e}-01$

$1.58061 \mathrm{e}+011.58061 \mathrm{e}+01$ 1.58061e+00 1.00000e-09 2.12000e-01

Element: 2214 \# of layers: 6

$\mathrm{Kx} \mathrm{Ky} \mathrm{Kz}$ Ss Por

5.00000e-04 5.00000e-04 5.00000e-05 1.00000e-09 1.00000e-01

$1.58061 \mathrm{e}+011.58061 \mathrm{e}+011.58061 \mathrm{e}+001.00000 \mathrm{e}-092.12000 \mathrm{e}-01$

$1.58061 \mathrm{e}+011.58061 \mathrm{e}+011.58061 \mathrm{e}+001.00000 \mathrm{e}-092.12000 \mathrm{e}-01$

$1.58061 \mathrm{e}+011.58061 \mathrm{e}+011.58061 \mathrm{e}+001.00000 \mathrm{e}-092.12000 \mathrm{e}-01$

$1.58061 \mathrm{e}+011.58061 \mathrm{e}+011.58061 \mathrm{e}+001.00000 \mathrm{e}-092.12000 \mathrm{e}-01$

$1.58061 \mathrm{e}+011.58061 \mathrm{e}+01$ 1.58061e+00 1.00000e-09 2.12000e-01

Element: 2215 \# of layers: 9

$\mathrm{Kx} \mathrm{Ky} \mathrm{Kz}$ Ss Por

5.00000e-04 5.00000e-04 5.00000e-05 1.00000e-09 1.00000e-01

$1.68992 \mathrm{e}+011.68992 \mathrm{e}+011.68992 \mathrm{e}+001.00000 \mathrm{e}-092.12000 \mathrm{e}-01$

$1.68992 \mathrm{e}+011.68992 \mathrm{e}+011.68992 \mathrm{e}+001.00000 \mathrm{e}-092.12000 \mathrm{e}-01$

$1.68992 \mathrm{e}+011.68992 \mathrm{e}+01$ 1.68992e+00 1.00000e-09 2.12000e-01

$1.68992 \mathrm{e}+011.68992 \mathrm{e}+011.68992 \mathrm{e}+001.00000 \mathrm{e}-092.12000 \mathrm{e}-01$

$1.68992 \mathrm{e}+011.68992 \mathrm{e}+011.68992 \mathrm{e}+001.00000 \mathrm{e}-092.12000 \mathrm{e}-01$

$1.00000 \mathrm{e}+001.00000 \mathrm{e}+001.00000 \mathrm{e}-011.00000 \mathrm{e}-091.00000 \mathrm{e}-01$

$1.00000 \mathrm{e}-05$ 1.00000e-05 1.00000e-06 1.00000e-09 1.00000e-01

$1.00000 \mathrm{e}+001.00000 \mathrm{e}+001.00000 \mathrm{e}-011.00000 \mathrm{e}-091.00000 \mathrm{e}-01$

Element: 2216 \# of layers: 9

$\mathrm{Kx} \mathrm{Ky} \mathrm{Kz}$ Ss Por

5.00000e-04 5.00000e-04 5.00000e-05 1.00000e-09 1.00000e-01

$1.68992 \mathrm{e}+011.68992 \mathrm{e}+011.68992 \mathrm{e}+001.00000 \mathrm{e}-092.12000 \mathrm{e}-01$

$1.68992 \mathrm{e}+011.68992 \mathrm{e}+011.68992 \mathrm{e}+001.00000 \mathrm{e}-092.12000 \mathrm{e}-01$

$1.68992 \mathrm{e}+01$ 1.68992e+01 1.68992e+00 1.00000e-09 2.12000e-01

$1.68992 \mathrm{e}+01$ 1.68992e+01 1.68992e+00 1.00000e-09 2.12000e-01

$1.00000 \mathrm{e}-02$ 1.00000e-02 1.00000e-03 1.00000e-09 1.00000e-01

$1.00000 \mathrm{e}+001.00000 \mathrm{e}+001.00000 \mathrm{e}-011.00000 \mathrm{e}-091.00000 \mathrm{e}-01$ 
$1.00000 \mathrm{e}-05$ 1.00000e-05 1.00000e-06 1.00000e-09 1.00000e-01 $1.00000 \mathrm{e}+001.00000 \mathrm{e}+001.00000 \mathrm{e}-01$ 1.00000e-09 1.00000e-01 Element: 2217 \# of layers: 9

Kx Ky Kz Ss Por 5.00000e-04 5.00000e-04 5.00000e-05 1.00000e-09 1.00000e-01 $1.68992 \mathrm{e}+01$ 1.68992e+01 1.68992e+00 1.00000e-09 2.12000e-01 $1.68992 \mathrm{e}+01$ 1.68992e+01 1.68992e+00 1.00000e-09 2.12000e-01 $1.68992 \mathrm{e}+011.68992 \mathrm{e}+011.68992 \mathrm{e}+001.00000 \mathrm{e}-092.12000 \mathrm{e}-01$ $1.68992 \mathrm{e}+01$ 1.68992e+01 1.68992e+00 1.00000e-09 2.12000e-01 $1.00000 \mathrm{e}-02$ 1.00000e-02 1.00000e-03 1.00000e-09 1.00000e-01 $1.00000 \mathrm{e}+001.00000 \mathrm{e}+001.00000 \mathrm{e}-011.00000 \mathrm{e}-091.00000 \mathrm{e}-01$ 1.00000e-05 1.00000e-05 1.00000e-06 1.00000e-09 1.00000e-01 $1.00000 \mathrm{e}+001.00000 \mathrm{e}+001.00000 \mathrm{e}-01$ 1.00000e-09 1.00000e-01 Element: 2218 \# of layers: 6

$\mathrm{Kx} \mathrm{Ky} \mathrm{Kz}$ Ss Por 5.00000e-04 5.00000e-04 5.00000e-05 1.00000e-09 1.00000e-01 $1.68992 \mathrm{e}+011.68992 \mathrm{e}+011.68992 \mathrm{e}+001.00000 \mathrm{e}-092.12000 \mathrm{e}-01$ $1.68992 \mathrm{e}+01$ 1.68992e+01 1.68992e+00 1.00000e-09 2.12000e-01 $1.68992 \mathrm{e}+01$ 1.68992e+01 1.68992e+00 1.00000e-09 2.12000e-01 $1.68992 \mathrm{e}+011.68992 \mathrm{e}+011.68992 \mathrm{e}+001.00000 \mathrm{e}-092.12000 \mathrm{e}-01$ $1.68992 \mathrm{e}+01$ 1.68992e+01 1.68992e+00 1.00000e-09 2.12000e-01 Element: 2219 \# of layers: 7

$\mathrm{Kx} \mathrm{Ky} \mathrm{Kz}$ Ss Por 5.00000e-04 5.00000e-04 5.00000e-05 1.00000e-09 1.00000e-01 5.00000e-04 5.00000e-04 5.00000e-05 1.00000e-09 1.00000e-01 $1.68992 \mathrm{e}+011.68992 \mathrm{e}+011.68992 \mathrm{e}+001.00000 \mathrm{e}-092.12000 \mathrm{e}-01$ $1.68992 \mathrm{e}+01$ 1.68992e+01 1.68992e+00 1.00000e-09 2.12000e-01 $1.68992 \mathrm{e}+01$ 1.68992e+01 1.68992e+00 1.00000e-09 2.12000e-01 $1.68992 \mathrm{e}+01$ 1.68992e+01 1.68992e+00 1.00000e-09 2.12000e-01 $1.68992 \mathrm{e}+01$ 1.68992e+01 1.68992e+00 1.00000e-09 2.12000e-01 Element: 2220 \# of layers: 7

$\mathrm{Kx} \mathrm{Ky} \mathrm{Kz}$ Ss Por

5.00000e-04 5.00000e-04 5.00000e-05 1.00000e-09 1.00000e-01 5.00000e-04 5.00000e-04 5.00000e-05 1.00000e-09 1.00000e-01 $1.68992 \mathrm{e}+011.68992 \mathrm{e}+011.68992 \mathrm{e}+001.00000 \mathrm{e}-092.12000 \mathrm{e}-01$ $1.68992 \mathrm{e}+01$ 1.68992e+01 1.68992e+00 1.00000e-09 2.12000e-01 $1.68992 \mathrm{e}+01$ 1.68992e+01 1.68992e+00 1.00000e-09 2.12000e-01 $1.68992 \mathrm{e}+011.68992 \mathrm{e}+011.68992 \mathrm{e}+001.00000 \mathrm{e}-092.12000 \mathrm{e}-01$ $1.68992 \mathrm{e}+01$ 1.68992e+01 1.68992e+00 1.00000e-09 2.12000e-01 Element: 2221 \# of layers: 7

$\mathrm{Kx} \mathrm{Ky} \mathrm{Kz}$ Ss Por 5.00000e-04 5.00000e-04 5.00000e-05 1.00000e-09 1.00000e-01 $5.00000 \mathrm{e}-04$ 5.00000e-04 5.00000e-05 1.00000e-09 1.00000e-01 $1.68992 \mathrm{e}+01$ 1.68992e+01 1.68992e+00 1.00000e-09 2.12000e-01 $1.68992 \mathrm{e}+011.68992 \mathrm{e}+011.68992 \mathrm{e}+001.00000 \mathrm{e}-092.12000 \mathrm{e}-01$ $1.68992 \mathrm{e}+011.68992 \mathrm{e}+011.68992 \mathrm{e}+001.00000 \mathrm{e}-092.12000 \mathrm{e}-01$ 
$1.68992 \mathrm{e}+01$ 1.68992e+01 1.68992e+00 1.00000e-09 2.12000e-01 $1.68992 \mathrm{e}+01$ 1.68992e+01 1.68992e+00 1.00000e-09 2.12000e-01 Element: 2222 \# of layers: 6

Kx Ky Kz Ss Por

5.00000e-04 5.00000e-04 5.00000e-05 1.00000e-09 1.00000e-01

$1.68992 \mathrm{e}+01$ 1.68992e+01 1.68992e+00 1.00000e-09 2.12000e-01

$1.68992 \mathrm{e}+011.68992 \mathrm{e}+01$ 1.68992e+00 1.00000e-09 2.12000e-01

$1.68992 \mathrm{e}+011.68992 \mathrm{e}+011.68992 \mathrm{e}+001.00000 \mathrm{e}-092.12000 \mathrm{e}-01$

$1.68992 \mathrm{e}+01$ 1.68992e+01 1.68992e+00 1.00000e-09 2.12000e-01

$1.68992 \mathrm{e}+01$ 1.68992e+01 1.68992e+00 1.00000e-09 2.12000e-01

Element: 2223 \# of layers: 6

$\mathrm{Kx} \mathrm{Ky} \mathrm{Kz}$ Ss Por

5.00000e-04 5.00000e-04 5.00000e-05 1.00000e-09 1.00000e-01

$1.68992 \mathrm{e}+011.68992 \mathrm{e}+011.68992 \mathrm{e}+001.00000 \mathrm{e}-092.12000 \mathrm{e}-01$

$1.68992 \mathrm{e}+01$ 1.68992e+01 1.68992e+00 1.00000e-09 2.12000e-01

$1.68992 \mathrm{e}+01$ 1.68992e+01 1.68992e+00 1.00000e-09 2.12000e-01

$1.68992 \mathrm{e}+01$ 1.68992e+01 1.68992e+00 1.00000e-09 2.12000e-01

$1.68992 \mathrm{e}+01$ 1.68992e+01 1.68992e+00 1.00000e-09 2.12000e-01

Element: 2224 \# of layers: 6

$\mathrm{Kx} \mathrm{Ky} \mathrm{Kz}$ Ss Por

5.00000e-04 5.00000e-04 5.00000e-05 1.00000e-09 1.00000e-01

$1.04965 \mathrm{e}+011.04965 \mathrm{e}+01$ 1.04965e+00 1.00000e-09 2.12000e-01

$1.04965 \mathrm{e}+01$ 1.04965e+01 1.04965e+00 1.00000e-09 2.12000e-01

$1.04965 \mathrm{e}+011.04965 \mathrm{e}+01 \quad 1.04965 \mathrm{e}+001.00000 \mathrm{e}-092.12000 \mathrm{e}-01$

$1.00000 \mathrm{e}-011.00000 \mathrm{e}-011.00000 \mathrm{e}-021.00000 \mathrm{e}-091.00000 \mathrm{e}-01$

$1.00000 \mathrm{e}+001.00000 \mathrm{e}+001.00000 \mathrm{e}-01$ 1.00000e-09 1.00000e-01

Element: 2225 \# of layers: 7

$\mathrm{Kx} \mathrm{Ky} \mathrm{Kz}$ Ss Por

$2.62696 \mathrm{e}+02$ 2.62696e+02 2.62696e+01 1.00000e-09 7.00000e-02

5.00000e-04 5.00000e-04 5.00000e-05 1.00000e-09 1.00000e-01

$1.04965 \mathrm{e}+011.04965 \mathrm{e}+011.04965 \mathrm{e}+001.00000 \mathrm{e}-092.12000 \mathrm{e}-01$

$1.04965 \mathrm{e}+011.04965 \mathrm{e}+01$ 1.04965e+00 1.00000e-09 2.12000e-01

$1.04965 \mathrm{e}+011.04965 \mathrm{e}+011.04965 \mathrm{e}+001.00000 \mathrm{e}-092.12000 \mathrm{e}-01$

$1.00000 \mathrm{e}-011.00000 \mathrm{e}-011.00000 \mathrm{e}-021.00000 \mathrm{e}-091.00000 \mathrm{e}-01$

$1.00000 \mathrm{e}+001.00000 \mathrm{e}+001.00000 \mathrm{e}-011.00000 \mathrm{e}-091.00000 \mathrm{e}-01$

Element: 2226 \# of layers: 8

$\mathrm{Kx} \mathrm{Ky} \mathrm{Kz}$ Ss Por

$2.62696 \mathrm{e}+02$ 2.62696e+02 2.62696e+01 1.00000e-09 7.00000e-02

5.00000e-04 5.00000e-04 5.00000e-05 1.00000e-09 1.00000e-01

5.00000e-04 5.00000e-04 5.00000e-05 1.00000e-09 1.00000e-01

$1.04965 \mathrm{e}+011.04965 \mathrm{e}+01 \quad 1.04965 \mathrm{e}+001.00000 \mathrm{e}-092.12000 \mathrm{e}-01$

$1.04965 \mathrm{e}+011.04965 \mathrm{e}+011.04965 \mathrm{e}+001.00000 \mathrm{e}-092.12000 \mathrm{e}-01$

$1.04965 \mathrm{e}+011.04965 \mathrm{e}+01$ 1.04965e+00 1.00000e-09 2.12000e-01

$1.00000 \mathrm{e}-011.00000 \mathrm{e}-011.00000 \mathrm{e}-021.00000 \mathrm{e}-091.00000 \mathrm{e}-01$

$1.00000 \mathrm{e}+001.00000 \mathrm{e}+001.00000 \mathrm{e}-011.00000 \mathrm{e}-09$ 1.00000e-01

Element: 2227 \# of layers: 9 
$\mathrm{Kx} \mathrm{Ky} \mathrm{Kz}$ Ss Por

2.62696e+02 2.62696e+02 2.62696e+01 1.00000e-09 7.00000e-02 5.00000e-04 5.00000e-04 5.00000e-05 1.00000e-09 1.00000e-01

$1.04965 \mathrm{e}+011.04965 \mathrm{e}+011.04965 \mathrm{e}+001.00000 \mathrm{e}-092.12000 \mathrm{e}-01$ $1.04965 \mathrm{e}+011.04965 \mathrm{e}+011.04965 \mathrm{e}+001.00000 \mathrm{e}-092.12000 \mathrm{e}-01$ $1.04965 \mathrm{e}+011.04965 \mathrm{e}+011.04965 \mathrm{e}+001.00000 \mathrm{e}-092.12000 \mathrm{e}-01$ $1.04965 \mathrm{e}+011.04965 \mathrm{e}+011.04965 \mathrm{e}+001.00000 \mathrm{e}-092.12000 \mathrm{e}-01$ $1.04965 \mathrm{e}+011.04965 \mathrm{e}+011.04965 \mathrm{e}+001.00000 \mathrm{e}-092.12000 \mathrm{e}-01$ 1.00000e-01 1.00000e-01 1.00000e-02 1.00000e-09 1.00000e-01 $1.00000 \mathrm{e}+001.00000 \mathrm{e}+001.00000 \mathrm{e}-011.00000 \mathrm{e}-091.00000 \mathrm{e}-01$ Element: 2228 \# of layers: 7

$\mathrm{Kx} \mathrm{Ky} \mathrm{Kz}$ Ss Por

2.62696e+02 2.62696e+02 2.62696e+01 1.00000e-09 7.00000e-02 5.00000e-04 5.00000e-04 5.00000e-05 1.00000e-09 1.00000e-01 $1.04965 \mathrm{e}+011.04965 \mathrm{e}+011.04965 \mathrm{e}+001.00000 \mathrm{e}-092.12000 \mathrm{e}-01$ $1.04965 \mathrm{e}+011.04965 \mathrm{e}+011.04965 \mathrm{e}+001.00000 \mathrm{e}-092.12000 \mathrm{e}-01$ $1.04965 \mathrm{e}+011.04965 \mathrm{e}+011.04965 \mathrm{e}+001.00000 \mathrm{e}-092.12000 \mathrm{e}-01$ $1.04965 \mathrm{e}+011.04965 \mathrm{e}+011.04965 \mathrm{e}+001.00000 \mathrm{e}-092.12000 \mathrm{e}-01$ $1.04965 \mathrm{e}+01$ 1.04965e+01 1.04965e+00 1.00000e-09 2.12000e-01 Element: 2229 \# of layers: 7

$\mathrm{Kx} \mathrm{Ky} \mathrm{Kz}$ Ss Por

$2.62696 \mathrm{e}+02$ 2.62696e+02 2.62696e+01 1.00000e-09 7.00000e-02 5.00000e-04 5.00000e-04 5.00000e-05 1.00000e-09 1.00000e-01 $1.04965 \mathrm{e}+011.04965 \mathrm{e}+011.04965 \mathrm{e}+001.00000 \mathrm{e}-092.12000 \mathrm{e}-01$ $1.04965 \mathrm{e}+011.04965 \mathrm{e}+011.04965 \mathrm{e}+001.00000 \mathrm{e}-092.12000 \mathrm{e}-01$ $1.04965 \mathrm{e}+011.04965 \mathrm{e}+011.04965 \mathrm{e}+001.00000 \mathrm{e}-092.12000 \mathrm{e}-01$ $1.04965 \mathrm{e}+011.04965 \mathrm{e}+011.04965 \mathrm{e}+001.00000 \mathrm{e}-092.12000 \mathrm{e}-01$ $1.04965 \mathrm{e}+011.04965 \mathrm{e}+01$ 1.04965e+00 1.00000e-09 2.12000e-01 Element: 2230 \# of layers: 7

$\mathrm{Kx} \mathrm{Ky} \mathrm{Kz}$ Ss Por

$2.62696 \mathrm{e}+02$ 2.62696e+02 2.62696e+01 1.00000e-09 7.00000e-02 5.00000e-04 5.00000e-04 5.00000e-05 1.00000e-09 1.00000e-01

$1.04965 \mathrm{e}+011.04965 \mathrm{e}+011.04965 \mathrm{e}+001.00000 \mathrm{e}-092.12000 \mathrm{e}-01$ $1.04965 \mathrm{e}+011.04965 \mathrm{e}+011.04965 \mathrm{e}+001.00000 \mathrm{e}-092.12000 \mathrm{e}-01$ $1.04965 \mathrm{e}+011.04965 \mathrm{e}+01$ 1.04965e+00 1.00000e-09 2.12000e-01 $1.04965 \mathrm{e}+011.04965 \mathrm{e}+01$ 1.04965e+00 1.00000e-09 2.12000e-01 $1.04965 \mathrm{e}+011.04965 \mathrm{e}+01$ 1.04965e+00 1.00000e-09 2.12000e-01 Element: 2231 \# of layers: 7

$\mathrm{Kx} \mathrm{Ky} \mathrm{Kz}$ Ss Por

$2.62696 \mathrm{e}+02$ 2.62696e+02 2.62696e+01 1.00000e-09 7.00000e-02 5.00000e-04 5.00000e-04 5.00000e-05 1.00000e-09 1.00000e-01 $1.04965 \mathrm{e}+011.04965 \mathrm{e}+011.04965 \mathrm{e}+001.00000 \mathrm{e}-092.12000 \mathrm{e}-01$ $1.04965 \mathrm{e}+011.04965 \mathrm{e}+011.04965 \mathrm{e}+001.00000 \mathrm{e}-092.12000 \mathrm{e}-01$ $1.04965 \mathrm{e}+011.04965 \mathrm{e}+011.04965 \mathrm{e}+001.00000 \mathrm{e}-092.12000 \mathrm{e}-01$ $1.04965 \mathrm{e}+01$ 1.04965e+01 1.04965e+00 1.00000e-09 2.12000e-01 $1.04965 \mathrm{e}+01$ 1.04965e+01 1.04965e+00 1.00000e-09 2.12000e-01 
Element: 2232 \# of layers: 9

$\mathrm{Kx} \mathrm{Ky} \mathrm{Kz}$ Ss Por

$2.62696 \mathrm{e}+02$ 2.62696e+02 2.62696e+01 1.00000e-09 7.00000e-02

5.00000e-04 5.00000e-04 5.00000e-05 1.00000e-09 1.00000e-01

$1.04965 \mathrm{e}+011.04965 \mathrm{e}+011.04965 \mathrm{e}+001.00000 \mathrm{e}-092.12000 \mathrm{e}-01$

$1.04965 \mathrm{e}+011.04965 \mathrm{e}+011.04965 \mathrm{e}+001.00000 \mathrm{e}-092.12000 \mathrm{e}-01$

$1.04965 \mathrm{e}+011.04965 \mathrm{e}+011.04965 \mathrm{e}+001.00000 \mathrm{e}-092.12000 \mathrm{e}-01$

$1.04965 \mathrm{e}+011.04965 \mathrm{e}+011.04965 \mathrm{e}+001.00000 \mathrm{e}-092.12000 \mathrm{e}-01$

$1.04965 \mathrm{e}+011.04965 \mathrm{e}+01$ 1.04965e+00 1.00000e-09 2.12000e-01

$1.00000 \mathrm{e}-011.00000 \mathrm{e}-01$ 1.00000e-02 1.00000e-09 1.00000e-01

$1.00000 \mathrm{e}+001.00000 \mathrm{e}+001.00000 \mathrm{e}-011.00000 \mathrm{e}-091.00000 \mathrm{e}-01$

Element: 2233 \# of layers: 8

$\mathrm{Kx} \mathrm{Ky} \mathrm{Kz}$ Ss Por

$2.19114 \mathrm{e}+02$ 2.19114e+02 2.19114e+01 1.00000e-09 7.00000e-02

5.00000e-04 5.00000e-04 5.00000e-05 1.00000e-09 1.00000e-01

5.00000e-04 5.00000e-04 5.00000e-05 1.00000e-09 1.00000e-01

$8.75494 \mathrm{e}+008.75494 \mathrm{e}+008.75494 \mathrm{e}-01$ 1.00000e-09 2.12000e-01

$8.75494 \mathrm{e}+008.75494 \mathrm{e}+008.75494 \mathrm{e}-01$ 1.00000e-09 2.12000e-01

$8.75494 \mathrm{e}+00$ 8.75494e+00 8.75494e-01 1.00000e-09 2.12000e-01

$1.00000 \mathrm{e}-011.00000 \mathrm{e}-01$ 1.00000e-02 1.00000e-09 1.00000e-01

$1.00000 \mathrm{e}+001.00000 \mathrm{e}+001.00000 \mathrm{e}-011.00000 \mathrm{e}-091.00000 \mathrm{e}-01$

Element: 2234 \# of layers: 9

$\mathrm{Kx} \mathrm{Ky} \mathrm{Kz}$ Ss Por

$2.19114 \mathrm{e}+02$ 2.19114e+02 2.19114e+01 1.00000e-09 7.00000e-02

$2.19114 \mathrm{e}+022.19114 \mathrm{e}+022.19114 \mathrm{e}+01 \quad 1.00000 \mathrm{e}-097.00000 \mathrm{e}-02$

5.00000e-04 5.00000e-04 5.00000e-05 1.00000e-09 1.00000e-01

5.00000e-04 5.00000e-04 5.00000e-05 1.00000e-09 1.00000e-01

$8.75494 \mathrm{e}+008.75494 \mathrm{e}+00$ 8.75494e-01 1.00000e-09 2.12000e-01

$8.75494 \mathrm{e}+008.75494 \mathrm{e}+00$ 8.75494e-01 1.00000e-09 2.12000e-01

$8.75494 \mathrm{e}+00$ 8.75494e+00 8.75494e-01 1.00000e-09 2.12000e-01

$1.00000 \mathrm{e}-011.00000 \mathrm{e}-01$ 1.00000e-02 1.00000e-09 1.00000e-01

$1.00000 \mathrm{e}+001.00000 \mathrm{e}+001.00000 \mathrm{e}-011.00000 \mathrm{e}-091.00000 \mathrm{e}-01$

Element: 2235 \# of layers: 8

$\mathrm{Kx} \mathrm{Ky} \mathrm{Kz}$ Ss Por

2.19114e+02 2.19114e+02 2.19114e+01 1.00000e-09 7.00000e-02

5.00000e-04 5.00000e-04 5.00000e-05 1.00000e-09 1.00000e-01

5.00000e-04 5.00000e-04 5.00000e-05 1.00000e-09 1.00000e-01

$8.75494 \mathrm{e}+008.75494 \mathrm{e}+008.75494 \mathrm{e}-01$ 1.00000e-09 2.12000e-01

$8.75494 \mathrm{e}+008.75494 \mathrm{e}+008.75494 \mathrm{e}-01$ 1.00000e-09 2.12000e-01

8.75494e+00 8.75494e+00 8.75494e-01 1.00000e-09 2.12000e-01

$1.00000 \mathrm{e}-011.00000 \mathrm{e}-01$ 1.00000e-02 1.00000e-09 1.00000e-01

$1.00000 \mathrm{e}+001.00000 \mathrm{e}+001.00000 \mathrm{e}-011.00000 \mathrm{e}-091.00000 \mathrm{e}-01$

Element: 2236 \# of layers: 11

$\mathrm{Kx} \mathrm{Ky} \mathrm{Kz}$ Ss Por

$2.19114 \mathrm{e}+02$ 2.19114e+02 2.19114e+01 1.00000e-09 7.00000e-02

$2.19114 \mathrm{e}+022.19114 \mathrm{e}+02$ 2.19114e+01 1.00000e-09 7.00000e-02 
5.00000e-04 5.00000e-04 5.00000e-05 1.00000e-09 1.00000e-01 5.00000e-04 5.00000e-04 5.00000e-05 1.00000e-09 1.00000e-01

$8.75494 \mathrm{e}+00$ 8.75494e+00 8.75494e-01 1.00000e-09 2.12000e-01

$8.75494 \mathrm{e}+00$ 8.75494e+00 8.75494e-01 1.00000e-09 2.12000e-01

$8.75494 \mathrm{e}+008.75494 \mathrm{e}+008.75494 \mathrm{e}-01$ 1.00000e-09 2.12000e-01

$8.75494 \mathrm{e}+008.75494 \mathrm{e}+008.75494 \mathrm{e}-01$ 1.00000e-09 2.12000e-01

$8.75494 \mathrm{e}+008.75494 \mathrm{e}+008.75494 \mathrm{e}-01$ 1.00000e-09 2.12000e-01

$1.00000 \mathrm{e}-011.00000 \mathrm{e}-01$ 1.00000e-02 1.00000e-09 1.00000e-01

$1.00000 \mathrm{e}+001.00000 \mathrm{e}+001.00000 \mathrm{e}-011.00000 \mathrm{e}-091.00000 \mathrm{e}-01$

Element: 2237 \# of layers: 9

$\mathrm{Kx} \mathrm{Ky} \mathrm{Kz}$ Ss Por

$2.19114 \mathrm{e}+02$ 2.19114e+02 2.19114e+01 1.00000e-09 7.00000e-02

$2.19114 \mathrm{e}+02$ 2.19114e+02 2.19114e+01 1.00000e-09 7.00000e-02

5.00000e-04 5.00000e-04 5.00000e-05 1.00000e-09 1.00000e-01

5.00000e-04 5.00000e-04 5.00000e-05 1.00000e-09 1.00000e-01

$8.75494 \mathrm{e}+008.75494 \mathrm{e}+00$ 8.75494e-01 1.00000e-09 2.12000e-01

$8.75494 \mathrm{e}+008.75494 \mathrm{e}+00$ 8.75494e-01 1.00000e-09 2.12000e-01

8.75494e+00 8.75494e+00 8.75494e-01 1.00000e-09 2.12000e-01

8.75494e+00 8.75494e+00 8.75494e-01 1.00000e-09 2.12000e-01

$8.75494 \mathrm{e}+008.75494 \mathrm{e}+00$ 8.75494e-01 1.00000e-09 2.12000e-01

Element: 2238 \# of layers: 9

$\mathrm{Kx} \mathrm{Ky} \mathrm{Kz}$ Ss Por

2.19114e+02 2.19114e+02 2.19114e+01 1.00000e-09 7.00000e-02

$2.19114 \mathrm{e}+022.19114 \mathrm{e}+022.19114 \mathrm{e}+01$ 1.00000e-09 7.00000e-02

5.00000e-04 5.00000e-04 5.00000e-05 1.00000e-09 1.00000e-01

5.00000e-04 5.00000e-04 5.00000e-05 1.00000e-09 1.00000e-01

$8.75494 \mathrm{e}+008.75494 \mathrm{e}+00$ 8.75494e-01 1.00000e-09 2.12000e-01

$8.75494 \mathrm{e}+008.75494 \mathrm{e}+00$ 8.75494e-01 1.00000e-09 2.12000e-01

$8.75494 \mathrm{e}+008.75494 \mathrm{e}+008.75494 \mathrm{e}-01$ 1.00000e-09 2.12000e-01

$8.75494 \mathrm{e}+00$ 8.75494e+00 8.75494e-01 1.00000e-09 2.12000e-01

8.75494e+00 8.75494e+00 8.75494e-01 1.00000e-09 2.12000e-01

Element: 2239 \# of layers: 7

$\mathrm{Kx} \mathrm{Ky} \mathrm{Kz}$ Ss Por

$2.19114 \mathrm{e}+02$ 2.19114e+02 2.19114e+01 1.00000e-09 7.00000e-02

5.00000e-04 5.00000e-04 5.00000e-05 1.00000e-09 1.00000e-01

$8.75494 \mathrm{e}+008.75494 \mathrm{e}+008.75494 \mathrm{e}-01$ 1.00000e-09 2.12000e-01

$8.75494 \mathrm{e}+008.75494 \mathrm{e}+00$ 8.75494e-01 1.00000e-09 2.12000e-01

$8.75494 \mathrm{e}+008.75494 \mathrm{e}+008.75494 \mathrm{e}-01$ 1.00000e-09 2.12000e-01

8.75494e+00 8.75494e+00 8.75494e-01 1.00000e-09 2.12000e-01

8.75494e+00 8.75494e+00 8.75494e-01 1.00000e-09 2.12000e-01

Element: 2240 \# of layers: 9

$\mathrm{Kx} \mathrm{Ky} \mathrm{Kz}$ Ss Por

$2.19114 \mathrm{e}+02$ 2.19114e+02 2.19114e+01 1.00000e-09 7.00000e-02

5.00000e-04 5.00000e-04 5.00000e-05 1.00000e-09 1.00000e-01

$8.75494 \mathrm{e}+00$ 8.75494e+00 8.75494e-01 1.00000e-09 2.12000e-01

$8.75494 \mathrm{e}+008.75494 \mathrm{e}+008.75494 \mathrm{e}-01$ 1.00000e-09 2.12000e-01 
$8.75494 \mathrm{e}+008.75494 \mathrm{e}+008.75494 \mathrm{e}-01$ 1.00000e-09 2.12000e-01 $8.75494 \mathrm{e}+008.75494 \mathrm{e}+008.75494 \mathrm{e}-011.00000 \mathrm{e}-092.12000 \mathrm{e}-01$ $8.75494 \mathrm{e}+008.75494 \mathrm{e}+00$ 8.75494e-01 1.00000e-09 2.12000e-01 $1.00000 \mathrm{e}-011.00000 \mathrm{e}-011.00000 \mathrm{e}-021.00000 \mathrm{e}-091.00000 \mathrm{e}-01$ $1.00000 \mathrm{e}+001.00000 \mathrm{e}+001.00000 \mathrm{e}-011.00000 \mathrm{e}-091.00000 \mathrm{e}-01$ Element: 2241 \# of layers: 11

Kx Ky Kz Ss Por

$2.19114 \mathrm{e}+022.19114 \mathrm{e}+022.19114 \mathrm{e}+01$ 1.00000e-09 7.00000e-02 $2.19114 \mathrm{e}+022.19114 \mathrm{e}+022.19114 \mathrm{e}+011.00000 \mathrm{e}-097.00000 \mathrm{e}-02$ 5.00000e-04 5.00000e-04 5.00000e-05 1.00000e-09 1.00000e-01 5.00000e-04 5.00000e-04 5.00000e-05 1.00000e-09 1.00000e-01 $8.75494 \mathrm{e}+008.75494 \mathrm{e}+008.75494 \mathrm{e}-01$ 1.00000e-09 2.12000e-01 $8.75494 \mathrm{e}+008.75494 \mathrm{e}+008.75494 \mathrm{e}-011.00000 \mathrm{e}-092.12000 \mathrm{e}-01$ $8.75494 \mathrm{e}+008.75494 \mathrm{e}+008.75494 \mathrm{e}-011.00000 \mathrm{e}-092.12000 \mathrm{e}-01$ $8.75494 \mathrm{e}+008.75494 \mathrm{e}+008.75494 \mathrm{e}-01$ 1.00000e-09 2.12000e-01 $8.75494 \mathrm{e}+008.75494 \mathrm{e}+008.75494 \mathrm{e}-011.00000 \mathrm{e}-092.12000 \mathrm{e}-01$ $1.00000 \mathrm{e}-011.00000 \mathrm{e}-011.00000 \mathrm{e}-021.00000 \mathrm{e}-091.00000 \mathrm{e}-01$ $1.00000 \mathrm{e}+001.00000 \mathrm{e}+001.00000 \mathrm{e}-011.00000 \mathrm{e}-091.00000 \mathrm{e}-01$ Element: 2242 \# of layers: 8

Kx Ky Kz Ss Por

$1.16580 \mathrm{e}+021.16580 \mathrm{e}+021.16580 \mathrm{e}+01$ 1.00000e-09 7.00000e-02 5.00000e-04 5.00000e-04 5.00000e-05 1.00000e-09 1.00000e-01 $5.00000 \mathrm{e}-04$ 5.00000e-04 5.00000e-05 1.00000e-09 1.00000e-01 $4.65828 \mathrm{e}+004.65828 \mathrm{e}+00$ 4.65828e-01 1.00000e-09 2.12000e-01 $4.65828 \mathrm{e}+004.65828 \mathrm{e}+004.65828 \mathrm{e}-011.00000 \mathrm{e}-092.12000 \mathrm{e}-01$ $4.65828 \mathrm{e}+004.65828 \mathrm{e}+00$ 4.65828e-01 1.00000e-09 2.12000e-01 $1.00000 \mathrm{e}-011.00000 \mathrm{e}-011.00000 \mathrm{e}-021.00000 \mathrm{e}-091.00000 \mathrm{e}-01$ $1.00000 \mathrm{e}+001.00000 \mathrm{e}+001.00000 \mathrm{e}-011.00000 \mathrm{e}-091.00000 \mathrm{e}-01$ Element: 2243 \# of layers: 9

Kx Ky Kz Ss Por

$1.16580 \mathrm{e}+021.16580 \mathrm{e}+02$ 1.16580e+01 1.00000e-09 7.00000e-02 5.00000e-04 5.00000e-04 5.00000e-05 1.00000e-09 1.00000e-01 5.00000e-04 5.00000e-04 5.00000e-05 1.00000e-09 1.00000e-01 $4.65828 \mathrm{e}+004.65828 \mathrm{e}+00$ 4.65828e-01 1.00000e-09 2.12000e-01 $4.65828 \mathrm{e}+004.65828 \mathrm{e}+004.65828 \mathrm{e}-011.00000 \mathrm{e}-092.12000 \mathrm{e}-01$ $4.65828 \mathrm{e}+004.65828 \mathrm{e}+004.65828 \mathrm{e}-011.00000 \mathrm{e}-09$ 2.12000e-01 $4.65828 \mathrm{e}+004.65828 \mathrm{e}+004.65828 \mathrm{e}-011.00000 \mathrm{e}-092.12000 \mathrm{e}-01$ $4.65828 \mathrm{e}+004.65828 \mathrm{e}+00$ 4.65828e-01 1.00000e-09 2.12000e-01 $1.00000 \mathrm{e}-01$ 1.00000e-01 1.00000e-02 1.00000e-09 1.00000e-01 Element: 2244 \# of layers: 8

Kx Ky Kz Ss Por

$1.16580 \mathrm{e}+021.16580 \mathrm{e}+02$ 1.16580e+01 1.00000e-09 7.00000e-02 5.00000e-04 5.00000e-04 5.00000e-05 1.00000e-09 1.00000e-01 $5.00000 \mathrm{e}-04$ 5.00000e-04 5.00000e-05 1.00000e-09 1.00000e-01 $4.65828 \mathrm{e}+004.65828 \mathrm{e}+00$ 4.65828e-01 1.00000e-09 2.12000e-01 $4.65828 \mathrm{e}+004.65828 \mathrm{e}+004.65828 \mathrm{e}-01$ 1.00000e-09 2.12000e-01 
4.65828e+00 4.65828e+00 4.65828e-01 1.00000e-09 2.12000e-01

$4.65828 \mathrm{e}+004.65828 \mathrm{e}+00$ 4.65828e-01 1.00000e-09 2.12000e-01

$4.65828 \mathrm{e}+00$ 4.65828e+00 4.65828e-01 1.00000e-09 2.12000e-01

Element: 2245 \# of layers: 16

$\mathrm{Kx} \mathrm{Ky} \mathrm{Kz}$ Ss Por

2.63398e+02 2.63398e+02 2.63398e+01 1.00000e-09 7.00000e-02

$2.63398 \mathrm{e}+02$ 2.63398e+02 2.63398e+01 1.00000e-09 7.00000e-02

$2.63398 \mathrm{e}+02$ 2.63398e+02 2.63398e+01 1.00000e-09 7.00000e-02

$2.63398 \mathrm{e}+02$ 2.63398e +02 2.63398e+01 1.00000e-09 7.00000e-02

$2.63398 \mathrm{e}+022.63398 \mathrm{e}+02$ 2.63398e+01 1.00000e-09 7.00000e-02

5.00000e-04 5.00000e-04 5.00000e-05 1.00000e-09 1.00000e-01

5.00000e-04 5.00000e-04 5.00000e-05 1.00000e-09 1.00000e-01

$1.05246 \mathrm{e}+011.05246 \mathrm{e}+011.05246 \mathrm{e}+001.00000 \mathrm{e}-092.12000 \mathrm{e}-01$

$1.05246 \mathrm{e}+011.05246 \mathrm{e}+011.05246 \mathrm{e}+001.00000 \mathrm{e}-092.12000 \mathrm{e}-01$

$1.05246 \mathrm{e}+011.05246 \mathrm{e}+011.05246 \mathrm{e}+001.00000 \mathrm{e}-092.12000 \mathrm{e}-01$

$1.05246 \mathrm{e}+011.05246 \mathrm{e}+011.05246 \mathrm{e}+001.00000 \mathrm{e}-092.12000 \mathrm{e}-01$

$1.05246 \mathrm{e}+011.05246 \mathrm{e}+011.05246 \mathrm{e}+001.00000 \mathrm{e}-092.12000 \mathrm{e}-01$

$1.00000 \mathrm{e}-011.00000 \mathrm{e}-01$ 1.00000e-02 1.00000e-09 1.00000e-01

$1.00000 \mathrm{e}+001.00000 \mathrm{e}+001.00000 \mathrm{e}-011.00000 \mathrm{e}-091.00000 \mathrm{e}-01$

1.00000e-05 1.00000e-05 1.00000e-06 1.00000e-09 1.00000e-01

$1.00000 \mathrm{e}+001.00000 \mathrm{e}+001.00000 \mathrm{e}-011.00000 \mathrm{e}-091.00000 \mathrm{e}-01$

Element: 2246 \# of layers: 15

$\mathrm{Kx} \mathrm{Ky} \mathrm{Kz}$ Ss Por

$2.63398 \mathrm{e}+02$ 2.63398e+02 2.63398e+01 1.00000e-09 7.00000e-02

$2.63398 \mathrm{e}+02$ 2.63398e+02 2.63398e+01 1.00000e-09 7.00000e-02

$2.63398 \mathrm{e}+022.63398 \mathrm{e}+02$ 2.63398e+01 1.00000e-09 7.00000e-02

$2.63398 \mathrm{e}+02$ 2.63398e+02 2.63398e+01 1.00000e-09 7.00000e-02

5.00000e-04 5.00000e-04 5.00000e-05 1.00000e-09 1.00000e-01

5.00000e-04 5.00000e-04 5.00000e-05 1.00000e-09 1.00000e-01

$1.05246 \mathrm{e}+011.05246 \mathrm{e}+011.05246 \mathrm{e}+001.00000 \mathrm{e}-092.12000 \mathrm{e}-01$

$1.05246 \mathrm{e}+011.05246 \mathrm{e}+011.05246 \mathrm{e}+001.00000 \mathrm{e}-092.12000 \mathrm{e}-01$

$1.05246 \mathrm{e}+011.05246 \mathrm{e}+011.05246 \mathrm{e}+001.00000 \mathrm{e}-092.12000 \mathrm{e}-01$

$1.05246 \mathrm{e}+011.05246 \mathrm{e}+011.05246 \mathrm{e}+001.00000 \mathrm{e}-092.12000 \mathrm{e}-01$

$1.05246 \mathrm{e}+011.05246 \mathrm{e}+011.05246 \mathrm{e}+001.00000 \mathrm{e}-092.12000 \mathrm{e}-01$

$1.00000 \mathrm{e}-011.00000 \mathrm{e}-01$ 1.00000e-02 1.00000e-09 1.00000e-01

$1.00000 \mathrm{e}+001.00000 \mathrm{e}+001.00000 \mathrm{e}-011.00000 \mathrm{e}-091.00000 \mathrm{e}-01$

$1.00000 \mathrm{e}-05$ 1.00000e-05 1.00000e-06 1.00000e-09 1.00000e-01

$1.00000 \mathrm{e}+001.00000 \mathrm{e}+001.00000 \mathrm{e}-011.00000 \mathrm{e}-091.00000 \mathrm{e}-01$

Element: 2247 \# of layers: 15

$\mathrm{Kx} \mathrm{Ky} \mathrm{Kz}$ Ss Por

$2.80986 \mathrm{e}+02$ 2.80986e+02 2.80986e+01 1.00000e-09 7.00000e-02

$2.80986 \mathrm{e}+02$ 2.80986e+02 2.80986e+01 1.00000e-09 7.00000e-02

$2.80986 \mathrm{e}+022.80986 \mathrm{e}+022.80986 \mathrm{e}+01$ 1.00000e-09 7.00000e-02

$2.80986 \mathrm{e}+02$ 2.80986e+02 2.80986e+01 1.00000e-09 7.00000e-02

5.00000e-04 5.00000e-04 5.00000e-05 1.00000e-09 1.00000e-01

5.00000e-04 5.00000e-04 5.00000e-05 1.00000e-09 1.00000e-01 
1.12273e+01 1.12273e+01 1.12273e+00 1.00000e-09 2.12000e-01 $1.12273 \mathrm{e}+01$ 1.12273e+01 1.12273e+00 1.00000e-09 2.12000e-01 $1.12273 \mathrm{e}+01$ 1.12273e+01 1.12273e+00 1.00000e-09 2.12000e-01 $1.12273 \mathrm{e}+01$ 1.12273e+01 1.12273e+00 1.00000e-09 2.12000e-01 $1.12273 \mathrm{e}+01$ 1.12273e+01 1.12273e+00 1.00000e-09 2.12000e-01 $1.00000 \mathrm{e}-011.00000 \mathrm{e}-01$ 1.00000e-02 1.00000e-09 1.00000e-01 $1.00000 \mathrm{e}+001.00000 \mathrm{e}+001.00000 \mathrm{e}-011.00000 \mathrm{e}-091.00000 \mathrm{e}-01$ $1.00000 \mathrm{e}-05$ 1.00000e-05 1.00000e-06 1.00000e-09 1.00000e-01 $1.00000 \mathrm{e}+001.00000 \mathrm{e}+001.00000 \mathrm{e}-011.00000 \mathrm{e}-091.00000 \mathrm{e}-01$ Element: 2248 \# of layers: 15

$\mathrm{Kx} \mathrm{Ky} \mathrm{Kz}$ Ss Por

$2.80986 \mathrm{e}+022.80986 \mathrm{e}+02$ 2.80986e+01 1.00000e-09 7.00000e-02 $2.80986 \mathrm{e}+022.80986 \mathrm{e}+022.80986 \mathrm{e}+01$ 1.00000e-09 7.00000e-02

$2.80986 \mathrm{e}+022.80986 \mathrm{e}+022.80986 \mathrm{e}+01$ 1.00000e-09 7.00000e-02 $2.80986 \mathrm{e}+022.80986 \mathrm{e}+022.80986 \mathrm{e}+01$ 1.00000e-09 7.00000e-02 5.00000e-04 5.00000e-04 5.00000e-05 1.00000e-09 1.00000e-01 5.00000e-04 5.00000e-04 5.00000e-05 1.00000e-09 1.00000e-01 $1.12273 \mathrm{e}+011.12273 \mathrm{e}+01$ 1.12273e+00 1.00000e-09 2.12000e-01 $1.12273 \mathrm{e}+01$ 1.12273e+01 1.12273e+00 1.00000e-09 2.12000e-01 $1.12273 \mathrm{e}+01$ 1.12273e+01 1.12273e+00 1.00000e-09 2.12000e-01 $1.12273 \mathrm{e}+011.12273 \mathrm{e}+011.12273 \mathrm{e}+001.00000 \mathrm{e}-092.12000 \mathrm{e}-01$ $1.12273 \mathrm{e}+01$ 1.12273e+01 1.12273e+00 1.00000e-09 2.12000e-01 $1.00000 \mathrm{e}-011.00000 \mathrm{e}-011.00000 \mathrm{e}-021.00000 \mathrm{e}-091.00000 \mathrm{e}-01$ $1.00000 \mathrm{e}+001.00000 \mathrm{e}+001.00000 \mathrm{e}-011.00000 \mathrm{e}-091.00000 \mathrm{e}-01$ $1.00000 \mathrm{e}-05$ 1.00000e-05 1.00000e-06 1.00000e-09 1.00000e-01 $1.00000 \mathrm{e}+001.00000 \mathrm{e}+001.00000 \mathrm{e}-01$ 1.00000e-09 1.00000e-01 Element: 2249 \# of layers: 16

$\mathrm{Kx} \mathrm{Ky} \mathrm{Kz}$ Ss Por

$2.33080 \mathrm{e}+02$ 2.33080e+02 2.33080e+01 1.00000e-09 7.00000e-02 $2.33080 \mathrm{e}+02$ 2.33080e+02 2.33080e+01 1.00000e-09 7.00000e-02 $2.33080 \mathrm{e}+022.33080 \mathrm{e}+02 \quad 2.33080 \mathrm{e}+01$ 1.00000e-09 7.00000e-02 $2.33080 \mathrm{e}+022.33080 \mathrm{e}+02 \quad 2.33080 \mathrm{e}+01$ 1.00000e-09 7.00000e-02 $2.33080 \mathrm{e}+02$ 2.33080e+02 2.33080e+01 1.00000e-09 7.00000e-02 5.00000e-04 5.00000e-04 5.00000e-05 1.00000e-09 1.00000e-01 5.00000e-04 5.00000e-04 5.00000e-05 1.00000e-09 1.00000e-01 9.31295e+00 9.31295e+00 9.31295e-01 1.00000e-09 2.12000e-01 $9.31295 \mathrm{e}+00$ 9.31295e+00 9.31295e-01 1.00000e-09 2.12000e-01 $9.31295 \mathrm{e}+00$ 9.31295e+00 9.31295e-01 1.00000e-09 2.12000e-01 9.31295e+00 9.31295e+00 9.31295e-01 1.00000e-09 2.12000e-01 9.31295e+00 9.31295e+00 9.31295e-01 1.00000e-09 2.12000e-01 1.00000e-01 1.00000e-01 1.00000e-02 1.00000e-09 1.00000e-01 $1.00000 \mathrm{e}+001.00000 \mathrm{e}+001.00000 \mathrm{e}-011.00000 \mathrm{e}-091.00000 \mathrm{e}-01$ $1.00000 \mathrm{e}-05$ 1.00000e-05 1.00000e-06 1.00000e-09 1.00000e-01 $1.00000 \mathrm{e}+001.00000 \mathrm{e}+001.00000 \mathrm{e}-011.00000 \mathrm{e}-091.00000 \mathrm{e}-01$ Element: 2250 \# of layers: 15

Kx Ky Kz Ss Por 
$2.61461 \mathrm{e}+02$ 2.61461e+02 2.61461e+01 1.00000e-09 7.00000e-02 $2.61461 \mathrm{e}+02$ 2.61461e+02 2.61461e+01 1.00000e-09 7.00000e-02 $2.61461 \mathrm{e}+022.61461 \mathrm{e}+02$ 2.61461e+01 1.00000e-09 7.00000e-02 $2.61461 \mathrm{e}+022.61461 \mathrm{e}+022.61461 \mathrm{e}+01$ 1.00000e-09 7.00000e-02 $5.00000 \mathrm{e}-04$ 5.00000e-04 5.00000e-05 1.00000e-09 1.00000e-01 5.00000e-04 5.00000e-04 5.00000e-05 1.00000e-09 1.00000e-01 $1.04472 \mathrm{e}+011.04472 \mathrm{e}+01$ 1.04472e+00 1.00000e-09 2.12000e-01 $1.04472 \mathrm{e}+011.04472 \mathrm{e}+011.04472 \mathrm{e}+001.00000 \mathrm{e}-092.12000 \mathrm{e}-01$ $1.04472 \mathrm{e}+01$ 1.04472e+01 1.04472e+00 1.00000e-09 2.12000e-01 $1.04472 \mathrm{e}+01$ 1.04472e+01 1.04472e+00 1.00000e-09 2.12000e-01 $1.04472 \mathrm{e}+01$ 1.04472e+01 1.04472e+00 1.00000e-09 2.12000e-01 $1.00000 \mathrm{e}-01$ 1.00000e-01 1.00000e-02 1.00000e-09 1.00000e-01 $1.00000 \mathrm{e}+001.00000 \mathrm{e}+001.00000 \mathrm{e}-011.00000 \mathrm{e}-091.00000 \mathrm{e}-01$ $1.00000 \mathrm{e}-05$ 1.00000e-05 1.00000e-06 1.00000e-09 1.00000e-01 $1.00000 \mathrm{e}+001.00000 \mathrm{e}+001.00000 \mathrm{e}-01$ 1.00000e-09 1.00000e-01 Element: 2251 \# of layers: 15

$\mathrm{Kx} \mathrm{Ky} \mathrm{Kz}$ Ss Por

$2.61461 \mathrm{e}+02$ 2.61461e+02 2.61461e+01 1.00000e-09 7.00000e-02 $2.61461 \mathrm{e}+02$ 2.61461e+02 2.61461e+01 1.00000e-09 7.00000e-02 $2.61461 \mathrm{e}+022.61461 \mathrm{e}+022.61461 \mathrm{e}+01$ 1.00000e-09 7.00000e-02 $2.61461 \mathrm{e}+022.61461 \mathrm{e}+022.61461 \mathrm{e}+01$ 1.00000e-09 7.00000e-02 $5.00000 \mathrm{e}-04$ 5.00000e-04 5.00000e-05 1.00000e-09 1.00000e-01 5.00000e-04 5.00000e-04 5.00000e-05 1.00000e-09 1.00000e-01 $1.04472 \mathrm{e}+011.04472 \mathrm{e}+011.04472 \mathrm{e}+001.00000 \mathrm{e}-092.12000 \mathrm{e}-01$ $1.04472 \mathrm{e}+01$ 1.04472e+01 1.04472e+00 1.00000e-09 2.12000e-01 $1.04472 \mathrm{e}+011.04472 \mathrm{e}+011.04472 \mathrm{e}+001.00000 \mathrm{e}-092.12000 \mathrm{e}-01$ $1.04472 \mathrm{e}+011.04472 \mathrm{e}+011.04472 \mathrm{e}+001.00000 \mathrm{e}-092.12000 \mathrm{e}-01$ $1.04472 \mathrm{e}+011.04472 \mathrm{e}+01$ 1.04472e+00 1.00000e-09 2.12000e-01 $1.00000 \mathrm{e}-011.00000 \mathrm{e}-01$ 1.00000e-02 1.00000e-09 1.00000e-01 $1.00000 \mathrm{e}+001.00000 \mathrm{e}+001.00000 \mathrm{e}-011.00000 \mathrm{e}-091.00000 \mathrm{e}-01$ $1.00000 \mathrm{e}-05$ 1.00000e-05 1.00000e-06 1.00000e-09 1.00000e-01 $1.00000 \mathrm{e}+001.00000 \mathrm{e}+001.00000 \mathrm{e}-011.00000 \mathrm{e}-091.00000 \mathrm{e}-01$ Element: 2252 \# of layers: 15

$\mathrm{Kx} \mathrm{Ky} \mathrm{Kz}$ Ss Por

$2.72318 \mathrm{e}+02$ 2.72318e+02 2.72318e+01 1.00000e-09 7.00000e-02 $2.72318 \mathrm{e}+02$ 2.72318e+02 2.72318e+01 1.00000e-09 7.00000e-02 $2.72318 \mathrm{e}+02$ 2.72318e+02 2.72318e+01 1.00000e-09 7.00000e-02 $2.72318 \mathrm{e}+022.72318 \mathrm{e}+022.72318 \mathrm{e}+01$ 1.00000e-09 7.00000e-02 5.00000e-04 5.00000e-04 5.00000e-05 1.00000e-09 1.00000e-01 5.00000e-04 5.00000e-04 5.00000e-05 1.00000e-09 1.00000e-01 $1.08808 \mathrm{e}+011.08808 \mathrm{e}+01 \quad 1.08808 \mathrm{e}+001.00000 \mathrm{e}-092.12000 \mathrm{e}-01$ $1.08808 \mathrm{e}+011.08808 \mathrm{e}+011.08808 \mathrm{e}+001.00000 \mathrm{e}-092.12000 \mathrm{e}-01$ $1.08808 \mathrm{e}+011.08808 \mathrm{e}+011.08808 \mathrm{e}+001.00000 \mathrm{e}-092.12000 \mathrm{e}-01$ $1.08808 \mathrm{e}+01$ 1.08808e+01 1.08808e+00 1.00000e-09 2.12000e-01 $1.08808 \mathrm{e}+011.08808 \mathrm{e}+011.08808 \mathrm{e}+001.00000 \mathrm{e}-092.12000 \mathrm{e}-01$ $1.00000 \mathrm{e}-01$ 1.00000e-01 1.00000e-02 1.00000e-09 1.00000e-01 
$1.00000 \mathrm{e}+001.00000 \mathrm{e}+001.00000 \mathrm{e}-011.00000 \mathrm{e}-091.00000 \mathrm{e}-01$ $1.00000 \mathrm{e}-05$ 1.00000e-05 1.00000e-06 1.00000e-09 1.00000e-01 $1.00000 \mathrm{e}+001.00000 \mathrm{e}+001.00000 \mathrm{e}-011.00000 \mathrm{e}-09$ 1.00000e-01 Element: 2253 \# of layers: 15

$\mathrm{Kx} \mathrm{Ky} \mathrm{Kz}$ Ss Por

$2.62434 \mathrm{e}+02$ 2.62434e+02 2.62434e+01 1.00000e-09 7.00000e-02 $2.62434 \mathrm{e}+022.62434 \mathrm{e}+02 \quad 2.62434 \mathrm{e}+01$ 1.00000e-09 7.00000e-02 $2.62434 \mathrm{e}+022.62434 \mathrm{e}+02 \quad 2.62434 \mathrm{e}+01$ 1.00000e-09 7.00000e-02 $2.62434 \mathrm{e}+022.62434 \mathrm{e}+022.62434 \mathrm{e}+01$ 1.00000e-09 7.00000e-02 5.00000e-04 5.00000e-04 5.00000e-05 1.00000e-09 1.00000e-01 5.00000e-04 5.00000e-04 5.00000e-05 1.00000e-09 1.00000e-01 $1.04859 \mathrm{e}+01$ 1.04859e+01 1.04859e+00 1.00000e-09 2.12000e-01 $1.04859 \mathrm{e}+01$ 1.04859e+01 1.04859e+00 1.00000e-09 2.12000e-01 $1.04859 \mathrm{e}+01$ 1.04859e+01 1.04859e+00 1.00000e-09 2.12000e-01 $1.04859 \mathrm{e}+01$ 1.04859e+01 1.04859e+00 1.00000e-09 2.12000e-01 $1.04859 \mathrm{e}+01$ 1.04859e+01 1.04859e+00 1.00000e-09 2.12000e-01 $1.00000 \mathrm{e}-01$ 1.00000e-01 1.00000e-02 1.00000e-09 1.00000e-01 $1.00000 \mathrm{e}+001.00000 \mathrm{e}+001.00000 \mathrm{e}-011.00000 \mathrm{e}-091.00000 \mathrm{e}-01$ $1.00000 \mathrm{e}-05$ 1.00000e-05 1.00000e-06 1.00000e-09 1.00000e-01 $1.00000 \mathrm{e}+001.00000 \mathrm{e}+001.00000 \mathrm{e}-011.00000 \mathrm{e}-091.00000 \mathrm{e}-01$ Element: 2254 \# of layers: 15

$\mathrm{Kx} \mathrm{Ky} \mathrm{Kz}$ Ss Por

$2.62434 \mathrm{e}+02$ 2.62434e+02 2.62434e+01 1.00000e-09 7.00000e-02 $2.62434 \mathrm{e}+022.62434 \mathrm{e}+022.62434 \mathrm{e}+01$ 1.00000e-09 7.00000e-02 $2.62434 \mathrm{e}+022.62434 \mathrm{e}+022.62434 \mathrm{e}+01 \quad 1.00000 \mathrm{e}-097.00000 \mathrm{e}-02$ $2.62434 \mathrm{e}+02$ 2.62434e+02 2.62434e+01 1.00000e-09 7.00000e-02 5.00000e-04 5.00000e-04 5.00000e-05 1.00000e-09 1.00000e-01 5.00000e-04 5.00000e-04 5.00000e-05 1.00000e-09 1.00000e-01 $1.04859 \mathrm{e}+01$ 1.04859e+01 1.04859e+00 1.00000e-09 2.12000e-01 $1.04859 \mathrm{e}+01$ 1.04859e+01 1.04859e+00 1.00000e-09 2.12000e-01 $1.04859 \mathrm{e}+01$ 1.04859e+01 1.04859e+00 1.00000e-09 2.12000e-01 $1.04859 \mathrm{e}+01$ 1.04859e+01 1.04859e+00 1.00000e-09 2.12000e-01 $1.04859 \mathrm{e}+01$ 1.04859e+01 1.04859e+00 1.00000e-09 2.12000e-01 1.00000e-01 1.00000e-01 1.00000e-02 1.00000e-09 1.00000e-01 $1.00000 \mathrm{e}+001.00000 \mathrm{e}+001.00000 \mathrm{e}-011.00000 \mathrm{e}-091.00000 \mathrm{e}-01$ 1.00000e-05 1.00000e-05 1.00000e-06 1.00000e-09 1.00000e-01 $1.00000 \mathrm{e}+001.00000 \mathrm{e}+001.00000 \mathrm{e}-011.00000 \mathrm{e}-091.00000 \mathrm{e}-01$ Element: 2255 \# of layers: 16

$\mathrm{Kx} \mathrm{Ky} \mathrm{Kz}$ Ss Por

3.06160e+02 3.06160e+02 3.06160e+01 1.00000e-09 7.00000e-02 $3.06160 \mathrm{e}+02$ 3.06160e+02 3.06160e+01 1.00000e-09 7.00000e-02 $3.06160 \mathrm{e}+02$ 3.06160e+02 3.06160e+01 1.00000e-09 7.00000e-02 $3.06160 \mathrm{e}+023.06160 \mathrm{e}+023.06160 \mathrm{e}+01$ 1.00000e-09 7.00000e-02 $3.06160 \mathrm{e}+023.06160 \mathrm{e}+023.06160 \mathrm{e}+01$ 1.00000e-09 7.00000e-02 $5.00000 \mathrm{e}-04$ 5.00000e-04 5.00000e-05 1.00000e-09 1.00000e-01 5.00000e-04 5.00000e-04 5.00000e-05 1.00000e-09 1.00000e-01 
$1.22331 \mathrm{e}+011.22331 \mathrm{e}+011.22331 \mathrm{e}+001.00000 \mathrm{e}-092.12000 \mathrm{e}-01$ $1.22331 \mathrm{e}+01$ 1.22331e+01 1.22331e+00 1.00000e-09 2.12000e-01 $1.22331 \mathrm{e}+011.22331 \mathrm{e}+011.22331 \mathrm{e}+001.00000 \mathrm{e}-092.12000 \mathrm{e}-01$ $1.22331 \mathrm{e}+011.22331 \mathrm{e}+011.22331 \mathrm{e}+001.00000 \mathrm{e}-092.12000 \mathrm{e}-01$ $1.22331 \mathrm{e}+011.22331 \mathrm{e}+011.22331 \mathrm{e}+001.00000 \mathrm{e}-092.12000 \mathrm{e}-01$ $1.00000 \mathrm{e}-02$ 1.00000e-02 1.00000e-03 1.00000e-09 1.00000e-01 $1.00000 \mathrm{e}+001.00000 \mathrm{e}+001.00000 \mathrm{e}-011.00000 \mathrm{e}-091.00000 \mathrm{e}-01$ $1.00000 \mathrm{e}-05$ 1.00000e-05 1.00000e-06 1.00000e-09 1.00000e-01 $1.00000 \mathrm{e}+001.00000 \mathrm{e}+001.00000 \mathrm{e}-011.00000 \mathrm{e}-091.00000 \mathrm{e}-01$ Element: 2256 \# of layers: 15

$\mathrm{Kx} \mathrm{Ky} \mathrm{Kz}$ Ss Por

3.06160e+02 3.06160e+02 3.06160e+01 1.00000e-09 7.00000e-02 $3.06160 \mathrm{e}+023.06160 \mathrm{e}+023.06160 \mathrm{e}+01$ 1.00000e-09 7.00000e-02 $3.06160 \mathrm{e}+02$ 3.06160e+02 3.06160e+01 1.00000e-09 7.00000e-02 $3.06160 \mathrm{e}+023.06160 \mathrm{e}+023.06160 \mathrm{e}+01$ 1.00000e-09 7.00000e-02 5.00000e-04 5.00000e-04 5.00000e-05 1.00000e-09 1.00000e-01 5.00000e-04 5.00000e-04 5.00000e-05 1.00000e-09 1.00000e-01 $1.22331 \mathrm{e}+011.22331 \mathrm{e}+011.22331 \mathrm{e}+001.00000 \mathrm{e}-092.12000 \mathrm{e}-01$ $1.22331 \mathrm{e}+011.22331 \mathrm{e}+01$ 1.22331e+00 1.00000e-09 2.12000e-01 $1.22331 \mathrm{e}+011.22331 \mathrm{e}+011.22331 \mathrm{e}+001.00000 \mathrm{e}-092.12000 \mathrm{e}-01$ $1.22331 \mathrm{e}+011.22331 \mathrm{e}+011.22331 \mathrm{e}+001.00000 \mathrm{e}-092.12000 \mathrm{e}-01$ $1.22331 \mathrm{e}+011.22331 \mathrm{e}+01$ 1.22331e+00 1.00000e-09 2.12000e-01 $1.00000 \mathrm{e}-021.00000 \mathrm{e}-021.00000 \mathrm{e}-031.00000 \mathrm{e}-091.00000 \mathrm{e}-01$ $1.00000 \mathrm{e}+001.00000 \mathrm{e}+001.00000 \mathrm{e}-011.00000 \mathrm{e}-091.00000 \mathrm{e}-01$ $1.00000 \mathrm{e}-05$ 1.00000e-05 1.00000e-06 1.00000e-09 1.00000e-01 $1.00000 \mathrm{e}+001.00000 \mathrm{e}+001.00000 \mathrm{e}-01$ 1.00000e-09 1.00000e-01 Element: 2257 \# of layers: 15

$\mathrm{Kx} \mathrm{Ky} \mathrm{Kz}$ Ss Por

$2.74454 \mathrm{e}+02$ 2.74454e+02 2.74454e+01 1.00000e-09 7.00000e-02 $2.74454 \mathrm{e}+02$ 2.74454e+02 2.74454e+01 1.00000e-09 7.00000e-02 $2.74454 \mathrm{e}+02$ 2.74454e+02 2.74454e+01 1.00000e-09 7.00000e-02 $2.74454 \mathrm{e}+02$ 2.74454e+02 2.74454e+01 1.00000e-09 7.00000e-02 5.00000e-04 5.00000e-04 5.00000e-05 1.00000e-09 1.00000e-01 5.00000e-04 5.00000e-04 5.00000e-05 1.00000e-09 1.00000e-01 $1.09663 \mathrm{e}+011.09663 \mathrm{e}+011.09663 \mathrm{e}+001.00000 \mathrm{e}-092.12000 \mathrm{e}-01$ $1.09663 \mathrm{e}+011.09663 \mathrm{e}+011.09663 \mathrm{e}+001.00000 \mathrm{e}-092.12000 \mathrm{e}-01$ $1.09663 \mathrm{e}+011.09663 \mathrm{e}+011.09663 \mathrm{e}+001.00000 \mathrm{e}-092.12000 \mathrm{e}-01$ $1.09663 \mathrm{e}+011.09663 \mathrm{e}+011.09663 \mathrm{e}+001.00000 \mathrm{e}-092.12000 \mathrm{e}-01$ $1.09663 \mathrm{e}+011.09663 \mathrm{e}+011.09663 \mathrm{e}+001.00000 \mathrm{e}-092.12000 \mathrm{e}-01$ 1.00000e-01 1.00000e-01 1.00000e-02 1.00000e-09 1.00000e-01 $1.00000 \mathrm{e}+001.00000 \mathrm{e}+001.00000 \mathrm{e}-011.00000 \mathrm{e}-091.00000 \mathrm{e}-01$ $1.00000 \mathrm{e}-05$ 1.00000e-05 1.00000e-06 1.00000e-09 1.00000e-01 $1.00000 \mathrm{e}+001.00000 \mathrm{e}+001.00000 \mathrm{e}-011.00000 \mathrm{e}-091.00000 \mathrm{e}-01$ Element: 2258 \# of layers: 16

$\mathrm{Kx} \mathrm{Ky} \mathrm{Kz}$ Ss Por

2.71697e+02 2.71697e+02 2.71697e+01 1.00000e-09 7.00000e-02 
$2.71697 \mathrm{e}+022.71697 \mathrm{e}+022.71697 \mathrm{e}+01$ 1.00000e-09 7.00000e-02 $2.71697 \mathrm{e}+022.71697 \mathrm{e}+022.71697 \mathrm{e}+01$ 1.00000e-09 7.00000e-02 $2.71697 \mathrm{e}+022.71697 \mathrm{e}+022.71697 \mathrm{e}+01$ 1.00000e-09 7.00000e-02 $2.71697 \mathrm{e}+022.71697 \mathrm{e}+022.71697 \mathrm{e}+01$ 1.00000e-09 7.00000e-02 $5.00000 \mathrm{e}-04$ 5.00000e-04 5.00000e-05 1.00000e-09 1.00000e-01 5.00000e-04 5.00000e-04 5.00000e-05 1.00000e-09 1.00000e-01 $1.08560 \mathrm{e}+011.08560 \mathrm{e}+011.08560 \mathrm{e}+001.00000 \mathrm{e}-092.12000 \mathrm{e}-01$ $1.08560 \mathrm{e}+011.08560 \mathrm{e}+011.08560 \mathrm{e}+001.00000 \mathrm{e}-092.12000 \mathrm{e}-01$ $1.08560 \mathrm{e}+011.08560 \mathrm{e}+011.08560 \mathrm{e}+001.00000 \mathrm{e}-092.12000 \mathrm{e}-01$ $1.08560 \mathrm{e}+011.08560 \mathrm{e}+011.08560 \mathrm{e}+001.00000 \mathrm{e}-092.12000 \mathrm{e}-01$ $1.08560 \mathrm{e}+011.08560 \mathrm{e}+011.08560 \mathrm{e}+001.00000 \mathrm{e}-092.12000 \mathrm{e}-01$ $1.00000 \mathrm{e}-021.00000 \mathrm{e}-02$ 1.00000e-03 1.00000e-09 1.00000e-01 $1.00000 \mathrm{e}+001.00000 \mathrm{e}+001.00000 \mathrm{e}-011.00000 \mathrm{e}-091.00000 \mathrm{e}-01$ $1.00000 \mathrm{e}-05$ 1.00000e-05 1.00000e-06 1.00000e-09 1.00000e-01 $1.00000 \mathrm{e}+001.00000 \mathrm{e}+001.00000 \mathrm{e}-011.00000 \mathrm{e}-091.00000 \mathrm{e}-01$ Element: 2259 \# of layers: 16

Kx Ky Kz Ss Por

$2.37801 \mathrm{e}+022.37801 \mathrm{e}+022.37801 \mathrm{e}+01$ 1.00000e-09 7.00000e-02 $2.37801 \mathrm{e}+022.37801 \mathrm{e}+022.37801 \mathrm{e}+011.00000 \mathrm{e}-097.00000 \mathrm{e}-02$ $2.37801 \mathrm{e}+022.37801 \mathrm{e}+022.37801 \mathrm{e}+011.00000 \mathrm{e}-097.00000 \mathrm{e}-02$ $2.37801 \mathrm{e}+022.37801 \mathrm{e}+022.37801 \mathrm{e}+011.00000 \mathrm{e}-097.00000 \mathrm{e}-02$ $2.37801 \mathrm{e}+022.37801 \mathrm{e}+022.37801 \mathrm{e}+011.00000 \mathrm{e}-097.00000 \mathrm{e}-02$ 5.00000e-04 5.00000e-04 5.00000e-05 1.00000e-09 1.00000e-01 5.00000e-04 5.00000e-04 5.00000e-05 1.00000e-09 1.00000e-01

$9.50150 \mathrm{e}+009.50150 \mathrm{e}+009.50150 \mathrm{e}-011.00000 \mathrm{e}-092.12000 \mathrm{e}-01$ $9.50150 \mathrm{e}+009.50150 \mathrm{e}+009.50150 \mathrm{e}-011.00000 \mathrm{e}-092.12000 \mathrm{e}-01$ $9.50150 \mathrm{e}+009.50150 \mathrm{e}+009.50150 \mathrm{e}-011.00000 \mathrm{e}-092.12000 \mathrm{e}-01$ $9.50150 \mathrm{e}+009.50150 \mathrm{e}+009.50150 \mathrm{e}-011.00000 \mathrm{e}-092.12000 \mathrm{e}-01$ $9.50150 \mathrm{e}+009.50150 \mathrm{e}+00$ 9.50150e-01 1.00000e-09 2.12000e-01 $1.00000 \mathrm{e}-02$ 1.00000e-02 1.00000e-03 1.00000e-09 1.00000e-01 $1.00000 \mathrm{e}+001.00000 \mathrm{e}+001.00000 \mathrm{e}-011.00000 \mathrm{e}-091.00000 \mathrm{e}-01$ $1.00000 \mathrm{e}-05$ 1.00000e-05 1.00000e-06 1.00000e-09 1.00000e-01 $1.00000 \mathrm{e}+001.00000 \mathrm{e}+001.00000 \mathrm{e}-011.00000 \mathrm{e}-091.00000 \mathrm{e}-01$ Element: 2260 \# of layers: 16

Kx Ky Kz Ss Por

$2.37801 \mathrm{e}+022.37801 \mathrm{e}+022.37801 \mathrm{e}+01$ 1.00000e-09 7.00000e-02 $2.37801 \mathrm{e}+022.37801 \mathrm{e}+022.37801 \mathrm{e}+01$ 1.00000e-09 7.00000e-02 $2.37801 \mathrm{e}+022.37801 \mathrm{e}+022.37801 \mathrm{e}+011.00000 \mathrm{e}-097.00000 \mathrm{e}-02$ $2.37801 \mathrm{e}+022.37801 \mathrm{e}+022.37801 \mathrm{e}+011.00000 \mathrm{e}-097.00000 \mathrm{e}-02$ $2.37801 \mathrm{e}+022.37801 \mathrm{e}+022.37801 \mathrm{e}+01$ 1.00000e-09 7.00000e-02 5.00000e-04 5.00000e-04 5.00000e-05 1.00000e-09 1.00000e-01 5.00000e-04 5.00000e-04 5.00000e-05 1.00000e-09 1.00000e-01 $9.50150 \mathrm{e}+009.50150 \mathrm{e}+00$ 9.50150e-01 1.00000e-09 2.12000e-01 $9.50150 \mathrm{e}+009.50150 \mathrm{e}+009.50150 \mathrm{e}-011.00000 \mathrm{e}-092.12000 \mathrm{e}-01$ $9.50150 \mathrm{e}+009.50150 \mathrm{e}+00$ 9.50150e-01 1.00000e-09 2.12000e-01 $9.50150 \mathrm{e}+009.50150 \mathrm{e}+00$ 9.50150e-01 1.00000e-09 2.12000e-01 
9.50150e+00 9.50150e+00 9.50150e-01 1.00000e-09 2.12000e-01 $1.00000 \mathrm{e}-02$ 1.00000e-02 1.00000e-03 1.00000e-09 1.00000e-01 $1.00000 \mathrm{e}+001.00000 \mathrm{e}+001.00000 \mathrm{e}-011.00000 \mathrm{e}-091.00000 \mathrm{e}-01$ $1.00000 \mathrm{e}-05$ 1.00000e-05 1.00000e-06 1.00000e-09 1.00000e-01 $1.00000 \mathrm{e}+001.00000 \mathrm{e}+001.00000 \mathrm{e}-011.00000 \mathrm{e}-091.00000 \mathrm{e}-01$ Element: 2261 \# of layers: 16

$\mathrm{Kx} \mathrm{Ky} \mathrm{Kz}$ Ss Por

$2.60290 \mathrm{e}+02$ 2.60290e+02 2.60290e+01 1.00000e-09 7.00000e-02 $2.60290 \mathrm{e}+022.60290 \mathrm{e}+02 \quad 2.60290 \mathrm{e}+01$ 1.00000e-09 7.00000e-02 $2.60290 \mathrm{e}+022.60290 \mathrm{e}+02 \quad 2.60290 \mathrm{e}+01$ 1.00000e-09 7.00000e-02 $2.60290 \mathrm{e}+022.60290 \mathrm{e}+02$ 2.60290e+01 1.00000e-09 7.00000e-02 $2.60290 \mathrm{e}+022.60290 \mathrm{e}+022.60290 \mathrm{e}+01$ 1.00000e-09 7.00000e-02 5.00000e-04 5.00000e-04 5.00000e-05 1.00000e-09 1.00000e-01 5.00000e-04 5.00000e-04 5.00000e-05 1.00000e-09 1.00000e-01 $1.04004 \mathrm{e}+011.04004 \mathrm{e}+011.04004 \mathrm{e}+001.00000 \mathrm{e}-092.12000 \mathrm{e}-01$ $1.04004 \mathrm{e}+011.04004 \mathrm{e}+011.04004 \mathrm{e}+001.00000 \mathrm{e}-092.12000 \mathrm{e}-01$ $1.04004 \mathrm{e}+011.04004 \mathrm{e}+011.04004 \mathrm{e}+001.00000 \mathrm{e}-092.12000 \mathrm{e}-01$ $1.04004 \mathrm{e}+011.04004 \mathrm{e}+011.04004 \mathrm{e}+001.00000 \mathrm{e}-092.12000 \mathrm{e}-01$ $1.04004 \mathrm{e}+011.04004 \mathrm{e}+011.04004 \mathrm{e}+001.00000 \mathrm{e}-092.12000 \mathrm{e}-01$ $1.00000 \mathrm{e}-02$ 1.00000e-02 1.00000e-03 1.00000e-09 1.00000e-01 $1.00000 \mathrm{e}+001.00000 \mathrm{e}+001.00000 \mathrm{e}-011.00000 \mathrm{e}-091.00000 \mathrm{e}-01$ $1.00000 \mathrm{e}-05$ 1.00000e-05 1.00000e-06 1.00000e-09 1.00000e-01 $1.00000 \mathrm{e}+001.00000 \mathrm{e}+001.00000 \mathrm{e}-01$ 1.00000e-09 1.00000e-01 Element: 2262 \# of layers: 16

$\mathrm{Kx} \mathrm{Ky} \mathrm{Kz}$ Ss Por

$2.60290 \mathrm{e}+02$ 2.60290e+02 2.60290e+01 1.00000e-09 7.00000e-02 $2.60290 \mathrm{e}+022.60290 \mathrm{e}+02$ 2.60290e+01 1.00000e-09 7.00000e-02 $2.60290 \mathrm{e}+022.60290 \mathrm{e}+02 \quad 2.60290 \mathrm{e}+01$ 1.00000e-09 7.00000e-02 $2.60290 \mathrm{e}+022.60290 \mathrm{e}+022.60290 \mathrm{e}+01$ 1.00000e-09 7.00000e-02 $2.60290 \mathrm{e}+022.60290 \mathrm{e}+02$ 2.60290e+01 1.00000e-09 7.00000e-02 5.00000e-04 5.00000e-04 5.00000e-05 1.00000e-09 1.00000e-01 5.00000e-04 5.00000e-04 5.00000e-05 1.00000e-09 1.00000e-01 $1.04004 \mathrm{e}+011.04004 \mathrm{e}+01 \quad 1.04004 \mathrm{e}+001.00000 \mathrm{e}-092.12000 \mathrm{e}-01$ $1.04004 \mathrm{e}+011.04004 \mathrm{e}+011.04004 \mathrm{e}+001.00000 \mathrm{e}-092.12000 \mathrm{e}-01$ $1.04004 \mathrm{e}+011.04004 \mathrm{e}+011.04004 \mathrm{e}+001.00000 \mathrm{e}-092.12000 \mathrm{e}-01$ $1.04004 \mathrm{e}+011.04004 \mathrm{e}+011.04004 \mathrm{e}+001.00000 \mathrm{e}-092.12000 \mathrm{e}-01$ $1.04004 \mathrm{e}+011.04004 \mathrm{e}+011.04004 \mathrm{e}+001.00000 \mathrm{e}-092.12000 \mathrm{e}-01$ $1.00000 \mathrm{e}-02$ 1.00000e-02 1.00000e-03 1.00000e-09 1.00000e-01 $1.00000 \mathrm{e}+001.00000 \mathrm{e}+001.00000 \mathrm{e}-011.00000 \mathrm{e}-091.00000 \mathrm{e}-01$ $1.00000 \mathrm{e}-05$ 1.00000e-05 1.00000e-06 1.00000e-09 1.00000e-01 $1.00000 \mathrm{e}+001.00000 \mathrm{e}+001.00000 \mathrm{e}-011.00000 \mathrm{e}-091.00000 \mathrm{e}-01$ Element: 2263 \# of layers: 16

$\mathrm{Kx} \mathrm{Ky} \mathrm{Kz}$ Ss Por

2.88374e+02 2.88374e+02 2.88374e+01 1.00000e-09 7.00000e-02 $2.88374 \mathrm{e}+022.88374 \mathrm{e}+02 \quad 2.88374 \mathrm{e}+01$ 1.00000e-09 7.00000e-02 $2.88374 \mathrm{e}+022.88374 \mathrm{e}+022.88374 \mathrm{e}+01$ 1.00000e-09 7.00000e-02 
2.88374e+02 2.88374e+02 2.88374e+01 1.00000e-09 7.00000e-02 $2.88374 \mathrm{e}+02$ 2.88374e+02 2.88374e+01 1.00000e-09 7.00000e-02 5.00000e-04 5.00000e-04 5.00000e-05 1.00000e-09 1.00000e-01 5.00000e-04 5.00000e-04 5.00000e-05 1.00000e-09 1.00000e-01 $1.15223 \mathrm{e}+011.15223 \mathrm{e}+01$ 1.15223e+00 1.00000e-09 2.12000e-01 $1.15223 \mathrm{e}+01$ 1.15223e+01 1.15223e+00 1.00000e-09 2.12000e-01 $1.15223 \mathrm{e}+011.15223 \mathrm{e}+01$ 1.15223e+00 1.00000e-09 2.12000e-01 $1.15223 \mathrm{e}+011.15223 \mathrm{e}+011.15223 \mathrm{e}+001.00000 \mathrm{e}-092.12000 \mathrm{e}-01$ $1.15223 \mathrm{e}+01$ 1.15223e+01 1.15223e+00 1.00000e-09 2.12000e-01 $1.00000 \mathrm{e}-02$ 1.00000e-02 1.00000e-03 1.00000e-09 1.00000e-01 $1.00000 \mathrm{e}+001.00000 \mathrm{e}+001.00000 \mathrm{e}-011.00000 \mathrm{e}-091.00000 \mathrm{e}-01$ $1.00000 \mathrm{e}-05$ 1.00000e-05 1.00000e-06 1.00000e-09 1.00000e-01 $1.00000 \mathrm{e}+001.00000 \mathrm{e}+001.00000 \mathrm{e}-011.00000 \mathrm{e}-091.00000 \mathrm{e}-01$ Element: 2264 \# of layers: 16

$\mathrm{Kx} \mathrm{Ky} \mathrm{Kz}$ Ss Por

$2.78526 \mathrm{e}+02$ 2.78526e+02 2.78526e+01 1.00000e-09 7.00000e-02 $2.78526 \mathrm{e}+02$ 2.78526e+02 2.78526e+01 1.00000e-09 7.00000e-02 $2.78526 \mathrm{e}+022.78526 \mathrm{e}+02$ 2.78526e+01 1.00000e-09 7.00000e-02 $2.78526 \mathrm{e}+02$ 2.78526e+02 2.78526e+01 1.00000e-09 7.00000e-02 $2.78526 \mathrm{e}+02$ 2.78526e+02 2.78526e+01 1.00000e-09 7.00000e-02 5.00000e-04 5.00000e-04 5.00000e-05 1.00000e-09 1.00000e-01 5.00000e-04 5.00000e-04 5.00000e-05 1.00000e-09 1.00000e-01 $1.11287 \mathrm{e}+01$ 1.11287e+01 1.11287e+00 1.00000e-09 2.12000e-01 $1.11287 \mathrm{e}+01$ 1.11287e+01 1.11287e+00 1.00000e-09 2.12000e-01 $1.11287 \mathrm{e}+011.11287 \mathrm{e}+011.11287 \mathrm{e}+001.00000 \mathrm{e}-092.12000 \mathrm{e}-01$ $1.11287 \mathrm{e}+01$ 1.11287e+01 1.11287e+00 1.00000e-09 2.12000e-01 $1.11287 \mathrm{e}+01$ 1.11287e+01 1.11287e+00 1.00000e-09 2.12000e-01 $1.00000 \mathrm{e}-02$ 1.00000e-02 1.00000e-03 1.00000e-09 1.00000e-01 $1.00000 \mathrm{e}+001.00000 \mathrm{e}+001.00000 \mathrm{e}-011.00000 \mathrm{e}-091.00000 \mathrm{e}-01$ $1.00000 \mathrm{e}-051.00000 \mathrm{e}-051.00000 \mathrm{e}-061.00000 \mathrm{e}-091.00000 \mathrm{e}-01$ $1.00000 \mathrm{e}+001.00000 \mathrm{e}+001.00000 \mathrm{e}-011.00000 \mathrm{e}-091.00000 \mathrm{e}-01$ Element: 2265 \# of layers: 16

$\mathrm{Kx} \mathrm{Ky} \mathrm{Kz}$ Ss Por

$2.78526 \mathrm{e}+02$ 2.78526e+02 2.78526e+01 1.00000e-09 7.00000e-02 $2.78526 \mathrm{e}+02$ 2.78526e+02 2.78526e+01 1.00000e-09 7.00000e-02 $2.78526 \mathrm{e}+022.78526 \mathrm{e}+02$ 2.78526e+01 1.00000e-09 7.00000e-02 $2.78526 \mathrm{e}+022.78526 \mathrm{e}+022.78526 \mathrm{e}+01$ 1.00000e-09 7.00000e-02 $2.78526 \mathrm{e}+022.78526 \mathrm{e}+022.78526 \mathrm{e}+01$ 1.00000e-09 7.00000e-02 5.00000e-04 5.00000e-04 5.00000e-05 1.00000e-09 1.00000e-01 5.00000e-04 5.00000e-04 5.00000e-05 1.00000e-09 1.00000e-01 $1.11287 \mathrm{e}+01$ 1.11287e+01 1.11287e+00 1.00000e-09 2.12000e-01 $1.11287 \mathrm{e}+01$ 1.11287e+01 1.11287e+00 1.00000e-09 2.12000e-01 $1.11287 \mathrm{e}+01$ 1.11287e+01 1.11287e+00 1.00000e-09 2.12000e-01 $1.11287 \mathrm{e}+01$ 1.11287e+01 1.11287e+00 1.00000e-09 2.12000e-01 $1.11287 \mathrm{e}+01$ 1.11287e+01 1.11287e+00 1.00000e-09 2.12000e-01 $1.00000 \mathrm{e}-02$ 1.00000e-02 1.00000e-03 1.00000e-09 1.00000e-01 
$1.00000 \mathrm{e}+001.00000 \mathrm{e}+001.00000 \mathrm{e}-011.00000 \mathrm{e}-091.00000 \mathrm{e}-01$ $1.00000 \mathrm{e}-05$ 1.00000e-05 1.00000e-06 1.00000e-09 1.00000e-01 $1.00000 \mathrm{e}+001.00000 \mathrm{e}+001.00000 \mathrm{e}-01$ 1.00000e-09 1.00000e-01 Element: 2266 \# of layers: 16

$\mathrm{Kx} \mathrm{Ky} \mathrm{Kz}$ Ss Por

$2.56965 \mathrm{e}+02$ 2.56965e+02 2.56965e+01 1.00000e-09 7.00000e-02 $2.56965 \mathrm{e}+022.56965 \mathrm{e}+022.56965 \mathrm{e}+01$ 1.00000e-09 7.00000e-02 $2.56965 \mathrm{e}+022.56965 \mathrm{e}+02 \quad 2.56965 \mathrm{e}+01$ 1.00000e-09 7.00000e-02 $2.56965 \mathrm{e}+022.56965 \mathrm{e}+02 \quad 2.56965 \mathrm{e}+01$ 1.00000e-09 7.00000e-02 $2.56965 \mathrm{e}+022.56965 \mathrm{e}+022.56965 \mathrm{e}+01$ 1.00000e-09 7.00000e-02 5.00000e-04 5.00000e-04 5.00000e-05 1.00000e-09 1.00000e-01 5.00000e-04 5.00000e-04 5.00000e-05 1.00000e-09 1.00000e-01 $1.02676 \mathrm{e}+011.02676 \mathrm{e}+011.02676 \mathrm{e}+001.00000 \mathrm{e}-092.12000 \mathrm{e}-01$ $1.02676 \mathrm{e}+011.02676 \mathrm{e}+011.02676 \mathrm{e}+001.00000 \mathrm{e}-092.12000 \mathrm{e}-01$ $1.02676 \mathrm{e}+011.02676 \mathrm{e}+011.02676 \mathrm{e}+001.00000 \mathrm{e}-092.12000 \mathrm{e}-01$ $1.02676 \mathrm{e}+011.02676 \mathrm{e}+011.02676 \mathrm{e}+001.00000 \mathrm{e}-092.12000 \mathrm{e}-01$ $1.02676 \mathrm{e}+011.02676 \mathrm{e}+01 \quad 1.02676 \mathrm{e}+001.00000 \mathrm{e}-092.12000 \mathrm{e}-01$ $1.00000 \mathrm{e}-02$ 1.00000e-02 1.00000e-03 1.00000e-09 1.00000e-01 $1.00000 \mathrm{e}+001.00000 \mathrm{e}+001.00000 \mathrm{e}-011.00000 \mathrm{e}-091.00000 \mathrm{e}-01$ $1.00000 \mathrm{e}-05$ 1.00000e-05 1.00000e-06 1.00000e-09 1.00000e-01 $1.00000 \mathrm{e}+001.00000 \mathrm{e}+001.00000 \mathrm{e}-011.00000 \mathrm{e}-091.00000 \mathrm{e}-01$ Element: 2267 \# of layers: 16

$\mathrm{Kx} \mathrm{Ky} \mathrm{Kz}$ Ss Por

$2.56965 \mathrm{e}+02$ 2.56965e+02 2.56965e+01 1.00000e-09 7.00000e-02 $2.56965 \mathrm{e}+022.56965 \mathrm{e}+022.56965 \mathrm{e}+01$ 1.00000e-09 7.00000e-02 $2.56965 \mathrm{e}+02$ 2.56965e+02 2.56965e+01 1.00000e-09 7.00000e-02 $2.56965 \mathrm{e}+022.56965 \mathrm{e}+02 \quad 2.56965 \mathrm{e}+01$ 1.00000e-09 7.00000e-02 $2.56965 \mathrm{e}+022.56965 \mathrm{e}+022.56965 \mathrm{e}+01$ 1.00000e-09 7.00000e-02 5.00000e-04 5.00000e-04 5.00000e-05 1.00000e-09 1.00000e-01 5.00000e-04 5.00000e-04 5.00000e-05 1.00000e-09 1.00000e-01 $1.02676 \mathrm{e}+011.02676 \mathrm{e}+011.02676 \mathrm{e}+001.00000 \mathrm{e}-092.12000 \mathrm{e}-01$ $1.02676 \mathrm{e}+011.02676 \mathrm{e}+011.02676 \mathrm{e}+001.00000 \mathrm{e}-092.12000 \mathrm{e}-01$ $1.02676 \mathrm{e}+011.02676 \mathrm{e}+011.02676 \mathrm{e}+001.00000 \mathrm{e}-092.12000 \mathrm{e}-01$ $1.02676 \mathrm{e}+011.02676 \mathrm{e}+011.02676 \mathrm{e}+001.00000 \mathrm{e}-092.12000 \mathrm{e}-01$ $1.02676 \mathrm{e}+011.02676 \mathrm{e}+011.02676 \mathrm{e}+001.00000 \mathrm{e}-092.12000 \mathrm{e}-01$ $1.00000 \mathrm{e}-02$ 1.00000e-02 1.00000e-03 1.00000e-09 1.00000e-01 $1.00000 \mathrm{e}+001.00000 \mathrm{e}+001.00000 \mathrm{e}-011.00000 \mathrm{e}-091.00000 \mathrm{e}-01$ 1.00000e-05 1.00000e-05 1.00000e-06 1.00000e-09 1.00000e-01 $1.00000 \mathrm{e}+001.00000 \mathrm{e}+001.00000 \mathrm{e}-011.00000 \mathrm{e}-091.00000 \mathrm{e}-01$ Element: 2268 \# of layers: 16

$\mathrm{Kx} \mathrm{Ky} \mathrm{Kz}$ Ss Por

$2.56965 \mathrm{e}+022.56965 \mathrm{e}+02$ 2.56965e+01 1.00000e-09 7.00000e-02 $2.56965 \mathrm{e}+02$ 2.56965e+02 2.56965e+01 1.00000e-09 7.00000e-02 $2.56965 \mathrm{e}+02$ 2.56965e+02 2.56965e+01 1.00000e-09 7.00000e-02 $2.56965 \mathrm{e}+022.56965 \mathrm{e}+022.56965 \mathrm{e}+01$ 1.00000e-09 7.00000e-02 $2.56965 \mathrm{e}+022.56965 \mathrm{e}+02$ 2.56965e+01 1.00000e-09 7.00000e-02 
5.00000e-04 5.00000e-04 5.00000e-05 1.00000e-09 1.00000e-01 5.00000e-04 5.00000e-04 5.00000e-05 1.00000e-09 1.00000e-01 $1.02676 \mathrm{e}+011.02676 \mathrm{e}+011.02676 \mathrm{e}+001.00000 \mathrm{e}-092.12000 \mathrm{e}-01$ $1.02676 \mathrm{e}+011.02676 \mathrm{e}+01 \quad 1.02676 \mathrm{e}+001.00000 \mathrm{e}-092.12000 \mathrm{e}-01$ $1.02676 \mathrm{e}+011.02676 \mathrm{e}+011.02676 \mathrm{e}+001.00000 \mathrm{e}-092.12000 \mathrm{e}-01$ $1.02676 \mathrm{e}+011.02676 \mathrm{e}+011.02676 \mathrm{e}+001.00000 \mathrm{e}-092.12000 \mathrm{e}-01$ $1.02676 \mathrm{e}+011.02676 \mathrm{e}+011.02676 \mathrm{e}+001.00000 \mathrm{e}-092.12000 \mathrm{e}-01$ $1.00000 \mathrm{e}-02$ 1.00000e-02 1.00000e-03 1.00000e-09 1.00000e-01 $1.00000 \mathrm{e}+001.00000 \mathrm{e}+001.00000 \mathrm{e}-01$ 1.00000e-09 1.00000e-01 $1.00000 \mathrm{e}-05$ 1.00000e-05 1.00000e-06 1.00000e-09 1.00000e-01 $1.00000 \mathrm{e}+001.00000 \mathrm{e}+00$ 1.00000e-01 1.00000e-09 1.00000e-01 Element: 2269 \# of layers: 16

$\mathrm{Kx} \mathrm{Ky} \mathrm{Kz}$ Ss Por

2.46279e+02 2.46279e+02 2.46279e+01 1.00000e-09 7.00000e-02 $2.46279 \mathrm{e}+02$ 2.46279e+02 2.46279e+01 1.00000e-09 7.00000e-02 $2.46279 \mathrm{e}+02$ 2.46279e+02 2.46279e+01 1.00000e-09 7.00000e-02 $2.46279 \mathrm{e}+02$ 2.46279e+02 2.46279e+01 1.00000e-09 7.00000e-02 $2.46279 \mathrm{e}+02$ 2.46279e+02 2.46279e+01 1.00000e-09 7.00000e-02 $5.00000 \mathrm{e}-045.00000 \mathrm{e}-045.00000 \mathrm{e}-051.00000 \mathrm{e}-091.00000 \mathrm{e}-01$ 5.00000e-04 5.00000e-04 5.00000e-05 1.00000e-09 1.00000e-01 $9.84058 \mathrm{e}+00$ 9.84058e+00 9.84058e-01 1.00000e-09 2.12000e-01 9.84058e+00 9.84058e+00 9.84058e-01 1.00000e-09 2.12000e-01 $9.84058 \mathrm{e}+00$ 9.84058e+00 9.84058e-01 1.00000e-09 2.12000e-01 9.84058e+00 9.84058e+00 9.84058e-01 1.00000e-09 2.12000e-01 $9.84058 \mathrm{e}+00$ 9.84058e+00 9.84058e-01 1.00000e-09 2.12000e-01 $1.00000 \mathrm{e}-02$ 1.00000e-02 1.00000e-03 1.00000e-09 1.00000e-01 $1.00000 \mathrm{e}+001.00000 \mathrm{e}+001.00000 \mathrm{e}-011.00000 \mathrm{e}-091.00000 \mathrm{e}-01$ $1.00000 \mathrm{e}-05$ 1.00000e-05 1.00000e-06 1.00000e-09 1.00000e-01 $1.00000 \mathrm{e}+001.00000 \mathrm{e}+001.00000 \mathrm{e}-011.00000 \mathrm{e}-091.00000 \mathrm{e}-01$ Element: 2270 \# of layers: 16

$\mathrm{Kx} \mathrm{Ky} \mathrm{Kz}$ Ss Por

2.46279e+02 2.46279e+02 2.46279e+01 1.00000e-09 7.00000e-02 $2.46279 \mathrm{e}+02$ 2.46279e+02 2.46279e+01 1.00000e-09 7.00000e-02 $2.46279 \mathrm{e}+02$ 2.46279e+02 2.46279e+01 1.00000e-09 7.00000e-02 $2.46279 \mathrm{e}+02$ 2.46279e+02 2.46279e+01 1.00000e-09 7.00000e-02 $2.46279 \mathrm{e}+02$ 2.46279e+02 2.46279e+01 1.00000e-09 7.00000e-02 5.00000e-04 5.00000e-04 5.00000e-05 1.00000e-09 1.00000e-01 5.00000e-04 5.00000e-04 5.00000e-05 1.00000e-09 1.00000e-01 $9.84058 \mathrm{e}+00$ 9.84058e+00 9.84058e-01 1.00000e-09 2.12000e-01 $9.84058 \mathrm{e}+00$ 9.84058e+00 9.84058e-01 1.00000e-09 2.12000e-01 $9.84058 \mathrm{e}+00$ 9.84058e+00 9.84058e-01 1.00000e-09 2.12000e-01 $9.84058 \mathrm{e}+00$ 9.84058e+00 9.84058e-01 1.00000e-09 2.12000e-01 9.84058e+00 9.84058e+00 9.84058e-01 1.00000e-09 2.12000e-01 $1.00000 \mathrm{e}-02$ 1.00000e-02 1.00000e-03 1.00000e-09 1.00000e-01 $1.00000 \mathrm{e}+001.00000 \mathrm{e}+001.00000 \mathrm{e}-011.00000 \mathrm{e}-091.00000 \mathrm{e}-01$ $1.00000 \mathrm{e}-05$ 1.00000e-05 1.00000e-06 1.00000e-09 1.00000e-01 
$1.00000 \mathrm{e}+001.00000 \mathrm{e}+00$ 1.00000e-01 1.00000e-09 1.00000e-01

Element: 2271 \# of layers: 16

$\mathrm{Kx} \mathrm{Ky} \mathrm{Kz}$ Ss Por

$2.56965 \mathrm{e}+02$ 2.56965e+02 2.56965e+01 1.00000e-09 7.00000e-02

$2.56965 \mathrm{e}+022.56965 \mathrm{e}+02$ 2.56965e+01 1.00000e-09 7.00000e-02

$2.56965 \mathrm{e}+022.56965 \mathrm{e}+02$ 2.56965e+01 1.00000e-09 7.00000e-02

$2.56965 \mathrm{e}+022.56965 \mathrm{e}+02$ 2.56965e+01 1.00000e-09 7.00000e-02

$2.56965 \mathrm{e}+022.56965 \mathrm{e}+02$ 2.56965e+01 1.00000e-09 7.00000e-02

5.00000e-04 5.00000e-04 5.00000e-05 1.00000e-09 1.00000e-01

$5.00000 \mathrm{e}-04$ 5.00000e-04 5.00000e-05 1.00000e-09 1.00000e-01

$1.02676 \mathrm{e}+011.02676 \mathrm{e}+011.02676 \mathrm{e}+001.00000 \mathrm{e}-092.12000 \mathrm{e}-01$

$1.02676 \mathrm{e}+011.02676 \mathrm{e}+01 \quad 1.02676 \mathrm{e}+001.00000 \mathrm{e}-092.12000 \mathrm{e}-01$

$1.02676 \mathrm{e}+01$ 1.02676e+01 1.02676e+00 1.00000e-09 2.12000e-01

$1.02676 \mathrm{e}+011.02676 \mathrm{e}+011.02676 \mathrm{e}+001.00000 \mathrm{e}-092.12000 \mathrm{e}-01$

$1.02676 \mathrm{e}+011.02676 \mathrm{e}+011.02676 \mathrm{e}+001.00000 \mathrm{e}-092.12000 \mathrm{e}-01$

$1.00000 \mathrm{e}-02$ 1.00000e-02 1.00000e-03 1.00000e-09 1.00000e-01

$1.00000 \mathrm{e}+001.00000 \mathrm{e}+001.00000 \mathrm{e}-011.00000 \mathrm{e}-091.00000 \mathrm{e}-01$

$1.00000 \mathrm{e}-05$ 1.00000e-05 1.00000e-06 1.00000e-09 1.00000e-01

$1.00000 \mathrm{e}+001.00000 \mathrm{e}+001.00000 \mathrm{e}-011.00000 \mathrm{e}-091.00000 \mathrm{e}-01$

Element: 2272 \# of layers: 16

$\mathrm{Kx} \mathrm{Ky} \mathrm{Kz}$ Ss Por

$2.56965 \mathrm{e}+02$ 2.56965e+02 2.56965e+01 1.00000e-09 7.00000e-02

$2.56965 \mathrm{e}+02$ 2.56965e+02 2.56965e+01 1.00000e-09 7.00000e-02

$2.56965 \mathrm{e}+022.56965 \mathrm{e}+022.56965 \mathrm{e}+01$ 1.00000e-09 7.00000e-02

$2.56965 \mathrm{e}+022.56965 \mathrm{e}+022.56965 \mathrm{e}+01$ 1.00000e-09 7.00000e-02

$2.56965 \mathrm{e}+02$ 2.56965e+02 2.56965e+01 1.00000e-09 7.00000e-02

5.00000e-04 5.00000e-04 5.00000e-05 1.00000e-09 1.00000e-01

5.00000e-04 5.00000e-04 5.00000e-05 1.00000e-09 1.00000e-01

$1.02676 \mathrm{e}+011.02676 \mathrm{e}+011.02676 \mathrm{e}+001.00000 \mathrm{e}-092.12000 \mathrm{e}-01$

$1.02676 \mathrm{e}+011.02676 \mathrm{e}+011.02676 \mathrm{e}+001.00000 \mathrm{e}-092.12000 \mathrm{e}-01$

$1.02676 \mathrm{e}+011.02676 \mathrm{e}+011.02676 \mathrm{e}+001.00000 \mathrm{e}-092.12000 \mathrm{e}-01$

$1.02676 \mathrm{e}+011.02676 \mathrm{e}+011.02676 \mathrm{e}+00$ 1.00000e-09 2.12000e-01

$1.02676 \mathrm{e}+011.02676 \mathrm{e}+011.02676 \mathrm{e}+001.00000 \mathrm{e}-092.12000 \mathrm{e}-01$

$1.00000 \mathrm{e}-02$ 1.00000e-02 1.00000e-03 1.00000e-09 1.00000e-01

$1.00000 \mathrm{e}+001.00000 \mathrm{e}+001.00000 \mathrm{e}-011.00000 \mathrm{e}-091.00000 \mathrm{e}-01$

1.00000e-05 1.00000e-05 1.00000e-06 1.00000e-09 1.00000e-01

$1.00000 \mathrm{e}+001.00000 \mathrm{e}+001.00000 \mathrm{e}-011.00000 \mathrm{e}-091.00000 \mathrm{e}-01$

Element: 2273 \# of layers: 15

$\mathrm{Kx} \mathrm{Ky} \mathrm{Kz}$ Ss Por

2.87987e+02 2.87987e+02 2.87987e+01 1.00000e-09 7.00000e-02

$2.87987 \mathrm{e}+02$ 2.87987e+02 2.87987e+01 1.00000e-09 7.00000e-02

$2.87987 \mathrm{e}+02$ 2.87987e+02 2.87987e+01 1.00000e-09 7.00000e-02

2.87987e+02 2.87987e+02 2.87987e+01 1.00000e-09 7.00000e-02

5.00000e-04 5.00000e-04 5.00000e-05 1.00000e-09 1.00000e-01

5.00000e-04 5.00000e-04 5.00000e-05 1.00000e-09 1.00000e-01

$1.15070 \mathrm{e}+011.15070 \mathrm{e}+01$ 1.15070e+00 1.00000e-09 2.12000e-01 
$1.15070 \mathrm{e}+011.15070 \mathrm{e}+01$ 1.15070e+00 1.00000e-09 2.12000e-01 $1.15070 \mathrm{e}+01$ 1.15070e+01 1.15070e+00 1.00000e-09 2.12000e-01 $1.15070 \mathrm{e}+011.15070 \mathrm{e}+01$ 1.15070e+00 1.00000e-09 2.12000e-01 $1.15070 \mathrm{e}+01$ 1.15070e+01 1.15070e+00 1.00000e-09 2.12000e-01 $1.00000 \mathrm{e}-02$ 1.00000e-02 1.00000e-03 1.00000e-09 1.00000e-01 $1.00000 \mathrm{e}+001.00000 \mathrm{e}+001.00000 \mathrm{e}-011.00000 \mathrm{e}-091.00000 \mathrm{e}-01$ $1.00000 \mathrm{e}-05$ 1.00000e-05 1.00000e-06 1.00000e-09 1.00000e-01 $1.00000 \mathrm{e}+001.00000 \mathrm{e}+001.00000 \mathrm{e}-011.00000 \mathrm{e}-091.00000 \mathrm{e}-01$ Element: 2274 \# of layers: 15

$\mathrm{Kx} \mathrm{Ky} \mathrm{Kz}$ Ss Por

2.87987e+02 2.87987e+02 2.87987e+01 1.00000e-09 7.00000e-02 $2.87987 \mathrm{e}+022.87987 \mathrm{e}+02$ 2.87987e+01 1.00000e-09 7.00000e-02 $2.87987 \mathrm{e}+02$ 2.87987e+02 2.87987e+01 1.00000e-09 7.00000e-02 $2.87987 \mathrm{e}+022.87987 \mathrm{e}+02$ 2.87987e+01 1.00000e-09 7.00000e-02 5.00000e-04 5.00000e-04 5.00000e-05 1.00000e-09 1.00000e-01 5.00000e-04 5.00000e-04 5.00000e-05 1.00000e-09 1.00000e-01

$1.15070 \mathrm{e}+011.15070 \mathrm{e}+011.15070 \mathrm{e}+001.00000 \mathrm{e}-092.12000 \mathrm{e}-01$ $1.15070 \mathrm{e}+011.15070 \mathrm{e}+011.15070 \mathrm{e}+001.00000 \mathrm{e}-092.12000 \mathrm{e}-01$ $1.15070 \mathrm{e}+01$ 1.15070e+01 1.15070e+00 1.00000e-09 2.12000e-01 $1.15070 \mathrm{e}+011.15070 \mathrm{e}+01$ 1.15070e+00 1.00000e-09 2.12000e-01 $1.15070 \mathrm{e}+01$ 1.15070e+01 1.15070e+00 1.00000e-09 2.12000e-01 $1.00000 \mathrm{e}-021.00000 \mathrm{e}-02$ 1.00000e-03 1.00000e-09 1.00000e-01 $1.00000 \mathrm{e}+001.00000 \mathrm{e}+001.00000 \mathrm{e}-011.00000 \mathrm{e}-091.00000 \mathrm{e}-01$ $1.00000 \mathrm{e}-05$ 1.00000e-05 1.00000e-06 1.00000e-09 1.00000e-01 $1.00000 \mathrm{e}+001.00000 \mathrm{e}+001.00000 \mathrm{e}-011.00000 \mathrm{e}-091.00000 \mathrm{e}-01$ Element: 2275 \# of layers: 15

$\mathrm{Kx} \mathrm{Ky} \mathrm{Kz}$ Ss Por

2.87987e+02 2.87987e+02 2.87987e+01 1.00000e-09 7.00000e-02 $2.87987 \mathrm{e}+02$ 2.87987e+02 2.87987e+01 1.00000e-09 7.00000e-02 $2.87987 \mathrm{e}+02$ 2.87987e+02 2.87987e+01 1.00000e-09 7.00000e-02 $2.87987 \mathrm{e}+022.87987 \mathrm{e}+02$ 2.87987e+01 1.00000e-09 7.00000e-02 5.00000e-04 5.00000e-04 5.00000e-05 1.00000e-09 1.00000e-01 5.00000e-04 5.00000e-04 5.00000e-05 1.00000e-09 1.00000e-01 $1.15070 \mathrm{e}+011.15070 \mathrm{e}+01$ 1.15070e+00 1.00000e-09 2.12000e-01 $1.15070 \mathrm{e}+011.15070 \mathrm{e}+011.15070 \mathrm{e}+00$ 1.00000e-09 2.12000e-01 $1.15070 \mathrm{e}+011.15070 \mathrm{e}+01$ 1.15070e+00 1.00000e-09 2.12000e-01 $1.15070 \mathrm{e}+011.15070 \mathrm{e}+011.15070 \mathrm{e}+001.00000 \mathrm{e}-092.12000 \mathrm{e}-01$ $1.15070 \mathrm{e}+011.15070 \mathrm{e}+011.15070 \mathrm{e}+001.00000 \mathrm{e}-092.12000 \mathrm{e}-01$ $1.00000 \mathrm{e}-02$ 1.00000e-02 1.00000e-03 1.00000e-09 1.00000e-01 $1.00000 \mathrm{e}+001.00000 \mathrm{e}+001.00000 \mathrm{e}-011.00000 \mathrm{e}-091.00000 \mathrm{e}-01$ $1.00000 \mathrm{e}-05$ 1.00000e-05 1.00000e-06 1.00000e-09 1.00000e-01 $1.00000 \mathrm{e}+001.00000 \mathrm{e}+001.00000 \mathrm{e}-011.00000 \mathrm{e}-091.00000 \mathrm{e}-01$ Element: 2276 \# of layers: 15

$\mathrm{Kx} \mathrm{Ky} \mathrm{Kz}$ Ss Por

2.87987e+02 2.87987e+02 2.87987e+01 1.00000e-09 7.00000e-02 $2.87987 \mathrm{e}+02$ 2.87987e+02 2.87987e+01 1.00000e-09 7.00000e-02 
$2.87987 \mathrm{e}+022.87987 \mathrm{e}+022.87987 \mathrm{e}+01$ 1.00000e-09 7.00000e-02 $2.87987 \mathrm{e}+022.87987 \mathrm{e}+022.87987 \mathrm{e}+01$ 1.00000e-09 7.00000e-02 5.00000e-04 5.00000e-04 5.00000e-05 1.00000e-09 1.00000e-01 5.00000e-04 5.00000e-04 5.00000e-05 1.00000e-09 1.00000e-01 $1.15070 \mathrm{e}+011.15070 \mathrm{e}+011.15070 \mathrm{e}+00$ 1.00000e-09 2.12000e-01 $1.15070 \mathrm{e}+011.15070 \mathrm{e}+011.15070 \mathrm{e}+001.00000 \mathrm{e}-092.12000 \mathrm{e}-01$ $1.15070 \mathrm{e}+011.15070 \mathrm{e}+011.15070 \mathrm{e}+00$ 1.00000e-09 2.12000e-01 $1.15070 \mathrm{e}+011.15070 \mathrm{e}+011.15070 \mathrm{e}+001.00000 \mathrm{e}-092.12000 \mathrm{e}-01$ $1.15070 \mathrm{e}+011.15070 \mathrm{e}+011.15070 \mathrm{e}+00$ 1.00000e-09 2.12000e-01 $1.00000 \mathrm{e}-021.00000 \mathrm{e}-02$ 1.00000e-03 1.00000e-09 1.00000e-01 $1.00000 \mathrm{e}+001.00000 \mathrm{e}+001.00000 \mathrm{e}-011.00000 \mathrm{e}-091.00000 \mathrm{e}-01$ $1.00000 \mathrm{e}-05$ 1.00000e-05 1.00000e-06 1.00000e-09 1.00000e-01 $1.00000 \mathrm{e}+001.00000 \mathrm{e}+001.00000 \mathrm{e}-011.00000 \mathrm{e}-091.00000 \mathrm{e}-01$ Element: 2277 \# of layers: 16

Kx Ky Kz Ss Por

$2.87987 \mathrm{e}+022.87987 \mathrm{e}+022.87987 \mathrm{e}+01$ 1.00000e-09 7.00000e-02 $2.87987 \mathrm{e}+022.87987 \mathrm{e}+022.87987 \mathrm{e}+01$ 1.00000e-09 7.00000e-02 $2.87987 \mathrm{e}+022.87987 \mathrm{e}+022.87987 \mathrm{e}+01$ 1.00000e-09 7.00000e-02 $2.87987 \mathrm{e}+022.87987 \mathrm{e}+022.87987 \mathrm{e}+01$ 1.00000e-09 7.00000e-02 $2.87987 \mathrm{e}+022.87987 \mathrm{e}+022.87987 \mathrm{e}+01$ 1.00000e-09 7.00000e-02 $5.00000 \mathrm{e}-04$ 5.00000e-04 5.00000e-05 1.00000e-09 1.00000e-01 5.00000e-04 5.00000e-04 5.00000e-05 1.00000e-09 1.00000e-01

$1.15070 \mathrm{e}+011.15070 \mathrm{e}+011.15070 \mathrm{e}+001.00000 \mathrm{e}-092.12000 \mathrm{e}-01$ $1.15070 \mathrm{e}+011.15070 \mathrm{e}+011.15070 \mathrm{e}+001.00000 \mathrm{e}-092.12000 \mathrm{e}-01$ $1.15070 \mathrm{e}+011.15070 \mathrm{e}+011.15070 \mathrm{e}+001.00000 \mathrm{e}-092.12000 \mathrm{e}-01$ $1.15070 \mathrm{e}+011.15070 \mathrm{e}+011.15070 \mathrm{e}+001.00000 \mathrm{e}-092.12000 \mathrm{e}-01$ $1.15070 \mathrm{e}+011.15070 \mathrm{e}+011.15070 \mathrm{e}+001.00000 \mathrm{e}-092.12000 \mathrm{e}-01$ $1.00000 \mathrm{e}-02$ 1.00000e-02 1.00000e-03 1.00000e-09 1.00000e-01 $1.00000 \mathrm{e}+001.00000 \mathrm{e}+001.00000 \mathrm{e}-011.00000 \mathrm{e}-091.00000 \mathrm{e}-01$ $1.00000 \mathrm{e}-05$ 1.00000e-05 1.00000e-06 1.00000e-09 1.00000e-01 $1.00000 \mathrm{e}+001.00000 \mathrm{e}+001.00000 \mathrm{e}-011.00000 \mathrm{e}-091.00000 \mathrm{e}-01$ Element: 2278 \# of layers: 16

Kx Ky Kz Ss Por

$2.87987 \mathrm{e}+022.87987 \mathrm{e}+022.87987 \mathrm{e}+01$ 1.00000e-09 7.00000e-02 $2.87987 \mathrm{e}+022.87987 \mathrm{e}+022.87987 \mathrm{e}+01$ 1.00000e-09 7.00000e-02 $2.87987 \mathrm{e}+022.87987 \mathrm{e}+022.87987 \mathrm{e}+01$ 1.00000e-09 7.00000e-02 $2.87987 \mathrm{e}+022.87987 \mathrm{e}+022.87987 \mathrm{e}+01$ 1.00000e-09 7.00000e-02 $2.87987 \mathrm{e}+022.87987 \mathrm{e}+022.87987 \mathrm{e}+01$ 1.00000e-09 7.00000e-02 5.00000e-04 5.00000e-04 5.00000e-05 1.00000e-09 1.00000e-01 5.00000e-04 5.00000e-04 5.00000e-05 1.00000e-09 1.00000e-01 $1.15070 \mathrm{e}+011.15070 \mathrm{e}+011.15070 \mathrm{e}+001.00000 \mathrm{e}-092.12000 \mathrm{e}-01$ $1.15070 \mathrm{e}+011.15070 \mathrm{e}+011.15070 \mathrm{e}+001.00000 \mathrm{e}-092.12000 \mathrm{e}-01$ $1.15070 \mathrm{e}+011.15070 \mathrm{e}+011.15070 \mathrm{e}+001.00000 \mathrm{e}-092.12000 \mathrm{e}-01$ $1.15070 \mathrm{e}+011.15070 \mathrm{e}+011.15070 \mathrm{e}+001.00000 \mathrm{e}-092.12000 \mathrm{e}-01$ $1.15070 \mathrm{e}+011.15070 \mathrm{e}+011.15070 \mathrm{e}+001.00000 \mathrm{e}-092.12000 \mathrm{e}-01$ $1.00000 \mathrm{e}-021.00000 \mathrm{e}-02$ 1.00000e-03 1.00000e-09 1.00000e-01 
$1.00000 \mathrm{e}+001.00000 \mathrm{e}+001.00000 \mathrm{e}-011.00000 \mathrm{e}-091.00000 \mathrm{e}-01$ $1.00000 \mathrm{e}-05$ 1.00000e-05 1.00000e-06 1.00000e-09 1.00000e-01 $1.00000 \mathrm{e}+001.00000 \mathrm{e}+001.00000 \mathrm{e}-011.00000 \mathrm{e}-09$ 1.00000e-01 Element: 2279 \# of layers: 16

$\mathrm{Kx} \mathrm{Ky} \mathrm{Kz}$ Ss Por

2.87987e+02 2.87987e+02 2.87987e+01 1.00000e-09 7.00000e-02 $2.87987 \mathrm{e}+02$ 2.87987e+02 2.87987e+01 1.00000e-09 7.00000e-02 $2.87987 \mathrm{e}+02$ 2.87987e+02 2.87987e+01 1.00000e-09 7.00000e-02 2.87987e+02 2.87987e+02 2.87987e+01 1.00000e-09 7.00000e-02 $2.87987 \mathrm{e}+02$ 2.87987e+02 2.87987e+01 1.00000e-09 7.00000e-02 5.00000e-04 5.00000e-04 5.00000e-05 1.00000e-09 1.00000e-01 5.00000e-04 5.00000e-04 5.00000e-05 1.00000e-09 1.00000e-01

$1.15070 \mathrm{e}+011.15070 \mathrm{e}+01$ 1.15070e+00 1.00000e-09 2.12000e-01 $1.15070 \mathrm{e}+01$ 1.15070e+01 1.15070e+00 1.00000e-09 2.12000e-01 $1.15070 \mathrm{e}+011.15070 \mathrm{e}+011.15070 \mathrm{e}+001.00000 \mathrm{e}-092.12000 \mathrm{e}-01$ $1.15070 \mathrm{e}+011.15070 \mathrm{e}+01$ 1.15070e+00 1.00000e-09 2.12000e-01 $1.15070 \mathrm{e}+011.15070 \mathrm{e}+011.15070 \mathrm{e}+001.00000 \mathrm{e}-092.12000 \mathrm{e}-01$ $1.00000 \mathrm{e}-02$ 1.00000e-02 1.00000e-03 1.00000e-09 1.00000e-01 $1.00000 \mathrm{e}+001.00000 \mathrm{e}+001.00000 \mathrm{e}-011.00000 \mathrm{e}-091.00000 \mathrm{e}-01$ $1.00000 \mathrm{e}-05$ 1.00000e-05 1.00000e-06 1.00000e-09 1.00000e-01 $1.00000 \mathrm{e}+001.00000 \mathrm{e}+001.00000 \mathrm{e}-011.00000 \mathrm{e}-091.00000 \mathrm{e}-01$ Element: 2280 \# of layers: 16

$\mathrm{Kx} \mathrm{Ky} \mathrm{Kz}$ Ss Por

2.87987e+02 2.87987e+02 2.87987e+01 1.00000e-09 7.00000e-02 $2.87987 \mathrm{e}+02$ 2.87987e+02 2.87987e+01 1.00000e-09 7.00000e-02 $2.87987 \mathrm{e}+022.87987 \mathrm{e}+02$ 2.87987e+01 1.00000e-09 7.00000e-02 $2.87987 \mathrm{e}+02$ 2.87987e+02 2.87987e+01 1.00000e-09 7.00000e-02 $2.87987 \mathrm{e}+02$ 2.87987e+02 2.87987e+01 1.00000e-09 7.00000e-02 5.00000e-04 5.00000e-04 5.00000e-05 1.00000e-09 1.00000e-01 5.00000e-04 5.00000e-04 5.00000e-05 1.00000e-09 1.00000e-01

$1.15070 \mathrm{e}+011.15070 \mathrm{e}+011.15070 \mathrm{e}+00$ 1.00000e-09 2.12000e-01 $1.15070 \mathrm{e}+011.15070 \mathrm{e}+011.15070 \mathrm{e}+00$ 1.00000e-09 2.12000e-01 $1.15070 \mathrm{e}+011.15070 \mathrm{e}+011.15070 \mathrm{e}+001.00000 \mathrm{e}-092.12000 \mathrm{e}-01$ $1.15070 \mathrm{e}+011.15070 \mathrm{e}+01$ 1.15070e+00 1.00000e-09 2.12000e-01 $1.15070 \mathrm{e}+011.15070 \mathrm{e}+011.15070 \mathrm{e}+001.00000 \mathrm{e}-092.12000 \mathrm{e}-01$ 1.00000e-02 1.00000e-02 1.00000e-03 1.00000e-09 1.00000e-01 $1.00000 \mathrm{e}+001.00000 \mathrm{e}+001.00000 \mathrm{e}-011.00000 \mathrm{e}-091.00000 \mathrm{e}-01$ $1.00000 \mathrm{e}-05$ 1.00000e-05 1.00000e-06 1.00000e-09 1.00000e-01 $1.00000 \mathrm{e}+001.00000 \mathrm{e}+001.00000 \mathrm{e}-011.00000 \mathrm{e}-091.00000 \mathrm{e}-01$ Element: 2281 \# of layers: 15

$\mathrm{Kx} \mathrm{Ky} \mathrm{Kz}$ Ss Por 2.87987e+02 2.87987e+02 2.87987e+01 1.00000e-09 7.00000e-02 $2.87987 \mathrm{e}+02$ 2.87987e+02 2.87987e+01 1.00000e-09 7.00000e-02 $2.87987 \mathrm{e}+022.87987 \mathrm{e}+02$ 2.87987e+01 1.00000e-09 7.00000e-02 $2.87987 \mathrm{e}+022.87987 \mathrm{e}+02$ 2.87987e+01 1.00000e-09 7.00000e-02 5.00000e-04 5.00000e-04 5.00000e-05 1.00000e-09 1.00000e-01 
5.00000e-04 5.00000e-04 5.00000e-05 1.00000e-09 1.00000e-01 $1.15070 \mathrm{e}+011.15070 \mathrm{e}+011.15070 \mathrm{e}+001.00000 \mathrm{e}-092.12000 \mathrm{e}-01$ $1.15070 \mathrm{e}+011.15070 \mathrm{e}+01$ 1.15070e+00 1.00000e-09 2.12000e-01 $1.15070 \mathrm{e}+011.15070 \mathrm{e}+011.15070 \mathrm{e}+001.00000 \mathrm{e}-092.12000 \mathrm{e}-01$ $1.15070 \mathrm{e}+011.15070 \mathrm{e}+011.15070 \mathrm{e}+001.00000 \mathrm{e}-092.12000 \mathrm{e}-01$ $1.15070 \mathrm{e}+011.15070 \mathrm{e}+011.15070 \mathrm{e}+001.00000 \mathrm{e}-092.12000 \mathrm{e}-01$ $1.00000 \mathrm{e}-02$ 1.00000e-02 1.00000e-03 1.00000e-09 1.00000e-01 $1.00000 \mathrm{e}+001.00000 \mathrm{e}+001.00000 \mathrm{e}-011.00000 \mathrm{e}-091.00000 \mathrm{e}-01$ $1.00000 \mathrm{e}-051.00000 \mathrm{e}-05$ 1.00000e-06 1.00000e-09 1.00000e-01 $1.00000 \mathrm{e}+001.00000 \mathrm{e}+001.00000 \mathrm{e}-011.00000 \mathrm{e}-091.00000 \mathrm{e}-01$ Element: 2282 \# of layers: 15

$\mathrm{Kx} \mathrm{Ky} \mathrm{Kz}$ Ss Por

1.61522e+02 1.61522e+02 1.61522e+01 1.00000e-09 7.00000e-02 $1.61522 \mathrm{e}+021.61522 \mathrm{e}+02$ 1.61522e+01 1.00000e-09 7.00000e-02 $1.61522 \mathrm{e}+02$ 1.61522e+02 1.61522e+01 1.00000e-09 7.00000e-02 $1.61522 \mathrm{e}+021.61522 \mathrm{e}+021.61522 \mathrm{e}+01$ 1.00000e-09 7.00000e-02 5.00000e-04 5.00000e-04 5.00000e-05 1.00000e-09 1.00000e-01 5.00000e-04 5.00000e-04 5.00000e-05 1.00000e-09 1.00000e-01 $6.45359 \mathrm{e}+006.45359 \mathrm{e}+006.45359 \mathrm{e}-01$ 1.00000e-09 2.12000e-01 6.45359e+00 6.45359e+00 6.45359e-01 1.00000e-09 2.12000e-01 $6.45359 \mathrm{e}+00$ 6.45359e+00 6.45359e-01 1.00000e-09 2.12000e-01 6.45359e+00 6.45359e+00 6.45359e-01 1.00000e-09 2.12000e-01 6.45359e+00 6.45359e+00 6.45359e-01 1.00000e-09 2.12000e-01 $1.00000 \mathrm{e}-02$ 1.00000e-02 1.00000e-03 1.00000e-09 1.00000e-01 $1.00000 \mathrm{e}+001.00000 \mathrm{e}+001.00000 \mathrm{e}-011.00000 \mathrm{e}-091.00000 \mathrm{e}-01$ $1.00000 \mathrm{e}-051.00000 \mathrm{e}-051.00000 \mathrm{e}-061.00000 \mathrm{e}-091.00000 \mathrm{e}-01$ $1.00000 \mathrm{e}+001.00000 \mathrm{e}+001.00000 \mathrm{e}-011.00000 \mathrm{e}-091.00000 \mathrm{e}-01$ Element: 2283 \# of layers: 15

$\mathrm{Kx} \mathrm{Ky} \mathrm{Kz}$ Ss Por

$1.61522 \mathrm{e}+021.61522 \mathrm{e}+02$ 1.61522e+01 1.00000e-09 7.00000e-02 $1.61522 \mathrm{e}+02$ 1.61522e+02 1.61522e+01 1.00000e-09 7.00000e-02 $1.61522 \mathrm{e}+02$ 1.61522e+02 1.61522e+01 1.00000e-09 7.00000e-02 $1.61522 \mathrm{e}+021.61522 \mathrm{e}+021.61522 \mathrm{e}+01$ 1.00000e-09 7.00000e-02 5.00000e-04 5.00000e-04 5.00000e-05 1.00000e-09 1.00000e-01 5.00000e-04 5.00000e-04 5.00000e-05 1.00000e-09 1.00000e-01 $6.45359 \mathrm{e}+006.45359 \mathrm{e}+00$ 6.45359e-01 1.00000e-09 2.12000e-01 $6.45359 \mathrm{e}+006.45359 \mathrm{e}+00$ 6.45359e-01 1.00000e-09 2.12000e-01 6.45359e+00 6.45359e+00 6.45359e-01 1.00000e-09 2.12000e-01 6.45359e+00 6.45359e+00 6.45359e-01 1.00000e-09 2.12000e-01 6.45359e+00 6.45359e+00 6.45359e-01 1.00000e-09 2.12000e-01 $1.00000 \mathrm{e}-02$ 1.00000e-02 1.00000e-03 1.00000e-09 1.00000e-01 $1.00000 \mathrm{e}+001.00000 \mathrm{e}+001.00000 \mathrm{e}-011.00000 \mathrm{e}-091.00000 \mathrm{e}-01$ $1.00000 \mathrm{e}-05$ 1.00000e-05 1.00000e-06 1.00000e-09 1.00000e-01 $1.00000 \mathrm{e}+001.00000 \mathrm{e}+001.00000 \mathrm{e}-011.00000 \mathrm{e}-091.00000 \mathrm{e}-01$ Element: 2284 \# of layers: 15

Kx Ky Kz Ss Por 
$1.61522 \mathrm{e}+02$ 1.61522e+02 1.61522e+01 1.00000e-09 7.00000e-02 $1.61522 \mathrm{e}+021.61522 \mathrm{e}+021.61522 \mathrm{e}+01$ 1.00000e-09 7.00000e-02 $1.61522 \mathrm{e}+021.61522 \mathrm{e}+021.61522 \mathrm{e}+01$ 1.00000e-09 7.00000e-02 $1.61522 \mathrm{e}+02$ 1.61522e+02 1.61522e+01 1.00000e-09 7.00000e-02 5.00000e-04 5.00000e-04 5.00000e-05 1.00000e-09 1.00000e-01 5.00000e-04 5.00000e-04 5.00000e-05 1.00000e-09 1.00000e-01 6.45359e+00 6.45359e+00 6.45359e-01 1.00000e-09 2.12000e-01 $6.45359 \mathrm{e}+00$ 6.45359e+00 6.45359e-01 1.00000e-09 2.12000e-01 6.45359e+00 6.45359e+00 6.45359e-01 1.00000e-09 2.12000e-01 6.45359e+00 6.45359e+00 6.45359e-01 1.00000e-09 2.12000e-01 6.45359e+00 6.45359e+00 6.45359e-01 1.00000e-09 2.12000e-01 $1.00000 \mathrm{e}-02$ 1.00000e-02 1.00000e-03 1.00000e-09 1.00000e-01 $1.00000 \mathrm{e}+001.00000 \mathrm{e}+001.00000 \mathrm{e}-011.00000 \mathrm{e}-091.00000 \mathrm{e}-01$ $1.00000 \mathrm{e}-05$ 1.00000e-05 1.00000e-06 1.00000e-09 1.00000e-01 $1.00000 \mathrm{e}+001.00000 \mathrm{e}+001.00000 \mathrm{e}-01$ 1.00000e-09 1.00000e-01 Element: 2285 \# of layers: 15

$\mathrm{Kx} \mathrm{Ky} \mathrm{Kz}$ Ss Por

1.61522e+02 1.61522e+02 1.61522e+01 1.00000e-09 7.00000e-02 $1.61522 \mathrm{e}+02$ 1.61522e+02 1.61522e+01 1.00000e-09 7.00000e-02 $1.61522 \mathrm{e}+021.61522 \mathrm{e}+02$ 1.61522e+01 1.00000e-09 7.00000e-02 $1.61522 \mathrm{e}+021.61522 \mathrm{e}+021.61522 \mathrm{e}+01$ 1.00000e-09 7.00000e-02 5.00000e-04 5.00000e-04 5.00000e-05 1.00000e-09 1.00000e-01 5.00000e-04 5.00000e-04 5.00000e-05 1.00000e-09 1.00000e-01 6.45359e+00 6.45359e+00 6.45359e-01 1.00000e-09 2.12000e-01 $6.45359 \mathrm{e}+006.45359 \mathrm{e}+00$ 6.45359e-01 1.00000e-09 2.12000e-01 $6.45359 \mathrm{e}+00$ 6.45359e+00 6.45359e-01 1.00000e-09 2.12000e-01 6.45359e+00 6.45359e+00 6.45359e-01 1.00000e-09 2.12000e-01 6.45359e+00 6.45359e+00 6.45359e-01 1.00000e-09 2.12000e-01 $1.00000 \mathrm{e}-02$ 1.00000e-02 1.00000e-03 1.00000e-09 1.00000e-01 $1.00000 \mathrm{e}+001.00000 \mathrm{e}+001.00000 \mathrm{e}-011.00000 \mathrm{e}-091.00000 \mathrm{e}-01$ $1.00000 \mathrm{e}-05$ 1.00000e-05 1.00000e-06 1.00000e-09 1.00000e-01 $1.00000 \mathrm{e}+001.00000 \mathrm{e}+001.00000 \mathrm{e}-01$ 1.00000e-09 1.00000e-01 Element: 2286 \# of layers: 15

$\mathrm{Kx} \mathrm{Ky} \mathrm{Kz}$ Ss Por

1.61522e+02 1.61522e+02 1.61522e+01 1.00000e-09 7.00000e-02 $1.61522 \mathrm{e}+02$ 1.61522e+02 1.61522e+01 1.00000e-09 7.00000e-02 $1.61522 \mathrm{e}+021.61522 \mathrm{e}+021.61522 \mathrm{e}+01$ 1.00000e-09 7.00000e-02 $1.61522 \mathrm{e}+021.61522 \mathrm{e}+021.61522 \mathrm{e}+01$ 1.00000e-09 7.00000e-02 5.00000e-04 5.00000e-04 5.00000e-05 1.00000e-09 1.00000e-01 5.00000e-04 5.00000e-04 5.00000e-05 1.00000e-09 1.00000e-01 $6.45359 \mathrm{e}+006.45359 \mathrm{e}+00$ 6.45359e-01 1.00000e-09 2.12000e-01 $6.45359 \mathrm{e}+00$ 6.45359e+00 6.45359e-01 1.00000e-09 2.12000e-01 6.45359e+00 6.45359e+00 6.45359e-01 1.00000e-09 2.12000e-01 $6.45359 \mathrm{e}+006.45359 \mathrm{e}+00$ 6.45359e-01 1.00000e-09 2.12000e-01 6.45359e+00 6.45359e+00 6.45359e-01 1.00000e-09 2.12000e-01 $1.00000 \mathrm{e}-02$ 1.00000e-02 1.00000e-03 1.00000e-09 1.00000e-01 
$1.00000 \mathrm{e}+001.00000 \mathrm{e}+001.00000 \mathrm{e}-011.00000 \mathrm{e}-091.00000 \mathrm{e}-01$ $1.00000 \mathrm{e}-05$ 1.00000e-05 1.00000e-06 1.00000e-09 1.00000e-01 $1.00000 \mathrm{e}+001.00000 \mathrm{e}+001.00000 \mathrm{e}-01$ 1.00000e-09 1.00000e-01 Element: 2287 \# of layers: 15

$\mathrm{Kx} \mathrm{Ky} \mathrm{Kz}$ Ss Por

1.61522e+02 1.61522e+02 1.61522e+01 1.00000e-09 7.00000e-02 $1.61522 \mathrm{e}+021.61522 \mathrm{e}+02$ 1.61522e+01 1.00000e-09 7.00000e-02 $1.61522 \mathrm{e}+02$ 1.61522e+02 1.61522e+01 1.00000e-09 7.00000e-02 $1.61522 \mathrm{e}+021.61522 \mathrm{e}+021.61522 \mathrm{e}+01$ 1.00000e-09 7.00000e-02 5.00000e-04 5.00000e-04 5.00000e-05 1.00000e-09 1.00000e-01 5.00000e-04 5.00000e-04 5.00000e-05 1.00000e-09 1.00000e-01 $6.45359 \mathrm{e}+006.45359 \mathrm{e}+00$ 6.45359e-01 1.00000e-09 2.12000e-01 $6.45359 \mathrm{e}+00$ 6.45359e+00 6.45359e-01 1.00000e-09 2.12000e-01 6.45359e+00 6.45359e+00 6.45359e-01 1.00000e-09 2.12000e-01 $6.45359 \mathrm{e}+006.45359 \mathrm{e}+00$ 6.45359e-01 1.00000e-09 2.12000e-01 6.45359e+00 6.45359e+00 6.45359e-01 1.00000e-09 2.12000e-01 $1.00000 \mathrm{e}-02$ 1.00000e-02 1.00000e-03 1.00000e-09 1.00000e-01 $1.00000 \mathrm{e}+001.00000 \mathrm{e}+001.00000 \mathrm{e}-011.00000 \mathrm{e}-091.00000 \mathrm{e}-01$ $1.00000 \mathrm{e}-05$ 1.00000e-05 1.00000e-06 1.00000e-09 1.00000e-01 $1.00000 \mathrm{e}+001.00000 \mathrm{e}+001.00000 \mathrm{e}-011.00000 \mathrm{e}-091.00000 \mathrm{e}-01$ Element: 2288 \# of layers: 15

$\mathrm{Kx} \mathrm{Ky} \mathrm{Kz}$ Ss Por

1.61522e+02 1.61522e+02 1.61522e+01 1.00000e-09 7.00000e-02 $1.61522 \mathrm{e}+02$ 1.61522e+02 1.61522e+01 1.00000e-09 7.00000e-02 $1.61522 \mathrm{e}+021.61522 \mathrm{e}+02$ 1.61522e+01 1.00000e-09 7.00000e-02 $1.61522 \mathrm{e}+021.61522 \mathrm{e}+021.61522 \mathrm{e}+01$ 1.00000e-09 7.00000e-02 5.00000e-04 5.00000e-04 5.00000e-05 1.00000e-09 1.00000e-01 5.00000e-04 5.00000e-04 5.00000e-05 1.00000e-09 1.00000e-01 6.45359e+00 6.45359e+00 6.45359e-01 1.00000e-09 2.12000e-01 6.45359e+00 6.45359e+00 6.45359e-01 1.00000e-09 2.12000e-01 6.45359e+00 6.45359e+00 6.45359e-01 1.00000e-09 2.12000e-01 6.45359e+00 6.45359e+00 6.45359e-01 1.00000e-09 2.12000e-01 $6.45359 \mathrm{e}+006.45359 \mathrm{e}+006.45359 \mathrm{e}-01$ 1.00000e-09 2.12000e-01 $1.00000 \mathrm{e}-02$ 1.00000e-02 1.00000e-03 1.00000e-09 1.00000e-01 $1.00000 \mathrm{e}+001.00000 \mathrm{e}+001.00000 \mathrm{e}-011.00000 \mathrm{e}-091.00000 \mathrm{e}-01$ $1.00000 \mathrm{e}-05$ 1.00000e-05 1.00000e-06 1.00000e-09 1.00000e-01 $1.00000 \mathrm{e}+001.00000 \mathrm{e}+001.00000 \mathrm{e}-011.00000 \mathrm{e}-091.00000 \mathrm{e}-01$ Element: 2289 \# of layers: 15

$\mathrm{Kx} \mathrm{Ky} \mathrm{Kz}$ Ss Por

1.61522e+02 1.61522e+02 1.61522e+01 1.00000e-09 7.00000e-02 $1.61522 \mathrm{e}+02$ 1.61522e+02 1.61522e+01 1.00000e-09 7.00000e-02 $1.61522 \mathrm{e}+02$ 1.61522e+02 1.61522e+01 1.00000e-09 7.00000e-02 $1.61522 \mathrm{e}+021.61522 \mathrm{e}+021.61522 \mathrm{e}+01$ 1.00000e-09 7.00000e-02 5.00000e-04 5.00000e-04 5.00000e-05 1.00000e-09 1.00000e-01 5.00000e-04 5.00000e-04 5.00000e-05 1.00000e-09 1.00000e-01 $6.45359 \mathrm{e}+006.45359 \mathrm{e}+00$ 6.45359e-01 1.00000e-09 2.12000e-01 
$6.45359 \mathrm{e}+006.45359 \mathrm{e}+00$ 6.45359e-01 1.00000e-09 2.12000e-01 $6.45359 \mathrm{e}+006.45359 \mathrm{e}+00$ 6.45359e-01 1.00000e-09 2.12000e-01 $6.45359 \mathrm{e}+006.45359 \mathrm{e}+00$ 6.45359e-01 1.00000e-09 2.12000e-01 $6.45359 \mathrm{e}+006.45359 \mathrm{e}+00$ 6.45359e-01 1.00000e-09 2.12000e-01 $1.00000 \mathrm{e}-02$ 1.00000e-02 1.00000e-03 1.00000e-09 1.00000e-01 $1.00000 \mathrm{e}+001.00000 \mathrm{e}+001.00000 \mathrm{e}-011.00000 \mathrm{e}-091.00000 \mathrm{e}-01$ $1.00000 \mathrm{e}-051.00000 \mathrm{e}-05$ 1.00000e-06 1.00000e-09 1.00000e-01 $1.00000 \mathrm{e}+001.00000 \mathrm{e}+001.00000 \mathrm{e}-011.00000 \mathrm{e}-091.00000 \mathrm{e}-01$ Element: 2290 \# of layers: 15

$\mathrm{Kx} \mathrm{Ky} \mathrm{Kz}$ Ss Por

$1.61522 \mathrm{e}+02$ 1.61522e+02 1.61522e+01 1.00000e-09 7.00000e-02 $1.61522 \mathrm{e}+021.61522 \mathrm{e}+02$ 1.61522e+01 1.00000e-09 7.00000e-02 $1.61522 \mathrm{e}+02$ 1.61522e+02 1.61522e+01 1.00000e-09 7.00000e-02 $1.61522 \mathrm{e}+021.61522 \mathrm{e}+021.61522 \mathrm{e}+01$ 1.00000e-09 7.00000e-02 5.00000e-04 5.00000e-04 5.00000e-05 1.00000e-09 1.00000e-01 5.00000e-04 5.00000e-04 5.00000e-05 1.00000e-09 1.00000e-01 $6.45359 \mathrm{e}+00$ 6.45359e+00 6.45359e-01 1.00000e-09 2.12000e-01 $6.45359 \mathrm{e}+006.45359 \mathrm{e}+00$ 6.45359e-01 1.00000e-09 2.12000e-01 $6.45359 \mathrm{e}+00$ 6.45359e+00 6.45359e-01 1.00000e-09 2.12000e-01 6.45359e+00 6.45359e+00 6.45359e-01 1.00000e-09 2.12000e-01 $6.45359 \mathrm{e}+00$ 6.45359e+00 6.45359e-01 1.00000e-09 2.12000e-01 $1.00000 \mathrm{e}-02$ 1.00000e-02 1.00000e-03 1.00000e-09 1.00000e-01 $1.00000 \mathrm{e}+001.00000 \mathrm{e}+001.00000 \mathrm{e}-011.00000 \mathrm{e}-091.00000 \mathrm{e}-01$ $1.00000 \mathrm{e}-05$ 1.00000e-05 1.00000e-06 1.00000e-09 1.00000e-01 $1.00000 \mathrm{e}+001.00000 \mathrm{e}+001.00000 \mathrm{e}-011.00000 \mathrm{e}-09$ 1.00000e-01 Element: 2291 \# of layers: 16

$\mathrm{Kx} \mathrm{Ky} \mathrm{Kz}$ Ss Por

$1.06264 \mathrm{e}+02$ 1.06264e+02 1.06264e+01 1.00000e-09 7.00000e-02 $1.06264 \mathrm{e}+02 \quad 1.06264 \mathrm{e}+021.06264 \mathrm{e}+01 \quad 1.00000 \mathrm{e}-097.00000 \mathrm{e}-02$ $1.06264 \mathrm{e}+021.06264 \mathrm{e}+021.06264 \mathrm{e}+01$ 1.00000e-09 7.00000e-02 $1.06264 \mathrm{e}+021.06264 \mathrm{e}+02 \quad 1.06264 \mathrm{e}+01$ 1.00000e-09 7.00000e-02 $1.06264 \mathrm{e}+021.06264 \mathrm{e}+021.06264 \mathrm{e}+01$ 1.00000e-09 7.00000e-02 5.00000e-04 5.00000e-04 5.00000e-05 1.00000e-09 1.00000e-01 5.00000e-04 5.00000e-04 5.00000e-05 1.00000e-09 1.00000e-01 4.24607e+00 4.24607e+00 4.24607e-01 1.00000e-09 2.12000e-01 4.24607e+00 4.24607e+00 4.24607e-01 1.00000e-09 2.12000e-01 $4.24607 \mathrm{e}+004.24607 \mathrm{e}+00$ 4.24607e-01 1.00000e-09 2.12000e-01 4.24607e+00 4.24607e+00 4.24607e-01 1.00000e-09 2.12000e-01 4.24607e+00 4.24607e+00 4.24607e-01 1.00000e-09 2.12000e-01 $1.00000 \mathrm{e}-02$ 1.00000e-02 1.00000e-03 1.00000e-09 1.00000e-01 $1.00000 \mathrm{e}+001.00000 \mathrm{e}+001.00000 \mathrm{e}-011.00000 \mathrm{e}-091.00000 \mathrm{e}-01$ $1.00000 \mathrm{e}-05$ 1.00000e-05 1.00000e-06 1.00000e-09 1.00000e-01 $1.00000 \mathrm{e}+001.00000 \mathrm{e}+001.00000 \mathrm{e}-011.00000 \mathrm{e}-091.00000 \mathrm{e}-01$ Element: 2292 \# of layers: 16

$\mathrm{Kx} \mathrm{Ky} \mathrm{Kz}$ Ss Por

$1.06264 \mathrm{e}+02$ 1.06264e+02 1.06264e+01 1.00000e-09 7.00000e-02 
$1.06264 \mathrm{e}+021.06264 \mathrm{e}+021.06264 \mathrm{e}+01$ 1.00000e-09 7.00000e-02 $1.06264 \mathrm{e}+021.06264 \mathrm{e}+021.06264 \mathrm{e}+01$ 1.00000e-09 7.00000e-02 $1.06264 \mathrm{e}+021.06264 \mathrm{e}+021.06264 \mathrm{e}+01$ 1.00000e-09 7.00000e-02 $1.06264 \mathrm{e}+02 \quad 1.06264 \mathrm{e}+02 \quad 1.06264 \mathrm{e}+011.00000 \mathrm{e}-097.00000 \mathrm{e}-02$ 5.00000e-04 5.00000e-04 5.00000e-05 1.00000e-09 1.00000e-01 5.00000e-04 5.00000e-04 5.00000e-05 1.00000e-09 1.00000e-01 4.24607e+00 4.24607e+00 4.24607e-01 1.00000e-09 2.12000e-01 4.24607e+00 4.24607e+00 4.24607e-01 1.00000e-09 2.12000e-01 4.24607e+00 4.24607e+00 4.24607e-01 1.00000e-09 2.12000e-01 $4.24607 \mathrm{e}+00$ 4.24607e+00 4.24607e-01 1.00000e-09 2.12000e-01 4.24607e+00 4.24607e+00 4.24607e-01 1.00000e-09 2.12000e-01 $1.00000 \mathrm{e}-02$ 1.00000e-02 1.00000e-03 1.00000e-09 1.00000e-01 $1.00000 \mathrm{e}+001.00000 \mathrm{e}+001.00000 \mathrm{e}-011.00000 \mathrm{e}-091.00000 \mathrm{e}-01$ $1.00000 \mathrm{e}-05$ 1.00000e-05 1.00000e-06 1.00000e-09 1.00000e-01 $1.00000 \mathrm{e}+001.00000 \mathrm{e}+001.00000 \mathrm{e}-01$ 1.00000e-09 1.00000e-01 Element: 2293 \# of layers: 16

$\mathrm{Kx} \mathrm{Ky} \mathrm{Kz}$ Ss Por

$1.06264 \mathrm{e}+021.06264 \mathrm{e}+021.06264 \mathrm{e}+01$ 1.00000e-09 7.00000e-02 $1.06264 \mathrm{e}+021.06264 \mathrm{e}+021.06264 \mathrm{e}+01$ 1.00000e-09 7.00000e-02 $1.06264 \mathrm{e}+021.06264 \mathrm{e}+021.06264 \mathrm{e}+01$ 1.00000e-09 7.00000e-02 $1.06264 \mathrm{e}+02 \quad 1.06264 \mathrm{e}+02 \quad 1.06264 \mathrm{e}+01 \quad 1.00000 \mathrm{e}-097.00000 \mathrm{e}-02$ $1.06264 \mathrm{e}+021.06264 \mathrm{e}+021.06264 \mathrm{e}+01$ 1.00000e-09 7.00000e-02 5.00000e-04 5.00000e-04 5.00000e-05 1.00000e-09 1.00000e-01 5.00000e-04 5.00000e-04 5.00000e-05 1.00000e-09 1.00000e-01 $4.24607 \mathrm{e}+00$ 4.24607e+00 4.24607e-01 1.00000e-09 2.12000e-01 4.24607e+00 4.24607e+00 4.24607e-01 1.00000e-09 2.12000e-01 4.24607e+00 4.24607e+00 4.24607e-01 1.00000e-09 2.12000e-01 4.24607e+00 4.24607e+00 4.24607e-01 1.00000e-09 2.12000e-01 $4.24607 \mathrm{e}+00$ 4.24607e+00 4.24607e-01 1.00000e-09 2.12000e-01 $1.00000 \mathrm{e}-021.00000 \mathrm{e}-021.00000 \mathrm{e}-031.00000 \mathrm{e}-091.00000 \mathrm{e}-01$ $1.00000 \mathrm{e}+001.00000 \mathrm{e}+001.00000 \mathrm{e}-01$ 1.00000e-09 1.00000e-01 1.00000e-05 1.00000e-05 1.00000e-06 1.00000e-09 1.00000e-01 $1.00000 \mathrm{e}+001.00000 \mathrm{e}+001.00000 \mathrm{e}-011.00000 \mathrm{e}-091.00000 \mathrm{e}-01$ Element: 2294 \# of layers: 15

$\mathrm{Kx} \mathrm{Ky} \mathrm{Kz}$ Ss Por

$1.06264 \mathrm{e}+021.06264 \mathrm{e}+02$ 1.06264e+01 1.00000e-09 7.00000e-02 $1.06264 \mathrm{e}+021.06264 \mathrm{e}+021.06264 \mathrm{e}+01$ 1.00000e-09 7.00000e-02 $1.06264 \mathrm{e}+021.06264 \mathrm{e}+021.06264 \mathrm{e}+01$ 1.00000e-09 7.00000e-02 $1.06264 \mathrm{e}+021.06264 \mathrm{e}+021.06264 \mathrm{e}+01$ 1.00000e-09 7.00000e-02 5.00000e-04 5.00000e-04 5.00000e-05 1.00000e-09 1.00000e-01 5.00000e-04 5.00000e-04 5.00000e-05 1.00000e-09 1.00000e-01 4.24607e+00 4.24607e+00 4.24607e-01 1.00000e-09 2.12000e-01 $4.24607 \mathrm{e}+00$ 4.24607e+00 4.24607e-01 1.00000e-09 2.12000e-01 4.24607e+00 4.24607e+00 4.24607e-01 1.00000e-09 2.12000e-01 4.24607e+00 4.24607e+00 4.24607e-01 1.00000e-09 2.12000e-01 $4.24607 \mathrm{e}+00$ 4.24607e+00 4.24607e-01 1.00000e-09 2.12000e-01 
$1.00000 \mathrm{e}-02$ 1.00000e-02 1.00000e-03 1.00000e-09 1.00000e-01 $1.00000 \mathrm{e}+001.00000 \mathrm{e}+001.00000 \mathrm{e}-011.00000 \mathrm{e}-091.00000 \mathrm{e}-01$ $1.00000 \mathrm{e}-051.00000 \mathrm{e}-05$ 1.00000e-06 1.00000e-09 1.00000e-01 $1.00000 \mathrm{e}+001.00000 \mathrm{e}+001.00000 \mathrm{e}-011.00000 \mathrm{e}-091.00000 \mathrm{e}-01$ Element: 2295 \# of layers: 15

Kx Ky Kz Ss Por

$1.06264 \mathrm{e}+021.06264 \mathrm{e}+021.06264 \mathrm{e}+01$ 1.00000e-09 7.00000e-02 $1.06264 \mathrm{e}+021.06264 \mathrm{e}+021.06264 \mathrm{e}+011.00000 \mathrm{e}-097.00000 \mathrm{e}-02$ $1.06264 \mathrm{e}+021.06264 \mathrm{e}+021.06264 \mathrm{e}+011.00000 \mathrm{e}-097.00000 \mathrm{e}-02$ $1.06264 \mathrm{e}+02 \quad 1.06264 \mathrm{e}+021.06264 \mathrm{e}+011.00000 \mathrm{e}-097.00000 \mathrm{e}-02$ 5.00000e-04 5.00000e-04 5.00000e-05 1.00000e-09 1.00000e-01 5.00000e-04 5.00000e-04 5.00000e-05 1.00000e-09 1.00000e-01 $4.24607 \mathrm{e}+004.24607 \mathrm{e}+00$ 4.24607e-01 1.00000e-09 2.12000e-01 $4.24607 \mathrm{e}+004.24607 \mathrm{e}+004.24607 \mathrm{e}-011.00000 \mathrm{e}-092.12000 \mathrm{e}-01$ $4.24607 \mathrm{e}+004.24607 \mathrm{e}+00$ 4.24607e-01 1.00000e-09 2.12000e-01 $4.24607 \mathrm{e}+004.24607 \mathrm{e}+00$ 4.24607e-01 1.00000e-09 2.12000e-01 $4.24607 \mathrm{e}+004.24607 \mathrm{e}+00$ 4.24607e-01 1.00000e-09 2.12000e-01 $1.00000 \mathrm{e}-02$ 1.00000e-02 1.00000e-03 1.00000e-09 1.00000e-01 $1.00000 \mathrm{e}+001.00000 \mathrm{e}+001.00000 \mathrm{e}-011.00000 \mathrm{e}-091.00000 \mathrm{e}-01$ $1.00000 \mathrm{e}-051.00000 \mathrm{e}-05$ 1.00000e-06 1.00000e-09 1.00000e-01 $1.00000 \mathrm{e}+001.00000 \mathrm{e}+001.00000 \mathrm{e}-011.00000 \mathrm{e}-091.00000 \mathrm{e}-01$ Element: 2296 \# of layers: 15

Kx Ky Kz Ss Por

$1.06264 \mathrm{e}+021.06264 \mathrm{e}+021.06264 \mathrm{e}+01$ 1.00000e-09 7.00000e-02 $1.06264 \mathrm{e}+021.06264 \mathrm{e}+021.06264 \mathrm{e}+011.00000 \mathrm{e}-097.00000 \mathrm{e}-02$ $1.06264 \mathrm{e}+021.06264 \mathrm{e}+021.06264 \mathrm{e}+011.00000 \mathrm{e}-097.00000 \mathrm{e}-02$ $1.06264 \mathrm{e}+021.06264 \mathrm{e}+021.06264 \mathrm{e}+011.00000 \mathrm{e}-097.00000 \mathrm{e}-02$ 5.00000e-04 5.00000e-04 5.00000e-05 1.00000e-09 1.00000e-01 5.00000e-04 5.00000e-04 5.00000e-05 1.00000e-09 1.00000e-01 $4.24607 \mathrm{e}+00 \quad 4.24607 \mathrm{e}+00$ 4.24607e-01 1.00000e-09 2.12000e-01 $4.24607 \mathrm{e}+004.24607 \mathrm{e}+004.24607 \mathrm{e}-011.00000 \mathrm{e}-092.12000 \mathrm{e}-01$ $4.24607 \mathrm{e}+004.24607 \mathrm{e}+00$ 4.24607e-01 1.00000e-09 2.12000e-01 $4.24607 \mathrm{e}+004.24607 \mathrm{e}+00$ 4.24607e-01 1.00000e-09 2.12000e-01 $4.24607 \mathrm{e}+00 \quad 4.24607 \mathrm{e}+00$ 4.24607e-01 1.00000e-09 2.12000e-01 $1.00000 \mathrm{e}-02$ 1.00000e-02 1.00000e-03 1.00000e-09 1.00000e-01 $1.00000 \mathrm{e}+001.00000 \mathrm{e}+001.00000 \mathrm{e}-011.00000 \mathrm{e}-091.00000 \mathrm{e}-01$ $1.00000 \mathrm{e}-05$ 1.00000e-05 1.00000e-06 1.00000e-09 1.00000e-01 $1.00000 \mathrm{e}+001.00000 \mathrm{e}+001.00000 \mathrm{e}-011.00000 \mathrm{e}-091.00000 \mathrm{e}-01$ Element: 2297 \# of layers: 16

Kx Ky Kz Ss Por

$1.06264 \mathrm{e}+021.06264 \mathrm{e}+021.06264 \mathrm{e}+01$ 1.00000e-09 7.00000e-02 $1.06264 \mathrm{e}+021.06264 \mathrm{e}+021.06264 \mathrm{e}+011.00000 \mathrm{e}-097.00000 \mathrm{e}-02$ $1.06264 \mathrm{e}+021.06264 \mathrm{e}+021.06264 \mathrm{e}+011.00000 \mathrm{e}-097.00000 \mathrm{e}-02$ $1.06264 \mathrm{e}+021.06264 \mathrm{e}+021.06264 \mathrm{e}+011.00000 \mathrm{e}-097.00000 \mathrm{e}-02$ $1.06264 \mathrm{e}+021.06264 \mathrm{e}+021.06264 \mathrm{e}+011.00000 \mathrm{e}-097.00000 \mathrm{e}-02$ 5.00000e-04 5.00000e-04 5.00000e-05 1.00000e-09 1.00000e-01 
5.00000e-04 5.00000e-04 5.00000e-05 1.00000e-09 1.00000e-01 $4.24607 \mathrm{e}+004.24607 \mathrm{e}+00$ 4.24607e-01 1.00000e-09 2.12000e-01 4.24607e+00 4.24607e+00 4.24607e-01 1.00000e-09 2.12000e-01 $4.24607 \mathrm{e}+00$ 4.24607e+00 4.24607e-01 1.00000e-09 2.12000e-01 4.24607e+00 4.24607e+00 4.24607e-01 1.00000e-09 2.12000e-01 4.24607e+00 4.24607e+00 4.24607e-01 1.00000e-09 2.12000e-01 $1.00000 \mathrm{e}-02$ 1.00000e-02 1.00000e-03 1.00000e-09 1.00000e-01 $1.00000 \mathrm{e}+001.00000 \mathrm{e}+001.00000 \mathrm{e}-011.00000 \mathrm{e}-091.00000 \mathrm{e}-01$ $1.00000 \mathrm{e}-05$ 1.00000e-05 1.00000e-06 1.00000e-09 1.00000e-01 $1.00000 \mathrm{e}+001.00000 \mathrm{e}+001.00000 \mathrm{e}-011.00000 \mathrm{e}-091.00000 \mathrm{e}-01$ Element: 2298 \# of layers: 16

$\mathrm{Kx} \mathrm{Ky} \mathrm{Kz}$ Ss Por

$1.06264 \mathrm{e}+02$ 1.06264e+02 1.06264e+01 1.00000e-09 7.00000e-02 $1.06264 \mathrm{e}+021.06264 \mathrm{e}+02 \quad 1.06264 \mathrm{e}+01$ 1.00000e-09 7.00000e-02 $1.06264 \mathrm{e}+021.06264 \mathrm{e}+021.06264 \mathrm{e}+01$ 1.00000e-09 7.00000e-02 $1.06264 \mathrm{e}+021.06264 \mathrm{e}+02 \quad 1.06264 \mathrm{e}+01$ 1.00000e-09 7.00000e-02 $1.06264 \mathrm{e}+02 \quad 1.06264 \mathrm{e}+02 \quad 1.06264 \mathrm{e}+01 \quad 1.00000 \mathrm{e}-097.00000 \mathrm{e}-02$ 5.00000e-04 5.00000e-04 5.00000e-05 1.00000e-09 1.00000e-01 5.00000e-04 5.00000e-04 5.00000e-05 1.00000e-09 1.00000e-01 $4.24607 \mathrm{e}+00$ 4.24607e+00 4.24607e-01 1.00000e-09 2.12000e-01 4.24607e+00 4.24607e+00 4.24607e-01 1.00000e-09 2.12000e-01 4.24607e+00 4.24607e+00 4.24607e-01 1.00000e-09 2.12000e-01 4.24607e+00 4.24607e+00 4.24607e-01 1.00000e-09 2.12000e-01 4.24607e+00 4.24607e+00 4.24607e-01 1.00000e-09 2.12000e-01 $1.00000 \mathrm{e}-021.00000 \mathrm{e}-02$ 1.00000e-03 1.00000e-09 1.00000e-01 $1.00000 \mathrm{e}+001.00000 \mathrm{e}+001.00000 \mathrm{e}-011.00000 \mathrm{e}-091.00000 \mathrm{e}-01$ $1.00000 \mathrm{e}-05$ 1.00000e-05 1.00000e-06 1.00000e-09 1.00000e-01 $1.00000 \mathrm{e}+001.00000 \mathrm{e}+001.00000 \mathrm{e}-011.00000 \mathrm{e}-091.00000 \mathrm{e}-01$ Element: 2299 \# of layers: 15

$\mathrm{Kx} \mathrm{Ky} \mathrm{Kz}$ Ss Por

$1.06264 \mathrm{e}+021.06264 \mathrm{e}+02 \quad 1.06264 \mathrm{e}+01$ 1.00000e-09 7.00000e-02 $1.06264 \mathrm{e}+021.06264 \mathrm{e}+02 \quad 1.06264 \mathrm{e}+01$ 1.00000e-09 7.00000e-02 $1.06264 \mathrm{e}+02 \quad 1.06264 \mathrm{e}+02 \quad 1.06264 \mathrm{e}+01$ 1.00000e-09 7.00000e-02 $1.06264 \mathrm{e}+021.06264 \mathrm{e}+021.06264 \mathrm{e}+01$ 1.00000e-09 7.00000e-02 $5.00000 \mathrm{e}-04$ 5.00000e-04 5.00000e-05 1.00000e-09 1.00000e-01 5.00000e-04 5.00000e-04 5.00000e-05 1.00000e-09 1.00000e-01 $4.24607 \mathrm{e}+00$ 4.24607e+00 4.24607e-01 1.00000e-09 2.12000e-01 4.24607e+00 4.24607e+00 4.24607e-01 1.00000e-09 2.12000e-01 4.24607e+00 4.24607e+00 4.24607e-01 1.00000e-09 2.12000e-01 4.24607e+00 4.24607e+00 4.24607e-01 1.00000e-09 2.12000e-01 4.24607e+00 4.24607e+00 4.24607e-01 1.00000e-09 2.12000e-01 $1.00000 \mathrm{e}-02$ 1.00000e-02 1.00000e-03 1.00000e-09 1.00000e-01 $1.00000 \mathrm{e}+001.00000 \mathrm{e}+001.00000 \mathrm{e}-011.00000 \mathrm{e}-091.00000 \mathrm{e}-01$ $1.00000 \mathrm{e}-05$ 1.00000e-05 1.00000e-06 1.00000e-09 1.00000e-01 $1.00000 \mathrm{e}+001.00000 \mathrm{e}+00$ 1.00000e-01 1.00000e-09 1.00000e-01 Element: 2300 \# of layers: 16 
$\mathrm{Kx} \mathrm{Ky} \mathrm{Kz}$ Ss Por

9.13704e+01 9.13704e+01 9.13704e+00 1.00000e-09 7.00000e-02

9.13704e+01 9.13704e+01 9.13704e+00 1.00000e-09 7.00000e-02

$9.13704 \mathrm{e}+019.13704 \mathrm{e}+019.13704 \mathrm{e}+001.00000 \mathrm{e}-09$ 7.00000e-02

$9.13704 \mathrm{e}+019.13704 \mathrm{e}+019.13704 \mathrm{e}+001.00000 \mathrm{e}-09$ 7.00000e-02

9.13704e+01 9.13704e+01 9.13704e+00 1.00000e-09 7.00000e-02

5.00000e-04 5.00000e-04 5.00000e-05 1.00000e-09 1.00000e-01

5.00000e-04 5.00000e-04 5.00000e-05 1.00000e-09 1.00000e-01

$3.65070 \mathrm{e}+003.65070 \mathrm{e}+003.65070 \mathrm{e}-01$ 1.00000e-09 2.12000e-01

$3.65070 \mathrm{e}+003.65070 \mathrm{e}+00$ 3.65070e-01 1.00000e-09 2.12000e-01

$3.65070 \mathrm{e}+003.65070 \mathrm{e}+003.65070 \mathrm{e}-01$ 1.00000e-09 2.12000e-01

$3.65070 \mathrm{e}+003.65070 \mathrm{e}+003.65070 \mathrm{e}-01$ 1.00000e-09 2.12000e-01

$3.65070 \mathrm{e}+003.65070 \mathrm{e}+003.65070 \mathrm{e}-01$ 1.00000e-09 2.12000e-01

$1.00000 \mathrm{e}-02$ 1.00000e-02 1.00000e-03 1.00000e-09 1.00000e-01

$1.00000 \mathrm{e}+001.00000 \mathrm{e}+001.00000 \mathrm{e}-011.00000 \mathrm{e}-091.00000 \mathrm{e}-01$

$1.00000 \mathrm{e}-05$ 1.00000e-05 1.00000e-06 1.00000e-09 1.00000e-01

$1.00000 \mathrm{e}+001.00000 \mathrm{e}+001.00000 \mathrm{e}-01$ 1.00000e-09 1.00000e-01

Element: 2301 \# of layers: 16

$\mathrm{Kx} \mathrm{Ky} \mathrm{Kz}$ Ss Por

9.13704e+01 9.13704e+01 9.13704e+00 1.00000e-09 7.00000e-02

$9.13704 \mathrm{e}+019.13704 \mathrm{e}+019.13704 \mathrm{e}+001.00000 \mathrm{e}-09$ 7.00000e-02

$9.13704 \mathrm{e}+019.13704 \mathrm{e}+019.13704 \mathrm{e}+001.00000 \mathrm{e}-09$ 7.00000e-02

9.13704e+01 9.13704e+01 9.13704e+00 1.00000e-09 7.00000e-02

$9.13704 \mathrm{e}+019.13704 \mathrm{e}+019.13704 \mathrm{e}+001.00000 \mathrm{e}-09$ 7.00000e-02

5.00000e-04 5.00000e-04 5.00000e-05 1.00000e-09 1.00000e-01

$5.00000 \mathrm{e}-04$ 5.00000e-04 5.00000e-05 1.00000e-09 1.00000e-01

$3.65070 \mathrm{e}+003.65070 \mathrm{e}+003.65070 \mathrm{e}-01$ 1.00000e-09 2.12000e-01

$3.65070 \mathrm{e}+003.65070 \mathrm{e}+003.65070 \mathrm{e}-01$ 1.00000e-09 2.12000e-01

$3.65070 \mathrm{e}+003.65070 \mathrm{e}+003.65070 \mathrm{e}-01$ 1.00000e-09 2.12000e-01

$3.65070 \mathrm{e}+003.65070 \mathrm{e}+00$ 3.65070e-01 1.00000e-09 2.12000e-01

$3.65070 \mathrm{e}+003.65070 \mathrm{e}+00$ 3.65070e-01 1.00000e-09 2.12000e-01

$1.00000 \mathrm{e}-02$ 1.00000e-02 1.00000e-03 1.00000e-09 1.00000e-01

$1.00000 \mathrm{e}+001.00000 \mathrm{e}+001.00000 \mathrm{e}-011.00000 \mathrm{e}-091.00000 \mathrm{e}-01$

$1.00000 \mathrm{e}-05$ 1.00000e-05 1.00000e-06 1.00000e-09 1.00000e-01

$1.00000 \mathrm{e}+001.00000 \mathrm{e}+001.00000 \mathrm{e}-011.00000 \mathrm{e}-091.00000 \mathrm{e}-01$

Element: 2302 \# of layers: 14

Kx Ky Kz Ss Por

9.13704e+01 9.13704e+01 9.13704e+00 1.00000e-09 7.00000e-02

9.13704e+01 9.13704e+01 9.13704e+00 1.00000e-09 7.00000e-02

$9.13704 \mathrm{e}+019.13704 \mathrm{e}+019.13704 \mathrm{e}+001.00000 \mathrm{e}-09$ 7.00000e-02

$9.13704 \mathrm{e}+019.13704 \mathrm{e}+019.13704 \mathrm{e}+001.00000 \mathrm{e}-09$ 7.00000e-02

5.00000e-04 5.00000e-04 5.00000e-05 1.00000e-09 1.00000e-01

$3.65070 \mathrm{e}+003.65070 \mathrm{e}+003.65070 \mathrm{e}-01$ 1.00000e-09 2.12000e-01

$3.65070 \mathrm{e}+003.65070 \mathrm{e}+00$ 3.65070e-01 1.00000e-09 2.12000e-01

$3.65070 \mathrm{e}+003.65070 \mathrm{e}+003.65070 \mathrm{e}-01$ 1.00000e-09 2.12000e-01

$3.65070 \mathrm{e}+003.65070 \mathrm{e}+00$ 3.65070e-01 1.00000e-09 2.12000e-01 
$3.65070 \mathrm{e}+00$ 3.65070e+00 3.65070e-01 1.00000e-09 2.12000e-01 $1.00000 \mathrm{e}-02$ 1.00000e-02 1.00000e-03 1.00000e-09 1.00000e-01 $1.00000 \mathrm{e}+001.00000 \mathrm{e}+001.00000 \mathrm{e}-011.00000 \mathrm{e}-091.00000 \mathrm{e}-01$ $1.00000 \mathrm{e}-05$ 1.00000e-05 1.00000e-06 1.00000e-09 1.00000e-01 $1.00000 \mathrm{e}+001.00000 \mathrm{e}+001.00000 \mathrm{e}-01$ 1.00000e-09 1.00000e-01 Element: 2303 \# of layers: 15

$\mathrm{Kx} \mathrm{Ky} \mathrm{Kz}$ Ss Por

9.13704e+01 9.13704e+01 9.13704e+00 1.00000e-09 7.00000e-02

9.13704e+01 9.13704e+01 9.13704e+00 1.00000e-09 7.00000e-02

$9.13704 \mathrm{e}+019.13704 \mathrm{e}+019.13704 \mathrm{e}+001.00000 \mathrm{e}-09$ 7.00000e-02

$9.13704 \mathrm{e}+019.13704 \mathrm{e}+019.13704 \mathrm{e}+001.00000 \mathrm{e}-09$ 7.00000e-02 5.00000e-04 5.00000e-04 5.00000e-05 1.00000e-09 1.00000e-01 5.00000e-04 5.00000e-04 5.00000e-05 1.00000e-09 1.00000e-01

$3.65070 \mathrm{e}+003.65070 \mathrm{e}+003.65070 \mathrm{e}-01$ 1.00000e-09 2.12000e-01 $3.65070 \mathrm{e}+003.65070 \mathrm{e}+003.65070 \mathrm{e}-01$ 1.00000e-09 2.12000e-01 $3.65070 \mathrm{e}+003.65070 \mathrm{e}+003.65070 \mathrm{e}-01$ 1.00000e-09 2.12000e-01 $3.65070 \mathrm{e}+003.65070 \mathrm{e}+003.65070 \mathrm{e}-01$ 1.00000e-09 2.12000e-01 $3.65070 \mathrm{e}+003.65070 \mathrm{e}+003.65070 \mathrm{e}-01$ 1.00000e-09 2.12000e-01 1.00000e-02 1.00000e-02 1.00000e-03 1.00000e-09 1.00000e-01 $1.00000 \mathrm{e}+001.00000 \mathrm{e}+001.00000 \mathrm{e}-011.00000 \mathrm{e}-091.00000 \mathrm{e}-01$ $1.00000 \mathrm{e}-05$ 1.00000e-05 1.00000e-06 1.00000e-09 1.00000e-01 $1.00000 \mathrm{e}+001.00000 \mathrm{e}+001.00000 \mathrm{e}-01$ 1.00000e-09 1.00000e-01 Element: 2304 \# of layers: 14

Kx Ky Kz Ss Por

9.13704e+01 9.13704e+01 9.13704e+00 1.00000e-09 7.00000e-02 $9.13704 \mathrm{e}+019.13704 \mathrm{e}+019.13704 \mathrm{e}+001.00000 \mathrm{e}-09$ 7.00000e-02 $9.13704 \mathrm{e}+019.13704 \mathrm{e}+019.13704 \mathrm{e}+001.00000 \mathrm{e}-09$ 7.00000e-02 5.00000e-04 5.00000e-04 5.00000e-05 1.00000e-09 1.00000e-01 5.00000e-04 5.00000e-04 5.00000e-05 1.00000e-09 1.00000e-01 $3.65070 \mathrm{e}+003.65070 \mathrm{e}+003.65070 \mathrm{e}-01$ 1.00000e-09 2.12000e-01 $3.65070 \mathrm{e}+003.65070 \mathrm{e}+00$ 3.65070e-01 1.00000e-09 2.12000e-01 $3.65070 \mathrm{e}+003.65070 \mathrm{e}+003.65070 \mathrm{e}-01$ 1.00000e-09 2.12000e-01 $3.65070 \mathrm{e}+003.65070 \mathrm{e}+003.65070 \mathrm{e}-01$ 1.00000e-09 2.12000e-01 $3.65070 \mathrm{e}+003.65070 \mathrm{e}+003.65070 \mathrm{e}-01$ 1.00000e-09 2.12000e-01 $1.00000 \mathrm{e}-02$ 1.00000e-02 1.00000e-03 1.00000e-09 1.00000e-01 $1.00000 \mathrm{e}+001.00000 \mathrm{e}+001.00000 \mathrm{e}-011.00000 \mathrm{e}-091.00000 \mathrm{e}-01$ $1.00000 \mathrm{e}-05$ 1.00000e-05 1.00000e-06 1.00000e-09 1.00000e-01 $1.00000 \mathrm{e}+001.00000 \mathrm{e}+001.00000 \mathrm{e}-011.00000 \mathrm{e}-091.00000 \mathrm{e}-01$ Element: 2305 \# of layers: 15

$\mathrm{Kx} \mathrm{Ky} \mathrm{Kz}$ Ss Por

9.13704e+01 9.13704e+01 9.13704e+00 1.00000e-09 7.00000e-02 9.13704e+01 9.13704e+01 9.13704e+00 1.00000e-09 7.00000e-02 $9.13704 \mathrm{e}+019.13704 \mathrm{e}+019.13704 \mathrm{e}+001.00000 \mathrm{e}-09$ 7.00000e-02 9.13704e+01 9.13704e+01 9.13704e+00 1.00000e-09 7.00000e-02 5.00000e-04 5.00000e-04 5.00000e-05 1.00000e-09 1.00000e-01 5.00000e-04 5.00000e-04 5.00000e-05 1.00000e-09 1.00000e-01 
$3.65070 \mathrm{e}+003.65070 \mathrm{e}+003.65070 \mathrm{e}-011.00000 \mathrm{e}-092.12000 \mathrm{e}-01$ $3.65070 \mathrm{e}+003.65070 \mathrm{e}+003.65070 \mathrm{e}-01$ 1.00000e-09 2.12000e-01 $3.65070 \mathrm{e}+003.65070 \mathrm{e}+003.65070 \mathrm{e}-01$ 1.00000e-09 2.12000e-01 $3.65070 \mathrm{e}+003.65070 \mathrm{e}+003.65070 \mathrm{e}-011.00000 \mathrm{e}-092.12000 \mathrm{e}-01$ $3.65070 \mathrm{e}+003.65070 \mathrm{e}+003.65070 \mathrm{e}-01$ 1.00000e-09 2.12000e-01 $1.00000 \mathrm{e}-021.00000 \mathrm{e}-02$ 1.00000e-03 1.00000e-09 1.00000e-01 $1.00000 \mathrm{e}+001.00000 \mathrm{e}+001.00000 \mathrm{e}-011.00000 \mathrm{e}-091.00000 \mathrm{e}-01$ $1.00000 \mathrm{e}-05$ 1.00000e-05 1.00000e-06 1.00000e-09 1.00000e-01 $1.00000 \mathrm{e}+001.00000 \mathrm{e}+001.00000 \mathrm{e}-011.00000 \mathrm{e}-091.00000 \mathrm{e}-01$ Element: 2306 \# of layers: 15

Kx Ky Kz Ss Por

$9.13704 \mathrm{e}+01$ 9.13704e+01 9.13704e+00 1.00000e-09 7.00000e-02

$9.13704 \mathrm{e}+019.13704 \mathrm{e}+019.13704 \mathrm{e}+00$ 1.00000e-09 7.00000e-02

$9.13704 \mathrm{e}+019.13704 \mathrm{e}+019.13704 \mathrm{e}+001.00000 \mathrm{e}-09$ 7.00000e-02

$9.13704 \mathrm{e}+019.13704 \mathrm{e}+019.13704 \mathrm{e}+001.00000 \mathrm{e}-09$ 7.00000e-02 5.00000e-04 5.00000e-04 5.00000e-05 1.00000e-09 1.00000e-01 5.00000e-04 5.00000e-04 5.00000e-05 1.00000e-09 1.00000e-01

$3.65070 \mathrm{e}+003.65070 \mathrm{e}+003.65070 \mathrm{e}-01$ 1.00000e-09 2.12000e-01 $3.65070 \mathrm{e}+003.65070 \mathrm{e}+003.65070 \mathrm{e}-01$ 1.00000e-09 2.12000e-01 $3.65070 \mathrm{e}+003.65070 \mathrm{e}+003.65070 \mathrm{e}-01$ 1.00000e-09 2.12000e-01 $3.65070 \mathrm{e}+003.65070 \mathrm{e}+003.65070 \mathrm{e}-011.00000 \mathrm{e}-092.12000 \mathrm{e}-01$ $3.65070 \mathrm{e}+003.65070 \mathrm{e}+003.65070 \mathrm{e}-01$ 1.00000e-09 2.12000e-01 $1.00000 \mathrm{e}-02$ 1.00000e-02 1.00000e-03 1.00000e-09 1.00000e-01 $1.00000 \mathrm{e}+001.00000 \mathrm{e}+001.00000 \mathrm{e}-011.00000 \mathrm{e}-091.00000 \mathrm{e}-01$ $1.00000 \mathrm{e}-05$ 1.00000e-05 1.00000e-06 1.00000e-09 1.00000e-01 $1.00000 \mathrm{e}+001.00000 \mathrm{e}+001.00000 \mathrm{e}-011.00000 \mathrm{e}-091.00000 \mathrm{e}-01$ Element: 2307 \# of layers: 15

Kx Ky Kz Ss Por

$9.13704 \mathrm{e}+01$ 9.13704e+01 9.13704e+00 1.00000e-09 7.00000e-02 $9.13704 \mathrm{e}+019.13704 \mathrm{e}+019.13704 \mathrm{e}+00$ 1.00000e-09 7.00000e-02 $9.13704 \mathrm{e}+019.13704 \mathrm{e}+019.13704 \mathrm{e}+001.00000 \mathrm{e}-09$ 7.00000e-02 $9.13704 \mathrm{e}+019.13704 \mathrm{e}+019.13704 \mathrm{e}+001.00000 \mathrm{e}-09$ 7.00000e-02 5.00000e-04 5.00000e-04 5.00000e-05 1.00000e-09 1.00000e-01 $5.00000 \mathrm{e}-04$ 5.00000e-04 5.00000e-05 1.00000e-09 1.00000e-01 $3.65070 \mathrm{e}+003.65070 \mathrm{e}+003.65070 \mathrm{e}-01$ 1.00000e-09 2.12000e-01 $3.65070 \mathrm{e}+003.65070 \mathrm{e}+003.65070 \mathrm{e}-01$ 1.00000e-09 2.12000e-01 $3.65070 \mathrm{e}+003.65070 \mathrm{e}+003.65070 \mathrm{e}-011.00000 \mathrm{e}-092.12000 \mathrm{e}-01$ $3.65070 \mathrm{e}+003.65070 \mathrm{e}+003.65070 \mathrm{e}-01$ 1.00000e-09 2.12000e-01 $3.65070 \mathrm{e}+003.65070 \mathrm{e}+003.65070 \mathrm{e}-01$ 1.00000e-09 2.12000e-01 $1.00000 \mathrm{e}-02$ 1.00000e-02 1.00000e-03 1.00000e-09 1.00000e-01 $1.00000 \mathrm{e}+001.00000 \mathrm{e}+001.00000 \mathrm{e}-011.00000 \mathrm{e}-091.00000 \mathrm{e}-01$ $1.00000 \mathrm{e}-05$ 1.00000e-05 1.00000e-06 1.00000e-09 1.00000e-01 $1.00000 \mathrm{e}+001.00000 \mathrm{e}+001.00000 \mathrm{e}-011.00000 \mathrm{e}-091.00000 \mathrm{e}-01$ Element: 2308 \# of layers: 15

Kx Ky Kz Ss Por

9.13704e+01 9.13704e+01 9.13704e+00 1.00000e-09 7.00000e-02 
9.13704e+01 9.13704e+01 9.13704e+00 1.00000e-09 7.00000e-02 $9.13704 \mathrm{e}+019.13704 \mathrm{e}+019.13704 \mathrm{e}+00$ 1.00000e-09 7.00000e-02 $9.13704 \mathrm{e}+019.13704 \mathrm{e}+019.13704 \mathrm{e}+001.00000 \mathrm{e}-09$ 7.00000e-02 5.00000e-04 5.00000e-04 5.00000e-05 1.00000e-09 1.00000e-01 $5.00000 \mathrm{e}-04$ 5.00000e-04 5.00000e-05 1.00000e-09 1.00000e-01 $3.65070 \mathrm{e}+003.65070 \mathrm{e}+003.65070 \mathrm{e}-011.00000 \mathrm{e}-092.12000 \mathrm{e}-01$ $3.65070 \mathrm{e}+003.65070 \mathrm{e}+003.65070 \mathrm{e}-011.00000 \mathrm{e}-092.12000 \mathrm{e}-01$ $3.65070 \mathrm{e}+003.65070 \mathrm{e}+003.65070 \mathrm{e}-011.00000 \mathrm{e}-092.12000 \mathrm{e}-01$ $3.65070 \mathrm{e}+003.65070 \mathrm{e}+003.65070 \mathrm{e}-011.00000 \mathrm{e}-092.12000 \mathrm{e}-01$ $3.65070 \mathrm{e}+003.65070 \mathrm{e}+003.65070 \mathrm{e}-01$ 1.00000e-09 2.12000e-01 $1.00000 \mathrm{e}-021.00000 \mathrm{e}-02$ 1.00000e-03 1.00000e-09 1.00000e-01 $1.00000 \mathrm{e}+001.00000 \mathrm{e}+001.00000 \mathrm{e}-011.00000 \mathrm{e}-091.00000 \mathrm{e}-01$ $1.00000 \mathrm{e}-05$ 1.00000e-05 1.00000e-06 1.00000e-09 1.00000e-01 $1.00000 \mathrm{e}+001.00000 \mathrm{e}+001.00000 \mathrm{e}-011.00000 \mathrm{e}-091.00000 \mathrm{e}-01$ Element: 2309 \# of layers: 15

Kx Ky Kz Ss Por $4.42607 \mathrm{e}+014.42607 \mathrm{e}+014.42607 \mathrm{e}+00$ 1.00000e-09 7.00000e-02 $4.42607 \mathrm{e}+014.42607 \mathrm{e}+014.42607 \mathrm{e}+001.00000 \mathrm{e}-09$ 7.00000e-02 $4.42607 \mathrm{e}+014.42607 \mathrm{e}+014.42607 \mathrm{e}+001.00000 \mathrm{e}-09$ 7.00000e-02 $4.42607 \mathrm{e}+014.42607 \mathrm{e}+014.42607 \mathrm{e}+001.00000 \mathrm{e}-09$ 7.00000e-02 5.00000e-04 5.00000e-04 5.00000e-05 1.00000e-09 1.00000e-01 $5.00000 \mathrm{e}-04$ 5.00000e-04 5.00000e-05 1.00000e-09 1.00000e-01 $1.76849 \mathrm{e}+001.76849 \mathrm{e}+00$ 1.76849e-01 1.00000e-09 2.12000e-01 $1.76849 \mathrm{e}+001.76849 \mathrm{e}+00$ 1.76849e-01 1.00000e-09 2.12000e-01 $1.76849 \mathrm{e}+001.76849 \mathrm{e}+001.76849 \mathrm{e}-011.00000 \mathrm{e}-092.12000 \mathrm{e}-01$ $1.76849 \mathrm{e}+001.76849 \mathrm{e}+00$ 1.76849e-01 1.00000e-09 2.12000e-01 $1.76849 \mathrm{e}+001.76849 \mathrm{e}+001.76849 \mathrm{e}-011.00000 \mathrm{e}-092.12000 \mathrm{e}-01$ $1.00000 \mathrm{e}-02$ 1.00000e-02 1.00000e-03 1.00000e-09 1.00000e-01 $1.00000 \mathrm{e}+001.00000 \mathrm{e}+001.00000 \mathrm{e}-011.00000 \mathrm{e}-091.00000 \mathrm{e}-01$ $1.00000 \mathrm{e}-05$ 1.00000e-05 1.00000e-06 1.00000e-09 1.00000e-01 $1.00000 \mathrm{e}+001.00000 \mathrm{e}+001.00000 \mathrm{e}-011.00000 \mathrm{e}-091.00000 \mathrm{e}-01$ Element: 2310 \# of layers: 15

Kx Ky Kz Ss Por $4.42607 \mathrm{e}+014.42607 \mathrm{e}+014.42607 \mathrm{e}+00$ 1.00000e-09 7.00000e-02 $4.42607 \mathrm{e}+014.42607 \mathrm{e}+014.42607 \mathrm{e}+001.00000 \mathrm{e}-09$ 7.00000e-02 $4.42607 \mathrm{e}+014.42607 \mathrm{e}+014.42607 \mathrm{e}+001.00000 \mathrm{e}-09$ 7.00000e-02 $4.42607 \mathrm{e}+014.42607 \mathrm{e}+014.42607 \mathrm{e}+001.00000 \mathrm{e}-09$ 7.00000e-02 5.00000e-04 5.00000e-04 5.00000e-05 1.00000e-09 1.00000e-01 $5.00000 \mathrm{e}-04$ 5.00000e-04 5.00000e-05 1.00000e-09 1.00000e-01 $1.76849 \mathrm{e}+001.76849 \mathrm{e}+00$ 1.76849e-01 1.00000e-09 2.12000e-01 $1.76849 \mathrm{e}+001.76849 \mathrm{e}+00$ 1.76849e-01 1.00000e-09 2.12000e-01 $1.76849 \mathrm{e}+001.76849 \mathrm{e}+00$ 1.76849e-01 1.00000e-09 2.12000e-01 $1.76849 \mathrm{e}+001.76849 \mathrm{e}+001.76849 \mathrm{e}-011.00000 \mathrm{e}-092.12000 \mathrm{e}-01$ $1.76849 \mathrm{e}+001.76849 \mathrm{e}+00$ 1.76849e-01 1.00000e-09 2.12000e-01 $1.00000 \mathrm{e}-021.00000 \mathrm{e}-02$ 1.00000e-03 1.00000e-09 1.00000e-01 $1.00000 \mathrm{e}+001.00000 \mathrm{e}+001.00000 \mathrm{e}-011.00000 \mathrm{e}-091.00000 \mathrm{e}-01$ 
$1.00000 \mathrm{e}-05$ 1.00000e-05 1.00000e-06 1.00000e-09 1.00000e-01 $1.00000 \mathrm{e}+001.00000 \mathrm{e}+001.00000 \mathrm{e}-01$ 1.00000e-09 1.00000e-01 Element: 2311 \# of layers: 15

$\mathrm{Kx} \mathrm{Ky} \mathrm{Kz}$ Ss Por

4.42607e+01 4.42607e+01 4.42607e+00 1.00000e-09 7.00000e-02 4.42607e+01 4.42607e+01 4.42607e+00 1.00000e-09 7.00000e-02 4.42607e+01 4.42607e+01 4.42607e+00 1.00000e-09 7.00000e-02 4.42607e+01 4.42607e+01 4.42607e+00 1.00000e-09 7.00000e-02 5.00000e-04 5.00000e-04 5.00000e-05 1.00000e-09 1.00000e-01 $5.00000 \mathrm{e}-04$ 5.00000e-04 5.00000e-05 1.00000e-09 1.00000e-01 $1.76849 \mathrm{e}+001.76849 \mathrm{e}+00$ 1.76849e-01 1.00000e-09 2.12000e-01 $1.76849 \mathrm{e}+001.76849 \mathrm{e}+00$ 1.76849e-01 1.00000e-09 2.12000e-01 $1.76849 \mathrm{e}+001.76849 \mathrm{e}+00$ 1.76849e-01 1.00000e-09 2.12000e-01 $1.76849 \mathrm{e}+00$ 1.76849e+00 1.76849e-01 1.00000e-09 2.12000e-01 $1.76849 \mathrm{e}+001.76849 \mathrm{e}+00$ 1.76849e-01 1.00000e-09 2.12000e-01 $1.00000 \mathrm{e}-02$ 1.00000e-02 1.00000e-03 1.00000e-09 1.00000e-01 $1.00000 \mathrm{e}+001.00000 \mathrm{e}+001.00000 \mathrm{e}-011.00000 \mathrm{e}-091.00000 \mathrm{e}-01$ $1.00000 \mathrm{e}-05$ 1.00000e-05 1.00000e-06 1.00000e-09 1.00000e-01 $1.00000 \mathrm{e}+001.00000 \mathrm{e}+001.00000 \mathrm{e}-011.00000 \mathrm{e}-091.00000 \mathrm{e}-01$ Element: 2312 \# of layers: 14

$\mathrm{Kx} \mathrm{Ky} \mathrm{Kz}$ Ss Por 4.42607e+01 4.42607e+01 4.42607e+00 1.00000e-09 7.00000e-02 4.42607e+01 4.42607e+01 4.42607e+00 1.00000e-09 7.00000e-02 4.42607e+01 4.42607e+01 4.42607e+00 1.00000e-09 7.00000e-02 $5.00000 \mathrm{e}-04$ 5.00000e-04 5.00000e-05 1.00000e-09 1.00000e-01 5.00000e-04 5.00000e-04 5.00000e-05 1.00000e-09 1.00000e-01

$1.76849 \mathrm{e}+00$ 1.76849e+00 1.76849e-01 1.00000e-09 2.12000e-01 $1.76849 \mathrm{e}+00$ 1.76849e+00 1.76849e-01 1.00000e-09 2.12000e-01 $1.76849 \mathrm{e}+001.76849 \mathrm{e}+00$ 1.76849e-01 1.00000e-09 2.12000e-01 $1.76849 \mathrm{e}+00$ 1.76849e+00 1.76849e-01 1.00000e-09 2.12000e-01 $1.76849 \mathrm{e}+00$ 1.76849e+00 1.76849e-01 1.00000e-09 2.12000e-01 $1.00000 \mathrm{e}-02$ 1.00000e-02 1.00000e-03 1.00000e-09 1.00000e-01 $1.00000 \mathrm{e}+001.00000 \mathrm{e}+001.00000 \mathrm{e}-011.00000 \mathrm{e}-091.00000 \mathrm{e}-01$ $1.00000 \mathrm{e}-05$ 1.00000e-05 1.00000e-06 1.00000e-09 1.00000e-01 $1.00000 \mathrm{e}+001.00000 \mathrm{e}+001.00000 \mathrm{e}-01$ 1.00000e-09 1.00000e-01 Element: 2313 \# of layers: 14

$\mathrm{Kx} \mathrm{Ky} \mathrm{Kz}$ Ss Por

4.42607e+01 4.42607e+01 4.42607e+00 1.00000e-09 7.00000e-02 4.42607e+01 4.42607e+01 4.42607e+00 1.00000e-09 7.00000e-02 4.42607e+01 4.42607e+01 4.42607e+00 1.00000e-09 7.00000e-02 5.00000e-04 5.00000e-04 5.00000e-05 1.00000e-09 1.00000e-01 5.00000e-04 5.00000e-04 5.00000e-05 1.00000e-09 1.00000e-01 $1.76849 \mathrm{e}+001.76849 \mathrm{e}+00$ 1.76849e-01 1.00000e-09 2.12000e-01 $1.76849 \mathrm{e}+00$ 1.76849e+00 1.76849e-01 1.00000e-09 2.12000e-01 $1.76849 \mathrm{e}+001.76849 \mathrm{e}+00$ 1.76849e-01 1.00000e-09 2.12000e-01 $1.76849 \mathrm{e}+001.76849 \mathrm{e}+001.76849 \mathrm{e}-01$ 1.00000e-09 2.12000e-01 
$1.76849 \mathrm{e}+00$ 1.76849e+00 1.76849e-01 1.00000e-09 2.12000e-01 $1.00000 \mathrm{e}-02$ 1.00000e-02 1.00000e-03 1.00000e-09 1.00000e-01 $1.00000 \mathrm{e}+001.00000 \mathrm{e}+001.00000 \mathrm{e}-011.00000 \mathrm{e}-091.00000 \mathrm{e}-01$ $1.00000 \mathrm{e}-05$ 1.00000e-05 1.00000e-06 1.00000e-09 1.00000e-01 $1.00000 \mathrm{e}+001.00000 \mathrm{e}+001.00000 \mathrm{e}-01$ 1.00000e-09 1.00000e-01 Element: 2314 \# of layers: 14

$\mathrm{Kx} \mathrm{Ky} \mathrm{Kz}$ Ss Por

4.42607e+01 4.42607e+01 4.42607e+00 1.00000e-09 7.00000e-02 4.42607e+01 4.42607e+01 4.42607e+00 1.00000e-09 7.00000e-02 4.42607e+01 4.42607e+01 4.42607e+00 1.00000e-09 7.00000e-02 5.00000e-04 5.00000e-04 5.00000e-05 1.00000e-09 1.00000e-01 5.00000e-04 5.00000e-04 5.00000e-05 1.00000e-09 1.00000e-01

$1.76849 \mathrm{e}+001.76849 \mathrm{e}+00$ 1.76849e-01 1.00000e-09 2.12000e-01

$1.76849 \mathrm{e}+001.76849 \mathrm{e}+00$ 1.76849e-01 1.00000e-09 2.12000e-01

$1.76849 \mathrm{e}+001.76849 \mathrm{e}+00$ 1.76849e-01 1.00000e-09 2.12000e-01

$1.76849 \mathrm{e}+00$ 1.76849e+00 1.76849e-01 1.00000e-09 2.12000e-01

$1.76849 \mathrm{e}+001.76849 \mathrm{e}+00 \quad 1.76849 \mathrm{e}-01$ 1.00000e-09 2.12000e-01 $1.00000 \mathrm{e}-02$ 1.00000e-02 1.00000e-03 1.00000e-09 1.00000e-01 $1.00000 \mathrm{e}+001.00000 \mathrm{e}+001.00000 \mathrm{e}-011.00000 \mathrm{e}-091.00000 \mathrm{e}-01$ $1.00000 \mathrm{e}-05$ 1.00000e-05 1.00000e-06 1.00000e-09 1.00000e-01 $1.00000 \mathrm{e}+001.00000 \mathrm{e}+001.00000 \mathrm{e}-011.00000 \mathrm{e}-091.00000 \mathrm{e}-01$ Element: 2315 \# of layers: 14

$\mathrm{Kx} \mathrm{Ky} \mathrm{Kz}$ Ss Por

4.42607e+01 4.42607e+01 4.42607e+00 1.00000e-09 7.00000e-02 4.42607e+01 4.42607e+01 4.42607e+00 1.00000e-09 7.00000e-02 4.42607e+01 4.42607e+01 4.42607e+00 1.00000e-09 7.00000e-02 5.00000e-04 5.00000e-04 5.00000e-05 1.00000e-09 1.00000e-01 5.00000e-04 5.00000e-04 5.00000e-05 1.00000e-09 1.00000e-01

$1.76849 \mathrm{e}+001.76849 \mathrm{e}+00$ 1.76849e-01 1.00000e-09 2.12000e-01

$1.76849 \mathrm{e}+00$ 1.76849e+00 1.76849e-01 1.00000e-09 2.12000e-01

$1.76849 \mathrm{e}+00$ 1.76849e+00 1.76849e-01 1.00000e-09 2.12000e-01

$1.76849 \mathrm{e}+00$ 1.76849e+00 1.76849e-01 1.00000e-09 2.12000e-01

$1.76849 \mathrm{e}+001.76849 \mathrm{e}+00$ 1.76849e-01 1.00000e-09 2.12000e-01 1.00000e-02 1.00000e-02 1.00000e-03 1.00000e-09 1.00000e-01 $1.00000 \mathrm{e}+001.00000 \mathrm{e}+001.00000 \mathrm{e}-011.00000 \mathrm{e}-091.00000 \mathrm{e}-01$ 1.00000e-05 1.00000e-05 1.00000e-06 1.00000e-09 1.00000e-01 $1.00000 \mathrm{e}+001.00000 \mathrm{e}+001.00000 \mathrm{e}-011.00000 \mathrm{e}-091.00000 \mathrm{e}-01$ Element: 2316 \# of layers: 15

$\mathrm{Kx} \mathrm{Ky} \mathrm{Kz}$ Ss Por

4.42607e+01 4.42607e+01 4.42607e+00 1.00000e-09 7.00000e-02 4.42607e+01 4.42607e+01 4.42607e+00 1.00000e-09 7.00000e-02 4.42607e+01 4.42607e+01 4.42607e+00 1.00000e-09 7.00000e-02 4.42607e+01 4.42607e+01 4.42607e+00 1.00000e-09 7.00000e-02 5.00000e-04 5.00000e-04 5.00000e-05 1.00000e-09 1.00000e-01 5.00000e-04 5.00000e-04 5.00000e-05 1.00000e-09 1.00000e-01 $1.76849 \mathrm{e}+001.76849 \mathrm{e}+00$ 1.76849e-01 1.00000e-09 2.12000e-01 
$1.76849 \mathrm{e}+001.76849 \mathrm{e}+00$ 1.76849e-01 1.00000e-09 2.12000e-01 $1.76849 \mathrm{e}+001.76849 \mathrm{e}+001.76849 \mathrm{e}-011.00000 \mathrm{e}-092.12000 \mathrm{e}-01$ $1.76849 \mathrm{e}+001.76849 \mathrm{e}+00$ 1.76849e-01 1.00000e-09 2.12000e-01 $1.76849 \mathrm{e}+001.76849 \mathrm{e}+001.76849 \mathrm{e}-011.00000 \mathrm{e}-09$ 2.12000e-01 $1.00000 \mathrm{e}-02$ 1.00000e-02 1.00000e-03 1.00000e-09 1.00000e-01 $1.00000 \mathrm{e}+001.00000 \mathrm{e}+001.00000 \mathrm{e}-011.00000 \mathrm{e}-091.00000 \mathrm{e}-01$ $1.00000 \mathrm{e}-051.00000 \mathrm{e}-05$ 1.00000e-06 1.00000e-09 1.00000e-01 $1.00000 \mathrm{e}+001.00000 \mathrm{e}+001.00000 \mathrm{e}-011.00000 \mathrm{e}-091.00000 \mathrm{e}-01$ Element: 2317 \# of layers: 14

Kx Ky Kz Ss Por

$4.42607 \mathrm{e}+01$ 4.42607e+01 4.42607e+00 1.00000e-09 7.00000e-02 $4.42607 \mathrm{e}+014.42607 \mathrm{e}+014.42607 \mathrm{e}+001.00000 \mathrm{e}-09$ 7.00000e-02 $4.42607 \mathrm{e}+014.42607 \mathrm{e}+014.42607 \mathrm{e}+001.00000 \mathrm{e}-097.00000 \mathrm{e}-02$ 5.00000e-04 5.00000e-04 5.00000e-05 1.00000e-09 1.00000e-01 $5.00000 \mathrm{e}-04$ 5.00000e-04 5.00000e-05 1.00000e-09 1.00000e-01 $1.76849 \mathrm{e}+001.76849 \mathrm{e}+00$ 1.76849e-01 1.00000e-09 2.12000e-01 $1.76849 \mathrm{e}+001.76849 \mathrm{e}+00$ 1.76849e-01 1.00000e-09 2.12000e-01 $1.76849 \mathrm{e}+001.76849 \mathrm{e}+00$ 1.76849e-01 1.00000e-09 2.12000e-01 $1.76849 \mathrm{e}+001.76849 \mathrm{e}+001.76849 \mathrm{e}-011.00000 \mathrm{e}-092.12000 \mathrm{e}-01$ $1.76849 \mathrm{e}+001.76849 \mathrm{e}+00$ 1.76849e-01 1.00000e-09 2.12000e-01 $1.00000 \mathrm{e}-021.00000 \mathrm{e}-02$ 1.00000e-03 1.00000e-09 1.00000e-01 $1.00000 \mathrm{e}+001.00000 \mathrm{e}+001.00000 \mathrm{e}-011.00000 \mathrm{e}-091.00000 \mathrm{e}-01$ $1.00000 \mathrm{e}-05$ 1.00000e-05 1.00000e-06 1.00000e-09 1.00000e-01 $1.00000 \mathrm{e}+001.00000 \mathrm{e}+001.00000 \mathrm{e}-011.00000 \mathrm{e}-091.00000 \mathrm{e}-01$ Element: 2318 \# of layers: 14

Kx Ky Kz Ss Por

4.79242e+01 4.79242e+01 4.79242e+00 1.00000e-09 7.00000e-02 $4.79242 \mathrm{e}+014.79242 \mathrm{e}+014.79242 \mathrm{e}+001.00000 \mathrm{e}-09$ 7.00000e-02 $4.79242 \mathrm{e}+014.79242 \mathrm{e}+014.79242 \mathrm{e}+001.00000 \mathrm{e}-09$ 7.00000e-02 5.00000e-04 5.00000e-04 5.00000e-05 1.00000e-09 1.00000e-01 5.00000e-04 5.00000e-04 5.00000e-05 1.00000e-09 1.00000e-01 $1.91488 \mathrm{e}+001.91488 \mathrm{e}+001.91488 \mathrm{e}-011.00000 \mathrm{e}-092.12000 \mathrm{e}-01$ $1.91488 \mathrm{e}+001.91488 \mathrm{e}+00$ 1.91488e-01 1.00000e-09 2.12000e-01 $1.91488 \mathrm{e}+001.91488 \mathrm{e}+00$ 1.91488e-01 1.00000e-09 2.12000e-01 $1.91488 \mathrm{e}+001.91488 \mathrm{e}+00$ 1.91488e-01 1.00000e-09 2.12000e-01 $1.91488 \mathrm{e}+001.91488 \mathrm{e}+00$ 1.91488e-01 1.00000e-09 2.12000e-01 $1.00000 \mathrm{e}-021.00000 \mathrm{e}-02$ 1.00000e-03 1.00000e-09 1.00000e-01 $1.00000 \mathrm{e}+001.00000 \mathrm{e}+001.00000 \mathrm{e}-011.00000 \mathrm{e}-091.00000 \mathrm{e}-01$ $1.00000 \mathrm{e}-05$ 1.00000e-05 1.00000e-06 1.00000e-09 1.00000e-01 $1.00000 \mathrm{e}+001.00000 \mathrm{e}+001.00000 \mathrm{e}-011.00000 \mathrm{e}-091.00000 \mathrm{e}-01$ Element: 2319 \# of layers: 15

Kx Ky Kz Ss Por

4.79242e+01 4.79242e+01 4.79242e+00 1.00000e-09 7.00000e-02 4.79242e+01 4.79242e+01 4.79242e+00 1.00000e-09 7.00000e-02 $4.79242 \mathrm{e}+014.79242 \mathrm{e}+014.79242 \mathrm{e}+001.00000 \mathrm{e}-09$ 7.00000e-02 $4.79242 \mathrm{e}+014.79242 \mathrm{e}+014.79242 \mathrm{e}+001.00000 \mathrm{e}-09$ 7.00000e-02 
5.00000e-04 5.00000e-04 5.00000e-05 1.00000e-09 1.00000e-01 5.00000e-04 5.00000e-04 5.00000e-05 1.00000e-09 1.00000e-01 $1.91488 \mathrm{e}+00$ 1.91488e+00 1.91488e-01 1.00000e-09 2.12000e-01 $1.91488 \mathrm{e}+00$ 1.91488e+00 1.91488e-01 1.00000e-09 2.12000e-01 $1.91488 \mathrm{e}+001.91488 \mathrm{e}+00$ 1.91488e-01 1.00000e-09 2.12000e-01 $1.91488 \mathrm{e}+001.91488 \mathrm{e}+00$ 1.91488e-01 1.00000e-09 2.12000e-01 $1.91488 \mathrm{e}+001.91488 \mathrm{e}+00$ 1.91488e-01 1.00000e-09 2.12000e-01 $1.00000 \mathrm{e}-02$ 1.00000e-02 1.00000e-03 1.00000e-09 1.00000e-01 $1.00000 \mathrm{e}+001.00000 \mathrm{e}+001.00000 \mathrm{e}-011.00000 \mathrm{e}-091.00000 \mathrm{e}-01$ $1.00000 \mathrm{e}-05$ 1.00000e-05 1.00000e-06 1.00000e-09 1.00000e-01 $1.00000 \mathrm{e}+001.00000 \mathrm{e}+001.00000 \mathrm{e}-011.00000 \mathrm{e}-091.00000 \mathrm{e}-01$ Element: 2320 \# of layers: 14

$\mathrm{Kx} \mathrm{Ky} \mathrm{Kz}$ Ss Por

4.79242e+01 4.79242e+01 4.79242e+00 1.00000e-09 7.00000e-02 4.79242e+01 4.79242e+01 4.79242e+00 1.00000e-09 7.00000e-02 $4.79242 \mathrm{e}+014.79242 \mathrm{e}+014.79242 \mathrm{e}+00$ 1.00000e-09 7.00000e-02 5.00000e-04 5.00000e-04 5.00000e-05 1.00000e-09 1.00000e-01 5.00000e-04 5.00000e-04 5.00000e-05 1.00000e-09 1.00000e-01 $1.91488 \mathrm{e}+001.91488 \mathrm{e}+00$ 1.91488e-01 1.00000e-09 2.12000e-01 $1.91488 \mathrm{e}+00$ 1.91488e+00 1.91488e-01 1.00000e-09 2.12000e-01 $1.91488 \mathrm{e}+001.91488 \mathrm{e}+00$ 1.91488e-01 1.00000e-09 2.12000e-01 $1.91488 \mathrm{e}+001.91488 \mathrm{e}+00$ 1.91488e-01 1.00000e-09 2.12000e-01 $1.91488 \mathrm{e}+001.91488 \mathrm{e}+00$ 1.91488e-01 1.00000e-09 2.12000e-01 $1.00000 \mathrm{e}-02$ 1.00000e-02 1.00000e-03 1.00000e-09 1.00000e-01 $1.00000 \mathrm{e}+001.00000 \mathrm{e}+001.00000 \mathrm{e}-011.00000 \mathrm{e}-091.00000 \mathrm{e}-01$ $1.00000 \mathrm{e}-05$ 1.00000e-05 1.00000e-06 1.00000e-09 1.00000e-01 $1.00000 \mathrm{e}+001.00000 \mathrm{e}+001.00000 \mathrm{e}-011.00000 \mathrm{e}-091.00000 \mathrm{e}-01$ Element: 2321 \# of layers: 14

$\mathrm{Kx} \mathrm{Ky} \mathrm{Kz}$ Ss Por

4.79242e+01 4.79242e+01 4.79242e+00 1.00000e-09 7.00000e-02 4.79242e+01 4.79242e+01 4.79242e+00 1.00000e-09 7.00000e-02 4.79242e+01 4.79242e+01 4.79242e+00 1.00000e-09 7.00000e-02 5.00000e-04 5.00000e-04 5.00000e-05 1.00000e-09 1.00000e-01 5.00000e-04 5.00000e-04 5.00000e-05 1.00000e-09 1.00000e-01 $1.91488 \mathrm{e}+001.91488 \mathrm{e}+00$ 1.91488e-01 1.00000e-09 2.12000e-01 $1.91488 \mathrm{e}+001.91488 \mathrm{e}+00$ 1.91488e-01 1.00000e-09 2.12000e-01 $1.91488 \mathrm{e}+001.91488 \mathrm{e}+00$ 1.91488e-01 1.00000e-09 2.12000e-01 $1.91488 \mathrm{e}+001.91488 \mathrm{e}+00$ 1.91488e-01 1.00000e-09 2.12000e-01 $1.91488 \mathrm{e}+00$ 1.91488e+00 1.91488e-01 1.00000e-09 2.12000e-01 $1.00000 \mathrm{e}-02$ 1.00000e-02 1.00000e-03 1.00000e-09 1.00000e-01 $1.00000 \mathrm{e}+001.00000 \mathrm{e}+001.00000 \mathrm{e}-011.00000 \mathrm{e}-091.00000 \mathrm{e}-01$ $1.00000 \mathrm{e}-05$ 1.00000e-05 1.00000e-06 1.00000e-09 1.00000e-01 $1.00000 \mathrm{e}+001.00000 \mathrm{e}+001.00000 \mathrm{e}-011.00000 \mathrm{e}-091.00000 \mathrm{e}-01$ Element: 2322 \# of layers: 14

$\mathrm{Kx} \mathrm{Ky} \mathrm{Kz}$ Ss Por

4.79242e+01 4.79242e+01 4.79242e+00 1.00000e-09 7.00000e-02 
4.79242e+01 4.79242e+01 4.79242e+00 1.00000e-09 7.00000e-02 4.79242e+01 4.79242e+01 4.79242e+00 1.00000e-09 7.00000e-02 5.00000e-04 5.00000e-04 5.00000e-05 1.00000e-09 1.00000e-01 5.00000e-04 5.00000e-04 5.00000e-05 1.00000e-09 1.00000e-01 $1.91488 \mathrm{e}+001.91488 \mathrm{e}+00$ 1.91488e-01 1.00000e-09 2.12000e-01 $1.91488 \mathrm{e}+001.91488 \mathrm{e}+00$ 1.91488e-01 1.00000e-09 2.12000e-01 $1.91488 \mathrm{e}+00$ 1.91488e+00 1.91488e-01 1.00000e-09 2.12000e-01 $1.91488 \mathrm{e}+00$ 1.91488e+00 1.91488e-01 1.00000e-09 2.12000e-01 $1.91488 \mathrm{e}+00$ 1.91488e+00 1.91488e-01 1.00000e-09 2.12000e-01 $1.00000 \mathrm{e}-02$ 1.00000e-02 1.00000e-03 1.00000e-09 1.00000e-01 $1.00000 \mathrm{e}+001.00000 \mathrm{e}+001.00000 \mathrm{e}-011.00000 \mathrm{e}-091.00000 \mathrm{e}-01$ $1.00000 \mathrm{e}-05$ 1.00000e-05 1.00000e-06 1.00000e-09 1.00000e-01 $1.00000 \mathrm{e}+001.00000 \mathrm{e}+001.00000 \mathrm{e}-011.00000 \mathrm{e}-091.00000 \mathrm{e}-01$ Element: 2323 \# of layers: 15

$\mathrm{Kx} \mathrm{Ky} \mathrm{Kz}$ Ss Por

4.79242e+01 4.79242e+01 4.79242e+00 1.00000e-09 7.00000e-02 4.79242e+01 4.79242e+01 4.79242e+00 1.00000e-09 7.00000e-02 4.79242e+01 4.79242e+01 4.79242e+00 1.00000e-09 7.00000e-02 4.79242e+01 4.79242e+01 4.79242e+00 1.00000e-09 7.00000e-02 5.00000e-04 5.00000e-04 5.00000e-05 1.00000e-09 1.00000e-01 5.00000e-04 5.00000e-04 5.00000e-05 1.00000e-09 1.00000e-01 $1.91488 \mathrm{e}+00$ 1.91488e+00 1.91488e-01 1.00000e-09 2.12000e-01 $1.91488 \mathrm{e}+001.91488 \mathrm{e}+00$ 1.91488e-01 1.00000e-09 2.12000e-01 $1.91488 \mathrm{e}+001.91488 \mathrm{e}+00$ 1.91488e-01 1.00000e-09 2.12000e-01 $1.91488 \mathrm{e}+001.91488 \mathrm{e}+00$ 1.91488e-01 1.00000e-09 2.12000e-01 $1.91488 \mathrm{e}+001.91488 \mathrm{e}+00$ 1.91488e-01 1.00000e-09 2.12000e-01 $1.00000 \mathrm{e}-02$ 1.00000e-02 1.00000e-03 1.00000e-09 1.00000e-01 $1.00000 \mathrm{e}+001.00000 \mathrm{e}+001.00000 \mathrm{e}-011.00000 \mathrm{e}-091.00000 \mathrm{e}-01$ $1.00000 \mathrm{e}-05$ 1.00000e-05 1.00000e-06 1.00000e-09 1.00000e-01 $1.00000 \mathrm{e}+001.00000 \mathrm{e}+001.00000 \mathrm{e}-011.00000 \mathrm{e}-091.00000 \mathrm{e}-01$ Element: 2324 \# of layers: 14

$\mathrm{Kx} \mathrm{Ky} \mathrm{Kz}$ Ss Por

4.79242e+01 4.79242e+01 4.79242e+00 1.00000e-09 7.00000e-02 4.79242e+01 4.79242e+01 4.79242e+00 1.00000e-09 7.00000e-02 4.79242e+01 4.79242e+01 4.79242e+00 1.00000e-09 7.00000e-02 5.00000e-04 5.00000e-04 5.00000e-05 1.00000e-09 1.00000e-01 5.00000e-04 5.00000e-04 5.00000e-05 1.00000e-09 1.00000e-01 $1.91488 \mathrm{e}+001.91488 \mathrm{e}+00$ 1.91488e-01 1.00000e-09 2.12000e-01 $1.91488 \mathrm{e}+00$ 1.91488e+00 1.91488e-01 1.00000e-09 2.12000e-01 $1.91488 \mathrm{e}+00$ 1.91488e+00 1.91488e-01 1.00000e-09 2.12000e-01 $1.91488 \mathrm{e}+001.91488 \mathrm{e}+00$ 1.91488e-01 1.00000e-09 2.12000e-01 $1.91488 \mathrm{e}+001.91488 \mathrm{e}+00$ 1.91488e-01 1.00000e-09 2.12000e-01 $1.00000 \mathrm{e}-02$ 1.00000e-02 1.00000e-03 1.00000e-09 1.00000e-01 $1.00000 \mathrm{e}+001.00000 \mathrm{e}+001.00000 \mathrm{e}-011.00000 \mathrm{e}-091.00000 \mathrm{e}-01$ $1.00000 \mathrm{e}-05$ 1.00000e-05 1.00000e-06 1.00000e-09 1.00000e-01 $1.00000 \mathrm{e}+001.00000 \mathrm{e}+001.00000 \mathrm{e}-011.00000 \mathrm{e}-091.00000 \mathrm{e}-01$ 
Element: 2325 \# of layers: 14

$\mathrm{Kx} \mathrm{Ky} \mathrm{Kz}$ Ss Por

4.79242e+01 4.79242e+01 4.79242e+00 1.00000e-09 7.00000e-02

$4.79242 \mathrm{e}+01$ 4.79242e+01 4.79242e+00 1.00000e-09 7.00000e-02

4.79242e+01 4.79242e+01 4.79242e+00 1.00000e-09 7.00000e-02

5.00000e-04 5.00000e-04 5.00000e-05 1.00000e-09 1.00000e-01

5.00000e-04 5.00000e-04 5.00000e-05 1.00000e-09 1.00000e-01

$1.91488 \mathrm{e}+00$ 1.91488e+00 1.91488e-01 1.00000e-09 2.12000e-01

$1.91488 \mathrm{e}+00$ 1.91488e+00 1.91488e-01 1.00000e-09 2.12000e-01

$1.91488 \mathrm{e}+001.91488 \mathrm{e}+00$ 1.91488e-01 1.00000e-09 2.12000e-01

$1.91488 \mathrm{e}+00$ 1.91488e+00 1.91488e-01 1.00000e-09 2.12000e-01

$1.91488 \mathrm{e}+001.91488 \mathrm{e}+00$ 1.91488e-01 1.00000e-09 2.12000e-01

$1.00000 \mathrm{e}-02$ 1.00000e-02 1.00000e-03 1.00000e-09 1.00000e-01

$1.00000 \mathrm{e}+001.00000 \mathrm{e}+001.00000 \mathrm{e}-011.00000 \mathrm{e}-091.00000 \mathrm{e}-01$

$1.00000 \mathrm{e}-05$ 1.00000e-05 1.00000e-06 1.00000e-09 1.00000e-01

$1.00000 \mathrm{e}+001.00000 \mathrm{e}+001.00000 \mathrm{e}-011.00000 \mathrm{e}-091.00000 \mathrm{e}-01$

Element: 2326 \# of layers: 15

$\mathrm{Kx} \mathrm{Ky} \mathrm{Kz}$ Ss Por

4.79242e+01 4.79242e+01 4.79242e+00 1.00000e-09 7.00000e-02

4.79242e+01 4.79242e+01 4.79242e+00 1.00000e-09 7.00000e-02

$4.79242 \mathrm{e}+014.79242 \mathrm{e}+014.79242 \mathrm{e}+00$ 1.00000e-09 7.00000e-02

4.79242e+01 4.79242e+01 4.79242e+00 1.00000e-09 7.00000e-02

$5.00000 \mathrm{e}-04$ 5.00000e-04 5.00000e-05 1.00000e-09 1.00000e-01

5.00000e-04 5.00000e-04 5.00000e-05 1.00000e-09 1.00000e-01

$1.91488 \mathrm{e}+001.91488 \mathrm{e}+00$ 1.91488e-01 1.00000e-09 2.12000e-01

$1.91488 \mathrm{e}+001.91488 \mathrm{e}+00$ 1.91488e-01 1.00000e-09 2.12000e-01

$1.91488 \mathrm{e}+001.91488 \mathrm{e}+00$ 1.91488e-01 1.00000e-09 2.12000e-01

$1.91488 \mathrm{e}+001.91488 \mathrm{e}+00$ 1.91488e-01 1.00000e-09 2.12000e-01

$1.91488 \mathrm{e}+001.91488 \mathrm{e}+00$ 1.91488e-01 1.00000e-09 2.12000e-01

$1.00000 \mathrm{e}-02$ 1.00000e-02 1.00000e-03 1.00000e-09 1.00000e-01

$1.00000 \mathrm{e}+001.00000 \mathrm{e}+001.00000 \mathrm{e}-01$ 1.00000e-09 1.00000e-01

$1.00000 \mathrm{e}-05$ 1.00000e-05 1.00000e-06 1.00000e-09 1.00000e-01

$1.00000 \mathrm{e}+001.00000 \mathrm{e}+001.00000 \mathrm{e}-011.00000 \mathrm{e}-091.00000 \mathrm{e}-01$

Element: 2327 \# of layers: 14

$\mathrm{Kx} \mathrm{Ky} \mathrm{Kz}$ Ss Por

3.96125e+01 3.96125e+01 3.96125e+00 1.00000e-09 7.00000e-02

$3.96125 \mathrm{e}+013.96125 \mathrm{e}+013.96125 \mathrm{e}+001.00000 \mathrm{e}-09$ 7.00000e-02

$3.96125 \mathrm{e}+013.96125 \mathrm{e}+013.96125 \mathrm{e}+001.00000 \mathrm{e}-09$ 7.00000e-02

5.00000e-04 5.00000e-04 5.00000e-05 1.00000e-09 1.00000e-01

5.00000e-04 5.00000e-04 5.00000e-05 1.00000e-09 1.00000e-01

$1.58277 \mathrm{e}+001.58277 \mathrm{e}+00$ 1.58277e-01 1.00000e-09 2.12000e-01

$1.58277 \mathrm{e}+001.58277 \mathrm{e}+00$ 1.58277e-01 1.00000e-09 2.12000e-01

$1.58277 \mathrm{e}+00$ 1.58277e+00 1.58277e-01 1.00000e-09 2.12000e-01

$1.58277 \mathrm{e}+00$ 1.58277e+00 1.58277e-01 1.00000e-09 2.12000e-01

$1.58277 \mathrm{e}+001.58277 \mathrm{e}+00$ 1.58277e-01 1.00000e-09 2.12000e-01

$1.00000 \mathrm{e}-02$ 1.00000e-02 1.00000e-03 1.00000e-09 1.00000e-01 
$1.00000 \mathrm{e}+001.00000 \mathrm{e}+001.00000 \mathrm{e}-011.00000 \mathrm{e}-091.00000 \mathrm{e}-01$ $1.00000 \mathrm{e}-05$ 1.00000e-05 1.00000e-06 1.00000e-09 1.00000e-01 $1.00000 \mathrm{e}+001.00000 \mathrm{e}+001.00000 \mathrm{e}-011.00000 \mathrm{e}-091.00000 \mathrm{e}-01$ Element: 2328 \# of layers: 13

$\mathrm{Kx} \mathrm{Ky} \mathrm{Kz}$ Ss Por

3.96125e+01 3.96125e+01 3.96125e+00 1.00000e-09 7.00000e-02 $3.96125 \mathrm{e}+013.96125 \mathrm{e}+013.96125 \mathrm{e}+001.00000 \mathrm{e}-09$ 7.00000e-02 5.00000e-04 5.00000e-04 5.00000e-05 1.00000e-09 1.00000e-01 5.00000e-04 5.00000e-04 5.00000e-05 1.00000e-09 1.00000e-01 $1.58277 \mathrm{e}+001.58277 \mathrm{e}+00$ 1.58277e-01 1.00000e-09 2.12000e-01 $1.58277 \mathrm{e}+001.58277 \mathrm{e}+00$ 1.58277e-01 1.00000e-09 2.12000e-01 $1.58277 \mathrm{e}+001.58277 \mathrm{e}+00$ 1.58277e-01 1.00000e-09 2.12000e-01 $1.58277 \mathrm{e}+001.58277 \mathrm{e}+00$ 1.58277e-01 1.00000e-09 2.12000e-01 $1.58277 \mathrm{e}+001.58277 \mathrm{e}+00$ 1.58277e-01 1.00000e-09 2.12000e-01 $1.00000 \mathrm{e}-02$ 1.00000e-02 1.00000e-03 1.00000e-09 1.00000e-01 $1.00000 \mathrm{e}+001.00000 \mathrm{e}+001.00000 \mathrm{e}-011.00000 \mathrm{e}-091.00000 \mathrm{e}-01$ $1.00000 \mathrm{e}-05$ 1.00000e-05 1.00000e-06 1.00000e-09 1.00000e-01 $1.00000 \mathrm{e}+001.00000 \mathrm{e}+001.00000 \mathrm{e}-01$ 1.00000e-09 1.00000e-01 Element: 2329 \# of layers: 13

$\mathrm{Kx} \mathrm{Ky} \mathrm{Kz}$ Ss Por

3.96125e+01 3.96125e+01 3.96125e+00 1.00000e-09 7.00000e-02 $3.96125 \mathrm{e}+013.96125 \mathrm{e}+013.96125 \mathrm{e}+001.00000 \mathrm{e}-09$ 7.00000e-02 5.00000e-04 5.00000e-04 5.00000e-05 1.00000e-09 1.00000e-01 5.00000e-04 5.00000e-04 5.00000e-05 1.00000e-09 1.00000e-01 $1.58277 \mathrm{e}+001.58277 \mathrm{e}+001.58277 \mathrm{e}-011.00000 \mathrm{e}-092.12000 \mathrm{e}-01$ $1.58277 \mathrm{e}+00$ 1.58277e+00 1.58277e-01 1.00000e-09 2.12000e-01 $1.58277 \mathrm{e}+001.58277 \mathrm{e}+00$ 1.58277e-01 1.00000e-09 2.12000e-01 $1.58277 \mathrm{e}+001.58277 \mathrm{e}+00$ 1.58277e-01 1.00000e-09 2.12000e-01 $1.58277 \mathrm{e}+001.58277 \mathrm{e}+00$ 1.58277e-01 1.00000e-09 2.12000e-01 $1.00000 \mathrm{e}-02$ 1.00000e-02 1.00000e-03 1.00000e-09 1.00000e-01 $1.00000 \mathrm{e}+001.00000 \mathrm{e}+001.00000 \mathrm{e}-01$ 1.00000e-09 1.00000e-01 $1.00000 \mathrm{e}-05$ 1.00000e-05 1.00000e-06 1.00000e-09 1.00000e-01 $1.00000 \mathrm{e}+001.00000 \mathrm{e}+001.00000 \mathrm{e}-011.00000 \mathrm{e}-091.00000 \mathrm{e}-01$ Element: 2330 \# of layers: 13

$\mathrm{Kx} \mathrm{Ky} \mathrm{Kz}$ Ss Por

3.96125e+01 3.96125e+01 3.96125e+00 1.00000e-09 7.00000e-02 $3.96125 \mathrm{e}+013.96125 \mathrm{e}+013.96125 \mathrm{e}+001.00000 \mathrm{e}-09$ 7.00000e-02 5.00000e-04 5.00000e-04 5.00000e-05 1.00000e-09 1.00000e-01 5.00000e-04 5.00000e-04 5.00000e-05 1.00000e-09 1.00000e-01 $1.58277 \mathrm{e}+001.58277 \mathrm{e}+00$ 1.58277e-01 1.00000e-09 2.12000e-01 $1.58277 \mathrm{e}+001.58277 \mathrm{e}+00$ 1.58277e-01 1.00000e-09 2.12000e-01 $1.58277 \mathrm{e}+001.58277 \mathrm{e}+00$ 1.58277e-01 1.00000e-09 2.12000e-01 $1.58277 \mathrm{e}+00$ 1.58277e+00 1.58277e-01 1.00000e-09 2.12000e-01 $1.58277 \mathrm{e}+001.58277 \mathrm{e}+001.58277 \mathrm{e}-01$ 1.00000e-09 2.12000e-01 1.00000e-02 1.00000e-02 1.00000e-03 1.00000e-09 1.00000e-01 $1.00000 \mathrm{e}+001.00000 \mathrm{e}+001.00000 \mathrm{e}-011.00000 \mathrm{e}-091.00000 \mathrm{e}-01$ 
$1.00000 \mathrm{e}-05$ 1.00000e-05 1.00000e-06 1.00000e-09 1.00000e-01 $1.00000 \mathrm{e}+001.00000 \mathrm{e}+001.00000 \mathrm{e}-01$ 1.00000e-09 1.00000e-01 Element: 2331 \# of layers: 13

Kx Ky Kz Ss Por

3.96125e+01 3.96125e+01 3.96125e+00 1.00000e-09 7.00000e-02 $3.96125 \mathrm{e}+013.96125 \mathrm{e}+013.96125 \mathrm{e}+00$ 1.00000e-09 7.00000e-02 5.00000e-04 5.00000e-04 5.00000e-05 1.00000e-09 1.00000e-01 5.00000e-04 5.00000e-04 5.00000e-05 1.00000e-09 1.00000e-01 $1.58277 \mathrm{e}+001.58277 \mathrm{e}+00$ 1.58277e-01 1.00000e-09 2.12000e-01 $1.58277 \mathrm{e}+001.58277 \mathrm{e}+00$ 1.58277e-01 1.00000e-09 2.12000e-01 $1.58277 \mathrm{e}+00$ 1.58277e+00 1.58277e-01 1.00000e-09 2.12000e-01 $1.58277 \mathrm{e}+001.58277 \mathrm{e}+00$ 1.58277e-01 1.00000e-09 2.12000e-01 $1.58277 \mathrm{e}+001.58277 \mathrm{e}+00$ 1.58277e-01 1.00000e-09 2.12000e-01 $1.00000 \mathrm{e}-02$ 1.00000e-02 1.00000e-03 1.00000e-09 1.00000e-01 $1.00000 \mathrm{e}+001.00000 \mathrm{e}+001.00000 \mathrm{e}-011.00000 \mathrm{e}-091.00000 \mathrm{e}-01$ $1.00000 \mathrm{e}-05$ 1.00000e-05 1.00000e-06 1.00000e-09 1.00000e-01 $1.00000 \mathrm{e}+001.00000 \mathrm{e}+001.00000 \mathrm{e}-011.00000 \mathrm{e}-091.00000 \mathrm{e}-01$ Element: 2332 \# of layers: 13

$\mathrm{Kx} \mathrm{Ky} \mathrm{Kz}$ Ss Por

3.96125e+01 3.96125e+01 3.96125e+00 1.00000e-09 7.00000e-02 $3.96125 \mathrm{e}+013.96125 \mathrm{e}+013.96125 \mathrm{e}+001.00000 \mathrm{e}-09$ 7.00000e-02 5.00000e-04 5.00000e-04 5.00000e-05 1.00000e-09 1.00000e-01 5.00000e-04 5.00000e-04 5.00000e-05 1.00000e-09 1.00000e-01 $1.58277 \mathrm{e}+001.58277 \mathrm{e}+00$ 1.58277e-01 1.00000e-09 2.12000e-01 $1.58277 \mathrm{e}+001.58277 \mathrm{e}+00$ 1.58277e-01 1.00000e-09 2.12000e-01 $1.58277 \mathrm{e}+001.58277 \mathrm{e}+00$ 1.58277e-01 1.00000e-09 2.12000e-01 $1.58277 \mathrm{e}+001.58277 \mathrm{e}+00$ 1.58277e-01 1.00000e-09 2.12000e-01 $1.58277 \mathrm{e}+001.58277 \mathrm{e}+00$ 1.58277e-01 1.00000e-09 2.12000e-01 $1.00000 \mathrm{e}-02$ 1.00000e-02 1.00000e-03 1.00000e-09 1.00000e-01 $1.00000 \mathrm{e}+001.00000 \mathrm{e}+001.00000 \mathrm{e}-011.00000 \mathrm{e}-091.00000 \mathrm{e}-01$ $1.00000 \mathrm{e}-05$ 1.00000e-05 1.00000e-06 1.00000e-09 1.00000e-01 $1.00000 \mathrm{e}+001.00000 \mathrm{e}+001.00000 \mathrm{e}-01$ 1.00000e-09 1.00000e-01 Element: 2333 \# of layers: 14

$\mathrm{Kx} \mathrm{Ky} \mathrm{Kz}$ Ss Por

3.96125e+01 3.96125e+01 3.96125e+00 1.00000e-09 7.00000e-02 $3.96125 \mathrm{e}+013.96125 \mathrm{e}+013.96125 \mathrm{e}+001.00000 \mathrm{e}-09$ 7.00000e-02 $3.96125 \mathrm{e}+013.96125 \mathrm{e}+013.96125 \mathrm{e}+001.00000 \mathrm{e}-09$ 7.00000e-02 5.00000e-04 5.00000e-04 5.00000e-05 1.00000e-09 1.00000e-01 5.00000e-04 5.00000e-04 5.00000e-05 1.00000e-09 1.00000e-01 $1.58277 \mathrm{e}+001.58277 \mathrm{e}+00$ 1.58277e-01 1.00000e-09 2.12000e-01 $1.58277 \mathrm{e}+001.58277 \mathrm{e}+00$ 1.58277e-01 1.00000e-09 2.12000e-01 $1.58277 \mathrm{e}+001.58277 \mathrm{e}+00$ 1.58277e-01 1.00000e-09 2.12000e-01 $1.58277 \mathrm{e}+00$ 1.58277e+00 1.58277e-01 1.00000e-09 2.12000e-01 $1.58277 \mathrm{e}+00$ 1.58277e+00 1.58277e-01 1.00000e-09 2.12000e-01 $1.00000 \mathrm{e}-02$ 1.00000e-02 1.00000e-03 1.00000e-09 1.00000e-01 $1.00000 \mathrm{e}+001.00000 \mathrm{e}+001.00000 \mathrm{e}-011.00000 \mathrm{e}-091.00000 \mathrm{e}-01$ 
$1.00000 \mathrm{e}-05$ 1.00000e-05 1.00000e-06 1.00000e-09 1.00000e-01 $1.00000 \mathrm{e}+001.00000 \mathrm{e}+001.00000 \mathrm{e}-01$ 1.00000e-09 1.00000e-01 Element: 2334 \# of layers: 14

Kx Ky Kz Ss Por

3.96125e+01 3.96125e+01 3.96125e+00 1.00000e-09 7.00000e-02 $3.96125 \mathrm{e}+013.96125 \mathrm{e}+013.96125 \mathrm{e}+00$ 1.00000e-09 7.00000e-02 $3.96125 \mathrm{e}+013.96125 \mathrm{e}+013.96125 \mathrm{e}+00$ 1.00000e-09 7.00000e-02 5.00000e-04 5.00000e-04 5.00000e-05 1.00000e-09 1.00000e-01 5.00000e-04 5.00000e-04 5.00000e-05 1.00000e-09 1.00000e-01 $1.58277 \mathrm{e}+001.58277 \mathrm{e}+00$ 1.58277e-01 1.00000e-09 2.12000e-01 $1.58277 \mathrm{e}+001.58277 \mathrm{e}+00$ 1.58277e-01 1.00000e-09 2.12000e-01 $1.58277 \mathrm{e}+001.58277 \mathrm{e}+00$ 1.58277e-01 1.00000e-09 2.12000e-01 $1.58277 \mathrm{e}+001.58277 \mathrm{e}+00$ 1.58277e-01 1.00000e-09 2.12000e-01 $1.58277 \mathrm{e}+001.58277 \mathrm{e}+00$ 1.58277e-01 1.00000e-09 2.12000e-01 $1.00000 \mathrm{e}-02$ 1.00000e-02 1.00000e-03 1.00000e-09 1.00000e-01 $1.00000 \mathrm{e}+001.00000 \mathrm{e}+001.00000 \mathrm{e}-011.00000 \mathrm{e}-091.00000 \mathrm{e}-01$ $1.00000 \mathrm{e}-05$ 1.00000e-05 1.00000e-06 1.00000e-09 1.00000e-01 $1.00000 \mathrm{e}+001.00000 \mathrm{e}+001.00000 \mathrm{e}-01$ 1.00000e-09 1.00000e-01 Element: 2335 \# of layers: 13

$\mathrm{Kx} \mathrm{Ky} \mathrm{Kz}$ Ss Por

3.96125e+01 3.96125e+01 3.96125e+00 1.00000e-09 7.00000e-02 $3.96125 \mathrm{e}+013.96125 \mathrm{e}+013.96125 \mathrm{e}+001.00000 \mathrm{e}-09$ 7.00000e-02 5.00000e-04 5.00000e-04 5.00000e-05 1.00000e-09 1.00000e-01 5.00000e-04 5.00000e-04 5.00000e-05 1.00000e-09 1.00000e-01

$1.58277 \mathrm{e}+001.58277 \mathrm{e}+001.58277 \mathrm{e}-01$ 1.00000e-09 2.12000e-01 $1.58277 \mathrm{e}+00$ 1.58277e+00 1.58277e-01 1.00000e-09 2.12000e-01 $1.58277 \mathrm{e}+001.58277 \mathrm{e}+00$ 1.58277e-01 1.00000e-09 2.12000e-01 $1.58277 \mathrm{e}+001.58277 \mathrm{e}+00$ 1.58277e-01 1.00000e-09 2.12000e-01 $1.58277 \mathrm{e}+001.58277 \mathrm{e}+00$ 1.58277e-01 1.00000e-09 2.12000e-01 $1.00000 \mathrm{e}-02$ 1.00000e-02 1.00000e-03 1.00000e-09 1.00000e-01 $1.00000 \mathrm{e}+001.00000 \mathrm{e}+001.00000 \mathrm{e}-01$ 1.00000e-09 1.00000e-01 $1.00000 \mathrm{e}-05$ 1.00000e-05 1.00000e-06 1.00000e-09 1.00000e-01 $1.00000 \mathrm{e}+001.00000 \mathrm{e}+001.00000 \mathrm{e}-011.00000 \mathrm{e}-091.00000 \mathrm{e}-01$ Element: 2336 \# of layers: 13

$\mathrm{Kx} \mathrm{Ky} \mathrm{Kz}$ Ss Por

4.96739e+01 4.96739e+01 4.96739e+00 1.00000e-09 7.00000e-02 $4.96739 \mathrm{e}+014.96739 \mathrm{e}+014.96739 \mathrm{e}+00$ 1.00000e-09 7.00000e-02 5.00000e-04 5.00000e-04 5.00000e-05 1.00000e-09 1.00000e-01 5.00000e-04 5.00000e-04 5.00000e-05 1.00000e-09 1.00000e-01 $1.98481 \mathrm{e}+001.98481 \mathrm{e}+00$ 1.98481e-01 1.00000e-09 2.12000e-01 $1.98481 \mathrm{e}+001.98481 \mathrm{e}+001.98481 \mathrm{e}-01$ 1.00000e-09 2.12000e-01 $1.98481 \mathrm{e}+001.98481 \mathrm{e}+001.98481 \mathrm{e}-01$ 1.00000e-09 2.12000e-01 $1.98481 \mathrm{e}+001.98481 \mathrm{e}+001.98481 \mathrm{e}-01$ 1.00000e-09 2.12000e-01 $1.98481 \mathrm{e}+001.98481 \mathrm{e}+00$ 1.98481e-01 1.00000e-09 2.12000e-01 $1.00000 \mathrm{e}-02$ 1.00000e-02 1.00000e-03 1.00000e-09 1.00000e-01 $1.00000 \mathrm{e}+001.00000 \mathrm{e}+001.00000 \mathrm{e}-011.00000 \mathrm{e}-091.00000 \mathrm{e}-01$ 
$1.00000 \mathrm{e}-05$ 1.00000e-05 1.00000e-06 1.00000e-09 1.00000e-01 $1.00000 \mathrm{e}+001.00000 \mathrm{e}+001.00000 \mathrm{e}-01$ 1.00000e-09 1.00000e-01 Element: 2337 \# of layers: 14

Kx Ky Kz Ss Por

4.96739e+01 4.96739e+01 4.96739e+00 1.00000e-09 7.00000e-02 $4.96739 \mathrm{e}+014.96739 \mathrm{e}+014.96739 \mathrm{e}+00$ 1.00000e-09 7.00000e-02 $4.96739 \mathrm{e}+014.96739 \mathrm{e}+014.96739 \mathrm{e}+00$ 1.00000e-09 7.00000e-02 5.00000e-04 5.00000e-04 5.00000e-05 1.00000e-09 1.00000e-01 5.00000e-04 5.00000e-04 5.00000e-05 1.00000e-09 1.00000e-01 $1.98481 \mathrm{e}+001.98481 \mathrm{e}+00$ 1.98481e-01 1.00000e-09 2.12000e-01 $1.98481 \mathrm{e}+001.98481 \mathrm{e}+00$ 1.98481e-01 1.00000e-09 2.12000e-01 $1.98481 \mathrm{e}+001.98481 \mathrm{e}+001.98481 \mathrm{e}-011.00000 \mathrm{e}-092.12000 \mathrm{e}-01$ $1.98481 \mathrm{e}+001.98481 \mathrm{e}+00$ 1.98481e-01 1.00000e-09 2.12000e-01 $1.98481 \mathrm{e}+001.98481 \mathrm{e}+001.98481 \mathrm{e}-01$ 1.00000e-09 2.12000e-01 $1.00000 \mathrm{e}-02$ 1.00000e-02 1.00000e-03 1.00000e-09 1.00000e-01 $1.00000 \mathrm{e}+001.00000 \mathrm{e}+001.00000 \mathrm{e}-011.00000 \mathrm{e}-091.00000 \mathrm{e}-01$ $1.00000 \mathrm{e}-05$ 1.00000e-05 1.00000e-06 1.00000e-09 1.00000e-01 $1.00000 \mathrm{e}+001.00000 \mathrm{e}+001.00000 \mathrm{e}-011.00000 \mathrm{e}-091.00000 \mathrm{e}-01$ Element: 2338 \# of layers: 12

$\mathrm{Kx} \mathrm{Ky} \mathrm{Kz}$ Ss Por

4.96739e+01 4.96739e+01 4.96739e+00 1.00000e-09 7.00000e-02 4.96739e+01 4.96739e+01 4.96739e+00 1.00000e-09 7.00000e-02 5.00000e-04 5.00000e-04 5.00000e-05 1.00000e-09 1.00000e-01 $1.98481 \mathrm{e}+001.98481 \mathrm{e}+001.98481 \mathrm{e}-01$ 1.00000e-09 2.12000e-01 $1.98481 \mathrm{e}+001.98481 \mathrm{e}+001.98481 \mathrm{e}-011.00000 \mathrm{e}-092.12000 \mathrm{e}-01$ $1.98481 \mathrm{e}+001.98481 \mathrm{e}+001.98481 \mathrm{e}-01$ 1.00000e-09 2.12000e-01 $1.98481 \mathrm{e}+001.98481 \mathrm{e}+001.98481 \mathrm{e}-011.00000 \mathrm{e}-092.12000 \mathrm{e}-01$ $1.98481 \mathrm{e}+001.98481 \mathrm{e}+001.98481 \mathrm{e}-01$ 1.00000e-09 2.12000e-01 $1.00000 \mathrm{e}-02$ 1.00000e-02 1.00000e-03 1.00000e-09 1.00000e-01 $1.00000 \mathrm{e}+001.00000 \mathrm{e}+001.00000 \mathrm{e}-011.00000 \mathrm{e}-091.00000 \mathrm{e}-01$ $1.00000 \mathrm{e}-05$ 1.00000e-05 1.00000e-06 1.00000e-09 1.00000e-01 $1.00000 \mathrm{e}+001.00000 \mathrm{e}+001.00000 \mathrm{e}-011.00000 \mathrm{e}-091.00000 \mathrm{e}-01$ Element: 2339 \# of layers: 12

$\mathrm{Kx} \mathrm{Ky} \mathrm{Kz}$ Ss Por

4.96739e+01 4.96739e+01 4.96739e+00 1.00000e-09 7.00000e-02 $4.96739 \mathrm{e}+014.96739 \mathrm{e}+014.96739 \mathrm{e}+00$ 1.00000e-09 7.00000e-02 5.00000e-04 5.00000e-04 5.00000e-05 1.00000e-09 1.00000e-01 $1.98481 \mathrm{e}+001.98481 \mathrm{e}+001.98481 \mathrm{e}-011.00000 \mathrm{e}-092.12000 \mathrm{e}-01$ $1.98481 \mathrm{e}+001.98481 \mathrm{e}+00$ 1.98481e-01 1.00000e-09 2.12000e-01 $1.98481 \mathrm{e}+001.98481 \mathrm{e}+00$ 1.98481e-01 1.00000e-09 2.12000e-01 $1.98481 \mathrm{e}+001.98481 \mathrm{e}+001.98481 \mathrm{e}-01$ 1.00000e-09 2.12000e-01 $1.98481 \mathrm{e}+001.98481 \mathrm{e}+001.98481 \mathrm{e}-011.00000 \mathrm{e}-092.12000 \mathrm{e}-01$ $1.00000 \mathrm{e}-021.00000 \mathrm{e}-021.00000 \mathrm{e}-031.00000 \mathrm{e}-091.00000 \mathrm{e}-01$ $1.00000 \mathrm{e}+001.00000 \mathrm{e}+001.00000 \mathrm{e}-011.00000 \mathrm{e}-091.00000 \mathrm{e}-01$ $1.00000 \mathrm{e}-05$ 1.00000e-05 1.00000e-06 1.00000e-09 1.00000e-01 $1.00000 \mathrm{e}+001.00000 \mathrm{e}+001.00000 \mathrm{e}-011.00000 \mathrm{e}-091.00000 \mathrm{e}-01$ 
Element: 2340 \# of layers: 13

$\mathrm{Kx} \mathrm{Ky} \mathrm{Kz}$ Ss Por

4.96739e+01 4.96739e+01 4.96739e+00 1.00000e-09 7.00000e-02

$4.96739 \mathrm{e}+014.96739 \mathrm{e}+014.96739 \mathrm{e}+001.00000 \mathrm{e}-09$ 7.00000e-02

5.00000e-04 5.00000e-04 5.00000e-05 1.00000e-09 1.00000e-01

5.00000e-04 5.00000e-04 5.00000e-05 1.00000e-09 1.00000e-01

$1.98481 \mathrm{e}+001.98481 \mathrm{e}+001.98481 \mathrm{e}-01$ 1.00000e-09 2.12000e-01

$1.98481 \mathrm{e}+001.98481 \mathrm{e}+001.98481 \mathrm{e}-011.00000 \mathrm{e}-092.12000 \mathrm{e}-01$

$1.98481 \mathrm{e}+001.98481 \mathrm{e}+00$ 1.98481e-01 1.00000e-09 2.12000e-01

$1.98481 \mathrm{e}+001.98481 \mathrm{e}+001.98481 \mathrm{e}-01$ 1.00000e-09 2.12000e-01

$1.98481 \mathrm{e}+001.98481 \mathrm{e}+001.98481 \mathrm{e}-01$ 1.00000e-09 2.12000e-01

$1.00000 \mathrm{e}-02$ 1.00000e-02 1.00000e-03 1.00000e-09 1.00000e-01

$1.00000 \mathrm{e}+001.00000 \mathrm{e}+001.00000 \mathrm{e}-011.00000 \mathrm{e}-091.00000 \mathrm{e}-01$

$1.00000 \mathrm{e}-05$ 1.00000e-05 1.00000e-06 1.00000e-09 1.00000e-01

$1.00000 \mathrm{e}+001.00000 \mathrm{e}+001.00000 \mathrm{e}-011.00000 \mathrm{e}-091.00000 \mathrm{e}-01$

Element: 2341 \# of layers: 14

$\mathrm{Kx} \mathrm{Ky} \mathrm{Kz}$ Ss Por

4.96739e+01 4.96739e+01 4.96739e+00 1.00000e-09 7.00000e-02 4.96739e+01 4.96739e+01 4.96739e+00 1.00000e-09 7.00000e-02

4.96739e+01 4.96739e+01 4.96739e+00 1.00000e-09 7.00000e-02

5.00000e-04 5.00000e-04 5.00000e-05 1.00000e-09 1.00000e-01

5.00000e-04 5.00000e-04 5.00000e-05 1.00000e-09 1.00000e-01

$1.98481 \mathrm{e}+001.98481 \mathrm{e}+00$ 1.98481e-01 1.00000e-09 2.12000e-01

$1.98481 \mathrm{e}+001.98481 \mathrm{e}+00$ 1.98481e-01 1.00000e-09 2.12000e-01

$1.98481 \mathrm{e}+001.98481 \mathrm{e}+001.98481 \mathrm{e}-011.00000 \mathrm{e}-092.12000 \mathrm{e}-01$

$1.98481 \mathrm{e}+001.98481 \mathrm{e}+001.98481 \mathrm{e}-01$ 1.00000e-09 2.12000e-01

$1.98481 \mathrm{e}+001.98481 \mathrm{e}+001.98481 \mathrm{e}-01$ 1.00000e-09 2.12000e-01

$1.00000 \mathrm{e}-02$ 1.00000e-02 1.00000e-03 1.00000e-09 1.00000e-01

$1.00000 \mathrm{e}+001.00000 \mathrm{e}+001.00000 \mathrm{e}-011.00000 \mathrm{e}-091.00000 \mathrm{e}-01$

$1.00000 \mathrm{e}-05$ 1.00000e-05 1.00000e-06 1.00000e-09 1.00000e-01

$1.00000 \mathrm{e}+001.00000 \mathrm{e}+001.00000 \mathrm{e}-011.00000 \mathrm{e}-091.00000 \mathrm{e}-01$

Element: 2342 \# of layers: 13

Kx Ky Kz Ss Por

4.96739e+01 4.96739e+01 4.96739e+00 1.00000e-09 7.00000e-02

$4.96739 \mathrm{e}+014.96739 \mathrm{e}+014.96739 \mathrm{e}+00$ 1.00000e-09 7.00000e-02

5.00000e-04 5.00000e-04 5.00000e-05 1.00000e-09 1.00000e-01

5.00000e-04 5.00000e-04 5.00000e-05 1.00000e-09 1.00000e-01

$1.98481 \mathrm{e}+001.98481 \mathrm{e}+001.98481 \mathrm{e}-011.00000 \mathrm{e}-092.12000 \mathrm{e}-01$

$1.98481 \mathrm{e}+001.98481 \mathrm{e}+00$ 1.98481e-01 1.00000e-09 2.12000e-01

$1.98481 \mathrm{e}+001.98481 \mathrm{e}+00$ 1.98481e-01 1.00000e-09 2.12000e-01

$1.98481 \mathrm{e}+001.98481 \mathrm{e}+001.98481 \mathrm{e}-01$ 1.00000e-09 2.12000e-01

$1.98481 \mathrm{e}+001.98481 \mathrm{e}+001.98481 \mathrm{e}-01$ 1.00000e-09 2.12000e-01

$1.00000 \mathrm{e}-021.00000 \mathrm{e}-021.00000 \mathrm{e}-031.00000 \mathrm{e}-091.00000 \mathrm{e}-01$

$1.00000 \mathrm{e}+001.00000 \mathrm{e}+001.00000 \mathrm{e}-011.00000 \mathrm{e}-091.00000 \mathrm{e}-01$

$1.00000 \mathrm{e}-05$ 1.00000e-05 1.00000e-06 1.00000e-09 1.00000e-01

$1.00000 \mathrm{e}+001.00000 \mathrm{e}+001.00000 \mathrm{e}-011.00000 \mathrm{e}-091.00000 \mathrm{e}-01$ 
Element: 2343 \# of layers: 13

$\mathrm{Kx} \mathrm{Ky} \mathrm{Kz}$ Ss Por

4.96739e+01 4.96739e+01 4.96739e+00 1.00000e-09 7.00000e-02

$4.96739 \mathrm{e}+014.96739 \mathrm{e}+014.96739 \mathrm{e}+001.00000 \mathrm{e}-09$ 7.00000e-02

5.00000e-04 5.00000e-04 5.00000e-05 1.00000e-09 1.00000e-01

5.00000e-04 5.00000e-04 5.00000e-05 1.00000e-09 1.00000e-01

$1.98481 \mathrm{e}+001.98481 \mathrm{e}+001.98481 \mathrm{e}-01$ 1.00000e-09 2.12000e-01

$1.98481 \mathrm{e}+001.98481 \mathrm{e}+001.98481 \mathrm{e}-011.00000 \mathrm{e}-092.12000 \mathrm{e}-01$

$1.98481 \mathrm{e}+001.98481 \mathrm{e}+00$ 1.98481e-01 1.00000e-09 2.12000e-01

$1.98481 \mathrm{e}+001.98481 \mathrm{e}+00$ 1.98481e-01 1.00000e-09 2.12000e-01

$1.98481 \mathrm{e}+001.98481 \mathrm{e}+001.98481 \mathrm{e}-01$ 1.00000e-09 2.12000e-01

$1.00000 \mathrm{e}-02$ 1.00000e-02 1.00000e-03 1.00000e-09 1.00000e-01

$1.00000 \mathrm{e}+001.00000 \mathrm{e}+001.00000 \mathrm{e}-011.00000 \mathrm{e}-091.00000 \mathrm{e}-01$

$1.00000 \mathrm{e}-05$ 1.00000e-05 1.00000e-06 1.00000e-09 1.00000e-01

$1.00000 \mathrm{e}+001.00000 \mathrm{e}+001.00000 \mathrm{e}-01$ 1.00000e-09 1.00000e-01

Element: 2344 \# of layers: 14

$\mathrm{Kx} \mathrm{Ky} \mathrm{Kz}$ Ss Por

4.96739e+01 4.96739e+01 4.96739e+00 1.00000e-09 7.00000e-02 4.96739e+01 4.96739e+01 4.96739e+00 1.00000e-09 7.00000e-02

4.96739e+01 4.96739e+01 4.96739e+00 1.00000e-09 7.00000e-02

5.00000e-04 5.00000e-04 5.00000e-05 1.00000e-09 1.00000e-01

5.00000e-04 5.00000e-04 5.00000e-05 1.00000e-09 1.00000e-01

$1.98481 \mathrm{e}+001.98481 \mathrm{e}+00$ 1.98481e-01 1.00000e-09 2.12000e-01

$1.98481 \mathrm{e}+001.98481 \mathrm{e}+001.98481 \mathrm{e}-01$ 1.00000e-09 2.12000e-01

$1.98481 \mathrm{e}+001.98481 \mathrm{e}+001.98481 \mathrm{e}-011.00000 \mathrm{e}-092.12000 \mathrm{e}-01$

$1.98481 \mathrm{e}+001.98481 \mathrm{e}+001.98481 \mathrm{e}-01$ 1.00000e-09 2.12000e-01

$1.98481 \mathrm{e}+001.98481 \mathrm{e}+001.98481 \mathrm{e}-01$ 1.00000e-09 2.12000e-01

$1.00000 \mathrm{e}-02$ 1.00000e-02 1.00000e-03 1.00000e-09 1.00000e-01

$1.00000 \mathrm{e}+001.00000 \mathrm{e}+001.00000 \mathrm{e}-011.00000 \mathrm{e}-091.00000 \mathrm{e}-01$

$1.00000 \mathrm{e}-05$ 1.00000e-05 1.00000e-06 1.00000e-09 1.00000e-01

$1.00000 \mathrm{e}+001.00000 \mathrm{e}+001.00000 \mathrm{e}-011.00000 \mathrm{e}-091.00000 \mathrm{e}-01$

Element: 2345 \# of layers: 12

Kx Ky Kz Ss Por

3.14512e+01 3.14512e+01 3.14512e+00 1.00000e-09 7.00000e-02

$3.14512 \mathrm{e}+013.14512 \mathrm{e}+013.14512 \mathrm{e}+00$ 1.00000e-09 7.00000e-02

5.00000e-04 5.00000e-04 5.00000e-05 1.00000e-09 1.00000e-01

$1.25667 \mathrm{e}+001.25667 \mathrm{e}+001.25667 \mathrm{e}-01$ 1.00000e-09 2.12000e-01

$1.25667 \mathrm{e}+001.25667 \mathrm{e}+00$ 1.25667e-01 1.00000e-09 2.12000e-01

$1.25667 \mathrm{e}+001.25667 \mathrm{e}+00$ 1.25667e-01 1.00000e-09 2.12000e-01

$1.25667 \mathrm{e}+001.25667 \mathrm{e}+00$ 1.25667e-01 1.00000e-09 2.12000e-01

$1.25667 \mathrm{e}+001.25667 \mathrm{e}+001.25667 \mathrm{e}-01$ 1.00000e-09 2.12000e-01

$1.00000 \mathrm{e}-021.00000 \mathrm{e}-02$ 1.00000e-03 1.00000e-09 1.00000e-01

$1.00000 \mathrm{e}+001.00000 \mathrm{e}+001.00000 \mathrm{e}-011.00000 \mathrm{e}-091.00000 \mathrm{e}-01$

$1.00000 \mathrm{e}-05$ 1.00000e-05 1.00000e-06 1.00000e-09 1.00000e-01

$1.00000 \mathrm{e}+001.00000 \mathrm{e}+001.00000 \mathrm{e}-011.00000 \mathrm{e}-09$ 1.00000e-01

Element: 2346 \# of layers: 12 
$\mathrm{Kx} \mathrm{Ky} \mathrm{Kz} \mathrm{Ss} \mathrm{Por}$

3.14512e+01 3.14512e+01 3.14512e+00 1.00000e-09 7.00000e-02

$3.14512 \mathrm{e}+013.14512 \mathrm{e}+013.14512 \mathrm{e}+001.00000 \mathrm{e}-09$ 7.00000e-02

5.00000e-04 5.00000e-04 5.00000e-05 1.00000e-09 1.00000e-01

$1.25667 \mathrm{e}+001.25667 \mathrm{e}+00$ 1.25667e-01 1.00000e-09 2.12000e-01

$1.25667 \mathrm{e}+001.25667 \mathrm{e}+00$ 1.25667e-01 1.00000e-09 2.12000e-01

$1.25667 \mathrm{e}+00$ 1.25667e+00 1.25667e-01 1.00000e-09 2.12000e-01

$1.25667 \mathrm{e}+001.25667 \mathrm{e}+00$ 1.25667e-01 1.00000e-09 2.12000e-01

$1.25667 \mathrm{e}+00$ 1.25667e+00 1.25667e-01 1.00000e-09 2.12000e-01

$1.00000 \mathrm{e}-02$ 1.00000e-02 1.00000e-03 1.00000e-09 1.00000e-01

$1.00000 \mathrm{e}+001.00000 \mathrm{e}+001.00000 \mathrm{e}-011.00000 \mathrm{e}-091.00000 \mathrm{e}-01$

$1.00000 \mathrm{e}-05$ 1.00000e-05 1.00000e-06 1.00000e-09 1.00000e-01

$1.00000 \mathrm{e}+001.00000 \mathrm{e}+001.00000 \mathrm{e}-011.00000 \mathrm{e}-091.00000 \mathrm{e}-01$

Element: 2347 \# of layers: 12

$\mathrm{Kx} \mathrm{Ky} \mathrm{Kz}$ Ss Por

3.14512e+01 3.14512e+01 3.14512e+00 1.00000e-09 7.00000e-02

5.00000e-04 5.00000e-04 5.00000e-05 1.00000e-09 1.00000e-01

5.00000e-04 5.00000e-04 5.00000e-05 1.00000e-09 1.00000e-01

$1.25667 \mathrm{e}+001.25667 \mathrm{e}+00$ 1.25667e-01 1.00000e-09 2.12000e-01

$1.25667 \mathrm{e}+001.25667 \mathrm{e}+00$ 1.25667e-01 1.00000e-09 2.12000e-01

$1.25667 \mathrm{e}+001.25667 \mathrm{e}+00$ 1.25667e-01 1.00000e-09 2.12000e-01

$1.25667 \mathrm{e}+00$ 1.25667e+00 1.25667e-01 1.00000e-09 2.12000e-01

$1.25667 \mathrm{e}+001.25667 \mathrm{e}+00$ 1.25667e-01 1.00000e-09 2.12000e-01

$1.00000 \mathrm{e}-021.00000 \mathrm{e}-021.00000 \mathrm{e}-031.00000 \mathrm{e}-091.00000 \mathrm{e}-01$

$1.00000 \mathrm{e}+001.00000 \mathrm{e}+001.00000 \mathrm{e}-011.00000 \mathrm{e}-091.00000 \mathrm{e}-01$

$1.00000 \mathrm{e}-05$ 1.00000e-05 1.00000e-06 1.00000e-09 1.00000e-01

$1.00000 \mathrm{e}+001.00000 \mathrm{e}+001.00000 \mathrm{e}-011.00000 \mathrm{e}-091.00000 \mathrm{e}-01$

Element: 2348 \# of layers: 13

Kx Ky Kz Ss Por

3.14512e+01 3.14512e+01 3.14512e+00 1.00000e-09 7.00000e-02

$3.14512 \mathrm{e}+013.14512 \mathrm{e}+013.14512 \mathrm{e}+001.00000 \mathrm{e}-097.00000 \mathrm{e}-02$

5.00000e-04 5.00000e-04 5.00000e-05 1.00000e-09 1.00000e-01

5.00000e-04 5.00000e-04 5.00000e-05 1.00000e-09 1.00000e-01

$1.25667 \mathrm{e}+00$ 1.25667e+00 1.25667e-01 1.00000e-09 2.12000e-01

$1.25667 \mathrm{e}+001.25667 \mathrm{e}+00$ 1.25667e-01 1.00000e-09 2.12000e-01

$1.25667 \mathrm{e}+001.25667 \mathrm{e}+00$ 1.25667e-01 1.00000e-09 2.12000e-01

$1.25667 \mathrm{e}+001.25667 \mathrm{e}+00$ 1.25667e-01 1.00000e-09 2.12000e-01

$1.25667 \mathrm{e}+001.25667 \mathrm{e}+00$ 1.25667e-01 1.00000e-09 2.12000e-01

$1.00000 \mathrm{e}-02$ 1.00000e-02 1.00000e-03 1.00000e-09 1.00000e-01

$1.00000 \mathrm{e}+001.00000 \mathrm{e}+001.00000 \mathrm{e}-011.00000 \mathrm{e}-091.00000 \mathrm{e}-01$

$1.00000 \mathrm{e}-05$ 1.00000e-05 1.00000e-06 1.00000e-09 1.00000e-01

$1.00000 \mathrm{e}+001.00000 \mathrm{e}+001.00000 \mathrm{e}-011.00000 \mathrm{e}-091.00000 \mathrm{e}-01$

Element: 2349 \# of layers: 13

$\mathrm{Kx} \mathrm{Ky} \mathrm{Kz}$ Ss Por

3.14512e+01 3.14512e+01 3.14512e+00 1.00000e-09 7.00000e-02

3.14512e+01 3.14512e+01 3.14512e+00 1.00000e-09 7.00000e-02 
5.00000e-04 5.00000e-04 5.00000e-05 1.00000e-09 1.00000e-01 5.00000e-04 5.00000e-04 5.00000e-05 1.00000e-09 1.00000e-01 $1.25667 \mathrm{e}+00$ 1.25667e+00 1.25667e-01 1.00000e-09 2.12000e-01 $1.25667 \mathrm{e}+001.25667 \mathrm{e}+00$ 1.25667e-01 1.00000e-09 2.12000e-01 $1.25667 \mathrm{e}+001.25667 \mathrm{e}+00$ 1.25667e-01 1.00000e-09 2.12000e-01 $1.25667 \mathrm{e}+001.25667 \mathrm{e}+00$ 1.25667e-01 1.00000e-09 2.12000e-01 $1.25667 \mathrm{e}+001.25667 \mathrm{e}+00$ 1.25667e-01 1.00000e-09 2.12000e-01 $1.00000 \mathrm{e}-02$ 1.00000e-02 1.00000e-03 1.00000e-09 1.00000e-01 $1.00000 \mathrm{e}+001.00000 \mathrm{e}+001.00000 \mathrm{e}-011.00000 \mathrm{e}-091.00000 \mathrm{e}-01$ $1.00000 \mathrm{e}-05$ 1.00000e-05 1.00000e-06 1.00000e-09 1.00000e-01 $1.00000 \mathrm{e}+001.00000 \mathrm{e}+001.00000 \mathrm{e}-011.00000 \mathrm{e}-091.00000 \mathrm{e}-01$ Element: 2350 \# of layers: 13

$\mathrm{Kx} \mathrm{Ky} \mathrm{Kz}$ Ss Por

3.14512e+01 3.14512e+01 3.14512e+00 1.00000e-09 7.00000e-02 $3.14512 \mathrm{e}+013.14512 \mathrm{e}+013.14512 \mathrm{e}+001.00000 \mathrm{e}-097.00000 \mathrm{e}-02$ 5.00000e-04 5.00000e-04 5.00000e-05 1.00000e-09 1.00000e-01 5.00000e-04 5.00000e-04 5.00000e-05 1.00000e-09 1.00000e-01 $1.25667 \mathrm{e}+001.25667 \mathrm{e}+00$ 1.25667e-01 1.00000e-09 2.12000e-01 $1.25667 \mathrm{e}+001.25667 \mathrm{e}+00$ 1.25667e-01 1.00000e-09 2.12000e-01 $1.25667 \mathrm{e}+001.25667 \mathrm{e}+00$ 1.25667e-01 1.00000e-09 2.12000e-01 $1.25667 \mathrm{e}+001.25667 \mathrm{e}+001.25667 \mathrm{e}-01$ 1.00000e-09 2.12000e-01 $1.25667 \mathrm{e}+001.25667 \mathrm{e}+00$ 1.25667e-01 1.00000e-09 2.12000e-01 $1.00000 \mathrm{e}-02$ 1.00000e-02 1.00000e-03 1.00000e-09 1.00000e-01 $1.00000 \mathrm{e}+001.00000 \mathrm{e}+001.00000 \mathrm{e}-011.00000 \mathrm{e}-091.00000 \mathrm{e}-01$ $1.00000 \mathrm{e}-05$ 1.00000e-05 1.00000e-06 1.00000e-09 1.00000e-01 $1.00000 \mathrm{e}+001.00000 \mathrm{e}+001.00000 \mathrm{e}-011.00000 \mathrm{e}-091.00000 \mathrm{e}-01$ Element: 2351 \# of layers: 13

$\mathrm{Kx} \mathrm{Ky} \mathrm{Kz}$ Ss Por

3.14512e+01 3.14512e+01 3.14512e+00 1.00000e-09 7.00000e-02 3.14512e+01 3.14512e+01 3.14512e+00 1.00000e-09 7.00000e-02 5.00000e-04 5.00000e-04 5.00000e-05 1.00000e-09 1.00000e-01 5.00000e-04 5.00000e-04 5.00000e-05 1.00000e-09 1.00000e-01 $1.25667 \mathrm{e}+001.25667 \mathrm{e}+00$ 1.25667e-01 1.00000e-09 2.12000e-01 $1.25667 \mathrm{e}+001.25667 \mathrm{e}+00$ 1.25667e-01 1.00000e-09 2.12000e-01 $1.25667 \mathrm{e}+001.25667 \mathrm{e}+00$ 1.25667e-01 1.00000e-09 2.12000e-01 $1.25667 \mathrm{e}+001.25667 \mathrm{e}+00$ 1.25667e-01 1.00000e-09 2.12000e-01 $1.25667 \mathrm{e}+001.25667 \mathrm{e}+00$ 1.25667e-01 1.00000e-09 2.12000e-01 $1.00000 \mathrm{e}-02$ 1.00000e-02 1.00000e-03 1.00000e-09 1.00000e-01 $1.00000 \mathrm{e}+001.00000 \mathrm{e}+001.00000 \mathrm{e}-011.00000 \mathrm{e}-091.00000 \mathrm{e}-01$ $1.00000 \mathrm{e}-05$ 1.00000e-05 1.00000e-06 1.00000e-09 1.00000e-01 $1.00000 \mathrm{e}+001.00000 \mathrm{e}+001.00000 \mathrm{e}-011.00000 \mathrm{e}-091.00000 \mathrm{e}-01$ Element: 2352 \# of layers: 13

$\mathrm{Kx} \mathrm{Ky} \mathrm{Kz}$ Ss Por

3.14512e+01 3.14512e+01 3.14512e+00 1.00000e-09 7.00000e-02 $3.14512 \mathrm{e}+013.14512 \mathrm{e}+013.14512 \mathrm{e}+001.00000 \mathrm{e}-09$ 7.00000e-02 5.00000e-04 5.00000e-04 5.00000e-05 1.00000e-09 1.00000e-01 
5.00000e-04 5.00000e-04 5.00000e-05 1.00000e-09 1.00000e-01 $1.25667 \mathrm{e}+001.25667 \mathrm{e}+00$ 1.25667e-01 1.00000e-09 2.12000e-01 $1.25667 \mathrm{e}+001.25667 \mathrm{e}+00$ 1.25667e-01 1.00000e-09 2.12000e-01 $1.25667 \mathrm{e}+00$ 1.25667e+00 1.25667e-01 1.00000e-09 2.12000e-01 $1.25667 \mathrm{e}+00$ 1.25667e+00 1.25667e-01 1.00000e-09 2.12000e-01 $1.25667 \mathrm{e}+001.25667 \mathrm{e}+00$ 1.25667e-01 1.00000e-09 2.12000e-01 $1.00000 \mathrm{e}-02$ 1.00000e-02 1.00000e-03 1.00000e-09 1.00000e-01 $1.00000 \mathrm{e}+001.00000 \mathrm{e}+001.00000 \mathrm{e}-011.00000 \mathrm{e}-091.00000 \mathrm{e}-01$ $1.00000 \mathrm{e}-05$ 1.00000e-05 1.00000e-06 1.00000e-09 1.00000e-01 $1.00000 \mathrm{e}+001.00000 \mathrm{e}+001.00000 \mathrm{e}-011.00000 \mathrm{e}-091.00000 \mathrm{e}-01$ Element: 2353 \# of layers: 13

Kx Ky Kz Ss Por

3.14512e+01 3.14512e+01 3.14512e+00 1.00000e-09 7.00000e-02 $3.14512 \mathrm{e}+013.14512 \mathrm{e}+013.14512 \mathrm{e}+001.00000 \mathrm{e}-09$ 7.00000e-02 5.00000e-04 5.00000e-04 5.00000e-05 1.00000e-09 1.00000e-01 5.00000e-04 5.00000e-04 5.00000e-05 1.00000e-09 1.00000e-01 $1.25667 \mathrm{e}+001.25667 \mathrm{e}+00$ 1.25667e-01 1.00000e-09 2.12000e-01 $1.25667 \mathrm{e}+001.25667 \mathrm{e}+00$ 1.25667e-01 1.00000e-09 2.12000e-01 $1.25667 \mathrm{e}+001.25667 \mathrm{e}+00$ 1.25667e-01 1.00000e-09 2.12000e-01 $1.25667 \mathrm{e}+001.25667 \mathrm{e}+00$ 1.25667e-01 1.00000e-09 2.12000e-01 $1.25667 \mathrm{e}+001.25667 \mathrm{e}+001.25667 \mathrm{e}-01$ 1.00000e-09 2.12000e-01 $1.00000 \mathrm{e}-021.00000 \mathrm{e}-021.00000 \mathrm{e}-031.00000 \mathrm{e}-091.00000 \mathrm{e}-01$ $1.00000 \mathrm{e}+001.00000 \mathrm{e}+001.00000 \mathrm{e}-011.00000 \mathrm{e}-091.00000 \mathrm{e}-01$ $1.00000 \mathrm{e}-05$ 1.00000e-05 1.00000e-06 1.00000e-09 1.00000e-01 $1.00000 \mathrm{e}+001.00000 \mathrm{e}+001.00000 \mathrm{e}-011.00000 \mathrm{e}-091.00000 \mathrm{e}-01$ Element: 2354 \# of layers: 12

$\mathrm{Kx} \mathrm{Ky} \mathrm{Kz}$ Ss Por

3.64527e+01 3.64527e+01 3.64527e+00 1.00000e-09 7.00000e-02 5.00000e-04 5.00000e-04 5.00000e-05 1.00000e-09 1.00000e-01 5.00000e-04 5.00000e-04 5.00000e-05 1.00000e-09 1.00000e-01 $1.45655 \mathrm{e}+001.45655 \mathrm{e}+00$ 1.45655e-01 1.00000e-09 2.12000e-01 $1.45655 \mathrm{e}+001.45655 \mathrm{e}+00$ 1.45655e-01 1.00000e-09 2.12000e-01 $1.45655 \mathrm{e}+001.45655 \mathrm{e}+001.45655 \mathrm{e}-011.00000 \mathrm{e}-092.12000 \mathrm{e}-01$ $1.45655 \mathrm{e}+001.45655 \mathrm{e}+001.45655 \mathrm{e}-011.00000 \mathrm{e}-092.12000 \mathrm{e}-01$ $1.45655 \mathrm{e}+001.45655 \mathrm{e}+001.45655 \mathrm{e}-01$ 1.00000e-09 2.12000e-01 1.00000e-02 1.00000e-02 1.00000e-03 1.00000e-09 1.00000e-01 $1.00000 \mathrm{e}+001.00000 \mathrm{e}+001.00000 \mathrm{e}-011.00000 \mathrm{e}-091.00000 \mathrm{e}-01$ $1.00000 \mathrm{e}-05$ 1.00000e-05 1.00000e-06 1.00000e-09 1.00000e-01 $1.00000 \mathrm{e}+001.00000 \mathrm{e}+001.00000 \mathrm{e}-011.00000 \mathrm{e}-091.00000 \mathrm{e}-01$ Element: 2355 \# of layers: 12

$\mathrm{Kx} \mathrm{Ky} \mathrm{Kz}$ Ss Por

3.64527e+01 3.64527e+01 3.64527e+00 1.00000e-09 7.00000e-02 $5.00000 \mathrm{e}-04$ 5.00000e-04 5.00000e-05 1.00000e-09 1.00000e-01 $5.00000 \mathrm{e}-04$ 5.00000e-04 5.00000e-05 1.00000e-09 1.00000e-01 $1.45655 \mathrm{e}+001.45655 \mathrm{e}+001.45655 \mathrm{e}-011.00000 \mathrm{e}-092.12000 \mathrm{e}-01$ $1.45655 \mathrm{e}+001.45655 \mathrm{e}+001.45655 \mathrm{e}-011.00000 \mathrm{e}-092.12000 \mathrm{e}-01$ 
$1.45655 \mathrm{e}+001.45655 \mathrm{e}+00$ 1.45655e-01 1.00000e-09 2.12000e-01 $1.45655 \mathrm{e}+001.45655 \mathrm{e}+00$ 1.45655e-01 1.00000e-09 2.12000e-01 $1.45655 \mathrm{e}+001.45655 \mathrm{e}+001.45655 \mathrm{e}-011.00000 \mathrm{e}-092.12000 \mathrm{e}-01$ $1.00000 \mathrm{e}-02$ 1.00000e-02 1.00000e-03 1.00000e-09 1.00000e-01 $1.00000 \mathrm{e}+001.00000 \mathrm{e}+001.00000 \mathrm{e}-011.00000 \mathrm{e}-091.00000 \mathrm{e}-01$ $1.00000 \mathrm{e}-05$ 1.00000e-05 1.00000e-06 1.00000e-09 1.00000e-01 $1.00000 \mathrm{e}+001.00000 \mathrm{e}+001.00000 \mathrm{e}-01$ 1.00000e-09 1.00000e-01 Element: 2356 \# of layers: 12

$\mathrm{Kx} \mathrm{Ky} \mathrm{Kz}$ Ss Por

3.64527e+01 3.64527e+01 3.64527e+00 1.00000e-09 7.00000e-02 5.00000e-04 5.00000e-04 5.00000e-05 1.00000e-09 1.00000e-01 5.00000e-04 5.00000e-04 5.00000e-05 1.00000e-09 1.00000e-01 $1.45655 \mathrm{e}+001.45655 \mathrm{e}+001.45655 \mathrm{e}-011.00000 \mathrm{e}-092.12000 \mathrm{e}-01$ $1.45655 \mathrm{e}+001.45655 \mathrm{e}+00$ 1.45655e-01 1.00000e-09 2.12000e-01 $1.45655 \mathrm{e}+001.45655 \mathrm{e}+00$ 1.45655e-01 1.00000e-09 2.12000e-01 $1.45655 \mathrm{e}+001.45655 \mathrm{e}+001.45655 \mathrm{e}-01$ 1.00000e-09 2.12000e-01 $1.45655 \mathrm{e}+001.45655 \mathrm{e}+001.45655 \mathrm{e}-01$ 1.00000e-09 2.12000e-01 $1.00000 \mathrm{e}-02$ 1.00000e-02 1.00000e-03 1.00000e-09 1.00000e-01 $1.00000 \mathrm{e}+001.00000 \mathrm{e}+001.00000 \mathrm{e}-011.00000 \mathrm{e}-091.00000 \mathrm{e}-01$ $1.00000 \mathrm{e}-05$ 1.00000e-05 1.00000e-06 1.00000e-09 1.00000e-01 $1.00000 \mathrm{e}+001.00000 \mathrm{e}+001.00000 \mathrm{e}-011.00000 \mathrm{e}-091.00000 \mathrm{e}-01$ Element: 2357 \# of layers: 13

$\mathrm{Kx} \mathrm{Ky} \mathrm{Kz}$ Ss Por

3.64527e+01 3.64527e+01 3.64527e+00 1.00000e-09 7.00000e-02 $3.64527 \mathrm{e}+013.64527 \mathrm{e}+013.64527 \mathrm{e}+00$ 1.00000e-09 7.00000e-02 $5.00000 \mathrm{e}-04$ 5.00000e-04 5.00000e-05 1.00000e-09 1.00000e-01 5.00000e-04 5.00000e-04 5.00000e-05 1.00000e-09 1.00000e-01 $1.45655 \mathrm{e}+001.45655 \mathrm{e}+001.45655 \mathrm{e}-01$ 1.00000e-09 2.12000e-01 $1.45655 \mathrm{e}+001.45655 \mathrm{e}+001.45655 \mathrm{e}-011.00000 \mathrm{e}-092.12000 \mathrm{e}-01$ $1.45655 \mathrm{e}+001.45655 \mathrm{e}+00$ 1.45655e-01 1.00000e-09 2.12000e-01 $1.45655 \mathrm{e}+001.45655 \mathrm{e}+00$ 1.45655e-01 1.00000e-09 2.12000e-01 $1.45655 \mathrm{e}+001.45655 \mathrm{e}+00$ 1.45655e-01 1.00000e-09 2.12000e-01 $1.00000 \mathrm{e}-02$ 1.00000e-02 1.00000e-03 1.00000e-09 1.00000e-01 $1.00000 \mathrm{e}+001.00000 \mathrm{e}+001.00000 \mathrm{e}-011.00000 \mathrm{e}-091.00000 \mathrm{e}-01$ $1.00000 \mathrm{e}-05$ 1.00000e-05 1.00000e-06 1.00000e-09 1.00000e-01 $1.00000 \mathrm{e}+001.00000 \mathrm{e}+001.00000 \mathrm{e}-011.00000 \mathrm{e}-091.00000 \mathrm{e}-01$ Element: 2358 \# of layers: 13

Kx Ky Kz Ss Por

3.64527e+01 3.64527e+01 3.64527e+00 1.00000e-09 7.00000e-02 $3.64527 \mathrm{e}+013.64527 \mathrm{e}+013.64527 \mathrm{e}+001.00000 \mathrm{e}-09$ 7.00000e-02 5.00000e-04 5.00000e-04 5.00000e-05 1.00000e-09 1.00000e-01 5.00000e-04 5.00000e-04 5.00000e-05 1.00000e-09 1.00000e-01 $1.45655 \mathrm{e}+001.45655 \mathrm{e}+00$ 1.45655e-01 1.00000e-09 2.12000e-01 $1.45655 \mathrm{e}+001.45655 \mathrm{e}+00$ 1.45655e-01 1.00000e-09 2.12000e-01 $1.45655 \mathrm{e}+001.45655 \mathrm{e}+001.45655 \mathrm{e}-011.00000 \mathrm{e}-092.12000 \mathrm{e}-01$ $1.45655 \mathrm{e}+001.45655 \mathrm{e}+001.45655 \mathrm{e}-011.00000 \mathrm{e}-092.12000 \mathrm{e}-01$ 
$1.45655 \mathrm{e}+00$ 1.45655e+00 1.45655e-01 1.00000e-09 2.12000e-01 $1.00000 \mathrm{e}-02$ 1.00000e-02 1.00000e-03 1.00000e-09 1.00000e-01 $1.00000 \mathrm{e}+001.00000 \mathrm{e}+001.00000 \mathrm{e}-011.00000 \mathrm{e}-091.00000 \mathrm{e}-01$ $1.00000 \mathrm{e}-05$ 1.00000e-05 1.00000e-06 1.00000e-09 1.00000e-01 $1.00000 \mathrm{e}+001.00000 \mathrm{e}+001.00000 \mathrm{e}-011.00000 \mathrm{e}-091.00000 \mathrm{e}-01$ Element: 2359 \# of layers: 13

$\mathrm{Kx} \mathrm{Ky} \mathrm{Kz}$ Ss Por

3.64527e+01 3.64527e+01 3.64527e+00 1.00000e-09 7.00000e-02 $3.64527 \mathrm{e}+013.64527 \mathrm{e}+013.64527 \mathrm{e}+001.00000 \mathrm{e}-09$ 7.00000e-02 5.00000e-04 5.00000e-04 5.00000e-05 1.00000e-09 1.00000e-01 5.00000e-04 5.00000e-04 5.00000e-05 1.00000e-09 1.00000e-01 $1.45655 \mathrm{e}+001.45655 \mathrm{e}+001.45655 \mathrm{e}-011.00000 \mathrm{e}-092.12000 \mathrm{e}-01$ $1.45655 \mathrm{e}+001.45655 \mathrm{e}+001.45655 \mathrm{e}-01$ 1.00000e-09 2.12000e-01 $1.45655 \mathrm{e}+001.45655 \mathrm{e}+00$ 1.45655e-01 1.00000e-09 2.12000e-01 $1.45655 \mathrm{e}+001.45655 \mathrm{e}+00$ 1.45655e-01 1.00000e-09 2.12000e-01 $1.45655 \mathrm{e}+001.45655 \mathrm{e}+001.45655 \mathrm{e}-011.00000 \mathrm{e}-092.12000 \mathrm{e}-01$ 1.00000e-02 1.00000e-02 1.00000e-03 1.00000e-09 1.00000e-01 $1.00000 \mathrm{e}+001.00000 \mathrm{e}+001.00000 \mathrm{e}-011.00000 \mathrm{e}-091.00000 \mathrm{e}-01$ $1.00000 \mathrm{e}-051.00000 \mathrm{e}-05$ 1.00000e-06 1.00000e-09 1.00000e-01 $1.00000 \mathrm{e}+001.00000 \mathrm{e}+001.00000 \mathrm{e}-011.00000 \mathrm{e}-091.00000 \mathrm{e}-01$ Element: 2360 \# of layers: 13

$\mathrm{Kx} \mathrm{Ky} \mathrm{Kz}$ Ss Por

3.64527e+01 3.64527e+01 3.64527e+00 1.00000e-09 7.00000e-02 $3.64527 \mathrm{e}+013.64527 \mathrm{e}+013.64527 \mathrm{e}+001.00000 \mathrm{e}-09$ 7.00000e-02 5.00000e-04 5.00000e-04 5.00000e-05 1.00000e-09 1.00000e-01 $5.00000 \mathrm{e}-04$ 5.00000e-04 5.00000e-05 1.00000e-09 1.00000e-01 $1.45655 \mathrm{e}+001.45655 \mathrm{e}+001.45655 \mathrm{e}-011.00000 \mathrm{e}-092.12000 \mathrm{e}-01$ $1.45655 \mathrm{e}+001.45655 \mathrm{e}+001.45655 \mathrm{e}-01$ 1.00000e-09 2.12000e-01 $1.45655 \mathrm{e}+001.45655 \mathrm{e}+001.45655 \mathrm{e}-011.00000 \mathrm{e}-092.12000 \mathrm{e}-01$ $1.45655 \mathrm{e}+001.45655 \mathrm{e}+001.45655 \mathrm{e}-011.00000 \mathrm{e}-092.12000 \mathrm{e}-01$ $1.45655 \mathrm{e}+001.45655 \mathrm{e}+001.45655 \mathrm{e}-01$ 1.00000e-09 2.12000e-01 $1.00000 \mathrm{e}-02$ 1.00000e-02 1.00000e-03 1.00000e-09 1.00000e-01 $1.00000 \mathrm{e}+001.00000 \mathrm{e}+001.00000 \mathrm{e}-011.00000 \mathrm{e}-091.00000 \mathrm{e}-01$ 1.00000e-05 1.00000e-05 1.00000e-06 1.00000e-09 1.00000e-01 $1.00000 \mathrm{e}+001.00000 \mathrm{e}+001.00000 \mathrm{e}-01$ 1.00000e-09 1.00000e-01 Element: 2361 \# of layers: 13

Kx Ky Kz Ss Por

3.64527e+01 3.64527e+01 3.64527e+00 1.00000e-09 7.00000e-02 $3.64527 \mathrm{e}+013.64527 \mathrm{e}+013.64527 \mathrm{e}+001.00000 \mathrm{e}-09$ 7.00000e-02 5.00000e-04 5.00000e-04 5.00000e-05 1.00000e-09 1.00000e-01 5.00000e-04 5.00000e-04 5.00000e-05 1.00000e-09 1.00000e-01 $1.45655 \mathrm{e}+001.45655 \mathrm{e}+001.45655 \mathrm{e}-011.00000 \mathrm{e}-092.12000 \mathrm{e}-01$ $1.45655 \mathrm{e}+001.45655 \mathrm{e}+00$ 1.45655e-01 1.00000e-09 2.12000e-01 $1.45655 \mathrm{e}+001.45655 \mathrm{e}+00$ 1.45655e-01 1.00000e-09 2.12000e-01 $1.45655 \mathrm{e}+001.45655 \mathrm{e}+001.45655 \mathrm{e}-01$ 1.00000e-09 2.12000e-01 $1.45655 \mathrm{e}+001.45655 \mathrm{e}+001.45655 \mathrm{e}-01$ 1.00000e-09 2.12000e-01 
$1.00000 \mathrm{e}-02$ 1.00000e-02 1.00000e-03 1.00000e-09 1.00000e-01 $1.00000 \mathrm{e}+001.00000 \mathrm{e}+001.00000 \mathrm{e}-011.00000 \mathrm{e}-091.00000 \mathrm{e}-01$ $1.00000 \mathrm{e}-05$ 1.00000e-05 1.00000e-06 1.00000e-09 1.00000e-01 $1.00000 \mathrm{e}+001.00000 \mathrm{e}+001.00000 \mathrm{e}-011.00000 \mathrm{e}-091.00000 \mathrm{e}-01$ Element: 2362 \# of layers: 13

$\mathrm{Kx} \mathrm{Ky} \mathrm{Kz}$ Ss Por

3.64527e+01 3.64527e+01 3.64527e+00 1.00000e-09 7.00000e-02 $3.64527 \mathrm{e}+013.64527 \mathrm{e}+013.64527 \mathrm{e}+001.00000 \mathrm{e}-09$ 7.00000e-02 5.00000e-04 5.00000e-04 5.00000e-05 1.00000e-09 1.00000e-01 $5.00000 \mathrm{e}-04$ 5.00000e-04 5.00000e-05 1.00000e-09 1.00000e-01 $1.45655 \mathrm{e}+001.45655 \mathrm{e}+001.45655 \mathrm{e}-01$ 1.00000e-09 2.12000e-01 $1.45655 \mathrm{e}+001.45655 \mathrm{e}+001.45655 \mathrm{e}-011.00000 \mathrm{e}-092.12000 \mathrm{e}-01$ $1.45655 \mathrm{e}+001.45655 \mathrm{e}+001.45655 \mathrm{e}-01$ 1.00000e-09 2.12000e-01 $1.45655 \mathrm{e}+001.45655 \mathrm{e}+00$ 1.45655e-01 1.00000e-09 2.12000e-01 $1.45655 \mathrm{e}+001.45655 \mathrm{e}+00$ 1.45655e-01 1.00000e-09 2.12000e-01 $1.00000 \mathrm{e}-02$ 1.00000e-02 1.00000e-03 1.00000e-09 1.00000e-01 $1.00000 \mathrm{e}+001.00000 \mathrm{e}+001.00000 \mathrm{e}-011.00000 \mathrm{e}-091.00000 \mathrm{e}-01$ $1.00000 \mathrm{e}-05$ 1.00000e-05 1.00000e-06 1.00000e-09 1.00000e-01 $1.00000 \mathrm{e}+001.00000 \mathrm{e}+001.00000 \mathrm{e}-01$ 1.00000e-09 1.00000e-01 Element: 2363 \# of layers: 12

$\mathrm{Kx} \mathrm{Ky} \mathrm{Kz}$ Ss Por

$3.69518 \mathrm{e}+013.69518 \mathrm{e}+013.69518 \mathrm{e}+001.00000 \mathrm{e}-09$ 7.00000e-02 5.00000e-04 5.00000e-04 5.00000e-05 1.00000e-09 1.00000e-01 5.00000e-04 5.00000e-04 5.00000e-05 1.00000e-09 1.00000e-01 $1.47648 \mathrm{e}+001.47648 \mathrm{e}+001.47648 \mathrm{e}-01$ 1.00000e-09 2.12000e-01 $1.47648 \mathrm{e}+001.47648 \mathrm{e}+00$ 1.47648e-01 1.00000e-09 2.12000e-01 $1.47648 \mathrm{e}+001.47648 \mathrm{e}+00$ 1.47648e-01 1.00000e-09 2.12000e-01 $1.47648 \mathrm{e}+001.47648 \mathrm{e}+00$ 1.47648e-01 1.00000e-09 2.12000e-01 $1.47648 \mathrm{e}+001.47648 \mathrm{e}+00$ 1.47648e-01 1.00000e-09 2.12000e-01 $1.00000 \mathrm{e}-021.00000 \mathrm{e}-021.00000 \mathrm{e}-031.00000 \mathrm{e}-091.00000 \mathrm{e}-01$ $1.00000 \mathrm{e}+001.00000 \mathrm{e}+001.00000 \mathrm{e}-011.00000 \mathrm{e}-091.00000 \mathrm{e}-01$ $1.00000 \mathrm{e}-05$ 1.00000e-05 1.00000e-06 1.00000e-09 1.00000e-01 $1.00000 \mathrm{e}+001.00000 \mathrm{e}+001.00000 \mathrm{e}-011.00000 \mathrm{e}-091.00000 \mathrm{e}-01$ Element: 2364 \# of layers: 11

$\mathrm{Kx} \mathrm{Ky} \mathrm{Kz}$ Ss Por

$3.69518 \mathrm{e}+013.69518 \mathrm{e}+013.69518 \mathrm{e}+001.00000 \mathrm{e}-09$ 7.00000e-02 5.00000e-04 5.00000e-04 5.00000e-05 1.00000e-09 1.00000e-01 $1.47648 \mathrm{e}+001.47648 \mathrm{e}+00$ 1.47648e-01 1.00000e-09 2.12000e-01 $1.47648 \mathrm{e}+001.47648 \mathrm{e}+00$ 1.47648e-01 1.00000e-09 2.12000e-01 $1.47648 \mathrm{e}+001.47648 \mathrm{e}+00$ 1.47648e-01 1.00000e-09 2.12000e-01 $1.47648 \mathrm{e}+001.47648 \mathrm{e}+00$ 1.47648e-01 1.00000e-09 2.12000e-01 $1.47648 \mathrm{e}+001.47648 \mathrm{e}+00$ 1.47648e-01 1.00000e-09 2.12000e-01 $1.00000 \mathrm{e}-021.00000 \mathrm{e}-021.00000 \mathrm{e}-031.00000 \mathrm{e}-091.00000 \mathrm{e}-01$ $1.00000 \mathrm{e}+001.00000 \mathrm{e}+001.00000 \mathrm{e}-011.00000 \mathrm{e}-091.00000 \mathrm{e}-01$ $1.00000 \mathrm{e}-05$ 1.00000e-05 1.00000e-06 1.00000e-09 1.00000e-01 $1.00000 \mathrm{e}+001.00000 \mathrm{e}+001.00000 \mathrm{e}-01$ 1.00000e-09 1.00000e-01 
Element: 2365 \# of layers: 12

$\mathrm{Kx} \mathrm{Ky} \mathrm{Kz}$ Ss Por

3.69518e+01 3.69518e+01 3.69518e+00 1.00000e-09 7.00000e-02

5.00000e-04 5.00000e-04 5.00000e-05 1.00000e-09 1.00000e-01

5.00000e-04 5.00000e-04 5.00000e-05 1.00000e-09 1.00000e-01

$1.47648 \mathrm{e}+001.47648 \mathrm{e}+00$ 1.47648e-01 1.00000e-09 2.12000e-01

$1.47648 \mathrm{e}+001.47648 \mathrm{e}+00$ 1.47648e-01 1.00000e-09 2.12000e-01

$1.47648 \mathrm{e}+001.47648 \mathrm{e}+00$ 1.47648e-01 1.00000e-09 2.12000e-01

$1.47648 \mathrm{e}+001.47648 \mathrm{e}+00$ 1.47648e-01 1.00000e-09 2.12000e-01

$1.47648 \mathrm{e}+001.47648 \mathrm{e}+00$ 1.47648e-01 1.00000e-09 2.12000e-01

$1.00000 \mathrm{e}-02$ 1.00000e-02 1.00000e-03 1.00000e-09 1.00000e-01

$1.00000 \mathrm{e}+001.00000 \mathrm{e}+001.00000 \mathrm{e}-011.00000 \mathrm{e}-091.00000 \mathrm{e}-01$

$1.00000 \mathrm{e}-05$ 1.00000e-05 1.00000e-06 1.00000e-09 1.00000e-01

$1.00000 \mathrm{e}+001.00000 \mathrm{e}+001.00000 \mathrm{e}-011.00000 \mathrm{e}-09$ 1.00000e-01

Element: 2366 \# of layers: 13

Kx Ky Kz Ss Por

$3.69518 \mathrm{e}+013.69518 \mathrm{e}+013.69518 \mathrm{e}+001.00000 \mathrm{e}-09$ 7.00000e-02

$3.69518 \mathrm{e}+013.69518 \mathrm{e}+013.69518 \mathrm{e}+001.00000 \mathrm{e}-09$ 7.00000e-02

5.00000e-04 5.00000e-04 5.00000e-05 1.00000e-09 1.00000e-01

5.00000e-04 5.00000e-04 5.00000e-05 1.00000e-09 1.00000e-01

$1.47648 \mathrm{e}+001.47648 \mathrm{e}+00$ 1.47648e-01 1.00000e-09 2.12000e-01

$1.47648 \mathrm{e}+001.47648 \mathrm{e}+00$ 1.47648e-01 1.00000e-09 2.12000e-01

$1.47648 \mathrm{e}+001.47648 \mathrm{e}+00$ 1.47648e-01 1.00000e-09 2.12000e-01

$1.47648 \mathrm{e}+001.47648 \mathrm{e}+00$ 1.47648e-01 1.00000e-09 2.12000e-01

$1.47648 \mathrm{e}+001.47648 \mathrm{e}+00$ 1.47648e-01 1.00000e-09 2.12000e-01

$1.00000 \mathrm{e}-021.00000 \mathrm{e}-021.00000 \mathrm{e}-031.00000 \mathrm{e}-091.00000 \mathrm{e}-01$

$1.00000 \mathrm{e}+001.00000 \mathrm{e}+001.00000 \mathrm{e}-011.00000 \mathrm{e}-091.00000 \mathrm{e}-01$

$1.00000 \mathrm{e}-05$ 1.00000e-05 1.00000e-06 1.00000e-09 1.00000e-01

$1.00000 \mathrm{e}+001.00000 \mathrm{e}+001.00000 \mathrm{e}-011.00000 \mathrm{e}-091.00000 \mathrm{e}-01$

Element: 2367 \# of layers: 13

$\mathrm{Kx} \mathrm{Ky} \mathrm{Kz}$ Ss Por

$3.69518 \mathrm{e}+013.69518 \mathrm{e}+013.69518 \mathrm{e}+001.00000 \mathrm{e}-09$ 7.00000e-02

$3.69518 \mathrm{e}+013.69518 \mathrm{e}+013.69518 \mathrm{e}+001.00000 \mathrm{e}-09$ 7.00000e-02

$5.00000 \mathrm{e}-04$ 5.00000e-04 5.00000e-05 1.00000e-09 1.00000e-01

5.00000e-04 5.00000e-04 5.00000e-05 1.00000e-09 1.00000e-01

$1.47648 \mathrm{e}+001.47648 \mathrm{e}+00$ 1.47648e-01 1.00000e-09 2.12000e-01

$1.47648 \mathrm{e}+001.47648 \mathrm{e}+00$ 1.47648e-01 1.00000e-09 2.12000e-01

$1.47648 \mathrm{e}+001.47648 \mathrm{e}+00$ 1.47648e-01 1.00000e-09 2.12000e-01

$1.47648 \mathrm{e}+001.47648 \mathrm{e}+001.47648 \mathrm{e}-01$ 1.00000e-09 2.12000e-01

$1.47648 \mathrm{e}+001.47648 \mathrm{e}+00$ 1.47648e-01 1.00000e-09 2.12000e-01

$1.00000 \mathrm{e}-02$ 1.00000e-02 1.00000e-03 1.00000e-09 1.00000e-01

$1.00000 \mathrm{e}+001.00000 \mathrm{e}+001.00000 \mathrm{e}-011.00000 \mathrm{e}-091.00000 \mathrm{e}-01$

$1.00000 \mathrm{e}-05$ 1.00000e-05 1.00000e-06 1.00000e-09 1.00000e-01

$1.00000 \mathrm{e}+001.00000 \mathrm{e}+001.00000 \mathrm{e}-01$ 1.00000e-09 1.00000e-01

Element: 2368 \# of layers: 13

Kx Ky Kz Ss Por 
$3.69518 \mathrm{e}+013.69518 \mathrm{e}+013.69518 \mathrm{e}+001.00000 \mathrm{e}-09$ 7.00000e-02 $3.69518 \mathrm{e}+013.69518 \mathrm{e}+013.69518 \mathrm{e}+001.00000 \mathrm{e}-09$ 7.00000e-02 5.00000e-04 5.00000e-04 5.00000e-05 1.00000e-09 1.00000e-01 5.00000e-04 5.00000e-04 5.00000e-05 1.00000e-09 1.00000e-01 $1.47648 \mathrm{e}+001.47648 \mathrm{e}+00$ 1.47648e-01 1.00000e-09 2.12000e-01 $1.47648 \mathrm{e}+001.47648 \mathrm{e}+00$ 1.47648e-01 1.00000e-09 2.12000e-01 $1.47648 \mathrm{e}+001.47648 \mathrm{e}+00$ 1.47648e-01 1.00000e-09 2.12000e-01 $1.47648 \mathrm{e}+001.47648 \mathrm{e}+00$ 1.47648e-01 1.00000e-09 2.12000e-01 $1.47648 \mathrm{e}+001.47648 \mathrm{e}+00$ 1.47648e-01 1.00000e-09 2.12000e-01 $1.00000 \mathrm{e}-02$ 1.00000e-02 1.00000e-03 1.00000e-09 1.00000e-01 $1.00000 \mathrm{e}+001.00000 \mathrm{e}+001.00000 \mathrm{e}-011.00000 \mathrm{e}-091.00000 \mathrm{e}-01$ $1.00000 \mathrm{e}-05$ 1.00000e-05 1.00000e-06 1.00000e-09 1.00000e-01 $1.00000 \mathrm{e}+001.00000 \mathrm{e}+001.00000 \mathrm{e}-011.00000 \mathrm{e}-091.00000 \mathrm{e}-01$ Element: 2369 \# of layers: 13

$\mathrm{Kx} \mathrm{Ky} \mathrm{Kz}$ Ss Por

3.69518e+01 3.69518e+01 3.69518e+00 1.00000e-09 7.00000e-02 $3.69518 \mathrm{e}+013.69518 \mathrm{e}+013.69518 \mathrm{e}+001.00000 \mathrm{e}-09$ 7.00000e-02 5.00000e-04 5.00000e-04 5.00000e-05 1.00000e-09 1.00000e-01 $5.00000 \mathrm{e}-04$ 5.00000e-04 5.00000e-05 1.00000e-09 1.00000e-01 $1.47648 \mathrm{e}+001.47648 \mathrm{e}+00$ 1.47648e-01 1.00000e-09 2.12000e-01 $1.47648 \mathrm{e}+001.47648 \mathrm{e}+001.47648 \mathrm{e}-011.00000 \mathrm{e}-092.12000 \mathrm{e}-01$ $1.47648 \mathrm{e}+001.47648 \mathrm{e}+00$ 1.47648e-01 1.00000e-09 2.12000e-01 $1.47648 \mathrm{e}+001.47648 \mathrm{e}+00$ 1.47648e-01 1.00000e-09 2.12000e-01 $1.47648 \mathrm{e}+001.47648 \mathrm{e}+00$ 1.47648e-01 1.00000e-09 2.12000e-01 $1.00000 \mathrm{e}-021.00000 \mathrm{e}-02$ 1.00000e-03 1.00000e-09 1.00000e-01 $1.00000 \mathrm{e}+001.00000 \mathrm{e}+001.00000 \mathrm{e}-011.00000 \mathrm{e}-091.00000 \mathrm{e}-01$ $1.00000 \mathrm{e}-05$ 1.00000e-05 1.00000e-06 1.00000e-09 1.00000e-01 $1.00000 \mathrm{e}+001.00000 \mathrm{e}+001.00000 \mathrm{e}-011.00000 \mathrm{e}-09$ 1.00000e-01 Element: 2370 \# of layers: 13

$\mathrm{Kx} \mathrm{Ky} \mathrm{Kz}$ Ss Por

3.69518e+01 3.69518e+01 3.69518e+00 1.00000e-09 7.00000e-02 $3.69518 \mathrm{e}+013.69518 \mathrm{e}+013.69518 \mathrm{e}+001.00000 \mathrm{e}-09$ 7.00000e-02 5.00000e-04 5.00000e-04 5.00000e-05 1.00000e-09 1.00000e-01 5.00000e-04 5.00000e-04 5.00000e-05 1.00000e-09 1.00000e-01 $1.47648 \mathrm{e}+001.47648 \mathrm{e}+00$ 1.47648e-01 1.00000e-09 2.12000e-01 $1.47648 \mathrm{e}+001.47648 \mathrm{e}+00$ 1.47648e-01 1.00000e-09 2.12000e-01 $1.47648 \mathrm{e}+001.47648 \mathrm{e}+00$ 1.47648e-01 1.00000e-09 2.12000e-01 $1.47648 \mathrm{e}+001.47648 \mathrm{e}+001.47648 \mathrm{e}-011.00000 \mathrm{e}-092.12000 \mathrm{e}-01$ $1.47648 \mathrm{e}+001.47648 \mathrm{e}+00$ 1.47648e-01 1.00000e-09 2.12000e-01 $1.00000 \mathrm{e}-02$ 1.00000e-02 1.00000e-03 1.00000e-09 1.00000e-01 $1.00000 \mathrm{e}+001.00000 \mathrm{e}+001.00000 \mathrm{e}-011.00000 \mathrm{e}-091.00000 \mathrm{e}-01$ $1.00000 \mathrm{e}-05$ 1.00000e-05 1.00000e-06 1.00000e-09 1.00000e-01 $1.00000 \mathrm{e}+001.00000 \mathrm{e}+001.00000 \mathrm{e}-011.00000 \mathrm{e}-091.00000 \mathrm{e}-01$ Element: 2371 \# of layers: 13

$\mathrm{Kx} \mathrm{Ky} \mathrm{Kz}$ Ss Por

3.69518e+01 3.69518e+01 3.69518e+00 1.00000e-09 7.00000e-02 
$3.69518 \mathrm{e}+013.69518 \mathrm{e}+013.69518 \mathrm{e}+001.00000 \mathrm{e}-09$ 7.00000e-02 5.00000e-04 5.00000e-04 5.00000e-05 1.00000e-09 1.00000e-01 5.00000e-04 5.00000e-04 5.00000e-05 1.00000e-09 1.00000e-01 $1.47648 \mathrm{e}+001.47648 \mathrm{e}+00$ 1.47648e-01 1.00000e-09 2.12000e-01 $1.47648 \mathrm{e}+001.47648 \mathrm{e}+00$ 1.47648e-01 1.00000e-09 2.12000e-01 $1.47648 \mathrm{e}+001.47648 \mathrm{e}+00$ 1.47648e-01 1.00000e-09 2.12000e-01 $1.47648 \mathrm{e}+001.47648 \mathrm{e}+00$ 1.47648e-01 1.00000e-09 2.12000e-01 $1.47648 \mathrm{e}+001.47648 \mathrm{e}+001.47648 \mathrm{e}-01$ 1.00000e-09 2.12000e-01 $1.00000 \mathrm{e}-02$ 1.00000e-02 1.00000e-03 1.00000e-09 1.00000e-01 $1.00000 \mathrm{e}+001.00000 \mathrm{e}+001.00000 \mathrm{e}-011.00000 \mathrm{e}-091.00000 \mathrm{e}-01$ $1.00000 \mathrm{e}-05$ 1.00000e-05 1.00000e-06 1.00000e-09 1.00000e-01 $1.00000 \mathrm{e}+001.00000 \mathrm{e}+001.00000 \mathrm{e}-011.00000 \mathrm{e}-091.00000 \mathrm{e}-01$ Element: 2372 \# of layers: 12

$\mathrm{Kx} \mathrm{Ky} \mathrm{Kz}$ Ss Por

4.12271e+01 4.12271e+01 4.12271e+00 1.00000e-09 7.00000e-02 5.00000e-04 5.00000e-04 5.00000e-05 1.00000e-09 1.00000e-01 5.00000e-04 5.00000e-04 5.00000e-05 1.00000e-09 1.00000e-01 $1.64728 \mathrm{e}+00$ 1.64728e+00 1.64728e-01 1.00000e-09 2.12000e-01 $1.64728 \mathrm{e}+001.64728 \mathrm{e}+00$ 1.64728e-01 1.00000e-09 2.12000e-01 $1.64728 \mathrm{e}+001.64728 \mathrm{e}+00$ 1.64728e-01 1.00000e-09 2.12000e-01 $1.64728 \mathrm{e}+001.64728 \mathrm{e}+00$ 1.64728e-01 1.00000e-09 2.12000e-01 $1.64728 \mathrm{e}+00$ 1.64728e+00 1.64728e-01 1.00000e-09 2.12000e-01 $1.00000 \mathrm{e}-02$ 1.00000e-02 1.00000e-03 1.00000e-09 1.00000e-01 $1.00000 \mathrm{e}+001.00000 \mathrm{e}+001.00000 \mathrm{e}-011.00000 \mathrm{e}-091.00000 \mathrm{e}-01$ $1.00000 \mathrm{e}-05$ 1.00000e-05 1.00000e-06 1.00000e-09 1.00000e-01 $1.00000 \mathrm{e}+001.00000 \mathrm{e}+001.00000 \mathrm{e}-011.00000 \mathrm{e}-091.00000 \mathrm{e}-01$ Element: 2373 \# of layers: 12

$\mathrm{Kx} \mathrm{Ky} \mathrm{Kz}$ Ss Por

4.12271e+01 4.12271e+01 4.12271e+00 1.00000e-09 7.00000e-02 $5.00000 \mathrm{e}-04$ 5.00000e-04 5.00000e-05 1.00000e-09 1.00000e-01 5.00000e-04 5.00000e-04 5.00000e-05 1.00000e-09 1.00000e-01 $1.64728 \mathrm{e}+001.64728 \mathrm{e}+00$ 1.64728e-01 1.00000e-09 2.12000e-01 $1.64728 \mathrm{e}+001.64728 \mathrm{e}+00$ 1.64728e-01 1.00000e-09 2.12000e-01 $1.64728 \mathrm{e}+001.64728 \mathrm{e}+00$ 1.64728e-01 1.00000e-09 2.12000e-01 $1.64728 \mathrm{e}+001.64728 \mathrm{e}+00$ 1.64728e-01 1.00000e-09 2.12000e-01 $1.64728 \mathrm{e}+001.64728 \mathrm{e}+00$ 1.64728e-01 1.00000e-09 2.12000e-01 $1.00000 \mathrm{e}-02$ 1.00000e-02 1.00000e-03 1.00000e-09 1.00000e-01 $1.00000 \mathrm{e}+001.00000 \mathrm{e}+001.00000 \mathrm{e}-011.00000 \mathrm{e}-091.00000 \mathrm{e}-01$ $1.00000 \mathrm{e}-05$ 1.00000e-05 1.00000e-06 1.00000e-09 1.00000e-01 $1.00000 \mathrm{e}+001.00000 \mathrm{e}+001.00000 \mathrm{e}-01$ 1.00000e-09 1.00000e-01 Element: 2374 \# of layers: 12

Kx Ky Kz Ss Por

4.12271e+01 4.12271e+01 4.12271e+00 1.00000e-09 7.00000e-02 5.00000e-04 5.00000e-04 5.00000e-05 1.00000e-09 1.00000e-01 5.00000e-04 5.00000e-04 5.00000e-05 1.00000e-09 1.00000e-01 $1.64728 \mathrm{e}+001.64728 \mathrm{e}+00$ 1.64728e-01 1.00000e-09 2.12000e-01 
$1.64728 \mathrm{e}+001.64728 \mathrm{e}+00$ 1.64728e-01 1.00000e-09 2.12000e-01 $1.64728 \mathrm{e}+001.64728 \mathrm{e}+00$ 1.64728e-01 1.00000e-09 2.12000e-01 $1.64728 \mathrm{e}+001.64728 \mathrm{e}+00$ 1.64728e-01 1.00000e-09 2.12000e-01 $1.64728 \mathrm{e}+001.64728 \mathrm{e}+00$ 1.64728e-01 1.00000e-09 2.12000e-01 $1.00000 \mathrm{e}-02$ 1.00000e-02 1.00000e-03 1.00000e-09 1.00000e-01 $1.00000 \mathrm{e}+001.00000 \mathrm{e}+001.00000 \mathrm{e}-011.00000 \mathrm{e}-091.00000 \mathrm{e}-01$ $1.00000 \mathrm{e}-05$ 1.00000e-05 1.00000e-06 1.00000e-09 1.00000e-01 $1.00000 \mathrm{e}+001.00000 \mathrm{e}+001.00000 \mathrm{e}-011.00000 \mathrm{e}-091.00000 \mathrm{e}-01$ Element: 2375 \# of layers: 13

$\mathrm{Kx} \mathrm{Ky} \mathrm{Kz}$ Ss Por

4.12271e+01 4.12271e+01 4.12271e+00 1.00000e-09 7.00000e-02 $4.12271 \mathrm{e}+014.12271 \mathrm{e}+014.12271 \mathrm{e}+001.00000 \mathrm{e}-09$ 7.00000e-02 5.00000e-04 5.00000e-04 5.00000e-05 1.00000e-09 1.00000e-01 5.00000e-04 5.00000e-04 5.00000e-05 1.00000e-09 1.00000e-01 $1.64728 \mathrm{e}+001.64728 \mathrm{e}+00$ 1.64728e-01 1.00000e-09 2.12000e-01 $1.64728 \mathrm{e}+001.64728 \mathrm{e}+001.64728 \mathrm{e}-01$ 1.00000e-09 2.12000e-01 $1.64728 \mathrm{e}+001.64728 \mathrm{e}+00$ 1.64728e-01 1.00000e-09 2.12000e-01 $1.64728 \mathrm{e}+001.64728 \mathrm{e}+00$ 1.64728e-01 1.00000e-09 2.12000e-01 $1.64728 \mathrm{e}+001.64728 \mathrm{e}+00$ 1.64728e-01 1.00000e-09 2.12000e-01 $1.00000 \mathrm{e}-021.00000 \mathrm{e}-021.00000 \mathrm{e}-031.00000 \mathrm{e}-091.00000 \mathrm{e}-01$ $1.00000 \mathrm{e}+001.00000 \mathrm{e}+001.00000 \mathrm{e}-011.00000 \mathrm{e}-091.00000 \mathrm{e}-01$ $1.00000 \mathrm{e}-05$ 1.00000e-05 1.00000e-06 1.00000e-09 1.00000e-01 $1.00000 \mathrm{e}+001.00000 \mathrm{e}+001.00000 \mathrm{e}-01$ 1.00000e-09 1.00000e-01 Element: 2376 \# of layers: 13

Kx Ky Kz Ss Por

4.12271e+01 4.12271e+01 4.12271e+00 1.00000e-09 7.00000e-02 4.12271e+01 4.12271e+01 4.12271e+00 1.00000e-09 7.00000e-02 5.00000e-04 5.00000e-04 5.00000e-05 1.00000e-09 1.00000e-01 5.00000e-04 5.00000e-04 5.00000e-05 1.00000e-09 1.00000e-01 $1.64728 \mathrm{e}+001.64728 \mathrm{e}+00$ 1.64728e-01 1.00000e-09 2.12000e-01 $1.64728 \mathrm{e}+001.64728 \mathrm{e}+00$ 1.64728e-01 1.00000e-09 2.12000e-01 $1.64728 \mathrm{e}+001.64728 \mathrm{e}+00$ 1.64728e-01 1.00000e-09 2.12000e-01 $1.64728 \mathrm{e}+001.64728 \mathrm{e}+00$ 1.64728e-01 1.00000e-09 2.12000e-01 $1.64728 \mathrm{e}+001.64728 \mathrm{e}+00$ 1.64728e-01 1.00000e-09 2.12000e-01 $1.00000 \mathrm{e}-02$ 1.00000e-02 1.00000e-03 1.00000e-09 1.00000e-01 $1.00000 \mathrm{e}+001.00000 \mathrm{e}+001.00000 \mathrm{e}-011.00000 \mathrm{e}-091.00000 \mathrm{e}-01$ $1.00000 \mathrm{e}-05$ 1.00000e-05 1.00000e-06 1.00000e-09 1.00000e-01 $1.00000 \mathrm{e}+001.00000 \mathrm{e}+001.00000 \mathrm{e}-011.00000 \mathrm{e}-09$ 1.00000e-01 Element: 2377 \# of layers: 13

$\mathrm{Kx} \mathrm{Ky} \mathrm{Kz}$ Ss Por

4.12271e+01 4.12271e+01 4.12271e+00 1.00000e-09 7.00000e-02 $4.12271 \mathrm{e}+014.12271 \mathrm{e}+014.12271 \mathrm{e}+00$ 1.00000e-09 7.00000e-02 5.00000e-04 5.00000e-04 5.00000e-05 1.00000e-09 1.00000e-01 $5.00000 \mathrm{e}-04$ 5.00000e-04 5.00000e-05 1.00000e-09 1.00000e-01 $1.64728 \mathrm{e}+001.64728 \mathrm{e}+00$ 1.64728e-01 1.00000e-09 2.12000e-01 $1.64728 \mathrm{e}+001.64728 \mathrm{e}+00$ 1.64728e-01 1.00000e-09 2.12000e-01 
$1.64728 \mathrm{e}+00$ 1.64728e+00 1.64728e-01 1.00000e-09 2.12000e-01 $1.64728 \mathrm{e}+001.64728 \mathrm{e}+00$ 1.64728e-01 1.00000e-09 2.12000e-01 $1.64728 \mathrm{e}+001.64728 \mathrm{e}+00$ 1.64728e-01 1.00000e-09 2.12000e-01 $1.00000 \mathrm{e}-02$ 1.00000e-02 1.00000e-03 1.00000e-09 1.00000e-01 $1.00000 \mathrm{e}+001.00000 \mathrm{e}+001.00000 \mathrm{e}-011.00000 \mathrm{e}-091.00000 \mathrm{e}-01$ $1.00000 \mathrm{e}-05$ 1.00000e-05 1.00000e-06 1.00000e-09 1.00000e-01 $1.00000 \mathrm{e}+001.00000 \mathrm{e}+001.00000 \mathrm{e}-011.00000 \mathrm{e}-091.00000 \mathrm{e}-01$ Element: 2378 \# of layers: 13

$\mathrm{Kx} \mathrm{Ky} \mathrm{Kz}$ Ss Por

4.12271e+01 4.12271e+01 4.12271e+00 1.00000e-09 7.00000e-02 $4.12271 \mathrm{e}+014.12271 \mathrm{e}+014.12271 \mathrm{e}+00$ 1.00000e-09 7.00000e-02 5.00000e-04 5.00000e-04 5.00000e-05 1.00000e-09 1.00000e-01 5.00000e-04 5.00000e-04 5.00000e-05 1.00000e-09 1.00000e-01 $1.64728 \mathrm{e}+001.64728 \mathrm{e}+00$ 1.64728e-01 1.00000e-09 2.12000e-01 $1.64728 \mathrm{e}+001.64728 \mathrm{e}+00$ 1.64728e-01 1.00000e-09 2.12000e-01 $1.64728 \mathrm{e}+001.64728 \mathrm{e}+00$ 1.64728e-01 1.00000e-09 2.12000e-01 $1.64728 \mathrm{e}+001.64728 \mathrm{e}+00$ 1.64728e-01 1.00000e-09 2.12000e-01 $1.64728 \mathrm{e}+001.64728 \mathrm{e}+00$ 1.64728e-01 1.00000e-09 2.12000e-01 $1.00000 \mathrm{e}-02$ 1.00000e-02 1.00000e-03 1.00000e-09 1.00000e-01 $1.00000 \mathrm{e}+001.00000 \mathrm{e}+001.00000 \mathrm{e}-011.00000 \mathrm{e}-091.00000 \mathrm{e}-01$ $1.00000 \mathrm{e}-05$ 1.00000e-05 1.00000e-06 1.00000e-09 1.00000e-01 $1.00000 \mathrm{e}+001.00000 \mathrm{e}+001.00000 \mathrm{e}-01$ 1.00000e-09 1.00000e-01 Element: 2379 \# of layers: 13

Kx Ky Kz Ss Por

4.12271e+01 4.12271e+01 4.12271e+00 1.00000e-09 7.00000e-02 4.12271e+01 4.12271e+01 4.12271e+00 1.00000e-09 7.00000e-02 5.00000e-04 5.00000e-04 5.00000e-05 1.00000e-09 1.00000e-01 5.00000e-04 5.00000e-04 5.00000e-05 1.00000e-09 1.00000e-01 $1.64728 \mathrm{e}+001.64728 \mathrm{e}+00$ 1.64728e-01 1.00000e-09 2.12000e-01 $1.64728 \mathrm{e}+00$ 1.64728e+00 1.64728e-01 1.00000e-09 2.12000e-01 $1.64728 \mathrm{e}+001.64728 \mathrm{e}+00$ 1.64728e-01 1.00000e-09 2.12000e-01 $1.64728 \mathrm{e}+001.64728 \mathrm{e}+00$ 1.64728e-01 1.00000e-09 2.12000e-01 $1.64728 \mathrm{e}+001.64728 \mathrm{e}+00$ 1.64728e-01 1.00000e-09 2.12000e-01 $1.00000 \mathrm{e}-02$ 1.00000e-02 1.00000e-03 1.00000e-09 1.00000e-01 $1.00000 \mathrm{e}+001.00000 \mathrm{e}+001.00000 \mathrm{e}-011.00000 \mathrm{e}-091.00000 \mathrm{e}-01$ $1.00000 \mathrm{e}-05$ 1.00000e-05 1.00000e-06 1.00000e-09 1.00000e-01 $1.00000 \mathrm{e}+001.00000 \mathrm{e}+001.00000 \mathrm{e}-011.00000 \mathrm{e}-091.00000 \mathrm{e}-01$ Element: 2380 \# of layers: 13

$\mathrm{Kx} \mathrm{Ky} \mathrm{Kz}$ Ss Por

4.12271e+01 4.12271e+01 4.12271e+00 1.00000e-09 7.00000e-02 4.12271e+01 4.12271e+01 4.12271e+00 1.00000e-09 7.00000e-02 5.00000e-04 5.00000e-04 5.00000e-05 1.00000e-09 1.00000e-01 $5.00000 \mathrm{e}-04$ 5.00000e-04 5.00000e-05 1.00000e-09 1.00000e-01 $1.64728 \mathrm{e}+001.64728 \mathrm{e}+00$ 1.64728e-01 1.00000e-09 2.12000e-01 $1.64728 \mathrm{e}+001.64728 \mathrm{e}+00$ 1.64728e-01 1.00000e-09 2.12000e-01 $1.64728 \mathrm{e}+001.64728 \mathrm{e}+00$ 1.64728e-01 1.00000e-09 2.12000e-01 
$1.64728 \mathrm{e}+001.64728 \mathrm{e}+00$ 1.64728e-01 1.00000e-09 2.12000e-01 $1.64728 \mathrm{e}+001.64728 \mathrm{e}+00$ 1.64728e-01 1.00000e-09 2.12000e-01 $1.00000 \mathrm{e}-02$ 1.00000e-02 1.00000e-03 1.00000e-09 1.00000e-01 $1.00000 \mathrm{e}+001.00000 \mathrm{e}+001.00000 \mathrm{e}-011.00000 \mathrm{e}-091.00000 \mathrm{e}-01$ $1.00000 \mathrm{e}-05$ 1.00000e-05 1.00000e-06 1.00000e-09 1.00000e-01 $1.00000 \mathrm{e}+001.00000 \mathrm{e}+001.00000 \mathrm{e}-011.00000 \mathrm{e}-091.00000 \mathrm{e}-01$ Element: 2381 \# of layers: 9

Kx Ky Kz Ss Por

6.50747e+01 6.50747e+01 6.50747e+00 1.00000e-09 7.00000e-02 5.00000e-04 5.00000e-04 5.00000e-05 1.00000e-09 1.00000e-01 5.00000e-04 5.00000e-04 5.00000e-05 1.00000e-09 1.00000e-01 $2.60016 \mathrm{e}+002.60016 \mathrm{e}+002.60016 \mathrm{e}-01$ 1.00000e-09 2.12000e-01 $2.60016 \mathrm{e}+002.60016 \mathrm{e}+002.60016 \mathrm{e}-01$ 1.00000e-09 2.12000e-01 $2.60016 \mathrm{e}+002.60016 \mathrm{e}+002.60016 \mathrm{e}-01$ 1.00000e-09 2.12000e-01 $2.60016 \mathrm{e}+002.60016 \mathrm{e}+002.60016 \mathrm{e}-01$ 1.00000e-09 2.12000e-01 $2.60016 \mathrm{e}+002.60016 \mathrm{e}+002.60016 \mathrm{e}-01$ 1.00000e-09 2.12000e-01 1.00000e-02 1.00000e-02 1.00000e-03 1.00000e-09 1.00000e-01 Element: 2382 \# of layers: 9

$\mathrm{Kx} \mathrm{Ky} \mathrm{Kz}$ Ss Por

6.50747e+01 6.50747e+01 6.50747e+00 1.00000e-09 7.00000e-02 5.00000e-04 5.00000e-04 5.00000e-05 1.00000e-09 1.00000e-01 5.00000e-04 5.00000e-04 5.00000e-05 1.00000e-09 1.00000e-01 $2.60016 \mathrm{e}+002.60016 \mathrm{e}+002.60016 \mathrm{e}-01$ 1.00000e-09 2.12000e-01 $2.60016 \mathrm{e}+002.60016 \mathrm{e}+002.60016 \mathrm{e}-01$ 1.00000e-09 2.12000e-01 $2.60016 \mathrm{e}+002.60016 \mathrm{e}+00$ 2.60016e-01 1.00000e-09 2.12000e-01 $2.60016 \mathrm{e}+002.60016 \mathrm{e}+002.60016 \mathrm{e}-01$ 1.00000e-09 2.12000e-01 $2.60016 \mathrm{e}+002.60016 \mathrm{e}+002.60016 \mathrm{e}-01$ 1.00000e-09 2.12000e-01 1.00000e-02 1.00000e-02 1.00000e-03 1.00000e-09 1.00000e-01 Element: 2383 \# of layers: 8

$\mathrm{Kx} \mathrm{Ky} \mathrm{Kz}$ Ss Por

6.50747e+01 6.50747e+01 6.50747e+00 1.00000e-09 7.00000e-02 5.00000e-04 5.00000e-04 5.00000e-05 1.00000e-09 1.00000e-01 $5.00000 \mathrm{e}-04$ 5.00000e-04 5.00000e-05 1.00000e-09 1.00000e-01

$2.60016 \mathrm{e}+002.60016 \mathrm{e}+002.60016 \mathrm{e}-01$ 1.00000e-09 2.12000e-01 $2.60016 \mathrm{e}+002.60016 \mathrm{e}+002.60016 \mathrm{e}-01$ 1.00000e-09 2.12000e-01 $2.60016 \mathrm{e}+002.60016 \mathrm{e}+002.60016 \mathrm{e}-01$ 1.00000e-09 2.12000e-01 $2.60016 \mathrm{e}+002.60016 \mathrm{e}+002.60016 \mathrm{e}-01$ 1.00000e-09 2.12000e-01 $2.60016 \mathrm{e}+002.60016 \mathrm{e}+002.60016 \mathrm{e}-01$ 1.00000e-09 2.12000e-01 Element: 2384 \# of layers: 8

$\mathrm{Kx} \mathrm{Ky} \mathrm{Kz}$ Ss Por 6.50747e+01 6.50747e+01 6.50747e+00 1.00000e-09 7.00000e-02 5.00000e-04 5.00000e-04 5.00000e-05 1.00000e-09 1.00000e-01 5.00000e-04 5.00000e-04 5.00000e-05 1.00000e-09 1.00000e-01 $2.60016 \mathrm{e}+002.60016 \mathrm{e}+002.60016 \mathrm{e}-01$ 1.00000e-09 2.12000e-01 $2.60016 \mathrm{e}+002.60016 \mathrm{e}+002.60016 \mathrm{e}-01$ 1.00000e-09 2.12000e-01 $2.60016 \mathrm{e}+002.60016 \mathrm{e}+00$ 2.60016e-01 1.00000e-09 2.12000e-01 
$2.60016 \mathrm{e}+002.60016 \mathrm{e}+002.60016 \mathrm{e}-011.00000 \mathrm{e}-092.12000 \mathrm{e}-01$ $2.60016 \mathrm{e}+002.60016 \mathrm{e}+00$ 2.60016e-01 1.00000e-09 2.12000e-01 Element: 2385 \# of layers: 9

Kx Ky Kz Ss Por

6.50747e+01 6.50747e+01 6.50747e+00 1.00000e-09 7.00000e-02 $5.00000 \mathrm{e}-04$ 5.00000e-04 5.00000e-05 1.00000e-09 1.00000e-01 $5.00000 \mathrm{e}-04$ 5.00000e-04 5.00000e-05 1.00000e-09 1.00000e-01 $2.60016 \mathrm{e}+002.60016 \mathrm{e}+002.60016 \mathrm{e}-011.00000 \mathrm{e}-092.12000 \mathrm{e}-01$ $2.60016 \mathrm{e}+002.60016 \mathrm{e}+002.60016 \mathrm{e}-011.00000 \mathrm{e}-092.12000 \mathrm{e}-01$ $2.60016 \mathrm{e}+002.60016 \mathrm{e}+002.60016 \mathrm{e}-011.00000 \mathrm{e}-092.12000 \mathrm{e}-01$ $2.60016 \mathrm{e}+002.60016 \mathrm{e}+002.60016 \mathrm{e}-011.00000 \mathrm{e}-092.12000 \mathrm{e}-01$ $2.60016 \mathrm{e}+002.60016 \mathrm{e}+002.60016 \mathrm{e}-011.00000 \mathrm{e}-092.12000 \mathrm{e}-01$ $1.00000 \mathrm{e}+001.00000 \mathrm{e}+001.00000 \mathrm{e}-011.00000 \mathrm{e}-091.00000 \mathrm{e}-01$ Element: 2386 \# of layers: 11

Kx Ky Kz Ss Por

6.50747e+01 6.50747e+01 6.50747e+00 1.00000e-09 7.00000e-02 $6.50747 \mathrm{e}+016.50747 \mathrm{e}+016.50747 \mathrm{e}+001.00000 \mathrm{e}-09$ 7.00000e-02 5.00000e-04 5.00000e-04 5.00000e-05 1.00000e-09 1.00000e-01 $5.00000 \mathrm{e}-04$ 5.00000e-04 5.00000e-05 1.00000e-09 1.00000e-01 $2.60016 \mathrm{e}+002.60016 \mathrm{e}+002.60016 \mathrm{e}-01$ 1.00000e-09 2.12000e-01 $2.60016 \mathrm{e}+002.60016 \mathrm{e}+002.60016 \mathrm{e}-011.00000 \mathrm{e}-092.12000 \mathrm{e}-01$ $2.60016 \mathrm{e}+002.60016 \mathrm{e}+002.60016 \mathrm{e}-011.00000 \mathrm{e}-092.12000 \mathrm{e}-01$ $2.60016 \mathrm{e}+002.60016 \mathrm{e}+002.60016 \mathrm{e}-011.00000 \mathrm{e}-092.12000 \mathrm{e}-01$ $2.60016 \mathrm{e}+002.60016 \mathrm{e}+002.60016 \mathrm{e}-01$ 1.00000e-09 2.12000e-01 $1.00000 \mathrm{e}-021.00000 \mathrm{e}-02$ 1.00000e-03 1.00000e-09 1.00000e-01 $1.00000 \mathrm{e}+001.00000 \mathrm{e}+001.00000 \mathrm{e}-011.00000 \mathrm{e}-091.00000 \mathrm{e}-01$ Element: 2387 \# of layers: 11

Kx Ky Kz Ss Por

$6.50747 \mathrm{e}+016.50747 \mathrm{e}+016.50747 \mathrm{e}+00$ 1.00000e-09 7.00000e-02 $6.50747 \mathrm{e}+016.50747 \mathrm{e}+016.50747 \mathrm{e}+001.00000 \mathrm{e}-097.00000 \mathrm{e}-02$ 5.00000e-04 5.00000e-04 5.00000e-05 1.00000e-09 1.00000e-01 5.00000e-04 5.00000e-04 5.00000e-05 1.00000e-09 1.00000e-01 $2.60016 \mathrm{e}+002.60016 \mathrm{e}+002.60016 \mathrm{e}-01$ 1.00000e-09 2.12000e-01 $2.60016 \mathrm{e}+002.60016 \mathrm{e}+002.60016 \mathrm{e}-011.00000 \mathrm{e}-092.12000 \mathrm{e}-01$ $2.60016 \mathrm{e}+002.60016 \mathrm{e}+002.60016 \mathrm{e}-011.00000 \mathrm{e}-092.12000 \mathrm{e}-01$ $2.60016 \mathrm{e}+002.60016 \mathrm{e}+002.60016 \mathrm{e}-01$ 1.00000e-09 2.12000e-01 $2.60016 \mathrm{e}+002.60016 \mathrm{e}+002.60016 \mathrm{e}-011.00000 \mathrm{e}-092.12000 \mathrm{e}-01$ $1.00000 \mathrm{e}-021.00000 \mathrm{e}-02$ 1.00000e-03 1.00000e-09 1.00000e-01 $1.00000 \mathrm{e}+001.00000 \mathrm{e}+001.00000 \mathrm{e}-011.00000 \mathrm{e}-091.00000 \mathrm{e}-01$ Element: 2388 \# of layers: 10

Kx Ky Kz Ss Por 6.50747e+01 6.50747e+01 6.50747e+00 1.00000e-09 7.00000e-02 $5.00000 \mathrm{e}-04$ 5.00000e-04 5.00000e-05 1.00000e-09 1.00000e-01 $5.00000 \mathrm{e}-04$ 5.00000e-04 5.00000e-05 1.00000e-09 1.00000e-01 $2.60016 \mathrm{e}+002.60016 \mathrm{e}+002.60016 \mathrm{e}-011.00000 \mathrm{e}-092.12000 \mathrm{e}-01$ $2.60016 \mathrm{e}+002.60016 \mathrm{e}+002.60016 \mathrm{e}-01$ 1.00000e-09 2.12000e-01 
$2.60016 \mathrm{e}+002.60016 \mathrm{e}+002.60016 \mathrm{e}-011.00000 \mathrm{e}-092.12000 \mathrm{e}-01$ $2.60016 \mathrm{e}+002.60016 \mathrm{e}+002.60016 \mathrm{e}-01$ 1.00000e-09 2.12000e-01 $2.60016 \mathrm{e}+002.60016 \mathrm{e}+002.60016 \mathrm{e}-01$ 1.00000e-09 2.12000e-01 $1.00000 \mathrm{e}-021.00000 \mathrm{e}-02$ 1.00000e-03 1.00000e-09 1.00000e-01 $1.00000 \mathrm{e}+001.00000 \mathrm{e}+001.00000 \mathrm{e}-011.00000 \mathrm{e}-091.00000 \mathrm{e}-01$ Element: 2389 \# of layers: 10

Kx Ky Kz Ss Por

6.50747e+01 6.50747e+01 6.50747e+00 1.00000e-09 7.00000e-02 5.00000e-04 5.00000e-04 5.00000e-05 1.00000e-09 1.00000e-01 $5.00000 \mathrm{e}-04$ 5.00000e-04 5.00000e-05 1.00000e-09 1.00000e-01 $2.60016 \mathrm{e}+002.60016 \mathrm{e}+002.60016 \mathrm{e}-011.00000 \mathrm{e}-092.12000 \mathrm{e}-01$ $2.60016 \mathrm{e}+002.60016 \mathrm{e}+002.60016 \mathrm{e}-01$ 1.00000e-09 2.12000e-01 $2.60016 \mathrm{e}+002.60016 \mathrm{e}+002.60016 \mathrm{e}-011.00000 \mathrm{e}-092.12000 \mathrm{e}-01$ $2.60016 \mathrm{e}+002.60016 \mathrm{e}+002.60016 \mathrm{e}-011.00000 \mathrm{e}-092.12000 \mathrm{e}-01$ $2.60016 \mathrm{e}+002.60016 \mathrm{e}+002.60016 \mathrm{e}-01$ 1.00000e-09 2.12000e-01 $1.00000 \mathrm{e}-02$ 1.00000e-02 1.00000e-03 1.00000e-09 1.00000e-01 $1.00000 \mathrm{e}+001.00000 \mathrm{e}+001.00000 \mathrm{e}-011.00000 \mathrm{e}-091.00000 \mathrm{e}-01$ Element: 2390 \# of layers: 9

$\mathrm{Kx} \mathrm{Ky} \mathrm{Kz}$ Ss Por

$1.44295 \mathrm{e}+021.44295 \mathrm{e}+02$ 1.44295e+01 1.00000e-09 7.00000e-02 $1.44295 \mathrm{e}+021.44295 \mathrm{e}+021.44295 \mathrm{e}+011.00000 \mathrm{e}-097.00000 \mathrm{e}-02$ 5.00000e-04 5.00000e-04 5.00000e-05 1.00000e-09 1.00000e-01 $5.00000 \mathrm{e}-04$ 5.00000e-04 5.00000e-05 1.00000e-09 1.00000e-01 $5.76552 \mathrm{e}+005.76552 \mathrm{e}+00$ 5.76552e-01 1.00000e-09 2.12000e-01 $5.76552 \mathrm{e}+005.76552 \mathrm{e}+00$ 5.76552e-01 1.00000e-09 2.12000e-01 $5.76552 \mathrm{e}+005.76552 \mathrm{e}+00$ 5.76552e-01 1.00000e-09 2.12000e-01 $5.76552 \mathrm{e}+00$ 5.76552e+00 5.76552e-01 1.00000e-09 2.12000e-01 $5.76552 \mathrm{e}+00$ 5.76552e+00 5.76552e-01 1.00000e-09 2.12000e-01 Element: 2391 \# of layers: 7

Kx Ky Kz Ss Por

$1.44295 \mathrm{e}+02$ 1.44295e+02 1.44295e+01 1.00000e-09 7.00000e-02 5.00000e-04 5.00000e-04 5.00000e-05 1.00000e-09 1.00000e-01

$5.76552 \mathrm{e}+005.76552 \mathrm{e}+00$ 5.76552e-01 1.00000e-09 2.12000e-01

$5.76552 \mathrm{e}+005.76552 \mathrm{e}+00$ 5.76552e-01 1.00000e-09 2.12000e-01

$5.76552 \mathrm{e}+005.76552 \mathrm{e}+00$ 5.76552e-01 1.00000e-09 2.12000e-01

$5.76552 \mathrm{e}+005.76552 \mathrm{e}+00$ 5.76552e-01 1.00000e-09 2.12000e-01

$5.76552 \mathrm{e}+005.76552 \mathrm{e}+00$ 5.76552e-01 1.00000e-09 2.12000e-01 Element: 2392 \# of layers: 7

Kx Ky Kz Ss Por

5.00000e-04 5.00000e-04 5.00000e-05 1.00000e-09 1.00000e-01 5.00000e-04 5.00000e-04 5.00000e-05 1.00000e-09 1.00000e-01

$5.76552 \mathrm{e}+005.76552 \mathrm{e}+00$ 5.76552e-01 1.00000e-09 2.12000e-01 $5.76552 \mathrm{e}+005.76552 \mathrm{e}+00$ 5.76552e-01 1.00000e-09 2.12000e-01 $5.76552 \mathrm{e}+005.76552 \mathrm{e}+00$ 5.76552e-01 1.00000e-09 2.12000e-01 $5.76552 \mathrm{e}+005.76552 \mathrm{e}+00$ 5.76552e-01 1.00000e-09 2.12000e-01 $5.76552 \mathrm{e}+005.76552 \mathrm{e}+00$ 5.76552e-01 1.00000e-09 2.12000e-01 
Element: 2393 \# of layers: 8

$\mathrm{Kx} \mathrm{Ky} \mathrm{Kz}$ Ss Por

$1.44295 \mathrm{e}+02$ 1.44295e+02 1.44295e+01 1.00000e-09 7.00000e-02

5.00000e-04 5.00000e-04 5.00000e-05 1.00000e-09 1.00000e-01

5.00000e-04 5.00000e-04 5.00000e-05 1.00000e-09 1.00000e-01

$5.76552 \mathrm{e}+005.76552 \mathrm{e}+00$ 5.76552e-01 1.00000e-09 2.12000e-01

5.76552e+00 5.76552e+00 5.76552e-01 1.00000e-09 2.12000e-01

$5.76552 \mathrm{e}+00$ 5.76552e+00 5.76552e-01 1.00000e-09 2.12000e-01

5.76552e+00 5.76552e+00 5.76552e-01 1.00000e-09 2.12000e-01

5.76552e+00 5.76552e+00 5.76552e-01 1.00000e-09 2.12000e-01

Element: 2394 \# of layers: 8

$\mathrm{Kx} \mathrm{Ky} \mathrm{Kz}$ Ss Por

1.44295e+02 1.44295e+02 1.44295e+01 1.00000e-09 7.00000e-02

5.00000e-04 5.00000e-04 5.00000e-05 1.00000e-09 1.00000e-01

5.00000e-04 5.00000e-04 5.00000e-05 1.00000e-09 1.00000e-01

$5.76552 \mathrm{e}+005.76552 \mathrm{e}+00$ 5.76552e-01 1.00000e-09 2.12000e-01

5.76552e+00 5.76552e+00 5.76552e-01 1.00000e-09 2.12000e-01

$5.76552 \mathrm{e}+005.76552 \mathrm{e}+00$ 5.76552e-01 1.00000e-09 2.12000e-01

5.76552e+00 5.76552e+00 5.76552e-01 1.00000e-09 2.12000e-01

5.76552e+00 5.76552e+00 5.76552e-01 1.00000e-09 2.12000e-01

Element: 2395 \# of layers: 8

$\mathrm{Kx} \mathrm{Ky} \mathrm{Kz}$ Ss Por

$1.44295 \mathrm{e}+02$ 1.44295e+02 1.44295e+01 1.00000e-09 7.00000e-02 5.00000e-04 5.00000e-04 5.00000e-05 1.00000e-09 1.00000e-01

5.00000e-04 5.00000e-04 5.00000e-05 1.00000e-09 1.00000e-01

5.76552e+00 5.76552e+00 5.76552e-01 1.00000e-09 2.12000e-01

5.76552e+00 5.76552e+00 5.76552e-01 1.00000e-09 2.12000e-01

$5.76552 \mathrm{e}+00$ 5.76552e+00 5.76552e-01 1.00000e-09 2.12000e-01

$5.76552 \mathrm{e}+00$ 5.76552e+00 5.76552e-01 1.00000e-09 2.12000e-01

5.76552e+00 5.76552e+00 5.76552e-01 1.00000e-09 2.12000e-01

Element: 2396 \# of layers: 9

$\mathrm{Kx} \mathrm{Ky} \mathrm{Kz}$ Ss Por

1.44295e+02 1.44295e+02 1.44295e+01 1.00000e-09 7.00000e-02

$1.44295 \mathrm{e}+02$ 1.44295e+02 1.44295e+01 1.00000e-09 7.00000e-02

5.00000e-04 5.00000e-04 5.00000e-05 1.00000e-09 1.00000e-01

5.00000e-04 5.00000e-04 5.00000e-05 1.00000e-09 1.00000e-01

$5.76552 \mathrm{e}+005.76552 \mathrm{e}+00$ 5.76552e-01 1.00000e-09 2.12000e-01

$5.76552 \mathrm{e}+00$ 5.76552e+00 5.76552e-01 1.00000e-09 2.12000e-01

5.76552e+00 5.76552e+00 5.76552e-01 1.00000e-09 2.12000e-01

5.76552e+00 5.76552e+00 5.76552e-01 1.00000e-09 2.12000e-01

5.76552e+00 5.76552e+00 5.76552e-01 1.00000e-09 2.12000e-01

Element: 2397 \# of layers: 9

$\mathrm{Kx} \mathrm{Ky} \mathrm{Kz}$ Ss Por

1.44295e+02 1.44295e+02 1.44295e+01 1.00000e-09 7.00000e-02 $1.44295 \mathrm{e}+021.44295 \mathrm{e}+02$ 1.44295e+01 1.00000e-09 7.00000e-02 5.00000e-04 5.00000e-04 5.00000e-05 1.00000e-09 1.00000e-01 
5.00000e-04 5.00000e-04 5.00000e-05 1.00000e-09 1.00000e-01

$5.76552 \mathrm{e}+005.76552 \mathrm{e}+00$ 5.76552e-01 1.00000e-09 2.12000e-01

$5.76552 \mathrm{e}+005.76552 \mathrm{e}+00$ 5.76552e-01 1.00000e-09 2.12000e-01

$5.76552 \mathrm{e}+00$ 5.76552e+00 5.76552e-01 1.00000e-09 2.12000e-01

$5.76552 \mathrm{e}+005.76552 \mathrm{e}+00$ 5.76552e-01 1.00000e-09 2.12000e-01

$5.76552 \mathrm{e}+005.76552 \mathrm{e}+00$ 5.76552e-01 1.00000e-09 2.12000e-01

Element: 2398 \# of layers: 8

Kx Ky Kz Ss Por

$1.44295 \mathrm{e}+021.44295 \mathrm{e}+021.44295 \mathrm{e}+011.00000 \mathrm{e}-097.00000 \mathrm{e}-02$

$5.00000 \mathrm{e}-04$ 5.00000e-04 5.00000e-05 1.00000e-09 1.00000e-01

$5.00000 \mathrm{e}-04$ 5.00000e-04 5.00000e-05 1.00000e-09 1.00000e-01

$5.76552 \mathrm{e}+00$ 5.76552e+00 5.76552e-01 1.00000e-09 2.12000e-01

$5.76552 \mathrm{e}+005.76552 \mathrm{e}+00$ 5.76552e-01 1.00000e-09 2.12000e-01

$5.76552 \mathrm{e}+005.76552 \mathrm{e}+00$ 5.76552e-01 1.00000e-09 2.12000e-01

$5.76552 \mathrm{e}+005.76552 \mathrm{e}+00$ 5.76552e-01 1.00000e-09 2.12000e-01

5.76552e+00 5.76552e+00 5.76552e-01 1.00000e-09 2.12000e-01

Element: 2399 \# of layers: 7

Kx Ky Kz Ss Por

5.00000e-04 5.00000e-04 5.00000e-05 1.00000e-09 1.00000e-01

5.00000e-04 5.00000e-04 5.00000e-05 1.00000e-09 1.00000e-01

$1.23766 \mathrm{e}+011.23766 \mathrm{e}+011.23766 \mathrm{e}+001.00000 \mathrm{e}-092.12000 \mathrm{e}-01$

$1.23766 \mathrm{e}+011.23766 \mathrm{e}+011.23766 \mathrm{e}+001.00000 \mathrm{e}-092.12000 \mathrm{e}-01$

$1.23766 \mathrm{e}+011.23766 \mathrm{e}+011.23766 \mathrm{e}+001.00000 \mathrm{e}-092.12000 \mathrm{e}-01$

$1.23766 \mathrm{e}+011.23766 \mathrm{e}+011.23766 \mathrm{e}+001.00000 \mathrm{e}-092.12000 \mathrm{e}-01$

$1.23766 \mathrm{e}+011.23766 \mathrm{e}+011.23766 \mathrm{e}+001.00000 \mathrm{e}-092.12000 \mathrm{e}-01$

Element: 2400 \# of layers: 7

Kx Ky Kz Ss Por

5.00000e-04 5.00000e-04 5.00000e-05 1.00000e-09 1.00000e-01

5.00000e-04 5.00000e-04 5.00000e-05 1.00000e-09 1.00000e-01

$1.23766 \mathrm{e}+011.23766 \mathrm{e}+011.23766 \mathrm{e}+001.00000 \mathrm{e}-092.12000 \mathrm{e}-01$

$1.23766 \mathrm{e}+011.23766 \mathrm{e}+011.23766 \mathrm{e}+001.00000 \mathrm{e}-092.12000 \mathrm{e}-01$

$1.23766 \mathrm{e}+011.23766 \mathrm{e}+011.23766 \mathrm{e}+001.00000 \mathrm{e}-092.12000 \mathrm{e}-01$

$1.23766 \mathrm{e}+011.23766 \mathrm{e}+011.23766 \mathrm{e}+001.00000 \mathrm{e}-092.12000 \mathrm{e}-01$

$1.23766 \mathrm{e}+011.23766 \mathrm{e}+011.23766 \mathrm{e}+001.00000 \mathrm{e}-092.12000 \mathrm{e}-01$

Element: 2401 \# of layers: 7

Kx Ky Kz Ss Por

5.00000e-04 5.00000e-04 5.00000e-05 1.00000e-09 1.00000e-01

$5.00000 \mathrm{e}-04$ 5.00000e-04 5.00000e-05 1.00000e-09 1.00000e-01

$1.23766 \mathrm{e}+011.23766 \mathrm{e}+011.23766 \mathrm{e}+001.00000 \mathrm{e}-092.12000 \mathrm{e}-01$

$1.23766 \mathrm{e}+011.23766 \mathrm{e}+011.23766 \mathrm{e}+001.00000 \mathrm{e}-092.12000 \mathrm{e}-01$

$1.23766 \mathrm{e}+011.23766 \mathrm{e}+011.23766 \mathrm{e}+001.00000 \mathrm{e}-092.12000 \mathrm{e}-01$

$1.23766 \mathrm{e}+011.23766 \mathrm{e}+011.23766 \mathrm{e}+001.00000 \mathrm{e}-092.12000 \mathrm{e}-01$

$1.23766 \mathrm{e}+011.23766 \mathrm{e}+011.23766 \mathrm{e}+001.00000 \mathrm{e}-092.12000 \mathrm{e}-01$

Element: 2402 \# of layers: 7

Kx Ky Kz Ss Por

5.00000e-04 5.00000e-04 5.00000e-05 1.00000e-09 1.00000e-01 
5.00000e-04 5.00000e-04 5.00000e-05 1.00000e-09 1.00000e-01 $1.23766 \mathrm{e}+011.23766 \mathrm{e}+011.23766 \mathrm{e}+001.00000 \mathrm{e}-092.12000 \mathrm{e}-01$ $1.23766 \mathrm{e}+011.23766 \mathrm{e}+011.23766 \mathrm{e}+001.00000 \mathrm{e}-092.12000 \mathrm{e}-01$ $1.23766 \mathrm{e}+011.23766 \mathrm{e}+011.23766 \mathrm{e}+001.00000 \mathrm{e}-092.12000 \mathrm{e}-01$ $1.23766 \mathrm{e}+011.23766 \mathrm{e}+011.23766 \mathrm{e}+001.00000 \mathrm{e}-092.12000 \mathrm{e}-01$ $1.23766 \mathrm{e}+011.23766 \mathrm{e}+011.23766 \mathrm{e}+001.00000 \mathrm{e}-092.12000 \mathrm{e}-01$ Element: 2403 \# of layers: 7

Kx Ky Kz Ss Por

5.00000e-04 5.00000e-04 5.00000e-05 1.00000e-09 1.00000e-01 5.00000e-04 5.00000e-04 5.00000e-05 1.00000e-09 1.00000e-01 $1.23766 \mathrm{e}+011.23766 \mathrm{e}+011.23766 \mathrm{e}+001.00000 \mathrm{e}-092.12000 \mathrm{e}-01$ $1.23766 \mathrm{e}+011.23766 \mathrm{e}+011.23766 \mathrm{e}+001.00000 \mathrm{e}-092.12000 \mathrm{e}-01$ $1.23766 \mathrm{e}+011.23766 \mathrm{e}+011.23766 \mathrm{e}+001.00000 \mathrm{e}-092.12000 \mathrm{e}-01$ $1.23766 \mathrm{e}+011.23766 \mathrm{e}+011.23766 \mathrm{e}+001.00000 \mathrm{e}-092.12000 \mathrm{e}-01$ $1.23766 \mathrm{e}+011.23766 \mathrm{e}+011.23766 \mathrm{e}+001.00000 \mathrm{e}-092.12000 \mathrm{e}-01$ Element: 2404 \# of layers: 8

Kx Ky Kz Ss Por

$3.09746 \mathrm{e}+023.09746 \mathrm{e}+023.09746 \mathrm{e}+01$ 1.00000e-09 7.00000e-02 5.00000e-04 5.00000e-04 5.00000e-05 1.00000e-09 1.00000e-01 5.00000e-04 5.00000e-04 5.00000e-05 1.00000e-09 1.00000e-01 $1.23766 \mathrm{e}+011.23766 \mathrm{e}+011.23766 \mathrm{e}+001.00000 \mathrm{e}-092.12000 \mathrm{e}-01$ $1.23766 \mathrm{e}+011.23766 \mathrm{e}+011.23766 \mathrm{e}+001.00000 \mathrm{e}-092.12000 \mathrm{e}-01$ $1.23766 \mathrm{e}+011.23766 \mathrm{e}+011.23766 \mathrm{e}+001.00000 \mathrm{e}-092.12000 \mathrm{e}-01$ $1.23766 \mathrm{e}+011.23766 \mathrm{e}+011.23766 \mathrm{e}+001.00000 \mathrm{e}-092.12000 \mathrm{e}-01$ $1.23766 \mathrm{e}+011.23766 \mathrm{e}+011.23766 \mathrm{e}+001.00000 \mathrm{e}-092.12000 \mathrm{e}-01$ Element: 2405 \# of layers: 8

Kx Ky Kz Ss Por

$3.09746 \mathrm{e}+023.09746 \mathrm{e}+023.09746 \mathrm{e}+01$ 1.00000e-09 7.00000e-02 5.00000e-04 5.00000e-04 5.00000e-05 1.00000e-09 1.00000e-01 5.00000e-04 5.00000e-04 5.00000e-05 1.00000e-09 1.00000e-01 $1.23766 \mathrm{e}+011.23766 \mathrm{e}+011.23766 \mathrm{e}+001.00000 \mathrm{e}-092.12000 \mathrm{e}-01$ $1.23766 \mathrm{e}+011.23766 \mathrm{e}+011.23766 \mathrm{e}+001.00000 \mathrm{e}-092.12000 \mathrm{e}-01$ $1.23766 \mathrm{e}+011.23766 \mathrm{e}+011.23766 \mathrm{e}+001.00000 \mathrm{e}-092.12000 \mathrm{e}-01$ $1.23766 \mathrm{e}+011.23766 \mathrm{e}+011.23766 \mathrm{e}+001.00000 \mathrm{e}-092.12000 \mathrm{e}-01$ $1.23766 \mathrm{e}+011.23766 \mathrm{e}+011.23766 \mathrm{e}+001.00000 \mathrm{e}-092.12000 \mathrm{e}-01$ Element: 2406 \# of layers: 7

Kx Ky Kz Ss Por 5.00000e-04 5.00000e-04 5.00000e-05 1.00000e-09 1.00000e-01 $5.00000 \mathrm{e}-04$ 5.00000e-04 5.00000e-05 1.00000e-09 1.00000e-01 $1.23766 \mathrm{e}+011.23766 \mathrm{e}+011.23766 \mathrm{e}+001.00000 \mathrm{e}-092.12000 \mathrm{e}-01$ $1.23766 \mathrm{e}+011.23766 \mathrm{e}+011.23766 \mathrm{e}+001.00000 \mathrm{e}-092.12000 \mathrm{e}-01$ $1.23766 \mathrm{e}+011.23766 \mathrm{e}+011.23766 \mathrm{e}+001.00000 \mathrm{e}-092.12000 \mathrm{e}-01$ $1.23766 \mathrm{e}+011.23766 \mathrm{e}+011.23766 \mathrm{e}+001.00000 \mathrm{e}-092.12000 \mathrm{e}-01$ $1.23766 \mathrm{e}+011.23766 \mathrm{e}+011.23766 \mathrm{e}+001.00000 \mathrm{e}-092.12000 \mathrm{e}-01$ Element: 2407 \# of layers: 7

Kx Ky Kz Ss Por 
5.00000e-04 5.00000e-04 5.00000e-05 1.00000e-09 1.00000e-01 5.00000e-04 5.00000e-04 5.00000e-05 1.00000e-09 1.00000e-01 $1.23766 \mathrm{e}+011.23766 \mathrm{e}+011.23766 \mathrm{e}+001.00000 \mathrm{e}-092.12000 \mathrm{e}-01$ $1.23766 \mathrm{e}+011.23766 \mathrm{e}+011.23766 \mathrm{e}+001.00000 \mathrm{e}-092.12000 \mathrm{e}-01$ $1.23766 \mathrm{e}+011.23766 \mathrm{e}+011.23766 \mathrm{e}+001.00000 \mathrm{e}-092.12000 \mathrm{e}-01$ $1.23766 \mathrm{e}+011.23766 \mathrm{e}+011.23766 \mathrm{e}+001.00000 \mathrm{e}-092.12000 \mathrm{e}-01$ $1.23766 \mathrm{e}+011.23766 \mathrm{e}+011.23766 \mathrm{e}+00$ 1.00000e-09 2.12000e-01 Element: 2408 \# of layers: 8

$\mathrm{Kx} \mathrm{Ky} \mathrm{Kz}$ Ss Por

$1.88048 \mathrm{e}+021.88048 \mathrm{e}+02$ 1.88048e+01 1.00000e-09 7.00000e-02 5.00000e-04 5.00000e-04 5.00000e-05 1.00000e-09 1.00000e-01 5.00000e-04 5.00000e-04 5.00000e-05 1.00000e-09 1.00000e-01

$7.51381 \mathrm{e}+007.51381 \mathrm{e}+00$ 7.51381e-01 1.00000e-09 2.12000e-01

7.51381e+00 7.51381e+00 7.51381e-01 1.00000e-09 2.12000e-01 7.51381e+00 7.51381e+00 7.51381e-01 1.00000e-09 2.12000e-01 $7.51381 \mathrm{e}+007.51381 \mathrm{e}+007.51381 \mathrm{e}-01$ 1.00000e-09 2.12000e-01 7.51381e+00 7.51381e+00 7.51381e-01 1.00000e-09 2.12000e-01 Element: 2409 \# of layers: 8

$\mathrm{Kx} \mathrm{Ky} \mathrm{Kz}$ Ss Por

$1.88048 \mathrm{e}+02$ 1.88048e+02 1.88048e+01 1.00000e-09 7.00000e-02 5.00000e-04 5.00000e-04 5.00000e-05 1.00000e-09 1.00000e-01 5.00000e-04 5.00000e-04 5.00000e-05 1.00000e-09 1.00000e-01 $7.51381 \mathrm{e}+007.51381 \mathrm{e}+00$ 7.51381e-01 1.00000e-09 2.12000e-01 $7.51381 \mathrm{e}+00$ 7.51381e+00 7.51381e-01 1.00000e-09 2.12000e-01 $7.51381 \mathrm{e}+007.51381 \mathrm{e}+00$ 7.51381e-01 1.00000e-09 2.12000e-01 7.51381e+00 7.51381e+00 7.51381e-01 1.00000e-09 2.12000e-01 7.51381e+00 7.51381e+00 7.51381e-01 1.00000e-09 2.12000e-01 Element: 2410 \# of layers: 7

Kx Ky Kz Ss Por

$1.88048 \mathrm{e}+021.88048 \mathrm{e}+02$ 1.88048e+01 1.00000e-09 7.00000e-02 5.00000e-04 5.00000e-04 5.00000e-05 1.00000e-09 1.00000e-01 $7.51381 \mathrm{e}+00$ 7.51381e+00 7.51381e-01 1.00000e-09 2.12000e-01 $7.51381 \mathrm{e}+007.51381 \mathrm{e}+00$ 7.51381e-01 1.00000e-09 2.12000e-01 $7.51381 \mathrm{e}+007.51381 \mathrm{e}+007.51381 \mathrm{e}-01$ 1.00000e-09 2.12000e-01 7.51381e+00 7.51381e+00 7.51381e-01 1.00000e-09 2.12000e-01 7.51381e+00 7.51381e+00 7.51381e-01 1.00000e-09 2.12000e-01 Element: 2411 \# of layers: 8

$\mathrm{Kx} \mathrm{Ky} \mathrm{Kz}$ Ss Por

$1.88048 \mathrm{e}+02$ 1.88048e+02 1.88048e+01 1.00000e-09 7.00000e-02 5.00000e-04 5.00000e-04 5.00000e-05 1.00000e-09 1.00000e-01 5.00000e-04 5.00000e-04 5.00000e-05 1.00000e-09 1.00000e-01

$7.51381 \mathrm{e}+007.51381 \mathrm{e}+007.51381 \mathrm{e}-01$ 1.00000e-09 2.12000e-01 7.51381e+00 7.51381e+00 7.51381e-01 1.00000e-09 2.12000e-01 $7.51381 \mathrm{e}+007.51381 \mathrm{e}+00$ 7.51381e-01 1.00000e-09 2.12000e-01 $7.51381 \mathrm{e}+00$ 7.51381e+00 7.51381e-01 1.00000e-09 2.12000e-01 $7.51381 \mathrm{e}+007.51381 \mathrm{e}+007.51381 \mathrm{e}-01$ 1.00000e-09 2.12000e-01 
Element: 2412 \# of layers: 8

$\mathrm{Kx} \mathrm{Ky} \mathrm{Kz}$ Ss Por

$1.88048 \mathrm{e}+02$ 1.88048e+02 1.88048e+01 1.00000e-09 7.00000e-02

5.00000e-04 5.00000e-04 5.00000e-05 1.00000e-09 1.00000e-01

5.00000e-04 5.00000e-04 5.00000e-05 1.00000e-09 1.00000e-01

7.51381e+00 7.51381e+00 7.51381e-01 1.00000e-09 2.12000e-01

$7.51381 \mathrm{e}+007.51381 \mathrm{e}+00$ 7.51381e-01 1.00000e-09 2.12000e-01

$7.51381 \mathrm{e}+007.51381 \mathrm{e}+00$ 7.51381e-01 1.00000e-09 2.12000e-01

$7.51381 \mathrm{e}+00$ 7.51381e+00 7.51381e-01 1.00000e-09 2.12000e-01

7.51381e+00 7.51381e+00 7.51381e-01 1.00000e-09 2.12000e-01

Element: 2413 \# of layers: 8

$\mathrm{Kx} \mathrm{Ky} \mathrm{Kz}$ Ss Por

1.88048e+02 1.88048e+02 1.88048e+01 1.00000e-09 7.00000e-02

$5.00000 \mathrm{e}-04$ 5.00000e-04 5.00000e-05 1.00000e-09 1.00000e-01

5.00000e-04 5.00000e-04 5.00000e-05 1.00000e-09 1.00000e-01

$7.51381 \mathrm{e}+007.51381 \mathrm{e}+00$ 7.51381e-01 1.00000e-09 2.12000e-01

$7.51381 \mathrm{e}+007.51381 \mathrm{e}+007.51381 \mathrm{e}-01$ 1.00000e-09 2.12000e-01

$7.51381 \mathrm{e}+00$ 7.51381e+00 7.51381e-01 1.00000e-09 2.12000e-01

7.51381e+00 7.51381e+00 7.51381e-01 1.00000e-09 2.12000e-01

7.51381e+00 7.51381e+00 7.51381e-01 1.00000e-09 2.12000e-01

Element: 2414 \# of layers: 8

$\mathrm{Kx} \mathrm{Ky} \mathrm{Kz}$ Ss Por

1.88048e+02 1.88048e+02 1.88048e+01 1.00000e-09 7.00000e-02 5.00000e-04 5.00000e-04 5.00000e-05 1.00000e-09 1.00000e-01

5.00000e-04 5.00000e-04 5.00000e-05 1.00000e-09 1.00000e-01

7.51381e+00 7.51381e+00 7.51381e-01 1.00000e-09 2.12000e-01

$7.51381 \mathrm{e}+00$ 7.51381e+00 7.51381e-01 1.00000e-09 2.12000e-01

$7.51381 \mathrm{e}+00$ 7.51381e+00 7.51381e-01 1.00000e-09 2.12000e-01

$7.51381 \mathrm{e}+007.51381 \mathrm{e}+00$ 7.51381e-01 1.00000e-09 2.12000e-01

$7.51381 \mathrm{e}+00$ 7.51381e+00 7.51381e-01 1.00000e-09 2.12000e-01

Element: 2415 \# of layers: 8

$\mathrm{Kx} \mathrm{Ky} \mathrm{Kz}$ Ss Por

$1.88048 \mathrm{e}+021.88048 \mathrm{e}+02$ 1.88048e+01 1.00000e-09 7.00000e-02

5.00000e-04 5.00000e-04 5.00000e-05 1.00000e-09 1.00000e-01

5.00000e-04 5.00000e-04 5.00000e-05 1.00000e-09 1.00000e-01

$7.51381 \mathrm{e}+00$ 7.51381e+00 7.51381e-01 1.00000e-09 2.12000e-01

$7.51381 \mathrm{e}+007.51381 \mathrm{e}+00$ 7.51381e-01 1.00000e-09 2.12000e-01

$7.51381 \mathrm{e}+007.51381 \mathrm{e}+00$ 7.51381e-01 1.00000e-09 2.12000e-01

7.51381e+00 7.51381e+00 7.51381e-01 1.00000e-09 2.12000e-01

7.51381e+00 7.51381e+00 7.51381e-01 1.00000e-09 2.12000e-01

Element: 2416 \# of layers: 8

$\mathrm{Kx} \mathrm{Ky} \mathrm{Kz}$ Ss Por

1.88048e+02 1.88048e+02 1.88048e+01 1.00000e-09 7.00000e-02

5.00000e-04 5.00000e-04 5.00000e-05 1.00000e-09 1.00000e-01

5.00000e-04 5.00000e-04 5.00000e-05 1.00000e-09 1.00000e-01

$7.51381 \mathrm{e}+007.51381 \mathrm{e}+00$ 7.51381e-01 1.00000e-09 2.12000e-01 
$7.51381 \mathrm{e}+007.51381 \mathrm{e}+00$ 7.51381e-01 1.00000e-09 2.12000e-01 $7.51381 \mathrm{e}+007.51381 \mathrm{e}+007.51381 \mathrm{e}-011.00000 \mathrm{e}-092.12000 \mathrm{e}-01$ $7.51381 \mathrm{e}+007.51381 \mathrm{e}+00$ 7.51381e-01 1.00000e-09 2.12000e-01 $7.51381 \mathrm{e}+007.51381 \mathrm{e}+00$ 7.51381e-01 1.00000e-09 2.12000e-01 Element: 2417 \# of layers: 8

Kx Ky Kz Ss Por

$1.18211 \mathrm{e}+021.18211 \mathrm{e}+021.18211 \mathrm{e}+01$ 1.00000e-09 7.00000e-02 5.00000e-04 5.00000e-04 5.00000e-05 1.00000e-09 1.00000e-01 $5.00000 \mathrm{e}-04$ 5.00000e-04 5.00000e-05 1.00000e-09 1.00000e-01 $4.72330 \mathrm{e}+004.72330 \mathrm{e}+004.72330 \mathrm{e}-011.00000 \mathrm{e}-092.12000 \mathrm{e}-01$ $4.72330 \mathrm{e}+004.72330 \mathrm{e}+004.72330 \mathrm{e}-011.00000 \mathrm{e}-092.12000 \mathrm{e}-01$ $4.72330 \mathrm{e}+004.72330 \mathrm{e}+004.72330 \mathrm{e}-011.00000 \mathrm{e}-092.12000 \mathrm{e}-01$ $4.72330 \mathrm{e}+004.72330 \mathrm{e}+004.72330 \mathrm{e}-011.00000 \mathrm{e}-092.12000 \mathrm{e}-01$ $4.72330 \mathrm{e}+004.72330 \mathrm{e}+00$ 4.72330e-01 1.00000e-09 2.12000e-01 Element: 2418 \# of layers: 9

Kx Ky Kz Ss Por

$1.18211 \mathrm{e}+021.18211 \mathrm{e}+021.18211 \mathrm{e}+01$ 1.00000e-09 7.00000e-02 $1.18211 \mathrm{e}+021.18211 \mathrm{e}+021.18211 \mathrm{e}+011.00000 \mathrm{e}-097.00000 \mathrm{e}-02$ 5.00000e-04 5.00000e-04 5.00000e-05 1.00000e-09 1.00000e-01 5.00000e-04 5.00000e-04 5.00000e-05 1.00000e-09 1.00000e-01

$4.72330 \mathrm{e}+00 \quad 4.72330 \mathrm{e}+00$ 4.72330e-01 1.00000e-09 2.12000e-01 $4.72330 \mathrm{e}+004.72330 \mathrm{e}+004.72330 \mathrm{e}-011.00000 \mathrm{e}-092.12000 \mathrm{e}-01$ $4.72330 \mathrm{e}+004.72330 \mathrm{e}+004.72330 \mathrm{e}-011.00000 \mathrm{e}-092.12000 \mathrm{e}-01$ $4.72330 \mathrm{e}+004.72330 \mathrm{e}+00$ 4.72330e-01 1.00000e-09 2.12000e-01 $4.72330 \mathrm{e}+00 \quad 4.72330 \mathrm{e}+00$ 4.72330e-01 1.00000e-09 2.12000e-01 Element: 2419 \# of layers: 8

Kx Ky Kz Ss Por

$1.18211 \mathrm{e}+021.18211 \mathrm{e}+021.18211 \mathrm{e}+01$ 1.00000e-09 7.00000e-02 5.00000e-04 5.00000e-04 5.00000e-05 1.00000e-09 1.00000e-01 $5.00000 \mathrm{e}-04$ 5.00000e-04 5.00000e-05 1.00000e-09 1.00000e-01 $4.72330 \mathrm{e}+004.72330 \mathrm{e}+004.72330 \mathrm{e}-011.00000 \mathrm{e}-092.12000 \mathrm{e}-01$ $4.72330 \mathrm{e}+004.72330 \mathrm{e}+004.72330 \mathrm{e}-01$ 1.00000e-09 2.12000e-01 $4.72330 \mathrm{e}+004.72330 \mathrm{e}+00$ 4.72330e-01 1.00000e-09 2.12000e-01 $4.72330 \mathrm{e}+004.72330 \mathrm{e}+004.72330 \mathrm{e}-011.00000 \mathrm{e}-092.12000 \mathrm{e}-01$ $4.72330 \mathrm{e}+004.72330 \mathrm{e}+00$ 4.72330e-01 1.00000e-09 2.12000e-01 Element: 2420 \# of layers: 7

Kx Ky Kz Ss Por

$1.18211 \mathrm{e}+021.18211 \mathrm{e}+021.18211 \mathrm{e}+01$ 1.00000e-09 7.00000e-02 5.00000e-04 5.00000e-04 5.00000e-05 1.00000e-09 1.00000e-01 $4.72330 \mathrm{e}+00 \quad 4.72330 \mathrm{e}+00$ 4.72330e-01 1.00000e-09 2.12000e-01 $4.72330 \mathrm{e}+004.72330 \mathrm{e}+00$ 4.72330e-01 1.00000e-09 2.12000e-01 $4.72330 \mathrm{e}+004.72330 \mathrm{e}+00$ 4.72330e-01 1.00000e-09 2.12000e-01 $4.72330 \mathrm{e}+004.72330 \mathrm{e}+004.72330 \mathrm{e}-011.00000 \mathrm{e}-092.12000 \mathrm{e}-01$ 4.72330e+00 4.72330e+00 4.72330e-01 1.00000e-09 2.12000e-01 Element: 2421 \# of layers: 7

Kx Ky Kz Ss Por 
$1.18211 \mathrm{e}+021.18211 \mathrm{e}+021.18211 \mathrm{e}+01$ 1.00000e-09 7.00000e-02 5.00000e-04 5.00000e-04 5.00000e-05 1.00000e-09 1.00000e-01 4.72330e+00 4.72330e+00 4.72330e-01 1.00000e-09 2.12000e-01 $4.72330 \mathrm{e}+004.72330 \mathrm{e}+00$ 4.72330e-01 1.00000e-09 2.12000e-01 4.72330e+00 4.72330e+00 4.72330e-01 1.00000e-09 2.12000e-01 $4.72330 \mathrm{e}+004.72330 \mathrm{e}+00$ 4.72330e-01 1.00000e-09 2.12000e-01 4.72330e+00 4.72330e+00 4.72330e-01 1.00000e-09 2.12000e-01 Element: 2422 \# of layers: 9

$\mathrm{Kx} \mathrm{Ky} \mathrm{Kz}$ Ss Por

$1.18211 \mathrm{e}+021.18211 \mathrm{e}+02$ 1.18211e+01 1.00000e-09 7.00000e-02 $1.18211 \mathrm{e}+021.18211 \mathrm{e}+021.18211 \mathrm{e}+01$ 1.00000e-09 7.00000e-02 5.00000e-04 5.00000e-04 5.00000e-05 1.00000e-09 1.00000e-01 5.00000e-04 5.00000e-04 5.00000e-05 1.00000e-09 1.00000e-01 4.72330e+00 4.72330e+00 4.72330e-01 1.00000e-09 2.12000e-01 4.72330e+00 4.72330e+00 4.72330e-01 1.00000e-09 2.12000e-01 $4.72330 \mathrm{e}+00$ 4.72330e+00 4.72330e-01 1.00000e-09 2.12000e-01 $4.72330 \mathrm{e}+00$ 4.72330e+00 4.72330e-01 1.00000e-09 2.12000e-01 4.72330e+00 4.72330e+00 4.72330e-01 1.00000e-09 2.12000e-01 Element: 2423 \# of layers: 8

$\mathrm{Kx} \mathrm{Ky} \mathrm{Kz}$ Ss Por

$1.18211 \mathrm{e}+021.18211 \mathrm{e}+02$ 1.18211e+01 1.00000e-09 7.00000e-02 5.00000e-04 5.00000e-04 5.00000e-05 1.00000e-09 1.00000e-01 5.00000e-04 5.00000e-04 5.00000e-05 1.00000e-09 1.00000e-01 $4.72330 \mathrm{e}+00$ 4.72330e+00 4.72330e-01 1.00000e-09 2.12000e-01 $4.72330 \mathrm{e}+004.72330 \mathrm{e}+00$ 4.72330e-01 1.00000e-09 2.12000e-01 4.72330e+00 4.72330e+00 4.72330e-01 1.00000e-09 2.12000e-01 4.72330e+00 4.72330e+00 4.72330e-01 1.00000e-09 2.12000e-01 $4.72330 \mathrm{e}+00$ 4.72330e+00 4.72330e-01 1.00000e-09 2.12000e-01 Element: 2424 \# of layers: 8

$\mathrm{Kx} \mathrm{Ky} \mathrm{Kz}$ Ss Por

1.18211e+02 1.18211e+02 1.18211e+01 1.00000e-09 7.00000e-02 5.00000e-04 5.00000e-04 5.00000e-05 1.00000e-09 1.00000e-01 5.00000e-04 5.00000e-04 5.00000e-05 1.00000e-09 1.00000e-01 $4.72330 \mathrm{e}+00$ 4.72330e+00 4.72330e-01 1.00000e-09 2.12000e-01 4.72330e+00 4.72330e+00 4.72330e-01 1.00000e-09 2.12000e-01 $4.72330 \mathrm{e}+00$ 4.72330e+00 4.72330e-01 1.00000e-09 2.12000e-01 $4.72330 \mathrm{e}+004.72330 \mathrm{e}+00$ 4.72330e-01 1.00000e-09 2.12000e-01 4.72330e+00 4.72330e+00 4.72330e-01 1.00000e-09 2.12000e-01 Element: 2425 \# of layers: 9

$\mathrm{Kx} \mathrm{Ky} \mathrm{Kz}$ Ss Por

1.18211e+02 1.18211e+02 1.18211e+01 1.00000e-09 7.00000e-02 $1.18211 \mathrm{e}+021.18211 \mathrm{e}+021.18211 \mathrm{e}+01$ 1.00000e-09 7.00000e-02 5.00000e-04 5.00000e-04 5.00000e-05 1.00000e-09 1.00000e-01 5.00000e-04 5.00000e-04 5.00000e-05 1.00000e-09 1.00000e-01 $4.72330 \mathrm{e}+004.72330 \mathrm{e}+00$ 4.72330e-01 1.00000e-09 2.12000e-01 $4.72330 \mathrm{e}+004.72330 \mathrm{e}+00$ 4.72330e-01 1.00000e-09 2.12000e-01 
$4.72330 \mathrm{e}+004.72330 \mathrm{e}+00$ 4.72330e-01 1.00000e-09 2.12000e-01 $4.72330 \mathrm{e}+004.72330 \mathrm{e}+004.72330 \mathrm{e}-011.00000 \mathrm{e}-092.12000 \mathrm{e}-01$ $4.72330 \mathrm{e}+004.72330 \mathrm{e}+00$ 4.72330e-01 1.00000e-09 2.12000e-01 Element: 2426 \# of layers: 8

Kx Ky Kz Ss Por

$8.41444 \mathrm{e}+018.41444 \mathrm{e}+018.41444 \mathrm{e}+00$ 1.00000e-09 7.00000e-02 5.00000e-04 5.00000e-04 5.00000e-05 1.00000e-09 1.00000e-01 5.00000e-04 5.00000e-04 5.00000e-05 1.00000e-09 1.00000e-01 $3.36202 \mathrm{e}+003.36202 \mathrm{e}+003.36202 \mathrm{e}-01$ 1.00000e-09 2.12000e-01 $3.36202 \mathrm{e}+003.36202 \mathrm{e}+003.36202 \mathrm{e}-011.00000 \mathrm{e}-092.12000 \mathrm{e}-01$ $3.36202 \mathrm{e}+003.36202 \mathrm{e}+003.36202 \mathrm{e}-01$ 1.00000e-09 2.12000e-01 $3.36202 \mathrm{e}+003.36202 \mathrm{e}+003.36202 \mathrm{e}-01$ 1.00000e-09 2.12000e-01 $3.36202 \mathrm{e}+003.36202 \mathrm{e}+00$ 3.36202e-01 1.00000e-09 2.12000e-01 Element: 2427 \# of layers: 7

Kx Ky Kz Ss Por

$8.41444 \mathrm{e}+01$ 8.41444e+01 8.41444e+00 1.00000e-09 7.00000e-02 5.00000e-04 5.00000e-04 5.00000e-05 1.00000e-09 1.00000e-01

$3.36202 \mathrm{e}+003.36202 \mathrm{e}+003.36202 \mathrm{e}-011.00000 \mathrm{e}-092.12000 \mathrm{e}-01$ $3.36202 \mathrm{e}+003.36202 \mathrm{e}+003.36202 \mathrm{e}-011.00000 \mathrm{e}-092.12000 \mathrm{e}-01$ $3.36202 \mathrm{e}+003.36202 \mathrm{e}+003.36202 \mathrm{e}-01$ 1.00000e-09 2.12000e-01 $3.36202 \mathrm{e}+003.36202 \mathrm{e}+003.36202 \mathrm{e}-01$ 1.00000e-09 2.12000e-01 $3.36202 \mathrm{e}+003.36202 \mathrm{e}+00$ 3.36202e-01 1.00000e-09 2.12000e-01 Element: 2428 \# of layers: 8

Kx Ky Kz Ss Por $8.41444 \mathrm{e}+018.41444 \mathrm{e}+018.41444 \mathrm{e}+001.00000 \mathrm{e}-09$ 7.00000e-02 $5.00000 \mathrm{e}-04$ 5.00000e-04 5.00000e-05 1.00000e-09 1.00000e-01 $5.00000 \mathrm{e}-04$ 5.00000e-04 5.00000e-05 1.00000e-09 1.00000e-01 $3.36202 \mathrm{e}+003.36202 \mathrm{e}+003.36202 \mathrm{e}-01$ 1.00000e-09 2.12000e-01 $3.36202 \mathrm{e}+003.36202 \mathrm{e}+003.36202 \mathrm{e}-01$ 1.00000e-09 2.12000e-01 $3.36202 \mathrm{e}+003.36202 \mathrm{e}+003.36202 \mathrm{e}-011.00000 \mathrm{e}-092.12000 \mathrm{e}-01$ $3.36202 \mathrm{e}+003.36202 \mathrm{e}+003.36202 \mathrm{e}-01$ 1.00000e-09 2.12000e-01 $3.36202 \mathrm{e}+003.36202 \mathrm{e}+003.36202 \mathrm{e}-01$ 1.00000e-09 2.12000e-01 Element: 2429 \# of layers: 7

$\mathrm{Kx} \mathrm{Ky} \mathrm{Kz}$ Ss Por

$1.92526 \mathrm{e}+021.92526 \mathrm{e}+021.92526 \mathrm{e}+01$ 1.00000e-09 7.00000e-02 5.00000e-04 5.00000e-04 5.00000e-05 1.00000e-09 1.00000e-01 $7.69291 \mathrm{e}+007.69291 \mathrm{e}+00$ 7.69291e-01 1.00000e-09 2.12000e-01 $1.00000 \mathrm{e}-02$ 1.00000e-02 1.00000e-03 1.00000e-09 1.00000e-01 $1.00000 \mathrm{e}+001.00000 \mathrm{e}+001.00000 \mathrm{e}-011.00000 \mathrm{e}-091.00000 \mathrm{e}-01$ $1.00000 \mathrm{e}-05$ 1.00000e-05 1.00000e-06 1.00000e-09 1.00000e-01 $1.00000 \mathrm{e}+001.00000 \mathrm{e}+001.00000 \mathrm{e}-011.00000 \mathrm{e}-091.00000 \mathrm{e}-01$ Element: 2430 \# of layers: 15

Kx Ky Kz Ss Por

$1.92526 \mathrm{e}+021.92526 \mathrm{e}+021.92526 \mathrm{e}+011.00000 \mathrm{e}-097.00000 \mathrm{e}-02$ $1.92526 \mathrm{e}+021.92526 \mathrm{e}+021.92526 \mathrm{e}+011.00000 \mathrm{e}-097.00000 \mathrm{e}-02$ $1.92526 \mathrm{e}+021.92526 \mathrm{e}+021.92526 \mathrm{e}+011.00000 \mathrm{e}-097.00000 \mathrm{e}-02$ 
$1.92526 \mathrm{e}+021.92526 \mathrm{e}+021.92526 \mathrm{e}+011.00000 \mathrm{e}-097.00000 \mathrm{e}-02$ 5.00000e-04 5.00000e-04 5.00000e-05 1.00000e-09 1.00000e-01 5.00000e-04 5.00000e-04 5.00000e-05 1.00000e-09 1.00000e-01 $7.69291 \mathrm{e}+007.69291 \mathrm{e}+00$ 7.69291e-01 1.00000e-09 2.12000e-01 7.69291e+00 7.69291e+00 7.69291e-01 1.00000e-09 2.12000e-01 $7.69291 \mathrm{e}+00$ 7.69291e+00 7.69291e-01 1.00000e-09 2.12000e-01 $7.69291 \mathrm{e}+00$ 7.69291e+00 7.69291e-01 1.00000e-09 2.12000e-01 $7.69291 \mathrm{e}+007.69291 \mathrm{e}+00$ 7.69291e-01 1.00000e-09 2.12000e-01 $1.00000 \mathrm{e}-01$ 1.00000e-01 1.00000e-02 1.00000e-09 1.00000e-01 $1.00000 \mathrm{e}+001.00000 \mathrm{e}+001.00000 \mathrm{e}-011.00000 \mathrm{e}-091.00000 \mathrm{e}-01$ $1.00000 \mathrm{e}-05$ 1.00000e-05 1.00000e-06 1.00000e-09 1.00000e-01 $1.00000 \mathrm{e}+001.00000 \mathrm{e}+001.00000 \mathrm{e}-011.00000 \mathrm{e}-091.00000 \mathrm{e}-01$ Element: 2431 \# of layers: 14

$\mathrm{Kx} \mathrm{Ky} \mathrm{Kz}$ Ss Por

3.71906e+02 3.71906e+02 3.71906e+01 1.00000e-09 7.00000e-02 $3.71906 \mathrm{e}+023.71906 \mathrm{e}+023.71906 \mathrm{e}+01$ 1.00000e-09 7.00000e-02 $3.71906 \mathrm{e}+023.71906 \mathrm{e}+02$ 3.71906e+01 1.00000e-09 7.00000e-02 5.00000e-04 5.00000e-04 5.00000e-05 1.00000e-09 1.00000e-01 5.00000e-04 5.00000e-04 5.00000e-05 1.00000e-09 1.00000e-01 $1.48602 \mathrm{e}+011.48602 \mathrm{e}+011.48602 \mathrm{e}+001.00000 \mathrm{e}-092.12000 \mathrm{e}-01$ $1.48602 \mathrm{e}+011.48602 \mathrm{e}+011.48602 \mathrm{e}+001.00000 \mathrm{e}-092.12000 \mathrm{e}-01$ $1.48602 \mathrm{e}+01$ 1.48602e+01 1.48602e+00 1.00000e-09 2.12000e-01 $1.48602 \mathrm{e}+01$ 1.48602e+01 1.48602e+00 1.00000e-09 2.12000e-01 $1.48602 \mathrm{e}+011.48602 \mathrm{e}+011.48602 \mathrm{e}+001.00000 \mathrm{e}-092.12000 \mathrm{e}-01$ $1.00000 \mathrm{e}-021.00000 \mathrm{e}-02$ 1.00000e-03 1.00000e-09 1.00000e-01 $1.00000 \mathrm{e}+001.00000 \mathrm{e}+001.00000 \mathrm{e}-011.00000 \mathrm{e}-091.00000 \mathrm{e}-01$ $1.00000 \mathrm{e}-05$ 1.00000e-05 1.00000e-06 1.00000e-09 1.00000e-01 $1.00000 \mathrm{e}+001.00000 \mathrm{e}+001.00000 \mathrm{e}-011.00000 \mathrm{e}-09$ 1.00000e-01 Element: 2432 \# of layers: 15

$\mathrm{Kx} \mathrm{Ky} \mathrm{Kz}$ Ss Por

3.71906e+02 3.71906e+02 3.71906e+01 1.00000e-09 7.00000e-02 $3.71906 \mathrm{e}+02$ 3.71906e+02 3.71906e+01 1.00000e-09 7.00000e-02 $3.71906 \mathrm{e}+02$ 3.71906e+02 3.71906e+01 1.00000e-09 7.00000e-02 $3.71906 \mathrm{e}+02$ 3.71906e+02 3.71906e+01 1.00000e-09 7.00000e-02 5.00000e-04 5.00000e-04 5.00000e-05 1.00000e-09 1.00000e-01 5.00000e-04 5.00000e-04 5.00000e-05 1.00000e-09 1.00000e-01 $1.48602 \mathrm{e}+011.48602 \mathrm{e}+01$ 1.48602e+00 1.00000e-09 2.12000e-01 $1.48602 \mathrm{e}+011.48602 \mathrm{e}+011.48602 \mathrm{e}+001.00000 \mathrm{e}-092.12000 \mathrm{e}-01$ $1.48602 \mathrm{e}+011.48602 \mathrm{e}+011.48602 \mathrm{e}+001.00000 \mathrm{e}-092.12000 \mathrm{e}-01$ $1.48602 \mathrm{e}+01$ 1.48602e+01 1.48602e+00 1.00000e-09 2.12000e-01 $1.48602 \mathrm{e}+01$ 1.48602e+01 1.48602e+00 1.00000e-09 2.12000e-01 $1.00000 \mathrm{e}-02$ 1.00000e-02 1.00000e-03 1.00000e-09 1.00000e-01 $1.00000 \mathrm{e}+001.00000 \mathrm{e}+001.00000 \mathrm{e}-011.00000 \mathrm{e}-091.00000 \mathrm{e}-01$ $1.00000 \mathrm{e}-05$ 1.00000e-05 1.00000e-06 1.00000e-09 1.00000e-01 $1.00000 \mathrm{e}+001.00000 \mathrm{e}+001.00000 \mathrm{e}-011.00000 \mathrm{e}-09$ 1.00000e-01 Element: 2433 \# of layers: 7 
$\mathrm{Kx} \mathrm{Ky} \mathrm{Kz}$ Ss Por

3.28234e+02 3.28234e+02 3.28234e+01 1.00000e-09 7.00000e-02 5.00000e-04 5.00000e-04 5.00000e-05 1.00000e-09 1.00000e-01

$1.31151 \mathrm{e}+011.31151 \mathrm{e}+011.31151 \mathrm{e}+001.00000 \mathrm{e}-092.12000 \mathrm{e}-01$ $1.00000 \mathrm{e}-02$ 1.00000e-02 1.00000e-03 1.00000e-09 1.00000e-01 $1.00000 \mathrm{e}+001.00000 \mathrm{e}+001.00000 \mathrm{e}-011.00000 \mathrm{e}-091.00000 \mathrm{e}-01$ $1.00000 \mathrm{e}-05$ 1.00000e-05 1.00000e-06 1.00000e-09 1.00000e-01 $1.00000 \mathrm{e}+001.00000 \mathrm{e}+001.00000 \mathrm{e}-011.00000 \mathrm{e}-091.00000 \mathrm{e}-01$ Element: 2434 \# of layers: 15

$\mathrm{Kx} \mathrm{Ky} \mathrm{Kz}$ Ss Por

3.43110e+02 3.43110e+02 3.43110e+01 1.00000e-09 7.00000e-02 $3.43110 \mathrm{e}+02$ 3.43110e+02 3.43110e+01 1.00000e-09 7.00000e-02 $3.43110 \mathrm{e}+02$ 3.43110e+02 3.43110e+01 1.00000e-09 7.00000e-02 $3.43110 \mathrm{e}+023.43110 \mathrm{e}+02$ 3.43110e+01 1.00000e-09 7.00000e-02 5.00000e-04 5.00000e-04 5.00000e-05 1.00000e-09 1.00000e-01 5.00000e-04 5.00000e-04 5.00000e-05 1.00000e-09 1.00000e-01

$1.37095 \mathrm{e}+01$ 1.37095e+01 1.37095e+00 1.00000e-09 2.12000e-01 $1.37095 \mathrm{e}+011.37095 \mathrm{e}+01$ 1.37095e+00 1.00000e-09 2.12000e-01 $1.37095 \mathrm{e}+01$ 1.37095e+01 1.37095e+00 1.00000e-09 2.12000e-01 $1.37095 \mathrm{e}+011.37095 \mathrm{e}+01$ 1.37095e+00 1.00000e-09 2.12000e-01 $1.37095 \mathrm{e}+011.37095 \mathrm{e}+011.37095 \mathrm{e}+001.00000 \mathrm{e}-092.12000 \mathrm{e}-01$ $1.00000 \mathrm{e}-01$ 1.00000e-01 1.00000e-02 1.00000e-09 1.00000e-01 $1.00000 \mathrm{e}+001.00000 \mathrm{e}+001.00000 \mathrm{e}-011.00000 \mathrm{e}-091.00000 \mathrm{e}-01$ $1.00000 \mathrm{e}-05$ 1.00000e-05 1.00000e-06 1.00000e-09 1.00000e-01 $1.00000 \mathrm{e}+001.00000 \mathrm{e}+001.00000 \mathrm{e}-011.00000 \mathrm{e}-091.00000 \mathrm{e}-01$ Element: 2435 \# of layers: 14

$\mathrm{Kx} \mathrm{Ky} \mathrm{Kz}$ Ss Por

3.31820e+02 3.31820e+02 3.31820e+01 1.00000e-09 7.00000e-02 $3.31820 \mathrm{e}+02$ 3.31820e+02 3.31820e+01 1.00000e-09 7.00000e-02 $3.31820 \mathrm{e}+02$ 3.31820e+02 3.31820e+01 1.00000e-09 7.00000e-02 5.00000e-04 5.00000e-04 5.00000e-05 1.00000e-09 1.00000e-01 5.00000e-04 5.00000e-04 5.00000e-05 1.00000e-09 1.00000e-01 $1.32584 \mathrm{e}+011.32584 \mathrm{e}+011.32584 \mathrm{e}+001.00000 \mathrm{e}-092.12000 \mathrm{e}-01$ $1.32584 \mathrm{e}+011.32584 \mathrm{e}+011.32584 \mathrm{e}+001.00000 \mathrm{e}-092.12000 \mathrm{e}-01$ $1.32584 \mathrm{e}+011.32584 \mathrm{e}+011.32584 \mathrm{e}+001.00000 \mathrm{e}-092.12000 \mathrm{e}-01$ $1.32584 \mathrm{e}+011.32584 \mathrm{e}+011.32584 \mathrm{e}+001.00000 \mathrm{e}-092.12000 \mathrm{e}-01$ $1.32584 \mathrm{e}+011.32584 \mathrm{e}+011.32584 \mathrm{e}+001.00000 \mathrm{e}-092.12000 \mathrm{e}-01$ $1.00000 \mathrm{e}-01$ 1.00000e-01 1.00000e-02 1.00000e-09 1.00000e-01 $1.00000 \mathrm{e}+001.00000 \mathrm{e}+001.00000 \mathrm{e}-011.00000 \mathrm{e}-091.00000 \mathrm{e}-01$ $1.00000 \mathrm{e}-05$ 1.00000e-05 1.00000e-06 1.00000e-09 1.00000e-01 $1.00000 \mathrm{e}+001.00000 \mathrm{e}+001.00000 \mathrm{e}-011.00000 \mathrm{e}-091.00000 \mathrm{e}-01$ Element: 2436 \# of layers: 14

$\mathrm{Kx} \mathrm{Ky} \mathrm{Kz}$ Ss Por

3.31820e+02 3.31820e+02 3.31820e+01 1.00000e-09 7.00000e-02 $3.31820 \mathrm{e}+02$ 3.31820e+02 3.31820e+01 1.00000e-09 7.00000e-02 $3.31820 \mathrm{e}+02$ 3.31820e+02 3.31820e+01 1.00000e-09 7.00000e-02 
5.00000e-04 5.00000e-04 5.00000e-05 1.00000e-09 1.00000e-01 5.00000e-04 5.00000e-04 5.00000e-05 1.00000e-09 1.00000e-01 $1.32584 \mathrm{e}+011.32584 \mathrm{e}+011.32584 \mathrm{e}+001.00000 \mathrm{e}-092.12000 \mathrm{e}-01$ $1.32584 \mathrm{e}+011.32584 \mathrm{e}+01 \quad 1.32584 \mathrm{e}+001.00000 \mathrm{e}-092.12000 \mathrm{e}-01$ $1.32584 \mathrm{e}+011.32584 \mathrm{e}+011.32584 \mathrm{e}+001.00000 \mathrm{e}-092.12000 \mathrm{e}-01$ $1.32584 \mathrm{e}+011.32584 \mathrm{e}+011.32584 \mathrm{e}+001.00000 \mathrm{e}-092.12000 \mathrm{e}-01$ $1.32584 \mathrm{e}+011.32584 \mathrm{e}+011.32584 \mathrm{e}+001.00000 \mathrm{e}-092.12000 \mathrm{e}-01$ $1.00000 \mathrm{e}-011.00000 \mathrm{e}-01$ 1.00000e-02 1.00000e-09 1.00000e-01 $1.00000 \mathrm{e}+001.00000 \mathrm{e}+001.00000 \mathrm{e}-011.00000 \mathrm{e}-091.00000 \mathrm{e}-01$ $1.00000 \mathrm{e}-05$ 1.00000e-05 1.00000e-06 1.00000e-09 1.00000e-01 $1.00000 \mathrm{e}+001.00000 \mathrm{e}+001.00000 \mathrm{e}-011.00000 \mathrm{e}-091.00000 \mathrm{e}-01$ Element: 2437 \# of layers: 14

$\mathrm{Kx} \mathrm{Ky} \mathrm{Kz}$ Ss Por

3.31820e+02 3.31820e+02 3.31820e+01 1.00000e-09 7.00000e-02 $3.31820 \mathrm{e}+023.31820 \mathrm{e}+023.31820 \mathrm{e}+01$ 1.00000e-09 7.00000e-02 $3.31820 \mathrm{e}+023.31820 \mathrm{e}+023.31820 \mathrm{e}+01$ 1.00000e-09 7.00000e-02 5.00000e-04 5.00000e-04 5.00000e-05 1.00000e-09 1.00000e-01 5.00000e-04 5.00000e-04 5.00000e-05 1.00000e-09 1.00000e-01 $1.32584 \mathrm{e}+01$ 1.32584e+01 1.32584e+00 1.00000e-09 2.12000e-01 $1.32584 \mathrm{e}+011.32584 \mathrm{e}+01 \quad 1.32584 \mathrm{e}+001.00000 \mathrm{e}-092.12000 \mathrm{e}-01$ $1.32584 \mathrm{e}+011.32584 \mathrm{e}+011.32584 \mathrm{e}+001.00000 \mathrm{e}-092.12000 \mathrm{e}-01$ $1.32584 \mathrm{e}+011.32584 \mathrm{e}+011.32584 \mathrm{e}+001.00000 \mathrm{e}-092.12000 \mathrm{e}-01$ $1.32584 \mathrm{e}+011.32584 \mathrm{e}+01$ 1.32584e+00 1.00000e-09 2.12000e-01 $1.00000 \mathrm{e}-01$ 1.00000e-01 1.00000e-02 1.00000e-09 1.00000e-01 $1.00000 \mathrm{e}+001.00000 \mathrm{e}+001.00000 \mathrm{e}-011.00000 \mathrm{e}-091.00000 \mathrm{e}-01$ $1.00000 \mathrm{e}-05$ 1.00000e-05 1.00000e-06 1.00000e-09 1.00000e-01 $1.00000 \mathrm{e}+001.00000 \mathrm{e}+001.00000 \mathrm{e}-011.00000 \mathrm{e}-091.00000 \mathrm{e}-01$ Element: 2438 \# of layers: 14

$\mathrm{Kx} \mathrm{Ky} \mathrm{Kz}$ Ss Por

4.01756e+02 4.01756e+02 4.01756e+01 1.00000e-09 7.00000e-02 $4.01756 \mathrm{e}+024.01756 \mathrm{e}+02$ 4.01756e+01 1.00000e-09 7.00000e-02 4.01756e+02 4.01756e+02 4.01756e+01 1.00000e-09 7.00000e-02 5.00000e-04 5.00000e-04 5.00000e-05 1.00000e-09 1.00000e-01 $5.00000 \mathrm{e}-04$ 5.00000e-04 5.00000e-05 1.00000e-09 1.00000e-01 $1.60525 \mathrm{e}+011.60525 \mathrm{e}+011.60525 \mathrm{e}+001.00000 \mathrm{e}-092.12000 \mathrm{e}-01$ $1.60525 \mathrm{e}+011.60525 \mathrm{e}+011.60525 \mathrm{e}+001.00000 \mathrm{e}-092.12000 \mathrm{e}-01$ $1.60525 \mathrm{e}+011.60525 \mathrm{e}+011.60525 \mathrm{e}+001.00000 \mathrm{e}-092.12000 \mathrm{e}-01$ $1.60525 \mathrm{e}+011.60525 \mathrm{e}+011.60525 \mathrm{e}+001.00000 \mathrm{e}-092.12000 \mathrm{e}-01$ $1.60525 \mathrm{e}+011.60525 \mathrm{e}+011.60525 \mathrm{e}+001.00000 \mathrm{e}-092.12000 \mathrm{e}-01$ $1.00000 \mathrm{e}-01$ 1.00000e-01 1.00000e-02 1.00000e-09 1.00000e-01 $1.00000 \mathrm{e}+001.00000 \mathrm{e}+001.00000 \mathrm{e}-011.00000 \mathrm{e}-091.00000 \mathrm{e}-01$ $1.00000 \mathrm{e}-05$ 1.00000e-05 1.00000e-06 1.00000e-09 1.00000e-01 $1.00000 \mathrm{e}+001.00000 \mathrm{e}+001.00000 \mathrm{e}-01$ 1.00000e-09 1.00000e-01 Element: 2439 \# of layers: 14

$\mathrm{Kx} \mathrm{Ky} \mathrm{Kz}$ Ss Por

4.01756e+02 4.01756e+02 4.01756e+01 1.00000e-09 7.00000e-02 
4.01756e+02 4.01756e+02 4.01756e+01 1.00000e-09 7.00000e-02 4.01756e+02 4.01756e+02 4.01756e+01 1.00000e-09 7.00000e-02 5.00000e-04 5.00000e-04 5.00000e-05 1.00000e-09 1.00000e-01 5.00000e-04 5.00000e-04 5.00000e-05 1.00000e-09 1.00000e-01 $1.60525 \mathrm{e}+011.60525 \mathrm{e}+011.60525 \mathrm{e}+001.00000 \mathrm{e}-092.12000 \mathrm{e}-01$ $1.60525 \mathrm{e}+011.60525 \mathrm{e}+011.60525 \mathrm{e}+001.00000 \mathrm{e}-092.12000 \mathrm{e}-01$ $1.60525 \mathrm{e}+011.60525 \mathrm{e}+011.60525 \mathrm{e}+001.00000 \mathrm{e}-092.12000 \mathrm{e}-01$ $1.60525 \mathrm{e}+011.60525 \mathrm{e}+011.60525 \mathrm{e}+001.00000 \mathrm{e}-092.12000 \mathrm{e}-01$ $1.60525 \mathrm{e}+011.60525 \mathrm{e}+011.60525 \mathrm{e}+001.00000 \mathrm{e}-092.12000 \mathrm{e}-01$ $1.00000 \mathrm{e}-011.00000 \mathrm{e}-01$ 1.00000e-02 1.00000e-09 1.00000e-01 $1.00000 \mathrm{e}+001.00000 \mathrm{e}+001.00000 \mathrm{e}-011.00000 \mathrm{e}-091.00000 \mathrm{e}-01$ $1.00000 \mathrm{e}-05$ 1.00000e-05 1.00000e-06 1.00000e-09 1.00000e-01 $1.00000 \mathrm{e}+001.00000 \mathrm{e}+001.00000 \mathrm{e}-011.00000 \mathrm{e}-091.00000 \mathrm{e}-01$ Element: 2440 \# of layers: 14

$\mathrm{Kx} \mathrm{Ky} \mathrm{Kz}$ Ss Por

4.38580e+02 4.38580e+02 4.38580e+01 1.00000e-09 7.00000e-02 $4.38580 \mathrm{e}+02$ 4.38580e+02 4.38580e+01 1.00000e-09 7.00000e-02

4.38580e+02 4.38580e+02 4.38580e+01 1.00000e-09 7.00000e-02 5.00000e-04 5.00000e-04 5.00000e-05 1.00000e-09 1.00000e-01 5.00000e-04 5.00000e-04 5.00000e-05 1.00000e-09 1.00000e-01 $1.75238 \mathrm{e}+01$ 1.75238e+01 1.75238e+00 1.00000e-09 2.12000e-01 $1.75238 \mathrm{e}+01$ 1.75238e+01 1.75238e+00 1.00000e-09 2.12000e-01 $1.75238 \mathrm{e}+01$ 1.75238e+01 1.75238e+00 1.00000e-09 2.12000e-01 $1.75238 \mathrm{e}+01$ 1.75238e+01 1.75238e+00 1.00000e-09 2.12000e-01 $1.75238 \mathrm{e}+01$ 1.75238e+01 1.75238e+00 1.00000e-09 2.12000e-01 $1.00000 \mathrm{e}-01$ 1.00000e-01 1.00000e-02 1.00000e-09 1.00000e-01 $1.00000 \mathrm{e}+001.00000 \mathrm{e}+001.00000 \mathrm{e}-011.00000 \mathrm{e}-091.00000 \mathrm{e}-01$ $1.00000 \mathrm{e}-05$ 1.00000e-05 1.00000e-06 1.00000e-09 1.00000e-01 $1.00000 \mathrm{e}+001.00000 \mathrm{e}+001.00000 \mathrm{e}-011.00000 \mathrm{e}-091.00000 \mathrm{e}-01$ Element: 2441 \# of layers: 15

$\mathrm{Kx} \mathrm{Ky} \mathrm{Kz}$ Ss Por

3.43110e+02 3.43110e+02 3.43110e+01 1.00000e-09 7.00000e-02 $3.43110 \mathrm{e}+023.43110 \mathrm{e}+023.43110 \mathrm{e}+01$ 1.00000e-09 7.00000e-02 $3.43110 \mathrm{e}+02$ 3.43110e+02 3.43110e+01 1.00000e-09 7.00000e-02 $3.43110 \mathrm{e}+023.43110 \mathrm{e}+02$ 3.43110e+01 1.00000e-09 7.00000e-02 5.00000e-04 5.00000e-04 5.00000e-05 1.00000e-09 1.00000e-01 5.00000e-04 5.00000e-04 5.00000e-05 1.00000e-09 1.00000e-01 $1.37095 \mathrm{e}+011.37095 \mathrm{e}+011.37095 \mathrm{e}+001.00000 \mathrm{e}-092.12000 \mathrm{e}-01$ $1.37095 \mathrm{e}+011.37095 \mathrm{e}+01$ 1.37095e+00 1.00000e-09 2.12000e-01 $1.37095 \mathrm{e}+011.37095 \mathrm{e}+01$ 1.37095e+00 1.00000e-09 2.12000e-01 $1.37095 \mathrm{e}+01$ 1.37095e+01 1.37095e+00 1.00000e-09 2.12000e-01 $1.37095 \mathrm{e}+01$ 1.37095e+01 1.37095e+00 1.00000e-09 2.12000e-01 $1.00000 \mathrm{e}-011.00000 \mathrm{e}-011.00000 \mathrm{e}-021.00000 \mathrm{e}-091.00000 \mathrm{e}-01$ $1.00000 \mathrm{e}+001.00000 \mathrm{e}+001.00000 \mathrm{e}-011.00000 \mathrm{e}-091.00000 \mathrm{e}-01$ $1.00000 \mathrm{e}-05$ 1.00000e-05 1.00000e-06 1.00000e-09 1.00000e-01 $1.00000 \mathrm{e}+001.00000 \mathrm{e}+001.00000 \mathrm{e}-011.00000 \mathrm{e}-091.00000 \mathrm{e}-01$ 
Element: 2442 \# of layers: 14

Kx Ky Kz Ss Por

$3.31820 \mathrm{e}+023.31820 \mathrm{e}+023.31820 \mathrm{e}+01$ 1.00000e-09 7.00000e-02

$3.31820 \mathrm{e}+023.31820 \mathrm{e}+023.31820 \mathrm{e}+01$ 1.00000e-09 7.00000e-02

$3.31820 \mathrm{e}+023.31820 \mathrm{e}+023.31820 \mathrm{e}+011.00000 \mathrm{e}-097.00000 \mathrm{e}-02$

5.00000e-04 5.00000e-04 5.00000e-05 1.00000e-09 1.00000e-01

5.00000e-04 5.00000e-04 5.00000e-05 1.00000e-09 1.00000e-01

$1.32584 \mathrm{e}+011.32584 \mathrm{e}+011.32584 \mathrm{e}+001.00000 \mathrm{e}-092.12000 \mathrm{e}-01$

$1.32584 \mathrm{e}+011.32584 \mathrm{e}+011.32584 \mathrm{e}+001.00000 \mathrm{e}-092.12000 \mathrm{e}-01$

$1.32584 \mathrm{e}+011.32584 \mathrm{e}+011.32584 \mathrm{e}+001.00000 \mathrm{e}-092.12000 \mathrm{e}-01$

$1.32584 \mathrm{e}+011.32584 \mathrm{e}+011.32584 \mathrm{e}+001.00000 \mathrm{e}-092.12000 \mathrm{e}-01$

$1.32584 \mathrm{e}+011.32584 \mathrm{e}+011.32584 \mathrm{e}+001.00000 \mathrm{e}-092.12000 \mathrm{e}-01$

$1.00000 \mathrm{e}-011.00000 \mathrm{e}-011.00000 \mathrm{e}-021.00000 \mathrm{e}-091.00000 \mathrm{e}-01$

$1.00000 \mathrm{e}+001.00000 \mathrm{e}+001.00000 \mathrm{e}-011.00000 \mathrm{e}-091.00000 \mathrm{e}-01$

$1.00000 \mathrm{e}-05$ 1.00000e-05 1.00000e-06 1.00000e-09 1.00000e-01

$1.00000 \mathrm{e}+001.00000 \mathrm{e}+001.00000 \mathrm{e}-011.00000 \mathrm{e}-091.00000 \mathrm{e}-01$

Element: 2443 \# of layers: 15

Kx Ky Kz Ss Por

$3.21513 \mathrm{e}+023.21513 \mathrm{e}+023.21513 \mathrm{e}+01$ 1.00000e-09 7.00000e-02

$3.21513 \mathrm{e}+023.21513 \mathrm{e}+023.21513 \mathrm{e}+01$ 1.00000e-09 7.00000e-02

$3.21513 \mathrm{e}+023.21513 \mathrm{e}+023.21513 \mathrm{e}+01$ 1.00000e-09 7.00000e-02

$3.21513 \mathrm{e}+023.21513 \mathrm{e}+023.21513 \mathrm{e}+01$ 1.00000e-09 7.00000e-02

5.00000e-04 5.00000e-04 5.00000e-05 1.00000e-09 1.00000e-01

5.00000e-04 5.00000e-04 5.00000e-05 1.00000e-09 1.00000e-01

$1.28467 \mathrm{e}+011.28467 \mathrm{e}+011.28467 \mathrm{e}+001.00000 \mathrm{e}-092.12000 \mathrm{e}-01$

$1.28467 \mathrm{e}+011.28467 \mathrm{e}+011.28467 \mathrm{e}+001.00000 \mathrm{e}-092.12000 \mathrm{e}-01$

$1.28467 \mathrm{e}+011.28467 \mathrm{e}+011.28467 \mathrm{e}+001.00000 \mathrm{e}-092.12000 \mathrm{e}-01$

$1.28467 \mathrm{e}+011.28467 \mathrm{e}+011.28467 \mathrm{e}+001.00000 \mathrm{e}-092.12000 \mathrm{e}-01$

$1.28467 \mathrm{e}+011.28467 \mathrm{e}+011.28467 \mathrm{e}+001.00000 \mathrm{e}-092.12000 \mathrm{e}-01$

$1.00000 \mathrm{e}-011.00000 \mathrm{e}-011.00000 \mathrm{e}-021.00000 \mathrm{e}-091.00000 \mathrm{e}-01$

$1.00000 \mathrm{e}+001.00000 \mathrm{e}+001.00000 \mathrm{e}-011.00000 \mathrm{e}-091.00000 \mathrm{e}-01$

$1.00000 \mathrm{e}-05$ 1.00000e-05 1.00000e-06 1.00000e-09 1.00000e-01

$1.00000 \mathrm{e}+001.00000 \mathrm{e}+001.00000 \mathrm{e}-011.00000 \mathrm{e}-091.00000 \mathrm{e}-01$

Element: 2444 \# of layers: 16

Kx Ky Kz Ss Por

$3.15305 \mathrm{e}+02$ 3.15305e+02 3.15305e+01 1.00000e-09 7.00000e-02

$3.15305 \mathrm{e}+023.15305 \mathrm{e}+023.15305 \mathrm{e}+01$ 1.00000e-09 7.00000e-02

$3.15305 \mathrm{e}+023.15305 \mathrm{e}+023.15305 \mathrm{e}+01$ 1.00000e-09 7.00000e-02

$3.15305 \mathrm{e}+023.15305 \mathrm{e}+023.15305 \mathrm{e}+01$ 1.00000e-09 7.00000e-02

$3.15305 \mathrm{e}+023.15305 \mathrm{e}+023.15305 \mathrm{e}+01$ 1.00000e-09 7.00000e-02

5.00000e-04 5.00000e-04 5.00000e-05 1.00000e-09 1.00000e-01

5.00000e-04 5.00000e-04 5.00000e-05 1.00000e-09 1.00000e-01

$1.25985 \mathrm{e}+011.25985 \mathrm{e}+011.25985 \mathrm{e}+001.00000 \mathrm{e}-092.12000 \mathrm{e}-01$

$1.25985 \mathrm{e}+011.25985 \mathrm{e}+011.25985 \mathrm{e}+001.00000 \mathrm{e}-092.12000 \mathrm{e}-01$

$1.25985 \mathrm{e}+011.25985 \mathrm{e}+011.25985 \mathrm{e}+001.00000 \mathrm{e}-092.12000 \mathrm{e}-01$

$1.25985 \mathrm{e}+011.25985 \mathrm{e}+011.25985 \mathrm{e}+001.00000 \mathrm{e}-092.12000 \mathrm{e}-01$ 
$1.25985 \mathrm{e}+011.25985 \mathrm{e}+01$ 1.25985e+00 1.00000e-09 2.12000e-01 $1.00000 \mathrm{e}-011.00000 \mathrm{e}-01$ 1.00000e-02 1.00000e-09 1.00000e-01 $1.00000 \mathrm{e}+001.00000 \mathrm{e}+001.00000 \mathrm{e}-011.00000 \mathrm{e}-091.00000 \mathrm{e}-01$ $1.00000 \mathrm{e}-05$ 1.00000e-05 1.00000e-06 1.00000e-09 1.00000e-01 $1.00000 \mathrm{e}+001.00000 \mathrm{e}+001.00000 \mathrm{e}-01$ 1.00000e-09 1.00000e-01 Element: 2445 \# of layers: 16

$\mathrm{Kx} \mathrm{Ky} \mathrm{Kz}$ Ss Por

3.15305e+02 3.15305e+02 3.15305e+01 1.00000e-09 7.00000e-02 $3.15305 \mathrm{e}+02$ 3.15305e+02 3.15305e+01 1.00000e-09 7.00000e-02 $3.15305 \mathrm{e}+02$ 3.15305e+02 3.15305e+01 1.00000e-09 7.00000e-02 3.15305e+02 3.15305e+02 3.15305e+01 1.00000e-09 7.00000e-02 $3.15305 \mathrm{e}+02$ 3.15305e+02 3.15305e+01 1.00000e-09 7.00000e-02 5.00000e-04 5.00000e-04 5.00000e-05 1.00000e-09 1.00000e-01 5.00000e-04 5.00000e-04 5.00000e-05 1.00000e-09 1.00000e-01 $1.25985 \mathrm{e}+011.25985 \mathrm{e}+011.25985 \mathrm{e}+001.00000 \mathrm{e}-092.12000 \mathrm{e}-01$ $1.25985 \mathrm{e}+011.25985 \mathrm{e}+011.25985 \mathrm{e}+001.00000 \mathrm{e}-092.12000 \mathrm{e}-01$ $1.25985 \mathrm{e}+011.25985 \mathrm{e}+01 \quad 1.25985 \mathrm{e}+001.00000 \mathrm{e}-092.12000 \mathrm{e}-01$ $1.25985 \mathrm{e}+01$ 1.25985e+01 1.25985e+00 1.00000e-09 2.12000e-01 $1.25985 \mathrm{e}+01$ 1.25985e+01 1.25985e+00 1.00000e-09 2.12000e-01 $1.00000 \mathrm{e}-01$ 1.00000e-01 1.00000e-02 1.00000e-09 1.00000e-01 $1.00000 \mathrm{e}+001.00000 \mathrm{e}+001.00000 \mathrm{e}-011.00000 \mathrm{e}-091.00000 \mathrm{e}-01$ $1.00000 \mathrm{e}-05$ 1.00000e-05 1.00000e-06 1.00000e-09 1.00000e-01 $1.00000 \mathrm{e}+001.00000 \mathrm{e}+001.00000 \mathrm{e}-01$ 1.00000e-09 1.00000e-01 Element: 2446 \# of layers: 15

$\mathrm{Kx} \mathrm{Ky} \mathrm{Kz}$ Ss Por

3.15305e+02 3.15305e+02 3.15305e+01 1.00000e-09 7.00000e-02 $3.15305 \mathrm{e}+02$ 3.15305e+02 3.15305e+01 1.00000e-09 7.00000e-02 $3.15305 \mathrm{e}+02$ 3.15305e+02 3.15305e+01 1.00000e-09 7.00000e-02 $3.15305 \mathrm{e}+02$ 3.15305e+02 3.15305e+01 1.00000e-09 7.00000e-02 5.00000e-04 5.00000e-04 5.00000e-05 1.00000e-09 1.00000e-01 5.00000e-04 5.00000e-04 5.00000e-05 1.00000e-09 1.00000e-01 $1.25985 \mathrm{e}+011.25985 \mathrm{e}+011.25985 \mathrm{e}+00$ 1.00000e-09 2.12000e-01 $1.25985 \mathrm{e}+011.25985 \mathrm{e}+011.25985 \mathrm{e}+001.00000 \mathrm{e}-092.12000 \mathrm{e}-01$ $1.25985 \mathrm{e}+011.25985 \mathrm{e}+011.25985 \mathrm{e}+001.00000 \mathrm{e}-092.12000 \mathrm{e}-01$ $1.25985 \mathrm{e}+01$ 1.25985e+01 1.25985e+00 1.00000e-09 2.12000e-01 $1.25985 \mathrm{e}+011.25985 \mathrm{e}+011.25985 \mathrm{e}+001.00000 \mathrm{e}-092.12000 \mathrm{e}-01$ $1.00000 \mathrm{e}-011.00000 \mathrm{e}-01$ 1.00000e-02 1.00000e-09 1.00000e-01 $1.00000 \mathrm{e}+001.00000 \mathrm{e}+001.00000 \mathrm{e}-011.00000 \mathrm{e}-091.00000 \mathrm{e}-01$ $1.00000 \mathrm{e}-05$ 1.00000e-05 1.00000e-06 1.00000e-09 1.00000e-01 $1.00000 \mathrm{e}+001.00000 \mathrm{e}+001.00000 \mathrm{e}-01$ 1.00000e-09 1.00000e-01 Element: 2447 \# of layers: 15

$\mathrm{Kx} \mathrm{Ky} \mathrm{Kz}$ Ss Por

3.59949e+02 3.59949e+02 3.59949e+01 1.00000e-09 7.00000e-02 3.59949e+02 3.59949e+02 3.59949e+01 1.00000e-09 7.00000e-02 $3.59949 \mathrm{e}+02$ 3.59949e+02 3.59949e+01 1.00000e-09 7.00000e-02 $3.59949 \mathrm{e}+02$ 3.59949e+02 3.59949e+01 1.00000e-09 7.00000e-02 
5.00000e-04 5.00000e-04 5.00000e-05 1.00000e-09 1.00000e-01 5.00000e-04 5.00000e-04 5.00000e-05 1.00000e-09 1.00000e-01 $1.43823 \mathrm{e}+011.43823 \mathrm{e}+01$ 1.43823e+00 1.00000e-09 2.12000e-01 $1.43823 \mathrm{e}+011.43823 \mathrm{e}+011.43823 \mathrm{e}+001.00000 \mathrm{e}-092.12000 \mathrm{e}-01$ $1.43823 \mathrm{e}+01$ 1.43823e+01 1.43823e+00 1.00000e-09 2.12000e-01 $1.43823 \mathrm{e}+01$ 1.43823e+01 1.43823e+00 1.00000e-09 2.12000e-01 $1.43823 \mathrm{e}+01$ 1.43823e+01 1.43823e+00 1.00000e-09 2.12000e-01 $1.00000 \mathrm{e}-02$ 1.00000e-02 1.00000e-03 1.00000e-09 1.00000e-01 $1.00000 \mathrm{e}+001.00000 \mathrm{e}+001.00000 \mathrm{e}-01$ 1.00000e-09 1.00000e-01 $1.00000 \mathrm{e}-05$ 1.00000e-05 1.00000e-06 1.00000e-09 1.00000e-01 $1.00000 \mathrm{e}+001.00000 \mathrm{e}+001.00000 \mathrm{e}-01$ 1.00000e-09 1.00000e-01 Element: 2448 \# of layers: 14

$\mathrm{Kx} \mathrm{Ky} \mathrm{Kz}$ Ss Por

3.59949e+02 3.59949e+02 3.59949e+01 1.00000e-09 7.00000e-02 $3.59949 \mathrm{e}+02$ 3.59949e+02 3.59949e+01 1.00000e-09 7.00000e-02 $3.59949 \mathrm{e}+02$ 3.59949e+02 3.59949e+01 1.00000e-09 7.00000e-02 $3.59949 \mathrm{e}+02$ 3.59949e+02 3.59949e+01 1.00000e-09 7.00000e-02 5.00000e-04 5.00000e-04 5.00000e-05 1.00000e-09 1.00000e-01 $1.43823 \mathrm{e}+01$ 1.43823e+01 1.43823e+00 1.00000e-09 2.12000e-01 $1.43823 \mathrm{e}+01$ 1.43823e+01 1.43823e+00 1.00000e-09 2.12000e-01 $1.43823 \mathrm{e}+01$ 1.43823e+01 1.43823e+00 1.00000e-09 2.12000e-01 $1.43823 \mathrm{e}+01$ 1.43823e+01 1.43823e+00 1.00000e-09 2.12000e-01 $1.43823 \mathrm{e}+01$ 1.43823e+01 1.43823e+00 1.00000e-09 2.12000e-01 $1.00000 \mathrm{e}-011.00000 \mathrm{e}-011.00000 \mathrm{e}-021.00000 \mathrm{e}-091.00000 \mathrm{e}-01$ $1.00000 \mathrm{e}+001.00000 \mathrm{e}+001.00000 \mathrm{e}-011.00000 \mathrm{e}-091.00000 \mathrm{e}-01$ $1.00000 \mathrm{e}-05$ 1.00000e-05 1.00000e-06 1.00000e-09 1.00000e-01 $1.00000 \mathrm{e}+001.00000 \mathrm{e}+001.00000 \mathrm{e}-01$ 1.00000e-09 1.00000e-01 Element: 2449 \# of layers: 14

Kx Ky Kz Ss Por

3.68446e+02 3.68446e+02 3.68446e+01 1.00000e-09 7.00000e-02 $3.68446 \mathrm{e}+023.68446 \mathrm{e}+023.68446 \mathrm{e}+01$ 1.00000e-09 7.00000e-02 $3.68446 \mathrm{e}+023.68446 \mathrm{e}+023.68446 \mathrm{e}+01$ 1.00000e-09 7.00000e-02 5.00000e-04 5.00000e-04 5.00000e-05 1.00000e-09 1.00000e-01 5.00000e-04 5.00000e-04 5.00000e-05 1.00000e-09 1.00000e-01 $1.47218 \mathrm{e}+01$ 1.47218e+01 1.47218e+00 1.00000e-09 2.12000e-01 $1.47218 \mathrm{e}+01$ 1.47218e+01 1.47218e+00 1.00000e-09 2.12000e-01 $1.47218 \mathrm{e}+01$ 1.47218e+01 1.47218e+00 1.00000e-09 2.12000e-01 $1.47218 \mathrm{e}+011.47218 \mathrm{e}+011.47218 \mathrm{e}+001.00000 \mathrm{e}-092.12000 \mathrm{e}-01$ $1.47218 \mathrm{e}+01$ 1.47218e+01 1.47218e+00 1.00000e-09 2.12000e-01 $1.00000 \mathrm{e}-01$ 1.00000e-01 1.00000e-02 1.00000e-09 1.00000e-01 $1.00000 \mathrm{e}+001.00000 \mathrm{e}+001.00000 \mathrm{e}-011.00000 \mathrm{e}-091.00000 \mathrm{e}-01$ $1.00000 \mathrm{e}-05$ 1.00000e-05 1.00000e-06 1.00000e-09 1.00000e-01 $1.00000 \mathrm{e}+001.00000 \mathrm{e}+001.00000 \mathrm{e}-011.00000 \mathrm{e}-091.00000 \mathrm{e}-01$ Element: 2450 \# of layers: 14

$\mathrm{Kx} \mathrm{Ky} \mathrm{Kz}$ Ss Por

3.21513e+02 3.21513e+02 3.21513e+01 1.00000e-09 7.00000e-02 
3.21513e+02 3.21513e+02 3.21513e+01 1.00000e-09 7.00000e-02 $3.21513 \mathrm{e}+02$ 3.21513e+02 3.21513e+01 1.00000e-09 7.00000e-02 5.00000e-04 5.00000e-04 5.00000e-05 1.00000e-09 1.00000e-01 5.00000e-04 5.00000e-04 5.00000e-05 1.00000e-09 1.00000e-01 $1.28467 \mathrm{e}+011.28467 \mathrm{e}+01$ 1.28467e+00 1.00000e-09 2.12000e-01 $1.28467 \mathrm{e}+01$ 1.28467e+01 1.28467e+00 1.00000e-09 2.12000e-01 $1.28467 \mathrm{e}+011.28467 \mathrm{e}+01$ 1.28467e+00 1.00000e-09 2.12000e-01 $1.28467 \mathrm{e}+01$ 1.28467e+01 1.28467e+00 1.00000e-09 2.12000e-01 $1.28467 \mathrm{e}+01$ 1.28467e+01 1.28467e+00 1.00000e-09 2.12000e-01 $1.00000 \mathrm{e}-011.00000 \mathrm{e}-01$ 1.00000e-02 1.00000e-09 1.00000e-01 $1.00000 \mathrm{e}+001.00000 \mathrm{e}+001.00000 \mathrm{e}-011.00000 \mathrm{e}-091.00000 \mathrm{e}-01$ $1.00000 \mathrm{e}-05$ 1.00000e-05 1.00000e-06 1.00000e-09 1.00000e-01 $1.00000 \mathrm{e}+001.00000 \mathrm{e}+001.00000 \mathrm{e}-011.00000 \mathrm{e}-091.00000 \mathrm{e}-01$ Element: 2451 \# of layers: 14

$\mathrm{Kx} \mathrm{Ky} \mathrm{Kz}$ Ss Por

3.15305e+02 3.15305e+02 3.15305e+01 1.00000e-09 7.00000e-02 3.15305e+02 3.15305e+02 3.15305e+01 1.00000e-09 7.00000e-02 3.15305e+02 3.15305e+02 3.15305e+01 1.00000e-09 7.00000e-02 3.15305e+02 3.15305e+02 3.15305e+01 1.00000e-09 7.00000e-02 5.00000e-04 5.00000e-04 5.00000e-05 1.00000e-09 1.00000e-01 $1.25985 \mathrm{e}+011.25985 \mathrm{e}+011.25985 \mathrm{e}+001.00000 \mathrm{e}-092.12000 \mathrm{e}-01$ $1.25985 \mathrm{e}+011.25985 \mathrm{e}+01$ 1.25985e+00 1.00000e-09 2.12000e-01 $1.25985 \mathrm{e}+01$ 1.25985e+01 1.25985e+00 1.00000e-09 2.12000e-01 $1.25985 \mathrm{e}+011.25985 \mathrm{e}+011.25985 \mathrm{e}+001.00000 \mathrm{e}-092.12000 \mathrm{e}-01$ $1.25985 \mathrm{e}+011.25985 \mathrm{e}+011.25985 \mathrm{e}+001.00000 \mathrm{e}-092.12000 \mathrm{e}-01$ $1.00000 \mathrm{e}-01$ 1.00000e-01 1.00000e-02 1.00000e-09 1.00000e-01 $1.00000 \mathrm{e}+001.00000 \mathrm{e}+001.00000 \mathrm{e}-011.00000 \mathrm{e}-091.00000 \mathrm{e}-01$ $1.00000 \mathrm{e}-05$ 1.00000e-05 1.00000e-06 1.00000e-09 1.00000e-01 $1.00000 \mathrm{e}+001.00000 \mathrm{e}+001.00000 \mathrm{e}-011.00000 \mathrm{e}-091.00000 \mathrm{e}-01$ Element: 2452 \# of layers: 16

$\mathrm{Kx} \mathrm{Ky} \mathrm{Kz}$ Ss Por

3.84313e+02 3.84313e+02 3.84313e+01 1.00000e-09 7.00000e-02 $3.84313 \mathrm{e}+023.84313 \mathrm{e}+02$ 3.84313e+01 1.00000e-09 7.00000e-02 $3.84313 \mathrm{e}+02$ 3.84313e+02 3.84313e+01 1.00000e-09 7.00000e-02 $3.84313 \mathrm{e}+02$ 3.84313e+02 3.84313e+01 1.00000e-09 7.00000e-02 $3.84313 \mathrm{e}+023.84313 \mathrm{e}+02$ 3.84313e+01 1.00000e-09 7.00000e-02 5.00000e-04 5.00000e-04 5.00000e-05 1.00000e-09 1.00000e-01 5.00000e-04 5.00000e-04 5.00000e-05 1.00000e-09 1.00000e-01 $1.53557 \mathrm{e}+011.53557 \mathrm{e}+01$ 1.53557e+00 1.00000e-09 2.12000e-01 $1.53557 \mathrm{e}+01$ 1.53557e+01 1.53557e+00 1.00000e-09 2.12000e-01 $1.53557 \mathrm{e}+01$ 1.53557e+01 1.53557e+00 1.00000e-09 2.12000e-01 $1.53557 \mathrm{e}+01$ 1.53557e+01 1.53557e+00 1.00000e-09 2.12000e-01 $1.53557 \mathrm{e}+01$ 1.53557e+01 1.53557e+00 1.00000e-09 2.12000e-01 $1.00000 \mathrm{e}-02$ 1.00000e-02 1.00000e-03 1.00000e-09 1.00000e-01 $1.00000 \mathrm{e}+001.00000 \mathrm{e}+001.00000 \mathrm{e}-011.00000 \mathrm{e}-091.00000 \mathrm{e}-01$ $1.00000 \mathrm{e}-05$ 1.00000e-05 1.00000e-06 1.00000e-09 1.00000e-01 
$1.00000 \mathrm{e}+001.00000 \mathrm{e}+00$ 1.00000e-01 1.00000e-09 1.00000e-01

Element: 2453 \# of layers: 16

$\mathrm{Kx} \mathrm{Ky} \mathrm{Kz}$ Ss Por

3.48903e+02 3.48903e+02 3.48903e+01 1.00000e-09 7.00000e-02

$3.48903 \mathrm{e}+023.48903 \mathrm{e}+023.48903 \mathrm{e}+01$ 1.00000e-09 7.00000e-02

$3.48903 \mathrm{e}+02$ 3.48903e+02 3.48903e+01 1.00000e-09 7.00000e-02

$3.48903 \mathrm{e}+02$ 3.48903e+02 3.48903e+01 1.00000e-09 7.00000e-02

$3.48903 \mathrm{e}+02$ 3.48903e+02 3.48903e+01 1.00000e-09 7.00000e-02

5.00000e-04 5.00000e-04 5.00000e-05 1.00000e-09 1.00000e-01

$5.00000 \mathrm{e}-04$ 5.00000e-04 5.00000e-05 1.00000e-09 1.00000e-01

$1.39409 \mathrm{e}+01$ 1.39409e+01 1.39409e+00 1.00000e-09 2.12000e-01

$1.39409 \mathrm{e}+01$ 1.39409e+01 1.39409e+00 1.00000e-09 2.12000e-01

$1.39409 \mathrm{e}+01$ 1.39409e+01 1.39409e+00 1.00000e-09 2.12000e-01

$1.39409 \mathrm{e}+01$ 1.39409e+01 1.39409e+00 1.00000e-09 2.12000e-01

$1.39409 \mathrm{e}+01$ 1.39409e+01 1.39409e+00 1.00000e-09 2.12000e-01

$1.00000 \mathrm{e}-02$ 1.00000e-02 1.00000e-03 1.00000e-09 1.00000e-01

$1.00000 \mathrm{e}+001.00000 \mathrm{e}+001.00000 \mathrm{e}-011.00000 \mathrm{e}-091.00000 \mathrm{e}-01$

$1.00000 \mathrm{e}-05$ 1.00000e-05 1.00000e-06 1.00000e-09 1.00000e-01

$1.00000 \mathrm{e}+001.00000 \mathrm{e}+001.00000 \mathrm{e}-011.00000 \mathrm{e}-091.00000 \mathrm{e}-01$

Element: 2454 \# of layers: 16

$\mathrm{Kx} \mathrm{Ky} \mathrm{Kz}$ Ss Por

3.48903e+02 3.48903e+02 3.48903e+01 1.00000e-09 7.00000e-02

3.48903e+02 3.48903e+02 3.48903e+01 1.00000e-09 7.00000e-02

$3.48903 \mathrm{e}+02$ 3.48903e+02 3.48903e+01 1.00000e-09 7.00000e-02

$3.48903 \mathrm{e}+02$ 3.48903e+02 3.48903e+01 1.00000e-09 7.00000e-02

$3.48903 \mathrm{e}+02$ 3.48903e+02 3.48903e+01 1.00000e-09 7.00000e-02

5.00000e-04 5.00000e-04 5.00000e-05 1.00000e-09 1.00000e-01

5.00000e-04 5.00000e-04 5.00000e-05 1.00000e-09 1.00000e-01

$1.39409 \mathrm{e}+011.39409 \mathrm{e}+01$ 1.39409e+00 1.00000e-09 2.12000e-01

$1.39409 \mathrm{e}+01$ 1.39409e+01 1.39409e+00 1.00000e-09 2.12000e-01

$1.39409 \mathrm{e}+01$ 1.39409e+01 1.39409e+00 1.00000e-09 2.12000e-01

$1.39409 \mathrm{e}+01$ 1.39409e+01 1.39409e+00 1.00000e-09 2.12000e-01

$1.39409 \mathrm{e}+01$ 1.39409e+01 1.39409e+00 1.00000e-09 2.12000e-01

$1.00000 \mathrm{e}-02$ 1.00000e-02 1.00000e-03 1.00000e-09 1.00000e-01

$1.00000 \mathrm{e}+001.00000 \mathrm{e}+001.00000 \mathrm{e}-011.00000 \mathrm{e}-091.00000 \mathrm{e}-01$

$1.00000 \mathrm{e}-05$ 1.00000e-05 1.00000e-06 1.00000e-09 1.00000e-01

$1.00000 \mathrm{e}+001.00000 \mathrm{e}+001.00000 \mathrm{e}-011.00000 \mathrm{e}-091.00000 \mathrm{e}-01$

Element: 2455 \# of layers: 16

$\mathrm{Kx} \mathrm{Ky} \mathrm{Kz}$ Ss Por

3.48903e+02 3.48903e+02 3.48903e+01 1.00000e-09 7.00000e-02

$3.48903 \mathrm{e}+02$ 3.48903e+02 3.48903e+01 1.00000e-09 7.00000e-02

$3.48903 \mathrm{e}+023.48903 \mathrm{e}+02$ 3.48903e+01 1.00000e-09 7.00000e-02

$3.48903 \mathrm{e}+02$ 3.48903e+02 3.48903e+01 1.00000e-09 7.00000e-02

3.48903e+02 3.48903e+02 3.48903e+01 1.00000e-09 7.00000e-02

5.00000e-04 5.00000e-04 5.00000e-05 1.00000e-09 1.00000e-01

5.00000e-04 5.00000e-04 5.00000e-05 1.00000e-09 1.00000e-01 
$1.39409 \mathrm{e}+01$ 1.39409e+01 1.39409e+00 1.00000e-09 2.12000e-01 $1.39409 \mathrm{e}+01$ 1.39409e+01 1.39409e+00 1.00000e-09 2.12000e-01 $1.39409 \mathrm{e}+01$ 1.39409e+01 1.39409e+00 1.00000e-09 2.12000e-01 $1.39409 \mathrm{e}+01$ 1.39409e+01 1.39409e+00 1.00000e-09 2.12000e-01 $1.39409 \mathrm{e}+01$ 1.39409e+01 1.39409e+00 1.00000e-09 2.12000e-01 $1.00000 \mathrm{e}-02$ 1.00000e-02 1.00000e-03 1.00000e-09 1.00000e-01 $1.00000 \mathrm{e}+001.00000 \mathrm{e}+001.00000 \mathrm{e}-011.00000 \mathrm{e}-091.00000 \mathrm{e}-01$ $1.00000 \mathrm{e}-05$ 1.00000e-05 1.00000e-06 1.00000e-09 1.00000e-01 $1.00000 \mathrm{e}+001.00000 \mathrm{e}+001.00000 \mathrm{e}-011.00000 \mathrm{e}-091.00000 \mathrm{e}-01$ Element: 2456 \# of layers: 16

$\mathrm{Kx} \mathrm{Ky} \mathrm{Kz}$ Ss Por

5.10236e+02 5.10236e+02 5.10236e+01 1.00000e-09 7.00000e-02 $5.10236 \mathrm{e}+02$ 5.10236e+02 5.10236e+01 1.00000e-09 7.00000e-02 $5.10236 \mathrm{e}+025.10236 \mathrm{e}+025.10236 \mathrm{e}+01$ 1.00000e-09 7.00000e-02 $5.10236 \mathrm{e}+025.10236 \mathrm{e}+025.10236 \mathrm{e}+01$ 1.00000e-09 7.00000e-02 $5.10236 \mathrm{e}+025.10236 \mathrm{e}+025.10236 \mathrm{e}+01$ 1.00000e-09 7.00000e-02 5.00000e-04 5.00000e-04 5.00000e-05 1.00000e-09 1.00000e-01 5.00000e-04 5.00000e-04 5.00000e-05 1.00000e-09 1.00000e-01 $2.03872 \mathrm{e}+012.03872 \mathrm{e}+012.03872 \mathrm{e}+00$ 1.00000e-09 2.12000e-01 $2.03872 \mathrm{e}+012.03872 \mathrm{e}+012.03872 \mathrm{e}+001.00000 \mathrm{e}-092.12000 \mathrm{e}-01$ $2.03872 \mathrm{e}+012.03872 \mathrm{e}+012.03872 \mathrm{e}+001.00000 \mathrm{e}-092.12000 \mathrm{e}-01$ $2.03872 \mathrm{e}+012.03872 \mathrm{e}+012.03872 \mathrm{e}+00$ 1.00000e-09 2.12000e-01 $2.03872 \mathrm{e}+012.03872 \mathrm{e}+012.03872 \mathrm{e}+00$ 1.00000e-09 2.12000e-01 $1.00000 \mathrm{e}-02$ 1.00000e-02 1.00000e-03 1.00000e-09 1.00000e-01 $1.00000 \mathrm{e}+001.00000 \mathrm{e}+001.00000 \mathrm{e}-011.00000 \mathrm{e}-091.00000 \mathrm{e}-01$ $1.00000 \mathrm{e}-05$ 1.00000e-05 1.00000e-06 1.00000e-09 1.00000e-01 $1.00000 \mathrm{e}+001.00000 \mathrm{e}+001.00000 \mathrm{e}-011.00000 \mathrm{e}-091.00000 \mathrm{e}-01$ Element: 2457 \# of layers: 15

$\mathrm{Kx} \mathrm{Ky} \mathrm{Kz}$ Ss Por

5.10236e+02 5.10236e+02 5.10236e+01 1.00000e-09 7.00000e-02 $5.10236 \mathrm{e}+025.10236 \mathrm{e}+025.10236 \mathrm{e}+01$ 1.00000e-09 7.00000e-02 $5.10236 \mathrm{e}+025.10236 \mathrm{e}+025.10236 \mathrm{e}+01$ 1.00000e-09 7.00000e-02 $5.10236 \mathrm{e}+025.10236 \mathrm{e}+025.10236 \mathrm{e}+01$ 1.00000e-09 7.00000e-02 5.00000e-04 5.00000e-04 5.00000e-05 1.00000e-09 1.00000e-01 5.00000e-04 5.00000e-04 5.00000e-05 1.00000e-09 1.00000e-01 $2.03872 \mathrm{e}+012.03872 \mathrm{e}+012.03872 \mathrm{e}+00$ 1.00000e-09 2.12000e-01 $2.03872 \mathrm{e}+012.03872 \mathrm{e}+012.03872 \mathrm{e}+001.00000 \mathrm{e}-092.12000 \mathrm{e}-01$ $2.03872 \mathrm{e}+012.03872 \mathrm{e}+012.03872 \mathrm{e}+001.00000 \mathrm{e}-092.12000 \mathrm{e}-01$ $2.03872 \mathrm{e}+012.03872 \mathrm{e}+012.03872 \mathrm{e}+001.00000 \mathrm{e}-092.12000 \mathrm{e}-01$ $2.03872 \mathrm{e}+012.03872 \mathrm{e}+012.03872 \mathrm{e}+00$ 1.00000e-09 2.12000e-01 $1.00000 \mathrm{e}-02$ 1.00000e-02 1.00000e-03 1.00000e-09 1.00000e-01 $1.00000 \mathrm{e}+001.00000 \mathrm{e}+001.00000 \mathrm{e}-011.00000 \mathrm{e}-091.00000 \mathrm{e}-01$ $1.00000 \mathrm{e}-05$ 1.00000e-05 1.00000e-06 1.00000e-09 1.00000e-01 $1.00000 \mathrm{e}+001.00000 \mathrm{e}+001.00000 \mathrm{e}-01$ 1.00000e-09 1.00000e-01 Element: 2458 \# of layers: 15

Kx Ky Kz Ss Por 
5.08371e+02 5.08371e+02 5.08371e+01 1.00000e-09 7.00000e-02 5.08371e+02 5.08371e+02 5.08371e+01 1.00000e-09 7.00000e-02 $5.08371 \mathrm{e}+025.08371 \mathrm{e}+025.08371 \mathrm{e}+01$ 1.00000e-09 7.00000e-02 $5.08371 \mathrm{e}+025.08371 \mathrm{e}+025.08371 \mathrm{e}+01$ 1.00000e-09 7.00000e-02 5.00000e-04 5.00000e-04 5.00000e-05 1.00000e-09 1.00000e-01 5.00000e-04 5.00000e-04 5.00000e-05 1.00000e-09 1.00000e-01 $2.03128 \mathrm{e}+012.03128 \mathrm{e}+012.03128 \mathrm{e}+00$ 1.00000e-09 2.12000e-01 $2.03128 \mathrm{e}+012.03128 \mathrm{e}+012.03128 \mathrm{e}+00$ 1.00000e-09 2.12000e-01 $2.03128 \mathrm{e}+012.03128 \mathrm{e}+012.03128 \mathrm{e}+001.00000 \mathrm{e}-092.12000 \mathrm{e}-01$ $2.03128 \mathrm{e}+012.03128 \mathrm{e}+012.03128 \mathrm{e}+00$ 1.00000e-09 2.12000e-01 $2.03128 \mathrm{e}+012.03128 \mathrm{e}+012.03128 \mathrm{e}+00$ 1.00000e-09 2.12000e-01 $1.00000 \mathrm{e}-02$ 1.00000e-02 1.00000e-03 1.00000e-09 1.00000e-01 $1.00000 \mathrm{e}+001.00000 \mathrm{e}+001.00000 \mathrm{e}-011.00000 \mathrm{e}-091.00000 \mathrm{e}-01$ $1.00000 \mathrm{e}-05$ 1.00000e-05 1.00000e-06 1.00000e-09 1.00000e-01 $1.00000 \mathrm{e}+001.00000 \mathrm{e}+001.00000 \mathrm{e}-01$ 1.00000e-09 1.00000e-01 Element: 2459 \# of layers: 15

$\mathrm{Kx} \mathrm{Ky} \mathrm{Kz}$ Ss Por

3.84313e+02 3.84313e+02 3.84313e+01 1.00000e-09 7.00000e-02 3.84313e+02 3.84313e+02 3.84313e+01 1.00000e-09 7.00000e-02 $3.84313 \mathrm{e}+02$ 3.84313e+02 3.84313e+01 1.00000e-09 7.00000e-02 $3.84313 \mathrm{e}+02$ 3.84313e+02 3.84313e+01 1.00000e-09 7.00000e-02 $5.00000 \mathrm{e}-04$ 5.00000e-04 5.00000e-05 1.00000e-09 1.00000e-01 5.00000e-04 5.00000e-04 5.00000e-05 1.00000e-09 1.00000e-01 $1.53557 \mathrm{e}+011.53557 \mathrm{e}+01$ 1.53557e+00 1.00000e-09 2.12000e-01 $1.53557 \mathrm{e}+011.53557 \mathrm{e}+01$ 1.53557e+00 1.00000e-09 2.12000e-01 $1.53557 \mathrm{e}+01$ 1.53557e+01 1.53557e+00 1.00000e-09 2.12000e-01 $1.53557 \mathrm{e}+01$ 1.53557e+01 1.53557e+00 1.00000e-09 2.12000e-01 $1.53557 \mathrm{e}+01$ 1.53557e+01 1.53557e+00 1.00000e-09 2.12000e-01 $1.00000 \mathrm{e}-02$ 1.00000e-02 1.00000e-03 1.00000e-09 1.00000e-01 $1.00000 \mathrm{e}+001.00000 \mathrm{e}+001.00000 \mathrm{e}-011.00000 \mathrm{e}-091.00000 \mathrm{e}-01$ $1.00000 \mathrm{e}-05$ 1.00000e-05 1.00000e-06 1.00000e-09 1.00000e-01 $1.00000 \mathrm{e}+001.00000 \mathrm{e}+001.00000 \mathrm{e}-011.00000 \mathrm{e}-091.00000 \mathrm{e}-01$ Element: 2460 \# of layers: 15

$\mathrm{Kx} \mathrm{Ky} \mathrm{Kz}$ Ss Por

3.48903e+02 3.48903e+02 3.48903e+01 1.00000e-09 7.00000e-02 $3.48903 \mathrm{e}+02$ 3.48903e+02 3.48903e+01 1.00000e-09 7.00000e-02 $3.48903 \mathrm{e}+02$ 3.48903e+02 3.48903e+01 1.00000e-09 7.00000e-02 $3.48903 \mathrm{e}+023.48903 \mathrm{e}+02$ 3.48903e+01 1.00000e-09 7.00000e-02 5.00000e-04 5.00000e-04 5.00000e-05 1.00000e-09 1.00000e-01 5.00000e-04 5.00000e-04 5.00000e-05 1.00000e-09 1.00000e-01 $1.39409 \mathrm{e}+01$ 1.39409e+01 1.39409e+00 1.00000e-09 2.12000e-01 $1.39409 \mathrm{e}+01$ 1.39409e+01 1.39409e+00 1.00000e-09 2.12000e-01 $1.39409 \mathrm{e}+01$ 1.39409e+01 1.39409e+00 1.00000e-09 2.12000e-01 $1.39409 \mathrm{e}+01$ 1.39409e+01 1.39409e+00 1.00000e-09 2.12000e-01 $1.39409 \mathrm{e}+01$ 1.39409e+01 1.39409e+00 1.00000e-09 2.12000e-01 $1.00000 \mathrm{e}-02$ 1.00000e-02 1.00000e-03 1.00000e-09 1.00000e-01 
$1.00000 \mathrm{e}+001.00000 \mathrm{e}+001.00000 \mathrm{e}-011.00000 \mathrm{e}-091.00000 \mathrm{e}-01$ $1.00000 \mathrm{e}-05$ 1.00000e-05 1.00000e-06 1.00000e-09 1.00000e-01 $1.00000 \mathrm{e}+001.00000 \mathrm{e}+001.00000 \mathrm{e}-01$ 1.00000e-09 1.00000e-01 Element: 2461 \# of layers: 15

$\mathrm{Kx} \mathrm{Ky} \mathrm{Kz}$ Ss Por

3.15719e+02 3.15719e+02 3.15719e+01 1.00000e-09 7.00000e-02 3.15719e+02 3.15719e+02 3.15719e+01 1.00000e-09 7.00000e-02 $3.15719 \mathrm{e}+02$ 3.15719e+02 3.15719e+01 1.00000e-09 7.00000e-02 $3.15719 \mathrm{e}+02$ 3.15719e+02 3.15719e+01 1.00000e-09 7.00000e-02 5.00000e-04 5.00000e-04 5.00000e-05 1.00000e-09 1.00000e-01 5.00000e-04 5.00000e-04 5.00000e-05 1.00000e-09 1.00000e-01 $1.26151 \mathrm{e}+011.26151 \mathrm{e}+011.26151 \mathrm{e}+001.00000 \mathrm{e}-092.12000 \mathrm{e}-01$ $1.26151 \mathrm{e}+011.26151 \mathrm{e}+011.26151 \mathrm{e}+001.00000 \mathrm{e}-092.12000 \mathrm{e}-01$ $1.26151 \mathrm{e}+011.26151 \mathrm{e}+011.26151 \mathrm{e}+001.00000 \mathrm{e}-092.12000 \mathrm{e}-01$ $1.26151 \mathrm{e}+011.26151 \mathrm{e}+011.26151 \mathrm{e}+001.00000 \mathrm{e}-092.12000 \mathrm{e}-01$ $1.26151 \mathrm{e}+011.26151 \mathrm{e}+011.26151 \mathrm{e}+001.00000 \mathrm{e}-092.12000 \mathrm{e}-01$ 1.00000e-02 1.00000e-02 1.00000e-03 1.00000e-09 1.00000e-01 $1.00000 \mathrm{e}+001.00000 \mathrm{e}+001.00000 \mathrm{e}-011.00000 \mathrm{e}-091.00000 \mathrm{e}-01$ $1.00000 \mathrm{e}-05$ 1.00000e-05 1.00000e-06 1.00000e-09 1.00000e-01 $1.00000 \mathrm{e}+001.00000 \mathrm{e}+001.00000 \mathrm{e}-011.00000 \mathrm{e}-091.00000 \mathrm{e}-01$ Element: 2462 \# of layers: 15

$\mathrm{Kx} \mathrm{Ky} \mathrm{Kz}$ Ss Por

$2.88816 \mathrm{e}+02$ 2.88816e+02 2.88816e+01 1.00000e-09 7.00000e-02 $2.88816 \mathrm{e}+022.88816 \mathrm{e}+022.88816 \mathrm{e}+01$ 1.00000e-09 7.00000e-02 $2.88816 \mathrm{e}+022.88816 \mathrm{e}+022.88816 \mathrm{e}+01$ 1.00000e-09 7.00000e-02 $2.88816 \mathrm{e}+022.88816 \mathrm{e}+022.88816 \mathrm{e}+01$ 1.00000e-09 7.00000e-02 5.00000e-04 5.00000e-04 5.00000e-05 1.00000e-09 1.00000e-01 5.00000e-04 5.00000e-04 5.00000e-05 1.00000e-09 1.00000e-01 $1.15403 \mathrm{e}+01$ 1.15403e+01 1.15403e+00 1.00000e-09 2.12000e-01 $1.15403 \mathrm{e}+01$ 1.15403e+01 1.15403e+00 1.00000e-09 2.12000e-01 $1.15403 \mathrm{e}+01$ 1.15403e+01 1.15403e+00 1.00000e-09 2.12000e-01 $1.15403 \mathrm{e}+01$ 1.15403e+01 1.15403e+00 1.00000e-09 2.12000e-01 $1.15403 \mathrm{e}+011.15403 \mathrm{e}+011.15403 \mathrm{e}+001.00000 \mathrm{e}-092.12000 \mathrm{e}-01$ $1.00000 \mathrm{e}-02$ 1.00000e-02 1.00000e-03 1.00000e-09 1.00000e-01 $1.00000 \mathrm{e}+001.00000 \mathrm{e}+001.00000 \mathrm{e}-011.00000 \mathrm{e}-091.00000 \mathrm{e}-01$ $1.00000 \mathrm{e}-05$ 1.00000e-05 1.00000e-06 1.00000e-09 1.00000e-01 $1.00000 \mathrm{e}+001.00000 \mathrm{e}+001.00000 \mathrm{e}-011.00000 \mathrm{e}-091.00000 \mathrm{e}-01$ Element: 2463 \# of layers: 16

$\mathrm{Kx} \mathrm{Ky} \mathrm{Kz}$ Ss Por

$2.88816 \mathrm{e}+02$ 2.88816e+02 2.88816e+01 1.00000e-09 7.00000e-02 $2.88816 \mathrm{e}+022.88816 \mathrm{e}+022.88816 \mathrm{e}+01$ 1.00000e-09 7.00000e-02 $2.88816 \mathrm{e}+02$ 2.88816e+02 2.88816e+01 1.00000e-09 7.00000e-02 $2.88816 \mathrm{e}+022.88816 \mathrm{e}+022.88816 \mathrm{e}+01$ 1.00000e-09 7.00000e-02 $2.88816 \mathrm{e}+02$ 2.88816e+02 2.88816e+01 1.00000e-09 7.00000e-02 $5.00000 \mathrm{e}-04$ 5.00000e-04 5.00000e-05 1.00000e-09 1.00000e-01 5.00000e-04 5.00000e-04 5.00000e-05 1.00000e-09 1.00000e-01 
1.15403e+01 1.15403e+01 1.15403e+00 1.00000e-09 2.12000e-01 $1.15403 \mathrm{e}+01$ 1.15403e+01 1.15403e+00 1.00000e-09 2.12000e-01 $1.15403 \mathrm{e}+011.15403 \mathrm{e}+01$ 1.15403e+00 1.00000e-09 2.12000e-01 $1.15403 \mathrm{e}+011.15403 \mathrm{e}+011.15403 \mathrm{e}+001.00000 \mathrm{e}-092.12000 \mathrm{e}-01$ $1.15403 \mathrm{e}+01$ 1.15403e+01 1.15403e+00 1.00000e-09 2.12000e-01 $1.00000 \mathrm{e}-02$ 1.00000e-02 1.00000e-03 1.00000e-09 1.00000e-01 $1.00000 \mathrm{e}+001.00000 \mathrm{e}+001.00000 \mathrm{e}-011.00000 \mathrm{e}-091.00000 \mathrm{e}-01$ $1.00000 \mathrm{e}-05$ 1.00000e-05 1.00000e-06 1.00000e-09 1.00000e-01 $1.00000 \mathrm{e}+001.00000 \mathrm{e}+001.00000 \mathrm{e}-011.00000 \mathrm{e}-091.00000 \mathrm{e}-01$ Element: 2464 \# of layers: 15

$\mathrm{Kx} \mathrm{Ky} \mathrm{Kz}$ Ss Por

$2.88816 \mathrm{e}+02$ 2.88816e+02 2.88816e+01 1.00000e-09 7.00000e-02 $2.88816 \mathrm{e}+022.88816 \mathrm{e}+022.88816 \mathrm{e}+01$ 1.00000e-09 7.00000e-02

$2.88816 \mathrm{e}+022.88816 \mathrm{e}+022.88816 \mathrm{e}+01$ 1.00000e-09 7.00000e-02 $2.88816 \mathrm{e}+022.88816 \mathrm{e}+022.88816 \mathrm{e}+01$ 1.00000e-09 7.00000e-02 5.00000e-04 5.00000e-04 5.00000e-05 1.00000e-09 1.00000e-01 5.00000e-04 5.00000e-04 5.00000e-05 1.00000e-09 1.00000e-01 $1.15403 \mathrm{e}+011.15403 \mathrm{e}+01$ 1.15403e+00 1.00000e-09 2.12000e-01 $1.15403 \mathrm{e}+01$ 1.15403e+01 1.15403e+00 1.00000e-09 2.12000e-01 $1.15403 \mathrm{e}+01$ 1.15403e+01 1.15403e+00 1.00000e-09 2.12000e-01 $1.15403 \mathrm{e}+011.15403 \mathrm{e}+011.15403 \mathrm{e}+001.00000 \mathrm{e}-092.12000 \mathrm{e}-01$ $1.15403 \mathrm{e}+01$ 1.15403e+01 1.15403e+00 1.00000e-09 2.12000e-01 $1.00000 \mathrm{e}-02$ 1.00000e-02 1.00000e-03 1.00000e-09 1.00000e-01 $1.00000 \mathrm{e}+001.00000 \mathrm{e}+001.00000 \mathrm{e}-011.00000 \mathrm{e}-091.00000 \mathrm{e}-01$ $1.00000 \mathrm{e}-05$ 1.00000e-05 1.00000e-06 1.00000e-09 1.00000e-01 $1.00000 \mathrm{e}+001.00000 \mathrm{e}+001.00000 \mathrm{e}-01$ 1.00000e-09 1.00000e-01 Element: 2465 \# of layers: 15

$\mathrm{Kx} \mathrm{Ky} \mathrm{Kz}$ Ss Por

3.19278e+02 3.19278e+02 3.19278e+01 1.00000e-09 7.00000e-02 3.19278e+02 3.19278e+02 3.19278e+01 1.00000e-09 7.00000e-02 $3.19278 \mathrm{e}+02$ 3.19278e+02 3.19278e+01 1.00000e-09 7.00000e-02 3.19278e+02 3.19278e+02 3.19278e+01 1.00000e-09 7.00000e-02 5.00000e-04 5.00000e-04 5.00000e-05 1.00000e-09 1.00000e-01 5.00000e-04 5.00000e-04 5.00000e-05 1.00000e-09 1.00000e-01 $1.27571 \mathrm{e}+011.27571 \mathrm{e}+011.27571 \mathrm{e}+001.00000 \mathrm{e}-092.12000 \mathrm{e}-01$ $1.27571 \mathrm{e}+011.27571 \mathrm{e}+011.27571 \mathrm{e}+001.00000 \mathrm{e}-092.12000 \mathrm{e}-01$ $1.27571 \mathrm{e}+011.27571 \mathrm{e}+011.27571 \mathrm{e}+001.00000 \mathrm{e}-092.12000 \mathrm{e}-01$ $1.27571 \mathrm{e}+011.27571 \mathrm{e}+011.27571 \mathrm{e}+001.00000 \mathrm{e}-092.12000 \mathrm{e}-01$ $1.27571 \mathrm{e}+011.27571 \mathrm{e}+011.27571 \mathrm{e}+001.00000 \mathrm{e}-092.12000 \mathrm{e}-01$ 1.00000e-02 1.00000e-02 1.00000e-03 1.00000e-09 1.00000e-01 $1.00000 \mathrm{e}+001.00000 \mathrm{e}+001.00000 \mathrm{e}-011.00000 \mathrm{e}-091.00000 \mathrm{e}-01$ $1.00000 \mathrm{e}-05$ 1.00000e-05 1.00000e-06 1.00000e-09 1.00000e-01 $1.00000 \mathrm{e}+001.00000 \mathrm{e}+001.00000 \mathrm{e}-011.00000 \mathrm{e}-091.00000 \mathrm{e}-01$ Element: 2466 \# of layers: 15

$\mathrm{Kx} \mathrm{Ky} \mathrm{Kz}$ Ss Por

3.19278e+02 3.19278e+02 3.19278e+01 1.00000e-09 7.00000e-02 
$3.19278 \mathrm{e}+023.19278 \mathrm{e}+023.19278 \mathrm{e}+01$ 1.00000e-09 7.00000e-02 $3.19278 \mathrm{e}+023.19278 \mathrm{e}+023.19278 \mathrm{e}+01$ 1.00000e-09 7.00000e-02 $3.19278 \mathrm{e}+023.19278 \mathrm{e}+023.19278 \mathrm{e}+01$ 1.00000e-09 7.00000e-02 5.00000e-04 5.00000e-04 5.00000e-05 1.00000e-09 1.00000e-01 5.00000e-04 5.00000e-04 5.00000e-05 1.00000e-09 1.00000e-01 $1.27571 \mathrm{e}+011.27571 \mathrm{e}+011.27571 \mathrm{e}+001.00000 \mathrm{e}-092.12000 \mathrm{e}-01$ $1.27571 \mathrm{e}+011.27571 \mathrm{e}+011.27571 \mathrm{e}+001.00000 \mathrm{e}-092.12000 \mathrm{e}-01$ $1.27571 \mathrm{e}+011.27571 \mathrm{e}+011.27571 \mathrm{e}+001.00000 \mathrm{e}-092.12000 \mathrm{e}-01$ $1.27571 \mathrm{e}+011.27571 \mathrm{e}+011.27571 \mathrm{e}+001.00000 \mathrm{e}-092.12000 \mathrm{e}-01$ $1.27571 \mathrm{e}+011.27571 \mathrm{e}+011.27571 \mathrm{e}+001.00000 \mathrm{e}-092.12000 \mathrm{e}-01$ $1.00000 \mathrm{e}-021.00000 \mathrm{e}-02$ 1.00000e-03 1.00000e-09 1.00000e-01 $1.00000 \mathrm{e}+001.00000 \mathrm{e}+001.00000 \mathrm{e}-011.00000 \mathrm{e}-091.00000 \mathrm{e}-01$ $1.00000 \mathrm{e}-05$ 1.00000e-05 1.00000e-06 1.00000e-09 1.00000e-01 $1.00000 \mathrm{e}+001.00000 \mathrm{e}+001.00000 \mathrm{e}-011.00000 \mathrm{e}-091.00000 \mathrm{e}-01$ Element: 2467 \# of layers: 15

Kx Ky Kz Ss Por

4.17613e+02 4.17613e+02 4.17614e+01 1.00000e-09 7.00000e-02 $4.17613 \mathrm{e}+024.17613 \mathrm{e}+024.17614 \mathrm{e}+01$ 1.00000e-09 7.00000e-02 $4.17613 \mathrm{e}+024.17613 \mathrm{e}+024.17614 \mathrm{e}+01$ 1.00000e-09 7.00000e-02 $4.17613 \mathrm{e}+024.17613 \mathrm{e}+024.17614 \mathrm{e}+011.00000 \mathrm{e}-09$ 7.00000e-02 5.00000e-04 5.00000e-04 5.00000e-05 1.00000e-09 1.00000e-01 $5.00000 \mathrm{e}-04$ 5.00000e-04 5.00000e-05 1.00000e-09 1.00000e-01 $1.66864 \mathrm{e}+011.66864 \mathrm{e}+011.66864 \mathrm{e}+001.00000 \mathrm{e}-092.12000 \mathrm{e}-01$ $1.66864 \mathrm{e}+011.66864 \mathrm{e}+011.66864 \mathrm{e}+001.00000 \mathrm{e}-092.12000 \mathrm{e}-01$ $1.66864 \mathrm{e}+011.66864 \mathrm{e}+011.66864 \mathrm{e}+001.00000 \mathrm{e}-092.12000 \mathrm{e}-01$ $1.66864 \mathrm{e}+011.66864 \mathrm{e}+011.66864 \mathrm{e}+001.00000 \mathrm{e}-092.12000 \mathrm{e}-01$ $1.66864 \mathrm{e}+011.66864 \mathrm{e}+011.66864 \mathrm{e}+001.00000 \mathrm{e}-092.12000 \mathrm{e}-01$ $1.00000 \mathrm{e}-021.00000 \mathrm{e}-02$ 1.00000e-03 1.00000e-09 1.00000e-01 $1.00000 \mathrm{e}+001.00000 \mathrm{e}+001.00000 \mathrm{e}-011.00000 \mathrm{e}-091.00000 \mathrm{e}-01$ $1.00000 \mathrm{e}-05$ 1.00000e-05 1.00000e-06 1.00000e-09 1.00000e-01 $1.00000 \mathrm{e}+001.00000 \mathrm{e}+001.00000 \mathrm{e}-011.00000 \mathrm{e}-091.00000 \mathrm{e}-01$ Element: 2468 \# of layers: 15

Kx Ky Kz Ss Por

$3.15719 \mathrm{e}+023.15719 \mathrm{e}+023.15719 \mathrm{e}+01$ 1.00000e-09 7.00000e-02 $3.15719 \mathrm{e}+023.15719 \mathrm{e}+023.15719 \mathrm{e}+01$ 1.00000e-09 7.00000e-02 $3.15719 \mathrm{e}+023.15719 \mathrm{e}+023.15719 \mathrm{e}+01$ 1.00000e-09 7.00000e-02 $3.15719 \mathrm{e}+023.15719 \mathrm{e}+023.15719 \mathrm{e}+01$ 1.00000e-09 7.00000e-02 5.00000e-04 5.00000e-04 5.00000e-05 1.00000e-09 1.00000e-01 5.00000e-04 5.00000e-04 5.00000e-05 1.00000e-09 1.00000e-01 $1.26151 \mathrm{e}+011.26151 \mathrm{e}+011.26151 \mathrm{e}+001.00000 \mathrm{e}-092.12000 \mathrm{e}-01$ $1.26151 \mathrm{e}+011.26151 \mathrm{e}+011.26151 \mathrm{e}+001.00000 \mathrm{e}-092.12000 \mathrm{e}-01$ $1.26151 \mathrm{e}+011.26151 \mathrm{e}+011.26151 \mathrm{e}+001.00000 \mathrm{e}-092.12000 \mathrm{e}-01$ $1.26151 \mathrm{e}+011.26151 \mathrm{e}+011.26151 \mathrm{e}+001.00000 \mathrm{e}-092.12000 \mathrm{e}-01$ $1.26151 \mathrm{e}+011.26151 \mathrm{e}+011.26151 \mathrm{e}+001.00000 \mathrm{e}-092.12000 \mathrm{e}-01$ $1.00000 \mathrm{e}-021.00000 \mathrm{e}-02$ 1.00000e-03 1.00000e-09 1.00000e-01 $1.00000 \mathrm{e}+001.00000 \mathrm{e}+001.00000 \mathrm{e}-011.00000 \mathrm{e}-091.00000 \mathrm{e}-01$ 
$1.00000 \mathrm{e}-05$ 1.00000e-05 1.00000e-06 1.00000e-09 1.00000e-01 $1.00000 \mathrm{e}+001.00000 \mathrm{e}+001.00000 \mathrm{e}-01$ 1.00000e-09 1.00000e-01 Element: 2469 \# of layers: 15

$\mathrm{Kx} \mathrm{Ky} \mathrm{Kz}$ Ss Por

$2.88816 \mathrm{e}+02$ 2.88816e+02 2.88816e+01 1.00000e-09 7.00000e-02

$2.88816 \mathrm{e}+022.88816 \mathrm{e}+022.88816 \mathrm{e}+01$ 1.00000e-09 7.00000e-02

$2.88816 \mathrm{e}+022.88816 \mathrm{e}+022.88816 \mathrm{e}+01$ 1.00000e-09 7.00000e-02

$2.88816 \mathrm{e}+022.88816 \mathrm{e}+022.88816 \mathrm{e}+01$ 1.00000e-09 7.00000e-02

5.00000e-04 5.00000e-04 5.00000e-05 1.00000e-09 1.00000e-01

5.00000e-04 5.00000e-04 5.00000e-05 1.00000e-09 1.00000e-01

$1.15403 \mathrm{e}+01$ 1.15403e+01 1.15403e+00 1.00000e-09 2.12000e-01

$1.15403 \mathrm{e}+011.15403 \mathrm{e}+011.15403 \mathrm{e}+001.00000 \mathrm{e}-092.12000 \mathrm{e}-01$

$1.15403 \mathrm{e}+011.15403 \mathrm{e}+011.15403 \mathrm{e}+001.00000 \mathrm{e}-092.12000 \mathrm{e}-01$

$1.15403 \mathrm{e}+01$ 1.15403e+01 1.15403e+00 1.00000e-09 2.12000e-01

$1.15403 \mathrm{e}+01$ 1.15403e+01 1.15403e+00 1.00000e-09 2.12000e-01 $1.00000 \mathrm{e}-02$ 1.00000e-02 1.00000e-03 1.00000e-09 1.00000e-01

$1.00000 \mathrm{e}+001.00000 \mathrm{e}+001.00000 \mathrm{e}-011.00000 \mathrm{e}-091.00000 \mathrm{e}-01$ $1.00000 \mathrm{e}-05$ 1.00000e-05 1.00000e-06 1.00000e-09 1.00000e-01

$1.00000 \mathrm{e}+001.00000 \mathrm{e}+001.00000 \mathrm{e}-011.00000 \mathrm{e}-091.00000 \mathrm{e}-01$

Element: 2470 \# of layers: 16

$\mathrm{Kx} \mathrm{Ky} \mathrm{Kz}$ Ss Por

$2.52433 \mathrm{e}+02$ 2.52433e+02 2.52433e+01 1.00000e-09 7.00000e-02

$2.52433 \mathrm{e}+02$ 2.52433e+02 2.52433e+01 1.00000e-09 7.00000e-02

$2.52433 \mathrm{e}+02$ 2.52433e+02 2.52433e+01 1.00000e-09 7.00000e-02

$2.52433 \mathrm{e}+02$ 2.52433e+02 2.52433e+01 1.00000e-09 7.00000e-02

$2.52433 \mathrm{e}+02$ 2.52433e+02 2.52433e+01 1.00000e-09 7.00000e-02

5.00000e-04 5.00000e-04 5.00000e-05 1.00000e-09 1.00000e-01

5.00000e-04 5.00000e-04 5.00000e-05 1.00000e-09 1.00000e-01

$1.00865 \mathrm{e}+011.00865 \mathrm{e}+011.00865 \mathrm{e}+001.00000 \mathrm{e}-092.12000 \mathrm{e}-01$

$1.00865 \mathrm{e}+011.00865 \mathrm{e}+011.00865 \mathrm{e}+001.00000 \mathrm{e}-092.12000 \mathrm{e}-01$

$1.00865 \mathrm{e}+011.00865 \mathrm{e}+011.00865 \mathrm{e}+001.00000 \mathrm{e}-092.12000 \mathrm{e}-01$

$1.00865 \mathrm{e}+011.00865 \mathrm{e}+011.00865 \mathrm{e}+001.00000 \mathrm{e}-092.12000 \mathrm{e}-01$

$1.00865 \mathrm{e}+011.00865 \mathrm{e}+011.00865 \mathrm{e}+001.00000 \mathrm{e}-092.12000 \mathrm{e}-01$

$1.00000 \mathrm{e}-02$ 1.00000e-02 1.00000e-03 1.00000e-09 1.00000e-01

$1.00000 \mathrm{e}+001.00000 \mathrm{e}+001.00000 \mathrm{e}-011.00000 \mathrm{e}-091.00000 \mathrm{e}-01$

$1.00000 \mathrm{e}-05$ 1.00000e-05 1.00000e-06 1.00000e-09 1.00000e-01

$1.00000 \mathrm{e}+001.00000 \mathrm{e}+001.00000 \mathrm{e}-011.00000 \mathrm{e}-091.00000 \mathrm{e}-01$

Element: 2471 \# of layers: 16

$\mathrm{Kx} \mathrm{Ky} \mathrm{Kz}$ Ss Por

$2.52433 \mathrm{e}+02$ 2.52433e+02 2.52433e+01 1.00000e-09 7.00000e-02

$2.52433 \mathrm{e}+02$ 2.52433e+02 2.52433e+01 1.00000e-09 7.00000e-02

$2.52433 \mathrm{e}+022.52433 \mathrm{e}+02$ 2.52433e+01 1.00000e-09 7.00000e-02

$2.52433 \mathrm{e}+02$ 2.52433e+02 2.52433e+01 1.00000e-09 7.00000e-02

2.52433e+02 2.52433e+02 2.52433e+01 1.00000e-09 7.00000e-02

5.00000e-04 5.00000e-04 5.00000e-05 1.00000e-09 1.00000e-01

5.00000e-04 5.00000e-04 5.00000e-05 1.00000e-09 1.00000e-01 
$1.00865 \mathrm{e}+011.00865 \mathrm{e}+011.00865 \mathrm{e}+001.00000 \mathrm{e}-092.12000 \mathrm{e}-01$ $1.00865 \mathrm{e}+011.00865 \mathrm{e}+011.00865 \mathrm{e}+001.00000 \mathrm{e}-092.12000 \mathrm{e}-01$ $1.00865 \mathrm{e}+011.00865 \mathrm{e}+011.00865 \mathrm{e}+001.00000 \mathrm{e}-092.12000 \mathrm{e}-01$ $1.00865 \mathrm{e}+011.00865 \mathrm{e}+011.00865 \mathrm{e}+001.00000 \mathrm{e}-092.12000 \mathrm{e}-01$ $1.00865 \mathrm{e}+011.00865 \mathrm{e}+011.00865 \mathrm{e}+001.00000 \mathrm{e}-092.12000 \mathrm{e}-01$ $1.00000 \mathrm{e}-02$ 1.00000e-02 1.00000e-03 1.00000e-09 1.00000e-01 $1.00000 \mathrm{e}+001.00000 \mathrm{e}+001.00000 \mathrm{e}-011.00000 \mathrm{e}-091.00000 \mathrm{e}-01$ $1.00000 \mathrm{e}-05$ 1.00000e-05 1.00000e-06 1.00000e-09 1.00000e-01 $1.00000 \mathrm{e}+001.00000 \mathrm{e}+001.00000 \mathrm{e}-011.00000 \mathrm{e}-091.00000 \mathrm{e}-01$ Element: 2472 \# of layers: 16

$\mathrm{Kx} \mathrm{Ky} \mathrm{Kz}$ Ss Por

$2.52433 \mathrm{e}+02$ 2.52433e+02 2.52433e+01 1.00000e-09 7.00000e-02 $2.52433 \mathrm{e}+02$ 2.52433e+02 2.52433e+01 1.00000e-09 7.00000e-02 $2.52433 \mathrm{e}+02$ 2.52433e+02 2.52433e+01 1.00000e-09 7.00000e-02 $2.52433 \mathrm{e}+02$ 2.52433e+02 2.52433e+01 1.00000e-09 7.00000e-02 $2.52433 \mathrm{e}+02$ 2.52433e+02 2.52433e+01 1.00000e-09 7.00000e-02 5.00000e-04 5.00000e-04 5.00000e-05 1.00000e-09 1.00000e-01 5.00000e-04 5.00000e-04 5.00000e-05 1.00000e-09 1.00000e-01 $1.00865 \mathrm{e}+011.00865 \mathrm{e}+011.00865 \mathrm{e}+001.00000 \mathrm{e}-092.12000 \mathrm{e}-01$ $1.00865 \mathrm{e}+011.00865 \mathrm{e}+01 \quad 1.00865 \mathrm{e}+001.00000 \mathrm{e}-092.12000 \mathrm{e}-01$ $1.00865 \mathrm{e}+011.00865 \mathrm{e}+011.00865 \mathrm{e}+001.00000 \mathrm{e}-092.12000 \mathrm{e}-01$ $1.00865 \mathrm{e}+011.00865 \mathrm{e}+011.00865 \mathrm{e}+001.00000 \mathrm{e}-092.12000 \mathrm{e}-01$ $1.00865 \mathrm{e}+011.00865 \mathrm{e}+011.00865 \mathrm{e}+001.00000 \mathrm{e}-092.12000 \mathrm{e}-01$ $1.00000 \mathrm{e}-02$ 1.00000e-02 1.00000e-03 1.00000e-09 1.00000e-01 $1.00000 \mathrm{e}+001.00000 \mathrm{e}+001.00000 \mathrm{e}-011.00000 \mathrm{e}-091.00000 \mathrm{e}-01$ $1.00000 \mathrm{e}-05$ 1.00000e-05 1.00000e-06 1.00000e-09 1.00000e-01 $1.00000 \mathrm{e}+001.00000 \mathrm{e}+001.00000 \mathrm{e}-01$ 1.00000e-09 1.00000e-01 Element: 2473 \# of layers: 16

$\mathrm{Kx} \mathrm{Ky} \mathrm{Kz}$ Ss Por

$2.63624 \mathrm{e}+02$ 2.63624e+02 2.63624e+01 1.00000e-09 7.00000e-02 $2.63624 \mathrm{e}+022.63624 \mathrm{e}+022.63624 \mathrm{e}+01$ 1.00000e-09 7.00000e-02 $2.63624 \mathrm{e}+022.63624 \mathrm{e}+022.63624 \mathrm{e}+01$ 1.00000e-09 7.00000e-02 $2.63624 \mathrm{e}+022.63624 \mathrm{e}+022.63624 \mathrm{e}+01$ 1.00000e-09 7.00000e-02 $2.63624 \mathrm{e}+022.63624 \mathrm{e}+022.63624 \mathrm{e}+01 \quad 1.00000 \mathrm{e}-097.00000 \mathrm{e}-02$ 5.00000e-04 5.00000e-04 5.00000e-05 1.00000e-09 1.00000e-01 5.00000e-04 5.00000e-04 5.00000e-05 1.00000e-09 1.00000e-01 $1.05336 \mathrm{e}+011.05336 \mathrm{e}+011.05336 \mathrm{e}+001.00000 \mathrm{e}-092.12000 \mathrm{e}-01$ $1.05336 \mathrm{e}+011.05336 \mathrm{e}+011.05336 \mathrm{e}+001.00000 \mathrm{e}-092.12000 \mathrm{e}-01$ $1.05336 \mathrm{e}+01$ 1.05336e+01 1.05336e+00 1.00000e-09 2.12000e-01 $1.05336 \mathrm{e}+011.05336 \mathrm{e}+011.05336 \mathrm{e}+001.00000 \mathrm{e}-092.12000 \mathrm{e}-01$ $1.05336 \mathrm{e}+011.05336 \mathrm{e}+01 \quad 1.05336 \mathrm{e}+001.00000 \mathrm{e}-092.12000 \mathrm{e}-01$ $1.00000 \mathrm{e}-02$ 1.00000e-02 1.00000e-03 1.00000e-09 1.00000e-01 $1.00000 \mathrm{e}+001.00000 \mathrm{e}+001.00000 \mathrm{e}-011.00000 \mathrm{e}-091.00000 \mathrm{e}-01$ $1.00000 \mathrm{e}-05$ 1.00000e-05 1.00000e-06 1.00000e-09 1.00000e-01 $1.00000 \mathrm{e}+001.00000 \mathrm{e}+001.00000 \mathrm{e}-011.00000 \mathrm{e}-09$ 1.00000e-01 Element: 2474 \# of layers: 16 
$\mathrm{Kx} \mathrm{Ky} \mathrm{Kz}$ Ss Por

$2.63624 \mathrm{e}+02$ 2.63624e+02 2.63624e+01 1.00000e-09 7.00000e-02

$2.63624 \mathrm{e}+022.63624 \mathrm{e}+022.63624 \mathrm{e}+01$ 1.00000e-09 7.00000e-02

$2.63624 \mathrm{e}+022.63624 \mathrm{e}+022.63624 \mathrm{e}+01 \quad 1.00000 \mathrm{e}-09$ 7.00000e-02

$2.63624 \mathrm{e}+022.63624 \mathrm{e}+022.63624 \mathrm{e}+01$ 1.00000e-09 7.00000e-02

$2.63624 \mathrm{e}+022.63624 \mathrm{e}+022.63624 \mathrm{e}+01$ 1.00000e-09 7.00000e-02

5.00000e-04 5.00000e-04 5.00000e-05 1.00000e-09 1.00000e-01

5.00000e-04 5.00000e-04 5.00000e-05 1.00000e-09 1.00000e-01

$1.05336 \mathrm{e}+011.05336 \mathrm{e}+011.05336 \mathrm{e}+001.00000 \mathrm{e}-092.12000 \mathrm{e}-01$

$1.05336 \mathrm{e}+011.05336 \mathrm{e}+011.05336 \mathrm{e}+001.00000 \mathrm{e}-092.12000 \mathrm{e}-01$

$1.05336 \mathrm{e}+011.05336 \mathrm{e}+011.05336 \mathrm{e}+001.00000 \mathrm{e}-092.12000 \mathrm{e}-01$

$1.05336 \mathrm{e}+011.05336 \mathrm{e}+011.05336 \mathrm{e}+001.00000 \mathrm{e}-092.12000 \mathrm{e}-01$

$1.05336 \mathrm{e}+011.05336 \mathrm{e}+011.05336 \mathrm{e}+001.00000 \mathrm{e}-092.12000 \mathrm{e}-01$

$1.00000 \mathrm{e}-02$ 1.00000e-02 1.00000e-03 1.00000e-09 1.00000e-01

$1.00000 \mathrm{e}+001.00000 \mathrm{e}+001.00000 \mathrm{e}-011.00000 \mathrm{e}-091.00000 \mathrm{e}-01$

$1.00000 \mathrm{e}-05$ 1.00000e-05 1.00000e-06 1.00000e-09 1.00000e-01

$1.00000 \mathrm{e}+001.00000 \mathrm{e}+001.00000 \mathrm{e}-01$ 1.00000e-09 1.00000e-01

Element: 2475 \# of layers: 16

$\mathrm{Kx} \mathrm{Ky} \mathrm{Kz}$ Ss Por

2.52433e+02 2.52433e+02 2.52433e+01 1.00000e-09 7.00000e-02

$2.52433 \mathrm{e}+02$ 2.52433e+02 2.52433e+01 1.00000e-09 7.00000e-02

$2.52433 \mathrm{e}+02$ 2.52433e+02 2.52433e+01 1.00000e-09 7.00000e-02

$2.52433 \mathrm{e}+02$ 2.52433e+02 2.52433e+01 1.00000e-09 7.00000e-02

$2.52433 \mathrm{e}+02$ 2.52433e+02 2.52433e+01 1.00000e-09 7.00000e-02

5.00000e-04 5.00000e-04 5.00000e-05 1.00000e-09 1.00000e-01

5.00000e-04 5.00000e-04 5.00000e-05 1.00000e-09 1.00000e-01

$1.00865 \mathrm{e}+011.00865 \mathrm{e}+011.00865 \mathrm{e}+001.00000 \mathrm{e}-092.12000 \mathrm{e}-01$

$1.00865 \mathrm{e}+011.00865 \mathrm{e}+011.00865 \mathrm{e}+001.00000 \mathrm{e}-092.12000 \mathrm{e}-01$

$1.00865 \mathrm{e}+011.00865 \mathrm{e}+011.00865 \mathrm{e}+001.00000 \mathrm{e}-092.12000 \mathrm{e}-01$

$1.00865 \mathrm{e}+011.00865 \mathrm{e}+011.00865 \mathrm{e}+001.00000 \mathrm{e}-092.12000 \mathrm{e}-01$

$1.00865 \mathrm{e}+011.00865 \mathrm{e}+011.00865 \mathrm{e}+001.00000 \mathrm{e}-092.12000 \mathrm{e}-01$

$1.00000 \mathrm{e}-02$ 1.00000e-02 1.00000e-03 1.00000e-09 1.00000e-01

$1.00000 \mathrm{e}+001.00000 \mathrm{e}+001.00000 \mathrm{e}-011.00000 \mathrm{e}-091.00000 \mathrm{e}-01$

$1.00000 \mathrm{e}-05$ 1.00000e-05 1.00000e-06 1.00000e-09 1.00000e-01

$1.00000 \mathrm{e}+001.00000 \mathrm{e}+001.00000 \mathrm{e}-011.00000 \mathrm{e}-091.00000 \mathrm{e}-01$

Element: 2476 \# of layers: 15

$\mathrm{Kx} \mathrm{Ky} \mathrm{Kz}$ Ss Por

2.92032e+02 2.92032e+02 2.92032e+01 1.00000e-09 7.00000e-02

$2.92032 \mathrm{e}+02$ 2.92032e+02 2.92032e+01 1.00000e-09 7.00000e-02

$2.92032 \mathrm{e}+02$ 2.92032e+02 2.92032e+01 1.00000e-09 7.00000e-02

$2.92032 \mathrm{e}+02$ 2.92032e+02 2.92032e+01 1.00000e-09 7.00000e-02

5.00000e-04 5.00000e-04 5.00000e-05 1.00000e-09 1.00000e-01

5.00000e-04 5.00000e-04 5.00000e-05 1.00000e-09 1.00000e-01

1.16687e+01 1.16687e+01 1.16687e+00 1.00000e-09 2.12000e-01

$1.16687 \mathrm{e}+01$ 1.16687e+01 1.16687e+00 1.00000e-09 2.12000e-01

$1.16687 \mathrm{e}+01$ 1.16687e+01 1.16687e+00 1.00000e-09 2.12000e-01 
$1.16687 \mathrm{e}+01$ 1.16687e+01 1.16687e+00 1.00000e-09 2.12000e-01 $1.16687 \mathrm{e}+01$ 1.16687e+01 1.16687e+00 1.00000e-09 2.12000e-01 $1.00000 \mathrm{e}-02$ 1.00000e-02 1.00000e-03 1.00000e-09 1.00000e-01 $1.00000 \mathrm{e}+001.00000 \mathrm{e}+001.00000 \mathrm{e}-011.00000 \mathrm{e}-091.00000 \mathrm{e}-01$ $1.00000 \mathrm{e}-05$ 1.00000e-05 1.00000e-06 1.00000e-09 1.00000e-01 $1.00000 \mathrm{e}+001.00000 \mathrm{e}+001.00000 \mathrm{e}-011.00000 \mathrm{e}-091.00000 \mathrm{e}-01$ Element: 2477 \# of layers: 16

$\mathrm{Kx} \mathrm{Ky} \mathrm{Kz}$ Ss Por

2.69832e+02 2.69832e+02 2.69832e+01 1.00000e-09 7.00000e-02

$2.69832 \mathrm{e}+02$ 2.69832e+02 2.69832e+01 1.00000e-09 7.00000e-02

$2.69832 \mathrm{e}+02$ 2.69832e+02 2.69832e+01 1.00000e-09 7.00000e-02

$2.69832 \mathrm{e}+02$ 2.69832e+02 2.69832e+01 1.00000e-09 7.00000e-02

$2.69832 \mathrm{e}+02$ 2.69832e+02 2.69832e+01 1.00000e-09 7.00000e-02

5.00000e-04 5.00000e-04 5.00000e-05 1.00000e-09 1.00000e-01

5.00000e-04 5.00000e-04 5.00000e-05 1.00000e-09 1.00000e-01

$1.07816 \mathrm{e}+011.07816 \mathrm{e}+011.07816 \mathrm{e}+001.00000 \mathrm{e}-092.12000 \mathrm{e}-01$

$1.07816 \mathrm{e}+011.07816 \mathrm{e}+011.07816 \mathrm{e}+001.00000 \mathrm{e}-092.12000 \mathrm{e}-01$

$1.07816 \mathrm{e}+011.07816 \mathrm{e}+011.07816 \mathrm{e}+001.00000 \mathrm{e}-092.12000 \mathrm{e}-01$

$1.07816 \mathrm{e}+011.07816 \mathrm{e}+011.07816 \mathrm{e}+001.00000 \mathrm{e}-092.12000 \mathrm{e}-01$

$1.07816 \mathrm{e}+011.07816 \mathrm{e}+01 \quad 1.07816 \mathrm{e}+001.00000 \mathrm{e}-092.12000 \mathrm{e}-01$

$1.00000 \mathrm{e}-02$ 1.00000e-02 1.00000e-03 1.00000e-09 1.00000e-01

$1.00000 \mathrm{e}+001.00000 \mathrm{e}+001.00000 \mathrm{e}-011.00000 \mathrm{e}-091.00000 \mathrm{e}-01$

$1.00000 \mathrm{e}-05$ 1.00000e-05 1.00000e-06 1.00000e-09 1.00000e-01

$1.00000 \mathrm{e}+001.00000 \mathrm{e}+001.00000 \mathrm{e}-011.00000 \mathrm{e}-091.00000 \mathrm{e}-01$

Element: 2478 \# of layers: 16

$\mathrm{Kx} \mathrm{Ky} \mathrm{Kz}$ Ss Por

2.52433e+02 2.52433e+02 2.52433e+01 1.00000e-09 7.00000e-02

$2.52433 \mathrm{e}+02$ 2.52433e+02 2.52433e+01 1.00000e-09 7.00000e-02

$2.52433 \mathrm{e}+022.52433 \mathrm{e}+02$ 2.52433e+01 1.00000e-09 7.00000e-02

$2.52433 \mathrm{e}+02$ 2.52433e+02 2.52433e+01 1.00000e-09 7.00000e-02

$2.52433 \mathrm{e}+022.52433 \mathrm{e}+022.52433 \mathrm{e}+01$ 1.00000e-09 7.00000e-02

5.00000e-04 5.00000e-04 5.00000e-05 1.00000e-09 1.00000e-01

5.00000e-04 5.00000e-04 5.00000e-05 1.00000e-09 1.00000e-01

$1.00865 \mathrm{e}+011.00865 \mathrm{e}+011.00865 \mathrm{e}+001.00000 \mathrm{e}-092.12000 \mathrm{e}-01$

$1.00865 \mathrm{e}+011.00865 \mathrm{e}+011.00865 \mathrm{e}+001.00000 \mathrm{e}-092.12000 \mathrm{e}-01$

$1.00865 \mathrm{e}+011.00865 \mathrm{e}+011.00865 \mathrm{e}+001.00000 \mathrm{e}-092.12000 \mathrm{e}-01$

$1.00865 \mathrm{e}+011.00865 \mathrm{e}+011.00865 \mathrm{e}+001.00000 \mathrm{e}-092.12000 \mathrm{e}-01$

$1.00865 \mathrm{e}+011.00865 \mathrm{e}+011.00865 \mathrm{e}+001.00000 \mathrm{e}-092.12000 \mathrm{e}-01$

$1.00000 \mathrm{e}-02$ 1.00000e-02 1.00000e-03 1.00000e-09 1.00000e-01

$1.00000 \mathrm{e}+001.00000 \mathrm{e}+001.00000 \mathrm{e}-011.00000 \mathrm{e}-091.00000 \mathrm{e}-01$

$1.00000 \mathrm{e}-05$ 1.00000e-05 1.00000e-06 1.00000e-09 1.00000e-01

$1.00000 \mathrm{e}+001.00000 \mathrm{e}+001.00000 \mathrm{e}-011.00000 \mathrm{e}-091.00000 \mathrm{e}-01$

Element: 2479 \# of layers: 16

$\mathrm{Kx} \mathrm{Ky} \mathrm{Kz}$ Ss Por

$2.64651 \mathrm{e}+02$ 2.64651e+02 2.64651e+01 1.00000e-09 7.00000e-02

$2.64651 \mathrm{e}+022.64651 \mathrm{e}+022.64651 \mathrm{e}+01$ 1.00000e-09 7.00000e-02 
2.64651e+02 2.64651e+02 2.64651e+01 1.00000e-09 7.00000e-02 $2.64651 \mathrm{e}+02$ 2.64651e+02 2.64651e+01 1.00000e-09 7.00000e-02 $2.64651 \mathrm{e}+022.64651 \mathrm{e}+022.64651 \mathrm{e}+01$ 1.00000e-09 7.00000e-02 5.00000e-04 5.00000e-04 5.00000e-05 1.00000e-09 1.00000e-01 5.00000e-04 5.00000e-04 5.00000e-05 1.00000e-09 1.00000e-01 $1.05743 \mathrm{e}+01$ 1.05743e+01 1.05743e+00 1.00000e-09 2.12000e-01 $1.05743 \mathrm{e}+01$ 1.05743e+01 1.05743e+00 1.00000e-09 2.12000e-01 $1.05743 \mathrm{e}+011.05743 \mathrm{e}+011.05743 \mathrm{e}+001.00000 \mathrm{e}-092.12000 \mathrm{e}-01$ $1.05743 \mathrm{e}+01$ 1.05743e+01 1.05743e+00 1.00000e-09 2.12000e-01 $1.05743 \mathrm{e}+01$ 1.05743e+01 1.05743e+00 1.00000e-09 2.12000e-01 $1.00000 \mathrm{e}-02$ 1.00000e-02 1.00000e-03 1.00000e-09 1.00000e-01 $1.00000 \mathrm{e}+001.00000 \mathrm{e}+001.00000 \mathrm{e}-011.00000 \mathrm{e}-091.00000 \mathrm{e}-01$ $1.00000 \mathrm{e}-05$ 1.00000e-05 1.00000e-06 1.00000e-09 1.00000e-01 $1.00000 \mathrm{e}+001.00000 \mathrm{e}+001.00000 \mathrm{e}-011.00000 \mathrm{e}-09$ 1.00000e-01 Element: 2480 \# of layers: 16

$\mathrm{Kx} \mathrm{Ky} \mathrm{Kz}$ Ss Por

$2.64651 \mathrm{e}+02$ 2.64651e+02 2.64651e+01 1.00000e-09 7.00000e-02 $2.64651 \mathrm{e}+022.64651 \mathrm{e}+02$ 2.64651e+01 1.00000e-09 7.00000e-02 $2.64651 \mathrm{e}+02$ 2.64651e+02 2.64651e+01 1.00000e-09 7.00000e-02 $2.64651 \mathrm{e}+022.64651 \mathrm{e}+022.64651 \mathrm{e}+01$ 1.00000e-09 7.00000e-02 $2.64651 \mathrm{e}+022.64651 \mathrm{e}+022.64651 \mathrm{e}+01$ 1.00000e-09 7.00000e-02 $5.00000 \mathrm{e}-04$ 5.00000e-04 5.00000e-05 1.00000e-09 1.00000e-01 5.00000e-04 5.00000e-04 5.00000e-05 1.00000e-09 1.00000e-01 $1.05743 \mathrm{e}+011.05743 \mathrm{e}+011.05743 \mathrm{e}+001.00000 \mathrm{e}-092.12000 \mathrm{e}-01$ $1.05743 \mathrm{e}+011.05743 \mathrm{e}+011.05743 \mathrm{e}+001.00000 \mathrm{e}-092.12000 \mathrm{e}-01$ $1.05743 \mathrm{e}+011.05743 \mathrm{e}+01$ 1.05743e+00 1.00000e-09 2.12000e-01 $1.05743 \mathrm{e}+011.05743 \mathrm{e}+01$ 1.05743e+00 1.00000e-09 2.12000e-01 $1.05743 \mathrm{e}+011.05743 \mathrm{e}+01$ 1.05743e+00 1.00000e-09 2.12000e-01 $1.00000 \mathrm{e}-02$ 1.00000e-02 1.00000e-03 1.00000e-09 1.00000e-01 $1.00000 \mathrm{e}+001.00000 \mathrm{e}+001.00000 \mathrm{e}-011.00000 \mathrm{e}-091.00000 \mathrm{e}-01$ $1.00000 \mathrm{e}-05$ 1.00000e-05 1.00000e-06 1.00000e-09 1.00000e-01 $1.00000 \mathrm{e}+001.00000 \mathrm{e}+001.00000 \mathrm{e}-011.00000 \mathrm{e}-091.00000 \mathrm{e}-01$ Element: 2481 \# of layers: 16

$\mathrm{Kx} \mathrm{Ky} \mathrm{Kz}$ Ss Por

$2.64651 \mathrm{e}+02$ 2.64651e+02 2.64651e+01 1.00000e-09 7.00000e-02 $2.64651 \mathrm{e}+022.64651 \mathrm{e}+022.64651 \mathrm{e}+01$ 1.00000e-09 7.00000e-02 $2.64651 \mathrm{e}+022.64651 \mathrm{e}+022.64651 \mathrm{e}+01$ 1.00000e-09 7.00000e-02 $2.64651 \mathrm{e}+022.64651 \mathrm{e}+022.64651 \mathrm{e}+01$ 1.00000e-09 7.00000e-02 $2.64651 \mathrm{e}+022.64651 \mathrm{e}+02$ 2.64651e+01 1.00000e-09 7.00000e-02 5.00000e-04 5.00000e-04 5.00000e-05 1.00000e-09 1.00000e-01 5.00000e-04 5.00000e-04 5.00000e-05 1.00000e-09 1.00000e-01 $1.05743 \mathrm{e}+011.05743 \mathrm{e}+011.05743 \mathrm{e}+001.00000 \mathrm{e}-092.12000 \mathrm{e}-01$ $1.05743 \mathrm{e}+011.05743 \mathrm{e}+01$ 1.05743e+00 1.00000e-09 2.12000e-01 $1.05743 \mathrm{e}+01$ 1.05743e+01 1.05743e+00 1.00000e-09 2.12000e-01 $1.05743 \mathrm{e}+011.05743 \mathrm{e}+01$ 1.05743e+00 1.00000e-09 2.12000e-01 $1.05743 \mathrm{e}+011.05743 \mathrm{e}+011.05743 \mathrm{e}+001.00000 \mathrm{e}-092.12000 \mathrm{e}-01$ 
$1.00000 \mathrm{e}-02$ 1.00000e-02 1.00000e-03 1.00000e-09 1.00000e-01 $1.00000 \mathrm{e}+001.00000 \mathrm{e}+001.00000 \mathrm{e}-011.00000 \mathrm{e}-091.00000 \mathrm{e}-01$ $1.00000 \mathrm{e}-051.00000 \mathrm{e}-05$ 1.00000e-06 1.00000e-09 1.00000e-01 $1.00000 \mathrm{e}+001.00000 \mathrm{e}+001.00000 \mathrm{e}-011.00000 \mathrm{e}-091.00000 \mathrm{e}-01$ Element: 2482 \# of layers: 16

Kx Ky Kz Ss Por

$2.64651 \mathrm{e}+022.64651 \mathrm{e}+022.64651 \mathrm{e}+01$ 1.00000e-09 7.00000e-02 $2.64651 \mathrm{e}+022.64651 \mathrm{e}+022.64651 \mathrm{e}+011.00000 \mathrm{e}-097.00000 \mathrm{e}-02$ $2.64651 \mathrm{e}+022.64651 \mathrm{e}+022.64651 \mathrm{e}+011.00000 \mathrm{e}-097.00000 \mathrm{e}-02$ $2.64651 \mathrm{e}+022.64651 \mathrm{e}+022.64651 \mathrm{e}+011.00000 \mathrm{e}-097.00000 \mathrm{e}-02$ $2.64651 \mathrm{e}+022.64651 \mathrm{e}+022.64651 \mathrm{e}+011.00000 \mathrm{e}-097.00000 \mathrm{e}-02$ 5.00000e-04 5.00000e-04 5.00000e-05 1.00000e-09 1.00000e-01 5.00000e-04 5.00000e-04 5.00000e-05 1.00000e-09 1.00000e-01 $1.05743 \mathrm{e}+011.05743 \mathrm{e}+011.05743 \mathrm{e}+001.00000 \mathrm{e}-092.12000 \mathrm{e}-01$ $1.05743 \mathrm{e}+011.05743 \mathrm{e}+011.05743 \mathrm{e}+001.00000 \mathrm{e}-092.12000 \mathrm{e}-01$ $1.05743 \mathrm{e}+011.05743 \mathrm{e}+011.05743 \mathrm{e}+001.00000 \mathrm{e}-092.12000 \mathrm{e}-01$ $1.05743 \mathrm{e}+011.05743 \mathrm{e}+011.05743 \mathrm{e}+001.00000 \mathrm{e}-092.12000 \mathrm{e}-01$ $1.05743 \mathrm{e}+011.05743 \mathrm{e}+011.05743 \mathrm{e}+001.00000 \mathrm{e}-092.12000 \mathrm{e}-01$ $1.00000 \mathrm{e}-02$ 1.00000e-02 1.00000e-03 1.00000e-09 1.00000e-01 $1.00000 \mathrm{e}+001.00000 \mathrm{e}+001.00000 \mathrm{e}-011.00000 \mathrm{e}-091.00000 \mathrm{e}-01$ $1.00000 \mathrm{e}-05$ 1.00000e-05 1.00000e-06 1.00000e-09 1.00000e-01 $1.00000 \mathrm{e}+001.00000 \mathrm{e}+001.00000 \mathrm{e}-011.00000 \mathrm{e}-091.00000 \mathrm{e}-01$ Element: 2483 \# of layers: 16

Kx Ky Kz Ss Por

$2.64651 \mathrm{e}+022.64651 \mathrm{e}+022.64651 \mathrm{e}+01$ 1.00000e-09 7.00000e-02 $2.64651 \mathrm{e}+022.64651 \mathrm{e}+022.64651 \mathrm{e}+01$ 1.00000e-09 7.00000e-02 $2.64651 \mathrm{e}+022.64651 \mathrm{e}+022.64651 \mathrm{e}+011.00000 \mathrm{e}-097.00000 \mathrm{e}-02$ $2.64651 \mathrm{e}+022.64651 \mathrm{e}+022.64651 \mathrm{e}+011.00000 \mathrm{e}-097.00000 \mathrm{e}-02$ $2.64651 \mathrm{e}+022.64651 \mathrm{e}+022.64651 \mathrm{e}+011.00000 \mathrm{e}-097.00000 \mathrm{e}-02$ 5.00000e-04 5.00000e-04 5.00000e-05 1.00000e-09 1.00000e-01 5.00000e-04 5.00000e-04 5.00000e-05 1.00000e-09 1.00000e-01 $1.05743 \mathrm{e}+011.05743 \mathrm{e}+011.05743 \mathrm{e}+001.00000 \mathrm{e}-092.12000 \mathrm{e}-01$ $1.05743 \mathrm{e}+011.05743 \mathrm{e}+011.05743 \mathrm{e}+001.00000 \mathrm{e}-092.12000 \mathrm{e}-01$ $1.05743 \mathrm{e}+011.05743 \mathrm{e}+011.05743 \mathrm{e}+001.00000 \mathrm{e}-092.12000 \mathrm{e}-01$ $1.05743 \mathrm{e}+011.05743 \mathrm{e}+011.05743 \mathrm{e}+001.00000 \mathrm{e}-092.12000 \mathrm{e}-01$ $1.05743 \mathrm{e}+011.05743 \mathrm{e}+011.05743 \mathrm{e}+00$ 1.00000e-09 2.12000e-01 $1.00000 \mathrm{e}-021.00000 \mathrm{e}-02$ 1.00000e-03 1.00000e-09 1.00000e-01 $1.00000 \mathrm{e}+001.00000 \mathrm{e}+001.00000 \mathrm{e}-011.00000 \mathrm{e}-091.00000 \mathrm{e}-01$ $1.00000 \mathrm{e}-05$ 1.00000e-05 1.00000e-06 1.00000e-09 1.00000e-01 $1.00000 \mathrm{e}+001.00000 \mathrm{e}+001.00000 \mathrm{e}-011.00000 \mathrm{e}-091.00000 \mathrm{e}-01$ Element: 2484 \# of layers: 16

Kx Ky Kz Ss Por $2.64651 \mathrm{e}+022.64651 \mathrm{e}+022.64651 \mathrm{e}+01$ 1.00000e-09 7.00000e-02 $2.64651 \mathrm{e}+022.64651 \mathrm{e}+022.64651 \mathrm{e}+011.00000 \mathrm{e}-097.00000 \mathrm{e}-02$ $2.64651 \mathrm{e}+022.64651 \mathrm{e}+022.64651 \mathrm{e}+011.00000 \mathrm{e}-097.00000 \mathrm{e}-02$ $2.64651 \mathrm{e}+022.64651 \mathrm{e}+022.64651 \mathrm{e}+01$ 1.00000e-09 7.00000e-02 
$2.64651 \mathrm{e}+02$ 2.64651e+02 2.64651e+01 1.00000e-09 7.00000e-02 5.00000e-04 5.00000e-04 5.00000e-05 1.00000e-09 1.00000e-01 5.00000e-04 5.00000e-04 5.00000e-05 1.00000e-09 1.00000e-01 $1.05743 \mathrm{e}+011.05743 \mathrm{e}+011.05743 \mathrm{e}+001.00000 \mathrm{e}-092.12000 \mathrm{e}-01$ $1.05743 \mathrm{e}+011.05743 \mathrm{e}+011.05743 \mathrm{e}+001.00000 \mathrm{e}-092.12000 \mathrm{e}-01$ $1.05743 \mathrm{e}+01$ 1.05743e+01 1.05743e+00 1.00000e-09 2.12000e-01 $1.05743 \mathrm{e}+011.05743 \mathrm{e}+011.05743 \mathrm{e}+001.00000 \mathrm{e}-092.12000 \mathrm{e}-01$ $1.05743 \mathrm{e}+011.05743 \mathrm{e}+011.05743 \mathrm{e}+001.00000 \mathrm{e}-092.12000 \mathrm{e}-01$ $1.00000 \mathrm{e}-021.00000 \mathrm{e}-021.00000 \mathrm{e}-031.00000 \mathrm{e}-091.00000 \mathrm{e}-01$ $1.00000 \mathrm{e}+001.00000 \mathrm{e}+001.00000 \mathrm{e}-011.00000 \mathrm{e}-091.00000 \mathrm{e}-01$ $1.00000 \mathrm{e}-05$ 1.00000e-05 1.00000e-06 1.00000e-09 1.00000e-01 $1.00000 \mathrm{e}+001.00000 \mathrm{e}+001.00000 \mathrm{e}-011.00000 \mathrm{e}-091.00000 \mathrm{e}-01$ Element: 2485 \# of layers: 16

$\mathrm{Kx} \mathrm{Ky} \mathrm{Kz}$ Ss Por

$2.64651 \mathrm{e}+02$ 2.64651e+02 2.64651e+01 1.00000e-09 7.00000e-02 $2.64651 \mathrm{e}+022.64651 \mathrm{e}+022.64651 \mathrm{e}+01$ 1.00000e-09 7.00000e-02 $2.64651 \mathrm{e}+02$ 2.64651e+02 2.64651e+01 1.00000e-09 7.00000e-02 $2.64651 \mathrm{e}+022.64651 \mathrm{e}+02$ 2.64651e+01 1.00000e-09 7.00000e-02 $2.64651 \mathrm{e}+02$ 2.64651e+02 2.64651e+01 1.00000e-09 7.00000e-02 5.00000e-04 5.00000e-04 5.00000e-05 1.00000e-09 1.00000e-01 5.00000e-04 5.00000e-04 5.00000e-05 1.00000e-09 1.00000e-01 $1.05743 \mathrm{e}+01$ 1.05743e+01 1.05743e+00 1.00000e-09 2.12000e-01 $1.05743 \mathrm{e}+01$ 1.05743e+01 1.05743e+00 1.00000e-09 2.12000e-01 $1.05743 \mathrm{e}+011.05743 \mathrm{e}+011.05743 \mathrm{e}+001.00000 \mathrm{e}-092.12000 \mathrm{e}-01$ $1.05743 \mathrm{e}+011.05743 \mathrm{e}+011.05743 \mathrm{e}+001.00000 \mathrm{e}-092.12000 \mathrm{e}-01$ $1.05743 \mathrm{e}+01$ 1.05743e+01 1.05743e+00 1.00000e-09 2.12000e-01 $1.00000 \mathrm{e}-02$ 1.00000e-02 1.00000e-03 1.00000e-09 1.00000e-01 $1.00000 \mathrm{e}+001.00000 \mathrm{e}+001.00000 \mathrm{e}-011.00000 \mathrm{e}-091.00000 \mathrm{e}-01$ $1.00000 \mathrm{e}-05$ 1.00000e-05 1.00000e-06 1.00000e-09 1.00000e-01 $1.00000 \mathrm{e}+001.00000 \mathrm{e}+001.00000 \mathrm{e}-011.00000 \mathrm{e}-091.00000 \mathrm{e}-01$ Element: 2486 \# of layers: 16

$\mathrm{Kx} \mathrm{Ky} \mathrm{Kz}$ Ss Por

$2.64651 \mathrm{e}+02$ 2.64651e+02 2.64651e+01 1.00000e-09 7.00000e-02 $2.64651 \mathrm{e}+022.64651 \mathrm{e}+022.64651 \mathrm{e}+01$ 1.00000e-09 7.00000e-02 $2.64651 \mathrm{e}+022.64651 \mathrm{e}+02$ 2.64651e+01 1.00000e-09 7.00000e-02 $2.64651 \mathrm{e}+022.64651 \mathrm{e}+022.64651 \mathrm{e}+01$ 1.00000e-09 7.00000e-02 $2.64651 \mathrm{e}+022.64651 \mathrm{e}+022.64651 \mathrm{e}+01$ 1.00000e-09 7.00000e-02 5.00000e-04 5.00000e-04 5.00000e-05 1.00000e-09 1.00000e-01 5.00000e-04 5.00000e-04 5.00000e-05 1.00000e-09 1.00000e-01 $1.05743 \mathrm{e}+01$ 1.05743e+01 1.05743e+00 1.00000e-09 2.12000e-01 $1.05743 \mathrm{e}+011.05743 \mathrm{e}+01$ 1.05743e+00 1.00000e-09 2.12000e-01 $1.05743 \mathrm{e}+011.05743 \mathrm{e}+01$ 1.05743e+00 1.00000e-09 2.12000e-01 $1.05743 \mathrm{e}+01$ 1.05743e+01 1.05743e+00 1.00000e-09 2.12000e-01 $1.05743 \mathrm{e}+01$ 1.05743e+01 1.05743e+00 1.00000e-09 2.12000e-01 $1.00000 \mathrm{e}-02$ 1.00000e-02 1.00000e-03 1.00000e-09 1.00000e-01 $1.00000 \mathrm{e}+001.00000 \mathrm{e}+001.00000 \mathrm{e}-011.00000 \mathrm{e}-091.00000 \mathrm{e}-01$ 
$1.00000 \mathrm{e}-05$ 1.00000e-05 1.00000e-06 1.00000e-09 1.00000e-01 $1.00000 \mathrm{e}+001.00000 \mathrm{e}+001.00000 \mathrm{e}-01$ 1.00000e-09 1.00000e-01 Element: 2487 \# of layers: 16

$\mathrm{Kx} \mathrm{Ky} \mathrm{Kz}$ Ss Por

$2.64651 \mathrm{e}+02$ 2.64651e+02 2.64651e+01 1.00000e-09 7.00000e-02

$2.64651 \mathrm{e}+022.64651 \mathrm{e}+02$ 2.64651e+01 1.00000e-09 7.00000e-02

$2.64651 \mathrm{e}+022.64651 \mathrm{e}+02$ 2.64651e+01 1.00000e-09 7.00000e-02

$2.64651 \mathrm{e}+022.64651 \mathrm{e}+022.64651 \mathrm{e}+01$ 1.00000e-09 7.00000e-02

$2.64651 \mathrm{e}+022.64651 \mathrm{e}+022.64651 \mathrm{e}+01$ 1.00000e-09 7.00000e-02

5.00000e-04 5.00000e-04 5.00000e-05 1.00000e-09 1.00000e-01

5.00000e-04 5.00000e-04 5.00000e-05 1.00000e-09 1.00000e-01

$1.05743 \mathrm{e}+011.05743 \mathrm{e}+011.05743 \mathrm{e}+001.00000 \mathrm{e}-092.12000 \mathrm{e}-01$

$1.05743 \mathrm{e}+011.05743 \mathrm{e}+011.05743 \mathrm{e}+001.00000 \mathrm{e}-092.12000 \mathrm{e}-01$

$1.05743 \mathrm{e}+011.05743 \mathrm{e}+01$ 1.05743e+00 1.00000e-09 2.12000e-01

$1.05743 \mathrm{e}+01$ 1.05743e+01 1.05743e+00 1.00000e-09 2.12000e-01

$1.05743 \mathrm{e}+01$ 1.05743e+01 1.05743e+00 1.00000e-09 2.12000e-01

$1.00000 \mathrm{e}-02$ 1.00000e-02 1.00000e-03 1.00000e-09 1.00000e-01

$1.00000 \mathrm{e}+001.00000 \mathrm{e}+001.00000 \mathrm{e}-011.00000 \mathrm{e}-091.00000 \mathrm{e}-01$

$1.00000 \mathrm{e}-051.00000 \mathrm{e}-051.00000 \mathrm{e}-061.00000 \mathrm{e}-091.00000 \mathrm{e}-01$

$1.00000 \mathrm{e}+001.00000 \mathrm{e}+001.00000 \mathrm{e}-011.00000 \mathrm{e}-091.00000 \mathrm{e}-01$

Element: 2488 \# of layers: 15

$\mathrm{Kx} \mathrm{Ky} \mathrm{Kz}$ Ss Por

$2.57920 \mathrm{e}+02$ 2.57920e+02 2.57920e+01 1.00000e-09 7.00000e-02

$2.57920 \mathrm{e}+022.57920 \mathrm{e}+02 \quad 2.57920 \mathrm{e}+01$ 1.00000e-09 7.00000e-02

$2.57920 \mathrm{e}+022.57920 \mathrm{e}+02 \quad 2.57920 \mathrm{e}+01$ 1.00000e-09 7.00000e-02

$2.57920 \mathrm{e}+022.57920 \mathrm{e}+02$ 2.57920e+01 1.00000e-09 7.00000e-02

5.00000e-04 5.00000e-04 5.00000e-05 1.00000e-09 1.00000e-01

5.00000e-04 5.00000e-04 5.00000e-05 1.00000e-09 1.00000e-01

$1.03054 \mathrm{e}+011.03054 \mathrm{e}+011.03054 \mathrm{e}+001.00000 \mathrm{e}-092.12000 \mathrm{e}-01$

$1.03054 \mathrm{e}+011.03054 \mathrm{e}+011.03054 \mathrm{e}+001.00000 \mathrm{e}-092.12000 \mathrm{e}-01$

$1.03054 \mathrm{e}+011.03054 \mathrm{e}+011.03054 \mathrm{e}+001.00000 \mathrm{e}-092.12000 \mathrm{e}-01$

$1.03054 \mathrm{e}+011.03054 \mathrm{e}+011.03054 \mathrm{e}+001.00000 \mathrm{e}-092.12000 \mathrm{e}-01$

$1.03054 \mathrm{e}+011.03054 \mathrm{e}+011.03054 \mathrm{e}+001.00000 \mathrm{e}-092.12000 \mathrm{e}-01$

$1.00000 \mathrm{e}-02$ 1.00000e-02 1.00000e-03 1.00000e-09 1.00000e-01

$1.00000 \mathrm{e}+001.00000 \mathrm{e}+001.00000 \mathrm{e}-011.00000 \mathrm{e}-091.00000 \mathrm{e}-01$

$1.00000 \mathrm{e}-05$ 1.00000e-05 1.00000e-06 1.00000e-09 1.00000e-01

$1.00000 \mathrm{e}+001.00000 \mathrm{e}+001.00000 \mathrm{e}-011.00000 \mathrm{e}-091.00000 \mathrm{e}-01$

Element: 2489 \# of layers: 15

$\mathrm{Kx} \mathrm{Ky} \mathrm{Kz}$ Ss Por

$2.57920 \mathrm{e}+02$ 2.57920e+02 2.57920e+01 1.00000e-09 7.00000e-02

$2.57920 \mathrm{e}+022.57920 \mathrm{e}+02$ 2.57920e+01 1.00000e-09 7.00000e-02

$2.57920 \mathrm{e}+022.57920 \mathrm{e}+02 \quad 2.57920 \mathrm{e}+01$ 1.00000e-09 7.00000e-02

$2.57920 \mathrm{e}+02$ 2.57920e+02 2.57920e+01 1.00000e-09 7.00000e-02

5.00000e-04 5.00000e-04 5.00000e-05 1.00000e-09 1.00000e-01

5.00000e-04 5.00000e-04 5.00000e-05 1.00000e-09 1.00000e-01

$1.03054 \mathrm{e}+011.03054 \mathrm{e}+011.03054 \mathrm{e}+001.00000 \mathrm{e}-092.12000 \mathrm{e}-01$ 
$1.03054 \mathrm{e}+011.03054 \mathrm{e}+011.03054 \mathrm{e}+001.00000 \mathrm{e}-092.12000 \mathrm{e}-01$ $1.03054 \mathrm{e}+011.03054 \mathrm{e}+011.03054 \mathrm{e}+001.00000 \mathrm{e}-092.12000 \mathrm{e}-01$ $1.03054 \mathrm{e}+011.03054 \mathrm{e}+01 \quad 1.03054 \mathrm{e}+001.00000 \mathrm{e}-092.12000 \mathrm{e}-01$ $1.03054 \mathrm{e}+011.03054 \mathrm{e}+01 \quad 1.03054 \mathrm{e}+001.00000 \mathrm{e}-092.12000 \mathrm{e}-01$ $1.00000 \mathrm{e}-021.00000 \mathrm{e}-02$ 1.00000e-03 1.00000e-09 1.00000e-01 $1.00000 \mathrm{e}+001.00000 \mathrm{e}+001.00000 \mathrm{e}-011.00000 \mathrm{e}-091.00000 \mathrm{e}-01$ $1.00000 \mathrm{e}-05$ 1.00000e-05 1.00000e-06 1.00000e-09 1.00000e-01 $1.00000 \mathrm{e}+001.00000 \mathrm{e}+001.00000 \mathrm{e}-011.00000 \mathrm{e}-091.00000 \mathrm{e}-01$ Element: 2490 \# of layers: 15

$\mathrm{Kx} \mathrm{Ky} \mathrm{Kz}$ Ss Por

$2.57920 \mathrm{e}+02$ 2.57920e+02 2.57920e+01 1.00000e-09 7.00000e-02 $2.57920 \mathrm{e}+02$ 2.57920e+02 2.57920e+01 1.00000e-09 7.00000e-02 $2.57920 \mathrm{e}+022.57920 \mathrm{e}+02 \quad 2.57920 \mathrm{e}+01$ 1.00000e-09 7.00000e-02

$2.57920 \mathrm{e}+022.57920 \mathrm{e}+022.57920 \mathrm{e}+01$ 1.00000e-09 7.00000e-02 5.00000e-04 5.00000e-04 5.00000e-05 1.00000e-09 1.00000e-01 5.00000e-04 5.00000e-04 5.00000e-05 1.00000e-09 1.00000e-01 $1.03054 \mathrm{e}+011.03054 \mathrm{e}+011.03054 \mathrm{e}+001.00000 \mathrm{e}-092.12000 \mathrm{e}-01$ $1.03054 \mathrm{e}+011.03054 \mathrm{e}+011.03054 \mathrm{e}+001.00000 \mathrm{e}-092.12000 \mathrm{e}-01$ $1.03054 \mathrm{e}+011.03054 \mathrm{e}+011.03054 \mathrm{e}+001.00000 \mathrm{e}-092.12000 \mathrm{e}-01$ $1.03054 \mathrm{e}+011.03054 \mathrm{e}+011.03054 \mathrm{e}+001.00000 \mathrm{e}-092.12000 \mathrm{e}-01$ $1.03054 \mathrm{e}+011.03054 \mathrm{e}+011.03054 \mathrm{e}+001.00000 \mathrm{e}-092.12000 \mathrm{e}-01$ $1.00000 \mathrm{e}-02$ 1.00000e-02 1.00000e-03 1.00000e-09 1.00000e-01 $1.00000 \mathrm{e}+001.00000 \mathrm{e}+001.00000 \mathrm{e}-011.00000 \mathrm{e}-091.00000 \mathrm{e}-01$ $1.00000 \mathrm{e}-05$ 1.00000e-05 1.00000e-06 1.00000e-09 1.00000e-01 $1.00000 \mathrm{e}+001.00000 \mathrm{e}+001.00000 \mathrm{e}-011.00000 \mathrm{e}-091.00000 \mathrm{e}-01$ Element: 2491 \# of layers: 15

$\mathrm{Kx} \mathrm{Ky} \mathrm{Kz}$ Ss Por

$2.57920 \mathrm{e}+02$ 2.57920e+02 2.57920e+01 1.00000e-09 7.00000e-02 $2.57920 \mathrm{e}+022.57920 \mathrm{e}+022.57920 \mathrm{e}+01 \quad 1.00000 \mathrm{e}-097.00000 \mathrm{e}-02$ $2.57920 \mathrm{e}+02$ 2.57920e+02 2.57920e+01 1.00000e-09 7.00000e-02 $2.57920 \mathrm{e}+022.57920 \mathrm{e}+02 \quad 2.57920 \mathrm{e}+01$ 1.00000e-09 7.00000e-02 5.00000e-04 5.00000e-04 5.00000e-05 1.00000e-09 1.00000e-01 5.00000e-04 5.00000e-04 5.00000e-05 1.00000e-09 1.00000e-01 $1.03054 \mathrm{e}+011.03054 \mathrm{e}+011.03054 \mathrm{e}+001.00000 \mathrm{e}-092.12000 \mathrm{e}-01$ $1.03054 \mathrm{e}+011.03054 \mathrm{e}+01 \quad 1.03054 \mathrm{e}+001.00000 \mathrm{e}-092.12000 \mathrm{e}-01$ $1.03054 \mathrm{e}+011.03054 \mathrm{e}+011.03054 \mathrm{e}+001.00000 \mathrm{e}-092.12000 \mathrm{e}-01$ $1.03054 \mathrm{e}+011.03054 \mathrm{e}+011.03054 \mathrm{e}+001.00000 \mathrm{e}-092.12000 \mathrm{e}-01$ $1.03054 \mathrm{e}+011.03054 \mathrm{e}+011.03054 \mathrm{e}+001.00000 \mathrm{e}-092.12000 \mathrm{e}-01$ $1.00000 \mathrm{e}-02$ 1.00000e-02 1.00000e-03 1.00000e-09 1.00000e-01 $1.00000 \mathrm{e}+001.00000 \mathrm{e}+001.00000 \mathrm{e}-011.00000 \mathrm{e}-091.00000 \mathrm{e}-01$ $1.00000 \mathrm{e}-05$ 1.00000e-05 1.00000e-06 1.00000e-09 1.00000e-01 $1.00000 \mathrm{e}+001.00000 \mathrm{e}+001.00000 \mathrm{e}-011.00000 \mathrm{e}-091.00000 \mathrm{e}-01$ Element: 2492 \# of layers: 15

$\mathrm{Kx} \mathrm{Ky} \mathrm{Kz}$ Ss Por

$2.57920 \mathrm{e}+02$ 2.57920e+02 2.57920e+01 1.00000e-09 7.00000e-02 $2.57920 \mathrm{e}+02$ 2.57920e+02 2.57920e+01 1.00000e-09 7.00000e-02 
$2.57920 \mathrm{e}+022.57920 \mathrm{e}+02 \quad 2.57920 \mathrm{e}+01$ 1.00000e-09 7.00000e-02 $2.57920 \mathrm{e}+022.57920 \mathrm{e}+022.57920 \mathrm{e}+01$ 1.00000e-09 7.00000e-02 5.00000e-04 5.00000e-04 5.00000e-05 1.00000e-09 1.00000e-01 5.00000e-04 5.00000e-04 5.00000e-05 1.00000e-09 1.00000e-01 $1.03054 \mathrm{e}+011.03054 \mathrm{e}+011.03054 \mathrm{e}+001.00000 \mathrm{e}-092.12000 \mathrm{e}-01$ $1.03054 \mathrm{e}+011.03054 \mathrm{e}+011.03054 \mathrm{e}+001.00000 \mathrm{e}-092.12000 \mathrm{e}-01$ $1.03054 \mathrm{e}+011.03054 \mathrm{e}+011.03054 \mathrm{e}+001.00000 \mathrm{e}-092.12000 \mathrm{e}-01$ $1.03054 \mathrm{e}+011.03054 \mathrm{e}+011.03054 \mathrm{e}+001.00000 \mathrm{e}-092.12000 \mathrm{e}-01$ $1.03054 \mathrm{e}+011.03054 \mathrm{e}+011.03054 \mathrm{e}+001.00000 \mathrm{e}-092.12000 \mathrm{e}-01$ $1.00000 \mathrm{e}-02$ 1.00000e-02 1.00000e-03 1.00000e-09 1.00000e-01 $1.00000 \mathrm{e}+001.00000 \mathrm{e}+001.00000 \mathrm{e}-011.00000 \mathrm{e}-091.00000 \mathrm{e}-01$ $1.00000 \mathrm{e}-05$ 1.00000e-05 1.00000e-06 1.00000e-09 1.00000e-01 $1.00000 \mathrm{e}+001.00000 \mathrm{e}+001.00000 \mathrm{e}-011.00000 \mathrm{e}-091.00000 \mathrm{e}-01$ Element: 2493 \# of layers: 15

$\mathrm{Kx} \mathrm{Ky} \mathrm{Kz}$ Ss Por

$2.57920 \mathrm{e}+02$ 2.57920e+02 2.57920e+01 1.00000e-09 7.00000e-02 $2.57920 \mathrm{e}+02$ 2.57920e+02 2.57920e+01 1.00000e-09 7.00000e-02 $2.57920 \mathrm{e}+022.57920 \mathrm{e}+02$ 2.57920e+01 1.00000e-09 7.00000e-02 $2.57920 \mathrm{e}+022.57920 \mathrm{e}+02$ 2.57920e+01 1.00000e-09 7.00000e-02 5.00000e-04 5.00000e-04 5.00000e-05 1.00000e-09 1.00000e-01 5.00000e-04 5.00000e-04 5.00000e-05 1.00000e-09 1.00000e-01 $1.03054 \mathrm{e}+011.03054 \mathrm{e}+011.03054 \mathrm{e}+001.00000 \mathrm{e}-092.12000 \mathrm{e}-01$ $1.03054 \mathrm{e}+011.03054 \mathrm{e}+011.03054 \mathrm{e}+001.00000 \mathrm{e}-092.12000 \mathrm{e}-01$ $1.03054 \mathrm{e}+011.03054 \mathrm{e}+011.03054 \mathrm{e}+001.00000 \mathrm{e}-092.12000 \mathrm{e}-01$ $1.03054 \mathrm{e}+011.03054 \mathrm{e}+011.03054 \mathrm{e}+001.00000 \mathrm{e}-092.12000 \mathrm{e}-01$ $1.03054 \mathrm{e}+011.03054 \mathrm{e}+011.03054 \mathrm{e}+001.00000 \mathrm{e}-092.12000 \mathrm{e}-01$ $1.00000 \mathrm{e}-02$ 1.00000e-02 1.00000e-03 1.00000e-09 1.00000e-01 $1.00000 \mathrm{e}+001.00000 \mathrm{e}+001.00000 \mathrm{e}-011.00000 \mathrm{e}-091.00000 \mathrm{e}-01$ $1.00000 \mathrm{e}-05$ 1.00000e-05 1.00000e-06 1.00000e-09 1.00000e-01 $1.00000 \mathrm{e}+001.00000 \mathrm{e}+001.00000 \mathrm{e}-011.00000 \mathrm{e}-091.00000 \mathrm{e}-01$ Element: 2494 \# of layers: 15

$\mathrm{Kx} \mathrm{Ky} \mathrm{Kz}$ Ss Por

$2.57920 \mathrm{e}+02$ 2.57920e+02 2.57920e+01 1.00000e-09 7.00000e-02 $2.57920 \mathrm{e}+02$ 2.57920e+02 2.57920e+01 1.00000e-09 7.00000e-02 $2.57920 \mathrm{e}+02$ 2.57920e+02 2.57920e+01 1.00000e-09 7.00000e-02 $2.57920 \mathrm{e}+022.57920 \mathrm{e}+022.57920 \mathrm{e}+01$ 1.00000e-09 7.00000e-02 5.00000e-04 5.00000e-04 5.00000e-05 1.00000e-09 1.00000e-01 5.00000e-04 5.00000e-04 5.00000e-05 1.00000e-09 1.00000e-01 $1.03054 \mathrm{e}+011.03054 \mathrm{e}+011.03054 \mathrm{e}+001.00000 \mathrm{e}-092.12000 \mathrm{e}-01$ $1.03054 \mathrm{e}+011.03054 \mathrm{e}+011.03054 \mathrm{e}+001.00000 \mathrm{e}-092.12000 \mathrm{e}-01$ $1.03054 \mathrm{e}+011.03054 \mathrm{e}+011.03054 \mathrm{e}+001.00000 \mathrm{e}-092.12000 \mathrm{e}-01$ $1.03054 \mathrm{e}+011.03054 \mathrm{e}+011.03054 \mathrm{e}+001.00000 \mathrm{e}-092.12000 \mathrm{e}-01$ $1.03054 \mathrm{e}+011.03054 \mathrm{e}+011.03054 \mathrm{e}+001.00000 \mathrm{e}-092.12000 \mathrm{e}-01$ $1.00000 \mathrm{e}-02$ 1.00000e-02 1.00000e-03 1.00000e-09 1.00000e-01 $1.00000 \mathrm{e}+001.00000 \mathrm{e}+001.00000 \mathrm{e}-011.00000 \mathrm{e}-091.00000 \mathrm{e}-01$ $1.00000 \mathrm{e}-05$ 1.00000e-05 1.00000e-06 1.00000e-09 1.00000e-01 
$1.00000 \mathrm{e}+001.00000 \mathrm{e}+00$ 1.00000e-01 1.00000e-09 1.00000e-01

Element: 2495 \# of layers: 15

$\mathrm{Kx} \mathrm{Ky} \mathrm{Kz}$ Ss Por

$2.57920 \mathrm{e}+02$ 2.57920e+02 2.57920e+01 1.00000e-09 7.00000e-02

$2.57920 \mathrm{e}+022.57920 \mathrm{e}+022.57920 \mathrm{e}+01$ 1.00000e-09 7.00000e-02

$2.57920 \mathrm{e}+02$ 2.57920e+02 2.57920e+01 1.00000e-09 7.00000e-02

$2.57920 \mathrm{e}+022.57920 \mathrm{e}+022.57920 \mathrm{e}+01$ 1.00000e-09 7.00000e-02

5.00000e-04 5.00000e-04 5.00000e-05 1.00000e-09 1.00000e-01

5.00000e-04 5.00000e-04 5.00000e-05 1.00000e-09 1.00000e-01

$1.03054 \mathrm{e}+011.03054 \mathrm{e}+011.03054 \mathrm{e}+001.00000 \mathrm{e}-092.12000 \mathrm{e}-01$

$1.03054 \mathrm{e}+011.03054 \mathrm{e}+011.03054 \mathrm{e}+001.00000 \mathrm{e}-092.12000 \mathrm{e}-01$

$1.03054 \mathrm{e}+011.03054 \mathrm{e}+01 \quad 1.03054 \mathrm{e}+001.00000 \mathrm{e}-092.12000 \mathrm{e}-01$

$1.03054 \mathrm{e}+011.03054 \mathrm{e}+011.03054 \mathrm{e}+001.00000 \mathrm{e}-092.12000 \mathrm{e}-01$

$1.03054 \mathrm{e}+011.03054 \mathrm{e}+011.03054 \mathrm{e}+001.00000 \mathrm{e}-092.12000 \mathrm{e}-01$

$1.00000 \mathrm{e}-02$ 1.00000e-02 1.00000e-03 1.00000e-09 1.00000e-01

$1.00000 \mathrm{e}+001.00000 \mathrm{e}+001.00000 \mathrm{e}-011.00000 \mathrm{e}-091.00000 \mathrm{e}-01$

$1.00000 \mathrm{e}-05$ 1.00000e-05 1.00000e-06 1.00000e-09 1.00000e-01

$1.00000 \mathrm{e}+001.00000 \mathrm{e}+001.00000 \mathrm{e}-01$ 1.00000e-09 1.00000e-01

Element: 2496 \# of layers: 15

$\mathrm{Kx} \mathrm{Ky} \mathrm{Kz}$ Ss Por

$2.57920 \mathrm{e}+02$ 2.57920e+02 2.57920e+01 1.00000e-09 7.00000e-02

$2.57920 \mathrm{e}+02$ 2.57920e+02 2.57920e+01 1.00000e-09 7.00000e-02

$2.57920 \mathrm{e}+02$ 2.57920e+02 2.57920e+01 1.00000e-09 7.00000e-02

$2.57920 \mathrm{e}+02$ 2.57920e+02 2.57920e+01 1.00000e-09 7.00000e-02

5.00000e-04 5.00000e-04 5.00000e-05 1.00000e-09 1.00000e-01

$5.00000 \mathrm{e}-04$ 5.00000e-04 5.00000e-05 1.00000e-09 1.00000e-01

$1.03054 \mathrm{e}+011.03054 \mathrm{e}+011.03054 \mathrm{e}+001.00000 \mathrm{e}-092.12000 \mathrm{e}-01$

$1.03054 \mathrm{e}+011.03054 \mathrm{e}+011.03054 \mathrm{e}+001.00000 \mathrm{e}-092.12000 \mathrm{e}-01$

$1.03054 \mathrm{e}+011.03054 \mathrm{e}+011.03054 \mathrm{e}+001.00000 \mathrm{e}-092.12000 \mathrm{e}-01$

$1.03054 \mathrm{e}+011.03054 \mathrm{e}+011.03054 \mathrm{e}+001.00000 \mathrm{e}-092.12000 \mathrm{e}-01$

$1.03054 \mathrm{e}+011.03054 \mathrm{e}+011.03054 \mathrm{e}+001.00000 \mathrm{e}-092.12000 \mathrm{e}-01$

$1.00000 \mathrm{e}-02$ 1.00000e-02 1.00000e-03 1.00000e-09 1.00000e-01

$1.00000 \mathrm{e}+001.00000 \mathrm{e}+001.00000 \mathrm{e}-011.00000 \mathrm{e}-091.00000 \mathrm{e}-01$

$1.00000 \mathrm{e}-05$ 1.00000e-05 1.00000e-06 1.00000e-09 1.00000e-01

$1.00000 \mathrm{e}+001.00000 \mathrm{e}+001.00000 \mathrm{e}-011.00000 \mathrm{e}-091.00000 \mathrm{e}-01$

Element: 2497 \# of layers: 16

Kx Ky Kz Ss Por

7.85294e+01 7.85294e+01 7.85294e+00 1.00000e-09 7.00000e-02

$7.85294 \mathrm{e}+017.85294 \mathrm{e}+01$ 7.85294e+00 1.00000e-09 7.00000e-02

$7.85294 \mathrm{e}+017.85294 \mathrm{e}+01$ 7.85294e+00 1.00000e-09 7.00000e-02

$7.85294 \mathrm{e}+017.85294 \mathrm{e}+01$ 7.85294e+00 1.00000e-09 7.00000e-02

$7.85294 \mathrm{e}+017.85294 \mathrm{e}+017.85294 \mathrm{e}+001.00000 \mathrm{e}-097.00000 \mathrm{e}-02$

5.00000e-04 5.00000e-04 5.00000e-05 1.00000e-09 1.00000e-01

5.00000e-04 5.00000e-04 5.00000e-05 1.00000e-09 1.00000e-01

$3.13769 \mathrm{e}+003.13769 \mathrm{e}+00$ 3.13769e-01 1.00000e-09 2.12000e-01

$3.13769 \mathrm{e}+003.13769 \mathrm{e}+00$ 3.13769e-01 1.00000e-09 2.12000e-01 
$3.13769 \mathrm{e}+003.13769 \mathrm{e}+00$ 3.13769e-01 1.00000e-09 2.12000e-01 $3.13769 \mathrm{e}+003.13769 \mathrm{e}+003.13769 \mathrm{e}-01$ 1.00000e-09 2.12000e-01 $3.13769 \mathrm{e}+003.13769 \mathrm{e}+00$ 3.13769e-01 1.00000e-09 2.12000e-01 $1.00000 \mathrm{e}-021.00000 \mathrm{e}-02$ 1.00000e-03 1.00000e-09 1.00000e-01 $1.00000 \mathrm{e}+001.00000 \mathrm{e}+001.00000 \mathrm{e}-011.00000 \mathrm{e}-091.00000 \mathrm{e}-01$ $1.00000 \mathrm{e}-05$ 1.00000e-05 1.00000e-06 1.00000e-09 1.00000e-01 $1.00000 \mathrm{e}+001.00000 \mathrm{e}+001.00000 \mathrm{e}-011.00000 \mathrm{e}-091.00000 \mathrm{e}-01$ Element: 2498 \# of layers: 15

Kx Ky Kz Ss Por

$7.85294 \mathrm{e}+017.85294 \mathrm{e}+01$ 7.85294e+00 1.00000e-09 7.00000e-02 $7.85294 \mathrm{e}+017.85294 \mathrm{e}+017.85294 \mathrm{e}+001.00000 \mathrm{e}-097.00000 \mathrm{e}-02$ $7.85294 \mathrm{e}+01$ 7.85294e+01 7.85294e+00 1.00000e-09 7.00000e-02 $7.85294 \mathrm{e}+017.85294 \mathrm{e}+017.85294 \mathrm{e}+001.00000 \mathrm{e}-097.00000 \mathrm{e}-02$ 5.00000e-04 5.00000e-04 5.00000e-05 1.00000e-09 1.00000e-01 5.00000e-04 5.00000e-04 5.00000e-05 1.00000e-09 1.00000e-01 $3.13769 \mathrm{e}+003.13769 \mathrm{e}+003.13769 \mathrm{e}-01$ 1.00000e-09 2.12000e-01 $3.13769 \mathrm{e}+003.13769 \mathrm{e}+003.13769 \mathrm{e}-01$ 1.00000e-09 2.12000e-01 $3.13769 \mathrm{e}+003.13769 \mathrm{e}+003.13769 \mathrm{e}-01$ 1.00000e-09 2.12000e-01 $3.13769 \mathrm{e}+003.13769 \mathrm{e}+003.13769 \mathrm{e}-01$ 1.00000e-09 2.12000e-01 $3.13769 \mathrm{e}+003.13769 \mathrm{e}+003.13769 \mathrm{e}-01$ 1.00000e-09 2.12000e-01 $1.00000 \mathrm{e}-021.00000 \mathrm{e}-02$ 1.00000e-03 1.00000e-09 1.00000e-01 $1.00000 \mathrm{e}+001.00000 \mathrm{e}+001.00000 \mathrm{e}-011.00000 \mathrm{e}-091.00000 \mathrm{e}-01$ $1.00000 \mathrm{e}-05$ 1.00000e-05 1.00000e-06 1.00000e-09 1.00000e-01 $1.00000 \mathrm{e}+001.00000 \mathrm{e}+001.00000 \mathrm{e}-011.00000 \mathrm{e}-091.00000 \mathrm{e}-01$ Element: 2499 \# of layers: 15

Kx Ky Kz Ss Por

$7.85294 \mathrm{e}+01$ 7.85294e+01 7.85294e+00 1.00000e-09 7.00000e-02 $7.85294 \mathrm{e}+017.85294 \mathrm{e}+017.85294 \mathrm{e}+001.00000 \mathrm{e}-097.00000 \mathrm{e}-02$ $7.85294 \mathrm{e}+017.85294 \mathrm{e}+017.85294 \mathrm{e}+001.00000 \mathrm{e}-097.00000 \mathrm{e}-02$ $7.85294 \mathrm{e}+017.85294 \mathrm{e}+017.85294 \mathrm{e}+001.00000 \mathrm{e}-097.00000 \mathrm{e}-02$ 5.00000e-04 5.00000e-04 5.00000e-05 1.00000e-09 1.00000e-01 5.00000e-04 5.00000e-04 5.00000e-05 1.00000e-09 1.00000e-01 $3.13769 \mathrm{e}+003.13769 \mathrm{e}+003.13769 \mathrm{e}-01$ 1.00000e-09 2.12000e-01 $3.13769 \mathrm{e}+003.13769 \mathrm{e}+003.13769 \mathrm{e}-01$ 1.00000e-09 2.12000e-01 $3.13769 \mathrm{e}+003.13769 \mathrm{e}+003.13769 \mathrm{e}-01$ 1.00000e-09 2.12000e-01 $3.13769 \mathrm{e}+003.13769 \mathrm{e}+00$ 3.13769e-01 1.00000e-09 2.12000e-01 $3.13769 \mathrm{e}+003.13769 \mathrm{e}+003.13769 \mathrm{e}-01$ 1.00000e-09 2.12000e-01 $1.00000 \mathrm{e}-02$ 1.00000e-02 1.00000e-03 1.00000e-09 1.00000e-01 $1.00000 \mathrm{e}+001.00000 \mathrm{e}+001.00000 \mathrm{e}-011.00000 \mathrm{e}-091.00000 \mathrm{e}-01$ $1.00000 \mathrm{e}-05$ 1.00000e-05 1.00000e-06 1.00000e-09 1.00000e-01 $1.00000 \mathrm{e}+001.00000 \mathrm{e}+001.00000 \mathrm{e}-011.00000 \mathrm{e}-091.00000 \mathrm{e}-01$ Element: 2500 \# of layers: 15

Kx Ky Kz Ss Por

$7.85294 \mathrm{e}+017.85294 \mathrm{e}+01$ 7.85294e+00 1.00000e-09 7.00000e-02 $7.85294 \mathrm{e}+017.85294 \mathrm{e}+017.85294 \mathrm{e}+001.00000 \mathrm{e}-097.00000 \mathrm{e}-02$ $7.85294 \mathrm{e}+01$ 7.85294e+01 7.85294e+00 1.00000e-09 7.00000e-02 
7.85294e+01 7.85294e+01 7.85294e+00 1.00000e-09 7.00000e-02 5.00000e-04 5.00000e-04 5.00000e-05 1.00000e-09 1.00000e-01 5.00000e-04 5.00000e-04 5.00000e-05 1.00000e-09 1.00000e-01

$3.13769 \mathrm{e}+003.13769 \mathrm{e}+00$ 3.13769e-01 1.00000e-09 2.12000e-01 $3.13769 \mathrm{e}+00$ 3.13769e+00 3.13769e-01 1.00000e-09 2.12000e-01 3.13769e+00 3.13769e+00 3.13769e-01 1.00000e-09 2.12000e-01 3.13769e+00 3.13769e+00 3.13769e-01 1.00000e-09 2.12000e-01 $3.13769 \mathrm{e}+003.13769 \mathrm{e}+003.13769 \mathrm{e}-01$ 1.00000e-09 2.12000e-01 $1.00000 \mathrm{e}-02$ 1.00000e-02 1.00000e-03 1.00000e-09 1.00000e-01 $1.00000 \mathrm{e}+001.00000 \mathrm{e}+001.00000 \mathrm{e}-011.00000 \mathrm{e}-091.00000 \mathrm{e}-01$ $1.00000 \mathrm{e}-05$ 1.00000e-05 1.00000e-06 1.00000e-09 1.00000e-01 $1.00000 \mathrm{e}+001.00000 \mathrm{e}+001.00000 \mathrm{e}-011.00000 \mathrm{e}-091.00000 \mathrm{e}-01$ Element: 2501 \# of layers: 15

$\mathrm{Kx} \mathrm{Ky} \mathrm{Kz}$ Ss Por

7.85294e+01 7.85294e+01 7.85294e+00 1.00000e-09 7.00000e-02 $7.85294 \mathrm{e}+017.85294 \mathrm{e}+017.85294 \mathrm{e}+001.00000 \mathrm{e}-09$ 7.00000e-02 $7.85294 \mathrm{e}+017.85294 \mathrm{e}+017.85294 \mathrm{e}+001.00000 \mathrm{e}-097.00000 \mathrm{e}-02$ $7.85294 \mathrm{e}+017.85294 \mathrm{e}+017.85294 \mathrm{e}+001.00000 \mathrm{e}-09$ 7.00000e-02 5.00000e-04 5.00000e-04 5.00000e-05 1.00000e-09 1.00000e-01 5.00000e-04 5.00000e-04 5.00000e-05 1.00000e-09 1.00000e-01

$3.13769 \mathrm{e}+003.13769 \mathrm{e}+00$ 3.13769e-01 1.00000e-09 2.12000e-01 3.13769e+00 3.13769e+00 3.13769e-01 1.00000e-09 2.12000e-01 3.13769e+00 3.13769e+00 3.13769e-01 1.00000e-09 2.12000e-01 3.13769e+00 3.13769e+00 3.13769e-01 1.00000e-09 2.12000e-01 $3.13769 \mathrm{e}+003.13769 \mathrm{e}+00$ 3.13769e-01 1.00000e-09 2.12000e-01 $1.00000 \mathrm{e}-02$ 1.00000e-02 1.00000e-03 1.00000e-09 1.00000e-01 $1.00000 \mathrm{e}+001.00000 \mathrm{e}+001.00000 \mathrm{e}-011.00000 \mathrm{e}-091.00000 \mathrm{e}-01$ $1.00000 \mathrm{e}-05$ 1.00000e-05 1.00000e-06 1.00000e-09 1.00000e-01 $1.00000 \mathrm{e}+001.00000 \mathrm{e}+001.00000 \mathrm{e}-011.00000 \mathrm{e}-091.00000 \mathrm{e}-01$ Element: 2502 \# of layers: 15

$\mathrm{Kx} \mathrm{Ky} \mathrm{Kz}$ Ss Por

7.85294e+01 7.85294e+01 7.85294e+00 1.00000e-09 7.00000e-02 $7.85294 \mathrm{e}+017.85294 \mathrm{e}+017.85294 \mathrm{e}+001.00000 \mathrm{e}-097.00000 \mathrm{e}-02$ $7.85294 \mathrm{e}+017.85294 \mathrm{e}+01$ 7.85294e+00 1.00000e-09 7.00000e-02 $7.85294 \mathrm{e}+017.85294 \mathrm{e}+017.85294 \mathrm{e}+001.00000 \mathrm{e}-09$ 7.00000e-02 5.00000e-04 5.00000e-04 5.00000e-05 1.00000e-09 1.00000e-01 5.00000e-04 5.00000e-04 5.00000e-05 1.00000e-09 1.00000e-01

$3.13769 \mathrm{e}+003.13769 \mathrm{e}+00$ 3.13769e-01 1.00000e-09 2.12000e-01 3.13769e+00 3.13769e+00 3.13769e-01 1.00000e-09 2.12000e-01 3.13769e+00 3.13769e+00 3.13769e-01 1.00000e-09 2.12000e-01 3.13769e+00 3.13769e+00 3.13769e-01 1.00000e-09 2.12000e-01 $3.13769 \mathrm{e}+003.13769 \mathrm{e}+003.13769 \mathrm{e}-01$ 1.00000e-09 2.12000e-01 $1.00000 \mathrm{e}-02$ 1.00000e-02 1.00000e-03 1.00000e-09 1.00000e-01 $1.00000 \mathrm{e}+001.00000 \mathrm{e}+001.00000 \mathrm{e}-011.00000 \mathrm{e}-091.00000 \mathrm{e}-01$ $1.00000 \mathrm{e}-05$ 1.00000e-05 1.00000e-06 1.00000e-09 1.00000e-01 $1.00000 \mathrm{e}+001.00000 \mathrm{e}+001.00000 \mathrm{e}-011.00000 \mathrm{e}-091.00000 \mathrm{e}-01$ 
Element: 2503 \# of layers: 16

$\mathrm{Kx} \mathrm{Ky} \mathrm{Kz}$ Ss Por

7.85294e+01 7.85294e+01 7.85294e+00 1.00000e-09 7.00000e-02

$7.85294 \mathrm{e}+017.85294 \mathrm{e}+017.85294 \mathrm{e}+001.00000 \mathrm{e}-09$ 7.00000e-02

$7.85294 \mathrm{e}+017.85294 \mathrm{e}+01$ 7.85294e+00 1.00000e-09 7.00000e-02

$7.85294 \mathrm{e}+017.85294 \mathrm{e}+01$ 7.85294e+00 1.00000e-09 7.00000e-02

$7.85294 \mathrm{e}+017.85294 \mathrm{e}+017.85294 \mathrm{e}+001.00000 \mathrm{e}-09$ 7.00000e-02

5.00000e-04 5.00000e-04 5.00000e-05 1.00000e-09 1.00000e-01

5.00000e-04 5.00000e-04 5.00000e-05 1.00000e-09 1.00000e-01

$3.13769 \mathrm{e}+003.13769 \mathrm{e}+003.13769 \mathrm{e}-01$ 1.00000e-09 2.12000e-01

3.13769e+00 3.13769e+00 3.13769e-01 1.00000e-09 2.12000e-01

$3.13769 \mathrm{e}+003.13769 \mathrm{e}+00$ 3.13769e-01 1.00000e-09 2.12000e-01

3.13769e+00 3.13769e+00 3.13769e-01 1.00000e-09 2.12000e-01

$3.13769 \mathrm{e}+003.13769 \mathrm{e}+00$ 3.13769e-01 1.00000e-09 2.12000e-01

$1.00000 \mathrm{e}-02$ 1.00000e-02 1.00000e-03 1.00000e-09 1.00000e-01

$1.00000 \mathrm{e}+001.00000 \mathrm{e}+001.00000 \mathrm{e}-011.00000 \mathrm{e}-091.00000 \mathrm{e}-01$

$1.00000 \mathrm{e}-05$ 1.00000e-05 1.00000e-06 1.00000e-09 1.00000e-01

$1.00000 \mathrm{e}+001.00000 \mathrm{e}+001.00000 \mathrm{e}-01$ 1.00000e-09 1.00000e-01

Element: 2504 \# of layers: 16

$\mathrm{Kx} \mathrm{Ky} \mathrm{Kz}$ Ss Por

$7.85294 \mathrm{e}+017.85294 \mathrm{e}+017.85294 \mathrm{e}+001.00000 \mathrm{e}-09$ 7.00000e-02

$7.85294 \mathrm{e}+01$ 7.85294e+01 7.85294e+00 1.00000e-09 7.00000e-02

$7.85294 \mathrm{e}+01$ 7.85294e+01 7.85294e+00 1.00000e-09 7.00000e-02

$7.85294 \mathrm{e}+017.85294 \mathrm{e}+01$ 7.85294e+00 1.00000e-09 7.00000e-02

$7.85294 \mathrm{e}+017.85294 \mathrm{e}+017.85294 \mathrm{e}+001.00000 \mathrm{e}-097.00000 \mathrm{e}-02$

5.00000e-04 5.00000e-04 5.00000e-05 1.00000e-09 1.00000e-01

5.00000e-04 5.00000e-04 5.00000e-05 1.00000e-09 1.00000e-01

$3.13769 \mathrm{e}+00$ 3.13769e+00 3.13769e-01 1.00000e-09 2.12000e-01

$3.13769 \mathrm{e}+003.13769 \mathrm{e}+00$ 3.13769e-01 1.00000e-09 2.12000e-01

3.13769e+00 3.13769e+00 3.13769e-01 1.00000e-09 2.12000e-01

3.13769e+00 3.13769e+00 3.13769e-01 1.00000e-09 2.12000e-01

3.13769e+00 3.13769e+00 3.13769e-01 1.00000e-09 2.12000e-01

$1.00000 \mathrm{e}-02$ 1.00000e-02 1.00000e-03 1.00000e-09 1.00000e-01

$1.00000 \mathrm{e}+001.00000 \mathrm{e}+001.00000 \mathrm{e}-011.00000 \mathrm{e}-091.00000 \mathrm{e}-01$

$1.00000 \mathrm{e}-05$ 1.00000e-05 1.00000e-06 1.00000e-09 1.00000e-01

$1.00000 \mathrm{e}+001.00000 \mathrm{e}+001.00000 \mathrm{e}-011.00000 \mathrm{e}-091.00000 \mathrm{e}-01$

Element: 2505 \# of layers: 15

$\mathrm{Kx} \mathrm{Ky} \mathrm{Kz}$ Ss Por

$7.85294 \mathrm{e}+01$ 7.85294e+01 7.85294e+00 1.00000e-09 7.00000e-02

$7.85294 \mathrm{e}+017.85294 \mathrm{e}+01$ 7.85294e+00 1.00000e-09 7.00000e-02

$7.85294 \mathrm{e}+017.85294 \mathrm{e}+017.85294 \mathrm{e}+001.00000 \mathrm{e}-09$ 7.00000e-02

$7.85294 \mathrm{e}+017.85294 \mathrm{e}+017.85294 \mathrm{e}+001.00000 \mathrm{e}-097.00000 \mathrm{e}-02$

5.00000e-04 5.00000e-04 5.00000e-05 1.00000e-09 1.00000e-01

5.00000e-04 5.00000e-04 5.00000e-05 1.00000e-09 1.00000e-01

$3.13769 \mathrm{e}+003.13769 \mathrm{e}+00$ 3.13769e-01 1.00000e-09 2.12000e-01

$3.13769 \mathrm{e}+003.13769 \mathrm{e}+00$ 3.13769e-01 1.00000e-09 2.12000e-01 
$3.13769 \mathrm{e}+003.13769 \mathrm{e}+00$ 3.13769e-01 1.00000e-09 2.12000e-01 $3.13769 \mathrm{e}+003.13769 \mathrm{e}+00$ 3.13769e-01 1.00000e-09 2.12000e-01 $3.13769 \mathrm{e}+003.13769 \mathrm{e}+00$ 3.13769e-01 1.00000e-09 2.12000e-01 $1.00000 \mathrm{e}-021.00000 \mathrm{e}-02$ 1.00000e-03 1.00000e-09 1.00000e-01 $1.00000 \mathrm{e}+001.00000 \mathrm{e}+001.00000 \mathrm{e}-011.00000 \mathrm{e}-091.00000 \mathrm{e}-01$ $1.00000 \mathrm{e}-05$ 1.00000e-05 1.00000e-06 1.00000e-09 1.00000e-01 $1.00000 \mathrm{e}+001.00000 \mathrm{e}+001.00000 \mathrm{e}-011.00000 \mathrm{e}-091.00000 \mathrm{e}-01$ Element: 2506 \# of layers: 15

Kx Ky Kz Ss Por

$8.21433 \mathrm{e}+01$ 8.21433e+01 8.21433e+00 1.00000e-09 7.00000e-02 $8.21433 \mathrm{e}+018.21433 \mathrm{e}+018.21433 \mathrm{e}+001.00000 \mathrm{e}-09$ 7.00000e-02 $8.21433 \mathrm{e}+018.21433 \mathrm{e}+018.21433 \mathrm{e}+001.00000 \mathrm{e}-09$ 7.00000e-02 $8.21433 \mathrm{e}+018.21433 \mathrm{e}+018.21433 \mathrm{e}+00$ 1.00000e-09 7.00000e-02 5.00000e-04 5.00000e-04 5.00000e-05 1.00000e-09 1.00000e-01 $5.00000 \mathrm{e}-04$ 5.00000e-04 5.00000e-05 1.00000e-09 1.00000e-01 $3.28215 \mathrm{e}+003.28215 \mathrm{e}+003.28215 \mathrm{e}-01$ 1.00000e-09 2.12000e-01 $3.28215 \mathrm{e}+003.28215 \mathrm{e}+003.28215 \mathrm{e}-011.00000 \mathrm{e}-09$ 2.12000e-01 $3.28215 \mathrm{e}+003.28215 \mathrm{e}+003.28215 \mathrm{e}-011.00000 \mathrm{e}-092.12000 \mathrm{e}-01$ $3.28215 \mathrm{e}+003.28215 \mathrm{e}+003.28215 \mathrm{e}-011.00000 \mathrm{e}-092.12000 \mathrm{e}-01$ $3.28215 \mathrm{e}+003.28215 \mathrm{e}+003.28215 \mathrm{e}-01$ 1.00000e-09 2.12000e-01 $1.00000 \mathrm{e}-021.00000 \mathrm{e}-02$ 1.00000e-03 1.00000e-09 1.00000e-01 $1.00000 \mathrm{e}+001.00000 \mathrm{e}+001.00000 \mathrm{e}-011.00000 \mathrm{e}-091.00000 \mathrm{e}-01$ $1.00000 \mathrm{e}-05$ 1.00000e-05 1.00000e-06 1.00000e-09 1.00000e-01 $1.00000 \mathrm{e}+001.00000 \mathrm{e}+001.00000 \mathrm{e}-011.00000 \mathrm{e}-091.00000 \mathrm{e}-01$ Element: 2507 \# of layers: 14

Kx Ky Kz Ss Por

$8.21433 \mathrm{e}+01$ 8.21433e+01 8.21433e+00 1.00000e-09 7.00000e-02 $8.21433 \mathrm{e}+018.21433 \mathrm{e}+018.21433 \mathrm{e}+001.00000 \mathrm{e}-09$ 7.00000e-02 $8.21433 \mathrm{e}+018.21433 \mathrm{e}+018.21433 \mathrm{e}+001.00000 \mathrm{e}-09$ 7.00000e-02 $5.00000 \mathrm{e}-04$ 5.00000e-04 5.00000e-05 1.00000e-09 1.00000e-01 5.00000e-04 5.00000e-04 5.00000e-05 1.00000e-09 1.00000e-01 $3.28215 \mathrm{e}+003.28215 \mathrm{e}+003.28215 \mathrm{e}-011.00000 \mathrm{e}-092.12000 \mathrm{e}-01$ $3.28215 \mathrm{e}+003.28215 \mathrm{e}+003.28215 \mathrm{e}-01$ 1.00000e-09 2.12000e-01 $3.28215 \mathrm{e}+003.28215 \mathrm{e}+003.28215 \mathrm{e}-01$ 1.00000e-09 2.12000e-01 $3.28215 \mathrm{e}+003.28215 \mathrm{e}+003.28215 \mathrm{e}-01$ 1.00000e-09 2.12000e-01 $3.28215 \mathrm{e}+003.28215 \mathrm{e}+003.28215 \mathrm{e}-01$ 1.00000e-09 2.12000e-01 $1.00000 \mathrm{e}-021.00000 \mathrm{e}-02$ 1.00000e-03 1.00000e-09 1.00000e-01 $1.00000 \mathrm{e}+001.00000 \mathrm{e}+001.00000 \mathrm{e}-011.00000 \mathrm{e}-091.00000 \mathrm{e}-01$ $1.00000 \mathrm{e}-05$ 1.00000e-05 1.00000e-06 1.00000e-09 1.00000e-01 $1.00000 \mathrm{e}+001.00000 \mathrm{e}+001.00000 \mathrm{e}-011.00000 \mathrm{e}-091.00000 \mathrm{e}-01$ Element: 2508 \# of layers: 14

Kx Ky Kz Ss Por 8.21433e+01 8.21433e+01 8.21433e+00 1.00000e-09 7.00000e-02 $8.21433 \mathrm{e}+018.21433 \mathrm{e}+018.21433 \mathrm{e}+001.00000 \mathrm{e}-09$ 7.00000e-02 $8.21433 \mathrm{e}+018.21433 \mathrm{e}+018.21433 \mathrm{e}+001.00000 \mathrm{e}-09$ 7.00000e-02 5.00000e-04 5.00000e-04 5.00000e-05 1.00000e-09 1.00000e-01 
5.00000e-04 5.00000e-04 5.00000e-05 1.00000e-09 1.00000e-01 $3.28215 \mathrm{e}+003.28215 \mathrm{e}+003.28215 \mathrm{e}-01$ 1.00000e-09 2.12000e-01 $3.28215 \mathrm{e}+003.28215 \mathrm{e}+00$ 3.28215e-01 1.00000e-09 2.12000e-01 $3.28215 \mathrm{e}+003.28215 \mathrm{e}+003.28215 \mathrm{e}-01$ 1.00000e-09 2.12000e-01 $3.28215 \mathrm{e}+003.28215 \mathrm{e}+003.28215 \mathrm{e}-01$ 1.00000e-09 2.12000e-01 $3.28215 \mathrm{e}+003.28215 \mathrm{e}+00$ 3.28215e-01 1.00000e-09 2.12000e-01 $1.00000 \mathrm{e}-01$ 1.00000e-01 1.00000e-02 1.00000e-09 1.00000e-01 $1.00000 \mathrm{e}+001.00000 \mathrm{e}+001.00000 \mathrm{e}-011.00000 \mathrm{e}-091.00000 \mathrm{e}-01$ $1.00000 \mathrm{e}-05$ 1.00000e-05 1.00000e-06 1.00000e-09 1.00000e-01 $1.00000 \mathrm{e}+001.00000 \mathrm{e}+001.00000 \mathrm{e}-011.00000 \mathrm{e}-091.00000 \mathrm{e}-01$ Element: 2509 \# of layers: 14

$\mathrm{Kx} \mathrm{Ky} \mathrm{Kz}$ Ss Por

8.21433e+01 8.21433e+01 8.21433e+00 1.00000e-09 7.00000e-02 8.21433e+01 8.21433e+01 8.21433e+00 1.00000e-09 7.00000e-02 8.21433e+01 8.21433e+01 8.21433e+00 1.00000e-09 7.00000e-02 5.00000e-04 5.00000e-04 5.00000e-05 1.00000e-09 1.00000e-01 5.00000e-04 5.00000e-04 5.00000e-05 1.00000e-09 1.00000e-01 $3.28215 \mathrm{e}+003.28215 \mathrm{e}+00$ 3.28215e-01 1.00000e-09 2.12000e-01 $3.28215 \mathrm{e}+003.28215 \mathrm{e}+003.28215 \mathrm{e}-01$ 1.00000e-09 2.12000e-01 $3.28215 \mathrm{e}+003.28215 \mathrm{e}+00$ 3.28215e-01 1.00000e-09 2.12000e-01 $3.28215 \mathrm{e}+003.28215 \mathrm{e}+00$ 3.28215e-01 1.00000e-09 2.12000e-01 $3.28215 \mathrm{e}+003.28215 \mathrm{e}+00$ 3.28215e-01 1.00000e-09 2.12000e-01 $1.00000 \mathrm{e}-011.00000 \mathrm{e}-011.00000 \mathrm{e}-021.00000 \mathrm{e}-091.00000 \mathrm{e}-01$ $1.00000 \mathrm{e}+001.00000 \mathrm{e}+001.00000 \mathrm{e}-011.00000 \mathrm{e}-091.00000 \mathrm{e}-01$ $1.00000 \mathrm{e}-05$ 1.00000e-05 1.00000e-06 1.00000e-09 1.00000e-01 $1.00000 \mathrm{e}+001.00000 \mathrm{e}+001.00000 \mathrm{e}-011.00000 \mathrm{e}-091.00000 \mathrm{e}-01$ Element: 2510 \# of layers: 14

$\mathrm{Kx} \mathrm{Ky} \mathrm{Kz}$ Ss Por

8.21433e+01 8.21433e+01 8.21433e+00 1.00000e-09 7.00000e-02 8.21433e+01 8.21433e+01 8.21433e+00 1.00000e-09 7.00000e-02 $8.21433 \mathrm{e}+018.21433 \mathrm{e}+018.21433 \mathrm{e}+00$ 1.00000e-09 7.00000e-02 5.00000e-04 5.00000e-04 5.00000e-05 1.00000e-09 1.00000e-01 5.00000e-04 5.00000e-04 5.00000e-05 1.00000e-09 1.00000e-01 $3.28215 \mathrm{e}+003.28215 \mathrm{e}+003.28215 \mathrm{e}-01$ 1.00000e-09 2.12000e-01 $3.28215 \mathrm{e}+003.28215 \mathrm{e}+00$ 3.28215e-01 1.00000e-09 2.12000e-01 $3.28215 \mathrm{e}+003.28215 \mathrm{e}+00$ 3.28215e-01 1.00000e-09 2.12000e-01 $3.28215 \mathrm{e}+003.28215 \mathrm{e}+003.28215 \mathrm{e}-01$ 1.00000e-09 2.12000e-01 $3.28215 \mathrm{e}+003.28215 \mathrm{e}+003.28215 \mathrm{e}-01$ 1.00000e-09 2.12000e-01 $1.00000 \mathrm{e}-02$ 1.00000e-02 1.00000e-03 1.00000e-09 1.00000e-01 $1.00000 \mathrm{e}+001.00000 \mathrm{e}+001.00000 \mathrm{e}-011.00000 \mathrm{e}-091.00000 \mathrm{e}-01$ $1.00000 \mathrm{e}-05$ 1.00000e-05 1.00000e-06 1.00000e-09 1.00000e-01 $1.00000 \mathrm{e}+001.00000 \mathrm{e}+001.00000 \mathrm{e}-011.00000 \mathrm{e}-091.00000 \mathrm{e}-01$ Element: 2511 \# of layers: 14

$\mathrm{Kx} \mathrm{Ky} \mathrm{Kz}$ Ss Por

8.21433e+01 8.21433e+01 8.21433e+00 1.00000e-09 7.00000e-02 $8.21433 \mathrm{e}+018.21433 \mathrm{e}+018.21433 \mathrm{e}+001.00000 \mathrm{e}-09$ 7.00000e-02 
8.21433e+01 8.21433e+01 8.21433e+00 1.00000e-09 7.00000e-02 5.00000e-04 5.00000e-04 5.00000e-05 1.00000e-09 1.00000e-01 5.00000e-04 5.00000e-04 5.00000e-05 1.00000e-09 1.00000e-01 $3.28215 \mathrm{e}+003.28215 \mathrm{e}+003.28215 \mathrm{e}-01$ 1.00000e-09 2.12000e-01 $3.28215 \mathrm{e}+003.28215 \mathrm{e}+003.28215 \mathrm{e}-01$ 1.00000e-09 2.12000e-01 $3.28215 \mathrm{e}+003.28215 \mathrm{e}+00$ 3.28215e-01 1.00000e-09 2.12000e-01 $3.28215 \mathrm{e}+003.28215 \mathrm{e}+00$ 3.28215e-01 1.00000e-09 2.12000e-01 $3.28215 \mathrm{e}+003.28215 \mathrm{e}+003.28215 \mathrm{e}-01$ 1.00000e-09 2.12000e-01 $1.00000 \mathrm{e}-02$ 1.00000e-02 1.00000e-03 1.00000e-09 1.00000e-01 $1.00000 \mathrm{e}+001.00000 \mathrm{e}+001.00000 \mathrm{e}-011.00000 \mathrm{e}-091.00000 \mathrm{e}-01$ $1.00000 \mathrm{e}-05$ 1.00000e-05 1.00000e-06 1.00000e-09 1.00000e-01 $1.00000 \mathrm{e}+001.00000 \mathrm{e}+001.00000 \mathrm{e}-011.00000 \mathrm{e}-091.00000 \mathrm{e}-01$ Element: 2512 \# of layers: 15

$\mathrm{Kx} \mathrm{Ky} \mathrm{Kz}$ Ss Por

8.21433e+01 8.21433e+01 8.21433e+00 1.00000e-09 7.00000e-02 8.21433e+01 8.21433e+01 8.21433e+00 1.00000e-09 7.00000e-02 8.21433e+01 8.21433e+01 8.21433e+00 1.00000e-09 7.00000e-02 8.21433e+01 8.21433e+01 8.21433e+00 1.00000e-09 7.00000e-02 $5.00000 \mathrm{e}-045.00000 \mathrm{e}-045.00000 \mathrm{e}-051.00000 \mathrm{e}-091.00000 \mathrm{e}-01$ 5.00000e-04 5.00000e-04 5.00000e-05 1.00000e-09 1.00000e-01 $3.28215 \mathrm{e}+003.28215 \mathrm{e}+003.28215 \mathrm{e}-01$ 1.00000e-09 2.12000e-01 $3.28215 \mathrm{e}+003.28215 \mathrm{e}+00$ 3.28215e-01 1.00000e-09 2.12000e-01 $3.28215 \mathrm{e}+003.28215 \mathrm{e}+00$ 3.28215e-01 1.00000e-09 2.12000e-01 $3.28215 \mathrm{e}+003.28215 \mathrm{e}+003.28215 \mathrm{e}-01$ 1.00000e-09 2.12000e-01 $3.28215 \mathrm{e}+003.28215 \mathrm{e}+003.28215 \mathrm{e}-01$ 1.00000e-09 2.12000e-01 $1.00000 \mathrm{e}-021.00000 \mathrm{e}-021.00000 \mathrm{e}-031.00000 \mathrm{e}-091.00000 \mathrm{e}-01$ $1.00000 \mathrm{e}+001.00000 \mathrm{e}+001.00000 \mathrm{e}-011.00000 \mathrm{e}-091.00000 \mathrm{e}-01$ $1.00000 \mathrm{e}-05$ 1.00000e-05 1.00000e-06 1.00000e-09 1.00000e-01 $1.00000 \mathrm{e}+001.00000 \mathrm{e}+001.00000 \mathrm{e}-011.00000 \mathrm{e}-091.00000 \mathrm{e}-01$ Element: 2513 \# of layers: 15

$\mathrm{Kx} \mathrm{Ky} \mathrm{Kz}$ Ss Por

8.21433e+01 8.21433e+01 8.21433e+00 1.00000e-09 7.00000e-02 $8.21433 \mathrm{e}+01$ 8.21433e+01 8.21433e+00 1.00000e-09 7.00000e-02 8.21433e+01 8.21433e+01 8.21433e+00 1.00000e-09 7.00000e-02 8.21433e+01 8.21433e+01 8.21433e+00 1.00000e-09 7.00000e-02 5.00000e-04 5.00000e-04 5.00000e-05 1.00000e-09 1.00000e-01 5.00000e-04 5.00000e-04 5.00000e-05 1.00000e-09 1.00000e-01 $3.28215 \mathrm{e}+003.28215 \mathrm{e}+003.28215 \mathrm{e}-01$ 1.00000e-09 2.12000e-01 $3.28215 \mathrm{e}+003.28215 \mathrm{e}+00$ 3.28215e-01 1.00000e-09 2.12000e-01 $3.28215 \mathrm{e}+003.28215 \mathrm{e}+00$ 3.28215e-01 1.00000e-09 2.12000e-01 $3.28215 \mathrm{e}+003.28215 \mathrm{e}+00$ 3.28215e-01 1.00000e-09 2.12000e-01 $3.28215 \mathrm{e}+003.28215 \mathrm{e}+003.28215 \mathrm{e}-01$ 1.00000e-09 2.12000e-01 $1.00000 \mathrm{e}-021.00000 \mathrm{e}-021.00000 \mathrm{e}-031.00000 \mathrm{e}-091.00000 \mathrm{e}-01$ $1.00000 \mathrm{e}+001.00000 \mathrm{e}+001.00000 \mathrm{e}-011.00000 \mathrm{e}-091.00000 \mathrm{e}-01$ $1.00000 \mathrm{e}-05$ 1.00000e-05 1.00000e-06 1.00000e-09 1.00000e-01 $1.00000 \mathrm{e}+001.00000 \mathrm{e}+001.00000 \mathrm{e}-01$ 1.00000e-09 1.00000e-01 
Element: 2514 \# of layers: 14

Kx Ky Kz Ss Por

$8.21433 \mathrm{e}+01$ 8.21433e+01 8.21433e+00 1.00000e-09 7.00000e-02

$8.21433 \mathrm{e}+018.21433 \mathrm{e}+018.21433 \mathrm{e}+001.00000 \mathrm{e}-09$ 7.00000e-02

$8.21433 \mathrm{e}+018.21433 \mathrm{e}+018.21433 \mathrm{e}+00$ 1.00000e-09 7.00000e-02

5.00000e-04 5.00000e-04 5.00000e-05 1.00000e-09 1.00000e-01

5.00000e-04 5.00000e-04 5.00000e-05 1.00000e-09 1.00000e-01

$3.28215 \mathrm{e}+003.28215 \mathrm{e}+003.28215 \mathrm{e}-01$ 1.00000e-09 2.12000e-01

$3.28215 \mathrm{e}+003.28215 \mathrm{e}+003.28215 \mathrm{e}-011.00000 \mathrm{e}-092.12000 \mathrm{e}-01$

$3.28215 \mathrm{e}+003.28215 \mathrm{e}+003.28215 \mathrm{e}-011.00000 \mathrm{e}-092.12000 \mathrm{e}-01$

$3.28215 \mathrm{e}+003.28215 \mathrm{e}+003.28215 \mathrm{e}-01$ 1.00000e-09 2.12000e-01

$3.28215 \mathrm{e}+003.28215 \mathrm{e}+003.28215 \mathrm{e}-01$ 1.00000e-09 2.12000e-01

$1.00000 \mathrm{e}-02$ 1.00000e-02 1.00000e-03 1.00000e-09 1.00000e-01

$1.00000 \mathrm{e}+001.00000 \mathrm{e}+001.00000 \mathrm{e}-011.00000 \mathrm{e}-091.00000 \mathrm{e}-01$

$1.00000 \mathrm{e}-05$ 1.00000e-05 1.00000e-06 1.00000e-09 1.00000e-01

$1.00000 \mathrm{e}+001.00000 \mathrm{e}+001.00000 \mathrm{e}-011.00000 \mathrm{e}-091.00000 \mathrm{e}-01$

Element: 2515 \# of layers: 14

Kx Ky Kz Ss Por

4.93379e+01 4.93379e+01 4.93379e+00 1.00000e-09 7.00000e-02 $4.93379 \mathrm{e}+014.93379 \mathrm{e}+014.93379 \mathrm{e}+001.00000 \mathrm{e}-09$ 7.00000e-02 $4.93379 \mathrm{e}+014.93379 \mathrm{e}+014.93379 \mathrm{e}+001.00000 \mathrm{e}-09$ 7.00000e-02 5.00000e-04 5.00000e-04 5.00000e-05 1.00000e-09 1.00000e-01 $5.00000 \mathrm{e}-04$ 5.00000e-04 5.00000e-05 1.00000e-09 1.00000e-01 $1.97136 \mathrm{e}+001.97136 \mathrm{e}+00$ 1.97136e-01 1.00000e-09 2.12000e-01 $1.97136 \mathrm{e}+001.97136 \mathrm{e}+001.97136 \mathrm{e}-011.00000 \mathrm{e}-092.12000 \mathrm{e}-01$ $1.97136 \mathrm{e}+001.97136 \mathrm{e}+001.97136 \mathrm{e}-011.00000 \mathrm{e}-092.12000 \mathrm{e}-01$ $1.97136 \mathrm{e}+001.97136 \mathrm{e}+001.97136 \mathrm{e}-011.00000 \mathrm{e}-092.12000 \mathrm{e}-01$ $1.97136 \mathrm{e}+001.97136 \mathrm{e}+001.97136 \mathrm{e}-011.00000 \mathrm{e}-092.12000 \mathrm{e}-01$ $1.00000 \mathrm{e}-021.00000 \mathrm{e}-02$ 1.00000e-03 1.00000e-09 1.00000e-01 $1.00000 \mathrm{e}+001.00000 \mathrm{e}+001.00000 \mathrm{e}-011.00000 \mathrm{e}-091.00000 \mathrm{e}-01$ $1.00000 \mathrm{e}-05$ 1.00000e-05 1.00000e-06 1.00000e-09 1.00000e-01 $1.00000 \mathrm{e}+001.00000 \mathrm{e}+001.00000 \mathrm{e}-011.00000 \mathrm{e}-091.00000 \mathrm{e}-01$ Element: 2516 \# of layers: 14

Kx Ky Kz Ss Por

4.93379e+01 4.93379e+01 4.93379e+00 1.00000e-09 7.00000e-02 $4.93379 \mathrm{e}+014.93379 \mathrm{e}+014.93379 \mathrm{e}+001.00000 \mathrm{e}-09$ 7.00000e-02 $4.93379 \mathrm{e}+014.93379 \mathrm{e}+014.93379 \mathrm{e}+001.00000 \mathrm{e}-09$ 7.00000e-02 5.00000e-04 5.00000e-04 5.00000e-05 1.00000e-09 1.00000e-01 5.00000e-04 5.00000e-04 5.00000e-05 1.00000e-09 1.00000e-01 $1.97136 \mathrm{e}+001.97136 \mathrm{e}+001.97136 \mathrm{e}-011.00000 \mathrm{e}-092.12000 \mathrm{e}-01$ $1.97136 \mathrm{e}+001.97136 \mathrm{e}+001.97136 \mathrm{e}-011.00000 \mathrm{e}-092.12000 \mathrm{e}-01$ $1.97136 \mathrm{e}+001.97136 \mathrm{e}+001.97136 \mathrm{e}-011.00000 \mathrm{e}-092.12000 \mathrm{e}-01$ $1.97136 \mathrm{e}+001.97136 \mathrm{e}+00$ 1.97136e-01 1.00000e-09 2.12000e-01 $1.97136 \mathrm{e}+001.97136 \mathrm{e}+00$ 1.97136e-01 1.00000e-09 2.12000e-01 $1.00000 \mathrm{e}-021.00000 \mathrm{e}-02$ 1.00000e-03 1.00000e-09 1.00000e-01 $1.00000 \mathrm{e}+001.00000 \mathrm{e}+001.00000 \mathrm{e}-011.00000 \mathrm{e}-091.00000 \mathrm{e}-01$ 
$1.00000 \mathrm{e}-05$ 1.00000e-05 1.00000e-06 1.00000e-09 1.00000e-01 $1.00000 \mathrm{e}+001.00000 \mathrm{e}+001.00000 \mathrm{e}-01$ 1.00000e-09 1.00000e-01 Element: 2517 \# of layers: 14

Kx Ky Kz Ss Por

4.93379e+01 4.93379e+01 4.93379e+00 1.00000e-09 7.00000e-02 4.93379e+01 4.93379e+01 4.93379e+00 1.00000e-09 7.00000e-02 $4.93379 \mathrm{e}+014.93379 \mathrm{e}+014.93379 \mathrm{e}+00$ 1.00000e-09 7.00000e-02 5.00000e-04 5.00000e-04 5.00000e-05 1.00000e-09 1.00000e-01 5.00000e-04 5.00000e-04 5.00000e-05 1.00000e-09 1.00000e-01 $1.97136 \mathrm{e}+001.97136 \mathrm{e}+00$ 1.97136e-01 1.00000e-09 2.12000e-01 $1.97136 \mathrm{e}+001.97136 \mathrm{e}+00$ 1.97136e-01 1.00000e-09 2.12000e-01 $1.97136 \mathrm{e}+001.97136 \mathrm{e}+001.97136 \mathrm{e}-011.00000 \mathrm{e}-092.12000 \mathrm{e}-01$ $1.97136 \mathrm{e}+001.97136 \mathrm{e}+00$ 1.97136e-01 1.00000e-09 2.12000e-01 $1.97136 \mathrm{e}+001.97136 \mathrm{e}+001.97136 \mathrm{e}-01$ 1.00000e-09 2.12000e-01 $1.00000 \mathrm{e}-02$ 1.00000e-02 1.00000e-03 1.00000e-09 1.00000e-01 $1.00000 \mathrm{e}+001.00000 \mathrm{e}+001.00000 \mathrm{e}-011.00000 \mathrm{e}-091.00000 \mathrm{e}-01$ $1.00000 \mathrm{e}-05$ 1.00000e-05 1.00000e-06 1.00000e-09 1.00000e-01 $1.00000 \mathrm{e}+001.00000 \mathrm{e}+001.00000 \mathrm{e}-011.00000 \mathrm{e}-091.00000 \mathrm{e}-01$ Element: 2518 \# of layers: 14

$\mathrm{Kx} \mathrm{Ky} \mathrm{Kz}$ Ss Por

4.93379e+01 4.93379e+01 4.93379e+00 1.00000e-09 7.00000e-02 4.93379e+01 4.93379e+01 4.93379e+00 1.00000e-09 7.00000e-02 4.93379e+01 4.93379e+01 4.93379e+00 1.00000e-09 7.00000e-02 5.00000e-04 5.00000e-04 5.00000e-05 1.00000e-09 1.00000e-01 5.00000e-04 5.00000e-04 5.00000e-05 1.00000e-09 1.00000e-01 $1.97136 \mathrm{e}+001.97136 \mathrm{e}+001.97136 \mathrm{e}-01$ 1.00000e-09 2.12000e-01 $1.97136 \mathrm{e}+001.97136 \mathrm{e}+00$ 1.97136e-01 1.00000e-09 2.12000e-01 $1.97136 \mathrm{e}+001.97136 \mathrm{e}+001.97136 \mathrm{e}-01$ 1.00000e-09 2.12000e-01 $1.97136 \mathrm{e}+001.97136 \mathrm{e}+001.97136 \mathrm{e}-011.00000 \mathrm{e}-092.12000 \mathrm{e}-01$ $1.97136 \mathrm{e}+00$ 1.97136e+00 1.97136e-01 1.00000e-09 2.12000e-01 $1.00000 \mathrm{e}-02$ 1.00000e-02 1.00000e-03 1.00000e-09 1.00000e-01 $1.00000 \mathrm{e}+001.00000 \mathrm{e}+001.00000 \mathrm{e}-011.00000 \mathrm{e}-091.00000 \mathrm{e}-01$ $1.00000 \mathrm{e}-05$ 1.00000e-05 1.00000e-06 1.00000e-09 1.00000e-01 $1.00000 \mathrm{e}+001.00000 \mathrm{e}+001.00000 \mathrm{e}-011.00000 \mathrm{e}-091.00000 \mathrm{e}-01$ Element: 2519 \# of layers: 14

$\mathrm{Kx} \mathrm{Ky} \mathrm{Kz}$ Ss Por 4.93379e+01 4.93379e+01 4.93379e+00 1.00000e-09 7.00000e-02 4.93379e+01 4.93379e+01 4.93379e+00 1.00000e-09 7.00000e-02 4.93379e+01 4.93379e+01 4.93379e+00 1.00000e-09 7.00000e-02 5.00000e-04 5.00000e-04 5.00000e-05 1.00000e-09 1.00000e-01 5.00000e-04 5.00000e-04 5.00000e-05 1.00000e-09 1.00000e-01 $1.97136 \mathrm{e}+001.97136 \mathrm{e}+001.97136 \mathrm{e}-01$ 1.00000e-09 2.12000e-01 $1.97136 \mathrm{e}+001.97136 \mathrm{e}+00$ 1.97136e-01 1.00000e-09 2.12000e-01 $1.97136 \mathrm{e}+001.97136 \mathrm{e}+00$ 1.97136e-01 1.00000e-09 2.12000e-01 $1.97136 \mathrm{e}+001.97136 \mathrm{e}+001.97136 \mathrm{e}-01$ 1.00000e-09 2.12000e-01 $1.97136 \mathrm{e}+001.97136 \mathrm{e}+001.97136 \mathrm{e}-011.00000 \mathrm{e}-092.12000 \mathrm{e}-01$ 
$1.00000 \mathrm{e}-02$ 1.00000e-02 1.00000e-03 1.00000e-09 1.00000e-01 $1.00000 \mathrm{e}+001.00000 \mathrm{e}+001.00000 \mathrm{e}-011.00000 \mathrm{e}-091.00000 \mathrm{e}-01$ $1.00000 \mathrm{e}-051.00000 \mathrm{e}-05$ 1.00000e-06 1.00000e-09 1.00000e-01 $1.00000 \mathrm{e}+001.00000 \mathrm{e}+001.00000 \mathrm{e}-011.00000 \mathrm{e}-091.00000 \mathrm{e}-01$ Element: 2520 \# of layers: 14

Kx Ky Kz Ss Por

4.93379e+01 4.93379e+01 4.93379e+00 1.00000e-09 7.00000e-02 $4.93379 \mathrm{e}+014.93379 \mathrm{e}+014.93379 \mathrm{e}+001.00000 \mathrm{e}-09$ 7.00000e-02 $4.93379 \mathrm{e}+014.93379 \mathrm{e}+014.93379 \mathrm{e}+00$ 1.00000e-09 7.00000e-02 5.00000e-04 5.00000e-04 5.00000e-05 1.00000e-09 1.00000e-01 5.00000e-04 5.00000e-04 5.00000e-05 1.00000e-09 1.00000e-01 $1.97136 \mathrm{e}+001.97136 \mathrm{e}+001.97136 \mathrm{e}-011.00000 \mathrm{e}-092.12000 \mathrm{e}-01$ $1.97136 \mathrm{e}+001.97136 \mathrm{e}+001.97136 \mathrm{e}-011.00000 \mathrm{e}-092.12000 \mathrm{e}-01$ $1.97136 \mathrm{e}+001.97136 \mathrm{e}+00$ 1.97136e-01 1.00000e-09 2.12000e-01 $1.97136 \mathrm{e}+001.97136 \mathrm{e}+001.97136 \mathrm{e}-011.00000 \mathrm{e}-092.12000 \mathrm{e}-01$ $1.97136 \mathrm{e}+001.97136 \mathrm{e}+001.97136 \mathrm{e}-011.00000 \mathrm{e}-092.12000 \mathrm{e}-01$ $1.00000 \mathrm{e}-02$ 1.00000e-02 1.00000e-03 1.00000e-09 1.00000e-01 $1.00000 \mathrm{e}+001.00000 \mathrm{e}+001.00000 \mathrm{e}-011.00000 \mathrm{e}-091.00000 \mathrm{e}-01$ $1.00000 \mathrm{e}-05$ 1.00000e-05 1.00000e-06 1.00000e-09 1.00000e-01 $1.00000 \mathrm{e}+001.00000 \mathrm{e}+001.00000 \mathrm{e}-011.00000 \mathrm{e}-091.00000 \mathrm{e}-01$ Element: 2521 \# of layers: 14

Kx Ky Kz Ss Por

$4.93379 \mathrm{e}+01$ 4.93379e+01 4.93379e+00 1.00000e-09 7.00000e-02 $4.93379 \mathrm{e}+014.93379 \mathrm{e}+014.93379 \mathrm{e}+00$ 1.00000e-09 7.00000e-02 $4.93379 \mathrm{e}+014.93379 \mathrm{e}+014.93379 \mathrm{e}+001.00000 \mathrm{e}-09$ 7.00000e-02 $5.00000 \mathrm{e}-04$ 5.00000e-04 5.00000e-05 1.00000e-09 1.00000e-01 $5.00000 \mathrm{e}-04$ 5.00000e-04 5.00000e-05 1.00000e-09 1.00000e-01 $1.97136 \mathrm{e}+001.97136 \mathrm{e}+001.97136 \mathrm{e}-011.00000 \mathrm{e}-092.12000 \mathrm{e}-01$ $1.97136 \mathrm{e}+001.97136 \mathrm{e}+001.97136 \mathrm{e}-011.00000 \mathrm{e}-092.12000 \mathrm{e}-01$ $1.97136 \mathrm{e}+001.97136 \mathrm{e}+001.97136 \mathrm{e}-011.00000 \mathrm{e}-092.12000 \mathrm{e}-01$ $1.97136 \mathrm{e}+001.97136 \mathrm{e}+001.97136 \mathrm{e}-011.00000 \mathrm{e}-092.12000 \mathrm{e}-01$ $1.97136 \mathrm{e}+001.97136 \mathrm{e}+001.97136 \mathrm{e}-011.00000 \mathrm{e}-09$ 2.12000e-01 $1.00000 \mathrm{e}-021.00000 \mathrm{e}-02$ 1.00000e-03 1.00000e-09 1.00000e-01 $1.00000 \mathrm{e}+001.00000 \mathrm{e}+001.00000 \mathrm{e}-011.00000 \mathrm{e}-091.00000 \mathrm{e}-01$ $1.00000 \mathrm{e}-05$ 1.00000e-05 1.00000e-06 1.00000e-09 1.00000e-01 $1.00000 \mathrm{e}+001.00000 \mathrm{e}+001.00000 \mathrm{e}-011.00000 \mathrm{e}-091.00000 \mathrm{e}-01$ Element: 2522 \# of layers: 14

Kx Ky Kz Ss Por 4.93379e+01 4.93379e+01 4.93379e+00 1.00000e-09 7.00000e-02 $4.93379 \mathrm{e}+014.93379 \mathrm{e}+014.93379 \mathrm{e}+001.00000 \mathrm{e}-09$ 7.00000e-02 $4.93379 \mathrm{e}+014.93379 \mathrm{e}+014.93379 \mathrm{e}+001.00000 \mathrm{e}-09$ 7.00000e-02 5.00000e-04 5.00000e-04 5.00000e-05 1.00000e-09 1.00000e-01 $5.00000 \mathrm{e}-04$ 5.00000e-04 5.00000e-05 1.00000e-09 1.00000e-01 $1.97136 \mathrm{e}+001.97136 \mathrm{e}+001.97136 \mathrm{e}-011.00000 \mathrm{e}-092.12000 \mathrm{e}-01$ $1.97136 \mathrm{e}+001.97136 \mathrm{e}+001.97136 \mathrm{e}-011.00000 \mathrm{e}-092.12000 \mathrm{e}-01$ $1.97136 \mathrm{e}+001.97136 \mathrm{e}+001.97136 \mathrm{e}-011.00000 \mathrm{e}-092.12000 \mathrm{e}-01$ 
$1.97136 \mathrm{e}+00$ 1.97136e+00 1.97136e-01 1.00000e-09 2.12000e-01 $1.97136 \mathrm{e}+001.97136 \mathrm{e}+001.97136 \mathrm{e}-01$ 1.00000e-09 2.12000e-01 $1.00000 \mathrm{e}-02$ 1.00000e-02 1.00000e-03 1.00000e-09 1.00000e-01 $1.00000 \mathrm{e}+001.00000 \mathrm{e}+001.00000 \mathrm{e}-011.00000 \mathrm{e}-091.00000 \mathrm{e}-01$ $1.00000 \mathrm{e}-05$ 1.00000e-05 1.00000e-06 1.00000e-09 1.00000e-01 $1.00000 \mathrm{e}+001.00000 \mathrm{e}+001.00000 \mathrm{e}-01$ 1.00000e-09 1.00000e-01 Element: 2523 \# of layers: 14

$\mathrm{Kx} \mathrm{Ky} \mathrm{Kz}$ Ss Por

4.93379e+01 4.93379e+01 4.93379e+00 1.00000e-09 7.00000e-02 $4.93379 \mathrm{e}+014.93379 \mathrm{e}+01$ 4.93379e+00 1.00000e-09 7.00000e-02 $4.93379 \mathrm{e}+014.93379 \mathrm{e}+014.93379 \mathrm{e}+00$ 1.00000e-09 7.00000e-02 5.00000e-04 5.00000e-04 5.00000e-05 1.00000e-09 1.00000e-01 5.00000e-04 5.00000e-04 5.00000e-05 1.00000e-09 1.00000e-01 $1.97136 \mathrm{e}+001.97136 \mathrm{e}+00$ 1.97136e-01 1.00000e-09 2.12000e-01 $1.97136 \mathrm{e}+001.97136 \mathrm{e}+001.97136 \mathrm{e}-01$ 1.00000e-09 2.12000e-01 $1.97136 \mathrm{e}+001.97136 \mathrm{e}+001.97136 \mathrm{e}-01$ 1.00000e-09 2.12000e-01 $1.97136 \mathrm{e}+001.97136 \mathrm{e}+00$ 1.97136e-01 1.00000e-09 2.12000e-01 $1.97136 \mathrm{e}+001.97136 \mathrm{e}+001.97136 \mathrm{e}-01$ 1.00000e-09 2.12000e-01 1.00000e-02 1.00000e-02 1.00000e-03 1.00000e-09 1.00000e-01 $1.00000 \mathrm{e}+001.00000 \mathrm{e}+001.00000 \mathrm{e}-011.00000 \mathrm{e}-091.00000 \mathrm{e}-01$ $1.00000 \mathrm{e}-05$ 1.00000e-05 1.00000e-06 1.00000e-09 1.00000e-01 $1.00000 \mathrm{e}+001.00000 \mathrm{e}+001.00000 \mathrm{e}-01$ 1.00000e-09 1.00000e-01 Element: 2524 \# of layers: 14

$\mathrm{Kx} \mathrm{Ky} \mathrm{Kz}$ Ss Por

5.29815e+01 5.29815e+01 5.29815e+00 1.00000e-09 7.00000e-02 $5.29815 \mathrm{e}+015.29815 \mathrm{e}+015.29815 \mathrm{e}+001.00000 \mathrm{e}-09$ 7.00000e-02 $5.29815 \mathrm{e}+015.29815 \mathrm{e}+015.29815 \mathrm{e}+001.00000 \mathrm{e}-097.00000 \mathrm{e}-02$ 5.00000e-04 5.00000e-04 5.00000e-05 1.00000e-09 1.00000e-01 5.00000e-04 5.00000e-04 5.00000e-05 1.00000e-09 1.00000e-01

$2.11696 \mathrm{e}+002.11696 \mathrm{e}+00$ 2.11696e-01 1.00000e-09 2.12000e-01 $2.11696 \mathrm{e}+002.11696 \mathrm{e}+00$ 2.11696e-01 1.00000e-09 2.12000e-01 $2.11696 \mathrm{e}+002.11696 \mathrm{e}+00$ 2.11696e-01 1.00000e-09 2.12000e-01 $2.11696 \mathrm{e}+002.11696 \mathrm{e}+00$ 2.11696e-01 1.00000e-09 2.12000e-01 $2.11696 \mathrm{e}+002.11696 \mathrm{e}+002.11696 \mathrm{e}-01$ 1.00000e-09 2.12000e-01 $1.00000 \mathrm{e}-02$ 1.00000e-02 1.00000e-03 1.00000e-09 1.00000e-01 $1.00000 \mathrm{e}+001.00000 \mathrm{e}+001.00000 \mathrm{e}-011.00000 \mathrm{e}-091.00000 \mathrm{e}-01$ $1.00000 \mathrm{e}-05$ 1.00000e-05 1.00000e-06 1.00000e-09 1.00000e-01 $1.00000 \mathrm{e}+001.00000 \mathrm{e}+001.00000 \mathrm{e}-011.00000 \mathrm{e}-091.00000 \mathrm{e}-01$ Element: 2525 \# of layers: 15

$\mathrm{Kx} \mathrm{Ky} \mathrm{Kz}$ Ss Por 5.29815e+01 5.29815e+01 5.29815e+00 1.00000e-09 7.00000e-02 $5.29815 \mathrm{e}+015.29815 \mathrm{e}+015.29815 \mathrm{e}+001.00000 \mathrm{e}-09$ 7.00000e-02 $5.29815 \mathrm{e}+015.29815 \mathrm{e}+015.29815 \mathrm{e}+001.00000 \mathrm{e}-09$ 7.00000e-02 $5.29815 \mathrm{e}+015.29815 \mathrm{e}+015.29815 \mathrm{e}+001.00000 \mathrm{e}-09$ 7.00000e-02 5.00000e-04 5.00000e-04 5.00000e-05 1.00000e-09 1.00000e-01 5.00000e-04 5.00000e-04 5.00000e-05 1.00000e-09 1.00000e-01 
2.11696e+00 2.11696e+00 2.11696e-01 1.00000e-09 2.12000e-01 $2.11696 \mathrm{e}+002.11696 \mathrm{e}+00$ 2.11696e-01 1.00000e-09 2.12000e-01 2.11696e+00 2.11696e+00 2.11696e-01 1.00000e-09 2.12000e-01 $2.11696 \mathrm{e}+002.11696 \mathrm{e}+00$ 2.11696e-01 1.00000e-09 2.12000e-01 $2.11696 \mathrm{e}+002.11696 \mathrm{e}+00$ 2.11696e-01 1.00000e-09 2.12000e-01 $1.00000 \mathrm{e}-02$ 1.00000e-02 1.00000e-03 1.00000e-09 1.00000e-01 $1.00000 \mathrm{e}+001.00000 \mathrm{e}+001.00000 \mathrm{e}-011.00000 \mathrm{e}-091.00000 \mathrm{e}-01$ $1.00000 \mathrm{e}-05$ 1.00000e-05 1.00000e-06 1.00000e-09 1.00000e-01 $1.00000 \mathrm{e}+001.00000 \mathrm{e}+001.00000 \mathrm{e}-011.00000 \mathrm{e}-091.00000 \mathrm{e}-01$ Element: 2526 \# of layers: 14

$\mathrm{Kx} \mathrm{Ky} \mathrm{Kz}$ Ss Por

5.29815e+01 5.29815e+01 5.29815e+00 1.00000e-09 7.00000e-02 $5.29815 \mathrm{e}+015.29815 \mathrm{e}+015.29815 \mathrm{e}+001.00000 \mathrm{e}-09$ 7.00000e-02 $5.29815 \mathrm{e}+015.29815 \mathrm{e}+015.29815 \mathrm{e}+001.00000 \mathrm{e}-09$ 7.00000e-02 5.00000e-04 5.00000e-04 5.00000e-05 1.00000e-09 1.00000e-01 5.00000e-04 5.00000e-04 5.00000e-05 1.00000e-09 1.00000e-01

$2.11696 \mathrm{e}+002.11696 \mathrm{e}+00$ 2.11696e-01 1.00000e-09 2.12000e-01 $2.11696 \mathrm{e}+002.11696 \mathrm{e}+00$ 2.11696e-01 1.00000e-09 2.12000e-01 $2.11696 \mathrm{e}+002.11696 \mathrm{e}+00$ 2.11696e-01 1.00000e-09 2.12000e-01 $2.11696 \mathrm{e}+002.11696 \mathrm{e}+00$ 2.11696e-01 1.00000e-09 2.12000e-01 $2.11696 \mathrm{e}+002.11696 \mathrm{e}+00$ 2.11696e-01 1.00000e-09 2.12000e-01 $1.00000 \mathrm{e}-02$ 1.00000e-02 1.00000e-03 1.00000e-09 1.00000e-01 $1.00000 \mathrm{e}+001.00000 \mathrm{e}+001.00000 \mathrm{e}-011.00000 \mathrm{e}-091.00000 \mathrm{e}-01$ $1.00000 \mathrm{e}-05$ 1.00000e-05 1.00000e-06 1.00000e-09 1.00000e-01 $1.00000 \mathrm{e}+001.00000 \mathrm{e}+001.00000 \mathrm{e}-011.00000 \mathrm{e}-091.00000 \mathrm{e}-01$ Element: 2527 \# of layers: 14

$\mathrm{Kx} \mathrm{Ky} \mathrm{Kz}$ Ss Por

5.29815e+01 5.29815e+01 5.29815e+00 1.00000e-09 7.00000e-02 $5.29815 \mathrm{e}+015.29815 \mathrm{e}+015.29815 \mathrm{e}+001.00000 \mathrm{e}-09$ 7.00000e-02 $5.29815 \mathrm{e}+015.29815 \mathrm{e}+015.29815 \mathrm{e}+001.00000 \mathrm{e}-09$ 7.00000e-02 5.00000e-04 5.00000e-04 5.00000e-05 1.00000e-09 1.00000e-01 5.00000e-04 5.00000e-04 5.00000e-05 1.00000e-09 1.00000e-01

$2.11696 \mathrm{e}+002.11696 \mathrm{e}+002.11696 \mathrm{e}-01$ 1.00000e-09 2.12000e-01 $2.11696 \mathrm{e}+002.11696 \mathrm{e}+00$ 2.11696e-01 1.00000e-09 2.12000e-01 2.11696e+00 2.11696e+00 2.11696e-01 1.00000e-09 2.12000e-01 $2.11696 \mathrm{e}+002.11696 \mathrm{e}+00$ 2.11696e-01 1.00000e-09 2.12000e-01 $2.11696 \mathrm{e}+002.11696 \mathrm{e}+002.11696 \mathrm{e}-01$ 1.00000e-09 2.12000e-01 $1.00000 \mathrm{e}-02$ 1.00000e-02 1.00000e-03 1.00000e-09 1.00000e-01 $1.00000 \mathrm{e}+001.00000 \mathrm{e}+001.00000 \mathrm{e}-011.00000 \mathrm{e}-091.00000 \mathrm{e}-01$ $1.00000 \mathrm{e}-051.00000 \mathrm{e}-05$ 1.00000e-06 1.00000e-09 1.00000e-01 $1.00000 \mathrm{e}+001.00000 \mathrm{e}+001.00000 \mathrm{e}-011.00000 \mathrm{e}-091.00000 \mathrm{e}-01$ Element: 2528 \# of layers: 14

$\mathrm{Kx} \mathrm{Ky} \mathrm{Kz}$ Ss Por

5.29815e+01 5.29815e+01 5.29815e+00 1.00000e-09 7.00000e-02 $5.29815 \mathrm{e}+015.29815 \mathrm{e}+015.29815 \mathrm{e}+001.00000 \mathrm{e}-09$ 7.00000e-02 $5.29815 \mathrm{e}+015.29815 \mathrm{e}+015.29815 \mathrm{e}+001.00000 \mathrm{e}-09$ 7.00000e-02 
5.00000e-04 5.00000e-04 5.00000e-05 1.00000e-09 1.00000e-01 5.00000e-04 5.00000e-04 5.00000e-05 1.00000e-09 1.00000e-01 $2.11696 \mathrm{e}+002.11696 \mathrm{e}+00$ 2.11696e-01 1.00000e-09 2.12000e-01 $2.11696 \mathrm{e}+002.11696 \mathrm{e}+00$ 2.11696e-01 1.00000e-09 2.12000e-01 $2.11696 \mathrm{e}+002.11696 \mathrm{e}+00$ 2.11696e-01 1.00000e-09 2.12000e-01 $2.11696 \mathrm{e}+002.11696 \mathrm{e}+002.11696 \mathrm{e}-01$ 1.00000e-09 2.12000e-01 $2.11696 \mathrm{e}+002.11696 \mathrm{e}+00$ 2.11696e-01 1.00000e-09 2.12000e-01 $1.00000 \mathrm{e}-02$ 1.00000e-02 1.00000e-03 1.00000e-09 1.00000e-01 $1.00000 \mathrm{e}+001.00000 \mathrm{e}+001.00000 \mathrm{e}-01$ 1.00000e-09 1.00000e-01 $1.00000 \mathrm{e}-05$ 1.00000e-05 1.00000e-06 1.00000e-09 1.00000e-01 $1.00000 \mathrm{e}+001.00000 \mathrm{e}+00$ 1.00000e-01 1.00000e-09 1.00000e-01 Element: 2529 \# of layers: 15

$\mathrm{Kx} \mathrm{Ky} \mathrm{Kz}$ Ss Por

5.29815e+01 5.29815e+01 5.29815e+00 1.00000e-09 7.00000e-02 $5.29815 \mathrm{e}+015.29815 \mathrm{e}+015.29815 \mathrm{e}+001.00000 \mathrm{e}-09$ 7.00000e-02 $5.29815 \mathrm{e}+015.29815 \mathrm{e}+015.29815 \mathrm{e}+001.00000 \mathrm{e}-09$ 7.00000e-02 $5.29815 \mathrm{e}+015.29815 \mathrm{e}+015.29815 \mathrm{e}+001.00000 \mathrm{e}-09$ 7.00000e-02 5.00000e-04 5.00000e-04 5.00000e-05 1.00000e-09 1.00000e-01 5.00000e-04 5.00000e-04 5.00000e-05 1.00000e-09 1.00000e-01 $2.11696 \mathrm{e}+002.11696 \mathrm{e}+00$ 2.11696e-01 1.00000e-09 2.12000e-01 $2.11696 \mathrm{e}+002.11696 \mathrm{e}+002.11696 \mathrm{e}-01$ 1.00000e-09 2.12000e-01 2.11696e+00 2.11696e+00 2.11696e-01 1.00000e-09 2.12000e-01 $2.11696 \mathrm{e}+00$ 2.11696e+00 2.11696e-01 1.00000e-09 2.12000e-01 $2.11696 \mathrm{e}+002.11696 \mathrm{e}+00$ 2.11696e-01 1.00000e-09 2.12000e-01 $1.00000 \mathrm{e}-02$ 1.00000e-02 1.00000e-03 1.00000e-09 1.00000e-01 $1.00000 \mathrm{e}+001.00000 \mathrm{e}+001.00000 \mathrm{e}-011.00000 \mathrm{e}-091.00000 \mathrm{e}-01$ $1.00000 \mathrm{e}-05$ 1.00000e-05 1.00000e-06 1.00000e-09 1.00000e-01 $1.00000 \mathrm{e}+001.00000 \mathrm{e}+00$ 1.00000e-01 1.00000e-09 1.00000e-01 Element: 2530 \# of layers: 14

$\mathrm{Kx} \mathrm{Ky} \mathrm{Kz}$ Ss Por

5.29815e+01 5.29815e+01 5.29815e+00 1.00000e-09 7.00000e-02 $5.29815 \mathrm{e}+015.29815 \mathrm{e}+015.29815 \mathrm{e}+00$ 1.00000e-09 7.00000e-02 $5.29815 \mathrm{e}+015.29815 \mathrm{e}+015.29815 \mathrm{e}+001.00000 \mathrm{e}-097.00000 \mathrm{e}-02$ 5.00000e-04 5.00000e-04 5.00000e-05 1.00000e-09 1.00000e-01 5.00000e-04 5.00000e-04 5.00000e-05 1.00000e-09 1.00000e-01 $2.11696 \mathrm{e}+002.11696 \mathrm{e}+00$ 2.11696e-01 1.00000e-09 2.12000e-01 $2.11696 \mathrm{e}+002.11696 \mathrm{e}+00$ 2.11696e-01 1.00000e-09 2.12000e-01 $2.11696 \mathrm{e}+002.11696 \mathrm{e}+00$ 2.11696e-01 1.00000e-09 2.12000e-01 2.11696e+00 2.11696e+00 2.11696e-01 1.00000e-09 2.12000e-01 $2.11696 \mathrm{e}+002.11696 \mathrm{e}+00$ 2.11696e-01 1.00000e-09 2.12000e-01 $1.00000 \mathrm{e}-02$ 1.00000e-02 1.00000e-03 1.00000e-09 1.00000e-01 $1.00000 \mathrm{e}+001.00000 \mathrm{e}+001.00000 \mathrm{e}-011.00000 \mathrm{e}-091.00000 \mathrm{e}-01$ $1.00000 \mathrm{e}-05$ 1.00000e-05 1.00000e-06 1.00000e-09 1.00000e-01 $1.00000 \mathrm{e}+001.00000 \mathrm{e}+001.00000 \mathrm{e}-011.00000 \mathrm{e}-091.00000 \mathrm{e}-01$ Element: 2531 \# of layers: 14

Kx Ky Kz Ss Por 
5.29815e+01 5.29815e+01 5.29815e+00 1.00000e-09 7.00000e-02 $5.29815 \mathrm{e}+015.29815 \mathrm{e}+015.29815 \mathrm{e}+00$ 1.00000e-09 7.00000e-02 $5.29815 \mathrm{e}+015.29815 \mathrm{e}+015.29815 \mathrm{e}+001.00000 \mathrm{e}-09$ 7.00000e-02 5.00000e-04 5.00000e-04 5.00000e-05 1.00000e-09 1.00000e-01 5.00000e-04 5.00000e-04 5.00000e-05 1.00000e-09 1.00000e-01 $2.11696 \mathrm{e}+002.11696 \mathrm{e}+00$ 2.11696e-01 1.00000e-09 2.12000e-01 $2.11696 \mathrm{e}+002.11696 \mathrm{e}+00$ 2.11696e-01 1.00000e-09 2.12000e-01 $2.11696 \mathrm{e}+002.11696 \mathrm{e}+00$ 2.11696e-01 1.00000e-09 2.12000e-01 2.11696e+00 2.11696e+00 2.11696e-01 1.00000e-09 2.12000e-01 $2.11696 \mathrm{e}+002.11696 \mathrm{e}+00$ 2.11696e-01 1.00000e-09 2.12000e-01 $1.00000 \mathrm{e}-02$ 1.00000e-02 1.00000e-03 1.00000e-09 1.00000e-01 $1.00000 \mathrm{e}+001.00000 \mathrm{e}+001.00000 \mathrm{e}-011.00000 \mathrm{e}-091.00000 \mathrm{e}-01$ $1.00000 \mathrm{e}-05$ 1.00000e-05 1.00000e-06 1.00000e-09 1.00000e-01 $1.00000 \mathrm{e}+001.00000 \mathrm{e}+001.00000 \mathrm{e}-011.00000 \mathrm{e}-09$ 1.00000e-01 Element: 2532 \# of layers: 15

Kx Ky Kz Ss Por

5.29815e+01 5.29815e+01 5.29815e+00 1.00000e-09 7.00000e-02 $5.29815 \mathrm{e}+015.29815 \mathrm{e}+015.29815 \mathrm{e}+001.00000 \mathrm{e}-09$ 7.00000e-02 $5.29815 \mathrm{e}+015.29815 \mathrm{e}+015.29815 \mathrm{e}+001.00000 \mathrm{e}-09$ 7.00000e-02 $5.29815 \mathrm{e}+015.29815 \mathrm{e}+015.29815 \mathrm{e}+001.00000 \mathrm{e}-09$ 7.00000e-02 5.00000e-04 5.00000e-04 5.00000e-05 1.00000e-09 1.00000e-01 5.00000e-04 5.00000e-04 5.00000e-05 1.00000e-09 1.00000e-01 $2.11696 \mathrm{e}+002.11696 \mathrm{e}+00$ 2.11696e-01 1.00000e-09 2.12000e-01 $2.11696 \mathrm{e}+002.11696 \mathrm{e}+00$ 2.11696e-01 1.00000e-09 2.12000e-01 $2.11696 \mathrm{e}+002.11696 \mathrm{e}+00$ 2.11696e-01 1.00000e-09 2.12000e-01 $2.11696 \mathrm{e}+002.11696 \mathrm{e}+00$ 2.11696e-01 1.00000e-09 2.12000e-01 $2.11696 \mathrm{e}+002.11696 \mathrm{e}+00$ 2.11696e-01 1.00000e-09 2.12000e-01 $1.00000 \mathrm{e}-02$ 1.00000e-02 1.00000e-03 1.00000e-09 1.00000e-01 $1.00000 \mathrm{e}+001.00000 \mathrm{e}+001.00000 \mathrm{e}-011.00000 \mathrm{e}-091.00000 \mathrm{e}-01$ $1.00000 \mathrm{e}-051.00000 \mathrm{e}-051.00000 \mathrm{e}-061.00000 \mathrm{e}-091.00000 \mathrm{e}-01$ $1.00000 \mathrm{e}+001.00000 \mathrm{e}+001.00000 \mathrm{e}-011.00000 \mathrm{e}-091.00000 \mathrm{e}-01$ Element: 2533 \# of layers: 14

Kx Ky Kz Ss Por 3.93827e+01 3.93827e+01 3.93827e+00 1.00000e-09 7.00000e-02 $3.93827 \mathrm{e}+013.93827 \mathrm{e}+013.93827 \mathrm{e}+00$ 1.00000e-09 7.00000e-02 $3.93827 \mathrm{e}+013.93827 \mathrm{e}+013.93827 \mathrm{e}+00$ 1.00000e-09 7.00000e-02 5.00000e-04 5.00000e-04 5.00000e-05 1.00000e-09 1.00000e-01 5.00000e-04 5.00000e-04 5.00000e-05 1.00000e-09 1.00000e-01 $1.57359 \mathrm{e}+001.57359 \mathrm{e}+00$ 1.57359e-01 1.00000e-09 2.12000e-01 $1.57359 \mathrm{e}+001.57359 \mathrm{e}+00$ 1.57359e-01 1.00000e-09 2.12000e-01 $1.57359 \mathrm{e}+001.57359 \mathrm{e}+00$ 1.57359e-01 1.00000e-09 2.12000e-01 $1.57359 \mathrm{e}+001.57359 \mathrm{e}+00$ 1.57359e-01 1.00000e-09 2.12000e-01 $1.57359 \mathrm{e}+001.57359 \mathrm{e}+00$ 1.57359e-01 1.00000e-09 2.12000e-01 $1.00000 \mathrm{e}-02$ 1.00000e-02 1.00000e-03 1.00000e-09 1.00000e-01 $1.00000 \mathrm{e}+001.00000 \mathrm{e}+001.00000 \mathrm{e}-011.00000 \mathrm{e}-091.00000 \mathrm{e}-01$ $1.00000 \mathrm{e}-05$ 1.00000e-05 1.00000e-06 1.00000e-09 1.00000e-01 
$1.00000 \mathrm{e}+001.00000 \mathrm{e}+00$ 1.00000e-01 1.00000e-09 1.00000e-01

Element: 2534 \# of layers: 13

Kx Ky Kz Ss Por

3.93827e+01 3.93827e+01 3.93827e+00 1.00000e-09 7.00000e-02

$3.93827 \mathrm{e}+013.93827 \mathrm{e}+013.93827 \mathrm{e}+001.00000 \mathrm{e}-09$ 7.00000e-02

5.00000e-04 5.00000e-04 5.00000e-05 1.00000e-09 1.00000e-01

5.00000e-04 5.00000e-04 5.00000e-05 1.00000e-09 1.00000e-01

$1.57359 \mathrm{e}+001.57359 \mathrm{e}+00$ 1.57359e-01 1.00000e-09 2.12000e-01

$1.57359 \mathrm{e}+00$ 1.57359e+00 1.57359e-01 1.00000e-09 2.12000e-01

$1.57359 \mathrm{e}+001.57359 \mathrm{e}+00$ 1.57359e-01 1.00000e-09 2.12000e-01

$1.57359 \mathrm{e}+001.57359 \mathrm{e}+00$ 1.57359e-01 1.00000e-09 2.12000e-01

$1.57359 \mathrm{e}+001.57359 \mathrm{e}+001.57359 \mathrm{e}-01$ 1.00000e-09 2.12000e-01

$1.00000 \mathrm{e}-02$ 1.00000e-02 1.00000e-03 1.00000e-09 1.00000e-01

$1.00000 \mathrm{e}+001.00000 \mathrm{e}+001.00000 \mathrm{e}-011.00000 \mathrm{e}-091.00000 \mathrm{e}-01$

$1.00000 \mathrm{e}-05$ 1.00000e-05 1.00000e-06 1.00000e-09 1.00000e-01

$1.00000 \mathrm{e}+001.00000 \mathrm{e}+001.00000 \mathrm{e}-011.00000 \mathrm{e}-091.00000 \mathrm{e}-01$

Element: 2535 \# of layers: 13

$\mathrm{Kx} \mathrm{Ky} \mathrm{Kz}$ Ss Por

3.93827e+01 3.93827e+01 3.93827e+00 1.00000e-09 7.00000e-02

$3.93827 \mathrm{e}+013.93827 \mathrm{e}+013.93827 \mathrm{e}+00$ 1.00000e-09 7.00000e-02

5.00000e-04 5.00000e-04 5.00000e-05 1.00000e-09 1.00000e-01

5.00000e-04 5.00000e-04 5.00000e-05 1.00000e-09 1.00000e-01

$1.57359 \mathrm{e}+001.57359 \mathrm{e}+00$ 1.57359e-01 1.00000e-09 2.12000e-01

$1.57359 \mathrm{e}+001.57359 \mathrm{e}+00$ 1.57359e-01 1.00000e-09 2.12000e-01

$1.57359 \mathrm{e}+001.57359 \mathrm{e}+001.57359 \mathrm{e}-011.00000 \mathrm{e}-092.12000 \mathrm{e}-01$

$1.57359 \mathrm{e}+001.57359 \mathrm{e}+00$ 1.57359e-01 1.00000e-09 2.12000e-01

$1.57359 \mathrm{e}+001.57359 \mathrm{e}+001.57359 \mathrm{e}-01$ 1.00000e-09 2.12000e-01

1.00000e-02 1.00000e-02 1.00000e-03 1.00000e-09 1.00000e-01

$1.00000 \mathrm{e}+001.00000 \mathrm{e}+001.00000 \mathrm{e}-011.00000 \mathrm{e}-091.00000 \mathrm{e}-01$

$1.00000 \mathrm{e}-05$ 1.00000e-05 1.00000e-06 1.00000e-09 1.00000e-01

$1.00000 \mathrm{e}+001.00000 \mathrm{e}+001.00000 \mathrm{e}-011.00000 \mathrm{e}-091.00000 \mathrm{e}-01$

Element: 2536 \# of layers: 13

Kx Ky Kz Ss Por

3.93827e+01 3.93827e+01 3.93827e+00 1.00000e-09 7.00000e-02

$3.93827 \mathrm{e}+013.93827 \mathrm{e}+013.93827 \mathrm{e}+00$ 1.00000e-09 7.00000e-02

5.00000e-04 5.00000e-04 5.00000e-05 1.00000e-09 1.00000e-01

5.00000e-04 5.00000e-04 5.00000e-05 1.00000e-09 1.00000e-01

$1.57359 \mathrm{e}+001.57359 \mathrm{e}+001.57359 \mathrm{e}-01$ 1.00000e-09 2.12000e-01

$1.57359 \mathrm{e}+001.57359 \mathrm{e}+00$ 1.57359e-01 1.00000e-09 2.12000e-01

$1.57359 \mathrm{e}+001.57359 \mathrm{e}+00$ 1.57359e-01 1.00000e-09 2.12000e-01

$1.57359 \mathrm{e}+001.57359 \mathrm{e}+00$ 1.57359e-01 1.00000e-09 2.12000e-01

$1.57359 \mathrm{e}+001.57359 \mathrm{e}+00$ 1.57359e-01 1.00000e-09 2.12000e-01

$1.00000 \mathrm{e}-02$ 1.00000e-02 1.00000e-03 1.00000e-09 1.00000e-01

$1.00000 \mathrm{e}+001.00000 \mathrm{e}+001.00000 \mathrm{e}-011.00000 \mathrm{e}-091.00000 \mathrm{e}-01$

$1.00000 \mathrm{e}-05$ 1.00000e-05 1.00000e-06 1.00000e-09 1.00000e-01

$1.00000 \mathrm{e}+001.00000 \mathrm{e}+001.00000 \mathrm{e}-011.00000 \mathrm{e}-091.00000 \mathrm{e}-01$ 
Element: 2537 \# of layers: 13

$\mathrm{Kx} \mathrm{Ky} \mathrm{Kz}$ Ss Por

3.93827e+01 3.93827e+01 3.93827e+00 1.00000e-09 7.00000e-02

$3.93827 \mathrm{e}+013.93827 \mathrm{e}+013.93827 \mathrm{e}+001.00000 \mathrm{e}-09$ 7.00000e-02

5.00000e-04 5.00000e-04 5.00000e-05 1.00000e-09 1.00000e-01

5.00000e-04 5.00000e-04 5.00000e-05 1.00000e-09 1.00000e-01

$1.57359 \mathrm{e}+001.57359 \mathrm{e}+00$ 1.57359e-01 1.00000e-09 2.12000e-01

$1.57359 \mathrm{e}+001.57359 \mathrm{e}+00$ 1.57359e-01 1.00000e-09 2.12000e-01

$1.57359 \mathrm{e}+00$ 1.57359e+00 1.57359e-01 1.00000e-09 2.12000e-01

$1.57359 \mathrm{e}+001.57359 \mathrm{e}+00$ 1.57359e-01 1.00000e-09 2.12000e-01

$1.57359 \mathrm{e}+001.57359 \mathrm{e}+001.57359 \mathrm{e}-01$ 1.00000e-09 2.12000e-01

$1.00000 \mathrm{e}-02$ 1.00000e-02 1.00000e-03 1.00000e-09 1.00000e-01

$1.00000 \mathrm{e}+001.00000 \mathrm{e}+001.00000 \mathrm{e}-011.00000 \mathrm{e}-091.00000 \mathrm{e}-01$

$1.00000 \mathrm{e}-05$ 1.00000e-05 1.00000e-06 1.00000e-09 1.00000e-01

$1.00000 \mathrm{e}+001.00000 \mathrm{e}+001.00000 \mathrm{e}-01$ 1.00000e-09 1.00000e-01

Element: 2538 \# of layers: 13

$\mathrm{Kx} \mathrm{Ky} \mathrm{Kz}$ Ss Por

3.93827e+01 3.93827e+01 3.93827e+00 1.00000e-09 7.00000e-02 $3.93827 \mathrm{e}+013.93827 \mathrm{e}+013.93827 \mathrm{e}+00$ 1.00000e-09 7.00000e-02 5.00000e-04 5.00000e-04 5.00000e-05 1.00000e-09 1.00000e-01

5.00000e-04 5.00000e-04 5.00000e-05 1.00000e-09 1.00000e-01

$1.57359 \mathrm{e}+001.57359 \mathrm{e}+00$ 1.57359e-01 1.00000e-09 2.12000e-01

$1.57359 \mathrm{e}+001.57359 \mathrm{e}+00$ 1.57359e-01 1.00000e-09 2.12000e-01

$1.57359 \mathrm{e}+001.57359 \mathrm{e}+00$ 1.57359e-01 1.00000e-09 2.12000e-01

$1.57359 \mathrm{e}+001.57359 \mathrm{e}+001.57359 \mathrm{e}-011.00000 \mathrm{e}-092.12000 \mathrm{e}-01$

$1.57359 \mathrm{e}+001.57359 \mathrm{e}+00$ 1.57359e-01 1.00000e-09 2.12000e-01

$1.00000 \mathrm{e}-02$ 1.00000e-02 1.00000e-03 1.00000e-09 1.00000e-01

$1.00000 \mathrm{e}+001.00000 \mathrm{e}+001.00000 \mathrm{e}-011.00000 \mathrm{e}-091.00000 \mathrm{e}-01$

$1.00000 \mathrm{e}-05$ 1.00000e-05 1.00000e-06 1.00000e-09 1.00000e-01

$1.00000 \mathrm{e}+001.00000 \mathrm{e}+001.00000 \mathrm{e}-011.00000 \mathrm{e}-091.00000 \mathrm{e}-01$

Element: 2539 \# of layers: 13

$\mathrm{Kx} \mathrm{Ky} \mathrm{Kz}$ Ss Por

3.93827e+01 3.93827e+01 3.93827e+00 1.00000e-09 7.00000e-02

$3.93827 \mathrm{e}+013.93827 \mathrm{e}+013.93827 \mathrm{e}+001.00000 \mathrm{e}-09$ 7.00000e-02

5.00000e-04 5.00000e-04 5.00000e-05 1.00000e-09 1.00000e-01

5.00000e-04 5.00000e-04 5.00000e-05 1.00000e-09 1.00000e-01

$1.57359 \mathrm{e}+001.57359 \mathrm{e}+001.57359 \mathrm{e}-01$ 1.00000e-09 2.12000e-01

$1.57359 \mathrm{e}+001.57359 \mathrm{e}+00$ 1.57359e-01 1.00000e-09 2.12000e-01

$1.57359 \mathrm{e}+001.57359 \mathrm{e}+00$ 1.57359e-01 1.00000e-09 2.12000e-01

$1.57359 \mathrm{e}+001.57359 \mathrm{e}+00$ 1.57359e-01 1.00000e-09 2.12000e-01

$1.57359 \mathrm{e}+001.57359 \mathrm{e}+001.57359 \mathrm{e}-01$ 1.00000e-09 2.12000e-01

$1.00000 \mathrm{e}-02$ 1.00000e-02 1.00000e-03 1.00000e-09 1.00000e-01

$1.00000 \mathrm{e}+001.00000 \mathrm{e}+001.00000 \mathrm{e}-011.00000 \mathrm{e}-091.00000 \mathrm{e}-01$

$1.00000 \mathrm{e}-051.00000 \mathrm{e}-051.00000 \mathrm{e}-061.00000 \mathrm{e}-091.00000 \mathrm{e}-01$

$1.00000 \mathrm{e}+001.00000 \mathrm{e}+001.00000 \mathrm{e}-011.00000 \mathrm{e}-09$ 1.00000e-01

Element: 2540 \# of layers: 13 
$\mathrm{Kx} \mathrm{Ky} \mathrm{Kz}$ Ss Por

3.93827e+01 3.93827e+01 3.93827e+00 1.00000e-09 7.00000e-02

$3.93827 \mathrm{e}+013.93827 \mathrm{e}+013.93827 \mathrm{e}+001.00000 \mathrm{e}-09$ 7.00000e-02

5.00000e-04 5.00000e-04 5.00000e-05 1.00000e-09 1.00000e-01

5.00000e-04 5.00000e-04 5.00000e-05 1.00000e-09 1.00000e-01

$1.57359 \mathrm{e}+001.57359 \mathrm{e}+00$ 1.57359e-01 1.00000e-09 2.12000e-01

$1.57359 \mathrm{e}+001.57359 \mathrm{e}+00$ 1.57359e-01 1.00000e-09 2.12000e-01

$1.57359 \mathrm{e}+001.57359 \mathrm{e}+00$ 1.57359e-01 1.00000e-09 2.12000e-01

$1.57359 \mathrm{e}+00$ 1.57359e+00 1.57359e-01 1.00000e-09 2.12000e-01

$1.57359 \mathrm{e}+001.57359 \mathrm{e}+00$ 1.57359e-01 1.00000e-09 2.12000e-01

$1.00000 \mathrm{e}-02$ 1.00000e-02 1.00000e-03 1.00000e-09 1.00000e-01

$1.00000 \mathrm{e}+001.00000 \mathrm{e}+001.00000 \mathrm{e}-011.00000 \mathrm{e}-091.00000 \mathrm{e}-01$

$1.00000 \mathrm{e}-05$ 1.00000e-05 1.00000e-06 1.00000e-09 1.00000e-01

$1.00000 \mathrm{e}+001.00000 \mathrm{e}+001.00000 \mathrm{e}-011.00000 \mathrm{e}-09$ 1.00000e-01

Element: 2541 \# of layers: 12

Kx Ky Kz Ss Por

3.93827e+01 3.93827e+01 3.93827e+00 1.00000e-09 7.00000e-02

$3.93827 \mathrm{e}+013.93827 \mathrm{e}+013.93827 \mathrm{e}+001.00000 \mathrm{e}-09$ 7.00000e-02

5.00000e-04 5.00000e-04 5.00000e-05 1.00000e-09 1.00000e-01

$1.57359 \mathrm{e}+001.57359 \mathrm{e}+00$ 1.57359e-01 1.00000e-09 2.12000e-01

$1.57359 \mathrm{e}+001.57359 \mathrm{e}+001.57359 \mathrm{e}-01$ 1.00000e-09 2.12000e-01

$1.57359 \mathrm{e}+001.57359 \mathrm{e}+00$ 1.57359e-01 1.00000e-09 2.12000e-01

$1.57359 \mathrm{e}+001.57359 \mathrm{e}+00$ 1.57359e-01 1.00000e-09 2.12000e-01

$1.57359 \mathrm{e}+001.57359 \mathrm{e}+001.57359 \mathrm{e}-01$ 1.00000e-09 2.12000e-01

$1.00000 \mathrm{e}-02$ 1.00000e-02 1.00000e-03 1.00000e-09 1.00000e-01

$1.00000 \mathrm{e}+001.00000 \mathrm{e}+001.00000 \mathrm{e}-011.00000 \mathrm{e}-091.00000 \mathrm{e}-01$

$1.00000 \mathrm{e}-05$ 1.00000e-05 1.00000e-06 1.00000e-09 1.00000e-01

$1.00000 \mathrm{e}+001.00000 \mathrm{e}+001.00000 \mathrm{e}-011.00000 \mathrm{e}-091.00000 \mathrm{e}-01$

Element: 2542 \# of layers: 13

$\mathrm{Kx} \mathrm{Ky} \mathrm{Kz}$ Ss Por

4.18127e+01 4.18127e+01 4.18127e+00 1.00000e-09 7.00000e-02

4.18127e+01 4.18127e+01 4.18127e+00 1.00000e-09 7.00000e-02

5.00000e-04 5.00000e-04 5.00000e-05 1.00000e-09 1.00000e-01

5.00000e-04 5.00000e-04 5.00000e-05 1.00000e-09 1.00000e-01

$1.67068 \mathrm{e}+001.67068 \mathrm{e}+00$ 1.67068e-01 1.00000e-09 2.12000e-01

$1.67068 \mathrm{e}+001.67068 \mathrm{e}+00$ 1.67068e-01 1.00000e-09 2.12000e-01

$1.67068 \mathrm{e}+001.67068 \mathrm{e}+00$ 1.67068e-01 1.00000e-09 2.12000e-01

$1.67068 \mathrm{e}+001.67068 \mathrm{e}+001.67068 \mathrm{e}-011.00000 \mathrm{e}-092.12000 \mathrm{e}-01$

$1.67068 \mathrm{e}+001.67068 \mathrm{e}+00$ 1.67068e-01 1.00000e-09 2.12000e-01

$1.00000 \mathrm{e}-02$ 1.00000e-02 1.00000e-03 1.00000e-09 1.00000e-01

$1.00000 \mathrm{e}+001.00000 \mathrm{e}+001.00000 \mathrm{e}-011.00000 \mathrm{e}-091.00000 \mathrm{e}-01$

$1.00000 \mathrm{e}-05$ 1.00000e-05 1.00000e-06 1.00000e-09 1.00000e-01

$1.00000 \mathrm{e}+001.00000 \mathrm{e}+001.00000 \mathrm{e}-01$ 1.00000e-09 1.00000e-01

Element: 2543 \# of layers: 14

$\mathrm{Kx} \mathrm{Ky} \mathrm{Kz}$ Ss Por

4.18127e+01 4.18127e+01 4.18127e+00 1.00000e-09 7.00000e-02 
4.18127e+01 4.18127e+01 4.18127e+00 1.00000e-09 7.00000e-02 4.18127e+01 4.18127e+01 4.18127e+00 1.00000e-09 7.00000e-02 5.00000e-04 5.00000e-04 5.00000e-05 1.00000e-09 1.00000e-01 5.00000e-04 5.00000e-04 5.00000e-05 1.00000e-09 1.00000e-01 $1.67068 \mathrm{e}+001.67068 \mathrm{e}+00$ 1.67068e-01 1.00000e-09 2.12000e-01 $1.67068 \mathrm{e}+001.67068 \mathrm{e}+00$ 1.67068e-01 1.00000e-09 2.12000e-01 $1.67068 \mathrm{e}+001.67068 \mathrm{e}+00$ 1.67068e-01 1.00000e-09 2.12000e-01 $1.67068 \mathrm{e}+001.67068 \mathrm{e}+00$ 1.67068e-01 1.00000e-09 2.12000e-01 $1.67068 \mathrm{e}+001.67068 \mathrm{e}+001.67068 \mathrm{e}-011.00000 \mathrm{e}-092.12000 \mathrm{e}-01$ $1.00000 \mathrm{e}-02$ 1.00000e-02 1.00000e-03 1.00000e-09 1.00000e-01 $1.00000 \mathrm{e}+001.00000 \mathrm{e}+001.00000 \mathrm{e}-011.00000 \mathrm{e}-091.00000 \mathrm{e}-01$ $1.00000 \mathrm{e}-05$ 1.00000e-05 1.00000e-06 1.00000e-09 1.00000e-01 $1.00000 \mathrm{e}+001.00000 \mathrm{e}+001.00000 \mathrm{e}-011.00000 \mathrm{e}-091.00000 \mathrm{e}-01$ Element: 2544 \# of layers: 14

$\mathrm{Kx} \mathrm{Ky} \mathrm{Kz}$ Ss Por

4.18127e+01 4.18127e+01 4.18127e+00 1.00000e-09 7.00000e-02 4.18127e+01 4.18127e+01 4.18127e+00 1.00000e-09 7.00000e-02 4.18127e+01 4.18127e+01 4.18127e+00 1.00000e-09 7.00000e-02 5.00000e-04 5.00000e-04 5.00000e-05 1.00000e-09 1.00000e-01 5.00000e-04 5.00000e-04 5.00000e-05 1.00000e-09 1.00000e-01

$1.67068 \mathrm{e}+001.67068 \mathrm{e}+00$ 1.67068e-01 1.00000e-09 2.12000e-01 $1.67068 \mathrm{e}+001.67068 \mathrm{e}+001.67068 \mathrm{e}-01$ 1.00000e-09 2.12000e-01 $1.67068 \mathrm{e}+001.67068 \mathrm{e}+00$ 1.67068e-01 1.00000e-09 2.12000e-01 $1.67068 \mathrm{e}+001.67068 \mathrm{e}+00$ 1.67068e-01 1.00000e-09 2.12000e-01 $1.67068 \mathrm{e}+001.67068 \mathrm{e}+001.67068 \mathrm{e}-011.00000 \mathrm{e}-092.12000 \mathrm{e}-01$ $1.00000 \mathrm{e}-02$ 1.00000e-02 1.00000e-03 1.00000e-09 1.00000e-01 $1.00000 \mathrm{e}+001.00000 \mathrm{e}+001.00000 \mathrm{e}-011.00000 \mathrm{e}-091.00000 \mathrm{e}-01$ $1.00000 \mathrm{e}-05$ 1.00000e-05 1.00000e-06 1.00000e-09 1.00000e-01 $1.00000 \mathrm{e}+001.00000 \mathrm{e}+001.00000 \mathrm{e}-011.00000 \mathrm{e}-091.00000 \mathrm{e}-01$ Element: 2545 \# of layers: 13

$\mathrm{Kx} \mathrm{Ky} \mathrm{Kz}$ Ss Por

4.18127e+01 4.18127e+01 4.18127e+00 1.00000e-09 7.00000e-02 4.18127e+01 4.18127e+01 4.18127e+00 1.00000e-09 7.00000e-02 $5.00000 \mathrm{e}-04$ 5.00000e-04 5.00000e-05 1.00000e-09 1.00000e-01 5.00000e-04 5.00000e-04 5.00000e-05 1.00000e-09 1.00000e-01 $1.67068 \mathrm{e}+001.67068 \mathrm{e}+001.67068 \mathrm{e}-011.00000 \mathrm{e}-092.12000 \mathrm{e}-01$ $1.67068 \mathrm{e}+001.67068 \mathrm{e}+001.67068 \mathrm{e}-011.00000 \mathrm{e}-092.12000 \mathrm{e}-01$ $1.67068 \mathrm{e}+001.67068 \mathrm{e}+00$ 1.67068e-01 1.00000e-09 2.12000e-01 $1.67068 \mathrm{e}+001.67068 \mathrm{e}+00$ 1.67068e-01 1.00000e-09 2.12000e-01 $1.67068 \mathrm{e}+001.67068 \mathrm{e}+00$ 1.67068e-01 1.00000e-09 2.12000e-01 $1.00000 \mathrm{e}-02$ 1.00000e-02 1.00000e-03 1.00000e-09 1.00000e-01 $1.00000 \mathrm{e}+001.00000 \mathrm{e}+001.00000 \mathrm{e}-011.00000 \mathrm{e}-091.00000 \mathrm{e}-01$ $1.00000 \mathrm{e}-05$ 1.00000e-05 1.00000e-06 1.00000e-09 1.00000e-01 $1.00000 \mathrm{e}+001.00000 \mathrm{e}+001.00000 \mathrm{e}-01$ 1.00000e-09 1.00000e-01 Element: 2546 \# of layers: 13

Kx Ky Kz Ss Por 
4.18127e+01 4.18127e+01 4.18127e+00 1.00000e-09 7.00000e-02 4.18127e+01 4.18127e+01 4.18127e+00 1.00000e-09 7.00000e-02 5.00000e-04 5.00000e-04 5.00000e-05 1.00000e-09 1.00000e-01 5.00000e-04 5.00000e-04 5.00000e-05 1.00000e-09 1.00000e-01 $1.67068 \mathrm{e}+001.67068 \mathrm{e}+00$ 1.67068e-01 1.00000e-09 2.12000e-01 $1.67068 \mathrm{e}+001.67068 \mathrm{e}+00$ 1.67068e-01 1.00000e-09 2.12000e-01 $1.67068 \mathrm{e}+001.67068 \mathrm{e}+00$ 1.67068e-01 1.00000e-09 2.12000e-01 $1.67068 \mathrm{e}+001.67068 \mathrm{e}+00$ 1.67068e-01 1.00000e-09 2.12000e-01 $1.67068 \mathrm{e}+001.67068 \mathrm{e}+001.67068 \mathrm{e}-011.00000 \mathrm{e}-092.12000 \mathrm{e}-01$ $1.00000 \mathrm{e}-02$ 1.00000e-02 1.00000e-03 1.00000e-09 1.00000e-01 $1.00000 \mathrm{e}+001.00000 \mathrm{e}+001.00000 \mathrm{e}-011.00000 \mathrm{e}-091.00000 \mathrm{e}-01$ $1.00000 \mathrm{e}-05$ 1.00000e-05 1.00000e-06 1.00000e-09 1.00000e-01 $1.00000 \mathrm{e}+001.00000 \mathrm{e}+001.00000 \mathrm{e}-011.00000 \mathrm{e}-09$ 1.00000e-01 Element: 2547 \# of layers: 13

$\mathrm{Kx} \mathrm{Ky} \mathrm{Kz}$ Ss Por

4.18127e+01 4.18127e+01 4.18127e+00 1.00000e-09 7.00000e-02 4.18127e+01 4.18127e+01 4.18127e+00 1.00000e-09 7.00000e-02 5.00000e-04 5.00000e-04 5.00000e-05 1.00000e-09 1.00000e-01 5.00000e-04 5.00000e-04 5.00000e-05 1.00000e-09 1.00000e-01 $1.67068 \mathrm{e}+001.67068 \mathrm{e}+00$ 1.67068e-01 1.00000e-09 2.12000e-01 $1.67068 \mathrm{e}+001.67068 \mathrm{e}+00$ 1.67068e-01 1.00000e-09 2.12000e-01 $1.67068 \mathrm{e}+001.67068 \mathrm{e}+001.67068 \mathrm{e}-01$ 1.00000e-09 2.12000e-01 $1.67068 \mathrm{e}+001.67068 \mathrm{e}+00$ 1.67068e-01 1.00000e-09 2.12000e-01 $1.67068 \mathrm{e}+001.67068 \mathrm{e}+00$ 1.67068e-01 1.00000e-09 2.12000e-01 $1.00000 \mathrm{e}-02$ 1.00000e-02 1.00000e-03 1.00000e-09 1.00000e-01 $1.00000 \mathrm{e}+001.00000 \mathrm{e}+001.00000 \mathrm{e}-011.00000 \mathrm{e}-091.00000 \mathrm{e}-01$ $1.00000 \mathrm{e}-05$ 1.00000e-05 1.00000e-06 1.00000e-09 1.00000e-01 $1.00000 \mathrm{e}+001.00000 \mathrm{e}+001.00000 \mathrm{e}-011.00000 \mathrm{e}-09$ 1.00000e-01 Element: 2548 \# of layers: 13

$\mathrm{Kx} \mathrm{Ky} \mathrm{Kz}$ Ss Por

4.18127e+01 4.18127e+01 4.18127e+00 1.00000e-09 7.00000e-02 4.18127e+01 4.18127e+01 4.18127e+00 1.00000e-09 7.00000e-02 5.00000e-04 5.00000e-04 5.00000e-05 1.00000e-09 1.00000e-01 5.00000e-04 5.00000e-04 5.00000e-05 1.00000e-09 1.00000e-01 $1.67068 \mathrm{e}+001.67068 \mathrm{e}+00$ 1.67068e-01 1.00000e-09 2.12000e-01 $1.67068 \mathrm{e}+001.67068 \mathrm{e}+00$ 1.67068e-01 1.00000e-09 2.12000e-01 $1.67068 \mathrm{e}+001.67068 \mathrm{e}+00$ 1.67068e-01 1.00000e-09 2.12000e-01 $1.67068 \mathrm{e}+001.67068 \mathrm{e}+001.67068 \mathrm{e}-011.00000 \mathrm{e}-092.12000 \mathrm{e}-01$ $1.67068 \mathrm{e}+001.67068 \mathrm{e}+001.67068 \mathrm{e}-01$ 1.00000e-09 2.12000e-01 $1.00000 \mathrm{e}-02$ 1.00000e-02 1.00000e-03 1.00000e-09 1.00000e-01 $1.00000 \mathrm{e}+001.00000 \mathrm{e}+001.00000 \mathrm{e}-011.00000 \mathrm{e}-091.00000 \mathrm{e}-01$ $1.00000 \mathrm{e}-05$ 1.00000e-05 1.00000e-06 1.00000e-09 1.00000e-01 $1.00000 \mathrm{e}+001.00000 \mathrm{e}+001.00000 \mathrm{e}-011.00000 \mathrm{e}-091.00000 \mathrm{e}-01$ Element: 2549 \# of layers: 13

$\mathrm{Kx} \mathrm{Ky} \mathrm{Kz}$ Ss Por

4.18127e+01 4.18127e+01 4.18127e+00 1.00000e-09 7.00000e-02 
4.18127e+01 4.18127e+01 4.18127e+00 1.00000e-09 7.00000e-02 5.00000e-04 5.00000e-04 5.00000e-05 1.00000e-09 1.00000e-01 5.00000e-04 5.00000e-04 5.00000e-05 1.00000e-09 1.00000e-01

$1.67068 \mathrm{e}+001.67068 \mathrm{e}+00$ 1.67068e-01 1.00000e-09 2.12000e-01 $1.67068 \mathrm{e}+001.67068 \mathrm{e}+00$ 1.67068e-01 1.00000e-09 2.12000e-01 $1.67068 \mathrm{e}+001.67068 \mathrm{e}+00$ 1.67068e-01 1.00000e-09 2.12000e-01 $1.67068 \mathrm{e}+001.67068 \mathrm{e}+00$ 1.67068e-01 1.00000e-09 2.12000e-01 $1.67068 \mathrm{e}+001.67068 \mathrm{e}+00$ 1.67068e-01 1.00000e-09 2.12000e-01 $1.00000 \mathrm{e}-02$ 1.00000e-02 1.00000e-03 1.00000e-09 1.00000e-01 $1.00000 \mathrm{e}+001.00000 \mathrm{e}+001.00000 \mathrm{e}-011.00000 \mathrm{e}-091.00000 \mathrm{e}-01$ $1.00000 \mathrm{e}-05$ 1.00000e-05 1.00000e-06 1.00000e-09 1.00000e-01 $1.00000 \mathrm{e}+001.00000 \mathrm{e}+001.00000 \mathrm{e}-011.00000 \mathrm{e}-091.00000 \mathrm{e}-01$ Element: 2550 \# of layers: 13

$\mathrm{Kx} \mathrm{Ky} \mathrm{Kz}$ Ss Por

4.18127e+01 4.18127e+01 4.18127e+00 1.00000e-09 7.00000e-02 $4.18127 \mathrm{e}+014.18127 \mathrm{e}+014.18127 \mathrm{e}+00$ 1.00000e-09 7.00000e-02 5.00000e-04 5.00000e-04 5.00000e-05 1.00000e-09 1.00000e-01 5.00000e-04 5.00000e-04 5.00000e-05 1.00000e-09 1.00000e-01 $1.67068 \mathrm{e}+001.67068 \mathrm{e}+00$ 1.67068e-01 1.00000e-09 2.12000e-01 $1.67068 \mathrm{e}+001.67068 \mathrm{e}+00$ 1.67068e-01 1.00000e-09 2.12000e-01 $1.67068 \mathrm{e}+001.67068 \mathrm{e}+00$ 1.67068e-01 1.00000e-09 2.12000e-01 $1.67068 \mathrm{e}+00$ 1.67068e+00 1.67068e-01 1.00000e-09 2.12000e-01 $1.67068 \mathrm{e}+001.67068 \mathrm{e}+00$ 1.67068e-01 1.00000e-09 2.12000e-01 $1.00000 \mathrm{e}-02$ 1.00000e-02 1.00000e-03 1.00000e-09 1.00000e-01 $1.00000 \mathrm{e}+001.00000 \mathrm{e}+001.00000 \mathrm{e}-011.00000 \mathrm{e}-091.00000 \mathrm{e}-01$ $1.00000 \mathrm{e}-05$ 1.00000e-05 1.00000e-06 1.00000e-09 1.00000e-01 $1.00000 \mathrm{e}+001.00000 \mathrm{e}+001.00000 \mathrm{e}-011.00000 \mathrm{e}-091.00000 \mathrm{e}-01$ Element: 2551 \# of layers: 14

$\mathrm{Kx} \mathrm{Ky} \mathrm{Kz}$ Ss Por

$2.26331 \mathrm{e}+012.26331 \mathrm{e}+012.26331 \mathrm{e}+00$ 1.00000e-09 7.00000e-02

$2.26331 \mathrm{e}+012.26331 \mathrm{e}+012.26331 \mathrm{e}+00$ 1.00000e-09 7.00000e-02

$2.26331 \mathrm{e}+012.26331 \mathrm{e}+012.26331 \mathrm{e}+00$ 1.00000e-09 7.00000e-02 5.00000e-04 5.00000e-04 5.00000e-05 1.00000e-09 1.00000e-01 5.00000e-04 5.00000e-04 5.00000e-05 1.00000e-09 1.00000e-01 9.04339e-01 9.04339e-01 9.04339e-02 1.00000e-09 2.12000e-01 9.04339e-01 9.04339e-01 9.04339e-02 1.00000e-09 2.12000e-01 9.04339e-01 9.04339e-01 9.04339e-02 1.00000e-09 2.12000e-01 9.04339e-01 9.04339e-01 9.04339e-02 1.00000e-09 2.12000e-01 9.04339e-01 9.04339e-01 9.04339e-02 1.00000e-09 2.12000e-01 $1.00000 \mathrm{e}-02$ 1.00000e-02 1.00000e-03 1.00000e-09 1.00000e-01 $1.00000 \mathrm{e}+001.00000 \mathrm{e}+001.00000 \mathrm{e}-011.00000 \mathrm{e}-091.00000 \mathrm{e}-01$ $1.00000 \mathrm{e}-05$ 1.00000e-05 1.00000e-06 1.00000e-09 1.00000e-01 $1.00000 \mathrm{e}+001.00000 \mathrm{e}+001.00000 \mathrm{e}-01$ 1.00000e-09 1.00000e-01 Element: 2552 \# of layers: 14

$\mathrm{Kx} \mathrm{Ky} \mathrm{Kz}$ Ss Por

2.26331e+01 2.26331e+01 2.26331e+00 1.00000e-09 7.00000e-02 
$2.26331 \mathrm{e}+012.26331 \mathrm{e}+012.26331 \mathrm{e}+00$ 1.00000e-09 7.00000e-02 $2.26331 \mathrm{e}+012.26331 \mathrm{e}+012.26331 \mathrm{e}+00$ 1.00000e-09 7.00000e-02 5.00000e-04 5.00000e-04 5.00000e-05 1.00000e-09 1.00000e-01 5.00000e-04 5.00000e-04 5.00000e-05 1.00000e-09 1.00000e-01 9.04339e-01 9.04339e-01 9.04339e-02 1.00000e-09 2.12000e-01 9.04339e-01 9.04339e-01 9.04339e-02 1.00000e-09 2.12000e-01 9.04339e-01 9.04339e-01 9.04339e-02 1.00000e-09 2.12000e-01 9.04339e-01 9.04339e-01 9.04339e-02 1.00000e-09 2.12000e-01 9.04339e-01 9.04339e-01 9.04339e-02 1.00000e-09 2.12000e-01 $1.00000 \mathrm{e}-02$ 1.00000e-02 1.00000e-03 1.00000e-09 1.00000e-01 $1.00000 \mathrm{e}+001.00000 \mathrm{e}+001.00000 \mathrm{e}-011.00000 \mathrm{e}-091.00000 \mathrm{e}-01$ $1.00000 \mathrm{e}-05$ 1.00000e-05 1.00000e-06 1.00000e-09 1.00000e-01 $1.00000 \mathrm{e}+001.00000 \mathrm{e}+001.00000 \mathrm{e}-011.00000 \mathrm{e}-091.00000 \mathrm{e}-01$ Element: 2553 \# of layers: 14

$\mathrm{Kx} \mathrm{Ky} \mathrm{Kz}$ Ss Por

$2.26331 \mathrm{e}+012.26331 \mathrm{e}+012.26331 \mathrm{e}+00$ 1.00000e-09 7.00000e-02 $2.26331 \mathrm{e}+012.26331 \mathrm{e}+012.26331 \mathrm{e}+00$ 1.00000e-09 7.00000e-02

$2.26331 \mathrm{e}+012.26331 \mathrm{e}+012.26331 \mathrm{e}+001.00000 \mathrm{e}-09$ 7.00000e-02 5.00000e-04 5.00000e-04 5.00000e-05 1.00000e-09 1.00000e-01 5.00000e-04 5.00000e-04 5.00000e-05 1.00000e-09 1.00000e-01 9.04339e-01 9.04339e-01 9.04339e-02 1.00000e-09 2.12000e-01 9.04339e-01 9.04339e-01 9.04339e-02 1.00000e-09 2.12000e-01 9.04339e-01 9.04339e-01 9.04339e-02 1.00000e-09 2.12000e-01 9.04339e-01 9.04339e-01 9.04339e-02 1.00000e-09 2.12000e-01 9.04339e-01 9.04339e-01 9.04339e-02 1.00000e-09 2.12000e-01 $1.00000 \mathrm{e}-02$ 1.00000e-02 1.00000e-03 1.00000e-09 1.00000e-01 $1.00000 \mathrm{e}+001.00000 \mathrm{e}+001.00000 \mathrm{e}-011.00000 \mathrm{e}-091.00000 \mathrm{e}-01$ $1.00000 \mathrm{e}-05$ 1.00000e-05 1.00000e-06 1.00000e-09 1.00000e-01 $1.00000 \mathrm{e}+001.00000 \mathrm{e}+001.00000 \mathrm{e}-011.00000 \mathrm{e}-091.00000 \mathrm{e}-01$ Element: 2554 \# of layers: 13

$\mathrm{Kx} \mathrm{Ky} \mathrm{Kz}$ Ss Por

$2.26331 \mathrm{e}+012.26331 \mathrm{e}+012.26331 \mathrm{e}+00$ 1.00000e-09 7.00000e-02 $2.26331 \mathrm{e}+012.26331 \mathrm{e}+012.26331 \mathrm{e}+001.00000 \mathrm{e}-09$ 7.00000e-02 5.00000e-04 5.00000e-04 5.00000e-05 1.00000e-09 1.00000e-01 5.00000e-04 5.00000e-04 5.00000e-05 1.00000e-09 1.00000e-01 9.04339e-01 9.04339e-01 9.04339e-02 1.00000e-09 2.12000e-01 9.04339e-01 9.04339e-01 9.04339e-02 1.00000e-09 2.12000e-01 9.04339e-01 9.04339e-01 9.04339e-02 1.00000e-09 2.12000e-01 9.04339e-01 9.04339e-01 9.04339e-02 1.00000e-09 2.12000e-01 9.04339e-01 9.04339e-01 9.04339e-02 1.00000e-09 2.12000e-01 $1.00000 \mathrm{e}-02$ 1.00000e-02 1.00000e-03 1.00000e-09 1.00000e-01 $1.00000 \mathrm{e}+001.00000 \mathrm{e}+001.00000 \mathrm{e}-011.00000 \mathrm{e}-091.00000 \mathrm{e}-01$ $1.00000 \mathrm{e}-05$ 1.00000e-05 1.00000e-06 1.00000e-09 1.00000e-01 $1.00000 \mathrm{e}+001.00000 \mathrm{e}+001.00000 \mathrm{e}-01$ 1.00000e-09 1.00000e-01 Element: 2555 \# of layers: 13

Kx Ky Kz Ss Por 
$2.26331 \mathrm{e}+012.26331 \mathrm{e}+012.26331 \mathrm{e}+00$ 1.00000e-09 7.00000e-02 $2.26331 \mathrm{e}+012.26331 \mathrm{e}+012.26331 \mathrm{e}+001.00000 \mathrm{e}-09$ 7.00000e-02 5.00000e-04 5.00000e-04 5.00000e-05 1.00000e-09 1.00000e-01 5.00000e-04 5.00000e-04 5.00000e-05 1.00000e-09 1.00000e-01 9.04339e-01 9.04339e-01 9.04339e-02 1.00000e-09 2.12000e-01 9.04339e-01 9.04339e-01 9.04339e-02 1.00000e-09 2.12000e-01 9.04339e-01 9.04339e-01 9.04339e-02 1.00000e-09 2.12000e-01 9.04339e-01 9.04339e-01 9.04339e-02 1.00000e-09 2.12000e-01 9.04339e-01 9.04339e-01 9.04339e-02 1.00000e-09 2.12000e-01 $1.00000 \mathrm{e}-02$ 1.00000e-02 1.00000e-03 1.00000e-09 1.00000e-01 $1.00000 \mathrm{e}+001.00000 \mathrm{e}+001.00000 \mathrm{e}-011.00000 \mathrm{e}-091.00000 \mathrm{e}-01$ $1.00000 \mathrm{e}-05$ 1.00000e-05 1.00000e-06 1.00000e-09 1.00000e-01 $1.00000 \mathrm{e}+001.00000 \mathrm{e}+001.00000 \mathrm{e}-011.00000 \mathrm{e}-09$ 1.00000e-01 Element: 2556 \# of layers: 13

$\mathrm{Kx} \mathrm{Ky} \mathrm{Kz}$ Ss Por

$2.26331 \mathrm{e}+012.26331 \mathrm{e}+012.26331 \mathrm{e}+00$ 1.00000e-09 7.00000e-02 $2.26331 \mathrm{e}+012.26331 \mathrm{e}+012.26331 \mathrm{e}+001.00000 \mathrm{e}-09$ 7.00000e-02 5.00000e-04 5.00000e-04 5.00000e-05 1.00000e-09 1.00000e-01 5.00000e-04 5.00000e-04 5.00000e-05 1.00000e-09 1.00000e-01 9.04339e-01 9.04339e-01 9.04339e-02 1.00000e-09 2.12000e-01 9.04339e-01 9.04339e-01 9.04339e-02 1.00000e-09 2.12000e-01 9.04339e-01 9.04339e-01 9.04339e-02 1.00000e-09 2.12000e-01 9.04339e-01 9.04339e-01 9.04339e-02 1.00000e-09 2.12000e-01 9.04339e-01 9.04339e-01 9.04339e-02 1.00000e-09 2.12000e-01 $1.00000 \mathrm{e}-02$ 1.00000e-02 1.00000e-03 1.00000e-09 1.00000e-01 $1.00000 \mathrm{e}+001.00000 \mathrm{e}+001.00000 \mathrm{e}-011.00000 \mathrm{e}-091.00000 \mathrm{e}-01$ $1.00000 \mathrm{e}-05$ 1.00000e-05 1.00000e-06 1.00000e-09 1.00000e-01 $1.00000 \mathrm{e}+001.00000 \mathrm{e}+001.00000 \mathrm{e}-011.00000 \mathrm{e}-09$ 1.00000e-01 Element: 2557 \# of layers: 13

$\mathrm{Kx} \mathrm{Ky} \mathrm{Kz}$ Ss Por

$2.26331 \mathrm{e}+012.26331 \mathrm{e}+012.26331 \mathrm{e}+00$ 1.00000e-09 7.00000e-02 $2.26331 \mathrm{e}+012.26331 \mathrm{e}+012.26331 \mathrm{e}+00$ 1.00000e-09 7.00000e-02 5.00000e-04 5.00000e-04 5.00000e-05 1.00000e-09 1.00000e-01 5.00000e-04 5.00000e-04 5.00000e-05 1.00000e-09 1.00000e-01 9.04339e-01 9.04339e-01 9.04339e-02 1.00000e-09 2.12000e-01 9.04339e-01 9.04339e-01 9.04339e-02 1.00000e-09 2.12000e-01 9.04339e-01 9.04339e-01 9.04339e-02 1.00000e-09 2.12000e-01 9.04339e-01 9.04339e-01 9.04339e-02 1.00000e-09 2.12000e-01 9.04339e-01 9.04339e-01 9.04339e-02 1.00000e-09 2.12000e-01 $1.00000 \mathrm{e}-02$ 1.00000e-02 1.00000e-03 1.00000e-09 1.00000e-01 $1.00000 \mathrm{e}+001.00000 \mathrm{e}+001.00000 \mathrm{e}-011.00000 \mathrm{e}-091.00000 \mathrm{e}-01$ $1.00000 \mathrm{e}-05$ 1.00000e-05 1.00000e-06 1.00000e-09 1.00000e-01 $1.00000 \mathrm{e}+001.00000 \mathrm{e}+001.00000 \mathrm{e}-011.00000 \mathrm{e}-091.00000 \mathrm{e}-01$ Element: 2558 \# of layers: 13

$\mathrm{Kx} \mathrm{Ky} \mathrm{Kz}$ Ss Por

2.26331e+01 2.26331e+01 2.26331e+00 1.00000e-09 7.00000e-02 
$2.26331 \mathrm{e}+012.26331 \mathrm{e}+012.26331 \mathrm{e}+001.00000 \mathrm{e}-09$ 7.00000e-02

5.00000e-04 5.00000e-04 5.00000e-05 1.00000e-09 1.00000e-01

5.00000e-04 5.00000e-04 5.00000e-05 1.00000e-09 1.00000e-01

9.04339e-01 9.04339e-01 9.04339e-02 1.00000e-09 2.12000e-01

9.04339e-01 9.04339e-01 9.04339e-02 1.00000e-09 2.12000e-01

9.04339e-01 9.04339e-01 9.04339e-02 1.00000e-09 2.12000e-01

9.04339e-01 9.04339e-01 9.04339e-02 1.00000e-09 2.12000e-01

9.04339e-01 9.04339e-01 9.04339e-02 1.00000e-09 2.12000e-01

$1.00000 \mathrm{e}-02$ 1.00000e-02 1.00000e-03 1.00000e-09 1.00000e-01

$1.00000 \mathrm{e}+001.00000 \mathrm{e}+001.00000 \mathrm{e}-011.00000 \mathrm{e}-091.00000 \mathrm{e}-01$

$1.00000 \mathrm{e}-05$ 1.00000e-05 1.00000e-06 1.00000e-09 1.00000e-01

$1.00000 \mathrm{e}+001.00000 \mathrm{e}+001.00000 \mathrm{e}-011.00000 \mathrm{e}-091.00000 \mathrm{e}-01$

Element: 2559 \# of layers: 13

$\mathrm{Kx} \mathrm{Ky} \mathrm{Kz}$ Ss Por

$2.26331 \mathrm{e}+012.26331 \mathrm{e}+012.26331 \mathrm{e}+00$ 1.00000e-09 7.00000e-02

$2.26331 \mathrm{e}+012.26331 \mathrm{e}+012.26331 \mathrm{e}+00$ 1.00000e-09 7.00000e-02

5.00000e-04 5.00000e-04 5.00000e-05 1.00000e-09 1.00000e-01

5.00000e-04 5.00000e-04 5.00000e-05 1.00000e-09 1.00000e-01

9.04339e-01 9.04339e-01 9.04339e-02 1.00000e-09 2.12000e-01

9.04339e-01 9.04339e-01 9.04339e-02 1.00000e-09 2.12000e-01

9.04339e-01 9.04339e-01 9.04339e-02 1.00000e-09 2.12000e-01

9.04339e-01 9.04339e-01 9.04339e-02 1.00000e-09 2.12000e-01

9.04339e-01 9.04339e-01 9.04339e-02 1.00000e-09 2.12000e-01

1.00000e-02 1.00000e-02 1.00000e-03 1.00000e-09 1.00000e-01

$1.00000 \mathrm{e}+001.00000 \mathrm{e}+001.00000 \mathrm{e}-011.00000 \mathrm{e}-091.00000 \mathrm{e}-01$

$1.00000 \mathrm{e}-05$ 1.00000e-05 1.00000e-06 1.00000e-09 1.00000e-01

$1.00000 \mathrm{e}+001.00000 \mathrm{e}+001.00000 \mathrm{e}-011.00000 \mathrm{e}-091.00000 \mathrm{e}-01$

Element: 2560 \# of layers: 14

Kx Ky Kz Ss Por

$2.56875 \mathrm{e}+012.56875 \mathrm{e}+012.56875 \mathrm{e}+00$ 1.00000e-09 7.00000e-02

$2.56875 \mathrm{e}+012.56875 \mathrm{e}+012.56875 \mathrm{e}+001.00000 \mathrm{e}-09$ 7.00000e-02

$2.56875 \mathrm{e}+012.56875 \mathrm{e}+012.56875 \mathrm{e}+00$ 1.00000e-09 7.00000e-02

5.00000e-04 5.00000e-04 5.00000e-05 1.00000e-09 1.00000e-01

5.00000e-04 5.00000e-04 5.00000e-05 1.00000e-09 1.00000e-01

$1.02638 \mathrm{e}+001.02638 \mathrm{e}+00$ 1.02638e-01 1.00000e-09 2.12000e-01

$1.02638 \mathrm{e}+001.02638 \mathrm{e}+00$ 1.02638e-01 1.00000e-09 2.12000e-01

$1.02638 \mathrm{e}+00$ 1.02638e+00 1.02638e-01 1.00000e-09 2.12000e-01

$1.02638 \mathrm{e}+001.02638 \mathrm{e}+00$ 1.02638e-01 1.00000e-09 2.12000e-01

$1.02638 \mathrm{e}+001.02638 \mathrm{e}+00$ 1.02638e-01 1.00000e-09 2.12000e-01

$1.00000 \mathrm{e}-02$ 1.00000e-02 1.00000e-03 1.00000e-09 1.00000e-01

$1.00000 \mathrm{e}+001.00000 \mathrm{e}+001.00000 \mathrm{e}-01$ 1.00000e-09 1.00000e-01

$1.00000 \mathrm{e}-05$ 1.00000e-05 1.00000e-06 1.00000e-09 1.00000e-01

$1.00000 \mathrm{e}+001.00000 \mathrm{e}+001.00000 \mathrm{e}-01$ 1.00000e-09 1.00000e-01

Element: 2561 \# of layers: 14

$\mathrm{Kx} \mathrm{Ky} \mathrm{Kz}$ Ss Por

$2.56875 \mathrm{e}+012.56875 \mathrm{e}+012.56875 \mathrm{e}+00$ 1.00000e-09 7.00000e-02 
$2.56875 \mathrm{e}+012.56875 \mathrm{e}+012.56875 \mathrm{e}+00$ 1.00000e-09 7.00000e-02 $2.56875 \mathrm{e}+012.56875 \mathrm{e}+012.56875 \mathrm{e}+001.00000 \mathrm{e}-09$ 7.00000e-02 5.00000e-04 5.00000e-04 5.00000e-05 1.00000e-09 1.00000e-01 5.00000e-04 5.00000e-04 5.00000e-05 1.00000e-09 1.00000e-01 $1.02638 \mathrm{e}+001.02638 \mathrm{e}+00$ 1.02638e-01 1.00000e-09 2.12000e-01 $1.02638 \mathrm{e}+001.02638 \mathrm{e}+00$ 1.02638e-01 1.00000e-09 2.12000e-01 $1.02638 \mathrm{e}+001.02638 \mathrm{e}+00$ 1.02638e-01 1.00000e-09 2.12000e-01 $1.02638 \mathrm{e}+001.02638 \mathrm{e}+00$ 1.02638e-01 1.00000e-09 2.12000e-01 $1.02638 \mathrm{e}+00$ 1.02638e+00 1.02638e-01 1.00000e-09 2.12000e-01 $1.00000 \mathrm{e}-02$ 1.00000e-02 1.00000e-03 1.00000e-09 1.00000e-01 $1.00000 \mathrm{e}+001.00000 \mathrm{e}+001.00000 \mathrm{e}-011.00000 \mathrm{e}-091.00000 \mathrm{e}-01$ $1.00000 \mathrm{e}-05$ 1.00000e-05 1.00000e-06 1.00000e-09 1.00000e-01 $1.00000 \mathrm{e}+001.00000 \mathrm{e}+001.00000 \mathrm{e}-011.00000 \mathrm{e}-091.00000 \mathrm{e}-01$ Element: 2562 \# of layers: 14

$\mathrm{Kx} \mathrm{Ky} \mathrm{Kz}$ Ss Por

$2.56875 \mathrm{e}+012.56875 \mathrm{e}+012.56875 \mathrm{e}+00$ 1.00000e-09 7.00000e-02 $2.56875 \mathrm{e}+012.56875 \mathrm{e}+012.56875 \mathrm{e}+001.00000 \mathrm{e}-09$ 7.00000e-02

$2.56875 \mathrm{e}+012.56875 \mathrm{e}+012.56875 \mathrm{e}+001.00000 \mathrm{e}-09$ 7.00000e-02 5.00000e-04 5.00000e-04 5.00000e-05 1.00000e-09 1.00000e-01 5.00000e-04 5.00000e-04 5.00000e-05 1.00000e-09 1.00000e-01 $1.02638 \mathrm{e}+001.02638 \mathrm{e}+00$ 1.02638e-01 1.00000e-09 2.12000e-01 $1.02638 \mathrm{e}+00$ 1.02638e+00 1.02638e-01 1.00000e-09 2.12000e-01 $1.02638 \mathrm{e}+001.02638 \mathrm{e}+00$ 1.02638e-01 1.00000e-09 2.12000e-01 $1.02638 \mathrm{e}+001.02638 \mathrm{e}+00$ 1.02638e-01 1.00000e-09 2.12000e-01 $1.02638 \mathrm{e}+001.02638 \mathrm{e}+00$ 1.02638e-01 1.00000e-09 2.12000e-01 $1.00000 \mathrm{e}-021.00000 \mathrm{e}-02$ 1.00000e-03 1.00000e-09 1.00000e-01 $1.00000 \mathrm{e}+001.00000 \mathrm{e}+001.00000 \mathrm{e}-011.00000 \mathrm{e}-091.00000 \mathrm{e}-01$ $1.00000 \mathrm{e}-05$ 1.00000e-05 1.00000e-06 1.00000e-09 1.00000e-01 $1.00000 \mathrm{e}+001.00000 \mathrm{e}+001.00000 \mathrm{e}-011.00000 \mathrm{e}-091.00000 \mathrm{e}-01$ Element: 2563 \# of layers: 13

$\mathrm{Kx} \mathrm{Ky} \mathrm{Kz}$ Ss Por

$2.56875 \mathrm{e}+012.56875 \mathrm{e}+012.56875 \mathrm{e}+00$ 1.00000e-09 7.00000e-02 $2.56875 \mathrm{e}+012.56875 \mathrm{e}+012.56875 \mathrm{e}+001.00000 \mathrm{e}-09$ 7.00000e-02 $5.00000 \mathrm{e}-04$ 5.00000e-04 5.00000e-05 1.00000e-09 1.00000e-01 5.00000e-04 5.00000e-04 5.00000e-05 1.00000e-09 1.00000e-01 $1.02638 \mathrm{e}+001.02638 \mathrm{e}+00$ 1.02638e-01 1.00000e-09 2.12000e-01 $1.02638 \mathrm{e}+001.02638 \mathrm{e}+00$ 1.02638e-01 1.00000e-09 2.12000e-01 $1.02638 \mathrm{e}+001.02638 \mathrm{e}+00$ 1.02638e-01 1.00000e-09 2.12000e-01 $1.02638 \mathrm{e}+001.02638 \mathrm{e}+00$ 1.02638e-01 1.00000e-09 2.12000e-01 $1.02638 \mathrm{e}+001.02638 \mathrm{e}+00$ 1.02638e-01 1.00000e-09 2.12000e-01 $1.00000 \mathrm{e}-02$ 1.00000e-02 1.00000e-03 1.00000e-09 1.00000e-01 $1.00000 \mathrm{e}+001.00000 \mathrm{e}+001.00000 \mathrm{e}-011.00000 \mathrm{e}-091.00000 \mathrm{e}-01$ $1.00000 \mathrm{e}-05$ 1.00000e-05 1.00000e-06 1.00000e-09 1.00000e-01 $1.00000 \mathrm{e}+001.00000 \mathrm{e}+001.00000 \mathrm{e}-01$ 1.00000e-09 1.00000e-01 Element: 2564 \# of layers: 13

Kx Ky Kz Ss Por 
$2.56875 \mathrm{e}+012.56875 \mathrm{e}+012.56875 \mathrm{e}+00$ 1.00000e-09 7.00000e-02 $2.56875 \mathrm{e}+012.56875 \mathrm{e}+012.56875 \mathrm{e}+001.00000 \mathrm{e}-09$ 7.00000e-02 5.00000e-04 5.00000e-04 5.00000e-05 1.00000e-09 1.00000e-01 5.00000e-04 5.00000e-04 5.00000e-05 1.00000e-09 1.00000e-01 $1.02638 \mathrm{e}+001.02638 \mathrm{e}+00$ 1.02638e-01 1.00000e-09 2.12000e-01 $1.02638 \mathrm{e}+001.02638 \mathrm{e}+00$ 1.02638e-01 1.00000e-09 2.12000e-01 $1.02638 \mathrm{e}+001.02638 \mathrm{e}+00$ 1.02638e-01 1.00000e-09 2.12000e-01 $1.02638 \mathrm{e}+001.02638 \mathrm{e}+00$ 1.02638e-01 1.00000e-09 2.12000e-01 $1.02638 \mathrm{e}+00$ 1.02638e+00 1.02638e-01 1.00000e-09 2.12000e-01 $1.00000 \mathrm{e}-02$ 1.00000e-02 1.00000e-03 1.00000e-09 1.00000e-01 $1.00000 \mathrm{e}+001.00000 \mathrm{e}+001.00000 \mathrm{e}-011.00000 \mathrm{e}-091.00000 \mathrm{e}-01$ $1.00000 \mathrm{e}-05$ 1.00000e-05 1.00000e-06 1.00000e-09 1.00000e-01 $1.00000 \mathrm{e}+001.00000 \mathrm{e}+001.00000 \mathrm{e}-01$ 1.00000e-09 1.00000e-01 Element: 2565 \# of layers: 13

$\mathrm{Kx} \mathrm{Ky} \mathrm{Kz}$ Ss Por

$2.56875 \mathrm{e}+012.56875 \mathrm{e}+012.56875 \mathrm{e}+00$ 1.00000e-09 7.00000e-02 $2.56875 \mathrm{e}+012.56875 \mathrm{e}+012.56875 \mathrm{e}+001.00000 \mathrm{e}-09$ 7.00000e-02 5.00000e-04 5.00000e-04 5.00000e-05 1.00000e-09 1.00000e-01 $5.00000 \mathrm{e}-04$ 5.00000e-04 5.00000e-05 1.00000e-09 1.00000e-01 $1.02638 \mathrm{e}+001.02638 \mathrm{e}+00$ 1.02638e-01 1.00000e-09 2.12000e-01 $1.02638 \mathrm{e}+001.02638 \mathrm{e}+001.02638 \mathrm{e}-011.00000 \mathrm{e}-092.12000 \mathrm{e}-01$ $1.02638 \mathrm{e}+00$ 1.02638e+00 1.02638e-01 1.00000e-09 2.12000e-01 $1.02638 \mathrm{e}+001.02638 \mathrm{e}+00$ 1.02638e-01 1.00000e-09 2.12000e-01 $1.02638 \mathrm{e}+001.02638 \mathrm{e}+00$ 1.02638e-01 1.00000e-09 2.12000e-01 $1.00000 \mathrm{e}-02$ 1.00000e-02 1.00000e-03 1.00000e-09 1.00000e-01 $1.00000 \mathrm{e}+001.00000 \mathrm{e}+001.00000 \mathrm{e}-011.00000 \mathrm{e}-091.00000 \mathrm{e}-01$ $1.00000 \mathrm{e}-05$ 1.00000e-05 1.00000e-06 1.00000e-09 1.00000e-01 $1.00000 \mathrm{e}+001.00000 \mathrm{e}+001.00000 \mathrm{e}-011.00000 \mathrm{e}-09$ 1.00000e-01 Element: 2566 \# of layers: 13

$\mathrm{Kx} \mathrm{Ky} \mathrm{Kz}$ Ss Por

$2.56875 \mathrm{e}+012.56875 \mathrm{e}+012.56875 \mathrm{e}+00$ 1.00000e-09 7.00000e-02 $2.56875 \mathrm{e}+012.56875 \mathrm{e}+012.56875 \mathrm{e}+001.00000 \mathrm{e}-09$ 7.00000e-02 5.00000e-04 5.00000e-04 5.00000e-05 1.00000e-09 1.00000e-01 5.00000e-04 5.00000e-04 5.00000e-05 1.00000e-09 1.00000e-01 $1.02638 \mathrm{e}+001.02638 \mathrm{e}+00$ 1.02638e-01 1.00000e-09 2.12000e-01 $1.02638 \mathrm{e}+001.02638 \mathrm{e}+00$ 1.02638e-01 1.00000e-09 2.12000e-01 $1.02638 \mathrm{e}+001.02638 \mathrm{e}+00$ 1.02638e-01 1.00000e-09 2.12000e-01 $1.02638 \mathrm{e}+001.02638 \mathrm{e}+001.02638 \mathrm{e}-011.00000 \mathrm{e}-092.12000 \mathrm{e}-01$ $1.02638 \mathrm{e}+001.02638 \mathrm{e}+00$ 1.02638e-01 1.00000e-09 2.12000e-01 $1.00000 \mathrm{e}-02$ 1.00000e-02 1.00000e-03 1.00000e-09 1.00000e-01 $1.00000 \mathrm{e}+001.00000 \mathrm{e}+001.00000 \mathrm{e}-011.00000 \mathrm{e}-091.00000 \mathrm{e}-01$ $1.00000 \mathrm{e}-05$ 1.00000e-05 1.00000e-06 1.00000e-09 1.00000e-01 $1.00000 \mathrm{e}+001.00000 \mathrm{e}+001.00000 \mathrm{e}-01$ 1.00000e-09 1.00000e-01 Element: 2567 \# of layers: 13

$\mathrm{Kx} \mathrm{Ky} \mathrm{Kz}$ Ss Por $2.56875 e+012.56875 e+012.56875 e+001.00000 e-09$ 7.00000e-02 
$2.56875 \mathrm{e}+012.56875 \mathrm{e}+012.56875 \mathrm{e}+001.00000 \mathrm{e}-09$ 7.00000e-02 5.00000e-04 5.00000e-04 5.00000e-05 1.00000e-09 1.00000e-01 5.00000e-04 5.00000e-04 5.00000e-05 1.00000e-09 1.00000e-01 $1.02638 \mathrm{e}+001.02638 \mathrm{e}+00$ 1.02638e-01 1.00000e-09 2.12000e-01 $1.02638 \mathrm{e}+001.02638 \mathrm{e}+00$ 1.02638e-01 1.00000e-09 2.12000e-01 $1.02638 \mathrm{e}+001.02638 \mathrm{e}+00$ 1.02638e-01 1.00000e-09 2.12000e-01 $1.02638 \mathrm{e}+001.02638 \mathrm{e}+00$ 1.02638e-01 1.00000e-09 2.12000e-01 $1.02638 \mathrm{e}+001.02638 \mathrm{e}+00$ 1.02638e-01 1.00000e-09 2.12000e-01 $1.00000 \mathrm{e}-02$ 1.00000e-02 1.00000e-03 1.00000e-09 1.00000e-01 $1.00000 \mathrm{e}+001.00000 \mathrm{e}+001.00000 \mathrm{e}-011.00000 \mathrm{e}-091.00000 \mathrm{e}-01$ $1.00000 \mathrm{e}-05$ 1.00000e-05 1.00000e-06 1.00000e-09 1.00000e-01 $1.00000 \mathrm{e}+001.00000 \mathrm{e}+001.00000 \mathrm{e}-011.00000 \mathrm{e}-091.00000 \mathrm{e}-01$ Element: 2568 \# of layers: 13

$\mathrm{Kx} \mathrm{Ky} \mathrm{Kz}$ Ss Por

$2.56875 \mathrm{e}+012.56875 \mathrm{e}+012.56875 \mathrm{e}+00$ 1.00000e-09 7.00000e-02 $2.56875 \mathrm{e}+012.56875 \mathrm{e}+012.56875 \mathrm{e}+001.00000 \mathrm{e}-09$ 7.00000e-02 5.00000e-04 5.00000e-04 5.00000e-05 1.00000e-09 1.00000e-01 5.00000e-04 5.00000e-04 5.00000e-05 1.00000e-09 1.00000e-01 $1.02638 \mathrm{e}+001.02638 \mathrm{e}+00$ 1.02638e-01 1.00000e-09 2.12000e-01 $1.02638 \mathrm{e}+001.02638 \mathrm{e}+00$ 1.02638e-01 1.00000e-09 2.12000e-01 $1.02638 \mathrm{e}+001.02638 \mathrm{e}+00$ 1.02638e-01 1.00000e-09 2.12000e-01 $1.02638 \mathrm{e}+001.02638 \mathrm{e}+00$ 1.02638e-01 1.00000e-09 2.12000e-01 $1.02638 \mathrm{e}+001.02638 \mathrm{e}+00$ 1.02638e-01 1.00000e-09 2.12000e-01 $1.00000 \mathrm{e}-02$ 1.00000e-02 1.00000e-03 1.00000e-09 1.00000e-01 $1.00000 \mathrm{e}+001.00000 \mathrm{e}+001.00000 \mathrm{e}-011.00000 \mathrm{e}-091.00000 \mathrm{e}-01$ $1.00000 \mathrm{e}-05$ 1.00000e-05 1.00000e-06 1.00000e-09 1.00000e-01 $1.00000 \mathrm{e}+001.00000 \mathrm{e}+001.00000 \mathrm{e}-011.00000 \mathrm{e}-091.00000 \mathrm{e}-01$ Element: 2569 \# of layers: 14

$\mathrm{Kx} \mathrm{Ky} \mathrm{Kz}$ Ss Por

2.72372e+01 2.72372e+01 2.72372e+00 1.00000e-09 7.00000e-02 $2.72372 \mathrm{e}+012.72372 \mathrm{e}+012.72372 \mathrm{e}+00$ 1.00000e-09 7.00000e-02 $2.72372 \mathrm{e}+012.72372 \mathrm{e}+012.72372 \mathrm{e}+00$ 1.00000e-09 7.00000e-02 5.00000e-04 5.00000e-04 5.00000e-05 1.00000e-09 1.00000e-01 5.00000e-04 5.00000e-04 5.00000e-05 1.00000e-09 1.00000e-01 $1.08830 \mathrm{e}+001.08830 \mathrm{e}+001.08830 \mathrm{e}-01$ 1.00000e-09 2.12000e-01 $1.08830 \mathrm{e}+001.08830 \mathrm{e}+001.08830 \mathrm{e}-01$ 1.00000e-09 2.12000e-01 $1.08830 \mathrm{e}+001.08830 \mathrm{e}+001.08830 \mathrm{e}-011.00000 \mathrm{e}-092.12000 \mathrm{e}-01$ $1.08830 \mathrm{e}+001.08830 \mathrm{e}+00$ 1.08830e-01 1.00000e-09 2.12000e-01 $1.08830 \mathrm{e}+001.08830 \mathrm{e}+001.08830 \mathrm{e}-01$ 1.00000e-09 2.12000e-01 $1.00000 \mathrm{e}-02$ 1.00000e-02 1.00000e-03 1.00000e-09 1.00000e-01 $1.00000 \mathrm{e}+001.00000 \mathrm{e}+001.00000 \mathrm{e}-011.00000 \mathrm{e}-091.00000 \mathrm{e}-01$ $1.00000 \mathrm{e}-05$ 1.00000e-05 1.00000e-06 1.00000e-09 1.00000e-01 $1.00000 \mathrm{e}+001.00000 \mathrm{e}+001.00000 \mathrm{e}-01$ 1.00000e-09 1.00000e-01 Element: 2570 \# of layers: 14

$\mathrm{Kx} \mathrm{Ky} \mathrm{Kz}$ Ss Por

2.72372e+01 2.72372e+01 2.72372e+00 1.00000e-09 7.00000e-02 
2.72372e+01 2.72372e+01 2.72372e+00 1.00000e-09 7.00000e-02 $2.72372 \mathrm{e}+012.72372 \mathrm{e}+012.72372 \mathrm{e}+001.00000 \mathrm{e}-09$ 7.00000e-02 5.00000e-04 5.00000e-04 5.00000e-05 1.00000e-09 1.00000e-01 5.00000e-04 5.00000e-04 5.00000e-05 1.00000e-09 1.00000e-01 $1.08830 \mathrm{e}+001.08830 \mathrm{e}+001.08830 \mathrm{e}-01$ 1.00000e-09 2.12000e-01 $1.08830 \mathrm{e}+001.08830 \mathrm{e}+001.08830 \mathrm{e}-011.00000 \mathrm{e}-092.12000 \mathrm{e}-01$ $1.08830 \mathrm{e}+001.08830 \mathrm{e}+001.08830 \mathrm{e}-01$ 1.00000e-09 2.12000e-01 $1.08830 \mathrm{e}+001.08830 \mathrm{e}+001.08830 \mathrm{e}-011.00000 \mathrm{e}-092.12000 \mathrm{e}-01$ $1.08830 \mathrm{e}+001.08830 \mathrm{e}+001.08830 \mathrm{e}-01$ 1.00000e-09 2.12000e-01 $1.00000 \mathrm{e}-02$ 1.00000e-02 1.00000e-03 1.00000e-09 1.00000e-01 $1.00000 \mathrm{e}+001.00000 \mathrm{e}+001.00000 \mathrm{e}-011.00000 \mathrm{e}-091.00000 \mathrm{e}-01$ $1.00000 \mathrm{e}-05$ 1.00000e-05 1.00000e-06 1.00000e-09 1.00000e-01 $1.00000 \mathrm{e}+001.00000 \mathrm{e}+001.00000 \mathrm{e}-01$ 1.00000e-09 1.00000e-01 Element: 2571 \# of layers: 14

$\mathrm{Kx} \mathrm{Ky} \mathrm{Kz}$ Ss Por

2.72372e+01 2.72372e+01 2.72372e+00 1.00000e-09 7.00000e-02 $2.72372 \mathrm{e}+012.72372 \mathrm{e}+012.72372 \mathrm{e}+00$ 1.00000e-09 7.00000e-02 $2.72372 \mathrm{e}+012.72372 \mathrm{e}+012.72372 \mathrm{e}+001.00000 \mathrm{e}-09$ 7.00000e-02 5.00000e-04 5.00000e-04 5.00000e-05 1.00000e-09 1.00000e-01 5.00000e-04 5.00000e-04 5.00000e-05 1.00000e-09 1.00000e-01 $1.08830 \mathrm{e}+001.08830 \mathrm{e}+001.08830 \mathrm{e}-011.00000 \mathrm{e}-092.12000 \mathrm{e}-01$ $1.08830 \mathrm{e}+001.08830 \mathrm{e}+001.08830 \mathrm{e}-01$ 1.00000e-09 2.12000e-01 $1.08830 \mathrm{e}+001.08830 \mathrm{e}+001.08830 \mathrm{e}-01$ 1.00000e-09 2.12000e-01 $1.08830 \mathrm{e}+001.08830 \mathrm{e}+001.08830 \mathrm{e}-011.00000 \mathrm{e}-092.12000 \mathrm{e}-01$ $1.08830 \mathrm{e}+001.08830 \mathrm{e}+001.08830 \mathrm{e}-011.00000 \mathrm{e}-092.12000 \mathrm{e}-01$ $1.00000 \mathrm{e}-02$ 1.00000e-02 1.00000e-03 1.00000e-09 1.00000e-01 $1.00000 \mathrm{e}+001.00000 \mathrm{e}+001.00000 \mathrm{e}-011.00000 \mathrm{e}-091.00000 \mathrm{e}-01$ $1.00000 \mathrm{e}-05$ 1.00000e-05 1.00000e-06 1.00000e-09 1.00000e-01 $1.00000 \mathrm{e}+001.00000 \mathrm{e}+001.00000 \mathrm{e}-011.00000 \mathrm{e}-091.00000 \mathrm{e}-01$ Element: 2572 \# of layers: 13

$\mathrm{Kx} \mathrm{Ky} \mathrm{Kz}$ Ss Por

$2.72372 \mathrm{e}+012.72372 \mathrm{e}+012.72372 \mathrm{e}+00$ 1.00000e-09 7.00000e-02 $2.72372 \mathrm{e}+012.72372 \mathrm{e}+012.72372 \mathrm{e}+00$ 1.00000e-09 7.00000e-02 $5.00000 \mathrm{e}-04$ 5.00000e-04 5.00000e-05 1.00000e-09 1.00000e-01 5.00000e-04 5.00000e-04 5.00000e-05 1.00000e-09 1.00000e-01 $1.08830 \mathrm{e}+001.08830 \mathrm{e}+001.08830 \mathrm{e}-01$ 1.00000e-09 2.12000e-01 $1.08830 \mathrm{e}+001.08830 \mathrm{e}+001.08830 \mathrm{e}-011.00000 \mathrm{e}-092.12000 \mathrm{e}-01$ $1.08830 \mathrm{e}+001.08830 \mathrm{e}+00$ 1.08830e-01 1.00000e-09 2.12000e-01 $1.08830 \mathrm{e}+001.08830 \mathrm{e}+001.08830 \mathrm{e}-011.00000 \mathrm{e}-092.12000 \mathrm{e}-01$ $1.08830 \mathrm{e}+001.08830 \mathrm{e}+001.08830 \mathrm{e}-01$ 1.00000e-09 2.12000e-01 $1.00000 \mathrm{e}-02$ 1.00000e-02 1.00000e-03 1.00000e-09 1.00000e-01 $1.00000 \mathrm{e}+001.00000 \mathrm{e}+001.00000 \mathrm{e}-011.00000 \mathrm{e}-091.00000 \mathrm{e}-01$ $1.00000 \mathrm{e}-05$ 1.00000e-05 1.00000e-06 1.00000e-09 1.00000e-01 $1.00000 \mathrm{e}+001.00000 \mathrm{e}+001.00000 \mathrm{e}-01$ 1.00000e-09 1.00000e-01 Element: 2573 \# of layers: 13

Kx Ky Kz Ss Por 
2.72372e+01 2.72372e+01 2.72372e+00 1.00000e-09 7.00000e-02 $2.72372 \mathrm{e}+012.72372 \mathrm{e}+012.72372 \mathrm{e}+001.00000 \mathrm{e}-09$ 7.00000e-02 5.00000e-04 5.00000e-04 5.00000e-05 1.00000e-09 1.00000e-01 5.00000e-04 5.00000e-04 5.00000e-05 1.00000e-09 1.00000e-01 $1.08830 \mathrm{e}+001.08830 \mathrm{e}+001.08830 \mathrm{e}-01$ 1.00000e-09 2.12000e-01 $1.08830 \mathrm{e}+001.08830 \mathrm{e}+001.08830 \mathrm{e}-011.00000 \mathrm{e}-092.12000 \mathrm{e}-01$ $1.08830 \mathrm{e}+001.08830 \mathrm{e}+001.08830 \mathrm{e}-01$ 1.00000e-09 2.12000e-01 $1.08830 \mathrm{e}+001.08830 \mathrm{e}+001.08830 \mathrm{e}-011.00000 \mathrm{e}-092.12000 \mathrm{e}-01$ $1.08830 \mathrm{e}+001.08830 \mathrm{e}+001.08830 \mathrm{e}-01$ 1.00000e-09 2.12000e-01 $1.00000 \mathrm{e}-02$ 1.00000e-02 1.00000e-03 1.00000e-09 1.00000e-01 $1.00000 \mathrm{e}+001.00000 \mathrm{e}+001.00000 \mathrm{e}-011.00000 \mathrm{e}-091.00000 \mathrm{e}-01$ $1.00000 \mathrm{e}-05$ 1.00000e-05 1.00000e-06 1.00000e-09 1.00000e-01 $1.00000 \mathrm{e}+001.00000 \mathrm{e}+001.00000 \mathrm{e}-011.00000 \mathrm{e}-091.00000 \mathrm{e}-01$ Element: 2574 \# of layers: 13

$\mathrm{Kx} \mathrm{Ky} \mathrm{Kz}$ Ss Por

2.72372e+01 2.72372e+01 2.72372e+00 1.00000e-09 7.00000e-02 $2.72372 \mathrm{e}+012.72372 \mathrm{e}+012.72372 \mathrm{e}+001.00000 \mathrm{e}-09$ 7.00000e-02 5.00000e-04 5.00000e-04 5.00000e-05 1.00000e-09 1.00000e-01 $5.00000 \mathrm{e}-04$ 5.00000e-04 5.00000e-05 1.00000e-09 1.00000e-01 $1.08830 \mathrm{e}+001.08830 \mathrm{e}+001.08830 \mathrm{e}-01$ 1.00000e-09 2.12000e-01 $1.08830 \mathrm{e}+001.08830 \mathrm{e}+001.08830 \mathrm{e}-011.00000 \mathrm{e}-092.12000 \mathrm{e}-01$ $1.08830 \mathrm{e}+001.08830 \mathrm{e}+00$ 1.08830e-01 1.00000e-09 2.12000e-01 $1.08830 \mathrm{e}+001.08830 \mathrm{e}+001.08830 \mathrm{e}-01$ 1.00000e-09 2.12000e-01 $1.08830 \mathrm{e}+001.08830 \mathrm{e}+001.08830 \mathrm{e}-011.00000 \mathrm{e}-092.12000 \mathrm{e}-01$ $1.00000 \mathrm{e}-02$ 1.00000e-02 1.00000e-03 1.00000e-09 1.00000e-01 $1.00000 \mathrm{e}+001.00000 \mathrm{e}+001.00000 \mathrm{e}-011.00000 \mathrm{e}-091.00000 \mathrm{e}-01$ $1.00000 \mathrm{e}-05$ 1.00000e-05 1.00000e-06 1.00000e-09 1.00000e-01 $1.00000 \mathrm{e}+001.00000 \mathrm{e}+001.00000 \mathrm{e}-011.00000 \mathrm{e}-09$ 1.00000e-01 Element: 2575 \# of layers: 13

$\mathrm{Kx} \mathrm{Ky} \mathrm{Kz}$ Ss Por

2.72372e+01 2.72372e+01 2.72372e+00 1.00000e-09 7.00000e-02 $2.72372 \mathrm{e}+012.72372 \mathrm{e}+012.72372 \mathrm{e}+00$ 1.00000e-09 7.00000e-02 5.00000e-04 5.00000e-04 5.00000e-05 1.00000e-09 1.00000e-01 $5.00000 \mathrm{e}-04$ 5.00000e-04 5.00000e-05 1.00000e-09 1.00000e-01 $1.08830 \mathrm{e}+001.08830 \mathrm{e}+001.08830 \mathrm{e}-011.00000 \mathrm{e}-092.12000 \mathrm{e}-01$ $1.08830 \mathrm{e}+001.08830 \mathrm{e}+001.08830 \mathrm{e}-01$ 1.00000e-09 2.12000e-01 $1.08830 \mathrm{e}+001.08830 \mathrm{e}+001.08830 \mathrm{e}-011.00000 \mathrm{e}-092.12000 \mathrm{e}-01$ $1.08830 \mathrm{e}+001.08830 \mathrm{e}+001.08830 \mathrm{e}-011.00000 \mathrm{e}-092.12000 \mathrm{e}-01$ $1.08830 \mathrm{e}+001.08830 \mathrm{e}+001.08830 \mathrm{e}-011.00000 \mathrm{e}-09$ 2.12000e-01 $1.00000 \mathrm{e}-02$ 1.00000e-02 1.00000e-03 1.00000e-09 1.00000e-01 $1.00000 \mathrm{e}+001.00000 \mathrm{e}+001.00000 \mathrm{e}-011.00000 \mathrm{e}-091.00000 \mathrm{e}-01$ $1.00000 \mathrm{e}-05$ 1.00000e-05 1.00000e-06 1.00000e-09 1.00000e-01 $1.00000 \mathrm{e}+001.00000 \mathrm{e}+001.00000 \mathrm{e}-01$ 1.00000e-09 1.00000e-01 Element: 2576 \# of layers: 13

$\mathrm{Kx} \mathrm{Ky} \mathrm{Kz}$ Ss Por

2.72372e+01 2.72372e+01 2.72372e+00 1.00000e-09 7.00000e-02 
$2.72372 \mathrm{e}+012.72372 \mathrm{e}+012.72372 \mathrm{e}+00$ 1.00000e-09 7.00000e-02 $5.00000 \mathrm{e}-04$ 5.00000e-04 5.00000e-05 1.00000e-09 1.00000e-01 5.00000e-04 5.00000e-04 5.00000e-05 1.00000e-09 1.00000e-01 $1.08830 \mathrm{e}+001.08830 \mathrm{e}+001.08830 \mathrm{e}-011.00000 \mathrm{e}-092.12000 \mathrm{e}-01$ $1.08830 \mathrm{e}+001.08830 \mathrm{e}+001.08830 \mathrm{e}-011.00000 \mathrm{e}-092.12000 \mathrm{e}-01$ $1.08830 \mathrm{e}+001.08830 \mathrm{e}+001.08830 \mathrm{e}-011.00000 \mathrm{e}-092.12000 \mathrm{e}-01$ $1.08830 \mathrm{e}+001.08830 \mathrm{e}+001.08830 \mathrm{e}-011.00000 \mathrm{e}-092.12000 \mathrm{e}-01$ $1.08830 \mathrm{e}+001.08830 \mathrm{e}+001.08830 \mathrm{e}-011.00000 \mathrm{e}-092.12000 \mathrm{e}-01$ $1.00000 \mathrm{e}-02$ 1.00000e-02 1.00000e-03 1.00000e-09 1.00000e-01 $1.00000 \mathrm{e}+001.00000 \mathrm{e}+001.00000 \mathrm{e}-011.00000 \mathrm{e}-091.00000 \mathrm{e}-01$ $1.00000 \mathrm{e}-05$ 1.00000e-05 1.00000e-06 1.00000e-09 1.00000e-01 $1.00000 \mathrm{e}+001.00000 \mathrm{e}+001.00000 \mathrm{e}-011.00000 \mathrm{e}-091.00000 \mathrm{e}-01$ Element: 2577 \# of layers: 13

Kx Ky Kz Ss Por

$2.72372 \mathrm{e}+012.72372 \mathrm{e}+012.72372 \mathrm{e}+00$ 1.00000e-09 7.00000e-02 $2.72372 \mathrm{e}+012.72372 \mathrm{e}+012.72372 \mathrm{e}+00$ 1.00000e-09 7.00000e-02 $5.00000 \mathrm{e}-04$ 5.00000e-04 5.00000e-05 1.00000e-09 1.00000e-01 5.00000e-04 5.00000e-04 5.00000e-05 1.00000e-09 1.00000e-01 $1.08830 \mathrm{e}+001.08830 \mathrm{e}+001.08830 \mathrm{e}-011.00000 \mathrm{e}-092.12000 \mathrm{e}-01$ $1.08830 \mathrm{e}+001.08830 \mathrm{e}+001.08830 \mathrm{e}-011.00000 \mathrm{e}-092.12000 \mathrm{e}-01$ $1.08830 \mathrm{e}+001.08830 \mathrm{e}+001.08830 \mathrm{e}-011.00000 \mathrm{e}-092.12000 \mathrm{e}-01$ $1.08830 \mathrm{e}+001.08830 \mathrm{e}+001.08830 \mathrm{e}-011.00000 \mathrm{e}-092.12000 \mathrm{e}-01$ $1.08830 \mathrm{e}+001.08830 \mathrm{e}+001.08830 \mathrm{e}-011.00000 \mathrm{e}-092.12000 \mathrm{e}-01$ $1.00000 \mathrm{e}-021.00000 \mathrm{e}-02$ 1.00000e-03 1.00000e-09 1.00000e-01 $1.00000 \mathrm{e}+001.00000 \mathrm{e}+001.00000 \mathrm{e}-011.00000 \mathrm{e}-091.00000 \mathrm{e}-01$ $1.00000 \mathrm{e}-05$ 1.00000e-05 1.00000e-06 1.00000e-09 1.00000e-01 $1.00000 \mathrm{e}+001.00000 \mathrm{e}+001.00000 \mathrm{e}-011.00000 \mathrm{e}-091.00000 \mathrm{e}-01$ Element: 2578 \# of layers: 14

Kx Ky Kz Ss Por

$2.83941 \mathrm{e}+012.83941 \mathrm{e}+012.83941 \mathrm{e}+00$ 1.00000e-09 7.00000e-02 $2.83941 \mathrm{e}+012.83941 \mathrm{e}+012.83941 \mathrm{e}+001.00000 \mathrm{e}-097.00000 \mathrm{e}-02$ $2.83941 \mathrm{e}+012.83941 \mathrm{e}+012.83941 \mathrm{e}+001.00000 \mathrm{e}-09$ 7.00000e-02 5.00000e-04 5.00000e-04 5.00000e-05 1.00000e-09 1.00000e-01 5.00000e-04 5.00000e-04 5.00000e-05 1.00000e-09 1.00000e-01 $1.13452 \mathrm{e}+001.13452 \mathrm{e}+00$ 1.13452e-01 1.00000e-09 2.12000e-01 $1.13452 \mathrm{e}+001.13452 \mathrm{e}+001.13452 \mathrm{e}-011.00000 \mathrm{e}-092.12000 \mathrm{e}-01$ $1.13452 \mathrm{e}+001.13452 \mathrm{e}+00$ 1.13452e-01 1.00000e-09 2.12000e-01 $1.13452 \mathrm{e}+001.13452 \mathrm{e}+00$ 1.13452e-01 1.00000e-09 2.12000e-01 $1.13452 \mathrm{e}+001.13452 \mathrm{e}+00$ 1.13452e-01 1.00000e-09 2.12000e-01 $1.00000 \mathrm{e}-02$ 1.00000e-02 1.00000e-03 1.00000e-09 1.00000e-01 $1.00000 \mathrm{e}+001.00000 \mathrm{e}+001.00000 \mathrm{e}-011.00000 \mathrm{e}-091.00000 \mathrm{e}-01$ $1.00000 \mathrm{e}-05$ 1.00000e-05 1.00000e-06 1.00000e-09 1.00000e-01 $1.00000 \mathrm{e}+001.00000 \mathrm{e}+001.00000 \mathrm{e}-011.00000 \mathrm{e}-091.00000 \mathrm{e}-01$ Element: 2579 \# of layers: 14

Kx Ky Kz Ss Por

$2.83941 \mathrm{e}+012.83941 \mathrm{e}+012.83941 \mathrm{e}+00$ 1.00000e-09 7.00000e-02 
$2.83941 \mathrm{e}+012.83941 \mathrm{e}+012.83941 \mathrm{e}+00$ 1.00000e-09 7.00000e-02 $2.83941 \mathrm{e}+012.83941 \mathrm{e}+012.83941 \mathrm{e}+001.00000 \mathrm{e}-09$ 7.00000e-02 5.00000e-04 5.00000e-04 5.00000e-05 1.00000e-09 1.00000e-01 5.00000e-04 5.00000e-04 5.00000e-05 1.00000e-09 1.00000e-01 $1.13452 \mathrm{e}+00$ 1.13452e+00 1.13452e-01 1.00000e-09 2.12000e-01 $1.13452 \mathrm{e}+001.13452 \mathrm{e}+001.13452 \mathrm{e}-01$ 1.00000e-09 2.12000e-01 $1.13452 \mathrm{e}+001.13452 \mathrm{e}+00$ 1.13452e-01 1.00000e-09 2.12000e-01 $1.13452 \mathrm{e}+001.13452 \mathrm{e}+00$ 1.13452e-01 1.00000e-09 2.12000e-01 $1.13452 \mathrm{e}+00$ 1.13452e+00 1.13452e-01 1.00000e-09 2.12000e-01 $1.00000 \mathrm{e}-02$ 1.00000e-02 1.00000e-03 1.00000e-09 1.00000e-01 $1.00000 \mathrm{e}+001.00000 \mathrm{e}+001.00000 \mathrm{e}-011.00000 \mathrm{e}-091.00000 \mathrm{e}-01$ $1.00000 \mathrm{e}-05$ 1.00000e-05 1.00000e-06 1.00000e-09 1.00000e-01 $1.00000 \mathrm{e}+001.00000 \mathrm{e}+001.00000 \mathrm{e}-011.00000 \mathrm{e}-091.00000 \mathrm{e}-01$ Element: 2580 \# of layers: 14

$\mathrm{Kx} \mathrm{Ky} \mathrm{Kz}$ Ss Por

$2.83941 \mathrm{e}+012.83941 \mathrm{e}+012.83941 \mathrm{e}+00$ 1.00000e-09 7.00000e-02 $2.83941 \mathrm{e}+012.83941 \mathrm{e}+012.83941 \mathrm{e}+001.00000 \mathrm{e}-09$ 7.00000e-02

$2.83941 \mathrm{e}+012.83941 \mathrm{e}+012.83941 \mathrm{e}+001.00000 \mathrm{e}-09$ 7.00000e-02 5.00000e-04 5.00000e-04 5.00000e-05 1.00000e-09 1.00000e-01 5.00000e-04 5.00000e-04 5.00000e-05 1.00000e-09 1.00000e-01

$1.13452 \mathrm{e}+001.13452 \mathrm{e}+00$ 1.13452e-01 1.00000e-09 2.12000e-01 $1.13452 \mathrm{e}+00$ 1.13452e+00 1.13452e-01 1.00000e-09 2.12000e-01 $1.13452 \mathrm{e}+001.13452 \mathrm{e}+00$ 1.13452e-01 1.00000e-09 2.12000e-01 $1.13452 \mathrm{e}+001.13452 \mathrm{e}+00$ 1.13452e-01 1.00000e-09 2.12000e-01 $1.13452 \mathrm{e}+001.13452 \mathrm{e}+001.13452 \mathrm{e}-011.00000 \mathrm{e}-092.12000 \mathrm{e}-01$ $1.00000 \mathrm{e}-02$ 1.00000e-02 1.00000e-03 1.00000e-09 1.00000e-01 $1.00000 \mathrm{e}+001.00000 \mathrm{e}+001.00000 \mathrm{e}-011.00000 \mathrm{e}-091.00000 \mathrm{e}-01$ $1.00000 \mathrm{e}-05$ 1.00000e-05 1.00000e-06 1.00000e-09 1.00000e-01 $1.00000 \mathrm{e}+001.00000 \mathrm{e}+001.00000 \mathrm{e}-011.00000 \mathrm{e}-091.00000 \mathrm{e}-01$ Element: 2581 \# of layers: 13

$\mathrm{Kx} \mathrm{Ky} \mathrm{Kz}$ Ss Por

$2.83941 \mathrm{e}+012.83941 \mathrm{e}+012.83941 \mathrm{e}+00$ 1.00000e-09 7.00000e-02 $2.83941 \mathrm{e}+012.83941 \mathrm{e}+012.83941 \mathrm{e}+001.00000 \mathrm{e}-09$ 7.00000e-02 $5.00000 \mathrm{e}-04$ 5.00000e-04 5.00000e-05 1.00000e-09 1.00000e-01 5.00000e-04 5.00000e-04 5.00000e-05 1.00000e-09 1.00000e-01 $1.13452 \mathrm{e}+001.13452 \mathrm{e}+00$ 1.13452e-01 1.00000e-09 2.12000e-01 $1.13452 \mathrm{e}+001.13452 \mathrm{e}+00$ 1.13452e-01 1.00000e-09 2.12000e-01 $1.13452 \mathrm{e}+001.13452 \mathrm{e}+00$ 1.13452e-01 1.00000e-09 2.12000e-01 $1.13452 \mathrm{e}+00$ 1.13452e+00 1.13452e-01 1.00000e-09 2.12000e-01 $1.13452 \mathrm{e}+001.13452 \mathrm{e}+00$ 1.13452e-01 1.00000e-09 2.12000e-01 $1.00000 \mathrm{e}-02$ 1.00000e-02 1.00000e-03 1.00000e-09 1.00000e-01 $1.00000 \mathrm{e}+001.00000 \mathrm{e}+001.00000 \mathrm{e}-011.00000 \mathrm{e}-091.00000 \mathrm{e}-01$ $1.00000 \mathrm{e}-05$ 1.00000e-05 1.00000e-06 1.00000e-09 1.00000e-01 $1.00000 \mathrm{e}+001.00000 \mathrm{e}+001.00000 \mathrm{e}-01$ 1.00000e-09 1.00000e-01 Element: 2582 \# of layers: 13

Kx Ky Kz Ss Por 
$2.83941 \mathrm{e}+012.83941 \mathrm{e}+012.83941 \mathrm{e}+00$ 1.00000e-09 7.00000e-02 $2.83941 \mathrm{e}+012.83941 \mathrm{e}+012.83941 \mathrm{e}+001.00000 \mathrm{e}-09$ 7.00000e-02 5.00000e-04 5.00000e-04 5.00000e-05 1.00000e-09 1.00000e-01 5.00000e-04 5.00000e-04 5.00000e-05 1.00000e-09 1.00000e-01 $1.13452 \mathrm{e}+00$ 1.13452e+00 1.13452e-01 1.00000e-09 2.12000e-01 $1.13452 \mathrm{e}+001.13452 \mathrm{e}+00$ 1.13452e-01 1.00000e-09 2.12000e-01 $1.13452 \mathrm{e}+001.13452 \mathrm{e}+00$ 1.13452e-01 1.00000e-09 2.12000e-01 $1.13452 \mathrm{e}+001.13452 \mathrm{e}+00$ 1.13452e-01 1.00000e-09 2.12000e-01 $1.13452 \mathrm{e}+00$ 1.13452e+00 1.13452e-01 1.00000e-09 2.12000e-01 $1.00000 \mathrm{e}-02$ 1.00000e-02 1.00000e-03 1.00000e-09 1.00000e-01 $1.00000 \mathrm{e}+001.00000 \mathrm{e}+001.00000 \mathrm{e}-011.00000 \mathrm{e}-091.00000 \mathrm{e}-01$ $1.00000 \mathrm{e}-05$ 1.00000e-05 1.00000e-06 1.00000e-09 1.00000e-01 $1.00000 \mathrm{e}+001.00000 \mathrm{e}+001.00000 \mathrm{e}-011.00000 \mathrm{e}-09$ 1.00000e-01 Element: 2583 \# of layers: 13

$\mathrm{Kx} \mathrm{Ky} \mathrm{Kz}$ Ss Por

$2.83941 \mathrm{e}+012.83941 \mathrm{e}+012.83941 \mathrm{e}+00$ 1.00000e-09 7.00000e-02 $2.83941 \mathrm{e}+012.83941 \mathrm{e}+012.83941 \mathrm{e}+001.00000 \mathrm{e}-09$ 7.00000e-02 5.00000e-04 5.00000e-04 5.00000e-05 1.00000e-09 1.00000e-01 5.00000e-04 5.00000e-04 5.00000e-05 1.00000e-09 1.00000e-01 $1.13452 \mathrm{e}+001.13452 \mathrm{e}+00$ 1.13452e-01 1.00000e-09 2.12000e-01 $1.13452 \mathrm{e}+001.13452 \mathrm{e}+00$ 1.13452e-01 1.00000e-09 2.12000e-01 $1.13452 \mathrm{e}+00$ 1.13452e+00 1.13452e-01 1.00000e-09 2.12000e-01 $1.13452 \mathrm{e}+001.13452 \mathrm{e}+00$ 1.13452e-01 1.00000e-09 2.12000e-01 $1.13452 \mathrm{e}+001.13452 \mathrm{e}+001.13452 \mathrm{e}-01$ 1.00000e-09 2.12000e-01 $1.00000 \mathrm{e}-02$ 1.00000e-02 1.00000e-03 1.00000e-09 1.00000e-01 $1.00000 \mathrm{e}+001.00000 \mathrm{e}+001.00000 \mathrm{e}-011.00000 \mathrm{e}-091.00000 \mathrm{e}-01$ $1.00000 \mathrm{e}-05$ 1.00000e-05 1.00000e-06 1.00000e-09 1.00000e-01 $1.00000 \mathrm{e}+001.00000 \mathrm{e}+001.00000 \mathrm{e}-011.00000 \mathrm{e}-09$ 1.00000e-01 Element: 2584 \# of layers: 13

$\mathrm{Kx} \mathrm{Ky} \mathrm{Kz}$ Ss Por

$2.83941 \mathrm{e}+012.83941 \mathrm{e}+012.83941 \mathrm{e}+00$ 1.00000e-09 7.00000e-02 $2.83941 \mathrm{e}+012.83941 \mathrm{e}+012.83941 \mathrm{e}+001.00000 \mathrm{e}-09$ 7.00000e-02 5.00000e-04 5.00000e-04 5.00000e-05 1.00000e-09 1.00000e-01 5.00000e-04 5.00000e-04 5.00000e-05 1.00000e-09 1.00000e-01 $1.13452 \mathrm{e}+00$ 1.13452e+00 1.13452e-01 1.00000e-09 2.12000e-01 $1.13452 \mathrm{e}+001.13452 \mathrm{e}+00$ 1.13452e-01 1.00000e-09 2.12000e-01 $1.13452 \mathrm{e}+001.13452 \mathrm{e}+001.13452 \mathrm{e}-01$ 1.00000e-09 2.12000e-01 $1.13452 \mathrm{e}+001.13452 \mathrm{e}+001.13452 \mathrm{e}-011.00000 \mathrm{e}-092.12000 \mathrm{e}-01$ $1.13452 \mathrm{e}+001.13452 \mathrm{e}+00$ 1.13452e-01 1.00000e-09 2.12000e-01 1.00000e-02 1.00000e-02 1.00000e-03 1.00000e-09 1.00000e-01 $1.00000 \mathrm{e}+001.00000 \mathrm{e}+001.00000 \mathrm{e}-011.00000 \mathrm{e}-091.00000 \mathrm{e}-01$ $1.00000 \mathrm{e}-05$ 1.00000e-05 1.00000e-06 1.00000e-09 1.00000e-01 $1.00000 \mathrm{e}+001.00000 \mathrm{e}+001.00000 \mathrm{e}-01$ 1.00000e-09 1.00000e-01 Element: 2585 \# of layers: 13

$\mathrm{Kx} \mathrm{Ky} \mathrm{Kz}$ Ss Por

$2.83941 \mathrm{e}+012.83941 \mathrm{e}+012.83941 \mathrm{e}+00$ 1.00000e-09 7.00000e-02 
$2.83941 \mathrm{e}+012.83941 \mathrm{e}+012.83941 \mathrm{e}+00$ 1.00000e-09 7.00000e-02 5.00000e-04 5.00000e-04 5.00000e-05 1.00000e-09 1.00000e-01 5.00000e-04 5.00000e-04 5.00000e-05 1.00000e-09 1.00000e-01 $1.13452 \mathrm{e}+001.13452 \mathrm{e}+00$ 1.13452e-01 1.00000e-09 2.12000e-01 $1.13452 \mathrm{e}+00$ 1.13452e+00 1.13452e-01 1.00000e-09 2.12000e-01 $1.13452 \mathrm{e}+001.13452 \mathrm{e}+00$ 1.13452e-01 1.00000e-09 2.12000e-01 $1.13452 \mathrm{e}+001.13452 \mathrm{e}+00$ 1.13452e-01 1.00000e-09 2.12000e-01 $1.13452 \mathrm{e}+001.13452 \mathrm{e}+001.13452 \mathrm{e}-01$ 1.00000e-09 2.12000e-01 $1.00000 \mathrm{e}-021.00000 \mathrm{e}-021.00000 \mathrm{e}-031.00000 \mathrm{e}-091.00000 \mathrm{e}-01$ $1.00000 \mathrm{e}+001.00000 \mathrm{e}+001.00000 \mathrm{e}-011.00000 \mathrm{e}-091.00000 \mathrm{e}-01$ $1.00000 \mathrm{e}-05$ 1.00000e-05 1.00000e-06 1.00000e-09 1.00000e-01 $1.00000 \mathrm{e}+001.00000 \mathrm{e}+001.00000 \mathrm{e}-011.00000 \mathrm{e}-091.00000 \mathrm{e}-01$ Element: 2586 \# of layers: 13

$\mathrm{Kx} \mathrm{Ky} \mathrm{Kz}$ Ss Por

$2.83941 \mathrm{e}+012.83941 \mathrm{e}+012.83941 \mathrm{e}+00$ 1.00000e-09 7.00000e-02 $2.83941 \mathrm{e}+012.83941 \mathrm{e}+012.83941 \mathrm{e}+00$ 1.00000e-09 7.00000e-02 5.00000e-04 5.00000e-04 5.00000e-05 1.00000e-09 1.00000e-01 5.00000e-04 5.00000e-04 5.00000e-05 1.00000e-09 1.00000e-01 $1.13452 \mathrm{e}+001.13452 \mathrm{e}+00$ 1.13452e-01 1.00000e-09 2.12000e-01 $1.13452 \mathrm{e}+001.13452 \mathrm{e}+00$ 1.13452e-01 1.00000e-09 2.12000e-01 $1.13452 \mathrm{e}+001.13452 \mathrm{e}+00$ 1.13452e-01 1.00000e-09 2.12000e-01 1.13452e+00 1.13452e+00 1.13452e-01 1.00000e-09 2.12000e-01 $1.13452 \mathrm{e}+001.13452 \mathrm{e}+00$ 1.13452e-01 1.00000e-09 2.12000e-01 $1.00000 \mathrm{e}-02$ 1.00000e-02 1.00000e-03 1.00000e-09 1.00000e-01 $1.00000 \mathrm{e}+001.00000 \mathrm{e}+001.00000 \mathrm{e}-011.00000 \mathrm{e}-091.00000 \mathrm{e}-01$ $1.00000 \mathrm{e}-05$ 1.00000e-05 1.00000e-06 1.00000e-09 1.00000e-01 $1.00000 \mathrm{e}+001.00000 \mathrm{e}+001.00000 \mathrm{e}-011.00000 \mathrm{e}-091.00000 \mathrm{e}-01$ Element: 2587 \# of layers: 14

Kx Ky Kz Ss Por

$3.65950 \mathrm{e}+013.65950 \mathrm{e}+013.65950 \mathrm{e}+001.00000 \mathrm{e}-097.00000 \mathrm{e}-02$ $3.65950 \mathrm{e}+013.65950 \mathrm{e}+013.65950 \mathrm{e}+001.00000 \mathrm{e}-097.00000 \mathrm{e}-02$ $3.65950 \mathrm{e}+013.65950 \mathrm{e}+013.65950 \mathrm{e}+001.00000 \mathrm{e}-09$ 7.00000e-02 5.00000e-04 5.00000e-04 5.00000e-05 1.00000e-09 1.00000e-01 5.00000e-04 5.00000e-04 5.00000e-05 1.00000e-09 1.00000e-01 $1.46222 \mathrm{e}+001.46222 \mathrm{e}+00$ 1.46222e-01 1.00000e-09 2.12000e-01 $1.46222 \mathrm{e}+001.46222 \mathrm{e}+00$ 1.46222e-01 1.00000e-09 2.12000e-01 $1.46222 \mathrm{e}+001.46222 \mathrm{e}+00$ 1.46222e-01 1.00000e-09 2.12000e-01 $1.46222 \mathrm{e}+00$ 1.46222e+00 1.46222e-01 1.00000e-09 2.12000e-01 $1.46222 \mathrm{e}+001.46222 \mathrm{e}+00$ 1.46222e-01 1.00000e-09 2.12000e-01 $1.00000 \mathrm{e}-02$ 1.00000e-02 1.00000e-03 1.00000e-09 1.00000e-01 $1.00000 \mathrm{e}+001.00000 \mathrm{e}+001.00000 \mathrm{e}-011.00000 \mathrm{e}-091.00000 \mathrm{e}-01$ $1.00000 \mathrm{e}-05$ 1.00000e-05 1.00000e-06 1.00000e-09 1.00000e-01 $1.00000 \mathrm{e}+001.00000 \mathrm{e}+001.00000 \mathrm{e}-011.00000 \mathrm{e}-091.00000 \mathrm{e}-01$ Element: 2588 \# of layers: 11

$\mathrm{Kx} \mathrm{Ky} \mathrm{Kz} \mathrm{Ss} \mathrm{Por}$

3.65950e+01 3.65950e+01 3.65950e+00 1.00000e-09 7.00000e-02 
$3.65950 \mathrm{e}+013.65950 \mathrm{e}+013.65950 \mathrm{e}+001.00000 \mathrm{e}-09$ 7.00000e-02 5.00000e-04 5.00000e-04 5.00000e-05 1.00000e-09 1.00000e-01 5.00000e-04 5.00000e-04 5.00000e-05 1.00000e-09 1.00000e-01 $1.46222 \mathrm{e}+001.46222 \mathrm{e}+00$ 1.46222e-01 1.00000e-09 2.12000e-01 $1.46222 \mathrm{e}+00$ 1.46222e+00 1.46222e-01 1.00000e-09 2.12000e-01 $1.46222 \mathrm{e}+001.46222 \mathrm{e}+001.46222 \mathrm{e}-01$ 1.00000e-09 2.12000e-01 $1.46222 \mathrm{e}+001.46222 \mathrm{e}+00$ 1.46222e-01 1.00000e-09 2.12000e-01 $1.46222 \mathrm{e}+001.46222 \mathrm{e}+001.46222 \mathrm{e}-01$ 1.00000e-09 2.12000e-01 $1.00000 \mathrm{e}-02$ 1.00000e-02 1.00000e-03 1.00000e-09 1.00000e-01 $1.00000 \mathrm{e}+001.00000 \mathrm{e}+001.00000 \mathrm{e}-011.00000 \mathrm{e}-091.00000 \mathrm{e}-01$ Element: 2589 \# of layers: 9

$\mathrm{Kx} \mathrm{Ky} \mathrm{Kz}$ Ss Por

$3.65950 \mathrm{e}+013.65950 \mathrm{e}+013.65950 \mathrm{e}+001.00000 \mathrm{e}-09$ 7.00000e-02 5.00000e-04 5.00000e-04 5.00000e-05 1.00000e-09 1.00000e-01 5.00000e-04 5.00000e-04 5.00000e-05 1.00000e-09 1.00000e-01 $1.46222 \mathrm{e}+001.46222 \mathrm{e}+001.46222 \mathrm{e}-01$ 1.00000e-09 2.12000e-01 $1.46222 \mathrm{e}+001.46222 \mathrm{e}+00$ 1.46222e-01 1.00000e-09 2.12000e-01 $1.46222 \mathrm{e}+001.46222 \mathrm{e}+001.46222 \mathrm{e}-01$ 1.00000e-09 2.12000e-01 $1.46222 \mathrm{e}+001.46222 \mathrm{e}+00$ 1.46222e-01 1.00000e-09 2.12000e-01 $1.46222 \mathrm{e}+001.46222 \mathrm{e}+001.46222 \mathrm{e}-01$ 1.00000e-09 2.12000e-01 $1.00000 \mathrm{e}+001.00000 \mathrm{e}+001.00000 \mathrm{e}-011.00000 \mathrm{e}-091.00000 \mathrm{e}-01$ Element: 2590 \# of layers: 10

$\mathrm{Kx} \mathrm{Ky} \mathrm{Kz}$ Ss Por

$3.65950 \mathrm{e}+013.65950 \mathrm{e}+013.65950 \mathrm{e}+001.00000 \mathrm{e}-09$ 7.00000e-02 $3.65950 \mathrm{e}+013.65950 \mathrm{e}+013.65950 \mathrm{e}+001.00000 \mathrm{e}-097.00000 \mathrm{e}-02$ $5.00000 \mathrm{e}-04$ 5.00000e-04 5.00000e-05 1.00000e-09 1.00000e-01 5.00000e-04 5.00000e-04 5.00000e-05 1.00000e-09 1.00000e-01 $1.46222 \mathrm{e}+001.46222 \mathrm{e}+00$ 1.46222e-01 1.00000e-09 2.12000e-01 $1.46222 \mathrm{e}+001.46222 \mathrm{e}+00$ 1.46222e-01 1.00000e-09 2.12000e-01 $1.46222 \mathrm{e}+00$ 1.46222e+00 1.46222e-01 1.00000e-09 2.12000e-01 $1.46222 \mathrm{e}+001.46222 \mathrm{e}+00$ 1.46222e-01 1.00000e-09 2.12000e-01 $1.46222 \mathrm{e}+001.46222 \mathrm{e}+00$ 1.46222e-01 1.00000e-09 2.12000e-01 $1.00000 \mathrm{e}+001.00000 \mathrm{e}+001.00000 \mathrm{e}-011.00000 \mathrm{e}-091.00000 \mathrm{e}-01$ Element: 2591 \# of layers: 10

$\mathrm{Kx} \mathrm{Ky} \mathrm{Kz}$ Ss Por

$3.65950 \mathrm{e}+013.65950 \mathrm{e}+013.65950 \mathrm{e}+001.00000 \mathrm{e}-09$ 7.00000e-02 $3.65950 \mathrm{e}+013.65950 \mathrm{e}+013.65950 \mathrm{e}+001.00000 \mathrm{e}-09$ 7.00000e-02 5.00000e-04 5.00000e-04 5.00000e-05 1.00000e-09 1.00000e-01 5.00000e-04 5.00000e-04 5.00000e-05 1.00000e-09 1.00000e-01 $1.46222 \mathrm{e}+001.46222 \mathrm{e}+00$ 1.46222e-01 1.00000e-09 2.12000e-01 $1.46222 \mathrm{e}+001.46222 \mathrm{e}+00$ 1.46222e-01 1.00000e-09 2.12000e-01 $1.46222 \mathrm{e}+001.46222 \mathrm{e}+00$ 1.46222e-01 1.00000e-09 2.12000e-01 $1.46222 \mathrm{e}+001.46222 \mathrm{e}+00$ 1.46222e-01 1.00000e-09 2.12000e-01 $1.46222 \mathrm{e}+001.46222 \mathrm{e}+00$ 1.46222e-01 1.00000e-09 2.12000e-01 $1.00000 \mathrm{e}+001.00000 \mathrm{e}+001.00000 \mathrm{e}-01$ 1.00000e-09 1.00000e-01 Element: 2592 \# of layers: 13 
$\mathrm{Kx} \mathrm{Ky} \mathrm{Kz}$ Ss Por

$3.65950 \mathrm{e}+013.65950 \mathrm{e}+013.65950 \mathrm{e}+001.00000 \mathrm{e}-09$ 7.00000e-02

$3.65950 \mathrm{e}+013.65950 \mathrm{e}+013.65950 \mathrm{e}+001.00000 \mathrm{e}-09$ 7.00000e-02

5.00000e-04 5.00000e-04 5.00000e-05 1.00000e-09 1.00000e-01

5.00000e-04 5.00000e-04 5.00000e-05 1.00000e-09 1.00000e-01

$1.46222 \mathrm{e}+001.46222 \mathrm{e}+001.46222 \mathrm{e}-01$ 1.00000e-09 2.12000e-01

$1.46222 \mathrm{e}+001.46222 \mathrm{e}+00$ 1.46222e-01 1.00000e-09 2.12000e-01

$1.46222 \mathrm{e}+001.46222 \mathrm{e}+001.46222 \mathrm{e}-01$ 1.00000e-09 2.12000e-01

$1.46222 \mathrm{e}+00$ 1.46222e+00 1.46222e-01 1.00000e-09 2.12000e-01

$1.46222 \mathrm{e}+001.46222 \mathrm{e}+00$ 1.46222e-01 1.00000e-09 2.12000e-01

$1.00000 \mathrm{e}-02$ 1.00000e-02 1.00000e-03 1.00000e-09 1.00000e-01

$1.00000 \mathrm{e}+001.00000 \mathrm{e}+001.00000 \mathrm{e}-011.00000 \mathrm{e}-091.00000 \mathrm{e}-01$

$1.00000 \mathrm{e}-05$ 1.00000e-05 1.00000e-06 1.00000e-09 1.00000e-01

$1.00000 \mathrm{e}+001.00000 \mathrm{e}+001.00000 \mathrm{e}-011.00000 \mathrm{e}-09$ 1.00000e-01

Element: 2593 \# of layers: 14

Kx Ky Kz Ss Por

3.65950e+01 3.65950e+01 3.65950e+00 1.00000e-09 7.00000e-02

$3.65950 \mathrm{e}+013.65950 \mathrm{e}+013.65950 \mathrm{e}+001.00000 \mathrm{e}-09$ 7.00000e-02

$3.65950 \mathrm{e}+013.65950 \mathrm{e}+013.65950 \mathrm{e}+001.00000 \mathrm{e}-097.00000 \mathrm{e}-02$

5.00000e-04 5.00000e-04 5.00000e-05 1.00000e-09 1.00000e-01

5.00000e-04 5.00000e-04 5.00000e-05 1.00000e-09 1.00000e-01

$1.46222 \mathrm{e}+001.46222 \mathrm{e}+00$ 1.46222e-01 1.00000e-09 2.12000e-01

$1.46222 \mathrm{e}+001.46222 \mathrm{e}+00$ 1.46222e-01 1.00000e-09 2.12000e-01

$1.46222 \mathrm{e}+001.46222 \mathrm{e}+00$ 1.46222e-01 1.00000e-09 2.12000e-01

$1.46222 \mathrm{e}+001.46222 \mathrm{e}+001.46222 \mathrm{e}-011.00000 \mathrm{e}-092.12000 \mathrm{e}-01$

$1.46222 \mathrm{e}+001.46222 \mathrm{e}+00$ 1.46222e-01 1.00000e-09 2.12000e-01

$1.00000 \mathrm{e}-02$ 1.00000e-02 1.00000e-03 1.00000e-09 1.00000e-01

$1.00000 \mathrm{e}+001.00000 \mathrm{e}+001.00000 \mathrm{e}-011.00000 \mathrm{e}-091.00000 \mathrm{e}-01$

$1.00000 \mathrm{e}-05$ 1.00000e-05 1.00000e-06 1.00000e-09 1.00000e-01

$1.00000 \mathrm{e}+001.00000 \mathrm{e}+001.00000 \mathrm{e}-011.00000 \mathrm{e}-091.00000 \mathrm{e}-01$

Element: 2594 \# of layers: 14

$\mathrm{Kx} \mathrm{Ky} \mathrm{Kz}$ Ss Por

3.65950e+01 3.65950e+01 3.65950e+00 1.00000e-09 7.00000e-02

$3.65950 \mathrm{e}+013.65950 \mathrm{e}+013.65950 \mathrm{e}+001.00000 \mathrm{e}-097.00000 \mathrm{e}-02$

$3.65950 \mathrm{e}+013.65950 \mathrm{e}+013.65950 \mathrm{e}+001.00000 \mathrm{e}-097.00000 \mathrm{e}-02$

5.00000e-04 5.00000e-04 5.00000e-05 1.00000e-09 1.00000e-01

5.00000e-04 5.00000e-04 5.00000e-05 1.00000e-09 1.00000e-01

$1.46222 \mathrm{e}+001.46222 \mathrm{e}+001.46222 \mathrm{e}-011.00000 \mathrm{e}-092.12000 \mathrm{e}-01$

$1.46222 \mathrm{e}+001.46222 \mathrm{e}+00$ 1.46222e-01 1.00000e-09 2.12000e-01

$1.46222 \mathrm{e}+001.46222 \mathrm{e}+00$ 1.46222e-01 1.00000e-09 2.12000e-01

$1.46222 \mathrm{e}+001.46222 \mathrm{e}+00$ 1.46222e-01 1.00000e-09 2.12000e-01

$1.46222 \mathrm{e}+001.46222 \mathrm{e}+001.46222 \mathrm{e}-01$ 1.00000e-09 2.12000e-01

$1.00000 \mathrm{e}-02$ 1.00000e-02 1.00000e-03 1.00000e-09 1.00000e-01

$1.00000 \mathrm{e}+001.00000 \mathrm{e}+001.00000 \mathrm{e}-011.00000 \mathrm{e}-091.00000 \mathrm{e}-01$

$1.00000 \mathrm{e}-05$ 1.00000e-05 1.00000e-06 1.00000e-09 1.00000e-01

$1.00000 \mathrm{e}+001.00000 \mathrm{e}+001.00000 \mathrm{e}-011.00000 \mathrm{e}-091.00000 \mathrm{e}-01$ 
Element: 2595 \# of layers: 13

$\mathrm{Kx} \mathrm{Ky} \mathrm{Kz}$ Ss Por

3.65950e+01 3.65950e+01 3.65950e+00 1.00000e-09 7.00000e-02

$3.65950 \mathrm{e}+013.65950 \mathrm{e}+013.65950 \mathrm{e}+001.00000 \mathrm{e}-097.00000 \mathrm{e}-02$

5.00000e-04 5.00000e-04 5.00000e-05 1.00000e-09 1.00000e-01

5.00000e-04 5.00000e-04 5.00000e-05 1.00000e-09 1.00000e-01

$1.46222 \mathrm{e}+001.46222 \mathrm{e}+00$ 1.46222e-01 1.00000e-09 2.12000e-01

$1.46222 \mathrm{e}+001.46222 \mathrm{e}+00$ 1.46222e-01 1.00000e-09 2.12000e-01

$1.46222 \mathrm{e}+00$ 1.46222e+00 1.46222e-01 1.00000e-09 2.12000e-01

$1.46222 \mathrm{e}+00$ 1.46222e+00 1.46222e-01 1.00000e-09 2.12000e-01

$1.46222 \mathrm{e}+00$ 1.46222e+00 1.46222e-01 1.00000e-09 2.12000e-01

$1.00000 \mathrm{e}-02$ 1.00000e-02 1.00000e-03 1.00000e-09 1.00000e-01

$1.00000 \mathrm{e}+001.00000 \mathrm{e}+001.00000 \mathrm{e}-011.00000 \mathrm{e}-091.00000 \mathrm{e}-01$

$1.00000 \mathrm{e}-05$ 1.00000e-05 1.00000e-06 1.00000e-09 1.00000e-01

$1.00000 \mathrm{e}+001.00000 \mathrm{e}+001.00000 \mathrm{e}-01$ 1.00000e-09 1.00000e-01

Element: 2596 \# of layers: 10

$\mathrm{Kx} \mathrm{Ky} \mathrm{Kz}$ Ss Por

6.09283e+01 6.09283e+01 6.09283e+00 1.00000e-09 7.00000e-02

$6.09283 \mathrm{e}+016.09283 \mathrm{e}+016.09283 \mathrm{e}+00$ 1.00000e-09 7.00000e-02

5.00000e-04 5.00000e-04 5.00000e-05 1.00000e-09 1.00000e-01

5.00000e-04 5.00000e-04 5.00000e-05 1.00000e-09 1.00000e-01

$2.43455 \mathrm{e}+002.43455 \mathrm{e}+00$ 2.43455e-01 1.00000e-09 2.12000e-01

$2.43455 \mathrm{e}+002.43455 \mathrm{e}+00$ 2.43455e-01 1.00000e-09 2.12000e-01

$2.43455 \mathrm{e}+002.43455 \mathrm{e}+00$ 2.43455e-01 1.00000e-09 2.12000e-01

$2.43455 \mathrm{e}+002.43455 \mathrm{e}+00$ 2.43455e-01 1.00000e-09 2.12000e-01

$2.43455 \mathrm{e}+002.43455 \mathrm{e}+002.43455 \mathrm{e}-01$ 1.00000e-09 2.12000e-01

$1.00000 \mathrm{e}+001.00000 \mathrm{e}+001.00000 \mathrm{e}-011.00000 \mathrm{e}-091.00000 \mathrm{e}-01$

Element: 2597 \# of layers: 9

$\mathrm{Kx} \mathrm{Ky} \mathrm{Kz}$ Ss Por

$6.09283 \mathrm{e}+016.09283 \mathrm{e}+016.09283 \mathrm{e}+00$ 1.00000e-09 7.00000e-02

$6.09283 \mathrm{e}+016.09283 \mathrm{e}+016.09283 \mathrm{e}+001.00000 \mathrm{e}-09$ 7.00000e-02

5.00000e-04 5.00000e-04 5.00000e-05 1.00000e-09 1.00000e-01

5.00000e-04 5.00000e-04 5.00000e-05 1.00000e-09 1.00000e-01

$2.43455 \mathrm{e}+002.43455 \mathrm{e}+002.43455 \mathrm{e}-01$ 1.00000e-09 2.12000e-01

$2.43455 \mathrm{e}+002.43455 \mathrm{e}+00$ 2.43455e-01 1.00000e-09 2.12000e-01

$2.43455 \mathrm{e}+002.43455 \mathrm{e}+002.43455 \mathrm{e}-01$ 1.00000e-09 2.12000e-01

$2.43455 \mathrm{e}+002.43455 \mathrm{e}+002.43455 \mathrm{e}-01$ 1.00000e-09 2.12000e-01

$2.43455 \mathrm{e}+002.43455 \mathrm{e}+00$ 2.43455e-01 1.00000e-09 2.12000e-01

Element: 2598 \# of layers: 9

$\mathrm{Kx} \mathrm{Ky} \mathrm{Kz}$ Ss Por

6.09283e+01 6.09283e+01 6.09283e+00 1.00000e-09 7.00000e-02

$6.09283 \mathrm{e}+016.09283 \mathrm{e}+016.09283 \mathrm{e}+00$ 1.00000e-09 7.00000e-02

5.00000e-04 5.00000e-04 5.00000e-05 1.00000e-09 1.00000e-01

$5.00000 \mathrm{e}-04$ 5.00000e-04 5.00000e-05 1.00000e-09 1.00000e-01

$2.43455 \mathrm{e}+002.43455 \mathrm{e}+002.43455 \mathrm{e}-01$ 1.00000e-09 2.12000e-01

$2.43455 \mathrm{e}+002.43455 \mathrm{e}+00$ 2.43455e-01 1.00000e-09 2.12000e-01 
$2.43455 \mathrm{e}+002.43455 \mathrm{e}+00$ 2.43455e-01 1.00000e-09 2.12000e-01

$2.43455 \mathrm{e}+002.43455 \mathrm{e}+002.43455 \mathrm{e}-01$ 1.00000e-09 2.12000e-01

$2.43455 \mathrm{e}+002.43455 \mathrm{e}+00$ 2.43455e-01 1.00000e-09 2.12000e-01

Element: 2599 \# of layers: 8

$\mathrm{Kx} \mathrm{Ky} \mathrm{Kz}$ Ss Por

$6.09283 \mathrm{e}+016.09283 \mathrm{e}+016.09283 \mathrm{e}+00$ 1.00000e-09 7.00000e-02

5.00000e-04 5.00000e-04 5.00000e-05 1.00000e-09 1.00000e-01

5.00000e-04 5.00000e-04 5.00000e-05 1.00000e-09 1.00000e-01

$2.43455 \mathrm{e}+002.43455 \mathrm{e}+002.43455 \mathrm{e}-01$ 1.00000e-09 2.12000e-01

$2.43455 \mathrm{e}+002.43455 \mathrm{e}+002.43455 \mathrm{e}-01$ 1.00000e-09 2.12000e-01

$2.43455 \mathrm{e}+002.43455 \mathrm{e}+00$ 2.43455e-01 1.00000e-09 2.12000e-01

$2.43455 \mathrm{e}+002.43455 \mathrm{e}+002.43455 \mathrm{e}-01$ 1.00000e-09 2.12000e-01

$2.43455 \mathrm{e}+002.43455 \mathrm{e}+00$ 2.43455e-01 1.00000e-09 2.12000e-01

Element: 2600 \# of layers: 8

$\mathrm{Kx} \mathrm{Ky} \mathrm{Kz}$ Ss Por

6.09283e+01 6.09283e+01 6.09283e+00 1.00000e-09 7.00000e-02

5.00000e-04 5.00000e-04 5.00000e-05 1.00000e-09 1.00000e-01

5.00000e-04 5.00000e-04 5.00000e-05 1.00000e-09 1.00000e-01

$2.43455 \mathrm{e}+002.43455 \mathrm{e}+00$ 2.43455e-01 1.00000e-09 2.12000e-01

$2.43455 \mathrm{e}+002.43455 \mathrm{e}+00$ 2.43455e-01 1.00000e-09 2.12000e-01

$2.43455 \mathrm{e}+002.43455 \mathrm{e}+00$ 2.43455e-01 1.00000e-09 2.12000e-01

$2.43455 \mathrm{e}+002.43455 \mathrm{e}+00$ 2.43455e-01 1.00000e-09 2.12000e-01

$2.43455 \mathrm{e}+00$ 2.43455e+00 2.43455e-01 1.00000e-09 2.12000e-01

Element: 2601 \# of layers: 9

$\mathrm{Kx} \mathrm{Ky} \mathrm{Kz}$ Ss Por

6.09283e+01 6.09283e+01 6.09283e+00 1.00000e-09 7.00000e-02

$5.00000 \mathrm{e}-04$ 5.00000e-04 5.00000e-05 1.00000e-09 1.00000e-01

5.00000e-04 5.00000e-04 5.00000e-05 1.00000e-09 1.00000e-01

$2.43455 \mathrm{e}+002.43455 \mathrm{e}+002.43455 \mathrm{e}-01$ 1.00000e-09 2.12000e-01

$2.43455 \mathrm{e}+002.43455 \mathrm{e}+002.43455 \mathrm{e}-01$ 1.00000e-09 2.12000e-01

$2.43455 \mathrm{e}+002.43455 \mathrm{e}+00$ 2.43455e-01 1.00000e-09 2.12000e-01

$2.43455 \mathrm{e}+002.43455 \mathrm{e}+00$ 2.43455e-01 1.00000e-09 2.12000e-01

$2.43455 \mathrm{e}+002.43455 \mathrm{e}+002.43455 \mathrm{e}-01$ 1.00000e-09 2.12000e-01

$1.00000 \mathrm{e}+001.00000 \mathrm{e}+001.00000 \mathrm{e}-011.00000 \mathrm{e}-091.00000 \mathrm{e}-01$

Element: 2602 \# of layers: 10

$\mathrm{Kx} \mathrm{Ky} \mathrm{Kz}$ Ss Por

6.09283e+01 6.09283e+01 6.09283e+00 1.00000e-09 7.00000e-02

$6.09283 \mathrm{e}+016.09283 \mathrm{e}+016.09283 \mathrm{e}+00$ 1.00000e-09 7.00000e-02

5.00000e-04 5.00000e-04 5.00000e-05 1.00000e-09 1.00000e-01

5.00000e-04 5.00000e-04 5.00000e-05 1.00000e-09 1.00000e-01

$2.43455 \mathrm{e}+002.43455 \mathrm{e}+002.43455 \mathrm{e}-01$ 1.00000e-09 2.12000e-01

$2.43455 \mathrm{e}+002.43455 \mathrm{e}+002.43455 \mathrm{e}-01$ 1.00000e-09 2.12000e-01

$2.43455 \mathrm{e}+002.43455 \mathrm{e}+00$ 2.43455e-01 1.00000e-09 2.12000e-01

$2.43455 \mathrm{e}+002.43455 \mathrm{e}+00$ 2.43455e-01 1.00000e-09 2.12000e-01

$2.43455 \mathrm{e}+002.43455 \mathrm{e}+002.43455 \mathrm{e}-01$ 1.00000e-09 2.12000e-01

$1.00000 \mathrm{e}+001.00000 \mathrm{e}+001.00000 \mathrm{e}-011.00000 \mathrm{e}-091.00000 \mathrm{e}-01$ 
Element: 2603 \# of layers: 9

$\mathrm{Kx} \mathrm{Ky} \mathrm{Kz}$ Ss Por

6.09283e+01 6.09283e+01 6.09283e+00 1.00000e-09 7.00000e-02

5.00000e-04 5.00000e-04 5.00000e-05 1.00000e-09 1.00000e-01

5.00000e-04 5.00000e-04 5.00000e-05 1.00000e-09 1.00000e-01

$2.43455 \mathrm{e}+002.43455 \mathrm{e}+00$ 2.43455e-01 1.00000e-09 2.12000e-01

$2.43455 \mathrm{e}+002.43455 \mathrm{e}+00$ 2.43455e-01 1.00000e-09 2.12000e-01

$2.43455 \mathrm{e}+002.43455 \mathrm{e}+002.43455 \mathrm{e}-01$ 1.00000e-09 2.12000e-01

$2.43455 \mathrm{e}+002.43455 \mathrm{e}+00$ 2.43455e-01 1.00000e-09 2.12000e-01

$2.43455 \mathrm{e}+002.43455 \mathrm{e}+00$ 2.43455e-01 1.00000e-09 2.12000e-01

$1.00000 \mathrm{e}+001.00000 \mathrm{e}+001.00000 \mathrm{e}-011.00000 \mathrm{e}-091.00000 \mathrm{e}-01$

Element: 2604 \# of layers: 8

$\mathrm{Kx} \mathrm{Ky} \mathrm{Kz}$ Ss Por

$6.09283 \mathrm{e}+016.09283 \mathrm{e}+016.09283 \mathrm{e}+00$ 1.00000e-09 7.00000e-02

5.00000e-04 5.00000e-04 5.00000e-05 1.00000e-09 1.00000e-01

$2.43455 \mathrm{e}+002.43455 \mathrm{e}+002.43455 \mathrm{e}-01$ 1.00000e-09 2.12000e-01

$2.43455 \mathrm{e}+002.43455 \mathrm{e}+002.43455 \mathrm{e}-01$ 1.00000e-09 2.12000e-01

$2.43455 \mathrm{e}+002.43455 \mathrm{e}+002.43455 \mathrm{e}-01$ 1.00000e-09 2.12000e-01

$2.43455 \mathrm{e}+002.43455 \mathrm{e}+00$ 2.43455e-01 1.00000e-09 2.12000e-01

$2.43455 \mathrm{e}+002.43455 \mathrm{e}+002.43455 \mathrm{e}-01$ 1.00000e-09 2.12000e-01

$1.00000 \mathrm{e}+001.00000 \mathrm{e}+001.00000 \mathrm{e}-011.00000 \mathrm{e}-091.00000 \mathrm{e}-01$

Element: 2605 \# of layers: 9

$\mathrm{Kx} \mathrm{Ky} \mathrm{Kz}$ Ss Por

$1.24563 \mathrm{e}+02$ 1.24563e+02 1.24563e+01 1.00000e-09 7.00000e-02

$1.24563 \mathrm{e}+02$ 1.24563e+02 1.24563e+01 1.00000e-09 7.00000e-02

5.00000e-04 5.00000e-04 5.00000e-05 1.00000e-09 1.00000e-01

5.00000e-04 5.00000e-04 5.00000e-05 1.00000e-09 1.00000e-01

$4.97711 \mathrm{e}+004.97711 \mathrm{e}+00$ 4.97711e-01 1.00000e-09 2.12000e-01

$4.97711 \mathrm{e}+004.97711 \mathrm{e}+004.97711 \mathrm{e}-011.00000 \mathrm{e}-092.12000 \mathrm{e}-01$

$4.97711 \mathrm{e}+004.97711 \mathrm{e}+004.97711 \mathrm{e}-01$ 1.00000e-09 2.12000e-01

$4.97711 \mathrm{e}+004.97711 \mathrm{e}+004.97711 \mathrm{e}-01$ 1.00000e-09 2.12000e-01

$4.97711 \mathrm{e}+004.97711 \mathrm{e}+00$ 4.97711e-01 1.00000e-09 2.12000e-01

Element: 2606 \# of layers: 9

$\mathrm{Kx} \mathrm{Ky} \mathrm{Kz}$ Ss Por

1.24563e+02 1.24563e+02 1.24563e+01 1.00000e-09 7.00000e-02

$1.24563 \mathrm{e}+02$ 1.24563e+02 1.24563e+01 1.00000e-09 7.00000e-02

5.00000e-04 5.00000e-04 5.00000e-05 1.00000e-09 1.00000e-01

5.00000e-04 5.00000e-04 5.00000e-05 1.00000e-09 1.00000e-01

$4.97711 \mathrm{e}+004.97711 \mathrm{e}+004.97711 \mathrm{e}-01$ 1.00000e-09 2.12000e-01

$4.97711 \mathrm{e}+004.97711 \mathrm{e}+004.97711 \mathrm{e}-01$ 1.00000e-09 2.12000e-01

$4.97711 \mathrm{e}+004.97711 \mathrm{e}+00$ 4.97711e-01 1.00000e-09 2.12000e-01

$4.97711 \mathrm{e}+004.97711 \mathrm{e}+004.97711 \mathrm{e}-01$ 1.00000e-09 2.12000e-01

$4.97711 \mathrm{e}+004.97711 \mathrm{e}+004.97711 \mathrm{e}-01$ 1.00000e-09 2.12000e-01

Element: 2607 \# of layers: 8

$\mathrm{Kx} \mathrm{Ky} \mathrm{Kz}$ Ss Por

$1.24563 e+02$ 1.24563e+02 1.24563e+01 1.00000e-09 7.00000e-02 
5.00000e-04 5.00000e-04 5.00000e-05 1.00000e-09 1.00000e-01 5.00000e-04 5.00000e-04 5.00000e-05 1.00000e-09 1.00000e-01 $4.97711 \mathrm{e}+004.97711 \mathrm{e}+00$ 4.97711e-01 1.00000e-09 2.12000e-01 $4.97711 \mathrm{e}+004.97711 \mathrm{e}+004.97711 \mathrm{e}-01$ 1.00000e-09 2.12000e-01 $4.97711 \mathrm{e}+004.97711 \mathrm{e}+00$ 4.97711e-01 1.00000e-09 2.12000e-01 $4.97711 \mathrm{e}+004.97711 \mathrm{e}+004.97711 \mathrm{e}-01$ 1.00000e-09 2.12000e-01 4.97711e+00 4.97711e+00 4.97711e-01 1.00000e-09 2.12000e-01 Element: 2608 \# of layers: 7

$\mathrm{Kx} \mathrm{Ky} \mathrm{Kz}$ Ss Por

1.24563e+02 1.24563e+02 1.24563e+01 1.00000e-09 7.00000e-02 5.00000e-04 5.00000e-04 5.00000e-05 1.00000e-09 1.00000e-01 $4.97711 \mathrm{e}+004.97711 \mathrm{e}+004.97711 \mathrm{e}-01$ 1.00000e-09 2.12000e-01 $4.97711 \mathrm{e}+004.97711 \mathrm{e}+00$ 4.97711e-01 1.00000e-09 2.12000e-01 $4.97711 \mathrm{e}+004.97711 \mathrm{e}+004.97711 \mathrm{e}-01$ 1.00000e-09 2.12000e-01 $4.97711 \mathrm{e}+004.97711 \mathrm{e}+004.97711 \mathrm{e}-01$ 1.00000e-09 2.12000e-01 $4.97711 \mathrm{e}+004.97711 \mathrm{e}+004.97711 \mathrm{e}-01$ 1.00000e-09 2.12000e-01

Element: 2609 \# of layers: 7

$\mathrm{Kx} \mathrm{Ky} \mathrm{Kz}$ Ss Por

1.24563e+02 1.24563e+02 1.24563e+01 1.00000e-09 7.00000e-02 5.00000e-04 5.00000e-04 5.00000e-05 1.00000e-09 1.00000e-01

$4.97711 \mathrm{e}+004.97711 \mathrm{e}+004.97711 \mathrm{e}-01$ 1.00000e-09 2.12000e-01 $4.97711 \mathrm{e}+004.97711 \mathrm{e}+00$ 4.97711e-01 1.00000e-09 2.12000e-01 $4.97711 \mathrm{e}+004.97711 \mathrm{e}+00$ 4.97711e-01 1.00000e-09 2.12000e-01 $4.97711 \mathrm{e}+004.97711 \mathrm{e}+00$ 4.97711e-01 1.00000e-09 2.12000e-01 $4.97711 \mathrm{e}+004.97711 \mathrm{e}+004.97711 \mathrm{e}-01$ 1.00000e-09 2.12000e-01 Element: 2610 \# of layers: 7

$\mathrm{Kx} \mathrm{Ky} \mathrm{Kz}$ Ss Por

$1.24563 \mathrm{e}+02$ 1.24563e+02 1.24563e+01 1.00000e-09 7.00000e-02 5.00000e-04 5.00000e-04 5.00000e-05 1.00000e-09 1.00000e-01 $4.97711 \mathrm{e}+004.97711 \mathrm{e}+00$ 4.97711e-01 1.00000e-09 2.12000e-01 $4.97711 \mathrm{e}+004.97711 \mathrm{e}+004.97711 \mathrm{e}-01$ 1.00000e-09 2.12000e-01 $4.97711 \mathrm{e}+004.97711 \mathrm{e}+004.97711 \mathrm{e}-01$ 1.00000e-09 2.12000e-01 $4.97711 \mathrm{e}+004.97711 \mathrm{e}+004.97711 \mathrm{e}-01$ 1.00000e-09 2.12000e-01 4.97711e+00 4.97711e+00 4.97711e-01 1.00000e-09 2.12000e-01 Element: 2611 \# of layers: 8

$\mathrm{Kx} \mathrm{Ky} \mathrm{Kz}$ Ss Por 1.24563e+02 1.24563e+02 1.24563e+01 1.00000e-09 7.00000e-02 5.00000e-04 5.00000e-04 5.00000e-05 1.00000e-09 1.00000e-01 5.00000e-04 5.00000e-04 5.00000e-05 1.00000e-09 1.00000e-01 $4.97711 \mathrm{e}+004.97711 \mathrm{e}+00$ 4.97711e-01 1.00000e-09 2.12000e-01 $4.97711 \mathrm{e}+004.97711 \mathrm{e}+00$ 4.97711e-01 1.00000e-09 2.12000e-01 $4.97711 \mathrm{e}+004.97711 \mathrm{e}+004.97711 \mathrm{e}-01$ 1.00000e-09 2.12000e-01 $4.97711 \mathrm{e}+004.97711 \mathrm{e}+004.97711 \mathrm{e}-01$ 1.00000e-09 2.12000e-01 4.97711e+00 4.97711e+00 4.97711e-01 1.00000e-09 2.12000e-01 Element: 2612 \# of layers: 8

Kx Ky Kz Ss Por 
$1.24563 \mathrm{e}+02$ 1.24563e+02 1.24563e+01 1.00000e-09 7.00000e-02 5.00000e-04 5.00000e-04 5.00000e-05 1.00000e-09 1.00000e-01 5.00000e-04 5.00000e-04 5.00000e-05 1.00000e-09 1.00000e-01 $4.97711 \mathrm{e}+004.97711 \mathrm{e}+004.97711 \mathrm{e}-01$ 1.00000e-09 2.12000e-01 $4.97711 \mathrm{e}+004.97711 \mathrm{e}+00$ 4.97711e-01 1.00000e-09 2.12000e-01 $4.97711 \mathrm{e}+004.97711 \mathrm{e}+004.97711 \mathrm{e}-01$ 1.00000e-09 2.12000e-01 $4.97711 \mathrm{e}+004.97711 \mathrm{e}+004.97711 \mathrm{e}-01$ 1.00000e-09 2.12000e-01 $4.97711 \mathrm{e}+004.97711 \mathrm{e}+00$ 4.97711e-01 1.00000e-09 2.12000e-01 Element: 2613 \# of layers: 8

$\mathrm{Kx} \mathrm{Ky} \mathrm{Kz}$ Ss Por

$1.24563 \mathrm{e}+02$ 1.24563e+02 1.24563e+01 1.00000e-09 7.00000e-02 5.00000e-04 5.00000e-04 5.00000e-05 1.00000e-09 1.00000e-01 5.00000e-04 5.00000e-04 5.00000e-05 1.00000e-09 1.00000e-01 $4.97711 \mathrm{e}+004.97711 \mathrm{e}+00$ 4.97711e-01 1.00000e-09 2.12000e-01 $4.97711 \mathrm{e}+004.97711 \mathrm{e}+00$ 4.97711e-01 1.00000e-09 2.12000e-01 $4.97711 \mathrm{e}+004.97711 \mathrm{e}+004.97711 \mathrm{e}-01$ 1.00000e-09 2.12000e-01 $4.97711 \mathrm{e}+004.97711 \mathrm{e}+004.97711 \mathrm{e}-01$ 1.00000e-09 2.12000e-01 4.97711e+00 4.97711e+00 4.97711e-01 1.00000e-09 2.12000e-01 Element: 2614 \# of layers: 7

$\mathrm{Kx} \mathrm{Ky} \mathrm{Kz}$ Ss Por 5.00000e-04 5.00000e-04 5.00000e-05 1.00000e-09 1.00000e-01 5.00000e-04 5.00000e-04 5.00000e-05 1.00000e-09 1.00000e-01 6.21463e+00 6.21463e+00 6.21463e-01 1.00000e-09 2.12000e-01 6.21463e+00 6.21463e+00 6.21463e-01 1.00000e-09 2.12000e-01 $6.21463 \mathrm{e}+006.21463 \mathrm{e}+00$ 6.21463e-01 1.00000e-09 2.12000e-01 6.21463e+00 6.21463e+00 6.21463e-01 1.00000e-09 2.12000e-01 6.21463e+00 6.21463e+00 6.21463e-01 1.00000e-09 2.12000e-01 Element: 2615 \# of layers: 9

Kx Ky Kz Ss Por

$1.55531 \mathrm{e}+02$ 1.55531e+02 1.55531e+01 1.00000e-09 7.00000e-02 $1.55531 \mathrm{e}+021.55531 \mathrm{e}+021.55531 \mathrm{e}+01$ 1.00000e-09 7.00000e-02 5.00000e-04 5.00000e-04 5.00000e-05 1.00000e-09 1.00000e-01 5.00000e-04 5.00000e-04 5.00000e-05 1.00000e-09 1.00000e-01 6.21463e+00 6.21463e+00 6.21463e-01 1.00000e-09 2.12000e-01 $6.21463 \mathrm{e}+006.21463 \mathrm{e}+00$ 6.21463e-01 1.00000e-09 2.12000e-01 6.21463e+00 6.21463e+00 6.21463e-01 1.00000e-09 2.12000e-01 6.21463e+00 6.21463e+00 6.21463e-01 1.00000e-09 2.12000e-01 $6.21463 \mathrm{e}+00$ 6.21463e+00 6.21463e-01 1.00000e-09 2.12000e-01 Element: 2616 \# of layers: 9

$\mathrm{Kx} \mathrm{Ky} \mathrm{Kz}$ Ss Por

1.55531e+02 1.55531e+02 1.55531e+01 1.00000e-09 7.00000e-02 $1.55531 \mathrm{e}+021.55531 \mathrm{e}+02$ 1.55531e+01 1.00000e-09 7.00000e-02 5.00000e-04 5.00000e-04 5.00000e-05 1.00000e-09 1.00000e-01 5.00000e-04 5.00000e-04 5.00000e-05 1.00000e-09 1.00000e-01 $6.21463 \mathrm{e}+006.21463 \mathrm{e}+00$ 6.21463e-01 1.00000e-09 2.12000e-01 $6.21463 \mathrm{e}+006.21463 \mathrm{e}+00$ 6.21463e-01 1.00000e-09 2.12000e-01 
$6.21463 \mathrm{e}+00$ 6.21463e+00 6.21463e-01 1.00000e-09 2.12000e-01 $6.21463 \mathrm{e}+006.21463 \mathrm{e}+00$ 6.21463e-01 1.00000e-09 2.12000e-01 $6.21463 \mathrm{e}+00$ 6.21463e+00 6.21463e-01 1.00000e-09 2.12000e-01 Element: 2617 \# of layers: 8

Kx Ky Kz Ss Por

$1.55531 \mathrm{e}+021.55531 \mathrm{e}+02$ 1.55531e+01 1.00000e-09 7.00000e-02 5.00000e-04 5.00000e-04 5.00000e-05 1.00000e-09 1.00000e-01 5.00000e-04 5.00000e-04 5.00000e-05 1.00000e-09 1.00000e-01 $6.21463 \mathrm{e}+006.21463 \mathrm{e}+00$ 6.21463e-01 1.00000e-09 2.12000e-01 $6.21463 \mathrm{e}+006.21463 \mathrm{e}+00$ 6.21463e-01 1.00000e-09 2.12000e-01 $6.21463 \mathrm{e}+006.21463 \mathrm{e}+00$ 6.21463e-01 1.00000e-09 2.12000e-01 $6.21463 \mathrm{e}+006.21463 \mathrm{e}+00$ 6.21463e-01 1.00000e-09 2.12000e-01 $6.21463 \mathrm{e}+006.21463 \mathrm{e}+00$ 6.21463e-01 1.00000e-09 2.12000e-01 Element: 2618 \# of layers: 8

Kx Ky Kz Ss Por

$1.55531 \mathrm{e}+021.55531 \mathrm{e}+021.55531 \mathrm{e}+01$ 1.00000e-09 7.00000e-02 5.00000e-04 5.00000e-04 5.00000e-05 1.00000e-09 1.00000e-01 $5.00000 \mathrm{e}-04$ 5.00000e-04 5.00000e-05 1.00000e-09 1.00000e-01 $6.21463 \mathrm{e}+006.21463 \mathrm{e}+00$ 6.21463e-01 1.00000e-09 2.12000e-01 $6.21463 \mathrm{e}+006.21463 \mathrm{e}+00$ 6.21463e-01 1.00000e-09 2.12000e-01 $6.21463 \mathrm{e}+006.21463 \mathrm{e}+00$ 6.21463e-01 1.00000e-09 2.12000e-01 $6.21463 \mathrm{e}+006.21463 \mathrm{e}+00$ 6.21463e-01 1.00000e-09 2.12000e-01 $6.21463 \mathrm{e}+006.21463 \mathrm{e}+00$ 6.21463e-01 1.00000e-09 2.12000e-01 Element: 2619 \# of layers: 8

Kx Ky Kz Ss Por

$1.55531 \mathrm{e}+021.55531 \mathrm{e}+02$ 1.55531e+01 1.00000e-09 7.00000e-02 $5.00000 \mathrm{e}-04$ 5.00000e-04 5.00000e-05 1.00000e-09 1.00000e-01 $5.00000 \mathrm{e}-04$ 5.00000e-04 5.00000e-05 1.00000e-09 1.00000e-01 $6.21463 \mathrm{e}+006.21463 \mathrm{e}+00$ 6.21463e-01 1.00000e-09 2.12000e-01 $6.21463 \mathrm{e}+006.21463 \mathrm{e}+00$ 6.21463e-01 1.00000e-09 2.12000e-01 $6.21463 \mathrm{e}+006.21463 \mathrm{e}+00$ 6.21463e-01 1.00000e-09 2.12000e-01 $6.21463 \mathrm{e}+006.21463 \mathrm{e}+00$ 6.21463e-01 1.00000e-09 2.12000e-01 $6.21463 \mathrm{e}+006.21463 \mathrm{e}+00$ 6.21463e-01 1.00000e-09 2.12000e-01 Element: 2620 \# of layers: 8

Kx Ky Kz Ss Por

$1.55531 \mathrm{e}+021.55531 \mathrm{e}+02$ 1.55531e+01 1.00000e-09 7.00000e-02 5.00000e-04 5.00000e-04 5.00000e-05 1.00000e-09 1.00000e-01 5.00000e-04 5.00000e-04 5.00000e-05 1.00000e-09 1.00000e-01 $6.21463 \mathrm{e}+006.21463 \mathrm{e}+00$ 6.21463e-01 1.00000e-09 2.12000e-01 $6.21463 \mathrm{e}+006.21463 \mathrm{e}+00$ 6.21463e-01 1.00000e-09 2.12000e-01 $6.21463 \mathrm{e}+006.21463 \mathrm{e}+00$ 6.21463e-01 1.00000e-09 2.12000e-01 $6.21463 \mathrm{e}+006.21463 \mathrm{e}+00$ 6.21463e-01 1.00000e-09 2.12000e-01 $6.21463 \mathrm{e}+006.21463 \mathrm{e}+00$ 6.21463e-01 1.00000e-09 2.12000e-01 Element: 2621 \# of layers: 7

Kx Ky Kz Ss Por

$1.55531 \mathrm{e}+021.55531 \mathrm{e}+02$ 1.55531e+01 1.00000e-09 7.00000e-02 
5.00000e-04 5.00000e-04 5.00000e-05 1.00000e-09 1.00000e-01 6.21463e+00 6.21463e+00 6.21463e-01 1.00000e-09 2.12000e-01 6.21463e+00 6.21463e+00 6.21463e-01 1.00000e-09 2.12000e-01 $6.21463 \mathrm{e}+00$ 6.21463e+00 6.21463e-01 1.00000e-09 2.12000e-01 $6.21463 \mathrm{e}+00$ 6.21463e+00 6.21463e-01 1.00000e-09 2.12000e-01 $6.21463 \mathrm{e}+00$ 6.21463e+00 6.21463e-01 1.00000e-09 2.12000e-01 Element: 2622 \# of layers: 8

$\mathrm{Kx} \mathrm{Ky} \mathrm{Kz}$ Ss Por

$1.55531 \mathrm{e}+021.55531 \mathrm{e}+02$ 1.55531e+01 1.00000e-09 7.00000e-02 5.00000e-04 5.00000e-04 5.00000e-05 1.00000e-09 1.00000e-01 5.00000e-04 5.00000e-04 5.00000e-05 1.00000e-09 1.00000e-01 6.21463e+00 6.21463e+00 6.21463e-01 1.00000e-09 2.12000e-01 6.21463e+00 6.21463e+00 6.21463e-01 1.00000e-09 2.12000e-01 $6.21463 \mathrm{e}+006.21463 \mathrm{e}+00$ 6.21463e-01 1.00000e-09 2.12000e-01 6.21463e+00 6.21463e+00 6.21463e-01 1.00000e-09 2.12000e-01 $6.21463 \mathrm{e}+00$ 6.21463e+00 6.21463e-01 1.00000e-09 2.12000e-01 Element: 2623 \# of layers: 9

$\mathrm{Kx} \mathrm{Ky} \mathrm{Kz}$ Ss Por

1.17635e+02 1.17635e+02 1.17635e+01 1.00000e-09 7.00000e-02 $1.17635 \mathrm{e}+02$ 1.17635e+02 1.17635e+01 1.00000e-09 7.00000e-02 5.00000e-04 5.00000e-04 5.00000e-05 1.00000e-09 1.00000e-01 5.00000e-04 5.00000e-04 5.00000e-05 1.00000e-09 1.00000e-01 4.70013e+00 4.70013e+00 4.70013e-01 1.00000e-09 2.12000e-01 4.70013e+00 4.70013e+00 4.70013e-01 1.00000e-09 2.12000e-01 $4.70013 e+00$ 4.70013e+00 4.70013e-01 1.00000e-09 2.12000e-01 4.70013e+00 4.70013e+00 4.70013e-01 1.00000e-09 2.12000e-01 4.70013e+00 4.70013e+00 4.70013e-01 1.00000e-09 2.12000e-01 Element: 2624 \# of layers: 9

Kx Ky Kz Ss Por

$1.17635 \mathrm{e}+02$ 1.17635e+02 1.17635e+01 1.00000e-09 7.00000e-02 $1.17635 \mathrm{e}+021.17635 \mathrm{e}+02$ 1.17635e+01 1.00000e-09 7.00000e-02 5.00000e-04 5.00000e-04 5.00000e-05 1.00000e-09 1.00000e-01 5.00000e-04 5.00000e-04 5.00000e-05 1.00000e-09 1.00000e-01 4.70013e+00 4.70013e+00 4.70013e-01 1.00000e-09 2.12000e-01 4.70013e+00 4.70013e+00 4.70013e-01 1.00000e-09 2.12000e-01 4.70013e+00 4.70013e+00 4.70013e-01 1.00000e-09 2.12000e-01 $4.70013 \mathrm{e}+00$ 4.70013e+00 4.70013e-01 1.00000e-09 2.12000e-01 4.70013e+00 4.70013e+00 4.70013e-01 1.00000e-09 2.12000e-01 Element: 2625 \# of layers: 7

$\mathrm{Kx} \mathrm{Ky} \mathrm{Kz}$ Ss Por

$1.17635 \mathrm{e}+02$ 1.17635e+02 1.17635e+01 1.00000e-09 7.00000e-02 5.00000e-04 5.00000e-04 5.00000e-05 1.00000e-09 1.00000e-01

4.70013e+00 4.70013e+00 4.70013e-01 1.00000e-09 2.12000e-01 4.70013e+00 4.70013e+00 4.70013e-01 1.00000e-09 2.12000e-01 $4.70013 \mathrm{e}+004.70013 \mathrm{e}+00$ 4.70013e-01 1.00000e-09 2.12000e-01 $4.70013 e+004.70013 e+00$ 4.70013e-01 1.00000e-09 2.12000e-01 
4.70013e+00 4.70013e+00 4.70013e-01 1.00000e-09 2.12000e-01

Element: 2626 \# of layers: 7

Kx Ky Kz Ss Por

$1.17635 \mathrm{e}+02$ 1.17635e+02 1.17635e+01 1.00000e-09 7.00000e-02 5.00000e-04 5.00000e-04 5.00000e-05 1.00000e-09 1.00000e-01

4.70013e+00 4.70013e+00 4.70013e-01 1.00000e-09 2.12000e-01

4.70013e+00 4.70013e+00 4.70013e-01 1.00000e-09 2.12000e-01

4.70013e+00 4.70013e+00 4.70013e-01 1.00000e-09 2.12000e-01

4.70013e+00 4.70013e+00 4.70013e-01 1.00000e-09 2.12000e-01

4.70013e+00 4.70013e+00 4.70013e-01 1.00000e-09 2.12000e-01

Element: 2627 \# of layers: 7

Kx Ky Kz Ss Por

$1.17635 \mathrm{e}+02$ 1.17635e+02 1.17635e+01 1.00000e-09 7.00000e-02

5.00000e-04 5.00000e-04 5.00000e-05 1.00000e-09 1.00000e-01

4.70013e+00 4.70013e+00 4.70013e-01 1.00000e-09 2.12000e-01

$4.70013 \mathrm{e}+00$ 4.70013e+00 4.70013e-01 1.00000e-09 2.12000e-01

4.70013e+00 4.70013e+00 4.70013e-01 1.00000e-09 2.12000e-01

4.70013e+00 4.70013e+00 4.70013e-01 1.00000e-09 2.12000e-01

4.70013e+00 4.70013e+00 4.70013e-01 1.00000e-09 2.12000e-01

Element: 2628 \# of layers: 8

$\mathrm{Kx} \mathrm{Ky} \mathrm{Kz}$ Ss Por

$1.17635 \mathrm{e}+021.17635 \mathrm{e}+02$ 1.17635e+01 1.00000e-09 7.00000e-02 5.00000e-04 5.00000e-04 5.00000e-05 1.00000e-09 1.00000e-01 5.00000e-04 5.00000e-04 5.00000e-05 1.00000e-09 1.00000e-01

$4.70013 \mathrm{e}+004.70013 \mathrm{e}+00$ 4.70013e-01 1.00000e-09 2.12000e-01

4.70013e+00 4.70013e+00 4.70013e-01 1.00000e-09 2.12000e-01

4.70013e+00 4.70013e+00 4.70013e-01 1.00000e-09 2.12000e-01

4.70013e+00 4.70013e+00 4.70013e-01 1.00000e-09 2.12000e-01

4.70013e+00 4.70013e+00 4.70013e-01 1.00000e-09 2.12000e-01

Element: 2629 \# of layers: 8

$\mathrm{Kx} \mathrm{Ky} \mathrm{Kz}$ Ss Por

$1.17635 \mathrm{e}+02$ 1.17635e+02 1.17635e+01 1.00000e-09 7.00000e-02 5.00000e-04 5.00000e-04 5.00000e-05 1.00000e-09 1.00000e-01 5.00000e-04 5.00000e-04 5.00000e-05 1.00000e-09 1.00000e-01

4.70013e+00 4.70013e+00 4.70013e-01 1.00000e-09 2.12000e-01

4.70013e+00 4.70013e+00 4.70013e-01 1.00000e-09 2.12000e-01

4.70013e+00 4.70013e+00 4.70013e-01 1.00000e-09 2.12000e-01

4.70013e+00 4.70013e+00 4.70013e-01 1.00000e-09 2.12000e-01

4.70013e+00 4.70013e+00 4.70013e-01 1.00000e-09 2.12000e-01

Element: 2630 \# of layers: 8

$\mathrm{Kx} \mathrm{Ky} \mathrm{Kz}$ Ss Por

1.17635e+02 1.17635e+02 1.17635e+01 1.00000e-09 7.00000e-02 5.00000e-04 5.00000e-04 5.00000e-05 1.00000e-09 1.00000e-01 5.00000e-04 5.00000e-04 5.00000e-05 1.00000e-09 1.00000e-01 4.70013e+00 4.70013e+00 4.70013e-01 1.00000e-09 2.12000e-01 $4.70013 \mathrm{e}+00$ 4.70013e+00 4.70013e-01 1.00000e-09 2.12000e-01 
$4.70013 \mathrm{e}+00$ 4.70013e+00 4.70013e-01 1.00000e-09 2.12000e-01 $4.70013 \mathrm{e}+004.70013 \mathrm{e}+00$ 4.70013e-01 1.00000e-09 2.12000e-01 4.70013e+00 4.70013e+00 4.70013e-01 1.00000e-09 2.12000e-01 Element: 2631 \# of layers: 8

Kx Ky Kz Ss Por

$1.17635 \mathrm{e}+021.17635 \mathrm{e}+021.17635 \mathrm{e}+01$ 1.00000e-09 7.00000e-02 5.00000e-04 5.00000e-04 5.00000e-05 1.00000e-09 1.00000e-01 5.00000e-04 5.00000e-04 5.00000e-05 1.00000e-09 1.00000e-01 $4.70013 \mathrm{e}+004.70013 \mathrm{e}+00$ 4.70013e-01 1.00000e-09 2.12000e-01 $4.70013 \mathrm{e}+004.70013 \mathrm{e}+00$ 4.70013e-01 1.00000e-09 2.12000e-01 $4.70013 \mathrm{e}+004.70013 \mathrm{e}+00$ 4.70013e-01 1.00000e-09 2.12000e-01 $4.70013 \mathrm{e}+004.70013 \mathrm{e}+00$ 4.70013e-01 1.00000e-09 2.12000e-01 $4.70013 \mathrm{e}+004.70013 \mathrm{e}+00$ 4.70013e-01 1.00000e-09 2.12000e-01 Element: 2632 \# of layers: 8

Kx Ky Kz Ss Por $1.10859 \mathrm{e}+02$ 1.10859e+02 1.10859e+01 1.00000e-09 7.00000e-02 5.00000e-04 5.00000e-04 5.00000e-05 1.00000e-09 1.00000e-01 5.00000e-04 5.00000e-04 5.00000e-05 1.00000e-09 1.00000e-01 $4.42967 \mathrm{e}+004.42967 \mathrm{e}+00$ 4.42967e-01 1.00000e-09 2.12000e-01 $4.42967 \mathrm{e}+004.42967 \mathrm{e}+00$ 4.42967e-01 1.00000e-09 2.12000e-01 $4.42967 \mathrm{e}+004.42967 \mathrm{e}+004.42967 \mathrm{e}-011.00000 \mathrm{e}-092.12000 \mathrm{e}-01$ $4.42967 \mathrm{e}+004.42967 \mathrm{e}+00$ 4.42967e-01 1.00000e-09 2.12000e-01 $4.42967 \mathrm{e}+00$ 4.42967e+00 4.42967e-01 1.00000e-09 2.12000e-01 Element: 2633 \# of layers: 7

Kx Ky Kz Ss Por $1.10859 \mathrm{e}+02$ 1.10859e+02 1.10859e+01 1.00000e-09 7.00000e-02 $5.00000 \mathrm{e}-04$ 5.00000e-04 5.00000e-05 1.00000e-09 1.00000e-01 $4.42967 \mathrm{e}+00 \quad 4.42967 \mathrm{e}+00$ 4.42967e-01 1.00000e-09 2.12000e-01 $4.42967 \mathrm{e}+004.42967 \mathrm{e}+00$ 4.42967e-01 1.00000e-09 2.12000e-01 $4.42967 \mathrm{e}+004.42967 \mathrm{e}+00$ 4.42967e-01 1.00000e-09 2.12000e-01 $4.42967 \mathrm{e}+004.42967 \mathrm{e}+004.42967 \mathrm{e}-01$ 1.00000e-09 2.12000e-01 $4.42967 \mathrm{e}+004.42967 \mathrm{e}+00$ 4.42967e-01 1.00000e-09 2.12000e-01 Element: 2634 \# of layers: 8

Kx Ky Kz Ss Por

$1.10859 \mathrm{e}+02$ 1.10859e+02 1.10859e+01 1.00000e-09 7.00000e-02 5.00000e-04 5.00000e-04 5.00000e-05 1.00000e-09 1.00000e-01 $5.00000 \mathrm{e}-04$ 5.00000e-04 5.00000e-05 1.00000e-09 1.00000e-01 $4.42967 \mathrm{e}+004.42967 \mathrm{e}+00$ 4.42967e-01 1.00000e-09 2.12000e-01 $4.42967 \mathrm{e}+004.42967 \mathrm{e}+00$ 4.42967e-01 1.00000e-09 2.12000e-01 $4.42967 \mathrm{e}+004.42967 \mathrm{e}+00$ 4.42967e-01 1.00000e-09 2.12000e-01 $4.42967 \mathrm{e}+004.42967 \mathrm{e}+00$ 4.42967e-01 1.00000e-09 2.12000e-01 $4.42967 \mathrm{e}+004.42967 \mathrm{e}+00$ 4.42967e-01 1.00000e-09 2.12000e-01 Element: 2635 \# of layers: 7

Kx Ky Kz Ss Por $6.54901 \mathrm{e}+026.54901 \mathrm{e}+026.54901 \mathrm{e}+01$ 1.00000e-09 7.00000e-02 5.00000e-04 5.00000e-04 5.00000e-05 1.00000e-09 1.00000e-01 
$2.61681 \mathrm{e}+012.61681 \mathrm{e}+012.61681 \mathrm{e}+001.00000 \mathrm{e}-092.12000 \mathrm{e}-01$ $1.00000 \mathrm{e}-02$ 1.00000e-02 1.00000e-03 1.00000e-09 1.00000e-01 $1.00000 \mathrm{e}+001.00000 \mathrm{e}+001.00000 \mathrm{e}-011.00000 \mathrm{e}-091.00000 \mathrm{e}-01$ $1.00000 \mathrm{e}-05$ 1.00000e-05 1.00000e-06 1.00000e-09 1.00000e-01 $1.00000 \mathrm{e}+001.00000 \mathrm{e}+001.00000 \mathrm{e}-01$ 1.00000e-09 1.00000e-01 Element: 2636 \# of layers: 12

$\mathrm{Kx} \mathrm{Ky} \mathrm{Kz}$ Ss Por

6.54901e+02 6.54901e+02 6.54901e+01 1.00000e-09 7.00000e-02 6.54901e+02 6.54901e+02 6.54901e+01 1.00000e-09 7.00000e-02 5.00000e-04 5.00000e-04 5.00000e-05 1.00000e-09 1.00000e-01

$2.61681 \mathrm{e}+012.61681 \mathrm{e}+012.61681 \mathrm{e}+001.00000 \mathrm{e}-092.12000 \mathrm{e}-01$ $2.61681 \mathrm{e}+012.61681 \mathrm{e}+012.61681 \mathrm{e}+001.00000 \mathrm{e}-092.12000 \mathrm{e}-01$ $2.61681 \mathrm{e}+012.61681 \mathrm{e}+012.61681 \mathrm{e}+001.00000 \mathrm{e}-092.12000 \mathrm{e}-01$ $2.61681 \mathrm{e}+012.61681 \mathrm{e}+012.61681 \mathrm{e}+001.00000 \mathrm{e}-092.12000 \mathrm{e}-01$ $2.61681 \mathrm{e}+012.61681 \mathrm{e}+012.61681 \mathrm{e}+001.00000 \mathrm{e}-092.12000 \mathrm{e}-01$ $1.00000 \mathrm{e}-02$ 1.00000e-02 1.00000e-03 1.00000e-09 1.00000e-01 $1.00000 \mathrm{e}+001.00000 \mathrm{e}+001.00000 \mathrm{e}-011.00000 \mathrm{e}-091.00000 \mathrm{e}-01$ $1.00000 \mathrm{e}-05$ 1.00000e-05 1.00000e-06 1.00000e-09 1.00000e-01 $1.00000 \mathrm{e}+001.00000 \mathrm{e}+001.00000 \mathrm{e}-011.00000 \mathrm{e}-091.00000 \mathrm{e}-01$ Element: 2637 \# of layers: 11

$\mathrm{Kx} \mathrm{Ky} \mathrm{Kz}$ Ss Por

6.34187e+02 6.34187e+02 6.34187e+01 1.00000e-09 7.00000e-02 5.00000e-04 5.00000e-04 5.00000e-05 1.00000e-09 1.00000e-01 $2.53400 \mathrm{e}+012.53400 \mathrm{e}+012.53400 \mathrm{e}+001.00000 \mathrm{e}-092.12000 \mathrm{e}-01$ $2.53400 \mathrm{e}+012.53400 \mathrm{e}+012.53400 \mathrm{e}+001.00000 \mathrm{e}-092.12000 \mathrm{e}-01$ $2.53400 \mathrm{e}+012.53400 \mathrm{e}+012.53400 \mathrm{e}+001.00000 \mathrm{e}-092.12000 \mathrm{e}-01$ $2.53400 \mathrm{e}+012.53400 \mathrm{e}+012.53400 \mathrm{e}+001.00000 \mathrm{e}-092.12000 \mathrm{e}-01$ $2.53400 \mathrm{e}+012.53400 \mathrm{e}+012.53400 \mathrm{e}+001.00000 \mathrm{e}-092.12000 \mathrm{e}-01$ $1.00000 \mathrm{e}-02$ 1.00000e-02 1.00000e-03 1.00000e-09 1.00000e-01 $1.00000 \mathrm{e}+001.00000 \mathrm{e}+001.00000 \mathrm{e}-011.00000 \mathrm{e}-091.00000 \mathrm{e}-01$ $1.00000 \mathrm{e}-05$ 1.00000e-05 1.00000e-06 1.00000e-09 1.00000e-01 $1.00000 \mathrm{e}+001.00000 \mathrm{e}+001.00000 \mathrm{e}-01$ 1.00000e-09 1.00000e-01 Element: 2638 \# of layers: 11

$\mathrm{Kx} \mathrm{Ky} \mathrm{Kz}$ Ss Por

6.34187e+02 6.34187e+02 6.34187e+01 1.00000e-09 7.00000e-02 5.00000e-04 5.00000e-04 5.00000e-05 1.00000e-09 1.00000e-01

$2.53400 \mathrm{e}+012.53400 \mathrm{e}+012.53400 \mathrm{e}+001.00000 \mathrm{e}-092.12000 \mathrm{e}-01$ $2.53400 \mathrm{e}+012.53400 \mathrm{e}+01 \quad 2.53400 \mathrm{e}+00 \quad 1.00000 \mathrm{e}-092.12000 \mathrm{e}-01$ $2.53400 \mathrm{e}+012.53400 \mathrm{e}+012.53400 \mathrm{e}+001.00000 \mathrm{e}-092.12000 \mathrm{e}-01$ $2.53400 \mathrm{e}+012.53400 \mathrm{e}+012.53400 \mathrm{e}+001.00000 \mathrm{e}-092.12000 \mathrm{e}-01$ $2.53400 \mathrm{e}+012.53400 \mathrm{e}+012.53400 \mathrm{e}+001.00000 \mathrm{e}-092.12000 \mathrm{e}-01$ $1.00000 \mathrm{e}-02$ 1.00000e-02 1.00000e-03 1.00000e-09 1.00000e-01 $1.00000 \mathrm{e}+001.00000 \mathrm{e}+001.00000 \mathrm{e}-011.00000 \mathrm{e}-091.00000 \mathrm{e}-01$ $1.00000 \mathrm{e}-05$ 1.00000e-05 1.00000e-06 1.00000e-09 1.00000e-01 $1.00000 \mathrm{e}+001.00000 \mathrm{e}+001.00000 \mathrm{e}-011.00000 \mathrm{e}-091.00000 \mathrm{e}-01$ Element: 2639 \# of layers: 10 
$\mathrm{Kx} \mathrm{Ky} \mathrm{Kz}$ Ss Por

5.00000e-04 5.00000e-04 5.00000e-05 1.00000e-09 1.00000e-01

$3.08032 \mathrm{e}+013.08032 \mathrm{e}+013.08032 \mathrm{e}+001.00000 \mathrm{e}-092.12000 \mathrm{e}-01$

$3.08032 \mathrm{e}+013.08032 \mathrm{e}+013.08032 \mathrm{e}+001.00000 \mathrm{e}-092.12000 \mathrm{e}-01$

$3.08032 \mathrm{e}+013.08032 \mathrm{e}+013.08032 \mathrm{e}+001.00000 \mathrm{e}-092.12000 \mathrm{e}-01$

$3.08032 \mathrm{e}+013.08032 \mathrm{e}+013.08032 \mathrm{e}+001.00000 \mathrm{e}-092.12000 \mathrm{e}-01$

$3.08032 \mathrm{e}+013.08032 \mathrm{e}+013.08032 \mathrm{e}+00$ 1.00000e-09 2.12000e-01

$1.00000 \mathrm{e}-02$ 1.00000e-02 1.00000e-03 1.00000e-09 1.00000e-01

$1.00000 \mathrm{e}+001.00000 \mathrm{e}+001.00000 \mathrm{e}-011.00000 \mathrm{e}-091.00000 \mathrm{e}-01$

$1.00000 \mathrm{e}-05$ 1.00000e-05 1.00000e-06 1.00000e-09 1.00000e-01

$1.00000 \mathrm{e}+001.00000 \mathrm{e}+001.00000 \mathrm{e}-011.00000 \mathrm{e}-091.00000 \mathrm{e}-01$

Element: 2640 \# of layers: 13

$\mathrm{Kx} \mathrm{Ky} \mathrm{Kz}$ Ss Por

8.99675e+02 8.99675e+02 8.99675e+01 1.00000e-09 7.00000e-02

$8.99675 \mathrm{e}+028.99675 \mathrm{e}+028.99675 \mathrm{e}+01$ 1.00000e-09 7.00000e-02

5.00000e-04 5.00000e-04 5.00000e-05 1.00000e-09 1.00000e-01

5.00000e-04 5.00000e-04 5.00000e-05 1.00000e-09 1.00000e-01

$3.59490 \mathrm{e}+013.59490 \mathrm{e}+013.59490 \mathrm{e}+001.00000 \mathrm{e}-092.12000 \mathrm{e}-01$

$3.59490 \mathrm{e}+013.59490 \mathrm{e}+013.59490 \mathrm{e}+001.00000 \mathrm{e}-092.12000 \mathrm{e}-01$

$3.59490 \mathrm{e}+013.59490 \mathrm{e}+013.59490 \mathrm{e}+001.00000 \mathrm{e}-092.12000 \mathrm{e}-01$

$3.59490 \mathrm{e}+013.59490 \mathrm{e}+013.59490 \mathrm{e}+00$ 1.00000e-09 2.12000e-01

$3.59490 \mathrm{e}+013.59490 \mathrm{e}+013.59490 \mathrm{e}+00$ 1.00000e-09 2.12000e-01

$1.00000 \mathrm{e}-02$ 1.00000e-02 1.00000e-03 1.00000e-09 1.00000e-01

$1.00000 \mathrm{e}+001.00000 \mathrm{e}+001.00000 \mathrm{e}-011.00000 \mathrm{e}-091.00000 \mathrm{e}-01$

$1.00000 \mathrm{e}-05$ 1.00000e-05 1.00000e-06 1.00000e-09 1.00000e-01

$1.00000 \mathrm{e}+001.00000 \mathrm{e}+001.00000 \mathrm{e}-01$ 1.00000e-09 1.00000e-01

Element: 2641 \# of layers: 13

$\mathrm{Kx} \mathrm{Ky} \mathrm{Kz}$ Ss Por

8.99675e+02 8.99675e+02 8.99675e+01 1.00000e-09 7.00000e-02

$8.99675 \mathrm{e}+02$ 8.99675e+02 8.99675e+01 1.00000e-09 7.00000e-02

5.00000e-04 5.00000e-04 5.00000e-05 1.00000e-09 1.00000e-01

5.00000e-04 5.00000e-04 5.00000e-05 1.00000e-09 1.00000e-01

$3.59490 \mathrm{e}+013.59490 \mathrm{e}+013.59490 \mathrm{e}+001.00000 \mathrm{e}-092.12000 \mathrm{e}-01$

$3.59490 \mathrm{e}+013.59490 \mathrm{e}+013.59490 \mathrm{e}+001.00000 \mathrm{e}-092.12000 \mathrm{e}-01$

$3.59490 \mathrm{e}+013.59490 \mathrm{e}+013.59490 \mathrm{e}+00$ 1.00000e-09 2.12000e-01

$3.59490 \mathrm{e}+013.59490 \mathrm{e}+013.59490 \mathrm{e}+001.00000 \mathrm{e}-092.12000 \mathrm{e}-01$

$3.59490 \mathrm{e}+013.59490 \mathrm{e}+013.59490 \mathrm{e}+001.00000 \mathrm{e}-092.12000 \mathrm{e}-01$

$1.00000 \mathrm{e}-02$ 1.00000e-02 1.00000e-03 1.00000e-09 1.00000e-01

$1.00000 \mathrm{e}+001.00000 \mathrm{e}+001.00000 \mathrm{e}-011.00000 \mathrm{e}-091.00000 \mathrm{e}-01$

$1.00000 \mathrm{e}-05$ 1.00000e-05 1.00000e-06 1.00000e-09 1.00000e-01

$1.00000 \mathrm{e}+001.00000 \mathrm{e}+001.00000 \mathrm{e}-011.00000 \mathrm{e}-091.00000 \mathrm{e}-01$

Element: 2642 \# of layers: 12

$\mathrm{Kx} \mathrm{Ky} \mathrm{Kz}$ Ss Por

7.26701e+02 7.26701e+02 7.26701e+01 1.00000e-09 7.00000e-02 5.00000e-04 5.00000e-04 5.00000e-05 1.00000e-09 1.00000e-01

5.00000e-04 5.00000e-04 5.00000e-05 1.00000e-09 1.00000e-01 
$2.90369 \mathrm{e}+012.90369 \mathrm{e}+012.90369 \mathrm{e}+00$ 1.00000e-09 2.12000e-01 $2.90369 \mathrm{e}+012.90369 \mathrm{e}+012.90369 \mathrm{e}+00$ 1.00000e-09 2.12000e-01 $2.90369 \mathrm{e}+012.90369 \mathrm{e}+012.90369 \mathrm{e}+00$ 1.00000e-09 2.12000e-01 $2.90369 \mathrm{e}+012.90369 \mathrm{e}+012.90369 \mathrm{e}+001.00000 \mathrm{e}-092.12000 \mathrm{e}-01$ $2.90369 \mathrm{e}+012.90369 \mathrm{e}+012.90369 \mathrm{e}+001.00000 \mathrm{e}-092.12000 \mathrm{e}-01$ $1.00000 \mathrm{e}-02$ 1.00000e-02 1.00000e-03 1.00000e-09 1.00000e-01 $1.00000 \mathrm{e}+001.00000 \mathrm{e}+001.00000 \mathrm{e}-011.00000 \mathrm{e}-091.00000 \mathrm{e}-01$ $1.00000 \mathrm{e}-05$ 1.00000e-05 1.00000e-06 1.00000e-09 1.00000e-01 $1.00000 \mathrm{e}+001.00000 \mathrm{e}+001.00000 \mathrm{e}-011.00000 \mathrm{e}-091.00000 \mathrm{e}-01$ Element: 2643 \# of layers: 13

$\mathrm{Kx} \mathrm{Ky} \mathrm{Kz}$ Ss Por

3.10584e+02 3.10584e+02 3.10584e+01 1.00000e-09 7.00000e-02 $3.10584 \mathrm{e}+02$ 3.10584e+02 3.10584e+01 1.00000e-09 7.00000e-02 5.00000e-04 5.00000e-04 5.00000e-05 1.00000e-09 1.00000e-01 5.00000e-04 5.00000e-04 5.00000e-05 1.00000e-09 1.00000e-01 $1.24097 \mathrm{e}+01$ 1.24097e+01 1.24097e+00 1.00000e-09 2.12000e-01 $1.24097 \mathrm{e}+01$ 1.24097e+01 1.24097e+00 1.00000e-09 2.12000e-01 $1.24097 \mathrm{e}+01$ 1.24097e+01 1.24097e+00 1.00000e-09 2.12000e-01 $1.24097 \mathrm{e}+01$ 1.24097e+01 1.24097e+00 1.00000e-09 2.12000e-01 $1.24097 \mathrm{e}+01$ 1.24097e+01 1.24097e+00 1.00000e-09 2.12000e-01 $1.00000 \mathrm{e}-02$ 1.00000e-02 1.00000e-03 1.00000e-09 1.00000e-01 $1.00000 \mathrm{e}+001.00000 \mathrm{e}+001.00000 \mathrm{e}-011.00000 \mathrm{e}-091.00000 \mathrm{e}-01$ $1.00000 \mathrm{e}-05$ 1.00000e-05 1.00000e-06 1.00000e-09 1.00000e-01 $1.00000 \mathrm{e}+001.00000 \mathrm{e}+001.00000 \mathrm{e}-011.00000 \mathrm{e}-091.00000 \mathrm{e}-01$ Element: 2644 \# of layers: 7

$\mathrm{Kx} \mathrm{Ky} \mathrm{Kz}$ Ss Por

3.10584e+02 3.10584e+02 3.10584e+01 1.00000e-09 7.00000e-02 5.00000e-04 5.00000e-04 5.00000e-05 1.00000e-09 1.00000e-01

$1.24097 \mathrm{e}+01$ 1.24097e+01 1.24097e+00 1.00000e-09 2.12000e-01 $1.00000 \mathrm{e}-021.00000 \mathrm{e}-021.00000 \mathrm{e}-031.00000 \mathrm{e}-091.00000 \mathrm{e}-01$ $1.00000 \mathrm{e}+001.00000 \mathrm{e}+001.00000 \mathrm{e}-01$ 1.00000e-09 1.00000e-01 $1.00000 \mathrm{e}-05$ 1.00000e-05 1.00000e-06 1.00000e-09 1.00000e-01 $1.00000 \mathrm{e}+001.00000 \mathrm{e}+001.00000 \mathrm{e}-011.00000 \mathrm{e}-091.00000 \mathrm{e}-01$ Element: 2645 \# of layers: 7

$\mathrm{Kx} \mathrm{Ky} \mathrm{Kz}$ Ss Por

4.35048e+02 4.35048e+02 4.35048e+01 1.00000e-09 7.00000e-02 5.00000e-04 5.00000e-04 5.00000e-05 1.00000e-09 1.00000e-01

$1.73830 \mathrm{e}+011.73830 \mathrm{e}+011.73830 \mathrm{e}+001.00000 \mathrm{e}-092.12000 \mathrm{e}-01$ $1.00000 \mathrm{e}-02$ 1.00000e-02 1.00000e-03 1.00000e-09 1.00000e-01 $1.00000 \mathrm{e}+001.00000 \mathrm{e}+001.00000 \mathrm{e}-011.00000 \mathrm{e}-091.00000 \mathrm{e}-01$ $1.00000 \mathrm{e}-05$ 1.00000e-05 1.00000e-06 1.00000e-09 1.00000e-01 $1.00000 \mathrm{e}+001.00000 \mathrm{e}+001.00000 \mathrm{e}-011.00000 \mathrm{e}-091.00000 \mathrm{e}-01$ Element: 2646 \# of layers: 14

$\mathrm{Kx} \mathrm{Ky} \mathrm{Kz}$ Ss Por

4.35048e+02 4.35048e+02 4.35048e+01 1.00000e-09 7.00000e-02 $4.35048 \mathrm{e}+02$ 4.35048e+02 4.35048e+01 1.00000e-09 7.00000e-02 
4.35048e+02 4.35048e+02 4.35048e+01 1.00000e-09 7.00000e-02 $5.00000 \mathrm{e}-04$ 5.00000e-04 5.00000e-05 1.00000e-09 1.00000e-01 5.00000e-04 5.00000e-04 5.00000e-05 1.00000e-09 1.00000e-01

$1.73830 \mathrm{e}+011.73830 \mathrm{e}+011.73830 \mathrm{e}+001.00000 \mathrm{e}-092.12000 \mathrm{e}-01$ $1.73830 \mathrm{e}+011.73830 \mathrm{e}+011.73830 \mathrm{e}+001.00000 \mathrm{e}-092.12000 \mathrm{e}-01$ $1.73830 \mathrm{e}+01$ 1.73830e+01 1.73830e+00 1.00000e-09 2.12000e-01 $1.73830 \mathrm{e}+01$ 1.73830e+01 1.73830e+00 1.00000e-09 2.12000e-01 $1.73830 \mathrm{e}+011.73830 \mathrm{e}+011.73830 \mathrm{e}+001.00000 \mathrm{e}-092.12000 \mathrm{e}-01$ $1.00000 \mathrm{e}-02$ 1.00000e-02 1.00000e-03 1.00000e-09 1.00000e-01 $1.00000 \mathrm{e}+001.00000 \mathrm{e}+001.00000 \mathrm{e}-011.00000 \mathrm{e}-091.00000 \mathrm{e}-01$ 1.00000e-05 1.00000e-05 1.00000e-06 1.00000e-09 1.00000e-01 $1.00000 \mathrm{e}+001.00000 \mathrm{e}+001.00000 \mathrm{e}-011.00000 \mathrm{e}-091.00000 \mathrm{e}-01$ Element: 2647 \# of layers: 13

$\mathrm{Kx} \mathrm{Ky} \mathrm{Kz}$ Ss Por

7.58957e+02 7.58957e+02 7.58957e+01 1.00000e-09 7.00000e-02 $7.58957 \mathrm{e}+02$ 7.58957e+02 7.58957e+01 1.00000e-09 7.00000e-02 5.00000e-04 5.00000e-04 5.00000e-05 1.00000e-09 1.00000e-01 5.00000e-04 5.00000e-04 5.00000e-05 1.00000e-09 1.00000e-01 $3.03262 \mathrm{e}+013.03262 \mathrm{e}+013.03262 \mathrm{e}+001.00000 \mathrm{e}-092.12000 \mathrm{e}-01$ $3.03262 \mathrm{e}+013.03262 \mathrm{e}+013.03262 \mathrm{e}+001.00000 \mathrm{e}-092.12000 \mathrm{e}-01$ $3.03262 \mathrm{e}+013.03262 \mathrm{e}+013.03262 \mathrm{e}+001.00000 \mathrm{e}-092.12000 \mathrm{e}-01$ $3.03262 \mathrm{e}+013.03262 \mathrm{e}+013.03262 \mathrm{e}+00$ 1.00000e-09 2.12000e-01 $3.03262 \mathrm{e}+013.03262 \mathrm{e}+013.03262 \mathrm{e}+00$ 1.00000e-09 2.12000e-01 $1.00000 \mathrm{e}-02$ 1.00000e-02 1.00000e-03 1.00000e-09 1.00000e-01 $1.00000 \mathrm{e}+001.00000 \mathrm{e}+001.00000 \mathrm{e}-011.00000 \mathrm{e}-091.00000 \mathrm{e}-01$ $1.00000 \mathrm{e}-05$ 1.00000e-05 1.00000e-06 1.00000e-09 1.00000e-01 $1.00000 \mathrm{e}+001.00000 \mathrm{e}+001.00000 \mathrm{e}-011.00000 \mathrm{e}-091.00000 \mathrm{e}-01$ Element: 2648 \# of layers: 14

$\mathrm{Kx} \mathrm{Ky} \mathrm{Kz}$ Ss Por

7.58957e+02 7.58957e+02 7.58957e+01 1.00000e-09 7.00000e-02 $7.58957 \mathrm{e}+02$ 7.58957e+02 7.58957e+01 1.00000e-09 7.00000e-02 7.58957e+02 7.58957e+02 7.58957e+01 1.00000e-09 7.00000e-02 5.00000e-04 5.00000e-04 5.00000e-05 1.00000e-09 1.00000e-01 $5.00000 \mathrm{e}-04$ 5.00000e-04 5.00000e-05 1.00000e-09 1.00000e-01 $3.03262 \mathrm{e}+013.03262 \mathrm{e}+013.03262 \mathrm{e}+00$ 1.00000e-09 2.12000e-01 $3.03262 \mathrm{e}+013.03262 \mathrm{e}+013.03262 \mathrm{e}+00$ 1.00000e-09 2.12000e-01 $3.03262 \mathrm{e}+013.03262 \mathrm{e}+013.03262 \mathrm{e}+001.00000 \mathrm{e}-092.12000 \mathrm{e}-01$ $3.03262 \mathrm{e}+013.03262 \mathrm{e}+013.03262 \mathrm{e}+001.00000 \mathrm{e}-092.12000 \mathrm{e}-01$ $3.03262 \mathrm{e}+013.03262 \mathrm{e}+013.03262 \mathrm{e}+001.00000 \mathrm{e}-092.12000 \mathrm{e}-01$ $1.00000 \mathrm{e}-02$ 1.00000e-02 1.00000e-03 1.00000e-09 1.00000e-01 $1.00000 \mathrm{e}+001.00000 \mathrm{e}+001.00000 \mathrm{e}-011.00000 \mathrm{e}-091.00000 \mathrm{e}-01$ $1.00000 \mathrm{e}-05$ 1.00000e-05 1.00000e-06 1.00000e-09 1.00000e-01 $1.00000 \mathrm{e}+001.00000 \mathrm{e}+001.00000 \mathrm{e}-01$ 1.00000e-09 1.00000e-01 Element: 2649 \# of layers: 14

$\mathrm{Kx} \mathrm{Ky} \mathrm{Kz}$ Ss Por

9.08659e+02 9.08659e+02 9.08659e+01 1.00000e-09 7.00000e-02 
9.08659e+02 9.08659e+02 9.08659e+01 1.00000e-09 7.00000e-02 9.08659e+02 9.08659e+02 9.08659e+01 1.00000e-09 7.00000e-02 5.00000e-04 5.00000e-04 5.00000e-05 1.00000e-09 1.00000e-01 5.00000e-04 5.00000e-04 5.00000e-05 1.00000e-09 1.00000e-01 $3.63090 \mathrm{e}+013.63090 \mathrm{e}+013.63090 \mathrm{e}+001.00000 \mathrm{e}-092.12000 \mathrm{e}-01$ $3.63090 \mathrm{e}+013.63090 \mathrm{e}+013.63090 \mathrm{e}+001.00000 \mathrm{e}-092.12000 \mathrm{e}-01$ $3.63090 \mathrm{e}+013.63090 \mathrm{e}+013.63090 \mathrm{e}+001.00000 \mathrm{e}-092.12000 \mathrm{e}-01$ $3.63090 \mathrm{e}+013.63090 \mathrm{e}+013.63090 \mathrm{e}+00$ 1.00000e-09 2.12000e-01 $3.63090 \mathrm{e}+013.63090 \mathrm{e}+013.63090 \mathrm{e}+001.00000 \mathrm{e}-092.12000 \mathrm{e}-01$ $1.00000 \mathrm{e}-02$ 1.00000e-02 1.00000e-03 1.00000e-09 1.00000e-01 $1.00000 \mathrm{e}+001.00000 \mathrm{e}+001.00000 \mathrm{e}-011.00000 \mathrm{e}-091.00000 \mathrm{e}-01$ $1.00000 \mathrm{e}-05$ 1.00000e-05 1.00000e-06 1.00000e-09 1.00000e-01 $1.00000 \mathrm{e}+001.00000 \mathrm{e}+001.00000 \mathrm{e}-011.00000 \mathrm{e}-091.00000 \mathrm{e}-01$ Element: 2650 \# of layers: 13

$\mathrm{Kx} \mathrm{Ky} \mathrm{Kz}$ Ss Por

3.61355e+02 3.61355e+02 3.61355e+01 1.00000e-09 7.00000e-02 $3.61355 \mathrm{e}+02$ 3.61355e+02 3.61355e+01 1.00000e-09 7.00000e-02 $3.61355 \mathrm{e}+02$ 3.61355e+02 3.61355e+01 1.00000e-09 7.00000e-02 5.00000e-04 5.00000e-04 5.00000e-05 1.00000e-09 1.00000e-01

$1.44386 \mathrm{e}+011.44386 \mathrm{e}+011.44386 \mathrm{e}+001.00000 \mathrm{e}-092.12000 \mathrm{e}-01$ $1.44386 \mathrm{e}+011.44386 \mathrm{e}+011.44386 \mathrm{e}+001.00000 \mathrm{e}-092.12000 \mathrm{e}-01$ $1.44386 \mathrm{e}+011.44386 \mathrm{e}+011.44386 \mathrm{e}+001.00000 \mathrm{e}-092.12000 \mathrm{e}-01$ $1.44386 \mathrm{e}+01$ 1.44386e+01 1.44386e+00 1.00000e-09 2.12000e-01 $1.44386 \mathrm{e}+011.44386 \mathrm{e}+01 \quad 1.44386 \mathrm{e}+001.00000 \mathrm{e}-092.12000 \mathrm{e}-01$ $1.00000 \mathrm{e}-021.00000 \mathrm{e}-02$ 1.00000e-03 1.00000e-09 1.00000e-01 $1.00000 \mathrm{e}+001.00000 \mathrm{e}+001.00000 \mathrm{e}-011.00000 \mathrm{e}-091.00000 \mathrm{e}-01$ $1.00000 \mathrm{e}-05$ 1.00000e-05 1.00000e-06 1.00000e-09 1.00000e-01 $1.00000 \mathrm{e}+001.00000 \mathrm{e}+001.00000 \mathrm{e}-011.00000 \mathrm{e}-09$ 1.00000e-01 Element: 2651 \# of layers: 15

$\mathrm{Kx} \mathrm{Ky} \mathrm{Kz}$ Ss Por

4.76034e+02 4.76034e+02 4.76034e+01 1.00000e-09 7.00000e-02 $4.76034 \mathrm{e}+02$ 4.76034e+02 4.76034e+01 1.00000e-09 7.00000e-02 $4.76034 \mathrm{e}+02$ 4.76034e+02 4.76034e+01 1.00000e-09 7.00000e-02 $4.76034 \mathrm{e}+02$ 4.76034e+02 4.76034e+01 1.00000e-09 7.00000e-02 5.00000e-04 5.00000e-04 5.00000e-05 1.00000e-09 1.00000e-01 5.00000e-04 5.00000e-04 5.00000e-05 1.00000e-09 1.00000e-01 $1.90206 \mathrm{e}+011.90206 \mathrm{e}+011.90206 \mathrm{e}+001.00000 \mathrm{e}-092.12000 \mathrm{e}-01$ $1.90206 \mathrm{e}+011.90206 \mathrm{e}+011.90206 \mathrm{e}+001.00000 \mathrm{e}-092.12000 \mathrm{e}-01$ $1.90206 \mathrm{e}+011.90206 \mathrm{e}+011.90206 \mathrm{e}+001.00000 \mathrm{e}-092.12000 \mathrm{e}-01$ $1.90206 \mathrm{e}+011.90206 \mathrm{e}+011.90206 \mathrm{e}+001.00000 \mathrm{e}-092.12000 \mathrm{e}-01$ $1.90206 \mathrm{e}+01$ 1.90206e+01 1.90206e+00 1.00000e-09 2.12000e-01 $1.00000 \mathrm{e}-02$ 1.00000e-02 1.00000e-03 1.00000e-09 1.00000e-01 $1.00000 \mathrm{e}+001.00000 \mathrm{e}+001.00000 \mathrm{e}-011.00000 \mathrm{e}-091.00000 \mathrm{e}-01$ $1.00000 \mathrm{e}-05$ 1.00000e-05 1.00000e-06 1.00000e-09 1.00000e-01 $1.00000 \mathrm{e}+001.00000 \mathrm{e}+001.00000 \mathrm{e}-01$ 1.00000e-09 1.00000e-01 Element: 2652 \# of layers: 14 
Kx Ky Kz Ss Por

4.76034e+02 4.76034e+02 4.76034e+01 1.00000e-09 7.00000e-02

$4.76034 \mathrm{e}+02$ 4.76034e+02 4.76034e+01 1.00000e-09 7.00000e-02

$4.76034 \mathrm{e}+02$ 4.76034e+02 4.76034e+01 1.00000e-09 7.00000e-02

5.00000e-04 5.00000e-04 5.00000e-05 1.00000e-09 1.00000e-01

5.00000e-04 5.00000e-04 5.00000e-05 1.00000e-09 1.00000e-01

$1.90206 \mathrm{e}+011.90206 \mathrm{e}+011.90206 \mathrm{e}+001.00000 \mathrm{e}-092.12000 \mathrm{e}-01$

$1.90206 \mathrm{e}+011.90206 \mathrm{e}+011.90206 \mathrm{e}+001.00000 \mathrm{e}-092.12000 \mathrm{e}-01$

$1.90206 \mathrm{e}+011.90206 \mathrm{e}+011.90206 \mathrm{e}+001.00000 \mathrm{e}-092.12000 \mathrm{e}-01$

$1.90206 \mathrm{e}+011.90206 \mathrm{e}+011.90206 \mathrm{e}+001.00000 \mathrm{e}-092.12000 \mathrm{e}-01$

$1.90206 \mathrm{e}+011.90206 \mathrm{e}+011.90206 \mathrm{e}+001.00000 \mathrm{e}-092.12000 \mathrm{e}-01$

$1.00000 \mathrm{e}-02$ 1.00000e-02 1.00000e-03 1.00000e-09 1.00000e-01

$1.00000 \mathrm{e}+001.00000 \mathrm{e}+001.00000 \mathrm{e}-011.00000 \mathrm{e}-091.00000 \mathrm{e}-01$

$1.00000 \mathrm{e}-05$ 1.00000e-05 1.00000e-06 1.00000e-09 1.00000e-01

$1.00000 \mathrm{e}+001.00000 \mathrm{e}+001.00000 \mathrm{e}-01$ 1.00000e-09 1.00000e-01

Element: 2653 \# of layers: 14

$\mathrm{Kx} \mathrm{Ky} \mathrm{Kz}$ Ss Por

4.76034e+02 4.76034e+02 4.76034e+01 1.00000e-09 7.00000e-02

4.76034e+02 4.76034e+02 4.76034e+01 1.00000e-09 7.00000e-02

4.76034e+02 4.76034e+02 4.76034e+01 1.00000e-09 7.00000e-02

5.00000e-04 5.00000e-04 5.00000e-05 1.00000e-09 1.00000e-01

5.00000e-04 5.00000e-04 5.00000e-05 1.00000e-09 1.00000e-01

$1.90206 \mathrm{e}+011.90206 \mathrm{e}+01$ 1.90206e+00 1.00000e-09 2.12000e-01

$1.90206 \mathrm{e}+011.90206 \mathrm{e}+011.90206 \mathrm{e}+001.00000 \mathrm{e}-092.12000 \mathrm{e}-01$

$1.90206 \mathrm{e}+011.90206 \mathrm{e}+011.90206 \mathrm{e}+001.00000 \mathrm{e}-092.12000 \mathrm{e}-01$

$1.90206 \mathrm{e}+011.90206 \mathrm{e}+011.90206 \mathrm{e}+001.00000 \mathrm{e}-092.12000 \mathrm{e}-01$

$1.90206 \mathrm{e}+011.90206 \mathrm{e}+011.90206 \mathrm{e}+001.00000 \mathrm{e}-092.12000 \mathrm{e}-01$

1.00000e-02 1.00000e-02 1.00000e-03 1.00000e-09 1.00000e-01

$1.00000 \mathrm{e}+001.00000 \mathrm{e}+001.00000 \mathrm{e}-011.00000 \mathrm{e}-091.00000 \mathrm{e}-01$

$1.00000 \mathrm{e}-05$ 1.00000e-05 1.00000e-06 1.00000e-09 1.00000e-01

$1.00000 \mathrm{e}+001.00000 \mathrm{e}+001.00000 \mathrm{e}-011.00000 \mathrm{e}-091.00000 \mathrm{e}-01$

Element: 2654 \# of layers: 14

$\mathrm{Kx} \mathrm{Ky} \mathrm{Kz}$ Ss Por

$5.56016 \mathrm{e}+025.56016 \mathrm{e}+025.56016 \mathrm{e}+01$ 1.00000e-09 7.00000e-02

$5.56016 \mathrm{e}+025.56016 \mathrm{e}+025.56016 \mathrm{e}+01$ 1.00000e-09 7.00000e-02

$5.56016 \mathrm{e}+025.56016 \mathrm{e}+025.56016 \mathrm{e}+01$ 1.00000e-09 7.00000e-02

5.00000e-04 5.00000e-04 5.00000e-05 1.00000e-09 1.00000e-01

5.00000e-04 5.00000e-04 5.00000e-05 1.00000e-09 1.00000e-01

$2.22165 \mathrm{e}+012.22165 \mathrm{e}+012.22165 \mathrm{e}+00$ 1.00000e-09 2.12000e-01

$2.22165 \mathrm{e}+012.22165 \mathrm{e}+012.22165 \mathrm{e}+00$ 1.00000e-09 2.12000e-01

$2.22165 \mathrm{e}+012.22165 \mathrm{e}+012.22165 \mathrm{e}+00$ 1.00000e-09 2.12000e-01

$2.22165 \mathrm{e}+012.22165 \mathrm{e}+012.22165 \mathrm{e}+00$ 1.00000e-09 2.12000e-01

$2.22165 \mathrm{e}+012.22165 \mathrm{e}+012.22165 \mathrm{e}+00$ 1.00000e-09 2.12000e-01

$1.00000 \mathrm{e}-02$ 1.00000e-02 1.00000e-03 1.00000e-09 1.00000e-01

$1.00000 \mathrm{e}+001.00000 \mathrm{e}+001.00000 \mathrm{e}-011.00000 \mathrm{e}-091.00000 \mathrm{e}-01$

$1.00000 \mathrm{e}-05$ 1.00000e-05 1.00000e-06 1.00000e-09 1.00000e-01 
$1.00000 \mathrm{e}+001.00000 \mathrm{e}+00$ 1.00000e-01 1.00000e-09 1.00000e-01

Element: 2655 \# of layers: 12

Kx Ky Kz Ss Por

$5.56016 \mathrm{e}+02$ 5.56016e+02 5.56016e+01 1.00000e-09 7.00000e-02

$5.56016 \mathrm{e}+025.56016 \mathrm{e}+025.56016 \mathrm{e}+01$ 1.00000e-09 7.00000e-02

5.00000e-04 5.00000e-04 5.00000e-05 1.00000e-09 1.00000e-01

5.00000e-04 5.00000e-04 5.00000e-05 1.00000e-09 1.00000e-01

$2.22165 \mathrm{e}+012.22165 \mathrm{e}+012.22165 \mathrm{e}+00$ 1.00000e-09 2.12000e-01

$2.22165 \mathrm{e}+012.22165 \mathrm{e}+012.22165 \mathrm{e}+001.00000 \mathrm{e}-092.12000 \mathrm{e}-01$

$2.22165 \mathrm{e}+012.22165 \mathrm{e}+012.22165 \mathrm{e}+00$ 1.00000e-09 2.12000e-01

$2.22165 \mathrm{e}+012.22165 \mathrm{e}+012.22165 \mathrm{e}+00$ 1.00000e-09 2.12000e-01

$1.00000 \mathrm{e}-02$ 1.00000e-02 1.00000e-03 1.00000e-09 1.00000e-01

$1.00000 \mathrm{e}+001.00000 \mathrm{e}+001.00000 \mathrm{e}-011.00000 \mathrm{e}-091.00000 \mathrm{e}-01$

$1.00000 \mathrm{e}-05$ 1.00000e-05 1.00000e-06 1.00000e-09 1.00000e-01

$1.00000 \mathrm{e}+001.00000 \mathrm{e}+001.00000 \mathrm{e}-01$ 1.00000e-09 1.00000e-01

Element: 2656 \# of layers: 13

$\mathrm{Kx} \mathrm{Ky} \mathrm{Kz}$ Ss Por

4.85134e+02 4.85134e+02 4.85134e+01 1.00000e-09 7.00000e-02

$4.85134 \mathrm{e}+02$ 4.85134e+02 4.85134e+01 1.00000e-09 7.00000e-02

5.00000e-04 5.00000e-04 5.00000e-05 1.00000e-09 1.00000e-01

5.00000e-04 5.00000e-04 5.00000e-05 1.00000e-09 1.00000e-01

$1.93842 \mathrm{e}+01$ 1.93842e+01 1.93842e+00 1.00000e-09 2.12000e-01

$1.93842 \mathrm{e}+01$ 1.93842e+01 1.93842e+00 1.00000e-09 2.12000e-01

$1.93842 \mathrm{e}+011.93842 \mathrm{e}+01$ 1.93842e+00 1.00000e-09 2.12000e-01

$1.93842 \mathrm{e}+011.93842 \mathrm{e}+01$ 1.93842e+00 1.00000e-09 2.12000e-01

$1.93842 \mathrm{e}+01$ 1.93842e+01 1.93842e+00 1.00000e-09 2.12000e-01

$1.00000 \mathrm{e}-02$ 1.00000e-02 1.00000e-03 1.00000e-09 1.00000e-01

$1.00000 \mathrm{e}+001.00000 \mathrm{e}+001.00000 \mathrm{e}-011.00000 \mathrm{e}-091.00000 \mathrm{e}-01$

1.00000e-05 1.00000e-05 1.00000e-06 1.00000e-09 1.00000e-01

$1.00000 \mathrm{e}+001.00000 \mathrm{e}+001.00000 \mathrm{e}-011.00000 \mathrm{e}-091.00000 \mathrm{e}-01$

Element: 2657 \# of layers: 14

$\mathrm{Kx} \mathrm{Ky} \mathrm{Kz}$ Ss Por

3.61355e+02 3.61355e+02 3.61355e+01 1.00000e-09 7.00000e-02

$3.61355 \mathrm{e}+02$ 3.61355e+02 3.61355e+01 1.00000e-09 7.00000e-02

$3.61355 \mathrm{e}+023.61355 \mathrm{e}+023.61355 \mathrm{e}+01$ 1.00000e-09 7.00000e-02

5.00000e-04 5.00000e-04 5.00000e-05 1.00000e-09 1.00000e-01

5.00000e-04 5.00000e-04 5.00000e-05 1.00000e-09 1.00000e-01

$1.44386 \mathrm{e}+011.44386 \mathrm{e}+011.44386 \mathrm{e}+001.00000 \mathrm{e}-092.12000 \mathrm{e}-01$

$1.44386 \mathrm{e}+011.44386 \mathrm{e}+011.44386 \mathrm{e}+001.00000 \mathrm{e}-092.12000 \mathrm{e}-01$

$1.44386 \mathrm{e}+011.44386 \mathrm{e}+011.44386 \mathrm{e}+001.00000 \mathrm{e}-092.12000 \mathrm{e}-01$

$1.44386 \mathrm{e}+011.44386 \mathrm{e}+011.44386 \mathrm{e}+001.00000 \mathrm{e}-092.12000 \mathrm{e}-01$

$1.44386 \mathrm{e}+011.44386 \mathrm{e}+01 \quad 1.44386 \mathrm{e}+001.00000 \mathrm{e}-092.12000 \mathrm{e}-01$

$1.00000 \mathrm{e}-02$ 1.00000e-02 1.00000e-03 1.00000e-09 1.00000e-01

$1.00000 \mathrm{e}+001.00000 \mathrm{e}+001.00000 \mathrm{e}-011.00000 \mathrm{e}-091.00000 \mathrm{e}-01$

$1.00000 \mathrm{e}-05$ 1.00000e-05 1.00000e-06 1.00000e-09 1.00000e-01

$1.00000 \mathrm{e}+001.00000 \mathrm{e}+001.00000 \mathrm{e}-011.00000 \mathrm{e}-091.00000 \mathrm{e}-01$ 
Element: 2658 \# of layers: 12

$\mathrm{Kx} \mathrm{Ky} \mathrm{Kz}$ Ss Por

4.76034e+02 4.76034e+02 4.76034e+01 1.00000e-09 7.00000e-02

$4.76034 \mathrm{e}+02$ 4.76034e+02 4.76034e+01 1.00000e-09 7.00000e-02

5.00000e-04 5.00000e-04 5.00000e-05 1.00000e-09 1.00000e-01

5.00000e-04 5.00000e-04 5.00000e-05 1.00000e-09 1.00000e-01

$1.90206 \mathrm{e}+011.90206 \mathrm{e}+011.90206 \mathrm{e}+001.00000 \mathrm{e}-092.12000 \mathrm{e}-01$

$1.90206 \mathrm{e}+011.90206 \mathrm{e}+011.90206 \mathrm{e}+001.00000 \mathrm{e}-092.12000 \mathrm{e}-01$

$1.90206 \mathrm{e}+011.90206 \mathrm{e}+011.90206 \mathrm{e}+001.00000 \mathrm{e}-092.12000 \mathrm{e}-01$

$1.90206 \mathrm{e}+011.90206 \mathrm{e}+011.90206 \mathrm{e}+001.00000 \mathrm{e}-092.12000 \mathrm{e}-01$

$1.00000 \mathrm{e}-02$ 1.00000e-02 1.00000e-03 1.00000e-09 1.00000e-01

$1.00000 \mathrm{e}+001.00000 \mathrm{e}+001.00000 \mathrm{e}-011.00000 \mathrm{e}-091.00000 \mathrm{e}-01$

$1.00000 \mathrm{e}-05$ 1.00000e-05 1.00000e-06 1.00000e-09 1.00000e-01

$1.00000 \mathrm{e}+001.00000 \mathrm{e}+001.00000 \mathrm{e}-011.00000 \mathrm{e}-091.00000 \mathrm{e}-01$

Element: 2659 \# of layers: 14

Kx Ky Kz Ss Por

4.64195e+02 4.64195e+02 4.64195e+01 1.00000e-09 7.00000e-02

4.64195e+02 4.64195e+02 4.64195e+01 1.00000e-09 7.00000e-02

4.64195e+02 4.64195e+02 4.64195e+01 1.00000e-09 7.00000e-02

5.00000e-04 5.00000e-04 5.00000e-05 1.00000e-09 1.00000e-01

5.00000e-04 5.00000e-04 5.00000e-05 1.00000e-09 1.00000e-01

$1.85474 \mathrm{e}+011.85474 \mathrm{e}+011.85474 \mathrm{e}+001.00000 \mathrm{e}-092.12000 \mathrm{e}-01$

$1.85474 \mathrm{e}+011.85474 \mathrm{e}+011.85474 \mathrm{e}+001.00000 \mathrm{e}-092.12000 \mathrm{e}-01$

$1.85474 \mathrm{e}+011.85474 \mathrm{e}+011.85474 \mathrm{e}+001.00000 \mathrm{e}-092.12000 \mathrm{e}-01$

$1.85474 \mathrm{e}+011.85474 \mathrm{e}+011.85474 \mathrm{e}+001.00000 \mathrm{e}-092.12000 \mathrm{e}-01$

$1.85474 \mathrm{e}+011.85474 \mathrm{e}+011.85474 \mathrm{e}+001.00000 \mathrm{e}-092.12000 \mathrm{e}-01$

$1.00000 \mathrm{e}-02$ 1.00000e-02 1.00000e-03 1.00000e-09 1.00000e-01

$1.00000 \mathrm{e}+001.00000 \mathrm{e}+001.00000 \mathrm{e}-011.00000 \mathrm{e}-091.00000 \mathrm{e}-01$

$1.00000 \mathrm{e}-05$ 1.00000e-05 1.00000e-06 1.00000e-09 1.00000e-01

$1.00000 \mathrm{e}+001.00000 \mathrm{e}+001.00000 \mathrm{e}-011.00000 \mathrm{e}-091.00000 \mathrm{e}-01$

Element: 2660 \# of layers: 14

$\mathrm{Kx} \mathrm{Ky} \mathrm{Kz}$ Ss Por

4.16983e+02 4.16983e+02 4.16983e+01 1.00000e-09 7.00000e-02

4.16983e+02 4.16983e+02 4.16983e+01 1.00000e-09 7.00000e-02

4.16983e+02 4.16983e+02 4.16983e+01 1.00000e-09 7.00000e-02

5.00000e-04 5.00000e-04 5.00000e-05 1.00000e-09 1.00000e-01

5.00000e-04 5.00000e-04 5.00000e-05 1.00000e-09 1.00000e-01

$1.66614 \mathrm{e}+011.66614 \mathrm{e}+011.66614 \mathrm{e}+001.00000 \mathrm{e}-092.12000 \mathrm{e}-01$

$1.66614 \mathrm{e}+011.66614 \mathrm{e}+011.66614 \mathrm{e}+001.00000 \mathrm{e}-092.12000 \mathrm{e}-01$

$1.66614 \mathrm{e}+011.66614 \mathrm{e}+011.66614 \mathrm{e}+001.00000 \mathrm{e}-092.12000 \mathrm{e}-01$

$1.66614 \mathrm{e}+011.66614 \mathrm{e}+011.66614 \mathrm{e}+001.00000 \mathrm{e}-092.12000 \mathrm{e}-01$

$1.66614 \mathrm{e}+011.66614 \mathrm{e}+011.66614 \mathrm{e}+001.00000 \mathrm{e}-092.12000 \mathrm{e}-01$

$1.00000 \mathrm{e}-01$ 1.00000e-01 1.00000e-02 1.00000e-09 1.00000e-01

$1.00000 \mathrm{e}+001.00000 \mathrm{e}+001.00000 \mathrm{e}-011.00000 \mathrm{e}-091.00000 \mathrm{e}-01$

$1.00000 \mathrm{e}-05$ 1.00000e-05 1.00000e-06 1.00000e-09 1.00000e-01

$1.00000 \mathrm{e}+001.00000 \mathrm{e}+001.00000 \mathrm{e}-011.00000 \mathrm{e}-091.00000 \mathrm{e}-01$ 
Element: 2661 \# of layers: 14

$\mathrm{Kx} \mathrm{Ky} \mathrm{Kz}$ Ss Por

4.16983e+02 4.16983e+02 4.16983e+01 1.00000e-09 7.00000e-02

$4.16983 \mathrm{e}+02$ 4.16983e+02 4.16983e+01 1.00000e-09 7.00000e-02

4.16983e+02 4.16983e+02 4.16983e+01 1.00000e-09 7.00000e-02

5.00000e-04 5.00000e-04 5.00000e-05 1.00000e-09 1.00000e-01

5.00000e-04 5.00000e-04 5.00000e-05 1.00000e-09 1.00000e-01

$1.66614 \mathrm{e}+011.66614 \mathrm{e}+011.66614 \mathrm{e}+001.00000 \mathrm{e}-092.12000 \mathrm{e}-01$

$1.66614 \mathrm{e}+011.66614 \mathrm{e}+011.66614 \mathrm{e}+001.00000 \mathrm{e}-092.12000 \mathrm{e}-01$

$1.66614 \mathrm{e}+011.66614 \mathrm{e}+011.66614 \mathrm{e}+001.00000 \mathrm{e}-092.12000 \mathrm{e}-01$

$1.66614 \mathrm{e}+011.66614 \mathrm{e}+011.66614 \mathrm{e}+001.00000 \mathrm{e}-092.12000 \mathrm{e}-01$

$1.66614 \mathrm{e}+011.66614 \mathrm{e}+011.66614 \mathrm{e}+001.00000 \mathrm{e}-092.12000 \mathrm{e}-01$

$1.00000 \mathrm{e}-01$ 1.00000e-01 1.00000e-02 1.00000e-09 1.00000e-01

$1.00000 \mathrm{e}+001.00000 \mathrm{e}+001.00000 \mathrm{e}-011.00000 \mathrm{e}-091.00000 \mathrm{e}-01$

$1.00000 \mathrm{e}-05$ 1.00000e-05 1.00000e-06 1.00000e-09 1.00000e-01

$1.00000 \mathrm{e}+001.00000 \mathrm{e}+001.00000 \mathrm{e}-011.00000 \mathrm{e}-091.00000 \mathrm{e}-01$

Element: 2662 \# of layers: 14

$\mathrm{Kx} \mathrm{Ky} \mathrm{Kz}$ Ss Por

4.16983e+02 4.16983e+02 4.16983e+01 1.00000e-09 7.00000e-02

4.16983e+02 4.16983e+02 4.16983e+01 1.00000e-09 7.00000e-02

$4.16983 \mathrm{e}+02$ 4.16983e+02 4.16983e+01 1.00000e-09 7.00000e-02

5.00000e-04 5.00000e-04 5.00000e-05 1.00000e-09 1.00000e-01

5.00000e-04 5.00000e-04 5.00000e-05 1.00000e-09 1.00000e-01

$1.66614 \mathrm{e}+011.66614 \mathrm{e}+011.66614 \mathrm{e}+001.00000 \mathrm{e}-092.12000 \mathrm{e}-01$

$1.66614 \mathrm{e}+011.66614 \mathrm{e}+011.66614 \mathrm{e}+001.00000 \mathrm{e}-092.12000 \mathrm{e}-01$

$1.66614 \mathrm{e}+011.66614 \mathrm{e}+011.66614 \mathrm{e}+001.00000 \mathrm{e}-092.12000 \mathrm{e}-01$

$1.66614 \mathrm{e}+011.66614 \mathrm{e}+011.66614 \mathrm{e}+001.00000 \mathrm{e}-092.12000 \mathrm{e}-01$

$1.66614 \mathrm{e}+011.66614 \mathrm{e}+011.66614 \mathrm{e}+001.00000 \mathrm{e}-092.12000 \mathrm{e}-01$

$1.00000 \mathrm{e}-01$ 1.00000e-01 1.00000e-02 1.00000e-09 1.00000e-01

$1.00000 \mathrm{e}+001.00000 \mathrm{e}+001.00000 \mathrm{e}-011.00000 \mathrm{e}-091.00000 \mathrm{e}-01$

$1.00000 \mathrm{e}-05$ 1.00000e-05 1.00000e-06 1.00000e-09 1.00000e-01

$1.00000 \mathrm{e}+001.00000 \mathrm{e}+001.00000 \mathrm{e}-01$ 1.00000e-09 1.00000e-01

Element: 2663 \# of layers: 14

$\mathrm{Kx} \mathrm{Ky} \mathrm{Kz}$ Ss Por

4.26687e+02 4.26687e+02 4.26687e+01 1.00000e-09 7.00000e-02

4.26687e+02 4.26687e+02 4.26687e+01 1.00000e-09 7.00000e-02

4.26687e+02 4.26687e+02 4.26687e+01 1.00000e-09 7.00000e-02

5.00000e-04 5.00000e-04 5.00000e-05 1.00000e-09 1.00000e-01

5.00000e-04 5.00000e-04 5.00000e-05 1.00000e-09 1.00000e-01

$1.70488 \mathrm{e}+01$ 1.70488e+01 1.70488e+00 1.00000e-09 2.12000e-01

$1.70488 \mathrm{e}+01$ 1.70488e+01 1.70488e+00 1.00000e-09 2.12000e-01

$1.70488 \mathrm{e}+01$ 1.70488e+01 1.70488e+00 1.00000e-09 2.12000e-01

$1.70488 \mathrm{e}+01$ 1.70488e+01 1.70488e+00 1.00000e-09 2.12000e-01

$1.70488 \mathrm{e}+01$ 1.70488e+01 1.70488e+00 1.00000e-09 2.12000e-01

$1.00000 \mathrm{e}-02$ 1.00000e-02 1.00000e-03 1.00000e-09 1.00000e-01

$1.00000 \mathrm{e}+001.00000 \mathrm{e}+001.00000 \mathrm{e}-011.00000 \mathrm{e}-091.00000 \mathrm{e}-01$ 
$1.00000 \mathrm{e}-05$ 1.00000e-05 1.00000e-06 1.00000e-09 1.00000e-01 $1.00000 \mathrm{e}+001.00000 \mathrm{e}+001.00000 \mathrm{e}-01$ 1.00000e-09 1.00000e-01 Element: 2664 \# of layers: 14

$\mathrm{Kx} \mathrm{Ky} \mathrm{Kz}$ Ss Por

4.26687e+02 4.26687e+02 4.26687e+01 1.00000e-09 7.00000e-02 4.26687e+02 4.26687e+02 4.26687e+01 1.00000e-09 7.00000e-02 4.26687e+02 4.26687e+02 4.26687e+01 1.00000e-09 7.00000e-02 5.00000e-04 5.00000e-04 5.00000e-05 1.00000e-09 1.00000e-01 5.00000e-04 5.00000e-04 5.00000e-05 1.00000e-09 1.00000e-01

$1.70488 \mathrm{e}+01$ 1.70488e+01 1.70488e+00 1.00000e-09 2.12000e-01 $1.70488 \mathrm{e}+01$ 1.70488e+01 1.70488e+00 1.00000e-09 2.12000e-01 $1.70488 \mathrm{e}+011.70488 \mathrm{e}+011.70488 \mathrm{e}+001.00000 \mathrm{e}-092.12000 \mathrm{e}-01$ $1.70488 \mathrm{e}+011.70488 \mathrm{e}+01$ 1.70488e+00 1.00000e-09 2.12000e-01 $1.70488 \mathrm{e}+01$ 1.70488e+01 1.70488e+00 1.00000e-09 2.12000e-01 $1.00000 \mathrm{e}-02$ 1.00000e-02 1.00000e-03 1.00000e-09 1.00000e-01 $1.00000 \mathrm{e}+001.00000 \mathrm{e}+001.00000 \mathrm{e}-011.00000 \mathrm{e}-091.00000 \mathrm{e}-01$ $1.00000 \mathrm{e}-05$ 1.00000e-05 1.00000e-06 1.00000e-09 1.00000e-01 $1.00000 \mathrm{e}+001.00000 \mathrm{e}+001.00000 \mathrm{e}-01$ 1.00000e-09 1.00000e-01 Element: 2665 \# of layers: 14

$\mathrm{Kx} \mathrm{Ky} \mathrm{Kz}$ Ss Por

4.83450e+02 4.83450e+02 4.83450e+01 1.00000e-09 7.00000e-02 4.83450e+02 4.83450e+02 4.83450e+01 1.00000e-09 7.00000e-02 $4.83450 \mathrm{e}+02$ 4.83450e+02 4.83450e+01 1.00000e-09 7.00000e-02 5.00000e-04 5.00000e-04 5.00000e-05 1.00000e-09 1.00000e-01 5.00000e-04 5.00000e-04 5.00000e-05 1.00000e-09 1.00000e-01 $1.93171 \mathrm{e}+011.93171 \mathrm{e}+011.93171 \mathrm{e}+001.00000 \mathrm{e}-092.12000 \mathrm{e}-01$ $1.93171 \mathrm{e}+011.93171 \mathrm{e}+011.93171 \mathrm{e}+001.00000 \mathrm{e}-092.12000 \mathrm{e}-01$ $1.93171 \mathrm{e}+011.93171 \mathrm{e}+01$ 1.93171e+00 1.00000e-09 2.12000e-01 $1.93171 \mathrm{e}+011.93171 \mathrm{e}+011.93171 \mathrm{e}+001.00000 \mathrm{e}-092.12000 \mathrm{e}-01$ $1.93171 \mathrm{e}+011.93171 \mathrm{e}+011.93171 \mathrm{e}+001.00000 \mathrm{e}-092.12000 \mathrm{e}-01$ $1.00000 \mathrm{e}-02$ 1.00000e-02 1.00000e-03 1.00000e-09 1.00000e-01 $1.00000 \mathrm{e}+001.00000 \mathrm{e}+001.00000 \mathrm{e}-011.00000 \mathrm{e}-091.00000 \mathrm{e}-01$ $1.00000 \mathrm{e}-05$ 1.00000e-05 1.00000e-06 1.00000e-09 1.00000e-01 $1.00000 \mathrm{e}+001.00000 \mathrm{e}+001.00000 \mathrm{e}-01$ 1.00000e-09 1.00000e-01 Element: 2666 \# of layers: 14

$\mathrm{Kx} \mathrm{Ky} \mathrm{Kz}$ Ss Por

4.64195e+02 4.64195e+02 4.64195e+01 1.00000e-09 7.00000e-02 $4.64195 \mathrm{e}+02$ 4.64195e+02 4.64195e+01 1.00000e-09 7.00000e-02 4.64195e+02 4.64195e+02 4.64195e+01 1.00000e-09 7.00000e-02 5.00000e-04 5.00000e-04 5.00000e-05 1.00000e-09 1.00000e-01 5.00000e-04 5.00000e-04 5.00000e-05 1.00000e-09 1.00000e-01 $1.85474 \mathrm{e}+011.85474 \mathrm{e}+011.85474 \mathrm{e}+001.00000 \mathrm{e}-092.12000 \mathrm{e}-01$ $1.85474 \mathrm{e}+011.85474 \mathrm{e}+011.85474 \mathrm{e}+001.00000 \mathrm{e}-092.12000 \mathrm{e}-01$ $1.85474 \mathrm{e}+011.85474 \mathrm{e}+01$ 1.85474e+00 1.00000e-09 2.12000e-01 $1.85474 \mathrm{e}+011.85474 \mathrm{e}+011.85474 \mathrm{e}+001.00000 \mathrm{e}-092.12000 \mathrm{e}-01$ $1.85474 \mathrm{e}+011.85474 \mathrm{e}+011.85474 \mathrm{e}+001.00000 \mathrm{e}-092.12000 \mathrm{e}-01$ 
$1.00000 \mathrm{e}-02$ 1.00000e-02 1.00000e-03 1.00000e-09 1.00000e-01 $1.00000 \mathrm{e}+001.00000 \mathrm{e}+001.00000 \mathrm{e}-011.00000 \mathrm{e}-091.00000 \mathrm{e}-01$ $1.00000 \mathrm{e}-05$ 1.00000e-05 1.00000e-06 1.00000e-09 1.00000e-01 $1.00000 \mathrm{e}+001.00000 \mathrm{e}+001.00000 \mathrm{e}-011.00000 \mathrm{e}-091.00000 \mathrm{e}-01$ Element: 2667 \# of layers: 14

Kx Ky Kz Ss Por

4.16983e+02 4.16983e+02 4.16983e+01 1.00000e-09 7.00000e-02 $4.16983 \mathrm{e}+02$ 4.16983e+02 4.16983e+01 1.00000e-09 7.00000e-02 $4.16983 \mathrm{e}+024.16983 \mathrm{e}+024.16983 \mathrm{e}+01$ 1.00000e-09 7.00000e-02 5.00000e-04 5.00000e-04 5.00000e-05 1.00000e-09 1.00000e-01 5.00000e-04 5.00000e-04 5.00000e-05 1.00000e-09 1.00000e-01 $1.66614 \mathrm{e}+011.66614 \mathrm{e}+011.66614 \mathrm{e}+001.00000 \mathrm{e}-092.12000 \mathrm{e}-01$ $1.66614 \mathrm{e}+011.66614 \mathrm{e}+011.66614 \mathrm{e}+001.00000 \mathrm{e}-092.12000 \mathrm{e}-01$ $1.66614 \mathrm{e}+011.66614 \mathrm{e}+011.66614 \mathrm{e}+001.00000 \mathrm{e}-092.12000 \mathrm{e}-01$ $1.66614 \mathrm{e}+011.66614 \mathrm{e}+011.66614 \mathrm{e}+001.00000 \mathrm{e}-092.12000 \mathrm{e}-01$ $1.66614 \mathrm{e}+011.66614 \mathrm{e}+011.66614 \mathrm{e}+001.00000 \mathrm{e}-092.12000 \mathrm{e}-01$ $1.00000 \mathrm{e}-02$ 1.00000e-02 1.00000e-03 1.00000e-09 1.00000e-01 $1.00000 \mathrm{e}+001.00000 \mathrm{e}+001.00000 \mathrm{e}-011.00000 \mathrm{e}-091.00000 \mathrm{e}-01$ $1.00000 \mathrm{e}-05$ 1.00000e-05 1.00000e-06 1.00000e-09 1.00000e-01 $1.00000 \mathrm{e}+001.00000 \mathrm{e}+001.00000 \mathrm{e}-011.00000 \mathrm{e}-091.00000 \mathrm{e}-01$ Element: 2668 \# of layers: 14

Kx Ky Kz Ss Por

$3.82529 \mathrm{e}+023.82529 \mathrm{e}+023.82529 \mathrm{e}+01$ 1.00000e-09 7.00000e-02 $3.82529 \mathrm{e}+023.82529 \mathrm{e}+023.82529 \mathrm{e}+01$ 1.00000e-09 7.00000e-02 $3.82529 \mathrm{e}+023.82529 \mathrm{e}+023.82529 \mathrm{e}+01$ 1.00000e-09 7.00000e-02 5.00000e-04 5.00000e-04 5.00000e-05 1.00000e-09 1.00000e-01 $5.00000 \mathrm{e}-04$ 5.00000e-04 5.00000e-05 1.00000e-09 1.00000e-01 $1.52844 \mathrm{e}+011.52844 \mathrm{e}+011.52844 \mathrm{e}+001.00000 \mathrm{e}-092.12000 \mathrm{e}-01$ $1.52844 \mathrm{e}+011.52844 \mathrm{e}+011.52844 \mathrm{e}+001.00000 \mathrm{e}-092.12000 \mathrm{e}-01$ $1.52844 \mathrm{e}+011.52844 \mathrm{e}+011.52844 \mathrm{e}+001.00000 \mathrm{e}-092.12000 \mathrm{e}-01$ $1.52844 \mathrm{e}+011.52844 \mathrm{e}+011.52844 \mathrm{e}+001.00000 \mathrm{e}-092.12000 \mathrm{e}-01$ $1.52844 \mathrm{e}+011.52844 \mathrm{e}+011.52844 \mathrm{e}+001.00000 \mathrm{e}-092.12000 \mathrm{e}-01$ $1.00000 \mathrm{e}-011.00000 \mathrm{e}-011.00000 \mathrm{e}-021.00000 \mathrm{e}-091.00000 \mathrm{e}-01$ $1.00000 \mathrm{e}+001.00000 \mathrm{e}+001.00000 \mathrm{e}-011.00000 \mathrm{e}-091.00000 \mathrm{e}-01$ $1.00000 \mathrm{e}-05$ 1.00000e-05 1.00000e-06 1.00000e-09 1.00000e-01 $1.00000 \mathrm{e}+001.00000 \mathrm{e}+001.00000 \mathrm{e}-011.00000 \mathrm{e}-091.00000 \mathrm{e}-01$ Element: 2669 \# of layers: 14

Kx Ky Kz Ss Por

$3.97521 \mathrm{e}+023.97521 \mathrm{e}+023.97521 \mathrm{e}+01$ 1.00000e-09 7.00000e-02 $3.97521 \mathrm{e}+023.97521 \mathrm{e}+023.97521 \mathrm{e}+01$ 1.00000e-09 7.00000e-02 $3.97521 \mathrm{e}+023.97521 \mathrm{e}+023.97521 \mathrm{e}+011.00000 \mathrm{e}-097.00000 \mathrm{e}-02$ 5.00000e-04 5.00000e-04 5.00000e-05 1.00000e-09 1.00000e-01 5.00000e-04 5.00000e-04 5.00000e-05 1.00000e-09 1.00000e-01 $1.58838 \mathrm{e}+011.58838 \mathrm{e}+011.58838 \mathrm{e}+001.00000 \mathrm{e}-092.12000 \mathrm{e}-01$ $1.58838 \mathrm{e}+011.58838 \mathrm{e}+011.58838 \mathrm{e}+001.00000 \mathrm{e}-092.12000 \mathrm{e}-01$ $1.58838 \mathrm{e}+011.58838 \mathrm{e}+011.58838 \mathrm{e}+001.00000 \mathrm{e}-092.12000 \mathrm{e}-01$ 
$1.58838 \mathrm{e}+01$ 1.58838e+01 1.58838e+00 1.00000e-09 2.12000e-01 $1.58838 \mathrm{e}+01$ 1.58838e+01 1.58838e+00 1.00000e-09 2.12000e-01 $1.00000 \mathrm{e}-02$ 1.00000e-02 1.00000e-03 1.00000e-09 1.00000e-01 $1.00000 \mathrm{e}+001.00000 \mathrm{e}+001.00000 \mathrm{e}-011.00000 \mathrm{e}-091.00000 \mathrm{e}-01$ $1.00000 \mathrm{e}-05$ 1.00000e-05 1.00000e-06 1.00000e-09 1.00000e-01 $1.00000 \mathrm{e}+001.00000 \mathrm{e}+001.00000 \mathrm{e}-011.00000 \mathrm{e}-091.00000 \mathrm{e}-01$ Element: 2670 \# of layers: 14

$\mathrm{Kx} \mathrm{Ky} \mathrm{Kz}$ Ss Por

3.97521e+02 3.97521e+02 3.97521e+01 1.00000e-09 7.00000e-02 $3.97521 \mathrm{e}+023.97521 \mathrm{e}+02$ 3.97521e+01 1.00000e-09 7.00000e-02 $3.97521 \mathrm{e}+023.97521 \mathrm{e}+023.97521 \mathrm{e}+01$ 1.00000e-09 7.00000e-02 5.00000e-04 5.00000e-04 5.00000e-05 1.00000e-09 1.00000e-01 5.00000e-04 5.00000e-04 5.00000e-05 1.00000e-09 1.00000e-01

$1.58838 \mathrm{e}+01$ 1.58838e+01 1.58838e+00 1.00000e-09 2.12000e-01 $1.58838 \mathrm{e}+01$ 1.58838e+01 1.58838e+00 1.00000e-09 2.12000e-01 $1.58838 \mathrm{e}+011.58838 \mathrm{e}+01$ 1.58838e+00 1.00000e-09 2.12000e-01 $1.58838 \mathrm{e}+01$ 1.58838e+01 1.58838e+00 1.00000e-09 2.12000e-01 $1.58838 \mathrm{e}+011.58838 \mathrm{e}+01$ 1.58838e+00 1.00000e-09 2.12000e-01 $1.00000 \mathrm{e}-021.00000 \mathrm{e}-021.00000 \mathrm{e}-031.00000 \mathrm{e}-091.00000 \mathrm{e}-01$ $1.00000 \mathrm{e}+001.00000 \mathrm{e}+001.00000 \mathrm{e}-011.00000 \mathrm{e}-091.00000 \mathrm{e}-01$ $1.00000 \mathrm{e}-05$ 1.00000e-05 1.00000e-06 1.00000e-09 1.00000e-01 $1.00000 \mathrm{e}+001.00000 \mathrm{e}+001.00000 \mathrm{e}-01$ 1.00000e-09 1.00000e-01 Element: 2671 \# of layers: 14

Kx Ky Kz Ss Por

3.97521e+02 3.97521e+02 3.97521e+01 1.00000e-09 7.00000e-02 $3.97521 \mathrm{e}+023.97521 \mathrm{e}+023.97521 \mathrm{e}+01$ 1.00000e-09 7.00000e-02 $3.97521 \mathrm{e}+02$ 3.97521e+02 3.97521e+01 1.00000e-09 7.00000e-02 5.00000e-04 5.00000e-04 5.00000e-05 1.00000e-09 1.00000e-01 5.00000e-04 5.00000e-04 5.00000e-05 1.00000e-09 1.00000e-01 $1.58838 \mathrm{e}+011.58838 \mathrm{e}+011.58838 \mathrm{e}+001.00000 \mathrm{e}-092.12000 \mathrm{e}-01$ $1.58838 \mathrm{e}+01$ 1.58838e+01 1.58838e+00 1.00000e-09 2.12000e-01 $1.58838 \mathrm{e}+011.58838 \mathrm{e}+01$ 1.58838e+00 1.00000e-09 2.12000e-01 $1.58838 \mathrm{e}+011.58838 \mathrm{e}+01$ 1.58838e+00 1.00000e-09 2.12000e-01 $1.58838 \mathrm{e}+011.58838 \mathrm{e}+011.58838 \mathrm{e}+001.00000 \mathrm{e}-092.12000 \mathrm{e}-01$ $1.00000 \mathrm{e}-02$ 1.00000e-02 1.00000e-03 1.00000e-09 1.00000e-01 $1.00000 \mathrm{e}+001.00000 \mathrm{e}+001.00000 \mathrm{e}-011.00000 \mathrm{e}-091.00000 \mathrm{e}-01$ $1.00000 \mathrm{e}-05$ 1.00000e-05 1.00000e-06 1.00000e-09 1.00000e-01 $1.00000 \mathrm{e}+001.00000 \mathrm{e}+001.00000 \mathrm{e}-011.00000 \mathrm{e}-09$ 1.00000e-01 Element: 2672 \# of layers: 15

$\mathrm{Kx} \mathrm{Ky} \mathrm{Kz}$ Ss Por

4.72773e+02 4.72773e+02 4.72773e+01 1.00000e-09 7.00000e-02 4.72773e+02 4.72773e+02 4.72773e+01 1.00000e-09 7.00000e-02 4.72773e+02 4.72773e+02 4.72773e+01 1.00000e-09 7.00000e-02 4.72773e+02 4.72773e+02 4.72773e+01 1.00000e-09 7.00000e-02 5.00000e-04 5.00000e-04 5.00000e-05 1.00000e-09 1.00000e-01 5.00000e-04 5.00000e-04 5.00000e-05 1.00000e-09 1.00000e-01 
$1.88903 \mathrm{e}+01$ 1.88903e+01 1.88903e+00 1.00000e-09 2.12000e-01 $1.88903 \mathrm{e}+01$ 1.88903e+01 1.88903e+00 1.00000e-09 2.12000e-01 $1.88903 \mathrm{e}+011.88903 \mathrm{e}+01$ 1.88903e+00 1.00000e-09 2.12000e-01 $1.88903 \mathrm{e}+011.88903 \mathrm{e}+011.88903 \mathrm{e}+001.00000 \mathrm{e}-092.12000 \mathrm{e}-01$ $1.88903 \mathrm{e}+011.88903 \mathrm{e}+01$ 1.88903e+00 1.00000e-09 2.12000e-01 $1.00000 \mathrm{e}-02$ 1.00000e-02 1.00000e-03 1.00000e-09 1.00000e-01 $1.00000 \mathrm{e}+001.00000 \mathrm{e}+001.00000 \mathrm{e}-011.00000 \mathrm{e}-091.00000 \mathrm{e}-01$ $1.00000 \mathrm{e}-05$ 1.00000e-05 1.00000e-06 1.00000e-09 1.00000e-01 $1.00000 \mathrm{e}+001.00000 \mathrm{e}+001.00000 \mathrm{e}-011.00000 \mathrm{e}-091.00000 \mathrm{e}-01$ Element: 2673 \# of layers: 14

$\mathrm{Kx} \mathrm{Ky} \mathrm{Kz}$ Ss Por

4.72773e+02 4.72773e+02 4.72773e+01 1.00000e-09 7.00000e-02 4.72773e+02 4.72773e+02 4.72773e+01 1.00000e-09 7.00000e-02 4.72773e+02 4.72773e+02 4.72773e+01 1.00000e-09 7.00000e-02 5.00000e-04 5.00000e-04 5.00000e-05 1.00000e-09 1.00000e-01 5.00000e-04 5.00000e-04 5.00000e-05 1.00000e-09 1.00000e-01 $1.88903 \mathrm{e}+011.88903 \mathrm{e}+011.88903 \mathrm{e}+001.00000 \mathrm{e}-092.12000 \mathrm{e}-01$ $1.88903 \mathrm{e}+011.88903 \mathrm{e}+01$ 1.88903e+00 1.00000e-09 2.12000e-01 $1.88903 \mathrm{e}+01$ 1.88903e+01 1.88903e+00 1.00000e-09 2.12000e-01 $1.88903 \mathrm{e}+011.88903 \mathrm{e}+01$ 1.88903e+00 1.00000e-09 2.12000e-01 $1.88903 \mathrm{e}+011.88903 \mathrm{e}+011.88903 \mathrm{e}+001.00000 \mathrm{e}-092.12000 \mathrm{e}-01$ $1.00000 \mathrm{e}-02$ 1.00000e-02 1.00000e-03 1.00000e-09 1.00000e-01 $1.00000 \mathrm{e}+001.00000 \mathrm{e}+001.00000 \mathrm{e}-011.00000 \mathrm{e}-091.00000 \mathrm{e}-01$ $1.00000 \mathrm{e}-051.00000 \mathrm{e}-05$ 1.00000e-06 1.00000e-09 1.00000e-01 $1.00000 \mathrm{e}+001.00000 \mathrm{e}+001.00000 \mathrm{e}-011.00000 \mathrm{e}-091.00000 \mathrm{e}-01$ Element: 2674 \# of layers: 14

$\mathrm{Kx} \mathrm{Ky} \mathrm{Kz}$ Ss Por

3.99918e+02 3.99918e+02 3.99918e+01 1.00000e-09 7.00000e-02 $3.99918 \mathrm{e}+02$ 3.99918e+02 3.99918e+01 1.00000e-09 7.00000e-02 $3.99918 \mathrm{e}+02$ 3.99918e+02 3.99918e+01 1.00000e-09 7.00000e-02 5.00000e-04 5.00000e-04 5.00000e-05 1.00000e-09 1.00000e-01 5.00000e-04 5.00000e-04 5.00000e-05 1.00000e-09 1.00000e-01 $1.59792 \mathrm{e}+01$ 1.59792e+01 1.59792e+00 1.00000e-09 2.12000e-01 $1.59792 \mathrm{e}+01$ 1.59792e+01 1.59792e+00 1.00000e-09 2.12000e-01 $1.59792 \mathrm{e}+011.59792 \mathrm{e}+01$ 1.59792e+00 1.00000e-09 2.12000e-01 $1.59792 \mathrm{e}+01$ 1.59792e+01 1.59792e+00 1.00000e-09 2.12000e-01 $1.59792 \mathrm{e}+011.59792 \mathrm{e}+01$ 1.59792e+00 1.00000e-09 2.12000e-01 $1.00000 \mathrm{e}-02$ 1.00000e-02 1.00000e-03 1.00000e-09 1.00000e-01 $1.00000 \mathrm{e}+001.00000 \mathrm{e}+001.00000 \mathrm{e}-011.00000 \mathrm{e}-091.00000 \mathrm{e}-01$ $1.00000 \mathrm{e}-05$ 1.00000e-05 1.00000e-06 1.00000e-09 1.00000e-01 $1.00000 \mathrm{e}+001.00000 \mathrm{e}+001.00000 \mathrm{e}-011.00000 \mathrm{e}-091.00000 \mathrm{e}-01$ Element: 2675 \# of layers: 14

$\mathrm{Kx} \mathrm{Ky} \mathrm{Kz}$ Ss Por

3.82529e+02 3.82529e+02 3.82529e+01 1.00000e-09 7.00000e-02 $3.82529 \mathrm{e}+02$ 3.82529e+02 3.82529e+01 1.00000e-09 7.00000e-02 $3.82529 \mathrm{e}+02$ 3.82529e+02 3.82529e+01 1.00000e-09 7.00000e-02 
5.00000e-04 5.00000e-04 5.00000e-05 1.00000e-09 1.00000e-01 5.00000e-04 5.00000e-04 5.00000e-05 1.00000e-09 1.00000e-01 $1.52844 \mathrm{e}+011.52844 \mathrm{e}+011.52844 \mathrm{e}+001.00000 \mathrm{e}-092.12000 \mathrm{e}-01$ $1.52844 \mathrm{e}+011.52844 \mathrm{e}+01 \quad 1.52844 \mathrm{e}+001.00000 \mathrm{e}-092.12000 \mathrm{e}-01$ $1.52844 \mathrm{e}+011.52844 \mathrm{e}+011.52844 \mathrm{e}+001.00000 \mathrm{e}-092.12000 \mathrm{e}-01$ $1.52844 \mathrm{e}+011.52844 \mathrm{e}+011.52844 \mathrm{e}+001.00000 \mathrm{e}-092.12000 \mathrm{e}-01$ $1.52844 \mathrm{e}+011.52844 \mathrm{e}+011.52844 \mathrm{e}+001.00000 \mathrm{e}-092.12000 \mathrm{e}-01$ $1.00000 \mathrm{e}-02$ 1.00000e-02 1.00000e-03 1.00000e-09 1.00000e-01 $1.00000 \mathrm{e}+001.00000 \mathrm{e}+001.00000 \mathrm{e}-011.00000 \mathrm{e}-091.00000 \mathrm{e}-01$ $1.00000 \mathrm{e}-05$ 1.00000e-05 1.00000e-06 1.00000e-09 1.00000e-01 $1.00000 \mathrm{e}+001.00000 \mathrm{e}+001.00000 \mathrm{e}-011.00000 \mathrm{e}-091.00000 \mathrm{e}-01$ Element: 2676 \# of layers: 14

$\mathrm{Kx} \mathrm{Ky} \mathrm{Kz}$ Ss Por

3.97521e+02 3.97521e+02 3.97521e+01 1.00000e-09 7.00000e-02 $3.97521 \mathrm{e}+023.97521 \mathrm{e}+023.97521 \mathrm{e}+01$ 1.00000e-09 7.00000e-02 $3.97521 \mathrm{e}+023.97521 \mathrm{e}+023.97521 \mathrm{e}+01$ 1.00000e-09 7.00000e-02 5.00000e-04 5.00000e-04 5.00000e-05 1.00000e-09 1.00000e-01 5.00000e-04 5.00000e-04 5.00000e-05 1.00000e-09 1.00000e-01 $1.58838 \mathrm{e}+01$ 1.58838e+01 1.58838e+00 1.00000e-09 2.12000e-01 $1.58838 \mathrm{e}+01$ 1.58838e+01 1.58838e+00 1.00000e-09 2.12000e-01 $1.58838 \mathrm{e}+011.58838 \mathrm{e}+01$ 1.58838e+00 1.00000e-09 2.12000e-01 $1.58838 \mathrm{e}+01$ 1.58838e+01 1.58838e+00 1.00000e-09 2.12000e-01 $1.58838 \mathrm{e}+01$ 1.58838e+01 1.58838e+00 1.00000e-09 2.12000e-01 $1.00000 \mathrm{e}-02$ 1.00000e-02 1.00000e-03 1.00000e-09 1.00000e-01 $1.00000 \mathrm{e}+001.00000 \mathrm{e}+001.00000 \mathrm{e}-011.00000 \mathrm{e}-091.00000 \mathrm{e}-01$ $1.00000 \mathrm{e}-051.00000 \mathrm{e}-051.00000 \mathrm{e}-061.00000 \mathrm{e}-091.00000 \mathrm{e}-01$ $1.00000 \mathrm{e}+001.00000 \mathrm{e}+001.00000 \mathrm{e}-011.00000 \mathrm{e}-091.00000 \mathrm{e}-01$ Element: 2677 \# of layers: 14

$\mathrm{Kx} \mathrm{Ky} \mathrm{Kz}$ Ss Por

5.82641e+02 5.82641e+02 5.82641e+01 1.00000e-09 7.00000e-02 $5.82641 \mathrm{e}+025.82641 \mathrm{e}+025.82641 \mathrm{e}+01$ 1.00000e-09 7.00000e-02 $5.82641 \mathrm{e}+025.82641 \mathrm{e}+025.82641 \mathrm{e}+01$ 1.00000e-09 7.00000e-02 5.00000e-04 5.00000e-04 5.00000e-05 1.00000e-09 1.00000e-01 5.00000e-04 5.00000e-04 5.00000e-05 1.00000e-09 1.00000e-01 $2.32812 \mathrm{e}+012.32812 \mathrm{e}+012.32813 \mathrm{e}+00$ 1.00000e-09 2.12000e-01 $2.32812 \mathrm{e}+012.32812 \mathrm{e}+012.32813 \mathrm{e}+00$ 1.00000e-09 2.12000e-01 $2.32812 \mathrm{e}+012.32812 \mathrm{e}+012.32813 \mathrm{e}+00$ 1.00000e-09 2.12000e-01 $2.32812 \mathrm{e}+012.32812 \mathrm{e}+012.32813 \mathrm{e}+00$ 1.00000e-09 2.12000e-01 $2.32812 \mathrm{e}+012.32812 \mathrm{e}+012.32813 \mathrm{e}+00$ 1.00000e-09 2.12000e-01 $1.00000 \mathrm{e}-02$ 1.00000e-02 1.00000e-03 1.00000e-09 1.00000e-01 $1.00000 \mathrm{e}+001.00000 \mathrm{e}+001.00000 \mathrm{e}-011.00000 \mathrm{e}-091.00000 \mathrm{e}-01$ $1.00000 \mathrm{e}-05$ 1.00000e-05 1.00000e-06 1.00000e-09 1.00000e-01 $1.00000 \mathrm{e}+001.00000 \mathrm{e}+001.00000 \mathrm{e}-011.00000 \mathrm{e}-091.00000 \mathrm{e}-01$ Element: 2678 \# of layers: 14

$\mathrm{Kx} \mathrm{Ky} \mathrm{Kz}$ Ss Por

5.32833e+02 5.32833e+02 5.32833e+01 1.00000e-09 7.00000e-02 
5.32833e+02 5.32833e+02 5.32833e+01 1.00000e-09 7.00000e-02 5.32833e+02 5.32833e+02 5.32833e+01 1.00000e-09 7.00000e-02 5.00000e-04 5.00000e-04 5.00000e-05 1.00000e-09 1.00000e-01 5.00000e-04 5.00000e-04 5.00000e-05 1.00000e-09 1.00000e-01

$2.12899 \mathrm{e}+012.12899 \mathrm{e}+012.12899 \mathrm{e}+00$ 1.00000e-09 2.12000e-01 $2.12899 \mathrm{e}+012.12899 \mathrm{e}+012.12899 \mathrm{e}+00$ 1.00000e-09 2.12000e-01 $2.12899 \mathrm{e}+012.12899 \mathrm{e}+012.12899 \mathrm{e}+00$ 1.00000e-09 2.12000e-01 $2.12899 \mathrm{e}+012.12899 \mathrm{e}+012.12899 \mathrm{e}+00$ 1.00000e-09 2.12000e-01 $2.12899 \mathrm{e}+012.12899 \mathrm{e}+012.12899 \mathrm{e}+00$ 1.00000e-09 2.12000e-01 $1.00000 \mathrm{e}-02$ 1.00000e-02 1.00000e-03 1.00000e-09 1.00000e-01 $1.00000 \mathrm{e}+001.00000 \mathrm{e}+001.00000 \mathrm{e}-011.00000 \mathrm{e}-091.00000 \mathrm{e}-01$ $1.00000 \mathrm{e}-05$ 1.00000e-05 1.00000e-06 1.00000e-09 1.00000e-01 $1.00000 \mathrm{e}+001.00000 \mathrm{e}+001.00000 \mathrm{e}-01$ 1.00000e-09 1.00000e-01 Element: 2679 \# of layers: 16

$\mathrm{Kx} \mathrm{Ky} \mathrm{Kz}$ Ss Por

5.32833e+02 5.32833e+02 5.32833e+01 1.00000e-09 7.00000e-02 $5.32833 \mathrm{e}+02$ 5.32833e+02 5.32833e+01 1.00000e-09 7.00000e-02 $5.32833 \mathrm{e}+02$ 5.32833e+02 5.32833e+01 1.00000e-09 7.00000e-02 5.32833e+02 5.32833e+02 5.32833e+01 1.00000e-09 7.00000e-02 5.32833e+02 5.32833e+02 5.32833e+01 1.00000e-09 7.00000e-02 5.00000e-04 5.00000e-04 5.00000e-05 1.00000e-09 1.00000e-01 5.00000e-04 5.00000e-04 5.00000e-05 1.00000e-09 1.00000e-01 $2.12899 \mathrm{e}+012.12899 \mathrm{e}+012.12899 \mathrm{e}+00$ 1.00000e-09 2.12000e-01 $2.12899 \mathrm{e}+012.12899 \mathrm{e}+012.12899 \mathrm{e}+00$ 1.00000e-09 2.12000e-01 $2.12899 \mathrm{e}+012.12899 \mathrm{e}+012.12899 \mathrm{e}+00$ 1.00000e-09 2.12000e-01 $2.12899 \mathrm{e}+012.12899 \mathrm{e}+012.12899 \mathrm{e}+001.00000 \mathrm{e}-092.12000 \mathrm{e}-01$ $2.12899 \mathrm{e}+012.12899 \mathrm{e}+012.12899 \mathrm{e}+00$ 1.00000e-09 2.12000e-01 $1.00000 \mathrm{e}-02$ 1.00000e-02 1.00000e-03 1.00000e-09 1.00000e-01 $1.00000 \mathrm{e}+001.00000 \mathrm{e}+001.00000 \mathrm{e}-011.00000 \mathrm{e}-091.00000 \mathrm{e}-01$ $1.00000 \mathrm{e}-05$ 1.00000e-05 1.00000e-06 1.00000e-09 1.00000e-01 $1.00000 \mathrm{e}+001.00000 \mathrm{e}+001.00000 \mathrm{e}-01$ 1.00000e-09 1.00000e-01 Element: 2680 \# of layers: 16

Kx Ky Kz Ss Por 5.32833e+02 5.32833e+02 5.32833e+01 1.00000e-09 7.00000e-02 $5.32833 \mathrm{e}+02$ 5.32833e+02 5.32833e+01 1.00000e-09 7.00000e-02 $5.32833 \mathrm{e}+025.32833 \mathrm{e}+02$ 5.32833e+01 1.00000e-09 7.00000e-02 $5.32833 \mathrm{e}+02$ 5.32833e+02 5.32833e+01 1.00000e-09 7.00000e-02 $5.32833 \mathrm{e}+025.32833 \mathrm{e}+02$ 5.32833e+01 1.00000e-09 7.00000e-02 5.00000e-04 5.00000e-04 5.00000e-05 1.00000e-09 1.00000e-01 5.00000e-04 5.00000e-04 5.00000e-05 1.00000e-09 1.00000e-01 $2.12899 \mathrm{e}+012.12899 \mathrm{e}+012.12899 \mathrm{e}+00$ 1.00000e-09 2.12000e-01 $2.12899 \mathrm{e}+012.12899 \mathrm{e}+012.12899 \mathrm{e}+00$ 1.00000e-09 2.12000e-01 $2.12899 \mathrm{e}+012.12899 \mathrm{e}+012.12899 \mathrm{e}+00$ 1.00000e-09 2.12000e-01 $2.12899 \mathrm{e}+012.12899 \mathrm{e}+012.12899 \mathrm{e}+00$ 1.00000e-09 2.12000e-01 $2.12899 \mathrm{e}+012.12899 \mathrm{e}+012.12899 \mathrm{e}+00$ 1.00000e-09 2.12000e-01 1.00000e-02 1.00000e-02 1.00000e-03 1.00000e-09 1.00000e-01 
$1.00000 \mathrm{e}+001.00000 \mathrm{e}+001.00000 \mathrm{e}-011.00000 \mathrm{e}-091.00000 \mathrm{e}-01$ $1.00000 \mathrm{e}-05$ 1.00000e-05 1.00000e-06 1.00000e-09 1.00000e-01 $1.00000 \mathrm{e}+001.00000 \mathrm{e}+001.00000 \mathrm{e}-011.00000 \mathrm{e}-091.00000 \mathrm{e}-01$ Element: 2681 \# of layers: 16

$\mathrm{Kx} \mathrm{Ky} \mathrm{Kz}$ Ss Por

5.23319e+02 5.23319e+02 5.23319e+01 1.00000e-09 7.00000e-02 $5.23319 \mathrm{e}+02$ 5.23319e+02 5.23319e+01 1.00000e-09 7.00000e-02 5.23319e+02 5.23319e+02 5.23319e+01 1.00000e-09 7.00000e-02 $5.23319 \mathrm{e}+02$ 5.23319e+02 5.23319e+01 1.00000e-09 7.00000e-02 $5.23319 \mathrm{e}+025.23319 \mathrm{e}+025.23319 \mathrm{e}+01$ 1.00000e-09 7.00000e-02 5.00000e-04 5.00000e-04 5.00000e-05 1.00000e-09 1.00000e-01 5.00000e-04 5.00000e-04 5.00000e-05 1.00000e-09 1.00000e-01 $2.09101 \mathrm{e}+012.09101 \mathrm{e}+012.09101 \mathrm{e}+001.00000 \mathrm{e}-092.12000 \mathrm{e}-01$ $2.09101 \mathrm{e}+012.09101 \mathrm{e}+012.09101 \mathrm{e}+001.00000 \mathrm{e}-092.12000 \mathrm{e}-01$ $2.09101 \mathrm{e}+012.09101 \mathrm{e}+012.09101 \mathrm{e}+001.00000 \mathrm{e}-092.12000 \mathrm{e}-01$ $2.09101 \mathrm{e}+012.09101 \mathrm{e}+012.09101 \mathrm{e}+001.00000 \mathrm{e}-092.12000 \mathrm{e}-01$ $2.09101 \mathrm{e}+012.09101 \mathrm{e}+012.09101 \mathrm{e}+001.00000 \mathrm{e}-092.12000 \mathrm{e}-01$ $1.00000 \mathrm{e}-02$ 1.00000e-02 1.00000e-03 1.00000e-09 1.00000e-01 $1.00000 \mathrm{e}+001.00000 \mathrm{e}+001.00000 \mathrm{e}-011.00000 \mathrm{e}-091.00000 \mathrm{e}-01$ $1.00000 \mathrm{e}-05$ 1.00000e-05 1.00000e-06 1.00000e-09 1.00000e-01 $1.00000 \mathrm{e}+001.00000 \mathrm{e}+001.00000 \mathrm{e}-011.00000 \mathrm{e}-091.00000 \mathrm{e}-01$ Element: 2682 \# of layers: 15

$\mathrm{Kx} \mathrm{Ky} \mathrm{Kz}$ Ss Por

5.23319e+02 5.23319e+02 5.23319e+01 1.00000e-09 7.00000e-02 $5.23319 \mathrm{e}+02$ 5.23319e+02 5.23319e+01 1.00000e-09 7.00000e-02 $5.23319 \mathrm{e}+02$ 5.23319e+02 5.23319e+01 1.00000e-09 7.00000e-02 $5.23319 \mathrm{e}+02$ 5.23319e+02 5.23319e+01 1.00000e-09 7.00000e-02 5.00000e-04 5.00000e-04 5.00000e-05 1.00000e-09 1.00000e-01 5.00000e-04 5.00000e-04 5.00000e-05 1.00000e-09 1.00000e-01 $2.09101 \mathrm{e}+012.09101 \mathrm{e}+012.09101 \mathrm{e}+001.00000 \mathrm{e}-092.12000 \mathrm{e}-01$ $2.09101 \mathrm{e}+012.09101 \mathrm{e}+012.09101 \mathrm{e}+001.00000 \mathrm{e}-092.12000 \mathrm{e}-01$ $2.09101 \mathrm{e}+012.09101 \mathrm{e}+012.09101 \mathrm{e}+001.00000 \mathrm{e}-092.12000 \mathrm{e}-01$ $2.09101 \mathrm{e}+012.09101 \mathrm{e}+012.09101 \mathrm{e}+001.00000 \mathrm{e}-092.12000 \mathrm{e}-01$ $2.09101 \mathrm{e}+012.09101 \mathrm{e}+012.09101 \mathrm{e}+001.00000 \mathrm{e}-092.12000 \mathrm{e}-01$ $1.00000 \mathrm{e}-02$ 1.00000e-02 1.00000e-03 1.00000e-09 1.00000e-01 $1.00000 \mathrm{e}+001.00000 \mathrm{e}+001.00000 \mathrm{e}-011.00000 \mathrm{e}-091.00000 \mathrm{e}-01$ $1.00000 \mathrm{e}-05$ 1.00000e-05 1.00000e-06 1.00000e-09 1.00000e-01 $1.00000 \mathrm{e}+001.00000 \mathrm{e}+001.00000 \mathrm{e}-011.00000 \mathrm{e}-091.00000 \mathrm{e}-01$ Element: 2683 \# of layers: 15

$\mathrm{Kx} \mathrm{Ky} \mathrm{Kz}$ Ss Por 6.00039e+02 6.00039e+02 6.00039e+01 1.00000e-09 7.00000e-02 6.00039e+02 6.00039e+02 6.00039e+01 1.00000e-09 7.00000e-02 6.00039e+02 6.00039e+02 6.00039e+01 1.00000e-09 7.00000e-02 6.00039e+02 6.00039e+02 6.00039e+01 1.00000e-09 7.00000e-02 5.00000e-04 5.00000e-04 5.00000e-05 1.00000e-09 1.00000e-01 5.00000e-04 5.00000e-04 5.00000e-05 1.00000e-09 1.00000e-01 
2.39743e+01 2.39743e+01 2.39743e+00 1.00000e-09 2.12000e-01 $2.39743 \mathrm{e}+012.39743 \mathrm{e}+01$ 2.39743e+00 1.00000e-09 2.12000e-01 $2.39743 \mathrm{e}+012.39743 \mathrm{e}+012.39743 \mathrm{e}+00$ 1.00000e-09 2.12000e-01 $2.39743 e+012.39743 e+012.39743 e+001.00000 e-092.12000 e-01$ $2.39743 \mathrm{e}+012.39743 \mathrm{e}+012.39743 \mathrm{e}+00$ 1.00000e-09 2.12000e-01 $1.00000 \mathrm{e}-02$ 1.00000e-02 1.00000e-03 1.00000e-09 1.00000e-01 $1.00000 \mathrm{e}+001.00000 \mathrm{e}+001.00000 \mathrm{e}-011.00000 \mathrm{e}-091.00000 \mathrm{e}-01$ $1.00000 \mathrm{e}-05$ 1.00000e-05 1.00000e-06 1.00000e-09 1.00000e-01 $1.00000 \mathrm{e}+001.00000 \mathrm{e}+001.00000 \mathrm{e}-011.00000 \mathrm{e}-091.00000 \mathrm{e}-01$ Element: 2684 \# of layers: 14

$\mathrm{Kx} \mathrm{Ky} \mathrm{Kz}$ Ss Por

5.82641e+02 5.82641e+02 5.82641e+01 1.00000e-09 7.00000e-02 $5.82641 \mathrm{e}+025.82641 \mathrm{e}+025.82641 \mathrm{e}+01$ 1.00000e-09 7.00000e-02 $5.82641 \mathrm{e}+025.82641 \mathrm{e}+025.82641 \mathrm{e}+01$ 1.00000e-09 7.00000e-02 5.00000e-04 5.00000e-04 5.00000e-05 1.00000e-09 1.00000e-01 5.00000e-04 5.00000e-04 5.00000e-05 1.00000e-09 1.00000e-01 $2.32812 \mathrm{e}+012.32812 \mathrm{e}+012.32813 \mathrm{e}+001.00000 \mathrm{e}-092.12000 \mathrm{e}-01$ $2.32812 \mathrm{e}+012.32812 \mathrm{e}+012.32813 \mathrm{e}+00$ 1.00000e-09 2.12000e-01 $2.32812 \mathrm{e}+012.32812 \mathrm{e}+012.32813 \mathrm{e}+00$ 1.00000e-09 2.12000e-01 $2.32812 \mathrm{e}+012.32812 \mathrm{e}+012.32813 \mathrm{e}+00$ 1.00000e-09 2.12000e-01 $2.32812 \mathrm{e}+012.32812 \mathrm{e}+012.32813 \mathrm{e}+001.00000 \mathrm{e}-092.12000 \mathrm{e}-01$ $1.00000 \mathrm{e}-02$ 1.00000e-02 1.00000e-03 1.00000e-09 1.00000e-01 $1.00000 \mathrm{e}+001.00000 \mathrm{e}+001.00000 \mathrm{e}-011.00000 \mathrm{e}-091.00000 \mathrm{e}-01$ $1.00000 \mathrm{e}-05$ 1.00000e-05 1.00000e-06 1.00000e-09 1.00000e-01 $1.00000 \mathrm{e}+001.00000 \mathrm{e}+001.00000 \mathrm{e}-011.00000 \mathrm{e}-091.00000 \mathrm{e}-01$ Element: 2685 \# of layers: 15

$\mathrm{Kx} \mathrm{Ky} \mathrm{Kz}$ Ss Por

5.32833e+02 5.32833e+02 5.32833e+01 1.00000e-09 7.00000e-02 $5.32833 \mathrm{e}+02$ 5.32833e+02 5.32833e+01 1.00000e-09 7.00000e-02 5.32833e+02 5.32833e+02 5.32833e+01 1.00000e-09 7.00000e-02 $5.32833 \mathrm{e}+02$ 5.32833e+02 5.32833e+01 1.00000e-09 7.00000e-02 5.00000e-04 5.00000e-04 5.00000e-05 1.00000e-09 1.00000e-01 5.00000e-04 5.00000e-04 5.00000e-05 1.00000e-09 1.00000e-01

$2.12899 \mathrm{e}+012.12899 \mathrm{e}+012.12899 \mathrm{e}+00$ 1.00000e-09 2.12000e-01 $2.12899 \mathrm{e}+012.12899 \mathrm{e}+012.12899 \mathrm{e}+00$ 1.00000e-09 2.12000e-01 $2.12899 \mathrm{e}+012.12899 \mathrm{e}+012.12899 \mathrm{e}+00$ 1.00000e-09 2.12000e-01 $2.12899 \mathrm{e}+012.12899 \mathrm{e}+012.12899 \mathrm{e}+00$ 1.00000e-09 2.12000e-01 $2.12899 \mathrm{e}+012.12899 \mathrm{e}+012.12899 \mathrm{e}+00$ 1.00000e-09 2.12000e-01 $1.00000 \mathrm{e}-02$ 1.00000e-02 1.00000e-03 1.00000e-09 1.00000e-01 $1.00000 \mathrm{e}+001.00000 \mathrm{e}+001.00000 \mathrm{e}-011.00000 \mathrm{e}-091.00000 \mathrm{e}-01$ $1.00000 \mathrm{e}-051.00000 \mathrm{e}-05$ 1.00000e-06 1.00000e-09 1.00000e-01 $1.00000 \mathrm{e}+001.00000 \mathrm{e}+001.00000 \mathrm{e}-011.00000 \mathrm{e}-091.00000 \mathrm{e}-01$ Element: 2686 \# of layers: 16

$\mathrm{Kx} \mathrm{Ky} \mathrm{Kz}$ Ss Por 4.92631e+02 4.92631e+02 4.92631e+01 1.00000e-09 7.00000e-02 $4.92631 \mathrm{e}+02$ 4.92631e+02 4.92631e+01 1.00000e-09 7.00000e-02 
4.92631e+02 4.92631e+02 4.92631e+01 1.00000e-09 7.00000e-02 4.92631e+02 4.92631e+02 4.92631e+01 1.00000e-09 7.00000e-02 4.92631e+02 4.92631e+02 4.92631e+01 1.00000e-09 7.00000e-02 5.00000e-04 5.00000e-04 5.00000e-05 1.00000e-09 1.00000e-01 5.00000e-04 5.00000e-04 5.00000e-05 1.00000e-09 1.00000e-01 $1.96839 \mathrm{e}+01$ 1.96839e+01 1.96839e+00 1.00000e-09 2.12000e-01 $1.96839 \mathrm{e}+01$ 1.96839e+01 1.96839e+00 1.00000e-09 2.12000e-01 $1.96839 \mathrm{e}+01$ 1.96839e+01 1.96839e+00 1.00000e-09 2.12000e-01 $1.96839 \mathrm{e}+01$ 1.96839e+01 1.96839e+00 1.00000e-09 2.12000e-01 $1.96839 \mathrm{e}+01$ 1.96839e+01 1.96839e+00 1.00000e-09 2.12000e-01 $1.00000 \mathrm{e}-02$ 1.00000e-02 1.00000e-03 1.00000e-09 1.00000e-01 $1.00000 \mathrm{e}+001.00000 \mathrm{e}+001.00000 \mathrm{e}-011.00000 \mathrm{e}-091.00000 \mathrm{e}-01$ $1.00000 \mathrm{e}-05$ 1.00000e-05 1.00000e-06 1.00000e-09 1.00000e-01 $1.00000 \mathrm{e}+001.00000 \mathrm{e}+001.00000 \mathrm{e}-011.00000 \mathrm{e}-09$ 1.00000e-01 Element: 2687 \# of layers: 15

$\mathrm{Kx} \mathrm{Ky} \mathrm{Kz}$ Ss Por

4.68682e+02 4.68682e+02 4.68682e+01 1.00000e-09 7.00000e-02 4.68682e+02 4.68682e+02 4.68682e+01 1.00000e-09 7.00000e-02 4.68682e+02 4.68682e+02 4.68682e+01 1.00000e-09 7.00000e-02 4.68682e+02 4.68682e+02 4.68682e+01 1.00000e-09 7.00000e-02 5.00000e-04 5.00000e-04 5.00000e-05 1.00000e-09 1.00000e-01 5.00000e-04 5.00000e-04 5.00000e-05 1.00000e-09 1.00000e-01 $1.87269 \mathrm{e}+01$ 1.87269e+01 1.87269e+00 1.00000e-09 2.12000e-01 $1.87269 \mathrm{e}+011.87269 \mathrm{e}+01 \quad 1.87269 \mathrm{e}+001.00000 \mathrm{e}-092.12000 \mathrm{e}-01$ $1.87269 \mathrm{e}+011.87269 \mathrm{e}+011.87269 \mathrm{e}+001.00000 \mathrm{e}-092.12000 \mathrm{e}-01$ $1.87269 \mathrm{e}+011.87269 \mathrm{e}+011.87269 \mathrm{e}+001.00000 \mathrm{e}-092.12000 \mathrm{e}-01$ $1.87269 \mathrm{e}+01$ 1.87269e+01 1.87269e+00 1.00000e-09 2.12000e-01 1.00000e-02 1.00000e-02 1.00000e-03 1.00000e-09 1.00000e-01 $1.00000 \mathrm{e}+001.00000 \mathrm{e}+001.00000 \mathrm{e}-011.00000 \mathrm{e}-091.00000 \mathrm{e}-01$ $1.00000 \mathrm{e}-05$ 1.00000e-05 1.00000e-06 1.00000e-09 1.00000e-01 $1.00000 \mathrm{e}+001.00000 \mathrm{e}+001.00000 \mathrm{e}-011.00000 \mathrm{e}-091.00000 \mathrm{e}-01$ Element: 2688 \# of layers: 15

$\mathrm{Kx} \mathrm{Ky} \mathrm{Kz}$ Ss Por 4.68682e+02 4.68682e+02 4.68682e+01 1.00000e-09 7.00000e-02 $4.68682 \mathrm{e}+02$ 4.68682e+02 4.68682e+01 1.00000e-09 7.00000e-02 $4.68682 \mathrm{e}+02$ 4.68682e+02 4.68682e+01 1.00000e-09 7.00000e-02 $4.68682 \mathrm{e}+02$ 4.68682e+02 4.68682e+01 1.00000e-09 7.00000e-02 5.00000e-04 5.00000e-04 5.00000e-05 1.00000e-09 1.00000e-01 5.00000e-04 5.00000e-04 5.00000e-05 1.00000e-09 1.00000e-01 $1.87269 \mathrm{e}+01$ 1.87269e+01 1.87269e+00 1.00000e-09 2.12000e-01 $1.87269 \mathrm{e}+01$ 1.87269e+01 1.87269e+00 1.00000e-09 2.12000e-01 $1.87269 \mathrm{e}+01$ 1.87269e+01 1.87269e+00 1.00000e-09 2.12000e-01 $1.87269 \mathrm{e}+01$ 1.87269e+01 1.87269e+00 1.00000e-09 2.12000e-01 $1.87269 \mathrm{e}+01$ 1.87269e+01 1.87269e+00 1.00000e-09 2.12000e-01 $1.00000 \mathrm{e}-02$ 1.00000e-02 1.00000e-03 1.00000e-09 1.00000e-01 $1.00000 \mathrm{e}+001.00000 \mathrm{e}+001.00000 \mathrm{e}-011.00000 \mathrm{e}-091.00000 \mathrm{e}-01$ 
$1.00000 \mathrm{e}-05$ 1.00000e-05 1.00000e-06 1.00000e-09 1.00000e-01 $1.00000 \mathrm{e}+001.00000 \mathrm{e}+001.00000 \mathrm{e}-01$ 1.00000e-09 1.00000e-01 Element: 2689 \# of layers: 15

Kx Ky Kz Ss Por

4.68682e+02 4.68682e+02 4.68682e+01 1.00000e-09 7.00000e-02 4.68682e+02 4.68682e+02 4.68682e+01 1.00000e-09 7.00000e-02 $4.68682 \mathrm{e}+02$ 4.68682e+02 4.68682e+01 1.00000e-09 7.00000e-02 $4.68682 \mathrm{e}+02$ 4.68682e+02 4.68682e+01 1.00000e-09 7.00000e-02 5.00000e-04 5.00000e-04 5.00000e-05 1.00000e-09 1.00000e-01 5.00000e-04 5.00000e-04 5.00000e-05 1.00000e-09 1.00000e-01 $1.87269 \mathrm{e}+01$ 1.87269e+01 1.87269e+00 1.00000e-09 2.12000e-01 $1.87269 \mathrm{e}+011.87269 \mathrm{e}+011.87269 \mathrm{e}+001.00000 \mathrm{e}-092.12000 \mathrm{e}-01$ $1.87269 \mathrm{e}+01$ 1.87269e+01 1.87269e+00 1.00000e-09 2.12000e-01 $1.87269 \mathrm{e}+01$ 1.87269e+01 1.87269e+00 1.00000e-09 2.12000e-01 $1.87269 \mathrm{e}+01$ 1.87269e+01 1.87269e+00 1.00000e-09 2.12000e-01 $1.00000 \mathrm{e}-02$ 1.00000e-02 1.00000e-03 1.00000e-09 1.00000e-01 $1.00000 \mathrm{e}+001.00000 \mathrm{e}+001.00000 \mathrm{e}-011.00000 \mathrm{e}-091.00000 \mathrm{e}-01$ $1.00000 \mathrm{e}-05$ 1.00000e-05 1.00000e-06 1.00000e-09 1.00000e-01 $1.00000 \mathrm{e}+001.00000 \mathrm{e}+001.00000 \mathrm{e}-011.00000 \mathrm{e}-091.00000 \mathrm{e}-01$ Element: 2690 \# of layers: 15

$\mathrm{Kx} \mathrm{Ky} \mathrm{Kz}$ Ss Por

4.96451e+02 4.96451e+02 4.96451e+01 1.00000e-09 7.00000e-02 4.96451e+02 4.96451e+02 4.96451e+01 1.00000e-09 7.00000e-02 4.96451e+02 4.96451e+02 4.96451e+01 1.00000e-09 7.00000e-02 $4.96451 \mathrm{e}+02$ 4.96451e+02 4.96451e+01 1.00000e-09 7.00000e-02 5.00000e-04 5.00000e-04 5.00000e-05 1.00000e-09 1.00000e-01 5.00000e-04 5.00000e-04 5.00000e-05 1.00000e-09 1.00000e-01 $1.98362 \mathrm{e}+01$ 1.98362e+01 1.98362e+00 1.00000e-09 2.12000e-01 $1.98362 \mathrm{e}+01$ 1.98362e+01 1.98362e+00 1.00000e-09 2.12000e-01 $1.98362 \mathrm{e}+01$ 1.98362e+01 1.98362e+00 1.00000e-09 2.12000e-01 $1.98362 \mathrm{e}+011.98362 \mathrm{e}+011.98362 \mathrm{e}+001.00000 \mathrm{e}-092.12000 \mathrm{e}-01$ $1.98362 \mathrm{e}+01$ 1.98362e+01 1.98362e+00 1.00000e-09 2.12000e-01 $1.00000 \mathrm{e}-02$ 1.00000e-02 1.00000e-03 1.00000e-09 1.00000e-01 $1.00000 \mathrm{e}+001.00000 \mathrm{e}+001.00000 \mathrm{e}-011.00000 \mathrm{e}-091.00000 \mathrm{e}-01$ $1.00000 \mathrm{e}-05$ 1.00000e-05 1.00000e-06 1.00000e-09 1.00000e-01 $1.00000 \mathrm{e}+001.00000 \mathrm{e}+001.00000 \mathrm{e}-011.00000 \mathrm{e}-091.00000 \mathrm{e}-01$ Element: 2691 \# of layers: 15

$\mathrm{Kx} \mathrm{Ky} \mathrm{Kz}$ Ss Por

4.96451e+02 4.96451e+02 4.96451e+01 1.00000e-09 7.00000e-02 4.96451e+02 4.96451e+02 4.96451e+01 1.00000e-09 7.00000e-02 4.96451e+02 4.96451e+02 4.96451e+01 1.00000e-09 7.00000e-02 $4.96451 \mathrm{e}+02$ 4.96451e+02 4.96451e+01 1.00000e-09 7.00000e-02 5.00000e-04 5.00000e-04 5.00000e-05 1.00000e-09 1.00000e-01 5.00000e-04 5.00000e-04 5.00000e-05 1.00000e-09 1.00000e-01 $1.98362 \mathrm{e}+011.98362 \mathrm{e}+011.98362 \mathrm{e}+001.00000 \mathrm{e}-092.12000 \mathrm{e}-01$ $1.98362 \mathrm{e}+011.98362 \mathrm{e}+011.98362 \mathrm{e}+001.00000 \mathrm{e}-092.12000 \mathrm{e}-01$ 
$1.98362 \mathrm{e}+01$ 1.98362e+01 1.98362e+00 1.00000e-09 2.12000e-01 $1.98362 \mathrm{e}+01$ 1.98362e+01 1.98362e+00 1.00000e-09 2.12000e-01 $1.98362 \mathrm{e}+011.98362 \mathrm{e}+01$ 1.98362e+00 1.00000e-09 2.12000e-01 $1.00000 \mathrm{e}-02$ 1.00000e-02 1.00000e-03 1.00000e-09 1.00000e-01 $1.00000 \mathrm{e}+001.00000 \mathrm{e}+001.00000 \mathrm{e}-011.00000 \mathrm{e}-091.00000 \mathrm{e}-01$ $1.00000 \mathrm{e}-05$ 1.00000e-05 1.00000e-06 1.00000e-09 1.00000e-01 $1.00000 \mathrm{e}+001.00000 \mathrm{e}+001.00000 \mathrm{e}-01$ 1.00000e-09 1.00000e-01 Element: 2692 \# of layers: 15

$\mathrm{Kx} \mathrm{Ky} \mathrm{Kz}$ Ss Por

4.92856e+02 4.92856e+02 4.92856e+01 1.00000e-09 7.00000e-02 4.92856e+02 4.92856e+02 4.92856e+01 1.00000e-09 7.00000e-02 $4.92856 \mathrm{e}+02$ 4.92856e+02 4.92856e+01 1.00000e-09 7.00000e-02 $4.92856 \mathrm{e}+02$ 4.92856e+02 4.92856e+01 1.00000e-09 7.00000e-02 5.00000e-04 5.00000e-04 5.00000e-05 1.00000e-09 1.00000e-01 5.00000e-04 5.00000e-04 5.00000e-05 1.00000e-09 1.00000e-01 $1.96929 \mathrm{e}+011.96929 \mathrm{e}+011.96929 \mathrm{e}+001.00000 \mathrm{e}-092.12000 \mathrm{e}-01$ $1.96929 \mathrm{e}+01$ 1.96929e+01 1.96929e+00 1.00000e-09 2.12000e-01 $1.96929 \mathrm{e}+01$ 1.96929e+01 1.96929e+00 1.00000e-09 2.12000e-01 $1.96929 \mathrm{e}+01$ 1.96929e+01 1.96929e+00 1.00000e-09 2.12000e-01 $1.96929 \mathrm{e}+01$ 1.96929e+01 1.96929e+00 1.00000e-09 2.12000e-01 $1.00000 \mathrm{e}-02$ 1.00000e-02 1.00000e-03 1.00000e-09 1.00000e-01 $1.00000 \mathrm{e}+001.00000 \mathrm{e}+001.00000 \mathrm{e}-011.00000 \mathrm{e}-091.00000 \mathrm{e}-01$ $1.00000 \mathrm{e}-05$ 1.00000e-05 1.00000e-06 1.00000e-09 1.00000e-01 $1.00000 \mathrm{e}+001.00000 \mathrm{e}+001.00000 \mathrm{e}-011.00000 \mathrm{e}-09$ 1.00000e-01 Element: 2693 \# of layers: 16

$\mathrm{Kx} \mathrm{Ky} \mathrm{Kz}$ Ss Por

4.92631e+02 4.92631e+02 4.92631e+01 1.00000e-09 7.00000e-02 4.92631e+02 4.92631e+02 4.92631e+01 1.00000e-09 7.00000e-02 $4.92631 \mathrm{e}+02$ 4.92631e+02 4.92631e+01 1.00000e-09 7.00000e-02 4.92631e+02 4.92631e+02 4.92631e+01 1.00000e-09 7.00000e-02 4.92631e+02 4.92631e+02 4.92631e+01 1.00000e-09 7.00000e-02 5.00000e-04 5.00000e-04 5.00000e-05 1.00000e-09 1.00000e-01 5.00000e-04 5.00000e-04 5.00000e-05 1.00000e-09 1.00000e-01 $1.96839 \mathrm{e}+011.96839 \mathrm{e}+01$ 1.96839e+00 1.00000e-09 2.12000e-01 $1.96839 \mathrm{e}+01$ 1.96839e+01 1.96839e+00 1.00000e-09 2.12000e-01 $1.96839 \mathrm{e}+01$ 1.96839e+01 1.96839e+00 1.00000e-09 2.12000e-01 $1.96839 \mathrm{e}+011.96839 \mathrm{e}+011.96839 \mathrm{e}+001.00000 \mathrm{e}-092.12000 \mathrm{e}-01$ $1.96839 \mathrm{e}+01$ 1.96839e+01 1.96839e+00 1.00000e-09 2.12000e-01 $1.00000 \mathrm{e}-02$ 1.00000e-02 1.00000e-03 1.00000e-09 1.00000e-01 $1.00000 \mathrm{e}+001.00000 \mathrm{e}+001.00000 \mathrm{e}-011.00000 \mathrm{e}-091.00000 \mathrm{e}-01$ $1.00000 \mathrm{e}-05$ 1.00000e-05 1.00000e-06 1.00000e-09 1.00000e-01 $1.00000 \mathrm{e}+001.00000 \mathrm{e}+001.00000 \mathrm{e}-011.00000 \mathrm{e}-091.00000 \mathrm{e}-01$ Element: 2694 \# of layers: 15

$\mathrm{Kx} \mathrm{Ky} \mathrm{Kz}$ Ss Por 4.68682e+02 4.68682e+02 4.68682e+01 1.00000e-09 7.00000e-02 $4.68682 \mathrm{e}+02$ 4.68682e+02 4.68682e+01 1.00000e-09 7.00000e-02 
4.68682e+02 4.68682e+02 4.68682e+01 1.00000e-09 7.00000e-02 $4.68682 \mathrm{e}+02$ 4.68682e+02 4.68682e+01 1.00000e-09 7.00000e-02 5.00000e-04 5.00000e-04 5.00000e-05 1.00000e-09 1.00000e-01 5.00000e-04 5.00000e-04 5.00000e-05 1.00000e-09 1.00000e-01 $1.87269 \mathrm{e}+011.87269 \mathrm{e}+01$ 1.87269e+00 1.00000e-09 2.12000e-01 $1.87269 \mathrm{e}+01$ 1.87269e+01 1.87269e+00 1.00000e-09 2.12000e-01 $1.87269 \mathrm{e}+011.87269 \mathrm{e}+011.87269 \mathrm{e}+001.00000 \mathrm{e}-092.12000 \mathrm{e}-01$ $1.87269 \mathrm{e}+011.87269 \mathrm{e}+011.87269 \mathrm{e}+001.00000 \mathrm{e}-092.12000 \mathrm{e}-01$ $1.87269 \mathrm{e}+011.87269 \mathrm{e}+01$ 1.87269e+00 1.00000e-09 2.12000e-01 $1.00000 \mathrm{e}-02$ 1.00000e-02 1.00000e-03 1.00000e-09 1.00000e-01 $1.00000 \mathrm{e}+001.00000 \mathrm{e}+001.00000 \mathrm{e}-011.00000 \mathrm{e}-091.00000 \mathrm{e}-01$ $1.00000 \mathrm{e}-05$ 1.00000e-05 1.00000e-06 1.00000e-09 1.00000e-01 $1.00000 \mathrm{e}+001.00000 \mathrm{e}+001.00000 \mathrm{e}-011.00000 \mathrm{e}-09$ 1.00000e-01 Element: 2695 \# of layers: 15

$\mathrm{Kx} \mathrm{Ky} \mathrm{Kz}$ Ss Por

$3.68140 \mathrm{e}+02$ 3.68140e+02 3.68140e+01 1.00000e-09 7.00000e-02 $3.68140 \mathrm{e}+023.68140 \mathrm{e}+023.68140 \mathrm{e}+01$ 1.00000e-09 7.00000e-02 $3.68140 \mathrm{e}+023.68140 \mathrm{e}+023.68140 \mathrm{e}+01$ 1.00000e-09 7.00000e-02 $3.68140 \mathrm{e}+023.68140 \mathrm{e}+023.68140 \mathrm{e}+01$ 1.00000e-09 7.00000e-02 5.00000e-04 5.00000e-04 5.00000e-05 1.00000e-09 1.00000e-01 5.00000e-04 5.00000e-04 5.00000e-05 1.00000e-09 1.00000e-01 $1.47097 \mathrm{e}+01$ 1.47097e+01 1.47097e+00 1.00000e-09 2.12000e-01 1.47097e+01 1.47097e+01 1.47097e+00 1.00000e-09 2.12000e-01 $1.47097 \mathrm{e}+01$ 1.47097e+01 1.47097e+00 1.00000e-09 2.12000e-01 $1.47097 \mathrm{e}+01$ 1.47097e+01 1.47097e+00 1.00000e-09 2.12000e-01 $1.47097 \mathrm{e}+01$ 1.47097e+01 1.47097e+00 1.00000e-09 2.12000e-01 $1.00000 \mathrm{e}-02$ 1.00000e-02 1.00000e-03 1.00000e-09 1.00000e-01 $1.00000 \mathrm{e}+001.00000 \mathrm{e}+001.00000 \mathrm{e}-011.00000 \mathrm{e}-091.00000 \mathrm{e}-01$ $1.00000 \mathrm{e}-05$ 1.00000e-05 1.00000e-06 1.00000e-09 1.00000e-01 $1.00000 \mathrm{e}+001.00000 \mathrm{e}+001.00000 \mathrm{e}-011.00000 \mathrm{e}-091.00000 \mathrm{e}-01$ Element: 2696 \# of layers: 15

$\mathrm{Kx} \mathrm{Ky} \mathrm{Kz}$ Ss Por

$2.88518 \mathrm{e}+02$ 2.88518e+02 2.88518e+01 1.00000e-09 7.00000e-02 $2.88518 \mathrm{e}+02$ 2.88518e+02 2.88518e+01 1.00000e-09 7.00000e-02

$2.88518 \mathrm{e}+022.88518 \mathrm{e}+022.88518 \mathrm{e}+01$ 1.00000e-09 7.00000e-02

$2.88518 \mathrm{e}+022.88518 \mathrm{e}+022.88518 \mathrm{e}+01$ 1.00000e-09 7.00000e-02 5.00000e-04 5.00000e-04 5.00000e-05 1.00000e-09 1.00000e-01 5.00000e-04 5.00000e-04 5.00000e-05 1.00000e-09 1.00000e-01 $1.15281 \mathrm{e}+011.15281 \mathrm{e}+011.15281 \mathrm{e}+001.00000 \mathrm{e}-092.12000 \mathrm{e}-01$ $1.15281 \mathrm{e}+011.15281 \mathrm{e}+011.15281 \mathrm{e}+001.00000 \mathrm{e}-092.12000 \mathrm{e}-01$ $1.15281 \mathrm{e}+011.15281 \mathrm{e}+011.15281 \mathrm{e}+001.00000 \mathrm{e}-092.12000 \mathrm{e}-01$ $1.15281 \mathrm{e}+011.15281 \mathrm{e}+011.15281 \mathrm{e}+001.00000 \mathrm{e}-092.12000 \mathrm{e}-01$ $1.15281 \mathrm{e}+011.15281 \mathrm{e}+01$ 1.15281e+00 1.00000e-09 2.12000e-01 $1.00000 \mathrm{e}-02$ 1.00000e-02 1.00000e-03 1.00000e-09 1.00000e-01 $1.00000 \mathrm{e}+001.00000 \mathrm{e}+001.00000 \mathrm{e}-011.00000 \mathrm{e}-091.00000 \mathrm{e}-01$ $1.00000 \mathrm{e}-05$ 1.00000e-05 1.00000e-06 1.00000e-09 1.00000e-01 
$1.00000 \mathrm{e}+001.00000 \mathrm{e}+00$ 1.00000e-01 1.00000e-09 1.00000e-01

Element: 2697 \# of layers: 15

$\mathrm{Kx} \mathrm{Ky} \mathrm{Kz}$ Ss Por

$2.88518 \mathrm{e}+02$ 2.88518e+02 2.88518e+01 1.00000e-09 7.00000e-02

$2.88518 \mathrm{e}+022.88518 \mathrm{e}+022.88518 \mathrm{e}+01$ 1.00000e-09 7.00000e-02

$2.88518 \mathrm{e}+022.88518 \mathrm{e}+02$ 2.88518e+01 1.00000e-09 7.00000e-02

$2.88518 \mathrm{e}+022.88518 \mathrm{e}+02$ 2.88518e+01 1.00000e-09 7.00000e-02

5.00000e-04 5.00000e-04 5.00000e-05 1.00000e-09 1.00000e-01

5.00000e-04 5.00000e-04 5.00000e-05 1.00000e-09 1.00000e-01

$1.15281 \mathrm{e}+011.15281 \mathrm{e}+011.15281 \mathrm{e}+001.00000 \mathrm{e}-092.12000 \mathrm{e}-01$

$1.15281 \mathrm{e}+011.15281 \mathrm{e}+01$ 1.15281e+00 1.00000e-09 2.12000e-01

$1.15281 \mathrm{e}+011.15281 \mathrm{e}+011.15281 \mathrm{e}+001.00000 \mathrm{e}-092.12000 \mathrm{e}-01$

$1.15281 \mathrm{e}+011.15281 \mathrm{e}+011.15281 \mathrm{e}+001.00000 \mathrm{e}-092.12000 \mathrm{e}-01$

$1.15281 \mathrm{e}+011.15281 \mathrm{e}+011.15281 \mathrm{e}+001.00000 \mathrm{e}-092.12000 \mathrm{e}-01$

$1.00000 \mathrm{e}-02$ 1.00000e-02 1.00000e-03 1.00000e-09 1.00000e-01

$1.00000 \mathrm{e}+001.00000 \mathrm{e}+001.00000 \mathrm{e}-011.00000 \mathrm{e}-091.00000 \mathrm{e}-01$

$1.00000 \mathrm{e}-05$ 1.00000e-05 1.00000e-06 1.00000e-09 1.00000e-01

$1.00000 \mathrm{e}+001.00000 \mathrm{e}+001.00000 \mathrm{e}-01$ 1.00000e-09 1.00000e-01

Element: 2698 \# of layers: 15

$\mathrm{Kx} \mathrm{Ky} \mathrm{Kz}$ Ss Por

$2.88518 \mathrm{e}+02$ 2.88518e+02 2.88518e+01 1.00000e-09 7.00000e-02

$2.88518 \mathrm{e}+02$ 2.88518e+02 2.88518e+01 1.00000e-09 7.00000e-02

$2.88518 \mathrm{e}+02$ 2.88518e+02 2.88518e+01 1.00000e-09 7.00000e-02

$2.88518 \mathrm{e}+02$ 2.88518e+02 2.88518e+01 1.00000e-09 7.00000e-02

5.00000e-04 5.00000e-04 5.00000e-05 1.00000e-09 1.00000e-01

5.00000e-04 5.00000e-04 5.00000e-05 1.00000e-09 1.00000e-01

$1.15281 \mathrm{e}+011.15281 \mathrm{e}+011.15281 \mathrm{e}+001.00000 \mathrm{e}-092.12000 \mathrm{e}-01$

$1.15281 \mathrm{e}+011.15281 \mathrm{e}+011.15281 \mathrm{e}+001.00000 \mathrm{e}-092.12000 \mathrm{e}-01$

$1.15281 \mathrm{e}+011.15281 \mathrm{e}+011.15281 \mathrm{e}+001.00000 \mathrm{e}-092.12000 \mathrm{e}-01$

$1.15281 \mathrm{e}+011.15281 \mathrm{e}+011.15281 \mathrm{e}+001.00000 \mathrm{e}-092.12000 \mathrm{e}-01$

$1.15281 \mathrm{e}+011.15281 \mathrm{e}+011.15281 \mathrm{e}+001.00000 \mathrm{e}-092.12000 \mathrm{e}-01$

$1.00000 \mathrm{e}-02$ 1.00000e-02 1.00000e-03 1.00000e-09 1.00000e-01

$1.00000 \mathrm{e}+001.00000 \mathrm{e}+001.00000 \mathrm{e}-011.00000 \mathrm{e}-091.00000 \mathrm{e}-01$

$1.00000 \mathrm{e}-05$ 1.00000e-05 1.00000e-06 1.00000e-09 1.00000e-01

$1.00000 \mathrm{e}+001.00000 \mathrm{e}+001.00000 \mathrm{e}-011.00000 \mathrm{e}-091.00000 \mathrm{e}-01$

Element: 2699 \# of layers: 15

$\mathrm{Kx} \mathrm{Ky} \mathrm{Kz}$ Ss Por

4.45202e+02 4.45202e+02 4.45202e+01 1.00000e-09 7.00000e-02

4.45202e+02 4.45202e+02 4.45202e+01 1.00000e-09 7.00000e-02

4.45202e+02 4.45202e+02 4.45202e+01 1.00000e-09 7.00000e-02

4.45202e+02 4.45202e+02 4.45202e+01 1.00000e-09 7.00000e-02

5.00000e-04 5.00000e-04 5.00000e-05 1.00000e-09 1.00000e-01

5.00000e-04 5.00000e-04 5.00000e-05 1.00000e-09 1.00000e-01

$1.77889 \mathrm{e}+01$ 1.77889e+01 1.77889e+00 1.00000e-09 2.12000e-01

$1.77889 \mathrm{e}+01$ 1.77889e+01 1.77889e+00 1.00000e-09 2.12000e-01

$1.77889 e+011.77889 e+011.77889 e+001.00000 e-092.12000 e-01$ 
$1.77889 \mathrm{e}+01$ 1.77889e+01 1.77889e+00 1.00000e-09 2.12000e-01 $1.77889 \mathrm{e}+01$ 1.77889e+01 1.77889e+00 1.00000e-09 2.12000e-01 $1.00000 \mathrm{e}-02$ 1.00000e-02 1.00000e-03 1.00000e-09 1.00000e-01 $1.00000 \mathrm{e}+001.00000 \mathrm{e}+001.00000 \mathrm{e}-011.00000 \mathrm{e}-091.00000 \mathrm{e}-01$ $1.00000 \mathrm{e}-05$ 1.00000e-05 1.00000e-06 1.00000e-09 1.00000e-01 $1.00000 \mathrm{e}+001.00000 \mathrm{e}+001.00000 \mathrm{e}-011.00000 \mathrm{e}-091.00000 \mathrm{e}-01$ Element: 2700 \# of layers: 15

$\mathrm{Kx} \mathrm{Ky} \mathrm{Kz}$ Ss Por

4.45202e+02 4.45202e+02 4.45202e+01 1.00000e-09 7.00000e-02 4.45202e+02 4.45202e+02 4.45202e+01 1.00000e-09 7.00000e-02 4.45202e+02 4.45202e+02 4.45202e+01 1.00000e-09 7.00000e-02 $4.45202 \mathrm{e}+02$ 4.45202e+02 4.45202e+01 1.00000e-09 7.00000e-02 5.00000e-04 5.00000e-04 5.00000e-05 1.00000e-09 1.00000e-01 5.00000e-04 5.00000e-04 5.00000e-05 1.00000e-09 1.00000e-01 $1.77889 \mathrm{e}+01$ 1.77889e+01 1.77889e+00 1.00000e-09 2.12000e-01 $1.77889 \mathrm{e}+011.77889 \mathrm{e}+011.77889 \mathrm{e}+001.00000 \mathrm{e}-092.12000 \mathrm{e}-01$ $1.77889 \mathrm{e}+01$ 1.77889e+01 1.77889e+00 1.00000e-09 2.12000e-01 $1.77889 \mathrm{e}+011.77889 \mathrm{e}+01$ 1.77889e+00 1.00000e-09 2.12000e-01 $1.77889 \mathrm{e}+01$ 1.77889e+01 1.77889e+00 1.00000e-09 2.12000e-01 $1.00000 \mathrm{e}-02$ 1.00000e-02 1.00000e-03 1.00000e-09 1.00000e-01 $1.00000 \mathrm{e}+001.00000 \mathrm{e}+001.00000 \mathrm{e}-011.00000 \mathrm{e}-091.00000 \mathrm{e}-01$ $1.00000 \mathrm{e}-05$ 1.00000e-05 1.00000e-06 1.00000e-09 1.00000e-01 $1.00000 \mathrm{e}+001.00000 \mathrm{e}+001.00000 \mathrm{e}-01$ 1.00000e-09 1.00000e-01 Element: 2701 \# of layers: 15

Kx Ky Kz Ss Por 4.87090e+02 4.87090e+02 4.87090e+01 1.00000e-09 7.00000e-02 $4.87090 \mathrm{e}+02$ 4.87090e+02 4.87090e+01 1.00000e-09 7.00000e-02 4.87090e+02 4.87090e+02 4.87090e+01 1.00000e-09 7.00000e-02 $4.87090 \mathrm{e}+02$ 4.87090e+02 4.87090e+01 1.00000e-09 7.00000e-02 5.00000e-04 5.00000e-04 5.00000e-05 1.00000e-09 1.00000e-01 5.00000e-04 5.00000e-04 5.00000e-05 1.00000e-09 1.00000e-01 $1.94625 \mathrm{e}+011.94625 \mathrm{e}+011.94625 \mathrm{e}+00$ 1.00000e-09 2.12000e-01 $1.94625 \mathrm{e}+011.94625 \mathrm{e}+011.94625 \mathrm{e}+001.00000 \mathrm{e}-092.12000 \mathrm{e}-01$ $1.94625 \mathrm{e}+011.94625 \mathrm{e}+01$ 1.94625e+00 1.00000e-09 2.12000e-01 $1.94625 \mathrm{e}+011.94625 \mathrm{e}+011.94625 \mathrm{e}+001.00000 \mathrm{e}-092.12000 \mathrm{e}-01$ $1.94625 \mathrm{e}+011.94625 \mathrm{e}+01$ 1.94625e+00 1.00000e-09 2.12000e-01 1.00000e-02 1.00000e-02 1.00000e-03 1.00000e-09 1.00000e-01 $1.00000 \mathrm{e}+001.00000 \mathrm{e}+001.00000 \mathrm{e}-011.00000 \mathrm{e}-091.00000 \mathrm{e}-01$ $1.00000 \mathrm{e}-05$ 1.00000e-05 1.00000e-06 1.00000e-09 1.00000e-01 $1.00000 \mathrm{e}+001.00000 \mathrm{e}+001.00000 \mathrm{e}-01$ 1.00000e-09 1.00000e-01 Element: 2702 \# of layers: 15

$\mathrm{Kx} \mathrm{Ky} \mathrm{Kz}$ Ss Por

3.68140e+02 3.68140e+02 3.68140e+01 1.00000e-09 7.00000e-02 $3.68140 \mathrm{e}+023.68140 \mathrm{e}+023.68140 \mathrm{e}+01$ 1.00000e-09 7.00000e-02 $3.68140 \mathrm{e}+023.68140 \mathrm{e}+02$ 3.68140e+01 1.00000e-09 7.00000e-02 $3.68140 \mathrm{e}+02$ 3.68140e+02 3.68140e+01 1.00000e-09 7.00000e-02 
5.00000e-04 5.00000e-04 5.00000e-05 1.00000e-09 1.00000e-01 5.00000e-04 5.00000e-04 5.00000e-05 1.00000e-09 1.00000e-01 $1.47097 \mathrm{e}+01$ 1.47097e+01 1.47097e+00 1.00000e-09 2.12000e-01 $1.47097 \mathrm{e}+01$ 1.47097e+01 1.47097e+00 1.00000e-09 2.12000e-01 $1.47097 \mathrm{e}+01$ 1.47097e+01 1.47097e+00 1.00000e-09 2.12000e-01 $1.47097 \mathrm{e}+01$ 1.47097e+01 1.47097e+00 1.00000e-09 2.12000e-01 $1.47097 \mathrm{e}+01$ 1.47097e+01 1.47097e+00 1.00000e-09 2.12000e-01 $1.00000 \mathrm{e}-02$ 1.00000e-02 1.00000e-03 1.00000e-09 1.00000e-01 $1.00000 \mathrm{e}+001.00000 \mathrm{e}+001.00000 \mathrm{e}-01$ 1.00000e-09 1.00000e-01 $1.00000 \mathrm{e}-05$ 1.00000e-05 1.00000e-06 1.00000e-09 1.00000e-01 $1.00000 \mathrm{e}+001.00000 \mathrm{e}+001.00000 \mathrm{e}-011.00000 \mathrm{e}-091.00000 \mathrm{e}-01$ Element: 2703 \# of layers: 15

$\mathrm{Kx} \mathrm{Ky} \mathrm{Kz}$ Ss Por

$2.88518 \mathrm{e}+02$ 2.88518e+02 2.88518e+01 1.00000e-09 7.00000e-02 $2.88518 \mathrm{e}+02$ 2.88518e+02 2.88518e+01 1.00000e-09 7.00000e-02 $2.88518 \mathrm{e}+022.88518 \mathrm{e}+022.88518 \mathrm{e}+01$ 1.00000e-09 7.00000e-02 $2.88518 \mathrm{e}+022.88518 \mathrm{e}+022.88518 \mathrm{e}+01$ 1.00000e-09 7.00000e-02 5.00000e-04 5.00000e-04 5.00000e-05 1.00000e-09 1.00000e-01 5.00000e-04 5.00000e-04 5.00000e-05 1.00000e-09 1.00000e-01 $1.15281 \mathrm{e}+011.15281 \mathrm{e}+011.15281 \mathrm{e}+001.00000 \mathrm{e}-092.12000 \mathrm{e}-01$ $1.15281 \mathrm{e}+011.15281 \mathrm{e}+011.15281 \mathrm{e}+001.00000 \mathrm{e}-092.12000 \mathrm{e}-01$ $1.15281 \mathrm{e}+011.15281 \mathrm{e}+011.15281 \mathrm{e}+001.00000 \mathrm{e}-092.12000 \mathrm{e}-01$ $1.15281 \mathrm{e}+011.15281 \mathrm{e}+01$ 1.15281e+00 1.00000e-09 2.12000e-01 $1.15281 \mathrm{e}+011.15281 \mathrm{e}+011.15281 \mathrm{e}+001.00000 \mathrm{e}-092.12000 \mathrm{e}-01$ $1.00000 \mathrm{e}-021.00000 \mathrm{e}-02$ 1.00000e-03 1.00000e-09 1.00000e-01 $1.00000 \mathrm{e}+001.00000 \mathrm{e}+001.00000 \mathrm{e}-011.00000 \mathrm{e}-091.00000 \mathrm{e}-01$ $1.00000 \mathrm{e}-05$ 1.00000e-05 1.00000e-06 1.00000e-09 1.00000e-01 $1.00000 \mathrm{e}+001.00000 \mathrm{e}+001.00000 \mathrm{e}-011.00000 \mathrm{e}-091.00000 \mathrm{e}-01$ Element: 2704 \# of layers: 16

$\mathrm{Kx} \mathrm{Ky} \mathrm{Kz}$ Ss Por

2.70733e+02 2.70733e+02 2.70733e+01 1.00000e-09 7.00000e-02 $2.70733 \mathrm{e}+02$ 2.70733e+02 2.70733e+01 1.00000e-09 7.00000e-02 $2.70733 \mathrm{e}+02$ 2.70733e+02 2.70733e+01 1.00000e-09 7.00000e-02 $2.70733 \mathrm{e}+02$ 2.70733e+02 2.70733e+01 1.00000e-09 7.00000e-02 $2.70733 \mathrm{e}+02$ 2.70733e+02 2.70733e+01 1.00000e-09 7.00000e-02 5.00000e-04 5.00000e-04 5.00000e-05 1.00000e-09 1.00000e-01 5.00000e-04 5.00000e-04 5.00000e-05 1.00000e-09 1.00000e-01 $1.08176 \mathrm{e}+011.08176 \mathrm{e}+011.08176 \mathrm{e}+001.00000 \mathrm{e}-092.12000 \mathrm{e}-01$ $1.08176 \mathrm{e}+011.08176 \mathrm{e}+011.08176 \mathrm{e}+001.00000 \mathrm{e}-092.12000 \mathrm{e}-01$ $1.08176 \mathrm{e}+011.08176 \mathrm{e}+011.08176 \mathrm{e}+001.00000 \mathrm{e}-092.12000 \mathrm{e}-01$ $1.08176 \mathrm{e}+011.08176 \mathrm{e}+011.08176 \mathrm{e}+001.00000 \mathrm{e}-092.12000 \mathrm{e}-01$ $1.08176 \mathrm{e}+011.08176 \mathrm{e}+011.08176 \mathrm{e}+001.00000 \mathrm{e}-092.12000 \mathrm{e}-01$ $1.00000 \mathrm{e}-021.00000 \mathrm{e}-021.00000 \mathrm{e}-031.00000 \mathrm{e}-091.00000 \mathrm{e}-01$ $1.00000 \mathrm{e}+001.00000 \mathrm{e}+001.00000 \mathrm{e}-011.00000 \mathrm{e}-091.00000 \mathrm{e}-01$ $1.00000 \mathrm{e}-05$ 1.00000e-05 1.00000e-06 1.00000e-09 1.00000e-01 $1.00000 \mathrm{e}+001.00000 \mathrm{e}+001.00000 \mathrm{e}-011.00000 \mathrm{e}-091.00000 \mathrm{e}-01$ 
Element: 2705 \# of layers: 16

$\mathrm{Kx} \mathrm{Ky} \mathrm{Kz}$ Ss Por

2.70733e+02 2.70733e+02 2.70733e+01 1.00000e-09 7.00000e-02

$2.70733 \mathrm{e}+02$ 2.70733e+02 2.70733e+01 1.00000e-09 7.00000e-02

$2.70733 \mathrm{e}+02$ 2.70733e+02 2.70733e+01 1.00000e-09 7.00000e-02

$2.70733 \mathrm{e}+02$ 2.70733e+02 2.70733e+01 1.00000e-09 7.00000e-02

$2.70733 \mathrm{e}+02$ 2.70733e+02 2.70733e+01 1.00000e-09 7.00000e-02

5.00000e-04 5.00000e-04 5.00000e-05 1.00000e-09 1.00000e-01

5.00000e-04 5.00000e-04 5.00000e-05 1.00000e-09 1.00000e-01

$1.08176 \mathrm{e}+011.08176 \mathrm{e}+011.08176 \mathrm{e}+001.00000 \mathrm{e}-092.12000 \mathrm{e}-01$

$1.08176 \mathrm{e}+011.08176 \mathrm{e}+011.08176 \mathrm{e}+001.00000 \mathrm{e}-092.12000 \mathrm{e}-01$

$1.08176 \mathrm{e}+011.08176 \mathrm{e}+011.08176 \mathrm{e}+001.00000 \mathrm{e}-092.12000 \mathrm{e}-01$

$1.08176 \mathrm{e}+011.08176 \mathrm{e}+011.08176 \mathrm{e}+001.00000 \mathrm{e}-092.12000 \mathrm{e}-01$

$1.08176 \mathrm{e}+011.08176 \mathrm{e}+011.08176 \mathrm{e}+001.00000 \mathrm{e}-092.12000 \mathrm{e}-01$

$1.00000 \mathrm{e}-02$ 1.00000e-02 1.00000e-03 1.00000e-09 1.00000e-01

$1.00000 \mathrm{e}+001.00000 \mathrm{e}+001.00000 \mathrm{e}-011.00000 \mathrm{e}-091.00000 \mathrm{e}-01$

$1.00000 \mathrm{e}-05$ 1.00000e-05 1.00000e-06 1.00000e-09 1.00000e-01

$1.00000 \mathrm{e}+001.00000 \mathrm{e}+001.00000 \mathrm{e}-01$ 1.00000e-09 1.00000e-01

Element: 2706 \# of layers: 15

$\mathrm{Kx} \mathrm{Ky} \mathrm{Kz}$ Ss Por

2.70733e+02 2.70733e+02 2.70733e+01 1.00000e-09 7.00000e-02

2.70733e+02 2.70733e+02 2.70733e+01 1.00000e-09 7.00000e-02

$2.70733 \mathrm{e}+02$ 2.70733e+02 2.70733e+01 1.00000e-09 7.00000e-02

2.70733e+02 2.70733e+02 2.70733e+01 1.00000e-09 7.00000e-02

$5.00000 \mathrm{e}-04$ 5.00000e-04 5.00000e-05 1.00000e-09 1.00000e-01

5.00000e-04 5.00000e-04 5.00000e-05 1.00000e-09 1.00000e-01

$1.08176 \mathrm{e}+011.08176 \mathrm{e}+011.08176 \mathrm{e}+001.00000 \mathrm{e}-092.12000 \mathrm{e}-01$

$1.08176 \mathrm{e}+011.08176 \mathrm{e}+011.08176 \mathrm{e}+001.00000 \mathrm{e}-092.12000 \mathrm{e}-01$

$1.08176 \mathrm{e}+011.08176 \mathrm{e}+011.08176 \mathrm{e}+001.00000 \mathrm{e}-092.12000 \mathrm{e}-01$

$1.08176 \mathrm{e}+011.08176 \mathrm{e}+011.08176 \mathrm{e}+001.00000 \mathrm{e}-092.12000 \mathrm{e}-01$

$1.08176 \mathrm{e}+011.08176 \mathrm{e}+011.08176 \mathrm{e}+001.00000 \mathrm{e}-092.12000 \mathrm{e}-01$

1.00000e-02 1.00000e-02 1.00000e-03 1.00000e-09 1.00000e-01

$1.00000 \mathrm{e}+001.00000 \mathrm{e}+001.00000 \mathrm{e}-011.00000 \mathrm{e}-091.00000 \mathrm{e}-01$

$1.00000 \mathrm{e}-05$ 1.00000e-05 1.00000e-06 1.00000e-09 1.00000e-01

$1.00000 \mathrm{e}+001.00000 \mathrm{e}+001.00000 \mathrm{e}-011.00000 \mathrm{e}-091.00000 \mathrm{e}-01$

Element: 2707 \# of layers: 15

Kx Ky Kz Ss Por

1.78921e+02 1.78921e+02 1.78921e+01 1.00000e-09 7.00000e-02

$1.78921 \mathrm{e}+021.78921 \mathrm{e}+02$ 1.78921e+01 1.00000e-09 7.00000e-02

$1.78921 \mathrm{e}+021.78921 \mathrm{e}+02$ 1.78921e+01 1.00000e-09 7.00000e-02

$1.78921 \mathrm{e}+021.78921 \mathrm{e}+021.78921 \mathrm{e}+01$ 1.00000e-09 7.00000e-02

5.00000e-04 5.00000e-04 5.00000e-05 1.00000e-09 1.00000e-01

5.00000e-04 5.00000e-04 5.00000e-05 1.00000e-09 1.00000e-01

7.14908e+00 7.14908e+00 7.14908e-01 1.00000e-09 2.12000e-01

7.14908e+00 7.14908e+00 7.14908e-01 1.00000e-09 2.12000e-01

$7.14908 \mathrm{e}+00$ 7.14908e+00 7.14908e-01 1.00000e-09 2.12000e-01 
$7.14908 \mathrm{e}+00$ 7.14908e+00 7.14908e-01 1.00000e-09 2.12000e-01 $7.14908 \mathrm{e}+00$ 7.14908e+00 7.14908e-01 1.00000e-09 2.12000e-01 $1.00000 \mathrm{e}-021.00000 \mathrm{e}-02$ 1.00000e-03 1.00000e-09 1.00000e-01 $1.00000 \mathrm{e}+001.00000 \mathrm{e}+001.00000 \mathrm{e}-011.00000 \mathrm{e}-091.00000 \mathrm{e}-01$ $1.00000 \mathrm{e}-05$ 1.00000e-05 1.00000e-06 1.00000e-09 1.00000e-01 $1.00000 \mathrm{e}+001.00000 \mathrm{e}+001.00000 \mathrm{e}-011.00000 \mathrm{e}-091.00000 \mathrm{e}-01$ Element: 2708 \# of layers: 15

Kx Ky Kz Ss Por

$1.78921 \mathrm{e}+021.78921 \mathrm{e}+021.78921 \mathrm{e}+01$ 1.00000e-09 7.00000e-02 $1.78921 \mathrm{e}+021.78921 \mathrm{e}+021.78921 \mathrm{e}+011.00000 \mathrm{e}-097.00000 \mathrm{e}-02$ $1.78921 \mathrm{e}+021.78921 \mathrm{e}+021.78921 \mathrm{e}+011.00000 \mathrm{e}-097.00000 \mathrm{e}-02$ $1.78921 \mathrm{e}+021.78921 \mathrm{e}+021.78921 \mathrm{e}+011.00000 \mathrm{e}-097.00000 \mathrm{e}-02$ 5.00000e-04 5.00000e-04 5.00000e-05 1.00000e-09 1.00000e-01 5.00000e-04 5.00000e-04 5.00000e-05 1.00000e-09 1.00000e-01 $7.14908 \mathrm{e}+007.14908 \mathrm{e}+00$ 7.14908e-01 1.00000e-09 2.12000e-01 $7.14908 \mathrm{e}+007.14908 \mathrm{e}+00$ 7.14908e-01 1.00000e-09 2.12000e-01 $7.14908 \mathrm{e}+007.14908 \mathrm{e}+007.14908 \mathrm{e}-011.00000 \mathrm{e}-092.12000 \mathrm{e}-01$ $7.14908 \mathrm{e}+007.14908 \mathrm{e}+00$ 7.14908e-01 1.00000e-09 2.12000e-01 $7.14908 \mathrm{e}+00$ 7.14908e+00 7.14908e-01 1.00000e-09 2.12000e-01 $1.00000 \mathrm{e}-021.00000 \mathrm{e}-02$ 1.00000e-03 1.00000e-09 1.00000e-01 $1.00000 \mathrm{e}+001.00000 \mathrm{e}+001.00000 \mathrm{e}-011.00000 \mathrm{e}-091.00000 \mathrm{e}-01$ $1.00000 \mathrm{e}-05$ 1.00000e-05 1.00000e-06 1.00000e-09 1.00000e-01 $1.00000 \mathrm{e}+001.00000 \mathrm{e}+001.00000 \mathrm{e}-011.00000 \mathrm{e}-091.00000 \mathrm{e}-01$ Element: 2709 \# of layers: 15

Kx Ky Kz Ss Por

$2.70733 \mathrm{e}+022.70733 \mathrm{e}+022.70733 \mathrm{e}+01$ 1.00000e-09 7.00000e-02 $2.70733 \mathrm{e}+022.70733 \mathrm{e}+022.70733 \mathrm{e}+01$ 1.00000e-09 7.00000e-02 $2.70733 \mathrm{e}+022.70733 \mathrm{e}+022.70733 \mathrm{e}+01$ 1.00000e-09 7.00000e-02 $2.70733 \mathrm{e}+022.70733 \mathrm{e}+022.70733 \mathrm{e}+01$ 1.00000e-09 7.00000e-02 5.00000e-04 5.00000e-04 5.00000e-05 1.00000e-09 1.00000e-01 5.00000e-04 5.00000e-04 5.00000e-05 1.00000e-09 1.00000e-01 $1.08176 \mathrm{e}+011.08176 \mathrm{e}+011.08176 \mathrm{e}+001.00000 \mathrm{e}-092.12000 \mathrm{e}-01$ $1.08176 \mathrm{e}+011.08176 \mathrm{e}+011.08176 \mathrm{e}+001.00000 \mathrm{e}-092.12000 \mathrm{e}-01$ $1.08176 \mathrm{e}+011.08176 \mathrm{e}+011.08176 \mathrm{e}+001.00000 \mathrm{e}-092.12000 \mathrm{e}-01$ $1.08176 \mathrm{e}+011.08176 \mathrm{e}+011.08176 \mathrm{e}+001.00000 \mathrm{e}-092.12000 \mathrm{e}-01$ $1.08176 \mathrm{e}+011.08176 \mathrm{e}+011.08176 \mathrm{e}+001.00000 \mathrm{e}-092.12000 \mathrm{e}-01$ $1.00000 \mathrm{e}-021.00000 \mathrm{e}-02$ 1.00000e-03 1.00000e-09 1.00000e-01 $1.00000 \mathrm{e}+001.00000 \mathrm{e}+001.00000 \mathrm{e}-011.00000 \mathrm{e}-091.00000 \mathrm{e}-01$ $1.00000 \mathrm{e}-05$ 1.00000e-05 1.00000e-06 1.00000e-09 1.00000e-01 $1.00000 \mathrm{e}+001.00000 \mathrm{e}+001.00000 \mathrm{e}-011.00000 \mathrm{e}-091.00000 \mathrm{e}-01$ Element: 2710 \# of layers: 15

Kx Ky Kz Ss Por

$3.92755 \mathrm{e}+023.92755 \mathrm{e}+023.92755 \mathrm{e}+01$ 1.00000e-09 7.00000e-02 $3.92755 \mathrm{e}+023.92755 \mathrm{e}+023.92755 \mathrm{e}+011.00000 \mathrm{e}-09$ 7.00000e-02 $3.92755 \mathrm{e}+023.92755 \mathrm{e}+023.92755 \mathrm{e}+01$ 1.00000e-09 7.00000e-02 $3.92755 \mathrm{e}+023.92755 \mathrm{e}+023.92755 \mathrm{e}+01$ 1.00000e-09 7.00000e-02 
5.00000e-04 5.00000e-04 5.00000e-05 1.00000e-09 1.00000e-01 5.00000e-04 5.00000e-04 5.00000e-05 1.00000e-09 1.00000e-01 $1.56932 \mathrm{e}+011.56932 \mathrm{e}+01$ 1.56932e+00 1.00000e-09 2.12000e-01 $1.56932 \mathrm{e}+01$ 1.56932e+01 1.56932e+00 1.00000e-09 2.12000e-01 $1.56932 \mathrm{e}+01$ 1.56932e+01 1.56932e+00 1.00000e-09 2.12000e-01 $1.56932 \mathrm{e}+01$ 1.56932e+01 1.56932e+00 1.00000e-09 2.12000e-01 $1.56932 \mathrm{e}+01$ 1.56932e+01 1.56932e+00 1.00000e-09 2.12000e-01 $1.00000 \mathrm{e}-02$ 1.00000e-02 1.00000e-03 1.00000e-09 1.00000e-01 $1.00000 \mathrm{e}+001.00000 \mathrm{e}+001.00000 \mathrm{e}-011.00000 \mathrm{e}-091.00000 \mathrm{e}-01$ $1.00000 \mathrm{e}-05$ 1.00000e-05 1.00000e-06 1.00000e-09 1.00000e-01 $1.00000 \mathrm{e}+001.00000 \mathrm{e}+001.00000 \mathrm{e}-011.00000 \mathrm{e}-091.00000 \mathrm{e}-01$ Element: 2711 \# of layers: 15

$\mathrm{Kx} \mathrm{Ky} \mathrm{Kz}$ Ss Por

$2.84689 \mathrm{e}+02$ 2.84689e+02 2.84689e+01 1.00000e-09 7.00000e-02 $2.84689 \mathrm{e}+02$ 2.84689e+02 2.84689e+01 1.00000e-09 7.00000e-02 $2.84689 \mathrm{e}+022.84689 \mathrm{e}+022.84689 \mathrm{e}+01$ 1.00000e-09 7.00000e-02 $2.84689 \mathrm{e}+02$ 2.84689e+02 2.84689e+01 1.00000e-09 7.00000e-02 5.00000e-04 5.00000e-04 5.00000e-05 1.00000e-09 1.00000e-01 5.00000e-04 5.00000e-04 5.00000e-05 1.00000e-09 1.00000e-01 $1.13753 \mathrm{e}+01$ 1.13753e+01 1.13753e+00 1.00000e-09 2.12000e-01 $1.13753 \mathrm{e}+011.13753 \mathrm{e}+011.13753 \mathrm{e}+001.00000 \mathrm{e}-092.12000 \mathrm{e}-01$ $1.13753 \mathrm{e}+01$ 1.13753e+01 1.13753e+00 1.00000e-09 2.12000e-01 $1.13753 \mathrm{e}+01$ 1.13753e+01 1.13753e+00 1.00000e-09 2.12000e-01 $1.13753 \mathrm{e}+011.13753 \mathrm{e}+01$ 1.13753e+00 1.00000e-09 2.12000e-01 $1.00000 \mathrm{e}-02$ 1.00000e-02 1.00000e-03 1.00000e-09 1.00000e-01 $1.00000 \mathrm{e}+001.00000 \mathrm{e}+001.00000 \mathrm{e}-011.00000 \mathrm{e}-091.00000 \mathrm{e}-01$ $1.00000 \mathrm{e}-05$ 1.00000e-05 1.00000e-06 1.00000e-09 1.00000e-01 $1.00000 \mathrm{e}+001.00000 \mathrm{e}+001.00000 \mathrm{e}-011.00000 \mathrm{e}-091.00000 \mathrm{e}-01$ Element: 2712 \# of layers: 15

$\mathrm{Kx} \mathrm{Ky} \mathrm{Kz}$ Ss Por

2.70733e+02 2.70733e+02 2.70733e+01 1.00000e-09 7.00000e-02 $2.70733 \mathrm{e}+02$ 2.70733e+02 2.70733e+01 1.00000e-09 7.00000e-02 $2.70733 \mathrm{e}+02$ 2.70733e+02 2.70733e+01 1.00000e-09 7.00000e-02 $2.70733 \mathrm{e}+02$ 2.70733e+02 2.70733e+01 1.00000e-09 7.00000e-02 5.00000e-04 5.00000e-04 5.00000e-05 1.00000e-09 1.00000e-01 5.00000e-04 5.00000e-04 5.00000e-05 1.00000e-09 1.00000e-01 $1.08176 \mathrm{e}+011.08176 \mathrm{e}+011.08176 \mathrm{e}+001.00000 \mathrm{e}-092.12000 \mathrm{e}-01$ $1.08176 \mathrm{e}+011.08176 \mathrm{e}+011.08176 \mathrm{e}+001.00000 \mathrm{e}-092.12000 \mathrm{e}-01$ $1.08176 \mathrm{e}+01$ 1.08176e+01 1.08176e+00 1.00000e-09 2.12000e-01 $1.08176 \mathrm{e}+011.08176 \mathrm{e}+011.08176 \mathrm{e}+001.00000 \mathrm{e}-092.12000 \mathrm{e}-01$ $1.08176 \mathrm{e}+011.08176 \mathrm{e}+01 \quad 1.08176 \mathrm{e}+001.00000 \mathrm{e}-092.12000 \mathrm{e}-01$ $1.00000 \mathrm{e}-02$ 1.00000e-02 1.00000e-03 1.00000e-09 1.00000e-01 $1.00000 \mathrm{e}+001.00000 \mathrm{e}+001.00000 \mathrm{e}-011.00000 \mathrm{e}-091.00000 \mathrm{e}-01$ $1.00000 \mathrm{e}-05$ 1.00000e-05 1.00000e-06 1.00000e-09 1.00000e-01 $1.00000 \mathrm{e}+001.00000 \mathrm{e}+001.00000 \mathrm{e}-011.00000 \mathrm{e}-09$ 1.00000e-01 Element: 2713 \# of layers: 15 
$\mathrm{Kx} \mathrm{Ky} \mathrm{Kz}$ Ss Por

1.85273e+02 1.85273e+02 1.85273e+01 1.00000e-09 7.00000e-02

$1.85273 \mathrm{e}+02$ 1.85273e+02 1.85273e+01 1.00000e-09 7.00000e-02

$1.85273 \mathrm{e}+02$ 1.85273e+02 1.85273e+01 1.00000e-09 7.00000e-02

$1.85273 \mathrm{e}+02$ 1.85273e+02 1.85273e+01 1.00000e-09 7.00000e-02

5.00000e-04 5.00000e-04 5.00000e-05 1.00000e-09 1.00000e-01

5.00000e-04 5.00000e-04 5.00000e-05 1.00000e-09 1.00000e-01

$7.40288 \mathrm{e}+007.40288 \mathrm{e}+00$ 7.40288e-01 1.00000e-09 2.12000e-01

$7.40288 \mathrm{e}+007.40288 \mathrm{e}+007.40288 \mathrm{e}-01$ 1.00000e-09 2.12000e-01

$7.40288 \mathrm{e}+00$ 7.40288e+00 7.40288e-01 1.00000e-09 2.12000e-01

$7.40288 \mathrm{e}+007.40288 \mathrm{e}+00$ 7.40288e-01 1.00000e-09 2.12000e-01

$7.40288 \mathrm{e}+007.40288 \mathrm{e}+00$ 7.40288e-01 1.00000e-09 2.12000e-01

$1.00000 \mathrm{e}-02$ 1.00000e-02 1.00000e-03 1.00000e-09 1.00000e-01

$1.00000 \mathrm{e}+001.00000 \mathrm{e}+001.00000 \mathrm{e}-011.00000 \mathrm{e}-091.00000 \mathrm{e}-01$

$1.00000 \mathrm{e}-05$ 1.00000e-05 1.00000e-06 1.00000e-09 1.00000e-01

$1.00000 \mathrm{e}+001.00000 \mathrm{e}+001.00000 \mathrm{e}-011.00000 \mathrm{e}-091.00000 \mathrm{e}-01$

Element: 2714 \# of layers: 15

$\mathrm{Kx} \mathrm{Ky} \mathrm{Kz}$ Ss Por

1.85273e+02 1.85273e+02 1.85273e+01 1.00000e-09 7.00000e-02

$1.85273 \mathrm{e}+021.85273 \mathrm{e}+02$ 1.85273e+01 1.00000e-09 7.00000e-02

$1.85273 \mathrm{e}+02$ 1.85273e+02 1.85273e+01 1.00000e-09 7.00000e-02

$1.85273 \mathrm{e}+021.85273 \mathrm{e}+02$ 1.85273e+01 1.00000e-09 7.00000e-02

5.00000e-04 5.00000e-04 5.00000e-05 1.00000e-09 1.00000e-01

5.00000e-04 5.00000e-04 5.00000e-05 1.00000e-09 1.00000e-01

$7.40288 \mathrm{e}+007.40288 \mathrm{e}+00$ 7.40288e-01 1.00000e-09 2.12000e-01

7.40288e+00 7.40288e+00 7.40288e-01 1.00000e-09 2.12000e-01

$7.40288 \mathrm{e}+00$ 7.40288e+00 7.40288e-01 1.00000e-09 2.12000e-01

$7.40288 \mathrm{e}+00$ 7.40288e+00 7.40288e-01 1.00000e-09 2.12000e-01

$7.40288 \mathrm{e}+00$ 7.40288e+00 7.40288e-01 1.00000e-09 2.12000e-01

$1.00000 \mathrm{e}-021.00000 \mathrm{e}-021.00000 \mathrm{e}-031.00000 \mathrm{e}-091.00000 \mathrm{e}-01$

$1.00000 \mathrm{e}+001.00000 \mathrm{e}+001.00000 \mathrm{e}-011.00000 \mathrm{e}-091.00000 \mathrm{e}-01$

$1.00000 \mathrm{e}-05$ 1.00000e-05 1.00000e-06 1.00000e-09 1.00000e-01

$1.00000 \mathrm{e}+001.00000 \mathrm{e}+001.00000 \mathrm{e}-011.00000 \mathrm{e}-091.00000 \mathrm{e}-01$

Element: 2715 \# of layers: 15

$\mathrm{Kx} \mathrm{Ky} \mathrm{Kz}$ Ss Por

$1.85273 \mathrm{e}+02$ 1.85273e+02 1.85273e+01 1.00000e-09 7.00000e-02

$1.85273 \mathrm{e}+021.85273 \mathrm{e}+02$ 1.85273e+01 1.00000e-09 7.00000e-02

$1.85273 \mathrm{e}+021.85273 \mathrm{e}+02$ 1.85273e+01 1.00000e-09 7.00000e-02

$1.85273 \mathrm{e}+02$ 1.85273e+02 1.85273e+01 1.00000e-09 7.00000e-02

5.00000e-04 5.00000e-04 5.00000e-05 1.00000e-09 1.00000e-01

5.00000e-04 5.00000e-04 5.00000e-05 1.00000e-09 1.00000e-01

$7.40288 \mathrm{e}+00$ 7.40288e+00 7.40288e-01 1.00000e-09 2.12000e-01

$7.40288 \mathrm{e}+00$ 7.40288e+00 7.40288e-01 1.00000e-09 2.12000e-01

$7.40288 \mathrm{e}+00$ 7.40288e+00 7.40288e-01 1.00000e-09 2.12000e-01

$7.40288 \mathrm{e}+00$ 7.40288e+00 7.40288e-01 1.00000e-09 2.12000e-01

$7.40288 \mathrm{e}+00$ 7.40288e+00 7.40288e-01 1.00000e-09 2.12000e-01 
$1.00000 \mathrm{e}-02$ 1.00000e-02 1.00000e-03 1.00000e-09 1.00000e-01 $1.00000 \mathrm{e}+001.00000 \mathrm{e}+001.00000 \mathrm{e}-011.00000 \mathrm{e}-091.00000 \mathrm{e}-01$ $1.00000 \mathrm{e}-051.00000 \mathrm{e}-05$ 1.00000e-06 1.00000e-09 1.00000e-01 $1.00000 \mathrm{e}+001.00000 \mathrm{e}+001.00000 \mathrm{e}-011.00000 \mathrm{e}-091.00000 \mathrm{e}-01$ Element: 2716 \# of layers: 15

Kx Ky Kz Ss Por

$1.85273 \mathrm{e}+02$ 1.85273e+02 1.85273e+01 1.00000e-09 7.00000e-02 $1.85273 \mathrm{e}+021.85273 \mathrm{e}+021.85273 \mathrm{e}+01$ 1.00000e-09 7.00000e-02 $1.85273 \mathrm{e}+021.85273 \mathrm{e}+021.85273 \mathrm{e}+011.00000 \mathrm{e}-097.00000 \mathrm{e}-02$ $1.85273 \mathrm{e}+021.85273 \mathrm{e}+021.85273 \mathrm{e}+011.00000 \mathrm{e}-09$ 7.00000e-02 5.00000e-04 5.00000e-04 5.00000e-05 1.00000e-09 1.00000e-01 5.00000e-04 5.00000e-04 5.00000e-05 1.00000e-09 1.00000e-01 $7.40288 \mathrm{e}+007.40288 \mathrm{e}+00$ 7.40288e-01 1.00000e-09 2.12000e-01 $7.40288 \mathrm{e}+007.40288 \mathrm{e}+007.40288 \mathrm{e}-011.00000 \mathrm{e}-092.12000 \mathrm{e}-01$ $7.40288 \mathrm{e}+007.40288 \mathrm{e}+00$ 7.40288e-01 1.00000e-09 2.12000e-01 $7.40288 \mathrm{e}+007.40288 \mathrm{e}+007.40288 \mathrm{e}-01$ 1.00000e-09 2.12000e-01 $7.40288 \mathrm{e}+00$ 7.40288e+00 7.40288e-01 1.00000e-09 2.12000e-01 $1.00000 \mathrm{e}-02$ 1.00000e-02 1.00000e-03 1.00000e-09 1.00000e-01 $1.00000 \mathrm{e}+001.00000 \mathrm{e}+001.00000 \mathrm{e}-011.00000 \mathrm{e}-091.00000 \mathrm{e}-01$ $1.00000 \mathrm{e}-051.00000 \mathrm{e}-05$ 1.00000e-06 1.00000e-09 1.00000e-01 $1.00000 \mathrm{e}+001.00000 \mathrm{e}+001.00000 \mathrm{e}-011.00000 \mathrm{e}-091.00000 \mathrm{e}-01$ Element: 2717 \# of layers: 15

Kx Ky Kz Ss Por

$1.85273 \mathrm{e}+02$ 1.85273e+02 1.85273e+01 1.00000e-09 7.00000e-02 $1.85273 \mathrm{e}+021.85273 \mathrm{e}+021.85273 \mathrm{e}+011.00000 \mathrm{e}-09$ 7.00000e-02 $1.85273 \mathrm{e}+021.85273 \mathrm{e}+021.85273 \mathrm{e}+011.00000 \mathrm{e}-09$ 7.00000e-02 $1.85273 \mathrm{e}+021.85273 \mathrm{e}+021.85273 \mathrm{e}+01$ 1.00000e-09 7.00000e-02 5.00000e-04 5.00000e-04 5.00000e-05 1.00000e-09 1.00000e-01 5.00000e-04 5.00000e-04 5.00000e-05 1.00000e-09 1.00000e-01 $7.40288 \mathrm{e}+007.40288 \mathrm{e}+00$ 7.40288e-01 1.00000e-09 2.12000e-01 $7.40288 \mathrm{e}+007.40288 \mathrm{e}+007.40288 \mathrm{e}-01$ 1.00000e-09 2.12000e-01 $7.40288 \mathrm{e}+007.40288 \mathrm{e}+007.40288 \mathrm{e}-01$ 1.00000e-09 2.12000e-01 $7.40288 \mathrm{e}+007.40288 \mathrm{e}+00$ 7.40288e-01 1.00000e-09 2.12000e-01 $7.40288 \mathrm{e}+00$ 7.40288e+00 7.40288e-01 1.00000e-09 2.12000e-01 $1.00000 \mathrm{e}-021.00000 \mathrm{e}-02$ 1.00000e-03 1.00000e-09 1.00000e-01 $1.00000 \mathrm{e}+001.00000 \mathrm{e}+001.00000 \mathrm{e}-011.00000 \mathrm{e}-091.00000 \mathrm{e}-01$ $1.00000 \mathrm{e}-05$ 1.00000e-05 1.00000e-06 1.00000e-09 1.00000e-01 $1.00000 \mathrm{e}+001.00000 \mathrm{e}+001.00000 \mathrm{e}-011.00000 \mathrm{e}-091.00000 \mathrm{e}-01$ Element: 2718 \# of layers: 15

Kx Ky Kz Ss Por $1.85273 \mathrm{e}+02$ 1.85273e+02 1.85273e+01 1.00000e-09 7.00000e-02 $1.85273 \mathrm{e}+021.85273 \mathrm{e}+021.85273 \mathrm{e}+01$ 1.00000e-09 7.00000e-02 $1.85273 \mathrm{e}+021.85273 \mathrm{e}+021.85273 \mathrm{e}+011.00000 \mathrm{e}-09$ 7.00000e-02 $1.85273 \mathrm{e}+021.85273 \mathrm{e}+021.85273 \mathrm{e}+01$ 1.00000e-09 7.00000e-02 5.00000e-04 5.00000e-04 5.00000e-05 1.00000e-09 1.00000e-01 5.00000e-04 5.00000e-04 5.00000e-05 1.00000e-09 1.00000e-01 
$7.40288 \mathrm{e}+007.40288 \mathrm{e}+00$ 7.40288e-01 1.00000e-09 2.12000e-01 $7.40288 \mathrm{e}+007.40288 \mathrm{e}+007.40288 \mathrm{e}-011.00000 \mathrm{e}-092.12000 \mathrm{e}-01$ $7.40288 \mathrm{e}+007.40288 \mathrm{e}+00$ 7.40288e-01 1.00000e-09 2.12000e-01 $7.40288 \mathrm{e}+007.40288 \mathrm{e}+007.40288 \mathrm{e}-011.00000 \mathrm{e}-092.12000 \mathrm{e}-01$ $7.40288 \mathrm{e}+00$ 7.40288e+00 7.40288e-01 1.00000e-09 2.12000e-01 $1.00000 \mathrm{e}-021.00000 \mathrm{e}-02$ 1.00000e-03 1.00000e-09 1.00000e-01 $1.00000 \mathrm{e}+001.00000 \mathrm{e}+001.00000 \mathrm{e}-011.00000 \mathrm{e}-091.00000 \mathrm{e}-01$ $1.00000 \mathrm{e}-05$ 1.00000e-05 1.00000e-06 1.00000e-09 1.00000e-01 $1.00000 \mathrm{e}+001.00000 \mathrm{e}+001.00000 \mathrm{e}-011.00000 \mathrm{e}-091.00000 \mathrm{e}-01$ Element: 2719 \# of layers: 15

Kx Ky Kz Ss Por

$1.85273 \mathrm{e}+02$ 1.85273e+02 1.85273e+01 1.00000e-09 7.00000e-02 $1.85273 \mathrm{e}+021.85273 \mathrm{e}+021.85273 \mathrm{e}+01$ 1.00000e-09 7.00000e-02 $1.85273 \mathrm{e}+021.85273 \mathrm{e}+021.85273 \mathrm{e}+01$ 1.00000e-09 7.00000e-02 $1.85273 \mathrm{e}+021.85273 \mathrm{e}+021.85273 \mathrm{e}+01$ 1.00000e-09 7.00000e-02 5.00000e-04 5.00000e-04 5.00000e-05 1.00000e-09 1.00000e-01 5.00000e-04 5.00000e-04 5.00000e-05 1.00000e-09 1.00000e-01

$7.40288 \mathrm{e}+007.40288 \mathrm{e}+00$ 7.40288e-01 1.00000e-09 2.12000e-01 $7.40288 \mathrm{e}+007.40288 \mathrm{e}+007.40288 \mathrm{e}-011.00000 \mathrm{e}-092.12000 \mathrm{e}-01$ $7.40288 \mathrm{e}+007.40288 \mathrm{e}+00$ 7.40288e-01 1.00000e-09 2.12000e-01 $7.40288 \mathrm{e}+007.40288 \mathrm{e}+007.40288 \mathrm{e}-011.00000 \mathrm{e}-092.12000 \mathrm{e}-01$ $7.40288 \mathrm{e}+007.40288 \mathrm{e}+00$ 7.40288e-01 1.00000e-09 2.12000e-01 $1.00000 \mathrm{e}-02$ 1.00000e-02 1.00000e-03 1.00000e-09 1.00000e-01 $1.00000 \mathrm{e}+001.00000 \mathrm{e}+001.00000 \mathrm{e}-011.00000 \mathrm{e}-091.00000 \mathrm{e}-01$ $1.00000 \mathrm{e}-05$ 1.00000e-05 1.00000e-06 1.00000e-09 1.00000e-01 $1.00000 \mathrm{e}+001.00000 \mathrm{e}+001.00000 \mathrm{e}-011.00000 \mathrm{e}-091.00000 \mathrm{e}-01$ Element: 2720 \# of layers: 15

Kx Ky Kz Ss Por

$1.85273 \mathrm{e}+02$ 1.85273e+02 1.85273e+01 1.00000e-09 7.00000e-02 $1.85273 \mathrm{e}+021.85273 \mathrm{e}+021.85273 \mathrm{e}+011.00000 \mathrm{e}-09$ 7.00000e-02 $1.85273 \mathrm{e}+021.85273 \mathrm{e}+021.85273 \mathrm{e}+011.00000 \mathrm{e}-09$ 7.00000e-02 $1.85273 \mathrm{e}+021.85273 \mathrm{e}+021.85273 \mathrm{e}+01$ 1.00000e-09 7.00000e-02 5.00000e-04 5.00000e-04 5.00000e-05 1.00000e-09 1.00000e-01 $5.00000 \mathrm{e}-04$ 5.00000e-04 5.00000e-05 1.00000e-09 1.00000e-01 $7.40288 \mathrm{e}+007.40288 \mathrm{e}+00$ 7.40288e-01 1.00000e-09 2.12000e-01 $7.40288 \mathrm{e}+007.40288 \mathrm{e}+00$ 7.40288e-01 1.00000e-09 2.12000e-01 $7.40288 \mathrm{e}+007.40288 \mathrm{e}+00$ 7.40288e-01 1.00000e-09 2.12000e-01 $7.40288 \mathrm{e}+007.40288 \mathrm{e}+00$ 7.40288e-01 1.00000e-09 2.12000e-01 $7.40288 \mathrm{e}+00$ 7.40288e+00 7.40288e-01 1.00000e-09 2.12000e-01 $1.00000 \mathrm{e}-02$ 1.00000e-02 1.00000e-03 1.00000e-09 1.00000e-01 $1.00000 \mathrm{e}+001.00000 \mathrm{e}+001.00000 \mathrm{e}-011.00000 \mathrm{e}-091.00000 \mathrm{e}-01$ $1.00000 \mathrm{e}-05$ 1.00000e-05 1.00000e-06 1.00000e-09 1.00000e-01 $1.00000 \mathrm{e}+001.00000 \mathrm{e}+001.00000 \mathrm{e}-011.00000 \mathrm{e}-091.00000 \mathrm{e}-01$ Element: 2721 \# of layers: 15

Kx Ky Kz Ss Por

$1.85273 \mathrm{e}+02$ 1.85273e+02 1.85273e+01 1.00000e-09 7.00000e-02 
$1.85273 \mathrm{e}+02$ 1.85273e+02 1.85273e+01 1.00000e-09 7.00000e-02 1.85273e+02 1.85273e+02 1.85273e+01 1.00000e-09 7.00000e-02 $1.85273 \mathrm{e}+02$ 1.85273e+02 1.85273e+01 1.00000e-09 7.00000e-02 5.00000e-04 5.00000e-04 5.00000e-05 1.00000e-09 1.00000e-01 5.00000e-04 5.00000e-04 5.00000e-05 1.00000e-09 1.00000e-01 $7.40288 \mathrm{e}+00$ 7.40288e+00 7.40288e-01 1.00000e-09 2.12000e-01 $7.40288 \mathrm{e}+00$ 7.40288e+00 7.40288e-01 1.00000e-09 2.12000e-01 $7.40288 \mathrm{e}+00$ 7.40288e+00 7.40288e-01 1.00000e-09 2.12000e-01 7.40288e+00 7.40288e+00 7.40288e-01 1.00000e-09 2.12000e-01 $7.40288 \mathrm{e}+00$ 7.40288e+00 7.40288e-01 1.00000e-09 2.12000e-01 $1.00000 \mathrm{e}-02$ 1.00000e-02 1.00000e-03 1.00000e-09 1.00000e-01 $1.00000 \mathrm{e}+001.00000 \mathrm{e}+001.00000 \mathrm{e}-011.00000 \mathrm{e}-091.00000 \mathrm{e}-01$ $1.00000 \mathrm{e}-05$ 1.00000e-05 1.00000e-06 1.00000e-09 1.00000e-01 $1.00000 \mathrm{e}+001.00000 \mathrm{e}+001.00000 \mathrm{e}-011.00000 \mathrm{e}-09$ 1.00000e-01 Element: 2722 \# of layers: 16

Kx Ky Kz Ss Por

$1.07030 \mathrm{e}+02$ 1.07030e+02 1.07030e+01 1.00000e-09 7.00000e-02 $1.07030 \mathrm{e}+021.07030 \mathrm{e}+021.07030 \mathrm{e}+01$ 1.00000e-09 7.00000e-02 $1.07030 \mathrm{e}+021.07030 \mathrm{e}+02$ 1.07030e+01 1.00000e-09 7.00000e-02 $1.07030 \mathrm{e}+021.07030 \mathrm{e}+021.07030 \mathrm{e}+01$ 1.00000e-09 7.00000e-02 $1.07030 \mathrm{e}+021.07030 \mathrm{e}+02 \quad 1.07030 \mathrm{e}+01$ 1.00000e-09 7.00000e-02 $5.00000 \mathrm{e}-04$ 5.00000e-04 5.00000e-05 1.00000e-09 1.00000e-01 5.00000e-04 5.00000e-04 5.00000e-05 1.00000e-09 1.00000e-01 $4.27644 \mathrm{e}+004.27644 \mathrm{e}+00$ 4.27644e-01 1.00000e-09 2.12000e-01 $4.27644 \mathrm{e}+004.27644 \mathrm{e}+00 \quad 4.27644 \mathrm{e}-01$ 1.00000e-09 2.12000e-01 $4.27644 \mathrm{e}+004.27644 \mathrm{e}+004.27644 \mathrm{e}-01$ 1.00000e-09 2.12000e-01 $4.27644 \mathrm{e}+004.27644 \mathrm{e}+004.27644 \mathrm{e}-01$ 1.00000e-09 2.12000e-01 $4.27644 \mathrm{e}+004.27644 \mathrm{e}+004.27644 \mathrm{e}-01$ 1.00000e-09 2.12000e-01 $1.00000 \mathrm{e}-02$ 1.00000e-02 1.00000e-03 1.00000e-09 1.00000e-01 $1.00000 \mathrm{e}+001.00000 \mathrm{e}+001.00000 \mathrm{e}-011.00000 \mathrm{e}-091.00000 \mathrm{e}-01$ $1.00000 \mathrm{e}-05$ 1.00000e-05 1.00000e-06 1.00000e-09 1.00000e-01 $1.00000 \mathrm{e}+001.00000 \mathrm{e}+001.00000 \mathrm{e}-01$ 1.00000e-09 1.00000e-01 Element: 2723 \# of layers: 15

$\mathrm{Kx} \mathrm{Ky} \mathrm{Kz}$ Ss Por

$1.07030 \mathrm{e}+02$ 1.07030e+02 1.07030e+01 1.00000e-09 7.00000e-02 $1.07030 \mathrm{e}+021.07030 \mathrm{e}+02 \quad 1.07030 \mathrm{e}+01$ 1.00000e-09 7.00000e-02 $1.07030 \mathrm{e}+021.07030 \mathrm{e}+02 \quad 1.07030 \mathrm{e}+01$ 1.00000e-09 7.00000e-02 $1.07030 \mathrm{e}+021.07030 \mathrm{e}+021.07030 \mathrm{e}+01$ 1.00000e-09 7.00000e-02 5.00000e-04 5.00000e-04 5.00000e-05 1.00000e-09 1.00000e-01 5.00000e-04 5.00000e-04 5.00000e-05 1.00000e-09 1.00000e-01 $4.27644 \mathrm{e}+004.27644 \mathrm{e}+004.27644 \mathrm{e}-01$ 1.00000e-09 2.12000e-01 $4.27644 \mathrm{e}+004.27644 \mathrm{e}+004.27644 \mathrm{e}-01$ 1.00000e-09 2.12000e-01 $4.27644 \mathrm{e}+004.27644 \mathrm{e}+004.27644 \mathrm{e}-01$ 1.00000e-09 2.12000e-01 $4.27644 \mathrm{e}+004.27644 \mathrm{e}+00$ 4.27644e-01 1.00000e-09 2.12000e-01 $4.27644 \mathrm{e}+004.27644 \mathrm{e}+004.27644 \mathrm{e}-01$ 1.00000e-09 2.12000e-01 $1.00000 \mathrm{e}-02$ 1.00000e-02 1.00000e-03 1.00000e-09 1.00000e-01 
$1.00000 \mathrm{e}+001.00000 \mathrm{e}+001.00000 \mathrm{e}-011.00000 \mathrm{e}-091.00000 \mathrm{e}-01$ $1.00000 \mathrm{e}-05$ 1.00000e-05 1.00000e-06 1.00000e-09 1.00000e-01 $1.00000 \mathrm{e}+001.00000 \mathrm{e}+001.00000 \mathrm{e}-01$ 1.00000e-09 1.00000e-01 Element: 2724 \# of layers: 15

$\mathrm{Kx} \mathrm{Ky} \mathrm{Kz}$ Ss Por

$1.07030 \mathrm{e}+02$ 1.07030e+02 1.07030e+01 1.00000e-09 7.00000e-02 $1.07030 \mathrm{e}+021.07030 \mathrm{e}+02 \quad 1.07030 \mathrm{e}+01$ 1.00000e-09 7.00000e-02 $1.07030 \mathrm{e}+021.07030 \mathrm{e}+02 \quad 1.07030 \mathrm{e}+01$ 1.00000e-09 7.00000e-02 $1.07030 \mathrm{e}+021.07030 \mathrm{e}+02 \quad 1.07030 \mathrm{e}+01$ 1.00000e-09 7.00000e-02 5.00000e-04 5.00000e-04 5.00000e-05 1.00000e-09 1.00000e-01 5.00000e-04 5.00000e-04 5.00000e-05 1.00000e-09 1.00000e-01 $4.27644 \mathrm{e}+004.27644 \mathrm{e}+004.27644 \mathrm{e}-01$ 1.00000e-09 2.12000e-01 $4.27644 \mathrm{e}+004.27644 \mathrm{e}+004.27644 \mathrm{e}-01$ 1.00000e-09 2.12000e-01 $4.27644 \mathrm{e}+004.27644 \mathrm{e}+004.27644 \mathrm{e}-01$ 1.00000e-09 2.12000e-01 $4.27644 \mathrm{e}+004.27644 \mathrm{e}+004.27644 \mathrm{e}-01$ 1.00000e-09 2.12000e-01 $4.27644 \mathrm{e}+004.27644 \mathrm{e}+004.27644 \mathrm{e}-01$ 1.00000e-09 2.12000e-01 $1.00000 \mathrm{e}-02$ 1.00000e-02 1.00000e-03 1.00000e-09 1.00000e-01 $1.00000 \mathrm{e}+001.00000 \mathrm{e}+001.00000 \mathrm{e}-011.00000 \mathrm{e}-091.00000 \mathrm{e}-01$ $1.00000 \mathrm{e}-05$ 1.00000e-05 1.00000e-06 1.00000e-09 1.00000e-01 $1.00000 \mathrm{e}+001.00000 \mathrm{e}+001.00000 \mathrm{e}-011.00000 \mathrm{e}-091.00000 \mathrm{e}-01$ Element: 2725 \# of layers: 15

$\mathrm{Kx} \mathrm{Ky} \mathrm{Kz}$ Ss Por

$1.07030 \mathrm{e}+02$ 1.07030e+02 1.07030e+01 1.00000e-09 7.00000e-02 $1.07030 \mathrm{e}+021.07030 \mathrm{e}+02 \quad 1.07030 \mathrm{e}+01$ 1.00000e-09 7.00000e-02 $1.07030 \mathrm{e}+021.07030 \mathrm{e}+02 \quad 1.07030 \mathrm{e}+01$ 1.00000e-09 7.00000e-02 $1.07030 \mathrm{e}+021.07030 \mathrm{e}+021.07030 \mathrm{e}+011.00000 \mathrm{e}-097.00000 \mathrm{e}-02$ 5.00000e-04 5.00000e-04 5.00000e-05 1.00000e-09 1.00000e-01 5.00000e-04 5.00000e-04 5.00000e-05 1.00000e-09 1.00000e-01 $4.27644 \mathrm{e}+004.27644 \mathrm{e}+00$ 4.27644e-01 1.00000e-09 2.12000e-01 $4.27644 \mathrm{e}+004.27644 \mathrm{e}+004.27644 \mathrm{e}-01$ 1.00000e-09 2.12000e-01 $4.27644 \mathrm{e}+004.27644 \mathrm{e}+004.27644 \mathrm{e}-01$ 1.00000e-09 2.12000e-01 $4.27644 \mathrm{e}+004.27644 \mathrm{e}+004.27644 \mathrm{e}-01$ 1.00000e-09 2.12000e-01 $4.27644 \mathrm{e}+004.27644 \mathrm{e}+004.27644 \mathrm{e}-01$ 1.00000e-09 2.12000e-01 1.00000e-02 1.00000e-02 1.00000e-03 1.00000e-09 1.00000e-01 $1.00000 \mathrm{e}+001.00000 \mathrm{e}+001.00000 \mathrm{e}-011.00000 \mathrm{e}-091.00000 \mathrm{e}-01$ $1.00000 \mathrm{e}-05$ 1.00000e-05 1.00000e-06 1.00000e-09 1.00000e-01 $1.00000 \mathrm{e}+001.00000 \mathrm{e}+001.00000 \mathrm{e}-011.00000 \mathrm{e}-091.00000 \mathrm{e}-01$ Element: 2726 \# of layers: 15

$\mathrm{Kx} \mathrm{Ky} \mathrm{Kz}$ Ss Por

$1.07030 \mathrm{e}+02$ 1.07030e+02 1.07030e+01 1.00000e-09 7.00000e-02 $1.07030 \mathrm{e}+02$ 1.07030e+02 1.07030e+01 1.00000e-09 7.00000e-02 $1.07030 \mathrm{e}+02$ 1.07030e+02 1.07030e+01 1.00000e-09 7.00000e-02 $1.07030 \mathrm{e}+021.07030 \mathrm{e}+021.07030 \mathrm{e}+011.00000 \mathrm{e}-097.00000 \mathrm{e}-02$ 5.00000e-04 5.00000e-04 5.00000e-05 1.00000e-09 1.00000e-01 5.00000e-04 5.00000e-04 5.00000e-05 1.00000e-09 1.00000e-01 $4.27644 \mathrm{e}+004.27644 \mathrm{e}+004.27644 \mathrm{e}-01$ 1.00000e-09 2.12000e-01 
$4.27644 \mathrm{e}+004.27644 \mathrm{e}+004.27644 \mathrm{e}-01$ 1.00000e-09 2.12000e-01 $4.27644 \mathrm{e}+004.27644 \mathrm{e}+004.27644 \mathrm{e}-01$ 1.00000e-09 2.12000e-01 $4.27644 \mathrm{e}+004.27644 \mathrm{e}+004.27644 \mathrm{e}-01$ 1.00000e-09 2.12000e-01 $4.27644 \mathrm{e}+004.27644 \mathrm{e}+004.27644 \mathrm{e}-01$ 1.00000e-09 2.12000e-01 $1.00000 \mathrm{e}-02$ 1.00000e-02 1.00000e-03 1.00000e-09 1.00000e-01 $1.00000 \mathrm{e}+001.00000 \mathrm{e}+001.00000 \mathrm{e}-011.00000 \mathrm{e}-091.00000 \mathrm{e}-01$ $1.00000 \mathrm{e}-05$ 1.00000e-05 1.00000e-06 1.00000e-09 1.00000e-01 $1.00000 \mathrm{e}+001.00000 \mathrm{e}+001.00000 \mathrm{e}-011.00000 \mathrm{e}-091.00000 \mathrm{e}-01$ Element: 2727 \# of layers: 15

$\mathrm{Kx} \mathrm{Ky} \mathrm{Kz}$ Ss Por

$1.07030 \mathrm{e}+02$ 1.07030e+02 1.07030e+01 1.00000e-09 7.00000e-02 $1.07030 \mathrm{e}+02 \quad 1.07030 \mathrm{e}+02 \quad 1.07030 \mathrm{e}+01 \quad 1.00000 \mathrm{e}-09$ 7.00000e-02 $1.07030 \mathrm{e}+021.07030 \mathrm{e}+021.07030 \mathrm{e}+01$ 1.00000e-09 7.00000e-02 $1.07030 \mathrm{e}+021.07030 \mathrm{e}+02 \quad 1.07030 \mathrm{e}+01$ 1.00000e-09 7.00000e-02 5.00000e-04 5.00000e-04 5.00000e-05 1.00000e-09 1.00000e-01 5.00000e-04 5.00000e-04 5.00000e-05 1.00000e-09 1.00000e-01 $4.27644 \mathrm{e}+004.27644 \mathrm{e}+004.27644 \mathrm{e}-01$ 1.00000e-09 2.12000e-01 $4.27644 \mathrm{e}+004.27644 \mathrm{e}+004.27644 \mathrm{e}-01$ 1.00000e-09 2.12000e-01 4.27644e+00 4.27644e+00 4.27644e-01 1.00000e-09 2.12000e-01 $4.27644 \mathrm{e}+004.27644 \mathrm{e}+004.27644 \mathrm{e}-01$ 1.00000e-09 2.12000e-01 $4.27644 \mathrm{e}+004.27644 \mathrm{e}+00 \quad 4.27644 \mathrm{e}-01$ 1.00000e-09 2.12000e-01 $1.00000 \mathrm{e}-021.00000 \mathrm{e}-021.00000 \mathrm{e}-031.00000 \mathrm{e}-091.00000 \mathrm{e}-01$ $1.00000 \mathrm{e}+001.00000 \mathrm{e}+001.00000 \mathrm{e}-011.00000 \mathrm{e}-091.00000 \mathrm{e}-01$ $1.00000 \mathrm{e}-05$ 1.00000e-05 1.00000e-06 1.00000e-09 1.00000e-01 $1.00000 \mathrm{e}+001.00000 \mathrm{e}+001.00000 \mathrm{e}-011.00000 \mathrm{e}-091.00000 \mathrm{e}-01$ Element: 2728 \# of layers: 16

$\mathrm{Kx} \mathrm{Ky} \mathrm{Kz}$ Ss Por

$1.07030 \mathrm{e}+02$ 1.07030e+02 1.07030e+01 1.00000e-09 7.00000e-02 $1.07030 \mathrm{e}+02$ 1.07030e+02 1.07030e+01 1.00000e-09 7.00000e-02 $1.07030 \mathrm{e}+021.07030 \mathrm{e}+021.07030 \mathrm{e}+01$ 1.00000e-09 7.00000e-02 $1.07030 \mathrm{e}+021.07030 \mathrm{e}+02 \quad 1.07030 \mathrm{e}+01$ 1.00000e-09 7.00000e-02 $1.07030 \mathrm{e}+021.07030 \mathrm{e}+02 \quad 1.07030 \mathrm{e}+01$ 1.00000e-09 7.00000e-02 5.00000e-04 5.00000e-04 5.00000e-05 1.00000e-09 1.00000e-01 5.00000e-04 5.00000e-04 5.00000e-05 1.00000e-09 1.00000e-01 $4.27644 \mathrm{e}+004.27644 \mathrm{e}+00 \quad 4.27644 \mathrm{e}-01$ 1.00000e-09 2.12000e-01 4.27644e+00 4.27644e+00 4.27644e-01 1.00000e-09 2.12000e-01 $4.27644 \mathrm{e}+004.27644 \mathrm{e}+004.27644 \mathrm{e}-01$ 1.00000e-09 2.12000e-01 $4.27644 \mathrm{e}+004.27644 \mathrm{e}+004.27644 \mathrm{e}-01$ 1.00000e-09 2.12000e-01 $4.27644 \mathrm{e}+004.27644 \mathrm{e}+004.27644 \mathrm{e}-01$ 1.00000e-09 2.12000e-01 $1.00000 \mathrm{e}-02$ 1.00000e-02 1.00000e-03 1.00000e-09 1.00000e-01 $1.00000 \mathrm{e}+001.00000 \mathrm{e}+001.00000 \mathrm{e}-011.00000 \mathrm{e}-091.00000 \mathrm{e}-01$ $1.00000 \mathrm{e}-05$ 1.00000e-05 1.00000e-06 1.00000e-09 1.00000e-01 $1.00000 \mathrm{e}+001.00000 \mathrm{e}+001.00000 \mathrm{e}-01$ 1.00000e-09 1.00000e-01 Element: 2729 \# of layers: 16

$\mathrm{Kx} \mathrm{Ky} \mathrm{Kz} \mathrm{Ss} \mathrm{Por}$

1.07030e+02 1.07030e+02 1.07030e+01 1.00000e-09 7.00000e-02 
$1.07030 \mathrm{e}+021.07030 \mathrm{e}+021.07030 \mathrm{e}+01$ 1.00000e-09 7.00000e-02 $1.07030 \mathrm{e}+021.07030 \mathrm{e}+021.07030 \mathrm{e}+01$ 1.00000e-09 7.00000e-02 $1.07030 \mathrm{e}+02$ 1.07030e+02 1.07030e+01 1.00000e-09 7.00000e-02 $1.07030 \mathrm{e}+02 \quad 1.07030 \mathrm{e}+02 \quad 1.07030 \mathrm{e}+01$ 1.00000e-09 7.00000e-02 5.00000e-04 5.00000e-04 5.00000e-05 1.00000e-09 1.00000e-01 5.00000e-04 5.00000e-04 5.00000e-05 1.00000e-09 1.00000e-01 $4.27644 \mathrm{e}+004.27644 \mathrm{e}+00$ 4.27644e-01 1.00000e-09 2.12000e-01 $4.27644 \mathrm{e}+004.27644 \mathrm{e}+004.27644 \mathrm{e}-01$ 1.00000e-09 2.12000e-01 $4.27644 \mathrm{e}+004.27644 \mathrm{e}+004.27644 \mathrm{e}-01$ 1.00000e-09 2.12000e-01 $4.27644 \mathrm{e}+004.27644 \mathrm{e}+004.27644 \mathrm{e}-01$ 1.00000e-09 2.12000e-01 $4.27644 \mathrm{e}+004.27644 \mathrm{e}+004.27644 \mathrm{e}-01$ 1.00000e-09 2.12000e-01 $1.00000 \mathrm{e}-02$ 1.00000e-02 1.00000e-03 1.00000e-09 1.00000e-01 $1.00000 \mathrm{e}+001.00000 \mathrm{e}+001.00000 \mathrm{e}-011.00000 \mathrm{e}-091.00000 \mathrm{e}-01$ $1.00000 \mathrm{e}-05$ 1.00000e-05 1.00000e-06 1.00000e-09 1.00000e-01 $1.00000 \mathrm{e}+001.00000 \mathrm{e}+001.00000 \mathrm{e}-01$ 1.00000e-09 1.00000e-01 Element: 2730 \# of layers: 15

$\mathrm{Kx} \mathrm{Ky} \mathrm{Kz}$ Ss Por

$1.07030 \mathrm{e}+02$ 1.07030e+02 1.07030e+01 1.00000e-09 7.00000e-02 $1.07030 \mathrm{e}+021.07030 \mathrm{e}+02$ 1.07030e+01 1.00000e-09 7.00000e-02 $1.07030 \mathrm{e}+021.07030 \mathrm{e}+021.07030 \mathrm{e}+01$ 1.00000e-09 7.00000e-02 $1.07030 \mathrm{e}+021.07030 \mathrm{e}+02 \quad 1.07030 \mathrm{e}+01$ 1.00000e-09 7.00000e-02 $5.00000 \mathrm{e}-04$ 5.00000e-04 5.00000e-05 1.00000e-09 1.00000e-01 5.00000e-04 5.00000e-04 5.00000e-05 1.00000e-09 1.00000e-01 $4.27644 \mathrm{e}+004.27644 \mathrm{e}+00$ 4.27644e-01 1.00000e-09 2.12000e-01 $4.27644 \mathrm{e}+004.27644 \mathrm{e}+00 \quad 4.27644 \mathrm{e}-01$ 1.00000e-09 2.12000e-01 $4.27644 \mathrm{e}+004.27644 \mathrm{e}+004.27644 \mathrm{e}-01$ 1.00000e-09 2.12000e-01 $4.27644 \mathrm{e}+004.27644 \mathrm{e}+004.27644 \mathrm{e}-01$ 1.00000e-09 2.12000e-01 $4.27644 \mathrm{e}+004.27644 \mathrm{e}+004.27644 \mathrm{e}-01$ 1.00000e-09 2.12000e-01 $1.00000 \mathrm{e}-02$ 1.00000e-02 1.00000e-03 1.00000e-09 1.00000e-01 $1.00000 \mathrm{e}+001.00000 \mathrm{e}+001.00000 \mathrm{e}-011.00000 \mathrm{e}-091.00000 \mathrm{e}-01$ $1.00000 \mathrm{e}-05$ 1.00000e-05 1.00000e-06 1.00000e-09 1.00000e-01 $1.00000 \mathrm{e}+001.00000 \mathrm{e}+001.00000 \mathrm{e}-01$ 1.00000e-09 1.00000e-01 Element: 2731 \# of layers: 15

$\mathrm{Kx} \mathrm{Ky} \mathrm{Kz}$ Ss Por

7.65463e+01 7.65463e+01 7.65463e+00 1.00000e-09 7.00000e-02 $7.65463 \mathrm{e}+017.65463 \mathrm{e}+017.65463 \mathrm{e}+001.00000 \mathrm{e}-09$ 7.00000e-02 $7.65463 \mathrm{e}+017.65463 \mathrm{e}+01$ 7.65463e+00 1.00000e-09 7.00000e-02 $7.65463 \mathrm{e}+017.65463 \mathrm{e}+017.65463 \mathrm{e}+001.00000 \mathrm{e}-09$ 7.00000e-02 5.00000e-04 5.00000e-04 5.00000e-05 1.00000e-09 1.00000e-01 5.00000e-04 5.00000e-04 5.00000e-05 1.00000e-09 1.00000e-01 $3.05849 \mathrm{e}+003.05849 \mathrm{e}+00$ 3.05849e-01 1.00000e-09 2.12000e-01 $3.05849 \mathrm{e}+003.05849 \mathrm{e}+00$ 3.05849e-01 1.00000e-09 2.12000e-01 $3.05849 \mathrm{e}+003.05849 \mathrm{e}+00$ 3.05849e-01 1.00000e-09 2.12000e-01 3.05849e+00 3.05849e+00 3.05849e-01 1.00000e-09 2.12000e-01 $3.05849 \mathrm{e}+00$ 3.05849e+00 3.05849e-01 1.00000e-09 2.12000e-01 $1.00000 \mathrm{e}-02$ 1.00000e-02 1.00000e-03 1.00000e-09 1.00000e-01 
$1.00000 \mathrm{e}+001.00000 \mathrm{e}+001.00000 \mathrm{e}-011.00000 \mathrm{e}-091.00000 \mathrm{e}-01$ $1.00000 \mathrm{e}-05$ 1.00000e-05 1.00000e-06 1.00000e-09 1.00000e-01 $1.00000 \mathrm{e}+001.00000 \mathrm{e}+001.00000 \mathrm{e}-01$ 1.00000e-09 1.00000e-01 Element: 2732 \# of layers: 14

$\mathrm{Kx} \mathrm{Ky} \mathrm{Kz}$ Ss Por

7.65463e+01 7.65463e+01 7.65463e+00 1.00000e-09 7.00000e-02 $7.65463 \mathrm{e}+017.65463 \mathrm{e}+017.65463 \mathrm{e}+001.00000 \mathrm{e}-097.00000 \mathrm{e}-02$ $7.65463 \mathrm{e}+01$ 7.65463e+01 7.65463e+00 1.00000e-09 7.00000e-02 5.00000e-04 5.00000e-04 5.00000e-05 1.00000e-09 1.00000e-01 5.00000e-04 5.00000e-04 5.00000e-05 1.00000e-09 1.00000e-01 $3.05849 \mathrm{e}+003.05849 \mathrm{e}+00$ 3.05849e-01 1.00000e-09 2.12000e-01 $3.05849 \mathrm{e}+003.05849 \mathrm{e}+003.05849 \mathrm{e}-01$ 1.00000e-09 2.12000e-01 $3.05849 \mathrm{e}+003.05849 \mathrm{e}+00$ 3.05849e-01 1.00000e-09 2.12000e-01 $3.05849 \mathrm{e}+003.05849 \mathrm{e}+00$ 3.05849e-01 1.00000e-09 2.12000e-01 3.05849e+00 3.05849e+00 3.05849e-01 1.00000e-09 2.12000e-01 $1.00000 \mathrm{e}-02$ 1.00000e-02 1.00000e-03 1.00000e-09 1.00000e-01 $1.00000 \mathrm{e}+001.00000 \mathrm{e}+001.00000 \mathrm{e}-011.00000 \mathrm{e}-091.00000 \mathrm{e}-01$ $1.00000 \mathrm{e}-05$ 1.00000e-05 1.00000e-06 1.00000e-09 1.00000e-01 $1.00000 \mathrm{e}+001.00000 \mathrm{e}+001.00000 \mathrm{e}-011.00000 \mathrm{e}-091.00000 \mathrm{e}-01$ Element: 2733 \# of layers: 14

$\mathrm{Kx} \mathrm{Ky} \mathrm{Kz}$ Ss Por

7.65463e+01 7.65463e+01 7.65463e+00 1.00000e-09 7.00000e-02 $7.65463 \mathrm{e}+01$ 7.65463e+01 7.65463e+00 1.00000e-09 7.00000e-02 $7.65463 \mathrm{e}+017.65463 \mathrm{e}+01$ 7.65463e+00 1.00000e-09 7.00000e-02 $5.00000 \mathrm{e}-04$ 5.00000e-04 5.00000e-05 1.00000e-09 1.00000e-01 $5.00000 \mathrm{e}-04$ 5.00000e-04 5.00000e-05 1.00000e-09 1.00000e-01 $3.05849 \mathrm{e}+003.05849 \mathrm{e}+00$ 3.05849e-01 1.00000e-09 2.12000e-01 $3.05849 \mathrm{e}+003.05849 \mathrm{e}+00$ 3.05849e-01 1.00000e-09 2.12000e-01 $3.05849 \mathrm{e}+003.05849 \mathrm{e}+00$ 3.05849e-01 1.00000e-09 2.12000e-01 $3.05849 \mathrm{e}+003.05849 \mathrm{e}+00$ 3.05849e-01 1.00000e-09 2.12000e-01 3.05849e+00 3.05849e+00 3.05849e-01 1.00000e-09 2.12000e-01 $1.00000 \mathrm{e}-02$ 1.00000e-02 1.00000e-03 1.00000e-09 1.00000e-01 $1.00000 \mathrm{e}+001.00000 \mathrm{e}+001.00000 \mathrm{e}-011.00000 \mathrm{e}-091.00000 \mathrm{e}-01$ $1.00000 \mathrm{e}-051.00000 \mathrm{e}-051.00000 \mathrm{e}-061.00000 \mathrm{e}-091.00000 \mathrm{e}-01$ $1.00000 \mathrm{e}+001.00000 \mathrm{e}+001.00000 \mathrm{e}-01$ 1.00000e-09 1.00000e-01 Element: 2734 \# of layers: 14

Kx Ky Kz Ss Por

7.65463e+01 7.65463e+01 7.65463e+00 1.00000e-09 7.00000e-02 $7.65463 \mathrm{e}+017.65463 \mathrm{e}+01$ 7.65463e+00 1.00000e-09 7.00000e-02 $7.65463 \mathrm{e}+017.65463 \mathrm{e}+017.65463 \mathrm{e}+001.00000 \mathrm{e}-09$ 7.00000e-02 5.00000e-04 5.00000e-04 5.00000e-05 1.00000e-09 1.00000e-01 5.00000e-04 5.00000e-04 5.00000e-05 1.00000e-09 1.00000e-01 $3.05849 \mathrm{e}+003.05849 \mathrm{e}+00$ 3.05849e-01 1.00000e-09 2.12000e-01 $3.05849 \mathrm{e}+003.05849 \mathrm{e}+00$ 3.05849e-01 1.00000e-09 2.12000e-01 $3.05849 \mathrm{e}+003.05849 \mathrm{e}+00$ 3.05849e-01 1.00000e-09 2.12000e-01 $3.05849 \mathrm{e}+003.05849 \mathrm{e}+00$ 3.05849e-01 1.00000e-09 2.12000e-01 
$3.05849 \mathrm{e}+00$ 3.05849e+00 3.05849e-01 1.00000e-09 2.12000e-01 $1.00000 \mathrm{e}-02$ 1.00000e-02 1.00000e-03 1.00000e-09 1.00000e-01 $1.00000 \mathrm{e}+001.00000 \mathrm{e}+001.00000 \mathrm{e}-011.00000 \mathrm{e}-091.00000 \mathrm{e}-01$ $1.00000 \mathrm{e}-05$ 1.00000e-05 1.00000e-06 1.00000e-09 1.00000e-01 $1.00000 \mathrm{e}+001.00000 \mathrm{e}+001.00000 \mathrm{e}-01$ 1.00000e-09 1.00000e-01 Element: 2735 \# of layers: 14

$\mathrm{Kx} \mathrm{Ky} \mathrm{Kz}$ Ss Por

7.65463e+01 7.65463e+01 7.65463e+00 1.00000e-09 7.00000e-02 $7.65463 \mathrm{e}+017.65463 \mathrm{e}+017.65463 \mathrm{e}+001.00000 \mathrm{e}-09$ 7.00000e-02

$7.65463 \mathrm{e}+017.65463 \mathrm{e}+017.65463 \mathrm{e}+001.00000 \mathrm{e}-09$ 7.00000e-02 5.00000e-04 5.00000e-04 5.00000e-05 1.00000e-09 1.00000e-01 5.00000e-04 5.00000e-04 5.00000e-05 1.00000e-09 1.00000e-01 $3.05849 \mathrm{e}+003.05849 \mathrm{e}+003.05849 \mathrm{e}-01$ 1.00000e-09 2.12000e-01 $3.05849 \mathrm{e}+003.05849 \mathrm{e}+00$ 3.05849e-01 1.00000e-09 2.12000e-01 $3.05849 \mathrm{e}+003.05849 \mathrm{e}+00$ 3.05849e-01 1.00000e-09 2.12000e-01 $3.05849 \mathrm{e}+003.05849 \mathrm{e}+00$ 3.05849e-01 1.00000e-09 2.12000e-01 $3.05849 \mathrm{e}+003.05849 \mathrm{e}+00$ 3.05849e-01 1.00000e-09 2.12000e-01 $1.00000 \mathrm{e}-02$ 1.00000e-02 1.00000e-03 1.00000e-09 1.00000e-01 $1.00000 \mathrm{e}+001.00000 \mathrm{e}+001.00000 \mathrm{e}-011.00000 \mathrm{e}-091.00000 \mathrm{e}-01$ $1.00000 \mathrm{e}-05$ 1.00000e-05 1.00000e-06 1.00000e-09 1.00000e-01 $1.00000 \mathrm{e}+001.00000 \mathrm{e}+001.00000 \mathrm{e}-011.00000 \mathrm{e}-091.00000 \mathrm{e}-01$ Element: 2736 \# of layers: 14

$\mathrm{Kx} \mathrm{Ky} \mathrm{Kz}$ Ss Por

7.65463e+01 7.65463e+01 7.65463e+00 1.00000e-09 7.00000e-02 $7.65463 \mathrm{e}+01$ 7.65463e+01 7.65463e+00 1.00000e-09 7.00000e-02 $7.65463 \mathrm{e}+017.65463 \mathrm{e}+01$ 7.65463e+00 1.00000e-09 7.00000e-02 5.00000e-04 5.00000e-04 5.00000e-05 1.00000e-09 1.00000e-01 5.00000e-04 5.00000e-04 5.00000e-05 1.00000e-09 1.00000e-01 $3.05849 \mathrm{e}+003.05849 \mathrm{e}+00$ 3.05849e-01 1.00000e-09 2.12000e-01 $3.05849 \mathrm{e}+003.05849 \mathrm{e}+00$ 3.05849e-01 1.00000e-09 2.12000e-01 $3.05849 \mathrm{e}+003.05849 \mathrm{e}+003.05849 \mathrm{e}-01$ 1.00000e-09 2.12000e-01 $3.05849 \mathrm{e}+003.05849 \mathrm{e}+00$ 3.05849e-01 1.00000e-09 2.12000e-01 $3.05849 \mathrm{e}+003.05849 \mathrm{e}+00$ 3.05849e-01 1.00000e-09 2.12000e-01 1.00000e-02 1.00000e-02 1.00000e-03 1.00000e-09 1.00000e-01 $1.00000 \mathrm{e}+001.00000 \mathrm{e}+001.00000 \mathrm{e}-011.00000 \mathrm{e}-091.00000 \mathrm{e}-01$ $1.00000 \mathrm{e}-05$ 1.00000e-05 1.00000e-06 1.00000e-09 1.00000e-01 $1.00000 \mathrm{e}+001.00000 \mathrm{e}+001.00000 \mathrm{e}-011.00000 \mathrm{e}-091.00000 \mathrm{e}-01$ Element: 2737 \# of layers: 15

$\mathrm{Kx} \mathrm{Ky} \mathrm{Kz}$ Ss Por

7.65463e+01 7.65463e+01 7.65463e+00 1.00000e-09 7.00000e-02 $7.65463 \mathrm{e}+01$ 7.65463e+01 7.65463e+00 1.00000e-09 7.00000e-02 $7.65463 \mathrm{e}+01$ 7.65463e+01 7.65463e+00 1.00000e-09 7.00000e-02 $7.65463 \mathrm{e}+01$ 7.65463e+01 7.65463e+00 1.00000e-09 7.00000e-02 $5.00000 \mathrm{e}-04$ 5.00000e-04 5.00000e-05 1.00000e-09 1.00000e-01 5.00000e-04 5.00000e-04 5.00000e-05 1.00000e-09 1.00000e-01 $3.05849 \mathrm{e}+003.05849 \mathrm{e}+00$ 3.05849e-01 1.00000e-09 2.12000e-01 
3.05849e+00 3.05849e+00 3.05849e-01 1.00000e-09 2.12000e-01 $3.05849 \mathrm{e}+003.05849 \mathrm{e}+003.05849 \mathrm{e}-01$ 1.00000e-09 2.12000e-01 $3.05849 \mathrm{e}+003.05849 \mathrm{e}+003.05849 \mathrm{e}-01$ 1.00000e-09 2.12000e-01 $3.05849 \mathrm{e}+003.05849 \mathrm{e}+00$ 3.05849e-01 1.00000e-09 2.12000e-01 $1.00000 \mathrm{e}-02$ 1.00000e-02 1.00000e-03 1.00000e-09 1.00000e-01 $1.00000 \mathrm{e}+001.00000 \mathrm{e}+001.00000 \mathrm{e}-011.00000 \mathrm{e}-091.00000 \mathrm{e}-01$ $1.00000 \mathrm{e}-05$ 1.00000e-05 1.00000e-06 1.00000e-09 1.00000e-01 $1.00000 \mathrm{e}+001.00000 \mathrm{e}+001.00000 \mathrm{e}-011.00000 \mathrm{e}-091.00000 \mathrm{e}-01$ Element: 2738 \# of layers: 15

$\mathrm{Kx} \mathrm{Ky} \mathrm{Kz}$ Ss Por

7.65463e+01 7.65463e+01 7.65463e+00 1.00000e-09 7.00000e-02

$7.65463 \mathrm{e}+017.65463 \mathrm{e}+017.65463 \mathrm{e}+001.00000 \mathrm{e}-09$ 7.00000e-02

$7.65463 \mathrm{e}+01$ 7.65463e+01 7.65463e+00 1.00000e-09 7.00000e-02

$7.65463 \mathrm{e}+017.65463 \mathrm{e}+017.65463 \mathrm{e}+001.00000 \mathrm{e}-09$ 7.00000e-02 5.00000e-04 5.00000e-04 5.00000e-05 1.00000e-09 1.00000e-01 5.00000e-04 5.00000e-04 5.00000e-05 1.00000e-09 1.00000e-01 $3.05849 \mathrm{e}+003.05849 \mathrm{e}+003.05849 \mathrm{e}-01$ 1.00000e-09 2.12000e-01 $3.05849 \mathrm{e}+00$ 3.05849e+00 3.05849e-01 1.00000e-09 2.12000e-01 $3.05849 \mathrm{e}+003.05849 \mathrm{e}+00$ 3.05849e-01 1.00000e-09 2.12000e-01 $3.05849 \mathrm{e}+003.05849 \mathrm{e}+003.05849 \mathrm{e}-01$ 1.00000e-09 2.12000e-01 $3.05849 \mathrm{e}+003.05849 \mathrm{e}+00$ 3.05849e-01 1.00000e-09 2.12000e-01 $1.00000 \mathrm{e}-02$ 1.00000e-02 1.00000e-03 1.00000e-09 1.00000e-01 $1.00000 \mathrm{e}+001.00000 \mathrm{e}+001.00000 \mathrm{e}-011.00000 \mathrm{e}-091.00000 \mathrm{e}-01$ $1.00000 \mathrm{e}-05$ 1.00000e-05 1.00000e-06 1.00000e-09 1.00000e-01 $1.00000 \mathrm{e}+001.00000 \mathrm{e}+001.00000 \mathrm{e}-011.00000 \mathrm{e}-091.00000 \mathrm{e}-01$ Element: 2739 \# of layers: 14

$\mathrm{Kx} \mathrm{Ky} \mathrm{Kz}$ Ss Por

7.65463e+01 7.65463e+01 7.65463e+00 1.00000e-09 7.00000e-02

$7.65463 \mathrm{e}+017.65463 \mathrm{e}+017.65463 \mathrm{e}+001.00000 \mathrm{e}-09$ 7.00000e-02

7.65463e+01 7.65463e+01 7.65463e+00 1.00000e-09 7.00000e-02 5.00000e-04 5.00000e-04 5.00000e-05 1.00000e-09 1.00000e-01 5.00000e-04 5.00000e-04 5.00000e-05 1.00000e-09 1.00000e-01 $3.05849 \mathrm{e}+003.05849 \mathrm{e}+003.05849 \mathrm{e}-01$ 1.00000e-09 2.12000e-01 $3.05849 \mathrm{e}+003.05849 \mathrm{e}+00$ 3.05849e-01 1.00000e-09 2.12000e-01 $3.05849 \mathrm{e}+003.05849 \mathrm{e}+00$ 3.05849e-01 1.00000e-09 2.12000e-01 $3.05849 \mathrm{e}+003.05849 \mathrm{e}+003.05849 \mathrm{e}-01$ 1.00000e-09 2.12000e-01 $3.05849 \mathrm{e}+003.05849 \mathrm{e}+00$ 3.05849e-01 1.00000e-09 2.12000e-01 $1.00000 \mathrm{e}-02$ 1.00000e-02 1.00000e-03 1.00000e-09 1.00000e-01 $1.00000 \mathrm{e}+001.00000 \mathrm{e}+001.00000 \mathrm{e}-011.00000 \mathrm{e}-091.00000 \mathrm{e}-01$ $1.00000 \mathrm{e}-051.00000 \mathrm{e}-05$ 1.00000e-06 1.00000e-09 1.00000e-01 $1.00000 \mathrm{e}+001.00000 \mathrm{e}+001.00000 \mathrm{e}-011.00000 \mathrm{e}-091.00000 \mathrm{e}-01$ Element: 2740 \# of layers: 14

$\mathrm{Kx} \mathrm{Ky} \mathrm{Kz}$ Ss Por

5.35392e+01 5.35392e+01 5.35392e+00 1.00000e-09 7.00000e-02 5.35392e+01 5.35392e+01 5.35392e+00 1.00000e-09 7.00000e-02 $5.35392 \mathrm{e}+015.35392 \mathrm{e}+015.35392 \mathrm{e}+001.00000 \mathrm{e}-09$ 7.00000e-02 
5.00000e-04 5.00000e-04 5.00000e-05 1.00000e-09 1.00000e-01 5.00000e-04 5.00000e-04 5.00000e-05 1.00000e-09 1.00000e-01 $2.13926 \mathrm{e}+002.13926 \mathrm{e}+00$ 2.13926e-01 1.00000e-09 2.12000e-01 $2.13926 \mathrm{e}+002.13926 \mathrm{e}+00$ 2.13926e-01 1.00000e-09 2.12000e-01 2.13926e+00 2.13926e+00 2.13926e-01 1.00000e-09 2.12000e-01 $2.13926 \mathrm{e}+002.13926 \mathrm{e}+00$ 2.13926e-01 1.00000e-09 2.12000e-01 $2.13926 \mathrm{e}+002.13926 \mathrm{e}+00$ 2.13926e-01 1.00000e-09 2.12000e-01 $1.00000 \mathrm{e}-02$ 1.00000e-02 1.00000e-03 1.00000e-09 1.00000e-01 $1.00000 \mathrm{e}+001.00000 \mathrm{e}+001.00000 \mathrm{e}-01$ 1.00000e-09 1.00000e-01 $1.00000 \mathrm{e}-05$ 1.00000e-05 1.00000e-06 1.00000e-09 1.00000e-01 $1.00000 \mathrm{e}+001.00000 \mathrm{e}+001.00000 \mathrm{e}-011.00000 \mathrm{e}-091.00000 \mathrm{e}-01$ Element: 2741 \# of layers: 14

$\mathrm{Kx} \mathrm{Ky} \mathrm{Kz}$ Ss Por

5.35392e+01 5.35392e+01 5.35392e+00 1.00000e-09 7.00000e-02 $5.35392 \mathrm{e}+015.35392 \mathrm{e}+015.35392 \mathrm{e}+001.00000 \mathrm{e}-09$ 7.00000e-02 $5.35392 \mathrm{e}+015.35392 \mathrm{e}+015.35392 \mathrm{e}+00$ 1.00000e-09 7.00000e-02 5.00000e-04 5.00000e-04 5.00000e-05 1.00000e-09 1.00000e-01 5.00000e-04 5.00000e-04 5.00000e-05 1.00000e-09 1.00000e-01 $2.13926 \mathrm{e}+002.13926 \mathrm{e}+00$ 2.13926e-01 1.00000e-09 2.12000e-01 $2.13926 \mathrm{e}+002.13926 \mathrm{e}+00$ 2.13926e-01 1.00000e-09 2.12000e-01 $2.13926 \mathrm{e}+002.13926 \mathrm{e}+00$ 2.13926e-01 1.00000e-09 2.12000e-01 2.13926e+00 2.13926e+00 2.13926e-01 1.00000e-09 2.12000e-01 $2.13926 \mathrm{e}+002.13926 \mathrm{e}+00$ 2.13926e-01 1.00000e-09 2.12000e-01 $1.00000 \mathrm{e}-02$ 1.00000e-02 1.00000e-03 1.00000e-09 1.00000e-01 $1.00000 \mathrm{e}+001.00000 \mathrm{e}+001.00000 \mathrm{e}-011.00000 \mathrm{e}-091.00000 \mathrm{e}-01$ $1.00000 \mathrm{e}-05$ 1.00000e-05 1.00000e-06 1.00000e-09 1.00000e-01 $1.00000 \mathrm{e}+001.00000 \mathrm{e}+001.00000 \mathrm{e}-011.00000 \mathrm{e}-091.00000 \mathrm{e}-01$ Element: 2742 \# of layers: 14

$\mathrm{Kx} \mathrm{Ky} \mathrm{Kz} \mathrm{Ss} \mathrm{Por}$

5.35392e+01 5.35392e+01 5.35392e+00 1.00000e-09 7.00000e-02 5.35392e+01 5.35392e+01 5.35392e+00 1.00000e-09 7.00000e-02 $5.35392 \mathrm{e}+015.35392 \mathrm{e}+015.35392 \mathrm{e}+001.00000 \mathrm{e}-09$ 7.00000e-02 5.00000e-04 5.00000e-04 5.00000e-05 1.00000e-09 1.00000e-01 5.00000e-04 5.00000e-04 5.00000e-05 1.00000e-09 1.00000e-01 $2.13926 \mathrm{e}+002.13926 \mathrm{e}+00$ 2.13926e-01 1.00000e-09 2.12000e-01 $2.13926 \mathrm{e}+002.13926 \mathrm{e}+00$ 2.13926e-01 1.00000e-09 2.12000e-01 $2.13926 \mathrm{e}+002.13926 \mathrm{e}+00$ 2.13926e-01 1.00000e-09 2.12000e-01 $2.13926 \mathrm{e}+002.13926 \mathrm{e}+00$ 2.13926e-01 1.00000e-09 2.12000e-01 2.13926e+00 2.13926e+00 2.13926e-01 1.00000e-09 2.12000e-01 $1.00000 \mathrm{e}-02$ 1.00000e-02 1.00000e-03 1.00000e-09 1.00000e-01 $1.00000 \mathrm{e}+001.00000 \mathrm{e}+001.00000 \mathrm{e}-011.00000 \mathrm{e}-091.00000 \mathrm{e}-01$ $1.00000 \mathrm{e}-05$ 1.00000e-05 1.00000e-06 1.00000e-09 1.00000e-01 $1.00000 \mathrm{e}+001.00000 \mathrm{e}+001.00000 \mathrm{e}-01$ 1.00000e-09 1.00000e-01 Element: 2743 \# of layers: 14

$\mathrm{Kx} \mathrm{Ky} \mathrm{Kz}$ Ss Por

5.35392e+01 5.35392e+01 5.35392e+00 1.00000e-09 7.00000e-02 
5.35392e+01 5.35392e+01 5.35392e+00 1.00000e-09 7.00000e-02 $5.35392 \mathrm{e}+015.35392 \mathrm{e}+015.35392 \mathrm{e}+001.00000 \mathrm{e}-09$ 7.00000e-02 5.00000e-04 5.00000e-04 5.00000e-05 1.00000e-09 1.00000e-01 5.00000e-04 5.00000e-04 5.00000e-05 1.00000e-09 1.00000e-01 $2.13926 \mathrm{e}+002.13926 \mathrm{e}+00$ 2.13926e-01 1.00000e-09 2.12000e-01 $2.13926 \mathrm{e}+002.13926 \mathrm{e}+00$ 2.13926e-01 1.00000e-09 2.12000e-01 2.13926e+00 2.13926e+00 2.13926e-01 1.00000e-09 2.12000e-01 $2.13926 \mathrm{e}+00$ 2.13926e+00 2.13926e-01 1.00000e-09 2.12000e-01 $2.13926 \mathrm{e}+002.13926 \mathrm{e}+00$ 2.13926e-01 1.00000e-09 2.12000e-01 $1.00000 \mathrm{e}-02$ 1.00000e-02 1.00000e-03 1.00000e-09 1.00000e-01 $1.00000 \mathrm{e}+001.00000 \mathrm{e}+001.00000 \mathrm{e}-011.00000 \mathrm{e}-091.00000 \mathrm{e}-01$ $1.00000 \mathrm{e}-05$ 1.00000e-05 1.00000e-06 1.00000e-09 1.00000e-01 $1.00000 \mathrm{e}+001.00000 \mathrm{e}+001.00000 \mathrm{e}-011.00000 \mathrm{e}-091.00000 \mathrm{e}-01$ Element: 2744 \# of layers: 14

$\mathrm{Kx} \mathrm{Ky} \mathrm{Kz}$ Ss Por

5.35392e+01 5.35392e+01 5.35392e+00 1.00000e-09 7.00000e-02 5.35392e+01 5.35392e+01 5.35392e+00 1.00000e-09 7.00000e-02 5.35392e+01 5.35392e+01 5.35392e+00 1.00000e-09 7.00000e-02 5.00000e-04 5.00000e-04 5.00000e-05 1.00000e-09 1.00000e-01 5.00000e-04 5.00000e-04 5.00000e-05 1.00000e-09 1.00000e-01

$2.13926 \mathrm{e}+002.13926 \mathrm{e}+00$ 2.13926e-01 1.00000e-09 2.12000e-01 2.13926e+00 2.13926e+00 2.13926e-01 1.00000e-09 2.12000e-01 $2.13926 \mathrm{e}+002.13926 \mathrm{e}+00$ 2.13926e-01 1.00000e-09 2.12000e-01 $2.13926 \mathrm{e}+002.13926 \mathrm{e}+00$ 2.13926e-01 1.00000e-09 2.12000e-01 $2.13926 \mathrm{e}+002.13926 \mathrm{e}+00 \quad 2.13926 \mathrm{e}-01$ 1.00000e-09 2.12000e-01 $1.00000 \mathrm{e}-02$ 1.00000e-02 1.00000e-03 1.00000e-09 1.00000e-01 $1.00000 \mathrm{e}+001.00000 \mathrm{e}+001.00000 \mathrm{e}-011.00000 \mathrm{e}-091.00000 \mathrm{e}-01$ $1.00000 \mathrm{e}-05$ 1.00000e-05 1.00000e-06 1.00000e-09 1.00000e-01 $1.00000 \mathrm{e}+001.00000 \mathrm{e}+001.00000 \mathrm{e}-011.00000 \mathrm{e}-091.00000 \mathrm{e}-01$ Element: 2745 \# of layers: 14

$\mathrm{Kx} \mathrm{Ky} \mathrm{Kz}$ Ss Por

5.35392e+01 5.35392e+01 5.35392e+00 1.00000e-09 7.00000e-02 $5.35392 \mathrm{e}+015.35392 \mathrm{e}+015.35392 \mathrm{e}+00$ 1.00000e-09 7.00000e-02 5.35392e+01 5.35392e+01 5.35392e+00 1.00000e-09 7.00000e-02 5.00000e-04 5.00000e-04 5.00000e-05 1.00000e-09 1.00000e-01 5.00000e-04 5.00000e-04 5.00000e-05 1.00000e-09 1.00000e-01 $2.13926 \mathrm{e}+002.13926 \mathrm{e}+002.13926 \mathrm{e}-01$ 1.00000e-09 2.12000e-01 2.13926e+00 2.13926e+00 2.13926e-01 1.00000e-09 2.12000e-01 $2.13926 \mathrm{e}+002.13926 \mathrm{e}+00$ 2.13926e-01 1.00000e-09 2.12000e-01 $2.13926 \mathrm{e}+002.13926 \mathrm{e}+00$ 2.13926e-01 1.00000e-09 2.12000e-01 2.13926e+00 2.13926e+00 2.13926e-01 1.00000e-09 2.12000e-01 $1.00000 \mathrm{e}-02$ 1.00000e-02 1.00000e-03 1.00000e-09 1.00000e-01 $1.00000 \mathrm{e}+001.00000 \mathrm{e}+001.00000 \mathrm{e}-011.00000 \mathrm{e}-091.00000 \mathrm{e}-01$ $1.00000 \mathrm{e}-05$ 1.00000e-05 1.00000e-06 1.00000e-09 1.00000e-01 $1.00000 \mathrm{e}+001.00000 \mathrm{e}+001.00000 \mathrm{e}-01$ 1.00000e-09 1.00000e-01 Element: 2746 \# of layers: 14 
$\mathrm{Kx} \mathrm{Ky} \mathrm{Kz}$ Ss Por

5.35392e+01 5.35392e+01 5.35392e+00 1.00000e-09 7.00000e-02

5.35392e+01 5.35392e+01 5.35392e+00 1.00000e-09 7.00000e-02

$5.35392 \mathrm{e}+015.35392 \mathrm{e}+015.35392 \mathrm{e}+001.00000 \mathrm{e}-09$ 7.00000e-02

$5.00000 \mathrm{e}-04$ 5.00000e-04 5.00000e-05 1.00000e-09 1.00000e-01

5.00000e-04 5.00000e-04 5.00000e-05 1.00000e-09 1.00000e-01

$2.13926 \mathrm{e}+002.13926 \mathrm{e}+00$ 2.13926e-01 1.00000e-09 2.12000e-01

$2.13926 \mathrm{e}+002.13926 \mathrm{e}+00$ 2.13926e-01 1.00000e-09 2.12000e-01

$2.13926 \mathrm{e}+002.13926 \mathrm{e}+00$ 2.13926e-01 1.00000e-09 2.12000e-01

$2.13926 \mathrm{e}+002.13926 \mathrm{e}+00$ 2.13926e-01 1.00000e-09 2.12000e-01

$2.13926 \mathrm{e}+002.13926 \mathrm{e}+00$ 2.13926e-01 1.00000e-09 2.12000e-01

$1.00000 \mathrm{e}-02$ 1.00000e-02 1.00000e-03 1.00000e-09 1.00000e-01

$1.00000 \mathrm{e}+001.00000 \mathrm{e}+001.00000 \mathrm{e}-011.00000 \mathrm{e}-091.00000 \mathrm{e}-01$

$1.00000 \mathrm{e}-05$ 1.00000e-05 1.00000e-06 1.00000e-09 1.00000e-01

$1.00000 \mathrm{e}+001.00000 \mathrm{e}+001.00000 \mathrm{e}-01$ 1.00000e-09 1.00000e-01

Element: 2747 \# of layers: 14

$\mathrm{Kx} \mathrm{Ky} \mathrm{Kz}$ Ss Por

5.35392e+01 5.35392e+01 5.35392e+00 1.00000e-09 7.00000e-02

5.35392e+01 5.35392e+01 5.35392e+00 1.00000e-09 7.00000e-02

$5.35392 \mathrm{e}+015.35392 \mathrm{e}+015.35392 \mathrm{e}+00$ 1.00000e-09 7.00000e-02

5.00000e-04 5.00000e-04 5.00000e-05 1.00000e-09 1.00000e-01

5.00000e-04 5.00000e-04 5.00000e-05 1.00000e-09 1.00000e-01

$2.13926 \mathrm{e}+00$ 2.13926e+00 2.13926e-01 1.00000e-09 2.12000e-01

$2.13926 \mathrm{e}+002.13926 \mathrm{e}+00$ 2.13926e-01 1.00000e-09 2.12000e-01

$2.13926 \mathrm{e}+002.13926 \mathrm{e}+00$ 2.13926e-01 1.00000e-09 2.12000e-01

$2.13926 \mathrm{e}+002.13926 \mathrm{e}+00$ 2.13926e-01 1.00000e-09 2.12000e-01

2.13926e+00 2.13926e+00 2.13926e-01 1.00000e-09 2.12000e-01

1.00000e-02 1.00000e-02 1.00000e-03 1.00000e-09 1.00000e-01

$1.00000 \mathrm{e}+001.00000 \mathrm{e}+001.00000 \mathrm{e}-011.00000 \mathrm{e}-091.00000 \mathrm{e}-01$

$1.00000 \mathrm{e}-05$ 1.00000e-05 1.00000e-06 1.00000e-09 1.00000e-01

$1.00000 \mathrm{e}+001.00000 \mathrm{e}+001.00000 \mathrm{e}-011.00000 \mathrm{e}-091.00000 \mathrm{e}-01$

Element: 2748 \# of layers: 14

Kx Ky Kz Ss Por

5.35392e+01 5.35392e+01 5.35392e+00 1.00000e-09 7.00000e-02

$5.35392 \mathrm{e}+015.35392 \mathrm{e}+01$ 5.35392e+00 1.00000e-09 7.00000e-02

$5.35392 \mathrm{e}+015.35392 \mathrm{e}+015.35392 \mathrm{e}+001.00000 \mathrm{e}-09$ 7.00000e-02

5.00000e-04 5.00000e-04 5.00000e-05 1.00000e-09 1.00000e-01

5.00000e-04 5.00000e-04 5.00000e-05 1.00000e-09 1.00000e-01

$2.13926 \mathrm{e}+002.13926 \mathrm{e}+002.13926 \mathrm{e}-01$ 1.00000e-09 2.12000e-01

2.13926e+00 2.13926e+00 2.13926e-01 1.00000e-09 2.12000e-01

$2.13926 \mathrm{e}+002.13926 \mathrm{e}+00$ 2.13926e-01 1.00000e-09 2.12000e-01

$2.13926 \mathrm{e}+002.13926 \mathrm{e}+00$ 2.13926e-01 1.00000e-09 2.12000e-01

2.13926e+00 2.13926e+00 2.13926e-01 1.00000e-09 2.12000e-01

$1.00000 \mathrm{e}-02$ 1.00000e-02 1.00000e-03 1.00000e-09 1.00000e-01

$1.00000 \mathrm{e}+001.00000 \mathrm{e}+001.00000 \mathrm{e}-011.00000 \mathrm{e}-091.00000 \mathrm{e}-01$

$1.00000 \mathrm{e}-05$ 1.00000e-05 1.00000e-06 1.00000e-09 1.00000e-01 
$1.00000 \mathrm{e}+001.00000 \mathrm{e}+00$ 1.00000e-01 1.00000e-09 1.00000e-01 Element: 2749 \# of layers: 14

$\mathrm{Kx} \mathrm{Ky} \mathrm{Kz}$ Ss Por

5.53809e+01 5.53809e+01 5.53809e+00 1.00000e-09 7.00000e-02

$5.53809 \mathrm{e}+015.53809 \mathrm{e}+015.53809 \mathrm{e}+001.00000 \mathrm{e}-097.00000 \mathrm{e}-02$

$5.53809 \mathrm{e}+015.53809 \mathrm{e}+015.53809 \mathrm{e}+001.00000 \mathrm{e}-097.00000 \mathrm{e}-02$ 5.00000e-04 5.00000e-04 5.00000e-05 1.00000e-09 1.00000e-01

5.00000e-04 5.00000e-04 5.00000e-05 1.00000e-09 1.00000e-01

$2.21283 \mathrm{e}+002.21283 \mathrm{e}+00$ 2.21283e-01 1.00000e-09 2.12000e-01

$2.21283 \mathrm{e}+00$ 2.21283e+00 2.21283e-01 1.00000e-09 2.12000e-01

$2.21283 \mathrm{e}+00$ 2.21283e+00 2.21283e-01 1.00000e-09 2.12000e-01

$2.21283 \mathrm{e}+002.21283 \mathrm{e}+00$ 2.21283e-01 1.00000e-09 2.12000e-01

$2.21283 \mathrm{e}+002.21283 \mathrm{e}+00$ 2.21283e-01 1.00000e-09 2.12000e-01

$1.00000 \mathrm{e}-02$ 1.00000e-02 1.00000e-03 1.00000e-09 1.00000e-01

$1.00000 \mathrm{e}+001.00000 \mathrm{e}+001.00000 \mathrm{e}-011.00000 \mathrm{e}-091.00000 \mathrm{e}-01$ $1.00000 \mathrm{e}-05$ 1.00000e-05 1.00000e-06 1.00000e-09 1.00000e-01

$1.00000 \mathrm{e}+001.00000 \mathrm{e}+001.00000 \mathrm{e}-011.00000 \mathrm{e}-091.00000 \mathrm{e}-01$

Element: 2750 \# of layers: 14

$\mathrm{Kx} \mathrm{Ky} \mathrm{Kz}$ Ss Por

5.53809e+01 5.53809e+01 5.53809e+00 1.00000e-09 7.00000e-02

$5.53809 \mathrm{e}+015.53809 \mathrm{e}+015.53809 \mathrm{e}+001.00000 \mathrm{e}-09$ 7.00000e-02

$5.53809 \mathrm{e}+015.53809 \mathrm{e}+015.53809 \mathrm{e}+001.00000 \mathrm{e}-09$ 7.00000e-02

5.00000e-04 5.00000e-04 5.00000e-05 1.00000e-09 1.00000e-01

5.00000e-04 5.00000e-04 5.00000e-05 1.00000e-09 1.00000e-01

$2.21283 \mathrm{e}+002.21283 \mathrm{e}+00$ 2.21283e-01 1.00000e-09 2.12000e-01

$2.21283 e+002.21283 \mathrm{e}+00$ 2.21283e-01 1.00000e-09 2.12000e-01

2.21283e+00 2.21283e+00 2.21283e-01 1.00000e-09 2.12000e-01

$2.21283 \mathrm{e}+00$ 2.21283e+00 2.21283e-01 1.00000e-09 2.12000e-01

$2.21283 \mathrm{e}+002.21283 \mathrm{e}+00$ 2.21283e-01 1.00000e-09 2.12000e-01

$1.00000 \mathrm{e}-02$ 1.00000e-02 1.00000e-03 1.00000e-09 1.00000e-01

$1.00000 \mathrm{e}+001.00000 \mathrm{e}+001.00000 \mathrm{e}-01$ 1.00000e-09 1.00000e-01

$1.00000 \mathrm{e}-05$ 1.00000e-05 1.00000e-06 1.00000e-09 1.00000e-01

$1.00000 \mathrm{e}+001.00000 \mathrm{e}+001.00000 \mathrm{e}-011.00000 \mathrm{e}-091.00000 \mathrm{e}-01$

Element: 2751 \# of layers: 13

$\mathrm{Kx} \mathrm{Ky} \mathrm{Kz}$ Ss Por

5.53809e+01 5.53809e+01 5.53809e+00 1.00000e-09 7.00000e-02

$5.53809 \mathrm{e}+015.53809 \mathrm{e}+015.53809 \mathrm{e}+001.00000 \mathrm{e}-09$ 7.00000e-02

5.00000e-04 5.00000e-04 5.00000e-05 1.00000e-09 1.00000e-01

5.00000e-04 5.00000e-04 5.00000e-05 1.00000e-09 1.00000e-01

$2.21283 \mathrm{e}+00$ 2.21283e+00 2.21283e-01 1.00000e-09 2.12000e-01

$2.21283 \mathrm{e}+002.21283 \mathrm{e}+00$ 2.21283e-01 1.00000e-09 2.12000e-01

$2.21283 \mathrm{e}+002.21283 \mathrm{e}+00$ 2.21283e-01 1.00000e-09 2.12000e-01

$2.21283 \mathrm{e}+00$ 2.21283e+00 2.21283e-01 1.00000e-09 2.12000e-01

$2.21283 \mathrm{e}+002.21283 \mathrm{e}+00$ 2.21283e-01 1.00000e-09 2.12000e-01

$1.00000 \mathrm{e}-02$ 1.00000e-02 1.00000e-03 1.00000e-09 1.00000e-01

$1.00000 \mathrm{e}+001.00000 \mathrm{e}+001.00000 \mathrm{e}-011.00000 \mathrm{e}-091.00000 \mathrm{e}-01$ 
$1.00000 \mathrm{e}-05$ 1.00000e-05 1.00000e-06 1.00000e-09 1.00000e-01 $1.00000 \mathrm{e}+001.00000 \mathrm{e}+001.00000 \mathrm{e}-01$ 1.00000e-09 1.00000e-01 Element: 2752 \# of layers: 13

Kx Ky Kz Ss Por

5.53809e+01 5.53809e+01 5.53809e+00 1.00000e-09 7.00000e-02

$5.53809 \mathrm{e}+015.53809 \mathrm{e}+015.53809 \mathrm{e}+001.00000 \mathrm{e}-097.00000 \mathrm{e}-02$ 5.00000e-04 5.00000e-04 5.00000e-05 1.00000e-09 1.00000e-01 5.00000e-04 5.00000e-04 5.00000e-05 1.00000e-09 1.00000e-01 $2.21283 \mathrm{e}+002.21283 \mathrm{e}+00$ 2.21283e-01 1.00000e-09 2.12000e-01 $2.21283 \mathrm{e}+002.21283 \mathrm{e}+00$ 2.21283e-01 1.00000e-09 2.12000e-01 $2.21283 \mathrm{e}+00$ 2.21283e+00 2.21283e-01 1.00000e-09 2.12000e-01 $2.21283 \mathrm{e}+002.21283 \mathrm{e}+00$ 2.21283e-01 1.00000e-09 2.12000e-01 $2.21283 \mathrm{e}+002.21283 \mathrm{e}+00$ 2.21283e-01 1.00000e-09 2.12000e-01 $1.00000 \mathrm{e}-02$ 1.00000e-02 1.00000e-03 1.00000e-09 1.00000e-01 $1.00000 \mathrm{e}+001.00000 \mathrm{e}+001.00000 \mathrm{e}-011.00000 \mathrm{e}-091.00000 \mathrm{e}-01$ $1.00000 \mathrm{e}-05$ 1.00000e-05 1.00000e-06 1.00000e-09 1.00000e-01 $1.00000 \mathrm{e}+001.00000 \mathrm{e}+001.00000 \mathrm{e}-01$ 1.00000e-09 1.00000e-01 Element: 2753 \# of layers: 13

$\mathrm{Kx} \mathrm{Ky} \mathrm{Kz}$ Ss Por

5.53809e+01 5.53809e+01 5.53809e+00 1.00000e-09 7.00000e-02 $5.53809 \mathrm{e}+015.53809 \mathrm{e}+015.53809 \mathrm{e}+001.00000 \mathrm{e}-09$ 7.00000e-02 5.00000e-04 5.00000e-04 5.00000e-05 1.00000e-09 1.00000e-01 5.00000e-04 5.00000e-04 5.00000e-05 1.00000e-09 1.00000e-01 $2.21283 \mathrm{e}+002.21283 \mathrm{e}+00$ 2.21283e-01 1.00000e-09 2.12000e-01 $2.21283 \mathrm{e}+002.21283 \mathrm{e}+00$ 2.21283e-01 1.00000e-09 2.12000e-01 $2.21283 e+002.21283 \mathrm{e}+00$ 2.21283e-01 1.00000e-09 2.12000e-01 $2.21283 \mathrm{e}+00$ 2.21283e+00 2.21283e-01 1.00000e-09 2.12000e-01 $2.21283 \mathrm{e}+00$ 2.21283e+00 2.21283e-01 1.00000e-09 2.12000e-01 $1.00000 \mathrm{e}-02$ 1.00000e-02 1.00000e-03 1.00000e-09 1.00000e-01 $1.00000 \mathrm{e}+001.00000 \mathrm{e}+001.00000 \mathrm{e}-011.00000 \mathrm{e}-091.00000 \mathrm{e}-01$ $1.00000 \mathrm{e}-05$ 1.00000e-05 1.00000e-06 1.00000e-09 1.00000e-01 $1.00000 \mathrm{e}+001.00000 \mathrm{e}+001.00000 \mathrm{e}-011.00000 \mathrm{e}-091.00000 \mathrm{e}-01$ Element: 2754 \# of layers: 13

$\mathrm{Kx} \mathrm{Ky} \mathrm{Kz}$ Ss Por

5.53809e+01 5.53809e+01 5.53809e+00 1.00000e-09 7.00000e-02 $5.53809 \mathrm{e}+015.53809 \mathrm{e}+015.53809 \mathrm{e}+001.00000 \mathrm{e}-09$ 7.00000e-02 5.00000e-04 5.00000e-04 5.00000e-05 1.00000e-09 1.00000e-01 5.00000e-04 5.00000e-04 5.00000e-05 1.00000e-09 1.00000e-01 $2.21283 \mathrm{e}+00$ 2.21283e+00 2.21283e-01 1.00000e-09 2.12000e-01 $2.21283 \mathrm{e}+00$ 2.21283e+00 2.21283e-01 1.00000e-09 2.12000e-01 $2.21283 \mathrm{e}+002.21283 \mathrm{e}+00$ 2.21283e-01 1.00000e-09 2.12000e-01 $2.21283 \mathrm{e}+002.21283 \mathrm{e}+00$ 2.21283e-01 1.00000e-09 2.12000e-01 $2.21283 \mathrm{e}+00$ 2.21283e+00 2.21283e-01 1.00000e-09 2.12000e-01 $1.00000 \mathrm{e}-02$ 1.00000e-02 1.00000e-03 1.00000e-09 1.00000e-01 $1.00000 \mathrm{e}+001.00000 \mathrm{e}+001.00000 \mathrm{e}-011.00000 \mathrm{e}-091.00000 \mathrm{e}-01$ $1.00000 \mathrm{e}-05$ 1.00000e-05 1.00000e-06 1.00000e-09 1.00000e-01 
$1.00000 \mathrm{e}+001.00000 \mathrm{e}+00$ 1.00000e-01 1.00000e-09 1.00000e-01 Element: 2755 \# of layers: 14

$\mathrm{Kx} \mathrm{Ky} \mathrm{Kz}$ Ss Por

5.53809e+01 5.53809e+01 5.53809e+00 1.00000e-09 7.00000e-02

$5.53809 \mathrm{e}+015.53809 \mathrm{e}+015.53809 \mathrm{e}+001.00000 \mathrm{e}-09$ 7.00000e-02

$5.53809 \mathrm{e}+015.53809 \mathrm{e}+015.53809 \mathrm{e}+001.00000 \mathrm{e}-097.00000 \mathrm{e}-02$ 5.00000e-04 5.00000e-04 5.00000e-05 1.00000e-09 1.00000e-01

5.00000e-04 5.00000e-04 5.00000e-05 1.00000e-09 1.00000e-01

$2.21283 \mathrm{e}+002.21283 \mathrm{e}+00$ 2.21283e-01 1.00000e-09 2.12000e-01

$2.21283 \mathrm{e}+00$ 2.21283e+00 2.21283e-01 1.00000e-09 2.12000e-01

$2.21283 \mathrm{e}+002.21283 \mathrm{e}+00$ 2.21283e-01 1.00000e-09 2.12000e-01

$2.21283 \mathrm{e}+002.21283 \mathrm{e}+00$ 2.21283e-01 1.00000e-09 2.12000e-01

$2.21283 \mathrm{e}+002.21283 \mathrm{e}+00$ 2.21283e-01 1.00000e-09 2.12000e-01

$1.00000 \mathrm{e}-02$ 1.00000e-02 1.00000e-03 1.00000e-09 1.00000e-01

$1.00000 \mathrm{e}+001.00000 \mathrm{e}+001.00000 \mathrm{e}-011.00000 \mathrm{e}-091.00000 \mathrm{e}-01$ $1.00000 \mathrm{e}-05$ 1.00000e-05 1.00000e-06 1.00000e-09 1.00000e-01

$1.00000 \mathrm{e}+001.00000 \mathrm{e}+001.00000 \mathrm{e}-011.00000 \mathrm{e}-091.00000 \mathrm{e}-01$

Element: 2756 \# of layers: 14

$\mathrm{Kx} \mathrm{Ky} \mathrm{Kz}$ Ss Por

5.53809e+01 5.53809e+01 5.53809e+00 1.00000e-09 7.00000e-02

$5.53809 \mathrm{e}+015.53809 \mathrm{e}+015.53809 \mathrm{e}+001.00000 \mathrm{e}-09$ 7.00000e-02

$5.53809 \mathrm{e}+015.53809 \mathrm{e}+015.53809 \mathrm{e}+001.00000 \mathrm{e}-09$ 7.00000e-02

5.00000e-04 5.00000e-04 5.00000e-05 1.00000e-09 1.00000e-01

5.00000e-04 5.00000e-04 5.00000e-05 1.00000e-09 1.00000e-01

$2.21283 \mathrm{e}+002.21283 \mathrm{e}+00$ 2.21283e-01 1.00000e-09 2.12000e-01

$2.21283 e+002.21283 \mathrm{e}+00$ 2.21283e-01 1.00000e-09 2.12000e-01

2.21283e+00 2.21283e+00 2.21283e-01 1.00000e-09 2.12000e-01

$2.21283 \mathrm{e}+00$ 2.21283e+00 2.21283e-01 1.00000e-09 2.12000e-01

$2.21283 \mathrm{e}+002.21283 \mathrm{e}+00$ 2.21283e-01 1.00000e-09 2.12000e-01

$1.00000 \mathrm{e}-02$ 1.00000e-02 1.00000e-03 1.00000e-09 1.00000e-01

$1.00000 \mathrm{e}+001.00000 \mathrm{e}+001.00000 \mathrm{e}-01$ 1.00000e-09 1.00000e-01

$1.00000 \mathrm{e}-05$ 1.00000e-05 1.00000e-06 1.00000e-09 1.00000e-01

$1.00000 \mathrm{e}+001.00000 \mathrm{e}+001.00000 \mathrm{e}-011.00000 \mathrm{e}-091.00000 \mathrm{e}-01$

Element: 2757 \# of layers: 13

$\mathrm{Kx} \mathrm{Ky} \mathrm{Kz}$ Ss Por

5.53809e+01 5.53809e+01 5.53809e+00 1.00000e-09 7.00000e-02

$5.53809 \mathrm{e}+015.53809 \mathrm{e}+015.53809 \mathrm{e}+001.00000 \mathrm{e}-09$ 7.00000e-02

5.00000e-04 5.00000e-04 5.00000e-05 1.00000e-09 1.00000e-01

5.00000e-04 5.00000e-04 5.00000e-05 1.00000e-09 1.00000e-01

$2.21283 \mathrm{e}+00$ 2.21283e+00 2.21283e-01 1.00000e-09 2.12000e-01

$2.21283 \mathrm{e}+002.21283 \mathrm{e}+00$ 2.21283e-01 1.00000e-09 2.12000e-01

$2.21283 \mathrm{e}+002.21283 \mathrm{e}+00$ 2.21283e-01 1.00000e-09 2.12000e-01

$2.21283 \mathrm{e}+00$ 2.21283e+00 2.21283e-01 1.00000e-09 2.12000e-01

$2.21283 \mathrm{e}+002.21283 \mathrm{e}+00$ 2.21283e-01 1.00000e-09 2.12000e-01

$1.00000 \mathrm{e}-02$ 1.00000e-02 1.00000e-03 1.00000e-09 1.00000e-01

$1.00000 \mathrm{e}+001.00000 \mathrm{e}+001.00000 \mathrm{e}-011.00000 \mathrm{e}-091.00000 \mathrm{e}-01$ 
$1.00000 \mathrm{e}-05$ 1.00000e-05 1.00000e-06 1.00000e-09 1.00000e-01 $1.00000 \mathrm{e}+001.00000 \mathrm{e}+001.00000 \mathrm{e}-01$ 1.00000e-09 1.00000e-01 Element: 2758 \# of layers: 13

$\mathrm{Kx} \mathrm{Ky} \mathrm{Kz}$ Ss Por

3.64283e+01 3.64283e+01 3.64283e+00 1.00000e-09 7.00000e-02

$3.64283 \mathrm{e}+013.64283 \mathrm{e}+013.64283 \mathrm{e}+001.00000 \mathrm{e}-09$ 7.00000e-02 5.00000e-04 5.00000e-04 5.00000e-05 1.00000e-09 1.00000e-01 5.00000e-04 5.00000e-04 5.00000e-05 1.00000e-09 1.00000e-01 $1.45556 \mathrm{e}+001.45556 \mathrm{e}+001.45556 \mathrm{e}-01$ 1.00000e-09 2.12000e-01 $1.45556 \mathrm{e}+001.45556 \mathrm{e}+001.45556 \mathrm{e}-01$ 1.00000e-09 2.12000e-01 $1.45556 \mathrm{e}+001.45556 \mathrm{e}+001.45556 \mathrm{e}-01$ 1.00000e-09 2.12000e-01 $1.45556 \mathrm{e}+001.45556 \mathrm{e}+001.45556 \mathrm{e}-011.00000 \mathrm{e}-092.12000 \mathrm{e}-01$ $1.45556 \mathrm{e}+001.45556 \mathrm{e}+001.45556 \mathrm{e}-01$ 1.00000e-09 2.12000e-01 $1.00000 \mathrm{e}-02$ 1.00000e-02 1.00000e-03 1.00000e-09 1.00000e-01 $1.00000 \mathrm{e}+001.00000 \mathrm{e}+001.00000 \mathrm{e}-011.00000 \mathrm{e}-091.00000 \mathrm{e}-01$ $1.00000 \mathrm{e}-05$ 1.00000e-05 1.00000e-06 1.00000e-09 1.00000e-01 $1.00000 \mathrm{e}+001.00000 \mathrm{e}+001.00000 \mathrm{e}-01$ 1.00000e-09 1.00000e-01 Element: 2759 \# of layers: 13

$\mathrm{Kx} \mathrm{Ky} \mathrm{Kz}$ Ss Por

3.64283e+01 3.64283e+01 3.64283e+00 1.00000e-09 7.00000e-02 $3.64283 \mathrm{e}+013.64283 \mathrm{e}+013.64283 \mathrm{e}+001.00000 \mathrm{e}-09$ 7.00000e-02 5.00000e-04 5.00000e-04 5.00000e-05 1.00000e-09 1.00000e-01 5.00000e-04 5.00000e-04 5.00000e-05 1.00000e-09 1.00000e-01 $1.45556 \mathrm{e}+001.45556 \mathrm{e}+001.45556 \mathrm{e}-011.00000 \mathrm{e}-092.12000 \mathrm{e}-01$ $1.45556 \mathrm{e}+001.45556 \mathrm{e}+001.45556 \mathrm{e}-011.00000 \mathrm{e}-092.12000 \mathrm{e}-01$ $1.45556 \mathrm{e}+001.45556 \mathrm{e}+001.45556 \mathrm{e}-01$ 1.00000e-09 2.12000e-01 $1.45556 \mathrm{e}+001.45556 \mathrm{e}+001.45556 \mathrm{e}-011.00000 \mathrm{e}-092.12000 \mathrm{e}-01$ $1.45556 \mathrm{e}+001.45556 \mathrm{e}+001.45556 \mathrm{e}-011.00000 \mathrm{e}-092.12000 \mathrm{e}-01$ $1.00000 \mathrm{e}-02$ 1.00000e-02 1.00000e-03 1.00000e-09 1.00000e-01 $1.00000 \mathrm{e}+001.00000 \mathrm{e}+001.00000 \mathrm{e}-011.00000 \mathrm{e}-091.00000 \mathrm{e}-01$ $1.00000 \mathrm{e}-05$ 1.00000e-05 1.00000e-06 1.00000e-09 1.00000e-01 $1.00000 \mathrm{e}+001.00000 \mathrm{e}+001.00000 \mathrm{e}-011.00000 \mathrm{e}-091.00000 \mathrm{e}-01$ Element: 2760 \# of layers: 13

$\mathrm{Kx} \mathrm{Ky} \mathrm{Kz}$ Ss Por

3.64283e+01 3.64283e+01 3.64283e+00 1.00000e-09 7.00000e-02 $3.64283 \mathrm{e}+013.64283 \mathrm{e}+013.64283 \mathrm{e}+001.00000 \mathrm{e}-09$ 7.00000e-02 5.00000e-04 5.00000e-04 5.00000e-05 1.00000e-09 1.00000e-01 5.00000e-04 5.00000e-04 5.00000e-05 1.00000e-09 1.00000e-01 $1.45556 \mathrm{e}+001.45556 \mathrm{e}+001.45556 \mathrm{e}-01$ 1.00000e-09 2.12000e-01 $1.45556 \mathrm{e}+001.45556 \mathrm{e}+001.45556 \mathrm{e}-01$ 1.00000e-09 2.12000e-01 $1.45556 \mathrm{e}+001.45556 \mathrm{e}+00$ 1.45556e-01 1.00000e-09 2.12000e-01 $1.45556 \mathrm{e}+001.45556 \mathrm{e}+00$ 1.45556e-01 1.00000e-09 2.12000e-01 $1.45556 \mathrm{e}+001.45556 \mathrm{e}+00$ 1.45556e-01 1.00000e-09 2.12000e-01 $1.00000 \mathrm{e}-02$ 1.00000e-02 1.00000e-03 1.00000e-09 1.00000e-01 $1.00000 \mathrm{e}+001.00000 \mathrm{e}+001.00000 \mathrm{e}-011.00000 \mathrm{e}-091.00000 \mathrm{e}-01$ $1.00000 \mathrm{e}-05$ 1.00000e-05 1.00000e-06 1.00000e-09 1.00000e-01 
$1.00000 \mathrm{e}+001.00000 \mathrm{e}+00$ 1.00000e-01 1.00000e-09 1.00000e-01 Element: 2761 \# of layers: 13

Kx Ky Kz Ss Por

$3.64283 e+01$ 3.64283e+01 3.64283e+00 1.00000e-09 7.00000e-02

$3.64283 \mathrm{e}+013.64283 \mathrm{e}+013.64283 \mathrm{e}+001.00000 \mathrm{e}-097.00000 \mathrm{e}-02$

5.00000e-04 5.00000e-04 5.00000e-05 1.00000e-09 1.00000e-01

5.00000e-04 5.00000e-04 5.00000e-05 1.00000e-09 1.00000e-01

$1.45556 \mathrm{e}+001.45556 \mathrm{e}+001.45556 \mathrm{e}-011.00000 \mathrm{e}-092.12000 \mathrm{e}-01$

$1.45556 \mathrm{e}+001.45556 \mathrm{e}+001.45556 \mathrm{e}-01$ 1.00000e-09 2.12000e-01

$1.45556 \mathrm{e}+001.45556 \mathrm{e}+001.45556 \mathrm{e}-01$ 1.00000e-09 2.12000e-01

$1.45556 \mathrm{e}+001.45556 \mathrm{e}+001.45556 \mathrm{e}-01$ 1.00000e-09 2.12000e-01

$1.45556 \mathrm{e}+001.45556 \mathrm{e}+001.45556 \mathrm{e}-011.00000 \mathrm{e}-092.12000 \mathrm{e}-01$

$1.00000 \mathrm{e}-02$ 1.00000e-02 1.00000e-03 1.00000e-09 1.00000e-01

$1.00000 \mathrm{e}+001.00000 \mathrm{e}+001.00000 \mathrm{e}-011.00000 \mathrm{e}-091.00000 \mathrm{e}-01$

$1.00000 \mathrm{e}-05$ 1.00000e-05 1.00000e-06 1.00000e-09 1.00000e-01

$1.00000 \mathrm{e}+001.00000 \mathrm{e}+001.00000 \mathrm{e}-011.00000 \mathrm{e}-091.00000 \mathrm{e}-01$

Element: 2762 \# of layers: 13

$\mathrm{Kx} \mathrm{Ky} \mathrm{Kz}$ Ss Por

3.64283e+01 3.64283e+01 3.64283e+00 1.00000e-09 7.00000e-02

$3.64283 \mathrm{e}+013.64283 \mathrm{e}+013.64283 \mathrm{e}+001.00000 \mathrm{e}-09$ 7.00000e-02

5.00000e-04 5.00000e-04 5.00000e-05 1.00000e-09 1.00000e-01

5.00000e-04 5.00000e-04 5.00000e-05 1.00000e-09 1.00000e-01

$1.45556 \mathrm{e}+001.45556 \mathrm{e}+001.45556 \mathrm{e}-01$ 1.00000e-09 2.12000e-01

$1.45556 \mathrm{e}+001.45556 \mathrm{e}+001.45556 \mathrm{e}-011.00000 \mathrm{e}-092.12000 \mathrm{e}-01$

$1.45556 \mathrm{e}+001.45556 \mathrm{e}+001.45556 \mathrm{e}-011.00000 \mathrm{e}-092.12000 \mathrm{e}-01$

$1.45556 \mathrm{e}+001.45556 \mathrm{e}+001.45556 \mathrm{e}-01$ 1.00000e-09 2.12000e-01

$1.45556 \mathrm{e}+001.45556 \mathrm{e}+001.45556 \mathrm{e}-01$ 1.00000e-09 2.12000e-01

1.00000e-02 1.00000e-02 1.00000e-03 1.00000e-09 1.00000e-01

$1.00000 \mathrm{e}+001.00000 \mathrm{e}+001.00000 \mathrm{e}-011.00000 \mathrm{e}-091.00000 \mathrm{e}-01$

$1.00000 \mathrm{e}-05$ 1.00000e-05 1.00000e-06 1.00000e-09 1.00000e-01

$1.00000 \mathrm{e}+001.00000 \mathrm{e}+001.00000 \mathrm{e}-01$ 1.00000e-09 1.00000e-01

Element: 2763 \# of layers: 13

Kx Ky Kz Ss Por

$3.64283 \mathrm{e}+01$ 3.64283e+01 3.64283e+00 1.00000e-09 7.00000e-02

$3.64283 \mathrm{e}+013.64283 \mathrm{e}+013.64283 \mathrm{e}+001.00000 \mathrm{e}-09$ 7.00000e-02

5.00000e-04 5.00000e-04 5.00000e-05 1.00000e-09 1.00000e-01

5.00000e-04 5.00000e-04 5.00000e-05 1.00000e-09 1.00000e-01

$1.45556 \mathrm{e}+001.45556 \mathrm{e}+001.45556 \mathrm{e}-011.00000 \mathrm{e}-092.12000 \mathrm{e}-01$

$1.45556 \mathrm{e}+001.45556 \mathrm{e}+001.45556 \mathrm{e}-011.00000 \mathrm{e}-092.12000 \mathrm{e}-01$

$1.45556 \mathrm{e}+001.45556 \mathrm{e}+001.45556 \mathrm{e}-01$ 1.00000e-09 2.12000e-01

$1.45556 \mathrm{e}+001.45556 \mathrm{e}+001.45556 \mathrm{e}-011.00000 \mathrm{e}-092.12000 \mathrm{e}-01$

$1.45556 \mathrm{e}+001.45556 \mathrm{e}+001.45556 \mathrm{e}-01 \quad 1.00000 \mathrm{e}-092.12000 \mathrm{e}-01$

$1.00000 \mathrm{e}-02$ 1.00000e-02 1.00000e-03 1.00000e-09 1.00000e-01

$1.00000 \mathrm{e}+001.00000 \mathrm{e}+001.00000 \mathrm{e}-011.00000 \mathrm{e}-091.00000 \mathrm{e}-01$

$1.00000 \mathrm{e}-05$ 1.00000e-05 1.00000e-06 1.00000e-09 1.00000e-01

$1.00000 \mathrm{e}+001.00000 \mathrm{e}+001.00000 \mathrm{e}-011.00000 \mathrm{e}-091.00000 \mathrm{e}-01$ 
Element: 2764 \# of layers: 13

Kx Ky Kz Ss Por

$3.64283 \mathrm{e}+013.64283 \mathrm{e}+013.64283 \mathrm{e}+00$ 1.00000e-09 7.00000e-02

$3.64283 \mathrm{e}+013.64283 \mathrm{e}+013.64283 \mathrm{e}+001.00000 \mathrm{e}-09$ 7.00000e-02

$5.00000 \mathrm{e}-04$ 5.00000e-04 5.00000e-05 1.00000e-09 1.00000e-01

5.00000e-04 5.00000e-04 5.00000e-05 1.00000e-09 1.00000e-01

$1.45556 \mathrm{e}+001.45556 \mathrm{e}+001.45556 \mathrm{e}-011.00000 \mathrm{e}-092.12000 \mathrm{e}-01$

$1.45556 \mathrm{e}+001.45556 \mathrm{e}+001.45556 \mathrm{e}-011.00000 \mathrm{e}-092.12000 \mathrm{e}-01$

$1.45556 \mathrm{e}+001.45556 \mathrm{e}+001.45556 \mathrm{e}-011.00000 \mathrm{e}-092.12000 \mathrm{e}-01$

$1.45556 \mathrm{e}+001.45556 \mathrm{e}+001.45556 \mathrm{e}-011.00000 \mathrm{e}-092.12000 \mathrm{e}-01$

$1.45556 \mathrm{e}+001.45556 \mathrm{e}+001.45556 \mathrm{e}-011.00000 \mathrm{e}-09$ 2.12000e-01

$1.00000 \mathrm{e}-021.00000 \mathrm{e}-02$ 1.00000e-03 1.00000e-09 1.00000e-01

$1.00000 \mathrm{e}+001.00000 \mathrm{e}+001.00000 \mathrm{e}-011.00000 \mathrm{e}-091.00000 \mathrm{e}-01$

$1.00000 \mathrm{e}-05$ 1.00000e-05 1.00000e-06 1.00000e-09 1.00000e-01

$1.00000 \mathrm{e}+001.00000 \mathrm{e}+001.00000 \mathrm{e}-011.00000 \mathrm{e}-091.00000 \mathrm{e}-01$

Element: 2765 \# of layers: 13

Kx Ky Kz Ss Por

$3.64283 \mathrm{e}+013.64283 \mathrm{e}+013.64283 \mathrm{e}+00$ 1.00000e-09 7.00000e-02

$3.64283 \mathrm{e}+013.64283 \mathrm{e}+013.64283 \mathrm{e}+00$ 1.00000e-09 7.00000e-02

5.00000e-04 5.00000e-04 5.00000e-05 1.00000e-09 1.00000e-01

5.00000e-04 5.00000e-04 5.00000e-05 1.00000e-09 1.00000e-01

$1.45556 \mathrm{e}+001.45556 \mathrm{e}+00$ 1.45556e-01 1.00000e-09 2.12000e-01

$1.45556 \mathrm{e}+001.45556 \mathrm{e}+001.45556 \mathrm{e}-011.00000 \mathrm{e}-092.12000 \mathrm{e}-01$

$1.45556 \mathrm{e}+001.45556 \mathrm{e}+001.45556 \mathrm{e}-011.00000 \mathrm{e}-092.12000 \mathrm{e}-01$

$1.45556 \mathrm{e}+001.45556 \mathrm{e}+001.45556 \mathrm{e}-011.00000 \mathrm{e}-092.12000 \mathrm{e}-01$

$1.45556 \mathrm{e}+001.45556 \mathrm{e}+001.45556 \mathrm{e}-011.00000 \mathrm{e}-092.12000 \mathrm{e}-01$

$1.00000 \mathrm{e}-02$ 1.00000e-02 1.00000e-03 1.00000e-09 1.00000e-01

$1.00000 \mathrm{e}+001.00000 \mathrm{e}+001.00000 \mathrm{e}-011.00000 \mathrm{e}-091.00000 \mathrm{e}-01$

$1.00000 \mathrm{e}-051.00000 \mathrm{e}-05$ 1.00000e-06 1.00000e-09 1.00000e-01

$1.00000 \mathrm{e}+001.00000 \mathrm{e}+001.00000 \mathrm{e}-011.00000 \mathrm{e}-091.00000 \mathrm{e}-01$

Element: 2766 \# of layers: 13

Kx Ky Kz Ss Por

$3.64283 \mathrm{e}+013.64283 \mathrm{e}+013.64283 \mathrm{e}+00$ 1.00000e-09 7.00000e-02

$3.64283 \mathrm{e}+013.64283 \mathrm{e}+013.64283 \mathrm{e}+001.00000 \mathrm{e}-09$ 7.00000e-02

5.00000e-04 5.00000e-04 5.00000e-05 1.00000e-09 1.00000e-01

5.00000e-04 5.00000e-04 5.00000e-05 1.00000e-09 1.00000e-01

$1.45556 \mathrm{e}+001.45556 \mathrm{e}+001.45556 \mathrm{e}-011.00000 \mathrm{e}-092.12000 \mathrm{e}-01$

$1.45556 \mathrm{e}+001.45556 \mathrm{e}+001.45556 \mathrm{e}-011.00000 \mathrm{e}-092.12000 \mathrm{e}-01$

$1.45556 \mathrm{e}+001.45556 \mathrm{e}+001.45556 \mathrm{e}-011.00000 \mathrm{e}-092.12000 \mathrm{e}-01$

$1.45556 \mathrm{e}+001.45556 \mathrm{e}+001.45556 \mathrm{e}-011.00000 \mathrm{e}-092.12000 \mathrm{e}-01$

$1.45556 \mathrm{e}+001.45556 \mathrm{e}+001.45556 \mathrm{e}-011.00000 \mathrm{e}-092.12000 \mathrm{e}-01$

$1.00000 \mathrm{e}-021.00000 \mathrm{e}-02$ 1.00000e-03 1.00000e-09 1.00000e-01

$1.00000 \mathrm{e}+001.00000 \mathrm{e}+001.00000 \mathrm{e}-011.00000 \mathrm{e}-091.00000 \mathrm{e}-01$

$1.00000 \mathrm{e}-05$ 1.00000e-05 1.00000e-06 1.00000e-09 1.00000e-01

$1.00000 \mathrm{e}+001.00000 \mathrm{e}+001.00000 \mathrm{e}-011.00000 \mathrm{e}-091.00000 \mathrm{e}-01$

Element: 2767 \# of layers: 13 
Kx Ky Kz Ss Por

3.41137e+01 3.41137e+01 3.41137e+00 1.00000e-09 7.00000e-02

$3.41137 \mathrm{e}+013.41137 \mathrm{e}+013.41137 \mathrm{e}+001.00000 \mathrm{e}-09$ 7.00000e-02

5.00000e-04 5.00000e-04 5.00000e-05 1.00000e-09 1.00000e-01

5.00000e-04 5.00000e-04 5.00000e-05 1.00000e-09 1.00000e-01

$1.36308 \mathrm{e}+001.36308 \mathrm{e}+00$ 1.36308e-01 1.00000e-09 2.12000e-01

$1.36308 \mathrm{e}+00$ 1.36308e+00 1.36308e-01 1.00000e-09 2.12000e-01

$1.36308 \mathrm{e}+001.36308 \mathrm{e}+00$ 1.36308e-01 1.00000e-09 2.12000e-01

$1.36308 \mathrm{e}+00$ 1.36308e+00 1.36308e-01 1.00000e-09 2.12000e-01

$1.36308 \mathrm{e}+001.36308 \mathrm{e}+00$ 1.36308e-01 1.00000e-09 2.12000e-01

$1.00000 \mathrm{e}-02$ 1.00000e-02 1.00000e-03 1.00000e-09 1.00000e-01

$1.00000 \mathrm{e}+001.00000 \mathrm{e}+001.00000 \mathrm{e}-011.00000 \mathrm{e}-091.00000 \mathrm{e}-01$

$1.00000 \mathrm{e}-05$ 1.00000e-05 1.00000e-06 1.00000e-09 1.00000e-01

$1.00000 \mathrm{e}+001.00000 \mathrm{e}+001.00000 \mathrm{e}-011.00000 \mathrm{e}-091.00000 \mathrm{e}-01$

Element: 2768 \# of layers: 13

Kx Ky Kz Ss Por

3.41137e+01 3.41137e+01 3.41137e+00 1.00000e-09 7.00000e-02

$3.41137 \mathrm{e}+013.41137 \mathrm{e}+013.41137 \mathrm{e}+001.00000 \mathrm{e}-09$ 7.00000e-02

$5.00000 \mathrm{e}-04$ 5.00000e-04 5.00000e-05 1.00000e-09 1.00000e-01

5.00000e-04 5.00000e-04 5.00000e-05 1.00000e-09 1.00000e-01

$1.36308 \mathrm{e}+001.36308 \mathrm{e}+00$ 1.36308e-01 1.00000e-09 2.12000e-01

$1.36308 \mathrm{e}+00$ 1.36308e+00 1.36308e-01 1.00000e-09 2.12000e-01

$1.36308 \mathrm{e}+001.36308 \mathrm{e}+00$ 1.36308e-01 1.00000e-09 2.12000e-01

$1.36308 \mathrm{e}+001.36308 \mathrm{e}+00$ 1.36308e-01 1.00000e-09 2.12000e-01

$1.36308 \mathrm{e}+001.36308 \mathrm{e}+00$ 1.36308e-01 1.00000e-09 2.12000e-01

$1.00000 \mathrm{e}-02$ 1.00000e-02 1.00000e-03 1.00000e-09 1.00000e-01

$1.00000 \mathrm{e}+001.00000 \mathrm{e}+001.00000 \mathrm{e}-011.00000 \mathrm{e}-091.00000 \mathrm{e}-01$

$1.00000 \mathrm{e}-05$ 1.00000e-05 1.00000e-06 1.00000e-09 1.00000e-01

$1.00000 \mathrm{e}+001.00000 \mathrm{e}+001.00000 \mathrm{e}-011.00000 \mathrm{e}-091.00000 \mathrm{e}-01$

Element: 2769 \# of layers: 13

$\mathrm{Kx} \mathrm{Ky} \mathrm{Kz}$ Ss Por

3.41137e+01 3.41137e+01 3.41137e+00 1.00000e-09 7.00000e-02

$3.41137 \mathrm{e}+013.41137 \mathrm{e}+013.41137 \mathrm{e}+001.00000 \mathrm{e}-09$ 7.00000e-02

5.00000e-04 5.00000e-04 5.00000e-05 1.00000e-09 1.00000e-01

5.00000e-04 5.00000e-04 5.00000e-05 1.00000e-09 1.00000e-01

$1.36308 \mathrm{e}+001.36308 \mathrm{e}+00$ 1.36308e-01 1.00000e-09 2.12000e-01

$1.36308 \mathrm{e}+001.36308 \mathrm{e}+00$ 1.36308e-01 1.00000e-09 2.12000e-01

$1.36308 \mathrm{e}+001.36308 \mathrm{e}+00$ 1.36308e-01 1.00000e-09 2.12000e-01

$1.36308 \mathrm{e}+001.36308 \mathrm{e}+00$ 1.36308e-01 1.00000e-09 2.12000e-01

$1.36308 \mathrm{e}+001.36308 \mathrm{e}+00$ 1.36308e-01 1.00000e-09 2.12000e-01

$1.00000 \mathrm{e}-02$ 1.00000e-02 1.00000e-03 1.00000e-09 1.00000e-01

$1.00000 \mathrm{e}+001.00000 \mathrm{e}+001.00000 \mathrm{e}-011.00000 \mathrm{e}-091.00000 \mathrm{e}-01$

$1.00000 \mathrm{e}-051.00000 \mathrm{e}-051.00000 \mathrm{e}-061.00000 \mathrm{e}-091.00000 \mathrm{e}-01$

$1.00000 \mathrm{e}+001.00000 \mathrm{e}+001.00000 \mathrm{e}-01$ 1.00000e-09 1.00000e-01

Element: 2770 \# of layers: 13

Kx Ky Kz Ss Por 
3.41137e+01 3.41137e+01 3.41137e+00 1.00000e-09 7.00000e-02 $3.41137 \mathrm{e}+013.41137 \mathrm{e}+013.41137 \mathrm{e}+00$ 1.00000e-09 7.00000e-02 5.00000e-04 5.00000e-04 5.00000e-05 1.00000e-09 1.00000e-01 5.00000e-04 5.00000e-04 5.00000e-05 1.00000e-09 1.00000e-01 $1.36308 \mathrm{e}+001.36308 \mathrm{e}+00$ 1.36308e-01 1.00000e-09 2.12000e-01 $1.36308 \mathrm{e}+001.36308 \mathrm{e}+00$ 1.36308e-01 1.00000e-09 2.12000e-01 $1.36308 \mathrm{e}+00$ 1.36308e+00 1.36308e-01 1.00000e-09 2.12000e-01 $1.36308 \mathrm{e}+001.36308 \mathrm{e}+00$ 1.36308e-01 1.00000e-09 2.12000e-01 $1.36308 \mathrm{e}+00$ 1.36308e+00 1.36308e-01 1.00000e-09 2.12000e-01 $1.00000 \mathrm{e}-02$ 1.00000e-02 1.00000e-03 1.00000e-09 1.00000e-01 $1.00000 \mathrm{e}+001.00000 \mathrm{e}+001.00000 \mathrm{e}-011.00000 \mathrm{e}-091.00000 \mathrm{e}-01$ $1.00000 \mathrm{e}-05$ 1.00000e-05 1.00000e-06 1.00000e-09 1.00000e-01 $1.00000 \mathrm{e}+001.00000 \mathrm{e}+001.00000 \mathrm{e}-011.00000 \mathrm{e}-09$ 1.00000e-01 Element: 2771 \# of layers: 13

Kx Ky Kz Ss Por

3.41137e+01 3.41137e+01 3.41137e+00 1.00000e-09 7.00000e-02 3.41137e+01 3.41137e+01 3.41137e+00 1.00000e-09 7.00000e-02 5.00000e-04 5.00000e-04 5.00000e-05 1.00000e-09 1.00000e-01 5.00000e-04 5.00000e-04 5.00000e-05 1.00000e-09 1.00000e-01 $1.36308 \mathrm{e}+001.36308 \mathrm{e}+00$ 1.36308e-01 1.00000e-09 2.12000e-01 $1.36308 \mathrm{e}+001.36308 \mathrm{e}+00$ 1.36308e-01 1.00000e-09 2.12000e-01 $1.36308 \mathrm{e}+001.36308 \mathrm{e}+00$ 1.36308e-01 1.00000e-09 2.12000e-01 $1.36308 \mathrm{e}+001.36308 \mathrm{e}+00$ 1.36308e-01 1.00000e-09 2.12000e-01 $1.36308 \mathrm{e}+001.36308 \mathrm{e}+001.36308 \mathrm{e}-01$ 1.00000e-09 2.12000e-01 $1.00000 \mathrm{e}-02$ 1.00000e-02 1.00000e-03 1.00000e-09 1.00000e-01 $1.00000 \mathrm{e}+001.00000 \mathrm{e}+001.00000 \mathrm{e}-011.00000 \mathrm{e}-091.00000 \mathrm{e}-01$ $1.00000 \mathrm{e}-05$ 1.00000e-05 1.00000e-06 1.00000e-09 1.00000e-01 $1.00000 \mathrm{e}+001.00000 \mathrm{e}+001.00000 \mathrm{e}-011.00000 \mathrm{e}-09$ 1.00000e-01 Element: 2772 \# of layers: 13

$\mathrm{Kx} \mathrm{Ky} \mathrm{Kz}$ Ss Por

3.41137e+01 3.41137e+01 3.41137e+00 1.00000e-09 7.00000e-02 3.41137e+01 3.41137e+01 3.41137e+00 1.00000e-09 7.00000e-02 5.00000e-04 5.00000e-04 5.00000e-05 1.00000e-09 1.00000e-01 5.00000e-04 5.00000e-04 5.00000e-05 1.00000e-09 1.00000e-01 $1.36308 \mathrm{e}+001.36308 \mathrm{e}+00$ 1.36308e-01 1.00000e-09 2.12000e-01 $1.36308 \mathrm{e}+001.36308 \mathrm{e}+00$ 1.36308e-01 1.00000e-09 2.12000e-01 $1.36308 \mathrm{e}+001.36308 \mathrm{e}+00$ 1.36308e-01 1.00000e-09 2.12000e-01 $1.36308 \mathrm{e}+001.36308 \mathrm{e}+00$ 1.36308e-01 1.00000e-09 2.12000e-01 $1.36308 \mathrm{e}+001.36308 \mathrm{e}+00$ 1.36308e-01 1.00000e-09 2.12000e-01 $1.00000 \mathrm{e}-02$ 1.00000e-02 1.00000e-03 1.00000e-09 1.00000e-01 $1.00000 \mathrm{e}+001.00000 \mathrm{e}+001.00000 \mathrm{e}-011.00000 \mathrm{e}-091.00000 \mathrm{e}-01$ $1.00000 \mathrm{e}-05$ 1.00000e-05 1.00000e-06 1.00000e-09 1.00000e-01 $1.00000 \mathrm{e}+001.00000 \mathrm{e}+001.00000 \mathrm{e}-01$ 1.00000e-09 1.00000e-01 Element: 2773 \# of layers: 13

Kx Ky Kz Ss Por

3.41137e+01 3.41137e+01 3.41137e+00 1.00000e-09 7.00000e-02 
3.41137e+01 3.41137e+01 3.41137e+00 1.00000e-09 7.00000e-02 5.00000e-04 5.00000e-04 5.00000e-05 1.00000e-09 1.00000e-01 5.00000e-04 5.00000e-04 5.00000e-05 1.00000e-09 1.00000e-01 $1.36308 \mathrm{e}+001.36308 \mathrm{e}+00$ 1.36308e-01 1.00000e-09 2.12000e-01 $1.36308 \mathrm{e}+001.36308 \mathrm{e}+00$ 1.36308e-01 1.00000e-09 2.12000e-01 $1.36308 \mathrm{e}+001.36308 \mathrm{e}+00$ 1.36308e-01 1.00000e-09 2.12000e-01 $1.36308 \mathrm{e}+00$ 1.36308e+00 1.36308e-01 1.00000e-09 2.12000e-01 $1.36308 \mathrm{e}+001.36308 \mathrm{e}+001.36308 \mathrm{e}-01$ 1.00000e-09 2.12000e-01 $1.00000 \mathrm{e}-02$ 1.00000e-02 1.00000e-03 1.00000e-09 1.00000e-01 $1.00000 \mathrm{e}+001.00000 \mathrm{e}+001.00000 \mathrm{e}-011.00000 \mathrm{e}-091.00000 \mathrm{e}-01$ 1.00000e-05 1.00000e-05 1.00000e-06 1.00000e-09 1.00000e-01 $1.00000 \mathrm{e}+001.00000 \mathrm{e}+001.00000 \mathrm{e}-011.00000 \mathrm{e}-091.00000 \mathrm{e}-01$ Element: 2774 \# of layers: 13

Kx Ky Kz Ss Por

3.41137e+01 3.41137e+01 3.41137e+00 1.00000e-09 7.00000e-02 $3.41137 \mathrm{e}+013.41137 \mathrm{e}+013.41137 \mathrm{e}+001.00000 \mathrm{e}-09$ 7.00000e-02 5.00000e-04 5.00000e-04 5.00000e-05 1.00000e-09 1.00000e-01 5.00000e-04 5.00000e-04 5.00000e-05 1.00000e-09 1.00000e-01 $1.36308 \mathrm{e}+001.36308 \mathrm{e}+00$ 1.36308e-01 1.00000e-09 2.12000e-01 $1.36308 \mathrm{e}+001.36308 \mathrm{e}+00$ 1.36308e-01 1.00000e-09 2.12000e-01 $1.36308 \mathrm{e}+001.36308 \mathrm{e}+00$ 1.36308e-01 1.00000e-09 2.12000e-01 $1.36308 \mathrm{e}+00$ 1.36308e+00 1.36308e-01 1.00000e-09 2.12000e-01 $1.36308 \mathrm{e}+001.36308 \mathrm{e}+00$ 1.36308e-01 1.00000e-09 2.12000e-01 $1.00000 \mathrm{e}-02$ 1.00000e-02 1.00000e-03 1.00000e-09 1.00000e-01 $1.00000 \mathrm{e}+001.00000 \mathrm{e}+001.00000 \mathrm{e}-011.00000 \mathrm{e}-091.00000 \mathrm{e}-01$ $1.00000 \mathrm{e}-05$ 1.00000e-05 1.00000e-06 1.00000e-09 1.00000e-01 $1.00000 \mathrm{e}+001.00000 \mathrm{e}+001.00000 \mathrm{e}-01$ 1.00000e-09 1.00000e-01 Element: 2775 \# of layers: 13

Kx Ky Kz Ss Por

3.41137e+01 3.41137e+01 3.41137e+00 1.00000e-09 7.00000e-02 $3.41137 \mathrm{e}+013.41137 \mathrm{e}+013.41137 \mathrm{e}+001.00000 \mathrm{e}-09$ 7.00000e-02 5.00000e-04 5.00000e-04 5.00000e-05 1.00000e-09 1.00000e-01 5.00000e-04 5.00000e-04 5.00000e-05 1.00000e-09 1.00000e-01 $1.36308 \mathrm{e}+001.36308 \mathrm{e}+00$ 1.36308e-01 1.00000e-09 2.12000e-01 $1.36308 \mathrm{e}+001.36308 \mathrm{e}+00$ 1.36308e-01 1.00000e-09 2.12000e-01 $1.36308 \mathrm{e}+001.36308 \mathrm{e}+00$ 1.36308e-01 1.00000e-09 2.12000e-01 $1.36308 \mathrm{e}+001.36308 \mathrm{e}+00$ 1.36308e-01 1.00000e-09 2.12000e-01 $1.36308 \mathrm{e}+001.36308 \mathrm{e}+001.36308 \mathrm{e}-01$ 1.00000e-09 2.12000e-01 $1.00000 \mathrm{e}-02$ 1.00000e-02 1.00000e-03 1.00000e-09 1.00000e-01 $1.00000 \mathrm{e}+001.00000 \mathrm{e}+001.00000 \mathrm{e}-011.00000 \mathrm{e}-091.00000 \mathrm{e}-01$ $1.00000 \mathrm{e}-05$ 1.00000e-05 1.00000e-06 1.00000e-09 1.00000e-01 $1.00000 \mathrm{e}+001.00000 \mathrm{e}+001.00000 \mathrm{e}-011.00000 \mathrm{e}-091.00000 \mathrm{e}-01$ Element: 2776 \# of layers: 13

$\mathrm{Kx} \mathrm{Ky} \mathrm{Kz}$ Ss Por

$1.95238 \mathrm{e}+01$ 1.95238e+01 1.95238e+00 1.00000e-09 7.00000e-02 $1.95238 \mathrm{e}+01$ 1.95238e+01 1.95238e+00 1.00000e-09 7.00000e-02 
5.00000e-04 5.00000e-04 5.00000e-05 1.00000e-09 1.00000e-01 5.00000e-04 5.00000e-04 5.00000e-05 1.00000e-09 1.00000e-01 7.80114e-01 7.80114e-01 7.80114e-02 1.00000e-09 2.12000e-01 7.80114e-01 7.80114e-01 7.80114e-02 1.00000e-09 2.12000e-01 7.80114e-01 7.80114e-01 7.80114e-02 1.00000e-09 2.12000e-01 7.80114e-01 7.80114e-01 7.80114e-02 1.00000e-09 2.12000e-01 7.80114e-01 7.80114e-01 7.80114e-02 1.00000e-09 2.12000e-01 $1.00000 \mathrm{e}-02$ 1.00000e-02 1.00000e-03 1.00000e-09 1.00000e-01 $1.00000 \mathrm{e}+001.00000 \mathrm{e}+001.00000 \mathrm{e}-011.00000 \mathrm{e}-091.00000 \mathrm{e}-01$ $1.00000 \mathrm{e}-05$ 1.00000e-05 1.00000e-06 1.00000e-09 1.00000e-01 $1.00000 \mathrm{e}+001.00000 \mathrm{e}+001.00000 \mathrm{e}-011.00000 \mathrm{e}-091.00000 \mathrm{e}-01$ Element: 2777 \# of layers: 13

$\mathrm{Kx} \mathrm{Ky} \mathrm{Kz}$ Ss Por

$1.95238 \mathrm{e}+01$ 1.95238e+01 1.95238e+00 1.00000e-09 7.00000e-02 $1.95238 \mathrm{e}+01$ 1.95238e+01 1.95238e+00 1.00000e-09 7.00000e-02 5.00000e-04 5.00000e-04 5.00000e-05 1.00000e-09 1.00000e-01 5.00000e-04 5.00000e-04 5.00000e-05 1.00000e-09 1.00000e-01 7.80114e-01 7.80114e-01 7.80114e-02 1.00000e-09 2.12000e-01 7.80114e-01 7.80114e-01 7.80114e-02 1.00000e-09 2.12000e-01 7.80114e-01 7.80114e-01 7.80114e-02 1.00000e-09 2.12000e-01 7.80114e-01 7.80114e-01 7.80114e-02 1.00000e-09 2.12000e-01 7.80114e-01 7.80114e-01 7.80114e-02 1.00000e-09 2.12000e-01 $1.00000 \mathrm{e}-02$ 1.00000e-02 1.00000e-03 1.00000e-09 1.00000e-01 $1.00000 \mathrm{e}+001.00000 \mathrm{e}+001.00000 \mathrm{e}-011.00000 \mathrm{e}-091.00000 \mathrm{e}-01$ $1.00000 \mathrm{e}-05$ 1.00000e-05 1.00000e-06 1.00000e-09 1.00000e-01 $1.00000 \mathrm{e}+001.00000 \mathrm{e}+001.00000 \mathrm{e}-011.00000 \mathrm{e}-091.00000 \mathrm{e}-01$ Element: 2778 \# of layers: 13

$\mathrm{Kx} \mathrm{Ky} \mathrm{Kz}$ Ss Por

$1.95238 \mathrm{e}+01$ 1.95238e+01 1.95238e+00 1.00000e-09 7.00000e-02 $1.95238 \mathrm{e}+01$ 1.95238e+01 1.95238e+00 1.00000e-09 7.00000e-02 5.00000e-04 5.00000e-04 5.00000e-05 1.00000e-09 1.00000e-01 5.00000e-04 5.00000e-04 5.00000e-05 1.00000e-09 1.00000e-01 7.80114e-01 7.80114e-01 7.80114e-02 1.00000e-09 2.12000e-01 7.80114e-01 7.80114e-01 7.80114e-02 1.00000e-09 2.12000e-01 7.80114e-01 7.80114e-01 7.80114e-02 1.00000e-09 2.12000e-01 7.80114e-01 7.80114e-01 7.80114e-02 1.00000e-09 2.12000e-01 7.80114e-01 7.80114e-01 7.80114e-02 1.00000e-09 2.12000e-01 $1.00000 \mathrm{e}-02$ 1.00000e-02 1.00000e-03 1.00000e-09 1.00000e-01 $1.00000 \mathrm{e}+001.00000 \mathrm{e}+001.00000 \mathrm{e}-011.00000 \mathrm{e}-091.00000 \mathrm{e}-01$ $1.00000 \mathrm{e}-05$ 1.00000e-05 1.00000e-06 1.00000e-09 1.00000e-01 $1.00000 \mathrm{e}+001.00000 \mathrm{e}+001.00000 \mathrm{e}-011.00000 \mathrm{e}-09$ 1.00000e-01 Element: 2779 \# of layers: 13

$\mathrm{Kx} \mathrm{Ky} \mathrm{Kz}$ Ss Por

1.95238e+01 1.95238e+01 1.95238e+00 1.00000e-09 7.00000e-02 $1.95238 \mathrm{e}+011.95238 \mathrm{e}+011.95238 \mathrm{e}+001.00000 \mathrm{e}-09$ 7.00000e-02 5.00000e-04 5.00000e-04 5.00000e-05 1.00000e-09 1.00000e-01 
5.00000e-04 5.00000e-04 5.00000e-05 1.00000e-09 1.00000e-01 7.80114e-01 7.80114e-01 7.80114e-02 1.00000e-09 2.12000e-01 7.80114e-01 7.80114e-01 7.80114e-02 1.00000e-09 2.12000e-01 7.80114e-01 7.80114e-01 7.80114e-02 1.00000e-09 2.12000e-01 7.80114e-01 7.80114e-01 7.80114e-02 1.00000e-09 2.12000e-01 7.80114e-01 7.80114e-01 7.80114e-02 1.00000e-09 2.12000e-01 $1.00000 \mathrm{e}-02$ 1.00000e-02 1.00000e-03 1.00000e-09 1.00000e-01 $1.00000 \mathrm{e}+001.00000 \mathrm{e}+001.00000 \mathrm{e}-011.00000 \mathrm{e}-091.00000 \mathrm{e}-01$ $1.00000 \mathrm{e}-051.00000 \mathrm{e}-051.00000 \mathrm{e}-061.00000 \mathrm{e}-091.00000 \mathrm{e}-01$ $1.00000 \mathrm{e}+001.00000 \mathrm{e}+001.00000 \mathrm{e}-011.00000 \mathrm{e}-091.00000 \mathrm{e}-01$ Element: 2780 \# of layers: 13

Kx Ky Kz Ss Por

1.95238e+01 1.95238e+01 1.95238e+00 1.00000e-09 7.00000e-02 $1.95238 \mathrm{e}+011.95238 \mathrm{e}+011.95238 \mathrm{e}+001.00000 \mathrm{e}-09$ 7.00000e-02 5.00000e-04 5.00000e-04 5.00000e-05 1.00000e-09 1.00000e-01 5.00000e-04 5.00000e-04 5.00000e-05 1.00000e-09 1.00000e-01 7.80114e-01 7.80114e-01 7.80114e-02 1.00000e-09 2.12000e-01 7.80114e-01 7.80114e-01 7.80114e-02 1.00000e-09 2.12000e-01 7.80114e-01 7.80114e-01 7.80114e-02 1.00000e-09 2.12000e-01 7.80114e-01 7.80114e-01 7.80114e-02 1.00000e-09 2.12000e-01 $7.80114 \mathrm{e}-01$ 7.80114e-01 7.80114e-02 1.00000e-09 2.12000e-01 $1.00000 \mathrm{e}-02$ 1.00000e-02 1.00000e-03 1.00000e-09 1.00000e-01 $1.00000 \mathrm{e}+001.00000 \mathrm{e}+001.00000 \mathrm{e}-011.00000 \mathrm{e}-091.00000 \mathrm{e}-01$ $1.00000 \mathrm{e}-05$ 1.00000e-05 1.00000e-06 1.00000e-09 1.00000e-01 $1.00000 \mathrm{e}+001.00000 \mathrm{e}+001.00000 \mathrm{e}-011.00000 \mathrm{e}-091.00000 \mathrm{e}-01$ Element: 2781 \# of layers: 13

$\mathrm{Kx} \mathrm{Ky} \mathrm{Kz}$ Ss Por

$1.95238 \mathrm{e}+01$ 1.95238e+01 1.95238e+00 1.00000e-09 7.00000e-02 $1.95238 \mathrm{e}+011.95238 \mathrm{e}+011.95238 \mathrm{e}+001.00000 \mathrm{e}-097.00000 \mathrm{e}-02$ 5.00000e-04 5.00000e-04 5.00000e-05 1.00000e-09 1.00000e-01 5.00000e-04 5.00000e-04 5.00000e-05 1.00000e-09 1.00000e-01 7.80114e-01 7.80114e-01 7.80114e-02 1.00000e-09 2.12000e-01 7.80114e-01 7.80114e-01 7.80114e-02 1.00000e-09 2.12000e-01 7.80114e-01 7.80114e-01 7.80114e-02 1.00000e-09 2.12000e-01 7.80114e-01 7.80114e-01 7.80114e-02 1.00000e-09 2.12000e-01 7.80114e-01 7.80114e-01 7.80114e-02 1.00000e-09 2.12000e-01 $1.00000 \mathrm{e}-02$ 1.00000e-02 1.00000e-03 1.00000e-09 1.00000e-01 $1.00000 \mathrm{e}+001.00000 \mathrm{e}+001.00000 \mathrm{e}-011.00000 \mathrm{e}-091.00000 \mathrm{e}-01$ $1.00000 \mathrm{e}-05$ 1.00000e-05 1.00000e-06 1.00000e-09 1.00000e-01 $1.00000 \mathrm{e}+001.00000 \mathrm{e}+001.00000 \mathrm{e}-01$ 1.00000e-09 1.00000e-01 Element: 2782 \# of layers: 13

$\mathrm{Kx} \mathrm{Ky} \mathrm{Kz}$ Ss Por

$1.95238 \mathrm{e}+01$ 1.95238e+01 1.95238e+00 1.00000e-09 7.00000e-02 $1.95238 \mathrm{e}+01$ 1.95238e+01 1.95238e+00 1.00000e-09 7.00000e-02 5.00000e-04 5.00000e-04 5.00000e-05 1.00000e-09 1.00000e-01 5.00000e-04 5.00000e-04 5.00000e-05 1.00000e-09 1.00000e-01 
7.80114e-01 7.80114e-01 7.80114e-02 1.00000e-09 2.12000e-01 7.80114e-01 7.80114e-01 7.80114e-02 1.00000e-09 2.12000e-01 7.80114e-01 7.80114e-01 7.80114e-02 1.00000e-09 2.12000e-01 7.80114e-01 7.80114e-01 7.80114e-02 1.00000e-09 2.12000e-01 7.80114e-01 7.80114e-01 7.80114e-02 1.00000e-09 2.12000e-01 $1.00000 \mathrm{e}-021.00000 \mathrm{e}-02$ 1.00000e-03 $1.00000 \mathrm{e}-091.00000 \mathrm{e}-01$ $1.00000 \mathrm{e}+001.00000 \mathrm{e}+001.00000 \mathrm{e}-011.00000 \mathrm{e}-091.00000 \mathrm{e}-01$ $1.00000 \mathrm{e}-05$ 1.00000e-05 1.00000e-06 1.00000e-09 1.00000e-01 $1.00000 \mathrm{e}+001.00000 \mathrm{e}+001.00000 \mathrm{e}-011.00000 \mathrm{e}-091.00000 \mathrm{e}-01$ Element: 2783 \# of layers: 13

Kx Ky Kz Ss Por

$1.95238 \mathrm{e}+011.95238 \mathrm{e}+011.95238 \mathrm{e}+00$ 1.00000e-09 7.00000e-02 $1.95238 \mathrm{e}+011.95238 \mathrm{e}+011.95238 \mathrm{e}+001.00000 \mathrm{e}-09$ 7.00000e-02 5.00000e-04 5.00000e-04 5.00000e-05 1.00000e-09 1.00000e-01 $5.00000 \mathrm{e}-04$ 5.00000e-04 5.00000e-05 1.00000e-09 1.00000e-01 7.80114e-01 7.80114e-01 7.80114e-02 1.00000e-09 2.12000e-01 7.80114e-01 7.80114e-01 7.80114e-02 1.00000e-09 2.12000e-01 7.80114e-01 7.80114e-01 7.80114e-02 1.00000e-09 2.12000e-01 7.80114e-01 7.80114e-01 7.80114e-02 1.00000e-09 2.12000e-01 7.80114e-01 7.80114e-01 7.80114e-02 1.00000e-09 2.12000e-01 $1.00000 \mathrm{e}-021.00000 \mathrm{e}-02$ 1.00000e-03 1.00000e-09 1.00000e-01 $1.00000 \mathrm{e}+001.00000 \mathrm{e}+001.00000 \mathrm{e}-011.00000 \mathrm{e}-091.00000 \mathrm{e}-01$ $1.00000 \mathrm{e}-05$ 1.00000e-05 1.00000e-06 1.00000e-09 1.00000e-01 $1.00000 \mathrm{e}+001.00000 \mathrm{e}+001.00000 \mathrm{e}-011.00000 \mathrm{e}-091.00000 \mathrm{e}-01$ Element: 2784 \# of layers: 13

Kx Ky Kz Ss Por

$1.95238 \mathrm{e}+011.95238 \mathrm{e}+011.95238 \mathrm{e}+00$ 1.00000e-09 7.00000e-02 $1.95238 \mathrm{e}+011.95238 \mathrm{e}+011.95238 \mathrm{e}+001.00000 \mathrm{e}-09$ 7.00000e-02 5.00000e-04 5.00000e-04 5.00000e-05 1.00000e-09 1.00000e-01 5.00000e-04 5.00000e-04 5.00000e-05 1.00000e-09 1.00000e-01 7.80114e-01 7.80114e-01 7.80114e-02 1.00000e-09 2.12000e-01 7.80114e-01 7.80114e-01 7.80114e-02 1.00000e-09 2.12000e-01 7.80114e-01 7.80114e-01 7.80114e-02 1.00000e-09 2.12000e-01 7.80114e-01 7.80114e-01 7.80114e-02 1.00000e-09 2.12000e-01 7.80114e-01 7.80114e-01 7.80114e-02 1.00000e-09 2.12000e-01 $1.00000 \mathrm{e}-021.00000 \mathrm{e}-02$ 1.00000e-03 1.00000e-09 1.00000e-01 $1.00000 \mathrm{e}+001.00000 \mathrm{e}+001.00000 \mathrm{e}-011.00000 \mathrm{e}-091.00000 \mathrm{e}-01$ $1.00000 \mathrm{e}-05$ 1.00000e-05 1.00000e-06 1.00000e-09 1.00000e-01 $1.00000 \mathrm{e}+001.00000 \mathrm{e}+001.00000 \mathrm{e}-011.00000 \mathrm{e}-091.00000 \mathrm{e}-01$ Element: 2785 \# of layers: 13

Kx Ky Kz Ss Por $1.91192 \mathrm{e}+011.91192 \mathrm{e}+011.91192 \mathrm{e}+00$ 1.00000e-09 7.00000e-02 $1.91192 \mathrm{e}+011.91192 \mathrm{e}+011.91192 \mathrm{e}+001.00000 \mathrm{e}-097.00000 \mathrm{e}-02$ $5.00000 \mathrm{e}-04$ 5.00000e-04 5.00000e-05 1.00000e-09 1.00000e-01 5.00000e-04 5.00000e-04 5.00000e-05 1.00000e-09 1.00000e-01 7.63936e-01 7.63936e-01 7.63936e-02 1.00000e-09 2.12000e-01 
7.63936e-01 7.63936e-01 7.63936e-02 1.00000e-09 2.12000e-01 7.63936e-01 7.63936e-01 7.63936e-02 1.00000e-09 2.12000e-01 7.63936e-01 7.63936e-01 7.63936e-02 1.00000e-09 2.12000e-01 7.63936e-01 7.63936e-01 7.63936e-02 1.00000e-09 2.12000e-01 $1.00000 \mathrm{e}-02$ 1.00000e-02 1.00000e-03 1.00000e-09 1.00000e-01 $1.00000 \mathrm{e}+001.00000 \mathrm{e}+001.00000 \mathrm{e}-011.00000 \mathrm{e}-091.00000 \mathrm{e}-01$ $1.00000 \mathrm{e}-05$ 1.00000e-05 1.00000e-06 1.00000e-09 1.00000e-01 $1.00000 \mathrm{e}+001.00000 \mathrm{e}+001.00000 \mathrm{e}-011.00000 \mathrm{e}-091.00000 \mathrm{e}-01$ Element: 2786 \# of layers: 13

$\mathrm{Kx} \mathrm{Ky} \mathrm{Kz}$ Ss Por

1.91192e+01 1.91192e+01 1.91192e+00 1.00000e-09 7.00000e-02 $1.91192 \mathrm{e}+01$ 1.91192e+01 1.91192e+00 1.00000e-09 7.00000e-02 5.00000e-04 5.00000e-04 5.00000e-05 1.00000e-09 1.00000e-01 5.00000e-04 5.00000e-04 5.00000e-05 1.00000e-09 1.00000e-01 7.63936e-01 7.63936e-01 7.63936e-02 1.00000e-09 2.12000e-01 7.63936e-01 7.63936e-01 7.63936e-02 1.00000e-09 2.12000e-01 7.63936e-01 7.63936e-01 7.63936e-02 1.00000e-09 2.12000e-01 7.63936e-01 7.63936e-01 7.63936e-02 1.00000e-09 2.12000e-01 7.63936e-01 7.63936e-01 7.63936e-02 1.00000e-09 2.12000e-01 $1.00000 \mathrm{e}-02$ 1.00000e-02 1.00000e-03 1.00000e-09 1.00000e-01 $1.00000 \mathrm{e}+001.00000 \mathrm{e}+001.00000 \mathrm{e}-011.00000 \mathrm{e}-091.00000 \mathrm{e}-01$ $1.00000 \mathrm{e}-05$ 1.00000e-05 1.00000e-06 1.00000e-09 1.00000e-01 $1.00000 \mathrm{e}+001.00000 \mathrm{e}+001.00000 \mathrm{e}-01$ 1.00000e-09 1.00000e-01 Element: 2787 \# of layers: 13

Kx Ky Kz Ss Por

$1.91192 \mathrm{e}+011.91192 \mathrm{e}+01$ 1.91192e+00 1.00000e-09 7.00000e-02 $1.91192 \mathrm{e}+01$ 1.91192e+01 1.91192e+00 1.00000e-09 7.00000e-02 5.00000e-04 5.00000e-04 5.00000e-05 1.00000e-09 1.00000e-01 5.00000e-04 5.00000e-04 5.00000e-05 1.00000e-09 1.00000e-01 7.63936e-01 7.63936e-01 7.63936e-02 1.00000e-09 2.12000e-01 7.63936e-01 7.63936e-01 7.63936e-02 1.00000e-09 2.12000e-01 7.63936e-01 7.63936e-01 7.63936e-02 1.00000e-09 2.12000e-01 7.63936e-01 7.63936e-01 7.63936e-02 1.00000e-09 2.12000e-01 7.63936e-01 7.63936e-01 7.63936e-02 1.00000e-09 2.12000e-01 $1.00000 \mathrm{e}-02$ 1.00000e-02 1.00000e-03 1.00000e-09 1.00000e-01 $1.00000 \mathrm{e}+001.00000 \mathrm{e}+001.00000 \mathrm{e}-011.00000 \mathrm{e}-091.00000 \mathrm{e}-01$ $1.00000 \mathrm{e}-05$ 1.00000e-05 1.00000e-06 1.00000e-09 1.00000e-01 $1.00000 \mathrm{e}+001.00000 \mathrm{e}+001.00000 \mathrm{e}-011.00000 \mathrm{e}-091.00000 \mathrm{e}-01$ Element: 2788 \# of layers: 13

$\mathrm{Kx} \mathrm{Ky} \mathrm{Kz}$ Ss Por

1.91192e+01 1.91192e+01 1.91192e+00 1.00000e-09 7.00000e-02 $1.91192 \mathrm{e}+01$ 1.91192e+01 1.91192e+00 1.00000e-09 7.00000e-02 5.00000e-04 5.00000e-04 5.00000e-05 1.00000e-09 1.00000e-01 5.00000e-04 5.00000e-04 5.00000e-05 1.00000e-09 1.00000e-01 7.63936e-01 7.63936e-01 7.63936e-02 1.00000e-09 2.12000e-01 7.63936e-01 7.63936e-01 7.63936e-02 1.00000e-09 2.12000e-01 
7.63936e-01 7.63936e-01 7.63936e-02 1.00000e-09 2.12000e-01 7.63936e-01 7.63936e-01 7.63936e-02 1.00000e-09 2.12000e-01 7.63936e-01 7.63936e-01 7.63936e-02 1.00000e-09 2.12000e-01 $1.00000 \mathrm{e}-02$ 1.00000e-02 1.00000e-03 1.00000e-09 1.00000e-01 $1.00000 \mathrm{e}+001.00000 \mathrm{e}+001.00000 \mathrm{e}-011.00000 \mathrm{e}-091.00000 \mathrm{e}-01$ $1.00000 \mathrm{e}-05$ 1.00000e-05 1.00000e-06 1.00000e-09 1.00000e-01 $1.00000 \mathrm{e}+001.00000 \mathrm{e}+00$ 1.00000e-01 1.00000e-09 1.00000e-01 Element: 2789 \# of layers: 11

$\mathrm{Kx} \mathrm{Ky} \mathrm{Kz}$ Ss Por

1.91192e+01 1.91192e+01 1.91192e+00 1.00000e-09 7.00000e-02 $1.91192 \mathrm{e}+011.91192 \mathrm{e}+011.91192 \mathrm{e}+001.00000 \mathrm{e}-09$ 7.00000e-02 5.00000e-04 5.00000e-04 5.00000e-05 1.00000e-09 1.00000e-01 5.00000e-04 5.00000e-04 5.00000e-05 1.00000e-09 1.00000e-01 7.63936e-01 7.63936e-01 7.63936e-02 1.00000e-09 2.12000e-01 7.63936e-01 7.63936e-01 7.63936e-02 1.00000e-09 2.12000e-01 7.63936e-01 7.63936e-01 7.63936e-02 1.00000e-09 2.12000e-01 7.63936e-01 7.63936e-01 7.63936e-02 1.00000e-09 2.12000e-01 7.63936e-01 7.63936e-01 7.63936e-02 1.00000e-09 2.12000e-01 $1.00000 \mathrm{e}-02$ 1.00000e-02 1.00000e-03 1.00000e-09 1.00000e-01 $1.00000 \mathrm{e}+001.00000 \mathrm{e}+001.00000 \mathrm{e}-011.00000 \mathrm{e}-091.00000 \mathrm{e}-01$ Element: 2790 \# of layers: 13

$\mathrm{Kx} \mathrm{Ky} \mathrm{Kz}$ Ss Por

1.91192e+01 1.91192e+01 1.91192e+00 1.00000e-09 7.00000e-02 $1.91192 \mathrm{e}+011.91192 \mathrm{e}+011.91192 \mathrm{e}+001.00000 \mathrm{e}-09$ 7.00000e-02 5.00000e-04 5.00000e-04 5.00000e-05 1.00000e-09 1.00000e-01 5.00000e-04 5.00000e-04 5.00000e-05 1.00000e-09 1.00000e-01 7.63936e-01 7.63936e-01 7.63936e-02 1.00000e-09 2.12000e-01 7.63936e-01 7.63936e-01 7.63936e-02 1.00000e-09 2.12000e-01 7.63936e-01 7.63936e-01 7.63936e-02 1.00000e-09 2.12000e-01 7.63936e-01 7.63936e-01 7.63936e-02 1.00000e-09 2.12000e-01 7.63936e-01 7.63936e-01 7.63936e-02 1.00000e-09 2.12000e-01 $1.00000 \mathrm{e}-02$ 1.00000e-02 1.00000e-03 1.00000e-09 1.00000e-01 $1.00000 \mathrm{e}+001.00000 \mathrm{e}+001.00000 \mathrm{e}-011.00000 \mathrm{e}-091.00000 \mathrm{e}-01$ 1.00000e-05 1.00000e-05 1.00000e-06 1.00000e-09 1.00000e-01 $1.00000 \mathrm{e}+001.00000 \mathrm{e}+001.00000 \mathrm{e}-01$ 1.00000e-09 1.00000e-01 Element: 2791 \# of layers: 13

Kx Ky Kz Ss Por

1.91192e+01 1.91192e+01 1.91192e+00 1.00000e-09 7.00000e-02 $1.91192 \mathrm{e}+01$ 1.91192e+01 1.91192e+00 1.00000e-09 7.00000e-02 5.00000e-04 5.00000e-04 5.00000e-05 1.00000e-09 1.00000e-01 5.00000e-04 5.00000e-04 5.00000e-05 1.00000e-09 1.00000e-01 7.63936e-01 7.63936e-01 7.63936e-02 1.00000e-09 2.12000e-01 7.63936e-01 7.63936e-01 7.63936e-02 1.00000e-09 2.12000e-01 7.63936e-01 7.63936e-01 7.63936e-02 1.00000e-09 2.12000e-01 7.63936e-01 7.63936e-01 7.63936e-02 1.00000e-09 2.12000e-01 7.63936e-01 7.63936e-01 7.63936e-02 1.00000e-09 2.12000e-01 
$1.00000 \mathrm{e}-02$ 1.00000e-02 1.00000e-03 1.00000e-09 1.00000e-01 $1.00000 \mathrm{e}+001.00000 \mathrm{e}+001.00000 \mathrm{e}-011.00000 \mathrm{e}-091.00000 \mathrm{e}-01$ $1.00000 \mathrm{e}-05$ 1.00000e-05 1.00000e-06 1.00000e-09 1.00000e-01 $1.00000 \mathrm{e}+001.00000 \mathrm{e}+001.00000 \mathrm{e}-011.00000 \mathrm{e}-091.00000 \mathrm{e}-01$ Element: 2792 \# of layers: 13

$\mathrm{Kx} \mathrm{Ky} \mathrm{Kz}$ Ss Por

$1.91192 \mathrm{e}+01$ 1.91192e+01 1.91192e+00 1.00000e-09 7.00000e-02 $1.91192 \mathrm{e}+01$ 1.91192e+01 1.91192e+00 1.00000e-09 7.00000e-02 5.00000e-04 5.00000e-04 5.00000e-05 1.00000e-09 1.00000e-01 5.00000e-04 5.00000e-04 5.00000e-05 1.00000e-09 1.00000e-01 7.63936e-01 7.63936e-01 7.63936e-02 1.00000e-09 2.12000e-01 7.63936e-01 7.63936e-01 7.63936e-02 1.00000e-09 2.12000e-01 7.63936e-01 7.63936e-01 7.63936e-02 1.00000e-09 2.12000e-01 7.63936e-01 7.63936e-01 7.63936e-02 1.00000e-09 2.12000e-01 7.63936e-01 7.63936e-01 7.63936e-02 1.00000e-09 2.12000e-01 $1.00000 \mathrm{e}-02$ 1.00000e-02 1.00000e-03 1.00000e-09 1.00000e-01 $1.00000 \mathrm{e}+001.00000 \mathrm{e}+001.00000 \mathrm{e}-011.00000 \mathrm{e}-091.00000 \mathrm{e}-01$ $1.00000 \mathrm{e}-05$ 1.00000e-05 1.00000e-06 1.00000e-09 1.00000e-01 $1.00000 \mathrm{e}+001.00000 \mathrm{e}+001.00000 \mathrm{e}-011.00000 \mathrm{e}-091.00000 \mathrm{e}-01$ Element: 2793 \# of layers: 13

$\mathrm{Kx} \mathrm{Ky} \mathrm{Kz}$ Ss Por

1.91192e+01 1.91192e+01 1.91192e+00 1.00000e-09 7.00000e-02 1.91192e+01 1.91192e+01 1.91192e+00 1.00000e-09 7.00000e-02 5.00000e-04 5.00000e-04 5.00000e-05 1.00000e-09 1.00000e-01 5.00000e-04 5.00000e-04 5.00000e-05 1.00000e-09 1.00000e-01 7.63936e-01 7.63936e-01 7.63936e-02 1.00000e-09 2.12000e-01 7.63936e-01 7.63936e-01 7.63936e-02 1.00000e-09 2.12000e-01 7.63936e-01 7.63936e-01 7.63936e-02 1.00000e-09 2.12000e-01 7.63936e-01 7.63936e-01 7.63936e-02 1.00000e-09 2.12000e-01 7.63936e-01 7.63936e-01 7.63936e-02 1.00000e-09 2.12000e-01 $1.00000 \mathrm{e}-02$ 1.00000e-02 1.00000e-03 1.00000e-09 1.00000e-01 $1.00000 \mathrm{e}+001.00000 \mathrm{e}+001.00000 \mathrm{e}-011.00000 \mathrm{e}-091.00000 \mathrm{e}-01$ $1.00000 \mathrm{e}-05$ 1.00000e-05 1.00000e-06 1.00000e-09 1.00000e-01 $1.00000 \mathrm{e}+001.00000 \mathrm{e}+001.00000 \mathrm{e}-011.00000 \mathrm{e}-091.00000 \mathrm{e}-01$ Element: 2794 \# of layers: 13

$\mathrm{Kx} \mathrm{Ky} \mathrm{Kz}$ Ss Por

2.07753e+01 2.07753e+01 2.07753e+00 1.00000e-09 7.00000e-02

$2.07753 \mathrm{e}+012.07753 \mathrm{e}+012.07753 \mathrm{e}+001.00000 \mathrm{e}-09$ 7.00000e-02

5.00000e-04 5.00000e-04 5.00000e-05 1.00000e-09 1.00000e-01

5.00000e-04 5.00000e-04 5.00000e-05 1.00000e-09 1.00000e-01 8.30110e-01 8.30110e-01 8.30110e-02 1.00000e-09 2.12000e-01 8.30110e-01 8.30110e-01 8.30110e-02 1.00000e-09 2.12000e-01 8.30110e-01 8.30110e-01 8.30110e-02 1.00000e-09 2.12000e-01 8.30110e-01 8.30110e-01 8.30110e-02 1.00000e-09 2.12000e-01 8.30110e-01 8.30110e-01 8.30110e-02 1.00000e-09 2.12000e-01 $1.00000 \mathrm{e}-02$ 1.00000e-02 1.00000e-03 1.00000e-09 1.00000e-01 
$1.00000 \mathrm{e}+001.00000 \mathrm{e}+001.00000 \mathrm{e}-011.00000 \mathrm{e}-091.00000 \mathrm{e}-01$ $1.00000 \mathrm{e}-05$ 1.00000e-05 1.00000e-06 1.00000e-09 1.00000e-01 $1.00000 \mathrm{e}+001.00000 \mathrm{e}+001.00000 \mathrm{e}-011.00000 \mathrm{e}-09$ 1.00000e-01 Element: 2795 \# of layers: 13

$\mathrm{Kx} \mathrm{Ky} \mathrm{Kz}$ Ss Por

$2.07753 \mathrm{e}+012.07753 \mathrm{e}+012.07753 \mathrm{e}+00$ 1.00000e-09 7.00000e-02 $2.07753 \mathrm{e}+012.07753 \mathrm{e}+012.07753 \mathrm{e}+001.00000 \mathrm{e}-09$ 7.00000e-02 5.00000e-04 5.00000e-04 5.00000e-05 1.00000e-09 1.00000e-01 5.00000e-04 5.00000e-04 5.00000e-05 1.00000e-09 1.00000e-01 8.30110e-01 8.30110e-01 8.30110e-02 1.00000e-09 2.12000e-01 8.30110e-01 8.30110e-01 8.30110e-02 1.00000e-09 2.12000e-01 8.30110e-01 8.30110e-01 8.30110e-02 1.00000e-09 2.12000e-01 8.30110e-01 8.30110e-01 8.30110e-02 1.00000e-09 2.12000e-01 8.30110e-01 8.30110e-01 8.30110e-02 1.00000e-09 2.12000e-01 $1.00000 \mathrm{e}-02$ 1.00000e-02 1.00000e-03 1.00000e-09 1.00000e-01 $1.00000 \mathrm{e}+001.00000 \mathrm{e}+001.00000 \mathrm{e}-011.00000 \mathrm{e}-091.00000 \mathrm{e}-01$ $1.00000 \mathrm{e}-05$ 1.00000e-05 1.00000e-06 1.00000e-09 1.00000e-01 $1.00000 \mathrm{e}+001.00000 \mathrm{e}+001.00000 \mathrm{e}-011.00000 \mathrm{e}-091.00000 \mathrm{e}-01$ Element: 2796 \# of layers: 13

$\mathrm{Kx} \mathrm{Ky} \mathrm{Kz}$ Ss Por

2.07753e+01 2.07753e+01 2.07753e+00 1.00000e-09 7.00000e-02 $2.07753 \mathrm{e}+012.07753 \mathrm{e}+012.07753 \mathrm{e}+00$ 1.00000e-09 7.00000e-02 5.00000e-04 5.00000e-04 5.00000e-05 1.00000e-09 1.00000e-01 5.00000e-04 5.00000e-04 5.00000e-05 1.00000e-09 1.00000e-01 8.30110e-01 8.30110e-01 8.30110e-02 1.00000e-09 2.12000e-01 8.30110e-01 8.30110e-01 8.30110e-02 1.00000e-09 2.12000e-01 8.30110e-01 8.30110e-01 8.30110e-02 1.00000e-09 2.12000e-01 8.30110e-01 8.30110e-01 8.30110e-02 1.00000e-09 2.12000e-01 8.30110e-01 8.30110e-01 8.30110e-02 1.00000e-09 2.12000e-01 $1.00000 \mathrm{e}-02$ 1.00000e-02 1.00000e-03 1.00000e-09 1.00000e-01 $1.00000 \mathrm{e}+001.00000 \mathrm{e}+001.00000 \mathrm{e}-01$ 1.00000e-09 1.00000e-01 $1.00000 \mathrm{e}-05$ 1.00000e-05 1.00000e-06 1.00000e-09 1.00000e-01 $1.00000 \mathrm{e}+001.00000 \mathrm{e}+001.00000 \mathrm{e}-011.00000 \mathrm{e}-09$ 1.00000e-01 Element: 2797 \# of layers: 13

Kx Ky Kz Ss Por

$2.07753 \mathrm{e}+012.07753 \mathrm{e}+012.07753 \mathrm{e}+00$ 1.00000e-09 7.00000e-02 $2.07753 \mathrm{e}+012.07753 \mathrm{e}+012.07753 \mathrm{e}+001.00000 \mathrm{e}-09$ 7.00000e-02 5.00000e-04 5.00000e-04 5.00000e-05 1.00000e-09 1.00000e-01 5.00000e-04 5.00000e-04 5.00000e-05 1.00000e-09 1.00000e-01 8.30110e-01 8.30110e-01 8.30110e-02 1.00000e-09 2.12000e-01 8.30110e-01 8.30110e-01 8.30110e-02 1.00000e-09 2.12000e-01 8.30110e-01 8.30110e-01 8.30110e-02 1.00000e-09 2.12000e-01 8.30110e-01 8.30110e-01 8.30110e-02 1.00000e-09 2.12000e-01 8.30110e-01 8.30110e-01 8.30110e-02 1.00000e-09 2.12000e-01 $1.00000 \mathrm{e}-02$ 1.00000e-02 1.00000e-03 1.00000e-09 1.00000e-01 $1.00000 \mathrm{e}+001.00000 \mathrm{e}+001.00000 \mathrm{e}-011.00000 \mathrm{e}-091.00000 \mathrm{e}-01$ 
$1.00000 \mathrm{e}-05$ 1.00000e-05 1.00000e-06 1.00000e-09 1.00000e-01 $1.00000 \mathrm{e}+001.00000 \mathrm{e}+001.00000 \mathrm{e}-01$ 1.00000e-09 1.00000e-01 Element: 2798 \# of layers: 13

Kx Ky Kz Ss Por

2.07753e+01 2.07753e+01 2.07753e+00 1.00000e-09 7.00000e-02

$2.07753 \mathrm{e}+012.07753 \mathrm{e}+012.07753 \mathrm{e}+001.00000 \mathrm{e}-09$ 7.00000e-02

5.00000e-04 5.00000e-04 5.00000e-05 1.00000e-09 1.00000e-01

5.00000e-04 5.00000e-04 5.00000e-05 1.00000e-09 1.00000e-01

8.30110e-01 8.30110e-01 8.30110e-02 1.00000e-09 2.12000e-01

8.30110e-01 8.30110e-01 8.30110e-02 1.00000e-09 2.12000e-01

8.30110e-01 8.30110e-01 8.30110e-02 1.00000e-09 2.12000e-01

8.30110e-01 8.30110e-01 8.30110e-02 1.00000e-09 2.12000e-01

8.30110e-01 8.30110e-01 8.30110e-02 1.00000e-09 2.12000e-01

$1.00000 \mathrm{e}-02$ 1.00000e-02 1.00000e-03 1.00000e-09 1.00000e-01

$1.00000 \mathrm{e}+001.00000 \mathrm{e}+001.00000 \mathrm{e}-011.00000 \mathrm{e}-091.00000 \mathrm{e}-01$

$1.00000 \mathrm{e}-05$ 1.00000e-05 1.00000e-06 1.00000e-09 1.00000e-01

$1.00000 \mathrm{e}+001.00000 \mathrm{e}+001.00000 \mathrm{e}-011.00000 \mathrm{e}-091.00000 \mathrm{e}-01$

Element: 2799 \# of layers: 11

$\mathrm{Kx} \mathrm{Ky} \mathrm{Kz}$ Ss Por

2.07753e+01 2.07753e+01 2.07753e+00 1.00000e-09 7.00000e-02

$2.07753 \mathrm{e}+012.07753 \mathrm{e}+012.07753 \mathrm{e}+00$ 1.00000e-09 7.00000e-02

5.00000e-04 5.00000e-04 5.00000e-05 1.00000e-09 1.00000e-01

5.00000e-04 5.00000e-04 5.00000e-05 1.00000e-09 1.00000e-01

8.30110e-01 8.30110e-01 8.30110e-02 1.00000e-09 2.12000e-01

8.30110e-01 8.30110e-01 8.30110e-02 1.00000e-09 2.12000e-01

8.30110e-01 8.30110e-01 8.30110e-02 1.00000e-09 2.12000e-01

8.30110e-01 8.30110e-01 8.30110e-02 1.00000e-09 2.12000e-01

8.30110e-01 8.30110e-01 8.30110e-02 1.00000e-09 2.12000e-01

$1.00000 \mathrm{e}-02$ 1.00000e-02 1.00000e-03 1.00000e-09 1.00000e-01

$1.00000 \mathrm{e}+001.00000 \mathrm{e}+001.00000 \mathrm{e}-011.00000 \mathrm{e}-091.00000 \mathrm{e}-01$

Element: 2800 \# of layers: 11

Kx Ky Kz Ss Por

2.07753e+01 2.07753e+01 2.07753e+00 1.00000e-09 7.00000e-02

$2.07753 \mathrm{e}+012.07753 \mathrm{e}+012.07753 \mathrm{e}+001.00000 \mathrm{e}-09$ 7.00000e-02

5.00000e-04 5.00000e-04 5.00000e-05 1.00000e-09 1.00000e-01

5.00000e-04 5.00000e-04 5.00000e-05 1.00000e-09 1.00000e-01

8.30110e-01 8.30110e-01 8.30110e-02 1.00000e-09 2.12000e-01

8.30110e-01 8.30110e-01 8.30110e-02 1.00000e-09 2.12000e-01

8.30110e-01 8.30110e-01 8.30110e-02 1.00000e-09 2.12000e-01

8.30110e-01 8.30110e-01 8.30110e-02 1.00000e-09 2.12000e-01

8.30110e-01 8.30110e-01 8.30110e-02 1.00000e-09 2.12000e-01

$1.00000 \mathrm{e}-02$ 1.00000e-02 1.00000e-03 1.00000e-09 1.00000e-01

$1.00000 \mathrm{e}+001.00000 \mathrm{e}+001.00000 \mathrm{e}-011.00000 \mathrm{e}-091.00000 \mathrm{e}-01$

Element: 2801 \# of layers: 11

$\mathrm{Kx} \mathrm{Ky} \mathrm{Kz}$ Ss Por

2.07753e+01 2.07753e+01 2.07753e+00 1.00000e-09 7.00000e-02 
$2.07753 \mathrm{e}+012.07753 \mathrm{e}+012.07753 \mathrm{e}+00$ 1.00000e-09 7.00000e-02 5.00000e-04 5.00000e-04 5.00000e-05 1.00000e-09 1.00000e-01 5.00000e-04 5.00000e-04 5.00000e-05 1.00000e-09 1.00000e-01 8.30110e-01 8.30110e-01 8.30110e-02 1.00000e-09 2.12000e-01 8.30110e-01 8.30110e-01 8.30110e-02 1.00000e-09 2.12000e-01 8.30110e-01 8.30110e-01 8.30110e-02 1.00000e-09 2.12000e-01 8.30110e-01 8.30110e-01 8.30110e-02 1.00000e-09 2.12000e-01 8.30110e-01 8.30110e-01 8.30110e-02 1.00000e-09 2.12000e-01 $1.00000 \mathrm{e}-02$ 1.00000e-02 1.00000e-03 1.00000e-09 1.00000e-01 $1.00000 \mathrm{e}+001.00000 \mathrm{e}+001.00000 \mathrm{e}-011.00000 \mathrm{e}-091.00000 \mathrm{e}-01$ Element: 2802 \# of layers: 11

$\mathrm{Kx} \mathrm{Ky} \mathrm{Kz}$ Ss Por

2.07753e+01 2.07753e+01 2.07753e+00 1.00000e-09 7.00000e-02 $2.07753 \mathrm{e}+012.07753 \mathrm{e}+012.07753 \mathrm{e}+001.00000 \mathrm{e}-09$ 7.00000e-02 5.00000e-04 5.00000e-04 5.00000e-05 1.00000e-09 1.00000e-01 5.00000e-04 5.00000e-04 5.00000e-05 1.00000e-09 1.00000e-01 8.30110e-01 8.30110e-01 8.30110e-02 1.00000e-09 2.12000e-01 8.30110e-01 8.30110e-01 8.30110e-02 1.00000e-09 2.12000e-01 8.30110e-01 8.30110e-01 8.30110e-02 1.00000e-09 2.12000e-01 8.30110e-01 8.30110e-01 8.30110e-02 1.00000e-09 2.12000e-01 8.30110e-01 8.30110e-01 8.30110e-02 1.00000e-09 2.12000e-01 $1.00000 \mathrm{e}-021.00000 \mathrm{e}-021.00000 \mathrm{e}-031.00000 \mathrm{e}-091.00000 \mathrm{e}-01$ $1.00000 \mathrm{e}+001.00000 \mathrm{e}+001.00000 \mathrm{e}-01$ 1.00000e-09 1.00000e-01 Element: 2803 \# of layers: 13

$\mathrm{Kx} \mathrm{Ky} \mathrm{Kz}$ Ss Por

$2.54154 \mathrm{e}+012.54154 \mathrm{e}+012.54154 \mathrm{e}+001.00000 \mathrm{e}-097.00000 \mathrm{e}-02$ $2.54154 \mathrm{e}+012.54154 \mathrm{e}+012.54154 \mathrm{e}+001.00000 \mathrm{e}-097.00000 \mathrm{e}-02$ 5.00000e-04 5.00000e-04 5.00000e-05 1.00000e-09 1.00000e-01 5.00000e-04 5.00000e-04 5.00000e-05 1.00000e-09 1.00000e-01 $1.01549 \mathrm{e}+001.01549 \mathrm{e}+00$ 1.01549e-01 1.00000e-09 2.12000e-01 $1.01549 \mathrm{e}+001.01549 \mathrm{e}+00$ 1.01549e-01 1.00000e-09 2.12000e-01 $1.01549 \mathrm{e}+001.01549 \mathrm{e}+00$ 1.01549e-01 1.00000e-09 2.12000e-01 $1.01549 \mathrm{e}+001.01549 \mathrm{e}+001.01549 \mathrm{e}-011.00000 \mathrm{e}-092.12000 \mathrm{e}-01$ $1.01549 \mathrm{e}+001.01549 \mathrm{e}+00 \quad 1.01549 \mathrm{e}-011.00000 \mathrm{e}-092.12000 \mathrm{e}-01$ $1.00000 \mathrm{e}-02$ 1.00000e-02 1.00000e-03 1.00000e-09 1.00000e-01 $1.00000 \mathrm{e}+001.00000 \mathrm{e}+001.00000 \mathrm{e}-011.00000 \mathrm{e}-091.00000 \mathrm{e}-01$ $1.00000 \mathrm{e}-05$ 1.00000e-05 1.00000e-06 1.00000e-09 1.00000e-01 $1.00000 \mathrm{e}+001.00000 \mathrm{e}+001.00000 \mathrm{e}-011.00000 \mathrm{e}-091.00000 \mathrm{e}-01$ Element: 2804 \# of layers: 13

$\mathrm{Kx} \mathrm{Ky} \mathrm{Kz}$ Ss Por

$2.54154 \mathrm{e}+012.54154 \mathrm{e}+012.54154 \mathrm{e}+00$ 1.00000e-09 7.00000e-02 $2.54154 \mathrm{e}+012.54154 \mathrm{e}+012.54154 \mathrm{e}+001.00000 \mathrm{e}-09$ 7.00000e-02 5.00000e-04 5.00000e-04 5.00000e-05 1.00000e-09 1.00000e-01 $5.00000 \mathrm{e}-04$ 5.00000e-04 5.00000e-05 1.00000e-09 1.00000e-01 $1.01549 \mathrm{e}+001.01549 \mathrm{e}+00$ 1.01549e-01 1.00000e-09 2.12000e-01 $1.01549 \mathrm{e}+001.01549 \mathrm{e}+001.01549 \mathrm{e}-01$ 1.00000e-09 2.12000e-01 
$1.01549 \mathrm{e}+00$ 1.01549e+00 1.01549e-01 1.00000e-09 2.12000e-01 $1.01549 \mathrm{e}+001.01549 \mathrm{e}+00$ 1.01549e-01 1.00000e-09 2.12000e-01 $1.01549 \mathrm{e}+001.01549 \mathrm{e}+001.01549 \mathrm{e}-01$ 1.00000e-09 2.12000e-01 $1.00000 \mathrm{e}-02$ 1.00000e-02 1.00000e-03 1.00000e-09 1.00000e-01 $1.00000 \mathrm{e}+001.00000 \mathrm{e}+001.00000 \mathrm{e}-011.00000 \mathrm{e}-091.00000 \mathrm{e}-01$ $1.00000 \mathrm{e}-05$ 1.00000e-05 1.00000e-06 1.00000e-09 1.00000e-01 $1.00000 \mathrm{e}+001.00000 \mathrm{e}+001.00000 \mathrm{e}-011.00000 \mathrm{e}-091.00000 \mathrm{e}-01$ Element: 2805 \# of layers: 13

$\mathrm{Kx} \mathrm{Ky} \mathrm{Kz}$ Ss Por

$2.54154 \mathrm{e}+012.54154 \mathrm{e}+012.54154 \mathrm{e}+001.00000 \mathrm{e}-09$ 7.00000e-02 $2.54154 \mathrm{e}+012.54154 \mathrm{e}+012.54154 \mathrm{e}+001.00000 \mathrm{e}-097.00000 \mathrm{e}-02$ 5.00000e-04 5.00000e-04 5.00000e-05 1.00000e-09 1.00000e-01 5.00000e-04 5.00000e-04 5.00000e-05 1.00000e-09 1.00000e-01 $1.01549 \mathrm{e}+001.01549 \mathrm{e}+00$ 1.01549e-01 1.00000e-09 2.12000e-01 $1.01549 \mathrm{e}+001.01549 \mathrm{e}+00$ 1.01549e-01 1.00000e-09 2.12000e-01 $1.01549 \mathrm{e}+001.01549 \mathrm{e}+00$ 1.01549e-01 1.00000e-09 2.12000e-01 $1.01549 \mathrm{e}+001.01549 \mathrm{e}+001.01549 \mathrm{e}-011.00000 \mathrm{e}-092.12000 \mathrm{e}-01$ $1.01549 \mathrm{e}+001.01549 \mathrm{e}+00$ 1.01549e-01 1.00000e-09 2.12000e-01 $1.00000 \mathrm{e}-02$ 1.00000e-02 1.00000e-03 1.00000e-09 1.00000e-01 $1.00000 \mathrm{e}+001.00000 \mathrm{e}+001.00000 \mathrm{e}-011.00000 \mathrm{e}-091.00000 \mathrm{e}-01$ 1.00000e-05 1.00000e-05 1.00000e-06 1.00000e-09 1.00000e-01 $1.00000 \mathrm{e}+001.00000 \mathrm{e}+001.00000 \mathrm{e}-01$ 1.00000e-09 1.00000e-01 Element: 2806 \# of layers: 13

$\mathrm{Kx} \mathrm{Ky} \mathrm{Kz}$ Ss Por

$2.54154 \mathrm{e}+012.54154 \mathrm{e}+012.54154 \mathrm{e}+001.00000 \mathrm{e}-09$ 7.00000e-02 $2.54154 \mathrm{e}+012.54154 \mathrm{e}+012.54154 \mathrm{e}+001.00000 \mathrm{e}-097.00000 \mathrm{e}-02$ 5.00000e-04 5.00000e-04 5.00000e-05 1.00000e-09 1.00000e-01 5.00000e-04 5.00000e-04 5.00000e-05 1.00000e-09 1.00000e-01 $1.01549 \mathrm{e}+001.01549 \mathrm{e}+001.01549 \mathrm{e}-01$ 1.00000e-09 2.12000e-01 $1.01549 \mathrm{e}+00$ 1.01549e+00 1.01549e-01 1.00000e-09 2.12000e-01 $1.01549 \mathrm{e}+001.01549 \mathrm{e}+00$ 1.01549e-01 1.00000e-09 2.12000e-01 $1.01549 \mathrm{e}+001.01549 \mathrm{e}+00$ 1.01549e-01 1.00000e-09 2.12000e-01 $1.01549 \mathrm{e}+001.01549 \mathrm{e}+001.01549 \mathrm{e}-01$ 1.00000e-09 2.12000e-01 $1.00000 \mathrm{e}-02$ 1.00000e-02 1.00000e-03 1.00000e-09 1.00000e-01 $1.00000 \mathrm{e}+001.00000 \mathrm{e}+001.00000 \mathrm{e}-011.00000 \mathrm{e}-091.00000 \mathrm{e}-01$ $1.00000 \mathrm{e}-05$ 1.00000e-05 1.00000e-06 1.00000e-09 1.00000e-01 $1.00000 \mathrm{e}+001.00000 \mathrm{e}+001.00000 \mathrm{e}-011.00000 \mathrm{e}-091.00000 \mathrm{e}-01$ Element: 2807 \# of layers: 13

$\mathrm{Kx} \mathrm{Ky} \mathrm{Kz}$ Ss Por

$2.54154 \mathrm{e}+012.54154 \mathrm{e}+012.54154 \mathrm{e}+001.00000 \mathrm{e}-09$ 7.00000e-02 $2.54154 \mathrm{e}+012.54154 \mathrm{e}+012.54154 \mathrm{e}+001.00000 \mathrm{e}-097.00000 \mathrm{e}-02$ 5.00000e-04 5.00000e-04 5.00000e-05 1.00000e-09 1.00000e-01 5.00000e-04 5.00000e-04 5.00000e-05 1.00000e-09 1.00000e-01 $1.01549 \mathrm{e}+001.01549 \mathrm{e}+00$ 1.01549e-01 1.00000e-09 2.12000e-01 $1.01549 \mathrm{e}+001.01549 \mathrm{e}+00$ 1.01549e-01 1.00000e-09 2.12000e-01 $1.01549 \mathrm{e}+001.01549 \mathrm{e}+001.01549 \mathrm{e}-01$ 1.00000e-09 2.12000e-01 
$1.01549 \mathrm{e}+00$ 1.01549e+00 1.01549e-01 1.00000e-09 2.12000e-01 $1.01549 \mathrm{e}+001.01549 \mathrm{e}+00$ 1.01549e-01 1.00000e-09 2.12000e-01 $1.00000 \mathrm{e}-02$ 1.00000e-02 1.00000e-03 1.00000e-09 1.00000e-01 $1.00000 \mathrm{e}+001.00000 \mathrm{e}+001.00000 \mathrm{e}-011.00000 \mathrm{e}-091.00000 \mathrm{e}-01$ $1.00000 \mathrm{e}-05$ 1.00000e-05 1.00000e-06 1.00000e-09 1.00000e-01 $1.00000 \mathrm{e}+001.00000 \mathrm{e}+001.00000 \mathrm{e}-011.00000 \mathrm{e}-091.00000 \mathrm{e}-01$ Element: 2808 \# of layers: 13

$\mathrm{Kx} \mathrm{Ky} \mathrm{Kz}$ Ss Por

$2.54154 \mathrm{e}+012.54154 \mathrm{e}+012.54154 \mathrm{e}+00$ 1.00000e-09 7.00000e-02

$2.54154 \mathrm{e}+012.54154 \mathrm{e}+012.54154 \mathrm{e}+001.00000 \mathrm{e}-097.00000 \mathrm{e}-02$ 5.00000e-04 5.00000e-04 5.00000e-05 1.00000e-09 1.00000e-01 5.00000e-04 5.00000e-04 5.00000e-05 1.00000e-09 1.00000e-01

$1.01549 \mathrm{e}+001.01549 \mathrm{e}+001.01549 \mathrm{e}-01$ 1.00000e-09 2.12000e-01 $1.01549 \mathrm{e}+001.01549 \mathrm{e}+00$ 1.01549e-01 1.00000e-09 2.12000e-01 $1.01549 \mathrm{e}+001.01549 \mathrm{e}+00$ 1.01549e-01 1.00000e-09 2.12000e-01 $1.01549 \mathrm{e}+001.01549 \mathrm{e}+00$ 1.01549e-01 1.00000e-09 2.12000e-01 $1.01549 \mathrm{e}+001.01549 \mathrm{e}+00 \quad 1.01549 \mathrm{e}-01$ 1.00000e-09 2.12000e-01 $1.00000 \mathrm{e}-02$ 1.00000e-02 1.00000e-03 1.00000e-09 1.00000e-01 $1.00000 \mathrm{e}+001.00000 \mathrm{e}+001.00000 \mathrm{e}-011.00000 \mathrm{e}-091.00000 \mathrm{e}-01$ $1.00000 \mathrm{e}-05$ 1.00000e-05 1.00000e-06 1.00000e-09 1.00000e-01 $1.00000 \mathrm{e}+001.00000 \mathrm{e}+001.00000 \mathrm{e}-011.00000 \mathrm{e}-091.00000 \mathrm{e}-01$ Element: 2809 \# of layers: 13

$\mathrm{Kx} \mathrm{Ky} \mathrm{Kz}$ Ss Por

$2.54154 \mathrm{e}+012.54154 \mathrm{e}+012.54154 \mathrm{e}+001.00000 \mathrm{e}-09$ 7.00000e-02 $2.54154 \mathrm{e}+012.54154 \mathrm{e}+012.54154 \mathrm{e}+001.00000 \mathrm{e}-097.00000 \mathrm{e}-02$ 5.00000e-04 5.00000e-04 5.00000e-05 1.00000e-09 1.00000e-01 5.00000e-04 5.00000e-04 5.00000e-05 1.00000e-09 1.00000e-01 $1.01549 \mathrm{e}+00$ 1.01549e+00 1.01549e-01 1.00000e-09 2.12000e-01 $1.01549 \mathrm{e}+001.01549 \mathrm{e}+00$ 1.01549e-01 1.00000e-09 2.12000e-01 $1.01549 \mathrm{e}+00$ 1.01549e+00 1.01549e-01 1.00000e-09 2.12000e-01 $1.01549 \mathrm{e}+001.01549 \mathrm{e}+00$ 1.01549e-01 1.00000e-09 2.12000e-01 $1.01549 \mathrm{e}+001.01549 \mathrm{e}+00$ 1.01549e-01 1.00000e-09 2.12000e-01 1.00000e-02 1.00000e-02 1.00000e-03 1.00000e-09 1.00000e-01 $1.00000 \mathrm{e}+001.00000 \mathrm{e}+001.00000 \mathrm{e}-011.00000 \mathrm{e}-091.00000 \mathrm{e}-01$ $1.00000 \mathrm{e}-05$ 1.00000e-05 1.00000e-06 1.00000e-09 1.00000e-01 $1.00000 \mathrm{e}+001.00000 \mathrm{e}+001.00000 \mathrm{e}-01$ 1.00000e-09 1.00000e-01 Element: 2810 \# of layers: 13

$\mathrm{Kx} \mathrm{Ky} \mathrm{Kz}$ Ss Por

$2.54154 \mathrm{e}+012.54154 \mathrm{e}+012.54154 \mathrm{e}+001.00000 \mathrm{e}-097.00000 \mathrm{e}-02$ $2.54154 \mathrm{e}+012.54154 \mathrm{e}+012.54154 \mathrm{e}+001.00000 \mathrm{e}-097.00000 \mathrm{e}-02$ 5.00000e-04 5.00000e-04 5.00000e-05 1.00000e-09 1.00000e-01 5.00000e-04 5.00000e-04 5.00000e-05 1.00000e-09 1.00000e-01 $1.01549 \mathrm{e}+001.01549 \mathrm{e}+00$ 1.01549e-01 1.00000e-09 2.12000e-01 $1.01549 \mathrm{e}+001.01549 \mathrm{e}+00$ 1.01549e-01 1.00000e-09 2.12000e-01 $1.01549 \mathrm{e}+001.01549 \mathrm{e}+00$ 1.01549e-01 1.00000e-09 2.12000e-01 $1.01549 \mathrm{e}+001.01549 \mathrm{e}+001.01549 \mathrm{e}-01$ 1.00000e-09 2.12000e-01 
$1.01549 \mathrm{e}+00$ 1.01549e+00 1.01549e-01 1.00000e-09 2.12000e-01 $1.00000 \mathrm{e}-02$ 1.00000e-02 1.00000e-03 1.00000e-09 1.00000e-01 $1.00000 \mathrm{e}+001.00000 \mathrm{e}+001.00000 \mathrm{e}-011.00000 \mathrm{e}-091.00000 \mathrm{e}-01$ $1.00000 \mathrm{e}-05$ 1.00000e-05 1.00000e-06 1.00000e-09 1.00000e-01 $1.00000 \mathrm{e}+001.00000 \mathrm{e}+001.00000 \mathrm{e}-011.00000 \mathrm{e}-091.00000 \mathrm{e}-01$ Element: 2811 \# of layers: 13

$\mathrm{Kx} \mathrm{Ky} \mathrm{Kz}$ Ss Por

$2.54154 \mathrm{e}+012.54154 \mathrm{e}+012.54154 \mathrm{e}+00$ 1.00000e-09 7.00000e-02

$2.54154 \mathrm{e}+012.54154 \mathrm{e}+012.54154 \mathrm{e}+001.00000 \mathrm{e}-09$ 7.00000e-02

5.00000e-04 5.00000e-04 5.00000e-05 1.00000e-09 1.00000e-01

5.00000e-04 5.00000e-04 5.00000e-05 1.00000e-09 1.00000e-01

$1.01549 \mathrm{e}+001.01549 \mathrm{e}+00$ 1.01549e-01 1.00000e-09 2.12000e-01

$1.01549 \mathrm{e}+001.01549 \mathrm{e}+001.01549 \mathrm{e}-01$ 1.00000e-09 2.12000e-01

$1.01549 \mathrm{e}+001.01549 \mathrm{e}+00$ 1.01549e-01 1.00000e-09 2.12000e-01

$1.01549 \mathrm{e}+001.01549 \mathrm{e}+00$ 1.01549e-01 1.00000e-09 2.12000e-01

$1.01549 \mathrm{e}+001.01549 \mathrm{e}+001.01549 \mathrm{e}-01$ 1.00000e-09 2.12000e-01

$1.00000 \mathrm{e}-02$ 1.00000e-02 1.00000e-03 1.00000e-09 1.00000e-01

$1.00000 \mathrm{e}+001.00000 \mathrm{e}+001.00000 \mathrm{e}-011.00000 \mathrm{e}-091.00000 \mathrm{e}-01$

$1.00000 \mathrm{e}-051.00000 \mathrm{e}-05$ 1.00000e-06 1.00000e-09 1.00000e-01

$1.00000 \mathrm{e}+001.00000 \mathrm{e}+001.00000 \mathrm{e}-011.00000 \mathrm{e}-091.00000 \mathrm{e}-01$

Element: 2812 \# of layers: 14

$\mathrm{Kx} \mathrm{Ky} \mathrm{Kz}$ Ss Por

3.17026e+01 3.17026e+01 3.17026e+00 1.00000e-09 7.00000e-02

$3.17026 \mathrm{e}+013.17026 \mathrm{e}+013.17026 \mathrm{e}+001.00000 \mathrm{e}-09$ 7.00000e-02

$3.17026 \mathrm{e}+013.17026 \mathrm{e}+013.17026 \mathrm{e}+001.00000 \mathrm{e}-097.00000 \mathrm{e}-02$

5.00000e-04 5.00000e-04 5.00000e-05 1.00000e-09 1.00000e-01

5.00000e-04 5.00000e-04 5.00000e-05 1.00000e-09 1.00000e-01

$1.26671 \mathrm{e}+001.26671 \mathrm{e}+001.26671 \mathrm{e}-01$ 1.00000e-09 2.12000e-01

$1.26671 \mathrm{e}+001.26671 \mathrm{e}+001.26671 \mathrm{e}-01$ 1.00000e-09 2.12000e-01

$1.26671 \mathrm{e}+001.26671 \mathrm{e}+001.26671 \mathrm{e}-01$ 1.00000e-09 2.12000e-01

$1.26671 \mathrm{e}+001.26671 \mathrm{e}+001.26671 \mathrm{e}-01$ 1.00000e-09 2.12000e-01

$1.26671 \mathrm{e}+001.26671 \mathrm{e}+001.26671 \mathrm{e}-01$ 1.00000e-09 2.12000e-01

$1.00000 \mathrm{e}-02$ 1.00000e-02 1.00000e-03 1.00000e-09 1.00000e-01

$1.00000 \mathrm{e}+001.00000 \mathrm{e}+001.00000 \mathrm{e}-011.00000 \mathrm{e}-091.00000 \mathrm{e}-01$

$1.00000 \mathrm{e}-05$ 1.00000e-05 1.00000e-06 1.00000e-09 1.00000e-01

$1.00000 \mathrm{e}+001.00000 \mathrm{e}+001.00000 \mathrm{e}-01$ 1.00000e-09 1.00000e-01

Element: 2813 \# of layers: 14

$\mathrm{Kx} \mathrm{Ky} \mathrm{Kz}$ Ss Por

$3.17026 \mathrm{e}+013.17026 \mathrm{e}+013.17026 \mathrm{e}+001.00000 \mathrm{e}-09$ 7.00000e-02

$3.17026 \mathrm{e}+013.17026 \mathrm{e}+013.17026 \mathrm{e}+001.00000 \mathrm{e}-09$ 7.00000e-02

$3.17026 \mathrm{e}+013.17026 \mathrm{e}+013.17026 \mathrm{e}+00$ 1.00000e-09 7.00000e-02

5.00000e-04 5.00000e-04 5.00000e-05 1.00000e-09 1.00000e-01

5.00000e-04 5.00000e-04 5.00000e-05 1.00000e-09 1.00000e-01

$1.26671 \mathrm{e}+001.26671 \mathrm{e}+00$ 1.26671e-01 1.00000e-09 2.12000e-01

$1.26671 \mathrm{e}+001.26671 \mathrm{e}+001.26671 \mathrm{e}-01$ 1.00000e-09 2.12000e-01

$1.26671 \mathrm{e}+001.26671 \mathrm{e}+001.26671 \mathrm{e}-01$ 1.00000e-09 2.12000e-01 
$1.26671 \mathrm{e}+00$ 1.26671e+00 1.26671e-01 1.00000e-09 2.12000e-01 $1.26671 \mathrm{e}+001.26671 \mathrm{e}+001.26671 \mathrm{e}-01$ 1.00000e-09 2.12000e-01 $1.00000 \mathrm{e}-02$ 1.00000e-02 1.00000e-03 1.00000e-09 1.00000e-01 $1.00000 \mathrm{e}+001.00000 \mathrm{e}+001.00000 \mathrm{e}-011.00000 \mathrm{e}-091.00000 \mathrm{e}-01$ $1.00000 \mathrm{e}-05$ 1.00000e-05 1.00000e-06 1.00000e-09 1.00000e-01 $1.00000 \mathrm{e}+001.00000 \mathrm{e}+001.00000 \mathrm{e}-011.00000 \mathrm{e}-091.00000 \mathrm{e}-01$ Element: 2814 \# of layers: 10

$\mathrm{Kx} \mathrm{Ky} \mathrm{Kz} \mathrm{Ss} \mathrm{Por}$

3.17026e+01 3.17026e+01 3.17026e+00 1.00000e-09 7.00000e-02 $3.17026 \mathrm{e}+013.17026 \mathrm{e}+013.17026 \mathrm{e}+001.00000 \mathrm{e}-09$ 7.00000e-02 5.00000e-04 5.00000e-04 5.00000e-05 1.00000e-09 1.00000e-01 5.00000e-04 5.00000e-04 5.00000e-05 1.00000e-09 1.00000e-01 $1.26671 \mathrm{e}+001.26671 \mathrm{e}+001.26671 \mathrm{e}-01$ 1.00000e-09 2.12000e-01 $1.26671 \mathrm{e}+001.26671 \mathrm{e}+001.26671 \mathrm{e}-01$ 1.00000e-09 2.12000e-01 $1.26671 \mathrm{e}+001.26671 \mathrm{e}+001.26671 \mathrm{e}-01$ 1.00000e-09 2.12000e-01 $1.26671 \mathrm{e}+001.26671 \mathrm{e}+001.26671 \mathrm{e}-01$ 1.00000e-09 2.12000e-01 $1.26671 \mathrm{e}+001.26671 \mathrm{e}+001.26671 \mathrm{e}-01$ 1.00000e-09 2.12000e-01 $1.00000 \mathrm{e}+001.00000 \mathrm{e}+001.00000 \mathrm{e}-01$ 1.00000e-09 1.00000e-01 Element: 2815 \# of layers: 10

$\mathrm{Kx} \mathrm{Ky} \mathrm{Kz}$ Ss Por

3.17026e+01 3.17026e+01 3.17026e+00 1.00000e-09 7.00000e-02

$3.17026 \mathrm{e}+013.17026 \mathrm{e}+013.17026 \mathrm{e}+001.00000 \mathrm{e}-09$ 7.00000e-02 5.00000e-04 5.00000e-04 5.00000e-05 1.00000e-09 1.00000e-01 5.00000e-04 5.00000e-04 5.00000e-05 1.00000e-09 1.00000e-01

$1.26671 \mathrm{e}+001.26671 \mathrm{e}+001.26671 \mathrm{e}-011.00000 \mathrm{e}-092.12000 \mathrm{e}-01$ $1.26671 \mathrm{e}+001.26671 \mathrm{e}+001.26671 \mathrm{e}-01$ 1.00000e-09 2.12000e-01 $1.26671 \mathrm{e}+001.26671 \mathrm{e}+001.26671 \mathrm{e}-01$ 1.00000e-09 2.12000e-01 $1.26671 \mathrm{e}+001.26671 \mathrm{e}+001.26671 \mathrm{e}-01$ 1.00000e-09 2.12000e-01 $1.26671 \mathrm{e}+001.26671 \mathrm{e}+001.26671 \mathrm{e}-01$ 1.00000e-09 2.12000e-01 $1.00000 \mathrm{e}+001.00000 \mathrm{e}+001.00000 \mathrm{e}-011.00000 \mathrm{e}-091.00000 \mathrm{e}-01$ Element: 2816 \# of layers: 10

$\mathrm{Kx} \mathrm{Ky} \mathrm{Kz}$ Ss Por

3.17026e+01 3.17026e+01 3.17026e+00 1.00000e-09 7.00000e-02

$3.17026 \mathrm{e}+013.17026 \mathrm{e}+013.17026 \mathrm{e}+001.00000 \mathrm{e}-09$ 7.00000e-02 5.00000e-04 5.00000e-04 5.00000e-05 1.00000e-09 1.00000e-01 5.00000e-04 5.00000e-04 5.00000e-05 1.00000e-09 1.00000e-01 $1.26671 \mathrm{e}+001.26671 \mathrm{e}+001.26671 \mathrm{e}-011.00000 \mathrm{e}-092.12000 \mathrm{e}-01$ $1.26671 \mathrm{e}+001.26671 \mathrm{e}+001.26671 \mathrm{e}-01$ 1.00000e-09 2.12000e-01 $1.26671 \mathrm{e}+001.26671 \mathrm{e}+00$ 1.26671e-01 1.00000e-09 2.12000e-01 $1.26671 \mathrm{e}+001.26671 \mathrm{e}+00$ 1.26671e-01 1.00000e-09 2.12000e-01 $1.26671 \mathrm{e}+001.26671 \mathrm{e}+001.26671 \mathrm{e}-011.00000 \mathrm{e}-092.12000 \mathrm{e}-01$ $1.00000 \mathrm{e}+001.00000 \mathrm{e}+001.00000 \mathrm{e}-011.00000 \mathrm{e}-091.00000 \mathrm{e}-01$ Element: 2817 \# of layers: 12

$\mathrm{Kx} \mathrm{Ky} \mathrm{Kz}$ Ss Por

3.17026e+01 3.17026e+01 3.17026e+00 1.00000e-09 7.00000e-02 $3.17026 \mathrm{e}+013.17026 \mathrm{e}+013.17026 \mathrm{e}+001.00000 \mathrm{e}-09$ 7.00000e-02 
$3.17026 \mathrm{e}+013.17026 \mathrm{e}+013.17026 \mathrm{e}+00$ 1.00000e-09 7.00000e-02 5.00000e-04 5.00000e-04 5.00000e-05 1.00000e-09 1.00000e-01 5.00000e-04 5.00000e-04 5.00000e-05 1.00000e-09 1.00000e-01 $1.26671 \mathrm{e}+001.26671 \mathrm{e}+001.26671 \mathrm{e}-011.00000 \mathrm{e}-092.12000 \mathrm{e}-01$ $1.26671 \mathrm{e}+001.26671 \mathrm{e}+001.26671 \mathrm{e}-011.00000 \mathrm{e}-092.12000 \mathrm{e}-01$ $1.26671 \mathrm{e}+001.26671 \mathrm{e}+001.26671 \mathrm{e}-011.00000 \mathrm{e}-092.12000 \mathrm{e}-01$ $1.26671 \mathrm{e}+001.26671 \mathrm{e}+001.26671 \mathrm{e}-011.00000 \mathrm{e}-092.12000 \mathrm{e}-01$ $1.26671 \mathrm{e}+001.26671 \mathrm{e}+001.26671 \mathrm{e}-011.00000 \mathrm{e}-09$ 2.12000e-01 $1.00000 \mathrm{e}-02$ 1.00000e-02 1.00000e-03 1.00000e-09 1.00000e-01 $1.00000 \mathrm{e}+001.00000 \mathrm{e}+001.00000 \mathrm{e}-011.00000 \mathrm{e}-091.00000 \mathrm{e}-01$ Element: 2818 \# of layers: 11

Kx Ky Kz Ss Por

$3.17026 \mathrm{e}+013.17026 \mathrm{e}+013.17026 \mathrm{e}+00$ 1.00000e-09 7.00000e-02 $3.17026 \mathrm{e}+013.17026 \mathrm{e}+013.17026 \mathrm{e}+001.00000 \mathrm{e}-09$ 7.00000e-02 $5.00000 \mathrm{e}-04$ 5.00000e-04 5.00000e-05 1.00000e-09 1.00000e-01 5.00000e-04 5.00000e-04 5.00000e-05 1.00000e-09 1.00000e-01 $1.26671 \mathrm{e}+001.26671 \mathrm{e}+001.26671 \mathrm{e}-011.00000 \mathrm{e}-092.12000 \mathrm{e}-01$ $1.26671 \mathrm{e}+001.26671 \mathrm{e}+001.26671 \mathrm{e}-011.00000 \mathrm{e}-092.12000 \mathrm{e}-01$ $1.26671 \mathrm{e}+001.26671 \mathrm{e}+001.26671 \mathrm{e}-011.00000 \mathrm{e}-092.12000 \mathrm{e}-01$ $1.26671 \mathrm{e}+001.26671 \mathrm{e}+001.26671 \mathrm{e}-011.00000 \mathrm{e}-092.12000 \mathrm{e}-01$ $1.26671 \mathrm{e}+001.26671 \mathrm{e}+001.26671 \mathrm{e}-011.00000 \mathrm{e}-092.12000 \mathrm{e}-01$ $1.00000 \mathrm{e}-02$ 1.00000e-02 1.00000e-03 1.00000e-09 1.00000e-01 $1.00000 \mathrm{e}+001.00000 \mathrm{e}+001.00000 \mathrm{e}-011.00000 \mathrm{e}-091.00000 \mathrm{e}-01$ Element: 2819 \# of layers: 13

Kx Ky Kz Ss Por

$3.17026 \mathrm{e}+013.17026 \mathrm{e}+013.17026 \mathrm{e}+00$ 1.00000e-09 7.00000e-02 $3.17026 \mathrm{e}+013.17026 \mathrm{e}+013.17026 \mathrm{e}+001.00000 \mathrm{e}-09$ 7.00000e-02 5.00000e-04 5.00000e-04 5.00000e-05 1.00000e-09 1.00000e-01 5.00000e-04 5.00000e-04 5.00000e-05 1.00000e-09 1.00000e-01 $1.26671 \mathrm{e}+001.26671 \mathrm{e}+001.26671 \mathrm{e}-011.00000 \mathrm{e}-092.12000 \mathrm{e}-01$ $1.26671 \mathrm{e}+001.26671 \mathrm{e}+001.26671 \mathrm{e}-011.00000 \mathrm{e}-092.12000 \mathrm{e}-01$ $1.26671 \mathrm{e}+001.26671 \mathrm{e}+001.26671 \mathrm{e}-011.00000 \mathrm{e}-092.12000 \mathrm{e}-01$ $1.26671 \mathrm{e}+001.26671 \mathrm{e}+001.26671 \mathrm{e}-011.00000 \mathrm{e}-092.12000 \mathrm{e}-01$ $1.26671 \mathrm{e}+001.26671 \mathrm{e}+001.26671 \mathrm{e}-011.00000 \mathrm{e}-092.12000 \mathrm{e}-01$ $1.00000 \mathrm{e}-021.00000 \mathrm{e}-02$ 1.00000e-03 1.00000e-09 1.00000e-01 $1.00000 \mathrm{e}+001.00000 \mathrm{e}+001.00000 \mathrm{e}-011.00000 \mathrm{e}-091.00000 \mathrm{e}-01$ $1.00000 \mathrm{e}-05$ 1.00000e-05 1.00000e-06 1.00000e-09 1.00000e-01 $1.00000 \mathrm{e}+001.00000 \mathrm{e}+001.00000 \mathrm{e}-011.00000 \mathrm{e}-091.00000 \mathrm{e}-01$ Element: 2820 \# of layers: 12

Kx Ky Kz Ss Por

$3.17026 \mathrm{e}+013.17026 \mathrm{e}+013.17026 \mathrm{e}+00$ 1.00000e-09 7.00000e-02 $3.17026 \mathrm{e}+013.17026 \mathrm{e}+013.17026 \mathrm{e}+001.00000 \mathrm{e}-09$ 7.00000e-02 $3.17026 \mathrm{e}+013.17026 \mathrm{e}+013.17026 \mathrm{e}+001.00000 \mathrm{e}-09$ 7.00000e-02 5.00000e-04 5.00000e-04 5.00000e-05 1.00000e-09 1.00000e-01 5.00000e-04 5.00000e-04 5.00000e-05 1.00000e-09 1.00000e-01 $1.26671 \mathrm{e}+001.26671 \mathrm{e}+001.26671 \mathrm{e}-011.00000 \mathrm{e}-092.12000 \mathrm{e}-01$ 
$1.26671 \mathrm{e}+00$ 1.26671e+00 1.26671e-01 1.00000e-09 2.12000e-01 $1.26671 \mathrm{e}+001.26671 \mathrm{e}+001.26671 \mathrm{e}-01$ 1.00000e-09 2.12000e-01 $1.26671 \mathrm{e}+001.26671 \mathrm{e}+001.26671 \mathrm{e}-01$ 1.00000e-09 2.12000e-01 $1.26671 \mathrm{e}+001.26671 \mathrm{e}+001.26671 \mathrm{e}-01$ 1.00000e-09 2.12000e-01 $1.00000 \mathrm{e}-02$ 1.00000e-02 1.00000e-03 1.00000e-09 1.00000e-01 $1.00000 \mathrm{e}+001.00000 \mathrm{e}+001.00000 \mathrm{e}-011.00000 \mathrm{e}-091.00000 \mathrm{e}-01$ Element: 2821 \# of layers: 10

$\mathrm{Kx} \mathrm{Ky} \mathrm{Kz}$ Ss Por

$3.98188 \mathrm{e}+013.98188 \mathrm{e}+013.98188 \mathrm{e}+001.00000 \mathrm{e}-09$ 7.00000e-02 $3.98188 \mathrm{e}+013.98188 \mathrm{e}+013.98188 \mathrm{e}+00$ 1.00000e-09 7.00000e-02 5.00000e-04 5.00000e-04 5.00000e-05 1.00000e-09 1.00000e-01 5.00000e-04 5.00000e-04 5.00000e-05 1.00000e-09 1.00000e-01

$1.59103 \mathrm{e}+001.59103 \mathrm{e}+00$ 1.59103e-01 1.00000e-09 2.12000e-01 $1.59103 \mathrm{e}+001.59103 \mathrm{e}+00$ 1.59103e-01 1.00000e-09 2.12000e-01 $1.59103 \mathrm{e}+001.59103 \mathrm{e}+00$ 1.59103e-01 1.00000e-09 2.12000e-01 $1.59103 \mathrm{e}+00$ 1.59103e+00 1.59103e-01 1.00000e-09 2.12000e-01 $1.59103 \mathrm{e}+001.59103 \mathrm{e}+00$ 1.59103e-01 1.00000e-09 2.12000e-01 $1.00000 \mathrm{e}+001.00000 \mathrm{e}+001.00000 \mathrm{e}-01$ 1.00000e-09 1.00000e-01 Element: 2822 \# of layers: 9

$\mathrm{Kx} \mathrm{Ky} \mathrm{Kz}$ Ss Por

$3.98188 \mathrm{e}+013.98188 \mathrm{e}+013.98188 \mathrm{e}+001.00000 \mathrm{e}-09$ 7.00000e-02 $5.00000 \mathrm{e}-04$ 5.00000e-04 5.00000e-05 1.00000e-09 1.00000e-01 5.00000e-04 5.00000e-04 5.00000e-05 1.00000e-09 1.00000e-01 $1.59103 \mathrm{e}+001.59103 \mathrm{e}+00$ 1.59103e-01 1.00000e-09 2.12000e-01 $1.59103 e+001.59103 e+001.59103 e-011.00000 e-092.12000 e-01$ $1.59103 \mathrm{e}+001.59103 \mathrm{e}+00$ 1.59103e-01 1.00000e-09 2.12000e-01 $1.59103 \mathrm{e}+001.59103 \mathrm{e}+00$ 1.59103e-01 1.00000e-09 2.12000e-01 $1.59103 \mathrm{e}+001.59103 \mathrm{e}+00$ 1.59103e-01 1.00000e-09 2.12000e-01 $1.00000 \mathrm{e}+001.00000 \mathrm{e}+001.00000 \mathrm{e}-011.00000 \mathrm{e}-091.00000 \mathrm{e}-01$ Element: 2823 \# of layers: 9

$\mathrm{Kx} \mathrm{Ky} \mathrm{Kz}$ Ss Por

3.98188e+01 3.98188e+01 3.98188e+00 1.00000e-09 7.00000e-02 5.00000e-04 5.00000e-04 5.00000e-05 1.00000e-09 1.00000e-01 5.00000e-04 5.00000e-04 5.00000e-05 1.00000e-09 1.00000e-01 $1.59103 \mathrm{e}+001.59103 \mathrm{e}+00$ 1.59103e-01 1.00000e-09 2.12000e-01 $1.59103 \mathrm{e}+001.59103 \mathrm{e}+00$ 1.59103e-01 1.00000e-09 2.12000e-01 $1.59103 \mathrm{e}+001.59103 \mathrm{e}+00$ 1.59103e-01 1.00000e-09 2.12000e-01 $1.59103 \mathrm{e}+001.59103 \mathrm{e}+00$ 1.59103e-01 1.00000e-09 2.12000e-01 $1.59103 \mathrm{e}+001.59103 \mathrm{e}+00$ 1.59103e-01 1.00000e-09 2.12000e-01 $1.00000 \mathrm{e}+001.00000 \mathrm{e}+001.00000 \mathrm{e}-011.00000 \mathrm{e}-091.00000 \mathrm{e}-01$ Element: 2824 \# of layers: 8

$\mathrm{Kx} \mathrm{Ky} \mathrm{Kz}$ Ss Por

3.98188e+01 3.98188e+01 3.98188e+00 1.00000e-09 7.00000e-02 5.00000e-04 5.00000e-04 5.00000e-05 1.00000e-09 1.00000e-01 $1.59103 \mathrm{e}+001.59103 \mathrm{e}+00$ 1.59103e-01 1.00000e-09 2.12000e-01 $1.59103 \mathrm{e}+001.59103 \mathrm{e}+00$ 1.59103e-01 1.00000e-09 2.12000e-01 
$1.59103 \mathrm{e}+001.59103 \mathrm{e}+00$ 1.59103e-01 1.00000e-09 2.12000e-01 $1.59103 \mathrm{e}+001.59103 \mathrm{e}+001.59103 \mathrm{e}-011.00000 \mathrm{e}-092.12000 \mathrm{e}-01$ $1.59103 \mathrm{e}+001.59103 \mathrm{e}+00$ 1.59103e-01 1.00000e-09 2.12000e-01 $1.00000 \mathrm{e}+001.00000 \mathrm{e}+001.00000 \mathrm{e}-011.00000 \mathrm{e}-091.00000 \mathrm{e}-01$ Element: 2825 \# of layers: 9

Kx Ky Kz Ss Por

$3.98188 \mathrm{e}+013.98188 \mathrm{e}+013.98188 \mathrm{e}+00$ 1.00000e-09 7.00000e-02 $3.98188 \mathrm{e}+013.98188 \mathrm{e}+013.98188 \mathrm{e}+001.00000 \mathrm{e}-09$ 7.00000e-02 $5.00000 \mathrm{e}-04$ 5.00000e-04 5.00000e-05 1.00000e-09 1.00000e-01

$1.59103 \mathrm{e}+001.59103 \mathrm{e}+001.59103 \mathrm{e}-011.00000 \mathrm{e}-092.12000 \mathrm{e}-01$ $1.59103 \mathrm{e}+001.59103 \mathrm{e}+001.59103 \mathrm{e}-011.00000 \mathrm{e}-09$ 2.12000e-01 $1.59103 \mathrm{e}+001.59103 \mathrm{e}+001.59103 \mathrm{e}-011.00000 \mathrm{e}-09$ 2.12000e-01 $1.59103 \mathrm{e}+001.59103 \mathrm{e}+001.59103 \mathrm{e}-011.00000 \mathrm{e}-092.12000 \mathrm{e}-01$ $1.59103 \mathrm{e}+001.59103 \mathrm{e}+001.59103 \mathrm{e}-011.00000 \mathrm{e}-092.12000 \mathrm{e}-01$ $1.00000 \mathrm{e}+001.00000 \mathrm{e}+001.00000 \mathrm{e}-011.00000 \mathrm{e}-091.00000 \mathrm{e}-01$ Element: 2826 \# of layers: 9

Kx Ky Kz Ss Por

$3.98188 \mathrm{e}+013.98188 \mathrm{e}+013.98188 \mathrm{e}+00$ 1.00000e-09 7.00000e-02 $3.98188 \mathrm{e}+013.98188 \mathrm{e}+013.98188 \mathrm{e}+001.00000 \mathrm{e}-09$ 7.00000e-02 5.00000e-04 5.00000e-04 5.00000e-05 1.00000e-09 1.00000e-01

$1.59103 \mathrm{e}+001.59103 \mathrm{e}+001.59103 \mathrm{e}-011.00000 \mathrm{e}-092.12000 \mathrm{e}-01$ $1.59103 \mathrm{e}+001.59103 \mathrm{e}+001.59103 \mathrm{e}-011.00000 \mathrm{e}-092.12000 \mathrm{e}-01$ $1.59103 \mathrm{e}+001.59103 \mathrm{e}+00$ 1.59103e-01 1.00000e-09 2.12000e-01 $1.59103 \mathrm{e}+001.59103 \mathrm{e}+00$ 1.59103e-01 1.00000e-09 2.12000e-01 $1.59103 \mathrm{e}+001.59103 \mathrm{e}+001.59103 \mathrm{e}-011.00000 \mathrm{e}-092.12000 \mathrm{e}-01$ $1.00000 \mathrm{e}+001.00000 \mathrm{e}+001.00000 \mathrm{e}-011.00000 \mathrm{e}-091.00000 \mathrm{e}-01$ Element: 2827 \# of layers: 10

Kx Ky Kz Ss Por

$3.98188 \mathrm{e}+013.98188 \mathrm{e}+013.98188 \mathrm{e}+00$ 1.00000e-09 7.00000e-02 $3.98188 \mathrm{e}+013.98188 \mathrm{e}+013.98188 \mathrm{e}+001.00000 \mathrm{e}-09$ 7.00000e-02 5.00000e-04 5.00000e-04 5.00000e-05 1.00000e-09 1.00000e-01 5.00000e-04 5.00000e-04 5.00000e-05 1.00000e-09 1.00000e-01 $1.59103 \mathrm{e}+001.59103 \mathrm{e}+00$ 1.59103e-01 1.00000e-09 2.12000e-01 $1.59103 \mathrm{e}+001.59103 \mathrm{e}+001.59103 \mathrm{e}-011.00000 \mathrm{e}-09$ 2.12000e-01 $1.59103 \mathrm{e}+001.59103 \mathrm{e}+001.59103 \mathrm{e}-011.00000 \mathrm{e}-092.12000 \mathrm{e}-01$ $1.59103 \mathrm{e}+001.59103 \mathrm{e}+00$ 1.59103e-01 1.00000e-09 2.12000e-01 $1.59103 \mathrm{e}+001.59103 \mathrm{e}+00$ 1.59103e-01 1.00000e-09 2.12000e-01 $1.00000 \mathrm{e}+001.00000 \mathrm{e}+001.00000 \mathrm{e}-011.00000 \mathrm{e}-091.00000 \mathrm{e}-01$ Element: 2828 \# of layers: 10

Kx Ky Kz Ss Por

$3.98188 \mathrm{e}+013.98188 \mathrm{e}+013.98188 \mathrm{e}+00$ 1.00000e-09 7.00000e-02 $3.98188 \mathrm{e}+013.98188 \mathrm{e}+013.98188 \mathrm{e}+001.00000 \mathrm{e}-09$ 7.00000e-02 5.00000e-04 5.00000e-04 5.00000e-05 1.00000e-09 1.00000e-01 $5.00000 \mathrm{e}-04$ 5.00000e-04 5.00000e-05 1.00000e-09 1.00000e-01 $1.59103 \mathrm{e}+001.59103 \mathrm{e}+00$ 1.59103e-01 1.00000e-09 2.12000e-01 $1.59103 \mathrm{e}+001.59103 \mathrm{e}+001.59103 \mathrm{e}-011.00000 \mathrm{e}-092.12000 \mathrm{e}-01$ 
$1.59103 \mathrm{e}+001.59103 \mathrm{e}+00$ 1.59103e-01 1.00000e-09 2.12000e-01 $1.59103 \mathrm{e}+001.59103 \mathrm{e}+001.59103 \mathrm{e}-011.00000 \mathrm{e}-092.12000 \mathrm{e}-01$ $1.59103 \mathrm{e}+001.59103 \mathrm{e}+00$ 1.59103e-01 1.00000e-09 2.12000e-01 $1.00000 \mathrm{e}+001.00000 \mathrm{e}+001.00000 \mathrm{e}-011.00000 \mathrm{e}-091.00000 \mathrm{e}-01$ Element: 2829 \# of layers: 9

Kx Ky Kz Ss Por

$3.98188 \mathrm{e}+013.98188 \mathrm{e}+013.98188 \mathrm{e}+00$ 1.00000e-09 7.00000e-02 $3.98188 \mathrm{e}+013.98188 \mathrm{e}+013.98188 \mathrm{e}+001.00000 \mathrm{e}-09$ 7.00000e-02 $5.00000 \mathrm{e}-04$ 5.00000e-04 5.00000e-05 1.00000e-09 1.00000e-01

$1.59103 \mathrm{e}+001.59103 \mathrm{e}+001.59103 \mathrm{e}-011.00000 \mathrm{e}-092.12000 \mathrm{e}-01$ $1.59103 \mathrm{e}+001.59103 \mathrm{e}+001.59103 \mathrm{e}-011.00000 \mathrm{e}-092.12000 \mathrm{e}-01$ $1.59103 \mathrm{e}+001.59103 \mathrm{e}+001.59103 \mathrm{e}-011.00000 \mathrm{e}-09$ 2.12000e-01 $1.59103 \mathrm{e}+001.59103 \mathrm{e}+00$ 1.59103e-01 1.00000e-09 2.12000e-01 $1.59103 \mathrm{e}+001.59103 \mathrm{e}+00$ 1.59103e-01 1.00000e-09 2.12000e-01 $1.00000 \mathrm{e}+001.00000 \mathrm{e}+001.00000 \mathrm{e}-011.00000 \mathrm{e}-091.00000 \mathrm{e}-01$ Element: 2830 \# of layers: 8

Kx Ky Kz Ss Por

$5.19562 \mathrm{e}+015.19562 \mathrm{e}+01$ 5.19562e+00 1.00000e-09 7.00000e-02 $5.00000 \mathrm{e}-04$ 5.00000e-04 5.00000e-05 1.00000e-09 1.00000e-01 $5.00000 \mathrm{e}-04$ 5.00000e-04 5.00000e-05 1.00000e-09 1.00000e-01 $2.07598 \mathrm{e}+002.07598 \mathrm{e}+002.07598 \mathrm{e}-011.00000 \mathrm{e}-092.12000 \mathrm{e}-01$ $2.07598 \mathrm{e}+002.07598 \mathrm{e}+002.07598 \mathrm{e}-01$ 1.00000e-09 2.12000e-01 $2.07598 \mathrm{e}+002.07598 \mathrm{e}+002.07598 \mathrm{e}-01$ 1.00000e-09 2.12000e-01 $2.07598 \mathrm{e}+002.07598 \mathrm{e}+002.07598 \mathrm{e}-01$ 1.00000e-09 2.12000e-01 $2.07598 \mathrm{e}+002.07598 \mathrm{e}+00$ 2.07598e-01 1.00000e-09 2.12000e-01 Element: 2831 \# of layers: 7

Kx Ky Kz Ss Por

$5.19562 \mathrm{e}+015.19562 \mathrm{e}+01$ 5.19562e+00 1.00000e-09 7.00000e-02 5.00000e-04 5.00000e-04 5.00000e-05 1.00000e-09 1.00000e-01 $2.07598 \mathrm{e}+002.07598 \mathrm{e}+002.07598 \mathrm{e}-011.00000 \mathrm{e}-092.12000 \mathrm{e}-01$ $2.07598 \mathrm{e}+002.07598 \mathrm{e}+002.07598 \mathrm{e}-011.00000 \mathrm{e}-092.12000 \mathrm{e}-01$ $2.07598 \mathrm{e}+002.07598 \mathrm{e}+002.07598 \mathrm{e}-01$ 1.00000e-09 2.12000e-01 $2.07598 \mathrm{e}+002.07598 \mathrm{e}+002.07598 \mathrm{e}-01$ 1.00000e-09 2.12000e-01 $2.07598 \mathrm{e}+002.07598 \mathrm{e}+00$ 2.07598e-01 1.00000e-09 2.12000e-01 Element: 2832 \# of layers: 8

Kx Ky Kz Ss Por

5.19562e+01 5.19562e+01 5.19562e+00 1.00000e-09 7.00000e-02 5.00000e-04 5.00000e-04 5.00000e-05 1.00000e-09 1.00000e-01 5.00000e-04 5.00000e-04 5.00000e-05 1.00000e-09 1.00000e-01 $2.07598 \mathrm{e}+002.07598 \mathrm{e}+002.07598 \mathrm{e}-01$ 1.00000e-09 2.12000e-01 $2.07598 \mathrm{e}+002.07598 \mathrm{e}+002.07598 \mathrm{e}-011.00000 \mathrm{e}-092.12000 \mathrm{e}-01$ $2.07598 \mathrm{e}+002.07598 \mathrm{e}+002.07598 \mathrm{e}-011.00000 \mathrm{e}-092.12000 \mathrm{e}-01$ $2.07598 \mathrm{e}+002.07598 \mathrm{e}+002.07598 \mathrm{e}-01$ 1.00000e-09 2.12000e-01 $2.07598 \mathrm{e}+002.07598 \mathrm{e}+00$ 2.07598e-01 1.00000e-09 2.12000e-01 Element: 2833 \# of layers: 8

Kx Ky Kz Ss Por 
5.19562e+01 5.19562e+01 5.19562e+00 1.00000e-09 7.00000e-02 5.00000e-04 5.00000e-04 5.00000e-05 1.00000e-09 1.00000e-01 5.00000e-04 5.00000e-04 5.00000e-05 1.00000e-09 1.00000e-01 $2.07598 \mathrm{e}+002.07598 \mathrm{e}+002.07598 \mathrm{e}-01$ 1.00000e-09 2.12000e-01 $2.07598 \mathrm{e}+002.07598 \mathrm{e}+00$ 2.07598e-01 1.00000e-09 2.12000e-01 $2.07598 \mathrm{e}+002.07598 \mathrm{e}+00$ 2.07598e-01 1.00000e-09 2.12000e-01 $2.07598 \mathrm{e}+002.07598 \mathrm{e}+00$ 2.07598e-01 1.00000e-09 2.12000e-01 2.07598e+00 2.07598e+00 2.07598e-01 1.00000e-09 2.12000e-01 Element: 2834 \# of layers: 8

$\mathrm{Kx} \mathrm{Ky} \mathrm{Kz}$ Ss Por

5.19562e+01 5.19562e+01 5.19562e+00 1.00000e-09 7.00000e-02 5.00000e-04 5.00000e-04 5.00000e-05 1.00000e-09 1.00000e-01 5.00000e-04 5.00000e-04 5.00000e-05 1.00000e-09 1.00000e-01 $2.07598 \mathrm{e}+002.07598 \mathrm{e}+00$ 2.07598e-01 1.00000e-09 2.12000e-01 $2.07598 \mathrm{e}+002.07598 \mathrm{e}+00$ 2.07598e-01 1.00000e-09 2.12000e-01 $2.07598 \mathrm{e}+002.07598 \mathrm{e}+00$ 2.07598e-01 1.00000e-09 2.12000e-01 $2.07598 \mathrm{e}+002.07598 \mathrm{e}+002.07598 \mathrm{e}-01$ 1.00000e-09 2.12000e-01 $2.07598 \mathrm{e}+002.07598 \mathrm{e}+00$ 2.07598e-01 1.00000e-09 2.12000e-01 Element: 2835 \# of layers: 8

$\mathrm{Kx} \mathrm{Ky} \mathrm{Kz}$ Ss Por

5.19562e+01 5.19562e+01 5.19562e+00 1.00000e-09 7.00000e-02

5.19562e+01 5.19562e+01 5.19562e+00 1.00000e-09 7.00000e-02 5.00000e-04 5.00000e-04 5.00000e-05 1.00000e-09 1.00000e-01 $2.07598 \mathrm{e}+002.07598 \mathrm{e}+00$ 2.07598e-01 1.00000e-09 2.12000e-01 $2.07598 \mathrm{e}+002.07598 \mathrm{e}+00$ 2.07598e-01 1.00000e-09 2.12000e-01 $2.07598 \mathrm{e}+002.07598 \mathrm{e}+00$ 2.07598e-01 1.00000e-09 2.12000e-01 $2.07598 \mathrm{e}+002.07598 \mathrm{e}+00$ 2.07598e-01 1.00000e-09 2.12000e-01 2.07598e+00 2.07598e+00 2.07598e-01 1.00000e-09 2.12000e-01 Element: 2836 \# of layers: 8

$\mathrm{Kx} \mathrm{Ky} \mathrm{Kz}$ Ss Por

5.19562e+01 5.19562e+01 5.19562e+00 1.00000e-09 7.00000e-02 $5.19562 \mathrm{e}+015.19562 \mathrm{e}+015.19562 \mathrm{e}+00$ 1.00000e-09 7.00000e-02 5.00000e-04 5.00000e-04 5.00000e-05 1.00000e-09 1.00000e-01 $2.07598 \mathrm{e}+002.07598 \mathrm{e}+002.07598 \mathrm{e}-01$ 1.00000e-09 2.12000e-01 $2.07598 \mathrm{e}+002.07598 \mathrm{e}+00$ 2.07598e-01 1.00000e-09 2.12000e-01 $2.07598 \mathrm{e}+002.07598 \mathrm{e}+00$ 2.07598e-01 1.00000e-09 2.12000e-01 $2.07598 \mathrm{e}+002.07598 \mathrm{e}+00$ 2.07598e-01 1.00000e-09 2.12000e-01 $2.07598 \mathrm{e}+002.07598 \mathrm{e}+00$ 2.07598e-01 1.00000e-09 2.12000e-01 Element: 2837 \# of layers: 7

$\mathrm{Kx} \mathrm{Ky} \mathrm{Kz}$ Ss Por

5.19562e+01 5.19562e+01 5.19562e+00 1.00000e-09 7.00000e-02 5.00000e-04 5.00000e-04 5.00000e-05 1.00000e-09 1.00000e-01 $2.07598 \mathrm{e}+002.07598 \mathrm{e}+002.07598 \mathrm{e}-01$ 1.00000e-09 2.12000e-01 2.07598e+00 2.07598e+00 2.07598e-01 1.00000e-09 2.12000e-01 $2.07598 \mathrm{e}+002.07598 \mathrm{e}+002.07598 \mathrm{e}-01$ 1.00000e-09 2.12000e-01 $2.07598 \mathrm{e}+002.07598 \mathrm{e}+00$ 2.07598e-01 1.00000e-09 2.12000e-01 
2.07598e+00 2.07598e+00 2.07598e-01 1.00000e-09 2.12000e-01

Element: 2838 \# of layers: 7

Kx Ky Kz Ss Por

5.19562e+01 5.19562e+01 5.19562e+00 1.00000e-09 7.00000e-02

5.00000e-04 5.00000e-04 5.00000e-05 1.00000e-09 1.00000e-01

$2.07598 \mathrm{e}+002.07598 \mathrm{e}+00$ 2.07598e-01 1.00000e-09 2.12000e-01

$2.07598 \mathrm{e}+002.07598 \mathrm{e}+00$ 2.07598e-01 1.00000e-09 2.12000e-01

$2.07598 \mathrm{e}+002.07598 \mathrm{e}+00$ 2.07598e-01 1.00000e-09 2.12000e-01

$2.07598 \mathrm{e}+002.07598 \mathrm{e}+00$ 2.07598e-01 1.00000e-09 2.12000e-01

2.07598e+00 2.07598e+00 2.07598e-01 1.00000e-09 2.12000e-01

Element: 2839 \# of layers: 8

Kx Ky Kz Ss Por

7.33270e+01 7.33270e+01 7.33270e+00 1.00000e-09 7.00000e-02

5.00000e-04 5.00000e-04 5.00000e-05 1.00000e-09 1.00000e-01

5.00000e-04 5.00000e-04 5.00000e-05 1.00000e-09 1.00000e-01

$2.92979 \mathrm{e}+002.92979 \mathrm{e}+002.92979 \mathrm{e}-01$ 1.00000e-09 2.12000e-01

$2.92979 \mathrm{e}+002.92979 \mathrm{e}+00$ 2.92979e-01 1.00000e-09 2.12000e-01

$2.92979 \mathrm{e}+00$ 2.92979e+00 2.92979e-01 1.00000e-09 2.12000e-01

2.92979e+00 2.92979e+00 2.92979e-01 1.00000e-09 2.12000e-01

$2.92979 \mathrm{e}+00$ 2.92979e+00 2.92979e-01 1.00000e-09 2.12000e-01

Element: 2840 \# of layers: 8

$\mathrm{Kx} \mathrm{Ky} \mathrm{Kz}$ Ss Por

7.33270e+01 7.33270e+01 7.33270e+00 1.00000e-09 7.00000e-02 5.00000e-04 5.00000e-04 5.00000e-05 1.00000e-09 1.00000e-01

5.00000e-04 5.00000e-04 5.00000e-05 1.00000e-09 1.00000e-01

$2.92979 \mathrm{e}+002.92979 \mathrm{e}+00$ 2.92979e-01 1.00000e-09 2.12000e-01

$2.92979 \mathrm{e}+002.92979 \mathrm{e}+00$ 2.92979e-01 1.00000e-09 2.12000e-01

$2.92979 \mathrm{e}+00$ 2.92979e+00 2.92979e-01 1.00000e-09 2.12000e-01

$2.92979 \mathrm{e}+002.92979 \mathrm{e}+00$ 2.92979e-01 1.00000e-09 2.12000e-01

$2.92979 \mathrm{e}+00$ 2.92979e+00 2.92979e-01 1.00000e-09 2.12000e-01

Element: 2841 \# of layers: 8

$\mathrm{Kx} \mathrm{Ky} \mathrm{Kz}$ Ss Por

7.33270e+01 7.33270e+01 7.33270e+00 1.00000e-09 7.00000e-02

$5.00000 \mathrm{e}-04$ 5.00000e-04 5.00000e-05 1.00000e-09 1.00000e-01

5.00000e-04 5.00000e-04 5.00000e-05 1.00000e-09 1.00000e-01

$2.92979 \mathrm{e}+002.92979 \mathrm{e}+00$ 2.92979e-01 1.00000e-09 2.12000e-01

$2.92979 \mathrm{e}+002.92979 \mathrm{e}+00$ 2.92979e-01 1.00000e-09 2.12000e-01

$2.92979 \mathrm{e}+00$ 2.92979e+00 2.92979e-01 1.00000e-09 2.12000e-01

$2.92979 \mathrm{e}+00$ 2.92979e+00 2.92979e-01 1.00000e-09 2.12000e-01

$2.92979 \mathrm{e}+002.92979 \mathrm{e}+00$ 2.92979e-01 1.00000e-09 2.12000e-01

Element: 2842 \# of layers: 7

$\mathrm{Kx} \mathrm{Ky} \mathrm{Kz}$ Ss Por

7.33270e+01 7.33270e+01 7.33270e+00 1.00000e-09 7.00000e-02

5.00000e-04 5.00000e-04 5.00000e-05 1.00000e-09 1.00000e-01

$2.92979 \mathrm{e}+002.92979 \mathrm{e}+00$ 2.92979e-01 1.00000e-09 2.12000e-01

$2.92979 \mathrm{e}+00$ 2.92979e+00 2.92979e-01 1.00000e-09 2.12000e-01 
$2.92979 \mathrm{e}+002.92979 \mathrm{e}+00$ 2.92979e-01 1.00000e-09 2.12000e-01 $2.92979 \mathrm{e}+002.92979 \mathrm{e}+00$ 2.92979e-01 1.00000e-09 2.12000e-01 $2.92979 \mathrm{e}+002.92979 \mathrm{e}+00$ 2.92979e-01 1.00000e-09 2.12000e-01 Element: 2843 \# of layers: 8

Kx Ky Kz Ss Por

7.33270e+01 7.33270e+01 7.33270e+00 1.00000e-09 7.00000e-02 5.00000e-04 5.00000e-04 5.00000e-05 1.00000e-09 1.00000e-01 5.00000e-04 5.00000e-04 5.00000e-05 1.00000e-09 1.00000e-01 $2.92979 \mathrm{e}+002.92979 \mathrm{e}+002.92979 \mathrm{e}-01$ 1.00000e-09 2.12000e-01 $2.92979 \mathrm{e}+002.92979 \mathrm{e}+002.92979 \mathrm{e}-011.00000 \mathrm{e}-092.12000 \mathrm{e}-01$ $2.92979 \mathrm{e}+002.92979 \mathrm{e}+002.92979 \mathrm{e}-01$ 1.00000e-09 2.12000e-01 $2.92979 \mathrm{e}+002.92979 \mathrm{e}+002.92979 \mathrm{e}-01$ 1.00000e-09 2.12000e-01 $2.92979 \mathrm{e}+002.92979 \mathrm{e}+00$ 2.92979e-01 1.00000e-09 2.12000e-01 Element: 2844 \# of layers: 7

Kx Ky Kz Ss Por

7.33270e+01 7.33270e+01 7.33270e+00 1.00000e-09 7.00000e-02 5.00000e-04 5.00000e-04 5.00000e-05 1.00000e-09 1.00000e-01

$2.92979 \mathrm{e}+002.92979 \mathrm{e}+002.92979 \mathrm{e}-011.00000 \mathrm{e}-09$ 2.12000e-01 $2.92979 \mathrm{e}+002.92979 \mathrm{e}+00$ 2.92979e-01 1.00000e-09 2.12000e-01 $2.92979 \mathrm{e}+002.92979 \mathrm{e}+002.92979 \mathrm{e}-01$ 1.00000e-09 2.12000e-01 $2.92979 \mathrm{e}+002.92979 \mathrm{e}+002.92979 \mathrm{e}-01$ 1.00000e-09 2.12000e-01 $2.92979 \mathrm{e}+002.92979 \mathrm{e}+00$ 2.92979e-01 1.00000e-09 2.12000e-01 Element: 2845 \# of layers: 8

Kx Ky Kz Ss Por

7.33270e+01 7.33270e+01 7.33270e+00 1.00000e-09 7.00000e-02 5.00000e-04 5.00000e-04 5.00000e-05 1.00000e-09 1.00000e-01 $5.00000 \mathrm{e}-04$ 5.00000e-04 5.00000e-05 1.00000e-09 1.00000e-01 $2.92979 \mathrm{e}+002.92979 \mathrm{e}+002.92979 \mathrm{e}-01$ 1.00000e-09 2.12000e-01 $2.92979 \mathrm{e}+002.92979 \mathrm{e}+002.92979 \mathrm{e}-01$ 1.00000e-09 2.12000e-01 $2.92979 \mathrm{e}+002.92979 \mathrm{e}+002.92979 \mathrm{e}-01$ 1.00000e-09 2.12000e-01 $2.92979 \mathrm{e}+002.92979 \mathrm{e}+002.92979 \mathrm{e}-01$ 1.00000e-09 2.12000e-01 $2.92979 \mathrm{e}+002.92979 \mathrm{e}+00$ 2.92979e-01 1.00000e-09 2.12000e-01 Element: 2846 \# of layers: 8

$\mathrm{Kx} \mathrm{Ky} \mathrm{Kz}$ Ss Por

7.33270e+01 7.33270e+01 7.33270e+00 1.00000e-09 7.00000e-02 5.00000e-04 5.00000e-04 5.00000e-05 1.00000e-09 1.00000e-01 5.00000e-04 5.00000e-04 5.00000e-05 1.00000e-09 1.00000e-01 $2.92979 \mathrm{e}+002.92979 \mathrm{e}+002.92979 \mathrm{e}-01$ 1.00000e-09 2.12000e-01 $2.92979 \mathrm{e}+002.92979 \mathrm{e}+002.92979 \mathrm{e}-011.00000 \mathrm{e}-092.12000 \mathrm{e}-01$ $2.92979 \mathrm{e}+002.92979 \mathrm{e}+00$ 2.92979e-01 1.00000e-09 2.12000e-01 $2.92979 \mathrm{e}+002.92979 \mathrm{e}+00$ 2.92979e-01 1.00000e-09 2.12000e-01 $2.92979 \mathrm{e}+002.92979 \mathrm{e}+00$ 2.92979e-01 1.00000e-09 2.12000e-01 Element: 2847 \# of layers: 7

Kx Ky Kz Ss Por

7.33270e+01 7.33270e+01 7.33270e+00 1.00000e-09 7.00000e-02 5.00000e-04 5.00000e-04 5.00000e-05 1.00000e-09 1.00000e-01 
$2.92979 \mathrm{e}+002.92979 \mathrm{e}+00$ 2.92979e-01 1.00000e-09 2.12000e-01 $2.92979 \mathrm{e}+002.92979 \mathrm{e}+002.92979 \mathrm{e}-01$ 1.00000e-09 2.12000e-01 $2.92979 \mathrm{e}+002.92979 \mathrm{e}+00$ 2.92979e-01 1.00000e-09 2.12000e-01 $2.92979 \mathrm{e}+002.92979 \mathrm{e}+002.92979 \mathrm{e}-01$ 1.00000e-09 2.12000e-01 $2.92979 \mathrm{e}+002.92979 \mathrm{e}+00$ 2.92979e-01 1.00000e-09 2.12000e-01 Element: 2848 \# of layers: 8

Kx Ky Kz Ss Por

$1.08291 \mathrm{e}+021.08291 \mathrm{e}+021.08291 \mathrm{e}+01$ 1.00000e-09 7.00000e-02 5.00000e-04 5.00000e-04 5.00000e-05 1.00000e-09 1.00000e-01 $5.00000 \mathrm{e}-04$ 5.00000e-04 5.00000e-05 1.00000e-09 1.00000e-01 $4.32684 \mathrm{e}+004.32684 \mathrm{e}+004.32684 \mathrm{e}-011.00000 \mathrm{e}-092.12000 \mathrm{e}-01$ $4.32684 \mathrm{e}+004.32684 \mathrm{e}+004.32684 \mathrm{e}-011.00000 \mathrm{e}-09$ 2.12000e-01 $4.32684 \mathrm{e}+004.32684 \mathrm{e}+004.32684 \mathrm{e}-011.00000 \mathrm{e}-092.12000 \mathrm{e}-01$ $4.32684 \mathrm{e}+004.32684 \mathrm{e}+004.32684 \mathrm{e}-011.00000 \mathrm{e}-092.12000 \mathrm{e}-01$ $4.32684 \mathrm{e}+004.32684 \mathrm{e}+00$ 4.32684e-01 1.00000e-09 2.12000e-01 Element: 2849 \# of layers: 8

Kx Ky Kz Ss Por $1.08291 \mathrm{e}+021.08291 \mathrm{e}+021.08291 \mathrm{e}+01$ 1.00000e-09 7.00000e-02 5.00000e-04 5.00000e-04 5.00000e-05 1.00000e-09 1.00000e-01 $5.00000 \mathrm{e}-04$ 5.00000e-04 5.00000e-05 1.00000e-09 1.00000e-01 $4.32684 \mathrm{e}+004.32684 \mathrm{e}+00$ 4.32684e-01 1.00000e-09 2.12000e-01 $4.32684 \mathrm{e}+004.32684 \mathrm{e}+004.32684 \mathrm{e}-011.00000 \mathrm{e}-092.12000 \mathrm{e}-01$ $4.32684 \mathrm{e}+004.32684 \mathrm{e}+004.32684 \mathrm{e}-011.00000 \mathrm{e}-092.12000 \mathrm{e}-01$ $4.32684 \mathrm{e}+004.32684 \mathrm{e}+004.32684 \mathrm{e}-011.00000 \mathrm{e}-092.12000 \mathrm{e}-01$ $4.32684 \mathrm{e}+004.32684 \mathrm{e}+00$ 4.32684e-01 1.00000e-09 2.12000e-01 Element: 2850 \# of layers: 7

Kx Ky Kz Ss Por

$1.08291 \mathrm{e}+021.08291 \mathrm{e}+021.08291 \mathrm{e}+011.00000 \mathrm{e}-097.00000 \mathrm{e}-02$ 5.00000e-04 5.00000e-04 5.00000e-05 1.00000e-09 1.00000e-01 $4.32684 \mathrm{e}+004.32684 \mathrm{e}+004.32684 \mathrm{e}-011.00000 \mathrm{e}-092.12000 \mathrm{e}-01$ $4.32684 \mathrm{e}+004.32684 \mathrm{e}+00$ 4.32684e-01 1.00000e-09 2.12000e-01 $4.32684 \mathrm{e}+004.32684 \mathrm{e}+004.32684 \mathrm{e}-011.00000 \mathrm{e}-092.12000 \mathrm{e}-01$ $4.32684 \mathrm{e}+004.32684 \mathrm{e}+004.32684 \mathrm{e}-01$ 1.00000e-09 2.12000e-01 $4.32684 \mathrm{e}+004.32684 \mathrm{e}+00$ 4.32684e-01 1.00000e-09 2.12000e-01 Element: 2851 \# of layers: 7

Kx Ky Kz Ss Por $1.08291 \mathrm{e}+021.08291 \mathrm{e}+021.08291 \mathrm{e}+01$ 1.00000e-09 7.00000e-02 5.00000e-04 5.00000e-04 5.00000e-05 1.00000e-09 1.00000e-01 $4.32684 \mathrm{e}+004.32684 \mathrm{e}+00$ 4.32684e-01 1.00000e-09 2.12000e-01 $4.32684 \mathrm{e}+004.32684 \mathrm{e}+00$ 4.32684e-01 1.00000e-09 2.12000e-01 $4.32684 \mathrm{e}+004.32684 \mathrm{e}+004.32684 \mathrm{e}-011.00000 \mathrm{e}-092.12000 \mathrm{e}-01$ $4.32684 \mathrm{e}+004.32684 \mathrm{e}+004.32684 \mathrm{e}-011.00000 \mathrm{e}-092.12000 \mathrm{e}-01$ $4.32684 \mathrm{e}+004.32684 \mathrm{e}+00$ 4.32684e-01 1.00000e-09 2.12000e-01 Element: 2852 \# of layers: 9

Kx Ky Kz Ss Por $1.08291 \mathrm{e}+021.08291 \mathrm{e}+021.08291 \mathrm{e}+01$ 1.00000e-09 7.00000e-02 
$1.08291 \mathrm{e}+021.08291 \mathrm{e}+02$ 1.08291e+01 1.00000e-09 7.00000e-02 5.00000e-04 5.00000e-04 5.00000e-05 1.00000e-09 1.00000e-01 5.00000e-04 5.00000e-04 5.00000e-05 1.00000e-09 1.00000e-01 $4.32684 \mathrm{e}+004.32684 \mathrm{e}+00$ 4.32684e-01 1.00000e-09 2.12000e-01 $4.32684 \mathrm{e}+004.32684 \mathrm{e}+004.32684 \mathrm{e}-01$ 1.00000e-09 2.12000e-01 $4.32684 \mathrm{e}+004.32684 \mathrm{e}+00$ 4.32684e-01 1.00000e-09 2.12000e-01 $4.32684 \mathrm{e}+00$ 4.32684e+00 4.32684e-01 1.00000e-09 2.12000e-01 $4.32684 \mathrm{e}+004.32684 \mathrm{e}+00$ 4.32684e-01 1.00000e-09 2.12000e-01 Element: 2853 \# of layers: 9

$\mathrm{Kx} \mathrm{Ky} \mathrm{Kz}$ Ss Por

$1.08291 \mathrm{e}+02$ 1.08291e+02 1.08291e+01 1.00000e-09 7.00000e-02 $1.08291 \mathrm{e}+021.08291 \mathrm{e}+021.08291 \mathrm{e}+01$ 1.00000e-09 7.00000e-02 5.00000e-04 5.00000e-04 5.00000e-05 1.00000e-09 1.00000e-01 5.00000e-04 5.00000e-04 5.00000e-05 1.00000e-09 1.00000e-01 $4.32684 \mathrm{e}+004.32684 \mathrm{e}+00$ 4.32684e-01 1.00000e-09 2.12000e-01 $4.32684 \mathrm{e}+004.32684 \mathrm{e}+004.32684 \mathrm{e}-01$ 1.00000e-09 2.12000e-01 $4.32684 \mathrm{e}+004.32684 \mathrm{e}+00$ 4.32684e-01 1.00000e-09 2.12000e-01 $4.32684 \mathrm{e}+004.32684 \mathrm{e}+00$ 4.32684e-01 1.00000e-09 2.12000e-01 4.32684e+00 4.32684e+00 4.32684e-01 1.00000e-09 2.12000e-01 Element: 2854 \# of layers: 8

$\mathrm{Kx} \mathrm{Ky} \mathrm{Kz}$ Ss Por

$1.08291 \mathrm{e}+021.08291 \mathrm{e}+02$ 1.08291e+01 1.00000e-09 7.00000e-02 5.00000e-04 5.00000e-04 5.00000e-05 1.00000e-09 1.00000e-01 5.00000e-04 5.00000e-04 5.00000e-05 1.00000e-09 1.00000e-01 $4.32684 \mathrm{e}+004.32684 \mathrm{e}+00 \quad 4.32684 \mathrm{e}-011.00000 \mathrm{e}-092.12000 \mathrm{e}-01$ $4.32684 \mathrm{e}+004.32684 \mathrm{e}+004.32684 \mathrm{e}-01$ 1.00000e-09 2.12000e-01 $4.32684 \mathrm{e}+004.32684 \mathrm{e}+00$ 4.32684e-01 1.00000e-09 2.12000e-01 $4.32684 \mathrm{e}+00$ 4.32684e+00 4.32684e-01 1.00000e-09 2.12000e-01 $4.32684 \mathrm{e}+004.32684 \mathrm{e}+004.32684 \mathrm{e}-01$ 1.00000e-09 2.12000e-01 Element: 2855 \# of layers: 8

$\mathrm{Kx} \mathrm{Ky} \mathrm{Kz}$ Ss Por

$1.08291 \mathrm{e}+021.08291 \mathrm{e}+021.08291 \mathrm{e}+01$ 1.00000e-09 7.00000e-02 5.00000e-04 5.00000e-04 5.00000e-05 1.00000e-09 1.00000e-01 5.00000e-04 5.00000e-04 5.00000e-05 1.00000e-09 1.00000e-01 $4.32684 \mathrm{e}+004.32684 \mathrm{e}+004.32684 \mathrm{e}-01$ 1.00000e-09 2.12000e-01 $4.32684 \mathrm{e}+004.32684 \mathrm{e}+00$ 4.32684e-01 1.00000e-09 2.12000e-01 $4.32684 \mathrm{e}+004.32684 \mathrm{e}+004.32684 \mathrm{e}-01$ 1.00000e-09 2.12000e-01 $4.32684 \mathrm{e}+004.32684 \mathrm{e}+004.32684 \mathrm{e}-01$ 1.00000e-09 2.12000e-01 4.32684e+00 4.32684e+00 4.32684e-01 1.00000e-09 2.12000e-01 Element: 2856 \# of layers: 8

$\mathrm{Kx} \mathrm{Ky} \mathrm{Kz}$ Ss Por $1.08291 \mathrm{e}+021.08291 \mathrm{e}+02$ 1.08291e+01 1.00000e-09 7.00000e-02 $5.00000 \mathrm{e}-04$ 5.00000e-04 5.00000e-05 1.00000e-09 1.00000e-01 5.00000e-04 5.00000e-04 5.00000e-05 1.00000e-09 1.00000e-01 $4.32684 \mathrm{e}+004.32684 \mathrm{e}+004.32684 \mathrm{e}-01$ 1.00000e-09 2.12000e-01 $4.32684 \mathrm{e}+004.32684 \mathrm{e}+004.32684 \mathrm{e}-01$ 1.00000e-09 2.12000e-01 
$4.32684 \mathrm{e}+004.32684 \mathrm{e}+00$ 4.32684e-01 1.00000e-09 2.12000e-01 4.32684e+00 4.32684e+00 4.32684e-01 1.00000e-09 2.12000e-01 $4.32684 \mathrm{e}+004.32684 \mathrm{e}+00$ 4.32684e-01 1.00000e-09 2.12000e-01 Element: 2857 \# of layers: 8

$\mathrm{Kx} \mathrm{Ky} \mathrm{Kz}$ Ss Por

1.72307e+02 1.72307e+02 1.72307e+01 1.00000e-09 7.00000e-02 5.00000e-04 5.00000e-04 5.00000e-05 1.00000e-09 1.00000e-01 5.00000e-04 5.00000e-04 5.00000e-05 1.00000e-09 1.00000e-01 $6.88470 \mathrm{e}+006.88470 \mathrm{e}+006.88470 \mathrm{e}-01$ 1.00000e-09 2.12000e-01 $6.88470 \mathrm{e}+006.88470 \mathrm{e}+00$ 6.88470e-01 1.00000e-09 2.12000e-01 $6.88470 \mathrm{e}+006.88470 \mathrm{e}+00$ 6.88470e-01 1.00000e-09 2.12000e-01 6.88470e+00 6.88470e+00 6.88470e-01 1.00000e-09 2.12000e-01 6.88470e+00 6.88470e+00 6.88470e-01 1.00000e-09 2.12000e-01 Element: 2858 \# of layers: 9

$\mathrm{Kx} \mathrm{Ky} \mathrm{Kz}$ Ss Por

1.72307e+02 1.72307e+02 1.72307e+01 1.00000e-09 7.00000e-02 $1.72307 \mathrm{e}+02$ 1.72307e+02 1.72307e+01 1.00000e-09 7.00000e-02 5.00000e-04 5.00000e-04 5.00000e-05 1.00000e-09 1.00000e-01 $5.00000 \mathrm{e}-04$ 5.00000e-04 5.00000e-05 1.00000e-09 1.00000e-01 $6.88470 \mathrm{e}+006.88470 \mathrm{e}+006.88470 \mathrm{e}-01$ 1.00000e-09 2.12000e-01 $6.88470 \mathrm{e}+006.88470 \mathrm{e}+006.88470 \mathrm{e}-01$ 1.00000e-09 2.12000e-01 6.88470e+00 6.88470e+00 6.88470e-01 1.00000e-09 2.12000e-01 $6.88470 \mathrm{e}+006.88470 \mathrm{e}+00$ 6.88470e-01 1.00000e-09 2.12000e-01 $6.88470 \mathrm{e}+006.88470 \mathrm{e}+00$ 6.88470e-01 1.00000e-09 2.12000e-01 Element: 2859 \# of layers: 9

$\mathrm{Kx} \mathrm{Ky} \mathrm{Kz}$ Ss Por

1.72307e+02 1.72307e+02 1.72307e+01 1.00000e-09 7.00000e-02 $1.72307 \mathrm{e}+02$ 1.72307e+02 1.72307e+01 1.00000e-09 7.00000e-02 5.00000e-04 5.00000e-04 5.00000e-05 1.00000e-09 1.00000e-01 $5.00000 \mathrm{e}-04$ 5.00000e-04 5.00000e-05 1.00000e-09 1.00000e-01 6.88470e+00 6.88470e+00 6.88470e-01 1.00000e-09 2.12000e-01 6.88470e+00 6.88470e+00 6.88470e-01 1.00000e-09 2.12000e-01 $6.88470 \mathrm{e}+006.88470 \mathrm{e}+006.88470 \mathrm{e}-01$ 1.00000e-09 2.12000e-01 $6.88470 \mathrm{e}+006.88470 \mathrm{e}+00$ 6.88470e-01 1.00000e-09 2.12000e-01 6.88470e+00 6.88470e+00 6.88470e-01 1.00000e-09 2.12000e-01 Element: 2860 \# of layers: 11

Kx Ky Kz Ss Por

3.11133e+03 3.11133e+03 3.11133e+02 1.00000e-09 7.00000e-02 5.00000e-04 5.00000e-04 5.00000e-05 1.00000e-09 1.00000e-01 $1.24317 \mathrm{e}+02$ 1.24317e+02 1.24317e+01 1.00000e-09 2.12000e-01 $1.24317 \mathrm{e}+02$ 1.24317e+02 1.24317e+01 1.00000e-09 2.12000e-01 $1.24317 \mathrm{e}+02$ 1.24317e+02 1.24317e+01 1.00000e-09 2.12000e-01 $1.24317 \mathrm{e}+02$ 1.24317e+02 1.24317e+01 1.00000e-09 2.12000e-01 1.24317e+02 1.24317e+02 1.24317e+01 1.00000e-09 2.12000e-01 $1.00000 \mathrm{e}-021.00000 \mathrm{e}-021.00000 \mathrm{e}-031.00000 \mathrm{e}-091.00000 \mathrm{e}-01$ $1.00000 \mathrm{e}+001.00000 \mathrm{e}+001.00000 \mathrm{e}-011.00000 \mathrm{e}-091.00000 \mathrm{e}-01$ 
$1.00000 \mathrm{e}-05$ 1.00000e-05 1.00000e-06 1.00000e-09 1.00000e-01 $1.00000 \mathrm{e}+001.00000 \mathrm{e}+001.00000 \mathrm{e}-01$ 1.00000e-09 1.00000e-01 Element: 2861 \# of layers: 11

Kx Ky Kz Ss Por

3.11133e+03 3.11133e+03 3.11133e+02 1.00000e-09 7.00000e-02 5.00000e-04 5.00000e-04 5.00000e-05 1.00000e-09 1.00000e-01

$1.24317 \mathrm{e}+02$ 1.24317e+02 1.24317e+01 1.00000e-09 2.12000e-01 $1.24317 \mathrm{e}+02$ 1.24317e+02 1.24317e+01 1.00000e-09 2.12000e-01 $1.24317 \mathrm{e}+02$ 1.24317e+02 1.24317e+01 1.00000e-09 2.12000e-01 $1.24317 \mathrm{e}+02$ 1.24317e+02 1.24317e+01 1.00000e-09 2.12000e-01 $1.24317 \mathrm{e}+02$ 1.24317e+02 1.24317e+01 1.00000e-09 2.12000e-01 $1.00000 \mathrm{e}-02$ 1.00000e-02 1.00000e-03 1.00000e-09 1.00000e-01 $1.00000 \mathrm{e}+001.00000 \mathrm{e}+001.00000 \mathrm{e}-011.00000 \mathrm{e}-091.00000 \mathrm{e}-01$ $1.00000 \mathrm{e}-05$ 1.00000e-05 1.00000e-06 1.00000e-09 1.00000e-01 $1.00000 \mathrm{e}+001.00000 \mathrm{e}+001.00000 \mathrm{e}-01$ 1.00000e-09 1.00000e-01 Element: 2862 \# of layers: 11

$\mathrm{Kx} \mathrm{Ky} \mathrm{Kz}$ Ss Por

4.64069e+03 4.64069e+03 4.64069e+02 1.00000e-09 7.00000e-02 5.00000e-04 5.00000e-04 5.00000e-05 1.00000e-09 1.00000e-01 $1.85424 \mathrm{e}+02 \quad 1.85424 \mathrm{e}+02 \quad 1.85424 \mathrm{e}+01 \quad 1.00000 \mathrm{e}-092.12000 \mathrm{e}-01$ $1.85424 \mathrm{e}+021.85424 \mathrm{e}+02 \quad 1.85424 \mathrm{e}+01 \quad 1.00000 \mathrm{e}-092.12000 \mathrm{e}-01$ $1.85424 \mathrm{e}+021.85424 \mathrm{e}+021.85424 \mathrm{e}+01$ 1.00000e-09 2.12000e-01 $1.85424 \mathrm{e}+021.85424 \mathrm{e}+02$ 1.85424e+01 1.00000e-09 2.12000e-01 $1.85424 \mathrm{e}+02 \quad 1.85424 \mathrm{e}+02 \quad 1.85424 \mathrm{e}+01$ 1.00000e-09 2.12000e-01 $1.00000 \mathrm{e}-021.00000 \mathrm{e}-02$ 1.00000e-03 1.00000e-09 1.00000e-01 $1.00000 \mathrm{e}+001.00000 \mathrm{e}+001.00000 \mathrm{e}-011.00000 \mathrm{e}-091.00000 \mathrm{e}-01$ $1.00000 \mathrm{e}-05$ 1.00000e-05 1.00000e-06 1.00000e-09 1.00000e-01 $1.00000 \mathrm{e}+001.00000 \mathrm{e}+001.00000 \mathrm{e}-011.00000 \mathrm{e}-091.00000 \mathrm{e}-01$ Element: 2863 \# of layers: 11

$\mathrm{Kx} \mathrm{Ky} \mathrm{Kz}$ Ss Por

4.64069e+03 4.64069e+03 4.64069e+02 1.00000e-09 7.00000e-02 5.00000e-04 5.00000e-04 5.00000e-05 1.00000e-09 1.00000e-01 $1.85424 \mathrm{e}+021.85424 \mathrm{e}+02 \quad 1.85424 \mathrm{e}+01$ 1.00000e-09 2.12000e-01 $1.85424 \mathrm{e}+02 \quad 1.85424 \mathrm{e}+02 \quad 1.85424 \mathrm{e}+01$ 1.00000e-09 2.12000e-01 $1.85424 \mathrm{e}+021.85424 \mathrm{e}+02 \quad 1.85424 \mathrm{e}+01$ 1.00000e-09 2.12000e-01 $1.85424 \mathrm{e}+021.85424 \mathrm{e}+02 \quad 1.85424 \mathrm{e}+01$ 1.00000e-09 2.12000e-01 $1.85424 \mathrm{e}+021.85424 \mathrm{e}+021.85424 \mathrm{e}+01$ 1.00000e-09 2.12000e-01 $1.00000 \mathrm{e}-02$ 1.00000e-02 1.00000e-03 1.00000e-09 1.00000e-01 $1.00000 \mathrm{e}+001.00000 \mathrm{e}+001.00000 \mathrm{e}-011.00000 \mathrm{e}-091.00000 \mathrm{e}-01$ $1.00000 \mathrm{e}-05$ 1.00000e-05 1.00000e-06 1.00000e-09 1.00000e-01 $1.00000 \mathrm{e}+001.00000 \mathrm{e}+001.00000 \mathrm{e}-011.00000 \mathrm{e}-091.00000 \mathrm{e}-01$ Element: 2864 \# of layers: 12

$\mathrm{Kx} \mathrm{Ky} \mathrm{Kz}$ Ss Por

8.35515e+03 8.35515e+03 8.35515e+02 1.00000e-09 7.00000e-02 5.00000e-04 5.00000e-04 5.00000e-05 1.00000e-09 1.00000e-01 5.00000e-04 5.00000e-04 5.00000e-05 1.00000e-09 1.00000e-01 
3.33840e+02 3.33840e+02 3.33840e+01 1.00000e-09 2.12000e-01 $3.33840 \mathrm{e}+02$ 3.33840e+02 3.33840e+01 1.00000e-09 2.12000e-01 $3.33840 \mathrm{e}+02$ 3.33840e+02 3.33840e+01 1.00000e-09 2.12000e-01 $3.33840 \mathrm{e}+02$ 3.33840e+02 3.33840e+01 1.00000e-09 2.12000e-01 $3.33840 \mathrm{e}+023.33840 \mathrm{e}+02$ 3.33840e+01 1.00000e-09 2.12000e-01 $1.00000 \mathrm{e}-02$ 1.00000e-02 1.00000e-03 1.00000e-09 1.00000e-01 $1.00000 \mathrm{e}+001.00000 \mathrm{e}+001.00000 \mathrm{e}-011.00000 \mathrm{e}-091.00000 \mathrm{e}-01$ $1.00000 \mathrm{e}-05$ 1.00000e-05 1.00000e-06 1.00000e-09 1.00000e-01 $1.00000 \mathrm{e}+001.00000 \mathrm{e}+001.00000 \mathrm{e}-011.00000 \mathrm{e}-091.00000 \mathrm{e}-01$ Element: 2865 \# of layers: 11

$\mathrm{Kx} \mathrm{Ky} \mathrm{Kz}$ Ss Por

8.35515e+03 8.35515e+03 8.35515e+02 1.00000e-09 7.00000e-02 5.00000e-04 5.00000e-04 5.00000e-05 1.00000e-09 1.00000e-01

$3.33840 \mathrm{e}+02$ 3.33840e+02 3.33840e+01 1.00000e-09 2.12000e-01 $3.33840 \mathrm{e}+02$ 3.33840e+02 3.33840e+01 1.00000e-09 2.12000e-01 $3.33840 \mathrm{e}+023.33840 \mathrm{e}+023.33840 \mathrm{e}+01$ 1.00000e-09 2.12000e-01 $3.33840 \mathrm{e}+02$ 3.33840e+02 3.33840e+01 1.00000e-09 2.12000e-01 $3.33840 \mathrm{e}+02$ 3.33840e+02 3.33840e+01 1.00000e-09 2.12000e-01 $1.00000 \mathrm{e}-02$ 1.00000e-02 1.00000e-03 1.00000e-09 1.00000e-01 $1.00000 \mathrm{e}+001.00000 \mathrm{e}+001.00000 \mathrm{e}-011.00000 \mathrm{e}-091.00000 \mathrm{e}-01$ $1.00000 \mathrm{e}-05$ 1.00000e-05 1.00000e-06 1.00000e-09 1.00000e-01 $1.00000 \mathrm{e}+001.00000 \mathrm{e}+001.00000 \mathrm{e}-011.00000 \mathrm{e}-091.00000 \mathrm{e}-01$ Element: 2866 \# of layers: 12

Kx Ky Kz Ss Por

3.11133e+03 3.11133e+03 3.11133e+02 1.00000e-09 7.00000e-02 $5.00000 \mathrm{e}-04$ 5.00000e-04 5.00000e-05 1.00000e-09 1.00000e-01 5.00000e-04 5.00000e-04 5.00000e-05 1.00000e-09 1.00000e-01 $1.24317 \mathrm{e}+02$ 1.24317e+02 1.24317e+01 1.00000e-09 2.12000e-01 $1.24317 \mathrm{e}+02$ 1.24317e+02 1.24317e+01 1.00000e-09 2.12000e-01 $1.24317 \mathrm{e}+02$ 1.24317e+02 1.24317e+01 1.00000e-09 2.12000e-01 $1.24317 \mathrm{e}+02$ 1.24317e+02 1.24317e+01 1.00000e-09 2.12000e-01 $1.24317 \mathrm{e}+02$ 1.24317e+02 1.24317e+01 1.00000e-09 2.12000e-01 $1.00000 \mathrm{e}-02$ 1.00000e-02 1.00000e-03 1.00000e-09 1.00000e-01 $1.00000 \mathrm{e}+001.00000 \mathrm{e}+001.00000 \mathrm{e}-011.00000 \mathrm{e}-091.00000 \mathrm{e}-01$ $1.00000 \mathrm{e}-05$ 1.00000e-05 1.00000e-06 1.00000e-09 1.00000e-01 $1.00000 \mathrm{e}+001.00000 \mathrm{e}+001.00000 \mathrm{e}-011.00000 \mathrm{e}-091.00000 \mathrm{e}-01$ Element: 2867 \# of layers: 12

Kx Ky Kz Ss Por

3.11133e+03 3.11133e+03 3.11133e+02 1.00000e-09 7.00000e-02 5.00000e-04 5.00000e-04 5.00000e-05 1.00000e-09 1.00000e-01 5.00000e-04 5.00000e-04 5.00000e-05 1.00000e-09 1.00000e-01 $1.24317 \mathrm{e}+02$ 1.24317e+02 1.24317e+01 1.00000e-09 2.12000e-01 $1.24317 \mathrm{e}+02$ 1.24317e+02 1.24317e+01 1.00000e-09 2.12000e-01 1.24317e+02 1.24317e+02 1.24317e+01 1.00000e-09 2.12000e-01 1.24317e+02 1.24317e+02 1.24317e+01 1.00000e-09 2.12000e-01 $1.24317 \mathrm{e}+02$ 1.24317e+02 1.24317e+01 1.00000e-09 2.12000e-01 
$1.00000 \mathrm{e}-02$ 1.00000e-02 1.00000e-03 1.00000e-09 1.00000e-01 $1.00000 \mathrm{e}+001.00000 \mathrm{e}+001.00000 \mathrm{e}-011.00000 \mathrm{e}-091.00000 \mathrm{e}-01$ $1.00000 \mathrm{e}-05$ 1.00000e-05 1.00000e-06 1.00000e-09 1.00000e-01 $1.00000 \mathrm{e}+001.00000 \mathrm{e}+001.00000 \mathrm{e}-011.00000 \mathrm{e}-091.00000 \mathrm{e}-01$ Element: 2868 \# of layers: 12

$\mathrm{Kx} \mathrm{Ky} \mathrm{Kz}$ Ss Por

$1.42322 \mathrm{e}+03$ 1.42322e+03 1.42322e+02 1.00000e-09 7.00000e-02 5.00000e-04 5.00000e-04 5.00000e-05 1.00000e-09 1.00000e-01 5.00000e-04 5.00000e-04 5.00000e-05 1.00000e-09 1.00000e-01

$5.68655 \mathrm{e}+015.68655 \mathrm{e}+015.68655 \mathrm{e}+001.00000 \mathrm{e}-092.12000 \mathrm{e}-01$ $5.68655 \mathrm{e}+015.68655 \mathrm{e}+015.68655 \mathrm{e}+001.00000 \mathrm{e}-092.12000 \mathrm{e}-01$ $5.68655 \mathrm{e}+015.68655 \mathrm{e}+015.68655 \mathrm{e}+001.00000 \mathrm{e}-092.12000 \mathrm{e}-01$ $5.68655 \mathrm{e}+015.68655 \mathrm{e}+015.68655 \mathrm{e}+001.00000 \mathrm{e}-092.12000 \mathrm{e}-01$ $5.68655 \mathrm{e}+015.68655 \mathrm{e}+015.68655 \mathrm{e}+001.00000 \mathrm{e}-092.12000 \mathrm{e}-01$ $1.00000 \mathrm{e}-02$ 1.00000e-02 1.00000e-03 1.00000e-09 1.00000e-01 $1.00000 \mathrm{e}+001.00000 \mathrm{e}+001.00000 \mathrm{e}-011.00000 \mathrm{e}-091.00000 \mathrm{e}-01$ $1.00000 \mathrm{e}-05$ 1.00000e-05 1.00000e-06 1.00000e-09 1.00000e-01 $1.00000 \mathrm{e}+001.00000 \mathrm{e}+001.00000 \mathrm{e}-011.00000 \mathrm{e}-091.00000 \mathrm{e}-01$ Element: 2869 \# of layers: 12

$\mathrm{Kx} \mathrm{Ky} \mathrm{Kz}$ Ss Por

1.16175e+03 1.16175e+03 1.16175e+02 1.00000e-09 7.00000e-02 5.00000e-04 5.00000e-04 5.00000e-05 1.00000e-09 1.00000e-01 $5.00000 \mathrm{e}-04$ 5.00000e-04 5.00000e-05 1.00000e-09 1.00000e-01 $4.64185 \mathrm{e}+014.64185 \mathrm{e}+014.64185 \mathrm{e}+00$ 1.00000e-09 2.12000e-01 $4.64185 \mathrm{e}+014.64185 \mathrm{e}+014.64185 \mathrm{e}+001.00000 \mathrm{e}-09$ 2.12000e-01 $4.64185 \mathrm{e}+014.64185 \mathrm{e}+014.64185 \mathrm{e}+001.00000 \mathrm{e}-092.12000 \mathrm{e}-01$ $4.64185 \mathrm{e}+014.64185 \mathrm{e}+014.64185 \mathrm{e}+001.00000 \mathrm{e}-092.12000 \mathrm{e}-01$ $4.64185 \mathrm{e}+014.64185 \mathrm{e}+014.64185 \mathrm{e}+00$ 1.00000e-09 2.12000e-01 $1.00000 \mathrm{e}-02$ 1.00000e-02 1.00000e-03 1.00000e-09 1.00000e-01 $1.00000 \mathrm{e}+001.00000 \mathrm{e}+001.00000 \mathrm{e}-011.00000 \mathrm{e}-091.00000 \mathrm{e}-01$ $1.00000 \mathrm{e}-05$ 1.00000e-05 1.00000e-06 1.00000e-09 1.00000e-01 $1.00000 \mathrm{e}+001.00000 \mathrm{e}+001.00000 \mathrm{e}-01$ 1.00000e-09 1.00000e-01 Element: 2870 \# of layers: 12

$\mathrm{Kx} \mathrm{Ky} \mathrm{Kz}$ Ss Por

$1.16175 \mathrm{e}+03$ 1.16175e+03 1.16175e+02 1.00000e-09 7.00000e-02 5.00000e-04 5.00000e-04 5.00000e-05 1.00000e-09 1.00000e-01 5.00000e-04 5.00000e-04 5.00000e-05 1.00000e-09 1.00000e-01 $4.64185 \mathrm{e}+014.64185 \mathrm{e}+014.64185 \mathrm{e}+00$ 1.00000e-09 2.12000e-01 $4.64185 \mathrm{e}+014.64185 \mathrm{e}+01$ 4.64185e+00 1.00000e-09 2.12000e-01 $4.64185 \mathrm{e}+014.64185 \mathrm{e}+014.64185 \mathrm{e}+00$ 1.00000e-09 2.12000e-01 $4.64185 \mathrm{e}+014.64185 \mathrm{e}+014.64185 \mathrm{e}+00$ 1.00000e-09 2.12000e-01 $4.64185 \mathrm{e}+014.64185 \mathrm{e}+014.64185 \mathrm{e}+001.00000 \mathrm{e}-092.12000 \mathrm{e}-01$ $1.00000 \mathrm{e}-021.00000 \mathrm{e}-021.00000 \mathrm{e}-031.00000 \mathrm{e}-091.00000 \mathrm{e}-01$ $1.00000 \mathrm{e}+001.00000 \mathrm{e}+001.00000 \mathrm{e}-011.00000 \mathrm{e}-091.00000 \mathrm{e}-01$ $1.00000 \mathrm{e}-05$ 1.00000e-05 1.00000e-06 1.00000e-09 1.00000e-01 $1.00000 \mathrm{e}+001.00000 \mathrm{e}+001.00000 \mathrm{e}-011.00000 \mathrm{e}-091.00000 \mathrm{e}-01$ 
Element: 2871 \# of layers: 12

$\mathrm{Kx} \mathrm{Ky} \mathrm{Kz}$ Ss Por

$1.16175 \mathrm{e}+03$ 1.16175e+03 1.16175e+02 1.00000e-09 7.00000e-02

5.00000e-04 5.00000e-04 5.00000e-05 1.00000e-09 1.00000e-01

5.00000e-04 5.00000e-04 5.00000e-05 1.00000e-09 1.00000e-01

$4.64185 \mathrm{e}+014.64185 \mathrm{e}+014.64185 \mathrm{e}+00$ 1.00000e-09 2.12000e-01

$4.64185 \mathrm{e}+014.64185 \mathrm{e}+014.64185 \mathrm{e}+00$ 1.00000e-09 2.12000e-01

$4.64185 \mathrm{e}+014.64185 \mathrm{e}+014.64185 \mathrm{e}+00$ 1.00000e-09 2.12000e-01

$4.64185 \mathrm{e}+014.64185 \mathrm{e}+014.64185 \mathrm{e}+001.00000 \mathrm{e}-092.12000 \mathrm{e}-01$

$4.64185 \mathrm{e}+014.64185 \mathrm{e}+014.64185 \mathrm{e}+00$ 1.00000e-09 2.12000e-01

$1.00000 \mathrm{e}-02$ 1.00000e-02 1.00000e-03 1.00000e-09 1.00000e-01

$1.00000 \mathrm{e}+001.00000 \mathrm{e}+001.00000 \mathrm{e}-011.00000 \mathrm{e}-091.00000 \mathrm{e}-01$

$1.00000 \mathrm{e}-05$ 1.00000e-05 1.00000e-06 1.00000e-09 1.00000e-01

$1.00000 \mathrm{e}+001.00000 \mathrm{e}+001.00000 \mathrm{e}-011.00000 \mathrm{e}-091.00000 \mathrm{e}-01$

Element: 2872 \# of layers: 12

Kx Ky Kz Ss Por

$1.26581 \mathrm{e}+03$ 1.26581e+03 1.26581e+02 1.00000e-09 7.00000e-02

5.00000e-04 5.00000e-04 5.00000e-05 1.00000e-09 1.00000e-01

$5.00000 \mathrm{e}-04$ 5.00000e-04 5.00000e-05 1.00000e-09 1.00000e-01

$5.05788 \mathrm{e}+015.05788 \mathrm{e}+015.05788 \mathrm{e}+001.00000 \mathrm{e}-092.12000 \mathrm{e}-01$

$5.05788 \mathrm{e}+015.05788 \mathrm{e}+015.05788 \mathrm{e}+001.00000 \mathrm{e}-092.12000 \mathrm{e}-01$

$5.05788 \mathrm{e}+015.05788 \mathrm{e}+015.05788 \mathrm{e}+001.00000 \mathrm{e}-092.12000 \mathrm{e}-01$

$5.05788 \mathrm{e}+015.05788 \mathrm{e}+015.05788 \mathrm{e}+001.00000 \mathrm{e}-092.12000 \mathrm{e}-01$

$5.05788 \mathrm{e}+015.05788 \mathrm{e}+015.05788 \mathrm{e}+001.00000 \mathrm{e}-092.12000 \mathrm{e}-01$

$1.00000 \mathrm{e}-021.00000 \mathrm{e}-02$ 1.00000e-03 1.00000e-09 1.00000e-01

$1.00000 \mathrm{e}+001.00000 \mathrm{e}+001.00000 \mathrm{e}-011.00000 \mathrm{e}-091.00000 \mathrm{e}-01$

$1.00000 \mathrm{e}-05$ 1.00000e-05 1.00000e-06 1.00000e-09 1.00000e-01

$1.00000 \mathrm{e}+001.00000 \mathrm{e}+001.00000 \mathrm{e}-011.00000 \mathrm{e}-091.00000 \mathrm{e}-01$

Element: 2873 \# of layers: 12

$\mathrm{Kx} \mathrm{Ky} \mathrm{Kz}$ Ss Por

$1.26581 \mathrm{e}+031.26581 \mathrm{e}+03$ 1.26581e+02 1.00000e-09 7.00000e-02

5.00000e-04 5.00000e-04 5.00000e-05 1.00000e-09 1.00000e-01

5.00000e-04 5.00000e-04 5.00000e-05 1.00000e-09 1.00000e-01

$5.05788 \mathrm{e}+015.05788 \mathrm{e}+015.05788 \mathrm{e}+001.00000 \mathrm{e}-092.12000 \mathrm{e}-01$

$5.05788 \mathrm{e}+015.05788 \mathrm{e}+015.05788 \mathrm{e}+00$ 1.00000e-09 2.12000e-01

$5.05788 \mathrm{e}+015.05788 \mathrm{e}+015.05788 \mathrm{e}+001.00000 \mathrm{e}-092.12000 \mathrm{e}-01$

$5.05788 \mathrm{e}+015.05788 \mathrm{e}+015.05788 \mathrm{e}+001.00000 \mathrm{e}-092.12000 \mathrm{e}-01$

$5.05788 \mathrm{e}+015.05788 \mathrm{e}+015.05788 \mathrm{e}+00$ 1.00000e-09 2.12000e-01

$1.00000 \mathrm{e}-02$ 1.00000e-02 1.00000e-03 1.00000e-09 1.00000e-01

$1.00000 \mathrm{e}+001.00000 \mathrm{e}+001.00000 \mathrm{e}-011.00000 \mathrm{e}-091.00000 \mathrm{e}-01$

$1.00000 \mathrm{e}-05$ 1.00000e-05 1.00000e-06 1.00000e-09 1.00000e-01

$1.00000 \mathrm{e}+001.00000 \mathrm{e}+001.00000 \mathrm{e}-011.00000 \mathrm{e}-091.00000 \mathrm{e}-01$

Element: 2874 \# of layers: 12

$\mathrm{Kx} \mathrm{Ky} \mathrm{Kz}$ Ss Por

$1.52783 e+031.52783 e+03$ 1.52783e+02 1.00000e-09 7.00000e-02

5.00000e-04 5.00000e-04 5.00000e-05 1.00000e-09 1.00000e-01 
5.00000e-04 5.00000e-04 5.00000e-05 1.00000e-09 1.00000e-01 $6.10461 \mathrm{e}+016.10461 \mathrm{e}+016.10461 \mathrm{e}+00$ 1.00000e-09 2.12000e-01 $6.10461 \mathrm{e}+016.10461 \mathrm{e}+016.10461 \mathrm{e}+00$ 1.00000e-09 2.12000e-01 $6.10461 \mathrm{e}+016.10461 \mathrm{e}+016.10461 \mathrm{e}+001.00000 \mathrm{e}-092.12000 \mathrm{e}-01$ $6.10461 \mathrm{e}+016.10461 \mathrm{e}+016.10461 \mathrm{e}+001.00000 \mathrm{e}-092.12000 \mathrm{e}-01$ $6.10461 \mathrm{e}+016.10461 \mathrm{e}+016.10461 \mathrm{e}+00$ 1.00000e-09 2.12000e-01 $1.00000 \mathrm{e}-02$ 1.00000e-02 1.00000e-03 1.00000e-09 1.00000e-01 $1.00000 \mathrm{e}+001.00000 \mathrm{e}+001.00000 \mathrm{e}-011.00000 \mathrm{e}-091.00000 \mathrm{e}-01$ $1.00000 \mathrm{e}-051.00000 \mathrm{e}-051.00000 \mathrm{e}-061.00000 \mathrm{e}-091.00000 \mathrm{e}-01$ $1.00000 \mathrm{e}+001.00000 \mathrm{e}+001.00000 \mathrm{e}-011.00000 \mathrm{e}-091.00000 \mathrm{e}-01$ Element: 2875 \# of layers: 12

$\mathrm{Kx} \mathrm{Ky} \mathrm{Kz}$ Ss Por

$1.42322 \mathrm{e}+03$ 1.42322e+03 1.42322e+02 1.00000e-09 7.00000e-02 5.00000e-04 5.00000e-04 5.00000e-05 1.00000e-09 1.00000e-01 5.00000e-04 5.00000e-04 5.00000e-05 1.00000e-09 1.00000e-01 $5.68655 \mathrm{e}+015.68655 \mathrm{e}+015.68655 \mathrm{e}+001.00000 \mathrm{e}-092.12000 \mathrm{e}-01$ $5.68655 \mathrm{e}+015.68655 \mathrm{e}+015.68655 \mathrm{e}+001.00000 \mathrm{e}-092.12000 \mathrm{e}-01$ $5.68655 \mathrm{e}+015.68655 \mathrm{e}+015.68655 \mathrm{e}+001.00000 \mathrm{e}-092.12000 \mathrm{e}-01$ $5.68655 \mathrm{e}+015.68655 \mathrm{e}+015.68655 \mathrm{e}+001.00000 \mathrm{e}-092.12000 \mathrm{e}-01$ $5.68655 \mathrm{e}+015.68655 \mathrm{e}+015.68655 \mathrm{e}+001.00000 \mathrm{e}-092.12000 \mathrm{e}-01$ $1.00000 \mathrm{e}-02$ 1.00000e-02 1.00000e-03 1.00000e-09 1.00000e-01 $1.00000 \mathrm{e}+001.00000 \mathrm{e}+001.00000 \mathrm{e}-011.00000 \mathrm{e}-091.00000 \mathrm{e}-01$ $1.00000 \mathrm{e}-05$ 1.00000e-05 1.00000e-06 1.00000e-09 1.00000e-01 $1.00000 \mathrm{e}+001.00000 \mathrm{e}+001.00000 \mathrm{e}-011.00000 \mathrm{e}-09$ 1.00000e-01 Element: 2876 \# of layers: 12

$\mathrm{Kx} \mathrm{Ky} \mathrm{Kz}$ Ss Por

$1.16175 \mathrm{e}+031.16175 \mathrm{e}+03$ 1.16175e+02 1.00000e-09 7.00000e-02 5.00000e-04 5.00000e-04 5.00000e-05 1.00000e-09 1.00000e-01 5.00000e-04 5.00000e-04 5.00000e-05 1.00000e-09 1.00000e-01 $4.64185 \mathrm{e}+014.64185 \mathrm{e}+014.64185 \mathrm{e}+00$ 1.00000e-09 2.12000e-01 $4.64185 \mathrm{e}+014.64185 \mathrm{e}+014.64185 \mathrm{e}+00$ 1.00000e-09 2.12000e-01 $4.64185 \mathrm{e}+014.64185 \mathrm{e}+014.64185 \mathrm{e}+00$ 1.00000e-09 2.12000e-01 $4.64185 \mathrm{e}+014.64185 \mathrm{e}+014.64185 \mathrm{e}+00$ 1.00000e-09 2.12000e-01 $4.64185 \mathrm{e}+014.64185 \mathrm{e}+014.64185 \mathrm{e}+00$ 1.00000e-09 2.12000e-01 $1.00000 \mathrm{e}-02$ 1.00000e-02 1.00000e-03 1.00000e-09 1.00000e-01 $1.00000 \mathrm{e}+001.00000 \mathrm{e}+001.00000 \mathrm{e}-011.00000 \mathrm{e}-091.00000 \mathrm{e}-01$ $1.00000 \mathrm{e}-05$ 1.00000e-05 1.00000e-06 1.00000e-09 1.00000e-01 $1.00000 \mathrm{e}+001.00000 \mathrm{e}+001.00000 \mathrm{e}-011.00000 \mathrm{e}-091.00000 \mathrm{e}-01$ Element: 2877 \# of layers: 13

$\mathrm{Kx} \mathrm{Ky} \mathrm{Kz}$ Ss Por 9.72539e+02 9.72539e+02 9.72539e+01 1.00000e-09 7.00000e-02 9.72539e+02 9.72539e+02 9.72539e+01 1.00000e-09 7.00000e-02 $5.00000 \mathrm{e}-04$ 5.00000e-04 5.00000e-05 1.00000e-09 1.00000e-01 5.00000e-04 5.00000e-04 5.00000e-05 1.00000e-09 1.00000e-01 $3.88583 \mathrm{e}+013.88583 \mathrm{e}+013.88583 \mathrm{e}+001.00000 \mathrm{e}-092.12000 \mathrm{e}-01$ $3.88583 e+013.88583 e+013.88583 e+00$ 1.00000e-09 2.12000e-01 
3.88583e+01 3.88583e+01 3.88583e+00 1.00000e-09 2.12000e-01 $3.88583 \mathrm{e}+013.88583 \mathrm{e}+013.88583 \mathrm{e}+00$ 1.00000e-09 2.12000e-01 $3.88583 e+013.88583 e+013.88583 e+001.00000 e-09$ 2.12000e-01 $1.00000 \mathrm{e}-02$ 1.00000e-02 1.00000e-03 1.00000e-09 1.00000e-01 $1.00000 \mathrm{e}+001.00000 \mathrm{e}+001.00000 \mathrm{e}-011.00000 \mathrm{e}-091.00000 \mathrm{e}-01$ $1.00000 \mathrm{e}-05$ 1.00000e-05 1.00000e-06 1.00000e-09 1.00000e-01 $1.00000 \mathrm{e}+001.00000 \mathrm{e}+001.00000 \mathrm{e}-011.00000 \mathrm{e}-091.00000 \mathrm{e}-01$ Element: 2878 \# of layers: 13

$\mathrm{Kx} \mathrm{Ky} \mathrm{Kz}$ Ss Por

8.19153e+02 8.19153e+02 8.19153e+01 1.00000e-09 7.00000e-02 8.19153e+02 8.19153e+02 8.19153e+01 1.00000e-09 7.00000e-02 5.00000e-04 5.00000e-04 5.00000e-05 1.00000e-09 1.00000e-01 5.00000e-04 5.00000e-04 5.00000e-05 1.00000e-09 1.00000e-01 $3.27314 \mathrm{e}+013.27314 \mathrm{e}+013.27314 \mathrm{e}+001.00000 \mathrm{e}-092.12000 \mathrm{e}-01$ $3.27314 \mathrm{e}+013.27314 \mathrm{e}+013.27314 \mathrm{e}+001.00000 \mathrm{e}-092.12000 \mathrm{e}-01$ $3.27314 \mathrm{e}+013.27314 \mathrm{e}+013.27314 \mathrm{e}+001.00000 \mathrm{e}-092.12000 \mathrm{e}-01$ $3.27314 \mathrm{e}+013.27314 \mathrm{e}+013.27314 \mathrm{e}+001.00000 \mathrm{e}-092.12000 \mathrm{e}-01$ $3.27314 \mathrm{e}+013.27314 \mathrm{e}+013.27314 \mathrm{e}+001.00000 \mathrm{e}-092.12000 \mathrm{e}-01$ $1.00000 \mathrm{e}-02$ 1.00000e-02 1.00000e-03 1.00000e-09 1.00000e-01 $1.00000 \mathrm{e}+001.00000 \mathrm{e}+001.00000 \mathrm{e}-011.00000 \mathrm{e}-091.00000 \mathrm{e}-01$ $1.00000 \mathrm{e}-05$ 1.00000e-05 1.00000e-06 1.00000e-09 1.00000e-01 $1.00000 \mathrm{e}+001.00000 \mathrm{e}+001.00000 \mathrm{e}-01$ 1.00000e-09 1.00000e-01 Element: 2879 \# of layers: 13

Kx Ky Kz Ss Por

8.19153e+02 8.19153e+02 8.19153e+01 1.00000e-09 7.00000e-02 8.19153e+02 8.19153e+02 8.19153e+01 1.00000e-09 7.00000e-02 5.00000e-04 5.00000e-04 5.00000e-05 1.00000e-09 1.00000e-01 5.00000e-04 5.00000e-04 5.00000e-05 1.00000e-09 1.00000e-01 $3.27314 \mathrm{e}+013.27314 \mathrm{e}+013.27314 \mathrm{e}+001.00000 \mathrm{e}-092.12000 \mathrm{e}-01$ $3.27314 \mathrm{e}+013.27314 \mathrm{e}+013.27314 \mathrm{e}+001.00000 \mathrm{e}-092.12000 \mathrm{e}-01$ $3.27314 \mathrm{e}+013.27314 \mathrm{e}+013.27314 \mathrm{e}+001.00000 \mathrm{e}-092.12000 \mathrm{e}-01$ $3.27314 \mathrm{e}+013.27314 \mathrm{e}+013.27314 \mathrm{e}+001.00000 \mathrm{e}-092.12000 \mathrm{e}-01$ $3.27314 \mathrm{e}+013.27314 \mathrm{e}+013.27314 \mathrm{e}+001.00000 \mathrm{e}-092.12000 \mathrm{e}-01$ $1.00000 \mathrm{e}-02$ 1.00000e-02 1.00000e-03 1.00000e-09 1.00000e-01 $1.00000 \mathrm{e}+001.00000 \mathrm{e}+001.00000 \mathrm{e}-011.00000 \mathrm{e}-091.00000 \mathrm{e}-01$ $1.00000 \mathrm{e}-05$ 1.00000e-05 1.00000e-06 1.00000e-09 1.00000e-01 $1.00000 \mathrm{e}+001.00000 \mathrm{e}+001.00000 \mathrm{e}-011.00000 \mathrm{e}-091.00000 \mathrm{e}-01$ Element: 2880 \# of layers: 13

Kx Ky Kz Ss Por 8.19153e+02 8.19153e+02 8.19153e+01 1.00000e-09 7.00000e-02 8.19153e+02 8.19153e+02 8.19153e+01 1.00000e-09 7.00000e-02 5.00000e-04 5.00000e-04 5.00000e-05 1.00000e-09 1.00000e-01 5.00000e-04 5.00000e-04 5.00000e-05 1.00000e-09 1.00000e-01 $3.27314 \mathrm{e}+013.27314 \mathrm{e}+013.27314 \mathrm{e}+00$ 1.00000e-09 2.12000e-01 $3.27314 \mathrm{e}+013.27314 \mathrm{e}+013.27314 \mathrm{e}+001.00000 \mathrm{e}-092.12000 \mathrm{e}-01$ $3.27314 \mathrm{e}+013.27314 \mathrm{e}+013.27314 \mathrm{e}+001.00000 \mathrm{e}-092.12000 \mathrm{e}-01$ 
3.27314e+01 3.27314e+01 3.27314e+00 1.00000e-09 2.12000e-01 $3.27314 \mathrm{e}+013.27314 \mathrm{e}+013.27314 \mathrm{e}+001.00000 \mathrm{e}-092.12000 \mathrm{e}-01$ $1.00000 \mathrm{e}-02$ 1.00000e-02 1.00000e-03 1.00000e-09 1.00000e-01 $1.00000 \mathrm{e}+001.00000 \mathrm{e}+001.00000 \mathrm{e}-011.00000 \mathrm{e}-091.00000 \mathrm{e}-01$ $1.00000 \mathrm{e}-05$ 1.00000e-05 1.00000e-06 1.00000e-09 1.00000e-01 $1.00000 \mathrm{e}+001.00000 \mathrm{e}+001.00000 \mathrm{e}-011.00000 \mathrm{e}-091.00000 \mathrm{e}-01$ Element: 2881 \# of layers: 13

$\mathrm{Kx} \mathrm{Ky} \mathrm{Kz}$ Ss Por

9.97948e+02 9.97948e+02 9.97948e+01 1.00000e-09 7.00000e-02 9.97948e+02 9.97948e+02 9.97948e+01 1.00000e-09 7.00000e-02 5.00000e-04 5.00000e-04 5.00000e-05 1.00000e-09 1.00000e-01 5.00000e-04 5.00000e-04 5.00000e-05 1.00000e-09 1.00000e-01 $3.98731 \mathrm{e}+013.98731 \mathrm{e}+013.98731 \mathrm{e}+001.00000 \mathrm{e}-092.12000 \mathrm{e}-01$ $3.98731 \mathrm{e}+013.98731 \mathrm{e}+013.98731 \mathrm{e}+001.00000 \mathrm{e}-092.12000 \mathrm{e}-01$ $3.98731 \mathrm{e}+013.98731 \mathrm{e}+013.98731 \mathrm{e}+001.00000 \mathrm{e}-092.12000 \mathrm{e}-01$ $3.98731 \mathrm{e}+013.98731 \mathrm{e}+013.98731 \mathrm{e}+001.00000 \mathrm{e}-092.12000 \mathrm{e}-01$ $3.98731 \mathrm{e}+013.98731 \mathrm{e}+013.98731 \mathrm{e}+001.00000 \mathrm{e}-092.12000 \mathrm{e}-01$ $1.00000 \mathrm{e}-02$ 1.00000e-02 1.00000e-03 1.00000e-09 1.00000e-01 $1.00000 \mathrm{e}+001.00000 \mathrm{e}+001.00000 \mathrm{e}-011.00000 \mathrm{e}-091.00000 \mathrm{e}-01$ $1.00000 \mathrm{e}-05$ 1.00000e-05 1.00000e-06 1.00000e-09 1.00000e-01 $1.00000 \mathrm{e}+001.00000 \mathrm{e}+001.00000 \mathrm{e}-011.00000 \mathrm{e}-091.00000 \mathrm{e}-01$ Element: 2882 \# of layers: 13

$\mathrm{Kx} \mathrm{Ky} \mathrm{Kz}$ Ss Por

9.97948e+02 9.97948e+02 9.97948e+01 1.00000e-09 7.00000e-02 9.97948e+02 9.97948e+02 9.97948e+01 1.00000e-09 7.00000e-02 5.00000e-04 5.00000e-04 5.00000e-05 1.00000e-09 1.00000e-01 $5.00000 \mathrm{e}-04$ 5.00000e-04 5.00000e-05 1.00000e-09 1.00000e-01 $3.98731 \mathrm{e}+013.98731 \mathrm{e}+013.98731 \mathrm{e}+001.00000 \mathrm{e}-09$ 2.12000e-01 $3.98731 \mathrm{e}+013.98731 \mathrm{e}+013.98731 \mathrm{e}+001.00000 \mathrm{e}-092.12000 \mathrm{e}-01$ $3.98731 \mathrm{e}+013.98731 \mathrm{e}+013.98731 \mathrm{e}+001.00000 \mathrm{e}-092.12000 \mathrm{e}-01$ $3.98731 \mathrm{e}+013.98731 \mathrm{e}+013.98731 \mathrm{e}+001.00000 \mathrm{e}-092.12000 \mathrm{e}-01$ $3.98731 \mathrm{e}+013.98731 \mathrm{e}+013.98731 \mathrm{e}+00$ 1.00000e-09 2.12000e-01 $1.00000 \mathrm{e}-02$ 1.00000e-02 1.00000e-03 1.00000e-09 1.00000e-01 $1.00000 \mathrm{e}+001.00000 \mathrm{e}+001.00000 \mathrm{e}-011.00000 \mathrm{e}-091.00000 \mathrm{e}-01$ $1.00000 \mathrm{e}-05$ 1.00000e-05 1.00000e-06 1.00000e-09 1.00000e-01 $1.00000 \mathrm{e}+001.00000 \mathrm{e}+001.00000 \mathrm{e}-011.00000 \mathrm{e}-091.00000 \mathrm{e}-01$ Element: 2883 \# of layers: 13

Kx Ky Kz Ss Por

$1.35015 \mathrm{e}+03$ 1.35015e+03 1.35015e+02 1.00000e-09 7.00000e-02 $1.35015 \mathrm{e}+031.35015 \mathrm{e}+031.35015 \mathrm{e}+02$ 1.00000e-09 7.00000e-02 5.00000e-04 5.00000e-04 5.00000e-05 1.00000e-09 1.00000e-01 5.00000e-04 5.00000e-04 5.00000e-05 1.00000e-09 1.00000e-01 $5.39472 \mathrm{e}+015.39472 \mathrm{e}+015.39472 \mathrm{e}+001.00000 \mathrm{e}-092.12000 \mathrm{e}-01$ 5.39472e+01 5.39472e+01 5.39472e+00 1.00000e-09 2.12000e-01 $5.39472 \mathrm{e}+015.39472 \mathrm{e}+015.39472 \mathrm{e}+001.00000 \mathrm{e}-092.12000 \mathrm{e}-01$ $5.39472 \mathrm{e}+015.39472 \mathrm{e}+015.39472 \mathrm{e}+00$ 1.00000e-09 2.12000e-01 
5.39472e+01 5.39472e+01 5.39472e+00 1.00000e-09 2.12000e-01 $1.00000 \mathrm{e}-021.00000 \mathrm{e}-02$ 1.00000e-03 1.00000e-09 1.00000e-01 $1.00000 \mathrm{e}+001.00000 \mathrm{e}+001.00000 \mathrm{e}-011.00000 \mathrm{e}-091.00000 \mathrm{e}-01$ $1.00000 \mathrm{e}-05$ 1.00000e-05 1.00000e-06 1.00000e-09 1.00000e-01 $1.00000 \mathrm{e}+001.00000 \mathrm{e}+001.00000 \mathrm{e}-011.00000 \mathrm{e}-091.00000 \mathrm{e}-01$ Element: 2884 \# of layers: 13

Kx Ky Kz Ss Por

$9.72539 \mathrm{e}+02$ 9.72539e+02 9.72539e+01 1.00000e-09 7.00000e-02

$9.72539 \mathrm{e}+02$ 9.72539e+02 9.72539e+01 1.00000e-09 7.00000e-02

$5.00000 \mathrm{e}-04$ 5.00000e-04 5.00000e-05 1.00000e-09 1.00000e-01

5.00000e-04 5.00000e-04 5.00000e-05 1.00000e-09 1.00000e-01

$3.88583 \mathrm{e}+013.88583 \mathrm{e}+013.88583 \mathrm{e}+00$ 1.00000e-09 2.12000e-01

$3.88583 \mathrm{e}+013.88583 \mathrm{e}+013.88583 \mathrm{e}+00$ 1.00000e-09 2.12000e-01

$3.88583 \mathrm{e}+013.88583 \mathrm{e}+013.88583 \mathrm{e}+00$ 1.00000e-09 2.12000e-01

$3.88583 \mathrm{e}+013.88583 \mathrm{e}+013.88583 \mathrm{e}+00$ 1.00000e-09 2.12000e-01

$3.88583 \mathrm{e}+013.88583 \mathrm{e}+013.88583 \mathrm{e}+00$ 1.00000e-09 2.12000e-01

$1.00000 \mathrm{e}-021.00000 \mathrm{e}-02$ 1.00000e-03 1.00000e-09 1.00000e-01

$1.00000 \mathrm{e}+001.00000 \mathrm{e}+001.00000 \mathrm{e}-011.00000 \mathrm{e}-091.00000 \mathrm{e}-01$

$1.00000 \mathrm{e}-05$ 1.00000e-05 1.00000e-06 1.00000e-09 1.00000e-01

$1.00000 \mathrm{e}+001.00000 \mathrm{e}+001.00000 \mathrm{e}-011.00000 \mathrm{e}-091.00000 \mathrm{e}-01$

Element: 2885 \# of layers: 13

Kx Ky Kz Ss Por

8.19153e+02 8.19153e+02 8.19153e+01 1.00000e-09 7.00000e-02

$8.19153 \mathrm{e}+02$ 8.19153e+02 8.19153e+01 1.00000e-09 7.00000e-02

5.00000e-04 5.00000e-04 5.00000e-05 1.00000e-09 1.00000e-01

5.00000e-04 5.00000e-04 5.00000e-05 1.00000e-09 1.00000e-01

$3.27314 \mathrm{e}+013.27314 \mathrm{e}+013.27314 \mathrm{e}+001.00000 \mathrm{e}-092.12000 \mathrm{e}-01$

$3.27314 \mathrm{e}+013.27314 \mathrm{e}+013.27314 \mathrm{e}+001.00000 \mathrm{e}-092.12000 \mathrm{e}-01$

$3.27314 \mathrm{e}+013.27314 \mathrm{e}+013.27314 \mathrm{e}+001.00000 \mathrm{e}-092.12000 \mathrm{e}-01$

$3.27314 \mathrm{e}+013.27314 \mathrm{e}+013.27314 \mathrm{e}+001.00000 \mathrm{e}-092.12000 \mathrm{e}-01$

$3.27314 \mathrm{e}+013.27314 \mathrm{e}+013.27314 \mathrm{e}+001.00000 \mathrm{e}-092.12000 \mathrm{e}-01$

$1.00000 \mathrm{e}-021.00000 \mathrm{e}-02$ 1.00000e-03 1.00000e-09 1.00000e-01

$1.00000 \mathrm{e}+001.00000 \mathrm{e}+001.00000 \mathrm{e}-011.00000 \mathrm{e}-091.00000 \mathrm{e}-01$

$1.00000 \mathrm{e}-05$ 1.00000e-05 1.00000e-06 1.00000e-09 1.00000e-01

$1.00000 \mathrm{e}+001.00000 \mathrm{e}+001.00000 \mathrm{e}-011.00000 \mathrm{e}-091.00000 \mathrm{e}-01$

Element: 2886 \# of layers: 13

Kx Ky Kz Ss Por

$6.92617 \mathrm{e}+026.92617 \mathrm{e}+026.92617 \mathrm{e}+01$ 1.00000e-09 7.00000e-02

$6.92617 \mathrm{e}+026.92617 \mathrm{e}+026.92617 \mathrm{e}+01$ 1.00000e-09 7.00000e-02

5.00000e-04 5.00000e-04 5.00000e-05 1.00000e-09 1.00000e-01

5.00000e-04 5.00000e-04 5.00000e-05 1.00000e-09 1.00000e-01

$2.76756 \mathrm{e}+012.76756 \mathrm{e}+012.76756 \mathrm{e}+001.00000 \mathrm{e}-092.12000 \mathrm{e}-01$

$2.76756 \mathrm{e}+012.76756 \mathrm{e}+012.76756 \mathrm{e}+001.00000 \mathrm{e}-092.12000 \mathrm{e}-01$

$2.76756 \mathrm{e}+012.76756 \mathrm{e}+012.76756 \mathrm{e}+001.00000 \mathrm{e}-092.12000 \mathrm{e}-01$

$2.76756 \mathrm{e}+012.76756 \mathrm{e}+012.76756 \mathrm{e}+001.00000 \mathrm{e}-092.12000 \mathrm{e}-01$

$2.76756 \mathrm{e}+012.76756 \mathrm{e}+012.76756 \mathrm{e}+001.00000 \mathrm{e}-092.12000 \mathrm{e}-01$ 
$1.00000 \mathrm{e}-02$ 1.00000e-02 1.00000e-03 1.00000e-09 1.00000e-01 $1.00000 \mathrm{e}+001.00000 \mathrm{e}+001.00000 \mathrm{e}-011.00000 \mathrm{e}-091.00000 \mathrm{e}-01$ $1.00000 \mathrm{e}-051.00000 \mathrm{e}-05$ 1.00000e-06 1.00000e-09 1.00000e-01 $1.00000 \mathrm{e}+001.00000 \mathrm{e}+001.00000 \mathrm{e}-011.00000 \mathrm{e}-091.00000 \mathrm{e}-01$ Element: 2887 \# of layers: 12

Kx Ky Kz Ss Por

$5.86605 \mathrm{e}+025.86605 \mathrm{e}+025.86605 \mathrm{e}+01$ 1.00000e-09 7.00000e-02 $5.86605 \mathrm{e}+025.86605 \mathrm{e}+025.86605 \mathrm{e}+011.00000 \mathrm{e}-097.00000 \mathrm{e}-02$ $5.00000 \mathrm{e}-04$ 5.00000e-04 5.00000e-05 1.00000e-09 1.00000e-01 5.00000e-04 5.00000e-04 5.00000e-05 1.00000e-09 1.00000e-01 $2.34387 \mathrm{e}+012.34387 \mathrm{e}+012.34387 \mathrm{e}+001.00000 \mathrm{e}-092.12000 \mathrm{e}-01$ $2.34387 \mathrm{e}+012.34387 \mathrm{e}+012.34387 \mathrm{e}+001.00000 \mathrm{e}-092.12000 \mathrm{e}-01$ $2.34387 \mathrm{e}+012.34387 \mathrm{e}+012.34387 \mathrm{e}+00$ 1.00000e-09 2.12000e-01 $2.34387 \mathrm{e}+012.34387 \mathrm{e}+012.34387 \mathrm{e}+001.00000 \mathrm{e}-092.12000 \mathrm{e}-01$ $1.00000 \mathrm{e}-021.00000 \mathrm{e}-02$ 1.00000e-03 1.00000e-09 1.00000e-01 $1.00000 \mathrm{e}+001.00000 \mathrm{e}+001.00000 \mathrm{e}-011.00000 \mathrm{e}-091.00000 \mathrm{e}-01$ $1.00000 \mathrm{e}-05$ 1.00000e-05 1.00000e-06 1.00000e-09 1.00000e-01 $1.00000 \mathrm{e}+001.00000 \mathrm{e}+001.00000 \mathrm{e}-011.00000 \mathrm{e}-091.00000 \mathrm{e}-01$ Element: 2888 \# of layers: 12

Kx Ky Kz Ss Por

$5.86605 \mathrm{e}+025.86605 \mathrm{e}+025.86605 \mathrm{e}+01$ 1.00000e-09 7.00000e-02

$5.86605 \mathrm{e}+025.86605 \mathrm{e}+025.86605 \mathrm{e}+011.00000 \mathrm{e}-09$ 7.00000e-02 $5.00000 \mathrm{e}-04$ 5.00000e-04 5.00000e-05 1.00000e-09 1.00000e-01 5.00000e-04 5.00000e-04 5.00000e-05 1.00000e-09 1.00000e-01 $2.34387 \mathrm{e}+012.34387 \mathrm{e}+012.34387 \mathrm{e}+00 \quad 1.00000 \mathrm{e}-092.12000 \mathrm{e}-01$ $2.34387 \mathrm{e}+012.34387 \mathrm{e}+012.34387 \mathrm{e}+001.00000 \mathrm{e}-092.12000 \mathrm{e}-01$ $2.34387 \mathrm{e}+012.34387 \mathrm{e}+012.34387 \mathrm{e}+001.00000 \mathrm{e}-092.12000 \mathrm{e}-01$ $2.34387 \mathrm{e}+012.34387 \mathrm{e}+012.34387 \mathrm{e}+001.00000 \mathrm{e}-092.12000 \mathrm{e}-01$ $1.00000 \mathrm{e}-021.00000 \mathrm{e}-02$ 1.00000e-03 1.00000e-09 1.00000e-01 $1.00000 \mathrm{e}+001.00000 \mathrm{e}+001.00000 \mathrm{e}-011.00000 \mathrm{e}-091.00000 \mathrm{e}-01$ $1.00000 \mathrm{e}-05$ 1.00000e-05 1.00000e-06 1.00000e-09 1.00000e-01 $1.00000 \mathrm{e}+001.00000 \mathrm{e}+001.00000 \mathrm{e}-011.00000 \mathrm{e}-091.00000 \mathrm{e}-01$ Element: 2889 \# of layers: 12

$\mathrm{Kx}$ Ky Kz Ss Por

$5.86605 \mathrm{e}+025.86605 \mathrm{e}+025.86605 \mathrm{e}+01$ 1.00000e-09 7.00000e-02 $5.86605 \mathrm{e}+025.86605 \mathrm{e}+025.86605 \mathrm{e}+01$ 1.00000e-09 7.00000e-02 5.00000e-04 5.00000e-04 5.00000e-05 1.00000e-09 1.00000e-01 5.00000e-04 5.00000e-04 5.00000e-05 1.00000e-09 1.00000e-01 $2.34387 \mathrm{e}+012.34387 \mathrm{e}+012.34387 \mathrm{e}+00$ 1.00000e-09 2.12000e-01 $2.34387 \mathrm{e}+012.34387 \mathrm{e}+012.34387 \mathrm{e}+00$ 1.00000e-09 2.12000e-01 $2.34387 \mathrm{e}+012.34387 \mathrm{e}+012.34387 \mathrm{e}+001.00000 \mathrm{e}-092.12000 \mathrm{e}-01$ $2.34387 \mathrm{e}+012.34387 \mathrm{e}+012.34387 \mathrm{e}+001.00000 \mathrm{e}-092.12000 \mathrm{e}-01$ $1.00000 \mathrm{e}-021.00000 \mathrm{e}-02$ 1.00000e-03 1.00000e-09 1.00000e-01 $1.00000 \mathrm{e}+001.00000 \mathrm{e}+001.00000 \mathrm{e}-011.00000 \mathrm{e}-091.00000 \mathrm{e}-01$ $1.00000 \mathrm{e}-05$ 1.00000e-05 1.00000e-06 1.00000e-09 1.00000e-01 $1.00000 \mathrm{e}+001.00000 \mathrm{e}+001.00000 \mathrm{e}-011.00000 \mathrm{e}-091.00000 \mathrm{e}-01$ 
Element: 2890 \# of layers: 11

$\mathrm{Kx} \mathrm{Ky} \mathrm{Kz}$ Ss Por

7.35640e+02 7.35640e+02 7.35640e+01 1.00000e-09 7.00000e-02

$7.35640 \mathrm{e}+02$ 7.35640e+02 7.35640e+01 1.00000e-09 7.00000e-02

5.00000e-04 5.00000e-04 5.00000e-05 1.00000e-09 1.00000e-01

$2.93946 \mathrm{e}+012.93946 \mathrm{e}+012.93946 \mathrm{e}+00$ 1.00000e-09 2.12000e-01

$2.93946 \mathrm{e}+012.93946 \mathrm{e}+012.93946 \mathrm{e}+00$ 1.00000e-09 2.12000e-01

$2.93946 \mathrm{e}+012.93946 \mathrm{e}+012.93946 \mathrm{e}+001.00000 \mathrm{e}-092.12000 \mathrm{e}-01$

$2.93946 \mathrm{e}+012.93946 \mathrm{e}+012.93946 \mathrm{e}+001.00000 \mathrm{e}-092.12000 \mathrm{e}-01$

$1.00000 \mathrm{e}-02$ 1.00000e-02 1.00000e-03 1.00000e-09 1.00000e-01

$1.00000 \mathrm{e}+001.00000 \mathrm{e}+001.00000 \mathrm{e}-011.00000 \mathrm{e}-091.00000 \mathrm{e}-01$

$1.00000 \mathrm{e}-05$ 1.00000e-05 1.00000e-06 1.00000e-09 1.00000e-01

$1.00000 \mathrm{e}+001.00000 \mathrm{e}+001.00000 \mathrm{e}-011.00000 \mathrm{e}-091.00000 \mathrm{e}-01$

Element: 2891 \# of layers: 11

$\mathrm{Kx} \mathrm{Ky} \mathrm{Kz}$ Ss Por

7.35640e+02 7.35640e+02 7.35640e+01 1.00000e-09 7.00000e-02

7.35640e+02 7.35640e+02 7.35640e+01 1.00000e-09 7.00000e-02

5.00000e-04 5.00000e-04 5.00000e-05 1.00000e-09 1.00000e-01

$2.93946 \mathrm{e}+012.93946 \mathrm{e}+012.93946 \mathrm{e}+00$ 1.00000e-09 2.12000e-01

$2.93946 \mathrm{e}+012.93946 \mathrm{e}+012.93946 \mathrm{e}+001.00000 \mathrm{e}-092.12000 \mathrm{e}-01$

$2.93946 \mathrm{e}+012.93946 \mathrm{e}+012.93946 \mathrm{e}+001.00000 \mathrm{e}-092.12000 \mathrm{e}-01$

$2.93946 \mathrm{e}+012.93946 \mathrm{e}+012.93946 \mathrm{e}+00$ 1.00000e-09 2.12000e-01

$1.00000 \mathrm{e}-02$ 1.00000e-02 1.00000e-03 1.00000e-09 1.00000e-01

$1.00000 \mathrm{e}+001.00000 \mathrm{e}+001.00000 \mathrm{e}-011.00000 \mathrm{e}-091.00000 \mathrm{e}-01$

$1.00000 \mathrm{e}-05$ 1.00000e-05 1.00000e-06 1.00000e-09 1.00000e-01

$1.00000 \mathrm{e}+001.00000 \mathrm{e}+001.00000 \mathrm{e}-01$ 1.00000e-09 1.00000e-01

Element: 2892 \# of layers: 13

$\mathrm{Kx} \mathrm{Ky} \mathrm{Kz}$ Ss Por

7.39604e+02 7.39604e+02 7.39604e+01 1.00000e-09 7.00000e-02

7.39604e+02 7.39604e+02 7.39604e+01 1.00000e-09 7.00000e-02

5.00000e-04 5.00000e-04 5.00000e-05 1.00000e-09 1.00000e-01

5.00000e-04 5.00000e-04 5.00000e-05 1.00000e-09 1.00000e-01

$2.95521 \mathrm{e}+012.95521 \mathrm{e}+012.95521 \mathrm{e}+001.00000 \mathrm{e}-092.12000 \mathrm{e}-01$

$2.95521 \mathrm{e}+012.95521 \mathrm{e}+012.95521 \mathrm{e}+001.00000 \mathrm{e}-092.12000 \mathrm{e}-01$

$2.95521 \mathrm{e}+012.95521 \mathrm{e}+012.95521 \mathrm{e}+001.00000 \mathrm{e}-092.12000 \mathrm{e}-01$

$2.95521 \mathrm{e}+012.95521 \mathrm{e}+012.95521 \mathrm{e}+001.00000 \mathrm{e}-092.12000 \mathrm{e}-01$

$2.95521 \mathrm{e}+012.95521 \mathrm{e}+012.95521 \mathrm{e}+001.00000 \mathrm{e}-092.12000 \mathrm{e}-01$

$1.00000 \mathrm{e}-02$ 1.00000e-02 1.00000e-03 1.00000e-09 1.00000e-01

$1.00000 \mathrm{e}+001.00000 \mathrm{e}+001.00000 \mathrm{e}-011.00000 \mathrm{e}-091.00000 \mathrm{e}-01$

$1.00000 \mathrm{e}-05$ 1.00000e-05 1.00000e-06 1.00000e-09 1.00000e-01

$1.00000 \mathrm{e}+001.00000 \mathrm{e}+001.00000 \mathrm{e}-011.00000 \mathrm{e}-091.00000 \mathrm{e}-01$

Element: 2893 \# of layers: 13

$\mathrm{Kx} \mathrm{Ky} \mathrm{Kz}$ Ss Por

6.92617e+02 6.92617e+02 6.92617e+01 1.00000e-09 7.00000e-02

6.92617e+02 6.92617e+02 6.92617e+01 1.00000e-09 7.00000e-02

5.00000e-04 5.00000e-04 5.00000e-05 1.00000e-09 1.00000e-01 
5.00000e-04 5.00000e-04 5.00000e-05 1.00000e-09 1.00000e-01 $2.76756 \mathrm{e}+012.76756 \mathrm{e}+012.76756 \mathrm{e}+001.00000 \mathrm{e}-092.12000 \mathrm{e}-01$ $2.76756 \mathrm{e}+012.76756 \mathrm{e}+012.76756 \mathrm{e}+001.00000 \mathrm{e}-092.12000 \mathrm{e}-01$ $2.76756 \mathrm{e}+012.76756 \mathrm{e}+012.76756 \mathrm{e}+001.00000 \mathrm{e}-092.12000 \mathrm{e}-01$ $2.76756 \mathrm{e}+012.76756 \mathrm{e}+012.76756 \mathrm{e}+001.00000 \mathrm{e}-092.12000 \mathrm{e}-01$ $2.76756 \mathrm{e}+012.76756 \mathrm{e}+012.76756 \mathrm{e}+001.00000 \mathrm{e}-092.12000 \mathrm{e}-01$ $1.00000 \mathrm{e}-021.00000 \mathrm{e}-02$ 1.00000e-03 1.00000e-09 1.00000e-01 $1.00000 \mathrm{e}+001.00000 \mathrm{e}+001.00000 \mathrm{e}-011.00000 \mathrm{e}-091.00000 \mathrm{e}-01$ $1.00000 \mathrm{e}-05$ 1.00000e-05 1.00000e-06 1.00000e-09 1.00000e-01 $1.00000 \mathrm{e}+001.00000 \mathrm{e}+001.00000 \mathrm{e}-011.00000 \mathrm{e}-091.00000 \mathrm{e}-01$ Element: 2894 \# of layers: 12

Kx Ky Kz Ss Por $5.86605 \mathrm{e}+025.86605 \mathrm{e}+025.86605 \mathrm{e}+01$ 1.00000e-09 7.00000e-02 $5.86605 \mathrm{e}+025.86605 \mathrm{e}+025.86605 \mathrm{e}+011.00000 \mathrm{e}-097.00000 \mathrm{e}-02$ $5.00000 \mathrm{e}-04$ 5.00000e-04 5.00000e-05 1.00000e-09 1.00000e-01 5.00000e-04 5.00000e-04 5.00000e-05 1.00000e-09 1.00000e-01 $2.34387 \mathrm{e}+012.34387 \mathrm{e}+012.34387 \mathrm{e}+001.00000 \mathrm{e}-092.12000 \mathrm{e}-01$ $2.34387 \mathrm{e}+012.34387 \mathrm{e}+012.34387 \mathrm{e}+00$ 1.00000e-09 2.12000e-01 $2.34387 \mathrm{e}+012.34387 \mathrm{e}+012.34387 \mathrm{e}+00$ 1.00000e-09 2.12000e-01 $2.34387 \mathrm{e}+012.34387 \mathrm{e}+012.34387 \mathrm{e}+001.00000 \mathrm{e}-092.12000 \mathrm{e}-01$ $1.00000 \mathrm{e}-021.00000 \mathrm{e}-02$ 1.00000e-03 1.00000e-09 1.00000e-01 $1.00000 \mathrm{e}+001.00000 \mathrm{e}+001.00000 \mathrm{e}-011.00000 \mathrm{e}-091.00000 \mathrm{e}-01$ $1.00000 \mathrm{e}-05$ 1.00000e-05 1.00000e-06 1.00000e-09 1.00000e-01 $1.00000 \mathrm{e}+001.00000 \mathrm{e}+001.00000 \mathrm{e}-011.00000 \mathrm{e}-091.00000 \mathrm{e}-01$ Element: 2895 \# of layers: 13

Kx Ky Kz Ss Por

$5.61341 \mathrm{e}+025.61341 \mathrm{e}+025.61341 \mathrm{e}+01$ 1.00000e-09 7.00000e-02 $5.61341 \mathrm{e}+025.61341 \mathrm{e}+025.61341 \mathrm{e}+011.00000 \mathrm{e}-097.00000 \mathrm{e}-02$ $5.61341 \mathrm{e}+025.61341 \mathrm{e}+025.61341 \mathrm{e}+011.00000 \mathrm{e}-097.00000 \mathrm{e}-02$ $5.00000 \mathrm{e}-04$ 5.00000e-04 5.00000e-05 1.00000e-09 1.00000e-01 5.00000e-04 5.00000e-04 5.00000e-05 1.00000e-09 1.00000e-01 $2.24291 \mathrm{e}+012.24291 \mathrm{e}+012.24291 \mathrm{e}+001.00000 \mathrm{e}-092.12000 \mathrm{e}-01$ $2.24291 \mathrm{e}+012.24291 \mathrm{e}+012.24291 \mathrm{e}+001.00000 \mathrm{e}-092.12000 \mathrm{e}-01$ $2.24291 \mathrm{e}+012.24291 \mathrm{e}+012.24291 \mathrm{e}+001.00000 \mathrm{e}-092.12000 \mathrm{e}-01$ $2.24291 \mathrm{e}+012.24291 \mathrm{e}+012.24291 \mathrm{e}+001.00000 \mathrm{e}-092.12000 \mathrm{e}-01$ $1.00000 \mathrm{e}-021.00000 \mathrm{e}-02$ 1.00000e-03 1.00000e-09 1.00000e-01 $1.00000 \mathrm{e}+001.00000 \mathrm{e}+001.00000 \mathrm{e}-011.00000 \mathrm{e}-091.00000 \mathrm{e}-01$ $1.00000 \mathrm{e}-05$ 1.00000e-05 1.00000e-06 1.00000e-09 1.00000e-01 $1.00000 \mathrm{e}+001.00000 \mathrm{e}+001.00000 \mathrm{e}-011.00000 \mathrm{e}-091.00000 \mathrm{e}-01$ Element: 2896 \# of layers: 14

Kx Ky Kz Ss Por $5.83857 \mathrm{e}+02$ 5.83857e+02 5.83857e+01 1.00000e-09 7.00000e-02 $5.83857 \mathrm{e}+025.83857 \mathrm{e}+025.83857 \mathrm{e}+011.00000 \mathrm{e}-09$ 7.00000e-02 $5.83857 \mathrm{e}+025.83857 \mathrm{e}+025.83857 \mathrm{e}+011.00000 \mathrm{e}-097.00000 \mathrm{e}-02$ 5.00000e-04 5.00000e-04 5.00000e-05 1.00000e-09 1.00000e-01 5.00000e-04 5.00000e-04 5.00000e-05 1.00000e-09 1.00000e-01 
$2.33285 \mathrm{e}+012.33285 \mathrm{e}+012.33285 \mathrm{e}+00$ 1.00000e-09 2.12000e-01 $2.33285 \mathrm{e}+012.33285 \mathrm{e}+012.33285 \mathrm{e}+00$ 1.00000e-09 2.12000e-01 $2.33285 \mathrm{e}+012.33285 \mathrm{e}+012.33285 \mathrm{e}+00$ 1.00000e-09 2.12000e-01 $2.33285 \mathrm{e}+012.33285 \mathrm{e}+012.33285 \mathrm{e}+001.00000 \mathrm{e}-092.12000 \mathrm{e}-01$ $2.33285 \mathrm{e}+012.33285 \mathrm{e}+012.33285 \mathrm{e}+001.00000 \mathrm{e}-092.12000 \mathrm{e}-01$ $1.00000 \mathrm{e}-02$ 1.00000e-02 1.00000e-03 1.00000e-09 1.00000e-01 $1.00000 \mathrm{e}+001.00000 \mathrm{e}+001.00000 \mathrm{e}-011.00000 \mathrm{e}-091.00000 \mathrm{e}-01$ $1.00000 \mathrm{e}-05$ 1.00000e-05 1.00000e-06 1.00000e-09 1.00000e-01 $1.00000 \mathrm{e}+001.00000 \mathrm{e}+001.00000 \mathrm{e}-011.00000 \mathrm{e}-091.00000 \mathrm{e}-01$ Element: 2897 \# of layers: 14

$\mathrm{Kx} \mathrm{Ky} \mathrm{Kz}$ Ss Por

5.83857e+02 5.83857e+02 5.83857e+01 1.00000e-09 7.00000e-02 $5.83857 \mathrm{e}+02$ 5.83857e+02 5.83857e+01 1.00000e-09 7.00000e-02 $5.83857 \mathrm{e}+02$ 5.83857e+02 5.83857e+01 1.00000e-09 7.00000e-02 5.00000e-04 5.00000e-04 5.00000e-05 1.00000e-09 1.00000e-01 5.00000e-04 5.00000e-04 5.00000e-05 1.00000e-09 1.00000e-01 $2.33285 \mathrm{e}+012.33285 \mathrm{e}+012.33285 \mathrm{e}+001.00000 \mathrm{e}-092.12000 \mathrm{e}-01$ $2.33285 \mathrm{e}+012.33285 \mathrm{e}+012.33285 \mathrm{e}+00$ 1.00000e-09 2.12000e-01 $2.33285 \mathrm{e}+012.33285 \mathrm{e}+012.33285 \mathrm{e}+00$ 1.00000e-09 2.12000e-01 $2.33285 \mathrm{e}+012.33285 \mathrm{e}+012.33285 \mathrm{e}+00$ 1.00000e-09 2.12000e-01 $2.33285 \mathrm{e}+012.33285 \mathrm{e}+012.33285 \mathrm{e}+001.00000 \mathrm{e}-092.12000 \mathrm{e}-01$ $1.00000 \mathrm{e}-02$ 1.00000e-02 1.00000e-03 1.00000e-09 1.00000e-01 $1.00000 \mathrm{e}+001.00000 \mathrm{e}+001.00000 \mathrm{e}-011.00000 \mathrm{e}-091.00000 \mathrm{e}-01$ $1.00000 \mathrm{e}-05$ 1.00000e-05 1.00000e-06 1.00000e-09 1.00000e-01 $1.00000 \mathrm{e}+001.00000 \mathrm{e}+001.00000 \mathrm{e}-011.00000 \mathrm{e}-091.00000 \mathrm{e}-01$ Element: 2898 \# of layers: 14

$\mathrm{Kx} \mathrm{Ky} \mathrm{Kz}$ Ss Por

5.83857e+02 5.83857e+02 5.83857e+01 1.00000e-09 7.00000e-02 $5.83857 \mathrm{e}+02$ 5.83857e+02 5.83857e+01 1.00000e-09 7.00000e-02 $5.83857 \mathrm{e}+02$ 5.83857e+02 5.83857e+01 1.00000e-09 7.00000e-02 5.00000e-04 5.00000e-04 5.00000e-05 1.00000e-09 1.00000e-01 5.00000e-04 5.00000e-04 5.00000e-05 1.00000e-09 1.00000e-01 $2.33285 \mathrm{e}+012.33285 \mathrm{e}+012.33285 \mathrm{e}+00$ 1.00000e-09 2.12000e-01 $2.33285 \mathrm{e}+012.33285 \mathrm{e}+012.33285 \mathrm{e}+00$ 1.00000e-09 2.12000e-01 $2.33285 \mathrm{e}+012.33285 \mathrm{e}+012.33285 \mathrm{e}+00$ 1.00000e-09 2.12000e-01 $2.33285 \mathrm{e}+012.33285 \mathrm{e}+012.33285 \mathrm{e}+00$ 1.00000e-09 2.12000e-01 $2.33285 \mathrm{e}+012.33285 \mathrm{e}+012.33285 \mathrm{e}+001.00000 \mathrm{e}-092.12000 \mathrm{e}-01$ $1.00000 \mathrm{e}-02$ 1.00000e-02 1.00000e-03 1.00000e-09 1.00000e-01 $1.00000 \mathrm{e}+001.00000 \mathrm{e}+001.00000 \mathrm{e}-011.00000 \mathrm{e}-091.00000 \mathrm{e}-01$ $1.00000 \mathrm{e}-05$ 1.00000e-05 1.00000e-06 1.00000e-09 1.00000e-01 $1.00000 \mathrm{e}+001.00000 \mathrm{e}+001.00000 \mathrm{e}-011.00000 \mathrm{e}-091.00000 \mathrm{e}-01$ Element: 2899 \# of layers: 14

$\mathrm{Kx} \mathrm{Ky} \mathrm{Kz}$ Ss Por

9.29201e+02 9.29201e+02 9.29201e+01 1.00000e-09 7.00000e-02 9.29201e+02 9.29201e+02 9.29201e+01 1.00000e-09 7.00000e-02 $9.29201 \mathrm{e}+02$ 9.29201e+02 9.29201e+01 1.00000e-09 7.00000e-02 
5.00000e-04 5.00000e-04 5.00000e-05 1.00000e-09 1.00000e-01 5.00000e-04 5.00000e-04 5.00000e-05 1.00000e-09 1.00000e-01 $3.71303 \mathrm{e}+013.71303 \mathrm{e}+013.71303 \mathrm{e}+00$ 1.00000e-09 2.12000e-01 $3.71303 \mathrm{e}+013.71303 \mathrm{e}+013.71303 \mathrm{e}+00$ 1.00000e-09 2.12000e-01 $3.71303 \mathrm{e}+013.71303 \mathrm{e}+013.71303 \mathrm{e}+001.00000 \mathrm{e}-092.12000 \mathrm{e}-01$ $3.71303 \mathrm{e}+013.71303 \mathrm{e}+013.71303 \mathrm{e}+00$ 1.00000e-09 2.12000e-01 $3.71303 \mathrm{e}+013.71303 \mathrm{e}+013.71303 \mathrm{e}+00$ 1.00000e-09 2.12000e-01 $1.00000 \mathrm{e}-02$ 1.00000e-02 1.00000e-03 1.00000e-09 1.00000e-01 $1.00000 \mathrm{e}+001.00000 \mathrm{e}+001.00000 \mathrm{e}-01$ 1.00000e-09 1.00000e-01 $1.00000 \mathrm{e}-05$ 1.00000e-05 1.00000e-06 1.00000e-09 1.00000e-01 $1.00000 \mathrm{e}+001.00000 \mathrm{e}+001.00000 \mathrm{e}-01$ 1.00000e-09 1.00000e-01 Element: 2900 \# of layers: 13

$\mathrm{Kx} \mathrm{Ky} \mathrm{Kz}$ Ss Por

9.29201e+02 9.29201e+02 9.29201e+01 1.00000e-09 7.00000e-02 9.29201e+02 9.29201e+02 9.29201e+01 1.00000e-09 7.00000e-02 $9.29201 \mathrm{e}+02$ 9.29201e+02 9.29201e+01 1.00000e-09 7.00000e-02 5.00000e-04 5.00000e-04 5.00000e-05 1.00000e-09 1.00000e-01 5.00000e-04 5.00000e-04 5.00000e-05 1.00000e-09 1.00000e-01 $3.71303 \mathrm{e}+013.71303 \mathrm{e}+013.71303 \mathrm{e}+00$ 1.00000e-09 2.12000e-01 $3.71303 \mathrm{e}+013.71303 \mathrm{e}+013.71303 \mathrm{e}+00$ 1.00000e-09 2.12000e-01 $3.71303 \mathrm{e}+013.71303 \mathrm{e}+013.71303 \mathrm{e}+001.00000 \mathrm{e}-092.12000 \mathrm{e}-01$ $3.71303 \mathrm{e}+013.71303 \mathrm{e}+013.71303 \mathrm{e}+00$ 1.00000e-09 2.12000e-01 $1.00000 \mathrm{e}-02$ 1.00000e-02 1.00000e-03 1.00000e-09 1.00000e-01 $1.00000 \mathrm{e}+001.00000 \mathrm{e}+001.00000 \mathrm{e}-011.00000 \mathrm{e}-091.00000 \mathrm{e}-01$ $1.00000 \mathrm{e}-05$ 1.00000e-05 1.00000e-06 1.00000e-09 1.00000e-01 $1.00000 \mathrm{e}+001.00000 \mathrm{e}+001.00000 \mathrm{e}-011.00000 \mathrm{e}-091.00000 \mathrm{e}-01$ Element: 2901 \# of layers: 13

$\mathrm{Kx} \mathrm{Ky} \mathrm{Kz}$ Ss Por

9.93713e+02 9.93713e+02 9.93713e+01 1.00000e-09 7.00000e-02 9.93713e+02 9.93713e+02 9.93713e+01 1.00000e-09 7.00000e-02 9.93713e+02 9.93713e+02 9.93713e+01 1.00000e-09 7.00000e-02 5.00000e-04 5.00000e-04 5.00000e-05 1.00000e-09 1.00000e-01 5.00000e-04 5.00000e-04 5.00000e-05 1.00000e-09 1.00000e-01 $3.97066 \mathrm{e}+013.97066 \mathrm{e}+013.97066 \mathrm{e}+001.00000 \mathrm{e}-092.12000 \mathrm{e}-01$ $3.97066 \mathrm{e}+013.97066 \mathrm{e}+013.97066 \mathrm{e}+00$ 1.00000e-09 2.12000e-01 $3.97066 \mathrm{e}+013.97066 \mathrm{e}+013.97066 \mathrm{e}+001.00000 \mathrm{e}-092.12000 \mathrm{e}-01$ $3.97066 \mathrm{e}+013.97066 \mathrm{e}+013.97066 \mathrm{e}+001.00000 \mathrm{e}-092.12000 \mathrm{e}-01$ $1.00000 \mathrm{e}-02$ 1.00000e-02 1.00000e-03 1.00000e-09 1.00000e-01 $1.00000 \mathrm{e}+001.00000 \mathrm{e}+001.00000 \mathrm{e}-011.00000 \mathrm{e}-091.00000 \mathrm{e}-01$ $1.00000 \mathrm{e}-05$ 1.00000e-05 1.00000e-06 1.00000e-09 1.00000e-01 $1.00000 \mathrm{e}+001.00000 \mathrm{e}+001.00000 \mathrm{e}-011.00000 \mathrm{e}-091.00000 \mathrm{e}-01$ Element: 2902 \# of layers: 13

$\mathrm{Kx} \mathrm{Ky} \mathrm{Kz}$ Ss Por

5.61341e+02 5.61341e+02 5.61341e+01 1.00000e-09 7.00000e-02 $5.61341 \mathrm{e}+025.61341 \mathrm{e}+025.61341 \mathrm{e}+01$ 1.00000e-09 7.00000e-02 $5.61341 \mathrm{e}+025.61341 \mathrm{e}+025.61341 \mathrm{e}+01$ 1.00000e-09 7.00000e-02 
5.00000e-04 5.00000e-04 5.00000e-05 1.00000e-09 1.00000e-01 5.00000e-04 5.00000e-04 5.00000e-05 1.00000e-09 1.00000e-01 $2.24291 \mathrm{e}+012.24291 \mathrm{e}+012.24291 \mathrm{e}+00$ 1.00000e-09 2.12000e-01 $2.24291 \mathrm{e}+012.24291 \mathrm{e}+012.24291 \mathrm{e}+001.00000 \mathrm{e}-092.12000 \mathrm{e}-01$ $2.24291 \mathrm{e}+012.24291 \mathrm{e}+012.24291 \mathrm{e}+001.00000 \mathrm{e}-092.12000 \mathrm{e}-01$ $2.24291 \mathrm{e}+012.24291 \mathrm{e}+012.24291 \mathrm{e}+00$ 1.00000e-09 2.12000e-01 1.00000e-02 1.00000e-02 1.00000e-03 1.00000e-09 1.00000e-01 $1.00000 \mathrm{e}+001.00000 \mathrm{e}+001.00000 \mathrm{e}-011.00000 \mathrm{e}-091.00000 \mathrm{e}-01$ $1.00000 \mathrm{e}-051.00000 \mathrm{e}-051.00000 \mathrm{e}-061.00000 \mathrm{e}-091.00000 \mathrm{e}-01$ $1.00000 \mathrm{e}+001.00000 \mathrm{e}+001.00000 \mathrm{e}-011.00000 \mathrm{e}-091.00000 \mathrm{e}-01$ Element: 2903 \# of layers: 13

$\mathrm{Kx} \mathrm{Ky} \mathrm{Kz}$ Ss Por

5.83857e+02 5.83857e+02 5.83857e+01 1.00000e-09 7.00000e-02 $5.83857 \mathrm{e}+02$ 5.83857e+02 5.83857e+01 1.00000e-09 7.00000e-02 $5.83857 \mathrm{e}+025.83857 \mathrm{e}+02$ 5.83857e+01 1.00000e-09 7.00000e-02 5.00000e-04 5.00000e-04 5.00000e-05 1.00000e-09 1.00000e-01 5.00000e-04 5.00000e-04 5.00000e-05 1.00000e-09 1.00000e-01 $2.33285 \mathrm{e}+012.33285 \mathrm{e}+012.33285 \mathrm{e}+00$ 1.00000e-09 2.12000e-01 $2.33285 \mathrm{e}+012.33285 \mathrm{e}+012.33285 \mathrm{e}+00$ 1.00000e-09 2.12000e-01 $2.33285 \mathrm{e}+012.33285 \mathrm{e}+012.33285 \mathrm{e}+00$ 1.00000e-09 2.12000e-01 $2.33285 \mathrm{e}+012.33285 \mathrm{e}+012.33285 \mathrm{e}+001.00000 \mathrm{e}-092.12000 \mathrm{e}-01$ $1.00000 \mathrm{e}-02$ 1.00000e-02 1.00000e-03 1.00000e-09 1.00000e-01 $1.00000 \mathrm{e}+001.00000 \mathrm{e}+001.00000 \mathrm{e}-011.00000 \mathrm{e}-091.00000 \mathrm{e}-01$ $1.00000 \mathrm{e}-05$ 1.00000e-05 1.00000e-06 1.00000e-09 1.00000e-01 $1.00000 \mathrm{e}+001.00000 \mathrm{e}+001.00000 \mathrm{e}-011.00000 \mathrm{e}-09$ 1.00000e-01 Element: 2904 \# of layers: 14

$\mathrm{Kx} \mathrm{Ky} \mathrm{Kz}$ Ss Por

4.52482e+02 4.52482e+02 4.52482e+01 1.00000e-09 7.00000e-02 $4.52482 \mathrm{e}+02$ 4.52482e+02 4.52482e+01 1.00000e-09 7.00000e-02 4.52482e+02 4.52482e+02 4.52482e+01 1.00000e-09 7.00000e-02 $5.00000 \mathrm{e}-04$ 5.00000e-04 5.00000e-05 1.00000e-09 1.00000e-01 5.00000e-04 5.00000e-04 5.00000e-05 1.00000e-09 1.00000e-01 $1.80798 \mathrm{e}+01$ 1.80798e+01 1.80798e+00 1.00000e-09 2.12000e-01 $1.80798 \mathrm{e}+01$ 1.80798e+01 1.80798e+00 1.00000e-09 2.12000e-01 $1.80798 \mathrm{e}+01$ 1.80798e+01 1.80798e+00 1.00000e-09 2.12000e-01 $1.80798 \mathrm{e}+01$ 1.80798e+01 1.80798e+00 1.00000e-09 2.12000e-01 $1.80798 \mathrm{e}+01$ 1.80798e+01 1.80798e+00 1.00000e-09 2.12000e-01 $1.00000 \mathrm{e}-02$ 1.00000e-02 1.00000e-03 1.00000e-09 1.00000e-01 $1.00000 \mathrm{e}+001.00000 \mathrm{e}+001.00000 \mathrm{e}-011.00000 \mathrm{e}-091.00000 \mathrm{e}-01$ $1.00000 \mathrm{e}-05$ 1.00000e-05 1.00000e-06 1.00000e-09 1.00000e-01 $1.00000 \mathrm{e}+001.00000 \mathrm{e}+001.00000 \mathrm{e}-011.00000 \mathrm{e}-091.00000 \mathrm{e}-01$ Element: 2905 \# of layers: 14

$\mathrm{Kx} \mathrm{Ky} \mathrm{Kz}$ Ss Por

5.39339e+02 5.39339e+02 5.39339e+01 1.00000e-09 7.00000e-02 5.39339e+02 5.39339e+02 5.39339e+01 1.00000e-09 7.00000e-02 $5.39339 \mathrm{e}+02$ 5.39339e+02 5.39339e+01 1.00000e-09 7.00000e-02 
5.00000e-04 5.00000e-04 5.00000e-05 1.00000e-09 1.00000e-01 5.00000e-04 5.00000e-04 5.00000e-05 1.00000e-09 1.00000e-01 $2.15503 \mathrm{e}+012.15503 \mathrm{e}+012.15503 \mathrm{e}+00$ 1.00000e-09 2.12000e-01 $2.15503 \mathrm{e}+012.15503 \mathrm{e}+012.15503 \mathrm{e}+001.00000 \mathrm{e}-092.12000 \mathrm{e}-01$ $2.15503 \mathrm{e}+012.15503 \mathrm{e}+012.15503 \mathrm{e}+001.00000 \mathrm{e}-092.12000 \mathrm{e}-01$ $2.15503 \mathrm{e}+012.15503 \mathrm{e}+012.15503 \mathrm{e}+00$ 1.00000e-09 2.12000e-01 $2.15503 \mathrm{e}+012.15503 \mathrm{e}+012.15503 \mathrm{e}+00$ 1.00000e-09 2.12000e-01 $1.00000 \mathrm{e}-02$ 1.00000e-02 1.00000e-03 1.00000e-09 1.00000e-01 $1.00000 \mathrm{e}+001.00000 \mathrm{e}+001.00000 \mathrm{e}-01$ 1.00000e-09 1.00000e-01 $1.00000 \mathrm{e}-05$ 1.00000e-05 1.00000e-06 1.00000e-09 1.00000e-01 $1.00000 \mathrm{e}+001.00000 \mathrm{e}+001.00000 \mathrm{e}-011.00000 \mathrm{e}-091.00000 \mathrm{e}-01$ Element: 2906 \# of layers: 15

$\mathrm{Kx} \mathrm{Ky} \mathrm{Kz}$ Ss Por

5.39339e+02 5.39339e+02 5.39339e+01 1.00000e-09 7.00000e-02 5.39339e+02 5.39339e+02 5.39339e+01 1.00000e-09 7.00000e-02 $5.39339 \mathrm{e}+02$ 5.39339e+02 5.39339e+01 1.00000e-09 7.00000e-02 5.39339e+02 5.39339e+02 5.39339e+01 1.00000e-09 7.00000e-02 5.00000e-04 5.00000e-04 5.00000e-05 1.00000e-09 1.00000e-01 5.00000e-04 5.00000e-04 5.00000e-05 1.00000e-09 1.00000e-01 $2.15503 \mathrm{e}+012.15503 \mathrm{e}+012.15503 \mathrm{e}+001.00000 \mathrm{e}-092.12000 \mathrm{e}-01$ $2.15503 e+012.15503 e+012.15503 e+001.00000 e-092.12000 e-01$ $2.15503 \mathrm{e}+012.15503 \mathrm{e}+012.15503 \mathrm{e}+00$ 1.00000e-09 2.12000e-01 $2.15503 \mathrm{e}+012.15503 \mathrm{e}+012.15503 \mathrm{e}+00$ 1.00000e-09 2.12000e-01 $2.15503 \mathrm{e}+012.15503 \mathrm{e}+012.15503 \mathrm{e}+00$ 1.00000e-09 2.12000e-01 $1.00000 \mathrm{e}-02$ 1.00000e-02 1.00000e-03 1.00000e-09 1.00000e-01 $1.00000 \mathrm{e}+001.00000 \mathrm{e}+001.00000 \mathrm{e}-011.00000 \mathrm{e}-091.00000 \mathrm{e}-01$ $1.00000 \mathrm{e}-05$ 1.00000e-05 1.00000e-06 1.00000e-09 1.00000e-01 $1.00000 \mathrm{e}+001.00000 \mathrm{e}+001.00000 \mathrm{e}-011.00000 \mathrm{e}-091.00000 \mathrm{e}-01$ Element: 2907 \# of layers: 14

$\mathrm{Kx} \mathrm{Ky} \mathrm{Kz}$ Ss Por

5.39339e+02 5.39339e+02 5.39339e+01 1.00000e-09 7.00000e-02 5.39339e+02 5.39339e+02 5.39339e+01 1.00000e-09 7.00000e-02 5.39339e+02 5.39339e+02 5.39339e+01 1.00000e-09 7.00000e-02 5.00000e-04 5.00000e-04 5.00000e-05 1.00000e-09 1.00000e-01 5.00000e-04 5.00000e-04 5.00000e-05 1.00000e-09 1.00000e-01 $2.15503 \mathrm{e}+012.15503 \mathrm{e}+012.15503 \mathrm{e}+00$ 1.00000e-09 2.12000e-01 $2.15503 \mathrm{e}+012.15503 \mathrm{e}+012.15503 \mathrm{e}+001.00000 \mathrm{e}-092.12000 \mathrm{e}-01$ $2.15503 \mathrm{e}+012.15503 \mathrm{e}+012.15503 \mathrm{e}+00$ 1.00000e-09 2.12000e-01 $2.15503 \mathrm{e}+012.15503 \mathrm{e}+012.15503 \mathrm{e}+00$ 1.00000e-09 2.12000e-01 $2.15503 \mathrm{e}+012.15503 \mathrm{e}+012.15503 \mathrm{e}+00$ 1.00000e-09 2.12000e-01 $1.00000 \mathrm{e}-02$ 1.00000e-02 1.00000e-03 1.00000e-09 1.00000e-01 $1.00000 \mathrm{e}+001.00000 \mathrm{e}+001.00000 \mathrm{e}-011.00000 \mathrm{e}-091.00000 \mathrm{e}-01$ $1.00000 \mathrm{e}-05$ 1.00000e-05 1.00000e-06 1.00000e-09 1.00000e-01 $1.00000 \mathrm{e}+001.00000 \mathrm{e}+001.00000 \mathrm{e}-01$ 1.00000e-09 1.00000e-01 Element: 2908 \# of layers: 14

Kx Ky Kz Ss Por 
7.80095e+02 7.80095e+02 7.80095e+01 1.00000e-09 7.00000e-02 $7.80095 \mathrm{e}+02$ 7.80095e+02 7.80095e+01 1.00000e-09 7.00000e-02 $7.80095 \mathrm{e}+02$ 7.80095e+02 7.80095e+01 1.00000e-09 7.00000e-02 5.00000e-04 5.00000e-04 5.00000e-05 1.00000e-09 1.00000e-01 5.00000e-04 5.00000e-04 5.00000e-05 1.00000e-09 1.00000e-01

$3.11699 \mathrm{e}+013.11699 \mathrm{e}+013.11699 \mathrm{e}+00$ 1.00000e-09 2.12000e-01 $3.11699 \mathrm{e}+013.11699 \mathrm{e}+013.11699 \mathrm{e}+00$ 1.00000e-09 2.12000e-01 $3.11699 \mathrm{e}+013.11699 \mathrm{e}+01$ 3.11699e+00 1.00000e-09 2.12000e-01 $3.11699 \mathrm{e}+013.11699 \mathrm{e}+013.11699 \mathrm{e}+001.00000 \mathrm{e}-092.12000 \mathrm{e}-01$ $3.11699 \mathrm{e}+013.11699 \mathrm{e}+013.11699 \mathrm{e}+00$ 1.00000e-09 2.12000e-01 $1.00000 \mathrm{e}-02$ 1.00000e-02 1.00000e-03 1.00000e-09 1.00000e-01 $1.00000 \mathrm{e}+001.00000 \mathrm{e}+001.00000 \mathrm{e}-011.00000 \mathrm{e}-091.00000 \mathrm{e}-01$ $1.00000 \mathrm{e}-05$ 1.00000e-05 1.00000e-06 1.00000e-09 1.00000e-01 $1.00000 \mathrm{e}+001.00000 \mathrm{e}+001.00000 \mathrm{e}-011.00000 \mathrm{e}-09$ 1.00000e-01 Element: 2909 \# of layers: 14

Kx Ky Kz Ss Por

7.80095e+02 7.80095e+02 7.80095e+01 1.00000e-09 7.00000e-02 $7.80095 \mathrm{e}+02$ 7.80095e+02 7.80095e+01 1.00000e-09 7.00000e-02 7.80095e+02 7.80095e+02 7.80095e+01 1.00000e-09 7.00000e-02 5.00000e-04 5.00000e-04 5.00000e-05 1.00000e-09 1.00000e-01 5.00000e-04 5.00000e-04 5.00000e-05 1.00000e-09 1.00000e-01

$3.11699 \mathrm{e}+013.11699 \mathrm{e}+013.11699 \mathrm{e}+00$ 1.00000e-09 2.12000e-01 $3.11699 \mathrm{e}+013.11699 \mathrm{e}+013.11699 \mathrm{e}+00$ 1.00000e-09 2.12000e-01 $3.11699 \mathrm{e}+013.11699 \mathrm{e}+01$ 3.11699e+00 1.00000e-09 2.12000e-01 $3.11699 \mathrm{e}+013.11699 \mathrm{e}+013.11699 \mathrm{e}+001.00000 \mathrm{e}-092.12000 \mathrm{e}-01$ $3.11699 \mathrm{e}+013.11699 \mathrm{e}+013.11699 \mathrm{e}+001.00000 \mathrm{e}-092.12000 \mathrm{e}-01$ $1.00000 \mathrm{e}-02$ 1.00000e-02 1.00000e-03 1.00000e-09 1.00000e-01 $1.00000 \mathrm{e}+001.00000 \mathrm{e}+001.00000 \mathrm{e}-011.00000 \mathrm{e}-091.00000 \mathrm{e}-01$ $1.00000 \mathrm{e}-05$ 1.00000e-05 1.00000e-06 1.00000e-09 1.00000e-01 $1.00000 \mathrm{e}+001.00000 \mathrm{e}+001.00000 \mathrm{e}-011.00000 \mathrm{e}-091.00000 \mathrm{e}-01$ Element: 2910 \# of layers: 14

$\mathrm{Kx} \mathrm{Ky} \mathrm{Kz}$ Ss Por

8.53427e+02 8.53427e+02 8.53427e+01 1.00000e-09 7.00000e-02 8.53427e+02 8.53427e+02 8.53427e+01 1.00000e-09 7.00000e-02 8.53427e+02 8.53427e+02 8.53427e+01 1.00000e-09 7.00000e-02 5.00000e-04 5.00000e-04 5.00000e-05 1.00000e-09 1.00000e-01 5.00000e-04 5.00000e-04 5.00000e-05 1.00000e-09 1.00000e-01 $3.40995 \mathrm{e}+013.40995 \mathrm{e}+013.40995 \mathrm{e}+001.00000 \mathrm{e}-092.12000 \mathrm{e}-01$ $3.40995 \mathrm{e}+013.40995 \mathrm{e}+013.40995 \mathrm{e}+00$ 1.00000e-09 2.12000e-01 $3.40995 \mathrm{e}+013.40995 \mathrm{e}+013.40995 \mathrm{e}+001.00000 \mathrm{e}-092.12000 \mathrm{e}-01$ $3.40995 \mathrm{e}+013.40995 \mathrm{e}+013.40995 \mathrm{e}+001.00000 \mathrm{e}-092.12000 \mathrm{e}-01$ $3.40995 \mathrm{e}+013.40995 \mathrm{e}+013.40995 \mathrm{e}+001.00000 \mathrm{e}-092.12000 \mathrm{e}-01$ $1.00000 \mathrm{e}-021.00000 \mathrm{e}-021.00000 \mathrm{e}-031.00000 \mathrm{e}-091.00000 \mathrm{e}-01$ $1.00000 \mathrm{e}+001.00000 \mathrm{e}+001.00000 \mathrm{e}-011.00000 \mathrm{e}-091.00000 \mathrm{e}-01$ $1.00000 \mathrm{e}-05$ 1.00000e-05 1.00000e-06 1.00000e-09 1.00000e-01 $1.00000 \mathrm{e}+001.00000 \mathrm{e}+001.00000 \mathrm{e}-011.00000 \mathrm{e}-091.00000 \mathrm{e}-01$ 
Element: 2911 \# of layers: 14

$\mathrm{Kx} \mathrm{Ky} \mathrm{Kz}$ Ss Por

4.52482e+02 4.52482e+02 4.52482e+01 1.00000e-09 7.00000e-02

$4.52482 \mathrm{e}+02$ 4.52482e+02 4.52482e+01 1.00000e-09 7.00000e-02

4.52482e+02 4.52482e+02 4.52482e+01 1.00000e-09 7.00000e-02

5.00000e-04 5.00000e-04 5.00000e-05 1.00000e-09 1.00000e-01

5.00000e-04 5.00000e-04 5.00000e-05 1.00000e-09 1.00000e-01

$1.80798 \mathrm{e}+011.80798 \mathrm{e}+011.80798 \mathrm{e}+001.00000 \mathrm{e}-092.12000 \mathrm{e}-01$

$1.80798 \mathrm{e}+01$ 1.80798e+01 1.80798e+00 1.00000e-09 2.12000e-01

$1.80798 \mathrm{e}+011.80798 \mathrm{e}+01$ 1.80798e+00 1.00000e-09 2.12000e-01

$1.80798 \mathrm{e}+01$ 1.80798e+01 1.80798e+00 1.00000e-09 2.12000e-01

$1.80798 \mathrm{e}+01$ 1.80798e+01 1.80798e+00 1.00000e-09 2.12000e-01

$1.00000 \mathrm{e}-02$ 1.00000e-02 1.00000e-03 1.00000e-09 1.00000e-01

$1.00000 \mathrm{e}+001.00000 \mathrm{e}+001.00000 \mathrm{e}-011.00000 \mathrm{e}-091.00000 \mathrm{e}-01$

$1.00000 \mathrm{e}-05$ 1.00000e-05 1.00000e-06 1.00000e-09 1.00000e-01

$1.00000 \mathrm{e}+001.00000 \mathrm{e}+001.00000 \mathrm{e}-011.00000 \mathrm{e}-091.00000 \mathrm{e}-01$

Element: 2912 \# of layers: 14

$\mathrm{Kx} \mathrm{Ky} \mathrm{Kz}$ Ss Por

5.39339e+02 5.39339e+02 5.39339e+01 1.00000e-09 7.00000e-02

5.39339e+02 5.39339e+02 5.39339e+01 1.00000e-09 7.00000e-02

5.39339e+02 5.39339e+02 5.39339e+01 1.00000e-09 7.00000e-02

5.00000e-04 5.00000e-04 5.00000e-05 1.00000e-09 1.00000e-01

5.00000e-04 5.00000e-04 5.00000e-05 1.00000e-09 1.00000e-01

$2.15503 \mathrm{e}+012.15503 \mathrm{e}+012.15503 \mathrm{e}+00$ 1.00000e-09 2.12000e-01

$2.15503 \mathrm{e}+012.15503 \mathrm{e}+012.15503 \mathrm{e}+00$ 1.00000e-09 2.12000e-01

$2.15503 \mathrm{e}+012.15503 \mathrm{e}+012.15503 \mathrm{e}+00$ 1.00000e-09 2.12000e-01

$2.15503 \mathrm{e}+012.15503 \mathrm{e}+012.15503 \mathrm{e}+00$ 1.00000e-09 2.12000e-01

$2.15503 \mathrm{e}+012.15503 \mathrm{e}+012.15503 \mathrm{e}+00$ 1.00000e-09 2.12000e-01

$1.00000 \mathrm{e}-02$ 1.00000e-02 1.00000e-03 1.00000e-09 1.00000e-01

$1.00000 \mathrm{e}+001.00000 \mathrm{e}+001.00000 \mathrm{e}-011.00000 \mathrm{e}-091.00000 \mathrm{e}-01$

$1.00000 \mathrm{e}-05$ 1.00000e-05 1.00000e-06 1.00000e-09 1.00000e-01

$1.00000 \mathrm{e}+001.00000 \mathrm{e}+001.00000 \mathrm{e}-011.00000 \mathrm{e}-091.00000 \mathrm{e}-01$

Element: 2913 \# of layers: 15

$\mathrm{Kx} \mathrm{Ky} \mathrm{Kz}$ Ss Por

5.83370e+02 5.83370e+02 5.83370e+01 1.00000e-09 7.00000e-02

$5.83370 \mathrm{e}+025.83370 \mathrm{e}+025.83370 \mathrm{e}+01$ 1.00000e-09 7.00000e-02

$5.83370 \mathrm{e}+025.83370 \mathrm{e}+025.83370 \mathrm{e}+01$ 1.00000e-09 7.00000e-02

$5.83370 \mathrm{e}+025.83370 \mathrm{e}+025.83370 \mathrm{e}+01$ 1.00000e-09 7.00000e-02

5.00000e-04 5.00000e-04 5.00000e-05 1.00000e-09 1.00000e-01

5.00000e-04 5.00000e-04 5.00000e-05 1.00000e-09 1.00000e-01

$2.33083 \mathrm{e}+012.33083 \mathrm{e}+012.33083 \mathrm{e}+00$ 1.00000e-09 2.12000e-01

$2.33083 \mathrm{e}+012.33083 \mathrm{e}+012.33083 \mathrm{e}+00$ 1.00000e-09 2.12000e-01

$2.33083 \mathrm{e}+012.33083 \mathrm{e}+012.33083 \mathrm{e}+00$ 1.00000e-09 2.12000e-01

$2.33083 \mathrm{e}+012.33083 \mathrm{e}+01$ 2.33083e+00 1.00000e-09 2.12000e-01

$2.33083 \mathrm{e}+012.33083 \mathrm{e}+012.33083 \mathrm{e}+00$ 1.00000e-09 2.12000e-01

$1.00000 \mathrm{e}-02$ 1.00000e-02 1.00000e-03 1.00000e-09 1.00000e-01 
$1.00000 \mathrm{e}+001.00000 \mathrm{e}+001.00000 \mathrm{e}-011.00000 \mathrm{e}-091.00000 \mathrm{e}-01$ $1.00000 \mathrm{e}-05$ 1.00000e-05 1.00000e-06 1.00000e-09 1.00000e-01 $1.00000 \mathrm{e}+001.00000 \mathrm{e}+001.00000 \mathrm{e}-011.00000 \mathrm{e}-09$ 1.00000e-01 Element: 2914 \# of layers: 15

$\mathrm{Kx} \mathrm{Ky} \mathrm{Kz}$ Ss Por

4.90829e+02 4.90829e+02 4.90829e+01 1.00000e-09 7.00000e-02 $4.90829 \mathrm{e}+02$ 4.90829e+02 4.90829e+01 1.00000e-09 7.00000e-02 4.90829e+02 4.90829e+02 4.90829e+01 1.00000e-09 7.00000e-02 4.90829e+02 4.90829e+02 4.90829e+01 1.00000e-09 7.00000e-02 5.00000e-04 5.00000e-04 5.00000e-05 1.00000e-09 1.00000e-01 5.00000e-04 5.00000e-04 5.00000e-05 1.00000e-09 1.00000e-01 $1.96119 \mathrm{e}+01$ 1.96119e+01 1.96119e+00 1.00000e-09 2.12000e-01 $1.96119 \mathrm{e}+01$ 1.96119e+01 1.96119e+00 1.00000e-09 2.12000e-01 $1.96119 \mathrm{e}+01$ 1.96119e+01 1.96119e+00 1.00000e-09 2.12000e-01 $1.96119 \mathrm{e}+01$ 1.96119e+01 1.96119e+00 1.00000e-09 2.12000e-01 $1.96119 \mathrm{e}+01$ 1.96119e+01 1.96119e+00 1.00000e-09 2.12000e-01 1.00000e-02 1.00000e-02 1.00000e-03 1.00000e-09 1.00000e-01 $1.00000 \mathrm{e}+001.00000 \mathrm{e}+001.00000 \mathrm{e}-011.00000 \mathrm{e}-091.00000 \mathrm{e}-01$ $1.00000 \mathrm{e}-05$ 1.00000e-05 1.00000e-06 1.00000e-09 1.00000e-01 $1.00000 \mathrm{e}+001.00000 \mathrm{e}+001.00000 \mathrm{e}-011.00000 \mathrm{e}-091.00000 \mathrm{e}-01$ Element: 2915 \# of layers: 16

$\mathrm{Kx} \mathrm{Ky} \mathrm{Kz}$ Ss Por 4.90829e+02 4.90829e+02 4.90829e+01 1.00000e-09 7.00000e-02 4.90829e+02 4.90829e+02 4.90829e+01 1.00000e-09 7.00000e-02 $4.90829 \mathrm{e}+02$ 4.90829e+02 4.90829e+01 1.00000e-09 7.00000e-02 $4.90829 \mathrm{e}+02$ 4.90829e+02 4.90829e+01 1.00000e-09 7.00000e-02 $4.90829 \mathrm{e}+024.90829 \mathrm{e}+02$ 4.90829e+01 1.00000e-09 7.00000e-02 5.00000e-04 5.00000e-04 5.00000e-05 1.00000e-09 1.00000e-01 5.00000e-04 5.00000e-04 5.00000e-05 1.00000e-09 1.00000e-01 $1.96119 \mathrm{e}+01$ 1.96119e+01 1.96119e+00 1.00000e-09 2.12000e-01 $1.96119 \mathrm{e}+01$ 1.96119e+01 1.96119e+00 1.00000e-09 2.12000e-01 $1.96119 \mathrm{e}+01$ 1.96119e+01 1.96119e+00 1.00000e-09 2.12000e-01 $1.96119 \mathrm{e}+01$ 1.96119e+01 1.96119e+00 1.00000e-09 2.12000e-01 $1.96119 \mathrm{e}+011.96119 \mathrm{e}+011.96119 \mathrm{e}+001.00000 \mathrm{e}-092.12000 \mathrm{e}-01$ $1.00000 \mathrm{e}-02$ 1.00000e-02 1.00000e-03 1.00000e-09 1.00000e-01 $1.00000 \mathrm{e}+001.00000 \mathrm{e}+001.00000 \mathrm{e}-011.00000 \mathrm{e}-091.00000 \mathrm{e}-01$ $1.00000 \mathrm{e}-051.00000 \mathrm{e}-05$ 1.00000e-06 1.00000e-09 1.00000e-01 $1.00000 \mathrm{e}+001.00000 \mathrm{e}+001.00000 \mathrm{e}-011.00000 \mathrm{e}-091.00000 \mathrm{e}-01$ Element: 2916 \# of layers: 16

$\mathrm{Kx} \mathrm{Ky} \mathrm{Kz}$ Ss Por 4.90829e+02 4.90829e+02 4.90829e+01 1.00000e-09 7.00000e-02 4.90829e+02 4.90829e+02 4.90829e+01 1.00000e-09 7.00000e-02 4.90829e+02 4.90829e+02 4.90829e+01 1.00000e-09 7.00000e-02 4.90829e+02 4.90829e+02 4.90829e+01 1.00000e-09 7.00000e-02 $4.90829 \mathrm{e}+02$ 4.90829e+02 4.90829e+01 1.00000e-09 7.00000e-02 5.00000e-04 5.00000e-04 5.00000e-05 1.00000e-09 1.00000e-01 
5.00000e-04 5.00000e-04 5.00000e-05 1.00000e-09 1.00000e-01 $1.96119 \mathrm{e}+01$ 1.96119e+01 1.96119e+00 1.00000e-09 2.12000e-01 $1.96119 \mathrm{e}+01$ 1.96119e+01 1.96119e+00 1.00000e-09 2.12000e-01 $1.96119 \mathrm{e}+01$ 1.96119e+01 1.96119e+00 1.00000e-09 2.12000e-01 $1.96119 \mathrm{e}+01$ 1.96119e+01 1.96119e+00 1.00000e-09 2.12000e-01 $1.96119 \mathrm{e}+01$ 1.96119e+01 1.96119e+00 1.00000e-09 2.12000e-01 $1.00000 \mathrm{e}-02$ 1.00000e-02 1.00000e-03 1.00000e-09 1.00000e-01 $1.00000 \mathrm{e}+001.00000 \mathrm{e}+001.00000 \mathrm{e}-011.00000 \mathrm{e}-091.00000 \mathrm{e}-01$ 1.00000e-05 1.00000e-05 1.00000e-06 1.00000e-09 1.00000e-01 $1.00000 \mathrm{e}+001.00000 \mathrm{e}+001.00000 \mathrm{e}-011.00000 \mathrm{e}-091.00000 \mathrm{e}-01$ Element: 2917 \# of layers: 16

Kx Ky Kz Ss Por

5.31842e+02 5.31842e+02 5.31842e+01 1.00000e-09 7.00000e-02 $5.31842 \mathrm{e}+02$ 5.31842e+02 5.31842e+01 1.00000e-09 7.00000e-02 $5.31842 \mathrm{e}+02$ 5.31842e+02 5.31842e+01 1.00000e-09 7.00000e-02 $5.31842 \mathrm{e}+025.31842 \mathrm{e}+02$ 5.31842e+01 1.00000e-09 7.00000e-02 5.31842e+02 5.31842e+02 5.31842e+01 1.00000e-09 7.00000e-02 5.00000e-04 5.00000e-04 5.00000e-05 1.00000e-09 1.00000e-01 5.00000e-04 5.00000e-04 5.00000e-05 1.00000e-09 1.00000e-01 $2.12504 \mathrm{e}+012.12504 \mathrm{e}+012.12504 \mathrm{e}+001.00000 \mathrm{e}-092.12000 \mathrm{e}-01$ $2.12504 \mathrm{e}+012.12504 \mathrm{e}+012.12504 \mathrm{e}+00 \quad 1.00000 \mathrm{e}-092.12000 \mathrm{e}-01$ $2.12504 \mathrm{e}+012.12504 \mathrm{e}+012.12504 \mathrm{e}+001.00000 \mathrm{e}-092.12000 \mathrm{e}-01$ $2.12504 \mathrm{e}+012.12504 \mathrm{e}+012.12504 \mathrm{e}+00$ 1.00000e-09 2.12000e-01 $2.12504 \mathrm{e}+012.12504 \mathrm{e}+012.12504 \mathrm{e}+001.00000 \mathrm{e}-092.12000 \mathrm{e}-01$ $1.00000 \mathrm{e}-02$ 1.00000e-02 1.00000e-03 1.00000e-09 1.00000e-01 $1.00000 \mathrm{e}+001.00000 \mathrm{e}+001.00000 \mathrm{e}-011.00000 \mathrm{e}-091.00000 \mathrm{e}-01$ $1.00000 \mathrm{e}-05$ 1.00000e-05 1.00000e-06 1.00000e-09 1.00000e-01 $1.00000 \mathrm{e}+001.00000 \mathrm{e}+001.00000 \mathrm{e}-011.00000 \mathrm{e}-091.00000 \mathrm{e}-01$ Element: 2918 \# of layers: 15

$\mathrm{Kx} \mathrm{Ky} \mathrm{Kz}$ Ss Por

5.31842e+02 5.31842e+02 5.31842e+01 1.00000e-09 7.00000e-02 5.31842e+02 5.31842e+02 5.31842e+01 1.00000e-09 7.00000e-02 $5.31842 \mathrm{e}+025.31842 \mathrm{e}+02$ 5.31842e+01 1.00000e-09 7.00000e-02 5.31842e+02 5.31842e+02 5.31842e+01 1.00000e-09 7.00000e-02 5.00000e-04 5.00000e-04 5.00000e-05 1.00000e-09 1.00000e-01 5.00000e-04 5.00000e-04 5.00000e-05 1.00000e-09 1.00000e-01 $2.12504 \mathrm{e}+012.12504 \mathrm{e}+012.12504 \mathrm{e}+001.00000 \mathrm{e}-092.12000 \mathrm{e}-01$ $2.12504 \mathrm{e}+012.12504 \mathrm{e}+012.12504 \mathrm{e}+001.00000 \mathrm{e}-092.12000 \mathrm{e}-01$ $2.12504 \mathrm{e}+012.12504 \mathrm{e}+012.12504 \mathrm{e}+00$ 1.00000e-09 2.12000e-01 $2.12504 \mathrm{e}+012.12504 \mathrm{e}+012.12504 \mathrm{e}+00$ 1.00000e-09 2.12000e-01 $2.12504 \mathrm{e}+012.12504 \mathrm{e}+012.12504 \mathrm{e}+001.00000 \mathrm{e}-092.12000 \mathrm{e}-01$ $1.00000 \mathrm{e}-02$ 1.00000e-02 1.00000e-03 1.00000e-09 1.00000e-01 $1.00000 \mathrm{e}+001.00000 \mathrm{e}+001.00000 \mathrm{e}-011.00000 \mathrm{e}-091.00000 \mathrm{e}-01$ $1.00000 \mathrm{e}-05$ 1.00000e-05 1.00000e-06 1.00000e-09 1.00000e-01 $1.00000 \mathrm{e}+001.00000 \mathrm{e}+001.00000 \mathrm{e}-011.00000 \mathrm{e}-09$ 1.00000e-01 Element: 2919 \# of layers: 15 
$\mathrm{Kx} \mathrm{Ky} \mathrm{Kz}$ Ss Por

6.60577e+02 6.60577e+02 6.60577e+01 1.00000e-09 7.00000e-02

6.60577e+02 6.60577e+02 6.60577e+01 1.00000e-09 7.00000e-02

$6.60577 \mathrm{e}+02$ 6.60577e+02 6.60577e+01 1.00000e-09 7.00000e-02

6.60577e+02 6.60577e+02 6.60577e+01 1.00000e-09 7.00000e-02

5.00000e-04 5.00000e-04 5.00000e-05 1.00000e-09 1.00000e-01

5.00000e-04 5.00000e-04 5.00000e-05 1.00000e-09 1.00000e-01

$2.63953 \mathrm{e}+012.63953 \mathrm{e}+012.63953 \mathrm{e}+001.00000 \mathrm{e}-092.12000 \mathrm{e}-01$

$2.63953 \mathrm{e}+012.63953 \mathrm{e}+012.63953 \mathrm{e}+001.00000 \mathrm{e}-092.12000 \mathrm{e}-01$

$2.63953 \mathrm{e}+012.63953 \mathrm{e}+012.63953 \mathrm{e}+00$ 1.00000e-09 2.12000e-01

$2.63953 \mathrm{e}+012.63953 \mathrm{e}+012.63953 \mathrm{e}+00$ 1.00000e-09 2.12000e-01

$2.63953 \mathrm{e}+012.63953 \mathrm{e}+012.63953 \mathrm{e}+001.00000 \mathrm{e}-092.12000 \mathrm{e}-01$

$1.00000 \mathrm{e}-02$ 1.00000e-02 1.00000e-03 1.00000e-09 1.00000e-01

$1.00000 \mathrm{e}+001.00000 \mathrm{e}+001.00000 \mathrm{e}-011.00000 \mathrm{e}-091.00000 \mathrm{e}-01$

$1.00000 \mathrm{e}-05$ 1.00000e-05 1.00000e-06 1.00000e-09 1.00000e-01

$1.00000 \mathrm{e}+001.00000 \mathrm{e}+001.00000 \mathrm{e}-011.00000 \mathrm{e}-091.00000 \mathrm{e}-01$

Element: 2920 \# of layers: 15

$\mathrm{Kx} \mathrm{Ky} \mathrm{Kz}$ Ss Por

5.83370e+02 5.83370e+02 5.83370e+01 1.00000e-09 7.00000e-02

$5.83370 \mathrm{e}+025.83370 \mathrm{e}+025.83370 \mathrm{e}+01$ 1.00000e-09 7.00000e-02

$5.83370 \mathrm{e}+025.83370 \mathrm{e}+025.83370 \mathrm{e}+01$ 1.00000e-09 7.00000e-02

$5.83370 \mathrm{e}+02$ 5.83370e+02 5.83370e+01 1.00000e-09 7.00000e-02

$5.00000 \mathrm{e}-04$ 5.00000e-04 5.00000e-05 1.00000e-09 1.00000e-01

5.00000e-04 5.00000e-04 5.00000e-05 1.00000e-09 1.00000e-01

$2.33083 e+012.33083 e+012.33083 e+001.00000 e-092.12000 e-01$

$2.33083 \mathrm{e}+012.33083 \mathrm{e}+012.33083 \mathrm{e}+00$ 1.00000e-09 2.12000e-01

$2.33083 \mathrm{e}+012.33083 \mathrm{e}+012.33083 \mathrm{e}+001.00000 \mathrm{e}-092.12000 \mathrm{e}-01$

$2.33083 \mathrm{e}+012.33083 \mathrm{e}+012.33083 \mathrm{e}+00$ 1.00000e-09 2.12000e-01

$2.33083 \mathrm{e}+012.33083 \mathrm{e}+012.33083 \mathrm{e}+001.00000 \mathrm{e}-092.12000 \mathrm{e}-01$

$1.00000 \mathrm{e}-02$ 1.00000e-02 1.00000e-03 1.00000e-09 1.00000e-01

$1.00000 \mathrm{e}+001.00000 \mathrm{e}+001.00000 \mathrm{e}-01$ 1.00000e-09 1.00000e-01

$1.00000 \mathrm{e}-05$ 1.00000e-05 1.00000e-06 1.00000e-09 1.00000e-01

$1.00000 \mathrm{e}+001.00000 \mathrm{e}+001.00000 \mathrm{e}-011.00000 \mathrm{e}-091.00000 \mathrm{e}-01$

Element: 2921 \# of layers: 15

$\mathrm{Kx} \mathrm{Ky} \mathrm{Kz}$ Ss Por

4.90829e+02 4.90829e+02 4.90829e+01 1.00000e-09 7.00000e-02 $4.90829 \mathrm{e}+02$ 4.90829e+02 4.90829e+01 1.00000e-09 7.00000e-02 $4.90829 \mathrm{e}+02$ 4.90829e+02 4.90829e+01 1.00000e-09 7.00000e-02 $4.90829 \mathrm{e}+02$ 4.90829e+02 4.90829e+01 1.00000e-09 7.00000e-02 5.00000e-04 5.00000e-04 5.00000e-05 1.00000e-09 1.00000e-01 5.00000e-04 5.00000e-04 5.00000e-05 1.00000e-09 1.00000e-01

$1.96119 \mathrm{e}+01$ 1.96119e+01 1.96119e+00 1.00000e-09 2.12000e-01 $1.96119 \mathrm{e}+01$ 1.96119e+01 1.96119e+00 1.00000e-09 2.12000e-01 $1.96119 \mathrm{e}+01$ 1.96119e+01 1.96119e+00 1.00000e-09 2.12000e-01 $1.96119 \mathrm{e}+01$ 1.96119e+01 1.96119e+00 1.00000e-09 2.12000e-01 $1.96119 \mathrm{e}+011.96119 \mathrm{e}+011.96119 \mathrm{e}+001.00000 \mathrm{e}-092.12000 \mathrm{e}-01$ 
$1.00000 \mathrm{e}-02$ 1.00000e-02 1.00000e-03 1.00000e-09 1.00000e-01 $1.00000 \mathrm{e}+001.00000 \mathrm{e}+001.00000 \mathrm{e}-011.00000 \mathrm{e}-091.00000 \mathrm{e}-01$ $1.00000 \mathrm{e}-05$ 1.00000e-05 1.00000e-06 1.00000e-09 1.00000e-01 $1.00000 \mathrm{e}+001.00000 \mathrm{e}+001.00000 \mathrm{e}-011.00000 \mathrm{e}-091.00000 \mathrm{e}-01$ Element: 2922 \# of layers: 15

$\mathrm{Kx} \mathrm{Ky} \mathrm{Kz}$ Ss Por

4.71664e+02 4.71664e+02 4.71664e+01 1.00000e-09 7.00000e-02 $4.71664 \mathrm{e}+02$ 4.71664e+02 4.71664e+01 1.00000e-09 7.00000e-02 4.71664e+02 4.71664e+02 4.71664e+01 1.00000e-09 7.00000e-02 $4.71664 \mathrm{e}+02$ 4.71664e+02 4.71664e+01 1.00000e-09 7.00000e-02 5.00000e-04 5.00000e-04 5.00000e-05 1.00000e-09 1.00000e-01 5.00000e-04 5.00000e-04 5.00000e-05 1.00000e-09 1.00000e-01 $1.88462 \mathrm{e}+011.88462 \mathrm{e}+011.88462 \mathrm{e}+001.00000 \mathrm{e}-092.12000 \mathrm{e}-01$ $1.88462 \mathrm{e}+01$ 1.88462e+01 1.88462e+00 1.00000e-09 2.12000e-01 $1.88462 \mathrm{e}+01$ 1.88462e+01 1.88462e+00 1.00000e-09 2.12000e-01 $1.88462 \mathrm{e}+011.88462 \mathrm{e}+011.88462 \mathrm{e}+001.00000 \mathrm{e}-092.12000 \mathrm{e}-01$ $1.88462 \mathrm{e}+01$ 1.88462e+01 1.88462e+00 1.00000e-09 2.12000e-01 $1.00000 \mathrm{e}-02$ 1.00000e-02 1.00000e-03 1.00000e-09 1.00000e-01 $1.00000 \mathrm{e}+001.00000 \mathrm{e}+001.00000 \mathrm{e}-011.00000 \mathrm{e}-091.00000 \mathrm{e}-01$ $1.00000 \mathrm{e}-05$ 1.00000e-05 1.00000e-06 1.00000e-09 1.00000e-01 $1.00000 \mathrm{e}+001.00000 \mathrm{e}+001.00000 \mathrm{e}-011.00000 \mathrm{e}-091.00000 \mathrm{e}-01$ Element: 2923 \# of layers: 15

$\mathrm{Kx} \mathrm{Ky} \mathrm{Kz}$ Ss Por

4.97929e+02 4.97929e+02 4.97929e+01 1.00000e-09 7.00000e-02 4.97929e+02 4.97929e+02 4.97929e+01 1.00000e-09 7.00000e-02 4.97929e+02 4.97929e+02 4.97929e+01 1.00000e-09 7.00000e-02 4.97929e+02 4.97929e+02 4.97929e+01 1.00000e-09 7.00000e-02 5.00000e-04 5.00000e-04 5.00000e-05 1.00000e-09 1.00000e-01 5.00000e-04 5.00000e-04 5.00000e-05 1.00000e-09 1.00000e-01 $1.98956 \mathrm{e}+01$ 1.98956e+01 1.98956e+00 1.00000e-09 2.12000e-01 $1.98956 \mathrm{e}+011.98956 \mathrm{e}+011.98956 \mathrm{e}+001.00000 \mathrm{e}-092.12000 \mathrm{e}-01$ $1.98956 \mathrm{e}+01$ 1.98956e+01 1.98956e+00 1.00000e-09 2.12000e-01 $1.98956 \mathrm{e}+011.98956 \mathrm{e}+011.98956 \mathrm{e}+001.00000 \mathrm{e}-092.12000 \mathrm{e}-01$ $1.98956 \mathrm{e}+011.98956 \mathrm{e}+01 \quad 1.98956 \mathrm{e}+001.00000 \mathrm{e}-092.12000 \mathrm{e}-01$ $1.00000 \mathrm{e}-02$ 1.00000e-02 1.00000e-03 1.00000e-09 1.00000e-01 $1.00000 \mathrm{e}+001.00000 \mathrm{e}+001.00000 \mathrm{e}-011.00000 \mathrm{e}-091.00000 \mathrm{e}-01$ $1.00000 \mathrm{e}-05$ 1.00000e-05 1.00000e-06 1.00000e-09 1.00000e-01 $1.00000 \mathrm{e}+001.00000 \mathrm{e}+001.00000 \mathrm{e}-011.00000 \mathrm{e}-091.00000 \mathrm{e}-01$ Element: 2924 \# of layers: 15

$\mathrm{Kx} \mathrm{Ky} \mathrm{Kz}$ Ss Por 4.97929e+02 4.97929e+02 4.97929e+01 1.00000e-09 7.00000e-02 4.97929e+02 4.97929e+02 4.97929e+01 1.00000e-09 7.00000e-02 4.97929e+02 4.97929e+02 4.97929e+01 1.00000e-09 7.00000e-02 4.97929e+02 4.97929e+02 4.97929e+01 1.00000e-09 7.00000e-02 5.00000e-04 5.00000e-04 5.00000e-05 1.00000e-09 1.00000e-01 5.00000e-04 5.00000e-04 5.00000e-05 1.00000e-09 1.00000e-01 
$1.98956 \mathrm{e}+01$ 1.98956e+01 1.98956e+00 1.00000e-09 2.12000e-01 $1.98956 \mathrm{e}+01$ 1.98956e+01 1.98956e+00 1.00000e-09 2.12000e-01 $1.98956 \mathrm{e}+011.98956 \mathrm{e}+011.98956 \mathrm{e}+001.00000 \mathrm{e}-092.12000 \mathrm{e}-01$ $1.98956 \mathrm{e}+011.98956 \mathrm{e}+011.98956 \mathrm{e}+001.00000 \mathrm{e}-092.12000 \mathrm{e}-01$ $1.98956 \mathrm{e}+011.98956 \mathrm{e}+011.98956 \mathrm{e}+001.00000 \mathrm{e}-092.12000 \mathrm{e}-01$ $1.00000 \mathrm{e}-02$ 1.00000e-02 1.00000e-03 1.00000e-09 1.00000e-01 $1.00000 \mathrm{e}+001.00000 \mathrm{e}+001.00000 \mathrm{e}-011.00000 \mathrm{e}-091.00000 \mathrm{e}-01$ $1.00000 \mathrm{e}-05$ 1.00000e-05 1.00000e-06 1.00000e-09 1.00000e-01 $1.00000 \mathrm{e}+001.00000 \mathrm{e}+001.00000 \mathrm{e}-011.00000 \mathrm{e}-09$ 1.00000e-01 Element: 2925 \# of layers: 15

$\mathrm{Kx} \mathrm{Ky} \mathrm{Kz}$ Ss Por

4.97929e+02 4.97929e+02 4.97929e+01 1.00000e-09 7.00000e-02 4.97929e+02 4.97929e+02 4.97929e+01 1.00000e-09 7.00000e-02 4.97929e+02 4.97929e+02 4.97929e+01 1.00000e-09 7.00000e-02 $4.97929 \mathrm{e}+02$ 4.97929e+02 4.97929e+01 1.00000e-09 7.00000e-02 5.00000e-04 5.00000e-04 5.00000e-05 1.00000e-09 1.00000e-01 5.00000e-04 5.00000e-04 5.00000e-05 1.00000e-09 1.00000e-01 $1.98956 \mathrm{e}+011.98956 \mathrm{e}+011.98956 \mathrm{e}+001.00000 \mathrm{e}-092.12000 \mathrm{e}-01$ $1.98956 \mathrm{e}+01$ 1.98956e+01 1.98956e+00 1.00000e-09 2.12000e-01 $1.98956 \mathrm{e}+011.98956 \mathrm{e}+011.98956 \mathrm{e}+001.00000 \mathrm{e}-092.12000 \mathrm{e}-01$ $1.98956 \mathrm{e}+011.98956 \mathrm{e}+011.98956 \mathrm{e}+001.00000 \mathrm{e}-092.12000 \mathrm{e}-01$ $1.98956 \mathrm{e}+01$ 1.98956e+01 1.98956e+00 1.00000e-09 2.12000e-01 $1.00000 \mathrm{e}-02$ 1.00000e-02 1.00000e-03 1.00000e-09 1.00000e-01 $1.00000 \mathrm{e}+001.00000 \mathrm{e}+001.00000 \mathrm{e}-011.00000 \mathrm{e}-091.00000 \mathrm{e}-01$ $1.00000 \mathrm{e}-05$ 1.00000e-05 1.00000e-06 1.00000e-09 1.00000e-01 $1.00000 \mathrm{e}+001.00000 \mathrm{e}+001.00000 \mathrm{e}-01$ 1.00000e-09 1.00000e-01 Element: 2926 \# of layers: 16

Kx Ky Kz Ss Por

4.47455e+02 4.47455e+02 4.47455e+01 1.00000e-09 7.00000e-02 $4.47455 \mathrm{e}+02$ 4.47455e+02 4.47455e+01 1.00000e-09 7.00000e-02 4.47455e+02 4.47455e+02 4.47455e+01 1.00000e-09 7.00000e-02 4.47455e+02 4.47455e+02 4.47455e+01 1.00000e-09 7.00000e-02 4.47455e+02 4.47455e+02 4.47455e+01 1.00000e-09 7.00000e-02 $5.00000 \mathrm{e}-04$ 5.00000e-04 5.00000e-05 1.00000e-09 1.00000e-01 5.00000e-04 5.00000e-04 5.00000e-05 1.00000e-09 1.00000e-01 $1.78787 \mathrm{e}+011.78787 \mathrm{e}+01$ 1.78787e+00 1.00000e-09 2.12000e-01 $1.78787 \mathrm{e}+01$ 1.78787e+01 1.78787e+00 1.00000e-09 2.12000e-01 $1.78787 \mathrm{e}+01$ 1.78787e+01 1.78787e+00 1.00000e-09 2.12000e-01 $1.78787 \mathrm{e}+01$ 1.78787e+01 1.78787e+00 1.00000e-09 2.12000e-01 $1.78787 \mathrm{e}+01$ 1.78787e+01 1.78787e+00 1.00000e-09 2.12000e-01 $1.00000 \mathrm{e}-02$ 1.00000e-02 1.00000e-03 1.00000e-09 1.00000e-01 $1.00000 \mathrm{e}+001.00000 \mathrm{e}+001.00000 \mathrm{e}-011.00000 \mathrm{e}-091.00000 \mathrm{e}-01$ $1.00000 \mathrm{e}-051.00000 \mathrm{e}-051.00000 \mathrm{e}-061.00000 \mathrm{e}-091.00000 \mathrm{e}-01$ $1.00000 \mathrm{e}+001.00000 \mathrm{e}+001.00000 \mathrm{e}-01$ 1.00000e-09 1.00000e-01 Element: 2927 \# of layers: 16

Kx Ky Kz Ss Por 
4.47455e+02 4.47455e+02 4.47455e+01 1.00000e-09 7.00000e-02 4.47455e+02 4.47455e+02 4.47455e+01 1.00000e-09 7.00000e-02 4.47455e+02 4.47455e+02 4.47455e+01 1.00000e-09 7.00000e-02 $4.47455 \mathrm{e}+02$ 4.47455e+02 4.47455e+01 1.00000e-09 7.00000e-02 4.47455e+02 4.47455e+02 4.47455e+01 1.00000e-09 7.00000e-02 5.00000e-04 5.00000e-04 5.00000e-05 1.00000e-09 1.00000e-01 5.00000e-04 5.00000e-04 5.00000e-05 1.00000e-09 1.00000e-01 $1.78787 \mathrm{e}+01$ 1.78787e+01 1.78787e+00 1.00000e-09 2.12000e-01 $1.78787 \mathrm{e}+01$ 1.78787e+01 1.78787e+00 1.00000e-09 2.12000e-01 $1.78787 \mathrm{e}+01$ 1.78787e+01 1.78787e+00 1.00000e-09 2.12000e-01 $1.78787 \mathrm{e}+01$ 1.78787e+01 1.78787e+00 1.00000e-09 2.12000e-01 $1.78787 \mathrm{e}+01$ 1.78787e+01 1.78787e+00 1.00000e-09 2.12000e-01 $1.00000 \mathrm{e}-02$ 1.00000e-02 1.00000e-03 1.00000e-09 1.00000e-01 $1.00000 \mathrm{e}+001.00000 \mathrm{e}+001.00000 \mathrm{e}-011.00000 \mathrm{e}-091.00000 \mathrm{e}-01$ $1.00000 \mathrm{e}-051.00000 \mathrm{e}-051.00000 \mathrm{e}-061.00000 \mathrm{e}-091.00000 \mathrm{e}-01$ $1.00000 \mathrm{e}+001.00000 \mathrm{e}+001.00000 \mathrm{e}-011.00000 \mathrm{e}-091.00000 \mathrm{e}-01$ Element: 2928 \# of layers: 16

$\mathrm{Kx} \mathrm{Ky} \mathrm{Kz}$ Ss Por

4.78503e+02 4.78503e+02 4.78503e+01 1.00000e-09 7.00000e-02 4.78503e+02 4.78503e+02 4.78503e+01 1.00000e-09 7.00000e-02 $4.78503 e+02$ 4.78503e+02 4.78503e+01 1.00000e-09 7.00000e-02 4.78503e+02 4.78503e+02 4.78503e+01 1.00000e-09 7.00000e-02 4.78503e+02 4.78503e+02 4.78503e+01 1.00000e-09 7.00000e-02 5.00000e-04 5.00000e-04 5.00000e-05 1.00000e-09 1.00000e-01 5.00000e-04 5.00000e-04 5.00000e-05 1.00000e-09 1.00000e-01 $1.91191 \mathrm{e}+011.91191 \mathrm{e}+011.91191 \mathrm{e}+001.00000 \mathrm{e}-092.12000 \mathrm{e}-01$ $1.91191 \mathrm{e}+011.91191 \mathrm{e}+01$ 1.91191e+00 1.00000e-09 2.12000e-01 $1.91191 \mathrm{e}+011.91191 \mathrm{e}+01$ 1.91191e+00 1.00000e-09 2.12000e-01 $1.91191 \mathrm{e}+011.91191 \mathrm{e}+011.91191 \mathrm{e}+001.00000 \mathrm{e}-092.12000 \mathrm{e}-01$ $1.91191 \mathrm{e}+01$ 1.91191e+01 1.91191e+00 1.00000e-09 2.12000e-01 $1.00000 \mathrm{e}-02$ 1.00000e-02 1.00000e-03 1.00000e-09 1.00000e-01 $1.00000 \mathrm{e}+001.00000 \mathrm{e}+001.00000 \mathrm{e}-011.00000 \mathrm{e}-091.00000 \mathrm{e}-01$ $1.00000 \mathrm{e}-05$ 1.00000e-05 1.00000e-06 1.00000e-09 1.00000e-01 $1.00000 \mathrm{e}+001.00000 \mathrm{e}+001.00000 \mathrm{e}-011.00000 \mathrm{e}-091.00000 \mathrm{e}-01$ Element: 2929 \# of layers: 16

$\mathrm{Kx} \mathrm{Ky} \mathrm{Kz}$ Ss Por

4.71664e+02 4.71664e+02 4.71664e+01 1.00000e-09 7.00000e-02 $4.71664 \mathrm{e}+02$ 4.71664e+02 4.71664e+01 1.00000e-09 7.00000e-02 $4.71664 \mathrm{e}+02$ 4.71664e+02 4.71664e+01 1.00000e-09 7.00000e-02 4.71664e+02 4.71664e+02 4.71664e+01 1.00000e-09 7.00000e-02 $4.71664 \mathrm{e}+02$ 4.71664e+02 4.71664e+01 1.00000e-09 7.00000e-02 5.00000e-04 5.00000e-04 5.00000e-05 1.00000e-09 1.00000e-01 $5.00000 \mathrm{e}-04$ 5.00000e-04 5.00000e-05 1.00000e-09 1.00000e-01 $1.88462 \mathrm{e}+01$ 1.88462e+01 1.88462e+00 1.00000e-09 2.12000e-01 $1.88462 \mathrm{e}+011.88462 \mathrm{e}+011.88462 \mathrm{e}+001.00000 \mathrm{e}-092.12000 \mathrm{e}-01$ $1.88462 \mathrm{e}+011.88462 \mathrm{e}+011.88462 \mathrm{e}+001.00000 \mathrm{e}-092.12000 \mathrm{e}-01$ 
$1.88462 \mathrm{e}+01$ 1.88462e+01 1.88462e+00 1.00000e-09 2.12000e-01 $1.88462 \mathrm{e}+01$ 1.88462e+01 1.88462e+00 1.00000e-09 2.12000e-01 $1.00000 \mathrm{e}-02$ 1.00000e-02 1.00000e-03 1.00000e-09 1.00000e-01 $1.00000 \mathrm{e}+001.00000 \mathrm{e}+001.00000 \mathrm{e}-011.00000 \mathrm{e}-091.00000 \mathrm{e}-01$ $1.00000 \mathrm{e}-05$ 1.00000e-05 1.00000e-06 1.00000e-09 1.00000e-01 $1.00000 \mathrm{e}+001.00000 \mathrm{e}+001.00000 \mathrm{e}-011.00000 \mathrm{e}-091.00000 \mathrm{e}-01$ Element: 2930 \# of layers: 16

$\mathrm{Kx} \mathrm{Ky} \mathrm{Kz}$ Ss Por

4.97929e+02 4.97929e+02 4.97929e+01 1.00000e-09 7.00000e-02 4.97929e+02 4.97929e+02 4.97929e+01 1.00000e-09 7.00000e-02 4.97929e+02 4.97929e+02 4.97929e+01 1.00000e-09 7.00000e-02 4.97929e+02 4.97929e+02 4.97929e+01 1.00000e-09 7.00000e-02 4.97929e+02 4.97929e+02 4.97929e+01 1.00000e-09 7.00000e-02 5.00000e-04 5.00000e-04 5.00000e-05 1.00000e-09 1.00000e-01 5.00000e-04 5.00000e-04 5.00000e-05 1.00000e-09 1.00000e-01 $1.98956 \mathrm{e}+011.98956 \mathrm{e}+011.98956 \mathrm{e}+001.00000 \mathrm{e}-092.12000 \mathrm{e}-01$ $1.98956 \mathrm{e}+011.98956 \mathrm{e}+011.98956 \mathrm{e}+001.00000 \mathrm{e}-092.12000 \mathrm{e}-01$ $1.98956 \mathrm{e}+011.98956 \mathrm{e}+011.98956 \mathrm{e}+001.00000 \mathrm{e}-092.12000 \mathrm{e}-01$ $1.98956 \mathrm{e}+01$ 1.98956e+01 1.98956e+00 1.00000e-09 2.12000e-01 $1.98956 \mathrm{e}+011.98956 \mathrm{e}+01 \quad 1.98956 \mathrm{e}+001.00000 \mathrm{e}-092.12000 \mathrm{e}-01$ $1.00000 \mathrm{e}-02$ 1.00000e-02 1.00000e-03 1.00000e-09 1.00000e-01 $1.00000 \mathrm{e}+001.00000 \mathrm{e}+001.00000 \mathrm{e}-011.00000 \mathrm{e}-091.00000 \mathrm{e}-01$ $1.00000 \mathrm{e}-051.00000 \mathrm{e}-051.00000 \mathrm{e}-061.00000 \mathrm{e}-091.00000 \mathrm{e}-01$ $1.00000 \mathrm{e}+001.00000 \mathrm{e}+001.00000 \mathrm{e}-011.00000 \mathrm{e}-091.00000 \mathrm{e}-01$ Element: 2931 \# of layers: 15

$\mathrm{Kx} \mathrm{Ky} \mathrm{Kz}$ Ss Por

5.08659e+02 5.08659e+02 5.08659e+01 1.00000e-09 7.00000e-02 $5.08659 \mathrm{e}+02$ 5.08659e+02 5.08659e+01 1.00000e-09 7.00000e-02 $5.08659 \mathrm{e}+02$ 5.08659e+02 5.08659e+01 1.00000e-09 7.00000e-02 $5.08659 \mathrm{e}+02$ 5.08659e+02 5.08659e+01 1.00000e-09 7.00000e-02 5.00000e-04 5.00000e-04 5.00000e-05 1.00000e-09 1.00000e-01 5.00000e-04 5.00000e-04 5.00000e-05 1.00000e-09 1.00000e-01 $2.03240 \mathrm{e}+012.03240 \mathrm{e}+012.03240 \mathrm{e}+001.00000 \mathrm{e}-092.12000 \mathrm{e}-01$ $2.03240 \mathrm{e}+012.03240 \mathrm{e}+012.03240 \mathrm{e}+001.00000 \mathrm{e}-092.12000 \mathrm{e}-01$ $2.03240 \mathrm{e}+012.03240 \mathrm{e}+012.03240 \mathrm{e}+00$ 1.00000e-09 2.12000e-01 $2.03240 \mathrm{e}+012.03240 \mathrm{e}+012.03240 \mathrm{e}+001.00000 \mathrm{e}-092.12000 \mathrm{e}-01$ $2.03240 \mathrm{e}+012.03240 \mathrm{e}+012.03240 \mathrm{e}+001.00000 \mathrm{e}-092.12000 \mathrm{e}-01$ $1.00000 \mathrm{e}-02$ 1.00000e-02 1.00000e-03 1.00000e-09 1.00000e-01 $1.00000 \mathrm{e}+001.00000 \mathrm{e}+001.00000 \mathrm{e}-011.00000 \mathrm{e}-091.00000 \mathrm{e}-01$ $1.00000 \mathrm{e}-05$ 1.00000e-05 1.00000e-06 1.00000e-09 1.00000e-01 $1.00000 \mathrm{e}+001.00000 \mathrm{e}+001.00000 \mathrm{e}-011.00000 \mathrm{e}-091.00000 \mathrm{e}-01$ Element: 2932 \# of layers: 15

$\mathrm{Kx} \mathrm{Ky} \mathrm{Kz}$ Ss Por 4.94946e+02 4.94946e+02 4.94946e+01 1.00000e-09 7.00000e-02 4.94946e+02 4.94946e+02 4.94946e+01 1.00000e-09 7.00000e-02 $4.94946 \mathrm{e}+02$ 4.94946e+02 4.94946e+01 1.00000e-09 7.00000e-02 
4.94946e+02 4.94946e+02 4.94946e+01 1.00000e-09 7.00000e-02 5.00000e-04 5.00000e-04 5.00000e-05 1.00000e-09 1.00000e-01 5.00000e-04 5.00000e-04 5.00000e-05 1.00000e-09 1.00000e-01 $1.97764 \mathrm{e}+011.97764 \mathrm{e}+011.97764 \mathrm{e}+001.00000 \mathrm{e}-092.12000 \mathrm{e}-01$ $1.97764 \mathrm{e}+011.97764 \mathrm{e}+011.97764 \mathrm{e}+001.00000 \mathrm{e}-092.12000 \mathrm{e}-01$ $1.97764 \mathrm{e}+011.97764 \mathrm{e}+011.97764 \mathrm{e}+001.00000 \mathrm{e}-092.12000 \mathrm{e}-01$ $1.97764 \mathrm{e}+011.97764 \mathrm{e}+011.97764 \mathrm{e}+001.00000 \mathrm{e}-092.12000 \mathrm{e}-01$ $1.97764 \mathrm{e}+011.97764 \mathrm{e}+01 \quad 1.97764 \mathrm{e}+001.00000 \mathrm{e}-092.12000 \mathrm{e}-01$ $1.00000 \mathrm{e}-02$ 1.00000e-02 1.00000e-03 1.00000e-09 1.00000e-01 $1.00000 \mathrm{e}+001.00000 \mathrm{e}+001.00000 \mathrm{e}-011.00000 \mathrm{e}-091.00000 \mathrm{e}-01$ $1.00000 \mathrm{e}-05$ 1.00000e-05 1.00000e-06 1.00000e-09 1.00000e-01 $1.00000 \mathrm{e}+001.00000 \mathrm{e}+001.00000 \mathrm{e}-011.00000 \mathrm{e}-091.00000 \mathrm{e}-01$ Element: 2933 \# of layers: 15

$\mathrm{Kx} \mathrm{Ky} \mathrm{Kz}$ Ss Por

4.94946e+02 4.94946e+02 4.94946e+01 1.00000e-09 7.00000e-02 $4.94946 \mathrm{e}+02$ 4.94946e+02 4.94946e+01 1.00000e-09 7.00000e-02 4.94946e+02 4.94946e+02 4.94946e+01 1.00000e-09 7.00000e-02 4.94946e+02 4.94946e+02 4.94946e+01 1.00000e-09 7.00000e-02 5.00000e-04 5.00000e-04 5.00000e-05 1.00000e-09 1.00000e-01 5.00000e-04 5.00000e-04 5.00000e-05 1.00000e-09 1.00000e-01

$1.97764 \mathrm{e}+011.97764 \mathrm{e}+011.97764 \mathrm{e}+001.00000 \mathrm{e}-092.12000 \mathrm{e}-01$ $1.97764 \mathrm{e}+011.97764 \mathrm{e}+011.97764 \mathrm{e}+001.00000 \mathrm{e}-092.12000 \mathrm{e}-01$ $1.97764 \mathrm{e}+011.97764 \mathrm{e}+011.97764 \mathrm{e}+001.00000 \mathrm{e}-092.12000 \mathrm{e}-01$ $1.97764 \mathrm{e}+011.97764 \mathrm{e}+011.97764 \mathrm{e}+001.00000 \mathrm{e}-092.12000 \mathrm{e}-01$ $1.97764 \mathrm{e}+011.97764 \mathrm{e}+011.97764 \mathrm{e}+001.00000 \mathrm{e}-092.12000 \mathrm{e}-01$ $1.00000 \mathrm{e}-02$ 1.00000e-02 1.00000e-03 1.00000e-09 1.00000e-01 $1.00000 \mathrm{e}+001.00000 \mathrm{e}+001.00000 \mathrm{e}-011.00000 \mathrm{e}-091.00000 \mathrm{e}-01$ $1.00000 \mathrm{e}-05$ 1.00000e-05 1.00000e-06 1.00000e-09 1.00000e-01 $1.00000 \mathrm{e}+001.00000 \mathrm{e}+001.00000 \mathrm{e}-011.00000 \mathrm{e}-091.00000 \mathrm{e}-01$ Element: 2934 \# of layers: 15

$\mathrm{Kx} \mathrm{Ky} \mathrm{Kz}$ Ss Por

4.94946e+02 4.94946e+02 4.94946e+01 1.00000e-09 7.00000e-02 4.94946e+02 4.94946e+02 4.94946e+01 1.00000e-09 7.00000e-02 4.94946e+02 4.94946e+02 4.94946e+01 1.00000e-09 7.00000e-02 4.94946e+02 4.94946e+02 4.94946e+01 1.00000e-09 7.00000e-02 5.00000e-04 5.00000e-04 5.00000e-05 1.00000e-09 1.00000e-01 5.00000e-04 5.00000e-04 5.00000e-05 1.00000e-09 1.00000e-01 $1.97764 \mathrm{e}+011.97764 \mathrm{e}+011.97764 \mathrm{e}+001.00000 \mathrm{e}-092.12000 \mathrm{e}-01$ $1.97764 \mathrm{e}+011.97764 \mathrm{e}+011.97764 \mathrm{e}+001.00000 \mathrm{e}-092.12000 \mathrm{e}-01$ $1.97764 \mathrm{e}+011.97764 \mathrm{e}+011.97764 \mathrm{e}+001.00000 \mathrm{e}-092.12000 \mathrm{e}-01$ $1.97764 \mathrm{e}+011.97764 \mathrm{e}+01 \quad 1.97764 \mathrm{e}+001.00000 \mathrm{e}-092.12000 \mathrm{e}-01$ $1.97764 \mathrm{e}+011.97764 \mathrm{e}+011.97764 \mathrm{e}+001.00000 \mathrm{e}-092.12000 \mathrm{e}-01$ $1.00000 \mathrm{e}-02$ 1.00000e-02 1.00000e-03 1.00000e-09 1.00000e-01 $1.00000 \mathrm{e}+001.00000 \mathrm{e}+001.00000 \mathrm{e}-011.00000 \mathrm{e}-091.00000 \mathrm{e}-01$ $1.00000 \mathrm{e}-05$ 1.00000e-05 1.00000e-06 1.00000e-09 1.00000e-01 $1.00000 \mathrm{e}+001.00000 \mathrm{e}+001.00000 \mathrm{e}-011.00000 \mathrm{e}-091.00000 \mathrm{e}-01$ 
Element: 2935 \# of layers: 15

Kx Ky Kz Ss Por

$4.86387 \mathrm{e}+02$ 4.86387e+02 4.86387e+01 1.00000e-09 7.00000e-02

$4.86387 \mathrm{e}+024.86387 \mathrm{e}+024.86387 \mathrm{e}+01$ 1.00000e-09 7.00000e-02

$4.86387 \mathrm{e}+024.86387 \mathrm{e}+024.86387 \mathrm{e}+011.00000 \mathrm{e}-09$ 7.00000e-02

$4.86387 \mathrm{e}+024.86387 \mathrm{e}+024.86387 \mathrm{e}+01$ 1.00000e-09 7.00000e-02

5.00000e-04 5.00000e-04 5.00000e-05 1.00000e-09 1.00000e-01

5.00000e-04 5.00000e-04 5.00000e-05 1.00000e-09 1.00000e-01

$1.94343 \mathrm{e}+011.94343 \mathrm{e}+011.94343 \mathrm{e}+00$ 1.00000e-09 2.12000e-01

$1.94343 \mathrm{e}+011.94343 \mathrm{e}+011.94343 \mathrm{e}+001.00000 \mathrm{e}-092.12000 \mathrm{e}-01$

$1.94343 \mathrm{e}+011.94343 \mathrm{e}+011.94343 \mathrm{e}+001.00000 \mathrm{e}-092.12000 \mathrm{e}-01$

$1.94343 \mathrm{e}+011.94343 \mathrm{e}+011.94343 \mathrm{e}+001.00000 \mathrm{e}-092.12000 \mathrm{e}-01$

$1.94343 \mathrm{e}+011.94343 \mathrm{e}+011.94343 \mathrm{e}+00$ 1.00000e-09 2.12000e-01

$1.00000 \mathrm{e}-021.00000 \mathrm{e}-02$ 1.00000e-03 1.00000e-09 1.00000e-01

$1.00000 \mathrm{e}+001.00000 \mathrm{e}+001.00000 \mathrm{e}-011.00000 \mathrm{e}-091.00000 \mathrm{e}-01$

$1.00000 \mathrm{e}-05$ 1.00000e-05 1.00000e-06 1.00000e-09 1.00000e-01

$1.00000 \mathrm{e}+001.00000 \mathrm{e}+001.00000 \mathrm{e}-011.00000 \mathrm{e}-091.00000 \mathrm{e}-01$

Element: 2936 \# of layers: 15

Kx Ky Kz Ss Por

$4.86387 \mathrm{e}+02$ 4.86387e+02 4.86387e+01 1.00000e-09 7.00000e-02

$4.86387 \mathrm{e}+024.86387 \mathrm{e}+024.86387 \mathrm{e}+01$ 1.00000e-09 7.00000e-02

$4.86387 \mathrm{e}+024.86387 \mathrm{e}+024.86387 \mathrm{e}+01$ 1.00000e-09 7.00000e-02

$4.86387 \mathrm{e}+024.86387 \mathrm{e}+024.86387 \mathrm{e}+01$ 1.00000e-09 7.00000e-02

5.00000e-04 5.00000e-04 5.00000e-05 1.00000e-09 1.00000e-01

5.00000e-04 5.00000e-04 5.00000e-05 1.00000e-09 1.00000e-01

$1.94343 \mathrm{e}+011.94343 \mathrm{e}+011.94343 \mathrm{e}+00$ 1.00000e-09 2.12000e-01

$1.94343 \mathrm{e}+011.94343 \mathrm{e}+011.94343 \mathrm{e}+001.00000 \mathrm{e}-092.12000 \mathrm{e}-01$

$1.94343 \mathrm{e}+011.94343 \mathrm{e}+011.94343 \mathrm{e}+001.00000 \mathrm{e}-092.12000 \mathrm{e}-01$

$1.94343 \mathrm{e}+011.94343 \mathrm{e}+011.94343 \mathrm{e}+001.00000 \mathrm{e}-092.12000 \mathrm{e}-01$

$1.94343 \mathrm{e}+011.94343 \mathrm{e}+011.94343 \mathrm{e}+001.00000 \mathrm{e}-092.12000 \mathrm{e}-01$

$1.00000 \mathrm{e}-02$ 1.00000e-02 1.00000e-03 1.00000e-09 1.00000e-01

$1.00000 \mathrm{e}+001.00000 \mathrm{e}+001.00000 \mathrm{e}-011.00000 \mathrm{e}-091.00000 \mathrm{e}-01$

$1.00000 \mathrm{e}-05$ 1.00000e-05 1.00000e-06 1.00000e-09 1.00000e-01

$1.00000 \mathrm{e}+001.00000 \mathrm{e}+001.00000 \mathrm{e}-011.00000 \mathrm{e}-091.00000 \mathrm{e}-01$

Element: 2937 \# of layers: 15

Kx Ky Kz Ss Por

$4.78665 \mathrm{e}+02$ 4.78665e+02 4.78665e+01 1.00000e-09 7.00000e-02

$4.78665 \mathrm{e}+02 \quad 4.78665 \mathrm{e}+024.78665 \mathrm{e}+011.00000 \mathrm{e}-09$ 7.00000e-02

$4.78665 \mathrm{e}+024.78665 \mathrm{e}+024.78665 \mathrm{e}+01$ 1.00000e-09 7.00000e-02

$4.78665 \mathrm{e}+024.78665 \mathrm{e}+024.78665 \mathrm{e}+01$ 1.00000e-09 7.00000e-02

5.00000e-04 5.00000e-04 5.00000e-05 1.00000e-09 1.00000e-01

5.00000e-04 5.00000e-04 5.00000e-05 1.00000e-09 1.00000e-01

$1.91256 \mathrm{e}+011.91256 \mathrm{e}+011.91256 \mathrm{e}+001.00000 \mathrm{e}-092.12000 \mathrm{e}-01$

$1.91256 \mathrm{e}+011.91256 \mathrm{e}+011.91256 \mathrm{e}+001.00000 \mathrm{e}-092.12000 \mathrm{e}-01$

$1.91256 \mathrm{e}+011.91256 \mathrm{e}+011.91256 \mathrm{e}+001.00000 \mathrm{e}-092.12000 \mathrm{e}-01$

$1.91256 \mathrm{e}+011.91256 \mathrm{e}+011.91256 \mathrm{e}+001.00000 \mathrm{e}-092.12000 \mathrm{e}-01$ 
$1.91256 \mathrm{e}+01$ 1.91256e+01 1.91256e+00 1.00000e-09 2.12000e-01 $1.00000 \mathrm{e}-02$ 1.00000e-02 1.00000e-03 1.00000e-09 1.00000e-01 $1.00000 \mathrm{e}+001.00000 \mathrm{e}+001.00000 \mathrm{e}-011.00000 \mathrm{e}-091.00000 \mathrm{e}-01$ $1.00000 \mathrm{e}-05$ 1.00000e-05 1.00000e-06 1.00000e-09 1.00000e-01 $1.00000 \mathrm{e}+001.00000 \mathrm{e}+001.00000 \mathrm{e}-011.00000 \mathrm{e}-091.00000 \mathrm{e}-01$ Element: 2938 \# of layers: 15

$\mathrm{Kx} \mathrm{Ky} \mathrm{Kz}$ Ss Por

5.08659e+02 5.08659e+02 5.08659e+01 1.00000e-09 7.00000e-02 $5.08659 \mathrm{e}+02$ 5.08659e+02 5.08659e+01 1.00000e-09 7.00000e-02 $5.08659 \mathrm{e}+02$ 5.08659e+02 5.08659e+01 1.00000e-09 7.00000e-02 $5.08659 \mathrm{e}+025.08659 \mathrm{e}+02$ 5.08659e+01 1.00000e-09 7.00000e-02 5.00000e-04 5.00000e-04 5.00000e-05 1.00000e-09 1.00000e-01 5.00000e-04 5.00000e-04 5.00000e-05 1.00000e-09 1.00000e-01 $2.03240 \mathrm{e}+012.03240 \mathrm{e}+012.03240 \mathrm{e}+00$ 1.00000e-09 2.12000e-01 $2.03240 \mathrm{e}+012.03240 \mathrm{e}+012.03240 \mathrm{e}+001.00000 \mathrm{e}-092.12000 \mathrm{e}-01$ $2.03240 \mathrm{e}+012.03240 \mathrm{e}+012.03240 \mathrm{e}+001.00000 \mathrm{e}-092.12000 \mathrm{e}-01$ $2.03240 \mathrm{e}+012.03240 \mathrm{e}+012.03240 \mathrm{e}+001.00000 \mathrm{e}-092.12000 \mathrm{e}-01$ $2.03240 \mathrm{e}+012.03240 \mathrm{e}+012.03240 \mathrm{e}+001.00000 \mathrm{e}-092.12000 \mathrm{e}-01$ $1.00000 \mathrm{e}-02$ 1.00000e-02 1.00000e-03 1.00000e-09 1.00000e-01 $1.00000 \mathrm{e}+001.00000 \mathrm{e}+001.00000 \mathrm{e}-011.00000 \mathrm{e}-091.00000 \mathrm{e}-01$ $1.00000 \mathrm{e}-05$ 1.00000e-05 1.00000e-06 1.00000e-09 1.00000e-01 $1.00000 \mathrm{e}+001.00000 \mathrm{e}+001.00000 \mathrm{e}-01$ 1.00000e-09 1.00000e-01 Element: 2939 \# of layers: 15

$\mathrm{Kx} \mathrm{Ky} \mathrm{Kz}$ Ss Por

4.94946e+02 4.94946e+02 4.94946e+01 1.00000e-09 7.00000e-02 4.94946e+02 4.94946e+02 4.94946e+01 1.00000e-09 7.00000e-02 $4.94946 \mathrm{e}+02$ 4.94946e+02 4.94946e+01 1.00000e-09 7.00000e-02 $4.94946 \mathrm{e}+02$ 4.94946e+02 4.94946e+01 1.00000e-09 7.00000e-02 5.00000e-04 5.00000e-04 5.00000e-05 1.00000e-09 1.00000e-01 5.00000e-04 5.00000e-04 5.00000e-05 1.00000e-09 1.00000e-01 $1.97764 \mathrm{e}+011.97764 \mathrm{e}+011.97764 \mathrm{e}+001.00000 \mathrm{e}-092.12000 \mathrm{e}-01$ $1.97764 \mathrm{e}+011.97764 \mathrm{e}+011.97764 \mathrm{e}+001.00000 \mathrm{e}-092.12000 \mathrm{e}-01$ $1.97764 \mathrm{e}+011.97764 \mathrm{e}+011.97764 \mathrm{e}+001.00000 \mathrm{e}-092.12000 \mathrm{e}-01$ $1.97764 \mathrm{e}+011.97764 \mathrm{e}+011.97764 \mathrm{e}+001.00000 \mathrm{e}-092.12000 \mathrm{e}-01$ $1.97764 \mathrm{e}+011.97764 \mathrm{e}+011.97764 \mathrm{e}+001.00000 \mathrm{e}-092.12000 \mathrm{e}-01$ 1.00000e-02 1.00000e-02 1.00000e-03 1.00000e-09 1.00000e-01 $1.00000 \mathrm{e}+001.00000 \mathrm{e}+001.00000 \mathrm{e}-011.00000 \mathrm{e}-091.00000 \mathrm{e}-01$ $1.00000 \mathrm{e}-05$ 1.00000e-05 1.00000e-06 1.00000e-09 1.00000e-01 $1.00000 \mathrm{e}+001.00000 \mathrm{e}+001.00000 \mathrm{e}-011.00000 \mathrm{e}-091.00000 \mathrm{e}-01$ Element: 2940 \# of layers: 15

$\mathrm{Kx} \mathrm{Ky} \mathrm{Kz}$ Ss Por 4.80062e+02 4.80062e+02 4.80062e+01 1.00000e-09 7.00000e-02 4.80062e+02 4.80062e+02 4.80062e+01 1.00000e-09 7.00000e-02 4.80062e+02 4.80062e+02 4.80062e+01 1.00000e-09 7.00000e-02 $4.80062 \mathrm{e}+024.80062 \mathrm{e}+02$ 4.80062e+01 1.00000e-09 7.00000e-02 5.00000e-04 5.00000e-04 5.00000e-05 1.00000e-09 1.00000e-01 
5.00000e-04 5.00000e-04 5.00000e-05 1.00000e-09 1.00000e-01 $1.91814 \mathrm{e}+011.91814 \mathrm{e}+011.91814 \mathrm{e}+001.00000 \mathrm{e}-092.12000 \mathrm{e}-01$ $1.91814 \mathrm{e}+011.91814 \mathrm{e}+011.91814 \mathrm{e}+001.00000 \mathrm{e}-092.12000 \mathrm{e}-01$ $1.91814 \mathrm{e}+011.91814 \mathrm{e}+011.91814 \mathrm{e}+001.00000 \mathrm{e}-092.12000 \mathrm{e}-01$ $1.91814 \mathrm{e}+011.91814 \mathrm{e}+011.91814 \mathrm{e}+001.00000 \mathrm{e}-092.12000 \mathrm{e}-01$ $1.91814 \mathrm{e}+011.91814 \mathrm{e}+011.91814 \mathrm{e}+001.00000 \mathrm{e}-092.12000 \mathrm{e}-01$ $1.00000 \mathrm{e}-02$ 1.00000e-02 1.00000e-03 1.00000e-09 1.00000e-01 $1.00000 \mathrm{e}+001.00000 \mathrm{e}+001.00000 \mathrm{e}-011.00000 \mathrm{e}-091.00000 \mathrm{e}-01$ $1.00000 \mathrm{e}-05$ 1.00000e-05 1.00000e-06 1.00000e-09 1.00000e-01 $1.00000 \mathrm{e}+001.00000 \mathrm{e}+001.00000 \mathrm{e}-011.00000 \mathrm{e}-091.00000 \mathrm{e}-01$ Element: 2941 \# of layers: 15

$\mathrm{Kx} \mathrm{Ky} \mathrm{Kz}$ Ss Por

$2.64380 \mathrm{e}+02$ 2.64380e+02 2.64380e+01 1.00000e-09 7.00000e-02 $2.64380 \mathrm{e}+02$ 2.64380e+02 2.64380e+01 1.00000e-09 7.00000e-02 $2.64380 \mathrm{e}+022.64380 \mathrm{e}+022.64380 \mathrm{e}+01$ 1.00000e-09 7.00000e-02 $2.64380 \mathrm{e}+022.64380 \mathrm{e}+022.64380 \mathrm{e}+01$ 1.00000e-09 7.00000e-02 5.00000e-04 5.00000e-04 5.00000e-05 1.00000e-09 1.00000e-01 5.00000e-04 5.00000e-04 5.00000e-05 1.00000e-09 1.00000e-01 $1.05638 \mathrm{e}+01$ 1.05638e+01 1.05638e+00 1.00000e-09 2.12000e-01 $1.05638 \mathrm{e}+01$ 1.05638e+01 1.05638e+00 1.00000e-09 2.12000e-01 $1.05638 \mathrm{e}+011.05638 \mathrm{e}+01$ 1.05638e+00 1.00000e-09 2.12000e-01 $1.05638 \mathrm{e}+01$ 1.05638e+01 1.05638e+00 1.00000e-09 2.12000e-01 $1.05638 \mathrm{e}+01$ 1.05638e+01 1.05638e+00 1.00000e-09 2.12000e-01 $1.00000 \mathrm{e}-02$ 1.00000e-02 1.00000e-03 1.00000e-09 1.00000e-01 $1.00000 \mathrm{e}+001.00000 \mathrm{e}+001.00000 \mathrm{e}-011.00000 \mathrm{e}-091.00000 \mathrm{e}-01$ $1.00000 \mathrm{e}-05$ 1.00000e-05 1.00000e-06 1.00000e-09 1.00000e-01 $1.00000 \mathrm{e}+001.00000 \mathrm{e}+001.00000 \mathrm{e}-011.00000 \mathrm{e}-091.00000 \mathrm{e}-01$ Element: 2942 \# of layers: 15

$\mathrm{Kx} \mathrm{Ky} \mathrm{Kz}$ Ss Por

$2.64380 \mathrm{e}+02$ 2.64380e+02 2.64380e+01 1.00000e-09 7.00000e-02 $2.64380 \mathrm{e}+022.64380 \mathrm{e}+02 \quad 2.64380 \mathrm{e}+01$ 1.00000e-09 7.00000e-02 $2.64380 \mathrm{e}+02$ 2.64380e+02 2.64380e+01 1.00000e-09 7.00000e-02 $2.64380 \mathrm{e}+022.64380 \mathrm{e}+02$ 2.64380e+01 1.00000e-09 7.00000e-02 $5.00000 \mathrm{e}-04$ 5.00000e-04 5.00000e-05 1.00000e-09 1.00000e-01 5.00000e-04 5.00000e-04 5.00000e-05 1.00000e-09 1.00000e-01 $1.05638 \mathrm{e}+01$ 1.05638e+01 1.05638e+00 1.00000e-09 2.12000e-01 $1.05638 \mathrm{e}+011.05638 \mathrm{e}+011.05638 \mathrm{e}+001.00000 \mathrm{e}-092.12000 \mathrm{e}-01$ $1.05638 \mathrm{e}+011.05638 \mathrm{e}+011.05638 \mathrm{e}+001.00000 \mathrm{e}-092.12000 \mathrm{e}-01$ $1.05638 \mathrm{e}+01$ 1.05638e+01 1.05638e+00 1.00000e-09 2.12000e-01 $1.05638 \mathrm{e}+01$ 1.05638e+01 1.05638e+00 1.00000e-09 2.12000e-01 $1.00000 \mathrm{e}-02$ 1.00000e-02 1.00000e-03 1.00000e-09 1.00000e-01 $1.00000 \mathrm{e}+001.00000 \mathrm{e}+001.00000 \mathrm{e}-011.00000 \mathrm{e}-091.00000 \mathrm{e}-01$ $1.00000 \mathrm{e}-05$ 1.00000e-05 1.00000e-06 1.00000e-09 1.00000e-01 $1.00000 \mathrm{e}+001.00000 \mathrm{e}+001.00000 \mathrm{e}-01$ 1.00000e-09 1.00000e-01 Element: 2943 \# of layers: 15

Kx Ky Kz Ss Por 
$2.64380 \mathrm{e}+02$ 2.64380e+02 2.64380e+01 1.00000e-09 7.00000e-02 $2.64380 \mathrm{e}+02$ 2.64380e+02 2.64380e+01 1.00000e-09 7.00000e-02 $2.64380 \mathrm{e}+022.64380 \mathrm{e}+02$ 2.64380e+01 1.00000e-09 7.00000e-02 $2.64380 \mathrm{e}+02$ 2.64380e+02 2.64380e+01 1.00000e-09 7.00000e-02 5.00000e-04 5.00000e-04 5.00000e-05 1.00000e-09 1.00000e-01 5.00000e-04 5.00000e-04 5.00000e-05 1.00000e-09 1.00000e-01 $1.05638 \mathrm{e}+011.05638 \mathrm{e}+011.05638 \mathrm{e}+001.00000 \mathrm{e}-092.12000 \mathrm{e}-01$ $1.05638 \mathrm{e}+01$ 1.05638e+01 1.05638e+00 1.00000e-09 2.12000e-01 $1.05638 \mathrm{e}+01$ 1.05638e+01 1.05638e+00 1.00000e-09 2.12000e-01 $1.05638 \mathrm{e}+01$ 1.05638e+01 1.05638e+00 1.00000e-09 2.12000e-01 $1.05638 \mathrm{e}+01$ 1.05638e+01 1.05638e+00 1.00000e-09 2.12000e-01 $1.00000 \mathrm{e}-02$ 1.00000e-02 1.00000e-03 1.00000e-09 1.00000e-01 $1.00000 \mathrm{e}+001.00000 \mathrm{e}+001.00000 \mathrm{e}-011.00000 \mathrm{e}-091.00000 \mathrm{e}-01$ $1.00000 \mathrm{e}-05$ 1.00000e-05 1.00000e-06 1.00000e-09 1.00000e-01 $1.00000 \mathrm{e}+001.00000 \mathrm{e}+001.00000 \mathrm{e}-01$ 1.00000e-09 1.00000e-01 Element: 2944 \# of layers: 15

$\mathrm{Kx} \mathrm{Ky} \mathrm{Kz}$ Ss Por

$2.98339 \mathrm{e}+02$ 2.98339e+02 2.98339e+01 1.00000e-09 7.00000e-02 $2.98339 \mathrm{e}+02$ 2.98339e+02 2.98339e+01 1.00000e-09 7.00000e-02 $2.98339 \mathrm{e}+02$ 2.98339e+02 2.98339e+01 1.00000e-09 7.00000e-02 $2.98339 \mathrm{e}+02$ 2.98339e+02 2.98339e+01 1.00000e-09 7.00000e-02 5.00000e-04 5.00000e-04 5.00000e-05 1.00000e-09 1.00000e-01 5.00000e-04 5.00000e-04 5.00000e-05 1.00000e-09 1.00000e-01 $1.19205 \mathrm{e}+011.19205 \mathrm{e}+01$ 1.19205e+00 1.00000e-09 2.12000e-01 $1.19205 \mathrm{e}+011.19205 \mathrm{e}+011.19205 \mathrm{e}+001.00000 \mathrm{e}-092.12000 \mathrm{e}-01$ $1.19205 \mathrm{e}+011.19205 \mathrm{e}+01$ 1.19205e+00 1.00000e-09 2.12000e-01 $1.19205 \mathrm{e}+01$ 1.19205e+01 1.19205e+00 1.00000e-09 2.12000e-01 $1.19205 \mathrm{e}+011.19205 \mathrm{e}+01$ 1.19205e+00 1.00000e-09 2.12000e-01 $1.00000 \mathrm{e}-02$ 1.00000e-02 1.00000e-03 1.00000e-09 1.00000e-01 $1.00000 \mathrm{e}+001.00000 \mathrm{e}+001.00000 \mathrm{e}-011.00000 \mathrm{e}-091.00000 \mathrm{e}-01$ $1.00000 \mathrm{e}-05$ 1.00000e-05 1.00000e-06 1.00000e-09 1.00000e-01 $1.00000 \mathrm{e}+001.00000 \mathrm{e}+001.00000 \mathrm{e}-011.00000 \mathrm{e}-091.00000 \mathrm{e}-01$ Element: 2945 \# of layers: 15

$\mathrm{Kx} \mathrm{Ky} \mathrm{Kz}$ Ss Por

$2.98339 \mathrm{e}+02$ 2.98339e+02 2.98339e+01 1.00000e-09 7.00000e-02 $2.98339 \mathrm{e}+02$ 2.98339e+02 2.98339e+01 1.00000e-09 7.00000e-02 $2.98339 \mathrm{e}+02$ 2.98339e+02 2.98339e+01 1.00000e-09 7.00000e-02 $2.98339 \mathrm{e}+02$ 2.98339e+02 2.98339e+01 1.00000e-09 7.00000e-02 5.00000e-04 5.00000e-04 5.00000e-05 1.00000e-09 1.00000e-01 5.00000e-04 5.00000e-04 5.00000e-05 1.00000e-09 1.00000e-01 $1.19205 \mathrm{e}+01$ 1.19205e+01 1.19205e+00 1.00000e-09 2.12000e-01 $1.19205 \mathrm{e}+011.19205 \mathrm{e}+011.19205 \mathrm{e}+001.00000 \mathrm{e}-092.12000 \mathrm{e}-01$ $1.19205 \mathrm{e}+011.19205 \mathrm{e}+01$ 1.19205e+00 1.00000e-09 2.12000e-01 $1.19205 \mathrm{e}+01$ 1.19205e+01 1.19205e+00 1.00000e-09 2.12000e-01 $1.19205 \mathrm{e}+011.19205 \mathrm{e}+01$ 1.19205e+00 1.00000e-09 2.12000e-01 $1.00000 \mathrm{e}-02$ 1.00000e-02 1.00000e-03 1.00000e-09 1.00000e-01 
$1.00000 \mathrm{e}+001.00000 \mathrm{e}+001.00000 \mathrm{e}-011.00000 \mathrm{e}-091.00000 \mathrm{e}-01$ $1.00000 \mathrm{e}-05$ 1.00000e-05 1.00000e-06 1.00000e-09 1.00000e-01 $1.00000 \mathrm{e}+001.00000 \mathrm{e}+001.00000 \mathrm{e}-011.00000 \mathrm{e}-091.00000 \mathrm{e}-01$ Element: 2946 \# of layers: 15

$\mathrm{Kx} \mathrm{Ky} \mathrm{Kz}$ Ss Por

4.82152e+02 4.82152e+02 4.82152e+01 1.00000e-09 7.00000e-02 $4.82152 \mathrm{e}+024.82152 \mathrm{e}+02$ 4.82152e+01 1.00000e-09 7.00000e-02 $4.82152 \mathrm{e}+02$ 4.82152e+02 4.82152e+01 1.00000e-09 7.00000e-02 $4.82152 \mathrm{e}+024.82152 \mathrm{e}+024.82152 \mathrm{e}+01$ 1.00000e-09 7.00000e-02 5.00000e-04 5.00000e-04 5.00000e-05 1.00000e-09 1.00000e-01 5.00000e-04 5.00000e-04 5.00000e-05 1.00000e-09 1.00000e-01 $1.92651 \mathrm{e}+011.92651 \mathrm{e}+011.92651 \mathrm{e}+001.00000 \mathrm{e}-092.12000 \mathrm{e}-01$ $1.92651 \mathrm{e}+011.92651 \mathrm{e}+011.92651 \mathrm{e}+001.00000 \mathrm{e}-092.12000 \mathrm{e}-01$ $1.92651 \mathrm{e}+011.92651 \mathrm{e}+011.92651 \mathrm{e}+001.00000 \mathrm{e}-092.12000 \mathrm{e}-01$ $1.92651 \mathrm{e}+011.92651 \mathrm{e}+011.92651 \mathrm{e}+001.00000 \mathrm{e}-092.12000 \mathrm{e}-01$ $1.92651 \mathrm{e}+011.92651 \mathrm{e}+011.92651 \mathrm{e}+001.00000 \mathrm{e}-092.12000 \mathrm{e}-01$ $1.00000 \mathrm{e}-02$ 1.00000e-02 1.00000e-03 1.00000e-09 1.00000e-01 $1.00000 \mathrm{e}+001.00000 \mathrm{e}+001.00000 \mathrm{e}-011.00000 \mathrm{e}-091.00000 \mathrm{e}-01$ $1.00000 \mathrm{e}-05$ 1.00000e-05 1.00000e-06 1.00000e-09 1.00000e-01 $1.00000 \mathrm{e}+001.00000 \mathrm{e}+001.00000 \mathrm{e}-011.00000 \mathrm{e}-091.00000 \mathrm{e}-01$ Element: 2947 \# of layers: 15

$\mathrm{Kx} \mathrm{Ky} \mathrm{Kz}$ Ss Por

4.80062e+02 4.80062e+02 4.80062e+01 1.00000e-09 7.00000e-02 4.80062e+02 4.80062e+02 4.80062e+01 1.00000e-09 7.00000e-02 $4.80062 \mathrm{e}+02$ 4.80062e+02 4.80062e+01 1.00000e-09 7.00000e-02 4.80062e+02 4.80062e+02 4.80062e+01 1.00000e-09 7.00000e-02 5.00000e-04 5.00000e-04 5.00000e-05 1.00000e-09 1.00000e-01 5.00000e-04 5.00000e-04 5.00000e-05 1.00000e-09 1.00000e-01 $1.91814 \mathrm{e}+011.91814 \mathrm{e}+011.91814 \mathrm{e}+001.00000 \mathrm{e}-092.12000 \mathrm{e}-01$ $1.91814 \mathrm{e}+011.91814 \mathrm{e}+011.91814 \mathrm{e}+001.00000 \mathrm{e}-092.12000 \mathrm{e}-01$ $1.91814 \mathrm{e}+011.91814 \mathrm{e}+011.91814 \mathrm{e}+001.00000 \mathrm{e}-092.12000 \mathrm{e}-01$ $1.91814 \mathrm{e}+011.91814 \mathrm{e}+011.91814 \mathrm{e}+001.00000 \mathrm{e}-092.12000 \mathrm{e}-01$ $1.91814 \mathrm{e}+011.91814 \mathrm{e}+01 \quad 1.91814 \mathrm{e}+001.00000 \mathrm{e}-092.12000 \mathrm{e}-01$ $1.00000 \mathrm{e}-02$ 1.00000e-02 1.00000e-03 1.00000e-09 1.00000e-01 $1.00000 \mathrm{e}+001.00000 \mathrm{e}+001.00000 \mathrm{e}-011.00000 \mathrm{e}-091.00000 \mathrm{e}-01$ $1.00000 \mathrm{e}-05$ 1.00000e-05 1.00000e-06 1.00000e-09 1.00000e-01 $1.00000 \mathrm{e}+001.00000 \mathrm{e}+001.00000 \mathrm{e}-011.00000 \mathrm{e}-091.00000 \mathrm{e}-01$ Element: 2948 \# of layers: 15

$\mathrm{Kx} \mathrm{Ky} \mathrm{Kz}$ Ss Por

$2.64380 \mathrm{e}+02$ 2.64380e+02 2.64380e+01 1.00000e-09 7.00000e-02 $2.64380 \mathrm{e}+022.64380 \mathrm{e}+02 \quad 2.64380 \mathrm{e}+01$ 1.00000e-09 7.00000e-02 $2.64380 \mathrm{e}+022.64380 \mathrm{e}+02 \quad 2.64380 \mathrm{e}+01$ 1.00000e-09 7.00000e-02 $2.64380 \mathrm{e}+022.64380 \mathrm{e}+02$ 2.64380e+01 1.00000e-09 7.00000e-02 5.00000e-04 5.00000e-04 5.00000e-05 1.00000e-09 1.00000e-01 5.00000e-04 5.00000e-04 5.00000e-05 1.00000e-09 1.00000e-01 $1.05638 \mathrm{e}+01$ 1.05638e+01 1.05638e+00 1.00000e-09 2.12000e-01 
$1.05638 \mathrm{e}+01$ 1.05638e+01 1.05638e+00 1.00000e-09 2.12000e-01 $1.05638 \mathrm{e}+01$ 1.05638e+01 1.05638e+00 1.00000e-09 2.12000e-01 $1.05638 \mathrm{e}+011.05638 \mathrm{e}+011.05638 \mathrm{e}+001.00000 \mathrm{e}-092.12000 \mathrm{e}-01$ $1.05638 \mathrm{e}+01$ 1.05638e+01 1.05638e+00 1.00000e-09 2.12000e-01 $1.00000 \mathrm{e}-02$ 1.00000e-02 1.00000e-03 1.00000e-09 1.00000e-01 $1.00000 \mathrm{e}+001.00000 \mathrm{e}+001.00000 \mathrm{e}-011.00000 \mathrm{e}-091.00000 \mathrm{e}-01$ 1.00000e-05 1.00000e-05 1.00000e-06 1.00000e-09 1.00000e-01 $1.00000 \mathrm{e}+001.00000 \mathrm{e}+001.00000 \mathrm{e}-011.00000 \mathrm{e}-091.00000 \mathrm{e}-01$ Element: 2949 \# of layers: 15

$\mathrm{Kx} \mathrm{Ky} \mathrm{Kz}$ Ss Por

$1.52575 \mathrm{e}+02$ 1.52575e+02 1.52575e+01 1.00000e-09 7.00000e-02 $1.52575 \mathrm{e}+021.52575 \mathrm{e}+021.52575 \mathrm{e}+01$ 1.00000e-09 7.00000e-02 $1.52575 \mathrm{e}+021.52575 \mathrm{e}+02$ 1.52575e+01 1.00000e-09 7.00000e-02 $1.52575 \mathrm{e}+021.52575 \mathrm{e}+02$ 1.52575e+01 1.00000e-09 7.00000e-02 5.00000e-04 5.00000e-04 5.00000e-05 1.00000e-09 1.00000e-01 5.00000e-04 5.00000e-04 5.00000e-05 1.00000e-09 1.00000e-01 $6.09628 \mathrm{e}+006.09628 \mathrm{e}+00$ 6.09628e-01 1.00000e-09 2.12000e-01 $6.09628 \mathrm{e}+006.09628 \mathrm{e}+00$ 6.09628e-01 1.00000e-09 2.12000e-01 $6.09628 \mathrm{e}+006.09628 \mathrm{e}+00$ 6.09628e-01 1.00000e-09 2.12000e-01 $6.09628 \mathrm{e}+006.09628 \mathrm{e}+00$ 6.09628e-01 1.00000e-09 2.12000e-01 $6.09628 \mathrm{e}+006.09628 \mathrm{e}+00$ 6.09628e-01 1.00000e-09 2.12000e-01 $1.00000 \mathrm{e}-02$ 1.00000e-02 1.00000e-03 1.00000e-09 1.00000e-01 $1.00000 \mathrm{e}+001.00000 \mathrm{e}+001.00000 \mathrm{e}-011.00000 \mathrm{e}-091.00000 \mathrm{e}-01$ $1.00000 \mathrm{e}-05$ 1.00000e-05 1.00000e-06 1.00000e-09 1.00000e-01 $1.00000 \mathrm{e}+001.00000 \mathrm{e}+001.00000 \mathrm{e}-011.00000 \mathrm{e}-091.00000 \mathrm{e}-01$ Element: 2950 \# of layers: 15

$\mathrm{Kx} \mathrm{Ky} \mathrm{Kz}$ Ss Por

$1.52575 \mathrm{e}+02$ 1.52575e+02 1.52575e+01 1.00000e-09 7.00000e-02 $1.52575 \mathrm{e}+02$ 1.52575e+02 1.52575e+01 1.00000e-09 7.00000e-02 $1.52575 \mathrm{e}+02$ 1.52575e+02 1.52575e+01 1.00000e-09 7.00000e-02 $1.52575 \mathrm{e}+021.52575 \mathrm{e}+02$ 1.52575e+01 1.00000e-09 7.00000e-02 5.00000e-04 5.00000e-04 5.00000e-05 1.00000e-09 1.00000e-01 5.00000e-04 5.00000e-04 5.00000e-05 1.00000e-09 1.00000e-01 $6.09628 \mathrm{e}+006.09628 \mathrm{e}+00$ 6.09628e-01 1.00000e-09 2.12000e-01 $6.09628 \mathrm{e}+006.09628 \mathrm{e}+00$ 6.09628e-01 1.00000e-09 2.12000e-01 $6.09628 \mathrm{e}+006.09628 \mathrm{e}+00$ 6.09628e-01 1.00000e-09 2.12000e-01 $6.09628 \mathrm{e}+006.09628 \mathrm{e}+00$ 6.09628e-01 1.00000e-09 2.12000e-01 6.09628e+00 6.09628e+00 6.09628e-01 1.00000e-09 2.12000e-01 $1.00000 \mathrm{e}-02$ 1.00000e-02 1.00000e-03 1.00000e-09 1.00000e-01 $1.00000 \mathrm{e}+001.00000 \mathrm{e}+001.00000 \mathrm{e}-011.00000 \mathrm{e}-091.00000 \mathrm{e}-01$ $1.00000 \mathrm{e}-05$ 1.00000e-05 1.00000e-06 1.00000e-09 1.00000e-01 $1.00000 \mathrm{e}+001.00000 \mathrm{e}+001.00000 \mathrm{e}-011.00000 \mathrm{e}-091.00000 \mathrm{e}-01$ Element: 2951 \# of layers: 15

$\mathrm{Kx} \mathrm{Ky} \mathrm{Kz}$ Ss Por

$1.52575 \mathrm{e}+02$ 1.52575e+02 1.52575e+01 1.00000e-09 7.00000e-02 $1.52575 \mathrm{e}+021.52575 \mathrm{e}+021.52575 \mathrm{e}+01$ 1.00000e-09 7.00000e-02 
$1.52575 \mathrm{e}+02$ 1.52575e+02 1.52575e+01 1.00000e-09 7.00000e-02 $1.52575 \mathrm{e}+021.52575 \mathrm{e}+02$ 1.52575e+01 1.00000e-09 7.00000e-02 5.00000e-04 5.00000e-04 5.00000e-05 1.00000e-09 1.00000e-01 5.00000e-04 5.00000e-04 5.00000e-05 1.00000e-09 1.00000e-01 $6.09628 \mathrm{e}+006.09628 \mathrm{e}+00$ 6.09628e-01 1.00000e-09 2.12000e-01 $6.09628 \mathrm{e}+006.09628 \mathrm{e}+006.09628 \mathrm{e}-01$ 1.00000e-09 2.12000e-01 $6.09628 \mathrm{e}+006.09628 \mathrm{e}+00$ 6.09628e-01 1.00000e-09 2.12000e-01 $6.09628 \mathrm{e}+00$ 6.09628e+00 6.09628e-01 1.00000e-09 2.12000e-01 6.09628e+00 6.09628e+00 6.09628e-01 1.00000e-09 2.12000e-01 $1.00000 \mathrm{e}-02$ 1.00000e-02 1.00000e-03 1.00000e-09 1.00000e-01 $1.00000 \mathrm{e}+001.00000 \mathrm{e}+001.00000 \mathrm{e}-011.00000 \mathrm{e}-091.00000 \mathrm{e}-01$ $1.00000 \mathrm{e}-05$ 1.00000e-05 1.00000e-06 1.00000e-09 1.00000e-01 $1.00000 \mathrm{e}+001.00000 \mathrm{e}+001.00000 \mathrm{e}-011.00000 \mathrm{e}-091.00000 \mathrm{e}-01$ Element: 2952 \# of layers: 15

$\mathrm{Kx} \mathrm{Ky} \mathrm{Kz}$ Ss Por

1.50233e+02 1.50233e+02 1.50233e+01 1.00000e-09 7.00000e-02 $1.50233 \mathrm{e}+02$ 1.50233e+02 1.50233e+01 1.00000e-09 7.00000e-02 $1.50233 \mathrm{e}+02$ 1.50233e+02 1.50233e+01 1.00000e-09 7.00000e-02 $1.50233 \mathrm{e}+02$ 1.50233e+02 1.50233e+01 1.00000e-09 7.00000e-02 5.00000e-04 5.00000e-04 5.00000e-05 1.00000e-09 1.00000e-01 5.00000e-04 5.00000e-04 5.00000e-05 1.00000e-09 1.00000e-01 $6.00268 \mathrm{e}+006.00268 \mathrm{e}+00$ 6.00268e-01 1.00000e-09 2.12000e-01 $6.00268 \mathrm{e}+006.00268 \mathrm{e}+00$ 6.00268e-01 1.00000e-09 2.12000e-01 $6.00268 \mathrm{e}+006.00268 \mathrm{e}+00$ 6.00268e-01 1.00000e-09 2.12000e-01 $6.00268 \mathrm{e}+006.00268 \mathrm{e}+00$ 6.00268e-01 1.00000e-09 2.12000e-01 $6.00268 \mathrm{e}+00$ 6.00268e+00 6.00268e-01 1.00000e-09 2.12000e-01 $1.00000 \mathrm{e}-02$ 1.00000e-02 1.00000e-03 1.00000e-09 1.00000e-01 $1.00000 \mathrm{e}+001.00000 \mathrm{e}+001.00000 \mathrm{e}-011.00000 \mathrm{e}-091.00000 \mathrm{e}-01$ $1.00000 \mathrm{e}-05$ 1.00000e-05 1.00000e-06 1.00000e-09 1.00000e-01 $1.00000 \mathrm{e}+001.00000 \mathrm{e}+001.00000 \mathrm{e}-011.00000 \mathrm{e}-091.00000 \mathrm{e}-01$ Element: 2953 \# of layers: 15

$\mathrm{Kx} \mathrm{Ky} \mathrm{Kz}$ Ss Por

$1.50233 \mathrm{e}+02$ 1.50233e+02 1.50233e+01 1.00000e-09 7.00000e-02 $1.50233 \mathrm{e}+02$ 1.50233e+02 1.50233e+01 1.00000e-09 7.00000e-02 $1.50233 \mathrm{e}+02$ 1.50233e+02 1.50233e+01 1.00000e-09 7.00000e-02 $1.50233 \mathrm{e}+02$ 1.50233e+02 1.50233e+01 1.00000e-09 7.00000e-02 5.00000e-04 5.00000e-04 5.00000e-05 1.00000e-09 1.00000e-01 5.00000e-04 5.00000e-04 5.00000e-05 1.00000e-09 1.00000e-01 $6.00268 \mathrm{e}+006.00268 \mathrm{e}+00$ 6.00268e-01 1.00000e-09 2.12000e-01 $6.00268 \mathrm{e}+006.00268 \mathrm{e}+00$ 6.00268e-01 1.00000e-09 2.12000e-01 $6.00268 \mathrm{e}+006.00268 \mathrm{e}+00$ 6.00268e-01 1.00000e-09 2.12000e-01 $6.00268 \mathrm{e}+006.00268 \mathrm{e}+00$ 6.00268e-01 1.00000e-09 2.12000e-01 6.00268e+00 6.00268e+00 6.00268e-01 1.00000e-09 2.12000e-01 $1.00000 \mathrm{e}-02$ 1.00000e-02 1.00000e-03 1.00000e-09 1.00000e-01 $1.00000 \mathrm{e}+001.00000 \mathrm{e}+001.00000 \mathrm{e}-011.00000 \mathrm{e}-091.00000 \mathrm{e}-01$ $1.00000 \mathrm{e}-05$ 1.00000e-05 1.00000e-06 1.00000e-09 1.00000e-01 
$1.00000 \mathrm{e}+001.00000 \mathrm{e}+00$ 1.00000e-01 1.00000e-09 1.00000e-01

Element: 2954 \# of layers: 15

Kx Ky Kz Ss Por

$1.52575 \mathrm{e}+02$ 1.52575e+02 1.52575e+01 1.00000e-09 7.00000e-02

$1.52575 \mathrm{e}+021.52575 \mathrm{e}+02$ 1.52575e+01 1.00000e-09 7.00000e-02

$1.52575 \mathrm{e}+021.52575 \mathrm{e}+02$ 1.52575e+01 1.00000e-09 7.00000e-02

$1.52575 \mathrm{e}+021.52575 \mathrm{e}+02$ 1.52575e+01 1.00000e-09 7.00000e-02

5.00000e-04 5.00000e-04 5.00000e-05 1.00000e-09 1.00000e-01

5.00000e-04 5.00000e-04 5.00000e-05 1.00000e-09 1.00000e-01

$6.09628 \mathrm{e}+006.09628 \mathrm{e}+00$ 6.09628e-01 1.00000e-09 2.12000e-01

$6.09628 \mathrm{e}+006.09628 \mathrm{e}+00$ 6.09628e-01 1.00000e-09 2.12000e-01

$6.09628 \mathrm{e}+00$ 6.09628e+00 6.09628e-01 1.00000e-09 2.12000e-01

$6.09628 \mathrm{e}+006.09628 \mathrm{e}+00$ 6.09628e-01 1.00000e-09 2.12000e-01

$6.09628 \mathrm{e}+006.09628 \mathrm{e}+00$ 6.09628e-01 1.00000e-09 2.12000e-01

$1.00000 \mathrm{e}-02$ 1.00000e-02 1.00000e-03 1.00000e-09 1.00000e-01

$1.00000 \mathrm{e}+001.00000 \mathrm{e}+001.00000 \mathrm{e}-011.00000 \mathrm{e}-091.00000 \mathrm{e}-01$

$1.00000 \mathrm{e}-05$ 1.00000e-05 1.00000e-06 1.00000e-09 1.00000e-01

$1.00000 \mathrm{e}+001.00000 \mathrm{e}+001.00000 \mathrm{e}-01$ 1.00000e-09 1.00000e-01

Element: 2955 \# of layers: 15

$\mathrm{Kx} \mathrm{Ky} \mathrm{Kz}$ Ss Por

$1.54503 e+021.54503 e+02$ 1.54503e+01 1.00000e-09 7.00000e-02

$1.54503 \mathrm{e}+02$ 1.54503e+02 1.54503e+01 1.00000e-09 7.00000e-02

$1.54503 \mathrm{e}+02$ 1.54503e+02 1.54503e+01 1.00000e-09 7.00000e-02

$1.54503 \mathrm{e}+02$ 1.54503e+02 1.54503e+01 1.00000e-09 7.00000e-02

5.00000e-04 5.00000e-04 5.00000e-05 1.00000e-09 1.00000e-01

$5.00000 \mathrm{e}-04$ 5.00000e-04 5.00000e-05 1.00000e-09 1.00000e-01

$6.17368 \mathrm{e}+006.17368 \mathrm{e}+00$ 6.17368e-01 1.00000e-09 2.12000e-01

6.17368e+00 6.17368e+00 6.17368e-01 1.00000e-09 2.12000e-01

$6.17368 \mathrm{e}+00$ 6.17368e+00 6.17368e-01 1.00000e-09 2.12000e-01

6.17368e+00 6.17368e+00 6.17368e-01 1.00000e-09 2.12000e-01

6.17368e+00 6.17368e+00 6.17368e-01 1.00000e-09 2.12000e-01

1.00000e-02 1.00000e-02 1.00000e-03 1.00000e-09 1.00000e-01

$1.00000 \mathrm{e}+001.00000 \mathrm{e}+001.00000 \mathrm{e}-011.00000 \mathrm{e}-091.00000 \mathrm{e}-01$

$1.00000 \mathrm{e}-05$ 1.00000e-05 1.00000e-06 1.00000e-09 1.00000e-01

$1.00000 \mathrm{e}+001.00000 \mathrm{e}+001.00000 \mathrm{e}-011.00000 \mathrm{e}-091.00000 \mathrm{e}-01$

Element: 2956 \# of layers: 15

Kx Ky Kz Ss Por

$1.52404 \mathrm{e}+02$ 1.52404e+02 1.52404e+01 1.00000e-09 7.00000e-02

$1.52404 \mathrm{e}+021.52404 \mathrm{e}+021.52404 \mathrm{e}+01$ 1.00000e-09 7.00000e-02

$1.52404 \mathrm{e}+021.52404 \mathrm{e}+021.52404 \mathrm{e}+01$ 1.00000e-09 7.00000e-02

$1.52404 \mathrm{e}+021.52404 \mathrm{e}+021.52404 \mathrm{e}+01$ 1.00000e-09 7.00000e-02

5.00000e-04 5.00000e-04 5.00000e-05 1.00000e-09 1.00000e-01

5.00000e-04 5.00000e-04 5.00000e-05 1.00000e-09 1.00000e-01

6.08953e+00 6.08953e+00 6.08953e-01 1.00000e-09 2.12000e-01

$6.08953 \mathrm{e}+00$ 6.08953e+00 6.08953e-01 1.00000e-09 2.12000e-01

$6.08953 \mathrm{e}+00$ 6.08953e+00 6.08953e-01 1.00000e-09 2.12000e-01 
$6.08953 \mathrm{e}+006.08953 \mathrm{e}+00$ 6.08953e-01 1.00000e-09 2.12000e-01 $6.08953 \mathrm{e}+006.08953 \mathrm{e}+00$ 6.08953e-01 1.00000e-09 2.12000e-01 $1.00000 \mathrm{e}-021.00000 \mathrm{e}-02$ 1.00000e-03 1.00000e-09 1.00000e-01 $1.00000 \mathrm{e}+001.00000 \mathrm{e}+001.00000 \mathrm{e}-011.00000 \mathrm{e}-091.00000 \mathrm{e}-01$ $1.00000 \mathrm{e}-05$ 1.00000e-05 1.00000e-06 1.00000e-09 1.00000e-01 $1.00000 \mathrm{e}+001.00000 \mathrm{e}+001.00000 \mathrm{e}-011.00000 \mathrm{e}-091.00000 \mathrm{e}-01$ Element: 2957 \# of layers: 15

Kx Ky Kz Ss Por

$1.52575 \mathrm{e}+021.52575 \mathrm{e}+021.52575 \mathrm{e}+01$ 1.00000e-09 7.00000e-02 $1.52575 \mathrm{e}+021.52575 \mathrm{e}+021.52575 \mathrm{e}+011.00000 \mathrm{e}-097.00000 \mathrm{e}-02$ $1.52575 \mathrm{e}+021.52575 \mathrm{e}+021.52575 \mathrm{e}+011.00000 \mathrm{e}-097.00000 \mathrm{e}-02$ $1.52575 \mathrm{e}+021.52575 \mathrm{e}+021.52575 \mathrm{e}+011.00000 \mathrm{e}-097.00000 \mathrm{e}-02$ 5.00000e-04 5.00000e-04 5.00000e-05 1.00000e-09 1.00000e-01 5.00000e-04 5.00000e-04 5.00000e-05 1.00000e-09 1.00000e-01 $6.09628 \mathrm{e}+006.09628 \mathrm{e}+006.09628 \mathrm{e}-011.00000 \mathrm{e}-092.12000 \mathrm{e}-01$ $6.09628 \mathrm{e}+006.09628 \mathrm{e}+006.09628 \mathrm{e}-011.00000 \mathrm{e}-092.12000 \mathrm{e}-01$ $6.09628 \mathrm{e}+006.09628 \mathrm{e}+006.09628 \mathrm{e}-011.00000 \mathrm{e}-092.12000 \mathrm{e}-01$ $6.09628 \mathrm{e}+006.09628 \mathrm{e}+00$ 6.09628e-01 1.00000e-09 2.12000e-01 $6.09628 \mathrm{e}+006.09628 \mathrm{e}+00$ 6.09628e-01 1.00000e-09 2.12000e-01 $1.00000 \mathrm{e}-021.00000 \mathrm{e}-02$ 1.00000e-03 1.00000e-09 1.00000e-01 $1.00000 \mathrm{e}+001.00000 \mathrm{e}+001.00000 \mathrm{e}-011.00000 \mathrm{e}-091.00000 \mathrm{e}-01$ $1.00000 \mathrm{e}-05$ 1.00000e-05 1.00000e-06 1.00000e-09 1.00000e-01 $1.00000 \mathrm{e}+001.00000 \mathrm{e}+001.00000 \mathrm{e}-011.00000 \mathrm{e}-091.00000 \mathrm{e}-01$ Element: 2958 \# of layers: 16

Kx Ky Kz Ss Por

7.37757e+01 7.37757e+01 7.37757e+00 1.00000e-09 7.00000e-02 $7.37757 \mathrm{e}+01$ 7.37757e+01 7.37757e+00 1.00000e-09 7.00000e-02 $7.37757 \mathrm{e}+01$ 7.37757e+01 7.37757e+00 1.00000e-09 7.00000e-02 $7.37757 \mathrm{e}+01$ 7.37757e+01 7.37757e+00 1.00000e-09 7.00000e-02 $7.37757 \mathrm{e}+01$ 7.37757e+01 7.37757e+00 1.00000e-09 7.00000e-02 5.00000e-04 5.00000e-04 5.00000e-05 1.00000e-09 1.00000e-01 5.00000e-04 5.00000e-04 5.00000e-05 1.00000e-09 1.00000e-01 $2.94779 \mathrm{e}+002.94779 \mathrm{e}+002.94779 \mathrm{e}-011.00000 \mathrm{e}-09$ 2.12000e-01 $2.94779 \mathrm{e}+002.94779 \mathrm{e}+002.94779 \mathrm{e}-01$ 1.00000e-09 2.12000e-01 $2.94779 \mathrm{e}+002.94779 \mathrm{e}+002.94779 \mathrm{e}-011.00000 \mathrm{e}-092.12000 \mathrm{e}-01$ $2.94779 \mathrm{e}+002.94779 \mathrm{e}+002.94779 \mathrm{e}-011.00000 \mathrm{e}-092.12000 \mathrm{e}-01$ $2.94779 \mathrm{e}+002.94779 \mathrm{e}+002.94779 \mathrm{e}-01$ 1.00000e-09 2.12000e-01 $1.00000 \mathrm{e}-021.00000 \mathrm{e}-02$ 1.00000e-03 1.00000e-09 1.00000e-01 $1.00000 \mathrm{e}+001.00000 \mathrm{e}+001.00000 \mathrm{e}-011.00000 \mathrm{e}-091.00000 \mathrm{e}-01$ $1.00000 \mathrm{e}-05$ 1.00000e-05 1.00000e-06 1.00000e-09 1.00000e-01 $1.00000 \mathrm{e}+001.00000 \mathrm{e}+001.00000 \mathrm{e}-011.00000 \mathrm{e}-091.00000 \mathrm{e}-01$ Element: 2959 \# of layers: 15

Kx Ky Kz Ss Por

7.37757e+01 7.37757e+01 7.37757e+00 1.00000e-09 7.00000e-02 $7.37757 \mathrm{e}+01$ 7.37757e+01 7.37757e+00 1.00000e-09 7.00000e-02 $7.37757 \mathrm{e}+01$ 7.37757e+01 7.37757e+00 1.00000e-09 7.00000e-02 
7.37757e+01 7.37757e+01 7.37757e+00 1.00000e-09 7.00000e-02 5.00000e-04 5.00000e-04 5.00000e-05 1.00000e-09 1.00000e-01 5.00000e-04 5.00000e-04 5.00000e-05 1.00000e-09 1.00000e-01 $2.94779 \mathrm{e}+002.94779 \mathrm{e}+00$ 2.94779e-01 1.00000e-09 2.12000e-01 $2.94779 \mathrm{e}+002.94779 \mathrm{e}+00$ 2.94779e-01 1.00000e-09 2.12000e-01 $2.94779 \mathrm{e}+002.94779 \mathrm{e}+00$ 2.94779e-01 1.00000e-09 2.12000e-01 $2.94779 \mathrm{e}+002.94779 \mathrm{e}+00$ 2.94779e-01 1.00000e-09 2.12000e-01 $2.94779 \mathrm{e}+00$ 2.94779e+00 2.94779e-01 1.00000e-09 2.12000e-01 $1.00000 \mathrm{e}-02$ 1.00000e-02 1.00000e-03 1.00000e-09 1.00000e-01 $1.00000 \mathrm{e}+001.00000 \mathrm{e}+001.00000 \mathrm{e}-011.00000 \mathrm{e}-091.00000 \mathrm{e}-01$ $1.00000 \mathrm{e}-05$ 1.00000e-05 1.00000e-06 1.00000e-09 1.00000e-01 $1.00000 \mathrm{e}+001.00000 \mathrm{e}+001.00000 \mathrm{e}-011.00000 \mathrm{e}-091.00000 \mathrm{e}-01$ Element: 2960 \# of layers: 15

$\mathrm{Kx} \mathrm{Ky} \mathrm{Kz}$ Ss Por

7.37757e+01 7.37757e+01 7.37757e+00 1.00000e-09 7.00000e-02 7.37757e+01 7.37757e+01 7.37757e+00 1.00000e-09 7.00000e-02 7.37757e+01 7.37757e+01 7.37757e+00 1.00000e-09 7.00000e-02 7.37757e+01 7.37757e+01 7.37757e+00 1.00000e-09 7.00000e-02 5.00000e-04 5.00000e-04 5.00000e-05 1.00000e-09 1.00000e-01 5.00000e-04 5.00000e-04 5.00000e-05 1.00000e-09 1.00000e-01 $2.94779 \mathrm{e}+00$ 2.94779e+00 2.94779e-01 1.00000e-09 2.12000e-01 2.94779e+00 2.94779e+00 2.94779e-01 1.00000e-09 2.12000e-01 $2.94779 \mathrm{e}+00$ 2.94779e+00 2.94779e-01 1.00000e-09 2.12000e-01 $2.94779 \mathrm{e}+002.94779 \mathrm{e}+00$ 2.94779e-01 1.00000e-09 2.12000e-01 $2.94779 \mathrm{e}+002.94779 \mathrm{e}+00$ 2.94779e-01 1.00000e-09 2.12000e-01 $1.00000 \mathrm{e}-02$ 1.00000e-02 1.00000e-03 1.00000e-09 1.00000e-01 $1.00000 \mathrm{e}+001.00000 \mathrm{e}+001.00000 \mathrm{e}-011.00000 \mathrm{e}-091.00000 \mathrm{e}-01$ $1.00000 \mathrm{e}-05$ 1.00000e-05 1.00000e-06 1.00000e-09 1.00000e-01 $1.00000 \mathrm{e}+001.00000 \mathrm{e}+001.00000 \mathrm{e}-011.00000 \mathrm{e}-091.00000 \mathrm{e}-01$ Element: 2961 \# of layers: 16

$\mathrm{Kx} \mathrm{Ky} \mathrm{Kz}$ Ss Por

7.37757e+01 7.37757e+01 7.37757e+00 1.00000e-09 7.00000e-02 7.37757e+01 7.37757e+01 7.37757e+00 1.00000e-09 7.00000e-02 7.37757e+01 7.37757e+01 7.37757e+00 1.00000e-09 7.00000e-02 7.37757e+01 7.37757e+01 7.37757e+00 1.00000e-09 7.00000e-02 7.37757e+01 7.37757e+01 7.37757e+00 1.00000e-09 7.00000e-02 5.00000e-04 5.00000e-04 5.00000e-05 1.00000e-09 1.00000e-01 5.00000e-04 5.00000e-04 5.00000e-05 1.00000e-09 1.00000e-01 $2.94779 \mathrm{e}+002.94779 \mathrm{e}+00$ 2.94779e-01 1.00000e-09 2.12000e-01 $2.94779 \mathrm{e}+00$ 2.94779e+00 2.94779e-01 1.00000e-09 2.12000e-01 $2.94779 \mathrm{e}+002.94779 \mathrm{e}+00$ 2.94779e-01 1.00000e-09 2.12000e-01 $2.94779 \mathrm{e}+00$ 2.94779e+00 2.94779e-01 1.00000e-09 2.12000e-01 2.94779e+00 2.94779e+00 2.94779e-01 1.00000e-09 2.12000e-01 $1.00000 \mathrm{e}-02$ 1.00000e-02 1.00000e-03 1.00000e-09 1.00000e-01 $1.00000 \mathrm{e}+001.00000 \mathrm{e}+001.00000 \mathrm{e}-011.00000 \mathrm{e}-091.00000 \mathrm{e}-01$ $1.00000 \mathrm{e}-05$ 1.00000e-05 1.00000e-06 1.00000e-09 1.00000e-01 
$1.00000 \mathrm{e}+001.00000 \mathrm{e}+00$ 1.00000e-01 1.00000e-09 1.00000e-01

Element: 2962 \# of layers: 15

Kx Ky Kz Ss Por

7.37757e+01 7.37757e+01 7.37757e+00 1.00000e-09 7.00000e-02

7.37757e+01 7.37757e+01 7.37757e+00 1.00000e-09 7.00000e-02

7.37757e+01 7.37757e+01 7.37757e+00 1.00000e-09 7.00000e-02

7.37757e+01 7.37757e+01 7.37757e+00 1.00000e-09 7.00000e-02

5.00000e-04 5.00000e-04 5.00000e-05 1.00000e-09 1.00000e-01

5.00000e-04 5.00000e-04 5.00000e-05 1.00000e-09 1.00000e-01

$2.94779 \mathrm{e}+002.94779 \mathrm{e}+00$ 2.94779e-01 1.00000e-09 2.12000e-01

$2.94779 \mathrm{e}+00$ 2.94779e+00 2.94779e-01 1.00000e-09 2.12000e-01

$2.94779 \mathrm{e}+00$ 2.94779e+00 2.94779e-01 1.00000e-09 2.12000e-01

$2.94779 \mathrm{e}+00$ 2.94779e+00 2.94779e-01 1.00000e-09 2.12000e-01

$2.94779 \mathrm{e}+00$ 2.94779e+00 2.94779e-01 1.00000e-09 2.12000e-01

$1.00000 \mathrm{e}-02$ 1.00000e-02 1.00000e-03 1.00000e-09 1.00000e-01

$1.00000 \mathrm{e}+001.00000 \mathrm{e}+001.00000 \mathrm{e}-011.00000 \mathrm{e}-091.00000 \mathrm{e}-01$

$1.00000 \mathrm{e}-05$ 1.00000e-05 1.00000e-06 1.00000e-09 1.00000e-01

$1.00000 \mathrm{e}+001.00000 \mathrm{e}+001.00000 \mathrm{e}-01$ 1.00000e-09 1.00000e-01

Element: 2963 \# of layers: 15

$\mathrm{Kx} \mathrm{Ky} \mathrm{Kz}$ Ss Por

7.37757e+01 7.37757e+01 7.37757e+00 1.00000e-09 7.00000e-02

7.37757e+01 7.37757e+01 7.37757e+00 1.00000e-09 7.00000e-02

7.37757e+01 7.37757e+01 7.37757e+00 1.00000e-09 7.00000e-02

7.37757e+01 7.37757e+01 7.37757e+00 1.00000e-09 7.00000e-02

5.00000e-04 5.00000e-04 5.00000e-05 1.00000e-09 1.00000e-01

5.00000e-04 5.00000e-04 5.00000e-05 1.00000e-09 1.00000e-01

$2.94779 \mathrm{e}+00$ 2.94779e+00 2.94779e-01 1.00000e-09 2.12000e-01

$2.94779 \mathrm{e}+00$ 2.94779e+00 2.94779e-01 1.00000e-09 2.12000e-01

$2.94779 \mathrm{e}+002.94779 \mathrm{e}+00$ 2.94779e-01 1.00000e-09 2.12000e-01

$2.94779 \mathrm{e}+00$ 2.94779e+00 2.94779e-01 1.00000e-09 2.12000e-01

$2.94779 \mathrm{e}+002.94779 \mathrm{e}+00$ 2.94779e-01 1.00000e-09 2.12000e-01

$1.00000 \mathrm{e}-02$ 1.00000e-02 1.00000e-03 1.00000e-09 1.00000e-01

$1.00000 \mathrm{e}+001.00000 \mathrm{e}+001.00000 \mathrm{e}-011.00000 \mathrm{e}-091.00000 \mathrm{e}-01$

$1.00000 \mathrm{e}-05$ 1.00000e-05 1.00000e-06 1.00000e-09 1.00000e-01

$1.00000 \mathrm{e}+001.00000 \mathrm{e}+001.00000 \mathrm{e}-011.00000 \mathrm{e}-091.00000 \mathrm{e}-01$

Element: 2964 \# of layers: 15

Kx Ky Kz Ss Por

7.37757e+01 7.37757e+01 7.37757e+00 1.00000e-09 7.00000e-02

7.37757e+01 7.37757e+01 7.37757e+00 1.00000e-09 7.00000e-02

7.37757e+01 7.37757e+01 7.37757e+00 1.00000e-09 7.00000e-02

7.37757e+01 7.37757e+01 7.37757e+00 1.00000e-09 7.00000e-02

5.00000e-04 5.00000e-04 5.00000e-05 1.00000e-09 1.00000e-01

5.00000e-04 5.00000e-04 5.00000e-05 1.00000e-09 1.00000e-01

$2.94779 \mathrm{e}+00$ 2.94779e+00 2.94779e-01 1.00000e-09 2.12000e-01

$2.94779 \mathrm{e}+00$ 2.94779e+00 2.94779e-01 1.00000e-09 2.12000e-01

$2.94779 \mathrm{e}+002.94779 \mathrm{e}+00$ 2.94779e-01 1.00000e-09 2.12000e-01 
$2.94779 \mathrm{e}+002.94779 \mathrm{e}+00$ 2.94779e-01 1.00000e-09 2.12000e-01 $2.94779 \mathrm{e}+002.94779 \mathrm{e}+002.94779 \mathrm{e}-01$ 1.00000e-09 2.12000e-01 $1.00000 \mathrm{e}-021.00000 \mathrm{e}-02$ 1.00000e-03 1.00000e-09 1.00000e-01 $1.00000 \mathrm{e}+001.00000 \mathrm{e}+001.00000 \mathrm{e}-011.00000 \mathrm{e}-091.00000 \mathrm{e}-01$ $1.00000 \mathrm{e}-05$ 1.00000e-05 1.00000e-06 1.00000e-09 1.00000e-01 $1.00000 \mathrm{e}+001.00000 \mathrm{e}+001.00000 \mathrm{e}-011.00000 \mathrm{e}-091.00000 \mathrm{e}-01$ Element: 2965 \# of layers: 16

Kx Ky Kz Ss Por

7.37757e+01 7.37757e+01 7.37757e+00 1.00000e-09 7.00000e-02 $7.37757 \mathrm{e}+01$ 7.37757e+01 7.37757e+00 1.00000e-09 7.00000e-02 $7.37757 \mathrm{e}+01$ 7.37757e+01 7.37757e+00 1.00000e-09 7.00000e-02 $7.37757 \mathrm{e}+017.37757 \mathrm{e}+017.37757 \mathrm{e}+001.00000 \mathrm{e}-09$ 7.00000e-02 $7.37757 \mathrm{e}+01$ 7.37757e+01 7.37757e+00 1.00000e-09 7.00000e-02 5.00000e-04 5.00000e-04 5.00000e-05 1.00000e-09 1.00000e-01 $5.00000 \mathrm{e}-04$ 5.00000e-04 5.00000e-05 1.00000e-09 1.00000e-01 $2.94779 \mathrm{e}+002.94779 \mathrm{e}+002.94779 \mathrm{e}-011.00000 \mathrm{e}-09$ 2.12000e-01 $2.94779 \mathrm{e}+002.94779 \mathrm{e}+002.94779 \mathrm{e}-011.00000 \mathrm{e}-092.12000 \mathrm{e}-01$ $2.94779 \mathrm{e}+002.94779 \mathrm{e}+002.94779 \mathrm{e}-01$ 1.00000e-09 2.12000e-01 $2.94779 \mathrm{e}+002.94779 \mathrm{e}+002.94779 \mathrm{e}-01$ 1.00000e-09 2.12000e-01 $2.94779 \mathrm{e}+002.94779 \mathrm{e}+002.94779 \mathrm{e}-01$ 1.00000e-09 2.12000e-01 $1.00000 \mathrm{e}-021.00000 \mathrm{e}-02$ 1.00000e-03 1.00000e-09 1.00000e-01 $1.00000 \mathrm{e}+001.00000 \mathrm{e}+001.00000 \mathrm{e}-011.00000 \mathrm{e}-091.00000 \mathrm{e}-01$ $1.00000 \mathrm{e}-05$ 1.00000e-05 1.00000e-06 1.00000e-09 1.00000e-01 $1.00000 \mathrm{e}+001.00000 \mathrm{e}+001.00000 \mathrm{e}-011.00000 \mathrm{e}-091.00000 \mathrm{e}-01$ Element: 2966 \# of layers: 16

Kx Ky Kz Ss Por

7.37757e+01 7.37757e+01 7.37757e+00 1.00000e-09 7.00000e-02 $7.37757 \mathrm{e}+01$ 7.37757e+01 7.37757e+00 1.00000e-09 7.00000e-02 $7.37757 \mathrm{e}+01$ 7.37757e+01 7.37757e+00 1.00000e-09 7.00000e-02 $7.37757 \mathrm{e}+01$ 7.37757e+01 7.37757e+00 1.00000e-09 7.00000e-02 $7.37757 \mathrm{e}+01$ 7.37757e+01 7.37757e+00 1.00000e-09 7.00000e-02 5.00000e-04 5.00000e-04 5.00000e-05 1.00000e-09 1.00000e-01 5.00000e-04 5.00000e-04 5.00000e-05 1.00000e-09 1.00000e-01 $2.94779 \mathrm{e}+002.94779 \mathrm{e}+002.94779 \mathrm{e}-01$ 1.00000e-09 2.12000e-01 $2.94779 \mathrm{e}+002.94779 \mathrm{e}+002.94779 \mathrm{e}-011.00000 \mathrm{e}-092.12000 \mathrm{e}-01$ $2.94779 \mathrm{e}+002.94779 \mathrm{e}+002.94779 \mathrm{e}-01$ 1.00000e-09 2.12000e-01 $2.94779 \mathrm{e}+002.94779 \mathrm{e}+002.94779 \mathrm{e}-01$ 1.00000e-09 2.12000e-01 $2.94779 \mathrm{e}+002.94779 \mathrm{e}+002.94779 \mathrm{e}-01$ 1.00000e-09 2.12000e-01 $1.00000 \mathrm{e}-02$ 1.00000e-02 1.00000e-03 1.00000e-09 1.00000e-01 $1.00000 \mathrm{e}+001.00000 \mathrm{e}+001.00000 \mathrm{e}-011.00000 \mathrm{e}-091.00000 \mathrm{e}-01$ $1.00000 \mathrm{e}-05$ 1.00000e-05 1.00000e-06 1.00000e-09 1.00000e-01 $1.00000 \mathrm{e}+001.00000 \mathrm{e}+001.00000 \mathrm{e}-011.00000 \mathrm{e}-091.00000 \mathrm{e}-01$ Element: 2967 \# of layers: 15

Kx Ky Kz Ss Por $6.01580 \mathrm{e}+016.01580 \mathrm{e}+016.01580 \mathrm{e}+001.00000 \mathrm{e}-09$ 7.00000e-02 $6.01580 \mathrm{e}+016.01580 \mathrm{e}+016.01580 \mathrm{e}+001.00000 \mathrm{e}-09$ 7.00000e-02 
$6.01580 \mathrm{e}+016.01580 \mathrm{e}+016.01580 \mathrm{e}+001.00000 \mathrm{e}-09$ 7.00000e-02 $6.01580 \mathrm{e}+016.01580 \mathrm{e}+016.01580 \mathrm{e}+001.00000 \mathrm{e}-09$ 7.00000e-02 5.00000e-04 5.00000e-04 5.00000e-05 1.00000e-09 1.00000e-01 5.00000e-04 5.00000e-04 5.00000e-05 1.00000e-09 1.00000e-01 $2.40373 \mathrm{e}+002.40373 \mathrm{e}+00$ 2.40373e-01 1.00000e-09 2.12000e-01 $2.40373 \mathrm{e}+002.40373 \mathrm{e}+00$ 2.40373e-01 1.00000e-09 2.12000e-01 $2.40373 \mathrm{e}+00$ 2.40373e+00 2.40373e-01 1.00000e-09 2.12000e-01 $2.40373 \mathrm{e}+002.40373 \mathrm{e}+00$ 2.40373e-01 1.00000e-09 2.12000e-01 $2.40373 \mathrm{e}+002.40373 \mathrm{e}+00$ 2.40373e-01 1.00000e-09 2.12000e-01 $1.00000 \mathrm{e}-02$ 1.00000e-02 1.00000e-03 1.00000e-09 1.00000e-01 $1.00000 \mathrm{e}+001.00000 \mathrm{e}+001.00000 \mathrm{e}-011.00000 \mathrm{e}-091.00000 \mathrm{e}-01$ $1.00000 \mathrm{e}-05$ 1.00000e-05 1.00000e-06 1.00000e-09 1.00000e-01 $1.00000 \mathrm{e}+001.00000 \mathrm{e}+001.00000 \mathrm{e}-011.00000 \mathrm{e}-091.00000 \mathrm{e}-01$ Element: 2968 \# of layers: 15

$\mathrm{Kx} \mathrm{Ky} \mathrm{Kz}$ Ss Por

6.01580e+01 6.01580e+01 6.01580e+00 1.00000e-09 7.00000e-02 $6.01580 \mathrm{e}+016.01580 \mathrm{e}+016.01580 \mathrm{e}+001.00000 \mathrm{e}-09$ 7.00000e-02 $6.01580 \mathrm{e}+016.01580 \mathrm{e}+016.01580 \mathrm{e}+001.00000 \mathrm{e}-09$ 7.00000e-02 6.01580e+01 6.01580e+01 6.01580e+00 1.00000e-09 7.00000e-02 5.00000e-04 5.00000e-04 5.00000e-05 1.00000e-09 1.00000e-01 5.00000e-04 5.00000e-04 5.00000e-05 1.00000e-09 1.00000e-01

$2.40373 \mathrm{e}+00$ 2.40373e+00 2.40373e-01 1.00000e-09 2.12000e-01 2.40373e+00 2.40373e+00 2.40373e-01 1.00000e-09 2.12000e-01 $2.40373 \mathrm{e}+00$ 2.40373e+00 2.40373e-01 1.00000e-09 2.12000e-01 $2.40373 \mathrm{e}+002.40373 \mathrm{e}+00$ 2.40373e-01 1.00000e-09 2.12000e-01 $2.40373 e+002.40373 e+00$ 2.40373e-01 1.00000e-09 2.12000e-01 $1.00000 \mathrm{e}-02$ 1.00000e-02 1.00000e-03 1.00000e-09 1.00000e-01 $1.00000 \mathrm{e}+001.00000 \mathrm{e}+001.00000 \mathrm{e}-011.00000 \mathrm{e}-091.00000 \mathrm{e}-01$ $1.00000 \mathrm{e}-05$ 1.00000e-05 1.00000e-06 1.00000e-09 1.00000e-01 $1.00000 \mathrm{e}+001.00000 \mathrm{e}+001.00000 \mathrm{e}-01$ 1.00000e-09 1.00000e-01 Element: 2969 \# of layers: 14

Kx Ky Kz Ss Por 6.01580e+01 6.01580e+01 6.01580e+00 1.00000e-09 7.00000e-02 $6.01580 \mathrm{e}+016.01580 \mathrm{e}+016.01580 \mathrm{e}+001.00000 \mathrm{e}-09$ 7.00000e-02 6.01580e+01 6.01580e+01 6.01580e+00 1.00000e-09 7.00000e-02 5.00000e-04 5.00000e-04 5.00000e-05 1.00000e-09 1.00000e-01 5.00000e-04 5.00000e-04 5.00000e-05 1.00000e-09 1.00000e-01 $2.40373 \mathrm{e}+002.40373 \mathrm{e}+00$ 2.40373e-01 1.00000e-09 2.12000e-01 $2.40373 \mathrm{e}+002.40373 \mathrm{e}+00$ 2.40373e-01 1.00000e-09 2.12000e-01 $2.40373 \mathrm{e}+00$ 2.40373e+00 2.40373e-01 1.00000e-09 2.12000e-01 $2.40373 \mathrm{e}+002.40373 \mathrm{e}+00$ 2.40373e-01 1.00000e-09 2.12000e-01 $2.40373 \mathrm{e}+00$ 2.40373e+00 2.40373e-01 1.00000e-09 2.12000e-01 $1.00000 \mathrm{e}-021.00000 \mathrm{e}-021.00000 \mathrm{e}-031.00000 \mathrm{e}-091.00000 \mathrm{e}-01$ $1.00000 \mathrm{e}+001.00000 \mathrm{e}+001.00000 \mathrm{e}-011.00000 \mathrm{e}-091.00000 \mathrm{e}-01$ $1.00000 \mathrm{e}-05$ 1.00000e-05 1.00000e-06 1.00000e-09 1.00000e-01 $1.00000 \mathrm{e}+001.00000 \mathrm{e}+001.00000 \mathrm{e}-011.00000 \mathrm{e}-091.00000 \mathrm{e}-01$ 
Element: 2970 \# of layers: 14

$\mathrm{Kx} \mathrm{Ky} \mathrm{Kz}$ Ss Por

6.01580e+01 6.01580e+01 6.01580e+00 1.00000e-09 7.00000e-02

$6.01580 \mathrm{e}+016.01580 \mathrm{e}+016.01580 \mathrm{e}+001.00000 \mathrm{e}-09$ 7.00000e-02

$6.01580 \mathrm{e}+016.01580 \mathrm{e}+016.01580 \mathrm{e}+001.00000 \mathrm{e}-097.00000 \mathrm{e}-02$

5.00000e-04 5.00000e-04 5.00000e-05 1.00000e-09 1.00000e-01

5.00000e-04 5.00000e-04 5.00000e-05 1.00000e-09 1.00000e-01

$2.40373 \mathrm{e}+002.40373 \mathrm{e}+00$ 2.40373e-01 1.00000e-09 2.12000e-01

$2.40373 \mathrm{e}+002.40373 \mathrm{e}+00$ 2.40373e-01 1.00000e-09 2.12000e-01

$2.40373 \mathrm{e}+002.40373 \mathrm{e}+00$ 2.40373e-01 1.00000e-09 2.12000e-01

$2.40373 \mathrm{e}+002.40373 \mathrm{e}+00$ 2.40373e-01 1.00000e-09 2.12000e-01

$2.40373 \mathrm{e}+002.40373 \mathrm{e}+00$ 2.40373e-01 1.00000e-09 2.12000e-01

$1.00000 \mathrm{e}-02$ 1.00000e-02 1.00000e-03 1.00000e-09 1.00000e-01

$1.00000 \mathrm{e}+001.00000 \mathrm{e}+001.00000 \mathrm{e}-011.00000 \mathrm{e}-091.00000 \mathrm{e}-01$

$1.00000 \mathrm{e}-05$ 1.00000e-05 1.00000e-06 1.00000e-09 1.00000e-01

$1.00000 \mathrm{e}+001.00000 \mathrm{e}+001.00000 \mathrm{e}-011.00000 \mathrm{e}-091.00000 \mathrm{e}-01$

Element: 2971 \# of layers: 15

$\mathrm{Kx} \mathrm{Ky} \mathrm{Kz}$ Ss Por

6.01580e+01 6.01580e+01 6.01580e+00 1.00000e-09 7.00000e-02

$6.01580 \mathrm{e}+016.01580 \mathrm{e}+016.01580 \mathrm{e}+001.00000 \mathrm{e}-09$ 7.00000e-02

$6.01580 \mathrm{e}+016.01580 \mathrm{e}+016.01580 \mathrm{e}+001.00000 \mathrm{e}-09$ 7.00000e-02

6.01580e+01 6.01580e+01 6.01580e+00 1.00000e-09 7.00000e-02

5.00000e-04 5.00000e-04 5.00000e-05 1.00000e-09 1.00000e-01

5.00000e-04 5.00000e-04 5.00000e-05 1.00000e-09 1.00000e-01

$2.40373 \mathrm{e}+002.40373 \mathrm{e}+00$ 2.40373e-01 1.00000e-09 2.12000e-01

$2.40373 \mathrm{e}+002.40373 \mathrm{e}+00$ 2.40373e-01 1.00000e-09 2.12000e-01

$2.40373 \mathrm{e}+002.40373 \mathrm{e}+00$ 2.40373e-01 1.00000e-09 2.12000e-01

$2.40373 \mathrm{e}+00$ 2.40373e+00 2.40373e-01 1.00000e-09 2.12000e-01

$2.40373 \mathrm{e}+002.40373 \mathrm{e}+00$ 2.40373e-01 1.00000e-09 2.12000e-01

$1.00000 \mathrm{e}-02$ 1.00000e-02 1.00000e-03 1.00000e-09 1.00000e-01

$1.00000 \mathrm{e}+001.00000 \mathrm{e}+001.00000 \mathrm{e}-01$ 1.00000e-09 1.00000e-01

$1.00000 \mathrm{e}-05$ 1.00000e-05 1.00000e-06 1.00000e-09 1.00000e-01

$1.00000 \mathrm{e}+001.00000 \mathrm{e}+001.00000 \mathrm{e}-011.00000 \mathrm{e}-091.00000 \mathrm{e}-01$

Element: 2972 \# of layers: 16

$\mathrm{Kx} \mathrm{Ky} \mathrm{Kz}$ Ss Por

6.01580e+01 6.01580e+01 6.01580e+00 1.00000e-09 7.00000e-02

$6.01580 \mathrm{e}+016.01580 \mathrm{e}+016.01580 \mathrm{e}+001.00000 \mathrm{e}-09$ 7.00000e-02

6.01580e+01 6.01580e+01 6.01580e+00 1.00000e-09 7.00000e-02

$6.01580 \mathrm{e}+016.01580 \mathrm{e}+016.01580 \mathrm{e}+001.00000 \mathrm{e}-09$ 7.00000e-02

$6.01580 \mathrm{e}+016.01580 \mathrm{e}+016.01580 \mathrm{e}+001.00000 \mathrm{e}-09$ 7.00000e-02

5.00000e-04 5.00000e-04 5.00000e-05 1.00000e-09 1.00000e-01

5.00000e-04 5.00000e-04 5.00000e-05 1.00000e-09 1.00000e-01

$2.40373 \mathrm{e}+002.40373 \mathrm{e}+00$ 2.40373e-01 1.00000e-09 2.12000e-01

2.40373e+00 2.40373e+00 2.40373e-01 1.00000e-09 2.12000e-01

$2.40373 \mathrm{e}+002.40373 \mathrm{e}+00$ 2.40373e-01 1.00000e-09 2.12000e-01

$2.40373 \mathrm{e}+002.40373 \mathrm{e}+00$ 2.40373e-01 1.00000e-09 2.12000e-01 
2.40373e+00 2.40373e+00 2.40373e-01 1.00000e-09 2.12000e-01 $1.00000 \mathrm{e}-02$ 1.00000e-02 1.00000e-03 1.00000e-09 1.00000e-01 $1.00000 \mathrm{e}+001.00000 \mathrm{e}+001.00000 \mathrm{e}-011.00000 \mathrm{e}-091.00000 \mathrm{e}-01$ $1.00000 \mathrm{e}-05$ 1.00000e-05 1.00000e-06 1.00000e-09 1.00000e-01 $1.00000 \mathrm{e}+001.00000 \mathrm{e}+001.00000 \mathrm{e}-01$ 1.00000e-09 1.00000e-01 Element: 2973 \# of layers: 15

$\mathrm{Kx} \mathrm{Ky} \mathrm{Kz}$ Ss Por

6.01580e+01 6.01580e+01 6.01580e+00 1.00000e-09 7.00000e-02 $6.01580 \mathrm{e}+016.01580 \mathrm{e}+016.01580 \mathrm{e}+00$ 1.00000e-09 7.00000e-02 $6.01580 \mathrm{e}+016.01580 \mathrm{e}+016.01580 \mathrm{e}+001.00000 \mathrm{e}-09$ 7.00000e-02 $6.01580 \mathrm{e}+016.01580 \mathrm{e}+016.01580 \mathrm{e}+001.00000 \mathrm{e}-09$ 7.00000e-02 5.00000e-04 5.00000e-04 5.00000e-05 1.00000e-09 1.00000e-01 5.00000e-04 5.00000e-04 5.00000e-05 1.00000e-09 1.00000e-01

$2.40373 \mathrm{e}+002.40373 \mathrm{e}+00$ 2.40373e-01 1.00000e-09 2.12000e-01 $2.40373 \mathrm{e}+002.40373 \mathrm{e}+00$ 2.40373e-01 1.00000e-09 2.12000e-01 $2.40373 \mathrm{e}+002.40373 \mathrm{e}+00$ 2.40373e-01 1.00000e-09 2.12000e-01 $2.40373 \mathrm{e}+002.40373 \mathrm{e}+00$ 2.40373e-01 1.00000e-09 2.12000e-01 $2.40373 \mathrm{e}+00$ 2.40373e+00 2.40373e-01 1.00000e-09 2.12000e-01 $1.00000 \mathrm{e}-02$ 1.00000e-02 1.00000e-03 1.00000e-09 1.00000e-01 $1.00000 \mathrm{e}+001.00000 \mathrm{e}+001.00000 \mathrm{e}-011.00000 \mathrm{e}-091.00000 \mathrm{e}-01$ $1.00000 \mathrm{e}-05$ 1.00000e-05 1.00000e-06 1.00000e-09 1.00000e-01 $1.00000 \mathrm{e}+001.00000 \mathrm{e}+001.00000 \mathrm{e}-01$ 1.00000e-09 1.00000e-01 Element: 2974 \# of layers: 16

$\mathrm{Kx} \mathrm{Ky} \mathrm{Kz}$ Ss Por

6.01580e+01 6.01580e+01 6.01580e+00 1.00000e-09 7.00000e-02 $6.01580 \mathrm{e}+016.01580 \mathrm{e}+016.01580 \mathrm{e}+001.00000 \mathrm{e}-09$ 7.00000e-02 $6.01580 \mathrm{e}+016.01580 \mathrm{e}+016.01580 \mathrm{e}+001.00000 \mathrm{e}-09$ 7.00000e-02 $6.01580 \mathrm{e}+016.01580 \mathrm{e}+016.01580 \mathrm{e}+001.00000 \mathrm{e}-09$ 7.00000e-02 $6.01580 \mathrm{e}+016.01580 \mathrm{e}+016.01580 \mathrm{e}+001.00000 \mathrm{e}-097.00000 \mathrm{e}-02$ 5.00000e-04 5.00000e-04 5.00000e-05 1.00000e-09 1.00000e-01 5.00000e-04 5.00000e-04 5.00000e-05 1.00000e-09 1.00000e-01 $2.40373 \mathrm{e}+00$ 2.40373e+00 2.40373e-01 1.00000e-09 2.12000e-01 $2.40373 \mathrm{e}+002.40373 \mathrm{e}+00$ 2.40373e-01 1.00000e-09 2.12000e-01 $2.40373 \mathrm{e}+002.40373 \mathrm{e}+00$ 2.40373e-01 1.00000e-09 2.12000e-01 $2.40373 \mathrm{e}+00$ 2.40373e+00 2.40373e-01 1.00000e-09 2.12000e-01 $2.40373 \mathrm{e}+00$ 2.40373e+00 2.40373e-01 1.00000e-09 2.12000e-01 $1.00000 \mathrm{e}-02$ 1.00000e-02 1.00000e-03 1.00000e-09 1.00000e-01 $1.00000 \mathrm{e}+001.00000 \mathrm{e}+001.00000 \mathrm{e}-011.00000 \mathrm{e}-091.00000 \mathrm{e}-01$ $1.00000 \mathrm{e}-05$ 1.00000e-05 1.00000e-06 1.00000e-09 1.00000e-01 $1.00000 \mathrm{e}+001.00000 \mathrm{e}+001.00000 \mathrm{e}-011.00000 \mathrm{e}-091.00000 \mathrm{e}-01$ Element: 2975 \# of layers: 16

$\mathrm{Kx} \mathrm{Ky} \mathrm{Kz}$ Ss Por 6.01580e+01 6.01580e+01 6.01580e+00 1.00000e-09 7.00000e-02 $6.01580 \mathrm{e}+016.01580 \mathrm{e}+016.01580 \mathrm{e}+001.00000 \mathrm{e}-09$ 7.00000e-02 6.01580e+01 6.01580e+01 6.01580e+00 1.00000e-09 7.00000e-02 $6.01580 \mathrm{e}+016.01580 \mathrm{e}+016.01580 \mathrm{e}+001.00000 \mathrm{e}-09$ 7.00000e-02 
6.01580e+01 6.01580e+01 6.01580e+00 1.00000e-09 7.00000e-02 5.00000e-04 5.00000e-04 5.00000e-05 1.00000e-09 1.00000e-01 5.00000e-04 5.00000e-04 5.00000e-05 1.00000e-09 1.00000e-01

$2.40373 \mathrm{e}+002.40373 \mathrm{e}+00$ 2.40373e-01 1.00000e-09 2.12000e-01 $2.40373 \mathrm{e}+002.40373 \mathrm{e}+00$ 2.40373e-01 1.00000e-09 2.12000e-01 $2.40373 \mathrm{e}+002.40373 \mathrm{e}+00$ 2.40373e-01 1.00000e-09 2.12000e-01 $2.40373 \mathrm{e}+002.40373 \mathrm{e}+00$ 2.40373e-01 1.00000e-09 2.12000e-01 $2.40373 \mathrm{e}+002.40373 \mathrm{e}+00$ 2.40373e-01 1.00000e-09 2.12000e-01 $1.00000 \mathrm{e}-02$ 1.00000e-02 1.00000e-03 1.00000e-09 1.00000e-01 $1.00000 \mathrm{e}+001.00000 \mathrm{e}+001.00000 \mathrm{e}-011.00000 \mathrm{e}-091.00000 \mathrm{e}-01$ $1.00000 \mathrm{e}-05$ 1.00000e-05 1.00000e-06 1.00000e-09 1.00000e-01 $1.00000 \mathrm{e}+001.00000 \mathrm{e}+001.00000 \mathrm{e}-011.00000 \mathrm{e}-091.00000 \mathrm{e}-01$ Element: 2976 \# of layers: 14

$\mathrm{Kx} \mathrm{Ky} \mathrm{Kz}$ Ss Por

4.96136e+01 4.96136e+01 4.96136e+00 1.00000e-09 7.00000e-02 $4.96136 \mathrm{e}+014.96136 \mathrm{e}+014.96136 \mathrm{e}+001.00000 \mathrm{e}-09$ 7.00000e-02 $4.96136 \mathrm{e}+014.96136 \mathrm{e}+014.96136 \mathrm{e}+001.00000 \mathrm{e}-09$ 7.00000e-02 5.00000e-04 5.00000e-04 5.00000e-05 1.00000e-09 1.00000e-01 $5.00000 \mathrm{e}-04$ 5.00000e-04 5.00000e-05 1.00000e-09 1.00000e-01 $1.98238 \mathrm{e}+001.98238 \mathrm{e}+00$ 1.98238e-01 1.00000e-09 2.12000e-01 $1.98238 \mathrm{e}+001.98238 \mathrm{e}+00$ 1.98238e-01 1.00000e-09 2.12000e-01 $1.98238 \mathrm{e}+00$ 1.98238e+00 1.98238e-01 1.00000e-09 2.12000e-01 $1.98238 \mathrm{e}+001.98238 \mathrm{e}+00$ 1.98238e-01 1.00000e-09 2.12000e-01 $1.98238 \mathrm{e}+001.98238 \mathrm{e}+00$ 1.98238e-01 1.00000e-09 2.12000e-01 $1.00000 \mathrm{e}-02$ 1.00000e-02 1.00000e-03 1.00000e-09 1.00000e-01 $1.00000 \mathrm{e}+001.00000 \mathrm{e}+001.00000 \mathrm{e}-011.00000 \mathrm{e}-091.00000 \mathrm{e}-01$ $1.00000 \mathrm{e}-05$ 1.00000e-05 1.00000e-06 1.00000e-09 1.00000e-01 $1.00000 \mathrm{e}+001.00000 \mathrm{e}+001.00000 \mathrm{e}-011.00000 \mathrm{e}-09$ 1.00000e-01 Element: 2977 \# of layers: 14

$\mathrm{Kx} \mathrm{Ky} \mathrm{Kz}$ Ss Por

4.96136e+01 4.96136e+01 4.96136e+00 1.00000e-09 7.00000e-02 $4.96136 \mathrm{e}+014.96136 \mathrm{e}+014.96136 \mathrm{e}+001.00000 \mathrm{e}-09$ 7.00000e-02 $4.96136 \mathrm{e}+014.96136 \mathrm{e}+014.96136 \mathrm{e}+001.00000 \mathrm{e}-09$ 7.00000e-02 $5.00000 \mathrm{e}-04$ 5.00000e-04 5.00000e-05 1.00000e-09 1.00000e-01 5.00000e-04 5.00000e-04 5.00000e-05 1.00000e-09 1.00000e-01 $1.98238 \mathrm{e}+001.98238 \mathrm{e}+00$ 1.98238e-01 1.00000e-09 2.12000e-01 $1.98238 \mathrm{e}+001.98238 \mathrm{e}+00$ 1.98238e-01 1.00000e-09 2.12000e-01 $1.98238 \mathrm{e}+00$ 1.98238e+00 1.98238e-01 1.00000e-09 2.12000e-01 $1.98238 \mathrm{e}+00$ 1.98238e+00 1.98238e-01 1.00000e-09 2.12000e-01 $1.98238 \mathrm{e}+001.98238 \mathrm{e}+00$ 1.98238e-01 1.00000e-09 2.12000e-01 $1.00000 \mathrm{e}-02$ 1.00000e-02 1.00000e-03 1.00000e-09 1.00000e-01 $1.00000 \mathrm{e}+001.00000 \mathrm{e}+001.00000 \mathrm{e}-011.00000 \mathrm{e}-091.00000 \mathrm{e}-01$ $1.00000 \mathrm{e}-05$ 1.00000e-05 1.00000e-06 1.00000e-09 1.00000e-01 $1.00000 \mathrm{e}+001.00000 \mathrm{e}+001.00000 \mathrm{e}-01$ 1.00000e-09 1.00000e-01 Element: 2978 \# of layers: 14

Kx Ky Kz Ss Por 
4.96136e+01 4.96136e+01 4.96136e+00 1.00000e-09 7.00000e-02 4.96136e+01 4.96136e+01 4.96136e+00 1.00000e-09 7.00000e-02 $4.96136 \mathrm{e}+014.96136 \mathrm{e}+014.96136 \mathrm{e}+001.00000 \mathrm{e}-09$ 7.00000e-02 5.00000e-04 5.00000e-04 5.00000e-05 1.00000e-09 1.00000e-01 5.00000e-04 5.00000e-04 5.00000e-05 1.00000e-09 1.00000e-01 $1.98238 \mathrm{e}+001.98238 \mathrm{e}+00$ 1.98238e-01 1.00000e-09 2.12000e-01 $1.98238 \mathrm{e}+00$ 1.98238e+00 1.98238e-01 1.00000e-09 2.12000e-01 $1.98238 \mathrm{e}+00$ 1.98238e+00 1.98238e-01 1.00000e-09 2.12000e-01 $1.98238 \mathrm{e}+00$ 1.98238e+00 1.98238e-01 1.00000e-09 2.12000e-01 $1.98238 \mathrm{e}+001.98238 \mathrm{e}+00$ 1.98238e-01 1.00000e-09 2.12000e-01 $1.00000 \mathrm{e}-02$ 1.00000e-02 1.00000e-03 1.00000e-09 1.00000e-01 $1.00000 \mathrm{e}+001.00000 \mathrm{e}+001.00000 \mathrm{e}-011.00000 \mathrm{e}-091.00000 \mathrm{e}-01$ $1.00000 \mathrm{e}-05$ 1.00000e-05 1.00000e-06 1.00000e-09 1.00000e-01 $1.00000 \mathrm{e}+001.00000 \mathrm{e}+001.00000 \mathrm{e}-011.00000 \mathrm{e}-09$ 1.00000e-01 Element: 2979 \# of layers: 14

Kx Ky Kz Ss Por

4.96136e+01 4.96136e+01 4.96136e+00 1.00000e-09 7.00000e-02 $4.96136 \mathrm{e}+014.96136 \mathrm{e}+014.96136 \mathrm{e}+001.00000 \mathrm{e}-09$ 7.00000e-02 $4.96136 \mathrm{e}+014.96136 \mathrm{e}+014.96136 \mathrm{e}+001.00000 \mathrm{e}-09$ 7.00000e-02 5.00000e-04 5.00000e-04 5.00000e-05 1.00000e-09 1.00000e-01 5.00000e-04 5.00000e-04 5.00000e-05 1.00000e-09 1.00000e-01 $1.98238 \mathrm{e}+00$ 1.98238e+00 1.98238e-01 1.00000e-09 2.12000e-01 $1.98238 \mathrm{e}+001.98238 \mathrm{e}+00$ 1.98238e-01 1.00000e-09 2.12000e-01 $1.98238 \mathrm{e}+00$ 1.98238e+00 1.98238e-01 1.00000e-09 2.12000e-01 $1.98238 \mathrm{e}+001.98238 \mathrm{e}+00$ 1.98238e-01 1.00000e-09 2.12000e-01 $1.98238 \mathrm{e}+00$ 1.98238e+00 1.98238e-01 1.00000e-09 2.12000e-01 $1.00000 \mathrm{e}-02$ 1.00000e-02 1.00000e-03 1.00000e-09 1.00000e-01 $1.00000 \mathrm{e}+001.00000 \mathrm{e}+001.00000 \mathrm{e}-011.00000 \mathrm{e}-091.00000 \mathrm{e}-01$ $1.00000 \mathrm{e}-05$ 1.00000e-05 1.00000e-06 1.00000e-09 1.00000e-01 $1.00000 \mathrm{e}+001.00000 \mathrm{e}+001.00000 \mathrm{e}-011.00000 \mathrm{e}-091.00000 \mathrm{e}-01$ Element: 2980 \# of layers: 14

$\mathrm{Kx} \mathrm{Ky} \mathrm{Kz}$ Ss Por

4.96136e+01 4.96136e+01 4.96136e+00 1.00000e-09 7.00000e-02 $4.96136 \mathrm{e}+014.96136 \mathrm{e}+014.96136 \mathrm{e}+001.00000 \mathrm{e}-09$ 7.00000e-02 $4.96136 \mathrm{e}+014.96136 \mathrm{e}+014.96136 \mathrm{e}+001.00000 \mathrm{e}-09$ 7.00000e-02 5.00000e-04 5.00000e-04 5.00000e-05 1.00000e-09 1.00000e-01 5.00000e-04 5.00000e-04 5.00000e-05 1.00000e-09 1.00000e-01 $1.98238 \mathrm{e}+001.98238 \mathrm{e}+00$ 1.98238e-01 1.00000e-09 2.12000e-01 $1.98238 \mathrm{e}+00$ 1.98238e+00 1.98238e-01 1.00000e-09 2.12000e-01 $1.98238 \mathrm{e}+001.98238 \mathrm{e}+00$ 1.98238e-01 1.00000e-09 2.12000e-01 $1.98238 \mathrm{e}+001.98238 \mathrm{e}+00$ 1.98238e-01 1.00000e-09 2.12000e-01 $1.98238 \mathrm{e}+001.98238 \mathrm{e}+00$ 1.98238e-01 1.00000e-09 2.12000e-01 $1.00000 \mathrm{e}-02$ 1.00000e-02 1.00000e-03 1.00000e-09 1.00000e-01 $1.00000 \mathrm{e}+001.00000 \mathrm{e}+001.00000 \mathrm{e}-011.00000 \mathrm{e}-091.00000 \mathrm{e}-01$ $1.00000 \mathrm{e}-05$ 1.00000e-05 1.00000e-06 1.00000e-09 1.00000e-01 $1.00000 \mathrm{e}+001.00000 \mathrm{e}+001.00000 \mathrm{e}-011.00000 \mathrm{e}-091.00000 \mathrm{e}-01$ 
Element: 2981 \# of layers: 14

$\mathrm{Kx} \mathrm{Ky} \mathrm{Kz}$ Ss Por

4.96136e+01 4.96136e+01 4.96136e+00 1.00000e-09 7.00000e-02

$4.96136 \mathrm{e}+014.96136 \mathrm{e}+014.96136 \mathrm{e}+001.00000 \mathrm{e}-09$ 7.00000e-02

$4.96136 \mathrm{e}+014.96136 \mathrm{e}+014.96136 \mathrm{e}+001.00000 \mathrm{e}-09$ 7.00000e-02

5.00000e-04 5.00000e-04 5.00000e-05 1.00000e-09 1.00000e-01

5.00000e-04 5.00000e-04 5.00000e-05 1.00000e-09 1.00000e-01

$1.98238 \mathrm{e}+00$ 1.98238e+00 1.98238e-01 1.00000e-09 2.12000e-01

$1.98238 \mathrm{e}+00$ 1.98238e+00 1.98238e-01 1.00000e-09 2.12000e-01

$1.98238 \mathrm{e}+00$ 1.98238e+00 1.98238e-01 1.00000e-09 2.12000e-01

$1.98238 \mathrm{e}+00$ 1.98238e+00 1.98238e-01 1.00000e-09 2.12000e-01

$1.98238 \mathrm{e}+001.98238 \mathrm{e}+00$ 1.98238e-01 1.00000e-09 2.12000e-01

$1.00000 \mathrm{e}-02$ 1.00000e-02 1.00000e-03 1.00000e-09 1.00000e-01

$1.00000 \mathrm{e}+001.00000 \mathrm{e}+001.00000 \mathrm{e}-011.00000 \mathrm{e}-091.00000 \mathrm{e}-01$

$1.00000 \mathrm{e}-05$ 1.00000e-05 1.00000e-06 1.00000e-09 1.00000e-01

$1.00000 \mathrm{e}+001.00000 \mathrm{e}+001.00000 \mathrm{e}-011.00000 \mathrm{e}-091.00000 \mathrm{e}-01$

Element: 2982 \# of layers: 14

$\mathrm{Kx} \mathrm{Ky} \mathrm{Kz}$ Ss Por

4.96136e+01 4.96136e+01 4.96136e+00 1.00000e-09 7.00000e-02

$4.96136 \mathrm{e}+014.96136 \mathrm{e}+014.96136 \mathrm{e}+001.00000 \mathrm{e}-09$ 7.00000e-02

$4.96136 \mathrm{e}+014.96136 \mathrm{e}+014.96136 \mathrm{e}+001.00000 \mathrm{e}-09$ 7.00000e-02

5.00000e-04 5.00000e-04 5.00000e-05 1.00000e-09 1.00000e-01

5.00000e-04 5.00000e-04 5.00000e-05 1.00000e-09 1.00000e-01

$1.98238 \mathrm{e}+001.98238 \mathrm{e}+00$ 1.98238e-01 1.00000e-09 2.12000e-01

$1.98238 \mathrm{e}+001.98238 \mathrm{e}+00$ 1.98238e-01 1.00000e-09 2.12000e-01

$1.98238 \mathrm{e}+00$ 1.98238e+00 1.98238e-01 1.00000e-09 2.12000e-01

$1.98238 \mathrm{e}+001.98238 \mathrm{e}+00$ 1.98238e-01 1.00000e-09 2.12000e-01

$1.98238 \mathrm{e}+001.98238 \mathrm{e}+00$ 1.98238e-01 1.00000e-09 2.12000e-01

$1.00000 \mathrm{e}-02$ 1.00000e-02 1.00000e-03 1.00000e-09 1.00000e-01

$1.00000 \mathrm{e}+001.00000 \mathrm{e}+001.00000 \mathrm{e}-011.00000 \mathrm{e}-091.00000 \mathrm{e}-01$

$1.00000 \mathrm{e}-05$ 1.00000e-05 1.00000e-06 1.00000e-09 1.00000e-01

$1.00000 \mathrm{e}+001.00000 \mathrm{e}+001.00000 \mathrm{e}-01$ 1.00000e-09 1.00000e-01

Element: 2983 \# of layers: 14

$\mathrm{Kx} \mathrm{Ky} \mathrm{Kz}$ Ss Por

4.96136e+01 4.96136e+01 4.96136e+00 1.00000e-09 7.00000e-02

$4.96136 \mathrm{e}+014.96136 \mathrm{e}+014.96136 \mathrm{e}+001.00000 \mathrm{e}-09$ 7.00000e-02

$4.96136 \mathrm{e}+014.96136 \mathrm{e}+014.96136 \mathrm{e}+001.00000 \mathrm{e}-09$ 7.00000e-02

5.00000e-04 5.00000e-04 5.00000e-05 1.00000e-09 1.00000e-01

5.00000e-04 5.00000e-04 5.00000e-05 1.00000e-09 1.00000e-01

$1.98238 \mathrm{e}+001.98238 \mathrm{e}+00$ 1.98238e-01 1.00000e-09 2.12000e-01

$1.98238 \mathrm{e}+00$ 1.98238e+00 1.98238e-01 1.00000e-09 2.12000e-01

$1.98238 \mathrm{e}+00$ 1.98238e+00 1.98238e-01 1.00000e-09 2.12000e-01

$1.98238 \mathrm{e}+001.98238 \mathrm{e}+00$ 1.98238e-01 1.00000e-09 2.12000e-01

$1.98238 \mathrm{e}+001.98238 \mathrm{e}+00$ 1.98238e-01 1.00000e-09 2.12000e-01

$1.00000 \mathrm{e}-02$ 1.00000e-02 1.00000e-03 1.00000e-09 1.00000e-01

$1.00000 \mathrm{e}+001.00000 \mathrm{e}+001.00000 \mathrm{e}-01$ 1.00000e-09 1.00000e-01 
$1.00000 \mathrm{e}-05$ 1.00000e-05 1.00000e-06 1.00000e-09 1.00000e-01 $1.00000 \mathrm{e}+001.00000 \mathrm{e}+001.00000 \mathrm{e}-011.00000 \mathrm{e}-091.00000 \mathrm{e}-01$ Element: 2984 \# of layers: 14

Kx Ky Kz Ss Por

4.96136e+01 4.96136e+01 4.96136e+00 1.00000e-09 7.00000e-02 $4.96136 \mathrm{e}+014.96136 \mathrm{e}+014.96136 \mathrm{e}+00$ 1.00000e-09 7.00000e-02 $4.96136 \mathrm{e}+014.96136 \mathrm{e}+014.96136 \mathrm{e}+00$ 1.00000e-09 7.00000e-02 5.00000e-04 5.00000e-04 5.00000e-05 1.00000e-09 1.00000e-01 5.00000e-04 5.00000e-04 5.00000e-05 1.00000e-09 1.00000e-01 $1.98238 \mathrm{e}+001.98238 \mathrm{e}+00$ 1.98238e-01 1.00000e-09 2.12000e-01 $1.98238 \mathrm{e}+00$ 1.98238e+00 1.98238e-01 1.00000e-09 2.12000e-01 $1.98238 \mathrm{e}+00$ 1.98238e+00 1.98238e-01 1.00000e-09 2.12000e-01 $1.98238 \mathrm{e}+00$ 1.98238e+00 1.98238e-01 1.00000e-09 2.12000e-01 $1.98238 \mathrm{e}+001.98238 \mathrm{e}+00$ 1.98238e-01 1.00000e-09 2.12000e-01 $1.00000 \mathrm{e}-02$ 1.00000e-02 1.00000e-03 1.00000e-09 1.00000e-01 $1.00000 \mathrm{e}+001.00000 \mathrm{e}+001.00000 \mathrm{e}-011.00000 \mathrm{e}-091.00000 \mathrm{e}-01$ $1.00000 \mathrm{e}-05$ 1.00000e-05 1.00000e-06 1.00000e-09 1.00000e-01 $1.00000 \mathrm{e}+001.00000 \mathrm{e}+001.00000 \mathrm{e}-01$ 1.00000e-09 1.00000e-01 Element: 2985 \# of layers: 14

$\mathrm{Kx} \mathrm{Ky} \mathrm{Kz}$ Ss Por

4.33985e+01 4.33985e+01 4.33985e+00 1.00000e-09 7.00000e-02 4.33985e+01 4.33985e+01 4.33985e+00 1.00000e-09 7.00000e-02 4.33985e+01 4.33985e+01 4.33985e+00 1.00000e-09 7.00000e-02 5.00000e-04 5.00000e-04 5.00000e-05 1.00000e-09 1.00000e-01 5.00000e-04 5.00000e-04 5.00000e-05 1.00000e-09 1.00000e-01 $1.73407 \mathrm{e}+001.73407 \mathrm{e}+00$ 1.73407e-01 1.00000e-09 2.12000e-01 $1.73407 \mathrm{e}+00$ 1.73407e+00 1.73407e-01 1.00000e-09 2.12000e-01 $1.73407 \mathrm{e}+00$ 1.73407e+00 1.73407e-01 1.00000e-09 2.12000e-01 $1.73407 \mathrm{e}+00$ 1.73407e+00 1.73407e-01 1.00000e-09 2.12000e-01 $1.73407 \mathrm{e}+001.73407 \mathrm{e}+00$ 1.73407e-01 1.00000e-09 2.12000e-01 $1.00000 \mathrm{e}-02$ 1.00000e-02 1.00000e-03 1.00000e-09 1.00000e-01 $1.00000 \mathrm{e}+001.00000 \mathrm{e}+001.00000 \mathrm{e}-011.00000 \mathrm{e}-091.00000 \mathrm{e}-01$ $1.00000 \mathrm{e}-05$ 1.00000e-05 1.00000e-06 1.00000e-09 1.00000e-01 $1.00000 \mathrm{e}+001.00000 \mathrm{e}+001.00000 \mathrm{e}-011.00000 \mathrm{e}-091.00000 \mathrm{e}-01$ Element: 2986 \# of layers: 15

$\mathrm{Kx} \mathrm{Ky} \mathrm{Kz}$ Ss Por 4.33985e+01 4.33985e+01 4.33985e+00 1.00000e-09 7.00000e-02 $4.33985 \mathrm{e}+014.33985 \mathrm{e}+014.33985 \mathrm{e}+00$ 1.00000e-09 7.00000e-02 4.33985e+01 4.33985e+01 4.33985e+00 1.00000e-09 7.00000e-02 4.33985e+01 4.33985e+01 4.33985e+00 1.00000e-09 7.00000e-02 5.00000e-04 5.00000e-04 5.00000e-05 1.00000e-09 1.00000e-01 5.00000e-04 5.00000e-04 5.00000e-05 1.00000e-09 1.00000e-01 1.73407e+00 1.73407e+00 1.73407e-01 1.00000e-09 2.12000e-01 1.73407e+00 1.73407e+00 1.73407e-01 1.00000e-09 2.12000e-01 $1.73407 \mathrm{e}+00$ 1.73407e+00 1.73407e-01 1.00000e-09 2.12000e-01 $1.73407 \mathrm{e}+001.73407 \mathrm{e}+00$ 1.73407e-01 1.00000e-09 2.12000e-01 
$1.73407 \mathrm{e}+00$ 1.73407e+00 1.73407e-01 1.00000e-09 2.12000e-01 $1.00000 \mathrm{e}-021.00000 \mathrm{e}-02$ 1.00000e-03 1.00000e-09 1.00000e-01 $1.00000 \mathrm{e}+001.00000 \mathrm{e}+001.00000 \mathrm{e}-011.00000 \mathrm{e}-091.00000 \mathrm{e}-01$ $1.00000 \mathrm{e}-05$ 1.00000e-05 1.00000e-06 1.00000e-09 1.00000e-01 $1.00000 \mathrm{e}+001.00000 \mathrm{e}+001.00000 \mathrm{e}-011.00000 \mathrm{e}-091.00000 \mathrm{e}-01$ Element: 2987 \# of layers: 14

Kx Ky Kz Ss Por

$4.33985 \mathrm{e}+01$ 4.33985e+01 4.33985e+00 1.00000e-09 7.00000e-02 $4.33985 \mathrm{e}+014.33985 \mathrm{e}+014.33985 \mathrm{e}+001.00000 \mathrm{e}-09$ 7.00000e-02 $4.33985 \mathrm{e}+014.33985 \mathrm{e}+014.33985 \mathrm{e}+001.00000 \mathrm{e}-09$ 7.00000e-02 5.00000e-04 5.00000e-04 5.00000e-05 1.00000e-09 1.00000e-01 5.00000e-04 5.00000e-04 5.00000e-05 1.00000e-09 1.00000e-01 $1.73407 \mathrm{e}+001.73407 \mathrm{e}+00$ 1.73407e-01 1.00000e-09 2.12000e-01 $1.73407 \mathrm{e}+001.73407 \mathrm{e}+00$ 1.73407e-01 1.00000e-09 2.12000e-01 $1.73407 \mathrm{e}+001.73407 \mathrm{e}+00$ 1.73407e-01 1.00000e-09 2.12000e-01 $1.73407 \mathrm{e}+001.73407 \mathrm{e}+001.73407 \mathrm{e}-011.00000 \mathrm{e}-092.12000 \mathrm{e}-01$ $1.73407 \mathrm{e}+001.73407 \mathrm{e}+00$ 1.73407e-01 1.00000e-09 2.12000e-01 $1.00000 \mathrm{e}-02$ 1.00000e-02 1.00000e-03 1.00000e-09 1.00000e-01 $1.00000 \mathrm{e}+001.00000 \mathrm{e}+001.00000 \mathrm{e}-011.00000 \mathrm{e}-091.00000 \mathrm{e}-01$ $1.00000 \mathrm{e}-051.00000 \mathrm{e}-05$ 1.00000e-06 1.00000e-09 1.00000e-01 $1.00000 \mathrm{e}+001.00000 \mathrm{e}+001.00000 \mathrm{e}-011.00000 \mathrm{e}-091.00000 \mathrm{e}-01$ Element: 2988 \# of layers: 15

Kx Ky Kz Ss Por

$4.33985 \mathrm{e}+014.33985 \mathrm{e}+014.33985 \mathrm{e}+001.00000 \mathrm{e}-09$ 7.00000e-02 $4.33985 \mathrm{e}+014.33985 \mathrm{e}+014.33985 \mathrm{e}+001.00000 \mathrm{e}-09$ 7.00000e-02 $4.33985 \mathrm{e}+014.33985 \mathrm{e}+014.33985 \mathrm{e}+001.00000 \mathrm{e}-09$ 7.00000e-02 $4.33985 \mathrm{e}+014.33985 \mathrm{e}+014.33985 \mathrm{e}+001.00000 \mathrm{e}-09$ 7.00000e-02 5.00000e-04 5.00000e-04 5.00000e-05 1.00000e-09 1.00000e-01 5.00000e-04 5.00000e-04 5.00000e-05 1.00000e-09 1.00000e-01 $1.73407 \mathrm{e}+001.73407 \mathrm{e}+00$ 1.73407e-01 1.00000e-09 2.12000e-01 $1.73407 \mathrm{e}+001.73407 \mathrm{e}+00$ 1.73407e-01 1.00000e-09 2.12000e-01 $1.73407 \mathrm{e}+001.73407 \mathrm{e}+00$ 1.73407e-01 1.00000e-09 2.12000e-01 $1.73407 \mathrm{e}+001.73407 \mathrm{e}+001.73407 \mathrm{e}-011.00000 \mathrm{e}-092.12000 \mathrm{e}-01$ $1.73407 \mathrm{e}+001.73407 \mathrm{e}+001.73407 \mathrm{e}-011.00000 \mathrm{e}-092.12000 \mathrm{e}-01$ $1.00000 \mathrm{e}-021.00000 \mathrm{e}-02$ 1.00000e-03 1.00000e-09 1.00000e-01 $1.00000 \mathrm{e}+001.00000 \mathrm{e}+001.00000 \mathrm{e}-011.00000 \mathrm{e}-091.00000 \mathrm{e}-01$ $1.00000 \mathrm{e}-05$ 1.00000e-05 1.00000e-06 1.00000e-09 1.00000e-01 $1.00000 \mathrm{e}+001.00000 \mathrm{e}+001.00000 \mathrm{e}-011.00000 \mathrm{e}-091.00000 \mathrm{e}-01$ Element: 2989 \# of layers: 14

Kx Ky Kz Ss Por $4.33985 \mathrm{e}+014.33985 \mathrm{e}+014.33985 \mathrm{e}+001.00000 \mathrm{e}-09$ 7.00000e-02 $4.33985 \mathrm{e}+014.33985 \mathrm{e}+014.33985 \mathrm{e}+001.00000 \mathrm{e}-09$ 7.00000e-02 $4.33985 \mathrm{e}+014.33985 \mathrm{e}+014.33985 \mathrm{e}+001.00000 \mathrm{e}-09$ 7.00000e-02 5.00000e-04 5.00000e-04 5.00000e-05 1.00000e-09 1.00000e-01 5.00000e-04 5.00000e-04 5.00000e-05 1.00000e-09 1.00000e-01 $1.73407 \mathrm{e}+001.73407 \mathrm{e}+00$ 1.73407e-01 1.00000e-09 2.12000e-01 
$1.73407 \mathrm{e}+001.73407 \mathrm{e}+00$ 1.73407e-01 1.00000e-09 2.12000e-01 $1.73407 \mathrm{e}+001.73407 \mathrm{e}+00$ 1.73407e-01 1.00000e-09 2.12000e-01 $1.73407 \mathrm{e}+001.73407 \mathrm{e}+001.73407 \mathrm{e}-011.00000 \mathrm{e}-092.12000 \mathrm{e}-01$ $1.73407 \mathrm{e}+001.73407 \mathrm{e}+00$ 1.73407e-01 1.00000e-09 2.12000e-01 $1.00000 \mathrm{e}-02$ 1.00000e-02 1.00000e-03 1.00000e-09 1.00000e-01 $1.00000 \mathrm{e}+001.00000 \mathrm{e}+001.00000 \mathrm{e}-011.00000 \mathrm{e}-091.00000 \mathrm{e}-01$ $1.00000 \mathrm{e}-051.00000 \mathrm{e}-05$ 1.00000e-06 1.00000e-09 1.00000e-01 $1.00000 \mathrm{e}+001.00000 \mathrm{e}+001.00000 \mathrm{e}-011.00000 \mathrm{e}-091.00000 \mathrm{e}-01$ Element: 2990 \# of layers: 14

Kx Ky Kz Ss Por

$4.33985 \mathrm{e}+014.33985 \mathrm{e}+014.33985 \mathrm{e}+00$ 1.00000e-09 7.00000e-02 $4.33985 \mathrm{e}+014.33985 \mathrm{e}+014.33985 \mathrm{e}+001.00000 \mathrm{e}-09$ 7.00000e-02 $4.33985 \mathrm{e}+014.33985 \mathrm{e}+014.33985 \mathrm{e}+001.00000 \mathrm{e}-09$ 7.00000e-02 5.00000e-04 5.00000e-04 5.00000e-05 1.00000e-09 1.00000e-01 $5.00000 \mathrm{e}-04$ 5.00000e-04 5.00000e-05 1.00000e-09 1.00000e-01 $1.73407 \mathrm{e}+001.73407 \mathrm{e}+00$ 1.73407e-01 1.00000e-09 2.12000e-01 $1.73407 \mathrm{e}+001.73407 \mathrm{e}+00$ 1.73407e-01 1.00000e-09 2.12000e-01 $1.73407 \mathrm{e}+001.73407 \mathrm{e}+001.73407 \mathrm{e}-011.00000 \mathrm{e}-092.12000 \mathrm{e}-01$ $1.73407 \mathrm{e}+001.73407 \mathrm{e}+00$ 1.73407e-01 1.00000e-09 2.12000e-01 $1.73407 \mathrm{e}+001.73407 \mathrm{e}+00$ 1.73407e-01 1.00000e-09 2.12000e-01 $1.00000 \mathrm{e}-021.00000 \mathrm{e}-02$ 1.00000e-03 1.00000e-09 1.00000e-01 $1.00000 \mathrm{e}+001.00000 \mathrm{e}+001.00000 \mathrm{e}-011.00000 \mathrm{e}-091.00000 \mathrm{e}-01$ $1.00000 \mathrm{e}-05$ 1.00000e-05 1.00000e-06 1.00000e-09 1.00000e-01 $1.00000 \mathrm{e}+001.00000 \mathrm{e}+001.00000 \mathrm{e}-011.00000 \mathrm{e}-091.00000 \mathrm{e}-01$ Element: 2991 \# of layers: 14

Kx Ky Kz Ss Por

$4.33985 \mathrm{e}+014.33985 \mathrm{e}+014.33985 \mathrm{e}+00$ 1.00000e-09 7.00000e-02 $4.33985 \mathrm{e}+014.33985 \mathrm{e}+014.33985 \mathrm{e}+001.00000 \mathrm{e}-09$ 7.00000e-02 $4.33985 \mathrm{e}+014.33985 \mathrm{e}+014.33985 \mathrm{e}+001.00000 \mathrm{e}-09$ 7.00000e-02 5.00000e-04 5.00000e-04 5.00000e-05 1.00000e-09 1.00000e-01 5.00000e-04 5.00000e-04 5.00000e-05 1.00000e-09 1.00000e-01 $1.73407 \mathrm{e}+001.73407 \mathrm{e}+00$ 1.73407e-01 1.00000e-09 2.12000e-01 $1.73407 \mathrm{e}+001.73407 \mathrm{e}+00$ 1.73407e-01 1.00000e-09 2.12000e-01 $1.73407 \mathrm{e}+001.73407 \mathrm{e}+00$ 1.73407e-01 1.00000e-09 2.12000e-01 $1.73407 \mathrm{e}+001.73407 \mathrm{e}+00$ 1.73407e-01 1.00000e-09 2.12000e-01 $1.73407 \mathrm{e}+001.73407 \mathrm{e}+00$ 1.73407e-01 1.00000e-09 2.12000e-01 $1.00000 \mathrm{e}-02$ 1.00000e-02 1.00000e-03 1.00000e-09 1.00000e-01 $1.00000 \mathrm{e}+001.00000 \mathrm{e}+001.00000 \mathrm{e}-011.00000 \mathrm{e}-091.00000 \mathrm{e}-01$ $1.00000 \mathrm{e}-05$ 1.00000e-05 1.00000e-06 1.00000e-09 1.00000e-01 $1.00000 \mathrm{e}+001.00000 \mathrm{e}+001.00000 \mathrm{e}-011.00000 \mathrm{e}-091.00000 \mathrm{e}-01$ Element: 2992 \# of layers: 14

Kx Ky Kz Ss Por

$4.33985 \mathrm{e}+014.33985 \mathrm{e}+014.33985 \mathrm{e}+00$ 1.00000e-09 7.00000e-02 $4.33985 \mathrm{e}+014.33985 \mathrm{e}+014.33985 \mathrm{e}+001.00000 \mathrm{e}-09$ 7.00000e-02 $4.33985 \mathrm{e}+014.33985 \mathrm{e}+014.33985 \mathrm{e}+001.00000 \mathrm{e}-09$ 7.00000e-02 5.00000e-04 5.00000e-04 5.00000e-05 1.00000e-09 1.00000e-01 
5.00000e-04 5.00000e-04 5.00000e-05 1.00000e-09 1.00000e-01 $1.73407 \mathrm{e}+00$ 1.73407e+00 1.73407e-01 1.00000e-09 2.12000e-01 $1.73407 \mathrm{e}+00$ 1.73407e+00 1.73407e-01 1.00000e-09 2.12000e-01 $1.73407 \mathrm{e}+001.73407 \mathrm{e}+00$ 1.73407e-01 1.00000e-09 2.12000e-01 1.73407e+00 1.73407e+00 1.73407e-01 1.00000e-09 2.12000e-01 $1.73407 \mathrm{e}+00$ 1.73407e+00 1.73407e-01 1.00000e-09 2.12000e-01 $1.00000 \mathrm{e}-02$ 1.00000e-02 1.00000e-03 1.00000e-09 1.00000e-01 $1.00000 \mathrm{e}+001.00000 \mathrm{e}+001.00000 \mathrm{e}-011.00000 \mathrm{e}-091.00000 \mathrm{e}-01$ $1.00000 \mathrm{e}-05$ 1.00000e-05 1.00000e-06 1.00000e-09 1.00000e-01 $1.00000 \mathrm{e}+001.00000 \mathrm{e}+001.00000 \mathrm{e}-011.00000 \mathrm{e}-091.00000 \mathrm{e}-01$ Element: 2993 \# of layers: 15

$\mathrm{Kx} \mathrm{Ky} \mathrm{Kz}$ Ss Por

4.33985e+01 4.33985e+01 4.33985e+00 1.00000e-09 7.00000e-02 $4.33985 \mathrm{e}+014.33985 \mathrm{e}+01$ 4.33985e+00 1.00000e-09 7.00000e-02 4.33985e+01 4.33985e+01 4.33985e+00 1.00000e-09 7.00000e-02 $4.33985 \mathrm{e}+014.33985 \mathrm{e}+014.33985 \mathrm{e}+00$ 1.00000e-09 7.00000e-02 5.00000e-04 5.00000e-04 5.00000e-05 1.00000e-09 1.00000e-01 5.00000e-04 5.00000e-04 5.00000e-05 1.00000e-09 1.00000e-01 1.73407e+00 1.73407e+00 1.73407e-01 1.00000e-09 2.12000e-01 $1.73407 \mathrm{e}+001.73407 \mathrm{e}+00$ 1.73407e-01 1.00000e-09 2.12000e-01 $1.73407 \mathrm{e}+001.73407 \mathrm{e}+00$ 1.73407e-01 1.00000e-09 2.12000e-01 1.73407e+00 1.73407e+00 1.73407e-01 1.00000e-09 2.12000e-01 $1.73407 \mathrm{e}+00$ 1.73407e+00 1.73407e-01 1.00000e-09 2.12000e-01 $1.00000 \mathrm{e}-02$ 1.00000e-02 1.00000e-03 1.00000e-09 1.00000e-01 $1.00000 \mathrm{e}+001.00000 \mathrm{e}+001.00000 \mathrm{e}-011.00000 \mathrm{e}-091.00000 \mathrm{e}-01$ $1.00000 \mathrm{e}-05$ 1.00000e-05 1.00000e-06 1.00000e-09 1.00000e-01 $1.00000 \mathrm{e}+001.00000 \mathrm{e}+001.00000 \mathrm{e}-011.00000 \mathrm{e}-091.00000 \mathrm{e}-01$ Element: 2994 \# of layers: 14

$\mathrm{Kx} \mathrm{Ky} \mathrm{Kz}$ Ss Por

3.16602e+01 3.16602e+01 3.16602e+00 1.00000e-09 7.00000e-02 $3.16602 \mathrm{e}+013.16602 \mathrm{e}+013.16602 \mathrm{e}+00$ 1.00000e-09 7.00000e-02 $3.16602 \mathrm{e}+013.16602 \mathrm{e}+013.16602 \mathrm{e}+00$ 1.00000e-09 7.00000e-02 5.00000e-04 5.00000e-04 5.00000e-05 1.00000e-09 1.00000e-01 5.00000e-04 5.00000e-04 5.00000e-05 1.00000e-09 1.00000e-01 $1.26502 \mathrm{e}+001.26502 \mathrm{e}+001.26502 \mathrm{e}-01$ 1.00000e-09 2.12000e-01 $1.26502 \mathrm{e}+001.26502 \mathrm{e}+00$ 1.26502e-01 1.00000e-09 2.12000e-01 $1.26502 \mathrm{e}+00$ 1.26502e+00 1.26502e-01 1.00000e-09 2.12000e-01 $1.26502 \mathrm{e}+00$ 1.26502e+00 1.26502e-01 1.00000e-09 2.12000e-01 $1.26502 \mathrm{e}+001.26502 \mathrm{e}+00$ 1.26502e-01 1.00000e-09 2.12000e-01 $1.00000 \mathrm{e}-02$ 1.00000e-02 1.00000e-03 1.00000e-09 1.00000e-01 $1.00000 \mathrm{e}+001.00000 \mathrm{e}+001.00000 \mathrm{e}-011.00000 \mathrm{e}-091.00000 \mathrm{e}-01$ $1.00000 \mathrm{e}-05$ 1.00000e-05 1.00000e-06 1.00000e-09 1.00000e-01 $1.00000 \mathrm{e}+001.00000 \mathrm{e}+001.00000 \mathrm{e}-011.00000 \mathrm{e}-091.00000 \mathrm{e}-01$ Element: 2995 \# of layers: 14

$\mathrm{Kx} \mathrm{Ky} \mathrm{Kz}$ Ss Por

3.16602e+01 3.16602e+01 3.16602e+00 1.00000e-09 7.00000e-02 
$3.16602 \mathrm{e}+013.16602 \mathrm{e}+013.16602 \mathrm{e}+00$ 1.00000e-09 7.00000e-02 $3.16602 \mathrm{e}+013.16602 \mathrm{e}+013.16602 \mathrm{e}+00$ 1.00000e-09 7.00000e-02 5.00000e-04 5.00000e-04 5.00000e-05 1.00000e-09 1.00000e-01 5.00000e-04 5.00000e-04 5.00000e-05 1.00000e-09 1.00000e-01 $1.26502 \mathrm{e}+001.26502 \mathrm{e}+00$ 1.26502e-01 1.00000e-09 2.12000e-01 $1.26502 \mathrm{e}+001.26502 \mathrm{e}+001.26502 \mathrm{e}-011.00000 \mathrm{e}-092.12000 \mathrm{e}-01$ $1.26502 \mathrm{e}+001.26502 \mathrm{e}+001.26502 \mathrm{e}-011.00000 \mathrm{e}-092.12000 \mathrm{e}-01$ $1.26502 \mathrm{e}+001.26502 \mathrm{e}+001.26502 \mathrm{e}-011.00000 \mathrm{e}-092.12000 \mathrm{e}-01$ $1.26502 \mathrm{e}+001.26502 \mathrm{e}+001.26502 \mathrm{e}-011.00000 \mathrm{e}-092.12000 \mathrm{e}-01$ $1.00000 \mathrm{e}-021.00000 \mathrm{e}-02$ 1.00000e-03 1.00000e-09 1.00000e-01 $1.00000 \mathrm{e}+001.00000 \mathrm{e}+001.00000 \mathrm{e}-011.00000 \mathrm{e}-091.00000 \mathrm{e}-01$ $1.00000 \mathrm{e}-05$ 1.00000e-05 1.00000e-06 1.00000e-09 1.00000e-01 $1.00000 \mathrm{e}+001.00000 \mathrm{e}+001.00000 \mathrm{e}-011.00000 \mathrm{e}-091.00000 \mathrm{e}-01$ Element: 2996 \# of layers: 14

Kx Ky Kz Ss Por

3.16602e+01 3.16602e+01 3.16602e+00 1.00000e-09 7.00000e-02 $3.16602 \mathrm{e}+013.16602 \mathrm{e}+013.16602 \mathrm{e}+00$ 1.00000e-09 7.00000e-02 $3.16602 \mathrm{e}+013.16602 \mathrm{e}+013.16602 \mathrm{e}+00$ 1.00000e-09 7.00000e-02 $5.00000 \mathrm{e}-04$ 5.00000e-04 5.00000e-05 1.00000e-09 1.00000e-01 5.00000e-04 5.00000e-04 5.00000e-05 1.00000e-09 1.00000e-01 $1.26502 \mathrm{e}+001.26502 \mathrm{e}+001.26502 \mathrm{e}-011.00000 \mathrm{e}-092.12000 \mathrm{e}-01$ $1.26502 \mathrm{e}+001.26502 \mathrm{e}+001.26502 \mathrm{e}-011.00000 \mathrm{e}-092.12000 \mathrm{e}-01$ $1.26502 \mathrm{e}+001.26502 \mathrm{e}+001.26502 \mathrm{e}-011.00000 \mathrm{e}-092.12000 \mathrm{e}-01$ $1.26502 \mathrm{e}+001.26502 \mathrm{e}+00$ 1.26502e-01 1.00000e-09 2.12000e-01 $1.26502 \mathrm{e}+001.26502 \mathrm{e}+001.26502 \mathrm{e}-011.00000 \mathrm{e}-092.12000 \mathrm{e}-01$ $1.00000 \mathrm{e}-021.00000 \mathrm{e}-021.00000 \mathrm{e}-031.00000 \mathrm{e}-091.00000 \mathrm{e}-01$ $1.00000 \mathrm{e}+001.00000 \mathrm{e}+001.00000 \mathrm{e}-011.00000 \mathrm{e}-091.00000 \mathrm{e}-01$ $1.00000 \mathrm{e}-051.00000 \mathrm{e}-05$ 1.00000e-06 1.00000e-09 1.00000e-01 $1.00000 \mathrm{e}+001.00000 \mathrm{e}+001.00000 \mathrm{e}-011.00000 \mathrm{e}-091.00000 \mathrm{e}-01$ Element: 2997 \# of layers: 15

Kx Ky Kz Ss Por

$3.16602 \mathrm{e}+013.16602 \mathrm{e}+013.16602 \mathrm{e}+00$ 1.00000e-09 7.00000e-02 $3.16602 \mathrm{e}+013.16602 \mathrm{e}+013.16602 \mathrm{e}+00$ 1.00000e-09 7.00000e-02 $3.16602 \mathrm{e}+013.16602 \mathrm{e}+013.16602 \mathrm{e}+00$ 1.00000e-09 7.00000e-02 $3.16602 \mathrm{e}+013.16602 \mathrm{e}+013.16602 \mathrm{e}+001.00000 \mathrm{e}-09$ 7.00000e-02 5.00000e-04 5.00000e-04 5.00000e-05 1.00000e-09 1.00000e-01 5.00000e-04 5.00000e-04 5.00000e-05 1.00000e-09 1.00000e-01 $1.26502 \mathrm{e}+001.26502 \mathrm{e}+00$ 1.26502e-01 1.00000e-09 2.12000e-01 $1.26502 \mathrm{e}+001.26502 \mathrm{e}+001.26502 \mathrm{e}-011.00000 \mathrm{e}-092.12000 \mathrm{e}-01$ $1.26502 \mathrm{e}+001.26502 \mathrm{e}+00$ 1.26502e-01 1.00000e-09 2.12000e-01 $1.26502 \mathrm{e}+001.26502 \mathrm{e}+00$ 1.26502e-01 1.00000e-09 2.12000e-01 $1.26502 \mathrm{e}+001.26502 \mathrm{e}+001.26502 \mathrm{e}-011.00000 \mathrm{e}-092.12000 \mathrm{e}-01$ $1.00000 \mathrm{e}-021.00000 \mathrm{e}-021.00000 \mathrm{e}-031.00000 \mathrm{e}-091.00000 \mathrm{e}-01$ $1.00000 \mathrm{e}+001.00000 \mathrm{e}+001.00000 \mathrm{e}-011.00000 \mathrm{e}-091.00000 \mathrm{e}-01$ $1.00000 \mathrm{e}-05$ 1.00000e-05 1.00000e-06 1.00000e-09 1.00000e-01 $1.00000 \mathrm{e}+001.00000 \mathrm{e}+001.00000 \mathrm{e}-011.00000 \mathrm{e}-091.00000 \mathrm{e}-01$ 
Element: 2998 \# of layers: 14

Kx Ky Kz Ss Por

$3.16602 \mathrm{e}+013.16602 \mathrm{e}+013.16602 \mathrm{e}+00$ 1.00000e-09 7.00000e-02

$3.16602 \mathrm{e}+013.16602 \mathrm{e}+013.16602 \mathrm{e}+001.00000 \mathrm{e}-09$ 7.00000e-02

$3.16602 \mathrm{e}+013.16602 \mathrm{e}+013.16602 \mathrm{e}+00$ 1.00000e-09 7.00000e-02

5.00000e-04 5.00000e-04 5.00000e-05 1.00000e-09 1.00000e-01

$5.00000 \mathrm{e}-04$ 5.00000e-04 5.00000e-05 1.00000e-09 1.00000e-01

$1.26502 \mathrm{e}+001.26502 \mathrm{e}+001.26502 \mathrm{e}-011.00000 \mathrm{e}-092.12000 \mathrm{e}-01$

$1.26502 \mathrm{e}+001.26502 \mathrm{e}+001.26502 \mathrm{e}-011.00000 \mathrm{e}-092.12000 \mathrm{e}-01$

$1.26502 \mathrm{e}+001.26502 \mathrm{e}+001.26502 \mathrm{e}-011.00000 \mathrm{e}-092.12000 \mathrm{e}-01$

$1.26502 \mathrm{e}+001.26502 \mathrm{e}+00$ 1.26502e-01 1.00000e-09 2.12000e-01

$1.26502 \mathrm{e}+001.26502 \mathrm{e}+001.26502 \mathrm{e}-011.00000 \mathrm{e}-092.12000 \mathrm{e}-01$

$1.00000 \mathrm{e}-021.00000 \mathrm{e}-02$ 1.00000e-03 1.00000e-09 1.00000e-01

$1.00000 \mathrm{e}+001.00000 \mathrm{e}+001.00000 \mathrm{e}-011.00000 \mathrm{e}-091.00000 \mathrm{e}-01$

$1.00000 \mathrm{e}-05$ 1.00000e-05 1.00000e-06 1.00000e-09 1.00000e-01

$1.00000 \mathrm{e}+001.00000 \mathrm{e}+001.00000 \mathrm{e}-011.00000 \mathrm{e}-091.00000 \mathrm{e}-01$

Element: 2999 \# of layers: 14

Kx Ky Kz Ss Por

$3.16602 \mathrm{e}+013.16602 \mathrm{e}+013.16602 \mathrm{e}+00$ 1.00000e-09 7.00000e-02

$3.16602 \mathrm{e}+013.16602 \mathrm{e}+013.16602 \mathrm{e}+001.00000 \mathrm{e}-09$ 7.00000e-02

$3.16602 \mathrm{e}+013.16602 \mathrm{e}+013.16602 \mathrm{e}+001.00000 \mathrm{e}-09$ 7.00000e-02

5.00000e-04 5.00000e-04 5.00000e-05 1.00000e-09 1.00000e-01

5.00000e-04 5.00000e-04 5.00000e-05 1.00000e-09 1.00000e-01

$1.26502 \mathrm{e}+001.26502 \mathrm{e}+001.26502 \mathrm{e}-011.00000 \mathrm{e}-092.12000 \mathrm{e}-01$

$1.26502 \mathrm{e}+001.26502 \mathrm{e}+001.26502 \mathrm{e}-011.00000 \mathrm{e}-092.12000 \mathrm{e}-01$

$1.26502 \mathrm{e}+001.26502 \mathrm{e}+001.26502 \mathrm{e}-011.00000 \mathrm{e}-092.12000 \mathrm{e}-01$

$1.26502 \mathrm{e}+001.26502 \mathrm{e}+00$ 1.26502e-01 1.00000e-09 2.12000e-01

$1.26502 \mathrm{e}+001.26502 \mathrm{e}+001.26502 \mathrm{e}-011.00000 \mathrm{e}-092.12000 \mathrm{e}-01$

$1.00000 \mathrm{e}-021.00000 \mathrm{e}-02$ 1.00000e-03 1.00000e-09 1.00000e-01

$1.00000 \mathrm{e}+001.00000 \mathrm{e}+001.00000 \mathrm{e}-011.00000 \mathrm{e}-091.00000 \mathrm{e}-01$

$1.00000 \mathrm{e}-05$ 1.00000e-05 1.00000e-06 1.00000e-09 1.00000e-01

$1.00000 \mathrm{e}+001.00000 \mathrm{e}+001.00000 \mathrm{e}-011.00000 \mathrm{e}-091.00000 \mathrm{e}-01$

Element: 3000 \# of layers: 14

Kx Ky Kz Ss Por

3.16602e+01 3.16602e+01 3.16602e+00 1.00000e-09 7.00000e-02

$3.16602 \mathrm{e}+013.16602 \mathrm{e}+013.16602 \mathrm{e}+001.00000 \mathrm{e}-09$ 7.00000e-02

$3.16602 \mathrm{e}+013.16602 \mathrm{e}+013.16602 \mathrm{e}+001.00000 \mathrm{e}-09$ 7.00000e-02

5.00000e-04 5.00000e-04 5.00000e-05 1.00000e-09 1.00000e-01

5.00000e-04 5.00000e-04 5.00000e-05 1.00000e-09 1.00000e-01

$1.26502 \mathrm{e}+001.26502 \mathrm{e}+001.26502 \mathrm{e}-011.00000 \mathrm{e}-092.12000 \mathrm{e}-01$

$1.26502 \mathrm{e}+001.26502 \mathrm{e}+001.26502 \mathrm{e}-011.00000 \mathrm{e}-092.12000 \mathrm{e}-01$

$1.26502 \mathrm{e}+001.26502 \mathrm{e}+00$ 1.26502e-01 1.00000e-09 2.12000e-01

$1.26502 \mathrm{e}+001.26502 \mathrm{e}+001.26502 \mathrm{e}-011.00000 \mathrm{e}-092.12000 \mathrm{e}-01$

$1.26502 \mathrm{e}+001.26502 \mathrm{e}+001.26502 \mathrm{e}-011.00000 \mathrm{e}-092.12000 \mathrm{e}-01$

$1.00000 \mathrm{e}-021.00000 \mathrm{e}-02$ 1.00000e-03 1.00000e-09 1.00000e-01

$1.00000 \mathrm{e}+001.00000 \mathrm{e}+001.00000 \mathrm{e}-011.00000 \mathrm{e}-091.00000 \mathrm{e}-01$ 
$1.00000 \mathrm{e}-05$ 1.00000e-05 1.00000e-06 1.00000e-09 1.00000e-01 $1.00000 \mathrm{e}+001.00000 \mathrm{e}+001.00000 \mathrm{e}-01$ 1.00000e-09 1.00000e-01 Element: 3001 \# of layers: 15

Kx Ky Kz Ss Por

3.16602e+01 3.16602e+01 3.16602e+00 1.00000e-09 7.00000e-02 $3.16602 \mathrm{e}+013.16602 \mathrm{e}+013.16602 \mathrm{e}+00$ 1.00000e-09 7.00000e-02 $3.16602 \mathrm{e}+013.16602 \mathrm{e}+013.16602 \mathrm{e}+00$ 1.00000e-09 7.00000e-02 $3.16602 \mathrm{e}+013.16602 \mathrm{e}+013.16602 \mathrm{e}+001.00000 \mathrm{e}-09$ 7.00000e-02 5.00000e-04 5.00000e-04 5.00000e-05 1.00000e-09 1.00000e-01 5.00000e-04 5.00000e-04 5.00000e-05 1.00000e-09 1.00000e-01 $1.26502 \mathrm{e}+001.26502 \mathrm{e}+00$ 1.26502e-01 1.00000e-09 2.12000e-01 $1.26502 \mathrm{e}+001.26502 \mathrm{e}+001.26502 \mathrm{e}-01$ 1.00000e-09 2.12000e-01 $1.26502 \mathrm{e}+001.26502 \mathrm{e}+00$ 1.26502e-01 1.00000e-09 2.12000e-01 $1.26502 \mathrm{e}+001.26502 \mathrm{e}+001.26502 \mathrm{e}-01$ 1.00000e-09 2.12000e-01 $1.26502 \mathrm{e}+001.26502 \mathrm{e}+00$ 1.26502e-01 1.00000e-09 2.12000e-01 $1.00000 \mathrm{e}-02$ 1.00000e-02 1.00000e-03 1.00000e-09 1.00000e-01 $1.00000 \mathrm{e}+001.00000 \mathrm{e}+001.00000 \mathrm{e}-011.00000 \mathrm{e}-091.00000 \mathrm{e}-01$ $1.00000 \mathrm{e}-05$ 1.00000e-05 1.00000e-06 1.00000e-09 1.00000e-01 $1.00000 \mathrm{e}+001.00000 \mathrm{e}+001.00000 \mathrm{e}-011.00000 \mathrm{e}-091.00000 \mathrm{e}-01$ Element: 3002 \# of layers: 15

$\mathrm{Kx} \mathrm{Ky} \mathrm{Kz}$ Ss Por

3.16602e+01 3.16602e+01 3.16602e+00 1.00000e-09 7.00000e-02 $3.16602 \mathrm{e}+013.16602 \mathrm{e}+013.16602 \mathrm{e}+001.00000 \mathrm{e}-09$ 7.00000e-02 $3.16602 \mathrm{e}+013.16602 \mathrm{e}+013.16602 \mathrm{e}+001.00000 \mathrm{e}-09$ 7.00000e-02 $3.16602 \mathrm{e}+013.16602 \mathrm{e}+013.16602 \mathrm{e}+001.00000 \mathrm{e}-09$ 7.00000e-02 $5.00000 \mathrm{e}-04$ 5.00000e-04 5.00000e-05 1.00000e-09 1.00000e-01 5.00000e-04 5.00000e-04 5.00000e-05 1.00000e-09 1.00000e-01 $1.26502 \mathrm{e}+001.26502 \mathrm{e}+00$ 1.26502e-01 1.00000e-09 2.12000e-01 $1.26502 \mathrm{e}+001.26502 \mathrm{e}+00$ 1.26502e-01 1.00000e-09 2.12000e-01 $1.26502 \mathrm{e}+00$ 1.26502e+00 1.26502e-01 1.00000e-09 2.12000e-01 $1.26502 \mathrm{e}+001.26502 \mathrm{e}+00$ 1.26502e-01 1.00000e-09 2.12000e-01 $1.26502 \mathrm{e}+001.26502 \mathrm{e}+00$ 1.26502e-01 1.00000e-09 2.12000e-01 $1.00000 \mathrm{e}-02$ 1.00000e-02 1.00000e-03 1.00000e-09 1.00000e-01 $1.00000 \mathrm{e}+001.00000 \mathrm{e}+001.00000 \mathrm{e}-011.00000 \mathrm{e}-091.00000 \mathrm{e}-01$ $1.00000 \mathrm{e}-05$ 1.00000e-05 1.00000e-06 1.00000e-09 1.00000e-01 $1.00000 \mathrm{e}+001.00000 \mathrm{e}+001.00000 \mathrm{e}-01$ 1.00000e-09 1.00000e-01 Element: 3003 \# of layers: 14

$\mathrm{Kx} \mathrm{Ky} \mathrm{Kz}$ Ss Por

$2.25989 \mathrm{e}+012.25989 \mathrm{e}+012.25989 \mathrm{e}+00$ 1.00000e-09 7.00000e-02 $2.25989 \mathrm{e}+012.25989 \mathrm{e}+012.25989 \mathrm{e}+00$ 1.00000e-09 7.00000e-02 $2.25989 \mathrm{e}+012.25989 \mathrm{e}+012.25989 \mathrm{e}+00$ 1.00000e-09 7.00000e-02 5.00000e-04 5.00000e-04 5.00000e-05 1.00000e-09 1.00000e-01 5.00000e-04 5.00000e-04 5.00000e-05 1.00000e-09 1.00000e-01 9.02967e-01 9.02967e-01 9.02967e-02 1.00000e-09 2.12000e-01 9.02967e-01 9.02967e-01 9.02967e-02 1.00000e-09 2.12000e-01 9.02967e-01 9.02967e-01 9.02967e-02 1.00000e-09 2.12000e-01 
9.02967e-01 9.02967e-01 9.02967e-02 1.00000e-09 2.12000e-01 9.02967e-01 9.02967e-01 9.02967e-02 1.00000e-09 2.12000e-01 $1.00000 \mathrm{e}-02$ 1.00000e-02 1.00000e-03 1.00000e-09 1.00000e-01 $1.00000 \mathrm{e}+001.00000 \mathrm{e}+001.00000 \mathrm{e}-011.00000 \mathrm{e}-091.00000 \mathrm{e}-01$ $1.00000 \mathrm{e}-05$ 1.00000e-05 1.00000e-06 1.00000e-09 1.00000e-01 $1.00000 \mathrm{e}+001.00000 \mathrm{e}+001.00000 \mathrm{e}-011.00000 \mathrm{e}-091.00000 \mathrm{e}-01$ Element: 3004 \# of layers: 14

$\mathrm{Kx} \mathrm{Ky} \mathrm{Kz}$ Ss Por

$2.25989 \mathrm{e}+012.25989 \mathrm{e}+012.25989 \mathrm{e}+00$ 1.00000e-09 7.00000e-02

$2.25989 \mathrm{e}+012.25989 \mathrm{e}+012.25989 \mathrm{e}+00$ 1.00000e-09 7.00000e-02

$2.25989 \mathrm{e}+012.25989 \mathrm{e}+012.25989 \mathrm{e}+00$ 1.00000e-09 7.00000e-02 5.00000e-04 5.00000e-04 5.00000e-05 1.00000e-09 1.00000e-01 5.00000e-04 5.00000e-04 5.00000e-05 1.00000e-09 1.00000e-01 9.02967e-01 9.02967e-01 9.02967e-02 1.00000e-09 2.12000e-01 9.02967e-01 9.02967e-01 9.02967e-02 1.00000e-09 2.12000e-01 9.02967e-01 9.02967e-01 9.02967e-02 1.00000e-09 2.12000e-01 9.02967e-01 9.02967e-01 9.02967e-02 1.00000e-09 2.12000e-01 9.02967e-01 9.02967e-01 9.02967e-02 1.00000e-09 2.12000e-01 $1.00000 \mathrm{e}-02$ 1.00000e-02 1.00000e-03 1.00000e-09 1.00000e-01 $1.00000 \mathrm{e}+001.00000 \mathrm{e}+001.00000 \mathrm{e}-011.00000 \mathrm{e}-091.00000 \mathrm{e}-01$ $1.00000 \mathrm{e}-05$ 1.00000e-05 1.00000e-06 1.00000e-09 1.00000e-01 $1.00000 \mathrm{e}+001.00000 \mathrm{e}+001.00000 \mathrm{e}-011.00000 \mathrm{e}-091.00000 \mathrm{e}-01$ Element: 3005 \# of layers: 14

$\mathrm{Kx} \mathrm{Ky} \mathrm{Kz}$ Ss Por

$2.25989 \mathrm{e}+012.25989 \mathrm{e}+012.25989 \mathrm{e}+00$ 1.00000e-09 7.00000e-02 $2.25989 \mathrm{e}+012.25989 \mathrm{e}+012.25989 \mathrm{e}+001.00000 \mathrm{e}-09$ 7.00000e-02 $2.25989 \mathrm{e}+012.25989 \mathrm{e}+012.25989 \mathrm{e}+00$ 1.00000e-09 7.00000e-02 5.00000e-04 5.00000e-04 5.00000e-05 1.00000e-09 1.00000e-01 5.00000e-04 5.00000e-04 5.00000e-05 1.00000e-09 1.00000e-01 9.02967e-01 9.02967e-01 9.02967e-02 1.00000e-09 2.12000e-01 9.02967e-01 9.02967e-01 9.02967e-02 1.00000e-09 2.12000e-01 9.02967e-01 9.02967e-01 9.02967e-02 1.00000e-09 2.12000e-01 9.02967e-01 9.02967e-01 9.02967e-02 1.00000e-09 2.12000e-01 9.02967e-01 9.02967e-01 9.02967e-02 1.00000e-09 2.12000e-01 $1.00000 \mathrm{e}-02$ 1.00000e-02 1.00000e-03 1.00000e-09 1.00000e-01 $1.00000 \mathrm{e}+001.00000 \mathrm{e}+001.00000 \mathrm{e}-011.00000 \mathrm{e}-091.00000 \mathrm{e}-01$ $1.00000 \mathrm{e}-05$ 1.00000e-05 1.00000e-06 1.00000e-09 1.00000e-01 $1.00000 \mathrm{e}+001.00000 \mathrm{e}+001.00000 \mathrm{e}-011.00000 \mathrm{e}-091.00000 \mathrm{e}-01$ Element: 3006 \# of layers: 14

$\mathrm{Kx} \mathrm{Ky} \mathrm{Kz}$ Ss Por

$2.25989 \mathrm{e}+012.25989 \mathrm{e}+012.25989 \mathrm{e}+00$ 1.00000e-09 7.00000e-02 $2.25989 \mathrm{e}+012.25989 \mathrm{e}+012.25989 \mathrm{e}+001.00000 \mathrm{e}-09$ 7.00000e-02

$2.25989 \mathrm{e}+012.25989 \mathrm{e}+012.25989 \mathrm{e}+00$ 1.00000e-09 7.00000e-02 5.00000e-04 5.00000e-04 5.00000e-05 1.00000e-09 1.00000e-01 5.00000e-04 5.00000e-04 5.00000e-05 1.00000e-09 1.00000e-01 9.02967e-01 9.02967e-01 9.02967e-02 1.00000e-09 2.12000e-01 
9.02967e-01 9.02967e-01 9.02967e-02 1.00000e-09 2.12000e-01 9.02967e-01 9.02967e-01 9.02967e-02 1.00000e-09 2.12000e-01 9.02967e-01 9.02967e-01 9.02967e-02 1.00000e-09 2.12000e-01 9.02967e-01 9.02967e-01 9.02967e-02 1.00000e-09 2.12000e-01 $1.00000 \mathrm{e}-02$ 1.00000e-02 1.00000e-03 1.00000e-09 1.00000e-01 $1.00000 \mathrm{e}+001.00000 \mathrm{e}+001.00000 \mathrm{e}-011.00000 \mathrm{e}-091.00000 \mathrm{e}-01$ $1.00000 \mathrm{e}-05$ 1.00000e-05 1.00000e-06 1.00000e-09 1.00000e-01 $1.00000 \mathrm{e}+001.00000 \mathrm{e}+001.00000 \mathrm{e}-011.00000 \mathrm{e}-091.00000 \mathrm{e}-01$ Element: 3007 \# of layers: 14

$\mathrm{Kx} \mathrm{Ky} \mathrm{Kz}$ Ss Por

$2.25989 \mathrm{e}+012.25989 \mathrm{e}+012.25989 \mathrm{e}+00$ 1.00000e-09 7.00000e-02 $2.25989 \mathrm{e}+012.25989 \mathrm{e}+012.25989 \mathrm{e}+001.00000 \mathrm{e}-09$ 7.00000e-02 $2.25989 \mathrm{e}+012.25989 \mathrm{e}+012.25989 \mathrm{e}+001.00000 \mathrm{e}-09$ 7.00000e-02 5.00000e-04 5.00000e-04 5.00000e-05 1.00000e-09 1.00000e-01 5.00000e-04 5.00000e-04 5.00000e-05 1.00000e-09 1.00000e-01 9.02967e-01 9.02967e-01 9.02967e-02 1.00000e-09 2.12000e-01 9.02967e-01 9.02967e-01 9.02967e-02 1.00000e-09 2.12000e-01 9.02967e-01 9.02967e-01 9.02967e-02 1.00000e-09 2.12000e-01 9.02967e-01 9.02967e-01 9.02967e-02 1.00000e-09 2.12000e-01 9.02967e-01 9.02967e-01 9.02967e-02 1.00000e-09 2.12000e-01 $1.00000 \mathrm{e}-02$ 1.00000e-02 1.00000e-03 1.00000e-09 1.00000e-01 $1.00000 \mathrm{e}+001.00000 \mathrm{e}+001.00000 \mathrm{e}-011.00000 \mathrm{e}-091.00000 \mathrm{e}-01$ $1.00000 \mathrm{e}-05$ 1.00000e-05 1.00000e-06 1.00000e-09 1.00000e-01 $1.00000 \mathrm{e}+001.00000 \mathrm{e}+001.00000 \mathrm{e}-011.00000 \mathrm{e}-091.00000 \mathrm{e}-01$ Element: 3008 \# of layers: 15

$\mathrm{Kx} \mathrm{Ky} \mathrm{Kz}$ Ss Por

$2.25989 \mathrm{e}+012.25989 \mathrm{e}+012.25989 \mathrm{e}+00$ 1.00000e-09 7.00000e-02 $2.25989 \mathrm{e}+012.25989 \mathrm{e}+012.25989 \mathrm{e}+00$ 1.00000e-09 7.00000e-02 $2.25989 \mathrm{e}+012.25989 \mathrm{e}+012.25989 \mathrm{e}+001.00000 \mathrm{e}-09$ 7.00000e-02 $2.25989 \mathrm{e}+012.25989 \mathrm{e}+012.25989 \mathrm{e}+00$ 1.00000e-09 7.00000e-02 5.00000e-04 5.00000e-04 5.00000e-05 1.00000e-09 1.00000e-01 5.00000e-04 5.00000e-04 5.00000e-05 1.00000e-09 1.00000e-01 9.02967e-01 9.02967e-01 9.02967e-02 1.00000e-09 2.12000e-01 9.02967e-01 9.02967e-01 9.02967e-02 1.00000e-09 2.12000e-01 9.02967e-01 9.02967e-01 9.02967e-02 1.00000e-09 2.12000e-01 9.02967e-01 9.02967e-01 9.02967e-02 1.00000e-09 2.12000e-01 9.02967e-01 9.02967e-01 9.02967e-02 1.00000e-09 2.12000e-01 $1.00000 \mathrm{e}-02$ 1.00000e-02 1.00000e-03 1.00000e-09 1.00000e-01 $1.00000 \mathrm{e}+001.00000 \mathrm{e}+001.00000 \mathrm{e}-011.00000 \mathrm{e}-091.00000 \mathrm{e}-01$ $1.00000 \mathrm{e}-05$ 1.00000e-05 1.00000e-06 1.00000e-09 1.00000e-01 $1.00000 \mathrm{e}+001.00000 \mathrm{e}+001.00000 \mathrm{e}-011.00000 \mathrm{e}-091.00000 \mathrm{e}-01$ Element: 3009 \# of layers: 14

$\mathrm{Kx} \mathrm{Ky} \mathrm{Kz}$ Ss Por

$2.25989 \mathrm{e}+012.25989 \mathrm{e}+01$ 2.25989e+00 1.00000e-09 7.00000e-02 $2.25989 \mathrm{e}+012.25989 \mathrm{e}+012.25989 \mathrm{e}+00$ 1.00000e-09 7.00000e-02 $2.25989 \mathrm{e}+012.25989 \mathrm{e}+012.25989 \mathrm{e}+001.00000 \mathrm{e}-09$ 7.00000e-02 
5.00000e-04 5.00000e-04 5.00000e-05 1.00000e-09 1.00000e-01 5.00000e-04 5.00000e-04 5.00000e-05 1.00000e-09 1.00000e-01 9.02967e-01 9.02967e-01 9.02967e-02 1.00000e-09 2.12000e-01 9.02967e-01 9.02967e-01 9.02967e-02 1.00000e-09 2.12000e-01 9.02967e-01 9.02967e-01 9.02967e-02 1.00000e-09 2.12000e-01 9.02967e-01 9.02967e-01 9.02967e-02 1.00000e-09 2.12000e-01 9.02967e-01 9.02967e-01 9.02967e-02 1.00000e-09 2.12000e-01 $1.00000 \mathrm{e}-02$ 1.00000e-02 1.00000e-03 1.00000e-09 1.00000e-01 $1.00000 \mathrm{e}+001.00000 \mathrm{e}+001.00000 \mathrm{e}-011.00000 \mathrm{e}-091.00000 \mathrm{e}-01$ $1.00000 \mathrm{e}-05$ 1.00000e-05 1.00000e-06 1.00000e-09 1.00000e-01 $1.00000 \mathrm{e}+001.00000 \mathrm{e}+001.00000 \mathrm{e}-01$ 1.00000e-09 1.00000e-01 Element: 3010 \# of layers: 15

$\mathrm{Kx} \mathrm{Ky} \mathrm{Kz}$ Ss Por

$2.25989 \mathrm{e}+012.25989 \mathrm{e}+012.25989 \mathrm{e}+00$ 1.00000e-09 7.00000e-02 $2.25989 \mathrm{e}+012.25989 \mathrm{e}+012.25989 \mathrm{e}+00$ 1.00000e-09 7.00000e-02 $2.25989 \mathrm{e}+012.25989 \mathrm{e}+012.25989 \mathrm{e}+001.00000 \mathrm{e}-09$ 7.00000e-02 $2.25989 \mathrm{e}+012.25989 \mathrm{e}+012.25989 \mathrm{e}+001.00000 \mathrm{e}-09$ 7.00000e-02 5.00000e-04 5.00000e-04 5.00000e-05 1.00000e-09 1.00000e-01 5.00000e-04 5.00000e-04 5.00000e-05 1.00000e-09 1.00000e-01 9.02967e-01 9.02967e-01 9.02967e-02 1.00000e-09 2.12000e-01 9.02967e-01 9.02967e-01 9.02967e-02 1.00000e-09 2.12000e-01 9.02967e-01 9.02967e-01 9.02967e-02 1.00000e-09 2.12000e-01 9.02967e-01 9.02967e-01 9.02967e-02 1.00000e-09 2.12000e-01 9.02967e-01 9.02967e-01 9.02967e-02 1.00000e-09 2.12000e-01 $1.00000 \mathrm{e}-02$ 1.00000e-02 1.00000e-03 1.00000e-09 1.00000e-01 $1.00000 \mathrm{e}+001.00000 \mathrm{e}+001.00000 \mathrm{e}-011.00000 \mathrm{e}-091.00000 \mathrm{e}-01$ $1.00000 \mathrm{e}-05$ 1.00000e-05 1.00000e-06 1.00000e-09 1.00000e-01 $1.00000 \mathrm{e}+001.00000 \mathrm{e}+001.00000 \mathrm{e}-011.00000 \mathrm{e}-091.00000 \mathrm{e}-01$ Element: 3011 \# of layers: 15

$\mathrm{Kx} \mathrm{Ky} \mathrm{Kz}$ Ss Por

$2.25989 \mathrm{e}+012.25989 \mathrm{e}+012.25989 \mathrm{e}+00$ 1.00000e-09 7.00000e-02 $2.25989 \mathrm{e}+012.25989 \mathrm{e}+012.25989 \mathrm{e}+001.00000 \mathrm{e}-09$ 7.00000e-02 $2.25989 \mathrm{e}+012.25989 \mathrm{e}+012.25989 \mathrm{e}+001.00000 \mathrm{e}-09$ 7.00000e-02 $2.25989 \mathrm{e}+012.25989 \mathrm{e}+012.25989 \mathrm{e}+001.00000 \mathrm{e}-09$ 7.00000e-02 5.00000e-04 5.00000e-04 5.00000e-05 1.00000e-09 1.00000e-01 5.00000e-04 5.00000e-04 5.00000e-05 1.00000e-09 1.00000e-01 9.02967e-01 9.02967e-01 9.02967e-02 1.00000e-09 2.12000e-01 9.02967e-01 9.02967e-01 9.02967e-02 1.00000e-09 2.12000e-01 9.02967e-01 9.02967e-01 9.02967e-02 1.00000e-09 2.12000e-01 9.02967e-01 9.02967e-01 9.02967e-02 1.00000e-09 2.12000e-01 9.02967e-01 9.02967e-01 9.02967e-02 1.00000e-09 2.12000e-01 $1.00000 \mathrm{e}-02$ 1.00000e-02 1.00000e-03 1.00000e-09 1.00000e-01 $1.00000 \mathrm{e}+001.00000 \mathrm{e}+001.00000 \mathrm{e}-011.00000 \mathrm{e}-091.00000 \mathrm{e}-01$ $1.00000 \mathrm{e}-05$ 1.00000e-05 1.00000e-06 1.00000e-09 1.00000e-01 $1.00000 \mathrm{e}+001.00000 \mathrm{e}+001.00000 \mathrm{e}-011.00000 \mathrm{e}-091.00000 \mathrm{e}-01$ Element: 3012 \# of layers: 13 
$\mathrm{Kx} \mathrm{Ky} \mathrm{Kz} \mathrm{Ss} \mathrm{Por}$

1.70893e+01 1.70893e+01 1.70893e+00 1.00000e-09 7.00000e-02

$1.70893 \mathrm{e}+011.70893 \mathrm{e}+01$ 1.70893e+00 1.00000e-09 7.00000e-02

5.00000e-04 5.00000e-04 5.00000e-05 1.00000e-09 1.00000e-01

5.00000e-04 5.00000e-04 5.00000e-05 1.00000e-09 1.00000e-01

6.82845e-01 6.82845e-01 6.82845e-02 1.00000e-09 2.12000e-01

6.82845e-01 6.82845e-01 6.82845e-02 1.00000e-09 2.12000e-01

6.82845e-01 6.82845e-01 6.82845e-02 1.00000e-09 2.12000e-01

6.82845e-01 6.82845e-01 6.82845e-02 1.00000e-09 2.12000e-01

6.82845e-01 6.82845e-01 6.82845e-02 1.00000e-09 2.12000e-01

$1.00000 \mathrm{e}-02$ 1.00000e-02 1.00000e-03 1.00000e-09 1.00000e-01

$1.00000 \mathrm{e}+001.00000 \mathrm{e}+001.00000 \mathrm{e}-011.00000 \mathrm{e}-091.00000 \mathrm{e}-01$

$1.00000 \mathrm{e}-05$ 1.00000e-05 1.00000e-06 1.00000e-09 1.00000e-01

$1.00000 \mathrm{e}+001.00000 \mathrm{e}+001.00000 \mathrm{e}-011.00000 \mathrm{e}-091.00000 \mathrm{e}-01$

Element: 3013 \# of layers: 13

Kx Ky Kz Ss Por

$1.70893 \mathrm{e}+01$ 1.70893e+01 1.70893e+00 1.00000e-09 7.00000e-02

$1.70893 \mathrm{e}+01$ 1.70893e+01 1.70893e+00 1.00000e-09 7.00000e-02

5.00000e-04 5.00000e-04 5.00000e-05 1.00000e-09 1.00000e-01

5.00000e-04 5.00000e-04 5.00000e-05 1.00000e-09 1.00000e-01

6.82845e-01 6.82845e-01 6.82845e-02 1.00000e-09 2.12000e-01

6.82845e-01 6.82845e-01 6.82845e-02 1.00000e-09 2.12000e-01

6.82845e-01 6.82845e-01 6.82845e-02 1.00000e-09 2.12000e-01

6.82845e-01 6.82845e-01 6.82845e-02 1.00000e-09 2.12000e-01

6.82845e-01 6.82845e-01 6.82845e-02 1.00000e-09 2.12000e-01

$1.00000 \mathrm{e}-02$ 1.00000e-02 1.00000e-03 1.00000e-09 1.00000e-01

$1.00000 \mathrm{e}+001.00000 \mathrm{e}+001.00000 \mathrm{e}-011.00000 \mathrm{e}-091.00000 \mathrm{e}-01$

1.00000e-05 1.00000e-05 1.00000e-06 1.00000e-09 1.00000e-01

$1.00000 \mathrm{e}+001.00000 \mathrm{e}+001.00000 \mathrm{e}-011.00000 \mathrm{e}-091.00000 \mathrm{e}-01$

Element: 3014 \# of layers: 13

$\mathrm{Kx} \mathrm{Ky} \mathrm{Kz}$ Ss Por

1.70893e+01 1.70893e+01 1.70893e+00 1.00000e-09 7.00000e-02

$1.70893 \mathrm{e}+011.70893 \mathrm{e}+01$ 1.70893e+00 1.00000e-09 7.00000e-02

$5.00000 \mathrm{e}-04$ 5.00000e-04 5.00000e-05 1.00000e-09 1.00000e-01

5.00000e-04 5.00000e-04 5.00000e-05 1.00000e-09 1.00000e-01

6.82845e-01 6.82845e-01 6.82845e-02 1.00000e-09 2.12000e-01

6.82845e-01 6.82845e-01 6.82845e-02 1.00000e-09 2.12000e-01

6.82845e-01 6.82845e-01 6.82845e-02 1.00000e-09 2.12000e-01

6.82845e-01 6.82845e-01 6.82845e-02 1.00000e-09 2.12000e-01

6.82845e-01 6.82845e-01 6.82845e-02 1.00000e-09 2.12000e-01

$1.00000 \mathrm{e}-021.00000 \mathrm{e}-021.00000 \mathrm{e}-031.00000 \mathrm{e}-091.00000 \mathrm{e}-01$

$1.00000 \mathrm{e}+001.00000 \mathrm{e}+001.00000 \mathrm{e}-011.00000 \mathrm{e}-091.00000 \mathrm{e}-01$

$1.00000 \mathrm{e}-05$ 1.00000e-05 1.00000e-06 1.00000e-09 1.00000e-01

$1.00000 \mathrm{e}+001.00000 \mathrm{e}+001.00000 \mathrm{e}-01$ 1.00000e-09 1.00000e-01

Element: 3015 \# of layers: 13

Kx Ky Kz Ss Por 
$1.70893 \mathrm{e}+01$ 1.70893e+01 1.70893e+00 1.00000e-09 7.00000e-02 $1.70893 \mathrm{e}+01$ 1.70893e+01 1.70893e+00 1.00000e-09 7.00000e-02 5.00000e-04 5.00000e-04 5.00000e-05 1.00000e-09 1.00000e-01 5.00000e-04 5.00000e-04 5.00000e-05 1.00000e-09 1.00000e-01 6.82845e-01 6.82845e-01 6.82845e-02 1.00000e-09 2.12000e-01 6.82845e-01 6.82845e-01 6.82845e-02 1.00000e-09 2.12000e-01 6.82845e-01 6.82845e-01 6.82845e-02 1.00000e-09 2.12000e-01 6.82845e-01 6.82845e-01 6.82845e-02 1.00000e-09 2.12000e-01 6.82845e-01 6.82845e-01 6.82845e-02 1.00000e-09 2.12000e-01 $1.00000 \mathrm{e}-02$ 1.00000e-02 1.00000e-03 1.00000e-09 1.00000e-01 $1.00000 \mathrm{e}+001.00000 \mathrm{e}+001.00000 \mathrm{e}-011.00000 \mathrm{e}-091.00000 \mathrm{e}-01$ $1.00000 \mathrm{e}-05$ 1.00000e-05 1.00000e-06 1.00000e-09 1.00000e-01 $1.00000 \mathrm{e}+001.00000 \mathrm{e}+001.00000 \mathrm{e}-01$ 1.00000e-09 1.00000e-01 Element: 3016 \# of layers: 13

$\mathrm{Kx} \mathrm{Ky} \mathrm{Kz}$ Ss Por

$1.70893 e+011.70893 e+01$ 1.70893e+00 1.00000e-09 7.00000e-02 $1.70893 \mathrm{e}+011.70893 \mathrm{e}+01$ 1.70893e+00 1.00000e-09 7.00000e-02 5.00000e-04 5.00000e-04 5.00000e-05 1.00000e-09 1.00000e-01 $5.00000 \mathrm{e}-04$ 5.00000e-04 5.00000e-05 1.00000e-09 1.00000e-01 6.82845e-01 6.82845e-01 6.82845e-02 1.00000e-09 2.12000e-01 6.82845e-01 6.82845e-01 6.82845e-02 1.00000e-09 2.12000e-01 6.82845e-01 6.82845e-01 6.82845e-02 1.00000e-09 2.12000e-01 6.82845e-01 6.82845e-01 6.82845e-02 1.00000e-09 2.12000e-01 6.82845e-01 6.82845e-01 6.82845e-02 1.00000e-09 2.12000e-01 $1.00000 \mathrm{e}-02$ 1.00000e-02 1.00000e-03 1.00000e-09 1.00000e-01 $1.00000 \mathrm{e}+001.00000 \mathrm{e}+001.00000 \mathrm{e}-011.00000 \mathrm{e}-091.00000 \mathrm{e}-01$ $1.00000 \mathrm{e}-05$ 1.00000e-05 1.00000e-06 1.00000e-09 1.00000e-01 $1.00000 \mathrm{e}+001.00000 \mathrm{e}+001.00000 \mathrm{e}-011.00000 \mathrm{e}-09$ 1.00000e-01 Element: 3017 \# of layers: 14

$\mathrm{Kx} \mathrm{Ky} \mathrm{Kz}$ Ss Por

1.70893e+01 1.70893e+01 1.70893e+00 1.00000e-09 7.00000e-02 $1.70893 \mathrm{e}+01$ 1.70893e+01 1.70893e+00 1.00000e-09 7.00000e-02 $1.70893 \mathrm{e}+011.70893 \mathrm{e}+01$ 1.70893e+00 1.00000e-09 7.00000e-02 $5.00000 \mathrm{e}-04$ 5.00000e-04 5.00000e-05 1.00000e-09 1.00000e-01 5.00000e-04 5.00000e-04 5.00000e-05 1.00000e-09 1.00000e-01 6.82845e-01 6.82845e-01 6.82845e-02 1.00000e-09 2.12000e-01 6.82845e-01 6.82845e-01 6.82845e-02 1.00000e-09 2.12000e-01 6.82845e-01 6.82845e-01 6.82845e-02 1.00000e-09 2.12000e-01 6.82845e-01 6.82845e-01 6.82845e-02 1.00000e-09 2.12000e-01 6.82845e-01 6.82845e-01 6.82845e-02 1.00000e-09 2.12000e-01 $1.00000 \mathrm{e}-02$ 1.00000e-02 1.00000e-03 1.00000e-09 1.00000e-01 $1.00000 \mathrm{e}+001.00000 \mathrm{e}+001.00000 \mathrm{e}-011.00000 \mathrm{e}-091.00000 \mathrm{e}-01$ $1.00000 \mathrm{e}-05$ 1.00000e-05 1.00000e-06 1.00000e-09 1.00000e-01 $1.00000 \mathrm{e}+001.00000 \mathrm{e}+001.00000 \mathrm{e}-01$ 1.00000e-09 1.00000e-01 Element: 3018 \# of layers: 14

Kx Ky Kz Ss Por 
$1.70893 \mathrm{e}+01$ 1.70893e+01 1.70893e+00 1.00000e-09 7.00000e-02 $1.70893 \mathrm{e}+01$ 1.70893e+01 1.70893e+00 1.00000e-09 7.00000e-02 $1.70893 \mathrm{e}+011.70893 \mathrm{e}+01$ 1.70893e+00 1.00000e-09 7.00000e-02 5.00000e-04 5.00000e-04 5.00000e-05 1.00000e-09 1.00000e-01 5.00000e-04 5.00000e-04 5.00000e-05 1.00000e-09 1.00000e-01 6.82845e-01 6.82845e-01 6.82845e-02 1.00000e-09 2.12000e-01 6.82845e-01 6.82845e-01 6.82845e-02 1.00000e-09 2.12000e-01 6.82845e-01 6.82845e-01 6.82845e-02 1.00000e-09 2.12000e-01 6.82845e-01 6.82845e-01 6.82845e-02 1.00000e-09 2.12000e-01 6.82845e-01 6.82845e-01 6.82845e-02 1.00000e-09 2.12000e-01 $1.00000 \mathrm{e}-02$ 1.00000e-02 1.00000e-03 1.00000e-09 1.00000e-01 $1.00000 \mathrm{e}+001.00000 \mathrm{e}+001.00000 \mathrm{e}-011.00000 \mathrm{e}-091.00000 \mathrm{e}-01$ $1.00000 \mathrm{e}-05$ 1.00000e-05 1.00000e-06 1.00000e-09 1.00000e-01 $1.00000 \mathrm{e}+001.00000 \mathrm{e}+001.00000 \mathrm{e}-011.00000 \mathrm{e}-091.00000 \mathrm{e}-01$ Element: 3019 \# of layers: 14

Kx Ky Kz Ss Por

$1.70893 \mathrm{e}+01$ 1.70893e+01 1.70893e+00 1.00000e-09 7.00000e-02 $1.70893 \mathrm{e}+01$ 1.70893e+01 1.70893e+00 1.00000e-09 7.00000e-02 $1.70893 \mathrm{e}+01$ 1.70893e+01 1.70893e+00 1.00000e-09 7.00000e-02 5.00000e-04 5.00000e-04 5.00000e-05 1.00000e-09 1.00000e-01 5.00000e-04 5.00000e-04 5.00000e-05 1.00000e-09 1.00000e-01 6.82845e-01 6.82845e-01 6.82845e-02 1.00000e-09 2.12000e-01 6.82845e-01 6.82845e-01 6.82845e-02 1.00000e-09 2.12000e-01 6.82845e-01 6.82845e-01 6.82845e-02 1.00000e-09 2.12000e-01 6.82845e-01 6.82845e-01 6.82845e-02 1.00000e-09 2.12000e-01 6.82845e-01 6.82845e-01 6.82845e-02 1.00000e-09 2.12000e-01 $1.00000 \mathrm{e}-02$ 1.00000e-02 1.00000e-03 1.00000e-09 1.00000e-01 $1.00000 \mathrm{e}+001.00000 \mathrm{e}+001.00000 \mathrm{e}-011.00000 \mathrm{e}-091.00000 \mathrm{e}-01$ $1.00000 \mathrm{e}-05$ 1.00000e-05 1.00000e-06 1.00000e-09 1.00000e-01 $1.00000 \mathrm{e}+001.00000 \mathrm{e}+001.00000 \mathrm{e}-011.00000 \mathrm{e}-091.00000 \mathrm{e}-01$ Element: 3020 \# of layers: 13

$\mathrm{Kx} \mathrm{Ky} \mathrm{Kz}$ Ss Por

1.70893e+01 1.70893e+01 1.70893e+00 1.00000e-09 7.00000e-02 $1.70893 \mathrm{e}+01$ 1.70893e+01 1.70893e+00 1.00000e-09 7.00000e-02 5.00000e-04 5.00000e-04 5.00000e-05 1.00000e-09 1.00000e-01 5.00000e-04 5.00000e-04 5.00000e-05 1.00000e-09 1.00000e-01 6.82845e-01 6.82845e-01 6.82845e-02 1.00000e-09 2.12000e-01 6.82845e-01 6.82845e-01 6.82845e-02 1.00000e-09 2.12000e-01 6.82845e-01 6.82845e-01 6.82845e-02 1.00000e-09 2.12000e-01 6.82845e-01 6.82845e-01 6.82845e-02 1.00000e-09 2.12000e-01 6.82845e-01 6.82845e-01 6.82845e-02 1.00000e-09 2.12000e-01 $1.00000 \mathrm{e}-02$ 1.00000e-02 1.00000e-03 1.00000e-09 1.00000e-01 $1.00000 \mathrm{e}+001.00000 \mathrm{e}+001.00000 \mathrm{e}-011.00000 \mathrm{e}-091.00000 \mathrm{e}-01$ $1.00000 \mathrm{e}-051.00000 \mathrm{e}-051.00000 \mathrm{e}-061.00000 \mathrm{e}-091.00000 \mathrm{e}-01$ $1.00000 \mathrm{e}+001.00000 \mathrm{e}+001.00000 \mathrm{e}-01$ 1.00000e-09 1.00000e-01 Element: 3021 \# of layers: 13 
Kx Ky Kz Ss Por

$1.73407 \mathrm{e}+01$ 1.73407e+01 1.73407e+00 1.00000e-09 7.00000e-02

$1.73407 \mathrm{e}+011.73407 \mathrm{e}+01$ 1.73407e+00 1.00000e-09 7.00000e-02

5.00000e-04 5.00000e-04 5.00000e-05 1.00000e-09 1.00000e-01

5.00000e-04 5.00000e-04 5.00000e-05 1.00000e-09 1.00000e-01

6.92880e-01 6.92880e-01 6.92880e-02 1.00000e-09 2.12000e-01

6.92880e-01 6.92880e-01 6.92880e-02 1.00000e-09 2.12000e-01

6.92880e-01 6.92880e-01 6.92880e-02 1.00000e-09 2.12000e-01

6.92880e-01 6.92880e-01 6.92880e-02 1.00000e-09 2.12000e-01

6.92880e-01 6.92880e-01 6.92880e-02 1.00000e-09 2.12000e-01

$1.00000 \mathrm{e}-02$ 1.00000e-02 1.00000e-03 1.00000e-09 1.00000e-01

$1.00000 \mathrm{e}+001.00000 \mathrm{e}+001.00000 \mathrm{e}-011.00000 \mathrm{e}-091.00000 \mathrm{e}-01$

$1.00000 \mathrm{e}-05$ 1.00000e-05 1.00000e-06 1.00000e-09 1.00000e-01

$1.00000 \mathrm{e}+001.00000 \mathrm{e}+001.00000 \mathrm{e}-011.00000 \mathrm{e}-091.00000 \mathrm{e}-01$

Element: 3022 \# of layers: 13

Kx Ky Kz Ss Por

$1.73407 \mathrm{e}+01$ 1.73407e+01 1.73407e+00 1.00000e-09 7.00000e-02

$1.73407 \mathrm{e}+01$ 1.73407e+01 1.73407e+00 1.00000e-09 7.00000e-02

5.00000e-04 5.00000e-04 5.00000e-05 1.00000e-09 1.00000e-01

5.00000e-04 5.00000e-04 5.00000e-05 1.00000e-09 1.00000e-01

6.92880e-01 6.92880e-01 6.92880e-02 1.00000e-09 2.12000e-01

6.92880e-01 6.92880e-01 6.92880e-02 1.00000e-09 2.12000e-01

6.92880e-01 6.92880e-01 6.92880e-02 1.00000e-09 2.12000e-01

6.92880e-01 6.92880e-01 6.92880e-02 1.00000e-09 2.12000e-01

6.92880e-01 6.92880e-01 6.92880e-02 1.00000e-09 2.12000e-01

$1.00000 \mathrm{e}-02$ 1.00000e-02 1.00000e-03 1.00000e-09 1.00000e-01

$1.00000 \mathrm{e}+001.00000 \mathrm{e}+001.00000 \mathrm{e}-011.00000 \mathrm{e}-091.00000 \mathrm{e}-01$

$1.00000 \mathrm{e}-05$ 1.00000e-05 1.00000e-06 1.00000e-09 1.00000e-01

$1.00000 \mathrm{e}+001.00000 \mathrm{e}+001.00000 \mathrm{e}-011.00000 \mathrm{e}-091.00000 \mathrm{e}-01$

Element: 3023 \# of layers: 11

$\mathrm{Kx} \mathrm{Ky} \mathrm{Kz}$ Ss Por

$1.73407 \mathrm{e}+01$ 1.73407e+01 1.73407e+00 1.00000e-09 7.00000e-02

$1.73407 \mathrm{e}+01$ 1.73407e+01 1.73407e+00 1.00000e-09 7.00000e-02

$5.00000 \mathrm{e}-045.00000 \mathrm{e}-045.00000 \mathrm{e}-051.00000 \mathrm{e}-091.00000 \mathrm{e}-01$

5.00000e-04 5.00000e-04 5.00000e-05 1.00000e-09 1.00000e-01

6.92880e-01 6.92880e-01 6.92880e-02 1.00000e-09 2.12000e-01

6.92880e-01 6.92880e-01 6.92880e-02 1.00000e-09 2.12000e-01

6.92880e-01 6.92880e-01 6.92880e-02 1.00000e-09 2.12000e-01

6.92880e-01 6.92880e-01 6.92880e-02 1.00000e-09 2.12000e-01

6.92880e-01 6.92880e-01 6.92880e-02 1.00000e-09 2.12000e-01

$1.00000 \mathrm{e}-02$ 1.00000e-02 1.00000e-03 1.00000e-09 1.00000e-01

$1.00000 \mathrm{e}+001.00000 \mathrm{e}+001.00000 \mathrm{e}-011.00000 \mathrm{e}-091.00000 \mathrm{e}-01$

Element: 3024 \# of layers: 13

$\mathrm{Kx} \mathrm{Ky} \mathrm{Kz}$ Ss Por

$1.73407 \mathrm{e}+01$ 1.73407e+01 1.73407e+00 1.00000e-09 7.00000e-02

$1.73407 \mathrm{e}+01$ 1.73407e+01 1.73407e+00 1.00000e-09 7.00000e-02 
5.00000e-04 5.00000e-04 5.00000e-05 1.00000e-09 1.00000e-01 5.00000e-04 5.00000e-04 5.00000e-05 1.00000e-09 1.00000e-01 6.92880e-01 6.92880e-01 6.92880e-02 1.00000e-09 2.12000e-01 6.92880e-01 6.92880e-01 6.92880e-02 1.00000e-09 2.12000e-01 6.92880e-01 6.92880e-01 6.92880e-02 1.00000e-09 2.12000e-01 6.92880e-01 6.92880e-01 6.92880e-02 1.00000e-09 2.12000e-01 6.92880e-01 6.92880e-01 6.92880e-02 1.00000e-09 2.12000e-01 $1.00000 \mathrm{e}-02$ 1.00000e-02 1.00000e-03 1.00000e-09 1.00000e-01 $1.00000 \mathrm{e}+001.00000 \mathrm{e}+001.00000 \mathrm{e}-011.00000 \mathrm{e}-091.00000 \mathrm{e}-01$ $1.00000 \mathrm{e}-05$ 1.00000e-05 1.00000e-06 1.00000e-09 1.00000e-01 $1.00000 \mathrm{e}+001.00000 \mathrm{e}+001.00000 \mathrm{e}-01$ 1.00000e-09 1.00000e-01 Element: 3025 \# of layers: 13

$\mathrm{Kx} \mathrm{Ky} \mathrm{Kz}$ Ss Por

$1.73407 \mathrm{e}+01$ 1.73407e+01 1.73407e+00 1.00000e-09 7.00000e-02 $1.73407 \mathrm{e}+01$ 1.73407e+01 1.73407e+00 1.00000e-09 7.00000e-02 5.00000e-04 5.00000e-04 5.00000e-05 1.00000e-09 1.00000e-01 5.00000e-04 5.00000e-04 5.00000e-05 1.00000e-09 1.00000e-01 6.92880e-01 6.92880e-01 6.92880e-02 1.00000e-09 2.12000e-01 6.92880e-01 6.92880e-01 6.92880e-02 1.00000e-09 2.12000e-01 6.92880e-01 6.92880e-01 6.92880e-02 1.00000e-09 2.12000e-01 6.92880e-01 6.92880e-01 6.92880e-02 1.00000e-09 2.12000e-01 6.92880e-01 6.92880e-01 6.92880e-02 1.00000e-09 2.12000e-01 $1.00000 \mathrm{e}-02$ 1.00000e-02 1.00000e-03 1.00000e-09 1.00000e-01 $1.00000 \mathrm{e}+001.00000 \mathrm{e}+001.00000 \mathrm{e}-011.00000 \mathrm{e}-091.00000 \mathrm{e}-01$ $1.00000 \mathrm{e}-05$ 1.00000e-05 1.00000e-06 1.00000e-09 1.00000e-01 $1.00000 \mathrm{e}+001.00000 \mathrm{e}+001.00000 \mathrm{e}-01$ 1.00000e-09 1.00000e-01 Element: 3026 \# of layers: 13

$\mathrm{Kx} \mathrm{Ky} \mathrm{Kz}$ Ss Por

1.73407e+01 1.73407e+01 1.73407e+00 1.00000e-09 7.00000e-02 $1.73407 \mathrm{e}+01$ 1.73407e+01 1.73407e+00 1.00000e-09 7.00000e-02 5.00000e-04 5.00000e-04 5.00000e-05 1.00000e-09 1.00000e-01 5.00000e-04 5.00000e-04 5.00000e-05 1.00000e-09 1.00000e-01 6.92880e-01 6.92880e-01 6.92880e-02 1.00000e-09 2.12000e-01 6.92880e-01 6.92880e-01 6.92880e-02 1.00000e-09 2.12000e-01 6.92880e-01 6.92880e-01 6.92880e-02 1.00000e-09 2.12000e-01 6.92880e-01 6.92880e-01 6.92880e-02 1.00000e-09 2.12000e-01 6.92880e-01 6.92880e-01 6.92880e-02 1.00000e-09 2.12000e-01 $1.00000 \mathrm{e}-02$ 1.00000e-02 1.00000e-03 1.00000e-09 1.00000e-01 $1.00000 \mathrm{e}+001.00000 \mathrm{e}+001.00000 \mathrm{e}-011.00000 \mathrm{e}-091.00000 \mathrm{e}-01$ $1.00000 \mathrm{e}-05$ 1.00000e-05 1.00000e-06 1.00000e-09 1.00000e-01 $1.00000 \mathrm{e}+001.00000 \mathrm{e}+001.00000 \mathrm{e}-011.00000 \mathrm{e}-091.00000 \mathrm{e}-01$ Element: 3027 \# of layers: 13

$\mathrm{Kx} \mathrm{Ky} \mathrm{Kz}$ Ss Por

1.73407e+01 1.73407e+01 1.73407e+00 1.00000e-09 7.00000e-02 $1.73407 \mathrm{e}+011.73407 \mathrm{e}+01$ 1.73407e+00 1.00000e-09 7.00000e-02 5.00000e-04 5.00000e-04 5.00000e-05 1.00000e-09 1.00000e-01 
5.00000e-04 5.00000e-04 5.00000e-05 1.00000e-09 1.00000e-01 6.92880e-01 6.92880e-01 6.92880e-02 1.00000e-09 2.12000e-01 6.92880e-01 6.92880e-01 6.92880e-02 1.00000e-09 2.12000e-01 $6.92880 \mathrm{e}-016.92880 \mathrm{e}-016.92880 \mathrm{e}-021.00000 \mathrm{e}-092.12000 \mathrm{e}-01$ $6.92880 \mathrm{e}-016.92880 \mathrm{e}-016.92880 \mathrm{e}-021.00000 \mathrm{e}-092.12000 \mathrm{e}-01$ 6.92880e-01 6.92880e-01 6.92880e-02 1.00000e-09 2.12000e-01 $1.00000 \mathrm{e}-021.00000 \mathrm{e}-02$ 1.00000e-03 1.00000e-09 1.00000e-01 $1.00000 \mathrm{e}+001.00000 \mathrm{e}+001.00000 \mathrm{e}-011.00000 \mathrm{e}-091.00000 \mathrm{e}-01$ $1.00000 \mathrm{e}-05$ 1.00000e-05 1.00000e-06 1.00000e-09 1.00000e-01 $1.00000 \mathrm{e}+001.00000 \mathrm{e}+001.00000 \mathrm{e}-011.00000 \mathrm{e}-091.00000 \mathrm{e}-01$ Element: 3028 \# of layers: 13

Kx Ky Kz Ss Por

$1.73407 \mathrm{e}+011.73407 \mathrm{e}+011.73407 \mathrm{e}+00$ 1.00000e-09 7.00000e-02 $1.73407 \mathrm{e}+011.73407 \mathrm{e}+011.73407 \mathrm{e}+001.00000 \mathrm{e}-09$ 7.00000e-02 $5.00000 \mathrm{e}-04$ 5.00000e-04 5.00000e-05 1.00000e-09 1.00000e-01 5.00000e-04 5.00000e-04 5.00000e-05 1.00000e-09 1.00000e-01 6.92880e-01 6.92880e-01 6.92880e-02 1.00000e-09 2.12000e-01 $6.92880 \mathrm{e}-01$ 6.92880e-01 6.92880e-02 1.00000e-09 2.12000e-01 6.92880e-01 6.92880e-01 6.92880e-02 1.00000e-09 2.12000e-01 $6.92880 \mathrm{e}-016.92880 \mathrm{e}-016.92880 \mathrm{e}-021.00000 \mathrm{e}-092.12000 \mathrm{e}-01$ 6.92880e-01 6.92880e-01 6.92880e-02 1.00000e-09 2.12000e-01 $1.00000 \mathrm{e}-02$ 1.00000e-02 1.00000e-03 1.00000e-09 1.00000e-01 $1.00000 \mathrm{e}+001.00000 \mathrm{e}+001.00000 \mathrm{e}-011.00000 \mathrm{e}-091.00000 \mathrm{e}-01$ $1.00000 \mathrm{e}-051.00000 \mathrm{e}-05$ 1.00000e-06 1.00000e-09 1.00000e-01 $1.00000 \mathrm{e}+001.00000 \mathrm{e}+001.00000 \mathrm{e}-011.00000 \mathrm{e}-091.00000 \mathrm{e}-01$ Element: 3029 \# of layers: 13

Kx Ky Kz Ss Por

$1.73407 \mathrm{e}+011.73407 \mathrm{e}+011.73407 \mathrm{e}+00$ 1.00000e-09 7.00000e-02 $1.73407 \mathrm{e}+011.73407 \mathrm{e}+011.73407 \mathrm{e}+001.00000 \mathrm{e}-09$ 7.00000e-02 5.00000e-04 5.00000e-04 5.00000e-05 1.00000e-09 1.00000e-01 5.00000e-04 5.00000e-04 5.00000e-05 1.00000e-09 1.00000e-01 6.92880e-01 6.92880e-01 6.92880e-02 1.00000e-09 2.12000e-01 6.92880e-01 6.92880e-01 6.92880e-02 1.00000e-09 2.12000e-01 6.92880e-01 6.92880e-01 6.92880e-02 1.00000e-09 2.12000e-01 6.92880e-01 6.92880e-01 6.92880e-02 1.00000e-09 2.12000e-01 6.92880e-01 6.92880e-01 6.92880e-02 1.00000e-09 2.12000e-01 $1.00000 \mathrm{e}-021.00000 \mathrm{e}-02$ 1.00000e-03 1.00000e-09 1.00000e-01 $1.00000 \mathrm{e}+001.00000 \mathrm{e}+001.00000 \mathrm{e}-011.00000 \mathrm{e}-091.00000 \mathrm{e}-01$ $1.00000 \mathrm{e}-05$ 1.00000e-05 1.00000e-06 1.00000e-09 1.00000e-01 $1.00000 \mathrm{e}+001.00000 \mathrm{e}+001.00000 \mathrm{e}-011.00000 \mathrm{e}-091.00000 \mathrm{e}-01$ Element: 3030 \# of layers: 11

Kx Ky Kz Ss Por $2.04932 \mathrm{e}+012.04932 \mathrm{e}+012.04933 \mathrm{e}+00$ 1.00000e-09 7.00000e-02 $2.04932 \mathrm{e}+012.04932 \mathrm{e}+012.04933 \mathrm{e}+001.00000 \mathrm{e}-09$ 7.00000e-02 5.00000e-04 5.00000e-04 5.00000e-05 1.00000e-09 1.00000e-01 5.00000e-04 5.00000e-04 5.00000e-05 1.00000e-09 1.00000e-01 
8.18838e-01 8.18838e-01 8.18838e-02 1.00000e-09 2.12000e-01 8.18838e-01 8.18838e-01 8.18838e-02 1.00000e-09 2.12000e-01 8.18838e-01 8.18838e-01 8.18838e-02 1.00000e-09 2.12000e-01 8.18838e-01 8.18838e-01 8.18838e-02 1.00000e-09 2.12000e-01 8.18838e-01 8.18838e-01 8.18838e-02 1.00000e-09 2.12000e-01 $1.00000 \mathrm{e}-02$ 1.00000e-02 1.00000e-03 1.00000e-09 1.00000e-01 $1.00000 \mathrm{e}+001.00000 \mathrm{e}+001.00000 \mathrm{e}-011.00000 \mathrm{e}-091.00000 \mathrm{e}-01$ Element: 3031 \# of layers: 13

$\mathrm{Kx}$ Ky Kz Ss Por

$2.04932 \mathrm{e}+012.04932 \mathrm{e}+012.04933 \mathrm{e}+00$ 1.00000e-09 7.00000e-02 $2.04932 \mathrm{e}+012.04932 \mathrm{e}+012.04933 \mathrm{e}+001.00000 \mathrm{e}-09$ 7.00000e-02 5.00000e-04 5.00000e-04 5.00000e-05 1.00000e-09 1.00000e-01 5.00000e-04 5.00000e-04 5.00000e-05 1.00000e-09 1.00000e-01 8.18838e-01 8.18838e-01 8.18838e-02 1.00000e-09 2.12000e-01 8.18838e-01 8.18838e-01 8.18838e-02 1.00000e-09 2.12000e-01 8.18838e-01 8.18838e-01 8.18838e-02 1.00000e-09 2.12000e-01 8.18838e-01 8.18838e-01 8.18838e-02 1.00000e-09 2.12000e-01 8.18838e-01 8.18838e-01 8.18838e-02 1.00000e-09 2.12000e-01 $1.00000 \mathrm{e}-021.00000 \mathrm{e}-02$ 1.00000e-03 1.00000e-09 1.00000e-01 $1.00000 \mathrm{e}+001.00000 \mathrm{e}+001.00000 \mathrm{e}-011.00000 \mathrm{e}-091.00000 \mathrm{e}-01$ $1.00000 \mathrm{e}-05$ 1.00000e-05 1.00000e-06 1.00000e-09 1.00000e-01 $1.00000 \mathrm{e}+001.00000 \mathrm{e}+001.00000 \mathrm{e}-011.00000 \mathrm{e}-091.00000 \mathrm{e}-01$ Element: 3032 \# of layers: 13

Kx Ky Kz Ss Por

$2.04932 \mathrm{e}+012.04932 \mathrm{e}+012.04933 \mathrm{e}+001.00000 \mathrm{e}-09$ 7.00000e-02 $2.04932 \mathrm{e}+012.04932 \mathrm{e}+012.04933 \mathrm{e}+001.00000 \mathrm{e}-097.00000 \mathrm{e}-02$ 5.00000e-04 5.00000e-04 5.00000e-05 1.00000e-09 1.00000e-01 5.00000e-04 5.00000e-04 5.00000e-05 1.00000e-09 1.00000e-01 8.18838e-01 8.18838e-01 8.18838e-02 1.00000e-09 2.12000e-01 8.18838e-01 8.18838e-01 8.18838e-02 1.00000e-09 2.12000e-01 8.18838e-01 8.18838e-01 8.18838e-02 1.00000e-09 2.12000e-01 8.18838e-01 8.18838e-01 8.18838e-02 1.00000e-09 2.12000e-01 8.18838e-01 8.18838e-01 8.18838e-02 1.00000e-09 2.12000e-01 $1.00000 \mathrm{e}-021.00000 \mathrm{e}-02$ 1.00000e-03 1.00000e-09 1.00000e-01 $1.00000 \mathrm{e}+001.00000 \mathrm{e}+001.00000 \mathrm{e}-011.00000 \mathrm{e}-091.00000 \mathrm{e}-01$ $1.00000 \mathrm{e}-05$ 1.00000e-05 1.00000e-06 1.00000e-09 1.00000e-01 $1.00000 \mathrm{e}+001.00000 \mathrm{e}+001.00000 \mathrm{e}-011.00000 \mathrm{e}-091.00000 \mathrm{e}-01$ Element: 3033 \# of layers: 13

Kx Ky Kz Ss Por $2.04932 \mathrm{e}+012.04932 \mathrm{e}+012.04933 \mathrm{e}+00$ 1.00000e-09 7.00000e-02 $2.04932 \mathrm{e}+012.04932 \mathrm{e}+012.04933 \mathrm{e}+001.00000 \mathrm{e}-09$ 7.00000e-02 5.00000e-04 5.00000e-04 5.00000e-05 1.00000e-09 1.00000e-01 5.00000e-04 5.00000e-04 5.00000e-05 1.00000e-09 1.00000e-01 8.18838e-01 8.18838e-01 8.18838e-02 1.00000e-09 2.12000e-01 8.18838e-01 8.18838e-01 8.18838e-02 1.00000e-09 2.12000e-01 8.18838e-01 8.18838e-01 8.18838e-02 1.00000e-09 2.12000e-01 
8.18838e-01 8.18838e-01 8.18838e-02 1.00000e-09 2.12000e-01 8.18838e-01 8.18838e-01 8.18838e-02 1.00000e-09 2.12000e-01 $1.00000 \mathrm{e}-021.00000 \mathrm{e}-02$ 1.00000e-03 $1.00000 \mathrm{e}-091.00000 \mathrm{e}-01$ $1.00000 \mathrm{e}+001.00000 \mathrm{e}+001.00000 \mathrm{e}-011.00000 \mathrm{e}-091.00000 \mathrm{e}-01$ $1.00000 \mathrm{e}-05$ 1.00000e-05 1.00000e-06 1.00000e-09 1.00000e-01 $1.00000 \mathrm{e}+001.00000 \mathrm{e}+001.00000 \mathrm{e}-011.00000 \mathrm{e}-091.00000 \mathrm{e}-01$ Element: 3034 \# of layers: 13

Kx Ky Kz Ss Por $2.04932 \mathrm{e}+012.04932 \mathrm{e}+012.04933 \mathrm{e}+00$ 1.00000e-09 7.00000e-02 $2.04932 \mathrm{e}+012.04932 \mathrm{e}+012.04933 \mathrm{e}+001.00000 \mathrm{e}-09$ 7.00000e-02 5.00000e-04 5.00000e-04 5.00000e-05 1.00000e-09 1.00000e-01 5.00000e-04 5.00000e-04 5.00000e-05 1.00000e-09 1.00000e-01 8.18838e-01 8.18838e-01 8.18838e-02 1.00000e-09 2.12000e-01 8.18838e-01 8.18838e-01 8.18838e-02 1.00000e-09 2.12000e-01 8.18838e-01 8.18838e-01 8.18838e-02 1.00000e-09 2.12000e-01 8.18838e-01 8.18838e-01 8.18838e-02 1.00000e-09 2.12000e-01 8.18838e-01 8.18838e-01 8.18838e-02 1.00000e-09 2.12000e-01 $1.00000 \mathrm{e}-02$ 1.00000e-02 1.00000e-03 1.00000e-09 1.00000e-01 $1.00000 \mathrm{e}+001.00000 \mathrm{e}+001.00000 \mathrm{e}-011.00000 \mathrm{e}-091.00000 \mathrm{e}-01$ $1.00000 \mathrm{e}-051.00000 \mathrm{e}-05$ 1.00000e-06 1.00000e-09 1.00000e-01 $1.00000 \mathrm{e}+001.00000 \mathrm{e}+001.00000 \mathrm{e}-011.00000 \mathrm{e}-091.00000 \mathrm{e}-01$ Element: 3035 \# of layers: 13

Kx Ky Kz Ss Por $2.04932 \mathrm{e}+012.04932 \mathrm{e}+012.04933 \mathrm{e}+001.00000 \mathrm{e}-09$ 7.00000e-02 $2.04932 \mathrm{e}+012.04932 \mathrm{e}+012.04933 \mathrm{e}+001.00000 \mathrm{e}-09$ 7.00000e-02 $5.00000 \mathrm{e}-04$ 5.00000e-04 5.00000e-05 1.00000e-09 1.00000e-01 5.00000e-04 5.00000e-04 5.00000e-05 1.00000e-09 1.00000e-01 8.18838e-01 8.18838e-01 8.18838e-02 1.00000e-09 2.12000e-01 8.18838e-01 8.18838e-01 8.18838e-02 1.00000e-09 2.12000e-01 8.18838e-01 8.18838e-01 8.18838e-02 1.00000e-09 2.12000e-01 8.18838e-01 8.18838e-01 8.18838e-02 1.00000e-09 2.12000e-01 8.18838e-01 8.18838e-01 8.18838e-02 1.00000e-09 2.12000e-01 $1.00000 \mathrm{e}-021.00000 \mathrm{e}-02$ 1.00000e-03 1.00000e-09 1.00000e-01 $1.00000 \mathrm{e}+001.00000 \mathrm{e}+001.00000 \mathrm{e}-011.00000 \mathrm{e}-091.00000 \mathrm{e}-01$ $1.00000 \mathrm{e}-05$ 1.00000e-05 1.00000e-06 1.00000e-09 1.00000e-01 $1.00000 \mathrm{e}+001.00000 \mathrm{e}+001.00000 \mathrm{e}-011.00000 \mathrm{e}-091.00000 \mathrm{e}-01$ Element: 3036 \# of layers: 13

Kx Ky Kz Ss Por $2.04932 \mathrm{e}+012.04932 \mathrm{e}+012.04933 \mathrm{e}+00$ 1.00000e-09 7.00000e-02 $2.04932 \mathrm{e}+012.04932 \mathrm{e}+012.04933 \mathrm{e}+001.00000 \mathrm{e}-09$ 7.00000e-02 5.00000e-04 5.00000e-04 5.00000e-05 1.00000e-09 1.00000e-01 5.00000e-04 5.00000e-04 5.00000e-05 1.00000e-09 1.00000e-01 8.18838e-01 8.18838e-01 8.18838e-02 1.00000e-09 2.12000e-01 8.18838e-01 8.18838e-01 8.18838e-02 1.00000e-09 2.12000e-01 8.18838e-01 8.18838e-01 8.18838e-02 1.00000e-09 2.12000e-01 8.18838e-01 8.18838e-01 8.18838e-02 1.00000e-09 2.12000e-01 
8.18838e-01 8.18838e-01 8.18838e-02 1.00000e-09 2.12000e-01 $1.00000 \mathrm{e}-02$ 1.00000e-02 1.00000e-03 1.00000e-09 1.00000e-01 $1.00000 \mathrm{e}+001.00000 \mathrm{e}+001.00000 \mathrm{e}-011.00000 \mathrm{e}-091.00000 \mathrm{e}-01$ $1.00000 \mathrm{e}-05$ 1.00000e-05 1.00000e-06 1.00000e-09 1.00000e-01 $1.00000 \mathrm{e}+001.00000 \mathrm{e}+001.00000 \mathrm{e}-011.00000 \mathrm{e}-091.00000 \mathrm{e}-01$ Element: 3037 \# of layers: 13

Kx Ky Kz Ss Por $2.04932 \mathrm{e}+012.04932 \mathrm{e}+012.04933 \mathrm{e}+00$ 1.00000e-09 7.00000e-02 $2.04932 \mathrm{e}+012.04932 \mathrm{e}+012.04933 \mathrm{e}+001.00000 \mathrm{e}-09$ 7.00000e-02 5.00000e-04 5.00000e-04 5.00000e-05 1.00000e-09 1.00000e-01 5.00000e-04 5.00000e-04 5.00000e-05 1.00000e-09 1.00000e-01 8.18838e-01 8.18838e-01 8.18838e-02 1.00000e-09 2.12000e-01 8.18838e-01 8.18838e-01 8.18838e-02 1.00000e-09 2.12000e-01 8.18838e-01 8.18838e-01 8.18838e-02 1.00000e-09 2.12000e-01 8.18838e-01 8.18838e-01 8.18838e-02 1.00000e-09 2.12000e-01 8.18838e-01 8.18838e-01 8.18838e-02 1.00000e-09 2.12000e-01 $1.00000 \mathrm{e}-021.00000 \mathrm{e}-02$ 1.00000e-03 1.00000e-09 1.00000e-01 $1.00000 \mathrm{e}+001.00000 \mathrm{e}+001.00000 \mathrm{e}-011.00000 \mathrm{e}-091.00000 \mathrm{e}-01$ $1.00000 \mathrm{e}-05$ 1.00000e-05 1.00000e-06 1.00000e-09 1.00000e-01 $1.00000 \mathrm{e}+001.00000 \mathrm{e}+001.00000 \mathrm{e}-011.00000 \mathrm{e}-091.00000 \mathrm{e}-01$ Element: 3038 \# of layers: 13

Kx Ky Kz Ss Por $2.04932 \mathrm{e}+012.04932 \mathrm{e}+012.04933 \mathrm{e}+00$ 1.00000e-09 7.00000e-02 $2.04932 \mathrm{e}+012.04932 \mathrm{e}+012.04933 \mathrm{e}+001.00000 \mathrm{e}-09$ 7.00000e-02 5.00000e-04 5.00000e-04 5.00000e-05 1.00000e-09 1.00000e-01 $5.00000 \mathrm{e}-04$ 5.00000e-04 5.00000e-05 1.00000e-09 1.00000e-01 8.18838e-01 8.18838e-01 8.18838e-02 1.00000e-09 2.12000e-01 8.18838e-01 8.18838e-01 8.18838e-02 1.00000e-09 2.12000e-01 8.18838e-01 8.18838e-01 8.18838e-02 1.00000e-09 2.12000e-01 8.18838e-01 8.18838e-01 8.18838e-02 1.00000e-09 2.12000e-01 8.18838e-01 8.18838e-01 8.18838e-02 1.00000e-09 2.12000e-01 $1.00000 \mathrm{e}-02$ 1.00000e-02 1.00000e-03 1.00000e-09 1.00000e-01 $1.00000 \mathrm{e}+001.00000 \mathrm{e}+001.00000 \mathrm{e}-011.00000 \mathrm{e}-091.00000 \mathrm{e}-01$ $1.00000 \mathrm{e}-05$ 1.00000e-05 1.00000e-06 1.00000e-09 1.00000e-01 $1.00000 \mathrm{e}+001.00000 \mathrm{e}+001.00000 \mathrm{e}-011.00000 \mathrm{e}-091.00000 \mathrm{e}-01$ Element: 3039 \# of layers: 13

Kx Ky Kz Ss Por

$2.49703 \mathrm{e}+012.49703 \mathrm{e}+012.49703 \mathrm{e}+00$ 1.00000e-09 7.00000e-02 $2.49703 \mathrm{e}+012.49703 \mathrm{e}+012.49703 \mathrm{e}+001.00000 \mathrm{e}-09$ 7.00000e-02 5.00000e-04 5.00000e-04 5.00000e-05 1.00000e-09 1.00000e-01 5.00000e-04 5.00000e-04 5.00000e-05 1.00000e-09 1.00000e-01 9.97716e-01 9.97716e-01 9.97716e-02 1.00000e-09 2.12000e-01 9.97716e-01 9.97716e-01 9.97716e-02 1.00000e-09 2.12000e-01 9.97716e-01 9.97716e-01 9.97716e-02 1.00000e-09 2.12000e-01 9.97716e-01 9.97716e-01 9.97716e-02 1.00000e-09 2.12000e-01 9.97716e-01 9.97716e-01 9.97716e-02 1.00000e-09 2.12000e-01 
$1.00000 \mathrm{e}-02$ 1.00000e-02 1.00000e-03 1.00000e-09 1.00000e-01 $1.00000 \mathrm{e}+001.00000 \mathrm{e}+001.00000 \mathrm{e}-011.00000 \mathrm{e}-091.00000 \mathrm{e}-01$ $1.00000 \mathrm{e}-05$ 1.00000e-05 1.00000e-06 1.00000e-09 1.00000e-01 $1.00000 \mathrm{e}+001.00000 \mathrm{e}+001.00000 \mathrm{e}-011.00000 \mathrm{e}-091.00000 \mathrm{e}-01$ Element: 3040 \# of layers: 13

$\mathrm{Kx} \mathrm{Ky} \mathrm{Kz}$ Ss Por

$2.49703 \mathrm{e}+012.49703 \mathrm{e}+012.49703 \mathrm{e}+00$ 1.00000e-09 7.00000e-02 $2.49703 \mathrm{e}+012.49703 \mathrm{e}+012.49703 \mathrm{e}+001.00000 \mathrm{e}-09$ 7.00000e-02 5.00000e-04 5.00000e-04 5.00000e-05 1.00000e-09 1.00000e-01 5.00000e-04 5.00000e-04 5.00000e-05 1.00000e-09 1.00000e-01 9.97716e-01 9.97716e-01 9.97716e-02 1.00000e-09 2.12000e-01 9.97716e-01 9.97716e-01 9.97716e-02 1.00000e-09 2.12000e-01 9.97716e-01 9.97716e-01 9.97716e-02 1.00000e-09 2.12000e-01 9.97716e-01 9.97716e-01 9.97716e-02 1.00000e-09 2.12000e-01 9.97716e-01 9.97716e-01 9.97716e-02 1.00000e-09 2.12000e-01 $1.00000 \mathrm{e}-02$ 1.00000e-02 1.00000e-03 1.00000e-09 1.00000e-01 $1.00000 \mathrm{e}+001.00000 \mathrm{e}+001.00000 \mathrm{e}-011.00000 \mathrm{e}-091.00000 \mathrm{e}-01$ $1.00000 \mathrm{e}-05$ 1.00000e-05 1.00000e-06 1.00000e-09 1.00000e-01 $1.00000 \mathrm{e}+001.00000 \mathrm{e}+001.00000 \mathrm{e}-011.00000 \mathrm{e}-091.00000 \mathrm{e}-01$ Element: 3041 \# of layers: 13

$\mathrm{Kx} \mathrm{Ky} \mathrm{Kz}$ Ss Por

2.49703e+01 2.49703e+01 2.49703e+00 1.00000e-09 7.00000e-02 $2.49703 \mathrm{e}+012.49703 \mathrm{e}+012.49703 \mathrm{e}+00$ 1.00000e-09 7.00000e-02 5.00000e-04 5.00000e-04 5.00000e-05 1.00000e-09 1.00000e-01 5.00000e-04 5.00000e-04 5.00000e-05 1.00000e-09 1.00000e-01 9.97716e-01 9.97716e-01 9.97716e-02 1.00000e-09 2.12000e-01 9.97716e-01 9.97716e-01 9.97716e-02 1.00000e-09 2.12000e-01 9.97716e-01 9.97716e-01 9.97716e-02 1.00000e-09 2.12000e-01 9.97716e-01 9.97716e-01 9.97716e-02 1.00000e-09 2.12000e-01 9.97716e-01 9.97716e-01 9.97716e-02 1.00000e-09 2.12000e-01 $1.00000 \mathrm{e}-02$ 1.00000e-02 1.00000e-03 1.00000e-09 1.00000e-01 $1.00000 \mathrm{e}+001.00000 \mathrm{e}+001.00000 \mathrm{e}-011.00000 \mathrm{e}-091.00000 \mathrm{e}-01$ $1.00000 \mathrm{e}-05$ 1.00000e-05 1.00000e-06 1.00000e-09 1.00000e-01 $1.00000 \mathrm{e}+001.00000 \mathrm{e}+001.00000 \mathrm{e}-011.00000 \mathrm{e}-091.00000 \mathrm{e}-01$ Element: 3042 \# of layers: 11

$\mathrm{Kx} \mathrm{Ky} \mathrm{Kz}$ Ss Por

$2.49703 \mathrm{e}+012.49703 \mathrm{e}+012.49703 \mathrm{e}+00$ 1.00000e-09 7.00000e-02 $2.49703 \mathrm{e}+012.49703 \mathrm{e}+012.49703 \mathrm{e}+00$ 1.00000e-09 7.00000e-02 5.00000e-04 5.00000e-04 5.00000e-05 1.00000e-09 1.00000e-01 5.00000e-04 5.00000e-04 5.00000e-05 1.00000e-09 1.00000e-01 9.97716e-01 9.97716e-01 9.97716e-02 1.00000e-09 2.12000e-01 9.97716e-01 9.97716e-01 9.97716e-02 1.00000e-09 2.12000e-01 9.97716e-01 9.97716e-01 9.97716e-02 1.00000e-09 2.12000e-01 9.97716e-01 9.97716e-01 9.97716e-02 1.00000e-09 2.12000e-01 9.97716e-01 9.97716e-01 9.97716e-02 1.00000e-09 2.12000e-01 $1.00000 \mathrm{e}-02$ 1.00000e-02 1.00000e-03 1.00000e-09 1.00000e-01 
$1.00000 \mathrm{e}+001.00000 \mathrm{e}+00$ 1.00000e-01 1.00000e-09 1.00000e-01

Element: 3043 \# of layers: 11

$\mathrm{Kx} \mathrm{Ky} \mathrm{Kz}$ Ss Por

$2.49703 e+012.49703 e+012.49703 e+001.00000 e-09$ 7.00000e-02

$2.49703 \mathrm{e}+012.49703 \mathrm{e}+012.49703 \mathrm{e}+001.00000 \mathrm{e}-09$ 7.00000e-02

5.00000e-04 5.00000e-04 5.00000e-05 1.00000e-09 1.00000e-01

5.00000e-04 5.00000e-04 5.00000e-05 1.00000e-09 1.00000e-01

9.97716e-01 9.97716e-01 9.97716e-02 1.00000e-09 2.12000e-01

9.97716e-01 9.97716e-01 9.97716e-02 1.00000e-09 2.12000e-01

9.97716e-01 9.97716e-01 9.97716e-02 1.00000e-09 2.12000e-01

9.97716e-01 9.97716e-01 9.97716e-02 1.00000e-09 2.12000e-01

9.97716e-01 9.97716e-01 9.97716e-02 1.00000e-09 2.12000e-01

$1.00000 \mathrm{e}-02$ 1.00000e-02 1.00000e-03 1.00000e-09 1.00000e-01

$1.00000 \mathrm{e}+001.00000 \mathrm{e}+001.00000 \mathrm{e}-011.00000 \mathrm{e}-09$ 1.00000e-01

Element: 3044 \# of layers: 13

Kx Ky Kz Ss Por

$2.49703 e+012.49703 e+012.49703 e+001.00000 e-09$ 7.00000e-02

$2.49703 \mathrm{e}+012.49703 \mathrm{e}+012.49703 \mathrm{e}+001.00000 \mathrm{e}-09$ 7.00000e-02

5.00000e-04 5.00000e-04 5.00000e-05 1.00000e-09 1.00000e-01

5.00000e-04 5.00000e-04 5.00000e-05 1.00000e-09 1.00000e-01

9.97716e-01 9.97716e-01 9.97716e-02 1.00000e-09 2.12000e-01

9.97716e-01 9.97716e-01 9.97716e-02 1.00000e-09 2.12000e-01

9.97716e-01 9.97716e-01 9.97716e-02 1.00000e-09 2.12000e-01

9.97716e-01 9.97716e-01 9.97716e-02 1.00000e-09 2.12000e-01

9.97716e-01 9.97716e-01 9.97716e-02 1.00000e-09 2.12000e-01

$1.00000 \mathrm{e}-02$ 1.00000e-02 1.00000e-03 1.00000e-09 1.00000e-01

$1.00000 \mathrm{e}+001.00000 \mathrm{e}+001.00000 \mathrm{e}-011.00000 \mathrm{e}-091.00000 \mathrm{e}-01$

$1.00000 \mathrm{e}-05$ 1.00000e-05 1.00000e-06 1.00000e-09 1.00000e-01

$1.00000 \mathrm{e}+001.00000 \mathrm{e}+001.00000 \mathrm{e}-011.00000 \mathrm{e}-091.00000 \mathrm{e}-01$

Element: 3045 \# of layers: 13

$\mathrm{Kx} \mathrm{Ky} \mathrm{Kz}$ Ss Por

$2.49703 \mathrm{e}+012.49703 \mathrm{e}+012.49703 \mathrm{e}+001.00000 \mathrm{e}-09$ 7.00000e-02

$2.49703 \mathrm{e}+012.49703 \mathrm{e}+012.49703 \mathrm{e}+001.00000 \mathrm{e}-09$ 7.00000e-02

5.00000e-04 5.00000e-04 5.00000e-05 1.00000e-09 1.00000e-01

5.00000e-04 5.00000e-04 5.00000e-05 1.00000e-09 1.00000e-01

9.97716e-01 9.97716e-01 9.97716e-02 1.00000e-09 2.12000e-01

9.97716e-01 9.97716e-01 9.97716e-02 1.00000e-09 2.12000e-01

9.97716e-01 9.97716e-01 9.97716e-02 1.00000e-09 2.12000e-01

9.97716e-01 9.97716e-01 9.97716e-02 1.00000e-09 2.12000e-01

9.97716e-01 9.97716e-01 9.97716e-02 1.00000e-09 2.12000e-01

$1.00000 \mathrm{e}-02$ 1.00000e-02 1.00000e-03 1.00000e-09 1.00000e-01

$1.00000 \mathrm{e}+001.00000 \mathrm{e}+001.00000 \mathrm{e}-011.00000 \mathrm{e}-091.00000 \mathrm{e}-01$

$1.00000 \mathrm{e}-05$ 1.00000e-05 1.00000e-06 1.00000e-09 1.00000e-01

$1.00000 \mathrm{e}+001.00000 \mathrm{e}+001.00000 \mathrm{e}-01$ 1.00000e-09 1.00000e-01

Element: 3046 \# of layers: 13

Kx Ky Kz Ss Por 
$2.49703 \mathrm{e}+012.49703 \mathrm{e}+012.49703 \mathrm{e}+00$ 1.00000e-09 7.00000e-02

$2.49703 \mathrm{e}+012.49703 \mathrm{e}+012.49703 \mathrm{e}+001.00000 \mathrm{e}-09$ 7.00000e-02 5.00000e-04 5.00000e-04 5.00000e-05 1.00000e-09 1.00000e-01 5.00000e-04 5.00000e-04 5.00000e-05 1.00000e-09 1.00000e-01 9.97716e-01 9.97716e-01 9.97716e-02 1.00000e-09 2.12000e-01 9.97716e-01 9.97716e-01 9.97716e-02 1.00000e-09 2.12000e-01 9.97716e-01 9.97716e-01 9.97716e-02 1.00000e-09 2.12000e-01 9.97716e-01 9.97716e-01 9.97716e-02 1.00000e-09 2.12000e-01 9.97716e-01 9.97716e-01 9.97716e-02 1.00000e-09 2.12000e-01 $1.00000 \mathrm{e}-021.00000 \mathrm{e}-02$ 1.00000e-03 1.00000e-09 1.00000e-01 $1.00000 \mathrm{e}+001.00000 \mathrm{e}+001.00000 \mathrm{e}-011.00000 \mathrm{e}-091.00000 \mathrm{e}-01$ $1.00000 \mathrm{e}-05$ 1.00000e-05 1.00000e-06 1.00000e-09 1.00000e-01 $1.00000 \mathrm{e}+001.00000 \mathrm{e}+001.00000 \mathrm{e}-011.00000 \mathrm{e}-091.00000 \mathrm{e}-01$ Element: 3047 \# of layers: 13

Kx Ky Kz Ss Por

$2.49703 \mathrm{e}+012.49703 \mathrm{e}+012.49703 \mathrm{e}+00$ 1.00000e-09 7.00000e-02 $2.49703 \mathrm{e}+012.49703 \mathrm{e}+012.49703 \mathrm{e}+001.00000 \mathrm{e}-09$ 7.00000e-02 5.00000e-04 5.00000e-04 5.00000e-05 1.00000e-09 1.00000e-01 5.00000e-04 5.00000e-04 5.00000e-05 1.00000e-09 1.00000e-01 9.97716e-01 9.97716e-01 9.97716e-02 1.00000e-09 2.12000e-01 9.97716e-01 9.97716e-01 9.97716e-02 1.00000e-09 2.12000e-01 9.97716e-01 9.97716e-01 9.97716e-02 1.00000e-09 2.12000e-01 9.97716e-01 9.97716e-01 9.97716e-02 1.00000e-09 2.12000e-01 9.97716e-01 9.97716e-01 9.97716e-02 1.00000e-09 2.12000e-01 $1.00000 \mathrm{e}-021.00000 \mathrm{e}-02$ 1.00000e-03 1.00000e-09 1.00000e-01 $1.00000 \mathrm{e}+001.00000 \mathrm{e}+001.00000 \mathrm{e}-011.00000 \mathrm{e}-091.00000 \mathrm{e}-01$ $1.00000 \mathrm{e}-05$ 1.00000e-05 1.00000e-06 1.00000e-09 1.00000e-01 $1.00000 \mathrm{e}+001.00000 \mathrm{e}+001.00000 \mathrm{e}-011.00000 \mathrm{e}-091.00000 \mathrm{e}-01$ Element: 3048 \# of layers: 11

Kx Ky Kz Ss Por

$2.64461 \mathrm{e}+012.64461 \mathrm{e}+012.64462 \mathrm{e}+00$ 1.00000e-09 7.00000e-02 $2.64461 \mathrm{e}+012.64461 \mathrm{e}+012.64462 \mathrm{e}+001.00000 \mathrm{e}-097.00000 \mathrm{e}-02$ 5.00000e-04 5.00000e-04 5.00000e-05 1.00000e-09 1.00000e-01 $5.00000 \mathrm{e}-04$ 5.00000e-04 5.00000e-05 1.00000e-09 1.00000e-01 $1.05669 \mathrm{e}+001.05669 \mathrm{e}+001.05669 \mathrm{e}-011.00000 \mathrm{e}-092.12000 \mathrm{e}-01$ $1.05669 \mathrm{e}+001.05669 \mathrm{e}+001.05669 \mathrm{e}-011.00000 \mathrm{e}-092.12000 \mathrm{e}-01$ $1.05669 \mathrm{e}+001.05669 \mathrm{e}+001.05669 \mathrm{e}-011.00000 \mathrm{e}-092.12000 \mathrm{e}-01$ $1.05669 \mathrm{e}+001.05669 \mathrm{e}+00$ 1.05669e-01 1.00000e-09 2.12000e-01 $1.05669 \mathrm{e}+001.05669 \mathrm{e}+001.05669 \mathrm{e}-011.00000 \mathrm{e}-092.12000 \mathrm{e}-01$ $1.00000 \mathrm{e}-02$ 1.00000e-02 1.00000e-03 1.00000e-09 1.00000e-01 $1.00000 \mathrm{e}+001.00000 \mathrm{e}+001.00000 \mathrm{e}-011.00000 \mathrm{e}-091.00000 \mathrm{e}-01$ Element: 3049 \# of layers: 12

Kx Ky Kz Ss Por

$2.64461 \mathrm{e}+012.64461 \mathrm{e}+012.64462 \mathrm{e}+001.00000 \mathrm{e}-09$ 7.00000e-02 $2.64461 \mathrm{e}+012.64461 \mathrm{e}+012.64462 \mathrm{e}+001.00000 \mathrm{e}-097.00000 \mathrm{e}-02$ $2.64461 \mathrm{e}+012.64461 \mathrm{e}+012.64462 \mathrm{e}+001.00000 \mathrm{e}-09$ 7.00000e-02 
5.00000e-04 5.00000e-04 5.00000e-05 1.00000e-09 1.00000e-01 5.00000e-04 5.00000e-04 5.00000e-05 1.00000e-09 1.00000e-01 $1.05669 \mathrm{e}+001.05669 \mathrm{e}+001.05669 \mathrm{e}-01$ 1.00000e-09 2.12000e-01 $1.05669 \mathrm{e}+001.05669 \mathrm{e}+00$ 1.05669e-01 1.00000e-09 2.12000e-01 $1.05669 \mathrm{e}+00$ 1.05669e+00 1.05669e-01 1.00000e-09 2.12000e-01 $1.05669 \mathrm{e}+001.05669 \mathrm{e}+00$ 1.05669e-01 1.00000e-09 2.12000e-01 $1.05669 \mathrm{e}+001.05669 \mathrm{e}+00$ 1.05669e-01 1.00000e-09 2.12000e-01 $1.00000 \mathrm{e}-02$ 1.00000e-02 1.00000e-03 1.00000e-09 1.00000e-01 $1.00000 \mathrm{e}+001.00000 \mathrm{e}+001.00000 \mathrm{e}-011.00000 \mathrm{e}-091.00000 \mathrm{e}-01$ Element: 3050 \# of layers: 10

$\mathrm{Kx} \mathrm{Ky} \mathrm{Kz}$ Ss Por

$2.64461 \mathrm{e}+012.64461 \mathrm{e}+012.64462 \mathrm{e}+001.00000 \mathrm{e}-09$ 7.00000e-02

$2.64461 \mathrm{e}+012.64461 \mathrm{e}+012.64462 \mathrm{e}+001.00000 \mathrm{e}-09$ 7.00000e-02

5.00000e-04 5.00000e-04 5.00000e-05 1.00000e-09 1.00000e-01

5.00000e-04 5.00000e-04 5.00000e-05 1.00000e-09 1.00000e-01

$1.05669 \mathrm{e}+001.05669 \mathrm{e}+001.05669 \mathrm{e}-011.00000 \mathrm{e}-092.12000 \mathrm{e}-01$

$1.05669 \mathrm{e}+001.05669 \mathrm{e}+00$ 1.05669e-01 1.00000e-09 2.12000e-01

$1.05669 \mathrm{e}+00$ 1.05669e+00 1.05669e-01 1.00000e-09 2.12000e-01

$1.05669 \mathrm{e}+001.05669 \mathrm{e}+00$ 1.05669e-01 1.00000e-09 2.12000e-01

$1.05669 \mathrm{e}+001.05669 \mathrm{e}+001.05669 \mathrm{e}-01$ 1.00000e-09 2.12000e-01 $1.00000 \mathrm{e}+001.00000 \mathrm{e}+001.00000 \mathrm{e}-011.00000 \mathrm{e}-091.00000 \mathrm{e}-01$ Element: 3051 \# of layers: 11

$\mathrm{Kx} \mathrm{Ky} \mathrm{Kz}$ Ss Por

$2.64461 \mathrm{e}+012.64461 \mathrm{e}+012.64462 \mathrm{e}+001.00000 \mathrm{e}-09$ 7.00000e-02

$2.64461 \mathrm{e}+012.64461 \mathrm{e}+012.64462 \mathrm{e}+001.00000 \mathrm{e}-097.00000 \mathrm{e}-02$

5.00000e-04 5.00000e-04 5.00000e-05 1.00000e-09 1.00000e-01

$5.00000 \mathrm{e}-04$ 5.00000e-04 5.00000e-05 1.00000e-09 1.00000e-01

$1.05669 \mathrm{e}+001.05669 \mathrm{e}+00$ 1.05669e-01 1.00000e-09 2.12000e-01

$1.05669 \mathrm{e}+001.05669 \mathrm{e}+001.05669 \mathrm{e}-01$ 1.00000e-09 2.12000e-01

$1.05669 \mathrm{e}+001.05669 \mathrm{e}+00$ 1.05669e-01 1.00000e-09 2.12000e-01

$1.05669 \mathrm{e}+001.05669 \mathrm{e}+00$ 1.05669e-01 1.00000e-09 2.12000e-01

$1.05669 \mathrm{e}+00$ 1.05669e+00 1.05669e-01 1.00000e-09 2.12000e-01

1.00000e-02 1.00000e-02 1.00000e-03 1.00000e-09 1.00000e-01

$1.00000 \mathrm{e}+001.00000 \mathrm{e}+001.00000 \mathrm{e}-011.00000 \mathrm{e}-091.00000 \mathrm{e}-01$

Element: 3052 \# of layers: 11

$\mathrm{Kx} \mathrm{Ky} \mathrm{Kz}$ Ss Por

$2.64461 \mathrm{e}+012.64461 \mathrm{e}+012.64462 \mathrm{e}+00$ 1.00000e-09 7.00000e-02

$2.64461 \mathrm{e}+012.64461 \mathrm{e}+012.64462 \mathrm{e}+001.00000 \mathrm{e}-09$ 7.00000e-02

5.00000e-04 5.00000e-04 5.00000e-05 1.00000e-09 1.00000e-01

5.00000e-04 5.00000e-04 5.00000e-05 1.00000e-09 1.00000e-01

$1.05669 \mathrm{e}+001.05669 \mathrm{e}+00$ 1.05669e-01 1.00000e-09 2.12000e-01

$1.05669 \mathrm{e}+001.05669 \mathrm{e}+001.05669 \mathrm{e}-011.00000 \mathrm{e}-092.12000 \mathrm{e}-01$

$1.05669 \mathrm{e}+001.05669 \mathrm{e}+00$ 1.05669e-01 1.00000e-09 2.12000e-01

$1.05669 \mathrm{e}+001.05669 \mathrm{e}+00$ 1.05669e-01 1.00000e-09 2.12000e-01

$1.05669 \mathrm{e}+001.05669 \mathrm{e}+001.05669 \mathrm{e}-01$ 1.00000e-09 2.12000e-01

$1.00000 \mathrm{e}-02$ 1.00000e-02 1.00000e-03 1.00000e-09 1.00000e-01 
$1.00000 \mathrm{e}+001.00000 \mathrm{e}+00$ 1.00000e-01 1.00000e-09 1.00000e-01 Element: 3053 \# of layers: 11

$\mathrm{Kx} \mathrm{Ky} \mathrm{Kz}$ Ss Por

$2.64461 \mathrm{e}+012.64461 \mathrm{e}+012.64462 \mathrm{e}+001.00000 \mathrm{e}-09$ 7.00000e-02

$2.64461 \mathrm{e}+012.64461 \mathrm{e}+012.64462 \mathrm{e}+001.00000 \mathrm{e}-09$ 7.00000e-02

$2.64461 \mathrm{e}+012.64461 \mathrm{e}+012.64462 \mathrm{e}+001.00000 \mathrm{e}-09$ 7.00000e-02

5.00000e-04 5.00000e-04 5.00000e-05 1.00000e-09 1.00000e-01

5.00000e-04 5.00000e-04 5.00000e-05 1.00000e-09 1.00000e-01

$1.05669 \mathrm{e}+001.05669 \mathrm{e}+00$ 1.05669e-01 1.00000e-09 2.12000e-01

$1.05669 \mathrm{e}+00$ 1.05669e+00 1.05669e-01 1.00000e-09 2.12000e-01

$1.05669 \mathrm{e}+001.05669 \mathrm{e}+001.05669 \mathrm{e}-01$ 1.00000e-09 2.12000e-01

$1.05669 \mathrm{e}+001.05669 \mathrm{e}+001.05669 \mathrm{e}-01$ 1.00000e-09 2.12000e-01

$1.00000 \mathrm{e}-02$ 1.00000e-02 1.00000e-03 1.00000e-09 1.00000e-01

$1.00000 \mathrm{e}+001.00000 \mathrm{e}+001.00000 \mathrm{e}-011.00000 \mathrm{e}-09$ 1.00000e-01

Element: 3054 \# of layers: 11

Kx Ky Kz Ss Por

$2.64461 \mathrm{e}+012.64461 \mathrm{e}+012.64462 \mathrm{e}+00$ 1.00000e-09 7.00000e-02

$2.64461 \mathrm{e}+012.64461 \mathrm{e}+012.64462 \mathrm{e}+001.00000 \mathrm{e}-09$ 7.00000e-02

5.00000e-04 5.00000e-04 5.00000e-05 1.00000e-09 1.00000e-01

5.00000e-04 5.00000e-04 5.00000e-05 1.00000e-09 1.00000e-01

$1.05669 \mathrm{e}+001.05669 \mathrm{e}+001.05669 \mathrm{e}-011.00000 \mathrm{e}-092.12000 \mathrm{e}-01$

$1.05669 \mathrm{e}+00$ 1.05669e+00 1.05669e-01 1.00000e-09 2.12000e-01

$1.05669 \mathrm{e}+001.05669 \mathrm{e}+00$ 1.05669e-01 1.00000e-09 2.12000e-01

$1.05669 \mathrm{e}+001.05669 \mathrm{e}+001.05669 \mathrm{e}-01$ 1.00000e-09 2.12000e-01

$1.05669 \mathrm{e}+001.05669 \mathrm{e}+001.05669 \mathrm{e}-01$ 1.00000e-09 2.12000e-01

$1.00000 \mathrm{e}-02$ 1.00000e-02 1.00000e-03 1.00000e-09 1.00000e-01

$1.00000 \mathrm{e}+001.00000 \mathrm{e}+001.00000 \mathrm{e}-01$ 1.00000e-09 1.00000e-01

Element: 3055 \# of layers: 11

$\mathrm{Kx} \mathrm{Ky} \mathrm{Kz}$ Ss Por

$2.64461 \mathrm{e}+012.64461 \mathrm{e}+012.64462 \mathrm{e}+001.00000 \mathrm{e}-09$ 7.00000e-02

$2.64461 \mathrm{e}+012.64461 \mathrm{e}+012.64462 \mathrm{e}+001.00000 \mathrm{e}-09$ 7.00000e-02

5.00000e-04 5.00000e-04 5.00000e-05 1.00000e-09 1.00000e-01

5.00000e-04 5.00000e-04 5.00000e-05 1.00000e-09 1.00000e-01

$1.05669 \mathrm{e}+001.05669 \mathrm{e}+00$ 1.05669e-01 1.00000e-09 2.12000e-01

$1.05669 \mathrm{e}+001.05669 \mathrm{e}+001.05669 \mathrm{e}-01$ 1.00000e-09 2.12000e-01

$1.05669 \mathrm{e}+001.05669 \mathrm{e}+001.05669 \mathrm{e}-01$ 1.00000e-09 2.12000e-01

$1.05669 \mathrm{e}+001.05669 \mathrm{e}+001.05669 \mathrm{e}-01$ 1.00000e-09 2.12000e-01

$1.05669 \mathrm{e}+001.05669 \mathrm{e}+001.05669 \mathrm{e}-011.00000 \mathrm{e}-092.12000 \mathrm{e}-01$

$1.00000 \mathrm{e}-02$ 1.00000e-02 1.00000e-03 1.00000e-09 1.00000e-01

$1.00000 \mathrm{e}+001.00000 \mathrm{e}+001.00000 \mathrm{e}-01$ 1.00000e-09 1.00000e-01

Element: 3056 \# of layers: 12

$\mathrm{Kx} \mathrm{Ky} \mathrm{Kz}$ Ss Por

$2.64461 \mathrm{e}+012.64461 \mathrm{e}+012.64462 \mathrm{e}+00$ 1.00000e-09 7.00000e-02

$2.64461 \mathrm{e}+012.64461 \mathrm{e}+012.64462 \mathrm{e}+00$ 1.00000e-09 7.00000e-02

$2.64461 \mathrm{e}+012.64461 \mathrm{e}+012.64462 \mathrm{e}+001.00000 \mathrm{e}-09$ 7.00000e-02

5.00000e-04 5.00000e-04 5.00000e-05 1.00000e-09 1.00000e-01 
5.00000e-04 5.00000e-04 5.00000e-05 1.00000e-09 1.00000e-01 $1.05669 \mathrm{e}+00$ 1.05669e+00 1.05669e-01 1.00000e-09 2.12000e-01 $1.05669 \mathrm{e}+001.05669 \mathrm{e}+00$ 1.05669e-01 1.00000e-09 2.12000e-01 $1.05669 \mathrm{e}+001.05669 \mathrm{e}+00$ 1.05669e-01 1.00000e-09 2.12000e-01 $1.05669 \mathrm{e}+00$ 1.05669e+00 1.05669e-01 1.00000e-09 2.12000e-01 $1.05669 \mathrm{e}+001.05669 \mathrm{e}+00$ 1.05669e-01 1.00000e-09 2.12000e-01 $1.00000 \mathrm{e}-02$ 1.00000e-02 1.00000e-03 1.00000e-09 1.00000e-01 $1.00000 \mathrm{e}+001.00000 \mathrm{e}+001.00000 \mathrm{e}-011.00000 \mathrm{e}-091.00000 \mathrm{e}-01$ Element: 3057 \# of layers: 10

$\mathrm{Kx} \mathrm{Ky} \mathrm{Kz}$ Ss Por

3.25189e+01 3.25189e+01 3.25189e+00 1.00000e-09 7.00000e-02 $3.25189 \mathrm{e}+013.25189 \mathrm{e}+013.25189 \mathrm{e}+001.00000 \mathrm{e}-09$ 7.00000e-02 5.00000e-04 5.00000e-04 5.00000e-05 1.00000e-09 1.00000e-01 5.00000e-04 5.00000e-04 5.00000e-05 1.00000e-09 1.00000e-01 $1.29934 \mathrm{e}+001.29934 \mathrm{e}+001.29934 \mathrm{e}-011.00000 \mathrm{e}-092.12000 \mathrm{e}-01$ $1.29934 \mathrm{e}+001.29934 \mathrm{e}+001.29934 \mathrm{e}-01$ 1.00000e-09 2.12000e-01 $1.29934 \mathrm{e}+001.29934 \mathrm{e}+001.29934 \mathrm{e}-01$ 1.00000e-09 2.12000e-01 $1.29934 \mathrm{e}+001.29934 \mathrm{e}+001.29934 \mathrm{e}-011.00000 \mathrm{e}-092.12000 \mathrm{e}-01$ $1.29934 \mathrm{e}+001.29934 \mathrm{e}+001.29934 \mathrm{e}-01$ 1.00000e-09 2.12000e-01 $1.00000 \mathrm{e}+001.00000 \mathrm{e}+001.00000 \mathrm{e}-01$ 1.00000e-09 1.00000e-01 Element: 3058 \# of layers: 9

$\mathrm{Kx} \mathrm{Ky} \mathrm{Kz}$ Ss Por

3.25189e+01 3.25189e+01 3.25189e+00 1.00000e-09 7.00000e-02 $3.25189 \mathrm{e}+013.25189 \mathrm{e}+013.25189 \mathrm{e}+001.00000 \mathrm{e}-09$ 7.00000e-02 5.00000e-04 5.00000e-04 5.00000e-05 1.00000e-09 1.00000e-01 $1.29934 \mathrm{e}+001.29934 \mathrm{e}+001.29934 \mathrm{e}-011.00000 \mathrm{e}-092.12000 \mathrm{e}-01$ $1.29934 \mathrm{e}+001.29934 \mathrm{e}+00$ 1.29934e-01 1.00000e-09 2.12000e-01 $1.29934 \mathrm{e}+001.29934 \mathrm{e}+001.29934 \mathrm{e}-01$ 1.00000e-09 2.12000e-01 $1.29934 \mathrm{e}+001.29934 \mathrm{e}+00 \quad 1.29934 \mathrm{e}-011.00000 \mathrm{e}-092.12000 \mathrm{e}-01$ $1.29934 \mathrm{e}+001.29934 \mathrm{e}+001.29934 \mathrm{e}-01$ 1.00000e-09 2.12000e-01 $1.00000 \mathrm{e}+001.00000 \mathrm{e}+001.00000 \mathrm{e}-011.00000 \mathrm{e}-091.00000 \mathrm{e}-01$ Element: 3059 \# of layers: 10

$\mathrm{Kx} \mathrm{Ky} \mathrm{Kz}$ Ss Por

3.25189e+01 3.25189e+01 3.25189e+00 1.00000e-09 7.00000e-02

$3.25189 \mathrm{e}+013.25189 \mathrm{e}+013.25189 \mathrm{e}+00$ 1.00000e-09 7.00000e-02 5.00000e-04 5.00000e-04 5.00000e-05 1.00000e-09 1.00000e-01 5.00000e-04 5.00000e-04 5.00000e-05 1.00000e-09 1.00000e-01 $1.29934 \mathrm{e}+001.29934 \mathrm{e}+001.29934 \mathrm{e}-011.00000 \mathrm{e}-092.12000 \mathrm{e}-01$ $1.29934 \mathrm{e}+001.29934 \mathrm{e}+001.29934 \mathrm{e}-011.00000 \mathrm{e}-092.12000 \mathrm{e}-01$ $1.29934 \mathrm{e}+001.29934 \mathrm{e}+001.29934 \mathrm{e}-01$ 1.00000e-09 2.12000e-01 $1.29934 \mathrm{e}+001.29934 \mathrm{e}+001.29934 \mathrm{e}-011.00000 \mathrm{e}-092.12000 \mathrm{e}-01$ $1.29934 \mathrm{e}+001.29934 \mathrm{e}+001.29934 \mathrm{e}-011.00000 \mathrm{e}-092.12000 \mathrm{e}-01$ $1.00000 \mathrm{e}+001.00000 \mathrm{e}+001.00000 \mathrm{e}-01$ 1.00000e-09 1.00000e-01 Element: 3060 \# of layers: 10

$\mathrm{Kx} \mathrm{Ky} \mathrm{Kz}$ Ss Por

3.25189e+01 3.25189e+01 3.25189e+00 1.00000e-09 7.00000e-02 
$3.25189 \mathrm{e}+013.25189 \mathrm{e}+013.25189 \mathrm{e}+001.00000 \mathrm{e}-09$ 7.00000e-02 $5.00000 \mathrm{e}-04$ 5.00000e-04 5.00000e-05 1.00000e-09 1.00000e-01 5.00000e-04 5.00000e-04 5.00000e-05 1.00000e-09 1.00000e-01 $1.29934 \mathrm{e}+001.29934 \mathrm{e}+001.29934 \mathrm{e}-011.00000 \mathrm{e}-092.12000 \mathrm{e}-01$ $1.29934 \mathrm{e}+001.29934 \mathrm{e}+001.29934 \mathrm{e}-01$ 1.00000e-09 2.12000e-01 $1.29934 \mathrm{e}+001.29934 \mathrm{e}+001.29934 \mathrm{e}-01$ 1.00000e-09 2.12000e-01 $1.29934 \mathrm{e}+001.29934 \mathrm{e}+001.29934 \mathrm{e}-01$ 1.00000e-09 2.12000e-01 $1.29934 \mathrm{e}+001.29934 \mathrm{e}+001.29934 \mathrm{e}-011.00000 \mathrm{e}-092.12000 \mathrm{e}-01$ $1.00000 \mathrm{e}+001.00000 \mathrm{e}+001.00000 \mathrm{e}-011.00000 \mathrm{e}-091.00000 \mathrm{e}-01$ Element: 3061 \# of layers: 10

$\mathrm{Kx} \mathrm{Ky} \mathrm{Kz}$ Ss Por

3.25189e+01 3.25189e+01 3.25189e+00 1.00000e-09 7.00000e-02 $3.25189 \mathrm{e}+013.25189 \mathrm{e}+013.25189 \mathrm{e}+001.00000 \mathrm{e}-09$ 7.00000e-02 5.00000e-04 5.00000e-04 5.00000e-05 1.00000e-09 1.00000e-01 5.00000e-04 5.00000e-04 5.00000e-05 1.00000e-09 1.00000e-01 $1.29934 \mathrm{e}+001.29934 \mathrm{e}+001.29934 \mathrm{e}-011.00000 \mathrm{e}-092.12000 \mathrm{e}-01$ $1.29934 \mathrm{e}+001.29934 \mathrm{e}+001.29934 \mathrm{e}-01$ 1.00000e-09 2.12000e-01 $1.29934 \mathrm{e}+001.29934 \mathrm{e}+001.29934 \mathrm{e}-01$ 1.00000e-09 2.12000e-01 $1.29934 \mathrm{e}+001.29934 \mathrm{e}+001.29934 \mathrm{e}-01$ 1.00000e-09 2.12000e-01 $1.29934 \mathrm{e}+001.29934 \mathrm{e}+001.29934 \mathrm{e}-011.00000 \mathrm{e}-092.12000 \mathrm{e}-01$ $1.00000 \mathrm{e}+001.00000 \mathrm{e}+001.00000 \mathrm{e}-011.00000 \mathrm{e}-091.00000 \mathrm{e}-01$ Element: 3062 \# of layers: 10

$\mathrm{Kx} \mathrm{Ky} \mathrm{Kz}$ Ss Por

3.25189e+01 3.25189e+01 3.25189e+00 1.00000e-09 7.00000e-02 $3.25189 \mathrm{e}+013.25189 \mathrm{e}+013.25189 \mathrm{e}+001.00000 \mathrm{e}-09$ 7.00000e-02 5.00000e-04 5.00000e-04 5.00000e-05 1.00000e-09 1.00000e-01 5.00000e-04 5.00000e-04 5.00000e-05 1.00000e-09 1.00000e-01 $1.29934 \mathrm{e}+001.29934 \mathrm{e}+001.29934 \mathrm{e}-011.00000 \mathrm{e}-092.12000 \mathrm{e}-01$ $1.29934 \mathrm{e}+001.29934 \mathrm{e}+001.29934 \mathrm{e}-011.00000 \mathrm{e}-092.12000 \mathrm{e}-01$ $1.29934 \mathrm{e}+001.29934 \mathrm{e}+001.29934 \mathrm{e}-01$ 1.00000e-09 2.12000e-01 $1.29934 \mathrm{e}+001.29934 \mathrm{e}+001.29934 \mathrm{e}-01$ 1.00000e-09 2.12000e-01 $1.29934 \mathrm{e}+001.29934 \mathrm{e}+001.29934 \mathrm{e}-01 \quad 1.00000 \mathrm{e}-092.12000 \mathrm{e}-01$ $1.00000 \mathrm{e}+001.00000 \mathrm{e}+001.00000 \mathrm{e}-01$ 1.00000e-09 1.00000e-01 Element: 3063 \# of layers: 10

$\mathrm{Kx} \mathrm{Ky} \mathrm{Kz}$ Ss Por

3.25189e+01 3.25189e+01 3.25189e+00 1.00000e-09 7.00000e-02 $3.25189 \mathrm{e}+013.25189 \mathrm{e}+013.25189 \mathrm{e}+001.00000 \mathrm{e}-09$ 7.00000e-02 5.00000e-04 5.00000e-04 5.00000e-05 1.00000e-09 1.00000e-01 5.00000e-04 5.00000e-04 5.00000e-05 1.00000e-09 1.00000e-01 $1.29934 \mathrm{e}+001.29934 \mathrm{e}+001.29934 \mathrm{e}-01$ 1.00000e-09 2.12000e-01 $1.29934 \mathrm{e}+001.29934 \mathrm{e}+001.29934 \mathrm{e}-011.00000 \mathrm{e}-092.12000 \mathrm{e}-01$ $1.29934 \mathrm{e}+001.29934 \mathrm{e}+001.29934 \mathrm{e}-011.00000 \mathrm{e}-092.12000 \mathrm{e}-01$ $1.29934 \mathrm{e}+001.29934 \mathrm{e}+001.29934 \mathrm{e}-01$ 1.00000e-09 2.12000e-01 $1.29934 \mathrm{e}+001.29934 \mathrm{e}+00$ 1.29934e-01 1.00000e-09 2.12000e-01 $1.00000 \mathrm{e}+001.00000 \mathrm{e}+001.00000 \mathrm{e}-01$ 1.00000e-09 1.00000e-01 Element: 3064 \# of layers: 10 
$\mathrm{Kx} \mathrm{Ky} \mathrm{Kz}$ Ss Por

3.25189e+01 3.25189e+01 3.25189e+00 1.00000e-09 7.00000e-02

$3.25189 \mathrm{e}+013.25189 \mathrm{e}+013.25189 \mathrm{e}+001.00000 \mathrm{e}-09$ 7.00000e-02

5.00000e-04 5.00000e-04 5.00000e-05 1.00000e-09 1.00000e-01

5.00000e-04 5.00000e-04 5.00000e-05 1.00000e-09 1.00000e-01

$1.29934 \mathrm{e}+001.29934 \mathrm{e}+001.29934 \mathrm{e}-011.00000 \mathrm{e}-092.12000 \mathrm{e}-01$

$1.29934 \mathrm{e}+001.29934 \mathrm{e}+001.29934 \mathrm{e}-01$ 1.00000e-09 2.12000e-01

$1.29934 \mathrm{e}+001.29934 \mathrm{e}+001.29934 \mathrm{e}-011.00000 \mathrm{e}-092.12000 \mathrm{e}-01$

$1.29934 \mathrm{e}+001.29934 \mathrm{e}+001.29934 \mathrm{e}-01$ 1.00000e-09 2.12000e-01

$1.29934 \mathrm{e}+001.29934 \mathrm{e}+001.29934 \mathrm{e}-011.00000 \mathrm{e}-092.12000 \mathrm{e}-01$

$1.00000 \mathrm{e}+001.00000 \mathrm{e}+001.00000 \mathrm{e}-01$ 1.00000e-09 1.00000e-01

Element: 3065 \# of layers: 10

$\mathrm{Kx} \mathrm{Ky} \mathrm{Kz}$ Ss Por

3.25189e+01 3.25189e+01 3.25189e+00 1.00000e-09 7.00000e-02

$3.25189 \mathrm{e}+013.25189 \mathrm{e}+013.25189 \mathrm{e}+001.00000 \mathrm{e}-09$ 7.00000e-02

5.00000e-04 5.00000e-04 5.00000e-05 1.00000e-09 1.00000e-01

5.00000e-04 5.00000e-04 5.00000e-05 1.00000e-09 1.00000e-01

$1.29934 \mathrm{e}+001.29934 \mathrm{e}+001.29934 \mathrm{e}-011.00000 \mathrm{e}-092.12000 \mathrm{e}-01$

$1.29934 \mathrm{e}+001.29934 \mathrm{e}+001.29934 \mathrm{e}-01$ 1.00000e-09 2.12000e-01

$1.29934 \mathrm{e}+001.29934 \mathrm{e}+00$ 1.29934e-01 1.00000e-09 2.12000e-01

$1.29934 \mathrm{e}+001.29934 \mathrm{e}+00 \quad 1.29934 \mathrm{e}-011.00000 \mathrm{e}-092.12000 \mathrm{e}-01$

$1.29934 \mathrm{e}+001.29934 \mathrm{e}+001.29934 \mathrm{e}-011.00000 \mathrm{e}-092.12000 \mathrm{e}-01$

$1.00000 \mathrm{e}+001.00000 \mathrm{e}+001.00000 \mathrm{e}-01$ 1.00000e-09 1.00000e-01

Element: 3066 \# of layers: 9

$\mathrm{Kx} \mathrm{Ky} \mathrm{Kz}$ Ss Por

4.21506e+01 4.21506e+01 4.21506e+00 1.00000e-09 7.00000e-02

4.21506e+01 4.21506e+01 4.21506e+00 1.00000e-09 7.00000e-02

5.00000e-04 5.00000e-04 5.00000e-05 1.00000e-09 1.00000e-01

5.00000e-04 5.00000e-04 5.00000e-05 1.00000e-09 1.00000e-01

$1.68418 \mathrm{e}+001.68418 \mathrm{e}+00$ 1.68418e-01 1.00000e-09 2.12000e-01

$1.68418 \mathrm{e}+001.68418 \mathrm{e}+00$ 1.68418e-01 1.00000e-09 2.12000e-01

$1.68418 \mathrm{e}+001.68418 \mathrm{e}+00$ 1.68418e-01 1.00000e-09 2.12000e-01

$1.68418 \mathrm{e}+001.68418 \mathrm{e}+001.68418 \mathrm{e}-01$ 1.00000e-09 2.12000e-01

$1.68418 \mathrm{e}+001.68418 \mathrm{e}+00$ 1.68418e-01 1.00000e-09 2.12000e-01

Element: 3067 \# of layers: 9

Kx Ky Kz Ss Por

4.21506e+01 4.21506e+01 4.21506e+00 1.00000e-09 7.00000e-02

$4.21506 \mathrm{e}+014.21506 \mathrm{e}+014.21506 \mathrm{e}+001.00000 \mathrm{e}-09$ 7.00000e-02

5.00000e-04 5.00000e-04 5.00000e-05 1.00000e-09 1.00000e-01

5.00000e-04 5.00000e-04 5.00000e-05 1.00000e-09 1.00000e-01

$1.68418 \mathrm{e}+001.68418 \mathrm{e}+00$ 1.68418e-01 1.00000e-09 2.12000e-01

$1.68418 \mathrm{e}+001.68418 \mathrm{e}+001.68418 \mathrm{e}-011.00000 \mathrm{e}-092.12000 \mathrm{e}-01$

$1.68418 \mathrm{e}+001.68418 \mathrm{e}+00$ 1.68418e-01 1.00000e-09 2.12000e-01

$1.68418 \mathrm{e}+001.68418 \mathrm{e}+00$ 1.68418e-01 1.00000e-09 2.12000e-01

$1.68418 \mathrm{e}+001.68418 \mathrm{e}+00$ 1.68418e-01 1.00000e-09 2.12000e-01

Element: 3068 \# of layers: 7 
$\mathrm{Kx} \mathrm{Ky} \mathrm{Kz}$ Ss Por

4.21506e+01 4.21506e+01 4.21506e+00 1.00000e-09 7.00000e-02 5.00000e-04 5.00000e-04 5.00000e-05 1.00000e-09 1.00000e-01

$1.68418 \mathrm{e}+001.68418 \mathrm{e}+00$ 1.68418e-01 1.00000e-09 2.12000e-01

$1.68418 \mathrm{e}+001.68418 \mathrm{e}+00$ 1.68418e-01 1.00000e-09 2.12000e-01

$1.68418 \mathrm{e}+001.68418 \mathrm{e}+001.68418 \mathrm{e}-01$ 1.00000e-09 2.12000e-01

$1.68418 \mathrm{e}+001.68418 \mathrm{e}+00$ 1.68418e-01 1.00000e-09 2.12000e-01

$1.68418 \mathrm{e}+001.68418 \mathrm{e}+00$ 1.68418e-01 1.00000e-09 2.12000e-01

Element: 3069 \# of layers: 7

$\mathrm{Kx} \mathrm{Ky} \mathrm{Kz}$ Ss Por

4.21506e+01 4.21506e+01 4.21506e+00 1.00000e-09 7.00000e-02 5.00000e-04 5.00000e-04 5.00000e-05 1.00000e-09 1.00000e-01

$1.68418 \mathrm{e}+001.68418 \mathrm{e}+001.68418 \mathrm{e}-01$ 1.00000e-09 2.12000e-01

$1.68418 \mathrm{e}+001.68418 \mathrm{e}+00$ 1.68418e-01 1.00000e-09 2.12000e-01

$1.68418 \mathrm{e}+001.68418 \mathrm{e}+00$ 1.68418e-01 1.00000e-09 2.12000e-01

$1.68418 \mathrm{e}+001.68418 \mathrm{e}+00$ 1.68418e-01 1.00000e-09 2.12000e-01

$1.68418 \mathrm{e}+001.68418 \mathrm{e}+00$ 1.68418e-01 1.00000e-09 2.12000e-01

Element: 3070 \# of layers: 8

$\mathrm{Kx} \mathrm{Ky} \mathrm{Kz}$ Ss Por

4.21506e+01 4.21506e+01 4.21506e+00 1.00000e-09 7.00000e-02

5.00000e-04 5.00000e-04 5.00000e-05 1.00000e-09 1.00000e-01

5.00000e-04 5.00000e-04 5.00000e-05 1.00000e-09 1.00000e-01

$1.68418 \mathrm{e}+001.68418 \mathrm{e}+00$ 1.68418e-01 1.00000e-09 2.12000e-01

$1.68418 \mathrm{e}+001.68418 \mathrm{e}+00$ 1.68418e-01 1.00000e-09 2.12000e-01

$1.68418 \mathrm{e}+001.68418 \mathrm{e}+00$ 1.68418e-01 1.00000e-09 2.12000e-01

$1.68418 \mathrm{e}+001.68418 \mathrm{e}+001.68418 \mathrm{e}-01$ 1.00000e-09 2.12000e-01

$1.68418 \mathrm{e}+001.68418 \mathrm{e}+00$ 1.68418e-01 1.00000e-09 2.12000e-01

Element: 3071 \# of layers: 8

$\mathrm{Kx} \mathrm{Ky} \mathrm{Kz}$ Ss Por

4.21506e+01 4.21506e+01 4.21506e+00 1.00000e-09 7.00000e-02

5.00000e-04 5.00000e-04 5.00000e-05 1.00000e-09 1.00000e-01

5.00000e-04 5.00000e-04 5.00000e-05 1.00000e-09 1.00000e-01

$1.68418 \mathrm{e}+001.68418 \mathrm{e}+001.68418 \mathrm{e}-011.00000 \mathrm{e}-092.12000 \mathrm{e}-01$

$1.68418 \mathrm{e}+001.68418 \mathrm{e}+00$ 1.68418e-01 1.00000e-09 2.12000e-01

$1.68418 \mathrm{e}+001.68418 \mathrm{e}+00$ 1.68418e-01 1.00000e-09 2.12000e-01

$1.68418 \mathrm{e}+001.68418 \mathrm{e}+001.68418 \mathrm{e}-01$ 1.00000e-09 2.12000e-01

$1.68418 \mathrm{e}+001.68418 \mathrm{e}+00$ 1.68418e-01 1.00000e-09 2.12000e-01

Element: 3072 \# of layers: 8

$\mathrm{Kx} \mathrm{Ky} \mathrm{Kz}$ Ss Por

4.21506e+01 4.21506e+01 4.21506e+00 1.00000e-09 7.00000e-02 5.00000e-04 5.00000e-04 5.00000e-05 1.00000e-09 1.00000e-01 5.00000e-04 5.00000e-04 5.00000e-05 1.00000e-09 1.00000e-01

$1.68418 \mathrm{e}+001.68418 \mathrm{e}+00$ 1.68418e-01 1.00000e-09 2.12000e-01

$1.68418 \mathrm{e}+001.68418 \mathrm{e}+00$ 1.68418e-01 1.00000e-09 2.12000e-01

$1.68418 \mathrm{e}+001.68418 \mathrm{e}+00$ 1.68418e-01 1.00000e-09 2.12000e-01

$1.68418 \mathrm{e}+001.68418 \mathrm{e}+00$ 1.68418e-01 1.00000e-09 2.12000e-01 
$1.68418 \mathrm{e}+00$ 1.68418e+00 1.68418e-01 1.00000e-09 2.12000e-01

Element: 3073 \# of layers: 9

$\mathrm{Kx} \mathrm{Ky} \mathrm{Kz}$ Ss Por

4.21506e+01 4.21506e+01 4.21506e+00 1.00000e-09 7.00000e-02

$4.21506 \mathrm{e}+014.21506 \mathrm{e}+014.21506 \mathrm{e}+001.00000 \mathrm{e}-09$ 7.00000e-02

5.00000e-04 5.00000e-04 5.00000e-05 1.00000e-09 1.00000e-01

5.00000e-04 5.00000e-04 5.00000e-05 1.00000e-09 1.00000e-01

$1.68418 \mathrm{e}+001.68418 \mathrm{e}+001.68418 \mathrm{e}-011.00000 \mathrm{e}-092.12000 \mathrm{e}-01$

$1.68418 \mathrm{e}+001.68418 \mathrm{e}+00$ 1.68418e-01 1.00000e-09 2.12000e-01

$1.68418 \mathrm{e}+001.68418 \mathrm{e}+00$ 1.68418e-01 1.00000e-09 2.12000e-01

$1.68418 \mathrm{e}+001.68418 \mathrm{e}+00$ 1.68418e-01 1.00000e-09 2.12000e-01

$1.68418 \mathrm{e}+001.68418 \mathrm{e}+00$ 1.68418e-01 1.00000e-09 2.12000e-01

Element: 3074 \# of layers: 8

$\mathrm{Kx} \mathrm{Ky} \mathrm{Kz}$ Ss Por

4.21506e+01 4.21506e+01 4.21506e+00 1.00000e-09 7.00000e-02

5.00000e-04 5.00000e-04 5.00000e-05 1.00000e-09 1.00000e-01

5.00000e-04 5.00000e-04 5.00000e-05 1.00000e-09 1.00000e-01

$1.68418 \mathrm{e}+001.68418 \mathrm{e}+00$ 1.68418e-01 1.00000e-09 2.12000e-01

$1.68418 \mathrm{e}+001.68418 \mathrm{e}+00$ 1.68418e-01 1.00000e-09 2.12000e-01

$1.68418 \mathrm{e}+001.68418 \mathrm{e}+00$ 1.68418e-01 1.00000e-09 2.12000e-01

$1.68418 \mathrm{e}+001.68418 \mathrm{e}+001.68418 \mathrm{e}-01$ 1.00000e-09 2.12000e-01

$1.68418 \mathrm{e}+001.68418 \mathrm{e}+00$ 1.68418e-01 1.00000e-09 2.12000e-01

Element: 3075 \# of layers: 7

Kx Ky Kz Ss Por

5.03470e+01 5.03470e+01 5.03470e+00 1.00000e-09 7.00000e-02

5.00000e-04 5.00000e-04 5.00000e-05 1.00000e-09 1.00000e-01

$2.01168 \mathrm{e}+002.01168 \mathrm{e}+00$ 2.01168e-01 1.00000e-09 2.12000e-01

$2.01168 \mathrm{e}+002.01168 \mathrm{e}+002.01168 \mathrm{e}-01$ 1.00000e-09 2.12000e-01

$2.01168 \mathrm{e}+002.01168 \mathrm{e}+002.01168 \mathrm{e}-01$ 1.00000e-09 2.12000e-01

$2.01168 \mathrm{e}+002.01168 \mathrm{e}+00$ 2.01168e-01 1.00000e-09 2.12000e-01

$2.01168 \mathrm{e}+00$ 2.01168e+00 2.01168e-01 1.00000e-09 2.12000e-01

Element: 3076 \# of layers: 8

$\mathrm{Kx} \mathrm{Ky} \mathrm{Kz}$ Ss Por

$5.03470 \mathrm{e}+015.03470 \mathrm{e}+015.03470 \mathrm{e}+001.00000 \mathrm{e}-09$ 7.00000e-02

5.00000e-04 5.00000e-04 5.00000e-05 1.00000e-09 1.00000e-01

5.00000e-04 5.00000e-04 5.00000e-05 1.00000e-09 1.00000e-01

$2.01168 \mathrm{e}+002.01168 \mathrm{e}+002.01168 \mathrm{e}-01$ 1.00000e-09 2.12000e-01

$2.01168 \mathrm{e}+002.01168 \mathrm{e}+002.01168 \mathrm{e}-01$ 1.00000e-09 2.12000e-01

$2.01168 \mathrm{e}+002.01168 \mathrm{e}+002.01168 \mathrm{e}-01$ 1.00000e-09 2.12000e-01

$2.01168 \mathrm{e}+002.01168 \mathrm{e}+00$ 2.01168e-01 1.00000e-09 2.12000e-01

2.01168e+00 2.01168e+00 2.01168e-01 1.00000e-09 2.12000e-01

Element: 3077 \# of layers: 8

$\mathrm{Kx} \mathrm{Ky} \mathrm{Kz}$ Ss Por

5.03470e+01 5.03470e+01 5.03470e+00 1.00000e-09 7.00000e-02

5.00000e-04 5.00000e-04 5.00000e-05 1.00000e-09 1.00000e-01

5.00000e-04 5.00000e-04 5.00000e-05 1.00000e-09 1.00000e-01 
2.01168e+00 2.01168e+00 2.01168e-01 1.00000e-09 2.12000e-01 $2.01168 \mathrm{e}+002.01168 \mathrm{e}+002.01168 \mathrm{e}-01$ 1.00000e-09 2.12000e-01 $2.01168 \mathrm{e}+002.01168 \mathrm{e}+002.01168 \mathrm{e}-01$ 1.00000e-09 2.12000e-01 $2.01168 \mathrm{e}+002.01168 \mathrm{e}+00$ 2.01168e-01 1.00000e-09 2.12000e-01 $2.01168 \mathrm{e}+002.01168 \mathrm{e}+00$ 2.01168e-01 1.00000e-09 2.12000e-01 Element: 3078 \# of layers: 8

$\mathrm{Kx} \mathrm{Ky} \mathrm{Kz}$ Ss Por

5.03470e+01 5.03470e+01 5.03470e+00 1.00000e-09 7.00000e-02 5.00000e-04 5.00000e-04 5.00000e-05 1.00000e-09 1.00000e-01 5.00000e-04 5.00000e-04 5.00000e-05 1.00000e-09 1.00000e-01 $2.01168 \mathrm{e}+002.01168 \mathrm{e}+00$ 2.01168e-01 1.00000e-09 2.12000e-01 $2.01168 \mathrm{e}+002.01168 \mathrm{e}+002.01168 \mathrm{e}-01$ 1.00000e-09 2.12000e-01 $2.01168 \mathrm{e}+002.01168 \mathrm{e}+002.01168 \mathrm{e}-01$ 1.00000e-09 2.12000e-01 $2.01168 \mathrm{e}+002.01168 \mathrm{e}+00$ 2.01168e-01 1.00000e-09 2.12000e-01 2.01168e+00 2.01168e+00 2.01168e-01 1.00000e-09 2.12000e-01 Element: 3079 \# of layers: 8

$\mathrm{Kx} \mathrm{Ky} \mathrm{Kz}$ Ss Por

$5.03470 \mathrm{e}+015.03470 \mathrm{e}+015.03470 \mathrm{e}+001.00000 \mathrm{e}-09$ 7.00000e-02 5.00000e-04 5.00000e-04 5.00000e-05 1.00000e-09 1.00000e-01 5.00000e-04 5.00000e-04 5.00000e-05 1.00000e-09 1.00000e-01 $2.01168 \mathrm{e}+002.01168 \mathrm{e}+00$ 2.01168e-01 1.00000e-09 2.12000e-01 $2.01168 \mathrm{e}+002.01168 \mathrm{e}+00$ 2.01168e-01 1.00000e-09 2.12000e-01 $2.01168 \mathrm{e}+002.01168 \mathrm{e}+00$ 2.01168e-01 1.00000e-09 2.12000e-01 $2.01168 \mathrm{e}+002.01168 \mathrm{e}+002.01168 \mathrm{e}-01$ 1.00000e-09 2.12000e-01 $2.01168 \mathrm{e}+002.01168 \mathrm{e}+00$ 2.01168e-01 1.00000e-09 2.12000e-01 Element: 3080 \# of layers: 8

$\mathrm{Kx} \mathrm{Ky} \mathrm{Kz}$ Ss Por

$5.03470 \mathrm{e}+015.03470 \mathrm{e}+015.03470 \mathrm{e}+001.00000 \mathrm{e}-09$ 7.00000e-02 5.00000e-04 5.00000e-04 5.00000e-05 1.00000e-09 1.00000e-01 5.00000e-04 5.00000e-04 5.00000e-05 1.00000e-09 1.00000e-01 $2.01168 \mathrm{e}+002.01168 \mathrm{e}+002.01168 \mathrm{e}-01$ 1.00000e-09 2.12000e-01 $2.01168 \mathrm{e}+002.01168 \mathrm{e}+00$ 2.01168e-01 1.00000e-09 2.12000e-01 $2.01168 \mathrm{e}+002.01168 \mathrm{e}+002.01168 \mathrm{e}-01$ 1.00000e-09 2.12000e-01 $2.01168 \mathrm{e}+002.01168 \mathrm{e}+00$ 2.01168e-01 1.00000e-09 2.12000e-01 $2.01168 \mathrm{e}+002.01168 \mathrm{e}+00$ 2.01168e-01 1.00000e-09 2.12000e-01 Element: 3081 \# of layers: 8

Kx Ky Kz Ss Por

5.03470e+01 5.03470e+01 5.03470e+00 1.00000e-09 7.00000e-02 5.00000e-04 5.00000e-04 5.00000e-05 1.00000e-09 1.00000e-01 5.00000e-04 5.00000e-04 5.00000e-05 1.00000e-09 1.00000e-01 $2.01168 \mathrm{e}+002.01168 \mathrm{e}+002.01168 \mathrm{e}-01$ 1.00000e-09 2.12000e-01 $2.01168 \mathrm{e}+002.01168 \mathrm{e}+002.01168 \mathrm{e}-01$ 1.00000e-09 2.12000e-01 $2.01168 \mathrm{e}+002.01168 \mathrm{e}+00$ 2.01168e-01 1.00000e-09 2.12000e-01 $2.01168 \mathrm{e}+002.01168 \mathrm{e}+00$ 2.01168e-01 1.00000e-09 2.12000e-01 $2.01168 \mathrm{e}+002.01168 \mathrm{e}+00$ 2.01168e-01 1.00000e-09 2.12000e-01 Element: 3082 \# of layers: 7 
$\mathrm{Kx} \mathrm{Ky} \mathrm{Kz} \mathrm{Ss} \mathrm{Por}$

$5.03470 \mathrm{e}+015.03470 \mathrm{e}+015.03470 \mathrm{e}+001.00000 \mathrm{e}-09$ 7.00000e-02 5.00000e-04 5.00000e-04 5.00000e-05 1.00000e-09 1.00000e-01

$2.01168 \mathrm{e}+002.01168 \mathrm{e}+002.01168 \mathrm{e}-01$ 1.00000e-09 2.12000e-01

$2.01168 \mathrm{e}+002.01168 \mathrm{e}+002.01168 \mathrm{e}-01$ 1.00000e-09 2.12000e-01

$2.01168 \mathrm{e}+002.01168 \mathrm{e}+00$ 2.01168e-01 1.00000e-09 2.12000e-01

$2.01168 \mathrm{e}+002.01168 \mathrm{e}+002.01168 \mathrm{e}-01$ 1.00000e-09 2.12000e-01

$2.01168 \mathrm{e}+002.01168 \mathrm{e}+00$ 2.01168e-01 1.00000e-09 2.12000e-01

Element: 3083 \# of layers: 8

$\mathrm{Kx} \mathrm{Ky} \mathrm{Kz}$ Ss Por

5.03470e+01 5.03470e+01 5.03470e+00 1.00000e-09 7.00000e-02

5.00000e-04 5.00000e-04 5.00000e-05 1.00000e-09 1.00000e-01

5.00000e-04 5.00000e-04 5.00000e-05 1.00000e-09 1.00000e-01

$2.01168 \mathrm{e}+002.01168 \mathrm{e}+00$ 2.01168e-01 1.00000e-09 2.12000e-01

$2.01168 \mathrm{e}+002.01168 \mathrm{e}+00$ 2.01168e-01 1.00000e-09 2.12000e-01

$2.01168 \mathrm{e}+002.01168 \mathrm{e}+002.01168 \mathrm{e}-01$ 1.00000e-09 2.12000e-01

$2.01168 \mathrm{e}+002.01168 \mathrm{e}+002.01168 \mathrm{e}-01$ 1.00000e-09 2.12000e-01

$2.01168 \mathrm{e}+00$ 2.01168e+00 2.01168e-01 1.00000e-09 2.12000e-01

Element: 3084 \# of layers: 8

$\mathrm{Kx} \mathrm{Ky} \mathrm{Kz}$ Ss Por

5.53989e+01 5.53989e+01 5.53989e+00 1.00000e-09 7.00000e-02

5.00000e-04 5.00000e-04 5.00000e-05 1.00000e-09 1.00000e-01

5.00000e-04 5.00000e-04 5.00000e-05 1.00000e-09 1.00000e-01

$2.21353 \mathrm{e}+002.21353 \mathrm{e}+00$ 2.21353e-01 1.00000e-09 2.12000e-01

$2.21353 \mathrm{e}+002.21353 \mathrm{e}+00$ 2.21353e-01 1.00000e-09 2.12000e-01

$2.21353 \mathrm{e}+00$ 2.21353e+00 2.21353e-01 1.00000e-09 2.12000e-01

$2.21353 \mathrm{e}+00$ 2.21353e+00 2.21353e-01 1.00000e-09 2.12000e-01

2.21353e+00 2.21353e+00 2.21353e-01 1.00000e-09 2.12000e-01

Element: 3085 \# of layers: 9

$\mathrm{Kx} \mathrm{Ky} \mathrm{Kz}$ Ss Por

5.53989e+01 5.53989e+01 5.53989e+00 1.00000e-09 7.00000e-02

$5.53989 \mathrm{e}+015.53989 \mathrm{e}+015.53989 \mathrm{e}+00$ 1.00000e-09 7.00000e-02

5.00000e-04 5.00000e-04 5.00000e-05 1.00000e-09 1.00000e-01

5.00000e-04 5.00000e-04 5.00000e-05 1.00000e-09 1.00000e-01

$2.21353 \mathrm{e}+002.21353 \mathrm{e}+00$ 2.21353e-01 1.00000e-09 2.12000e-01

$2.21353 \mathrm{e}+00$ 2.21353e+00 2.21353e-01 1.00000e-09 2.12000e-01

$2.21353 \mathrm{e}+002.21353 \mathrm{e}+00$ 2.21353e-01 1.00000e-09 2.12000e-01

$2.21353 \mathrm{e}+002.21353 \mathrm{e}+00$ 2.21353e-01 1.00000e-09 2.12000e-01

2.21353e+00 2.21353e+00 2.21353e-01 1.00000e-09 2.12000e-01

Element: 3086 \# of layers: 9

$\mathrm{Kx} \mathrm{Ky} \mathrm{Kz}$ Ss Por

5.53989e+01 5.53989e+01 5.53989e+00 1.00000e-09 7.00000e-02

$5.53989 \mathrm{e}+01$ 5.53989e+01 5.53989e+00 1.00000e-09 7.00000e-02

5.00000e-04 5.00000e-04 5.00000e-05 1.00000e-09 1.00000e-01

5.00000e-04 5.00000e-04 5.00000e-05 1.00000e-09 1.00000e-01

$2.21353 \mathrm{e}+002.21353 \mathrm{e}+00$ 2.21353e-01 1.00000e-09 2.12000e-01 
$2.21353 \mathrm{e}+002.21353 \mathrm{e}+00$ 2.21353e-01 1.00000e-09 2.12000e-01 $2.21353 \mathrm{e}+002.21353 \mathrm{e}+002.21353 \mathrm{e}-011.00000 \mathrm{e}-092.12000 \mathrm{e}-01$ $2.21353 \mathrm{e}+002.21353 \mathrm{e}+00$ 2.21353e-01 1.00000e-09 2.12000e-01 $2.21353 \mathrm{e}+002.21353 \mathrm{e}+00$ 2.21353e-01 1.00000e-09 2.12000e-01 Element: 3090 \# of layers: 8

Kx Ky Kz Ss Por

$5.03470 \mathrm{e}+015.03470 \mathrm{e}+015.03470 \mathrm{e}+00$ 1.00000e-09 7.00000e-02 5.00000e-04 5.00000e-04 5.00000e-05 1.00000e-09 1.00000e-01 $5.00000 \mathrm{e}-04$ 5.00000e-04 5.00000e-05 1.00000e-09 1.00000e-01 $2.01168 \mathrm{e}+002.01168 \mathrm{e}+002.01168 \mathrm{e}-011.00000 \mathrm{e}-092.12000 \mathrm{e}-01$ $2.01168 \mathrm{e}+002.01168 \mathrm{e}+002.01168 \mathrm{e}-011.00000 \mathrm{e}-092.12000 \mathrm{e}-01$ $2.01168 \mathrm{e}+002.01168 \mathrm{e}+002.01168 \mathrm{e}-011.00000 \mathrm{e}-092.12000 \mathrm{e}-01$ $2.01168 \mathrm{e}+002.01168 \mathrm{e}+002.01168 \mathrm{e}-011.00000 \mathrm{e}-092.12000 \mathrm{e}-01$ $2.01168 \mathrm{e}+002.01168 \mathrm{e}+002.01168 \mathrm{e}-01$ 1.00000e-09 2.12000e-01 Element: 3091 \# of layers: 8

Kx Ky Kz Ss Por

$5.03470 \mathrm{e}+015.03470 \mathrm{e}+015.03470 \mathrm{e}+00$ 1.00000e-09 7.00000e-02 5.00000e-04 5.00000e-04 5.00000e-05 1.00000e-09 1.00000e-01 $5.00000 \mathrm{e}-04$ 5.00000e-04 5.00000e-05 1.00000e-09 1.00000e-01 $2.01168 \mathrm{e}+002.01168 \mathrm{e}+002.01168 \mathrm{e}-011.00000 \mathrm{e}-092.12000 \mathrm{e}-01$ $2.01168 \mathrm{e}+002.01168 \mathrm{e}+002.01168 \mathrm{e}-011.00000 \mathrm{e}-092.12000 \mathrm{e}-01$ $2.01168 \mathrm{e}+002.01168 \mathrm{e}+002.01168 \mathrm{e}-011.00000 \mathrm{e}-092.12000 \mathrm{e}-01$ $2.01168 \mathrm{e}+002.01168 \mathrm{e}+002.01168 \mathrm{e}-011.00000 \mathrm{e}-092.12000 \mathrm{e}-01$ $2.01168 \mathrm{e}+002.01168 \mathrm{e}+00$ 2.01168e-01 1.00000e-09 2.12000e-01 Element: 3093 \# of layers: 8

Kx Ky Kz Ss Por

4.38985e+01 4.38985e+01 4.38985e+00 1.00000e-09 7.00000e-02 5.00000e-04 5.00000e-04 5.00000e-05 1.00000e-09 1.00000e-01 5.00000e-04 5.00000e-04 5.00000e-05 1.00000e-09 1.00000e-01 $1.75405 \mathrm{e}+001.75405 \mathrm{e}+001.75405 \mathrm{e}-011.00000 \mathrm{e}-092.12000 \mathrm{e}-01$ $1.75405 \mathrm{e}+001.75405 \mathrm{e}+001.75405 \mathrm{e}-011.00000 \mathrm{e}-092.12000 \mathrm{e}-01$ $1.75405 \mathrm{e}+001.75405 \mathrm{e}+001.75405 \mathrm{e}-011.00000 \mathrm{e}-092.12000 \mathrm{e}-01$ $1.75405 \mathrm{e}+001.75405 \mathrm{e}+00$ 1.75405e-01 1.00000e-09 2.12000e-01 $1.75405 \mathrm{e}+001.75405 \mathrm{e}+00$ 1.75405e-01 1.00000e-09 2.12000e-01 Element: 3094 \# of layers: 9

Kx Ky Kz Ss Por $4.38985 \mathrm{e}+014.38985 \mathrm{e}+014.38985 \mathrm{e}+00$ 1.00000e-09 7.00000e-02 $4.38985 \mathrm{e}+014.38985 \mathrm{e}+014.38985 \mathrm{e}+00$ 1.00000e-09 7.00000e-02 5.00000e-04 5.00000e-04 5.00000e-05 1.00000e-09 1.00000e-01 $5.00000 \mathrm{e}-04$ 5.00000e-04 5.00000e-05 1.00000e-09 1.00000e-01 $1.75405 \mathrm{e}+001.75405 \mathrm{e}+001.75405 \mathrm{e}-011.00000 \mathrm{e}-092.12000 \mathrm{e}-01$ $1.75405 \mathrm{e}+001.75405 \mathrm{e}+001.75405 \mathrm{e}-011.00000 \mathrm{e}-092.12000 \mathrm{e}-01$ $1.75405 \mathrm{e}+001.75405 \mathrm{e}+001.75405 \mathrm{e}-011.00000 \mathrm{e}-092.12000 \mathrm{e}-01$ $1.75405 \mathrm{e}+001.75405 \mathrm{e}+001.75405 \mathrm{e}-011.00000 \mathrm{e}-092.12000 \mathrm{e}-01$ $1.75405 \mathrm{e}+001.75405 \mathrm{e}+00$ 1.75405e-01 1.00000e-09 2.12000e-01 Element: 3095 \# of layers: 9 
$\mathrm{Kx} \mathrm{Ky} \mathrm{Kz}$ Ss Por

4.38985e+01 4.38985e+01 4.38985e+00 1.00000e-09 7.00000e-02

4.38985e+01 4.38985e+01 4.38985e+00 1.00000e-09 7.00000e-02

5.00000e-04 5.00000e-04 5.00000e-05 1.00000e-09 1.00000e-01

5.00000e-04 5.00000e-04 5.00000e-05 1.00000e-09 1.00000e-01

$1.75405 \mathrm{e}+001.75405 \mathrm{e}+00$ 1.75405e-01 1.00000e-09 2.12000e-01

$1.75405 \mathrm{e}+001.75405 \mathrm{e}+00$ 1.75405e-01 1.00000e-09 2.12000e-01

$1.75405 \mathrm{e}+001.75405 \mathrm{e}+00$ 1.75405e-01 1.00000e-09 2.12000e-01

$1.75405 \mathrm{e}+001.75405 \mathrm{e}+00$ 1.75405e-01 1.00000e-09 2.12000e-01

$1.75405 \mathrm{e}+00$ 1.75405e+00 1.75405e-01 1.00000e-09 2.12000e-01

Element: 3096 \# of layers: 8

Kx Ky Kz Ss Por

6.67740e+01 6.67740e+01 6.67740e+00 1.00000e-09 7.00000e-02

5.00000e-04 5.00000e-04 5.00000e-05 1.00000e-09 1.00000e-01

5.00000e-04 5.00000e-04 5.00000e-05 1.00000e-09 1.00000e-01

$2.66811 \mathrm{e}+002.66811 \mathrm{e}+002.66811 \mathrm{e}-01$ 1.00000e-09 2.12000e-01

$2.66811 \mathrm{e}+002.66811 \mathrm{e}+002.66811 \mathrm{e}-01$ 1.00000e-09 2.12000e-01

$2.66811 \mathrm{e}+002.66811 \mathrm{e}+002.66811 \mathrm{e}-01$ 1.00000e-09 2.12000e-01

$2.66811 \mathrm{e}+002.66811 \mathrm{e}+002.66811 \mathrm{e}-01$ 1.00000e-09 2.12000e-01

$2.66811 \mathrm{e}+002.66811 \mathrm{e}+00$ 2.66811e-01 1.00000e-09 2.12000e-01

Element: 3097 \# of layers: 8

$\mathrm{Kx} \mathrm{Ky} \mathrm{Kz}$ Ss Por

6.67740e+01 6.67740e+01 6.67740e+00 1.00000e-09 7.00000e-02 5.00000e-04 5.00000e-04 5.00000e-05 1.00000e-09 1.00000e-01

$5.00000 \mathrm{e}-04$ 5.00000e-04 5.00000e-05 1.00000e-09 1.00000e-01

$2.66811 \mathrm{e}+002.66811 \mathrm{e}+002.66811 \mathrm{e}-01$ 1.00000e-09 2.12000e-01

$2.66811 \mathrm{e}+002.66811 \mathrm{e}+002.66811 \mathrm{e}-01$ 1.00000e-09 2.12000e-01

$2.66811 \mathrm{e}+002.66811 \mathrm{e}+002.66811 \mathrm{e}-01$ 1.00000e-09 2.12000e-01

$2.66811 \mathrm{e}+002.66811 \mathrm{e}+002.66811 \mathrm{e}-01$ 1.00000e-09 2.12000e-01

$2.66811 \mathrm{e}+002.66811 \mathrm{e}+002.66811 \mathrm{e}-01$ 1.00000e-09 2.12000e-01

Element: 3098 \# of layers: 8

$\mathrm{Kx} \mathrm{Ky} \mathrm{Kz}$ Ss Por

6.67740e+01 6.67740e+01 6.67740e+00 1.00000e-09 7.00000e-02

$5.00000 \mathrm{e}-04$ 5.00000e-04 5.00000e-05 1.00000e-09 1.00000e-01

5.00000e-04 5.00000e-04 5.00000e-05 1.00000e-09 1.00000e-01

$2.66811 \mathrm{e}+002.66811 \mathrm{e}+002.66811 \mathrm{e}-01$ 1.00000e-09 2.12000e-01

$2.66811 \mathrm{e}+002.66811 \mathrm{e}+002.66811 \mathrm{e}-01$ 1.00000e-09 2.12000e-01

$2.66811 \mathrm{e}+002.66811 \mathrm{e}+002.66811 \mathrm{e}-01$ 1.00000e-09 2.12000e-01

$2.66811 \mathrm{e}+002.66811 \mathrm{e}+002.66811 \mathrm{e}-01$ 1.00000e-09 2.12000e-01

$2.66811 \mathrm{e}+002.66811 \mathrm{e}+00$ 2.66811e-01 1.00000e-09 2.12000e-01

Element: 3099 \# of layers: 5

$\mathrm{Kx} \mathrm{Ky} \mathrm{Kz}$ Ss Por

$1.97311 \mathrm{e}+011.97311 \mathrm{e}+011.97311 \mathrm{e}+001.00000 \mathrm{e}-092.12000 \mathrm{e}-01$

$1.00000 \mathrm{e}-02$ 1.00000e-02 1.00000e-03 1.00000e-09 1.00000e-01

$1.00000 \mathrm{e}+001.00000 \mathrm{e}+001.00000 \mathrm{e}-011.00000 \mathrm{e}-091.00000 \mathrm{e}-01$

$1.00000 \mathrm{e}-05$ 1.00000e-05 1.00000e-06 1.00000e-09 1.00000e-01 
$1.00000 \mathrm{e}+001.00000 \mathrm{e}+00$ 1.00000e-01 1.00000e-09 1.00000e-01

Element: 3100 \# of layers: 9

Kx Ky Kz Ss Por

$1.97311 \mathrm{e}+01$ 1.97311e+01 1.97311e+00 1.00000e-09 2.12000e-01

$1.97311 \mathrm{e}+011.97311 \mathrm{e}+011.97311 \mathrm{e}+001.00000 \mathrm{e}-092.12000 \mathrm{e}-01$

$1.97311 \mathrm{e}+011.97311 \mathrm{e}+011.97311 \mathrm{e}+001.00000 \mathrm{e}-092.12000 \mathrm{e}-01$

$1.97311 \mathrm{e}+011.97311 \mathrm{e}+011.97311 \mathrm{e}+001.00000 \mathrm{e}-092.12000 \mathrm{e}-01$

$1.97311 \mathrm{e}+011.97311 \mathrm{e}+011.97311 \mathrm{e}+001.00000 \mathrm{e}-092.12000 \mathrm{e}-01$

$1.00000 \mathrm{e}-02$ 1.00000e-02 1.00000e-03 1.00000e-09 1.00000e-01

$1.00000 \mathrm{e}+001.00000 \mathrm{e}+001.00000 \mathrm{e}-011.00000 \mathrm{e}-091.00000 \mathrm{e}-01$

$1.00000 \mathrm{e}-05$ 1.00000e-05 1.00000e-06 1.00000e-09 1.00000e-01

$1.00000 \mathrm{e}+001.00000 \mathrm{e}+001.00000 \mathrm{e}-011.00000 \mathrm{e}-091.00000 \mathrm{e}-01$

Element: 3101 \# of layers: 9

$\mathrm{Kx} \mathrm{Ky} \mathrm{Kz}$ Ss Por

$2.02131 \mathrm{e}+012.02131 \mathrm{e}+012.02131 \mathrm{e}+001.00000 \mathrm{e}-092.12000 \mathrm{e}-01$

$2.02131 \mathrm{e}+012.02131 \mathrm{e}+012.02131 \mathrm{e}+001.00000 \mathrm{e}-092.12000 \mathrm{e}-01$

$2.02131 \mathrm{e}+012.02131 \mathrm{e}+012.02131 \mathrm{e}+001.00000 \mathrm{e}-092.12000 \mathrm{e}-01$

$2.02131 \mathrm{e}+012.02131 \mathrm{e}+012.02131 \mathrm{e}+001.00000 \mathrm{e}-092.12000 \mathrm{e}-01$

$2.02131 \mathrm{e}+012.02131 \mathrm{e}+012.02131 \mathrm{e}+001.00000 \mathrm{e}-092.12000 \mathrm{e}-01$

$1.00000 \mathrm{e}-02$ 1.00000e-02 1.00000e-03 1.00000e-09 1.00000e-01

$1.00000 \mathrm{e}+001.00000 \mathrm{e}+001.00000 \mathrm{e}-011.00000 \mathrm{e}-091.00000 \mathrm{e}-01$

$1.00000 \mathrm{e}-05$ 1.00000e-05 1.00000e-06 1.00000e-09 1.00000e-01

$1.00000 \mathrm{e}+001.00000 \mathrm{e}+001.00000 \mathrm{e}-011.00000 \mathrm{e}-091.00000 \mathrm{e}-01$

Element: 3102 \# of layers: 9

$\mathrm{Kx} \mathrm{Ky} \mathrm{Kz}$ Ss Por

$2.02131 \mathrm{e}+012.02131 \mathrm{e}+012.02131 \mathrm{e}+001.00000 \mathrm{e}-092.12000 \mathrm{e}-01$

$2.02131 \mathrm{e}+012.02131 \mathrm{e}+012.02131 \mathrm{e}+001.00000 \mathrm{e}-092.12000 \mathrm{e}-01$

$2.02131 \mathrm{e}+012.02131 \mathrm{e}+012.02131 \mathrm{e}+001.00000 \mathrm{e}-092.12000 \mathrm{e}-01$

$2.02131 \mathrm{e}+012.02131 \mathrm{e}+012.02131 \mathrm{e}+001.00000 \mathrm{e}-092.12000 \mathrm{e}-01$

$2.02131 \mathrm{e}+012.02131 \mathrm{e}+012.02131 \mathrm{e}+001.00000 \mathrm{e}-09$ 2.12000e-01

$1.00000 \mathrm{e}-02$ 1.00000e-02 1.00000e-03 1.00000e-09 1.00000e-01

$1.00000 \mathrm{e}+001.00000 \mathrm{e}+001.00000 \mathrm{e}-011.00000 \mathrm{e}-091.00000 \mathrm{e}-01$

1.00000e-05 1.00000e-05 1.00000e-06 1.00000e-09 1.00000e-01

$1.00000 \mathrm{e}+001.00000 \mathrm{e}+001.00000 \mathrm{e}-011.00000 \mathrm{e}-091.00000 \mathrm{e}-01$

Element: 3103 \# of layers: 9

Kx Ky Kz Ss Por

$1.68313 \mathrm{e}+01$ 1.68313e+01 1.68313e+00 1.00000e-09 2.12000e-01

$1.68313 \mathrm{e}+011.68313 \mathrm{e}+011.68313 \mathrm{e}+001.00000 \mathrm{e}-092.12000 \mathrm{e}-01$

$1.68313 \mathrm{e}+011.68313 \mathrm{e}+011.68313 \mathrm{e}+001.00000 \mathrm{e}-092.12000 \mathrm{e}-01$

$1.68313 \mathrm{e}+011.68313 \mathrm{e}+01$ 1.68313e+00 1.00000e-09 2.12000e-01

$1.68313 \mathrm{e}+01$ 1.68313e+01 1.68313e+00 1.00000e-09 2.12000e-01

$1.00000 \mathrm{e}-02$ 1.00000e-02 1.00000e-03 1.00000e-09 1.00000e-01

$1.00000 \mathrm{e}+001.00000 \mathrm{e}+001.00000 \mathrm{e}-011.00000 \mathrm{e}-091.00000 \mathrm{e}-01$

$1.00000 \mathrm{e}-05$ 1.00000e-05 1.00000e-06 1.00000e-09 1.00000e-01

$1.00000 \mathrm{e}+001.00000 \mathrm{e}+001.00000 \mathrm{e}-01$ 1.00000e-09 1.00000e-01

Element: 3104 \# of layers: 9 
Kx Ky Kz Ss Por

4.21974e+00 4.21974e+00 4.21974e-01 1.00000e-09 2.12000e-01 $4.21974 \mathrm{e}+004.21974 \mathrm{e}+004.21974 \mathrm{e}-01$ 1.00000e-09 2.12000e-01 $4.21974 \mathrm{e}+004.21974 \mathrm{e}+00 \quad 4.21974 \mathrm{e}-01$ 1.00000e-09 2.12000e-01 $4.21974 \mathrm{e}+004.21974 \mathrm{e}+004.21974 \mathrm{e}-01$ 1.00000e-09 2.12000e-01 $4.21974 \mathrm{e}+004.21974 \mathrm{e}+004.21974 \mathrm{e}-01$ 1.00000e-09 2.12000e-01 $1.00000 \mathrm{e}-02$ 1.00000e-02 1.00000e-03 1.00000e-09 1.00000e-01 $1.00000 \mathrm{e}+001.00000 \mathrm{e}+001.00000 \mathrm{e}-011.00000 \mathrm{e}-091.00000 \mathrm{e}-01$ $1.00000 \mathrm{e}-05$ 1.00000e-05 1.00000e-06 1.00000e-09 1.00000e-01 $1.00000 \mathrm{e}+001.00000 \mathrm{e}+001.00000 \mathrm{e}-011.00000 \mathrm{e}-091.00000 \mathrm{e}-01$ Element: 3105 \# of layers: 9

$\mathrm{Kx} \mathrm{Ky} \mathrm{Kz}$ Ss Por

4.21974e+00 4.21974e+00 4.21974e-01 1.00000e-09 2.12000e-01 $4.21974 \mathrm{e}+004.21974 \mathrm{e}+004.21974 \mathrm{e}-01$ 1.00000e-09 2.12000e-01 $4.21974 \mathrm{e}+004.21974 \mathrm{e}+004.21974 \mathrm{e}-01$ 1.00000e-09 2.12000e-01 $4.21974 \mathrm{e}+004.21974 \mathrm{e}+004.21974 \mathrm{e}-01$ 1.00000e-09 2.12000e-01 $4.21974 \mathrm{e}+00 \quad 4.21974 \mathrm{e}+00 \quad 4.21974 \mathrm{e}-01$ 1.00000e-09 2.12000e-01 $1.00000 \mathrm{e}-02$ 1.00000e-02 1.00000e-03 1.00000e-09 1.00000e-01 $1.00000 \mathrm{e}+001.00000 \mathrm{e}+001.00000 \mathrm{e}-011.00000 \mathrm{e}-091.00000 \mathrm{e}-01$ $1.00000 \mathrm{e}-05$ 1.00000e-05 1.00000e-06 1.00000e-09 1.00000e-01 $1.00000 \mathrm{e}+001.00000 \mathrm{e}+001.00000 \mathrm{e}-011.00000 \mathrm{e}-091.00000 \mathrm{e}-01$ Element: 3106 \# of layers: 9

$\mathrm{Kx} \mathrm{Ky} \mathrm{Kz}$ Ss Por

$1.76773 \mathrm{e}+01$ 1.76773e+01 1.76773e+00 1.00000e-09 2.12000e-01 $1.76773 \mathrm{e}+01$ 1.76773e+01 1.76773e+00 1.00000e-09 2.12000e-01 $1.76773 \mathrm{e}+01$ 1.76773e+01 1.76773e+00 1.00000e-09 2.12000e-01 $1.76773 \mathrm{e}+01$ 1.76773e+01 1.76773e+00 1.00000e-09 2.12000e-01 $1.76773 \mathrm{e}+01$ 1.76773e+01 1.76773e+00 1.00000e-09 2.12000e-01 $1.00000 \mathrm{e}-02$ 1.00000e-02 1.00000e-03 1.00000e-09 1.00000e-01 $1.00000 \mathrm{e}+001.00000 \mathrm{e}+001.00000 \mathrm{e}-011.00000 \mathrm{e}-091.00000 \mathrm{e}-01$ $1.00000 \mathrm{e}-05$ 1.00000e-05 1.00000e-06 1.00000e-09 1.00000e-01 $1.00000 \mathrm{e}+001.00000 \mathrm{e}+001.00000 \mathrm{e}-01$ 1.00000e-09 1.00000e-01 Element: 3107 \# of layers: 9

$\mathrm{Kx} \mathrm{Ky} \mathrm{Kz}$ Ss Por

$1.73701 \mathrm{e}+01$ 1.73701e+01 1.73701e+00 1.00000e-09 2.12000e-01 $1.73701 \mathrm{e}+011.73701 \mathrm{e}+011.73701 \mathrm{e}+001.00000 \mathrm{e}-092.12000 \mathrm{e}-01$ $1.73701 \mathrm{e}+011.73701 \mathrm{e}+011.73701 \mathrm{e}+001.00000 \mathrm{e}-092.12000 \mathrm{e}-01$ $1.73701 \mathrm{e}+011.73701 \mathrm{e}+011.73701 \mathrm{e}+001.00000 \mathrm{e}-092.12000 \mathrm{e}-01$ $1.73701 \mathrm{e}+01$ 1.73701e+01 1.73701e+00 1.00000e-09 2.12000e-01 $1.00000 \mathrm{e}-02$ 1.00000e-02 1.00000e-03 1.00000e-09 1.00000e-01 $1.00000 \mathrm{e}+001.00000 \mathrm{e}+001.00000 \mathrm{e}-011.00000 \mathrm{e}-091.00000 \mathrm{e}-01$ $1.00000 \mathrm{e}-05$ 1.00000e-05 1.00000e-06 1.00000e-09 1.00000e-01 $1.00000 \mathrm{e}+001.00000 \mathrm{e}+001.00000 \mathrm{e}-01$ 1.00000e-09 1.00000e-01 Element: 3108 \# of layers: 5

$\mathrm{Kx} \mathrm{Ky} \mathrm{Kz}$ Ss Por

$1.73701 \mathrm{e}+01$ 1.73701e+01 1.73701e+00 1.00000e-09 2.12000e-01 
$1.00000 \mathrm{e}-02$ 1.00000e-02 1.00000e-03 1.00000e-09 1.00000e-01 $1.00000 \mathrm{e}+001.00000 \mathrm{e}+001.00000 \mathrm{e}-011.00000 \mathrm{e}-091.00000 \mathrm{e}-01$ $1.00000 \mathrm{e}-051.00000 \mathrm{e}-05$ 1.00000e-06 1.00000e-09 1.00000e-01 $1.00000 \mathrm{e}+001.00000 \mathrm{e}+001.00000 \mathrm{e}-011.00000 \mathrm{e}-091.00000 \mathrm{e}-01$ Element: 3109 \# of layers: 9

Kx Ky Kz Ss Por

$4.28589 \mathrm{e}+00$ 4.28589e+00 4.28589e-01 1.00000e-09 2.12000e-01 $4.28589 \mathrm{e}+004.28589 \mathrm{e}+00$ 4.28589e-01 1.00000e-09 2.12000e-01 $4.28589 \mathrm{e}+004.28589 \mathrm{e}+00$ 4.28589e-01 1.00000e-09 2.12000e-01 $4.28589 \mathrm{e}+004.28589 \mathrm{e}+00$ 4.28589e-01 1.00000e-09 2.12000e-01 $4.28589 \mathrm{e}+004.28589 \mathrm{e}+00$ 4.28589e-01 1.00000e-09 2.12000e-01 $1.00000 \mathrm{e}-02$ 1.00000e-02 1.00000e-03 1.00000e-09 1.00000e-01 $1.00000 \mathrm{e}+001.00000 \mathrm{e}+001.00000 \mathrm{e}-011.00000 \mathrm{e}-091.00000 \mathrm{e}-01$ $1.00000 \mathrm{e}-05$ 1.00000e-05 1.00000e-06 1.00000e-09 1.00000e-01 $1.00000 \mathrm{e}+001.00000 \mathrm{e}+001.00000 \mathrm{e}-011.00000 \mathrm{e}-091.00000 \mathrm{e}-01$ Element: 3110 \# of layers: 9

Kx Ky Kz Ss Por

$4.28589 \mathrm{e}+00$ 4.28589e+00 4.28589e-01 1.00000e-09 2.12000e-01 $4.28589 \mathrm{e}+004.28589 \mathrm{e}+00$ 4.28589e-01 1.00000e-09 2.12000e-01 $4.28589 \mathrm{e}+004.28589 \mathrm{e}+00$ 4.28589e-01 1.00000e-09 2.12000e-01 $4.28589 \mathrm{e}+004.28589 \mathrm{e}+004.28589 \mathrm{e}-011.00000 \mathrm{e}-092.12000 \mathrm{e}-01$ $4.28589 \mathrm{e}+004.28589 \mathrm{e}+00$ 4.28589e-01 1.00000e-09 2.12000e-01 $1.00000 \mathrm{e}-02$ 1.00000e-02 1.00000e-03 1.00000e-09 1.00000e-01 $1.00000 \mathrm{e}+001.00000 \mathrm{e}+001.00000 \mathrm{e}-011.00000 \mathrm{e}-091.00000 \mathrm{e}-01$ $1.00000 \mathrm{e}-05$ 1.00000e-05 1.00000e-06 1.00000e-09 1.00000e-01 $1.00000 \mathrm{e}+001.00000 \mathrm{e}+001.00000 \mathrm{e}-011.00000 \mathrm{e}-091.00000 \mathrm{e}-01$ Element: 3111 \# of layers: 9

Kx Ky Kz Ss Por

$4.26609 \mathrm{e}+00$ 4.26609e+00 4.26609e-01 1.00000e-09 2.12000e-01 $4.26609 \mathrm{e}+004.26609 \mathrm{e}+00$ 4.26609e-01 1.00000e-09 2.12000e-01 $4.26609 \mathrm{e}+004.26609 \mathrm{e}+00$ 4.26609e-01 1.00000e-09 2.12000e-01 $4.26609 \mathrm{e}+004.26609 \mathrm{e}+00$ 4.26609e-01 1.00000e-09 2.12000e-01 $4.26609 \mathrm{e}+004.26609 \mathrm{e}+00$ 4.26609e-01 1.00000e-09 2.12000e-01 $1.00000 \mathrm{e}-021.00000 \mathrm{e}-02$ 1.00000e-03 1.00000e-09 1.00000e-01 $1.00000 \mathrm{e}+001.00000 \mathrm{e}+001.00000 \mathrm{e}-011.00000 \mathrm{e}-091.00000 \mathrm{e}-01$ $1.00000 \mathrm{e}-05$ 1.00000e-05 1.00000e-06 1.00000e-09 1.00000e-01 $1.00000 \mathrm{e}+001.00000 \mathrm{e}+001.00000 \mathrm{e}-011.00000 \mathrm{e}-091.00000 \mathrm{e}-01$ Element: 3112 \# of layers: 9

Kx Ky Kz Ss Por

$4.27239 \mathrm{e}+00$ 4.27239e+00 4.27239e-01 1.00000e-09 2.12000e-01 $4.27239 \mathrm{e}+004.27239 \mathrm{e}+00$ 4.27239e-01 1.00000e-09 2.12000e-01 $4.27239 \mathrm{e}+004.27239 \mathrm{e}+00$ 4.27239e-01 1.00000e-09 2.12000e-01 $4.27239 \mathrm{e}+004.27239 \mathrm{e}+00$ 4.27239e-01 1.00000e-09 2.12000e-01 $4.27239 \mathrm{e}+004.27239 \mathrm{e}+00$ 4.27239e-01 1.00000e-09 2.12000e-01 $1.00000 \mathrm{e}-021.00000 \mathrm{e}-02$ 1.00000e-03 1.00000e-09 1.00000e-01 $1.00000 \mathrm{e}+001.00000 \mathrm{e}+001.00000 \mathrm{e}-011.00000 \mathrm{e}-091.00000 \mathrm{e}-01$ 
$1.00000 \mathrm{e}-05$ 1.00000e-05 1.00000e-06 1.00000e-09 1.00000e-01 $1.00000 \mathrm{e}+001.00000 \mathrm{e}+001.00000 \mathrm{e}-01$ 1.00000e-09 1.00000e-01 Element: 3113 \# of layers: 9

Kx Ky Kz Ss Por

$3.32580 \mathrm{e}+013.32580 \mathrm{e}+013.32580 \mathrm{e}+001.00000 \mathrm{e}-092.12000 \mathrm{e}-01$ $3.32580 \mathrm{e}+013.32580 \mathrm{e}+013.32580 \mathrm{e}+00$ 1.00000e-09 2.12000e-01 $3.32580 \mathrm{e}+013.32580 \mathrm{e}+013.32580 \mathrm{e}+00$ 1.00000e-09 2.12000e-01 $3.32580 \mathrm{e}+013.32580 \mathrm{e}+013.32580 \mathrm{e}+001.00000 \mathrm{e}-092.12000 \mathrm{e}-01$ $3.32580 \mathrm{e}+013.32580 \mathrm{e}+013.32580 \mathrm{e}+001.00000 \mathrm{e}-092.12000 \mathrm{e}-01$ $1.00000 \mathrm{e}-02$ 1.00000e-02 1.00000e-03 1.00000e-09 1.00000e-01 $1.00000 \mathrm{e}+001.00000 \mathrm{e}+001.00000 \mathrm{e}-011.00000 \mathrm{e}-091.00000 \mathrm{e}-01$ $1.00000 \mathrm{e}-05$ 1.00000e-05 1.00000e-06 1.00000e-09 1.00000e-01 $1.00000 \mathrm{e}+001.00000 \mathrm{e}+001.00000 \mathrm{e}-01$ 1.00000e-09 1.00000e-01 Element: 3114 \# of layers: 9

$\mathrm{Kx} \mathrm{Ky} \mathrm{Kz}$ Ss Por

3.32580e+01 3.32580e+01 3.32580e+00 1.00000e-09 2.12000e-01 $3.32580 \mathrm{e}+013.32580 \mathrm{e}+013.32580 \mathrm{e}+00$ 1.00000e-09 2.12000e-01 $3.32580 \mathrm{e}+013.32580 \mathrm{e}+013.32580 \mathrm{e}+001.00000 \mathrm{e}-092.12000 \mathrm{e}-01$ $3.32580 \mathrm{e}+013.32580 \mathrm{e}+013.32580 \mathrm{e}+001.00000 \mathrm{e}-092.12000 \mathrm{e}-01$ $3.32580 \mathrm{e}+013.32580 \mathrm{e}+013.32580 \mathrm{e}+001.00000 \mathrm{e}-092.12000 \mathrm{e}-01$ $1.00000 \mathrm{e}-02$ 1.00000e-02 1.00000e-03 1.00000e-09 1.00000e-01 $1.00000 \mathrm{e}+001.00000 \mathrm{e}+001.00000 \mathrm{e}-011.00000 \mathrm{e}-091.00000 \mathrm{e}-01$ $1.00000 \mathrm{e}-05$ 1.00000e-05 1.00000e-06 1.00000e-09 1.00000e-01 $1.00000 \mathrm{e}+001.00000 \mathrm{e}+001.00000 \mathrm{e}-011.00000 \mathrm{e}-09$ 1.00000e-01 Element: 3115 \# of layers: 9

$\mathrm{Kx} \mathrm{Ky} \mathrm{Kz}$ Ss Por

$1.29740 \mathrm{e}+01$ 1.29740e+01 1.29740e+00 1.00000e-09 2.12000e-01 $1.29740 \mathrm{e}+011.29740 \mathrm{e}+011.29740 \mathrm{e}+001.00000 \mathrm{e}-092.12000 \mathrm{e}-01$ $1.29740 \mathrm{e}+011.29740 \mathrm{e}+011.29740 \mathrm{e}+001.00000 \mathrm{e}-092.12000 \mathrm{e}-01$ $1.29740 \mathrm{e}+011.29740 \mathrm{e}+011.29740 \mathrm{e}+001.00000 \mathrm{e}-092.12000 \mathrm{e}-01$ $1.29740 \mathrm{e}+011.29740 \mathrm{e}+01 \quad 1.29740 \mathrm{e}+001.00000 \mathrm{e}-092.12000 \mathrm{e}-01$ $1.00000 \mathrm{e}-02$ 1.00000e-02 1.00000e-03 1.00000e-09 1.00000e-01 $1.00000 \mathrm{e}+001.00000 \mathrm{e}+001.00000 \mathrm{e}-011.00000 \mathrm{e}-091.00000 \mathrm{e}-01$ $1.00000 \mathrm{e}-05$ 1.00000e-05 1.00000e-06 1.00000e-09 1.00000e-01 $1.00000 \mathrm{e}+001.00000 \mathrm{e}+001.00000 \mathrm{e}-011.00000 \mathrm{e}-091.00000 \mathrm{e}-01$ Element: 3116 \# of layers: 9

Kx Ky Kz Ss Por

$2.38415 \mathrm{e}+012.38415 \mathrm{e}+012.38415 \mathrm{e}+00$ 1.00000e-09 2.12000e-01

$2.38415 \mathrm{e}+012.38415 \mathrm{e}+012.38415 \mathrm{e}+00$ 1.00000e-09 2.12000e-01 $2.38415 \mathrm{e}+012.38415 \mathrm{e}+012.38415 \mathrm{e}+00$ 1.00000e-09 2.12000e-01 $2.38415 \mathrm{e}+012.38415 \mathrm{e}+012.38415 \mathrm{e}+00$ 1.00000e-09 2.12000e-01 $2.38415 \mathrm{e}+012.38415 \mathrm{e}+012.38415 \mathrm{e}+001.00000 \mathrm{e}-092.12000 \mathrm{e}-01$ $1.00000 \mathrm{e}-02$ 1.00000e-02 1.00000e-03 1.00000e-09 1.00000e-01 $1.00000 \mathrm{e}+001.00000 \mathrm{e}+001.00000 \mathrm{e}-011.00000 \mathrm{e}-091.00000 \mathrm{e}-01$ $1.00000 \mathrm{e}-05$ 1.00000e-05 1.00000e-06 1.00000e-09 1.00000e-01 $1.00000 \mathrm{e}+001.00000 \mathrm{e}+001.00000 \mathrm{e}-011.00000 \mathrm{e}-091.00000 \mathrm{e}-01$ 
Element: 3117 \# of layers: 9

$\mathrm{Kx} \mathrm{Ky} \mathrm{Kz}$ Ss Por

3.46687e+01 3.46687e+01 3.46687e+00 1.00000e-09 2.12000e-01

$3.46687 \mathrm{e}+01$ 3.46687e+01 3.46687e+00 1.00000e-09 2.12000e-01

$3.46687 \mathrm{e}+013.46687 \mathrm{e}+01$ 3.46687e+00 1.00000e-09 2.12000e-01

$3.46687 \mathrm{e}+013.46687 \mathrm{e}+01$ 3.46687e+00 1.00000e-09 2.12000e-01

$3.46687 \mathrm{e}+013.46687 \mathrm{e}+01$ 3.46687e+00 1.00000e-09 2.12000e-01

$1.00000 \mathrm{e}-02$ 1.00000e-02 1.00000e-03 1.00000e-09 1.00000e-01

$1.00000 \mathrm{e}+001.00000 \mathrm{e}+001.00000 \mathrm{e}-011.00000 \mathrm{e}-091.00000 \mathrm{e}-01$

$1.00000 \mathrm{e}-05$ 1.00000e-05 1.00000e-06 1.00000e-09 1.00000e-01

$1.00000 \mathrm{e}+001.00000 \mathrm{e}+001.00000 \mathrm{e}-011.00000 \mathrm{e}-091.00000 \mathrm{e}-01$

Element: 3118 \# of layers: 9

$\mathrm{Kx} \mathrm{Ky} \mathrm{Kz}$ Ss Por

3.46687e+01 3.46687e+01 3.46687e+00 1.00000e-09 2.12000e-01

$3.46687 \mathrm{e}+013.46687 \mathrm{e}+01$ 3.46687e+00 1.00000e-09 2.12000e-01

$3.46687 \mathrm{e}+013.46687 \mathrm{e}+013.46687 \mathrm{e}+001.00000 \mathrm{e}-092.12000 \mathrm{e}-01$

$3.46687 \mathrm{e}+013.46687 \mathrm{e}+01$ 3.46687e+00 1.00000e-09 2.12000e-01

$3.46687 \mathrm{e}+013.46687 \mathrm{e}+01$ 3.46687e+00 1.00000e-09 2.12000e-01

$1.00000 \mathrm{e}-02$ 1.00000e-02 1.00000e-03 1.00000e-09 1.00000e-01

$1.00000 \mathrm{e}+001.00000 \mathrm{e}+001.00000 \mathrm{e}-011.00000 \mathrm{e}-091.00000 \mathrm{e}-01$

$1.00000 \mathrm{e}-051.00000 \mathrm{e}-051.00000 \mathrm{e}-061.00000 \mathrm{e}-091.00000 \mathrm{e}-01$

$1.00000 \mathrm{e}+001.00000 \mathrm{e}+001.00000 \mathrm{e}-011.00000 \mathrm{e}-09$ 1.00000e-01

Element: 3119 \# of layers: 9

Kx Ky Kz Ss Por

$3.45022 \mathrm{e}+013.45022 \mathrm{e}+013.45022 \mathrm{e}+00$ 1.00000e-09 2.12000e-01

$3.45022 \mathrm{e}+013.45022 \mathrm{e}+013.45022 \mathrm{e}+001.00000 \mathrm{e}-092.12000 \mathrm{e}-01$

$3.45022 \mathrm{e}+013.45022 \mathrm{e}+013.45022 \mathrm{e}+001.00000 \mathrm{e}-092.12000 \mathrm{e}-01$

$3.45022 \mathrm{e}+013.45022 \mathrm{e}+013.45022 \mathrm{e}+00$ 1.00000e-09 2.12000e-01

$3.45022 \mathrm{e}+013.45022 \mathrm{e}+013.45022 \mathrm{e}+00$ 1.00000e-09 2.12000e-01

$1.00000 \mathrm{e}-02$ 1.00000e-02 1.00000e-03 1.00000e-09 1.00000e-01

$1.00000 \mathrm{e}+001.00000 \mathrm{e}+001.00000 \mathrm{e}-011.00000 \mathrm{e}-091.00000 \mathrm{e}-01$

$1.00000 \mathrm{e}-05$ 1.00000e-05 1.00000e-06 1.00000e-09 1.00000e-01

$1.00000 \mathrm{e}+001.00000 \mathrm{e}+001.00000 \mathrm{e}-011.00000 \mathrm{e}-091.00000 \mathrm{e}-01$

Element: 3120 \# of layers: 9

$\mathrm{Kx} \mathrm{Ky} \mathrm{Kz}$ Ss Por

3.30870e+01 3.30870e+01 3.30870e+00 1.00000e-09 2.12000e-01

$3.30870 \mathrm{e}+013.30870 \mathrm{e}+013.30870 \mathrm{e}+001.00000 \mathrm{e}-092.12000 \mathrm{e}-01$

$3.30870 \mathrm{e}+013.30870 \mathrm{e}+013.30870 \mathrm{e}+00$ 1.00000e-09 2.12000e-01

$3.30870 \mathrm{e}+013.30870 \mathrm{e}+013.30870 \mathrm{e}+00$ 1.00000e-09 2.12000e-01

$3.30870 \mathrm{e}+013.30870 \mathrm{e}+013.30870 \mathrm{e}+00$ 1.00000e-09 2.12000e-01

$1.00000 \mathrm{e}-02$ 1.00000e-02 1.00000e-03 1.00000e-09 1.00000e-01

$1.00000 \mathrm{e}+001.00000 \mathrm{e}+001.00000 \mathrm{e}-011.00000 \mathrm{e}-091.00000 \mathrm{e}-01$

$1.00000 \mathrm{e}-05$ 1.00000e-05 1.00000e-06 1.00000e-09 1.00000e-01

$1.00000 \mathrm{e}+001.00000 \mathrm{e}+001.00000 \mathrm{e}-01$ 1.00000e-09 1.00000e-01

Element: 3121 \# of layers: 9

Kx Ky Kz Ss Por 
9.41398e+02 9.41398e+02 9.41398e+01 1.00000e-09 2.12000e-01 9.41398e+02 9.41398e+02 9.41398e+01 1.00000e-09 2.12000e-01 9.41398e+02 9.41398e+02 9.41398e+01 1.00000e-09 2.12000e-01 $9.41398 \mathrm{e}+02$ 9.41398e+02 9.41398e+01 1.00000e-09 2.12000e-01 9.41398e+02 9.41398e+02 9.41398e+01 1.00000e-09 2.12000e-01 $1.00000 \mathrm{e}-02$ 1.00000e-02 1.00000e-03 1.00000e-09 1.00000e-01 $1.00000 \mathrm{e}+001.00000 \mathrm{e}+001.00000 \mathrm{e}-011.00000 \mathrm{e}-091.00000 \mathrm{e}-01$ $1.00000 \mathrm{e}-05$ 1.00000e-05 1.00000e-06 1.00000e-09 1.00000e-01 $1.00000 \mathrm{e}+001.00000 \mathrm{e}+001.00000 \mathrm{e}-011.00000 \mathrm{e}-091.00000 \mathrm{e}-01$ Element: 3122 \# of layers: 9

$\mathrm{Kx} \mathrm{Ky} \mathrm{Kz}$ Ss Por

9.41398e+02 9.41398e+02 9.41398e+01 1.00000e-09 2.12000e-01 9.41398e+02 9.41398e+02 9.41398e+01 1.00000e-09 2.12000e-01 9.41398e+02 9.41398e+02 9.41398e+01 1.00000e-09 2.12000e-01 9.41398e+02 9.41398e+02 9.41398e+01 1.00000e-09 2.12000e-01 $9.41398 \mathrm{e}+02$ 9.41398e+02 9.41398e+01 1.00000e-09 2.12000e-01 $1.00000 \mathrm{e}-02$ 1.00000e-02 1.00000e-03 1.00000e-09 1.00000e-01 $1.00000 \mathrm{e}+001.00000 \mathrm{e}+001.00000 \mathrm{e}-011.00000 \mathrm{e}-091.00000 \mathrm{e}-01$ $1.00000 \mathrm{e}-05$ 1.00000e-05 1.00000e-06 1.00000e-09 1.00000e-01 $1.00000 \mathrm{e}+001.00000 \mathrm{e}+001.00000 \mathrm{e}-011.00000 \mathrm{e}-091.00000 \mathrm{e}-01$ Element: 3123 \# of layers: 9

$\mathrm{Kx} \mathrm{Ky} \mathrm{Kz}$ Ss Por

3.84893e+01 3.84893e+01 3.84893e+00 1.00000e-09 2.12000e-01 $3.84893 \mathrm{e}+013.84893 \mathrm{e}+013.84893 \mathrm{e}+001.00000 \mathrm{e}-092.12000 \mathrm{e}-01$ $3.84893 e+013.84893 e+013.84893 e+001.00000 e-092.12000 \mathrm{e}-01$ $3.84893 \mathrm{e}+013.84893 \mathrm{e}+013.84893 \mathrm{e}+001.00000 \mathrm{e}-092.12000 \mathrm{e}-01$ $3.84893 \mathrm{e}+013.84893 \mathrm{e}+013.84893 \mathrm{e}+00$ 1.00000e-09 2.12000e-01 $1.00000 \mathrm{e}-02$ 1.00000e-02 1.00000e-03 1.00000e-09 1.00000e-01 $1.00000 \mathrm{e}+001.00000 \mathrm{e}+001.00000 \mathrm{e}-011.00000 \mathrm{e}-091.00000 \mathrm{e}-01$ $1.00000 \mathrm{e}-05$ 1.00000e-05 1.00000e-06 1.00000e-09 1.00000e-01 $1.00000 \mathrm{e}+001.00000 \mathrm{e}+001.00000 \mathrm{e}-011.00000 \mathrm{e}-091.00000 \mathrm{e}-01$ Element: 3124 \# of layers: 9

Kx Ky Kz Ss Por

3.10912e+01 3.10912e+01 3.10912e+00 1.00000e-09 2.12000e-01 $3.10912 \mathrm{e}+013.10912 \mathrm{e}+013.10912 \mathrm{e}+00$ 1.00000e-09 2.12000e-01 $3.10912 \mathrm{e}+013.10912 \mathrm{e}+013.10912 \mathrm{e}+00$ 1.00000e-09 2.12000e-01 $3.10912 \mathrm{e}+013.10912 \mathrm{e}+013.10912 \mathrm{e}+00$ 1.00000e-09 2.12000e-01 $3.10912 \mathrm{e}+013.10912 \mathrm{e}+013.10912 \mathrm{e}+00$ 1.00000e-09 2.12000e-01 $1.00000 \mathrm{e}-02$ 1.00000e-02 1.00000e-03 1.00000e-09 1.00000e-01 $1.00000 \mathrm{e}+001.00000 \mathrm{e}+001.00000 \mathrm{e}-011.00000 \mathrm{e}-091.00000 \mathrm{e}-01$ $1.00000 \mathrm{e}-05$ 1.00000e-05 1.00000e-06 1.00000e-09 1.00000e-01 $1.00000 \mathrm{e}+001.00000 \mathrm{e}+001.00000 \mathrm{e}-011.00000 \mathrm{e}-091.00000 \mathrm{e}-01$ Element: 3125 \# of layers: 9

$\mathrm{Kx} \mathrm{Ky} \mathrm{Kz}$ Ss Por

$1.44701 \mathrm{e}+03$ 1.44701e+03 1.44701e+02 1.00000e-09 2.12000e-01 $1.44701 \mathrm{e}+031.44701 \mathrm{e}+031.44701 \mathrm{e}+021.00000 \mathrm{e}-092.12000 \mathrm{e}-01$ 
$1.44701 \mathrm{e}+031.44701 \mathrm{e}+03$ 1.44701e+02 1.00000e-09 2.12000e-01 $1.44701 \mathrm{e}+031.44701 \mathrm{e}+031.44701 \mathrm{e}+021.00000 \mathrm{e}-092.12000 \mathrm{e}-01$ $1.44701 \mathrm{e}+031.44701 \mathrm{e}+03$ 1.44701e+02 1.00000e-09 2.12000e-01 $1.00000 \mathrm{e}-02$ 1.00000e-02 1.00000e-03 1.00000e-09 1.00000e-01 $1.00000 \mathrm{e}+001.00000 \mathrm{e}+001.00000 \mathrm{e}-011.00000 \mathrm{e}-091.00000 \mathrm{e}-01$ $1.00000 \mathrm{e}-05$ 1.00000e-05 1.00000e-06 1.00000e-09 1.00000e-01 $1.00000 \mathrm{e}+001.00000 \mathrm{e}+001.00000 \mathrm{e}-01$ 1.00000e-09 1.00000e-01 Element: 3126 \# of layers: 9

$\mathrm{Kx} \mathrm{Ky} \mathrm{Kz}$ Ss Por

$1.44701 \mathrm{e}+031.44701 \mathrm{e}+03$ 1.44701e+02 1.00000e-09 2.12000e-01 $1.44701 \mathrm{e}+03$ 1.44701e+03 1.44701e+02 1.00000e-09 2.12000e-01 $1.44701 \mathrm{e}+031.44701 \mathrm{e}+031.44701 \mathrm{e}+02$ 1.00000e-09 2.12000e-01 $1.44701 \mathrm{e}+03$ 1.44701e+03 1.44701e+02 1.00000e-09 2.12000e-01 $1.44701 \mathrm{e}+031.44701 \mathrm{e}+031.44701 \mathrm{e}+02$ 1.00000e-09 2.12000e-01 $1.00000 \mathrm{e}-021.00000 \mathrm{e}-021.00000 \mathrm{e}-031.00000 \mathrm{e}-091.00000 \mathrm{e}-01$ $1.00000 \mathrm{e}+001.00000 \mathrm{e}+001.00000 \mathrm{e}-011.00000 \mathrm{e}-091.00000 \mathrm{e}-01$ $1.00000 \mathrm{e}-05$ 1.00000e-05 1.00000e-06 1.00000e-09 1.00000e-01 $1.00000 \mathrm{e}+001.00000 \mathrm{e}+001.00000 \mathrm{e}-01$ 1.00000e-09 1.00000e-01 Element: 3127 \# of layers: 9

$\mathrm{Kx} \mathrm{Ky} \mathrm{Kz}$ Ss Por

$1.46339 \mathrm{e}+03$ 1.46339e+03 1.46339e+02 1.00000e-09 2.12000e-01 $1.46339 \mathrm{e}+03$ 1.46339e+03 1.46339e+02 1.00000e-09 2.12000e-01 $1.46339 \mathrm{e}+031.46339 \mathrm{e}+03$ 1.46339e+02 1.00000e-09 2.12000e-01 $1.46339 \mathrm{e}+031.46339 \mathrm{e}+03$ 1.46339e+02 1.00000e-09 2.12000e-01 $1.46339 \mathrm{e}+031.46339 \mathrm{e}+03$ 1.46339e+02 1.00000e-09 2.12000e-01 $1.00000 \mathrm{e}-02$ 1.00000e-02 1.00000e-03 1.00000e-09 1.00000e-01 $1.00000 \mathrm{e}+001.00000 \mathrm{e}+001.00000 \mathrm{e}-011.00000 \mathrm{e}-091.00000 \mathrm{e}-01$ $1.00000 \mathrm{e}-05$ 1.00000e-05 1.00000e-06 1.00000e-09 1.00000e-01 $1.00000 \mathrm{e}+001.00000 \mathrm{e}+001.00000 \mathrm{e}-011.00000 \mathrm{e}-091.00000 \mathrm{e}-01$ Element: 3128 \# of layers: 9

$\mathrm{Kx} \mathrm{Ky} \mathrm{Kz}$ Ss Por

$1.14755 \mathrm{e}+03$ 1.14755e+03 1.14755e+02 1.00000e-09 2.12000e-01 $1.14755 \mathrm{e}+031.14755 \mathrm{e}+03$ 1.14755e+02 1.00000e-09 2.12000e-01 $1.14755 \mathrm{e}+03$ 1.14755e+03 1.14755e+02 1.00000e-09 2.12000e-01 $1.14755 \mathrm{e}+03$ 1.14755e+03 1.14755e+02 1.00000e-09 2.12000e-01 $1.14755 \mathrm{e}+03$ 1.14755e+03 1.14755e+02 1.00000e-09 2.12000e-01 $1.00000 \mathrm{e}-02$ 1.00000e-02 1.00000e-03 1.00000e-09 1.00000e-01 $1.00000 \mathrm{e}+001.00000 \mathrm{e}+001.00000 \mathrm{e}-011.00000 \mathrm{e}-091.00000 \mathrm{e}-01$ $1.00000 \mathrm{e}-05$ 1.00000e-05 1.00000e-06 1.00000e-09 1.00000e-01 $1.00000 \mathrm{e}+001.00000 \mathrm{e}+001.00000 \mathrm{e}-011.00000 \mathrm{e}-091.00000 \mathrm{e}-01$ Element: 3129 \# of layers: 11

$\mathrm{Kx} \mathrm{Ky} \mathrm{Kz}$ Ss Por

$2.11059 \mathrm{e}+042.11059 \mathrm{e}+042.11059 \mathrm{e}+03$ 1.00000e-09 7.00000e-02 5.00000e-04 5.00000e-04 5.00000e-05 1.00000e-09 1.00000e-01 $8.43318 \mathrm{e}+02$ 8.43318e+02 8.43318e+01 1.00000e-09 2.12000e-01 $8.43318 \mathrm{e}+02$ 8.43318e+02 8.43318e+01 1.00000e-09 2.12000e-01 
8.43318e+02 8.43318e+02 8.43318e+01 1.00000e-09 2.12000e-01 8.43318e+02 8.43318e+02 8.43318e+01 1.00000e-09 2.12000e-01 8.43318e+02 8.43318e+02 8.43318e+01 1.00000e-09 2.12000e-01 $1.00000 \mathrm{e}-02$ 1.00000e-02 1.00000e-03 1.00000e-09 1.00000e-01 $1.00000 \mathrm{e}+001.00000 \mathrm{e}+001.00000 \mathrm{e}-011.00000 \mathrm{e}-091.00000 \mathrm{e}-01$ $1.00000 \mathrm{e}-05$ 1.00000e-05 1.00000e-06 1.00000e-09 1.00000e-01 $1.00000 \mathrm{e}+001.00000 \mathrm{e}+001.00000 \mathrm{e}-01$ 1.00000e-09 1.00000e-01 Element: 3130 \# of layers: 11

$\mathrm{Kx} \mathrm{Ky} \mathrm{Kz}$ Ss Por

2.11059e+04 2.11059e+04 2.11059e+03 1.00000e-09 7.00000e-02 5.00000e-04 5.00000e-04 5.00000e-05 1.00000e-09 1.00000e-01 $8.43318 \mathrm{e}+02$ 8.43318e+02 8.43318e+01 1.00000e-09 2.12000e-01 8.43318e+02 8.43318e+02 8.43318e+01 1.00000e-09 2.12000e-01 $8.43318 \mathrm{e}+02$ 8.43318e+02 8.43318e+01 1.00000e-09 2.12000e-01 8.43318e+02 8.43318e+02 8.43318e+01 1.00000e-09 2.12000e-01 $8.43318 \mathrm{e}+028.43318 \mathrm{e}+028.43318 \mathrm{e}+01$ 1.00000e-09 2.12000e-01 $1.00000 \mathrm{e}-021.00000 \mathrm{e}-021.00000 \mathrm{e}-031.00000 \mathrm{e}-091.00000 \mathrm{e}-01$ $1.00000 \mathrm{e}+001.00000 \mathrm{e}+001.00000 \mathrm{e}-011.00000 \mathrm{e}-091.00000 \mathrm{e}-01$ $1.00000 \mathrm{e}-05$ 1.00000e-05 1.00000e-06 1.00000e-09 1.00000e-01 $1.00000 \mathrm{e}+001.00000 \mathrm{e}+001.00000 \mathrm{e}-01$ 1.00000e-09 1.00000e-01 Element: 3131 \# of layers: 11

$\mathrm{Kx} \mathrm{Ky} \mathrm{Kz}$ Ss Por

$1.67388 \mathrm{e}+04$ 1.67388e+04 1.67388e+03 1.00000e-09 7.00000e-02 $5.00000 \mathrm{e}-04$ 5.00000e-04 5.00000e-05 1.00000e-09 1.00000e-01 $6.68804 \mathrm{e}+026.68804 \mathrm{e}+026.68804 \mathrm{e}+01$ 1.00000e-09 2.12000e-01 $6.68804 \mathrm{e}+02$ 6.68804e+02 6.68804e+01 1.00000e-09 2.12000e-01 $6.68804 \mathrm{e}+02$ 6.68804e+02 6.68804e+01 1.00000e-09 2.12000e-01 $6.68804 \mathrm{e}+026.68804 \mathrm{e}+026.68804 \mathrm{e}+01$ 1.00000e-09 2.12000e-01 $6.68804 \mathrm{e}+026.68804 \mathrm{e}+026.68804 \mathrm{e}+01$ 1.00000e-09 2.12000e-01 $1.00000 \mathrm{e}-021.00000 \mathrm{e}-021.00000 \mathrm{e}-031.00000 \mathrm{e}-091.00000 \mathrm{e}-01$ $1.00000 \mathrm{e}+001.00000 \mathrm{e}+001.00000 \mathrm{e}-011.00000 \mathrm{e}-091.00000 \mathrm{e}-01$ $1.00000 \mathrm{e}-05$ 1.00000e-05 1.00000e-06 1.00000e-09 1.00000e-01 $1.00000 \mathrm{e}+001.00000 \mathrm{e}+001.00000 \mathrm{e}-011.00000 \mathrm{e}-091.00000 \mathrm{e}-01$ Element: 3132 \# of layers: 11

$\mathrm{Kx} \mathrm{Ky} \mathrm{Kz}$ Ss Por

$1.67388 \mathrm{e}+04$ 1.67388e+04 1.67388e+03 1.00000e-09 7.00000e-02 5.00000e-04 5.00000e-04 5.00000e-05 1.00000e-09 1.00000e-01 $6.68804 \mathrm{e}+026.68804 \mathrm{e}+026.68804 \mathrm{e}+01$ 1.00000e-09 2.12000e-01 $6.68804 \mathrm{e}+026.68804 \mathrm{e}+02$ 6.68804e+01 1.00000e-09 2.12000e-01 $6.68804 \mathrm{e}+026.68804 \mathrm{e}+02$ 6.68804e+01 1.00000e-09 2.12000e-01 $6.68804 \mathrm{e}+026.68804 \mathrm{e}+026.68804 \mathrm{e}+01$ 1.00000e-09 2.12000e-01 $6.68804 \mathrm{e}+02$ 6.68804e+02 6.68804e+01 1.00000e-09 2.12000e-01 $1.00000 \mathrm{e}-02$ 1.00000e-02 1.00000e-03 1.00000e-09 1.00000e-01 $1.00000 \mathrm{e}+001.00000 \mathrm{e}+001.00000 \mathrm{e}-011.00000 \mathrm{e}-091.00000 \mathrm{e}-01$ $1.00000 \mathrm{e}-051.00000 \mathrm{e}-051.00000 \mathrm{e}-061.00000 \mathrm{e}-091.00000 \mathrm{e}-01$ $1.00000 \mathrm{e}+001.00000 \mathrm{e}+001.00000 \mathrm{e}-011.00000 \mathrm{e}-091.00000 \mathrm{e}-01$ 
Element: 3133 \# of layers: 9

$\mathrm{Kx} \mathrm{Ky} \mathrm{Kz}$ Ss Por

1.44197e+03 1.44197e+03 1.44197e+02 1.00000e-09 2.12000e-01

$1.44197 \mathrm{e}+03$ 1.44197e+03 1.44197e+02 1.00000e-09 2.12000e-01

$1.44197 \mathrm{e}+03$ 1.44197e+03 1.44197e+02 1.00000e-09 2.12000e-01

$1.44197 \mathrm{e}+03$ 1.44197e+03 1.44197e+02 1.00000e-09 2.12000e-01

$1.44197 \mathrm{e}+03$ 1.44197e+03 1.44197e+02 1.00000e-09 2.12000e-01

$1.00000 \mathrm{e}-02$ 1.00000e-02 1.00000e-03 1.00000e-09 1.00000e-01

$1.00000 \mathrm{e}+001.00000 \mathrm{e}+001.00000 \mathrm{e}-011.00000 \mathrm{e}-091.00000 \mathrm{e}-01$

$1.00000 \mathrm{e}-05$ 1.00000e-05 1.00000e-06 1.00000e-09 1.00000e-01

$1.00000 \mathrm{e}+001.00000 \mathrm{e}+001.00000 \mathrm{e}-011.00000 \mathrm{e}-091.00000 \mathrm{e}-01$

Element: 3134 \# of layers: 12

$\mathrm{Kx} \mathrm{Ky} \mathrm{Kz}$ Ss Por

9.66683e+03 9.66683e+03 9.66683e+02 1.00000e-09 7.00000e-02

$9.66683 \mathrm{e}+03$ 9.66683e+03 9.66683e+02 1.00000e-09 7.00000e-02

5.00000e-04 5.00000e-04 5.00000e-05 1.00000e-09 1.00000e-01

$3.86243 \mathrm{e}+02$ 3.86243e+02 3.86243e+01 1.00000e-09 2.12000e-01

$3.86243 \mathrm{e}+02$ 3.86243e+02 3.86243e+01 1.00000e-09 2.12000e-01

$3.86243 \mathrm{e}+02$ 3.86243e+02 3.86243e+01 1.00000e-09 2.12000e-01

$3.86243 \mathrm{e}+02$ 3.86243e+02 3.86243e+01 1.00000e-09 2.12000e-01

$3.86243 \mathrm{e}+02$ 3.86243e+02 3.86243e+01 1.00000e-09 2.12000e-01

$1.00000 \mathrm{e}-02$ 1.00000e-02 1.00000e-03 1.00000e-09 1.00000e-01

$1.00000 \mathrm{e}+001.00000 \mathrm{e}+001.00000 \mathrm{e}-011.00000 \mathrm{e}-091.00000 \mathrm{e}-01$

$1.00000 \mathrm{e}-05$ 1.00000e-05 1.00000e-06 1.00000e-09 1.00000e-01

$1.00000 \mathrm{e}+001.00000 \mathrm{e}+001.00000 \mathrm{e}-011.00000 \mathrm{e}-091.00000 \mathrm{e}-01$

Element: 3135 \# of layers: 11

$\mathrm{Kx} \mathrm{Ky} \mathrm{Kz}$ Ss Por

5.74099e+03 5.74099e+03 5.74099e+02 1.00000e-09 7.00000e-02

5.00000e-04 5.00000e-04 5.00000e-05 1.00000e-09 1.00000e-01

$2.29392 \mathrm{e}+02$ 2.29392e+02 2.29392e+01 1.00000e-09 2.12000e-01

$2.29392 \mathrm{e}+02$ 2.29392e+02 2.29392e+01 1.00000e-09 2.12000e-01

$2.29392 \mathrm{e}+02$ 2.29392e+02 2.29392e+01 1.00000e-09 2.12000e-01

$2.29392 \mathrm{e}+02$ 2.29392e+02 2.29392e+01 1.00000e-09 2.12000e-01

$2.29392 \mathrm{e}+02$ 2.29392e+02 2.29392e+01 1.00000e-09 2.12000e-01

$1.00000 \mathrm{e}-02$ 1.00000e-02 1.00000e-03 1.00000e-09 1.00000e-01

$1.00000 \mathrm{e}+001.00000 \mathrm{e}+001.00000 \mathrm{e}-011.00000 \mathrm{e}-091.00000 \mathrm{e}-01$

$1.00000 \mathrm{e}-05$ 1.00000e-05 1.00000e-06 1.00000e-09 1.00000e-01

$1.00000 \mathrm{e}+001.00000 \mathrm{e}+001.00000 \mathrm{e}-011.00000 \mathrm{e}-09$ 1.00000e-01

Element: 3136 \# of layers: 11

$\mathrm{Kx} \mathrm{Ky} \mathrm{Kz}$ Ss Por

5.74099e+03 5.74099e+03 5.74099e+02 1.00000e-09 7.00000e-02

5.00000e-04 5.00000e-04 5.00000e-05 1.00000e-09 1.00000e-01

$2.29392 \mathrm{e}+02$ 2.29392e+02 2.29392e+01 1.00000e-09 2.12000e-01

2.29392e+02 2.29392e+02 2.29392e+01 1.00000e-09 2.12000e-01

$2.29392 \mathrm{e}+02$ 2.29392e+02 2.29392e+01 1.00000e-09 2.12000e-01

$2.29392 \mathrm{e}+02$ 2.29392e+02 2.29392e+01 1.00000e-09 2.12000e-01 
$2.29392 \mathrm{e}+02$ 2.29392e+02 2.29392e+01 1.00000e-09 2.12000e-01 $1.00000 \mathrm{e}-02$ 1.00000e-02 1.00000e-03 1.00000e-09 1.00000e-01 $1.00000 \mathrm{e}+001.00000 \mathrm{e}+001.00000 \mathrm{e}-011.00000 \mathrm{e}-091.00000 \mathrm{e}-01$ $1.00000 \mathrm{e}-05$ 1.00000e-05 1.00000e-06 1.00000e-09 1.00000e-01 $1.00000 \mathrm{e}+001.00000 \mathrm{e}+001.00000 \mathrm{e}-01$ 1.00000e-09 1.00000e-01 Element: 3137 \# of layers: 12

$\mathrm{Kx} \mathrm{Ky} \mathrm{Kz}$ Ss Por

5.74099e+03 5.74099e+03 5.74099e+02 1.00000e-09 7.00000e-02 5.00000e-04 5.00000e-04 5.00000e-05 1.00000e-09 1.00000e-01 5.00000e-04 5.00000e-04 5.00000e-05 1.00000e-09 1.00000e-01 $2.29392 \mathrm{e}+02$ 2.29392e+02 2.29392e+01 1.00000e-09 2.12000e-01 $2.29392 \mathrm{e}+02$ 2.29392e+02 2.29392e+01 1.00000e-09 2.12000e-01 $2.29392 \mathrm{e}+02$ 2.29392e+02 2.29392e+01 1.00000e-09 2.12000e-01 $2.29392 \mathrm{e}+02$ 2.29392e+02 2.29392e+01 1.00000e-09 2.12000e-01 $2.29392 \mathrm{e}+02$ 2.29392e+02 2.29392e+01 1.00000e-09 2.12000e-01 $1.00000 \mathrm{e}-02$ 1.00000e-02 1.00000e-03 1.00000e-09 1.00000e-01 $1.00000 \mathrm{e}+001.00000 \mathrm{e}+001.00000 \mathrm{e}-011.00000 \mathrm{e}-091.00000 \mathrm{e}-01$ $1.00000 \mathrm{e}-05$ 1.00000e-05 1.00000e-06 1.00000e-09 1.00000e-01 $1.00000 \mathrm{e}+001.00000 \mathrm{e}+001.00000 \mathrm{e}-011.00000 \mathrm{e}-091.00000 \mathrm{e}-01$ Element: 3138 \# of layers: 12

Kx Ky Kz Ss Por

7.35108e+03 7.35108e+03 7.35108e+02 1.00000e-09 7.00000e-02 5.00000e-04 5.00000e-04 5.00000e-05 1.00000e-09 1.00000e-01 5.00000e-04 5.00000e-04 5.00000e-05 1.00000e-09 1.00000e-01 $2.93721 \mathrm{e}+022.93721 \mathrm{e}+022.93721 \mathrm{e}+01$ 1.00000e-09 2.12000e-01 $2.93721 \mathrm{e}+02$ 2.93721e+02 2.93721e+01 1.00000e-09 2.12000e-01 $2.93721 \mathrm{e}+02$ 2.93721e+02 2.93721e+01 1.00000e-09 2.12000e-01 $2.93721 \mathrm{e}+02$ 2.93721e+02 2.93721e+01 1.00000e-09 2.12000e-01 $2.93721 \mathrm{e}+022.93721 \mathrm{e}+022.93721 \mathrm{e}+01$ 1.00000e-09 2.12000e-01 $1.00000 \mathrm{e}-02$ 1.00000e-02 1.00000e-03 1.00000e-09 1.00000e-01 $1.00000 \mathrm{e}+001.00000 \mathrm{e}+001.00000 \mathrm{e}-01$ 1.00000e-09 1.00000e-01 1.00000e-05 1.00000e-05 1.00000e-06 1.00000e-09 1.00000e-01 $1.00000 \mathrm{e}+001.00000 \mathrm{e}+001.00000 \mathrm{e}-011.00000 \mathrm{e}-091.00000 \mathrm{e}-01$ Element: 3139 \# of layers: 12

$\mathrm{Kx} \mathrm{Ky} \mathrm{Kz}$ Ss Por

7.35108e+03 7.35108e+03 7.35108e+02 1.00000e-09 7.00000e-02 5.00000e-04 5.00000e-04 5.00000e-05 1.00000e-09 1.00000e-01 5.00000e-04 5.00000e-04 5.00000e-05 1.00000e-09 1.00000e-01 $2.93721 \mathrm{e}+02$ 2.93721e+02 2.93721e+01 1.00000e-09 2.12000e-01 $2.93721 \mathrm{e}+02$ 2.93721e+02 2.93721e+01 1.00000e-09 2.12000e-01 $2.93721 \mathrm{e}+02$ 2.93721e+02 2.93721e+01 1.00000e-09 2.12000e-01 $2.93721 \mathrm{e}+022.93721 \mathrm{e}+022.93721 \mathrm{e}+01$ 1.00000e-09 2.12000e-01 $2.93721 \mathrm{e}+02$ 2.93721e+02 2.93721e+01 1.00000e-09 2.12000e-01 $1.00000 \mathrm{e}-02$ 1.00000e-02 1.00000e-03 1.00000e-09 1.00000e-01 $1.00000 \mathrm{e}+001.00000 \mathrm{e}+001.00000 \mathrm{e}-011.00000 \mathrm{e}-091.00000 \mathrm{e}-01$ $1.00000 \mathrm{e}-05$ 1.00000e-05 1.00000e-06 1.00000e-09 1.00000e-01 
$1.00000 \mathrm{e}+001.00000 \mathrm{e}+00$ 1.00000e-01 1.00000e-09 1.00000e-01

Element: 3140 \# of layers: 13

$\mathrm{Kx} \mathrm{Ky} \mathrm{Kz}$ Ss Por

9.83982e+03 9.83982e+03 9.83982e+02 1.00000e-09 7.00000e-02

9.83982e+03 9.83982e+03 9.83982e+02 1.00000e-09 7.00000e-02

5.00000e-04 5.00000e-04 5.00000e-05 1.00000e-09 1.00000e-01

5.00000e-04 5.00000e-04 5.00000e-05 1.00000e-09 1.00000e-01

$3.93151 \mathrm{e}+023.93151 \mathrm{e}+023.93151 \mathrm{e}+01$ 1.00000e-09 2.12000e-01

$3.93151 \mathrm{e}+02$ 3.93151e+02 3.93151e+01 1.00000e-09 2.12000e-01

$3.93151 \mathrm{e}+02$ 3.93151e+02 3.93151e+01 1.00000e-09 2.12000e-01

$3.93151 \mathrm{e}+02$ 3.93151e+02 3.93151e+01 1.00000e-09 2.12000e-01

$3.93151 \mathrm{e}+023.93151 \mathrm{e}+023.93151 \mathrm{e}+01$ 1.00000e-09 2.12000e-01

$1.00000 \mathrm{e}-02$ 1.00000e-02 1.00000e-03 1.00000e-09 1.00000e-01

$1.00000 \mathrm{e}+001.00000 \mathrm{e}+001.00000 \mathrm{e}-011.00000 \mathrm{e}-091.00000 \mathrm{e}-01$

$1.00000 \mathrm{e}-051.00000 \mathrm{e}-051.00000 \mathrm{e}-061.00000 \mathrm{e}-091.00000 \mathrm{e}-01$

$1.00000 \mathrm{e}+001.00000 \mathrm{e}+001.00000 \mathrm{e}-011.00000 \mathrm{e}-091.00000 \mathrm{e}-01$

Element: 3141 \# of layers: 12

$\mathrm{Kx} \mathrm{Ky} \mathrm{Kz}$ Ss Por

9.66683e+03 9.66683e+03 9.66683e+02 1.00000e-09 7.00000e-02

$9.66683 \mathrm{e}+03$ 9.66683e+03 9.66683e+02 1.00000e-09 7.00000e-02

5.00000e-04 5.00000e-04 5.00000e-05 1.00000e-09 1.00000e-01

$3.86243 \mathrm{e}+02$ 3.86243e+02 3.86243e+01 1.00000e-09 2.12000e-01

$3.86243 \mathrm{e}+02$ 3.86243e+02 3.86243e+01 1.00000e-09 2.12000e-01

$3.86243 \mathrm{e}+02$ 3.86243e+02 3.86243e+01 1.00000e-09 2.12000e-01

$3.86243 \mathrm{e}+023.86243 \mathrm{e}+023.86243 \mathrm{e}+01$ 1.00000e-09 2.12000e-01

$3.86243 \mathrm{e}+02$ 3.86243e+02 3.86243e+01 1.00000e-09 2.12000e-01

$1.00000 \mathrm{e}-02$ 1.00000e-02 1.00000e-03 1.00000e-09 1.00000e-01

$1.00000 \mathrm{e}+001.00000 \mathrm{e}+001.00000 \mathrm{e}-011.00000 \mathrm{e}-091.00000 \mathrm{e}-01$

$1.00000 \mathrm{e}-05$ 1.00000e-05 1.00000e-06 1.00000e-09 1.00000e-01

$1.00000 \mathrm{e}+001.00000 \mathrm{e}+001.00000 \mathrm{e}-011.00000 \mathrm{e}-091.00000 \mathrm{e}-01$

Element: 3142 \# of layers: 11

$\mathrm{Kx} \mathrm{Ky} \mathrm{Kz}$ Ss Por

5.74099e+03 5.74099e+03 5.74099e+02 1.00000e-09 7.00000e-02

5.00000e-04 5.00000e-04 5.00000e-05 1.00000e-09 1.00000e-01

$2.29392 \mathrm{e}+02$ 2.29392e+02 2.29392e+01 1.00000e-09 2.12000e-01

$2.29392 \mathrm{e}+02$ 2.29392e+02 2.29392e+01 1.00000e-09 2.12000e-01

$2.29392 \mathrm{e}+02$ 2.29392e+02 2.29392e+01 1.00000e-09 2.12000e-01

$2.29392 \mathrm{e}+02$ 2.29392e+02 2.29392e+01 1.00000e-09 2.12000e-01

$2.29392 \mathrm{e}+02$ 2.29392e+02 2.29392e+01 1.00000e-09 2.12000e-01

$1.00000 \mathrm{e}-02$ 1.00000e-02 1.00000e-03 1.00000e-09 1.00000e-01

$1.00000 \mathrm{e}+001.00000 \mathrm{e}+001.00000 \mathrm{e}-011.00000 \mathrm{e}-091.00000 \mathrm{e}-01$

$1.00000 \mathrm{e}-05$ 1.00000e-05 1.00000e-06 1.00000e-09 1.00000e-01

$1.00000 \mathrm{e}+001.00000 \mathrm{e}+001.00000 \mathrm{e}-011.00000 \mathrm{e}-091.00000 \mathrm{e}-01$

Element: 3143 \# of layers: 12

$\mathrm{Kx} \mathrm{Ky} \mathrm{Kz}$ Ss Por

2.34413e+03 2.34413e+03 2.34413e+02 1.00000e-09 7.00000e-02 
5.00000e-04 5.00000e-04 5.00000e-05 1.00000e-09 1.00000e-01 5.00000e-04 5.00000e-04 5.00000e-05 1.00000e-09 1.00000e-01 9.36627e+01 9.36627e+01 9.36627e+00 1.00000e-09 2.12000e-01 $9.36627 e+019.36627 e+019.36627 e+001.00000 e-092.12000 e-01$ 9.36627e+01 9.36627e+01 9.36627e+00 1.00000e-09 2.12000e-01 $9.36627 \mathrm{e}+019.36627 \mathrm{e}+01$ 9.36627e+00 1.00000e-09 2.12000e-01 $9.36627 \mathrm{e}+019.36627 \mathrm{e}+01$ 9.36627e+00 1.00000e-09 2.12000e-01 $1.00000 \mathrm{e}-02$ 1.00000e-02 1.00000e-03 1.00000e-09 1.00000e-01 $1.00000 \mathrm{e}+001.00000 \mathrm{e}+001.00000 \mathrm{e}-01$ 1.00000e-09 1.00000e-01 $1.00000 \mathrm{e}-05$ 1.00000e-05 1.00000e-06 1.00000e-09 1.00000e-01 $1.00000 \mathrm{e}+001.00000 \mathrm{e}+001.00000 \mathrm{e}-011.00000 \mathrm{e}-091.00000 \mathrm{e}-01$ Element: 3144 \# of layers: 12

$\mathrm{Kx} \mathrm{Ky} \mathrm{Kz}$ Ss Por

2.35999e+03 2.35999e+03 2.35999e+02 1.00000e-09 7.00000e-02 5.00000e-04 5.00000e-04 5.00000e-05 1.00000e-09 1.00000e-01 5.00000e-04 5.00000e-04 5.00000e-05 1.00000e-09 1.00000e-01 9.42973e+01 9.42973e+01 9.42973e+00 1.00000e-09 2.12000e-01 9.42973e+01 9.42973e+01 9.42973e+00 1.00000e-09 2.12000e-01 9.42973e+01 9.42973e+01 9.42973e+00 1.00000e-09 2.12000e-01 9.42973e+01 9.42973e+01 9.42973e+00 1.00000e-09 2.12000e-01 $9.42973 e+019.42973 e+019.42973 e+001.00000 e-092.12000 e-01$ $1.00000 \mathrm{e}-02$ 1.00000e-02 1.00000e-03 1.00000e-09 1.00000e-01 $1.00000 \mathrm{e}+001.00000 \mathrm{e}+001.00000 \mathrm{e}-011.00000 \mathrm{e}-091.00000 \mathrm{e}-01$ $1.00000 \mathrm{e}-05$ 1.00000e-05 1.00000e-06 1.00000e-09 1.00000e-01 $1.00000 \mathrm{e}+001.00000 \mathrm{e}+001.00000 \mathrm{e}-011.00000 \mathrm{e}-091.00000 \mathrm{e}-01$ Element: 3145 \# of layers: 12

$\mathrm{Kx} \mathrm{Ky} \mathrm{Kz}$ Ss Por

2.35999e+03 2.35999e+03 2.35999e+02 1.00000e-09 7.00000e-02 5.00000e-04 5.00000e-04 5.00000e-05 1.00000e-09 1.00000e-01 5.00000e-04 5.00000e-04 5.00000e-05 1.00000e-09 1.00000e-01 9.42973e+01 9.42973e+01 9.42973e+00 1.00000e-09 2.12000e-01 9.42973e+01 9.42973e+01 9.42973e+00 1.00000e-09 2.12000e-01 $9.42973 \mathrm{e}+019.42973 \mathrm{e}+01$ 9.42973e+00 1.00000e-09 2.12000e-01 9.42973e+01 9.42973e+01 9.42973e+00 1.00000e-09 2.12000e-01 9.42973e+01 9.42973e+01 9.42973e+00 1.00000e-09 2.12000e-01 1.00000e-02 1.00000e-02 1.00000e-03 1.00000e-09 1.00000e-01 $1.00000 \mathrm{e}+001.00000 \mathrm{e}+001.00000 \mathrm{e}-011.00000 \mathrm{e}-091.00000 \mathrm{e}-01$ $1.00000 \mathrm{e}-05$ 1.00000e-05 1.00000e-06 1.00000e-09 1.00000e-01 $1.00000 \mathrm{e}+001.00000 \mathrm{e}+001.00000 \mathrm{e}-011.00000 \mathrm{e}-091.00000 \mathrm{e}-01$ Element: 3146 \# of layers: 12

$\mathrm{Kx} \mathrm{Ky} \mathrm{Kz}$ Ss Por

2.35999e+03 2.35999e+03 2.35999e+02 1.00000e-09 7.00000e-02 5.00000e-04 5.00000e-04 5.00000e-05 1.00000e-09 1.00000e-01 5.00000e-04 5.00000e-04 5.00000e-05 1.00000e-09 1.00000e-01 9.42973e+01 9.42973e+01 9.42973e+00 1.00000e-09 2.12000e-01 $9.42973 e+019.42973 e+019.42973 e+001.00000 e-092.12000 e-01$ 
9.42973e+01 9.42973e+01 9.42973e+00 1.00000e-09 2.12000e-01 9.42973e+01 9.42973e+01 9.42973e+00 1.00000e-09 2.12000e-01 9.42973e+01 9.42973e+01 9.42973e+00 1.00000e-09 2.12000e-01 $1.00000 \mathrm{e}-02$ 1.00000e-02 1.00000e-03 1.00000e-09 1.00000e-01 $1.00000 \mathrm{e}+001.00000 \mathrm{e}+001.00000 \mathrm{e}-011.00000 \mathrm{e}-091.00000 \mathrm{e}-01$ $1.00000 \mathrm{e}-05$ 1.00000e-05 1.00000e-06 1.00000e-09 1.00000e-01 $1.00000 \mathrm{e}+001.00000 \mathrm{e}+001.00000 \mathrm{e}-011.00000 \mathrm{e}-091.00000 \mathrm{e}-01$ Element: 3147 \# of layers: 12

$\mathrm{Kx} \mathrm{Ky} \mathrm{Kz}$ Ss Por

3.46786e+03 3.46786e+03 3.46786e+02 1.00000e-09 7.00000e-02 5.00000e-04 5.00000e-04 5.00000e-05 1.00000e-09 1.00000e-01 5.00000e-04 5.00000e-04 5.00000e-05 1.00000e-09 1.00000e-01 $1.38562 \mathrm{e}+02$ 1.38562e+02 1.38563e+01 1.00000e-09 2.12000e-01 $1.38562 \mathrm{e}+02$ 1.38562e+02 1.38563e+01 1.00000e-09 2.12000e-01 $1.38562 \mathrm{e}+02$ 1.38562e+02 1.38563e+01 1.00000e-09 2.12000e-01 $1.38562 \mathrm{e}+021.38562 \mathrm{e}+02$ 1.38563e+01 1.00000e-09 2.12000e-01 $1.38562 \mathrm{e}+02$ 1.38562e+02 1.38563e+01 1.00000e-09 2.12000e-01 $1.00000 \mathrm{e}-02$ 1.00000e-02 1.00000e-03 1.00000e-09 1.00000e-01 $1.00000 \mathrm{e}+001.00000 \mathrm{e}+001.00000 \mathrm{e}-011.00000 \mathrm{e}-091.00000 \mathrm{e}-01$ $1.00000 \mathrm{e}-05$ 1.00000e-05 1.00000e-06 1.00000e-09 1.00000e-01 $1.00000 \mathrm{e}+001.00000 \mathrm{e}+001.00000 \mathrm{e}-011.00000 \mathrm{e}-091.00000 \mathrm{e}-01$ Element: 3148 \# of layers: 12

$\mathrm{Kx} \mathrm{Ky} \mathrm{Kz}$ Ss Por

3.46786e+03 3.46786e+03 3.46786e+02 1.00000e-09 7.00000e-02 5.00000e-04 5.00000e-04 5.00000e-05 1.00000e-09 1.00000e-01 $5.00000 \mathrm{e}-04$ 5.00000e-04 5.00000e-05 1.00000e-09 1.00000e-01

$1.38562 \mathrm{e}+021.38562 \mathrm{e}+02$ 1.38563e+01 1.00000e-09 2.12000e-01 $1.38562 \mathrm{e}+02$ 1.38562e+02 1.38563e+01 1.00000e-09 2.12000e-01 $1.38562 \mathrm{e}+02$ 1.38562e+02 1.38563e+01 1.00000e-09 2.12000e-01 $1.38562 \mathrm{e}+02$ 1.38562e+02 1.38563e+01 1.00000e-09 2.12000e-01 $1.38562 \mathrm{e}+02$ 1.38562e+02 1.38563e+01 1.00000e-09 2.12000e-01 $1.00000 \mathrm{e}-02$ 1.00000e-02 1.00000e-03 1.00000e-09 1.00000e-01 $1.00000 \mathrm{e}+001.00000 \mathrm{e}+001.00000 \mathrm{e}-011.00000 \mathrm{e}-091.00000 \mathrm{e}-01$ $1.00000 \mathrm{e}-051.00000 \mathrm{e}-051.00000 \mathrm{e}-061.00000 \mathrm{e}-091.00000 \mathrm{e}-01$ $1.00000 \mathrm{e}+001.00000 \mathrm{e}+001.00000 \mathrm{e}-01$ 1.00000e-09 1.00000e-01 Element: 3149 \# of layers: 12

Kx Ky Kz Ss Por

4.78566e+03 4.78566e+03 4.78566e+02 1.00000e-09 7.00000e-02 5.00000e-04 5.00000e-04 5.00000e-05 1.00000e-09 1.00000e-01 5.00000e-04 5.00000e-04 5.00000e-05 1.00000e-09 1.00000e-01 $1.91218 \mathrm{e}+02$ 1.91218e+02 1.91218e+01 1.00000e-09 2.12000e-01 $1.91218 \mathrm{e}+02$ 1.91218e+02 1.91218e+01 1.00000e-09 2.12000e-01 $1.91218 \mathrm{e}+02$ 1.91218e+02 1.91218e+01 1.00000e-09 2.12000e-01 $1.91218 \mathrm{e}+02$ 1.91218e+02 1.91218e+01 1.00000e-09 2.12000e-01 $1.91218 \mathrm{e}+02$ 1.91218e+02 1.91218e+01 1.00000e-09 2.12000e-01 $1.00000 \mathrm{e}-02$ 1.00000e-02 1.00000e-03 1.00000e-09 1.00000e-01 
$1.00000 \mathrm{e}+001.00000 \mathrm{e}+001.00000 \mathrm{e}-011.00000 \mathrm{e}-091.00000 \mathrm{e}-01$ $1.00000 \mathrm{e}-05$ 1.00000e-05 1.00000e-06 1.00000e-09 1.00000e-01 $1.00000 \mathrm{e}+001.00000 \mathrm{e}+001.00000 \mathrm{e}-011.00000 \mathrm{e}-09$ 1.00000e-01 Element: 3150 \# of layers: 12

$\mathrm{Kx} \mathrm{Ky} \mathrm{Kz}$ Ss Por

$2.34413 \mathrm{e}+032.34413 \mathrm{e}+03$ 2.34413e+02 1.00000e-09 7.00000e-02 5.00000e-04 5.00000e-04 5.00000e-05 1.00000e-09 1.00000e-01 5.00000e-04 5.00000e-04 5.00000e-05 1.00000e-09 1.00000e-01 $9.36627 \mathrm{e}+019.36627 \mathrm{e}+01$ 9.36627e+00 1.00000e-09 2.12000e-01 $9.36627 \mathrm{e}+019.36627 \mathrm{e}+01$ 9.36627e+00 1.00000e-09 2.12000e-01 9.36627e+01 9.36627e+01 9.36627e+00 1.00000e-09 2.12000e-01 $9.36627 \mathrm{e}+019.36627 \mathrm{e}+019.36627 \mathrm{e}+00$ 1.00000e-09 2.12000e-01 9.36627e+01 9.36627e+01 9.36627e+00 1.00000e-09 2.12000e-01 $1.00000 \mathrm{e}-02$ 1.00000e-02 1.00000e-03 1.00000e-09 1.00000e-01 $1.00000 \mathrm{e}+001.00000 \mathrm{e}+001.00000 \mathrm{e}-011.00000 \mathrm{e}-091.00000 \mathrm{e}-01$ $1.00000 \mathrm{e}-051.00000 \mathrm{e}-05$ 1.00000e-06 1.00000e-09 1.00000e-01 $1.00000 \mathrm{e}+001.00000 \mathrm{e}+001.00000 \mathrm{e}-01$ 1.00000e-09 1.00000e-01 Element: 3151 \# of layers: 12

$\mathrm{Kx} \mathrm{Ky} \mathrm{Kz}$ Ss Por

2.35999e+03 2.35999e+03 2.35999e+02 1.00000e-09 7.00000e-02 5.00000e-04 5.00000e-04 5.00000e-05 1.00000e-09 1.00000e-01 5.00000e-04 5.00000e-04 5.00000e-05 1.00000e-09 1.00000e-01 9.42973e+01 9.42973e+01 9.42973e+00 1.00000e-09 2.12000e-01 9.42973e+01 9.42973e+01 9.42973e+00 1.00000e-09 2.12000e-01 $9.42973 e+019.42973 e+019.42973 e+001.00000 e-092.12000 e-01$ 9.42973e+01 9.42973e+01 9.42973e+00 1.00000e-09 2.12000e-01 $9.42973 \mathrm{e}+01$ 9.42973e+01 9.42973e+00 1.00000e-09 2.12000e-01 $1.00000 \mathrm{e}-02$ 1.00000e-02 1.00000e-03 1.00000e-09 1.00000e-01 $1.00000 \mathrm{e}+001.00000 \mathrm{e}+001.00000 \mathrm{e}-011.00000 \mathrm{e}-091.00000 \mathrm{e}-01$ $1.00000 \mathrm{e}-05$ 1.00000e-05 1.00000e-06 1.00000e-09 1.00000e-01 $1.00000 \mathrm{e}+001.00000 \mathrm{e}+001.00000 \mathrm{e}-011.00000 \mathrm{e}-091.00000 \mathrm{e}-01$ Element: 3152 \# of layers: 12

$\mathrm{Kx} \mathrm{Ky} \mathrm{Kz}$ Ss Por

2.36702e+03 2.36702e+03 2.36702e+02 1.00000e-09 7.00000e-02 5.00000e-04 5.00000e-04 5.00000e-05 1.00000e-09 1.00000e-01 5.00000e-04 5.00000e-04 5.00000e-05 1.00000e-09 1.00000e-01 9.45763e+01 9.45763e+01 9.45763e+00 1.00000e-09 2.12000e-01 $9.45763 \mathrm{e}+019.45763 \mathrm{e}+019.45763 \mathrm{e}+001.00000 \mathrm{e}-092.12000 \mathrm{e}-01$ 9.45763e+01 9.45763e+01 9.45763e+00 1.00000e-09 2.12000e-01 9.45763e+01 9.45763e+01 9.45763e+00 1.00000e-09 2.12000e-01 9.45763e+01 9.45763e+01 9.45763e+00 1.00000e-09 2.12000e-01 $1.00000 \mathrm{e}-02$ 1.00000e-02 1.00000e-03 1.00000e-09 1.00000e-01 $1.00000 \mathrm{e}+001.00000 \mathrm{e}+001.00000 \mathrm{e}-011.00000 \mathrm{e}-091.00000 \mathrm{e}-01$ $1.00000 \mathrm{e}-05$ 1.00000e-05 1.00000e-06 1.00000e-09 1.00000e-01 $1.00000 \mathrm{e}+001.00000 \mathrm{e}+001.00000 \mathrm{e}-011.00000 \mathrm{e}-09$ 1.00000e-01 Element: 3153 \# of layers: 14 
$\mathrm{Kx} \mathrm{Ky} \mathrm{Kz}$ Ss Por

$1.92868 \mathrm{e}+03$ 1.92868e+03 1.92868e+02 1.00000e-09 7.00000e-02 $1.92868 \mathrm{e}+03$ 1.92868e+03 1.92868e+02 1.00000e-09 7.00000e-02 $1.92868 \mathrm{e}+03$ 1.92868e+03 1.92868e+02 1.00000e-09 7.00000e-02 5.00000e-04 5.00000e-04 5.00000e-05 1.00000e-09 1.00000e-01 5.00000e-04 5.00000e-04 5.00000e-05 1.00000e-09 1.00000e-01 $7.70641 \mathrm{e}+01$ 7.70641e+01 7.70641e+00 1.00000e-09 2.12000e-01 $7.70641 \mathrm{e}+017.70641 \mathrm{e}+01$ 7.70641e+00 1.00000e-09 2.12000e-01 7.70641e+01 7.70641e+01 7.70641e+00 1.00000e-09 2.12000e-01 $7.70641 \mathrm{e}+017.70641 \mathrm{e}+017.70641 \mathrm{e}+001.00000 \mathrm{e}-092.12000 \mathrm{e}-01$ $7.70641 \mathrm{e}+017.70641 \mathrm{e}+017.70641 \mathrm{e}+00$ 1.00000e-09 2.12000e-01 $1.00000 \mathrm{e}-02$ 1.00000e-02 1.00000e-03 1.00000e-09 1.00000e-01 $1.00000 \mathrm{e}+001.00000 \mathrm{e}+001.00000 \mathrm{e}-011.00000 \mathrm{e}-091.00000 \mathrm{e}-01$ $1.00000 \mathrm{e}-05$ 1.00000e-05 1.00000e-06 1.00000e-09 1.00000e-01 $1.00000 \mathrm{e}+001.00000 \mathrm{e}+001.00000 \mathrm{e}-01$ 1.00000e-09 1.00000e-01 Element: 3154 \# of layers: 14

$\mathrm{Kx} \mathrm{Ky} \mathrm{Kz}$ Ss Por

$1.92868 \mathrm{e}+03$ 1.92868e+03 1.92868e+02 1.00000e-09 7.00000e-02 $1.92868 \mathrm{e}+031.92868 \mathrm{e}+03$ 1.92868e+02 1.00000e-09 7.00000e-02 $1.92868 \mathrm{e}+031.92868 \mathrm{e}+03$ 1.92868e+02 1.00000e-09 7.00000e-02 5.00000e-04 5.00000e-04 5.00000e-05 1.00000e-09 1.00000e-01 5.00000e-04 5.00000e-04 5.00000e-05 1.00000e-09 1.00000e-01 $7.70641 \mathrm{e}+01$ 7.70641e+01 7.70641e+00 1.00000e-09 2.12000e-01 $7.70641 \mathrm{e}+01$ 7.70641e+01 7.70641e+00 1.00000e-09 2.12000e-01 $7.70641 \mathrm{e}+017.70641 \mathrm{e}+017.70641 \mathrm{e}+001.00000 \mathrm{e}-092.12000 \mathrm{e}-01$ $7.70641 \mathrm{e}+017.70641 \mathrm{e}+01$ 7.70641e+00 1.00000e-09 2.12000e-01 $7.70641 \mathrm{e}+01$ 7.70641e+01 7.70641e+00 1.00000e-09 2.12000e-01 $1.00000 \mathrm{e}-02$ 1.00000e-02 1.00000e-03 1.00000e-09 1.00000e-01 $1.00000 \mathrm{e}+001.00000 \mathrm{e}+001.00000 \mathrm{e}-011.00000 \mathrm{e}-091.00000 \mathrm{e}-01$ $1.00000 \mathrm{e}-05$ 1.00000e-05 1.00000e-06 1.00000e-09 1.00000e-01 $1.00000 \mathrm{e}+001.00000 \mathrm{e}+001.00000 \mathrm{e}-011.00000 \mathrm{e}-091.00000 \mathrm{e}-01$ Element: 3155 \# of layers: 14

$\mathrm{Kx} \mathrm{Ky} \mathrm{Kz}$ Ss Por

$1.92868 \mathrm{e}+03$ 1.92868e+03 1.92868e+02 1.00000e-09 7.00000e-02 $1.92868 \mathrm{e}+031.92868 \mathrm{e}+03$ 1.92868e+02 1.00000e-09 7.00000e-02 $1.92868 \mathrm{e}+031.92868 \mathrm{e}+03$ 1.92868e+02 1.00000e-09 7.00000e-02 5.00000e-04 5.00000e-04 5.00000e-05 1.00000e-09 1.00000e-01 5.00000e-04 5.00000e-04 5.00000e-05 1.00000e-09 1.00000e-01 $7.70641 \mathrm{e}+01$ 7.70641e+01 7.70641e+00 1.00000e-09 2.12000e-01 $7.70641 \mathrm{e}+01$ 7.70641e+01 7.70641e+00 1.00000e-09 2.12000e-01 $7.70641 \mathrm{e}+017.70641 \mathrm{e}+01$ 7.70641e+00 1.00000e-09 2.12000e-01 $7.70641 \mathrm{e}+01$ 7.70641e+01 7.70641e+00 1.00000e-09 2.12000e-01 7.70641e+01 7.70641e+01 7.70641e+00 1.00000e-09 2.12000e-01 $1.00000 \mathrm{e}-02$ 1.00000e-02 1.00000e-03 1.00000e-09 1.00000e-01 $1.00000 \mathrm{e}+001.00000 \mathrm{e}+001.00000 \mathrm{e}-011.00000 \mathrm{e}-091.00000 \mathrm{e}-01$ $1.00000 \mathrm{e}-05$ 1.00000e-05 1.00000e-06 1.00000e-09 1.00000e-01 
$1.00000 \mathrm{e}+001.00000 \mathrm{e}+00$ 1.00000e-01 1.00000e-09 1.00000e-01

Element: 3156 \# of layers: 13

$\mathrm{Kx} \mathrm{Ky} \mathrm{Kz}$ Ss Por

$2.57650 \mathrm{e}+03$ 2.57650e+03 2.57650e+02 1.00000e-09 7.00000e-02

$2.57650 \mathrm{e}+032.57650 \mathrm{e}+032.57650 \mathrm{e}+021.00000 \mathrm{e}-097.00000 \mathrm{e}-02$

5.00000e-04 5.00000e-04 5.00000e-05 1.00000e-09 1.00000e-01

5.00000e-04 5.00000e-04 5.00000e-05 1.00000e-09 1.00000e-01

$1.02946 \mathrm{e}+02 \quad 1.02946 \mathrm{e}+02 \quad 1.02946 \mathrm{e}+01$ 1.00000e-09 2.12000e-01

$1.02946 \mathrm{e}+021.02946 \mathrm{e}+02$ 1.02946e+01 1.00000e-09 2.12000e-01

$1.02946 \mathrm{e}+02$ 1.02946e+02 1.02946e+01 1.00000e-09 2.12000e-01

$1.02946 \mathrm{e}+02$ 1.02946e+02 1.02946e+01 1.00000e-09 2.12000e-01

$1.02946 \mathrm{e}+02 \quad 1.02946 \mathrm{e}+02 \quad 1.02946 \mathrm{e}+01$ 1.00000e-09 2.12000e-01

$1.00000 \mathrm{e}-02$ 1.00000e-02 1.00000e-03 1.00000e-09 1.00000e-01

$1.00000 \mathrm{e}+001.00000 \mathrm{e}+001.00000 \mathrm{e}-011.00000 \mathrm{e}-091.00000 \mathrm{e}-01$

$1.00000 \mathrm{e}-05$ 1.00000e-05 1.00000e-06 1.00000e-09 1.00000e-01

$1.00000 \mathrm{e}+001.00000 \mathrm{e}+001.00000 \mathrm{e}-011.00000 \mathrm{e}-091.00000 \mathrm{e}-01$

Element: 3157 \# of layers: 12

$\mathrm{Kx} \mathrm{Ky} \mathrm{Kz}$ Ss Por

$2.57650 \mathrm{e}+032.57650 \mathrm{e}+032.57650 \mathrm{e}+02$ 1.00000e-09 7.00000e-02

5.00000e-04 5.00000e-04 5.00000e-05 1.00000e-09 1.00000e-01

5.00000e-04 5.00000e-04 5.00000e-05 1.00000e-09 1.00000e-01

$1.02946 \mathrm{e}+021.02946 \mathrm{e}+02$ 1.02946e+01 1.00000e-09 2.12000e-01

$1.02946 \mathrm{e}+021.02946 \mathrm{e}+02$ 1.02946e+01 1.00000e-09 2.12000e-01

$1.02946 \mathrm{e}+02$ 1.02946e+02 1.02946e+01 1.00000e-09 2.12000e-01

$1.02946 \mathrm{e}+021.02946 \mathrm{e}+021.02946 \mathrm{e}+01$ 1.00000e-09 2.12000e-01

$1.02946 \mathrm{e}+021.02946 \mathrm{e}+02$ 1.02946e+01 1.00000e-09 2.12000e-01

$1.00000 \mathrm{e}-02$ 1.00000e-02 1.00000e-03 1.00000e-09 1.00000e-01

$1.00000 \mathrm{e}+001.00000 \mathrm{e}+001.00000 \mathrm{e}-011.00000 \mathrm{e}-091.00000 \mathrm{e}-01$

$1.00000 \mathrm{e}-05$ 1.00000e-05 1.00000e-06 1.00000e-09 1.00000e-01

$1.00000 \mathrm{e}+001.00000 \mathrm{e}+001.00000 \mathrm{e}-011.00000 \mathrm{e}-091.00000 \mathrm{e}-01$

Element: 3158 \# of layers: 12

$\mathrm{Kx} \mathrm{Ky} \mathrm{Kz}$ Ss Por

2.75490e+03 2.75490e+03 2.75490e+02 1.00000e-09 7.00000e-02

$5.00000 \mathrm{e}-045.00000 \mathrm{e}-045.00000 \mathrm{e}-051.00000 \mathrm{e}-091.00000 \mathrm{e}-01$

5.00000e-04 5.00000e-04 5.00000e-05 1.00000e-09 1.00000e-01

$1.10075 \mathrm{e}+021.10075 \mathrm{e}+02$ 1.10075e+01 1.00000e-09 2.12000e-01

$1.10075 \mathrm{e}+021.10075 \mathrm{e}+021.10075 \mathrm{e}+01$ 1.00000e-09 2.12000e-01

$1.10075 \mathrm{e}+021.10075 \mathrm{e}+021.10075 \mathrm{e}+01$ 1.00000e-09 2.12000e-01

$1.10075 \mathrm{e}+02$ 1.10075e+02 1.10075e+01 1.00000e-09 2.12000e-01

$1.10075 \mathrm{e}+021.10075 \mathrm{e}+02$ 1.10075e+01 1.00000e-09 2.12000e-01

$1.00000 \mathrm{e}-021.00000 \mathrm{e}-021.00000 \mathrm{e}-031.00000 \mathrm{e}-091.00000 \mathrm{e}-01$

$1.00000 \mathrm{e}+001.00000 \mathrm{e}+001.00000 \mathrm{e}-011.00000 \mathrm{e}-091.00000 \mathrm{e}-01$

$1.00000 \mathrm{e}-05$ 1.00000e-05 1.00000e-06 1.00000e-09 1.00000e-01

$1.00000 \mathrm{e}+001.00000 \mathrm{e}+001.00000 \mathrm{e}-01$ 1.00000e-09 1.00000e-01

Element: 3159 \# of layers: 12

Kx Ky Kz Ss Por 
2.36702e+03 2.36702e+03 2.36702e+02 1.00000e-09 7.00000e-02 5.00000e-04 5.00000e-04 5.00000e-05 1.00000e-09 1.00000e-01 5.00000e-04 5.00000e-04 5.00000e-05 1.00000e-09 1.00000e-01 $9.45763 e+019.45763 e+019.45763 e+001.00000 e-092.12000 e-01$ $9.45763 \mathrm{e}+019.45763 \mathrm{e}+01$ 9.45763e+00 1.00000e-09 2.12000e-01 $9.45763 \mathrm{e}+019.45763 \mathrm{e}+01$ 9.45763e+00 1.00000e-09 2.12000e-01 9.45763e+01 9.45763e+01 9.45763e+00 1.00000e-09 2.12000e-01 $9.45763 \mathrm{e}+019.45763 \mathrm{e}+019.45763 \mathrm{e}+001.00000 \mathrm{e}-092.12000 \mathrm{e}-01$ $1.00000 \mathrm{e}-021.00000 \mathrm{e}-021.00000 \mathrm{e}-031.00000 \mathrm{e}-091.00000 \mathrm{e}-01$ $1.00000 \mathrm{e}+001.00000 \mathrm{e}+001.00000 \mathrm{e}-011.00000 \mathrm{e}-091.00000 \mathrm{e}-01$ $1.00000 \mathrm{e}-05$ 1.00000e-05 1.00000e-06 1.00000e-09 1.00000e-01 $1.00000 \mathrm{e}+001.00000 \mathrm{e}+001.00000 \mathrm{e}-011.00000 \mathrm{e}-091.00000 \mathrm{e}-01$ Element: 3160 \# of layers: 13

$\mathrm{Kx} \mathrm{Ky} \mathrm{Kz}$ Ss Por

$1.92868 \mathrm{e}+03$ 1.92868e+03 1.92868e+02 1.00000e-09 7.00000e-02 $1.92868 \mathrm{e}+031.92868 \mathrm{e}+03$ 1.92868e+02 1.00000e-09 7.00000e-02 5.00000e-04 5.00000e-04 5.00000e-05 1.00000e-09 1.00000e-01 5.00000e-04 5.00000e-04 5.00000e-05 1.00000e-09 1.00000e-01 $7.70641 \mathrm{e}+01$ 7.70641e+01 7.70641e+00 1.00000e-09 2.12000e-01 $7.70641 \mathrm{e}+01$ 7.70641e+01 7.70641e+00 1.00000e-09 2.12000e-01 $7.70641 \mathrm{e}+01$ 7.70641e+01 7.70641e+00 1.00000e-09 2.12000e-01 $7.70641 \mathrm{e}+01$ 7.70641e+01 7.70641e+00 1.00000e-09 2.12000e-01 $7.70641 \mathrm{e}+01$ 7.70641e+01 7.70641e+00 1.00000e-09 2.12000e-01 $1.00000 \mathrm{e}-02$ 1.00000e-02 1.00000e-03 1.00000e-09 1.00000e-01 $1.00000 \mathrm{e}+001.00000 \mathrm{e}+001.00000 \mathrm{e}-011.00000 \mathrm{e}-091.00000 \mathrm{e}-01$ $1.00000 \mathrm{e}-05$ 1.00000e-05 1.00000e-06 1.00000e-09 1.00000e-01 $1.00000 \mathrm{e}+001.00000 \mathrm{e}+001.00000 \mathrm{e}-011.00000 \mathrm{e}-091.00000 \mathrm{e}-01$ Element: 3161 \# of layers: 13

Kx Ky Kz Ss Por

$1.65685 \mathrm{e}+031.65685 \mathrm{e}+03$ 1.65685e+02 1.00000e-09 7.00000e-02 $1.65685 \mathrm{e}+031.65685 \mathrm{e}+03$ 1.65685e+02 1.00000e-09 7.00000e-02 5.00000e-04 5.00000e-04 5.00000e-05 1.00000e-09 1.00000e-01 5.00000e-04 5.00000e-04 5.00000e-05 1.00000e-09 1.00000e-01 $6.62032 \mathrm{e}+016.62032 \mathrm{e}+016.62032 \mathrm{e}+00$ 1.00000e-09 2.12000e-01 $6.62032 \mathrm{e}+016.62032 \mathrm{e}+016.62032 \mathrm{e}+00$ 1.00000e-09 2.12000e-01 $6.62032 \mathrm{e}+016.62032 \mathrm{e}+016.62032 \mathrm{e}+00$ 1.00000e-09 2.12000e-01 $6.62032 \mathrm{e}+016.62032 \mathrm{e}+016.62032 \mathrm{e}+001.00000 \mathrm{e}-092.12000 \mathrm{e}-01$ $6.62032 \mathrm{e}+016.62032 \mathrm{e}+016.62032 \mathrm{e}+00$ 1.00000e-09 2.12000e-01 $1.00000 \mathrm{e}-02$ 1.00000e-02 1.00000e-03 1.00000e-09 1.00000e-01 $1.00000 \mathrm{e}+001.00000 \mathrm{e}+001.00000 \mathrm{e}-011.00000 \mathrm{e}-091.00000 \mathrm{e}-01$ $1.00000 \mathrm{e}-05$ 1.00000e-05 1.00000e-06 1.00000e-09 1.00000e-01 $1.00000 \mathrm{e}+001.00000 \mathrm{e}+001.00000 \mathrm{e}-011.00000 \mathrm{e}-091.00000 \mathrm{e}-01$ Element: 3162 \# of layers: 11

$\mathrm{Kx} \mathrm{Ky} \mathrm{Kz}$ Ss Por

$1.62468 \mathrm{e}+03$ 1.62468e+03 1.62468e+02 1.00000e-09 7.00000e-02 $1.62468 \mathrm{e}+03$ 1.62468e+03 1.62468e+02 1.00000e-09 7.00000e-02 
5.00000e-04 5.00000e-04 5.00000e-05 1.00000e-09 1.00000e-01 $6.49161 \mathrm{e}+016.49161 \mathrm{e}+016.49161 \mathrm{e}+001.00000 \mathrm{e}-092.12000 \mathrm{e}-01$ $6.49161 \mathrm{e}+016.49161 \mathrm{e}+016.49161 \mathrm{e}+001.00000 \mathrm{e}-09$ 2.12000e-01 $6.49161 \mathrm{e}+016.49161 \mathrm{e}+016.49161 \mathrm{e}+001.00000 \mathrm{e}-092.12000 \mathrm{e}-01$ 6.49161e+01 6.49161e+01 6.49161e+00 1.00000e-09 2.12000e-01 $1.00000 \mathrm{e}-02$ 1.00000e-02 1.00000e-03 1.00000e-09 1.00000e-01 $1.00000 \mathrm{e}+001.00000 \mathrm{e}+001.00000 \mathrm{e}-011.00000 \mathrm{e}-091.00000 \mathrm{e}-01$ $1.00000 \mathrm{e}-05$ 1.00000e-05 1.00000e-06 1.00000e-09 1.00000e-01 $1.00000 \mathrm{e}+001.00000 \mathrm{e}+001.00000 \mathrm{e}-011.00000 \mathrm{e}-091.00000 \mathrm{e}-01$ Element: 3163 \# of layers: 12

$\mathrm{Kx} \mathrm{Ky} \mathrm{Kz}$ Ss Por

$1.62468 \mathrm{e}+03$ 1.62468e+03 1.62468e+02 1.00000e-09 7.00000e-02 $1.62468 \mathrm{e}+03$ 1.62468e+03 1.62468e+02 1.00000e-09 7.00000e-02 5.00000e-04 5.00000e-04 5.00000e-05 1.00000e-09 1.00000e-01 5.00000e-04 5.00000e-04 5.00000e-05 1.00000e-09 1.00000e-01 $6.49161 \mathrm{e}+016.49161 \mathrm{e}+016.49161 \mathrm{e}+001.00000 \mathrm{e}-092.12000 \mathrm{e}-01$ $6.49161 \mathrm{e}+016.49161 \mathrm{e}+016.49161 \mathrm{e}+001.00000 \mathrm{e}-092.12000 \mathrm{e}-01$ $6.49161 \mathrm{e}+016.49161 \mathrm{e}+016.49161 \mathrm{e}+001.00000 \mathrm{e}-092.12000 \mathrm{e}-01$ 6.49161e+01 6.49161e+01 6.49161e+00 1.00000e-09 2.12000e-01 $1.00000 \mathrm{e}-02$ 1.00000e-02 1.00000e-03 1.00000e-09 1.00000e-01 $1.00000 \mathrm{e}+001.00000 \mathrm{e}+001.00000 \mathrm{e}-011.00000 \mathrm{e}-091.00000 \mathrm{e}-01$ $1.00000 \mathrm{e}-05$ 1.00000e-05 1.00000e-06 1.00000e-09 1.00000e-01 $1.00000 \mathrm{e}+001.00000 \mathrm{e}+001.00000 \mathrm{e}-01$ 1.00000e-09 1.00000e-01 Element: 3164 \# of layers: 12

$\mathrm{Kx} \mathrm{Ky} \mathrm{Kz}$ Ss Por $1.62468 \mathrm{e}+031.62468 \mathrm{e}+03$ 1.62468e+02 1.00000e-09 7.00000e-02 $1.62468 \mathrm{e}+031.62468 \mathrm{e}+03$ 1.62468e+02 1.00000e-09 7.00000e-02 5.00000e-04 5.00000e-04 5.00000e-05 1.00000e-09 1.00000e-01 5.00000e-04 5.00000e-04 5.00000e-05 1.00000e-09 1.00000e-01 $6.49161 \mathrm{e}+016.49161 \mathrm{e}+016.49161 \mathrm{e}+00$ 1.00000e-09 2.12000e-01 $6.49161 \mathrm{e}+016.49161 \mathrm{e}+016.49161 \mathrm{e}+001.00000 \mathrm{e}-092.12000 \mathrm{e}-01$ $6.49161 \mathrm{e}+016.49161 \mathrm{e}+016.49161 \mathrm{e}+00$ 1.00000e-09 2.12000e-01 $6.49161 \mathrm{e}+016.49161 \mathrm{e}+016.49161 \mathrm{e}+00$ 1.00000e-09 2.12000e-01 $1.00000 \mathrm{e}-02$ 1.00000e-02 1.00000e-03 1.00000e-09 1.00000e-01 $1.00000 \mathrm{e}+001.00000 \mathrm{e}+001.00000 \mathrm{e}-011.00000 \mathrm{e}-091.00000 \mathrm{e}-01$ $1.00000 \mathrm{e}-05$ 1.00000e-05 1.00000e-06 1.00000e-09 1.00000e-01 $1.00000 \mathrm{e}+001.00000 \mathrm{e}+001.00000 \mathrm{e}-011.00000 \mathrm{e}-091.00000 \mathrm{e}-01$ Element: 3165 \# of layers: 12

$\mathrm{Kx} \mathrm{Ky} \mathrm{Kz}$ Ss Por

2.19808e+03 2.19808e+03 2.19808e+02 1.00000e-09 7.00000e-02 $2.19808 \mathrm{e}+032.19808 \mathrm{e}+032.19808 \mathrm{e}+02$ 1.00000e-09 7.00000e-02 5.00000e-04 5.00000e-04 5.00000e-05 1.00000e-09 1.00000e-01 5.00000e-04 5.00000e-04 5.00000e-05 1.00000e-09 1.00000e-01 8.78261e+01 8.78261e+01 8.78261e+00 1.00000e-09 2.12000e-01 $8.78261 \mathrm{e}+018.78261 \mathrm{e}+018.78261 \mathrm{e}+001.00000 \mathrm{e}-092.12000 \mathrm{e}-01$ $8.78261 \mathrm{e}+018.78261 \mathrm{e}+018.78261 \mathrm{e}+001.00000 \mathrm{e}-092.12000 \mathrm{e}-01$ 
8.78261e+01 8.78261e+01 8.78261e+00 1.00000e-09 2.12000e-01 $1.00000 \mathrm{e}-02$ 1.00000e-02 1.00000e-03 1.00000e-09 1.00000e-01 $1.00000 \mathrm{e}+001.00000 \mathrm{e}+001.00000 \mathrm{e}-011.00000 \mathrm{e}-091.00000 \mathrm{e}-01$ $1.00000 \mathrm{e}-05$ 1.00000e-05 1.00000e-06 1.00000e-09 1.00000e-01 $1.00000 \mathrm{e}+001.00000 \mathrm{e}+001.00000 \mathrm{e}-01$ 1.00000e-09 1.00000e-01 Element: 3166 \# of layers: 12

$\mathrm{Kx} \mathrm{Ky} \mathrm{Kz}$ Ss Por

2.19808e+03 2.19808e+03 2.19808e+02 1.00000e-09 7.00000e-02 $2.19808 \mathrm{e}+032.19808 \mathrm{e}+032.19808 \mathrm{e}+02$ 1.00000e-09 7.00000e-02 5.00000e-04 5.00000e-04 5.00000e-05 1.00000e-09 1.00000e-01 5.00000e-04 5.00000e-04 5.00000e-05 1.00000e-09 1.00000e-01 $8.78261 \mathrm{e}+018.78261 \mathrm{e}+018.78261 \mathrm{e}+001.00000 \mathrm{e}-092.12000 \mathrm{e}-01$ $8.78261 \mathrm{e}+018.78261 \mathrm{e}+018.78261 \mathrm{e}+001.00000 \mathrm{e}-092.12000 \mathrm{e}-01$ $8.78261 \mathrm{e}+018.78261 \mathrm{e}+018.78261 \mathrm{e}+001.00000 \mathrm{e}-092.12000 \mathrm{e}-01$ $8.78261 \mathrm{e}+018.78261 \mathrm{e}+018.78261 \mathrm{e}+001.00000 \mathrm{e}-092.12000 \mathrm{e}-01$ $1.00000 \mathrm{e}-02$ 1.00000e-02 1.00000e-03 1.00000e-09 1.00000e-01 $1.00000 \mathrm{e}+001.00000 \mathrm{e}+001.00000 \mathrm{e}-011.00000 \mathrm{e}-091.00000 \mathrm{e}-01$ $1.00000 \mathrm{e}-05$ 1.00000e-05 1.00000e-06 1.00000e-09 1.00000e-01 $1.00000 \mathrm{e}+001.00000 \mathrm{e}+001.00000 \mathrm{e}-01$ 1.00000e-09 1.00000e-01 Element: 3167 \# of layers: 13

$\mathrm{Kx} \mathrm{Ky} \mathrm{Kz}$ Ss Por

$2.64155 \mathrm{e}+03$ 2.64155e+03 2.64155e+02 1.00000e-09 7.00000e-02 $2.64155 \mathrm{e}+032.64155 \mathrm{e}+032.64155 \mathrm{e}+02$ 1.00000e-09 7.00000e-02 5.00000e-04 5.00000e-04 5.00000e-05 1.00000e-09 1.00000e-01 $5.00000 \mathrm{e}-04$ 5.00000e-04 5.00000e-05 1.00000e-09 1.00000e-01 $1.05548 \mathrm{e}+02$ 1.05548e+02 1.05548e+01 1.00000e-09 2.12000e-01 $1.05548 \mathrm{e}+02$ 1.05548e+02 1.05548e+01 1.00000e-09 2.12000e-01 $1.05548 \mathrm{e}+02$ 1.05548e+02 1.05548e+01 1.00000e-09 2.12000e-01 $1.05548 \mathrm{e}+021.05548 \mathrm{e}+02 \quad 1.05548 \mathrm{e}+01$ 1.00000e-09 2.12000e-01 $1.05548 \mathrm{e}+02$ 1.05548e+02 1.05548e+01 1.00000e-09 2.12000e-01 $1.00000 \mathrm{e}-02$ 1.00000e-02 1.00000e-03 1.00000e-09 1.00000e-01 $1.00000 \mathrm{e}+001.00000 \mathrm{e}+001.00000 \mathrm{e}-011.00000 \mathrm{e}-091.00000 \mathrm{e}-01$ $1.00000 \mathrm{e}-05$ 1.00000e-05 1.00000e-06 1.00000e-09 1.00000e-01 $1.00000 \mathrm{e}+001.00000 \mathrm{e}+001.00000 \mathrm{e}-011.00000 \mathrm{e}-091.00000 \mathrm{e}-01$ Element: 3168 \# of layers: 13

Kx Ky Kz Ss Por

$1.65685 \mathrm{e}+031.65685 \mathrm{e}+03$ 1.65685e+02 1.00000e-09 7.00000e-02 $1.65685 \mathrm{e}+031.65685 \mathrm{e}+031.65685 \mathrm{e}+021.00000 \mathrm{e}-097.00000 \mathrm{e}-02$ 5.00000e-04 5.00000e-04 5.00000e-05 1.00000e-09 1.00000e-01 5.00000e-04 5.00000e-04 5.00000e-05 1.00000e-09 1.00000e-01 $6.62032 \mathrm{e}+016.62032 \mathrm{e}+016.62032 \mathrm{e}+00$ 1.00000e-09 2.12000e-01 $6.62032 \mathrm{e}+016.62032 \mathrm{e}+016.62032 \mathrm{e}+00$ 1.00000e-09 2.12000e-01 $6.62032 \mathrm{e}+016.62032 \mathrm{e}+01$ 6.62032e+00 1.00000e-09 2.12000e-01 $6.62032 \mathrm{e}+016.62032 \mathrm{e}+01$ 6.62032e+00 1.00000e-09 2.12000e-01 $6.62032 \mathrm{e}+016.62032 \mathrm{e}+016.62032 \mathrm{e}+001.00000 \mathrm{e}-092.12000 \mathrm{e}-01$ $1.00000 \mathrm{e}-02$ 1.00000e-02 1.00000e-03 1.00000e-09 1.00000e-01 
$1.00000 \mathrm{e}+001.00000 \mathrm{e}+001.00000 \mathrm{e}-011.00000 \mathrm{e}-091.00000 \mathrm{e}-01$ $1.00000 \mathrm{e}-05$ 1.00000e-05 1.00000e-06 1.00000e-09 1.00000e-01 $1.00000 \mathrm{e}+001.00000 \mathrm{e}+001.00000 \mathrm{e}-011.00000 \mathrm{e}-09$ 1.00000e-01 Element: 3169 \# of layers: 12

$\mathrm{Kx} \mathrm{Ky} \mathrm{Kz}$ Ss Por

$1.62468 \mathrm{e}+031.62468 \mathrm{e}+03$ 1.62468e+02 1.00000e-09 7.00000e-02 $1.62468 \mathrm{e}+031.62468 \mathrm{e}+03$ 1.62468e+02 1.00000e-09 7.00000e-02 5.00000e-04 5.00000e-04 5.00000e-05 1.00000e-09 1.00000e-01 5.00000e-04 5.00000e-04 5.00000e-05 1.00000e-09 1.00000e-01 $6.49161 \mathrm{e}+016.49161 \mathrm{e}+016.49161 \mathrm{e}+00$ 1.00000e-09 2.12000e-01 $6.49161 \mathrm{e}+016.49161 \mathrm{e}+016.49161 \mathrm{e}+00$ 1.00000e-09 2.12000e-01 $6.49161 \mathrm{e}+016.49161 \mathrm{e}+016.49161 \mathrm{e}+001.00000 \mathrm{e}-092.12000 \mathrm{e}-01$ $6.49161 \mathrm{e}+016.49161 \mathrm{e}+016.49161 \mathrm{e}+001.00000 \mathrm{e}-092.12000 \mathrm{e}-01$ $1.00000 \mathrm{e}-02$ 1.00000e-02 1.00000e-03 1.00000e-09 1.00000e-01 $1.00000 \mathrm{e}+001.00000 \mathrm{e}+001.00000 \mathrm{e}-011.00000 \mathrm{e}-091.00000 \mathrm{e}-01$ $1.00000 \mathrm{e}-051.00000 \mathrm{e}-05$ 1.00000e-06 1.00000e-09 1.00000e-01 $1.00000 \mathrm{e}+001.00000 \mathrm{e}+001.00000 \mathrm{e}-011.00000 \mathrm{e}-091.00000 \mathrm{e}-01$ Element: 3170 \# of layers: 13

$\mathrm{Kx} \mathrm{Ky} \mathrm{Kz}$ Ss Por

1.23122e+03 1.23122e+03 1.23122e+02 1.00000e-09 7.00000e-02 $1.23122 \mathrm{e}+03$ 1.23122e+03 1.23122e+02 1.00000e-09 7.00000e-02 $1.23122 \mathrm{e}+031.23122 \mathrm{e}+031.23122 \mathrm{e}+021.00000 \mathrm{e}-097.00000 \mathrm{e}-02$ 5.00000e-04 5.00000e-04 5.00000e-05 1.00000e-09 1.00000e-01 5.00000e-04 5.00000e-04 5.00000e-05 1.00000e-09 1.00000e-01 $4.91928 \mathrm{e}+014.91928 \mathrm{e}+014.91928 \mathrm{e}+001.00000 \mathrm{e}-09$ 2.12000e-01 $4.91928 \mathrm{e}+014.91928 \mathrm{e}+01$ 4.91928e+00 1.00000e-09 2.12000e-01 $4.91928 \mathrm{e}+014.91928 \mathrm{e}+014.91928 \mathrm{e}+00$ 1.00000e-09 2.12000e-01 $4.91928 \mathrm{e}+014.91928 \mathrm{e}+014.91928 \mathrm{e}+00$ 1.00000e-09 2.12000e-01 $1.00000 \mathrm{e}-02$ 1.00000e-02 1.00000e-03 1.00000e-09 1.00000e-01 $1.00000 \mathrm{e}+001.00000 \mathrm{e}+001.00000 \mathrm{e}-011.00000 \mathrm{e}-091.00000 \mathrm{e}-01$ $1.00000 \mathrm{e}-05$ 1.00000e-05 1.00000e-06 1.00000e-09 1.00000e-01 $1.00000 \mathrm{e}+001.00000 \mathrm{e}+00$ 1.00000e-01 1.00000e-09 1.00000e-01 Element: 3171 \# of layers: 13

$\mathrm{Kx} \mathrm{Ky} \mathrm{Kz}$ Ss Por

9.93983e+02 9.93983e+02 9.93983e+01 1.00000e-09 7.00000e-02 9.93983e+02 9.93983e+02 9.93983e+01 1.00000e-09 7.00000e-02 9.93983e+02 9.93983e+02 9.93983e+01 1.00000e-09 7.00000e-02 5.00000e-04 5.00000e-04 5.00000e-05 1.00000e-09 1.00000e-01 5.00000e-04 5.00000e-04 5.00000e-05 1.00000e-09 1.00000e-01 $3.97156 \mathrm{e}+013.97156 \mathrm{e}+013.97156 \mathrm{e}+001.00000 \mathrm{e}-092.12000 \mathrm{e}-01$ $3.97156 \mathrm{e}+013.97156 \mathrm{e}+013.97156 \mathrm{e}+001.00000 \mathrm{e}-092.12000 \mathrm{e}-01$ $3.97156 \mathrm{e}+013.97156 \mathrm{e}+013.97156 \mathrm{e}+001.00000 \mathrm{e}-092.12000 \mathrm{e}-01$ $3.97156 \mathrm{e}+013.97156 \mathrm{e}+013.97156 \mathrm{e}+001.00000 \mathrm{e}-092.12000 \mathrm{e}-01$ $1.00000 \mathrm{e}-02$ 1.00000e-02 1.00000e-03 1.00000e-09 1.00000e-01 $1.00000 \mathrm{e}+001.00000 \mathrm{e}+001.00000 \mathrm{e}-011.00000 \mathrm{e}-091.00000 \mathrm{e}-01$ $1.00000 \mathrm{e}-05$ 1.00000e-05 1.00000e-06 1.00000e-09 1.00000e-01 
$1.00000 \mathrm{e}+001.00000 \mathrm{e}+00$ 1.00000e-01 1.00000e-09 1.00000e-01

Element: 3172 \# of layers: 14

$\mathrm{Kx} \mathrm{Ky} \mathrm{Kz}$ Ss Por

9.93983e+02 9.93983e+02 9.93983e+01 1.00000e-09 7.00000e-02

$9.93983 \mathrm{e}+02$ 9.93983e+02 9.93983e+01 1.00000e-09 7.00000e-02

9.93983e+02 9.93983e+02 9.93983e+01 1.00000e-09 7.00000e-02

5.00000e-04 5.00000e-04 5.00000e-05 1.00000e-09 1.00000e-01

5.00000e-04 5.00000e-04 5.00000e-05 1.00000e-09 1.00000e-01

$3.97156 \mathrm{e}+013.97156 \mathrm{e}+013.97156 \mathrm{e}+001.00000 \mathrm{e}-092.12000 \mathrm{e}-01$

$3.97156 \mathrm{e}+013.97156 \mathrm{e}+013.97156 \mathrm{e}+001.00000 \mathrm{e}-092.12000 \mathrm{e}-01$

$3.97156 \mathrm{e}+013.97156 \mathrm{e}+013.97156 \mathrm{e}+001.00000 \mathrm{e}-092.12000 \mathrm{e}-01$

$3.97156 \mathrm{e}+013.97156 \mathrm{e}+013.97156 \mathrm{e}+001.00000 \mathrm{e}-092.12000 \mathrm{e}-01$

$3.97156 \mathrm{e}+013.97156 \mathrm{e}+013.97156 \mathrm{e}+00$ 1.00000e-09 2.12000e-01

$1.00000 \mathrm{e}-02$ 1.00000e-02 1.00000e-03 1.00000e-09 1.00000e-01

$1.00000 \mathrm{e}+001.00000 \mathrm{e}+001.00000 \mathrm{e}-011.00000 \mathrm{e}-091.00000 \mathrm{e}-01$

$1.00000 \mathrm{e}-05$ 1.00000e-05 1.00000e-06 1.00000e-09 1.00000e-01

$1.00000 \mathrm{e}+001.00000 \mathrm{e}+001.00000 \mathrm{e}-01$ 1.00000e-09 1.00000e-01

Element: 3173 \# of layers: 13

$\mathrm{Kx} \mathrm{Ky} \mathrm{Kz}$ Ss Por

9.93983e+02 9.93983e+02 9.93983e+01 1.00000e-09 7.00000e-02

9.93983e+02 9.93983e+02 9.93983e+01 1.00000e-09 7.00000e-02

9.93983e+02 9.93983e+02 9.93983e+01 1.00000e-09 7.00000e-02

5.00000e-04 5.00000e-04 5.00000e-05 1.00000e-09 1.00000e-01

5.00000e-04 5.00000e-04 5.00000e-05 1.00000e-09 1.00000e-01

$3.97156 \mathrm{e}+013.97156 \mathrm{e}+013.97156 \mathrm{e}+001.00000 \mathrm{e}-092.12000 \mathrm{e}-01$

$3.97156 \mathrm{e}+013.97156 \mathrm{e}+013.97156 \mathrm{e}+001.00000 \mathrm{e}-092.12000 \mathrm{e}-01$

$3.97156 \mathrm{e}+013.97156 \mathrm{e}+013.97156 \mathrm{e}+001.00000 \mathrm{e}-092.12000 \mathrm{e}-01$

$3.97156 \mathrm{e}+013.97156 \mathrm{e}+013.97156 \mathrm{e}+001.00000 \mathrm{e}-092.12000 \mathrm{e}-01$

$1.00000 \mathrm{e}-02$ 1.00000e-02 1.00000e-03 1.00000e-09 1.00000e-01

$1.00000 \mathrm{e}+001.00000 \mathrm{e}+001.00000 \mathrm{e}-011.00000 \mathrm{e}-091.00000 \mathrm{e}-01$

$1.00000 \mathrm{e}-05$ 1.00000e-05 1.00000e-06 1.00000e-09 1.00000e-01

$1.00000 \mathrm{e}+001.00000 \mathrm{e}+001.00000 \mathrm{e}-01$ 1.00000e-09 1.00000e-01

Element: 3174 \# of layers: 14

$\mathrm{Kx} \mathrm{Ky} \mathrm{Kz}$ Ss Por

4.01044e+03 4.01044e+03 4.01044e+02 1.00000e-09 7.00000e-02 $4.01044 \mathrm{e}+034.01044 \mathrm{e}+03$ 4.01044e+02 1.00000e-09 7.00000e-02 $4.01044 \mathrm{e}+034.01044 \mathrm{e}+034.01044 \mathrm{e}+02$ 1.00000e-09 7.00000e-02 5.00000e-04 5.00000e-04 5.00000e-05 1.00000e-09 1.00000e-01 $5.00000 \mathrm{e}-04$ 5.00000e-04 5.00000e-05 1.00000e-09 1.00000e-01 $1.60242 \mathrm{e}+021.60242 \mathrm{e}+02$ 1.60242e+01 1.00000e-09 2.12000e-01 $1.60242 \mathrm{e}+021.60242 \mathrm{e}+02$ 1.60242e+01 1.00000e-09 2.12000e-01 $1.60242 \mathrm{e}+021.60242 \mathrm{e}+02$ 1.60242e+01 1.00000e-09 2.12000e-01 $1.60242 \mathrm{e}+02$ 1.60242e+02 1.60242e+01 1.00000e-09 2.12000e-01 1.60242e+02 1.60242e+02 1.60242e+01 1.00000e-09 2.12000e-01 $1.00000 \mathrm{e}-02$ 1.00000e-02 1.00000e-03 1.00000e-09 1.00000e-01 $1.00000 \mathrm{e}+001.00000 \mathrm{e}+001.00000 \mathrm{e}-011.00000 \mathrm{e}-091.00000 \mathrm{e}-01$ 
$1.00000 \mathrm{e}-05$ 1.00000e-05 1.00000e-06 1.00000e-09 1.00000e-01 $1.00000 \mathrm{e}+001.00000 \mathrm{e}+001.00000 \mathrm{e}-01$ 1.00000e-09 1.00000e-01 Element: 3175 \# of layers: 14

Kx Ky Kz Ss Por

4.01044e+03 4.01044e+03 4.01044e+02 1.00000e-09 7.00000e-02 $4.01044 \mathrm{e}+034.01044 \mathrm{e}+034.01044 \mathrm{e}+02$ 1.00000e-09 7.00000e-02 $4.01044 \mathrm{e}+034.01044 \mathrm{e}+034.01044 \mathrm{e}+02$ 1.00000e-09 7.00000e-02 5.00000e-04 5.00000e-04 5.00000e-05 1.00000e-09 1.00000e-01 5.00000e-04 5.00000e-04 5.00000e-05 1.00000e-09 1.00000e-01 $1.60242 \mathrm{e}+021.60242 \mathrm{e}+02$ 1.60242e+01 1.00000e-09 2.12000e-01 $1.60242 \mathrm{e}+021.60242 \mathrm{e}+02$ 1.60242e+01 1.00000e-09 2.12000e-01 $1.60242 \mathrm{e}+02$ 1.60242e+02 1.60242e+01 1.00000e-09 2.12000e-01 $1.60242 \mathrm{e}+02$ 1.60242e+02 1.60242e+01 1.00000e-09 2.12000e-01 $1.60242 \mathrm{e}+021.60242 \mathrm{e}+02$ 1.60242e+01 1.00000e-09 2.12000e-01 $1.00000 \mathrm{e}-02$ 1.00000e-02 1.00000e-03 1.00000e-09 1.00000e-01 $1.00000 \mathrm{e}+001.00000 \mathrm{e}+001.00000 \mathrm{e}-011.00000 \mathrm{e}-091.00000 \mathrm{e}-01$ $1.00000 \mathrm{e}-05$ 1.00000e-05 1.00000e-06 1.00000e-09 1.00000e-01 $1.00000 \mathrm{e}+001.00000 \mathrm{e}+001.00000 \mathrm{e}-01$ 1.00000e-09 1.00000e-01 Element: 3176 \# of layers: 12

$\mathrm{Kx} \mathrm{Ky} \mathrm{Kz}$ Ss Por

$2.18348 \mathrm{e}+03$ 2.18348e+03 2.18348e+02 1.00000e-09 7.00000e-02

$2.18348 \mathrm{e}+032.18348 \mathrm{e}+03$ 2.18348e+02 1.00000e-09 7.00000e-02 5.00000e-04 5.00000e-04 5.00000e-05 1.00000e-09 1.00000e-01 5.00000e-04 5.00000e-04 5.00000e-05 1.00000e-09 1.00000e-01 $8.72456 \mathrm{e}+018.72456 \mathrm{e}+018.72456 \mathrm{e}+001.00000 \mathrm{e}-092.12000 \mathrm{e}-01$ $8.72456 \mathrm{e}+018.72456 \mathrm{e}+018.72456 \mathrm{e}+001.00000 \mathrm{e}-092.12000 \mathrm{e}-01$ $8.72456 \mathrm{e}+018.72456 \mathrm{e}+018.72456 \mathrm{e}+001.00000 \mathrm{e}-092.12000 \mathrm{e}-01$ $8.72456 \mathrm{e}+018.72456 \mathrm{e}+018.72456 \mathrm{e}+001.00000 \mathrm{e}-092.12000 \mathrm{e}-01$ $1.00000 \mathrm{e}-02$ 1.00000e-02 1.00000e-03 1.00000e-09 1.00000e-01 $1.00000 \mathrm{e}+001.00000 \mathrm{e}+001.00000 \mathrm{e}-011.00000 \mathrm{e}-091.00000 \mathrm{e}-01$ $1.00000 \mathrm{e}-05$ 1.00000e-05 1.00000e-06 1.00000e-09 1.00000e-01 $1.00000 \mathrm{e}+001.00000 \mathrm{e}+001.00000 \mathrm{e}-011.00000 \mathrm{e}-091.00000 \mathrm{e}-01$ Element: 3177 \# of layers: 12

$\mathrm{Kx} \mathrm{Ky} \mathrm{Kz}$ Ss Por

1.23122e+03 1.23122e+03 1.23122e+02 1.00000e-09 7.00000e-02 $1.23122 \mathrm{e}+03$ 1.23122e+03 1.23122e+02 1.00000e-09 7.00000e-02 5.00000e-04 5.00000e-04 5.00000e-05 1.00000e-09 1.00000e-01 5.00000e-04 5.00000e-04 5.00000e-05 1.00000e-09 1.00000e-01 $4.91928 \mathrm{e}+014.91928 \mathrm{e}+014.91928 \mathrm{e}+00$ 1.00000e-09 2.12000e-01 $4.91928 \mathrm{e}+014.91928 \mathrm{e}+01$ 4.91928e+00 1.00000e-09 2.12000e-01 $4.91928 \mathrm{e}+014.91928 \mathrm{e}+01$ 4.91928e+00 1.00000e-09 2.12000e-01 $4.91928 \mathrm{e}+014.91928 \mathrm{e}+014.91928 \mathrm{e}+00$ 1.00000e-09 2.12000e-01 $1.00000 \mathrm{e}-02$ 1.00000e-02 1.00000e-03 1.00000e-09 1.00000e-01 $1.00000 \mathrm{e}+001.00000 \mathrm{e}+001.00000 \mathrm{e}-011.00000 \mathrm{e}-091.00000 \mathrm{e}-01$ $1.00000 \mathrm{e}-05$ 1.00000e-05 1.00000e-06 1.00000e-09 1.00000e-01 $1.00000 \mathrm{e}+001.00000 \mathrm{e}+001.00000 \mathrm{e}-011.00000 \mathrm{e}-091.00000 \mathrm{e}-01$ 
Element: 3178 \# of layers: 13

$\mathrm{Kx} \mathrm{Ky} \mathrm{Kz}$ Ss Por

9.93983e+02 9.93983e+02 9.93983e+01 1.00000e-09 7.00000e-02

$9.93983 e+02$ 9.93983e+02 9.93983e+01 1.00000e-09 7.00000e-02

$9.93983 \mathrm{e}+02$ 9.93983e+02 9.93983e+01 1.00000e-09 7.00000e-02

5.00000e-04 5.00000e-04 5.00000e-05 1.00000e-09 1.00000e-01

5.00000e-04 5.00000e-04 5.00000e-05 1.00000e-09 1.00000e-01

$3.97156 \mathrm{e}+013.97156 \mathrm{e}+013.97156 \mathrm{e}+001.00000 \mathrm{e}-092.12000 \mathrm{e}-01$

$3.97156 \mathrm{e}+013.97156 \mathrm{e}+013.97156 \mathrm{e}+001.00000 \mathrm{e}-092.12000 \mathrm{e}-01$

$3.97156 \mathrm{e}+013.97156 \mathrm{e}+013.97156 \mathrm{e}+001.00000 \mathrm{e}-092.12000 \mathrm{e}-01$

$3.97156 \mathrm{e}+013.97156 \mathrm{e}+013.97156 \mathrm{e}+00$ 1.00000e-09 2.12000e-01

$1.00000 \mathrm{e}-02$ 1.00000e-02 1.00000e-03 1.00000e-09 1.00000e-01

$1.00000 \mathrm{e}+001.00000 \mathrm{e}+001.00000 \mathrm{e}-011.00000 \mathrm{e}-091.00000 \mathrm{e}-01$

$1.00000 \mathrm{e}-05$ 1.00000e-05 1.00000e-06 1.00000e-09 1.00000e-01

$1.00000 \mathrm{e}+001.00000 \mathrm{e}+001.00000 \mathrm{e}-01$ 1.00000e-09 1.00000e-01

Element: 3179 \# of layers: 14

$\mathrm{Kx} \mathrm{Ky} \mathrm{Kz}$ Ss Por

8.90593e+02 8.90593e+02 8.90593e+01 1.00000e-09 7.00000e-02

$8.90593 \mathrm{e}+02$ 8.90593e+02 8.90593e+01 1.00000e-09 7.00000e-02

8.90593e+02 8.90593e+02 8.90593e+01 1.00000e-09 7.00000e-02

5.00000e-04 5.00000e-04 5.00000e-05 1.00000e-09 1.00000e-01

5.00000e-04 5.00000e-04 5.00000e-05 1.00000e-09 1.00000e-01

$3.55845 \mathrm{e}+013.55845 \mathrm{e}+013.55845 \mathrm{e}+001.00000 \mathrm{e}-092.12000 \mathrm{e}-01$

$3.55845 \mathrm{e}+013.55845 \mathrm{e}+013.55845 \mathrm{e}+001.00000 \mathrm{e}-092.12000 \mathrm{e}-01$

$3.55845 \mathrm{e}+013.55845 \mathrm{e}+013.55845 \mathrm{e}+001.00000 \mathrm{e}-092.12000 \mathrm{e}-01$

$3.55845 \mathrm{e}+013.55845 \mathrm{e}+013.55845 \mathrm{e}+001.00000 \mathrm{e}-092.12000 \mathrm{e}-01$

$3.55845 \mathrm{e}+013.55845 \mathrm{e}+013.55845 \mathrm{e}+001.00000 \mathrm{e}-092.12000 \mathrm{e}-01$

$1.00000 \mathrm{e}-02$ 1.00000e-02 1.00000e-03 1.00000e-09 1.00000e-01

$1.00000 \mathrm{e}+001.00000 \mathrm{e}+001.00000 \mathrm{e}-011.00000 \mathrm{e}-091.00000 \mathrm{e}-01$

$1.00000 \mathrm{e}-051.00000 \mathrm{e}-051.00000 \mathrm{e}-061.00000 \mathrm{e}-091.00000 \mathrm{e}-01$

$1.00000 \mathrm{e}+001.00000 \mathrm{e}+001.00000 \mathrm{e}-011.00000 \mathrm{e}-091.00000 \mathrm{e}-01$

Element: 3180 \# of layers: 14

$\mathrm{Kx} \mathrm{Ky} \mathrm{Kz}$ Ss Por

7.86555e+02 7.86555e+02 7.86555e+01 1.00000e-09 7.00000e-02

$7.86555 \mathrm{e}+02$ 7.86555e+02 7.86555e+01 1.00000e-09 7.00000e-02

$7.86555 \mathrm{e}+02$ 7.86555e+02 7.86555e+01 1.00000e-09 7.00000e-02

5.00000e-04 5.00000e-04 5.00000e-05 1.00000e-09 1.00000e-01

5.00000e-04 5.00000e-04 5.00000e-05 1.00000e-09 1.00000e-01

$3.14287 \mathrm{e}+013.14287 \mathrm{e}+013.14287 \mathrm{e}+00$ 1.00000e-09 2.12000e-01

$3.14287 \mathrm{e}+013.14287 \mathrm{e}+01$ 3.14287e+00 1.00000e-09 2.12000e-01

$3.14287 \mathrm{e}+013.14287 \mathrm{e}+01$ 3.14287e+00 1.00000e-09 2.12000e-01

$3.14287 \mathrm{e}+013.14287 \mathrm{e}+01$ 3.14287e+00 1.00000e-09 2.12000e-01

3.14287e+01 3.14287e+01 3.14287e+00 1.00000e-09 2.12000e-01

$1.00000 \mathrm{e}-02$ 1.00000e-02 1.00000e-03 1.00000e-09 1.00000e-01

$1.00000 \mathrm{e}+001.00000 \mathrm{e}+001.00000 \mathrm{e}-011.00000 \mathrm{e}-091.00000 \mathrm{e}-01$

$1.00000 \mathrm{e}-05$ 1.00000e-05 1.00000e-06 1.00000e-09 1.00000e-01 
$1.00000 \mathrm{e}+001.00000 \mathrm{e}+00$ 1.00000e-01 1.00000e-09 1.00000e-01

Element: 3181 \# of layers: 14

Kx Ky Kz Ss Por

7.86555e+02 7.86555e+02 7.86555e+01 1.00000e-09 7.00000e-02

$7.86555 \mathrm{e}+02$ 7.86555e+02 7.86555e+01 1.00000e-09 7.00000e-02

$7.86555 \mathrm{e}+02$ 7.86555e+02 7.86555e+01 1.00000e-09 7.00000e-02

5.00000e-04 5.00000e-04 5.00000e-05 1.00000e-09 1.00000e-01

5.00000e-04 5.00000e-04 5.00000e-05 1.00000e-09 1.00000e-01

$3.14287 \mathrm{e}+013.14287 \mathrm{e}+013.14287 \mathrm{e}+00$ 1.00000e-09 2.12000e-01

$3.14287 \mathrm{e}+013.14287 \mathrm{e}+01$ 3.14287e+00 1.00000e-09 2.12000e-01

3.14287e+01 3.14287e+01 3.14287e+00 1.00000e-09 2.12000e-01

$3.14287 \mathrm{e}+013.14287 \mathrm{e}+013.14287 \mathrm{e}+00$ 1.00000e-09 2.12000e-01

3.14287e+01 3.14287e+01 3.14287e+00 1.00000e-09 2.12000e-01

$1.00000 \mathrm{e}-01$ 1.00000e-01 1.00000e-02 1.00000e-09 1.00000e-01

$1.00000 \mathrm{e}+001.00000 \mathrm{e}+001.00000 \mathrm{e}-011.00000 \mathrm{e}-091.00000 \mathrm{e}-01$

$1.00000 \mathrm{e}-05$ 1.00000e-05 1.00000e-06 1.00000e-09 1.00000e-01

$1.00000 \mathrm{e}+001.00000 \mathrm{e}+001.00000 \mathrm{e}-01$ 1.00000e-09 1.00000e-01

Element: 3182 \# of layers: 14

$\mathrm{Kx} \mathrm{Ky} \mathrm{Kz}$ Ss Por

7.86555e+02 7.86555e+02 7.86555e+01 1.00000e-09 7.00000e-02

7.86555e+02 7.86555e+02 7.86555e+01 1.00000e-09 7.00000e-02

7.86555e+02 7.86555e+02 7.86555e+01 1.00000e-09 7.00000e-02

5.00000e-04 5.00000e-04 5.00000e-05 1.00000e-09 1.00000e-01

5.00000e-04 5.00000e-04 5.00000e-05 1.00000e-09 1.00000e-01

$3.14287 \mathrm{e}+013.14287 \mathrm{e}+013.14287 \mathrm{e}+001.00000 \mathrm{e}-092.12000 \mathrm{e}-01$

$3.14287 \mathrm{e}+013.14287 \mathrm{e}+01$ 3.14287e+00 1.00000e-09 2.12000e-01

$3.14287 \mathrm{e}+013.14287 \mathrm{e}+013.14287 \mathrm{e}+00$ 1.00000e-09 2.12000e-01

3.14287e+01 3.14287e+01 3.14287e+00 1.00000e-09 2.12000e-01

$3.14287 \mathrm{e}+013.14287 \mathrm{e}+013.14287 \mathrm{e}+00$ 1.00000e-09 2.12000e-01

$1.00000 \mathrm{e}-011.00000 \mathrm{e}-011.00000 \mathrm{e}-021.00000 \mathrm{e}-091.00000 \mathrm{e}-01$

$1.00000 \mathrm{e}+001.00000 \mathrm{e}+001.00000 \mathrm{e}-01$ 1.00000e-09 1.00000e-01

1.00000e-05 1.00000e-05 1.00000e-06 1.00000e-09 1.00000e-01

$1.00000 \mathrm{e}+001.00000 \mathrm{e}+001.00000 \mathrm{e}-011.00000 \mathrm{e}-091.00000 \mathrm{e}-01$

Element: 3183 \# of layers: 14

$\mathrm{Kx} \mathrm{Ky} \mathrm{Kz}$ Ss Por

$2.41225 \mathrm{e}+03$ 2.41225e+03 2.41225e+02 1.00000e-09 7.00000e-02

$2.41225 \mathrm{e}+032.41225 \mathrm{e}+032.41225 \mathrm{e}+02$ 1.00000e-09 7.00000e-02

$2.41225 \mathrm{e}+032.41225 \mathrm{e}+032.41225 \mathrm{e}+02$ 1.00000e-09 7.00000e-02

5.00000e-04 5.00000e-04 5.00000e-05 1.00000e-09 1.00000e-01

5.00000e-04 5.00000e-04 5.00000e-05 1.00000e-09 1.00000e-01

$9.63853 \mathrm{e}+019.63853 \mathrm{e}+01$ 9.63853e+00 1.00000e-09 2.12000e-01

$9.63853 \mathrm{e}+019.63853 \mathrm{e}+019.63853 \mathrm{e}+001.00000 \mathrm{e}-092.12000 \mathrm{e}-01$

9.63853e+01 9.63853e+01 9.63853e+00 1.00000e-09 2.12000e-01

9.63853e+01 9.63853e+01 9.63853e+00 1.00000e-09 2.12000e-01

$9.63853 \mathrm{e}+019.63853 \mathrm{e}+01$ 9.63853e+00 1.00000e-09 2.12000e-01

$1.00000 \mathrm{e}-01$ 1.00000e-01 1.00000e-02 1.00000e-09 1.00000e-01 
$1.00000 \mathrm{e}+001.00000 \mathrm{e}+001.00000 \mathrm{e}-011.00000 \mathrm{e}-091.00000 \mathrm{e}-01$ $1.00000 \mathrm{e}-05$ 1.00000e-05 1.00000e-06 1.00000e-09 1.00000e-01 $1.00000 \mathrm{e}+001.00000 \mathrm{e}+001.00000 \mathrm{e}-01$ 1.00000e-09 1.00000e-01 Element: 3184 \# of layers: 13

$\mathrm{Kx} \mathrm{Ky} \mathrm{Kz}$ Ss Por

$2.41225 \mathrm{e}+03$ 2.41225e+03 2.41225e+02 1.00000e-09 7.00000e-02 $2.41225 \mathrm{e}+032.41225 \mathrm{e}+032.41225 \mathrm{e}+02$ 1.00000e-09 7.00000e-02 $2.41225 \mathrm{e}+032.41225 \mathrm{e}+032.41225 \mathrm{e}+021.00000 \mathrm{e}-097.00000 \mathrm{e}-02$ 5.00000e-04 5.00000e-04 5.00000e-05 1.00000e-09 1.00000e-01 5.00000e-04 5.00000e-04 5.00000e-05 1.00000e-09 1.00000e-01 $9.63853 \mathrm{e}+019.63853 \mathrm{e}+01$ 9.63853e+00 1.00000e-09 2.12000e-01 $9.63853 \mathrm{e}+019.63853 \mathrm{e}+019.63853 \mathrm{e}+001.00000 \mathrm{e}-092.12000 \mathrm{e}-01$ $9.63853 \mathrm{e}+019.63853 \mathrm{e}+01$ 9.63853e+00 1.00000e-09 2.12000e-01 $9.63853 \mathrm{e}+019.63853 \mathrm{e}+01$ 9.63853e+00 1.00000e-09 2.12000e-01 $1.00000 \mathrm{e}-01$ 1.00000e-01 1.00000e-02 1.00000e-09 1.00000e-01 $1.00000 \mathrm{e}+001.00000 \mathrm{e}+001.00000 \mathrm{e}-011.00000 \mathrm{e}-091.00000 \mathrm{e}-01$ $1.00000 \mathrm{e}-05$ 1.00000e-05 1.00000e-06 1.00000e-09 1.00000e-01 $1.00000 \mathrm{e}+001.00000 \mathrm{e}+001.00000 \mathrm{e}-01$ 1.00000e-09 1.00000e-01 Element: 3185 \# of layers: 14

$\mathrm{Kx} \mathrm{Ky} \mathrm{Kz}$ Ss Por

3.27207e+03 3.27207e+03 3.27207e+02 1.00000e-09 7.00000e-02 $3.27207 \mathrm{e}+03$ 3.27207e+03 3.27207e+02 1.00000e-09 7.00000e-02 3.27207e+03 3.27207e+03 3.27207e+02 1.00000e-09 7.00000e-02 $5.00000 \mathrm{e}-04$ 5.00000e-04 5.00000e-05 1.00000e-09 1.00000e-01 5.00000e-04 5.00000e-04 5.00000e-05 1.00000e-09 1.00000e-01 $1.30739 \mathrm{e}+02$ 1.30739e+02 1.30739e+01 1.00000e-09 2.12000e-01 $1.30739 \mathrm{e}+02$ 1.30739e+02 1.30739e+01 1.00000e-09 2.12000e-01 $1.30739 \mathrm{e}+02$ 1.30739e+02 1.30739e+01 1.00000e-09 2.12000e-01 $1.30739 \mathrm{e}+02$ 1.30739e+02 1.30739e+01 1.00000e-09 2.12000e-01 $1.30739 \mathrm{e}+02$ 1.30739e+02 1.30739e+01 1.00000e-09 2.12000e-01 $1.00000 \mathrm{e}-02$ 1.00000e-02 1.00000e-03 1.00000e-09 1.00000e-01 $1.00000 \mathrm{e}+001.00000 \mathrm{e}+001.00000 \mathrm{e}-011.00000 \mathrm{e}-091.00000 \mathrm{e}-01$ $1.00000 \mathrm{e}-05$ 1.00000e-05 1.00000e-06 1.00000e-09 1.00000e-01 $1.00000 \mathrm{e}+001.00000 \mathrm{e}+001.00000 \mathrm{e}-011.00000 \mathrm{e}-091.00000 \mathrm{e}-01$ Element: 3186 \# of layers: 13

$\mathrm{Kx} \mathrm{Ky} \mathrm{Kz}$ Ss Por 8.90593e+02 8.90593e+02 8.90593e+01 1.00000e-09 7.00000e-02 8.90593e+02 8.90593e+02 8.90593e+01 1.00000e-09 7.00000e-02 8.90593e+02 8.90593e+02 8.90593e+01 1.00000e-09 7.00000e-02 5.00000e-04 5.00000e-04 5.00000e-05 1.00000e-09 1.00000e-01 5.00000e-04 5.00000e-04 5.00000e-05 1.00000e-09 1.00000e-01 $3.55845 \mathrm{e}+013.55845 \mathrm{e}+013.55845 \mathrm{e}+001.00000 \mathrm{e}-092.12000 \mathrm{e}-01$ $3.55845 \mathrm{e}+013.55845 \mathrm{e}+013.55845 \mathrm{e}+001.00000 \mathrm{e}-092.12000 \mathrm{e}-01$ $3.55845 \mathrm{e}+013.55845 \mathrm{e}+01$ 3.55845e+00 1.00000e-09 2.12000e-01 $3.55845 \mathrm{e}+013.55845 \mathrm{e}+013.55845 \mathrm{e}+001.00000 \mathrm{e}-092.12000 \mathrm{e}-01$ $1.00000 \mathrm{e}-02$ 1.00000e-02 1.00000e-03 1.00000e-09 1.00000e-01 
$1.00000 \mathrm{e}+001.00000 \mathrm{e}+001.00000 \mathrm{e}-011.00000 \mathrm{e}-091.00000 \mathrm{e}-01$ $1.00000 \mathrm{e}-05$ 1.00000e-05 1.00000e-06 1.00000e-09 1.00000e-01 $1.00000 \mathrm{e}+001.00000 \mathrm{e}+001.00000 \mathrm{e}-011.00000 \mathrm{e}-09$ 1.00000e-01 Element: 3187 \# of layers: 14

$\mathrm{Kx} \mathrm{Ky} \mathrm{Kz}$ Ss Por

7.86555e+02 7.86555e+02 7.86555e+01 1.00000e-09 7.00000e-02 $7.86555 \mathrm{e}+02$ 7.86555e+02 7.86555e+01 1.00000e-09 7.00000e-02 $7.86555 \mathrm{e}+02$ 7.86555e+02 7.86555e+01 1.00000e-09 7.00000e-02 5.00000e-04 5.00000e-04 5.00000e-05 1.00000e-09 1.00000e-01 5.00000e-04 5.00000e-04 5.00000e-05 1.00000e-09 1.00000e-01 $3.14287 \mathrm{e}+013.14287 \mathrm{e}+013.14287 \mathrm{e}+00$ 1.00000e-09 2.12000e-01 $3.14287 \mathrm{e}+013.14287 \mathrm{e}+01$ 3.14287e+00 1.00000e-09 2.12000e-01 $3.14287 \mathrm{e}+013.14287 \mathrm{e}+01$ 3.14287e+00 1.00000e-09 2.12000e-01 $3.14287 \mathrm{e}+013.14287 \mathrm{e}+013.14287 \mathrm{e}+00$ 1.00000e-09 2.12000e-01 $3.14287 \mathrm{e}+013.14287 \mathrm{e}+013.14287 \mathrm{e}+00$ 1.00000e-09 2.12000e-01 $1.00000 \mathrm{e}-01$ 1.00000e-01 1.00000e-02 1.00000e-09 1.00000e-01 $1.00000 \mathrm{e}+001.00000 \mathrm{e}+001.00000 \mathrm{e}-011.00000 \mathrm{e}-091.00000 \mathrm{e}-01$ $1.00000 \mathrm{e}-05$ 1.00000e-05 1.00000e-06 1.00000e-09 1.00000e-01 $1.00000 \mathrm{e}+001.00000 \mathrm{e}+001.00000 \mathrm{e}-011.00000 \mathrm{e}-091.00000 \mathrm{e}-01$ Element: 3188 \# of layers: 15

$\mathrm{Kx} \mathrm{Ky} \mathrm{Kz}$ Ss Por 6.61343e+02 6.61343e+02 6.61343e+01 1.00000e-09 7.00000e-02 6.61343e+02 6.61343e+02 6.61343e+01 1.00000e-09 7.00000e-02 6.61343e+02 6.61343e+02 6.61343e+01 1.00000e-09 7.00000e-02 6.61343e+02 6.61343e+02 6.61343e+01 1.00000e-09 7.00000e-02 5.00000e-04 5.00000e-04 5.00000e-05 1.00000e-09 1.00000e-01 5.00000e-04 5.00000e-04 5.00000e-05 1.00000e-09 1.00000e-01 $2.64246 \mathrm{e}+012.64246 \mathrm{e}+012.64246 \mathrm{e}+00$ 1.00000e-09 2.12000e-01 $2.64246 \mathrm{e}+012.64246 \mathrm{e}+012.64246 \mathrm{e}+001.00000 \mathrm{e}-092.12000 \mathrm{e}-01$ $2.64246 \mathrm{e}+012.64246 \mathrm{e}+012.64246 \mathrm{e}+001.00000 \mathrm{e}-092.12000 \mathrm{e}-01$ $2.64246 \mathrm{e}+012.64246 \mathrm{e}+012.64246 \mathrm{e}+00$ 1.00000e-09 2.12000e-01 $2.64246 \mathrm{e}+012.64246 \mathrm{e}+012.64246 \mathrm{e}+00$ 1.00000e-09 2.12000e-01 $1.00000 \mathrm{e}-02$ 1.00000e-02 1.00000e-03 1.00000e-09 1.00000e-01 $1.00000 \mathrm{e}+001.00000 \mathrm{e}+001.00000 \mathrm{e}-011.00000 \mathrm{e}-091.00000 \mathrm{e}-01$ $1.00000 \mathrm{e}-05$ 1.00000e-05 1.00000e-06 1.00000e-09 1.00000e-01 $1.00000 \mathrm{e}+001.00000 \mathrm{e}+001.00000 \mathrm{e}-011.00000 \mathrm{e}-091.00000 \mathrm{e}-01$ Element: 3189 \# of layers: 15

$\mathrm{Kx} \mathrm{Ky} \mathrm{Kz}$ Ss Por

5.30166e+02 5.30166e+02 5.30166e+01 1.00000e-09 7.00000e-02 $5.30166 \mathrm{e}+025.30166 \mathrm{e}+025.30166 \mathrm{e}+01$ 1.00000e-09 7.00000e-02 $5.30166 \mathrm{e}+02$ 5.30166e+02 5.30166e+01 1.00000e-09 7.00000e-02 5.30166e+02 5.30166e+02 5.30166e+01 1.00000e-09 7.00000e-02 $5.00000 \mathrm{e}-04$ 5.00000e-04 5.00000e-05 1.00000e-09 1.00000e-01 5.00000e-04 5.00000e-04 5.00000e-05 1.00000e-09 1.00000e-01 $2.11835 \mathrm{e}+012.11835 \mathrm{e}+012.11835 \mathrm{e}+00$ 1.00000e-09 2.12000e-01 $2.11835 \mathrm{e}+012.11835 \mathrm{e}+012.11835 \mathrm{e}+00$ 1.00000e-09 2.12000e-01 
$2.11835 \mathrm{e}+012.11835 \mathrm{e}+012.11835 \mathrm{e}+00$ 1.00000e-09 2.12000e-01 $2.11835 \mathrm{e}+012.11835 \mathrm{e}+012.11835 \mathrm{e}+00$ 1.00000e-09 2.12000e-01 $2.11835 \mathrm{e}+012.11835 \mathrm{e}+012.11835 \mathrm{e}+00$ 1.00000e-09 2.12000e-01 $1.00000 \mathrm{e}-02$ 1.00000e-02 1.00000e-03 1.00000e-09 1.00000e-01 $1.00000 \mathrm{e}+001.00000 \mathrm{e}+001.00000 \mathrm{e}-011.00000 \mathrm{e}-091.00000 \mathrm{e}-01$ $1.00000 \mathrm{e}-05$ 1.00000e-05 1.00000e-06 1.00000e-09 1.00000e-01 $1.00000 \mathrm{e}+001.00000 \mathrm{e}+001.00000 \mathrm{e}-011.00000 \mathrm{e}-091.00000 \mathrm{e}-01$ Element: 3190 \# of layers: 16

$\mathrm{Kx} \mathrm{Ky} \mathrm{Kz}$ Ss Por

5.30166e+02 5.30166e+02 5.30166e+01 1.00000e-09 7.00000e-02 $5.30166 \mathrm{e}+025.30166 \mathrm{e}+025.30166 \mathrm{e}+01$ 1.00000e-09 7.00000e-02 $5.30166 \mathrm{e}+02$ 5.30166e+02 5.30166e+01 1.00000e-09 7.00000e-02 5.30166e+02 5.30166e+02 5.30166e+01 1.00000e-09 7.00000e-02 $5.30166 \mathrm{e}+025.30166 \mathrm{e}+025.30166 \mathrm{e}+01$ 1.00000e-09 7.00000e-02 5.00000e-04 5.00000e-04 5.00000e-05 1.00000e-09 1.00000e-01 5.00000e-04 5.00000e-04 5.00000e-05 1.00000e-09 1.00000e-01

$2.11835 \mathrm{e}+012.11835 \mathrm{e}+012.11835 \mathrm{e}+001.00000 \mathrm{e}-092.12000 \mathrm{e}-01$ $2.11835 \mathrm{e}+012.11835 \mathrm{e}+012.11835 \mathrm{e}+00$ 1.00000e-09 2.12000e-01 $2.11835 \mathrm{e}+012.11835 \mathrm{e}+012.11835 \mathrm{e}+00$ 1.00000e-09 2.12000e-01 $2.11835 \mathrm{e}+012.11835 \mathrm{e}+012.11835 \mathrm{e}+00$ 1.00000e-09 2.12000e-01 $2.11835 \mathrm{e}+012.11835 \mathrm{e}+012.11835 \mathrm{e}+001.00000 \mathrm{e}-092.12000 \mathrm{e}-01$ $1.00000 \mathrm{e}-02$ 1.00000e-02 1.00000e-03 1.00000e-09 1.00000e-01 $1.00000 \mathrm{e}+001.00000 \mathrm{e}+001.00000 \mathrm{e}-011.00000 \mathrm{e}-091.00000 \mathrm{e}-01$ $1.00000 \mathrm{e}-05$ 1.00000e-05 1.00000e-06 1.00000e-09 1.00000e-01 $1.00000 \mathrm{e}+001.00000 \mathrm{e}+001.00000 \mathrm{e}-011.00000 \mathrm{e}-091.00000 \mathrm{e}-01$ Element: 3191 \# of layers: 16

$\mathrm{Kx} \mathrm{Ky} \mathrm{Kz}$ Ss Por

5.30166e+02 5.30166e+02 5.30166e+01 1.00000e-09 7.00000e-02 $5.30166 \mathrm{e}+02$ 5.30166e+02 5.30166e+01 1.00000e-09 7.00000e-02 5.30166e+02 5.30166e+02 5.30166e+01 1.00000e-09 7.00000e-02 $5.30166 \mathrm{e}+025.30166 \mathrm{e}+025.30166 \mathrm{e}+01$ 1.00000e-09 7.00000e-02 $5.30166 \mathrm{e}+025.30166 \mathrm{e}+025.30166 \mathrm{e}+01$ 1.00000e-09 7.00000e-02 5.00000e-04 5.00000e-04 5.00000e-05 1.00000e-09 1.00000e-01 5.00000e-04 5.00000e-04 5.00000e-05 1.00000e-09 1.00000e-01 $2.11835 \mathrm{e}+012.11835 \mathrm{e}+012.11835 \mathrm{e}+00$ 1.00000e-09 2.12000e-01 $2.11835 \mathrm{e}+012.11835 \mathrm{e}+012.11835 \mathrm{e}+00$ 1.00000e-09 2.12000e-01 $2.11835 \mathrm{e}+012.11835 \mathrm{e}+012.11835 \mathrm{e}+001.00000 \mathrm{e}-092.12000 \mathrm{e}-01$ $2.11835 \mathrm{e}+012.11835 \mathrm{e}+012.11835 \mathrm{e}+001.00000 \mathrm{e}-092.12000 \mathrm{e}-01$ $2.11835 \mathrm{e}+012.11835 \mathrm{e}+012.11835 \mathrm{e}+00$ 1.00000e-09 2.12000e-01 $1.00000 \mathrm{e}-02$ 1.00000e-02 1.00000e-03 1.00000e-09 1.00000e-01 $1.00000 \mathrm{e}+001.00000 \mathrm{e}+001.00000 \mathrm{e}-011.00000 \mathrm{e}-091.00000 \mathrm{e}-01$ $1.00000 \mathrm{e}-05$ 1.00000e-05 1.00000e-06 1.00000e-09 1.00000e-01 $1.00000 \mathrm{e}+001.00000 \mathrm{e}+001.00000 \mathrm{e}-011.00000 \mathrm{e}-091.00000 \mathrm{e}-01$ Element: 3192 \# of layers: 16

$\mathrm{Kx} \mathrm{Ky} \mathrm{Kz}$ Ss Por

5.78946e+02 5.78946e+02 5.78946e+01 1.00000e-09 7.00000e-02 
5.78946e+02 5.78946e+02 5.78946e+01 1.00000e-09 7.00000e-02 5.78946e+02 5.78946e+02 5.78946e+01 1.00000e-09 7.00000e-02 $5.78946 \mathrm{e}+02$ 5.78946e+02 5.78946e+01 1.00000e-09 7.00000e-02 $5.78946 \mathrm{e}+025.78946 \mathrm{e}+025.78946 \mathrm{e}+01$ 1.00000e-09 7.00000e-02 5.00000e-04 5.00000e-04 5.00000e-05 1.00000e-09 1.00000e-01 5.00000e-04 5.00000e-04 5.00000e-05 1.00000e-09 1.00000e-01 $2.31327 \mathrm{e}+012.31327 \mathrm{e}+012.31327 \mathrm{e}+00$ 1.00000e-09 2.12000e-01 $2.31327 \mathrm{e}+012.31327 \mathrm{e}+012.31327 \mathrm{e}+00$ 1.00000e-09 2.12000e-01 $2.31327 \mathrm{e}+012.31327 \mathrm{e}+01$ 2.31327e+00 1.00000e-09 2.12000e-01 $2.31327 \mathrm{e}+012.31327 \mathrm{e}+012.31327 \mathrm{e}+00$ 1.00000e-09 2.12000e-01 $2.31327 \mathrm{e}+012.31327 \mathrm{e}+012.31327 \mathrm{e}+00$ 1.00000e-09 2.12000e-01 $1.00000 \mathrm{e}-02$ 1.00000e-02 1.00000e-03 1.00000e-09 1.00000e-01 $1.00000 \mathrm{e}+001.00000 \mathrm{e}+001.00000 \mathrm{e}-011.00000 \mathrm{e}-091.00000 \mathrm{e}-01$ $1.00000 \mathrm{e}-05$ 1.00000e-05 1.00000e-06 1.00000e-09 1.00000e-01 $1.00000 \mathrm{e}+001.00000 \mathrm{e}+001.00000 \mathrm{e}-01$ 1.00000e-09 1.00000e-01 Element: 3193 \# of layers: 15

$\mathrm{Kx} \mathrm{Ky} \mathrm{Kz}$ Ss Por

5.78946e+02 5.78946e+02 5.78946e+01 1.00000e-09 7.00000e-02 $5.78946 \mathrm{e}+02$ 5.78946e+02 5.78946e+01 1.00000e-09 7.00000e-02 $5.78946 \mathrm{e}+025.78946 \mathrm{e}+025.78946 \mathrm{e}+01$ 1.00000e-09 7.00000e-02 $5.78946 \mathrm{e}+025.78946 \mathrm{e}+025.78946 \mathrm{e}+01$ 1.00000e-09 7.00000e-02 $5.00000 \mathrm{e}-04$ 5.00000e-04 5.00000e-05 1.00000e-09 1.00000e-01 5.00000e-04 5.00000e-04 5.00000e-05 1.00000e-09 1.00000e-01 $2.31327 \mathrm{e}+012.31327 \mathrm{e}+012.31327 \mathrm{e}+00$ 1.00000e-09 2.12000e-01 $2.31327 \mathrm{e}+012.31327 \mathrm{e}+012.31327 \mathrm{e}+00$ 1.00000e-09 2.12000e-01 $2.31327 \mathrm{e}+012.31327 \mathrm{e}+012.31327 \mathrm{e}+00$ 1.00000e-09 2.12000e-01 $2.31327 \mathrm{e}+012.31327 \mathrm{e}+012.31327 \mathrm{e}+00$ 1.00000e-09 2.12000e-01 $2.31327 \mathrm{e}+012.31327 \mathrm{e}+012.31327 \mathrm{e}+00$ 1.00000e-09 2.12000e-01 $1.00000 \mathrm{e}-02$ 1.00000e-02 1.00000e-03 1.00000e-09 1.00000e-01 $1.00000 \mathrm{e}+001.00000 \mathrm{e}+001.00000 \mathrm{e}-011.00000 \mathrm{e}-091.00000 \mathrm{e}-01$ $1.00000 \mathrm{e}-05$ 1.00000e-05 1.00000e-06 1.00000e-09 1.00000e-01 $1.00000 \mathrm{e}+001.00000 \mathrm{e}+001.00000 \mathrm{e}-011.00000 \mathrm{e}-091.00000 \mathrm{e}-01$ Element: 3194 \# of layers: 15

$\mathrm{Kx} \mathrm{Ky} \mathrm{Kz}$ Ss Por

1.38168e+03 1.38168e+03 1.38168e+02 1.00000e-09 7.00000e-02 $1.38168 \mathrm{e}+031.38168 \mathrm{e}+03$ 1.38168e+02 1.00000e-09 7.00000e-02 $1.38168 \mathrm{e}+031.38168 \mathrm{e}+03$ 1.38168e+02 1.00000e-09 7.00000e-02 $1.38168 \mathrm{e}+031.38168 \mathrm{e}+03$ 1.38168e+02 1.00000e-09 7.00000e-02 5.00000e-04 5.00000e-04 5.00000e-05 1.00000e-09 1.00000e-01 5.00000e-04 5.00000e-04 5.00000e-05 1.00000e-09 1.00000e-01 $5.52072 \mathrm{e}+015.52072 \mathrm{e}+015.52072 \mathrm{e}+001.00000 \mathrm{e}-092.12000 \mathrm{e}-01$ $5.52072 \mathrm{e}+015.52072 \mathrm{e}+015.52072 \mathrm{e}+001.00000 \mathrm{e}-092.12000 \mathrm{e}-01$ $5.52072 \mathrm{e}+015.52072 \mathrm{e}+015.52072 \mathrm{e}+001.00000 \mathrm{e}-092.12000 \mathrm{e}-01$ 5.52072e+01 5.52072e+01 5.52072e+00 1.00000e-09 2.12000e-01 $5.52072 \mathrm{e}+015.52072 \mathrm{e}+015.52072 \mathrm{e}+001.00000 \mathrm{e}-092.12000 \mathrm{e}-01$ $1.00000 \mathrm{e}-01$ 1.00000e-01 1.00000e-02 1.00000e-09 1.00000e-01 
$1.00000 \mathrm{e}+001.00000 \mathrm{e}+001.00000 \mathrm{e}-011.00000 \mathrm{e}-091.00000 \mathrm{e}-01$ $1.00000 \mathrm{e}-05$ 1.00000e-05 1.00000e-06 1.00000e-09 1.00000e-01 $1.00000 \mathrm{e}+001.00000 \mathrm{e}+001.00000 \mathrm{e}-01$ 1.00000e-09 1.00000e-01 Element: 3195 \# of layers: 15

$\mathrm{Kx} \mathrm{Ky} \mathrm{Kz}$ Ss Por

6.61343e+02 6.61343e+02 6.61343e+01 1.00000e-09 7.00000e-02 $6.61343 \mathrm{e}+026.61343 \mathrm{e}+02$ 6.61343e+01 1.00000e-09 7.00000e-02 $6.61343 \mathrm{e}+02$ 6.61343e+02 6.61343e+01 1.00000e-09 7.00000e-02 $6.61343 \mathrm{e}+026.61343 \mathrm{e}+026.61343 \mathrm{e}+01$ 1.00000e-09 7.00000e-02 5.00000e-04 5.00000e-04 5.00000e-05 1.00000e-09 1.00000e-01 5.00000e-04 5.00000e-04 5.00000e-05 1.00000e-09 1.00000e-01 $2.64246 \mathrm{e}+012.64246 \mathrm{e}+012.64246 \mathrm{e}+001.00000 \mathrm{e}-092.12000 \mathrm{e}-01$ $2.64246 \mathrm{e}+012.64246 \mathrm{e}+012.64246 \mathrm{e}+001.00000 \mathrm{e}-092.12000 \mathrm{e}-01$ $2.64246 \mathrm{e}+012.64246 \mathrm{e}+012.64246 \mathrm{e}+00$ 1.00000e-09 2.12000e-01 $2.64246 \mathrm{e}+012.64246 \mathrm{e}+012.64246 \mathrm{e}+001.00000 \mathrm{e}-092.12000 \mathrm{e}-01$ $2.64246 \mathrm{e}+012.64246 \mathrm{e}+012.64246 \mathrm{e}+001.00000 \mathrm{e}-092.12000 \mathrm{e}-01$ $1.00000 \mathrm{e}-02$ 1.00000e-02 1.00000e-03 1.00000e-09 1.00000e-01 $1.00000 \mathrm{e}+001.00000 \mathrm{e}+001.00000 \mathrm{e}-011.00000 \mathrm{e}-091.00000 \mathrm{e}-01$ $1.00000 \mathrm{e}-051.00000 \mathrm{e}-05$ 1.00000e-06 1.00000e-09 1.00000e-01 $1.00000 \mathrm{e}+001.00000 \mathrm{e}+001.00000 \mathrm{e}-011.00000 \mathrm{e}-091.00000 \mathrm{e}-01$ Element: 3196 \# of layers: 15

$\mathrm{Kx} \mathrm{Ky} \mathrm{Kz}$ Ss Por

5.30166e+02 5.30166e+02 5.30166e+01 1.00000e-09 7.00000e-02 $5.30166 \mathrm{e}+025.30166 \mathrm{e}+025.30166 \mathrm{e}+01$ 1.00000e-09 7.00000e-02 $5.30166 \mathrm{e}+02$ 5.30166e+02 5.30166e+01 1.00000e-09 7.00000e-02 $5.30166 \mathrm{e}+025.30166 \mathrm{e}+025.30166 \mathrm{e}+01$ 1.00000e-09 7.00000e-02 5.00000e-04 5.00000e-04 5.00000e-05 1.00000e-09 1.00000e-01 5.00000e-04 5.00000e-04 5.00000e-05 1.00000e-09 1.00000e-01

$2.11835 \mathrm{e}+012.11835 \mathrm{e}+012.11835 \mathrm{e}+001.00000 \mathrm{e}-092.12000 \mathrm{e}-01$ $2.11835 \mathrm{e}+012.11835 \mathrm{e}+012.11835 \mathrm{e}+00$ 1.00000e-09 2.12000e-01 $2.11835 \mathrm{e}+012.11835 \mathrm{e}+012.11835 \mathrm{e}+00$ 1.00000e-09 2.12000e-01 $2.11835 \mathrm{e}+012.11835 \mathrm{e}+012.11835 \mathrm{e}+00$ 1.00000e-09 2.12000e-01 $2.11835 \mathrm{e}+012.11835 \mathrm{e}+012.11835 \mathrm{e}+00$ 1.00000e-09 2.12000e-01 $1.00000 \mathrm{e}-02$ 1.00000e-02 1.00000e-03 1.00000e-09 1.00000e-01 $1.00000 \mathrm{e}+001.00000 \mathrm{e}+001.00000 \mathrm{e}-011.00000 \mathrm{e}-091.00000 \mathrm{e}-01$ $1.00000 \mathrm{e}-05$ 1.00000e-05 1.00000e-06 1.00000e-09 1.00000e-01 $1.00000 \mathrm{e}+001.00000 \mathrm{e}+001.00000 \mathrm{e}-011.00000 \mathrm{e}-091.00000 \mathrm{e}-01$ Element: 3197 \# of layers: 16

$\mathrm{Kx} \mathrm{Ky} \mathrm{Kz}$ Ss Por 3.94683e+02 3.94683e+02 3.94683e+01 1.00000e-09 7.00000e-02 $3.94683 e+02$ 3.94683e+02 3.94683e+01 1.00000e-09 7.00000e-02 $3.94683 \mathrm{e}+02$ 3.94683e+02 3.94683e+01 1.00000e-09 7.00000e-02 $3.94683 \mathrm{e}+02$ 3.94683e+02 3.94683e+01 1.00000e-09 7.00000e-02 3.94683e+02 3.94683e+02 3.94683e+01 1.00000e-09 7.00000e-02 5.00000e-04 5.00000e-04 5.00000e-05 1.00000e-09 1.00000e-01 5.00000e-04 5.00000e-04 5.00000e-05 1.00000e-09 1.00000e-01 
$1.57701 \mathrm{e}+011.57701 \mathrm{e}+011.57701 \mathrm{e}+001.00000 \mathrm{e}-092.12000 \mathrm{e}-01$ $1.57701 \mathrm{e}+011.57701 \mathrm{e}+011.57701 \mathrm{e}+001.00000 \mathrm{e}-092.12000 \mathrm{e}-01$ $1.57701 \mathrm{e}+011.57701 \mathrm{e}+011.57701 \mathrm{e}+001.00000 \mathrm{e}-092.12000 \mathrm{e}-01$ $1.57701 \mathrm{e}+011.57701 \mathrm{e}+011.57701 \mathrm{e}+001.00000 \mathrm{e}-092.12000 \mathrm{e}-01$ $1.57701 \mathrm{e}+011.57701 \mathrm{e}+011.57701 \mathrm{e}+001.00000 \mathrm{e}-092.12000 \mathrm{e}-01$ $1.00000 \mathrm{e}-02$ 1.00000e-02 1.00000e-03 1.00000e-09 1.00000e-01 $1.00000 \mathrm{e}+001.00000 \mathrm{e}+001.00000 \mathrm{e}-011.00000 \mathrm{e}-091.00000 \mathrm{e}-01$ $1.00000 \mathrm{e}-05$ 1.00000e-05 1.00000e-06 1.00000e-09 1.00000e-01 $1.00000 \mathrm{e}+001.00000 \mathrm{e}+001.00000 \mathrm{e}-011.00000 \mathrm{e}-091.00000 \mathrm{e}-01$ Element: 3198 \# of layers: 16

$\mathrm{Kx} \mathrm{Ky} \mathrm{Kz}$ Ss Por

$3.79474 \mathrm{e}+02$ 3.79474e+02 3.79474e+01 1.00000e-09 7.00000e-02 $3.79474 \mathrm{e}+02$ 3.79474e+02 3.79474e+01 1.00000e-09 7.00000e-02 $3.79474 \mathrm{e}+023.79474 \mathrm{e}+02$ 3.79474e+01 1.00000e-09 7.00000e-02 $3.79474 \mathrm{e}+02$ 3.79474e+02 3.79474e+01 1.00000e-09 7.00000e-02 $3.79474 \mathrm{e}+023.79474 \mathrm{e}+023.79474 \mathrm{e}+01$ 1.00000e-09 7.00000e-02 5.00000e-04 5.00000e-04 5.00000e-05 1.00000e-09 1.00000e-01 5.00000e-04 5.00000e-04 5.00000e-05 1.00000e-09 1.00000e-01 $1.51624 \mathrm{e}+011.51624 \mathrm{e}+011.51624 \mathrm{e}+001.00000 \mathrm{e}-092.12000 \mathrm{e}-01$ $1.51624 \mathrm{e}+011.51624 \mathrm{e}+011.51624 \mathrm{e}+001.00000 \mathrm{e}-092.12000 \mathrm{e}-01$ $1.51624 \mathrm{e}+011.51624 \mathrm{e}+011.51624 \mathrm{e}+001.00000 \mathrm{e}-092.12000 \mathrm{e}-01$ $1.51624 \mathrm{e}+011.51624 \mathrm{e}+011.51624 \mathrm{e}+001.00000 \mathrm{e}-092.12000 \mathrm{e}-01$ $1.51624 \mathrm{e}+011.51624 \mathrm{e}+011.51624 \mathrm{e}+001.00000 \mathrm{e}-092.12000 \mathrm{e}-01$ $1.00000 \mathrm{e}-02$ 1.00000e-02 1.00000e-03 1.00000e-09 1.00000e-01 $1.00000 \mathrm{e}+001.00000 \mathrm{e}+001.00000 \mathrm{e}-011.00000 \mathrm{e}-091.00000 \mathrm{e}-01$ $1.00000 \mathrm{e}-05$ 1.00000e-05 1.00000e-06 1.00000e-09 1.00000e-01 $1.00000 \mathrm{e}+001.00000 \mathrm{e}+001.00000 \mathrm{e}-01$ 1.00000e-09 1.00000e-01 Element: 3199 \# of layers: 16

$\mathrm{Kx} \mathrm{Ky} \mathrm{Kz}$ Ss Por

3.79474e+02 3.79474e+02 3.79474e+01 1.00000e-09 7.00000e-02 $3.79474 \mathrm{e}+023.79474 \mathrm{e}+023.79474 \mathrm{e}+01$ 1.00000e-09 7.00000e-02 $3.79474 \mathrm{e}+023.79474 \mathrm{e}+023.79474 \mathrm{e}+01$ 1.00000e-09 7.00000e-02 $3.79474 \mathrm{e}+023.79474 \mathrm{e}+023.79474 \mathrm{e}+01$ 1.00000e-09 7.00000e-02 $3.79474 \mathrm{e}+023.79474 \mathrm{e}+023.79474 \mathrm{e}+01$ 1.00000e-09 7.00000e-02 5.00000e-04 5.00000e-04 5.00000e-05 1.00000e-09 1.00000e-01 5.00000e-04 5.00000e-04 5.00000e-05 1.00000e-09 1.00000e-01 $1.51624 \mathrm{e}+011.51624 \mathrm{e}+011.51624 \mathrm{e}+001.00000 \mathrm{e}-092.12000 \mathrm{e}-01$ $1.51624 \mathrm{e}+011.51624 \mathrm{e}+011.51624 \mathrm{e}+001.00000 \mathrm{e}-092.12000 \mathrm{e}-01$ $1.51624 \mathrm{e}+011.51624 \mathrm{e}+011.51624 \mathrm{e}+001.00000 \mathrm{e}-092.12000 \mathrm{e}-01$ $1.51624 \mathrm{e}+011.51624 \mathrm{e}+011.51624 \mathrm{e}+001.00000 \mathrm{e}-092.12000 \mathrm{e}-01$ $1.51624 \mathrm{e}+011.51624 \mathrm{e}+01 \quad 1.51624 \mathrm{e}+001.00000 \mathrm{e}-092.12000 \mathrm{e}-01$ $1.00000 \mathrm{e}-02$ 1.00000e-02 1.00000e-03 1.00000e-09 1.00000e-01 $1.00000 \mathrm{e}+001.00000 \mathrm{e}+001.00000 \mathrm{e}-011.00000 \mathrm{e}-091.00000 \mathrm{e}-01$ $1.00000 \mathrm{e}-05$ 1.00000e-05 1.00000e-06 1.00000e-09 1.00000e-01 $1.00000 \mathrm{e}+001.00000 \mathrm{e}+001.00000 \mathrm{e}-011.00000 \mathrm{e}-09$ 1.00000e-01 Element: 3200 \# of layers: 16 
$\mathrm{Kx} \mathrm{Ky} \mathrm{Kz}$ Ss Por

3.79474e+02 3.79474e+02 3.79474e+01 1.00000e-09 7.00000e-02

$3.79474 \mathrm{e}+023.79474 \mathrm{e}+02$ 3.79474e+01 1.00000e-09 7.00000e-02

$3.79474 \mathrm{e}+02$ 3.79474e+02 3.79474e+01 1.00000e-09 7.00000e-02

$3.79474 \mathrm{e}+023.79474 \mathrm{e}+023.79474 \mathrm{e}+01$ 1.00000e-09 7.00000e-02

$3.79474 \mathrm{e}+023.79474 \mathrm{e}+023.79474 \mathrm{e}+01$ 1.00000e-09 7.00000e-02

5.00000e-04 5.00000e-04 5.00000e-05 1.00000e-09 1.00000e-01

5.00000e-04 5.00000e-04 5.00000e-05 1.00000e-09 1.00000e-01

$1.51624 \mathrm{e}+011.51624 \mathrm{e}+011.51624 \mathrm{e}+001.00000 \mathrm{e}-092.12000 \mathrm{e}-01$

$1.51624 \mathrm{e}+011.51624 \mathrm{e}+011.51624 \mathrm{e}+001.00000 \mathrm{e}-092.12000 \mathrm{e}-01$

$1.51624 \mathrm{e}+011.51624 \mathrm{e}+011.51624 \mathrm{e}+001.00000 \mathrm{e}-092.12000 \mathrm{e}-01$

$1.51624 \mathrm{e}+011.51624 \mathrm{e}+011.51624 \mathrm{e}+001.00000 \mathrm{e}-092.12000 \mathrm{e}-01$

$1.51624 \mathrm{e}+011.51624 \mathrm{e}+011.51624 \mathrm{e}+001.00000 \mathrm{e}-092.12000 \mathrm{e}-01$

$1.00000 \mathrm{e}-02$ 1.00000e-02 1.00000e-03 1.00000e-09 1.00000e-01

$1.00000 \mathrm{e}+001.00000 \mathrm{e}+001.00000 \mathrm{e}-011.00000 \mathrm{e}-091.00000 \mathrm{e}-01$

$1.00000 \mathrm{e}-05$ 1.00000e-05 1.00000e-06 1.00000e-09 1.00000e-01

$1.00000 \mathrm{e}+001.00000 \mathrm{e}+001.00000 \mathrm{e}-01$ 1.00000e-09 1.00000e-01

Element: 3201 \# of layers: 16

$\mathrm{Kx} \mathrm{Ky} \mathrm{Kz}$ Ss Por

3.92332e+02 3.92332e+02 3.92332e+01 1.00000e-09 7.00000e-02

$3.92332 \mathrm{e}+02$ 3.92332e+02 3.92332e+01 1.00000e-09 7.00000e-02

3.92332e+02 3.92332e+02 3.92332e+01 1.00000e-09 7.00000e-02

3.92332e+02 3.92332e+02 3.92332e+01 1.00000e-09 7.00000e-02

3.92332e+02 3.92332e+02 3.92332e+01 1.00000e-09 7.00000e-02

5.00000e-04 5.00000e-04 5.00000e-05 1.00000e-09 1.00000e-01

5.00000e-04 5.00000e-04 5.00000e-05 1.00000e-09 1.00000e-01

$1.56763 \mathrm{e}+011.56763 \mathrm{e}+011.56763 \mathrm{e}+001.00000 \mathrm{e}-09$ 2.12000e-01

$1.56763 \mathrm{e}+01$ 1.56763e+01 1.56763e+00 1.00000e-09 2.12000e-01

$1.56763 \mathrm{e}+011.56763 \mathrm{e}+011.56763 \mathrm{e}+001.00000 \mathrm{e}-092.12000 \mathrm{e}-01$

$1.56763 \mathrm{e}+01$ 1.56763e+01 1.56763e+00 1.00000e-09 2.12000e-01

$1.56763 \mathrm{e}+011.56763 \mathrm{e}+011.56763 \mathrm{e}+001.00000 \mathrm{e}-092.12000 \mathrm{e}-01$

$1.00000 \mathrm{e}-02$ 1.00000e-02 1.00000e-03 1.00000e-09 1.00000e-01

$1.00000 \mathrm{e}+001.00000 \mathrm{e}+001.00000 \mathrm{e}-011.00000 \mathrm{e}-091.00000 \mathrm{e}-01$

$1.00000 \mathrm{e}-05$ 1.00000e-05 1.00000e-06 1.00000e-09 1.00000e-01

$1.00000 \mathrm{e}+001.00000 \mathrm{e}+001.00000 \mathrm{e}-011.00000 \mathrm{e}-091.00000 \mathrm{e}-01$

Element: 3202 \# of layers: 16

Kx Ky Kz Ss Por

3.92332e+02 3.92332e+02 3.92332e+01 1.00000e-09 7.00000e-02

3.92332e+02 3.92332e+02 3.92332e+01 1.00000e-09 7.00000e-02

3.92332e+02 3.92332e+02 3.92332e+01 1.00000e-09 7.00000e-02

3.92332e+02 3.92332e+02 3.92332e+01 1.00000e-09 7.00000e-02

3.92332e+02 3.92332e+02 3.92332e+01 1.00000e-09 7.00000e-02

5.00000e-04 5.00000e-04 5.00000e-05 1.00000e-09 1.00000e-01

5.00000e-04 5.00000e-04 5.00000e-05 1.00000e-09 1.00000e-01

$1.56763 \mathrm{e}+01$ 1.56763e+01 1.56763e+00 1.00000e-09 2.12000e-01

$1.56763 e+011.56763 e+011.56763 e+001.00000 e-092.12000 e-01$ 
$1.56763 \mathrm{e}+01$ 1.56763e+01 1.56763e+00 1.00000e-09 2.12000e-01 $1.56763 \mathrm{e}+01$ 1.56763e+01 1.56763e+00 1.00000e-09 2.12000e-01 $1.56763 \mathrm{e}+011.56763 \mathrm{e}+01$ 1.56763e+00 1.00000e-09 2.12000e-01 $1.00000 \mathrm{e}-02$ 1.00000e-02 1.00000e-03 1.00000e-09 1.00000e-01 $1.00000 \mathrm{e}+001.00000 \mathrm{e}+001.00000 \mathrm{e}-011.00000 \mathrm{e}-091.00000 \mathrm{e}-01$ $1.00000 \mathrm{e}-05$ 1.00000e-05 1.00000e-06 1.00000e-09 1.00000e-01 $1.00000 \mathrm{e}+001.00000 \mathrm{e}+001.00000 \mathrm{e}-01$ 1.00000e-09 1.00000e-01 Element: 3203 \# of layers: 16

$\mathrm{Kx} \mathrm{Ky} \mathrm{Kz}$ Ss Por

4.36976e+02 4.36976e+02 4.36976e+01 1.00000e-09 7.00000e-02 4.36976e+02 4.36976e+02 4.36976e+01 1.00000e-09 7.00000e-02 4.36976e+02 4.36976e+02 4.36976e+01 1.00000e-09 7.00000e-02 4.36976e+02 4.36976e+02 4.36976e+01 1.00000e-09 7.00000e-02

4.36976e+02 4.36976e+02 4.36976e+01 1.00000e-09 7.00000e-02 5.00000e-04 5.00000e-04 5.00000e-05 1.00000e-09 1.00000e-01 5.00000e-04 5.00000e-04 5.00000e-05 1.00000e-09 1.00000e-01 $1.74601 \mathrm{e}+011.74601 \mathrm{e}+011.74602 \mathrm{e}+001.00000 \mathrm{e}-092.12000 \mathrm{e}-01$ $1.74601 \mathrm{e}+011.74601 \mathrm{e}+01$ 1.74602e+00 1.00000e-09 2.12000e-01 $1.74601 \mathrm{e}+01$ 1.74601e+01 1.74602e+00 1.00000e-09 2.12000e-01 $1.74601 \mathrm{e}+011.74601 \mathrm{e}+011.74602 \mathrm{e}+001.00000 \mathrm{e}-092.12000 \mathrm{e}-01$ $1.74601 \mathrm{e}+011.74601 \mathrm{e}+011.74602 \mathrm{e}+001.00000 \mathrm{e}-092.12000 \mathrm{e}-01$ $1.00000 \mathrm{e}-02$ 1.00000e-02 1.00000e-03 1.00000e-09 1.00000e-01 $1.00000 \mathrm{e}+001.00000 \mathrm{e}+001.00000 \mathrm{e}-011.00000 \mathrm{e}-091.00000 \mathrm{e}-01$ $1.00000 \mathrm{e}-051.00000 \mathrm{e}-05$ 1.00000e-06 1.00000e-09 1.00000e-01 $1.00000 \mathrm{e}+001.00000 \mathrm{e}+001.00000 \mathrm{e}-011.00000 \mathrm{e}-091.00000 \mathrm{e}-01$ Element: 3204 \# of layers: 16

$\mathrm{Kx} \mathrm{Ky} \mathrm{Kz}$ Ss Por

3.94683e+02 3.94683e+02 3.94683e+01 1.00000e-09 7.00000e-02 $3.94683 \mathrm{e}+02$ 3.94683e+02 3.94683e+01 1.00000e-09 7.00000e-02 $3.94683 \mathrm{e}+02$ 3.94683e+02 3.94683e+01 1.00000e-09 7.00000e-02 $3.94683 \mathrm{e}+02$ 3.94683e+02 3.94683e+01 1.00000e-09 7.00000e-02 $3.94683 \mathrm{e}+02$ 3.94683e+02 3.94683e+01 1.00000e-09 7.00000e-02 5.00000e-04 5.00000e-04 5.00000e-05 1.00000e-09 1.00000e-01 5.00000e-04 5.00000e-04 5.00000e-05 1.00000e-09 1.00000e-01 $1.57701 \mathrm{e}+011.57701 \mathrm{e}+011.57701 \mathrm{e}+001.00000 \mathrm{e}-092.12000 \mathrm{e}-01$ $1.57701 \mathrm{e}+011.57701 \mathrm{e}+011.57701 \mathrm{e}+001.00000 \mathrm{e}-092.12000 \mathrm{e}-01$ $1.57701 \mathrm{e}+011.57701 \mathrm{e}+011.57701 \mathrm{e}+001.00000 \mathrm{e}-092.12000 \mathrm{e}-01$ $1.57701 \mathrm{e}+011.57701 \mathrm{e}+011.57701 \mathrm{e}+001.00000 \mathrm{e}-092.12000 \mathrm{e}-01$ $1.57701 \mathrm{e}+011.57701 \mathrm{e}+011.57701 \mathrm{e}+001.00000 \mathrm{e}-092.12000 \mathrm{e}-01$ $1.00000 \mathrm{e}-02$ 1.00000e-02 1.00000e-03 1.00000e-09 1.00000e-01 $1.00000 \mathrm{e}+001.00000 \mathrm{e}+001.00000 \mathrm{e}-011.00000 \mathrm{e}-091.00000 \mathrm{e}-01$ $1.00000 \mathrm{e}-05$ 1.00000e-05 1.00000e-06 1.00000e-09 1.00000e-01 $1.00000 \mathrm{e}+001.00000 \mathrm{e}+001.00000 \mathrm{e}-011.00000 \mathrm{e}-091.00000 \mathrm{e}-01$ Element: 3205 \# of layers: 16

$\mathrm{Kx} \mathrm{Ky} \mathrm{Kz}$ Ss Por

3.79474e+02 3.79474e+02 3.79474e+01 1.00000e-09 7.00000e-02 
3.79474e+02 3.79474e+02 3.79474e+01 1.00000e-09 7.00000e-02 $3.79474 \mathrm{e}+023.79474 \mathrm{e}+023.79474 \mathrm{e}+01$ 1.00000e-09 7.00000e-02 $3.79474 \mathrm{e}+023.79474 \mathrm{e}+02$ 3.79474e+01 1.00000e-09 7.00000e-02 $3.79474 \mathrm{e}+02$ 3.79474e+02 3.79474e+01 1.00000e-09 7.00000e-02 5.00000e-04 5.00000e-04 5.00000e-05 1.00000e-09 1.00000e-01 5.00000e-04 5.00000e-04 5.00000e-05 1.00000e-09 1.00000e-01 $1.51624 \mathrm{e}+011.51624 \mathrm{e}+011.51624 \mathrm{e}+001.00000 \mathrm{e}-092.12000 \mathrm{e}-01$ $1.51624 \mathrm{e}+011.51624 \mathrm{e}+011.51624 \mathrm{e}+001.00000 \mathrm{e}-092.12000 \mathrm{e}-01$ $1.51624 \mathrm{e}+011.51624 \mathrm{e}+011.51624 \mathrm{e}+001.00000 \mathrm{e}-092.12000 \mathrm{e}-01$ $1.51624 \mathrm{e}+011.51624 \mathrm{e}+011.51624 \mathrm{e}+001.00000 \mathrm{e}-092.12000 \mathrm{e}-01$ $1.51624 \mathrm{e}+011.51624 \mathrm{e}+011.51624 \mathrm{e}+001.00000 \mathrm{e}-092.12000 \mathrm{e}-01$ $1.00000 \mathrm{e}-02$ 1.00000e-02 1.00000e-03 1.00000e-09 1.00000e-01 $1.00000 \mathrm{e}+001.00000 \mathrm{e}+001.00000 \mathrm{e}-011.00000 \mathrm{e}-091.00000 \mathrm{e}-01$ $1.00000 \mathrm{e}-05$ 1.00000e-05 1.00000e-06 1.00000e-09 1.00000e-01 $1.00000 \mathrm{e}+001.00000 \mathrm{e}+001.00000 \mathrm{e}-01$ 1.00000e-09 1.00000e-01 Element: 3206 \# of layers: 16

$\mathrm{Kx} \mathrm{Ky} \mathrm{Kz}$ Ss Por

4.28597e+02 4.28597e+02 4.28597e+01 1.00000e-09 7.00000e-02 4.28597e+02 4.28597e+02 4.28597e+01 1.00000e-09 7.00000e-02 4.28597e+02 4.28597e+02 4.28597e+01 1.00000e-09 7.00000e-02 4.28597e+02 4.28597e+02 4.28597e+01 1.00000e-09 7.00000e-02 4.28597e+02 4.28597e+02 4.28597e+01 1.00000e-09 7.00000e-02 5.00000e-04 5.00000e-04 5.00000e-05 1.00000e-09 1.00000e-01 5.00000e-04 5.00000e-04 5.00000e-05 1.00000e-09 1.00000e-01

$1.71253 \mathrm{e}+011.71253 \mathrm{e}+011.71253 \mathrm{e}+001.00000 \mathrm{e}-092.12000 \mathrm{e}-01$ $1.71253 \mathrm{e}+01$ 1.71253e+01 1.71253e+00 1.00000e-09 2.12000e-01 $1.71253 \mathrm{e}+01$ 1.71253e+01 1.71253e+00 1.00000e-09 2.12000e-01 $1.71253 \mathrm{e}+011.71253 \mathrm{e}+01$ 1.71253e+00 1.00000e-09 2.12000e-01 $1.71253 \mathrm{e}+011.71253 \mathrm{e}+011.71253 \mathrm{e}+001.00000 \mathrm{e}-092.12000 \mathrm{e}-01$ $1.00000 \mathrm{e}-02$ 1.00000e-02 1.00000e-03 1.00000e-09 1.00000e-01 $1.00000 \mathrm{e}+001.00000 \mathrm{e}+001.00000 \mathrm{e}-01$ 1.00000e-09 1.00000e-01 $1.00000 \mathrm{e}-05$ 1.00000e-05 1.00000e-06 1.00000e-09 1.00000e-01 $1.00000 \mathrm{e}+001.00000 \mathrm{e}+001.00000 \mathrm{e}-011.00000 \mathrm{e}-091.00000 \mathrm{e}-01$ Element: 3207 \# of layers: 15

$\mathrm{Kx} \mathrm{Ky} \mathrm{Kz}$ Ss Por

4.58050e+02 4.58050e+02 4.58050e+01 1.00000e-09 7.00000e-02 $4.58050 \mathrm{e}+02$ 4.58050e+02 4.58050e+01 1.00000e-09 7.00000e-02 $4.58050 \mathrm{e}+02$ 4.58050e+02 4.58050e+01 1.00000e-09 7.00000e-02 $4.58050 \mathrm{e}+02$ 4.58050e+02 4.58050e+01 1.00000e-09 7.00000e-02 5.00000e-04 5.00000e-04 5.00000e-05 1.00000e-09 1.00000e-01 5.00000e-04 5.00000e-04 5.00000e-05 1.00000e-09 1.00000e-01 $1.83021 \mathrm{e}+011.83021 \mathrm{e}+011.83021 \mathrm{e}+001.00000 \mathrm{e}-092.12000 \mathrm{e}-01$ $1.83021 \mathrm{e}+011.83021 \mathrm{e}+011.83021 \mathrm{e}+001.00000 \mathrm{e}-092.12000 \mathrm{e}-01$ $1.83021 \mathrm{e}+011.83021 \mathrm{e}+01$ 1.83021e+00 1.00000e-09 2.12000e-01 $1.83021 \mathrm{e}+011.83021 \mathrm{e}+011.83021 \mathrm{e}+001.00000 \mathrm{e}-092.12000 \mathrm{e}-01$ $1.83021 \mathrm{e}+011.83021 \mathrm{e}+011.83021 \mathrm{e}+001.00000 \mathrm{e}-092.12000 \mathrm{e}-01$ 
$1.00000 \mathrm{e}-02$ 1.00000e-02 1.00000e-03 1.00000e-09 1.00000e-01 $1.00000 \mathrm{e}+001.00000 \mathrm{e}+001.00000 \mathrm{e}-011.00000 \mathrm{e}-091.00000 \mathrm{e}-01$ $1.00000 \mathrm{e}-051.00000 \mathrm{e}-05$ 1.00000e-06 1.00000e-09 1.00000e-01 $1.00000 \mathrm{e}+001.00000 \mathrm{e}+001.00000 \mathrm{e}-011.00000 \mathrm{e}-091.00000 \mathrm{e}-01$ Element: 3208 \# of layers: 15

Kx Ky Kz Ss Por

$4.58050 \mathrm{e}+024.58050 \mathrm{e}+024.58050 \mathrm{e}+01$ 1.00000e-09 7.00000e-02 $4.58050 \mathrm{e}+024.58050 \mathrm{e}+024.58050 \mathrm{e}+01$ 1.00000e-09 7.00000e-02 $4.58050 \mathrm{e}+024.58050 \mathrm{e}+024.58050 \mathrm{e}+011.00000 \mathrm{e}-097.00000 \mathrm{e}-02$ $4.58050 \mathrm{e}+024.58050 \mathrm{e}+024.58050 \mathrm{e}+011.00000 \mathrm{e}-097.00000 \mathrm{e}-02$ 5.00000e-04 5.00000e-04 5.00000e-05 1.00000e-09 1.00000e-01 5.00000e-04 5.00000e-04 5.00000e-05 1.00000e-09 1.00000e-01 $1.83021 \mathrm{e}+011.83021 \mathrm{e}+011.83021 \mathrm{e}+001.00000 \mathrm{e}-092.12000 \mathrm{e}-01$ $1.83021 \mathrm{e}+011.83021 \mathrm{e}+011.83021 \mathrm{e}+001.00000 \mathrm{e}-092.12000 \mathrm{e}-01$ $1.83021 \mathrm{e}+011.83021 \mathrm{e}+011.83021 \mathrm{e}+001.00000 \mathrm{e}-092.12000 \mathrm{e}-01$ $1.83021 \mathrm{e}+011.83021 \mathrm{e}+011.83021 \mathrm{e}+001.00000 \mathrm{e}-092.12000 \mathrm{e}-01$ $1.83021 \mathrm{e}+011.83021 \mathrm{e}+011.83021 \mathrm{e}+001.00000 \mathrm{e}-092.12000 \mathrm{e}-01$ $1.00000 \mathrm{e}-02$ 1.00000e-02 1.00000e-03 1.00000e-09 1.00000e-01 $1.00000 \mathrm{e}+001.00000 \mathrm{e}+001.00000 \mathrm{e}-011.00000 \mathrm{e}-091.00000 \mathrm{e}-01$ $1.00000 \mathrm{e}-051.00000 \mathrm{e}-05$ 1.00000e-06 1.00000e-09 1.00000e-01 $1.00000 \mathrm{e}+001.00000 \mathrm{e}+001.00000 \mathrm{e}-011.00000 \mathrm{e}-091.00000 \mathrm{e}-01$ Element: 3209 \# of layers: 15

Kx Ky Kz Ss Por

$4.58050 \mathrm{e}+024.58050 \mathrm{e}+024.58050 \mathrm{e}+01$ 1.00000e-09 7.00000e-02 $4.58050 \mathrm{e}+024.58050 \mathrm{e}+024.58050 \mathrm{e}+01$ 1.00000e-09 7.00000e-02 $4.58050 \mathrm{e}+024.58050 \mathrm{e}+024.58050 \mathrm{e}+011.00000 \mathrm{e}-097.00000 \mathrm{e}-02$ $4.58050 \mathrm{e}+02 \quad 4.58050 \mathrm{e}+024.58050 \mathrm{e}+011.00000 \mathrm{e}-097.00000 \mathrm{e}-02$ $5.00000 \mathrm{e}-04$ 5.00000e-04 5.00000e-05 1.00000e-09 1.00000e-01 5.00000e-04 5.00000e-04 5.00000e-05 1.00000e-09 1.00000e-01 $1.83021 \mathrm{e}+011.83021 \mathrm{e}+011.83021 \mathrm{e}+001.00000 \mathrm{e}-092.12000 \mathrm{e}-01$ $1.83021 \mathrm{e}+011.83021 \mathrm{e}+011.83021 \mathrm{e}+001.00000 \mathrm{e}-092.12000 \mathrm{e}-01$ $1.83021 \mathrm{e}+011.83021 \mathrm{e}+011.83021 \mathrm{e}+001.00000 \mathrm{e}-092.12000 \mathrm{e}-01$ $1.83021 \mathrm{e}+011.83021 \mathrm{e}+011.83021 \mathrm{e}+001.00000 \mathrm{e}-092.12000 \mathrm{e}-01$ $1.83021 \mathrm{e}+011.83021 \mathrm{e}+011.83021 \mathrm{e}+001.00000 \mathrm{e}-092.12000 \mathrm{e}-01$ $1.00000 \mathrm{e}-021.00000 \mathrm{e}-02$ 1.00000e-03 1.00000e-09 1.00000e-01 $1.00000 \mathrm{e}+001.00000 \mathrm{e}+001.00000 \mathrm{e}-011.00000 \mathrm{e}-091.00000 \mathrm{e}-01$ $1.00000 \mathrm{e}-05$ 1.00000e-05 1.00000e-06 1.00000e-09 1.00000e-01 $1.00000 \mathrm{e}+001.00000 \mathrm{e}+001.00000 \mathrm{e}-011.00000 \mathrm{e}-091.00000 \mathrm{e}-01$ Element: 3210 \# of layers: 15

Kx Ky Kz Ss Por

$2.23556 \mathrm{e}+022.23556 \mathrm{e}+022.23556 \mathrm{e}+01$ 1.00000e-09 7.00000e-02 $2.23556 \mathrm{e}+022.23556 \mathrm{e}+022.23556 \mathrm{e}+01 \quad 1.00000 \mathrm{e}-097.00000 \mathrm{e}-02$ $2.23556 \mathrm{e}+022.23556 \mathrm{e}+022.23556 \mathrm{e}+011.00000 \mathrm{e}-09$ 7.00000e-02 $2.23556 \mathrm{e}+022.23556 \mathrm{e}+022.23556 \mathrm{e}+011.00000 \mathrm{e}-097.00000 \mathrm{e}-02$ 5.00000e-04 5.00000e-04 5.00000e-05 1.00000e-09 1.00000e-01 5.00000e-04 5.00000e-04 5.00000e-05 1.00000e-09 1.00000e-01 
$8.93269 \mathrm{e}+008.93269 \mathrm{e}+00$ 8.93269e-01 1.00000e-09 2.12000e-01 $8.93269 \mathrm{e}+008.93269 \mathrm{e}+00$ 8.93269e-01 1.00000e-09 2.12000e-01 $8.93269 \mathrm{e}+008.93269 \mathrm{e}+00$ 8.93269e-01 1.00000e-09 2.12000e-01 $8.93269 \mathrm{e}+008.93269 \mathrm{e}+008.93269 \mathrm{e}-011.00000 \mathrm{e}-09$ 2.12000e-01 $8.93269 \mathrm{e}+008.93269 \mathrm{e}+00$ 8.93269e-01 1.00000e-09 2.12000e-01 $1.00000 \mathrm{e}-021.00000 \mathrm{e}-02$ 1.00000e-03 1.00000e-09 1.00000e-01 $1.00000 \mathrm{e}+001.00000 \mathrm{e}+001.00000 \mathrm{e}-011.00000 \mathrm{e}-091.00000 \mathrm{e}-01$ $1.00000 \mathrm{e}-05$ 1.00000e-05 1.00000e-06 1.00000e-09 1.00000e-01 $1.00000 \mathrm{e}+001.00000 \mathrm{e}+001.00000 \mathrm{e}-011.00000 \mathrm{e}-091.00000 \mathrm{e}-01$ Element: 3211 \# of layers: 15

Kx Ky Kz Ss Por

$2.23556 \mathrm{e}+022.23556 \mathrm{e}+022.23556 \mathrm{e}+01$ 1.00000e-09 7.00000e-02 $2.23556 \mathrm{e}+022.23556 \mathrm{e}+022.23556 \mathrm{e}+01$ 1.00000e-09 7.00000e-02

$2.23556 \mathrm{e}+022.23556 \mathrm{e}+022.23556 \mathrm{e}+011.00000 \mathrm{e}-097.00000 \mathrm{e}-02$ $2.23556 \mathrm{e}+022.23556 \mathrm{e}+022.23556 \mathrm{e}+011.00000 \mathrm{e}-097.00000 \mathrm{e}-02$ 5.00000e-04 5.00000e-04 5.00000e-05 1.00000e-09 1.00000e-01 5.00000e-04 5.00000e-04 5.00000e-05 1.00000e-09 1.00000e-01 $8.93269 \mathrm{e}+008.93269 \mathrm{e}+00$ 8.93269e-01 1.00000e-09 2.12000e-01 $8.93269 \mathrm{e}+008.93269 \mathrm{e}+00$ 8.93269e-01 1.00000e-09 2.12000e-01 $8.93269 \mathrm{e}+008.93269 \mathrm{e}+00$ 8.93269e-01 1.00000e-09 2.12000e-01 $8.93269 \mathrm{e}+008.93269 \mathrm{e}+008.93269 \mathrm{e}-011.00000 \mathrm{e}-092.12000 \mathrm{e}-01$ $8.93269 \mathrm{e}+008.93269 \mathrm{e}+00$ 8.93269e-01 1.00000e-09 2.12000e-01 $1.00000 \mathrm{e}-021.00000 \mathrm{e}-02$ 1.00000e-03 1.00000e-09 1.00000e-01 $1.00000 \mathrm{e}+001.00000 \mathrm{e}+001.00000 \mathrm{e}-011.00000 \mathrm{e}-091.00000 \mathrm{e}-01$ $1.00000 \mathrm{e}-05$ 1.00000e-05 1.00000e-06 1.00000e-09 1.00000e-01 $1.00000 \mathrm{e}+001.00000 \mathrm{e}+001.00000 \mathrm{e}-011.00000 \mathrm{e}-091.00000 \mathrm{e}-01$ Element: 3212 \# of layers: 16

Kx Ky Kz Ss Por

$3.78717 \mathrm{e}+023.78717 \mathrm{e}+023.78717 \mathrm{e}+01$ 1.00000e-09 7.00000e-02 $3.78717 \mathrm{e}+023.78717 \mathrm{e}+023.78717 \mathrm{e}+01$ 1.00000e-09 7.00000e-02 $3.78717 \mathrm{e}+023.78717 \mathrm{e}+023.78717 \mathrm{e}+011.00000 \mathrm{e}-09$ 7.00000e-02 $3.78717 \mathrm{e}+023.78717 \mathrm{e}+023.78717 \mathrm{e}+01$ 1.00000e-09 7.00000e-02 $3.78717 \mathrm{e}+023.78717 \mathrm{e}+023.78717 \mathrm{e}+01$ 1.00000e-09 7.00000e-02 $5.00000 \mathrm{e}-04$ 5.00000e-04 5.00000e-05 1.00000e-09 1.00000e-01 5.00000e-04 5.00000e-04 5.00000e-05 1.00000e-09 1.00000e-01 $1.51322 \mathrm{e}+011.51322 \mathrm{e}+011.51323 \mathrm{e}+001.00000 \mathrm{e}-092.12000 \mathrm{e}-01$ $1.51322 \mathrm{e}+011.51322 \mathrm{e}+011.51323 \mathrm{e}+001.00000 \mathrm{e}-092.12000 \mathrm{e}-01$ $1.51322 \mathrm{e}+011.51322 \mathrm{e}+011.51323 \mathrm{e}+001.00000 \mathrm{e}-092.12000 \mathrm{e}-01$ $1.51322 \mathrm{e}+011.51322 \mathrm{e}+011.51323 \mathrm{e}+001.00000 \mathrm{e}-092.12000 \mathrm{e}-01$ $1.51322 \mathrm{e}+011.51322 \mathrm{e}+011.51323 \mathrm{e}+001.00000 \mathrm{e}-092.12000 \mathrm{e}-01$ $1.00000 \mathrm{e}-021.00000 \mathrm{e}-02$ 1.00000e-03 1.00000e-09 1.00000e-01 $1.00000 \mathrm{e}+001.00000 \mathrm{e}+001.00000 \mathrm{e}-011.00000 \mathrm{e}-091.00000 \mathrm{e}-01$ $1.00000 \mathrm{e}-05$ 1.00000e-05 1.00000e-06 1.00000e-09 1.00000e-01 $1.00000 \mathrm{e}+001.00000 \mathrm{e}+001.00000 \mathrm{e}-011.00000 \mathrm{e}-091.00000 \mathrm{e}-01$ Element: 3213 \# of layers: 16

Kx Ky Kz Ss Por 
4.28597e+02 4.28597e+02 4.28597e+01 1.00000e-09 7.00000e-02 4.28597e+02 4.28597e+02 4.28597e+01 1.00000e-09 7.00000e-02 4.28597e+02 4.28597e+02 4.28597e+01 1.00000e-09 7.00000e-02 4.28597e+02 4.28597e+02 4.28597e+01 1.00000e-09 7.00000e-02 4.28597e+02 4.28597e+02 4.28597e+01 1.00000e-09 7.00000e-02 5.00000e-04 5.00000e-04 5.00000e-05 1.00000e-09 1.00000e-01 5.00000e-04 5.00000e-04 5.00000e-05 1.00000e-09 1.00000e-01 $1.71253 \mathrm{e}+011.71253 \mathrm{e}+01$ 1.71253e+00 1.00000e-09 2.12000e-01 $1.71253 \mathrm{e}+011.71253 \mathrm{e}+01$ 1.71253e+00 1.00000e-09 2.12000e-01 $1.71253 \mathrm{e}+01$ 1.71253e+01 1.71253e+00 1.00000e-09 2.12000e-01 $1.71253 \mathrm{e}+011.71253 \mathrm{e}+01$ 1.71253e+00 1.00000e-09 2.12000e-01 $1.71253 \mathrm{e}+011.71253 \mathrm{e}+011.71253 \mathrm{e}+001.00000 \mathrm{e}-092.12000 \mathrm{e}-01$ $1.00000 \mathrm{e}-02$ 1.00000e-02 1.00000e-03 1.00000e-09 1.00000e-01 $1.00000 \mathrm{e}+001.00000 \mathrm{e}+001.00000 \mathrm{e}-011.00000 \mathrm{e}-091.00000 \mathrm{e}-01$ $1.00000 \mathrm{e}-05$ 1.00000e-05 1.00000e-06 1.00000e-09 1.00000e-01 $1.00000 \mathrm{e}+001.00000 \mathrm{e}+001.00000 \mathrm{e}-011.00000 \mathrm{e}-091.00000 \mathrm{e}-01$ Element: 3214 \# of layers: 15

$\mathrm{Kx} \mathrm{Ky} \mathrm{Kz}$ Ss Por

4.58050e+02 4.58050e+02 4.58050e+01 1.00000e-09 7.00000e-02 $4.58050 \mathrm{e}+02$ 4.58050e+02 4.58050e+01 1.00000e-09 7.00000e-02 $4.58050 \mathrm{e}+02$ 4.58050e+02 4.58050e+01 1.00000e-09 7.00000e-02 4.58050e+02 4.58050e+02 4.58050e+01 1.00000e-09 7.00000e-02 5.00000e-04 5.00000e-04 5.00000e-05 1.00000e-09 1.00000e-01 5.00000e-04 5.00000e-04 5.00000e-05 1.00000e-09 1.00000e-01 $1.83021 \mathrm{e}+011.83021 \mathrm{e}+011.83021 \mathrm{e}+001.00000 \mathrm{e}-092.12000 \mathrm{e}-01$ $1.83021 \mathrm{e}+011.83021 \mathrm{e}+011.83021 \mathrm{e}+001.00000 \mathrm{e}-092.12000 \mathrm{e}-01$ $1.83021 \mathrm{e}+011.83021 \mathrm{e}+011.83021 \mathrm{e}+001.00000 \mathrm{e}-092.12000 \mathrm{e}-01$ $1.83021 \mathrm{e}+011.83021 \mathrm{e}+011.83021 \mathrm{e}+001.00000 \mathrm{e}-092.12000 \mathrm{e}-01$ $1.83021 \mathrm{e}+011.83021 \mathrm{e}+011.83021 \mathrm{e}+001.00000 \mathrm{e}-092.12000 \mathrm{e}-01$ $1.00000 \mathrm{e}-02$ 1.00000e-02 1.00000e-03 1.00000e-09 1.00000e-01 $1.00000 \mathrm{e}+001.00000 \mathrm{e}+001.00000 \mathrm{e}-011.00000 \mathrm{e}-091.00000 \mathrm{e}-01$ 1.00000e-05 1.00000e-05 1.00000e-06 1.00000e-09 1.00000e-01 $1.00000 \mathrm{e}+001.00000 \mathrm{e}+001.00000 \mathrm{e}-011.00000 \mathrm{e}-091.00000 \mathrm{e}-01$ Element: 3215 \# of layers: 15

$\mathrm{Kx} \mathrm{Ky} \mathrm{Kz}$ Ss Por

3.51129e+02 3.51129e+02 3.51129e+01 1.00000e-09 7.00000e-02 $3.51129 \mathrm{e}+023.51129 \mathrm{e}+023.51129 \mathrm{e}+01$ 1.00000e-09 7.00000e-02 $3.51129 \mathrm{e}+023.51129 \mathrm{e}+023.51129 \mathrm{e}+01$ 1.00000e-09 7.00000e-02 $3.51129 \mathrm{e}+02$ 3.51129e+02 3.51129e+01 1.00000e-09 7.00000e-02 5.00000e-04 5.00000e-04 5.00000e-05 1.00000e-09 1.00000e-01 5.00000e-04 5.00000e-04 5.00000e-05 1.00000e-09 1.00000e-01 $1.40297 \mathrm{e}+01$ 1.40297e+01 1.40297e+00 1.00000e-09 2.12000e-01 $1.40297 \mathrm{e}+01$ 1.40297e+01 1.40297e+00 1.00000e-09 2.12000e-01 1.40297e+01 1.40297e+01 1.40297e+00 1.00000e-09 2.12000e-01 $1.40297 \mathrm{e}+01$ 1.40297e+01 1.40297e+00 1.00000e-09 2.12000e-01 $1.40297 \mathrm{e}+01$ 1.40297e+01 1.40297e+00 1.00000e-09 2.12000e-01 
$1.00000 \mathrm{e}-02$ 1.00000e-02 1.00000e-03 1.00000e-09 1.00000e-01 $1.00000 \mathrm{e}+001.00000 \mathrm{e}+001.00000 \mathrm{e}-011.00000 \mathrm{e}-091.00000 \mathrm{e}-01$ $1.00000 \mathrm{e}-051.00000 \mathrm{e}-05$ 1.00000e-06 1.00000e-09 1.00000e-01 $1.00000 \mathrm{e}+001.00000 \mathrm{e}+001.00000 \mathrm{e}-011.00000 \mathrm{e}-091.00000 \mathrm{e}-01$ Element: 3216 \# of layers: 15

Kx Ky Kz Ss Por

$1.80362 \mathrm{e}+021.80362 \mathrm{e}+021.80362 \mathrm{e}+01$ 1.00000e-09 7.00000e-02 $1.80362 \mathrm{e}+021.80362 \mathrm{e}+021.80362 \mathrm{e}+011.00000 \mathrm{e}-097.00000 \mathrm{e}-02$ $1.80362 \mathrm{e}+021.80362 \mathrm{e}+021.80362 \mathrm{e}+011.00000 \mathrm{e}-097.00000 \mathrm{e}-02$ $1.80362 \mathrm{e}+021.80362 \mathrm{e}+021.80362 \mathrm{e}+011.00000 \mathrm{e}-09$ 7.00000e-02 5.00000e-04 5.00000e-04 5.00000e-05 1.00000e-09 1.00000e-01 5.00000e-04 5.00000e-04 5.00000e-05 1.00000e-09 1.00000e-01 $7.20668 \mathrm{e}+007.20668 \mathrm{e}+00$ 7.20668e-01 1.00000e-09 2.12000e-01 $7.20668 \mathrm{e}+007.20668 \mathrm{e}+007.20668 \mathrm{e}-01$ 1.00000e-09 2.12000e-01 $7.20668 \mathrm{e}+007.20668 \mathrm{e}+00$ 7.20668e-01 1.00000e-09 2.12000e-01 $7.20668 \mathrm{e}+007.20668 \mathrm{e}+00$ 7.20668e-01 1.00000e-09 2.12000e-01 $7.20668 \mathrm{e}+00$ 7.20668e+00 7.20668e-01 1.00000e-09 2.12000e-01 $1.00000 \mathrm{e}-02$ 1.00000e-02 1.00000e-03 1.00000e-09 1.00000e-01 $1.00000 \mathrm{e}+001.00000 \mathrm{e}+001.00000 \mathrm{e}-011.00000 \mathrm{e}-091.00000 \mathrm{e}-01$ $1.00000 \mathrm{e}-051.00000 \mathrm{e}-05$ 1.00000e-06 1.00000e-09 1.00000e-01 $1.00000 \mathrm{e}+001.00000 \mathrm{e}+001.00000 \mathrm{e}-011.00000 \mathrm{e}-091.00000 \mathrm{e}-01$ Element: 3217 \# of layers: 15

Kx Ky Kz Ss Por

$1.80362 \mathrm{e}+021.80362 \mathrm{e}+021.80362 \mathrm{e}+01$ 1.00000e-09 7.00000e-02 $1.80362 \mathrm{e}+021.80362 \mathrm{e}+021.80362 \mathrm{e}+011.00000 \mathrm{e}-09$ 7.00000e-02 $1.80362 \mathrm{e}+021.80362 \mathrm{e}+021.80362 \mathrm{e}+011.00000 \mathrm{e}-097.00000 \mathrm{e}-02$ $1.80362 \mathrm{e}+021.80362 \mathrm{e}+021.80362 \mathrm{e}+011.00000 \mathrm{e}-097.00000 \mathrm{e}-02$ 5.00000e-04 5.00000e-04 5.00000e-05 1.00000e-09 1.00000e-01 5.00000e-04 5.00000e-04 5.00000e-05 1.00000e-09 1.00000e-01 $7.20668 \mathrm{e}+007.20668 \mathrm{e}+00$ 7.20668e-01 1.00000e-09 2.12000e-01 $7.20668 \mathrm{e}+007.20668 \mathrm{e}+007.20668 \mathrm{e}-01$ 1.00000e-09 2.12000e-01 $7.20668 \mathrm{e}+007.20668 \mathrm{e}+00$ 7.20668e-01 1.00000e-09 2.12000e-01 $7.20668 \mathrm{e}+007.20668 \mathrm{e}+00$ 7.20668e-01 1.00000e-09 2.12000e-01 $7.20668 \mathrm{e}+00$ 7.20668e+00 7.20668e-01 1.00000e-09 2.12000e-01 $1.00000 \mathrm{e}-02$ 1.00000e-02 1.00000e-03 1.00000e-09 1.00000e-01 $1.00000 \mathrm{e}+001.00000 \mathrm{e}+001.00000 \mathrm{e}-011.00000 \mathrm{e}-091.00000 \mathrm{e}-01$ $1.00000 \mathrm{e}-05$ 1.00000e-05 1.00000e-06 1.00000e-09 1.00000e-01 $1.00000 \mathrm{e}+001.00000 \mathrm{e}+001.00000 \mathrm{e}-011.00000 \mathrm{e}-091.00000 \mathrm{e}-01$ Element: 3218 \# of layers: 15

Kx Ky Kz Ss Por $1.80362 \mathrm{e}+021.80362 \mathrm{e}+021.80362 \mathrm{e}+01$ 1.00000e-09 7.00000e-02 $1.80362 \mathrm{e}+021.80362 \mathrm{e}+021.80362 \mathrm{e}+011.00000 \mathrm{e}-097.00000 \mathrm{e}-02$ $1.80362 \mathrm{e}+021.80362 \mathrm{e}+021.80362 \mathrm{e}+011.00000 \mathrm{e}-097.00000 \mathrm{e}-02$ $1.80362 \mathrm{e}+021.80362 \mathrm{e}+021.80362 \mathrm{e}+011.00000 \mathrm{e}-09$ 7.00000e-02 5.00000e-04 5.00000e-04 5.00000e-05 1.00000e-09 1.00000e-01 5.00000e-04 5.00000e-04 5.00000e-05 1.00000e-09 1.00000e-01 
$7.20668 \mathrm{e}+00$ 7.20668e+00 7.20668e-01 1.00000e-09 2.12000e-01 $7.20668 \mathrm{e}+00$ 7.20668e+00 7.20668e-01 1.00000e-09 2.12000e-01 $7.20668 \mathrm{e}+007.20668 \mathrm{e}+00$ 7.20668e-01 1.00000e-09 2.12000e-01 $7.20668 \mathrm{e}+007.20668 \mathrm{e}+007.20668 \mathrm{e}-011.00000 \mathrm{e}-092.12000 \mathrm{e}-01$ $7.20668 \mathrm{e}+00$ 7.20668e+00 7.20668e-01 1.00000e-09 2.12000e-01 $1.00000 \mathrm{e}-021.00000 \mathrm{e}-02$ 1.00000e-03 1.00000e-09 1.00000e-01 $1.00000 \mathrm{e}+001.00000 \mathrm{e}+001.00000 \mathrm{e}-011.00000 \mathrm{e}-091.00000 \mathrm{e}-01$ $1.00000 \mathrm{e}-05$ 1.00000e-05 1.00000e-06 1.00000e-09 1.00000e-01 $1.00000 \mathrm{e}+001.00000 \mathrm{e}+001.00000 \mathrm{e}-011.00000 \mathrm{e}-091.00000 \mathrm{e}-01$ Element: 3219 \# of layers: 15

Kx Ky Kz Ss Por

$1.46782 \mathrm{e}+02$ 1.46782e+02 1.46782e+01 1.00000e-09 7.00000e-02 $1.46782 \mathrm{e}+021.46782 \mathrm{e}+021.46782 \mathrm{e}+01$ 1.00000e-09 7.00000e-02 $1.46782 \mathrm{e}+021.46782 \mathrm{e}+021.46782 \mathrm{e}+011.00000 \mathrm{e}-097.00000 \mathrm{e}-02$ $1.46782 \mathrm{e}+021.46782 \mathrm{e}+021.46782 \mathrm{e}+011.00000 \mathrm{e}-097.00000 \mathrm{e}-02$ $5.00000 \mathrm{e}-04$ 5.00000e-04 5.00000e-05 1.00000e-09 1.00000e-01 5.00000e-04 5.00000e-04 5.00000e-05 1.00000e-09 1.00000e-01

$5.86497 \mathrm{e}+005.86497 \mathrm{e}+00$ 5.86498e-01 1.00000e-09 2.12000e-01 $5.86497 \mathrm{e}+005.86497 \mathrm{e}+00$ 5.86498e-01 1.00000e-09 2.12000e-01 $5.86497 \mathrm{e}+005.86497 \mathrm{e}+00$ 5.86498e-01 1.00000e-09 2.12000e-01 $5.86497 \mathrm{e}+005.86497 \mathrm{e}+00$ 5.86498e-01 1.00000e-09 2.12000e-01 $5.86497 \mathrm{e}+00$ 5.86497e+00 5.86498e-01 1.00000e-09 2.12000e-01 $1.00000 \mathrm{e}-02$ 1.00000e-02 1.00000e-03 1.00000e-09 1.00000e-01 $1.00000 \mathrm{e}+001.00000 \mathrm{e}+001.00000 \mathrm{e}-011.00000 \mathrm{e}-091.00000 \mathrm{e}-01$ $1.00000 \mathrm{e}-05$ 1.00000e-05 1.00000e-06 1.00000e-09 1.00000e-01 $1.00000 \mathrm{e}+001.00000 \mathrm{e}+001.00000 \mathrm{e}-011.00000 \mathrm{e}-091.00000 \mathrm{e}-01$ Element: 3220 \# of layers: 15

Kx Ky Kz Ss Por

$1.46782 \mathrm{e}+021.46782 \mathrm{e}+02$ 1.46782e+01 1.00000e-09 7.00000e-02 $1.46782 \mathrm{e}+021.46782 \mathrm{e}+021.46782 \mathrm{e}+011.00000 \mathrm{e}-097.00000 \mathrm{e}-02$ $1.46782 \mathrm{e}+021.46782 \mathrm{e}+021.46782 \mathrm{e}+011.00000 \mathrm{e}-097.00000 \mathrm{e}-02$ $1.46782 \mathrm{e}+021.46782 \mathrm{e}+021.46782 \mathrm{e}+01$ 1.00000e-09 7.00000e-02 5.00000e-04 5.00000e-04 5.00000e-05 1.00000e-09 1.00000e-01 $5.00000 \mathrm{e}-04$ 5.00000e-04 5.00000e-05 1.00000e-09 1.00000e-01 $5.86497 \mathrm{e}+005.86497 \mathrm{e}+00$ 5.86498e-01 1.00000e-09 2.12000e-01 $5.86497 \mathrm{e}+005.86497 \mathrm{e}+00$ 5.86498e-01 1.00000e-09 2.12000e-01 $5.86497 \mathrm{e}+005.86497 \mathrm{e}+00$ 5.86498e-01 1.00000e-09 2.12000e-01 $5.86497 \mathrm{e}+005.86497 \mathrm{e}+00$ 5.86498e-01 1.00000e-09 2.12000e-01 $5.86497 \mathrm{e}+005.86497 \mathrm{e}+00$ 5.86498e-01 1.00000e-09 2.12000e-01 $1.00000 \mathrm{e}-02$ 1.00000e-02 1.00000e-03 1.00000e-09 1.00000e-01 $1.00000 \mathrm{e}+001.00000 \mathrm{e}+001.00000 \mathrm{e}-011.00000 \mathrm{e}-091.00000 \mathrm{e}-01$ $1.00000 \mathrm{e}-05$ 1.00000e-05 1.00000e-06 1.00000e-09 1.00000e-01 $1.00000 \mathrm{e}+001.00000 \mathrm{e}+001.00000 \mathrm{e}-011.00000 \mathrm{e}-091.00000 \mathrm{e}-01$ Element: 3221 \# of layers: 15

Kx Ky Kz Ss Por

$1.49061 \mathrm{e}+021.49061 \mathrm{e}+021.49061 \mathrm{e}+01$ 1.00000e-09 7.00000e-02 
$1.49061 \mathrm{e}+02$ 1.49061e+02 1.49061e+01 1.00000e-09 7.00000e-02 $1.49061 \mathrm{e}+021.49061 \mathrm{e}+02$ 1.49061e+01 1.00000e-09 7.00000e-02 $1.49061 \mathrm{e}+021.49061 \mathrm{e}+02$ 1.49061e+01 1.00000e-09 7.00000e-02 5.00000e-04 5.00000e-04 5.00000e-05 1.00000e-09 1.00000e-01 $5.00000 \mathrm{e}-04$ 5.00000e-04 5.00000e-05 1.00000e-09 1.00000e-01 $5.95588 \mathrm{e}+00$ 5.95588e+00 5.95588e-01 1.00000e-09 2.12000e-01 5.95588e+00 5.95588e+00 5.95588e-01 1.00000e-09 2.12000e-01 $5.95588 \mathrm{e}+00$ 5.95588e+00 5.95588e-01 1.00000e-09 2.12000e-01 5.95588e+00 5.95588e+00 5.95588e-01 1.00000e-09 2.12000e-01 5.95588e+00 5.95588e+00 5.95588e-01 1.00000e-09 2.12000e-01 1.00000e-02 1.00000e-02 1.00000e-03 1.00000e-09 1.00000e-01 $1.00000 \mathrm{e}+001.00000 \mathrm{e}+001.00000 \mathrm{e}-011.00000 \mathrm{e}-091.00000 \mathrm{e}-01$ $1.00000 \mathrm{e}-05$ 1.00000e-05 1.00000e-06 1.00000e-09 1.00000e-01 $1.00000 \mathrm{e}+001.00000 \mathrm{e}+001.00000 \mathrm{e}-011.00000 \mathrm{e}-09$ 1.00000e-01 Element: 3222 \# of layers: 15

Kx Ky Kz Ss Por

3.51129e+02 3.51129e+02 3.51129e+01 1.00000e-09 7.00000e-02 $3.51129 \mathrm{e}+023.51129 \mathrm{e}+023.51129 \mathrm{e}+01$ 1.00000e-09 7.00000e-02 $3.51129 \mathrm{e}+023.51129 \mathrm{e}+023.51129 \mathrm{e}+01$ 1.00000e-09 7.00000e-02 $3.51129 \mathrm{e}+02$ 3.51129e+02 3.51129e+01 1.00000e-09 7.00000e-02 5.00000e-04 5.00000e-04 5.00000e-05 1.00000e-09 1.00000e-01 5.00000e-04 5.00000e-04 5.00000e-05 1.00000e-09 1.00000e-01 $1.40297 \mathrm{e}+01$ 1.40297e+01 1.40297e+00 1.00000e-09 2.12000e-01 $1.40297 \mathrm{e}+011.40297 \mathrm{e}+01$ 1.40297e+00 1.00000e-09 2.12000e-01 $1.40297 \mathrm{e}+01$ 1.40297e+01 1.40297e+00 1.00000e-09 2.12000e-01 $1.40297 \mathrm{e}+01$ 1.40297e+01 1.40297e+00 1.00000e-09 2.12000e-01 $1.40297 \mathrm{e}+01$ 1.40297e+01 1.40297e+00 1.00000e-09 2.12000e-01 $1.00000 \mathrm{e}-02$ 1.00000e-02 1.00000e-03 1.00000e-09 1.00000e-01 $1.00000 \mathrm{e}+001.00000 \mathrm{e}+001.00000 \mathrm{e}-011.00000 \mathrm{e}-091.00000 \mathrm{e}-01$ $1.00000 \mathrm{e}-05$ 1.00000e-05 1.00000e-06 1.00000e-09 1.00000e-01 $1.00000 \mathrm{e}+001.00000 \mathrm{e}+001.00000 \mathrm{e}-011.00000 \mathrm{e}-091.00000 \mathrm{e}-01$ Element: 3223 \# of layers: 15

Kx Ky Kz Ss Por

1.80362e+02 1.80362e+02 1.80362e+01 1.00000e-09 7.00000e-02 $1.80362 \mathrm{e}+021.80362 \mathrm{e}+02$ 1.80362e+01 1.00000e-09 7.00000e-02 $1.80362 \mathrm{e}+021.80362 \mathrm{e}+02$ 1.80362e+01 1.00000e-09 7.00000e-02 $1.80362 \mathrm{e}+021.80362 \mathrm{e}+021.80362 \mathrm{e}+01$ 1.00000e-09 7.00000e-02 5.00000e-04 5.00000e-04 5.00000e-05 1.00000e-09 1.00000e-01 5.00000e-04 5.00000e-04 5.00000e-05 1.00000e-09 1.00000e-01 $7.20668 \mathrm{e}+00$ 7.20668e+00 7.20668e-01 1.00000e-09 2.12000e-01 $7.20668 \mathrm{e}+00$ 7.20668e+00 7.20668e-01 1.00000e-09 2.12000e-01 $7.20668 \mathrm{e}+00$ 7.20668e+00 7.20668e-01 1.00000e-09 2.12000e-01 7.20668e+00 7.20668e+00 7.20668e-01 1.00000e-09 2.12000e-01 $7.20668 \mathrm{e}+00$ 7.20668e+00 7.20668e-01 1.00000e-09 2.12000e-01 $1.00000 \mathrm{e}-02$ 1.00000e-02 1.00000e-03 1.00000e-09 1.00000e-01 $1.00000 \mathrm{e}+001.00000 \mathrm{e}+001.00000 \mathrm{e}-011.00000 \mathrm{e}-091.00000 \mathrm{e}-01$ 
$1.00000 \mathrm{e}-05$ 1.00000e-05 1.00000e-06 1.00000e-09 1.00000e-01 $1.00000 \mathrm{e}+001.00000 \mathrm{e}+001.00000 \mathrm{e}-01$ 1.00000e-09 1.00000e-01 Element: 3224 \# of layers: 15

$\mathrm{Kx} \mathrm{Ky} \mathrm{Kz}$ Ss Por

1.49899e+02 1.49899e+02 1.49899e+01 1.00000e-09 7.00000e-02 1.49899e+02 1.49899e+02 1.49899e+01 1.00000e-09 7.00000e-02 $1.49899 \mathrm{e}+02$ 1.49899e+02 1.49899e+01 1.00000e-09 7.00000e-02 $1.49899 \mathrm{e}+02$ 1.49899e+02 1.49899e+01 1.00000e-09 7.00000e-02 5.00000e-04 5.00000e-04 5.00000e-05 1.00000e-09 1.00000e-01 5.00000e-04 5.00000e-04 5.00000e-05 1.00000e-09 1.00000e-01 $5.98963 \mathrm{e}+00$ 5.98963e+00 5.98963e-01 1.00000e-09 2.12000e-01 $5.98963 \mathrm{e}+00$ 5.98963e+00 5.98963e-01 1.00000e-09 2.12000e-01 $5.98963 \mathrm{e}+00$ 5.98963e+00 5.98963e-01 1.00000e-09 2.12000e-01 5.98963e+00 5.98963e+00 5.98963e-01 1.00000e-09 2.12000e-01 5.98963e+00 5.98963e+00 5.98963e-01 1.00000e-09 2.12000e-01 $1.00000 \mathrm{e}-02$ 1.00000e-02 1.00000e-03 1.00000e-09 1.00000e-01 $1.00000 \mathrm{e}+001.00000 \mathrm{e}+001.00000 \mathrm{e}-011.00000 \mathrm{e}-091.00000 \mathrm{e}-01$ $1.00000 \mathrm{e}-05$ 1.00000e-05 1.00000e-06 1.00000e-09 1.00000e-01 $1.00000 \mathrm{e}+001.00000 \mathrm{e}+001.00000 \mathrm{e}-01$ 1.00000e-09 1.00000e-01 Element: 3225 \# of layers: 15

$\mathrm{Kx} \mathrm{Ky} \mathrm{Kz}$ Ss Por

1.37799e+02 1.37799e+02 1.37799e+01 1.00000e-09 7.00000e-02 1.37799e+02 1.37799e+02 1.37799e+01 1.00000e-09 7.00000e-02 $1.37799 \mathrm{e}+02$ 1.37799e+02 1.37799e+01 1.00000e-09 7.00000e-02 $1.37799 \mathrm{e}+02$ 1.37799e+02 1.37799e+01 1.00000e-09 7.00000e-02 $5.00000 \mathrm{e}-04$ 5.00000e-04 5.00000e-05 1.00000e-09 1.00000e-01 5.00000e-04 5.00000e-04 5.00000e-05 1.00000e-09 1.00000e-01 5.50609e+00 5.50609e+00 5.50609e-01 1.00000e-09 2.12000e-01 $5.50609 \mathrm{e}+00$ 5.50609e+00 5.50609e-01 1.00000e-09 2.12000e-01 $5.50609 \mathrm{e}+00$ 5.50609e+00 5.50609e-01 1.00000e-09 2.12000e-01 $5.50609 \mathrm{e}+00$ 5.50609e+00 5.50609e-01 1.00000e-09 2.12000e-01 $5.50609 \mathrm{e}+00$ 5.50609e+00 5.50609e-01 1.00000e-09 2.12000e-01 $1.00000 \mathrm{e}-02$ 1.00000e-02 1.00000e-03 1.00000e-09 1.00000e-01 $1.00000 \mathrm{e}+001.00000 \mathrm{e}+001.00000 \mathrm{e}-011.00000 \mathrm{e}-091.00000 \mathrm{e}-01$ $1.00000 \mathrm{e}-05$ 1.00000e-05 1.00000e-06 1.00000e-09 1.00000e-01 $1.00000 \mathrm{e}+001.00000 \mathrm{e}+001.00000 \mathrm{e}-01$ 1.00000e-09 1.00000e-01 Element: 3226 \# of layers: 15

Kx Ky Kz Ss Por

1.37799e+02 1.37799e+02 1.37799e+01 1.00000e-09 7.00000e-02 1.37799e+02 1.37799e+02 1.37799e+01 1.00000e-09 7.00000e-02 $1.37799 \mathrm{e}+02$ 1.37799e+02 1.37799e+01 1.00000e-09 7.00000e-02 $1.37799 \mathrm{e}+02$ 1.37799e+02 1.37799e+01 1.00000e-09 7.00000e-02 $5.00000 \mathrm{e}-04$ 5.00000e-04 5.00000e-05 1.00000e-09 1.00000e-01 5.00000e-04 5.00000e-04 5.00000e-05 1.00000e-09 1.00000e-01 $5.50609 \mathrm{e}+00$ 5.50609e+00 5.50609e-01 1.00000e-09 2.12000e-01 $5.50609 \mathrm{e}+00$ 5.50609e+00 5.50609e-01 1.00000e-09 2.12000e-01 
$5.50609 \mathrm{e}+00$ 5.50609e+00 5.50609e-01 1.00000e-09 2.12000e-01 $5.50609 \mathrm{e}+005.50609 \mathrm{e}+00$ 5.50609e-01 1.00000e-09 2.12000e-01 $5.50609 \mathrm{e}+005.50609 \mathrm{e}+00$ 5.50609e-01 1.00000e-09 2.12000e-01 $1.00000 \mathrm{e}-021.00000 \mathrm{e}-02$ 1.00000e-03 1.00000e-09 1.00000e-01 $1.00000 \mathrm{e}+001.00000 \mathrm{e}+001.00000 \mathrm{e}-011.00000 \mathrm{e}-091.00000 \mathrm{e}-01$ $1.00000 \mathrm{e}-05$ 1.00000e-05 1.00000e-06 1.00000e-09 1.00000e-01 $1.00000 \mathrm{e}+001.00000 \mathrm{e}+001.00000 \mathrm{e}-011.00000 \mathrm{e}-091.00000 \mathrm{e}-01$ Element: 3227 \# of layers: 15

Kx Ky Kz Ss Por

$1.37799 \mathrm{e}+02$ 1.37799e+02 1.37799e+01 1.00000e-09 7.00000e-02 $1.37799 \mathrm{e}+02$ 1.37799e+02 1.37799e+01 1.00000e-09 7.00000e-02 $1.37799 \mathrm{e}+02$ 1.37799e+02 1.37799e+01 1.00000e-09 7.00000e-02 $1.37799 \mathrm{e}+021.37799 \mathrm{e}+021.37799 \mathrm{e}+01$ 1.00000e-09 7.00000e-02 5.00000e-04 5.00000e-04 5.00000e-05 1.00000e-09 1.00000e-01 $5.00000 \mathrm{e}-04$ 5.00000e-04 5.00000e-05 1.00000e-09 1.00000e-01 $5.50609 \mathrm{e}+005.50609 \mathrm{e}+00$ 5.50609e-01 1.00000e-09 2.12000e-01 $5.50609 \mathrm{e}+005.50609 \mathrm{e}+00$ 5.50609e-01 1.00000e-09 2.12000e-01 $5.50609 \mathrm{e}+005.50609 \mathrm{e}+00$ 5.50609e-01 1.00000e-09 2.12000e-01 $5.50609 \mathrm{e}+005.50609 \mathrm{e}+00$ 5.50609e-01 1.00000e-09 2.12000e-01 $5.50609 \mathrm{e}+00$ 5.50609e+00 5.50609e-01 1.00000e-09 2.12000e-01 $1.00000 \mathrm{e}-021.00000 \mathrm{e}-02$ 1.00000e-03 1.00000e-09 1.00000e-01 $1.00000 \mathrm{e}+001.00000 \mathrm{e}+001.00000 \mathrm{e}-011.00000 \mathrm{e}-091.00000 \mathrm{e}-01$ $1.00000 \mathrm{e}-05$ 1.00000e-05 1.00000e-06 1.00000e-09 1.00000e-01 $1.00000 \mathrm{e}+001.00000 \mathrm{e}+001.00000 \mathrm{e}-011.00000 \mathrm{e}-091.00000 \mathrm{e}-01$ Element: 3228 \# of layers: 16

$\mathrm{Kx} \mathrm{Ky} \mathrm{Kz}$ Ss Por

1.17770e+02 1.17770e+02 1.17770e+01 1.00000e-09 7.00000e-02 $1.17770 \mathrm{e}+02$ 1.17770e+02 1.17770e+01 1.00000e-09 7.00000e-02 $1.17770 \mathrm{e}+02$ 1.17770e+02 1.17770e+01 1.00000e-09 7.00000e-02 1.17770e+02 1.17770e+02 1.17770e+01 1.00000e-09 7.00000e-02 $1.17770 \mathrm{e}+021.17770 \mathrm{e}+02 \quad 1.17770 \mathrm{e}+01$ 1.00000e-09 7.00000e-02 5.00000e-04 5.00000e-04 5.00000e-05 1.00000e-09 1.00000e-01 5.00000e-04 5.00000e-04 5.00000e-05 1.00000e-09 1.00000e-01

$4.70575 \mathrm{e}+00$ 4.70575e+00 4.70575e-01 1.00000e-09 2.12000e-01 4.70575e+00 4.70575e+00 4.70575e-01 1.00000e-09 2.12000e-01 4.70575e+00 4.70575e+00 4.70575e-01 1.00000e-09 2.12000e-01 $4.70575 \mathrm{e}+004.70575 \mathrm{e}+00$ 4.70575e-01 1.00000e-09 2.12000e-01 $4.70575 \mathrm{e}+004.70575 \mathrm{e}+00$ 4.70575e-01 1.00000e-09 2.12000e-01 $1.00000 \mathrm{e}-02$ 1.00000e-02 1.00000e-03 1.00000e-09 1.00000e-01 $1.00000 \mathrm{e}+001.00000 \mathrm{e}+001.00000 \mathrm{e}-011.00000 \mathrm{e}-091.00000 \mathrm{e}-01$ $1.00000 \mathrm{e}-05$ 1.00000e-05 1.00000e-06 1.00000e-09 1.00000e-01 $1.00000 \mathrm{e}+001.00000 \mathrm{e}+001.00000 \mathrm{e}-011.00000 \mathrm{e}-091.00000 \mathrm{e}-01$ Element: 3229 \# of layers: 16

$\mathrm{Kx} \mathrm{Ky} \mathrm{Kz}$ Ss Por

1.17770e+02 1.17770e+02 1.17770e+01 1.00000e-09 7.00000e-02 $1.17770 \mathrm{e}+02$ 1.17770e+02 1.17770e+01 1.00000e-09 7.00000e-02 
1.17770e+02 1.17770e+02 1.17770e+01 1.00000e-09 7.00000e-02 $1.17770 \mathrm{e}+02$ 1.17770e+02 1.17770e+01 1.00000e-09 7.00000e-02 $1.17770 \mathrm{e}+02$ 1.17770e+02 1.17770e+01 1.00000e-09 7.00000e-02 5.00000e-04 5.00000e-04 5.00000e-05 1.00000e-09 1.00000e-01 5.00000e-04 5.00000e-04 5.00000e-05 1.00000e-09 1.00000e-01 $4.70575 \mathrm{e}+00$ 4.70575e+00 4.70575e-01 1.00000e-09 2.12000e-01 $4.70575 \mathrm{e}+00$ 4.70575e+00 4.70575e-01 1.00000e-09 2.12000e-01 $4.70575 \mathrm{e}+00$ 4.70575e+00 4.70575e-01 1.00000e-09 2.12000e-01 $4.70575 \mathrm{e}+00$ 4.70575e+00 4.70575e-01 1.00000e-09 2.12000e-01 $4.70575 \mathrm{e}+00$ 4.70575e+00 4.70575e-01 1.00000e-09 2.12000e-01 $1.00000 \mathrm{e}-02$ 1.00000e-02 1.00000e-03 1.00000e-09 1.00000e-01 $1.00000 \mathrm{e}+001.00000 \mathrm{e}+001.00000 \mathrm{e}-011.00000 \mathrm{e}-091.00000 \mathrm{e}-01$ 1.00000e-05 1.00000e-05 1.00000e-06 1.00000e-09 1.00000e-01 $1.00000 \mathrm{e}+001.00000 \mathrm{e}+001.00000 \mathrm{e}-011.00000 \mathrm{e}-091.00000 \mathrm{e}-01$ Element: 3230 \# of layers: 15

Kx Ky Kz Ss Por

$1.37484 \mathrm{e}+02$ 1.37484e+02 1.37484e+01 1.00000e-09 7.00000e-02 $1.37484 \mathrm{e}+021.37484 \mathrm{e}+02$ 1.37484e+01 1.00000e-09 7.00000e-02 $1.37484 \mathrm{e}+02$ 1.37484e+02 1.37484e+01 1.00000e-09 7.00000e-02 $1.37484 \mathrm{e}+021.37484 \mathrm{e}+02$ 1.37484e+01 1.00000e-09 7.00000e-02 5.00000e-04 5.00000e-04 5.00000e-05 1.00000e-09 1.00000e-01 5.00000e-04 5.00000e-04 5.00000e-05 1.00000e-09 1.00000e-01 5.49327e+00 5.49327e+00 5.49327e-01 1.00000e-09 2.12000e-01 $5.49327 \mathrm{e}+00$ 5.49327e+00 5.49327e-01 1.00000e-09 2.12000e-01 $5.49327 \mathrm{e}+00$ 5.49327e+00 5.49327e-01 1.00000e-09 2.12000e-01 5.49327e+00 5.49327e+00 5.49327e-01 1.00000e-09 2.12000e-01 5.49327e+00 5.49327e+00 5.49327e-01 1.00000e-09 2.12000e-01 $1.00000 \mathrm{e}-021.00000 \mathrm{e}-021.00000 \mathrm{e}-031.00000 \mathrm{e}-091.00000 \mathrm{e}-01$ $1.00000 \mathrm{e}+001.00000 \mathrm{e}+001.00000 \mathrm{e}-011.00000 \mathrm{e}-091.00000 \mathrm{e}-01$ $1.00000 \mathrm{e}-051.00000 \mathrm{e}-051.00000 \mathrm{e}-061.00000 \mathrm{e}-091.00000 \mathrm{e}-01$ $1.00000 \mathrm{e}+001.00000 \mathrm{e}+001.00000 \mathrm{e}-011.00000 \mathrm{e}-091.00000 \mathrm{e}-01$ Element: 3231 \# of layers: 15

Kx Ky Kz Ss Por

$1.49899 \mathrm{e}+02$ 1.49899e+02 1.49899e+01 1.00000e-09 7.00000e-02 $1.49899 \mathrm{e}+02$ 1.49899e+02 1.49899e+01 1.00000e-09 7.00000e-02 $1.49899 \mathrm{e}+02$ 1.49899e+02 1.49899e+01 1.00000e-09 7.00000e-02 $1.49899 \mathrm{e}+021.49899 \mathrm{e}+021.49899 \mathrm{e}+01$ 1.00000e-09 7.00000e-02 5.00000e-04 5.00000e-04 5.00000e-05 1.00000e-09 1.00000e-01 5.00000e-04 5.00000e-04 5.00000e-05 1.00000e-09 1.00000e-01 5.98963e+00 5.98963e+00 5.98963e-01 1.00000e-09 2.12000e-01 5.98963e+00 5.98963e+00 5.98963e-01 1.00000e-09 2.12000e-01 5.98963e+00 5.98963e+00 5.98963e-01 1.00000e-09 2.12000e-01 5.98963e+00 5.98963e+00 5.98963e-01 1.00000e-09 2.12000e-01 5.98963e+00 5.98963e+00 5.98963e-01 1.00000e-09 2.12000e-01 $1.00000 \mathrm{e}-02$ 1.00000e-02 1.00000e-03 1.00000e-09 1.00000e-01 $1.00000 \mathrm{e}+001.00000 \mathrm{e}+001.00000 \mathrm{e}-011.00000 \mathrm{e}-091.00000 \mathrm{e}-01$ 
$1.00000 \mathrm{e}-05$ 1.00000e-05 1.00000e-06 1.00000e-09 1.00000e-01 $1.00000 \mathrm{e}+001.00000 \mathrm{e}+001.00000 \mathrm{e}-01$ 1.00000e-09 1.00000e-01 Element: 3232 \# of layers: 15

$\mathrm{Kx} \mathrm{Ky} \mathrm{Kz}$ Ss Por

1.37799e+02 1.37799e+02 1.37799e+01 1.00000e-09 7.00000e-02 $1.37799 \mathrm{e}+02$ 1.37799e+02 1.37799e+01 1.00000e-09 7.00000e-02 $1.37799 \mathrm{e}+02$ 1.37799e+02 1.37799e+01 1.00000e-09 7.00000e-02 $1.37799 \mathrm{e}+02$ 1.37799e+02 1.37799e+01 1.00000e-09 7.00000e-02 5.00000e-04 5.00000e-04 5.00000e-05 1.00000e-09 1.00000e-01 5.00000e-04 5.00000e-04 5.00000e-05 1.00000e-09 1.00000e-01 $5.50609 \mathrm{e}+00$ 5.50609e+00 5.50609e-01 1.00000e-09 2.12000e-01 $5.50609 \mathrm{e}+005.50609 \mathrm{e}+00$ 5.50609e-01 1.00000e-09 2.12000e-01 $5.50609 \mathrm{e}+00$ 5.50609e+00 5.50609e-01 1.00000e-09 2.12000e-01 $5.50609 \mathrm{e}+00$ 5.50609e+00 5.50609e-01 1.00000e-09 2.12000e-01 5.50609e+00 5.50609e+00 5.50609e-01 1.00000e-09 2.12000e-01 $1.00000 \mathrm{e}-02$ 1.00000e-02 1.00000e-03 1.00000e-09 1.00000e-01 $1.00000 \mathrm{e}+001.00000 \mathrm{e}+001.00000 \mathrm{e}-011.00000 \mathrm{e}-091.00000 \mathrm{e}-01$ $1.00000 \mathrm{e}-05$ 1.00000e-05 1.00000e-06 1.00000e-09 1.00000e-01 $1.00000 \mathrm{e}+001.00000 \mathrm{e}+001.00000 \mathrm{e}-01$ 1.00000e-09 1.00000e-01 Element: 3233 \# of layers: 15

$\mathrm{Kx} \mathrm{Ky} \mathrm{Kz}$ Ss Por

8.13062e+01 8.13062e+01 8.13062e+00 1.00000e-09 7.00000e-02 8.13062e+01 8.13062e+01 8.13062e+00 1.00000e-09 7.00000e-02 8.13062e+01 8.13062e+01 8.13062e+00 1.00000e-09 7.00000e-02 8.13062e+01 8.13062e+01 8.13062e+00 1.00000e-09 7.00000e-02 5.00000e-04 5.00000e-04 5.00000e-05 1.00000e-09 1.00000e-01 5.00000e-04 5.00000e-04 5.00000e-05 1.00000e-09 1.00000e-01 $3.24862 \mathrm{e}+00$ 3.24862e+00 3.24862e-01 1.00000e-09 2.12000e-01 $3.24862 \mathrm{e}+003.24862 \mathrm{e}+00$ 3.24862e-01 1.00000e-09 2.12000e-01 3.24862e+00 3.24862e+00 3.24862e-01 1.00000e-09 2.12000e-01 $3.24862 \mathrm{e}+003.24862 \mathrm{e}+00$ 3.24862e-01 1.00000e-09 2.12000e-01 $3.24862 \mathrm{e}+00$ 3.24862e+00 3.24862e-01 1.00000e-09 2.12000e-01 $1.00000 \mathrm{e}-02$ 1.00000e-02 1.00000e-03 1.00000e-09 1.00000e-01 $1.00000 \mathrm{e}+001.00000 \mathrm{e}+001.00000 \mathrm{e}-011.00000 \mathrm{e}-091.00000 \mathrm{e}-01$ $1.00000 \mathrm{e}-05$ 1.00000e-05 1.00000e-06 1.00000e-09 1.00000e-01 $1.00000 \mathrm{e}+001.00000 \mathrm{e}+001.00000 \mathrm{e}-011.00000 \mathrm{e}-091.00000 \mathrm{e}-01$ Element: 3234 \# of layers: 15

$\mathrm{Kx} \mathrm{Ky} \mathrm{Kz}$ Ss Por

8.13062e+01 8.13062e+01 8.13062e+00 1.00000e-09 7.00000e-02 8.13062e+01 8.13062e+01 8.13062e+00 1.00000e-09 7.00000e-02 8.13062e+01 8.13062e+01 8.13062e+00 1.00000e-09 7.00000e-02 8.13062e+01 8.13062e+01 8.13062e+00 1.00000e-09 7.00000e-02 5.00000e-04 5.00000e-04 5.00000e-05 1.00000e-09 1.00000e-01 $5.00000 \mathrm{e}-04$ 5.00000e-04 5.00000e-05 1.00000e-09 1.00000e-01 $3.24862 \mathrm{e}+00$ 3.24862e+00 3.24862e-01 1.00000e-09 2.12000e-01 $3.24862 \mathrm{e}+003.24862 \mathrm{e}+00$ 3.24862e-01 1.00000e-09 2.12000e-01 
$3.24862 \mathrm{e}+003.24862 \mathrm{e}+003.24862 \mathrm{e}-01$ 1.00000e-09 2.12000e-01 $3.24862 \mathrm{e}+003.24862 \mathrm{e}+003.24862 \mathrm{e}-01$ 1.00000e-09 2.12000e-01 $3.24862 \mathrm{e}+003.24862 \mathrm{e}+003.24862 \mathrm{e}-01$ 1.00000e-09 2.12000e-01 $1.00000 \mathrm{e}-021.00000 \mathrm{e}-02$ 1.00000e-03 1.00000e-09 1.00000e-01 $1.00000 \mathrm{e}+001.00000 \mathrm{e}+001.00000 \mathrm{e}-011.00000 \mathrm{e}-091.00000 \mathrm{e}-01$ $1.00000 \mathrm{e}-05$ 1.00000e-05 1.00000e-06 1.00000e-09 1.00000e-01 $1.00000 \mathrm{e}+001.00000 \mathrm{e}+001.00000 \mathrm{e}-011.00000 \mathrm{e}-091.00000 \mathrm{e}-01$ Element: 3235 \# of layers: 15

Kx Ky Kz Ss Por

8.13062e+01 8.13062e+01 8.13062e+00 1.00000e-09 7.00000e-02 $8.13062 \mathrm{e}+018.13062 \mathrm{e}+018.13062 \mathrm{e}+00$ 1.00000e-09 7.00000e-02 $8.13062 \mathrm{e}+018.13062 \mathrm{e}+018.13062 \mathrm{e}+00$ 1.00000e-09 7.00000e-02 $8.13062 \mathrm{e}+018.13062 \mathrm{e}+018.13062 \mathrm{e}+00$ 1.00000e-09 7.00000e-02 5.00000e-04 5.00000e-04 5.00000e-05 1.00000e-09 1.00000e-01 $5.00000 \mathrm{e}-04$ 5.00000e-04 5.00000e-05 1.00000e-09 1.00000e-01 $3.24862 \mathrm{e}+003.24862 \mathrm{e}+003.24862 \mathrm{e}-01$ 1.00000e-09 2.12000e-01 $3.24862 \mathrm{e}+003.24862 \mathrm{e}+003.24862 \mathrm{e}-01$ 1.00000e-09 2.12000e-01 $3.24862 \mathrm{e}+003.24862 \mathrm{e}+003.24862 \mathrm{e}-01$ 1.00000e-09 2.12000e-01 $3.24862 \mathrm{e}+003.24862 \mathrm{e}+003.24862 \mathrm{e}-011.00000 \mathrm{e}-092.12000 \mathrm{e}-01$ $3.24862 \mathrm{e}+003.24862 \mathrm{e}+003.24862 \mathrm{e}-01$ 1.00000e-09 2.12000e-01 $1.00000 \mathrm{e}-021.00000 \mathrm{e}-02$ 1.00000e-03 1.00000e-09 1.00000e-01 $1.00000 \mathrm{e}+001.00000 \mathrm{e}+001.00000 \mathrm{e}-011.00000 \mathrm{e}-091.00000 \mathrm{e}-01$ $1.00000 \mathrm{e}-05$ 1.00000e-05 1.00000e-06 1.00000e-09 1.00000e-01 $1.00000 \mathrm{e}+001.00000 \mathrm{e}+001.00000 \mathrm{e}-011.00000 \mathrm{e}-091.00000 \mathrm{e}-01$ Element: 3236 \# of layers: 15

Kx Ky Kz Ss Por

$9.86955 \mathrm{e}+01$ 9.86955e+01 9.86955e+00 1.00000e-09 7.00000e-02 $9.86955 \mathrm{e}+019.86955 \mathrm{e}+019.86955 \mathrm{e}+001.00000 \mathrm{e}-09$ 7.00000e-02 $9.86955 \mathrm{e}+019.86955 \mathrm{e}+019.86955 \mathrm{e}+001.00000 \mathrm{e}-09$ 7.00000e-02 $9.86955 \mathrm{e}+019.86955 \mathrm{e}+019.86955 \mathrm{e}+001.00000 \mathrm{e}-09$ 7.00000e-02 5.00000e-04 5.00000e-04 5.00000e-05 1.00000e-09 1.00000e-01 5.00000e-04 5.00000e-04 5.00000e-05 1.00000e-09 1.00000e-01 $3.94366 \mathrm{e}+003.94366 \mathrm{e}+003.94366 \mathrm{e}-01$ 1.00000e-09 2.12000e-01 $3.94366 \mathrm{e}+003.94366 \mathrm{e}+003.94366 \mathrm{e}-01$ 1.00000e-09 2.12000e-01 $3.94366 \mathrm{e}+003.94366 \mathrm{e}+003.94366 \mathrm{e}-011.00000 \mathrm{e}-092.12000 \mathrm{e}-01$ $3.94366 \mathrm{e}+003.94366 \mathrm{e}+003.94366 \mathrm{e}-01$ 1.00000e-09 2.12000e-01 $3.94366 \mathrm{e}+003.94366 \mathrm{e}+003.94366 \mathrm{e}-011.00000 \mathrm{e}-092.12000 \mathrm{e}-01$ $1.00000 \mathrm{e}-021.00000 \mathrm{e}-02$ 1.00000e-03 1.00000e-09 1.00000e-01 $1.00000 \mathrm{e}+001.00000 \mathrm{e}+001.00000 \mathrm{e}-011.00000 \mathrm{e}-091.00000 \mathrm{e}-01$ $1.00000 \mathrm{e}-05$ 1.00000e-05 1.00000e-06 1.00000e-09 1.00000e-01 $1.00000 \mathrm{e}+001.00000 \mathrm{e}+001.00000 \mathrm{e}-011.00000 \mathrm{e}-091.00000 \mathrm{e}-01$ Element: 3237 \# of layers: 15

Kx Ky Kz Ss Por $9.86955 \mathrm{e}+019.86955 \mathrm{e}+01$ 9.86955e+00 1.00000e-09 7.00000e-02 $9.86955 \mathrm{e}+019.86955 \mathrm{e}+019.86955 \mathrm{e}+001.00000 \mathrm{e}-09$ 7.00000e-02 $9.86955 \mathrm{e}+019.86955 \mathrm{e}+019.86955 \mathrm{e}+001.00000 \mathrm{e}-09$ 7.00000e-02 
9.86955e+01 9.86955e+01 9.86955e+00 1.00000e-09 7.00000e-02 5.00000e-04 5.00000e-04 5.00000e-05 1.00000e-09 1.00000e-01 5.00000e-04 5.00000e-04 5.00000e-05 1.00000e-09 1.00000e-01 $3.94366 \mathrm{e}+003.94366 \mathrm{e}+00$ 3.94366e-01 1.00000e-09 2.12000e-01 $3.94366 \mathrm{e}+003.94366 \mathrm{e}+00$ 3.94366e-01 1.00000e-09 2.12000e-01 $3.94366 \mathrm{e}+003.94366 \mathrm{e}+00$ 3.94366e-01 1.00000e-09 2.12000e-01 3.94366e+00 3.94366e+00 3.94366e-01 1.00000e-09 2.12000e-01 $3.94366 \mathrm{e}+003.94366 \mathrm{e}+00$ 3.94366e-01 1.00000e-09 2.12000e-01 $1.00000 \mathrm{e}-02$ 1.00000e-02 1.00000e-03 1.00000e-09 1.00000e-01 $1.00000 \mathrm{e}+001.00000 \mathrm{e}+001.00000 \mathrm{e}-011.00000 \mathrm{e}-091.00000 \mathrm{e}-01$ $1.00000 \mathrm{e}-05$ 1.00000e-05 1.00000e-06 1.00000e-09 1.00000e-01 $1.00000 \mathrm{e}+001.00000 \mathrm{e}+001.00000 \mathrm{e}-011.00000 \mathrm{e}-091.00000 \mathrm{e}-01$ Element: 3238 \# of layers: 15

$\mathrm{Kx} \mathrm{Ky} \mathrm{Kz}$ Ss Por

8.13062e+01 8.13062e+01 8.13062e+00 1.00000e-09 7.00000e-02 $8.13062 \mathrm{e}+018.13062 \mathrm{e}+018.13062 \mathrm{e}+00$ 1.00000e-09 7.00000e-02 8.13062e+01 8.13062e+01 8.13062e+00 1.00000e-09 7.00000e-02 8.13062e+01 8.13062e+01 8.13062e+00 1.00000e-09 7.00000e-02 5.00000e-04 5.00000e-04 5.00000e-05 1.00000e-09 1.00000e-01 5.00000e-04 5.00000e-04 5.00000e-05 1.00000e-09 1.00000e-01 $3.24862 \mathrm{e}+003.24862 \mathrm{e}+00$ 3.24862e-01 1.00000e-09 2.12000e-01 3.24862e+00 3.24862e+00 3.24862e-01 1.00000e-09 2.12000e-01 $3.24862 \mathrm{e}+003.24862 \mathrm{e}+003.24862 \mathrm{e}-01$ 1.00000e-09 2.12000e-01 $3.24862 \mathrm{e}+003.24862 \mathrm{e}+00$ 3.24862e-01 1.00000e-09 2.12000e-01 $3.24862 \mathrm{e}+003.24862 \mathrm{e}+003.24862 \mathrm{e}-01$ 1.00000e-09 2.12000e-01 $1.00000 \mathrm{e}-021.00000 \mathrm{e}-021.00000 \mathrm{e}-031.00000 \mathrm{e}-091.00000 \mathrm{e}-01$ $1.00000 \mathrm{e}+001.00000 \mathrm{e}+001.00000 \mathrm{e}-011.00000 \mathrm{e}-091.00000 \mathrm{e}-01$ $1.00000 \mathrm{e}-05$ 1.00000e-05 1.00000e-06 1.00000e-09 1.00000e-01 $1.00000 \mathrm{e}+001.00000 \mathrm{e}+001.00000 \mathrm{e}-011.00000 \mathrm{e}-091.00000 \mathrm{e}-01$ Element: 3239 \# of layers: 16

$\mathrm{Kx} \mathrm{Ky} \mathrm{Kz}$ Ss Por

$1.15905 \mathrm{e}+02$ 1.15905e+02 1.15905e+01 1.00000e-09 7.00000e-02 $1.15905 \mathrm{e}+021.15905 \mathrm{e}+02$ 1.15905e+01 1.00000e-09 7.00000e-02 $1.15905 \mathrm{e}+02$ 1.15905e+02 1.15905e+01 1.00000e-09 7.00000e-02 $1.15905 \mathrm{e}+02$ 1.15905e+02 1.15905e+01 1.00000e-09 7.00000e-02 $1.15905 \mathrm{e}+021.15905 \mathrm{e}+021.15905 \mathrm{e}+01$ 1.00000e-09 7.00000e-02 5.00000e-04 5.00000e-04 5.00000e-05 1.00000e-09 1.00000e-01 5.00000e-04 5.00000e-04 5.00000e-05 1.00000e-09 1.00000e-01 $4.63105 \mathrm{e}+004.63105 \mathrm{e}+00$ 4.63105e-01 1.00000e-09 2.12000e-01 $4.63105 \mathrm{e}+00$ 4.63105e+00 4.63105e-01 1.00000e-09 2.12000e-01 $4.63105 \mathrm{e}+004.63105 \mathrm{e}+00$ 4.63105e-01 1.00000e-09 2.12000e-01 $4.63105 \mathrm{e}+004.63105 \mathrm{e}+00$ 4.63105e-01 1.00000e-09 2.12000e-01 4.63105e+00 4.63105e+00 4.63105e-01 1.00000e-09 2.12000e-01 $1.00000 \mathrm{e}-02$ 1.00000e-02 1.00000e-03 1.00000e-09 1.00000e-01 $1.00000 \mathrm{e}+001.00000 \mathrm{e}+001.00000 \mathrm{e}-011.00000 \mathrm{e}-091.00000 \mathrm{e}-01$ $1.00000 \mathrm{e}-05$ 1.00000e-05 1.00000e-06 1.00000e-09 1.00000e-01 
$1.00000 \mathrm{e}+001.00000 \mathrm{e}+00$ 1.00000e-01 1.00000e-09 1.00000e-01

Element: 3240 \# of layers: 15

Kx Ky Kz Ss Por

$1.07670 \mathrm{e}+02$ 1.07670e+02 1.07670e+01 1.00000e-09 7.00000e-02

$1.07670 \mathrm{e}+021.07670 \mathrm{e}+021.07670 \mathrm{e}+01$ 1.00000e-09 7.00000e-02

$1.07670 \mathrm{e}+021.07670 \mathrm{e}+02$ 1.07670e+01 1.00000e-09 7.00000e-02

$1.07670 \mathrm{e}+021.07670 \mathrm{e}+02$ 1.07670e+01 1.00000e-09 7.00000e-02

5.00000e-04 5.00000e-04 5.00000e-05 1.00000e-09 1.00000e-01

5.00000e-04 5.00000e-04 5.00000e-05 1.00000e-09 1.00000e-01

$4.30209 \mathrm{e}+00$ 4.30209e+00 4.30209e-01 1.00000e-09 2.12000e-01

4.30209e+00 4.30209e+00 4.30209e-01 1.00000e-09 2.12000e-01

$4.30209 \mathrm{e}+00$ 4.30209e+00 4.30209e-01 1.00000e-09 2.12000e-01

4.30209e+00 4.30209e+00 4.30209e-01 1.00000e-09 2.12000e-01

4.30209e+00 4.30209e+00 4.30209e-01 1.00000e-09 2.12000e-01

$1.00000 \mathrm{e}-02$ 1.00000e-02 1.00000e-03 1.00000e-09 1.00000e-01

$1.00000 \mathrm{e}+001.00000 \mathrm{e}+001.00000 \mathrm{e}-011.00000 \mathrm{e}-091.00000 \mathrm{e}-01$

$1.00000 \mathrm{e}-05$ 1.00000e-05 1.00000e-06 1.00000e-09 1.00000e-01

$1.00000 \mathrm{e}+001.00000 \mathrm{e}+001.00000 \mathrm{e}-01$ 1.00000e-09 1.00000e-01

Element: 3241 \# of layers: 15

$\mathrm{Kx} \mathrm{Ky} \mathrm{Kz}$ Ss Por

8.13062e+01 8.13062e+01 8.13062e+00 1.00000e-09 7.00000e-02

8.13062e+01 8.13062e+01 8.13062e+00 1.00000e-09 7.00000e-02

8.13062e+01 8.13062e+01 8.13062e+00 1.00000e-09 7.00000e-02

8.13062e+01 8.13062e+01 8.13062e+00 1.00000e-09 7.00000e-02

5.00000e-04 5.00000e-04 5.00000e-05 1.00000e-09 1.00000e-01

5.00000e-04 5.00000e-04 5.00000e-05 1.00000e-09 1.00000e-01

$3.24862 \mathrm{e}+003.24862 \mathrm{e}+00$ 3.24862e-01 1.00000e-09 2.12000e-01

3.24862e+00 3.24862e+00 3.24862e-01 1.00000e-09 2.12000e-01

$3.24862 \mathrm{e}+003.24862 \mathrm{e}+00$ 3.24862e-01 1.00000e-09 2.12000e-01

$3.24862 \mathrm{e}+00$ 3.24862e+00 3.24862e-01 1.00000e-09 2.12000e-01

$3.24862 \mathrm{e}+003.24862 \mathrm{e}+00$ 3.24862e-01 1.00000e-09 2.12000e-01

$1.00000 \mathrm{e}-02$ 1.00000e-02 1.00000e-03 1.00000e-09 1.00000e-01

$1.00000 \mathrm{e}+001.00000 \mathrm{e}+001.00000 \mathrm{e}-011.00000 \mathrm{e}-091.00000 \mathrm{e}-01$

$1.00000 \mathrm{e}-05$ 1.00000e-05 1.00000e-06 1.00000e-09 1.00000e-01

$1.00000 \mathrm{e}+001.00000 \mathrm{e}+001.00000 \mathrm{e}-011.00000 \mathrm{e}-091.00000 \mathrm{e}-01$

Element: 3242 \# of layers: 15

Kx Ky Kz Ss Por

4.73403e+01 4.73403e+01 4.73403e+00 1.00000e-09 7.00000e-02

4.73403e+01 4.73403e+01 4.73403e+00 1.00000e-09 7.00000e-02

4.73403e+01 4.73403e+01 4.73403e+00 1.00000e-09 7.00000e-02

4.73403e+01 4.73403e+01 4.73403e+00 1.00000e-09 7.00000e-02

5.00000e-04 5.00000e-04 5.00000e-05 1.00000e-09 1.00000e-01

5.00000e-04 5.00000e-04 5.00000e-05 1.00000e-09 1.00000e-01

$1.89155 \mathrm{e}+001.89155 \mathrm{e}+00$ 1.89155e-01 1.00000e-09 2.12000e-01

$1.89155 \mathrm{e}+001.89155 \mathrm{e}+001.89155 \mathrm{e}-01$ 1.00000e-09 2.12000e-01

$1.89155 \mathrm{e}+001.89155 \mathrm{e}+001.89155 \mathrm{e}-01$ 1.00000e-09 2.12000e-01 
$1.89155 \mathrm{e}+001.89155 \mathrm{e}+00$ 1.89155e-01 1.00000e-09 2.12000e-01 $1.89155 \mathrm{e}+001.89155 \mathrm{e}+001.89155 \mathrm{e}-01$ 1.00000e-09 2.12000e-01 $1.00000 \mathrm{e}-02$ 1.00000e-02 1.00000e-03 1.00000e-09 1.00000e-01 $1.00000 \mathrm{e}+001.00000 \mathrm{e}+001.00000 \mathrm{e}-011.00000 \mathrm{e}-091.00000 \mathrm{e}-01$ $1.00000 \mathrm{e}-05$ 1.00000e-05 1.00000e-06 1.00000e-09 1.00000e-01 $1.00000 \mathrm{e}+001.00000 \mathrm{e}+001.00000 \mathrm{e}-011.00000 \mathrm{e}-091.00000 \mathrm{e}-01$ Element: 3243 \# of layers: 16

$\mathrm{Kx} \mathrm{Ky} \mathrm{Kz}$ Ss Por

4.73403e+01 4.73403e+01 4.73403e+00 1.00000e-09 7.00000e-02 $4.73403 \mathrm{e}+014.73403 \mathrm{e}+01$ 4.73403e+00 1.00000e-09 7.00000e-02 $4.73403 \mathrm{e}+01$ 4.73403e+01 4.73403e+00 1.00000e-09 7.00000e-02 4.73403e+01 4.73403e+01 4.73403e+00 1.00000e-09 7.00000e-02 4.73403e+01 4.73403e+01 4.73403e+00 1.00000e-09 7.00000e-02 5.00000e-04 5.00000e-04 5.00000e-05 1.00000e-09 1.00000e-01 5.00000e-04 5.00000e-04 5.00000e-05 1.00000e-09 1.00000e-01 $1.89155 \mathrm{e}+001.89155 \mathrm{e}+001.89155 \mathrm{e}-01$ 1.00000e-09 2.12000e-01 $1.89155 \mathrm{e}+001.89155 \mathrm{e}+00$ 1.89155e-01 1.00000e-09 2.12000e-01 $1.89155 \mathrm{e}+001.89155 \mathrm{e}+00$ 1.89155e-01 1.00000e-09 2.12000e-01 $1.89155 \mathrm{e}+001.89155 \mathrm{e}+001.89155 \mathrm{e}-011.00000 \mathrm{e}-092.12000 \mathrm{e}-01$ $1.89155 \mathrm{e}+001.89155 \mathrm{e}+001.89155 \mathrm{e}-011.00000 \mathrm{e}-092.12000 \mathrm{e}-01$ $1.00000 \mathrm{e}-02$ 1.00000e-02 1.00000e-03 1.00000e-09 1.00000e-01 $1.00000 \mathrm{e}+001.00000 \mathrm{e}+001.00000 \mathrm{e}-011.00000 \mathrm{e}-091.00000 \mathrm{e}-01$ $1.00000 \mathrm{e}-05$ 1.00000e-05 1.00000e-06 1.00000e-09 1.00000e-01 $1.00000 \mathrm{e}+001.00000 \mathrm{e}+001.00000 \mathrm{e}-011.00000 \mathrm{e}-09$ 1.00000e-01 Element: 3244 \# of layers: 15

$\mathrm{Kx} \mathrm{Ky} \mathrm{Kz}$ Ss Por

4.73403e+01 4.73403e+01 4.73403e+00 1.00000e-09 7.00000e-02 $4.73403 \mathrm{e}+01$ 4.73403e+01 4.73403e+00 1.00000e-09 7.00000e-02 4.73403e+01 4.73403e+01 4.73403e+00 1.00000e-09 7.00000e-02 4.73403e+01 4.73403e+01 4.73403e+00 1.00000e-09 7.00000e-02 $5.00000 \mathrm{e}-04$ 5.00000e-04 5.00000e-05 1.00000e-09 1.00000e-01 5.00000e-04 5.00000e-04 5.00000e-05 1.00000e-09 1.00000e-01 $1.89155 \mathrm{e}+001.89155 \mathrm{e}+001.89155 \mathrm{e}-01$ 1.00000e-09 2.12000e-01 $1.89155 \mathrm{e}+001.89155 \mathrm{e}+00$ 1.89155e-01 1.00000e-09 2.12000e-01 $1.89155 \mathrm{e}+001.89155 \mathrm{e}+00$ 1.89155e-01 1.00000e-09 2.12000e-01 $1.89155 \mathrm{e}+001.89155 \mathrm{e}+00$ 1.89155e-01 1.00000e-09 2.12000e-01 $1.89155 \mathrm{e}+001.89155 \mathrm{e}+001.89155 \mathrm{e}-011.00000 \mathrm{e}-092.12000 \mathrm{e}-01$ $1.00000 \mathrm{e}-02$ 1.00000e-02 1.00000e-03 1.00000e-09 1.00000e-01 $1.00000 \mathrm{e}+001.00000 \mathrm{e}+001.00000 \mathrm{e}-011.00000 \mathrm{e}-091.00000 \mathrm{e}-01$ $1.00000 \mathrm{e}-05$ 1.00000e-05 1.00000e-06 1.00000e-09 1.00000e-01 $1.00000 \mathrm{e}+001.00000 \mathrm{e}+001.00000 \mathrm{e}-011.00000 \mathrm{e}-091.00000 \mathrm{e}-01$ Element: 3245 \# of layers: 15

$\mathrm{Kx} \mathrm{Ky} \mathrm{Kz}$ Ss Por

4.73403e+01 4.73403e+01 4.73403e+00 1.00000e-09 7.00000e-02 4.73403e+01 4.73403e+01 4.73403e+00 1.00000e-09 7.00000e-02 $4.73403 e+014.73403 e+014.73403 e+00$ 1.00000e-09 7.00000e-02 
4.73403e+01 4.73403e+01 4.73403e+00 1.00000e-09 7.00000e-02 5.00000e-04 5.00000e-04 5.00000e-05 1.00000e-09 1.00000e-01 5.00000e-04 5.00000e-04 5.00000e-05 1.00000e-09 1.00000e-01 $1.89155 \mathrm{e}+001.89155 \mathrm{e}+001.89155 \mathrm{e}-01$ 1.00000e-09 2.12000e-01 $1.89155 \mathrm{e}+001.89155 \mathrm{e}+00$ 1.89155e-01 1.00000e-09 2.12000e-01 $1.89155 \mathrm{e}+001.89155 \mathrm{e}+001.89155 \mathrm{e}-01$ 1.00000e-09 2.12000e-01 $1.89155 \mathrm{e}+001.89155 \mathrm{e}+001.89155 \mathrm{e}-01$ 1.00000e-09 2.12000e-01 $1.89155 \mathrm{e}+001.89155 \mathrm{e}+001.89155 \mathrm{e}-01$ 1.00000e-09 2.12000e-01 $1.00000 \mathrm{e}-021.00000 \mathrm{e}-021.00000 \mathrm{e}-031.00000 \mathrm{e}-091.00000 \mathrm{e}-01$ $1.00000 \mathrm{e}+001.00000 \mathrm{e}+001.00000 \mathrm{e}-011.00000 \mathrm{e}-091.00000 \mathrm{e}-01$ $1.00000 \mathrm{e}-05$ 1.00000e-05 1.00000e-06 1.00000e-09 1.00000e-01 $1.00000 \mathrm{e}+001.00000 \mathrm{e}+001.00000 \mathrm{e}-011.00000 \mathrm{e}-091.00000 \mathrm{e}-01$ Element: 3246 \# of layers: 15

$\mathrm{Kx} \mathrm{Ky} \mathrm{Kz}$ Ss Por

4.73403e+01 4.73403e+01 4.73403e+00 1.00000e-09 7.00000e-02 $4.73403 \mathrm{e}+014.73403 \mathrm{e}+014.73403 \mathrm{e}+00$ 1.00000e-09 7.00000e-02 4.73403e+01 4.73403e+01 4.73403e+00 1.00000e-09 7.00000e-02 4.73403e+01 4.73403e+01 4.73403e+00 1.00000e-09 7.00000e-02 $5.00000 \mathrm{e}-045.00000 \mathrm{e}-045.00000 \mathrm{e}-051.00000 \mathrm{e}-091.00000 \mathrm{e}-01$ 5.00000e-04 5.00000e-04 5.00000e-05 1.00000e-09 1.00000e-01 $1.89155 \mathrm{e}+001.89155 \mathrm{e}+001.89155 \mathrm{e}-011.00000 \mathrm{e}-092.12000 \mathrm{e}-01$ $1.89155 \mathrm{e}+001.89155 \mathrm{e}+00$ 1.89155e-01 1.00000e-09 2.12000e-01 $1.89155 \mathrm{e}+001.89155 \mathrm{e}+00$ 1.89155e-01 1.00000e-09 2.12000e-01 $1.89155 \mathrm{e}+001.89155 \mathrm{e}+001.89155 \mathrm{e}-01$ 1.00000e-09 2.12000e-01 $1.89155 \mathrm{e}+001.89155 \mathrm{e}+001.89155 \mathrm{e}-011.00000 \mathrm{e}-092.12000 \mathrm{e}-01$ $1.00000 \mathrm{e}-02$ 1.00000e-02 1.00000e-03 1.00000e-09 1.00000e-01 $1.00000 \mathrm{e}+001.00000 \mathrm{e}+001.00000 \mathrm{e}-011.00000 \mathrm{e}-091.00000 \mathrm{e}-01$ $1.00000 \mathrm{e}-05$ 1.00000e-05 1.00000e-06 1.00000e-09 1.00000e-01 $1.00000 \mathrm{e}+001.00000 \mathrm{e}+001.00000 \mathrm{e}-011.00000 \mathrm{e}-091.00000 \mathrm{e}-01$ Element: 3247 \# of layers: 16

$\mathrm{Kx} \mathrm{Ky} \mathrm{Kz}$ Ss Por

4.73403e+01 4.73403e+01 4.73403e+00 1.00000e-09 7.00000e-02 4.73403e+01 4.73403e+01 4.73403e+00 1.00000e-09 7.00000e-02 4.73403e+01 4.73403e+01 4.73403e+00 1.00000e-09 7.00000e-02 4.73403e+01 4.73403e+01 4.73403e+00 1.00000e-09 7.00000e-02 4.73403e+01 4.73403e+01 4.73403e+00 1.00000e-09 7.00000e-02 5.00000e-04 5.00000e-04 5.00000e-05 1.00000e-09 1.00000e-01 5.00000e-04 5.00000e-04 5.00000e-05 1.00000e-09 1.00000e-01 $1.89155 \mathrm{e}+001.89155 \mathrm{e}+001.89155 \mathrm{e}-01$ 1.00000e-09 2.12000e-01 $1.89155 \mathrm{e}+001.89155 \mathrm{e}+00$ 1.89155e-01 1.00000e-09 2.12000e-01 $1.89155 \mathrm{e}+001.89155 \mathrm{e}+001.89155 \mathrm{e}-01$ 1.00000e-09 2.12000e-01 $1.89155 \mathrm{e}+001.89155 \mathrm{e}+00$ 1.89155e-01 1.00000e-09 2.12000e-01 $1.89155 \mathrm{e}+001.89155 \mathrm{e}+001.89155 \mathrm{e}-01$ 1.00000e-09 2.12000e-01 $1.00000 \mathrm{e}-02$ 1.00000e-02 1.00000e-03 1.00000e-09 1.00000e-01 $1.00000 \mathrm{e}+001.00000 \mathrm{e}+001.00000 \mathrm{e}-011.00000 \mathrm{e}-091.00000 \mathrm{e}-01$ $1.00000 \mathrm{e}-05$ 1.00000e-05 1.00000e-06 1.00000e-09 1.00000e-01 
$1.00000 \mathrm{e}+001.00000 \mathrm{e}+00$ 1.00000e-01 1.00000e-09 1.00000e-01

Element: 3248 \# of layers: 15

$\mathrm{Kx} \mathrm{Ky} \mathrm{Kz}$ Ss Por

4.73403e+01 4.73403e+01 4.73403e+00 1.00000e-09 7.00000e-02

4.73403e+01 4.73403e+01 4.73403e+00 1.00000e-09 7.00000e-02

4.73403e+01 4.73403e+01 4.73403e+00 1.00000e-09 7.00000e-02

4.73403e+01 4.73403e+01 4.73403e+00 1.00000e-09 7.00000e-02

5.00000e-04 5.00000e-04 5.00000e-05 1.00000e-09 1.00000e-01

5.00000e-04 5.00000e-04 5.00000e-05 1.00000e-09 1.00000e-01

$1.89155 \mathrm{e}+001.89155 \mathrm{e}+001.89155 \mathrm{e}-01$ 1.00000e-09 2.12000e-01

$1.89155 \mathrm{e}+001.89155 \mathrm{e}+00$ 1.89155e-01 1.00000e-09 2.12000e-01

$1.89155 \mathrm{e}+001.89155 \mathrm{e}+001.89155 \mathrm{e}-01$ 1.00000e-09 2.12000e-01

$1.89155 \mathrm{e}+001.89155 \mathrm{e}+00$ 1.89155e-01 1.00000e-09 2.12000e-01

$1.89155 \mathrm{e}+001.89155 \mathrm{e}+001.89155 \mathrm{e}-01$ 1.00000e-09 2.12000e-01

$1.00000 \mathrm{e}-02$ 1.00000e-02 1.00000e-03 1.00000e-09 1.00000e-01

$1.00000 \mathrm{e}+001.00000 \mathrm{e}+001.00000 \mathrm{e}-011.00000 \mathrm{e}-091.00000 \mathrm{e}-01$

$1.00000 \mathrm{e}-05$ 1.00000e-05 1.00000e-06 1.00000e-09 1.00000e-01

$1.00000 \mathrm{e}+001.00000 \mathrm{e}+001.00000 \mathrm{e}-01$ 1.00000e-09 1.00000e-01

Element: 3249 \# of layers: 15

$\mathrm{Kx} \mathrm{Ky} \mathrm{Kz}$ Ss Por

4.73403e+01 4.73403e+01 4.73403e+00 1.00000e-09 7.00000e-02

4.73403e+01 4.73403e+01 4.73403e+00 1.00000e-09 7.00000e-02

4.73403e+01 4.73403e+01 4.73403e+00 1.00000e-09 7.00000e-02

4.73403e+01 4.73403e+01 4.73403e+00 1.00000e-09 7.00000e-02

5.00000e-04 5.00000e-04 5.00000e-05 1.00000e-09 1.00000e-01

$5.00000 \mathrm{e}-04$ 5.00000e-04 5.00000e-05 1.00000e-09 1.00000e-01

$1.89155 \mathrm{e}+001.89155 \mathrm{e}+00$ 1.89155e-01 1.00000e-09 2.12000e-01

$1.89155 \mathrm{e}+001.89155 \mathrm{e}+00$ 1.89155e-01 1.00000e-09 2.12000e-01

$1.89155 \mathrm{e}+001.89155 \mathrm{e}+001.89155 \mathrm{e}-01$ 1.00000e-09 2.12000e-01

$1.89155 \mathrm{e}+001.89155 \mathrm{e}+00$ 1.89155e-01 1.00000e-09 2.12000e-01

$1.89155 \mathrm{e}+001.89155 \mathrm{e}+001.89155 \mathrm{e}-01$ 1.00000e-09 2.12000e-01

1.00000e-02 1.00000e-02 1.00000e-03 1.00000e-09 1.00000e-01

$1.00000 \mathrm{e}+001.00000 \mathrm{e}+001.00000 \mathrm{e}-011.00000 \mathrm{e}-091.00000 \mathrm{e}-01$

$1.00000 \mathrm{e}-05$ 1.00000e-05 1.00000e-06 1.00000e-09 1.00000e-01

$1.00000 \mathrm{e}+001.00000 \mathrm{e}+001.00000 \mathrm{e}-011.00000 \mathrm{e}-091.00000 \mathrm{e}-01$

Element: 3250 \# of layers: 16

Kx Ky Kz Ss Por

4.73403e+01 4.73403e+01 4.73403e+00 1.00000e-09 7.00000e-02

4.73403e+01 4.73403e+01 4.73403e+00 1.00000e-09 7.00000e-02

4.73403e+01 4.73403e+01 4.73403e+00 1.00000e-09 7.00000e-02

$4.73403 \mathrm{e}+01$ 4.73403e+01 4.73403e+00 1.00000e-09 7.00000e-02

4.73403e+01 4.73403e+01 4.73403e+00 1.00000e-09 7.00000e-02

$5.00000 \mathrm{e}-04$ 5.00000e-04 5.00000e-05 1.00000e-09 1.00000e-01

$5.00000 \mathrm{e}-04$ 5.00000e-04 5.00000e-05 1.00000e-09 1.00000e-01

$1.89155 \mathrm{e}+001.89155 \mathrm{e}+001.89155 \mathrm{e}-01$ 1.00000e-09 2.12000e-01

$1.89155 \mathrm{e}+001.89155 \mathrm{e}+001.89155 \mathrm{e}-01$ 1.00000e-09 2.12000e-01 
$1.89155 \mathrm{e}+001.89155 \mathrm{e}+00$ 1.89155e-01 1.00000e-09 2.12000e-01 $1.89155 \mathrm{e}+001.89155 \mathrm{e}+00$ 1.89155e-01 1.00000e-09 2.12000e-01 $1.89155 \mathrm{e}+001.89155 \mathrm{e}+001.89155 \mathrm{e}-01$ 1.00000e-09 2.12000e-01 $1.00000 \mathrm{e}-02$ 1.00000e-02 1.00000e-03 1.00000e-09 1.00000e-01 $1.00000 \mathrm{e}+001.00000 \mathrm{e}+001.00000 \mathrm{e}-011.00000 \mathrm{e}-091.00000 \mathrm{e}-01$ $1.00000 \mathrm{e}-05$ 1.00000e-05 1.00000e-06 1.00000e-09 1.00000e-01 $1.00000 \mathrm{e}+001.00000 \mathrm{e}+001.00000 \mathrm{e}-011.00000 \mathrm{e}-091.00000 \mathrm{e}-01$ Element: 3251 \# of layers: 15

$\mathrm{Kx} \mathrm{Ky} \mathrm{Kz}$ Ss Por

4.30354e+01 4.30354e+01 4.30354e+00 1.00000e-09 7.00000e-02 $4.30354 \mathrm{e}+014.30354 \mathrm{e}+014.30354 \mathrm{e}+00$ 1.00000e-09 7.00000e-02 $4.30354 \mathrm{e}+014.30354 \mathrm{e}+014.30354 \mathrm{e}+001.00000 \mathrm{e}-09$ 7.00000e-02 $4.30354 \mathrm{e}+014.30354 \mathrm{e}+014.30354 \mathrm{e}+001.00000 \mathrm{e}-09$ 7.00000e-02 5.00000e-04 5.00000e-04 5.00000e-05 1.00000e-09 1.00000e-01 5.00000e-04 5.00000e-04 5.00000e-05 1.00000e-09 1.00000e-01 $1.71955 \mathrm{e}+001.71955 \mathrm{e}+00$ 1.71955e-01 1.00000e-09 2.12000e-01 $1.71955 \mathrm{e}+001.71955 \mathrm{e}+00$ 1.71955e-01 1.00000e-09 2.12000e-01 $1.71955 \mathrm{e}+001.71955 \mathrm{e}+00$ 1.71955e-01 1.00000e-09 2.12000e-01 $1.71955 \mathrm{e}+001.71955 \mathrm{e}+00$ 1.71955e-01 1.00000e-09 2.12000e-01 $1.71955 \mathrm{e}+001.71955 \mathrm{e}+001.71955 \mathrm{e}-011.00000 \mathrm{e}-092.12000 \mathrm{e}-01$ $1.00000 \mathrm{e}-02$ 1.00000e-02 1.00000e-03 1.00000e-09 1.00000e-01 $1.00000 \mathrm{e}+001.00000 \mathrm{e}+001.00000 \mathrm{e}-011.00000 \mathrm{e}-091.00000 \mathrm{e}-01$ $1.00000 \mathrm{e}-051.00000 \mathrm{e}-05$ 1.00000e-06 1.00000e-09 1.00000e-01 $1.00000 \mathrm{e}+001.00000 \mathrm{e}+001.00000 \mathrm{e}-011.00000 \mathrm{e}-09$ 1.00000e-01 Element: 3252 \# of layers: 14

$\mathrm{Kx} \mathrm{Ky} \mathrm{Kz}$ Ss Por

4.30354e+01 4.30354e+01 4.30354e+00 1.00000e-09 7.00000e-02 4.30354e+01 4.30354e+01 4.30354e+00 1.00000e-09 7.00000e-02 $4.30354 \mathrm{e}+014.30354 \mathrm{e}+014.30354 \mathrm{e}+001.00000 \mathrm{e}-097.00000 \mathrm{e}-02$ 5.00000e-04 5.00000e-04 5.00000e-05 1.00000e-09 1.00000e-01 5.00000e-04 5.00000e-04 5.00000e-05 1.00000e-09 1.00000e-01 $1.71955 \mathrm{e}+001.71955 \mathrm{e}+00$ 1.71955e-01 1.00000e-09 2.12000e-01 $1.71955 \mathrm{e}+001.71955 \mathrm{e}+00$ 1.71955e-01 1.00000e-09 2.12000e-01 $1.71955 \mathrm{e}+00$ 1.71955e+00 1.71955e-01 1.00000e-09 2.12000e-01 $1.71955 \mathrm{e}+001.71955 \mathrm{e}+00$ 1.71955e-01 1.00000e-09 2.12000e-01 $1.71955 \mathrm{e}+001.71955 \mathrm{e}+00$ 1.71955e-01 1.00000e-09 2.12000e-01 $1.00000 \mathrm{e}-02$ 1.00000e-02 1.00000e-03 1.00000e-09 1.00000e-01 $1.00000 \mathrm{e}+001.00000 \mathrm{e}+001.00000 \mathrm{e}-011.00000 \mathrm{e}-091.00000 \mathrm{e}-01$ $1.00000 \mathrm{e}-05$ 1.00000e-05 1.00000e-06 1.00000e-09 1.00000e-01 $1.00000 \mathrm{e}+001.00000 \mathrm{e}+001.00000 \mathrm{e}-01$ 1.00000e-09 1.00000e-01 Element: 3253 \# of layers: 14

$\mathrm{Kx} \mathrm{Ky} \mathrm{Kz}$ Ss Por

4.30354e+01 4.30354e+01 4.30354e+00 1.00000e-09 7.00000e-02 4.30354e+01 4.30354e+01 4.30354e+00 1.00000e-09 7.00000e-02 $4.30354 \mathrm{e}+014.30354 \mathrm{e}+014.30354 \mathrm{e}+001.00000 \mathrm{e}-09$ 7.00000e-02 5.00000e-04 5.00000e-04 5.00000e-05 1.00000e-09 1.00000e-01 
5.00000e-04 5.00000e-04 5.00000e-05 1.00000e-09 1.00000e-01 $1.71955 \mathrm{e}+001.71955 \mathrm{e}+00$ 1.71955e-01 1.00000e-09 2.12000e-01 $1.71955 \mathrm{e}+001.71955 \mathrm{e}+00$ 1.71955e-01 1.00000e-09 2.12000e-01 $1.71955 \mathrm{e}+001.71955 \mathrm{e}+001.71955 \mathrm{e}-01$ 1.00000e-09 2.12000e-01 $1.71955 \mathrm{e}+001.71955 \mathrm{e}+00$ 1.71955e-01 1.00000e-09 2.12000e-01 $1.71955 \mathrm{e}+001.71955 \mathrm{e}+001.71955 \mathrm{e}-01$ 1.00000e-09 2.12000e-01 $1.00000 \mathrm{e}-02$ 1.00000e-02 1.00000e-03 1.00000e-09 1.00000e-01 $1.00000 \mathrm{e}+001.00000 \mathrm{e}+001.00000 \mathrm{e}-011.00000 \mathrm{e}-091.00000 \mathrm{e}-01$ $1.00000 \mathrm{e}-05$ 1.00000e-05 1.00000e-06 1.00000e-09 1.00000e-01 $1.00000 \mathrm{e}+001.00000 \mathrm{e}+001.00000 \mathrm{e}-011.00000 \mathrm{e}-091.00000 \mathrm{e}-01$ Element: 3254 \# of layers: 14

$\mathrm{Kx} \mathrm{Ky} \mathrm{Kz}$ Ss Por

4.30354e+01 4.30354e+01 4.30354e+00 1.00000e-09 7.00000e-02 $4.30354 \mathrm{e}+014.30354 \mathrm{e}+014.30354 \mathrm{e}+001.00000 \mathrm{e}-097.00000 \mathrm{e}-02$ $4.30354 \mathrm{e}+014.30354 \mathrm{e}+014.30354 \mathrm{e}+001.00000 \mathrm{e}-097.00000 \mathrm{e}-02$ 5.00000e-04 5.00000e-04 5.00000e-05 1.00000e-09 1.00000e-01 5.00000e-04 5.00000e-04 5.00000e-05 1.00000e-09 1.00000e-01

$1.71955 \mathrm{e}+001.71955 \mathrm{e}+00$ 1.71955e-01 1.00000e-09 2.12000e-01 $1.71955 \mathrm{e}+001.71955 \mathrm{e}+00$ 1.71955e-01 1.00000e-09 2.12000e-01 $1.71955 \mathrm{e}+001.71955 \mathrm{e}+001.71955 \mathrm{e}-01$ 1.00000e-09 2.12000e-01 $1.71955 \mathrm{e}+001.71955 \mathrm{e}+001.71955 \mathrm{e}-01$ 1.00000e-09 2.12000e-01 $1.71955 \mathrm{e}+00$ 1.71955e+00 1.71955e-01 1.00000e-09 2.12000e-01 $1.00000 \mathrm{e}-02$ 1.00000e-02 1.00000e-03 1.00000e-09 1.00000e-01 $1.00000 \mathrm{e}+001.00000 \mathrm{e}+001.00000 \mathrm{e}-011.00000 \mathrm{e}-091.00000 \mathrm{e}-01$ $1.00000 \mathrm{e}-05$ 1.00000e-05 1.00000e-06 1.00000e-09 1.00000e-01 $1.00000 \mathrm{e}+001.00000 \mathrm{e}+001.00000 \mathrm{e}-011.00000 \mathrm{e}-091.00000 \mathrm{e}-01$ Element: 3255 \# of layers: 14

$\mathrm{Kx} \mathrm{Ky} \mathrm{Kz}$ Ss Por

4.30354e+01 4.30354e+01 4.30354e+00 1.00000e-09 7.00000e-02 $4.30354 \mathrm{e}+014.30354 \mathrm{e}+014.30354 \mathrm{e}+001.00000 \mathrm{e}-09$ 7.00000e-02 $4.30354 \mathrm{e}+014.30354 \mathrm{e}+014.30354 \mathrm{e}+001.00000 \mathrm{e}-097.00000 \mathrm{e}-02$ 5.00000e-04 5.00000e-04 5.00000e-05 1.00000e-09 1.00000e-01 5.00000e-04 5.00000e-04 5.00000e-05 1.00000e-09 1.00000e-01

$1.71955 \mathrm{e}+001.71955 \mathrm{e}+00$ 1.71955e-01 1.00000e-09 2.12000e-01 $1.71955 \mathrm{e}+001.71955 \mathrm{e}+00$ 1.71955e-01 1.00000e-09 2.12000e-01 $1.71955 \mathrm{e}+001.71955 \mathrm{e}+00$ 1.71955e-01 1.00000e-09 2.12000e-01 $1.71955 \mathrm{e}+001.71955 \mathrm{e}+001.71955 \mathrm{e}-01$ 1.00000e-09 2.12000e-01 $1.71955 \mathrm{e}+001.71955 \mathrm{e}+001.71955 \mathrm{e}-01$ 1.00000e-09 2.12000e-01 $1.00000 \mathrm{e}-02$ 1.00000e-02 1.00000e-03 1.00000e-09 1.00000e-01 $1.00000 \mathrm{e}+001.00000 \mathrm{e}+001.00000 \mathrm{e}-011.00000 \mathrm{e}-091.00000 \mathrm{e}-01$ $1.00000 \mathrm{e}-05$ 1.00000e-05 1.00000e-06 1.00000e-09 1.00000e-01 $1.00000 \mathrm{e}+001.00000 \mathrm{e}+001.00000 \mathrm{e}-011.00000 \mathrm{e}-091.00000 \mathrm{e}-01$ Element: 3256 \# of layers: 15

$\mathrm{Kx} \mathrm{Ky} \mathrm{Kz}$ Ss Por

4.30354e+01 4.30354e+01 4.30354e+00 1.00000e-09 7.00000e-02 $4.30354 \mathrm{e}+014.30354 \mathrm{e}+014.30354 \mathrm{e}+001.00000 \mathrm{e}-09$ 7.00000e-02 
4.30354e+01 4.30354e+01 4.30354e+00 1.00000e-09 7.00000e-02 4.30354e+01 4.30354e+01 4.30354e+00 1.00000e-09 7.00000e-02 5.00000e-04 5.00000e-04 5.00000e-05 1.00000e-09 1.00000e-01 5.00000e-04 5.00000e-04 5.00000e-05 1.00000e-09 1.00000e-01 $1.71955 \mathrm{e}+001.71955 \mathrm{e}+00$ 1.71955e-01 1.00000e-09 2.12000e-01 $1.71955 \mathrm{e}+001.71955 \mathrm{e}+001.71955 \mathrm{e}-01$ 1.00000e-09 2.12000e-01 $1.71955 \mathrm{e}+001.71955 \mathrm{e}+00$ 1.71955e-01 1.00000e-09 2.12000e-01 $1.71955 \mathrm{e}+001.71955 \mathrm{e}+00$ 1.71955e-01 1.00000e-09 2.12000e-01 $1.71955 \mathrm{e}+00$ 1.71955e+00 1.71955e-01 1.00000e-09 2.12000e-01 $1.00000 \mathrm{e}-02$ 1.00000e-02 1.00000e-03 1.00000e-09 1.00000e-01 $1.00000 \mathrm{e}+001.00000 \mathrm{e}+001.00000 \mathrm{e}-011.00000 \mathrm{e}-091.00000 \mathrm{e}-01$ $1.00000 \mathrm{e}-05$ 1.00000e-05 1.00000e-06 1.00000e-09 1.00000e-01 $1.00000 \mathrm{e}+001.00000 \mathrm{e}+001.00000 \mathrm{e}-011.00000 \mathrm{e}-09$ 1.00000e-01 Element: 3257 \# of layers: 15

Kx Ky Kz Ss Por

4.30354e+01 4.30354e+01 4.30354e+00 1.00000e-09 7.00000e-02 $4.30354 \mathrm{e}+014.30354 \mathrm{e}+014.30354 \mathrm{e}+001.00000 \mathrm{e}-09$ 7.00000e-02 $4.30354 \mathrm{e}+014.30354 \mathrm{e}+014.30354 \mathrm{e}+00$ 1.00000e-09 7.00000e-02 $4.30354 \mathrm{e}+014.30354 \mathrm{e}+014.30354 \mathrm{e}+001.00000 \mathrm{e}-09$ 7.00000e-02 5.00000e-04 5.00000e-04 5.00000e-05 1.00000e-09 1.00000e-01 5.00000e-04 5.00000e-04 5.00000e-05 1.00000e-09 1.00000e-01 $1.71955 \mathrm{e}+001.71955 \mathrm{e}+00$ 1.71955e-01 1.00000e-09 2.12000e-01 $1.71955 \mathrm{e}+001.71955 \mathrm{e}+00$ 1.71955e-01 1.00000e-09 2.12000e-01 $1.71955 \mathrm{e}+001.71955 \mathrm{e}+00$ 1.71955e-01 1.00000e-09 2.12000e-01 $1.71955 \mathrm{e}+001.71955 \mathrm{e}+00$ 1.71955e-01 1.00000e-09 2.12000e-01 $1.71955 \mathrm{e}+001.71955 \mathrm{e}+00$ 1.71955e-01 1.00000e-09 2.12000e-01 $1.00000 \mathrm{e}-02$ 1.00000e-02 1.00000e-03 1.00000e-09 1.00000e-01 $1.00000 \mathrm{e}+001.00000 \mathrm{e}+001.00000 \mathrm{e}-011.00000 \mathrm{e}-091.00000 \mathrm{e}-01$ $1.00000 \mathrm{e}-05$ 1.00000e-05 1.00000e-06 1.00000e-09 1.00000e-01 $1.00000 \mathrm{e}+001.00000 \mathrm{e}+001.00000 \mathrm{e}-011.00000 \mathrm{e}-091.00000 \mathrm{e}-01$ Element: 3258 \# of layers: 15

$\mathrm{Kx} \mathrm{Ky} \mathrm{Kz}$ Ss Por

4.30354e+01 4.30354e+01 4.30354e+00 1.00000e-09 7.00000e-02 $4.30354 \mathrm{e}+014.30354 \mathrm{e}+014.30354 \mathrm{e}+001.00000 \mathrm{e}-09$ 7.00000e-02 $4.30354 \mathrm{e}+014.30354 \mathrm{e}+014.30354 \mathrm{e}+00$ 1.00000e-09 7.00000e-02 $4.30354 \mathrm{e}+014.30354 \mathrm{e}+014.30354 \mathrm{e}+001.00000 \mathrm{e}-097.00000 \mathrm{e}-02$ 5.00000e-04 5.00000e-04 5.00000e-05 1.00000e-09 1.00000e-01 5.00000e-04 5.00000e-04 5.00000e-05 1.00000e-09 1.00000e-01 $1.71955 \mathrm{e}+001.71955 \mathrm{e}+00$ 1.71955e-01 1.00000e-09 2.12000e-01 $1.71955 \mathrm{e}+001.71955 \mathrm{e}+00$ 1.71955e-01 1.00000e-09 2.12000e-01 $1.71955 \mathrm{e}+001.71955 \mathrm{e}+00$ 1.71955e-01 1.00000e-09 2.12000e-01 $1.71955 \mathrm{e}+001.71955 \mathrm{e}+00$ 1.71955e-01 1.00000e-09 2.12000e-01 $1.71955 \mathrm{e}+001.71955 \mathrm{e}+00$ 1.71955e-01 1.00000e-09 2.12000e-01 $1.00000 \mathrm{e}-021.00000 \mathrm{e}-021.00000 \mathrm{e}-031.00000 \mathrm{e}-091.00000 \mathrm{e}-01$ $1.00000 \mathrm{e}+001.00000 \mathrm{e}+001.00000 \mathrm{e}-011.00000 \mathrm{e}-091.00000 \mathrm{e}-01$ $1.00000 \mathrm{e}-05$ 1.00000e-05 1.00000e-06 1.00000e-09 1.00000e-01 
$1.00000 \mathrm{e}+001.00000 \mathrm{e}+00$ 1.00000e-01 1.00000e-09 1.00000e-01

Element: 3259 \# of layers: 15

$\mathrm{Kx} \mathrm{Ky} \mathrm{Kz}$ Ss Por

4.30354e+01 4.30354e+01 4.30354e+00 1.00000e-09 7.00000e-02

4.30354e+01 4.30354e+01 4.30354e+00 1.00000e-09 7.00000e-02

$4.30354 \mathrm{e}+014.30354 \mathrm{e}+014.30354 \mathrm{e}+001.00000 \mathrm{e}-09$ 7.00000e-02

$4.30354 \mathrm{e}+014.30354 \mathrm{e}+014.30354 \mathrm{e}+001.00000 \mathrm{e}-09$ 7.00000e-02

5.00000e-04 5.00000e-04 5.00000e-05 1.00000e-09 1.00000e-01

5.00000e-04 5.00000e-04 5.00000e-05 1.00000e-09 1.00000e-01

$1.71955 \mathrm{e}+001.71955 \mathrm{e}+00$ 1.71955e-01 1.00000e-09 2.12000e-01

$1.71955 \mathrm{e}+001.71955 \mathrm{e}+00$ 1.71955e-01 1.00000e-09 2.12000e-01

$1.71955 \mathrm{e}+001.71955 \mathrm{e}+001.71955 \mathrm{e}-011.00000 \mathrm{e}-092.12000 \mathrm{e}-01$

$1.71955 \mathrm{e}+001.71955 \mathrm{e}+00$ 1.71955e-01 1.00000e-09 2.12000e-01

$1.71955 \mathrm{e}+001.71955 \mathrm{e}+00$ 1.71955e-01 1.00000e-09 2.12000e-01

$1.00000 \mathrm{e}-02$ 1.00000e-02 1.00000e-03 1.00000e-09 1.00000e-01

$1.00000 \mathrm{e}+001.00000 \mathrm{e}+001.00000 \mathrm{e}-011.00000 \mathrm{e}-091.00000 \mathrm{e}-01$

$1.00000 \mathrm{e}-05$ 1.00000e-05 1.00000e-06 1.00000e-09 1.00000e-01

$1.00000 \mathrm{e}+001.00000 \mathrm{e}+001.00000 \mathrm{e}-01$ 1.00000e-09 1.00000e-01

Element: 3260 \# of layers: 14

$\mathrm{Kx} \mathrm{Ky} \mathrm{Kz}$ Ss Por

$2.99168 \mathrm{e}+012.99168 \mathrm{e}+012.99168 \mathrm{e}+001.00000 \mathrm{e}-09$ 7.00000e-02

$2.99168 \mathrm{e}+012.99168 \mathrm{e}+012.99168 \mathrm{e}+001.00000 \mathrm{e}-09$ 7.00000e-02

$2.99168 \mathrm{e}+012.99168 \mathrm{e}+012.99168 \mathrm{e}+001.00000 \mathrm{e}-09$ 7.00000e-02

5.00000e-04 5.00000e-04 5.00000e-05 1.00000e-09 1.00000e-01

5.00000e-04 5.00000e-04 5.00000e-05 1.00000e-09 1.00000e-01

$1.19538 \mathrm{e}+00$ 1.19538e+00 1.19538e-01 1.00000e-09 2.12000e-01

$1.19538 \mathrm{e}+001.19538 \mathrm{e}+00$ 1.19538e-01 1.00000e-09 2.12000e-01

$1.19538 \mathrm{e}+00$ 1.19538e+00 1.19538e-01 1.00000e-09 2.12000e-01

$1.19538 \mathrm{e}+001.19538 \mathrm{e}+00$ 1.19538e-01 1.00000e-09 2.12000e-01

$1.19538 \mathrm{e}+00$ 1.19538e+00 1.19538e-01 1.00000e-09 2.12000e-01

$1.00000 \mathrm{e}-02$ 1.00000e-02 1.00000e-03 1.00000e-09 1.00000e-01

$1.00000 \mathrm{e}+001.00000 \mathrm{e}+001.00000 \mathrm{e}-011.00000 \mathrm{e}-091.00000 \mathrm{e}-01$

$1.00000 \mathrm{e}-05$ 1.00000e-05 1.00000e-06 1.00000e-09 1.00000e-01

$1.00000 \mathrm{e}+001.00000 \mathrm{e}+001.00000 \mathrm{e}-011.00000 \mathrm{e}-091.00000 \mathrm{e}-01$

Element: 3261 \# of layers: 14

$\mathrm{Kx} \mathrm{Ky} \mathrm{Kz}$ Ss Por

$2.99168 \mathrm{e}+012.99168 \mathrm{e}+012.99168 \mathrm{e}+00$ 1.00000e-09 7.00000e-02

$2.99168 \mathrm{e}+012.99168 \mathrm{e}+012.99168 \mathrm{e}+001.00000 \mathrm{e}-09$ 7.00000e-02

$2.99168 \mathrm{e}+012.99168 \mathrm{e}+012.99168 \mathrm{e}+001.00000 \mathrm{e}-09$ 7.00000e-02

5.00000e-04 5.00000e-04 5.00000e-05 1.00000e-09 1.00000e-01

5.00000e-04 5.00000e-04 5.00000e-05 1.00000e-09 1.00000e-01

$1.19538 \mathrm{e}+001.19538 \mathrm{e}+00$ 1.19538e-01 1.00000e-09 2.12000e-01

$1.19538 \mathrm{e}+00$ 1.19538e+00 1.19538e-01 1.00000e-09 2.12000e-01

$1.19538 \mathrm{e}+00$ 1.19538e+00 1.19538e-01 1.00000e-09 2.12000e-01

$1.19538 \mathrm{e}+00$ 1.19538e+00 1.19538e-01 1.00000e-09 2.12000e-01

$1.19538 \mathrm{e}+001.19538 \mathrm{e}+00$ 1.19538e-01 1.00000e-09 2.12000e-01 
$1.00000 \mathrm{e}-02$ 1.00000e-02 1.00000e-03 1.00000e-09 1.00000e-01 $1.00000 \mathrm{e}+001.00000 \mathrm{e}+001.00000 \mathrm{e}-011.00000 \mathrm{e}-091.00000 \mathrm{e}-01$ $1.00000 \mathrm{e}-051.00000 \mathrm{e}-05$ 1.00000e-06 1.00000e-09 1.00000e-01 $1.00000 \mathrm{e}+001.00000 \mathrm{e}+001.00000 \mathrm{e}-011.00000 \mathrm{e}-091.00000 \mathrm{e}-01$ Element: 3262 \# of layers: 14

Kx Ky Kz Ss Por

$2.99168 \mathrm{e}+012.99168 \mathrm{e}+012.99168 \mathrm{e}+00$ 1.00000e-09 7.00000e-02 $2.99168 \mathrm{e}+012.99168 \mathrm{e}+012.99168 \mathrm{e}+001.00000 \mathrm{e}-09$ 7.00000e-02 $2.99168 \mathrm{e}+012.99168 \mathrm{e}+012.99168 \mathrm{e}+001.00000 \mathrm{e}-09$ 7.00000e-02 5.00000e-04 5.00000e-04 5.00000e-05 1.00000e-09 1.00000e-01 5.00000e-04 5.00000e-04 5.00000e-05 1.00000e-09 1.00000e-01 $1.19538 \mathrm{e}+001.19538 \mathrm{e}+00$ 1.19538e-01 1.00000e-09 2.12000e-01 $1.19538 \mathrm{e}+001.19538 \mathrm{e}+00$ 1.19538e-01 1.00000e-09 2.12000e-01 $1.19538 \mathrm{e}+001.19538 \mathrm{e}+00$ 1.19538e-01 1.00000e-09 2.12000e-01 $1.19538 \mathrm{e}+001.19538 \mathrm{e}+00$ 1.19538e-01 1.00000e-09 2.12000e-01 $1.19538 \mathrm{e}+001.19538 \mathrm{e}+00$ 1.19538e-01 1.00000e-09 2.12000e-01 $1.00000 \mathrm{e}-021.00000 \mathrm{e}-02$ 1.00000e-03 1.00000e-09 1.00000e-01 $1.00000 \mathrm{e}+001.00000 \mathrm{e}+001.00000 \mathrm{e}-011.00000 \mathrm{e}-091.00000 \mathrm{e}-01$ $1.00000 \mathrm{e}-05$ 1.00000e-05 1.00000e-06 1.00000e-09 1.00000e-01 $1.00000 \mathrm{e}+001.00000 \mathrm{e}+001.00000 \mathrm{e}-011.00000 \mathrm{e}-091.00000 \mathrm{e}-01$ Element: 3263 \# of layers: 14

Kx Ky Kz Ss Por

$2.99168 \mathrm{e}+012.99168 \mathrm{e}+012.99168 \mathrm{e}+00$ 1.00000e-09 7.00000e-02 $2.99168 \mathrm{e}+012.99168 \mathrm{e}+012.99168 \mathrm{e}+001.00000 \mathrm{e}-09$ 7.00000e-02 $2.99168 \mathrm{e}+012.99168 \mathrm{e}+012.99168 \mathrm{e}+001.00000 \mathrm{e}-09$ 7.00000e-02 $5.00000 \mathrm{e}-04$ 5.00000e-04 5.00000e-05 1.00000e-09 1.00000e-01 5.00000e-04 5.00000e-04 5.00000e-05 1.00000e-09 1.00000e-01 $1.19538 \mathrm{e}+001.19538 \mathrm{e}+00$ 1.19538e-01 1.00000e-09 2.12000e-01 $1.19538 \mathrm{e}+001.19538 \mathrm{e}+00$ 1.19538e-01 1.00000e-09 2.12000e-01 $1.19538 \mathrm{e}+001.19538 \mathrm{e}+00$ 1.19538e-01 1.00000e-09 2.12000e-01 $1.19538 \mathrm{e}+001.19538 \mathrm{e}+00$ 1.19538e-01 1.00000e-09 2.12000e-01 $1.19538 \mathrm{e}+001.19538 \mathrm{e}+00$ 1.19538e-01 1.00000e-09 2.12000e-01 $1.00000 \mathrm{e}-021.00000 \mathrm{e}-02$ 1.00000e-03 1.00000e-09 1.00000e-01 $1.00000 \mathrm{e}+001.00000 \mathrm{e}+001.00000 \mathrm{e}-011.00000 \mathrm{e}-091.00000 \mathrm{e}-01$ $1.00000 \mathrm{e}-05$ 1.00000e-05 1.00000e-06 1.00000e-09 1.00000e-01 $1.00000 \mathrm{e}+001.00000 \mathrm{e}+001.00000 \mathrm{e}-011.00000 \mathrm{e}-091.00000 \mathrm{e}-01$ Element: 3264 \# of layers: 14

Kx Ky Kz Ss Por

$2.99168 \mathrm{e}+012.99168 \mathrm{e}+012.99168 \mathrm{e}+00$ 1.00000e-09 7.00000e-02 $2.99168 \mathrm{e}+012.99168 \mathrm{e}+012.99168 \mathrm{e}+001.00000 \mathrm{e}-09$ 7.00000e-02 $2.99168 \mathrm{e}+012.99168 \mathrm{e}+012.99168 \mathrm{e}+001.00000 \mathrm{e}-09$ 7.00000e-02 5.00000e-04 5.00000e-04 5.00000e-05 1.00000e-09 1.00000e-01 $5.00000 \mathrm{e}-04$ 5.00000e-04 5.00000e-05 1.00000e-09 1.00000e-01 $1.19538 \mathrm{e}+001.19538 \mathrm{e}+00$ 1.19538e-01 1.00000e-09 2.12000e-01 $1.19538 \mathrm{e}+001.19538 \mathrm{e}+00$ 1.19538e-01 1.00000e-09 2.12000e-01 $1.19538 \mathrm{e}+001.19538 \mathrm{e}+00$ 1.19538e-01 1.00000e-09 2.12000e-01 
$1.19538 \mathrm{e}+00$ 1.19538e+00 1.19538e-01 1.00000e-09 2.12000e-01 $1.19538 \mathrm{e}+001.19538 \mathrm{e}+00$ 1.19538e-01 1.00000e-09 2.12000e-01 $1.00000 \mathrm{e}-02$ 1.00000e-02 1.00000e-03 1.00000e-09 1.00000e-01 $1.00000 \mathrm{e}+001.00000 \mathrm{e}+001.00000 \mathrm{e}-011.00000 \mathrm{e}-091.00000 \mathrm{e}-01$ $1.00000 \mathrm{e}-05$ 1.00000e-05 1.00000e-06 1.00000e-09 1.00000e-01 $1.00000 \mathrm{e}+001.00000 \mathrm{e}+001.00000 \mathrm{e}-011.00000 \mathrm{e}-091.00000 \mathrm{e}-01$ Element: 3265 \# of layers: 14

$\mathrm{Kx} \mathrm{Ky} \mathrm{Kz}$ Ss Por

$2.99168 \mathrm{e}+012.99168 \mathrm{e}+012.99168 \mathrm{e}+00$ 1.00000e-09 7.00000e-02 $2.99168 \mathrm{e}+012.99168 \mathrm{e}+012.99168 \mathrm{e}+00$ 1.00000e-09 7.00000e-02 $2.99168 \mathrm{e}+012.99168 \mathrm{e}+012.99168 \mathrm{e}+001.00000 \mathrm{e}-09$ 7.00000e-02 5.00000e-04 5.00000e-04 5.00000e-05 1.00000e-09 1.00000e-01 5.00000e-04 5.00000e-04 5.00000e-05 1.00000e-09 1.00000e-01 $1.19538 \mathrm{e}+00$ 1.19538e+00 1.19538e-01 1.00000e-09 2.12000e-01 $1.19538 \mathrm{e}+00$ 1.19538e+00 1.19538e-01 1.00000e-09 2.12000e-01 $1.19538 \mathrm{e}+00$ 1.19538e+00 1.19538e-01 1.00000e-09 2.12000e-01 $1.19538 \mathrm{e}+001.19538 \mathrm{e}+00$ 1.19538e-01 1.00000e-09 2.12000e-01 $1.19538 \mathrm{e}+00$ 1.19538e+00 1.19538e-01 1.00000e-09 2.12000e-01 1.00000e-02 1.00000e-02 1.00000e-03 1.00000e-09 1.00000e-01 $1.00000 \mathrm{e}+001.00000 \mathrm{e}+001.00000 \mathrm{e}-011.00000 \mathrm{e}-091.00000 \mathrm{e}-01$ $1.00000 \mathrm{e}-05$ 1.00000e-05 1.00000e-06 1.00000e-09 1.00000e-01 $1.00000 \mathrm{e}+001.00000 \mathrm{e}+001.00000 \mathrm{e}-01$ 1.00000e-09 1.00000e-01 Element: 3266 \# of layers: 14

$\mathrm{Kx} \mathrm{Ky} \mathrm{Kz}$ Ss Por

$2.99168 \mathrm{e}+012.99168 \mathrm{e}+012.99168 \mathrm{e}+001.00000 \mathrm{e}-09$ 7.00000e-02 $2.99168 \mathrm{e}+012.99168 \mathrm{e}+012.99168 \mathrm{e}+001.00000 \mathrm{e}-09$ 7.00000e-02 $2.99168 \mathrm{e}+012.99168 \mathrm{e}+012.99168 \mathrm{e}+001.00000 \mathrm{e}-09$ 7.00000e-02 5.00000e-04 5.00000e-04 5.00000e-05 1.00000e-09 1.00000e-01 5.00000e-04 5.00000e-04 5.00000e-05 1.00000e-09 1.00000e-01 $1.19538 \mathrm{e}+001.19538 \mathrm{e}+00$ 1.19538e-01 1.00000e-09 2.12000e-01 $1.19538 \mathrm{e}+00$ 1.19538e+00 1.19538e-01 1.00000e-09 2.12000e-01 $1.19538 \mathrm{e}+00$ 1.19538e+00 1.19538e-01 1.00000e-09 2.12000e-01 $1.19538 \mathrm{e}+001.19538 \mathrm{e}+00$ 1.19538e-01 1.00000e-09 2.12000e-01 $1.19538 \mathrm{e}+001.19538 \mathrm{e}+00$ 1.19538e-01 1.00000e-09 2.12000e-01 $1.00000 \mathrm{e}-02$ 1.00000e-02 1.00000e-03 1.00000e-09 1.00000e-01 $1.00000 \mathrm{e}+001.00000 \mathrm{e}+001.00000 \mathrm{e}-011.00000 \mathrm{e}-091.00000 \mathrm{e}-01$ $1.00000 \mathrm{e}-05$ 1.00000e-05 1.00000e-06 1.00000e-09 1.00000e-01 $1.00000 \mathrm{e}+001.00000 \mathrm{e}+001.00000 \mathrm{e}-01$ 1.00000e-09 1.00000e-01 Element: 3267 \# of layers: 14

$\mathrm{Kx} \mathrm{Ky} \mathrm{Kz}$ Ss Por

$2.99168 \mathrm{e}+012.99168 \mathrm{e}+012.99168 \mathrm{e}+00$ 1.00000e-09 7.00000e-02 $2.99168 \mathrm{e}+012.99168 \mathrm{e}+012.99168 \mathrm{e}+001.00000 \mathrm{e}-09$ 7.00000e-02 $2.99168 \mathrm{e}+012.99168 \mathrm{e}+012.99168 \mathrm{e}+001.00000 \mathrm{e}-09$ 7.00000e-02 5.00000e-04 5.00000e-04 5.00000e-05 1.00000e-09 1.00000e-01 5.00000e-04 5.00000e-04 5.00000e-05 1.00000e-09 1.00000e-01 $1.19538 \mathrm{e}+001.19538 \mathrm{e}+00$ 1.19538e-01 1.00000e-09 2.12000e-01 
$1.19538 \mathrm{e}+00$ 1.19538e+00 1.19538e-01 1.00000e-09 2.12000e-01 $1.19538 \mathrm{e}+001.19538 \mathrm{e}+00$ 1.19538e-01 1.00000e-09 2.12000e-01 $1.19538 \mathrm{e}+00$ 1.19538e+00 1.19538e-01 1.00000e-09 2.12000e-01 $1.19538 \mathrm{e}+001.19538 \mathrm{e}+00$ 1.19538e-01 1.00000e-09 2.12000e-01 $1.00000 \mathrm{e}-02$ 1.00000e-02 1.00000e-03 1.00000e-09 1.00000e-01 $1.00000 \mathrm{e}+001.00000 \mathrm{e}+001.00000 \mathrm{e}-011.00000 \mathrm{e}-091.00000 \mathrm{e}-01$ $1.00000 \mathrm{e}-05$ 1.00000e-05 1.00000e-06 1.00000e-09 1.00000e-01 $1.00000 \mathrm{e}+001.00000 \mathrm{e}+001.00000 \mathrm{e}-011.00000 \mathrm{e}-091.00000 \mathrm{e}-01$ Element: 3268 \# of layers: 14

$\mathrm{Kx} \mathrm{Ky} \mathrm{Kz}$ Ss Por

$2.99168 \mathrm{e}+012.99168 \mathrm{e}+012.99168 \mathrm{e}+00$ 1.00000e-09 7.00000e-02 $2.99168 \mathrm{e}+012.99168 \mathrm{e}+012.99168 \mathrm{e}+001.00000 \mathrm{e}-09$ 7.00000e-02 $2.99168 \mathrm{e}+012.99168 \mathrm{e}+012.99168 \mathrm{e}+001.00000 \mathrm{e}-09$ 7.00000e-02 5.00000e-04 5.00000e-04 5.00000e-05 1.00000e-09 1.00000e-01 5.00000e-04 5.00000e-04 5.00000e-05 1.00000e-09 1.00000e-01 $1.19538 \mathrm{e}+001.19538 \mathrm{e}+00$ 1.19538e-01 1.00000e-09 2.12000e-01 $1.19538 \mathrm{e}+00$ 1.19538e+00 1.19538e-01 1.00000e-09 2.12000e-01 $1.19538 \mathrm{e}+00$ 1.19538e+00 1.19538e-01 1.00000e-09 2.12000e-01 $1.19538 \mathrm{e}+001.19538 \mathrm{e}+00$ 1.19538e-01 1.00000e-09 2.12000e-01 $1.19538 \mathrm{e}+001.19538 \mathrm{e}+001.19538 \mathrm{e}-01$ 1.00000e-09 2.12000e-01 $1.00000 \mathrm{e}-02$ 1.00000e-02 1.00000e-03 1.00000e-09 1.00000e-01 $1.00000 \mathrm{e}+001.00000 \mathrm{e}+001.00000 \mathrm{e}-011.00000 \mathrm{e}-091.00000 \mathrm{e}-01$ $1.00000 \mathrm{e}-05$ 1.00000e-05 1.00000e-06 1.00000e-09 1.00000e-01 $1.00000 \mathrm{e}+001.00000 \mathrm{e}+001.00000 \mathrm{e}-011.00000 \mathrm{e}-091.00000 \mathrm{e}-01$ Element: 3269 \# of layers: 14

$\mathrm{Kx} \mathrm{Ky} \mathrm{Kz}$ Ss Por

$2.78328 \mathrm{e}+012.78328 \mathrm{e}+012.78328 \mathrm{e}+00$ 1.00000e-09 7.00000e-02 $2.78328 \mathrm{e}+012.78328 \mathrm{e}+012.78328 \mathrm{e}+00$ 1.00000e-09 7.00000e-02 $2.78328 \mathrm{e}+012.78328 \mathrm{e}+012.78328 \mathrm{e}+001.00000 \mathrm{e}-097.00000 \mathrm{e}-02$ $5.00000 \mathrm{e}-04$ 5.00000e-04 5.00000e-05 1.00000e-09 1.00000e-01 5.00000e-04 5.00000e-04 5.00000e-05 1.00000e-09 1.00000e-01 $1.11211 \mathrm{e}+001.11211 \mathrm{e}+001.11211 \mathrm{e}-01$ 1.00000e-09 2.12000e-01 $1.11211 \mathrm{e}+001.11211 \mathrm{e}+001.11211 \mathrm{e}-011.00000 \mathrm{e}-092.12000 \mathrm{e}-01$ $1.11211 \mathrm{e}+001.11211 \mathrm{e}+00$ 1.11211e-01 1.00000e-09 2.12000e-01 $1.11211 \mathrm{e}+001.11211 \mathrm{e}+001.11211 \mathrm{e}-01$ 1.00000e-09 2.12000e-01 $1.11211 \mathrm{e}+001.11211 \mathrm{e}+001.11211 \mathrm{e}-011.00000 \mathrm{e}-092.12000 \mathrm{e}-01$ $1.00000 \mathrm{e}-02$ 1.00000e-02 1.00000e-03 1.00000e-09 1.00000e-01 $1.00000 \mathrm{e}+001.00000 \mathrm{e}+001.00000 \mathrm{e}-011.00000 \mathrm{e}-091.00000 \mathrm{e}-01$ $1.00000 \mathrm{e}-05$ 1.00000e-05 1.00000e-06 1.00000e-09 1.00000e-01 $1.00000 \mathrm{e}+001.00000 \mathrm{e}+001.00000 \mathrm{e}-01$ 1.00000e-09 1.00000e-01 Element: 3270 \# of layers: 14

$\mathrm{Kx} \mathrm{Ky} \mathrm{Kz}$ Ss Por

$2.78328 \mathrm{e}+012.78328 \mathrm{e}+012.78328 \mathrm{e}+00$ 1.00000e-09 7.00000e-02 $2.78328 \mathrm{e}+012.78328 \mathrm{e}+012.78328 \mathrm{e}+00$ 1.00000e-09 7.00000e-02 $2.78328 \mathrm{e}+012.78328 \mathrm{e}+012.78328 \mathrm{e}+001.00000 \mathrm{e}-09$ 7.00000e-02 5.00000e-04 5.00000e-04 5.00000e-05 1.00000e-09 1.00000e-01 
5.00000e-04 5.00000e-04 5.00000e-05 1.00000e-09 1.00000e-01 $1.11211 \mathrm{e}+001.11211 \mathrm{e}+001.11211 \mathrm{e}-01$ 1.00000e-09 2.12000e-01 $1.11211 \mathrm{e}+001.11211 \mathrm{e}+001.11211 \mathrm{e}-01$ 1.00000e-09 2.12000e-01 $1.11211 \mathrm{e}+001.11211 \mathrm{e}+001.11211 \mathrm{e}-01$ 1.00000e-09 2.12000e-01 $1.11211 \mathrm{e}+001.11211 \mathrm{e}+001.11211 \mathrm{e}-01$ 1.00000e-09 2.12000e-01 $1.11211 \mathrm{e}+001.11211 \mathrm{e}+001.11211 \mathrm{e}-011.00000 \mathrm{e}-092.12000 \mathrm{e}-01$ $1.00000 \mathrm{e}-02$ 1.00000e-02 1.00000e-03 1.00000e-09 1.00000e-01 $1.00000 \mathrm{e}+001.00000 \mathrm{e}+001.00000 \mathrm{e}-011.00000 \mathrm{e}-091.00000 \mathrm{e}-01$ $1.00000 \mathrm{e}-05$ 1.00000e-05 1.00000e-06 1.00000e-09 1.00000e-01 $1.00000 \mathrm{e}+001.00000 \mathrm{e}+001.00000 \mathrm{e}-011.00000 \mathrm{e}-091.00000 \mathrm{e}-01$ Element: 3271 \# of layers: 14

Kx Ky Kz Ss Por

$2.78328 \mathrm{e}+012.78328 \mathrm{e}+012.78328 \mathrm{e}+00$ 1.00000e-09 7.00000e-02

$2.78328 \mathrm{e}+012.78328 \mathrm{e}+012.78328 \mathrm{e}+00$ 1.00000e-09 7.00000e-02

$2.78328 \mathrm{e}+012.78328 \mathrm{e}+012.78328 \mathrm{e}+001.00000 \mathrm{e}-09$ 7.00000e-02 5.00000e-04 5.00000e-04 5.00000e-05 1.00000e-09 1.00000e-01 5.00000e-04 5.00000e-04 5.00000e-05 1.00000e-09 1.00000e-01

$1.11211 \mathrm{e}+001.11211 \mathrm{e}+001.11211 \mathrm{e}-011.00000 \mathrm{e}-092.12000 \mathrm{e}-01$ $1.11211 \mathrm{e}+001.11211 \mathrm{e}+001.11211 \mathrm{e}-011.00000 \mathrm{e}-092.12000 \mathrm{e}-01$ $1.11211 \mathrm{e}+001.11211 \mathrm{e}+001.11211 \mathrm{e}-011.00000 \mathrm{e}-092.12000 \mathrm{e}-01$ $1.11211 \mathrm{e}+001.11211 \mathrm{e}+001.11211 \mathrm{e}-011.00000 \mathrm{e}-092.12000 \mathrm{e}-01$ $1.11211 \mathrm{e}+001.11211 \mathrm{e}+001.11211 \mathrm{e}-01$ 1.00000e-09 2.12000e-01 $1.00000 \mathrm{e}-02$ 1.00000e-02 1.00000e-03 1.00000e-09 1.00000e-01 $1.00000 \mathrm{e}+001.00000 \mathrm{e}+001.00000 \mathrm{e}-011.00000 \mathrm{e}-091.00000 \mathrm{e}-01$ $1.00000 \mathrm{e}-05$ 1.00000e-05 1.00000e-06 1.00000e-09 1.00000e-01 $1.00000 \mathrm{e}+001.00000 \mathrm{e}+001.00000 \mathrm{e}-011.00000 \mathrm{e}-091.00000 \mathrm{e}-01$ Element: 3272 \# of layers: 14

$\mathrm{Kx} \mathrm{Ky} \mathrm{Kz}$ Ss Por

$2.78328 \mathrm{e}+012.78328 \mathrm{e}+012.78328 \mathrm{e}+00$ 1.00000e-09 7.00000e-02

$2.78328 \mathrm{e}+012.78328 \mathrm{e}+012.78328 \mathrm{e}+001.00000 \mathrm{e}-09$ 7.00000e-02

$2.78328 \mathrm{e}+012.78328 \mathrm{e}+012.78328 \mathrm{e}+001.00000 \mathrm{e}-09$ 7.00000e-02 5.00000e-04 5.00000e-04 5.00000e-05 1.00000e-09 1.00000e-01 5.00000e-04 5.00000e-04 5.00000e-05 1.00000e-09 1.00000e-01

$1.11211 \mathrm{e}+001.11211 \mathrm{e}+001.11211 \mathrm{e}-01$ 1.00000e-09 2.12000e-01 $1.11211 \mathrm{e}+001.11211 \mathrm{e}+001.11211 \mathrm{e}-01$ 1.00000e-09 2.12000e-01 $1.11211 \mathrm{e}+001.11211 \mathrm{e}+001.11211 \mathrm{e}-01$ 1.00000e-09 2.12000e-01 $1.11211 \mathrm{e}+001.11211 \mathrm{e}+001.11211 \mathrm{e}-01$ 1.00000e-09 2.12000e-01 $1.11211 \mathrm{e}+001.11211 \mathrm{e}+001.11211 \mathrm{e}-011.00000 \mathrm{e}-092.12000 \mathrm{e}-01$ $1.00000 \mathrm{e}-02$ 1.00000e-02 1.00000e-03 1.00000e-09 1.00000e-01 $1.00000 \mathrm{e}+001.00000 \mathrm{e}+001.00000 \mathrm{e}-011.00000 \mathrm{e}-091.00000 \mathrm{e}-01$ $1.00000 \mathrm{e}-05$ 1.00000e-05 1.00000e-06 1.00000e-09 1.00000e-01 $1.00000 \mathrm{e}+001.00000 \mathrm{e}+001.00000 \mathrm{e}-011.00000 \mathrm{e}-091.00000 \mathrm{e}-01$ Element: 3273 \# of layers: 14

$\mathrm{Kx} \mathrm{Ky} \mathrm{Kz}$ Ss Por

$2.78328 \mathrm{e}+012.78328 \mathrm{e}+012.78328 \mathrm{e}+00$ 1.00000e-09 7.00000e-02 $2.78328 \mathrm{e}+012.78328 \mathrm{e}+012.78328 \mathrm{e}+001.00000 \mathrm{e}-09$ 7.00000e-02 
$2.78328 \mathrm{e}+012.78328 \mathrm{e}+012.78328 \mathrm{e}+00$ 1.00000e-09 7.00000e-02 5.00000e-04 5.00000e-04 5.00000e-05 1.00000e-09 1.00000e-01 5.00000e-04 5.00000e-04 5.00000e-05 1.00000e-09 1.00000e-01 $1.11211 \mathrm{e}+001.11211 \mathrm{e}+001.11211 \mathrm{e}-011.00000 \mathrm{e}-092.12000 \mathrm{e}-01$ $1.11211 \mathrm{e}+001.11211 \mathrm{e}+001.11211 \mathrm{e}-011.00000 \mathrm{e}-092.12000 \mathrm{e}-01$ $1.11211 \mathrm{e}+001.11211 \mathrm{e}+001.11211 \mathrm{e}-011.00000 \mathrm{e}-092.12000 \mathrm{e}-01$ $1.11211 \mathrm{e}+001.11211 \mathrm{e}+001.11211 \mathrm{e}-011.00000 \mathrm{e}-092.12000 \mathrm{e}-01$ $1.11211 \mathrm{e}+001.11211 \mathrm{e}+001.11211 \mathrm{e}-011.00000 \mathrm{e}-092.12000 \mathrm{e}-01$ $1.00000 \mathrm{e}-02$ 1.00000e-02 1.00000e-03 1.00000e-09 1.00000e-01 $1.00000 \mathrm{e}+001.00000 \mathrm{e}+001.00000 \mathrm{e}-011.00000 \mathrm{e}-091.00000 \mathrm{e}-01$ $1.00000 \mathrm{e}-05$ 1.00000e-05 1.00000e-06 1.00000e-09 1.00000e-01 $1.00000 \mathrm{e}+001.00000 \mathrm{e}+001.00000 \mathrm{e}-011.00000 \mathrm{e}-091.00000 \mathrm{e}-01$ Element: 3274 \# of layers: 14

Kx Ky Kz Ss Por

$2.78328 \mathrm{e}+012.78328 \mathrm{e}+012.78328 \mathrm{e}+00$ 1.00000e-09 7.00000e-02 $2.78328 \mathrm{e}+012.78328 \mathrm{e}+012.78328 \mathrm{e}+001.00000 \mathrm{e}-09$ 7.00000e-02 $2.78328 \mathrm{e}+012.78328 \mathrm{e}+012.78328 \mathrm{e}+001.00000 \mathrm{e}-09$ 7.00000e-02 5.00000e-04 5.00000e-04 5.00000e-05 1.00000e-09 1.00000e-01 5.00000e-04 5.00000e-04 5.00000e-05 1.00000e-09 1.00000e-01 $1.11211 \mathrm{e}+001.11211 \mathrm{e}+001.11211 \mathrm{e}-011.00000 \mathrm{e}-092.12000 \mathrm{e}-01$ $1.11211 \mathrm{e}+001.11211 \mathrm{e}+001.11211 \mathrm{e}-011.00000 \mathrm{e}-092.12000 \mathrm{e}-01$ $1.11211 \mathrm{e}+001.11211 \mathrm{e}+001.11211 \mathrm{e}-011.00000 \mathrm{e}-092.12000 \mathrm{e}-01$ $1.11211 \mathrm{e}+001.11211 \mathrm{e}+001.11211 \mathrm{e}-011.00000 \mathrm{e}-092.12000 \mathrm{e}-01$ $1.11211 \mathrm{e}+001.11211 \mathrm{e}+001.11211 \mathrm{e}-011.00000 \mathrm{e}-09$ 2.12000e-01 $1.00000 \mathrm{e}-021.00000 \mathrm{e}-02$ 1.00000e-03 1.00000e-09 1.00000e-01 $1.00000 \mathrm{e}+001.00000 \mathrm{e}+001.00000 \mathrm{e}-011.00000 \mathrm{e}-091.00000 \mathrm{e}-01$ $1.00000 \mathrm{e}-05$ 1.00000e-05 1.00000e-06 1.00000e-09 1.00000e-01 $1.00000 \mathrm{e}+001.00000 \mathrm{e}+001.00000 \mathrm{e}-011.00000 \mathrm{e}-091.00000 \mathrm{e}-01$ Element: 3275 \# of layers: 14

Kx Ky Kz Ss Por

$2.78328 \mathrm{e}+012.78328 \mathrm{e}+012.78328 \mathrm{e}+00$ 1.00000e-09 7.00000e-02 $2.78328 \mathrm{e}+012.78328 \mathrm{e}+012.78328 \mathrm{e}+001.00000 \mathrm{e}-09$ 7.00000e-02 $2.78328 \mathrm{e}+012.78328 \mathrm{e}+012.78328 \mathrm{e}+001.00000 \mathrm{e}-09$ 7.00000e-02 $5.00000 \mathrm{e}-04$ 5.00000e-04 5.00000e-05 1.00000e-09 1.00000e-01 5.00000e-04 5.00000e-04 5.00000e-05 1.00000e-09 1.00000e-01 $1.11211 \mathrm{e}+001.11211 \mathrm{e}+001.11211 \mathrm{e}-011.00000 \mathrm{e}-092.12000 \mathrm{e}-01$ $1.11211 \mathrm{e}+001.11211 \mathrm{e}+001.11211 \mathrm{e}-011.00000 \mathrm{e}-092.12000 \mathrm{e}-01$ $1.11211 \mathrm{e}+001.11211 \mathrm{e}+00$ 1.11211e-01 1.00000e-09 2.12000e-01 $1.11211 \mathrm{e}+001.11211 \mathrm{e}+001.11211 \mathrm{e}-011.00000 \mathrm{e}-092.12000 \mathrm{e}-01$ $1.11211 \mathrm{e}+001.11211 \mathrm{e}+001.11211 \mathrm{e}-011.00000 \mathrm{e}-09$ 2.12000e-01 $1.00000 \mathrm{e}-021.00000 \mathrm{e}-02$ 1.00000e-03 1.00000e-09 1.00000e-01 $1.00000 \mathrm{e}+001.00000 \mathrm{e}+001.00000 \mathrm{e}-011.00000 \mathrm{e}-091.00000 \mathrm{e}-01$ $1.00000 \mathrm{e}-05$ 1.00000e-05 1.00000e-06 1.00000e-09 1.00000e-01 $1.00000 \mathrm{e}+001.00000 \mathrm{e}+001.00000 \mathrm{e}-011.00000 \mathrm{e}-091.00000 \mathrm{e}-01$ Element: 3276 \# of layers: 14

Kx Ky Kz Ss Por 
$2.78328 \mathrm{e}+012.78328 \mathrm{e}+012.78328 \mathrm{e}+00$ 1.00000e-09 7.00000e-02 $2.78328 \mathrm{e}+012.78328 \mathrm{e}+012.78328 \mathrm{e}+00$ 1.00000e-09 7.00000e-02 $2.78328 \mathrm{e}+012.78328 \mathrm{e}+012.78328 \mathrm{e}+001.00000 \mathrm{e}-09$ 7.00000e-02 5.00000e-04 5.00000e-04 5.00000e-05 1.00000e-09 1.00000e-01 5.00000e-04 5.00000e-04 5.00000e-05 1.00000e-09 1.00000e-01

$1.11211 \mathrm{e}+001.11211 \mathrm{e}+001.11211 \mathrm{e}-011.00000 \mathrm{e}-092.12000 \mathrm{e}-01$ $1.11211 \mathrm{e}+001.11211 \mathrm{e}+001.11211 \mathrm{e}-01$ 1.00000e-09 2.12000e-01 $1.11211 \mathrm{e}+001.11211 \mathrm{e}+001.11211 \mathrm{e}-01$ 1.00000e-09 2.12000e-01 $1.11211 \mathrm{e}+001.11211 \mathrm{e}+00$ 1.11211e-01 1.00000e-09 2.12000e-01 $1.11211 \mathrm{e}+001.11211 \mathrm{e}+001.11211 \mathrm{e}-01$ 1.00000e-09 2.12000e-01 $1.00000 \mathrm{e}-02$ 1.00000e-02 1.00000e-03 1.00000e-09 1.00000e-01 $1.00000 \mathrm{e}+001.00000 \mathrm{e}+001.00000 \mathrm{e}-011.00000 \mathrm{e}-091.00000 \mathrm{e}-01$ 1.00000e-05 1.00000e-05 1.00000e-06 1.00000e-09 1.00000e-01 $1.00000 \mathrm{e}+001.00000 \mathrm{e}+001.00000 \mathrm{e}-011.00000 \mathrm{e}-09$ 1.00000e-01 Element: 3277 \# of layers: 14

Kx Ky Kz Ss Por

$2.78328 \mathrm{e}+012.78328 \mathrm{e}+012.78328 \mathrm{e}+00$ 1.00000e-09 7.00000e-02

$2.78328 \mathrm{e}+012.78328 \mathrm{e}+012.78328 \mathrm{e}+00$ 1.00000e-09 7.00000e-02

$2.78328 \mathrm{e}+012.78328 \mathrm{e}+012.78328 \mathrm{e}+001.00000 \mathrm{e}-09$ 7.00000e-02 5.00000e-04 5.00000e-04 5.00000e-05 1.00000e-09 1.00000e-01 5.00000e-04 5.00000e-04 5.00000e-05 1.00000e-09 1.00000e-01

$1.11211 \mathrm{e}+001.11211 \mathrm{e}+001.11211 \mathrm{e}-01$ 1.00000e-09 2.12000e-01 $1.11211 \mathrm{e}+001.11211 \mathrm{e}+001.11211 \mathrm{e}-011.00000 \mathrm{e}-092.12000 \mathrm{e}-01$ $1.11211 \mathrm{e}+001.11211 \mathrm{e}+001.11211 \mathrm{e}-01$ 1.00000e-09 2.12000e-01 $1.11211 \mathrm{e}+001.11211 \mathrm{e}+001.11211 \mathrm{e}-011.00000 \mathrm{e}-092.12000 \mathrm{e}-01$ $1.11211 \mathrm{e}+001.11211 \mathrm{e}+001.11211 \mathrm{e}-01$ 1.00000e-09 2.12000e-01 $1.00000 \mathrm{e}-02$ 1.00000e-02 1.00000e-03 1.00000e-09 1.00000e-01 $1.00000 \mathrm{e}+001.00000 \mathrm{e}+001.00000 \mathrm{e}-011.00000 \mathrm{e}-091.00000 \mathrm{e}-01$ $1.00000 \mathrm{e}-05$ 1.00000e-05 1.00000e-06 1.00000e-09 1.00000e-01 $1.00000 \mathrm{e}+001.00000 \mathrm{e}+001.00000 \mathrm{e}-011.00000 \mathrm{e}-091.00000 \mathrm{e}-01$ Element: 3278 \# of layers: 14

$\mathrm{Kx} \mathrm{Ky} \mathrm{Kz}$ Ss Por

$1.48917 \mathrm{e}+01$ 1.48917e+01 1.48917e+00 1.00000e-09 7.00000e-02 $1.48917 \mathrm{e}+01$ 1.48917e+01 1.48917e+00 1.00000e-09 7.00000e-02 $1.48917 \mathrm{e}+011.48917 \mathrm{e}+011.48917 \mathrm{e}+001.00000 \mathrm{e}-09$ 7.00000e-02 5.00000e-04 5.00000e-04 5.00000e-05 1.00000e-09 1.00000e-01 5.00000e-04 5.00000e-04 5.00000e-05 1.00000e-09 1.00000e-01 5.95025e-01 5.95025e-01 5.95025e-02 1.00000e-09 2.12000e-01 5.95025e-01 5.95025e-01 5.95025e-02 1.00000e-09 2.12000e-01 5.95025e-01 5.95025e-01 5.95025e-02 1.00000e-09 2.12000e-01 5.95025e-01 5.95025e-01 5.95025e-02 1.00000e-09 2.12000e-01 5.95025e-01 5.95025e-01 5.95025e-02 1.00000e-09 2.12000e-01 $1.00000 \mathrm{e}-02$ 1.00000e-02 1.00000e-03 1.00000e-09 1.00000e-01 $1.00000 \mathrm{e}+001.00000 \mathrm{e}+001.00000 \mathrm{e}-011.00000 \mathrm{e}-091.00000 \mathrm{e}-01$ $1.00000 \mathrm{e}-05$ 1.00000e-05 1.00000e-06 1.00000e-09 1.00000e-01 $1.00000 \mathrm{e}+001.00000 \mathrm{e}+001.00000 \mathrm{e}-011.00000 \mathrm{e}-091.00000 \mathrm{e}-01$ 
Element: 3279 \# of layers: 15

Kx Ky Kz Ss Por

$1.48917 \mathrm{e}+011.48917 \mathrm{e}+01$ 1.48917e+00 1.00000e-09 7.00000e-02

$1.48917 \mathrm{e}+011.48917 \mathrm{e}+011.48917 \mathrm{e}+001.00000 \mathrm{e}-09$ 7.00000e-02

$1.48917 \mathrm{e}+011.48917 \mathrm{e}+011.48917 \mathrm{e}+001.00000 \mathrm{e}-09$ 7.00000e-02

$1.48917 \mathrm{e}+011.48917 \mathrm{e}+011.48917 \mathrm{e}+001.00000 \mathrm{e}-097.00000 \mathrm{e}-02$

5.00000e-04 5.00000e-04 5.00000e-05 1.00000e-09 1.00000e-01

5.00000e-04 5.00000e-04 5.00000e-05 1.00000e-09 1.00000e-01

5.95025e-01 5.95025e-01 5.95025e-02 1.00000e-09 2.12000e-01

5.95025e-01 5.95025e-01 5.95025e-02 1.00000e-09 2.12000e-01

5.95025e-01 5.95025e-01 5.95025e-02 1.00000e-09 2.12000e-01

5.95025e-01 5.95025e-01 5.95025e-02 1.00000e-09 2.12000e-01

5.95025e-01 5.95025e-01 5.95025e-02 1.00000e-09 2.12000e-01

$1.00000 \mathrm{e}-02$ 1.00000e-02 1.00000e-03 1.00000e-09 1.00000e-01

$1.00000 \mathrm{e}+001.00000 \mathrm{e}+001.00000 \mathrm{e}-011.00000 \mathrm{e}-091.00000 \mathrm{e}-01$

$1.00000 \mathrm{e}-051.00000 \mathrm{e}-05$ 1.00000e-06 1.00000e-09 1.00000e-01

$1.00000 \mathrm{e}+001.00000 \mathrm{e}+001.00000 \mathrm{e}-011.00000 \mathrm{e}-091.00000 \mathrm{e}-01$

Element: 3280 \# of layers: 14

Kx Ky Kz Ss Por

$1.48917 \mathrm{e}+011.48917 \mathrm{e}+011.48917 \mathrm{e}+00$ 1.00000e-09 7.00000e-02

$1.48917 \mathrm{e}+011.48917 \mathrm{e}+011.48917 \mathrm{e}+001.00000 \mathrm{e}-09$ 7.00000e-02

$1.48917 \mathrm{e}+011.48917 \mathrm{e}+011.48917 \mathrm{e}+001.00000 \mathrm{e}-09$ 7.00000e-02

5.00000e-04 5.00000e-04 5.00000e-05 1.00000e-09 1.00000e-01

$5.00000 \mathrm{e}-04$ 5.00000e-04 5.00000e-05 1.00000e-09 1.00000e-01

5.95025e-01 5.95025e-01 5.95025e-02 1.00000e-09 2.12000e-01

5.95025e-01 5.95025e-01 5.95025e-02 1.00000e-09 2.12000e-01

5.95025e-01 5.95025e-01 5.95025e-02 1.00000e-09 2.12000e-01

5.95025e-01 5.95025e-01 5.95025e-02 1.00000e-09 2.12000e-01

5.95025e-01 5.95025e-01 5.95025e-02 1.00000e-09 2.12000e-01

$1.00000 \mathrm{e}-02$ 1.00000e-02 1.00000e-03 1.00000e-09 1.00000e-01

$1.00000 \mathrm{e}+001.00000 \mathrm{e}+001.00000 \mathrm{e}-011.00000 \mathrm{e}-091.00000 \mathrm{e}-01$

$1.00000 \mathrm{e}-05$ 1.00000e-05 1.00000e-06 1.00000e-09 1.00000e-01

$1.00000 \mathrm{e}+001.00000 \mathrm{e}+001.00000 \mathrm{e}-011.00000 \mathrm{e}-091.00000 \mathrm{e}-01$

Element: 3281 \# of layers: 14

Kx Ky Kz Ss Por

$1.48917 \mathrm{e}+011.48917 \mathrm{e}+01$ 1.48917e+00 1.00000e-09 7.00000e-02

$1.48917 \mathrm{e}+011.48917 \mathrm{e}+011.48917 \mathrm{e}+001.00000 \mathrm{e}-09$ 7.00000e-02

$1.48917 \mathrm{e}+011.48917 \mathrm{e}+011.48917 \mathrm{e}+001.00000 \mathrm{e}-09$ 7.00000e-02

5.00000e-04 5.00000e-04 5.00000e-05 1.00000e-09 1.00000e-01

$5.00000 \mathrm{e}-04$ 5.00000e-04 5.00000e-05 1.00000e-09 1.00000e-01

5.95025e-01 5.95025e-01 5.95025e-02 1.00000e-09 2.12000e-01

5.95025e-01 5.95025e-01 5.95025e-02 1.00000e-09 2.12000e-01

5.95025e-01 5.95025e-01 5.95025e-02 1.00000e-09 2.12000e-01

5.95025e-01 5.95025e-01 5.95025e-02 1.00000e-09 2.12000e-01

5.95025e-01 5.95025e-01 5.95025e-02 1.00000e-09 2.12000e-01

$1.00000 \mathrm{e}-02$ 1.00000e-02 1.00000e-03 1.00000e-09 1.00000e-01 
$1.00000 \mathrm{e}+001.00000 \mathrm{e}+001.00000 \mathrm{e}-011.00000 \mathrm{e}-091.00000 \mathrm{e}-01$ $1.00000 \mathrm{e}-05$ 1.00000e-05 1.00000e-06 1.00000e-09 1.00000e-01 $1.00000 \mathrm{e}+001.00000 \mathrm{e}+001.00000 \mathrm{e}-01$ 1.00000e-09 1.00000e-01 Element: 3282 \# of layers: 14

$\mathrm{Kx} \mathrm{Ky} \mathrm{Kz}$ Ss Por

$1.48917 \mathrm{e}+01$ 1.48917e+01 1.48917e+00 1.00000e-09 7.00000e-02 $1.48917 \mathrm{e}+01$ 1.48917e+01 1.48917e+00 1.00000e-09 7.00000e-02 $1.48917 \mathrm{e}+011.48917 \mathrm{e}+011.48917 \mathrm{e}+001.00000 \mathrm{e}-09$ 7.00000e-02 5.00000e-04 5.00000e-04 5.00000e-05 1.00000e-09 1.00000e-01 5.00000e-04 5.00000e-04 5.00000e-05 1.00000e-09 1.00000e-01 5.95025e-01 5.95025e-01 5.95025e-02 1.00000e-09 2.12000e-01 5.95025e-01 5.95025e-01 5.95025e-02 1.00000e-09 2.12000e-01 5.95025e-01 5.95025e-01 5.95025e-02 1.00000e-09 2.12000e-01 5.95025e-01 5.95025e-01 5.95025e-02 1.00000e-09 2.12000e-01 5.95025e-01 5.95025e-01 5.95025e-02 1.00000e-09 2.12000e-01 $1.00000 \mathrm{e}-02$ 1.00000e-02 1.00000e-03 1.00000e-09 1.00000e-01 $1.00000 \mathrm{e}+001.00000 \mathrm{e}+001.00000 \mathrm{e}-011.00000 \mathrm{e}-091.00000 \mathrm{e}-01$ $1.00000 \mathrm{e}-05$ 1.00000e-05 1.00000e-06 1.00000e-09 1.00000e-01 $1.00000 \mathrm{e}+001.00000 \mathrm{e}+001.00000 \mathrm{e}-011.00000 \mathrm{e}-091.00000 \mathrm{e}-01$ Element: 3283 \# of layers: 15

$\mathrm{Kx} \mathrm{Ky} \mathrm{Kz}$ Ss Por

$1.48917 \mathrm{e}+01$ 1.48917e+01 1.48917e+00 1.00000e-09 7.00000e-02 $1.48917 \mathrm{e}+01$ 1.48917e+01 1.48917e+00 1.00000e-09 7.00000e-02 $1.48917 \mathrm{e}+011.48917 \mathrm{e}+01$ 1.48917e+00 1.00000e-09 7.00000e-02 $1.48917 \mathrm{e}+011.48917 \mathrm{e}+011.48917 \mathrm{e}+001.00000 \mathrm{e}-09$ 7.00000e-02 $5.00000 \mathrm{e}-04$ 5.00000e-04 5.00000e-05 1.00000e-09 1.00000e-01 5.00000e-04 5.00000e-04 5.00000e-05 1.00000e-09 1.00000e-01 5.95025e-01 5.95025e-01 5.95025e-02 1.00000e-09 2.12000e-01 5.95025e-01 5.95025e-01 5.95025e-02 1.00000e-09 2.12000e-01 5.95025e-01 5.95025e-01 5.95025e-02 1.00000e-09 2.12000e-01 5.95025e-01 5.95025e-01 5.95025e-02 1.00000e-09 2.12000e-01 5.95025e-01 5.95025e-01 5.95025e-02 1.00000e-09 2.12000e-01 1.00000e-02 1.00000e-02 1.00000e-03 1.00000e-09 1.00000e-01 $1.00000 \mathrm{e}+001.00000 \mathrm{e}+001.00000 \mathrm{e}-011.00000 \mathrm{e}-091.00000 \mathrm{e}-01$ $1.00000 \mathrm{e}-05$ 1.00000e-05 1.00000e-06 1.00000e-09 1.00000e-01 $1.00000 \mathrm{e}+001.00000 \mathrm{e}+001.00000 \mathrm{e}-01$ 1.00000e-09 1.00000e-01 Element: 3284 \# of layers: 14

$\mathrm{Kx} \mathrm{Ky} \mathrm{Kz}$ Ss Por $1.48917 \mathrm{e}+01$ 1.48917e+01 1.48917e+00 1.00000e-09 7.00000e-02 $1.48917 \mathrm{e}+01$ 1.48917e+01 1.48917e+00 1.00000e-09 7.00000e-02 $1.48917 \mathrm{e}+011.48917 \mathrm{e}+01$ 1.48917e+00 1.00000e-09 7.00000e-02 5.00000e-04 5.00000e-04 5.00000e-05 1.00000e-09 1.00000e-01 5.00000e-04 5.00000e-04 5.00000e-05 1.00000e-09 1.00000e-01 5.95025e-01 5.95025e-01 5.95025e-02 1.00000e-09 2.12000e-01 5.95025e-01 5.95025e-01 5.95025e-02 1.00000e-09 2.12000e-01 5.95025e-01 5.95025e-01 5.95025e-02 1.00000e-09 2.12000e-01 
5.95025e-01 5.95025e-01 5.95025e-02 1.00000e-09 2.12000e-01 5.95025e-01 5.95025e-01 5.95025e-02 1.00000e-09 2.12000e-01 $1.00000 \mathrm{e}-02$ 1.00000e-02 1.00000e-03 1.00000e-09 1.00000e-01 $1.00000 \mathrm{e}+001.00000 \mathrm{e}+001.00000 \mathrm{e}-011.00000 \mathrm{e}-091.00000 \mathrm{e}-01$ $1.00000 \mathrm{e}-05$ 1.00000e-05 1.00000e-06 1.00000e-09 1.00000e-01 $1.00000 \mathrm{e}+001.00000 \mathrm{e}+001.00000 \mathrm{e}-011.00000 \mathrm{e}-091.00000 \mathrm{e}-01$ Element: 3285 \# of layers: 14

Kx Ky Kz Ss Por

$1.48917 \mathrm{e}+011.48917 \mathrm{e}+011.48917 \mathrm{e}+00$ 1.00000e-09 7.00000e-02 $1.48917 \mathrm{e}+011.48917 \mathrm{e}+011.48917 \mathrm{e}+001.00000 \mathrm{e}-09$ 7.00000e-02 $1.48917 \mathrm{e}+011.48917 \mathrm{e}+011.48917 \mathrm{e}+001.00000 \mathrm{e}-09$ 7.00000e-02 5.00000e-04 5.00000e-04 5.00000e-05 1.00000e-09 1.00000e-01 5.00000e-04 5.00000e-04 5.00000e-05 1.00000e-09 1.00000e-01 5.95025e-01 5.95025e-01 5.95025e-02 1.00000e-09 2.12000e-01 5.95025e-01 5.95025e-01 5.95025e-02 1.00000e-09 2.12000e-01 5.95025e-01 5.95025e-01 5.95025e-02 1.00000e-09 2.12000e-01 5.95025e-01 5.95025e-01 5.95025e-02 1.00000e-09 2.12000e-01 5.95025e-01 5.95025e-01 5.95025e-02 1.00000e-09 2.12000e-01 $1.00000 \mathrm{e}-02$ 1.00000e-02 1.00000e-03 1.00000e-09 1.00000e-01 $1.00000 \mathrm{e}+001.00000 \mathrm{e}+001.00000 \mathrm{e}-011.00000 \mathrm{e}-091.00000 \mathrm{e}-01$ $1.00000 \mathrm{e}-05$ 1.00000e-05 1.00000e-06 1.00000e-09 1.00000e-01 $1.00000 \mathrm{e}+001.00000 \mathrm{e}+001.00000 \mathrm{e}-011.00000 \mathrm{e}-091.00000 \mathrm{e}-01$ Element: 3286 \# of layers: 15

Kx Ky Kz Ss Por

$1.48917 \mathrm{e}+011.48917 \mathrm{e}+01$ 1.48917e+00 1.00000e-09 7.00000e-02 $1.48917 \mathrm{e}+011.48917 \mathrm{e}+011.48917 \mathrm{e}+001.00000 \mathrm{e}-09$ 7.00000e-02 $1.48917 \mathrm{e}+011.48917 \mathrm{e}+011.48917 \mathrm{e}+001.00000 \mathrm{e}-09$ 7.00000e-02 $1.48917 \mathrm{e}+011.48917 \mathrm{e}+011.48917 \mathrm{e}+001.00000 \mathrm{e}-09$ 7.00000e-02 5.00000e-04 5.00000e-04 5.00000e-05 1.00000e-09 1.00000e-01 $5.00000 \mathrm{e}-04$ 5.00000e-04 5.00000e-05 1.00000e-09 1.00000e-01 5.95025e-01 5.95025e-01 5.95025e-02 1.00000e-09 2.12000e-01 5.95025e-01 5.95025e-01 5.95025e-02 1.00000e-09 2.12000e-01 5.95025e-01 5.95025e-01 5.95025e-02 1.00000e-09 2.12000e-01 5.95025e-01 5.95025e-01 5.95025e-02 1.00000e-09 2.12000e-01 5.95025e-01 5.95025e-01 5.95025e-02 1.00000e-09 2.12000e-01 $1.00000 \mathrm{e}-02$ 1.00000e-02 1.00000e-03 1.00000e-09 1.00000e-01 $1.00000 \mathrm{e}+001.00000 \mathrm{e}+001.00000 \mathrm{e}-011.00000 \mathrm{e}-091.00000 \mathrm{e}-01$ $1.00000 \mathrm{e}-05$ 1.00000e-05 1.00000e-06 1.00000e-09 1.00000e-01 $1.00000 \mathrm{e}+001.00000 \mathrm{e}+001.00000 \mathrm{e}-011.00000 \mathrm{e}-091.00000 \mathrm{e}-01$ Element: 3287 \# of layers: 14

Kx Ky Kz Ss Por

$1.56306 \mathrm{e}+011.56306 \mathrm{e}+011.56306 \mathrm{e}+001.00000 \mathrm{e}-09$ 7.00000e-02 $1.56306 \mathrm{e}+011.56306 \mathrm{e}+011.56306 \mathrm{e}+001.00000 \mathrm{e}-097.00000 \mathrm{e}-02$ $1.56306 \mathrm{e}+011.56306 \mathrm{e}+011.56306 \mathrm{e}+001.00000 \mathrm{e}-097.00000 \mathrm{e}-02$ 5.00000e-04 5.00000e-04 5.00000e-05 1.00000e-09 1.00000e-01 5.00000e-04 5.00000e-04 5.00000e-05 1.00000e-09 1.00000e-01 
6.24546e-01 6.24546e-01 6.24546e-02 1.00000e-09 2.12000e-01 6.24546e-01 6.24546e-01 6.24546e-02 1.00000e-09 2.12000e-01 6.24546e-01 6.24546e-01 6.24546e-02 1.00000e-09 2.12000e-01 6.24546e-01 6.24546e-01 6.24546e-02 1.00000e-09 2.12000e-01 6.24546e-01 6.24546e-01 6.24546e-02 1.00000e-09 2.12000e-01 $1.00000 \mathrm{e}-02$ 1.00000e-02 1.00000e-03 1.00000e-09 1.00000e-01 $1.00000 \mathrm{e}+001.00000 \mathrm{e}+001.00000 \mathrm{e}-011.00000 \mathrm{e}-091.00000 \mathrm{e}-01$ $1.00000 \mathrm{e}-05$ 1.00000e-05 1.00000e-06 1.00000e-09 1.00000e-01 $1.00000 \mathrm{e}+001.00000 \mathrm{e}+001.00000 \mathrm{e}-011.00000 \mathrm{e}-091.00000 \mathrm{e}-01$ Element: 3288 \# of layers: 14

$\mathrm{Kx} \mathrm{Ky} \mathrm{Kz}$ Ss Por

$1.56306 \mathrm{e}+011.56306 \mathrm{e}+011.56306 \mathrm{e}+001.00000 \mathrm{e}-09$ 7.00000e-02 $1.56306 \mathrm{e}+011.56306 \mathrm{e}+01$ 1.56306e+00 1.00000e-09 7.00000e-02

$1.56306 \mathrm{e}+011.56306 \mathrm{e}+011.56306 \mathrm{e}+001.00000 \mathrm{e}-09$ 7.00000e-02 5.00000e-04 5.00000e-04 5.00000e-05 1.00000e-09 1.00000e-01 5.00000e-04 5.00000e-04 5.00000e-05 1.00000e-09 1.00000e-01 6.24546e-01 6.24546e-01 6.24546e-02 1.00000e-09 2.12000e-01 6.24546e-01 6.24546e-01 6.24546e-02 1.00000e-09 2.12000e-01 6.24546e-01 6.24546e-01 6.24546e-02 1.00000e-09 2.12000e-01 6.24546e-01 6.24546e-01 6.24546e-02 1.00000e-09 2.12000e-01 6.24546e-01 6.24546e-01 6.24546e-02 1.00000e-09 2.12000e-01 $1.00000 \mathrm{e}-02$ 1.00000e-02 1.00000e-03 1.00000e-09 1.00000e-01 $1.00000 \mathrm{e}+001.00000 \mathrm{e}+001.00000 \mathrm{e}-011.00000 \mathrm{e}-091.00000 \mathrm{e}-01$ 1.00000e-05 1.00000e-05 1.00000e-06 1.00000e-09 1.00000e-01 $1.00000 \mathrm{e}+001.00000 \mathrm{e}+001.00000 \mathrm{e}-011.00000 \mathrm{e}-091.00000 \mathrm{e}-01$ Element: 3289 \# of layers: 13

$\mathrm{Kx} \mathrm{Ky} \mathrm{Kz}$ Ss Por

$1.56306 \mathrm{e}+011.56306 \mathrm{e}+011.56306 \mathrm{e}+001.00000 \mathrm{e}-09$ 7.00000e-02 $1.56306 \mathrm{e}+011.56306 \mathrm{e}+011.56306 \mathrm{e}+001.00000 \mathrm{e}-097.00000 \mathrm{e}-02$ 5.00000e-04 5.00000e-04 5.00000e-05 1.00000e-09 1.00000e-01 5.00000e-04 5.00000e-04 5.00000e-05 1.00000e-09 1.00000e-01 6.24546e-01 6.24546e-01 6.24546e-02 1.00000e-09 2.12000e-01 6.24546e-01 6.24546e-01 6.24546e-02 1.00000e-09 2.12000e-01 6.24546e-01 6.24546e-01 6.24546e-02 1.00000e-09 2.12000e-01 6.24546e-01 6.24546e-01 6.24546e-02 1.00000e-09 2.12000e-01 6.24546e-01 6.24546e-01 6.24546e-02 1.00000e-09 2.12000e-01 $1.00000 \mathrm{e}-02$ 1.00000e-02 1.00000e-03 1.00000e-09 1.00000e-01 $1.00000 \mathrm{e}+001.00000 \mathrm{e}+001.00000 \mathrm{e}-011.00000 \mathrm{e}-091.00000 \mathrm{e}-01$ $1.00000 \mathrm{e}-05$ 1.00000e-05 1.00000e-06 1.00000e-09 1.00000e-01 $1.00000 \mathrm{e}+001.00000 \mathrm{e}+001.00000 \mathrm{e}-011.00000 \mathrm{e}-091.00000 \mathrm{e}-01$ Element: 3290 \# of layers: 13

$\mathrm{Kx} \mathrm{Ky} \mathrm{Kz}$ Ss Por

$1.56306 \mathrm{e}+01$ 1.56306e+01 1.56306e+00 1.00000e-09 7.00000e-02 $1.56306 \mathrm{e}+01$ 1.56306e+01 1.56306e+00 1.00000e-09 7.00000e-02 5.00000e-04 5.00000e-04 5.00000e-05 1.00000e-09 1.00000e-01 5.00000e-04 5.00000e-04 5.00000e-05 1.00000e-09 1.00000e-01 
6.24546e-01 6.24546e-01 6.24546e-02 1.00000e-09 2.12000e-01 6.24546e-01 6.24546e-01 6.24546e-02 1.00000e-09 2.12000e-01 6.24546e-01 6.24546e-01 6.24546e-02 1.00000e-09 2.12000e-01 6.24546e-01 6.24546e-01 6.24546e-02 1.00000e-09 2.12000e-01 6.24546e-01 6.24546e-01 6.24546e-02 1.00000e-09 2.12000e-01 $1.00000 \mathrm{e}-02$ 1.00000e-02 1.00000e-03 1.00000e-09 1.00000e-01 $1.00000 \mathrm{e}+001.00000 \mathrm{e}+001.00000 \mathrm{e}-011.00000 \mathrm{e}-091.00000 \mathrm{e}-01$ $1.00000 \mathrm{e}-05$ 1.00000e-05 1.00000e-06 1.00000e-09 1.00000e-01 $1.00000 \mathrm{e}+001.00000 \mathrm{e}+001.00000 \mathrm{e}-011.00000 \mathrm{e}-091.00000 \mathrm{e}-01$ Element: 3291 \# of layers: 12

$\mathrm{Kx} \mathrm{Ky} \mathrm{Kz}$ Ss Por

$1.56306 \mathrm{e}+011.56306 \mathrm{e}+011.56306 \mathrm{e}+001.00000 \mathrm{e}-09$ 7.00000e-02 $1.56306 \mathrm{e}+011.56306 \mathrm{e}+011.56306 \mathrm{e}+001.00000 \mathrm{e}-09$ 7.00000e-02 5.00000e-04 5.00000e-04 5.00000e-05 1.00000e-09 1.00000e-01 5.00000e-04 5.00000e-04 5.00000e-05 1.00000e-09 1.00000e-01 6.24546e-01 6.24546e-01 6.24546e-02 1.00000e-09 2.12000e-01 6.24546e-01 6.24546e-01 6.24546e-02 1.00000e-09 2.12000e-01 6.24546e-01 6.24546e-01 6.24546e-02 1.00000e-09 2.12000e-01 6.24546e-01 6.24546e-01 6.24546e-02 1.00000e-09 2.12000e-01 $1.00000 \mathrm{e}-02$ 1.00000e-02 1.00000e-03 1.00000e-09 1.00000e-01 $1.00000 \mathrm{e}+001.00000 \mathrm{e}+001.00000 \mathrm{e}-011.00000 \mathrm{e}-091.00000 \mathrm{e}-01$ $1.00000 \mathrm{e}-05$ 1.00000e-05 1.00000e-06 1.00000e-09 1.00000e-01 $1.00000 \mathrm{e}+001.00000 \mathrm{e}+001.00000 \mathrm{e}-01$ 1.00000e-09 1.00000e-01 Element: 3292 \# of layers: 14

Kx Ky Kz Ss Por

$1.56306 \mathrm{e}+01$ 1.56306e+01 1.56306e+00 1.00000e-09 7.00000e-02 $1.56306 \mathrm{e}+011.56306 \mathrm{e}+011.56306 \mathrm{e}+001.00000 \mathrm{e}-097.00000 \mathrm{e}-02$ $1.56306 \mathrm{e}+011.56306 \mathrm{e}+011.56306 \mathrm{e}+001.00000 \mathrm{e}-097.00000 \mathrm{e}-02$ 5.00000e-04 5.00000e-04 5.00000e-05 1.00000e-09 1.00000e-01 5.00000e-04 5.00000e-04 5.00000e-05 1.00000e-09 1.00000e-01 6.24546e-01 6.24546e-01 6.24546e-02 1.00000e-09 2.12000e-01 6.24546e-01 6.24546e-01 6.24546e-02 1.00000e-09 2.12000e-01 6.24546e-01 6.24546e-01 6.24546e-02 1.00000e-09 2.12000e-01 6.24546e-01 6.24546e-01 6.24546e-02 1.00000e-09 2.12000e-01 6.24546e-01 6.24546e-01 6.24546e-02 1.00000e-09 2.12000e-01 $1.00000 \mathrm{e}-02$ 1.00000e-02 1.00000e-03 1.00000e-09 1.00000e-01 $1.00000 \mathrm{e}+001.00000 \mathrm{e}+001.00000 \mathrm{e}-011.00000 \mathrm{e}-091.00000 \mathrm{e}-01$ $1.00000 \mathrm{e}-05$ 1.00000e-05 1.00000e-06 1.00000e-09 1.00000e-01 $1.00000 \mathrm{e}+001.00000 \mathrm{e}+001.00000 \mathrm{e}-011.00000 \mathrm{e}-091.00000 \mathrm{e}-01$ Element: 3293 \# of layers: 14

$\mathrm{Kx} \mathrm{Ky} \mathrm{Kz}$ Ss Por

$1.56306 \mathrm{e}+011.56306 \mathrm{e}+01$ 1.56306e+00 1.00000e-09 7.00000e-02 $1.56306 \mathrm{e}+011.56306 \mathrm{e}+011.56306 \mathrm{e}+001.00000 \mathrm{e}-09$ 7.00000e-02 $1.56306 \mathrm{e}+01$ 1.56306e+01 1.56306e+00 1.00000e-09 7.00000e-02 5.00000e-04 5.00000e-04 5.00000e-05 1.00000e-09 1.00000e-01 5.00000e-04 5.00000e-04 5.00000e-05 1.00000e-09 1.00000e-01 
6.24546e-01 6.24546e-01 6.24546e-02 1.00000e-09 2.12000e-01 6.24546e-01 6.24546e-01 6.24546e-02 1.00000e-09 2.12000e-01 6.24546e-01 6.24546e-01 6.24546e-02 1.00000e-09 2.12000e-01 6.24546e-01 6.24546e-01 6.24546e-02 1.00000e-09 2.12000e-01 6.24546e-01 6.24546e-01 6.24546e-02 1.00000e-09 2.12000e-01 $1.00000 \mathrm{e}-02$ 1.00000e-02 1.00000e-03 1.00000e-09 1.00000e-01 $1.00000 \mathrm{e}+001.00000 \mathrm{e}+001.00000 \mathrm{e}-011.00000 \mathrm{e}-091.00000 \mathrm{e}-01$ $1.00000 \mathrm{e}-05$ 1.00000e-05 1.00000e-06 1.00000e-09 1.00000e-01 $1.00000 \mathrm{e}+001.00000 \mathrm{e}+001.00000 \mathrm{e}-011.00000 \mathrm{e}-091.00000 \mathrm{e}-01$ Element: 3294 \# of layers: 14

$\mathrm{Kx} \mathrm{Ky} \mathrm{Kz}$ Ss Por

$1.56306 \mathrm{e}+011.56306 \mathrm{e}+011.56306 \mathrm{e}+001.00000 \mathrm{e}-09$ 7.00000e-02 $1.56306 \mathrm{e}+011.56306 \mathrm{e}+01$ 1.56306e+00 1.00000e-09 7.00000e-02

$1.56306 \mathrm{e}+011.56306 \mathrm{e}+011.56306 \mathrm{e}+001.00000 \mathrm{e}-09$ 7.00000e-02 5.00000e-04 5.00000e-04 5.00000e-05 1.00000e-09 1.00000e-01 5.00000e-04 5.00000e-04 5.00000e-05 1.00000e-09 1.00000e-01 6.24546e-01 6.24546e-01 6.24546e-02 1.00000e-09 2.12000e-01 6.24546e-01 6.24546e-01 6.24546e-02 1.00000e-09 2.12000e-01 6.24546e-01 6.24546e-01 6.24546e-02 1.00000e-09 2.12000e-01 6.24546e-01 6.24546e-01 6.24546e-02 1.00000e-09 2.12000e-01 6.24546e-01 6.24546e-01 6.24546e-02 1.00000e-09 2.12000e-01 $1.00000 \mathrm{e}-02$ 1.00000e-02 1.00000e-03 1.00000e-09 1.00000e-01 $1.00000 \mathrm{e}+001.00000 \mathrm{e}+001.00000 \mathrm{e}-011.00000 \mathrm{e}-091.00000 \mathrm{e}-01$ 1.00000e-05 1.00000e-05 1.00000e-06 1.00000e-09 1.00000e-01 $1.00000 \mathrm{e}+001.00000 \mathrm{e}+001.00000 \mathrm{e}-011.00000 \mathrm{e}-091.00000 \mathrm{e}-01$ Element: 3295 \# of layers: 14

$\mathrm{Kx} \mathrm{Ky} \mathrm{Kz}$ Ss Por

$1.56306 \mathrm{e}+011.56306 \mathrm{e}+011.56306 \mathrm{e}+001.00000 \mathrm{e}-09$ 7.00000e-02 $1.56306 \mathrm{e}+011.56306 \mathrm{e}+011.56306 \mathrm{e}+001.00000 \mathrm{e}-09$ 7.00000e-02 $1.56306 \mathrm{e}+011.56306 \mathrm{e}+011.56306 \mathrm{e}+001.00000 \mathrm{e}-09$ 7.00000e-02 5.00000e-04 5.00000e-04 5.00000e-05 1.00000e-09 1.00000e-01 5.00000e-04 5.00000e-04 5.00000e-05 1.00000e-09 1.00000e-01 6.24546e-01 6.24546e-01 6.24546e-02 1.00000e-09 2.12000e-01 6.24546e-01 6.24546e-01 6.24546e-02 1.00000e-09 2.12000e-01 6.24546e-01 6.24546e-01 6.24546e-02 1.00000e-09 2.12000e-01 6.24546e-01 6.24546e-01 6.24546e-02 1.00000e-09 2.12000e-01 6.24546e-01 6.24546e-01 6.24546e-02 1.00000e-09 2.12000e-01 $1.00000 \mathrm{e}-02$ 1.00000e-02 1.00000e-03 1.00000e-09 1.00000e-01 $1.00000 \mathrm{e}+001.00000 \mathrm{e}+001.00000 \mathrm{e}-011.00000 \mathrm{e}-091.00000 \mathrm{e}-01$ $1.00000 \mathrm{e}-05$ 1.00000e-05 1.00000e-06 1.00000e-09 1.00000e-01 $1.00000 \mathrm{e}+001.00000 \mathrm{e}+001.00000 \mathrm{e}-011.00000 \mathrm{e}-091.00000 \mathrm{e}-01$ Element: 3296 \# of layers: 13

$\mathrm{Kx} \mathrm{Ky} \mathrm{Kz}$ Ss Por

$1.73280 \mathrm{e}+01$ 1.73280e+01 1.73280e+00 1.00000e-09 7.00000e-02 $1.73280 \mathrm{e}+011.73280 \mathrm{e}+011.73280 \mathrm{e}+001.00000 \mathrm{e}-097.00000 \mathrm{e}-02$ 5.00000e-04 5.00000e-04 5.00000e-05 1.00000e-09 1.00000e-01 
5.00000e-04 5.00000e-04 5.00000e-05 1.00000e-09 1.00000e-01 6.92362e-01 6.92362e-01 6.92362e-02 1.00000e-09 2.12000e-01 6.92362e-01 6.92362e-01 6.92362e-02 1.00000e-09 2.12000e-01 6.92362e-01 6.92362e-01 6.92362e-02 1.00000e-09 2.12000e-01 6.92362e-01 6.92362e-01 6.92362e-02 1.00000e-09 2.12000e-01 6.92362e-01 6.92362e-01 6.92362e-02 1.00000e-09 2.12000e-01 $1.00000 \mathrm{e}-021.00000 \mathrm{e}-02$ 1.00000e-03 1.00000e-09 1.00000e-01 $1.00000 \mathrm{e}+001.00000 \mathrm{e}+001.00000 \mathrm{e}-011.00000 \mathrm{e}-091.00000 \mathrm{e}-01$ $1.00000 \mathrm{e}-05$ 1.00000e-05 1.00000e-06 1.00000e-09 1.00000e-01 $1.00000 \mathrm{e}+001.00000 \mathrm{e}+001.00000 \mathrm{e}-011.00000 \mathrm{e}-091.00000 \mathrm{e}-01$ Element: 3297 \# of layers: 13

Kx Ky Kz Ss Por

$1.73280 \mathrm{e}+011.73280 \mathrm{e}+011.73280 \mathrm{e}+00$ 1.00000e-09 7.00000e-02 $1.73280 \mathrm{e}+011.73280 \mathrm{e}+011.73280 \mathrm{e}+001.00000 \mathrm{e}-09$ 7.00000e-02 $5.00000 \mathrm{e}-04$ 5.00000e-04 5.00000e-05 1.00000e-09 1.00000e-01 5.00000e-04 5.00000e-04 5.00000e-05 1.00000e-09 1.00000e-01 6.92362e-01 6.92362e-01 6.92362e-02 1.00000e-09 2.12000e-01 6.92362e-01 6.92362e-01 6.92362e-02 1.00000e-09 2.12000e-01 6.92362e-01 6.92362e-01 6.92362e-02 1.00000e-09 2.12000e-01 6.92362e-01 6.92362e-01 6.92362e-02 1.00000e-09 2.12000e-01 6.92362e-01 6.92362e-01 6.92362e-02 1.00000e-09 2.12000e-01 $1.00000 \mathrm{e}-02$ 1.00000e-02 1.00000e-03 1.00000e-09 1.00000e-01 $1.00000 \mathrm{e}+001.00000 \mathrm{e}+001.00000 \mathrm{e}-011.00000 \mathrm{e}-091.00000 \mathrm{e}-01$ $1.00000 \mathrm{e}-051.00000 \mathrm{e}-05$ 1.00000e-06 1.00000e-09 1.00000e-01 $1.00000 \mathrm{e}+001.00000 \mathrm{e}+001.00000 \mathrm{e}-011.00000 \mathrm{e}-091.00000 \mathrm{e}-01$ Element: 3298 \# of layers: 13

Kx Ky Kz Ss Por

$1.73280 \mathrm{e}+011.73280 \mathrm{e}+011.73280 \mathrm{e}+001.00000 \mathrm{e}-09$ 7.00000e-02 $1.73280 \mathrm{e}+011.73280 \mathrm{e}+011.73280 \mathrm{e}+001.00000 \mathrm{e}-09$ 7.00000e-02 5.00000e-04 5.00000e-04 5.00000e-05 1.00000e-09 1.00000e-01 5.00000e-04 5.00000e-04 5.00000e-05 1.00000e-09 1.00000e-01 6.92362e-01 6.92362e-01 6.92362e-02 1.00000e-09 2.12000e-01 6.92362e-01 6.92362e-01 6.92362e-02 1.00000e-09 2.12000e-01 6.92362e-01 6.92362e-01 6.92362e-02 1.00000e-09 2.12000e-01 6.92362e-01 6.92362e-01 6.92362e-02 1.00000e-09 2.12000e-01 6.92362e-01 6.92362e-01 6.92362e-02 1.00000e-09 2.12000e-01 $1.00000 \mathrm{e}-021.00000 \mathrm{e}-02$ 1.00000e-03 1.00000e-09 1.00000e-01 $1.00000 \mathrm{e}+001.00000 \mathrm{e}+001.00000 \mathrm{e}-011.00000 \mathrm{e}-091.00000 \mathrm{e}-01$ $1.00000 \mathrm{e}-05$ 1.00000e-05 1.00000e-06 1.00000e-09 1.00000e-01 $1.00000 \mathrm{e}+001.00000 \mathrm{e}+001.00000 \mathrm{e}-011.00000 \mathrm{e}-091.00000 \mathrm{e}-01$ Element: 3299 \# of layers: 13

Kx Ky Kz Ss Por

$1.73280 \mathrm{e}+011.73280 \mathrm{e}+011.73280 \mathrm{e}+001.00000 \mathrm{e}-097.00000 \mathrm{e}-02$ $1.73280 \mathrm{e}+011.73280 \mathrm{e}+011.73280 \mathrm{e}+001.00000 \mathrm{e}-09$ 7.00000e-02 5.00000e-04 5.00000e-04 5.00000e-05 1.00000e-09 1.00000e-01 5.00000e-04 5.00000e-04 5.00000e-05 1.00000e-09 1.00000e-01 
6.92362e-01 6.92362e-01 6.92362e-02 1.00000e-09 2.12000e-01 6.92362e-01 6.92362e-01 6.92362e-02 1.00000e-09 2.12000e-01 6.92362e-01 6.92362e-01 6.92362e-02 1.00000e-09 2.12000e-01 6.92362e-01 6.92362e-01 6.92362e-02 1.00000e-09 2.12000e-01 6.92362e-01 6.92362e-01 6.92362e-02 1.00000e-09 2.12000e-01 $1.00000 \mathrm{e}-021.00000 \mathrm{e}-02$ 1.00000e-03 1.00000e-09 1.00000e-01 $1.00000 \mathrm{e}+001.00000 \mathrm{e}+001.00000 \mathrm{e}-011.00000 \mathrm{e}-091.00000 \mathrm{e}-01$ $1.00000 \mathrm{e}-05$ 1.00000e-05 1.00000e-06 1.00000e-09 1.00000e-01 $1.00000 \mathrm{e}+001.00000 \mathrm{e}+001.00000 \mathrm{e}-011.00000 \mathrm{e}-091.00000 \mathrm{e}-01$ Element: 3300 \# of layers: 12

Kx Ky Kz Ss Por

$1.73280 \mathrm{e}+011.73280 \mathrm{e}+011.73280 \mathrm{e}+00$ 1.00000e-09 7.00000e-02 $1.73280 \mathrm{e}+011.73280 \mathrm{e}+011.73280 \mathrm{e}+001.00000 \mathrm{e}-097.00000 \mathrm{e}-02$ 5.00000e-04 5.00000e-04 5.00000e-05 1.00000e-09 1.00000e-01 $5.00000 \mathrm{e}-04$ 5.00000e-04 5.00000e-05 1.00000e-09 1.00000e-01 6.92362e-01 6.92362e-01 6.92362e-02 1.00000e-09 2.12000e-01 6.92362e-01 6.92362e-01 6.92362e-02 1.00000e-09 2.12000e-01 6.92362e-01 6.92362e-01 6.92362e-02 1.00000e-09 2.12000e-01 6.92362e-01 6.92362e-01 6.92362e-02 1.00000e-09 2.12000e-01 $1.00000 \mathrm{e}-021.00000 \mathrm{e}-02$ 1.00000e-03 1.00000e-09 1.00000e-01 $1.00000 \mathrm{e}+001.00000 \mathrm{e}+001.00000 \mathrm{e}-011.00000 \mathrm{e}-091.00000 \mathrm{e}-01$ $1.00000 \mathrm{e}-05$ 1.00000e-05 1.00000e-06 1.00000e-09 1.00000e-01 $1.00000 \mathrm{e}+001.00000 \mathrm{e}+001.00000 \mathrm{e}-011.00000 \mathrm{e}-091.00000 \mathrm{e}-01$ Element: 3301 \# of layers: 12

Kx Ky Kz Ss Por

$1.73280 \mathrm{e}+011.73280 \mathrm{e}+011.73280 \mathrm{e}+00$ 1.00000e-09 7.00000e-02 $1.73280 \mathrm{e}+011.73280 \mathrm{e}+011.73280 \mathrm{e}+001.00000 \mathrm{e}-097.00000 \mathrm{e}-02$ 5.00000e-04 5.00000e-04 5.00000e-05 1.00000e-09 1.00000e-01 5.00000e-04 5.00000e-04 5.00000e-05 1.00000e-09 1.00000e-01 6.92362e-01 6.92362e-01 6.92362e-02 1.00000e-09 2.12000e-01 6.92362e-01 6.92362e-01 6.92362e-02 1.00000e-09 2.12000e-01 6.92362e-01 6.92362e-01 6.92362e-02 1.00000e-09 2.12000e-01 6.92362e-01 6.92362e-01 6.92362e-02 1.00000e-09 2.12000e-01 $1.00000 \mathrm{e}-021.00000 \mathrm{e}-02$ 1.00000e-03 1.00000e-09 1.00000e-01 $1.00000 \mathrm{e}+001.00000 \mathrm{e}+001.00000 \mathrm{e}-011.00000 \mathrm{e}-091.00000 \mathrm{e}-01$ $1.00000 \mathrm{e}-05$ 1.00000e-05 1.00000e-06 1.00000e-09 1.00000e-01 $1.00000 \mathrm{e}+001.00000 \mathrm{e}+001.00000 \mathrm{e}-011.00000 \mathrm{e}-091.00000 \mathrm{e}-01$ Element: 3302 \# of layers: 12

Kx Ky Kz Ss Por

$1.73280 \mathrm{e}+011.73280 \mathrm{e}+011.73280 \mathrm{e}+00$ 1.00000e-09 7.00000e-02 $1.73280 \mathrm{e}+011.73280 \mathrm{e}+011.73280 \mathrm{e}+001.00000 \mathrm{e}-097.00000 \mathrm{e}-02$ 5.00000e-04 5.00000e-04 5.00000e-05 1.00000e-09 1.00000e-01 $5.00000 \mathrm{e}-04$ 5.00000e-04 5.00000e-05 1.00000e-09 1.00000e-01 6.92362e-01 6.92362e-01 6.92362e-02 1.00000e-09 2.12000e-01 6.92362e-01 6.92362e-01 6.92362e-02 1.00000e-09 2.12000e-01 6.92362e-01 6.92362e-01 6.92362e-02 1.00000e-09 2.12000e-01 
6.92362e-01 6.92362e-01 6.92362e-02 1.00000e-09 2.12000e-01 $1.00000 \mathrm{e}-02$ 1.00000e-02 1.00000e-03 1.00000e-09 1.00000e-01 $1.00000 \mathrm{e}+001.00000 \mathrm{e}+001.00000 \mathrm{e}-011.00000 \mathrm{e}-091.00000 \mathrm{e}-01$ $1.00000 \mathrm{e}-05$ 1.00000e-05 1.00000e-06 1.00000e-09 1.00000e-01 $1.00000 \mathrm{e}+001.00000 \mathrm{e}+001.00000 \mathrm{e}-011.00000 \mathrm{e}-091.00000 \mathrm{e}-01$ Element: 3303 \# of layers: 13

Kx Ky Kz Ss Por

$1.73280 \mathrm{e}+011.73280 \mathrm{e}+011.73280 \mathrm{e}+00$ 1.00000e-09 7.00000e-02

$1.73280 \mathrm{e}+011.73280 \mathrm{e}+011.73280 \mathrm{e}+001.00000 \mathrm{e}-097.00000 \mathrm{e}-02$

$5.00000 \mathrm{e}-04$ 5.00000e-04 5.00000e-05 1.00000e-09 1.00000e-01

5.00000e-04 5.00000e-04 5.00000e-05 1.00000e-09 1.00000e-01 6.92362e-01 6.92362e-01 6.92362e-02 1.00000e-09 2.12000e-01 6.92362e-01 6.92362e-01 6.92362e-02 1.00000e-09 2.12000e-01 6.92362e-01 6.92362e-01 6.92362e-02 1.00000e-09 2.12000e-01 6.92362e-01 6.92362e-01 6.92362e-02 1.00000e-09 2.12000e-01 6.92362e-01 6.92362e-01 6.92362e-02 1.00000e-09 2.12000e-01 $1.00000 \mathrm{e}-021.00000 \mathrm{e}-02$ 1.00000e-03 1.00000e-09 1.00000e-01 $1.00000 \mathrm{e}+001.00000 \mathrm{e}+001.00000 \mathrm{e}-011.00000 \mathrm{e}-091.00000 \mathrm{e}-01$ $1.00000 \mathrm{e}-05$ 1.00000e-05 1.00000e-06 1.00000e-09 1.00000e-01 $1.00000 \mathrm{e}+001.00000 \mathrm{e}+001.00000 \mathrm{e}-011.00000 \mathrm{e}-091.00000 \mathrm{e}-01$ Element: 3304 \# of layers: 13

Kx Ky Kz Ss Por

$1.73280 \mathrm{e}+011.73280 \mathrm{e}+011.73280 \mathrm{e}+00$ 1.00000e-09 7.00000e-02 $1.73280 \mathrm{e}+011.73280 \mathrm{e}+011.73280 \mathrm{e}+001.00000 \mathrm{e}-097.00000 \mathrm{e}-02$ 5.00000e-04 5.00000e-04 5.00000e-05 1.00000e-09 1.00000e-01 5.00000e-04 5.00000e-04 5.00000e-05 1.00000e-09 1.00000e-01 6.92362e-01 6.92362e-01 6.92362e-02 1.00000e-09 2.12000e-01 6.92362e-01 6.92362e-01 6.92362e-02 1.00000e-09 2.12000e-01 6.92362e-01 6.92362e-01 6.92362e-02 1.00000e-09 2.12000e-01 6.92362e-01 6.92362e-01 6.92362e-02 1.00000e-09 2.12000e-01 6.92362e-01 6.92362e-01 6.92362e-02 1.00000e-09 2.12000e-01 $1.00000 \mathrm{e}-021.00000 \mathrm{e}-02$ 1.00000e-03 1.00000e-09 1.00000e-01 $1.00000 \mathrm{e}+001.00000 \mathrm{e}+001.00000 \mathrm{e}-011.00000 \mathrm{e}-091.00000 \mathrm{e}-01$ $1.00000 \mathrm{e}-05$ 1.00000e-05 1.00000e-06 1.00000e-09 1.00000e-01 $1.00000 \mathrm{e}+001.00000 \mathrm{e}+001.00000 \mathrm{e}-011.00000 \mathrm{e}-091.00000 \mathrm{e}-01$ Element: 3305 \# of layers: 13

Kx Ky Kz Ss Por

$2.29485 \mathrm{e}+012.29485 \mathrm{e}+012.29485 \mathrm{e}+00$ 1.00000e-09 7.00000e-02

$2.29485 \mathrm{e}+012.29485 \mathrm{e}+012.29485 \mathrm{e}+001.00000 \mathrm{e}-09$ 7.00000e-02

5.00000e-04 5.00000e-04 5.00000e-05 1.00000e-09 1.00000e-01 5.00000e-04 5.00000e-04 5.00000e-05 1.00000e-09 1.00000e-01 9.16917e-01 9.16917e-01 9.16917e-02 1.00000e-09 2.12000e-01 9.16917e-01 9.16917e-01 9.16917e-02 1.00000e-09 2.12000e-01 9.16917e-01 9.16917e-01 9.16917e-02 1.00000e-09 2.12000e-01 9.16917e-01 9.16917e-01 9.16917e-02 1.00000e-09 2.12000e-01 9.16917e-01 9.16917e-01 9.16917e-02 1.00000e-09 2.12000e-01 
$1.00000 \mathrm{e}-02$ 1.00000e-02 1.00000e-03 1.00000e-09 1.00000e-01 $1.00000 \mathrm{e}+001.00000 \mathrm{e}+001.00000 \mathrm{e}-011.00000 \mathrm{e}-091.00000 \mathrm{e}-01$ $1.00000 \mathrm{e}-05$ 1.00000e-05 1.00000e-06 1.00000e-09 1.00000e-01 $1.00000 \mathrm{e}+001.00000 \mathrm{e}+001.00000 \mathrm{e}-011.00000 \mathrm{e}-091.00000 \mathrm{e}-01$ Element: 3306 \# of layers: 13

$\mathrm{Kx} \mathrm{Ky} \mathrm{Kz}$ Ss Por

$2.29485 \mathrm{e}+012.29485 \mathrm{e}+012.29485 \mathrm{e}+00$ 1.00000e-09 7.00000e-02 $2.29485 \mathrm{e}+012.29485 \mathrm{e}+012.29485 \mathrm{e}+001.00000 \mathrm{e}-09$ 7.00000e-02 5.00000e-04 5.00000e-04 5.00000e-05 1.00000e-09 1.00000e-01 5.00000e-04 5.00000e-04 5.00000e-05 1.00000e-09 1.00000e-01 9.16917e-01 9.16917e-01 9.16917e-02 1.00000e-09 2.12000e-01 9.16917e-01 9.16917e-01 9.16917e-02 1.00000e-09 2.12000e-01 9.16917e-01 9.16917e-01 9.16917e-02 1.00000e-09 2.12000e-01 9.16917e-01 9.16917e-01 9.16917e-02 1.00000e-09 2.12000e-01 9.16917e-01 9.16917e-01 9.16917e-02 1.00000e-09 2.12000e-01 $1.00000 \mathrm{e}-02$ 1.00000e-02 1.00000e-03 1.00000e-09 1.00000e-01 $1.00000 \mathrm{e}+001.00000 \mathrm{e}+001.00000 \mathrm{e}-011.00000 \mathrm{e}-091.00000 \mathrm{e}-01$ $1.00000 \mathrm{e}-05$ 1.00000e-05 1.00000e-06 1.00000e-09 1.00000e-01 $1.00000 \mathrm{e}+001.00000 \mathrm{e}+001.00000 \mathrm{e}-01$ 1.00000e-09 1.00000e-01 Element: 3307 \# of layers: 13

$\mathrm{Kx} \mathrm{Ky} \mathrm{Kz}$ Ss Por

$2.29485 \mathrm{e}+012.29485 \mathrm{e}+01$ 2.29485e+00 1.00000e-09 7.00000e-02 $2.29485 \mathrm{e}+012.29485 \mathrm{e}+012.29485 \mathrm{e}+00$ 1.00000e-09 7.00000e-02 5.00000e-04 5.00000e-04 5.00000e-05 1.00000e-09 1.00000e-01 5.00000e-04 5.00000e-04 5.00000e-05 1.00000e-09 1.00000e-01 9.16917e-01 9.16917e-01 9.16917e-02 1.00000e-09 2.12000e-01 9.16917e-01 9.16917e-01 9.16917e-02 1.00000e-09 2.12000e-01 9.16917e-01 9.16917e-01 9.16917e-02 1.00000e-09 2.12000e-01 9.16917e-01 9.16917e-01 9.16917e-02 1.00000e-09 2.12000e-01 9.16917e-01 9.16917e-01 9.16917e-02 1.00000e-09 2.12000e-01 $1.00000 \mathrm{e}-02$ 1.00000e-02 1.00000e-03 1.00000e-09 1.00000e-01 $1.00000 \mathrm{e}+001.00000 \mathrm{e}+001.00000 \mathrm{e}-011.00000 \mathrm{e}-091.00000 \mathrm{e}-01$ $1.00000 \mathrm{e}-05$ 1.00000e-05 1.00000e-06 1.00000e-09 1.00000e-01 $1.00000 \mathrm{e}+001.00000 \mathrm{e}+001.00000 \mathrm{e}-011.00000 \mathrm{e}-091.00000 \mathrm{e}-01$ Element: 3308 \# of layers: 13

$\mathrm{Kx} \mathrm{Ky} \mathrm{Kz}$ Ss Por

$2.29485 \mathrm{e}+012.29485 \mathrm{e}+012.29485 \mathrm{e}+00$ 1.00000e-09 7.00000e-02 $2.29485 \mathrm{e}+012.29485 \mathrm{e}+012.29485 \mathrm{e}+001.00000 \mathrm{e}-09$ 7.00000e-02 5.00000e-04 5.00000e-04 5.00000e-05 1.00000e-09 1.00000e-01 5.00000e-04 5.00000e-04 5.00000e-05 1.00000e-09 1.00000e-01 9.16917e-01 9.16917e-01 9.16917e-02 1.00000e-09 2.12000e-01 9.16917e-01 9.16917e-01 9.16917e-02 1.00000e-09 2.12000e-01 9.16917e-01 9.16917e-01 9.16917e-02 1.00000e-09 2.12000e-01 9.16917e-01 9.16917e-01 9.16917e-02 1.00000e-09 2.12000e-01 9.16917e-01 9.16917e-01 9.16917e-02 1.00000e-09 2.12000e-01 $1.00000 \mathrm{e}-02$ 1.00000e-02 1.00000e-03 1.00000e-09 1.00000e-01 
$1.00000 \mathrm{e}+001.00000 \mathrm{e}+001.00000 \mathrm{e}-011.00000 \mathrm{e}-091.00000 \mathrm{e}-01$ $1.00000 \mathrm{e}-05$ 1.00000e-05 1.00000e-06 1.00000e-09 1.00000e-01 $1.00000 \mathrm{e}+001.00000 \mathrm{e}+001.00000 \mathrm{e}-011.00000 \mathrm{e}-09$ 1.00000e-01 Element: 3309 \# of layers: 13

$\mathrm{Kx} \mathrm{Ky} \mathrm{Kz}$ Ss Por

$2.29485 \mathrm{e}+012.29485 \mathrm{e}+01$ 2.29485e+00 1.00000e-09 7.00000e-02 $2.29485 \mathrm{e}+012.29485 \mathrm{e}+012.29485 \mathrm{e}+001.00000 \mathrm{e}-09$ 7.00000e-02 5.00000e-04 5.00000e-04 5.00000e-05 1.00000e-09 1.00000e-01 5.00000e-04 5.00000e-04 5.00000e-05 1.00000e-09 1.00000e-01 9.16917e-01 9.16917e-01 9.16917e-02 1.00000e-09 2.12000e-01 9.16917e-01 9.16917e-01 9.16917e-02 1.00000e-09 2.12000e-01 9.16917e-01 9.16917e-01 9.16917e-02 1.00000e-09 2.12000e-01 9.16917e-01 9.16917e-01 9.16917e-02 1.00000e-09 2.12000e-01 9.16917e-01 9.16917e-01 9.16917e-02 1.00000e-09 2.12000e-01 $1.00000 \mathrm{e}-02$ 1.00000e-02 1.00000e-03 1.00000e-09 1.00000e-01 $1.00000 \mathrm{e}+001.00000 \mathrm{e}+001.00000 \mathrm{e}-011.00000 \mathrm{e}-091.00000 \mathrm{e}-01$ $1.00000 \mathrm{e}-05$ 1.00000e-05 1.00000e-06 1.00000e-09 1.00000e-01 $1.00000 \mathrm{e}+001.00000 \mathrm{e}+001.00000 \mathrm{e}-011.00000 \mathrm{e}-091.00000 \mathrm{e}-01$ Element: 3310 \# of layers: 13

$\mathrm{Kx} \mathrm{Ky} \mathrm{Kz}$ Ss Por

$2.29485 \mathrm{e}+012.29485 \mathrm{e}+012.29485 \mathrm{e}+00$ 1.00000e-09 7.00000e-02 $2.29485 \mathrm{e}+012.29485 \mathrm{e}+012.29485 \mathrm{e}+00$ 1.00000e-09 7.00000e-02 5.00000e-04 5.00000e-04 5.00000e-05 1.00000e-09 1.00000e-01 5.00000e-04 5.00000e-04 5.00000e-05 1.00000e-09 1.00000e-01 9.16917e-01 9.16917e-01 9.16917e-02 1.00000e-09 2.12000e-01 9.16917e-01 9.16917e-01 9.16917e-02 1.00000e-09 2.12000e-01 9.16917e-01 9.16917e-01 9.16917e-02 1.00000e-09 2.12000e-01 9.16917e-01 9.16917e-01 9.16917e-02 1.00000e-09 2.12000e-01 9.16917e-01 9.16917e-01 9.16917e-02 1.00000e-09 2.12000e-01 $1.00000 \mathrm{e}-02$ 1.00000e-02 1.00000e-03 1.00000e-09 1.00000e-01 $1.00000 \mathrm{e}+001.00000 \mathrm{e}+001.00000 \mathrm{e}-011.00000 \mathrm{e}-091.00000 \mathrm{e}-01$ $1.00000 \mathrm{e}-05$ 1.00000e-05 1.00000e-06 1.00000e-09 1.00000e-01 $1.00000 \mathrm{e}+001.00000 \mathrm{e}+001.00000 \mathrm{e}-011.00000 \mathrm{e}-091.00000 \mathrm{e}-01$ Element: 3311 \# of layers: 13

$\mathrm{Kx} \mathrm{Ky} \mathrm{Kz}$ Ss Por

$2.29485 \mathrm{e}+012.29485 \mathrm{e}+012.29485 \mathrm{e}+00$ 1.00000e-09 7.00000e-02 $2.29485 \mathrm{e}+012.29485 \mathrm{e}+012.29485 \mathrm{e}+001.00000 \mathrm{e}-09$ 7.00000e-02 5.00000e-04 5.00000e-04 5.00000e-05 1.00000e-09 1.00000e-01 5.00000e-04 5.00000e-04 5.00000e-05 1.00000e-09 1.00000e-01 9.16917e-01 9.16917e-01 9.16917e-02 1.00000e-09 2.12000e-01 9.16917e-01 9.16917e-01 9.16917e-02 1.00000e-09 2.12000e-01 9.16917e-01 9.16917e-01 9.16917e-02 1.00000e-09 2.12000e-01 9.16917e-01 9.16917e-01 9.16917e-02 1.00000e-09 2.12000e-01 9.16917e-01 9.16917e-01 9.16917e-02 1.00000e-09 2.12000e-01 $1.00000 \mathrm{e}-02$ 1.00000e-02 1.00000e-03 1.00000e-09 1.00000e-01 $1.00000 \mathrm{e}+001.00000 \mathrm{e}+001.00000 \mathrm{e}-011.00000 \mathrm{e}-091.00000 \mathrm{e}-01$ 
$1.00000 \mathrm{e}-05$ 1.00000e-05 1.00000e-06 1.00000e-09 1.00000e-01 $1.00000 \mathrm{e}+001.00000 \mathrm{e}+001.00000 \mathrm{e}-01$ 1.00000e-09 1.00000e-01 Element: 3312 \# of layers: 13

Kx Ky Kz Ss Por

$2.29485 \mathrm{e}+012.29485 \mathrm{e}+012.29485 \mathrm{e}+00$ 1.00000e-09 7.00000e-02

$2.29485 \mathrm{e}+012.29485 \mathrm{e}+012.29485 \mathrm{e}+00$ 1.00000e-09 7.00000e-02

5.00000e-04 5.00000e-04 5.00000e-05 1.00000e-09 1.00000e-01

5.00000e-04 5.00000e-04 5.00000e-05 1.00000e-09 1.00000e-01

9.16917e-01 9.16917e-01 9.16917e-02 1.00000e-09 2.12000e-01

9.16917e-01 9.16917e-01 9.16917e-02 1.00000e-09 2.12000e-01

9.16917e-01 9.16917e-01 9.16917e-02 1.00000e-09 2.12000e-01

9.16917e-01 9.16917e-01 9.16917e-02 1.00000e-09 2.12000e-01

9.16917e-01 9.16917e-01 9.16917e-02 1.00000e-09 2.12000e-01

$1.00000 \mathrm{e}-02$ 1.00000e-02 1.00000e-03 1.00000e-09 1.00000e-01

$1.00000 \mathrm{e}+001.00000 \mathrm{e}+001.00000 \mathrm{e}-011.00000 \mathrm{e}-091.00000 \mathrm{e}-01$ $1.00000 \mathrm{e}-05$ 1.00000e-05 1.00000e-06 1.00000e-09 1.00000e-01

$1.00000 \mathrm{e}+001.00000 \mathrm{e}+001.00000 \mathrm{e}-011.00000 \mathrm{e}-091.00000 \mathrm{e}-01$

Element: 3313 \# of layers: 13

$\mathrm{Kx} \mathrm{Ky} \mathrm{Kz}$ Ss Por

$2.29485 \mathrm{e}+012.29485 \mathrm{e}+012.29485 \mathrm{e}+00$ 1.00000e-09 7.00000e-02

$2.29485 \mathrm{e}+012.29485 \mathrm{e}+012.29485 \mathrm{e}+001.00000 \mathrm{e}-097.00000 \mathrm{e}-02$

5.00000e-04 5.00000e-04 5.00000e-05 1.00000e-09 1.00000e-01

5.00000e-04 5.00000e-04 5.00000e-05 1.00000e-09 1.00000e-01

9.16917e-01 9.16917e-01 9.16917e-02 1.00000e-09 2.12000e-01

9.16917e-01 9.16917e-01 9.16917e-02 1.00000e-09 2.12000e-01

9.16917e-01 9.16917e-01 9.16917e-02 1.00000e-09 2.12000e-01

9.16917e-01 9.16917e-01 9.16917e-02 1.00000e-09 2.12000e-01

9.16917e-01 9.16917e-01 9.16917e-02 1.00000e-09 2.12000e-01

$1.00000 \mathrm{e}-02$ 1.00000e-02 1.00000e-03 1.00000e-09 1.00000e-01

$1.00000 \mathrm{e}+001.00000 \mathrm{e}+001.00000 \mathrm{e}-011.00000 \mathrm{e}-091.00000 \mathrm{e}-01$

$1.00000 \mathrm{e}-05$ 1.00000e-05 1.00000e-06 1.00000e-09 1.00000e-01

$1.00000 \mathrm{e}+001.00000 \mathrm{e}+001.00000 \mathrm{e}-01$ 1.00000e-09 1.00000e-01

Element: 3314 \# of layers: 13

$\mathrm{Kx} \mathrm{Ky} \mathrm{Kz}$ Ss Por

$2.86040 \mathrm{e}+012.86040 \mathrm{e}+012.86041 \mathrm{e}+00$ 1.00000e-09 7.00000e-02

$2.86040 \mathrm{e}+012.86040 \mathrm{e}+012.86041 \mathrm{e}+001.00000 \mathrm{e}-09$ 7.00000e-02

5.00000e-04 5.00000e-04 5.00000e-05 1.00000e-09 1.00000e-01

5.00000e-04 5.00000e-04 5.00000e-05 1.00000e-09 1.00000e-01

$1.14291 \mathrm{e}+001.14291 \mathrm{e}+001.14291 \mathrm{e}-011.00000 \mathrm{e}-092.12000 \mathrm{e}-01$

$1.14291 \mathrm{e}+001.14291 \mathrm{e}+00$ 1.14291e-01 1.00000e-09 2.12000e-01

$1.14291 \mathrm{e}+001.14291 \mathrm{e}+001.14291 \mathrm{e}-01$ 1.00000e-09 2.12000e-01

$1.14291 \mathrm{e}+001.14291 \mathrm{e}+001.14291 \mathrm{e}-011.00000 \mathrm{e}-092.12000 \mathrm{e}-01$

$1.14291 \mathrm{e}+001.14291 \mathrm{e}+001.14291 \mathrm{e}-01$ 1.00000e-09 2.12000e-01

$1.00000 \mathrm{e}-02$ 1.00000e-02 1.00000e-03 1.00000e-09 1.00000e-01

$1.00000 \mathrm{e}+001.00000 \mathrm{e}+001.00000 \mathrm{e}-011.00000 \mathrm{e}-091.00000 \mathrm{e}-01$

$1.00000 \mathrm{e}-05$ 1.00000e-05 1.00000e-06 1.00000e-09 1.00000e-01 
$1.00000 \mathrm{e}+001.00000 \mathrm{e}+00$ 1.00000e-01 1.00000e-09 1.00000e-01

Element: 3315 \# of layers: 13

Kx Ky Kz Ss Por

$2.86040 \mathrm{e}+012.86040 \mathrm{e}+012.86041 \mathrm{e}+001.00000 \mathrm{e}-09$ 7.00000e-02

$2.86040 \mathrm{e}+012.86040 \mathrm{e}+012.86041 \mathrm{e}+001.00000 \mathrm{e}-09$ 7.00000e-02

5.00000e-04 5.00000e-04 5.00000e-05 1.00000e-09 1.00000e-01

5.00000e-04 5.00000e-04 5.00000e-05 1.00000e-09 1.00000e-01

$1.14291 \mathrm{e}+001.14291 \mathrm{e}+001.14291 \mathrm{e}-01$ 1.00000e-09 2.12000e-01

$1.14291 \mathrm{e}+00$ 1.14291e+00 1.14291e-01 1.00000e-09 2.12000e-01

$1.14291 \mathrm{e}+001.14291 \mathrm{e}+001.14291 \mathrm{e}-01$ 1.00000e-09 2.12000e-01

$1.14291 \mathrm{e}+001.14291 \mathrm{e}+00$ 1.14291e-01 1.00000e-09 2.12000e-01

$1.14291 \mathrm{e}+001.14291 \mathrm{e}+001.14291 \mathrm{e}-011.00000 \mathrm{e}-092.12000 \mathrm{e}-01$

$1.00000 \mathrm{e}-02$ 1.00000e-02 1.00000e-03 1.00000e-09 1.00000e-01

$1.00000 \mathrm{e}+001.00000 \mathrm{e}+001.00000 \mathrm{e}-011.00000 \mathrm{e}-091.00000 \mathrm{e}-01$

$1.00000 \mathrm{e}-05$ 1.00000e-05 1.00000e-06 1.00000e-09 1.00000e-01

$1.00000 \mathrm{e}+001.00000 \mathrm{e}+001.00000 \mathrm{e}-011.00000 \mathrm{e}-091.00000 \mathrm{e}-01$

Element: 3316 \# of layers: 11

$\mathrm{Kx} \mathrm{Ky} \mathrm{Kz}$ Ss Por

$2.86040 \mathrm{e}+012.86040 \mathrm{e}+012.86041 \mathrm{e}+00$ 1.00000e-09 7.00000e-02

$2.86040 \mathrm{e}+012.86040 \mathrm{e}+012.86041 \mathrm{e}+001.00000 \mathrm{e}-09$ 7.00000e-02

5.00000e-04 5.00000e-04 5.00000e-05 1.00000e-09 1.00000e-01

5.00000e-04 5.00000e-04 5.00000e-05 1.00000e-09 1.00000e-01

$1.14291 \mathrm{e}+001.14291 \mathrm{e}+00$ 1.14291e-01 1.00000e-09 2.12000e-01

$1.14291 \mathrm{e}+001.14291 \mathrm{e}+001.14291 \mathrm{e}-01$ 1.00000e-09 2.12000e-01

$1.14291 \mathrm{e}+001.14291 \mathrm{e}+001.14291 \mathrm{e}-011.00000 \mathrm{e}-092.12000 \mathrm{e}-01$

$1.14291 \mathrm{e}+001.14291 \mathrm{e}+001.14291 \mathrm{e}-01$ 1.00000e-09 2.12000e-01

$1.14291 \mathrm{e}+001.14291 \mathrm{e}+001.14291 \mathrm{e}-01$ 1.00000e-09 2.12000e-01

$1.00000 \mathrm{e}-02$ 1.00000e-02 1.00000e-03 1.00000e-09 1.00000e-01

$1.00000 \mathrm{e}+001.00000 \mathrm{e}+001.00000 \mathrm{e}-011.00000 \mathrm{e}-091.00000 \mathrm{e}-01$

Element: 3317 \# of layers: 11

$\mathrm{Kx} \mathrm{Ky} \mathrm{Kz}$ Ss Por

$2.86040 \mathrm{e}+012.86040 \mathrm{e}+012.86041 \mathrm{e}+001.00000 \mathrm{e}-09$ 7.00000e-02

$2.86040 \mathrm{e}+012.86040 \mathrm{e}+012.86041 \mathrm{e}+001.00000 \mathrm{e}-09$ 7.00000e-02

$5.00000 \mathrm{e}-04$ 5.00000e-04 5.00000e-05 1.00000e-09 1.00000e-01

5.00000e-04 5.00000e-04 5.00000e-05 1.00000e-09 1.00000e-01

$1.14291 \mathrm{e}+001.14291 \mathrm{e}+001.14291 \mathrm{e}-01$ 1.00000e-09 2.12000e-01

$1.14291 \mathrm{e}+001.14291 \mathrm{e}+001.14291 \mathrm{e}-01$ 1.00000e-09 2.12000e-01

$1.14291 \mathrm{e}+001.14291 \mathrm{e}+001.14291 \mathrm{e}-01$ 1.00000e-09 2.12000e-01

$1.14291 \mathrm{e}+001.14291 \mathrm{e}+00$ 1.14291e-01 1.00000e-09 2.12000e-01

$1.14291 \mathrm{e}+001.14291 \mathrm{e}+001.14291 \mathrm{e}-01$ 1.00000e-09 2.12000e-01

$1.00000 \mathrm{e}-02$ 1.00000e-02 1.00000e-03 1.00000e-09 1.00000e-01

$1.00000 \mathrm{e}+001.00000 \mathrm{e}+001.00000 \mathrm{e}-011.00000 \mathrm{e}-091.00000 \mathrm{e}-01$

Element: 3318 \# of layers: 13

$\mathrm{Kx} \mathrm{Ky} \mathrm{Kz}$ Ss Por

$2.86040 \mathrm{e}+012.86040 \mathrm{e}+012.86041 \mathrm{e}+001.00000 \mathrm{e}-09$ 7.00000e-02

$2.86040 \mathrm{e}+012.86040 \mathrm{e}+012.86041 \mathrm{e}+001.00000 \mathrm{e}-09$ 7.00000e-02 
5.00000e-04 5.00000e-04 5.00000e-05 1.00000e-09 1.00000e-01 5.00000e-04 5.00000e-04 5.00000e-05 1.00000e-09 1.00000e-01 $1.14291 \mathrm{e}+001.14291 \mathrm{e}+00$ 1.14291e-01 1.00000e-09 2.12000e-01 $1.14291 \mathrm{e}+001.14291 \mathrm{e}+001.14291 \mathrm{e}-011.00000 \mathrm{e}-092.12000 \mathrm{e}-01$ $1.14291 \mathrm{e}+001.14291 \mathrm{e}+00$ 1.14291e-01 1.00000e-09 2.12000e-01 $1.14291 \mathrm{e}+001.14291 \mathrm{e}+001.14291 \mathrm{e}-01$ 1.00000e-09 2.12000e-01 $1.14291 \mathrm{e}+001.14291 \mathrm{e}+001.14291 \mathrm{e}-01$ 1.00000e-09 2.12000e-01 $1.00000 \mathrm{e}-02$ 1.00000e-02 1.00000e-03 1.00000e-09 1.00000e-01 $1.00000 \mathrm{e}+001.00000 \mathrm{e}+001.00000 \mathrm{e}-011.00000 \mathrm{e}-091.00000 \mathrm{e}-01$ $1.00000 \mathrm{e}-05$ 1.00000e-05 1.00000e-06 1.00000e-09 1.00000e-01 $1.00000 \mathrm{e}+001.00000 \mathrm{e}+001.00000 \mathrm{e}-011.00000 \mathrm{e}-091.00000 \mathrm{e}-01$ Element: 3319 \# of layers: 13

$\mathrm{Kx} \mathrm{Ky} \mathrm{Kz}$ Ss Por

$2.86040 \mathrm{e}+012.86040 \mathrm{e}+012.86041 \mathrm{e}+00$ 1.00000e-09 7.00000e-02 $2.86040 \mathrm{e}+012.86040 \mathrm{e}+012.86041 \mathrm{e}+001.00000 \mathrm{e}-09$ 7.00000e-02 5.00000e-04 5.00000e-04 5.00000e-05 1.00000e-09 1.00000e-01 5.00000e-04 5.00000e-04 5.00000e-05 1.00000e-09 1.00000e-01 $1.14291 \mathrm{e}+001.14291 \mathrm{e}+001.14291 \mathrm{e}-01$ 1.00000e-09 2.12000e-01 $1.14291 \mathrm{e}+001.14291 \mathrm{e}+00$ 1.14291e-01 1.00000e-09 2.12000e-01 $1.14291 \mathrm{e}+001.14291 \mathrm{e}+001.14291 \mathrm{e}-01$ 1.00000e-09 2.12000e-01 $1.14291 \mathrm{e}+001.14291 \mathrm{e}+001.14291 \mathrm{e}-011.00000 \mathrm{e}-092.12000 \mathrm{e}-01$ $1.14291 \mathrm{e}+001.14291 \mathrm{e}+001.14291 \mathrm{e}-01$ 1.00000e-09 2.12000e-01 $1.00000 \mathrm{e}-02$ 1.00000e-02 1.00000e-03 1.00000e-09 1.00000e-01 $1.00000 \mathrm{e}+001.00000 \mathrm{e}+001.00000 \mathrm{e}-011.00000 \mathrm{e}-091.00000 \mathrm{e}-01$ $1.00000 \mathrm{e}-05$ 1.00000e-05 1.00000e-06 1.00000e-09 1.00000e-01 $1.00000 \mathrm{e}+001.00000 \mathrm{e}+001.00000 \mathrm{e}-01$ 1.00000e-09 1.00000e-01 Element: 3320 \# of layers: 13

$\mathrm{Kx} \mathrm{Ky} \mathrm{Kz}$ Ss Por

$2.86040 \mathrm{e}+012.86040 \mathrm{e}+012.86041 \mathrm{e}+001.00000 \mathrm{e}-09$ 7.00000e-02 $2.86040 \mathrm{e}+012.86040 \mathrm{e}+012.86041 \mathrm{e}+001.00000 \mathrm{e}-097.00000 \mathrm{e}-02$ 5.00000e-04 5.00000e-04 5.00000e-05 1.00000e-09 1.00000e-01 5.00000e-04 5.00000e-04 5.00000e-05 1.00000e-09 1.00000e-01 $1.14291 \mathrm{e}+001.14291 \mathrm{e}+001.14291 \mathrm{e}-01$ 1.00000e-09 2.12000e-01 $1.14291 \mathrm{e}+001.14291 \mathrm{e}+001.14291 \mathrm{e}-011.00000 \mathrm{e}-092.12000 \mathrm{e}-01$ $1.14291 \mathrm{e}+001.14291 \mathrm{e}+001.14291 \mathrm{e}-01$ 1.00000e-09 2.12000e-01 $1.14291 \mathrm{e}+001.14291 \mathrm{e}+001.14291 \mathrm{e}-01$ 1.00000e-09 2.12000e-01 $1.14291 \mathrm{e}+001.14291 \mathrm{e}+001.14291 \mathrm{e}-01$ 1.00000e-09 2.12000e-01 $1.00000 \mathrm{e}-02$ 1.00000e-02 1.00000e-03 1.00000e-09 1.00000e-01 $1.00000 \mathrm{e}+001.00000 \mathrm{e}+001.00000 \mathrm{e}-011.00000 \mathrm{e}-091.00000 \mathrm{e}-01$ $1.00000 \mathrm{e}-05$ 1.00000e-05 1.00000e-06 1.00000e-09 1.00000e-01 $1.00000 \mathrm{e}+001.00000 \mathrm{e}+001.00000 \mathrm{e}-011.00000 \mathrm{e}-09$ 1.00000e-01 Element: 3321 \# of layers: 13

$\mathrm{Kx} \mathrm{Ky} \mathrm{Kz}$ Ss Por

$2.86040 \mathrm{e}+012.86040 \mathrm{e}+012.86041 \mathrm{e}+00$ 1.00000e-09 7.00000e-02 $2.86040 \mathrm{e}+012.86040 \mathrm{e}+012.86041 \mathrm{e}+001.00000 \mathrm{e}-09$ 7.00000e-02 5.00000e-04 5.00000e-04 5.00000e-05 1.00000e-09 1.00000e-01 
5.00000e-04 5.00000e-04 5.00000e-05 1.00000e-09 1.00000e-01 $1.14291 \mathrm{e}+001.14291 \mathrm{e}+001.14291 \mathrm{e}-01$ 1.00000e-09 2.12000e-01 $1.14291 \mathrm{e}+001.14291 \mathrm{e}+00$ 1.14291e-01 1.00000e-09 2.12000e-01 $1.14291 \mathrm{e}+001.14291 \mathrm{e}+001.14291 \mathrm{e}-01$ 1.00000e-09 2.12000e-01 $1.14291 \mathrm{e}+001.14291 \mathrm{e}+00$ 1.14291e-01 1.00000e-09 2.12000e-01 $1.14291 \mathrm{e}+001.14291 \mathrm{e}+001.14291 \mathrm{e}-01$ 1.00000e-09 2.12000e-01 $1.00000 \mathrm{e}-02$ 1.00000e-02 1.00000e-03 1.00000e-09 1.00000e-01 $1.00000 \mathrm{e}+001.00000 \mathrm{e}+001.00000 \mathrm{e}-011.00000 \mathrm{e}-091.00000 \mathrm{e}-01$ $1.00000 \mathrm{e}-05$ 1.00000e-05 1.00000e-06 1.00000e-09 1.00000e-01 $1.00000 \mathrm{e}+001.00000 \mathrm{e}+001.00000 \mathrm{e}-011.00000 \mathrm{e}-091.00000 \mathrm{e}-01$ Element: 3322 \# of layers: 13

$\mathrm{Kx} \mathrm{Ky} \mathrm{Kz}$ Ss Por

$2.86040 \mathrm{e}+012.86040 \mathrm{e}+012.86041 \mathrm{e}+00$ 1.00000e-09 7.00000e-02

$2.86040 \mathrm{e}+012.86040 \mathrm{e}+012.86041 \mathrm{e}+001.00000 \mathrm{e}-09$ 7.00000e-02

5.00000e-04 5.00000e-04 5.00000e-05 1.00000e-09 1.00000e-01 5.00000e-04 5.00000e-04 5.00000e-05 1.00000e-09 1.00000e-01

$1.14291 \mathrm{e}+001.14291 \mathrm{e}+001.14291 \mathrm{e}-011.00000 \mathrm{e}-092.12000 \mathrm{e}-01$ $1.14291 \mathrm{e}+001.14291 \mathrm{e}+001.14291 \mathrm{e}-01$ 1.00000e-09 2.12000e-01 $1.14291 \mathrm{e}+001.14291 \mathrm{e}+00$ 1.14291e-01 1.00000e-09 2.12000e-01 $1.14291 \mathrm{e}+001.14291 \mathrm{e}+001.14291 \mathrm{e}-01$ 1.00000e-09 2.12000e-01 $1.14291 \mathrm{e}+001.14291 \mathrm{e}+001.14291 \mathrm{e}-01$ 1.00000e-09 2.12000e-01 $1.00000 \mathrm{e}-02$ 1.00000e-02 1.00000e-03 1.00000e-09 1.00000e-01 $1.00000 \mathrm{e}+001.00000 \mathrm{e}+001.00000 \mathrm{e}-011.00000 \mathrm{e}-091.00000 \mathrm{e}-01$ 1.00000e-05 1.00000e-05 1.00000e-06 1.00000e-09 1.00000e-01 $1.00000 \mathrm{e}+001.00000 \mathrm{e}+001.00000 \mathrm{e}-011.00000 \mathrm{e}-091.00000 \mathrm{e}-01$ Element: 3323 \# of layers: 11

$\mathrm{Kx} \mathrm{Ky} \mathrm{Kz}$ Ss Por

3.11052e+01 3.11052e+01 3.11052e+00 1.00000e-09 7.00000e-02 $3.11052 \mathrm{e}+013.11052 \mathrm{e}+013.11052 \mathrm{e}+001.00000 \mathrm{e}-09$ 7.00000e-02 5.00000e-04 5.00000e-04 5.00000e-05 1.00000e-09 1.00000e-01 5.00000e-04 5.00000e-04 5.00000e-05 1.00000e-09 1.00000e-01 $1.24286 \mathrm{e}+001.24286 \mathrm{e}+00 \quad 1.24286 \mathrm{e}-01$ 1.00000e-09 2.12000e-01 $1.24286 \mathrm{e}+001.24286 \mathrm{e}+001.24286 \mathrm{e}-011.00000 \mathrm{e}-092.12000 \mathrm{e}-01$ $1.24286 \mathrm{e}+001.24286 \mathrm{e}+001.24286 \mathrm{e}-01$ 1.00000e-09 2.12000e-01 $1.24286 \mathrm{e}+001.24286 \mathrm{e}+001.24286 \mathrm{e}-01$ 1.00000e-09 2.12000e-01 $1.24286 \mathrm{e}+001.24286 \mathrm{e}+001.24286 \mathrm{e}-01$ 1.00000e-09 2.12000e-01 $1.00000 \mathrm{e}-02$ 1.00000e-02 1.00000e-03 1.00000e-09 1.00000e-01 $1.00000 \mathrm{e}+001.00000 \mathrm{e}+001.00000 \mathrm{e}-01$ 1.00000e-09 1.00000e-01 Element: 3324 \# of layers: 12

$\mathrm{Kx} \mathrm{Ky} \mathrm{Kz}$ Ss Por

3.11052e+01 3.11052e+01 3.11052e+00 1.00000e-09 7.00000e-02 $3.11052 \mathrm{e}+013.11052 \mathrm{e}+013.11052 \mathrm{e}+00$ 1.00000e-09 7.00000e-02 $3.11052 \mathrm{e}+013.11052 \mathrm{e}+013.11052 \mathrm{e}+001.00000 \mathrm{e}-097.00000 \mathrm{e}-02$ $5.00000 \mathrm{e}-04$ 5.00000e-04 5.00000e-05 1.00000e-09 1.00000e-01 5.00000e-04 5.00000e-04 5.00000e-05 1.00000e-09 1.00000e-01 $1.24286 \mathrm{e}+001.24286 \mathrm{e}+001.24286 \mathrm{e}-01$ 1.00000e-09 2.12000e-01 
$1.24286 \mathrm{e}+00$ 1.24286e+00 1.24286e-01 1.00000e-09 2.12000e-01 $1.24286 \mathrm{e}+001.24286 \mathrm{e}+001.24286 \mathrm{e}-01$ 1.00000e-09 2.12000e-01 $1.24286 \mathrm{e}+001.24286 \mathrm{e}+001.24286 \mathrm{e}-01$ 1.00000e-09 2.12000e-01 $1.24286 \mathrm{e}+001.24286 \mathrm{e}+001.24286 \mathrm{e}-01$ 1.00000e-09 2.12000e-01 $1.00000 \mathrm{e}-021.00000 \mathrm{e}-021.00000 \mathrm{e}-031.00000 \mathrm{e}-091.00000 \mathrm{e}-01$ $1.00000 \mathrm{e}+001.00000 \mathrm{e}+001.00000 \mathrm{e}-011.00000 \mathrm{e}-091.00000 \mathrm{e}-01$ Element: 3325 \# of layers: 10

$\mathrm{Kx} \mathrm{Ky} \mathrm{Kz}$ Ss Por

3.11052e+01 3.11052e+01 3.11052e+00 1.00000e-09 7.00000e-02 $3.11052 \mathrm{e}+013.11052 \mathrm{e}+013.11052 \mathrm{e}+00$ 1.00000e-09 7.00000e-02 5.00000e-04 5.00000e-04 5.00000e-05 1.00000e-09 1.00000e-01 5.00000e-04 5.00000e-04 5.00000e-05 1.00000e-09 1.00000e-01 $1.24286 \mathrm{e}+001.24286 \mathrm{e}+001.24286 \mathrm{e}-01$ 1.00000e-09 2.12000e-01 $1.24286 \mathrm{e}+001.24286 \mathrm{e}+001.24286 \mathrm{e}-01$ 1.00000e-09 2.12000e-01 $1.24286 \mathrm{e}+001.24286 \mathrm{e}+00$ 1.24286e-01 1.00000e-09 2.12000e-01 $1.24286 \mathrm{e}+001.24286 \mathrm{e}+001.24286 \mathrm{e}-01$ 1.00000e-09 2.12000e-01 $1.00000 \mathrm{e}-02$ 1.00000e-02 1.00000e-03 1.00000e-09 1.00000e-01 $1.00000 \mathrm{e}+001.00000 \mathrm{e}+001.00000 \mathrm{e}-01$ 1.00000e-09 1.00000e-01 Element: 3326 \# of layers: 11

$\mathrm{Kx} \mathrm{Ky} \mathrm{Kz}$ Ss Por

3.11052e+01 3.11052e+01 3.11052e+00 1.00000e-09 7.00000e-02 $3.11052 \mathrm{e}+013.11052 \mathrm{e}+013.11052 \mathrm{e}+001.00000 \mathrm{e}-097.00000 \mathrm{e}-02$ 5.00000e-04 5.00000e-04 5.00000e-05 1.00000e-09 1.00000e-01 5.00000e-04 5.00000e-04 5.00000e-05 1.00000e-09 1.00000e-01 $1.24286 \mathrm{e}+001.24286 \mathrm{e}+001.24286 \mathrm{e}-01$ 1.00000e-09 2.12000e-01 $1.24286 \mathrm{e}+001.24286 \mathrm{e}+00$ 1.24286e-01 1.00000e-09 2.12000e-01 $1.24286 \mathrm{e}+001.24286 \mathrm{e}+00$ 1.24286e-01 1.00000e-09 2.12000e-01 $1.24286 \mathrm{e}+001.24286 \mathrm{e}+00$ 1.24286e-01 1.00000e-09 2.12000e-01 $1.24286 \mathrm{e}+001.24286 \mathrm{e}+001.24286 \mathrm{e}-01$ 1.00000e-09 2.12000e-01 $1.00000 \mathrm{e}-021.00000 \mathrm{e}-021.00000 \mathrm{e}-031.00000 \mathrm{e}-091.00000 \mathrm{e}-01$ $1.00000 \mathrm{e}+001.00000 \mathrm{e}+001.00000 \mathrm{e}-011.00000 \mathrm{e}-091.00000 \mathrm{e}-01$ Element: 3327 \# of layers: 11

Kx Ky Kz Ss Por

3.11052e+01 3.11052e+01 3.11052e+00 1.00000e-09 7.00000e-02 $3.11052 \mathrm{e}+013.11052 \mathrm{e}+013.11052 \mathrm{e}+00$ 1.00000e-09 7.00000e-02 5.00000e-04 5.00000e-04 5.00000e-05 1.00000e-09 1.00000e-01 5.00000e-04 5.00000e-04 5.00000e-05 1.00000e-09 1.00000e-01 $1.24286 \mathrm{e}+001.24286 \mathrm{e}+001.24286 \mathrm{e}-01$ 1.00000e-09 2.12000e-01 $1.24286 \mathrm{e}+001.24286 \mathrm{e}+00$ 1.24286e-01 1.00000e-09 2.12000e-01 $1.24286 \mathrm{e}+001.24286 \mathrm{e}+00$ 1.24286e-01 1.00000e-09 2.12000e-01 $1.24286 \mathrm{e}+001.24286 \mathrm{e}+00$ 1.24286e-01 1.00000e-09 2.12000e-01 $1.24286 \mathrm{e}+001.24286 \mathrm{e}+00 \quad 1.24286 \mathrm{e}-01 \quad 1.00000 \mathrm{e}-092.12000 \mathrm{e}-01$ $1.00000 \mathrm{e}-021.00000 \mathrm{e}-021.00000 \mathrm{e}-031.00000 \mathrm{e}-091.00000 \mathrm{e}-01$ $1.00000 \mathrm{e}+001.00000 \mathrm{e}+001.00000 \mathrm{e}-01$ 1.00000e-09 1.00000e-01 Element: 3328 \# of layers: 11

Kx Ky Kz Ss Por 
$3.11052 \mathrm{e}+013.11052 \mathrm{e}+013.11052 \mathrm{e}+00$ 1.00000e-09 7.00000e-02 $3.11052 \mathrm{e}+013.11052 \mathrm{e}+013.11052 \mathrm{e}+00$ 1.00000e-09 7.00000e-02 5.00000e-04 5.00000e-04 5.00000e-05 1.00000e-09 1.00000e-01 5.00000e-04 5.00000e-04 5.00000e-05 1.00000e-09 1.00000e-01 $1.24286 \mathrm{e}+001.24286 \mathrm{e}+001.24286 \mathrm{e}-011.00000 \mathrm{e}-092.12000 \mathrm{e}-01$ $1.24286 \mathrm{e}+001.24286 \mathrm{e}+001.24286 \mathrm{e}-011.00000 \mathrm{e}-092.12000 \mathrm{e}-01$ $1.24286 \mathrm{e}+001.24286 \mathrm{e}+00$ 1.24286e-01 1.00000e-09 2.12000e-01 $1.24286 \mathrm{e}+001.24286 \mathrm{e}+001.24286 \mathrm{e}-011.00000 \mathrm{e}-092.12000 \mathrm{e}-01$ $1.24286 \mathrm{e}+001.24286 \mathrm{e}+001.24286 \mathrm{e}-011.00000 \mathrm{e}-092.12000 \mathrm{e}-01$ $1.00000 \mathrm{e}-021.00000 \mathrm{e}-02$ 1.00000e-03 1.00000e-09 1.00000e-01 $1.00000 \mathrm{e}+001.00000 \mathrm{e}+001.00000 \mathrm{e}-011.00000 \mathrm{e}-091.00000 \mathrm{e}-01$ Element: 3329 \# of layers: 10

Kx Ky Kz Ss Por

$3.11052 \mathrm{e}+013.11052 \mathrm{e}+013.11052 \mathrm{e}+00$ 1.00000e-09 7.00000e-02 $5.00000 \mathrm{e}-04$ 5.00000e-04 5.00000e-05 1.00000e-09 1.00000e-01 $5.00000 \mathrm{e}-04$ 5.00000e-04 5.00000e-05 1.00000e-09 1.00000e-01 $1.24286 \mathrm{e}+001.24286 \mathrm{e}+001.24286 \mathrm{e}-011.00000 \mathrm{e}-092.12000 \mathrm{e}-01$ $1.24286 \mathrm{e}+001.24286 \mathrm{e}+001.24286 \mathrm{e}-011.00000 \mathrm{e}-092.12000 \mathrm{e}-01$ $1.24286 \mathrm{e}+001.24286 \mathrm{e}+001.24286 \mathrm{e}-011.00000 \mathrm{e}-092.12000 \mathrm{e}-01$ $1.24286 \mathrm{e}+001.24286 \mathrm{e}+00$ 1.24286e-01 1.00000e-09 2.12000e-01 $1.24286 \mathrm{e}+001.24286 \mathrm{e}+001.24286 \mathrm{e}-011.00000 \mathrm{e}-092.12000 \mathrm{e}-01$ $1.00000 \mathrm{e}-02$ 1.00000e-02 1.00000e-03 1.00000e-09 1.00000e-01 $1.00000 \mathrm{e}+001.00000 \mathrm{e}+001.00000 \mathrm{e}-011.00000 \mathrm{e}-091.00000 \mathrm{e}-01$ Element: 3330 \# of layers: 11

Kx Ky Kz Ss Por

$3.11052 \mathrm{e}+013.11052 \mathrm{e}+013.11052 \mathrm{e}+00$ 1.00000e-09 7.00000e-02 $3.11052 \mathrm{e}+013.11052 \mathrm{e}+013.11052 \mathrm{e}+001.00000 \mathrm{e}-09$ 7.00000e-02 5.00000e-04 5.00000e-04 5.00000e-05 1.00000e-09 1.00000e-01 5.00000e-04 5.00000e-04 5.00000e-05 1.00000e-09 1.00000e-01 $1.24286 \mathrm{e}+001.24286 \mathrm{e}+00$ 1.24286e-01 1.00000e-09 2.12000e-01 $1.24286 \mathrm{e}+001.24286 \mathrm{e}+001.24286 \mathrm{e}-011.00000 \mathrm{e}-092.12000 \mathrm{e}-01$ $1.24286 \mathrm{e}+001.24286 \mathrm{e}+00$ 1.24286e-01 1.00000e-09 2.12000e-01 $1.24286 \mathrm{e}+001.24286 \mathrm{e}+001.24286 \mathrm{e}-011.00000 \mathrm{e}-092.12000 \mathrm{e}-01$ $1.24286 \mathrm{e}+001.24286 \mathrm{e}+001.24286 \mathrm{e}-011.00000 \mathrm{e}-092.12000 \mathrm{e}-01$ $1.00000 \mathrm{e}-021.00000 \mathrm{e}-02$ 1.00000e-03 1.00000e-09 1.00000e-01 $1.00000 \mathrm{e}+001.00000 \mathrm{e}+001.00000 \mathrm{e}-011.00000 \mathrm{e}-091.00000 \mathrm{e}-01$ Element: 3331 \# of layers: 12

Kx Ky Kz Ss Por

3.11052e+01 3.11052e+01 3.11052e+00 1.00000e-09 7.00000e-02 $3.11052 \mathrm{e}+013.11052 \mathrm{e}+013.11052 \mathrm{e}+00$ 1.00000e-09 7.00000e-02 $3.11052 \mathrm{e}+013.11052 \mathrm{e}+013.11052 \mathrm{e}+001.00000 \mathrm{e}-09$ 7.00000e-02 5.00000e-04 5.00000e-04 5.00000e-05 1.00000e-09 1.00000e-01 $5.00000 \mathrm{e}-04$ 5.00000e-04 5.00000e-05 1.00000e-09 1.00000e-01 $1.24286 \mathrm{e}+001.24286 \mathrm{e}+001.24286 \mathrm{e}-011.00000 \mathrm{e}-092.12000 \mathrm{e}-01$ $1.24286 \mathrm{e}+001.24286 \mathrm{e}+001.24286 \mathrm{e}-011.00000 \mathrm{e}-092.12000 \mathrm{e}-01$ $1.24286 \mathrm{e}+001.24286 \mathrm{e}+00$ 1.24286e-01 1.00000e-09 2.12000e-01 
$1.24286 \mathrm{e}+001.24286 \mathrm{e}+00$ 1.24286e-01 1.00000e-09 2.12000e-01 $1.24286 \mathrm{e}+001.24286 \mathrm{e}+00$ 1.24286e-01 1.00000e-09 2.12000e-01 $1.00000 \mathrm{e}-02$ 1.00000e-02 1.00000e-03 1.00000e-09 1.00000e-01 $1.00000 \mathrm{e}+001.00000 \mathrm{e}+001.00000 \mathrm{e}-011.00000 \mathrm{e}-091.00000 \mathrm{e}-01$ Element: 3332 \# of layers: 10

Kx Ky Kz Ss Por

$3.44137 \mathrm{e}+013.44137 \mathrm{e}+013.44137 \mathrm{e}+00$ 1.00000e-09 7.00000e-02 $3.44137 \mathrm{e}+013.44137 \mathrm{e}+013.44137 \mathrm{e}+001.00000 \mathrm{e}-09$ 7.00000e-02 5.00000e-04 5.00000e-04 5.00000e-05 1.00000e-09 1.00000e-01 5.00000e-04 5.00000e-04 5.00000e-05 1.00000e-09 1.00000e-01 $1.37505 \mathrm{e}+001.37505 \mathrm{e}+001.37505 \mathrm{e}-011.00000 \mathrm{e}-092.12000 \mathrm{e}-01$ $1.37505 \mathrm{e}+001.37505 \mathrm{e}+001.37505 \mathrm{e}-011.00000 \mathrm{e}-092.12000 \mathrm{e}-01$ $1.37505 \mathrm{e}+001.37505 \mathrm{e}+001.37505 \mathrm{e}-011.00000 \mathrm{e}-092.12000 \mathrm{e}-01$ $1.37505 \mathrm{e}+001.37505 \mathrm{e}+001.37505 \mathrm{e}-011.00000 \mathrm{e}-092.12000 \mathrm{e}-01$ $1.37505 \mathrm{e}+001.37505 \mathrm{e}+001.37505 \mathrm{e}-011.00000 \mathrm{e}-092.12000 \mathrm{e}-01$ $1.00000 \mathrm{e}+001.00000 \mathrm{e}+001.00000 \mathrm{e}-011.00000 \mathrm{e}-091.00000 \mathrm{e}-01$ Element: 3333 \# of layers: 10

Kx Ky Kz Ss Por

$3.44137 \mathrm{e}+013.44137 \mathrm{e}+013.44137 \mathrm{e}+00$ 1.00000e-09 7.00000e-02 $3.44137 \mathrm{e}+013.44137 \mathrm{e}+013.44137 \mathrm{e}+001.00000 \mathrm{e}-09$ 7.00000e-02 5.00000e-04 5.00000e-04 5.00000e-05 1.00000e-09 1.00000e-01 $5.00000 \mathrm{e}-04$ 5.00000e-04 5.00000e-05 1.00000e-09 1.00000e-01 $1.37505 \mathrm{e}+001.37505 \mathrm{e}+001.37505 \mathrm{e}-011.00000 \mathrm{e}-092.12000 \mathrm{e}-01$ $1.37505 \mathrm{e}+001.37505 \mathrm{e}+001.37505 \mathrm{e}-011.00000 \mathrm{e}-092.12000 \mathrm{e}-01$ $1.37505 \mathrm{e}+001.37505 \mathrm{e}+001.37505 \mathrm{e}-011.00000 \mathrm{e}-092.12000 \mathrm{e}-01$ $1.37505 \mathrm{e}+001.37505 \mathrm{e}+001.37505 \mathrm{e}-011.00000 \mathrm{e}-092.12000 \mathrm{e}-01$ $1.37505 \mathrm{e}+001.37505 \mathrm{e}+001.37505 \mathrm{e}-011.00000 \mathrm{e}-092.12000 \mathrm{e}-01$ $1.00000 \mathrm{e}+001.00000 \mathrm{e}+001.00000 \mathrm{e}-011.00000 \mathrm{e}-091.00000 \mathrm{e}-01$ Element: 3334 \# of layers: 9

Kx Ky Kz Ss Por

$3.44137 \mathrm{e}+013.44137 \mathrm{e}+013.44137 \mathrm{e}+00$ 1.00000e-09 7.00000e-02 $3.44137 \mathrm{e}+013.44137 \mathrm{e}+013.44137 \mathrm{e}+001.00000 \mathrm{e}-09$ 7.00000e-02 5.00000e-04 5.00000e-04 5.00000e-05 1.00000e-09 1.00000e-01 $1.37505 \mathrm{e}+001.37505 \mathrm{e}+001.37505 \mathrm{e}-011.00000 \mathrm{e}-092.12000 \mathrm{e}-01$ $1.37505 \mathrm{e}+001.37505 \mathrm{e}+001.37505 \mathrm{e}-011.00000 \mathrm{e}-092.12000 \mathrm{e}-01$ $1.37505 \mathrm{e}+001.37505 \mathrm{e}+001.37505 \mathrm{e}-011.00000 \mathrm{e}-092.12000 \mathrm{e}-01$ $1.37505 \mathrm{e}+001.37505 \mathrm{e}+001.37505 \mathrm{e}-011.00000 \mathrm{e}-092.12000 \mathrm{e}-01$ $1.37505 \mathrm{e}+001.37505 \mathrm{e}+001.37505 \mathrm{e}-011.00000 \mathrm{e}-092.12000 \mathrm{e}-01$ $1.00000 \mathrm{e}+001.00000 \mathrm{e}+001.00000 \mathrm{e}-011.00000 \mathrm{e}-091.00000 \mathrm{e}-01$ Element: 3335 \# of layers: 10

Kx Ky Kz Ss Por $3.44137 \mathrm{e}+013.44137 \mathrm{e}+013.44137 \mathrm{e}+00$ 1.00000e-09 7.00000e-02 $3.44137 \mathrm{e}+013.44137 \mathrm{e}+013.44137 \mathrm{e}+001.00000 \mathrm{e}-09$ 7.00000e-02 5.00000e-04 5.00000e-04 5.00000e-05 1.00000e-09 1.00000e-01 5.00000e-04 5.00000e-04 5.00000e-05 1.00000e-09 1.00000e-01 $1.37505 \mathrm{e}+001.37505 \mathrm{e}+00$ 1.37505e-01 1.00000e-09 2.12000e-01 
$1.37505 \mathrm{e}+00$ 1.37505e+00 1.37505e-01 1.00000e-09 2.12000e-01 $1.37505 \mathrm{e}+001.37505 \mathrm{e}+00$ 1.37505e-01 1.00000e-09 2.12000e-01 $1.37505 \mathrm{e}+001.37505 \mathrm{e}+00$ 1.37505e-01 1.00000e-09 2.12000e-01 $1.37505 \mathrm{e}+001.37505 \mathrm{e}+001.37505 \mathrm{e}-01$ 1.00000e-09 2.12000e-01 $1.00000 \mathrm{e}+001.00000 \mathrm{e}+001.00000 \mathrm{e}-011.00000 \mathrm{e}-091.00000 \mathrm{e}-01$ Element: 3336 \# of layers: 10

$\mathrm{Kx} \mathrm{Ky} \mathrm{Kz}$ Ss Por

3.44137e+01 3.44137e+01 3.44137e+00 1.00000e-09 7.00000e-02 $3.44137 \mathrm{e}+013.44137 \mathrm{e}+013.44137 \mathrm{e}+001.00000 \mathrm{e}-09$ 7.00000e-02 5.00000e-04 5.00000e-04 5.00000e-05 1.00000e-09 1.00000e-01 5.00000e-04 5.00000e-04 5.00000e-05 1.00000e-09 1.00000e-01 $1.37505 \mathrm{e}+001.37505 \mathrm{e}+00$ 1.37505e-01 1.00000e-09 2.12000e-01 $1.37505 \mathrm{e}+001.37505 \mathrm{e}+00$ 1.37505e-01 1.00000e-09 2.12000e-01 $1.37505 \mathrm{e}+001.37505 \mathrm{e}+00$ 1.37505e-01 1.00000e-09 2.12000e-01 $1.37505 \mathrm{e}+001.37505 \mathrm{e}+00$ 1.37505e-01 1.00000e-09 2.12000e-01 $1.37505 \mathrm{e}+001.37505 \mathrm{e}+00$ 1.37505e-01 1.00000e-09 2.12000e-01 $1.00000 \mathrm{e}+001.00000 \mathrm{e}+001.00000 \mathrm{e}-01$ 1.00000e-09 1.00000e-01 Element: 3337 \# of layers: 11

$\mathrm{Kx} \mathrm{Ky} \mathrm{Kz}$ Ss Por

3.44137e+01 3.44137e+01 3.44137e+00 1.00000e-09 7.00000e-02 3.44137e+01 3.44137e+01 3.44137e+00 1.00000e-09 7.00000e-02 $5.00000 \mathrm{e}-04$ 5.00000e-04 5.00000e-05 1.00000e-09 1.00000e-01 5.00000e-04 5.00000e-04 5.00000e-05 1.00000e-09 1.00000e-01 $1.37505 \mathrm{e}+001.37505 \mathrm{e}+00$ 1.37505e-01 1.00000e-09 2.12000e-01 $1.37505 \mathrm{e}+001.37505 \mathrm{e}+00$ 1.37505e-01 1.00000e-09 2.12000e-01 $1.37505 \mathrm{e}+001.37505 \mathrm{e}+00$ 1.37505e-01 1.00000e-09 2.12000e-01 $1.37505 \mathrm{e}+001.37505 \mathrm{e}+00$ 1.37505e-01 1.00000e-09 2.12000e-01 $1.37505 \mathrm{e}+001.37505 \mathrm{e}+00$ 1.37505e-01 1.00000e-09 2.12000e-01 $1.00000 \mathrm{e}-02$ 1.00000e-02 1.00000e-03 1.00000e-09 1.00000e-01 $1.00000 \mathrm{e}+001.00000 \mathrm{e}+001.00000 \mathrm{e}-011.00000 \mathrm{e}-091.00000 \mathrm{e}-01$ Element: 3338 \# of layers: 11

$\mathrm{Kx} \mathrm{Ky} \mathrm{Kz}$ Ss Por

3.44137e+01 3.44137e+01 3.44137e+00 1.00000e-09 7.00000e-02 $3.44137 \mathrm{e}+013.44137 \mathrm{e}+013.44137 \mathrm{e}+001.00000 \mathrm{e}-09$ 7.00000e-02 5.00000e-04 5.00000e-04 5.00000e-05 1.00000e-09 1.00000e-01 5.00000e-04 5.00000e-04 5.00000e-05 1.00000e-09 1.00000e-01 $1.37505 \mathrm{e}+001.37505 \mathrm{e}+001.37505 \mathrm{e}-011.00000 \mathrm{e}-092.12000 \mathrm{e}-01$ $1.37505 \mathrm{e}+001.37505 \mathrm{e}+00$ 1.37505e-01 1.00000e-09 2.12000e-01 $1.37505 \mathrm{e}+001.37505 \mathrm{e}+00$ 1.37505e-01 1.00000e-09 2.12000e-01 $1.37505 \mathrm{e}+001.37505 \mathrm{e}+00$ 1.37505e-01 1.00000e-09 2.12000e-01 $1.37505 \mathrm{e}+001.37505 \mathrm{e}+00$ 1.37505e-01 1.00000e-09 2.12000e-01 $1.00000 \mathrm{e}-02$ 1.00000e-02 1.00000e-03 1.00000e-09 1.00000e-01 $1.00000 \mathrm{e}+001.00000 \mathrm{e}+001.00000 \mathrm{e}-011.00000 \mathrm{e}-091.00000 \mathrm{e}-01$ Element: 3339 \# of layers: 11

$\mathrm{Kx} \mathrm{Ky} \mathrm{Kz} \mathrm{Ss} \mathrm{Por}$

3.44137e+01 3.44137e+01 3.44137e+00 1.00000e-09 7.00000e-02 
3.44137e+01 3.44137e+01 3.44137e+00 1.00000e-09 7.00000e-02 5.00000e-04 5.00000e-04 5.00000e-05 1.00000e-09 1.00000e-01 5.00000e-04 5.00000e-04 5.00000e-05 1.00000e-09 1.00000e-01 $1.37505 \mathrm{e}+001.37505 \mathrm{e}+001.37505 \mathrm{e}-01$ 1.00000e-09 2.12000e-01 $1.37505 \mathrm{e}+001.37505 \mathrm{e}+00$ 1.37505e-01 1.00000e-09 2.12000e-01 $1.37505 \mathrm{e}+001.37505 \mathrm{e}+00$ 1.37505e-01 1.00000e-09 2.12000e-01 $1.37505 \mathrm{e}+001.37505 \mathrm{e}+00$ 1.37505e-01 1.00000e-09 2.12000e-01 $1.37505 \mathrm{e}+001.37505 \mathrm{e}+001.37505 \mathrm{e}-01$ 1.00000e-09 2.12000e-01 $1.00000 \mathrm{e}-02$ 1.00000e-02 1.00000e-03 1.00000e-09 1.00000e-01 $1.00000 \mathrm{e}+001.00000 \mathrm{e}+001.00000 \mathrm{e}-011.00000 \mathrm{e}-091.00000 \mathrm{e}-01$ Element: 3340 \# of layers: 10

Kx Ky Kz Ss Por

3.44137e+01 3.44137e+01 3.44137e+00 1.00000e-09 7.00000e-02 $3.44137 \mathrm{e}+013.44137 \mathrm{e}+013.44137 \mathrm{e}+001.00000 \mathrm{e}-09$ 7.00000e-02 5.00000e-04 5.00000e-04 5.00000e-05 1.00000e-09 1.00000e-01 5.00000e-04 5.00000e-04 5.00000e-05 1.00000e-09 1.00000e-01

$1.37505 \mathrm{e}+001.37505 \mathrm{e}+00$ 1.37505e-01 1.00000e-09 2.12000e-01 $1.37505 \mathrm{e}+001.37505 \mathrm{e}+00$ 1.37505e-01 1.00000e-09 2.12000e-01 $1.37505 \mathrm{e}+001.37505 \mathrm{e}+00$ 1.37505e-01 1.00000e-09 2.12000e-01 $1.37505 \mathrm{e}+001.37505 \mathrm{e}+00$ 1.37505e-01 1.00000e-09 2.12000e-01 $1.37505 \mathrm{e}+001.37505 \mathrm{e}+001.37505 \mathrm{e}-011.00000 \mathrm{e}-092.12000 \mathrm{e}-01$ $1.00000 \mathrm{e}+001.00000 \mathrm{e}+001.00000 \mathrm{e}-01$ 1.00000e-09 1.00000e-01 Element: 3341 \# of layers: 8

$\mathrm{Kx} \mathrm{Ky} \mathrm{Kz}$ Ss Por

4.24254e+01 4.24254e+01 4.24254e+00 1.00000e-09 7.00000e-02 $5.00000 \mathrm{e}-04$ 5.00000e-04 5.00000e-05 1.00000e-09 1.00000e-01 5.00000e-04 5.00000e-04 5.00000e-05 1.00000e-09 1.00000e-01 $1.69516 \mathrm{e}+001.69516 \mathrm{e}+00$ 1.69516e-01 1.00000e-09 2.12000e-01 $1.69516 \mathrm{e}+001.69516 \mathrm{e}+001.69516 \mathrm{e}-011.00000 \mathrm{e}-092.12000 \mathrm{e}-01$ $1.69516 \mathrm{e}+001.69516 \mathrm{e}+001.69516 \mathrm{e}-011.00000 \mathrm{e}-092.12000 \mathrm{e}-01$ $1.69516 \mathrm{e}+001.69516 \mathrm{e}+001.69516 \mathrm{e}-01$ 1.00000e-09 2.12000e-01 $1.69516 \mathrm{e}+001.69516 \mathrm{e}+00$ 1.69516e-01 1.00000e-09 2.12000e-01 Element: 3342 \# of layers: 8

$\mathrm{Kx} \mathrm{Ky} \mathrm{Kz}$ Ss Por

4.24254e+01 4.24254e+01 4.24254e+00 1.00000e-09 7.00000e-02 5.00000e-04 5.00000e-04 5.00000e-05 1.00000e-09 1.00000e-01 5.00000e-04 5.00000e-04 5.00000e-05 1.00000e-09 1.00000e-01 $1.69516 \mathrm{e}+001.69516 \mathrm{e}+001.69516 \mathrm{e}-011.00000 \mathrm{e}-092.12000 \mathrm{e}-01$ $1.69516 \mathrm{e}+001.69516 \mathrm{e}+001.69516 \mathrm{e}-01$ 1.00000e-09 2.12000e-01 $1.69516 \mathrm{e}+001.69516 \mathrm{e}+00$ 1.69516e-01 1.00000e-09 2.12000e-01 $1.69516 \mathrm{e}+001.69516 \mathrm{e}+001.69516 \mathrm{e}-011.00000 \mathrm{e}-092.12000 \mathrm{e}-01$ $1.69516 \mathrm{e}+001.69516 \mathrm{e}+00$ 1.69516e-01 1.00000e-09 2.12000e-01 Element: 3343 \# of layers: 8

$\mathrm{Kx} \mathrm{Ky} \mathrm{Kz}$ Ss Por 4.24254e+01 4.24254e+01 4.24254e+00 1.00000e-09 7.00000e-02 5.00000e-04 5.00000e-04 5.00000e-05 1.00000e-09 1.00000e-01 
5.00000e-04 5.00000e-04 5.00000e-05 1.00000e-09 1.00000e-01

$1.69516 \mathrm{e}+001.69516 \mathrm{e}+00$ 1.69516e-01 1.00000e-09 2.12000e-01

$1.69516 \mathrm{e}+001.69516 \mathrm{e}+001.69516 \mathrm{e}-01$ 1.00000e-09 2.12000e-01

$1.69516 \mathrm{e}+001.69516 \mathrm{e}+001.69516 \mathrm{e}-011.00000 \mathrm{e}-092.12000 \mathrm{e}-01$

$1.69516 \mathrm{e}+001.69516 \mathrm{e}+001.69516 \mathrm{e}-01$ 1.00000e-09 2.12000e-01

$1.69516 \mathrm{e}+001.69516 \mathrm{e}+001.69516 \mathrm{e}-01$ 1.00000e-09 2.12000e-01

Element: 3344 \# of layers: 8

$\mathrm{Kx} \mathrm{Ky} \mathrm{Kz}$ Ss Por

4.24254e+01 4.24254e+01 4.24254e+00 1.00000e-09 7.00000e-02

$5.00000 \mathrm{e}-04$ 5.00000e-04 5.00000e-05 1.00000e-09 1.00000e-01

5.00000e-04 5.00000e-04 5.00000e-05 1.00000e-09 1.00000e-01

$1.69516 \mathrm{e}+001.69516 \mathrm{e}+001.69516 \mathrm{e}-011.00000 \mathrm{e}-092.12000 \mathrm{e}-01$

$1.69516 \mathrm{e}+001.69516 \mathrm{e}+001.69516 \mathrm{e}-011.00000 \mathrm{e}-092.12000 \mathrm{e}-01$

$1.69516 \mathrm{e}+001.69516 \mathrm{e}+001.69516 \mathrm{e}-01$ 1.00000e-09 2.12000e-01

$1.69516 \mathrm{e}+001.69516 \mathrm{e}+001.69516 \mathrm{e}-01$ 1.00000e-09 2.12000e-01

$1.69516 \mathrm{e}+001.69516 \mathrm{e}+00$ 1.69516e-01 1.00000e-09 2.12000e-01

Element: 3345 \# of layers: 8

$\mathrm{Kx} \mathrm{Ky} \mathrm{Kz}$ Ss Por

4.24254e+01 4.24254e+01 4.24254e+00 1.00000e-09 7.00000e-02 5.00000e-04 5.00000e-04 5.00000e-05 1.00000e-09 1.00000e-01

5.00000e-04 5.00000e-04 5.00000e-05 1.00000e-09 1.00000e-01

$1.69516 \mathrm{e}+001.69516 \mathrm{e}+00$ 1.69516e-01 1.00000e-09 2.12000e-01

$1.69516 \mathrm{e}+001.69516 \mathrm{e}+00$ 1.69516e-01 1.00000e-09 2.12000e-01

$1.69516 \mathrm{e}+001.69516 \mathrm{e}+001.69516 \mathrm{e}-011.00000 \mathrm{e}-092.12000 \mathrm{e}-01$

$1.69516 \mathrm{e}+001.69516 \mathrm{e}+001.69516 \mathrm{e}-011.00000 \mathrm{e}-092.12000 \mathrm{e}-01$

$1.69516 \mathrm{e}+001.69516 \mathrm{e}+00$ 1.69516e-01 1.00000e-09 2.12000e-01

Element: 3346 \# of layers: 8

$\mathrm{Kx} \mathrm{Ky} \mathrm{Kz}$ Ss Por

4.24254e+01 4.24254e+01 4.24254e+00 1.00000e-09 7.00000e-02

5.00000e-04 5.00000e-04 5.00000e-05 1.00000e-09 1.00000e-01

5.00000e-04 5.00000e-04 5.00000e-05 1.00000e-09 1.00000e-01

$1.69516 \mathrm{e}+001.69516 \mathrm{e}+001.69516 \mathrm{e}-011.00000 \mathrm{e}-092.12000 \mathrm{e}-01$

$1.69516 \mathrm{e}+001.69516 \mathrm{e}+001.69516 \mathrm{e}-011.00000 \mathrm{e}-092.12000 \mathrm{e}-01$

$1.69516 \mathrm{e}+001.69516 \mathrm{e}+00$ 1.69516e-01 1.00000e-09 2.12000e-01

$1.69516 \mathrm{e}+001.69516 \mathrm{e}+001.69516 \mathrm{e}-01$ 1.00000e-09 2.12000e-01

$1.69516 \mathrm{e}+001.69516 \mathrm{e}+00$ 1.69516e-01 1.00000e-09 2.12000e-01

Element: 3347 \# of layers: 9

Kx Ky Kz Ss Por

4.24254e+01 4.24254e+01 4.24254e+00 1.00000e-09 7.00000e-02 $4.24254 \mathrm{e}+014.24254 \mathrm{e}+014.24254 \mathrm{e}+001.00000 \mathrm{e}-09$ 7.00000e-02 5.00000e-04 5.00000e-04 5.00000e-05 1.00000e-09 1.00000e-01 5.00000e-04 5.00000e-04 5.00000e-05 1.00000e-09 1.00000e-01

$1.69516 \mathrm{e}+001.69516 \mathrm{e}+001.69516 \mathrm{e}-01$ 1.00000e-09 2.12000e-01

$1.69516 \mathrm{e}+001.69516 \mathrm{e}+001.69516 \mathrm{e}-01$ 1.00000e-09 2.12000e-01

$1.69516 \mathrm{e}+001.69516 \mathrm{e}+001.69516 \mathrm{e}-011.00000 \mathrm{e}-092.12000 \mathrm{e}-01$

$1.69516 \mathrm{e}+001.69516 \mathrm{e}+001.69516 \mathrm{e}-011.00000 \mathrm{e}-092.12000 \mathrm{e}-01$ 
$1.69516 \mathrm{e}+001.69516 \mathrm{e}+00$ 1.69516e-01 1.00000e-09 2.12000e-01

Element: 3348 \# of layers: 9

$\mathrm{Kx} \mathrm{Ky} \mathrm{Kz}$ Ss Por

4.24254e+01 4.24254e+01 4.24254e+00 1.00000e-09 7.00000e-02

$4.24254 \mathrm{e}+014.24254 \mathrm{e}+014.24254 \mathrm{e}+001.00000 \mathrm{e}-09$ 7.00000e-02

5.00000e-04 5.00000e-04 5.00000e-05 1.00000e-09 1.00000e-01

5.00000e-04 5.00000e-04 5.00000e-05 1.00000e-09 1.00000e-01

$1.69516 \mathrm{e}+001.69516 \mathrm{e}+001.69516 \mathrm{e}-011.00000 \mathrm{e}-092.12000 \mathrm{e}-01$

$1.69516 \mathrm{e}+001.69516 \mathrm{e}+001.69516 \mathrm{e}-01$ 1.00000e-09 2.12000e-01

$1.69516 \mathrm{e}+001.69516 \mathrm{e}+001.69516 \mathrm{e}-01$ 1.00000e-09 2.12000e-01

$1.69516 \mathrm{e}+001.69516 \mathrm{e}+001.69516 \mathrm{e}-01$ 1.00000e-09 2.12000e-01

$1.69516 \mathrm{e}+001.69516 \mathrm{e}+00$ 1.69516e-01 1.00000e-09 2.12000e-01

Element: 3349 \# of layers: 8

$\mathrm{Kx} \mathrm{Ky} \mathrm{Kz}$ Ss Por

4.24254e+01 4.24254e+01 4.24254e+00 1.00000e-09 7.00000e-02

5.00000e-04 5.00000e-04 5.00000e-05 1.00000e-09 1.00000e-01

5.00000e-04 5.00000e-04 5.00000e-05 1.00000e-09 1.00000e-01

$1.69516 \mathrm{e}+001.69516 \mathrm{e}+001.69516 \mathrm{e}-01$ 1.00000e-09 2.12000e-01

$1.69516 \mathrm{e}+001.69516 \mathrm{e}+001.69516 \mathrm{e}-011.00000 \mathrm{e}-092.12000 \mathrm{e}-01$

$1.69516 \mathrm{e}+001.69516 \mathrm{e}+00$ 1.69516e-01 1.00000e-09 2.12000e-01

$1.69516 \mathrm{e}+001.69516 \mathrm{e}+001.69516 \mathrm{e}-011.00000 \mathrm{e}-092.12000 \mathrm{e}-01$

$1.69516 \mathrm{e}+001.69516 \mathrm{e}+00$ 1.69516e-01 1.00000e-09 2.12000e-01

Element: 3350 \# of layers: 8

Kx Ky Kz Ss Por

5.03010e+01 5.03010e+01 5.03010e+00 1.00000e-09 7.00000e-02

5.00000e-04 5.00000e-04 5.00000e-05 1.00000e-09 1.00000e-01

5.00000e-04 5.00000e-04 5.00000e-05 1.00000e-09 1.00000e-01

$2.00986 \mathrm{e}+002.00986 \mathrm{e}+002.00986 \mathrm{e}-01$ 1.00000e-09 2.12000e-01

$2.00986 \mathrm{e}+002.00986 \mathrm{e}+002.00986 \mathrm{e}-01 \quad 1.00000 \mathrm{e}-092.12000 \mathrm{e}-01$

$2.00986 \mathrm{e}+002.00986 \mathrm{e}+00$ 2.00986e-01 1.00000e-09 2.12000e-01

$2.00986 \mathrm{e}+002.00986 \mathrm{e}+00$ 2.00986e-01 1.00000e-09 2.12000e-01

$2.00986 \mathrm{e}+00$ 2.00986e+00 2.00986e-01 1.00000e-09 2.12000e-01

Element: 3351 \# of layers: 8

$\mathrm{Kx} \mathrm{Ky} \mathrm{Kz}$ Ss Por

$5.03010 \mathrm{e}+015.03010 \mathrm{e}+015.03010 \mathrm{e}+001.00000 \mathrm{e}-09$ 7.00000e-02

5.00000e-04 5.00000e-04 5.00000e-05 1.00000e-09 1.00000e-01

5.00000e-04 5.00000e-04 5.00000e-05 1.00000e-09 1.00000e-01

$2.00986 \mathrm{e}+002.00986 \mathrm{e}+002.00986 \mathrm{e}-01$ 1.00000e-09 2.12000e-01

$2.00986 \mathrm{e}+002.00986 \mathrm{e}+002.00986 \mathrm{e}-01$ 1.00000e-09 2.12000e-01

$2.00986 \mathrm{e}+002.00986 \mathrm{e}+002.00986 \mathrm{e}-01$ 1.00000e-09 2.12000e-01

$2.00986 \mathrm{e}+002.00986 \mathrm{e}+002.00986 \mathrm{e}-01$ 1.00000e-09 2.12000e-01

$2.00986 \mathrm{e}+002.00986 \mathrm{e}+00$ 2.00986e-01 1.00000e-09 2.12000e-01

Element: 3352 \# of layers: 8

$\mathrm{Kx} \mathrm{Ky} \mathrm{Kz}$ Ss Por

$5.03010 \mathrm{e}+015.03010 \mathrm{e}+015.03010 \mathrm{e}+001.00000 \mathrm{e}-09$ 7.00000e-02

5.00000e-04 5.00000e-04 5.00000e-05 1.00000e-09 1.00000e-01 
5.00000e-04 5.00000e-04 5.00000e-05 1.00000e-09 1.00000e-01 $2.00986 \mathrm{e}+002.00986 \mathrm{e}+00$ 2.00986e-01 1.00000e-09 2.12000e-01 $2.00986 \mathrm{e}+002.00986 \mathrm{e}+002.00986 \mathrm{e}-01$ 1.00000e-09 2.12000e-01 $2.00986 \mathrm{e}+002.00986 \mathrm{e}+002.00986 \mathrm{e}-01$ 1.00000e-09 2.12000e-01 $2.00986 \mathrm{e}+002.00986 \mathrm{e}+002.00986 \mathrm{e}-01$ 1.00000e-09 2.12000e-01 $2.00986 \mathrm{e}+002.00986 \mathrm{e}+00$ 2.00986e-01 1.00000e-09 2.12000e-01 Element: 3353 \# of layers: 8

Kx Ky Kz Ss Por

$5.03010 \mathrm{e}+015.03010 \mathrm{e}+015.03010 \mathrm{e}+001.00000 \mathrm{e}-097.00000 \mathrm{e}-02$ 5.00000e-04 5.00000e-04 5.00000e-05 1.00000e-09 1.00000e-01 5.00000e-04 5.00000e-04 5.00000e-05 1.00000e-09 1.00000e-01 $2.00986 \mathrm{e}+002.00986 \mathrm{e}+002.00986 \mathrm{e}-01$ 1.00000e-09 2.12000e-01 $2.00986 \mathrm{e}+002.00986 \mathrm{e}+002.00986 \mathrm{e}-01$ 1.00000e-09 2.12000e-01 $2.00986 \mathrm{e}+002.00986 \mathrm{e}+002.00986 \mathrm{e}-01$ 1.00000e-09 2.12000e-01 $2.00986 \mathrm{e}+002.00986 \mathrm{e}+002.00986 \mathrm{e}-01$ 1.00000e-09 2.12000e-01 $2.00986 \mathrm{e}+002.00986 \mathrm{e}+00$ 2.00986e-01 1.00000e-09 2.12000e-01 Element: 3354 \# of layers: 7

$\mathrm{Kx} \mathrm{Ky} \mathrm{Kz}$ Ss Por

$5.03010 \mathrm{e}+015.03010 \mathrm{e}+015.03010 \mathrm{e}+001.00000 \mathrm{e}-09$ 7.00000e-02 5.00000e-04 5.00000e-04 5.00000e-05 1.00000e-09 1.00000e-01

$2.00986 \mathrm{e}+002.00986 \mathrm{e}+002.00986 \mathrm{e}-01$ 1.00000e-09 2.12000e-01 $2.00986 \mathrm{e}+002.00986 \mathrm{e}+00$ 2.00986e-01 1.00000e-09 2.12000e-01 $2.00986 \mathrm{e}+002.00986 \mathrm{e}+00$ 2.00986e-01 1.00000e-09 2.12000e-01 $2.00986 \mathrm{e}+002.00986 \mathrm{e}+002.00986 \mathrm{e}-01$ 1.00000e-09 2.12000e-01 $2.00986 \mathrm{e}+002.00986 \mathrm{e}+00$ 2.00986e-01 1.00000e-09 2.12000e-01 Element: 3355 \# of layers: 8

$\mathrm{Kx} \mathrm{Ky} \mathrm{Kz}$ Ss Por

$5.03010 \mathrm{e}+015.03010 \mathrm{e}+015.03010 \mathrm{e}+001.00000 \mathrm{e}-09$ 7.00000e-02 5.00000e-04 5.00000e-04 5.00000e-05 1.00000e-09 1.00000e-01 5.00000e-04 5.00000e-04 5.00000e-05 1.00000e-09 1.00000e-01 $2.00986 \mathrm{e}+002.00986 \mathrm{e}+002.00986 \mathrm{e}-01$ 1.00000e-09 2.12000e-01 $2.00986 \mathrm{e}+002.00986 \mathrm{e}+00$ 2.00986e-01 1.00000e-09 2.12000e-01 $2.00986 \mathrm{e}+002.00986 \mathrm{e}+002.00986 \mathrm{e}-01$ 1.00000e-09 2.12000e-01 $2.00986 \mathrm{e}+002.00986 \mathrm{e}+00$ 2.00986e-01 1.00000e-09 2.12000e-01 $2.00986 \mathrm{e}+002.00986 \mathrm{e}+00$ 2.00986e-01 1.00000e-09 2.12000e-01 Element: 3356 \# of layers: 8

Kx Ky Kz Ss Por 5.03010e+01 5.03010e+01 5.03010e+00 1.00000e-09 7.00000e-02 5.00000e-04 5.00000e-04 5.00000e-05 1.00000e-09 1.00000e-01 5.00000e-04 5.00000e-04 5.00000e-05 1.00000e-09 1.00000e-01 $2.00986 \mathrm{e}+002.00986 \mathrm{e}+002.00986 \mathrm{e}-01$ 1.00000e-09 2.12000e-01 $2.00986 \mathrm{e}+002.00986 \mathrm{e}+002.00986 \mathrm{e}-01$ 1.00000e-09 2.12000e-01 $2.00986 \mathrm{e}+002.00986 \mathrm{e}+00$ 2.00986e-01 1.00000e-09 2.12000e-01 $2.00986 \mathrm{e}+002.00986 \mathrm{e}+00$ 2.00986e-01 1.00000e-09 2.12000e-01 $2.00986 \mathrm{e}+00$ 2.00986e+00 2.00986e-01 1.00000e-09 2.12000e-01 Element: 3357 \# of layers: 8 
$\mathrm{Kx} \mathrm{Ky} \mathrm{Kz} \mathrm{Ss} \mathrm{Por}$

$5.03010 \mathrm{e}+015.03010 \mathrm{e}+015.03010 \mathrm{e}+001.00000 \mathrm{e}-09$ 7.00000e-02 5.00000e-04 5.00000e-04 5.00000e-05 1.00000e-09 1.00000e-01 5.00000e-04 5.00000e-04 5.00000e-05 1.00000e-09 1.00000e-01 $2.00986 \mathrm{e}+002.00986 \mathrm{e}+002.00986 \mathrm{e}-01$ 1.00000e-09 2.12000e-01 $2.00986 \mathrm{e}+002.00986 \mathrm{e}+002.00986 \mathrm{e}-01$ 1.00000e-09 2.12000e-01 $2.00986 \mathrm{e}+002.00986 \mathrm{e}+002.00986 \mathrm{e}-01$ 1.00000e-09 2.12000e-01 $2.00986 \mathrm{e}+002.00986 \mathrm{e}+002.00986 \mathrm{e}-01 \quad 1.00000 \mathrm{e}-092.12000 \mathrm{e}-01$ $2.00986 \mathrm{e}+002.00986 \mathrm{e}+00$ 2.00986e-01 1.00000e-09 2.12000e-01 Element: 3358 \# of layers: 8

$\mathrm{Kx} \mathrm{Ky} \mathrm{Kz}$ Ss Por

5.03010e+01 5.03010e+01 5.03010e+00 1.00000e-09 7.00000e-02 5.00000e-04 5.00000e-04 5.00000e-05 1.00000e-09 1.00000e-01 5.00000e-04 5.00000e-04 5.00000e-05 1.00000e-09 1.00000e-01 $2.00986 \mathrm{e}+002.00986 \mathrm{e}+002.00986 \mathrm{e}-01$ 1.00000e-09 2.12000e-01 $2.00986 \mathrm{e}+002.00986 \mathrm{e}+002.00986 \mathrm{e}-01$ 1.00000e-09 2.12000e-01 $2.00986 \mathrm{e}+002.00986 \mathrm{e}+002.00986 \mathrm{e}-01$ 1.00000e-09 2.12000e-01 $2.00986 \mathrm{e}+002.00986 \mathrm{e}+002.00986 \mathrm{e}-01$ 1.00000e-09 2.12000e-01 $2.00986 \mathrm{e}+00$ 2.00986e+00 2.00986e-01 1.00000e-09 2.12000e-01 Element: 3359 \# of layers: 9

$\mathrm{Kx} \mathrm{Ky} \mathrm{Kz}$ Ss Por

3.93476e+01 3.93476e+01 3.93476e+00 1.00000e-09 7.00000e-02 $3.93476 \mathrm{e}+013.93476 \mathrm{e}+013.93476 \mathrm{e}+001.00000 \mathrm{e}-09$ 7.00000e-02 5.00000e-04 5.00000e-04 5.00000e-05 1.00000e-09 1.00000e-01 5.00000e-04 5.00000e-04 5.00000e-05 1.00000e-09 1.00000e-01 $1.57218 \mathrm{e}+001.57218 \mathrm{e}+00$ 1.57218e-01 1.00000e-09 2.12000e-01 $1.57218 \mathrm{e}+001.57218 \mathrm{e}+001.57218 \mathrm{e}-01$ 1.00000e-09 2.12000e-01 $1.57218 \mathrm{e}+001.57218 \mathrm{e}+001.57218 \mathrm{e}-01$ 1.00000e-09 2.12000e-01 $1.57218 \mathrm{e}+001.57218 \mathrm{e}+001.57218 \mathrm{e}-011.00000 \mathrm{e}-092.12000 \mathrm{e}-01$ $1.57218 \mathrm{e}+001.57218 \mathrm{e}+00$ 1.57218e-01 1.00000e-09 2.12000e-01 Element: 3360 \# of layers: 9

$\mathrm{Kx} \mathrm{Ky} \mathrm{Kz}$ Ss Por

3.93476e+01 3.93476e+01 3.93476e+00 1.00000e-09 7.00000e-02 $3.93476 \mathrm{e}+013.93476 \mathrm{e}+013.93476 \mathrm{e}+001.00000 \mathrm{e}-09$ 7.00000e-02 $5.00000 \mathrm{e}-04$ 5.00000e-04 5.00000e-05 1.00000e-09 1.00000e-01 5.00000e-04 5.00000e-04 5.00000e-05 1.00000e-09 1.00000e-01 $1.57218 \mathrm{e}+001.57218 \mathrm{e}+001.57218 \mathrm{e}-011.00000 \mathrm{e}-092.12000 \mathrm{e}-01$ $1.57218 \mathrm{e}+001.57218 \mathrm{e}+00$ 1.57218e-01 1.00000e-09 2.12000e-01 $1.57218 \mathrm{e}+001.57218 \mathrm{e}+00$ 1.57218e-01 1.00000e-09 2.12000e-01 $1.57218 \mathrm{e}+001.57218 \mathrm{e}+00$ 1.57218e-01 1.00000e-09 2.12000e-01 $1.57218 \mathrm{e}+001.57218 \mathrm{e}+00$ 1.57218e-01 1.00000e-09 2.12000e-01 Element: 3361 \# of layers: 9

$\mathrm{Kx} \mathrm{Ky} \mathrm{Kz}$ Ss Por

3.93476e+01 3.93476e+01 3.93476e+00 1.00000e-09 7.00000e-02 3.93476e+01 3.93476e+01 3.93476e+00 1.00000e-09 7.00000e-02 5.00000e-04 5.00000e-04 5.00000e-05 1.00000e-09 1.00000e-01 
5.00000e-04 5.00000e-04 5.00000e-05 1.00000e-09 1.00000e-01

$1.57218 \mathrm{e}+001.57218 \mathrm{e}+001.57218 \mathrm{e}-01$ 1.00000e-09 2.12000e-01

$1.57218 \mathrm{e}+001.57218 \mathrm{e}+00$ 1.57218e-01 1.00000e-09 2.12000e-01

$1.57218 \mathrm{e}+001.57218 \mathrm{e}+00$ 1.57218e-01 1.00000e-09 2.12000e-01

$1.57218 \mathrm{e}+001.57218 \mathrm{e}+00$ 1.57218e-01 1.00000e-09 2.12000e-01

$1.57218 \mathrm{e}+001.57218 \mathrm{e}+00$ 1.57218e-01 1.00000e-09 2.12000e-01

Element: 3362 \# of layers: 7

$\mathrm{Kx} \mathrm{Ky} \mathrm{Kz}$ Ss Por

$1.93972 \mathrm{e}+01$ 1.93972e+01 1.93972e+00 1.00000e-09 2.12000e-01 $1.93972 \mathrm{e}+01$ 1.93972e+01 1.93972e+00 1.00000e-09 2.12000e-01 $1.93972 \mathrm{e}+01$ 1.93972e+01 1.93972e+00 1.00000e-09 2.12000e-01 $1.93972 \mathrm{e}+01$ 1.93972e+01 1.93972e+00 1.00000e-09 2.12000e-01 $1.93972 \mathrm{e}+01$ 1.93972e+01 1.93972e+00 1.00000e-09 2.12000e-01 $1.00000 \mathrm{e}-05$ 1.00000e-05 1.00000e-06 1.00000e-09 1.00000e-01 $1.00000 \mathrm{e}+001.00000 \mathrm{e}+001.00000 \mathrm{e}-01$ 1.00000e-09 1.00000e-01 Element: 3363 \# of layers: 7

$\mathrm{Kx} \mathrm{Ky} \mathrm{Kz}$ Ss Por

1.93972e+01 1.93972e+01 1.93972e+00 1.00000e-09 2.12000e-01 $1.93972 \mathrm{e}+01$ 1.93972e+01 1.93972e+00 1.00000e-09 2.12000e-01 $1.93972 \mathrm{e}+01$ 1.93972e+01 1.93972e+00 1.00000e-09 2.12000e-01 $1.93972 \mathrm{e}+01$ 1.93972e+01 1.93972e+00 1.00000e-09 2.12000e-01 $1.93972 \mathrm{e}+01$ 1.93972e+01 1.93972e+00 1.00000e-09 2.12000e-01 $1.00000 \mathrm{e}-05$ 1.00000e-05 1.00000e-06 1.00000e-09 1.00000e-01 $1.00000 \mathrm{e}+001.00000 \mathrm{e}+001.00000 \mathrm{e}-011.00000 \mathrm{e}-09$ 1.00000e-01

Element: 3364 \# of layers: 7

$\mathrm{Kx} \mathrm{Ky} \mathrm{Kz}$ Ss Por

$2.00392 \mathrm{e}+012.00392 \mathrm{e}+012.00392 \mathrm{e}+00$ 1.00000e-09 2.12000e-01 $2.00392 \mathrm{e}+012.00392 \mathrm{e}+012.00392 \mathrm{e}+001.00000 \mathrm{e}-092.12000 \mathrm{e}-01$ $2.00392 \mathrm{e}+012.00392 \mathrm{e}+012.00392 \mathrm{e}+001.00000 \mathrm{e}-092.12000 \mathrm{e}-01$ $2.00392 \mathrm{e}+012.00392 \mathrm{e}+012.00392 \mathrm{e}+001.00000 \mathrm{e}-092.12000 \mathrm{e}-01$ $2.00392 \mathrm{e}+012.00392 \mathrm{e}+012.00392 \mathrm{e}+001.00000 \mathrm{e}-092.12000 \mathrm{e}-01$ $1.00000 \mathrm{e}-05$ 1.00000e-05 1.00000e-06 1.00000e-09 1.00000e-01 $1.00000 \mathrm{e}+001.00000 \mathrm{e}+001.00000 \mathrm{e}-011.00000 \mathrm{e}-091.00000 \mathrm{e}-01$ Element: 3365 \# of layers: 7

$\mathrm{Kx} \mathrm{Ky} \mathrm{Kz}$ Ss Por

$2.00392 \mathrm{e}+012.00392 \mathrm{e}+012.00392 \mathrm{e}+00$ 1.00000e-09 2.12000e-01 $2.00392 \mathrm{e}+012.00392 \mathrm{e}+012.00392 \mathrm{e}+001.00000 \mathrm{e}-092.12000 \mathrm{e}-01$ $2.00392 \mathrm{e}+012.00392 \mathrm{e}+012.00392 \mathrm{e}+001.00000 \mathrm{e}-092.12000 \mathrm{e}-01$ $2.00392 \mathrm{e}+012.00392 \mathrm{e}+012.00392 \mathrm{e}+001.00000 \mathrm{e}-092.12000 \mathrm{e}-01$ $2.00392 \mathrm{e}+012.00392 \mathrm{e}+012.00392 \mathrm{e}+00$ 1.00000e-09 2.12000e-01 $1.00000 \mathrm{e}-05$ 1.00000e-05 1.00000e-06 1.00000e-09 1.00000e-01 $1.00000 \mathrm{e}+001.00000 \mathrm{e}+001.00000 \mathrm{e}-011.00000 \mathrm{e}-091.00000 \mathrm{e}-01$ Element: 3366 \# of layers: 7

$\mathrm{Kx} \mathrm{Ky} \mathrm{Kz}$ Ss Por

$2.02034 \mathrm{e}+012.02034 \mathrm{e}+012.02034 \mathrm{e}+00$ 1.00000e-09 2.12000e-01 $2.02034 \mathrm{e}+012.02034 \mathrm{e}+012.02034 \mathrm{e}+001.00000 \mathrm{e}-092.12000 \mathrm{e}-01$ 
$2.02034 \mathrm{e}+012.02034 \mathrm{e}+012.02034 \mathrm{e}+00$ 1.00000e-09 2.12000e-01 $2.02034 \mathrm{e}+012.02034 \mathrm{e}+012.02034 \mathrm{e}+001.00000 \mathrm{e}-092.12000 \mathrm{e}-01$ $2.02034 \mathrm{e}+012.02034 \mathrm{e}+012.02034 \mathrm{e}+001.00000 \mathrm{e}-092.12000 \mathrm{e}-01$ $1.00000 \mathrm{e}-05$ 1.00000e-05 1.00000e-06 1.00000e-09 1.00000e-01 $1.00000 \mathrm{e}+001.00000 \mathrm{e}+001.00000 \mathrm{e}-01$ 1.00000e-09 1.00000e-01 Element: 3367 \# of layers: 7

$\mathrm{Kx} \mathrm{Ky} \mathrm{Kz}$ Ss Por

$2.48000 \mathrm{e}+012.48000 \mathrm{e}+012.48000 \mathrm{e}+00$ 1.00000e-09 2.12000e-01 $2.48000 \mathrm{e}+012.48000 \mathrm{e}+012.48000 \mathrm{e}+001.00000 \mathrm{e}-092.12000 \mathrm{e}-01$

$2.48000 \mathrm{e}+012.48000 \mathrm{e}+012.48000 \mathrm{e}+001.00000 \mathrm{e}-092.12000 \mathrm{e}-01$

$2.48000 \mathrm{e}+012.48000 \mathrm{e}+012.48000 \mathrm{e}+001.00000 \mathrm{e}-092.12000 \mathrm{e}-01$

$2.48000 \mathrm{e}+012.48000 \mathrm{e}+012.48000 \mathrm{e}+001.00000 \mathrm{e}-092.12000 \mathrm{e}-01$ $1.00000 \mathrm{e}-05$ 1.00000e-05 1.00000e-06 1.00000e-09 1.00000e-01 $1.00000 \mathrm{e}+001.00000 \mathrm{e}+001.00000 \mathrm{e}-011.00000 \mathrm{e}-091.00000 \mathrm{e}-01$ Element: 3368 \# of layers: 7

Kx Ky Kz Ss Por

$2.48000 \mathrm{e}+012.48000 \mathrm{e}+012.48000 \mathrm{e}+00$ 1.00000e-09 2.12000e-01

$2.48000 \mathrm{e}+012.48000 \mathrm{e}+012.48000 \mathrm{e}+001.00000 \mathrm{e}-092.12000 \mathrm{e}-01$

$2.48000 \mathrm{e}+012.48000 \mathrm{e}+012.48000 \mathrm{e}+001.00000 \mathrm{e}-092.12000 \mathrm{e}-01$

$2.48000 \mathrm{e}+012.48000 \mathrm{e}+012.48000 \mathrm{e}+001.00000 \mathrm{e}-092.12000 \mathrm{e}-01$

$2.48000 \mathrm{e}+012.48000 \mathrm{e}+012.48000 \mathrm{e}+001.00000 \mathrm{e}-092.12000 \mathrm{e}-01$ $1.00000 \mathrm{e}-05$ 1.00000e-05 1.00000e-06 1.00000e-09 1.00000e-01

$1.00000 \mathrm{e}+001.00000 \mathrm{e}+001.00000 \mathrm{e}-011.00000 \mathrm{e}-091.00000 \mathrm{e}-01$ Element: 3369 \# of layers: 7

$\mathrm{Kx} \mathrm{Ky} \mathrm{Kz}$ Ss Por

$2.68386 \mathrm{e}+012.68386 \mathrm{e}+012.68386 \mathrm{e}+001.00000 \mathrm{e}-092.12000 \mathrm{e}-01$

$2.68386 \mathrm{e}+012.68386 \mathrm{e}+012.68386 \mathrm{e}+001.00000 \mathrm{e}-092.12000 \mathrm{e}-01$

$2.68386 \mathrm{e}+012.68386 \mathrm{e}+012.68386 \mathrm{e}+001.00000 \mathrm{e}-092.12000 \mathrm{e}-01$

$2.68386 \mathrm{e}+012.68386 \mathrm{e}+012.68386 \mathrm{e}+001.00000 \mathrm{e}-092.12000 \mathrm{e}-01$

$2.68386 \mathrm{e}+012.68386 \mathrm{e}+012.68386 \mathrm{e}+001.00000 \mathrm{e}-092.12000 \mathrm{e}-01$

$1.00000 \mathrm{e}-05$ 1.00000e-05 1.00000e-06 1.00000e-09 1.00000e-01

$1.00000 \mathrm{e}+001.00000 \mathrm{e}+001.00000 \mathrm{e}-011.00000 \mathrm{e}-091.00000 \mathrm{e}-01$

Element: 3370 \# of layers: 7

$\mathrm{Kx} \mathrm{Ky} \mathrm{Kz}$ Ss Por

$1.19163 \mathrm{e}+01$ 1.19163e+01 1.19163e+00 1.00000e-09 2.12000e-01

$1.19163 \mathrm{e}+011.19163 \mathrm{e}+01$ 1.19163e+00 1.00000e-09 2.12000e-01

$1.19163 \mathrm{e}+01$ 1.19163e+01 1.19163e+00 1.00000e-09 2.12000e-01

$1.19163 \mathrm{e}+011.19163 \mathrm{e}+01$ 1.19163e+00 1.00000e-09 2.12000e-01

$1.19163 \mathrm{e}+01$ 1.19163e+01 1.19163e+00 1.00000e-09 2.12000e-01

$1.00000 \mathrm{e}-05$ 1.00000e-05 1.00000e-06 1.00000e-09 1.00000e-01

$1.00000 \mathrm{e}+001.00000 \mathrm{e}+001.00000 \mathrm{e}-011.00000 \mathrm{e}-091.00000 \mathrm{e}-01$

Element: 3371 \# of layers: 7

$\mathrm{Kx} \mathrm{Ky} \mathrm{Kz}$ Ss Por

1.19163e+01 1.19163e+01 1.19163e+00 1.00000e-09 2.12000e-01 $1.19163 \mathrm{e}+011.19163 \mathrm{e}+01$ 1.19163e+00 1.00000e-09 2.12000e-01 $1.19163 e+011.19163 e+011.19163 e+001.00000 e-092.12000 e-01$ 
$1.19163 \mathrm{e}+01$ 1.19163e+01 1.19163e+00 1.00000e-09 2.12000e-01 $1.19163 \mathrm{e}+01$ 1.19163e+01 1.19163e+00 1.00000e-09 2.12000e-01 $1.00000 \mathrm{e}-05$ 1.00000e-05 1.00000e-06 1.00000e-09 1.00000e-01 $1.00000 \mathrm{e}+001.00000 \mathrm{e}+001.00000 \mathrm{e}-011.00000 \mathrm{e}-091.00000 \mathrm{e}-01$ Element: 3372 \# of layers: 7

$\mathrm{Kx} \mathrm{Ky} \mathrm{Kz}$ Ss Por

$1.52268 \mathrm{e}+01$ 1.52268e+01 1.52268e+00 1.00000e-09 2.12000e-01 $1.52268 \mathrm{e}+011.52268 \mathrm{e}+011.52268 \mathrm{e}+001.00000 \mathrm{e}-092.12000 \mathrm{e}-01$ $1.52268 \mathrm{e}+01$ 1.52268e+01 1.52268e+00 1.00000e-09 2.12000e-01 $1.52268 \mathrm{e}+01$ 1.52268e+01 1.52268e+00 1.00000e-09 2.12000e-01 $1.52268 \mathrm{e}+011.52268 \mathrm{e}+01$ 1.52268e+00 1.00000e-09 2.12000e-01 $1.00000 \mathrm{e}-05$ 1.00000e-05 1.00000e-06 1.00000e-09 1.00000e-01 $1.00000 \mathrm{e}+001.00000 \mathrm{e}+001.00000 \mathrm{e}-01$ 1.00000e-09 1.00000e-01 Element: 3373 \# of layers: 7

$\mathrm{Kx} \mathrm{Ky} \mathrm{Kz}$ Ss Por

$1.52268 \mathrm{e}+01$ 1.52268e+01 1.52268e+00 1.00000e-09 2.12000e-01 $1.52268 \mathrm{e}+011.52268 \mathrm{e}+011.52268 \mathrm{e}+001.00000 \mathrm{e}-092.12000 \mathrm{e}-01$ $1.52268 \mathrm{e}+011.52268 \mathrm{e}+011.52268 \mathrm{e}+001.00000 \mathrm{e}-092.12000 \mathrm{e}-01$ $1.52268 \mathrm{e}+01$ 1.52268e+01 1.52268e+00 1.00000e-09 2.12000e-01 $1.52268 \mathrm{e}+01$ 1.52268e+01 1.52268e+00 1.00000e-09 2.12000e-01 $1.00000 \mathrm{e}-05$ 1.00000e-05 1.00000e-06 1.00000e-09 1.00000e-01 $1.00000 \mathrm{e}+001.00000 \mathrm{e}+001.00000 \mathrm{e}-011.00000 \mathrm{e}-091.00000 \mathrm{e}-01$ Element: 3374 \# of layers: 7

Kx Ky Kz Ss Por

$2.69691 \mathrm{e}+012.69691 \mathrm{e}+012.69691 \mathrm{e}+00$ 1.00000e-09 2.12000e-01

$2.69691 \mathrm{e}+012.69691 \mathrm{e}+012.69691 \mathrm{e}+001.00000 \mathrm{e}-092.12000 \mathrm{e}-01$

$2.69691 \mathrm{e}+012.69691 \mathrm{e}+012.69691 \mathrm{e}+001.00000 \mathrm{e}-092.12000 \mathrm{e}-01$

$2.69691 \mathrm{e}+012.69691 \mathrm{e}+012.69691 \mathrm{e}+00$ 1.00000e-09 2.12000e-01

$2.69691 \mathrm{e}+012.69691 \mathrm{e}+012.69691 \mathrm{e}+001.00000 \mathrm{e}-092.12000 \mathrm{e}-01$ $1.00000 \mathrm{e}-05$ 1.00000e-05 1.00000e-06 1.00000e-09 1.00000e-01

$1.00000 \mathrm{e}+001.00000 \mathrm{e}+001.00000 \mathrm{e}-01$ 1.00000e-09 1.00000e-01 Element: 3375 \# of layers: 7

Kx Ky Kz Ss Por

$1.08806 \mathrm{e}+011.08806 \mathrm{e}+011.08806 \mathrm{e}+001.00000 \mathrm{e}-092.12000 \mathrm{e}-01$ $1.08806 \mathrm{e}+011.08806 \mathrm{e}+011.08806 \mathrm{e}+001.00000 \mathrm{e}-092.12000 \mathrm{e}-01$ $1.08806 \mathrm{e}+011.08806 \mathrm{e}+011.08806 \mathrm{e}+001.00000 \mathrm{e}-092.12000 \mathrm{e}-01$ $1.08806 \mathrm{e}+011.08806 \mathrm{e}+011.08806 \mathrm{e}+001.00000 \mathrm{e}-092.12000 \mathrm{e}-01$ $1.08806 \mathrm{e}+011.08806 \mathrm{e}+011.08806 \mathrm{e}+001.00000 \mathrm{e}-092.12000 \mathrm{e}-01$ $1.00000 \mathrm{e}-05$ 1.00000e-05 1.00000e-06 1.00000e-09 1.00000e-01 $1.00000 \mathrm{e}+001.00000 \mathrm{e}+001.00000 \mathrm{e}-01$ 1.00000e-09 1.00000e-01 Element: 3376 \# of layers: 7

$\mathrm{Kx} \mathrm{Ky} \mathrm{Kz}$ Ss Por

$1.29657 \mathrm{e}+01$ 1.29657e+01 1.29657e+00 1.00000e-09 2.12000e-01 $1.29657 \mathrm{e}+01$ 1.29657e+01 1.29657e+00 1.00000e-09 2.12000e-01 $1.29657 \mathrm{e}+01$ 1.29657e+01 1.29657e+00 1.00000e-09 2.12000e-01 $1.29657 \mathrm{e}+01$ 1.29657e+01 1.29657e+00 1.00000e-09 2.12000e-01 
$1.29657 \mathrm{e}+011.29657 \mathrm{e}+011.29657 \mathrm{e}+00$ 1.00000e-09 2.12000e-01 $1.00000 \mathrm{e}-05$ 1.00000e-05 1.00000e-06 1.00000e-09 1.00000e-01 $1.00000 \mathrm{e}+001.00000 \mathrm{e}+001.00000 \mathrm{e}-011.00000 \mathrm{e}-091.00000 \mathrm{e}-01$ Element: 3377 \# of layers: 7

Kx Ky Kz Ss Por

$1.29657 \mathrm{e}+011.29657 \mathrm{e}+011.29657 \mathrm{e}+00$ 1.00000e-09 2.12000e-01 $1.29657 \mathrm{e}+011.29657 \mathrm{e}+011.29657 \mathrm{e}+001.00000 \mathrm{e}-092.12000 \mathrm{e}-01$ $1.29657 \mathrm{e}+011.29657 \mathrm{e}+011.29657 \mathrm{e}+001.00000 \mathrm{e}-092.12000 \mathrm{e}-01$ $1.29657 \mathrm{e}+011.29657 \mathrm{e}+011.29657 \mathrm{e}+001.00000 \mathrm{e}-092.12000 \mathrm{e}-01$ $1.29657 \mathrm{e}+011.29657 \mathrm{e}+011.29657 \mathrm{e}+001.00000 \mathrm{e}-092.12000 \mathrm{e}-01$ $1.00000 \mathrm{e}-05$ 1.00000e-05 1.00000e-06 1.00000e-09 1.00000e-01 $1.00000 \mathrm{e}+001.00000 \mathrm{e}+001.00000 \mathrm{e}-011.00000 \mathrm{e}-091.00000 \mathrm{e}-01$ Element: 3378 \# of layers: 7

Kx Ky Kz Ss Por

$1.22695 \mathrm{e}+011.22695 \mathrm{e}+011.22695 \mathrm{e}+00$ 1.00000e-09 2.12000e-01 $1.22695 \mathrm{e}+011.22695 \mathrm{e}+011.22695 \mathrm{e}+001.00000 \mathrm{e}-092.12000 \mathrm{e}-01$ $1.22695 \mathrm{e}+011.22695 \mathrm{e}+011.22695 \mathrm{e}+001.00000 \mathrm{e}-092.12000 \mathrm{e}-01$ $1.22695 \mathrm{e}+011.22695 \mathrm{e}+011.22695 \mathrm{e}+001.00000 \mathrm{e}-092.12000 \mathrm{e}-01$ $1.22695 \mathrm{e}+011.22695 \mathrm{e}+011.22695 \mathrm{e}+00$ 1.00000e-09 2.12000e-01 $1.00000 \mathrm{e}-05$ 1.00000e-05 1.00000e-06 1.00000e-09 1.00000e-01 $1.00000 \mathrm{e}+001.00000 \mathrm{e}+001.00000 \mathrm{e}-011.00000 \mathrm{e}-091.00000 \mathrm{e}-01$ Element: 3379 \# of layers: 7

Kx Ky Kz Ss Por

$1.24655 \mathrm{e}+011.24655 \mathrm{e}+011.24655 \mathrm{e}+00$ 1.00000e-09 2.12000e-01 $1.24655 \mathrm{e}+011.24655 \mathrm{e}+011.24655 \mathrm{e}+001.00000 \mathrm{e}-092.12000 \mathrm{e}-01$ $1.24655 \mathrm{e}+011.24655 \mathrm{e}+011.24655 \mathrm{e}+001.00000 \mathrm{e}-092.12000 \mathrm{e}-01$ $1.24655 \mathrm{e}+011.24655 \mathrm{e}+011.24655 \mathrm{e}+00$ 1.00000e-09 2.12000e-01 $1.24655 \mathrm{e}+011.24655 \mathrm{e}+011.24655 \mathrm{e}+001.00000 \mathrm{e}-092.12000 \mathrm{e}-01$ $1.00000 \mathrm{e}-05$ 1.00000e-05 1.00000e-06 1.00000e-09 1.00000e-01 $1.00000 \mathrm{e}+001.00000 \mathrm{e}+001.00000 \mathrm{e}-011.00000 \mathrm{e}-091.00000 \mathrm{e}-01$ Element: 3380 \# of layers: 7

Kx Ky Kz Ss Por

$1.45918 \mathrm{e}+011.45918 \mathrm{e}+011.45918 \mathrm{e}+00$ 1.00000e-09 2.12000e-01 $1.45918 \mathrm{e}+011.45918 \mathrm{e}+011.45918 \mathrm{e}+001.00000 \mathrm{e}-092.12000 \mathrm{e}-01$ $1.45918 \mathrm{e}+011.45918 \mathrm{e}+011.45918 \mathrm{e}+001.00000 \mathrm{e}-092.12000 \mathrm{e}-01$ $1.45918 \mathrm{e}+011.45918 \mathrm{e}+011.45918 \mathrm{e}+001.00000 \mathrm{e}-092.12000 \mathrm{e}-01$ $1.45918 \mathrm{e}+011.45918 \mathrm{e}+011.45918 \mathrm{e}+001.00000 \mathrm{e}-092.12000 \mathrm{e}-01$ $1.00000 \mathrm{e}-05$ 1.00000e-05 1.00000e-06 1.00000e-09 1.00000e-01 $1.00000 \mathrm{e}+001.00000 \mathrm{e}+001.00000 \mathrm{e}-011.00000 \mathrm{e}-091.00000 \mathrm{e}-01$ Element: 3381 \# of layers: 7

Kx Ky Kz Ss Por $1.45918 \mathrm{e}+011.45918 \mathrm{e}+011.45918 \mathrm{e}+00$ 1.00000e-09 2.12000e-01 $1.45918 \mathrm{e}+011.45918 \mathrm{e}+011.45918 \mathrm{e}+001.00000 \mathrm{e}-092.12000 \mathrm{e}-01$ $1.45918 \mathrm{e}+011.45918 \mathrm{e}+011.45918 \mathrm{e}+001.00000 \mathrm{e}-092.12000 \mathrm{e}-01$ $1.45918 \mathrm{e}+011.45918 \mathrm{e}+011.45918 \mathrm{e}+001.00000 \mathrm{e}-092.12000 \mathrm{e}-01$ $1.45918 \mathrm{e}+011.45918 \mathrm{e}+011.45918 \mathrm{e}+001.00000 \mathrm{e}-092.12000 \mathrm{e}-01$ 
$1.00000 \mathrm{e}-05$ 1.00000e-05 1.00000e-06 1.00000e-09 1.00000e-01 $1.00000 \mathrm{e}+001.00000 \mathrm{e}+001.00000 \mathrm{e}-01$ 1.00000e-09 1.00000e-01 Element: 3382 \# of layers: 7

Kx Ky Kz Ss Por

$1.40084 \mathrm{e}+011.40084 \mathrm{e}+011.40084 \mathrm{e}+001.00000 \mathrm{e}-092.12000 \mathrm{e}-01$ $1.40084 \mathrm{e}+011.40084 \mathrm{e}+011.40084 \mathrm{e}+001.00000 \mathrm{e}-092.12000 \mathrm{e}-01$ $1.40084 \mathrm{e}+011.40084 \mathrm{e}+011.40084 \mathrm{e}+001.00000 \mathrm{e}-092.12000 \mathrm{e}-01$ $1.40084 \mathrm{e}+011.40084 \mathrm{e}+011.40084 \mathrm{e}+001.00000 \mathrm{e}-092.12000 \mathrm{e}-01$ $1.40084 \mathrm{e}+011.40084 \mathrm{e}+011.40084 \mathrm{e}+001.00000 \mathrm{e}-092.12000 \mathrm{e}-01$ $1.00000 \mathrm{e}-05$ 1.00000e-05 1.00000e-06 1.00000e-09 1.00000e-01 $1.00000 \mathrm{e}+001.00000 \mathrm{e}+001.00000 \mathrm{e}-011.00000 \mathrm{e}-091.00000 \mathrm{e}-01$ Element: 3383 \# of layers: 7

$\mathrm{Kx} \mathrm{Ky} \mathrm{Kz}$ Ss Por

$1.53712 \mathrm{e}+01$ 1.53712e+01 1.53712e+00 1.00000e-09 2.12000e-01 $1.53712 \mathrm{e}+01$ 1.53712e+01 1.53712e+00 1.00000e-09 2.12000e-01 $1.53712 \mathrm{e}+011.53712 \mathrm{e}+011.53712 \mathrm{e}+001.00000 \mathrm{e}-092.12000 \mathrm{e}-01$ $1.53712 \mathrm{e}+01$ 1.53712e+01 1.53712e+00 1.00000e-09 2.12000e-01 $1.53712 \mathrm{e}+01$ 1.53712e+01 1.53712e+00 1.00000e-09 2.12000e-01 $1.00000 \mathrm{e}-05$ 1.00000e-05 1.00000e-06 1.00000e-09 1.00000e-01 $1.00000 \mathrm{e}+001.00000 \mathrm{e}+001.00000 \mathrm{e}-011.00000 \mathrm{e}-091.00000 \mathrm{e}-01$ Element: 3384 \# of layers: 9

$\mathrm{Kx} \mathrm{Ky} \mathrm{Kz}$ Ss Por

$1.39384 \mathrm{e}+01$ 1.39384e+01 1.39384e+00 1.00000e-09 2.12000e-01 $1.39384 \mathrm{e}+011.39384 \mathrm{e}+011.39384 \mathrm{e}+001.00000 \mathrm{e}-092.12000 \mathrm{e}-01$ $1.39384 \mathrm{e}+011.39384 \mathrm{e}+011.39384 \mathrm{e}+001.00000 \mathrm{e}-092.12000 \mathrm{e}-01$ $1.39384 \mathrm{e}+011.39384 \mathrm{e}+01$ 1.39384e+00 1.00000e-09 2.12000e-01 $1.39384 \mathrm{e}+011.39384 \mathrm{e}+011.39384 \mathrm{e}+001.00000 \mathrm{e}-092.12000 \mathrm{e}-01$ $1.00000 \mathrm{e}-02$ 1.00000e-02 1.00000e-03 1.00000e-09 1.00000e-01 $1.00000 \mathrm{e}+001.00000 \mathrm{e}+001.00000 \mathrm{e}-011.00000 \mathrm{e}-091.00000 \mathrm{e}-01$ $1.00000 \mathrm{e}-05$ 1.00000e-05 1.00000e-06 1.00000e-09 1.00000e-01 $1.00000 \mathrm{e}+001.00000 \mathrm{e}+001.00000 \mathrm{e}-011.00000 \mathrm{e}-091.00000 \mathrm{e}-01$ Element: 3385 \# of layers: 7

Kx Ky Kz Ss Por

$1.39384 \mathrm{e}+011.39384 \mathrm{e}+011.39384 \mathrm{e}+001.00000 \mathrm{e}-092.12000 \mathrm{e}-01$ $1.39384 \mathrm{e}+011.39384 \mathrm{e}+011.39384 \mathrm{e}+001.00000 \mathrm{e}-092.12000 \mathrm{e}-01$ $1.39384 \mathrm{e}+011.39384 \mathrm{e}+011.39384 \mathrm{e}+001.00000 \mathrm{e}-092.12000 \mathrm{e}-01$ $1.39384 \mathrm{e}+011.39384 \mathrm{e}+01 \quad 1.39384 \mathrm{e}+001.00000 \mathrm{e}-092.12000 \mathrm{e}-01$ $1.39384 \mathrm{e}+011.39384 \mathrm{e}+011.39384 \mathrm{e}+001.00000 \mathrm{e}-092.12000 \mathrm{e}-01$ $1.00000 \mathrm{e}-05$ 1.00000e-05 1.00000e-06 1.00000e-09 1.00000e-01 $1.00000 \mathrm{e}+001.00000 \mathrm{e}+001.00000 \mathrm{e}-01$ 1.00000e-09 1.00000e-01 Element: 3386 \# of layers: 7

$\mathrm{Kx} \mathrm{Ky} \mathrm{Kz}$ Ss Por $1.44527 \mathrm{e}+01$ 1.44527e+01 1.44527e+00 1.00000e-09 2.12000e-01 1.44527e+01 1.44527e+01 1.44527e+00 1.00000e-09 2.12000e-01 $1.44527 \mathrm{e}+011.44527 \mathrm{e}+01$ 1.44527e+00 1.00000e-09 2.12000e-01 $1.44527 \mathrm{e}+01$ 1.44527e+01 1.44527e+00 1.00000e-09 2.12000e-01 
$1.44527 \mathrm{e}+01$ 1.44527e+01 1.44527e+00 1.00000e-09 2.12000e-01 $1.00000 \mathrm{e}-05$ 1.00000e-05 1.00000e-06 1.00000e-09 1.00000e-01 $1.00000 \mathrm{e}+001.00000 \mathrm{e}+001.00000 \mathrm{e}-01$ 1.00000e-09 1.00000e-01 Element: 3387 \# of layers: 7

$\mathrm{Kx} \mathrm{Ky} \mathrm{Kz}$ Ss Por

$1.44527 \mathrm{e}+01$ 1.44527e+01 1.44527e+00 1.00000e-09 2.12000e-01 $1.44527 \mathrm{e}+011.44527 \mathrm{e}+01$ 1.44527e+00 1.00000e-09 2.12000e-01 $1.44527 \mathrm{e}+011.44527 \mathrm{e}+011.44527 \mathrm{e}+001.00000 \mathrm{e}-092.12000 \mathrm{e}-01$ $1.44527 \mathrm{e}+01$ 1.44527e+01 1.44527e+00 1.00000e-09 2.12000e-01 $1.44527 \mathrm{e}+01$ 1.44527e+01 1.44527e+00 1.00000e-09 2.12000e-01 $1.00000 \mathrm{e}-05$ 1.00000e-05 1.00000e-06 1.00000e-09 1.00000e-01 $1.00000 \mathrm{e}+001.00000 \mathrm{e}+001.00000 \mathrm{e}-011.00000 \mathrm{e}-091.00000 \mathrm{e}-01$ Element: 3388 \# of layers: 7

$\mathrm{Kx} \mathrm{Ky} \mathrm{Kz}$ Ss Por

$1.48305 \mathrm{e}+011.48305 \mathrm{e}+01$ 1.48305e+00 1.00000e-09 2.12000e-01 $1.48305 \mathrm{e}+011.48305 \mathrm{e}+011.48305 \mathrm{e}+001.00000 \mathrm{e}-092.12000 \mathrm{e}-01$ $1.48305 \mathrm{e}+011.48305 \mathrm{e}+011.48305 \mathrm{e}+001.00000 \mathrm{e}-092.12000 \mathrm{e}-01$ $1.48305 \mathrm{e}+011.48305 \mathrm{e}+011.48305 \mathrm{e}+001.00000 \mathrm{e}-092.12000 \mathrm{e}-01$ $1.48305 \mathrm{e}+01$ 1.48305e+01 1.48305e+00 1.00000e-09 2.12000e-01 $1.00000 \mathrm{e}-051.00000 \mathrm{e}-051.00000 \mathrm{e}-061.00000 \mathrm{e}-091.00000 \mathrm{e}-01$ $1.00000 \mathrm{e}+001.00000 \mathrm{e}+001.00000 \mathrm{e}-011.00000 \mathrm{e}-091.00000 \mathrm{e}-01$ Element: 3389 \# of layers: 9

$\mathrm{Kx} \mathrm{Ky} \mathrm{Kz}$ Ss Por

$1.71654 \mathrm{e}+01$ 1.71654e+01 1.71654e+00 1.00000e-09 2.12000e-01 $1.71654 \mathrm{e}+011.71654 \mathrm{e}+011.71654 \mathrm{e}+001.00000 \mathrm{e}-092.12000 \mathrm{e}-01$ $1.71654 \mathrm{e}+011.71654 \mathrm{e}+011.71654 \mathrm{e}+001.00000 \mathrm{e}-092.12000 \mathrm{e}-01$ $1.71654 \mathrm{e}+011.71654 \mathrm{e}+011.71654 \mathrm{e}+001.00000 \mathrm{e}-092.12000 \mathrm{e}-01$ $1.71654 \mathrm{e}+011.71654 \mathrm{e}+011.71654 \mathrm{e}+001.00000 \mathrm{e}-092.12000 \mathrm{e}-01$ $1.00000 \mathrm{e}-021.00000 \mathrm{e}-02$ 1.00000e-03 1.00000e-09 1.00000e-01 $1.00000 \mathrm{e}+001.00000 \mathrm{e}+001.00000 \mathrm{e}-011.00000 \mathrm{e}-091.00000 \mathrm{e}-01$ $1.00000 \mathrm{e}-05$ 1.00000e-05 1.00000e-06 1.00000e-09 1.00000e-01 $1.00000 \mathrm{e}+001.00000 \mathrm{e}+001.00000 \mathrm{e}-011.00000 \mathrm{e}-091.00000 \mathrm{e}-01$ Element: 3390 \# of layers: 9

$\mathrm{Kx} \mathrm{Ky} \mathrm{Kz}$ Ss Por

$2.03706 \mathrm{e}+012.03706 \mathrm{e}+012.03706 \mathrm{e}+00$ 1.00000e-09 2.12000e-01 $2.03706 \mathrm{e}+012.03706 \mathrm{e}+012.03706 \mathrm{e}+001.00000 \mathrm{e}-092.12000 \mathrm{e}-01$ $2.03706 \mathrm{e}+012.03706 \mathrm{e}+012.03706 \mathrm{e}+001.00000 \mathrm{e}-092.12000 \mathrm{e}-01$ $2.03706 \mathrm{e}+012.03706 \mathrm{e}+012.03706 \mathrm{e}+001.00000 \mathrm{e}-092.12000 \mathrm{e}-01$ $2.03706 \mathrm{e}+012.03706 \mathrm{e}+012.03706 \mathrm{e}+001.00000 \mathrm{e}-092.12000 \mathrm{e}-01$ $1.00000 \mathrm{e}-02$ 1.00000e-02 1.00000e-03 1.00000e-09 1.00000e-01 $1.00000 \mathrm{e}+001.00000 \mathrm{e}+001.00000 \mathrm{e}-011.00000 \mathrm{e}-091.00000 \mathrm{e}-01$ $1.00000 \mathrm{e}-05$ 1.00000e-05 1.00000e-06 1.00000e-09 1.00000e-01 $1.00000 \mathrm{e}+001.00000 \mathrm{e}+001.00000 \mathrm{e}-011.00000 \mathrm{e}-091.00000 \mathrm{e}-01$ Element: 3391 \# of layers: 7

$\mathrm{Kx} \mathrm{Ky} \mathrm{Kz}$ Ss Por $2.00263 e+012.00263 e+012.00263 e+001.00000 e-092.12000 e-01$ 
$2.00263 \mathrm{e}+012.00263 \mathrm{e}+012.00263 \mathrm{e}+00$ 1.00000e-09 2.12000e-01 $2.00263 \mathrm{e}+012.00263 \mathrm{e}+012.00263 \mathrm{e}+001.00000 \mathrm{e}-092.12000 \mathrm{e}-01$ $2.00263 \mathrm{e}+012.00263 \mathrm{e}+012.00263 \mathrm{e}+001.00000 \mathrm{e}-092.12000 \mathrm{e}-01$ $2.00263 \mathrm{e}+012.00263 \mathrm{e}+012.00263 \mathrm{e}+001.00000 \mathrm{e}-092.12000 \mathrm{e}-01$ $1.00000 \mathrm{e}-051.00000 \mathrm{e}-05$ 1.00000e-06 1.00000e-09 1.00000e-01 $1.00000 \mathrm{e}+001.00000 \mathrm{e}+001.00000 \mathrm{e}-01$ 1.00000e-09 1.00000e-01 Element: 3392 \# of layers: 7

$\mathrm{Kx} \mathrm{Ky} \mathrm{Kz}$ Ss Por

$1.74244 \mathrm{e}+01$ 1.74244e+01 1.74244e+00 1.00000e-09 2.12000e-01 $1.74244 \mathrm{e}+011.74244 \mathrm{e}+011.74244 \mathrm{e}+001.00000 \mathrm{e}-092.12000 \mathrm{e}-01$ $1.74244 \mathrm{e}+011.74244 \mathrm{e}+011.74244 \mathrm{e}+001.00000 \mathrm{e}-092.12000 \mathrm{e}-01$ $1.74244 \mathrm{e}+011.74244 \mathrm{e}+011.74244 \mathrm{e}+001.00000 \mathrm{e}-092.12000 \mathrm{e}-01$ $1.74244 \mathrm{e}+011.74244 \mathrm{e}+011.74244 \mathrm{e}+001.00000 \mathrm{e}-092.12000 \mathrm{e}-01$ $1.00000 \mathrm{e}-05$ 1.00000e-05 1.00000e-06 1.00000e-09 1.00000e-01 $1.00000 \mathrm{e}+001.00000 \mathrm{e}+001.00000 \mathrm{e}-01$ 1.00000e-09 1.00000e-01 Element: 3393 \# of layers: 7

$\mathrm{Kx} \mathrm{Ky} \mathrm{Kz}$ Ss Por

$1.71654 \mathrm{e}+01$ 1.71654e+01 1.71654e+00 1.00000e-09 2.12000e-01 $1.71654 \mathrm{e}+011.71654 \mathrm{e}+011.71654 \mathrm{e}+001.00000 \mathrm{e}-092.12000 \mathrm{e}-01$ $1.71654 \mathrm{e}+011.71654 \mathrm{e}+011.71654 \mathrm{e}+001.00000 \mathrm{e}-092.12000 \mathrm{e}-01$ $1.71654 \mathrm{e}+011.71654 \mathrm{e}+011.71654 \mathrm{e}+001.00000 \mathrm{e}-092.12000 \mathrm{e}-01$ $1.71654 \mathrm{e}+011.71654 \mathrm{e}+011.71654 \mathrm{e}+001.00000 \mathrm{e}-092.12000 \mathrm{e}-01$ $1.00000 \mathrm{e}-051.00000 \mathrm{e}-051.00000 \mathrm{e}-061.00000 \mathrm{e}-091.00000 \mathrm{e}-01$ $1.00000 \mathrm{e}+001.00000 \mathrm{e}+001.00000 \mathrm{e}-011.00000 \mathrm{e}-09$ 1.00000e-01 Element: 3394 \# of layers: 7

$\mathrm{Kx} \mathrm{Ky} \mathrm{Kz}$ Ss Por

$2.03706 \mathrm{e}+012.03706 \mathrm{e}+012.03706 \mathrm{e}+00$ 1.00000e-09 2.12000e-01 $2.03706 \mathrm{e}+012.03706 \mathrm{e}+012.03706 \mathrm{e}+001.00000 \mathrm{e}-092.12000 \mathrm{e}-01$ $2.03706 \mathrm{e}+012.03706 \mathrm{e}+012.03706 \mathrm{e}+001.00000 \mathrm{e}-092.12000 \mathrm{e}-01$ $2.03706 \mathrm{e}+012.03706 \mathrm{e}+012.03706 \mathrm{e}+001.00000 \mathrm{e}-092.12000 \mathrm{e}-01$ $2.03706 \mathrm{e}+012.03706 \mathrm{e}+012.03706 \mathrm{e}+00 \quad 1.00000 \mathrm{e}-092.12000 \mathrm{e}-01$ 1.00000e-05 1.00000e-05 1.00000e-06 1.00000e-09 1.00000e-01 $1.00000 \mathrm{e}+001.00000 \mathrm{e}+001.00000 \mathrm{e}-011.00000 \mathrm{e}-091.00000 \mathrm{e}-01$ Element: 3395 \# of layers: 9

$\mathrm{Kx} \mathrm{Ky} \mathrm{Kz}$ Ss Por

1.52972e+03 1.52972e+03 1.52972e+02 1.00000e-09 2.12000e-01 $1.52972 \mathrm{e}+031.52972 \mathrm{e}+03$ 1.52972e+02 1.00000e-09 2.12000e-01 $1.52972 \mathrm{e}+03$ 1.52972e+03 1.52972e+02 1.00000e-09 2.12000e-01 $1.52972 \mathrm{e}+03$ 1.52972e+03 1.52972e+02 1.00000e-09 2.12000e-01 $1.52972 \mathrm{e}+03$ 1.52972e+03 1.52972e+02 1.00000e-09 2.12000e-01 $1.00000 \mathrm{e}-02$ 1.00000e-02 1.00000e-03 1.00000e-09 1.00000e-01 $1.00000 \mathrm{e}+001.00000 \mathrm{e}+001.00000 \mathrm{e}-011.00000 \mathrm{e}-091.00000 \mathrm{e}-01$ $1.00000 \mathrm{e}-05$ 1.00000e-05 1.00000e-06 1.00000e-09 1.00000e-01 $1.00000 \mathrm{e}+001.00000 \mathrm{e}+001.00000 \mathrm{e}-01$ 1.00000e-09 1.00000e-01 Element: 3396 \# of layers: 9

Kx Ky Kz Ss Por 
$1.53280 \mathrm{e}+03$ 1.53280e+03 1.53280e+02 1.00000e-09 2.12000e-01 $1.53280 \mathrm{e}+031.53280 \mathrm{e}+031.53280 \mathrm{e}+021.00000 \mathrm{e}-092.12000 \mathrm{e}-01$ $1.53280 \mathrm{e}+03$ 1.53280e+03 1.53280e+02 1.00000e-09 2.12000e-01 $1.53280 \mathrm{e}+03$ 1.53280e+03 1.53280e+02 1.00000e-09 2.12000e-01 $1.53280 \mathrm{e}+031.53280 \mathrm{e}+03$ 1.53280e+02 1.00000e-09 2.12000e-01 $1.00000 \mathrm{e}-02$ 1.00000e-02 1.00000e-03 1.00000e-09 1.00000e-01 $1.00000 \mathrm{e}+001.00000 \mathrm{e}+001.00000 \mathrm{e}-011.00000 \mathrm{e}-091.00000 \mathrm{e}-01$ $1.00000 \mathrm{e}-05$ 1.00000e-05 1.00000e-06 1.00000e-09 1.00000e-01 $1.00000 \mathrm{e}+001.00000 \mathrm{e}+001.00000 \mathrm{e}-011.00000 \mathrm{e}-091.00000 \mathrm{e}-01$ Element: 3397 \# of layers: 9

$\mathrm{Kx} \mathrm{Ky} \mathrm{Kz}$ Ss Por

$1.53280 \mathrm{e}+03$ 1.53280e+03 1.53280e+02 1.00000e-09 2.12000e-01 $1.53280 \mathrm{e}+03$ 1.53280e+03 1.53280e+02 1.00000e-09 2.12000e-01 $1.53280 \mathrm{e}+03$ 1.53280e+03 1.53280e+02 1.00000e-09 2.12000e-01 $1.53280 \mathrm{e}+031.53280 \mathrm{e}+03$ 1.53280e+02 1.00000e-09 2.12000e-01 $1.53280 \mathrm{e}+031.53280 \mathrm{e}+031.53280 \mathrm{e}+021.00000 \mathrm{e}-092.12000 \mathrm{e}-01$ $1.00000 \mathrm{e}-02$ 1.00000e-02 1.00000e-03 1.00000e-09 1.00000e-01 $1.00000 \mathrm{e}+001.00000 \mathrm{e}+001.00000 \mathrm{e}-011.00000 \mathrm{e}-091.00000 \mathrm{e}-01$ $1.00000 \mathrm{e}-05$ 1.00000e-05 1.00000e-06 1.00000e-09 1.00000e-01 $1.00000 \mathrm{e}+001.00000 \mathrm{e}+001.00000 \mathrm{e}-011.00000 \mathrm{e}-091.00000 \mathrm{e}-01$ Element: 3398 \# of layers: 9

$\mathrm{Kx} \mathrm{Ky} \mathrm{Kz}$ Ss Por

$1.53280 \mathrm{e}+031.53280 \mathrm{e}+03$ 1.53280e+02 1.00000e-09 2.12000e-01 $1.53280 \mathrm{e}+03$ 1.53280e+03 1.53280e+02 1.00000e-09 2.12000e-01 $1.53280 \mathrm{e}+03$ 1.53280e+03 1.53280e+02 1.00000e-09 2.12000e-01 $1.53280 \mathrm{e}+03$ 1.53280e+03 1.53280e+02 1.00000e-09 2.12000e-01 $1.53280 \mathrm{e}+031.53280 \mathrm{e}+031.53280 \mathrm{e}+021.00000 \mathrm{e}-092.12000 \mathrm{e}-01$ $1.00000 \mathrm{e}-02$ 1.00000e-02 1.00000e-03 1.00000e-09 1.00000e-01 $1.00000 \mathrm{e}+001.00000 \mathrm{e}+001.00000 \mathrm{e}-011.00000 \mathrm{e}-091.00000 \mathrm{e}-01$ $1.00000 \mathrm{e}-051.00000 \mathrm{e}-051.00000 \mathrm{e}-061.00000 \mathrm{e}-091.00000 \mathrm{e}-01$ $1.00000 \mathrm{e}+001.00000 \mathrm{e}+001.00000 \mathrm{e}-011.00000 \mathrm{e}-091.00000 \mathrm{e}-01$ Element: 3399 \# of layers: 9

Kx Ky Kz Ss Por

$1.66042 \mathrm{e}+03$ 1.66042e+03 1.66042e+02 1.00000e-09 2.12000e-01 $1.66042 \mathrm{e}+031.66042 \mathrm{e}+03$ 1.66042e+02 1.00000e-09 2.12000e-01 $1.66042 \mathrm{e}+03$ 1.66042e+03 1.66042e+02 1.00000e-09 2.12000e-01 $1.66042 \mathrm{e}+031.66042 \mathrm{e}+03$ 1.66042e+02 1.00000e-09 2.12000e-01 $1.66042 \mathrm{e}+031.66042 \mathrm{e}+03$ 1.66042e+02 1.00000e-09 2.12000e-01 $1.00000 \mathrm{e}-02$ 1.00000e-02 1.00000e-03 1.00000e-09 1.00000e-01 $1.00000 \mathrm{e}+001.00000 \mathrm{e}+001.00000 \mathrm{e}-011.00000 \mathrm{e}-091.00000 \mathrm{e}-01$ $1.00000 \mathrm{e}-05$ 1.00000e-05 1.00000e-06 1.00000e-09 1.00000e-01 $1.00000 \mathrm{e}+001.00000 \mathrm{e}+001.00000 \mathrm{e}-011.00000 \mathrm{e}-091.00000 \mathrm{e}-01$ Element: 3400 \# of layers: 9

$\mathrm{Kx} \mathrm{Ky} \mathrm{Kz}$ Ss Por $1.66042 \mathrm{e}+03$ 1.66042e+03 1.66042e+02 1.00000e-09 2.12000e-01 $1.66042 \mathrm{e}+03$ 1.66042e+03 1.66042e+02 1.00000e-09 2.12000e-01 
$1.66042 \mathrm{e}+03$ 1.66042e+03 1.66042e+02 1.00000e-09 2.12000e-01 $1.66042 \mathrm{e}+031.66042 \mathrm{e}+03$ 1.66042e+02 1.00000e-09 2.12000e-01 $1.66042 \mathrm{e}+03$ 1.66042e+03 1.66042e+02 1.00000e-09 2.12000e-01 $1.00000 \mathrm{e}-02$ 1.00000e-02 1.00000e-03 1.00000e-09 1.00000e-01 $1.00000 \mathrm{e}+001.00000 \mathrm{e}+001.00000 \mathrm{e}-011.00000 \mathrm{e}-091.00000 \mathrm{e}-01$ $1.00000 \mathrm{e}-05$ 1.00000e-05 1.00000e-06 1.00000e-09 1.00000e-01 $1.00000 \mathrm{e}+001.00000 \mathrm{e}+001.00000 \mathrm{e}-01$ 1.00000e-09 1.00000e-01 Element: 3401 \# of layers: 9

$\mathrm{Kx} \mathrm{Ky} \mathrm{Kz}$ Ss Por

1.16892e+03 1.16892e+03 1.16892e+02 1.00000e-09 2.12000e-01 $1.16892 \mathrm{e}+03$ 1.16892e+03 1.16892e+02 1.00000e-09 2.12000e-01 $1.16892 \mathrm{e}+031.16892 \mathrm{e}+03$ 1.16892e+02 1.00000e-09 2.12000e-01 $1.16892 \mathrm{e}+03$ 1.16892e+03 1.16892e+02 1.00000e-09 2.12000e-01 $1.16892 \mathrm{e}+03$ 1.16892e+03 1.16892e+02 1.00000e-09 2.12000e-01 $1.00000 \mathrm{e}-02$ 1.00000e-02 1.00000e-03 1.00000e-09 1.00000e-01 $1.00000 \mathrm{e}+001.00000 \mathrm{e}+001.00000 \mathrm{e}-011.00000 \mathrm{e}-091.00000 \mathrm{e}-01$ $1.00000 \mathrm{e}-05$ 1.00000e-05 1.00000e-06 1.00000e-09 1.00000e-01 $1.00000 \mathrm{e}+001.00000 \mathrm{e}+001.00000 \mathrm{e}-01$ 1.00000e-09 1.00000e-01 Element: 3402 \# of layers: 9

$\mathrm{Kx} \mathrm{Ky} \mathrm{Kz}$ Ss Por

1.52972e+03 1.52972e+03 1.52972e+02 1.00000e-09 2.12000e-01 $1.52972 \mathrm{e}+03$ 1.52972e+03 1.52972e+02 1.00000e-09 2.12000e-01 $1.52972 \mathrm{e}+03$ 1.52972e+03 1.52972e+02 1.00000e-09 2.12000e-01 $1.52972 \mathrm{e}+031.52972 \mathrm{e}+03$ 1.52972e+02 1.00000e-09 2.12000e-01 $1.52972 \mathrm{e}+031.52972 \mathrm{e}+03$ 1.52972e+02 1.00000e-09 2.12000e-01 $1.00000 \mathrm{e}-021.00000 \mathrm{e}-021.00000 \mathrm{e}-031.00000 \mathrm{e}-091.00000 \mathrm{e}-01$ $1.00000 \mathrm{e}+001.00000 \mathrm{e}+001.00000 \mathrm{e}-011.00000 \mathrm{e}-091.00000 \mathrm{e}-01$ $1.00000 \mathrm{e}-05$ 1.00000e-05 1.00000e-06 1.00000e-09 1.00000e-01 $1.00000 \mathrm{e}+001.00000 \mathrm{e}+001.00000 \mathrm{e}-011.00000 \mathrm{e}-091.00000 \mathrm{e}-01$ Element: 3403 \# of layers: 9

$\mathrm{Kx} \mathrm{Ky} \mathrm{Kz}$ Ss Por

$1.53280 \mathrm{e}+03$ 1.53280e+03 1.53280e+02 1.00000e-09 2.12000e-01 $1.53280 \mathrm{e}+031.53280 \mathrm{e}+031.53280 \mathrm{e}+02$ 1.00000e-09 2.12000e-01 $1.53280 \mathrm{e}+03$ 1.53280e+03 1.53280e+02 1.00000e-09 2.12000e-01 $1.53280 \mathrm{e}+03$ 1.53280e+03 1.53280e+02 1.00000e-09 2.12000e-01 $1.53280 \mathrm{e}+03$ 1.53280e+03 1.53280e+02 1.00000e-09 2.12000e-01 1.00000e-02 1.00000e-02 1.00000e-03 1.00000e-09 1.00000e-01 $1.00000 \mathrm{e}+001.00000 \mathrm{e}+001.00000 \mathrm{e}-011.00000 \mathrm{e}-091.00000 \mathrm{e}-01$ $1.00000 \mathrm{e}-05$ 1.00000e-05 1.00000e-06 1.00000e-09 1.00000e-01 $1.00000 \mathrm{e}+001.00000 \mathrm{e}+001.00000 \mathrm{e}-01$ 1.00000e-09 1.00000e-01 Element: 3404 \# of layers: 9

$\mathrm{Kx} \mathrm{Ky} \mathrm{Kz}$ Ss Por

$1.56045 \mathrm{e}+03$ 1.56045e+03 1.56045e+02 1.00000e-09 2.12000e-01 $1.56045 \mathrm{e}+031.56045 \mathrm{e}+03$ 1.56045e+02 1.00000e-09 2.12000e-01 $1.56045 \mathrm{e}+03$ 1.56045e+03 1.56045e+02 1.00000e-09 2.12000e-01 $1.56045 \mathrm{e}+031.56045 \mathrm{e}+031.56045 \mathrm{e}+02$ 1.00000e-09 2.12000e-01 
$1.56045 \mathrm{e}+03$ 1.56045e+03 1.56045e+02 1.00000e-09 2.12000e-01 $1.00000 \mathrm{e}-02$ 1.00000e-02 1.00000e-03 1.00000e-09 1.00000e-01 $1.00000 \mathrm{e}+001.00000 \mathrm{e}+001.00000 \mathrm{e}-011.00000 \mathrm{e}-091.00000 \mathrm{e}-01$ $1.00000 \mathrm{e}-05$ 1.00000e-05 1.00000e-06 1.00000e-09 1.00000e-01 $1.00000 \mathrm{e}+001.00000 \mathrm{e}+001.00000 \mathrm{e}-01$ 1.00000e-09 1.00000e-01 Element: 3405 \# of layers: 11

$\mathrm{Kx} \mathrm{Ky} \mathrm{Kz}$ Ss Por

$1.89552 \mathrm{e}+04$ 1.89552e+04 1.89552e+03 1.00000e-09 7.00000e-02 5.00000e-04 5.00000e-04 5.00000e-05 1.00000e-09 1.00000e-01

$7.57389 \mathrm{e}+02$ 7.57389e+02 7.57389e+01 1.00000e-09 2.12000e-01 $7.57389 \mathrm{e}+02$ 7.57389e+02 7.57389e+01 1.00000e-09 2.12000e-01 $7.57389 \mathrm{e}+02$ 7.57389e+02 7.57389e+01 1.00000e-09 2.12000e-01 $7.57389 \mathrm{e}+02$ 7.57389e+02 7.57389e+01 1.00000e-09 2.12000e-01 $7.57389 \mathrm{e}+02$ 7.57389e+02 7.57389e+01 1.00000e-09 2.12000e-01 $1.00000 \mathrm{e}-02$ 1.00000e-02 1.00000e-03 1.00000e-09 1.00000e-01 $1.00000 \mathrm{e}+001.00000 \mathrm{e}+001.00000 \mathrm{e}-011.00000 \mathrm{e}-091.00000 \mathrm{e}-01$ $1.00000 \mathrm{e}-05$ 1.00000e-05 1.00000e-06 1.00000e-09 1.00000e-01 $1.00000 \mathrm{e}+001.00000 \mathrm{e}+001.00000 \mathrm{e}-011.00000 \mathrm{e}-091.00000 \mathrm{e}-01$ Element: 3406 \# of layers: 11

$\mathrm{Kx} \mathrm{Ky} \mathrm{Kz}$ Ss Por

$1.89552 \mathrm{e}+04$ 1.89552e+04 1.89552e+03 1.00000e-09 7.00000e-02 5.00000e-04 5.00000e-04 5.00000e-05 1.00000e-09 1.00000e-01

$7.57389 \mathrm{e}+02$ 7.57389e+02 7.57389e+01 1.00000e-09 2.12000e-01 $7.57389 \mathrm{e}+02$ 7.57389e+02 7.57389e+01 1.00000e-09 2.12000e-01 $7.57389 \mathrm{e}+02$ 7.57389e+02 7.57389e+01 1.00000e-09 2.12000e-01 $7.57389 \mathrm{e}+02$ 7.57389e+02 7.57389e+01 1.00000e-09 2.12000e-01 $7.57389 \mathrm{e}+02$ 7.57389e+02 7.57389e+01 1.00000e-09 2.12000e-01 $1.00000 \mathrm{e}-02$ 1.00000e-02 1.00000e-03 1.00000e-09 1.00000e-01 $1.00000 \mathrm{e}+001.00000 \mathrm{e}+001.00000 \mathrm{e}-011.00000 \mathrm{e}-091.00000 \mathrm{e}-01$ $1.00000 \mathrm{e}-05$ 1.00000e-05 1.00000e-06 1.00000e-09 1.00000e-01 $1.00000 \mathrm{e}+001.00000 \mathrm{e}+001.00000 \mathrm{e}-011.00000 \mathrm{e}-091.00000 \mathrm{e}-01$ Element: 3407 \# of layers: 11

Kx Ky Kz Ss Por

$1.89552 \mathrm{e}+041.89552 \mathrm{e}+041.89552 \mathrm{e}+03$ 1.00000e-09 7.00000e-02 5.00000e-04 5.00000e-04 5.00000e-05 1.00000e-09 1.00000e-01 $7.57389 \mathrm{e}+02$ 7.57389e+02 7.57389e+01 1.00000e-09 2.12000e-01 $7.57389 \mathrm{e}+02$ 7.57389e+02 7.57389e+01 1.00000e-09 2.12000e-01 $7.57389 \mathrm{e}+02$ 7.57389e+02 7.57389e+01 1.00000e-09 2.12000e-01 7.57389e+02 7.57389e+02 7.57389e+01 1.00000e-09 2.12000e-01 7.57389e+02 7.57389e+02 7.57389e+01 1.00000e-09 2.12000e-01 $1.00000 \mathrm{e}-02$ 1.00000e-02 1.00000e-03 1.00000e-09 1.00000e-01 $1.00000 \mathrm{e}+001.00000 \mathrm{e}+001.00000 \mathrm{e}-011.00000 \mathrm{e}-091.00000 \mathrm{e}-01$ $1.00000 \mathrm{e}-051.00000 \mathrm{e}-051.00000 \mathrm{e}-061.00000 \mathrm{e}-091.00000 \mathrm{e}-01$ $1.00000 \mathrm{e}+001.00000 \mathrm{e}+001.00000 \mathrm{e}-01$ 1.00000e-09 1.00000e-01 Element: 3408 \# of layers: 10

Kx Ky Kz Ss Por 
$1.84408 \mathrm{e}+04$ 1.84408e+04 1.84408e+03 1.00000e-09 7.00000e-02 7.36823e+02 7.36823e+02 7.36823e+01 1.00000e-09 2.12000e-01 7.36823e+02 7.36823e+02 7.36823e+01 1.00000e-09 2.12000e-01 $7.36823 \mathrm{e}+02$ 7.36823e+02 7.36823e+01 1.00000e-09 2.12000e-01 7.36823e+02 7.36823e+02 7.36823e+01 1.00000e-09 2.12000e-01 $7.36823 \mathrm{e}+02$ 7.36823e+02 7.36823e+01 1.00000e-09 2.12000e-01 $1.00000 \mathrm{e}-02$ 1.00000e-02 1.00000e-03 1.00000e-09 1.00000e-01 $1.00000 \mathrm{e}+001.00000 \mathrm{e}+001.00000 \mathrm{e}-011.00000 \mathrm{e}-091.00000 \mathrm{e}-01$ $1.00000 \mathrm{e}-051.00000 \mathrm{e}-051.00000 \mathrm{e}-061.00000 \mathrm{e}-091.00000 \mathrm{e}-01$ $1.00000 \mathrm{e}+001.00000 \mathrm{e}+001.00000 \mathrm{e}-011.00000 \mathrm{e}-091.00000 \mathrm{e}-01$ Element: 3409 \# of layers: 10

$\mathrm{Kx} \mathrm{Ky} \mathrm{Kz}$ Ss Por

$1.84408 \mathrm{e}+04$ 1.84408e+04 1.84408e+03 1.00000e-09 7.00000e-02 7.36823e+02 7.36823e+02 7.36823e+01 1.00000e-09 2.12000e-01 7.36823e+02 7.36823e+02 7.36823e+01 1.00000e-09 2.12000e-01 $7.36823 \mathrm{e}+02$ 7.36823e+02 7.36823e+01 1.00000e-09 2.12000e-01 7.36823e+02 7.36823e+02 7.36823e+01 1.00000e-09 2.12000e-01 7.36823e+02 7.36823e+02 7.36823e+01 1.00000e-09 2.12000e-01 $1.00000 \mathrm{e}-02$ 1.00000e-02 1.00000e-03 1.00000e-09 1.00000e-01 $1.00000 \mathrm{e}+001.00000 \mathrm{e}+001.00000 \mathrm{e}-011.00000 \mathrm{e}-091.00000 \mathrm{e}-01$ $1.00000 \mathrm{e}-05$ 1.00000e-05 1.00000e-06 1.00000e-09 1.00000e-01 $1.00000 \mathrm{e}+001.00000 \mathrm{e}+001.00000 \mathrm{e}-01$ 1.00000e-09 1.00000e-01 Element: 3410 \# of layers: 9

Kx Ky Kz Ss Por

$1.66555 \mathrm{e}+03$ 1.66555e+03 1.66555e+02 1.00000e-09 2.12000e-01 $1.66555 \mathrm{e}+031.66555 \mathrm{e}+03$ 1.66555e+02 1.00000e-09 2.12000e-01 $1.66555 \mathrm{e}+031.66555 \mathrm{e}+031.66555 \mathrm{e}+021.00000 \mathrm{e}-092.12000 \mathrm{e}-01$ $1.66555 \mathrm{e}+03$ 1.66555e+03 1.66555e+02 1.00000e-09 2.12000e-01 $1.66555 \mathrm{e}+03$ 1.66555e+03 1.66555e+02 1.00000e-09 2.12000e-01 $1.00000 \mathrm{e}-02$ 1.00000e-02 1.00000e-03 1.00000e-09 1.00000e-01 $1.00000 \mathrm{e}+001.00000 \mathrm{e}+001.00000 \mathrm{e}-01$ 1.00000e-09 1.00000e-01 1.00000e-05 1.00000e-05 1.00000e-06 1.00000e-09 1.00000e-01 $1.00000 \mathrm{e}+001.00000 \mathrm{e}+001.00000 \mathrm{e}-011.00000 \mathrm{e}-091.00000 \mathrm{e}-01$ Element: 3411 \# of layers: 9

$\mathrm{Kx} \mathrm{Ky} \mathrm{Kz}$ Ss Por

$1.56045 \mathrm{e}+031.56045 \mathrm{e}+03$ 1.56045e+02 1.00000e-09 2.12000e-01 $1.56045 \mathrm{e}+031.56045 \mathrm{e}+031.56045 \mathrm{e}+02$ 1.00000e-09 2.12000e-01 $1.56045 \mathrm{e}+03$ 1.56045e+03 1.56045e+02 1.00000e-09 2.12000e-01 $1.56045 \mathrm{e}+03$ 1.56045e+03 1.56045e+02 1.00000e-09 2.12000e-01 $1.56045 \mathrm{e}+031.56045 \mathrm{e}+031.56045 \mathrm{e}+02$ 1.00000e-09 2.12000e-01 $1.00000 \mathrm{e}-02$ 1.00000e-02 1.00000e-03 1.00000e-09 1.00000e-01 $1.00000 \mathrm{e}+001.00000 \mathrm{e}+001.00000 \mathrm{e}-011.00000 \mathrm{e}-091.00000 \mathrm{e}-01$ $1.00000 \mathrm{e}-05$ 1.00000e-05 1.00000e-06 1.00000e-09 1.00000e-01 $1.00000 \mathrm{e}+001.00000 \mathrm{e}+001.00000 \mathrm{e}-01$ 1.00000e-09 1.00000e-01 Element: 3412 \# of layers: 11

Kx Ky Kz Ss Por 
$1.89552 \mathrm{e}+041.89552 \mathrm{e}+041.89552 \mathrm{e}+03$ 1.00000e-09 7.00000e-02 5.00000e-04 5.00000e-04 5.00000e-05 1.00000e-09 1.00000e-01 $7.57389 \mathrm{e}+02$ 7.57389e+02 7.57389e+01 1.00000e-09 2.12000e-01 $7.57389 \mathrm{e}+02$ 7.57389e+02 7.57389e+01 1.00000e-09 2.12000e-01 7.57389e+02 7.57389e+02 7.57389e+01 1.00000e-09 2.12000e-01 $7.57389 \mathrm{e}+02$ 7.57389e+02 7.57389e+01 1.00000e-09 2.12000e-01 $7.57389 \mathrm{e}+02$ 7.57389e+02 7.57389e+01 1.00000e-09 2.12000e-01 $1.00000 \mathrm{e}-02$ 1.00000e-02 1.00000e-03 1.00000e-09 1.00000e-01 $1.00000 \mathrm{e}+001.00000 \mathrm{e}+001.00000 \mathrm{e}-011.00000 \mathrm{e}-091.00000 \mathrm{e}-01$ $1.00000 \mathrm{e}-05$ 1.00000e-05 1.00000e-06 1.00000e-09 1.00000e-01 $1.00000 \mathrm{e}+001.00000 \mathrm{e}+001.00000 \mathrm{e}-011.00000 \mathrm{e}-091.00000 \mathrm{e}-01$ Element: 3413 \# of layers: 13

$\mathrm{Kx} \mathrm{Ky} \mathrm{Kz}$ Ss Por

$1.05723 \mathrm{e}+041.05723 \mathrm{e}+04$ 1.05723e+03 1.00000e-09 7.00000e-02 $1.05723 \mathrm{e}+041.05723 \mathrm{e}+041.05723 \mathrm{e}+03$ 1.00000e-09 7.00000e-02 5.00000e-04 5.00000e-04 5.00000e-05 1.00000e-09 1.00000e-01 5.00000e-04 5.00000e-04 5.00000e-05 1.00000e-09 1.00000e-01 4.22447e+02 4.22447e+02 4.22447e+01 1.00000e-09 2.12000e-01 4.22447e+02 4.22447e+02 4.22447e+01 1.00000e-09 2.12000e-01 4.22447e+02 4.22447e+02 4.22447e+01 1.00000e-09 2.12000e-01 4.22447e+02 4.22447e+02 4.22447e+01 1.00000e-09 2.12000e-01 4.22447e+02 4.22447e+02 4.22447e+01 1.00000e-09 2.12000e-01 $1.00000 \mathrm{e}-021.00000 \mathrm{e}-02$ 1.00000e-03 1.00000e-09 1.00000e-01 $1.00000 \mathrm{e}+001.00000 \mathrm{e}+001.00000 \mathrm{e}-011.00000 \mathrm{e}-091.00000 \mathrm{e}-01$ $1.00000 \mathrm{e}-05$ 1.00000e-05 1.00000e-06 1.00000e-09 1.00000e-01 $1.00000 \mathrm{e}+001.00000 \mathrm{e}+001.00000 \mathrm{e}-01$ 1.00000e-09 1.00000e-01 Element: 3414 \# of layers: 12

$\mathrm{Kx} \mathrm{Ky} \mathrm{Kz}$ Ss Por

8.75078e+03 8.75078e+03 8.75078e+02 1.00000e-09 7.00000e-02 $5.00000 \mathrm{e}-04$ 5.00000e-04 5.00000e-05 1.00000e-09 1.00000e-01 5.00000e-04 5.00000e-04 5.00000e-05 1.00000e-09 1.00000e-01 $3.49657 \mathrm{e}+02$ 3.49657e+02 3.49657e+01 1.00000e-09 2.12000e-01 $3.49657 \mathrm{e}+02$ 3.49657e+02 3.49657e+01 1.00000e-09 2.12000e-01 $3.49657 \mathrm{e}+02$ 3.49657e+02 3.49657e+01 1.00000e-09 2.12000e-01 3.49657e+02 3.49657e+02 3.49657e+01 1.00000e-09 2.12000e-01 3.49657e+02 3.49657e+02 3.49657e+01 1.00000e-09 2.12000e-01 $1.00000 \mathrm{e}-02$ 1.00000e-02 1.00000e-03 1.00000e-09 1.00000e-01 $1.00000 \mathrm{e}+001.00000 \mathrm{e}+001.00000 \mathrm{e}-011.00000 \mathrm{e}-091.00000 \mathrm{e}-01$ $1.00000 \mathrm{e}-05$ 1.00000e-05 1.00000e-06 1.00000e-09 1.00000e-01 $1.00000 \mathrm{e}+001.00000 \mathrm{e}+001.00000 \mathrm{e}-01$ 1.00000e-09 1.00000e-01 Element: 3415 \# of layers: 12

$\mathrm{Kx} \mathrm{Ky} \mathrm{Kz}$ Ss Por

8.75078e+03 8.75078e+03 8.75078e+02 1.00000e-09 7.00000e-02 5.00000e-04 5.00000e-04 5.00000e-05 1.00000e-09 1.00000e-01 5.00000e-04 5.00000e-04 5.00000e-05 1.00000e-09 1.00000e-01 $3.49657 \mathrm{e}+02$ 3.49657e+02 3.49657e+01 1.00000e-09 2.12000e-01 
3.49657e+02 3.49657e+02 3.49657e+01 1.00000e-09 2.12000e-01 $3.49657 \mathrm{e}+02$ 3.49657e+02 3.49657e+01 1.00000e-09 2.12000e-01 $3.49657 \mathrm{e}+02$ 3.49657e+02 3.49657e+01 1.00000e-09 2.12000e-01 3.49657e+02 3.49657e+02 3.49657e+01 1.00000e-09 2.12000e-01 $1.00000 \mathrm{e}-02$ 1.00000e-02 1.00000e-03 1.00000e-09 1.00000e-01 $1.00000 \mathrm{e}+001.00000 \mathrm{e}+001.00000 \mathrm{e}-011.00000 \mathrm{e}-091.00000 \mathrm{e}-01$ $1.00000 \mathrm{e}-05$ 1.00000e-05 1.00000e-06 1.00000e-09 1.00000e-01 $1.00000 \mathrm{e}+001.00000 \mathrm{e}+001.00000 \mathrm{e}-011.00000 \mathrm{e}-091.00000 \mathrm{e}-01$ Element: 3416 \# of layers: 11

$\mathrm{Kx} \mathrm{Ky} \mathrm{Kz}$ Ss Por

8.75078e+03 8.75078e+03 8.75078e+02 1.00000e-09 7.00000e-02 5.00000e-04 5.00000e-04 5.00000e-05 1.00000e-09 1.00000e-01 $3.49657 \mathrm{e}+02$ 3.49657e+02 3.49657e+01 1.00000e-09 2.12000e-01 $3.49657 \mathrm{e}+02$ 3.49657e+02 3.49657e+01 1.00000e-09 2.12000e-01 $3.49657 \mathrm{e}+02$ 3.49657e+02 3.49657e+01 1.00000e-09 2.12000e-01 $3.49657 \mathrm{e}+023.49657 \mathrm{e}+02$ 3.49657e+01 1.00000e-09 2.12000e-01 $3.49657 \mathrm{e}+02$ 3.49657e+02 3.49657e+01 1.00000e-09 2.12000e-01 $1.00000 \mathrm{e}-02$ 1.00000e-02 1.00000e-03 1.00000e-09 1.00000e-01 $1.00000 \mathrm{e}+001.00000 \mathrm{e}+001.00000 \mathrm{e}-011.00000 \mathrm{e}-091.00000 \mathrm{e}-01$ $1.00000 \mathrm{e}-05$ 1.00000e-05 1.00000e-06 1.00000e-09 1.00000e-01 $1.00000 \mathrm{e}+001.00000 \mathrm{e}+001.00000 \mathrm{e}-011.00000 \mathrm{e}-091.00000 \mathrm{e}-01$ Element: 3417 \# of layers: 12

$\mathrm{Kx} \mathrm{Ky} \mathrm{Kz}$ Ss Por 9.08839e+03 9.08839e+03 9.08839e+02 1.00000e-09 7.00000e-02 5.00000e-04 5.00000e-04 5.00000e-05 1.00000e-09 1.00000e-01 $5.00000 \mathrm{e}-04$ 5.00000e-04 5.00000e-05 1.00000e-09 1.00000e-01 $3.63135 \mathrm{e}+023.63135 \mathrm{e}+023.63135 \mathrm{e}+01$ 1.00000e-09 2.12000e-01 $3.63135 \mathrm{e}+02$ 3.63135e+02 3.63135e+01 1.00000e-09 2.12000e-01 $3.63135 \mathrm{e}+02$ 3.63135e+02 3.63135e+01 1.00000e-09 2.12000e-01 $3.63135 \mathrm{e}+02$ 3.63135e+02 3.63135e+01 1.00000e-09 2.12000e-01 $3.63135 \mathrm{e}+023.63135 \mathrm{e}+02$ 3.63135e+01 1.00000e-09 2.12000e-01 $1.00000 \mathrm{e}-02$ 1.00000e-02 1.00000e-03 1.00000e-09 1.00000e-01 $1.00000 \mathrm{e}+001.00000 \mathrm{e}+001.00000 \mathrm{e}-011.00000 \mathrm{e}-091.00000 \mathrm{e}-01$ $1.00000 \mathrm{e}-051.00000 \mathrm{e}-051.00000 \mathrm{e}-061.00000 \mathrm{e}-091.00000 \mathrm{e}-01$ $1.00000 \mathrm{e}+001.00000 \mathrm{e}+001.00000 \mathrm{e}-01$ 1.00000e-09 1.00000e-01 Element: 3418 \# of layers: 11

Kx Ky Kz Ss Por 9.08839e+03 9.08839e+03 9.08839e+02 1.00000e-09 7.00000e-02 5.00000e-04 5.00000e-04 5.00000e-05 1.00000e-09 1.00000e-01 $3.63135 \mathrm{e}+02$ 3.63135e+02 3.63135e+01 1.00000e-09 2.12000e-01 $3.63135 \mathrm{e}+023.63135 \mathrm{e}+023.63135 \mathrm{e}+01$ 1.00000e-09 2.12000e-01 $3.63135 \mathrm{e}+023.63135 \mathrm{e}+023.63135 \mathrm{e}+01$ 1.00000e-09 2.12000e-01 $3.63135 \mathrm{e}+02$ 3.63135e+02 3.63135e+01 1.00000e-09 2.12000e-01 3.63135e+02 3.63135e+02 3.63135e+01 1.00000e-09 2.12000e-01 $1.00000 \mathrm{e}-02$ 1.00000e-02 1.00000e-03 1.00000e-09 1.00000e-01 $1.00000 \mathrm{e}+001.00000 \mathrm{e}+001.00000 \mathrm{e}-011.00000 \mathrm{e}-091.00000 \mathrm{e}-01$ 
$1.00000 \mathrm{e}-05$ 1.00000e-05 1.00000e-06 1.00000e-09 1.00000e-01 $1.00000 \mathrm{e}+001.00000 \mathrm{e}+001.00000 \mathrm{e}-01$ 1.00000e-09 1.00000e-01 Element: 3419 \# of layers: 11

Kx Ky Kz Ss Por

9.44789e+03 9.44789e+03 9.44789e+02 1.00000e-09 7.00000e-02

9.44789e+03 9.44789e+03 9.44789e+02 1.00000e-09 7.00000e-02

$3.77513 \mathrm{e}+02$ 3.77513e+02 3.77513e+01 1.00000e-09 2.12000e-01

$3.77513 \mathrm{e}+02$ 3.77513e+02 3.77513e+01 1.00000e-09 2.12000e-01

$3.77513 \mathrm{e}+02$ 3.77513e+02 3.77513e+01 1.00000e-09 2.12000e-01

$3.77513 \mathrm{e}+02$ 3.77513e+02 3.77513e+01 1.00000e-09 2.12000e-01

$3.77513 \mathrm{e}+02$ 3.77513e+02 3.77513e+01 1.00000e-09 2.12000e-01

$1.00000 \mathrm{e}-02$ 1.00000e-02 1.00000e-03 1.00000e-09 1.00000e-01

$1.00000 \mathrm{e}+001.00000 \mathrm{e}+001.00000 \mathrm{e}-011.00000 \mathrm{e}-091.00000 \mathrm{e}-01$

$1.00000 \mathrm{e}-05$ 1.00000e-05 1.00000e-06 1.00000e-09 1.00000e-01

$1.00000 \mathrm{e}+001.00000 \mathrm{e}+001.00000 \mathrm{e}-01$ 1.00000e-09 1.00000e-01

Element: 3420 \# of layers: 12

$\mathrm{Kx} \mathrm{Ky} \mathrm{Kz}$ Ss Por

$1.05723 \mathrm{e}+041.05723 \mathrm{e}+041.05723 \mathrm{e}+03$ 1.00000e-09 7.00000e-02 $1.05723 \mathrm{e}+041.05723 \mathrm{e}+041.05723 \mathrm{e}+03$ 1.00000e-09 7.00000e-02 5.00000e-04 5.00000e-04 5.00000e-05 1.00000e-09 1.00000e-01

4.22447e+02 4.22447e+02 4.22447e+01 1.00000e-09 2.12000e-01 4.22447e+02 4.22447e+02 4.22447e+01 1.00000e-09 2.12000e-01 4.22447e+02 4.22447e+02 4.22447e+01 1.00000e-09 2.12000e-01 4.22447e+02 4.22447e+02 4.22447e+01 1.00000e-09 2.12000e-01 4.22447e+02 4.22447e+02 4.22447e+01 1.00000e-09 2.12000e-01 $1.00000 \mathrm{e}-02$ 1.00000e-02 1.00000e-03 1.00000e-09 1.00000e-01 $1.00000 \mathrm{e}+001.00000 \mathrm{e}+001.00000 \mathrm{e}-011.00000 \mathrm{e}-091.00000 \mathrm{e}-01$ 1.00000e-05 1.00000e-05 1.00000e-06 1.00000e-09 1.00000e-01 $1.00000 \mathrm{e}+001.00000 \mathrm{e}+001.00000 \mathrm{e}-011.00000 \mathrm{e}-091.00000 \mathrm{e}-01$ Element: 3421 \# of layers: 11

$\mathrm{Kx} \mathrm{Ky} \mathrm{Kz}$ Ss Por

8.75078e+03 8.75078e+03 8.75078e+02 1.00000e-09 7.00000e-02 5.00000e-04 5.00000e-04 5.00000e-05 1.00000e-09 1.00000e-01 $3.49657 \mathrm{e}+02$ 3.49657e+02 3.49657e+01 1.00000e-09 2.12000e-01 $3.49657 \mathrm{e}+02$ 3.49657e+02 3.49657e+01 1.00000e-09 2.12000e-01 $3.49657 \mathrm{e}+02$ 3.49657e+02 3.49657e+01 1.00000e-09 2.12000e-01 $3.49657 \mathrm{e}+023.49657 \mathrm{e}+02$ 3.49657e+01 1.00000e-09 2.12000e-01 $3.49657 \mathrm{e}+02$ 3.49657e+02 3.49657e+01 1.00000e-09 2.12000e-01 $1.00000 \mathrm{e}-02$ 1.00000e-02 1.00000e-03 1.00000e-09 1.00000e-01 $1.00000 \mathrm{e}+001.00000 \mathrm{e}+001.00000 \mathrm{e}-011.00000 \mathrm{e}-091.00000 \mathrm{e}-01$ $1.00000 \mathrm{e}-05$ 1.00000e-05 1.00000e-06 1.00000e-09 1.00000e-01 $1.00000 \mathrm{e}+001.00000 \mathrm{e}+001.00000 \mathrm{e}-011.00000 \mathrm{e}-091.00000 \mathrm{e}-01$ Element: 3422 \# of layers: 12

$\mathrm{Kx} \mathrm{Ky} \mathrm{Kz}$ Ss Por 5.89038e+03 5.89038e+03 5.89038e+02 1.00000e-09 7.00000e-02 5.00000e-04 5.00000e-04 5.00000e-05 1.00000e-09 1.00000e-01 
5.00000e-04 5.00000e-04 5.00000e-05 1.00000e-09 1.00000e-01 $2.35355 \mathrm{e}+022.35355 \mathrm{e}+022.35355 \mathrm{e}+01$ 1.00000e-09 2.12000e-01 $2.35355 \mathrm{e}+022.35355 \mathrm{e}+022.35355 \mathrm{e}+01$ 1.00000e-09 2.12000e-01 $2.35355 \mathrm{e}+02 \quad 2.35355 \mathrm{e}+02 \quad 2.35355 \mathrm{e}+01 \quad 1.00000 \mathrm{e}-092.12000 \mathrm{e}-01$ $2.35355 \mathrm{e}+022.35355 \mathrm{e}+022.35355 \mathrm{e}+01$ 1.00000e-09 2.12000e-01 $2.35355 \mathrm{e}+022.35355 \mathrm{e}+022.35355 \mathrm{e}+01$ 1.00000e-09 2.12000e-01 $1.00000 \mathrm{e}-021.00000 \mathrm{e}-02$ 1.00000e-03 1.00000e-09 1.00000e-01 $1.00000 \mathrm{e}+001.00000 \mathrm{e}+001.00000 \mathrm{e}-011.00000 \mathrm{e}-091.00000 \mathrm{e}-01$ $1.00000 \mathrm{e}-05$ 1.00000e-05 1.00000e-06 1.00000e-09 1.00000e-01 $1.00000 \mathrm{e}+001.00000 \mathrm{e}+001.00000 \mathrm{e}-011.00000 \mathrm{e}-091.00000 \mathrm{e}-01$ Element: 3423 \# of layers: 12

Kx Ky Kz Ss Por

4.41553e+03 4.41553e+03 4.41553e+02 1.00000e-09 7.00000e-02 5.00000e-04 5.00000e-04 5.00000e-05 1.00000e-09 1.00000e-01 5.00000e-04 5.00000e-04 5.00000e-05 1.00000e-09 1.00000e-01 $1.76428 \mathrm{e}+02 \quad 1.76428 \mathrm{e}+021.76428 \mathrm{e}+01$ 1.00000e-09 2.12000e-01 $1.76428 \mathrm{e}+021.76428 \mathrm{e}+021.76428 \mathrm{e}+011.00000 \mathrm{e}-092.12000 \mathrm{e}-01$ $1.76428 \mathrm{e}+021.76428 \mathrm{e}+021.76428 \mathrm{e}+01$ 1.00000e-09 2.12000e-01 $1.76428 \mathrm{e}+021.76428 \mathrm{e}+021.76428 \mathrm{e}+011.00000 \mathrm{e}-092.12000 \mathrm{e}-01$ $1.76428 \mathrm{e}+02 \quad 1.76428 \mathrm{e}+021.76428 \mathrm{e}+01$ 1.00000e-09 2.12000e-01 $1.00000 \mathrm{e}-021.00000 \mathrm{e}-02$ 1.00000e-03 1.00000e-09 1.00000e-01 $1.00000 \mathrm{e}+001.00000 \mathrm{e}+001.00000 \mathrm{e}-011.00000 \mathrm{e}-091.00000 \mathrm{e}-01$ $1.00000 \mathrm{e}-05$ 1.00000e-05 1.00000e-06 1.00000e-09 1.00000e-01 $1.00000 \mathrm{e}+001.00000 \mathrm{e}+001.00000 \mathrm{e}-011.00000 \mathrm{e}-091.00000 \mathrm{e}-01$

Element: 3424 \# of layers: 12

Kx Ky Kz Ss Por

$4.41553 \mathrm{e}+03$ 4.41553e+03 4.41553e+02 1.00000e-09 7.00000e-02 5.00000e-04 5.00000e-04 5.00000e-05 1.00000e-09 1.00000e-01 5.00000e-04 5.00000e-04 5.00000e-05 1.00000e-09 1.00000e-01 $1.76428 \mathrm{e}+021.76428 \mathrm{e}+02 \quad 1.76428 \mathrm{e}+011.00000 \mathrm{e}-092.12000 \mathrm{e}-01$ $1.76428 \mathrm{e}+02 \quad 1.76428 \mathrm{e}+021.76428 \mathrm{e}+011.00000 \mathrm{e}-092.12000 \mathrm{e}-01$ $1.76428 \mathrm{e}+02 \quad 1.76428 \mathrm{e}+021.76428 \mathrm{e}+01$ 1.00000e-09 2.12000e-01 $1.76428 \mathrm{e}+02 \quad 1.76428 \mathrm{e}+021.76428 \mathrm{e}+01$ 1.00000e-09 2.12000e-01 $1.76428 \mathrm{e}+02 \quad 1.76428 \mathrm{e}+02 \quad 1.76428 \mathrm{e}+011.00000 \mathrm{e}-092.12000 \mathrm{e}-01$ $1.00000 \mathrm{e}-021.00000 \mathrm{e}-02$ 1.00000e-03 1.00000e-09 1.00000e-01 $1.00000 \mathrm{e}+001.00000 \mathrm{e}+001.00000 \mathrm{e}-011.00000 \mathrm{e}-091.00000 \mathrm{e}-01$ $1.00000 \mathrm{e}-05$ 1.00000e-05 1.00000e-06 1.00000e-09 1.00000e-01 $1.00000 \mathrm{e}+001.00000 \mathrm{e}+001.00000 \mathrm{e}-011.00000 \mathrm{e}-091.00000 \mathrm{e}-01$ Element: 3425 \# of layers: 12

Kx Ky Kz Ss Por 4.41553e+03 4.41553e+03 4.41553e+02 1.00000e-09 7.00000e-02 5.00000e-04 5.00000e-04 5.00000e-05 1.00000e-09 1.00000e-01 $5.00000 \mathrm{e}-04$ 5.00000e-04 5.00000e-05 1.00000e-09 1.00000e-01 $1.76428 \mathrm{e}+021.76428 \mathrm{e}+021.76428 \mathrm{e}+011.00000 \mathrm{e}-092.12000 \mathrm{e}-01$ $1.76428 \mathrm{e}+021.76428 \mathrm{e}+021.76428 \mathrm{e}+011.00000 \mathrm{e}-092.12000 \mathrm{e}-01$ $1.76428 \mathrm{e}+021.76428 \mathrm{e}+021.76428 \mathrm{e}+01$ 1.00000e-09 2.12000e-01 
$1.76428 \mathrm{e}+02$ 1.76428e+02 1.76428e+01 1.00000e-09 2.12000e-01 $1.76428 \mathrm{e}+02$ 1.76428e+02 1.76428e+01 1.00000e-09 2.12000e-01 $1.00000 \mathrm{e}-02$ 1.00000e-02 1.00000e-03 1.00000e-09 1.00000e-01 $1.00000 \mathrm{e}+001.00000 \mathrm{e}+001.00000 \mathrm{e}-011.00000 \mathrm{e}-091.00000 \mathrm{e}-01$ $1.00000 \mathrm{e}-05$ 1.00000e-05 1.00000e-06 1.00000e-09 1.00000e-01 $1.00000 \mathrm{e}+001.00000 \mathrm{e}+001.00000 \mathrm{e}-011.00000 \mathrm{e}-091.00000 \mathrm{e}-01$ Element: 3426 \# of layers: 11

$\mathrm{Kx} \mathrm{Ky} \mathrm{Kz}$ Ss Por

$6.26510 \mathrm{e}+036.26510 \mathrm{e}+036.26510 \mathrm{e}+02$ 1.00000e-09 7.00000e-02 $5.00000 \mathrm{e}-04$ 5.00000e-04 5.00000e-05 1.00000e-09 1.00000e-01 $2.50340 \mathrm{e}+02$ 2.50340e+02 2.50340e+01 1.00000e-09 2.12000e-01 $2.50340 \mathrm{e}+02 \quad 2.50340 \mathrm{e}+02 \quad 2.50340 \mathrm{e}+01$ 1.00000e-09 2.12000e-01 $2.50340 \mathrm{e}+02$ 2.50340e+02 2.50340e+01 1.00000e-09 2.12000e-01 $2.50340 \mathrm{e}+02$ 2.50340e+02 2.50340e+01 1.00000e-09 2.12000e-01 $2.50340 \mathrm{e}+022.50340 \mathrm{e}+022.50340 \mathrm{e}+01$ 1.00000e-09 2.12000e-01 $1.00000 \mathrm{e}-02$ 1.00000e-02 1.00000e-03 1.00000e-09 1.00000e-01 $1.00000 \mathrm{e}+001.00000 \mathrm{e}+001.00000 \mathrm{e}-011.00000 \mathrm{e}-091.00000 \mathrm{e}-01$ $1.00000 \mathrm{e}-05$ 1.00000e-05 1.00000e-06 1.00000e-09 1.00000e-01 $1.00000 \mathrm{e}+001.00000 \mathrm{e}+001.00000 \mathrm{e}-011.00000 \mathrm{e}-091.00000 \mathrm{e}-01$ Element: 3427 \# of layers: 11

$\mathrm{Kx} \mathrm{Ky} \mathrm{Kz}$ Ss Por

6.26510e+03 6.26510e+03 6.26510e+02 1.00000e-09 7.00000e-02 5.00000e-04 5.00000e-04 5.00000e-05 1.00000e-09 1.00000e-01 $2.50340 \mathrm{e}+022.50340 \mathrm{e}+022.50340 \mathrm{e}+01$ 1.00000e-09 2.12000e-01 $2.50340 \mathrm{e}+02 \quad 2.50340 \mathrm{e}+02 \quad 2.50340 \mathrm{e}+01 \quad 1.00000 \mathrm{e}-092.12000 \mathrm{e}-01$ $2.50340 \mathrm{e}+022.50340 \mathrm{e}+02$ 2.50340e+01 1.00000e-09 2.12000e-01 $2.50340 \mathrm{e}+02$ 2.50340e+02 2.50340e+01 1.00000e-09 2.12000e-01 $2.50340 \mathrm{e}+022.50340 \mathrm{e}+022.50340 \mathrm{e}+01$ 1.00000e-09 2.12000e-01 1.00000e-02 1.00000e-02 1.00000e-03 1.00000e-09 1.00000e-01 $1.00000 \mathrm{e}+001.00000 \mathrm{e}+001.00000 \mathrm{e}-011.00000 \mathrm{e}-091.00000 \mathrm{e}-01$ $1.00000 \mathrm{e}-05$ 1.00000e-05 1.00000e-06 1.00000e-09 1.00000e-01 $1.00000 \mathrm{e}+001.00000 \mathrm{e}+001.00000 \mathrm{e}-011.00000 \mathrm{e}-091.00000 \mathrm{e}-01$ Element: 3428 \# of layers: 12

$\mathrm{Kx} \mathrm{Ky} \mathrm{Kz}$ Ss Por

7.79041e+03 7.79041e+03 7.79041e+02 1.00000e-09 7.00000e-02 5.00000e-04 5.00000e-04 5.00000e-05 1.00000e-09 1.00000e-01 5.00000e-04 5.00000e-04 5.00000e-05 1.00000e-09 1.00000e-01

$3.11272 \mathrm{e}+02$ 3.11272e+02 3.11272e+01 1.00000e-09 2.12000e-01 3.11272e+02 3.11272e+02 3.11272e+01 1.00000e-09 2.12000e-01 3.11272e+02 3.11272e+02 3.11272e+01 1.00000e-09 2.12000e-01 $3.11272 \mathrm{e}+02$ 3.11272e+02 3.11272e+01 1.00000e-09 2.12000e-01 $3.11272 \mathrm{e}+023.11272 \mathrm{e}+02$ 3.11272e+01 1.00000e-09 2.12000e-01 $1.00000 \mathrm{e}-02$ 1.00000e-02 1.00000e-03 1.00000e-09 1.00000e-01 $1.00000 \mathrm{e}+001.00000 \mathrm{e}+001.00000 \mathrm{e}-011.00000 \mathrm{e}-091.00000 \mathrm{e}-01$ $1.00000 \mathrm{e}-05$ 1.00000e-05 1.00000e-06 1.00000e-09 1.00000e-01 $1.00000 \mathrm{e}+001.00000 \mathrm{e}+001.00000 \mathrm{e}-011.00000 \mathrm{e}-091.00000 \mathrm{e}-01$ 
Element: 3429 \# of layers: 12

$\mathrm{Kx} \mathrm{Ky} \mathrm{Kz}$ Ss Por

5.89038e+03 5.89038e+03 5.89038e+02 1.00000e-09 7.00000e-02

$5.00000 \mathrm{e}-04$ 5.00000e-04 5.00000e-05 1.00000e-09 1.00000e-01

5.00000e-04 5.00000e-04 5.00000e-05 1.00000e-09 1.00000e-01

$2.35355 \mathrm{e}+02$ 2.35355e+02 2.35355e+01 1.00000e-09 2.12000e-01

$2.35355 \mathrm{e}+02$ 2.35355e+02 2.35355e+01 1.00000e-09 2.12000e-01

$2.35355 \mathrm{e}+02$ 2.35355e+02 2.35355e+01 1.00000e-09 2.12000e-01

$2.35355 \mathrm{e}+02$ 2.35355e+02 2.35355e+01 1.00000e-09 2.12000e-01

$2.35355 \mathrm{e}+02$ 2.35355e+02 2.35355e+01 1.00000e-09 2.12000e-01

$1.00000 \mathrm{e}-02$ 1.00000e-02 1.00000e-03 1.00000e-09 1.00000e-01

$1.00000 \mathrm{e}+001.00000 \mathrm{e}+001.00000 \mathrm{e}-011.00000 \mathrm{e}-091.00000 \mathrm{e}-01$

$1.00000 \mathrm{e}-05$ 1.00000e-05 1.00000e-06 1.00000e-09 1.00000e-01

$1.00000 \mathrm{e}+001.00000 \mathrm{e}+001.00000 \mathrm{e}-011.00000 \mathrm{e}-09$ 1.00000e-01

Element: 3430 \# of layers: 12

Kx Ky Kz Ss Por

4.41553e+03 4.41553e+03 4.41553e+02 1.00000e-09 7.00000e-02

5.00000e-04 5.00000e-04 5.00000e-05 1.00000e-09 1.00000e-01

5.00000e-04 5.00000e-04 5.00000e-05 1.00000e-09 1.00000e-01

$1.76428 \mathrm{e}+02$ 1.76428e+02 1.76428e+01 1.00000e-09 2.12000e-01

$1.76428 \mathrm{e}+02$ 1.76428e+02 1.76428e+01 1.00000e-09 2.12000e-01

$1.76428 \mathrm{e}+021.76428 \mathrm{e}+02$ 1.76428e+01 1.00000e-09 2.12000e-01

$1.76428 \mathrm{e}+02$ 1.76428e+02 1.76428e+01 1.00000e-09 2.12000e-01

$1.76428 \mathrm{e}+02$ 1.76428e+02 1.76428e+01 1.00000e-09 2.12000e-01

$1.00000 \mathrm{e}-02$ 1.00000e-02 1.00000e-03 1.00000e-09 1.00000e-01

$1.00000 \mathrm{e}+001.00000 \mathrm{e}+001.00000 \mathrm{e}-011.00000 \mathrm{e}-091.00000 \mathrm{e}-01$

$1.00000 \mathrm{e}-05$ 1.00000e-05 1.00000e-06 1.00000e-09 1.00000e-01

$1.00000 \mathrm{e}+001.00000 \mathrm{e}+001.00000 \mathrm{e}-011.00000 \mathrm{e}-09$ 1.00000e-01

Element: 3431 \# of layers: 12

$\mathrm{Kx} \mathrm{Ky} \mathrm{Kz}$ Ss Por

3.69545e+03 3.69545e+03 3.69545e+02 1.00000e-09 7.00000e-02

5.00000e-04 5.00000e-04 5.00000e-05 1.00000e-09 1.00000e-01

5.00000e-04 5.00000e-04 5.00000e-05 1.00000e-09 1.00000e-01

$1.47657 \mathrm{e}+02$ 1.47657e+02 1.47657e+01 1.00000e-09 2.12000e-01

$1.47657 \mathrm{e}+02$ 1.47657e+02 1.47657e+01 1.00000e-09 2.12000e-01

$1.47657 \mathrm{e}+02$ 1.47657e+02 1.47657e+01 1.00000e-09 2.12000e-01

$1.47657 \mathrm{e}+02$ 1.47657e+02 1.47657e+01 1.00000e-09 2.12000e-01

$1.47657 \mathrm{e}+021.47657 \mathrm{e}+02$ 1.47657e+01 1.00000e-09 2.12000e-01

$1.00000 \mathrm{e}-02$ 1.00000e-02 1.00000e-03 1.00000e-09 1.00000e-01

$1.00000 \mathrm{e}+001.00000 \mathrm{e}+001.00000 \mathrm{e}-011.00000 \mathrm{e}-091.00000 \mathrm{e}-01$

$1.00000 \mathrm{e}-05$ 1.00000e-05 1.00000e-06 1.00000e-09 1.00000e-01

$1.00000 \mathrm{e}+001.00000 \mathrm{e}+001.00000 \mathrm{e}-011.00000 \mathrm{e}-091.00000 \mathrm{e}-01$

Element: 3432 \# of layers: 12

$\mathrm{Kx} \mathrm{Ky} \mathrm{Kz}$ Ss Por

3.87106e+03 3.87106e+03 3.87106e+02 1.00000e-09 7.00000e-02

5.00000e-04 5.00000e-04 5.00000e-05 1.00000e-09 1.00000e-01 
5.00000e-04 5.00000e-04 5.00000e-05 1.00000e-09 1.00000e-01 $1.54673 \mathrm{e}+02$ 1.54673e+02 1.54673e+01 1.00000e-09 2.12000e-01 $1.54673 \mathrm{e}+02$ 1.54673e+02 1.54673e+01 1.00000e-09 2.12000e-01 $1.54673 \mathrm{e}+02$ 1.54673e+02 1.54673e+01 1.00000e-09 2.12000e-01 $1.54673 \mathrm{e}+02$ 1.54673e+02 1.54673e+01 1.00000e-09 2.12000e-01 $1.54673 \mathrm{e}+02$ 1.54673e+02 1.54673e+01 1.00000e-09 2.12000e-01 $1.00000 \mathrm{e}-02$ 1.00000e-02 1.00000e-03 1.00000e-09 1.00000e-01 $1.00000 \mathrm{e}+001.00000 \mathrm{e}+001.00000 \mathrm{e}-011.00000 \mathrm{e}-091.00000 \mathrm{e}-01$ $1.00000 \mathrm{e}-05$ 1.00000e-05 1.00000e-06 1.00000e-09 1.00000e-01 $1.00000 \mathrm{e}+001.00000 \mathrm{e}+001.00000 \mathrm{e}-011.00000 \mathrm{e}-091.00000 \mathrm{e}-01$ Element: 3433 \# of layers: 12

$\mathrm{Kx} \mathrm{Ky} \mathrm{Kz}$ Ss Por

3.87106e+03 3.87106e+03 3.87106e+02 1.00000e-09 7.00000e-02 5.00000e-04 5.00000e-04 5.00000e-05 1.00000e-09 1.00000e-01 5.00000e-04 5.00000e-04 5.00000e-05 1.00000e-09 1.00000e-01 $1.54673 \mathrm{e}+02$ 1.54673e+02 1.54673e+01 1.00000e-09 2.12000e-01 $1.54673 \mathrm{e}+02$ 1.54673e+02 1.54673e+01 1.00000e-09 2.12000e-01 $1.54673 \mathrm{e}+02$ 1.54673e+02 1.54673e+01 1.00000e-09 2.12000e-01 $1.54673 \mathrm{e}+02$ 1.54673e+02 1.54673e+01 1.00000e-09 2.12000e-01 $1.54673 \mathrm{e}+02$ 1.54673e+02 1.54673e+01 1.00000e-09 2.12000e-01 $1.00000 \mathrm{e}-02$ 1.00000e-02 1.00000e-03 1.00000e-09 1.00000e-01 $1.00000 \mathrm{e}+001.00000 \mathrm{e}+001.00000 \mathrm{e}-011.00000 \mathrm{e}-091.00000 \mathrm{e}-01$ $1.00000 \mathrm{e}-05$ 1.00000e-05 1.00000e-06 1.00000e-09 1.00000e-01 $1.00000 \mathrm{e}+001.00000 \mathrm{e}+001.00000 \mathrm{e}-011.00000 \mathrm{e}-09$ 1.00000e-01 Element: 3434 \# of layers: 12

$\mathrm{Kx} \mathrm{Ky} \mathrm{Kz}$ Ss Por

3.87106e+03 3.87106e+03 3.87106e+02 1.00000e-09 7.00000e-02 5.00000e-04 5.00000e-04 5.00000e-05 1.00000e-09 1.00000e-01 5.00000e-04 5.00000e-04 5.00000e-05 1.00000e-09 1.00000e-01 $1.54673 \mathrm{e}+02$ 1.54673e+02 1.54673e+01 1.00000e-09 2.12000e-01 $1.54673 \mathrm{e}+02$ 1.54673e+02 1.54673e+01 1.00000e-09 2.12000e-01 $1.54673 \mathrm{e}+02$ 1.54673e+02 1.54673e+01 1.00000e-09 2.12000e-01 $1.54673 \mathrm{e}+02$ 1.54673e+02 1.54673e+01 1.00000e-09 2.12000e-01 $1.54673 \mathrm{e}+02$ 1.54673e+02 1.54673e+01 1.00000e-09 2.12000e-01 $1.00000 \mathrm{e}-02$ 1.00000e-02 1.00000e-03 1.00000e-09 1.00000e-01 $1.00000 \mathrm{e}+001.00000 \mathrm{e}+001.00000 \mathrm{e}-011.00000 \mathrm{e}-091.00000 \mathrm{e}-01$ $1.00000 \mathrm{e}-05$ 1.00000e-05 1.00000e-06 1.00000e-09 1.00000e-01 $1.00000 \mathrm{e}+001.00000 \mathrm{e}+001.00000 \mathrm{e}-01$ 1.00000e-09 1.00000e-01 Element: 3435 \# of layers: 13

$\mathrm{Kx} \mathrm{Ky} \mathrm{Kz}$ Ss Por

5.46330e+03 5.46330e+03 5.46330e+02 1.00000e-09 7.00000e-02 $5.46330 \mathrm{e}+035.46330 \mathrm{e}+035.46330 \mathrm{e}+021.00000 \mathrm{e}-097.00000 \mathrm{e}-02$ $5.00000 \mathrm{e}-04$ 5.00000e-04 5.00000e-05 1.00000e-09 1.00000e-01 5.00000e-04 5.00000e-04 5.00000e-05 1.00000e-09 1.00000e-01 $2.18293 \mathrm{e}+022.18293 \mathrm{e}+02$ 2.18293e+01 1.00000e-09 2.12000e-01 $2.18293 \mathrm{e}+02$ 2.18293e+02 2.18293e+01 1.00000e-09 2.12000e-01 
$2.18293 \mathrm{e}+022.18293 \mathrm{e}+022.18293 \mathrm{e}+01$ 1.00000e-09 2.12000e-01 $2.18293 \mathrm{e}+022.18293 \mathrm{e}+022.18293 \mathrm{e}+01$ 1.00000e-09 2.12000e-01 $2.18293 \mathrm{e}+022.18293 \mathrm{e}+022.18293 \mathrm{e}+01$ 1.00000e-09 2.12000e-01 $1.00000 \mathrm{e}-021.00000 \mathrm{e}-02$ 1.00000e-03 1.00000e-09 1.00000e-01 $1.00000 \mathrm{e}+001.00000 \mathrm{e}+001.00000 \mathrm{e}-011.00000 \mathrm{e}-091.00000 \mathrm{e}-01$ $1.00000 \mathrm{e}-05$ 1.00000e-05 1.00000e-06 1.00000e-09 1.00000e-01 $1.00000 \mathrm{e}+001.00000 \mathrm{e}+001.00000 \mathrm{e}-011.00000 \mathrm{e}-091.00000 \mathrm{e}-01$ Element: 3436 \# of layers: 13

Kx Ky Kz Ss Por

$5.46330 \mathrm{e}+03$ 5.46330e+03 5.46330e+02 1.00000e-09 7.00000e-02 $5.46330 \mathrm{e}+03$ 5.46330e+03 5.46330e+02 1.00000e-09 7.00000e-02 5.00000e-04 5.00000e-04 5.00000e-05 1.00000e-09 1.00000e-01 5.00000e-04 5.00000e-04 5.00000e-05 1.00000e-09 1.00000e-01 $2.18293 \mathrm{e}+022.18293 \mathrm{e}+022.18293 \mathrm{e}+01$ 1.00000e-09 2.12000e-01 $2.18293 \mathrm{e}+022.18293 \mathrm{e}+022.18293 \mathrm{e}+01$ 1.00000e-09 2.12000e-01 $2.18293 \mathrm{e}+022.18293 \mathrm{e}+022.18293 \mathrm{e}+01$ 1.00000e-09 2.12000e-01 $2.18293 \mathrm{e}+022.18293 \mathrm{e}+022.18293 \mathrm{e}+01$ 1.00000e-09 2.12000e-01 $2.18293 \mathrm{e}+022.18293 \mathrm{e}+022.18293 \mathrm{e}+01$ 1.00000e-09 2.12000e-01 $1.00000 \mathrm{e}-02$ 1.00000e-02 1.00000e-03 1.00000e-09 1.00000e-01 $1.00000 \mathrm{e}+001.00000 \mathrm{e}+001.00000 \mathrm{e}-011.00000 \mathrm{e}-091.00000 \mathrm{e}-01$ $1.00000 \mathrm{e}-05$ 1.00000e-05 1.00000e-06 1.00000e-09 1.00000e-01 $1.00000 \mathrm{e}+001.00000 \mathrm{e}+001.00000 \mathrm{e}-011.00000 \mathrm{e}-091.00000 \mathrm{e}-01$ Element: 3437 \# of layers: 12

Kx Ky Kz Ss Por

$6.92689 \mathrm{e}+03$ 6.92689e+03 6.92689e+02 1.00000e-09 7.00000e-02 $6.92689 \mathrm{e}+036.92689 \mathrm{e}+036.92689 \mathrm{e}+021.00000 \mathrm{e}-09$ 7.00000e-02 5.00000e-04 5.00000e-04 5.00000e-05 1.00000e-09 1.00000e-01 $2.76778 \mathrm{e}+022.76778 \mathrm{e}+022.76778 \mathrm{e}+01$ 1.00000e-09 2.12000e-01 $2.76778 \mathrm{e}+022.76778 \mathrm{e}+022.76778 \mathrm{e}+01$ 1.00000e-09 2.12000e-01 $2.76778 \mathrm{e}+022.76778 \mathrm{e}+022.76778 \mathrm{e}+01$ 1.00000e-09 2.12000e-01 $2.76778 \mathrm{e}+022.76778 \mathrm{e}+022.76778 \mathrm{e}+01$ 1.00000e-09 2.12000e-01 $2.76778 \mathrm{e}+022.76778 \mathrm{e}+022.76778 \mathrm{e}+01$ 1.00000e-09 2.12000e-01 $1.00000 \mathrm{e}-021.00000 \mathrm{e}-02$ 1.00000e-03 1.00000e-09 1.00000e-01 $1.00000 \mathrm{e}+001.00000 \mathrm{e}+001.00000 \mathrm{e}-011.00000 \mathrm{e}-091.00000 \mathrm{e}-01$ $1.00000 \mathrm{e}-05$ 1.00000e-05 1.00000e-06 1.00000e-09 1.00000e-01 $1.00000 \mathrm{e}+001.00000 \mathrm{e}+001.00000 \mathrm{e}-011.00000 \mathrm{e}-091.00000 \mathrm{e}-01$ Element: 3438 \# of layers: 12

Kx Ky Kz Ss Por $3.69545 \mathrm{e}+03$ 3.69545e+03 3.69545e+02 1.00000e-09 7.00000e-02 5.00000e-04 5.00000e-04 5.00000e-05 1.00000e-09 1.00000e-01 5.00000e-04 5.00000e-04 5.00000e-05 1.00000e-09 1.00000e-01 $1.47657 \mathrm{e}+02 \quad 1.47657 \mathrm{e}+02 \quad 1.47657 \mathrm{e}+01 \quad 1.00000 \mathrm{e}-092.12000 \mathrm{e}-01$ $1.47657 \mathrm{e}+021.47657 \mathrm{e}+021.47657 \mathrm{e}+011.00000 \mathrm{e}-092.12000 \mathrm{e}-01$ $1.47657 \mathrm{e}+021.47657 \mathrm{e}+021.47657 \mathrm{e}+011.00000 \mathrm{e}-092.12000 \mathrm{e}-01$ $1.47657 \mathrm{e}+021.47657 \mathrm{e}+02 \quad 1.47657 \mathrm{e}+011.00000 \mathrm{e}-092.12000 \mathrm{e}-01$ $1.47657 \mathrm{e}+02 \quad 1.47657 \mathrm{e}+021.47657 \mathrm{e}+01 \quad 1.00000 \mathrm{e}-092.12000 \mathrm{e}-01$ 
$1.00000 \mathrm{e}-02$ 1.00000e-02 1.00000e-03 1.00000e-09 1.00000e-01 $1.00000 \mathrm{e}+001.00000 \mathrm{e}+001.00000 \mathrm{e}-011.00000 \mathrm{e}-091.00000 \mathrm{e}-01$ $1.00000 \mathrm{e}-051.00000 \mathrm{e}-05$ 1.00000e-06 1.00000e-09 1.00000e-01 $1.00000 \mathrm{e}+001.00000 \mathrm{e}+001.00000 \mathrm{e}-011.00000 \mathrm{e}-091.00000 \mathrm{e}-01$ Element: 3439 \# of layers: 11

Kx Ky Kz Ss Por

$3.87106 \mathrm{e}+033.87106 \mathrm{e}+033.87106 \mathrm{e}+02$ 1.00000e-09 7.00000e-02 5.00000e-04 5.00000e-04 5.00000e-05 1.00000e-09 1.00000e-01

$1.54673 \mathrm{e}+021.54673 \mathrm{e}+021.54673 \mathrm{e}+01$ 1.00000e-09 2.12000e-01 $1.54673 \mathrm{e}+021.54673 \mathrm{e}+021.54673 \mathrm{e}+011.00000 \mathrm{e}-092.12000 \mathrm{e}-01$ $1.54673 \mathrm{e}+021.54673 \mathrm{e}+021.54673 \mathrm{e}+011.00000 \mathrm{e}-092.12000 \mathrm{e}-01$ $1.54673 \mathrm{e}+021.54673 \mathrm{e}+021.54673 \mathrm{e}+011.00000 \mathrm{e}-092.12000 \mathrm{e}-01$ $1.54673 \mathrm{e}+02$ 1.54673e+02 1.54673e+01 1.00000e-09 2.12000e-01 $1.00000 \mathrm{e}-021.00000 \mathrm{e}-02$ 1.00000e-03 1.00000e-09 1.00000e-01 $1.00000 \mathrm{e}+001.00000 \mathrm{e}+001.00000 \mathrm{e}-011.00000 \mathrm{e}-091.00000 \mathrm{e}-01$ $1.00000 \mathrm{e}-05$ 1.00000e-05 1.00000e-06 1.00000e-09 1.00000e-01 $1.00000 \mathrm{e}+001.00000 \mathrm{e}+001.00000 \mathrm{e}-011.00000 \mathrm{e}-091.00000 \mathrm{e}-01$ Element: 3440 \# of layers: 13

$\mathrm{Kx} \mathrm{Ky} \mathrm{Kz}$ Ss Por

$3.07367 \mathrm{e}+033.07367 \mathrm{e}+03$ 3.07367e+02 1.00000e-09 7.00000e-02 $3.07367 \mathrm{e}+033.07367 \mathrm{e}+033.07367 \mathrm{e}+021.00000 \mathrm{e}-097.00000 \mathrm{e}-02$ $5.00000 \mathrm{e}-04$ 5.00000e-04 5.00000e-05 1.00000e-09 1.00000e-01 $5.00000 \mathrm{e}-04$ 5.00000e-04 5.00000e-05 1.00000e-09 1.00000e-01 $1.22812 \mathrm{e}+02 \quad 1.22812 \mathrm{e}+02 \quad 1.22812 \mathrm{e}+01$ 1.00000e-09 2.12000e-01 $1.22812 \mathrm{e}+02 \quad 1.22812 \mathrm{e}+021.22812 \mathrm{e}+011.00000 \mathrm{e}-092.12000 \mathrm{e}-01$ $1.22812 \mathrm{e}+021.22812 \mathrm{e}+021.22812 \mathrm{e}+011.00000 \mathrm{e}-092.12000 \mathrm{e}-01$ $1.22812 \mathrm{e}+02 \quad 1.22812 \mathrm{e}+021.22812 \mathrm{e}+011.00000 \mathrm{e}-092.12000 \mathrm{e}-01$ $1.22812 \mathrm{e}+021.22812 \mathrm{e}+021.22812 \mathrm{e}+011.00000 \mathrm{e}-092.12000 \mathrm{e}-01$ $1.00000 \mathrm{e}-021.00000 \mathrm{e}-02$ 1.00000e-03 1.00000e-09 1.00000e-01 $1.00000 \mathrm{e}+001.00000 \mathrm{e}+001.00000 \mathrm{e}-011.00000 \mathrm{e}-091.00000 \mathrm{e}-01$ $1.00000 \mathrm{e}-05$ 1.00000e-05 1.00000e-06 1.00000e-09 1.00000e-01 $1.00000 \mathrm{e}+001.00000 \mathrm{e}+001.00000 \mathrm{e}-011.00000 \mathrm{e}-091.00000 \mathrm{e}-01$ Element: 3441 \# of layers: 12

Kx Ky Kz Ss Por

$2.97006 \mathrm{e}+032.97006 \mathrm{e}+032.97006 \mathrm{e}+02$ 1.00000e-09 7.00000e-02 $2.97006 \mathrm{e}+032.97006 \mathrm{e}+032.97006 \mathrm{e}+021.00000 \mathrm{e}-097.00000 \mathrm{e}-02$ 5.00000e-04 5.00000e-04 5.00000e-05 1.00000e-09 1.00000e-01 5.00000e-04 5.00000e-04 5.00000e-05 1.00000e-09 1.00000e-01 $1.18674 \mathrm{e}+021.18674 \mathrm{e}+021.18674 \mathrm{e}+01 \quad 1.00000 \mathrm{e}-092.12000 \mathrm{e}-01$ $1.18674 \mathrm{e}+021.18674 \mathrm{e}+021.18674 \mathrm{e}+011.00000 \mathrm{e}-092.12000 \mathrm{e}-01$ $1.18674 \mathrm{e}+02 \quad 1.18674 \mathrm{e}+021.18674 \mathrm{e}+011.00000 \mathrm{e}-092.12000 \mathrm{e}-01$ $1.18674 \mathrm{e}+02 \quad 1.18674 \mathrm{e}+021.18674 \mathrm{e}+011.00000 \mathrm{e}-092.12000 \mathrm{e}-01$ $1.00000 \mathrm{e}-021.00000 \mathrm{e}-02$ 1.00000e-03 1.00000e-09 1.00000e-01 $1.00000 \mathrm{e}+001.00000 \mathrm{e}+001.00000 \mathrm{e}-011.00000 \mathrm{e}-091.00000 \mathrm{e}-01$ $1.00000 \mathrm{e}-05$ 1.00000e-05 1.00000e-06 1.00000e-09 1.00000e-01 $1.00000 \mathrm{e}+001.00000 \mathrm{e}+001.00000 \mathrm{e}-011.00000 \mathrm{e}-091.00000 \mathrm{e}-01$ 
Element: 3442 \# of layers: 12

$\mathrm{Kx} \mathrm{Ky} \mathrm{Kz}$ Ss Por

$2.97006 \mathrm{e}+03$ 2.97006e+03 2.97006e+02 1.00000e-09 7.00000e-02

$2.97006 \mathrm{e}+032.97006 \mathrm{e}+032.97006 \mathrm{e}+021.00000 \mathrm{e}-097.00000 \mathrm{e}-02$

5.00000e-04 5.00000e-04 5.00000e-05 1.00000e-09 1.00000e-01

5.00000e-04 5.00000e-04 5.00000e-05 1.00000e-09 1.00000e-01

$1.18674 \mathrm{e}+021.18674 \mathrm{e}+02 \quad 1.18674 \mathrm{e}+01$ 1.00000e-09 2.12000e-01

$1.18674 \mathrm{e}+02$ 1.18674e+02 1.18674e+01 1.00000e-09 2.12000e-01

$1.18674 \mathrm{e}+02$ 1.18674e+02 1.18674e+01 1.00000e-09 2.12000e-01

$1.18674 \mathrm{e}+021.18674 \mathrm{e}+02 \quad 1.18674 \mathrm{e}+01$ 1.00000e-09 2.12000e-01

$1.00000 \mathrm{e}-02$ 1.00000e-02 1.00000e-03 1.00000e-09 1.00000e-01

$1.00000 \mathrm{e}+001.00000 \mathrm{e}+001.00000 \mathrm{e}-011.00000 \mathrm{e}-091.00000 \mathrm{e}-01$

$1.00000 \mathrm{e}-05$ 1.00000e-05 1.00000e-06 1.00000e-09 1.00000e-01

$1.00000 \mathrm{e}+001.00000 \mathrm{e}+001.00000 \mathrm{e}-011.00000 \mathrm{e}-09$ 1.00000e-01

Element: 3443 \# of layers: 12

Kx Ky Kz Ss Por

$2.97006 \mathrm{e}+032.97006 \mathrm{e}+032.97006 \mathrm{e}+02$ 1.00000e-09 7.00000e-02

$2.97006 \mathrm{e}+032.97006 \mathrm{e}+032.97006 \mathrm{e}+02$ 1.00000e-09 7.00000e-02

5.00000e-04 5.00000e-04 5.00000e-05 1.00000e-09 1.00000e-01

5.00000e-04 5.00000e-04 5.00000e-05 1.00000e-09 1.00000e-01

$1.18674 \mathrm{e}+021.18674 \mathrm{e}+02 \quad 1.18674 \mathrm{e}+01 \quad 1.00000 \mathrm{e}-092.12000 \mathrm{e}-01$

$1.18674 \mathrm{e}+021.18674 \mathrm{e}+02$ 1.18674e+01 1.00000e-09 2.12000e-01

$1.18674 \mathrm{e}+021.18674 \mathrm{e}+02$ 1.18674e+01 1.00000e-09 2.12000e-01

$1.18674 \mathrm{e}+021.18674 \mathrm{e}+02 \quad 1.18674 \mathrm{e}+01$ 1.00000e-09 2.12000e-01

$1.00000 \mathrm{e}-02$ 1.00000e-02 1.00000e-03 1.00000e-09 1.00000e-01

$1.00000 \mathrm{e}+001.00000 \mathrm{e}+001.00000 \mathrm{e}-011.00000 \mathrm{e}-091.00000 \mathrm{e}-01$

$1.00000 \mathrm{e}-05$ 1.00000e-05 1.00000e-06 1.00000e-09 1.00000e-01

$1.00000 \mathrm{e}+001.00000 \mathrm{e}+001.00000 \mathrm{e}-011.00000 \mathrm{e}-091.00000 \mathrm{e}-01$

Element: 3444 \# of layers: 13

$\mathrm{Kx} \mathrm{Ky} \mathrm{Kz}$ Ss Por

7.59624e+03 7.59624e+03 7.59624e+02 1.00000e-09 7.00000e-02

$7.59624 \mathrm{e}+037.59624 \mathrm{e}+037.59624 \mathrm{e}+02$ 1.00000e-09 7.00000e-02

5.00000e-04 5.00000e-04 5.00000e-05 1.00000e-09 1.00000e-01

$5.00000 \mathrm{e}-04$ 5.00000e-04 5.00000e-05 1.00000e-09 1.00000e-01

$3.03509 \mathrm{e}+02$ 3.03509e+02 3.03509e+01 1.00000e-09 2.12000e-01

$3.03509 \mathrm{e}+02$ 3.03509e+02 3.03509e+01 1.00000e-09 2.12000e-01

$3.03509 \mathrm{e}+023.03509 \mathrm{e}+023.03509 \mathrm{e}+01$ 1.00000e-09 2.12000e-01

$3.03509 \mathrm{e}+023.03509 \mathrm{e}+023.03509 \mathrm{e}+01$ 1.00000e-09 2.12000e-01

$3.03509 \mathrm{e}+02$ 3.03509e+02 3.03509e+01 1.00000e-09 2.12000e-01

$1.00000 \mathrm{e}-02$ 1.00000e-02 1.00000e-03 1.00000e-09 1.00000e-01

$1.00000 \mathrm{e}+001.00000 \mathrm{e}+001.00000 \mathrm{e}-011.00000 \mathrm{e}-091.00000 \mathrm{e}-01$

$1.00000 \mathrm{e}-05$ 1.00000e-05 1.00000e-06 1.00000e-09 1.00000e-01

$1.00000 \mathrm{e}+001.00000 \mathrm{e}+001.00000 \mathrm{e}-011.00000 \mathrm{e}-091.00000 \mathrm{e}-01$

Element: 3445 \# of layers: 13

$\mathrm{Kx} \mathrm{Ky} \mathrm{Kz} \mathrm{Ss} \mathrm{Por}$

7.59624e+03 7.59624e+03 7.59624e+02 1.00000e-09 7.00000e-02 
7.59624e+03 7.59624e+03 7.59624e+02 1.00000e-09 7.00000e-02 5.00000e-04 5.00000e-04 5.00000e-05 1.00000e-09 1.00000e-01 5.00000e-04 5.00000e-04 5.00000e-05 1.00000e-09 1.00000e-01 $3.03509 \mathrm{e}+02$ 3.03509e+02 3.03509e+01 1.00000e-09 2.12000e-01 $3.03509 \mathrm{e}+02$ 3.03509e+02 3.03509e+01 1.00000e-09 2.12000e-01 $3.03509 \mathrm{e}+02$ 3.03509e+02 3.03509e+01 1.00000e-09 2.12000e-01 $3.03509 \mathrm{e}+02$ 3.03509e+02 3.03509e+01 1.00000e-09 2.12000e-01 $3.03509 \mathrm{e}+02$ 3.03509e+02 3.03509e+01 1.00000e-09 2.12000e-01 $1.00000 \mathrm{e}-021.00000 \mathrm{e}-021.00000 \mathrm{e}-031.00000 \mathrm{e}-091.00000 \mathrm{e}-01$ $1.00000 \mathrm{e}+001.00000 \mathrm{e}+001.00000 \mathrm{e}-011.00000 \mathrm{e}-091.00000 \mathrm{e}-01$ $1.00000 \mathrm{e}-05$ 1.00000e-05 1.00000e-06 1.00000e-09 1.00000e-01 $1.00000 \mathrm{e}+001.00000 \mathrm{e}+001.00000 \mathrm{e}-011.00000 \mathrm{e}-091.00000 \mathrm{e}-01$ Element: 3446 \# of layers: 12

$\mathrm{Kx} \mathrm{Ky} \mathrm{Kz}$ Ss Por

3.77843e+03 3.77843e+03 3.77843e+02 1.00000e-09 7.00000e-02 5.00000e-04 5.00000e-04 5.00000e-05 1.00000e-09 1.00000e-01 5.00000e-04 5.00000e-04 5.00000e-05 1.00000e-09 1.00000e-01 $1.50974 \mathrm{e}+021.50974 \mathrm{e}+02 \quad 1.50974 \mathrm{e}+01$ 1.00000e-09 2.12000e-01 $1.50974 \mathrm{e}+021.50974 \mathrm{e}+02$ 1.50974e+01 1.00000e-09 2.12000e-01 $1.50974 \mathrm{e}+02 \quad 1.50974 \mathrm{e}+02 \quad 1.50974 \mathrm{e}+01$ 1.00000e-09 2.12000e-01 $1.50974 \mathrm{e}+021.50974 \mathrm{e}+021.50974 \mathrm{e}+01$ 1.00000e-09 2.12000e-01 $1.50974 \mathrm{e}+021.50974 \mathrm{e}+02$ 1.50974e+01 1.00000e-09 2.12000e-01 $1.00000 \mathrm{e}-02$ 1.00000e-02 1.00000e-03 1.00000e-09 1.00000e-01 $1.00000 \mathrm{e}+001.00000 \mathrm{e}+001.00000 \mathrm{e}-011.00000 \mathrm{e}-091.00000 \mathrm{e}-01$ $1.00000 \mathrm{e}-05$ 1.00000e-05 1.00000e-06 1.00000e-09 1.00000e-01 $1.00000 \mathrm{e}+001.00000 \mathrm{e}+001.00000 \mathrm{e}-011.00000 \mathrm{e}-091.00000 \mathrm{e}-01$ Element: 3447 \# of layers: 13

$\mathrm{Kx} \mathrm{Ky} \mathrm{Kz}$ Ss Por

3.07367e+03 3.07367e+03 3.07367e+02 1.00000e-09 7.00000e-02 3.07367e+03 3.07367e+03 3.07367e+02 1.00000e-09 7.00000e-02 5.00000e-04 5.00000e-04 5.00000e-05 1.00000e-09 1.00000e-01 5.00000e-04 5.00000e-04 5.00000e-05 1.00000e-09 1.00000e-01 $1.22812 \mathrm{e}+021.22812 \mathrm{e}+021.22812 \mathrm{e}+01$ 1.00000e-09 2.12000e-01 $1.22812 \mathrm{e}+02$ 1.22812e+02 1.22812e+01 1.00000e-09 2.12000e-01 $1.22812 \mathrm{e}+02$ 1.22812e+02 1.22812e+01 1.00000e-09 2.12000e-01 $1.22812 \mathrm{e}+02$ 1.22812e+02 1.22812e+01 1.00000e-09 2.12000e-01 $1.22812 \mathrm{e}+021.22812 \mathrm{e}+021.22812 \mathrm{e}+01$ 1.00000e-09 2.12000e-01 $1.00000 \mathrm{e}-02$ 1.00000e-02 1.00000e-03 1.00000e-09 1.00000e-01 $1.00000 \mathrm{e}+001.00000 \mathrm{e}+001.00000 \mathrm{e}-011.00000 \mathrm{e}-091.00000 \mathrm{e}-01$ $1.00000 \mathrm{e}-05$ 1.00000e-05 1.00000e-06 1.00000e-09 1.00000e-01 $1.00000 \mathrm{e}+001.00000 \mathrm{e}+001.00000 \mathrm{e}-011.00000 \mathrm{e}-091.00000 \mathrm{e}-01$ Element: 3448 \# of layers: 12

$\mathrm{Kx} \mathrm{Ky} \mathrm{Kz}$ Ss Por

2.97006e+03 2.97006e+03 2.97006e+02 1.00000e-09 7.00000e-02 $2.97006 \mathrm{e}+032.97006 \mathrm{e}+032.97006 \mathrm{e}+02$ 1.00000e-09 7.00000e-02 5.00000e-04 5.00000e-04 5.00000e-05 1.00000e-09 1.00000e-01 
5.00000e-04 5.00000e-04 5.00000e-05 1.00000e-09 1.00000e-01 $1.18674 \mathrm{e}+021.18674 \mathrm{e}+02$ 1.18674e+01 1.00000e-09 2.12000e-01 $1.18674 \mathrm{e}+02$ 1.18674e+02 1.18674e+01 1.00000e-09 2.12000e-01 $1.18674 \mathrm{e}+021.18674 \mathrm{e}+02 \quad 1.18674 \mathrm{e}+01$ 1.00000e-09 2.12000e-01 $1.18674 \mathrm{e}+02$ 1.18674e+02 1.18674e+01 1.00000e-09 2.12000e-01 $1.00000 \mathrm{e}-02$ 1.00000e-02 1.00000e-03 1.00000e-09 1.00000e-01 $1.00000 \mathrm{e}+001.00000 \mathrm{e}+001.00000 \mathrm{e}-011.00000 \mathrm{e}-091.00000 \mathrm{e}-01$ $1.00000 \mathrm{e}-05$ 1.00000e-05 1.00000e-06 1.00000e-09 1.00000e-01 $1.00000 \mathrm{e}+001.00000 \mathrm{e}+001.00000 \mathrm{e}-011.00000 \mathrm{e}-091.00000 \mathrm{e}-01$ Element: 3449 \# of layers: 12

$\mathrm{Kx} \mathrm{Ky} \mathrm{Kz}$ Ss Por

$5.54620 \mathrm{e}+03$ 5.54620e+03 5.54620e+02 1.00000e-09 7.00000e-02 $5.54620 \mathrm{e}+03$ 5.54620e+03 5.54620e+02 1.00000e-09 7.00000e-02 5.00000e-04 5.00000e-04 5.00000e-05 1.00000e-09 1.00000e-01 5.00000e-04 5.00000e-04 5.00000e-05 1.00000e-09 1.00000e-01 $2.21607 \mathrm{e}+022.21607 \mathrm{e}+022.21607 \mathrm{e}+01$ 1.00000e-09 2.12000e-01 $2.21607 \mathrm{e}+02$ 2.21607e+02 2.21607e+01 1.00000e-09 2.12000e-01 $2.21607 \mathrm{e}+02$ 2.21607e+02 2.21607e+01 1.00000e-09 2.12000e-01 $2.21607 \mathrm{e}+02$ 2.21607e+02 2.21607e+01 1.00000e-09 2.12000e-01 $1.00000 \mathrm{e}-02$ 1.00000e-02 1.00000e-03 1.00000e-09 1.00000e-01 $1.00000 \mathrm{e}+001.00000 \mathrm{e}+001.00000 \mathrm{e}-011.00000 \mathrm{e}-091.00000 \mathrm{e}-01$ $1.00000 \mathrm{e}-05$ 1.00000e-05 1.00000e-06 1.00000e-09 1.00000e-01 $1.00000 \mathrm{e}+001.00000 \mathrm{e}+001.00000 \mathrm{e}-01$ 1.00000e-09 1.00000e-01 Element: 3450 \# of layers: 13

$\mathrm{Kx} \mathrm{Ky} \mathrm{Kz}$ Ss Por

$5.28860 \mathrm{e}+035.28860 \mathrm{e}+035.28860 \mathrm{e}+021.00000 \mathrm{e}-097.00000 \mathrm{e}-02$ $5.28860 \mathrm{e}+035.28860 \mathrm{e}+035.28860 \mathrm{e}+021.00000 \mathrm{e}-097.00000 \mathrm{e}-02$ 5.00000e-04 5.00000e-04 5.00000e-05 1.00000e-09 1.00000e-01 5.00000e-04 5.00000e-04 5.00000e-05 1.00000e-09 1.00000e-01 $2.11313 \mathrm{e}+02$ 2.11313e+02 2.11313e+01 1.00000e-09 2.12000e-01 $2.11313 \mathrm{e}+02$ 2.11313e+02 2.11313e+01 1.00000e-09 2.12000e-01 $2.11313 \mathrm{e}+02$ 2.11313e+02 2.11313e+01 1.00000e-09 2.12000e-01 $2.11313 \mathrm{e}+02$ 2.11313e+02 2.11313e+01 1.00000e-09 2.12000e-01 2.11313e+02 2.11313e+02 2.11313e+01 1.00000e-09 2.12000e-01 $1.00000 \mathrm{e}-02$ 1.00000e-02 1.00000e-03 1.00000e-09 1.00000e-01 $1.00000 \mathrm{e}+001.00000 \mathrm{e}+001.00000 \mathrm{e}-011.00000 \mathrm{e}-091.00000 \mathrm{e}-01$ $1.00000 \mathrm{e}-05$ 1.00000e-05 1.00000e-06 1.00000e-09 1.00000e-01 $1.00000 \mathrm{e}+001.00000 \mathrm{e}+001.00000 \mathrm{e}-011.00000 \mathrm{e}-091.00000 \mathrm{e}-01$ Element: 3451 \# of layers: 13

$\mathrm{Kx} \mathrm{Ky} \mathrm{Kz}$ Ss Por

5.28860e+03 5.28860e+03 5.28860e+02 1.00000e-09 7.00000e-02 $5.28860 \mathrm{e}+03$ 5.28860e+03 5.28860e+02 1.00000e-09 7.00000e-02 $5.28860 \mathrm{e}+03$ 5.28860e+03 5.28860e+02 1.00000e-09 7.00000e-02 5.00000e-04 5.00000e-04 5.00000e-05 1.00000e-09 1.00000e-01 5.00000e-04 5.00000e-04 5.00000e-05 1.00000e-09 1.00000e-01 $2.11313 \mathrm{e}+022.11313 \mathrm{e}+022.11313 \mathrm{e}+01$ 1.00000e-09 2.12000e-01 
$2.11313 \mathrm{e}+022.11313 \mathrm{e}+022.11313 \mathrm{e}+01$ 1.00000e-09 2.12000e-01 $2.11313 \mathrm{e}+022.11313 \mathrm{e}+022.11313 \mathrm{e}+01$ 1.00000e-09 2.12000e-01 $2.11313 \mathrm{e}+022.11313 \mathrm{e}+022.11313 \mathrm{e}+01$ 1.00000e-09 2.12000e-01 $1.00000 \mathrm{e}-021.00000 \mathrm{e}-02$ 1.00000e-03 1.00000e-09 1.00000e-01 $1.00000 \mathrm{e}+001.00000 \mathrm{e}+001.00000 \mathrm{e}-011.00000 \mathrm{e}-091.00000 \mathrm{e}-01$ $1.00000 \mathrm{e}-05$ 1.00000e-05 1.00000e-06 1.00000e-09 1.00000e-01 $1.00000 \mathrm{e}+001.00000 \mathrm{e}+001.00000 \mathrm{e}-011.00000 \mathrm{e}-091.00000 \mathrm{e}-01$ Element: 3452 \# of layers: 11

Kx Ky Kz Ss Por

$5.28860 \mathrm{e}+03$ 5.28860e+03 5.28860e+02 1.00000e-09 7.00000e-02 $5.28860 \mathrm{e}+03$ 5.28860e+03 5.28860e+02 1.00000e-09 7.00000e-02 5.00000e-04 5.00000e-04 5.00000e-05 1.00000e-09 1.00000e-01 5.00000e-04 5.00000e-04 5.00000e-05 1.00000e-09 1.00000e-01 $2.11313 \mathrm{e}+022.11313 \mathrm{e}+022.11313 \mathrm{e}+01$ 1.00000e-09 2.12000e-01 $2.11313 \mathrm{e}+022.11313 \mathrm{e}+022.11313 \mathrm{e}+01$ 1.00000e-09 2.12000e-01 $2.11313 \mathrm{e}+022.11313 \mathrm{e}+022.11313 \mathrm{e}+01$ 1.00000e-09 2.12000e-01 $1.00000 \mathrm{e}-02$ 1.00000e-02 1.00000e-03 1.00000e-09 1.00000e-01 $1.00000 \mathrm{e}+001.00000 \mathrm{e}+001.00000 \mathrm{e}-011.00000 \mathrm{e}-091.00000 \mathrm{e}-01$ $1.00000 \mathrm{e}-05$ 1.00000e-05 1.00000e-06 1.00000e-09 1.00000e-01 $1.00000 \mathrm{e}+001.00000 \mathrm{e}+001.00000 \mathrm{e}-011.00000 \mathrm{e}-091.00000 \mathrm{e}-01$ Element: 3453 \# of layers: 12

Kx Ky Kz Ss Por $6.07860 \mathrm{e}+03$ 6.07860e+03 6.07860e+02 1.00000e-09 7.00000e-02 $6.07860 \mathrm{e}+036.07860 \mathrm{e}+036.07860 \mathrm{e}+021.00000 \mathrm{e}-097.00000 \mathrm{e}-02$ 5.00000e-04 5.00000e-04 5.00000e-05 1.00000e-09 1.00000e-01 5.00000e-04 5.00000e-04 5.00000e-05 1.00000e-09 1.00000e-01 $2.42870 \mathrm{e}+022.42870 \mathrm{e}+022.42870 \mathrm{e}+01$ 1.00000e-09 2.12000e-01 $2.42870 \mathrm{e}+022.42870 \mathrm{e}+022.42870 \mathrm{e}+011.00000 \mathrm{e}-092.12000 \mathrm{e}-01$ $2.42870 \mathrm{e}+022.42870 \mathrm{e}+02 \quad 2.42870 \mathrm{e}+01$ 1.00000e-09 2.12000e-01 $2.42870 \mathrm{e}+022.42870 \mathrm{e}+022.42870 \mathrm{e}+01$ 1.00000e-09 2.12000e-01 $1.00000 \mathrm{e}-021.00000 \mathrm{e}-02$ 1.00000e-03 1.00000e-09 1.00000e-01 $1.00000 \mathrm{e}+001.00000 \mathrm{e}+001.00000 \mathrm{e}-011.00000 \mathrm{e}-091.00000 \mathrm{e}-01$ $1.00000 \mathrm{e}-05$ 1.00000e-05 1.00000e-06 1.00000e-09 1.00000e-01 $1.00000 \mathrm{e}+001.00000 \mathrm{e}+001.00000 \mathrm{e}-011.00000 \mathrm{e}-091.00000 \mathrm{e}-01$ Element: 3454 \# of layers: 12

Kx Ky Kz Ss Por

$6.07860 \mathrm{e}+036.07860 \mathrm{e}+036.07860 \mathrm{e}+02$ 1.00000e-09 7.00000e-02 $6.07860 \mathrm{e}+036.07860 \mathrm{e}+036.07860 \mathrm{e}+021.00000 \mathrm{e}-097.00000 \mathrm{e}-02$ $5.00000 \mathrm{e}-04$ 5.00000e-04 5.00000e-05 1.00000e-09 1.00000e-01 5.00000e-04 5.00000e-04 5.00000e-05 1.00000e-09 1.00000e-01 $2.42870 \mathrm{e}+022.42870 \mathrm{e}+022.42870 \mathrm{e}+01$ 1.00000e-09 2.12000e-01 $2.42870 \mathrm{e}+022.42870 \mathrm{e}+022.42870 \mathrm{e}+01$ 1.00000e-09 2.12000e-01 $2.42870 \mathrm{e}+022.42870 \mathrm{e}+022.42870 \mathrm{e}+011.00000 \mathrm{e}-092.12000 \mathrm{e}-01$ $2.42870 \mathrm{e}+022.42870 \mathrm{e}+022.42870 \mathrm{e}+01$ 1.00000e-09 2.12000e-01 $1.00000 \mathrm{e}-02$ 1.00000e-02 1.00000e-03 1.00000e-09 1.00000e-01 $1.00000 \mathrm{e}+001.00000 \mathrm{e}+001.00000 \mathrm{e}-011.00000 \mathrm{e}-091.00000 \mathrm{e}-01$ 
$1.00000 \mathrm{e}-05$ 1.00000e-05 1.00000e-06 1.00000e-09 1.00000e-01 $1.00000 \mathrm{e}+001.00000 \mathrm{e}+001.00000 \mathrm{e}-01$ 1.00000e-09 1.00000e-01 Element: 3455 \# of layers: 13

Kx Ky Kz Ss Por

7.29693e+03 7.29693e+03 7.29693e+02 1.00000e-09 7.00000e-02

$7.29693 \mathrm{e}+03$ 7.29693e+03 7.29693e+02 1.00000e-09 7.00000e-02

5.00000e-04 5.00000e-04 5.00000e-05 1.00000e-09 1.00000e-01

5.00000e-04 5.00000e-04 5.00000e-05 1.00000e-09 1.00000e-01

$2.91561 \mathrm{e}+02$ 2.91561e+02 2.91561e+01 1.00000e-09 2.12000e-01

$2.91561 \mathrm{e}+02$ 2.91561e+02 2.91561e+01 1.00000e-09 2.12000e-01

$2.91561 \mathrm{e}+02$ 2.91561e+02 2.91561e+01 1.00000e-09 2.12000e-01

$2.91561 \mathrm{e}+02$ 2.91561e+02 2.91561e+01 1.00000e-09 2.12000e-01

$2.91561 \mathrm{e}+02$ 2.91561e+02 2.91561e+01 1.00000e-09 2.12000e-01

$1.00000 \mathrm{e}-02$ 1.00000e-02 1.00000e-03 1.00000e-09 1.00000e-01

$1.00000 \mathrm{e}+001.00000 \mathrm{e}+001.00000 \mathrm{e}-011.00000 \mathrm{e}-091.00000 \mathrm{e}-01$

$1.00000 \mathrm{e}-05$ 1.00000e-05 1.00000e-06 1.00000e-09 1.00000e-01

$1.00000 \mathrm{e}+001.00000 \mathrm{e}+001.00000 \mathrm{e}-011.00000 \mathrm{e}-091.00000 \mathrm{e}-01$

Element: 3456 \# of layers: 12

$\mathrm{Kx} \mathrm{Ky} \mathrm{Kz}$ Ss Por

$5.54620 \mathrm{e}+03$ 5.54620e+03 5.54620e+02 1.00000e-09 7.00000e-02

$5.54620 \mathrm{e}+03$ 5.54620e+03 5.54620e+02 1.00000e-09 7.00000e-02

$5.00000 \mathrm{e}-04$ 5.00000e-04 5.00000e-05 1.00000e-09 1.00000e-01

5.00000e-04 5.00000e-04 5.00000e-05 1.00000e-09 1.00000e-01

$2.21607 \mathrm{e}+022.21607 \mathrm{e}+02$ 2.21607e+01 1.00000e-09 2.12000e-01

$2.21607 \mathrm{e}+02$ 2.21607e+02 2.21607e+01 1.00000e-09 2.12000e-01

$2.21607 \mathrm{e}+02$ 2.21607e+02 2.21607e+01 1.00000e-09 2.12000e-01

$2.21607 \mathrm{e}+02$ 2.21607e+02 2.21607e+01 1.00000e-09 2.12000e-01

$1.00000 \mathrm{e}-02$ 1.00000e-02 1.00000e-03 1.00000e-09 1.00000e-01

$1.00000 \mathrm{e}+001.00000 \mathrm{e}+001.00000 \mathrm{e}-011.00000 \mathrm{e}-091.00000 \mathrm{e}-01$

$1.00000 \mathrm{e}-05$ 1.00000e-05 1.00000e-06 1.00000e-09 1.00000e-01

$1.00000 \mathrm{e}+001.00000 \mathrm{e}+001.00000 \mathrm{e}-011.00000 \mathrm{e}-091.00000 \mathrm{e}-01$

Element: 3457 \# of layers: 11

$\mathrm{Kx} \mathrm{Ky} \mathrm{Kz}$ Ss Por

$5.28860 \mathrm{e}+03$ 5.28860e+03 5.28860e+02 1.00000e-09 7.00000e-02

$5.28860 \mathrm{e}+035.28860 \mathrm{e}+035.28860 \mathrm{e}+02$ 1.00000e-09 7.00000e-02

5.00000e-04 5.00000e-04 5.00000e-05 1.00000e-09 1.00000e-01

5.00000e-04 5.00000e-04 5.00000e-05 1.00000e-09 1.00000e-01

$2.11313 \mathrm{e}+022.11313 \mathrm{e}+02$ 2.11313e+01 1.00000e-09 2.12000e-01

2.11313e+02 2.11313e+02 2.11313e+01 1.00000e-09 2.12000e-01

$2.11313 \mathrm{e}+02$ 2.11313e+02 2.11313e+01 1.00000e-09 2.12000e-01 $1.00000 \mathrm{e}-02$ 1.00000e-02 1.00000e-03 1.00000e-09 1.00000e-01

$1.00000 \mathrm{e}+001.00000 \mathrm{e}+001.00000 \mathrm{e}-011.00000 \mathrm{e}-091.00000 \mathrm{e}-01$ $1.00000 \mathrm{e}-05$ 1.00000e-05 1.00000e-06 1.00000e-09 1.00000e-01

$1.00000 \mathrm{e}+001.00000 \mathrm{e}+001.00000 \mathrm{e}-01$ 1.00000e-09 1.00000e-01

Element: 3458 \# of layers: 13

Kx Ky Kz Ss Por 
4.57194e+03 4.57194e+03 4.57194e+02 1.00000e-09 7.00000e-02 $4.57194 \mathrm{e}+03$ 4.57194e+03 4.57194e+02 1.00000e-09 7.00000e-02

$4.57194 \mathrm{e}+03$ 4.57194e+03 4.57194e+02 1.00000e-09 7.00000e-02 5.00000e-04 5.00000e-04 5.00000e-05 1.00000e-09 1.00000e-01 5.00000e-04 5.00000e-04 5.00000e-05 1.00000e-09 1.00000e-01 $1.82679 \mathrm{e}+02$ 1.82679e+02 1.82679e+01 1.00000e-09 2.12000e-01 $1.82679 \mathrm{e}+02$ 1.82679e+02 1.82679e+01 1.00000e-09 2.12000e-01 $1.82679 \mathrm{e}+02$ 1.82679e+02 1.82679e+01 1.00000e-09 2.12000e-01 $1.82679 \mathrm{e}+02$ 1.82679e+02 1.82679e+01 1.00000e-09 2.12000e-01 $1.00000 \mathrm{e}-02$ 1.00000e-02 1.00000e-03 1.00000e-09 1.00000e-01 $1.00000 \mathrm{e}+001.00000 \mathrm{e}+001.00000 \mathrm{e}-011.00000 \mathrm{e}-091.00000 \mathrm{e}-01$ $1.00000 \mathrm{e}-05$ 1.00000e-05 1.00000e-06 1.00000e-09 1.00000e-01 $1.00000 \mathrm{e}+001.00000 \mathrm{e}+001.00000 \mathrm{e}-011.00000 \mathrm{e}-09$ 1.00000e-01 Element: 3459 \# of layers: 13

$\mathrm{Kx} \mathrm{Ky} \mathrm{Kz}$ Ss Por

3.03556e+03 3.03556e+03 3.03556e+02 1.00000e-09 7.00000e-02 $3.03556 \mathrm{e}+03$ 3.03556e+03 3.03556e+02 1.00000e-09 7.00000e-02 $3.03556 \mathrm{e}+03$ 3.03556e+03 3.03556e+02 1.00000e-09 7.00000e-02 $5.00000 \mathrm{e}-04$ 5.00000e-04 5.00000e-05 1.00000e-09 1.00000e-01 5.00000e-04 5.00000e-04 5.00000e-05 1.00000e-09 1.00000e-01 $1.21291 \mathrm{e}+021.21291 \mathrm{e}+021.21291 \mathrm{e}+01$ 1.00000e-09 2.12000e-01 $1.21291 \mathrm{e}+02$ 1.21291e+02 1.21291e+01 1.00000e-09 2.12000e-01 $1.21291 \mathrm{e}+021.21291 \mathrm{e}+02$ 1.21291e+01 1.00000e-09 2.12000e-01 $1.21291 \mathrm{e}+021.21291 \mathrm{e}+02$ 1.21291e+01 1.00000e-09 2.12000e-01 $1.00000 \mathrm{e}-011.00000 \mathrm{e}-011.00000 \mathrm{e}-021.00000 \mathrm{e}-091.00000 \mathrm{e}-01$ $1.00000 \mathrm{e}+001.00000 \mathrm{e}+001.00000 \mathrm{e}-011.00000 \mathrm{e}-091.00000 \mathrm{e}-01$ $1.00000 \mathrm{e}-05$ 1.00000e-05 1.00000e-06 1.00000e-09 1.00000e-01 $1.00000 \mathrm{e}+001.00000 \mathrm{e}+001.00000 \mathrm{e}-011.00000 \mathrm{e}-09$ 1.00000e-01 Element: 3460 \# of layers: 14

$\mathrm{Kx} \mathrm{Ky} \mathrm{Kz}$ Ss Por

3.03556e+03 3.03556e+03 3.03556e+02 1.00000e-09 7.00000e-02 $3.03556 \mathrm{e}+03$ 3.03556e+03 3.03556e+02 1.00000e-09 7.00000e-02 $3.03556 \mathrm{e}+033.03556 \mathrm{e}+033.03556 \mathrm{e}+02$ 1.00000e-09 7.00000e-02 $5.00000 \mathrm{e}-04$ 5.00000e-04 5.00000e-05 1.00000e-09 1.00000e-01 5.00000e-04 5.00000e-04 5.00000e-05 1.00000e-09 1.00000e-01 $1.21291 \mathrm{e}+021.21291 \mathrm{e}+02$ 1.21291e+01 1.00000e-09 2.12000e-01 $1.21291 \mathrm{e}+021.21291 \mathrm{e}+021.21291 \mathrm{e}+01$ 1.00000e-09 2.12000e-01 $1.21291 \mathrm{e}+02$ 1.21291e+02 1.21291e+01 1.00000e-09 2.12000e-01 $1.21291 \mathrm{e}+02$ 1.21291e+02 1.21291e+01 1.00000e-09 2.12000e-01 $1.21291 \mathrm{e}+021.21291 \mathrm{e}+021.21291 \mathrm{e}+01$ 1.00000e-09 2.12000e-01 $1.00000 \mathrm{e}-01$ 1.00000e-01 1.00000e-02 1.00000e-09 1.00000e-01 $1.00000 \mathrm{e}+001.00000 \mathrm{e}+001.00000 \mathrm{e}-011.00000 \mathrm{e}-091.00000 \mathrm{e}-01$ $1.00000 \mathrm{e}-05$ 1.00000e-05 1.00000e-06 1.00000e-09 1.00000e-01 $1.00000 \mathrm{e}+001.00000 \mathrm{e}+001.00000 \mathrm{e}-01$ 1.00000e-09 1.00000e-01 Element: 3461 \# of layers: 14

Kx Ky Kz Ss Por 
3.03556e+03 3.03556e+03 3.03556e+02 1.00000e-09 7.00000e-02 $3.03556 \mathrm{e}+033.03556 \mathrm{e}+033.03556 \mathrm{e}+02$ 1.00000e-09 7.00000e-02 $3.03556 \mathrm{e}+03$ 3.03556e+03 3.03556e+02 1.00000e-09 7.00000e-02 $5.00000 \mathrm{e}-04$ 5.00000e-04 5.00000e-05 1.00000e-09 1.00000e-01 5.00000e-04 5.00000e-04 5.00000e-05 1.00000e-09 1.00000e-01 $1.21291 \mathrm{e}+021.21291 \mathrm{e}+02$ 1.21291e+01 1.00000e-09 2.12000e-01 $1.21291 \mathrm{e}+021.21291 \mathrm{e}+02$ 1.21291e+01 1.00000e-09 2.12000e-01 $1.21291 \mathrm{e}+02$ 1.21291e+02 1.21291e+01 1.00000e-09 2.12000e-01 $1.21291 \mathrm{e}+02$ 1.21291e+02 1.21291e+01 1.00000e-09 2.12000e-01 $1.21291 \mathrm{e}+021.21291 \mathrm{e}+02$ 1.21291e+01 1.00000e-09 2.12000e-01 1.00000e-01 1.00000e-01 1.00000e-02 1.00000e-09 1.00000e-01 $1.00000 \mathrm{e}+001.00000 \mathrm{e}+001.00000 \mathrm{e}-011.00000 \mathrm{e}-091.00000 \mathrm{e}-01$ 1.00000e-05 1.00000e-05 1.00000e-06 1.00000e-09 1.00000e-01 $1.00000 \mathrm{e}+001.00000 \mathrm{e}+001.00000 \mathrm{e}-011.00000 \mathrm{e}-09$ 1.00000e-01 Element: 3462 \# of layers: 15

Kx Ky Kz Ss Por

$1.39430 \mathrm{e}+03$ 1.39430e+03 1.39430e+02 1.00000e-09 7.00000e-02 $1.39430 \mathrm{e}+03$ 1.39430e+03 1.39430e+02 1.00000e-09 7.00000e-02 $1.39430 \mathrm{e}+031.39430 \mathrm{e}+03$ 1.39430e+02 1.00000e-09 7.00000e-02 $1.39430 \mathrm{e}+031.39430 \mathrm{e}+031.39430 \mathrm{e}+02$ 1.00000e-09 7.00000e-02 5.00000e-04 5.00000e-04 5.00000e-05 1.00000e-09 1.00000e-01 5.00000e-04 5.00000e-04 5.00000e-05 1.00000e-09 1.00000e-01 $5.57089 \mathrm{e}+015.57089 \mathrm{e}+015.57089 \mathrm{e}+001.00000 \mathrm{e}-092.12000 \mathrm{e}-01$ $5.57089 \mathrm{e}+015.57089 \mathrm{e}+015.57089 \mathrm{e}+001.00000 \mathrm{e}-092.12000 \mathrm{e}-01$ $5.57089 \mathrm{e}+015.57089 \mathrm{e}+015.57089 \mathrm{e}+001.00000 \mathrm{e}-092.12000 \mathrm{e}-01$ $5.57089 \mathrm{e}+015.57089 \mathrm{e}+015.57089 \mathrm{e}+001.00000 \mathrm{e}-092.12000 \mathrm{e}-01$ $5.57089 \mathrm{e}+015.57089 \mathrm{e}+015.57089 \mathrm{e}+001.00000 \mathrm{e}-092.12000 \mathrm{e}-01$ 1.00000e-01 1.00000e-01 1.00000e-02 1.00000e-09 1.00000e-01 $1.00000 \mathrm{e}+001.00000 \mathrm{e}+001.00000 \mathrm{e}-011.00000 \mathrm{e}-091.00000 \mathrm{e}-01$ $1.00000 \mathrm{e}-051.00000 \mathrm{e}-051.00000 \mathrm{e}-061.00000 \mathrm{e}-091.00000 \mathrm{e}-01$ $1.00000 \mathrm{e}+001.00000 \mathrm{e}+001.00000 \mathrm{e}-011.00000 \mathrm{e}-091.00000 \mathrm{e}-01$ Element: 3463 \# of layers: 13

Kx Ky Kz Ss Por

$1.39430 \mathrm{e}+03$ 1.39430e+03 1.39430e+02 1.00000e-09 7.00000e-02 $1.39430 \mathrm{e}+031.39430 \mathrm{e}+03$ 1.39430e+02 1.00000e-09 7.00000e-02 $1.39430 \mathrm{e}+031.39430 \mathrm{e}+03$ 1.39430e+02 1.00000e-09 7.00000e-02 $1.39430 \mathrm{e}+031.39430 \mathrm{e}+031.39430 \mathrm{e}+02$ 1.00000e-09 7.00000e-02 5.00000e-04 5.00000e-04 5.00000e-05 1.00000e-09 1.00000e-01 5.00000e-04 5.00000e-04 5.00000e-05 1.00000e-09 1.00000e-01 $5.57089 \mathrm{e}+015.57089 \mathrm{e}+015.57089 \mathrm{e}+001.00000 \mathrm{e}-092.12000 \mathrm{e}-01$ $5.57089 \mathrm{e}+015.57089 \mathrm{e}+015.57089 \mathrm{e}+001.00000 \mathrm{e}-092.12000 \mathrm{e}-01$ $5.57089 \mathrm{e}+015.57089 \mathrm{e}+015.57089 \mathrm{e}+001.00000 \mathrm{e}-092.12000 \mathrm{e}-01$ 1.00000e-01 1.00000e-01 1.00000e-02 1.00000e-09 1.00000e-01 $1.00000 \mathrm{e}+001.00000 \mathrm{e}+001.00000 \mathrm{e}-011.00000 \mathrm{e}-091.00000 \mathrm{e}-01$ $1.00000 \mathrm{e}-05$ 1.00000e-05 1.00000e-06 1.00000e-09 1.00000e-01 $1.00000 \mathrm{e}+001.00000 \mathrm{e}+001.00000 \mathrm{e}-011.00000 \mathrm{e}-091.00000 \mathrm{e}-01$ 
Element: 3464 \# of layers: 13

$\mathrm{Kx} \mathrm{Ky} \mathrm{Kz}$ Ss Por

3.13359e+03 3.13359e+03 3.13359e+02 1.00000e-09 7.00000e-02

$3.13359 \mathrm{e}+03$ 3.13359e+03 3.13359e+02 1.00000e-09 7.00000e-02

$3.13359 \mathrm{e}+033.13359 \mathrm{e}+033.13359 \mathrm{e}+02$ 1.00000e-09 7.00000e-02

5.00000e-04 5.00000e-04 5.00000e-05 1.00000e-09 1.00000e-01

5.00000e-04 5.00000e-04 5.00000e-05 1.00000e-09 1.00000e-01

$1.25206 \mathrm{e}+02 \quad 1.25206 \mathrm{e}+02 \quad 1.25206 \mathrm{e}+01$ 1.00000e-09 2.12000e-01

$1.25206 \mathrm{e}+021.25206 \mathrm{e}+021.25206 \mathrm{e}+01$ 1.00000e-09 2.12000e-01

$1.25206 \mathrm{e}+021.25206 \mathrm{e}+02 \quad 1.25206 \mathrm{e}+01$ 1.00000e-09 2.12000e-01

$1.25206 \mathrm{e}+021.25206 \mathrm{e}+02 \quad 1.25206 \mathrm{e}+01$ 1.00000e-09 2.12000e-01

$1.00000 \mathrm{e}-02$ 1.00000e-02 1.00000e-03 1.00000e-09 1.00000e-01

$1.00000 \mathrm{e}+001.00000 \mathrm{e}+001.00000 \mathrm{e}-011.00000 \mathrm{e}-091.00000 \mathrm{e}-01$

$1.00000 \mathrm{e}-05$ 1.00000e-05 1.00000e-06 1.00000e-09 1.00000e-01

$1.00000 \mathrm{e}+001.00000 \mathrm{e}+001.00000 \mathrm{e}-01$ 1.00000e-09 1.00000e-01

Element: 3465 \# of layers: 12

$\mathrm{Kx} \mathrm{Ky} \mathrm{Kz}$ Ss Por

4.57194e+03 4.57194e+03 4.57194e+02 1.00000e-09 7.00000e-02

$4.57194 \mathrm{e}+034.57194 \mathrm{e}+03$ 4.57194e+02 1.00000e-09 7.00000e-02

$4.57194 \mathrm{e}+034.57194 \mathrm{e}+03$ 4.57194e+02 1.00000e-09 7.00000e-02

5.00000e-04 5.00000e-04 5.00000e-05 1.00000e-09 1.00000e-01

5.00000e-04 5.00000e-04 5.00000e-05 1.00000e-09 1.00000e-01

$1.82679 \mathrm{e}+02$ 1.82679e+02 1.82679e+01 1.00000e-09 2.12000e-01

$1.82679 \mathrm{e}+02$ 1.82679e+02 1.82679e+01 1.00000e-09 2.12000e-01

$1.82679 \mathrm{e}+02$ 1.82679e+02 1.82679e+01 1.00000e-09 2.12000e-01

$1.00000 \mathrm{e}-011.00000 \mathrm{e}-011.00000 \mathrm{e}-021.00000 \mathrm{e}-091.00000 \mathrm{e}-01$

$1.00000 \mathrm{e}+001.00000 \mathrm{e}+001.00000 \mathrm{e}-011.00000 \mathrm{e}-091.00000 \mathrm{e}-01$

$1.00000 \mathrm{e}-05$ 1.00000e-05 1.00000e-06 1.00000e-09 1.00000e-01

$1.00000 \mathrm{e}+001.00000 \mathrm{e}+001.00000 \mathrm{e}-011.00000 \mathrm{e}-091.00000 \mathrm{e}-01$

Element: 3466 \# of layers: 11

$\mathrm{Kx} \mathrm{Ky} \mathrm{Kz}$ Ss Por

3.03556e+03 3.03556e+03 3.03556e+02 1.00000e-09 7.00000e-02

$3.03556 \mathrm{e}+033.03556 \mathrm{e}+033.03556 \mathrm{e}+02$ 1.00000e-09 7.00000e-02

$3.03556 \mathrm{e}+033.03556 \mathrm{e}+033.03556 \mathrm{e}+021.00000 \mathrm{e}-097.00000 \mathrm{e}-02$

5.00000e-04 5.00000e-04 5.00000e-05 1.00000e-09 1.00000e-01

5.00000e-04 5.00000e-04 5.00000e-05 1.00000e-09 1.00000e-01

$1.21291 \mathrm{e}+021.21291 \mathrm{e}+021.21291 \mathrm{e}+01$ 1.00000e-09 2.12000e-01

$1.21291 \mathrm{e}+021.21291 \mathrm{e}+021.21291 \mathrm{e}+01$ 1.00000e-09 2.12000e-01

$1.00000 \mathrm{e}-01$ 1.00000e-01 1.00000e-02 1.00000e-09 1.00000e-01

$1.00000 \mathrm{e}+001.00000 \mathrm{e}+001.00000 \mathrm{e}-011.00000 \mathrm{e}-091.00000 \mathrm{e}-01$

$1.00000 \mathrm{e}-05$ 1.00000e-05 1.00000e-06 1.00000e-09 1.00000e-01

$1.00000 \mathrm{e}+001.00000 \mathrm{e}+001.00000 \mathrm{e}-011.00000 \mathrm{e}-091.00000 \mathrm{e}-01$

Element: 3467 \# of layers: 15

$\mathrm{Kx} \mathrm{Ky} \mathrm{Kz}$ Ss Por

$1.25942 \mathrm{e}+03$ 1.25942e+03 1.25942e+02 1.00000e-09 7.00000e-02

$1.25942 \mathrm{e}+03$ 1.25942e+03 1.25942e+02 1.00000e-09 7.00000e-02 
1.25942e+03 1.25942e+03 1.25942e+02 1.00000e-09 7.00000e-02 $1.25942 \mathrm{e}+03$ 1.25942e+03 1.25942e+02 1.00000e-09 7.00000e-02 5.00000e-04 5.00000e-04 5.00000e-05 1.00000e-09 1.00000e-01 5.00000e-04 5.00000e-04 5.00000e-05 1.00000e-09 1.00000e-01 $5.03223 \mathrm{e}+015.03223 \mathrm{e}+015.03223 \mathrm{e}+001.00000 \mathrm{e}-092.12000 \mathrm{e}-01$ $5.03223 \mathrm{e}+015.03223 \mathrm{e}+015.03223 \mathrm{e}+001.00000 \mathrm{e}-092.12000 \mathrm{e}-01$ $5.03223 \mathrm{e}+015.03223 \mathrm{e}+015.03223 \mathrm{e}+001.00000 \mathrm{e}-092.12000 \mathrm{e}-01$ $5.03223 \mathrm{e}+015.03223 \mathrm{e}+015.03223 \mathrm{e}+001.00000 \mathrm{e}-092.12000 \mathrm{e}-01$ 5.03223e+01 5.03223e+01 5.03223e+00 1.00000e-09 2.12000e-01 $1.00000 \mathrm{e}-011.00000 \mathrm{e}-01$ 1.00000e-02 1.00000e-09 1.00000e-01 $1.00000 \mathrm{e}+001.00000 \mathrm{e}+001.00000 \mathrm{e}-011.00000 \mathrm{e}-091.00000 \mathrm{e}-01$ $1.00000 \mathrm{e}-05$ 1.00000e-05 1.00000e-06 1.00000e-09 1.00000e-01 $1.00000 \mathrm{e}+001.00000 \mathrm{e}+001.00000 \mathrm{e}-011.00000 \mathrm{e}-09$ 1.00000e-01 Element: 3468 \# of layers: 15

$\mathrm{Kx} \mathrm{Ky} \mathrm{Kz}$ Ss Por

1.02047e+03 1.02047e+03 1.02047e+02 1.00000e-09 7.00000e-02 $1.02047 \mathrm{e}+03$ 1.02047e+03 1.02047e+02 1.00000e-09 7.00000e-02 $1.02047 \mathrm{e}+03$ 1.02047e+03 1.02047e+02 1.00000e-09 7.00000e-02 $1.02047 \mathrm{e}+03$ 1.02047e+03 1.02047e+02 1.00000e-09 7.00000e-02 5.00000e-04 5.00000e-04 5.00000e-05 1.00000e-09 1.00000e-01 5.00000e-04 5.00000e-04 5.00000e-05 1.00000e-09 1.00000e-01 4.07731e+01 4.07731e+01 4.07731e+00 1.00000e-09 2.12000e-01 $4.07731 \mathrm{e}+014.07731 \mathrm{e}+014.07731 \mathrm{e}+001.00000 \mathrm{e}-092.12000 \mathrm{e}-01$ $4.07731 \mathrm{e}+014.07731 \mathrm{e}+014.07731 \mathrm{e}+001.00000 \mathrm{e}-092.12000 \mathrm{e}-01$ $4.07731 \mathrm{e}+014.07731 \mathrm{e}+014.07731 \mathrm{e}+001.00000 \mathrm{e}-092.12000 \mathrm{e}-01$ $4.07731 \mathrm{e}+014.07731 \mathrm{e}+014.07731 \mathrm{e}+001.00000 \mathrm{e}-092.12000 \mathrm{e}-01$ $1.00000 \mathrm{e}-02$ 1.00000e-02 1.00000e-03 1.00000e-09 1.00000e-01 $1.00000 \mathrm{e}+001.00000 \mathrm{e}+001.00000 \mathrm{e}-011.00000 \mathrm{e}-091.00000 \mathrm{e}-01$ $1.00000 \mathrm{e}-05$ 1.00000e-05 1.00000e-06 1.00000e-09 1.00000e-01 $1.00000 \mathrm{e}+001.00000 \mathrm{e}+001.00000 \mathrm{e}-011.00000 \mathrm{e}-091.00000 \mathrm{e}-01$ Element: 3469 \# of layers: 16

$\mathrm{Kx} \mathrm{Ky} \mathrm{Kz}$ Ss Por

1.02047e+03 1.02047e+03 1.02047e+02 1.00000e-09 7.00000e-02 $1.02047 \mathrm{e}+03$ 1.02047e+03 1.02047e+02 1.00000e-09 7.00000e-02 $1.02047 \mathrm{e}+03$ 1.02047e+03 1.02047e+02 1.00000e-09 7.00000e-02 $1.02047 \mathrm{e}+031.02047 \mathrm{e}+03$ 1.02047e+02 1.00000e-09 7.00000e-02 $1.02047 \mathrm{e}+031.02047 \mathrm{e}+03$ 1.02047e+02 1.00000e-09 7.00000e-02 5.00000e-04 5.00000e-04 5.00000e-05 1.00000e-09 1.00000e-01 5.00000e-04 5.00000e-04 5.00000e-05 1.00000e-09 1.00000e-01 $4.07731 \mathrm{e}+014.07731 \mathrm{e}+014.07731 \mathrm{e}+001.00000 \mathrm{e}-09$ 2.12000e-01 $4.07731 \mathrm{e}+014.07731 \mathrm{e}+014.07731 \mathrm{e}+001.00000 \mathrm{e}-092.12000 \mathrm{e}-01$ $4.07731 \mathrm{e}+014.07731 \mathrm{e}+014.07731 \mathrm{e}+00$ 1.00000e-09 2.12000e-01 $4.07731 \mathrm{e}+014.07731 \mathrm{e}+014.07731 \mathrm{e}+001.00000 \mathrm{e}-09$ 2.12000e-01 4.07731e+01 4.07731e+01 4.07731e+00 1.00000e-09 2.12000e-01 $1.00000 \mathrm{e}-021.00000 \mathrm{e}-021.00000 \mathrm{e}-031.00000 \mathrm{e}-091.00000 \mathrm{e}-01$ $1.00000 \mathrm{e}+001.00000 \mathrm{e}+001.00000 \mathrm{e}-011.00000 \mathrm{e}-091.00000 \mathrm{e}-01$ 
$1.00000 \mathrm{e}-05$ 1.00000e-05 1.00000e-06 1.00000e-09 1.00000e-01 $1.00000 \mathrm{e}+001.00000 \mathrm{e}+001.00000 \mathrm{e}-01$ 1.00000e-09 1.00000e-01 Element: 3470 \# of layers: 15

$\mathrm{Kx} \mathrm{Ky} \mathrm{Kz}$ Ss Por

$1.02047 \mathrm{e}+03$ 1.02047e+03 1.02047e+02 1.00000e-09 7.00000e-02 $1.02047 \mathrm{e}+031.02047 \mathrm{e}+03$ 1.02047e+02 1.00000e-09 7.00000e-02 $1.02047 \mathrm{e}+03$ 1.02047e+03 1.02047e+02 1.00000e-09 7.00000e-02 $1.02047 \mathrm{e}+031.02047 \mathrm{e}+03$ 1.02047e+02 1.00000e-09 7.00000e-02 5.00000e-04 5.00000e-04 5.00000e-05 1.00000e-09 1.00000e-01 5.00000e-04 5.00000e-04 5.00000e-05 1.00000e-09 1.00000e-01 $4.07731 \mathrm{e}+014.07731 \mathrm{e}+014.07731 \mathrm{e}+001.00000 \mathrm{e}-09$ 2.12000e-01 $4.07731 \mathrm{e}+014.07731 \mathrm{e}+014.07731 \mathrm{e}+001.00000 \mathrm{e}-092.12000 \mathrm{e}-01$ $4.07731 \mathrm{e}+014.07731 \mathrm{e}+014.07731 \mathrm{e}+00$ 1.00000e-09 2.12000e-01 $4.07731 \mathrm{e}+014.07731 \mathrm{e}+014.07731 \mathrm{e}+001.00000 \mathrm{e}-092.12000 \mathrm{e}-01$ $4.07731 \mathrm{e}+014.07731 \mathrm{e}+014.07731 \mathrm{e}+001.00000 \mathrm{e}-092.12000 \mathrm{e}-01$ $1.00000 \mathrm{e}-02$ 1.00000e-02 1.00000e-03 1.00000e-09 1.00000e-01 $1.00000 \mathrm{e}+001.00000 \mathrm{e}+001.00000 \mathrm{e}-011.00000 \mathrm{e}-091.00000 \mathrm{e}-01$ $1.00000 \mathrm{e}-05$ 1.00000e-05 1.00000e-06 1.00000e-09 1.00000e-01 $1.00000 \mathrm{e}+001.00000 \mathrm{e}+001.00000 \mathrm{e}-01$ 1.00000e-09 1.00000e-01 Element: 3471 \# of layers: 15

$\mathrm{Kx} \mathrm{Ky} \mathrm{Kz}$ Ss Por

9.83712e+02 9.83712e+02 9.83712e+01 1.00000e-09 7.00000e-02 9.83712e+02 9.83712e+02 9.83712e+01 1.00000e-09 7.00000e-02 9.83712e+02 9.83712e+02 9.83712e+01 1.00000e-09 7.00000e-02 $9.83712 \mathrm{e}+02$ 9.83712e+02 9.83712e+01 1.00000e-09 7.00000e-02 $5.00000 \mathrm{e}-04$ 5.00000e-04 5.00000e-05 1.00000e-09 1.00000e-01 5.00000e-04 5.00000e-04 5.00000e-05 1.00000e-09 1.00000e-01 $3.93083 \mathrm{e}+013.93083 \mathrm{e}+013.93083 \mathrm{e}+001.00000 \mathrm{e}-09$ 2.12000e-01 $3.93083 \mathrm{e}+013.93083 \mathrm{e}+013.93083 \mathrm{e}+001.00000 \mathrm{e}-092.12000 \mathrm{e}-01$ $3.93083 \mathrm{e}+013.93083 \mathrm{e}+01$ 3.93083e+00 1.00000e-09 2.12000e-01 $3.93083 \mathrm{e}+013.93083 \mathrm{e}+013.93083 \mathrm{e}+001.00000 \mathrm{e}-092.12000 \mathrm{e}-01$ $3.93083 \mathrm{e}+013.93083 \mathrm{e}+013.93083 \mathrm{e}+00$ 1.00000e-09 2.12000e-01 $1.00000 \mathrm{e}-02$ 1.00000e-02 1.00000e-03 1.00000e-09 1.00000e-01 $1.00000 \mathrm{e}+001.00000 \mathrm{e}+001.00000 \mathrm{e}-011.00000 \mathrm{e}-091.00000 \mathrm{e}-01$ $1.00000 \mathrm{e}-05$ 1.00000e-05 1.00000e-06 1.00000e-09 1.00000e-01 $1.00000 \mathrm{e}+001.00000 \mathrm{e}+001.00000 \mathrm{e}-011.00000 \mathrm{e}-091.00000 \mathrm{e}-01$ Element: 3472 \# of layers: 14

Kx Ky Kz Ss Por

9.83712e+02 9.83712e+02 9.83712e+01 1.00000e-09 7.00000e-02 9.83712e+02 9.83712e+02 9.83712e+01 1.00000e-09 7.00000e-02 9.83712e+02 9.83712e+02 9.83712e+01 1.00000e-09 7.00000e-02 5.00000e-04 5.00000e-04 5.00000e-05 1.00000e-09 1.00000e-01 5.00000e-04 5.00000e-04 5.00000e-05 1.00000e-09 1.00000e-01 $3.93083 \mathrm{e}+013.93083 \mathrm{e}+01$ 3.93083e+00 1.00000e-09 2.12000e-01 $3.93083 \mathrm{e}+013.93083 \mathrm{e}+013.93083 \mathrm{e}+00$ 1.00000e-09 2.12000e-01 $3.93083 e+013.93083 e+013.93083 e+001.00000 e-092.12000 e-01$ 
$3.93083 \mathrm{e}+013.93083 \mathrm{e}+013.93083 \mathrm{e}+00$ 1.00000e-09 2.12000e-01 $3.93083 \mathrm{e}+013.93083 \mathrm{e}+013.93083 \mathrm{e}+00$ 1.00000e-09 2.12000e-01 $1.00000 \mathrm{e}-021.00000 \mathrm{e}-02$ 1.00000e-03 1.00000e-09 1.00000e-01 $1.00000 \mathrm{e}+001.00000 \mathrm{e}+001.00000 \mathrm{e}-011.00000 \mathrm{e}-091.00000 \mathrm{e}-01$ $1.00000 \mathrm{e}-05$ 1.00000e-05 1.00000e-06 1.00000e-09 1.00000e-01 $1.00000 \mathrm{e}+001.00000 \mathrm{e}+001.00000 \mathrm{e}-011.00000 \mathrm{e}-091.00000 \mathrm{e}-01$ Element: 3473 \# of layers: 14

Kx Ky Kz Ss Por

$1.27419 \mathrm{e}+031.27419 \mathrm{e}+03$ 1.27419e+02 1.00000e-09 7.00000e-02 $1.27419 \mathrm{e}+03$ 1.27419e+03 1.27419e+02 1.00000e-09 7.00000e-02 $1.27419 \mathrm{e}+03$ 1.27419e+03 1.27419e+02 1.00000e-09 7.00000e-02 5.00000e-04 5.00000e-04 5.00000e-05 1.00000e-09 1.00000e-01 5.00000e-04 5.00000e-04 5.00000e-05 1.00000e-09 1.00000e-01 $5.09141 \mathrm{e}+015.09141 \mathrm{e}+015.09141 \mathrm{e}+001.00000 \mathrm{e}-092.12000 \mathrm{e}-01$ $5.09141 \mathrm{e}+015.09141 \mathrm{e}+015.09141 \mathrm{e}+001.00000 \mathrm{e}-092.12000 \mathrm{e}-01$ $5.09141 \mathrm{e}+015.09141 \mathrm{e}+015.09141 \mathrm{e}+001.00000 \mathrm{e}-092.12000 \mathrm{e}-01$ $5.09141 \mathrm{e}+015.09141 \mathrm{e}+015.09141 \mathrm{e}+001.00000 \mathrm{e}-092.12000 \mathrm{e}-01$ $5.09141 \mathrm{e}+015.09141 \mathrm{e}+015.09141 \mathrm{e}+00$ 1.00000e-09 2.12000e-01 $1.00000 \mathrm{e}-011.00000 \mathrm{e}-011.00000 \mathrm{e}-021.00000 \mathrm{e}-091.00000 \mathrm{e}-01$ $1.00000 \mathrm{e}+001.00000 \mathrm{e}+001.00000 \mathrm{e}-011.00000 \mathrm{e}-091.00000 \mathrm{e}-01$ $1.00000 \mathrm{e}-05$ 1.00000e-05 1.00000e-06 1.00000e-09 1.00000e-01 $1.00000 \mathrm{e}+001.00000 \mathrm{e}+001.00000 \mathrm{e}-011.00000 \mathrm{e}-091.00000 \mathrm{e}-01$ Element: 3474 \# of layers: 14

Kx Ky Kz Ss Por

$1.25942 \mathrm{e}+03$ 1.25942e+03 1.25942e+02 1.00000e-09 7.00000e-02 $1.25942 \mathrm{e}+03 \quad 1.25942 \mathrm{e}+03 \quad 1.25942 \mathrm{e}+021.00000 \mathrm{e}-097.00000 \mathrm{e}-02$ $1.25942 \mathrm{e}+03 \quad 1.25942 \mathrm{e}+03 \quad 1.25942 \mathrm{e}+021.00000 \mathrm{e}-097.00000 \mathrm{e}-02$ 5.00000e-04 5.00000e-04 5.00000e-05 1.00000e-09 1.00000e-01 5.00000e-04 5.00000e-04 5.00000e-05 1.00000e-09 1.00000e-01 $5.03223 \mathrm{e}+015.03223 \mathrm{e}+015.03223 \mathrm{e}+001.00000 \mathrm{e}-092.12000 \mathrm{e}-01$ $5.03223 \mathrm{e}+015.03223 \mathrm{e}+015.03223 \mathrm{e}+00$ 1.00000e-09 2.12000e-01 $5.03223 \mathrm{e}+015.03223 \mathrm{e}+015.03223 \mathrm{e}+00$ 1.00000e-09 2.12000e-01 $5.03223 \mathrm{e}+015.03223 \mathrm{e}+015.03223 \mathrm{e}+001.00000 \mathrm{e}-092.12000 \mathrm{e}-01$ $5.03223 \mathrm{e}+015.03223 \mathrm{e}+015.03223 \mathrm{e}+00$ 1.00000e-09 2.12000e-01 $1.00000 \mathrm{e}-011.00000 \mathrm{e}-011.00000 \mathrm{e}-021.00000 \mathrm{e}-091.00000 \mathrm{e}-01$ $1.00000 \mathrm{e}+001.00000 \mathrm{e}+001.00000 \mathrm{e}-011.00000 \mathrm{e}-091.00000 \mathrm{e}-01$ $1.00000 \mathrm{e}-05$ 1.00000e-05 1.00000e-06 1.00000e-09 1.00000e-01 $1.00000 \mathrm{e}+001.00000 \mathrm{e}+001.00000 \mathrm{e}-011.00000 \mathrm{e}-091.00000 \mathrm{e}-01$ Element: 3475 \# of layers: 14

Kx Ky Kz Ss Por $1.02047 \mathrm{e}+03$ 1.02047e+03 1.02047e+02 1.00000e-09 7.00000e-02 $1.02047 \mathrm{e}+031.02047 \mathrm{e}+03 \quad 1.02047 \mathrm{e}+021.00000 \mathrm{e}-097.00000 \mathrm{e}-02$ $1.02047 \mathrm{e}+03 \quad 1.02047 \mathrm{e}+03 \quad 1.02047 \mathrm{e}+021.00000 \mathrm{e}-097.00000 \mathrm{e}-02$ $5.00000 \mathrm{e}-04$ 5.00000e-04 5.00000e-05 1.00000e-09 1.00000e-01 5.00000e-04 5.00000e-04 5.00000e-05 1.00000e-09 1.00000e-01 $4.07731 \mathrm{e}+014.07731 \mathrm{e}+014.07731 \mathrm{e}+001.00000 \mathrm{e}-092.12000 \mathrm{e}-01$ 
4.07731e+01 4.07731e+01 4.07731e+00 1.00000e-09 2.12000e-01 $4.07731 \mathrm{e}+014.07731 \mathrm{e}+014.07731 \mathrm{e}+001.00000 \mathrm{e}-092.12000 \mathrm{e}-01$ $4.07731 \mathrm{e}+014.07731 \mathrm{e}+014.07731 \mathrm{e}+001.00000 \mathrm{e}-092.12000 \mathrm{e}-01$ $4.07731 \mathrm{e}+014.07731 \mathrm{e}+014.07731 \mathrm{e}+001.00000 \mathrm{e}-092.12000 \mathrm{e}-01$ $1.00000 \mathrm{e}-021.00000 \mathrm{e}-021.00000 \mathrm{e}-031.00000 \mathrm{e}-091.00000 \mathrm{e}-01$ $1.00000 \mathrm{e}+001.00000 \mathrm{e}+001.00000 \mathrm{e}-011.00000 \mathrm{e}-091.00000 \mathrm{e}-01$ 1.00000e-05 1.00000e-05 1.00000e-06 1.00000e-09 1.00000e-01 $1.00000 \mathrm{e}+001.00000 \mathrm{e}+001.00000 \mathrm{e}-011.00000 \mathrm{e}-091.00000 \mathrm{e}-01$ Element: 3476 \# of layers: 16

$\mathrm{Kx} \mathrm{Ky} \mathrm{Kz}$ Ss Por

9.02802e+02 9.02802e+02 9.02802e+01 1.00000e-09 7.00000e-02 $9.02802 \mathrm{e}+02$ 9.02802e+02 9.02802e+01 1.00000e-09 7.00000e-02 9.02802e+02 9.02802e+02 9.02802e+01 1.00000e-09 7.00000e-02 9.02802e+02 9.02802e+02 9.02802e+01 1.00000e-09 7.00000e-02 $9.02802 \mathrm{e}+02$ 9.02802e+02 9.02802e+01 1.00000e-09 7.00000e-02 5.00000e-04 5.00000e-04 5.00000e-05 1.00000e-09 1.00000e-01 5.00000e-04 5.00000e-04 5.00000e-05 1.00000e-09 1.00000e-01 $3.60728 \mathrm{e}+013.60728 \mathrm{e}+013.60728 \mathrm{e}+001.00000 \mathrm{e}-09$ 2.12000e-01 $3.60728 \mathrm{e}+013.60728 \mathrm{e}+013.60728 \mathrm{e}+001.00000 \mathrm{e}-092.12000 \mathrm{e}-01$ $3.60728 \mathrm{e}+013.60728 \mathrm{e}+013.60728 \mathrm{e}+001.00000 \mathrm{e}-092.12000 \mathrm{e}-01$ $3.60728 \mathrm{e}+013.60728 \mathrm{e}+013.60728 \mathrm{e}+001.00000 \mathrm{e}-092.12000 \mathrm{e}-01$ $3.60728 \mathrm{e}+013.60728 \mathrm{e}+013.60728 \mathrm{e}+00$ 1.00000e-09 2.12000e-01 $1.00000 \mathrm{e}-02$ 1.00000e-02 1.00000e-03 1.00000e-09 1.00000e-01 $1.00000 \mathrm{e}+001.00000 \mathrm{e}+001.00000 \mathrm{e}-011.00000 \mathrm{e}-091.00000 \mathrm{e}-01$ $1.00000 \mathrm{e}-05$ 1.00000e-05 1.00000e-06 1.00000e-09 1.00000e-01 $1.00000 \mathrm{e}+001.00000 \mathrm{e}+001.00000 \mathrm{e}-01$ 1.00000e-09 1.00000e-01 Element: 3477 \# of layers: 16

$\mathrm{Kx} \mathrm{Ky} \mathrm{Kz}$ Ss Por

5.34095e+02 5.34095e+02 5.34095e+01 1.00000e-09 7.00000e-02 5.34095e+02 5.34095e+02 5.34095e+01 1.00000e-09 7.00000e-02 5.34095e+02 5.34095e+02 5.34095e+01 1.00000e-09 7.00000e-02 5.34095e+02 5.34095e+02 5.34095e+01 1.00000e-09 7.00000e-02 $5.34095 \mathrm{e}+025.34095 \mathrm{e}+02$ 5.34095e+01 1.00000e-09 7.00000e-02 5.00000e-04 5.00000e-04 5.00000e-05 1.00000e-09 1.00000e-01 5.00000e-04 5.00000e-04 5.00000e-05 1.00000e-09 1.00000e-01 $2.13406 \mathrm{e}+012.13406 \mathrm{e}+012.13406 \mathrm{e}+00$ 1.00000e-09 2.12000e-01 $2.13406 \mathrm{e}+012.13406 \mathrm{e}+012.13406 \mathrm{e}+001.00000 \mathrm{e}-092.12000 \mathrm{e}-01$ $2.13406 \mathrm{e}+012.13406 \mathrm{e}+012.13406 \mathrm{e}+00$ 1.00000e-09 2.12000e-01 $2.13406 \mathrm{e}+012.13406 \mathrm{e}+012.13406 \mathrm{e}+001.00000 \mathrm{e}-092.12000 \mathrm{e}-01$ $2.13406 \mathrm{e}+012.13406 \mathrm{e}+012.13406 \mathrm{e}+00$ 1.00000e-09 2.12000e-01 $1.00000 \mathrm{e}-021.00000 \mathrm{e}-021.00000 \mathrm{e}-031.00000 \mathrm{e}-091.00000 \mathrm{e}-01$ $1.00000 \mathrm{e}+001.00000 \mathrm{e}+001.00000 \mathrm{e}-011.00000 \mathrm{e}-091.00000 \mathrm{e}-01$ $1.00000 \mathrm{e}-05$ 1.00000e-05 1.00000e-06 1.00000e-09 1.00000e-01 $1.00000 \mathrm{e}+001.00000 \mathrm{e}+001.00000 \mathrm{e}-01$ 1.00000e-09 1.00000e-01 Element: 3478 \# of layers: 16

Kx Ky Kz Ss Por 
5.34095e+02 5.34095e+02 5.34095e+01 1.00000e-09 7.00000e-02 5.34095e+02 5.34095e+02 5.34095e+01 1.00000e-09 7.00000e-02 $5.34095 \mathrm{e}+02$ 5.34095e+02 5.34095e+01 1.00000e-09 7.00000e-02 $5.34095 \mathrm{e}+02$ 5.34095e+02 5.34095e+01 1.00000e-09 7.00000e-02 $5.34095 \mathrm{e}+025.34095 \mathrm{e}+02$ 5.34095e+01 1.00000e-09 7.00000e-02 5.00000e-04 5.00000e-04 5.00000e-05 1.00000e-09 1.00000e-01 5.00000e-04 5.00000e-04 5.00000e-05 1.00000e-09 1.00000e-01 $2.13406 \mathrm{e}+012.13406 \mathrm{e}+012.13406 \mathrm{e}+00$ 1.00000e-09 2.12000e-01 $2.13406 \mathrm{e}+012.13406 \mathrm{e}+012.13406 \mathrm{e}+001.00000 \mathrm{e}-092.12000 \mathrm{e}-01$ $2.13406 \mathrm{e}+012.13406 \mathrm{e}+012.13406 \mathrm{e}+00$ 1.00000e-09 2.12000e-01 $2.13406 \mathrm{e}+012.13406 \mathrm{e}+012.13406 \mathrm{e}+00$ 1.00000e-09 2.12000e-01 $2.13406 \mathrm{e}+012.13406 \mathrm{e}+012.13406 \mathrm{e}+001.00000 \mathrm{e}-092.12000 \mathrm{e}-01$ $1.00000 \mathrm{e}-02$ 1.00000e-02 1.00000e-03 1.00000e-09 1.00000e-01 $1.00000 \mathrm{e}+001.00000 \mathrm{e}+001.00000 \mathrm{e}-011.00000 \mathrm{e}-091.00000 \mathrm{e}-01$ $1.00000 \mathrm{e}-05$ 1.00000e-05 1.00000e-06 1.00000e-09 1.00000e-01 $1.00000 \mathrm{e}+001.00000 \mathrm{e}+001.00000 \mathrm{e}-011.00000 \mathrm{e}-091.00000 \mathrm{e}-01$ Element: 3479 \# of layers: 15

$\mathrm{Kx} \mathrm{Ky} \mathrm{Kz}$ Ss Por

5.34095e+02 5.34095e+02 5.34095e+01 1.00000e-09 7.00000e-02 5.34095e+02 5.34095e+02 5.34095e+01 1.00000e-09 7.00000e-02 $5.34095 \mathrm{e}+025.34095 \mathrm{e}+02$ 5.34095e+01 1.00000e-09 7.00000e-02 5.34095e+02 5.34095e+02 5.34095e+01 1.00000e-09 7.00000e-02 5.00000e-04 5.00000e-04 5.00000e-05 1.00000e-09 1.00000e-01 5.00000e-04 5.00000e-04 5.00000e-05 1.00000e-09 1.00000e-01

$2.13406 \mathrm{e}+012.13406 \mathrm{e}+012.13406 \mathrm{e}+001.00000 \mathrm{e}-092.12000 \mathrm{e}-01$ $2.13406 \mathrm{e}+012.13406 \mathrm{e}+012.13406 \mathrm{e}+001.00000 \mathrm{e}-092.12000 \mathrm{e}-01$ $2.13406 \mathrm{e}+012.13406 \mathrm{e}+012.13406 \mathrm{e}+001.00000 \mathrm{e}-092.12000 \mathrm{e}-01$ $2.13406 \mathrm{e}+012.13406 \mathrm{e}+012.13406 \mathrm{e}+001.00000 \mathrm{e}-092.12000 \mathrm{e}-01$ $2.13406 \mathrm{e}+012.13406 \mathrm{e}+012.13406 \mathrm{e}+001.00000 \mathrm{e}-092.12000 \mathrm{e}-01$ $1.00000 \mathrm{e}-02$ 1.00000e-02 1.00000e-03 1.00000e-09 1.00000e-01 $1.00000 \mathrm{e}+001.00000 \mathrm{e}+001.00000 \mathrm{e}-01$ 1.00000e-09 1.00000e-01 $1.00000 \mathrm{e}-05$ 1.00000e-05 1.00000e-06 1.00000e-09 1.00000e-01 $1.00000 \mathrm{e}+001.00000 \mathrm{e}+001.00000 \mathrm{e}-011.00000 \mathrm{e}-091.00000 \mathrm{e}-01$ Element: 3480 \# of layers: 15

$\mathrm{Kx} \mathrm{Ky} \mathrm{Kz}$ Ss Por

$1.46503 \mathrm{e}+02$ 1.46503e+02 1.46503e+01 1.00000e-09 7.00000e-02 $1.46503 \mathrm{e}+021.46503 \mathrm{e}+021.46503 \mathrm{e}+01$ 1.00000e-09 7.00000e-02 $1.46503 \mathrm{e}+02$ 1.46503e+02 1.46503e+01 1.00000e-09 7.00000e-02 $1.46503 \mathrm{e}+021.46503 \mathrm{e}+02$ 1.46503e+01 1.00000e-09 7.00000e-02 5.00000e-04 5.00000e-04 5.00000e-05 1.00000e-09 1.00000e-01 5.00000e-04 5.00000e-04 5.00000e-05 1.00000e-09 1.00000e-01 $5.85350 \mathrm{e}+005.85350 \mathrm{e}+00$ 5.85350e-01 1.00000e-09 2.12000e-01 $5.85350 \mathrm{e}+00$ 5.85350e+00 5.85350e-01 1.00000e-09 2.12000e-01 $5.85350 \mathrm{e}+005.85350 \mathrm{e}+00$ 5.85350e-01 1.00000e-09 2.12000e-01 $5.85350 \mathrm{e}+005.85350 \mathrm{e}+00$ 5.85350e-01 1.00000e-09 2.12000e-01 $5.85350 \mathrm{e}+00$ 5.85350e+00 5.85350e-01 1.00000e-09 2.12000e-01 
$1.00000 \mathrm{e}-02$ 1.00000e-02 1.00000e-03 1.00000e-09 1.00000e-01 $1.00000 \mathrm{e}+001.00000 \mathrm{e}+001.00000 \mathrm{e}-011.00000 \mathrm{e}-091.00000 \mathrm{e}-01$ $1.00000 \mathrm{e}-05$ 1.00000e-05 1.00000e-06 1.00000e-09 1.00000e-01 $1.00000 \mathrm{e}+001.00000 \mathrm{e}+001.00000 \mathrm{e}-011.00000 \mathrm{e}-091.00000 \mathrm{e}-01$ Element: 3481 \# of layers: 15

$\mathrm{Kx} \mathrm{Ky} \mathrm{Kz}$ Ss Por

$1.46503 \mathrm{e}+02$ 1.46503e+02 1.46503e+01 1.00000e-09 7.00000e-02 $1.46503 \mathrm{e}+02$ 1.46503e+02 1.46503e+01 1.00000e-09 7.00000e-02 $1.46503 \mathrm{e}+021.46503 \mathrm{e}+02$ 1.46503e+01 1.00000e-09 7.00000e-02 $1.46503 \mathrm{e}+02$ 1.46503e+02 1.46503e+01 1.00000e-09 7.00000e-02 5.00000e-04 5.00000e-04 5.00000e-05 1.00000e-09 1.00000e-01 5.00000e-04 5.00000e-04 5.00000e-05 1.00000e-09 1.00000e-01 $5.85350 \mathrm{e}+005.85350 \mathrm{e}+005.85350 \mathrm{e}-01$ 1.00000e-09 2.12000e-01 $5.85350 \mathrm{e}+005.85350 \mathrm{e}+00$ 5.85350e-01 1.00000e-09 2.12000e-01 $5.85350 \mathrm{e}+005.85350 \mathrm{e}+00$ 5.85350e-01 1.00000e-09 2.12000e-01 $5.85350 \mathrm{e}+005.85350 \mathrm{e}+005.85350 \mathrm{e}-011.00000 \mathrm{e}-092.12000 \mathrm{e}-01$ $5.85350 \mathrm{e}+005.85350 \mathrm{e}+00$ 5.85350e-01 1.00000e-09 2.12000e-01 $1.00000 \mathrm{e}-02$ 1.00000e-02 1.00000e-03 1.00000e-09 1.00000e-01 $1.00000 \mathrm{e}+001.00000 \mathrm{e}+001.00000 \mathrm{e}-011.00000 \mathrm{e}-091.00000 \mathrm{e}-01$ $1.00000 \mathrm{e}-05$ 1.00000e-05 1.00000e-06 1.00000e-09 1.00000e-01 $1.00000 \mathrm{e}+001.00000 \mathrm{e}+001.00000 \mathrm{e}-011.00000 \mathrm{e}-091.00000 \mathrm{e}-01$ Element: 3482 \# of layers: 15

$\mathrm{Kx} \mathrm{Ky} \mathrm{Kz}$ Ss Por

3.55435e+02 3.55435e+02 3.55435e+01 1.00000e-09 7.00000e-02 $3.55435 \mathrm{e}+02$ 3.55435e+02 3.55435e+01 1.00000e-09 7.00000e-02 $3.55435 \mathrm{e}+02$ 3.55435e+02 3.55435e+01 1.00000e-09 7.00000e-02 $3.55435 \mathrm{e}+023.55435 \mathrm{e}+023.55435 \mathrm{e}+01$ 1.00000e-09 7.00000e-02 5.00000e-04 5.00000e-04 5.00000e-05 1.00000e-09 1.00000e-01 5.00000e-04 5.00000e-04 5.00000e-05 1.00000e-09 1.00000e-01 $1.42018 \mathrm{e}+01$ 1.42018e+01 1.42019e+00 1.00000e-09 2.12000e-01 $1.42018 \mathrm{e}+01$ 1.42018e+01 1.42019e+00 1.00000e-09 2.12000e-01 $1.42018 \mathrm{e}+01$ 1.42018e+01 1.42019e+00 1.00000e-09 2.12000e-01 $1.42018 \mathrm{e}+011.42018 \mathrm{e}+011.42019 \mathrm{e}+001.00000 \mathrm{e}-092.12000 \mathrm{e}-01$ $1.42018 \mathrm{e}+011.42018 \mathrm{e}+01$ 1.42019e+00 1.00000e-09 2.12000e-01 $1.00000 \mathrm{e}-02$ 1.00000e-02 1.00000e-03 1.00000e-09 1.00000e-01 $1.00000 \mathrm{e}+001.00000 \mathrm{e}+001.00000 \mathrm{e}-011.00000 \mathrm{e}-091.00000 \mathrm{e}-01$ $1.00000 \mathrm{e}-05$ 1.00000e-05 1.00000e-06 1.00000e-09 1.00000e-01 $1.00000 \mathrm{e}+001.00000 \mathrm{e}+001.00000 \mathrm{e}-011.00000 \mathrm{e}-091.00000 \mathrm{e}-01$ Element: 3483 \# of layers: 15

$\mathrm{Kx} \mathrm{Ky} \mathrm{Kz}$ Ss Por 9.02802e+02 9.02802e+02 9.02802e+01 1.00000e-09 7.00000e-02 $9.02802 \mathrm{e}+02$ 9.02802e+02 9.02802e+01 1.00000e-09 7.00000e-02 $9.02802 \mathrm{e}+02$ 9.02802e+02 9.02802e+01 1.00000e-09 7.00000e-02 9.02802e+02 9.02802e+02 9.02802e+01 1.00000e-09 7.00000e-02 $5.00000 \mathrm{e}-04$ 5.00000e-04 5.00000e-05 1.00000e-09 1.00000e-01 5.00000e-04 5.00000e-04 5.00000e-05 1.00000e-09 1.00000e-01 
3.60728e+01 3.60728e+01 3.60728e+00 1.00000e-09 2.12000e-01 $3.60728 \mathrm{e}+013.60728 \mathrm{e}+013.60728 \mathrm{e}+001.00000 \mathrm{e}-092.12000 \mathrm{e}-01$ $3.60728 \mathrm{e}+013.60728 \mathrm{e}+013.60728 \mathrm{e}+001.00000 \mathrm{e}-092.12000 \mathrm{e}-01$ $3.60728 \mathrm{e}+013.60728 \mathrm{e}+013.60728 \mathrm{e}+001.00000 \mathrm{e}-092.12000 \mathrm{e}-01$ $3.60728 \mathrm{e}+013.60728 \mathrm{e}+013.60728 \mathrm{e}+001.00000 \mathrm{e}-092.12000 \mathrm{e}-01$ $1.00000 \mathrm{e}-02$ 1.00000e-02 1.00000e-03 1.00000e-09 1.00000e-01 $1.00000 \mathrm{e}+001.00000 \mathrm{e}+001.00000 \mathrm{e}-011.00000 \mathrm{e}-091.00000 \mathrm{e}-01$ $1.00000 \mathrm{e}-05$ 1.00000e-05 1.00000e-06 1.00000e-09 1.00000e-01 $1.00000 \mathrm{e}+001.00000 \mathrm{e}+001.00000 \mathrm{e}-011.00000 \mathrm{e}-091.00000 \mathrm{e}-01$ Element: 3484 \# of layers: 15

$\mathrm{Kx} \mathrm{Ky} \mathrm{Kz}$ Ss Por

5.34095e+02 5.34095e+02 5.34095e+01 1.00000e-09 7.00000e-02 5.34095e+02 5.34095e+02 5.34095e+01 1.00000e-09 7.00000e-02 $5.34095 \mathrm{e}+02$ 5.34095e+02 5.34095e+01 1.00000e-09 7.00000e-02 $5.34095 \mathrm{e}+025.34095 \mathrm{e}+02$ 5.34095e+01 1.00000e-09 7.00000e-02 5.00000e-04 5.00000e-04 5.00000e-05 1.00000e-09 1.00000e-01 5.00000e-04 5.00000e-04 5.00000e-05 1.00000e-09 1.00000e-01

$2.13406 \mathrm{e}+012.13406 \mathrm{e}+012.13406 \mathrm{e}+00$ 1.00000e-09 2.12000e-01 $2.13406 \mathrm{e}+012.13406 \mathrm{e}+012.13406 \mathrm{e}+00$ 1.00000e-09 2.12000e-01 $2.13406 \mathrm{e}+012.13406 \mathrm{e}+012.13406 \mathrm{e}+00$ 1.00000e-09 2.12000e-01 $2.13406 \mathrm{e}+012.13406 \mathrm{e}+012.13406 \mathrm{e}+001.00000 \mathrm{e}-092.12000 \mathrm{e}-01$ $2.13406 \mathrm{e}+012.13406 \mathrm{e}+012.13406 \mathrm{e}+00$ 1.00000e-09 2.12000e-01 $1.00000 \mathrm{e}-02$ 1.00000e-02 1.00000e-03 1.00000e-09 1.00000e-01 $1.00000 \mathrm{e}+001.00000 \mathrm{e}+001.00000 \mathrm{e}-011.00000 \mathrm{e}-091.00000 \mathrm{e}-01$ $1.00000 \mathrm{e}-05$ 1.00000e-05 1.00000e-06 1.00000e-09 1.00000e-01 $1.00000 \mathrm{e}+001.00000 \mathrm{e}+001.00000 \mathrm{e}-01$ 1.00000e-09 1.00000e-01 Element: 3485 \# of layers: 16

$\mathrm{Kx} \mathrm{Ky} \mathrm{Kz}$ Ss Por

$1.65189 \mathrm{e}+02$ 1.65189e+02 1.65189e+01 1.00000e-09 7.00000e-02 $1.65189 \mathrm{e}+02$ 1.65189e+02 1.65189e+01 1.00000e-09 7.00000e-02 $1.65189 \mathrm{e}+02$ 1.65189e+02 1.65189e+01 1.00000e-09 7.00000e-02 $1.65189 \mathrm{e}+02$ 1.65189e+02 1.65189e+01 1.00000e-09 7.00000e-02 $1.65189 \mathrm{e}+021.65189 \mathrm{e}+02 \quad 1.65189 \mathrm{e}+01$ 1.00000e-09 7.00000e-02 5.00000e-04 5.00000e-04 5.00000e-05 1.00000e-09 1.00000e-01 5.00000e-04 5.00000e-04 5.00000e-05 1.00000e-09 1.00000e-01 $6.60052 \mathrm{e}+006.60052 \mathrm{e}+006.60052 \mathrm{e}-01$ 1.00000e-09 2.12000e-01 $6.60052 \mathrm{e}+006.60052 \mathrm{e}+00$ 6.60052e-01 1.00000e-09 2.12000e-01 6.60052e+00 6.60052e+00 6.60052e-01 1.00000e-09 2.12000e-01 $6.60052 \mathrm{e}+006.60052 \mathrm{e}+00$ 6.60052e-01 1.00000e-09 2.12000e-01 6.60052e+00 6.60052e+00 6.60052e-01 1.00000e-09 2.12000e-01 $1.00000 \mathrm{e}-02$ 1.00000e-02 1.00000e-03 1.00000e-09 1.00000e-01 $1.00000 \mathrm{e}+001.00000 \mathrm{e}+001.00000 \mathrm{e}-011.00000 \mathrm{e}-091.00000 \mathrm{e}-01$ $1.00000 \mathrm{e}-05$ 1.00000e-05 1.00000e-06 1.00000e-09 1.00000e-01 $1.00000 \mathrm{e}+001.00000 \mathrm{e}+001.00000 \mathrm{e}-011.00000 \mathrm{e}-091.00000 \mathrm{e}-01$ Element: 3486 \# of layers: 15

Kx Ky Kz Ss Por 
1.41403e+02 1.41403e+02 1.41403e+01 1.00000e-09 7.00000e-02 $1.41403 \mathrm{e}+02$ 1.41403e+02 1.41403e+01 1.00000e-09 7.00000e-02 $1.41403 \mathrm{e}+02$ 1.41403e+02 1.41403e+01 1.00000e-09 7.00000e-02 $1.41403 \mathrm{e}+02$ 1.41403e+02 1.41403e+01 1.00000e-09 7.00000e-02 5.00000e-04 5.00000e-04 5.00000e-05 1.00000e-09 1.00000e-01 5.00000e-04 5.00000e-04 5.00000e-05 1.00000e-09 1.00000e-01 5.64987e+00 5.64987e+00 5.64987e-01 1.00000e-09 2.12000e-01 $5.64987 \mathrm{e}+00$ 5.64987e+00 5.64987e-01 1.00000e-09 2.12000e-01 5.64987e+00 5.64987e+00 5.64987e-01 1.00000e-09 2.12000e-01 5.64987e+00 5.64987e+00 5.64987e-01 1.00000e-09 2.12000e-01 5.64987e+00 5.64987e+00 5.64987e-01 1.00000e-09 2.12000e-01 $1.00000 \mathrm{e}-02$ 1.00000e-02 1.00000e-03 1.00000e-09 1.00000e-01 $1.00000 \mathrm{e}+001.00000 \mathrm{e}+001.00000 \mathrm{e}-011.00000 \mathrm{e}-091.00000 \mathrm{e}-01$ $1.00000 \mathrm{e}-05$ 1.00000e-05 1.00000e-06 1.00000e-09 1.00000e-01 $1.00000 \mathrm{e}+001.00000 \mathrm{e}+001.00000 \mathrm{e}-01$ 1.00000e-09 1.00000e-01 Element: 3487 \# of layers: 15

$\mathrm{Kx} \mathrm{Ky} \mathrm{Kz}$ Ss Por

$1.41403 \mathrm{e}+02$ 1.41403e+02 1.41403e+01 1.00000e-09 7.00000e-02 $1.41403 \mathrm{e}+02$ 1.41403e+02 1.41403e+01 1.00000e-09 7.00000e-02 $1.41403 \mathrm{e}+021.41403 \mathrm{e}+02$ 1.41403e+01 1.00000e-09 7.00000e-02 $1.41403 \mathrm{e}+02$ 1.41403e+02 1.41403e+01 1.00000e-09 7.00000e-02 5.00000e-04 5.00000e-04 5.00000e-05 1.00000e-09 1.00000e-01 5.00000e-04 5.00000e-04 5.00000e-05 1.00000e-09 1.00000e-01 5.64987e+00 5.64987e+00 5.64987e-01 1.00000e-09 2.12000e-01 $5.64987 \mathrm{e}+00$ 5.64987e+00 5.64987e-01 1.00000e-09 2.12000e-01 5.64987e+00 5.64987e+00 5.64987e-01 1.00000e-09 2.12000e-01 5.64987e+00 5.64987e+00 5.64987e-01 1.00000e-09 2.12000e-01 5.64987e+00 5.64987e+00 5.64987e-01 1.00000e-09 2.12000e-01 $1.00000 \mathrm{e}-02$ 1.00000e-02 1.00000e-03 1.00000e-09 1.00000e-01 $1.00000 \mathrm{e}+001.00000 \mathrm{e}+001.00000 \mathrm{e}-011.00000 \mathrm{e}-091.00000 \mathrm{e}-01$ $1.00000 \mathrm{e}-05$ 1.00000e-05 1.00000e-06 1.00000e-09 1.00000e-01 $1.00000 \mathrm{e}+001.00000 \mathrm{e}+001.00000 \mathrm{e}-01$ 1.00000e-09 1.00000e-01 Element: 3488 \# of layers: 15

$\mathrm{Kx} \mathrm{Ky} \mathrm{Kz}$ Ss Por

1.41403e+02 1.41403e+02 1.41403e+01 1.00000e-09 7.00000e-02 $1.41403 \mathrm{e}+02$ 1.41403e+02 1.41403e+01 1.00000e-09 7.00000e-02 $1.41403 \mathrm{e}+021.41403 \mathrm{e}+02$ 1.41403e+01 1.00000e-09 7.00000e-02 $1.41403 \mathrm{e}+021.41403 \mathrm{e}+021.41403 \mathrm{e}+01$ 1.00000e-09 7.00000e-02 5.00000e-04 5.00000e-04 5.00000e-05 1.00000e-09 1.00000e-01 5.00000e-04 5.00000e-04 5.00000e-05 1.00000e-09 1.00000e-01 $5.64987 \mathrm{e}+00$ 5.64987e+00 5.64987e-01 1.00000e-09 2.12000e-01 $5.64987 \mathrm{e}+00$ 5.64987e+00 5.64987e-01 1.00000e-09 2.12000e-01 5.64987e+00 5.64987e+00 5.64987e-01 1.00000e-09 2.12000e-01 5.64987e+00 5.64987e+00 5.64987e-01 1.00000e-09 2.12000e-01 5.64987e+00 5.64987e+00 5.64987e-01 1.00000e-09 2.12000e-01 $1.00000 \mathrm{e}-02$ 1.00000e-02 1.00000e-03 1.00000e-09 1.00000e-01 
$1.00000 \mathrm{e}+001.00000 \mathrm{e}+001.00000 \mathrm{e}-011.00000 \mathrm{e}-091.00000 \mathrm{e}-01$ $1.00000 \mathrm{e}-05$ 1.00000e-05 1.00000e-06 1.00000e-09 1.00000e-01 $1.00000 \mathrm{e}+001.00000 \mathrm{e}+001.00000 \mathrm{e}-01$ 1.00000e-09 1.00000e-01 Element: 3489 \# of layers: 15

$\mathrm{Kx} \mathrm{Ky} \mathrm{Kz}$ Ss Por

1.40187e+02 1.40187e+02 1.40187e+01 1.00000e-09 7.00000e-02 $1.40187 \mathrm{e}+02$ 1.40187e+02 1.40187e+01 1.00000e-09 7.00000e-02 $1.40187 \mathrm{e}+02$ 1.40187e+02 1.40187e+01 1.00000e-09 7.00000e-02 $1.40187 \mathrm{e}+02$ 1.40187e+02 1.40187e+01 1.00000e-09 7.00000e-02 5.00000e-04 5.00000e-04 5.00000e-05 1.00000e-09 1.00000e-01 5.00000e-04 5.00000e-04 5.00000e-05 1.00000e-09 1.00000e-01 $5.60149 \mathrm{e}+005.60149 \mathrm{e}+00$ 5.60149e-01 1.00000e-09 2.12000e-01 5.60149e+00 5.60149e+00 5.60149e-01 1.00000e-09 2.12000e-01 $5.60149 \mathrm{e}+00$ 5.60149e+00 5.60149e-01 1.00000e-09 2.12000e-01 $5.60149 \mathrm{e}+005.60149 \mathrm{e}+00$ 5.60149e-01 1.00000e-09 2.12000e-01 $5.60149 \mathrm{e}+005.60149 \mathrm{e}+00$ 5.60149e-01 1.00000e-09 2.12000e-01 $1.00000 \mathrm{e}-02$ 1.00000e-02 1.00000e-03 1.00000e-09 1.00000e-01 $1.00000 \mathrm{e}+001.00000 \mathrm{e}+001.00000 \mathrm{e}-011.00000 \mathrm{e}-091.00000 \mathrm{e}-01$ $1.00000 \mathrm{e}-05$ 1.00000e-05 1.00000e-06 1.00000e-09 1.00000e-01 $1.00000 \mathrm{e}+001.00000 \mathrm{e}+001.00000 \mathrm{e}-011.00000 \mathrm{e}-091.00000 \mathrm{e}-01$ Element: 3490 \# of layers: 15

$\mathrm{Kx} \mathrm{Ky} \mathrm{Kz}$ Ss Por

1.40187e+02 1.40187e+02 1.40187e+01 1.00000e-09 7.00000e-02 $1.40187 \mathrm{e}+02$ 1.40187e+02 1.40187e+01 1.00000e-09 7.00000e-02 $1.40187 \mathrm{e}+02$ 1.40187e+02 1.40187e+01 1.00000e-09 7.00000e-02 $1.40187 \mathrm{e}+021.40187 \mathrm{e}+02$ 1.40187e+01 1.00000e-09 7.00000e-02 5.00000e-04 5.00000e-04 5.00000e-05 1.00000e-09 1.00000e-01 5.00000e-04 5.00000e-04 5.00000e-05 1.00000e-09 1.00000e-01

$5.60149 \mathrm{e}+00$ 5.60149e+00 5.60149e-01 1.00000e-09 2.12000e-01 5.60149e+00 5.60149e+00 5.60149e-01 1.00000e-09 2.12000e-01 $5.60149 \mathrm{e}+005.60149 \mathrm{e}+00$ 5.60149e-01 1.00000e-09 2.12000e-01 $5.60149 \mathrm{e}+005.60149 \mathrm{e}+00$ 5.60149e-01 1.00000e-09 2.12000e-01 $5.60149 \mathrm{e}+005.60149 \mathrm{e}+00$ 5.60149e-01 1.00000e-09 2.12000e-01 1.00000e-02 1.00000e-02 1.00000e-03 1.00000e-09 1.00000e-01 $1.00000 \mathrm{e}+001.00000 \mathrm{e}+001.00000 \mathrm{e}-011.00000 \mathrm{e}-091.00000 \mathrm{e}-01$ $1.00000 \mathrm{e}-05$ 1.00000e-05 1.00000e-06 1.00000e-09 1.00000e-01 $1.00000 \mathrm{e}+001.00000 \mathrm{e}+001.00000 \mathrm{e}-011.00000 \mathrm{e}-091.00000 \mathrm{e}-01$ Element: 3491 \# of layers: 15

$\mathrm{Kx} \mathrm{Ky} \mathrm{Kz}$ Ss Por 1.40259e+02 1.40259e+02 1.40259e+01 1.00000e-09 7.00000e-02 $1.40259 \mathrm{e}+02$ 1.40259e+02 1.40259e+01 1.00000e-09 7.00000e-02 $1.40259 \mathrm{e}+02$ 1.40259e+02 1.40259e+01 1.00000e-09 7.00000e-02 $1.40259 \mathrm{e}+021.40259 \mathrm{e}+02$ 1.40259e+01 1.00000e-09 7.00000e-02 5.00000e-04 5.00000e-04 5.00000e-05 1.00000e-09 1.00000e-01 5.00000e-04 5.00000e-04 5.00000e-05 1.00000e-09 1.00000e-01 $5.60420 \mathrm{e}+005.60420 \mathrm{e}+005.60420 \mathrm{e}-011.00000 \mathrm{e}-092.12000 \mathrm{e}-01$ 
$5.60420 \mathrm{e}+005.60420 \mathrm{e}+005.60420 \mathrm{e}-011.00000 \mathrm{e}-092.12000 \mathrm{e}-01$ $5.60420 \mathrm{e}+005.60420 \mathrm{e}+005.60420 \mathrm{e}-011.00000 \mathrm{e}-092.12000 \mathrm{e}-01$ $5.60420 \mathrm{e}+005.60420 \mathrm{e}+005.60420 \mathrm{e}-011.00000 \mathrm{e}-092.12000 \mathrm{e}-01$ $5.60420 \mathrm{e}+005.60420 \mathrm{e}+00$ 5.60420e-01 1.00000e-09 2.12000e-01 $1.00000 \mathrm{e}-02$ 1.00000e-02 1.00000e-03 1.00000e-09 1.00000e-01 $1.00000 \mathrm{e}+001.00000 \mathrm{e}+001.00000 \mathrm{e}-011.00000 \mathrm{e}-091.00000 \mathrm{e}-01$ $1.00000 \mathrm{e}-051.00000 \mathrm{e}-05$ 1.00000e-06 1.00000e-09 1.00000e-01 $1.00000 \mathrm{e}+001.00000 \mathrm{e}+001.00000 \mathrm{e}-011.00000 \mathrm{e}-091.00000 \mathrm{e}-01$ Element: 3492 \# of layers: 15

Kx Ky Kz Ss Por

$1.65189 \mathrm{e}+021.65189 \mathrm{e}+021.65189 \mathrm{e}+01$ 1.00000e-09 7.00000e-02 $1.65189 \mathrm{e}+021.65189 \mathrm{e}+021.65189 \mathrm{e}+01$ 1.00000e-09 7.00000e-02 $1.65189 \mathrm{e}+021.65189 \mathrm{e}+021.65189 \mathrm{e}+011.00000 \mathrm{e}-09$ 7.00000e-02 $1.65189 \mathrm{e}+021.65189 \mathrm{e}+021.65189 \mathrm{e}+011.00000 \mathrm{e}-097.00000 \mathrm{e}-02$ 5.00000e-04 5.00000e-04 5.00000e-05 1.00000e-09 1.00000e-01 5.00000e-04 5.00000e-04 5.00000e-05 1.00000e-09 1.00000e-01 $6.60052 \mathrm{e}+006.60052 \mathrm{e}+00$ 6.60052e-01 1.00000e-09 2.12000e-01 $6.60052 \mathrm{e}+006.60052 \mathrm{e}+006.60052 \mathrm{e}-011.00000 \mathrm{e}-092.12000 \mathrm{e}-01$ $6.60052 \mathrm{e}+006.60052 \mathrm{e}+006.60052 \mathrm{e}-011.00000 \mathrm{e}-092.12000 \mathrm{e}-01$ $6.60052 \mathrm{e}+006.60052 \mathrm{e}+00$ 6.60052e-01 1.00000e-09 2.12000e-01 $6.60052 \mathrm{e}+006.60052 \mathrm{e}+006.60052 \mathrm{e}-011.00000 \mathrm{e}-092.12000 \mathrm{e}-01$ $1.00000 \mathrm{e}-02$ 1.00000e-02 1.00000e-03 1.00000e-09 1.00000e-01 $1.00000 \mathrm{e}+001.00000 \mathrm{e}+001.00000 \mathrm{e}-011.00000 \mathrm{e}-091.00000 \mathrm{e}-01$ $1.00000 \mathrm{e}-05$ 1.00000e-05 1.00000e-06 1.00000e-09 1.00000e-01 $1.00000 \mathrm{e}+001.00000 \mathrm{e}+001.00000 \mathrm{e}-011.00000 \mathrm{e}-091.00000 \mathrm{e}-01$ Element: 3493 \# of layers: 15

$\mathrm{Kx} \mathrm{Ky} \mathrm{Kz}$ Ss Por

$1.41403 \mathrm{e}+02$ 1.41403e+02 1.41403e+01 1.00000e-09 7.00000e-02 $1.41403 \mathrm{e}+02$ 1.41403e+02 1.41403e+01 1.00000e-09 7.00000e-02 $1.41403 \mathrm{e}+02$ 1.41403e+02 1.41403e+01 1.00000e-09 7.00000e-02 $1.41403 \mathrm{e}+02$ 1.41403e+02 1.41403e+01 1.00000e-09 7.00000e-02 5.00000e-04 5.00000e-04 5.00000e-05 1.00000e-09 1.00000e-01 5.00000e-04 5.00000e-04 5.00000e-05 1.00000e-09 1.00000e-01 $5.64987 \mathrm{e}+00$ 5.64987e+00 5.64987e-01 1.00000e-09 2.12000e-01 5.64987e+00 5.64987e+00 5.64987e-01 1.00000e-09 2.12000e-01 5.64987e+00 5.64987e+00 5.64987e-01 1.00000e-09 2.12000e-01 $5.64987 \mathrm{e}+00$ 5.64987e+00 5.64987e-01 1.00000e-09 2.12000e-01 5.64987e+00 5.64987e+00 5.64987e-01 1.00000e-09 2.12000e-01 $1.00000 \mathrm{e}-02$ 1.00000e-02 1.00000e-03 1.00000e-09 1.00000e-01 $1.00000 \mathrm{e}+001.00000 \mathrm{e}+001.00000 \mathrm{e}-011.00000 \mathrm{e}-091.00000 \mathrm{e}-01$ $1.00000 \mathrm{e}-05$ 1.00000e-05 1.00000e-06 1.00000e-09 1.00000e-01 $1.00000 \mathrm{e}+001.00000 \mathrm{e}+001.00000 \mathrm{e}-011.00000 \mathrm{e}-091.00000 \mathrm{e}-01$ Element: 3494 \# of layers: 15

$\mathrm{Kx} \mathrm{Ky} \mathrm{Kz}$ Ss Por

$1.42601 \mathrm{e}+02$ 1.42601e+02 1.42601e+01 1.00000e-09 7.00000e-02 $1.42601 \mathrm{e}+021.42601 \mathrm{e}+021.42601 \mathrm{e}+011.00000 \mathrm{e}-097.00000 \mathrm{e}-02$ 
$1.42601 \mathrm{e}+021.42601 \mathrm{e}+021.42601 \mathrm{e}+01$ 1.00000e-09 7.00000e-02 $1.42601 \mathrm{e}+021.42601 \mathrm{e}+021.42601 \mathrm{e}+01$ 1.00000e-09 7.00000e-02 5.00000e-04 5.00000e-04 5.00000e-05 1.00000e-09 1.00000e-01 $5.00000 \mathrm{e}-04$ 5.00000e-04 5.00000e-05 1.00000e-09 1.00000e-01 5.69802e+00 5.69802e+00 5.69802e-01 1.00000e-09 2.12000e-01 $5.69802 \mathrm{e}+00$ 5.69802e+00 5.69802e-01 1.00000e-09 2.12000e-01 $5.69802 \mathrm{e}+00$ 5.69802e+00 5.69802e-01 1.00000e-09 2.12000e-01 $5.69802 \mathrm{e}+00$ 5.69802e+00 5.69802e-01 1.00000e-09 2.12000e-01 5.69802e+00 5.69802e+00 5.69802e-01 1.00000e-09 2.12000e-01 $1.00000 \mathrm{e}-02$ 1.00000e-02 1.00000e-03 1.00000e-09 1.00000e-01 $1.00000 \mathrm{e}+001.00000 \mathrm{e}+001.00000 \mathrm{e}-011.00000 \mathrm{e}-091.00000 \mathrm{e}-01$ $1.00000 \mathrm{e}-05$ 1.00000e-05 1.00000e-06 1.00000e-09 1.00000e-01 $1.00000 \mathrm{e}+001.00000 \mathrm{e}+001.00000 \mathrm{e}-01$ 1.00000e-09 1.00000e-01 Element: 3495 \# of layers: 15

$\mathrm{Kx} \mathrm{Ky} \mathrm{Kz}$ Ss Por

1.36249e+02 1.36249e+02 1.36249e+01 1.00000e-09 7.00000e-02 $1.36249 \mathrm{e}+02$ 1.36249e+02 1.36249e+01 1.00000e-09 7.00000e-02 $1.36249 \mathrm{e}+02$ 1.36249e+02 1.36249e+01 1.00000e-09 7.00000e-02 $1.36249 \mathrm{e}+02$ 1.36249e+02 1.36249e+01 1.00000e-09 7.00000e-02 5.00000e-04 5.00000e-04 5.00000e-05 1.00000e-09 1.00000e-01 5.00000e-04 5.00000e-04 5.00000e-05 1.00000e-09 1.00000e-01

$5.44399 \mathrm{e}+00$ 5.44399e+00 5.44399e-01 1.00000e-09 2.12000e-01 5.44399e+00 5.44399e+00 5.44399e-01 1.00000e-09 2.12000e-01 $5.44399 \mathrm{e}+00$ 5.44399e+00 5.44399e-01 1.00000e-09 2.12000e-01 $5.44399 \mathrm{e}+00$ 5.44399e+00 5.44399e-01 1.00000e-09 2.12000e-01 $5.44399 \mathrm{e}+00$ 5.44399e+00 5.44399e-01 1.00000e-09 2.12000e-01 $1.00000 \mathrm{e}-02$ 1.00000e-02 1.00000e-03 1.00000e-09 1.00000e-01 $1.00000 \mathrm{e}+001.00000 \mathrm{e}+001.00000 \mathrm{e}-011.00000 \mathrm{e}-091.00000 \mathrm{e}-01$ $1.00000 \mathrm{e}-05$ 1.00000e-05 1.00000e-06 1.00000e-09 1.00000e-01 $1.00000 \mathrm{e}+001.00000 \mathrm{e}+001.00000 \mathrm{e}-011.00000 \mathrm{e}-091.00000 \mathrm{e}-01$ Element: 3496 \# of layers: 16

$\mathrm{Kx} \mathrm{Ky} \mathrm{Kz}$ Ss Por

1.36249e+02 1.36249e+02 1.36249e+01 1.00000e-09 7.00000e-02 $1.36249 \mathrm{e}+02$ 1.36249e+02 1.36249e+01 1.00000e-09 7.00000e-02 $1.36249 \mathrm{e}+02$ 1.36249e+02 1.36249e+01 1.00000e-09 7.00000e-02 $1.36249 \mathrm{e}+021.36249 \mathrm{e}+02 \quad 1.36249 \mathrm{e}+01$ 1.00000e-09 7.00000e-02 $1.36249 \mathrm{e}+021.36249 \mathrm{e}+021.36249 \mathrm{e}+01$ 1.00000e-09 7.00000e-02 5.00000e-04 5.00000e-04 5.00000e-05 1.00000e-09 1.00000e-01 5.00000e-04 5.00000e-04 5.00000e-05 1.00000e-09 1.00000e-01 $5.44399 \mathrm{e}+00$ 5.44399e+00 5.44399e-01 1.00000e-09 2.12000e-01 $5.44399 \mathrm{e}+00$ 5.44399e+00 5.44399e-01 1.00000e-09 2.12000e-01 $5.44399 \mathrm{e}+00$ 5.44399e+00 5.44399e-01 1.00000e-09 2.12000e-01 $5.44399 \mathrm{e}+00$ 5.44399e+00 5.44399e-01 1.00000e-09 2.12000e-01 5.44399e+00 5.44399e+00 5.44399e-01 1.00000e-09 2.12000e-01 $1.00000 \mathrm{e}-021.00000 \mathrm{e}-021.00000 \mathrm{e}-031.00000 \mathrm{e}-091.00000 \mathrm{e}-01$ $1.00000 \mathrm{e}+001.00000 \mathrm{e}+001.00000 \mathrm{e}-011.00000 \mathrm{e}-091.00000 \mathrm{e}-01$ 
$1.00000 \mathrm{e}-05$ 1.00000e-05 1.00000e-06 1.00000e-09 1.00000e-01 $1.00000 \mathrm{e}+001.00000 \mathrm{e}+001.00000 \mathrm{e}-01$ 1.00000e-09 1.00000e-01 Element: 3497 \# of layers: 16

Kx Ky Kz Ss Por

1.36249e+02 1.36249e+02 1.36249e+01 1.00000e-09 7.00000e-02 $1.36249 \mathrm{e}+02$ 1.36249e+02 1.36249e+01 1.00000e-09 7.00000e-02 $1.36249 \mathrm{e}+02$ 1.36249e+02 1.36249e+01 1.00000e-09 7.00000e-02 $1.36249 \mathrm{e}+02$ 1.36249e+02 1.36249e+01 1.00000e-09 7.00000e-02 $1.36249 \mathrm{e}+02$ 1.36249e+02 1.36249e+01 1.00000e-09 7.00000e-02 5.00000e-04 5.00000e-04 5.00000e-05 1.00000e-09 1.00000e-01 5.00000e-04 5.00000e-04 5.00000e-05 1.00000e-09 1.00000e-01 5.44399e+00 5.44399e+00 5.44399e-01 1.00000e-09 2.12000e-01 $5.44399 \mathrm{e}+00$ 5.44399e+00 5.44399e-01 1.00000e-09 2.12000e-01 5.44399e+00 5.44399e+00 5.44399e-01 1.00000e-09 2.12000e-01 5.44399e+00 5.44399e+00 5.44399e-01 1.00000e-09 2.12000e-01 $5.44399 \mathrm{e}+005.44399 \mathrm{e}+00$ 5.44399e-01 1.00000e-09 2.12000e-01 $1.00000 \mathrm{e}-02$ 1.00000e-02 1.00000e-03 1.00000e-09 1.00000e-01 $1.00000 \mathrm{e}+001.00000 \mathrm{e}+001.00000 \mathrm{e}-011.00000 \mathrm{e}-091.00000 \mathrm{e}-01$ $1.00000 \mathrm{e}-05$ 1.00000e-05 1.00000e-06 1.00000e-09 1.00000e-01 $1.00000 \mathrm{e}+001.00000 \mathrm{e}+001.00000 \mathrm{e}-011.00000 \mathrm{e}-091.00000 \mathrm{e}-01$ Element: 3498 \# of layers: 16

$\mathrm{Kx} \mathrm{Ky} \mathrm{Kz}$ Ss Por

$2.00445 \mathrm{e}+02$ 2.00445e+02 2.00445e+01 1.00000e-09 7.00000e-02 $2.00445 \mathrm{e}+022.00445 \mathrm{e}+022.00445 \mathrm{e}+01$ 1.00000e-09 7.00000e-02 $2.00445 \mathrm{e}+022.00445 \mathrm{e}+022.00445 \mathrm{e}+01$ 1.00000e-09 7.00000e-02 $2.00445 \mathrm{e}+022.00445 \mathrm{e}+02$ 2.00445e+01 1.00000e-09 7.00000e-02 $2.00445 \mathrm{e}+022.00445 \mathrm{e}+022.00445 \mathrm{e}+01$ 1.00000e-09 7.00000e-02 5.00000e-04 5.00000e-04 5.00000e-05 1.00000e-09 1.00000e-01 5.00000e-04 5.00000e-04 5.00000e-05 1.00000e-09 1.00000e-01 $8.00905 \mathrm{e}+00$ 8.00905e+00 8.00905e-01 1.00000e-09 2.12000e-01 8.00905e+00 8.00905e+00 8.00905e-01 1.00000e-09 2.12000e-01 8.00905e+00 8.00905e+00 8.00905e-01 1.00000e-09 2.12000e-01 $8.00905 \mathrm{e}+008.00905 \mathrm{e}+00$ 8.00905e-01 1.00000e-09 2.12000e-01 $8.00905 \mathrm{e}+00$ 8.00905e+00 8.00905e-01 1.00000e-09 2.12000e-01 $1.00000 \mathrm{e}-02$ 1.00000e-02 1.00000e-03 1.00000e-09 1.00000e-01 $1.00000 \mathrm{e}+001.00000 \mathrm{e}+001.00000 \mathrm{e}-011.00000 \mathrm{e}-091.00000 \mathrm{e}-01$ $1.00000 \mathrm{e}-05$ 1.00000e-05 1.00000e-06 1.00000e-09 1.00000e-01 $1.00000 \mathrm{e}+001.00000 \mathrm{e}+001.00000 \mathrm{e}-011.00000 \mathrm{e}-091.00000 \mathrm{e}-01$ Element: 3499 \# of layers: 15

$\mathrm{Kx} \mathrm{Ky} \mathrm{Kz}$ Ss Por $2.00445 \mathrm{e}+02$ 2.00445e+02 2.00445e+01 1.00000e-09 7.00000e-02 $2.00445 \mathrm{e}+022.00445 \mathrm{e}+02$ 2.00445e+01 1.00000e-09 7.00000e-02 $2.00445 \mathrm{e}+02$ 2.00445e+02 2.00445e+01 1.00000e-09 7.00000e-02 $2.00445 \mathrm{e}+02$ 2.00445e+02 2.00445e+01 1.00000e-09 7.00000e-02 5.00000e-04 5.00000e-04 5.00000e-05 1.00000e-09 1.00000e-01 5.00000e-04 5.00000e-04 5.00000e-05 1.00000e-09 1.00000e-01 
8.00905e+00 8.00905e+00 8.00905e-01 1.00000e-09 2.12000e-01 $8.00905 \mathrm{e}+00$ 8.00905e+00 8.00905e-01 1.00000e-09 2.12000e-01 $8.00905 \mathrm{e}+00$ 8.00905e+00 8.00905e-01 1.00000e-09 2.12000e-01 $8.00905 \mathrm{e}+008.00905 \mathrm{e}+00$ 8.00905e-01 1.00000e-09 2.12000e-01 8.00905e+00 8.00905e+00 8.00905e-01 1.00000e-09 2.12000e-01 $1.00000 \mathrm{e}-02$ 1.00000e-02 1.00000e-03 1.00000e-09 1.00000e-01 $1.00000 \mathrm{e}+001.00000 \mathrm{e}+001.00000 \mathrm{e}-011.00000 \mathrm{e}-091.00000 \mathrm{e}-01$ $1.00000 \mathrm{e}-05$ 1.00000e-05 1.00000e-06 1.00000e-09 1.00000e-01 $1.00000 \mathrm{e}+001.00000 \mathrm{e}+001.00000 \mathrm{e}-011.00000 \mathrm{e}-091.00000 \mathrm{e}-01$ Element: 3500 \# of layers: 15

$\mathrm{Kx} \mathrm{Ky} \mathrm{Kz}$ Ss Por

$1.50440 \mathrm{e}+02$ 1.50440e+02 1.50440e+01 1.00000e-09 7.00000e-02 $1.50440 \mathrm{e}+02$ 1.50440e+02 1.50440e+01 1.00000e-09 7.00000e-02 $1.50440 \mathrm{e}+021.50440 \mathrm{e}+02$ 1.50440e+01 1.00000e-09 7.00000e-02 $1.50440 \mathrm{e}+021.50440 \mathrm{e}+021.50440 \mathrm{e}+01$ 1.00000e-09 7.00000e-02 5.00000e-04 5.00000e-04 5.00000e-05 1.00000e-09 1.00000e-01 5.00000e-04 5.00000e-04 5.00000e-05 1.00000e-09 1.00000e-01 $6.01100 \mathrm{e}+006.01100 \mathrm{e}+006.01100 \mathrm{e}-01$ 1.00000e-09 2.12000e-01 $6.01100 \mathrm{e}+006.01100 \mathrm{e}+006.01100 \mathrm{e}-01$ 1.00000e-09 2.12000e-01 6.01100e+00 6.01100e+00 6.01100e-01 1.00000e-09 2.12000e-01 $6.01100 \mathrm{e}+006.01100 \mathrm{e}+00$ 6.01100e-01 1.00000e-09 2.12000e-01 6.01100e+00 6.01100e+00 6.01100e-01 1.00000e-09 2.12000e-01 $1.00000 \mathrm{e}-02$ 1.00000e-02 1.00000e-03 1.00000e-09 1.00000e-01 $1.00000 \mathrm{e}+001.00000 \mathrm{e}+001.00000 \mathrm{e}-011.00000 \mathrm{e}-091.00000 \mathrm{e}-01$ $1.00000 \mathrm{e}-05$ 1.00000e-05 1.00000e-06 1.00000e-09 1.00000e-01 $1.00000 \mathrm{e}+001.00000 \mathrm{e}+001.00000 \mathrm{e}-011.00000 \mathrm{e}-091.00000 \mathrm{e}-01$ Element: 3501 \# of layers: 15

$\mathrm{Kx} \mathrm{Ky} \mathrm{Kz}$ Ss Por

$1.42601 \mathrm{e}+02$ 1.42601e+02 1.42601e+01 1.00000e-09 7.00000e-02 $1.42601 \mathrm{e}+02$ 1.42601e+02 1.42601e+01 1.00000e-09 7.00000e-02 $1.42601 \mathrm{e}+021.42601 \mathrm{e}+021.42601 \mathrm{e}+01$ 1.00000e-09 7.00000e-02 $1.42601 \mathrm{e}+021.42601 \mathrm{e}+021.42601 \mathrm{e}+01$ 1.00000e-09 7.00000e-02 5.00000e-04 5.00000e-04 5.00000e-05 1.00000e-09 1.00000e-01 $5.00000 \mathrm{e}-04$ 5.00000e-04 5.00000e-05 1.00000e-09 1.00000e-01

$5.69802 \mathrm{e}+00$ 5.69802e+00 5.69802e-01 1.00000e-09 2.12000e-01 $5.69802 \mathrm{e}+005.69802 \mathrm{e}+00$ 5.69802e-01 1.00000e-09 2.12000e-01 $5.69802 \mathrm{e}+00$ 5.69802e+00 5.69802e-01 1.00000e-09 2.12000e-01 5.69802e+00 5.69802e+00 5.69802e-01 1.00000e-09 2.12000e-01 5.69802e+00 5.69802e+00 5.69802e-01 1.00000e-09 2.12000e-01 $1.00000 \mathrm{e}-02$ 1.00000e-02 1.00000e-03 1.00000e-09 1.00000e-01 $1.00000 \mathrm{e}+001.00000 \mathrm{e}+001.00000 \mathrm{e}-011.00000 \mathrm{e}-091.00000 \mathrm{e}-01$ $1.00000 \mathrm{e}-05$ 1.00000e-05 1.00000e-06 1.00000e-09 1.00000e-01 $1.00000 \mathrm{e}+001.00000 \mathrm{e}+001.00000 \mathrm{e}-01$ 1.00000e-09 1.00000e-01 Element: 3502 \# of layers: 15

$\mathrm{Kx} \mathrm{Ky} \mathrm{Kz}$ Ss Por

1.36249e+02 1.36249e+02 1.36249e+01 1.00000e-09 7.00000e-02 
$1.36249 \mathrm{e}+02$ 1.36249e+02 1.36249e+01 1.00000e-09 7.00000e-02 1.36249e+02 1.36249e+02 1.36249e+01 1.00000e-09 7.00000e-02 $1.36249 \mathrm{e}+02$ 1.36249e+02 1.36249e+01 1.00000e-09 7.00000e-02 5.00000e-04 5.00000e-04 5.00000e-05 1.00000e-09 1.00000e-01 5.00000e-04 5.00000e-04 5.00000e-05 1.00000e-09 1.00000e-01 5.44399e+00 5.44399e+00 5.44399e-01 1.00000e-09 2.12000e-01 5.44399e+00 5.44399e+00 5.44399e-01 1.00000e-09 2.12000e-01 $5.44399 \mathrm{e}+00$ 5.44399e+00 5.44399e-01 1.00000e-09 2.12000e-01 $5.44399 \mathrm{e}+00$ 5.44399e+00 5.44399e-01 1.00000e-09 2.12000e-01 5.44399e+00 5.44399e+00 5.44399e-01 1.00000e-09 2.12000e-01 $1.00000 \mathrm{e}-02$ 1.00000e-02 1.00000e-03 1.00000e-09 1.00000e-01 $1.00000 \mathrm{e}+001.00000 \mathrm{e}+001.00000 \mathrm{e}-011.00000 \mathrm{e}-091.00000 \mathrm{e}-01$ $1.00000 \mathrm{e}-05$ 1.00000e-05 1.00000e-06 1.00000e-09 1.00000e-01 $1.00000 \mathrm{e}+001.00000 \mathrm{e}+001.00000 \mathrm{e}-011.00000 \mathrm{e}-09$ 1.00000e-01 Element: 3503 \# of layers: 16

Kx Ky Kz Ss Por

1.13571e+02 1.13571e+02 1.13571e+01 1.00000e-09 7.00000e-02 $1.13571 \mathrm{e}+02$ 1.13571e+02 1.13571e+01 1.00000e-09 7.00000e-02 $1.13571 \mathrm{e}+021.13571 \mathrm{e}+02$ 1.13571e+01 1.00000e-09 7.00000e-02 $1.13571 \mathrm{e}+021.13571 \mathrm{e}+02$ 1.13571e+01 1.00000e-09 7.00000e-02 $1.13571 \mathrm{e}+021.13571 \mathrm{e}+021.13571 \mathrm{e}+01$ 1.00000e-09 7.00000e-02 5.00000e-04 5.00000e-04 5.00000e-05 1.00000e-09 1.00000e-01 5.00000e-04 5.00000e-04 5.00000e-05 1.00000e-09 1.00000e-01 $4.53790 \mathrm{e}+00$ 4.53790e+00 4.53790e-01 1.00000e-09 2.12000e-01 $4.53790 \mathrm{e}+004.53790 \mathrm{e}+00$ 4.53790e-01 1.00000e-09 2.12000e-01 $4.53790 \mathrm{e}+004.53790 \mathrm{e}+00$ 4.53790e-01 1.00000e-09 2.12000e-01 4.53790e+00 4.53790e+00 4.53790e-01 1.00000e-09 2.12000e-01 $4.53790 \mathrm{e}+004.53790 \mathrm{e}+00$ 4.53790e-01 1.00000e-09 2.12000e-01 $1.00000 \mathrm{e}-02$ 1.00000e-02 1.00000e-03 1.00000e-09 1.00000e-01 $1.00000 \mathrm{e}+001.00000 \mathrm{e}+001.00000 \mathrm{e}-011.00000 \mathrm{e}-091.00000 \mathrm{e}-01$ $1.00000 \mathrm{e}-05$ 1.00000e-05 1.00000e-06 1.00000e-09 1.00000e-01 $1.00000 \mathrm{e}+001.00000 \mathrm{e}+001.00000 \mathrm{e}-011.00000 \mathrm{e}-091.00000 \mathrm{e}-01$ Element: 3504 \# of layers: 16

$\mathrm{Kx} \mathrm{Ky} \mathrm{Kz}$ Ss Por

$1.10661 \mathrm{e}+021.10661 \mathrm{e}+02$ 1.10661e+01 1.00000e-09 7.00000e-02 $1.10661 \mathrm{e}+021.10661 \mathrm{e}+02$ 1.10661e+01 1.00000e-09 7.00000e-02 $1.10661 \mathrm{e}+021.10661 \mathrm{e}+021.10661 \mathrm{e}+01$ 1.00000e-09 7.00000e-02 $1.10661 \mathrm{e}+021.10661 \mathrm{e}+021.10661 \mathrm{e}+01$ 1.00000e-09 7.00000e-02 $1.10661 \mathrm{e}+021.10661 \mathrm{e}+02$ 1.10661e+01 1.00000e-09 7.00000e-02 5.00000e-04 5.00000e-04 5.00000e-05 1.00000e-09 1.00000e-01 5.00000e-04 5.00000e-04 5.00000e-05 1.00000e-09 1.00000e-01 $4.42157 \mathrm{e}+00$ 4.42157e+00 4.42157e-01 1.00000e-09 2.12000e-01 4.42157e+00 4.42157e+00 4.42157e-01 1.00000e-09 2.12000e-01 4.42157e+00 4.42157e+00 4.42157e-01 1.00000e-09 2.12000e-01 4.42157e+00 4.42157e+00 4.42157e-01 1.00000e-09 2.12000e-01 $4.42157 \mathrm{e}+004.42157 \mathrm{e}+00$ 4.42157e-01 1.00000e-09 2.12000e-01 
$1.00000 \mathrm{e}-02$ 1.00000e-02 1.00000e-03 1.00000e-09 1.00000e-01 $1.00000 \mathrm{e}+001.00000 \mathrm{e}+001.00000 \mathrm{e}-011.00000 \mathrm{e}-091.00000 \mathrm{e}-01$ $1.00000 \mathrm{e}-05$ 1.00000e-05 1.00000e-06 1.00000e-09 1.00000e-01 $1.00000 \mathrm{e}+001.00000 \mathrm{e}+001.00000 \mathrm{e}-011.00000 \mathrm{e}-091.00000 \mathrm{e}-01$ Element: 3505 \# of layers: 16

$\mathrm{Kx} \mathrm{Ky} \mathrm{Kz}$ Ss Por

$1.10661 \mathrm{e}+02$ 1.10661e+02 1.10661e+01 1.00000e-09 7.00000e-02 $1.10661 \mathrm{e}+021.10661 \mathrm{e}+021.10661 \mathrm{e}+01$ 1.00000e-09 7.00000e-02 $1.10661 \mathrm{e}+02$ 1.10661e+02 1.10661e+01 1.00000e-09 7.00000e-02 $1.10661 \mathrm{e}+021.10661 \mathrm{e}+02$ 1.10661e+01 1.00000e-09 7.00000e-02 $1.10661 \mathrm{e}+021.10661 \mathrm{e}+021.10661 \mathrm{e}+01$ 1.00000e-09 7.00000e-02 5.00000e-04 5.00000e-04 5.00000e-05 1.00000e-09 1.00000e-01 5.00000e-04 5.00000e-04 5.00000e-05 1.00000e-09 1.00000e-01 4.42157e+00 4.42157e+00 4.42157e-01 1.00000e-09 2.12000e-01 4.42157e+00 4.42157e+00 4.42157e-01 1.00000e-09 2.12000e-01 $4.42157 \mathrm{e}+004.42157 \mathrm{e}+00$ 4.42157e-01 1.00000e-09 2.12000e-01 4.42157e+00 4.42157e+00 4.42157e-01 1.00000e-09 2.12000e-01 4.42157e+00 4.42157e+00 4.42157e-01 1.00000e-09 2.12000e-01 $1.00000 \mathrm{e}-021.00000 \mathrm{e}-021.00000 \mathrm{e}-031.00000 \mathrm{e}-091.00000 \mathrm{e}-01$ $1.00000 \mathrm{e}+001.00000 \mathrm{e}+001.00000 \mathrm{e}-011.00000 \mathrm{e}-091.00000 \mathrm{e}-01$ $1.00000 \mathrm{e}-05$ 1.00000e-05 1.00000e-06 1.00000e-09 1.00000e-01 $1.00000 \mathrm{e}+001.00000 \mathrm{e}+001.00000 \mathrm{e}-011.00000 \mathrm{e}-091.00000 \mathrm{e}-01$ Element: 3506 \# of layers: 16

$\mathrm{Kx} \mathrm{Ky} \mathrm{Kz}$ Ss Por

$1.10661 \mathrm{e}+02$ 1.10661e+02 1.10661e+01 1.00000e-09 7.00000e-02 $1.10661 \mathrm{e}+021.10661 \mathrm{e}+02$ 1.10661e+01 1.00000e-09 7.00000e-02 $1.10661 \mathrm{e}+02$ 1.10661e+02 1.10661e+01 1.00000e-09 7.00000e-02 $1.10661 \mathrm{e}+02$ 1.10661e+02 1.10661e+01 1.00000e-09 7.00000e-02 $1.10661 \mathrm{e}+021.10661 \mathrm{e}+021.10661 \mathrm{e}+011.00000 \mathrm{e}-097.00000 \mathrm{e}-02$ 5.00000e-04 5.00000e-04 5.00000e-05 1.00000e-09 1.00000e-01 5.00000e-04 5.00000e-04 5.00000e-05 1.00000e-09 1.00000e-01 4.42157e+00 4.42157e+00 4.42157e-01 1.00000e-09 2.12000e-01 $4.42157 \mathrm{e}+004.42157 \mathrm{e}+00$ 4.42157e-01 1.00000e-09 2.12000e-01 $4.42157 \mathrm{e}+00$ 4.42157e+00 4.42157e-01 1.00000e-09 2.12000e-01 4.42157e+00 4.42157e+00 4.42157e-01 1.00000e-09 2.12000e-01 4.42157e+00 4.42157e+00 4.42157e-01 1.00000e-09 2.12000e-01 1.00000e-02 1.00000e-02 1.00000e-03 1.00000e-09 1.00000e-01 $1.00000 \mathrm{e}+001.00000 \mathrm{e}+001.00000 \mathrm{e}-011.00000 \mathrm{e}-091.00000 \mathrm{e}-01$ $1.00000 \mathrm{e}-05$ 1.00000e-05 1.00000e-06 1.00000e-09 1.00000e-01 $1.00000 \mathrm{e}+001.00000 \mathrm{e}+001.00000 \mathrm{e}-01$ 1.00000e-09 1.00000e-01 Element: 3507 \# of layers: 16

$\mathrm{Kx} \mathrm{Ky} \mathrm{Kz}$ Ss Por

$1.23824 \mathrm{e}+02$ 1.23824e+02 1.23824e+01 1.00000e-09 7.00000e-02 $1.23824 \mathrm{e}+02$ 1.23824e+02 1.23824e+01 1.00000e-09 7.00000e-02 $1.23824 \mathrm{e}+02 \quad 1.23824 \mathrm{e}+02 \quad 1.23824 \mathrm{e}+01$ 1.00000e-09 7.00000e-02 $1.23824 \mathrm{e}+021.23824 \mathrm{e}+021.23824 \mathrm{e}+01 \quad 1.00000 \mathrm{e}-097.00000 \mathrm{e}-02$ 
$1.23824 \mathrm{e}+021.23824 \mathrm{e}+02$ 1.23824e+01 1.00000e-09 7.00000e-02 5.00000e-04 5.00000e-04 5.00000e-05 1.00000e-09 1.00000e-01 5.00000e-04 5.00000e-04 5.00000e-05 1.00000e-09 1.00000e-01 $4.94785 \mathrm{e}+004.94785 \mathrm{e}+00$ 4.94786e-01 1.00000e-09 2.12000e-01 $4.94785 \mathrm{e}+00$ 4.94785e+00 4.94786e-01 1.00000e-09 2.12000e-01 $4.94785 \mathrm{e}+004.94785 \mathrm{e}+00$ 4.94786e-01 1.00000e-09 2.12000e-01 $4.94785 \mathrm{e}+00$ 4.94785e+00 4.94786e-01 1.00000e-09 2.12000e-01 $4.94785 \mathrm{e}+00$ 4.94785e+00 4.94786e-01 1.00000e-09 2.12000e-01 $1.00000 \mathrm{e}-02$ 1.00000e-02 1.00000e-03 1.00000e-09 1.00000e-01 $1.00000 \mathrm{e}+001.00000 \mathrm{e}+001.00000 \mathrm{e}-011.00000 \mathrm{e}-091.00000 \mathrm{e}-01$ $1.00000 \mathrm{e}-05$ 1.00000e-05 1.00000e-06 1.00000e-09 1.00000e-01 $1.00000 \mathrm{e}+001.00000 \mathrm{e}+001.00000 \mathrm{e}-011.00000 \mathrm{e}-091.00000 \mathrm{e}-01$ Element: 3508 \# of layers: 16

$\mathrm{Kx} \mathrm{Ky} \mathrm{Kz}$ Ss Por

$1.23824 \mathrm{e}+02$ 1.23824e+02 1.23824e+01 1.00000e-09 7.00000e-02 $1.23824 \mathrm{e}+021.23824 \mathrm{e}+02 \quad 1.23824 \mathrm{e}+01$ 1.00000e-09 7.00000e-02 $1.23824 \mathrm{e}+02 \quad 1.23824 \mathrm{e}+02 \quad 1.23824 \mathrm{e}+01$ 1.00000e-09 7.00000e-02 $1.23824 \mathrm{e}+021.23824 \mathrm{e}+02 \quad 1.23824 \mathrm{e}+01$ 1.00000e-09 7.00000e-02 $1.23824 \mathrm{e}+021.23824 \mathrm{e}+021.23824 \mathrm{e}+01$ 1.00000e-09 7.00000e-02 5.00000e-04 5.00000e-04 5.00000e-05 1.00000e-09 1.00000e-01 5.00000e-04 5.00000e-04 5.00000e-05 1.00000e-09 1.00000e-01 4.94785e+00 4.94785e+00 4.94786e-01 1.00000e-09 2.12000e-01 4.94785e+00 4.94785e+00 4.94786e-01 1.00000e-09 2.12000e-01 $4.94785 \mathrm{e}+004.94785 \mathrm{e}+00$ 4.94786e-01 1.00000e-09 2.12000e-01 $4.94785 \mathrm{e}+004.94785 \mathrm{e}+004.94786 \mathrm{e}-01$ 1.00000e-09 2.12000e-01 $4.94785 \mathrm{e}+00$ 4.94785e+00 4.94786e-01 1.00000e-09 2.12000e-01 $1.00000 \mathrm{e}-02$ 1.00000e-02 1.00000e-03 1.00000e-09 1.00000e-01 $1.00000 \mathrm{e}+001.00000 \mathrm{e}+001.00000 \mathrm{e}-01$ 1.00000e-09 1.00000e-01 $1.00000 \mathrm{e}-05$ 1.00000e-05 1.00000e-06 1.00000e-09 1.00000e-01 $1.00000 \mathrm{e}+001.00000 \mathrm{e}+001.00000 \mathrm{e}-01$ 1.00000e-09 1.00000e-01 Element: 3509 \# of layers: 16

$\mathrm{Kx} \mathrm{Ky} \mathrm{Kz}$ Ss Por

1.56378e+02 1.56378e+02 1.56378e+01 1.00000e-09 7.00000e-02 $1.56378 \mathrm{e}+02$ 1.56378e+02 1.56378e+01 1.00000e-09 7.00000e-02 $1.56378 \mathrm{e}+02$ 1.56378e+02 1.56378e+01 1.00000e-09 7.00000e-02 $1.56378 \mathrm{e}+02$ 1.56378e+02 1.56378e+01 1.00000e-09 7.00000e-02 $1.56378 \mathrm{e}+021.56378 \mathrm{e}+02$ 1.56378e+01 1.00000e-09 7.00000e-02 5.00000e-04 5.00000e-04 5.00000e-05 1.00000e-09 1.00000e-01 5.00000e-04 5.00000e-04 5.00000e-05 1.00000e-09 1.00000e-01 6.24838e+00 6.24838e+00 6.24838e-01 1.00000e-09 2.12000e-01 $6.24838 \mathrm{e}+00$ 6.24838e+00 6.24838e-01 1.00000e-09 2.12000e-01 $6.24838 \mathrm{e}+00$ 6.24838e+00 6.24838e-01 1.00000e-09 2.12000e-01 6.24838e+00 6.24838e+00 6.24838e-01 1.00000e-09 2.12000e-01 $6.24838 \mathrm{e}+006.24838 \mathrm{e}+00$ 6.24838e-01 1.00000e-09 2.12000e-01 $1.00000 \mathrm{e}-02$ 1.00000e-02 1.00000e-03 1.00000e-09 1.00000e-01 $1.00000 \mathrm{e}+001.00000 \mathrm{e}+001.00000 \mathrm{e}-011.00000 \mathrm{e}-091.00000 \mathrm{e}-01$ 
$1.00000 \mathrm{e}-05$ 1.00000e-05 1.00000e-06 1.00000e-09 1.00000e-01 $1.00000 \mathrm{e}+001.00000 \mathrm{e}+001.00000 \mathrm{e}-01$ 1.00000e-09 1.00000e-01 Element: 3510 \# of layers: 16

Kx Ky Kz Ss Por

1.13571e+02 1.13571e+02 1.13571e+01 1.00000e-09 7.00000e-02 $1.13571 \mathrm{e}+021.13571 \mathrm{e}+021.13571 \mathrm{e}+01$ 1.00000e-09 7.00000e-02 $1.13571 \mathrm{e}+02$ 1.13571e+02 1.13571e+01 1.00000e-09 7.00000e-02 $1.13571 \mathrm{e}+021.13571 \mathrm{e}+021.13571 \mathrm{e}+01$ 1.00000e-09 7.00000e-02 $1.13571 \mathrm{e}+021.13571 \mathrm{e}+021.13571 \mathrm{e}+01$ 1.00000e-09 7.00000e-02 5.00000e-04 5.00000e-04 5.00000e-05 1.00000e-09 1.00000e-01 5.00000e-04 5.00000e-04 5.00000e-05 1.00000e-09 1.00000e-01 $4.53790 \mathrm{e}+004.53790 \mathrm{e}+00$ 4.53790e-01 1.00000e-09 2.12000e-01 4.53790e+00 4.53790e+00 4.53790e-01 1.00000e-09 2.12000e-01 4.53790e+00 4.53790e+00 4.53790e-01 1.00000e-09 2.12000e-01 4.53790e+00 4.53790e+00 4.53790e-01 1.00000e-09 2.12000e-01 $4.53790 \mathrm{e}+004.53790 \mathrm{e}+004.53790 \mathrm{e}-01$ 1.00000e-09 2.12000e-01 $1.00000 \mathrm{e}-02$ 1.00000e-02 1.00000e-03 1.00000e-09 1.00000e-01 $1.00000 \mathrm{e}+001.00000 \mathrm{e}+001.00000 \mathrm{e}-011.00000 \mathrm{e}-091.00000 \mathrm{e}-01$ $1.00000 \mathrm{e}-05$ 1.00000e-05 1.00000e-06 1.00000e-09 1.00000e-01 $1.00000 \mathrm{e}+001.00000 \mathrm{e}+001.00000 \mathrm{e}-011.00000 \mathrm{e}-091.00000 \mathrm{e}-01$ Element: 3511 \# of layers: 16

$\mathrm{Kx} \mathrm{Ky} \mathrm{Kz}$ Ss Por

1.10661e+02 1.10661e+02 1.10661e+01 1.00000e-09 7.00000e-02 $1.10661 \mathrm{e}+021.10661 \mathrm{e}+02$ 1.10661e+01 1.00000e-09 7.00000e-02 $1.10661 \mathrm{e}+021.10661 \mathrm{e}+021.10661 \mathrm{e}+011.00000 \mathrm{e}-09$ 7.00000e-02 $1.10661 \mathrm{e}+021.10661 \mathrm{e}+02$ 1.10661e+01 1.00000e-09 7.00000e-02 $1.10661 \mathrm{e}+021.10661 \mathrm{e}+021.10661 \mathrm{e}+01$ 1.00000e-09 7.00000e-02 5.00000e-04 5.00000e-04 5.00000e-05 1.00000e-09 1.00000e-01 5.00000e-04 5.00000e-04 5.00000e-05 1.00000e-09 1.00000e-01 4.42157e+00 4.42157e+00 4.42157e-01 1.00000e-09 2.12000e-01 4.42157e+00 4.42157e+00 4.42157e-01 1.00000e-09 2.12000e-01 4.42157e+00 4.42157e+00 4.42157e-01 1.00000e-09 2.12000e-01 4.42157e+00 4.42157e+00 4.42157e-01 1.00000e-09 2.12000e-01 $4.42157 \mathrm{e}+00$ 4.42157e+00 4.42157e-01 1.00000e-09 2.12000e-01 $1.00000 \mathrm{e}-02$ 1.00000e-02 1.00000e-03 1.00000e-09 1.00000e-01 $1.00000 \mathrm{e}+001.00000 \mathrm{e}+001.00000 \mathrm{e}-011.00000 \mathrm{e}-091.00000 \mathrm{e}-01$ $1.00000 \mathrm{e}-05$ 1.00000e-05 1.00000e-06 1.00000e-09 1.00000e-01 $1.00000 \mathrm{e}+001.00000 \mathrm{e}+001.00000 \mathrm{e}-011.00000 \mathrm{e}-091.00000 \mathrm{e}-01$ Element: 3512 \# of layers: 16

$\mathrm{Kx} \mathrm{Ky} \mathrm{Kz}$ Ss Por

1.14058e+02 1.14058e+02 1.14058e+01 1.00000e-09 7.00000e-02 $1.14058 \mathrm{e}+02$ 1.14058e+02 1.14058e+01 1.00000e-09 7.00000e-02 $1.14058 \mathrm{e}+02$ 1.14058e+02 1.14058e+01 1.00000e-09 7.00000e-02 1.14058e+02 1.14058e+02 1.14058e+01 1.00000e-09 7.00000e-02 $1.14058 \mathrm{e}+02$ 1.14058e+02 1.14058e+01 1.00000e-09 7.00000e-02 5.00000e-04 5.00000e-04 5.00000e-05 1.00000e-09 1.00000e-01 
5.00000e-04 5.00000e-04 5.00000e-05 1.00000e-09 1.00000e-01 $4.55747 \mathrm{e}+004.55747 \mathrm{e}+00$ 4.55747e-01 1.00000e-09 2.12000e-01 $4.55747 \mathrm{e}+004.55747 \mathrm{e}+004.55747 \mathrm{e}-011.00000 \mathrm{e}-092.12000 \mathrm{e}-01$ $4.55747 \mathrm{e}+004.55747 \mathrm{e}+004.55747 \mathrm{e}-011.00000 \mathrm{e}-092.12000 \mathrm{e}-01$ $4.55747 \mathrm{e}+004.55747 \mathrm{e}+004.55747 \mathrm{e}-011.00000 \mathrm{e}-092.12000 \mathrm{e}-01$ $4.55747 \mathrm{e}+00 \quad 4.55747 \mathrm{e}+00 \quad 4.55747 \mathrm{e}-011.00000 \mathrm{e}-092.12000 \mathrm{e}-01$ $1.00000 \mathrm{e}-02$ 1.00000e-02 1.00000e-03 1.00000e-09 1.00000e-01 $1.00000 \mathrm{e}+001.00000 \mathrm{e}+001.00000 \mathrm{e}-011.00000 \mathrm{e}-091.00000 \mathrm{e}-01$ $1.00000 \mathrm{e}-05$ 1.00000e-05 1.00000e-06 1.00000e-09 1.00000e-01 $1.00000 \mathrm{e}+001.00000 \mathrm{e}+001.00000 \mathrm{e}-011.00000 \mathrm{e}-091.00000 \mathrm{e}-01$ Element: 3513 \# of layers: 15

Kx Ky Kz Ss Por

8.54598e+01 8.54598e+01 8.54598e+00 1.00000e-09 7.00000e-02 $8.54598 \mathrm{e}+018.54598 \mathrm{e}+018.54598 \mathrm{e}+001.00000 \mathrm{e}-097.00000 \mathrm{e}-02$ $8.54598 \mathrm{e}+018.54598 \mathrm{e}+018.54598 \mathrm{e}+001.00000 \mathrm{e}-09$ 7.00000e-02 $8.54598 \mathrm{e}+018.54598 \mathrm{e}+018.54598 \mathrm{e}+001.00000 \mathrm{e}-09$ 7.00000e-02 $5.00000 \mathrm{e}-04$ 5.00000e-04 5.00000e-05 1.00000e-09 1.00000e-01 5.00000e-04 5.00000e-04 5.00000e-05 1.00000e-09 1.00000e-01 $3.41467 \mathrm{e}+003.41467 \mathrm{e}+003.41467 \mathrm{e}-01$ 1.00000e-09 2.12000e-01 $3.41467 \mathrm{e}+003.41467 \mathrm{e}+003.41467 \mathrm{e}-011.00000 \mathrm{e}-092.12000 \mathrm{e}-01$ $3.41467 \mathrm{e}+003.41467 \mathrm{e}+003.41467 \mathrm{e}-011.00000 \mathrm{e}-092.12000 \mathrm{e}-01$ $3.41467 \mathrm{e}+003.41467 \mathrm{e}+003.41467 \mathrm{e}-011.00000 \mathrm{e}-092.12000 \mathrm{e}-01$ $3.41467 \mathrm{e}+003.41467 \mathrm{e}+003.41467 \mathrm{e}-01$ 1.00000e-09 2.12000e-01 $1.00000 \mathrm{e}-02$ 1.00000e-02 1.00000e-03 1.00000e-09 1.00000e-01 $1.00000 \mathrm{e}+001.00000 \mathrm{e}+001.00000 \mathrm{e}-011.00000 \mathrm{e}-091.00000 \mathrm{e}-01$ $1.00000 \mathrm{e}-05$ 1.00000e-05 1.00000e-06 1.00000e-09 1.00000e-01 $1.00000 \mathrm{e}+001.00000 \mathrm{e}+001.00000 \mathrm{e}-011.00000 \mathrm{e}-091.00000 \mathrm{e}-01$ Element: 3514 \# of layers: 15

Kx Ky Kz Ss Por

$8.54598 \mathrm{e}+018.54598 \mathrm{e}+018.54598 \mathrm{e}+00$ 1.00000e-09 7.00000e-02 $8.54598 \mathrm{e}+018.54598 \mathrm{e}+018.54598 \mathrm{e}+001.00000 \mathrm{e}-09$ 7.00000e-02 $8.54598 \mathrm{e}+018.54598 \mathrm{e}+018.54598 \mathrm{e}+001.00000 \mathrm{e}-097.00000 \mathrm{e}-02$ $8.54598 \mathrm{e}+018.54598 \mathrm{e}+018.54598 \mathrm{e}+001.00000 \mathrm{e}-09$ 7.00000e-02 $5.00000 \mathrm{e}-04$ 5.00000e-04 5.00000e-05 1.00000e-09 1.00000e-01 5.00000e-04 5.00000e-04 5.00000e-05 1.00000e-09 1.00000e-01 $3.41467 \mathrm{e}+003.41467 \mathrm{e}+003.41467 \mathrm{e}-01$ 1.00000e-09 2.12000e-01 $3.41467 \mathrm{e}+003.41467 \mathrm{e}+003.41467 \mathrm{e}-011.00000 \mathrm{e}-092.12000 \mathrm{e}-01$ $3.41467 \mathrm{e}+003.41467 \mathrm{e}+003.41467 \mathrm{e}-01$ 1.00000e-09 2.12000e-01 $3.41467 \mathrm{e}+003.41467 \mathrm{e}+003.41467 \mathrm{e}-011.00000 \mathrm{e}-092.12000 \mathrm{e}-01$ $3.41467 \mathrm{e}+003.41467 \mathrm{e}+003.41467 \mathrm{e}-01$ 1.00000e-09 2.12000e-01 $1.00000 \mathrm{e}-021.00000 \mathrm{e}-02$ 1.00000e-03 1.00000e-09 1.00000e-01 $1.00000 \mathrm{e}+001.00000 \mathrm{e}+001.00000 \mathrm{e}-011.00000 \mathrm{e}-091.00000 \mathrm{e}-01$ $1.00000 \mathrm{e}-05$ 1.00000e-05 1.00000e-06 1.00000e-09 1.00000e-01 $1.00000 \mathrm{e}+001.00000 \mathrm{e}+001.00000 \mathrm{e}-011.00000 \mathrm{e}-091.00000 \mathrm{e}-01$ Element: 3515 \# of layers: 15

Kx Ky Kz Ss Por 
8.54598e+01 8.54598e+01 8.54598e+00 1.00000e-09 7.00000e-02 $8.54598 \mathrm{e}+018.54598 \mathrm{e}+018.54598 \mathrm{e}+00$ 1.00000e-09 7.00000e-02 8.54598e+01 8.54598e+01 8.54598e+00 1.00000e-09 7.00000e-02 $8.54598 \mathrm{e}+018.54598 \mathrm{e}+018.54598 \mathrm{e}+001.00000 \mathrm{e}-09$ 7.00000e-02 5.00000e-04 5.00000e-04 5.00000e-05 1.00000e-09 1.00000e-01 5.00000e-04 5.00000e-04 5.00000e-05 1.00000e-09 1.00000e-01 3.41467e+00 3.41467e+00 3.41467e-01 1.00000e-09 2.12000e-01 $3.41467 \mathrm{e}+003.41467 \mathrm{e}+003.41467 \mathrm{e}-01$ 1.00000e-09 2.12000e-01 $3.41467 \mathrm{e}+003.41467 \mathrm{e}+00$ 3.41467e-01 1.00000e-09 2.12000e-01 $3.41467 \mathrm{e}+003.41467 \mathrm{e}+00$ 3.41467e-01 1.00000e-09 2.12000e-01 3.41467e+00 3.41467e+00 3.41467e-01 1.00000e-09 2.12000e-01 $1.00000 \mathrm{e}-02$ 1.00000e-02 1.00000e-03 1.00000e-09 1.00000e-01 $1.00000 \mathrm{e}+001.00000 \mathrm{e}+001.00000 \mathrm{e}-011.00000 \mathrm{e}-091.00000 \mathrm{e}-01$ $1.00000 \mathrm{e}-05$ 1.00000e-05 1.00000e-06 1.00000e-09 1.00000e-01 $1.00000 \mathrm{e}+001.00000 \mathrm{e}+001.00000 \mathrm{e}-01$ 1.00000e-09 1.00000e-01 Element: 3516 \# of layers: 15

$\mathrm{Kx} \mathrm{Ky} \mathrm{Kz}$ Ss Por

6.25970e+01 6.25970e+01 6.25970e+00 1.00000e-09 7.00000e-02 $6.25970 \mathrm{e}+016.25970 \mathrm{e}+01$ 6.25970e+00 1.00000e-09 7.00000e-02 6.25970e+01 6.25970e+01 6.25970e+00 1.00000e-09 7.00000e-02 $6.25970 \mathrm{e}+016.25970 \mathrm{e}+016.25970 \mathrm{e}+001.00000 \mathrm{e}-09$ 7.00000e-02 5.00000e-04 5.00000e-04 5.00000e-05 1.00000e-09 1.00000e-01 5.00000e-04 5.00000e-04 5.00000e-05 1.00000e-09 1.00000e-01 $2.50115 \mathrm{e}+002.50115 \mathrm{e}+002.50115 \mathrm{e}-01$ 1.00000e-09 2.12000e-01 $2.50115 \mathrm{e}+002.50115 \mathrm{e}+002.50115 \mathrm{e}-01$ 1.00000e-09 2.12000e-01 $2.50115 \mathrm{e}+002.50115 \mathrm{e}+002.50115 \mathrm{e}-01$ 1.00000e-09 2.12000e-01 $2.50115 \mathrm{e}+002.50115 \mathrm{e}+002.50115 \mathrm{e}-01$ 1.00000e-09 2.12000e-01 $2.50115 \mathrm{e}+002.50115 \mathrm{e}+002.50115 \mathrm{e}-01$ 1.00000e-09 2.12000e-01 $1.00000 \mathrm{e}-02$ 1.00000e-02 1.00000e-03 1.00000e-09 1.00000e-01 $1.00000 \mathrm{e}+001.00000 \mathrm{e}+001.00000 \mathrm{e}-011.00000 \mathrm{e}-091.00000 \mathrm{e}-01$ $1.00000 \mathrm{e}-05$ 1.00000e-05 1.00000e-06 1.00000e-09 1.00000e-01 $1.00000 \mathrm{e}+001.00000 \mathrm{e}+001.00000 \mathrm{e}-01$ 1.00000e-09 1.00000e-01 Element: 3517 \# of layers: 15

$\mathrm{Kx} \mathrm{Ky} \mathrm{Kz}$ Ss Por

6.25970e+01 6.25970e+01 6.25970e+00 1.00000e-09 7.00000e-02 6.25970e+01 6.25970e+01 6.25970e+00 1.00000e-09 7.00000e-02 $6.25970 \mathrm{e}+016.25970 \mathrm{e}+016.25970 \mathrm{e}+00$ 1.00000e-09 7.00000e-02 $6.25970 \mathrm{e}+016.25970 \mathrm{e}+016.25970 \mathrm{e}+001.00000 \mathrm{e}-09$ 7.00000e-02 5.00000e-04 5.00000e-04 5.00000e-05 1.00000e-09 1.00000e-01 5.00000e-04 5.00000e-04 5.00000e-05 1.00000e-09 1.00000e-01 $2.50115 \mathrm{e}+002.50115 \mathrm{e}+002.50115 \mathrm{e}-01$ 1.00000e-09 2.12000e-01 $2.50115 \mathrm{e}+002.50115 \mathrm{e}+002.50115 \mathrm{e}-01$ 1.00000e-09 2.12000e-01 $2.50115 \mathrm{e}+002.50115 \mathrm{e}+00$ 2.50115e-01 1.00000e-09 2.12000e-01 $2.50115 \mathrm{e}+002.50115 \mathrm{e}+00$ 2.50115e-01 1.00000e-09 2.12000e-01 $2.50115 \mathrm{e}+002.50115 \mathrm{e}+002.50115 \mathrm{e}-01$ 1.00000e-09 2.12000e-01 $1.00000 \mathrm{e}-02$ 1.00000e-02 1.00000e-03 1.00000e-09 1.00000e-01 
$1.00000 \mathrm{e}+001.00000 \mathrm{e}+001.00000 \mathrm{e}-011.00000 \mathrm{e}-091.00000 \mathrm{e}-01$ $1.00000 \mathrm{e}-05$ 1.00000e-05 1.00000e-06 1.00000e-09 1.00000e-01 $1.00000 \mathrm{e}+001.00000 \mathrm{e}+001.00000 \mathrm{e}-011.00000 \mathrm{e}-09$ 1.00000e-01 Element: 3518 \# of layers: 16

$\mathrm{Kx} \mathrm{Ky} \mathrm{Kz}$ Ss Por

$1.14139 \mathrm{e}+02$ 1.14139e+02 1.14139e+01 1.00000e-09 7.00000e-02 $1.14139 \mathrm{e}+02$ 1.14139e+02 1.14139e+01 1.00000e-09 7.00000e-02 $1.14139 \mathrm{e}+02$ 1.14139e+02 1.14139e+01 1.00000e-09 7.00000e-02 $1.14139 \mathrm{e}+02$ 1.14139e+02 1.14139e+01 1.00000e-09 7.00000e-02 $1.14139 \mathrm{e}+02$ 1.14139e+02 1.14139e+01 1.00000e-09 7.00000e-02 5.00000e-04 5.00000e-04 5.00000e-05 1.00000e-09 1.00000e-01 5.00000e-04 5.00000e-04 5.00000e-05 1.00000e-09 1.00000e-01 4.56062e+00 4.56062e+00 4.56062e-01 1.00000e-09 2.12000e-01 $4.56062 \mathrm{e}+004.56062 \mathrm{e}+004.56062 \mathrm{e}-01$ 1.00000e-09 2.12000e-01 4.56062e+00 4.56062e+00 4.56062e-01 1.00000e-09 2.12000e-01 $4.56062 \mathrm{e}+004.56062 \mathrm{e}+004.56062 \mathrm{e}-01$ 1.00000e-09 2.12000e-01 $4.56062 \mathrm{e}+004.56062 \mathrm{e}+00$ 4.56062e-01 1.00000e-09 2.12000e-01 $1.00000 \mathrm{e}-02$ 1.00000e-02 1.00000e-03 1.00000e-09 1.00000e-01 $1.00000 \mathrm{e}+001.00000 \mathrm{e}+001.00000 \mathrm{e}-011.00000 \mathrm{e}-091.00000 \mathrm{e}-01$ $1.00000 \mathrm{e}-05$ 1.00000e-05 1.00000e-06 1.00000e-09 1.00000e-01 $1.00000 \mathrm{e}+001.00000 \mathrm{e}+001.00000 \mathrm{e}-011.00000 \mathrm{e}-091.00000 \mathrm{e}-01$ Element: 3519 \# of layers: 16

$\mathrm{Kx} \mathrm{Ky} \mathrm{Kz}$ Ss Por

$1.14058 \mathrm{e}+02$ 1.14058e+02 1.14058e+01 1.00000e-09 7.00000e-02 $1.14058 \mathrm{e}+02$ 1.14058e+02 1.14058e+01 1.00000e-09 7.00000e-02 $1.14058 \mathrm{e}+02$ 1.14058e+02 1.14058e+01 1.00000e-09 7.00000e-02 $1.14058 \mathrm{e}+02$ 1.14058e+02 1.14058e+01 1.00000e-09 7.00000e-02 $1.14058 \mathrm{e}+02$ 1.14058e+02 1.14058e+01 1.00000e-09 7.00000e-02 5.00000e-04 5.00000e-04 5.00000e-05 1.00000e-09 1.00000e-01 5.00000e-04 5.00000e-04 5.00000e-05 1.00000e-09 1.00000e-01 4.55747e+00 4.55747e+00 4.55747e-01 1.00000e-09 2.12000e-01 4.55747e+00 4.55747e+00 4.55747e-01 1.00000e-09 2.12000e-01 $4.55747 \mathrm{e}+004.55747 \mathrm{e}+00$ 4.55747e-01 1.00000e-09 2.12000e-01 4.55747e+00 4.55747e+00 4.55747e-01 1.00000e-09 2.12000e-01 4.55747e+00 4.55747e+00 4.55747e-01 1.00000e-09 2.12000e-01 1.00000e-02 1.00000e-02 1.00000e-03 1.00000e-09 1.00000e-01 $1.00000 \mathrm{e}+001.00000 \mathrm{e}+001.00000 \mathrm{e}-011.00000 \mathrm{e}-091.00000 \mathrm{e}-01$ $1.00000 \mathrm{e}-051.00000 \mathrm{e}-05$ 1.00000e-06 1.00000e-09 1.00000e-01 $1.00000 \mathrm{e}+001.00000 \mathrm{e}+001.00000 \mathrm{e}-011.00000 \mathrm{e}-091.00000 \mathrm{e}-01$ Element: 3520 \# of layers: 15

$\mathrm{Kx} \mathrm{Ky} \mathrm{Kz}$ Ss Por

8.54598e+01 8.54598e+01 8.54598e+00 1.00000e-09 7.00000e-02 $8.54598 \mathrm{e}+018.54598 \mathrm{e}+018.54598 \mathrm{e}+001.00000 \mathrm{e}-09$ 7.00000e-02 $8.54598 \mathrm{e}+018.54598 \mathrm{e}+018.54598 \mathrm{e}+00$ 1.00000e-09 7.00000e-02 $8.54598 \mathrm{e}+018.54598 \mathrm{e}+018.54598 \mathrm{e}+001.00000 \mathrm{e}-09$ 7.00000e-02 5.00000e-04 5.00000e-04 5.00000e-05 1.00000e-09 1.00000e-01 
5.00000e-04 5.00000e-04 5.00000e-05 1.00000e-09 1.00000e-01 $3.41467 \mathrm{e}+003.41467 \mathrm{e}+00$ 3.41467e-01 1.00000e-09 2.12000e-01 3.41467e+00 3.41467e+00 3.41467e-01 1.00000e-09 2.12000e-01 $3.41467 \mathrm{e}+003.41467 \mathrm{e}+00$ 3.41467e-01 1.00000e-09 2.12000e-01 3.41467e+00 3.41467e+00 3.41467e-01 1.00000e-09 2.12000e-01 $3.41467 \mathrm{e}+003.41467 \mathrm{e}+00$ 3.41467e-01 1.00000e-09 2.12000e-01 $1.00000 \mathrm{e}-02$ 1.00000e-02 1.00000e-03 1.00000e-09 1.00000e-01 $1.00000 \mathrm{e}+001.00000 \mathrm{e}+001.00000 \mathrm{e}-011.00000 \mathrm{e}-091.00000 \mathrm{e}-01$ $1.00000 \mathrm{e}-05$ 1.00000e-05 1.00000e-06 1.00000e-09 1.00000e-01 $1.00000 \mathrm{e}+001.00000 \mathrm{e}+001.00000 \mathrm{e}-011.00000 \mathrm{e}-091.00000 \mathrm{e}-01$ Element: 3521 \# of layers: 15

$\mathrm{Kx} \mathrm{Ky} \mathrm{Kz}$ Ss Por

6.44125e+01 6.44125e+01 6.44125e+00 1.00000e-09 7.00000e-02 $6.44125 \mathrm{e}+016.44125 \mathrm{e}+016.44125 \mathrm{e}+001.00000 \mathrm{e}-09$ 7.00000e-02 $6.44125 \mathrm{e}+016.44125 \mathrm{e}+016.44125 \mathrm{e}+001.00000 \mathrm{e}-09$ 7.00000e-02 $6.44125 \mathrm{e}+016.44125 \mathrm{e}+016.44125 \mathrm{e}+001.00000 \mathrm{e}-09$ 7.00000e-02 5.00000e-04 5.00000e-04 5.00000e-05 1.00000e-09 1.00000e-01 5.00000e-04 5.00000e-04 5.00000e-05 1.00000e-09 1.00000e-01 $2.57361 \mathrm{e}+002.57361 \mathrm{e}+00$ 2.57361e-01 1.00000e-09 2.12000e-01 $2.57361 \mathrm{e}+002.57361 \mathrm{e}+002.57361 \mathrm{e}-01$ 1.00000e-09 2.12000e-01 $2.57361 \mathrm{e}+002.57361 \mathrm{e}+002.57361 \mathrm{e}-01$ 1.00000e-09 2.12000e-01 2.57361e+00 2.57361e+00 2.57361e-01 1.00000e-09 2.12000e-01 $2.57361 \mathrm{e}+002.57361 \mathrm{e}+00$ 2.57361e-01 1.00000e-09 2.12000e-01 $1.00000 \mathrm{e}-02$ 1.00000e-02 1.00000e-03 1.00000e-09 1.00000e-01 $1.00000 \mathrm{e}+001.00000 \mathrm{e}+001.00000 \mathrm{e}-011.00000 \mathrm{e}-091.00000 \mathrm{e}-01$ $1.00000 \mathrm{e}-05$ 1.00000e-05 1.00000e-06 1.00000e-09 1.00000e-01 $1.00000 \mathrm{e}+001.00000 \mathrm{e}+001.00000 \mathrm{e}-01$ 1.00000e-09 1.00000e-01 Element: 3522 \# of layers: 16

$\mathrm{Kx} \mathrm{Ky} \mathrm{Kz}$ Ss Por

6.44125e+01 6.44125e+01 6.44125e+00 1.00000e-09 7.00000e-02 $6.44125 \mathrm{e}+016.44125 \mathrm{e}+016.44125 \mathrm{e}+00$ 1.00000e-09 7.00000e-02 $6.44125 \mathrm{e}+016.44125 \mathrm{e}+016.44125 \mathrm{e}+00$ 1.00000e-09 7.00000e-02 $6.44125 \mathrm{e}+016.44125 \mathrm{e}+016.44125 \mathrm{e}+00$ 1.00000e-09 7.00000e-02 6.44125e+01 6.44125e+01 6.44125e+00 1.00000e-09 7.00000e-02 5.00000e-04 5.00000e-04 5.00000e-05 1.00000e-09 1.00000e-01 5.00000e-04 5.00000e-04 5.00000e-05 1.00000e-09 1.00000e-01 $2.57361 \mathrm{e}+002.57361 \mathrm{e}+002.57361 \mathrm{e}-01$ 1.00000e-09 2.12000e-01 $2.57361 \mathrm{e}+002.57361 \mathrm{e}+00$ 2.57361e-01 1.00000e-09 2.12000e-01 $2.57361 \mathrm{e}+002.57361 \mathrm{e}+00$ 2.57361e-01 1.00000e-09 2.12000e-01 $2.57361 \mathrm{e}+002.57361 \mathrm{e}+00$ 2.57361e-01 1.00000e-09 2.12000e-01 $2.57361 \mathrm{e}+002.57361 \mathrm{e}+002.57361 \mathrm{e}-01$ 1.00000e-09 2.12000e-01 $1.00000 \mathrm{e}-02$ 1.00000e-02 1.00000e-03 1.00000e-09 1.00000e-01 $1.00000 \mathrm{e}+001.00000 \mathrm{e}+001.00000 \mathrm{e}-011.00000 \mathrm{e}-091.00000 \mathrm{e}-01$ $1.00000 \mathrm{e}-051.00000 \mathrm{e}-051.00000 \mathrm{e}-061.00000 \mathrm{e}-091.00000 \mathrm{e}-01$ $1.00000 \mathrm{e}+001.00000 \mathrm{e}+001.00000 \mathrm{e}-01$ 1.00000e-09 1.00000e-01 Element: 3523 \# of layers: 15 
$\mathrm{Kx} \mathrm{Ky} \mathrm{Kz}$ Ss Por

6.44125e+01 6.44125e+01 6.44125e+00 1.00000e-09 7.00000e-02 $6.44125 \mathrm{e}+016.44125 \mathrm{e}+016.44125 \mathrm{e}+00$ 1.00000e-09 7.00000e-02 $6.44125 \mathrm{e}+016.44125 \mathrm{e}+016.44125 \mathrm{e}+001.00000 \mathrm{e}-09$ 7.00000e-02 $6.44125 \mathrm{e}+016.44125 \mathrm{e}+016.44125 \mathrm{e}+001.00000 \mathrm{e}-09$ 7.00000e-02 5.00000e-04 5.00000e-04 5.00000e-05 1.00000e-09 1.00000e-01 5.00000e-04 5.00000e-04 5.00000e-05 1.00000e-09 1.00000e-01

$2.57361 \mathrm{e}+002.57361 \mathrm{e}+002.57361 \mathrm{e}-011.00000 \mathrm{e}-092.12000 \mathrm{e}-01$ $2.57361 \mathrm{e}+002.57361 \mathrm{e}+00$ 2.57361e-01 1.00000e-09 2.12000e-01 $2.57361 \mathrm{e}+002.57361 \mathrm{e}+00$ 2.57361e-01 1.00000e-09 2.12000e-01 $2.57361 \mathrm{e}+002.57361 \mathrm{e}+002.57361 \mathrm{e}-01$ 1.00000e-09 2.12000e-01 $2.57361 \mathrm{e}+002.57361 \mathrm{e}+002.57361 \mathrm{e}-011.00000 \mathrm{e}-092.12000 \mathrm{e}-01$ $1.00000 \mathrm{e}-02$ 1.00000e-02 1.00000e-03 1.00000e-09 1.00000e-01 $1.00000 \mathrm{e}+001.00000 \mathrm{e}+001.00000 \mathrm{e}-011.00000 \mathrm{e}-091.00000 \mathrm{e}-01$ $1.00000 \mathrm{e}-05$ 1.00000e-05 1.00000e-06 1.00000e-09 1.00000e-01 $1.00000 \mathrm{e}+001.00000 \mathrm{e}+001.00000 \mathrm{e}-011.00000 \mathrm{e}-091.00000 \mathrm{e}-01$ Element: 3524 \# of layers: 15

$\mathrm{Kx} \mathrm{Ky} \mathrm{Kz}$ Ss Por

7.03285e+01 7.03285e+01 7.03285e+00 1.00000e-09 7.00000e-02 $7.03285 \mathrm{e}+017.03285 \mathrm{e}+017.03285 \mathrm{e}+001.00000 \mathrm{e}-09$ 7.00000e-02 $7.03285 \mathrm{e}+017.03285 \mathrm{e}+017.03285 \mathrm{e}+001.00000 \mathrm{e}-09$ 7.00000e-02 $7.03285 \mathrm{e}+01$ 7.03285e+01 7.03285e+00 1.00000e-09 7.00000e-02 5.00000e-04 5.00000e-04 5.00000e-05 1.00000e-09 1.00000e-01 5.00000e-04 5.00000e-04 5.00000e-05 1.00000e-09 1.00000e-01

$2.81009 \mathrm{e}+002.81009 \mathrm{e}+002.81009 \mathrm{e}-01$ 1.00000e-09 2.12000e-01 $2.81009 \mathrm{e}+002.81009 \mathrm{e}+002.81009 \mathrm{e}-01$ 1.00000e-09 2.12000e-01 $2.81009 \mathrm{e}+002.81009 \mathrm{e}+002.81009 \mathrm{e}-01$ 1.00000e-09 2.12000e-01 $2.81009 \mathrm{e}+002.81009 \mathrm{e}+002.81009 \mathrm{e}-01$ 1.00000e-09 2.12000e-01 $2.81009 \mathrm{e}+002.81009 \mathrm{e}+002.81009 \mathrm{e}-01$ 1.00000e-09 2.12000e-01 $1.00000 \mathrm{e}-02$ 1.00000e-02 1.00000e-03 1.00000e-09 1.00000e-01 $1.00000 \mathrm{e}+001.00000 \mathrm{e}+001.00000 \mathrm{e}-011.00000 \mathrm{e}-091.00000 \mathrm{e}-01$ 1.00000e-05 1.00000e-05 1.00000e-06 1.00000e-09 1.00000e-01 $1.00000 \mathrm{e}+001.00000 \mathrm{e}+001.00000 \mathrm{e}-011.00000 \mathrm{e}-091.00000 \mathrm{e}-01$ Element: 3525 \# of layers: 15

$\mathrm{Kx} \mathrm{Ky} \mathrm{Kz}$ Ss Por

7.03285e+01 7.03285e+01 7.03285e+00 1.00000e-09 7.00000e-02 $7.03285 \mathrm{e}+017.03285 \mathrm{e}+017.03285 \mathrm{e}+001.00000 \mathrm{e}-097.00000 \mathrm{e}-02$ $7.03285 \mathrm{e}+017.03285 \mathrm{e}+017.03285 \mathrm{e}+001.00000 \mathrm{e}-097.00000 \mathrm{e}-02$ $7.03285 \mathrm{e}+017.03285 \mathrm{e}+017.03285 \mathrm{e}+001.00000 \mathrm{e}-09$ 7.00000e-02 5.00000e-04 5.00000e-04 5.00000e-05 1.00000e-09 1.00000e-01 5.00000e-04 5.00000e-04 5.00000e-05 1.00000e-09 1.00000e-01 $2.81009 \mathrm{e}+002.81009 \mathrm{e}+00$ 2.81009e-01 1.00000e-09 2.12000e-01 $2.81009 \mathrm{e}+002.81009 \mathrm{e}+002.81009 \mathrm{e}-01$ 1.00000e-09 2.12000e-01 $2.81009 \mathrm{e}+002.81009 \mathrm{e}+00$ 2.81009e-01 1.00000e-09 2.12000e-01 $2.81009 \mathrm{e}+002.81009 \mathrm{e}+002.81009 \mathrm{e}-01$ 1.00000e-09 2.12000e-01 $2.81009 \mathrm{e}+002.81009 \mathrm{e}+00$ 2.81009e-01 1.00000e-09 2.12000e-01 
$1.00000 \mathrm{e}-02$ 1.00000e-02 1.00000e-03 1.00000e-09 1.00000e-01 $1.00000 \mathrm{e}+001.00000 \mathrm{e}+001.00000 \mathrm{e}-011.00000 \mathrm{e}-091.00000 \mathrm{e}-01$ $1.00000 \mathrm{e}-051.00000 \mathrm{e}-05$ 1.00000e-06 1.00000e-09 1.00000e-01 $1.00000 \mathrm{e}+001.00000 \mathrm{e}+001.00000 \mathrm{e}-011.00000 \mathrm{e}-091.00000 \mathrm{e}-01$ Element: 3526 \# of layers: 16

Kx Ky Kz Ss Por

$6.44125 \mathrm{e}+016.44125 \mathrm{e}+016.44125 \mathrm{e}+00$ 1.00000e-09 7.00000e-02 $6.44125 \mathrm{e}+016.44125 \mathrm{e}+016.44125 \mathrm{e}+001.00000 \mathrm{e}-09$ 7.00000e-02 $6.44125 \mathrm{e}+016.44125 \mathrm{e}+016.44125 \mathrm{e}+001.00000 \mathrm{e}-09$ 7.00000e-02 $6.44125 \mathrm{e}+016.44125 \mathrm{e}+016.44125 \mathrm{e}+001.00000 \mathrm{e}-09$ 7.00000e-02 $6.44125 \mathrm{e}+016.44125 \mathrm{e}+016.44125 \mathrm{e}+001.00000 \mathrm{e}-09$ 7.00000e-02 5.00000e-04 5.00000e-04 5.00000e-05 1.00000e-09 1.00000e-01 $5.00000 \mathrm{e}-04$ 5.00000e-04 5.00000e-05 1.00000e-09 1.00000e-01

$2.57361 \mathrm{e}+002.57361 \mathrm{e}+002.57361 \mathrm{e}-011.00000 \mathrm{e}-092.12000 \mathrm{e}-01$ $2.57361 \mathrm{e}+002.57361 \mathrm{e}+002.57361 \mathrm{e}-01$ 1.00000e-09 2.12000e-01 $2.57361 \mathrm{e}+002.57361 \mathrm{e}+002.57361 \mathrm{e}-011.00000 \mathrm{e}-092.12000 \mathrm{e}-01$ $2.57361 \mathrm{e}+002.57361 \mathrm{e}+002.57361 \mathrm{e}-011.00000 \mathrm{e}-092.12000 \mathrm{e}-01$ $2.57361 \mathrm{e}+002.57361 \mathrm{e}+002.57361 \mathrm{e}-011.00000 \mathrm{e}-092.12000 \mathrm{e}-01$ $1.00000 \mathrm{e}-021.00000 \mathrm{e}-02$ 1.00000e-03 1.00000e-09 1.00000e-01 $1.00000 \mathrm{e}+001.00000 \mathrm{e}+001.00000 \mathrm{e}-011.00000 \mathrm{e}-091.00000 \mathrm{e}-01$ $1.00000 \mathrm{e}-05$ 1.00000e-05 1.00000e-06 1.00000e-09 1.00000e-01 $1.00000 \mathrm{e}+001.00000 \mathrm{e}+001.00000 \mathrm{e}-011.00000 \mathrm{e}-091.00000 \mathrm{e}-01$ Element: 3527 \# of layers: 15

Kx Ky Kz Ss Por

$6.35647 \mathrm{e}+016.35647 \mathrm{e}+016.35647 \mathrm{e}+00$ 1.00000e-09 7.00000e-02 $6.35647 \mathrm{e}+016.35647 \mathrm{e}+016.35647 \mathrm{e}+001.00000 \mathrm{e}-09$ 7.00000e-02 $6.35647 \mathrm{e}+016.35647 \mathrm{e}+016.35647 \mathrm{e}+001.00000 \mathrm{e}-09$ 7.00000e-02 $6.35647 \mathrm{e}+016.35647 \mathrm{e}+016.35647 \mathrm{e}+001.00000 \mathrm{e}-09$ 7.00000e-02 5.00000e-04 5.00000e-04 5.00000e-05 1.00000e-09 1.00000e-01 5.00000e-04 5.00000e-04 5.00000e-05 1.00000e-09 1.00000e-01 $2.53985 \mathrm{e}+002.53985 \mathrm{e}+002.53985 \mathrm{e}-01$ 1.00000e-09 2.12000e-01 $2.53985 \mathrm{e}+002.53985 \mathrm{e}+002.53985 \mathrm{e}-011.00000 \mathrm{e}-092.12000 \mathrm{e}-01$ $2.53985 \mathrm{e}+002.53985 \mathrm{e}+002.53985 \mathrm{e}-011.00000 \mathrm{e}-092.12000 \mathrm{e}-01$ $2.53985 \mathrm{e}+002.53985 \mathrm{e}+002.53985 \mathrm{e}-01$ 1.00000e-09 2.12000e-01 $2.53985 \mathrm{e}+002.53985 \mathrm{e}+002.53985 \mathrm{e}-01$ 1.00000e-09 2.12000e-01 $1.00000 \mathrm{e}-021.00000 \mathrm{e}-02$ 1.00000e-03 1.00000e-09 1.00000e-01 $1.00000 \mathrm{e}+001.00000 \mathrm{e}+001.00000 \mathrm{e}-011.00000 \mathrm{e}-091.00000 \mathrm{e}-01$ $1.00000 \mathrm{e}-05$ 1.00000e-05 1.00000e-06 1.00000e-09 1.00000e-01 $1.00000 \mathrm{e}+001.00000 \mathrm{e}+001.00000 \mathrm{e}-011.00000 \mathrm{e}-091.00000 \mathrm{e}-01$ Element: 3528 \# of layers: 15

Kx Ky Kz Ss Por

$6.13905 \mathrm{e}+016.13905 \mathrm{e}+016.13905 \mathrm{e}+00$ 1.00000e-09 7.00000e-02 $6.13905 \mathrm{e}+016.13905 \mathrm{e}+016.13905 \mathrm{e}+001.00000 \mathrm{e}-097.00000 \mathrm{e}-02$ $6.13905 \mathrm{e}+016.13905 \mathrm{e}+016.13905 \mathrm{e}+001.00000 \mathrm{e}-09$ 7.00000e-02 $6.13905 \mathrm{e}+016.13905 \mathrm{e}+016.13905 \mathrm{e}+001.00000 \mathrm{e}-09$ 7.00000e-02 5.00000e-04 5.00000e-04 5.00000e-05 1.00000e-09 1.00000e-01 
5.00000e-04 5.00000e-04 5.00000e-05 1.00000e-09 1.00000e-01

$2.45300 \mathrm{e}+002.45300 \mathrm{e}+002.45300 \mathrm{e}-011.00000 \mathrm{e}-092.12000 \mathrm{e}-01$

$2.45300 \mathrm{e}+002.45300 \mathrm{e}+002.45300 \mathrm{e}-01$ 1.00000e-09 2.12000e-01

$2.45300 \mathrm{e}+002.45300 \mathrm{e}+002.45300 \mathrm{e}-011.00000 \mathrm{e}-092.12000 \mathrm{e}-01$

$2.45300 \mathrm{e}+002.45300 \mathrm{e}+002.45300 \mathrm{e}-011.00000 \mathrm{e}-092.12000 \mathrm{e}-01$

$2.45300 \mathrm{e}+002.45300 \mathrm{e}+002.45300 \mathrm{e}-011.00000 \mathrm{e}-092.12000 \mathrm{e}-01$

$1.00000 \mathrm{e}-021.00000 \mathrm{e}-02$ 1.00000e-03 1.00000e-09 1.00000e-01

$1.00000 \mathrm{e}+001.00000 \mathrm{e}+001.00000 \mathrm{e}-011.00000 \mathrm{e}-091.00000 \mathrm{e}-01$

$1.00000 \mathrm{e}-05$ 1.00000e-05 1.00000e-06 1.00000e-09 1.00000e-01

$1.00000 \mathrm{e}+001.00000 \mathrm{e}+001.00000 \mathrm{e}-011.00000 \mathrm{e}-091.00000 \mathrm{e}-01$

Element: 3529 \# of layers: 16

Kx Ky Kz Ss Por

$6.44125 \mathrm{e}+016.44125 \mathrm{e}+016.44125 \mathrm{e}+00$ 1.00000e-09 7.00000e-02

$6.44125 \mathrm{e}+016.44125 \mathrm{e}+016.44125 \mathrm{e}+001.00000 \mathrm{e}-09$ 7.00000e-02

$6.44125 \mathrm{e}+016.44125 \mathrm{e}+016.44125 \mathrm{e}+001.00000 \mathrm{e}-09$ 7.00000e-02

$6.44125 \mathrm{e}+016.44125 \mathrm{e}+016.44125 \mathrm{e}+001.00000 \mathrm{e}-09$ 7.00000e-02

$6.44125 \mathrm{e}+016.44125 \mathrm{e}+016.44125 \mathrm{e}+001.00000 \mathrm{e}-09$ 7.00000e-02

5.00000e-04 5.00000e-04 5.00000e-05 1.00000e-09 1.00000e-01

$5.00000 \mathrm{e}-04$ 5.00000e-04 5.00000e-05 1.00000e-09 1.00000e-01

$2.57361 \mathrm{e}+002.57361 \mathrm{e}+002.57361 \mathrm{e}-011.00000 \mathrm{e}-092.12000 \mathrm{e}-01$

$2.57361 \mathrm{e}+002.57361 \mathrm{e}+002.57361 \mathrm{e}-011.00000 \mathrm{e}-092.12000 \mathrm{e}-01$

$2.57361 \mathrm{e}+002.57361 \mathrm{e}+002.57361 \mathrm{e}-011.00000 \mathrm{e}-092.12000 \mathrm{e}-01$

$2.57361 \mathrm{e}+002.57361 \mathrm{e}+002.57361 \mathrm{e}-011.00000 \mathrm{e}-092.12000 \mathrm{e}-01$

$2.57361 \mathrm{e}+002.57361 \mathrm{e}+002.57361 \mathrm{e}-011.00000 \mathrm{e}-092.12000 \mathrm{e}-01$

$1.00000 \mathrm{e}-021.00000 \mathrm{e}-02$ 1.00000e-03 1.00000e-09 1.00000e-01

$1.00000 \mathrm{e}+001.00000 \mathrm{e}+001.00000 \mathrm{e}-011.00000 \mathrm{e}-091.00000 \mathrm{e}-01$

$1.00000 \mathrm{e}-051.00000 \mathrm{e}-05$ 1.00000e-06 1.00000e-09 1.00000e-01

$1.00000 \mathrm{e}+001.00000 \mathrm{e}+001.00000 \mathrm{e}-011.00000 \mathrm{e}-091.00000 \mathrm{e}-01$

Element: 3530 \# of layers: 15

Kx Ky Kz Ss Por

$4.88135 \mathrm{e}+014.88135 \mathrm{e}+014.88135 \mathrm{e}+00$ 1.00000e-09 7.00000e-02

$4.88135 \mathrm{e}+014.88135 \mathrm{e}+014.88135 \mathrm{e}+001.00000 \mathrm{e}-09$ 7.00000e-02

$4.88135 \mathrm{e}+014.88135 \mathrm{e}+014.88135 \mathrm{e}+001.00000 \mathrm{e}-09$ 7.00000e-02

$4.88135 \mathrm{e}+014.88135 \mathrm{e}+014.88135 \mathrm{e}+001.00000 \mathrm{e}-09$ 7.00000e-02

5.00000e-04 5.00000e-04 5.00000e-05 1.00000e-09 1.00000e-01

5.00000e-04 5.00000e-04 5.00000e-05 1.00000e-09 1.00000e-01

$1.95043 \mathrm{e}+001.95043 \mathrm{e}+00$ 1.95043e-01 1.00000e-09 2.12000e-01

$1.95043 \mathrm{e}+001.95043 \mathrm{e}+001.95043 \mathrm{e}-011.00000 \mathrm{e}-092.12000 \mathrm{e}-01$

$1.95043 \mathrm{e}+001.95043 \mathrm{e}+001.95043 \mathrm{e}-011.00000 \mathrm{e}-092.12000 \mathrm{e}-01$

$1.95043 \mathrm{e}+001.95043 \mathrm{e}+00$ 1.95043e-01 1.00000e-09 2.12000e-01

$1.95043 \mathrm{e}+001.95043 \mathrm{e}+00$ 1.95043e-01 1.00000e-09 2.12000e-01

$1.00000 \mathrm{e}-021.00000 \mathrm{e}-02$ 1.00000e-03 1.00000e-09 1.00000e-01

$1.00000 \mathrm{e}+001.00000 \mathrm{e}+001.00000 \mathrm{e}-011.00000 \mathrm{e}-091.00000 \mathrm{e}-01$

$1.00000 \mathrm{e}-05$ 1.00000e-05 1.00000e-06 1.00000e-09 1.00000e-01

$1.00000 \mathrm{e}+001.00000 \mathrm{e}+001.00000 \mathrm{e}-011.00000 \mathrm{e}-091.00000 \mathrm{e}-01$

Element: 3531 \# of layers: 15 
$\mathrm{Kx} \mathrm{Ky} \mathrm{Kz}$ Ss Por

4.88135e+01 4.88135e+01 4.88135e+00 1.00000e-09 7.00000e-02 4.88135e+01 4.88135e+01 4.88135e+00 1.00000e-09 7.00000e-02 $4.88135 \mathrm{e}+014.88135 \mathrm{e}+014.88135 \mathrm{e}+001.00000 \mathrm{e}-09$ 7.00000e-02 $4.88135 \mathrm{e}+014.88135 \mathrm{e}+014.88135 \mathrm{e}+001.00000 \mathrm{e}-09$ 7.00000e-02 5.00000e-04 5.00000e-04 5.00000e-05 1.00000e-09 1.00000e-01 5.00000e-04 5.00000e-04 5.00000e-05 1.00000e-09 1.00000e-01 $1.95043 \mathrm{e}+00$ 1.95043e+00 1.95043e-01 1.00000e-09 2.12000e-01 $1.95043 \mathrm{e}+00$ 1.95043e+00 1.95043e-01 1.00000e-09 2.12000e-01 $1.95043 \mathrm{e}+00$ 1.95043e+00 1.95043e-01 1.00000e-09 2.12000e-01 $1.95043 \mathrm{e}+00$ 1.95043e+00 1.95043e-01 1.00000e-09 2.12000e-01 $1.95043 \mathrm{e}+00$ 1.95043e+00 1.95043e-01 1.00000e-09 2.12000e-01 $1.00000 \mathrm{e}-02$ 1.00000e-02 1.00000e-03 1.00000e-09 1.00000e-01 $1.00000 \mathrm{e}+001.00000 \mathrm{e}+001.00000 \mathrm{e}-011.00000 \mathrm{e}-091.00000 \mathrm{e}-01$ $1.00000 \mathrm{e}-05$ 1.00000e-05 1.00000e-06 1.00000e-09 1.00000e-01 $1.00000 \mathrm{e}+001.00000 \mathrm{e}+001.00000 \mathrm{e}-011.00000 \mathrm{e}-091.00000 \mathrm{e}-01$ Element: 3532 \# of layers: 14

$\mathrm{Kx} \mathrm{Ky} \mathrm{Kz}$ Ss Por

4.88135e+01 4.88135e+01 4.88135e+00 1.00000e-09 7.00000e-02 $4.88135 \mathrm{e}+014.88135 \mathrm{e}+014.88135 \mathrm{e}+00$ 1.00000e-09 7.00000e-02 $4.88135 \mathrm{e}+014.88135 \mathrm{e}+014.88135 \mathrm{e}+001.00000 \mathrm{e}-09$ 7.00000e-02 $5.00000 \mathrm{e}-04$ 5.00000e-04 5.00000e-05 1.00000e-09 1.00000e-01 $5.00000 \mathrm{e}-04$ 5.00000e-04 5.00000e-05 1.00000e-09 1.00000e-01 $1.95043 \mathrm{e}+00$ 1.95043e+00 1.95043e-01 1.00000e-09 2.12000e-01 $1.95043 \mathrm{e}+001.95043 \mathrm{e}+00$ 1.95043e-01 1.00000e-09 2.12000e-01 $1.95043 \mathrm{e}+00$ 1.95043e+00 1.95043e-01 1.00000e-09 2.12000e-01 $1.95043 \mathrm{e}+001.95043 \mathrm{e}+00$ 1.95043e-01 1.00000e-09 2.12000e-01 $1.95043 \mathrm{e}+00$ 1.95043e+00 1.95043e-01 1.00000e-09 2.12000e-01 $1.00000 \mathrm{e}-02$ 1.00000e-02 1.00000e-03 1.00000e-09 1.00000e-01 $1.00000 \mathrm{e}+001.00000 \mathrm{e}+001.00000 \mathrm{e}-011.00000 \mathrm{e}-091.00000 \mathrm{e}-01$ $1.00000 \mathrm{e}-05$ 1.00000e-05 1.00000e-06 1.00000e-09 1.00000e-01 $1.00000 \mathrm{e}+001.00000 \mathrm{e}+001.00000 \mathrm{e}-01$ 1.00000e-09 1.00000e-01 Element: 3533 \# of layers: 14

$\mathrm{Kx} \mathrm{Ky} \mathrm{Kz}$ Ss Por

4.88135e+01 4.88135e+01 4.88135e+00 1.00000e-09 7.00000e-02 $4.88135 \mathrm{e}+014.88135 \mathrm{e}+014.88135 \mathrm{e}+00$ 1.00000e-09 7.00000e-02 $4.88135 \mathrm{e}+014.88135 \mathrm{e}+014.88135 \mathrm{e}+001.00000 \mathrm{e}-09$ 7.00000e-02 5.00000e-04 5.00000e-04 5.00000e-05 1.00000e-09 1.00000e-01 5.00000e-04 5.00000e-04 5.00000e-05 1.00000e-09 1.00000e-01 $1.95043 \mathrm{e}+001.95043 \mathrm{e}+00$ 1.95043e-01 1.00000e-09 2.12000e-01 $1.95043 \mathrm{e}+00$ 1.95043e+00 1.95043e-01 1.00000e-09 2.12000e-01 $1.95043 \mathrm{e}+001.95043 \mathrm{e}+00$ 1.95043e-01 1.00000e-09 2.12000e-01 1.95043e+00 1.95043e+00 1.95043e-01 1.00000e-09 2.12000e-01 $1.95043 \mathrm{e}+00$ 1.95043e+00 1.95043e-01 1.00000e-09 2.12000e-01 $1.00000 \mathrm{e}-02$ 1.00000e-02 1.00000e-03 1.00000e-09 1.00000e-01 $1.00000 \mathrm{e}+001.00000 \mathrm{e}+001.00000 \mathrm{e}-011.00000 \mathrm{e}-091.00000 \mathrm{e}-01$ 
$1.00000 \mathrm{e}-05$ 1.00000e-05 1.00000e-06 1.00000e-09 1.00000e-01 $1.00000 \mathrm{e}+001.00000 \mathrm{e}+001.00000 \mathrm{e}-01$ 1.00000e-09 1.00000e-01 Element: 3534 \# of layers: 13

Kx Ky Kz Ss Por

4.88135e+01 4.88135e+01 4.88135e+00 1.00000e-09 7.00000e-02 $4.88135 \mathrm{e}+014.88135 \mathrm{e}+014.88135 \mathrm{e}+00$ 1.00000e-09 7.00000e-02 $4.88135 \mathrm{e}+014.88135 \mathrm{e}+014.88135 \mathrm{e}+00$ 1.00000e-09 7.00000e-02 5.00000e-04 5.00000e-04 5.00000e-05 1.00000e-09 1.00000e-01 5.00000e-04 5.00000e-04 5.00000e-05 1.00000e-09 1.00000e-01 $1.95043 \mathrm{e}+001.95043 \mathrm{e}+00$ 1.95043e-01 1.00000e-09 2.12000e-01 $1.95043 \mathrm{e}+00$ 1.95043e+00 1.95043e-01 1.00000e-09 2.12000e-01 $1.95043 \mathrm{e}+00$ 1.95043e+00 1.95043e-01 1.00000e-09 2.12000e-01 $1.95043 \mathrm{e}+001.95043 \mathrm{e}+00$ 1.95043e-01 1.00000e-09 2.12000e-01 $1.00000 \mathrm{e}-02$ 1.00000e-02 1.00000e-03 1.00000e-09 1.00000e-01 $1.00000 \mathrm{e}+001.00000 \mathrm{e}+001.00000 \mathrm{e}-011.00000 \mathrm{e}-091.00000 \mathrm{e}-01$ $1.00000 \mathrm{e}-05$ 1.00000e-05 1.00000e-06 1.00000e-09 1.00000e-01 $1.00000 \mathrm{e}+001.00000 \mathrm{e}+001.00000 \mathrm{e}-011.00000 \mathrm{e}-091.00000 \mathrm{e}-01$ Element: 3535 \# of layers: 14

$\mathrm{Kx} \mathrm{Ky} \mathrm{Kz}$ Ss Por

4.88135e+01 4.88135e+01 4.88135e+00 1.00000e-09 7.00000e-02 $4.88135 \mathrm{e}+014.88135 \mathrm{e}+014.88135 \mathrm{e}+001.00000 \mathrm{e}-09$ 7.00000e-02 4.88135e+01 4.88135e+01 4.88135e+00 1.00000e-09 7.00000e-02 5.00000e-04 5.00000e-04 5.00000e-05 1.00000e-09 1.00000e-01 5.00000e-04 5.00000e-04 5.00000e-05 1.00000e-09 1.00000e-01

$1.95043 \mathrm{e}+001.95043 \mathrm{e}+001.95043 \mathrm{e}-01$ 1.00000e-09 2.12000e-01 $1.95043 \mathrm{e}+00$ 1.95043e+00 1.95043e-01 1.00000e-09 2.12000e-01 $1.95043 \mathrm{e}+001.95043 \mathrm{e}+00$ 1.95043e-01 1.00000e-09 2.12000e-01 $1.95043 \mathrm{e}+00$ 1.95043e+00 1.95043e-01 1.00000e-09 2.12000e-01 $1.95043 \mathrm{e}+001.95043 \mathrm{e}+00$ 1.95043e-01 1.00000e-09 2.12000e-01 $1.00000 \mathrm{e}-02$ 1.00000e-02 1.00000e-03 1.00000e-09 1.00000e-01 $1.00000 \mathrm{e}+001.00000 \mathrm{e}+001.00000 \mathrm{e}-01$ 1.00000e-09 1.00000e-01 $1.00000 \mathrm{e}-05$ 1.00000e-05 1.00000e-06 1.00000e-09 1.00000e-01 $1.00000 \mathrm{e}+001.00000 \mathrm{e}+001.00000 \mathrm{e}-011.00000 \mathrm{e}-091.00000 \mathrm{e}-01$ Element: 3536 \# of layers: 15

$\mathrm{Kx} \mathrm{Ky} \mathrm{Kz}$ Ss Por

4.88135e+01 4.88135e+01 4.88135e+00 1.00000e-09 7.00000e-02 $4.88135 \mathrm{e}+014.88135 \mathrm{e}+014.88135 \mathrm{e}+00$ 1.00000e-09 7.00000e-02 $4.88135 \mathrm{e}+014.88135 \mathrm{e}+014.88135 \mathrm{e}+00$ 1.00000e-09 7.00000e-02 $4.88135 \mathrm{e}+014.88135 \mathrm{e}+014.88135 \mathrm{e}+001.00000 \mathrm{e}-09$ 7.00000e-02 5.00000e-04 5.00000e-04 5.00000e-05 1.00000e-09 1.00000e-01 5.00000e-04 5.00000e-04 5.00000e-05 1.00000e-09 1.00000e-01 $1.95043 \mathrm{e}+00$ 1.95043e+00 1.95043e-01 1.00000e-09 2.12000e-01 $1.95043 \mathrm{e}+00$ 1.95043e+00 1.95043e-01 1.00000e-09 2.12000e-01 $1.95043 \mathrm{e}+00$ 1.95043e+00 1.95043e-01 1.00000e-09 2.12000e-01 $1.95043 \mathrm{e}+001.95043 \mathrm{e}+00$ 1.95043e-01 1.00000e-09 2.12000e-01 $1.95043 \mathrm{e}+001.95043 \mathrm{e}+00$ 1.95043e-01 1.00000e-09 2.12000e-01 
$1.00000 \mathrm{e}-02$ 1.00000e-02 1.00000e-03 1.00000e-09 1.00000e-01 $1.00000 \mathrm{e}+001.00000 \mathrm{e}+001.00000 \mathrm{e}-011.00000 \mathrm{e}-091.00000 \mathrm{e}-01$ $1.00000 \mathrm{e}-05$ 1.00000e-05 1.00000e-06 1.00000e-09 1.00000e-01 $1.00000 \mathrm{e}+001.00000 \mathrm{e}+001.00000 \mathrm{e}-011.00000 \mathrm{e}-091.00000 \mathrm{e}-01$ Element: 3537 \# of layers: 15

$\mathrm{Kx} \mathrm{Ky} \mathrm{Kz}$ Ss Por

4.88135e+01 4.88135e+01 4.88135e+00 1.00000e-09 7.00000e-02 $4.88135 \mathrm{e}+014.88135 \mathrm{e}+014.88135 \mathrm{e}+00$ 1.00000e-09 7.00000e-02 $4.88135 \mathrm{e}+014.88135 \mathrm{e}+014.88135 \mathrm{e}+001.00000 \mathrm{e}-09$ 7.00000e-02 $4.88135 \mathrm{e}+014.88135 \mathrm{e}+014.88135 \mathrm{e}+00$ 1.00000e-09 7.00000e-02 5.00000e-04 5.00000e-04 5.00000e-05 1.00000e-09 1.00000e-01 5.00000e-04 5.00000e-04 5.00000e-05 1.00000e-09 1.00000e-01 $1.95043 \mathrm{e}+001.95043 \mathrm{e}+00$ 1.95043e-01 1.00000e-09 2.12000e-01 $1.95043 \mathrm{e}+00$ 1.95043e+00 1.95043e-01 1.00000e-09 2.12000e-01 $1.95043 \mathrm{e}+00$ 1.95043e+00 1.95043e-01 1.00000e-09 2.12000e-01 $1.95043 \mathrm{e}+00$ 1.95043e+00 1.95043e-01 1.00000e-09 2.12000e-01 $1.95043 \mathrm{e}+001.95043 \mathrm{e}+001.95043 \mathrm{e}-01$ 1.00000e-09 2.12000e-01 $1.00000 \mathrm{e}-02$ 1.00000e-02 1.00000e-03 1.00000e-09 1.00000e-01 $1.00000 \mathrm{e}+001.00000 \mathrm{e}+001.00000 \mathrm{e}-011.00000 \mathrm{e}-091.00000 \mathrm{e}-01$ $1.00000 \mathrm{e}-05$ 1.00000e-05 1.00000e-06 1.00000e-09 1.00000e-01 $1.00000 \mathrm{e}+001.00000 \mathrm{e}+001.00000 \mathrm{e}-011.00000 \mathrm{e}-091.00000 \mathrm{e}-01$ Element: 3538 \# of layers: 15

$\mathrm{Kx} \mathrm{Ky} \mathrm{Kz}$ Ss Por

4.88135e+01 4.88135e+01 4.88135e+00 1.00000e-09 7.00000e-02 $4.88135 \mathrm{e}+014.88135 \mathrm{e}+014.88135 \mathrm{e}+001.00000 \mathrm{e}-09$ 7.00000e-02 $4.88135 \mathrm{e}+014.88135 \mathrm{e}+014.88135 \mathrm{e}+001.00000 \mathrm{e}-09$ 7.00000e-02 $4.88135 \mathrm{e}+014.88135 \mathrm{e}+014.88135 \mathrm{e}+001.00000 \mathrm{e}-09$ 7.00000e-02 5.00000e-04 5.00000e-04 5.00000e-05 1.00000e-09 1.00000e-01 5.00000e-04 5.00000e-04 5.00000e-05 1.00000e-09 1.00000e-01 $1.95043 \mathrm{e}+001.95043 \mathrm{e}+00$ 1.95043e-01 1.00000e-09 2.12000e-01 $1.95043 \mathrm{e}+00$ 1.95043e+00 1.95043e-01 1.00000e-09 2.12000e-01 $1.95043 \mathrm{e}+00$ 1.95043e+00 1.95043e-01 1.00000e-09 2.12000e-01 $1.95043 \mathrm{e}+001.95043 \mathrm{e}+00$ 1.95043e-01 1.00000e-09 2.12000e-01 $1.95043 \mathrm{e}+00$ 1.95043e+00 1.95043e-01 1.00000e-09 2.12000e-01 $1.00000 \mathrm{e}-02$ 1.00000e-02 1.00000e-03 1.00000e-09 1.00000e-01 $1.00000 \mathrm{e}+001.00000 \mathrm{e}+001.00000 \mathrm{e}-011.00000 \mathrm{e}-091.00000 \mathrm{e}-01$ $1.00000 \mathrm{e}-05$ 1.00000e-05 1.00000e-06 1.00000e-09 1.00000e-01 $1.00000 \mathrm{e}+001.00000 \mathrm{e}+001.00000 \mathrm{e}-011.00000 \mathrm{e}-091.00000 \mathrm{e}-01$ Element: 3539 \# of layers: 14

$\mathrm{Kx} \mathrm{Ky} \mathrm{Kz}$ Ss Por

$2.74219 \mathrm{e}+012.74219 \mathrm{e}+012.74219 \mathrm{e}+00$ 1.00000e-09 7.00000e-02 $2.74219 \mathrm{e}+012.74219 \mathrm{e}+012.74219 \mathrm{e}+001.00000 \mathrm{e}-09$ 7.00000e-02 $2.74219 \mathrm{e}+012.74219 \mathrm{e}+012.74219 \mathrm{e}+00$ 1.00000e-09 7.00000e-02 5.00000e-04 5.00000e-04 5.00000e-05 1.00000e-09 1.00000e-01 5.00000e-04 5.00000e-04 5.00000e-05 1.00000e-09 1.00000e-01 $1.09571 \mathrm{e}+001.09571 \mathrm{e}+001.09571 \mathrm{e}-011.00000 \mathrm{e}-092.12000 \mathrm{e}-01$ 
$1.09571 \mathrm{e}+00$ 1.09571e+00 1.09571e-01 1.00000e-09 2.12000e-01 $1.09571 \mathrm{e}+001.09571 \mathrm{e}+001.09571 \mathrm{e}-01$ 1.00000e-09 2.12000e-01 $1.09571 \mathrm{e}+001.09571 \mathrm{e}+001.09571 \mathrm{e}-01$ 1.00000e-09 2.12000e-01 $1.09571 \mathrm{e}+001.09571 \mathrm{e}+001.09571 \mathrm{e}-011.00000 \mathrm{e}-092.12000 \mathrm{e}-01$ $1.00000 \mathrm{e}-02$ 1.00000e-02 1.00000e-03 1.00000e-09 1.00000e-01 $1.00000 \mathrm{e}+001.00000 \mathrm{e}+001.00000 \mathrm{e}-011.00000 \mathrm{e}-091.00000 \mathrm{e}-01$ $1.00000 \mathrm{e}-05$ 1.00000e-05 1.00000e-06 1.00000e-09 1.00000e-01 $1.00000 \mathrm{e}+001.00000 \mathrm{e}+001.00000 \mathrm{e}-011.00000 \mathrm{e}-091.00000 \mathrm{e}-01$ Element: 3540 \# of layers: 14

$\mathrm{Kx} \mathrm{Ky} \mathrm{Kz}$ Ss Por

$2.74219 \mathrm{e}+012.74219 \mathrm{e}+012.74219 \mathrm{e}+00$ 1.00000e-09 7.00000e-02 $2.74219 \mathrm{e}+012.74219 \mathrm{e}+012.74219 \mathrm{e}+001.00000 \mathrm{e}-09$ 7.00000e-02 $2.74219 \mathrm{e}+012.74219 \mathrm{e}+012.74219 \mathrm{e}+001.00000 \mathrm{e}-09$ 7.00000e-02 5.00000e-04 5.00000e-04 5.00000e-05 1.00000e-09 1.00000e-01 5.00000e-04 5.00000e-04 5.00000e-05 1.00000e-09 1.00000e-01 $1.09571 \mathrm{e}+001.09571 \mathrm{e}+001.09571 \mathrm{e}-011.00000 \mathrm{e}-092.12000 \mathrm{e}-01$ $1.09571 \mathrm{e}+001.09571 \mathrm{e}+001.09571 \mathrm{e}-01$ 1.00000e-09 2.12000e-01 $1.09571 \mathrm{e}+001.09571 \mathrm{e}+001.09571 \mathrm{e}-01$ 1.00000e-09 2.12000e-01 $1.09571 \mathrm{e}+001.09571 \mathrm{e}+00$ 1.09571e-01 1.00000e-09 2.12000e-01 $1.09571 \mathrm{e}+001.09571 \mathrm{e}+001.09571 \mathrm{e}-011.00000 \mathrm{e}-092.12000 \mathrm{e}-01$ $1.00000 \mathrm{e}-02$ 1.00000e-02 1.00000e-03 1.00000e-09 1.00000e-01 $1.00000 \mathrm{e}+001.00000 \mathrm{e}+001.00000 \mathrm{e}-011.00000 \mathrm{e}-091.00000 \mathrm{e}-01$ $1.00000 \mathrm{e}-05$ 1.00000e-05 1.00000e-06 1.00000e-09 1.00000e-01 $1.00000 \mathrm{e}+001.00000 \mathrm{e}+001.00000 \mathrm{e}-011.00000 \mathrm{e}-091.00000 \mathrm{e}-01$ Element: 3541 \# of layers: 14

$\mathrm{Kx} \mathrm{Ky} \mathrm{Kz}$ Ss Por

$2.74219 \mathrm{e}+012.74219 \mathrm{e}+012.74219 \mathrm{e}+00$ 1.00000e-09 7.00000e-02 $2.74219 \mathrm{e}+012.74219 \mathrm{e}+012.74219 \mathrm{e}+00$ 1.00000e-09 7.00000e-02 $2.74219 \mathrm{e}+012.74219 \mathrm{e}+012.74219 \mathrm{e}+001.00000 \mathrm{e}-09$ 7.00000e-02 $5.00000 \mathrm{e}-04$ 5.00000e-04 5.00000e-05 1.00000e-09 1.00000e-01 5.00000e-04 5.00000e-04 5.00000e-05 1.00000e-09 1.00000e-01 $1.09571 \mathrm{e}+001.09571 \mathrm{e}+001.09571 \mathrm{e}-01$ 1.00000e-09 2.12000e-01 $1.09571 \mathrm{e}+001.09571 \mathrm{e}+001.09571 \mathrm{e}-011.00000 \mathrm{e}-092.12000 \mathrm{e}-01$ $1.09571 \mathrm{e}+001.09571 \mathrm{e}+00$ 1.09571e-01 1.00000e-09 2.12000e-01 $1.09571 \mathrm{e}+001.09571 \mathrm{e}+001.09571 \mathrm{e}-01$ 1.00000e-09 2.12000e-01 $1.09571 \mathrm{e}+001.09571 \mathrm{e}+001.09571 \mathrm{e}-01$ 1.00000e-09 2.12000e-01 $1.00000 \mathrm{e}-02$ 1.00000e-02 1.00000e-03 1.00000e-09 1.00000e-01 $1.00000 \mathrm{e}+001.00000 \mathrm{e}+001.00000 \mathrm{e}-011.00000 \mathrm{e}-091.00000 \mathrm{e}-01$ $1.00000 \mathrm{e}-05$ 1.00000e-05 1.00000e-06 1.00000e-09 1.00000e-01 $1.00000 \mathrm{e}+001.00000 \mathrm{e}+001.00000 \mathrm{e}-01$ 1.00000e-09 1.00000e-01 Element: 3542 \# of layers: 14

$\mathrm{Kx} \mathrm{Ky} \mathrm{Kz}$ Ss Por

2.74219e+01 2.74219e+01 2.74219e+00 1.00000e-09 7.00000e-02 $2.74219 \mathrm{e}+012.74219 \mathrm{e}+012.74219 \mathrm{e}+00$ 1.00000e-09 7.00000e-02 $2.74219 \mathrm{e}+012.74219 \mathrm{e}+012.74219 \mathrm{e}+001.00000 \mathrm{e}-09$ 7.00000e-02 5.00000e-04 5.00000e-04 5.00000e-05 1.00000e-09 1.00000e-01 
5.00000e-04 5.00000e-04 5.00000e-05 1.00000e-09 1.00000e-01 $1.09571 \mathrm{e}+001.09571 \mathrm{e}+001.09571 \mathrm{e}-01$ 1.00000e-09 2.12000e-01 $1.09571 \mathrm{e}+001.09571 \mathrm{e}+001.09571 \mathrm{e}-01$ 1.00000e-09 2.12000e-01 $1.09571 \mathrm{e}+001.09571 \mathrm{e}+001.09571 \mathrm{e}-011.00000 \mathrm{e}-092.12000 \mathrm{e}-01$ $1.09571 \mathrm{e}+001.09571 \mathrm{e}+001.09571 \mathrm{e}-01$ 1.00000e-09 2.12000e-01 $1.09571 \mathrm{e}+001.09571 \mathrm{e}+001.09571 \mathrm{e}-01$ 1.00000e-09 2.12000e-01 $1.00000 \mathrm{e}-02$ 1.00000e-02 1.00000e-03 1.00000e-09 1.00000e-01 $1.00000 \mathrm{e}+001.00000 \mathrm{e}+001.00000 \mathrm{e}-011.00000 \mathrm{e}-091.00000 \mathrm{e}-01$ $1.00000 \mathrm{e}-05$ 1.00000e-05 1.00000e-06 1.00000e-09 1.00000e-01 $1.00000 \mathrm{e}+001.00000 \mathrm{e}+001.00000 \mathrm{e}-011.00000 \mathrm{e}-091.00000 \mathrm{e}-01$ Element: 3543 \# of layers: 13

$\mathrm{Kx} \mathrm{Ky} \mathrm{Kz}$ Ss Por

$2.74219 \mathrm{e}+012.74219 \mathrm{e}+012.74219 \mathrm{e}+00$ 1.00000e-09 7.00000e-02

$2.74219 \mathrm{e}+012.74219 \mathrm{e}+012.74219 \mathrm{e}+00$ 1.00000e-09 7.00000e-02

$2.74219 \mathrm{e}+012.74219 \mathrm{e}+012.74219 \mathrm{e}+001.00000 \mathrm{e}-09$ 7.00000e-02 5.00000e-04 5.00000e-04 5.00000e-05 1.00000e-09 1.00000e-01 5.00000e-04 5.00000e-04 5.00000e-05 1.00000e-09 1.00000e-01 $1.09571 \mathrm{e}+001.09571 \mathrm{e}+001.09571 \mathrm{e}-01$ 1.00000e-09 2.12000e-01 $1.09571 \mathrm{e}+001.09571 \mathrm{e}+00$ 1.09571e-01 1.00000e-09 2.12000e-01 $1.09571 \mathrm{e}+001.09571 \mathrm{e}+001.09571 \mathrm{e}-011.00000 \mathrm{e}-092.12000 \mathrm{e}-01$ $1.09571 \mathrm{e}+001.09571 \mathrm{e}+001.09571 \mathrm{e}-011.00000 \mathrm{e}-092.12000 \mathrm{e}-01$ $1.00000 \mathrm{e}-02$ 1.00000e-02 1.00000e-03 1.00000e-09 1.00000e-01 $1.00000 \mathrm{e}+001.00000 \mathrm{e}+001.00000 \mathrm{e}-011.00000 \mathrm{e}-091.00000 \mathrm{e}-01$ $1.00000 \mathrm{e}-05$ 1.00000e-05 1.00000e-06 1.00000e-09 1.00000e-01 $1.00000 \mathrm{e}+001.00000 \mathrm{e}+001.00000 \mathrm{e}-011.00000 \mathrm{e}-09$ 1.00000e-01 Element: 3544 \# of layers: 13

$\mathrm{Kx} \mathrm{Ky} \mathrm{Kz}$ Ss Por

$2.74219 \mathrm{e}+012.74219 \mathrm{e}+012.74219 \mathrm{e}+00$ 1.00000e-09 7.00000e-02 $2.74219 \mathrm{e}+012.74219 \mathrm{e}+012.74219 \mathrm{e}+001.00000 \mathrm{e}-09$ 7.00000e-02 $2.74219 \mathrm{e}+012.74219 \mathrm{e}+012.74219 \mathrm{e}+00$ 1.00000e-09 7.00000e-02 5.00000e-04 5.00000e-04 5.00000e-05 1.00000e-09 1.00000e-01 5.00000e-04 5.00000e-04 5.00000e-05 1.00000e-09 1.00000e-01 $1.09571 \mathrm{e}+001.09571 \mathrm{e}+001.09571 \mathrm{e}-011.00000 \mathrm{e}-092.12000 \mathrm{e}-01$ $1.09571 \mathrm{e}+001.09571 \mathrm{e}+001.09571 \mathrm{e}-011.00000 \mathrm{e}-092.12000 \mathrm{e}-01$ $1.09571 \mathrm{e}+001.09571 \mathrm{e}+001.09571 \mathrm{e}-01$ 1.00000e-09 2.12000e-01 $1.09571 \mathrm{e}+001.09571 \mathrm{e}+001.09571 \mathrm{e}-01$ 1.00000e-09 2.12000e-01 $1.00000 \mathrm{e}-02$ 1.00000e-02 1.00000e-03 1.00000e-09 1.00000e-01 $1.00000 \mathrm{e}+001.00000 \mathrm{e}+001.00000 \mathrm{e}-011.00000 \mathrm{e}-091.00000 \mathrm{e}-01$ $1.00000 \mathrm{e}-05$ 1.00000e-05 1.00000e-06 1.00000e-09 1.00000e-01 $1.00000 \mathrm{e}+001.00000 \mathrm{e}+001.00000 \mathrm{e}-01$ 1.00000e-09 1.00000e-01 Element: 3545 \# of layers: 13

$\mathrm{Kx} \mathrm{Ky} \mathrm{Kz}$ Ss Por

2.74219e+01 2.74219e+01 2.74219e+00 1.00000e-09 7.00000e-02 $2.74219 \mathrm{e}+012.74219 \mathrm{e}+012.74219 \mathrm{e}+00$ 1.00000e-09 7.00000e-02 $2.74219 \mathrm{e}+012.74219 \mathrm{e}+012.74219 \mathrm{e}+001.00000 \mathrm{e}-09$ 7.00000e-02 5.00000e-04 5.00000e-04 5.00000e-05 1.00000e-09 1.00000e-01 
5.00000e-04 5.00000e-04 5.00000e-05 1.00000e-09 1.00000e-01 $1.09571 \mathrm{e}+001.09571 \mathrm{e}+001.09571 \mathrm{e}-01$ 1.00000e-09 2.12000e-01 $1.09571 \mathrm{e}+001.09571 \mathrm{e}+001.09571 \mathrm{e}-01$ 1.00000e-09 2.12000e-01 $1.09571 \mathrm{e}+001.09571 \mathrm{e}+001.09571 \mathrm{e}-011.00000 \mathrm{e}-092.12000 \mathrm{e}-01$ $1.09571 \mathrm{e}+001.09571 \mathrm{e}+001.09571 \mathrm{e}-01$ 1.00000e-09 2.12000e-01 $1.00000 \mathrm{e}-02$ 1.00000e-02 1.00000e-03 1.00000e-09 1.00000e-01 $1.00000 \mathrm{e}+001.00000 \mathrm{e}+001.00000 \mathrm{e}-011.00000 \mathrm{e}-091.00000 \mathrm{e}-01$ $1.00000 \mathrm{e}-05$ 1.00000e-05 1.00000e-06 1.00000e-09 1.00000e-01 $1.00000 \mathrm{e}+001.00000 \mathrm{e}+001.00000 \mathrm{e}-011.00000 \mathrm{e}-091.00000 \mathrm{e}-01$ Element: 3546 \# of layers: 14

$\mathrm{Kx} \mathrm{Ky} \mathrm{Kz}$ Ss Por

$2.74219 \mathrm{e}+012.74219 \mathrm{e}+012.74219 \mathrm{e}+00$ 1.00000e-09 7.00000e-02 $2.74219 \mathrm{e}+012.74219 \mathrm{e}+012.74219 \mathrm{e}+001.00000 \mathrm{e}-09$ 7.00000e-02

$2.74219 \mathrm{e}+012.74219 \mathrm{e}+012.74219 \mathrm{e}+001.00000 \mathrm{e}-09$ 7.00000e-02 5.00000e-04 5.00000e-04 5.00000e-05 1.00000e-09 1.00000e-01 5.00000e-04 5.00000e-04 5.00000e-05 1.00000e-09 1.00000e-01 $1.09571 \mathrm{e}+001.09571 \mathrm{e}+001.09571 \mathrm{e}-01$ 1.00000e-09 2.12000e-01 $1.09571 \mathrm{e}+001.09571 \mathrm{e}+00$ 1.09571e-01 1.00000e-09 2.12000e-01 $1.09571 \mathrm{e}+001.09571 \mathrm{e}+00$ 1.09571e-01 1.00000e-09 2.12000e-01 $1.09571 \mathrm{e}+001.09571 \mathrm{e}+001.09571 \mathrm{e}-011.00000 \mathrm{e}-092.12000 \mathrm{e}-01$ $1.09571 \mathrm{e}+001.09571 \mathrm{e}+001.09571 \mathrm{e}-011.00000 \mathrm{e}-092.12000 \mathrm{e}-01$ $1.00000 \mathrm{e}-02$ 1.00000e-02 1.00000e-03 1.00000e-09 1.00000e-01 $1.00000 \mathrm{e}+001.00000 \mathrm{e}+001.00000 \mathrm{e}-011.00000 \mathrm{e}-091.00000 \mathrm{e}-01$ $1.00000 \mathrm{e}-05$ 1.00000e-05 1.00000e-06 1.00000e-09 1.00000e-01 $1.00000 \mathrm{e}+001.00000 \mathrm{e}+001.00000 \mathrm{e}-011.00000 \mathrm{e}-091.00000 \mathrm{e}-01$ Element: 3547 \# of layers: 14

$\mathrm{Kx} \mathrm{Ky} \mathrm{Kz}$ Ss Por

$2.74219 \mathrm{e}+012.74219 \mathrm{e}+012.74219 \mathrm{e}+00$ 1.00000e-09 7.00000e-02 $2.74219 \mathrm{e}+012.74219 \mathrm{e}+012.74219 \mathrm{e}+001.00000 \mathrm{e}-09$ 7.00000e-02 $2.74219 \mathrm{e}+012.74219 \mathrm{e}+012.74219 \mathrm{e}+00$ 1.00000e-09 7.00000e-02 5.00000e-04 5.00000e-04 5.00000e-05 1.00000e-09 1.00000e-01 5.00000e-04 5.00000e-04 5.00000e-05 1.00000e-09 1.00000e-01 $1.09571 \mathrm{e}+001.09571 \mathrm{e}+001.09571 \mathrm{e}-011.00000 \mathrm{e}-092.12000 \mathrm{e}-01$ $1.09571 \mathrm{e}+001.09571 \mathrm{e}+001.09571 \mathrm{e}-011.00000 \mathrm{e}-092.12000 \mathrm{e}-01$ $1.09571 \mathrm{e}+001.09571 \mathrm{e}+001.09571 \mathrm{e}-01$ 1.00000e-09 2.12000e-01 $1.09571 \mathrm{e}+001.09571 \mathrm{e}+001.09571 \mathrm{e}-01$ 1.00000e-09 2.12000e-01 $1.09571 \mathrm{e}+001.09571 \mathrm{e}+001.09571 \mathrm{e}-01$ 1.00000e-09 2.12000e-01 $1.00000 \mathrm{e}-02$ 1.00000e-02 1.00000e-03 1.00000e-09 1.00000e-01 $1.00000 \mathrm{e}+001.00000 \mathrm{e}+001.00000 \mathrm{e}-011.00000 \mathrm{e}-091.00000 \mathrm{e}-01$ $1.00000 \mathrm{e}-05$ 1.00000e-05 1.00000e-06 1.00000e-09 1.00000e-01 $1.00000 \mathrm{e}+001.00000 \mathrm{e}+001.00000 \mathrm{e}-011.00000 \mathrm{e}-091.00000 \mathrm{e}-01$ Element: 3548 \# of layers: 14

$\mathrm{Kx} \mathrm{Ky} \mathrm{Kz}$ Ss Por

2.14816e+01 2.14816e+01 2.14816e+00 1.00000e-09 7.00000e-02 $2.14816 \mathrm{e}+012.14816 \mathrm{e}+012.14816 \mathrm{e}+001.00000 \mathrm{e}-09$ 7.00000e-02 $2.14816 \mathrm{e}+012.14816 \mathrm{e}+012.14816 \mathrm{e}+001.00000 \mathrm{e}-09$ 7.00000e-02 
5.00000e-04 5.00000e-04 5.00000e-05 1.00000e-09 1.00000e-01 5.00000e-04 5.00000e-04 5.00000e-05 1.00000e-09 1.00000e-01 8.58348e-01 8.58348e-01 8.58348e-02 1.00000e-09 2.12000e-01 8.58348e-01 8.58348e-01 8.58348e-02 1.00000e-09 2.12000e-01 8.58348e-01 8.58348e-01 8.58348e-02 1.00000e-09 2.12000e-01 8.58348e-01 8.58348e-01 8.58348e-02 1.00000e-09 2.12000e-01 8.58348e-01 8.58348e-01 8.58348e-02 1.00000e-09 2.12000e-01 $1.00000 \mathrm{e}-021.00000 \mathrm{e}-02$ 1.00000e-03 1.00000e-09 1.00000e-01 $1.00000 \mathrm{e}+001.00000 \mathrm{e}+001.00000 \mathrm{e}-011.00000 \mathrm{e}-091.00000 \mathrm{e}-01$ $1.00000 \mathrm{e}-05$ 1.00000e-05 1.00000e-06 1.00000e-09 1.00000e-01 $1.00000 \mathrm{e}+001.00000 \mathrm{e}+001.00000 \mathrm{e}-011.00000 \mathrm{e}-091.00000 \mathrm{e}-01$ Element: 3549 \# of layers: 14

Kx Ky Kz Ss Por

$2.14816 \mathrm{e}+012.14816 \mathrm{e}+012.14816 \mathrm{e}+00$ 1.00000e-09 7.00000e-02 $2.14816 \mathrm{e}+012.14816 \mathrm{e}+012.14816 \mathrm{e}+001.00000 \mathrm{e}-09$ 7.00000e-02 $2.14816 \mathrm{e}+012.14816 \mathrm{e}+012.14816 \mathrm{e}+001.00000 \mathrm{e}-09$ 7.00000e-02 5.00000e-04 5.00000e-04 5.00000e-05 1.00000e-09 1.00000e-01 5.00000e-04 5.00000e-04 5.00000e-05 1.00000e-09 1.00000e-01 8.58348e-01 8.58348e-01 8.58348e-02 1.00000e-09 2.12000e-01 8.58348e-01 8.58348e-01 8.58348e-02 1.00000e-09 2.12000e-01 8.58348e-01 8.58348e-01 8.58348e-02 1.00000e-09 2.12000e-01 8.58348e-01 8.58348e-01 8.58348e-02 1.00000e-09 2.12000e-01 8.58348e-01 8.58348e-01 8.58348e-02 1.00000e-09 2.12000e-01 $1.00000 \mathrm{e}-021.00000 \mathrm{e}-02$ 1.00000e-03 $1.00000 \mathrm{e}-091.00000 \mathrm{e}-01$ $1.00000 \mathrm{e}+001.00000 \mathrm{e}+001.00000 \mathrm{e}-011.00000 \mathrm{e}-091.00000 \mathrm{e}-01$ $1.00000 \mathrm{e}-05$ 1.00000e-05 1.00000e-06 1.00000e-09 1.00000e-01 $1.00000 \mathrm{e}+001.00000 \mathrm{e}+001.00000 \mathrm{e}-011.00000 \mathrm{e}-091.00000 \mathrm{e}-01$ Element: 3550 \# of layers: 14

Kx Ky Kz Ss Por

$2.14816 \mathrm{e}+012.14816 \mathrm{e}+012.14816 \mathrm{e}+00$ 1.00000e-09 7.00000e-02 $2.14816 \mathrm{e}+012.14816 \mathrm{e}+012.14816 \mathrm{e}+001.00000 \mathrm{e}-09$ 7.00000e-02 $2.14816 \mathrm{e}+012.14816 \mathrm{e}+012.14816 \mathrm{e}+001.00000 \mathrm{e}-09$ 7.00000e-02 5.00000e-04 5.00000e-04 5.00000e-05 1.00000e-09 1.00000e-01 $5.00000 \mathrm{e}-04$ 5.00000e-04 5.00000e-05 1.00000e-09 1.00000e-01 8.58348e-01 8.58348e-01 8.58348e-02 1.00000e-09 2.12000e-01 8.58348e-01 8.58348e-01 8.58348e-02 1.00000e-09 2.12000e-01 8.58348e-01 8.58348e-01 8.58348e-02 1.00000e-09 2.12000e-01 8.58348e-01 8.58348e-01 8.58348e-02 1.00000e-09 2.12000e-01 8.58348e-01 8.58348e-01 8.58348e-02 1.00000e-09 2.12000e-01 $1.00000 \mathrm{e}-021.00000 \mathrm{e}-02$ 1.00000e-03 1.00000e-09 1.00000e-01 $1.00000 \mathrm{e}+001.00000 \mathrm{e}+001.00000 \mathrm{e}-011.00000 \mathrm{e}-091.00000 \mathrm{e}-01$ $1.00000 \mathrm{e}-05$ 1.00000e-05 1.00000e-06 1.00000e-09 1.00000e-01 $1.00000 \mathrm{e}+001.00000 \mathrm{e}+001.00000 \mathrm{e}-011.00000 \mathrm{e}-091.00000 \mathrm{e}-01$ Element: 3551 \# of layers: 14

Kx Ky Kz Ss Por

$2.14816 \mathrm{e}+012.14816 \mathrm{e}+012.14816 \mathrm{e}+00$ 1.00000e-09 7.00000e-02 
$2.14816 \mathrm{e}+012.14816 \mathrm{e}+012.14816 \mathrm{e}+00$ 1.00000e-09 7.00000e-02 $2.14816 \mathrm{e}+012.14816 \mathrm{e}+012.14816 \mathrm{e}+00$ 1.00000e-09 7.00000e-02 5.00000e-04 5.00000e-04 5.00000e-05 1.00000e-09 1.00000e-01 5.00000e-04 5.00000e-04 5.00000e-05 1.00000e-09 1.00000e-01 8.58348e-01 8.58348e-01 8.58348e-02 1.00000e-09 2.12000e-01 8.58348e-01 8.58348e-01 8.58348e-02 1.00000e-09 2.12000e-01 8.58348e-01 8.58348e-01 8.58348e-02 1.00000e-09 2.12000e-01 8.58348e-01 8.58348e-01 8.58348e-02 1.00000e-09 2.12000e-01 8.58348e-01 8.58348e-01 8.58348e-02 1.00000e-09 2.12000e-01 $1.00000 \mathrm{e}-02$ 1.00000e-02 1.00000e-03 1.00000e-09 1.00000e-01 $1.00000 \mathrm{e}+001.00000 \mathrm{e}+001.00000 \mathrm{e}-011.00000 \mathrm{e}-091.00000 \mathrm{e}-01$ $1.00000 \mathrm{e}-05$ 1.00000e-05 1.00000e-06 1.00000e-09 1.00000e-01 $1.00000 \mathrm{e}+001.00000 \mathrm{e}+001.00000 \mathrm{e}-011.00000 \mathrm{e}-09$ 1.00000e-01 Element: 3552 \# of layers: 13

$\mathrm{Kx} \mathrm{Ky} \mathrm{Kz}$ Ss Por

$2.14816 \mathrm{e}+012.14816 \mathrm{e}+012.14816 \mathrm{e}+00$ 1.00000e-09 7.00000e-02 $2.14816 \mathrm{e}+012.14816 \mathrm{e}+012.14816 \mathrm{e}+001.00000 \mathrm{e}-09$ 7.00000e-02 $2.14816 \mathrm{e}+012.14816 \mathrm{e}+012.14816 \mathrm{e}+001.00000 \mathrm{e}-09$ 7.00000e-02 5.00000e-04 5.00000e-04 5.00000e-05 1.00000e-09 1.00000e-01 5.00000e-04 5.00000e-04 5.00000e-05 1.00000e-09 1.00000e-01 8.58348e-01 8.58348e-01 8.58348e-02 1.00000e-09 2.12000e-01 8.58348e-01 8.58348e-01 8.58348e-02 1.00000e-09 2.12000e-01 8.58348e-01 8.58348e-01 8.58348e-02 1.00000e-09 2.12000e-01 8.58348e-01 8.58348e-01 8.58348e-02 1.00000e-09 2.12000e-01 $1.00000 \mathrm{e}-02$ 1.00000e-02 1.00000e-03 1.00000e-09 1.00000e-01 $1.00000 \mathrm{e}+001.00000 \mathrm{e}+001.00000 \mathrm{e}-011.00000 \mathrm{e}-091.00000 \mathrm{e}-01$ $1.00000 \mathrm{e}-05$ 1.00000e-05 1.00000e-06 1.00000e-09 1.00000e-01 $1.00000 \mathrm{e}+001.00000 \mathrm{e}+001.00000 \mathrm{e}-01$ 1.00000e-09 1.00000e-01 Element: 3553 \# of layers: 13

$\mathrm{Kx} \mathrm{Ky} \mathrm{Kz}$ Ss Por

$2.14816 \mathrm{e}+012.14816 \mathrm{e}+012.14816 \mathrm{e}+00$ 1.00000e-09 7.00000e-02 $2.14816 \mathrm{e}+012.14816 \mathrm{e}+012.14816 \mathrm{e}+00$ 1.00000e-09 7.00000e-02 $2.14816 \mathrm{e}+012.14816 \mathrm{e}+012.14816 \mathrm{e}+001.00000 \mathrm{e}-09$ 7.00000e-02 5.00000e-04 5.00000e-04 5.00000e-05 1.00000e-09 1.00000e-01 5.00000e-04 5.00000e-04 5.00000e-05 1.00000e-09 1.00000e-01 8.58348e-01 8.58348e-01 8.58348e-02 1.00000e-09 2.12000e-01 8.58348e-01 8.58348e-01 8.58348e-02 1.00000e-09 2.12000e-01 8.58348e-01 8.58348e-01 8.58348e-02 1.00000e-09 2.12000e-01 8.58348e-01 8.58348e-01 8.58348e-02 1.00000e-09 2.12000e-01 $1.00000 \mathrm{e}-02$ 1.00000e-02 1.00000e-03 1.00000e-09 1.00000e-01 $1.00000 \mathrm{e}+001.00000 \mathrm{e}+001.00000 \mathrm{e}-011.00000 \mathrm{e}-091.00000 \mathrm{e}-01$ $1.00000 \mathrm{e}-05$ 1.00000e-05 1.00000e-06 1.00000e-09 1.00000e-01 $1.00000 \mathrm{e}+001.00000 \mathrm{e}+001.00000 \mathrm{e}-011.00000 \mathrm{e}-091.00000 \mathrm{e}-01$ Element: 3554 \# of layers: 13

$\mathrm{Kx} \mathrm{Ky} \mathrm{Kz}$ Ss Por

2.14816e+01 2.14816e+01 2.14816e+00 1.00000e-09 7.00000e-02 
$2.14816 \mathrm{e}+012.14816 \mathrm{e}+012.14816 \mathrm{e}+00$ 1.00000e-09 7.00000e-02 $2.14816 \mathrm{e}+012.14816 \mathrm{e}+012.14816 \mathrm{e}+00$ 1.00000e-09 7.00000e-02 5.00000e-04 5.00000e-04 5.00000e-05 1.00000e-09 1.00000e-01 5.00000e-04 5.00000e-04 5.00000e-05 1.00000e-09 1.00000e-01 8.58348e-01 8.58348e-01 8.58348e-02 1.00000e-09 2.12000e-01 8.58348e-01 8.58348e-01 8.58348e-02 1.00000e-09 2.12000e-01 8.58348e-01 8.58348e-01 8.58348e-02 1.00000e-09 2.12000e-01 8.58348e-01 8.58348e-01 8.58348e-02 1.00000e-09 2.12000e-01 $1.00000 \mathrm{e}-02$ 1.00000e-02 1.00000e-03 1.00000e-09 1.00000e-01 $1.00000 \mathrm{e}+001.00000 \mathrm{e}+001.00000 \mathrm{e}-011.00000 \mathrm{e}-091.00000 \mathrm{e}-01$ $1.00000 \mathrm{e}-05$ 1.00000e-05 1.00000e-06 1.00000e-09 1.00000e-01 $1.00000 \mathrm{e}+001.00000 \mathrm{e}+001.00000 \mathrm{e}-011.00000 \mathrm{e}-091.00000 \mathrm{e}-01$ Element: 3555 \# of layers: 14

$\mathrm{Kx} \mathrm{Ky} \mathrm{Kz}$ Ss Por

$2.14816 \mathrm{e}+012.14816 \mathrm{e}+012.14816 \mathrm{e}+00$ 1.00000e-09 7.00000e-02 $2.14816 \mathrm{e}+012.14816 \mathrm{e}+012.14816 \mathrm{e}+001.00000 \mathrm{e}-09$ 7.00000e-02 $2.14816 \mathrm{e}+012.14816 \mathrm{e}+012.14816 \mathrm{e}+001.00000 \mathrm{e}-09$ 7.00000e-02 5.00000e-04 5.00000e-04 5.00000e-05 1.00000e-09 1.00000e-01 5.00000e-04 5.00000e-04 5.00000e-05 1.00000e-09 1.00000e-01 8.58348e-01 8.58348e-01 8.58348e-02 1.00000e-09 2.12000e-01 8.58348e-01 8.58348e-01 8.58348e-02 1.00000e-09 2.12000e-01 8.58348e-01 8.58348e-01 8.58348e-02 1.00000e-09 2.12000e-01 8.58348e-01 8.58348e-01 8.58348e-02 1.00000e-09 2.12000e-01 8.58348e-01 8.58348e-01 8.58348e-02 1.00000e-09 2.12000e-01 $1.00000 \mathrm{e}-02$ 1.00000e-02 1.00000e-03 1.00000e-09 1.00000e-01 $1.00000 \mathrm{e}+001.00000 \mathrm{e}+001.00000 \mathrm{e}-011.00000 \mathrm{e}-091.00000 \mathrm{e}-01$ $1.00000 \mathrm{e}-05$ 1.00000e-05 1.00000e-06 1.00000e-09 1.00000e-01 $1.00000 \mathrm{e}+001.00000 \mathrm{e}+001.00000 \mathrm{e}-011.00000 \mathrm{e}-09$ 1.00000e-01 Element: 3556 \# of layers: 14

$\mathrm{Kx} \mathrm{Ky} \mathrm{Kz}$ Ss Por

$2.14816 \mathrm{e}+012.14816 \mathrm{e}+012.14816 \mathrm{e}+00$ 1.00000e-09 7.00000e-02 $2.14816 \mathrm{e}+012.14816 \mathrm{e}+012.14816 \mathrm{e}+00$ 1.00000e-09 7.00000e-02 $2.14816 \mathrm{e}+012.14816 \mathrm{e}+012.14816 \mathrm{e}+001.00000 \mathrm{e}-09$ 7.00000e-02 5.00000e-04 5.00000e-04 5.00000e-05 1.00000e-09 1.00000e-01 5.00000e-04 5.00000e-04 5.00000e-05 1.00000e-09 1.00000e-01 8.58348e-01 8.58348e-01 8.58348e-02 1.00000e-09 2.12000e-01 8.58348e-01 8.58348e-01 8.58348e-02 1.00000e-09 2.12000e-01 8.58348e-01 8.58348e-01 8.58348e-02 1.00000e-09 2.12000e-01 8.58348e-01 8.58348e-01 8.58348e-02 1.00000e-09 2.12000e-01 8.58348e-01 8.58348e-01 8.58348e-02 1.00000e-09 2.12000e-01 $1.00000 \mathrm{e}-02$ 1.00000e-02 1.00000e-03 1.00000e-09 1.00000e-01 $1.00000 \mathrm{e}+001.00000 \mathrm{e}+001.00000 \mathrm{e}-011.00000 \mathrm{e}-091.00000 \mathrm{e}-01$ $1.00000 \mathrm{e}-05$ 1.00000e-05 1.00000e-06 1.00000e-09 1.00000e-01 $1.00000 \mathrm{e}+001.00000 \mathrm{e}+001.00000 \mathrm{e}-01$ 1.00000e-09 1.00000e-01 Element: 3557 \# of layers: 14

Kx Ky Kz Ss Por 
$1.42484 \mathrm{e}+011.42484 \mathrm{e}+011.42484 \mathrm{e}+001.00000 \mathrm{e}-09$ 7.00000e-02 $1.42484 \mathrm{e}+011.42484 \mathrm{e}+011.42484 \mathrm{e}+001.00000 \mathrm{e}-097.00000 \mathrm{e}-02$ $1.42484 \mathrm{e}+011.42484 \mathrm{e}+011.42484 \mathrm{e}+001.00000 \mathrm{e}-09$ 7.00000e-02 $5.00000 \mathrm{e}-04$ 5.00000e-04 5.00000e-05 1.00000e-09 1.00000e-01 5.00000e-04 5.00000e-04 5.00000e-05 1.00000e-09 1.00000e-01 5.69330e-01 5.69330e-01 5.69330e-02 1.00000e-09 2.12000e-01 5.69330e-01 5.69330e-01 5.69330e-02 1.00000e-09 2.12000e-01 5.69330e-01 5.69330e-01 5.69330e-02 1.00000e-09 2.12000e-01 5.69330e-01 5.69330e-01 5.69330e-02 1.00000e-09 2.12000e-01 5.69330e-01 5.69330e-01 5.69330e-02 1.00000e-09 2.12000e-01 $1.00000 \mathrm{e}-02$ 1.00000e-02 1.00000e-03 1.00000e-09 1.00000e-01 $1.00000 \mathrm{e}+001.00000 \mathrm{e}+001.00000 \mathrm{e}-011.00000 \mathrm{e}-091.00000 \mathrm{e}-01$ $1.00000 \mathrm{e}-05$ 1.00000e-05 1.00000e-06 1.00000e-09 1.00000e-01 $1.00000 \mathrm{e}+001.00000 \mathrm{e}+001.00000 \mathrm{e}-011.00000 \mathrm{e}-09$ 1.00000e-01 Element: 3558 \# of layers: 15

Kx Ky Kz Ss Por

$1.42484 \mathrm{e}+011.42484 \mathrm{e}+011.42484 \mathrm{e}+001.00000 \mathrm{e}-09$ 7.00000e-02 $1.42484 \mathrm{e}+011.42484 \mathrm{e}+011.42484 \mathrm{e}+001.00000 \mathrm{e}-09$ 7.00000e-02 $1.42484 \mathrm{e}+011.42484 \mathrm{e}+01$ 1.42484e+00 1.00000e-09 7.00000e-02 $1.42484 \mathrm{e}+011.42484 \mathrm{e}+011.42484 \mathrm{e}+001.00000 \mathrm{e}-097.00000 \mathrm{e}-02$ 5.00000e-04 5.00000e-04 5.00000e-05 1.00000e-09 1.00000e-01 5.00000e-04 5.00000e-04 5.00000e-05 1.00000e-09 1.00000e-01 5.69330e-01 5.69330e-01 5.69330e-02 1.00000e-09 2.12000e-01 5.69330e-01 5.69330e-01 5.69330e-02 1.00000e-09 2.12000e-01 $5.69330 \mathrm{e}-015.69330 \mathrm{e}-015.69330 \mathrm{e}-02$ 1.00000e-09 2.12000e-01 5.69330e-01 5.69330e-01 5.69330e-02 1.00000e-09 2.12000e-01 5.69330e-01 5.69330e-01 5.69330e-02 1.00000e-09 2.12000e-01 $1.00000 \mathrm{e}-02$ 1.00000e-02 1.00000e-03 1.00000e-09 1.00000e-01 $1.00000 \mathrm{e}+001.00000 \mathrm{e}+001.00000 \mathrm{e}-011.00000 \mathrm{e}-091.00000 \mathrm{e}-01$ $1.00000 \mathrm{e}-05$ 1.00000e-05 1.00000e-06 1.00000e-09 1.00000e-01 $1.00000 \mathrm{e}+001.00000 \mathrm{e}+001.00000 \mathrm{e}-011.00000 \mathrm{e}-091.00000 \mathrm{e}-01$ Element: 3559 \# of layers: 14

Kx Ky Kz Ss Por

$1.42484 \mathrm{e}+011.42484 \mathrm{e}+011.42484 \mathrm{e}+001.00000 \mathrm{e}-09$ 7.00000e-02 $1.42484 \mathrm{e}+011.42484 \mathrm{e}+011.42484 \mathrm{e}+001.00000 \mathrm{e}-097.00000 \mathrm{e}-02$ $1.42484 \mathrm{e}+011.42484 \mathrm{e}+011.42484 \mathrm{e}+001.00000 \mathrm{e}-09$ 7.00000e-02 5.00000e-04 5.00000e-04 5.00000e-05 1.00000e-09 1.00000e-01 5.00000e-04 5.00000e-04 5.00000e-05 1.00000e-09 1.00000e-01 5.69330e-01 5.69330e-01 5.69330e-02 1.00000e-09 2.12000e-01 5.69330e-01 5.69330e-01 5.69330e-02 1.00000e-09 2.12000e-01 5.69330e-01 5.69330e-01 5.69330e-02 1.00000e-09 2.12000e-01 5.69330e-01 5.69330e-01 5.69330e-02 1.00000e-09 2.12000e-01 5.69330e-01 5.69330e-01 5.69330e-02 1.00000e-09 2.12000e-01 $1.00000 \mathrm{e}-02$ 1.00000e-02 1.00000e-03 1.00000e-09 1.00000e-01 $1.00000 \mathrm{e}+001.00000 \mathrm{e}+001.00000 \mathrm{e}-011.00000 \mathrm{e}-091.00000 \mathrm{e}-01$ $1.00000 \mathrm{e}-05$ 1.00000e-05 1.00000e-06 1.00000e-09 1.00000e-01 
$1.00000 \mathrm{e}+001.00000 \mathrm{e}+00$ 1.00000e-01 1.00000e-09 1.00000e-01 Element: 3560 \# of layers: 14

Kx Ky Kz Ss Por

$1.42484 \mathrm{e}+011.42484 \mathrm{e}+011.42484 \mathrm{e}+001.00000 \mathrm{e}-09$ 7.00000e-02 $1.42484 \mathrm{e}+011.42484 \mathrm{e}+011.42484 \mathrm{e}+001.00000 \mathrm{e}-097.00000 \mathrm{e}-02$ $1.42484 \mathrm{e}+011.42484 \mathrm{e}+011.42484 \mathrm{e}+001.00000 \mathrm{e}-097.00000 \mathrm{e}-02$ 5.00000e-04 5.00000e-04 5.00000e-05 1.00000e-09 1.00000e-01 5.00000e-04 5.00000e-04 5.00000e-05 1.00000e-09 1.00000e-01 5.69330e-01 5.69330e-01 5.69330e-02 1.00000e-09 2.12000e-01 5.69330e-01 5.69330e-01 5.69330e-02 1.00000e-09 2.12000e-01 5.69330e-01 5.69330e-01 5.69330e-02 1.00000e-09 2.12000e-01 5.69330e-01 5.69330e-01 5.69330e-02 1.00000e-09 2.12000e-01 5.69330e-01 5.69330e-01 5.69330e-02 1.00000e-09 2.12000e-01 $1.00000 \mathrm{e}-02$ 1.00000e-02 1.00000e-03 1.00000e-09 1.00000e-01 $1.00000 \mathrm{e}+001.00000 \mathrm{e}+001.00000 \mathrm{e}-011.00000 \mathrm{e}-091.00000 \mathrm{e}-01$ $1.00000 \mathrm{e}-05$ 1.00000e-05 1.00000e-06 1.00000e-09 1.00000e-01 $1.00000 \mathrm{e}+001.00000 \mathrm{e}+001.00000 \mathrm{e}-01$ 1.00000e-09 1.00000e-01 Element: 3561 \# of layers: 13

$\mathrm{Kx} \mathrm{Ky} \mathrm{Kz}$ Ss Por

$1.42484 \mathrm{e}+01$ 1.42484e+01 1.42484e+00 1.00000e-09 7.00000e-02 $1.42484 \mathrm{e}+011.42484 \mathrm{e}+011.42484 \mathrm{e}+001.00000 \mathrm{e}-097.00000 \mathrm{e}-02$ $1.42484 \mathrm{e}+011.42484 \mathrm{e}+011.42484 \mathrm{e}+001.00000 \mathrm{e}-09$ 7.00000e-02 5.00000e-04 5.00000e-04 5.00000e-05 1.00000e-09 1.00000e-01 5.00000e-04 5.00000e-04 5.00000e-05 1.00000e-09 1.00000e-01 5.69330e-01 5.69330e-01 5.69330e-02 1.00000e-09 2.12000e-01 5.69330e-01 5.69330e-01 5.69330e-02 1.00000e-09 2.12000e-01 5.69330e-01 5.69330e-01 5.69330e-02 1.00000e-09 2.12000e-01 5.69330e-01 5.69330e-01 5.69330e-02 1.00000e-09 2.12000e-01 $1.00000 \mathrm{e}-02$ 1.00000e-02 1.00000e-03 1.00000e-09 1.00000e-01 $1.00000 \mathrm{e}+001.00000 \mathrm{e}+001.00000 \mathrm{e}-011.00000 \mathrm{e}-091.00000 \mathrm{e}-01$ $1.00000 \mathrm{e}-05$ 1.00000e-05 1.00000e-06 1.00000e-09 1.00000e-01 $1.00000 \mathrm{e}+001.00000 \mathrm{e}+001.00000 \mathrm{e}-011.00000 \mathrm{e}-091.00000 \mathrm{e}-01$ Element: 3562 \# of layers: 14

$\mathrm{Kx} \mathrm{Ky} \mathrm{Kz}$ Ss Por

$1.42484 \mathrm{e}+011.42484 \mathrm{e}+011.42484 \mathrm{e}+001.00000 \mathrm{e}-09$ 7.00000e-02 $1.42484 \mathrm{e}+011.42484 \mathrm{e}+011.42484 \mathrm{e}+001.00000 \mathrm{e}-097.00000 \mathrm{e}-02$ $1.42484 \mathrm{e}+011.42484 \mathrm{e}+011.42484 \mathrm{e}+001.00000 \mathrm{e}-097.00000 \mathrm{e}-02$ $1.42484 \mathrm{e}+011.42484 \mathrm{e}+011.42484 \mathrm{e}+001.00000 \mathrm{e}-097.00000 \mathrm{e}-02$ 5.00000e-04 5.00000e-04 5.00000e-05 1.00000e-09 1.00000e-01 5.00000e-04 5.00000e-04 5.00000e-05 1.00000e-09 1.00000e-01 5.69330e-01 5.69330e-01 5.69330e-02 1.00000e-09 2.12000e-01 5.69330e-01 5.69330e-01 5.69330e-02 1.00000e-09 2.12000e-01 5.69330e-01 5.69330e-01 5.69330e-02 1.00000e-09 2.12000e-01 5.69330e-01 5.69330e-01 5.69330e-02 1.00000e-09 2.12000e-01 $1.00000 \mathrm{e}-02$ 1.00000e-02 1.00000e-03 1.00000e-09 1.00000e-01 $1.00000 \mathrm{e}+001.00000 \mathrm{e}+001.00000 \mathrm{e}-011.00000 \mathrm{e}-091.00000 \mathrm{e}-01$ 
$1.00000 \mathrm{e}-05$ 1.00000e-05 1.00000e-06 1.00000e-09 1.00000e-01 $1.00000 \mathrm{e}+001.00000 \mathrm{e}+001.00000 \mathrm{e}-01$ 1.00000e-09 1.00000e-01 Element: 3563 \# of layers: 13

Kx Ky Kz Ss Por

$1.42484 \mathrm{e}+011.42484 \mathrm{e}+01$ 1.42484e+00 1.00000e-09 7.00000e-02 $1.42484 \mathrm{e}+011.42484 \mathrm{e}+011.42484 \mathrm{e}+001.00000 \mathrm{e}-097.00000 \mathrm{e}-02$ $1.42484 \mathrm{e}+011.42484 \mathrm{e}+011.42484 \mathrm{e}+001.00000 \mathrm{e}-097.00000 \mathrm{e}-02$ 5.00000e-04 5.00000e-04 5.00000e-05 1.00000e-09 1.00000e-01 5.00000e-04 5.00000e-04 5.00000e-05 1.00000e-09 1.00000e-01 5.69330e-01 5.69330e-01 5.69330e-02 1.00000e-09 2.12000e-01 5.69330e-01 5.69330e-01 5.69330e-02 1.00000e-09 2.12000e-01 5.69330e-01 5.69330e-01 5.69330e-02 1.00000e-09 2.12000e-01 5.69330e-01 5.69330e-01 5.69330e-02 1.00000e-09 2.12000e-01 $1.00000 \mathrm{e}-02$ 1.00000e-02 1.00000e-03 1.00000e-09 1.00000e-01 $1.00000 \mathrm{e}+001.00000 \mathrm{e}+001.00000 \mathrm{e}-011.00000 \mathrm{e}-091.00000 \mathrm{e}-01$ $1.00000 \mathrm{e}-05$ 1.00000e-05 1.00000e-06 1.00000e-09 1.00000e-01 $1.00000 \mathrm{e}+001.00000 \mathrm{e}+001.00000 \mathrm{e}-011.00000 \mathrm{e}-091.00000 \mathrm{e}-01$ Element: 3564 \# of layers: 14

$\mathrm{Kx} \mathrm{Ky} \mathrm{Kz}$ Ss Por

$1.42484 \mathrm{e}+01$ 1.42484e+01 1.42484e+00 1.00000e-09 7.00000e-02 $1.42484 \mathrm{e}+011.42484 \mathrm{e}+011.42484 \mathrm{e}+001.00000 \mathrm{e}-097.00000 \mathrm{e}-02$ $1.42484 \mathrm{e}+011.42484 \mathrm{e}+011.42484 \mathrm{e}+001.00000 \mathrm{e}-09$ 7.00000e-02 5.00000e-04 5.00000e-04 5.00000e-05 1.00000e-09 1.00000e-01 5.00000e-04 5.00000e-04 5.00000e-05 1.00000e-09 1.00000e-01 $5.69330 \mathrm{e}-01$ 5.69330e-01 5.69330e-02 1.00000e-09 2.12000e-01 5.69330e-01 5.69330e-01 5.69330e-02 1.00000e-09 2.12000e-01 5.69330e-01 5.69330e-01 5.69330e-02 1.00000e-09 2.12000e-01 5.69330e-01 5.69330e-01 5.69330e-02 1.00000e-09 2.12000e-01 5.69330e-01 5.69330e-01 5.69330e-02 1.00000e-09 2.12000e-01 $1.00000 \mathrm{e}-02$ 1.00000e-02 1.00000e-03 1.00000e-09 1.00000e-01 $1.00000 \mathrm{e}+001.00000 \mathrm{e}+001.00000 \mathrm{e}-01$ 1.00000e-09 1.00000e-01 $1.00000 \mathrm{e}-05$ 1.00000e-05 1.00000e-06 1.00000e-09 1.00000e-01 $1.00000 \mathrm{e}+001.00000 \mathrm{e}+001.00000 \mathrm{e}-011.00000 \mathrm{e}-091.00000 \mathrm{e}-01$ Element: 3565 \# of layers: 15

$\mathrm{Kx} \mathrm{Ky} \mathrm{Kz}$ Ss Por

$1.42484 \mathrm{e}+011.42484 \mathrm{e}+011.42484 \mathrm{e}+001.00000 \mathrm{e}-09$ 7.00000e-02 $1.42484 \mathrm{e}+011.42484 \mathrm{e}+011.42484 \mathrm{e}+001.00000 \mathrm{e}-097.00000 \mathrm{e}-02$ $1.42484 \mathrm{e}+011.42484 \mathrm{e}+011.42484 \mathrm{e}+001.00000 \mathrm{e}-097.00000 \mathrm{e}-02$ $1.42484 \mathrm{e}+011.42484 \mathrm{e}+011.42484 \mathrm{e}+001.00000 \mathrm{e}-097.00000 \mathrm{e}-02$ 5.00000e-04 5.00000e-04 5.00000e-05 1.00000e-09 1.00000e-01 5.00000e-04 5.00000e-04 5.00000e-05 1.00000e-09 1.00000e-01 5.69330e-01 5.69330e-01 5.69330e-02 1.00000e-09 2.12000e-01 5.69330e-01 5.69330e-01 5.69330e-02 1.00000e-09 2.12000e-01 5.69330e-01 5.69330e-01 5.69330e-02 1.00000e-09 2.12000e-01 5.69330e-01 5.69330e-01 5.69330e-02 1.00000e-09 2.12000e-01 5.69330e-01 5.69330e-01 5.69330e-02 1.00000e-09 2.12000e-01 
$1.00000 \mathrm{e}-02$ 1.00000e-02 1.00000e-03 1.00000e-09 1.00000e-01 $1.00000 \mathrm{e}+001.00000 \mathrm{e}+001.00000 \mathrm{e}-011.00000 \mathrm{e}-091.00000 \mathrm{e}-01$ $1.00000 \mathrm{e}-05$ 1.00000e-05 1.00000e-06 1.00000e-09 1.00000e-01 $1.00000 \mathrm{e}+001.00000 \mathrm{e}+001.00000 \mathrm{e}-011.00000 \mathrm{e}-091.00000 \mathrm{e}-01$ Element: 3566 \# of layers: 14

$\mathrm{Kx} \mathrm{Ky} \mathrm{Kz}$ Ss Por

$1.96193 \mathrm{e}+01$ 1.96193e+01 1.96193e+00 1.00000e-09 7.00000e-02 $1.96193 \mathrm{e}+01$ 1.96193e+01 1.96193e+00 1.00000e-09 7.00000e-02 $1.96193 \mathrm{e}+011.96193 \mathrm{e}+01$ 1.96193e+00 1.00000e-09 7.00000e-02 5.00000e-04 5.00000e-04 5.00000e-05 1.00000e-09 1.00000e-01 5.00000e-04 5.00000e-04 5.00000e-05 1.00000e-09 1.00000e-01 7.83939e-01 7.83939e-01 7.83939e-02 1.00000e-09 2.12000e-01 7.83939e-01 7.83939e-01 7.83939e-02 1.00000e-09 2.12000e-01 7.83939e-01 7.83939e-01 7.83939e-02 1.00000e-09 2.12000e-01 7.83939e-01 7.83939e-01 7.83939e-02 1.00000e-09 2.12000e-01 7.83939e-01 7.83939e-01 7.83939e-02 1.00000e-09 2.12000e-01 $1.00000 \mathrm{e}-02$ 1.00000e-02 1.00000e-03 1.00000e-09 1.00000e-01 $1.00000 \mathrm{e}+001.00000 \mathrm{e}+001.00000 \mathrm{e}-011.00000 \mathrm{e}-091.00000 \mathrm{e}-01$ $1.00000 \mathrm{e}-05$ 1.00000e-05 1.00000e-06 1.00000e-09 1.00000e-01 $1.00000 \mathrm{e}+001.00000 \mathrm{e}+001.00000 \mathrm{e}-011.00000 \mathrm{e}-091.00000 \mathrm{e}-01$ Element: 3567 \# of layers: 14

$\mathrm{Kx} \mathrm{Ky} \mathrm{Kz}$ Ss Por

1.96193e+01 1.96193e+01 1.96193e+00 1.00000e-09 7.00000e-02 $1.96193 \mathrm{e}+011.96193 \mathrm{e}+01$ 1.96193e+00 1.00000e-09 7.00000e-02 $1.96193 \mathrm{e}+011.96193 \mathrm{e}+011.96193 \mathrm{e}+001.00000 \mathrm{e}-09$ 7.00000e-02 5.00000e-04 5.00000e-04 5.00000e-05 1.00000e-09 1.00000e-01 5.00000e-04 5.00000e-04 5.00000e-05 1.00000e-09 1.00000e-01 7.83939e-01 7.83939e-01 7.83939e-02 1.00000e-09 2.12000e-01 7.83939e-01 7.83939e-01 7.83939e-02 1.00000e-09 2.12000e-01 7.83939e-01 7.83939e-01 7.83939e-02 1.00000e-09 2.12000e-01 7.83939e-01 7.83939e-01 7.83939e-02 1.00000e-09 2.12000e-01 7.83939e-01 7.83939e-01 7.83939e-02 1.00000e-09 2.12000e-01 $1.00000 \mathrm{e}-02$ 1.00000e-02 1.00000e-03 1.00000e-09 1.00000e-01 $1.00000 \mathrm{e}+001.00000 \mathrm{e}+001.00000 \mathrm{e}-011.00000 \mathrm{e}-091.00000 \mathrm{e}-01$ $1.00000 \mathrm{e}-05$ 1.00000e-05 1.00000e-06 1.00000e-09 1.00000e-01 $1.00000 \mathrm{e}+001.00000 \mathrm{e}+001.00000 \mathrm{e}-01$ 1.00000e-09 1.00000e-01 Element: 3568 \# of layers: 12

$\mathrm{Kx} \mathrm{Ky} \mathrm{Kz}$ Ss Por

$1.96193 \mathrm{e}+01$ 1.96193e+01 1.96193e+00 1.00000e-09 7.00000e-02 $1.96193 \mathrm{e}+01$ 1.96193e+01 1.96193e+00 1.00000e-09 7.00000e-02 5.00000e-04 5.00000e-04 5.00000e-05 1.00000e-09 1.00000e-01 5.00000e-04 5.00000e-04 5.00000e-05 1.00000e-09 1.00000e-01 7.83939e-01 7.83939e-01 7.83939e-02 1.00000e-09 2.12000e-01 7.83939e-01 7.83939e-01 7.83939e-02 1.00000e-09 2.12000e-01 7.83939e-01 7.83939e-01 7.83939e-02 1.00000e-09 2.12000e-01 7.83939e-01 7.83939e-01 7.83939e-02 1.00000e-09 2.12000e-01 
$1.00000 \mathrm{e}-02$ 1.00000e-02 1.00000e-03 1.00000e-09 1.00000e-01 $1.00000 \mathrm{e}+001.00000 \mathrm{e}+001.00000 \mathrm{e}-011.00000 \mathrm{e}-091.00000 \mathrm{e}-01$ $1.00000 \mathrm{e}-05$ 1.00000e-05 1.00000e-06 1.00000e-09 1.00000e-01 $1.00000 \mathrm{e}+001.00000 \mathrm{e}+001.00000 \mathrm{e}-011.00000 \mathrm{e}-091.00000 \mathrm{e}-01$ Element: 3569 \# of layers: 12

$\mathrm{Kx} \mathrm{Ky} \mathrm{Kz}$ Ss Por

$1.96193 \mathrm{e}+01$ 1.96193e+01 1.96193e+00 1.00000e-09 7.00000e-02 $1.96193 \mathrm{e}+01$ 1.96193e+01 1.96193e+00 1.00000e-09 7.00000e-02 5.00000e-04 5.00000e-04 5.00000e-05 1.00000e-09 1.00000e-01 5.00000e-04 5.00000e-04 5.00000e-05 1.00000e-09 1.00000e-01 7.83939e-01 7.83939e-01 7.83939e-02 1.00000e-09 2.12000e-01 7.83939e-01 7.83939e-01 7.83939e-02 1.00000e-09 2.12000e-01 7.83939e-01 7.83939e-01 7.83939e-02 1.00000e-09 2.12000e-01 7.83939e-01 7.83939e-01 7.83939e-02 1.00000e-09 2.12000e-01 $1.00000 \mathrm{e}-02$ 1.00000e-02 1.00000e-03 1.00000e-09 1.00000e-01 $1.00000 \mathrm{e}+001.00000 \mathrm{e}+001.00000 \mathrm{e}-011.00000 \mathrm{e}-091.00000 \mathrm{e}-01$ $1.00000 \mathrm{e}-05$ 1.00000e-05 1.00000e-06 1.00000e-09 1.00000e-01 $1.00000 \mathrm{e}+001.00000 \mathrm{e}+001.00000 \mathrm{e}-011.00000 \mathrm{e}-091.00000 \mathrm{e}-01$ Element: 3570 \# of layers: 12

$\mathrm{Kx} \mathrm{Ky} \mathrm{Kz}$ Ss Por

$1.96193 \mathrm{e}+011.96193 \mathrm{e}+011.96193 \mathrm{e}+001.00000 \mathrm{e}-09$ 7.00000e-02 $1.96193 \mathrm{e}+01$ 1.96193e+01 1.96193e+00 1.00000e-09 7.00000e-02 5.00000e-04 5.00000e-04 5.00000e-05 1.00000e-09 1.00000e-01 5.00000e-04 5.00000e-04 5.00000e-05 1.00000e-09 1.00000e-01 7.83939e-01 7.83939e-01 7.83939e-02 1.00000e-09 2.12000e-01 7.83939e-01 7.83939e-01 7.83939e-02 1.00000e-09 2.12000e-01 7.83939e-01 7.83939e-01 7.83939e-02 1.00000e-09 2.12000e-01 7.83939e-01 7.83939e-01 7.83939e-02 1.00000e-09 2.12000e-01 $1.00000 \mathrm{e}-02$ 1.00000e-02 1.00000e-03 1.00000e-09 1.00000e-01 $1.00000 \mathrm{e}+001.00000 \mathrm{e}+001.00000 \mathrm{e}-011.00000 \mathrm{e}-091.00000 \mathrm{e}-01$ $1.00000 \mathrm{e}-05$ 1.00000e-05 1.00000e-06 1.00000e-09 1.00000e-01 $1.00000 \mathrm{e}+001.00000 \mathrm{e}+001.00000 \mathrm{e}-011.00000 \mathrm{e}-091.00000 \mathrm{e}-01$ Element: 3571 \# of layers: 12

$\mathrm{Kx} \mathrm{Ky} \mathrm{Kz}$ Ss Por

$1.96193 \mathrm{e}+01$ 1.96193e+01 1.96193e+00 1.00000e-09 7.00000e-02 $1.96193 \mathrm{e}+01$ 1.96193e+01 1.96193e+00 1.00000e-09 7.00000e-02 5.00000e-04 5.00000e-04 5.00000e-05 1.00000e-09 1.00000e-01 5.00000e-04 5.00000e-04 5.00000e-05 1.00000e-09 1.00000e-01 7.83939e-01 7.83939e-01 7.83939e-02 1.00000e-09 2.12000e-01 7.83939e-01 7.83939e-01 7.83939e-02 1.00000e-09 2.12000e-01 7.83939e-01 7.83939e-01 7.83939e-02 1.00000e-09 2.12000e-01 7.83939e-01 7.83939e-01 7.83939e-02 1.00000e-09 2.12000e-01 $1.00000 \mathrm{e}-021.00000 \mathrm{e}-021.00000 \mathrm{e}-031.00000 \mathrm{e}-091.00000 \mathrm{e}-01$ $1.00000 \mathrm{e}+001.00000 \mathrm{e}+001.00000 \mathrm{e}-011.00000 \mathrm{e}-091.00000 \mathrm{e}-01$ $1.00000 \mathrm{e}-05$ 1.00000e-05 1.00000e-06 1.00000e-09 1.00000e-01 $1.00000 \mathrm{e}+001.00000 \mathrm{e}+001.00000 \mathrm{e}-011.00000 \mathrm{e}-091.00000 \mathrm{e}-01$ 
Element: 3572 \# of layers: 13

$\mathrm{Kx} \mathrm{Ky} \mathrm{Kz}$ Ss Por

1.96193e+01 1.96193e+01 1.96193e+00 1.00000e-09 7.00000e-02

$1.96193 \mathrm{e}+011.96193 \mathrm{e}+011.96193 \mathrm{e}+001.00000 \mathrm{e}-09$ 7.00000e-02

$1.96193 \mathrm{e}+01$ 1.96193e+01 1.96193e+00 1.00000e-09 7.00000e-02

5.00000e-04 5.00000e-04 5.00000e-05 1.00000e-09 1.00000e-01

5.00000e-04 5.00000e-04 5.00000e-05 1.00000e-09 1.00000e-01

7.83939e-01 7.83939e-01 7.83939e-02 1.00000e-09 2.12000e-01

7.83939e-01 7.83939e-01 7.83939e-02 1.00000e-09 2.12000e-01

7.83939e-01 7.83939e-01 7.83939e-02 1.00000e-09 2.12000e-01

7.83939e-01 7.83939e-01 7.83939e-02 1.00000e-09 2.12000e-01

$1.00000 \mathrm{e}-02$ 1.00000e-02 1.00000e-03 1.00000e-09 1.00000e-01

$1.00000 \mathrm{e}+001.00000 \mathrm{e}+001.00000 \mathrm{e}-011.00000 \mathrm{e}-091.00000 \mathrm{e}-01$

$1.00000 \mathrm{e}-05$ 1.00000e-05 1.00000e-06 1.00000e-09 1.00000e-01

$1.00000 \mathrm{e}+001.00000 \mathrm{e}+001.00000 \mathrm{e}-01$ 1.00000e-09 1.00000e-01

Element: 3573 \# of layers: 13

$\mathrm{Kx} \mathrm{Ky} \mathrm{Kz}$ Ss Por

$1.96193 \mathrm{e}+01$ 1.96193e+01 1.96193e+00 1.00000e-09 7.00000e-02

$1.96193 \mathrm{e}+01$ 1.96193e+01 1.96193e+00 1.00000e-09 7.00000e-02

$1.96193 \mathrm{e}+01$ 1.96193e+01 1.96193e+00 1.00000e-09 7.00000e-02

5.00000e-04 5.00000e-04 5.00000e-05 1.00000e-09 1.00000e-01

5.00000e-04 5.00000e-04 5.00000e-05 1.00000e-09 1.00000e-01

7.83939e-01 7.83939e-01 7.83939e-02 1.00000e-09 2.12000e-01

7.83939e-01 7.83939e-01 7.83939e-02 1.00000e-09 2.12000e-01

7.83939e-01 7.83939e-01 7.83939e-02 1.00000e-09 2.12000e-01

7.83939e-01 7.83939e-01 7.83939e-02 1.00000e-09 2.12000e-01

$1.00000 \mathrm{e}-02$ 1.00000e-02 1.00000e-03 1.00000e-09 1.00000e-01

$1.00000 \mathrm{e}+001.00000 \mathrm{e}+001.00000 \mathrm{e}-011.00000 \mathrm{e}-091.00000 \mathrm{e}-01$

$1.00000 \mathrm{e}-05$ 1.00000e-05 1.00000e-06 1.00000e-09 1.00000e-01

$1.00000 \mathrm{e}+001.00000 \mathrm{e}+001.00000 \mathrm{e}-011.00000 \mathrm{e}-091.00000 \mathrm{e}-01$

Element: 3574 \# of layers: 12

$\mathrm{Kx} \mathrm{Ky} \mathrm{Kz}$ Ss Por

1.96193e+01 1.96193e+01 1.96193e+00 1.00000e-09 7.00000e-02

$1.96193 \mathrm{e}+01$ 1.96193e+01 1.96193e+00 1.00000e-09 7.00000e-02

5.00000e-04 5.00000e-04 5.00000e-05 1.00000e-09 1.00000e-01

5.00000e-04 5.00000e-04 5.00000e-05 1.00000e-09 1.00000e-01

7.83939e-01 7.83939e-01 7.83939e-02 1.00000e-09 2.12000e-01

7.83939e-01 7.83939e-01 7.83939e-02 1.00000e-09 2.12000e-01

7.83939e-01 7.83939e-01 7.83939e-02 1.00000e-09 2.12000e-01

7.83939e-01 7.83939e-01 7.83939e-02 1.00000e-09 2.12000e-01

$1.00000 \mathrm{e}-02$ 1.00000e-02 1.00000e-03 1.00000e-09 1.00000e-01

$1.00000 \mathrm{e}+001.00000 \mathrm{e}+001.00000 \mathrm{e}-011.00000 \mathrm{e}-091.00000 \mathrm{e}-01$

$1.00000 \mathrm{e}-05$ 1.00000e-05 1.00000e-06 1.00000e-09 1.00000e-01

$1.00000 \mathrm{e}+001.00000 \mathrm{e}+001.00000 \mathrm{e}-01$ 1.00000e-09 1.00000e-01

Element: 3575 \# of layers: 12

Kx Ky Kz Ss Por 
$1.92102 \mathrm{e}+011.92102 \mathrm{e}+01$ 1.92102e+00 1.00000e-09 7.00000e-02 $1.92102 \mathrm{e}+011.92102 \mathrm{e}+011.92102 \mathrm{e}+001.00000 \mathrm{e}-097.00000 \mathrm{e}-02$ 5.00000e-04 5.00000e-04 5.00000e-05 1.00000e-09 1.00000e-01 5.00000e-04 5.00000e-04 5.00000e-05 1.00000e-09 1.00000e-01 7.67559e-01 7.67559e-01 7.67559e-02 1.00000e-09 2.12000e-01 7.67559e-01 7.67559e-01 7.67559e-02 1.00000e-09 2.12000e-01 7.67559e-01 7.67559e-01 7.67559e-02 1.00000e-09 2.12000e-01 7.67559e-01 7.67559e-01 7.67559e-02 1.00000e-09 2.12000e-01 $1.00000 \mathrm{e}-02$ 1.00000e-02 1.00000e-03 1.00000e-09 1.00000e-01 $1.00000 \mathrm{e}+001.00000 \mathrm{e}+001.00000 \mathrm{e}-011.00000 \mathrm{e}-091.00000 \mathrm{e}-01$ $1.00000 \mathrm{e}-05$ 1.00000e-05 1.00000e-06 1.00000e-09 1.00000e-01 $1.00000 \mathrm{e}+001.00000 \mathrm{e}+001.00000 \mathrm{e}-01$ 1.00000e-09 1.00000e-01 Element: 3576 \# of layers: 12

$\mathrm{Kx} \mathrm{Ky} \mathrm{Kz}$ Ss Por

1.92102e+01 1.92102e+01 1.92102e+00 1.00000e-09 7.00000e-02 $1.92102 \mathrm{e}+011.92102 \mathrm{e}+011.92102 \mathrm{e}+001.00000 \mathrm{e}-09$ 7.00000e-02 5.00000e-04 5.00000e-04 5.00000e-05 1.00000e-09 1.00000e-01 5.00000e-04 5.00000e-04 5.00000e-05 1.00000e-09 1.00000e-01 7.67559e-01 7.67559e-01 7.67559e-02 1.00000e-09 2.12000e-01 7.67559e-01 7.67559e-01 7.67559e-02 1.00000e-09 2.12000e-01 7.67559e-01 7.67559e-01 7.67559e-02 1.00000e-09 2.12000e-01 7.67559e-01 7.67559e-01 7.67559e-02 1.00000e-09 2.12000e-01 $1.00000 \mathrm{e}-02$ 1.00000e-02 1.00000e-03 1.00000e-09 1.00000e-01 $1.00000 \mathrm{e}+001.00000 \mathrm{e}+001.00000 \mathrm{e}-011.00000 \mathrm{e}-091.00000 \mathrm{e}-01$ $1.00000 \mathrm{e}-05$ 1.00000e-05 1.00000e-06 1.00000e-09 1.00000e-01 $1.00000 \mathrm{e}+001.00000 \mathrm{e}+001.00000 \mathrm{e}-011.00000 \mathrm{e}-091.00000 \mathrm{e}-01$ Element: 3577 \# of layers: 12

$\mathrm{Kx} \mathrm{Ky} \mathrm{Kz}$ Ss Por

$1.92102 \mathrm{e}+01$ 1.92102e+01 1.92102e+00 1.00000e-09 7.00000e-02 $1.92102 \mathrm{e}+01$ 1.92102e+01 1.92102e+00 1.00000e-09 7.00000e-02 5.00000e-04 5.00000e-04 5.00000e-05 1.00000e-09 1.00000e-01 5.00000e-04 5.00000e-04 5.00000e-05 1.00000e-09 1.00000e-01 7.67559e-01 7.67559e-01 7.67559e-02 1.00000e-09 2.12000e-01 7.67559e-01 7.67559e-01 7.67559e-02 1.00000e-09 2.12000e-01 7.67559e-01 7.67559e-01 7.67559e-02 1.00000e-09 2.12000e-01 7.67559e-01 7.67559e-01 7.67559e-02 1.00000e-09 2.12000e-01 $1.00000 \mathrm{e}-02$ 1.00000e-02 1.00000e-03 1.00000e-09 1.00000e-01 $1.00000 \mathrm{e}+001.00000 \mathrm{e}+001.00000 \mathrm{e}-011.00000 \mathrm{e}-091.00000 \mathrm{e}-01$ $1.00000 \mathrm{e}-05$ 1.00000e-05 1.00000e-06 1.00000e-09 1.00000e-01 $1.00000 \mathrm{e}+001.00000 \mathrm{e}+001.00000 \mathrm{e}-01$ 1.00000e-09 1.00000e-01 Element: 3578 \# of layers: 13

$\mathrm{Kx} \mathrm{Ky} \mathrm{Kz}$ Ss Por $1.92102 \mathrm{e}+01$ 1.92102e+01 1.92102e+00 1.00000e-09 7.00000e-02 $1.92102 \mathrm{e}+01$ 1.92102e+01 1.92102e+00 1.00000e-09 7.00000e-02 5.00000e-04 5.00000e-04 5.00000e-05 1.00000e-09 1.00000e-01 5.00000e-04 5.00000e-04 5.00000e-05 1.00000e-09 1.00000e-01 
7.67559e-01 7.67559e-01 7.67559e-02 1.00000e-09 2.12000e-01

7.67559e-01 7.67559e-01 7.67559e-02 1.00000e-09 2.12000e-01

7.67559e-01 7.67559e-01 7.67559e-02 1.00000e-09 2.12000e-01

7.67559e-01 7.67559e-01 7.67559e-02 1.00000e-09 2.12000e-01

7.67559e-01 7.67559e-01 7.67559e-02 1.00000e-09 2.12000e-01

$1.00000 \mathrm{e}-02$ 1.00000e-02 1.00000e-03 1.00000e-09 1.00000e-01

$1.00000 \mathrm{e}+001.00000 \mathrm{e}+001.00000 \mathrm{e}-011.00000 \mathrm{e}-091.00000 \mathrm{e}-01$

$1.00000 \mathrm{e}-05$ 1.00000e-05 1.00000e-06 1.00000e-09 1.00000e-01

$1.00000 \mathrm{e}+001.00000 \mathrm{e}+001.00000 \mathrm{e}-01$ 1.00000e-09 1.00000e-01

Element: 3579 \# of layers: 12

$\mathrm{Kx} \mathrm{Ky} \mathrm{Kz}$ Ss Por

$1.92102 \mathrm{e}+01$ 1.92102e+01 1.92102e+00 1.00000e-09 7.00000e-02

$1.92102 \mathrm{e}+011.92102 \mathrm{e}+011.92102 \mathrm{e}+001.00000 \mathrm{e}-09$ 7.00000e-02

5.00000e-04 5.00000e-04 5.00000e-05 1.00000e-09 1.00000e-01

5.00000e-04 5.00000e-04 5.00000e-05 1.00000e-09 1.00000e-01

7.67559e-01 7.67559e-01 7.67559e-02 1.00000e-09 2.12000e-01

7.67559e-01 7.67559e-01 7.67559e-02 1.00000e-09 2.12000e-01

7.67559e-01 7.67559e-01 7.67559e-02 1.00000e-09 2.12000e-01

7.67559e-01 7.67559e-01 7.67559e-02 1.00000e-09 2.12000e-01

$1.00000 \mathrm{e}-02$ 1.00000e-02 1.00000e-03 1.00000e-09 1.00000e-01

$1.00000 \mathrm{e}+001.00000 \mathrm{e}+001.00000 \mathrm{e}-011.00000 \mathrm{e}-091.00000 \mathrm{e}-01$

$1.00000 \mathrm{e}-05$ 1.00000e-05 1.00000e-06 1.00000e-09 1.00000e-01

$1.00000 \mathrm{e}+001.00000 \mathrm{e}+001.00000 \mathrm{e}-01$ 1.00000e-09 1.00000e-01

Element: 3580 \# of layers: 12

$\mathrm{Kx} \mathrm{Ky} \mathrm{Kz}$ Ss Por

$1.92102 \mathrm{e}+011.92102 \mathrm{e}+011.92102 \mathrm{e}+001.00000 \mathrm{e}-097.00000 \mathrm{e}-02$

$1.92102 \mathrm{e}+011.92102 \mathrm{e}+01$ 1.92102e+00 1.00000e-09 7.00000e-02

5.00000e-04 5.00000e-04 5.00000e-05 1.00000e-09 1.00000e-01

5.00000e-04 5.00000e-04 5.00000e-05 1.00000e-09 1.00000e-01

7.67559e-01 7.67559e-01 7.67559e-02 1.00000e-09 2.12000e-01

7.67559e-01 7.67559e-01 7.67559e-02 1.00000e-09 2.12000e-01

7.67559e-01 7.67559e-01 7.67559e-02 1.00000e-09 2.12000e-01

7.67559e-01 7.67559e-01 7.67559e-02 1.00000e-09 2.12000e-01

$1.00000 \mathrm{e}-021.00000 \mathrm{e}-021.00000 \mathrm{e}-031.00000 \mathrm{e}-091.00000 \mathrm{e}-01$

$1.00000 \mathrm{e}+001.00000 \mathrm{e}+001.00000 \mathrm{e}-011.00000 \mathrm{e}-091.00000 \mathrm{e}-01$

$1.00000 \mathrm{e}-05$ 1.00000e-05 1.00000e-06 1.00000e-09 1.00000e-01

$1.00000 \mathrm{e}+001.00000 \mathrm{e}+001.00000 \mathrm{e}-011.00000 \mathrm{e}-091.00000 \mathrm{e}-01$

Element: 3581 \# of layers: 12

$\mathrm{Kx} \mathrm{Ky} \mathrm{Kz}$ Ss Por

1.92102e+01 1.92102e+01 1.92102e+00 1.00000e-09 7.00000e-02

$1.92102 \mathrm{e}+011.92102 \mathrm{e}+01$ 1.92102e+00 1.00000e-09 7.00000e-02

5.00000e-04 5.00000e-04 5.00000e-05 1.00000e-09 1.00000e-01

5.00000e-04 5.00000e-04 5.00000e-05 1.00000e-09 1.00000e-01

7.67559e-01 7.67559e-01 7.67559e-02 1.00000e-09 2.12000e-01

7.67559e-01 7.67559e-01 7.67559e-02 1.00000e-09 2.12000e-01

7.67559e-01 7.67559e-01 7.67559e-02 1.00000e-09 2.12000e-01 
7.67559e-01 7.67559e-01 7.67559e-02 1.00000e-09 2.12000e-01 $1.00000 \mathrm{e}-02$ 1.00000e-02 1.00000e-03 1.00000e-09 1.00000e-01 $1.00000 \mathrm{e}+001.00000 \mathrm{e}+001.00000 \mathrm{e}-011.00000 \mathrm{e}-091.00000 \mathrm{e}-01$ $1.00000 \mathrm{e}-05$ 1.00000e-05 1.00000e-06 1.00000e-09 1.00000e-01 $1.00000 \mathrm{e}+001.00000 \mathrm{e}+001.00000 \mathrm{e}-011.00000 \mathrm{e}-091.00000 \mathrm{e}-01$ Element: 3582 \# of layers: 12

$\mathrm{Kx} \mathrm{Ky} \mathrm{Kz}$ Ss Por

$1.92102 \mathrm{e}+01$ 1.92102e+01 1.92102e+00 1.00000e-09 7.00000e-02 $1.92102 \mathrm{e}+011.92102 \mathrm{e}+011.92102 \mathrm{e}+001.00000 \mathrm{e}-09$ 7.00000e-02 5.00000e-04 5.00000e-04 5.00000e-05 1.00000e-09 1.00000e-01 5.00000e-04 5.00000e-04 5.00000e-05 1.00000e-09 1.00000e-01 7.67559e-01 7.67559e-01 7.67559e-02 1.00000e-09 2.12000e-01 7.67559e-01 7.67559e-01 7.67559e-02 1.00000e-09 2.12000e-01 7.67559e-01 7.67559e-01 7.67559e-02 1.00000e-09 2.12000e-01 7.67559e-01 7.67559e-01 7.67559e-02 1.00000e-09 2.12000e-01 $1.00000 \mathrm{e}-021.00000 \mathrm{e}-02$ 1.00000e-03 1.00000e-09 1.00000e-01 $1.00000 \mathrm{e}+001.00000 \mathrm{e}+001.00000 \mathrm{e}-011.00000 \mathrm{e}-091.00000 \mathrm{e}-01$ $1.00000 \mathrm{e}-05$ 1.00000e-05 1.00000e-06 1.00000e-09 1.00000e-01 $1.00000 \mathrm{e}+001.00000 \mathrm{e}+001.00000 \mathrm{e}-01$ 1.00000e-09 1.00000e-01 Element: 3583 \# of layers: 13

$\mathrm{Kx} \mathrm{Ky} \mathrm{Kz}$ Ss Por

$1.92102 \mathrm{e}+01$ 1.92102e+01 1.92102e+00 1.00000e-09 7.00000e-02 $1.92102 \mathrm{e}+011.92102 \mathrm{e}+01$ 1.92102e+00 1.00000e-09 7.00000e-02 5.00000e-04 5.00000e-04 5.00000e-05 1.00000e-09 1.00000e-01 5.00000e-04 5.00000e-04 5.00000e-05 1.00000e-09 1.00000e-01 7.67559e-01 7.67559e-01 7.67559e-02 1.00000e-09 2.12000e-01 7.67559e-01 7.67559e-01 7.67559e-02 1.00000e-09 2.12000e-01 7.67559e-01 7.67559e-01 7.67559e-02 1.00000e-09 2.12000e-01 7.67559e-01 7.67559e-01 7.67559e-02 1.00000e-09 2.12000e-01 7.67559e-01 7.67559e-01 7.67559e-02 1.00000e-09 2.12000e-01 $1.00000 \mathrm{e}-02$ 1.00000e-02 1.00000e-03 1.00000e-09 1.00000e-01 $1.00000 \mathrm{e}+001.00000 \mathrm{e}+001.00000 \mathrm{e}-011.00000 \mathrm{e}-091.00000 \mathrm{e}-01$ $1.00000 \mathrm{e}-05$ 1.00000e-05 1.00000e-06 1.00000e-09 1.00000e-01 $1.00000 \mathrm{e}+001.00000 \mathrm{e}+001.00000 \mathrm{e}-011.00000 \mathrm{e}-091.00000 \mathrm{e}-01$ Element: 3584 \# of layers: 13

$\mathrm{Kx} \mathrm{Ky} \mathrm{Kz}$ Ss Por

$2.48829 \mathrm{e}+012.48829 \mathrm{e}+012.48829 \mathrm{e}+00$ 1.00000e-09 7.00000e-02 $2.48829 \mathrm{e}+012.48829 \mathrm{e}+012.48829 \mathrm{e}+001.00000 \mathrm{e}-09$ 7.00000e-02 5.00000e-04 5.00000e-04 5.00000e-05 1.00000e-09 1.00000e-01 5.00000e-04 5.00000e-04 5.00000e-05 1.00000e-09 1.00000e-01 9.94251e-01 9.94251e-01 9.94251e-02 1.00000e-09 2.12000e-01 9.94251e-01 9.94251e-01 9.94251e-02 1.00000e-09 2.12000e-01 9.94251e-01 9.94251e-01 9.94251e-02 1.00000e-09 2.12000e-01 9.94251e-01 9.94251e-01 9.94251e-02 1.00000e-09 2.12000e-01 9.94251e-01 9.94251e-01 9.94251e-02 1.00000e-09 2.12000e-01 $1.00000 \mathrm{e}-02$ 1.00000e-02 1.00000e-03 1.00000e-09 1.00000e-01 
$1.00000 \mathrm{e}+001.00000 \mathrm{e}+001.00000 \mathrm{e}-011.00000 \mathrm{e}-091.00000 \mathrm{e}-01$ $1.00000 \mathrm{e}-05$ 1.00000e-05 1.00000e-06 1.00000e-09 1.00000e-01 $1.00000 \mathrm{e}+001.00000 \mathrm{e}+001.00000 \mathrm{e}-011.00000 \mathrm{e}-09$ 1.00000e-01 Element: 3585 \# of layers: 13

$\mathrm{Kx} \mathrm{Ky} \mathrm{Kz}$ Ss Por

$2.48829 \mathrm{e}+012.48829 \mathrm{e}+012.48829 \mathrm{e}+00$ 1.00000e-09 7.00000e-02

$2.48829 \mathrm{e}+012.48829 \mathrm{e}+012.48829 \mathrm{e}+001.00000 \mathrm{e}-09$ 7.00000e-02 5.00000e-04 5.00000e-04 5.00000e-05 1.00000e-09 1.00000e-01 5.00000e-04 5.00000e-04 5.00000e-05 1.00000e-09 1.00000e-01 9.94251e-01 9.94251e-01 9.94251e-02 1.00000e-09 2.12000e-01 9.94251e-01 9.94251e-01 9.94251e-02 1.00000e-09 2.12000e-01 9.94251e-01 9.94251e-01 9.94251e-02 1.00000e-09 2.12000e-01 9.94251e-01 9.94251e-01 9.94251e-02 1.00000e-09 2.12000e-01 9.94251e-01 9.94251e-01 9.94251e-02 1.00000e-09 2.12000e-01 $1.00000 \mathrm{e}-02$ 1.00000e-02 1.00000e-03 1.00000e-09 1.00000e-01 $1.00000 \mathrm{e}+001.00000 \mathrm{e}+001.00000 \mathrm{e}-011.00000 \mathrm{e}-091.00000 \mathrm{e}-01$ $1.00000 \mathrm{e}-05$ 1.00000e-05 1.00000e-06 1.00000e-09 1.00000e-01 $1.00000 \mathrm{e}+001.00000 \mathrm{e}+001.00000 \mathrm{e}-011.00000 \mathrm{e}-091.00000 \mathrm{e}-01$ Element: 3586 \# of layers: 13

$\mathrm{Kx} \mathrm{Ky} \mathrm{Kz} \mathrm{Ss} \mathrm{Por}$

$2.48829 \mathrm{e}+012.48829 \mathrm{e}+012.48829 \mathrm{e}+00$ 1.00000e-09 7.00000e-02

$2.48829 \mathrm{e}+012.48829 \mathrm{e}+012.48829 \mathrm{e}+00$ 1.00000e-09 7.00000e-02

5.00000e-04 5.00000e-04 5.00000e-05 1.00000e-09 1.00000e-01 5.00000e-04 5.00000e-04 5.00000e-05 1.00000e-09 1.00000e-01 9.94251e-01 9.94251e-01 9.94251e-02 1.00000e-09 2.12000e-01 9.94251e-01 9.94251e-01 9.94251e-02 1.00000e-09 2.12000e-01 9.94251e-01 9.94251e-01 9.94251e-02 1.00000e-09 2.12000e-01 9.94251e-01 9.94251e-01 9.94251e-02 1.00000e-09 2.12000e-01 9.94251e-01 9.94251e-01 9.94251e-02 1.00000e-09 2.12000e-01 $1.00000 \mathrm{e}-02$ 1.00000e-02 1.00000e-03 1.00000e-09 1.00000e-01 $1.00000 \mathrm{e}+001.00000 \mathrm{e}+001.00000 \mathrm{e}-01$ 1.00000e-09 1.00000e-01 $1.00000 \mathrm{e}-05$ 1.00000e-05 1.00000e-06 1.00000e-09 1.00000e-01 $1.00000 \mathrm{e}+001.00000 \mathrm{e}+001.00000 \mathrm{e}-011.00000 \mathrm{e}-091.00000 \mathrm{e}-01$ Element: 3587 \# of layers: 11

$\mathrm{Kx} \mathrm{Ky} \mathrm{Kz}$ Ss Por

$2.48829 \mathrm{e}+012.48829 \mathrm{e}+012.48829 \mathrm{e}+00$ 1.00000e-09 7.00000e-02 $2.48829 \mathrm{e}+012.48829 \mathrm{e}+012.48829 \mathrm{e}+001.00000 \mathrm{e}-09$ 7.00000e-02 5.00000e-04 5.00000e-04 5.00000e-05 1.00000e-09 1.00000e-01 9.94251e-01 9.94251e-01 9.94251e-02 1.00000e-09 2.12000e-01 9.94251e-01 9.94251e-01 9.94251e-02 1.00000e-09 2.12000e-01 9.94251e-01 9.94251e-01 9.94251e-02 1.00000e-09 2.12000e-01 9.94251e-01 9.94251e-01 9.94251e-02 1.00000e-09 2.12000e-01 $1.00000 \mathrm{e}-02$ 1.00000e-02 1.00000e-03 1.00000e-09 1.00000e-01 $1.00000 \mathrm{e}+001.00000 \mathrm{e}+001.00000 \mathrm{e}-011.00000 \mathrm{e}-091.00000 \mathrm{e}-01$ $1.00000 \mathrm{e}-05$ 1.00000e-05 1.00000e-06 1.00000e-09 1.00000e-01 $1.00000 \mathrm{e}+001.00000 \mathrm{e}+001.00000 \mathrm{e}-01$ 1.00000e-09 1.00000e-01 
Element: 3588 \# of layers: 12

$\mathrm{Kx} \mathrm{Ky} \mathrm{Kz}$ Ss Por

$2.48829 \mathrm{e}+012.48829 \mathrm{e}+012.48829 \mathrm{e}+00$ 1.00000e-09 7.00000e-02

$2.48829 \mathrm{e}+012.48829 \mathrm{e}+012.48829 \mathrm{e}+001.00000 \mathrm{e}-09$ 7.00000e-02

5.00000e-04 5.00000e-04 5.00000e-05 1.00000e-09 1.00000e-01

5.00000e-04 5.00000e-04 5.00000e-05 1.00000e-09 1.00000e-01

9.94251e-01 9.94251e-01 9.94251e-02 1.00000e-09 2.12000e-01

9.94251e-01 9.94251e-01 9.94251e-02 1.00000e-09 2.12000e-01

9.94251e-01 9.94251e-01 9.94251e-02 1.00000e-09 2.12000e-01

9.94251e-01 9.94251e-01 9.94251e-02 1.00000e-09 2.12000e-01

$1.00000 \mathrm{e}-02$ 1.00000e-02 1.00000e-03 1.00000e-09 1.00000e-01

$1.00000 \mathrm{e}+001.00000 \mathrm{e}+001.00000 \mathrm{e}-011.00000 \mathrm{e}-091.00000 \mathrm{e}-01$

$1.00000 \mathrm{e}-05$ 1.00000e-05 1.00000e-06 1.00000e-09 1.00000e-01

$1.00000 \mathrm{e}+001.00000 \mathrm{e}+001.00000 \mathrm{e}-011.00000 \mathrm{e}-091.00000 \mathrm{e}-01$

Element: 3589 \# of layers: 12

Kx Ky Kz Ss Por

$2.48829 \mathrm{e}+012.48829 \mathrm{e}+012.48829 \mathrm{e}+00$ 1.00000e-09 7.00000e-02

$2.48829 \mathrm{e}+012.48829 \mathrm{e}+012.48829 \mathrm{e}+001.00000 \mathrm{e}-09$ 7.00000e-02

5.00000e-04 5.00000e-04 5.00000e-05 1.00000e-09 1.00000e-01

5.00000e-04 5.00000e-04 5.00000e-05 1.00000e-09 1.00000e-01

9.94251e-01 9.94251e-01 9.94251e-02 1.00000e-09 2.12000e-01

9.94251e-01 9.94251e-01 9.94251e-02 1.00000e-09 2.12000e-01

9.94251e-01 9.94251e-01 9.94251e-02 1.00000e-09 2.12000e-01

9.94251e-01 9.94251e-01 9.94251e-02 1.00000e-09 2.12000e-01

$1.00000 \mathrm{e}-02$ 1.00000e-02 1.00000e-03 1.00000e-09 1.00000e-01

$1.00000 \mathrm{e}+001.00000 \mathrm{e}+001.00000 \mathrm{e}-011.00000 \mathrm{e}-091.00000 \mathrm{e}-01$

$1.00000 \mathrm{e}-05$ 1.00000e-05 1.00000e-06 1.00000e-09 1.00000e-01

$1.00000 \mathrm{e}+001.00000 \mathrm{e}+001.00000 \mathrm{e}-011.00000 \mathrm{e}-091.00000 \mathrm{e}-01$

Element: 3590 \# of layers: 12

$\mathrm{Kx} \mathrm{Ky} \mathrm{Kz}$ Ss Por

$2.48829 \mathrm{e}+012.48829 \mathrm{e}+012.48829 \mathrm{e}+00$ 1.00000e-09 7.00000e-02

$2.48829 \mathrm{e}+012.48829 \mathrm{e}+012.48829 \mathrm{e}+00$ 1.00000e-09 7.00000e-02

5.00000e-04 5.00000e-04 5.00000e-05 1.00000e-09 1.00000e-01

5.00000e-04 5.00000e-04 5.00000e-05 1.00000e-09 1.00000e-01

9.94251e-01 9.94251e-01 9.94251e-02 1.00000e-09 2.12000e-01

9.94251e-01 9.94251e-01 9.94251e-02 1.00000e-09 2.12000e-01

9.94251e-01 9.94251e-01 9.94251e-02 1.00000e-09 2.12000e-01

9.94251e-01 9.94251e-01 9.94251e-02 1.00000e-09 2.12000e-01

$1.00000 \mathrm{e}-02$ 1.00000e-02 1.00000e-03 1.00000e-09 1.00000e-01

$1.00000 \mathrm{e}+001.00000 \mathrm{e}+001.00000 \mathrm{e}-011.00000 \mathrm{e}-091.00000 \mathrm{e}-01$

$1.00000 \mathrm{e}-051.00000 \mathrm{e}-05$ 1.00000e-06 1.00000e-09 1.00000e-01

$1.00000 \mathrm{e}+001.00000 \mathrm{e}+001.00000 \mathrm{e}-011.00000 \mathrm{e}-091.00000 \mathrm{e}-01$

Element: 3591 \# of layers: 13

$\mathrm{Kx} \mathrm{Ky} \mathrm{Kz}$ Ss Por

$2.48829 \mathrm{e}+012.48829 \mathrm{e}+012.48829 \mathrm{e}+00$ 1.00000e-09 7.00000e-02

$2.48829 \mathrm{e}+012.48829 \mathrm{e}+012.48829 \mathrm{e}+001.00000 \mathrm{e}-09$ 7.00000e-02 
5.00000e-04 5.00000e-04 5.00000e-05 1.00000e-09 1.00000e-01 5.00000e-04 5.00000e-04 5.00000e-05 1.00000e-09 1.00000e-01 9.94251e-01 9.94251e-01 9.94251e-02 1.00000e-09 2.12000e-01 9.94251e-01 9.94251e-01 9.94251e-02 1.00000e-09 2.12000e-01 9.94251e-01 9.94251e-01 9.94251e-02 1.00000e-09 2.12000e-01 9.94251e-01 9.94251e-01 9.94251e-02 1.00000e-09 2.12000e-01 9.94251e-01 9.94251e-01 9.94251e-02 1.00000e-09 2.12000e-01 $1.00000 \mathrm{e}-02$ 1.00000e-02 1.00000e-03 1.00000e-09 1.00000e-01 $1.00000 \mathrm{e}+001.00000 \mathrm{e}+001.00000 \mathrm{e}-011.00000 \mathrm{e}-091.00000 \mathrm{e}-01$ $1.00000 \mathrm{e}-05$ 1.00000e-05 1.00000e-06 1.00000e-09 1.00000e-01 $1.00000 \mathrm{e}+001.00000 \mathrm{e}+001.00000 \mathrm{e}-011.00000 \mathrm{e}-091.00000 \mathrm{e}-01$ Element: 3592 \# of layers: 12

$\mathrm{Kx} \mathrm{Ky} \mathrm{Kz}$ Ss Por

$2.48829 \mathrm{e}+012.48829 \mathrm{e}+012.48829 \mathrm{e}+00$ 1.00000e-09 7.00000e-02 $2.48829 \mathrm{e}+012.48829 \mathrm{e}+012.48829 \mathrm{e}+001.00000 \mathrm{e}-097.00000 \mathrm{e}-02$ 5.00000e-04 5.00000e-04 5.00000e-05 1.00000e-09 1.00000e-01 5.00000e-04 5.00000e-04 5.00000e-05 1.00000e-09 1.00000e-01 9.94251e-01 9.94251e-01 9.94251e-02 1.00000e-09 2.12000e-01 9.94251e-01 9.94251e-01 9.94251e-02 1.00000e-09 2.12000e-01 9.94251e-01 9.94251e-01 9.94251e-02 1.00000e-09 2.12000e-01 9.94251e-01 9.94251e-01 9.94251e-02 1.00000e-09 2.12000e-01 $1.00000 \mathrm{e}-02$ 1.00000e-02 1.00000e-03 1.00000e-09 1.00000e-01 $1.00000 \mathrm{e}+001.00000 \mathrm{e}+001.00000 \mathrm{e}-011.00000 \mathrm{e}-091.00000 \mathrm{e}-01$ $1.00000 \mathrm{e}-05$ 1.00000e-05 1.00000e-06 1.00000e-09 1.00000e-01 $1.00000 \mathrm{e}+001.00000 \mathrm{e}+001.00000 \mathrm{e}-011.00000 \mathrm{e}-091.00000 \mathrm{e}-01$ Element: 3593 \# of layers: 13

$\mathrm{Kx} \mathrm{Ky} \mathrm{Kz}$ Ss Por

3.14053e+01 3.14053e+01 3.14053e+00 1.00000e-09 7.00000e-02 $3.14053 \mathrm{e}+013.14053 \mathrm{e}+013.14053 \mathrm{e}+001.00000 \mathrm{e}-09$ 7.00000e-02 5.00000e-04 5.00000e-04 5.00000e-05 1.00000e-09 1.00000e-01 5.00000e-04 5.00000e-04 5.00000e-05 1.00000e-09 1.00000e-01 $1.25483 \mathrm{e}+001.25483 \mathrm{e}+00$ 1.25483e-01 1.00000e-09 2.12000e-01 $1.25483 \mathrm{e}+001.25483 \mathrm{e}+00$ 1.25483e-01 1.00000e-09 2.12000e-01 $1.25483 \mathrm{e}+001.25483 \mathrm{e}+00$ 1.25483e-01 1.00000e-09 2.12000e-01 $1.25483 \mathrm{e}+001.25483 \mathrm{e}+00$ 1.25483e-01 1.00000e-09 2.12000e-01 $1.25483 \mathrm{e}+001.25483 \mathrm{e}+00$ 1.25483e-01 1.00000e-09 2.12000e-01 $1.00000 \mathrm{e}-02$ 1.00000e-02 1.00000e-03 1.00000e-09 1.00000e-01 $1.00000 \mathrm{e}+001.00000 \mathrm{e}+001.00000 \mathrm{e}-011.00000 \mathrm{e}-091.00000 \mathrm{e}-01$ $1.00000 \mathrm{e}-05$ 1.00000e-05 1.00000e-06 1.00000e-09 1.00000e-01 $1.00000 \mathrm{e}+001.00000 \mathrm{e}+001.00000 \mathrm{e}-01$ 1.00000e-09 1.00000e-01 Element: 3594 \# of layers: 13

$\mathrm{Kx} \mathrm{Ky} \mathrm{Kz}$ Ss Por

3.14053e+01 3.14053e+01 3.14053e+00 1.00000e-09 7.00000e-02 3.14053e+01 3.14053e+01 3.14053e+00 1.00000e-09 7.00000e-02 $5.00000 \mathrm{e}-04$ 5.00000e-04 5.00000e-05 1.00000e-09 1.00000e-01 5.00000e-04 5.00000e-04 5.00000e-05 1.00000e-09 1.00000e-01 
$1.25483 \mathrm{e}+00$ 1.25483e+00 1.25483e-01 1.00000e-09 2.12000e-01 $1.25483 \mathrm{e}+00$ 1.25483e+00 1.25483e-01 1.00000e-09 2.12000e-01 $1.25483 \mathrm{e}+001.25483 \mathrm{e}+00$ 1.25483e-01 1.00000e-09 2.12000e-01 $1.25483 \mathrm{e}+001.25483 \mathrm{e}+00$ 1.25483e-01 1.00000e-09 2.12000e-01 $1.25483 \mathrm{e}+001.25483 \mathrm{e}+001.25483 \mathrm{e}-01$ 1.00000e-09 2.12000e-01 $1.00000 \mathrm{e}-02$ 1.00000e-02 1.00000e-03 1.00000e-09 1.00000e-01 $1.00000 \mathrm{e}+001.00000 \mathrm{e}+001.00000 \mathrm{e}-011.00000 \mathrm{e}-091.00000 \mathrm{e}-01$ $1.00000 \mathrm{e}-05$ 1.00000e-05 1.00000e-06 1.00000e-09 1.00000e-01 $1.00000 \mathrm{e}+001.00000 \mathrm{e}+00$ 1.00000e-01 1.00000e-09 1.00000e-01 Element: 3595 \# of layers: 12

$\mathrm{Kx} \mathrm{Ky} \mathrm{Kz}$ Ss Por

3.14053e+01 3.14053e+01 3.14053e+00 1.00000e-09 7.00000e-02 5.00000e-04 5.00000e-04 5.00000e-05 1.00000e-09 1.00000e-01 5.00000e-04 5.00000e-04 5.00000e-05 1.00000e-09 1.00000e-01 $1.25483 \mathrm{e}+001.25483 \mathrm{e}+00$ 1.25483e-01 1.00000e-09 2.12000e-01 $1.25483 \mathrm{e}+001.25483 \mathrm{e}+00$ 1.25483e-01 1.00000e-09 2.12000e-01 $1.25483 \mathrm{e}+001.25483 \mathrm{e}+00$ 1.25483e-01 1.00000e-09 2.12000e-01 $1.25483 \mathrm{e}+00$ 1.25483e+00 1.25483e-01 1.00000e-09 2.12000e-01 $1.25483 \mathrm{e}+001.25483 \mathrm{e}+00$ 1.25483e-01 1.00000e-09 2.12000e-01 $1.00000 \mathrm{e}-02$ 1.00000e-02 1.00000e-03 1.00000e-09 1.00000e-01 $1.00000 \mathrm{e}+001.00000 \mathrm{e}+001.00000 \mathrm{e}-011.00000 \mathrm{e}-091.00000 \mathrm{e}-01$ $1.00000 \mathrm{e}-05$ 1.00000e-05 1.00000e-06 1.00000e-09 1.00000e-01 $1.00000 \mathrm{e}+001.00000 \mathrm{e}+001.00000 \mathrm{e}-01$ 1.00000e-09 1.00000e-01 Element: 3596 \# of layers: 11

Kx Ky Kz Ss Por

3.14053e+01 3.14053e+01 3.14053e+00 1.00000e-09 7.00000e-02 5.00000e-04 5.00000e-04 5.00000e-05 1.00000e-09 1.00000e-01 5.00000e-04 5.00000e-04 5.00000e-05 1.00000e-09 1.00000e-01 $1.25483 \mathrm{e}+001.25483 \mathrm{e}+001.25483 \mathrm{e}-01$ 1.00000e-09 2.12000e-01 $1.25483 \mathrm{e}+00$ 1.25483e+00 1.25483e-01 1.00000e-09 2.12000e-01 $1.25483 \mathrm{e}+001.25483 \mathrm{e}+00$ 1.25483e-01 1.00000e-09 2.12000e-01 $1.25483 \mathrm{e}+001.25483 \mathrm{e}+001.25483 \mathrm{e}-01$ 1.00000e-09 2.12000e-01 $1.00000 \mathrm{e}-02$ 1.00000e-02 1.00000e-03 1.00000e-09 1.00000e-01 $1.00000 \mathrm{e}+001.00000 \mathrm{e}+001.00000 \mathrm{e}-011.00000 \mathrm{e}-091.00000 \mathrm{e}-01$ $1.00000 \mathrm{e}-05$ 1.00000e-05 1.00000e-06 1.00000e-09 1.00000e-01 $1.00000 \mathrm{e}+001.00000 \mathrm{e}+001.00000 \mathrm{e}-011.00000 \mathrm{e}-091.00000 \mathrm{e}-01$ Element: 3597 \# of layers: 11

Kx Ky Kz Ss Por

3.14053e+01 3.14053e+01 3.14053e+00 1.00000e-09 7.00000e-02 5.00000e-04 5.00000e-04 5.00000e-05 1.00000e-09 1.00000e-01 5.00000e-04 5.00000e-04 5.00000e-05 1.00000e-09 1.00000e-01 $1.25483 \mathrm{e}+001.25483 \mathrm{e}+00$ 1.25483e-01 1.00000e-09 2.12000e-01 $1.25483 \mathrm{e}+00$ 1.25483e+00 1.25483e-01 1.00000e-09 2.12000e-01 $1.25483 \mathrm{e}+001.25483 \mathrm{e}+00$ 1.25483e-01 1.00000e-09 2.12000e-01 $1.25483 \mathrm{e}+001.25483 \mathrm{e}+001.25483 \mathrm{e}-01$ 1.00000e-09 2.12000e-01 $1.00000 \mathrm{e}-02$ 1.00000e-02 1.00000e-03 1.00000e-09 1.00000e-01 
$1.00000 \mathrm{e}+001.00000 \mathrm{e}+001.00000 \mathrm{e}-011.00000 \mathrm{e}-091.00000 \mathrm{e}-01$ $1.00000 \mathrm{e}-05$ 1.00000e-05 1.00000e-06 1.00000e-09 1.00000e-01 $1.00000 \mathrm{e}+001.00000 \mathrm{e}+001.00000 \mathrm{e}-01$ 1.00000e-09 1.00000e-01 Element: 3598 \# of layers: 11

$\mathrm{Kx} \mathrm{Ky} \mathrm{Kz}$ Ss Por

3.14053e+01 3.14053e+01 3.14053e+00 1.00000e-09 7.00000e-02 5.00000e-04 5.00000e-04 5.00000e-05 1.00000e-09 1.00000e-01 5.00000e-04 5.00000e-04 5.00000e-05 1.00000e-09 1.00000e-01 $1.25483 \mathrm{e}+001.25483 \mathrm{e}+00$ 1.25483e-01 1.00000e-09 2.12000e-01 $1.25483 \mathrm{e}+00$ 1.25483e+00 1.25483e-01 1.00000e-09 2.12000e-01 $1.25483 \mathrm{e}+00$ 1.25483e+00 1.25483e-01 1.00000e-09 2.12000e-01 $1.25483 \mathrm{e}+001.25483 \mathrm{e}+001.25483 \mathrm{e}-01$ 1.00000e-09 2.12000e-01 1.00000e-02 1.00000e-02 1.00000e-03 1.00000e-09 1.00000e-01 $1.00000 \mathrm{e}+001.00000 \mathrm{e}+001.00000 \mathrm{e}-011.00000 \mathrm{e}-091.00000 \mathrm{e}-01$ $1.00000 \mathrm{e}-05$ 1.00000e-05 1.00000e-06 1.00000e-09 1.00000e-01 $1.00000 \mathrm{e}+001.00000 \mathrm{e}+001.00000 \mathrm{e}-011.00000 \mathrm{e}-091.00000 \mathrm{e}-01$ Element: 3599 \# of layers: 12

$\mathrm{Kx} \mathrm{Ky} \mathrm{Kz}$ Ss Por

3.14053e+01 3.14053e+01 3.14053e+00 1.00000e-09 7.00000e-02 $3.14053 \mathrm{e}+013.14053 \mathrm{e}+013.14053 \mathrm{e}+001.00000 \mathrm{e}-09$ 7.00000e-02 5.00000e-04 5.00000e-04 5.00000e-05 1.00000e-09 1.00000e-01 5.00000e-04 5.00000e-04 5.00000e-05 1.00000e-09 1.00000e-01 $1.25483 \mathrm{e}+001.25483 \mathrm{e}+00$ 1.25483e-01 1.00000e-09 2.12000e-01 $1.25483 \mathrm{e}+001.25483 \mathrm{e}+00$ 1.25483e-01 1.00000e-09 2.12000e-01 $1.25483 \mathrm{e}+001.25483 \mathrm{e}+00$ 1.25483e-01 1.00000e-09 2.12000e-01 $1.25483 \mathrm{e}+001.25483 \mathrm{e}+00$ 1.25483e-01 1.00000e-09 2.12000e-01 $1.00000 \mathrm{e}-02$ 1.00000e-02 1.00000e-03 1.00000e-09 1.00000e-01 $1.00000 \mathrm{e}+001.00000 \mathrm{e}+001.00000 \mathrm{e}-01$ 1.00000e-09 1.00000e-01 $1.00000 \mathrm{e}-05$ 1.00000e-05 1.00000e-06 1.00000e-09 1.00000e-01 $1.00000 \mathrm{e}+001.00000 \mathrm{e}+001.00000 \mathrm{e}-011.00000 \mathrm{e}-091.00000 \mathrm{e}-01$ Element: 3600 \# of layers: 12

$\mathrm{Kx} \mathrm{Ky} \mathrm{Kz}$ Ss Por

3.14053e+01 3.14053e+01 3.14053e+00 1.00000e-09 7.00000e-02 $3.14053 \mathrm{e}+013.14053 \mathrm{e}+013.14053 \mathrm{e}+001.00000 \mathrm{e}-09$ 7.00000e-02 5.00000e-04 5.00000e-04 5.00000e-05 1.00000e-09 1.00000e-01 5.00000e-04 5.00000e-04 5.00000e-05 1.00000e-09 1.00000e-01 $1.25483 \mathrm{e}+001.25483 \mathrm{e}+00$ 1.25483e-01 1.00000e-09 2.12000e-01 $1.25483 \mathrm{e}+00$ 1.25483e+00 1.25483e-01 1.00000e-09 2.12000e-01 $1.25483 \mathrm{e}+001.25483 \mathrm{e}+00$ 1.25483e-01 1.00000e-09 2.12000e-01 $1.25483 \mathrm{e}+001.25483 \mathrm{e}+00$ 1.25483e-01 1.00000e-09 2.12000e-01 $1.00000 \mathrm{e}-02$ 1.00000e-02 1.00000e-03 1.00000e-09 1.00000e-01 $1.00000 \mathrm{e}+001.00000 \mathrm{e}+001.00000 \mathrm{e}-011.00000 \mathrm{e}-091.00000 \mathrm{e}-01$ $1.00000 \mathrm{e}-05$ 1.00000e-05 1.00000e-06 1.00000e-09 1.00000e-01 $1.00000 \mathrm{e}+001.00000 \mathrm{e}+001.00000 \mathrm{e}-01$ 1.00000e-09 1.00000e-01 Element: 3601 \# of layers: 11

Kx Ky Kz Ss Por 
$3.14053 \mathrm{e}+013.14053 \mathrm{e}+013.14053 \mathrm{e}+00$ 1.00000e-09 7.00000e-02 5.00000e-04 5.00000e-04 5.00000e-05 1.00000e-09 1.00000e-01 5.00000e-04 5.00000e-04 5.00000e-05 1.00000e-09 1.00000e-01 $1.25483 \mathrm{e}+001.25483 \mathrm{e}+00$ 1.25483e-01 1.00000e-09 2.12000e-01 $1.25483 \mathrm{e}+001.25483 \mathrm{e}+001.25483 \mathrm{e}-011.00000 \mathrm{e}-092.12000 \mathrm{e}-01$ $1.25483 \mathrm{e}+001.25483 \mathrm{e}+001.25483 \mathrm{e}-011.00000 \mathrm{e}-092.12000 \mathrm{e}-01$ $1.25483 \mathrm{e}+001.25483 \mathrm{e}+00$ 1.25483e-01 1.00000e-09 2.12000e-01 $1.00000 \mathrm{e}-021.00000 \mathrm{e}-02$ 1.00000e-03 1.00000e-09 1.00000e-01 $1.00000 \mathrm{e}+001.00000 \mathrm{e}+001.00000 \mathrm{e}-011.00000 \mathrm{e}-091.00000 \mathrm{e}-01$ $1.00000 \mathrm{e}-05$ 1.00000e-05 1.00000e-06 1.00000e-09 1.00000e-01 $1.00000 \mathrm{e}+001.00000 \mathrm{e}+001.00000 \mathrm{e}-011.00000 \mathrm{e}-091.00000 \mathrm{e}-01$ Element: 3602 \# of layers: 10

Kx Ky Kz Ss Por

$3.83970 \mathrm{e}+013.83970 \mathrm{e}+013.83970 \mathrm{e}+00$ 1.00000e-09 7.00000e-02 $5.00000 \mathrm{e}-04$ 5.00000e-04 5.00000e-05 1.00000e-09 1.00000e-01 5.00000e-04 5.00000e-04 5.00000e-05 1.00000e-09 1.00000e-01 $1.53422 \mathrm{e}+001.53422 \mathrm{e}+001.53422 \mathrm{e}-011.00000 \mathrm{e}-092.12000 \mathrm{e}-01$ $1.53422 \mathrm{e}+001.53422 \mathrm{e}+001.53422 \mathrm{e}-011.00000 \mathrm{e}-092.12000 \mathrm{e}-01$ $1.53422 \mathrm{e}+001.53422 \mathrm{e}+001.53422 \mathrm{e}-011.00000 \mathrm{e}-092.12000 \mathrm{e}-01$ $1.53422 \mathrm{e}+001.53422 \mathrm{e}+001.53422 \mathrm{e}-011.00000 \mathrm{e}-092.12000 \mathrm{e}-01$ $1.53422 \mathrm{e}+001.53422 \mathrm{e}+001.53422 \mathrm{e}-011.00000 \mathrm{e}-092.12000 \mathrm{e}-01$ $1.00000 \mathrm{e}-021.00000 \mathrm{e}-021.00000 \mathrm{e}-031.00000 \mathrm{e}-091.00000 \mathrm{e}-01$ $1.00000 \mathrm{e}+001.00000 \mathrm{e}+001.00000 \mathrm{e}-011.00000 \mathrm{e}-091.00000 \mathrm{e}-01$ Element: 3603 \# of layers: 9

Kx Ky Kz Ss Por $3.83970 \mathrm{e}+013.83970 \mathrm{e}+013.83970 \mathrm{e}+00$ 1.00000e-09 7.00000e-02 5.00000e-04 5.00000e-04 5.00000e-05 1.00000e-09 1.00000e-01 $1.53422 \mathrm{e}+001.53422 \mathrm{e}+001.53422 \mathrm{e}-011.00000 \mathrm{e}-092.12000 \mathrm{e}-01$ $1.53422 \mathrm{e}+001.53422 \mathrm{e}+001.53422 \mathrm{e}-011.00000 \mathrm{e}-092.12000 \mathrm{e}-01$ $1.53422 \mathrm{e}+001.53422 \mathrm{e}+001.53422 \mathrm{e}-011.00000 \mathrm{e}-092.12000 \mathrm{e}-01$ $1.53422 \mathrm{e}+001.53422 \mathrm{e}+001.53422 \mathrm{e}-011.00000 \mathrm{e}-092.12000 \mathrm{e}-01$ $1.53422 \mathrm{e}+001.53422 \mathrm{e}+001.53422 \mathrm{e}-011.00000 \mathrm{e}-092.12000 \mathrm{e}-01$ $1.00000 \mathrm{e}-021.00000 \mathrm{e}-02$ 1.00000e-03 1.00000e-09 1.00000e-01 $1.00000 \mathrm{e}+001.00000 \mathrm{e}+001.00000 \mathrm{e}-011.00000 \mathrm{e}-091.00000 \mathrm{e}-01$ Element: 3604 \# of layers: 11

Kx Ky Kz Ss Por $3.83970 \mathrm{e}+013.83970 \mathrm{e}+013.83970 \mathrm{e}+00$ 1.00000e-09 7.00000e-02 $3.83970 \mathrm{e}+013.83970 \mathrm{e}+013.83970 \mathrm{e}+001.00000 \mathrm{e}-09$ 7.00000e-02 5.00000e-04 5.00000e-04 5.00000e-05 1.00000e-09 1.00000e-01 5.00000e-04 5.00000e-04 5.00000e-05 1.00000e-09 1.00000e-01 $1.53422 \mathrm{e}+001.53422 \mathrm{e}+001.53422 \mathrm{e}-011.00000 \mathrm{e}-092.12000 \mathrm{e}-01$ $1.53422 \mathrm{e}+001.53422 \mathrm{e}+001.53422 \mathrm{e}-011.00000 \mathrm{e}-092.12000 \mathrm{e}-01$ $1.53422 \mathrm{e}+001.53422 \mathrm{e}+001.53422 \mathrm{e}-011.00000 \mathrm{e}-092.12000 \mathrm{e}-01$ $1.53422 \mathrm{e}+001.53422 \mathrm{e}+001.53422 \mathrm{e}-011.00000 \mathrm{e}-092.12000 \mathrm{e}-01$ $1.53422 \mathrm{e}+001.53422 \mathrm{e}+001.53422 \mathrm{e}-011.00000 \mathrm{e}-092.12000 \mathrm{e}-01$ $1.00000 \mathrm{e}-021.00000 \mathrm{e}-02$ 1.00000e-03 1.00000e-09 1.00000e-01 
$1.00000 \mathrm{e}+001.00000 \mathrm{e}+00$ 1.00000e-01 1.00000e-09 1.00000e-01 Element: 3605 \# of layers: 9

Kx Ky Kz Ss Por

3.83970e+01 3.83970e+01 3.83970e+00 1.00000e-09 7.00000e-02

5.00000e-04 5.00000e-04 5.00000e-05 1.00000e-09 1.00000e-01

5.00000e-04 5.00000e-04 5.00000e-05 1.00000e-09 1.00000e-01

$1.53422 \mathrm{e}+001.53422 \mathrm{e}+00$ 1.53422e-01 1.00000e-09 2.12000e-01

$1.53422 \mathrm{e}+001.53422 \mathrm{e}+001.53422 \mathrm{e}-01$ 1.00000e-09 2.12000e-01

$1.53422 \mathrm{e}+00$ 1.53422e+00 1.53422e-01 1.00000e-09 2.12000e-01

$1.53422 \mathrm{e}+001.53422 \mathrm{e}+00$ 1.53422e-01 1.00000e-09 2.12000e-01

$1.00000 \mathrm{e}-02$ 1.00000e-02 1.00000e-03 1.00000e-09 1.00000e-01

$1.00000 \mathrm{e}+001.00000 \mathrm{e}+001.00000 \mathrm{e}-011.00000 \mathrm{e}-091.00000 \mathrm{e}-01$

Element: 3606 \# of layers: 9

$\mathrm{Kx} \mathrm{Ky} \mathrm{Kz}$ Ss Por

3.83970e+01 3.83970e+01 3.83970e+00 1.00000e-09 7.00000e-02 5.00000e-04 5.00000e-04 5.00000e-05 1.00000e-09 1.00000e-01 5.00000e-04 5.00000e-04 5.00000e-05 1.00000e-09 1.00000e-01

$1.53422 \mathrm{e}+00$ 1.53422e+00 1.53422e-01 1.00000e-09 2.12000e-01

$1.53422 \mathrm{e}+001.53422 \mathrm{e}+00$ 1.53422e-01 1.00000e-09 2.12000e-01

$1.53422 \mathrm{e}+001.53422 \mathrm{e}+001.53422 \mathrm{e}-01$ 1.00000e-09 2.12000e-01

$1.53422 \mathrm{e}+001.53422 \mathrm{e}+00$ 1.53422e-01 1.00000e-09 2.12000e-01

$1.00000 \mathrm{e}-02$ 1.00000e-02 1.00000e-03 1.00000e-09 1.00000e-01

$1.00000 \mathrm{e}+001.00000 \mathrm{e}+001.00000 \mathrm{e}-01$ 1.00000e-09 1.00000e-01

Element: 3607 \# of layers: 9

Kx Ky Kz Ss Por

$3.83970 \mathrm{e}+013.83970 \mathrm{e}+013.83970 \mathrm{e}+001.00000 \mathrm{e}-097.00000 \mathrm{e}-02$

5.00000e-04 5.00000e-04 5.00000e-05 1.00000e-09 1.00000e-01

5.00000e-04 5.00000e-04 5.00000e-05 1.00000e-09 1.00000e-01

$1.53422 \mathrm{e}+001.53422 \mathrm{e}+001.53422 \mathrm{e}-01$ 1.00000e-09 2.12000e-01

$1.53422 \mathrm{e}+00$ 1.53422e+00 1.53422e-01 1.00000e-09 2.12000e-01

$1.53422 \mathrm{e}+001.53422 \mathrm{e}+00$ 1.53422e-01 1.00000e-09 2.12000e-01

$1.53422 \mathrm{e}+001.53422 \mathrm{e}+00$ 1.53422e-01 1.00000e-09 2.12000e-01

1.00000e-02 1.00000e-02 1.00000e-03 1.00000e-09 1.00000e-01

$1.00000 \mathrm{e}+001.00000 \mathrm{e}+001.00000 \mathrm{e}-011.00000 \mathrm{e}-091.00000 \mathrm{e}-01$

Element: 3608 \# of layers: 11

Kx Ky Kz Ss Por

3.83970e+01 3.83970e+01 3.83970e+00 1.00000e-09 7.00000e-02

5.00000e-04 5.00000e-04 5.00000e-05 1.00000e-09 1.00000e-01

5.00000e-04 5.00000e-04 5.00000e-05 1.00000e-09 1.00000e-01

$1.53422 \mathrm{e}+001.53422 \mathrm{e}+00$ 1.53422e-01 1.00000e-09 2.12000e-01

$1.53422 \mathrm{e}+001.53422 \mathrm{e}+00$ 1.53422e-01 1.00000e-09 2.12000e-01

$1.53422 \mathrm{e}+001.53422 \mathrm{e}+00$ 1.53422e-01 1.00000e-09 2.12000e-01

$1.53422 \mathrm{e}+00$ 1.53422e+00 1.53422e-01 1.00000e-09 2.12000e-01

$1.00000 \mathrm{e}-02$ 1.00000e-02 1.00000e-03 1.00000e-09 1.00000e-01

$1.00000 \mathrm{e}+001.00000 \mathrm{e}+001.00000 \mathrm{e}-011.00000 \mathrm{e}-091.00000 \mathrm{e}-01$

$1.00000 \mathrm{e}-05$ 1.00000e-05 1.00000e-06 1.00000e-09 1.00000e-01 
$1.00000 \mathrm{e}+001.00000 \mathrm{e}+00$ 1.00000e-01 1.00000e-09 1.00000e-01 Element: 3609 \# of layers: 9

Kx Ky Kz Ss Por

3.83970e+01 3.83970e+01 3.83970e+00 1.00000e-09 7.00000e-02

5.00000e-04 5.00000e-04 5.00000e-05 1.00000e-09 1.00000e-01

5.00000e-04 5.00000e-04 5.00000e-05 1.00000e-09 1.00000e-01

$1.53422 \mathrm{e}+001.53422 \mathrm{e}+00$ 1.53422e-01 1.00000e-09 2.12000e-01

$1.53422 \mathrm{e}+001.53422 \mathrm{e}+001.53422 \mathrm{e}-01$ 1.00000e-09 2.12000e-01

$1.53422 \mathrm{e}+00$ 1.53422e+00 1.53422e-01 1.00000e-09 2.12000e-01

$1.53422 \mathrm{e}+001.53422 \mathrm{e}+00$ 1.53422e-01 1.00000e-09 2.12000e-01

$1.00000 \mathrm{e}-02$ 1.00000e-02 1.00000e-03 1.00000e-09 1.00000e-01

$1.00000 \mathrm{e}+001.00000 \mathrm{e}+001.00000 \mathrm{e}-011.00000 \mathrm{e}-091.00000 \mathrm{e}-01$

Element: 3610 \# of layers: 9

$\mathrm{Kx} \mathrm{Ky} \mathrm{Kz}$ Ss Por

$3.83970 \mathrm{e}+013.83970 \mathrm{e}+013.83970 \mathrm{e}+001.00000 \mathrm{e}-09$ 7.00000e-02 5.00000e-04 5.00000e-04 5.00000e-05 1.00000e-09 1.00000e-01 5.00000e-04 5.00000e-04 5.00000e-05 1.00000e-09 1.00000e-01

$1.53422 \mathrm{e}+00$ 1.53422e+00 1.53422e-01 1.00000e-09 2.12000e-01

$1.53422 \mathrm{e}+001.53422 \mathrm{e}+00$ 1.53422e-01 1.00000e-09 2.12000e-01

$1.53422 \mathrm{e}+001.53422 \mathrm{e}+001.53422 \mathrm{e}-01$ 1.00000e-09 2.12000e-01

$1.53422 \mathrm{e}+001.53422 \mathrm{e}+00$ 1.53422e-01 1.00000e-09 2.12000e-01

$1.00000 \mathrm{e}-02$ 1.00000e-02 1.00000e-03 1.00000e-09 1.00000e-01

$1.00000 \mathrm{e}+001.00000 \mathrm{e}+001.00000 \mathrm{e}-01$ 1.00000e-09 1.00000e-01

Element: 3611 \# of layers: 11

$\mathrm{Kx} \mathrm{Ky} \mathrm{Kz}$ Ss Por

3.33226e+01 3.33226e+01 3.33226e+00 1.00000e-09 7.00000e-02

$3.33226 \mathrm{e}+013.33226 \mathrm{e}+013.33226 \mathrm{e}+001.00000 \mathrm{e}-09$ 7.00000e-02

5.00000e-04 5.00000e-04 5.00000e-05 1.00000e-09 1.00000e-01

5.00000e-04 5.00000e-04 5.00000e-05 1.00000e-09 1.00000e-01

$1.33147 \mathrm{e}+001.33147 \mathrm{e}+00$ 1.33147e-01 1.00000e-09 2.12000e-01

$1.33147 \mathrm{e}+001.33147 \mathrm{e}+00$ 1.33147e-01 1.00000e-09 2.12000e-01

1.33147e+00 1.33147e+00 1.33147e-01 1.00000e-09 2.12000e-01

$1.33147 \mathrm{e}+001.33147 \mathrm{e}+00$ 1.33147e-01 1.00000e-09 2.12000e-01

$1.33147 \mathrm{e}+00$ 1.33147e+00 1.33147e-01 1.00000e-09 2.12000e-01

$1.00000 \mathrm{e}-02$ 1.00000e-02 1.00000e-03 1.00000e-09 1.00000e-01

$1.00000 \mathrm{e}+001.00000 \mathrm{e}+001.00000 \mathrm{e}-011.00000 \mathrm{e}-091.00000 \mathrm{e}-01$

Element: 3612 \# of layers: 11

Kx Ky Kz Ss Por

3.33226e+01 3.33226e+01 3.33226e+00 1.00000e-09 7.00000e-02

$3.33226 \mathrm{e}+013.33226 \mathrm{e}+013.33226 \mathrm{e}+001.00000 \mathrm{e}-09$ 7.00000e-02

5.00000e-04 5.00000e-04 5.00000e-05 1.00000e-09 1.00000e-01

5.00000e-04 5.00000e-04 5.00000e-05 1.00000e-09 1.00000e-01

$1.33147 \mathrm{e}+001.33147 \mathrm{e}+00$ 1.33147e-01 1.00000e-09 2.12000e-01

1.33147e+00 1.33147e+00 1.33147e-01 1.00000e-09 2.12000e-01

$1.33147 \mathrm{e}+001.33147 \mathrm{e}+00$ 1.33147e-01 1.00000e-09 2.12000e-01

$1.33147 \mathrm{e}+001.33147 \mathrm{e}+00$ 1.33147e-01 1.00000e-09 2.12000e-01 
$1.33147 \mathrm{e}+001.33147 \mathrm{e}+00$ 1.33147e-01 1.00000e-09 2.12000e-01 $1.00000 \mathrm{e}-021.00000 \mathrm{e}-02$ 1.00000e-03 1.00000e-09 1.00000e-01 $1.00000 \mathrm{e}+001.00000 \mathrm{e}+001.00000 \mathrm{e}-011.00000 \mathrm{e}-091.00000 \mathrm{e}-01$ Element: 3613 \# of layers: 11

Kx Ky Kz Ss Por

$3.33226 \mathrm{e}+013.33226 \mathrm{e}+013.33226 \mathrm{e}+00$ 1.00000e-09 7.00000e-02 $3.33226 \mathrm{e}+013.33226 \mathrm{e}+013.33226 \mathrm{e}+001.00000 \mathrm{e}-097.00000 \mathrm{e}-02$ 5.00000e-04 5.00000e-04 5.00000e-05 1.00000e-09 1.00000e-01 5.00000e-04 5.00000e-04 5.00000e-05 1.00000e-09 1.00000e-01 $1.33147 \mathrm{e}+001.33147 \mathrm{e}+001.33147 \mathrm{e}-011.00000 \mathrm{e}-09$ 2.12000e-01 $1.33147 \mathrm{e}+001.33147 \mathrm{e}+00$ 1.33147e-01 1.00000e-09 2.12000e-01 $1.33147 \mathrm{e}+001.33147 \mathrm{e}+001.33147 \mathrm{e}-011.00000 \mathrm{e}-092.12000 \mathrm{e}-01$ $1.33147 \mathrm{e}+001.33147 \mathrm{e}+001.33147 \mathrm{e}-011.00000 \mathrm{e}-092.12000 \mathrm{e}-01$ $1.33147 \mathrm{e}+001.33147 \mathrm{e}+001.33147 \mathrm{e}-011.00000 \mathrm{e}-092.12000 \mathrm{e}-01$ $1.00000 \mathrm{e}-02$ 1.00000e-02 1.00000e-03 1.00000e-09 1.00000e-01 $1.00000 \mathrm{e}+001.00000 \mathrm{e}+001.00000 \mathrm{e}-011.00000 \mathrm{e}-091.00000 \mathrm{e}-01$ Element: 3614 \# of layers: 10

Kx Ky Kz Ss Por

$3.33226 \mathrm{e}+013.33226 \mathrm{e}+013.33226 \mathrm{e}+00$ 1.00000e-09 7.00000e-02 $3.33226 \mathrm{e}+013.33226 \mathrm{e}+013.33226 \mathrm{e}+001.00000 \mathrm{e}-097.00000 \mathrm{e}-02$ 5.00000e-04 5.00000e-04 5.00000e-05 1.00000e-09 1.00000e-01 5.00000e-04 5.00000e-04 5.00000e-05 1.00000e-09 1.00000e-01 $1.33147 \mathrm{e}+001.33147 \mathrm{e}+001.33147 \mathrm{e}-011.00000 \mathrm{e}-092.12000 \mathrm{e}-01$ $1.33147 \mathrm{e}+001.33147 \mathrm{e}+001.33147 \mathrm{e}-011.00000 \mathrm{e}-092.12000 \mathrm{e}-01$ $1.33147 \mathrm{e}+001.33147 \mathrm{e}+001.33147 \mathrm{e}-011.00000 \mathrm{e}-092.12000 \mathrm{e}-01$ $1.33147 \mathrm{e}+001.33147 \mathrm{e}+001.33147 \mathrm{e}-011.00000 \mathrm{e}-092.12000 \mathrm{e}-01$ $1.33147 \mathrm{e}+001.33147 \mathrm{e}+001.33147 \mathrm{e}-011.00000 \mathrm{e}-092.12000 \mathrm{e}-01$ $1.00000 \mathrm{e}-02$ 1.00000e-02 1.00000e-03 1.00000e-09 1.00000e-01

Element: 3615 \# of layers: 11

Kx Ky Kz Ss Por

$3.33226 \mathrm{e}+013.33226 \mathrm{e}+013.33226 \mathrm{e}+00$ 1.00000e-09 7.00000e-02 $3.33226 \mathrm{e}+013.33226 \mathrm{e}+013.33226 \mathrm{e}+001.00000 \mathrm{e}-097.00000 \mathrm{e}-02$ 5.00000e-04 5.00000e-04 5.00000e-05 1.00000e-09 1.00000e-01 5.00000e-04 5.00000e-04 5.00000e-05 1.00000e-09 1.00000e-01 $1.33147 \mathrm{e}+001.33147 \mathrm{e}+001.33147 \mathrm{e}-011.00000 \mathrm{e}-09$ 2.12000e-01 $1.33147 \mathrm{e}+001.33147 \mathrm{e}+00$ 1.33147e-01 1.00000e-09 2.12000e-01 $1.33147 \mathrm{e}+001.33147 \mathrm{e}+001.33147 \mathrm{e}-011.00000 \mathrm{e}-092.12000 \mathrm{e}-01$ $1.33147 \mathrm{e}+001.33147 \mathrm{e}+001.33147 \mathrm{e}-011.00000 \mathrm{e}-092.12000 \mathrm{e}-01$ $1.33147 \mathrm{e}+001.33147 \mathrm{e}+00$ 1.33147e-01 1.00000e-09 2.12000e-01 $1.00000 \mathrm{e}-02$ 1.00000e-02 1.00000e-03 1.00000e-09 1.00000e-01 $1.00000 \mathrm{e}+001.00000 \mathrm{e}+001.00000 \mathrm{e}-011.00000 \mathrm{e}-091.00000 \mathrm{e}-01$ Element: 3616 \# of layers: 11

Kx Ky Kz Ss Por

$3.33226 \mathrm{e}+013.33226 \mathrm{e}+013.33226 \mathrm{e}+00$ 1.00000e-09 7.00000e-02 $3.33226 \mathrm{e}+013.33226 \mathrm{e}+013.33226 \mathrm{e}+001.00000 \mathrm{e}-097.00000 \mathrm{e}-02$ 5.00000e-04 5.00000e-04 5.00000e-05 1.00000e-09 1.00000e-01 
5.00000e-04 5.00000e-04 5.00000e-05 1.00000e-09 1.00000e-01 1.33147e+00 1.33147e+00 1.33147e-01 1.00000e-09 2.12000e-01 $1.33147 \mathrm{e}+00$ 1.33147e+00 1.33147e-01 1.00000e-09 2.12000e-01 $1.33147 \mathrm{e}+00$ 1.33147e+00 1.33147e-01 1.00000e-09 2.12000e-01 $1.33147 \mathrm{e}+001.33147 \mathrm{e}+00$ 1.33147e-01 1.00000e-09 2.12000e-01 $1.33147 \mathrm{e}+00$ 1.33147e+00 1.33147e-01 1.00000e-09 2.12000e-01 $1.00000 \mathrm{e}-02$ 1.00000e-02 1.00000e-03 1.00000e-09 1.00000e-01 $1.00000 \mathrm{e}+001.00000 \mathrm{e}+001.00000 \mathrm{e}-011.00000 \mathrm{e}-091.00000 \mathrm{e}-01$ Element: 3617 \# of layers: 10

$\mathrm{Kx} \mathrm{Ky} \mathrm{Kz}$ Ss Por

3.33226e+01 3.33226e+01 3.33226e+00 1.00000e-09 7.00000e-02 5.00000e-04 5.00000e-04 5.00000e-05 1.00000e-09 1.00000e-01 5.00000e-04 5.00000e-04 5.00000e-05 1.00000e-09 1.00000e-01 $1.33147 \mathrm{e}+001.33147 \mathrm{e}+00$ 1.33147e-01 1.00000e-09 2.12000e-01 1.33147e+00 1.33147e+00 1.33147e-01 1.00000e-09 2.12000e-01 $1.33147 \mathrm{e}+001.33147 \mathrm{e}+00$ 1.33147e-01 1.00000e-09 2.12000e-01 $1.33147 \mathrm{e}+00$ 1.33147e+00 1.33147e-01 1.00000e-09 2.12000e-01 $1.33147 \mathrm{e}+00$ 1.33147e+00 1.33147e-01 1.00000e-09 2.12000e-01 $1.00000 \mathrm{e}-02$ 1.00000e-02 1.00000e-03 1.00000e-09 1.00000e-01 $1.00000 \mathrm{e}+001.00000 \mathrm{e}+001.00000 \mathrm{e}-011.00000 \mathrm{e}-091.00000 \mathrm{e}-01$ Element: 3618 \# of layers: 11

$\mathrm{Kx} \mathrm{Ky} \mathrm{Kz}$ Ss Por

3.33226e+01 3.33226e+01 3.33226e+00 1.00000e-09 7.00000e-02 $3.33226 \mathrm{e}+013.33226 \mathrm{e}+013.33226 \mathrm{e}+001.00000 \mathrm{e}-09$ 7.00000e-02 $5.00000 \mathrm{e}-04$ 5.00000e-04 5.00000e-05 1.00000e-09 1.00000e-01 5.00000e-04 5.00000e-04 5.00000e-05 1.00000e-09 1.00000e-01 $1.33147 \mathrm{e}+001.33147 \mathrm{e}+00$ 1.33147e-01 1.00000e-09 2.12000e-01 $1.33147 \mathrm{e}+00$ 1.33147e+00 1.33147e-01 1.00000e-09 2.12000e-01 $1.33147 \mathrm{e}+00$ 1.33147e+00 1.33147e-01 1.00000e-09 2.12000e-01 $1.33147 \mathrm{e}+00$ 1.33147e+00 1.33147e-01 1.00000e-09 2.12000e-01 $1.33147 \mathrm{e}+00$ 1.33147e+00 1.33147e-01 1.00000e-09 2.12000e-01 1.00000e-02 1.00000e-02 1.00000e-03 1.00000e-09 1.00000e-01 $1.00000 \mathrm{e}+001.00000 \mathrm{e}+001.00000 \mathrm{e}-011.00000 \mathrm{e}-091.00000 \mathrm{e}-01$ Element: 3619 \# of layers: 11

$\mathrm{Kx} \mathrm{Ky} \mathrm{Kz}$ Ss Por

3.33226e+01 3.33226e+01 3.33226e+00 1.00000e-09 7.00000e-02 $3.33226 \mathrm{e}+013.33226 \mathrm{e}+013.33226 \mathrm{e}+001.00000 \mathrm{e}-09$ 7.00000e-02 5.00000e-04 5.00000e-04 5.00000e-05 1.00000e-09 1.00000e-01 5.00000e-04 5.00000e-04 5.00000e-05 1.00000e-09 1.00000e-01 $1.33147 \mathrm{e}+00$ 1.33147e+00 1.33147e-01 1.00000e-09 2.12000e-01 $1.33147 \mathrm{e}+001.33147 \mathrm{e}+00$ 1.33147e-01 1.00000e-09 2.12000e-01 $1.33147 \mathrm{e}+001.33147 \mathrm{e}+00$ 1.33147e-01 1.00000e-09 2.12000e-01 1.33147e+00 1.33147e+00 1.33147e-01 1.00000e-09 2.12000e-01 1.33147e+00 1.33147e+00 1.33147e-01 1.00000e-09 2.12000e-01 $1.00000 \mathrm{e}-02$ 1.00000e-02 1.00000e-03 1.00000e-09 1.00000e-01 $1.00000 \mathrm{e}+001.00000 \mathrm{e}+001.00000 \mathrm{e}-011.00000 \mathrm{e}-091.00000 \mathrm{e}-01$ 
Element: 3620 \# of layers: 9

$\mathrm{Kx} \mathrm{Ky} \mathrm{Kz}$ Ss Por

3.30252e+01 3.30252e+01 3.30252e+00 1.00000e-09 7.00000e-02

$3.30252 \mathrm{e}+013.30252 \mathrm{e}+013.30252 \mathrm{e}+001.00000 \mathrm{e}-09$ 7.00000e-02

5.00000e-04 5.00000e-04 5.00000e-05 1.00000e-09 1.00000e-01

5.00000e-04 5.00000e-04 5.00000e-05 1.00000e-09 1.00000e-01

$1.31956 \mathrm{e}+001.31956 \mathrm{e}+00$ 1.31956e-01 1.00000e-09 2.12000e-01

$1.31956 \mathrm{e}+001.31956 \mathrm{e}+001.31956 \mathrm{e}-01$ 1.00000e-09 2.12000e-01

$1.31956 \mathrm{e}+00$ 1.31956e+00 1.31956e-01 1.00000e-09 2.12000e-01

$1.31956 \mathrm{e}+001.31956 \mathrm{e}+00$ 1.31956e-01 1.00000e-09 2.12000e-01

$1.31956 \mathrm{e}+00$ 1.31956e+00 1.31956e-01 1.00000e-09 2.12000e-01

Element: 3621 \# of layers: 9

$\mathrm{Kx} \mathrm{Ky} \mathrm{Kz}$ Ss Por

3.30252e+01 3.30252e+01 3.30252e+00 1.00000e-09 7.00000e-02

$3.30252 \mathrm{e}+013.30252 \mathrm{e}+013.30252 \mathrm{e}+00$ 1.00000e-09 7.00000e-02

5.00000e-04 5.00000e-04 5.00000e-05 1.00000e-09 1.00000e-01

5.00000e-04 5.00000e-04 5.00000e-05 1.00000e-09 1.00000e-01

$1.31956 \mathrm{e}+001.31956 \mathrm{e}+00$ 1.31956e-01 1.00000e-09 2.12000e-01

$1.31956 \mathrm{e}+001.31956 \mathrm{e}+00$ 1.31956e-01 1.00000e-09 2.12000e-01

$1.31956 \mathrm{e}+001.31956 \mathrm{e}+00$ 1.31956e-01 1.00000e-09 2.12000e-01

$1.31956 \mathrm{e}+001.31956 \mathrm{e}+00$ 1.31956e-01 1.00000e-09 2.12000e-01

$1.31956 \mathrm{e}+00$ 1.31956e+00 1.31956e-01 1.00000e-09 2.12000e-01

Element: 3622 \# of layers: 7

$\mathrm{Kx} \mathrm{Ky} \mathrm{Kz}$ Ss Por

3.30252e+01 3.30252e+01 3.30252e+00 1.00000e-09 7.00000e-02

5.00000e-04 5.00000e-04 5.00000e-05 1.00000e-09 1.00000e-01

$1.31956 \mathrm{e}+001.31956 \mathrm{e}+00$ 1.31956e-01 1.00000e-09 2.12000e-01

$1.31956 \mathrm{e}+001.31956 \mathrm{e}+00$ 1.31956e-01 1.00000e-09 2.12000e-01

$1.31956 \mathrm{e}+001.31956 \mathrm{e}+00$ 1.31956e-01 1.00000e-09 2.12000e-01

$1.31956 \mathrm{e}+00$ 1.31956e+00 1.31956e-01 1.00000e-09 2.12000e-01

$1.31956 \mathrm{e}+00$ 1.31956e+00 1.31956e-01 1.00000e-09 2.12000e-01

Element: 3623 \# of layers: 8

$\mathrm{Kx} \mathrm{Ky} \mathrm{Kz}$ Ss Por

3.30252e+01 3.30252e+01 3.30252e+00 1.00000e-09 7.00000e-02

$3.30252 \mathrm{e}+013.30252 \mathrm{e}+013.30252 \mathrm{e}+00$ 1.00000e-09 7.00000e-02

5.00000e-04 5.00000e-04 5.00000e-05 1.00000e-09 1.00000e-01

$1.31956 \mathrm{e}+001.31956 \mathrm{e}+001.31956 \mathrm{e}-011.00000 \mathrm{e}-092.12000 \mathrm{e}-01$

$1.31956 \mathrm{e}+001.31956 \mathrm{e}+00$ 1.31956e-01 1.00000e-09 2.12000e-01

$1.31956 \mathrm{e}+001.31956 \mathrm{e}+00$ 1.31956e-01 1.00000e-09 2.12000e-01

$1.31956 \mathrm{e}+001.31956 \mathrm{e}+00$ 1.31956e-01 1.00000e-09 2.12000e-01

$1.31956 \mathrm{e}+00$ 1.31956e+00 1.31956e-01 1.00000e-09 2.12000e-01

Element: 3624 \# of layers: 9

$\mathrm{Kx} \mathrm{Ky} \mathrm{Kz}$ Ss Por

3.30252e+01 3.30252e+01 3.30252e+00 1.00000e-09 7.00000e-02

$3.30252 \mathrm{e}+013.30252 \mathrm{e}+013.30252 \mathrm{e}+001.00000 \mathrm{e}-09$ 7.00000e-02

5.00000e-04 5.00000e-04 5.00000e-05 1.00000e-09 1.00000e-01 
5.00000e-04 5.00000e-04 5.00000e-05 1.00000e-09 1.00000e-01 $1.31956 \mathrm{e}+00$ 1.31956e+00 1.31956e-01 1.00000e-09 2.12000e-01 $1.31956 \mathrm{e}+001.31956 \mathrm{e}+00$ 1.31956e-01 1.00000e-09 2.12000e-01 $1.31956 \mathrm{e}+001.31956 \mathrm{e}+001.31956 \mathrm{e}-01$ 1.00000e-09 2.12000e-01 $1.31956 \mathrm{e}+00$ 1.31956e+00 1.31956e-01 1.00000e-09 2.12000e-01 $1.31956 \mathrm{e}+00$ 1.31956e+00 1.31956e-01 1.00000e-09 2.12000e-01 Element: 3625 \# of layers: 10

$\mathrm{Kx} \mathrm{Ky} \mathrm{Kz}$ Ss Por

3.30252e+01 3.30252e+01 3.30252e+00 1.00000e-09 7.00000e-02

$3.30252 \mathrm{e}+013.30252 \mathrm{e}+013.30252 \mathrm{e}+00$ 1.00000e-09 7.00000e-02 5.00000e-04 5.00000e-04 5.00000e-05 1.00000e-09 1.00000e-01 5.00000e-04 5.00000e-04 5.00000e-05 1.00000e-09 1.00000e-01

$1.31956 \mathrm{e}+001.31956 \mathrm{e}+001.31956 \mathrm{e}-01$ 1.00000e-09 2.12000e-01 $1.31956 \mathrm{e}+001.31956 \mathrm{e}+00$ 1.31956e-01 1.00000e-09 2.12000e-01 $1.31956 \mathrm{e}+001.31956 \mathrm{e}+00$ 1.31956e-01 1.00000e-09 2.12000e-01 $1.31956 \mathrm{e}+001.31956 \mathrm{e}+00$ 1.31956e-01 1.00000e-09 2.12000e-01 $1.31956 \mathrm{e}+001.31956 \mathrm{e}+00$ 1.31956e-01 1.00000e-09 2.12000e-01 1.00000e-02 1.00000e-02 1.00000e-03 1.00000e-09 1.00000e-01 Element: 3626 \# of layers: 10

$\mathrm{Kx} \mathrm{Ky} \mathrm{Kz}$ Ss Por

$3.30252 \mathrm{e}+013.30252 \mathrm{e}+013.30252 \mathrm{e}+00$ 1.00000e-09 7.00000e-02 $3.30252 \mathrm{e}+013.30252 \mathrm{e}+013.30252 \mathrm{e}+001.00000 \mathrm{e}-09$ 7.00000e-02 5.00000e-04 5.00000e-04 5.00000e-05 1.00000e-09 1.00000e-01 5.00000e-04 5.00000e-04 5.00000e-05 1.00000e-09 1.00000e-01

$1.31956 \mathrm{e}+001.31956 \mathrm{e}+001.31956 \mathrm{e}-01$ 1.00000e-09 2.12000e-01 $1.31956 \mathrm{e}+00$ 1.31956e+00 1.31956e-01 1.00000e-09 2.12000e-01 $1.31956 \mathrm{e}+001.31956 \mathrm{e}+00$ 1.31956e-01 1.00000e-09 2.12000e-01 $1.31956 \mathrm{e}+001.31956 \mathrm{e}+00$ 1.31956e-01 1.00000e-09 2.12000e-01 $1.31956 \mathrm{e}+001.31956 \mathrm{e}+001.31956 \mathrm{e}-01$ 1.00000e-09 2.12000e-01 1.00000e-02 1.00000e-02 1.00000e-03 1.00000e-09 1.00000e-01 Element: 3627 \# of layers: 9

$\mathrm{Kx} \mathrm{Ky} \mathrm{Kz}$ Ss Por

3.30252e+01 3.30252e+01 3.30252e+00 1.00000e-09 7.00000e-02 $3.30252 \mathrm{e}+013.30252 \mathrm{e}+013.30252 \mathrm{e}+001.00000 \mathrm{e}-09$ 7.00000e-02 5.00000e-04 5.00000e-04 5.00000e-05 1.00000e-09 1.00000e-01 5.00000e-04 5.00000e-04 5.00000e-05 1.00000e-09 1.00000e-01 $1.31956 \mathrm{e}+001.31956 \mathrm{e}+00$ 1.31956e-01 1.00000e-09 2.12000e-01 $1.31956 \mathrm{e}+001.31956 \mathrm{e}+00$ 1.31956e-01 1.00000e-09 2.12000e-01 $1.31956 \mathrm{e}+001.31956 \mathrm{e}+00$ 1.31956e-01 1.00000e-09 2.12000e-01 $1.31956 \mathrm{e}+001.31956 \mathrm{e}+00$ 1.31956e-01 1.00000e-09 2.12000e-01 $1.31956 \mathrm{e}+001.31956 \mathrm{e}+00$ 1.31956e-01 1.00000e-09 2.12000e-01 Element: 3628 \# of layers: 9

$\mathrm{Kx} \mathrm{Ky} \mathrm{Kz}$ Ss Por

3.30252e+01 3.30252e+01 3.30252e+00 1.00000e-09 7.00000e-02 $3.30252 \mathrm{e}+013.30252 \mathrm{e}+013.30252 \mathrm{e}+001.00000 \mathrm{e}-09$ 7.00000e-02 5.00000e-04 5.00000e-04 5.00000e-05 1.00000e-09 1.00000e-01 
5.00000e-04 5.00000e-04 5.00000e-05 1.00000e-09 1.00000e-01 $1.31956 \mathrm{e}+00$ 1.31956e+00 1.31956e-01 1.00000e-09 2.12000e-01 $1.31956 \mathrm{e}+001.31956 \mathrm{e}+00$ 1.31956e-01 1.00000e-09 2.12000e-01 $1.31956 \mathrm{e}+001.31956 \mathrm{e}+001.31956 \mathrm{e}-01$ 1.00000e-09 2.12000e-01 $1.31956 \mathrm{e}+00$ 1.31956e+00 1.31956e-01 1.00000e-09 2.12000e-01 $1.31956 \mathrm{e}+00$ 1.31956e+00 1.31956e-01 1.00000e-09 2.12000e-01 Element: 3629 \# of layers: 7

$\mathrm{Kx} \mathrm{Ky} \mathrm{Kz}$ Ss Por

$3.93710 \mathrm{e}+013.93710 \mathrm{e}+013.93710 \mathrm{e}+001.00000 \mathrm{e}-097.00000 \mathrm{e}-02$ 5.00000e-04 5.00000e-04 5.00000e-05 1.00000e-09 1.00000e-01

$1.57314 \mathrm{e}+001.57314 \mathrm{e}+001.57314 \mathrm{e}-011.00000 \mathrm{e}-092.12000 \mathrm{e}-01$ $1.57314 \mathrm{e}+001.57314 \mathrm{e}+001.57314 \mathrm{e}-011.00000 \mathrm{e}-092.12000 \mathrm{e}-01$ $1.57314 \mathrm{e}+001.57314 \mathrm{e}+001.57314 \mathrm{e}-011.00000 \mathrm{e}-092.12000 \mathrm{e}-01$ $1.57314 \mathrm{e}+001.57314 \mathrm{e}+001.57314 \mathrm{e}-011.00000 \mathrm{e}-092.12000 \mathrm{e}-01$ $1.57314 \mathrm{e}+001.57314 \mathrm{e}+001.57314 \mathrm{e}-01$ 1.00000e-09 2.12000e-01 Element: 3630 \# of layers: 7

$\mathrm{Kx} \mathrm{Ky} \mathrm{Kz}$ Ss Por

$3.93710 \mathrm{e}+013.93710 \mathrm{e}+013.93710 \mathrm{e}+001.00000 \mathrm{e}-09$ 7.00000e-02 5.00000e-04 5.00000e-04 5.00000e-05 1.00000e-09 1.00000e-01

$1.57314 \mathrm{e}+001.57314 \mathrm{e}+00 \quad 1.57314 \mathrm{e}-011.00000 \mathrm{e}-092.12000 \mathrm{e}-01$ $1.57314 \mathrm{e}+001.57314 \mathrm{e}+001.57314 \mathrm{e}-011.00000 \mathrm{e}-092.12000 \mathrm{e}-01$ $1.57314 \mathrm{e}+001.57314 \mathrm{e}+001.57314 \mathrm{e}-01$ 1.00000e-09 2.12000e-01 $1.57314 \mathrm{e}+001.57314 \mathrm{e}+001.57314 \mathrm{e}-01$ 1.00000e-09 2.12000e-01 $1.57314 \mathrm{e}+001.57314 \mathrm{e}+001.57314 \mathrm{e}-011.00000 \mathrm{e}-092.12000 \mathrm{e}-01$ Element: 3631 \# of layers: 7

$\mathrm{Kx} \mathrm{Ky} \mathrm{Kz}$ Ss Por

$3.93710 \mathrm{e}+013.93710 \mathrm{e}+013.93710 \mathrm{e}+001.00000 \mathrm{e}-09$ 7.00000e-02 5.00000e-04 5.00000e-04 5.00000e-05 1.00000e-09 1.00000e-01

$1.57314 \mathrm{e}+001.57314 \mathrm{e}+001.57314 \mathrm{e}-011.00000 \mathrm{e}-092.12000 \mathrm{e}-01$ $1.57314 \mathrm{e}+001.57314 \mathrm{e}+001.57314 \mathrm{e}-011.00000 \mathrm{e}-092.12000 \mathrm{e}-01$ $1.57314 \mathrm{e}+001.57314 \mathrm{e}+001.57314 \mathrm{e}-011.00000 \mathrm{e}-092.12000 \mathrm{e}-01$ $1.57314 \mathrm{e}+001.57314 \mathrm{e}+001.57314 \mathrm{e}-011.00000 \mathrm{e}-092.12000 \mathrm{e}-01$ $1.57314 \mathrm{e}+001.57314 \mathrm{e}+001.57314 \mathrm{e}-01$ 1.00000e-09 2.12000e-01 Element: 3635 \# of layers: 9

$\mathrm{Kx} \mathrm{Ky} \mathrm{Kz}$ Ss Por

3.93710e+01 3.93710e+01 3.93710e+00 1.00000e-09 7.00000e-02 $3.93710 \mathrm{e}+013.93710 \mathrm{e}+013.93710 \mathrm{e}+001.00000 \mathrm{e}-09$ 7.00000e-02 5.00000e-04 5.00000e-04 5.00000e-05 1.00000e-09 1.00000e-01 5.00000e-04 5.00000e-04 5.00000e-05 1.00000e-09 1.00000e-01 $1.57314 \mathrm{e}+001.57314 \mathrm{e}+001.57314 \mathrm{e}-011.00000 \mathrm{e}-092.12000 \mathrm{e}-01$ $1.57314 \mathrm{e}+001.57314 \mathrm{e}+001.57314 \mathrm{e}-011.00000 \mathrm{e}-092.12000 \mathrm{e}-01$ $1.57314 \mathrm{e}+001.57314 \mathrm{e}+001.57314 \mathrm{e}-011.00000 \mathrm{e}-092.12000 \mathrm{e}-01$ $1.57314 \mathrm{e}+001.57314 \mathrm{e}+001.57314 \mathrm{e}-01$ 1.00000e-09 2.12000e-01 $1.57314 \mathrm{e}+001.57314 \mathrm{e}+00$ 1.57314e-01 1.00000e-09 2.12000e-01 Element: 3636 \# of layers: 7

Kx Ky Kz Ss Por 
$3.93710 \mathrm{e}+013.93710 \mathrm{e}+013.93710 \mathrm{e}+001.00000 \mathrm{e}-09$ 7.00000e-02 5.00000e-04 5.00000e-04 5.00000e-05 1.00000e-09 1.00000e-01

$1.57314 \mathrm{e}+001.57314 \mathrm{e}+001.57314 \mathrm{e}-011.00000 \mathrm{e}-092.12000 \mathrm{e}-01$

$1.57314 \mathrm{e}+001.57314 \mathrm{e}+001.57314 \mathrm{e}-011.00000 \mathrm{e}-092.12000 \mathrm{e}-01$

$1.57314 \mathrm{e}+001.57314 \mathrm{e}+001.57314 \mathrm{e}-011.00000 \mathrm{e}-092.12000 \mathrm{e}-01$

$1.57314 \mathrm{e}+001.57314 \mathrm{e}+001.57314 \mathrm{e}-011.00000 \mathrm{e}-092.12000 \mathrm{e}-01$

$1.57314 \mathrm{e}+001.57314 \mathrm{e}+001.57314 \mathrm{e}-011.00000 \mathrm{e}-092.12000 \mathrm{e}-01$

Element: 3638 \# of layers: 9

$\mathrm{Kx} \mathrm{Ky} \mathrm{Kz}$ Ss Por

3.12683e+01 3.12683e+01 3.12683e+00 1.00000e-09 7.00000e-02

$3.12683 \mathrm{e}+013.12683 \mathrm{e}+013.12683 \mathrm{e}+00$ 1.00000e-09 7.00000e-02

5.00000e-04 5.00000e-04 5.00000e-05 1.00000e-09 1.00000e-01

5.00000e-04 5.00000e-04 5.00000e-05 1.00000e-09 1.00000e-01

$1.24936 \mathrm{e}+001.24936 \mathrm{e}+00$ 1.24936e-01 1.00000e-09 2.12000e-01

$1.24936 \mathrm{e}+001.24936 \mathrm{e}+00$ 1.24936e-01 1.00000e-09 2.12000e-01

$1.24936 \mathrm{e}+001.24936 \mathrm{e}+00$ 1.24936e-01 1.00000e-09 2.12000e-01

$1.24936 \mathrm{e}+001.24936 \mathrm{e}+001.24936 \mathrm{e}-01$ 1.00000e-09 2.12000e-01

$1.24936 \mathrm{e}+001.24936 \mathrm{e}+00$ 1.24936e-01 1.00000e-09 2.12000e-01

Element: 3639 \# of layers: 9

$\mathrm{Kx} \mathrm{Ky} \mathrm{Kz}$ Ss Por

$3.12683 e+013.12683 e+013.12683 e+001.00000 e-09$ 7.00000e-02

$3.12683 \mathrm{e}+013.12683 \mathrm{e}+013.12683 \mathrm{e}+00$ 1.00000e-09 7.00000e-02

5.00000e-04 5.00000e-04 5.00000e-05 1.00000e-09 1.00000e-01

5.00000e-04 5.00000e-04 5.00000e-05 1.00000e-09 1.00000e-01

$1.24936 \mathrm{e}+001.24936 \mathrm{e}+00$ 1.24936e-01 1.00000e-09 2.12000e-01

$1.24936 \mathrm{e}+001.24936 \mathrm{e}+00$ 1.24936e-01 1.00000e-09 2.12000e-01

$1.24936 \mathrm{e}+001.24936 \mathrm{e}+00$ 1.24936e-01 1.00000e-09 2.12000e-01

$1.24936 \mathrm{e}+001.24936 \mathrm{e}+00$ 1.24936e-01 1.00000e-09 2.12000e-01

$1.24936 \mathrm{e}+001.24936 \mathrm{e}+00$ 1.24936e-01 1.00000e-09 2.12000e-01

Element: 3640 \# of layers: 10

$\mathrm{Kx} \mathrm{Ky} \mathrm{Kz}$ Ss Por

3.12683e+01 3.12683e+01 3.12683e+00 1.00000e-09 7.00000e-02

$3.12683 \mathrm{e}+013.12683 \mathrm{e}+013.12683 \mathrm{e}+00$ 1.00000e-09 7.00000e-02

$3.12683 \mathrm{e}+013.12683 \mathrm{e}+013.12683 \mathrm{e}+001.00000 \mathrm{e}-09$ 7.00000e-02

5.00000e-04 5.00000e-04 5.00000e-05 1.00000e-09 1.00000e-01

5.00000e-04 5.00000e-04 5.00000e-05 1.00000e-09 1.00000e-01

$1.24936 \mathrm{e}+001.24936 \mathrm{e}+001.24936 \mathrm{e}-011.00000 \mathrm{e}-092.12000 \mathrm{e}-01$

$1.24936 \mathrm{e}+001.24936 \mathrm{e}+001.24936 \mathrm{e}-01$ 1.00000e-09 2.12000e-01

$1.24936 \mathrm{e}+001.24936 \mathrm{e}+001.24936 \mathrm{e}-011.00000 \mathrm{e}-092.12000 \mathrm{e}-01$

$1.24936 \mathrm{e}+001.24936 \mathrm{e}+00$ 1.24936e-01 1.00000e-09 2.12000e-01

$1.24936 \mathrm{e}+00$ 1.24936e+00 1.24936e-01 1.00000e-09 2.12000e-01

Element: 3641 \# of layers: 9

$\mathrm{Kx} \mathrm{Ky} \mathrm{Kz}$ Ss Por

3.61130e+01 3.61130e+01 3.61130e+00 1.00000e-09 7.00000e-02

$3.61130 \mathrm{e}+013.61130 \mathrm{e}+013.61130 \mathrm{e}+001.00000 \mathrm{e}-097.00000 \mathrm{e}-02$

5.00000e-04 5.00000e-04 5.00000e-05 1.00000e-09 1.00000e-01 
5.00000e-04 5.00000e-04 5.00000e-05 1.00000e-09 1.00000e-01 $1.44296 \mathrm{e}+001.44296 \mathrm{e}+00$ 1.44296e-01 1.00000e-09 2.12000e-01 $1.44296 \mathrm{e}+001.44296 \mathrm{e}+00$ 1.44296e-01 1.00000e-09 2.12000e-01 $1.44296 \mathrm{e}+001.44296 \mathrm{e}+001.44296 \mathrm{e}-01$ 1.00000e-09 2.12000e-01 $1.44296 \mathrm{e}+001.44296 \mathrm{e}+001.44296 \mathrm{e}-01$ 1.00000e-09 2.12000e-01 $1.44296 \mathrm{e}+001.44296 \mathrm{e}+00$ 1.44296e-01 1.00000e-09 2.12000e-01 Element: 3642 \# of layers: 9

Kx Ky Kz Ss Por

$3.61130 \mathrm{e}+013.61130 \mathrm{e}+013.61130 \mathrm{e}+001.00000 \mathrm{e}-09$ 7.00000e-02 $3.61130 \mathrm{e}+013.61130 \mathrm{e}+013.61130 \mathrm{e}+001.00000 \mathrm{e}-097.00000 \mathrm{e}-02$ 5.00000e-04 5.00000e-04 5.00000e-05 1.00000e-09 1.00000e-01 5.00000e-04 5.00000e-04 5.00000e-05 1.00000e-09 1.00000e-01 $1.44296 \mathrm{e}+001.44296 \mathrm{e}+001.44296 \mathrm{e}-01$ 1.00000e-09 2.12000e-01 $1.44296 \mathrm{e}+001.44296 \mathrm{e}+00$ 1.44296e-01 1.00000e-09 2.12000e-01 $1.44296 \mathrm{e}+001.44296 \mathrm{e}+00$ 1.44296e-01 1.00000e-09 2.12000e-01 $1.44296 \mathrm{e}+001.44296 \mathrm{e}+001.44296 \mathrm{e}-01$ 1.00000e-09 2.12000e-01 $1.44296 \mathrm{e}+001.44296 \mathrm{e}+00$ 1.44296e-01 1.00000e-09 2.12000e-01 Element: 3643 \# of layers: 9

$\mathrm{Kx} \mathrm{Ky} \mathrm{Kz}$ Ss Por

3.61130e+01 3.61130e+01 3.61130e+00 1.00000e-09 7.00000e-02 $3.61130 \mathrm{e}+013.61130 \mathrm{e}+013.61130 \mathrm{e}+001.00000 \mathrm{e}-09$ 7.00000e-02 $5.00000 \mathrm{e}-04$ 5.00000e-04 5.00000e-05 1.00000e-09 1.00000e-01 5.00000e-04 5.00000e-04 5.00000e-05 1.00000e-09 1.00000e-01 $1.44296 \mathrm{e}+001.44296 \mathrm{e}+001.44296 \mathrm{e}-01$ 1.00000e-09 2.12000e-01 $1.44296 \mathrm{e}+001.44296 \mathrm{e}+001.44296 \mathrm{e}-01$ 1.00000e-09 2.12000e-01 $1.44296 \mathrm{e}+001.44296 \mathrm{e}+00$ 1.44296e-01 1.00000e-09 2.12000e-01 $1.44296 \mathrm{e}+001.44296 \mathrm{e}+00$ 1.44296e-01 1.00000e-09 2.12000e-01 $1.44296 \mathrm{e}+001.44296 \mathrm{e}+00$ 1.44296e-01 1.00000e-09 2.12000e-01 Element: 3644 \# of layers: 7

$\mathrm{Kx} \mathrm{Ky} \mathrm{Kz}$ Ss Por

$1.99174 \mathrm{e}+01$ 1.99174e+01 1.99174e+00 1.00000e-09 2.12000e-01 $1.99174 \mathrm{e}+011.99174 \mathrm{e}+011.99174 \mathrm{e}+001.00000 \mathrm{e}-092.12000 \mathrm{e}-01$ $1.99174 \mathrm{e}+011.99174 \mathrm{e}+011.99174 \mathrm{e}+001.00000 \mathrm{e}-092.12000 \mathrm{e}-01$ $1.99174 \mathrm{e}+011.99174 \mathrm{e}+011.99174 \mathrm{e}+001.00000 \mathrm{e}-092.12000 \mathrm{e}-01$ $1.99174 \mathrm{e}+011.99174 \mathrm{e}+011.99174 \mathrm{e}+001.00000 \mathrm{e}-092.12000 \mathrm{e}-01$ 1.00000e-05 1.00000e-05 1.00000e-06 1.00000e-09 1.00000e-01 $1.00000 \mathrm{e}+001.00000 \mathrm{e}+001.00000 \mathrm{e}-011.00000 \mathrm{e}-091.00000 \mathrm{e}-01$ Element: 3645 \# of layers: 7

$\mathrm{Kx} \mathrm{Ky} \mathrm{Kz}$ Ss Por

$1.99174 \mathrm{e}+011.99174 \mathrm{e}+011.99174 \mathrm{e}+001.00000 \mathrm{e}-092.12000 \mathrm{e}-01$ $1.99174 \mathrm{e}+011.99174 \mathrm{e}+011.99174 \mathrm{e}+001.00000 \mathrm{e}-092.12000 \mathrm{e}-01$ $1.99174 \mathrm{e}+011.99174 \mathrm{e}+011.99174 \mathrm{e}+001.00000 \mathrm{e}-092.12000 \mathrm{e}-01$ $1.99174 \mathrm{e}+011.99174 \mathrm{e}+011.99174 \mathrm{e}+001.00000 \mathrm{e}-092.12000 \mathrm{e}-01$ $1.99174 \mathrm{e}+01$ 1.99174e+01 1.99174e+00 1.00000e-09 2.12000e-01 $1.00000 \mathrm{e}-05$ 1.00000e-05 1.00000e-06 1.00000e-09 1.00000e-01 $1.00000 \mathrm{e}+001.00000 \mathrm{e}+001.00000 \mathrm{e}-011.00000 \mathrm{e}-091.00000 \mathrm{e}-01$ 
Element: 3646 \# of layers: 7

$\mathrm{Kx} \mathrm{Ky} \mathrm{Kz}$ Ss Por

$1.98938 \mathrm{e}+01$ 1.98938e+01 1.98938e+00 1.00000e-09 2.12000e-01

$1.98938 \mathrm{e}+011.98938 \mathrm{e}+01$ 1.98938e+00 1.00000e-09 2.12000e-01

$1.98938 \mathrm{e}+01$ 1.98938e+01 1.98938e+00 1.00000e-09 2.12000e-01

$1.98938 \mathrm{e}+01$ 1.98938e+01 1.98938e+00 1.00000e-09 2.12000e-01

$1.98938 \mathrm{e}+01$ 1.98938e+01 1.98938e+00 1.00000e-09 2.12000e-01

$1.00000 \mathrm{e}-05$ 1.00000e-05 1.00000e-06 1.00000e-09 1.00000e-01

$1.00000 \mathrm{e}+001.00000 \mathrm{e}+001.00000 \mathrm{e}-011.00000 \mathrm{e}-091.00000 \mathrm{e}-01$

Element: 3647 \# of layers: 7

$\mathrm{Kx} \mathrm{Ky} \mathrm{Kz}$ Ss Por

$1.98938 \mathrm{e}+01$ 1.98938e+01 1.98938e+00 1.00000e-09 2.12000e-01

$1.98938 \mathrm{e}+01$ 1.98938e+01 1.98938e+00 1.00000e-09 2.12000e-01

$1.98938 \mathrm{e}+01$ 1.98938e+01 1.98938e+00 1.00000e-09 2.12000e-01

$1.98938 \mathrm{e}+01$ 1.98938e+01 1.98938e+00 1.00000e-09 2.12000e-01

$1.98938 \mathrm{e}+01$ 1.98938e+01 1.98938e+00 1.00000e-09 2.12000e-01

$1.00000 \mathrm{e}-05$ 1.00000e-05 1.00000e-06 1.00000e-09 1.00000e-01

$1.00000 \mathrm{e}+001.00000 \mathrm{e}+001.00000 \mathrm{e}-011.00000 \mathrm{e}-091.00000 \mathrm{e}-01$

Element: 3648 \# of layers: 7

$\mathrm{Kx} \mathrm{Ky} \mathrm{Kz}$ Ss Por

$1.94175 \mathrm{e}+01$ 1.94175e+01 1.94175e+00 1.00000e-09 2.12000e-01

$1.94175 \mathrm{e}+01$ 1.94175e+01 1.94175e+00 1.00000e-09 2.12000e-01

$1.94175 \mathrm{e}+01$ 1.94175e+01 1.94175e+00 1.00000e-09 2.12000e-01

$1.94175 \mathrm{e}+011.94175 \mathrm{e}+01$ 1.94175e+00 1.00000e-09 2.12000e-01

$1.94175 \mathrm{e}+011.94175 \mathrm{e}+011.94175 \mathrm{e}+001.00000 \mathrm{e}-092.12000 \mathrm{e}-01$

$1.00000 \mathrm{e}-05$ 1.00000e-05 1.00000e-06 1.00000e-09 1.00000e-01

$1.00000 \mathrm{e}+001.00000 \mathrm{e}+001.00000 \mathrm{e}-011.00000 \mathrm{e}-091.00000 \mathrm{e}-01$

Element: 3649 \# of layers: 7

$\mathrm{Kx} \mathrm{Ky} \mathrm{Kz}$ Ss Por

$2.01816 \mathrm{e}+012.01816 \mathrm{e}+012.01816 \mathrm{e}+001.00000 \mathrm{e}-092.12000 \mathrm{e}-01$

$2.01816 \mathrm{e}+012.01816 \mathrm{e}+012.01816 \mathrm{e}+001.00000 \mathrm{e}-092.12000 \mathrm{e}-01$

$2.01816 \mathrm{e}+012.01816 \mathrm{e}+012.01816 \mathrm{e}+001.00000 \mathrm{e}-092.12000 \mathrm{e}-01$

$2.01816 \mathrm{e}+012.01816 \mathrm{e}+012.01816 \mathrm{e}+001.00000 \mathrm{e}-092.12000 \mathrm{e}-01$

$2.01816 \mathrm{e}+012.01816 \mathrm{e}+012.01816 \mathrm{e}+001.00000 \mathrm{e}-092.12000 \mathrm{e}-01$

$1.00000 \mathrm{e}-05$ 1.00000e-05 1.00000e-06 1.00000e-09 1.00000e-01

$1.00000 \mathrm{e}+001.00000 \mathrm{e}+001.00000 \mathrm{e}-011.00000 \mathrm{e}-091.00000 \mathrm{e}-01$

Element: 3650 \# of layers: 7

$\mathrm{Kx} \mathrm{Ky} \mathrm{Kz}$ Ss Por

$2.02756 \mathrm{e}+012.02756 \mathrm{e}+012.02756 \mathrm{e}+00$ 1.00000e-09 2.12000e-01

$2.02756 \mathrm{e}+012.02756 \mathrm{e}+012.02756 \mathrm{e}+001.00000 \mathrm{e}-092.12000 \mathrm{e}-01$

$2.02756 \mathrm{e}+012.02756 \mathrm{e}+012.02756 \mathrm{e}+001.00000 \mathrm{e}-092.12000 \mathrm{e}-01$

$2.02756 \mathrm{e}+012.02756 \mathrm{e}+012.02756 \mathrm{e}+001.00000 \mathrm{e}-092.12000 \mathrm{e}-01$

$2.02756 \mathrm{e}+012.02756 \mathrm{e}+012.02756 \mathrm{e}+001.00000 \mathrm{e}-092.12000 \mathrm{e}-01$

$1.00000 \mathrm{e}-05$ 1.00000e-05 1.00000e-06 1.00000e-09 1.00000e-01

$1.00000 \mathrm{e}+001.00000 \mathrm{e}+001.00000 \mathrm{e}-011.00000 \mathrm{e}-09$ 1.00000e-01

Element: 3651 \# of layers: 7 
$\mathrm{Kx} \mathrm{Ky} \mathrm{Kz}$ Ss Por

$2.02756 \mathrm{e}+012.02756 \mathrm{e}+012.02756 \mathrm{e}+00$ 1.00000e-09 2.12000e-01

$2.02756 \mathrm{e}+012.02756 \mathrm{e}+012.02756 \mathrm{e}+001.00000 \mathrm{e}-092.12000 \mathrm{e}-01$

$2.02756 \mathrm{e}+012.02756 \mathrm{e}+012.02756 \mathrm{e}+001.00000 \mathrm{e}-092.12000 \mathrm{e}-01$

$2.02756 \mathrm{e}+012.02756 \mathrm{e}+012.02756 \mathrm{e}+001.00000 \mathrm{e}-092.12000 \mathrm{e}-01$

$2.02756 \mathrm{e}+012.02756 \mathrm{e}+012.02756 \mathrm{e}+001.00000 \mathrm{e}-092.12000 \mathrm{e}-01$

$1.00000 \mathrm{e}-05$ 1.00000e-05 1.00000e-06 1.00000e-09 1.00000e-01

$1.00000 \mathrm{e}+001.00000 \mathrm{e}+001.00000 \mathrm{e}-01$ 1.00000e-09 1.00000e-01

Element: 3652 \# of layers: 7

$\mathrm{Kx} \mathrm{Ky} \mathrm{Kz}$ Ss Por

$2.03233 \mathrm{e}+012.03233 \mathrm{e}+012.03233 \mathrm{e}+00$ 1.00000e-09 2.12000e-01 $2.03233 \mathrm{e}+012.03233 \mathrm{e}+012.03233 \mathrm{e}+00$ 1.00000e-09 2.12000e-01 $2.03233 \mathrm{e}+012.03233 \mathrm{e}+012.03233 \mathrm{e}+00$ 1.00000e-09 2.12000e-01 $2.03233 \mathrm{e}+012.03233 \mathrm{e}+012.03233 \mathrm{e}+001.00000 \mathrm{e}-092.12000 \mathrm{e}-01$ $2.03233 \mathrm{e}+012.03233 \mathrm{e}+012.03233 \mathrm{e}+001.00000 \mathrm{e}-092.12000 \mathrm{e}-01$ $1.00000 \mathrm{e}-05$ 1.00000e-05 1.00000e-06 1.00000e-09 1.00000e-01 $1.00000 \mathrm{e}+001.00000 \mathrm{e}+001.00000 \mathrm{e}-01$ 1.00000e-09 1.00000e-01 Element: 3653 \# of layers: 7

$\mathrm{Kx} \mathrm{Ky} \mathrm{Kz}$ Ss Por

$2.01816 \mathrm{e}+012.01816 \mathrm{e}+012.01816 \mathrm{e}+00$ 1.00000e-09 2.12000e-01 $2.01816 \mathrm{e}+012.01816 \mathrm{e}+012.01816 \mathrm{e}+001.00000 \mathrm{e}-092.12000 \mathrm{e}-01$ $2.01816 \mathrm{e}+012.01816 \mathrm{e}+012.01816 \mathrm{e}+001.00000 \mathrm{e}-092.12000 \mathrm{e}-01$ $2.01816 \mathrm{e}+012.01816 \mathrm{e}+012.01816 \mathrm{e}+001.00000 \mathrm{e}-092.12000 \mathrm{e}-01$ $2.01816 \mathrm{e}+012.01816 \mathrm{e}+012.01816 \mathrm{e}+001.00000 \mathrm{e}-092.12000 \mathrm{e}-01$ $1.00000 \mathrm{e}-05$ 1.00000e-05 1.00000e-06 1.00000e-09 1.00000e-01 $1.00000 \mathrm{e}+001.00000 \mathrm{e}+001.00000 \mathrm{e}-01$ 1.00000e-09 1.00000e-01 Element: 3654 \# of layers: 7

$\mathrm{Kx} \mathrm{Ky} \mathrm{Kz} \mathrm{Ss} \mathrm{Por}$

$2.02756 \mathrm{e}+012.02756 \mathrm{e}+012.02756 \mathrm{e}+001.00000 \mathrm{e}-092.12000 \mathrm{e}-01$ $2.02756 \mathrm{e}+012.02756 \mathrm{e}+012.02756 \mathrm{e}+001.00000 \mathrm{e}-092.12000 \mathrm{e}-01$ $2.02756 \mathrm{e}+012.02756 \mathrm{e}+012.02756 \mathrm{e}+001.00000 \mathrm{e}-092.12000 \mathrm{e}-01$ $2.02756 \mathrm{e}+012.02756 \mathrm{e}+012.02756 \mathrm{e}+001.00000 \mathrm{e}-092.12000 \mathrm{e}-01$ $2.02756 \mathrm{e}+012.02756 \mathrm{e}+012.02756 \mathrm{e}+001.00000 \mathrm{e}-092.12000 \mathrm{e}-01$ $1.00000 \mathrm{e}-05$ 1.00000e-05 1.00000e-06 1.00000e-09 1.00000e-01 $1.00000 \mathrm{e}+001.00000 \mathrm{e}+001.00000 \mathrm{e}-011.00000 \mathrm{e}-09$ 1.00000e-01 Element: 3655 \# of layers: 9

Kx Ky Kz Ss Por

7.45868e+02 7.45868e+02 7.45868e+01 1.00000e-09 2.12000e-01 $7.45868 \mathrm{e}+02$ 7.45868e+02 7.45868e+01 1.00000e-09 2.12000e-01 $7.45868 \mathrm{e}+02$ 7.45868e+02 7.45868e+01 1.00000e-09 2.12000e-01 $7.45868 \mathrm{e}+02$ 7.45868e+02 7.45868e+01 1.00000e-09 2.12000e-01 $7.45868 \mathrm{e}+02$ 7.45868e+02 7.45868e+01 1.00000e-09 2.12000e-01 $1.00000 \mathrm{e}-02$ 1.00000e-02 1.00000e-03 1.00000e-09 1.00000e-01 $1.00000 \mathrm{e}+001.00000 \mathrm{e}+001.00000 \mathrm{e}-011.00000 \mathrm{e}-091.00000 \mathrm{e}-01$ $1.00000 \mathrm{e}-05$ 1.00000e-05 1.00000e-06 1.00000e-09 1.00000e-01 $1.00000 \mathrm{e}+001.00000 \mathrm{e}+001.00000 \mathrm{e}-011.00000 \mathrm{e}-091.00000 \mathrm{e}-01$ 
Element: 3656 \# of layers: 9

$\mathrm{Kx} \mathrm{Ky} \mathrm{Kz}$ Ss Por

$1.85710 \mathrm{e}+031.85710 \mathrm{e}+03$ 1.85710e+02 1.00000e-09 2.12000e-01

$1.85710 \mathrm{e}+031.85710 \mathrm{e}+03$ 1.85710e+02 1.00000e-09 2.12000e-01

$1.85710 \mathrm{e}+031.85710 \mathrm{e}+031.85710 \mathrm{e}+02$ 1.00000e-09 2.12000e-01

$1.85710 \mathrm{e}+031.85710 \mathrm{e}+03$ 1.85710e+02 1.00000e-09 2.12000e-01

$1.85710 \mathrm{e}+031.85710 \mathrm{e}+031.85710 \mathrm{e}+021.00000 \mathrm{e}-092.12000 \mathrm{e}-01$

$1.00000 \mathrm{e}-02$ 1.00000e-02 1.00000e-03 1.00000e-09 1.00000e-01

$1.00000 \mathrm{e}+001.00000 \mathrm{e}+001.00000 \mathrm{e}-011.00000 \mathrm{e}-091.00000 \mathrm{e}-01$

$1.00000 \mathrm{e}-05$ 1.00000e-05 1.00000e-06 1.00000e-09 1.00000e-01

$1.00000 \mathrm{e}+001.00000 \mathrm{e}+001.00000 \mathrm{e}-011.00000 \mathrm{e}-091.00000 \mathrm{e}-01$

Element: 3657 \# of layers: 9

$\mathrm{Kx} \mathrm{Ky} \mathrm{Kz}$ Ss Por

$1.85710 \mathrm{e}+03$ 1.85710e+03 1.85710e+02 1.00000e-09 2.12000e-01

$1.85710 \mathrm{e}+031.85710 \mathrm{e}+031.85710 \mathrm{e}+021.00000 \mathrm{e}-092.12000 \mathrm{e}-01$

$1.85710 \mathrm{e}+031.85710 \mathrm{e}+031.85710 \mathrm{e}+021.00000 \mathrm{e}-092.12000 \mathrm{e}-01$

$1.85710 \mathrm{e}+031.85710 \mathrm{e}+03$ 1.85710e+02 1.00000e-09 2.12000e-01

$1.85710 \mathrm{e}+031.85710 \mathrm{e}+031.85710 \mathrm{e}+02$ 1.00000e-09 2.12000e-01

$1.00000 \mathrm{e}-02$ 1.00000e-02 1.00000e-03 1.00000e-09 1.00000e-01

$1.00000 \mathrm{e}+001.00000 \mathrm{e}+001.00000 \mathrm{e}-011.00000 \mathrm{e}-091.00000 \mathrm{e}-01$

$1.00000 \mathrm{e}-05$ 1.00000e-05 1.00000e-06 1.00000e-09 1.00000e-01

$1.00000 \mathrm{e}+001.00000 \mathrm{e}+001.00000 \mathrm{e}-01$ 1.00000e-09 1.00000e-01

Element: 3658 \# of layers: 8

Kx Ky Kz Ss Por

$1.85710 \mathrm{e}+03$ 1.85710e+03 1.85710e+02 1.00000e-09 2.12000e-01

$1.85710 \mathrm{e}+031.85710 \mathrm{e}+03$ 1.85710e+02 1.00000e-09 2.12000e-01

$1.85710 \mathrm{e}+031.85710 \mathrm{e}+031.85710 \mathrm{e}+021.00000 \mathrm{e}-092.12000 \mathrm{e}-01$

$1.85710 \mathrm{e}+031.85710 \mathrm{e}+031.85710 \mathrm{e}+021.00000 \mathrm{e}-092.12000 \mathrm{e}-01$

$1.00000 \mathrm{e}-02$ 1.00000e-02 1.00000e-03 1.00000e-09 1.00000e-01

$1.00000 \mathrm{e}+001.00000 \mathrm{e}+001.00000 \mathrm{e}-011.00000 \mathrm{e}-091.00000 \mathrm{e}-01$

$1.00000 \mathrm{e}-051.00000 \mathrm{e}-051.00000 \mathrm{e}-061.00000 \mathrm{e}-091.00000 \mathrm{e}-01$

$1.00000 \mathrm{e}+001.00000 \mathrm{e}+001.00000 \mathrm{e}-011.00000 \mathrm{e}-091.00000 \mathrm{e}-01$

Element: 3659 \# of layers: 8

$\mathrm{Kx} \mathrm{Ky} \mathrm{Kz} \mathrm{Ss} \mathrm{Por}$

$1.73224 \mathrm{e}+03$ 1.73224e+03 1.73224e+02 1.00000e-09 2.12000e-01

$1.73224 \mathrm{e}+031.73224 \mathrm{e}+03 \quad 1.73224 \mathrm{e}+02$ 1.00000e-09 2.12000e-01

$1.73224 \mathrm{e}+031.73224 \mathrm{e}+031.73224 \mathrm{e}+02$ 1.00000e-09 2.12000e-01

$1.73224 \mathrm{e}+031.73224 \mathrm{e}+031.73224 \mathrm{e}+02$ 1.00000e-09 2.12000e-01

$1.00000 \mathrm{e}-02$ 1.00000e-02 1.00000e-03 1.00000e-09 1.00000e-01

$1.00000 \mathrm{e}+001.00000 \mathrm{e}+001.00000 \mathrm{e}-011.00000 \mathrm{e}-091.00000 \mathrm{e}-01$

$1.00000 \mathrm{e}-05$ 1.00000e-05 1.00000e-06 1.00000e-09 1.00000e-01

$1.00000 \mathrm{e}+001.00000 \mathrm{e}+001.00000 \mathrm{e}-011.00000 \mathrm{e}-091.00000 \mathrm{e}-01$

Element: 3660 \# of layers: 9

$\mathrm{Kx} \mathrm{Ky} \mathrm{Kz}$ Ss Por

$1.73224 \mathrm{e}+03$ 1.73224e+03 1.73224e+02 1.00000e-09 2.12000e-01

$1.73224 \mathrm{e}+031.73224 \mathrm{e}+03 \quad 1.73224 \mathrm{e}+02$ 1.00000e-09 2.12000e-01 
$1.73224 \mathrm{e}+03$ 1.73224e+03 1.73224e+02 1.00000e-09 2.12000e-01 $1.73224 \mathrm{e}+031.73224 \mathrm{e}+031.73224 \mathrm{e}+02$ 1.00000e-09 2.12000e-01 $1.73224 \mathrm{e}+03$ 1.73224e+03 1.73224e+02 1.00000e-09 2.12000e-01 $1.00000 \mathrm{e}-02$ 1.00000e-02 1.00000e-03 1.00000e-09 1.00000e-01 $1.00000 \mathrm{e}+001.00000 \mathrm{e}+001.00000 \mathrm{e}-011.00000 \mathrm{e}-091.00000 \mathrm{e}-01$ $1.00000 \mathrm{e}-05$ 1.00000e-05 1.00000e-06 1.00000e-09 1.00000e-01 $1.00000 \mathrm{e}+001.00000 \mathrm{e}+001.00000 \mathrm{e}-01$ 1.00000e-09 1.00000e-01 Element: 3661 \# of layers: 8

$\mathrm{Kx} \mathrm{Ky} \mathrm{Kz}$ Ss Por

5.64154e+02 5.64154e+02 5.64154e+01 1.00000e-09 2.12000e-01 $5.64154 \mathrm{e}+025.64154 \mathrm{e}+02$ 5.64154e+01 1.00000e-09 2.12000e-01 $5.64154 \mathrm{e}+025.64154 \mathrm{e}+025.64154 \mathrm{e}+01$ 1.00000e-09 2.12000e-01 $5.64154 \mathrm{e}+02$ 5.64154e+02 5.64154e+01 1.00000e-09 2.12000e-01 $1.00000 \mathrm{e}-02$ 1.00000e-02 1.00000e-03 1.00000e-09 1.00000e-01 $1.00000 \mathrm{e}+001.00000 \mathrm{e}+001.00000 \mathrm{e}-011.00000 \mathrm{e}-091.00000 \mathrm{e}-01$ $1.00000 \mathrm{e}-05$ 1.00000e-05 1.00000e-06 1.00000e-09 1.00000e-01 $1.00000 \mathrm{e}+001.00000 \mathrm{e}+001.00000 \mathrm{e}-011.00000 \mathrm{e}-09$ 1.00000e-01 Element: 3662 \# of layers: 8

$\mathrm{Kx} \mathrm{Ky} \mathrm{Kz}$ Ss Por

7.45868e+02 7.45868e+02 7.45868e+01 1.00000e-09 2.12000e-01 $7.45868 \mathrm{e}+02$ 7.45868e+02 7.45868e+01 1.00000e-09 2.12000e-01 $7.45868 \mathrm{e}+02$ 7.45868e+02 7.45868e+01 1.00000e-09 2.12000e-01 $7.45868 \mathrm{e}+02$ 7.45868e+02 7.45868e+01 1.00000e-09 2.12000e-01 $1.00000 \mathrm{e}-021.00000 \mathrm{e}-021.00000 \mathrm{e}-031.00000 \mathrm{e}-091.00000 \mathrm{e}-01$ $1.00000 \mathrm{e}+001.00000 \mathrm{e}+001.00000 \mathrm{e}-011.00000 \mathrm{e}-091.00000 \mathrm{e}-01$ $1.00000 \mathrm{e}-05$ 1.00000e-05 1.00000e-06 1.00000e-09 1.00000e-01 $1.00000 \mathrm{e}+001.00000 \mathrm{e}+001.00000 \mathrm{e}-011.00000 \mathrm{e}-091.00000 \mathrm{e}-01$ Element: 3663 \# of layers: 9

Kx Ky Kz Ss Por

$1.85710 \mathrm{e}+031.85710 \mathrm{e}+03$ 1.85710e+02 1.00000e-09 2.12000e-01 $1.85710 \mathrm{e}+031.85710 \mathrm{e}+031.85710 \mathrm{e}+021.00000 \mathrm{e}-092.12000 \mathrm{e}-01$ $1.85710 \mathrm{e}+031.85710 \mathrm{e}+03 \quad 1.85710 \mathrm{e}+02$ 1.00000e-09 2.12000e-01 $1.85710 \mathrm{e}+031.85710 \mathrm{e}+03 \quad 1.85710 \mathrm{e}+02$ 1.00000e-09 2.12000e-01 $1.85710 \mathrm{e}+031.85710 \mathrm{e}+031.85710 \mathrm{e}+02$ 1.00000e-09 2.12000e-01 $1.00000 \mathrm{e}-02$ 1.00000e-02 1.00000e-03 1.00000e-09 1.00000e-01 $1.00000 \mathrm{e}+001.00000 \mathrm{e}+001.00000 \mathrm{e}-011.00000 \mathrm{e}-091.00000 \mathrm{e}-01$ $1.00000 \mathrm{e}-05$ 1.00000e-05 1.00000e-06 1.00000e-09 1.00000e-01 $1.00000 \mathrm{e}+001.00000 \mathrm{e}+001.00000 \mathrm{e}-011.00000 \mathrm{e}-091.00000 \mathrm{e}-01$ Element: 3664 \# of layers: 9

$\mathrm{Kx} \mathrm{Ky} \mathrm{Kz}$ Ss Por $1.80524 \mathrm{e}+031.80524 \mathrm{e}+03$ 1.80524e+02 1.00000e-09 2.12000e-01 $1.80524 \mathrm{e}+031.80524 \mathrm{e}+031.80524 \mathrm{e}+021.00000 \mathrm{e}-092.12000 \mathrm{e}-01$ $1.80524 \mathrm{e}+031.80524 \mathrm{e}+031.80524 \mathrm{e}+02$ 1.00000e-09 2.12000e-01 $1.80524 \mathrm{e}+031.80524 \mathrm{e}+031.80524 \mathrm{e}+02$ 1.00000e-09 2.12000e-01 $1.80524 \mathrm{e}+031.80524 \mathrm{e}+031.80524 \mathrm{e}+021.00000 \mathrm{e}-092.12000 \mathrm{e}-01$ $1.00000 \mathrm{e}-02$ 1.00000e-02 1.00000e-03 1.00000e-09 1.00000e-01 
$1.00000 \mathrm{e}+001.00000 \mathrm{e}+001.00000 \mathrm{e}-011.00000 \mathrm{e}-091.00000 \mathrm{e}-01$ $1.00000 \mathrm{e}-05$ 1.00000e-05 1.00000e-06 1.00000e-09 1.00000e-01 $1.00000 \mathrm{e}+001.00000 \mathrm{e}+001.00000 \mathrm{e}-011.00000 \mathrm{e}-09$ 1.00000e-01 Element: 3665 \# of layers: 9

$\mathrm{Kx} \mathrm{Ky} \mathrm{Kz}$ Ss Por

8.11637e+02 8.11637e+02 8.11637e+01 1.00000e-09 2.12000e-01 8.11637e+02 8.11637e+02 8.11637e+01 1.00000e-09 2.12000e-01 8.11637e+02 8.11637e+02 8.11637e+01 1.00000e-09 2.12000e-01 8.11637e+02 8.11637e+02 8.11637e+01 1.00000e-09 2.12000e-01 8.11637e+02 8.11637e+02 8.11637e+01 1.00000e-09 2.12000e-01 $1.00000 \mathrm{e}-02$ 1.00000e-02 1.00000e-03 1.00000e-09 1.00000e-01 $1.00000 \mathrm{e}+001.00000 \mathrm{e}+001.00000 \mathrm{e}-011.00000 \mathrm{e}-091.00000 \mathrm{e}-01$ 1.00000e-05 1.00000e-05 1.00000e-06 1.00000e-09 1.00000e-01 $1.00000 \mathrm{e}+001.00000 \mathrm{e}+001.00000 \mathrm{e}-01$ 1.00000e-09 1.00000e-01 Element: 3666 \# of layers: 10

Kx Ky Kz Ss Por

$2.03130 \mathrm{e}+042.03130 \mathrm{e}+042.03130 \mathrm{e}+03$ 1.00000e-09 7.00000e-02 8.11637e+02 8.11637e+02 8.11637e+01 1.00000e-09 2.12000e-01 8.11637e+02 8.11637e+02 8.11637e+01 1.00000e-09 2.12000e-01 8.11637e+02 8.11637e+02 8.11637e+01 1.00000e-09 2.12000e-01 8.11637e+02 8.11637e+02 8.11637e+01 1.00000e-09 2.12000e-01 8.11637e+02 8.11637e+02 8.11637e+01 1.00000e-09 2.12000e-01 $1.00000 \mathrm{e}-02$ 1.00000e-02 1.00000e-03 1.00000e-09 1.00000e-01 $1.00000 \mathrm{e}+001.00000 \mathrm{e}+001.00000 \mathrm{e}-011.00000 \mathrm{e}-091.00000 \mathrm{e}-01$ $1.00000 \mathrm{e}-05$ 1.00000e-05 1.00000e-06 1.00000e-09 1.00000e-01 $1.00000 \mathrm{e}+001.00000 \mathrm{e}+001.00000 \mathrm{e}-01$ 1.00000e-09 1.00000e-01 Element: 3667 \# of layers: 9

$\mathrm{Kx} \mathrm{Ky} \mathrm{Kz}$ Ss Por

2.03130e+04 2.03130e+04 2.03130e+03 1.00000e-09 7.00000e-02 8.11637e+02 8.11637e+02 8.11637e+01 1.00000e-09 2.12000e-01 8.11637e+02 8.11637e+02 8.11637e+01 1.00000e-09 2.12000e-01 8.11637e+02 8.11637e+02 8.11637e+01 1.00000e-09 2.12000e-01 8.11637e+02 8.11637e+02 8.11637e+01 1.00000e-09 2.12000e-01 $1.00000 \mathrm{e}-02$ 1.00000e-02 1.00000e-03 1.00000e-09 1.00000e-01 $1.00000 \mathrm{e}+001.00000 \mathrm{e}+001.00000 \mathrm{e}-011.00000 \mathrm{e}-091.00000 \mathrm{e}-01$ $1.00000 \mathrm{e}-05$ 1.00000e-05 1.00000e-06 1.00000e-09 1.00000e-01 $1.00000 \mathrm{e}+001.00000 \mathrm{e}+001.00000 \mathrm{e}-011.00000 \mathrm{e}-091.00000 \mathrm{e}-01$ Element: 3668 \# of layers: 8

$\mathrm{Kx} \mathrm{Ky} \mathrm{Kz}$ Ss Por

$1.17275 \mathrm{e}+03$ 1.17275e+03 1.17275e+02 1.00000e-09 2.12000e-01 $1.17275 \mathrm{e}+03$ 1.17275e+03 1.17275e+02 1.00000e-09 2.12000e-01 $1.17275 \mathrm{e}+03$ 1.17275e+03 1.17275e+02 1.00000e-09 2.12000e-01 $1.17275 \mathrm{e}+031.17275 \mathrm{e}+03$ 1.17275e+02 1.00000e-09 2.12000e-01 $1.00000 \mathrm{e}-02$ 1.00000e-02 1.00000e-03 1.00000e-09 1.00000e-01 $1.00000 \mathrm{e}+001.00000 \mathrm{e}+001.00000 \mathrm{e}-011.00000 \mathrm{e}-091.00000 \mathrm{e}-01$ $1.00000 \mathrm{e}-05$ 1.00000e-05 1.00000e-06 1.00000e-09 1.00000e-01 
$1.00000 \mathrm{e}+001.00000 \mathrm{e}+00$ 1.00000e-01 1.00000e-09 1.00000e-01

Element: 3669 \# of layers: 8

Kx Ky Kz Ss Por

$1.17275 e+03$ 1.17275e+03 1.17275e+02 1.00000e-09 2.12000e-01

$1.17275 \mathrm{e}+031.17275 \mathrm{e}+03$ 1.17275e+02 1.00000e-09 2.12000e-01

$1.17275 \mathrm{e}+031.17275 \mathrm{e}+03$ 1.17275e+02 1.00000e-09 2.12000e-01

$1.17275 \mathrm{e}+03$ 1.17275e+03 1.17275e+02 1.00000e-09 2.12000e-01

$1.00000 \mathrm{e}-02$ 1.00000e-02 1.00000e-03 1.00000e-09 1.00000e-01

$1.00000 \mathrm{e}+001.00000 \mathrm{e}+001.00000 \mathrm{e}-011.00000 \mathrm{e}-091.00000 \mathrm{e}-01$

$1.00000 \mathrm{e}-05$ 1.00000e-05 1.00000e-06 1.00000e-09 1.00000e-01

$1.00000 \mathrm{e}+001.00000 \mathrm{e}+001.00000 \mathrm{e}-011.00000 \mathrm{e}-091.00000 \mathrm{e}-01$

Element: 3670 \# of layers: 8

$\mathrm{Kx} \mathrm{Ky} \mathrm{Kz}$ Ss Por

1.39143e+03 1.39143e+03 1.39143e+02 1.00000e-09 2.12000e-01

$1.39143 \mathrm{e}+03$ 1.39143e+03 1.39143e+02 1.00000e-09 2.12000e-01

$1.39143 \mathrm{e}+031.39143 \mathrm{e}+03$ 1.39143e+02 1.00000e-09 2.12000e-01

$1.39143 \mathrm{e}+03$ 1.39143e+03 1.39143e+02 1.00000e-09 2.12000e-01

$1.00000 \mathrm{e}-021.00000 \mathrm{e}-021.00000 \mathrm{e}-031.00000 \mathrm{e}-091.00000 \mathrm{e}-01$

$1.00000 \mathrm{e}+001.00000 \mathrm{e}+001.00000 \mathrm{e}-011.00000 \mathrm{e}-091.00000 \mathrm{e}-01$

$1.00000 \mathrm{e}-05$ 1.00000e-05 1.00000e-06 1.00000e-09 1.00000e-01

$1.00000 \mathrm{e}+001.00000 \mathrm{e}+001.00000 \mathrm{e}-011.00000 \mathrm{e}-091.00000 \mathrm{e}-01$

Element: 3671 \# of layers: 8

$\mathrm{Kx} \mathrm{Ky} \mathrm{Kz}$ Ss Por

$1.80524 \mathrm{e}+031.80524 \mathrm{e}+03$ 1.80524e+02 1.00000e-09 2.12000e-01

$1.80524 \mathrm{e}+03 \quad 1.80524 \mathrm{e}+03 \quad 1.80524 \mathrm{e}+02 \quad 1.00000 \mathrm{e}-092.12000 \mathrm{e}-01$

$1.80524 \mathrm{e}+031.80524 \mathrm{e}+031.80524 \mathrm{e}+02$ 1.00000e-09 2.12000e-01

$1.80524 \mathrm{e}+031.80524 \mathrm{e}+031.80524 \mathrm{e}+021.00000 \mathrm{e}-092.12000 \mathrm{e}-01$

$1.00000 \mathrm{e}-02$ 1.00000e-02 1.00000e-03 1.00000e-09 1.00000e-01

$1.00000 \mathrm{e}+001.00000 \mathrm{e}+001.00000 \mathrm{e}-011.00000 \mathrm{e}-091.00000 \mathrm{e}-01$

$1.00000 \mathrm{e}-05$ 1.00000e-05 1.00000e-06 1.00000e-09 1.00000e-01

$1.00000 \mathrm{e}+001.00000 \mathrm{e}+001.00000 \mathrm{e}-011.00000 \mathrm{e}-091.00000 \mathrm{e}-01$

Element: 3672 \# of layers: 8

Kx Ky Kz Ss Por

8.11637e+02 8.11637e+02 8.11637e+01 1.00000e-09 2.12000e-01

8.11637e+02 8.11637e+02 8.11637e+01 1.00000e-09 2.12000e-01

8.11637e+02 8.11637e+02 8.11637e+01 1.00000e-09 2.12000e-01

8.11637e+02 8.11637e+02 8.11637e+01 1.00000e-09 2.12000e-01

$1.00000 \mathrm{e}-02$ 1.00000e-02 1.00000e-03 1.00000e-09 1.00000e-01

$1.00000 \mathrm{e}+001.00000 \mathrm{e}+001.00000 \mathrm{e}-011.00000 \mathrm{e}-091.00000 \mathrm{e}-01$

$1.00000 \mathrm{e}-05$ 1.00000e-05 1.00000e-06 1.00000e-09 1.00000e-01

$1.00000 \mathrm{e}+001.00000 \mathrm{e}+001.00000 \mathrm{e}-011.00000 \mathrm{e}-091.00000 \mathrm{e}-01$

Element: 3673 \# of layers: 10

$\mathrm{Kx} \mathrm{Ky} \mathrm{Kz}$ Ss Por

$1.00128 \mathrm{e}+041.00128 \mathrm{e}+04$ 1.00128e+03 1.00000e-09 7.00000e-02

$1.00128 \mathrm{e}+041.00128 \mathrm{e}+041.00128 \mathrm{e}+03$ 1.00000e-09 7.00000e-02

$4.00103 e+024.00103 e+024.00103 e+01$ 1.00000e-09 2.12000e-01 
4.00103e+02 4.00103e+02 4.00103e+01 1.00000e-09 2.12000e-01 4.00103e+02 4.00103e+02 4.00103e+01 1.00000e-09 2.12000e-01 4.00103e+02 4.00103e+02 4.00103e+01 1.00000e-09 2.12000e-01 $1.00000 \mathrm{e}-02$ 1.00000e-02 1.00000e-03 1.00000e-09 1.00000e-01 $1.00000 \mathrm{e}+001.00000 \mathrm{e}+001.00000 \mathrm{e}-011.00000 \mathrm{e}-091.00000 \mathrm{e}-01$ $1.00000 \mathrm{e}-05$ 1.00000e-05 1.00000e-06 1.00000e-09 1.00000e-01 $1.00000 \mathrm{e}+001.00000 \mathrm{e}+001.00000 \mathrm{e}-011.00000 \mathrm{e}-091.00000 \mathrm{e}-01$ Element: 3674 \# of layers: 9

$\mathrm{Kx} \mathrm{Ky} \mathrm{Kz}$ Ss Por

$1.24230 \mathrm{e}+04$ 1.24230e+04 1.24230e+03 1.00000e-09 7.00000e-02 $4.96383 \mathrm{e}+02$ 4.96383e+02 4.96383e+01 1.00000e-09 2.12000e-01 $4.96383 \mathrm{e}+02$ 4.96383e+02 4.96383e+01 1.00000e-09 2.12000e-01 4.96383e+02 4.96383e+02 4.96383e+01 1.00000e-09 2.12000e-01 $4.96383 \mathrm{e}+02$ 4.96383e+02 4.96383e+01 1.00000e-09 2.12000e-01 $1.00000 \mathrm{e}-02$ 1.00000e-02 1.00000e-03 1.00000e-09 1.00000e-01 $1.00000 \mathrm{e}+001.00000 \mathrm{e}+001.00000 \mathrm{e}-011.00000 \mathrm{e}-091.00000 \mathrm{e}-01$ $1.00000 \mathrm{e}-05$ 1.00000e-05 1.00000e-06 1.00000e-09 1.00000e-01 $1.00000 \mathrm{e}+001.00000 \mathrm{e}+001.00000 \mathrm{e}-01$ 1.00000e-09 1.00000e-01 Element: 3675 \# of layers: 11

$\mathrm{Kx} \mathrm{Ky} \mathrm{Kz}$ Ss Por

$1.24230 \mathrm{e}+041.24230 \mathrm{e}+041.24230 \mathrm{e}+03$ 1.00000e-09 7.00000e-02 5.00000e-04 5.00000e-04 5.00000e-05 1.00000e-09 1.00000e-01 5.00000e-04 5.00000e-04 5.00000e-05 1.00000e-09 1.00000e-01 $4.96383 \mathrm{e}+02$ 4.96383e+02 4.96383e+01 1.00000e-09 2.12000e-01 $4.96383 \mathrm{e}+02$ 4.96383e+02 4.96383e+01 1.00000e-09 2.12000e-01 4.96383e+02 4.96383e+02 4.96383e+01 1.00000e-09 2.12000e-01 $4.96383 \mathrm{e}+02$ 4.96383e+02 4.96383e+01 1.00000e-09 2.12000e-01 $1.00000 \mathrm{e}-02$ 1.00000e-02 1.00000e-03 1.00000e-09 1.00000e-01 $1.00000 \mathrm{e}+001.00000 \mathrm{e}+001.00000 \mathrm{e}-011.00000 \mathrm{e}-091.00000 \mathrm{e}-01$ $1.00000 \mathrm{e}-05$ 1.00000e-05 1.00000e-06 1.00000e-09 1.00000e-01 $1.00000 \mathrm{e}+001.00000 \mathrm{e}+001.00000 \mathrm{e}-011.00000 \mathrm{e}-091.00000 \mathrm{e}-01$ Element: 3676 \# of layers: 9

$\mathrm{Kx} \mathrm{Ky} \mathrm{Kz}$ Ss Por

$1.24230 \mathrm{e}+041.24230 \mathrm{e}+041.24230 \mathrm{e}+03$ 1.00000e-09 7.00000e-02 4.96383e+02 4.96383e+02 4.96383e+01 1.00000e-09 2.12000e-01 4.96383e+02 4.96383e+02 4.96383e+01 1.00000e-09 2.12000e-01 $4.96383 \mathrm{e}+02$ 4.96383e+02 4.96383e+01 1.00000e-09 2.12000e-01 4.96383e+02 4.96383e+02 4.96383e+01 1.00000e-09 2.12000e-01 $1.00000 \mathrm{e}-02$ 1.00000e-02 1.00000e-03 1.00000e-09 1.00000e-01 $1.00000 \mathrm{e}+001.00000 \mathrm{e}+001.00000 \mathrm{e}-011.00000 \mathrm{e}-091.00000 \mathrm{e}-01$ $1.00000 \mathrm{e}-05$ 1.00000e-05 1.00000e-06 1.00000e-09 1.00000e-01 $1.00000 \mathrm{e}+001.00000 \mathrm{e}+001.00000 \mathrm{e}-011.00000 \mathrm{e}-091.00000 \mathrm{e}-01$ Element: 3677 \# of layers: 10

$\mathrm{Kx} \mathrm{Ky} \mathrm{Kz}$ Ss Por

$2.20060 \mathrm{e}+042.20060 \mathrm{e}+042.20060 \mathrm{e}+03$ 1.00000e-09 7.00000e-02 $2.20060 \mathrm{e}+042.20060 \mathrm{e}+042.20060 \mathrm{e}+03$ 1.00000e-09 7.00000e-02 
$8.79274 \mathrm{e}+028.79274 \mathrm{e}+028.79274 \mathrm{e}+01$ 1.00000e-09 2.12000e-01 $8.79274 \mathrm{e}+028.79274 \mathrm{e}+028.79274 \mathrm{e}+01$ 1.00000e-09 2.12000e-01 $8.79274 \mathrm{e}+028.79274 \mathrm{e}+028.79274 \mathrm{e}+01$ 1.00000e-09 2.12000e-01 $8.79274 \mathrm{e}+028.79274 \mathrm{e}+028.79274 \mathrm{e}+01$ 1.00000e-09 2.12000e-01 $1.00000 \mathrm{e}-021.00000 \mathrm{e}-021.00000 \mathrm{e}-031.00000 \mathrm{e}-091.00000 \mathrm{e}-01$ $1.00000 \mathrm{e}+001.00000 \mathrm{e}+001.00000 \mathrm{e}-011.00000 \mathrm{e}-091.00000 \mathrm{e}-01$ $1.00000 \mathrm{e}-05$ 1.00000e-05 1.00000e-06 1.00000e-09 1.00000e-01 $1.00000 \mathrm{e}+001.00000 \mathrm{e}+001.00000 \mathrm{e}-011.00000 \mathrm{e}-091.00000 \mathrm{e}-01$ Element: 3678 \# of layers: 10

Kx Ky Kz Ss Por

$2.20060 \mathrm{e}+042.20060 \mathrm{e}+042.20060 \mathrm{e}+03$ 1.00000e-09 7.00000e-02 $2.20060 \mathrm{e}+042.20060 \mathrm{e}+042.20060 \mathrm{e}+03$ 1.00000e-09 7.00000e-02 $8.79274 \mathrm{e}+028.79274 \mathrm{e}+028.79274 \mathrm{e}+01$ 1.00000e-09 2.12000e-01 $8.79274 \mathrm{e}+028.79274 \mathrm{e}+028.79274 \mathrm{e}+01$ 1.00000e-09 2.12000e-01 $8.79274 \mathrm{e}+028.79274 \mathrm{e}+028.79274 \mathrm{e}+01$ 1.00000e-09 2.12000e-01 $8.79274 \mathrm{e}+028.79274 \mathrm{e}+028.79274 \mathrm{e}+01$ 1.00000e-09 2.12000e-01 $1.00000 \mathrm{e}-02$ 1.00000e-02 1.00000e-03 1.00000e-09 1.00000e-01 $1.00000 \mathrm{e}+001.00000 \mathrm{e}+001.00000 \mathrm{e}-011.00000 \mathrm{e}-091.00000 \mathrm{e}-01$ $1.00000 \mathrm{e}-05$ 1.00000e-05 1.00000e-06 1.00000e-09 1.00000e-01 $1.00000 \mathrm{e}+001.00000 \mathrm{e}+001.00000 \mathrm{e}-011.00000 \mathrm{e}-091.00000 \mathrm{e}-01$ Element: 3679 \# of layers: 10

Kx Ky Kz Ss Por

$1.60063 \mathrm{e}+04$ 1.60063e+04 1.60063e+03 1.00000e-09 7.00000e-02 $1.60063 \mathrm{e}+041.60063 \mathrm{e}+041.60063 \mathrm{e}+03$ 1.00000e-09 7.00000e-02 $6.39554 \mathrm{e}+026.39554 \mathrm{e}+026.39554 \mathrm{e}+01 \quad 1.00000 \mathrm{e}-092.12000 \mathrm{e}-01$ $6.39554 \mathrm{e}+026.39554 \mathrm{e}+026.39554 \mathrm{e}+01$ 1.00000e-09 2.12000e-01 $6.39554 \mathrm{e}+026.39554 \mathrm{e}+026.39554 \mathrm{e}+01$ 1.00000e-09 2.12000e-01 $6.39554 \mathrm{e}+026.39554 \mathrm{e}+026.39554 \mathrm{e}+01$ 1.00000e-09 2.12000e-01 $1.00000 \mathrm{e}-021.00000 \mathrm{e}-02$ 1.00000e-03 1.00000e-09 1.00000e-01 $1.00000 \mathrm{e}+001.00000 \mathrm{e}+001.00000 \mathrm{e}-011.00000 \mathrm{e}-091.00000 \mathrm{e}-01$ $1.00000 \mathrm{e}-05$ 1.00000e-05 1.00000e-06 1.00000e-09 1.00000e-01 $1.00000 \mathrm{e}+001.00000 \mathrm{e}+001.00000 \mathrm{e}-011.00000 \mathrm{e}-091.00000 \mathrm{e}-01$ Element: 3680 \# of layers: 10

Kx Ky Kz Ss Por $1.00128 \mathrm{e}+041.00128 \mathrm{e}+041.00128 \mathrm{e}+03$ 1.00000e-09 7.00000e-02 $1.00128 \mathrm{e}+041.00128 \mathrm{e}+041.00128 \mathrm{e}+03$ 1.00000e-09 7.00000e-02 $4.00103 \mathrm{e}+02$ 4.00103e+02 4.00103e+01 1.00000e-09 2.12000e-01 $4.00103 \mathrm{e}+02$ 4.00103e+02 4.00103e+01 1.00000e-09 2.12000e-01 $4.00103 \mathrm{e}+024.00103 \mathrm{e}+024.00103 \mathrm{e}+01$ 1.00000e-09 2.12000e-01 $4.00103 \mathrm{e}+02$ 4.00103e+02 4.00103e+01 1.00000e-09 2.12000e-01 $1.00000 \mathrm{e}-021.00000 \mathrm{e}-02$ 1.00000e-03 1.00000e-09 1.00000e-01 $1.00000 \mathrm{e}+001.00000 \mathrm{e}+001.00000 \mathrm{e}-011.00000 \mathrm{e}-091.00000 \mathrm{e}-01$ $1.00000 \mathrm{e}-05$ 1.00000e-05 1.00000e-06 1.00000e-09 1.00000e-01 $1.00000 \mathrm{e}+001.00000 \mathrm{e}+001.00000 \mathrm{e}-011.00000 \mathrm{e}-091.00000 \mathrm{e}-01$ Element: 3681 \# of layers: 9

Kx Ky Kz Ss Por 
$1.24230 \mathrm{e}+041.24230 \mathrm{e}+041.24230 \mathrm{e}+03$ 1.00000e-09 7.00000e-02 4.96383e+02 4.96383e+02 4.96383e+01 1.00000e-09 2.12000e-01 4.96383e+02 4.96383e+02 4.96383e+01 1.00000e-09 2.12000e-01 $4.96383 \mathrm{e}+02$ 4.96383e+02 4.96383e+01 1.00000e-09 2.12000e-01 4.96383e+02 4.96383e+02 4.96383e+01 1.00000e-09 2.12000e-01 $1.00000 \mathrm{e}-02$ 1.00000e-02 1.00000e-03 1.00000e-09 1.00000e-01 $1.00000 \mathrm{e}+001.00000 \mathrm{e}+001.00000 \mathrm{e}-011.00000 \mathrm{e}-091.00000 \mathrm{e}-01$ $1.00000 \mathrm{e}-05$ 1.00000e-05 1.00000e-06 1.00000e-09 1.00000e-01 $1.00000 \mathrm{e}+001.00000 \mathrm{e}+001.00000 \mathrm{e}-011.00000 \mathrm{e}-091.00000 \mathrm{e}-01$ Element: 3682 \# of layers: 11

$\mathrm{Kx} \mathrm{Ky} \mathrm{Kz}$ Ss Por

$2.34683 e+042.34683 e+042.34683 e+03$ 1.00000e-09 7.00000e-02 5.00000e-04 5.00000e-04 5.00000e-05 1.00000e-09 1.00000e-01 5.00000e-04 5.00000e-04 5.00000e-05 1.00000e-09 1.00000e-01 9.37708e+02 9.37708e+02 9.37708e+01 1.00000e-09 2.12000e-01 $9.37708 \mathrm{e}+02$ 9.37708e+02 9.37708e+01 1.00000e-09 2.12000e-01 9.37708e+02 9.37708e+02 9.37708e+01 1.00000e-09 2.12000e-01 9.37708e+02 9.37708e+02 9.37708e+01 1.00000e-09 2.12000e-01 $1.00000 \mathrm{e}-02$ 1.00000e-02 1.00000e-03 1.00000e-09 1.00000e-01 $1.00000 \mathrm{e}+001.00000 \mathrm{e}+001.00000 \mathrm{e}-011.00000 \mathrm{e}-091.00000 \mathrm{e}-01$ $1.00000 \mathrm{e}-05$ 1.00000e-05 1.00000e-06 1.00000e-09 1.00000e-01 $1.00000 \mathrm{e}+001.00000 \mathrm{e}+001.00000 \mathrm{e}-011.00000 \mathrm{e}-09$ 1.00000e-01 Element: 3683 \# of layers: 10

$\mathrm{Kx} \mathrm{Ky} \mathrm{Kz}$ Ss Por

$1.83209 \mathrm{e}+04$ 1.83209e+04 1.83209e+03 1.00000e-09 7.00000e-02 5.00000e-04 5.00000e-04 5.00000e-05 1.00000e-09 1.00000e-01

7.32053e+02 7.32053e+02 7.32053e+01 1.00000e-09 2.12000e-01 7.32053e+02 7.32053e+02 7.32053e+01 1.00000e-09 2.12000e-01 $7.32053 \mathrm{e}+02$ 7.32053e+02 7.32053e+01 1.00000e-09 2.12000e-01 7.32053e+02 7.32053e+02 7.32053e+01 1.00000e-09 2.12000e-01 $1.00000 \mathrm{e}-02$ 1.00000e-02 1.00000e-03 1.00000e-09 1.00000e-01 $1.00000 \mathrm{e}+001.00000 \mathrm{e}+001.00000 \mathrm{e}-011.00000 \mathrm{e}-091.00000 \mathrm{e}-01$ $1.00000 \mathrm{e}-05$ 1.00000e-05 1.00000e-06 1.00000e-09 1.00000e-01 $1.00000 \mathrm{e}+001.00000 \mathrm{e}+001.00000 \mathrm{e}-011.00000 \mathrm{e}-091.00000 \mathrm{e}-01$ Element: 3684 \# of layers: 10

$\mathrm{Kx} \mathrm{Ky} \mathrm{Kz}$ Ss Por $1.83209 \mathrm{e}+041.83209 \mathrm{e}+041.83209 \mathrm{e}+03$ 1.00000e-09 7.00000e-02 5.00000e-04 5.00000e-04 5.00000e-05 1.00000e-09 1.00000e-01 7.32053e+02 7.32053e+02 7.32053e+01 1.00000e-09 2.12000e-01 7.32053e+02 7.32053e+02 7.32053e+01 1.00000e-09 2.12000e-01 $7.32053 \mathrm{e}+02$ 7.32053e+02 7.32053e+01 1.00000e-09 2.12000e-01 7.32053e+02 7.32053e+02 7.32053e+01 1.00000e-09 2.12000e-01 $1.00000 \mathrm{e}-02$ 1.00000e-02 1.00000e-03 1.00000e-09 1.00000e-01 $1.00000 \mathrm{e}+001.00000 \mathrm{e}+001.00000 \mathrm{e}-011.00000 \mathrm{e}-091.00000 \mathrm{e}-01$ $1.00000 \mathrm{e}-05$ 1.00000e-05 1.00000e-06 1.00000e-09 1.00000e-01 $1.00000 \mathrm{e}+001.00000 \mathrm{e}+001.00000 \mathrm{e}-011.00000 \mathrm{e}-091.00000 \mathrm{e}-01$ 
Element: 3685 \# of layers: 9

$\mathrm{Kx} \mathrm{Ky} \mathrm{Kz}$ Ss Por

5.00000e-04 5.00000e-04 5.00000e-05 1.00000e-09 1.00000e-01

$7.32053 \mathrm{e}+02$ 7.32053e+02 7.32053e+01 1.00000e-09 2.12000e-01

7.32053e+02 7.32053e+02 7.32053e+01 1.00000e-09 2.12000e-01

7.32053e+02 7.32053e+02 7.32053e+01 1.00000e-09 2.12000e-01

7.32053e+02 7.32053e+02 7.32053e+01 1.00000e-09 2.12000e-01

$1.00000 \mathrm{e}-02$ 1.00000e-02 1.00000e-03 1.00000e-09 1.00000e-01

$1.00000 \mathrm{e}+001.00000 \mathrm{e}+001.00000 \mathrm{e}-011.00000 \mathrm{e}-091.00000 \mathrm{e}-01$

$1.00000 \mathrm{e}-05$ 1.00000e-05 1.00000e-06 1.00000e-09 1.00000e-01

$1.00000 \mathrm{e}+001.00000 \mathrm{e}+001.00000 \mathrm{e}-011.00000 \mathrm{e}-091.00000 \mathrm{e}-01$

Element: 3686 \# of layers: 8

$\mathrm{Kx} \mathrm{Ky} \mathrm{Kz}$ Ss Por

$3.56768 \mathrm{e}+03$ 3.56768e+03 3.56768e+02 1.00000e-09 2.12000e-01

$3.56768 \mathrm{e}+03$ 3.56768e+03 3.56768e+02 1.00000e-09 2.12000e-01

$3.56768 \mathrm{e}+033.56768 \mathrm{e}+03$ 3.56768e+02 1.00000e-09 2.12000e-01

$3.56768 \mathrm{e}+03$ 3.56768e+03 3.56768e+02 1.00000e-09 2.12000e-01

$1.00000 \mathrm{e}-02$ 1.00000e-02 1.00000e-03 1.00000e-09 1.00000e-01

$1.00000 \mathrm{e}+001.00000 \mathrm{e}+001.00000 \mathrm{e}-011.00000 \mathrm{e}-091.00000 \mathrm{e}-01$

$1.00000 \mathrm{e}-051.00000 \mathrm{e}-051.00000 \mathrm{e}-061.00000 \mathrm{e}-091.00000 \mathrm{e}-01$

$1.00000 \mathrm{e}+001.00000 \mathrm{e}+001.00000 \mathrm{e}-011.00000 \mathrm{e}-091.00000 \mathrm{e}-01$

Element: 3687 \# of layers: 9

$\mathrm{Kx} \mathrm{Ky} \mathrm{Kz}$ Ss Por

4.91667e+04 4.91667e+04 4.91667e+03 1.00000e-09 7.00000e-02

$3.56768 \mathrm{e}+03$ 3.56768e+03 3.56768e+02 1.00000e-09 2.12000e-01

$3.56768 \mathrm{e}+03$ 3.56768e+03 3.56768e+02 1.00000e-09 2.12000e-01

$3.56768 \mathrm{e}+033.56768 \mathrm{e}+033.56768 \mathrm{e}+02$ 1.00000e-09 2.12000e-01

$3.56768 \mathrm{e}+03$ 3.56768e+03 3.56768e+02 1.00000e-09 2.12000e-01

$1.00000 \mathrm{e}-02$ 1.00000e-02 1.00000e-03 1.00000e-09 1.00000e-01

$1.00000 \mathrm{e}+001.00000 \mathrm{e}+001.00000 \mathrm{e}-011.00000 \mathrm{e}-091.00000 \mathrm{e}-01$

$1.00000 \mathrm{e}-05$ 1.00000e-05 1.00000e-06 1.00000e-09 1.00000e-01

$1.00000 \mathrm{e}+001.00000 \mathrm{e}+001.00000 \mathrm{e}-01$ 1.00000e-09 1.00000e-01

Element: 3688 \# of layers: 9

$\mathrm{Kx} \mathrm{Ky} \mathrm{Kz}$ Ss Por

4.91667e+04 4.91667e+04 4.91667e+03 1.00000e-09 7.00000e-02

$1.96454 \mathrm{e}+031.96454 \mathrm{e}+03$ 1.96454e+02 1.00000e-09 2.12000e-01

$1.96454 \mathrm{e}+031.96454 \mathrm{e}+031.96454 \mathrm{e}+02$ 1.00000e-09 2.12000e-01

$1.96454 \mathrm{e}+031.96454 \mathrm{e}+031.96454 \mathrm{e}+02$ 1.00000e-09 2.12000e-01

$1.96454 \mathrm{e}+031.96454 \mathrm{e}+031.96454 \mathrm{e}+02$ 1.00000e-09 2.12000e-01

$1.00000 \mathrm{e}-02$ 1.00000e-02 1.00000e-03 1.00000e-09 1.00000e-01

$1.00000 \mathrm{e}+001.00000 \mathrm{e}+001.00000 \mathrm{e}-011.00000 \mathrm{e}-091.00000 \mathrm{e}-01$

$1.00000 \mathrm{e}-05$ 1.00000e-05 1.00000e-06 1.00000e-09 1.00000e-01

$1.00000 \mathrm{e}+001.00000 \mathrm{e}+001.00000 \mathrm{e}-01$ 1.00000e-09 1.00000e-01

Element: 3689 \# of layers: 10

$\mathrm{Kx} \mathrm{Ky} \mathrm{Kz}$ Ss Por

2.34683e+04 2.34683e+04 2.34683e+03 1.00000e-09 7.00000e-02 
5.00000e-04 5.00000e-04 5.00000e-05 1.00000e-09 1.00000e-01 $9.37708 \mathrm{e}+02$ 9.37708e+02 9.37708e+01 1.00000e-09 2.12000e-01 $9.37708 \mathrm{e}+02$ 9.37708e+02 9.37708e+01 1.00000e-09 2.12000e-01 $9.37708 \mathrm{e}+02$ 9.37708e+02 9.37708e+01 1.00000e-09 2.12000e-01 $9.37708 \mathrm{e}+02$ 9.37708e+02 9.37708e+01 1.00000e-09 2.12000e-01 $1.00000 \mathrm{e}-021.00000 \mathrm{e}-02$ 1.00000e-03 1.00000e-09 1.00000e-01 $1.00000 \mathrm{e}+001.00000 \mathrm{e}+001.00000 \mathrm{e}-011.00000 \mathrm{e}-091.00000 \mathrm{e}-01$ $1.00000 \mathrm{e}-05$ 1.00000e-05 1.00000e-06 1.00000e-09 1.00000e-01 $1.00000 \mathrm{e}+001.00000 \mathrm{e}+001.00000 \mathrm{e}-011.00000 \mathrm{e}-091.00000 \mathrm{e}-01$ Element: 3690 \# of layers: 10

Kx Ky Kz Ss Por

$1.83209 \mathrm{e}+04$ 1.83209e+04 1.83209e+03 1.00000e-09 7.00000e-02 5.00000e-04 5.00000e-04 5.00000e-05 1.00000e-09 1.00000e-01 $7.32053 \mathrm{e}+02$ 7.32053e+02 7.32053e+01 1.00000e-09 2.12000e-01 $7.32053 \mathrm{e}+02$ 7.32053e+02 7.32053e+01 1.00000e-09 2.12000e-01 $7.32053 \mathrm{e}+02$ 7.32053e+02 7.32053e+01 1.00000e-09 2.12000e-01 $7.32053 \mathrm{e}+02$ 7.32053e+02 7.32053e+01 1.00000e-09 2.12000e-01 $1.00000 \mathrm{e}-02$ 1.00000e-02 1.00000e-03 1.00000e-09 1.00000e-01 $1.00000 \mathrm{e}+001.00000 \mathrm{e}+001.00000 \mathrm{e}-011.00000 \mathrm{e}-091.00000 \mathrm{e}-01$ $1.00000 \mathrm{e}-05$ 1.00000e-05 1.00000e-06 1.00000e-09 1.00000e-01 $1.00000 \mathrm{e}+001.00000 \mathrm{e}+001.00000 \mathrm{e}-011.00000 \mathrm{e}-091.00000 \mathrm{e}-01$ Element: 3691 \# of layers: 11

$\mathrm{Kx}$ Ky Kz Ss Por

$2.00022 \mathrm{e}+042.00022 \mathrm{e}+042.00022 \mathrm{e}+03$ 1.00000e-09 7.00000e-02 $2.00022 \mathrm{e}+042.00022 \mathrm{e}+042.00022 \mathrm{e}+03$ 1.00000e-09 7.00000e-02 $5.00000 \mathrm{e}-04$ 5.00000e-04 5.00000e-05 1.00000e-09 1.00000e-01

$7.99217 \mathrm{e}+02$ 7.99217e+02 7.99217e+01 1.00000e-09 2.12000e-01 $7.99217 \mathrm{e}+02$ 7.99217e+02 7.99217e+01 1.00000e-09 2.12000e-01 $7.99217 \mathrm{e}+02$ 7.99217e+02 7.99217e+01 1.00000e-09 2.12000e-01 $7.99217 \mathrm{e}+02$ 7.99217e+02 7.99217e+01 1.00000e-09 2.12000e-01 $1.00000 \mathrm{e}-021.00000 \mathrm{e}-02$ 1.00000e-03 1.00000e-09 1.00000e-01 $1.00000 \mathrm{e}+001.00000 \mathrm{e}+001.00000 \mathrm{e}-011.00000 \mathrm{e}-091.00000 \mathrm{e}-01$ $1.00000 \mathrm{e}-05$ 1.00000e-05 1.00000e-06 1.00000e-09 1.00000e-01 $1.00000 \mathrm{e}+001.00000 \mathrm{e}+001.00000 \mathrm{e}-011.00000 \mathrm{e}-091.00000 \mathrm{e}-01$ Element: 3692 \# of layers: 12

Kx Ky Kz Ss Por

$1.29744 \mathrm{e}+041.29744 \mathrm{e}+041.29744 \mathrm{e}+03$ 1.00000e-09 7.00000e-02 $1.29744 \mathrm{e}+041.29744 \mathrm{e}+041.29744 \mathrm{e}+03$ 1.00000e-09 7.00000e-02 5.00000e-04 5.00000e-04 5.00000e-05 1.00000e-09 1.00000e-01 5.00000e-04 5.00000e-04 5.00000e-05 1.00000e-09 1.00000e-01 $5.18434 \mathrm{e}+025.18434 \mathrm{e}+025.18434 \mathrm{e}+01$ 1.00000e-09 2.12000e-01 $5.18434 \mathrm{e}+025.18434 \mathrm{e}+025.18434 \mathrm{e}+01$ 1.00000e-09 2.12000e-01 $5.18434 \mathrm{e}+025.18434 \mathrm{e}+025.18434 \mathrm{e}+01$ 1.00000e-09 2.12000e-01 $5.18434 \mathrm{e}+02$ 5.18434e+02 5.18434e+01 1.00000e-09 2.12000e-01 $1.00000 \mathrm{e}-021.00000 \mathrm{e}-02$ 1.00000e-03 1.00000e-09 1.00000e-01 $1.00000 \mathrm{e}+001.00000 \mathrm{e}+001.00000 \mathrm{e}-011.00000 \mathrm{e}-091.00000 \mathrm{e}-01$ 
$1.00000 \mathrm{e}-05$ 1.00000e-05 1.00000e-06 1.00000e-09 1.00000e-01 $1.00000 \mathrm{e}+001.00000 \mathrm{e}+001.00000 \mathrm{e}-01$ 1.00000e-09 1.00000e-01 Element: 3693 \# of layers: 13

Kx Ky Kz Ss Por

$1.29744 \mathrm{e}+041.29744 \mathrm{e}+041.29744 \mathrm{e}+03$ 1.00000e-09 7.00000e-02 $1.29744 \mathrm{e}+041.29744 \mathrm{e}+041.29744 \mathrm{e}+03$ 1.00000e-09 7.00000e-02 5.00000e-04 5.00000e-04 5.00000e-05 1.00000e-09 1.00000e-01 5.00000e-04 5.00000e-04 5.00000e-05 1.00000e-09 1.00000e-01 $5.18434 \mathrm{e}+025.18434 \mathrm{e}+025.18434 \mathrm{e}+01$ 1.00000e-09 2.12000e-01 $5.18434 \mathrm{e}+025.18434 \mathrm{e}+025.18434 \mathrm{e}+01$ 1.00000e-09 2.12000e-01 $5.18434 \mathrm{e}+02$ 5.18434e+02 5.18434e+01 1.00000e-09 2.12000e-01 $5.18434 \mathrm{e}+02$ 5.18434e+02 5.18434e+01 1.00000e-09 2.12000e-01 $5.18434 \mathrm{e}+02$ 5.18434e+02 5.18434e+01 1.00000e-09 2.12000e-01 $1.00000 \mathrm{e}-02$ 1.00000e-02 1.00000e-03 1.00000e-09 1.00000e-01 $1.00000 \mathrm{e}+001.00000 \mathrm{e}+001.00000 \mathrm{e}-011.00000 \mathrm{e}-091.00000 \mathrm{e}-01$ $1.00000 \mathrm{e}-05$ 1.00000e-05 1.00000e-06 1.00000e-09 1.00000e-01 $1.00000 \mathrm{e}+001.00000 \mathrm{e}+001.00000 \mathrm{e}-011.00000 \mathrm{e}-091.00000 \mathrm{e}-01$ Element: 3694 \# of layers: 9

$\mathrm{Kx} \mathrm{Ky} \mathrm{Kz}$ Ss Por

5.18434e+02 5.18434e+02 5.18434e+01 1.00000e-09 2.12000e-01 $5.18434 \mathrm{e}+025.18434 \mathrm{e}+025.18434 \mathrm{e}+01$ 1.00000e-09 2.12000e-01 $5.18434 \mathrm{e}+02$ 5.18434e+02 5.18434e+01 1.00000e-09 2.12000e-01 5.18434e+02 5.18434e+02 5.18434e+01 1.00000e-09 2.12000e-01 $5.18434 \mathrm{e}+02$ 5.18434e+02 5.18434e+01 1.00000e-09 2.12000e-01 $1.00000 \mathrm{e}-02$ 1.00000e-02 1.00000e-03 1.00000e-09 1.00000e-01 $1.00000 \mathrm{e}+001.00000 \mathrm{e}+001.00000 \mathrm{e}-011.00000 \mathrm{e}-091.00000 \mathrm{e}-01$ $1.00000 \mathrm{e}-05$ 1.00000e-05 1.00000e-06 1.00000e-09 1.00000e-01 $1.00000 \mathrm{e}+001.00000 \mathrm{e}+001.00000 \mathrm{e}-011.00000 \mathrm{e}-091.00000 \mathrm{e}-01$ Element: 3695 \# of layers: 10

$\mathrm{Kx} \mathrm{Ky} \mathrm{Kz}$ Ss Por

$2.77318 \mathrm{e}+03$ 2.77318e+03 2.77318e+02 1.00000e-09 2.12000e-01 $2.77318 \mathrm{e}+032.77318 \mathrm{e}+032.77318 \mathrm{e}+02$ 1.00000e-09 2.12000e-01 $2.77318 \mathrm{e}+032.77318 \mathrm{e}+032.77318 \mathrm{e}+02$ 1.00000e-09 2.12000e-01 $2.77318 \mathrm{e}+032.77318 \mathrm{e}+03$ 2.77318e+02 1.00000e-09 2.12000e-01 $2.77318 \mathrm{e}+032.77318 \mathrm{e}+03$ 2.77318e+02 1.00000e-09 2.12000e-01 $2.77318 \mathrm{e}+032.77318 \mathrm{e}+032.77318 \mathrm{e}+02$ 1.00000e-09 2.12000e-01 $1.00000 \mathrm{e}-02$ 1.00000e-02 1.00000e-03 1.00000e-09 1.00000e-01 $1.00000 \mathrm{e}+001.00000 \mathrm{e}+001.00000 \mathrm{e}-011.00000 \mathrm{e}-091.00000 \mathrm{e}-01$ $1.00000 \mathrm{e}-05$ 1.00000e-05 1.00000e-06 1.00000e-09 1.00000e-01 $1.00000 \mathrm{e}+001.00000 \mathrm{e}+001.00000 \mathrm{e}-01$ 1.00000e-09 1.00000e-01 Element: 3696 \# of layers: 10

$\mathrm{Kx} \mathrm{Ky} \mathrm{Kz}$ Ss Por

$2.77318 \mathrm{e}+03$ 2.77318e+03 2.77318e+02 1.00000e-09 2.12000e-01 2.77318e+03 2.77318e+03 2.77318e+02 1.00000e-09 2.12000e-01 $2.77318 \mathrm{e}+032.77318 \mathrm{e}+032.77318 \mathrm{e}+02$ 1.00000e-09 2.12000e-01 $2.77318 \mathrm{e}+032.77318 \mathrm{e}+032.77318 \mathrm{e}+02$ 1.00000e-09 2.12000e-01 
$2.77318 \mathrm{e}+032.77318 \mathrm{e}+032.77318 \mathrm{e}+02$ 1.00000e-09 2.12000e-01 $2.77318 \mathrm{e}+032.77318 \mathrm{e}+032.77318 \mathrm{e}+02$ 1.00000e-09 2.12000e-01 $1.00000 \mathrm{e}-02$ 1.00000e-02 1.00000e-03 1.00000e-09 1.00000e-01 $1.00000 \mathrm{e}+001.00000 \mathrm{e}+001.00000 \mathrm{e}-011.00000 \mathrm{e}-091.00000 \mathrm{e}-01$ $1.00000 \mathrm{e}-05$ 1.00000e-05 1.00000e-06 1.00000e-09 1.00000e-01 $1.00000 \mathrm{e}+001.00000 \mathrm{e}+001.00000 \mathrm{e}-011.00000 \mathrm{e}-091.00000 \mathrm{e}-01$ Element: 3697 \# of layers: 9

Kx Ky Kz Ss Por

$3.27067 \mathrm{e}+03$ 3.27067e+03 3.27067e+02 1.00000e-09 2.12000e-01 $3.27067 \mathrm{e}+033.27067 \mathrm{e}+033.27067 \mathrm{e}+02$ 1.00000e-09 2.12000e-01 $3.27067 \mathrm{e}+033.27067 \mathrm{e}+033.27067 \mathrm{e}+02$ 1.00000e-09 2.12000e-01 $3.27067 \mathrm{e}+033.27067 \mathrm{e}+033.27067 \mathrm{e}+02$ 1.00000e-09 2.12000e-01 $3.27067 \mathrm{e}+03$ 3.27067e+03 3.27067e+02 1.00000e-09 2.12000e-01 $1.00000 \mathrm{e}-021.00000 \mathrm{e}-02$ 1.00000e-03 1.00000e-09 1.00000e-01 $1.00000 \mathrm{e}+001.00000 \mathrm{e}+001.00000 \mathrm{e}-011.00000 \mathrm{e}-091.00000 \mathrm{e}-01$ $1.00000 \mathrm{e}-05$ 1.00000e-05 1.00000e-06 1.00000e-09 1.00000e-01 $1.00000 \mathrm{e}+001.00000 \mathrm{e}+001.00000 \mathrm{e}-011.00000 \mathrm{e}-091.00000 \mathrm{e}-01$ Element: 3698 \# of layers: 9

Kx Ky Kz Ss Por

7.99217e+02 7.99217e+02 7.99217e+01 1.00000e-09 2.12000e-01 $7.99217 \mathrm{e}+02$ 7.99217e+02 7.99217e+01 1.00000e-09 2.12000e-01 $7.99217 \mathrm{e}+02$ 7.99217e+02 7.99217e+01 1.00000e-09 2.12000e-01 $7.99217 \mathrm{e}+02$ 7.99217e+02 7.99217e+01 1.00000e-09 2.12000e-01 $7.99217 \mathrm{e}+02$ 7.99217e+02 7.99217e+01 1.00000e-09 2.12000e-01 $1.00000 \mathrm{e}-021.00000 \mathrm{e}-02$ 1.00000e-03 1.00000e-09 1.00000e-01 $1.00000 \mathrm{e}+001.00000 \mathrm{e}+001.00000 \mathrm{e}-011.00000 \mathrm{e}-091.00000 \mathrm{e}-01$ $1.00000 \mathrm{e}-05$ 1.00000e-05 1.00000e-06 1.00000e-09 1.00000e-01 $1.00000 \mathrm{e}+001.00000 \mathrm{e}+001.00000 \mathrm{e}-011.00000 \mathrm{e}-091.00000 \mathrm{e}-01$ Element: 3699 \# of layers: 9

Kx Ky Kz Ss Por

$5.18434 \mathrm{e}+02$ 5.18434e+02 5.18434e+01 1.00000e-09 2.12000e-01 $5.18434 \mathrm{e}+025.18434 \mathrm{e}+025.18434 \mathrm{e}+01$ 1.00000e-09 2.12000e-01 $5.18434 \mathrm{e}+025.18434 \mathrm{e}+025.18434 \mathrm{e}+01$ 1.00000e-09 2.12000e-01 $5.18434 \mathrm{e}+025.18434 \mathrm{e}+025.18434 \mathrm{e}+01$ 1.00000e-09 2.12000e-01 $5.18434 \mathrm{e}+02$ 5.18434e+02 5.18434e+01 1.00000e-09 2.12000e-01 $1.00000 \mathrm{e}-02$ 1.00000e-02 1.00000e-03 1.00000e-09 1.00000e-01 $1.00000 \mathrm{e}+001.00000 \mathrm{e}+001.00000 \mathrm{e}-011.00000 \mathrm{e}-091.00000 \mathrm{e}-01$ $1.00000 \mathrm{e}-05$ 1.00000e-05 1.00000e-06 1.00000e-09 1.00000e-01 $1.00000 \mathrm{e}+001.00000 \mathrm{e}+001.00000 \mathrm{e}-011.00000 \mathrm{e}-091.00000 \mathrm{e}-01$ Element: 3700 \# of layers: 11

Kx Ky Kz Ss Por $1.09264 \mathrm{e}+041.09264 \mathrm{e}+041.09264 \mathrm{e}+03$ 1.00000e-09 7.00000e-02 5.00000e-04 5.00000e-04 5.00000e-05 1.00000e-09 1.00000e-01 $4.36577 \mathrm{e}+02$ 4.36577e+02 4.36577e+01 1.00000e-09 2.12000e-01 $4.36577 \mathrm{e}+02$ 4.36577e+02 4.36577e+01 1.00000e-09 2.12000e-01 $4.36577 \mathrm{e}+02$ 4.36577e+02 4.36577e+01 1.00000e-09 2.12000e-01 
4.36577e+02 4.36577e+02 4.36577e+01 1.00000e-09 2.12000e-01 4.36577e+02 4.36577e+02 4.36577e+01 1.00000e-09 2.12000e-01 $1.00000 \mathrm{e}-02$ 1.00000e-02 1.00000e-03 1.00000e-09 1.00000e-01 $1.00000 \mathrm{e}+001.00000 \mathrm{e}+001.00000 \mathrm{e}-011.00000 \mathrm{e}-091.00000 \mathrm{e}-01$ $1.00000 \mathrm{e}-05$ 1.00000e-05 1.00000e-06 1.00000e-09 1.00000e-01 $1.00000 \mathrm{e}+001.00000 \mathrm{e}+001.00000 \mathrm{e}-011.00000 \mathrm{e}-091.00000 \mathrm{e}-01$ Element: 3701 \# of layers: 12

Kx Ky Kz Ss Por

$1.18761 \mathrm{e}+041.18761 \mathrm{e}+041.18761 \mathrm{e}+03$ 1.00000e-09 7.00000e-02 5.00000e-04 5.00000e-04 5.00000e-05 1.00000e-09 1.00000e-01 5.00000e-04 5.00000e-04 5.00000e-05 1.00000e-09 1.00000e-01 4.74513e+02 4.74513e+02 4.74513e+01 1.00000e-09 2.12000e-01 4.74513e+02 4.74513e+02 4.74513e+01 1.00000e-09 2.12000e-01 4.74513e+02 4.74513e+02 4.74513e+01 1.00000e-09 2.12000e-01 4.74513e+02 4.74513e+02 4.74513e+01 1.00000e-09 2.12000e-01 4.74513e+02 4.74513e+02 4.74513e+01 1.00000e-09 2.12000e-01 $1.00000 \mathrm{e}-02$ 1.00000e-02 1.00000e-03 1.00000e-09 1.00000e-01 $1.00000 \mathrm{e}+001.00000 \mathrm{e}+001.00000 \mathrm{e}-011.00000 \mathrm{e}-091.00000 \mathrm{e}-01$ $1.00000 \mathrm{e}-05$ 1.00000e-05 1.00000e-06 1.00000e-09 1.00000e-01 $1.00000 \mathrm{e}+001.00000 \mathrm{e}+001.00000 \mathrm{e}-011.00000 \mathrm{e}-091.00000 \mathrm{e}-01$ Element: 3702 \# of layers: 13

$\mathrm{Kx} \mathrm{Ky} \mathrm{Kz}$ Ss Por

1.18761e+04 1.18761e+04 1.18761e+03 1.00000e-09 7.00000e-02 $1.18761 \mathrm{e}+041.18761 \mathrm{e}+041.18761 \mathrm{e}+03$ 1.00000e-09 7.00000e-02 $5.00000 \mathrm{e}-04$ 5.00000e-04 5.00000e-05 1.00000e-09 1.00000e-01 5.00000e-04 5.00000e-04 5.00000e-05 1.00000e-09 1.00000e-01 4.74513e+02 4.74513e+02 4.74513e+01 1.00000e-09 2.12000e-01 4.74513e+02 4.74513e+02 4.74513e+01 1.00000e-09 2.12000e-01 $4.74513 \mathrm{e}+02$ 4.74513e+02 4.74513e+01 1.00000e-09 2.12000e-01 4.74513e+02 4.74513e+02 4.74513e+01 1.00000e-09 2.12000e-01 $4.74513 \mathrm{e}+02$ 4.74513e+02 4.74513e+01 1.00000e-09 2.12000e-01 $1.00000 \mathrm{e}-02$ 1.00000e-02 1.00000e-03 1.00000e-09 1.00000e-01 $1.00000 \mathrm{e}+001.00000 \mathrm{e}+001.00000 \mathrm{e}-011.00000 \mathrm{e}-091.00000 \mathrm{e}-01$ $1.00000 \mathrm{e}-05$ 1.00000e-05 1.00000e-06 1.00000e-09 1.00000e-01 $1.00000 \mathrm{e}+001.00000 \mathrm{e}+001.00000 \mathrm{e}-011.00000 \mathrm{e}-091.00000 \mathrm{e}-01$ Element: 3703 \# of layers: 11

Kx Ky Kz Ss Por

$1.18761 \mathrm{e}+041.18761 \mathrm{e}+041.18761 \mathrm{e}+03$ 1.00000e-09 7.00000e-02 5.00000e-04 5.00000e-04 5.00000e-05 1.00000e-09 1.00000e-01 5.00000e-04 5.00000e-04 5.00000e-05 1.00000e-09 1.00000e-01 4.74513e+02 4.74513e+02 4.74513e+01 1.00000e-09 2.12000e-01 4.74513e+02 4.74513e+02 4.74513e+01 1.00000e-09 2.12000e-01 4.74513e+02 4.74513e+02 4.74513e+01 1.00000e-09 2.12000e-01 4.74513e+02 4.74513e+02 4.74513e+01 1.00000e-09 2.12000e-01 $1.00000 \mathrm{e}-02$ 1.00000e-02 1.00000e-03 1.00000e-09 1.00000e-01 $1.00000 \mathrm{e}+001.00000 \mathrm{e}+001.00000 \mathrm{e}-011.00000 \mathrm{e}-091.00000 \mathrm{e}-01$ 
$1.00000 \mathrm{e}-05$ 1.00000e-05 1.00000e-06 1.00000e-09 1.00000e-01 $1.00000 \mathrm{e}+001.00000 \mathrm{e}+001.00000 \mathrm{e}-01$ 1.00000e-09 1.00000e-01 Element: 3704 \# of layers: 12

$\mathrm{Kx} \mathrm{Ky} \mathrm{Kz}$ Ss Por

$1.97229 \mathrm{e}+04$ 1.97229e+04 1.97229e+03 1.00000e-09 7.00000e-02 $1.97229 \mathrm{e}+041.97229 \mathrm{e}+041.97229 \mathrm{e}+03$ 1.00000e-09 7.00000e-02 5.00000e-04 5.00000e-04 5.00000e-05 1.00000e-09 1.00000e-01 5.00000e-04 5.00000e-04 5.00000e-05 1.00000e-09 1.00000e-01 $7.88057 \mathrm{e}+02$ 7.88057e+02 7.88057e+01 1.00000e-09 2.12000e-01 $7.88057 \mathrm{e}+02$ 7.88057e+02 7.88057e+01 1.00000e-09 2.12000e-01 $7.88057 \mathrm{e}+02$ 7.88057e+02 7.88057e+01 1.00000e-09 2.12000e-01 $7.88057 \mathrm{e}+02$ 7.88057e+02 7.88057e+01 1.00000e-09 2.12000e-01 $1.00000 \mathrm{e}-02$ 1.00000e-02 1.00000e-03 1.00000e-09 1.00000e-01 $1.00000 \mathrm{e}+001.00000 \mathrm{e}+001.00000 \mathrm{e}-011.00000 \mathrm{e}-091.00000 \mathrm{e}-01$ $1.00000 \mathrm{e}-05$ 1.00000e-05 1.00000e-06 1.00000e-09 1.00000e-01 $1.00000 \mathrm{e}+001.00000 \mathrm{e}+001.00000 \mathrm{e}-011.00000 \mathrm{e}-091.00000 \mathrm{e}-01$ Element: 3705 \# of layers: 12

$\mathrm{Kx} \mathrm{Ky} \mathrm{Kz}$ Ss Por

$1.97229 \mathrm{e}+041.97229 \mathrm{e}+04$ 1.97229e+03 1.00000e-09 7.00000e-02 $1.97229 \mathrm{e}+041.97229 \mathrm{e}+041.97229 \mathrm{e}+03$ 1.00000e-09 7.00000e-02 5.00000e-04 5.00000e-04 5.00000e-05 1.00000e-09 1.00000e-01 7.88057e+02 7.88057e+02 7.88057e+01 1.00000e-09 2.12000e-01 $7.88057 \mathrm{e}+02$ 7.88057e+02 7.88057e+01 1.00000e-09 2.12000e-01 $7.88057 \mathrm{e}+02$ 7.88057e+02 7.88057e+01 1.00000e-09 2.12000e-01 $7.88057 \mathrm{e}+02$ 7.88057e+02 7.88057e+01 1.00000e-09 2.12000e-01 7.88057e+02 7.88057e+02 7.88057e+01 1.00000e-09 2.12000e-01 $1.00000 \mathrm{e}-02$ 1.00000e-02 1.00000e-03 1.00000e-09 1.00000e-01 $1.00000 \mathrm{e}+001.00000 \mathrm{e}+001.00000 \mathrm{e}-011.00000 \mathrm{e}-091.00000 \mathrm{e}-01$ $1.00000 \mathrm{e}-05$ 1.00000e-05 1.00000e-06 1.00000e-09 1.00000e-01 $1.00000 \mathrm{e}+001.00000 \mathrm{e}+001.00000 \mathrm{e}-011.00000 \mathrm{e}-091.00000 \mathrm{e}-01$ Element: 3706 \# of layers: 10

$\mathrm{Kx} \mathrm{Ky} \mathrm{Kz}$ Ss Por

5.00000e-04 5.00000e-04 5.00000e-05 1.00000e-09 1.00000e-01

$2.16763 \mathrm{e}+032.16763 \mathrm{e}+032.16763 \mathrm{e}+02$ 1.00000e-09 2.12000e-01 $2.16763 \mathrm{e}+032.16763 \mathrm{e}+03$ 2.16763e+02 1.00000e-09 2.12000e-01 $2.16763 e+032.16763 e+03$ 2.16763e+02 1.00000e-09 2.12000e-01 $2.16763 \mathrm{e}+032.16763 \mathrm{e}+032.16763 \mathrm{e}+02$ 1.00000e-09 2.12000e-01 $2.16763 \mathrm{e}+032.16763 \mathrm{e}+032.16763 \mathrm{e}+02$ 1.00000e-09 2.12000e-01 $1.00000 \mathrm{e}-02$ 1.00000e-02 1.00000e-03 1.00000e-09 1.00000e-01 $1.00000 \mathrm{e}+001.00000 \mathrm{e}+001.00000 \mathrm{e}-011.00000 \mathrm{e}-091.00000 \mathrm{e}-01$ $1.00000 \mathrm{e}-05$ 1.00000e-05 1.00000e-06 1.00000e-09 1.00000e-01 $1.00000 \mathrm{e}+001.00000 \mathrm{e}+001.00000 \mathrm{e}-011.00000 \mathrm{e}-091.00000 \mathrm{e}-01$ Element: 3707 \# of layers: 10

$\mathrm{Kx} \mathrm{Ky} \mathrm{Kz}$ Ss Por $1.09264 \mathrm{e}+041.09264 \mathrm{e}+041.09264 \mathrm{e}+03$ 1.00000e-09 7.00000e-02 5.00000e-04 5.00000e-04 5.00000e-05 1.00000e-09 1.00000e-01 
4.36577e+02 4.36577e+02 4.36577e+01 1.00000e-09 2.12000e-01 4.36577e+02 4.36577e+02 4.36577e+01 1.00000e-09 2.12000e-01 4.36577e+02 4.36577e+02 4.36577e+01 1.00000e-09 2.12000e-01 4.36577e+02 4.36577e+02 4.36577e+01 1.00000e-09 2.12000e-01 $1.00000 \mathrm{e}-02$ 1.00000e-02 1.00000e-03 1.00000e-09 1.00000e-01 $1.00000 \mathrm{e}+001.00000 \mathrm{e}+001.00000 \mathrm{e}-011.00000 \mathrm{e}-091.00000 \mathrm{e}-01$ $1.00000 \mathrm{e}-05$ 1.00000e-05 1.00000e-06 1.00000e-09 1.00000e-01 $1.00000 \mathrm{e}+001.00000 \mathrm{e}+001.00000 \mathrm{e}-011.00000 \mathrm{e}-091.00000 \mathrm{e}-01$ Element: 3708 \# of layers: 11

$\mathrm{Kx} \mathrm{Ky} \mathrm{Kz}$ Ss Por

$1.18761 \mathrm{e}+041.18761 \mathrm{e}+041.18761 \mathrm{e}+03$ 1.00000e-09 7.00000e-02 5.00000e-04 5.00000e-04 5.00000e-05 1.00000e-09 1.00000e-01

4.74513e+02 4.74513e+02 4.74513e+01 1.00000e-09 2.12000e-01 4.74513e+02 4.74513e+02 4.74513e+01 1.00000e-09 2.12000e-01 4.74513e+02 4.74513e+02 4.74513e+01 1.00000e-09 2.12000e-01 4.74513e+02 4.74513e+02 4.74513e+01 1.00000e-09 2.12000e-01 4.74513e+02 4.74513e+02 4.74513e+01 1.00000e-09 2.12000e-01 $1.00000 \mathrm{e}-02$ 1.00000e-02 1.00000e-03 1.00000e-09 1.00000e-01 $1.00000 \mathrm{e}+001.00000 \mathrm{e}+001.00000 \mathrm{e}-011.00000 \mathrm{e}-091.00000 \mathrm{e}-01$ $1.00000 \mathrm{e}-05$ 1.00000e-05 1.00000e-06 1.00000e-09 1.00000e-01 $1.00000 \mathrm{e}+001.00000 \mathrm{e}+001.00000 \mathrm{e}-011.00000 \mathrm{e}-091.00000 \mathrm{e}-01$ Element: 3709 \# of layers: 12

$\mathrm{Kx} \mathrm{Ky} \mathrm{Kz}$ Ss Por 9.03343e+03 9.03343e+03 9.03343e+02 1.00000e-09 7.00000e-02 $9.03343 \mathrm{e}+03$ 9.03343e+03 9.03343e+02 1.00000e-09 7.00000e-02 $5.00000 \mathrm{e}-04$ 5.00000e-04 5.00000e-05 1.00000e-09 1.00000e-01 $5.00000 \mathrm{e}-04$ 5.00000e-04 5.00000e-05 1.00000e-09 1.00000e-01 $3.60930 \mathrm{e}+023.60930 \mathrm{e}+023.60930 \mathrm{e}+01$ 1.00000e-09 2.12000e-01 $3.60930 \mathrm{e}+02$ 3.60930e+02 3.60930e+01 1.00000e-09 2.12000e-01 $3.60930 \mathrm{e}+023.60930 \mathrm{e}+023.60930 \mathrm{e}+01$ 1.00000e-09 2.12000e-01 $3.60930 \mathrm{e}+023.60930 \mathrm{e}+02$ 3.60930e+01 1.00000e-09 2.12000e-01 $1.00000 \mathrm{e}-02$ 1.00000e-02 1.00000e-03 1.00000e-09 1.00000e-01 $1.00000 \mathrm{e}+001.00000 \mathrm{e}+001.00000 \mathrm{e}-011.00000 \mathrm{e}-091.00000 \mathrm{e}-01$ $1.00000 \mathrm{e}-05$ 1.00000e-05 1.00000e-06 1.00000e-09 1.00000e-01 $1.00000 \mathrm{e}+001.00000 \mathrm{e}+001.00000 \mathrm{e}-01$ 1.00000e-09 1.00000e-01 Element: 3710 \# of layers: 12

Kx Ky Kz Ss Por

6.13374e+03 6.13374e+03 6.13374e+02 1.00000e-09 7.00000e-02 $6.13374 \mathrm{e}+036.13374 \mathrm{e}+036.13374 \mathrm{e}+02$ 1.00000e-09 7.00000e-02 5.00000e-04 5.00000e-04 5.00000e-05 1.00000e-09 1.00000e-01 5.00000e-04 5.00000e-04 5.00000e-05 1.00000e-09 1.00000e-01 $2.45075 \mathrm{e}+022.45075 \mathrm{e}+02 \quad 2.45075 \mathrm{e}+01$ 1.00000e-09 2.12000e-01 $2.45075 \mathrm{e}+022.45075 \mathrm{e}+02$ 2.45075e+01 1.00000e-09 2.12000e-01 $2.45075 \mathrm{e}+02$ 2.45075e+02 2.45075e+01 1.00000e-09 2.12000e-01 $2.45075 \mathrm{e}+022.45075 \mathrm{e}+02$ 2.45075e+01 1.00000e-09 2.12000e-01 $1.00000 \mathrm{e}-02$ 1.00000e-02 1.00000e-03 1.00000e-09 1.00000e-01 
$1.00000 \mathrm{e}+001.00000 \mathrm{e}+001.00000 \mathrm{e}-011.00000 \mathrm{e}-091.00000 \mathrm{e}-01$ $1.00000 \mathrm{e}-05$ 1.00000e-05 1.00000e-06 1.00000e-09 1.00000e-01 $1.00000 \mathrm{e}+001.00000 \mathrm{e}+001.00000 \mathrm{e}-01$ 1.00000e-09 1.00000e-01

Element: 3711 \# of layers: 12

$\mathrm{Kx} \mathrm{Ky} \mathrm{Kz}$ Ss Por

6.13374e+03 6.13374e+03 6.13374e+02 1.00000e-09 7.00000e-02 $6.13374 \mathrm{e}+036.13374 \mathrm{e}+036.13374 \mathrm{e}+02$ 1.00000e-09 7.00000e-02 5.00000e-04 5.00000e-04 5.00000e-05 1.00000e-09 1.00000e-01 5.00000e-04 5.00000e-04 5.00000e-05 1.00000e-09 1.00000e-01

$2.45075 \mathrm{e}+022.45075 \mathrm{e}+02$ 2.45075e+01 1.00000e-09 2.12000e-01 $2.45075 \mathrm{e}+02$ 2.45075e+02 2.45075e+01 1.00000e-09 2.12000e-01 $2.45075 \mathrm{e}+022.45075 \mathrm{e}+02 \quad 2.45075 \mathrm{e}+01$ 1.00000e-09 2.12000e-01 $2.45075 \mathrm{e}+02$ 2.45075e+02 2.45075e+01 1.00000e-09 2.12000e-01 $1.00000 \mathrm{e}-02$ 1.00000e-02 1.00000e-03 1.00000e-09 1.00000e-01 $1.00000 \mathrm{e}+001.00000 \mathrm{e}+001.00000 \mathrm{e}-011.00000 \mathrm{e}-091.00000 \mathrm{e}-01$ $1.00000 \mathrm{e}-05$ 1.00000e-05 1.00000e-06 1.00000e-09 1.00000e-01 $1.00000 \mathrm{e}+001.00000 \mathrm{e}+001.00000 \mathrm{e}-011.00000 \mathrm{e}-091.00000 \mathrm{e}-01$ Element: 3712 \# of layers: 10

$\mathrm{Kx} \mathrm{Ky} \mathrm{Kz}$ Ss Por

6.13374e+03 6.13374e+03 6.13374e+02 1.00000e-09 7.00000e-02 $6.13374 \mathrm{e}+036.13374 \mathrm{e}+036.13374 \mathrm{e}+02$ 1.00000e-09 7.00000e-02 5.00000e-04 5.00000e-04 5.00000e-05 1.00000e-09 1.00000e-01 5.00000e-04 5.00000e-04 5.00000e-05 1.00000e-09 1.00000e-01 $2.45075 \mathrm{e}+02$ 2.45075e+02 2.45075e+01 1.00000e-09 2.12000e-01 $2.45075 \mathrm{e}+02$ 2.45075e+02 2.45075e+01 1.00000e-09 2.12000e-01 $1.00000 \mathrm{e}-02$ 1.00000e-02 1.00000e-03 1.00000e-09 1.00000e-01 $1.00000 \mathrm{e}+001.00000 \mathrm{e}+001.00000 \mathrm{e}-011.00000 \mathrm{e}-091.00000 \mathrm{e}-01$ $1.00000 \mathrm{e}-05$ 1.00000e-05 1.00000e-06 1.00000e-09 1.00000e-01 $1.00000 \mathrm{e}+001.00000 \mathrm{e}+001.00000 \mathrm{e}-011.00000 \mathrm{e}-091.00000 \mathrm{e}-01$ Element: 3713 \# of layers: 11

$\mathrm{Kx} \mathrm{Ky} \mathrm{Kz}$ Ss Por

3.74104e+03 3.74104e+03 3.74104e+02 1.00000e-09 7.00000e-02 $3.74104 \mathrm{e}+033.74104 \mathrm{e}+03 \quad 3.74104 \mathrm{e}+02$ 1.00000e-09 7.00000e-02 5.00000e-04 5.00000e-04 5.00000e-05 1.00000e-09 1.00000e-01 5.00000e-04 5.00000e-04 5.00000e-05 1.00000e-09 1.00000e-01 $1.49480 \mathrm{e}+021.49480 \mathrm{e}+02$ 1.49480e+01 1.00000e-09 2.12000e-01 $1.49480 \mathrm{e}+02$ 1.49480e+02 1.49480e+01 1.00000e-09 2.12000e-01 $1.49480 \mathrm{e}+02$ 1.49480e+02 1.49480e+01 1.00000e-09 2.12000e-01 $1.00000 \mathrm{e}-02$ 1.00000e-02 1.00000e-03 1.00000e-09 1.00000e-01 $1.00000 \mathrm{e}+001.00000 \mathrm{e}+001.00000 \mathrm{e}-011.00000 \mathrm{e}-091.00000 \mathrm{e}-01$ $1.00000 \mathrm{e}-051.00000 \mathrm{e}-05$ 1.00000e-06 1.00000e-09 1.00000e-01 $1.00000 \mathrm{e}+001.00000 \mathrm{e}+001.00000 \mathrm{e}-011.00000 \mathrm{e}-091.00000 \mathrm{e}-01$ Element: 3714 \# of layers: 11

$\mathrm{Kx} \mathrm{Ky} \mathrm{Kz}$ Ss Por

3.74104e+03 3.74104e+03 3.74104e+02 1.00000e-09 7.00000e-02 $3.74104 \mathrm{e}+033.74104 \mathrm{e}+03$ 3.74104e+02 1.00000e-09 7.00000e-02 
5.00000e-04 5.00000e-04 5.00000e-05 1.00000e-09 1.00000e-01 $5.00000 \mathrm{e}-04$ 5.00000e-04 5.00000e-05 1.00000e-09 1.00000e-01 $1.49480 \mathrm{e}+02 \quad 1.49480 \mathrm{e}+021.49480 \mathrm{e}+01$ 1.00000e-09 2.12000e-01 $1.49480 \mathrm{e}+02 \quad 1.49480 \mathrm{e}+021.49480 \mathrm{e}+011.00000 \mathrm{e}-092.12000 \mathrm{e}-01$ $1.49480 \mathrm{e}+02 \quad 1.49480 \mathrm{e}+02 \quad 1.49480 \mathrm{e}+011.00000 \mathrm{e}-092.12000 \mathrm{e}-01$ $1.00000 \mathrm{e}-021.00000 \mathrm{e}-02$ 1.00000e-03 1.00000e-09 1.00000e-01 $1.00000 \mathrm{e}+001.00000 \mathrm{e}+001.00000 \mathrm{e}-011.00000 \mathrm{e}-091.00000 \mathrm{e}-01$ $1.00000 \mathrm{e}-05$ 1.00000e-05 1.00000e-06 1.00000e-09 1.00000e-01 $1.00000 \mathrm{e}+001.00000 \mathrm{e}+001.00000 \mathrm{e}-011.00000 \mathrm{e}-091.00000 \mathrm{e}-01$ Element: 3715 \# of layers: 11

Kx Ky Kz Ss Por

$1.18833 \mathrm{e}+04$ 1.18833e+04 1.18833e+03 1.00000e-09 7.00000e-02 5.00000e-04 5.00000e-04 5.00000e-05 1.00000e-09 1.00000e-01 5.00000e-04 5.00000e-04 5.00000e-05 1.00000e-09 1.00000e-01 $4.74828 \mathrm{e}+02 \quad 4.74828 \mathrm{e}+024.74828 \mathrm{e}+01$ 1.00000e-09 2.12000e-01 $4.74828 \mathrm{e}+02 \quad 4.74828 \mathrm{e}+024.74828 \mathrm{e}+01$ 1.00000e-09 2.12000e-01 $4.74828 \mathrm{e}+02 \quad 4.74828 \mathrm{e}+024.74828 \mathrm{e}+01$ 1.00000e-09 2.12000e-01 $4.74828 \mathrm{e}+02 \quad 4.74828 \mathrm{e}+024.74828 \mathrm{e}+01$ 1.00000e-09 2.12000e-01 $1.00000 \mathrm{e}-02$ 1.00000e-02 1.00000e-03 1.00000e-09 1.00000e-01 $1.00000 \mathrm{e}+001.00000 \mathrm{e}+001.00000 \mathrm{e}-011.00000 \mathrm{e}-091.00000 \mathrm{e}-01$ $1.00000 \mathrm{e}-05$ 1.00000e-05 1.00000e-06 1.00000e-09 1.00000e-01 $1.00000 \mathrm{e}+001.00000 \mathrm{e}+001.00000 \mathrm{e}-011.00000 \mathrm{e}-091.00000 \mathrm{e}-01$ Element: 3716 \# of layers: 11

Kx Ky Kz Ss Por

$9.03343 \mathrm{e}+03$ 9.03343e+03 9.03343e+02 1.00000e-09 7.00000e-02 $9.03343 \mathrm{e}+03$ 9.03343e+03 9.03343e+02 1.00000e-09 7.00000e-02 5.00000e-04 5.00000e-04 5.00000e-05 1.00000e-09 1.00000e-01 5.00000e-04 5.00000e-04 5.00000e-05 1.00000e-09 1.00000e-01 $3.60930 \mathrm{e}+02$ 3.60930e+02 3.60930e+01 1.00000e-09 2.12000e-01 $3.60930 \mathrm{e}+023.60930 \mathrm{e}+023.60930 \mathrm{e}+01$ 1.00000e-09 2.12000e-01 $3.60930 \mathrm{e}+023.60930 \mathrm{e}+023.60930 \mathrm{e}+01$ 1.00000e-09 2.12000e-01 $1.00000 \mathrm{e}-02$ 1.00000e-02 1.00000e-03 1.00000e-09 1.00000e-01 $1.00000 \mathrm{e}+001.00000 \mathrm{e}+001.00000 \mathrm{e}-011.00000 \mathrm{e}-091.00000 \mathrm{e}-01$ $1.00000 \mathrm{e}-05$ 1.00000e-05 1.00000e-06 1.00000e-09 1.00000e-01 $1.00000 \mathrm{e}+001.00000 \mathrm{e}+001.00000 \mathrm{e}-011.00000 \mathrm{e}-091.00000 \mathrm{e}-01$ Element: 3717 \# of layers: 11

Kx Ky Kz Ss Por

$6.13374 \mathrm{e}+03$ 6.13374e+03 6.13374e+02 1.00000e-09 7.00000e-02 $6.13374 \mathrm{e}+036.13374 \mathrm{e}+036.13374 \mathrm{e}+021.00000 \mathrm{e}-097.00000 \mathrm{e}-02$ 5.00000e-04 5.00000e-04 5.00000e-05 1.00000e-09 1.00000e-01 5.00000e-04 5.00000e-04 5.00000e-05 1.00000e-09 1.00000e-01 $2.45075 \mathrm{e}+022.45075 \mathrm{e}+022.45075 \mathrm{e}+01$ 1.00000e-09 2.12000e-01 $2.45075 \mathrm{e}+022.45075 \mathrm{e}+022.45075 \mathrm{e}+01$ 1.00000e-09 2.12000e-01 $2.45075 \mathrm{e}+022.45075 \mathrm{e}+022.45075 \mathrm{e}+01$ 1.00000e-09 2.12000e-01 $1.00000 \mathrm{e}-021.00000 \mathrm{e}-02$ 1.00000e-03 1.00000e-09 1.00000e-01 $1.00000 \mathrm{e}+001.00000 \mathrm{e}+001.00000 \mathrm{e}-011.00000 \mathrm{e}-091.00000 \mathrm{e}-01$ 
$1.00000 \mathrm{e}-05$ 1.00000e-05 1.00000e-06 1.00000e-09 1.00000e-01 $1.00000 \mathrm{e}+001.00000 \mathrm{e}+001.00000 \mathrm{e}-01$ 1.00000e-09 1.00000e-01 Element: 3718 \# of layers: 11

Kx Ky Kz Ss Por

7.12078e+02 7.12078e+02 7.12078e+01 1.00000e-09 7.00000e-02 7.12078e+02 7.12078e+02 7.12078e+01 1.00000e-09 7.00000e-02 5.00000e-04 5.00000e-04 5.00000e-05 1.00000e-09 1.00000e-01 5.00000e-04 5.00000e-04 5.00000e-05 1.00000e-09 1.00000e-01 $2.84519 \mathrm{e}+012.84519 \mathrm{e}+012.84519 \mathrm{e}+00$ 1.00000e-09 2.12000e-01 $2.84519 \mathrm{e}+012.84519 \mathrm{e}+012.84519 \mathrm{e}+00$ 1.00000e-09 2.12000e-01 $2.84519 \mathrm{e}+012.84519 \mathrm{e}+012.84519 \mathrm{e}+00$ 1.00000e-09 2.12000e-01 $1.00000 \mathrm{e}-02$ 1.00000e-02 1.00000e-03 1.00000e-09 1.00000e-01 $1.00000 \mathrm{e}+001.00000 \mathrm{e}+001.00000 \mathrm{e}-011.00000 \mathrm{e}-091.00000 \mathrm{e}-01$ $1.00000 \mathrm{e}-05$ 1.00000e-05 1.00000e-06 1.00000e-09 1.00000e-01 $1.00000 \mathrm{e}+001.00000 \mathrm{e}+001.00000 \mathrm{e}-01$ 1.00000e-09 1.00000e-01 Element: 3719 \# of layers: 12

$\mathrm{Kx} \mathrm{Ky} \mathrm{Kz}$ Ss Por

5.78748e+02 5.78748e+02 5.78748e+01 1.00000e-09 7.00000e-02 $5.78748 \mathrm{e}+02$ 5.78748e+02 5.78748e+01 1.00000e-09 7.00000e-02 $5.78748 \mathrm{e}+02$ 5.78748e+02 5.78748e+01 1.00000e-09 7.00000e-02 5.00000e-04 5.00000e-04 5.00000e-05 1.00000e-09 1.00000e-01 5.00000e-04 5.00000e-04 5.00000e-05 1.00000e-09 1.00000e-01 $2.31260 \mathrm{e}+012.31260 \mathrm{e}+012.31260 \mathrm{e}+001.00000 \mathrm{e}-092.12000 \mathrm{e}-01$ $2.31260 \mathrm{e}+012.31260 \mathrm{e}+012.31260 \mathrm{e}+001.00000 \mathrm{e}-092.12000 \mathrm{e}-01$ $2.31260 \mathrm{e}+012.31260 \mathrm{e}+012.31260 \mathrm{e}+001.00000 \mathrm{e}-092.12000 \mathrm{e}-01$ $1.00000 \mathrm{e}-01$ 1.00000e-01 1.00000e-02 1.00000e-09 1.00000e-01 $1.00000 \mathrm{e}+001.00000 \mathrm{e}+001.00000 \mathrm{e}-011.00000 \mathrm{e}-091.00000 \mathrm{e}-01$ $1.00000 \mathrm{e}-05$ 1.00000e-05 1.00000e-06 1.00000e-09 1.00000e-01 $1.00000 \mathrm{e}+001.00000 \mathrm{e}+001.00000 \mathrm{e}-011.00000 \mathrm{e}-091.00000 \mathrm{e}-01$ Element: 3720 \# of layers: 12

$\mathrm{Kx} \mathrm{Ky} \mathrm{Kz}$ Ss Por

5.78748e+02 5.78748e+02 5.78748e+01 1.00000e-09 7.00000e-02 $5.78748 \mathrm{e}+025.78748 \mathrm{e}+02$ 5.78748e+01 1.00000e-09 7.00000e-02 5.78748e+02 5.78748e+02 5.78748e+01 1.00000e-09 7.00000e-02 $5.78748 \mathrm{e}+02$ 5.78748e+02 5.78748e+01 1.00000e-09 7.00000e-02 5.00000e-04 5.00000e-04 5.00000e-05 1.00000e-09 1.00000e-01 5.00000e-04 5.00000e-04 5.00000e-05 1.00000e-09 1.00000e-01 $2.31260 \mathrm{e}+012.31260 \mathrm{e}+012.31260 \mathrm{e}+001.00000 \mathrm{e}-092.12000 \mathrm{e}-01$ $2.31260 \mathrm{e}+012.31260 \mathrm{e}+012.31260 \mathrm{e}+001.00000 \mathrm{e}-092.12000 \mathrm{e}-01$ $1.00000 \mathrm{e}-01$ 1.00000e-01 1.00000e-02 1.00000e-09 1.00000e-01 $1.00000 \mathrm{e}+001.00000 \mathrm{e}+001.00000 \mathrm{e}-011.00000 \mathrm{e}-091.00000 \mathrm{e}-01$ $1.00000 \mathrm{e}-05$ 1.00000e-05 1.00000e-06 1.00000e-09 1.00000e-01 $1.00000 \mathrm{e}+001.00000 \mathrm{e}+001.00000 \mathrm{e}-011.00000 \mathrm{e}-091.00000 \mathrm{e}-01$ Element: 3721 \# of layers: 11

$\mathrm{Kx} \mathrm{Ky} \mathrm{Kz}$ Ss Por

5.78748e+02 5.78748e+02 5.78748e+01 1.00000e-09 7.00000e-02 
5.78748e+02 5.78748e+02 5.78748e+01 1.00000e-09 7.00000e-02 $5.78748 \mathrm{e}+02$ 5.78748e+02 5.78748e+01 1.00000e-09 7.00000e-02 5.00000e-04 5.00000e-04 5.00000e-05 1.00000e-09 1.00000e-01 5.00000e-04 5.00000e-04 5.00000e-05 1.00000e-09 1.00000e-01 $2.31260 \mathrm{e}+012.31260 \mathrm{e}+012.31260 \mathrm{e}+001.00000 \mathrm{e}-092.12000 \mathrm{e}-01$ $2.31260 \mathrm{e}+012.31260 \mathrm{e}+012.31260 \mathrm{e}+001.00000 \mathrm{e}-092.12000 \mathrm{e}-01$ $1.00000 \mathrm{e}-01$ 1.00000e-01 1.00000e-02 1.00000e-09 1.00000e-01 $1.00000 \mathrm{e}+001.00000 \mathrm{e}+001.00000 \mathrm{e}-011.00000 \mathrm{e}-091.00000 \mathrm{e}-01$ $1.00000 \mathrm{e}-05$ 1.00000e-05 1.00000e-06 1.00000e-09 1.00000e-01 $1.00000 \mathrm{e}+001.00000 \mathrm{e}+001.00000 \mathrm{e}-011.00000 \mathrm{e}-091.00000 \mathrm{e}-01$ Element: 3722 \# of layers: 10

$\mathrm{Kx} \mathrm{Ky} \mathrm{Kz}$ Ss Por

6.83616e+02 6.83616e+02 6.83616e+01 1.00000e-09 7.00000e-02 $6.83616 \mathrm{e}+026.83616 \mathrm{e}+026.83616 \mathrm{e}+01$ 1.00000e-09 7.00000e-02 5.00000e-04 5.00000e-04 5.00000e-05 1.00000e-09 1.00000e-01 5.00000e-04 5.00000e-04 5.00000e-05 1.00000e-09 1.00000e-01 $2.73156 \mathrm{e}+012.73156 \mathrm{e}+012.73156 \mathrm{e}+00$ 1.00000e-09 2.12000e-01 $2.73156 \mathrm{e}+012.73156 \mathrm{e}+012.73156 \mathrm{e}+00$ 1.00000e-09 2.12000e-01 $1.00000 \mathrm{e}-02$ 1.00000e-02 1.00000e-03 1.00000e-09 1.00000e-01 $1.00000 \mathrm{e}+001.00000 \mathrm{e}+001.00000 \mathrm{e}-011.00000 \mathrm{e}-091.00000 \mathrm{e}-01$ $1.00000 \mathrm{e}-05$ 1.00000e-05 1.00000e-06 1.00000e-09 1.00000e-01 $1.00000 \mathrm{e}+001.00000 \mathrm{e}+001.00000 \mathrm{e}-01$ 1.00000e-09 1.00000e-01 Element: 3723 \# of layers: 10

Kx Ky Kz Ss Por

6.83616e+02 6.83616e+02 6.83616e+01 1.00000e-09 7.00000e-02 6.83616e+02 6.83616e+02 6.83616e+01 1.00000e-09 7.00000e-02 5.00000e-04 5.00000e-04 5.00000e-05 1.00000e-09 1.00000e-01 5.00000e-04 5.00000e-04 5.00000e-05 1.00000e-09 1.00000e-01 $2.73156 \mathrm{e}+012.73156 \mathrm{e}+012.73156 \mathrm{e}+001.00000 \mathrm{e}-092.12000 \mathrm{e}-01$ $2.73156 \mathrm{e}+012.73156 \mathrm{e}+012.73156 \mathrm{e}+00$ 1.00000e-09 2.12000e-01 $1.00000 \mathrm{e}-02$ 1.00000e-02 1.00000e-03 1.00000e-09 1.00000e-01 $1.00000 \mathrm{e}+001.00000 \mathrm{e}+001.00000 \mathrm{e}-011.00000 \mathrm{e}-091.00000 \mathrm{e}-01$ $1.00000 \mathrm{e}-05$ 1.00000e-05 1.00000e-06 1.00000e-09 1.00000e-01 $1.00000 \mathrm{e}+001.00000 \mathrm{e}+001.00000 \mathrm{e}-011.00000 \mathrm{e}-091.00000 \mathrm{e}-01$ Element: 3724 \# of layers: 11

$\mathrm{Kx} \mathrm{Ky} \mathrm{Kz}$ Ss Por

8.51679e+02 8.51679e+02 8.51679e+01 1.00000e-09 7.00000e-02 $8.51679 \mathrm{e}+028.51679 \mathrm{e}+028.51679 \mathrm{e}+01$ 1.00000e-09 7.00000e-02 5.00000e-04 5.00000e-04 5.00000e-05 1.00000e-09 1.00000e-01 5.00000e-04 5.00000e-04 5.00000e-05 1.00000e-09 1.00000e-01 $3.40297 \mathrm{e}+013.40297 \mathrm{e}+01$ 3.40297e+00 1.00000e-09 2.12000e-01 $3.40297 \mathrm{e}+013.40297 \mathrm{e}+01$ 3.40297e+00 1.00000e-09 2.12000e-01 $3.40297 \mathrm{e}+013.40297 \mathrm{e}+013.40297 \mathrm{e}+00$ 1.00000e-09 2.12000e-01 $1.00000 \mathrm{e}-02$ 1.00000e-02 1.00000e-03 1.00000e-09 1.00000e-01 $1.00000 \mathrm{e}+001.00000 \mathrm{e}+001.00000 \mathrm{e}-011.00000 \mathrm{e}-091.00000 \mathrm{e}-01$ $1.00000 \mathrm{e}-05$ 1.00000e-05 1.00000e-06 1.00000e-09 1.00000e-01 
$1.00000 \mathrm{e}+001.00000 \mathrm{e}+00$ 1.00000e-01 1.00000e-09 1.00000e-01

Element: 3725 \# of layers: 11

$\mathrm{Kx} \mathrm{Ky} \mathrm{Kz}$ Ss Por

7.12078e+02 7.12078e+02 7.12078e+01 1.00000e-09 7.00000e-02

$7.12078 \mathrm{e}+02$ 7.12078e+02 7.12078e+01 1.00000e-09 7.00000e-02

5.00000e-04 5.00000e-04 5.00000e-05 1.00000e-09 1.00000e-01

5.00000e-04 5.00000e-04 5.00000e-05 1.00000e-09 1.00000e-01

$2.84519 \mathrm{e}+012.84519 \mathrm{e}+012.84519 \mathrm{e}+00$ 1.00000e-09 2.12000e-01

$2.84519 \mathrm{e}+012.84519 \mathrm{e}+012.84519 \mathrm{e}+00$ 1.00000e-09 2.12000e-01

$2.84519 \mathrm{e}+012.84519 \mathrm{e}+012.84519 \mathrm{e}+00$ 1.00000e-09 2.12000e-01

$1.00000 \mathrm{e}-02$ 1.00000e-02 1.00000e-03 1.00000e-09 1.00000e-01

$1.00000 \mathrm{e}+001.00000 \mathrm{e}+001.00000 \mathrm{e}-011.00000 \mathrm{e}-091.00000 \mathrm{e}-01$

$1.00000 \mathrm{e}-05$ 1.00000e-05 1.00000e-06 1.00000e-09 1.00000e-01

$1.00000 \mathrm{e}+001.00000 \mathrm{e}+001.00000 \mathrm{e}-011.00000 \mathrm{e}-09$ 1.00000e-01

Element: 3726 \# of layers: 10

Kx Ky Kz Ss Por

5.78748e+02 5.78748e+02 5.78748e+01 1.00000e-09 7.00000e-02

$5.78748 \mathrm{e}+02$ 5.78748e+02 5.78748e+01 1.00000e-09 7.00000e-02

5.00000e-04 5.00000e-04 5.00000e-05 1.00000e-09 1.00000e-01

5.00000e-04 5.00000e-04 5.00000e-05 1.00000e-09 1.00000e-01

$2.31260 \mathrm{e}+012.31260 \mathrm{e}+012.31260 \mathrm{e}+001.00000 \mathrm{e}-092.12000 \mathrm{e}-01$

$2.31260 \mathrm{e}+012.31260 \mathrm{e}+012.31260 \mathrm{e}+001.00000 \mathrm{e}-092.12000 \mathrm{e}-01$

$1.00000 \mathrm{e}-011.00000 \mathrm{e}-011.00000 \mathrm{e}-021.00000 \mathrm{e}-091.00000 \mathrm{e}-01$

$1.00000 \mathrm{e}+001.00000 \mathrm{e}+001.00000 \mathrm{e}-011.00000 \mathrm{e}-091.00000 \mathrm{e}-01$

$1.00000 \mathrm{e}-05$ 1.00000e-05 1.00000e-06 1.00000e-09 1.00000e-01

$1.00000 \mathrm{e}+001.00000 \mathrm{e}+001.00000 \mathrm{e}-01$ 1.00000e-09 1.00000e-01

Element: 3727 \# of layers: 14

$\mathrm{Kx} \mathrm{Ky} \mathrm{Kz}$ Ss Por

5.59161e+02 5.59161e+02 5.59161e+01 1.00000e-09 7.00000e-02

5.59161e+02 5.59161e+02 5.59161e+01 1.00000e-09 7.00000e-02

$5.59161 \mathrm{e}+025.59161 \mathrm{e}+025.59161 \mathrm{e}+01$ 1.00000e-09 7.00000e-02

5.00000e-04 5.00000e-04 5.00000e-05 1.00000e-09 1.00000e-01

5.00000e-04 5.00000e-04 5.00000e-05 1.00000e-09 1.00000e-01

$2.23421 \mathrm{e}+012.23421 \mathrm{e}+012.23421 \mathrm{e}+00$ 1.00000e-09 2.12000e-01

$2.23421 \mathrm{e}+012.23421 \mathrm{e}+012.23421 \mathrm{e}+00$ 1.00000e-09 2.12000e-01

$2.23421 \mathrm{e}+012.23421 \mathrm{e}+012.23421 \mathrm{e}+00$ 1.00000e-09 2.12000e-01

$2.23421 \mathrm{e}+012.23421 \mathrm{e}+012.23421 \mathrm{e}+00$ 1.00000e-09 2.12000e-01

$2.23421 \mathrm{e}+012.23421 \mathrm{e}+012.23421 \mathrm{e}+00$ 1.00000e-09 2.12000e-01

$1.00000 \mathrm{e}-02$ 1.00000e-02 1.00000e-03 1.00000e-09 1.00000e-01

$1.00000 \mathrm{e}+001.00000 \mathrm{e}+001.00000 \mathrm{e}-011.00000 \mathrm{e}-091.00000 \mathrm{e}-01$

$1.00000 \mathrm{e}-05$ 1.00000e-05 1.00000e-06 1.00000e-09 1.00000e-01

$1.00000 \mathrm{e}+001.00000 \mathrm{e}+001.00000 \mathrm{e}-011.00000 \mathrm{e}-091.00000 \mathrm{e}-01$

Element: 3728 \# of layers: 14

$\mathrm{Kx} \mathrm{Ky} \mathrm{Kz}$ Ss Por

1.38502e+02 1.38502e+02 1.38502e+01 1.00000e-09 7.00000e-02

$1.38502 \mathrm{e}+02$ 1.38502e+02 1.38502e+01 1.00000e-09 7.00000e-02 
$1.38502 \mathrm{e}+02$ 1.38502e+02 1.38502e+01 1.00000e-09 7.00000e-02 5.00000e-04 5.00000e-04 5.00000e-05 1.00000e-09 1.00000e-01 5.00000e-04 5.00000e-04 5.00000e-05 1.00000e-09 1.00000e-01

$5.53399 \mathrm{e}+00$ 5.53399e+00 5.53399e-01 1.00000e-09 2.12000e-01 5.53399e+00 5.53399e+00 5.53399e-01 1.00000e-09 2.12000e-01 5.53399e+00 5.53399e+00 5.53399e-01 1.00000e-09 2.12000e-01 5.53399e+00 5.53399e+00 5.53399e-01 1.00000e-09 2.12000e-01 $5.53399 \mathrm{e}+00$ 5.53399e+00 5.53399e-01 1.00000e-09 2.12000e-01 $1.00000 \mathrm{e}-02$ 1.00000e-02 1.00000e-03 1.00000e-09 1.00000e-01 $1.00000 \mathrm{e}+001.00000 \mathrm{e}+001.00000 \mathrm{e}-011.00000 \mathrm{e}-091.00000 \mathrm{e}-01$ 1.00000e-05 1.00000e-05 1.00000e-06 1.00000e-09 1.00000e-01 $1.00000 \mathrm{e}+001.00000 \mathrm{e}+001.00000 \mathrm{e}-011.00000 \mathrm{e}-091.00000 \mathrm{e}-01$ Element: 3729 \# of layers: 14

$\mathrm{Kx} \mathrm{Ky} \mathrm{Kz}$ Ss Por

1.38502e+02 1.38502e+02 1.38502e+01 1.00000e-09 7.00000e-02 $1.38502 \mathrm{e}+021.38502 \mathrm{e}+02$ 1.38502e+01 1.00000e-09 7.00000e-02 $1.38502 \mathrm{e}+02$ 1.38502e+02 1.38502e+01 1.00000e-09 7.00000e-02 5.00000e-04 5.00000e-04 5.00000e-05 1.00000e-09 1.00000e-01 $5.00000 \mathrm{e}-04$ 5.00000e-04 5.00000e-05 1.00000e-09 1.00000e-01 $5.53399 \mathrm{e}+00$ 5.53399e+00 5.53399e-01 1.00000e-09 2.12000e-01 $5.53399 \mathrm{e}+00$ 5.53399e+00 5.53399e-01 1.00000e-09 2.12000e-01 5.53399e+00 5.53399e+00 5.53399e-01 1.00000e-09 2.12000e-01 5.53399e+00 5.53399e+00 5.53399e-01 1.00000e-09 2.12000e-01 $5.53399 \mathrm{e}+00$ 5.53399e+00 5.53399e-01 1.00000e-09 2.12000e-01 $1.00000 \mathrm{e}-02$ 1.00000e-02 1.00000e-03 1.00000e-09 1.00000e-01 $1.00000 \mathrm{e}+001.00000 \mathrm{e}+001.00000 \mathrm{e}-011.00000 \mathrm{e}-091.00000 \mathrm{e}-01$ $1.00000 \mathrm{e}-05$ 1.00000e-05 1.00000e-06 1.00000e-09 1.00000e-01 $1.00000 \mathrm{e}+001.00000 \mathrm{e}+001.00000 \mathrm{e}-011.00000 \mathrm{e}-091.00000 \mathrm{e}-01$ Element: 3730 \# of layers: 14

$\mathrm{Kx} \mathrm{Ky} \mathrm{Kz}$ Ss Por

1.38502e+02 1.38502e+02 1.38502e+01 1.00000e-09 7.00000e-02 $1.38502 \mathrm{e}+02$ 1.38502e+02 1.38502e+01 1.00000e-09 7.00000e-02 $1.38502 \mathrm{e}+021.38502 \mathrm{e}+02$ 1.38502e+01 1.00000e-09 7.00000e-02 5.00000e-04 5.00000e-04 5.00000e-05 1.00000e-09 1.00000e-01 5.00000e-04 5.00000e-04 5.00000e-05 1.00000e-09 1.00000e-01 5.53399e+00 5.53399e+00 5.53399e-01 1.00000e-09 2.12000e-01 5.53399e+00 5.53399e+00 5.53399e-01 1.00000e-09 2.12000e-01 5.53399e+00 5.53399e+00 5.53399e-01 1.00000e-09 2.12000e-01 5.53399e+00 5.53399e+00 5.53399e-01 1.00000e-09 2.12000e-01 5.53399e+00 5.53399e+00 5.53399e-01 1.00000e-09 2.12000e-01 $1.00000 \mathrm{e}-02$ 1.00000e-02 1.00000e-03 1.00000e-09 1.00000e-01 $1.00000 \mathrm{e}+001.00000 \mathrm{e}+001.00000 \mathrm{e}-011.00000 \mathrm{e}-091.00000 \mathrm{e}-01$ $1.00000 \mathrm{e}-051.00000 \mathrm{e}-051.00000 \mathrm{e}-061.00000 \mathrm{e}-091.00000 \mathrm{e}-01$ $1.00000 \mathrm{e}+001.00000 \mathrm{e}+001.00000 \mathrm{e}-011.00000 \mathrm{e}-091.00000 \mathrm{e}-01$ Element: 3731 \# of layers: 15

Kx Ky Kz Ss Por 
$1.08156 \mathrm{e}+011.08156 \mathrm{e}+011.08156 \mathrm{e}+001.00000 \mathrm{e}-097.00000 \mathrm{e}-02$ $1.08156 \mathrm{e}+011.08156 \mathrm{e}+011.08156 \mathrm{e}+001.00000 \mathrm{e}-09$ 7.00000e-02 $1.08156 \mathrm{e}+011.08156 \mathrm{e}+011.08156 \mathrm{e}+001.00000 \mathrm{e}-09$ 7.00000e-02 $1.08156 \mathrm{e}+011.08156 \mathrm{e}+011.08156 \mathrm{e}+001.00000 \mathrm{e}-097.00000 \mathrm{e}-02$ 5.00000e-04 5.00000e-04 5.00000e-05 1.00000e-09 1.00000e-01 5.00000e-04 5.00000e-04 5.00000e-05 1.00000e-09 1.00000e-01 4.32144e-01 4.32144e-01 4.32144e-02 1.00000e-09 2.12000e-01 4.32144e-01 4.32144e-01 4.32144e-02 1.00000e-09 2.12000e-01 4.32144e-01 4.32144e-01 4.32144e-02 1.00000e-09 2.12000e-01 4.32144e-01 4.32144e-01 4.32144e-02 1.00000e-09 2.12000e-01 4.32144e-01 4.32144e-01 4.32144e-02 1.00000e-09 2.12000e-01 $1.00000 \mathrm{e}-02$ 1.00000e-02 1.00000e-03 1.00000e-09 1.00000e-01 $1.00000 \mathrm{e}+001.00000 \mathrm{e}+001.00000 \mathrm{e}-011.00000 \mathrm{e}-091.00000 \mathrm{e}-01$ $1.00000 \mathrm{e}-05$ 1.00000e-05 1.00000e-06 1.00000e-09 1.00000e-01 $1.00000 \mathrm{e}+001.00000 \mathrm{e}+001.00000 \mathrm{e}-01$ 1.00000e-09 1.00000e-01 Element: 3732 \# of layers: 14

$\mathrm{Kx} \mathrm{Ky} \mathrm{Kz}$ Ss Por $1.08156 \mathrm{e}+011.08156 \mathrm{e}+011.08156 \mathrm{e}+001.00000 \mathrm{e}-09$ 7.00000e-02 $1.08156 \mathrm{e}+011.08156 \mathrm{e}+011.08156 \mathrm{e}+001.00000 \mathrm{e}-09$ 7.00000e-02 $1.08156 \mathrm{e}+011.08156 \mathrm{e}+011.08156 \mathrm{e}+001.00000 \mathrm{e}-097.00000 \mathrm{e}-02$ 5.00000e-04 5.00000e-04 5.00000e-05 1.00000e-09 1.00000e-01 5.00000e-04 5.00000e-04 5.00000e-05 1.00000e-09 1.00000e-01 4.32144e-01 4.32144e-01 4.32144e-02 1.00000e-09 2.12000e-01 4.32144e-01 4.32144e-01 4.32144e-02 1.00000e-09 2.12000e-01 4.32144e-01 4.32144e-01 4.32144e-02 1.00000e-09 2.12000e-01 4.32144e-01 4.32144e-01 4.32144e-02 1.00000e-09 2.12000e-01 4.32144e-01 4.32144e-01 4.32144e-02 1.00000e-09 2.12000e-01 1.00000e-02 1.00000e-02 1.00000e-03 1.00000e-09 1.00000e-01 $1.00000 \mathrm{e}+001.00000 \mathrm{e}+001.00000 \mathrm{e}-011.00000 \mathrm{e}-091.00000 \mathrm{e}-01$ $1.00000 \mathrm{e}-05$ 1.00000e-05 1.00000e-06 1.00000e-09 1.00000e-01 $1.00000 \mathrm{e}+001.00000 \mathrm{e}+001.00000 \mathrm{e}-011.00000 \mathrm{e}-091.00000 \mathrm{e}-01$ Element: 3733 \# of layers: 14

$\mathrm{Kx} \mathrm{Ky} \mathrm{Kz}$ Ss Por

3.53255e+02 3.53255e+02 3.53255e+01 1.00000e-09 7.00000e-02 $3.53255 \mathrm{e}+02$ 3.53255e+02 3.53255e+01 1.00000e-09 7.00000e-02 $3.53255 \mathrm{e}+023.53255 \mathrm{e}+023.53255 \mathrm{e}+01$ 1.00000e-09 7.00000e-02 5.00000e-04 5.00000e-04 5.00000e-05 1.00000e-09 1.00000e-01 5.00000e-04 5.00000e-04 5.00000e-05 1.00000e-09 1.00000e-01 $1.41148 \mathrm{e}+01$ 1.41148e+01 1.41148e+00 1.00000e-09 2.12000e-01 $1.41148 \mathrm{e}+01$ 1.41148e+01 1.41148e+00 1.00000e-09 2.12000e-01 $1.41148 \mathrm{e}+01$ 1.41148e+01 1.41148e+00 1.00000e-09 2.12000e-01 $1.41148 \mathrm{e}+01$ 1.41148e+01 1.41148e+00 1.00000e-09 2.12000e-01 $1.41148 \mathrm{e}+01$ 1.41148e+01 1.41148e+00 1.00000e-09 2.12000e-01 $1.00000 \mathrm{e}-02$ 1.00000e-02 1.00000e-03 1.00000e-09 1.00000e-01 $1.00000 \mathrm{e}+001.00000 \mathrm{e}+001.00000 \mathrm{e}-011.00000 \mathrm{e}-091.00000 \mathrm{e}-01$ $1.00000 \mathrm{e}-05$ 1.00000e-05 1.00000e-06 1.00000e-09 1.00000e-01 
$1.00000 \mathrm{e}+001.00000 \mathrm{e}+00$ 1.00000e-01 1.00000e-09 1.00000e-01

Element: 3734 \# of layers: 14

Kx Ky Kz Ss Por

5.59161e+02 5.59161e+02 5.59161e+01 1.00000e-09 7.00000e-02

$5.59161 \mathrm{e}+025.59161 \mathrm{e}+02$ 5.59161e+01 1.00000e-09 7.00000e-02

$5.59161 \mathrm{e}+025.59161 \mathrm{e}+025.59161 \mathrm{e}+01$ 1.00000e-09 7.00000e-02

5.00000e-04 5.00000e-04 5.00000e-05 1.00000e-09 1.00000e-01

5.00000e-04 5.00000e-04 5.00000e-05 1.00000e-09 1.00000e-01

$2.23421 \mathrm{e}+012.23421 \mathrm{e}+012.23421 \mathrm{e}+001.00000 \mathrm{e}-092.12000 \mathrm{e}-01$

$2.23421 \mathrm{e}+012.23421 \mathrm{e}+012.23421 \mathrm{e}+00$ 1.00000e-09 2.12000e-01

$2.23421 \mathrm{e}+012.23421 \mathrm{e}+012.23421 \mathrm{e}+001.00000 \mathrm{e}-092.12000 \mathrm{e}-01$

$2.23421 \mathrm{e}+012.23421 \mathrm{e}+012.23421 \mathrm{e}+001.00000 \mathrm{e}-092.12000 \mathrm{e}-01$

$2.23421 \mathrm{e}+012.23421 \mathrm{e}+012.23421 \mathrm{e}+001.00000 \mathrm{e}-092.12000 \mathrm{e}-01$

$1.00000 \mathrm{e}-02$ 1.00000e-02 1.00000e-03 1.00000e-09 1.00000e-01

$1.00000 \mathrm{e}+001.00000 \mathrm{e}+001.00000 \mathrm{e}-011.00000 \mathrm{e}-091.00000 \mathrm{e}-01$

$1.00000 \mathrm{e}-05$ 1.00000e-05 1.00000e-06 1.00000e-09 1.00000e-01

$1.00000 \mathrm{e}+001.00000 \mathrm{e}+001.00000 \mathrm{e}-01$ 1.00000e-09 1.00000e-01

Element: 3735 \# of layers: 14

$\mathrm{Kx} \mathrm{Ky} \mathrm{Kz}$ Ss Por

1.38502e+02 1.38502e+02 1.38502e+01 1.00000e-09 7.00000e-02

$1.38502 \mathrm{e}+021.38502 \mathrm{e}+02$ 1.38502e+01 1.00000e-09 7.00000e-02

$1.38502 \mathrm{e}+02$ 1.38502e+02 1.38502e+01 1.00000e-09 7.00000e-02

5.00000e-04 5.00000e-04 5.00000e-05 1.00000e-09 1.00000e-01

5.00000e-04 5.00000e-04 5.00000e-05 1.00000e-09 1.00000e-01

$5.53399 \mathrm{e}+00$ 5.53399e+00 5.53399e-01 1.00000e-09 2.12000e-01

$5.53399 \mathrm{e}+00$ 5.53399e+00 5.53399e-01 1.00000e-09 2.12000e-01

5.53399e+00 5.53399e+00 5.53399e-01 1.00000e-09 2.12000e-01

$5.53399 \mathrm{e}+00$ 5.53399e+00 5.53399e-01 1.00000e-09 2.12000e-01

$5.53399 \mathrm{e}+00$ 5.53399e+00 5.53399e-01 1.00000e-09 2.12000e-01

$1.00000 \mathrm{e}-02$ 1.00000e-02 1.00000e-03 1.00000e-09 1.00000e-01

$1.00000 \mathrm{e}+001.00000 \mathrm{e}+001.00000 \mathrm{e}-01$ 1.00000e-09 1.00000e-01

1.00000e-05 1.00000e-05 1.00000e-06 1.00000e-09 1.00000e-01

$1.00000 \mathrm{e}+001.00000 \mathrm{e}+001.00000 \mathrm{e}-011.00000 \mathrm{e}-091.00000 \mathrm{e}-01$

Element: 3736 \# of layers: 15

$\mathrm{Kx} \mathrm{Ky} \mathrm{Kz}$ Ss Por

$1.49584 \mathrm{e}+02$ 1.49584e+02 1.49584e+01 1.00000e-09 7.00000e-02 $1.49584 \mathrm{e}+021.49584 \mathrm{e}+021.49584 \mathrm{e}+01$ 1.00000e-09 7.00000e-02 $1.49584 \mathrm{e}+021.49584 \mathrm{e}+02 \quad 1.49584 \mathrm{e}+01$ 1.00000e-09 7.00000e-02 $1.49584 \mathrm{e}+021.49584 \mathrm{e}+021.49584 \mathrm{e}+01$ 1.00000e-09 7.00000e-02 5.00000e-04 5.00000e-04 5.00000e-05 1.00000e-09 1.00000e-01 5.00000e-04 5.00000e-04 5.00000e-05 1.00000e-09 1.00000e-01

$5.97680 \mathrm{e}+005.97680 \mathrm{e}+00$ 5.97680e-01 1.00000e-09 2.12000e-01 $5.97680 \mathrm{e}+00$ 5.97680e+00 5.97680e-01 1.00000e-09 2.12000e-01 5.97680e+00 5.97680e+00 5.97680e-01 1.00000e-09 2.12000e-01 $5.97680 \mathrm{e}+005.97680 \mathrm{e}+00$ 5.97680e-01 1.00000e-09 2.12000e-01 $5.97680 \mathrm{e}+00$ 5.97680e+00 5.97680e-01 1.00000e-09 2.12000e-01 
$1.00000 \mathrm{e}-02$ 1.00000e-02 1.00000e-03 1.00000e-09 1.00000e-01 $1.00000 \mathrm{e}+001.00000 \mathrm{e}+001.00000 \mathrm{e}-011.00000 \mathrm{e}-091.00000 \mathrm{e}-01$ $1.00000 \mathrm{e}-05$ 1.00000e-05 1.00000e-06 1.00000e-09 1.00000e-01 $1.00000 \mathrm{e}+001.00000 \mathrm{e}+001.00000 \mathrm{e}-011.00000 \mathrm{e}-091.00000 \mathrm{e}-01$ Element: 3737 \# of layers: 15

$\mathrm{Kx} \mathrm{Ky} \mathrm{Kz}$ Ss Por

$1.48494 \mathrm{e}+02$ 1.48494e+02 1.48494e+01 1.00000e-09 7.00000e-02 $1.48494 \mathrm{e}+02$ 1.48494e+02 1.48494e+01 1.00000e-09 7.00000e-02 $1.48494 \mathrm{e}+02$ 1.48494e+02 1.48494e+01 1.00000e-09 7.00000e-02 $1.48494 \mathrm{e}+02$ 1.48494e+02 1.48494e+01 1.00000e-09 7.00000e-02 5.00000e-04 5.00000e-04 5.00000e-05 1.00000e-09 1.00000e-01 5.00000e-04 5.00000e-04 5.00000e-05 1.00000e-09 1.00000e-01 $5.93315 \mathrm{e}+00$ 5.93315e+00 5.93315e-01 1.00000e-09 2.12000e-01 $5.93315 \mathrm{e}+00$ 5.93315e+00 5.93315e-01 1.00000e-09 2.12000e-01 5.93315e+00 5.93315e+00 5.93315e-01 1.00000e-09 2.12000e-01 $5.93315 \mathrm{e}+00$ 5.93315e+00 5.93315e-01 1.00000e-09 2.12000e-01 $5.93315 \mathrm{e}+00$ 5.93315e+00 5.93315e-01 1.00000e-09 2.12000e-01 $1.00000 \mathrm{e}-02$ 1.00000e-02 1.00000e-03 1.00000e-09 1.00000e-01 $1.00000 \mathrm{e}+001.00000 \mathrm{e}+001.00000 \mathrm{e}-011.00000 \mathrm{e}-091.00000 \mathrm{e}-01$ $1.00000 \mathrm{e}-05$ 1.00000e-05 1.00000e-06 1.00000e-09 1.00000e-01 $1.00000 \mathrm{e}+001.00000 \mathrm{e}+001.00000 \mathrm{e}-011.00000 \mathrm{e}-091.00000 \mathrm{e}-01$ Element: 3738 \# of layers: 15

$\mathrm{Kx} \mathrm{Ky} \mathrm{Kz}$ Ss Por

$1.48494 \mathrm{e}+02$ 1.48494e+02 1.48494e+01 1.00000e-09 7.00000e-02 $1.48494 \mathrm{e}+021.48494 \mathrm{e}+021.48494 \mathrm{e}+01$ 1.00000e-09 7.00000e-02 $1.48494 \mathrm{e}+02$ 1.48494e+02 1.48494e+01 1.00000e-09 7.00000e-02 $1.48494 \mathrm{e}+02$ 1.48494e+02 1.48494e+01 1.00000e-09 7.00000e-02 5.00000e-04 5.00000e-04 5.00000e-05 1.00000e-09 1.00000e-01 5.00000e-04 5.00000e-04 5.00000e-05 1.00000e-09 1.00000e-01 $5.93315 \mathrm{e}+00$ 5.93315e+00 5.93315e-01 1.00000e-09 2.12000e-01 5.93315e+00 5.93315e+00 5.93315e-01 1.00000e-09 2.12000e-01 5.93315e+00 5.93315e+00 5.93315e-01 1.00000e-09 2.12000e-01 $5.93315 \mathrm{e}+00$ 5.93315e+00 5.93315e-01 1.00000e-09 2.12000e-01 $5.93315 \mathrm{e}+005.93315 \mathrm{e}+00$ 5.93315e-01 1.00000e-09 2.12000e-01 $1.00000 \mathrm{e}-02$ 1.00000e-02 1.00000e-03 1.00000e-09 1.00000e-01 $1.00000 \mathrm{e}+001.00000 \mathrm{e}+001.00000 \mathrm{e}-011.00000 \mathrm{e}-091.00000 \mathrm{e}-01$ $1.00000 \mathrm{e}-05$ 1.00000e-05 1.00000e-06 1.00000e-09 1.00000e-01 $1.00000 \mathrm{e}+001.00000 \mathrm{e}+001.00000 \mathrm{e}-011.00000 \mathrm{e}-091.00000 \mathrm{e}-01$ Element: 3739 \# of layers: 15

$\mathrm{Kx} \mathrm{Ky} \mathrm{Kz}$ Ss Por $1.48494 \mathrm{e}+02$ 1.48494e+02 1.48494e+01 1.00000e-09 7.00000e-02 $1.48494 \mathrm{e}+02$ 1.48494e+02 1.48494e+01 1.00000e-09 7.00000e-02 $1.48494 \mathrm{e}+02$ 1.48494e+02 1.48494e+01 1.00000e-09 7.00000e-02 $1.48494 \mathrm{e}+021.48494 \mathrm{e}+021.48494 \mathrm{e}+01$ 1.00000e-09 7.00000e-02 5.00000e-04 5.00000e-04 5.00000e-05 1.00000e-09 1.00000e-01 5.00000e-04 5.00000e-04 5.00000e-05 1.00000e-09 1.00000e-01 
5.93315e+00 5.93315e+00 5.93315e-01 1.00000e-09 2.12000e-01 5.93315e+00 5.93315e+00 5.93315e-01 1.00000e-09 2.12000e-01 $5.93315 \mathrm{e}+00$ 5.93315e+00 5.93315e-01 1.00000e-09 2.12000e-01 $5.93315 \mathrm{e}+00$ 5.93315e+00 5.93315e-01 1.00000e-09 2.12000e-01 5.93315e+00 5.93315e+00 5.93315e-01 1.00000e-09 2.12000e-01 $1.00000 \mathrm{e}-02$ 1.00000e-02 1.00000e-03 1.00000e-09 1.00000e-01 $1.00000 \mathrm{e}+001.00000 \mathrm{e}+001.00000 \mathrm{e}-011.00000 \mathrm{e}-091.00000 \mathrm{e}-01$ $1.00000 \mathrm{e}-05$ 1.00000e-05 1.00000e-06 1.00000e-09 1.00000e-01 $1.00000 \mathrm{e}+001.00000 \mathrm{e}+001.00000 \mathrm{e}-011.00000 \mathrm{e}-091.00000 \mathrm{e}-01$ Element: 3740 \# of layers: 15

$\mathrm{Kx} \mathrm{Ky} \mathrm{Kz}$ Ss Por

5.73387e+01 5.73387e+01 5.73387e+00 1.00000e-09 7.00000e-02 $5.73387 \mathrm{e}+015.73387 \mathrm{e}+01$ 5.73387e+00 1.00000e-09 7.00000e-02 5.73387e+01 5.73387e+01 5.73387e+00 1.00000e-09 7.00000e-02 $5.73387 \mathrm{e}+015.73387 \mathrm{e}+015.73387 \mathrm{e}+001.00000 \mathrm{e}-09$ 7.00000e-02 5.00000e-04 5.00000e-04 5.00000e-05 1.00000e-09 1.00000e-01 5.00000e-04 5.00000e-04 5.00000e-05 1.00000e-09 1.00000e-01

$2.29100 \mathrm{e}+002.29100 \mathrm{e}+002.29100 \mathrm{e}-01$ 1.00000e-09 2.12000e-01 $2.29100 \mathrm{e}+002.29100 \mathrm{e}+002.29100 \mathrm{e}-01$ 1.00000e-09 2.12000e-01 $2.29100 \mathrm{e}+002.29100 \mathrm{e}+00$ 2.29100e-01 1.00000e-09 2.12000e-01 $2.29100 \mathrm{e}+002.29100 \mathrm{e}+00 \quad 2.29100 \mathrm{e}-01$ 1.00000e-09 2.12000e-01 $2.29100 \mathrm{e}+002.29100 \mathrm{e}+00$ 2.29100e-01 1.00000e-09 2.12000e-01 $1.00000 \mathrm{e}-02$ 1.00000e-02 1.00000e-03 1.00000e-09 1.00000e-01 $1.00000 \mathrm{e}+001.00000 \mathrm{e}+001.00000 \mathrm{e}-011.00000 \mathrm{e}-091.00000 \mathrm{e}-01$ $1.00000 \mathrm{e}-05$ 1.00000e-05 1.00000e-06 1.00000e-09 1.00000e-01 $1.00000 \mathrm{e}+001.00000 \mathrm{e}+001.00000 \mathrm{e}-01$ 1.00000e-09 1.00000e-01 Element: 3741 \# of layers: 15

$\mathrm{Kx} \mathrm{Ky} \mathrm{Kz}$ Ss Por

5.73387e+01 5.73387e+01 5.73387e+00 1.00000e-09 7.00000e-02 5.73387e+01 5.73387e+01 5.73387e+00 1.00000e-09 7.00000e-02 $5.73387 \mathrm{e}+015.73387 \mathrm{e}+01$ 5.73387e+00 1.00000e-09 7.00000e-02 $5.73387 \mathrm{e}+015.73387 \mathrm{e}+015.73387 \mathrm{e}+00$ 1.00000e-09 7.00000e-02 5.00000e-04 5.00000e-04 5.00000e-05 1.00000e-09 1.00000e-01 5.00000e-04 5.00000e-04 5.00000e-05 1.00000e-09 1.00000e-01 $2.29100 \mathrm{e}+002.29100 \mathrm{e}+00$ 2.29100e-01 1.00000e-09 2.12000e-01 $2.29100 \mathrm{e}+002.29100 \mathrm{e}+00$ 2.29100e-01 1.00000e-09 2.12000e-01 $2.29100 \mathrm{e}+002.29100 \mathrm{e}+002.29100 \mathrm{e}-01$ 1.00000e-09 2.12000e-01 $2.29100 \mathrm{e}+002.29100 \mathrm{e}+002.29100 \mathrm{e}-01$ 1.00000e-09 2.12000e-01 $2.29100 \mathrm{e}+002.29100 \mathrm{e}+002.29100 \mathrm{e}-01$ 1.00000e-09 2.12000e-01 $1.00000 \mathrm{e}-02$ 1.00000e-02 1.00000e-03 1.00000e-09 1.00000e-01 $1.00000 \mathrm{e}+001.00000 \mathrm{e}+001.00000 \mathrm{e}-011.00000 \mathrm{e}-091.00000 \mathrm{e}-01$ $1.00000 \mathrm{e}-05$ 1.00000e-05 1.00000e-06 1.00000e-09 1.00000e-01 $1.00000 \mathrm{e}+001.00000 \mathrm{e}+001.00000 \mathrm{e}-011.00000 \mathrm{e}-091.00000 \mathrm{e}-01$ Element: 3742 \# of layers: 16

$\mathrm{Kx} \mathrm{Ky} \mathrm{Kz}$ Ss Por

$1.26816 \mathrm{e}+011.26816 \mathrm{e}+011.26816 \mathrm{e}+001.00000 \mathrm{e}-09$ 7.00000e-02 
$1.26816 \mathrm{e}+01$ 1.26816e+01 1.26816e+00 1.00000e-09 7.00000e-02 $1.26816 \mathrm{e}+01$ 1.26816e+01 1.26816e+00 1.00000e-09 7.00000e-02 $1.26816 \mathrm{e}+011.26816 \mathrm{e}+011.26816 \mathrm{e}+001.00000 \mathrm{e}-09$ 7.00000e-02 $1.26816 \mathrm{e}+011.26816 \mathrm{e}+011.26816 \mathrm{e}+001.00000 \mathrm{e}-097.00000 \mathrm{e}-02$ 5.00000e-04 5.00000e-04 5.00000e-05 1.00000e-09 1.00000e-01 5.00000e-04 5.00000e-04 5.00000e-05 1.00000e-09 1.00000e-01 5.06688e-01 5.06688e-01 5.06688e-02 1.00000e-09 2.12000e-01 5.06688e-01 5.06688e-01 5.06688e-02 1.00000e-09 2.12000e-01 5.06688e-01 5.06688e-01 5.06688e-02 1.00000e-09 2.12000e-01 5.06688e-01 5.06688e-01 5.06688e-02 1.00000e-09 2.12000e-01 5.06688e-01 5.06688e-01 5.06688e-02 1.00000e-09 2.12000e-01 $1.00000 \mathrm{e}-02$ 1.00000e-02 1.00000e-03 1.00000e-09 1.00000e-01 $1.00000 \mathrm{e}+001.00000 \mathrm{e}+001.00000 \mathrm{e}-011.00000 \mathrm{e}-091.00000 \mathrm{e}-01$ $1.00000 \mathrm{e}-05$ 1.00000e-05 1.00000e-06 1.00000e-09 1.00000e-01 $1.00000 \mathrm{e}+001.00000 \mathrm{e}+001.00000 \mathrm{e}-01$ 1.00000e-09 1.00000e-01 Element: 3743 \# of layers: 15

$\mathrm{Kx} \mathrm{Ky} \mathrm{Kz}$ Ss Por

$1.49584 \mathrm{e}+02$ 1.49584e+02 1.49584e+01 1.00000e-09 7.00000e-02 $1.49584 \mathrm{e}+021.49584 \mathrm{e}+02$ 1.49584e+01 1.00000e-09 7.00000e-02 $1.49584 \mathrm{e}+02 \quad 1.49584 \mathrm{e}+02 \quad 1.49584 \mathrm{e}+01$ 1.00000e-09 7.00000e-02 $1.49584 \mathrm{e}+021.49584 \mathrm{e}+02 \quad 1.49584 \mathrm{e}+01 \quad 1.00000 \mathrm{e}-097.00000 \mathrm{e}-02$ 5.00000e-04 5.00000e-04 5.00000e-05 1.00000e-09 1.00000e-01 5.00000e-04 5.00000e-04 5.00000e-05 1.00000e-09 1.00000e-01 $5.97680 \mathrm{e}+00$ 5.97680e+00 5.97680e-01 1.00000e-09 2.12000e-01 $5.97680 \mathrm{e}+00$ 5.97680e+00 5.97680e-01 1.00000e-09 2.12000e-01 $5.97680 \mathrm{e}+005.97680 \mathrm{e}+00$ 5.97680e-01 1.00000e-09 2.12000e-01 $5.97680 \mathrm{e}+005.97680 \mathrm{e}+00$ 5.97680e-01 1.00000e-09 2.12000e-01 $5.97680 \mathrm{e}+005.97680 \mathrm{e}+00$ 5.97680e-01 1.00000e-09 2.12000e-01 $1.00000 \mathrm{e}-02$ 1.00000e-02 1.00000e-03 1.00000e-09 1.00000e-01 $1.00000 \mathrm{e}+001.00000 \mathrm{e}+001.00000 \mathrm{e}-011.00000 \mathrm{e}-091.00000 \mathrm{e}-01$ $1.00000 \mathrm{e}-05$ 1.00000e-05 1.00000e-06 1.00000e-09 1.00000e-01 $1.00000 \mathrm{e}+001.00000 \mathrm{e}+001.00000 \mathrm{e}-011.00000 \mathrm{e}-091.00000 \mathrm{e}-01$ Element: 3744 \# of layers: 15

$\mathrm{Kx} \mathrm{Ky} \mathrm{Kz}$ Ss Por

$1.48494 \mathrm{e}+02$ 1.48494e+02 1.48494e+01 1.00000e-09 7.00000e-02 $1.48494 \mathrm{e}+02$ 1.48494e+02 1.48494e+01 1.00000e-09 7.00000e-02 $1.48494 \mathrm{e}+021.48494 \mathrm{e}+021.48494 \mathrm{e}+01$ 1.00000e-09 7.00000e-02 $1.48494 \mathrm{e}+021.48494 \mathrm{e}+021.48494 \mathrm{e}+01$ 1.00000e-09 7.00000e-02 5.00000e-04 5.00000e-04 5.00000e-05 1.00000e-09 1.00000e-01 5.00000e-04 5.00000e-04 5.00000e-05 1.00000e-09 1.00000e-01 $5.93315 \mathrm{e}+00$ 5.93315e+00 5.93315e-01 1.00000e-09 2.12000e-01 $5.93315 \mathrm{e}+00$ 5.93315e+00 5.93315e-01 1.00000e-09 2.12000e-01 5.93315e+00 5.93315e+00 5.93315e-01 1.00000e-09 2.12000e-01 5.93315e+00 5.93315e+00 5.93315e-01 1.00000e-09 2.12000e-01 $5.93315 \mathrm{e}+00$ 5.93315e+00 5.93315e-01 1.00000e-09 2.12000e-01 $1.00000 \mathrm{e}-02$ 1.00000e-02 1.00000e-03 1.00000e-09 1.00000e-01 
$1.00000 \mathrm{e}+001.00000 \mathrm{e}+001.00000 \mathrm{e}-011.00000 \mathrm{e}-091.00000 \mathrm{e}-01$ $1.00000 \mathrm{e}-05$ 1.00000e-05 1.00000e-06 1.00000e-09 1.00000e-01 $1.00000 \mathrm{e}+001.00000 \mathrm{e}+001.00000 \mathrm{e}-011.00000 \mathrm{e}-09$ 1.00000e-01 Element: 3745 \# of layers: 15

$\mathrm{Kx} \mathrm{Ky} \mathrm{Kz}$ Ss Por

$1.40826 \mathrm{e}+02$ 1.40826e+02 1.40826e+01 1.00000e-09 7.00000e-02 $1.40826 \mathrm{e}+021.40826 \mathrm{e}+02 \quad 1.40826 \mathrm{e}+01$ 1.00000e-09 7.00000e-02 $1.40826 \mathrm{e}+021.40826 \mathrm{e}+02$ 1.40826e+01 1.00000e-09 7.00000e-02 $1.40826 \mathrm{e}+021.40826 \mathrm{e}+02 \quad 1.40826 \mathrm{e}+01$ 1.00000e-09 7.00000e-02 5.00000e-04 5.00000e-04 5.00000e-05 1.00000e-09 1.00000e-01 5.00000e-04 5.00000e-04 5.00000e-05 1.00000e-09 1.00000e-01 $5.62692 \mathrm{e}+005.62692 \mathrm{e}+00$ 5.62692e-01 1.00000e-09 2.12000e-01 $5.62692 \mathrm{e}+00$ 5.62692e+00 5.62692e-01 1.00000e-09 2.12000e-01 $5.62692 \mathrm{e}+005.62692 \mathrm{e}+00$ 5.62692e-01 1.00000e-09 2.12000e-01 5.62692e+00 5.62692e+00 5.62692e-01 1.00000e-09 2.12000e-01 5.62692e+00 5.62692e+00 5.62692e-01 1.00000e-09 2.12000e-01 $1.00000 \mathrm{e}-02$ 1.00000e-02 1.00000e-03 1.00000e-09 1.00000e-01 $1.00000 \mathrm{e}+001.00000 \mathrm{e}+001.00000 \mathrm{e}-011.00000 \mathrm{e}-091.00000 \mathrm{e}-01$ $1.00000 \mathrm{e}-05$ 1.00000e-05 1.00000e-06 1.00000e-09 1.00000e-01 $1.00000 \mathrm{e}+001.00000 \mathrm{e}+001.00000 \mathrm{e}-011.00000 \mathrm{e}-091.00000 \mathrm{e}-01$ Element: 3746 \# of layers: 15

$\mathrm{Kx} \mathrm{Ky} \mathrm{Kz}$ Ss Por

1.52593e+02 1.52593e+02 1.52593e+01 1.00000e-09 7.00000e-02 $1.52593 \mathrm{e}+02$ 1.52593e+02 1.52593e+01 1.00000e-09 7.00000e-02 $1.52593 \mathrm{e}+021.52593 \mathrm{e}+02 \quad 1.52593 \mathrm{e}+01$ 1.00000e-09 7.00000e-02 $1.52593 \mathrm{e}+021.52593 \mathrm{e}+02$ 1.52593e+01 1.00000e-09 7.00000e-02 5.00000e-04 5.00000e-04 5.00000e-05 1.00000e-09 1.00000e-01 5.00000e-04 5.00000e-04 5.00000e-05 1.00000e-09 1.00000e-01 $6.09718 \mathrm{e}+00$ 6.09718e+00 6.09718e-01 1.00000e-09 2.12000e-01 $6.09718 \mathrm{e}+006.09718 \mathrm{e}+00$ 6.09718e-01 1.00000e-09 2.12000e-01 $6.09718 \mathrm{e}+006.09718 \mathrm{e}+00$ 6.09718e-01 1.00000e-09 2.12000e-01 $6.09718 \mathrm{e}+006.09718 \mathrm{e}+00$ 6.09718e-01 1.00000e-09 2.12000e-01 $6.09718 \mathrm{e}+006.09718 \mathrm{e}+00$ 6.09718e-01 1.00000e-09 2.12000e-01 $1.00000 \mathrm{e}-02$ 1.00000e-02 1.00000e-03 1.00000e-09 1.00000e-01 $1.00000 \mathrm{e}+001.00000 \mathrm{e}+001.00000 \mathrm{e}-011.00000 \mathrm{e}-091.00000 \mathrm{e}-01$ $1.00000 \mathrm{e}-05$ 1.00000e-05 1.00000e-06 1.00000e-09 1.00000e-01 $1.00000 \mathrm{e}+001.00000 \mathrm{e}+001.00000 \mathrm{e}-011.00000 \mathrm{e}-091.00000 \mathrm{e}-01$ Element: 3747 \# of layers: 15

$\mathrm{Kx} \mathrm{Ky} \mathrm{Kz}$ Ss Por

$1.52593 \mathrm{e}+02$ 1.52593e+02 1.52593e+01 1.00000e-09 7.00000e-02 $1.52593 \mathrm{e}+02$ 1.52593e+02 1.52593e+01 1.00000e-09 7.00000e-02 $1.52593 \mathrm{e}+02$ 1.52593e+02 1.52593e+01 1.00000e-09 7.00000e-02 $1.52593 \mathrm{e}+02$ 1.52593e+02 1.52593e+01 1.00000e-09 7.00000e-02 5.00000e-04 5.00000e-04 5.00000e-05 1.00000e-09 1.00000e-01 $5.00000 \mathrm{e}-04$ 5.00000e-04 5.00000e-05 1.00000e-09 1.00000e-01 $6.09718 \mathrm{e}+006.09718 \mathrm{e}+00$ 6.09718e-01 1.00000e-09 2.12000e-01 
$6.09718 \mathrm{e}+006.09718 \mathrm{e}+00$ 6.09718e-01 1.00000e-09 2.12000e-01 $6.09718 \mathrm{e}+006.09718 \mathrm{e}+006.09718 \mathrm{e}-011.00000 \mathrm{e}-092.12000 \mathrm{e}-01$ $6.09718 \mathrm{e}+006.09718 \mathrm{e}+00$ 6.09718e-01 1.00000e-09 2.12000e-01 $6.09718 \mathrm{e}+006.09718 \mathrm{e}+00$ 6.09718e-01 1.00000e-09 2.12000e-01 $1.00000 \mathrm{e}-02$ 1.00000e-02 1.00000e-03 1.00000e-09 1.00000e-01 $1.00000 \mathrm{e}+001.00000 \mathrm{e}+001.00000 \mathrm{e}-011.00000 \mathrm{e}-091.00000 \mathrm{e}-01$ $1.00000 \mathrm{e}-051.00000 \mathrm{e}-05$ 1.00000e-06 1.00000e-09 1.00000e-01 $1.00000 \mathrm{e}+001.00000 \mathrm{e}+001.00000 \mathrm{e}-011.00000 \mathrm{e}-091.00000 \mathrm{e}-01$ Element: 3748 \# of layers: 15

Kx Ky Kz Ss Por

$1.52593 \mathrm{e}+021.52593 \mathrm{e}+02$ 1.52593e+01 1.00000e-09 7.00000e-02 $1.52593 \mathrm{e}+021.52593 \mathrm{e}+021.52593 \mathrm{e}+011.00000 \mathrm{e}-09$ 7.00000e-02 $1.52593 \mathrm{e}+021.52593 \mathrm{e}+021.52593 \mathrm{e}+011.00000 \mathrm{e}-09$ 7.00000e-02 $1.52593 \mathrm{e}+021.52593 \mathrm{e}+021.52593 \mathrm{e}+01$ 1.00000e-09 7.00000e-02 5.00000e-04 5.00000e-04 5.00000e-05 1.00000e-09 1.00000e-01 $5.00000 \mathrm{e}-04$ 5.00000e-04 5.00000e-05 1.00000e-09 1.00000e-01 $6.09718 \mathrm{e}+006.09718 \mathrm{e}+00$ 6.09718e-01 1.00000e-09 2.12000e-01 $6.09718 \mathrm{e}+006.09718 \mathrm{e}+006.09718 \mathrm{e}-011.00000 \mathrm{e}-092.12000 \mathrm{e}-01$ $6.09718 \mathrm{e}+006.09718 \mathrm{e}+00$ 6.09718e-01 1.00000e-09 2.12000e-01 $6.09718 \mathrm{e}+006.09718 \mathrm{e}+00$ 6.09718e-01 1.00000e-09 2.12000e-01 $6.09718 \mathrm{e}+006.09718 \mathrm{e}+00$ 6.09718e-01 1.00000e-09 2.12000e-01 $1.00000 \mathrm{e}-02$ 1.00000e-02 1.00000e-03 1.00000e-09 1.00000e-01 $1.00000 \mathrm{e}+001.00000 \mathrm{e}+001.00000 \mathrm{e}-011.00000 \mathrm{e}-091.00000 \mathrm{e}-01$ $1.00000 \mathrm{e}-05$ 1.00000e-05 1.00000e-06 1.00000e-09 1.00000e-01 $1.00000 \mathrm{e}+001.00000 \mathrm{e}+001.00000 \mathrm{e}-011.00000 \mathrm{e}-091.00000 \mathrm{e}-01$ Element: 3749 \# of layers: 15

Kx Ky Kz Ss Por

$2.50992 \mathrm{e}+022.50992 \mathrm{e}+022.50992 \mathrm{e}+01$ 1.00000e-09 7.00000e-02 $2.50992 \mathrm{e}+022.50992 \mathrm{e}+022.50992 \mathrm{e}+01$ 1.00000e-09 7.00000e-02 $2.50992 \mathrm{e}+022.50992 \mathrm{e}+022.50992 \mathrm{e}+011.00000 \mathrm{e}-09$ 7.00000e-02 $2.50992 \mathrm{e}+022.50992 \mathrm{e}+022.50992 \mathrm{e}+01$ 1.00000e-09 7.00000e-02 5.00000e-04 5.00000e-04 5.00000e-05 1.00000e-09 1.00000e-01 5.00000e-04 5.00000e-04 5.00000e-05 1.00000e-09 1.00000e-01 $1.00287 \mathrm{e}+011.00287 \mathrm{e}+011.00287 \mathrm{e}+001.00000 \mathrm{e}-092.12000 \mathrm{e}-01$ $1.00287 \mathrm{e}+011.00287 \mathrm{e}+011.00287 \mathrm{e}+001.00000 \mathrm{e}-092.12000 \mathrm{e}-01$ $1.00287 \mathrm{e}+011.00287 \mathrm{e}+011.00287 \mathrm{e}+001.00000 \mathrm{e}-092.12000 \mathrm{e}-01$ $1.00287 \mathrm{e}+011.00287 \mathrm{e}+011.00287 \mathrm{e}+001.00000 \mathrm{e}-092.12000 \mathrm{e}-01$ $1.00287 \mathrm{e}+011.00287 \mathrm{e}+011.00287 \mathrm{e}+001.00000 \mathrm{e}-092.12000 \mathrm{e}-01$ $1.00000 \mathrm{e}-02$ 1.00000e-02 1.00000e-03 1.00000e-09 1.00000e-01 $1.00000 \mathrm{e}+001.00000 \mathrm{e}+001.00000 \mathrm{e}-011.00000 \mathrm{e}-091.00000 \mathrm{e}-01$ $1.00000 \mathrm{e}-05$ 1.00000e-05 1.00000e-06 1.00000e-09 1.00000e-01 $1.00000 \mathrm{e}+001.00000 \mathrm{e}+001.00000 \mathrm{e}-011.00000 \mathrm{e}-091.00000 \mathrm{e}-01$ Element: 3750 \# of layers: 15

Kx Ky Kz Ss Por $2.50992 \mathrm{e}+022.50992 \mathrm{e}+022.50992 \mathrm{e}+01$ 1.00000e-09 7.00000e-02 $2.50992 \mathrm{e}+022.50992 \mathrm{e}+02$ 2.50992e+01 1.00000e-09 7.00000e-02 
$2.50992 \mathrm{e}+02$ 2.50992e+02 2.50992e+01 1.00000e-09 7.00000e-02 $2.50992 \mathrm{e}+02$ 2.50992e+02 2.50992e+01 1.00000e-09 7.00000e-02 5.00000e-04 5.00000e-04 5.00000e-05 1.00000e-09 1.00000e-01 5.00000e-04 5.00000e-04 5.00000e-05 1.00000e-09 1.00000e-01 $1.00287 \mathrm{e}+011.00287 \mathrm{e}+01$ 1.00287e+00 1.00000e-09 2.12000e-01 $1.00287 \mathrm{e}+01$ 1.00287e+01 1.00287e+00 1.00000e-09 2.12000e-01 $1.00287 \mathrm{e}+011.00287 \mathrm{e}+01$ 1.00287e+00 1.00000e-09 2.12000e-01 $1.00287 \mathrm{e}+01$ 1.00287e+01 1.00287e+00 1.00000e-09 2.12000e-01 $1.00287 \mathrm{e}+01$ 1.00287e+01 1.00287e+00 1.00000e-09 2.12000e-01 $1.00000 \mathrm{e}-02$ 1.00000e-02 1.00000e-03 1.00000e-09 1.00000e-01 $1.00000 \mathrm{e}+001.00000 \mathrm{e}+001.00000 \mathrm{e}-011.00000 \mathrm{e}-091.00000 \mathrm{e}-01$ $1.00000 \mathrm{e}-05$ 1.00000e-05 1.00000e-06 1.00000e-09 1.00000e-01 $1.00000 \mathrm{e}+001.00000 \mathrm{e}+001.00000 \mathrm{e}-011.00000 \mathrm{e}-09$ 1.00000e-01 Element: 3751 \# of layers: 15

$\mathrm{Kx} \mathrm{Ky} \mathrm{Kz}$ Ss Por

1.27455e+02 1.27455e+02 1.27455e+01 1.00000e-09 7.00000e-02 $1.27455 \mathrm{e}+02$ 1.27455e+02 1.27455e+01 1.00000e-09 7.00000e-02 $1.27455 \mathrm{e}+02$ 1.27455e+02 1.27455e+01 1.00000e-09 7.00000e-02 $1.27455 \mathrm{e}+021.27455 \mathrm{e}+02$ 1.27455e+01 1.00000e-09 7.00000e-02 5.00000e-04 5.00000e-04 5.00000e-05 1.00000e-09 1.00000e-01 5.00000e-04 5.00000e-04 5.00000e-05 1.00000e-09 1.00000e-01 5.09276e+00 5.09276e+00 5.09276e-01 1.00000e-09 2.12000e-01 $5.09276 \mathrm{e}+005.09276 \mathrm{e}+00$ 5.09276e-01 1.00000e-09 2.12000e-01 $5.09276 \mathrm{e}+005.09276 \mathrm{e}+00$ 5.09276e-01 1.00000e-09 2.12000e-01 $5.09276 \mathrm{e}+00$ 5.09276e+00 5.09276e-01 1.00000e-09 2.12000e-01 5.09276e+00 5.09276e+00 5.09276e-01 1.00000e-09 2.12000e-01 $1.00000 \mathrm{e}-02$ 1.00000e-02 1.00000e-03 1.00000e-09 1.00000e-01 $1.00000 \mathrm{e}+001.00000 \mathrm{e}+001.00000 \mathrm{e}-011.00000 \mathrm{e}-091.00000 \mathrm{e}-01$ $1.00000 \mathrm{e}-05$ 1.00000e-05 1.00000e-06 1.00000e-09 1.00000e-01 $1.00000 \mathrm{e}+001.00000 \mathrm{e}+001.00000 \mathrm{e}-011.00000 \mathrm{e}-091.00000 \mathrm{e}-01$ Element: 3752 \# of layers: 15

$\mathrm{Kx} \mathrm{Ky} \mathrm{Kz}$ Ss Por

$1.40826 \mathrm{e}+021.40826 \mathrm{e}+02$ 1.40826e+01 1.00000e-09 7.00000e-02 $1.40826 \mathrm{e}+021.40826 \mathrm{e}+02$ 1.40826e+01 1.00000e-09 7.00000e-02 $1.40826 \mathrm{e}+021.40826 \mathrm{e}+02 \quad 1.40826 \mathrm{e}+01$ 1.00000e-09 7.00000e-02 $1.40826 \mathrm{e}+021.40826 \mathrm{e}+02$ 1.40826e+01 1.00000e-09 7.00000e-02 5.00000e-04 5.00000e-04 5.00000e-05 1.00000e-09 1.00000e-01 5.00000e-04 5.00000e-04 5.00000e-05 1.00000e-09 1.00000e-01 $5.62692 \mathrm{e}+00$ 5.62692e+00 5.62692e-01 1.00000e-09 2.12000e-01 5.62692e+00 5.62692e+00 5.62692e-01 1.00000e-09 2.12000e-01 $5.62692 \mathrm{e}+00$ 5.62692e+00 5.62692e-01 1.00000e-09 2.12000e-01 $5.62692 \mathrm{e}+00$ 5.62692e+00 5.62692e-01 1.00000e-09 2.12000e-01 5.62692e+00 5.62692e+00 5.62692e-01 1.00000e-09 2.12000e-01 $1.00000 \mathrm{e}-02$ 1.00000e-02 1.00000e-03 1.00000e-09 1.00000e-01 $1.00000 \mathrm{e}+001.00000 \mathrm{e}+001.00000 \mathrm{e}-011.00000 \mathrm{e}-091.00000 \mathrm{e}-01$ $1.00000 \mathrm{e}-05$ 1.00000e-05 1.00000e-06 1.00000e-09 1.00000e-01 
$1.00000 \mathrm{e}+001.00000 \mathrm{e}+00$ 1.00000e-01 1.00000e-09 1.00000e-01 Element: 3753 \# of layers: 15

$\mathrm{Kx} \mathrm{Ky} \mathrm{Kz}$ Ss Por

$1.52593 e+02$ 1.52593e+02 1.52593e+01 1.00000e-09 7.00000e-02

$1.52593 \mathrm{e}+02$ 1.52593e+02 1.52593e+01 1.00000e-09 7.00000e-02

$1.52593 \mathrm{e}+021.52593 \mathrm{e}+02$ 1.52593e+01 1.00000e-09 7.00000e-02

$1.52593 \mathrm{e}+02$ 1.52593e+02 1.52593e+01 1.00000e-09 7.00000e-02

5.00000e-04 5.00000e-04 5.00000e-05 1.00000e-09 1.00000e-01

5.00000e-04 5.00000e-04 5.00000e-05 1.00000e-09 1.00000e-01

$6.09718 \mathrm{e}+006.09718 \mathrm{e}+00$ 6.09718e-01 1.00000e-09 2.12000e-01

$6.09718 \mathrm{e}+006.09718 \mathrm{e}+00$ 6.09718e-01 1.00000e-09 2.12000e-01

$6.09718 \mathrm{e}+006.09718 \mathrm{e}+00$ 6.09718e-01 1.00000e-09 2.12000e-01

6.09718e+00 6.09718e+00 6.09718e-01 1.00000e-09 2.12000e-01

$6.09718 \mathrm{e}+006.09718 \mathrm{e}+00$ 6.09718e-01 1.00000e-09 2.12000e-01

$1.00000 \mathrm{e}-02$ 1.00000e-02 1.00000e-03 1.00000e-09 1.00000e-01

$1.00000 \mathrm{e}+001.00000 \mathrm{e}+001.00000 \mathrm{e}-011.00000 \mathrm{e}-091.00000 \mathrm{e}-01$

$1.00000 \mathrm{e}-05$ 1.00000e-05 1.00000e-06 1.00000e-09 1.00000e-01

$1.00000 \mathrm{e}+001.00000 \mathrm{e}+001.00000 \mathrm{e}-01$ 1.00000e-09 1.00000e-01

Element: 3754 \# of layers: 15

$\mathrm{Kx} \mathrm{Ky} \mathrm{Kz}$ Ss Por

$2.43198 \mathrm{e}+022.43198 \mathrm{e}+02$ 2.43198e+01 1.00000e-09 7.00000e-02

$2.43198 \mathrm{e}+02$ 2.43198e+02 2.43198e+01 1.00000e-09 7.00000e-02

2.43198e+02 2.43198e+02 2.43198e+01 1.00000e-09 7.00000e-02

$2.43198 \mathrm{e}+02$ 2.43198e+02 2.43198e+01 1.00000e-09 7.00000e-02

$5.00000 \mathrm{e}-04$ 5.00000e-04 5.00000e-05 1.00000e-09 1.00000e-01

5.00000e-04 5.00000e-04 5.00000e-05 1.00000e-09 1.00000e-01

$9.71728 \mathrm{e}+00$ 9.71728e+00 9.71728e-01 1.00000e-09 2.12000e-01

$9.71728 \mathrm{e}+00$ 9.71728e+00 9.71728e-01 1.00000e-09 2.12000e-01

$9.71728 \mathrm{e}+00$ 9.71728e+00 9.71728e-01 1.00000e-09 2.12000e-01

$9.71728 \mathrm{e}+00$ 9.71728e+00 9.71728e-01 1.00000e-09 2.12000e-01

$9.71728 \mathrm{e}+00$ 9.71728e+00 9.71728e-01 1.00000e-09 2.12000e-01

$1.00000 \mathrm{e}-02$ 1.00000e-02 1.00000e-03 1.00000e-09 1.00000e-01

$1.00000 \mathrm{e}+001.00000 \mathrm{e}+001.00000 \mathrm{e}-011.00000 \mathrm{e}-091.00000 \mathrm{e}-01$

$1.00000 \mathrm{e}-05$ 1.00000e-05 1.00000e-06 1.00000e-09 1.00000e-01

$1.00000 \mathrm{e}+001.00000 \mathrm{e}+001.00000 \mathrm{e}-01$ 1.00000e-09 1.00000e-01

Element: 3755 \# of layers: 15

$\mathrm{Kx} \mathrm{Ky} \mathrm{Kz}$ Ss Por

2.71228e+02 2.71228e+02 2.71228e+01 1.00000e-09 7.00000e-02

$2.71228 \mathrm{e}+02$ 2.71228e+02 2.71228e+01 1.00000e-09 7.00000e-02

$2.71228 \mathrm{e}+02$ 2.71228e+02 2.71228e+01 1.00000e-09 7.00000e-02

$2.71228 \mathrm{e}+02$ 2.71228e+02 2.71228e+01 1.00000e-09 7.00000e-02

5.00000e-04 5.00000e-04 5.00000e-05 1.00000e-09 1.00000e-01

$5.00000 \mathrm{e}-04$ 5.00000e-04 5.00000e-05 1.00000e-09 1.00000e-01

$1.08374 \mathrm{e}+011.08374 \mathrm{e}+011.08374 \mathrm{e}+001.00000 \mathrm{e}-092.12000 \mathrm{e}-01$

$1.08374 \mathrm{e}+011.08374 \mathrm{e}+011.08374 \mathrm{e}+001.00000 \mathrm{e}-092.12000 \mathrm{e}-01$

$1.08374 \mathrm{e}+011.08374 \mathrm{e}+011.08374 \mathrm{e}+001.00000 \mathrm{e}-092.12000 \mathrm{e}-01$ 
$1.08374 \mathrm{e}+011.08374 \mathrm{e}+011.08374 \mathrm{e}+001.00000 \mathrm{e}-092.12000 \mathrm{e}-01$ $1.08374 \mathrm{e}+011.08374 \mathrm{e}+011.08374 \mathrm{e}+001.00000 \mathrm{e}-092.12000 \mathrm{e}-01$ $1.00000 \mathrm{e}-02$ 1.00000e-02 1.00000e-03 1.00000e-09 1.00000e-01 $1.00000 \mathrm{e}+001.00000 \mathrm{e}+001.00000 \mathrm{e}-011.00000 \mathrm{e}-091.00000 \mathrm{e}-01$ $1.00000 \mathrm{e}-05$ 1.00000e-05 1.00000e-06 1.00000e-09 1.00000e-01 $1.00000 \mathrm{e}+001.00000 \mathrm{e}+001.00000 \mathrm{e}-011.00000 \mathrm{e}-091.00000 \mathrm{e}-01$ Element: 3756 \# of layers: 15

$\mathrm{Kx} \mathrm{Ky} \mathrm{Kz}$ Ss Por

2.71228e+02 2.71228e+02 2.71228e+01 1.00000e-09 7.00000e-02 $2.71228 \mathrm{e}+02$ 2.71228e+02 2.71228e+01 1.00000e-09 7.00000e-02 $2.71228 \mathrm{e}+022.71228 \mathrm{e}+02 \quad 2.71228 \mathrm{e}+01$ 1.00000e-09 7.00000e-02 $2.71228 \mathrm{e}+02$ 2.71228e+02 2.71228e+01 1.00000e-09 7.00000e-02 5.00000e-04 5.00000e-04 5.00000e-05 1.00000e-09 1.00000e-01 5.00000e-04 5.00000e-04 5.00000e-05 1.00000e-09 1.00000e-01 $1.08374 \mathrm{e}+011.08374 \mathrm{e}+011.08374 \mathrm{e}+001.00000 \mathrm{e}-092.12000 \mathrm{e}-01$ $1.08374 \mathrm{e}+011.08374 \mathrm{e}+011.08374 \mathrm{e}+001.00000 \mathrm{e}-092.12000 \mathrm{e}-01$ $1.08374 \mathrm{e}+011.08374 \mathrm{e}+011.08374 \mathrm{e}+001.00000 \mathrm{e}-092.12000 \mathrm{e}-01$ $1.08374 \mathrm{e}+011.08374 \mathrm{e}+011.08374 \mathrm{e}+001.00000 \mathrm{e}-092.12000 \mathrm{e}-01$ $1.08374 \mathrm{e}+011.08374 \mathrm{e}+011.08374 \mathrm{e}+001.00000 \mathrm{e}-092.12000 \mathrm{e}-01$ $1.00000 \mathrm{e}-02$ 1.00000e-02 1.00000e-03 1.00000e-09 1.00000e-01 $1.00000 \mathrm{e}+001.00000 \mathrm{e}+001.00000 \mathrm{e}-011.00000 \mathrm{e}-091.00000 \mathrm{e}-01$ $1.00000 \mathrm{e}-05$ 1.00000e-05 1.00000e-06 1.00000e-09 1.00000e-01 $1.00000 \mathrm{e}+001.00000 \mathrm{e}+001.00000 \mathrm{e}-01$ 1.00000e-09 1.00000e-01 Element: 3757 \# of layers: 15

$\mathrm{Kx} \mathrm{Ky} \mathrm{Kz}$ Ss Por

$2.71228 \mathrm{e}+02$ 2.71228e+02 2.71228e+01 1.00000e-09 7.00000e-02 $2.71228 \mathrm{e}+02$ 2.71228e+02 2.71228e+01 1.00000e-09 7.00000e-02 $2.71228 \mathrm{e}+02$ 2.71228e+02 2.71228e+01 1.00000e-09 7.00000e-02 $2.71228 \mathrm{e}+02$ 2.71228e+02 2.71228e+01 1.00000e-09 7.00000e-02 $5.00000 \mathrm{e}-04$ 5.00000e-04 5.00000e-05 1.00000e-09 1.00000e-01 5.00000e-04 5.00000e-04 5.00000e-05 1.00000e-09 1.00000e-01 $1.08374 \mathrm{e}+011.08374 \mathrm{e}+011.08374 \mathrm{e}+001.00000 \mathrm{e}-092.12000 \mathrm{e}-01$ $1.08374 \mathrm{e}+011.08374 \mathrm{e}+011.08374 \mathrm{e}+001.00000 \mathrm{e}-092.12000 \mathrm{e}-01$ $1.08374 \mathrm{e}+011.08374 \mathrm{e}+011.08374 \mathrm{e}+001.00000 \mathrm{e}-092.12000 \mathrm{e}-01$ $1.08374 \mathrm{e}+011.08374 \mathrm{e}+011.08374 \mathrm{e}+001.00000 \mathrm{e}-092.12000 \mathrm{e}-01$ $1.08374 \mathrm{e}+011.08374 \mathrm{e}+011.08374 \mathrm{e}+001.00000 \mathrm{e}-092.12000 \mathrm{e}-01$ $1.00000 \mathrm{e}-02$ 1.00000e-02 1.00000e-03 1.00000e-09 1.00000e-01 $1.00000 \mathrm{e}+001.00000 \mathrm{e}+001.00000 \mathrm{e}-011.00000 \mathrm{e}-091.00000 \mathrm{e}-01$ $1.00000 \mathrm{e}-05$ 1.00000e-05 1.00000e-06 1.00000e-09 1.00000e-01 $1.00000 \mathrm{e}+001.00000 \mathrm{e}+001.00000 \mathrm{e}-01$ 1.00000e-09 1.00000e-01 Element: 3758 \# of layers: 15

$\mathrm{Kx} \mathrm{Ky} \mathrm{Kz}$ Ss Por 3.00646e+02 3.00646e+02 3.00646e+01 1.00000e-09 7.00000e-02 3.00646e+02 3.00646e+02 3.00646e+01 1.00000e-09 7.00000e-02 $3.00646 \mathrm{e}+02$ 3.00646e+02 3.00646e+01 1.00000e-09 7.00000e-02 $3.00646 \mathrm{e}+02$ 3.00646e+02 3.00646e+01 1.00000e-09 7.00000e-02 
5.00000e-04 5.00000e-04 5.00000e-05 1.00000e-09 1.00000e-01 5.00000e-04 5.00000e-04 5.00000e-05 1.00000e-09 1.00000e-01 $1.20128 \mathrm{e}+011.20128 \mathrm{e}+011.20128 \mathrm{e}+001.00000 \mathrm{e}-09$ 2.12000e-01 $1.20128 \mathrm{e}+011.20128 \mathrm{e}+01 \quad 1.20128 \mathrm{e}+001.00000 \mathrm{e}-092.12000 \mathrm{e}-01$ $1.20128 \mathrm{e}+011.20128 \mathrm{e}+01$ 1.20128e+00 1.00000e-09 2.12000e-01 $1.20128 \mathrm{e}+011.20128 \mathrm{e}+011.20128 \mathrm{e}+00$ 1.00000e-09 2.12000e-01 $1.20128 \mathrm{e}+011.20128 \mathrm{e}+01$ 1.20128e+00 1.00000e-09 2.12000e-01 $1.00000 \mathrm{e}-02$ 1.00000e-02 1.00000e-03 1.00000e-09 1.00000e-01 $1.00000 \mathrm{e}+001.00000 \mathrm{e}+001.00000 \mathrm{e}-011.00000 \mathrm{e}-091.00000 \mathrm{e}-01$ $1.00000 \mathrm{e}-05$ 1.00000e-05 1.00000e-06 1.00000e-09 1.00000e-01 $1.00000 \mathrm{e}+001.00000 \mathrm{e}+001.00000 \mathrm{e}-011.00000 \mathrm{e}-091.00000 \mathrm{e}-01$ Element: 3759 \# of layers: 15

$\mathrm{Kx} \mathrm{Ky} \mathrm{Kz}$ Ss Por

3.00646e+02 3.00646e+02 3.00646e+01 1.00000e-09 7.00000e-02 $3.00646 \mathrm{e}+023.00646 \mathrm{e}+023.00646 \mathrm{e}+01$ 1.00000e-09 7.00000e-02 $3.00646 \mathrm{e}+023.00646 \mathrm{e}+023.00646 \mathrm{e}+01$ 1.00000e-09 7.00000e-02 $3.00646 \mathrm{e}+02$ 3.00646e+02 3.00646e+01 1.00000e-09 7.00000e-02 5.00000e-04 5.00000e-04 5.00000e-05 1.00000e-09 1.00000e-01 5.00000e-04 5.00000e-04 5.00000e-05 1.00000e-09 1.00000e-01 $1.20128 \mathrm{e}+01$ 1.20128e+01 1.20128e+00 1.00000e-09 2.12000e-01 $1.20128 \mathrm{e}+011.20128 \mathrm{e}+011.20128 \mathrm{e}+001.00000 \mathrm{e}-092.12000 \mathrm{e}-01$ $1.20128 \mathrm{e}+011.20128 \mathrm{e}+01$ 1.20128e+00 1.00000e-09 2.12000e-01 $1.20128 \mathrm{e}+01$ 1.20128e+01 1.20128e+00 1.00000e-09 2.12000e-01 $1.20128 \mathrm{e}+011.20128 \mathrm{e}+011.20128 \mathrm{e}+001.00000 \mathrm{e}-092.12000 \mathrm{e}-01$ $1.00000 \mathrm{e}-021.00000 \mathrm{e}-02$ 1.00000e-03 1.00000e-09 1.00000e-01 $1.00000 \mathrm{e}+001.00000 \mathrm{e}+001.00000 \mathrm{e}-011.00000 \mathrm{e}-091.00000 \mathrm{e}-01$ $1.00000 \mathrm{e}-05$ 1.00000e-05 1.00000e-06 1.00000e-09 1.00000e-01 $1.00000 \mathrm{e}+001.00000 \mathrm{e}+001.00000 \mathrm{e}-011.00000 \mathrm{e}-091.00000 \mathrm{e}-01$ Element: 3760 \# of layers: 15

$\mathrm{Kx} \mathrm{Ky} \mathrm{Kz}$ Ss Por

$2.82166 \mathrm{e}+02$ 2.82166e+02 2.82166e+01 1.00000e-09 7.00000e-02 $2.82166 \mathrm{e}+022.82166 \mathrm{e}+022.82166 \mathrm{e}+01$ 1.00000e-09 7.00000e-02 $2.82166 \mathrm{e}+022.82166 \mathrm{e}+022.82166 \mathrm{e}+01$ 1.00000e-09 7.00000e-02 $2.82166 \mathrm{e}+022.82166 \mathrm{e}+022.82166 \mathrm{e}+01$ 1.00000e-09 7.00000e-02 5.00000e-04 5.00000e-04 5.00000e-05 1.00000e-09 1.00000e-01 5.00000e-04 5.00000e-04 5.00000e-05 1.00000e-09 1.00000e-01 $1.12743 \mathrm{e}+011.12743 \mathrm{e}+01$ 1.12743e+00 1.00000e-09 2.12000e-01 $1.12743 \mathrm{e}+011.12743 \mathrm{e}+01$ 1.12743e+00 1.00000e-09 2.12000e-01 $1.12743 \mathrm{e}+01$ 1.12743e+01 1.12743e+00 1.00000e-09 2.12000e-01 $1.12743 \mathrm{e}+01$ 1.12743e+01 1.12743e+00 1.00000e-09 2.12000e-01 $1.12743 \mathrm{e}+01$ 1.12743e+01 1.12743e+00 1.00000e-09 2.12000e-01 $1.00000 \mathrm{e}-02$ 1.00000e-02 1.00000e-03 1.00000e-09 1.00000e-01 $1.00000 \mathrm{e}+001.00000 \mathrm{e}+001.00000 \mathrm{e}-011.00000 \mathrm{e}-091.00000 \mathrm{e}-01$ $1.00000 \mathrm{e}-05$ 1.00000e-05 1.00000e-06 1.00000e-09 1.00000e-01 $1.00000 \mathrm{e}+001.00000 \mathrm{e}+001.00000 \mathrm{e}-011.00000 \mathrm{e}-09$ 1.00000e-01 Element: 3761 \# of layers: 15 
$\mathrm{Kx} \mathrm{Ky} \mathrm{Kz}$ Ss Por

2.43198e+02 2.43198e+02 2.43198e+01 1.00000e-09 7.00000e-02

$2.43198 \mathrm{e}+02$ 2.43198e+02 2.43198e+01 1.00000e-09 7.00000e-02

$2.43198 \mathrm{e}+02$ 2.43198e+02 2.43198e+01 1.00000e-09 7.00000e-02

$2.43198 \mathrm{e}+022.43198 \mathrm{e}+02$ 2.43198e+01 1.00000e-09 7.00000e-02

5.00000e-04 5.00000e-04 5.00000e-05 1.00000e-09 1.00000e-01

5.00000e-04 5.00000e-04 5.00000e-05 1.00000e-09 1.00000e-01

$9.71728 \mathrm{e}+00$ 9.71728e+00 9.71728e-01 1.00000e-09 2.12000e-01

$9.71728 \mathrm{e}+00$ 9.71728e+00 9.71728e-01 1.00000e-09 2.12000e-01

9.71728e+00 9.71728e+00 9.71728e-01 1.00000e-09 2.12000e-01

$9.71728 \mathrm{e}+00$ 9.71728e+00 9.71728e-01 1.00000e-09 2.12000e-01

$9.71728 \mathrm{e}+009.71728 \mathrm{e}+00$ 9.71728e-01 1.00000e-09 2.12000e-01

$1.00000 \mathrm{e}-02$ 1.00000e-02 1.00000e-03 1.00000e-09 1.00000e-01

$1.00000 \mathrm{e}+001.00000 \mathrm{e}+001.00000 \mathrm{e}-011.00000 \mathrm{e}-091.00000 \mathrm{e}-01$

$1.00000 \mathrm{e}-05$ 1.00000e-05 1.00000e-06 1.00000e-09 1.00000e-01

$1.00000 \mathrm{e}+001.00000 \mathrm{e}+001.00000 \mathrm{e}-011.00000 \mathrm{e}-091.00000 \mathrm{e}-01$

Element: 3762 \# of layers: 15

$\mathrm{Kx} \mathrm{Ky} \mathrm{Kz}$ Ss Por

2.71228e+02 2.71228e+02 2.71228e+01 1.00000e-09 7.00000e-02

$2.71228 \mathrm{e}+02$ 2.71228e+02 2.71228e+01 1.00000e-09 7.00000e-02

$2.71228 \mathrm{e}+02$ 2.71228e+02 2.71228e+01 1.00000e-09 7.00000e-02

$2.71228 \mathrm{e}+02$ 2.71228e+02 2.71228e+01 1.00000e-09 7.00000e-02

5.00000e-04 5.00000e-04 5.00000e-05 1.00000e-09 1.00000e-01

5.00000e-04 5.00000e-04 5.00000e-05 1.00000e-09 1.00000e-01

$1.08374 \mathrm{e}+011.08374 \mathrm{e}+011.08374 \mathrm{e}+001.00000 \mathrm{e}-092.12000 \mathrm{e}-01$

$1.08374 \mathrm{e}+011.08374 \mathrm{e}+011.08374 \mathrm{e}+001.00000 \mathrm{e}-092.12000 \mathrm{e}-01$

$1.08374 \mathrm{e}+011.08374 \mathrm{e}+011.08374 \mathrm{e}+001.00000 \mathrm{e}-092.12000 \mathrm{e}-01$

$1.08374 \mathrm{e}+011.08374 \mathrm{e}+011.08374 \mathrm{e}+001.00000 \mathrm{e}-092.12000 \mathrm{e}-01$

$1.08374 \mathrm{e}+011.08374 \mathrm{e}+011.08374 \mathrm{e}+001.00000 \mathrm{e}-092.12000 \mathrm{e}-01$

$1.00000 \mathrm{e}-02$ 1.00000e-02 1.00000e-03 1.00000e-09 1.00000e-01

$1.00000 \mathrm{e}+001.00000 \mathrm{e}+001.00000 \mathrm{e}-011.00000 \mathrm{e}-091.00000 \mathrm{e}-01$

$1.00000 \mathrm{e}-05$ 1.00000e-05 1.00000e-06 1.00000e-09 1.00000e-01

$1.00000 \mathrm{e}+001.00000 \mathrm{e}+001.00000 \mathrm{e}-011.00000 \mathrm{e}-091.00000 \mathrm{e}-01$

Element: 3763 \# of layers: 16

$\mathrm{Kx} \mathrm{Ky} \mathrm{Kz}$ Ss Por

$2.97303 e+02$ 2.97303e+02 2.97303e+01 1.00000e-09 7.00000e-02

$2.97303 \mathrm{e}+02$ 2.97303e+02 2.97303e+01 1.00000e-09 7.00000e-02

$2.97303 \mathrm{e}+02$ 2.97303e+02 2.97303e+01 1.00000e-09 7.00000e-02

$2.97303 \mathrm{e}+02$ 2.97303e+02 2.97303e+01 1.00000e-09 7.00000e-02

$2.97303 \mathrm{e}+02$ 2.97303e+02 2.97303e+01 1.00000e-09 7.00000e-02

5.00000e-04 5.00000e-04 5.00000e-05 1.00000e-09 1.00000e-01

5.00000e-04 5.00000e-04 5.00000e-05 1.00000e-09 1.00000e-01

$1.18791 \mathrm{e}+011.18791 \mathrm{e}+011.18791 \mathrm{e}+001.00000 \mathrm{e}-092.12000 \mathrm{e}-01$

$1.18791 \mathrm{e}+01$ 1.18791e+01 1.18791e+00 1.00000e-09 2.12000e-01

$1.18791 \mathrm{e}+011.18791 \mathrm{e}+01$ 1.18791e+00 1.00000e-09 2.12000e-01

$1.18791 \mathrm{e}+011.18791 \mathrm{e}+011.18791 \mathrm{e}+001.00000 \mathrm{e}-092.12000 \mathrm{e}-01$ 
$1.18791 \mathrm{e}+01$ 1.18791e+01 1.18791e+00 1.00000e-09 2.12000e-01 $1.00000 \mathrm{e}-02$ 1.00000e-02 1.00000e-03 1.00000e-09 1.00000e-01 $1.00000 \mathrm{e}+001.00000 \mathrm{e}+001.00000 \mathrm{e}-011.00000 \mathrm{e}-091.00000 \mathrm{e}-01$ $1.00000 \mathrm{e}-05$ 1.00000e-05 1.00000e-06 1.00000e-09 1.00000e-01 $1.00000 \mathrm{e}+001.00000 \mathrm{e}+001.00000 \mathrm{e}-011.00000 \mathrm{e}-091.00000 \mathrm{e}-01$ Element: 3764 \# of layers: 16

$\mathrm{Kx} \mathrm{Ky} \mathrm{Kz}$ Ss Por

3.07628e+02 3.07628e+02 3.07628e+01 1.00000e-09 7.00000e-02 $3.07628 \mathrm{e}+02$ 3.07628e+02 3.07628e+01 1.00000e-09 7.00000e-02 $3.07628 \mathrm{e}+02$ 3.07628e+02 3.07628e+01 1.00000e-09 7.00000e-02 $3.07628 \mathrm{e}+02$ 3.07628e+02 3.07628e+01 1.00000e-09 7.00000e-02 $3.07628 \mathrm{e}+02$ 3.07628e+02 3.07628e+01 1.00000e-09 7.00000e-02 5.00000e-04 5.00000e-04 5.00000e-05 1.00000e-09 1.00000e-01 5.00000e-04 5.00000e-04 5.00000e-05 1.00000e-09 1.00000e-01 $1.22916 \mathrm{e}+011.22916 \mathrm{e}+011.22916 \mathrm{e}+001.00000 \mathrm{e}-092.12000 \mathrm{e}-01$ $1.22916 \mathrm{e}+011.22916 \mathrm{e}+011.22916 \mathrm{e}+001.00000 \mathrm{e}-092.12000 \mathrm{e}-01$ $1.22916 \mathrm{e}+01$ 1.22916e+01 1.22916e+00 1.00000e-09 2.12000e-01 $1.22916 \mathrm{e}+01$ 1.22916e+01 1.22916e+00 1.00000e-09 2.12000e-01 $1.22916 \mathrm{e}+01$ 1.22916e+01 1.22916e+00 1.00000e-09 2.12000e-01 $1.00000 \mathrm{e}-02$ 1.00000e-02 1.00000e-03 1.00000e-09 1.00000e-01 $1.00000 \mathrm{e}+001.00000 \mathrm{e}+001.00000 \mathrm{e}-011.00000 \mathrm{e}-091.00000 \mathrm{e}-01$ $1.00000 \mathrm{e}-051.00000 \mathrm{e}-051.00000 \mathrm{e}-061.00000 \mathrm{e}-091.00000 \mathrm{e}-01$ $1.00000 \mathrm{e}+001.00000 \mathrm{e}+001.00000 \mathrm{e}-01$ 1.00000e-09 1.00000e-01 Element: 3765 \# of layers: 16

$\mathrm{Kx} \mathrm{Ky} \mathrm{Kz}$ Ss Por

3.07628e+02 3.07628e+02 3.07628e+01 1.00000e-09 7.00000e-02 $3.07628 \mathrm{e}+023.07628 \mathrm{e}+023.07628 \mathrm{e}+01$ 1.00000e-09 7.00000e-02 $3.07628 \mathrm{e}+02$ 3.07628e+02 3.07628e+01 1.00000e-09 7.00000e-02 $3.07628 \mathrm{e}+02$ 3.07628e+02 3.07628e+01 1.00000e-09 7.00000e-02 $3.07628 \mathrm{e}+02$ 3.07628e+02 3.07628e+01 1.00000e-09 7.00000e-02 5.00000e-04 5.00000e-04 5.00000e-05 1.00000e-09 1.00000e-01 5.00000e-04 5.00000e-04 5.00000e-05 1.00000e-09 1.00000e-01 $1.22916 \mathrm{e}+011.22916 \mathrm{e}+011.22916 \mathrm{e}+001.00000 \mathrm{e}-092.12000 \mathrm{e}-01$ $1.22916 \mathrm{e}+011.22916 \mathrm{e}+01 \quad 1.22916 \mathrm{e}+001.00000 \mathrm{e}-092.12000 \mathrm{e}-01$ $1.22916 \mathrm{e}+011.22916 \mathrm{e}+011.22916 \mathrm{e}+00$ 1.00000e-09 2.12000e-01 $1.22916 \mathrm{e}+011.22916 \mathrm{e}+011.22916 \mathrm{e}+00$ 1.00000e-09 2.12000e-01 $1.22916 \mathrm{e}+011.22916 \mathrm{e}+01 \quad 1.22916 \mathrm{e}+001.00000 \mathrm{e}-092.12000 \mathrm{e}-01$ $1.00000 \mathrm{e}-02$ 1.00000e-02 1.00000e-03 1.00000e-09 1.00000e-01 $1.00000 \mathrm{e}+001.00000 \mathrm{e}+001.00000 \mathrm{e}-011.00000 \mathrm{e}-091.00000 \mathrm{e}-01$ $1.00000 \mathrm{e}-05$ 1.00000e-05 1.00000e-06 1.00000e-09 1.00000e-01 $1.00000 \mathrm{e}+001.00000 \mathrm{e}+001.00000 \mathrm{e}-011.00000 \mathrm{e}-091.00000 \mathrm{e}-01$ Element: 3766 \# of layers: 15

$\mathrm{Kx} \mathrm{Ky} \mathrm{Kz}$ Ss Por

3.07628e+02 3.07628e+02 3.07628e+01 1.00000e-09 7.00000e-02 $3.07628 \mathrm{e}+02$ 3.07628e+02 3.07628e+01 1.00000e-09 7.00000e-02 $3.07628 \mathrm{e}+02$ 3.07628e+02 3.07628e+01 1.00000e-09 7.00000e-02 
3.07628e+02 3.07628e+02 3.07628e+01 1.00000e-09 7.00000e-02 5.00000e-04 5.00000e-04 5.00000e-05 1.00000e-09 1.00000e-01 5.00000e-04 5.00000e-04 5.00000e-05 1.00000e-09 1.00000e-01 $1.22916 \mathrm{e}+011.22916 \mathrm{e}+011.22916 \mathrm{e}+001.00000 \mathrm{e}-092.12000 \mathrm{e}-01$ $1.22916 \mathrm{e}+011.22916 \mathrm{e}+011.22916 \mathrm{e}+001.00000 \mathrm{e}-092.12000 \mathrm{e}-01$ $1.22916 \mathrm{e}+011.22916 \mathrm{e}+011.22916 \mathrm{e}+001.00000 \mathrm{e}-092.12000 \mathrm{e}-01$ $1.22916 \mathrm{e}+011.22916 \mathrm{e}+011.22916 \mathrm{e}+00$ 1.00000e-09 2.12000e-01 $1.22916 \mathrm{e}+011.22916 \mathrm{e}+011.22916 \mathrm{e}+001.00000 \mathrm{e}-092.12000 \mathrm{e}-01$ $1.00000 \mathrm{e}-02$ 1.00000e-02 1.00000e-03 1.00000e-09 1.00000e-01 $1.00000 \mathrm{e}+001.00000 \mathrm{e}+001.00000 \mathrm{e}-011.00000 \mathrm{e}-091.00000 \mathrm{e}-01$ $1.00000 \mathrm{e}-05$ 1.00000e-05 1.00000e-06 1.00000e-09 1.00000e-01 $1.00000 \mathrm{e}+001.00000 \mathrm{e}+001.00000 \mathrm{e}-011.00000 \mathrm{e}-091.00000 \mathrm{e}-01$ Element: 3767 \# of layers: 14

$\mathrm{Kx} \mathrm{Ky} \mathrm{Kz}$ Ss Por

3.10674e+02 3.10674e+02 3.10674e+01 1.00000e-09 7.00000e-02 $3.10674 \mathrm{e}+023.10674 \mathrm{e}+023.10674 \mathrm{e}+01$ 1.00000e-09 7.00000e-02 $3.10674 \mathrm{e}+023.10674 \mathrm{e}+023.10674 \mathrm{e}+01$ 1.00000e-09 7.00000e-02 5.00000e-04 5.00000e-04 5.00000e-05 1.00000e-09 1.00000e-01 5.00000e-04 5.00000e-04 5.00000e-05 1.00000e-09 1.00000e-01 $1.24133 \mathrm{e}+01$ 1.24133e+01 1.24133e+00 1.00000e-09 2.12000e-01 $1.24133 \mathrm{e}+011.24133 \mathrm{e}+011.24133 \mathrm{e}+001.00000 \mathrm{e}-092.12000 \mathrm{e}-01$ $1.24133 \mathrm{e}+01$ 1.24133e+01 1.24133e+00 1.00000e-09 2.12000e-01 $1.24133 \mathrm{e}+01$ 1.24133e+01 1.24133e+00 1.00000e-09 2.12000e-01 $1.24133 \mathrm{e}+011.24133 \mathrm{e}+01$ 1.24133e+00 1.00000e-09 2.12000e-01 $1.00000 \mathrm{e}-02$ 1.00000e-02 1.00000e-03 1.00000e-09 1.00000e-01 $1.00000 \mathrm{e}+001.00000 \mathrm{e}+001.00000 \mathrm{e}-011.00000 \mathrm{e}-091.00000 \mathrm{e}-01$ $1.00000 \mathrm{e}-05$ 1.00000e-05 1.00000e-06 1.00000e-09 1.00000e-01 $1.00000 \mathrm{e}+001.00000 \mathrm{e}+001.00000 \mathrm{e}-011.00000 \mathrm{e}-09$ 1.00000e-01 Element: 3768 \# of layers: 14

$\mathrm{Kx} \mathrm{Ky} \mathrm{Kz}$ Ss Por

3.10674e+02 3.10674e+02 3.10674e+01 1.00000e-09 7.00000e-02 $3.10674 \mathrm{e}+023.10674 \mathrm{e}+023.10674 \mathrm{e}+01$ 1.00000e-09 7.00000e-02 $3.10674 \mathrm{e}+02$ 3.10674e+02 3.10674e+01 1.00000e-09 7.00000e-02 $5.00000 \mathrm{e}-04$ 5.00000e-04 5.00000e-05 1.00000e-09 1.00000e-01 5.00000e-04 5.00000e-04 5.00000e-05 1.00000e-09 1.00000e-01 $1.24133 \mathrm{e}+01$ 1.24133e+01 1.24133e+00 1.00000e-09 2.12000e-01 $1.24133 \mathrm{e}+01$ 1.24133e+01 1.24133e+00 1.00000e-09 2.12000e-01 $1.24133 \mathrm{e}+011.24133 \mathrm{e}+01$ 1.24133e+00 1.00000e-09 2.12000e-01 $1.24133 \mathrm{e}+011.24133 \mathrm{e}+01$ 1.24133e+00 1.00000e-09 2.12000e-01 $1.24133 \mathrm{e}+01$ 1.24133e+01 1.24133e+00 1.00000e-09 2.12000e-01 $1.00000 \mathrm{e}-021.00000 \mathrm{e}-021.00000 \mathrm{e}-031.00000 \mathrm{e}-091.00000 \mathrm{e}-01$ $1.00000 \mathrm{e}+001.00000 \mathrm{e}+001.00000 \mathrm{e}-011.00000 \mathrm{e}-091.00000 \mathrm{e}-01$ $1.00000 \mathrm{e}-05$ 1.00000e-05 1.00000e-06 1.00000e-09 1.00000e-01 $1.00000 \mathrm{e}+001.00000 \mathrm{e}+001.00000 \mathrm{e}-01$ 1.00000e-09 1.00000e-01 Element: 3769 \# of layers: 15

Kx Ky Kz Ss Por 
3.39992e+02 3.39992e+02 3.39992e+01 1.00000e-09 7.00000e-02 3.39992e+02 3.39992e+02 3.39992e+01 1.00000e-09 7.00000e-02 $3.39992 \mathrm{e}+02$ 3.39992e+02 3.39992e+01 1.00000e-09 7.00000e-02 $3.39992 \mathrm{e}+02$ 3.39992e+02 3.39992e+01 1.00000e-09 7.00000e-02 5.00000e-04 5.00000e-04 5.00000e-05 1.00000e-09 1.00000e-01 5.00000e-04 5.00000e-04 5.00000e-05 1.00000e-09 1.00000e-01 $1.35851 \mathrm{e}+011.35851 \mathrm{e}+011.35851 \mathrm{e}+001.00000 \mathrm{e}-092.12000 \mathrm{e}-01$ $1.35851 \mathrm{e}+011.35851 \mathrm{e}+011.35851 \mathrm{e}+001.00000 \mathrm{e}-092.12000 \mathrm{e}-01$ $1.35851 \mathrm{e}+011.35851 \mathrm{e}+01$ 1.35851e+00 1.00000e-09 2.12000e-01 $1.35851 \mathrm{e}+01$ 1.35851e+01 1.35851e+00 1.00000e-09 2.12000e-01 $1.35851 \mathrm{e}+011.35851 \mathrm{e}+011.35851 \mathrm{e}+001.00000 \mathrm{e}-092.12000 \mathrm{e}-01$ $1.00000 \mathrm{e}-02$ 1.00000e-02 1.00000e-03 1.00000e-09 1.00000e-01 $1.00000 \mathrm{e}+001.00000 \mathrm{e}+001.00000 \mathrm{e}-011.00000 \mathrm{e}-091.00000 \mathrm{e}-01$ $1.00000 \mathrm{e}-05$ 1.00000e-05 1.00000e-06 1.00000e-09 1.00000e-01 $1.00000 \mathrm{e}+001.00000 \mathrm{e}+001.00000 \mathrm{e}-01$ 1.00000e-09 1.00000e-01 Element: 3770 \# of layers: 15

$\mathrm{Kx} \mathrm{Ky} \mathrm{Kz}$ Ss Por

2.97303e+02 2.97303e+02 2.97303e+01 1.00000e-09 7.00000e-02 2.97303e+02 2.97303e+02 2.97303e+01 1.00000e-09 7.00000e-02 $2.97303 \mathrm{e}+02$ 2.97303e+02 2.97303e+01 1.00000e-09 7.00000e-02 $2.97303 \mathrm{e}+02$ 2.97303e+02 2.97303e+01 1.00000e-09 7.00000e-02 5.00000e-04 5.00000e-04 5.00000e-05 1.00000e-09 1.00000e-01 5.00000e-04 5.00000e-04 5.00000e-05 1.00000e-09 1.00000e-01 $1.18791 \mathrm{e}+011.18791 \mathrm{e}+011.18791 \mathrm{e}+001.00000 \mathrm{e}-092.12000 \mathrm{e}-01$ $1.18791 \mathrm{e}+011.18791 \mathrm{e}+011.18791 \mathrm{e}+001.00000 \mathrm{e}-092.12000 \mathrm{e}-01$ $1.18791 \mathrm{e}+011.18791 \mathrm{e}+01$ 1.18791e+00 1.00000e-09 2.12000e-01 $1.18791 \mathrm{e}+011.18791 \mathrm{e}+01$ 1.18791e+00 1.00000e-09 2.12000e-01 $1.18791 \mathrm{e}+011.18791 \mathrm{e}+01$ 1.18791e+00 1.00000e-09 2.12000e-01 $1.00000 \mathrm{e}-02$ 1.00000e-02 1.00000e-03 1.00000e-09 1.00000e-01 $1.00000 \mathrm{e}+001.00000 \mathrm{e}+001.00000 \mathrm{e}-011.00000 \mathrm{e}-091.00000 \mathrm{e}-01$ $1.00000 \mathrm{e}-05$ 1.00000e-05 1.00000e-06 1.00000e-09 1.00000e-01 $1.00000 \mathrm{e}+001.00000 \mathrm{e}+001.00000 \mathrm{e}-01$ 1.00000e-09 1.00000e-01 Element: 3771 \# of layers: 14

$\mathrm{Kx} \mathrm{Ky} \mathrm{Kz}$ Ss Por

3.07628e+02 3.07628e+02 3.07628e+01 1.00000e-09 7.00000e-02 $3.07628 \mathrm{e}+023.07628 \mathrm{e}+02$ 3.07628e+01 1.00000e-09 7.00000e-02 $3.07628 \mathrm{e}+023.07628 \mathrm{e}+02$ 3.07628e+01 1.00000e-09 7.00000e-02 5.00000e-04 5.00000e-04 5.00000e-05 1.00000e-09 1.00000e-01 5.00000e-04 5.00000e-04 5.00000e-05 1.00000e-09 1.00000e-01 $1.22916 \mathrm{e}+011.22916 \mathrm{e}+011.22916 \mathrm{e}+001.00000 \mathrm{e}-092.12000 \mathrm{e}-01$ $1.22916 \mathrm{e}+011.22916 \mathrm{e}+011.22916 \mathrm{e}+001.00000 \mathrm{e}-092.12000 \mathrm{e}-01$ $1.22916 \mathrm{e}+011.22916 \mathrm{e}+011.22916 \mathrm{e}+001.00000 \mathrm{e}-092.12000 \mathrm{e}-01$ $1.22916 \mathrm{e}+01$ 1.22916e+01 1.22916e+00 1.00000e-09 2.12000e-01 $1.22916 \mathrm{e}+01$ 1.22916e+01 1.22916e+00 1.00000e-09 2.12000e-01 $1.00000 \mathrm{e}-02$ 1.00000e-02 1.00000e-03 1.00000e-09 1.00000e-01 $1.00000 \mathrm{e}+001.00000 \mathrm{e}+001.00000 \mathrm{e}-011.00000 \mathrm{e}-091.00000 \mathrm{e}-01$ 
$1.00000 \mathrm{e}-05$ 1.00000e-05 1.00000e-06 1.00000e-09 1.00000e-01 $1.00000 \mathrm{e}+001.00000 \mathrm{e}+001.00000 \mathrm{e}-01$ 1.00000e-09 1.00000e-01 Element: 3772 \# of layers: 16

Kx Ky Kz Ss Por

$1.50134 \mathrm{e}+021.50134 \mathrm{e}+02$ 1.50134e+01 1.00000e-09 7.00000e-02 $1.50134 \mathrm{e}+021.50134 \mathrm{e}+02$ 1.50134e+01 1.00000e-09 7.00000e-02 $1.50134 \mathrm{e}+021.50134 \mathrm{e}+02$ 1.50134e+01 1.00000e-09 7.00000e-02 $1.50134 \mathrm{e}+02 \quad 1.50134 \mathrm{e}+02 \quad 1.50134 \mathrm{e}+011.00000 \mathrm{e}-09$ 7.00000e-02 $1.50134 \mathrm{e}+021.50134 \mathrm{e}+021.50134 \mathrm{e}+01$ 1.00000e-09 7.00000e-02 5.00000e-04 5.00000e-04 5.00000e-05 1.00000e-09 1.00000e-01 5.00000e-04 5.00000e-04 5.00000e-05 1.00000e-09 1.00000e-01 $5.99885 \mathrm{e}+00$ 5.99885e+00 5.99885e-01 1.00000e-09 2.12000e-01 $5.99885 \mathrm{e}+00$ 5.99885e+00 5.99885e-01 1.00000e-09 2.12000e-01 $5.99885 \mathrm{e}+00$ 5.99885e+00 5.99885e-01 1.00000e-09 2.12000e-01 5.99885e+00 5.99885e+00 5.99885e-01 1.00000e-09 2.12000e-01 $5.99885 \mathrm{e}+00$ 5.99885e+00 5.99885e-01 1.00000e-09 2.12000e-01 $1.00000 \mathrm{e}-02$ 1.00000e-02 1.00000e-03 1.00000e-09 1.00000e-01 $1.00000 \mathrm{e}+001.00000 \mathrm{e}+001.00000 \mathrm{e}-011.00000 \mathrm{e}-091.00000 \mathrm{e}-01$ $1.00000 \mathrm{e}-05$ 1.00000e-05 1.00000e-06 1.00000e-09 1.00000e-01 $1.00000 \mathrm{e}+001.00000 \mathrm{e}+001.00000 \mathrm{e}-01$ 1.00000e-09 1.00000e-01 Element: 3773 \# of layers: 15

$\mathrm{Kx} \mathrm{Ky} \mathrm{Kz}$ Ss Por

7.40514e+01 7.40514e+01 7.40514e+00 1.00000e-09 7.00000e-02 $7.40514 \mathrm{e}+017.40514 \mathrm{e}+017.40514 \mathrm{e}+001.00000 \mathrm{e}-097.00000 \mathrm{e}-02$ $7.40514 \mathrm{e}+017.40514 \mathrm{e}+017.40514 \mathrm{e}+001.00000 \mathrm{e}-097.00000 \mathrm{e}-02$ $7.40514 \mathrm{e}+017.40514 \mathrm{e}+017.40514 \mathrm{e}+001.00000 \mathrm{e}-097.00000 \mathrm{e}-02$ $5.00000 \mathrm{e}-04$ 5.00000e-04 5.00000e-05 1.00000e-09 1.00000e-01 5.00000e-04 5.00000e-04 5.00000e-05 1.00000e-09 1.00000e-01 $2.95881 \mathrm{e}+002.95881 \mathrm{e}+002.95881 \mathrm{e}-01$ 1.00000e-09 2.12000e-01 $2.95881 \mathrm{e}+002.95881 \mathrm{e}+002.95881 \mathrm{e}-01$ 1.00000e-09 2.12000e-01 $2.95881 \mathrm{e}+002.95881 \mathrm{e}+002.95881 \mathrm{e}-01$ 1.00000e-09 2.12000e-01 $2.95881 \mathrm{e}+002.95881 \mathrm{e}+00$ 2.95881e-01 1.00000e-09 2.12000e-01 $2.95881 \mathrm{e}+002.95881 \mathrm{e}+002.95881 \mathrm{e}-01$ 1.00000e-09 2.12000e-01 $1.00000 \mathrm{e}-02$ 1.00000e-02 1.00000e-03 1.00000e-09 1.00000e-01 $1.00000 \mathrm{e}+001.00000 \mathrm{e}+001.00000 \mathrm{e}-011.00000 \mathrm{e}-091.00000 \mathrm{e}-01$ 1.00000e-05 1.00000e-05 1.00000e-06 1.00000e-09 1.00000e-01 $1.00000 \mathrm{e}+001.00000 \mathrm{e}+001.00000 \mathrm{e}-011.00000 \mathrm{e}-091.00000 \mathrm{e}-01$ Element: 3774 \# of layers: 15

$\mathrm{Kx} \mathrm{Ky} \mathrm{Kz}$ Ss Por

7.40514e+01 7.40514e+01 7.40514e+00 1.00000e-09 7.00000e-02 $7.40514 \mathrm{e}+017.40514 \mathrm{e}+017.40514 \mathrm{e}+001.00000 \mathrm{e}-097.00000 \mathrm{e}-02$ $7.40514 \mathrm{e}+017.40514 \mathrm{e}+017.40514 \mathrm{e}+001.00000 \mathrm{e}-097.00000 \mathrm{e}-02$ $7.40514 \mathrm{e}+017.40514 \mathrm{e}+017.40514 \mathrm{e}+001.00000 \mathrm{e}-097.00000 \mathrm{e}-02$ 5.00000e-04 5.00000e-04 5.00000e-05 1.00000e-09 1.00000e-01 5.00000e-04 5.00000e-04 5.00000e-05 1.00000e-09 1.00000e-01 $2.95881 \mathrm{e}+002.95881 \mathrm{e}+002.95881 \mathrm{e}-011.00000 \mathrm{e}-092.12000 \mathrm{e}-01$ 
$2.95881 \mathrm{e}+002.95881 \mathrm{e}+002.95881 \mathrm{e}-011.00000 \mathrm{e}-092.12000 \mathrm{e}-01$ $2.95881 \mathrm{e}+002.95881 \mathrm{e}+002.95881 \mathrm{e}-01$ 1.00000e-09 2.12000e-01 $2.95881 \mathrm{e}+002.95881 \mathrm{e}+002.95881 \mathrm{e}-01$ 1.00000e-09 2.12000e-01 $2.95881 \mathrm{e}+002.95881 \mathrm{e}+002.95881 \mathrm{e}-011.00000 \mathrm{e}-092.12000 \mathrm{e}-01$ $1.00000 \mathrm{e}-02$ 1.00000e-02 1.00000e-03 1.00000e-09 1.00000e-01 $1.00000 \mathrm{e}+001.00000 \mathrm{e}+001.00000 \mathrm{e}-011.00000 \mathrm{e}-091.00000 \mathrm{e}-01$ $1.00000 \mathrm{e}-051.00000 \mathrm{e}-05$ 1.00000e-06 1.00000e-09 1.00000e-01 $1.00000 \mathrm{e}+001.00000 \mathrm{e}+001.00000 \mathrm{e}-011.00000 \mathrm{e}-091.00000 \mathrm{e}-01$ Element: 3775 \# of layers: 15

Kx Ky Kz Ss Por

$7.40514 \mathrm{e}+017.40514 \mathrm{e}+01$ 7.40514e+00 1.00000e-09 7.00000e-02 $7.40514 \mathrm{e}+017.40514 \mathrm{e}+017.40514 \mathrm{e}+001.00000 \mathrm{e}-097.00000 \mathrm{e}-02$ $7.40514 \mathrm{e}+017.40514 \mathrm{e}+017.40514 \mathrm{e}+001.00000 \mathrm{e}-097.00000 \mathrm{e}-02$ $7.40514 \mathrm{e}+017.40514 \mathrm{e}+017.40514 \mathrm{e}+001.00000 \mathrm{e}-097.00000 \mathrm{e}-02$ $5.00000 \mathrm{e}-04$ 5.00000e-04 5.00000e-05 1.00000e-09 1.00000e-01 $5.00000 \mathrm{e}-04$ 5.00000e-04 5.00000e-05 1.00000e-09 1.00000e-01 $2.95881 \mathrm{e}+002.95881 \mathrm{e}+002.95881 \mathrm{e}-011.00000 \mathrm{e}-092.12000 \mathrm{e}-01$ $2.95881 \mathrm{e}+002.95881 \mathrm{e}+002.95881 \mathrm{e}-01$ 1.00000e-09 2.12000e-01 $2.95881 \mathrm{e}+002.95881 \mathrm{e}+002.95881 \mathrm{e}-01$ 1.00000e-09 2.12000e-01 $2.95881 \mathrm{e}+002.95881 \mathrm{e}+002.95881 \mathrm{e}-01$ 1.00000e-09 2.12000e-01 $2.95881 \mathrm{e}+002.95881 \mathrm{e}+002.95881 \mathrm{e}-011.00000 \mathrm{e}-092.12000 \mathrm{e}-01$ $1.00000 \mathrm{e}-02$ 1.00000e-02 1.00000e-03 1.00000e-09 1.00000e-01 $1.00000 \mathrm{e}+001.00000 \mathrm{e}+001.00000 \mathrm{e}-011.00000 \mathrm{e}-091.00000 \mathrm{e}-01$ $1.00000 \mathrm{e}-05$ 1.00000e-05 1.00000e-06 1.00000e-09 1.00000e-01 $1.00000 \mathrm{e}+001.00000 \mathrm{e}+001.00000 \mathrm{e}-011.00000 \mathrm{e}-091.00000 \mathrm{e}-01$ Element: 3776 \# of layers: 14

Kx Ky Kz Ss Por

$1.85543 \mathrm{e}+021.85543 \mathrm{e}+021.85543 \mathrm{e}+01$ 1.00000e-09 7.00000e-02 $1.85543 \mathrm{e}+021.85543 \mathrm{e}+021.85543 \mathrm{e}+011.00000 \mathrm{e}-09$ 7.00000e-02 $1.85543 \mathrm{e}+021.85543 \mathrm{e}+021.85543 \mathrm{e}+011.00000 \mathrm{e}-097.00000 \mathrm{e}-02$ $5.00000 \mathrm{e}-04$ 5.00000e-04 5.00000e-05 1.00000e-09 1.00000e-01 5.00000e-04 5.00000e-04 5.00000e-05 1.00000e-09 1.00000e-01 $7.41368 \mathrm{e}+007.41368 \mathrm{e}+00$ 7.41368e-01 1.00000e-09 2.12000e-01 $7.41368 \mathrm{e}+007.41368 \mathrm{e}+007.41368 \mathrm{e}-011.00000 \mathrm{e}-092.12000 \mathrm{e}-01$ $7.41368 \mathrm{e}+007.41368 \mathrm{e}+007.41368 \mathrm{e}-011.00000 \mathrm{e}-092.12000 \mathrm{e}-01$ $7.41368 \mathrm{e}+007.41368 \mathrm{e}+007.41368 \mathrm{e}-01$ 1.00000e-09 2.12000e-01 $7.41368 \mathrm{e}+007.41368 \mathrm{e}+00$ 7.41368e-01 1.00000e-09 2.12000e-01 $1.00000 \mathrm{e}-021.00000 \mathrm{e}-02$ 1.00000e-03 1.00000e-09 1.00000e-01 $1.00000 \mathrm{e}+001.00000 \mathrm{e}+001.00000 \mathrm{e}-011.00000 \mathrm{e}-091.00000 \mathrm{e}-01$ $1.00000 \mathrm{e}-05$ 1.00000e-05 1.00000e-06 1.00000e-09 1.00000e-01 $1.00000 \mathrm{e}+001.00000 \mathrm{e}+001.00000 \mathrm{e}-011.00000 \mathrm{e}-091.00000 \mathrm{e}-01$ Element: 3777 \# of layers: 15

Kx Ky Kz Ss Por

$1.85543 \mathrm{e}+021.85543 \mathrm{e}+021.85543 \mathrm{e}+01$ 1.00000e-09 7.00000e-02 $1.85543 \mathrm{e}+021.85543 \mathrm{e}+021.85543 \mathrm{e}+01$ 1.00000e-09 7.00000e-02 $1.85543 \mathrm{e}+021.85543 \mathrm{e}+021.85543 \mathrm{e}+01$ 1.00000e-09 7.00000e-02 
$1.85543 \mathrm{e}+02$ 1.85543e+02 1.85543e+01 1.00000e-09 7.00000e-02 5.00000e-04 5.00000e-04 5.00000e-05 1.00000e-09 1.00000e-01 5.00000e-04 5.00000e-04 5.00000e-05 1.00000e-09 1.00000e-01

$7.41368 \mathrm{e}+00$ 7.41368e+00 7.41368e-01 1.00000e-09 2.12000e-01 7.41368e+00 7.41368e+00 7.41368e-01 1.00000e-09 2.12000e-01 $7.41368 \mathrm{e}+00$ 7.41368e+00 7.41368e-01 1.00000e-09 2.12000e-01 $7.41368 \mathrm{e}+00$ 7.41368e+00 7.41368e-01 1.00000e-09 2.12000e-01 $7.41368 \mathrm{e}+007.41368 \mathrm{e}+00$ 7.41368e-01 1.00000e-09 2.12000e-01 $1.00000 \mathrm{e}-02$ 1.00000e-02 1.00000e-03 1.00000e-09 1.00000e-01 $1.00000 \mathrm{e}+001.00000 \mathrm{e}+001.00000 \mathrm{e}-011.00000 \mathrm{e}-091.00000 \mathrm{e}-01$ $1.00000 \mathrm{e}-05$ 1.00000e-05 1.00000e-06 1.00000e-09 1.00000e-01 $1.00000 \mathrm{e}+001.00000 \mathrm{e}+001.00000 \mathrm{e}-011.00000 \mathrm{e}-091.00000 \mathrm{e}-01$ Element: 3778 \# of layers: 15

$\mathrm{Kx} \mathrm{Ky} \mathrm{Kz}$ Ss Por

1.94859e+02 1.94859e+02 1.94859e+01 1.00000e-09 7.00000e-02 $1.94859 \mathrm{e}+02$ 1.94859e+02 1.94859e+01 1.00000e-09 7.00000e-02 $1.94859 \mathrm{e}+02$ 1.94859e+02 1.94859e+01 1.00000e-09 7.00000e-02 $1.94859 \mathrm{e}+02$ 1.94859e+02 1.94859e+01 1.00000e-09 7.00000e-02 5.00000e-04 5.00000e-04 5.00000e-05 1.00000e-09 1.00000e-01 5.00000e-04 5.00000e-04 5.00000e-05 1.00000e-09 1.00000e-01 $7.78607 \mathrm{e}+00$ 7.78607e+00 7.78607e-01 1.00000e-09 2.12000e-01 7.78607e+00 7.78607e+00 7.78607e-01 1.00000e-09 2.12000e-01 7.78607e+00 7.78607e+00 7.78607e-01 1.00000e-09 2.12000e-01 7.78607e+00 7.78607e+00 7.78607e-01 1.00000e-09 2.12000e-01 7.78607e+00 7.78607e+00 7.78607e-01 1.00000e-09 2.12000e-01 $1.00000 \mathrm{e}-021.00000 \mathrm{e}-021.00000 \mathrm{e}-031.00000 \mathrm{e}-091.00000 \mathrm{e}-01$ $1.00000 \mathrm{e}+001.00000 \mathrm{e}+001.00000 \mathrm{e}-011.00000 \mathrm{e}-091.00000 \mathrm{e}-01$ $1.00000 \mathrm{e}-05$ 1.00000e-05 1.00000e-06 1.00000e-09 1.00000e-01 $1.00000 \mathrm{e}+001.00000 \mathrm{e}+001.00000 \mathrm{e}-011.00000 \mathrm{e}-091.00000 \mathrm{e}-01$ Element: 3779 \# of layers: 16

$\mathrm{Kx} \mathrm{Ky} \mathrm{Kz}$ Ss Por

$1.50134 \mathrm{e}+02$ 1.50134e+02 1.50134e+01 1.00000e-09 7.00000e-02 $1.50134 \mathrm{e}+021.50134 \mathrm{e}+021.50134 \mathrm{e}+01$ 1.00000e-09 7.00000e-02 $1.50134 \mathrm{e}+021.50134 \mathrm{e}+02$ 1.50134e+01 1.00000e-09 7.00000e-02 $1.50134 \mathrm{e}+021.50134 \mathrm{e}+02 \quad 1.50134 \mathrm{e}+01$ 1.00000e-09 7.00000e-02 $1.50134 \mathrm{e}+021.50134 \mathrm{e}+021.50134 \mathrm{e}+01$ 1.00000e-09 7.00000e-02 5.00000e-04 5.00000e-04 5.00000e-05 1.00000e-09 1.00000e-01 5.00000e-04 5.00000e-04 5.00000e-05 1.00000e-09 1.00000e-01 $5.99885 \mathrm{e}+00$ 5.99885e+00 5.99885e-01 1.00000e-09 2.12000e-01 5.99885e+00 5.99885e+00 5.99885e-01 1.00000e-09 2.12000e-01 $5.99885 \mathrm{e}+00$ 5.99885e+00 5.99885e-01 1.00000e-09 2.12000e-01 $5.99885 \mathrm{e}+00$ 5.99885e+00 5.99885e-01 1.00000e-09 2.12000e-01 5.99885e+00 5.99885e+00 5.99885e-01 1.00000e-09 2.12000e-01 $1.00000 \mathrm{e}-02$ 1.00000e-02 1.00000e-03 1.00000e-09 1.00000e-01 $1.00000 \mathrm{e}+001.00000 \mathrm{e}+001.00000 \mathrm{e}-011.00000 \mathrm{e}-091.00000 \mathrm{e}-01$ $1.00000 \mathrm{e}-05$ 1.00000e-05 1.00000e-06 1.00000e-09 1.00000e-01 
$1.00000 \mathrm{e}+001.00000 \mathrm{e}+00$ 1.00000e-01 1.00000e-09 1.00000e-01 Element: 3780 \# of layers: 15

$\mathrm{Kx} \mathrm{Ky} \mathrm{Kz}$ Ss Por

7.40514e+01 7.40514e+01 7.40514e+00 1.00000e-09 7.00000e-02 $7.40514 \mathrm{e}+017.40514 \mathrm{e}+017.40514 \mathrm{e}+001.00000 \mathrm{e}-097.00000 \mathrm{e}-02$ $7.40514 \mathrm{e}+017.40514 \mathrm{e}+017.40514 \mathrm{e}+001.00000 \mathrm{e}-097.00000 \mathrm{e}-02$ $7.40514 \mathrm{e}+017.40514 \mathrm{e}+017.40514 \mathrm{e}+001.00000 \mathrm{e}-097.00000 \mathrm{e}-02$ 5.00000e-04 5.00000e-04 5.00000e-05 1.00000e-09 1.00000e-01 5.00000e-04 5.00000e-04 5.00000e-05 1.00000e-09 1.00000e-01 $2.95881 \mathrm{e}+002.95881 \mathrm{e}+00$ 2.95881e-01 1.00000e-09 2.12000e-01 $2.95881 \mathrm{e}+002.95881 \mathrm{e}+00$ 2.95881e-01 1.00000e-09 2.12000e-01 $2.95881 \mathrm{e}+002.95881 \mathrm{e}+002.95881 \mathrm{e}-01$ 1.00000e-09 2.12000e-01 $2.95881 \mathrm{e}+002.95881 \mathrm{e}+002.95881 \mathrm{e}-01$ 1.00000e-09 2.12000e-01 $2.95881 \mathrm{e}+002.95881 \mathrm{e}+002.95881 \mathrm{e}-01$ 1.00000e-09 2.12000e-01 $1.00000 \mathrm{e}-02$ 1.00000e-02 1.00000e-03 1.00000e-09 1.00000e-01 $1.00000 \mathrm{e}+001.00000 \mathrm{e}+001.00000 \mathrm{e}-011.00000 \mathrm{e}-091.00000 \mathrm{e}-01$ $1.00000 \mathrm{e}-05$ 1.00000e-05 1.00000e-06 1.00000e-09 1.00000e-01 $1.00000 \mathrm{e}+001.00000 \mathrm{e}+001.00000 \mathrm{e}-01$ 1.00000e-09 1.00000e-01 Element: 3781 \# of layers: 15

$\mathrm{Kx} \mathrm{Ky} \mathrm{Kz}$ Ss Por

7.09583e+01 7.09583e+01 7.09583e+00 1.00000e-09 7.00000e-02 7.09583e+01 7.09583e+01 7.09583e+00 1.00000e-09 7.00000e-02 7.09583e+01 7.09583e+01 7.09583e+00 1.00000e-09 7.00000e-02 7.09583e+01 7.09583e+01 7.09583e+00 1.00000e-09 7.00000e-02 5.00000e-04 5.00000e-04 5.00000e-05 1.00000e-09 1.00000e-01 $5.00000 \mathrm{e}-04$ 5.00000e-04 5.00000e-05 1.00000e-09 1.00000e-01 $2.83528 \mathrm{e}+002.83528 \mathrm{e}+00$ 2.83528e-01 1.00000e-09 2.12000e-01 $2.83528 \mathrm{e}+002.83528 \mathrm{e}+002.83528 \mathrm{e}-01$ 1.00000e-09 2.12000e-01 $2.83528 \mathrm{e}+002.83528 \mathrm{e}+002.83528 \mathrm{e}-01$ 1.00000e-09 2.12000e-01 $2.83528 \mathrm{e}+00$ 2.83528e+00 2.83528e-01 1.00000e-09 2.12000e-01 $2.83528 \mathrm{e}+002.83528 \mathrm{e}+00$ 2.83528e-01 1.00000e-09 2.12000e-01 $1.00000 \mathrm{e}-02$ 1.00000e-02 1.00000e-03 1.00000e-09 1.00000e-01 $1.00000 \mathrm{e}+001.00000 \mathrm{e}+001.00000 \mathrm{e}-011.00000 \mathrm{e}-091.00000 \mathrm{e}-01$ $1.00000 \mathrm{e}-05$ 1.00000e-05 1.00000e-06 1.00000e-09 1.00000e-01 $1.00000 \mathrm{e}+001.00000 \mathrm{e}+001.00000 \mathrm{e}-011.00000 \mathrm{e}-091.00000 \mathrm{e}-01$ Element: 3782 \# of layers: 16

Kx Ky Kz Ss Por

7.50146e+01 7.50146e+01 7.50146e+00 1.00000e-09 7.00000e-02 7.50146e+01 7.50146e+01 7.50146e+00 1.00000e-09 7.00000e-02 $7.50146 \mathrm{e}+017.50146 \mathrm{e}+01$ 7.50146e+00 1.00000e-09 7.00000e-02 $7.50146 \mathrm{e}+017.50146 \mathrm{e}+01$ 7.50146e+00 1.00000e-09 7.00000e-02 $7.50146 \mathrm{e}+017.50146 \mathrm{e}+017.50146 \mathrm{e}+001.00000 \mathrm{e}-09$ 7.00000e-02 5.00000e-04 5.00000e-04 5.00000e-05 1.00000e-09 1.00000e-01 5.00000e-04 5.00000e-04 5.00000e-05 1.00000e-09 1.00000e-01 $2.99729 \mathrm{e}+002.99729 \mathrm{e}+002.99729 \mathrm{e}-01$ 1.00000e-09 2.12000e-01 $2.99729 \mathrm{e}+002.99729 \mathrm{e}+00$ 2.99729e-01 1.00000e-09 2.12000e-01 
$2.99729 \mathrm{e}+002.99729 \mathrm{e}+002.99729 \mathrm{e}-01$ 1.00000e-09 2.12000e-01 $2.99729 \mathrm{e}+002.99729 \mathrm{e}+002.99729 \mathrm{e}-01$ 1.00000e-09 2.12000e-01 $2.99729 \mathrm{e}+002.99729 \mathrm{e}+002.99729 \mathrm{e}-01$ 1.00000e-09 2.12000e-01 $1.00000 \mathrm{e}-021.00000 \mathrm{e}-02$ 1.00000e-03 1.00000e-09 1.00000e-01 $1.00000 \mathrm{e}+001.00000 \mathrm{e}+001.00000 \mathrm{e}-011.00000 \mathrm{e}-091.00000 \mathrm{e}-01$ $1.00000 \mathrm{e}-05$ 1.00000e-05 1.00000e-06 1.00000e-09 1.00000e-01 $1.00000 \mathrm{e}+001.00000 \mathrm{e}+001.00000 \mathrm{e}-011.00000 \mathrm{e}-091.00000 \mathrm{e}-01$ Element: 3783 \# of layers: 15

Kx Ky Kz Ss Por

7.50146e+01 7.50146e+01 7.50146e+00 1.00000e-09 7.00000e-02 $7.50146 \mathrm{e}+017.50146 \mathrm{e}+017.50146 \mathrm{e}+001.00000 \mathrm{e}-097.00000 \mathrm{e}-02$ $7.50146 \mathrm{e}+017.50146 \mathrm{e}+017.50146 \mathrm{e}+001.00000 \mathrm{e}-09$ 7.00000e-02 $7.50146 \mathrm{e}+017.50146 \mathrm{e}+017.50146 \mathrm{e}+001.00000 \mathrm{e}-097.00000 \mathrm{e}-02$ 5.00000e-04 5.00000e-04 5.00000e-05 1.00000e-09 1.00000e-01 $5.00000 \mathrm{e}-04$ 5.00000e-04 5.00000e-05 1.00000e-09 1.00000e-01 $2.99729 \mathrm{e}+002.99729 \mathrm{e}+002.99729 \mathrm{e}-01$ 1.00000e-09 2.12000e-01 $2.99729 \mathrm{e}+002.99729 \mathrm{e}+002.99729 \mathrm{e}-01$ 1.00000e-09 2.12000e-01 $2.99729 \mathrm{e}+002.99729 \mathrm{e}+002.99729 \mathrm{e}-01$ 1.00000e-09 2.12000e-01 $2.99729 \mathrm{e}+002.99729 \mathrm{e}+002.99729 \mathrm{e}-01$ 1.00000e-09 2.12000e-01 $2.99729 \mathrm{e}+002.99729 \mathrm{e}+002.99729 \mathrm{e}-01$ 1.00000e-09 2.12000e-01 $1.00000 \mathrm{e}-021.00000 \mathrm{e}-02$ 1.00000e-03 1.00000e-09 1.00000e-01 $1.00000 \mathrm{e}+001.00000 \mathrm{e}+001.00000 \mathrm{e}-011.00000 \mathrm{e}-091.00000 \mathrm{e}-01$ $1.00000 \mathrm{e}-05$ 1.00000e-05 1.00000e-06 1.00000e-09 1.00000e-01 $1.00000 \mathrm{e}+001.00000 \mathrm{e}+001.00000 \mathrm{e}-011.00000 \mathrm{e}-091.00000 \mathrm{e}-01$ Element: 3784 \# of layers: 15

Kx Ky Kz Ss Por

7.50146e+01 7.50146e+01 7.50146e+00 1.00000e-09 7.00000e-02 $7.50146 \mathrm{e}+017.50146 \mathrm{e}+017.50146 \mathrm{e}+001.00000 \mathrm{e}-09$ 7.00000e-02 $7.50146 \mathrm{e}+017.50146 \mathrm{e}+017.50146 \mathrm{e}+001.00000 \mathrm{e}-09$ 7.00000e-02 $7.50146 \mathrm{e}+017.50146 \mathrm{e}+017.50146 \mathrm{e}+001.00000 \mathrm{e}-097.00000 \mathrm{e}-02$ 5.00000e-04 5.00000e-04 5.00000e-05 1.00000e-09 1.00000e-01 5.00000e-04 5.00000e-04 5.00000e-05 1.00000e-09 1.00000e-01 $2.99729 \mathrm{e}+002.99729 \mathrm{e}+002.99729 \mathrm{e}-01$ 1.00000e-09 2.12000e-01 $2.99729 \mathrm{e}+002.99729 \mathrm{e}+002.99729 \mathrm{e}-011.00000 \mathrm{e}-092.12000 \mathrm{e}-01$ $2.99729 \mathrm{e}+002.99729 \mathrm{e}+002.99729 \mathrm{e}-011.00000 \mathrm{e}-092.12000 \mathrm{e}-01$ $2.99729 \mathrm{e}+002.99729 \mathrm{e}+002.99729 \mathrm{e}-011.00000 \mathrm{e}-092.12000 \mathrm{e}-01$ $2.99729 \mathrm{e}+002.99729 \mathrm{e}+002.99729 \mathrm{e}-01$ 1.00000e-09 2.12000e-01 $1.00000 \mathrm{e}-021.00000 \mathrm{e}-02$ 1.00000e-03 1.00000e-09 1.00000e-01 $1.00000 \mathrm{e}+001.00000 \mathrm{e}+001.00000 \mathrm{e}-011.00000 \mathrm{e}-091.00000 \mathrm{e}-01$ $1.00000 \mathrm{e}-05$ 1.00000e-05 1.00000e-06 1.00000e-09 1.00000e-01 $1.00000 \mathrm{e}+001.00000 \mathrm{e}+001.00000 \mathrm{e}-011.00000 \mathrm{e}-091.00000 \mathrm{e}-01$ Element: 3785 \# of layers: 15

Kx Ky Kz Ss Por

$6.57667 \mathrm{e}+016.57667 \mathrm{e}+016.57667 \mathrm{e}+00$ 1.00000e-09 7.00000e-02 $6.57667 \mathrm{e}+016.57667 \mathrm{e}+016.57667 \mathrm{e}+001.00000 \mathrm{e}-09$ 7.00000e-02 $6.57667 \mathrm{e}+016.57667 \mathrm{e}+016.57667 \mathrm{e}+001.00000 \mathrm{e}-09$ 7.00000e-02 
6.57667e+01 6.57667e+01 6.57667e+00 1.00000e-09 7.00000e-02 5.00000e-04 5.00000e-04 5.00000e-05 1.00000e-09 1.00000e-01 5.00000e-04 5.00000e-04 5.00000e-05 1.00000e-09 1.00000e-01 $2.62783 \mathrm{e}+002.62783 \mathrm{e}+002.62783 \mathrm{e}-01$ 1.00000e-09 2.12000e-01 $2.62783 \mathrm{e}+002.62783 \mathrm{e}+00$ 2.62783e-01 1.00000e-09 2.12000e-01 $2.62783 \mathrm{e}+002.62783 \mathrm{e}+00$ 2.62783e-01 1.00000e-09 2.12000e-01 $2.62783 \mathrm{e}+002.62783 \mathrm{e}+00$ 2.62783e-01 1.00000e-09 2.12000e-01 $2.62783 \mathrm{e}+002.62783 \mathrm{e}+00$ 2.62783e-01 1.00000e-09 2.12000e-01 $1.00000 \mathrm{e}-02$ 1.00000e-02 1.00000e-03 1.00000e-09 1.00000e-01 $1.00000 \mathrm{e}+001.00000 \mathrm{e}+001.00000 \mathrm{e}-011.00000 \mathrm{e}-091.00000 \mathrm{e}-01$ $1.00000 \mathrm{e}-05$ 1.00000e-05 1.00000e-06 1.00000e-09 1.00000e-01 $1.00000 \mathrm{e}+001.00000 \mathrm{e}+001.00000 \mathrm{e}-011.00000 \mathrm{e}-091.00000 \mathrm{e}-01$ Element: 3786 \# of layers: 13

$\mathrm{Kx} \mathrm{Ky} \mathrm{Kz}$ Ss Por

6.57667e+01 6.57667e+01 6.57667e+00 1.00000e-09 7.00000e-02 $6.57667 \mathrm{e}+016.57667 \mathrm{e}+016.57667 \mathrm{e}+00$ 1.00000e-09 7.00000e-02 $6.57667 \mathrm{e}+016.57667 \mathrm{e}+016.57667 \mathrm{e}+001.00000 \mathrm{e}-09$ 7.00000e-02 5.00000e-04 5.00000e-04 5.00000e-05 1.00000e-09 1.00000e-01 $2.62783 \mathrm{e}+002.62783 \mathrm{e}+00$ 2.62783e-01 1.00000e-09 2.12000e-01 $2.62783 \mathrm{e}+002.62783 \mathrm{e}+00$ 2.62783e-01 1.00000e-09 2.12000e-01 $2.62783 \mathrm{e}+002.62783 \mathrm{e}+00$ 2.62783e-01 1.00000e-09 2.12000e-01 $2.62783 \mathrm{e}+002.62783 \mathrm{e}+00$ 2.62783e-01 1.00000e-09 2.12000e-01 $2.62783 \mathrm{e}+002.62783 \mathrm{e}+00$ 2.62783e-01 1.00000e-09 2.12000e-01 1.00000e-02 1.00000e-02 1.00000e-03 1.00000e-09 1.00000e-01 $1.00000 \mathrm{e}+001.00000 \mathrm{e}+001.00000 \mathrm{e}-011.00000 \mathrm{e}-091.00000 \mathrm{e}-01$ $1.00000 \mathrm{e}-05$ 1.00000e-05 1.00000e-06 1.00000e-09 1.00000e-01 $1.00000 \mathrm{e}+001.00000 \mathrm{e}+001.00000 \mathrm{e}-011.00000 \mathrm{e}-091.00000 \mathrm{e}-01$ Element: 3787 \# of layers: 14

Kx Ky Kz Ss Por

1.30167e+02 1.30167e+02 1.30167e+01 1.00000e-09 7.00000e-02 $1.30167 \mathrm{e}+02$ 1.30167e+02 1.30167e+01 1.00000e-09 7.00000e-02 $1.30167 \mathrm{e}+02$ 1.30167e+02 1.30167e+01 1.00000e-09 7.00000e-02 5.00000e-04 5.00000e-04 5.00000e-05 1.00000e-09 1.00000e-01 5.00000e-04 5.00000e-04 5.00000e-05 1.00000e-09 1.00000e-01 $5.20099 \mathrm{e}+00$ 5.20099e+00 5.20099e-01 1.00000e-09 2.12000e-01 5.20099e+00 5.20099e+00 5.20099e-01 1.00000e-09 2.12000e-01 $5.20099 \mathrm{e}+00$ 5.20099e+00 5.20099e-01 1.00000e-09 2.12000e-01 $5.20099 \mathrm{e}+00$ 5.20099e+00 5.20099e-01 1.00000e-09 2.12000e-01 5.20099e+00 5.20099e+00 5.20099e-01 1.00000e-09 2.12000e-01 1.00000e-02 1.00000e-02 1.00000e-03 1.00000e-09 1.00000e-01 $1.00000 \mathrm{e}+001.00000 \mathrm{e}+001.00000 \mathrm{e}-011.00000 \mathrm{e}-091.00000 \mathrm{e}-01$ $1.00000 \mathrm{e}-05$ 1.00000e-05 1.00000e-06 1.00000e-09 1.00000e-01 $1.00000 \mathrm{e}+001.00000 \mathrm{e}+001.00000 \mathrm{e}-011.00000 \mathrm{e}-091.00000 \mathrm{e}-01$ Element: 3788 \# of layers: 15

$\mathrm{Kx} \mathrm{Ky} \mathrm{Kz} \mathrm{Ss} \mathrm{Por}$

7.09583e+01 7.09583e+01 7.09583e+00 1.00000e-09 7.00000e-02 
7.09583e+01 7.09583e+01 7.09583e+00 1.00000e-09 7.00000e-02 $7.09583 \mathrm{e}+01$ 7.09583e+01 7.09583e+00 1.00000e-09 7.00000e-02 $7.09583 \mathrm{e}+01$ 7.09583e+01 7.09583e+00 1.00000e-09 7.00000e-02 5.00000e-04 5.00000e-04 5.00000e-05 1.00000e-09 1.00000e-01 5.00000e-04 5.00000e-04 5.00000e-05 1.00000e-09 1.00000e-01 $2.83528 \mathrm{e}+002.83528 \mathrm{e}+002.83528 \mathrm{e}-01$ 1.00000e-09 2.12000e-01 $2.83528 \mathrm{e}+002.83528 \mathrm{e}+00$ 2.83528e-01 1.00000e-09 2.12000e-01 $2.83528 \mathrm{e}+002.83528 \mathrm{e}+00$ 2.83528e-01 1.00000e-09 2.12000e-01 $2.83528 \mathrm{e}+002.83528 \mathrm{e}+00$ 2.83528e-01 1.00000e-09 2.12000e-01 $2.83528 \mathrm{e}+002.83528 \mathrm{e}+00$ 2.83528e-01 1.00000e-09 2.12000e-01 $1.00000 \mathrm{e}-02$ 1.00000e-02 1.00000e-03 1.00000e-09 1.00000e-01 $1.00000 \mathrm{e}+001.00000 \mathrm{e}+001.00000 \mathrm{e}-011.00000 \mathrm{e}-091.00000 \mathrm{e}-01$ $1.00000 \mathrm{e}-05$ 1.00000e-05 1.00000e-06 1.00000e-09 1.00000e-01 $1.00000 \mathrm{e}+001.00000 \mathrm{e}+001.00000 \mathrm{e}-011.00000 \mathrm{e}-09$ 1.00000e-01 Element: 3789 \# of layers: 15

Kx Ky Kz Ss Por

7.50146e+01 7.50146e+01 7.50146e+00 1.00000e-09 7.00000e-02 $7.50146 \mathrm{e}+017.50146 \mathrm{e}+01$ 7.50146e+00 1.00000e-09 7.00000e-02 $7.50146 \mathrm{e}+01$ 7.50146e+01 7.50146e+00 1.00000e-09 7.00000e-02 7.50146e+01 7.50146e+01 7.50146e+00 1.00000e-09 7.00000e-02 5.00000e-04 5.00000e-04 5.00000e-05 1.00000e-09 1.00000e-01 5.00000e-04 5.00000e-04 5.00000e-05 1.00000e-09 1.00000e-01 $2.99729 \mathrm{e}+002.99729 \mathrm{e}+00$ 2.99729e-01 1.00000e-09 2.12000e-01 $2.99729 \mathrm{e}+002.99729 \mathrm{e}+002.99729 \mathrm{e}-01$ 1.00000e-09 2.12000e-01 $2.99729 \mathrm{e}+002.99729 \mathrm{e}+00$ 2.99729e-01 1.00000e-09 2.12000e-01 $2.99729 \mathrm{e}+002.99729 \mathrm{e}+00$ 2.99729e-01 1.00000e-09 2.12000e-01 $2.99729 \mathrm{e}+002.99729 \mathrm{e}+00$ 2.99729e-01 1.00000e-09 2.12000e-01 $1.00000 \mathrm{e}-02$ 1.00000e-02 1.00000e-03 1.00000e-09 1.00000e-01 $1.00000 \mathrm{e}+001.00000 \mathrm{e}+001.00000 \mathrm{e}-011.00000 \mathrm{e}-091.00000 \mathrm{e}-01$ $1.00000 \mathrm{e}-05$ 1.00000e-05 1.00000e-06 1.00000e-09 1.00000e-01 $1.00000 \mathrm{e}+001.00000 \mathrm{e}+001.00000 \mathrm{e}-011.00000 \mathrm{e}-091.00000 \mathrm{e}-01$ Element: 3790 \# of layers: 14

$\mathrm{Kx} \mathrm{Ky} \mathrm{Kz}$ Ss Por

4.24677e+01 4.24677e+01 4.24677e+00 1.00000e-09 7.00000e-02 4.24677e+01 4.24677e+01 4.24677e+00 1.00000e-09 7.00000e-02 4.24677e+01 4.24677e+01 4.24677e+00 1.00000e-09 7.00000e-02 5.00000e-04 5.00000e-04 5.00000e-05 1.00000e-09 1.00000e-01 5.00000e-04 5.00000e-04 5.00000e-05 1.00000e-09 1.00000e-01 $1.69685 \mathrm{e}+001.69685 \mathrm{e}+001.69685 \mathrm{e}-011.00000 \mathrm{e}-092.12000 \mathrm{e}-01$ $1.69685 \mathrm{e}+001.69685 \mathrm{e}+00$ 1.69685e-01 1.00000e-09 2.12000e-01 $1.69685 \mathrm{e}+001.69685 \mathrm{e}+00$ 1.69685e-01 1.00000e-09 2.12000e-01 $1.69685 \mathrm{e}+001.69685 \mathrm{e}+001.69685 \mathrm{e}-011.00000 \mathrm{e}-092.12000 \mathrm{e}-01$ $1.69685 \mathrm{e}+001.69685 \mathrm{e}+00$ 1.69685e-01 1.00000e-09 2.12000e-01 $1.00000 \mathrm{e}-02$ 1.00000e-02 1.00000e-03 1.00000e-09 1.00000e-01 $1.00000 \mathrm{e}+001.00000 \mathrm{e}+001.00000 \mathrm{e}-011.00000 \mathrm{e}-091.00000 \mathrm{e}-01$ $1.00000 \mathrm{e}-05$ 1.00000e-05 1.00000e-06 1.00000e-09 1.00000e-01 
$1.00000 \mathrm{e}+001.00000 \mathrm{e}+00$ 1.00000e-01 1.00000e-09 1.00000e-01 Element: 3791 \# of layers: 14

$\mathrm{Kx} \mathrm{Ky} \mathrm{Kz}$ Ss Por

4.24677e+01 4.24677e+01 4.24677e+00 1.00000e-09 7.00000e-02 4.24677e+01 4.24677e+01 4.24677e+00 1.00000e-09 7.00000e-02 4.24677e+01 4.24677e+01 4.24677e+00 1.00000e-09 7.00000e-02 5.00000e-04 5.00000e-04 5.00000e-05 1.00000e-09 1.00000e-01 5.00000e-04 5.00000e-04 5.00000e-05 1.00000e-09 1.00000e-01 $1.69685 \mathrm{e}+001.69685 \mathrm{e}+00$ 1.69685e-01 1.00000e-09 2.12000e-01 $1.69685 \mathrm{e}+001.69685 \mathrm{e}+001.69685 \mathrm{e}-01$ 1.00000e-09 2.12000e-01 $1.69685 \mathrm{e}+001.69685 \mathrm{e}+00$ 1.69685e-01 1.00000e-09 2.12000e-01 $1.69685 \mathrm{e}+001.69685 \mathrm{e}+00$ 1.69685e-01 1.00000e-09 2.12000e-01 $1.69685 \mathrm{e}+001.69685 \mathrm{e}+001.69685 \mathrm{e}-01$ 1.00000e-09 2.12000e-01 $1.00000 \mathrm{e}-02$ 1.00000e-02 1.00000e-03 1.00000e-09 1.00000e-01 $1.00000 \mathrm{e}+001.00000 \mathrm{e}+001.00000 \mathrm{e}-011.00000 \mathrm{e}-091.00000 \mathrm{e}-01$ $1.00000 \mathrm{e}-05$ 1.00000e-05 1.00000e-06 1.00000e-09 1.00000e-01 $1.00000 \mathrm{e}+001.00000 \mathrm{e}+001.00000 \mathrm{e}-01$ 1.00000e-09 1.00000e-01 Element: 3792 \# of layers: 13

$\mathrm{Kx} \mathrm{Ky} \mathrm{Kz}$ Ss Por

2.91735e+01 2.91735e+01 2.91735e+00 1.00000e-09 7.00000e-02 $2.91735 \mathrm{e}+012.91735 \mathrm{e}+012.91735 \mathrm{e}+001.00000 \mathrm{e}-09$ 7.00000e-02 $2.91735 \mathrm{e}+012.91735 \mathrm{e}+012.91735 \mathrm{e}+001.00000 \mathrm{e}-09$ 7.00000e-02 5.00000e-04 5.00000e-04 5.00000e-05 1.00000e-09 1.00000e-01 5.00000e-04 5.00000e-04 5.00000e-05 1.00000e-09 1.00000e-01

$1.16568 \mathrm{e}+001.16568 \mathrm{e}+00$ 1.16568e-01 1.00000e-09 2.12000e-01 $1.16568 \mathrm{e}+001.16568 \mathrm{e}+00$ 1.16568e-01 1.00000e-09 2.12000e-01 $1.16568 \mathrm{e}+001.16568 \mathrm{e}+00$ 1.16568e-01 1.00000e-09 2.12000e-01 $1.16568 \mathrm{e}+001.16568 \mathrm{e}+00$ 1.16568e-01 1.00000e-09 2.12000e-01 $1.00000 \mathrm{e}-02$ 1.00000e-02 1.00000e-03 1.00000e-09 1.00000e-01 $1.00000 \mathrm{e}+001.00000 \mathrm{e}+001.00000 \mathrm{e}-011.00000 \mathrm{e}-091.00000 \mathrm{e}-01$ $1.00000 \mathrm{e}-05$ 1.00000e-05 1.00000e-06 1.00000e-09 1.00000e-01 $1.00000 \mathrm{e}+001.00000 \mathrm{e}+001.00000 \mathrm{e}-011.00000 \mathrm{e}-091.00000 \mathrm{e}-01$ Element: 3793 \# of layers: 14

$\mathrm{Kx} \mathrm{Ky} \mathrm{Kz}$ Ss Por

$2.91735 \mathrm{e}+012.91735 \mathrm{e}+012.91735 \mathrm{e}+00$ 1.00000e-09 7.00000e-02 $2.91735 \mathrm{e}+012.91735 \mathrm{e}+012.91735 \mathrm{e}+001.00000 \mathrm{e}-09$ 7.00000e-02 $2.91735 \mathrm{e}+012.91735 \mathrm{e}+012.91735 \mathrm{e}+001.00000 \mathrm{e}-09$ 7.00000e-02 $2.91735 \mathrm{e}+012.91735 \mathrm{e}+012.91735 \mathrm{e}+001.00000 \mathrm{e}-09$ 7.00000e-02 5.00000e-04 5.00000e-04 5.00000e-05 1.00000e-09 1.00000e-01 5.00000e-04 5.00000e-04 5.00000e-05 1.00000e-09 1.00000e-01 $1.16568 \mathrm{e}+001.16568 \mathrm{e}+00$ 1.16568e-01 1.00000e-09 2.12000e-01 $1.16568 \mathrm{e}+001.16568 \mathrm{e}+001.16568 \mathrm{e}-011.00000 \mathrm{e}-092.12000 \mathrm{e}-01$ $1.16568 \mathrm{e}+001.16568 \mathrm{e}+00$ 1.16568e-01 1.00000e-09 2.12000e-01 $1.16568 \mathrm{e}+001.16568 \mathrm{e}+001.16568 \mathrm{e}-01$ 1.00000e-09 2.12000e-01 1.00000e-02 1.00000e-02 1.00000e-03 1.00000e-09 1.00000e-01 $1.00000 \mathrm{e}+001.00000 \mathrm{e}+001.00000 \mathrm{e}-011.00000 \mathrm{e}-091.00000 \mathrm{e}-01$ 
$1.00000 \mathrm{e}-05$ 1.00000e-05 1.00000e-06 1.00000e-09 1.00000e-01 $1.00000 \mathrm{e}+001.00000 \mathrm{e}+001.00000 \mathrm{e}-01$ 1.00000e-09 1.00000e-01 Element: 3794 \# of layers: 13

Kx Ky Kz Ss Por

$2.91735 \mathrm{e}+012.91735 \mathrm{e}+012.91735 \mathrm{e}+00$ 1.00000e-09 7.00000e-02 $2.91735 \mathrm{e}+012.91735 \mathrm{e}+012.91735 \mathrm{e}+00$ 1.00000e-09 7.00000e-02 $2.91735 \mathrm{e}+012.91735 \mathrm{e}+012.91735 \mathrm{e}+00$ 1.00000e-09 7.00000e-02 5.00000e-04 5.00000e-04 5.00000e-05 1.00000e-09 1.00000e-01 5.00000e-04 5.00000e-04 5.00000e-05 1.00000e-09 1.00000e-01 $1.16568 \mathrm{e}+001.16568 \mathrm{e}+00$ 1.16568e-01 1.00000e-09 2.12000e-01 $1.16568 \mathrm{e}+001.16568 \mathrm{e}+00$ 1.16568e-01 1.00000e-09 2.12000e-01 $1.16568 \mathrm{e}+001.16568 \mathrm{e}+00$ 1.16568e-01 1.00000e-09 2.12000e-01 $1.16568 \mathrm{e}+001.16568 \mathrm{e}+00$ 1.16568e-01 1.00000e-09 2.12000e-01 $1.00000 \mathrm{e}-02$ 1.00000e-02 1.00000e-03 1.00000e-09 1.00000e-01 $1.00000 \mathrm{e}+001.00000 \mathrm{e}+001.00000 \mathrm{e}-011.00000 \mathrm{e}-091.00000 \mathrm{e}-01$ $1.00000 \mathrm{e}-05$ 1.00000e-05 1.00000e-06 1.00000e-09 1.00000e-01 $1.00000 \mathrm{e}+001.00000 \mathrm{e}+001.00000 \mathrm{e}-011.00000 \mathrm{e}-091.00000 \mathrm{e}-01$ Element: 3795 \# of layers: 14

$\mathrm{Kx} \mathrm{Ky} \mathrm{Kz}$ Ss Por

$2.79445 \mathrm{e}+012.79445 \mathrm{e}+012.79445 \mathrm{e}+00$ 1.00000e-09 7.00000e-02 $2.79445 \mathrm{e}+012.79445 \mathrm{e}+012.79445 \mathrm{e}+001.00000 \mathrm{e}-09$ 7.00000e-02

$2.79445 \mathrm{e}+012.79445 \mathrm{e}+012.79445 \mathrm{e}+00$ 1.00000e-09 7.00000e-02 5.00000e-04 5.00000e-04 5.00000e-05 1.00000e-09 1.00000e-01 5.00000e-04 5.00000e-04 5.00000e-05 1.00000e-09 1.00000e-01

$1.11656 \mathrm{e}+001.11656 \mathrm{e}+001.11656 \mathrm{e}-011.00000 \mathrm{e}-092.12000 \mathrm{e}-01$ $1.11656 \mathrm{e}+001.11656 \mathrm{e}+001.11656 \mathrm{e}-01$ 1.00000e-09 2.12000e-01 $1.11656 \mathrm{e}+001.11656 \mathrm{e}+001.11656 \mathrm{e}-01$ 1.00000e-09 2.12000e-01 $1.11656 \mathrm{e}+001.11656 \mathrm{e}+001.11656 \mathrm{e}-01$ 1.00000e-09 2.12000e-01 $1.11656 \mathrm{e}+001.11656 \mathrm{e}+001.11656 \mathrm{e}-011.00000 \mathrm{e}-092.12000 \mathrm{e}-01$ $1.00000 \mathrm{e}-021.00000 \mathrm{e}-021.00000 \mathrm{e}-031.00000 \mathrm{e}-091.00000 \mathrm{e}-01$ $1.00000 \mathrm{e}+001.00000 \mathrm{e}+001.00000 \mathrm{e}-01$ 1.00000e-09 1.00000e-01 $1.00000 \mathrm{e}-05$ 1.00000e-05 1.00000e-06 1.00000e-09 1.00000e-01 $1.00000 \mathrm{e}+001.00000 \mathrm{e}+001.00000 \mathrm{e}-011.00000 \mathrm{e}-09$ 1.00000e-01 Element: 3796 \# of layers: 14

$\mathrm{Kx} \mathrm{Ky} \mathrm{Kz}$ Ss Por

$2.79445 \mathrm{e}+012.79445 \mathrm{e}+012.79445 \mathrm{e}+00$ 1.00000e-09 7.00000e-02 $2.79445 \mathrm{e}+012.79445 \mathrm{e}+012.79445 \mathrm{e}+001.00000 \mathrm{e}-09$ 7.00000e-02 $2.79445 \mathrm{e}+012.79445 \mathrm{e}+012.79445 \mathrm{e}+001.00000 \mathrm{e}-09$ 7.00000e-02 5.00000e-04 5.00000e-04 5.00000e-05 1.00000e-09 1.00000e-01 5.00000e-04 5.00000e-04 5.00000e-05 1.00000e-09 1.00000e-01 $1.11656 \mathrm{e}+001.11656 \mathrm{e}+00$ 1.11656e-01 1.00000e-09 2.12000e-01 $1.11656 \mathrm{e}+001.11656 \mathrm{e}+00$ 1.11656e-01 1.00000e-09 2.12000e-01 $1.11656 \mathrm{e}+001.11656 \mathrm{e}+00$ 1.11656e-01 1.00000e-09 2.12000e-01 $1.11656 \mathrm{e}+001.11656 \mathrm{e}+00$ 1.11656e-01 1.00000e-09 2.12000e-01 $1.11656 \mathrm{e}+001.11656 \mathrm{e}+001.11656 \mathrm{e}-011.00000 \mathrm{e}-092.12000 \mathrm{e}-01$ $1.00000 \mathrm{e}-02$ 1.00000e-02 1.00000e-03 1.00000e-09 1.00000e-01 
$1.00000 \mathrm{e}+001.00000 \mathrm{e}+001.00000 \mathrm{e}-011.00000 \mathrm{e}-091.00000 \mathrm{e}-01$ $1.00000 \mathrm{e}-05$ 1.00000e-05 1.00000e-06 1.00000e-09 1.00000e-01 $1.00000 \mathrm{e}+001.00000 \mathrm{e}+001.00000 \mathrm{e}-011.00000 \mathrm{e}-09$ 1.00000e-01 Element: 3797 \# of layers: 15

$\mathrm{Kx} \mathrm{Ky} \mathrm{Kz}$ Ss Por

$2.91735 \mathrm{e}+012.91735 \mathrm{e}+012.91735 \mathrm{e}+00$ 1.00000e-09 7.00000e-02 $2.91735 \mathrm{e}+012.91735 \mathrm{e}+012.91735 \mathrm{e}+001.00000 \mathrm{e}-09$ 7.00000e-02 $2.91735 \mathrm{e}+012.91735 \mathrm{e}+012.91735 \mathrm{e}+001.00000 \mathrm{e}-09$ 7.00000e-02 $2.91735 \mathrm{e}+012.91735 \mathrm{e}+012.91735 \mathrm{e}+001.00000 \mathrm{e}-09$ 7.00000e-02 5.00000e-04 5.00000e-04 5.00000e-05 1.00000e-09 1.00000e-01 5.00000e-04 5.00000e-04 5.00000e-05 1.00000e-09 1.00000e-01 $1.16568 \mathrm{e}+001.16568 \mathrm{e}+00$ 1.16568e-01 1.00000e-09 2.12000e-01 $1.16568 \mathrm{e}+001.16568 \mathrm{e}+00$ 1.16568e-01 1.00000e-09 2.12000e-01 $1.16568 \mathrm{e}+001.16568 \mathrm{e}+00$ 1.16568e-01 1.00000e-09 2.12000e-01 $1.16568 \mathrm{e}+001.16568 \mathrm{e}+00$ 1.16568e-01 1.00000e-09 2.12000e-01 $1.16568 \mathrm{e}+001.16568 \mathrm{e}+00$ 1.16568e-01 1.00000e-09 2.12000e-01 $1.00000 \mathrm{e}-02$ 1.00000e-02 1.00000e-03 1.00000e-09 1.00000e-01 $1.00000 \mathrm{e}+001.00000 \mathrm{e}+001.00000 \mathrm{e}-011.00000 \mathrm{e}-091.00000 \mathrm{e}-01$ $1.00000 \mathrm{e}-05$ 1.00000e-05 1.00000e-06 1.00000e-09 1.00000e-01 $1.00000 \mathrm{e}+001.00000 \mathrm{e}+001.00000 \mathrm{e}-011.00000 \mathrm{e}-091.00000 \mathrm{e}-01$ Element: 3798 \# of layers: 15

$\mathrm{Kx} \mathrm{Ky} \mathrm{Kz}$ Ss Por

$2.91735 \mathrm{e}+012.91735 \mathrm{e}+012.91735 \mathrm{e}+00$ 1.00000e-09 7.00000e-02 $2.91735 \mathrm{e}+012.91735 \mathrm{e}+012.91735 \mathrm{e}+001.00000 \mathrm{e}-09$ 7.00000e-02 $2.91735 \mathrm{e}+012.91735 \mathrm{e}+012.91735 \mathrm{e}+001.00000 \mathrm{e}-097.00000 \mathrm{e}-02$ $2.91735 \mathrm{e}+012.91735 \mathrm{e}+012.91735 \mathrm{e}+001.00000 \mathrm{e}-09$ 7.00000e-02 5.00000e-04 5.00000e-04 5.00000e-05 1.00000e-09 1.00000e-01 5.00000e-04 5.00000e-04 5.00000e-05 1.00000e-09 1.00000e-01

$1.16568 \mathrm{e}+001.16568 \mathrm{e}+00$ 1.16568e-01 1.00000e-09 2.12000e-01 $1.16568 \mathrm{e}+001.16568 \mathrm{e}+00$ 1.16568e-01 1.00000e-09 2.12000e-01 $1.16568 \mathrm{e}+001.16568 \mathrm{e}+00$ 1.16568e-01 1.00000e-09 2.12000e-01 $1.16568 \mathrm{e}+001.16568 \mathrm{e}+00$ 1.16568e-01 1.00000e-09 2.12000e-01 $1.16568 \mathrm{e}+001.16568 \mathrm{e}+001.16568 \mathrm{e}-011.00000 \mathrm{e}-092.12000 \mathrm{e}-01$ 1.00000e-02 1.00000e-02 1.00000e-03 1.00000e-09 1.00000e-01 $1.00000 \mathrm{e}+001.00000 \mathrm{e}+001.00000 \mathrm{e}-011.00000 \mathrm{e}-091.00000 \mathrm{e}-01$ $1.00000 \mathrm{e}-05$ 1.00000e-05 1.00000e-06 1.00000e-09 1.00000e-01 $1.00000 \mathrm{e}+001.00000 \mathrm{e}+001.00000 \mathrm{e}-011.00000 \mathrm{e}-091.00000 \mathrm{e}-01$ Element: 3799 \# of layers: 13

$\mathrm{Kx} \mathrm{Ky} \mathrm{Kz}$ Ss Por

$2.91059 \mathrm{e}+012.91059 \mathrm{e}+012.91059 \mathrm{e}+00$ 1.00000e-09 7.00000e-02 $2.91059 \mathrm{e}+012.91059 \mathrm{e}+012.91059 \mathrm{e}+00$ 1.00000e-09 7.00000e-02 $2.91059 \mathrm{e}+012.91059 \mathrm{e}+012.91059 \mathrm{e}+001.00000 \mathrm{e}-09$ 7.00000e-02 5.00000e-04 5.00000e-04 5.00000e-05 1.00000e-09 1.00000e-01 $5.00000 \mathrm{e}-04$ 5.00000e-04 5.00000e-05 1.00000e-09 1.00000e-01 $1.16298 \mathrm{e}+001.16298 \mathrm{e}+00$ 1.16298e-01 1.00000e-09 2.12000e-01 $1.16298 \mathrm{e}+001.16298 \mathrm{e}+00$ 1.16298e-01 1.00000e-09 2.12000e-01 
$1.16298 \mathrm{e}+00$ 1.16298e+00 1.16298e-01 1.00000e-09 2.12000e-01 $1.16298 \mathrm{e}+001.16298 \mathrm{e}+00$ 1.16298e-01 1.00000e-09 2.12000e-01 $1.00000 \mathrm{e}-02$ 1.00000e-02 1.00000e-03 1.00000e-09 1.00000e-01 $1.00000 \mathrm{e}+001.00000 \mathrm{e}+001.00000 \mathrm{e}-011.00000 \mathrm{e}-091.00000 \mathrm{e}-01$ $1.00000 \mathrm{e}-05$ 1.00000e-05 1.00000e-06 1.00000e-09 1.00000e-01 $1.00000 \mathrm{e}+001.00000 \mathrm{e}+001.00000 \mathrm{e}-011.00000 \mathrm{e}-091.00000 \mathrm{e}-01$ Element: 3800 \# of layers: 13

$\mathrm{Kx} \mathrm{Ky} \mathrm{Kz}$ Ss Por

$2.91059 \mathrm{e}+012.91059 \mathrm{e}+012.91059 \mathrm{e}+00$ 1.00000e-09 7.00000e-02 $2.91059 \mathrm{e}+012.91059 \mathrm{e}+012.91059 \mathrm{e}+00$ 1.00000e-09 7.00000e-02 $2.91059 \mathrm{e}+012.91059 \mathrm{e}+012.91059 \mathrm{e}+00$ 1.00000e-09 7.00000e-02 5.00000e-04 5.00000e-04 5.00000e-05 1.00000e-09 1.00000e-01 5.00000e-04 5.00000e-04 5.00000e-05 1.00000e-09 1.00000e-01 $1.16298 \mathrm{e}+00$ 1.16298e+00 1.16298e-01 1.00000e-09 2.12000e-01 $1.16298 \mathrm{e}+001.16298 \mathrm{e}+00$ 1.16298e-01 1.00000e-09 2.12000e-01 $1.16298 \mathrm{e}+00$ 1.16298e+00 1.16298e-01 1.00000e-09 2.12000e-01 $1.16298 \mathrm{e}+00$ 1.16298e+00 1.16298e-01 1.00000e-09 2.12000e-01 $1.00000 \mathrm{e}-02$ 1.00000e-02 1.00000e-03 1.00000e-09 1.00000e-01 $1.00000 \mathrm{e}+001.00000 \mathrm{e}+001.00000 \mathrm{e}-011.00000 \mathrm{e}-091.00000 \mathrm{e}-01$ $1.00000 \mathrm{e}-05$ 1.00000e-05 1.00000e-06 1.00000e-09 1.00000e-01 $1.00000 \mathrm{e}+001.00000 \mathrm{e}+001.00000 \mathrm{e}-011.00000 \mathrm{e}-091.00000 \mathrm{e}-01$ Element: 3801 \# of layers: 12

$\mathrm{Kx} \mathrm{Ky} \mathrm{Kz}$ Ss Por

$2.91059 \mathrm{e}+012.91059 \mathrm{e}+012.91059 \mathrm{e}+00$ 1.00000e-09 7.00000e-02 $2.91059 \mathrm{e}+012.91059 \mathrm{e}+012.91059 \mathrm{e}+001.00000 \mathrm{e}-09$ 7.00000e-02 $2.91059 \mathrm{e}+012.91059 \mathrm{e}+012.91059 \mathrm{e}+001.00000 \mathrm{e}-09$ 7.00000e-02 5.00000e-04 5.00000e-04 5.00000e-05 1.00000e-09 1.00000e-01 5.00000e-04 5.00000e-04 5.00000e-05 1.00000e-09 1.00000e-01

$1.16298 \mathrm{e}+001.16298 \mathrm{e}+00$ 1.16298e-01 1.00000e-09 2.12000e-01 $1.16298 \mathrm{e}+001.16298 \mathrm{e}+00$ 1.16298e-01 1.00000e-09 2.12000e-01 $1.16298 \mathrm{e}+00$ 1.16298e+00 1.16298e-01 1.00000e-09 2.12000e-01 $1.00000 \mathrm{e}-02$ 1.00000e-02 1.00000e-03 1.00000e-09 1.00000e-01 $1.00000 \mathrm{e}+001.00000 \mathrm{e}+001.00000 \mathrm{e}-011.00000 \mathrm{e}-091.00000 \mathrm{e}-01$ 1.00000e-05 1.00000e-05 1.00000e-06 1.00000e-09 1.00000e-01 $1.00000 \mathrm{e}+001.00000 \mathrm{e}+001.00000 \mathrm{e}-01$ 1.00000e-09 1.00000e-01 Element: 3802 \# of layers: 13

Kx Ky Kz Ss Por

$2.91059 \mathrm{e}+012.91059 \mathrm{e}+012.91059 \mathrm{e}+00$ 1.00000e-09 7.00000e-02 $2.91059 \mathrm{e}+012.91059 \mathrm{e}+012.91059 \mathrm{e}+00$ 1.00000e-09 7.00000e-02 $2.91059 \mathrm{e}+012.91059 \mathrm{e}+012.91059 \mathrm{e}+001.00000 \mathrm{e}-09$ 7.00000e-02 $2.91059 \mathrm{e}+012.91059 \mathrm{e}+012.91059 \mathrm{e}+00$ 1.00000e-09 7.00000e-02 5.00000e-04 5.00000e-04 5.00000e-05 1.00000e-09 1.00000e-01 5.00000e-04 5.00000e-04 5.00000e-05 1.00000e-09 1.00000e-01 $1.16298 \mathrm{e}+001.16298 \mathrm{e}+00$ 1.16298e-01 1.00000e-09 2.12000e-01 $1.16298 \mathrm{e}+001.16298 \mathrm{e}+00$ 1.16298e-01 1.00000e-09 2.12000e-01 $1.16298 \mathrm{e}+001.16298 \mathrm{e}+00$ 1.16298e-01 1.00000e-09 2.12000e-01 
$1.00000 \mathrm{e}-02$ 1.00000e-02 1.00000e-03 1.00000e-09 1.00000e-01 $1.00000 \mathrm{e}+001.00000 \mathrm{e}+001.00000 \mathrm{e}-011.00000 \mathrm{e}-091.00000 \mathrm{e}-01$ $1.00000 \mathrm{e}-051.00000 \mathrm{e}-05$ 1.00000e-06 1.00000e-09 1.00000e-01 $1.00000 \mathrm{e}+001.00000 \mathrm{e}+001.00000 \mathrm{e}-011.00000 \mathrm{e}-091.00000 \mathrm{e}-01$ Element: 3803 \# of layers: 12

Kx Ky Kz Ss Por

$2.91059 \mathrm{e}+012.91059 \mathrm{e}+012.91059 \mathrm{e}+00$ 1.00000e-09 7.00000e-02 $2.91059 \mathrm{e}+012.91059 \mathrm{e}+012.91059 \mathrm{e}+001.00000 \mathrm{e}-09$ 7.00000e-02 $2.91059 \mathrm{e}+012.91059 \mathrm{e}+012.91059 \mathrm{e}+001.00000 \mathrm{e}-09$ 7.00000e-02 5.00000e-04 5.00000e-04 5.00000e-05 1.00000e-09 1.00000e-01 5.00000e-04 5.00000e-04 5.00000e-05 1.00000e-09 1.00000e-01 $1.16298 \mathrm{e}+001.16298 \mathrm{e}+00$ 1.16298e-01 1.00000e-09 2.12000e-01 $1.16298 \mathrm{e}+001.16298 \mathrm{e}+00$ 1.16298e-01 1.00000e-09 2.12000e-01 $1.16298 \mathrm{e}+001.16298 \mathrm{e}+00$ 1.16298e-01 1.00000e-09 2.12000e-01 $1.00000 \mathrm{e}-021.00000 \mathrm{e}-02$ 1.00000e-03 1.00000e-09 1.00000e-01 $1.00000 \mathrm{e}+001.00000 \mathrm{e}+001.00000 \mathrm{e}-011.00000 \mathrm{e}-091.00000 \mathrm{e}-01$ $1.00000 \mathrm{e}-05$ 1.00000e-05 1.00000e-06 1.00000e-09 1.00000e-01 $1.00000 \mathrm{e}+001.00000 \mathrm{e}+001.00000 \mathrm{e}-011.00000 \mathrm{e}-091.00000 \mathrm{e}-01$ Element: 3804 \# of layers: 13

Kx Ky Kz Ss Por $2.91059 \mathrm{e}+012.91059 \mathrm{e}+012.91059 \mathrm{e}+00$ 1.00000e-09 7.00000e-02 $2.91059 \mathrm{e}+012.91059 \mathrm{e}+012.91059 \mathrm{e}+001.00000 \mathrm{e}-09$ 7.00000e-02 $2.91059 \mathrm{e}+012.91059 \mathrm{e}+012.91059 \mathrm{e}+001.00000 \mathrm{e}-09$ 7.00000e-02 5.00000e-04 5.00000e-04 5.00000e-05 1.00000e-09 1.00000e-01 5.00000e-04 5.00000e-04 5.00000e-05 1.00000e-09 1.00000e-01 $1.16298 \mathrm{e}+001.16298 \mathrm{e}+00$ 1.16298e-01 1.00000e-09 2.12000e-01 $1.16298 \mathrm{e}+001.16298 \mathrm{e}+00$ 1.16298e-01 1.00000e-09 2.12000e-01 $1.16298 \mathrm{e}+001.16298 \mathrm{e}+001.16298 \mathrm{e}-011.00000 \mathrm{e}-092.12000 \mathrm{e}-01$ $1.16298 \mathrm{e}+001.16298 \mathrm{e}+00$ 1.16298e-01 1.00000e-09 2.12000e-01 $1.00000 \mathrm{e}-021.00000 \mathrm{e}-02$ 1.00000e-03 1.00000e-09 1.00000e-01 $1.00000 \mathrm{e}+001.00000 \mathrm{e}+001.00000 \mathrm{e}-011.00000 \mathrm{e}-091.00000 \mathrm{e}-01$ $1.00000 \mathrm{e}-05$ 1.00000e-05 1.00000e-06 1.00000e-09 1.00000e-01 $1.00000 \mathrm{e}+001.00000 \mathrm{e}+001.00000 \mathrm{e}-011.00000 \mathrm{e}-091.00000 \mathrm{e}-01$ Element: 3805 \# of layers: 13

Kx Ky Kz Ss Por

$2.91059 \mathrm{e}+012.91059 \mathrm{e}+012.91059 \mathrm{e}+00$ 1.00000e-09 7.00000e-02 $2.91059 \mathrm{e}+012.91059 \mathrm{e}+012.91059 \mathrm{e}+001.00000 \mathrm{e}-09$ 7.00000e-02 $2.91059 \mathrm{e}+012.91059 \mathrm{e}+012.91059 \mathrm{e}+001.00000 \mathrm{e}-09$ 7.00000e-02 5.00000e-04 5.00000e-04 5.00000e-05 1.00000e-09 1.00000e-01 5.00000e-04 5.00000e-04 5.00000e-05 1.00000e-09 1.00000e-01 $1.16298 \mathrm{e}+001.16298 \mathrm{e}+00$ 1.16298e-01 1.00000e-09 2.12000e-01 $1.16298 \mathrm{e}+001.16298 \mathrm{e}+00$ 1.16298e-01 1.00000e-09 2.12000e-01 $1.16298 \mathrm{e}+001.16298 \mathrm{e}+00$ 1.16298e-01 1.00000e-09 2.12000e-01 $1.16298 \mathrm{e}+001.16298 \mathrm{e}+00$ 1.16298e-01 1.00000e-09 2.12000e-01 $1.00000 \mathrm{e}-021.00000 \mathrm{e}-02$ 1.00000e-03 1.00000e-09 1.00000e-01 $1.00000 \mathrm{e}+001.00000 \mathrm{e}+001.00000 \mathrm{e}-011.00000 \mathrm{e}-091.00000 \mathrm{e}-01$ 
$1.00000 \mathrm{e}-05$ 1.00000e-05 1.00000e-06 1.00000e-09 1.00000e-01 $1.00000 \mathrm{e}+001.00000 \mathrm{e}+001.00000 \mathrm{e}-01$ 1.00000e-09 1.00000e-01 Element: 3806 \# of layers: 14

Kx Ky Kz Ss Por

$2.91059 \mathrm{e}+012.91059 \mathrm{e}+012.91059 \mathrm{e}+00$ 1.00000e-09 7.00000e-02 $2.91059 \mathrm{e}+012.91059 \mathrm{e}+012.91059 \mathrm{e}+00$ 1.00000e-09 7.00000e-02 $2.91059 \mathrm{e}+012.91059 \mathrm{e}+012.91059 \mathrm{e}+00$ 1.00000e-09 7.00000e-02 $2.91059 \mathrm{e}+012.91059 \mathrm{e}+012.91059 \mathrm{e}+001.00000 \mathrm{e}-09$ 7.00000e-02 5.00000e-04 5.00000e-04 5.00000e-05 1.00000e-09 1.00000e-01 5.00000e-04 5.00000e-04 5.00000e-05 1.00000e-09 1.00000e-01 $1.16298 \mathrm{e}+001.16298 \mathrm{e}+00$ 1.16298e-01 1.00000e-09 2.12000e-01 $1.16298 \mathrm{e}+001.16298 \mathrm{e}+00$ 1.16298e-01 1.00000e-09 2.12000e-01 $1.16298 \mathrm{e}+001.16298 \mathrm{e}+00$ 1.16298e-01 1.00000e-09 2.12000e-01 $1.16298 \mathrm{e}+001.16298 \mathrm{e}+00$ 1.16298e-01 1.00000e-09 2.12000e-01 $1.00000 \mathrm{e}-02$ 1.00000e-02 1.00000e-03 1.00000e-09 1.00000e-01 $1.00000 \mathrm{e}+001.00000 \mathrm{e}+001.00000 \mathrm{e}-011.00000 \mathrm{e}-091.00000 \mathrm{e}-01$ $1.00000 \mathrm{e}-05$ 1.00000e-05 1.00000e-06 1.00000e-09 1.00000e-01 $1.00000 \mathrm{e}+001.00000 \mathrm{e}+001.00000 \mathrm{e}-01$ 1.00000e-09 1.00000e-01 Element: 3807 \# of layers: 14

$\mathrm{Kx} \mathrm{Ky} \mathrm{Kz}$ Ss Por

$2.91059 \mathrm{e}+012.91059 \mathrm{e}+012.91059 \mathrm{e}+00$ 1.00000e-09 7.00000e-02 $2.91059 \mathrm{e}+012.91059 \mathrm{e}+012.91059 \mathrm{e}+00$ 1.00000e-09 7.00000e-02 $2.91059 \mathrm{e}+012.91059 \mathrm{e}+012.91059 \mathrm{e}+00$ 1.00000e-09 7.00000e-02 $2.91059 \mathrm{e}+012.91059 \mathrm{e}+012.91059 \mathrm{e}+001.00000 \mathrm{e}-09$ 7.00000e-02 5.00000e-04 5.00000e-04 5.00000e-05 1.00000e-09 1.00000e-01 5.00000e-04 5.00000e-04 5.00000e-05 1.00000e-09 1.00000e-01

$1.16298 \mathrm{e}+001.16298 \mathrm{e}+00$ 1.16298e-01 1.00000e-09 2.12000e-01 $1.16298 \mathrm{e}+001.16298 \mathrm{e}+00$ 1.16298e-01 1.00000e-09 2.12000e-01 $1.16298 \mathrm{e}+00$ 1.16298e+00 1.16298e-01 1.00000e-09 2.12000e-01 $1.16298 \mathrm{e}+00$ 1.16298e+00 1.16298e-01 1.00000e-09 2.12000e-01 $1.00000 \mathrm{e}-02$ 1.00000e-02 1.00000e-03 1.00000e-09 1.00000e-01 $1.00000 \mathrm{e}+001.00000 \mathrm{e}+001.00000 \mathrm{e}-011.00000 \mathrm{e}-091.00000 \mathrm{e}-01$ $1.00000 \mathrm{e}-05$ 1.00000e-05 1.00000e-06 1.00000e-09 1.00000e-01 $1.00000 \mathrm{e}+001.00000 \mathrm{e}+001.00000 \mathrm{e}-011.00000 \mathrm{e}-091.00000 \mathrm{e}-01$ Element: 3808 \# of layers: 12

$\mathrm{Kx} \mathrm{Ky} \mathrm{Kz}$ Ss Por

$1.62162 \mathrm{e}+011.62162 \mathrm{e}+01$ 1.62162e+00 1.00000e-09 7.00000e-02 $1.62162 \mathrm{e}+011.62162 \mathrm{e}+011.62162 \mathrm{e}+001.00000 \mathrm{e}-09$ 7.00000e-02 $1.62162 \mathrm{e}+011.62162 \mathrm{e}+011.62162 \mathrm{e}+001.00000 \mathrm{e}-09$ 7.00000e-02 5.00000e-04 5.00000e-04 5.00000e-05 1.00000e-09 1.00000e-01 5.00000e-04 5.00000e-04 5.00000e-05 1.00000e-09 1.00000e-01 6.47946e-01 6.47946e-01 6.47946e-02 1.00000e-09 2.12000e-01 6.47946e-01 6.47946e-01 6.47946e-02 1.00000e-09 2.12000e-01 6.47946e-01 6.47946e-01 6.47946e-02 1.00000e-09 2.12000e-01 $1.00000 \mathrm{e}-02$ 1.00000e-02 1.00000e-03 1.00000e-09 1.00000e-01 $1.00000 \mathrm{e}+001.00000 \mathrm{e}+001.00000 \mathrm{e}-011.00000 \mathrm{e}-091.00000 \mathrm{e}-01$ 
$1.00000 \mathrm{e}-05$ 1.00000e-05 1.00000e-06 1.00000e-09 1.00000e-01 $1.00000 \mathrm{e}+001.00000 \mathrm{e}+001.00000 \mathrm{e}-01$ 1.00000e-09 1.00000e-01 Element: 3809 \# of layers: 12

$\mathrm{Kx} \mathrm{Ky} \mathrm{Kz}$ Ss Por

$1.62162 \mathrm{e}+011.62162 \mathrm{e}+01$ 1.62162e+00 1.00000e-09 7.00000e-02 $1.62162 \mathrm{e}+011.62162 \mathrm{e}+011.62162 \mathrm{e}+001.00000 \mathrm{e}-09$ 7.00000e-02 $1.62162 \mathrm{e}+011.62162 \mathrm{e}+011.62162 \mathrm{e}+001.00000 \mathrm{e}-09$ 7.00000e-02 5.00000e-04 5.00000e-04 5.00000e-05 1.00000e-09 1.00000e-01 5.00000e-04 5.00000e-04 5.00000e-05 1.00000e-09 1.00000e-01 6.47946e-01 6.47946e-01 6.47946e-02 1.00000e-09 2.12000e-01 6.47946e-01 6.47946e-01 6.47946e-02 1.00000e-09 2.12000e-01 6.47946e-01 6.47946e-01 6.47946e-02 1.00000e-09 2.12000e-01 $1.00000 \mathrm{e}-02$ 1.00000e-02 1.00000e-03 1.00000e-09 1.00000e-01 $1.00000 \mathrm{e}+001.00000 \mathrm{e}+001.00000 \mathrm{e}-011.00000 \mathrm{e}-091.00000 \mathrm{e}-01$ $1.00000 \mathrm{e}-05$ 1.00000e-05 1.00000e-06 1.00000e-09 1.00000e-01 $1.00000 \mathrm{e}+001.00000 \mathrm{e}+001.00000 \mathrm{e}-011.00000 \mathrm{e}-091.00000 \mathrm{e}-01$ Element: 3810 \# of layers: 12

$\mathrm{Kx} \mathrm{Ky} \mathrm{Kz}$ Ss Por

1.62162e+01 1.62162e+01 1.62162e+00 1.00000e-09 7.00000e-02 $1.62162 \mathrm{e}+011.62162 \mathrm{e}+011.62162 \mathrm{e}+001.00000 \mathrm{e}-09$ 7.00000e-02 $1.62162 \mathrm{e}+011.62162 \mathrm{e}+011.62162 \mathrm{e}+001.00000 \mathrm{e}-097.00000 \mathrm{e}-02$ 5.00000e-04 5.00000e-04 5.00000e-05 1.00000e-09 1.00000e-01 5.00000e-04 5.00000e-04 5.00000e-05 1.00000e-09 1.00000e-01 6.47946e-01 6.47946e-01 6.47946e-02 1.00000e-09 2.12000e-01 6.47946e-01 6.47946e-01 6.47946e-02 1.00000e-09 2.12000e-01 6.47946e-01 6.47946e-01 6.47946e-02 1.00000e-09 2.12000e-01 $1.00000 \mathrm{e}-02$ 1.00000e-02 1.00000e-03 1.00000e-09 1.00000e-01 $1.00000 \mathrm{e}+001.00000 \mathrm{e}+001.00000 \mathrm{e}-011.00000 \mathrm{e}-091.00000 \mathrm{e}-01$ $1.00000 \mathrm{e}-05$ 1.00000e-05 1.00000e-06 1.00000e-09 1.00000e-01 $1.00000 \mathrm{e}+001.00000 \mathrm{e}+001.00000 \mathrm{e}-011.00000 \mathrm{e}-091.00000 \mathrm{e}-01$ Element: 3811 \# of layers: 13

$\mathrm{Kx} \mathrm{Ky} \mathrm{Kz}$ Ss Por

$1.62162 \mathrm{e}+011.62162 \mathrm{e}+011.62162 \mathrm{e}+00$ 1.00000e-09 7.00000e-02 $1.62162 \mathrm{e}+011.62162 \mathrm{e}+011.62162 \mathrm{e}+001.00000 \mathrm{e}-09$ 7.00000e-02 $1.62162 \mathrm{e}+011.62162 \mathrm{e}+011.62162 \mathrm{e}+001.00000 \mathrm{e}-09$ 7.00000e-02 $1.62162 \mathrm{e}+011.62162 \mathrm{e}+011.62162 \mathrm{e}+001.00000 \mathrm{e}-09$ 7.00000e-02 5.00000e-04 5.00000e-04 5.00000e-05 1.00000e-09 1.00000e-01 5.00000e-04 5.00000e-04 5.00000e-05 1.00000e-09 1.00000e-01 6.47946e-01 6.47946e-01 6.47946e-02 1.00000e-09 2.12000e-01 6.47946e-01 6.47946e-01 6.47946e-02 1.00000e-09 2.12000e-01 6.47946e-01 6.47946e-01 6.47946e-02 1.00000e-09 2.12000e-01 $1.00000 \mathrm{e}-02$ 1.00000e-02 1.00000e-03 1.00000e-09 1.00000e-01 $1.00000 \mathrm{e}+001.00000 \mathrm{e}+001.00000 \mathrm{e}-011.00000 \mathrm{e}-091.00000 \mathrm{e}-01$ $1.00000 \mathrm{e}-05$ 1.00000e-05 1.00000e-06 1.00000e-09 1.00000e-01 $1.00000 \mathrm{e}+001.00000 \mathrm{e}+001.00000 \mathrm{e}-01$ 1.00000e-09 1.00000e-01 Element: 3812 \# of layers: 11 
Kx Ky Kz Ss Por

$1.62162 \mathrm{e}+011.62162 \mathrm{e}+011.62162 \mathrm{e}+001.00000 \mathrm{e}-09$ 7.00000e-02

$1.62162 \mathrm{e}+011.62162 \mathrm{e}+011.62162 \mathrm{e}+001.00000 \mathrm{e}-097.00000 \mathrm{e}-02$

$1.62162 \mathrm{e}+011.62162 \mathrm{e}+011.62162 \mathrm{e}+001.00000 \mathrm{e}-09$ 7.00000e-02

5.00000e-04 5.00000e-04 5.00000e-05 1.00000e-09 1.00000e-01

5.00000e-04 5.00000e-04 5.00000e-05 1.00000e-09 1.00000e-01

6.47946e-01 6.47946e-01 6.47946e-02 1.00000e-09 2.12000e-01

6.47946e-01 6.47946e-01 6.47946e-02 1.00000e-09 2.12000e-01

$1.00000 \mathrm{e}-02$ 1.00000e-02 1.00000e-03 1.00000e-09 1.00000e-01

$1.00000 \mathrm{e}+001.00000 \mathrm{e}+001.00000 \mathrm{e}-011.00000 \mathrm{e}-091.00000 \mathrm{e}-01$

$1.00000 \mathrm{e}-05$ 1.00000e-05 1.00000e-06 1.00000e-09 1.00000e-01

$1.00000 \mathrm{e}+001.00000 \mathrm{e}+001.00000 \mathrm{e}-011.00000 \mathrm{e}-091.00000 \mathrm{e}-01$

Element: 3813 \# of layers: 11

$\mathrm{Kx} \mathrm{Ky} \mathrm{Kz}$ Ss Por

$1.62162 \mathrm{e}+011.62162 \mathrm{e}+011.62162 \mathrm{e}+001.00000 \mathrm{e}-09$ 7.00000e-02

$1.62162 \mathrm{e}+011.62162 \mathrm{e}+011.62162 \mathrm{e}+001.00000 \mathrm{e}-09$ 7.00000e-02

$1.62162 \mathrm{e}+011.62162 \mathrm{e}+011.62162 \mathrm{e}+001.00000 \mathrm{e}-09$ 7.00000e-02

5.00000e-04 5.00000e-04 5.00000e-05 1.00000e-09 1.00000e-01

5.00000e-04 5.00000e-04 5.00000e-05 1.00000e-09 1.00000e-01

6.47946e-01 6.47946e-01 6.47946e-02 1.00000e-09 2.12000e-01

6.47946e-01 6.47946e-01 6.47946e-02 1.00000e-09 2.12000e-01

$1.00000 \mathrm{e}-02$ 1.00000e-02 1.00000e-03 1.00000e-09 1.00000e-01

$1.00000 \mathrm{e}+001.00000 \mathrm{e}+001.00000 \mathrm{e}-011.00000 \mathrm{e}-091.00000 \mathrm{e}-01$

$1.00000 \mathrm{e}-05$ 1.00000e-05 1.00000e-06 1.00000e-09 1.00000e-01

$1.00000 \mathrm{e}+001.00000 \mathrm{e}+001.00000 \mathrm{e}-011.00000 \mathrm{e}-091.00000 \mathrm{e}-01$

Element: 3814 \# of layers: 11

$\mathrm{Kx} \mathrm{Ky} \mathrm{Kz}$ Ss Por

$1.62162 \mathrm{e}+011.62162 \mathrm{e}+011.62162 \mathrm{e}+001.00000 \mathrm{e}-09$ 7.00000e-02

$1.62162 \mathrm{e}+011.62162 \mathrm{e}+011.62162 \mathrm{e}+001.00000 \mathrm{e}-09$ 7.00000e-02

$1.62162 \mathrm{e}+011.62162 \mathrm{e}+01$ 1.62162e+00 1.00000e-09 7.00000e-02

5.00000e-04 5.00000e-04 5.00000e-05 1.00000e-09 1.00000e-01

5.00000e-04 5.00000e-04 5.00000e-05 1.00000e-09 1.00000e-01

6.47946e-01 6.47946e-01 6.47946e-02 1.00000e-09 2.12000e-01

6.47946e-01 6.47946e-01 6.47946e-02 1.00000e-09 2.12000e-01

$1.00000 \mathrm{e}-02$ 1.00000e-02 1.00000e-03 1.00000e-09 1.00000e-01

$1.00000 \mathrm{e}+001.00000 \mathrm{e}+001.00000 \mathrm{e}-011.00000 \mathrm{e}-091.00000 \mathrm{e}-01$

1.00000e-05 1.00000e-05 1.00000e-06 1.00000e-09 1.00000e-01

$1.00000 \mathrm{e}+001.00000 \mathrm{e}+001.00000 \mathrm{e}-011.00000 \mathrm{e}-091.00000 \mathrm{e}-01$

Element: 3815 \# of layers: 13

$\mathrm{Kx} \mathrm{Ky} \mathrm{Kz}$ Ss Por

1.62162e+01 1.62162e+01 1.62162e+00 1.00000e-09 7.00000e-02

$1.62162 \mathrm{e}+011.62162 \mathrm{e}+011.62162 \mathrm{e}+001.00000 \mathrm{e}-09$ 7.00000e-02

$1.62162 \mathrm{e}+011.62162 \mathrm{e}+011.62162 \mathrm{e}+001.00000 \mathrm{e}-09$ 7.00000e-02

$1.62162 \mathrm{e}+01$ 1.62162e+01 1.62162e+00 1.00000e-09 7.00000e-02

5.00000e-04 5.00000e-04 5.00000e-05 1.00000e-09 1.00000e-01

5.00000e-04 5.00000e-04 5.00000e-05 1.00000e-09 1.00000e-01 
6.47946e-01 6.47946e-01 6.47946e-02 1.00000e-09 2.12000e-01 6.47946e-01 6.47946e-01 6.47946e-02 1.00000e-09 2.12000e-01 6.47946e-01 6.47946e-01 6.47946e-02 1.00000e-09 2.12000e-01 $1.00000 \mathrm{e}-021.00000 \mathrm{e}-02$ 1.00000e-03 1.00000e-09 1.00000e-01 $1.00000 \mathrm{e}+001.00000 \mathrm{e}+001.00000 \mathrm{e}-011.00000 \mathrm{e}-091.00000 \mathrm{e}-01$ $1.00000 \mathrm{e}-05$ 1.00000e-05 1.00000e-06 1.00000e-09 1.00000e-01 $1.00000 \mathrm{e}+001.00000 \mathrm{e}+001.00000 \mathrm{e}-011.00000 \mathrm{e}-091.00000 \mathrm{e}-01$ Element: 3816 \# of layers: 13

Kx Ky Kz Ss Por

$1.62162 \mathrm{e}+011.62162 \mathrm{e}+011.62162 \mathrm{e}+001.00000 \mathrm{e}-097.00000 \mathrm{e}-02$ $1.62162 \mathrm{e}+011.62162 \mathrm{e}+011.62162 \mathrm{e}+001.00000 \mathrm{e}-097.00000 \mathrm{e}-02$ $1.62162 \mathrm{e}+011.62162 \mathrm{e}+011.62162 \mathrm{e}+001.00000 \mathrm{e}-09$ 7.00000e-02 $1.62162 \mathrm{e}+011.62162 \mathrm{e}+011.62162 \mathrm{e}+001.00000 \mathrm{e}-097.00000 \mathrm{e}-02$ 5.00000e-04 5.00000e-04 5.00000e-05 1.00000e-09 1.00000e-01 5.00000e-04 5.00000e-04 5.00000e-05 1.00000e-09 1.00000e-01 6.47946e-01 6.47946e-01 6.47946e-02 1.00000e-09 2.12000e-01 6.47946e-01 6.47946e-01 6.47946e-02 1.00000e-09 2.12000e-01 6.47946e-01 6.47946e-01 6.47946e-02 1.00000e-09 2.12000e-01 $1.00000 \mathrm{e}-02$ 1.00000e-02 1.00000e-03 1.00000e-09 1.00000e-01 $1.00000 \mathrm{e}+001.00000 \mathrm{e}+001.00000 \mathrm{e}-011.00000 \mathrm{e}-091.00000 \mathrm{e}-01$ $1.00000 \mathrm{e}-05$ 1.00000e-05 1.00000e-06 1.00000e-09 1.00000e-01 $1.00000 \mathrm{e}+001.00000 \mathrm{e}+001.00000 \mathrm{e}-011.00000 \mathrm{e}-091.00000 \mathrm{e}-01$ Element: 3817 \# of layers: 12

Kx Ky Kz Ss Por

$1.67991 \mathrm{e}+011.67991 \mathrm{e}+011.67991 \mathrm{e}+001.00000 \mathrm{e}-09$ 7.00000e-02 $1.67991 \mathrm{e}+011.67991 \mathrm{e}+011.67991 \mathrm{e}+001.00000 \mathrm{e}-097.00000 \mathrm{e}-02$ $1.67991 \mathrm{e}+011.67991 \mathrm{e}+011.67991 \mathrm{e}+001.00000 \mathrm{e}-097.00000 \mathrm{e}-02$ 5.00000e-04 5.00000e-04 5.00000e-05 1.00000e-09 1.00000e-01 5.00000e-04 5.00000e-04 5.00000e-05 1.00000e-09 1.00000e-01 6.71212e-01 6.71212e-01 6.71212e-02 1.00000e-09 2.12000e-01 6.71212e-01 6.71212e-01 6.71212e-02 1.00000e-09 2.12000e-01 6.71212e-01 6.71212e-01 6.71212e-02 1.00000e-09 2.12000e-01 $1.00000 \mathrm{e}-021.00000 \mathrm{e}-02$ 1.00000e-03 1.00000e-09 1.00000e-01 $1.00000 \mathrm{e}+001.00000 \mathrm{e}+001.00000 \mathrm{e}-011.00000 \mathrm{e}-091.00000 \mathrm{e}-01$ $1.00000 \mathrm{e}-05$ 1.00000e-05 1.00000e-06 1.00000e-09 1.00000e-01 $1.00000 \mathrm{e}+001.00000 \mathrm{e}+001.00000 \mathrm{e}-011.00000 \mathrm{e}-091.00000 \mathrm{e}-01$ Element: 3818 \# of layers: 13

Kx Ky Kz Ss Por

$1.67991 \mathrm{e}+011.67991 \mathrm{e}+011.67991 \mathrm{e}+00$ 1.00000e-09 7.00000e-02 $1.67991 \mathrm{e}+011.67991 \mathrm{e}+011.67991 \mathrm{e}+001.00000 \mathrm{e}-097.00000 \mathrm{e}-02$ $1.67991 \mathrm{e}+011.67991 \mathrm{e}+011.67991 \mathrm{e}+001.00000 \mathrm{e}-09$ 7.00000e-02 $1.67991 \mathrm{e}+011.67991 \mathrm{e}+011.67991 \mathrm{e}+001.00000 \mathrm{e}-097.00000 \mathrm{e}-02$ 5.00000e-04 5.00000e-04 5.00000e-05 1.00000e-09 1.00000e-01 5.00000e-04 5.00000e-04 5.00000e-05 1.00000e-09 1.00000e-01 6.71212e-01 6.71212e-01 6.71212e-02 1.00000e-09 2.12000e-01 6.71212e-01 6.71212e-01 6.71212e-02 1.00000e-09 2.12000e-01 
6.71212e-01 6.71212e-01 6.71212e-02 1.00000e-09 2.12000e-01 $1.00000 \mathrm{e}-021.00000 \mathrm{e}-021.00000 \mathrm{e}-031.00000 \mathrm{e}-091.00000 \mathrm{e}-01$ $1.00000 \mathrm{e}+001.00000 \mathrm{e}+001.00000 \mathrm{e}-011.00000 \mathrm{e}-091.00000 \mathrm{e}-01$ $1.00000 \mathrm{e}-05$ 1.00000e-05 1.00000e-06 1.00000e-09 1.00000e-01 $1.00000 \mathrm{e}+001.00000 \mathrm{e}+001.00000 \mathrm{e}-011.00000 \mathrm{e}-091.00000 \mathrm{e}-01$ Element: 3819 \# of layers: 12

Kx Ky Kz Ss Por

$1.67991 \mathrm{e}+011.67991 \mathrm{e}+011.67991 \mathrm{e}+00$ 1.00000e-09 7.00000e-02 $1.67991 \mathrm{e}+011.67991 \mathrm{e}+011.67991 \mathrm{e}+001.00000 \mathrm{e}-097.00000 \mathrm{e}-02$ $1.67991 \mathrm{e}+011.67991 \mathrm{e}+011.67991 \mathrm{e}+001.00000 \mathrm{e}-097.00000 \mathrm{e}-02$ 5.00000e-04 5.00000e-04 5.00000e-05 1.00000e-09 1.00000e-01 5.00000e-04 5.00000e-04 5.00000e-05 1.00000e-09 1.00000e-01 6.71212e-01 6.71212e-01 6.71212e-02 1.00000e-09 2.12000e-01 6.71212e-01 6.71212e-01 6.71212e-02 1.00000e-09 2.12000e-01 6.71212e-01 6.71212e-01 6.71212e-02 1.00000e-09 2.12000e-01 $1.00000 \mathrm{e}-02$ 1.00000e-02 1.00000e-03 1.00000e-09 1.00000e-01 $1.00000 \mathrm{e}+001.00000 \mathrm{e}+001.00000 \mathrm{e}-011.00000 \mathrm{e}-091.00000 \mathrm{e}-01$ $1.00000 \mathrm{e}-05$ 1.00000e-05 1.00000e-06 1.00000e-09 1.00000e-01 $1.00000 \mathrm{e}+001.00000 \mathrm{e}+001.00000 \mathrm{e}-011.00000 \mathrm{e}-091.00000 \mathrm{e}-01$ Element: 3820 \# of layers: 12

Kx Ky Kz Ss Por

$1.67991 \mathrm{e}+011.67991 \mathrm{e}+011.67991 \mathrm{e}+00$ 1.00000e-09 7.00000e-02 $1.67991 \mathrm{e}+011.67991 \mathrm{e}+011.67991 \mathrm{e}+001.00000 \mathrm{e}-097.00000 \mathrm{e}-02$ $1.67991 \mathrm{e}+011.67991 \mathrm{e}+011.67991 \mathrm{e}+001.00000 \mathrm{e}-097.00000 \mathrm{e}-02$ 5.00000e-04 5.00000e-04 5.00000e-05 1.00000e-09 1.00000e-01 5.00000e-04 5.00000e-04 5.00000e-05 1.00000e-09 1.00000e-01 6.71212e-01 6.71212e-01 6.71212e-02 1.00000e-09 2.12000e-01 6.71212e-01 6.71212e-01 6.71212e-02 1.00000e-09 2.12000e-01 6.71212e-01 6.71212e-01 6.71212e-02 1.00000e-09 2.12000e-01 $1.00000 \mathrm{e}-02$ 1.00000e-02 1.00000e-03 1.00000e-09 1.00000e-01 $1.00000 \mathrm{e}+001.00000 \mathrm{e}+001.00000 \mathrm{e}-011.00000 \mathrm{e}-091.00000 \mathrm{e}-01$ $1.00000 \mathrm{e}-05$ 1.00000e-05 1.00000e-06 1.00000e-09 1.00000e-01 $1.00000 \mathrm{e}+001.00000 \mathrm{e}+001.00000 \mathrm{e}-011.00000 \mathrm{e}-091.00000 \mathrm{e}-01$ Element: 3821 \# of layers: 10

Kx Ky Kz Ss Por

$1.67991 \mathrm{e}+011.67991 \mathrm{e}+011.67991 \mathrm{e}+00$ 1.00000e-09 7.00000e-02 $1.67991 \mathrm{e}+011.67991 \mathrm{e}+011.67991 \mathrm{e}+001.00000 \mathrm{e}-097.00000 \mathrm{e}-02$ 5.00000e-04 5.00000e-04 5.00000e-05 1.00000e-09 1.00000e-01 5.00000e-04 5.00000e-04 5.00000e-05 1.00000e-09 1.00000e-01 6.71212e-01 6.71212e-01 6.71212e-02 1.00000e-09 2.12000e-01 6.71212e-01 6.71212e-01 6.71212e-02 1.00000e-09 2.12000e-01 $1.00000 \mathrm{e}-021.00000 \mathrm{e}-02$ 1.00000e-03 1.00000e-09 1.00000e-01 $1.00000 \mathrm{e}+001.00000 \mathrm{e}+001.00000 \mathrm{e}-011.00000 \mathrm{e}-091.00000 \mathrm{e}-01$ $1.00000 \mathrm{e}-05$ 1.00000e-05 1.00000e-06 1.00000e-09 1.00000e-01 $1.00000 \mathrm{e}+001.00000 \mathrm{e}+001.00000 \mathrm{e}-011.00000 \mathrm{e}-091.00000 \mathrm{e}-01$ Element: 3822 \# of layers: 11 
$\mathrm{Kx} \mathrm{Ky} \mathrm{Kz}$ Ss Por

$1.67991 \mathrm{e}+011.67991 \mathrm{e}+01$ 1.67991e+00 1.00000e-09 7.00000e-02

$1.67991 \mathrm{e}+011.67991 \mathrm{e}+011.67991 \mathrm{e}+001.00000 \mathrm{e}-097.00000 \mathrm{e}-02$

$1.67991 \mathrm{e}+011.67991 \mathrm{e}+011.67991 \mathrm{e}+001.00000 \mathrm{e}-097.00000 \mathrm{e}-02$

5.00000e-04 5.00000e-04 5.00000e-05 1.00000e-09 1.00000e-01

5.00000e-04 5.00000e-04 5.00000e-05 1.00000e-09 1.00000e-01

6.71212e-01 6.71212e-01 6.71212e-02 1.00000e-09 2.12000e-01

6.71212e-01 6.71212e-01 6.71212e-02 1.00000e-09 2.12000e-01

$1.00000 \mathrm{e}-02$ 1.00000e-02 1.00000e-03 1.00000e-09 1.00000e-01

$1.00000 \mathrm{e}+001.00000 \mathrm{e}+001.00000 \mathrm{e}-011.00000 \mathrm{e}-091.00000 \mathrm{e}-01$

$1.00000 \mathrm{e}-05$ 1.00000e-05 1.00000e-06 1.00000e-09 1.00000e-01

$1.00000 \mathrm{e}+001.00000 \mathrm{e}+001.00000 \mathrm{e}-01$ 1.00000e-09 1.00000e-01

Element: 3823 \# of layers: 11

$\mathrm{Kx} \mathrm{Ky} \mathrm{Kz}$ Ss Por

$1.67991 \mathrm{e}+011.67991 \mathrm{e}+01$ 1.67991e+00 1.00000e-09 7.00000e-02

$1.67991 \mathrm{e}+011.67991 \mathrm{e}+011.67991 \mathrm{e}+001.00000 \mathrm{e}-09$ 7.00000e-02

$1.67991 \mathrm{e}+011.67991 \mathrm{e}+011.67991 \mathrm{e}+001.00000 \mathrm{e}-09$ 7.00000e-02

5.00000e-04 5.00000e-04 5.00000e-05 1.00000e-09 1.00000e-01

5.00000e-04 5.00000e-04 5.00000e-05 1.00000e-09 1.00000e-01

6.71212e-01 6.71212e-01 6.71212e-02 1.00000e-09 2.12000e-01

6.71212e-01 6.71212e-01 6.71212e-02 1.00000e-09 2.12000e-01

$1.00000 \mathrm{e}-02$ 1.00000e-02 1.00000e-03 1.00000e-09 1.00000e-01

$1.00000 \mathrm{e}+001.00000 \mathrm{e}+001.00000 \mathrm{e}-011.00000 \mathrm{e}-091.00000 \mathrm{e}-01$

$1.00000 \mathrm{e}-05$ 1.00000e-05 1.00000e-06 1.00000e-09 1.00000e-01

$1.00000 \mathrm{e}+001.00000 \mathrm{e}+001.00000 \mathrm{e}-011.00000 \mathrm{e}-091.00000 \mathrm{e}-01$

Element: 3824 \# of layers: 12

$\mathrm{Kx} \mathrm{Ky} \mathrm{Kz}$ Ss Por

$1.67991 \mathrm{e}+011.67991 \mathrm{e}+011.67991 \mathrm{e}+00$ 1.00000e-09 7.00000e-02

$1.67991 \mathrm{e}+011.67991 \mathrm{e}+011.67991 \mathrm{e}+001.00000 \mathrm{e}-097.00000 \mathrm{e}-02$

$1.67991 \mathrm{e}+011.67991 \mathrm{e}+011.67991 \mathrm{e}+001.00000 \mathrm{e}-09$ 7.00000e-02

$1.67991 \mathrm{e}+011.67991 \mathrm{e}+011.67991 \mathrm{e}+001.00000 \mathrm{e}-097.00000 \mathrm{e}-02$

5.00000e-04 5.00000e-04 5.00000e-05 1.00000e-09 1.00000e-01

5.00000e-04 5.00000e-04 5.00000e-05 1.00000e-09 1.00000e-01

6.71212e-01 6.71212e-01 6.71212e-02 1.00000e-09 2.12000e-01

6.71212e-01 6.71212e-01 6.71212e-02 1.00000e-09 2.12000e-01

$1.00000 \mathrm{e}-02$ 1.00000e-02 1.00000e-03 1.00000e-09 1.00000e-01

$1.00000 \mathrm{e}+001.00000 \mathrm{e}+001.00000 \mathrm{e}-011.00000 \mathrm{e}-091.00000 \mathrm{e}-01$

$1.00000 \mathrm{e}-05$ 1.00000e-05 1.00000e-06 1.00000e-09 1.00000e-01

$1.00000 \mathrm{e}+001.00000 \mathrm{e}+001.00000 \mathrm{e}-011.00000 \mathrm{e}-091.00000 \mathrm{e}-01$

Element: 3825 \# of layers: 13

$\mathrm{Kx} \mathrm{Ky} \mathrm{Kz}$ Ss Por

$1.67991 \mathrm{e}+011.67991 \mathrm{e}+011.67991 \mathrm{e}+001.00000 \mathrm{e}-09$ 7.00000e-02

$1.67991 \mathrm{e}+011.67991 \mathrm{e}+011.67991 \mathrm{e}+001.00000 \mathrm{e}-097.00000 \mathrm{e}-02$

$1.67991 \mathrm{e}+011.67991 \mathrm{e}+01$ 1.67991e+00 1.00000e-09 7.00000e-02

$1.67991 \mathrm{e}+011.67991 \mathrm{e}+011.67991 \mathrm{e}+001.00000 \mathrm{e}-09$ 7.00000e-02

5.00000e-04 5.00000e-04 5.00000e-05 1.00000e-09 1.00000e-01 
5.00000e-04 5.00000e-04 5.00000e-05 1.00000e-09 1.00000e-01 6.71212e-01 6.71212e-01 6.71212e-02 1.00000e-09 2.12000e-01 6.71212e-01 6.71212e-01 6.71212e-02 1.00000e-09 2.12000e-01 6.71212e-01 6.71212e-01 6.71212e-02 1.00000e-09 2.12000e-01 $1.00000 \mathrm{e}-02$ 1.00000e-02 1.00000e-03 1.00000e-09 1.00000e-01 $1.00000 \mathrm{e}+001.00000 \mathrm{e}+001.00000 \mathrm{e}-011.00000 \mathrm{e}-091.00000 \mathrm{e}-01$ $1.00000 \mathrm{e}-05$ 1.00000e-05 1.00000e-06 1.00000e-09 1.00000e-01 $1.00000 \mathrm{e}+001.00000 \mathrm{e}+001.00000 \mathrm{e}-011.00000 \mathrm{e}-091.00000 \mathrm{e}-01$ Element: 3826 \# of layers: 11

$\mathrm{Kx} \mathrm{Ky} \mathrm{Kz}$ Ss Por

$2.73904 \mathrm{e}+012.73904 \mathrm{e}+012.73904 \mathrm{e}+00$ 1.00000e-09 7.00000e-02 $2.73904 \mathrm{e}+012.73904 \mathrm{e}+012.73904 \mathrm{e}+001.00000 \mathrm{e}-097.00000 \mathrm{e}-02$ 5.00000e-04 5.00000e-04 5.00000e-05 1.00000e-09 1.00000e-01 5.00000e-04 5.00000e-04 5.00000e-05 1.00000e-09 1.00000e-01 $1.09442 \mathrm{e}+001.09442 \mathrm{e}+00$ 1.09442e-01 1.00000e-09 2.12000e-01 $1.09442 \mathrm{e}+00$ 1.09442e+00 1.09442e-01 1.00000e-09 2.12000e-01 $1.09442 \mathrm{e}+00$ 1.09442e+00 1.09442e-01 1.00000e-09 2.12000e-01 $1.00000 \mathrm{e}-02$ 1.00000e-02 1.00000e-03 1.00000e-09 1.00000e-01 $1.00000 \mathrm{e}+001.00000 \mathrm{e}+001.00000 \mathrm{e}-011.00000 \mathrm{e}-091.00000 \mathrm{e}-01$ $1.00000 \mathrm{e}-05$ 1.00000e-05 1.00000e-06 1.00000e-09 1.00000e-01 $1.00000 \mathrm{e}+001.00000 \mathrm{e}+001.00000 \mathrm{e}-011.00000 \mathrm{e}-091.00000 \mathrm{e}-01$ Element: 3827 \# of layers: 11

$\mathrm{Kx} \mathrm{Ky} \mathrm{Kz}$ Ss Por

$2.73904 \mathrm{e}+012.73904 \mathrm{e}+012.73904 \mathrm{e}+00$ 1.00000e-09 7.00000e-02 $2.73904 \mathrm{e}+012.73904 \mathrm{e}+012.73904 \mathrm{e}+001.00000 \mathrm{e}-097.00000 \mathrm{e}-02$ $5.00000 \mathrm{e}-04$ 5.00000e-04 5.00000e-05 1.00000e-09 1.00000e-01 5.00000e-04 5.00000e-04 5.00000e-05 1.00000e-09 1.00000e-01 $1.09442 \mathrm{e}+001.09442 \mathrm{e}+00$ 1.09442e-01 1.00000e-09 2.12000e-01 $1.09442 \mathrm{e}+00$ 1.09442e+00 1.09442e-01 1.00000e-09 2.12000e-01 $1.09442 \mathrm{e}+00$ 1.09442e+00 1.09442e-01 1.00000e-09 2.12000e-01 $1.00000 \mathrm{e}-02$ 1.00000e-02 1.00000e-03 1.00000e-09 1.00000e-01 $1.00000 \mathrm{e}+001.00000 \mathrm{e}+001.00000 \mathrm{e}-011.00000 \mathrm{e}-091.00000 \mathrm{e}-01$ $1.00000 \mathrm{e}-05$ 1.00000e-05 1.00000e-06 1.00000e-09 1.00000e-01 $1.00000 \mathrm{e}+001.00000 \mathrm{e}+001.00000 \mathrm{e}-011.00000 \mathrm{e}-091.00000 \mathrm{e}-01$ Element: 3828 \# of layers: 11

$\mathrm{Kx} \mathrm{Ky} \mathrm{Kz}$ Ss Por

$2.73904 \mathrm{e}+012.73904 \mathrm{e}+012.73904 \mathrm{e}+00$ 1.00000e-09 7.00000e-02 $2.73904 \mathrm{e}+012.73904 \mathrm{e}+012.73904 \mathrm{e}+001.00000 \mathrm{e}-09$ 7.00000e-02 5.00000e-04 5.00000e-04 5.00000e-05 1.00000e-09 1.00000e-01 5.00000e-04 5.00000e-04 5.00000e-05 1.00000e-09 1.00000e-01 $1.09442 \mathrm{e}+001.09442 \mathrm{e}+00$ 1.09442e-01 1.00000e-09 2.12000e-01 $1.09442 \mathrm{e}+001.09442 \mathrm{e}+00$ 1.09442e-01 1.00000e-09 2.12000e-01 $1.09442 \mathrm{e}+001.09442 \mathrm{e}+00$ 1.09442e-01 1.00000e-09 2.12000e-01 $1.00000 \mathrm{e}-021.00000 \mathrm{e}-02$ 1.00000e-03 1.00000e-09 1.00000e-01 $1.00000 \mathrm{e}+001.00000 \mathrm{e}+001.00000 \mathrm{e}-011.00000 \mathrm{e}-091.00000 \mathrm{e}-01$ $1.00000 \mathrm{e}-05$ 1.00000e-05 1.00000e-06 1.00000e-09 1.00000e-01 
$1.00000 \mathrm{e}+001.00000 \mathrm{e}+00$ 1.00000e-01 1.00000e-09 1.00000e-01

Element: 3829 \# of layers: 11

Kx Ky Kz Ss Por

$2.73904 \mathrm{e}+012.73904 \mathrm{e}+012.73904 \mathrm{e}+00$ 1.00000e-09 7.00000e-02

$2.73904 \mathrm{e}+012.73904 \mathrm{e}+012.73904 \mathrm{e}+001.00000 \mathrm{e}-09$ 7.00000e-02

5.00000e-04 5.00000e-04 5.00000e-05 1.00000e-09 1.00000e-01

5.00000e-04 5.00000e-04 5.00000e-05 1.00000e-09 1.00000e-01

$1.09442 \mathrm{e}+001.09442 \mathrm{e}+001.09442 \mathrm{e}-01$ 1.00000e-09 2.12000e-01

$1.09442 \mathrm{e}+00$ 1.09442e+00 1.09442e-01 1.00000e-09 2.12000e-01

$1.09442 \mathrm{e}+001.09442 \mathrm{e}+00$ 1.09442e-01 1.00000e-09 2.12000e-01

$1.00000 \mathrm{e}-02$ 1.00000e-02 1.00000e-03 1.00000e-09 1.00000e-01

$1.00000 \mathrm{e}+001.00000 \mathrm{e}+001.00000 \mathrm{e}-011.00000 \mathrm{e}-091.00000 \mathrm{e}-01$

$1.00000 \mathrm{e}-05$ 1.00000e-05 1.00000e-06 1.00000e-09 1.00000e-01

$1.00000 \mathrm{e}+001.00000 \mathrm{e}+001.00000 \mathrm{e}-011.00000 \mathrm{e}-09$ 1.00000e-01

Element: 3830 \# of layers: 10

Kx Ky Kz Ss Por

$2.73904 \mathrm{e}+012.73904 \mathrm{e}+012.73904 \mathrm{e}+00$ 1.00000e-09 7.00000e-02

$2.73904 \mathrm{e}+012.73904 \mathrm{e}+012.73904 \mathrm{e}+001.00000 \mathrm{e}-09$ 7.00000e-02

5.00000e-04 5.00000e-04 5.00000e-05 1.00000e-09 1.00000e-01

5.00000e-04 5.00000e-04 5.00000e-05 1.00000e-09 1.00000e-01

$1.09442 \mathrm{e}+001.09442 \mathrm{e}+00$ 1.09442e-01 1.00000e-09 2.12000e-01

$1.09442 \mathrm{e}+00$ 1.09442e+00 1.09442e-01 1.00000e-09 2.12000e-01

$1.00000 \mathrm{e}-02$ 1.00000e-02 1.00000e-03 1.00000e-09 1.00000e-01

$1.00000 \mathrm{e}+001.00000 \mathrm{e}+001.00000 \mathrm{e}-011.00000 \mathrm{e}-091.00000 \mathrm{e}-01$

$1.00000 \mathrm{e}-05$ 1.00000e-05 1.00000e-06 1.00000e-09 1.00000e-01

$1.00000 \mathrm{e}+001.00000 \mathrm{e}+001.00000 \mathrm{e}-01$ 1.00000e-09 1.00000e-01

Element: 3831 \# of layers: 10

$\mathrm{Kx} \mathrm{Ky} \mathrm{Kz}$ Ss Por

$2.73904 \mathrm{e}+012.73904 \mathrm{e}+012.73904 \mathrm{e}+00$ 1.00000e-09 7.00000e-02

$2.73904 \mathrm{e}+012.73904 \mathrm{e}+012.73904 \mathrm{e}+001.00000 \mathrm{e}-097.00000 \mathrm{e}-02$

5.00000e-04 5.00000e-04 5.00000e-05 1.00000e-09 1.00000e-01

5.00000e-04 5.00000e-04 5.00000e-05 1.00000e-09 1.00000e-01

$1.09442 \mathrm{e}+001.09442 \mathrm{e}+001.09442 \mathrm{e}-011.00000 \mathrm{e}-092.12000 \mathrm{e}-01$

$1.09442 \mathrm{e}+001.09442 \mathrm{e}+001.09442 \mathrm{e}-01$ 1.00000e-09 2.12000e-01

$1.00000 \mathrm{e}-02$ 1.00000e-02 1.00000e-03 1.00000e-09 1.00000e-01

$1.00000 \mathrm{e}+001.00000 \mathrm{e}+001.00000 \mathrm{e}-011.00000 \mathrm{e}-091.00000 \mathrm{e}-01$

1.00000e-05 1.00000e-05 1.00000e-06 1.00000e-09 1.00000e-01

$1.00000 \mathrm{e}+001.00000 \mathrm{e}+001.00000 \mathrm{e}-011.00000 \mathrm{e}-091.00000 \mathrm{e}-01$

Element: 3832 \# of layers: 10

$\mathrm{Kx} \mathrm{Ky} \mathrm{Kz}$ Ss Por

$2.73904 \mathrm{e}+012.73904 \mathrm{e}+012.73904 \mathrm{e}+00$ 1.00000e-09 7.00000e-02

$2.73904 \mathrm{e}+012.73904 \mathrm{e}+012.73904 \mathrm{e}+001.00000 \mathrm{e}-09$ 7.00000e-02

$5.00000 \mathrm{e}-04$ 5.00000e-04 5.00000e-05 1.00000e-09 1.00000e-01

5.00000e-04 5.00000e-04 5.00000e-05 1.00000e-09 1.00000e-01

$1.09442 \mathrm{e}+001.09442 \mathrm{e}+001.09442 \mathrm{e}-01$ 1.00000e-09 2.12000e-01

$1.09442 \mathrm{e}+001.09442 \mathrm{e}+00$ 1.09442e-01 1.00000e-09 2.12000e-01 
$1.00000 \mathrm{e}-02$ 1.00000e-02 1.00000e-03 1.00000e-09 1.00000e-01 $1.00000 \mathrm{e}+001.00000 \mathrm{e}+001.00000 \mathrm{e}-011.00000 \mathrm{e}-091.00000 \mathrm{e}-01$ $1.00000 \mathrm{e}-05$ 1.00000e-05 1.00000e-06 1.00000e-09 1.00000e-01 $1.00000 \mathrm{e}+001.00000 \mathrm{e}+001.00000 \mathrm{e}-011.00000 \mathrm{e}-091.00000 \mathrm{e}-01$ Element: 3833 \# of layers: 11

$\mathrm{Kx} \mathrm{Ky} \mathrm{Kz}$ Ss Por

$2.73904 \mathrm{e}+012.73904 \mathrm{e}+012.73904 \mathrm{e}+00$ 1.00000e-09 7.00000e-02 $2.73904 \mathrm{e}+012.73904 \mathrm{e}+012.73904 \mathrm{e}+001.00000 \mathrm{e}-09$ 7.00000e-02 5.00000e-04 5.00000e-04 5.00000e-05 1.00000e-09 1.00000e-01 5.00000e-04 5.00000e-04 5.00000e-05 1.00000e-09 1.00000e-01 $1.09442 \mathrm{e}+001.09442 \mathrm{e}+00$ 1.09442e-01 1.00000e-09 2.12000e-01 $1.09442 \mathrm{e}+001.09442 \mathrm{e}+00$ 1.09442e-01 1.00000e-09 2.12000e-01 $1.09442 \mathrm{e}+001.09442 \mathrm{e}+00$ 1.09442e-01 1.00000e-09 2.12000e-01 $1.00000 \mathrm{e}-02$ 1.00000e-02 1.00000e-03 1.00000e-09 1.00000e-01 $1.00000 \mathrm{e}+001.00000 \mathrm{e}+001.00000 \mathrm{e}-011.00000 \mathrm{e}-091.00000 \mathrm{e}-01$ 1.00000e-05 1.00000e-05 1.00000e-06 1.00000e-09 1.00000e-01 $1.00000 \mathrm{e}+001.00000 \mathrm{e}+001.00000 \mathrm{e}-011.00000 \mathrm{e}-091.00000 \mathrm{e}-01$ Element: 3834 \# of layers: 11

$\mathrm{Kx} \mathrm{Ky} \mathrm{Kz}$ Ss Por

$2.73904 \mathrm{e}+012.73904 \mathrm{e}+012.73904 \mathrm{e}+00$ 1.00000e-09 7.00000e-02 $2.73904 \mathrm{e}+012.73904 \mathrm{e}+012.73904 \mathrm{e}+001.00000 \mathrm{e}-097.00000 \mathrm{e}-02$ 5.00000e-04 5.00000e-04 5.00000e-05 1.00000e-09 1.00000e-01 $5.00000 \mathrm{e}-04$ 5.00000e-04 5.00000e-05 1.00000e-09 1.00000e-01 $1.09442 \mathrm{e}+00$ 1.09442e+00 1.09442e-01 1.00000e-09 2.12000e-01 $1.09442 \mathrm{e}+001.09442 \mathrm{e}+00$ 1.09442e-01 1.00000e-09 2.12000e-01 $1.09442 \mathrm{e}+001.09442 \mathrm{e}+001.09442 \mathrm{e}-01$ 1.00000e-09 2.12000e-01 $1.00000 \mathrm{e}-02$ 1.00000e-02 1.00000e-03 1.00000e-09 1.00000e-01 $1.00000 \mathrm{e}+001.00000 \mathrm{e}+001.00000 \mathrm{e}-01$ 1.00000e-09 1.00000e-01 $1.00000 \mathrm{e}-05$ 1.00000e-05 1.00000e-06 1.00000e-09 1.00000e-01 $1.00000 \mathrm{e}+001.00000 \mathrm{e}+001.00000 \mathrm{e}-011.00000 \mathrm{e}-091.00000 \mathrm{e}-01$ Element: 3835 \# of layers: 11

$\mathrm{Kx} \mathrm{Ky} \mathrm{Kz}$ Ss Por

$2.96979 e+012.96979 e+012.96979 e+001.00000 e-09$ 7.00000e-02 $2.96979 \mathrm{e}+012.96979 \mathrm{e}+012.96979 \mathrm{e}+00$ 1.00000e-09 7.00000e-02 5.00000e-04 5.00000e-04 5.00000e-05 1.00000e-09 1.00000e-01 5.00000e-04 5.00000e-04 5.00000e-05 1.00000e-09 1.00000e-01 $1.18661 \mathrm{e}+001.18661 \mathrm{e}+001.18661 \mathrm{e}-011.00000 \mathrm{e}-092.12000 \mathrm{e}-01$ $1.18661 \mathrm{e}+001.18661 \mathrm{e}+00$ 1.18661e-01 1.00000e-09 2.12000e-01 $1.18661 \mathrm{e}+001.18661 \mathrm{e}+001.18661 \mathrm{e}-01$ 1.00000e-09 2.12000e-01 $1.00000 \mathrm{e}-02$ 1.00000e-02 1.00000e-03 1.00000e-09 1.00000e-01 $1.00000 \mathrm{e}+001.00000 \mathrm{e}+001.00000 \mathrm{e}-011.00000 \mathrm{e}-091.00000 \mathrm{e}-01$ $1.00000 \mathrm{e}-05$ 1.00000e-05 1.00000e-06 1.00000e-09 1.00000e-01 $1.00000 \mathrm{e}+001.00000 \mathrm{e}+001.00000 \mathrm{e}-01$ 1.00000e-09 1.00000e-01 Element: 3836 \# of layers: 11

$\mathrm{Kx} \mathrm{Ky} \mathrm{Kz}$ Ss Por

2.96979e+01 2.96979e+01 2.96979e+00 1.00000e-09 7.00000e-02 
$2.96979 \mathrm{e}+012.96979 \mathrm{e}+012.96979 \mathrm{e}+00$ 1.00000e-09 7.00000e-02 5.00000e-04 5.00000e-04 5.00000e-05 1.00000e-09 1.00000e-01 5.00000e-04 5.00000e-04 5.00000e-05 1.00000e-09 1.00000e-01

$1.18661 \mathrm{e}+001.18661 \mathrm{e}+001.18661 \mathrm{e}-011.00000 \mathrm{e}-092.12000 \mathrm{e}-01$ $1.18661 \mathrm{e}+001.18661 \mathrm{e}+00$ 1.18661e-01 1.00000e-09 2.12000e-01 $1.18661 \mathrm{e}+001.18661 \mathrm{e}+001.18661 \mathrm{e}-01$ 1.00000e-09 2.12000e-01 $1.00000 \mathrm{e}-02$ 1.00000e-02 1.00000e-03 1.00000e-09 1.00000e-01 $1.00000 \mathrm{e}+001.00000 \mathrm{e}+001.00000 \mathrm{e}-011.00000 \mathrm{e}-091.00000 \mathrm{e}-01$ $1.00000 \mathrm{e}-051.00000 \mathrm{e}-051.00000 \mathrm{e}-061.00000 \mathrm{e}-091.00000 \mathrm{e}-01$ $1.00000 \mathrm{e}+001.00000 \mathrm{e}+001.00000 \mathrm{e}-011.00000 \mathrm{e}-091.00000 \mathrm{e}-01$ Element: 3837 \# of layers: 12

$\mathrm{Kx} \mathrm{Ky} \mathrm{Kz}$ Ss Por

$2.96979 \mathrm{e}+012.96979 \mathrm{e}+01$ 2.96979e+00 1.00000e-09 7.00000e-02

$2.96979 \mathrm{e}+012.96979 \mathrm{e}+012.96979 \mathrm{e}+001.00000 \mathrm{e}-09$ 7.00000e-02 5.00000e-04 5.00000e-04 5.00000e-05 1.00000e-09 1.00000e-01 5.00000e-04 5.00000e-04 5.00000e-05 1.00000e-09 1.00000e-01

$1.18661 \mathrm{e}+001.18661 \mathrm{e}+001.18661 \mathrm{e}-011.00000 \mathrm{e}-092.12000 \mathrm{e}-01$ $1.18661 \mathrm{e}+001.18661 \mathrm{e}+00$ 1.18661e-01 1.00000e-09 2.12000e-01 $1.18661 \mathrm{e}+001.18661 \mathrm{e}+001.18661 \mathrm{e}-01$ 1.00000e-09 2.12000e-01 $1.18661 \mathrm{e}+001.18661 \mathrm{e}+001.18661 \mathrm{e}-011.00000 \mathrm{e}-092.12000 \mathrm{e}-01$ $1.00000 \mathrm{e}-02$ 1.00000e-02 1.00000e-03 1.00000e-09 1.00000e-01 $1.00000 \mathrm{e}+001.00000 \mathrm{e}+001.00000 \mathrm{e}-011.00000 \mathrm{e}-091.00000 \mathrm{e}-01$ $1.00000 \mathrm{e}-05$ 1.00000e-05 1.00000e-06 1.00000e-09 1.00000e-01 $1.00000 \mathrm{e}+001.00000 \mathrm{e}+001.00000 \mathrm{e}-011.00000 \mathrm{e}-09$ 1.00000e-01 Element: 3838 \# of layers: 12

$\mathrm{Kx} \mathrm{Ky} \mathrm{Kz}$ Ss Por

$2.96979 \mathrm{e}+012.96979 \mathrm{e}+012.96979 \mathrm{e}+00$ 1.00000e-09 7.00000e-02 $2.96979 \mathrm{e}+012.96979 \mathrm{e}+012.96979 \mathrm{e}+00$ 1.00000e-09 7.00000e-02 5.00000e-04 5.00000e-04 5.00000e-05 1.00000e-09 1.00000e-01 5.00000e-04 5.00000e-04 5.00000e-05 1.00000e-09 1.00000e-01

$1.18661 \mathrm{e}+001.18661 \mathrm{e}+001.18661 \mathrm{e}-01$ 1.00000e-09 2.12000e-01 $1.18661 \mathrm{e}+001.18661 \mathrm{e}+001.18661 \mathrm{e}-01$ 1.00000e-09 2.12000e-01 $1.18661 \mathrm{e}+001.18661 \mathrm{e}+001.18661 \mathrm{e}-011.00000 \mathrm{e}-092.12000 \mathrm{e}-01$ $1.18661 \mathrm{e}+00$ 1.18661e+00 1.18661e-01 1.00000e-09 2.12000e-01 $1.00000 \mathrm{e}-02$ 1.00000e-02 1.00000e-03 1.00000e-09 1.00000e-01 $1.00000 \mathrm{e}+001.00000 \mathrm{e}+001.00000 \mathrm{e}-011.00000 \mathrm{e}-091.00000 \mathrm{e}-01$ $1.00000 \mathrm{e}-05$ 1.00000e-05 1.00000e-06 1.00000e-09 1.00000e-01 $1.00000 \mathrm{e}+001.00000 \mathrm{e}+001.00000 \mathrm{e}-011.00000 \mathrm{e}-091.00000 \mathrm{e}-01$ Element: 3839 \# of layers: 11

$\mathrm{Kx} \mathrm{Ky} \mathrm{Kz}$ Ss Por

$2.96979 e+012.96979 e+012.96979 e+001.00000 e-09$ 7.00000e-02 $2.96979 \mathrm{e}+012.96979 \mathrm{e}+012.96979 \mathrm{e}+00$ 1.00000e-09 7.00000e-02 5.00000e-04 5.00000e-04 5.00000e-05 1.00000e-09 1.00000e-01 5.00000e-04 5.00000e-04 5.00000e-05 1.00000e-09 1.00000e-01 $1.18661 \mathrm{e}+001.18661 \mathrm{e}+001.18661 \mathrm{e}-01$ 1.00000e-09 2.12000e-01 $1.18661 \mathrm{e}+001.18661 \mathrm{e}+001.18661 \mathrm{e}-01$ 1.00000e-09 2.12000e-01 
$1.18661 \mathrm{e}+00$ 1.18661e+00 1.18661e-01 1.00000e-09 2.12000e-01 $1.00000 \mathrm{e}-02$ 1.00000e-02 1.00000e-03 1.00000e-09 1.00000e-01 $1.00000 \mathrm{e}+001.00000 \mathrm{e}+001.00000 \mathrm{e}-011.00000 \mathrm{e}-091.00000 \mathrm{e}-01$ $1.00000 \mathrm{e}-05$ 1.00000e-05 1.00000e-06 1.00000e-09 1.00000e-01 $1.00000 \mathrm{e}+001.00000 \mathrm{e}+001.00000 \mathrm{e}-01$ 1.00000e-09 1.00000e-01 Element: 3840 \# of layers: 10

$\mathrm{Kx} \mathrm{Ky} \mathrm{Kz}$ Ss Por

$2.96979 e+012.96979 e+012.96979 e+001.00000 e-09$ 7.00000e-02

$2.96979 \mathrm{e}+012.96979 \mathrm{e}+012.96979 \mathrm{e}+001.00000 \mathrm{e}-09$ 7.00000e-02

5.00000e-04 5.00000e-04 5.00000e-05 1.00000e-09 1.00000e-01

5.00000e-04 5.00000e-04 5.00000e-05 1.00000e-09 1.00000e-01

$1.18661 \mathrm{e}+001.18661 \mathrm{e}+001.18661 \mathrm{e}-01$ 1.00000e-09 2.12000e-01

$1.18661 \mathrm{e}+001.18661 \mathrm{e}+001.18661 \mathrm{e}-01$ 1.00000e-09 2.12000e-01

$1.00000 \mathrm{e}-02$ 1.00000e-02 1.00000e-03 1.00000e-09 1.00000e-01

$1.00000 \mathrm{e}+001.00000 \mathrm{e}+001.00000 \mathrm{e}-011.00000 \mathrm{e}-091.00000 \mathrm{e}-01$ $1.00000 \mathrm{e}-05$ 1.00000e-05 1.00000e-06 1.00000e-09 1.00000e-01

$1.00000 \mathrm{e}+001.00000 \mathrm{e}+001.00000 \mathrm{e}-011.00000 \mathrm{e}-091.00000 \mathrm{e}-01$

Element: 3841 \# of layers: 10

$\mathrm{Kx} \mathrm{Ky} \mathrm{Kz}$ Ss Por

$2.96979 \mathrm{e}+012.96979 \mathrm{e}+012.96979 \mathrm{e}+00$ 1.00000e-09 7.00000e-02

$2.96979 \mathrm{e}+012.96979 \mathrm{e}+012.96979 \mathrm{e}+001.00000 \mathrm{e}-09$ 7.00000e-02

5.00000e-04 5.00000e-04 5.00000e-05 1.00000e-09 1.00000e-01

5.00000e-04 5.00000e-04 5.00000e-05 1.00000e-09 1.00000e-01

$1.18661 \mathrm{e}+001.18661 \mathrm{e}+001.18661 \mathrm{e}-011.00000 \mathrm{e}-092.12000 \mathrm{e}-01$

$1.18661 \mathrm{e}+001.18661 \mathrm{e}+001.18661 \mathrm{e}-011.00000 \mathrm{e}-092.12000 \mathrm{e}-01$

$1.00000 \mathrm{e}-02$ 1.00000e-02 1.00000e-03 1.00000e-09 1.00000e-01

$1.00000 \mathrm{e}+001.00000 \mathrm{e}+001.00000 \mathrm{e}-011.00000 \mathrm{e}-091.00000 \mathrm{e}-01$

$1.00000 \mathrm{e}-05$ 1.00000e-05 1.00000e-06 1.00000e-09 1.00000e-01

$1.00000 \mathrm{e}+001.00000 \mathrm{e}+001.00000 \mathrm{e}-011.00000 \mathrm{e}-091.00000 \mathrm{e}-01$

Element: 3842 \# of layers: 11

$\mathrm{Kx} \mathrm{Ky} \mathrm{Kz}$ Ss Por

$2.96979 \mathrm{e}+012.96979 \mathrm{e}+012.96979 \mathrm{e}+00$ 1.00000e-09 7.00000e-02

$2.96979 \mathrm{e}+012.96979 \mathrm{e}+012.96979 \mathrm{e}+00$ 1.00000e-09 7.00000e-02

5.00000e-04 5.00000e-04 5.00000e-05 1.00000e-09 1.00000e-01

5.00000e-04 5.00000e-04 5.00000e-05 1.00000e-09 1.00000e-01

$1.18661 \mathrm{e}+001.18661 \mathrm{e}+001.18661 \mathrm{e}-01$ 1.00000e-09 2.12000e-01

$1.18661 \mathrm{e}+001.18661 \mathrm{e}+001.18661 \mathrm{e}-01$ 1.00000e-09 2.12000e-01

$1.18661 \mathrm{e}+001.18661 \mathrm{e}+001.18661 \mathrm{e}-01$ 1.00000e-09 2.12000e-01

$1.00000 \mathrm{e}-02$ 1.00000e-02 1.00000e-03 1.00000e-09 1.00000e-01

$1.00000 \mathrm{e}+001.00000 \mathrm{e}+001.00000 \mathrm{e}-011.00000 \mathrm{e}-091.00000 \mathrm{e}-01$

$1.00000 \mathrm{e}-05$ 1.00000e-05 1.00000e-06 1.00000e-09 1.00000e-01

$1.00000 \mathrm{e}+001.00000 \mathrm{e}+001.00000 \mathrm{e}-011.00000 \mathrm{e}-091.00000 \mathrm{e}-01$

Element: 3843 \# of layers: 11

$\mathrm{Kx} \mathrm{Ky} \mathrm{Kz}$ Ss Por

$2.96979 \mathrm{e}+012.96979 \mathrm{e}+012.96979 \mathrm{e}+00$ 1.00000e-09 7.00000e-02

$2.96979 \mathrm{e}+012.96979 \mathrm{e}+012.96979 \mathrm{e}+001.00000 \mathrm{e}-09$ 7.00000e-02 
5.00000e-04 5.00000e-04 5.00000e-05 1.00000e-09 1.00000e-01 5.00000e-04 5.00000e-04 5.00000e-05 1.00000e-09 1.00000e-01 $1.18661 \mathrm{e}+001.18661 \mathrm{e}+00$ 1.18661e-01 1.00000e-09 2.12000e-01 $1.18661 \mathrm{e}+001.18661 \mathrm{e}+001.18661 \mathrm{e}-011.00000 \mathrm{e}-092.12000 \mathrm{e}-01$ $1.18661 \mathrm{e}+001.18661 \mathrm{e}+001.18661 \mathrm{e}-01$ 1.00000e-09 2.12000e-01 $1.00000 \mathrm{e}-02$ 1.00000e-02 1.00000e-03 1.00000e-09 1.00000e-01 $1.00000 \mathrm{e}+001.00000 \mathrm{e}+001.00000 \mathrm{e}-011.00000 \mathrm{e}-091.00000 \mathrm{e}-01$ $1.00000 \mathrm{e}-05$ 1.00000e-05 1.00000e-06 1.00000e-09 1.00000e-01 $1.00000 \mathrm{e}+001.00000 \mathrm{e}+00$ 1.00000e-01 1.00000e-09 1.00000e-01 Element: 3844 \# of layers: 12

$\mathrm{Kx} \mathrm{Ky} \mathrm{Kz}$ Ss Por

$2.84284 \mathrm{e}+012.84284 \mathrm{e}+012.84284 \mathrm{e}+00$ 1.00000e-09 7.00000e-02 $2.84284 \mathrm{e}+012.84284 \mathrm{e}+012.84284 \mathrm{e}+001.00000 \mathrm{e}-09$ 7.00000e-02 5.00000e-04 5.00000e-04 5.00000e-05 1.00000e-09 1.00000e-01 5.00000e-04 5.00000e-04 5.00000e-05 1.00000e-09 1.00000e-01 $1.13589 \mathrm{e}+001.13589 \mathrm{e}+00$ 1.13589e-01 1.00000e-09 2.12000e-01 $1.13589 \mathrm{e}+00$ 1.13589e+00 1.13589e-01 1.00000e-09 2.12000e-01 $1.13589 \mathrm{e}+001.13589 \mathrm{e}+00$ 1.13589e-01 1.00000e-09 2.12000e-01 $1.13589 \mathrm{e}+001.13589 \mathrm{e}+00$ 1.13589e-01 1.00000e-09 2.12000e-01 $1.00000 \mathrm{e}-02$ 1.00000e-02 1.00000e-03 1.00000e-09 1.00000e-01 $1.00000 \mathrm{e}+001.00000 \mathrm{e}+001.00000 \mathrm{e}-011.00000 \mathrm{e}-091.00000 \mathrm{e}-01$ $1.00000 \mathrm{e}-05$ 1.00000e-05 1.00000e-06 1.00000e-09 1.00000e-01 $1.00000 \mathrm{e}+001.00000 \mathrm{e}+001.00000 \mathrm{e}-01$ 1.00000e-09 1.00000e-01 Element: 3845 \# of layers: 12

$\mathrm{Kx} \mathrm{Ky} \mathrm{Kz}$ Ss Por

$2.84284 \mathrm{e}+012.84284 \mathrm{e}+012.84284 \mathrm{e}+001.00000 \mathrm{e}-097.00000 \mathrm{e}-02$ $2.84284 \mathrm{e}+012.84284 \mathrm{e}+012.84284 \mathrm{e}+001.00000 \mathrm{e}-097.00000 \mathrm{e}-02$ 5.00000e-04 5.00000e-04 5.00000e-05 1.00000e-09 1.00000e-01 5.00000e-04 5.00000e-04 5.00000e-05 1.00000e-09 1.00000e-01 $1.13589 \mathrm{e}+00$ 1.13589e+00 1.13589e-01 1.00000e-09 2.12000e-01 $1.13589 \mathrm{e}+00$ 1.13589e+00 1.13589e-01 1.00000e-09 2.12000e-01 $1.13589 \mathrm{e}+00$ 1.13589e+00 1.13589e-01 1.00000e-09 2.12000e-01 $1.13589 \mathrm{e}+001.13589 \mathrm{e}+001.13589 \mathrm{e}-01$ 1.00000e-09 2.12000e-01 1.00000e-02 1.00000e-02 1.00000e-03 1.00000e-09 1.00000e-01 $1.00000 \mathrm{e}+001.00000 \mathrm{e}+001.00000 \mathrm{e}-011.00000 \mathrm{e}-091.00000 \mathrm{e}-01$ $1.00000 \mathrm{e}-05$ 1.00000e-05 1.00000e-06 1.00000e-09 1.00000e-01 $1.00000 \mathrm{e}+001.00000 \mathrm{e}+001.00000 \mathrm{e}-011.00000 \mathrm{e}-091.00000 \mathrm{e}-01$ Element: 3846 \# of layers: 12

$\mathrm{Kx} \mathrm{Ky} \mathrm{Kz}$ Ss Por

$2.84284 \mathrm{e}+012.84284 \mathrm{e}+012.84284 \mathrm{e}+00$ 1.00000e-09 7.00000e-02 $2.84284 \mathrm{e}+012.84284 \mathrm{e}+012.84284 \mathrm{e}+001.00000 \mathrm{e}-097.00000 \mathrm{e}-02$ 5.00000e-04 5.00000e-04 5.00000e-05 1.00000e-09 1.00000e-01 5.00000e-04 5.00000e-04 5.00000e-05 1.00000e-09 1.00000e-01 $1.13589 \mathrm{e}+00$ 1.13589e+00 1.13589e-01 1.00000e-09 2.12000e-01 $1.13589 \mathrm{e}+00$ 1.13589e+00 1.13589e-01 1.00000e-09 2.12000e-01 $1.13589 \mathrm{e}+001.13589 \mathrm{e}+00$ 1.13589e-01 1.00000e-09 2.12000e-01 
$1.13589 \mathrm{e}+00$ 1.13589e+00 1.13589e-01 1.00000e-09 2.12000e-01 $1.00000 \mathrm{e}-02$ 1.00000e-02 1.00000e-03 1.00000e-09 1.00000e-01 $1.00000 \mathrm{e}+001.00000 \mathrm{e}+001.00000 \mathrm{e}-011.00000 \mathrm{e}-091.00000 \mathrm{e}-01$ $1.00000 \mathrm{e}-05$ 1.00000e-05 1.00000e-06 1.00000e-09 1.00000e-01 $1.00000 \mathrm{e}+001.00000 \mathrm{e}+001.00000 \mathrm{e}-011.00000 \mathrm{e}-091.00000 \mathrm{e}-01$ Element: 3847 \# of layers: 12

$\mathrm{Kx} \mathrm{Ky} \mathrm{Kz}$ Ss Por

$2.84284 \mathrm{e}+012.84284 \mathrm{e}+012.84284 \mathrm{e}+00$ 1.00000e-09 7.00000e-02

$2.84284 \mathrm{e}+012.84284 \mathrm{e}+012.84284 \mathrm{e}+001.00000 \mathrm{e}-09$ 7.00000e-02

5.00000e-04 5.00000e-04 5.00000e-05 1.00000e-09 1.00000e-01

5.00000e-04 5.00000e-04 5.00000e-05 1.00000e-09 1.00000e-01

$1.13589 \mathrm{e}+001.13589 \mathrm{e}+00$ 1.13589e-01 1.00000e-09 2.12000e-01

$1.13589 \mathrm{e}+001.13589 \mathrm{e}+00$ 1.13589e-01 1.00000e-09 2.12000e-01

$1.13589 \mathrm{e}+00$ 1.13589e+00 1.13589e-01 1.00000e-09 2.12000e-01

$1.13589 \mathrm{e}+001.13589 \mathrm{e}+00$ 1.13589e-01 1.00000e-09 2.12000e-01 $1.00000 \mathrm{e}-02$ 1.00000e-02 1.00000e-03 1.00000e-09 1.00000e-01

$1.00000 \mathrm{e}+001.00000 \mathrm{e}+001.00000 \mathrm{e}-011.00000 \mathrm{e}-091.00000 \mathrm{e}-01$ $1.00000 \mathrm{e}-05$ 1.00000e-05 1.00000e-06 1.00000e-09 1.00000e-01

$1.00000 \mathrm{e}+001.00000 \mathrm{e}+001.00000 \mathrm{e}-011.00000 \mathrm{e}-091.00000 \mathrm{e}-01$ Element: 3848 \# of layers: 11

$\mathrm{Kx} \mathrm{Ky} \mathrm{Kz}$ Ss Por

$2.84284 \mathrm{e}+012.84284 \mathrm{e}+012.84284 \mathrm{e}+00$ 1.00000e-09 7.00000e-02

$2.84284 \mathrm{e}+012.84284 \mathrm{e}+012.84284 \mathrm{e}+001.00000 \mathrm{e}-097.00000 \mathrm{e}-02$ $5.00000 \mathrm{e}-04$ 5.00000e-04 5.00000e-05 1.00000e-09 1.00000e-01 5.00000e-04 5.00000e-04 5.00000e-05 1.00000e-09 1.00000e-01

$1.13589 \mathrm{e}+00$ 1.13589e+00 1.13589e-01 1.00000e-09 2.12000e-01

$1.13589 \mathrm{e}+00$ 1.13589e+00 1.13589e-01 1.00000e-09 2.12000e-01

$1.13589 \mathrm{e}+001.13589 \mathrm{e}+00$ 1.13589e-01 1.00000e-09 2.12000e-01 $1.00000 \mathrm{e}-02$ 1.00000e-02 1.00000e-03 1.00000e-09 1.00000e-01 $1.00000 \mathrm{e}+001.00000 \mathrm{e}+001.00000 \mathrm{e}-011.00000 \mathrm{e}-091.00000 \mathrm{e}-01$ $1.00000 \mathrm{e}-05$ 1.00000e-05 1.00000e-06 1.00000e-09 1.00000e-01 $1.00000 \mathrm{e}+001.00000 \mathrm{e}+001.00000 \mathrm{e}-01$ 1.00000e-09 1.00000e-01 Element: 3849 \# of layers: 11

$\mathrm{Kx} \mathrm{Ky} \mathrm{Kz}$ Ss Por

$2.84284 \mathrm{e}+012.84284 \mathrm{e}+012.84284 \mathrm{e}+00$ 1.00000e-09 7.00000e-02 $2.84284 \mathrm{e}+012.84284 \mathrm{e}+012.84284 \mathrm{e}+001.00000 \mathrm{e}-097.00000 \mathrm{e}-02$ 5.00000e-04 5.00000e-04 5.00000e-05 1.00000e-09 1.00000e-01 5.00000e-04 5.00000e-04 5.00000e-05 1.00000e-09 1.00000e-01 $1.13589 \mathrm{e}+001.13589 \mathrm{e}+00$ 1.13589e-01 1.00000e-09 2.12000e-01 $1.13589 \mathrm{e}+001.13589 \mathrm{e}+00$ 1.13589e-01 1.00000e-09 2.12000e-01 $1.13589 \mathrm{e}+001.13589 \mathrm{e}+00$ 1.13589e-01 1.00000e-09 2.12000e-01 $1.00000 \mathrm{e}-02$ 1.00000e-02 1.00000e-03 1.00000e-09 1.00000e-01 $1.00000 \mathrm{e}+001.00000 \mathrm{e}+001.00000 \mathrm{e}-011.00000 \mathrm{e}-091.00000 \mathrm{e}-01$ $1.00000 \mathrm{e}-05$ 1.00000e-05 1.00000e-06 1.00000e-09 1.00000e-01 $1.00000 \mathrm{e}+001.00000 \mathrm{e}+001.00000 \mathrm{e}-01$ 1.00000e-09 1.00000e-01 Element: 3850 \# of layers: 11 
$\mathrm{Kx} \mathrm{Ky} \mathrm{Kz}$ Ss Por

$2.84284 \mathrm{e}+012.84284 \mathrm{e}+012.84284 \mathrm{e}+00$ 1.00000e-09 7.00000e-02

$2.84284 \mathrm{e}+012.84284 \mathrm{e}+012.84284 \mathrm{e}+001.00000 \mathrm{e}-09$ 7.00000e-02

5.00000e-04 5.00000e-04 5.00000e-05 1.00000e-09 1.00000e-01

5.00000e-04 5.00000e-04 5.00000e-05 1.00000e-09 1.00000e-01

$1.13589 \mathrm{e}+001.13589 \mathrm{e}+00$ 1.13589e-01 1.00000e-09 2.12000e-01

$1.13589 \mathrm{e}+00$ 1.13589e+00 1.13589e-01 1.00000e-09 2.12000e-01

$1.13589 \mathrm{e}+001.13589 \mathrm{e}+001.13589 \mathrm{e}-01$ 1.00000e-09 2.12000e-01

$1.00000 \mathrm{e}-02$ 1.00000e-02 1.00000e-03 1.00000e-09 1.00000e-01

$1.00000 \mathrm{e}+001.00000 \mathrm{e}+001.00000 \mathrm{e}-011.00000 \mathrm{e}-091.00000 \mathrm{e}-01$

$1.00000 \mathrm{e}-05$ 1.00000e-05 1.00000e-06 1.00000e-09 1.00000e-01

$1.00000 \mathrm{e}+001.00000 \mathrm{e}+001.00000 \mathrm{e}-01$ 1.00000e-09 1.00000e-01

Element: 3851 \# of layers: 12

$\mathrm{Kx} \mathrm{Ky} \mathrm{Kz}$ Ss Por

$2.84284 \mathrm{e}+012.84284 \mathrm{e}+012.84284 \mathrm{e}+00$ 1.00000e-09 7.00000e-02

$2.84284 \mathrm{e}+012.84284 \mathrm{e}+012.84284 \mathrm{e}+001.00000 \mathrm{e}-09$ 7.00000e-02

5.00000e-04 5.00000e-04 5.00000e-05 1.00000e-09 1.00000e-01

5.00000e-04 5.00000e-04 5.00000e-05 1.00000e-09 1.00000e-01

$1.13589 \mathrm{e}+001.13589 \mathrm{e}+00$ 1.13589e-01 1.00000e-09 2.12000e-01

$1.13589 \mathrm{e}+001.13589 \mathrm{e}+00$ 1.13589e-01 1.00000e-09 2.12000e-01

$1.13589 \mathrm{e}+001.13589 \mathrm{e}+001.13589 \mathrm{e}-01$ 1.00000e-09 2.12000e-01

$1.13589 \mathrm{e}+00$ 1.13589e+00 1.13589e-01 1.00000e-09 2.12000e-01

$1.00000 \mathrm{e}-02$ 1.00000e-02 1.00000e-03 1.00000e-09 1.00000e-01

$1.00000 \mathrm{e}+001.00000 \mathrm{e}+001.00000 \mathrm{e}-011.00000 \mathrm{e}-091.00000 \mathrm{e}-01$

$1.00000 \mathrm{e}-05$ 1.00000e-05 1.00000e-06 1.00000e-09 1.00000e-01

$1.00000 \mathrm{e}+001.00000 \mathrm{e}+001.00000 \mathrm{e}-011.00000 \mathrm{e}-091.00000 \mathrm{e}-01$

Element: 3852 \# of layers: 12

$\mathrm{Kx} \mathrm{Ky} \mathrm{Kz}$ Ss Por

$2.84284 \mathrm{e}+012.84284 \mathrm{e}+012.84284 \mathrm{e}+001.00000 \mathrm{e}-09$ 7.00000e-02

$2.84284 \mathrm{e}+012.84284 \mathrm{e}+012.84284 \mathrm{e}+001.00000 \mathrm{e}-09$ 7.00000e-02

5.00000e-04 5.00000e-04 5.00000e-05 1.00000e-09 1.00000e-01

5.00000e-04 5.00000e-04 5.00000e-05 1.00000e-09 1.00000e-01

$1.13589 \mathrm{e}+001.13589 \mathrm{e}+001.13589 \mathrm{e}-01$ 1.00000e-09 2.12000e-01

$1.13589 \mathrm{e}+001.13589 \mathrm{e}+00$ 1.13589e-01 1.00000e-09 2.12000e-01

$1.13589 \mathrm{e}+00$ 1.13589e+00 1.13589e-01 1.00000e-09 2.12000e-01

$1.13589 \mathrm{e}+001.13589 \mathrm{e}+001.13589 \mathrm{e}-01$ 1.00000e-09 2.12000e-01

$1.00000 \mathrm{e}-02$ 1.00000e-02 1.00000e-03 1.00000e-09 1.00000e-01

$1.00000 \mathrm{e}+001.00000 \mathrm{e}+001.00000 \mathrm{e}-011.00000 \mathrm{e}-091.00000 \mathrm{e}-01$

$1.00000 \mathrm{e}-05$ 1.00000e-05 1.00000e-06 1.00000e-09 1.00000e-01

$1.00000 \mathrm{e}+001.00000 \mathrm{e}+001.00000 \mathrm{e}-01$ 1.00000e-09 1.00000e-01

Element: 3853 \# of layers: 12

$\mathrm{Kx} \mathrm{Ky} \mathrm{Kz}$ Ss Por

3.39524e+01 3.39524e+01 3.39524e+00 1.00000e-09 7.00000e-02

$3.39524 \mathrm{e}+013.39524 \mathrm{e}+013.39524 \mathrm{e}+001.00000 \mathrm{e}-09$ 7.00000e-02

5.00000e-04 5.00000e-04 5.00000e-05 1.00000e-09 1.00000e-01

5.00000e-04 5.00000e-04 5.00000e-05 1.00000e-09 1.00000e-01 
$1.35662 \mathrm{e}+001.35662 \mathrm{e}+00$ 1.35662e-01 1.00000e-09 2.12000e-01 $1.35662 \mathrm{e}+001.35662 \mathrm{e}+001.35662 \mathrm{e}-011.00000 \mathrm{e}-092.12000 \mathrm{e}-01$ $1.35662 \mathrm{e}+001.35662 \mathrm{e}+001.35662 \mathrm{e}-011.00000 \mathrm{e}-092.12000 \mathrm{e}-01$ $1.35662 \mathrm{e}+001.35662 \mathrm{e}+001.35662 \mathrm{e}-011.00000 \mathrm{e}-092.12000 \mathrm{e}-01$ $1.00000 \mathrm{e}-02$ 1.00000e-02 1.00000e-03 1.00000e-09 1.00000e-01 $1.00000 \mathrm{e}+001.00000 \mathrm{e}+001.00000 \mathrm{e}-011.00000 \mathrm{e}-091.00000 \mathrm{e}-01$ $1.00000 \mathrm{e}-051.00000 \mathrm{e}-05$ 1.00000e-06 1.00000e-09 1.00000e-01 $1.00000 \mathrm{e}+001.00000 \mathrm{e}+001.00000 \mathrm{e}-011.00000 \mathrm{e}-091.00000 \mathrm{e}-01$ Element: 3854 \# of layers: 11

Kx Ky Kz Ss Por

$3.39524 \mathrm{e}+013.39524 \mathrm{e}+013.39524 \mathrm{e}+00$ 1.00000e-09 7.00000e-02 5.00000e-04 5.00000e-04 5.00000e-05 1.00000e-09 1.00000e-01 5.00000e-04 5.00000e-04 5.00000e-05 1.00000e-09 1.00000e-01 $1.35662 \mathrm{e}+001.35662 \mathrm{e}+001.35662 \mathrm{e}-011.00000 \mathrm{e}-092.12000 \mathrm{e}-01$ $1.35662 \mathrm{e}+001.35662 \mathrm{e}+001.35662 \mathrm{e}-011.00000 \mathrm{e}-092.12000 \mathrm{e}-01$ $1.35662 \mathrm{e}+001.35662 \mathrm{e}+001.35662 \mathrm{e}-011.00000 \mathrm{e}-092.12000 \mathrm{e}-01$ $1.35662 \mathrm{e}+001.35662 \mathrm{e}+001.35662 \mathrm{e}-011.00000 \mathrm{e}-09$ 2.12000e-01 $1.00000 \mathrm{e}-02$ 1.00000e-02 1.00000e-03 1.00000e-09 1.00000e-01 $1.00000 \mathrm{e}+001.00000 \mathrm{e}+001.00000 \mathrm{e}-011.00000 \mathrm{e}-091.00000 \mathrm{e}-01$ $1.00000 \mathrm{e}-05$ 1.00000e-05 1.00000e-06 1.00000e-09 1.00000e-01 $1.00000 \mathrm{e}+001.00000 \mathrm{e}+001.00000 \mathrm{e}-011.00000 \mathrm{e}-091.00000 \mathrm{e}-01$ Element: 3855 \# of layers: 11

Kx Ky Kz Ss Por

$3.39524 \mathrm{e}+013.39524 \mathrm{e}+013.39524 \mathrm{e}+00$ 1.00000e-09 7.00000e-02 5.00000e-04 5.00000e-04 5.00000e-05 1.00000e-09 1.00000e-01 $5.00000 \mathrm{e}-04$ 5.00000e-04 5.00000e-05 1.00000e-09 1.00000e-01 $1.35662 \mathrm{e}+001.35662 \mathrm{e}+001.35662 \mathrm{e}-011.00000 \mathrm{e}-092.12000 \mathrm{e}-01$ $1.35662 \mathrm{e}+001.35662 \mathrm{e}+001.35662 \mathrm{e}-011.00000 \mathrm{e}-092.12000 \mathrm{e}-01$ $1.35662 \mathrm{e}+001.35662 \mathrm{e}+001.35662 \mathrm{e}-011.00000 \mathrm{e}-092.12000 \mathrm{e}-01$ $1.35662 \mathrm{e}+001.35662 \mathrm{e}+001.35662 \mathrm{e}-011.00000 \mathrm{e}-092.12000 \mathrm{e}-01$ $1.00000 \mathrm{e}-021.00000 \mathrm{e}-02$ 1.00000e-03 1.00000e-09 1.00000e-01 $1.00000 \mathrm{e}+001.00000 \mathrm{e}+001.00000 \mathrm{e}-011.00000 \mathrm{e}-091.00000 \mathrm{e}-01$ $1.00000 \mathrm{e}-05$ 1.00000e-05 1.00000e-06 1.00000e-09 1.00000e-01 $1.00000 \mathrm{e}+001.00000 \mathrm{e}+001.00000 \mathrm{e}-011.00000 \mathrm{e}-091.00000 \mathrm{e}-01$ Element: 3856 \# of layers: 11

Kx Ky Kz Ss Por $3.39524 \mathrm{e}+013.39524 \mathrm{e}+013.39524 \mathrm{e}+00$ 1.00000e-09 7.00000e-02 5.00000e-04 5.00000e-04 5.00000e-05 1.00000e-09 1.00000e-01 5.00000e-04 5.00000e-04 5.00000e-05 1.00000e-09 1.00000e-01 $1.35662 \mathrm{e}+001.35662 \mathrm{e}+001.35662 \mathrm{e}-011.00000 \mathrm{e}-092.12000 \mathrm{e}-01$ $1.35662 \mathrm{e}+001.35662 \mathrm{e}+001.35662 \mathrm{e}-011.00000 \mathrm{e}-092.12000 \mathrm{e}-01$ $1.35662 \mathrm{e}+001.35662 \mathrm{e}+001.35662 \mathrm{e}-011.00000 \mathrm{e}-092.12000 \mathrm{e}-01$ $1.35662 \mathrm{e}+001.35662 \mathrm{e}+001.35662 \mathrm{e}-011.00000 \mathrm{e}-092.12000 \mathrm{e}-01$ $1.00000 \mathrm{e}-02$ 1.00000e-02 1.00000e-03 1.00000e-09 1.00000e-01 $1.00000 \mathrm{e}+001.00000 \mathrm{e}+001.00000 \mathrm{e}-011.00000 \mathrm{e}-091.00000 \mathrm{e}-01$ $1.00000 \mathrm{e}-05$ 1.00000e-05 1.00000e-06 1.00000e-09 1.00000e-01 
$1.00000 \mathrm{e}+001.00000 \mathrm{e}+00$ 1.00000e-01 1.00000e-09 1.00000e-01 Element: 3857 \# of layers: 11

$\mathrm{Kx} \mathrm{Ky} \mathrm{Kz}$ Ss Por

$3.39524 \mathrm{e}+01$ 3.39524e+01 3.39524e+00 1.00000e-09 7.00000e-02

$3.39524 \mathrm{e}+013.39524 \mathrm{e}+013.39524 \mathrm{e}+001.00000 \mathrm{e}-097.00000 \mathrm{e}-02$

5.00000e-04 5.00000e-04 5.00000e-05 1.00000e-09 1.00000e-01

5.00000e-04 5.00000e-04 5.00000e-05 1.00000e-09 1.00000e-01

$1.35662 \mathrm{e}+001.35662 \mathrm{e}+001.35662 \mathrm{e}-01$ 1.00000e-09 2.12000e-01

$1.35662 \mathrm{e}+00$ 1.35662e+00 1.35662e-01 1.00000e-09 2.12000e-01

$1.35662 \mathrm{e}+001.35662 \mathrm{e}+00$ 1.35662e-01 1.00000e-09 2.12000e-01

1.00000e-02 1.00000e-02 1.00000e-03 1.00000e-09 1.00000e-01

$1.00000 \mathrm{e}+001.00000 \mathrm{e}+001.00000 \mathrm{e}-011.00000 \mathrm{e}-091.00000 \mathrm{e}-01$

$1.00000 \mathrm{e}-05$ 1.00000e-05 1.00000e-06 1.00000e-09 1.00000e-01

$1.00000 \mathrm{e}+001.00000 \mathrm{e}+001.00000 \mathrm{e}-011.00000 \mathrm{e}-091.00000 \mathrm{e}-01$

Element: 3858 \# of layers: 11

Kx Ky Kz Ss Por

3.39524e+01 3.39524e+01 3.39524e+00 1.00000e-09 7.00000e-02

$3.39524 \mathrm{e}+013.39524 \mathrm{e}+013.39524 \mathrm{e}+001.00000 \mathrm{e}-09$ 7.00000e-02

5.00000e-04 5.00000e-04 5.00000e-05 1.00000e-09 1.00000e-01

5.00000e-04 5.00000e-04 5.00000e-05 1.00000e-09 1.00000e-01

$1.35662 \mathrm{e}+001.35662 \mathrm{e}+00$ 1.35662e-01 1.00000e-09 2.12000e-01

1.35662e+00 1.35662e+00 1.35662e-01 1.00000e-09 2.12000e-01

$1.35662 \mathrm{e}+001.35662 \mathrm{e}+00$ 1.35662e-01 1.00000e-09 2.12000e-01

1.00000e-02 1.00000e-02 1.00000e-03 1.00000e-09 1.00000e-01

$1.00000 \mathrm{e}+001.00000 \mathrm{e}+001.00000 \mathrm{e}-011.00000 \mathrm{e}-091.00000 \mathrm{e}-01$

$1.00000 \mathrm{e}-05$ 1.00000e-05 1.00000e-06 1.00000e-09 1.00000e-01

$1.00000 \mathrm{e}+001.00000 \mathrm{e}+001.00000 \mathrm{e}-01$ 1.00000e-09 1.00000e-01

Element: 3859 \# of layers: 11

$\mathrm{Kx} \mathrm{Ky} \mathrm{Kz}$ Ss Por

$3.39524 \mathrm{e}+013.39524 \mathrm{e}+013.39524 \mathrm{e}+00$ 1.00000e-09 7.00000e-02

$3.39524 \mathrm{e}+013.39524 \mathrm{e}+013.39524 \mathrm{e}+001.00000 \mathrm{e}-097.00000 \mathrm{e}-02$

5.00000e-04 5.00000e-04 5.00000e-05 1.00000e-09 1.00000e-01

5.00000e-04 5.00000e-04 5.00000e-05 1.00000e-09 1.00000e-01

$1.35662 \mathrm{e}+001.35662 \mathrm{e}+00$ 1.35662e-01 1.00000e-09 2.12000e-01

$1.35662 \mathrm{e}+00$ 1.35662e+00 1.35662e-01 1.00000e-09 2.12000e-01

$1.35662 \mathrm{e}+001.35662 \mathrm{e}+00$ 1.35662e-01 1.00000e-09 2.12000e-01

1.00000e-02 1.00000e-02 1.00000e-03 1.00000e-09 1.00000e-01

$1.00000 \mathrm{e}+001.00000 \mathrm{e}+001.00000 \mathrm{e}-011.00000 \mathrm{e}-091.00000 \mathrm{e}-01$

$1.00000 \mathrm{e}-05$ 1.00000e-05 1.00000e-06 1.00000e-09 1.00000e-01

$1.00000 \mathrm{e}+001.00000 \mathrm{e}+001.00000 \mathrm{e}-01$ 1.00000e-09 1.00000e-01

Element: 3860 \# of layers: 12

$\mathrm{Kx} \mathrm{Ky} \mathrm{Kz}$ Ss Por

$3.39524 \mathrm{e}+013.39524 \mathrm{e}+013.39524 \mathrm{e}+001.00000 \mathrm{e}-097.00000 \mathrm{e}-02$

$3.39524 \mathrm{e}+013.39524 \mathrm{e}+013.39524 \mathrm{e}+001.00000 \mathrm{e}-09$ 7.00000e-02

5.00000e-04 5.00000e-04 5.00000e-05 1.00000e-09 1.00000e-01

5.00000e-04 5.00000e-04 5.00000e-05 1.00000e-09 1.00000e-01 
$1.35662 \mathrm{e}+001.35662 \mathrm{e}+00$ 1.35662e-01 1.00000e-09 2.12000e-01 $1.35662 \mathrm{e}+001.35662 \mathrm{e}+001.35662 \mathrm{e}-011.00000 \mathrm{e}-092.12000 \mathrm{e}-01$ $1.35662 \mathrm{e}+001.35662 \mathrm{e}+001.35662 \mathrm{e}-011.00000 \mathrm{e}-092.12000 \mathrm{e}-01$ $1.35662 \mathrm{e}+001.35662 \mathrm{e}+001.35662 \mathrm{e}-011.00000 \mathrm{e}-092.12000 \mathrm{e}-01$ $1.00000 \mathrm{e}-02$ 1.00000e-02 1.00000e-03 1.00000e-09 1.00000e-01 $1.00000 \mathrm{e}+001.00000 \mathrm{e}+001.00000 \mathrm{e}-011.00000 \mathrm{e}-091.00000 \mathrm{e}-01$ $1.00000 \mathrm{e}-051.00000 \mathrm{e}-05$ 1.00000e-06 1.00000e-09 1.00000e-01 $1.00000 \mathrm{e}+001.00000 \mathrm{e}+001.00000 \mathrm{e}-011.00000 \mathrm{e}-091.00000 \mathrm{e}-01$ Element: 3861 \# of layers: 12

Kx Ky Kz Ss Por

$3.39524 \mathrm{e}+013.39524 \mathrm{e}+013.39524 \mathrm{e}+00$ 1.00000e-09 7.00000e-02 $3.39524 \mathrm{e}+013.39524 \mathrm{e}+013.39524 \mathrm{e}+001.00000 \mathrm{e}-097.00000 \mathrm{e}-02$ 5.00000e-04 5.00000e-04 5.00000e-05 1.00000e-09 1.00000e-01 5.00000e-04 5.00000e-04 5.00000e-05 1.00000e-09 1.00000e-01 $1.35662 \mathrm{e}+001.35662 \mathrm{e}+001.35662 \mathrm{e}-011.00000 \mathrm{e}-092.12000 \mathrm{e}-01$ $1.35662 \mathrm{e}+001.35662 \mathrm{e}+001.35662 \mathrm{e}-011.00000 \mathrm{e}-092.12000 \mathrm{e}-01$ $1.35662 \mathrm{e}+001.35662 \mathrm{e}+001.35662 \mathrm{e}-011.00000 \mathrm{e}-092.12000 \mathrm{e}-01$ $1.35662 \mathrm{e}+001.35662 \mathrm{e}+001.35662 \mathrm{e}-011.00000 \mathrm{e}-092.12000 \mathrm{e}-01$ $1.00000 \mathrm{e}-021.00000 \mathrm{e}-02$ 1.00000e-03 1.00000e-09 1.00000e-01 $1.00000 \mathrm{e}+001.00000 \mathrm{e}+001.00000 \mathrm{e}-011.00000 \mathrm{e}-091.00000 \mathrm{e}-01$ $1.00000 \mathrm{e}-05$ 1.00000e-05 1.00000e-06 1.00000e-09 1.00000e-01 $1.00000 \mathrm{e}+001.00000 \mathrm{e}+001.00000 \mathrm{e}-011.00000 \mathrm{e}-091.00000 \mathrm{e}-01$ Element: 3862 \# of layers: 11

Kx Ky Kz Ss Por

$3.76843 \mathrm{e}+013.76843 \mathrm{e}+013.76843 \mathrm{e}+00$ 1.00000e-09 7.00000e-02 $5.00000 \mathrm{e}-04$ 5.00000e-04 5.00000e-05 1.00000e-09 1.00000e-01 $5.00000 \mathrm{e}-04$ 5.00000e-04 5.00000e-05 1.00000e-09 1.00000e-01 $1.50573 \mathrm{e}+001.50573 \mathrm{e}+00$ 1.50573e-01 1.00000e-09 2.12000e-01 $1.50573 \mathrm{e}+001.50573 \mathrm{e}+00$ 1.50573e-01 1.00000e-09 2.12000e-01 $1.50573 \mathrm{e}+001.50573 \mathrm{e}+00$ 1.50573e-01 1.00000e-09 2.12000e-01 $1.50573 \mathrm{e}+001.50573 \mathrm{e}+001.50573 \mathrm{e}-011.00000 \mathrm{e}-092.12000 \mathrm{e}-01$ $1.00000 \mathrm{e}-021.00000 \mathrm{e}-02$ 1.00000e-03 1.00000e-09 1.00000e-01 $1.00000 \mathrm{e}+001.00000 \mathrm{e}+001.00000 \mathrm{e}-011.00000 \mathrm{e}-091.00000 \mathrm{e}-01$ $1.00000 \mathrm{e}-05$ 1.00000e-05 1.00000e-06 1.00000e-09 1.00000e-01 $1.00000 \mathrm{e}+001.00000 \mathrm{e}+001.00000 \mathrm{e}-011.00000 \mathrm{e}-091.00000 \mathrm{e}-01$ Element: 3863 \# of layers: 9

Kx Ky Kz Ss Por

$3.76843 \mathrm{e}+013.76843 \mathrm{e}+013.76843 \mathrm{e}+00$ 1.00000e-09 7.00000e-02 $5.00000 \mathrm{e}-04$ 5.00000e-04 5.00000e-05 1.00000e-09 1.00000e-01 5.00000e-04 5.00000e-04 5.00000e-05 1.00000e-09 1.00000e-01 $1.50573 \mathrm{e}+001.50573 \mathrm{e}+00$ 1.50573e-01 1.00000e-09 2.12000e-01 $1.50573 \mathrm{e}+001.50573 \mathrm{e}+00$ 1.50573e-01 1.00000e-09 2.12000e-01 $1.50573 \mathrm{e}+001.50573 \mathrm{e}+00$ 1.50573e-01 1.00000e-09 2.12000e-01 $1.50573 \mathrm{e}+001.50573 \mathrm{e}+00$ 1.50573e-01 1.00000e-09 2.12000e-01 $1.00000 \mathrm{e}-021.00000 \mathrm{e}-02$ 1.00000e-03 1.00000e-09 1.00000e-01 $1.00000 \mathrm{e}+001.00000 \mathrm{e}+001.00000 \mathrm{e}-011.00000 \mathrm{e}-091.00000 \mathrm{e}-01$ 
Element: 3864 \# of layers: 9

$\mathrm{Kx} \mathrm{Ky} \mathrm{Kz}$ Ss Por

3.76843e+01 3.76843e+01 3.76843e+00 1.00000e-09 7.00000e-02

5.00000e-04 5.00000e-04 5.00000e-05 1.00000e-09 1.00000e-01

5.00000e-04 5.00000e-04 5.00000e-05 1.00000e-09 1.00000e-01

$1.50573 \mathrm{e}+00$ 1.50573e+00 1.50573e-01 1.00000e-09 2.12000e-01

$1.50573 \mathrm{e}+001.50573 \mathrm{e}+00$ 1.50573e-01 1.00000e-09 2.12000e-01

$1.50573 \mathrm{e}+00$ 1.50573e+00 1.50573e-01 1.00000e-09 2.12000e-01

$1.50573 \mathrm{e}+00$ 1.50573e+00 1.50573e-01 1.00000e-09 2.12000e-01

$1.00000 \mathrm{e}-02$ 1.00000e-02 1.00000e-03 1.00000e-09 1.00000e-01

$1.00000 \mathrm{e}+001.00000 \mathrm{e}+001.00000 \mathrm{e}-011.00000 \mathrm{e}-091.00000 \mathrm{e}-01$

Element: 3865 \# of layers: 9

$\mathrm{Kx} \mathrm{Ky} \mathrm{Kz}$ Ss Por

3.76843e+01 3.76843e+01 3.76843e+00 1.00000e-09 7.00000e-02

5.00000e-04 5.00000e-04 5.00000e-05 1.00000e-09 1.00000e-01

5.00000e-04 5.00000e-04 5.00000e-05 1.00000e-09 1.00000e-01

$1.50573 \mathrm{e}+00$ 1.50573e+00 1.50573e-01 1.00000e-09 2.12000e-01

$1.50573 \mathrm{e}+001.50573 \mathrm{e}+00$ 1.50573e-01 1.00000e-09 2.12000e-01

$1.50573 \mathrm{e}+00$ 1.50573e+00 1.50573e-01 1.00000e-09 2.12000e-01

$1.50573 \mathrm{e}+001.50573 \mathrm{e}+00$ 1.50573e-01 1.00000e-09 2.12000e-01

$1.00000 \mathrm{e}-02$ 1.00000e-02 1.00000e-03 1.00000e-09 1.00000e-01

$1.00000 \mathrm{e}+001.00000 \mathrm{e}+001.00000 \mathrm{e}-01$ 1.00000e-09 1.00000e-01

Element: 3866 \# of layers: 10

Kx Ky Kz Ss Por

3.76843e+01 3.76843e+01 3.76843e+00 1.00000e-09 7.00000e-02

$3.76843 \mathrm{e}+013.76843 \mathrm{e}+01$ 3.76843e+00 1.00000e-09 7.00000e-02

5.00000e-04 5.00000e-04 5.00000e-05 1.00000e-09 1.00000e-01

5.00000e-04 5.00000e-04 5.00000e-05 1.00000e-09 1.00000e-01

$1.50573 \mathrm{e}+001.50573 \mathrm{e}+00$ 1.50573e-01 1.00000e-09 2.12000e-01

$1.50573 \mathrm{e}+00$ 1.50573e+00 1.50573e-01 1.00000e-09 2.12000e-01

$1.50573 \mathrm{e}+001.50573 \mathrm{e}+00$ 1.50573e-01 1.00000e-09 2.12000e-01

$1.50573 \mathrm{e}+00$ 1.50573e+00 1.50573e-01 1.00000e-09 2.12000e-01

$1.00000 \mathrm{e}-02$ 1.00000e-02 1.00000e-03 1.00000e-09 1.00000e-01

$1.00000 \mathrm{e}+001.00000 \mathrm{e}+001.00000 \mathrm{e}-01$ 1.00000e-09 1.00000e-01

Element: 3867 \# of layers: 11

$\mathrm{Kx} \mathrm{Ky} \mathrm{Kz}$ Ss Por

3.76843e+01 3.76843e+01 3.76843e+00 1.00000e-09 7.00000e-02

5.00000e-04 5.00000e-04 5.00000e-05 1.00000e-09 1.00000e-01

5.00000e-04 5.00000e-04 5.00000e-05 1.00000e-09 1.00000e-01

$1.50573 \mathrm{e}+00$ 1.50573e+00 1.50573e-01 1.00000e-09 2.12000e-01

$1.50573 \mathrm{e}+001.50573 \mathrm{e}+00$ 1.50573e-01 1.00000e-09 2.12000e-01

$1.50573 \mathrm{e}+00$ 1.50573e+00 1.50573e-01 1.00000e-09 2.12000e-01

1.50573e+00 1.50573e+00 1.50573e-01 1.00000e-09 2.12000e-01

$1.00000 \mathrm{e}-02$ 1.00000e-02 1.00000e-03 1.00000e-09 1.00000e-01

$1.00000 \mathrm{e}+001.00000 \mathrm{e}+001.00000 \mathrm{e}-011.00000 \mathrm{e}-091.00000 \mathrm{e}-01$

$1.00000 \mathrm{e}-05$ 1.00000e-05 1.00000e-06 1.00000e-09 1.00000e-01 
$1.00000 \mathrm{e}+001.00000 \mathrm{e}+00$ 1.00000e-01 1.00000e-09 1.00000e-01

Element: 3868 \# of layers: 11

Kx Ky Kz Ss Por

3.76843e+01 3.76843e+01 3.76843e+00 1.00000e-09 7.00000e-02

5.00000e-04 5.00000e-04 5.00000e-05 1.00000e-09 1.00000e-01

5.00000e-04 5.00000e-04 5.00000e-05 1.00000e-09 1.00000e-01

$1.50573 \mathrm{e}+001.50573 \mathrm{e}+00$ 1.50573e-01 1.00000e-09 2.12000e-01

$1.50573 \mathrm{e}+001.50573 \mathrm{e}+00$ 1.50573e-01 1.00000e-09 2.12000e-01

$1.50573 \mathrm{e}+00$ 1.50573e+00 1.50573e-01 1.00000e-09 2.12000e-01

$1.50573 \mathrm{e}+00$ 1.50573e+00 1.50573e-01 1.00000e-09 2.12000e-01

$1.00000 \mathrm{e}-02$ 1.00000e-02 1.00000e-03 1.00000e-09 1.00000e-01

$1.00000 \mathrm{e}+001.00000 \mathrm{e}+001.00000 \mathrm{e}-011.00000 \mathrm{e}-091.00000 \mathrm{e}-01$

$1.00000 \mathrm{e}-05$ 1.00000e-05 1.00000e-06 1.00000e-09 1.00000e-01

$1.00000 \mathrm{e}+001.00000 \mathrm{e}+001.00000 \mathrm{e}-011.00000 \mathrm{e}-09$ 1.00000e-01

Element: 3869 \# of layers: 11

Kx Ky Kz Ss Por

3.76843e+01 3.76843e+01 3.76843e+00 1.00000e-09 7.00000e-02

5.00000e-04 5.00000e-04 5.00000e-05 1.00000e-09 1.00000e-01

5.00000e-04 5.00000e-04 5.00000e-05 1.00000e-09 1.00000e-01

$1.50573 \mathrm{e}+001.50573 \mathrm{e}+00$ 1.50573e-01 1.00000e-09 2.12000e-01

$1.50573 \mathrm{e}+001.50573 \mathrm{e}+00$ 1.50573e-01 1.00000e-09 2.12000e-01

$1.50573 \mathrm{e}+00$ 1.50573e+00 1.50573e-01 1.00000e-09 2.12000e-01

$1.50573 \mathrm{e}+00$ 1.50573e+00 1.50573e-01 1.00000e-09 2.12000e-01 1.00000e-02 1.00000e-02 1.00000e-03 1.00000e-09 1.00000e-01

$1.00000 \mathrm{e}+001.00000 \mathrm{e}+001.00000 \mathrm{e}-011.00000 \mathrm{e}-091.00000 \mathrm{e}-01$

$1.00000 \mathrm{e}-05$ 1.00000e-05 1.00000e-06 1.00000e-09 1.00000e-01

$1.00000 \mathrm{e}+001.00000 \mathrm{e}+001.00000 \mathrm{e}-01$ 1.00000e-09 1.00000e-01

Element: 3870 \# of layers: 10

$\mathrm{Kx} \mathrm{Ky} \mathrm{Kz}$ Ss Por

3.76843e+01 3.76843e+01 3.76843e+00 1.00000e-09 7.00000e-02

5.00000e-04 5.00000e-04 5.00000e-05 1.00000e-09 1.00000e-01

5.00000e-04 5.00000e-04 5.00000e-05 1.00000e-09 1.00000e-01

$1.50573 \mathrm{e}+001.50573 \mathrm{e}+00$ 1.50573e-01 1.00000e-09 2.12000e-01

$1.50573 \mathrm{e}+00$ 1.50573e+00 1.50573e-01 1.00000e-09 2.12000e-01

$1.50573 \mathrm{e}+00$ 1.50573e+00 1.50573e-01 1.00000e-09 2.12000e-01

$1.50573 \mathrm{e}+00$ 1.50573e+00 1.50573e-01 1.00000e-09 2.12000e-01

1.00000e-02 1.00000e-02 1.00000e-03 1.00000e-09 1.00000e-01

$1.00000 \mathrm{e}+001.00000 \mathrm{e}+001.00000 \mathrm{e}-011.00000 \mathrm{e}-091.00000 \mathrm{e}-01$

$1.00000 \mathrm{e}-05$ 1.00000e-05 1.00000e-06 1.00000e-09 1.00000e-01

Element: 3871 \# of layers: 10

$\mathrm{Kx} \mathrm{Ky} \mathrm{Kz}$ Ss Por

2.95051e+01 2.95051e+01 2.95051e+00 1.00000e-09 7.00000e-02

5.00000e-04 5.00000e-04 5.00000e-05 1.00000e-09 1.00000e-01

5.00000e-04 5.00000e-04 5.00000e-05 1.00000e-09 1.00000e-01

$1.17891 \mathrm{e}+001.17891 \mathrm{e}+001.17891 \mathrm{e}-01$ 1.00000e-09 2.12000e-01

$1.17891 \mathrm{e}+001.17891 \mathrm{e}+001.17891 \mathrm{e}-011.00000 \mathrm{e}-092.12000 \mathrm{e}-01$ 
$1.17891 \mathrm{e}+001.17891 \mathrm{e}+001.17891 \mathrm{e}-011.00000 \mathrm{e}-092.12000 \mathrm{e}-01$ $1.17891 \mathrm{e}+001.17891 \mathrm{e}+001.17891 \mathrm{e}-011.00000 \mathrm{e}-092.12000 \mathrm{e}-01$ $1.17891 \mathrm{e}+001.17891 \mathrm{e}+001.17891 \mathrm{e}-011.00000 \mathrm{e}-09$ 2.12000e-01 $1.00000 \mathrm{e}-021.00000 \mathrm{e}-02$ 1.00000e-03 1.00000e-09 1.00000e-01 $1.00000 \mathrm{e}+001.00000 \mathrm{e}+001.00000 \mathrm{e}-011.00000 \mathrm{e}-091.00000 \mathrm{e}-01$ Element: 3872 \# of layers: 9

Kx Ky Kz Ss Por

$2.95051 \mathrm{e}+012.95051 \mathrm{e}+012.95051 \mathrm{e}+00$ 1.00000e-09 7.00000e-02 $5.00000 \mathrm{e}-04$ 5.00000e-04 5.00000e-05 1.00000e-09 1.00000e-01 5.00000e-04 5.00000e-04 5.00000e-05 1.00000e-09 1.00000e-01 $1.17891 \mathrm{e}+001.17891 \mathrm{e}+001.17891 \mathrm{e}-011.00000 \mathrm{e}-092.12000 \mathrm{e}-01$ $1.17891 \mathrm{e}+001.17891 \mathrm{e}+001.17891 \mathrm{e}-011.00000 \mathrm{e}-092.12000 \mathrm{e}-01$ $1.17891 \mathrm{e}+001.17891 \mathrm{e}+001.17891 \mathrm{e}-011.00000 \mathrm{e}-092.12000 \mathrm{e}-01$ $1.17891 \mathrm{e}+001.17891 \mathrm{e}+001.17891 \mathrm{e}-011.00000 \mathrm{e}-09$ 2.12000e-01 $1.00000 \mathrm{e}-021.00000 \mathrm{e}-02$ 1.00000e-03 1.00000e-09 1.00000e-01 $1.00000 \mathrm{e}+001.00000 \mathrm{e}+001.00000 \mathrm{e}-011.00000 \mathrm{e}-091.00000 \mathrm{e}-01$ Element: 3873 \# of layers: 12

Kx Ky Kz Ss Por

$2.95051 \mathrm{e}+012.95051 \mathrm{e}+012.95051 \mathrm{e}+00$ 1.00000e-09 7.00000e-02 $2.95051 \mathrm{e}+012.95051 \mathrm{e}+012.95051 \mathrm{e}+001.00000 \mathrm{e}-097.00000 \mathrm{e}-02$ $2.95051 \mathrm{e}+012.95051 \mathrm{e}+012.95051 \mathrm{e}+001.00000 \mathrm{e}-097.00000 \mathrm{e}-02$ 5.00000e-04 5.00000e-04 5.00000e-05 1.00000e-09 1.00000e-01 $5.00000 \mathrm{e}-04$ 5.00000e-04 5.00000e-05 1.00000e-09 1.00000e-01 $1.17891 \mathrm{e}+001.17891 \mathrm{e}+001.17891 \mathrm{e}-011.00000 \mathrm{e}-092.12000 \mathrm{e}-01$ $1.17891 \mathrm{e}+001.17891 \mathrm{e}+001.17891 \mathrm{e}-011.00000 \mathrm{e}-092.12000 \mathrm{e}-01$ $1.17891 \mathrm{e}+001.17891 \mathrm{e}+001.17891 \mathrm{e}-011.00000 \mathrm{e}-092.12000 \mathrm{e}-01$ $1.17891 \mathrm{e}+001.17891 \mathrm{e}+00$ 1.17891e-01 1.00000e-09 2.12000e-01 $1.17891 \mathrm{e}+001.17891 \mathrm{e}+001.17891 \mathrm{e}-011.00000 \mathrm{e}-09$ 2.12000e-01 $1.00000 \mathrm{e}-021.00000 \mathrm{e}-02$ 1.00000e-03 1.00000e-09 1.00000e-01 $1.00000 \mathrm{e}+001.00000 \mathrm{e}+001.00000 \mathrm{e}-011.00000 \mathrm{e}-091.00000 \mathrm{e}-01$ Element: 3874 \# of layers: 10

Kx Ky Kz Ss Por

$2.95051 \mathrm{e}+012.95051 \mathrm{e}+012.95051 \mathrm{e}+00$ 1.00000e-09 7.00000e-02 $2.95051 \mathrm{e}+012.95051 \mathrm{e}+012.95051 \mathrm{e}+001.00000 \mathrm{e}-097.00000 \mathrm{e}-02$ 5.00000e-04 5.00000e-04 5.00000e-05 1.00000e-09 1.00000e-01 5.00000e-04 5.00000e-04 5.00000e-05 1.00000e-09 1.00000e-01 $1.17891 \mathrm{e}+001.17891 \mathrm{e}+001.17891 \mathrm{e}-011.00000 \mathrm{e}-092.12000 \mathrm{e}-01$ $1.17891 \mathrm{e}+001.17891 \mathrm{e}+001.17891 \mathrm{e}-011.00000 \mathrm{e}-092.12000 \mathrm{e}-01$ $1.17891 \mathrm{e}+001.17891 \mathrm{e}+001.17891 \mathrm{e}-011.00000 \mathrm{e}-092.12000 \mathrm{e}-01$ $1.17891 \mathrm{e}+001.17891 \mathrm{e}+001.17891 \mathrm{e}-011.00000 \mathrm{e}-09$ 2.12000e-01 $1.00000 \mathrm{e}-021.00000 \mathrm{e}-021.00000 \mathrm{e}-031.00000 \mathrm{e}-091.00000 \mathrm{e}-01$ $1.00000 \mathrm{e}+001.00000 \mathrm{e}+001.00000 \mathrm{e}-011.00000 \mathrm{e}-091.00000 \mathrm{e}-01$ Element: 3875 \# of layers: 10

$\mathrm{Kx} \mathrm{Ky} \mathrm{Kz}$ Ss Por

$2.95051 \mathrm{e}+012.95051 \mathrm{e}+012.95051 \mathrm{e}+00$ 1.00000e-09 7.00000e-02 $2.95051 \mathrm{e}+012.95051 \mathrm{e}+012.95051 \mathrm{e}+001.00000 \mathrm{e}-09$ 7.00000e-02 
5.00000e-04 5.00000e-04 5.00000e-05 1.00000e-09 1.00000e-01 5.00000e-04 5.00000e-04 5.00000e-05 1.00000e-09 1.00000e-01 $1.17891 \mathrm{e}+001.17891 \mathrm{e}+001.17891 \mathrm{e}-01$ 1.00000e-09 2.12000e-01 $1.17891 \mathrm{e}+001.17891 \mathrm{e}+001.17891 \mathrm{e}-01$ 1.00000e-09 2.12000e-01 $1.17891 \mathrm{e}+001.17891 \mathrm{e}+00$ 1.17891e-01 1.00000e-09 2.12000e-01 $1.17891 \mathrm{e}+001.17891 \mathrm{e}+001.17891 \mathrm{e}-01$ 1.00000e-09 2.12000e-01 $1.00000 \mathrm{e}-02$ 1.00000e-02 1.00000e-03 1.00000e-09 1.00000e-01 $1.00000 \mathrm{e}+001.00000 \mathrm{e}+001.00000 \mathrm{e}-011.00000 \mathrm{e}-091.00000 \mathrm{e}-01$ Element: 3876 \# of layers: 10

$\mathrm{Kx} \mathrm{Ky} \mathrm{Kz}$ Ss Por

$2.95051 \mathrm{e}+012.95051 \mathrm{e}+012.95051 \mathrm{e}+00$ 1.00000e-09 7.00000e-02 $2.95051 \mathrm{e}+012.95051 \mathrm{e}+012.95051 \mathrm{e}+001.00000 \mathrm{e}-097.00000 \mathrm{e}-02$ 5.00000e-04 5.00000e-04 5.00000e-05 1.00000e-09 1.00000e-01 5.00000e-04 5.00000e-04 5.00000e-05 1.00000e-09 1.00000e-01 $1.17891 \mathrm{e}+001.17891 \mathrm{e}+001.17891 \mathrm{e}-01$ 1.00000e-09 2.12000e-01 $1.17891 \mathrm{e}+001.17891 \mathrm{e}+001.17891 \mathrm{e}-01$ 1.00000e-09 2.12000e-01 $1.17891 \mathrm{e}+001.17891 \mathrm{e}+001.17891 \mathrm{e}-01$ 1.00000e-09 2.12000e-01 $1.17891 \mathrm{e}+001.17891 \mathrm{e}+001.17891 \mathrm{e}-01$ 1.00000e-09 2.12000e-01 $1.00000 \mathrm{e}-02$ 1.00000e-02 1.00000e-03 1.00000e-09 1.00000e-01 $1.00000 \mathrm{e}+001.00000 \mathrm{e}+001.00000 \mathrm{e}-011.00000 \mathrm{e}-091.00000 \mathrm{e}-01$ Element: 3877 \# of layers: 11

$\mathrm{Kx} \mathrm{Ky} \mathrm{Kz}$ Ss Por

$2.95051 \mathrm{e}+012.95051 \mathrm{e}+012.95051 \mathrm{e}+00$ 1.00000e-09 7.00000e-02 $2.95051 \mathrm{e}+012.95051 \mathrm{e}+012.95051 \mathrm{e}+001.00000 \mathrm{e}-09$ 7.00000e-02 5.00000e-04 5.00000e-04 5.00000e-05 1.00000e-09 1.00000e-01 5.00000e-04 5.00000e-04 5.00000e-05 1.00000e-09 1.00000e-01

$1.17891 \mathrm{e}+001.17891 \mathrm{e}+001.17891 \mathrm{e}-01$ 1.00000e-09 2.12000e-01 $1.17891 \mathrm{e}+001.17891 \mathrm{e}+001.17891 \mathrm{e}-01$ 1.00000e-09 2.12000e-01 $1.17891 \mathrm{e}+001.17891 \mathrm{e}+001.17891 \mathrm{e}-01$ 1.00000e-09 2.12000e-01 $1.17891 \mathrm{e}+001.17891 \mathrm{e}+001.17891 \mathrm{e}-011.00000 \mathrm{e}-092.12000 \mathrm{e}-01$ $1.17891 \mathrm{e}+001.17891 \mathrm{e}+001.17891 \mathrm{e}-01$ 1.00000e-09 2.12000e-01 $1.00000 \mathrm{e}-02$ 1.00000e-02 1.00000e-03 1.00000e-09 1.00000e-01 $1.00000 \mathrm{e}+001.00000 \mathrm{e}+001.00000 \mathrm{e}-011.00000 \mathrm{e}-091.00000 \mathrm{e}-01$ Element: 3878 \# of layers: 11

$\mathrm{Kx} \mathrm{Ky} \mathrm{Kz}$ Ss Por

$2.95051 \mathrm{e}+012.95051 \mathrm{e}+012.95051 \mathrm{e}+00$ 1.00000e-09 7.00000e-02 $2.95051 \mathrm{e}+012.95051 \mathrm{e}+012.95051 \mathrm{e}+001.00000 \mathrm{e}-09$ 7.00000e-02 5.00000e-04 5.00000e-04 5.00000e-05 1.00000e-09 1.00000e-01 5.00000e-04 5.00000e-04 5.00000e-05 1.00000e-09 1.00000e-01 $1.17891 \mathrm{e}+001.17891 \mathrm{e}+001.17891 \mathrm{e}-01$ 1.00000e-09 2.12000e-01 $1.17891 \mathrm{e}+001.17891 \mathrm{e}+001.17891 \mathrm{e}-01$ 1.00000e-09 2.12000e-01 $1.17891 \mathrm{e}+001.17891 \mathrm{e}+001.17891 \mathrm{e}-011.00000 \mathrm{e}-092.12000 \mathrm{e}-01$ $1.17891 \mathrm{e}+001.17891 \mathrm{e}+001.17891 \mathrm{e}-01$ 1.00000e-09 2.12000e-01 $1.17891 \mathrm{e}+001.17891 \mathrm{e}+001.17891 \mathrm{e}-01$ 1.00000e-09 2.12000e-01 $1.00000 \mathrm{e}-02$ 1.00000e-02 1.00000e-03 1.00000e-09 1.00000e-01 $1.00000 \mathrm{e}+001.00000 \mathrm{e}+001.00000 \mathrm{e}-011.00000 \mathrm{e}-091.00000 \mathrm{e}-01$ 
Element: 3879 \# of layers: 10

$\mathrm{Kx} \mathrm{Ky} \mathrm{Kz}$ Ss Por

$2.95051 \mathrm{e}+012.95051 \mathrm{e}+012.95051 \mathrm{e}+00$ 1.00000e-09 7.00000e-02

$2.95051 \mathrm{e}+012.95051 \mathrm{e}+012.95051 \mathrm{e}+001.00000 \mathrm{e}-097.00000 \mathrm{e}-02$

5.00000e-04 5.00000e-04 5.00000e-05 1.00000e-09 1.00000e-01

5.00000e-04 5.00000e-04 5.00000e-05 1.00000e-09 1.00000e-01

$1.17891 \mathrm{e}+001.17891 \mathrm{e}+001.17891 \mathrm{e}-01$ 1.00000e-09 2.12000e-01

$1.17891 \mathrm{e}+001.17891 \mathrm{e}+001.17891 \mathrm{e}-011.00000 \mathrm{e}-092.12000 \mathrm{e}-01$

$1.17891 \mathrm{e}+001.17891 \mathrm{e}+00$ 1.17891e-01 1.00000e-09 2.12000e-01

$1.17891 \mathrm{e}+001.17891 \mathrm{e}+001.17891 \mathrm{e}-01$ 1.00000e-09 2.12000e-01

$1.00000 \mathrm{e}-02$ 1.00000e-02 1.00000e-03 1.00000e-09 1.00000e-01

$1.00000 \mathrm{e}+001.00000 \mathrm{e}+001.00000 \mathrm{e}-011.00000 \mathrm{e}-091.00000 \mathrm{e}-01$

Element: 3880 \# of layers: 11

$\mathrm{Kx} \mathrm{Ky} \mathrm{Kz}$ Ss Por

$2.46631 \mathrm{e}+012.46631 \mathrm{e}+012.46631 \mathrm{e}+001.00000 \mathrm{e}-09$ 7.00000e-02

$2.46631 \mathrm{e}+012.46631 \mathrm{e}+012.46631 \mathrm{e}+001.00000 \mathrm{e}-09$ 7.00000e-02

$2.46631 \mathrm{e}+012.46631 \mathrm{e}+012.46631 \mathrm{e}+001.00000 \mathrm{e}-09$ 7.00000e-02

5.00000e-04 5.00000e-04 5.00000e-05 1.00000e-09 1.00000e-01

5.00000e-04 5.00000e-04 5.00000e-05 1.00000e-09 1.00000e-01

9.85431e-01 9.85431e-01 9.85431e-02 1.00000e-09 2.12000e-01

9.85431e-01 9.85431e-01 9.85431e-02 1.00000e-09 2.12000e-01

9.85431e-01 9.85431e-01 9.85431e-02 1.00000e-09 2.12000e-01

9.85431e-01 9.85431e-01 9.85431e-02 1.00000e-09 2.12000e-01

9.85431e-01 9.85431e-01 9.85431e-02 1.00000e-09 2.12000e-01

$1.00000 \mathrm{e}-02$ 1.00000e-02 1.00000e-03 1.00000e-09 1.00000e-01

Element: 3881 \# of layers: 11

$\mathrm{Kx} \mathrm{Ky} \mathrm{Kz}$ Ss Por

$2.46631 \mathrm{e}+012.46631 \mathrm{e}+012.46631 \mathrm{e}+00$ 1.00000e-09 7.00000e-02

$2.46631 \mathrm{e}+012.46631 \mathrm{e}+012.46631 \mathrm{e}+001.00000 \mathrm{e}-097.00000 \mathrm{e}-02$

$2.46631 \mathrm{e}+012.46631 \mathrm{e}+012.46631 \mathrm{e}+001.00000 \mathrm{e}-097.00000 \mathrm{e}-02$

5.00000e-04 5.00000e-04 5.00000e-05 1.00000e-09 1.00000e-01

5.00000e-04 5.00000e-04 5.00000e-05 1.00000e-09 1.00000e-01

9.85431e-01 9.85431e-01 9.85431e-02 1.00000e-09 2.12000e-01

9.85431e-01 9.85431e-01 9.85431e-02 1.00000e-09 2.12000e-01

9.85431e-01 9.85431e-01 9.85431e-02 1.00000e-09 2.12000e-01

9.85431e-01 9.85431e-01 9.85431e-02 1.00000e-09 2.12000e-01

9.85431e-01 9.85431e-01 9.85431e-02 1.00000e-09 2.12000e-01

$1.00000 \mathrm{e}-02$ 1.00000e-02 1.00000e-03 1.00000e-09 1.00000e-01

Element: 3882 \# of layers: 10

$\mathrm{Kx} \mathrm{Ky} \mathrm{Kz}$ Ss Por

$2.46631 \mathrm{e}+012.46631 \mathrm{e}+012.46631 \mathrm{e}+00$ 1.00000e-09 7.00000e-02

$2.46631 \mathrm{e}+012.46631 \mathrm{e}+012.46631 \mathrm{e}+001.00000 \mathrm{e}-09$ 7.00000e-02

$2.46631 \mathrm{e}+012.46631 \mathrm{e}+012.46631 \mathrm{e}+001.00000 \mathrm{e}-09$ 7.00000e-02

5.00000e-04 5.00000e-04 5.00000e-05 1.00000e-09 1.00000e-01

5.00000e-04 5.00000e-04 5.00000e-05 1.00000e-09 1.00000e-01

9.85431e-01 9.85431e-01 9.85431e-02 1.00000e-09 2.12000e-01 
9.85431e-01 9.85431e-01 9.85431e-02 1.00000e-09 2.12000e-01 9.85431e-01 9.85431e-01 9.85431e-02 1.00000e-09 2.12000e-01 9.85431e-01 9.85431e-01 9.85431e-02 1.00000e-09 2.12000e-01 9.85431e-01 9.85431e-01 9.85431e-02 1.00000e-09 2.12000e-01 Element: 3886 \# of layers: 9

$\mathrm{Kx} \mathrm{Ky} \mathrm{Kz}$ Ss Por

$2.46631 \mathrm{e}+012.46631 \mathrm{e}+012.46631 \mathrm{e}+00$ 1.00000e-09 7.00000e-02

$2.46631 \mathrm{e}+012.46631 \mathrm{e}+012.46631 \mathrm{e}+001.00000 \mathrm{e}-09$ 7.00000e-02

5.00000e-04 5.00000e-04 5.00000e-05 1.00000e-09 1.00000e-01

5.00000e-04 5.00000e-04 5.00000e-05 1.00000e-09 1.00000e-01

9.85431e-01 9.85431e-01 9.85431e-02 1.00000e-09 2.12000e-01

9.85431e-01 9.85431e-01 9.85431e-02 1.00000e-09 2.12000e-01

9.85431e-01 9.85431e-01 9.85431e-02 1.00000e-09 2.12000e-01

9.85431e-01 9.85431e-01 9.85431e-02 1.00000e-09 2.12000e-01

1.00000e-02 1.00000e-02 1.00000e-03 1.00000e-09 1.00000e-01

Element: 3887 \# of layers: 9

$\mathrm{Kx} \mathrm{Ky} \mathrm{Kz}$ Ss Por

$2.46631 \mathrm{e}+012.46631 \mathrm{e}+012.46631 \mathrm{e}+00$ 1.00000e-09 7.00000e-02

$2.46631 \mathrm{e}+012.46631 \mathrm{e}+012.46631 \mathrm{e}+001.00000 \mathrm{e}-09$ 7.00000e-02

5.00000e-04 5.00000e-04 5.00000e-05 1.00000e-09 1.00000e-01

5.00000e-04 5.00000e-04 5.00000e-05 1.00000e-09 1.00000e-01

9.85431e-01 9.85431e-01 9.85431e-02 1.00000e-09 2.12000e-01

9.85431e-01 9.85431e-01 9.85431e-02 1.00000e-09 2.12000e-01

9.85431e-01 9.85431e-01 9.85431e-02 1.00000e-09 2.12000e-01

9.85431e-01 9.85431e-01 9.85431e-02 1.00000e-09 2.12000e-01

1.00000e-02 1.00000e-02 1.00000e-03 1.00000e-09 1.00000e-01

Element: 3889 \# of layers: 9

$\mathrm{Kx} \mathrm{Ky} \mathrm{Kz}$ Ss Por

$2.04788 \mathrm{e}+012.04788 \mathrm{e}+012.04788 \mathrm{e}+00$ 1.00000e-09 7.00000e-02

$2.04788 \mathrm{e}+012.04788 \mathrm{e}+012.04788 \mathrm{e}+001.00000 \mathrm{e}-09$ 7.00000e-02

5.00000e-04 5.00000e-04 5.00000e-05 1.00000e-09 1.00000e-01

5.00000e-04 5.00000e-04 5.00000e-05 1.00000e-09 1.00000e-01

8.18252e-01 8.18252e-01 8.18252e-02 1.00000e-09 2.12000e-01

8.18252e-01 8.18252e-01 8.18252e-02 1.00000e-09 2.12000e-01

8.18252e-01 8.18252e-01 8.18252e-02 1.00000e-09 2.12000e-01

8.18252e-01 8.18252e-01 8.18252e-02 1.00000e-09 2.12000e-01

1.00000e-02 1.00000e-02 1.00000e-03 1.00000e-09 1.00000e-01

Element: 3890 \# of layers: 9

$\mathrm{Kx} \mathrm{Ky} \mathrm{Kz}$ Ss Por

$2.04788 \mathrm{e}+012.04788 \mathrm{e}+012.04788 \mathrm{e}+00$ 1.00000e-09 7.00000e-02

$2.04788 \mathrm{e}+012.04788 \mathrm{e}+012.04788 \mathrm{e}+001.00000 \mathrm{e}-09$ 7.00000e-02

5.00000e-04 5.00000e-04 5.00000e-05 1.00000e-09 1.00000e-01

5.00000e-04 5.00000e-04 5.00000e-05 1.00000e-09 1.00000e-01

8.18252e-01 8.18252e-01 8.18252e-02 1.00000e-09 2.12000e-01

8.18252e-01 8.18252e-01 8.18252e-02 1.00000e-09 2.12000e-01

8.18252e-01 8.18252e-01 8.18252e-02 1.00000e-09 2.12000e-01 
8.18252e-01 8.18252e-01 8.18252e-02 1.00000e-09 2.12000e-01 $1.00000 \mathrm{e}-02$ 1.00000e-02 1.00000e-03 1.00000e-09 1.00000e-01 Element: 3891 \# of layers: 9

Kx Ky Kz Ss Por

$2.04788 \mathrm{e}+012.04788 \mathrm{e}+012.04788 \mathrm{e}+00$ 1.00000e-09 7.00000e-02

$2.04788 \mathrm{e}+012.04788 \mathrm{e}+012.04788 \mathrm{e}+001.00000 \mathrm{e}-09$ 7.00000e-02

5.00000e-04 5.00000e-04 5.00000e-05 1.00000e-09 1.00000e-01

5.00000e-04 5.00000e-04 5.00000e-05 1.00000e-09 1.00000e-01

8.18252e-01 8.18252e-01 8.18252e-02 1.00000e-09 2.12000e-01

8.18252e-01 8.18252e-01 8.18252e-02 1.00000e-09 2.12000e-01

8.18252e-01 8.18252e-01 8.18252e-02 1.00000e-09 2.12000e-01

8.18252e-01 8.18252e-01 8.18252e-02 1.00000e-09 2.12000e-01

$1.00000 \mathrm{e}-02$ 1.00000e-02 1.00000e-03 1.00000e-09 1.00000e-01

Element: 3892 \# of layers: 10

Kx Ky Kz Ss Por

$2.35278 \mathrm{e}+012.35278 \mathrm{e}+012.35278 \mathrm{e}+00$ 1.00000e-09 7.00000e-02

$2.35278 \mathrm{e}+012.35278 \mathrm{e}+012.35278 \mathrm{e}+001.00000 \mathrm{e}-09$ 7.00000e-02

$2.35278 \mathrm{e}+012.35278 \mathrm{e}+012.35278 \mathrm{e}+001.00000 \mathrm{e}-09$ 7.00000e-02

$5.00000 \mathrm{e}-04$ 5.00000e-04 5.00000e-05 1.00000e-09 1.00000e-01

5.00000e-04 5.00000e-04 5.00000e-05 1.00000e-09 1.00000e-01

9.40093e-01 9.40093e-01 9.40093e-02 1.00000e-09 2.12000e-01

9.40093e-01 9.40093e-01 9.40093e-02 1.00000e-09 2.12000e-01

9.40093e-01 9.40093e-01 9.40093e-02 1.00000e-09 2.12000e-01

9.40093e-01 9.40093e-01 9.40093e-02 1.00000e-09 2.12000e-01

9.40093e-01 9.40093e-01 9.40093e-02 1.00000e-09 2.12000e-01

Element: 3893 \# of layers: 10

Kx Ky Kz Ss Por

$2.35278 \mathrm{e}+012.35278 \mathrm{e}+012.35278 \mathrm{e}+00$ 1.00000e-09 7.00000e-02

$2.35278 \mathrm{e}+012.35278 \mathrm{e}+012.35278 \mathrm{e}+001.00000 \mathrm{e}-09$ 7.00000e-02

5.00000e-04 5.00000e-04 5.00000e-05 1.00000e-09 1.00000e-01

5.00000e-04 5.00000e-04 5.00000e-05 1.00000e-09 1.00000e-01

9.40093e-01 9.40093e-01 9.40093e-02 1.00000e-09 2.12000e-01

9.40093e-01 9.40093e-01 9.40093e-02 1.00000e-09 2.12000e-01

9.40093e-01 9.40093e-01 9.40093e-02 1.00000e-09 2.12000e-01

9.40093e-01 9.40093e-01 9.40093e-02 1.00000e-09 2.12000e-01

9.40093e-01 9.40093e-01 9.40093e-02 1.00000e-09 2.12000e-01

$1.00000 \mathrm{e}-02$ 1.00000e-02 1.00000e-03 1.00000e-09 1.00000e-01

Element: 3894 \# of layers: 9

Kx Ky Kz Ss Por

$2.35278 \mathrm{e}+012.35278 \mathrm{e}+012.35278 \mathrm{e}+00$ 1.00000e-09 7.00000e-02

$2.35278 \mathrm{e}+012.35278 \mathrm{e}+012.35278 \mathrm{e}+001.00000 \mathrm{e}-09$ 7.00000e-02

5.00000e-04 5.00000e-04 5.00000e-05 1.00000e-09 1.00000e-01

5.00000e-04 5.00000e-04 5.00000e-05 1.00000e-09 1.00000e-01

9.40093e-01 9.40093e-01 9.40093e-02 1.00000e-09 2.12000e-01

9.40093e-01 9.40093e-01 9.40093e-02 1.00000e-09 2.12000e-01

9.40093e-01 9.40093e-01 9.40093e-02 1.00000e-09 2.12000e-01 
9.40093e-01 9.40093e-01 9.40093e-02 1.00000e-09 2.12000e-01 1.00000e-02 1.00000e-02 1.00000e-03 1.00000e-09 1.00000e-01

Element: 3895 \# of layers: 7

$\mathrm{Kx} \mathrm{Ky} \mathrm{Kz} \mathrm{Ss} \mathrm{Por}$

7.78607e+00 7.78607e+00 7.78607e-01 1.00000e-09 2.12000e-01

7.78607e+00 7.78607e+00 7.78607e-01 1.00000e-09 2.12000e-01

7.78607e+00 7.78607e+00 7.78607e-01 1.00000e-09 2.12000e-01

$7.78607 \mathrm{e}+00$ 7.78607e+00 7.78607e-01 1.00000e-09 2.12000e-01

7.78607e+00 7.78607e+00 7.78607e-01 1.00000e-09 2.12000e-01

$1.00000 \mathrm{e}-051.00000 \mathrm{e}-051.00000 \mathrm{e}-061.00000 \mathrm{e}-091.00000 \mathrm{e}-01$

$1.00000 \mathrm{e}+001.00000 \mathrm{e}+001.00000 \mathrm{e}-01$ 1.00000e-09 1.00000e-01

Element: 3896 \# of layers: 7

$\mathrm{Kx} \mathrm{Ky} \mathrm{Kz}$ Ss Por

7.78607e+00 7.78607e+00 7.78607e-01 1.00000e-09 2.12000e-01

7.78607e+00 7.78607e+00 7.78607e-01 1.00000e-09 2.12000e-01

$7.78607 \mathrm{e}+00$ 7.78607e+00 7.78607e-01 1.00000e-09 2.12000e-01

7.78607e+00 7.78607e+00 7.78607e-01 1.00000e-09 2.12000e-01

7.78607e+00 7.78607e+00 7.78607e-01 1.00000e-09 2.12000e-01

$1.00000 \mathrm{e}-051.00000 \mathrm{e}-051.00000 \mathrm{e}-061.00000 \mathrm{e}-091.00000 \mathrm{e}-01$

$1.00000 \mathrm{e}+001.00000 \mathrm{e}+001.00000 \mathrm{e}-011.00000 \mathrm{e}-091.00000 \mathrm{e}-01$

Element: 3897 \# of layers: 7

$\mathrm{Kx} \mathrm{Ky} \mathrm{Kz}$ Ss Por

8.91716e+00 8.91716e+00 8.91716e-01 1.00000e-09 2.12000e-01

$8.91716 \mathrm{e}+00$ 8.91716e+00 8.91716e-01 1.00000e-09 2.12000e-01

$8.91716 \mathrm{e}+00$ 8.91716e+00 8.91716e-01 1.00000e-09 2.12000e-01

$8.91716 \mathrm{e}+00$ 8.91716e+00 8.91716e-01 1.00000e-09 2.12000e-01

8.91716e+00 8.91716e+00 8.91716e-01 1.00000e-09 2.12000e-01

$1.00000 \mathrm{e}-05$ 1.00000e-05 1.00000e-06 1.00000e-09 1.00000e-01

$1.00000 \mathrm{e}+001.00000 \mathrm{e}+001.00000 \mathrm{e}-011.00000 \mathrm{e}-091.00000 \mathrm{e}-01$

Element: 3898 \# of layers: 7

$\mathrm{Kx} \mathrm{Ky} \mathrm{Kz}$ Ss Por

8.91716e+00 8.91716e+00 8.91716e-01 1.00000e-09 2.12000e-01

$8.91716 \mathrm{e}+008.91716 \mathrm{e}+008.91716 \mathrm{e}-01$ 1.00000e-09 2.12000e-01

8.91716e+00 8.91716e+00 8.91716e-01 1.00000e-09 2.12000e-01

8.91716e+00 8.91716e+00 8.91716e-01 1.00000e-09 2.12000e-01

8.91716e+00 8.91716e+00 8.91716e-01 1.00000e-09 2.12000e-01 $1.00000 \mathrm{e}-05$ 1.00000e-05 1.00000e-06 1.00000e-09 1.00000e-01

$1.00000 \mathrm{e}+001.00000 \mathrm{e}+001.00000 \mathrm{e}-01$ 1.00000e-09 1.00000e-01

Element: 3899 \# of layers: 7

$\mathrm{Kx} \mathrm{Ky} \mathrm{Kz}$ Ss Por

7.38241e+00 7.38241e+00 7.38241e-01 1.00000e-09 2.12000e-01

7.38241e+00 7.38241e+00 7.38241e-01 1.00000e-09 2.12000e-01

7.38241e+00 7.38241e+00 7.38241e-01 1.00000e-09 2.12000e-01

$7.38241 \mathrm{e}+00$ 7.38241e+00 7.38241e-01 1.00000e-09 2.12000e-01

7.38241e+00 7.38241e+00 7.38241e-01 1.00000e-09 2.12000e-01

$1.00000 \mathrm{e}-05$ 1.00000e-05 1.00000e-06 1.00000e-09 1.00000e-01 
$1.00000 \mathrm{e}+001.00000 \mathrm{e}+00$ 1.00000e-01 1.00000e-09 1.00000e-01

Element: 3900 \# of layers: 7

Kx Ky Kz Ss Por

$1.68337 e+01$ 1.68337e+01 1.68337e+00 1.00000e-09 2.12000e-01

$1.68337 \mathrm{e}+01$ 1.68337e+01 1.68337e+00 1.00000e-09 2.12000e-01

$1.68337 \mathrm{e}+01$ 1.68337e+01 1.68337e+00 1.00000e-09 2.12000e-01

$1.68337 \mathrm{e}+011.68337 \mathrm{e}+01$ 1.68337e+00 1.00000e-09 2.12000e-01

$1.68337 \mathrm{e}+01$ 1.68337e+01 1.68337e+00 1.00000e-09 2.12000e-01

$1.00000 \mathrm{e}-05$ 1.00000e-05 1.00000e-06 1.00000e-09 1.00000e-01

$1.00000 \mathrm{e}+001.00000 \mathrm{e}+001.00000 \mathrm{e}-011.00000 \mathrm{e}-091.00000 \mathrm{e}-01$

Element: 3901 \# of layers: 7

Kx Ky Kz Ss Por

$1.91587 \mathrm{e}+01$ 1.91587e+01 1.91587e+00 1.00000e-09 2.12000e-01 $1.91587 \mathrm{e}+01$ 1.91587e+01 1.91587e+00 1.00000e-09 2.12000e-01 $1.91587 \mathrm{e}+01$ 1.91587e+01 1.91587e+00 1.00000e-09 2.12000e-01 $1.91587 \mathrm{e}+01$ 1.91587e+01 1.91587e+00 1.00000e-09 2.12000e-01 $1.91587 \mathrm{e}+01$ 1.91587e+01 1.91587e+00 1.00000e-09 2.12000e-01 $1.00000 \mathrm{e}-05$ 1.00000e-05 1.00000e-06 1.00000e-09 1.00000e-01

$1.00000 \mathrm{e}+001.00000 \mathrm{e}+001.00000 \mathrm{e}-011.00000 \mathrm{e}-091.00000 \mathrm{e}-01$

Element: 3902 \# of layers: 7

$\mathrm{Kx} \mathrm{Ky} \mathrm{Kz}$ Ss Por

$1.91587 \mathrm{e}+01$ 1.91587e+01 1.91587e+00 1.00000e-09 2.12000e-01 $1.91587 \mathrm{e}+01$ 1.91587e+01 1.91587e+00 1.00000e-09 2.12000e-01 $1.91587 \mathrm{e}+01$ 1.91587e+01 1.91587e+00 1.00000e-09 2.12000e-01 $1.91587 \mathrm{e}+01$ 1.91587e+01 1.91587e+00 1.00000e-09 2.12000e-01 $1.91587 \mathrm{e}+01$ 1.91587e+01 1.91587e+00 1.00000e-09 2.12000e-01 $1.00000 \mathrm{e}-05$ 1.00000e-05 1.00000e-06 1.00000e-09 1.00000e-01 $1.00000 \mathrm{e}+001.00000 \mathrm{e}+001.00000 \mathrm{e}-011.00000 \mathrm{e}-09$ 1.00000e-01 Element: 3903 \# of layers: 7

$\mathrm{Kx} \mathrm{Ky} \mathrm{Kz}$ Ss Por

$1.56644 \mathrm{e}+011.56644 \mathrm{e}+011.56644 \mathrm{e}+001.00000 \mathrm{e}-092.12000 \mathrm{e}-01$ $1.56644 \mathrm{e}+011.56644 \mathrm{e}+011.56644 \mathrm{e}+001.00000 \mathrm{e}-092.12000 \mathrm{e}-01$ $1.56644 \mathrm{e}+011.56644 \mathrm{e}+011.56644 \mathrm{e}+001.00000 \mathrm{e}-092.12000 \mathrm{e}-01$ $1.56644 \mathrm{e}+011.56644 \mathrm{e}+011.56644 \mathrm{e}+001.00000 \mathrm{e}-092.12000 \mathrm{e}-01$ $1.56644 \mathrm{e}+011.56644 \mathrm{e}+011.56644 \mathrm{e}+001.00000 \mathrm{e}-092.12000 \mathrm{e}-01$ $1.00000 \mathrm{e}-05$ 1.00000e-05 1.00000e-06 1.00000e-09 1.00000e-01 $1.00000 \mathrm{e}+001.00000 \mathrm{e}+001.00000 \mathrm{e}-011.00000 \mathrm{e}-091.00000 \mathrm{e}-01$ Element: 3904 \# of layers: 7

$\mathrm{Kx} \mathrm{Ky} \mathrm{Kz}$ Ss Por

$1.68337 \mathrm{e}+01$ 1.68337e+01 1.68337e+00 1.00000e-09 2.12000e-01 $1.68337 \mathrm{e}+01$ 1.68337e+01 1.68337e+00 1.00000e-09 2.12000e-01 $1.68337 \mathrm{e}+01$ 1.68337e+01 1.68337e+00 1.00000e-09 2.12000e-01 $1.68337 \mathrm{e}+01$ 1.68337e+01 1.68337e+00 1.00000e-09 2.12000e-01 1.68337e+01 1.68337e+01 1.68337e+00 1.00000e-09 2.12000e-01 $1.00000 \mathrm{e}-05$ 1.00000e-05 1.00000e-06 1.00000e-09 1.00000e-01 $1.00000 \mathrm{e}+001.00000 \mathrm{e}+001.00000 \mathrm{e}-011.00000 \mathrm{e}-091.00000 \mathrm{e}-01$ 
Element: 3905 \# of layers: 7

$\mathrm{Kx} \mathrm{Ky} \mathrm{Kz}$ Ss Por

1.91587e+01 1.91587e+01 1.91587e+00 1.00000e-09 2.12000e-01

$1.91587 \mathrm{e}+01$ 1.91587e+01 1.91587e+00 1.00000e-09 2.12000e-01

$1.91587 \mathrm{e}+01$ 1.91587e+01 1.91587e+00 1.00000e-09 2.12000e-01

$1.91587 \mathrm{e}+01$ 1.91587e+01 1.91587e+00 1.00000e-09 2.12000e-01

$1.91587 \mathrm{e}+01$ 1.91587e+01 1.91587e+00 1.00000e-09 2.12000e-01

$1.00000 \mathrm{e}-05$ 1.00000e-05 1.00000e-06 1.00000e-09 1.00000e-01

$1.00000 \mathrm{e}+001.00000 \mathrm{e}+001.00000 \mathrm{e}-011.00000 \mathrm{e}-091.00000 \mathrm{e}-01$

Element: 3906 \# of layers: 7

$\mathrm{Kx} \mathrm{Ky} \mathrm{Kz}$ Ss Por

8.47143e+01 8.47143e+01 8.47143e+00 1.00000e-09 2.12000e-01

8.47143e+01 8.47143e+01 8.47143e+00 1.00000e-09 2.12000e-01

8.47143e+01 8.47143e+01 8.47143e+00 1.00000e-09 2.12000e-01

$1.00000 \mathrm{e}-02$ 1.00000e-02 1.00000e-03 1.00000e-09 1.00000e-01

$1.00000 \mathrm{e}+001.00000 \mathrm{e}+001.00000 \mathrm{e}-011.00000 \mathrm{e}-091.00000 \mathrm{e}-01$

$1.00000 \mathrm{e}-05$ 1.00000e-05 1.00000e-06 1.00000e-09 1.00000e-01

$1.00000 \mathrm{e}+001.00000 \mathrm{e}+001.00000 \mathrm{e}-01$ 1.00000e-09 1.00000e-01

Element: 3907 \# of layers: 8

$\mathrm{Kx} \mathrm{Ky} \mathrm{Kz}$ Ss Por

8.47143e+01 8.47143e+01 8.47143e+00 1.00000e-09 2.12000e-01

8.47143e+01 8.47143e+01 8.47143e+00 1.00000e-09 2.12000e-01

8.47143e+01 8.47143e+01 8.47143e+00 1.00000e-09 2.12000e-01

8.47143e+01 8.47143e+01 8.47143e+00 1.00000e-09 2.12000e-01

$1.00000 \mathrm{e}-021.00000 \mathrm{e}-02$ 1.00000e-03 1.00000e-09 1.00000e-01

$1.00000 \mathrm{e}+001.00000 \mathrm{e}+001.00000 \mathrm{e}-011.00000 \mathrm{e}-091.00000 \mathrm{e}-01$

$1.00000 \mathrm{e}-05$ 1.00000e-05 1.00000e-06 1.00000e-09 1.00000e-01

$1.00000 \mathrm{e}+001.00000 \mathrm{e}+001.00000 \mathrm{e}-011.00000 \mathrm{e}-09$ 1.00000e-01

Element: 3908 \# of layers: 9

$\mathrm{Kx} \mathrm{Ky} \mathrm{Kz}$ Ss Por

6.16879e+03 6.16879e+03 6.16879e+02 1.00000e-09 7.00000e-02

$2.46493 \mathrm{e}+02$ 2.46493e+02 2.46493e+01 1.00000e-09 2.12000e-01

$2.46493 \mathrm{e}+02$ 2.46493e+02 2.46493e+01 1.00000e-09 2.12000e-01

$2.46493 \mathrm{e}+02$ 2.46493e+02 2.46493e+01 1.00000e-09 2.12000e-01

$2.46493 \mathrm{e}+02$ 2.46493e+02 2.46493e+01 1.00000e-09 2.12000e-01

$1.00000 \mathrm{e}-02$ 1.00000e-02 1.00000e-03 1.00000e-09 1.00000e-01

$1.00000 \mathrm{e}+001.00000 \mathrm{e}+001.00000 \mathrm{e}-011.00000 \mathrm{e}-091.00000 \mathrm{e}-01$

$1.00000 \mathrm{e}-05$ 1.00000e-05 1.00000e-06 1.00000e-09 1.00000e-01

$1.00000 \mathrm{e}+001.00000 \mathrm{e}+001.00000 \mathrm{e}-011.00000 \mathrm{e}-09$ 1.00000e-01

Element: 3909 \# of layers: 8

$\mathrm{Kx} \mathrm{Ky} \mathrm{Kz}$ Ss Por

6.16879e+03 6.16879e+03 6.16879e+02 1.00000e-09 7.00000e-02

$2.46493 \mathrm{e}+02$ 2.46493e+02 2.46493e+01 1.00000e-09 2.12000e-01

2.46493e+02 2.46493e+02 2.46493e+01 1.00000e-09 2.12000e-01

$2.46493 \mathrm{e}+02$ 2.46493e+02 2.46493e+01 1.00000e-09 2.12000e-01

$2.46493 e+022.46493 e+022.46493 e+01$ 1.00000e-09 2.12000e-01 
1.00000e-02 1.00000e-02 1.00000e-03 1.00000e-09 1.00000e-01 $1.00000 \mathrm{e}-05$ 1.00000e-05 1.00000e-06 1.00000e-09 1.00000e-01 $1.00000 \mathrm{e}+001.00000 \mathrm{e}+00$ 1.00000e-01 1.00000e-09 1.00000e-01 Element: 3910 \# of layers: 7

$\mathrm{Kx} \mathrm{Ky} \mathrm{Kz}$ Ss Por

2.71769e+03 2.71769e+03 2.71769e+02 1.00000e-09 7.00000e-02 $1.08587 \mathrm{e}+02$ 1.08587e+02 1.08587e+01 1.00000e-09 2.12000e-01 $1.08587 \mathrm{e}+02$ 1.08587e+02 1.08587e+01 1.00000e-09 2.12000e-01 $1.08587 \mathrm{e}+02$ 1.08587e+02 1.08587e+01 1.00000e-09 2.12000e-01 $1.08587 \mathrm{e}+02$ 1.08587e+02 1.08587e+01 1.00000e-09 2.12000e-01 $1.00000 \mathrm{e}-05$ 1.00000e-05 1.00000e-06 1.00000e-09 1.00000e-01 $1.00000 \mathrm{e}+001.00000 \mathrm{e}+001.00000 \mathrm{e}-011.00000 \mathrm{e}-091.00000 \mathrm{e}-01$ Element: 3911 \# of layers: 8

Kx Ky Kz Ss Por

8.47143e+01 8.47143e+01 8.47143e+00 1.00000e-09 2.12000e-01 $8.47143 \mathrm{e}+018.47143 \mathrm{e}+018.47143 \mathrm{e}+001.00000 \mathrm{e}-092.12000 \mathrm{e}-01$ 8.47143e+01 8.47143e+01 8.47143e+00 1.00000e-09 2.12000e-01 8.47143e+01 8.47143e+01 8.47143e+00 1.00000e-09 2.12000e-01 $1.00000 \mathrm{e}-02$ 1.00000e-02 1.00000e-03 1.00000e-09 1.00000e-01 $1.00000 \mathrm{e}+001.00000 \mathrm{e}+001.00000 \mathrm{e}-011.00000 \mathrm{e}-091.00000 \mathrm{e}-01$ $1.00000 \mathrm{e}-05$ 1.00000e-05 1.00000e-06 1.00000e-09 1.00000e-01 $1.00000 \mathrm{e}+001.00000 \mathrm{e}+001.00000 \mathrm{e}-011.00000 \mathrm{e}-091.00000 \mathrm{e}-01$ Element: 3912 \# of layers: 7

$\mathrm{Kx} \mathrm{Ky} \mathrm{Kz}$ Ss Por

$2.57630 \mathrm{e}+02$ 2.57630e+02 2.57630e+01 1.00000e-09 2.12000e-01

$2.57630 \mathrm{e}+022.57630 \mathrm{e}+02$ 2.57630e+01 1.00000e-09 2.12000e-01

$2.57630 \mathrm{e}+02$ 2.57630e+02 2.57630e+01 1.00000e-09 2.12000e-01 $1.00000 \mathrm{e}-02$ 1.00000e-02 1.00000e-03 1.00000e-09 1.00000e-01

$1.00000 \mathrm{e}+001.00000 \mathrm{e}+001.00000 \mathrm{e}-011.00000 \mathrm{e}-091.00000 \mathrm{e}-01$ $1.00000 \mathrm{e}-05$ 1.00000e-05 1.00000e-06 1.00000e-09 1.00000e-01 $1.00000 \mathrm{e}+001.00000 \mathrm{e}+001.00000 \mathrm{e}-011.00000 \mathrm{e}-091.00000 \mathrm{e}-01$ Element: 3913 \# of layers: 9

Kx Ky Kz Ss Por

$1.51991 \mathrm{e}+03$ 1.51991e+03 1.51991e+02 1.00000e-09 2.12000e-01 $1.51991 \mathrm{e}+031.51991 \mathrm{e}+03$ 1.51991e+02 1.00000e-09 2.12000e-01 $1.51991 \mathrm{e}+03$ 1.51991e+03 1.51991e+02 1.00000e-09 2.12000e-01 $1.51991 \mathrm{e}+031.51991 \mathrm{e}+031.51991 \mathrm{e}+02$ 1.00000e-09 2.12000e-01 $1.51991 \mathrm{e}+031.51991 \mathrm{e}+03$ 1.51991e+02 1.00000e-09 2.12000e-01 $1.00000 \mathrm{e}-02$ 1.00000e-02 1.00000e-03 1.00000e-09 1.00000e-01 $1.00000 \mathrm{e}+001.00000 \mathrm{e}+001.00000 \mathrm{e}-011.00000 \mathrm{e}-091.00000 \mathrm{e}-01$ $1.00000 \mathrm{e}-05$ 1.00000e-05 1.00000e-06 1.00000e-09 1.00000e-01 $1.00000 \mathrm{e}+001.00000 \mathrm{e}+001.00000 \mathrm{e}-011.00000 \mathrm{e}-091.00000 \mathrm{e}-01$ Element: 3914 \# of layers: 9

$\mathrm{Kx} \mathrm{Ky} \mathrm{Kz}$ Ss Por

$1.51991 \mathrm{e}+03$ 1.51991e+03 1.51991e+02 1.00000e-09 2.12000e-01 $1.51991 \mathrm{e}+031.51991 \mathrm{e}+031.51991 \mathrm{e}+021.00000 \mathrm{e}-092.12000 \mathrm{e}-01$ 
1.51991e+03 1.51991e+03 1.51991e+02 1.00000e-09 2.12000e-01 $1.51991 \mathrm{e}+031.51991 \mathrm{e}+03$ 1.51991e+02 1.00000e-09 2.12000e-01 $1.51991 \mathrm{e}+03$ 1.51991e+03 1.51991e+02 1.00000e-09 2.12000e-01 $1.00000 \mathrm{e}-02$ 1.00000e-02 1.00000e-03 1.00000e-09 1.00000e-01 $1.00000 \mathrm{e}+001.00000 \mathrm{e}+001.00000 \mathrm{e}-011.00000 \mathrm{e}-091.00000 \mathrm{e}-01$ $1.00000 \mathrm{e}-05$ 1.00000e-05 1.00000e-06 1.00000e-09 1.00000e-01 $1.00000 \mathrm{e}+001.00000 \mathrm{e}+001.00000 \mathrm{e}-01$ 1.00000e-09 1.00000e-01 Element: 3915 \# of layers: 9

$\mathrm{Kx} \mathrm{Ky} \mathrm{Kz}$ Ss Por

8.15008e+03 8.15008e+03 8.15009e+02 1.00000e-09 7.00000e-02 $1.51991 \mathrm{e}+03$ 1.51991e+03 1.51991e+02 1.00000e-09 2.12000e-01 $1.51991 \mathrm{e}+031.51991 \mathrm{e}+031.51991 \mathrm{e}+02$ 1.00000e-09 2.12000e-01 $1.51991 \mathrm{e}+031.51991 \mathrm{e}+03$ 1.51991e+02 1.00000e-09 2.12000e-01 $1.51991 \mathrm{e}+031.51991 \mathrm{e}+03$ 1.51991e+02 1.00000e-09 2.12000e-01 $1.00000 \mathrm{e}-02$ 1.00000e-02 1.00000e-03 1.00000e-09 1.00000e-01 $1.00000 \mathrm{e}+001.00000 \mathrm{e}+001.00000 \mathrm{e}-011.00000 \mathrm{e}-091.00000 \mathrm{e}-01$ $1.00000 \mathrm{e}-05$ 1.00000e-05 1.00000e-06 1.00000e-09 1.00000e-01 $1.00000 \mathrm{e}+001.00000 \mathrm{e}+001.00000 \mathrm{e}-01$ 1.00000e-09 1.00000e-01 Element: 3916 \# of layers: 9

$\mathrm{Kx} \mathrm{Ky} \mathrm{Kz}$ Ss Por

8.15008e+03 8.15008e+03 8.15009e+02 1.00000e-09 7.00000e-02 $3.25649 \mathrm{e}+02$ 3.25649e+02 3.25649e+01 1.00000e-09 2.12000e-01 $3.25649 \mathrm{e}+02$ 3.25649e+02 3.25649e+01 1.00000e-09 2.12000e-01 $3.25649 \mathrm{e}+02$ 3.25649e+02 3.25649e+01 1.00000e-09 2.12000e-01 $3.25649 \mathrm{e}+02$ 3.25649e+02 3.25649e+01 1.00000e-09 2.12000e-01 $1.00000 \mathrm{e}-02$ 1.00000e-02 1.00000e-03 1.00000e-09 1.00000e-01 $1.00000 \mathrm{e}+001.00000 \mathrm{e}+001.00000 \mathrm{e}-011.00000 \mathrm{e}-091.00000 \mathrm{e}-01$ $1.00000 \mathrm{e}-05$ 1.00000e-05 1.00000e-06 1.00000e-09 1.00000e-01 $1.00000 \mathrm{e}+001.00000 \mathrm{e}+001.00000 \mathrm{e}-011.00000 \mathrm{e}-091.00000 \mathrm{e}-01$ Element: 3917 \# of layers: 9

$\mathrm{Kx} \mathrm{Ky} \mathrm{Kz}$ Ss Por

8.15008e+03 8.15008e+03 8.15009e+02 1.00000e-09 7.00000e-02 $3.25649 \mathrm{e}+02$ 3.25649e+02 3.25649e+01 1.00000e-09 2.12000e-01 $3.25649 \mathrm{e}+02$ 3.25649e+02 3.25649e+01 1.00000e-09 2.12000e-01 $3.25649 \mathrm{e}+02$ 3.25649e+02 3.25649e+01 1.00000e-09 2.12000e-01 $3.25649 \mathrm{e}+02$ 3.25649e+02 3.25649e+01 1.00000e-09 2.12000e-01 $1.00000 \mathrm{e}-02$ 1.00000e-02 1.00000e-03 1.00000e-09 1.00000e-01 $1.00000 \mathrm{e}+001.00000 \mathrm{e}+001.00000 \mathrm{e}-011.00000 \mathrm{e}-091.00000 \mathrm{e}-01$ $1.00000 \mathrm{e}-05$ 1.00000e-05 1.00000e-06 1.00000e-09 1.00000e-01 $1.00000 \mathrm{e}+001.00000 \mathrm{e}+001.00000 \mathrm{e}-01$ 1.00000e-09 1.00000e-01 Element: 3918 \# of layers: 9

$\mathrm{Kx} \mathrm{Ky} \mathrm{Kz}$ Ss Por

6.10599e+03 6.10599e+03 6.10599e+02 1.00000e-09 7.00000e-02 2.43973e+02 2.43973e+02 2.43973e+01 1.00000e-09 2.12000e-01 $2.43973 \mathrm{e}+02$ 2.43973e+02 2.43973e+01 1.00000e-09 2.12000e-01 $2.43973 e+02$ 2.43973e+02 2.43973e+01 1.00000e-09 2.12000e-01 
2.43973e+02 2.43973e+02 2.43973e+01 1.00000e-09 2.12000e-01 $1.00000 \mathrm{e}-02$ 1.00000e-02 1.00000e-03 1.00000e-09 1.00000e-01 $1.00000 \mathrm{e}+001.00000 \mathrm{e}+001.00000 \mathrm{e}-011.00000 \mathrm{e}-091.00000 \mathrm{e}-01$ $1.00000 \mathrm{e}-05$ 1.00000e-05 1.00000e-06 1.00000e-09 1.00000e-01 $1.00000 \mathrm{e}+001.00000 \mathrm{e}+001.00000 \mathrm{e}-01$ 1.00000e-09 1.00000e-01 Element: 3919 \# of layers: 8

$\mathrm{Kx} \mathrm{Ky} \mathrm{Kz}$ Ss Por

$2.57630 \mathrm{e}+02$ 2.57630e+02 2.57630e+01 1.00000e-09 2.12000e-01

$2.57630 \mathrm{e}+022.57630 \mathrm{e}+02$ 2.57630e+01 1.00000e-09 2.12000e-01

$2.57630 \mathrm{e}+022.57630 \mathrm{e}+02$ 2.57630e+01 1.00000e-09 2.12000e-01

$2.57630 \mathrm{e}+022.57630 \mathrm{e}+022.57630 \mathrm{e}+01$ 1.00000e-09 2.12000e-01 $1.00000 \mathrm{e}-02$ 1.00000e-02 1.00000e-03 1.00000e-09 1.00000e-01 $1.00000 \mathrm{e}+001.00000 \mathrm{e}+001.00000 \mathrm{e}-011.00000 \mathrm{e}-091.00000 \mathrm{e}-01$ $1.00000 \mathrm{e}-05$ 1.00000e-05 1.00000e-06 1.00000e-09 1.00000e-01 $1.00000 \mathrm{e}+001.00000 \mathrm{e}+001.00000 \mathrm{e}-01$ 1.00000e-09 1.00000e-01 Element: 3920 \# of layers: 8

$\mathrm{Kx} \mathrm{Ky} \mathrm{Kz}$ Ss Por

$1.51991 \mathrm{e}+031.51991 \mathrm{e}+03$ 1.51991e+02 1.00000e-09 2.12000e-01 $1.51991 \mathrm{e}+031.51991 \mathrm{e}+03$ 1.51991e+02 1.00000e-09 2.12000e-01 $1.51991 \mathrm{e}+031.51991 \mathrm{e}+03$ 1.51991e+02 1.00000e-09 2.12000e-01 $1.51991 \mathrm{e}+031.51991 \mathrm{e}+031.51991 \mathrm{e}+02$ 1.00000e-09 2.12000e-01 $1.00000 \mathrm{e}-02$ 1.00000e-02 1.00000e-03 1.00000e-09 1.00000e-01 $1.00000 \mathrm{e}+001.00000 \mathrm{e}+001.00000 \mathrm{e}-011.00000 \mathrm{e}-091.00000 \mathrm{e}-01$ $1.00000 \mathrm{e}-05$ 1.00000e-05 1.00000e-06 1.00000e-09 1.00000e-01 $1.00000 \mathrm{e}+001.00000 \mathrm{e}+001.00000 \mathrm{e}-011.00000 \mathrm{e}-091.00000 \mathrm{e}-01$ Element: 3921 \# of layers: 9

$\mathrm{Kx} \mathrm{Ky} \mathrm{Kz}$ Ss Por

$1.40954 \mathrm{e}+03$ 1.40954e+03 1.40954e+02 1.00000e-09 2.12000e-01 $1.40954 \mathrm{e}+03 \quad 1.40954 \mathrm{e}+03 \quad 1.40954 \mathrm{e}+021.00000 \mathrm{e}-092.12000 \mathrm{e}-01$ $1.40954 \mathrm{e}+03 \quad 1.40954 \mathrm{e}+03 \quad 1.40954 \mathrm{e}+021.00000 \mathrm{e}-092.12000 \mathrm{e}-01$ $1.40954 \mathrm{e}+03$ 1.40954e+03 1.40954e+02 1.00000e-09 2.12000e-01 $1.40954 \mathrm{e}+031.40954 \mathrm{e}+03$ 1.40954e+02 1.00000e-09 2.12000e-01 1.00000e-02 1.00000e-02 1.00000e-03 1.00000e-09 1.00000e-01 $1.00000 \mathrm{e}+001.00000 \mathrm{e}+001.00000 \mathrm{e}-011.00000 \mathrm{e}-091.00000 \mathrm{e}-01$ $1.00000 \mathrm{e}-05$ 1.00000e-05 1.00000e-06 1.00000e-09 1.00000e-01 $1.00000 \mathrm{e}+001.00000 \mathrm{e}+001.00000 \mathrm{e}-011.00000 \mathrm{e}-091.00000 \mathrm{e}-01$ Element: 3922 \# of layers: 9

Kx Ky Kz Ss Por

$1.66668 \mathrm{e}+03$ 1.66668e+03 1.66668e+02 1.00000e-09 2.12000e-01 $1.66668 \mathrm{e}+03$ 1.66668e+03 1.66668e+02 1.00000e-09 2.12000e-01 $1.66668 \mathrm{e}+031.66668 \mathrm{e}+03$ 1.66668e+02 1.00000e-09 2.12000e-01 $1.66668 \mathrm{e}+031.66668 \mathrm{e}+03$ 1.66668e+02 1.00000e-09 2.12000e-01 $1.66668 \mathrm{e}+03$ 1.66668e+03 1.66668e+02 1.00000e-09 2.12000e-01 $1.00000 \mathrm{e}-02$ 1.00000e-02 1.00000e-03 1.00000e-09 1.00000e-01 $1.00000 \mathrm{e}+001.00000 \mathrm{e}+001.00000 \mathrm{e}-011.00000 \mathrm{e}-091.00000 \mathrm{e}-01$ $1.00000 \mathrm{e}-05$ 1.00000e-05 1.00000e-06 1.00000e-09 1.00000e-01 
$1.00000 \mathrm{e}+001.00000 \mathrm{e}+00$ 1.00000e-01 1.00000e-09 1.00000e-01

Element: 3923 \# of layers: 9

$\mathrm{Kx} \mathrm{Ky} \mathrm{Kz}$ Ss Por

$1.66668 \mathrm{e}+03$ 1.66668e+03 1.66668e+02 1.00000e-09 2.12000e-01

$1.66668 \mathrm{e}+03$ 1.66668e+03 1.66668e+02 1.00000e-09 2.12000e-01

$1.66668 \mathrm{e}+031.66668 \mathrm{e}+03$ 1.66668e+02 1.00000e-09 2.12000e-01

$1.66668 \mathrm{e}+03$ 1.66668e+03 1.66668e+02 1.00000e-09 2.12000e-01

$1.66668 \mathrm{e}+031.66668 \mathrm{e}+03$ 1.66668e+02 1.00000e-09 2.12000e-01

$1.00000 \mathrm{e}-02$ 1.00000e-02 1.00000e-03 1.00000e-09 1.00000e-01

$1.00000 \mathrm{e}+001.00000 \mathrm{e}+001.00000 \mathrm{e}-01$ 1.00000e-09 1.00000e-01

$1.00000 \mathrm{e}-05$ 1.00000e-05 1.00000e-06 1.00000e-09 1.00000e-01

$1.00000 \mathrm{e}+001.00000 \mathrm{e}+001.00000 \mathrm{e}-011.00000 \mathrm{e}-091.00000 \mathrm{e}-01$

Element: 3924 \# of layers: 8

$\mathrm{Kx} \mathrm{Ky} \mathrm{Kz}$ Ss Por

$1.66668 \mathrm{e}+03$ 1.66668e+03 1.66668e+02 1.00000e-09 2.12000e-01

$1.66668 \mathrm{e}+031.66668 \mathrm{e}+03$ 1.66668e+02 1.00000e-09 2.12000e-01

$1.66668 \mathrm{e}+03$ 1.66668e+03 1.66668e+02 1.00000e-09 2.12000e-01

$1.66668 \mathrm{e}+031.66668 \mathrm{e}+03$ 1.66668e+02 1.00000e-09 2.12000e-01

$1.00000 \mathrm{e}-02$ 1.00000e-02 1.00000e-03 1.00000e-09 1.00000e-01

$1.00000 \mathrm{e}+001.00000 \mathrm{e}+001.00000 \mathrm{e}-011.00000 \mathrm{e}-091.00000 \mathrm{e}-01$

$1.00000 \mathrm{e}-05$ 1.00000e-05 1.00000e-06 1.00000e-09 1.00000e-01

$1.00000 \mathrm{e}+001.00000 \mathrm{e}+001.00000 \mathrm{e}-011.00000 \mathrm{e}-09$ 1.00000e-01

Element: 3925 \# of layers: 10

Kx Ky Kz Ss Por

8.38714e+03 8.38714e+03 8.38714e+02 1.00000e-09 7.00000e-02

$3.35122 \mathrm{e}+02$ 3.35122e+02 3.35122e+01 1.00000e-09 2.12000e-01

$3.35122 \mathrm{e}+02$ 3.35122e+02 3.35122e+01 1.00000e-09 2.12000e-01

3.35122e+02 3.35122e+02 3.35122e+01 1.00000e-09 2.12000e-01

$3.35122 \mathrm{e}+02$ 3.35122e+02 3.35122e+01 1.00000e-09 2.12000e-01

$1.00000 \mathrm{e}-02$ 1.00000e-02 1.00000e-03 1.00000e-09 1.00000e-01

$1.00000 \mathrm{e}+001.00000 \mathrm{e}+001.00000 \mathrm{e}-01$ 1.00000e-09 1.00000e-01

$1.00000 \mathrm{e}-05$ 1.00000e-05 1.00000e-06 1.00000e-09 1.00000e-01

$1.00000 \mathrm{e}+001.00000 \mathrm{e}+001.00000 \mathrm{e}-011.00000 \mathrm{e}-091.00000 \mathrm{e}-01$

1.00000e-06 1.00000e-06 1.00000e-06 1.00000e-09 5.00000e-02

Element: 3926 \# of layers: 9

Kx Ky Kz Ss Por

8.38714e+03 8.38714e+03 8.38714e+02 1.00000e-09 7.00000e-02

$3.35122 \mathrm{e}+02$ 3.35122e+02 3.35122e+01 1.00000e-09 2.12000e-01

3.35122e+02 3.35122e+02 3.35122e+01 1.00000e-09 2.12000e-01

$3.35122 \mathrm{e}+02$ 3.35122e+02 3.35122e+01 1.00000e-09 2.12000e-01

$3.35122 \mathrm{e}+02$ 3.35122e+02 3.35122e+01 1.00000e-09 2.12000e-01

$1.00000 \mathrm{e}-02$ 1.00000e-02 1.00000e-03 1.00000e-09 1.00000e-01

$1.00000 \mathrm{e}+001.00000 \mathrm{e}+001.00000 \mathrm{e}-011.00000 \mathrm{e}-091.00000 \mathrm{e}-01$

$1.00000 \mathrm{e}-05$ 1.00000e-05 1.00000e-06 1.00000e-09 1.00000e-01

$1.00000 \mathrm{e}+001.00000 \mathrm{e}+001.00000 \mathrm{e}-011.00000 \mathrm{e}-09$ 1.00000e-01

Element: 3927 \# of layers: 9 
$\mathrm{Kx} \mathrm{Ky} \mathrm{Kz}$ Ss Por

6.12572e+03 6.12572e+03 6.12572e+02 1.00000e-09 7.00000e-02 $2.44760 \mathrm{e}+02$ 2.44760e+02 2.44760e+01 1.00000e-09 2.12000e-01 $2.44760 \mathrm{e}+02$ 2.44760e+02 2.44760e+01 1.00000e-09 2.12000e-01 $2.44760 \mathrm{e}+022.44760 \mathrm{e}+02$ 2.44760e+01 1.00000e-09 2.12000e-01 $2.44760 \mathrm{e}+02$ 2.44760e+02 2.44760e+01 1.00000e-09 2.12000e-01 $1.00000 \mathrm{e}-02$ 1.00000e-02 1.00000e-03 1.00000e-09 1.00000e-01 $1.00000 \mathrm{e}+001.00000 \mathrm{e}+001.00000 \mathrm{e}-011.00000 \mathrm{e}-091.00000 \mathrm{e}-01$ $1.00000 \mathrm{e}-05$ 1.00000e-05 1.00000e-06 1.00000e-09 1.00000e-01 $1.00000 \mathrm{e}+001.00000 \mathrm{e}+001.00000 \mathrm{e}-011.00000 \mathrm{e}-091.00000 \mathrm{e}-01$ Element: 3928 \# of layers: 9

$\mathrm{Kx} \mathrm{Ky} \mathrm{Kz}$ Ss Por

6.12572e+03 6.12572e+03 6.12572e+02 1.00000e-09 7.00000e-02 $1.40954 \mathrm{e}+031.40954 \mathrm{e}+03$ 1.40954e+02 1.00000e-09 2.12000e-01 $1.40954 \mathrm{e}+031.40954 \mathrm{e}+03$ 1.40954e+02 1.00000e-09 2.12000e-01 $1.40954 \mathrm{e}+031.40954 \mathrm{e}+031.40954 \mathrm{e}+021.00000 \mathrm{e}-092.12000 \mathrm{e}-01$ $1.40954 \mathrm{e}+03$ 1.40954e+03 1.40954e+02 1.00000e-09 2.12000e-01 $1.00000 \mathrm{e}-02$ 1.00000e-02 1.00000e-03 1.00000e-09 1.00000e-01 $1.00000 \mathrm{e}+001.00000 \mathrm{e}+001.00000 \mathrm{e}-011.00000 \mathrm{e}-091.00000 \mathrm{e}-01$ $1.00000 \mathrm{e}-05$ 1.00000e-05 1.00000e-06 1.00000e-09 1.00000e-01 $1.00000 \mathrm{e}+001.00000 \mathrm{e}+001.00000 \mathrm{e}-011.00000 \mathrm{e}-091.00000 \mathrm{e}-01$ Element: 3929 \# of layers: 9

$\mathrm{Kx} \mathrm{Ky} \mathrm{Kz}$ Ss Por

8.38714e+03 8.38714e+03 8.38714e+02 1.00000e-09 7.00000e-02 $1.66668 \mathrm{e}+03$ 1.66668e+03 1.66668e+02 1.00000e-09 2.12000e-01 $1.66668 \mathrm{e}+03$ 1.66668e +03 1.66668e+02 1.00000e-09 2.12000e-01 $1.66668 \mathrm{e}+031.66668 \mathrm{e}+03$ 1.66668e+02 1.00000e-09 2.12000e-01 $1.66668 \mathrm{e}+031.66668 \mathrm{e}+03$ 1.66668e+02 1.00000e-09 2.12000e-01 $1.00000 \mathrm{e}-02$ 1.00000e-02 1.00000e-03 1.00000e-09 1.00000e-01 $1.00000 \mathrm{e}+001.00000 \mathrm{e}+001.00000 \mathrm{e}-011.00000 \mathrm{e}-091.00000 \mathrm{e}-01$ $1.00000 \mathrm{e}-05$ 1.00000e-05 1.00000e-06 1.00000e-09 1.00000e-01 $1.00000 \mathrm{e}+001.00000 \mathrm{e}+001.00000 \mathrm{e}-01$ 1.00000e-09 1.00000e-01 Element: 3930 \# of layers: 10

$\mathrm{Kx} \mathrm{Ky} \mathrm{Kz}$ Ss Por

3.04277e+04 3.04277e+04 3.04277e+03 1.00000e-09 7.00000e-02 $1.21579 \mathrm{e}+03$ 1.21579e+03 1.21579e+02 1.00000e-09 2.12000e-01 $1.21579 \mathrm{e}+03$ 1.21579e+03 1.21579e+02 1.00000e-09 2.12000e-01 $1.21579 \mathrm{e}+03$ 1.21579e+03 1.21579e+02 1.00000e-09 2.12000e-01 $1.21579 \mathrm{e}+03$ 1.21579e+03 1.21579e+02 1.00000e-09 2.12000e-01 $1.21579 \mathrm{e}+031.21579 \mathrm{e}+03$ 1.21579e+02 1.00000e-09 2.12000e-01 $1.00000 \mathrm{e}-02$ 1.00000e-02 1.00000e-03 1.00000e-09 1.00000e-01 $1.00000 \mathrm{e}+001.00000 \mathrm{e}+001.00000 \mathrm{e}-011.00000 \mathrm{e}-091.00000 \mathrm{e}-01$ $1.00000 \mathrm{e}-05$ 1.00000e-05 1.00000e-06 1.00000e-09 1.00000e-01 $1.00000 \mathrm{e}+001.00000 \mathrm{e}+001.00000 \mathrm{e}-01$ 1.00000e-09 1.00000e-01 Element: 3931 \# of layers: 10

Kx Ky Kz Ss Por 
5.49060e+04 5.49060e+04 5.49060e+03 1.00000e-09 7.00000e-02 $2.19386 \mathrm{e}+032.19386 \mathrm{e}+03$ 2.19386e+02 1.00000e-09 2.12000e-01 $2.19386 \mathrm{e}+032.19386 \mathrm{e}+03$ 2.19386e+02 1.00000e-09 2.12000e-01 $2.19386 \mathrm{e}+032.19386 \mathrm{e}+032.19386 \mathrm{e}+02$ 1.00000e-09 2.12000e-01 $2.19386 \mathrm{e}+032.19386 \mathrm{e}+032.19386 \mathrm{e}+02$ 1.00000e-09 2.12000e-01 $2.19386 \mathrm{e}+032.19386 \mathrm{e}+032.19386 \mathrm{e}+02$ 1.00000e-09 2.12000e-01 $1.00000 \mathrm{e}-02$ 1.00000e-02 1.00000e-03 1.00000e-09 1.00000e-01 $1.00000 \mathrm{e}+001.00000 \mathrm{e}+001.00000 \mathrm{e}-011.00000 \mathrm{e}-091.00000 \mathrm{e}-01$ $1.00000 \mathrm{e}-05$ 1.00000e-05 1.00000e-06 1.00000e-09 1.00000e-01 $1.00000 \mathrm{e}+001.00000 \mathrm{e}+001.00000 \mathrm{e}-011.00000 \mathrm{e}-091.00000 \mathrm{e}-01$ Element: 3932 \# of layers: 10

Kx Ky Kz Ss Por

5.49060e+04 5.49060e+04 5.49060e+03 1.00000e-09 7.00000e-02 $2.19386 \mathrm{e}+032.19386 \mathrm{e}+032.19386 \mathrm{e}+02$ 1.00000e-09 2.12000e-01 $2.19386 \mathrm{e}+032.19386 \mathrm{e}+032.19386 \mathrm{e}+02$ 1.00000e-09 2.12000e-01 $2.19386 \mathrm{e}+032.19386 \mathrm{e}+032.19386 \mathrm{e}+02$ 1.00000e-09 2.12000e-01 $2.19386 \mathrm{e}+032.19386 \mathrm{e}+032.19386 \mathrm{e}+02$ 1.00000e-09 2.12000e-01 $2.19386 \mathrm{e}+032.19386 \mathrm{e}+032.19386 \mathrm{e}+02$ 1.00000e-09 2.12000e-01 $1.00000 \mathrm{e}-02$ 1.00000e-02 1.00000e-03 1.00000e-09 1.00000e-01 $1.00000 \mathrm{e}+001.00000 \mathrm{e}+001.00000 \mathrm{e}-011.00000 \mathrm{e}-091.00000 \mathrm{e}-01$ $1.00000 \mathrm{e}-05$ 1.00000e-05 1.00000e-06 1.00000e-09 1.00000e-01 $1.00000 \mathrm{e}+001.00000 \mathrm{e}+001.00000 \mathrm{e}-01$ 1.00000e-09 1.00000e-01 Element: 3933 \# of layers: 8

Kx Ky Kz Ss Por

$2.19386 \mathrm{e}+03$ 2.19386e+03 2.19386e+02 1.00000e-09 2.12000e-01 $2.19386 \mathrm{e}+032.19386 \mathrm{e}+03$ 2.19386e+02 1.00000e-09 2.12000e-01 $2.19386 \mathrm{e}+032.19386 \mathrm{e}+032.19386 \mathrm{e}+02$ 1.00000e-09 2.12000e-01 $2.19386 \mathrm{e}+032.19386 \mathrm{e}+032.19386 \mathrm{e}+02$ 1.00000e-09 2.12000e-01 $1.00000 \mathrm{e}-02$ 1.00000e-02 1.00000e-03 1.00000e-09 1.00000e-01 $1.00000 \mathrm{e}+001.00000 \mathrm{e}+001.00000 \mathrm{e}-011.00000 \mathrm{e}-091.00000 \mathrm{e}-01$ $1.00000 \mathrm{e}-05$ 1.00000e-05 1.00000e-06 1.00000e-09 1.00000e-01 $1.00000 \mathrm{e}+001.00000 \mathrm{e}+001.00000 \mathrm{e}-01$ 1.00000e-09 1.00000e-01 Element: 3934 \# of layers: 9

$\mathrm{Kx} \mathrm{Ky} \mathrm{Kz}$ Ss Por

1.94467e+03 1.94467e+03 1.94467e+02 1.00000e-09 2.12000e-01 $1.94467 \mathrm{e}+03$ 1.94467e+03 1.94467e+02 1.00000e-09 2.12000e-01 $1.94467 \mathrm{e}+031.94467 \mathrm{e}+03$ 1.94467e+02 1.00000e-09 2.12000e-01 $1.94467 \mathrm{e}+03$ 1.94467e+03 1.94467e+02 1.00000e-09 2.12000e-01 $1.00000 \mathrm{e}-021.00000 \mathrm{e}-021.00000 \mathrm{e}-031.00000 \mathrm{e}-091.00000 \mathrm{e}-01$ $1.00000 \mathrm{e}+001.00000 \mathrm{e}+001.00000 \mathrm{e}-011.00000 \mathrm{e}-091.00000 \mathrm{e}-01$ $1.00000 \mathrm{e}-05$ 1.00000e-05 1.00000e-06 1.00000e-09 1.00000e-01 $1.00000 \mathrm{e}+001.00000 \mathrm{e}+001.00000 \mathrm{e}-011.00000 \mathrm{e}-091.00000 \mathrm{e}-01$ 1.00000e-06 1.00000e-06 1.00000e-06 1.00000e-09 5.00000e-02 Element: 3935 \# of layers: 9

$\mathrm{Kx} \mathrm{Ky} \mathrm{Kz}$ Ss Por

1.94467e+03 1.94467e+03 1.94467e+02 1.00000e-09 2.12000e-01 
1.94467e+03 1.94467e+03 1.94467e+02 1.00000e-09 2.12000e-01 $1.94467 \mathrm{e}+03$ 1.94467e+03 1.94467e+02 1.00000e-09 2.12000e-01 $1.94467 \mathrm{e}+03$ 1.94467e+03 1.94467e+02 1.00000e-09 2.12000e-01 $1.00000 \mathrm{e}-02$ 1.00000e-02 1.00000e-03 1.00000e-09 1.00000e-01 $1.00000 \mathrm{e}+001.00000 \mathrm{e}+001.00000 \mathrm{e}-011.00000 \mathrm{e}-091.00000 \mathrm{e}-01$ $1.00000 \mathrm{e}-05$ 1.00000e-05 1.00000e-06 1.00000e-09 1.00000e-01 $1.00000 \mathrm{e}+001.00000 \mathrm{e}+001.00000 \mathrm{e}-011.00000 \mathrm{e}-091.00000 \mathrm{e}-01$ 1.00000e-06 1.00000e-06 1.00000e-06 1.00000e-09 5.00000e-02 Element: 3936 \# of layers: 10

$\mathrm{Kx} \mathrm{Ky} \mathrm{Kz}$ Ss Por

2.29971e+04 2.29971e+04 2.29971e+03 1.00000e-09 7.00000e-02 9.18897e+02 9.18897e+02 9.18897e+01 1.00000e-09 2.12000e-01 9.18897e+02 9.18897e+02 9.18897e+01 1.00000e-09 2.12000e-01 9.18897e+02 9.18897e+02 9.18897e+01 1.00000e-09 2.12000e-01 9.18897e+02 9.18897e+02 9.18897e+01 1.00000e-09 2.12000e-01 $1.00000 \mathrm{e}-02$ 1.00000e-02 1.00000e-03 1.00000e-09 1.00000e-01 $1.00000 \mathrm{e}+001.00000 \mathrm{e}+001.00000 \mathrm{e}-011.00000 \mathrm{e}-091.00000 \mathrm{e}-01$ $1.00000 \mathrm{e}-05$ 1.00000e-05 1.00000e-06 1.00000e-09 1.00000e-01 $1.00000 \mathrm{e}+001.00000 \mathrm{e}+001.00000 \mathrm{e}-011.00000 \mathrm{e}-091.00000 \mathrm{e}-01$ 1.00000e-06 1.00000e-06 1.00000e-06 1.00000e-09 5.00000e-02 Element: 3937 \# of layers: 8

$\mathrm{Kx} \mathrm{Ky} \mathrm{Kz}$ Ss Por

1.21579e+03 1.21579e+03 1.21579e+02 1.00000e-09 2.12000e-01 $1.21579 \mathrm{e}+031.21579 \mathrm{e}+03$ 1.21579e+02 1.00000e-09 2.12000e-01 $1.21579 \mathrm{e}+03$ 1.21579e+03 1.21579e+02 1.00000e-09 2.12000e-01 $1.21579 \mathrm{e}+031.21579 \mathrm{e}+03$ 1.21579e+02 1.00000e-09 2.12000e-01 $1.00000 \mathrm{e}-02$ 1.00000e-02 1.00000e-03 1.00000e-09 1.00000e-01 $1.00000 \mathrm{e}+001.00000 \mathrm{e}+001.00000 \mathrm{e}-011.00000 \mathrm{e}-091.00000 \mathrm{e}-01$ $1.00000 \mathrm{e}-05$ 1.00000e-05 1.00000e-06 1.00000e-09 1.00000e-01 $1.00000 \mathrm{e}+001.00000 \mathrm{e}+001.00000 \mathrm{e}-011.00000 \mathrm{e}-091.00000 \mathrm{e}-01$ Element: 3938 \# of layers: 8

$\mathrm{Kx} \mathrm{Ky} \mathrm{Kz}$ Ss Por

$2.19386 \mathrm{e}+032.19386 \mathrm{e}+032.19386 \mathrm{e}+02$ 1.00000e-09 2.12000e-01 $2.19386 \mathrm{e}+032.19386 \mathrm{e}+032.19386 \mathrm{e}+02$ 1.00000e-09 2.12000e-01 $2.19386 \mathrm{e}+032.19386 \mathrm{e}+032.19386 \mathrm{e}+02$ 1.00000e-09 2.12000e-01 $2.19386 \mathrm{e}+032.19386 \mathrm{e}+032.19386 \mathrm{e}+02$ 1.00000e-09 2.12000e-01 1.00000e-02 1.00000e-02 1.00000e-03 1.00000e-09 1.00000e-01 $1.00000 \mathrm{e}+001.00000 \mathrm{e}+001.00000 \mathrm{e}-011.00000 \mathrm{e}-091.00000 \mathrm{e}-01$ $1.00000 \mathrm{e}-05$ 1.00000e-05 1.00000e-06 1.00000e-09 1.00000e-01 $1.00000 \mathrm{e}+001.00000 \mathrm{e}+001.00000 \mathrm{e}-01$ 1.00000e-09 1.00000e-01 Element: 3939 \# of layers: 8

$\mathrm{Kx} \mathrm{Ky} \mathrm{Kz}$ Ss Por

4.07169e+03 4.07169e+03 4.07169e+02 1.00000e-09 2.12000e-01 4.07169e+03 4.07169e+03 4.07169e+02 1.00000e-09 2.12000e-01 $4.07169 \mathrm{e}+03$ 4.07169e+03 4.07169e+02 1.00000e-09 2.12000e-01 $4.07169 \mathrm{e}+03$ 4.07169e+03 4.07169e+02 1.00000e-09 2.12000e-01 
$1.00000 \mathrm{e}-02$ 1.00000e-02 1.00000e-03 1.00000e-09 1.00000e-01 $1.00000 \mathrm{e}+001.00000 \mathrm{e}+001.00000 \mathrm{e}-011.00000 \mathrm{e}-091.00000 \mathrm{e}-01$ $1.00000 \mathrm{e}-051.00000 \mathrm{e}-05$ 1.00000e-06 1.00000e-09 1.00000e-01 $1.00000 \mathrm{e}+001.00000 \mathrm{e}+001.00000 \mathrm{e}-011.00000 \mathrm{e}-091.00000 \mathrm{e}-01$ Element: 3940 \# of layers: 8

$\mathrm{Kx} \mathrm{Ky} \mathrm{Kz}$ Ss Por

4.21412e+03 4.21412e+03 4.21412e+02 1.00000e-09 2.12000e-01 $4.21412 \mathrm{e}+03$ 4.21412e+03 4.21412e+02 1.00000e-09 2.12000e-01 4.21412e+03 4.21412e+03 4.21412e+02 1.00000e-09 2.12000e-01 $4.21412 \mathrm{e}+034.21412 \mathrm{e}+034.21412 \mathrm{e}+02$ 1.00000e-09 2.12000e-01 $1.00000 \mathrm{e}-02$ 1.00000e-02 1.00000e-03 1.00000e-09 1.00000e-01 $1.00000 \mathrm{e}+001.00000 \mathrm{e}+001.00000 \mathrm{e}-011.00000 \mathrm{e}-091.00000 \mathrm{e}-01$ 1.00000e-05 1.00000e-05 1.00000e-06 1.00000e-09 1.00000e-01 $1.00000 \mathrm{e}+001.00000 \mathrm{e}+001.00000 \mathrm{e}-01$ 1.00000e-09 1.00000e-01 Element: 3941 \# of layers: 7

Kx Ky Kz Ss Por

4.21412e+03 4.21412e+03 4.21412e+02 1.00000e-09 2.12000e-01 4.21412e+03 4.21412e+03 4.21412e+02 1.00000e-09 2.12000e-01 4.21412e+03 4.21412e+03 4.21412e+02 1.00000e-09 2.12000e-01 $1.00000 \mathrm{e}-02$ 1.00000e-02 1.00000e-03 1.00000e-09 1.00000e-01 $1.00000 \mathrm{e}+001.00000 \mathrm{e}+001.00000 \mathrm{e}-011.00000 \mathrm{e}-091.00000 \mathrm{e}-01$ $1.00000 \mathrm{e}-051.00000 \mathrm{e}-051.00000 \mathrm{e}-061.00000 \mathrm{e}-091.00000 \mathrm{e}-01$ $1.00000 \mathrm{e}+001.00000 \mathrm{e}+001.00000 \mathrm{e}-01$ 1.00000e-09 1.00000e-01 Element: 3942 \# of layers: 9

$\mathrm{Kx} \mathrm{Ky} \mathrm{Kz}$ Ss Por

$2.38008 \mathrm{e}+042.38008 \mathrm{e}+042.38008 \mathrm{e}+03$ 1.00000e-09 7.00000e-02 5.00000e-04 5.00000e-04 5.00000e-05 1.00000e-09 1.00000e-01 $4.21412 \mathrm{e}+034.21412 \mathrm{e}+03$ 4.21412e+02 1.00000e-09 2.12000e-01 $4.21412 \mathrm{e}+03$ 4.21412e+03 4.21412e+02 1.00000e-09 2.12000e-01 4.21412e+03 4.21412e+03 4.21412e+02 1.00000e-09 2.12000e-01 $1.00000 \mathrm{e}-02$ 1.00000e-02 1.00000e-03 1.00000e-09 1.00000e-01 $1.00000 \mathrm{e}+001.00000 \mathrm{e}+001.00000 \mathrm{e}-011.00000 \mathrm{e}-091.00000 \mathrm{e}-01$ $1.00000 \mathrm{e}-05$ 1.00000e-05 1.00000e-06 1.00000e-09 1.00000e-01 $1.00000 \mathrm{e}+001.00000 \mathrm{e}+001.00000 \mathrm{e}-011.00000 \mathrm{e}-091.00000 \mathrm{e}-01$ Element: 3943 \# of layers: 10

$\mathrm{Kx} \mathrm{Ky} \mathrm{Kz}$ Ss Por

$2.38008 \mathrm{e}+042.38008 \mathrm{e}+042.38008 \mathrm{e}+03$ 1.00000e-09 7.00000e-02 5.00000e-04 5.00000e-04 5.00000e-05 1.00000e-09 1.00000e-01 $9.51005 \mathrm{e}+02$ 9.51005e+02 9.51005e+01 1.00000e-09 2.12000e-01 9.51005e+02 9.51005e+02 9.51005e+01 1.00000e-09 2.12000e-01 9.51005e+02 9.51005e+02 9.51005e+01 1.00000e-09 2.12000e-01 $1.00000 \mathrm{e}-02$ 1.00000e-02 1.00000e-03 1.00000e-09 1.00000e-01 $1.00000 \mathrm{e}+001.00000 \mathrm{e}+001.00000 \mathrm{e}-011.00000 \mathrm{e}-091.00000 \mathrm{e}-01$ $1.00000 \mathrm{e}-05$ 1.00000e-05 1.00000e-06 1.00000e-09 1.00000e-01 $1.00000 \mathrm{e}+001.00000 \mathrm{e}+001.00000 \mathrm{e}-011.00000 \mathrm{e}-091.00000 \mathrm{e}-01$ $1.00000 \mathrm{e}-06$ 1.00000e-06 1.00000e-06 1.00000e-09 5.00000e-02 
Element: 3944 \# of layers: 9

$\mathrm{Kx} \mathrm{Ky} \mathrm{Kz}$ Ss Por

$2.38008 \mathrm{e}+042.38008 \mathrm{e}+042.38008 \mathrm{e}+03$ 1.00000e-09 7.00000e-02

$9.51005 \mathrm{e}+02$ 9.51005e+02 9.51005e+01 1.00000e-09 2.12000e-01

9.51005e+02 9.51005e+02 9.51005e+01 1.00000e-09 2.12000e-01

$9.51005 \mathrm{e}+02$ 9.51005e+02 9.51005e+01 1.00000e-09 2.12000e-01

$1.00000 \mathrm{e}-02$ 1.00000e-02 1.00000e-03 1.00000e-09 1.00000e-01

$1.00000 \mathrm{e}+001.00000 \mathrm{e}+001.00000 \mathrm{e}-011.00000 \mathrm{e}-091.00000 \mathrm{e}-01$

$1.00000 \mathrm{e}-05$ 1.00000e-05 1.00000e-06 1.00000e-09 1.00000e-01

$1.00000 \mathrm{e}+001.00000 \mathrm{e}+001.00000 \mathrm{e}-011.00000 \mathrm{e}-091.00000 \mathrm{e}-01$

1.00000e-06 1.00000e-06 1.00000e-06 1.00000e-09 5.00000e-02

Element: 3945 \# of layers: 10

$\mathrm{Kx} \mathrm{Ky} \mathrm{Kz}$ Ss Por

2.73318e+04 2.73318e+04 2.73318e+03 1.00000e-09 7.00000e-02

$1.09208 \mathrm{e}+031.09208 \mathrm{e}+03$ 1.09208e+02 1.00000e-09 2.12000e-01

$1.09208 \mathrm{e}+031.09208 \mathrm{e}+03 \quad 1.09208 \mathrm{e}+02$ 1.00000e-09 2.12000e-01

$1.09208 \mathrm{e}+031.09208 \mathrm{e}+03$ 1.09208e+02 1.00000e-09 2.12000e-01

$1.09208 \mathrm{e}+031.09208 \mathrm{e}+03$ 1.09208e+02 1.00000e-09 2.12000e-01

$1.00000 \mathrm{e}-02$ 1.00000e-02 1.00000e-03 1.00000e-09 1.00000e-01

$1.00000 \mathrm{e}+001.00000 \mathrm{e}+001.00000 \mathrm{e}-011.00000 \mathrm{e}-091.00000 \mathrm{e}-01$

$1.00000 \mathrm{e}-05$ 1.00000e-05 1.00000e-06 1.00000e-09 1.00000e-01

$1.00000 \mathrm{e}+001.00000 \mathrm{e}+001.00000 \mathrm{e}-011.00000 \mathrm{e}-091.00000 \mathrm{e}-01$

$1.00000 \mathrm{e}-06$ 1.00000e-06 1.00000e-06 1.00000e-09 5.00000e-02

Element: 3946 \# of layers: 7

Kx Ky Kz Ss Por

4.07169e+03 4.07169e+03 4.07169e+02 1.00000e-09 2.12000e-01

$4.07169 \mathrm{e}+03$ 4.07169e+03 4.07169e+02 1.00000e-09 2.12000e-01

$4.07169 \mathrm{e}+03$ 4.07169e+03 4.07169e+02 1.00000e-09 2.12000e-01

$1.00000 \mathrm{e}-02$ 1.00000e-02 1.00000e-03 1.00000e-09 1.00000e-01

$1.00000 \mathrm{e}+001.00000 \mathrm{e}+001.00000 \mathrm{e}-011.00000 \mathrm{e}-091.00000 \mathrm{e}-01$

$1.00000 \mathrm{e}-05$ 1.00000e-05 1.00000e-06 1.00000e-09 1.00000e-01

$1.00000 \mathrm{e}+001.00000 \mathrm{e}+001.00000 \mathrm{e}-01$ 1.00000e-09 1.00000e-01

Element: 3947 \# of layers: 8

$\mathrm{Kx} \mathrm{Ky} \mathrm{Kz}$ Ss Por

$2.38008 \mathrm{e}+042.38008 \mathrm{e}+042.38008 \mathrm{e}+03$ 1.00000e-09 7.00000e-02

$4.21412 \mathrm{e}+03$ 4.21412e+03 4.21412e+02 1.00000e-09 2.12000e-01

$4.21412 \mathrm{e}+034.21412 \mathrm{e}+034.21412 \mathrm{e}+02$ 1.00000e-09 2.12000e-01

4.21412e+03 4.21412e+03 4.21412e+02 1.00000e-09 2.12000e-01

$1.00000 \mathrm{e}-02$ 1.00000e-02 1.00000e-03 1.00000e-09 1.00000e-01

$1.00000 \mathrm{e}+001.00000 \mathrm{e}+001.00000 \mathrm{e}-011.00000 \mathrm{e}-091.00000 \mathrm{e}-01$

$1.00000 \mathrm{e}-05$ 1.00000e-05 1.00000e-06 1.00000e-09 1.00000e-01

$1.00000 \mathrm{e}+001.00000 \mathrm{e}+001.00000 \mathrm{e}-011.00000 \mathrm{e}-091.00000 \mathrm{e}-01$

Element: 3948 \# of layers: 8

$\mathrm{Kx} \mathrm{Ky} \mathrm{Kz}$ Ss Por

4.49020e+03 4.49020e+03 4.49020e+02 1.00000e-09 2.12000e-01

$4.49020 \mathrm{e}+03$ 4.49020e+03 4.49020e+02 1.00000e-09 2.12000e-01 
$4.49020 \mathrm{e}+03$ 4.49020e+03 4.49020e+02 1.00000e-09 2.12000e-01 $4.49020 \mathrm{e}+034.49020 \mathrm{e}+034.49020 \mathrm{e}+02$ 1.00000e-09 2.12000e-01 $1.00000 \mathrm{e}-021.00000 \mathrm{e}-02$ 1.00000e-03 1.00000e-09 1.00000e-01 $1.00000 \mathrm{e}+001.00000 \mathrm{e}+001.00000 \mathrm{e}-011.00000 \mathrm{e}-091.00000 \mathrm{e}-01$ $1.00000 \mathrm{e}-05$ 1.00000e-05 1.00000e-06 1.00000e-09 1.00000e-01 $1.00000 \mathrm{e}+001.00000 \mathrm{e}+001.00000 \mathrm{e}-011.00000 \mathrm{e}-091.00000 \mathrm{e}-01$ Element: 3949 \# of layers: 8

$\mathrm{Kx} \mathrm{Ky} \mathrm{Kz}$ Ss Por

4.82230e+03 4.82230e+03 4.82230e+02 1.00000e-09 2.12000e-01 $4.82230 \mathrm{e}+03$ 4.82230e+03 4.82230e+02 1.00000e-09 2.12000e-01 $4.82230 \mathrm{e}+03$ 4.82230e+03 4.82230e+02 1.00000e-09 2.12000e-01 $4.82230 \mathrm{e}+03$ 4.82230e+03 4.82230e+02 1.00000e-09 2.12000e-01 $1.00000 \mathrm{e}-02$ 1.00000e-02 1.00000e-03 1.00000e-09 1.00000e-01 $1.00000 \mathrm{e}+001.00000 \mathrm{e}+001.00000 \mathrm{e}-011.00000 \mathrm{e}-091.00000 \mathrm{e}-01$ $1.00000 \mathrm{e}-05$ 1.00000e-05 1.00000e-06 1.00000e-09 1.00000e-01 $1.00000 \mathrm{e}+001.00000 \mathrm{e}+001.00000 \mathrm{e}-011.00000 \mathrm{e}-091.00000 \mathrm{e}-01$ Element: 3950 \# of layers: 8

$\mathrm{Kx} \mathrm{Ky} \mathrm{Kz}$ Ss Por

4.82230e+03 4.82230e+03 4.82230e+02 1.00000e-09 2.12000e-01 $4.82230 \mathrm{e}+034.82230 \mathrm{e}+034.82230 \mathrm{e}+02$ 1.00000e-09 2.12000e-01 $4.82230 \mathrm{e}+034.82230 \mathrm{e}+034.82230 \mathrm{e}+02$ 1.00000e-09 2.12000e-01 $4.82230 \mathrm{e}+03$ 4.82230e+03 4.82230e+02 1.00000e-09 2.12000e-01 $1.00000 \mathrm{e}-02$ 1.00000e-02 1.00000e-03 1.00000e-09 1.00000e-01 $1.00000 \mathrm{e}+001.00000 \mathrm{e}+001.00000 \mathrm{e}-011.00000 \mathrm{e}-091.00000 \mathrm{e}-01$ $1.00000 \mathrm{e}-05$ 1.00000e-05 1.00000e-06 1.00000e-09 1.00000e-01 $1.00000 \mathrm{e}+001.00000 \mathrm{e}+001.00000 \mathrm{e}-01$ 1.00000e-09 1.00000e-01 Element: 3951 \# of layers: 8

$\mathrm{Kx} \mathrm{Ky} \mathrm{Kz}$ Ss Por

4.82230e+03 4.82230e+03 4.82230e+02 1.00000e-09 2.12000e-01 $4.82230 \mathrm{e}+03$ 4.82230e+03 4.82230e+02 1.00000e-09 2.12000e-01 $4.82230 \mathrm{e}+03$ 4.82230e+03 4.82230e+02 1.00000e-09 2.12000e-01 $4.82230 \mathrm{e}+03$ 4.82230e+03 4.82230e+02 1.00000e-09 2.12000e-01 $1.00000 \mathrm{e}-02$ 1.00000e-02 1.00000e-03 1.00000e-09 1.00000e-01 $1.00000 \mathrm{e}+001.00000 \mathrm{e}+001.00000 \mathrm{e}-011.00000 \mathrm{e}-091.00000 \mathrm{e}-01$ $1.00000 \mathrm{e}-05$ 1.00000e-05 1.00000e-06 1.00000e-09 1.00000e-01 $1.00000 \mathrm{e}+001.00000 \mathrm{e}+001.00000 \mathrm{e}-011.00000 \mathrm{e}-091.00000 \mathrm{e}-01$ Element: 3952 \# of layers: 9

$\mathrm{Kx} \mathrm{Ky} \mathrm{Kz}$ Ss Por 5.00000e-04 5.00000e-04 5.00000e-05 1.00000e-09 1.00000e-01 7.74602e+03 7.74602e+03 7.74602e+02 1.00000e-09 2.12000e-01 $7.74602 \mathrm{e}+03$ 7.74602e+03 7.74602e+02 1.00000e-09 2.12000e-01 7.74602e+03 7.74602e+03 7.74602e+02 1.00000e-09 2.12000e-01 $1.00000 \mathrm{e}-02$ 1.00000e-02 1.00000e-03 1.00000e-09 1.00000e-01 $1.00000 \mathrm{e}+001.00000 \mathrm{e}+001.00000 \mathrm{e}-011.00000 \mathrm{e}-091.00000 \mathrm{e}-01$ $1.00000 \mathrm{e}-05$ 1.00000e-05 1.00000e-06 1.00000e-09 1.00000e-01 $1.00000 \mathrm{e}+001.00000 \mathrm{e}+001.00000 \mathrm{e}-011.00000 \mathrm{e}-091.00000 \mathrm{e}-01$ 
1.00000e-06 1.00000e-06 1.00000e-06 1.00000e-09 5.00000e-02

Element: 3953 \# of layers: 10

$\mathrm{Kx} \mathrm{Ky} \mathrm{Kz}$ Ss Por

5.00000e-04 5.00000e-04 5.00000e-05 1.00000e-09 1.00000e-01

7.74602e+03 7.74602e+03 7.74602e+02 1.00000e-09 2.12000e-01

7.74602e+03 7.74602e+03 7.74602e+02 1.00000e-09 2.12000e-01

7.74602e+03 7.74602e+03 7.74602e+02 1.00000e-09 2.12000e-01

$7.74602 \mathrm{e}+03$ 7.74602e+03 7.74602e+02 1.00000e-09 2.12000e-01

$1.00000 \mathrm{e}-02$ 1.00000e-02 1.00000e-03 1.00000e-09 1.00000e-01

$1.00000 \mathrm{e}+001.00000 \mathrm{e}+001.00000 \mathrm{e}-011.00000 \mathrm{e}-091.00000 \mathrm{e}-01$

$1.00000 \mathrm{e}-05$ 1.00000e-05 1.00000e-06 1.00000e-09 1.00000e-01

$1.00000 \mathrm{e}+001.00000 \mathrm{e}+001.00000 \mathrm{e}-011.00000 \mathrm{e}-091.00000 \mathrm{e}-01$

1.00000e-06 1.00000e-06 1.00000e-06 1.00000e-09 5.00000e-02

Element: 3954 \# of layers: 11

$\mathrm{Kx} \mathrm{Ky} \mathrm{Kz}$ Ss Por

4.46689e+04 4.46689e+04 4.46689e+03 1.00000e-09 7.00000e-02

5.00000e-04 5.00000e-04 5.00000e-05 1.00000e-09 1.00000e-01

$1.78481 \mathrm{e}+03$ 1.78481e+03 1.78481e+02 1.00000e-09 2.12000e-01

$1.78481 \mathrm{e}+031.78481 \mathrm{e}+03$ 1.78481e+02 1.00000e-09 2.12000e-01

$1.78481 \mathrm{e}+031.78481 \mathrm{e}+03$ 1.78481e+02 1.00000e-09 2.12000e-01

$1.78481 \mathrm{e}+031.78481 \mathrm{e}+031.78481 \mathrm{e}+02$ 1.00000e-09 2.12000e-01

$1.00000 \mathrm{e}-02$ 1.00000e-02 1.00000e-03 1.00000e-09 1.00000e-01

$1.00000 \mathrm{e}+001.00000 \mathrm{e}+001.00000 \mathrm{e}-011.00000 \mathrm{e}-091.00000 \mathrm{e}-01$

$1.00000 \mathrm{e}-05$ 1.00000e-05 1.00000e-06 1.00000e-09 1.00000e-01

$1.00000 \mathrm{e}+001.00000 \mathrm{e}+001.00000 \mathrm{e}-011.00000 \mathrm{e}-091.00000 \mathrm{e}-01$

1.00000e-06 1.00000e-06 1.00000e-06 1.00000e-09 5.00000e-02

Element: 3955 \# of layers: 8

$\mathrm{Kx} \mathrm{Ky} \mathrm{Kz}$ Ss Por

5.00000e-04 5.00000e-04 5.00000e-05 1.00000e-09 1.00000e-01

$4.49020 \mathrm{e}+03$ 4.49020e+03 4.49020e+02 1.00000e-09 2.12000e-01

$4.49020 \mathrm{e}+03$ 4.49020e+03 4.49020e+02 1.00000e-09 2.12000e-01

$4.49020 \mathrm{e}+03$ 4.49020e+03 4.49020e+02 1.00000e-09 2.12000e-01

1.00000e-02 1.00000e-02 1.00000e-03 1.00000e-09 1.00000e-01

$1.00000 \mathrm{e}+001.00000 \mathrm{e}+001.00000 \mathrm{e}-011.00000 \mathrm{e}-091.00000 \mathrm{e}-01$

$1.00000 \mathrm{e}-05$ 1.00000e-05 1.00000e-06 1.00000e-09 1.00000e-01

$1.00000 \mathrm{e}+001.00000 \mathrm{e}+00$ 1.00000e-01 1.00000e-09 1.00000e-01

Element: 3956 \# of layers: 7

Kx Ky Kz Ss Por

4.82230e+03 4.82230e+03 4.82230e+02 1.00000e-09 2.12000e-01

$4.82230 \mathrm{e}+03$ 4.82230e+03 4.82230e+02 1.00000e-09 2.12000e-01

$4.82230 \mathrm{e}+034.82230 \mathrm{e}+034.82230 \mathrm{e}+02$ 1.00000e-09 2.12000e-01

$1.00000 \mathrm{e}-02$ 1.00000e-02 1.00000e-03 1.00000e-09 1.00000e-01

$1.00000 \mathrm{e}+001.00000 \mathrm{e}+001.00000 \mathrm{e}-011.00000 \mathrm{e}-091.00000 \mathrm{e}-01$

$1.00000 \mathrm{e}-05$ 1.00000e-05 1.00000e-06 1.00000e-09 1.00000e-01

$1.00000 \mathrm{e}+001.00000 \mathrm{e}+001.00000 \mathrm{e}-01$ 1.00000e-09 1.00000e-01

Element: 3957 \# of layers: 9 
$\mathrm{Kx} \mathrm{Ky} \mathrm{Kz}$ Ss Por

5.00000e-04 5.00000e-04 5.00000e-05 1.00000e-09 1.00000e-01

$5.25994 \mathrm{e}+03$ 5.25994e+03 5.25994e+02 1.00000e-09 2.12000e-01

$5.25994 \mathrm{e}+03$ 5.25994e+03 5.25994e+02 1.00000e-09 2.12000e-01

$5.25994 \mathrm{e}+03$ 5.25994e+03 5.25994e+02 1.00000e-09 2.12000e-01

$5.25994 \mathrm{e}+035.25994 \mathrm{e}+035.25994 \mathrm{e}+02$ 1.00000e-09 2.12000e-01

$1.00000 \mathrm{e}-02$ 1.00000e-02 1.00000e-03 1.00000e-09 1.00000e-01

$1.00000 \mathrm{e}+001.00000 \mathrm{e}+001.00000 \mathrm{e}-011.00000 \mathrm{e}-091.00000 \mathrm{e}-01$

$1.00000 \mathrm{e}-051.00000 \mathrm{e}-051.00000 \mathrm{e}-061.00000 \mathrm{e}-091.00000 \mathrm{e}-01$

$1.00000 \mathrm{e}+001.00000 \mathrm{e}+001.00000 \mathrm{e}-011.00000 \mathrm{e}-091.00000 \mathrm{e}-01$

Element: 3958 \# of layers: 10

$\mathrm{Kx} \mathrm{Ky} \mathrm{Kz}$ Ss Por

2.20394e+04 2.20394e+04 2.20394e+03 1.00000e-09 7.00000e-02

5.00000e-04 5.00000e-04 5.00000e-05 1.00000e-09 1.00000e-01

$8.80601 \mathrm{e}+028.80601 \mathrm{e}+028.80601 \mathrm{e}+01$ 1.00000e-09 2.12000e-01

$8.80601 \mathrm{e}+028.80601 \mathrm{e}+028.80601 \mathrm{e}+01$ 1.00000e-09 2.12000e-01

$8.80601 \mathrm{e}+028.80601 \mathrm{e}+028.80601 \mathrm{e}+01$ 1.00000e-09 2.12000e-01

$8.80601 \mathrm{e}+028.80601 \mathrm{e}+028.80601 \mathrm{e}+01$ 1.00000e-09 2.12000e-01

$1.00000 \mathrm{e}-02$ 1.00000e-02 1.00000e-03 1.00000e-09 1.00000e-01

$1.00000 \mathrm{e}+001.00000 \mathrm{e}+001.00000 \mathrm{e}-011.00000 \mathrm{e}-091.00000 \mathrm{e}-01$

$1.00000 \mathrm{e}-05$ 1.00000e-05 1.00000e-06 1.00000e-09 1.00000e-01

$1.00000 \mathrm{e}+001.00000 \mathrm{e}+001.00000 \mathrm{e}-011.00000 \mathrm{e}-09$ 1.00000e-01

Element: 3959 \# of layers: 11

$\mathrm{Kx} \mathrm{Ky} \mathrm{Kz}$ Ss Por

$2.20394 \mathrm{e}+042.20394 \mathrm{e}+042.20394 \mathrm{e}+03$ 1.00000e-09 7.00000e-02

$2.20394 \mathrm{e}+042.20394 \mathrm{e}+042.20394 \mathrm{e}+03$ 1.00000e-09 7.00000e-02

5.00000e-04 5.00000e-04 5.00000e-05 1.00000e-09 1.00000e-01

$8.80601 \mathrm{e}+02$ 8.80601e+02 8.80601e+01 1.00000e-09 2.12000e-01

$8.80601 \mathrm{e}+028.80601 \mathrm{e}+028.80601 \mathrm{e}+01$ 1.00000e-09 2.12000e-01

$8.80601 \mathrm{e}+02$ 8.80601e+02 8.80601e+01 1.00000e-09 2.12000e-01

$8.80601 \mathrm{e}+028.80601 \mathrm{e}+028.80601 \mathrm{e}+01$ 1.00000e-09 2.12000e-01

$1.00000 \mathrm{e}-02$ 1.00000e-02 1.00000e-03 1.00000e-09 1.00000e-01

$1.00000 \mathrm{e}+001.00000 \mathrm{e}+001.00000 \mathrm{e}-011.00000 \mathrm{e}-091.00000 \mathrm{e}-01$

$1.00000 \mathrm{e}-05$ 1.00000e-05 1.00000e-06 1.00000e-09 1.00000e-01

$1.00000 \mathrm{e}+001.00000 \mathrm{e}+001.00000 \mathrm{e}-01$ 1.00000e-09 1.00000e-01

Element: 3960 \# of layers: 9

$\mathrm{Kx} \mathrm{Ky} \mathrm{Kz}$ Ss Por

$2.20394 \mathrm{e}+042.20394 \mathrm{e}+042.20394 \mathrm{e}+03$ 1.00000e-09 7.00000e-02

$2.20394 \mathrm{e}+042.20394 \mathrm{e}+042.20394 \mathrm{e}+03$ 1.00000e-09 7.00000e-02

5.00000e-04 5.00000e-04 5.00000e-05 1.00000e-09 1.00000e-01

$8.80601 \mathrm{e}+02$ 8.80601e+02 8.80601e+01 1.00000e-09 2.12000e-01

$8.80601 \mathrm{e}+028.80601 \mathrm{e}+028.80601 \mathrm{e}+01$ 1.00000e-09 2.12000e-01

$1.00000 \mathrm{e}-021.00000 \mathrm{e}-021.00000 \mathrm{e}-031.00000 \mathrm{e}-091.00000 \mathrm{e}-01$

$1.00000 \mathrm{e}+001.00000 \mathrm{e}+001.00000 \mathrm{e}-011.00000 \mathrm{e}-091.00000 \mathrm{e}-01$

$1.00000 \mathrm{e}-05$ 1.00000e-05 1.00000e-06 1.00000e-09 1.00000e-01

$1.00000 \mathrm{e}+001.00000 \mathrm{e}+001.00000 \mathrm{e}-01$ 1.00000e-09 1.00000e-01 
Element: 3961 \# of layers: 10

$\mathrm{Kx} \mathrm{Ky} \mathrm{Kz}$ Ss Por

3.78150e+04 3.78150e+04 3.78150e+03 1.00000e-09 7.00000e-02

5.00000e-04 5.00000e-04 5.00000e-05 1.00000e-09 1.00000e-01

$1.51095 \mathrm{e}+03$ 1.51095e+03 1.51095e+02 1.00000e-09 2.12000e-01

$1.51095 \mathrm{e}+031.51095 \mathrm{e}+03$ 1.51095e+02 1.00000e-09 2.12000e-01

$1.51095 \mathrm{e}+03$ 1.51095e+03 1.51095e+02 1.00000e-09 2.12000e-01

$1.00000 \mathrm{e}-02$ 1.00000e-02 1.00000e-03 1.00000e-09 1.00000e-01

$1.00000 \mathrm{e}+001.00000 \mathrm{e}+001.00000 \mathrm{e}-011.00000 \mathrm{e}-091.00000 \mathrm{e}-01$

$1.00000 \mathrm{e}-05$ 1.00000e-05 1.00000e-06 1.00000e-09 1.00000e-01

$1.00000 \mathrm{e}+001.00000 \mathrm{e}+001.00000 \mathrm{e}-011.00000 \mathrm{e}-091.00000 \mathrm{e}-01$

1.00000e-06 1.00000e-06 1.00000e-06 1.00000e-09 5.00000e-02

Element: 3962 \# of layers: 10

$\mathrm{Kx} \mathrm{Ky} \mathrm{Kz}$ Ss Por

3.78150e+04 3.78150e+04 3.78150e+03 1.00000e-09 7.00000e-02

5.00000e-04 5.00000e-04 5.00000e-05 1.00000e-09 1.00000e-01

$1.51095 \mathrm{e}+03$ 1.51095e+03 1.51095e+02 1.00000e-09 2.12000e-01

$1.51095 \mathrm{e}+031.51095 \mathrm{e}+03$ 1.51095e+02 1.00000e-09 2.12000e-01

$1.51095 \mathrm{e}+031.51095 \mathrm{e}+03$ 1.51095e+02 1.00000e-09 2.12000e-01

$1.00000 \mathrm{e}-02$ 1.00000e-02 1.00000e-03 1.00000e-09 1.00000e-01

$1.00000 \mathrm{e}+001.00000 \mathrm{e}+001.00000 \mathrm{e}-011.00000 \mathrm{e}-091.00000 \mathrm{e}-01$

$1.00000 \mathrm{e}-05$ 1.00000e-05 1.00000e-06 1.00000e-09 1.00000e-01

$1.00000 \mathrm{e}+001.00000 \mathrm{e}+001.00000 \mathrm{e}-011.00000 \mathrm{e}-091.00000 \mathrm{e}-01$

1.00000e-06 1.00000e-06 1.00000e-06 1.00000e-09 5.00000e-02

Element: 3963 \# of layers: 10

$\mathrm{Kx} \mathrm{Ky} \mathrm{Kz}$ Ss Por

$2.23088 \mathrm{e}+042.23088 \mathrm{e}+042.23088 \mathrm{e}+03$ 1.00000e-09 7.00000e-02

5.00000e-04 5.00000e-04 5.00000e-05 1.00000e-09 1.00000e-01

$9.08029 \mathrm{e}+03$ 9.08029e+03 9.08029e+02 1.00000e-09 2.12000e-01

$9.08029 \mathrm{e}+03$ 9.08029e+03 9.08029e+02 1.00000e-09 2.12000e-01

$9.08029 \mathrm{e}+03$ 9.08029e+03 9.08029e+02 1.00000e-09 2.12000e-01

$1.00000 \mathrm{e}-02$ 1.00000e-02 1.00000e-03 1.00000e-09 1.00000e-01

$1.00000 \mathrm{e}+001.00000 \mathrm{e}+001.00000 \mathrm{e}-011.00000 \mathrm{e}-091.00000 \mathrm{e}-01$

$1.00000 \mathrm{e}-05$ 1.00000e-05 1.00000e-06 1.00000e-09 1.00000e-01

$1.00000 \mathrm{e}+001.00000 \mathrm{e}+001.00000 \mathrm{e}-011.00000 \mathrm{e}-091.00000 \mathrm{e}-01$

1.00000e-06 1.00000e-06 1.00000e-06 1.00000e-09 5.00000e-02

Element: 3964 \# of layers: 8

$\mathrm{Kx} \mathrm{Ky} \mathrm{Kz}$ Ss Por

5.00000e-04 5.00000e-04 5.00000e-05 1.00000e-09 1.00000e-01

$5.25994 \mathrm{e}+035.25994 \mathrm{e}+03$ 5.25994e+02 1.00000e-09 2.12000e-01

$5.25994 \mathrm{e}+035.25994 \mathrm{e}+03$ 5.25994e+02 1.00000e-09 2.12000e-01

$5.25994 \mathrm{e}+03$ 5.25994e+03 5.25994e+02 1.00000e-09 2.12000e-01

$1.00000 \mathrm{e}-02$ 1.00000e-02 1.00000e-03 1.00000e-09 1.00000e-01

$1.00000 \mathrm{e}+001.00000 \mathrm{e}+001.00000 \mathrm{e}-011.00000 \mathrm{e}-091.00000 \mathrm{e}-01$

$1.00000 \mathrm{e}-05$ 1.00000e-05 1.00000e-06 1.00000e-09 1.00000e-01

$1.00000 \mathrm{e}+001.00000 \mathrm{e}+001.00000 \mathrm{e}-011.00000 \mathrm{e}-091.00000 \mathrm{e}-01$ 
Element: 3965 \# of layers: 7

$\mathrm{Kx} \mathrm{Ky} \mathrm{Kz}$ Ss Por

5.00000e-04 5.00000e-04 5.00000e-05 1.00000e-09 1.00000e-01

$8.80601 \mathrm{e}+028.80601 \mathrm{e}+028.80601 \mathrm{e}+01$ 1.00000e-09 2.12000e-01

$8.80601 \mathrm{e}+028.80601 \mathrm{e}+028.80601 \mathrm{e}+01$ 1.00000e-09 2.12000e-01

$1.00000 \mathrm{e}-02$ 1.00000e-02 1.00000e-03 1.00000e-09 1.00000e-01

$1.00000 \mathrm{e}+001.00000 \mathrm{e}+001.00000 \mathrm{e}-011.00000 \mathrm{e}-091.00000 \mathrm{e}-01$

$1.00000 \mathrm{e}-05$ 1.00000e-05 1.00000e-06 1.00000e-09 1.00000e-01

$1.00000 \mathrm{e}+001.00000 \mathrm{e}+001.00000 \mathrm{e}-011.00000 \mathrm{e}-091.00000 \mathrm{e}-01$

Element: 3966 \# of layers: 9

$\mathrm{Kx} \mathrm{Ky} \mathrm{Kz}$ Ss Por

8.59996e+03 8.59996e+03 8.59996e+02 1.00000e-09 7.00000e-02

5.00000e-04 5.00000e-04 5.00000e-05 1.00000e-09 1.00000e-01

$3.43627 \mathrm{e}+02$ 3.43627e+02 3.43627e+01 1.00000e-09 2.12000e-01

$3.43627 \mathrm{e}+02$ 3.43627e+02 3.43627e+01 1.00000e-09 2.12000e-01

$3.43627 \mathrm{e}+023.43627 \mathrm{e}+02$ 3.43627e+01 1.00000e-09 2.12000e-01

$1.00000 \mathrm{e}-02$ 1.00000e-02 1.00000e-03 1.00000e-09 1.00000e-01

$1.00000 \mathrm{e}+001.00000 \mathrm{e}+001.00000 \mathrm{e}-011.00000 \mathrm{e}-091.00000 \mathrm{e}-01$

$1.00000 \mathrm{e}-05$ 1.00000e-05 1.00000e-06 1.00000e-09 1.00000e-01

$1.00000 \mathrm{e}+001.00000 \mathrm{e}+001.00000 \mathrm{e}-01$ 1.00000e-09 1.00000e-01

Element: 3967 \# of layers: 10

$\mathrm{Kx} \mathrm{Ky} \mathrm{Kz}$ Ss Por

$1.56224 \mathrm{e}+031.56224 \mathrm{e}+031.56224 \mathrm{e}+02$ 1.00000e-09 7.00000e-02 5.00000e-04 5.00000e-04 5.00000e-05 1.00000e-09 1.00000e-01

5.00000e-04 5.00000e-04 5.00000e-05 1.00000e-09 1.00000e-01

$6.24208 \mathrm{e}+016.24208 \mathrm{e}+016.24208 \mathrm{e}+00$ 1.00000e-09 2.12000e-01

$6.24208 \mathrm{e}+016.24208 \mathrm{e}+01$ 6.24208e+00 1.00000e-09 2.12000e-01

$6.24208 \mathrm{e}+016.24208 \mathrm{e}+016.24208 \mathrm{e}+00$ 1.00000e-09 2.12000e-01

$1.00000 \mathrm{e}-02$ 1.00000e-02 1.00000e-03 1.00000e-09 1.00000e-01

$1.00000 \mathrm{e}+001.00000 \mathrm{e}+001.00000 \mathrm{e}-011.00000 \mathrm{e}-091.00000 \mathrm{e}-01$

$1.00000 \mathrm{e}-05$ 1.00000e-05 1.00000e-06 1.00000e-09 1.00000e-01

$1.00000 \mathrm{e}+001.00000 \mathrm{e}+001.00000 \mathrm{e}-01$ 1.00000e-09 1.00000e-01

Element: 3968 \# of layers: 10

$\mathrm{Kx} \mathrm{Ky} \mathrm{Kz}$ Ss Por

$1.56224 \mathrm{e}+031.56224 \mathrm{e}+031.56224 \mathrm{e}+02$ 1.00000e-09 7.00000e-02

5.00000e-04 5.00000e-04 5.00000e-05 1.00000e-09 1.00000e-01

5.00000e-04 5.00000e-04 5.00000e-05 1.00000e-09 1.00000e-01

$6.24208 \mathrm{e}+016.24208 \mathrm{e}+016.24208 \mathrm{e}+00$ 1.00000e-09 2.12000e-01

$6.24208 \mathrm{e}+016.24208 \mathrm{e}+01$ 6.24208e+00 1.00000e-09 2.12000e-01

$6.24208 \mathrm{e}+016.24208 \mathrm{e}+01$ 6.24208e+00 1.00000e-09 2.12000e-01

$1.00000 \mathrm{e}-02$ 1.00000e-02 1.00000e-03 1.00000e-09 1.00000e-01

$1.00000 \mathrm{e}+001.00000 \mathrm{e}+001.00000 \mathrm{e}-011.00000 \mathrm{e}-091.00000 \mathrm{e}-01$

$1.00000 \mathrm{e}-05$ 1.00000e-05 1.00000e-06 1.00000e-09 1.00000e-01

$1.00000 \mathrm{e}+001.00000 \mathrm{e}+001.00000 \mathrm{e}-01$ 1.00000e-09 1.00000e-01

Element: 3969 \# of layers: 8

Kx Ky Kz Ss Por 
$1.56224 \mathrm{e}+031.56224 \mathrm{e}+03$ 1.56224e+02 1.00000e-09 7.00000e-02 5.00000e-04 5.00000e-04 5.00000e-05 1.00000e-09 1.00000e-01 5.00000e-04 5.00000e-04 5.00000e-05 1.00000e-09 1.00000e-01 $6.24208 \mathrm{e}+016.24208 \mathrm{e}+016.24208 \mathrm{e}+00$ 1.00000e-09 2.12000e-01 $1.00000 \mathrm{e}-02$ 1.00000e-02 1.00000e-03 1.00000e-09 1.00000e-01 $1.00000 \mathrm{e}+001.00000 \mathrm{e}+001.00000 \mathrm{e}-011.00000 \mathrm{e}-091.00000 \mathrm{e}-01$ $1.00000 \mathrm{e}-05$ 1.00000e-05 1.00000e-06 1.00000e-09 1.00000e-01 $1.00000 \mathrm{e}+001.00000 \mathrm{e}+001.00000 \mathrm{e}-011.00000 \mathrm{e}-091.00000 \mathrm{e}-01$ Element: 3970 \# of layers: 10

$\mathrm{Kx} \mathrm{Ky} \mathrm{Kz}$ Ss Por

$2.32755 \mathrm{e}+03$ 2.32755e+03 2.32755e+02 1.00000e-09 7.00000e-02 $2.32755 \mathrm{e}+032.32755 \mathrm{e}+032.32755 \mathrm{e}+02$ 1.00000e-09 7.00000e-02 5.00000e-04 5.00000e-04 5.00000e-05 1.00000e-09 1.00000e-01

$9.30035 \mathrm{e}+019.30035 \mathrm{e}+01$ 9.30035e+00 1.00000e-09 2.12000e-01 $9.30035 \mathrm{e}+019.30035 \mathrm{e}+01$ 9.30035e+00 1.00000e-09 2.12000e-01 $1.00000 \mathrm{e}-02$ 1.00000e-02 1.00000e-03 1.00000e-09 1.00000e-01 $1.00000 \mathrm{e}+001.00000 \mathrm{e}+001.00000 \mathrm{e}-011.00000 \mathrm{e}-091.00000 \mathrm{e}-01$ $1.00000 \mathrm{e}-05$ 1.00000e-05 1.00000e-06 1.00000e-09 1.00000e-01 $1.00000 \mathrm{e}+001.00000 \mathrm{e}+001.00000 \mathrm{e}-011.00000 \mathrm{e}-091.00000 \mathrm{e}-01$ 1.00000e-06 1.00000e-06 1.00000e-06 1.00000e-09 5.00000e-02 Element: 3971 \# of layers: 10

$\mathrm{Kx} \mathrm{Ky} \mathrm{Kz}$ Ss Por

$2.32755 \mathrm{e}+03$ 2.32755e+03 2.32755e+02 1.00000e-09 7.00000e-02 $2.32755 \mathrm{e}+032.32755 \mathrm{e}+032.32755 \mathrm{e}+02$ 1.00000e-09 7.00000e-02 5.00000e-04 5.00000e-04 5.00000e-05 1.00000e-09 1.00000e-01 $9.30035 \mathrm{e}+019.30035 \mathrm{e}+01$ 9.30035e+00 1.00000e-09 2.12000e-01 $9.30035 \mathrm{e}+019.30035 \mathrm{e}+01$ 9.30035e+00 1.00000e-09 2.12000e-01 $1.00000 \mathrm{e}-02$ 1.00000e-02 1.00000e-03 1.00000e-09 1.00000e-01 $1.00000 \mathrm{e}+001.00000 \mathrm{e}+001.00000 \mathrm{e}-011.00000 \mathrm{e}-091.00000 \mathrm{e}-01$ $1.00000 \mathrm{e}-05$ 1.00000e-05 1.00000e-06 1.00000e-09 1.00000e-01 $1.00000 \mathrm{e}+001.00000 \mathrm{e}+001.00000 \mathrm{e}-01$ 1.00000e-09 1.00000e-01 1.00000e-06 1.00000e-06 1.00000e-06 1.00000e-09 5.00000e-02 Element: 3972 \# of layers: 10

$\mathrm{Kx} \mathrm{Ky} \mathrm{Kz}$ Ss Por

7.53209e+03 7.53209e+03 7.53209e+02 1.00000e-09 7.00000e-02 $7.53209 \mathrm{e}+03$ 7.53209e+03 7.53209e+02 1.00000e-09 7.00000e-02 5.00000e-04 5.00000e-04 5.00000e-05 1.00000e-09 1.00000e-01 $3.00966 \mathrm{e}+023.00966 \mathrm{e}+023.00966 \mathrm{e}+01$ 1.00000e-09 2.12000e-01 $3.00966 \mathrm{e}+023.00966 \mathrm{e}+023.00966 \mathrm{e}+01$ 1.00000e-09 2.12000e-01 $1.00000 \mathrm{e}-02$ 1.00000e-02 1.00000e-03 1.00000e-09 1.00000e-01 $1.00000 \mathrm{e}+001.00000 \mathrm{e}+001.00000 \mathrm{e}-011.00000 \mathrm{e}-091.00000 \mathrm{e}-01$ $1.00000 \mathrm{e}-05$ 1.00000e-05 1.00000e-06 1.00000e-09 1.00000e-01 $1.00000 \mathrm{e}+001.00000 \mathrm{e}+001.00000 \mathrm{e}-011.00000 \mathrm{e}-091.00000 \mathrm{e}-01$ 1.00000e-06 1.00000e-06 1.00000e-06 1.00000e-09 5.00000e-02 Element: 3973 \# of layers: 9

Kx Ky Kz Ss Por 
8.59996e+03 8.59996e+03 8.59996e+02 1.00000e-09 7.00000e-02 $8.59996 \mathrm{e}+038.59996 \mathrm{e}+03$ 8.59996e+02 1.00000e-09 7.00000e-02 5.00000e-04 5.00000e-04 5.00000e-05 1.00000e-09 1.00000e-01

$3.43627 \mathrm{e}+02$ 3.43627e+02 3.43627e+01 1.00000e-09 2.12000e-01 $3.43627 \mathrm{e}+02$ 3.43627e+02 3.43627e+01 1.00000e-09 2.12000e-01 $1.00000 \mathrm{e}-02$ 1.00000e-02 1.00000e-03 1.00000e-09 1.00000e-01 $1.00000 \mathrm{e}+001.00000 \mathrm{e}+001.00000 \mathrm{e}-011.00000 \mathrm{e}-091.00000 \mathrm{e}-01$ $1.00000 \mathrm{e}-05$ 1.00000e-05 1.00000e-06 1.00000e-09 1.00000e-01 $1.00000 \mathrm{e}+001.00000 \mathrm{e}+001.00000 \mathrm{e}-011.00000 \mathrm{e}-091.00000 \mathrm{e}-01$ Element: 3974 \# of layers: 9

$\mathrm{Kx} \mathrm{Ky} \mathrm{Kz}$ Ss Por

$1.56224 \mathrm{e}+03$ 1.56224e+03 1.56224e+02 1.00000e-09 7.00000e-02 5.00000e-04 5.00000e-04 5.00000e-05 1.00000e-09 1.00000e-01 5.00000e-04 5.00000e-04 5.00000e-05 1.00000e-09 1.00000e-01 $6.24208 \mathrm{e}+016.24208 \mathrm{e}+016.24208 \mathrm{e}+00$ 1.00000e-09 2.12000e-01 $6.24208 \mathrm{e}+016.24208 \mathrm{e}+016.24208 \mathrm{e}+00$ 1.00000e-09 2.12000e-01 $1.00000 \mathrm{e}-021.00000 \mathrm{e}-02$ 1.00000e-03 1.00000e-09 1.00000e-01 $1.00000 \mathrm{e}+001.00000 \mathrm{e}+001.00000 \mathrm{e}-011.00000 \mathrm{e}-091.00000 \mathrm{e}-01$ $1.00000 \mathrm{e}-05$ 1.00000e-05 1.00000e-06 1.00000e-09 1.00000e-01 $1.00000 \mathrm{e}+001.00000 \mathrm{e}+001.00000 \mathrm{e}-01$ 1.00000e-09 1.00000e-01 Element: 3975 \# of layers: 10

$\mathrm{Kx} \mathrm{Ky} \mathrm{Kz} \mathrm{Ss} \mathrm{Por}$

1.15058e+03 1.15058e+03 1.15058e+02 1.00000e-09 7.00000e-02 $1.15058 \mathrm{e}+031.15058 \mathrm{e}+03$ 1.15058e+02 1.00000e-09 7.00000e-02 5.00000e-04 5.00000e-04 5.00000e-05 1.00000e-09 1.00000e-01 5.00000e-04 5.00000e-04 5.00000e-05 1.00000e-09 1.00000e-01 $4.59730 \mathrm{e}+014.59730 \mathrm{e}+014.59730 \mathrm{e}+001.00000 \mathrm{e}-092.12000 \mathrm{e}-01$ $4.59730 \mathrm{e}+014.59730 \mathrm{e}+014.59730 \mathrm{e}+001.00000 \mathrm{e}-092.12000 \mathrm{e}-01$ $1.00000 \mathrm{e}-02$ 1.00000e-02 1.00000e-03 1.00000e-09 1.00000e-01 $1.00000 \mathrm{e}+001.00000 \mathrm{e}+001.00000 \mathrm{e}-011.00000 \mathrm{e}-091.00000 \mathrm{e}-01$ $1.00000 \mathrm{e}-05$ 1.00000e-05 1.00000e-06 1.00000e-09 1.00000e-01 $1.00000 \mathrm{e}+001.00000 \mathrm{e}+001.00000 \mathrm{e}-011.00000 \mathrm{e}-091.00000 \mathrm{e}-01$ Element: 3976 \# of layers: 11

$\mathrm{Kx} \mathrm{Ky} \mathrm{Kz}$ Ss Por

8.81998e+02 8.81998e+02 8.81998e+01 1.00000e-09 7.00000e-02 $8.81998 \mathrm{e}+02$ 8.81998e+02 8.81998e+01 1.00000e-09 7.00000e-02 $8.81998 \mathrm{e}+02$ 8.81998e+02 8.81998e+01 1.00000e-09 7.00000e-02 5.00000e-04 5.00000e-04 5.00000e-05 1.00000e-09 1.00000e-01 5.00000e-04 5.00000e-04 5.00000e-05 1.00000e-09 1.00000e-01 $3.52425 \mathrm{e}+013.52425 \mathrm{e}+013.52425 \mathrm{e}+001.00000 \mathrm{e}-092.12000 \mathrm{e}-01$ $3.52425 \mathrm{e}+013.52425 \mathrm{e}+013.52425 \mathrm{e}+001.00000 \mathrm{e}-092.12000 \mathrm{e}-01$ $1.00000 \mathrm{e}-02$ 1.00000e-02 1.00000e-03 1.00000e-09 1.00000e-01 $1.00000 \mathrm{e}+001.00000 \mathrm{e}+001.00000 \mathrm{e}-011.00000 \mathrm{e}-091.00000 \mathrm{e}-01$ $1.00000 \mathrm{e}-05$ 1.00000e-05 1.00000e-06 1.00000e-09 1.00000e-01 $1.00000 \mathrm{e}+001.00000 \mathrm{e}+001.00000 \mathrm{e}-01$ 1.00000e-09 1.00000e-01 Element: 3977 \# of layers: 11 
$\mathrm{Kx} \mathrm{Ky} \mathrm{Kz}$ Ss Por

8.81998e+02 8.81998e+02 8.81998e+01 1.00000e-09 7.00000e-02

8.81998e+02 8.81998e+02 8.81998e+01 1.00000e-09 7.00000e-02

$8.81998 \mathrm{e}+02$ 8.81998e+02 8.81998e+01 1.00000e-09 7.00000e-02

5.00000e-04 5.00000e-04 5.00000e-05 1.00000e-09 1.00000e-01

5.00000e-04 5.00000e-04 5.00000e-05 1.00000e-09 1.00000e-01

$3.52425 \mathrm{e}+013.52425 \mathrm{e}+013.52425 \mathrm{e}+001.00000 \mathrm{e}-092.12000 \mathrm{e}-01$

$3.52425 \mathrm{e}+013.52425 \mathrm{e}+013.52425 \mathrm{e}+001.00000 \mathrm{e}-092.12000 \mathrm{e}-01$

$1.00000 \mathrm{e}-02$ 1.00000e-02 1.00000e-03 1.00000e-09 1.00000e-01

$1.00000 \mathrm{e}+001.00000 \mathrm{e}+001.00000 \mathrm{e}-011.00000 \mathrm{e}-091.00000 \mathrm{e}-01$

$1.00000 \mathrm{e}-05$ 1.00000e-05 1.00000e-06 1.00000e-09 1.00000e-01

$1.00000 \mathrm{e}+001.00000 \mathrm{e}+001.00000 \mathrm{e}-01$ 1.00000e-09 1.00000e-01

Element: 3978 \# of layers: 11

$\mathrm{Kx} \mathrm{Ky} \mathrm{Kz}$ Ss Por

8.81998e+02 8.81998e+02 8.81998e+01 1.00000e-09 7.00000e-02

$8.81998 \mathrm{e}+02$ 8.81998e+02 8.81998e+01 1.00000e-09 7.00000e-02

8.81998e+02 8.81998e+02 8.81998e+01 1.00000e-09 7.00000e-02

5.00000e-04 5.00000e-04 5.00000e-05 1.00000e-09 1.00000e-01

5.00000e-04 5.00000e-04 5.00000e-05 1.00000e-09 1.00000e-01

$3.52425 \mathrm{e}+013.52425 \mathrm{e}+013.52425 \mathrm{e}+001.00000 \mathrm{e}-092.12000 \mathrm{e}-01$

$3.52425 \mathrm{e}+013.52425 \mathrm{e}+013.52425 \mathrm{e}+00$ 1.00000e-09 2.12000e-01

$1.00000 \mathrm{e}-02$ 1.00000e-02 1.00000e-03 1.00000e-09 1.00000e-01

$1.00000 \mathrm{e}+001.00000 \mathrm{e}+001.00000 \mathrm{e}-011.00000 \mathrm{e}-091.00000 \mathrm{e}-01$

$1.00000 \mathrm{e}-051.00000 \mathrm{e}-05$ 1.00000e-06 1.00000e-09 1.00000e-01

$1.00000 \mathrm{e}+001.00000 \mathrm{e}+001.00000 \mathrm{e}-011.00000 \mathrm{e}-091.00000 \mathrm{e}-01$

Element: 3979 \# of layers: 10

$\mathrm{Kx} \mathrm{Ky} \mathrm{Kz}$ Ss Por

$1.01435 \mathrm{e}+03$ 1.01435e+03 1.01435e+02 1.00000e-09 7.00000e-02

5.00000e-04 5.00000e-04 5.00000e-05 1.00000e-09 1.00000e-01

5.00000e-04 5.00000e-04 5.00000e-05 1.00000e-09 1.00000e-01

$4.05301 \mathrm{e}+014.05301 \mathrm{e}+014.05301 \mathrm{e}+001.00000 \mathrm{e}-092.12000 \mathrm{e}-01$

$4.05301 \mathrm{e}+014.05301 \mathrm{e}+014.05301 \mathrm{e}+001.00000 \mathrm{e}-092.12000 \mathrm{e}-01$

$1.00000 \mathrm{e}-02$ 1.00000e-02 1.00000e-03 1.00000e-09 1.00000e-01

$1.00000 \mathrm{e}+001.00000 \mathrm{e}+001.00000 \mathrm{e}-011.00000 \mathrm{e}-091.00000 \mathrm{e}-01$

$1.00000 \mathrm{e}-05$ 1.00000e-05 1.00000e-06 1.00000e-09 1.00000e-01

$1.00000 \mathrm{e}+001.00000 \mathrm{e}+001.00000 \mathrm{e}-011.00000 \mathrm{e}-091.00000 \mathrm{e}-01$

1.00000e-06 1.00000e-06 1.00000e-06 1.00000e-09 5.00000e-02

Element: 3980 \# of layers: 10

$\mathrm{Kx} \mathrm{Ky} \mathrm{Kz}$ Ss Por

$1.01435 \mathrm{e}+03$ 1.01435e+03 1.01435e+02 1.00000e-09 7.00000e-02 5.00000e-04 5.00000e-04 5.00000e-05 1.00000e-09 1.00000e-01 5.00000e-04 5.00000e-04 5.00000e-05 1.00000e-09 1.00000e-01 $4.05301 \mathrm{e}+014.05301 \mathrm{e}+014.05301 \mathrm{e}+001.00000 \mathrm{e}-09$ 2.12000e-01 4.05301e+01 4.05301e+01 4.05301e+00 1.00000e-09 2.12000e-01 $1.00000 \mathrm{e}-02$ 1.00000e-02 1.00000e-03 1.00000e-09 1.00000e-01 $1.00000 \mathrm{e}+001.00000 \mathrm{e}+001.00000 \mathrm{e}-011.00000 \mathrm{e}-091.00000 \mathrm{e}-01$ 
$1.00000 \mathrm{e}-05$ 1.00000e-05 1.00000e-06 1.00000e-09 1.00000e-01 $1.00000 \mathrm{e}+001.00000 \mathrm{e}+001.00000 \mathrm{e}-011.00000 \mathrm{e}-091.00000 \mathrm{e}-01$ 1.00000e-06 1.00000e-06 1.00000e-06 1.00000e-09 5.00000e-02 Element: 3981 \# of layers: 10

$\mathrm{Kx} \mathrm{Ky} \mathrm{Kz}$ Ss Por

$1.68712 \mathrm{e}+031.68712 \mathrm{e}+03$ 1.68712e+02 1.00000e-09 7.00000e-02 $5.00000 \mathrm{e}-04$ 5.00000e-04 5.00000e-05 1.00000e-09 1.00000e-01 5.00000e-04 5.00000e-04 5.00000e-05 1.00000e-09 1.00000e-01 $6.74092 \mathrm{e}+016.74092 \mathrm{e}+016.74092 \mathrm{e}+00$ 1.00000e-09 2.12000e-01 $6.74092 \mathrm{e}+016.74092 \mathrm{e}+016.74092 \mathrm{e}+00$ 1.00000e-09 2.12000e-01 $1.00000 \mathrm{e}-02$ 1.00000e-02 1.00000e-03 1.00000e-09 1.00000e-01 $1.00000 \mathrm{e}+001.00000 \mathrm{e}+001.00000 \mathrm{e}-011.00000 \mathrm{e}-091.00000 \mathrm{e}-01$ $1.00000 \mathrm{e}-051.00000 \mathrm{e}-05$ 1.00000e-06 1.00000e-09 1.00000e-01 $1.00000 \mathrm{e}+001.00000 \mathrm{e}+001.00000 \mathrm{e}-011.00000 \mathrm{e}-091.00000 \mathrm{e}-01$ 1.00000e-06 1.00000e-06 1.00000e-06 1.00000e-09 5.00000e-02 Element: 3982 \# of layers: 8

$\mathrm{Kx} \mathrm{Ky} \mathrm{Kz}$ Ss Por

$1.15058 \mathrm{e}+031.15058 \mathrm{e}+03$ 1.15058e+02 1.00000e-09 7.00000e-02 5.00000e-04 5.00000e-04 5.00000e-05 1.00000e-09 1.00000e-01 5.00000e-04 5.00000e-04 5.00000e-05 1.00000e-09 1.00000e-01 $4.59730 \mathrm{e}+014.59730 \mathrm{e}+014.59730 \mathrm{e}+001.00000 \mathrm{e}-092.12000 \mathrm{e}-01$ $1.00000 \mathrm{e}-02$ 1.00000e-02 1.00000e-03 1.00000e-09 1.00000e-01 $1.00000 \mathrm{e}+001.00000 \mathrm{e}+001.00000 \mathrm{e}-011.00000 \mathrm{e}-091.00000 \mathrm{e}-01$ $1.00000 \mathrm{e}-05$ 1.00000e-05 1.00000e-06 1.00000e-09 1.00000e-01 $1.00000 \mathrm{e}+001.00000 \mathrm{e}+001.00000 \mathrm{e}-011.00000 \mathrm{e}-091.00000 \mathrm{e}-01$ Element: 3983 \# of layers: 9

$\mathrm{Kx} \mathrm{Ky} \mathrm{Kz}$ Ss Por

8.81998e+02 8.81998e+02 8.81998e+01 1.00000e-09 7.00000e-02 $8.81998 \mathrm{e}+02$ 8.81998e+02 8.81998e+01 1.00000e-09 7.00000e-02 5.00000e-04 5.00000e-04 5.00000e-05 1.00000e-09 1.00000e-01 5.00000e-04 5.00000e-04 5.00000e-05 1.00000e-09 1.00000e-01 $3.52425 \mathrm{e}+013.52425 \mathrm{e}+013.52425 \mathrm{e}+00$ 1.00000e-09 2.12000e-01 $1.00000 \mathrm{e}-02$ 1.00000e-02 1.00000e-03 1.00000e-09 1.00000e-01 $1.00000 \mathrm{e}+001.00000 \mathrm{e}+001.00000 \mathrm{e}-011.00000 \mathrm{e}-091.00000 \mathrm{e}-01$ $1.00000 \mathrm{e}-05$ 1.00000e-05 1.00000e-06 1.00000e-09 1.00000e-01 $1.00000 \mathrm{e}+001.00000 \mathrm{e}+001.00000 \mathrm{e}-01$ 1.00000e-09 1.00000e-01 Element: 3984 \# of layers: 10

$\mathrm{Kx} \mathrm{Ky} \mathrm{Kz}$ Ss Por

2.71147e+02 2.71147e+02 2.71147e+01 1.00000e-09 7.00000e-02 $2.71147 \mathrm{e}+02$ 2.71147e+02 2.71147e+01 1.00000e-09 7.00000e-02 5.00000e-04 5.00000e-04 5.00000e-05 1.00000e-09 1.00000e-01 5.00000e-04 5.00000e-04 5.00000e-05 1.00000e-09 1.00000e-01 $1.08340 \mathrm{e}+011.08340 \mathrm{e}+011.08340 \mathrm{e}+001.00000 \mathrm{e}-092.12000 \mathrm{e}-01$ $1.08340 \mathrm{e}+01$ 1.08340e+01 1.08340e+00 1.00000e-09 2.12000e-01 $1.00000 \mathrm{e}-02$ 1.00000e-02 1.00000e-03 1.00000e-09 1.00000e-01 $1.00000 \mathrm{e}+001.00000 \mathrm{e}+001.00000 \mathrm{e}-011.00000 \mathrm{e}-091.00000 \mathrm{e}-01$ 
$1.00000 \mathrm{e}-05$ 1.00000e-05 1.00000e-06 1.00000e-09 1.00000e-01 $1.00000 \mathrm{e}+001.00000 \mathrm{e}+001.00000 \mathrm{e}-01$ 1.00000e-09 1.00000e-01 Element: 3985 \# of layers: 14

Kx Ky Kz Ss Por

1.27392e+01 1.27392e+01 1.27392e+00 1.00000e-09 7.00000e-02 $1.27392 \mathrm{e}+01$ 1.27392e+01 1.27392e+00 1.00000e-09 7.00000e-02 $1.27392 \mathrm{e}+01$ 1.27392e+01 1.27392e+00 1.00000e-09 7.00000e-02 5.00000e-04 5.00000e-04 5.00000e-05 1.00000e-09 1.00000e-01 5.00000e-04 5.00000e-04 5.00000e-05 1.00000e-09 1.00000e-01 5.09006e-01 5.09006e-01 5.09006e-02 1.00000e-09 2.12000e-01 5.09006e-01 5.09006e-01 5.09006e-02 1.00000e-09 2.12000e-01 5.09006e-01 5.09006e-01 5.09006e-02 1.00000e-09 2.12000e-01 5.09006e-01 5.09006e-01 5.09006e-02 1.00000e-09 2.12000e-01 5.09006e-01 5.09006e-01 5.09006e-02 1.00000e-09 2.12000e-01 $1.00000 \mathrm{e}-02$ 1.00000e-02 1.00000e-03 1.00000e-09 1.00000e-01 $1.00000 \mathrm{e}+001.00000 \mathrm{e}+001.00000 \mathrm{e}-011.00000 \mathrm{e}-091.00000 \mathrm{e}-01$ $1.00000 \mathrm{e}-05$ 1.00000e-05 1.00000e-06 1.00000e-09 1.00000e-01 $1.00000 \mathrm{e}+001.00000 \mathrm{e}+001.00000 \mathrm{e}-01$ 1.00000e-09 1.00000e-01 Element: 3986 \# of layers: 15

$\mathrm{Kx} \mathrm{Ky} \mathrm{Kz}$ Ss Por

$1.27392 \mathrm{e}+01$ 1.27392e+01 1.27392e+00 1.00000e-09 7.00000e-02 $1.27392 \mathrm{e}+011.27392 \mathrm{e}+01$ 1.27392e+00 1.00000e-09 7.00000e-02 1.27392e+01 1.27392e+01 1.27392e+00 1.00000e-09 7.00000e-02 $1.27392 \mathrm{e}+011.27392 \mathrm{e}+011.27392 \mathrm{e}+001.00000 \mathrm{e}-09$ 7.00000e-02 $5.00000 \mathrm{e}-04$ 5.00000e-04 5.00000e-05 1.00000e-09 1.00000e-01 $5.00000 \mathrm{e}-04$ 5.00000e-04 5.00000e-05 1.00000e-09 1.00000e-01 5.09006e-01 5.09006e-01 5.09006e-02 1.00000e-09 2.12000e-01 5.09006e-01 5.09006e-01 5.09006e-02 1.00000e-09 2.12000e-01 5.09006e-01 5.09006e-01 5.09006e-02 1.00000e-09 2.12000e-01 5.09006e-01 5.09006e-01 5.09006e-02 1.00000e-09 2.12000e-01 5.09006e-01 5.09006e-01 5.09006e-02 1.00000e-09 2.12000e-01 $1.00000 \mathrm{e}-02$ 1.00000e-02 1.00000e-03 1.00000e-09 1.00000e-01 $1.00000 \mathrm{e}+001.00000 \mathrm{e}+001.00000 \mathrm{e}-011.00000 \mathrm{e}-091.00000 \mathrm{e}-01$ $1.00000 \mathrm{e}-05$ 1.00000e-05 1.00000e-06 1.00000e-09 1.00000e-01 $1.00000 \mathrm{e}+001.00000 \mathrm{e}+001.00000 \mathrm{e}-01$ 1.00000e-09 1.00000e-01 Element: 3987 \# of layers: 14

Kx Ky Kz Ss Por

1.27392e+01 1.27392e+01 1.27392e+00 1.00000e-09 7.00000e-02 $1.27392 \mathrm{e}+01$ 1.27392e+01 1.27392e+00 1.00000e-09 7.00000e-02 $1.27392 \mathrm{e}+011.27392 \mathrm{e}+011.27392 \mathrm{e}+001.00000 \mathrm{e}-09$ 7.00000e-02 5.00000e-04 5.00000e-04 5.00000e-05 1.00000e-09 1.00000e-01 5.00000e-04 5.00000e-04 5.00000e-05 1.00000e-09 1.00000e-01 5.09006e-01 5.09006e-01 5.09006e-02 1.00000e-09 2.12000e-01 5.09006e-01 5.09006e-01 5.09006e-02 1.00000e-09 2.12000e-01 5.09006e-01 5.09006e-01 5.09006e-02 1.00000e-09 2.12000e-01 5.09006e-01 5.09006e-01 5.09006e-02 1.00000e-09 2.12000e-01 
5.09006e-01 5.09006e-01 5.09006e-02 1.00000e-09 2.12000e-01 $1.00000 \mathrm{e}-02$ 1.00000e-02 1.00000e-03 1.00000e-09 1.00000e-01 $1.00000 \mathrm{e}+001.00000 \mathrm{e}+001.00000 \mathrm{e}-011.00000 \mathrm{e}-091.00000 \mathrm{e}-01$ $1.00000 \mathrm{e}-05$ 1.00000e-05 1.00000e-06 1.00000e-09 1.00000e-01 $1.00000 \mathrm{e}+001.00000 \mathrm{e}+001.00000 \mathrm{e}-011.00000 \mathrm{e}-091.00000 \mathrm{e}-01$ Element: 3988 \# of layers: 14

Kx Ky Kz Ss Por

$1.61603 \mathrm{e}+011.61603 \mathrm{e}+01$ 1.61603e+00 1.00000e-09 7.00000e-02 $1.61603 \mathrm{e}+011.61603 \mathrm{e}+011.61603 \mathrm{e}+001.00000 \mathrm{e}-09$ 7.00000e-02 $1.61603 \mathrm{e}+011.61603 \mathrm{e}+011.61603 \mathrm{e}+001.00000 \mathrm{e}-09$ 7.00000e-02 5.00000e-04 5.00000e-04 5.00000e-05 1.00000e-09 1.00000e-01 5.00000e-04 5.00000e-04 5.00000e-05 1.00000e-09 1.00000e-01 6.45719e-01 6.45719e-01 6.45719e-02 1.00000e-09 2.12000e-01 6.45719e-01 6.45719e-01 6.45719e-02 1.00000e-09 2.12000e-01 6.45719e-01 6.45719e-01 6.45719e-02 1.00000e-09 2.12000e-01 6.45719e-01 6.45719e-01 6.45719e-02 1.00000e-09 2.12000e-01 6.45719e-01 6.45719e-01 6.45719e-02 1.00000e-09 2.12000e-01 $1.00000 \mathrm{e}-02$ 1.00000e-02 1.00000e-03 1.00000e-09 1.00000e-01 $1.00000 \mathrm{e}+001.00000 \mathrm{e}+001.00000 \mathrm{e}-011.00000 \mathrm{e}-091.00000 \mathrm{e}-01$ $1.00000 \mathrm{e}-05$ 1.00000e-05 1.00000e-06 1.00000e-09 1.00000e-01 $1.00000 \mathrm{e}+001.00000 \mathrm{e}+001.00000 \mathrm{e}-011.00000 \mathrm{e}-091.00000 \mathrm{e}-01$ Element: 3989 \# of layers: 10

Kx Ky Kz Ss Por

$1.61603 \mathrm{e}+011.61603 \mathrm{e}+011.61603 \mathrm{e}+00$ 1.00000e-09 7.00000e-02 $1.61603 \mathrm{e}+011.61603 \mathrm{e}+011.61603 \mathrm{e}+001.00000 \mathrm{e}-09$ 7.00000e-02 $5.00000 \mathrm{e}-04$ 5.00000e-04 5.00000e-05 1.00000e-09 1.00000e-01 $5.00000 \mathrm{e}-04$ 5.00000e-04 5.00000e-05 1.00000e-09 1.00000e-01 6.45719e-01 6.45719e-01 6.45719e-02 1.00000e-09 2.12000e-01 6.45719e-01 6.45719e-01 6.45719e-02 1.00000e-09 2.12000e-01 $1.00000 \mathrm{e}-021.00000 \mathrm{e}-02$ 1.00000e-03 1.00000e-09 1.00000e-01 $1.00000 \mathrm{e}+001.00000 \mathrm{e}+001.00000 \mathrm{e}-011.00000 \mathrm{e}-091.00000 \mathrm{e}-01$ $1.00000 \mathrm{e}-05$ 1.00000e-05 1.00000e-06 1.00000e-09 1.00000e-01 $1.00000 \mathrm{e}+001.00000 \mathrm{e}+001.00000 \mathrm{e}-011.00000 \mathrm{e}-091.00000 \mathrm{e}-01$ Element: 3990 \# of layers: 10

Kx Ky Kz Ss Por

$1.17977 \mathrm{e}+02$ 1.17977e+02 1.17977e+01 1.00000e-09 7.00000e-02 $1.17977 \mathrm{e}+021.17977 \mathrm{e}+021.17977 \mathrm{e}+01$ 1.00000e-09 7.00000e-02 5.00000e-04 5.00000e-04 5.00000e-05 1.00000e-09 1.00000e-01 $5.00000 \mathrm{e}-04$ 5.00000e-04 5.00000e-05 1.00000e-09 1.00000e-01 $4.71385 \mathrm{e}+004.71385 \mathrm{e}+004.71385 \mathrm{e}-011.00000 \mathrm{e}-09$ 2.12000e-01 $4.71385 \mathrm{e}+004.71385 \mathrm{e}+004.71385 \mathrm{e}-011.00000 \mathrm{e}-092.12000 \mathrm{e}-01$ $1.00000 \mathrm{e}-021.00000 \mathrm{e}-02$ 1.00000e-03 1.00000e-09 1.00000e-01 $1.00000 \mathrm{e}+001.00000 \mathrm{e}+001.00000 \mathrm{e}-011.00000 \mathrm{e}-091.00000 \mathrm{e}-01$ $1.00000 \mathrm{e}-05$ 1.00000e-05 1.00000e-06 1.00000e-09 1.00000e-01 $1.00000 \mathrm{e}+001.00000 \mathrm{e}+001.00000 \mathrm{e}-011.00000 \mathrm{e}-091.00000 \mathrm{e}-01$ Element: 3991 \# of layers: 10 
Kx Ky Kz Ss Por

2.71147e+02 2.71147e+02 2.71147e+01 1.00000e-09 7.00000e-02

$2.71147 \mathrm{e}+02$ 2.71147e+02 2.71147e+01 1.00000e-09 7.00000e-02

5.00000e-04 5.00000e-04 5.00000e-05 1.00000e-09 1.00000e-01

5.00000e-04 5.00000e-04 5.00000e-05 1.00000e-09 1.00000e-01

$1.08340 \mathrm{e}+011.08340 \mathrm{e}+011.08340 \mathrm{e}+001.00000 \mathrm{e}-092.12000 \mathrm{e}-01$

$1.08340 \mathrm{e}+011.08340 \mathrm{e}+011.08340 \mathrm{e}+001.00000 \mathrm{e}-092.12000 \mathrm{e}-01$

$1.00000 \mathrm{e}-02$ 1.00000e-02 1.00000e-03 1.00000e-09 1.00000e-01

$1.00000 \mathrm{e}+001.00000 \mathrm{e}+001.00000 \mathrm{e}-011.00000 \mathrm{e}-091.00000 \mathrm{e}-01$

$1.00000 \mathrm{e}-05$ 1.00000e-05 1.00000e-06 1.00000e-09 1.00000e-01

$1.00000 \mathrm{e}+001.00000 \mathrm{e}+001.00000 \mathrm{e}-011.00000 \mathrm{e}-091.00000 \mathrm{e}-01$

Element: 3992 \# of layers: 13

$\mathrm{Kx} \mathrm{Ky} \mathrm{Kz}$ Ss Por

$1.27392 \mathrm{e}+01$ 1.27392e+01 1.27392e+00 1.00000e-09 7.00000e-02

$1.27392 \mathrm{e}+011.27392 \mathrm{e}+011.27392 \mathrm{e}+001.00000 \mathrm{e}-09$ 7.00000e-02

5.00000e-04 5.00000e-04 5.00000e-05 1.00000e-09 1.00000e-01

5.00000e-04 5.00000e-04 5.00000e-05 1.00000e-09 1.00000e-01

5.09006e-01 5.09006e-01 5.09006e-02 1.00000e-09 2.12000e-01

5.09006e-01 5.09006e-01 5.09006e-02 1.00000e-09 2.12000e-01

5.09006e-01 5.09006e-01 5.09006e-02 1.00000e-09 2.12000e-01

5.09006e-01 5.09006e-01 5.09006e-02 1.00000e-09 2.12000e-01

5.09006e-01 5.09006e-01 5.09006e-02 1.00000e-09 2.12000e-01

$1.00000 \mathrm{e}-02$ 1.00000e-02 1.00000e-03 1.00000e-09 1.00000e-01

$1.00000 \mathrm{e}+001.00000 \mathrm{e}+001.00000 \mathrm{e}-011.00000 \mathrm{e}-091.00000 \mathrm{e}-01$

$1.00000 \mathrm{e}-05$ 1.00000e-05 1.00000e-06 1.00000e-09 1.00000e-01

$1.00000 \mathrm{e}+001.00000 \mathrm{e}+001.00000 \mathrm{e}-01$ 1.00000e-09 1.00000e-01

Element: 3993 \# of layers: 15

$\mathrm{Kx} \mathrm{Ky} \mathrm{Kz}$ Ss Por

$1.02597 \mathrm{e}+01$ 1.02597e+01 1.02597e+00 1.00000e-09 7.00000e-02

$1.02597 \mathrm{e}+01$ 1.02597e+01 1.02597e+00 1.00000e-09 7.00000e-02

$1.02597 \mathrm{e}+01$ 1.02597e+01 1.02597e+00 1.00000e-09 7.00000e-02

$1.02597 \mathrm{e}+011.02597 \mathrm{e}+01$ 1.02597e+00 1.00000e-09 7.00000e-02

5.00000e-04 5.00000e-04 5.00000e-05 1.00000e-09 1.00000e-01

5.00000e-04 5.00000e-04 5.00000e-05 1.00000e-09 1.00000e-01

4.09936e-01 4.09936e-01 4.09936e-02 1.00000e-09 2.12000e-01

4.09936e-01 4.09936e-01 4.09936e-02 1.00000e-09 2.12000e-01

4.09936e-01 4.09936e-01 4.09936e-02 1.00000e-09 2.12000e-01

4.09936e-01 4.09936e-01 4.09936e-02 1.00000e-09 2.12000e-01

4.09936e-01 4.09936e-01 4.09936e-02 1.00000e-09 2.12000e-01

$1.00000 \mathrm{e}-02$ 1.00000e-02 1.00000e-03 1.00000e-09 1.00000e-01

$1.00000 \mathrm{e}+001.00000 \mathrm{e}+001.00000 \mathrm{e}-011.00000 \mathrm{e}-091.00000 \mathrm{e}-01$

$1.00000 \mathrm{e}-05$ 1.00000e-05 1.00000e-06 1.00000e-09 1.00000e-01

$1.00000 \mathrm{e}+001.00000 \mathrm{e}+001.00000 \mathrm{e}-01$ 1.00000e-09 1.00000e-01

Element: 3994 \# of layers: 15

$\mathrm{Kx} \mathrm{Ky} \mathrm{Kz}$ Ss Por

8.77178e+00 8.77178e+00 8.77178e-01 1.00000e-09 7.00000e-02 
8.77178e+00 8.77178e+00 8.77178e-01 1.00000e-09 7.00000e-02 $8.77178 \mathrm{e}+008.77178 \mathrm{e}+00$ 8.77178e-01 1.00000e-09 7.00000e-02 $8.77178 \mathrm{e}+008.77178 \mathrm{e}+00$ 8.77178e-01 1.00000e-09 7.00000e-02 5.00000e-04 5.00000e-04 5.00000e-05 1.00000e-09 1.00000e-01 5.00000e-04 5.00000e-04 5.00000e-05 1.00000e-09 1.00000e-01 3.50490e-01 3.50490e-01 3.50490e-02 1.00000e-09 2.12000e-01 3.50490e-01 3.50490e-01 3.50490e-02 1.00000e-09 2.12000e-01 3.50490e-01 3.50490e-01 3.50490e-02 1.00000e-09 2.12000e-01 3.50490e-01 3.50490e-01 3.50490e-02 1.00000e-09 2.12000e-01 3.50490e-01 3.50490e-01 3.50490e-02 1.00000e-09 2.12000e-01 $1.00000 \mathrm{e}-021.00000 \mathrm{e}-02$ 1.00000e-03 1.00000e-09 1.00000e-01 $1.00000 \mathrm{e}+001.00000 \mathrm{e}+001.00000 \mathrm{e}-011.00000 \mathrm{e}-091.00000 \mathrm{e}-01$ $1.00000 \mathrm{e}-05$ 1.00000e-05 1.00000e-06 1.00000e-09 1.00000e-01 $1.00000 \mathrm{e}+001.00000 \mathrm{e}+001.00000 \mathrm{e}-011.00000 \mathrm{e}-091.00000 \mathrm{e}-01$ Element: 3995 \# of layers: 16

Kx Ky Kz Ss Por

$8.77178 \mathrm{e}+008.77178 \mathrm{e}+00$ 8.77178e-01 1.00000e-09 7.00000e-02 $8.77178 \mathrm{e}+008.77178 \mathrm{e}+008.77178 \mathrm{e}-011.00000 \mathrm{e}-09$ 7.00000e-02 $8.77178 \mathrm{e}+008.77178 \mathrm{e}+008.77178 \mathrm{e}-011.00000 \mathrm{e}-09$ 7.00000e-02 $8.77178 \mathrm{e}+008.77178 \mathrm{e}+00$ 8.77178e-01 1.00000e-09 7.00000e-02 $8.77178 \mathrm{e}+008.77178 \mathrm{e}+00$ 8.77178e-01 1.00000e-09 7.00000e-02 $5.00000 \mathrm{e}-04$ 5.00000e-04 5.00000e-05 1.00000e-09 1.00000e-01 5.00000e-04 5.00000e-04 5.00000e-05 1.00000e-09 1.00000e-01 3.50490e-01 3.50490e-01 3.50490e-02 1.00000e-09 2.12000e-01 3.50490e-01 3.50490e-01 3.50490e-02 1.00000e-09 2.12000e-01 3.50490e-01 3.50490e-01 3.50490e-02 1.00000e-09 2.12000e-01 3.50490e-01 3.50490e-01 3.50490e-02 1.00000e-09 2.12000e-01 3.50490e-01 3.50490e-01 3.50490e-02 1.00000e-09 2.12000e-01 $1.00000 \mathrm{e}-021.00000 \mathrm{e}-02$ 1.00000e-03 1.00000e-09 1.00000e-01 $1.00000 \mathrm{e}+001.00000 \mathrm{e}+001.00000 \mathrm{e}-011.00000 \mathrm{e}-091.00000 \mathrm{e}-01$ $1.00000 \mathrm{e}-05$ 1.00000e-05 1.00000e-06 1.00000e-09 1.00000e-01 $1.00000 \mathrm{e}+001.00000 \mathrm{e}+001.00000 \mathrm{e}-011.00000 \mathrm{e}-091.00000 \mathrm{e}-01$ Element: 3996 \# of layers: 15

$\mathrm{Kx} \mathrm{Ky} \mathrm{Kz}$ Ss Por

8.77178e+00 8.77178e+00 8.77178e-01 1.00000e-09 7.00000e-02 8.77178e+00 8.77178e+00 8.77178e-01 1.00000e-09 7.00000e-02 8.77178e+00 8.77178e+00 8.77178e-01 1.00000e-09 7.00000e-02 $8.77178 \mathrm{e}+00$ 8.77178e+00 8.77178e-01 1.00000e-09 7.00000e-02 5.00000e-04 5.00000e-04 5.00000e-05 1.00000e-09 1.00000e-01 5.00000e-04 5.00000e-04 5.00000e-05 1.00000e-09 1.00000e-01 3.50490e-01 3.50490e-01 3.50490e-02 1.00000e-09 2.12000e-01 3.50490e-01 3.50490e-01 3.50490e-02 1.00000e-09 2.12000e-01 3.50490e-01 3.50490e-01 3.50490e-02 1.00000e-09 2.12000e-01 3.50490e-01 3.50490e-01 3.50490e-02 1.00000e-09 2.12000e-01 3.50490e-01 3.50490e-01 3.50490e-02 1.00000e-09 2.12000e-01 $1.00000 \mathrm{e}-021.00000 \mathrm{e}-02$ 1.00000e-03 1.00000e-09 1.00000e-01 
$1.00000 \mathrm{e}+001.00000 \mathrm{e}+001.00000 \mathrm{e}-011.00000 \mathrm{e}-091.00000 \mathrm{e}-01$ $1.00000 \mathrm{e}-05$ 1.00000e-05 1.00000e-06 1.00000e-09 1.00000e-01 $1.00000 \mathrm{e}+001.00000 \mathrm{e}+00$ 1.00000e-01 1.00000e-09 1.00000e-01 Element: 3997 \# of layers: 15

$\mathrm{Kx} \mathrm{Ky} \mathrm{Kz}$ Ss Por

3.70140e+01 3.70140e+01 3.70140e+00 1.00000e-09 7.00000e-02 $3.70140 \mathrm{e}+013.70140 \mathrm{e}+013.70140 \mathrm{e}+001.00000 \mathrm{e}-09$ 7.00000e-02 $3.70140 \mathrm{e}+013.70140 \mathrm{e}+013.70140 \mathrm{e}+001.00000 \mathrm{e}-09$ 7.00000e-02 $3.70140 \mathrm{e}+013.70140 \mathrm{e}+013.70140 \mathrm{e}+001.00000 \mathrm{e}-09$ 7.00000e-02 5.00000e-04 5.00000e-04 5.00000e-05 1.00000e-09 1.00000e-01 5.00000e-04 5.00000e-04 5.00000e-05 1.00000e-09 1.00000e-01 $1.47896 \mathrm{e}+001.47896 \mathrm{e}+001.47896 \mathrm{e}-011.00000 \mathrm{e}-092.12000 \mathrm{e}-01$ $1.47896 \mathrm{e}+001.47896 \mathrm{e}+00$ 1.47896e-01 1.00000e-09 2.12000e-01 $1.47896 \mathrm{e}+001.47896 \mathrm{e}+001.47896 \mathrm{e}-01$ 1.00000e-09 2.12000e-01 $1.47896 \mathrm{e}+001.47896 \mathrm{e}+00$ 1.47896e-01 1.00000e-09 2.12000e-01 $1.47896 \mathrm{e}+001.47896 \mathrm{e}+00 \quad 1.47896 \mathrm{e}-011.00000 \mathrm{e}-092.12000 \mathrm{e}-01$ 1.00000e-02 1.00000e-02 1.00000e-03 1.00000e-09 1.00000e-01 $1.00000 \mathrm{e}+001.00000 \mathrm{e}+001.00000 \mathrm{e}-011.00000 \mathrm{e}-091.00000 \mathrm{e}-01$ $1.00000 \mathrm{e}-05$ 1.00000e-05 1.00000e-06 1.00000e-09 1.00000e-01 $1.00000 \mathrm{e}+001.00000 \mathrm{e}+001.00000 \mathrm{e}-011.00000 \mathrm{e}-091.00000 \mathrm{e}-01$ Element: 3998 \# of layers: 15

$\mathrm{Kx} \mathrm{Ky} \mathrm{Kz}$ Ss Por

3.70140e+01 3.70140e+01 3.70140e+00 1.00000e-09 7.00000e-02 $3.70140 \mathrm{e}+013.70140 \mathrm{e}+013.70140 \mathrm{e}+001.00000 \mathrm{e}-09$ 7.00000e-02 $3.70140 \mathrm{e}+013.70140 \mathrm{e}+013.70140 \mathrm{e}+001.00000 \mathrm{e}-09$ 7.00000e-02 $3.70140 \mathrm{e}+013.70140 \mathrm{e}+013.70140 \mathrm{e}+001.00000 \mathrm{e}-097.00000 \mathrm{e}-02$ 5.00000e-04 5.00000e-04 5.00000e-05 1.00000e-09 1.00000e-01 5.00000e-04 5.00000e-04 5.00000e-05 1.00000e-09 1.00000e-01 $1.47896 \mathrm{e}+001.47896 \mathrm{e}+001.47896 \mathrm{e}-01$ 1.00000e-09 2.12000e-01 $1.47896 \mathrm{e}+001.47896 \mathrm{e}+001.47896 \mathrm{e}-011.00000 \mathrm{e}-092.12000 \mathrm{e}-01$ $1.47896 \mathrm{e}+001.47896 \mathrm{e}+001.47896 \mathrm{e}-01$ 1.00000e-09 2.12000e-01 $1.47896 \mathrm{e}+001.47896 \mathrm{e}+001.47896 \mathrm{e}-01$ 1.00000e-09 2.12000e-01 $1.47896 \mathrm{e}+001.47896 \mathrm{e}+001.47896 \mathrm{e}-011.00000 \mathrm{e}-092.12000 \mathrm{e}-01$ $1.00000 \mathrm{e}-02$ 1.00000e-02 1.00000e-03 1.00000e-09 1.00000e-01 $1.00000 \mathrm{e}+001.00000 \mathrm{e}+001.00000 \mathrm{e}-011.00000 \mathrm{e}-091.00000 \mathrm{e}-01$ $1.00000 \mathrm{e}-05$ 1.00000e-05 1.00000e-06 1.00000e-09 1.00000e-01 $1.00000 \mathrm{e}+001.00000 \mathrm{e}+001.00000 \mathrm{e}-011.00000 \mathrm{e}-091.00000 \mathrm{e}-01$ Element: 3999 \# of layers: 15

$\mathrm{Kx} \mathrm{Ky} \mathrm{Kz}$ Ss Por

$1.26681 \mathrm{e}+011.26681 \mathrm{e}+011.26681 \mathrm{e}+00$ 1.00000e-09 7.00000e-02 $1.26681 \mathrm{e}+011.26681 \mathrm{e}+011.26681 \mathrm{e}+001.00000 \mathrm{e}-09$ 7.00000e-02 $1.26681 \mathrm{e}+011.26681 \mathrm{e}+011.26681 \mathrm{e}+001.00000 \mathrm{e}-09$ 7.00000e-02 $1.26681 \mathrm{e}+011.26681 \mathrm{e}+011.26681 \mathrm{e}+001.00000 \mathrm{e}-097.00000 \mathrm{e}-02$ 5.00000e-04 5.00000e-04 5.00000e-05 1.00000e-09 1.00000e-01 5.00000e-04 5.00000e-04 5.00000e-05 1.00000e-09 1.00000e-01 5.06171e-01 5.06171e-01 5.06171e-02 1.00000e-09 2.12000e-01 
5.06171e-01 5.06171e-01 5.06171e-02 1.00000e-09 2.12000e-01 5.06171e-01 5.06171e-01 5.06171e-02 1.00000e-09 2.12000e-01 5.06171e-01 5.06171e-01 5.06171e-02 1.00000e-09 2.12000e-01 5.06171e-01 5.06171e-01 5.06171e-02 1.00000e-09 2.12000e-01 $1.00000 \mathrm{e}-02$ 1.00000e-02 1.00000e-03 1.00000e-09 1.00000e-01 $1.00000 \mathrm{e}+001.00000 \mathrm{e}+001.00000 \mathrm{e}-011.00000 \mathrm{e}-091.00000 \mathrm{e}-01$ $1.00000 \mathrm{e}-051.00000 \mathrm{e}-05$ 1.00000e-06 1.00000e-09 1.00000e-01 $1.00000 \mathrm{e}+001.00000 \mathrm{e}+001.00000 \mathrm{e}-011.00000 \mathrm{e}-091.00000 \mathrm{e}-01$ Element: 4000 \# of layers: 14

Kx Ky Kz Ss Por

$1.02597 \mathrm{e}+011.02597 \mathrm{e}+011.02597 \mathrm{e}+00$ 1.00000e-09 7.00000e-02 $1.02597 \mathrm{e}+011.02597 \mathrm{e}+011.02597 \mathrm{e}+001.00000 \mathrm{e}-09$ 7.00000e-02 $1.02597 \mathrm{e}+011.02597 \mathrm{e}+011.02597 \mathrm{e}+001.00000 \mathrm{e}-09$ 7.00000e-02 5.00000e-04 5.00000e-04 5.00000e-05 1.00000e-09 1.00000e-01 $5.00000 \mathrm{e}-04$ 5.00000e-04 5.00000e-05 1.00000e-09 1.00000e-01 4.09936e-01 4.09936e-01 4.09936e-02 1.00000e-09 2.12000e-01 4.09936e-01 4.09936e-01 4.09936e-02 1.00000e-09 2.12000e-01 4.09936e-01 4.09936e-01 4.09936e-02 1.00000e-09 2.12000e-01 4.09936e-01 4.09936e-01 4.09936e-02 1.00000e-09 2.12000e-01 4.09936e-01 4.09936e-01 4.09936e-02 1.00000e-09 2.12000e-01 $1.00000 \mathrm{e}-021.00000 \mathrm{e}-02$ 1.00000e-03 1.00000e-09 1.00000e-01 $1.00000 \mathrm{e}+001.00000 \mathrm{e}+001.00000 \mathrm{e}-011.00000 \mathrm{e}-091.00000 \mathrm{e}-01$ $1.00000 \mathrm{e}-05$ 1.00000e-05 1.00000e-06 1.00000e-09 1.00000e-01 $1.00000 \mathrm{e}+001.00000 \mathrm{e}+001.00000 \mathrm{e}-011.00000 \mathrm{e}-091.00000 \mathrm{e}-01$ Element: 4001 \# of layers: 14

Kx Ky Kz Ss Por

8.77178e+00 8.77178e+00 8.77178e-01 1.00000e-09 7.00000e-02 $8.77178 \mathrm{e}+008.77178 \mathrm{e}+008.77178 \mathrm{e}-011.00000 \mathrm{e}-09$ 7.00000e-02 $8.77178 \mathrm{e}+008.77178 \mathrm{e}+00$ 8.77178e-01 1.00000e-09 7.00000e-02 $5.00000 \mathrm{e}-04$ 5.00000e-04 5.00000e-05 1.00000e-09 1.00000e-01 5.00000e-04 5.00000e-04 5.00000e-05 1.00000e-09 1.00000e-01 3.50490e-01 3.50490e-01 3.50490e-02 1.00000e-09 2.12000e-01 3.50490e-01 3.50490e-01 3.50490e-02 1.00000e-09 2.12000e-01 3.50490e-01 3.50490e-01 3.50490e-02 1.00000e-09 2.12000e-01 3.50490e-01 3.50490e-01 3.50490e-02 1.00000e-09 2.12000e-01 3.50490e-01 3.50490e-01 3.50490e-02 1.00000e-09 2.12000e-01 $1.00000 \mathrm{e}-02$ 1.00000e-02 1.00000e-03 1.00000e-09 1.00000e-01 $1.00000 \mathrm{e}+001.00000 \mathrm{e}+001.00000 \mathrm{e}-011.00000 \mathrm{e}-091.00000 \mathrm{e}-01$ $1.00000 \mathrm{e}-05$ 1.00000e-05 1.00000e-06 1.00000e-09 1.00000e-01 $1.00000 \mathrm{e}+001.00000 \mathrm{e}+001.00000 \mathrm{e}-011.00000 \mathrm{e}-091.00000 \mathrm{e}-01$ Element: 4002 \# of layers: 16

Kx Ky Kz Ss Por

$1.13139 \mathrm{e}+02$ 1.13139e+02 1.13139e+01 1.00000e-09 7.00000e-02 $1.13139 \mathrm{e}+021.13139 \mathrm{e}+021.13139 \mathrm{e}+011.00000 \mathrm{e}-09$ 7.00000e-02 $1.13139 \mathrm{e}+021.13139 \mathrm{e}+02$ 1.13139e+01 1.00000e-09 7.00000e-02 $1.13139 \mathrm{e}+02$ 1.13139e+02 1.13139e+01 1.00000e-09 7.00000e-02 
$1.13139 \mathrm{e}+02$ 1.13139e+02 1.13139e+01 1.00000e-09 7.00000e-02 5.00000e-04 5.00000e-04 5.00000e-05 1.00000e-09 1.00000e-01 5.00000e-04 5.00000e-04 5.00000e-05 1.00000e-09 1.00000e-01 $4.52080 \mathrm{e}+004.52080 \mathrm{e}+00$ 4.52080e-01 1.00000e-09 2.12000e-01 $4.52080 \mathrm{e}+004.52080 \mathrm{e}+00$ 4.52080e-01 1.00000e-09 2.12000e-01 $4.52080 \mathrm{e}+004.52080 \mathrm{e}+004.52080 \mathrm{e}-01$ 1.00000e-09 2.12000e-01 $4.52080 \mathrm{e}+004.52080 \mathrm{e}+00$ 4.52080e-01 1.00000e-09 2.12000e-01 $4.52080 \mathrm{e}+004.52080 \mathrm{e}+00$ 4.52080e-01 1.00000e-09 2.12000e-01 $1.00000 \mathrm{e}-02$ 1.00000e-02 1.00000e-03 1.00000e-09 1.00000e-01 $1.00000 \mathrm{e}+001.00000 \mathrm{e}+001.00000 \mathrm{e}-011.00000 \mathrm{e}-091.00000 \mathrm{e}-01$ $1.00000 \mathrm{e}-05$ 1.00000e-05 1.00000e-06 1.00000e-09 1.00000e-01 $1.00000 \mathrm{e}+001.00000 \mathrm{e}+001.00000 \mathrm{e}-011.00000 \mathrm{e}-091.00000 \mathrm{e}-01$ Element: 4003 \# of layers: 16

$\mathrm{Kx} \mathrm{Ky} \mathrm{Kz}$ Ss Por

2.18366e+02 2.18366e+02 2.18366e+01 1.00000e-09 7.00000e-02 $2.18366 \mathrm{e}+022.18366 \mathrm{e}+022.18366 \mathrm{e}+01$ 1.00000e-09 7.00000e-02 $2.18366 \mathrm{e}+02$ 2.18366e+02 2.18366e+01 1.00000e-09 7.00000e-02 $2.18366 \mathrm{e}+02$ 2.18366e+02 2.18366e+01 1.00000e-09 7.00000e-02 $2.18366 \mathrm{e}+02$ 2.18366e+02 2.18366e+01 1.00000e-09 7.00000e-02 5.00000e-04 5.00000e-04 5.00000e-05 1.00000e-09 1.00000e-01 5.00000e-04 5.00000e-04 5.00000e-05 1.00000e-09 1.00000e-01 $8.72524 \mathrm{e}+008.72524 \mathrm{e}+008.72524 \mathrm{e}-01$ 1.00000e-09 2.12000e-01 $8.72524 \mathrm{e}+008.72524 \mathrm{e}+008.72524 \mathrm{e}-01$ 1.00000e-09 2.12000e-01 $8.72524 \mathrm{e}+008.72524 \mathrm{e}+008.72524 \mathrm{e}-01$ 1.00000e-09 2.12000e-01 $8.72524 \mathrm{e}+008.72524 \mathrm{e}+00 \quad 8.72524 \mathrm{e}-011.00000 \mathrm{e}-092.12000 \mathrm{e}-01$ $8.72524 \mathrm{e}+008.72524 \mathrm{e}+008.72524 \mathrm{e}-01$ 1.00000e-09 2.12000e-01 $1.00000 \mathrm{e}-02$ 1.00000e-02 1.00000e-03 1.00000e-09 1.00000e-01 $1.00000 \mathrm{e}+001.00000 \mathrm{e}+001.00000 \mathrm{e}-011.00000 \mathrm{e}-091.00000 \mathrm{e}-01$ $1.00000 \mathrm{e}-05$ 1.00000e-05 1.00000e-06 1.00000e-09 1.00000e-01 $1.00000 \mathrm{e}+001.00000 \mathrm{e}+001.00000 \mathrm{e}-011.00000 \mathrm{e}-091.00000 \mathrm{e}-01$ Element: 4004 \# of layers: 16

$\mathrm{Kx} \mathrm{Ky} \mathrm{Kz}$ Ss Por

2.18366e+02 2.18366e+02 2.18366e+01 1.00000e-09 7.00000e-02 $2.18366 \mathrm{e}+02$ 2.18366e+02 2.18366e+01 1.00000e-09 7.00000e-02 $2.18366 \mathrm{e}+02$ 2.18366e+02 2.18366e+01 1.00000e-09 7.00000e-02 $2.18366 \mathrm{e}+02$ 2.18366e+02 2.18366e+01 1.00000e-09 7.00000e-02 $2.18366 \mathrm{e}+022.18366 \mathrm{e}+022.18366 \mathrm{e}+01$ 1.00000e-09 7.00000e-02 5.00000e-04 5.00000e-04 5.00000e-05 1.00000e-09 1.00000e-01 5.00000e-04 5.00000e-04 5.00000e-05 1.00000e-09 1.00000e-01 $8.72524 \mathrm{e}+008.72524 \mathrm{e}+008.72524 \mathrm{e}-01$ 1.00000e-09 2.12000e-01 $8.72524 \mathrm{e}+008.72524 \mathrm{e}+008.72524 \mathrm{e}-01$ 1.00000e-09 2.12000e-01 $8.72524 \mathrm{e}+008.72524 \mathrm{e}+008.72524 \mathrm{e}-01$ 1.00000e-09 2.12000e-01 $8.72524 \mathrm{e}+008.72524 \mathrm{e}+00$ 8.72524e-01 1.00000e-09 2.12000e-01 $8.72524 \mathrm{e}+008.72524 \mathrm{e}+00$ 8.72524e-01 1.00000e-09 2.12000e-01 $1.00000 \mathrm{e}-02$ 1.00000e-02 1.00000e-03 1.00000e-09 1.00000e-01 $1.00000 \mathrm{e}+001.00000 \mathrm{e}+001.00000 \mathrm{e}-011.00000 \mathrm{e}-091.00000 \mathrm{e}-01$ 
$1.00000 \mathrm{e}-05$ 1.00000e-05 1.00000e-06 1.00000e-09 1.00000e-01 $1.00000 \mathrm{e}+001.00000 \mathrm{e}+001.00000 \mathrm{e}-01$ 1.00000e-09 1.00000e-01 Element: 4005 \# of layers: 15

Kx Ky Kz Ss Por

2.18366e+02 2.18366e+02 2.18366e+01 1.00000e-09 7.00000e-02

$2.18366 \mathrm{e}+02$ 2.18366e+02 2.18366e+01 1.00000e-09 7.00000e-02

$2.18366 \mathrm{e}+022.18366 \mathrm{e}+02 \quad 2.18366 \mathrm{e}+01$ 1.00000e-09 7.00000e-02

$2.18366 \mathrm{e}+022.18366 \mathrm{e}+022.18366 \mathrm{e}+01$ 1.00000e-09 7.00000e-02

5.00000e-04 5.00000e-04 5.00000e-05 1.00000e-09 1.00000e-01

$5.00000 \mathrm{e}-04$ 5.00000e-04 5.00000e-05 1.00000e-09 1.00000e-01

$8.72524 \mathrm{e}+008.72524 \mathrm{e}+00 \quad 8.72524 \mathrm{e}-01$ 1.00000e-09 2.12000e-01

$8.72524 \mathrm{e}+008.72524 \mathrm{e}+008.72524 \mathrm{e}-01$ 1.00000e-09 2.12000e-01

$8.72524 \mathrm{e}+008.72524 \mathrm{e}+00 \quad 8.72524 \mathrm{e}-01$ 1.00000e-09 2.12000e-01

$8.72524 \mathrm{e}+008.72524 \mathrm{e}+008.72524 \mathrm{e}-01$ 1.00000e-09 2.12000e-01

$8.72524 \mathrm{e}+008.72524 \mathrm{e}+008.72524 \mathrm{e}-01$ 1.00000e-09 2.12000e-01

$1.00000 \mathrm{e}-02$ 1.00000e-02 1.00000e-03 1.00000e-09 1.00000e-01

$1.00000 \mathrm{e}+001.00000 \mathrm{e}+001.00000 \mathrm{e}-011.00000 \mathrm{e}-091.00000 \mathrm{e}-01$

$1.00000 \mathrm{e}-05$ 1.00000e-05 1.00000e-06 1.00000e-09 1.00000e-01

$1.00000 \mathrm{e}+001.00000 \mathrm{e}+001.00000 \mathrm{e}-011.00000 \mathrm{e}-091.00000 \mathrm{e}-01$

Element: 4006 \# of layers: 14

$\mathrm{Kx} \mathrm{Ky} \mathrm{Kz}$ Ss Por

2.20457e+02 2.20457e+02 2.20457e+01 1.00000e-09 7.00000e-02

2.20457e+02 2.20457e+02 2.20457e+01 1.00000e-09 7.00000e-02

2.20457e+02 2.20457e+02 2.20457e+01 1.00000e-09 7.00000e-02

$5.00000 \mathrm{e}-04$ 5.00000e-04 5.00000e-05 1.00000e-09 1.00000e-01

$5.00000 \mathrm{e}-04$ 5.00000e-04 5.00000e-05 1.00000e-09 1.00000e-01

$8.80871 \mathrm{e}+008.80871 \mathrm{e}+008.80871 \mathrm{e}-01$ 1.00000e-09 2.12000e-01

$8.80871 \mathrm{e}+008.80871 \mathrm{e}+00$ 8.80871e-01 1.00000e-09 2.12000e-01

$8.80871 \mathrm{e}+008.80871 \mathrm{e}+008.80871 \mathrm{e}-01$ 1.00000e-09 2.12000e-01

$8.80871 \mathrm{e}+00$ 8.80871e+00 8.80871e-01 1.00000e-09 2.12000e-01

$8.80871 \mathrm{e}+00$ 8.80871e+00 8.80871e-01 1.00000e-09 2.12000e-01

$1.00000 \mathrm{e}-02$ 1.00000e-02 1.00000e-03 1.00000e-09 1.00000e-01

$1.00000 \mathrm{e}+001.00000 \mathrm{e}+001.00000 \mathrm{e}-011.00000 \mathrm{e}-091.00000 \mathrm{e}-01$

$1.00000 \mathrm{e}-051.00000 \mathrm{e}-051.00000 \mathrm{e}-061.00000 \mathrm{e}-091.00000 \mathrm{e}-01$

$1.00000 \mathrm{e}+001.00000 \mathrm{e}+001.00000 \mathrm{e}-011.00000 \mathrm{e}-091.00000 \mathrm{e}-01$

Element: 4007 \# of layers: 14

$\mathrm{Kx} \mathrm{Ky} \mathrm{Kz}$ Ss Por

2.20457e+02 2.20457e+02 2.20457e+01 1.00000e-09 7.00000e-02

$2.20457 \mathrm{e}+02$ 2.20457e+02 2.20457e+01 1.00000e-09 7.00000e-02

$2.20457 \mathrm{e}+02$ 2.20457e+02 2.20457e+01 1.00000e-09 7.00000e-02

5.00000e-04 5.00000e-04 5.00000e-05 1.00000e-09 1.00000e-01

5.00000e-04 5.00000e-04 5.00000e-05 1.00000e-09 1.00000e-01

$8.80871 \mathrm{e}+008.80871 \mathrm{e}+008.80871 \mathrm{e}-01$ 1.00000e-09 2.12000e-01

$8.80871 \mathrm{e}+008.80871 \mathrm{e}+00$ 8.80871e-01 1.00000e-09 2.12000e-01

$8.80871 \mathrm{e}+008.80871 \mathrm{e}+008.80871 \mathrm{e}-01$ 1.00000e-09 2.12000e-01

$8.80871 \mathrm{e}+008.80871 \mathrm{e}+008.80871 \mathrm{e}-01$ 1.00000e-09 2.12000e-01 
8.80871e+00 8.80871e+00 8.80871e-01 1.00000e-09 2.12000e-01 $1.00000 \mathrm{e}-02$ 1.00000e-02 1.00000e-03 1.00000e-09 1.00000e-01 $1.00000 \mathrm{e}+001.00000 \mathrm{e}+001.00000 \mathrm{e}-011.00000 \mathrm{e}-091.00000 \mathrm{e}-01$ $1.00000 \mathrm{e}-05$ 1.00000e-05 1.00000e-06 1.00000e-09 1.00000e-01 $1.00000 \mathrm{e}+001.00000 \mathrm{e}+001.00000 \mathrm{e}-01$ 1.00000e-09 1.00000e-01 Element: 4008 \# of layers: 14

$\mathrm{Kx} \mathrm{Ky} \mathrm{Kz}$ Ss Por

2.18348e+02 2.18348e+02 2.18348e+01 1.00000e-09 7.00000e-02

$2.18348 \mathrm{e}+02$ 2.18348e+02 2.18348e+01 1.00000e-09 7.00000e-02

$2.18348 \mathrm{e}+02$ 2.18348e+02 2.18348e+01 1.00000e-09 7.00000e-02 5.00000e-04 5.00000e-04 5.00000e-05 1.00000e-09 1.00000e-01 5.00000e-04 5.00000e-04 5.00000e-05 1.00000e-09 1.00000e-01

$8.72456 \mathrm{e}+00$ 8.72456e+00 8.72456e-01 1.00000e-09 2.12000e-01 $8.72456 \mathrm{e}+00$ 8.72456e+00 8.72456e-01 1.00000e-09 2.12000e-01 8.72456e+00 8.72456e+00 8.72456e-01 1.00000e-09 2.12000e-01 $8.72456 \mathrm{e}+008.72456 \mathrm{e}+00$ 8.72456e-01 1.00000e-09 2.12000e-01 $8.72456 \mathrm{e}+008.72456 \mathrm{e}+00$ 8.72456e-01 1.00000e-09 2.12000e-01 $1.00000 \mathrm{e}-02$ 1.00000e-02 1.00000e-03 1.00000e-09 1.00000e-01 $1.00000 \mathrm{e}+001.00000 \mathrm{e}+001.00000 \mathrm{e}-011.00000 \mathrm{e}-091.00000 \mathrm{e}-01$ $1.00000 \mathrm{e}-05$ 1.00000e-05 1.00000e-06 1.00000e-09 1.00000e-01 $1.00000 \mathrm{e}+001.00000 \mathrm{e}+001.00000 \mathrm{e}-011.00000 \mathrm{e}-091.00000 \mathrm{e}-01$ Element: 4009 \# of layers: 15

$\mathrm{Kx} \mathrm{Ky} \mathrm{Kz}$ Ss Por

1.13139e+02 1.13139e+02 1.13139e+01 1.00000e-09 7.00000e-02 $1.13139 \mathrm{e}+02$ 1.13139e+02 1.13139e+01 1.00000e-09 7.00000e-02 $1.13139 \mathrm{e}+02$ 1.13139e+02 1.13139e+01 1.00000e-09 7.00000e-02 $1.13139 \mathrm{e}+021.13139 \mathrm{e}+02$ 1.13139e+01 1.00000e-09 7.00000e-02 5.00000e-04 5.00000e-04 5.00000e-05 1.00000e-09 1.00000e-01 5.00000e-04 5.00000e-04 5.00000e-05 1.00000e-09 1.00000e-01 $4.52080 \mathrm{e}+004.52080 \mathrm{e}+00$ 4.52080e-01 1.00000e-09 2.12000e-01 $4.52080 \mathrm{e}+004.52080 \mathrm{e}+004.52080 \mathrm{e}-01$ 1.00000e-09 2.12000e-01 $4.52080 \mathrm{e}+004.52080 \mathrm{e}+00$ 4.52080e-01 1.00000e-09 2.12000e-01 $4.52080 \mathrm{e}+004.52080 \mathrm{e}+00$ 4.52080e-01 1.00000e-09 2.12000e-01 $4.52080 \mathrm{e}+004.52080 \mathrm{e}+00$ 4.52080e-01 1.00000e-09 2.12000e-01 $1.00000 \mathrm{e}-02$ 1.00000e-02 1.00000e-03 1.00000e-09 1.00000e-01 $1.00000 \mathrm{e}+001.00000 \mathrm{e}+001.00000 \mathrm{e}-011.00000 \mathrm{e}-091.00000 \mathrm{e}-01$ $1.00000 \mathrm{e}-05$ 1.00000e-05 1.00000e-06 1.00000e-09 1.00000e-01 $1.00000 \mathrm{e}+001.00000 \mathrm{e}+001.00000 \mathrm{e}-01$ 1.00000e-09 1.00000e-01 Element: 4010 \# of layers: 15

$\mathrm{Kx} \mathrm{Ky} \mathrm{Kz}$ Ss Por

$2.18366 \mathrm{e}+02$ 2.18366e+02 2.18366e+01 1.00000e-09 7.00000e-02 $2.18366 \mathrm{e}+022.18366 \mathrm{e}+02 \quad 2.18366 \mathrm{e}+01$ 1.00000e-09 7.00000e-02 $2.18366 \mathrm{e}+02$ 2.18366e+02 2.18366e+01 1.00000e-09 7.00000e-02 2.18366e+02 2.18366e+02 2.18366e+01 1.00000e-09 7.00000e-02 5.00000e-04 5.00000e-04 5.00000e-05 1.00000e-09 1.00000e-01 5.00000e-04 5.00000e-04 5.00000e-05 1.00000e-09 1.00000e-01 
$8.72524 \mathrm{e}+008.72524 \mathrm{e}+008.72524 \mathrm{e}-011.00000 \mathrm{e}-092.12000 \mathrm{e}-01$ $8.72524 \mathrm{e}+008.72524 \mathrm{e}+008.72524 \mathrm{e}-01$ 1.00000e-09 2.12000e-01 $8.72524 \mathrm{e}+008.72524 \mathrm{e}+008.72524 \mathrm{e}-01$ 1.00000e-09 2.12000e-01 $8.72524 \mathrm{e}+008.72524 \mathrm{e}+008.72524 \mathrm{e}-011.00000 \mathrm{e}-092.12000 \mathrm{e}-01$ $8.72524 \mathrm{e}+008.72524 \mathrm{e}+00$ 8.72524e-01 1.00000e-09 2.12000e-01 $1.00000 \mathrm{e}-021.00000 \mathrm{e}-02$ 1.00000e-03 1.00000e-09 1.00000e-01 $1.00000 \mathrm{e}+001.00000 \mathrm{e}+001.00000 \mathrm{e}-011.00000 \mathrm{e}-091.00000 \mathrm{e}-01$ $1.00000 \mathrm{e}-05$ 1.00000e-05 1.00000e-06 1.00000e-09 1.00000e-01 $1.00000 \mathrm{e}+001.00000 \mathrm{e}+001.00000 \mathrm{e}-011.00000 \mathrm{e}-091.00000 \mathrm{e}-01$ Element: 4011 \# of layers: 15

Kx Ky Kz Ss Por

$2.77013 \mathrm{e}+022.77013 \mathrm{e}+022.77013 \mathrm{e}+01$ 1.00000e-09 7.00000e-02 $2.77013 \mathrm{e}+022.77013 \mathrm{e}+022.77013 \mathrm{e}+01$ 1.00000e-09 7.00000e-02 $2.77013 \mathrm{e}+022.77013 \mathrm{e}+022.77013 \mathrm{e}+01$ 1.00000e-09 7.00000e-02 $2.77013 \mathrm{e}+022.77013 \mathrm{e}+022.77013 \mathrm{e}+01$ 1.00000e-09 7.00000e-02 5.00000e-04 5.00000e-04 5.00000e-05 1.00000e-09 1.00000e-01 5.00000e-04 5.00000e-04 5.00000e-05 1.00000e-09 1.00000e-01 $1.10684 \mathrm{e}+011.10684 \mathrm{e}+011.10684 \mathrm{e}+001.00000 \mathrm{e}-092.12000 \mathrm{e}-01$ $1.10684 \mathrm{e}+011.10684 \mathrm{e}+011.10684 \mathrm{e}+001.00000 \mathrm{e}-092.12000 \mathrm{e}-01$ $1.10684 \mathrm{e}+011.10684 \mathrm{e}+011.10684 \mathrm{e}+001.00000 \mathrm{e}-092.12000 \mathrm{e}-01$ $1.10684 \mathrm{e}+011.10684 \mathrm{e}+011.10684 \mathrm{e}+001.00000 \mathrm{e}-092.12000 \mathrm{e}-01$ $1.10684 \mathrm{e}+011.10684 \mathrm{e}+011.10684 \mathrm{e}+001.00000 \mathrm{e}-092.12000 \mathrm{e}-01$ $1.00000 \mathrm{e}-021.00000 \mathrm{e}-02$ 1.00000e-03 1.00000e-09 1.00000e-01 $1.00000 \mathrm{e}+001.00000 \mathrm{e}+001.00000 \mathrm{e}-011.00000 \mathrm{e}-091.00000 \mathrm{e}-01$ $1.00000 \mathrm{e}-05$ 1.00000e-05 1.00000e-06 1.00000e-09 1.00000e-01 $1.00000 \mathrm{e}+001.00000 \mathrm{e}+001.00000 \mathrm{e}-011.00000 \mathrm{e}-091.00000 \mathrm{e}-01$ Element: 4012 \# of layers: 15

Kx Ky Kz Ss Por

$3.28784 \mathrm{e}+023.28784 \mathrm{e}+023.28784 \mathrm{e}+01$ 1.00000e-09 7.00000e-02 $3.28784 \mathrm{e}+023.28784 \mathrm{e}+023.28784 \mathrm{e}+01$ 1.00000e-09 7.00000e-02 $3.28784 \mathrm{e}+023.28784 \mathrm{e}+023.28784 \mathrm{e}+01$ 1.00000e-09 7.00000e-02 $3.28784 \mathrm{e}+023.28784 \mathrm{e}+023.28784 \mathrm{e}+01$ 1.00000e-09 7.00000e-02 5.00000e-04 5.00000e-04 5.00000e-05 1.00000e-09 1.00000e-01 5.00000e-04 5.00000e-04 5.00000e-05 1.00000e-09 1.00000e-01 $1.31371 \mathrm{e}+011.31371 \mathrm{e}+011.31371 \mathrm{e}+001.00000 \mathrm{e}-092.12000 \mathrm{e}-01$ $1.31371 \mathrm{e}+011.31371 \mathrm{e}+011.31371 \mathrm{e}+001.00000 \mathrm{e}-092.12000 \mathrm{e}-01$ $1.31371 \mathrm{e}+011.31371 \mathrm{e}+011.31371 \mathrm{e}+001.00000 \mathrm{e}-092.12000 \mathrm{e}-01$ $1.31371 \mathrm{e}+011.31371 \mathrm{e}+011.31371 \mathrm{e}+001.00000 \mathrm{e}-092.12000 \mathrm{e}-01$ $1.31371 \mathrm{e}+011.31371 \mathrm{e}+011.31371 \mathrm{e}+00$ 1.00000e-09 2.12000e-01 $1.00000 \mathrm{e}-02$ 1.00000e-02 1.00000e-03 1.00000e-09 1.00000e-01 $1.00000 \mathrm{e}+001.00000 \mathrm{e}+001.00000 \mathrm{e}-011.00000 \mathrm{e}-091.00000 \mathrm{e}-01$ $1.00000 \mathrm{e}-05$ 1.00000e-05 1.00000e-06 1.00000e-09 1.00000e-01 $1.00000 \mathrm{e}+001.00000 \mathrm{e}+001.00000 \mathrm{e}-011.00000 \mathrm{e}-091.00000 \mathrm{e}-01$ Element: 4013 \# of layers: 15

Kx Ky Kz Ss Por 3.28784e+02 3.28784e+02 3.28784e+01 1.00000e-09 7.00000e-02 
3.28784e+02 3.28784e+02 3.28784e+01 1.00000e-09 7.00000e-02 $3.28784 \mathrm{e}+02$ 3.28784e+02 3.28784e+01 1.00000e-09 7.00000e-02 $3.28784 \mathrm{e}+02$ 3.28784e+02 3.28784e+01 1.00000e-09 7.00000e-02 5.00000e-04 5.00000e-04 5.00000e-05 1.00000e-09 1.00000e-01 5.00000e-04 5.00000e-04 5.00000e-05 1.00000e-09 1.00000e-01 $1.31371 \mathrm{e}+011.31371 \mathrm{e}+011.31371 \mathrm{e}+00$ 1.00000e-09 2.12000e-01 $1.31371 \mathrm{e}+011.31371 \mathrm{e}+01$ 1.31371e+00 1.00000e-09 2.12000e-01 $1.31371 \mathrm{e}+011.31371 \mathrm{e}+011.31371 \mathrm{e}+001.00000 \mathrm{e}-092.12000 \mathrm{e}-01$ $1.31371 \mathrm{e}+011.31371 \mathrm{e}+01$ 1.31371e+00 1.00000e-09 2.12000e-01 $1.31371 \mathrm{e}+011.31371 \mathrm{e}+011.31371 \mathrm{e}+001.00000 \mathrm{e}-092.12000 \mathrm{e}-01$ $1.00000 \mathrm{e}-02$ 1.00000e-02 1.00000e-03 1.00000e-09 1.00000e-01 $1.00000 \mathrm{e}+001.00000 \mathrm{e}+001.00000 \mathrm{e}-011.00000 \mathrm{e}-091.00000 \mathrm{e}-01$ 1.00000e-05 1.00000e-05 1.00000e-06 1.00000e-09 1.00000e-01 $1.00000 \mathrm{e}+001.00000 \mathrm{e}+001.00000 \mathrm{e}-011.00000 \mathrm{e}-091.00000 \mathrm{e}-01$ Element: 4014 \# of layers: 14

Kx Ky Kz Ss Por

3.28784e+02 3.28784e+02 3.28784e+01 1.00000e-09 7.00000e-02 $3.28784 \mathrm{e}+023.28784 \mathrm{e}+02$ 3.28784e+01 1.00000e-09 7.00000e-02 $3.28784 \mathrm{e}+023.28784 \mathrm{e}+023.28784 \mathrm{e}+01$ 1.00000e-09 7.00000e-02 5.00000e-04 5.00000e-04 5.00000e-05 1.00000e-09 1.00000e-01 5.00000e-04 5.00000e-04 5.00000e-05 1.00000e-09 1.00000e-01 $1.31371 \mathrm{e}+011.31371 \mathrm{e}+011.31371 \mathrm{e}+001.00000 \mathrm{e}-092.12000 \mathrm{e}-01$ $1.31371 \mathrm{e}+01$ 1.31371e+01 1.31371e+00 1.00000e-09 2.12000e-01 $1.31371 \mathrm{e}+011.31371 \mathrm{e}+011.31371 \mathrm{e}+001.00000 \mathrm{e}-092.12000 \mathrm{e}-01$ $1.31371 \mathrm{e}+011.31371 \mathrm{e}+011.31371 \mathrm{e}+001.00000 \mathrm{e}-092.12000 \mathrm{e}-01$ $1.31371 \mathrm{e}+011.31371 \mathrm{e}+011.31371 \mathrm{e}+001.00000 \mathrm{e}-092.12000 \mathrm{e}-01$ $1.00000 \mathrm{e}-02$ 1.00000e-02 1.00000e-03 1.00000e-09 1.00000e-01 $1.00000 \mathrm{e}+001.00000 \mathrm{e}+001.00000 \mathrm{e}-011.00000 \mathrm{e}-091.00000 \mathrm{e}-01$ $1.00000 \mathrm{e}-05$ 1.00000e-05 1.00000e-06 1.00000e-09 1.00000e-01 $1.00000 \mathrm{e}+001.00000 \mathrm{e}+001.00000 \mathrm{e}-011.00000 \mathrm{e}-091.00000 \mathrm{e}-01$ Element: 4015 \# of layers: 14

$\mathrm{Kx} \mathrm{Ky} \mathrm{Kz}$ Ss Por

$2.48514 \mathrm{e}+022.48514 \mathrm{e}+022.48514 \mathrm{e}+01$ 1.00000e-09 7.00000e-02 $2.48514 \mathrm{e}+02 \quad 2.48514 \mathrm{e}+02 \quad 2.48514 \mathrm{e}+01 \quad 1.00000 \mathrm{e}-097.00000 \mathrm{e}-02$ $2.48514 \mathrm{e}+022.48514 \mathrm{e}+022.48514 \mathrm{e}+01$ 1.00000e-09 7.00000e-02 5.00000e-04 5.00000e-04 5.00000e-05 1.00000e-09 1.00000e-01 5.00000e-04 5.00000e-04 5.00000e-05 1.00000e-09 1.00000e-01 $9.92969 \mathrm{e}+00$ 9.92969e+00 9.92969e-01 1.00000e-09 2.12000e-01 $9.92969 \mathrm{e}+00$ 9.92969e+00 9.92969e-01 1.00000e-09 2.12000e-01 9.92969e+00 9.92969e+00 9.92969e-01 1.00000e-09 2.12000e-01 9.92969e+00 9.92969e+00 9.92969e-01 1.00000e-09 2.12000e-01 $9.92969 \mathrm{e}+00$ 9.92969e+00 9.92969e-01 1.00000e-09 2.12000e-01 $1.00000 \mathrm{e}-02$ 1.00000e-02 1.00000e-03 1.00000e-09 1.00000e-01 $1.00000 \mathrm{e}+001.00000 \mathrm{e}+001.00000 \mathrm{e}-011.00000 \mathrm{e}-091.00000 \mathrm{e}-01$ $1.00000 \mathrm{e}-05$ 1.00000e-05 1.00000e-06 1.00000e-09 1.00000e-01 $1.00000 \mathrm{e}+001.00000 \mathrm{e}+001.00000 \mathrm{e}-011.00000 \mathrm{e}-091.00000 \mathrm{e}-01$ 
Element: 4016 \# of layers: 14

$\mathrm{Kx} \mathrm{Ky} \mathrm{Kz}$ Ss Por

$2.48514 \mathrm{e}+022.48514 \mathrm{e}+02$ 2.48514e+01 1.00000e-09 7.00000e-02

$2.48514 \mathrm{e}+02 \quad 2.48514 \mathrm{e}+02 \quad 2.48514 \mathrm{e}+01 \quad 1.00000 \mathrm{e}-097.00000 \mathrm{e}-02$

$2.48514 \mathrm{e}+022.48514 \mathrm{e}+022.48514 \mathrm{e}+01$ 1.00000e-09 7.00000e-02

5.00000e-04 5.00000e-04 5.00000e-05 1.00000e-09 1.00000e-01

5.00000e-04 5.00000e-04 5.00000e-05 1.00000e-09 1.00000e-01

$9.92969 \mathrm{e}+00$ 9.92969e+00 9.92969e-01 1.00000e-09 2.12000e-01

9.92969e+00 9.92969e+00 9.92969e-01 1.00000e-09 2.12000e-01

9.92969e+00 9.92969e+00 9.92969e-01 1.00000e-09 2.12000e-01

9.92969e+00 9.92969e+00 9.92969e-01 1.00000e-09 2.12000e-01

$9.92969 \mathrm{e}+00$ 9.92969e+00 9.92969e-01 1.00000e-09 2.12000e-01

$1.00000 \mathrm{e}-02$ 1.00000e-02 1.00000e-03 1.00000e-09 1.00000e-01

$1.00000 \mathrm{e}+001.00000 \mathrm{e}+001.00000 \mathrm{e}-011.00000 \mathrm{e}-091.00000 \mathrm{e}-01$

$1.00000 \mathrm{e}-05$ 1.00000e-05 1.00000e-06 1.00000e-09 1.00000e-01

$1.00000 \mathrm{e}+001.00000 \mathrm{e}+001.00000 \mathrm{e}-011.00000 \mathrm{e}-091.00000 \mathrm{e}-01$

Element: 4017 \# of layers: 14

$\mathrm{Kx} \mathrm{Ky} \mathrm{Kz}$ Ss Por

2.23331e+02 2.23331e+02 2.23331e+01 1.00000e-09 7.00000e-02

$2.23331 \mathrm{e}+02$ 2.23331e+02 2.23331e+01 1.00000e-09 7.00000e-02

$2.23331 \mathrm{e}+02$ 2.23331e+02 2.23331e+01 1.00000e-09 7.00000e-02

5.00000e-04 5.00000e-04 5.00000e-05 1.00000e-09 1.00000e-01

5.00000e-04 5.00000e-04 5.00000e-05 1.00000e-09 1.00000e-01

$8.92346 \mathrm{e}+00$ 8.92346e+00 8.92346e-01 1.00000e-09 2.12000e-01

$8.92346 \mathrm{e}+008.92346 \mathrm{e}+00$ 8.92346e-01 1.00000e-09 2.12000e-01

$8.92346 \mathrm{e}+00$ 8.92346e+00 8.92346e-01 1.00000e-09 2.12000e-01

8.92346e+00 8.92346e+00 8.92346e-01 1.00000e-09 2.12000e-01

8.92346e+00 8.92346e+00 8.92346e-01 1.00000e-09 2.12000e-01

$1.00000 \mathrm{e}-021.00000 \mathrm{e}-02$ 1.00000e-03 1.00000e-09 1.00000e-01

$1.00000 \mathrm{e}+001.00000 \mathrm{e}+001.00000 \mathrm{e}-011.00000 \mathrm{e}-091.00000 \mathrm{e}-01$

$1.00000 \mathrm{e}-05$ 1.00000e-05 1.00000e-06 1.00000e-09 1.00000e-01

$1.00000 \mathrm{e}+001.00000 \mathrm{e}+001.00000 \mathrm{e}-011.00000 \mathrm{e}-091.00000 \mathrm{e}-01$

Element: 4018 \# of layers: 14

$\mathrm{Kx} \mathrm{Ky} \mathrm{Kz}$ Ss Por

2.77013e+02 2.77013e+02 2.77013e+01 1.00000e-09 7.00000e-02

$2.77013 \mathrm{e}+02$ 2.77013e+02 2.77013e+01 1.00000e-09 7.00000e-02

$2.77013 \mathrm{e}+02$ 2.77013e+02 2.77013e+01 1.00000e-09 7.00000e-02

5.00000e-04 5.00000e-04 5.00000e-05 1.00000e-09 1.00000e-01

5.00000e-04 5.00000e-04 5.00000e-05 1.00000e-09 1.00000e-01

$1.10684 \mathrm{e}+011.10684 \mathrm{e}+011.10684 \mathrm{e}+001.00000 \mathrm{e}-092.12000 \mathrm{e}-01$

$1.10684 \mathrm{e}+011.10684 \mathrm{e}+011.10684 \mathrm{e}+001.00000 \mathrm{e}-092.12000 \mathrm{e}-01$

$1.10684 \mathrm{e}+011.10684 \mathrm{e}+011.10684 \mathrm{e}+001.00000 \mathrm{e}-092.12000 \mathrm{e}-01$

$1.10684 \mathrm{e}+011.10684 \mathrm{e}+011.10684 \mathrm{e}+001.00000 \mathrm{e}-092.12000 \mathrm{e}-01$

$1.10684 \mathrm{e}+01$ 1.10684e+01 1.10684e+00 1.00000e-09 2.12000e-01

1.00000e-02 1.00000e-02 1.00000e-03 1.00000e-09 1.00000e-01

$1.00000 \mathrm{e}+001.00000 \mathrm{e}+001.00000 \mathrm{e}-011.00000 \mathrm{e}-091.00000 \mathrm{e}-01$ 
$1.00000 \mathrm{e}-05$ 1.00000e-05 1.00000e-06 1.00000e-09 1.00000e-01 $1.00000 \mathrm{e}+001.00000 \mathrm{e}+001.00000 \mathrm{e}-01$ 1.00000e-09 1.00000e-01 Element: 4019 \# of layers: 14

Kx Ky Kz Ss Por

3.28784e+02 3.28784e+02 3.28784e+01 1.00000e-09 7.00000e-02 $3.28784 \mathrm{e}+02$ 3.28784e+02 3.28784e+01 1.00000e-09 7.00000e-02 $3.28784 \mathrm{e}+023.28784 \mathrm{e}+023.28784 \mathrm{e}+01$ 1.00000e-09 7.00000e-02 5.00000e-04 5.00000e-04 5.00000e-05 1.00000e-09 1.00000e-01 5.00000e-04 5.00000e-04 5.00000e-05 1.00000e-09 1.00000e-01 $1.31371 \mathrm{e}+011.31371 \mathrm{e}+011.31371 \mathrm{e}+00$ 1.00000e-09 2.12000e-01 $1.31371 \mathrm{e}+01$ 1.31371e+01 1.31371e+00 1.00000e-09 2.12000e-01 $1.31371 \mathrm{e}+011.31371 \mathrm{e}+011.31371 \mathrm{e}+001.00000 \mathrm{e}-092.12000 \mathrm{e}-01$ $1.31371 \mathrm{e}+011.31371 \mathrm{e}+011.31371 \mathrm{e}+001.00000 \mathrm{e}-092.12000 \mathrm{e}-01$ $1.31371 \mathrm{e}+011.31371 \mathrm{e}+011.31371 \mathrm{e}+001.00000 \mathrm{e}-092.12000 \mathrm{e}-01$ $1.00000 \mathrm{e}-02$ 1.00000e-02 1.00000e-03 1.00000e-09 1.00000e-01 $1.00000 \mathrm{e}+001.00000 \mathrm{e}+001.00000 \mathrm{e}-011.00000 \mathrm{e}-091.00000 \mathrm{e}-01$ $1.00000 \mathrm{e}-05$ 1.00000e-05 1.00000e-06 1.00000e-09 1.00000e-01 $1.00000 \mathrm{e}+001.00000 \mathrm{e}+001.00000 \mathrm{e}-011.00000 \mathrm{e}-091.00000 \mathrm{e}-01$ Element: 4020 \# of layers: 14

$\mathrm{Kx} \mathrm{Ky} \mathrm{Kz}$ Ss Por

3.49363e+02 3.49363e+02 3.49363e+01 1.00000e-09 7.00000e-02 $3.49363 \mathrm{e}+02$ 3.49363e+02 3.49363e+01 1.00000e-09 7.00000e-02 $3.49363 \mathrm{e}+023.49363 \mathrm{e}+02$ 3.49363e+01 1.00000e-09 7.00000e-02 5.00000e-04 5.00000e-04 5.00000e-05 1.00000e-09 1.00000e-01 5.00000e-04 5.00000e-04 5.00000e-05 1.00000e-09 1.00000e-01 $1.39591 \mathrm{e}+011.39591 \mathrm{e}+01$ 1.39591e+00 1.00000e-09 2.12000e-01 $1.39591 \mathrm{e}+011.39591 \mathrm{e}+01$ 1.39591e+00 1.00000e-09 2.12000e-01 $1.39591 \mathrm{e}+011.39591 \mathrm{e}+01$ 1.39591e+00 1.00000e-09 2.12000e-01 $1.39591 \mathrm{e}+011.39591 \mathrm{e}+011.39591 \mathrm{e}+001.00000 \mathrm{e}-092.12000 \mathrm{e}-01$ $1.39591 \mathrm{e}+011.39591 \mathrm{e}+011.39591 \mathrm{e}+001.00000 \mathrm{e}-092.12000 \mathrm{e}-01$ 1.00000e-02 1.00000e-02 1.00000e-03 1.00000e-09 1.00000e-01 $1.00000 \mathrm{e}+001.00000 \mathrm{e}+001.00000 \mathrm{e}-011.00000 \mathrm{e}-091.00000 \mathrm{e}-01$ $1.00000 \mathrm{e}-05$ 1.00000e-05 1.00000e-06 1.00000e-09 1.00000e-01 $1.00000 \mathrm{e}+001.00000 \mathrm{e}+001.00000 \mathrm{e}-011.00000 \mathrm{e}-091.00000 \mathrm{e}-01$ Element: 4021 \# of layers: 14

$\mathrm{Kx} \mathrm{Ky} \mathrm{Kz}$ Ss Por

2.29494e+02 2.29494e+02 2.29494e+01 1.00000e-09 7.00000e-02 $2.29494 \mathrm{e}+02$ 2.29494e+02 2.29494e+01 1.00000e-09 7.00000e-02 $2.29494 \mathrm{e}+022.29494 \mathrm{e}+02$ 2.29494e+01 1.00000e-09 7.00000e-02 5.00000e-04 5.00000e-04 5.00000e-05 1.00000e-09 1.00000e-01 5.00000e-04 5.00000e-04 5.00000e-05 1.00000e-09 1.00000e-01

$9.16985 e+009.16985 e+00$ 9.16985e-01 1.00000e-09 2.12000e-01

$9.16985 \mathrm{e}+00$ 9.16985e+00 9.16985e-01 1.00000e-09 2.12000e-01 9.16985e+00 9.16985e+00 9.16985e-01 1.00000e-09 2.12000e-01 9.16985e+00 9.16985e+00 9.16985e-01 1.00000e-09 2.12000e-01 $9.16985 \mathrm{e}+00$ 9.16985e+00 9.16985e-01 1.00000e-09 2.12000e-01 
$1.00000 \mathrm{e}-02$ 1.00000e-02 1.00000e-03 1.00000e-09 1.00000e-01 $1.00000 \mathrm{e}+001.00000 \mathrm{e}+001.00000 \mathrm{e}-011.00000 \mathrm{e}-091.00000 \mathrm{e}-01$ $1.00000 \mathrm{e}-05$ 1.00000e-05 1.00000e-06 1.00000e-09 1.00000e-01 $1.00000 \mathrm{e}+001.00000 \mathrm{e}+001.00000 \mathrm{e}-011.00000 \mathrm{e}-091.00000 \mathrm{e}-01$ Element: 4022 \# of layers: 14

$\mathrm{Kx} \mathrm{Ky} \mathrm{Kz}$ Ss Por

$2.29494 \mathrm{e}+02$ 2.29494e+02 2.29494e+01 1.00000e-09 7.00000e-02 $2.29494 \mathrm{e}+02$ 2.29494e+02 2.29494e+01 1.00000e-09 7.00000e-02 $2.29494 \mathrm{e}+02$ 2.29494e+02 2.29494e+01 1.00000e-09 7.00000e-02 5.00000e-04 5.00000e-04 5.00000e-05 1.00000e-09 1.00000e-01 5.00000e-04 5.00000e-04 5.00000e-05 1.00000e-09 1.00000e-01 $9.16985 e+009.16985 e+009.16985 e-01$ 1.00000e-09 2.12000e-01 9.16985e+00 9.16985e+00 9.16985e-01 1.00000e-09 2.12000e-01 9.16985e+00 9.16985e+00 9.16985e-01 1.00000e-09 2.12000e-01 9.16985e+00 9.16985e+00 9.16985e-01 1.00000e-09 2.12000e-01 $9.16985 \mathrm{e}+009.16985 \mathrm{e}+00$ 9.16985e-01 1.00000e-09 2.12000e-01 $1.00000 \mathrm{e}-02$ 1.00000e-02 1.00000e-03 1.00000e-09 1.00000e-01 $1.00000 \mathrm{e}+001.00000 \mathrm{e}+001.00000 \mathrm{e}-011.00000 \mathrm{e}-091.00000 \mathrm{e}-01$ $1.00000 \mathrm{e}-05$ 1.00000e-05 1.00000e-06 1.00000e-09 1.00000e-01 $1.00000 \mathrm{e}+001.00000 \mathrm{e}+001.00000 \mathrm{e}-011.00000 \mathrm{e}-091.00000 \mathrm{e}-01$ Element: 4023 \# of layers: 14

$\mathrm{Kx} \mathrm{Ky} \mathrm{Kz}$ Ss Por

2.29494e+02 2.29494e+02 2.29494e+01 1.00000e-09 7.00000e-02 $2.29494 \mathrm{e}+02$ 2.29494e+02 2.29494e+01 1.00000e-09 7.00000e-02 $2.29494 \mathrm{e}+02$ 2.29494e+02 2.29494e+01 1.00000e-09 7.00000e-02 $5.00000 \mathrm{e}-04$ 5.00000e-04 5.00000e-05 1.00000e-09 1.00000e-01 5.00000e-04 5.00000e-04 5.00000e-05 1.00000e-09 1.00000e-01 9.16985e+00 9.16985e+00 9.16985e-01 1.00000e-09 2.12000e-01 $9.16985 \mathrm{e}+009.16985 \mathrm{e}+00$ 9.16985e-01 1.00000e-09 2.12000e-01 9.16985e+00 9.16985e+00 9.16985e-01 1.00000e-09 2.12000e-01 9.16985e+00 9.16985e+00 9.16985e-01 1.00000e-09 2.12000e-01 9.16985e+00 9.16985e+00 9.16985e-01 1.00000e-09 2.12000e-01 $1.00000 \mathrm{e}-02$ 1.00000e-02 1.00000e-03 1.00000e-09 1.00000e-01 $1.00000 \mathrm{e}+001.00000 \mathrm{e}+001.00000 \mathrm{e}-011.00000 \mathrm{e}-091.00000 \mathrm{e}-01$ $1.00000 \mathrm{e}-05$ 1.00000e-05 1.00000e-06 1.00000e-09 1.00000e-01 $1.00000 \mathrm{e}+001.00000 \mathrm{e}+001.00000 \mathrm{e}-01$ 1.00000e-09 1.00000e-01 Element: 4024 \# of layers: 14

$\mathrm{Kx} \mathrm{Ky} \mathrm{Kz}$ Ss Por

2.18276e+02 2.18276e+02 2.18276e+01 1.00000e-09 7.00000e-02 $2.18276 \mathrm{e}+02$ 2.18276e+02 2.18276e+01 1.00000e-09 7.00000e-02 $2.18276 \mathrm{e}+02$ 2.18276e+02 2.18276e+01 1.00000e-09 7.00000e-02 5.00000e-04 5.00000e-04 5.00000e-05 1.00000e-09 1.00000e-01 5.00000e-04 5.00000e-04 5.00000e-05 1.00000e-09 1.00000e-01 $8.72164 \mathrm{e}+008.72164 \mathrm{e}+00$ 8.72164e-01 1.00000e-09 2.12000e-01 $8.72164 \mathrm{e}+008.72164 \mathrm{e}+00$ 8.72164e-01 1.00000e-09 2.12000e-01 $8.72164 \mathrm{e}+008.72164 \mathrm{e}+008.72164 \mathrm{e}-01$ 1.00000e-09 2.12000e-01 
$8.72164 \mathrm{e}+008.72164 \mathrm{e}+008.72164 \mathrm{e}-011.00000 \mathrm{e}-092.12000 \mathrm{e}-01$ $8.72164 \mathrm{e}+008.72164 \mathrm{e}+00$ 8.72164e-01 1.00000e-09 2.12000e-01 $1.00000 \mathrm{e}-021.00000 \mathrm{e}-02$ 1.00000e-03 1.00000e-09 1.00000e-01 $1.00000 \mathrm{e}+001.00000 \mathrm{e}+001.00000 \mathrm{e}-011.00000 \mathrm{e}-091.00000 \mathrm{e}-01$ $1.00000 \mathrm{e}-05$ 1.00000e-05 1.00000e-06 1.00000e-09 1.00000e-01 $1.00000 \mathrm{e}+001.00000 \mathrm{e}+001.00000 \mathrm{e}-011.00000 \mathrm{e}-091.00000 \mathrm{e}-01$ Element: 4025 \# of layers: 14

Kx Ky Kz Ss Por

$2.18276 \mathrm{e}+022.18276 \mathrm{e}+022.18276 \mathrm{e}+01$ 1.00000e-09 7.00000e-02

$2.18276 \mathrm{e}+022.18276 \mathrm{e}+022.18276 \mathrm{e}+01$ 1.00000e-09 7.00000e-02

$2.18276 \mathrm{e}+022.18276 \mathrm{e}+022.18276 \mathrm{e}+01$ 1.00000e-09 7.00000e-02 5.00000e-04 5.00000e-04 5.00000e-05 1.00000e-09 1.00000e-01 5.00000e-04 5.00000e-04 5.00000e-05 1.00000e-09 1.00000e-01

$8.72164 \mathrm{e}+008.72164 \mathrm{e}+008.72164 \mathrm{e}-011.00000 \mathrm{e}-092.12000 \mathrm{e}-01$

$8.72164 \mathrm{e}+008.72164 \mathrm{e}+008.72164 \mathrm{e}-01$ 1.00000e-09 2.12000e-01

$8.72164 \mathrm{e}+008.72164 \mathrm{e}+008.72164 \mathrm{e}-011.00000 \mathrm{e}-092.12000 \mathrm{e}-01$

$8.72164 \mathrm{e}+008.72164 \mathrm{e}+008.72164 \mathrm{e}-011.00000 \mathrm{e}-092.12000 \mathrm{e}-01$

$8.72164 \mathrm{e}+008.72164 \mathrm{e}+008.72164 \mathrm{e}-011.00000 \mathrm{e}-092.12000 \mathrm{e}-01$ $1.00000 \mathrm{e}-02$ 1.00000e-02 1.00000e-03 1.00000e-09 1.00000e-01 $1.00000 \mathrm{e}+001.00000 \mathrm{e}+001.00000 \mathrm{e}-011.00000 \mathrm{e}-091.00000 \mathrm{e}-01$ $1.00000 \mathrm{e}-05$ 1.00000e-05 1.00000e-06 1.00000e-09 1.00000e-01 $1.00000 \mathrm{e}+001.00000 \mathrm{e}+001.00000 \mathrm{e}-011.00000 \mathrm{e}-091.00000 \mathrm{e}-01$ Element: 4026 \# of layers: 14

Kx Ky Kz Ss Por

$2.38576 \mathrm{e}+022.38576 \mathrm{e}+022.38576 \mathrm{e}+01$ 1.00000e-09 7.00000e-02

$2.38576 \mathrm{e}+022.38576 \mathrm{e}+022.38576 \mathrm{e}+011.00000 \mathrm{e}-09$ 7.00000e-02

$2.38576 \mathrm{e}+022.38576 \mathrm{e}+022.38576 \mathrm{e}+01$ 1.00000e-09 7.00000e-02 5.00000e-04 5.00000e-04 5.00000e-05 1.00000e-09 1.00000e-01 5.00000e-04 5.00000e-04 5.00000e-05 1.00000e-09 1.00000e-01 $9.53278 \mathrm{e}+009.53278 \mathrm{e}+00$ 9.53278e-01 1.00000e-09 2.12000e-01 $9.53278 \mathrm{e}+009.53278 \mathrm{e}+00$ 9.53278e-01 1.00000e-09 2.12000e-01 $9.53278 \mathrm{e}+009.53278 \mathrm{e}+00$ 9.53278e-01 1.00000e-09 2.12000e-01 $9.53278 \mathrm{e}+009.53278 \mathrm{e}+00$ 9.53278e-01 1.00000e-09 2.12000e-01 $9.53278 \mathrm{e}+00$ 9.53278e+00 9.53278e-01 1.00000e-09 2.12000e-01 $1.00000 \mathrm{e}-021.00000 \mathrm{e}-02$ 1.00000e-03 1.00000e-09 1.00000e-01 $1.00000 \mathrm{e}+001.00000 \mathrm{e}+001.00000 \mathrm{e}-011.00000 \mathrm{e}-091.00000 \mathrm{e}-01$ $1.00000 \mathrm{e}-05$ 1.00000e-05 1.00000e-06 1.00000e-09 1.00000e-01 $1.00000 \mathrm{e}+001.00000 \mathrm{e}+001.00000 \mathrm{e}-011.00000 \mathrm{e}-091.00000 \mathrm{e}-01$ Element: 4027 \# of layers: 14

Kx Ky Kz Ss Por $3.49363 \mathrm{e}+02$ 3.49363e $+023.49363 \mathrm{e}+01$ 1.00000e-09 7.00000e-02 $3.49363 \mathrm{e}+023.49363 \mathrm{e}+023.49363 \mathrm{e}+01$ 1.00000e-09 7.00000e-02 $3.49363 \mathrm{e}+023.49363 \mathrm{e}+023.49363 \mathrm{e}+01$ 1.00000e-09 7.00000e-02 5.00000e-04 5.00000e-04 5.00000e-05 1.00000e-09 1.00000e-01 5.00000e-04 5.00000e-04 5.00000e-05 1.00000e-09 1.00000e-01 $1.39591 \mathrm{e}+011.39591 \mathrm{e}+011.39591 \mathrm{e}+001.00000 \mathrm{e}-092.12000 \mathrm{e}-01$ 
$1.39591 \mathrm{e}+01$ 1.39591e+01 1.39591e+00 1.00000e-09 2.12000e-01 $1.39591 \mathrm{e}+011.39591 \mathrm{e}+01$ 1.39591e+00 1.00000e-09 2.12000e-01 $1.39591 \mathrm{e}+011.39591 \mathrm{e}+01$ 1.39591e+00 1.00000e-09 2.12000e-01 $1.39591 \mathrm{e}+011.39591 \mathrm{e}+011.39591 \mathrm{e}+001.00000 \mathrm{e}-092.12000 \mathrm{e}-01$ $1.00000 \mathrm{e}-02$ 1.00000e-02 1.00000e-03 1.00000e-09 1.00000e-01 $1.00000 \mathrm{e}+001.00000 \mathrm{e}+001.00000 \mathrm{e}-011.00000 \mathrm{e}-091.00000 \mathrm{e}-01$ $1.00000 \mathrm{e}-05$ 1.00000e-05 1.00000e-06 1.00000e-09 1.00000e-01 $1.00000 \mathrm{e}+001.00000 \mathrm{e}+001.00000 \mathrm{e}-011.00000 \mathrm{e}-091.00000 \mathrm{e}-01$ Element: 4028 \# of layers: 14

$\mathrm{Kx} \mathrm{Ky} \mathrm{Kz}$ Ss Por

$2.29494 \mathrm{e}+02$ 2.29494e+02 2.29494e+01 1.00000e-09 7.00000e-02 $2.29494 \mathrm{e}+02$ 2.29494e+02 2.29494e+01 1.00000e-09 7.00000e-02 $2.29494 \mathrm{e}+02$ 2.29494e+02 2.29494e+01 1.00000e-09 7.00000e-02 5.00000e-04 5.00000e-04 5.00000e-05 1.00000e-09 1.00000e-01 5.00000e-04 5.00000e-04 5.00000e-05 1.00000e-09 1.00000e-01 $9.16985 e+009.16985 e+00$ 9.16985e-01 1.00000e-09 2.12000e-01 $9.16985 \mathrm{e}+00$ 9.16985e+00 9.16985e-01 1.00000e-09 2.12000e-01 9.16985e+00 9.16985e+00 9.16985e-01 1.00000e-09 2.12000e-01 9.16985e+00 9.16985e+00 9.16985e-01 1.00000e-09 2.12000e-01 9.16985e+00 9.16985e+00 9.16985e-01 1.00000e-09 2.12000e-01 $1.00000 \mathrm{e}-02$ 1.00000e-02 1.00000e-03 1.00000e-09 1.00000e-01 $1.00000 \mathrm{e}+001.00000 \mathrm{e}+001.00000 \mathrm{e}-011.00000 \mathrm{e}-091.00000 \mathrm{e}-01$ $1.00000 \mathrm{e}-05$ 1.00000e-05 1.00000e-06 1.00000e-09 1.00000e-01 $1.00000 \mathrm{e}+001.00000 \mathrm{e}+001.00000 \mathrm{e}-011.00000 \mathrm{e}-091.00000 \mathrm{e}-01$ Element: 4029 \# of layers: 14

$\mathrm{Kx} \mathrm{Ky} \mathrm{Kz}$ Ss Por

2.13222e+02 2.13222e+02 2.13222e+01 1.00000e-09 7.00000e-02 2.13222e+02 2.13222e+02 2.13222e+01 1.00000e-09 7.00000e-02 $2.13222 \mathrm{e}+02$ 2.13222e+02 2.13222e+01 1.00000e-09 7.00000e-02 5.00000e-04 5.00000e-04 5.00000e-05 1.00000e-09 1.00000e-01 5.00000e-04 5.00000e-04 5.00000e-05 1.00000e-09 1.00000e-01 8.51958e+00 8.51958e+00 8.51958e-01 1.00000e-09 2.12000e-01 8.51958e+00 8.51958e+00 8.51958e-01 1.00000e-09 2.12000e-01 8.51958e+00 8.51958e+00 8.51958e-01 1.00000e-09 2.12000e-01 8.51958e+00 8.51958e+00 8.51958e-01 1.00000e-09 2.12000e-01 8.51958e+00 8.51958e+00 8.51958e-01 1.00000e-09 2.12000e-01 $1.00000 \mathrm{e}-02$ 1.00000e-02 1.00000e-03 1.00000e-09 1.00000e-01 $1.00000 \mathrm{e}+001.00000 \mathrm{e}+001.00000 \mathrm{e}-011.00000 \mathrm{e}-091.00000 \mathrm{e}-01$ $1.00000 \mathrm{e}-05$ 1.00000e-05 1.00000e-06 1.00000e-09 1.00000e-01 $1.00000 \mathrm{e}+001.00000 \mathrm{e}+001.00000 \mathrm{e}-01$ 1.00000e-09 1.00000e-01 Element: 4030 \# of layers: 14

$\mathrm{Kx} \mathrm{Ky} \mathrm{Kz}$ Ss Por

2.16862e+02 2.16862e+02 2.16862e+01 1.00000e-09 7.00000e-02 2.16862e+02 2.16862e+02 2.16862e+01 1.00000e-09 7.00000e-02 $2.16862 \mathrm{e}+02$ 2.16862e+02 2.16862e+01 1.00000e-09 7.00000e-02 5.00000e-04 5.00000e-04 5.00000e-05 1.00000e-09 1.00000e-01 
5.00000e-04 5.00000e-04 5.00000e-05 1.00000e-09 1.00000e-01 $8.66516 \mathrm{e}+008.66516 \mathrm{e}+008.66516 \mathrm{e}-01$ 1.00000e-09 2.12000e-01 $8.66516 \mathrm{e}+008.66516 \mathrm{e}+00$ 8.66516e-01 1.00000e-09 2.12000e-01 $8.66516 \mathrm{e}+008.66516 \mathrm{e}+008.66516 \mathrm{e}-01$ 1.00000e-09 2.12000e-01 $8.66516 \mathrm{e}+008.66516 \mathrm{e}+008.66516 \mathrm{e}-01$ 1.00000e-09 2.12000e-01 $8.66516 \mathrm{e}+008.66516 \mathrm{e}+008.66516 \mathrm{e}-01$ 1.00000e-09 2.12000e-01 $1.00000 \mathrm{e}-02$ 1.00000e-02 1.00000e-03 1.00000e-09 1.00000e-01 $1.00000 \mathrm{e}+001.00000 \mathrm{e}+001.00000 \mathrm{e}-011.00000 \mathrm{e}-091.00000 \mathrm{e}-01$ $1.00000 \mathrm{e}-05$ 1.00000e-05 1.00000e-06 1.00000e-09 1.00000e-01 $1.00000 \mathrm{e}+001.00000 \mathrm{e}+001.00000 \mathrm{e}-011.00000 \mathrm{e}-091.00000 \mathrm{e}-01$ Element: 4031 \# of layers: 14

$\mathrm{Kx} \mathrm{Ky} \mathrm{Kz}$ Ss Por

2.16862e+02 2.16862e+02 2.16862e+01 1.00000e-09 7.00000e-02

$2.16862 \mathrm{e}+02$ 2.16862e+02 2.16862e+01 1.00000e-09 7.00000e-02

$2.16862 \mathrm{e}+022.16862 \mathrm{e}+022.16862 \mathrm{e}+01$ 1.00000e-09 7.00000e-02 5.00000e-04 5.00000e-04 5.00000e-05 1.00000e-09 1.00000e-01 5.00000e-04 5.00000e-04 5.00000e-05 1.00000e-09 1.00000e-01

$8.66516 \mathrm{e}+008.66516 \mathrm{e}+00$ 8.66516e-01 1.00000e-09 2.12000e-01 $8.66516 \mathrm{e}+00$ 8.66516e+00 8.66516e-01 1.00000e-09 2.12000e-01 $8.66516 \mathrm{e}+008.66516 \mathrm{e}+00$ 8.66516e-01 1.00000e-09 2.12000e-01 $8.66516 \mathrm{e}+008.66516 \mathrm{e}+00$ 8.66516e-01 1.00000e-09 2.12000e-01 8.66516e+00 8.66516e+00 8.66516e-01 1.00000e-09 2.12000e-01 $1.00000 \mathrm{e}-02$ 1.00000e-02 1.00000e-03 1.00000e-09 1.00000e-01 $1.00000 \mathrm{e}+001.00000 \mathrm{e}+001.00000 \mathrm{e}-011.00000 \mathrm{e}-091.00000 \mathrm{e}-01$ $1.00000 \mathrm{e}-05$ 1.00000e-05 1.00000e-06 1.00000e-09 1.00000e-01 $1.00000 \mathrm{e}+001.00000 \mathrm{e}+001.00000 \mathrm{e}-011.00000 \mathrm{e}-091.00000 \mathrm{e}-01$ Element: 4032 \# of layers: 14

$\mathrm{Kx} \mathrm{Ky} \mathrm{Kz}$ Ss Por

2.16862e+02 2.16862e+02 2.16862e+01 1.00000e-09 7.00000e-02 $2.16862 \mathrm{e}+02$ 2.16862e+02 2.16862e+01 1.00000e-09 7.00000e-02 $2.16862 \mathrm{e}+022.16862 \mathrm{e}+022.16862 \mathrm{e}+01$ 1.00000e-09 7.00000e-02 5.00000e-04 5.00000e-04 5.00000e-05 1.00000e-09 1.00000e-01 5.00000e-04 5.00000e-04 5.00000e-05 1.00000e-09 1.00000e-01 $8.66516 \mathrm{e}+008.66516 \mathrm{e}+00$ 8.66516e-01 1.00000e-09 2.12000e-01 $8.66516 \mathrm{e}+00$ 8.66516e+00 8.66516e-01 1.00000e-09 2.12000e-01 $8.66516 \mathrm{e}+008.66516 \mathrm{e}+00$ 8.66516e-01 1.00000e-09 2.12000e-01 $8.66516 \mathrm{e}+008.66516 \mathrm{e}+008.66516 \mathrm{e}-01$ 1.00000e-09 2.12000e-01 $8.66516 \mathrm{e}+00$ 8.66516e+00 8.66516e-01 1.00000e-09 2.12000e-01 $1.00000 \mathrm{e}-02$ 1.00000e-02 1.00000e-03 1.00000e-09 1.00000e-01 $1.00000 \mathrm{e}+001.00000 \mathrm{e}+001.00000 \mathrm{e}-011.00000 \mathrm{e}-091.00000 \mathrm{e}-01$ $1.00000 \mathrm{e}-05$ 1.00000e-05 1.00000e-06 1.00000e-09 1.00000e-01 $1.00000 \mathrm{e}+001.00000 \mathrm{e}+001.00000 \mathrm{e}-011.00000 \mathrm{e}-091.00000 \mathrm{e}-01$ Element: 4033 \# of layers: 14

$\mathrm{Kx} \mathrm{Ky} \mathrm{Kz}$ Ss Por

$2.24439 \mathrm{e}+02$ 2.24439e+02 2.24439e+01 1.00000e-09 7.00000e-02 $2.24439 \mathrm{e}+02$ 2.24439e+02 2.24439e+01 1.00000e-09 7.00000e-02 
$2.24439 \mathrm{e}+02$ 2.24439e+02 2.24439e+01 1.00000e-09 7.00000e-02 5.00000e-04 5.00000e-04 5.00000e-05 1.00000e-09 1.00000e-01 5.00000e-04 5.00000e-04 5.00000e-05 1.00000e-09 1.00000e-01 $8.96802 \mathrm{e}+00$ 8.96802e+00 8.96802e-01 1.00000e-09 2.12000e-01 8.96802e+00 8.96802e+00 8.96802e-01 1.00000e-09 2.12000e-01 8.96802e+00 8.96802e+00 8.96802e-01 1.00000e-09 2.12000e-01 8.96802e+00 8.96802e+00 8.96802e-01 1.00000e-09 2.12000e-01 $8.96802 \mathrm{e}+00$ 8.96802e+00 8.96802e-01 1.00000e-09 2.12000e-01 $1.00000 \mathrm{e}-021.00000 \mathrm{e}-021.00000 \mathrm{e}-031.00000 \mathrm{e}-091.00000 \mathrm{e}-01$ $1.00000 \mathrm{e}+001.00000 \mathrm{e}+001.00000 \mathrm{e}-011.00000 \mathrm{e}-091.00000 \mathrm{e}-01$ $1.00000 \mathrm{e}-05$ 1.00000e-05 1.00000e-06 1.00000e-09 1.00000e-01 $1.00000 \mathrm{e}+001.00000 \mathrm{e}+001.00000 \mathrm{e}-011.00000 \mathrm{e}-091.00000 \mathrm{e}-01$ Element: 4034 \# of layers: 14

$\mathrm{Kx} \mathrm{Ky} \mathrm{Kz}$ Ss Por

2.24439e+02 2.24439e+02 2.24439e+01 1.00000e-09 7.00000e-02 $2.24439 \mathrm{e}+02$ 2.24439e+02 2.24439e+01 1.00000e-09 7.00000e-02 $2.24439 \mathrm{e}+02$ 2.24439e+02 2.24439e+01 1.00000e-09 7.00000e-02 5.00000e-04 5.00000e-04 5.00000e-05 1.00000e-09 1.00000e-01 $5.00000 \mathrm{e}-04$ 5.00000e-04 5.00000e-05 1.00000e-09 1.00000e-01 $8.96802 \mathrm{e}+00$ 8.96802e+00 8.96802e-01 1.00000e-09 2.12000e-01 $8.96802 \mathrm{e}+008.96802 \mathrm{e}+00$ 8.96802e-01 1.00000e-09 2.12000e-01 $8.96802 \mathrm{e}+00$ 8.96802e+00 8.96802e-01 1.00000e-09 2.12000e-01 8.96802e+00 8.96802e+00 8.96802e-01 1.00000e-09 2.12000e-01 8.96802e+00 8.96802e+00 8.96802e-01 1.00000e-09 2.12000e-01 $1.00000 \mathrm{e}-021.00000 \mathrm{e}-02$ 1.00000e-03 1.00000e-09 1.00000e-01 $1.00000 \mathrm{e}+001.00000 \mathrm{e}+001.00000 \mathrm{e}-011.00000 \mathrm{e}-091.00000 \mathrm{e}-01$ $1.00000 \mathrm{e}-05$ 1.00000e-05 1.00000e-06 1.00000e-09 1.00000e-01 $1.00000 \mathrm{e}+001.00000 \mathrm{e}+001.00000 \mathrm{e}-011.00000 \mathrm{e}-09$ 1.00000e-01 Element: 4035 \# of layers: 14

$\mathrm{Kx} \mathrm{Ky} \mathrm{Kz}$ Ss Por

2.24412e+02 2.24412e+02 2.24412e+01 1.00000e-09 7.00000e-02 $2.24412 \mathrm{e}+02$ 2.24412e+02 2.24412e+01 1.00000e-09 7.00000e-02 $2.24412 \mathrm{e}+02$ 2.24412e+02 2.24412e+01 1.00000e-09 7.00000e-02 $5.00000 \mathrm{e}-045.00000 \mathrm{e}-045.00000 \mathrm{e}-051.00000 \mathrm{e}-091.00000 \mathrm{e}-01$ 5.00000e-04 5.00000e-04 5.00000e-05 1.00000e-09 1.00000e-01 8.96667e+00 8.96667e+00 8.96667e-01 1.00000e-09 2.12000e-01 8.96667e+00 8.96667e+00 8.96667e-01 1.00000e-09 2.12000e-01 8.96667e+00 8.96667e+00 8.96667e-01 1.00000e-09 2.12000e-01 8.96667e+00 8.96667e+00 8.96667e-01 1.00000e-09 2.12000e-01 8.96667e+00 8.96667e+00 8.96667e-01 1.00000e-09 2.12000e-01 $1.00000 \mathrm{e}-02$ 1.00000e-02 1.00000e-03 1.00000e-09 1.00000e-01 $1.00000 \mathrm{e}+001.00000 \mathrm{e}+001.00000 \mathrm{e}-011.00000 \mathrm{e}-091.00000 \mathrm{e}-01$ $1.00000 \mathrm{e}-05$ 1.00000e-05 1.00000e-06 1.00000e-09 1.00000e-01 $1.00000 \mathrm{e}+001.00000 \mathrm{e}+001.00000 \mathrm{e}-01$ 1.00000e-09 1.00000e-01 Element: 4036 \# of layers: 14

Kx Ky Kz Ss Por 
$2.13222 \mathrm{e}+022.13222 \mathrm{e}+022.13222 \mathrm{e}+01$ 1.00000e-09 7.00000e-02 2.13222e+02 2.13222e+02 2.13222e+01 1.00000e-09 7.00000e-02 $2.13222 \mathrm{e}+022.13222 \mathrm{e}+022.13222 \mathrm{e}+01$ 1.00000e-09 7.00000e-02 5.00000e-04 5.00000e-04 5.00000e-05 1.00000e-09 1.00000e-01 $5.00000 \mathrm{e}-04$ 5.00000e-04 5.00000e-05 1.00000e-09 1.00000e-01 $8.51958 \mathrm{e}+008.51958 \mathrm{e}+008.51958 \mathrm{e}-011.00000 \mathrm{e}-092.12000 \mathrm{e}-01$ $8.51958 \mathrm{e}+008.51958 \mathrm{e}+008.51958 \mathrm{e}-011.00000 \mathrm{e}-092.12000 \mathrm{e}-01$ $8.51958 \mathrm{e}+008.51958 \mathrm{e}+008.51958 \mathrm{e}-011.00000 \mathrm{e}-092.12000 \mathrm{e}-01$ $8.51958 \mathrm{e}+008.51958 \mathrm{e}+008.51958 \mathrm{e}-011.00000 \mathrm{e}-092.12000 \mathrm{e}-01$ $8.51958 \mathrm{e}+008.51958 \mathrm{e}+00$ 8.51958e-01 1.00000e-09 2.12000e-01 $1.00000 \mathrm{e}-021.00000 \mathrm{e}-02$ 1.00000e-03 1.00000e-09 1.00000e-01 $1.00000 \mathrm{e}+001.00000 \mathrm{e}+001.00000 \mathrm{e}-011.00000 \mathrm{e}-091.00000 \mathrm{e}-01$ $1.00000 \mathrm{e}-05$ 1.00000e-05 1.00000e-06 1.00000e-09 1.00000e-01 $1.00000 \mathrm{e}+001.00000 \mathrm{e}+001.00000 \mathrm{e}-011.00000 \mathrm{e}-091.00000 \mathrm{e}-01$ Element: 4037 \# of layers: 14

Kx Ky Kz Ss Por

$2.16862 \mathrm{e}+022.16862 \mathrm{e}+022.16862 \mathrm{e}+01$ 1.00000e-09 7.00000e-02 $2.16862 \mathrm{e}+022.16862 \mathrm{e}+022.16862 \mathrm{e}+01$ 1.00000e-09 7.00000e-02 $2.16862 \mathrm{e}+022.16862 \mathrm{e}+022.16862 \mathrm{e}+01$ 1.00000e-09 7.00000e-02 5.00000e-04 5.00000e-04 5.00000e-05 1.00000e-09 1.00000e-01 5.00000e-04 5.00000e-04 5.00000e-05 1.00000e-09 1.00000e-01 $8.66516 \mathrm{e}+008.66516 \mathrm{e}+008.66516 \mathrm{e}-01$ 1.00000e-09 2.12000e-01 $8.66516 \mathrm{e}+008.66516 \mathrm{e}+00$ 8.66516e-01 1.00000e-09 2.12000e-01 $8.66516 \mathrm{e}+008.66516 \mathrm{e}+008.66516 \mathrm{e}-011.00000 \mathrm{e}-092.12000 \mathrm{e}-01$ $8.66516 \mathrm{e}+008.66516 \mathrm{e}+008.66516 \mathrm{e}-011.00000 \mathrm{e}-092.12000 \mathrm{e}-01$ $8.66516 \mathrm{e}+008.66516 \mathrm{e}+00$ 8.66516e-01 1.00000e-09 2.12000e-01 $1.00000 \mathrm{e}-021.00000 \mathrm{e}-02$ 1.00000e-03 1.00000e-09 1.00000e-01 $1.00000 \mathrm{e}+001.00000 \mathrm{e}+001.00000 \mathrm{e}-011.00000 \mathrm{e}-091.00000 \mathrm{e}-01$ $1.00000 \mathrm{e}-05$ 1.00000e-05 1.00000e-06 1.00000e-09 1.00000e-01 $1.00000 \mathrm{e}+001.00000 \mathrm{e}+001.00000 \mathrm{e}-011.00000 \mathrm{e}-091.00000 \mathrm{e}-01$ Element: 4038 \# of layers: 14

Kx Ky Kz Ss Por $2.01995 \mathrm{e}+022.01995 \mathrm{e}+022.01995 \mathrm{e}+01$ 1.00000e-09 7.00000e-02 $2.01995 \mathrm{e}+022.01995 \mathrm{e}+022.01995 \mathrm{e}+01$ 1.00000e-09 7.00000e-02 $2.01995 \mathrm{e}+022.01995 \mathrm{e}+022.01995 \mathrm{e}+01$ 1.00000e-09 7.00000e-02 5.00000e-04 5.00000e-04 5.00000e-05 1.00000e-09 1.00000e-01 $5.00000 \mathrm{e}-04$ 5.00000e-04 5.00000e-05 1.00000e-09 1.00000e-01 $8.07115 \mathrm{e}+008.07115 \mathrm{e}+00$ 8.07115e-01 1.00000e-09 2.12000e-01 $8.07115 \mathrm{e}+008.07115 \mathrm{e}+008.07115 \mathrm{e}-011.00000 \mathrm{e}-092.12000 \mathrm{e}-01$ $8.07115 \mathrm{e}+008.07115 \mathrm{e}+00$ 8.07115e-01 1.00000e-09 2.12000e-01 $8.07115 \mathrm{e}+008.07115 \mathrm{e}+00$ 8.07115e-01 1.00000e-09 2.12000e-01 $8.07115 \mathrm{e}+008.07115 \mathrm{e}+008.07115 \mathrm{e}-011.00000 \mathrm{e}-092.12000 \mathrm{e}-01$ $1.00000 \mathrm{e}-021.00000 \mathrm{e}-02$ 1.00000e-03 1.00000e-09 1.00000e-01 $1.00000 \mathrm{e}+001.00000 \mathrm{e}+001.00000 \mathrm{e}-011.00000 \mathrm{e}-091.00000 \mathrm{e}-01$ $1.00000 \mathrm{e}-05$ 1.00000e-05 1.00000e-06 1.00000e-09 1.00000e-01 $1.00000 \mathrm{e}+001.00000 \mathrm{e}+001.00000 \mathrm{e}-011.00000 \mathrm{e}-091.00000 \mathrm{e}-01$ 
Element: 4039 \# of layers: 14

$\mathrm{Kx} \mathrm{Ky} \mathrm{Kz}$ Ss Por

4.24659e+01 4.24659e+01 4.24659e+00 1.00000e-09 7.00000e-02

$4.24659 \mathrm{e}+01$ 4.24659e+01 4.24659e+00 1.00000e-09 7.00000e-02

$4.24659 \mathrm{e}+014.24659 \mathrm{e}+014.24659 \mathrm{e}+001.00000 \mathrm{e}-09$ 7.00000e-02

5.00000e-04 5.00000e-04 5.00000e-05 1.00000e-09 1.00000e-01

5.00000e-04 5.00000e-04 5.00000e-05 1.00000e-09 1.00000e-01

$1.69678 \mathrm{e}+001.69678 \mathrm{e}+00$ 1.69678e-01 1.00000e-09 2.12000e-01

$1.69678 \mathrm{e}+001.69678 \mathrm{e}+00$ 1.69678e-01 1.00000e-09 2.12000e-01

$1.69678 \mathrm{e}+001.69678 \mathrm{e}+00$ 1.69678e-01 1.00000e-09 2.12000e-01

$1.69678 \mathrm{e}+001.69678 \mathrm{e}+00$ 1.69678e-01 1.00000e-09 2.12000e-01

$1.69678 \mathrm{e}+001.69678 \mathrm{e}+001.69678 \mathrm{e}-01$ 1.00000e-09 2.12000e-01

$1.00000 \mathrm{e}-02$ 1.00000e-02 1.00000e-03 1.00000e-09 1.00000e-01

$1.00000 \mathrm{e}+001.00000 \mathrm{e}+001.00000 \mathrm{e}-011.00000 \mathrm{e}-091.00000 \mathrm{e}-01$

$1.00000 \mathrm{e}-05$ 1.00000e-05 1.00000e-06 1.00000e-09 1.00000e-01

$1.00000 \mathrm{e}+001.00000 \mathrm{e}+001.00000 \mathrm{e}-011.00000 \mathrm{e}-091.00000 \mathrm{e}-01$

Element: 4040 \# of layers: 15

$\mathrm{Kx} \mathrm{Ky} \mathrm{Kz}$ Ss Por

4.24659e+01 4.24659e+01 4.24659e+00 1.00000e-09 7.00000e-02

$4.24659 \mathrm{e}+014.24659 \mathrm{e}+014.24659 \mathrm{e}+00$ 1.00000e-09 7.00000e-02

$4.24659 \mathrm{e}+014.24659 \mathrm{e}+014.24659 \mathrm{e}+00$ 1.00000e-09 7.00000e-02

4.24659e+01 4.24659e+01 4.24659e+00 1.00000e-09 7.00000e-02

5.00000e-04 5.00000e-04 5.00000e-05 1.00000e-09 1.00000e-01

5.00000e-04 5.00000e-04 5.00000e-05 1.00000e-09 1.00000e-01

$1.69678 \mathrm{e}+001.69678 \mathrm{e}+00$ 1.69678e-01 1.00000e-09 2.12000e-01

$1.69678 \mathrm{e}+001.69678 \mathrm{e}+00$ 1.69678e-01 1.00000e-09 2.12000e-01

$1.69678 \mathrm{e}+001.69678 \mathrm{e}+00$ 1.69678e-01 1.00000e-09 2.12000e-01

$1.69678 \mathrm{e}+001.69678 \mathrm{e}+00$ 1.69678e-01 1.00000e-09 2.12000e-01

$1.69678 \mathrm{e}+001.69678 \mathrm{e}+001.69678 \mathrm{e}-01$ 1.00000e-09 2.12000e-01

$1.00000 \mathrm{e}-02$ 1.00000e-02 1.00000e-03 1.00000e-09 1.00000e-01

$1.00000 \mathrm{e}+001.00000 \mathrm{e}+001.00000 \mathrm{e}-011.00000 \mathrm{e}-091.00000 \mathrm{e}-01$

$1.00000 \mathrm{e}-05$ 1.00000e-05 1.00000e-06 1.00000e-09 1.00000e-01

$1.00000 \mathrm{e}+001.00000 \mathrm{e}+001.00000 \mathrm{e}-011.00000 \mathrm{e}-091.00000 \mathrm{e}-01$

Element: 4041 \# of layers: 15

$\mathrm{Kx} \mathrm{Ky} \mathrm{Kz}$ Ss Por

4.24659e+01 4.24659e+01 4.24659e+00 1.00000e-09 7.00000e-02 $4.24659 \mathrm{e}+014.24659 \mathrm{e}+014.24659 \mathrm{e}+00$ 1.00000e-09 7.00000e-02 4.24659e+01 4.24659e+01 4.24659e+00 1.00000e-09 7.00000e-02 4.24659e+01 4.24659e+01 4.24659e+00 1.00000e-09 7.00000e-02 5.00000e-04 5.00000e-04 5.00000e-05 1.00000e-09 1.00000e-01 5.00000e-04 5.00000e-04 5.00000e-05 1.00000e-09 1.00000e-01

$1.69678 \mathrm{e}+001.69678 \mathrm{e}+00$ 1.69678e-01 1.00000e-09 2.12000e-01 $1.69678 \mathrm{e}+00$ 1.69678e+00 1.69678e-01 1.00000e-09 2.12000e-01 $1.69678 \mathrm{e}+001.69678 \mathrm{e}+00$ 1.69678e-01 1.00000e-09 2.12000e-01 $1.69678 \mathrm{e}+001.69678 \mathrm{e}+00$ 1.69678e-01 1.00000e-09 2.12000e-01 $1.69678 \mathrm{e}+001.69678 \mathrm{e}+00$ 1.69678e-01 1.00000e-09 2.12000e-01 
$1.00000 \mathrm{e}-02$ 1.00000e-02 1.00000e-03 1.00000e-09 1.00000e-01 $1.00000 \mathrm{e}+001.00000 \mathrm{e}+001.00000 \mathrm{e}-011.00000 \mathrm{e}-091.00000 \mathrm{e}-01$ $1.00000 \mathrm{e}-051.00000 \mathrm{e}-05$ 1.00000e-06 1.00000e-09 1.00000e-01 $1.00000 \mathrm{e}+001.00000 \mathrm{e}+001.00000 \mathrm{e}-011.00000 \mathrm{e}-091.00000 \mathrm{e}-01$ Element: 4042 \# of layers: 15

Kx Ky Kz Ss Por

$2.82761 \mathrm{e}+012.82761 \mathrm{e}+012.82761 \mathrm{e}+00$ 1.00000e-09 7.00000e-02 $2.82761 \mathrm{e}+012.82761 \mathrm{e}+012.82761 \mathrm{e}+001.00000 \mathrm{e}-097.00000 \mathrm{e}-02$ $2.82761 \mathrm{e}+012.82761 \mathrm{e}+012.82761 \mathrm{e}+001.00000 \mathrm{e}-097.00000 \mathrm{e}-02$ $2.82761 \mathrm{e}+012.82761 \mathrm{e}+012.82761 \mathrm{e}+001.00000 \mathrm{e}-097.00000 \mathrm{e}-02$ 5.00000e-04 5.00000e-04 5.00000e-05 1.00000e-09 1.00000e-01 5.00000e-04 5.00000e-04 5.00000e-05 1.00000e-09 1.00000e-01

$1.12982 \mathrm{e}+001.12982 \mathrm{e}+00$ 1.12982e-01 1.00000e-09 2.12000e-01 $1.12982 \mathrm{e}+001.12982 \mathrm{e}+00$ 1.12982e-01 1.00000e-09 2.12000e-01 $1.12982 \mathrm{e}+001.12982 \mathrm{e}+00$ 1.12982e-01 1.00000e-09 2.12000e-01 $1.12982 \mathrm{e}+001.12982 \mathrm{e}+00$ 1.12982e-01 1.00000e-09 2.12000e-01 $1.12982 \mathrm{e}+001.12982 \mathrm{e}+00$ 1.12982e-01 1.00000e-09 2.12000e-01 $1.00000 \mathrm{e}-02$ 1.00000e-02 1.00000e-03 1.00000e-09 1.00000e-01 $1.00000 \mathrm{e}+001.00000 \mathrm{e}+001.00000 \mathrm{e}-011.00000 \mathrm{e}-091.00000 \mathrm{e}-01$ $1.00000 \mathrm{e}-051.00000 \mathrm{e}-05$ 1.00000e-06 1.00000e-09 1.00000e-01 $1.00000 \mathrm{e}+001.00000 \mathrm{e}+001.00000 \mathrm{e}-011.00000 \mathrm{e}-091.00000 \mathrm{e}-01$ Element: 4043 \# of layers: 14

Kx Ky Kz Ss Por

$2.82761 \mathrm{e}+012.82761 \mathrm{e}+012.82761 \mathrm{e}+00$ 1.00000e-09 7.00000e-02 $2.82761 \mathrm{e}+012.82761 \mathrm{e}+012.82761 \mathrm{e}+001.00000 \mathrm{e}-09$ 7.00000e-02 $2.82761 \mathrm{e}+012.82761 \mathrm{e}+012.82761 \mathrm{e}+001.00000 \mathrm{e}-097.00000 \mathrm{e}-02$ 5.00000e-04 5.00000e-04 5.00000e-05 1.00000e-09 1.00000e-01 5.00000e-04 5.00000e-04 5.00000e-05 1.00000e-09 1.00000e-01

$1.12982 \mathrm{e}+001.12982 \mathrm{e}+00$ 1.12982e-01 1.00000e-09 2.12000e-01 $1.12982 \mathrm{e}+001.12982 \mathrm{e}+00$ 1.12982e-01 1.00000e-09 2.12000e-01 $1.12982 \mathrm{e}+001.12982 \mathrm{e}+00$ 1.12982e-01 1.00000e-09 2.12000e-01 $1.12982 \mathrm{e}+001.12982 \mathrm{e}+00$ 1.12982e-01 1.00000e-09 2.12000e-01 $1.12982 \mathrm{e}+001.12982 \mathrm{e}+00$ 1.12982e-01 1.00000e-09 2.12000e-01 $1.00000 \mathrm{e}-021.00000 \mathrm{e}-02$ 1.00000e-03 1.00000e-09 1.00000e-01 $1.00000 \mathrm{e}+001.00000 \mathrm{e}+001.00000 \mathrm{e}-011.00000 \mathrm{e}-091.00000 \mathrm{e}-01$ $1.00000 \mathrm{e}-05$ 1.00000e-05 1.00000e-06 1.00000e-09 1.00000e-01 $1.00000 \mathrm{e}+001.00000 \mathrm{e}+001.00000 \mathrm{e}-011.00000 \mathrm{e}-091.00000 \mathrm{e}-01$ Element: 4044 \# of layers: 14

Kx Ky Kz Ss Por

$9.99029 \mathrm{e}+01$ 9.99029e+01 9.99029e+00 1.00000e-09 7.00000e-02 $9.99029 \mathrm{e}+019.99029 \mathrm{e}+019.99029 \mathrm{e}+001.00000 \mathrm{e}-09$ 7.00000e-02 $9.99029 \mathrm{e}+019.99029 \mathrm{e}+019.99029 \mathrm{e}+001.00000 \mathrm{e}-09$ 7.00000e-02 5.00000e-04 5.00000e-04 5.00000e-05 1.00000e-09 1.00000e-01 5.00000e-04 5.00000e-04 5.00000e-05 1.00000e-09 1.00000e-01 $3.99181 \mathrm{e}+003.99181 \mathrm{e}+003.99181 \mathrm{e}-011.00000 \mathrm{e}-092.12000 \mathrm{e}-01$ $3.99181 \mathrm{e}+003.99181 \mathrm{e}+003.99181 \mathrm{e}-01$ 1.00000e-09 2.12000e-01 
$3.99181 \mathrm{e}+003.99181 \mathrm{e}+003.99181 \mathrm{e}-011.00000 \mathrm{e}-092.12000 \mathrm{e}-01$ $3.99181 \mathrm{e}+003.99181 \mathrm{e}+003.99181 \mathrm{e}-01$ 1.00000e-09 2.12000e-01 $3.99181 \mathrm{e}+003.99181 \mathrm{e}+003.99181 \mathrm{e}-01$ 1.00000e-09 2.12000e-01 $1.00000 \mathrm{e}-021.00000 \mathrm{e}-02$ 1.00000e-03 1.00000e-09 1.00000e-01 $1.00000 \mathrm{e}+001.00000 \mathrm{e}+001.00000 \mathrm{e}-011.00000 \mathrm{e}-091.00000 \mathrm{e}-01$ $1.00000 \mathrm{e}-05$ 1.00000e-05 1.00000e-06 1.00000e-09 1.00000e-01 $1.00000 \mathrm{e}+001.00000 \mathrm{e}+001.00000 \mathrm{e}-011.00000 \mathrm{e}-091.00000 \mathrm{e}-01$ Element: 4045 \# of layers: 14

Kx Ky Kz Ss Por

$2.01995 \mathrm{e}+022.01995 \mathrm{e}+022.01995 \mathrm{e}+01$ 1.00000e-09 7.00000e-02 $2.01995 \mathrm{e}+022.01995 \mathrm{e}+022.01995 \mathrm{e}+01$ 1.00000e-09 7.00000e-02 $2.01995 \mathrm{e}+022.01995 \mathrm{e}+022.01995 \mathrm{e}+01$ 1.00000e-09 7.00000e-02 5.00000e-04 5.00000e-04 5.00000e-05 1.00000e-09 1.00000e-01 $5.00000 \mathrm{e}-04$ 5.00000e-04 5.00000e-05 1.00000e-09 1.00000e-01 $8.07115 \mathrm{e}+008.07115 \mathrm{e}+008.07115 \mathrm{e}-011.00000 \mathrm{e}-092.12000 \mathrm{e}-01$ $8.07115 \mathrm{e}+008.07115 \mathrm{e}+008.07115 \mathrm{e}-011.00000 \mathrm{e}-092.12000 \mathrm{e}-01$ $8.07115 \mathrm{e}+008.07115 \mathrm{e}+008.07115 \mathrm{e}-011.00000 \mathrm{e}-092.12000 \mathrm{e}-01$ $8.07115 \mathrm{e}+008.07115 \mathrm{e}+00$ 8.07115e-01 1.00000e-09 2.12000e-01 $8.07115 \mathrm{e}+008.07115 \mathrm{e}+00$ 8.07115e-01 1.00000e-09 2.12000e-01 $1.00000 \mathrm{e}-021.00000 \mathrm{e}-02$ 1.00000e-03 1.00000e-09 1.00000e-01 $1.00000 \mathrm{e}+001.00000 \mathrm{e}+001.00000 \mathrm{e}-011.00000 \mathrm{e}-091.00000 \mathrm{e}-01$ $1.00000 \mathrm{e}-05$ 1.00000e-05 1.00000e-06 1.00000e-09 1.00000e-01 $1.00000 \mathrm{e}+001.00000 \mathrm{e}+001.00000 \mathrm{e}-011.00000 \mathrm{e}-091.00000 \mathrm{e}-01$ Element: 4046 \# of layers: 14

Kx Ky Kz Ss Por 4.24659e+01 4.24659e+01 4.24659e+00 1.00000e-09 7.00000e-02 $4.24659 \mathrm{e}+014.24659 \mathrm{e}+014.24659 \mathrm{e}+001.00000 \mathrm{e}-09$ 7.00000e-02 $4.24659 \mathrm{e}+014.24659 \mathrm{e}+014.24659 \mathrm{e}+001.00000 \mathrm{e}-09$ 7.00000e-02 5.00000e-04 5.00000e-04 5.00000e-05 1.00000e-09 1.00000e-01 5.00000e-04 5.00000e-04 5.00000e-05 1.00000e-09 1.00000e-01 $1.69678 \mathrm{e}+001.69678 \mathrm{e}+001.69678 \mathrm{e}-011.00000 \mathrm{e}-092.12000 \mathrm{e}-01$ $1.69678 \mathrm{e}+001.69678 \mathrm{e}+001.69678 \mathrm{e}-011.00000 \mathrm{e}-092.12000 \mathrm{e}-01$ $1.69678 \mathrm{e}+001.69678 \mathrm{e}+001.69678 \mathrm{e}-011.00000 \mathrm{e}-092.12000 \mathrm{e}-01$ $1.69678 \mathrm{e}+001.69678 \mathrm{e}+001.69678 \mathrm{e}-011.00000 \mathrm{e}-092.12000 \mathrm{e}-01$ $1.69678 \mathrm{e}+001.69678 \mathrm{e}+00$ 1.69678e-01 1.00000e-09 2.12000e-01 $1.00000 \mathrm{e}-021.00000 \mathrm{e}-02$ 1.00000e-03 1.00000e-09 1.00000e-01 $1.00000 \mathrm{e}+001.00000 \mathrm{e}+001.00000 \mathrm{e}-011.00000 \mathrm{e}-091.00000 \mathrm{e}-01$ $1.00000 \mathrm{e}-05$ 1.00000e-05 1.00000e-06 1.00000e-09 1.00000e-01 $1.00000 \mathrm{e}+001.00000 \mathrm{e}+001.00000 \mathrm{e}-011.00000 \mathrm{e}-091.00000 \mathrm{e}-01$ Element: 4047 \# of layers: 14

Kx Ky Kz Ss Por $3.02610 \mathrm{e}+013.02610 \mathrm{e}+013.02610 \mathrm{e}+00$ 1.00000e-09 7.00000e-02 $3.02610 \mathrm{e}+013.02610 \mathrm{e}+013.02610 \mathrm{e}+001.00000 \mathrm{e}-097.00000 \mathrm{e}-02$ $3.02610 \mathrm{e}+013.02610 \mathrm{e}+013.02610 \mathrm{e}+001.00000 \mathrm{e}-09$ 7.00000e-02 5.00000e-04 5.00000e-04 5.00000e-05 1.00000e-09 1.00000e-01 5.00000e-04 5.00000e-04 5.00000e-05 1.00000e-09 1.00000e-01 
$1.20913 \mathrm{e}+00$ 1.20913e+00 1.20913e-01 1.00000e-09 2.12000e-01 $1.20913 \mathrm{e}+00$ 1.20913e+00 1.20913e-01 1.00000e-09 2.12000e-01 $1.20913 \mathrm{e}+00$ 1.20913e+00 1.20913e-01 1.00000e-09 2.12000e-01 $1.20913 \mathrm{e}+00$ 1.20913e+00 1.20913e-01 1.00000e-09 2.12000e-01 $1.20913 \mathrm{e}+00$ 1.20913e+00 1.20913e-01 1.00000e-09 2.12000e-01 $1.00000 \mathrm{e}-02$ 1.00000e-02 1.00000e-03 1.00000e-09 1.00000e-01 $1.00000 \mathrm{e}+001.00000 \mathrm{e}+001.00000 \mathrm{e}-011.00000 \mathrm{e}-091.00000 \mathrm{e}-01$ $1.00000 \mathrm{e}-05$ 1.00000e-05 1.00000e-06 1.00000e-09 1.00000e-01 $1.00000 \mathrm{e}+001.00000 \mathrm{e}+001.00000 \mathrm{e}-011.00000 \mathrm{e}-091.00000 \mathrm{e}-01$ Element: 4048 \# of layers: 14

$\mathrm{Kx} \mathrm{Ky} \mathrm{Kz}$ Ss Por

$3.02610 \mathrm{e}+013.02610 \mathrm{e}+013.02610 \mathrm{e}+001.00000 \mathrm{e}-09$ 7.00000e-02 $3.02610 \mathrm{e}+013.02610 \mathrm{e}+013.02610 \mathrm{e}+001.00000 \mathrm{e}-09$ 7.00000e-02 $3.02610 \mathrm{e}+013.02610 \mathrm{e}+013.02610 \mathrm{e}+001.00000 \mathrm{e}-09$ 7.00000e-02 5.00000e-04 5.00000e-04 5.00000e-05 1.00000e-09 1.00000e-01 5.00000e-04 5.00000e-04 5.00000e-05 1.00000e-09 1.00000e-01 $1.20913 \mathrm{e}+00$ 1.20913e+00 1.20913e-01 1.00000e-09 2.12000e-01 $1.20913 \mathrm{e}+001.20913 \mathrm{e}+00$ 1.20913e-01 1.00000e-09 2.12000e-01 $1.20913 \mathrm{e}+001.20913 \mathrm{e}+00$ 1.20913e-01 1.00000e-09 2.12000e-01 $1.20913 \mathrm{e}+00$ 1.20913e+00 1.20913e-01 1.00000e-09 2.12000e-01 $1.20913 \mathrm{e}+001.20913 \mathrm{e}+001.20913 \mathrm{e}-01$ 1.00000e-09 2.12000e-01 $1.00000 \mathrm{e}-02$ 1.00000e-02 1.00000e-03 1.00000e-09 1.00000e-01 $1.00000 \mathrm{e}+001.00000 \mathrm{e}+001.00000 \mathrm{e}-011.00000 \mathrm{e}-091.00000 \mathrm{e}-01$ $1.00000 \mathrm{e}-05$ 1.00000e-05 1.00000e-06 1.00000e-09 1.00000e-01 $1.00000 \mathrm{e}+001.00000 \mathrm{e}+001.00000 \mathrm{e}-011.00000 \mathrm{e}-091.00000 \mathrm{e}-01$ Element: 4049 \# of layers: 13

$\mathrm{Kx} \mathrm{Ky} \mathrm{Kz}$ Ss Por

$3.02610 \mathrm{e}+013.02610 \mathrm{e}+013.02610 \mathrm{e}+001.00000 \mathrm{e}-09$ 7.00000e-02 $3.02610 \mathrm{e}+013.02610 \mathrm{e}+013.02610 \mathrm{e}+001.00000 \mathrm{e}-097.00000 \mathrm{e}-02$ $3.02610 \mathrm{e}+013.02610 \mathrm{e}+013.02610 \mathrm{e}+001.00000 \mathrm{e}-09$ 7.00000e-02 5.00000e-04 5.00000e-04 5.00000e-05 1.00000e-09 1.00000e-01 5.00000e-04 5.00000e-04 5.00000e-05 1.00000e-09 1.00000e-01 $1.20913 \mathrm{e}+001.20913 \mathrm{e}+00$ 1.20913e-01 1.00000e-09 2.12000e-01 $1.20913 \mathrm{e}+001.20913 \mathrm{e}+00$ 1.20913e-01 1.00000e-09 2.12000e-01 $1.20913 \mathrm{e}+001.20913 \mathrm{e}+00$ 1.20913e-01 1.00000e-09 2.12000e-01 $1.20913 \mathrm{e}+001.20913 \mathrm{e}+00$ 1.20913e-01 1.00000e-09 2.12000e-01 $1.00000 \mathrm{e}-02$ 1.00000e-02 1.00000e-03 1.00000e-09 1.00000e-01 $1.00000 \mathrm{e}+001.00000 \mathrm{e}+001.00000 \mathrm{e}-011.00000 \mathrm{e}-091.00000 \mathrm{e}-01$ $1.00000 \mathrm{e}-05$ 1.00000e-05 1.00000e-06 1.00000e-09 1.00000e-01 $1.00000 \mathrm{e}+001.00000 \mathrm{e}+001.00000 \mathrm{e}-01$ 1.00000e-09 1.00000e-01 Element: 4050 \# of layers: 12

$\mathrm{Kx} \mathrm{Ky} \mathrm{Kz}$ Ss Por

3.36758e+01 3.36758e+01 3.36758e+00 1.00000e-09 7.00000e-02 3.36758e+01 3.36758e+01 3.36758e+00 1.00000e-09 7.00000e-02 $3.36758 \mathrm{e}+013.36758 \mathrm{e}+013.36758 \mathrm{e}+001.00000 \mathrm{e}-09$ 7.00000e-02 5.00000e-04 5.00000e-04 5.00000e-05 1.00000e-09 1.00000e-01 
5.00000e-04 5.00000e-04 5.00000e-05 1.00000e-09 1.00000e-01 $1.34555 \mathrm{e}+001.34555 \mathrm{e}+00$ 1.34555e-01 1.00000e-09 2.12000e-01 $1.34555 \mathrm{e}+001.34555 \mathrm{e}+00$ 1.34555e-01 1.00000e-09 2.12000e-01 $1.34555 \mathrm{e}+001.34555 \mathrm{e}+00 \quad 1.34555 \mathrm{e}-01$ 1.00000e-09 2.12000e-01 $1.00000 \mathrm{e}-02$ 1.00000e-02 1.00000e-03 1.00000e-09 1.00000e-01 $1.00000 \mathrm{e}+001.00000 \mathrm{e}+001.00000 \mathrm{e}-011.00000 \mathrm{e}-091.00000 \mathrm{e}-01$ $1.00000 \mathrm{e}-05$ 1.00000e-05 1.00000e-06 1.00000e-09 1.00000e-01 $1.00000 \mathrm{e}+001.00000 \mathrm{e}+001.00000 \mathrm{e}-011.00000 \mathrm{e}-091.00000 \mathrm{e}-01$ Element: 4051 \# of layers: 12

$\mathrm{Kx} \mathrm{Ky} \mathrm{Kz}$ Ss Por

3.36758e+01 3.36758e+01 3.36758e+00 1.00000e-09 7.00000e-02 $3.36758 \mathrm{e}+013.36758 \mathrm{e}+013.36758 \mathrm{e}+001.00000 \mathrm{e}-09$ 7.00000e-02 $3.36758 \mathrm{e}+013.36758 \mathrm{e}+013.36758 \mathrm{e}+001.00000 \mathrm{e}-09$ 7.00000e-02 5.00000e-04 5.00000e-04 5.00000e-05 1.00000e-09 1.00000e-01 5.00000e-04 5.00000e-04 5.00000e-05 1.00000e-09 1.00000e-01 $1.34555 \mathrm{e}+001.34555 \mathrm{e}+001.34555 \mathrm{e}-011.00000 \mathrm{e}-092.12000 \mathrm{e}-01$ $1.34555 \mathrm{e}+001.34555 \mathrm{e}+00$ 1.34555e-01 1.00000e-09 2.12000e-01 $1.34555 \mathrm{e}+001.34555 \mathrm{e}+001.34555 \mathrm{e}-01$ 1.00000e-09 2.12000e-01 $1.00000 \mathrm{e}-021.00000 \mathrm{e}-021.00000 \mathrm{e}-031.00000 \mathrm{e}-091.00000 \mathrm{e}-01$ $1.00000 \mathrm{e}+001.00000 \mathrm{e}+001.00000 \mathrm{e}-011.00000 \mathrm{e}-091.00000 \mathrm{e}-01$ $1.00000 \mathrm{e}-05$ 1.00000e-05 1.00000e-06 1.00000e-09 1.00000e-01 $1.00000 \mathrm{e}+001.00000 \mathrm{e}+001.00000 \mathrm{e}-011.00000 \mathrm{e}-091.00000 \mathrm{e}-01$ Element: 4052 \# of layers: 14

Kx Ky Kz Ss Por

$3.02610 \mathrm{e}+013.02610 \mathrm{e}+013.02610 \mathrm{e}+001.00000 \mathrm{e}-09$ 7.00000e-02 $3.02610 \mathrm{e}+013.02610 \mathrm{e}+013.02610 \mathrm{e}+001.00000 \mathrm{e}-097.00000 \mathrm{e}-02$ $3.02610 \mathrm{e}+013.02610 \mathrm{e}+013.02610 \mathrm{e}+001.00000 \mathrm{e}-09$ 7.00000e-02 5.00000e-04 5.00000e-04 5.00000e-05 1.00000e-09 1.00000e-01 5.00000e-04 5.00000e-04 5.00000e-05 1.00000e-09 1.00000e-01 $1.20913 \mathrm{e}+00$ 1.20913e+00 1.20913e-01 1.00000e-09 2.12000e-01 $1.20913 \mathrm{e}+00$ 1.20913e+00 1.20913e-01 1.00000e-09 2.12000e-01 $1.20913 \mathrm{e}+00$ 1.20913e+00 1.20913e-01 1.00000e-09 2.12000e-01 $1.20913 \mathrm{e}+001.20913 \mathrm{e}+00$ 1.20913e-01 1.00000e-09 2.12000e-01 $1.20913 \mathrm{e}+00$ 1.20913e+00 1.20913e-01 1.00000e-09 2.12000e-01 $1.00000 \mathrm{e}-02$ 1.00000e-02 1.00000e-03 1.00000e-09 1.00000e-01 $1.00000 \mathrm{e}+001.00000 \mathrm{e}+001.00000 \mathrm{e}-011.00000 \mathrm{e}-091.00000 \mathrm{e}-01$ $1.00000 \mathrm{e}-05$ 1.00000e-05 1.00000e-06 1.00000e-09 1.00000e-01 $1.00000 \mathrm{e}+001.00000 \mathrm{e}+001.00000 \mathrm{e}-011.00000 \mathrm{e}-091.00000 \mathrm{e}-01$ Element: 4053 \# of layers: 14

$\mathrm{Kx} \mathrm{Ky} \mathrm{Kz}$ Ss Por

$2.90654 \mathrm{e}+012.90654 \mathrm{e}+012.90654 \mathrm{e}+00$ 1.00000e-09 7.00000e-02 $2.90654 \mathrm{e}+012.90654 \mathrm{e}+012.90654 \mathrm{e}+001.00000 \mathrm{e}-097.00000 \mathrm{e}-02$

$2.90654 \mathrm{e}+012.90654 \mathrm{e}+012.90654 \mathrm{e}+001.00000 \mathrm{e}-09$ 7.00000e-02 5.00000e-04 5.00000e-04 5.00000e-05 1.00000e-09 1.00000e-01 5.00000e-04 5.00000e-04 5.00000e-05 1.00000e-09 1.00000e-01 $1.16134 \mathrm{e}+001.16134 \mathrm{e}+001.16134 \mathrm{e}-011.00000 \mathrm{e}-092.12000 \mathrm{e}-01$ 
$1.16134 \mathrm{e}+001.16134 \mathrm{e}+001.16134 \mathrm{e}-011.00000 \mathrm{e}-092.12000 \mathrm{e}-01$ $1.16134 \mathrm{e}+001.16134 \mathrm{e}+001.16134 \mathrm{e}-01$ 1.00000e-09 2.12000e-01 $1.16134 \mathrm{e}+001.16134 \mathrm{e}+001.16134 \mathrm{e}-011.00000 \mathrm{e}-092.12000 \mathrm{e}-01$ $1.16134 \mathrm{e}+001.16134 \mathrm{e}+001.16134 \mathrm{e}-011.00000 \mathrm{e}-092.12000 \mathrm{e}-01$ $1.00000 \mathrm{e}-021.00000 \mathrm{e}-02$ 1.00000e-03 1.00000e-09 1.00000e-01 $1.00000 \mathrm{e}+001.00000 \mathrm{e}+001.00000 \mathrm{e}-011.00000 \mathrm{e}-091.00000 \mathrm{e}-01$ $1.00000 \mathrm{e}-05$ 1.00000e-05 1.00000e-06 1.00000e-09 1.00000e-01 $1.00000 \mathrm{e}+001.00000 \mathrm{e}+001.00000 \mathrm{e}-011.00000 \mathrm{e}-091.00000 \mathrm{e}-01$ Element: 4054 \# of layers: 14

$\mathrm{Kx} \mathrm{Ky} \mathrm{Kz}$ Ss Por

$2.84509 \mathrm{e}+012.84509 \mathrm{e}+012.84509 \mathrm{e}+00$ 1.00000e-09 7.00000e-02 $2.84509 \mathrm{e}+012.84509 \mathrm{e}+012.84509 \mathrm{e}+001.00000 \mathrm{e}-09$ 7.00000e-02 $2.84509 \mathrm{e}+012.84509 \mathrm{e}+012.84509 \mathrm{e}+001.00000 \mathrm{e}-09$ 7.00000e-02 5.00000e-04 5.00000e-04 5.00000e-05 1.00000e-09 1.00000e-01 5.00000e-04 5.00000e-04 5.00000e-05 1.00000e-09 1.00000e-01 $1.13681 \mathrm{e}+001.13681 \mathrm{e}+001.13681 \mathrm{e}-011.00000 \mathrm{e}-092.12000 \mathrm{e}-01$ $1.13681 \mathrm{e}+001.13681 \mathrm{e}+001.13681 \mathrm{e}-01$ 1.00000e-09 2.12000e-01 $1.13681 \mathrm{e}+001.13681 \mathrm{e}+00$ 1.13681e-01 1.00000e-09 2.12000e-01 $1.13681 \mathrm{e}+001.13681 \mathrm{e}+00$ 1.13681e-01 1.00000e-09 2.12000e-01 $1.13681 \mathrm{e}+001.13681 \mathrm{e}+001.13681 \mathrm{e}-011.00000 \mathrm{e}-092.12000 \mathrm{e}-01$ $1.00000 \mathrm{e}-02$ 1.00000e-02 1.00000e-03 1.00000e-09 1.00000e-01 $1.00000 \mathrm{e}+001.00000 \mathrm{e}+001.00000 \mathrm{e}-011.00000 \mathrm{e}-091.00000 \mathrm{e}-01$ $1.00000 \mathrm{e}-05$ 1.00000e-05 1.00000e-06 1.00000e-09 1.00000e-01 $1.00000 \mathrm{e}+001.00000 \mathrm{e}+001.00000 \mathrm{e}-011.00000 \mathrm{e}-091.00000 \mathrm{e}-01$ Element: 4055 \# of layers: 14

$\mathrm{Kx} \mathrm{Ky} \mathrm{Kz}$ Ss Por

$3.02610 \mathrm{e}+013.02610 \mathrm{e}+013.02610 \mathrm{e}+001.00000 \mathrm{e}-097.00000 \mathrm{e}-02$ $3.02610 \mathrm{e}+013.02610 \mathrm{e}+013.02610 \mathrm{e}+001.00000 \mathrm{e}-097.00000 \mathrm{e}-02$ $3.02610 \mathrm{e}+013.02610 \mathrm{e}+013.02610 \mathrm{e}+001.00000 \mathrm{e}-097.00000 \mathrm{e}-02$ $5.00000 \mathrm{e}-04$ 5.00000e-04 5.00000e-05 1.00000e-09 1.00000e-01 5.00000e-04 5.00000e-04 5.00000e-05 1.00000e-09 1.00000e-01 $1.20913 \mathrm{e}+00$ 1.20913e+00 1.20913e-01 1.00000e-09 2.12000e-01 $1.20913 \mathrm{e}+001.20913 \mathrm{e}+00$ 1.20913e-01 1.00000e-09 2.12000e-01 $1.20913 \mathrm{e}+00$ 1.20913e+00 1.20913e-01 1.00000e-09 2.12000e-01 $1.20913 \mathrm{e}+001.20913 \mathrm{e}+00$ 1.20913e-01 1.00000e-09 2.12000e-01 $1.20913 \mathrm{e}+001.20913 \mathrm{e}+00$ 1.20913e-01 1.00000e-09 2.12000e-01 $1.00000 \mathrm{e}-02$ 1.00000e-02 1.00000e-03 1.00000e-09 1.00000e-01 $1.00000 \mathrm{e}+001.00000 \mathrm{e}+001.00000 \mathrm{e}-011.00000 \mathrm{e}-091.00000 \mathrm{e}-01$ $1.00000 \mathrm{e}-05$ 1.00000e-05 1.00000e-06 1.00000e-09 1.00000e-01 $1.00000 \mathrm{e}+001.00000 \mathrm{e}+001.00000 \mathrm{e}-01$ 1.00000e-09 1.00000e-01 Element: 4056 \# of layers: 13

$\mathrm{Kx} \mathrm{Ky} \mathrm{Kz}$ Ss Por

$2.38044 \mathrm{e}+012.38044 \mathrm{e}+012.38044 \mathrm{e}+001.00000 \mathrm{e}-09$ 7.00000e-02 $2.38044 \mathrm{e}+012.38044 \mathrm{e}+012.38044 \mathrm{e}+00$ 1.00000e-09 7.00000e-02 $2.38044 \mathrm{e}+012.38044 \mathrm{e}+012.38044 \mathrm{e}+001.00000 \mathrm{e}-09$ 7.00000e-02 5.00000e-04 5.00000e-04 5.00000e-05 1.00000e-09 1.00000e-01 
5.00000e-04 5.00000e-04 5.00000e-05 1.00000e-09 1.00000e-01 9.51140e-01 9.51140e-01 9.51140e-02 1.00000e-09 2.12000e-01 9.51140e-01 9.51140e-01 9.51140e-02 1.00000e-09 2.12000e-01 9.51140e-01 9.51140e-01 9.51140e-02 1.00000e-09 2.12000e-01 9.51140e-01 9.51140e-01 9.51140e-02 1.00000e-09 2.12000e-01 $1.00000 \mathrm{e}-02$ 1.00000e-02 1.00000e-03 1.00000e-09 1.00000e-01 $1.00000 \mathrm{e}+001.00000 \mathrm{e}+001.00000 \mathrm{e}-011.00000 \mathrm{e}-091.00000 \mathrm{e}-01$ $1.00000 \mathrm{e}-05$ 1.00000e-05 1.00000e-06 1.00000e-09 1.00000e-01 $1.00000 \mathrm{e}+001.00000 \mathrm{e}+001.00000 \mathrm{e}-011.00000 \mathrm{e}-091.00000 \mathrm{e}-01$ Element: 4057 \# of layers: 13

$\mathrm{Kx} \mathrm{Ky} \mathrm{Kz}$ Ss Por

$2.38044 \mathrm{e}+012.38044 \mathrm{e}+012.38044 \mathrm{e}+00$ 1.00000e-09 7.00000e-02

$2.38044 \mathrm{e}+012.38044 \mathrm{e}+012.38044 \mathrm{e}+001.00000 \mathrm{e}-09$ 7.00000e-02

$2.38044 \mathrm{e}+012.38044 \mathrm{e}+012.38044 \mathrm{e}+001.00000 \mathrm{e}-09$ 7.00000e-02

5.00000e-04 5.00000e-04 5.00000e-05 1.00000e-09 1.00000e-01 5.00000e-04 5.00000e-04 5.00000e-05 1.00000e-09 1.00000e-01

9.51140e-01 9.51140e-01 9.51140e-02 1.00000e-09 2.12000e-01

9.51140e-01 9.51140e-01 9.51140e-02 1.00000e-09 2.12000e-01

9.51140e-01 9.51140e-01 9.51140e-02 1.00000e-09 2.12000e-01

9.51140e-01 9.51140e-01 9.51140e-02 1.00000e-09 2.12000e-01 $1.00000 \mathrm{e}-02$ 1.00000e-02 1.00000e-03 1.00000e-09 1.00000e-01 $1.00000 \mathrm{e}+001.00000 \mathrm{e}+001.00000 \mathrm{e}-011.00000 \mathrm{e}-091.00000 \mathrm{e}-01$ $1.00000 \mathrm{e}-05$ 1.00000e-05 1.00000e-06 1.00000e-09 1.00000e-01 $1.00000 \mathrm{e}+001.00000 \mathrm{e}+001.00000 \mathrm{e}-011.00000 \mathrm{e}-09$ 1.00000e-01 Element: 4058 \# of layers: 12

$\mathrm{Kx} \mathrm{Ky} \mathrm{Kz}$ Ss Por

$2.38044 \mathrm{e}+012.38044 \mathrm{e}+012.38044 \mathrm{e}+00$ 1.00000e-09 7.00000e-02 $2.38044 \mathrm{e}+012.38044 \mathrm{e}+012.38044 \mathrm{e}+001.00000 \mathrm{e}-09$ 7.00000e-02 $2.38044 \mathrm{e}+012.38044 \mathrm{e}+012.38044 \mathrm{e}+001.00000 \mathrm{e}-097.00000 \mathrm{e}-02$ 5.00000e-04 5.00000e-04 5.00000e-05 1.00000e-09 1.00000e-01 5.00000e-04 5.00000e-04 5.00000e-05 1.00000e-09 1.00000e-01 9.51140e-01 9.51140e-01 9.51140e-02 1.00000e-09 2.12000e-01 9.51140e-01 9.51140e-01 9.51140e-02 1.00000e-09 2.12000e-01 9.51140e-01 9.51140e-01 9.51140e-02 1.00000e-09 2.12000e-01 $1.00000 \mathrm{e}-02$ 1.00000e-02 1.00000e-03 1.00000e-09 1.00000e-01 $1.00000 \mathrm{e}+001.00000 \mathrm{e}+001.00000 \mathrm{e}-011.00000 \mathrm{e}-091.00000 \mathrm{e}-01$ $1.00000 \mathrm{e}-05$ 1.00000e-05 1.00000e-06 1.00000e-09 1.00000e-01 $1.00000 \mathrm{e}+001.00000 \mathrm{e}+001.00000 \mathrm{e}-011.00000 \mathrm{e}-091.00000 \mathrm{e}-01$ Element: 4059 \# of layers: 12

$\mathrm{Kx} \mathrm{Ky} \mathrm{Kz}$ Ss Por

$2.38044 \mathrm{e}+012.38044 \mathrm{e}+012.38044 \mathrm{e}+00$ 1.00000e-09 7.00000e-02 $2.38044 \mathrm{e}+012.38044 \mathrm{e}+012.38044 \mathrm{e}+001.00000 \mathrm{e}-09$ 7.00000e-02

$2.38044 \mathrm{e}+012.38044 \mathrm{e}+012.38044 \mathrm{e}+001.00000 \mathrm{e}-09$ 7.00000e-02 5.00000e-04 5.00000e-04 5.00000e-05 1.00000e-09 1.00000e-01 5.00000e-04 5.00000e-04 5.00000e-05 1.00000e-09 1.00000e-01 9.51140e-01 9.51140e-01 9.51140e-02 1.00000e-09 2.12000e-01 
9.51140e-01 9.51140e-01 9.51140e-02 1.00000e-09 2.12000e-01

9.51140e-01 9.51140e-01 9.51140e-02 1.00000e-09 2.12000e-01 $1.00000 \mathrm{e}-02$ 1.00000e-02 1.00000e-03 1.00000e-09 1.00000e-01 $1.00000 \mathrm{e}+001.00000 \mathrm{e}+001.00000 \mathrm{e}-011.00000 \mathrm{e}-091.00000 \mathrm{e}-01$ $1.00000 \mathrm{e}-05$ 1.00000e-05 1.00000e-06 1.00000e-09 1.00000e-01 $1.00000 \mathrm{e}+001.00000 \mathrm{e}+001.00000 \mathrm{e}-011.00000 \mathrm{e}-091.00000 \mathrm{e}-01$ Element: 4060 \# of layers: 11

$\mathrm{Kx} \mathrm{Ky} \mathrm{Kz}$ Ss Por

$2.38044 \mathrm{e}+012.38044 \mathrm{e}+012.38044 \mathrm{e}+001.00000 \mathrm{e}-09$ 7.00000e-02

$2.38044 \mathrm{e}+012.38044 \mathrm{e}+012.38044 \mathrm{e}+001.00000 \mathrm{e}-097.00000 \mathrm{e}-02$ 5.00000e-04 5.00000e-04 5.00000e-05 1.00000e-09 1.00000e-01 5.00000e-04 5.00000e-04 5.00000e-05 1.00000e-09 1.00000e-01 9.51140e-01 9.51140e-01 9.51140e-02 1.00000e-09 2.12000e-01 9.51140e-01 9.51140e-01 9.51140e-02 1.00000e-09 2.12000e-01 9.51140e-01 9.51140e-01 9.51140e-02 1.00000e-09 2.12000e-01 $1.00000 \mathrm{e}-02$ 1.00000e-02 1.00000e-03 1.00000e-09 1.00000e-01 $1.00000 \mathrm{e}+001.00000 \mathrm{e}+001.00000 \mathrm{e}-011.00000 \mathrm{e}-091.00000 \mathrm{e}-01$ $1.00000 \mathrm{e}-05$ 1.00000e-05 1.00000e-06 1.00000e-09 1.00000e-01 $1.00000 \mathrm{e}+001.00000 \mathrm{e}+001.00000 \mathrm{e}-011.00000 \mathrm{e}-091.00000 \mathrm{e}-01$ Element: 4061 \# of layers: 11

$\mathrm{Kx} \mathrm{Ky} \mathrm{Kz}$ Ss Por

$2.38044 \mathrm{e}+012.38044 \mathrm{e}+012.38044 \mathrm{e}+00$ 1.00000e-09 7.00000e-02 $2.38044 \mathrm{e}+012.38044 \mathrm{e}+012.38044 \mathrm{e}+001.00000 \mathrm{e}-097.00000 \mathrm{e}-02$ 5.00000e-04 5.00000e-04 5.00000e-05 1.00000e-09 1.00000e-01 5.00000e-04 5.00000e-04 5.00000e-05 1.00000e-09 1.00000e-01 9.51140e-01 9.51140e-01 9.51140e-02 1.00000e-09 2.12000e-01 9.51140e-01 9.51140e-01 9.51140e-02 1.00000e-09 2.12000e-01 9.51140e-01 9.51140e-01 9.51140e-02 1.00000e-09 2.12000e-01 $1.00000 \mathrm{e}-02$ 1.00000e-02 1.00000e-03 1.00000e-09 1.00000e-01 $1.00000 \mathrm{e}+001.00000 \mathrm{e}+001.00000 \mathrm{e}-011.00000 \mathrm{e}-091.00000 \mathrm{e}-01$ $1.00000 \mathrm{e}-05$ 1.00000e-05 1.00000e-06 1.00000e-09 1.00000e-01 $1.00000 \mathrm{e}+001.00000 \mathrm{e}+001.00000 \mathrm{e}-01$ 1.00000e-09 1.00000e-01 Element: 4062 \# of layers: 12

$\mathrm{Kx} \mathrm{Ky} \mathrm{Kz}$ Ss Por

$2.38044 \mathrm{e}+012.38044 \mathrm{e}+012.38044 \mathrm{e}+00$ 1.00000e-09 7.00000e-02 $2.38044 \mathrm{e}+012.38044 \mathrm{e}+012.38044 \mathrm{e}+001.00000 \mathrm{e}-09$ 7.00000e-02 $2.38044 \mathrm{e}+012.38044 \mathrm{e}+012.38044 \mathrm{e}+001.00000 \mathrm{e}-09$ 7.00000e-02 5.00000e-04 5.00000e-04 5.00000e-05 1.00000e-09 1.00000e-01 5.00000e-04 5.00000e-04 5.00000e-05 1.00000e-09 1.00000e-01 9.51140e-01 9.51140e-01 9.51140e-02 1.00000e-09 2.12000e-01 9.51140e-01 9.51140e-01 9.51140e-02 1.00000e-09 2.12000e-01 9.51140e-01 9.51140e-01 9.51140e-02 1.00000e-09 2.12000e-01 $1.00000 \mathrm{e}-02$ 1.00000e-02 1.00000e-03 1.00000e-09 1.00000e-01 $1.00000 \mathrm{e}+001.00000 \mathrm{e}+001.00000 \mathrm{e}-011.00000 \mathrm{e}-091.00000 \mathrm{e}-01$ $1.00000 \mathrm{e}-05$ 1.00000e-05 1.00000e-06 1.00000e-09 1.00000e-01 $1.00000 \mathrm{e}+001.00000 \mathrm{e}+001.00000 \mathrm{e}-011.00000 \mathrm{e}-091.00000 \mathrm{e}-01$ 
Element: 4063 \# of layers: 12

$\mathrm{Kx} \mathrm{Ky} \mathrm{Kz}$ Ss Por

$2.38044 \mathrm{e}+012.38044 \mathrm{e}+012.38044 \mathrm{e}+00$ 1.00000e-09 7.00000e-02

$2.38044 \mathrm{e}+012.38044 \mathrm{e}+012.38044 \mathrm{e}+001.00000 \mathrm{e}-09$ 7.00000e-02

$2.38044 \mathrm{e}+012.38044 \mathrm{e}+012.38044 \mathrm{e}+001.00000 \mathrm{e}-097.00000 \mathrm{e}-02$

5.00000e-04 5.00000e-04 5.00000e-05 1.00000e-09 1.00000e-01

5.00000e-04 5.00000e-04 5.00000e-05 1.00000e-09 1.00000e-01

9.51140e-01 9.51140e-01 9.51140e-02 1.00000e-09 2.12000e-01

9.51140e-01 9.51140e-01 9.51140e-02 1.00000e-09 2.12000e-01

9.51140e-01 9.51140e-01 9.51140e-02 1.00000e-09 2.12000e-01

$1.00000 \mathrm{e}-02$ 1.00000e-02 1.00000e-03 1.00000e-09 1.00000e-01

$1.00000 \mathrm{e}+001.00000 \mathrm{e}+001.00000 \mathrm{e}-011.00000 \mathrm{e}-091.00000 \mathrm{e}-01$

$1.00000 \mathrm{e}-05$ 1.00000e-05 1.00000e-06 1.00000e-09 1.00000e-01

$1.00000 \mathrm{e}+001.00000 \mathrm{e}+001.00000 \mathrm{e}-011.00000 \mathrm{e}-091.00000 \mathrm{e}-01$

Element: 4064 \# of layers: 12

Kx Ky Kz Ss Por

$2.38044 \mathrm{e}+012.38044 \mathrm{e}+012.38044 \mathrm{e}+00$ 1.00000e-09 7.00000e-02

$2.38044 \mathrm{e}+012.38044 \mathrm{e}+012.38044 \mathrm{e}+001.00000 \mathrm{e}-09$ 7.00000e-02

$2.38044 \mathrm{e}+012.38044 \mathrm{e}+012.38044 \mathrm{e}+001.00000 \mathrm{e}-09$ 7.00000e-02

5.00000e-04 5.00000e-04 5.00000e-05 1.00000e-09 1.00000e-01

5.00000e-04 5.00000e-04 5.00000e-05 1.00000e-09 1.00000e-01

9.51140e-01 9.51140e-01 9.51140e-02 1.00000e-09 2.12000e-01

9.51140e-01 9.51140e-01 9.51140e-02 1.00000e-09 2.12000e-01

9.51140e-01 9.51140e-01 9.51140e-02 1.00000e-09 2.12000e-01

$1.00000 \mathrm{e}-02$ 1.00000e-02 1.00000e-03 1.00000e-09 1.00000e-01

$1.00000 \mathrm{e}+001.00000 \mathrm{e}+001.00000 \mathrm{e}-011.00000 \mathrm{e}-091.00000 \mathrm{e}-01$

$1.00000 \mathrm{e}-05$ 1.00000e-05 1.00000e-06 1.00000e-09 1.00000e-01

$1.00000 \mathrm{e}+001.00000 \mathrm{e}+001.00000 \mathrm{e}-011.00000 \mathrm{e}-091.00000 \mathrm{e}-01$

Element: 4065 \# of layers: 11

$\mathrm{Kx} \mathrm{Ky} \mathrm{Kz}$ Ss Por

$1.87174 \mathrm{e}+011.87174 \mathrm{e}+011.87174 \mathrm{e}+001.00000 \mathrm{e}-09$ 7.00000e-02

$1.87174 \mathrm{e}+011.87174 \mathrm{e}+011.87174 \mathrm{e}+001.00000 \mathrm{e}-09$ 7.00000e-02

$1.87174 \mathrm{e}+011.87174 \mathrm{e}+011.87174 \mathrm{e}+001.00000 \mathrm{e}-097.00000 \mathrm{e}-02$

5.00000e-04 5.00000e-04 5.00000e-05 1.00000e-09 1.00000e-01

5.00000e-04 5.00000e-04 5.00000e-05 1.00000e-09 1.00000e-01

7.47871e-01 7.47871e-01 7.47871e-02 1.00000e-09 2.12000e-01

7.47871e-01 7.47871e-01 7.47871e-02 1.00000e-09 2.12000e-01

$1.00000 \mathrm{e}-02$ 1.00000e-02 1.00000e-03 1.00000e-09 1.00000e-01

$1.00000 \mathrm{e}+001.00000 \mathrm{e}+001.00000 \mathrm{e}-011.00000 \mathrm{e}-091.00000 \mathrm{e}-01$

$1.00000 \mathrm{e}-051.00000 \mathrm{e}-05$ 1.00000e-06 1.00000e-09 1.00000e-01

$1.00000 \mathrm{e}+001.00000 \mathrm{e}+001.00000 \mathrm{e}-011.00000 \mathrm{e}-091.00000 \mathrm{e}-01$

Element: 4066 \# of layers: 11

$\mathrm{Kx} \mathrm{Ky} \mathrm{Kz}$ Ss Por

$1.87174 \mathrm{e}+011.87174 \mathrm{e}+01$ 1.87174e+00 1.00000e-09 7.00000e-02

$1.87174 \mathrm{e}+011.87174 \mathrm{e}+011.87174 \mathrm{e}+001.00000 \mathrm{e}-097.00000 \mathrm{e}-02$

$1.87174 \mathrm{e}+011.87174 \mathrm{e}+011.87174 \mathrm{e}+001.00000 \mathrm{e}-097.00000 \mathrm{e}-02$ 
5.00000e-04 5.00000e-04 5.00000e-05 1.00000e-09 1.00000e-01 5.00000e-04 5.00000e-04 5.00000e-05 1.00000e-09 1.00000e-01 7.47871e-01 7.47871e-01 7.47871e-02 1.00000e-09 2.12000e-01 7.47871e-01 7.47871e-01 7.47871e-02 1.00000e-09 2.12000e-01 $1.00000 \mathrm{e}-02$ 1.00000e-02 1.00000e-03 1.00000e-09 1.00000e-01 $1.00000 \mathrm{e}+001.00000 \mathrm{e}+001.00000 \mathrm{e}-011.00000 \mathrm{e}-091.00000 \mathrm{e}-01$ $1.00000 \mathrm{e}-051.00000 \mathrm{e}-05$ 1.00000e-06 1.00000e-09 1.00000e-01 $1.00000 \mathrm{e}+001.00000 \mathrm{e}+001.00000 \mathrm{e}-011.00000 \mathrm{e}-091.00000 \mathrm{e}-01$ Element: 4067 \# of layers: 11

Kx Ky Kz Ss Por

$1.87174 \mathrm{e}+011.87174 \mathrm{e}+011.87174 \mathrm{e}+001.00000 \mathrm{e}-097.00000 \mathrm{e}-02$ $1.87174 \mathrm{e}+011.87174 \mathrm{e}+011.87174 \mathrm{e}+001.00000 \mathrm{e}-097.00000 \mathrm{e}-02$ $1.87174 \mathrm{e}+011.87174 \mathrm{e}+011.87174 \mathrm{e}+001.00000 \mathrm{e}-097.00000 \mathrm{e}-02$ 5.00000e-04 5.00000e-04 5.00000e-05 1.00000e-09 1.00000e-01 5.00000e-04 5.00000e-04 5.00000e-05 1.00000e-09 1.00000e-01 7.47871e-01 7.47871e-01 7.47871e-02 1.00000e-09 2.12000e-01 7.47871e-01 7.47871e-01 7.47871e-02 1.00000e-09 2.12000e-01 $1.00000 \mathrm{e}-02$ 1.00000e-02 1.00000e-03 1.00000e-09 1.00000e-01 $1.00000 \mathrm{e}+001.00000 \mathrm{e}+001.00000 \mathrm{e}-011.00000 \mathrm{e}-091.00000 \mathrm{e}-01$ $1.00000 \mathrm{e}-05$ 1.00000e-05 1.00000e-06 1.00000e-09 1.00000e-01 $1.00000 \mathrm{e}+001.00000 \mathrm{e}+001.00000 \mathrm{e}-011.00000 \mathrm{e}-091.00000 \mathrm{e}-01$ Element: 4068 \# of layers: 10

Kx Ky Kz Ss Por

$1.87174 \mathrm{e}+011.87174 \mathrm{e}+011.87174 \mathrm{e}+001.00000 \mathrm{e}-097.00000 \mathrm{e}-02$ $1.87174 \mathrm{e}+011.87174 \mathrm{e}+011.87174 \mathrm{e}+001.00000 \mathrm{e}-097.00000 \mathrm{e}-02$ $5.00000 \mathrm{e}-04$ 5.00000e-04 5.00000e-05 1.00000e-09 1.00000e-01 5.00000e-04 5.00000e-04 5.00000e-05 1.00000e-09 1.00000e-01 7.47871e-01 7.47871e-01 7.47871e-02 1.00000e-09 2.12000e-01 7.47871e-01 7.47871e-01 7.47871e-02 1.00000e-09 2.12000e-01 $1.00000 \mathrm{e}-021.00000 \mathrm{e}-02$ 1.00000e-03 1.00000e-09 1.00000e-01 $1.00000 \mathrm{e}+001.00000 \mathrm{e}+001.00000 \mathrm{e}-011.00000 \mathrm{e}-091.00000 \mathrm{e}-01$ $1.00000 \mathrm{e}-05$ 1.00000e-05 1.00000e-06 1.00000e-09 1.00000e-01 $1.00000 \mathrm{e}+001.00000 \mathrm{e}+001.00000 \mathrm{e}-011.00000 \mathrm{e}-091.00000 \mathrm{e}-01$ Element: 4069 \# of layers: 11

Kx Ky Kz Ss Por

$1.87174 \mathrm{e}+011.87174 \mathrm{e}+011.87174 \mathrm{e}+00$ 1.00000e-09 7.00000e-02 $1.87174 \mathrm{e}+011.87174 \mathrm{e}+011.87174 \mathrm{e}+001.00000 \mathrm{e}-097.00000 \mathrm{e}-02$ $1.87174 \mathrm{e}+011.87174 \mathrm{e}+011.87174 \mathrm{e}+001.00000 \mathrm{e}-097.00000 \mathrm{e}-02$ 5.00000e-04 5.00000e-04 5.00000e-05 1.00000e-09 1.00000e-01 5.00000e-04 5.00000e-04 5.00000e-05 1.00000e-09 1.00000e-01 7.47871e-01 7.47871e-01 7.47871e-02 1.00000e-09 2.12000e-01 7.47871e-01 7.47871e-01 7.47871e-02 1.00000e-09 2.12000e-01 $1.00000 \mathrm{e}-021.00000 \mathrm{e}-021.00000 \mathrm{e}-031.00000 \mathrm{e}-091.00000 \mathrm{e}-01$ $1.00000 \mathrm{e}+001.00000 \mathrm{e}+001.00000 \mathrm{e}-011.00000 \mathrm{e}-091.00000 \mathrm{e}-01$ $1.00000 \mathrm{e}-05$ 1.00000e-05 1.00000e-06 1.00000e-09 1.00000e-01 $1.00000 \mathrm{e}+001.00000 \mathrm{e}+001.00000 \mathrm{e}-011.00000 \mathrm{e}-091.00000 \mathrm{e}-01$ 
Element: 4070 \# of layers: 10

Kx Ky Kz Ss Por

$1.87174 \mathrm{e}+011.87174 \mathrm{e}+011.87174 \mathrm{e}+00$ 1.00000e-09 7.00000e-02

$1.87174 \mathrm{e}+011.87174 \mathrm{e}+011.87174 \mathrm{e}+001.00000 \mathrm{e}-097.00000 \mathrm{e}-02$

$5.00000 \mathrm{e}-04$ 5.00000e-04 5.00000e-05 1.00000e-09 1.00000e-01

5.00000e-04 5.00000e-04 5.00000e-05 1.00000e-09 1.00000e-01

7.47871e-01 7.47871e-01 7.47871e-02 1.00000e-09 2.12000e-01

7.47871e-01 7.47871e-01 7.47871e-02 1.00000e-09 2.12000e-01

$1.00000 \mathrm{e}-02$ 1.00000e-02 1.00000e-03 1.00000e-09 1.00000e-01

$1.00000 \mathrm{e}+001.00000 \mathrm{e}+001.00000 \mathrm{e}-011.00000 \mathrm{e}-091.00000 \mathrm{e}-01$

$1.00000 \mathrm{e}-05$ 1.00000e-05 1.00000e-06 1.00000e-09 1.00000e-01

$1.00000 \mathrm{e}+001.00000 \mathrm{e}+001.00000 \mathrm{e}-011.00000 \mathrm{e}-091.00000 \mathrm{e}-01$

Element: 4071 \# of layers: 10

Kx Ky Kz Ss Por

$1.87174 \mathrm{e}+011.87174 \mathrm{e}+011.87174 \mathrm{e}+001.00000 \mathrm{e}-09$ 7.00000e-02

$1.87174 \mathrm{e}+011.87174 \mathrm{e}+011.87174 \mathrm{e}+001.00000 \mathrm{e}-097.00000 \mathrm{e}-02$

$5.00000 \mathrm{e}-04$ 5.00000e-04 5.00000e-05 1.00000e-09 1.00000e-01

5.00000e-04 5.00000e-04 5.00000e-05 1.00000e-09 1.00000e-01

7.47871e-01 7.47871e-01 7.47871e-02 1.00000e-09 2.12000e-01

7.47871e-01 7.47871e-01 7.47871e-02 1.00000e-09 2.12000e-01

$1.00000 \mathrm{e}-021.00000 \mathrm{e}-02$ 1.00000e-03 $1.00000 \mathrm{e}-091.00000 \mathrm{e}-01$

$1.00000 \mathrm{e}+001.00000 \mathrm{e}+001.00000 \mathrm{e}-011.00000 \mathrm{e}-091.00000 \mathrm{e}-01$

$1.00000 \mathrm{e}-05$ 1.00000e-05 1.00000e-06 1.00000e-09 1.00000e-01

$1.00000 \mathrm{e}+001.00000 \mathrm{e}+001.00000 \mathrm{e}-011.00000 \mathrm{e}-091.00000 \mathrm{e}-01$

Element: 4072 \# of layers: 11

Kx Ky Kz Ss Por

$1.87174 \mathrm{e}+011.87174 \mathrm{e}+011.87174 \mathrm{e}+00$ 1.00000e-09 7.00000e-02

$1.87174 \mathrm{e}+011.87174 \mathrm{e}+011.87174 \mathrm{e}+001.00000 \mathrm{e}-097.00000 \mathrm{e}-02$

$1.87174 \mathrm{e}+011.87174 \mathrm{e}+011.87174 \mathrm{e}+001.00000 \mathrm{e}-097.00000 \mathrm{e}-02$

$5.00000 \mathrm{e}-04$ 5.00000e-04 5.00000e-05 1.00000e-09 1.00000e-01

5.00000e-04 5.00000e-04 5.00000e-05 1.00000e-09 1.00000e-01

7.47871e-01 7.47871e-01 7.47871e-02 1.00000e-09 2.12000e-01

7.47871e-01 7.47871e-01 7.47871e-02 1.00000e-09 2.12000e-01

$1.00000 \mathrm{e}-021.00000 \mathrm{e}-02$ 1.00000e-03 1.00000e-09 1.00000e-01

$1.00000 \mathrm{e}+001.00000 \mathrm{e}+001.00000 \mathrm{e}-011.00000 \mathrm{e}-091.00000 \mathrm{e}-01$

$1.00000 \mathrm{e}-05$ 1.00000e-05 1.00000e-06 1.00000e-09 1.00000e-01

$1.00000 \mathrm{e}+001.00000 \mathrm{e}+001.00000 \mathrm{e}-011.00000 \mathrm{e}-091.00000 \mathrm{e}-01$

Element: 4073 \# of layers: 11

Kx Ky Kz Ss Por

$1.87174 \mathrm{e}+011.87174 \mathrm{e}+011.87174 \mathrm{e}+001.00000 \mathrm{e}-09$ 7.00000e-02

$1.87174 \mathrm{e}+011.87174 \mathrm{e}+011.87174 \mathrm{e}+001.00000 \mathrm{e}-097.00000 \mathrm{e}-02$

$1.87174 \mathrm{e}+011.87174 \mathrm{e}+011.87174 \mathrm{e}+001.00000 \mathrm{e}-097.00000 \mathrm{e}-02$

$5.00000 \mathrm{e}-04$ 5.00000e-04 5.00000e-05 1.00000e-09 1.00000e-01

5.00000e-04 5.00000e-04 5.00000e-05 1.00000e-09 1.00000e-01

7.47871e-01 7.47871e-01 7.47871e-02 1.00000e-09 2.12000e-01

7.47871e-01 7.47871e-01 7.47871e-02 1.00000e-09 2.12000e-01 
$1.00000 \mathrm{e}-02$ 1.00000e-02 1.00000e-03 1.00000e-09 1.00000e-01 $1.00000 \mathrm{e}+001.00000 \mathrm{e}+001.00000 \mathrm{e}-011.00000 \mathrm{e}-091.00000 \mathrm{e}-01$ $1.00000 \mathrm{e}-051.00000 \mathrm{e}-05$ 1.00000e-06 1.00000e-09 1.00000e-01 $1.00000 \mathrm{e}+001.00000 \mathrm{e}+001.00000 \mathrm{e}-011.00000 \mathrm{e}-091.00000 \mathrm{e}-01$ Element: 4074 \# of layers: 10

Kx Ky Kz Ss Por

$2.30187 \mathrm{e}+012.30187 \mathrm{e}+012.30187 \mathrm{e}+00$ 1.00000e-09 7.00000e-02 $2.30187 \mathrm{e}+012.30187 \mathrm{e}+012.30187 \mathrm{e}+001.00000 \mathrm{e}-09$ 7.00000e-02 5.00000e-04 5.00000e-04 5.00000e-05 1.00000e-09 1.00000e-01 5.00000e-04 5.00000e-04 5.00000e-05 1.00000e-09 1.00000e-01 9.19752e-01 9.19752e-01 9.19752e-02 1.00000e-09 2.12000e-01 9.19752e-01 9.19752e-01 9.19752e-02 1.00000e-09 2.12000e-01 $1.00000 \mathrm{e}-02$ 1.00000e-02 1.00000e-03 1.00000e-09 1.00000e-01 $1.00000 \mathrm{e}+001.00000 \mathrm{e}+001.00000 \mathrm{e}-011.00000 \mathrm{e}-091.00000 \mathrm{e}-01$ $1.00000 \mathrm{e}-05$ 1.00000e-05 1.00000e-06 1.00000e-09 1.00000e-01 $1.00000 \mathrm{e}+001.00000 \mathrm{e}+001.00000 \mathrm{e}-011.00000 \mathrm{e}-091.00000 \mathrm{e}-01$ Element: 4075 \# of layers: 9

Kx Ky Kz Ss Por

$2.30187 \mathrm{e}+012.30187 \mathrm{e}+012.30187 \mathrm{e}+00$ 1.00000e-09 7.00000e-02 $2.30187 \mathrm{e}+012.30187 \mathrm{e}+012.30187 \mathrm{e}+001.00000 \mathrm{e}-09$ 7.00000e-02 5.00000e-04 5.00000e-04 5.00000e-05 1.00000e-09 1.00000e-01 5.00000e-04 5.00000e-04 5.00000e-05 1.00000e-09 1.00000e-01 9.19752e-01 9.19752e-01 9.19752e-02 1.00000e-09 2.12000e-01 $1.00000 \mathrm{e}-02$ 1.00000e-02 $1.00000 \mathrm{e}-031.00000 \mathrm{e}-091.00000 \mathrm{e}-01$ $1.00000 \mathrm{e}+001.00000 \mathrm{e}+001.00000 \mathrm{e}-011.00000 \mathrm{e}-091.00000 \mathrm{e}-01$ $1.00000 \mathrm{e}-05$ 1.00000e-05 1.00000e-06 1.00000e-09 1.00000e-01 $1.00000 \mathrm{e}+001.00000 \mathrm{e}+001.00000 \mathrm{e}-011.00000 \mathrm{e}-091.00000 \mathrm{e}-01$ Element: 4076 \# of layers: 10

Kx Ky Kz Ss Por

$2.30187 \mathrm{e}+012.30187 \mathrm{e}+012.30187 \mathrm{e}+00$ 1.00000e-09 7.00000e-02

$2.30187 \mathrm{e}+012.30187 \mathrm{e}+012.30187 \mathrm{e}+001.00000 \mathrm{e}-09$ 7.00000e-02 5.00000e-04 5.00000e-04 5.00000e-05 1.00000e-09 1.00000e-01 5.00000e-04 5.00000e-04 5.00000e-05 1.00000e-09 1.00000e-01 9.19752e-01 9.19752e-01 9.19752e-02 1.00000e-09 2.12000e-01 9.19752e-01 9.19752e-01 9.19752e-02 1.00000e-09 2.12000e-01 $1.00000 \mathrm{e}-021.00000 \mathrm{e}-02$ 1.00000e-03 1.00000e-09 1.00000e-01 $1.00000 \mathrm{e}+001.00000 \mathrm{e}+001.00000 \mathrm{e}-011.00000 \mathrm{e}-091.00000 \mathrm{e}-01$ $1.00000 \mathrm{e}-05$ 1.00000e-05 1.00000e-06 1.00000e-09 1.00000e-01 $1.00000 \mathrm{e}+001.00000 \mathrm{e}+001.00000 \mathrm{e}-011.00000 \mathrm{e}-091.00000 \mathrm{e}-01$ Element: 4077 \# of layers: 9

Kx Ky Kz Ss Por

$2.30187 \mathrm{e}+012.30187 \mathrm{e}+012.30187 \mathrm{e}+00$ 1.00000e-09 7.00000e-02

$2.30187 \mathrm{e}+012.30187 \mathrm{e}+012.30187 \mathrm{e}+001.00000 \mathrm{e}-09$ 7.00000e-02 5.00000e-04 5.00000e-04 5.00000e-05 1.00000e-09 1.00000e-01 5.00000e-04 5.00000e-04 5.00000e-05 1.00000e-09 1.00000e-01 9.19752e-01 9.19752e-01 9.19752e-02 1.00000e-09 2.12000e-01 
$1.00000 \mathrm{e}-02$ 1.00000e-02 1.00000e-03 1.00000e-09 1.00000e-01 $1.00000 \mathrm{e}+001.00000 \mathrm{e}+001.00000 \mathrm{e}-011.00000 \mathrm{e}-091.00000 \mathrm{e}-01$ $1.00000 \mathrm{e}-05$ 1.00000e-05 1.00000e-06 1.00000e-09 1.00000e-01 $1.00000 \mathrm{e}+001.00000 \mathrm{e}+001.00000 \mathrm{e}-011.00000 \mathrm{e}-091.00000 \mathrm{e}-01$ Element: 4078 \# of layers: 9

Kx Ky Kz Ss Por

$2.30187 \mathrm{e}+012.30187 \mathrm{e}+012.30187 \mathrm{e}+00$ 1.00000e-09 7.00000e-02 $2.30187 \mathrm{e}+012.30187 \mathrm{e}+012.30187 \mathrm{e}+001.00000 \mathrm{e}-09$ 7.00000e-02 5.00000e-04 5.00000e-04 5.00000e-05 1.00000e-09 1.00000e-01 5.00000e-04 5.00000e-04 5.00000e-05 1.00000e-09 1.00000e-01 9.19752e-01 9.19752e-01 9.19752e-02 1.00000e-09 2.12000e-01 $1.00000 \mathrm{e}-021.00000 \mathrm{e}-02$ 1.00000e-03 1.00000e-09 1.00000e-01 $1.00000 \mathrm{e}+001.00000 \mathrm{e}+001.00000 \mathrm{e}-011.00000 \mathrm{e}-091.00000 \mathrm{e}-01$ $1.00000 \mathrm{e}-05$ 1.00000e-05 1.00000e-06 1.00000e-09 1.00000e-01 $1.00000 \mathrm{e}+001.00000 \mathrm{e}+001.00000 \mathrm{e}-011.00000 \mathrm{e}-091.00000 \mathrm{e}-01$ Element: 4079 \# of layers: 9

Kx Ky Kz Ss Por

$2.30187 \mathrm{e}+012.30187 \mathrm{e}+012.30187 \mathrm{e}+00$ 1.00000e-09 7.00000e-02 $2.30187 \mathrm{e}+012.30187 \mathrm{e}+012.30187 \mathrm{e}+001.00000 \mathrm{e}-09$ 7.00000e-02 $5.00000 \mathrm{e}-04$ 5.00000e-04 5.00000e-05 1.00000e-09 1.00000e-01 5.00000e-04 5.00000e-04 5.00000e-05 1.00000e-09 1.00000e-01 9.19752e-01 9.19752e-01 9.19752e-02 1.00000e-09 2.12000e-01 $1.00000 \mathrm{e}-021.00000 \mathrm{e}-02$ 1.00000e-03 1.00000e-09 1.00000e-01 $1.00000 \mathrm{e}+001.00000 \mathrm{e}+001.00000 \mathrm{e}-011.00000 \mathrm{e}-091.00000 \mathrm{e}-01$ $1.00000 \mathrm{e}-05$ 1.00000e-05 1.00000e-06 1.00000e-09 1.00000e-01 $1.00000 \mathrm{e}+001.00000 \mathrm{e}+001.00000 \mathrm{e}-011.00000 \mathrm{e}-091.00000 \mathrm{e}-01$ Element: 4080 \# of layers: 11

Kx Ky Kz Ss Por

$2.30187 \mathrm{e}+012.30187 \mathrm{e}+012.30187 \mathrm{e}+00$ 1.00000e-09 7.00000e-02 $2.30187 \mathrm{e}+012.30187 \mathrm{e}+012.30187 \mathrm{e}+001.00000 \mathrm{e}-09$ 7.00000e-02

$2.30187 \mathrm{e}+012.30187 \mathrm{e}+012.30187 \mathrm{e}+001.00000 \mathrm{e}-09$ 7.00000e-02 5.00000e-04 5.00000e-04 5.00000e-05 1.00000e-09 1.00000e-01 5.00000e-04 5.00000e-04 5.00000e-05 1.00000e-09 1.00000e-01 9.19752e-01 9.19752e-01 9.19752e-02 1.00000e-09 2.12000e-01 9.19752e-01 9.19752e-01 9.19752e-02 1.00000e-09 2.12000e-01 $1.00000 \mathrm{e}-021.00000 \mathrm{e}-02$ 1.00000e-03 1.00000e-09 1.00000e-01 $1.00000 \mathrm{e}+001.00000 \mathrm{e}+001.00000 \mathrm{e}-011.00000 \mathrm{e}-091.00000 \mathrm{e}-01$ $1.00000 \mathrm{e}-05$ 1.00000e-05 1.00000e-06 1.00000e-09 1.00000e-01 $1.00000 \mathrm{e}+001.00000 \mathrm{e}+001.00000 \mathrm{e}-011.00000 \mathrm{e}-091.00000 \mathrm{e}-01$ Element: 4081 \# of layers: 10

Kx Ky Kz Ss Por $2.30187 \mathrm{e}+012.30187 \mathrm{e}+012.30187 \mathrm{e}+00$ 1.00000e-09 7.00000e-02 $2.30187 \mathrm{e}+012.30187 \mathrm{e}+012.30187 \mathrm{e}+001.00000 \mathrm{e}-09$ 7.00000e-02 5.00000e-04 5.00000e-04 5.00000e-05 1.00000e-09 1.00000e-01 5.00000e-04 5.00000e-04 5.00000e-05 1.00000e-09 1.00000e-01 9.19752e-01 9.19752e-01 9.19752e-02 1.00000e-09 2.12000e-01 
9.19752e-01 9.19752e-01 9.19752e-02 1.00000e-09 2.12000e-01 $1.00000 \mathrm{e}-02$ 1.00000e-02 1.00000e-03 1.00000e-09 1.00000e-01 $1.00000 \mathrm{e}+001.00000 \mathrm{e}+001.00000 \mathrm{e}-011.00000 \mathrm{e}-091.00000 \mathrm{e}-01$ $1.00000 \mathrm{e}-05$ 1.00000e-05 1.00000e-06 1.00000e-09 1.00000e-01 $1.00000 \mathrm{e}+001.00000 \mathrm{e}+001.00000 \mathrm{e}-011.00000 \mathrm{e}-091.00000 \mathrm{e}-01$ Element: 4082 \# of layers: 9

$\mathrm{Kx} \mathrm{Ky} \mathrm{Kz}$ Ss Por

2.30187e+01 2.30187e+01 2.30187e+00 1.00000e-09 7.00000e-02

$2.30187 \mathrm{e}+012.30187 \mathrm{e}+012.30187 \mathrm{e}+001.00000 \mathrm{e}-09$ 7.00000e-02

5.00000e-04 5.00000e-04 5.00000e-05 1.00000e-09 1.00000e-01

5.00000e-04 5.00000e-04 5.00000e-05 1.00000e-09 1.00000e-01

9.19752e-01 9.19752e-01 9.19752e-02 1.00000e-09 2.12000e-01

$1.00000 \mathrm{e}-02$ 1.00000e-02 1.00000e-03 1.00000e-09 1.00000e-01

$1.00000 \mathrm{e}+001.00000 \mathrm{e}+001.00000 \mathrm{e}-011.00000 \mathrm{e}-091.00000 \mathrm{e}-01$

$1.00000 \mathrm{e}-05$ 1.00000e-05 1.00000e-06 1.00000e-09 1.00000e-01

$1.00000 \mathrm{e}+001.00000 \mathrm{e}+001.00000 \mathrm{e}-011.00000 \mathrm{e}-091.00000 \mathrm{e}-01$

Element: 4083 \# of layers: 9

$\mathrm{Kx} \mathrm{Ky} \mathrm{Kz}$ Ss Por

$2.69498 \mathrm{e}+012.69498 \mathrm{e}+012.69498 \mathrm{e}+00$ 1.00000e-09 7.00000e-02

$2.69498 \mathrm{e}+012.69498 \mathrm{e}+012.69498 \mathrm{e}+001.00000 \mathrm{e}-09$ 7.00000e-02

5.00000e-04 5.00000e-04 5.00000e-05 1.00000e-09 1.00000e-01

$1.07683 \mathrm{e}+001.07683 \mathrm{e}+00$ 1.07683e-01 1.00000e-09 2.12000e-01

$1.07683 \mathrm{e}+001.07683 \mathrm{e}+00$ 1.07683e-01 1.00000e-09 2.12000e-01 $1.00000 \mathrm{e}-02$ 1.00000e-02 1.00000e-03 1.00000e-09 1.00000e-01

$1.00000 \mathrm{e}+001.00000 \mathrm{e}+001.00000 \mathrm{e}-011.00000 \mathrm{e}-091.00000 \mathrm{e}-01$ $1.00000 \mathrm{e}-05$ 1.00000e-05 1.00000e-06 1.00000e-09 1.00000e-01

$1.00000 \mathrm{e}+001.00000 \mathrm{e}+001.00000 \mathrm{e}-011.00000 \mathrm{e}-091.00000 \mathrm{e}-01$

Element: 4084 \# of layers: 9

$\mathrm{Kx} \mathrm{Ky} \mathrm{Kz}$ Ss Por

$2.69498 \mathrm{e}+012.69498 \mathrm{e}+012.69498 \mathrm{e}+00$ 1.00000e-09 7.00000e-02

$2.69498 \mathrm{e}+012.69498 \mathrm{e}+012.69498 \mathrm{e}+00$ 1.00000e-09 7.00000e-02

5.00000e-04 5.00000e-04 5.00000e-05 1.00000e-09 1.00000e-01

$1.07683 \mathrm{e}+001.07683 \mathrm{e}+00$ 1.07683e-01 1.00000e-09 2.12000e-01

$1.07683 \mathrm{e}+001.07683 \mathrm{e}+00$ 1.07683e-01 1.00000e-09 2.12000e-01

$1.00000 \mathrm{e}-02$ 1.00000e-02 1.00000e-03 1.00000e-09 1.00000e-01

$1.00000 \mathrm{e}+001.00000 \mathrm{e}+001.00000 \mathrm{e}-011.00000 \mathrm{e}-091.00000 \mathrm{e}-01$

$1.00000 \mathrm{e}-05$ 1.00000e-05 1.00000e-06 1.00000e-09 1.00000e-01

$1.00000 \mathrm{e}+001.00000 \mathrm{e}+001.00000 \mathrm{e}-011.00000 \mathrm{e}-091.00000 \mathrm{e}-01$

Element: 4085 \# of layers: 9

$\mathrm{Kx} \mathrm{Ky} \mathrm{Kz}$ Ss Por

$2.69498 \mathrm{e}+012.69498 \mathrm{e}+012.69498 \mathrm{e}+00$ 1.00000e-09 7.00000e-02

$2.69498 \mathrm{e}+012.69498 \mathrm{e}+012.69498 \mathrm{e}+00$ 1.00000e-09 7.00000e-02

5.00000e-04 5.00000e-04 5.00000e-05 1.00000e-09 1.00000e-01

$1.07683 \mathrm{e}+001.07683 \mathrm{e}+00$ 1.07683e-01 1.00000e-09 2.12000e-01

$1.07683 \mathrm{e}+001.07683 \mathrm{e}+00$ 1.07683e-01 1.00000e-09 2.12000e-01

$1.00000 \mathrm{e}-02$ 1.00000e-02 1.00000e-03 1.00000e-09 1.00000e-01 
$1.00000 \mathrm{e}+001.00000 \mathrm{e}+001.00000 \mathrm{e}-011.00000 \mathrm{e}-091.00000 \mathrm{e}-01$ $1.00000 \mathrm{e}-05$ 1.00000e-05 1.00000e-06 1.00000e-09 1.00000e-01 $1.00000 \mathrm{e}+001.00000 \mathrm{e}+001.00000 \mathrm{e}-01$ 1.00000e-09 1.00000e-01 Element: 4086 \# of layers: 9

$\mathrm{Kx} \mathrm{Ky} \mathrm{Kz}$ Ss Por

$2.69498 \mathrm{e}+012.69498 \mathrm{e}+012.69498 \mathrm{e}+00$ 1.00000e-09 7.00000e-02

$2.69498 \mathrm{e}+012.69498 \mathrm{e}+012.69498 \mathrm{e}+00$ 1.00000e-09 7.00000e-02

5.00000e-04 5.00000e-04 5.00000e-05 1.00000e-09 1.00000e-01

$1.07683 \mathrm{e}+001.07683 \mathrm{e}+00$ 1.07683e-01 1.00000e-09 2.12000e-01

$1.07683 \mathrm{e}+001.07683 \mathrm{e}+00$ 1.07683e-01 1.00000e-09 2.12000e-01

$1.00000 \mathrm{e}-02$ 1.00000e-02 1.00000e-03 1.00000e-09 1.00000e-01

$1.00000 \mathrm{e}+001.00000 \mathrm{e}+001.00000 \mathrm{e}-011.00000 \mathrm{e}-091.00000 \mathrm{e}-01$

1.00000e-05 1.00000e-05 1.00000e-06 1.00000e-09 1.00000e-01

$1.00000 \mathrm{e}+001.00000 \mathrm{e}+001.00000 \mathrm{e}-01$ 1.00000e-09 1.00000e-01

Element: 4087 \# of layers: 7

$\mathrm{Kx} \mathrm{Ky} \mathrm{Kz}$ Ss Por

$2.69498 \mathrm{e}+012.69498 \mathrm{e}+012.69498 \mathrm{e}+00$ 1.00000e-09 7.00000e-02

$2.69498 \mathrm{e}+012.69498 \mathrm{e}+012.69498 \mathrm{e}+001.00000 \mathrm{e}-09$ 7.00000e-02

5.00000e-04 5.00000e-04 5.00000e-05 1.00000e-09 1.00000e-01

$1.07683 \mathrm{e}+001.07683 \mathrm{e}+00$ 1.07683e-01 1.00000e-09 2.12000e-01

$1.07683 \mathrm{e}+001.07683 \mathrm{e}+00$ 1.07683e-01 1.00000e-09 2.12000e-01

$1.00000 \mathrm{e}-02$ 1.00000e-02 1.00000e-03 1.00000e-09 1.00000e-01

$1.00000 \mathrm{e}+001.00000 \mathrm{e}+001.00000 \mathrm{e}-011.00000 \mathrm{e}-091.00000 \mathrm{e}-01$

Element: 4088 \# of layers: 7

$\mathrm{Kx} \mathrm{Ky} \mathrm{Kz}$ Ss Por

$2.69498 \mathrm{e}+012.69498 \mathrm{e}+012.69498 \mathrm{e}+00$ 1.00000e-09 7.00000e-02

$2.69498 \mathrm{e}+012.69498 \mathrm{e}+012.69498 \mathrm{e}+001.00000 \mathrm{e}-09$ 7.00000e-02

5.00000e-04 5.00000e-04 5.00000e-05 1.00000e-09 1.00000e-01

$1.07683 \mathrm{e}+001.07683 \mathrm{e}+00$ 1.07683e-01 1.00000e-09 2.12000e-01

$1.07683 \mathrm{e}+001.07683 \mathrm{e}+00$ 1.07683e-01 1.00000e-09 2.12000e-01

$1.00000 \mathrm{e}-02$ 1.00000e-02 1.00000e-03 1.00000e-09 1.00000e-01

$1.00000 \mathrm{e}+001.00000 \mathrm{e}+001.00000 \mathrm{e}-01$ 1.00000e-09 1.00000e-01

Element: 4089 \# of layers: 9

$\mathrm{Kx} \mathrm{Ky} \mathrm{Kz}$ Ss Por

$2.69498 \mathrm{e}+012.69498 \mathrm{e}+012.69498 \mathrm{e}+00$ 1.00000e-09 7.00000e-02

$2.69498 \mathrm{e}+012.69498 \mathrm{e}+012.69498 \mathrm{e}+001.00000 \mathrm{e}-09$ 7.00000e-02

5.00000e-04 5.00000e-04 5.00000e-05 1.00000e-09 1.00000e-01

$1.07683 \mathrm{e}+001.07683 \mathrm{e}+00$ 1.07683e-01 1.00000e-09 2.12000e-01

$1.07683 \mathrm{e}+001.07683 \mathrm{e}+00$ 1.07683e-01 1.00000e-09 2.12000e-01

$1.00000 \mathrm{e}-02$ 1.00000e-02 1.00000e-03 1.00000e-09 1.00000e-01

$1.00000 \mathrm{e}+001.00000 \mathrm{e}+001.00000 \mathrm{e}-01$ 1.00000e-09 1.00000e-01

$1.00000 \mathrm{e}-05$ 1.00000e-05 1.00000e-06 1.00000e-09 1.00000e-01

$1.00000 \mathrm{e}+001.00000 \mathrm{e}+001.00000 \mathrm{e}-011.00000 \mathrm{e}-091.00000 \mathrm{e}-01$

Element: 4090 \# of layers: 8

$\mathrm{Kx} \mathrm{Ky} \mathrm{Kz}$ Ss Por

2.69498e+01 2.69498e+01 2.69498e+00 1.00000e-09 7.00000e-02 
$2.69498 \mathrm{e}+012.69498 \mathrm{e}+012.69498 \mathrm{e}+001.00000 \mathrm{e}-09$ 7.00000e-02 5.00000e-04 5.00000e-04 5.00000e-05 1.00000e-09 1.00000e-01 $1.07683 \mathrm{e}+001.07683 \mathrm{e}+00$ 1.07683e-01 1.00000e-09 2.12000e-01 $1.00000 \mathrm{e}-02$ 1.00000e-02 1.00000e-03 1.00000e-09 1.00000e-01 $1.00000 \mathrm{e}+001.00000 \mathrm{e}+001.00000 \mathrm{e}-011.00000 \mathrm{e}-091.00000 \mathrm{e}-01$ $1.00000 \mathrm{e}-05$ 1.00000e-05 1.00000e-06 1.00000e-09 1.00000e-01 $1.00000 \mathrm{e}+001.00000 \mathrm{e}+001.00000 \mathrm{e}-01$ 1.00000e-09 1.00000e-01 Element: 4091 \# of layers: 9

$\mathrm{Kx} \mathrm{Ky} \mathrm{Kz}$ Ss Por

$2.69498 \mathrm{e}+012.69498 \mathrm{e}+012.69498 \mathrm{e}+00$ 1.00000e-09 7.00000e-02 $2.69498 \mathrm{e}+012.69498 \mathrm{e}+012.69498 \mathrm{e}+00$ 1.00000e-09 7.00000e-02 5.00000e-04 5.00000e-04 5.00000e-05 1.00000e-09 1.00000e-01 $1.07683 \mathrm{e}+001.07683 \mathrm{e}+001.07683 \mathrm{e}-011.00000 \mathrm{e}-092.12000 \mathrm{e}-01$ $1.07683 \mathrm{e}+001.07683 \mathrm{e}+00$ 1.07683e-01 1.00000e-09 2.12000e-01 $1.00000 \mathrm{e}-02$ 1.00000e-02 1.00000e-03 1.00000e-09 1.00000e-01 $1.00000 \mathrm{e}+001.00000 \mathrm{e}+001.00000 \mathrm{e}-011.00000 \mathrm{e}-091.00000 \mathrm{e}-01$ $1.00000 \mathrm{e}-05$ 1.00000e-05 1.00000e-06 1.00000e-09 1.00000e-01 $1.00000 \mathrm{e}+001.00000 \mathrm{e}+001.00000 \mathrm{e}-01$ 1.00000e-09 1.00000e-01 Element: 4092 \# of layers: 9

$\mathrm{Kx} \mathrm{Ky} \mathrm{Kz}$ Ss Por

$2.80752 \mathrm{e}+012.80752 \mathrm{e}+012.80752 \mathrm{e}+00$ 1.00000e-09 7.00000e-02

$2.80752 \mathrm{e}+012.80752 \mathrm{e}+012.80752 \mathrm{e}+00$ 1.00000e-09 7.00000e-02

5.00000e-04 5.00000e-04 5.00000e-05 1.00000e-09 1.00000e-01

$1.12178 \mathrm{e}+001.12178 \mathrm{e}+00$ 1.12178e-01 1.00000e-09 2.12000e-01

$1.12178 \mathrm{e}+001.12178 \mathrm{e}+001.12178 \mathrm{e}-01$ 1.00000e-09 2.12000e-01

$1.00000 \mathrm{e}-021.00000 \mathrm{e}-021.00000 \mathrm{e}-031.00000 \mathrm{e}-091.00000 \mathrm{e}-01$

$1.00000 \mathrm{e}+001.00000 \mathrm{e}+001.00000 \mathrm{e}-011.00000 \mathrm{e}-091.00000 \mathrm{e}-01$ $1.00000 \mathrm{e}-05$ 1.00000e-05 1.00000e-06 1.00000e-09 1.00000e-01 $1.00000 \mathrm{e}+001.00000 \mathrm{e}+001.00000 \mathrm{e}-011.00000 \mathrm{e}-091.00000 \mathrm{e}-01$ Element: 4093 \# of layers: 9

$\mathrm{Kx} \mathrm{Ky} \mathrm{Kz}$ Ss Por

$2.80752 \mathrm{e}+012.80752 \mathrm{e}+012.80752 \mathrm{e}+00$ 1.00000e-09 7.00000e-02 $2.80752 \mathrm{e}+012.80752 \mathrm{e}+012.80752 \mathrm{e}+00$ 1.00000e-09 7.00000e-02 5.00000e-04 5.00000e-04 5.00000e-05 1.00000e-09 1.00000e-01

$1.12178 \mathrm{e}+001.12178 \mathrm{e}+00$ 1.12178e-01 1.00000e-09 2.12000e-01 $1.12178 \mathrm{e}+001.12178 \mathrm{e}+00$ 1.12178e-01 1.00000e-09 2.12000e-01 $1.00000 \mathrm{e}-02$ 1.00000e-02 1.00000e-03 1.00000e-09 1.00000e-01 $1.00000 \mathrm{e}+001.00000 \mathrm{e}+001.00000 \mathrm{e}-011.00000 \mathrm{e}-091.00000 \mathrm{e}-01$ $1.00000 \mathrm{e}-05$ 1.00000e-05 1.00000e-06 1.00000e-09 1.00000e-01 $1.00000 \mathrm{e}+001.00000 \mathrm{e}+001.00000 \mathrm{e}-01$ 1.00000e-09 1.00000e-01 Element: 4094 \# of layers: 10

$\mathrm{Kx} \mathrm{Ky} \mathrm{Kz}$ Ss Por

$2.80752 \mathrm{e}+012.80752 \mathrm{e}+012.80752 \mathrm{e}+00$ 1.00000e-09 7.00000e-02 $2.80752 \mathrm{e}+012.80752 \mathrm{e}+012.80752 \mathrm{e}+001.00000 \mathrm{e}-09$ 7.00000e-02 5.00000e-04 5.00000e-04 5.00000e-05 1.00000e-09 1.00000e-01 $1.12178 \mathrm{e}+001.12178 \mathrm{e}+00$ 1.12178e-01 1.00000e-09 2.12000e-01 
$1.12178 \mathrm{e}+001.12178 \mathrm{e}+00$ 1.12178e-01 1.00000e-09 2.12000e-01 $1.12178 \mathrm{e}+001.12178 \mathrm{e}+00$ 1.12178e-01 1.00000e-09 2.12000e-01 $1.00000 \mathrm{e}-021.00000 \mathrm{e}-02$ 1.00000e-03 1.00000e-09 1.00000e-01 $1.00000 \mathrm{e}+001.00000 \mathrm{e}+001.00000 \mathrm{e}-011.00000 \mathrm{e}-091.00000 \mathrm{e}-01$ $1.00000 \mathrm{e}-05$ 1.00000e-05 1.00000e-06 1.00000e-09 1.00000e-01 $1.00000 \mathrm{e}+001.00000 \mathrm{e}+001.00000 \mathrm{e}-011.00000 \mathrm{e}-091.00000 \mathrm{e}-01$ Element: 4095 \# of layers: 8

Kx Ky Kz Ss Por

$2.80752 \mathrm{e}+012.80752 \mathrm{e}+012.80752 \mathrm{e}+00$ 1.00000e-09 7.00000e-02

$2.80752 \mathrm{e}+012.80752 \mathrm{e}+012.80752 \mathrm{e}+001.00000 \mathrm{e}-097.00000 \mathrm{e}-02$ 5.00000e-04 5.00000e-04 5.00000e-05 1.00000e-09 1.00000e-01

$1.12178 \mathrm{e}+001.12178 \mathrm{e}+00$ 1.12178e-01 1.00000e-09 2.12000e-01 $1.12178 \mathrm{e}+001.12178 \mathrm{e}+00$ 1.12178e-01 1.00000e-09 2.12000e-01 $1.12178 \mathrm{e}+001.12178 \mathrm{e}+001.12178 \mathrm{e}-011.00000 \mathrm{e}-092.12000 \mathrm{e}-01$ $1.00000 \mathrm{e}-021.00000 \mathrm{e}-02$ 1.00000e-03 1.00000e-09 1.00000e-01 $1.00000 \mathrm{e}+001.00000 \mathrm{e}+001.00000 \mathrm{e}-011.00000 \mathrm{e}-091.00000 \mathrm{e}-01$ Element: 4096 \# of layers: 8

Kx Ky Kz Ss Por

$2.80752 \mathrm{e}+012.80752 \mathrm{e}+012.80752 \mathrm{e}+00$ 1.00000e-09 7.00000e-02 $2.80752 \mathrm{e}+012.80752 \mathrm{e}+012.80752 \mathrm{e}+001.00000 \mathrm{e}-097.00000 \mathrm{e}-02$ 5.00000e-04 5.00000e-04 5.00000e-05 1.00000e-09 1.00000e-01

$1.12178 \mathrm{e}+001.12178 \mathrm{e}+00$ 1.12178e-01 1.00000e-09 2.12000e-01 $1.12178 \mathrm{e}+001.12178 \mathrm{e}+001.12178 \mathrm{e}-011.00000 \mathrm{e}-092.12000 \mathrm{e}-01$ $1.12178 \mathrm{e}+001.12178 \mathrm{e}+00$ 1.12178e-01 1.00000e-09 2.12000e-01 $1.00000 \mathrm{e}-021.00000 \mathrm{e}-02$ 1.00000e-03 1.00000e-09 1.00000e-01 $1.00000 \mathrm{e}+001.00000 \mathrm{e}+001.00000 \mathrm{e}-011.00000 \mathrm{e}-091.00000 \mathrm{e}-01$ Element: 4097 \# of layers: 7

Kx Ky Kz Ss Por

$2.80752 \mathrm{e}+012.80752 \mathrm{e}+012.80752 \mathrm{e}+00$ 1.00000e-09 7.00000e-02 $2.80752 \mathrm{e}+012.80752 \mathrm{e}+012.80752 \mathrm{e}+001.00000 \mathrm{e}-097.00000 \mathrm{e}-02$ 5.00000e-04 5.00000e-04 5.00000e-05 1.00000e-09 1.00000e-01 $1.12178 \mathrm{e}+001.12178 \mathrm{e}+00$ 1.12178e-01 1.00000e-09 2.12000e-01 $1.12178 \mathrm{e}+001.12178 \mathrm{e}+00$ 1.12178e-01 1.00000e-09 2.12000e-01 $1.00000 \mathrm{e}-021.00000 \mathrm{e}-02$ 1.00000e-03 1.00000e-09 1.00000e-01 $1.00000 \mathrm{e}+001.00000 \mathrm{e}+001.00000 \mathrm{e}-011.00000 \mathrm{e}-091.00000 \mathrm{e}-01$ Element: 4098 \# of layers: 7

Kx Ky Kz Ss Por

$2.80752 \mathrm{e}+012.80752 \mathrm{e}+012.80752 \mathrm{e}+00$ 1.00000e-09 7.00000e-02

$2.80752 \mathrm{e}+012.80752 \mathrm{e}+012.80752 \mathrm{e}+001.00000 \mathrm{e}-097.00000 \mathrm{e}-02$ 5.00000e-04 5.00000e-04 5.00000e-05 1.00000e-09 1.00000e-01 $1.12178 \mathrm{e}+001.12178 \mathrm{e}+00$ 1.12178e-01 1.00000e-09 2.12000e-01 $1.12178 \mathrm{e}+001.12178 \mathrm{e}+00$ 1.12178e-01 1.00000e-09 2.12000e-01 $1.00000 \mathrm{e}-02$ 1.00000e-02 1.00000e-03 1.00000e-09 1.00000e-01 $1.00000 \mathrm{e}+001.00000 \mathrm{e}+001.00000 \mathrm{e}-011.00000 \mathrm{e}-091.00000 \mathrm{e}-01$ Element: 4099 \# of layers: 7

Kx Ky Kz Ss Por 
$2.80752 \mathrm{e}+012.80752 \mathrm{e}+012.80752 \mathrm{e}+00$ 1.00000e-09 7.00000e-02 $2.80752 \mathrm{e}+012.80752 \mathrm{e}+012.80752 \mathrm{e}+001.00000 \mathrm{e}-097.00000 \mathrm{e}-02$ 5.00000e-04 5.00000e-04 5.00000e-05 1.00000e-09 1.00000e-01

$1.12178 \mathrm{e}+001.12178 \mathrm{e}+00$ 1.12178e-01 1.00000e-09 2.12000e-01 $1.12178 \mathrm{e}+001.12178 \mathrm{e}+001.12178 \mathrm{e}-01$ 1.00000e-09 2.12000e-01 $1.00000 \mathrm{e}-02$ 1.00000e-02 1.00000e-03 1.00000e-09 1.00000e-01 $1.00000 \mathrm{e}+001.00000 \mathrm{e}+001.00000 \mathrm{e}-01$ 1.00000e-09 1.00000e-01 Element: 4100 \# of layers: 7

$\mathrm{Kx} \mathrm{Ky} \mathrm{Kz}$ Ss Por

2.80752e+01 2.80752e+01 2.80752e+00 1.00000e-09 7.00000e-02 $2.80752 \mathrm{e}+012.80752 \mathrm{e}+012.80752 \mathrm{e}+00$ 1.00000e-09 7.00000e-02 5.00000e-04 5.00000e-04 5.00000e-05 1.00000e-09 1.00000e-01

$1.12178 \mathrm{e}+001.12178 \mathrm{e}+00$ 1.12178e-01 1.00000e-09 2.12000e-01 $1.12178 \mathrm{e}+001.12178 \mathrm{e}+00$ 1.12178e-01 1.00000e-09 2.12000e-01 $1.00000 \mathrm{e}-02$ 1.00000e-02 1.00000e-03 1.00000e-09 1.00000e-01 $1.00000 \mathrm{e}+001.00000 \mathrm{e}+001.00000 \mathrm{e}-011.00000 \mathrm{e}-091.00000 \mathrm{e}-01$ Element: 4101 \# of layers: 10

$\mathrm{Kx} \mathrm{Ky} \mathrm{Kz}$ Ss Por

$2.91230 \mathrm{e}+012.91230 \mathrm{e}+012.91230 \mathrm{e}+00$ 1.00000e-09 7.00000e-02 $2.91230 \mathrm{e}+012.91230 \mathrm{e}+012.91230 \mathrm{e}+001.00000 \mathrm{e}-09$ 7.00000e-02 5.00000e-04 5.00000e-04 5.00000e-05 1.00000e-09 1.00000e-01 $1.16366 \mathrm{e}+001.16366 \mathrm{e}+00$ 1.16366e-01 1.00000e-09 2.12000e-01 $1.16366 \mathrm{e}+001.16366 \mathrm{e}+00$ 1.16366e-01 1.00000e-09 2.12000e-01 $1.16366 \mathrm{e}+001.16366 \mathrm{e}+001.16366 \mathrm{e}-011.00000 \mathrm{e}-092.12000 \mathrm{e}-01$ $1.00000 \mathrm{e}-02$ 1.00000e-02 1.00000e-03 1.00000e-09 1.00000e-01 $1.00000 \mathrm{e}+001.00000 \mathrm{e}+001.00000 \mathrm{e}-011.00000 \mathrm{e}-091.00000 \mathrm{e}-01$ $1.00000 \mathrm{e}-05$ 1.00000e-05 1.00000e-06 1.00000e-09 1.00000e-01 $1.00000 \mathrm{e}+001.00000 \mathrm{e}+001.00000 \mathrm{e}-011.00000 \mathrm{e}-09$ 1.00000e-01 Element: 4102 \# of layers: 10

$\mathrm{Kx} \mathrm{Ky} \mathrm{Kz}$ Ss Por

$2.91230 \mathrm{e}+012.91230 \mathrm{e}+012.91230 \mathrm{e}+001.00000 \mathrm{e}-09$ 7.00000e-02 $2.91230 \mathrm{e}+012.91230 \mathrm{e}+012.91230 \mathrm{e}+001.00000 \mathrm{e}-09$ 7.00000e-02 5.00000e-04 5.00000e-04 5.00000e-05 1.00000e-09 1.00000e-01

$1.16366 \mathrm{e}+001.16366 \mathrm{e}+00$ 1.16366e-01 1.00000e-09 2.12000e-01 $1.16366 \mathrm{e}+001.16366 \mathrm{e}+00$ 1.16366e-01 1.00000e-09 2.12000e-01 $1.16366 \mathrm{e}+001.16366 \mathrm{e}+001.16366 \mathrm{e}-011.00000 \mathrm{e}-092.12000 \mathrm{e}-01$ $1.00000 \mathrm{e}-02$ 1.00000e-02 1.00000e-03 1.00000e-09 1.00000e-01 $1.00000 \mathrm{e}+001.00000 \mathrm{e}+001.00000 \mathrm{e}-011.00000 \mathrm{e}-091.00000 \mathrm{e}-01$ $1.00000 \mathrm{e}-05$ 1.00000e-05 1.00000e-06 1.00000e-09 1.00000e-01 $1.00000 \mathrm{e}+001.00000 \mathrm{e}+001.00000 \mathrm{e}-01$ 1.00000e-09 1.00000e-01 Element: 4103 \# of layers: 10

$\mathrm{Kx} \mathrm{Ky} \mathrm{Kz}$ Ss Por

$2.91230 \mathrm{e}+012.91230 \mathrm{e}+012.91230 \mathrm{e}+001.00000 \mathrm{e}-09$ 7.00000e-02 $2.91230 \mathrm{e}+012.91230 \mathrm{e}+012.91230 \mathrm{e}+001.00000 \mathrm{e}-09$ 7.00000e-02 5.00000e-04 5.00000e-04 5.00000e-05 1.00000e-09 1.00000e-01 $1.16366 \mathrm{e}+001.16366 \mathrm{e}+001.16366 \mathrm{e}-011.00000 \mathrm{e}-092.12000 \mathrm{e}-01$ 
$1.16366 \mathrm{e}+00$ 1.16366e+00 1.16366e-01 1.00000e-09 2.12000e-01 $1.16366 \mathrm{e}+001.16366 \mathrm{e}+001.16366 \mathrm{e}-01$ 1.00000e-09 2.12000e-01 $1.00000 \mathrm{e}-02$ 1.00000e-02 1.00000e-03 1.00000e-09 1.00000e-01 $1.00000 \mathrm{e}+001.00000 \mathrm{e}+001.00000 \mathrm{e}-011.00000 \mathrm{e}-091.00000 \mathrm{e}-01$ $1.00000 \mathrm{e}-05$ 1.00000e-05 1.00000e-06 1.00000e-09 1.00000e-01 $1.00000 \mathrm{e}+001.00000 \mathrm{e}+001.00000 \mathrm{e}-011.00000 \mathrm{e}-091.00000 \mathrm{e}-01$ Element: 4104 \# of layers: 8

$\mathrm{Kx} \mathrm{Ky} \mathrm{Kz}$ Ss Por

$2.91230 \mathrm{e}+012.91230 \mathrm{e}+012.91230 \mathrm{e}+00$ 1.00000e-09 7.00000e-02 $2.91230 \mathrm{e}+012.91230 \mathrm{e}+012.91230 \mathrm{e}+001.00000 \mathrm{e}-09$ 7.00000e-02 5.00000e-04 5.00000e-04 5.00000e-05 1.00000e-09 1.00000e-01

$1.16366 \mathrm{e}+001.16366 \mathrm{e}+001.16366 \mathrm{e}-011.00000 \mathrm{e}-092.12000 \mathrm{e}-01$ $1.16366 \mathrm{e}+001.16366 \mathrm{e}+00$ 1.16366e-01 1.00000e-09 2.12000e-01 $1.16366 \mathrm{e}+001.16366 \mathrm{e}+001.16366 \mathrm{e}-01$ 1.00000e-09 2.12000e-01 $1.00000 \mathrm{e}-02$ 1.00000e-02 1.00000e-03 1.00000e-09 1.00000e-01 $1.00000 \mathrm{e}+001.00000 \mathrm{e}+001.00000 \mathrm{e}-011.00000 \mathrm{e}-091.00000 \mathrm{e}-01$ Element: 4105 \# of layers: 8

$\mathrm{Kx} \mathrm{Ky} \mathrm{Kz}$ Ss Por

$2.91230 \mathrm{e}+012.91230 \mathrm{e}+012.91230 \mathrm{e}+00$ 1.00000e-09 7.00000e-02 $2.91230 \mathrm{e}+012.91230 \mathrm{e}+012.91230 \mathrm{e}+001.00000 \mathrm{e}-097.00000 \mathrm{e}-02$ 5.00000e-04 5.00000e-04 5.00000e-05 1.00000e-09 1.00000e-01

$1.16366 \mathrm{e}+001.16366 \mathrm{e}+00$ 1.16366e-01 1.00000e-09 2.12000e-01 $1.16366 \mathrm{e}+001.16366 \mathrm{e}+00$ 1.16366e-01 1.00000e-09 2.12000e-01 $1.16366 \mathrm{e}+001.16366 \mathrm{e}+001.16366 \mathrm{e}-01$ 1.00000e-09 2.12000e-01 $1.00000 \mathrm{e}-02$ 1.00000e-02 1.00000e-03 1.00000e-09 1.00000e-01 $1.00000 \mathrm{e}+001.00000 \mathrm{e}+001.00000 \mathrm{e}-011.00000 \mathrm{e}-091.00000 \mathrm{e}-01$ Element: 4106 \# of layers: 8

$\mathrm{Kx} \mathrm{Ky} \mathrm{Kz}$ Ss Por

$2.91230 \mathrm{e}+012.91230 \mathrm{e}+012.91230 \mathrm{e}+001.00000 \mathrm{e}-09$ 7.00000e-02 $2.91230 \mathrm{e}+012.91230 \mathrm{e}+012.91230 \mathrm{e}+001.00000 \mathrm{e}-09$ 7.00000e-02 5.00000e-04 5.00000e-04 5.00000e-05 1.00000e-09 1.00000e-01 $1.16366 \mathrm{e}+001.16366 \mathrm{e}+00$ 1.16366e-01 1.00000e-09 2.12000e-01 $1.16366 \mathrm{e}+001.16366 \mathrm{e}+001.16366 \mathrm{e}-011.00000 \mathrm{e}-092.12000 \mathrm{e}-01$ $1.16366 \mathrm{e}+001.16366 \mathrm{e}+00 \quad 1.16366 \mathrm{e}-011.00000 \mathrm{e}-092.12000 \mathrm{e}-01$ $1.00000 \mathrm{e}-02$ 1.00000e-02 1.00000e-03 1.00000e-09 1.00000e-01 $1.00000 \mathrm{e}+001.00000 \mathrm{e}+001.00000 \mathrm{e}-01$ 1.00000e-09 1.00000e-01 Element: 4107 \# of layers: 7

$\mathrm{Kx} \mathrm{Ky} \mathrm{Kz}$ Ss Por

$2.91230 \mathrm{e}+012.91230 \mathrm{e}+012.91230 \mathrm{e}+001.00000 \mathrm{e}-09$ 7.00000e-02 $2.91230 \mathrm{e}+012.91230 \mathrm{e}+012.91230 \mathrm{e}+001.00000 \mathrm{e}-097.00000 \mathrm{e}-02$ 5.00000e-04 5.00000e-04 5.00000e-05 1.00000e-09 1.00000e-01

$1.16366 \mathrm{e}+001.16366 \mathrm{e}+001.16366 \mathrm{e}-011.00000 \mathrm{e}-092.12000 \mathrm{e}-01$ $1.16366 \mathrm{e}+00$ 1.16366e+00 1.16366e-01 1.00000e-09 2.12000e-01 $1.00000 \mathrm{e}-02$ 1.00000e-02 1.00000e-03 1.00000e-09 1.00000e-01 $1.00000 \mathrm{e}+001.00000 \mathrm{e}+001.00000 \mathrm{e}-011.00000 \mathrm{e}-09$ 1.00000e-01 Element: 4108 \# of layers: 7 
$\mathrm{Kx} \mathrm{Ky} \mathrm{Kz}$ Ss Por

$2.91230 \mathrm{e}+012.91230 \mathrm{e}+012.91230 \mathrm{e}+00$ 1.00000e-09 7.00000e-02

$2.91230 \mathrm{e}+012.91230 \mathrm{e}+012.91230 \mathrm{e}+001.00000 \mathrm{e}-09$ 7.00000e-02

5.00000e-04 5.00000e-04 5.00000e-05 1.00000e-09 1.00000e-01

$1.16366 \mathrm{e}+001.16366 \mathrm{e}+001.16366 \mathrm{e}-01$ 1.00000e-09 2.12000e-01

$1.16366 \mathrm{e}+001.16366 \mathrm{e}+001.16366 \mathrm{e}-01$ 1.00000e-09 2.12000e-01

$1.00000 \mathrm{e}-02$ 1.00000e-02 1.00000e-03 1.00000e-09 1.00000e-01

$1.00000 \mathrm{e}+001.00000 \mathrm{e}+001.00000 \mathrm{e}-01$ 1.00000e-09 1.00000e-01

Element: 4109 \# of layers: 7

$\mathrm{Kx} \mathrm{Ky} \mathrm{Kz}$ Ss Por

$2.91230 \mathrm{e}+012.91230 \mathrm{e}+012.91230 \mathrm{e}+001.00000 \mathrm{e}-09$ 7.00000e-02

$2.91230 \mathrm{e}+012.91230 \mathrm{e}+012.91230 \mathrm{e}+001.00000 \mathrm{e}-09$ 7.00000e-02

5.00000e-04 5.00000e-04 5.00000e-05 1.00000e-09 1.00000e-01

$1.16366 \mathrm{e}+001.16366 \mathrm{e}+00$ 1.16366e-01 1.00000e-09 2.12000e-01

$1.16366 \mathrm{e}+001.16366 \mathrm{e}+001.16366 \mathrm{e}-01$ 1.00000e-09 2.12000e-01

1.00000e-02 1.00000e-02 1.00000e-03 1.00000e-09 1.00000e-01

$1.00000 \mathrm{e}+001.00000 \mathrm{e}+001.00000 \mathrm{e}-011.00000 \mathrm{e}-091.00000 \mathrm{e}-01$

Element: 4110 \# of layers: 10

$\mathrm{Kx} \mathrm{Ky} \mathrm{Kz}$ Ss Por

3.01745e+01 3.01745e+01 3.01745e+00 1.00000e-09 7.00000e-02

$3.01745 \mathrm{e}+013.01745 \mathrm{e}+013.01745 \mathrm{e}+001.00000 \mathrm{e}-09$ 7.00000e-02

5.00000e-04 5.00000e-04 5.00000e-05 1.00000e-09 1.00000e-01

$1.20569 \mathrm{e}+001.20569 \mathrm{e}+00$ 1.20569e-01 1.00000e-09 2.12000e-01

$1.20569 \mathrm{e}+001.20569 \mathrm{e}+00$ 1.20569e-01 1.00000e-09 2.12000e-01

$1.20569 \mathrm{e}+001.20569 \mathrm{e}+001.20569 \mathrm{e}-01$ 1.00000e-09 2.12000e-01

$1.00000 \mathrm{e}-02$ 1.00000e-02 1.00000e-03 1.00000e-09 1.00000e-01

$1.00000 \mathrm{e}+001.00000 \mathrm{e}+001.00000 \mathrm{e}-011.00000 \mathrm{e}-091.00000 \mathrm{e}-01$

$1.00000 \mathrm{e}-05$ 1.00000e-05 1.00000e-06 1.00000e-09 1.00000e-01

$1.00000 \mathrm{e}+001.00000 \mathrm{e}+001.00000 \mathrm{e}-011.00000 \mathrm{e}-091.00000 \mathrm{e}-01$

Element: 4111 \# of layers: 10

$\mathrm{Kx} \mathrm{Ky} \mathrm{Kz}$ Ss Por

3.01745e+01 3.01745e+01 3.01745e+00 1.00000e-09 7.00000e-02

$3.01745 \mathrm{e}+013.01745 \mathrm{e}+013.01745 \mathrm{e}+001.00000 \mathrm{e}-09$ 7.00000e-02

5.00000e-04 5.00000e-04 5.00000e-05 1.00000e-09 1.00000e-01

$1.20569 \mathrm{e}+001.20569 \mathrm{e}+00$ 1.20569e-01 1.00000e-09 2.12000e-01

$1.20569 \mathrm{e}+001.20569 \mathrm{e}+00$ 1.20569e-01 1.00000e-09 2.12000e-01

$1.20569 \mathrm{e}+001.20569 \mathrm{e}+00$ 1.20569e-01 1.00000e-09 2.12000e-01

$1.00000 \mathrm{e}-02$ 1.00000e-02 1.00000e-03 1.00000e-09 1.00000e-01

$1.00000 \mathrm{e}+001.00000 \mathrm{e}+001.00000 \mathrm{e}-011.00000 \mathrm{e}-091.00000 \mathrm{e}-01$

$1.00000 \mathrm{e}-05$ 1.00000e-05 1.00000e-06 1.00000e-09 1.00000e-01

$1.00000 \mathrm{e}+001.00000 \mathrm{e}+001.00000 \mathrm{e}-011.00000 \mathrm{e}-091.00000 \mathrm{e}-01$

Element: 4112 \# of layers: 11

$\mathrm{Kx} \mathrm{Ky} \mathrm{Kz}$ Ss Por

3.01745e+01 3.01745e+01 3.01745e+00 1.00000e-09 7.00000e-02

$3.01745 \mathrm{e}+013.01745 \mathrm{e}+013.01745 \mathrm{e}+001.00000 \mathrm{e}-09$ 7.00000e-02

5.00000e-04 5.00000e-04 5.00000e-05 1.00000e-09 1.00000e-01 
$1.20569 \mathrm{e}+001.20569 \mathrm{e}+00$ 1.20569e-01 1.00000e-09 2.12000e-01 $1.20569 \mathrm{e}+001.20569 \mathrm{e}+001.20569 \mathrm{e}-011.00000 \mathrm{e}-092.12000 \mathrm{e}-01$ $1.20569 \mathrm{e}+001.20569 \mathrm{e}+00$ 1.20569e-01 1.00000e-09 2.12000e-01 $1.20569 \mathrm{e}+001.20569 \mathrm{e}+001.20569 \mathrm{e}-011.00000 \mathrm{e}-09$ 2.12000e-01 $1.00000 \mathrm{e}-02$ 1.00000e-02 1.00000e-03 1.00000e-09 1.00000e-01 $1.00000 \mathrm{e}+001.00000 \mathrm{e}+001.00000 \mathrm{e}-011.00000 \mathrm{e}-091.00000 \mathrm{e}-01$ $1.00000 \mathrm{e}-051.00000 \mathrm{e}-05$ 1.00000e-06 1.00000e-09 1.00000e-01 $1.00000 \mathrm{e}+001.00000 \mathrm{e}+001.00000 \mathrm{e}-011.00000 \mathrm{e}-091.00000 \mathrm{e}-01$ Element: 4113 \# of layers: 11

Kx Ky Kz Ss Por

$3.01745 \mathrm{e}+013.01745 \mathrm{e}+013.01745 \mathrm{e}+00$ 1.00000e-09 7.00000e-02 $3.01745 \mathrm{e}+013.01745 \mathrm{e}+013.01745 \mathrm{e}+001.00000 \mathrm{e}-097.00000 \mathrm{e}-02$ 5.00000e-04 5.00000e-04 5.00000e-05 1.00000e-09 1.00000e-01

$1.20569 \mathrm{e}+001.20569 \mathrm{e}+00$ 1.20569e-01 1.00000e-09 2.12000e-01 $1.20569 \mathrm{e}+001.20569 \mathrm{e}+001.20569 \mathrm{e}-011.00000 \mathrm{e}-092.12000 \mathrm{e}-01$ $1.20569 \mathrm{e}+001.20569 \mathrm{e}+00$ 1.20569e-01 1.00000e-09 2.12000e-01 $1.20569 \mathrm{e}+001.20569 \mathrm{e}+001.20569 \mathrm{e}-011.00000 \mathrm{e}-092.12000 \mathrm{e}-01$ $1.00000 \mathrm{e}-02$ 1.00000e-02 1.00000e-03 1.00000e-09 1.00000e-01 $1.00000 \mathrm{e}+001.00000 \mathrm{e}+001.00000 \mathrm{e}-011.00000 \mathrm{e}-091.00000 \mathrm{e}-01$ $1.00000 \mathrm{e}-05$ 1.00000e-05 1.00000e-06 1.00000e-09 1.00000e-01 $1.00000 \mathrm{e}+001.00000 \mathrm{e}+001.00000 \mathrm{e}-011.00000 \mathrm{e}-091.00000 \mathrm{e}-01$ Element: 4114 \# of layers: 9

Kx Ky Kz Ss Por

$3.01745 \mathrm{e}+013.01745 \mathrm{e}+013.01745 \mathrm{e}+00$ 1.00000e-09 7.00000e-02 $3.01745 \mathrm{e}+013.01745 \mathrm{e}+013.01745 \mathrm{e}+001.00000 \mathrm{e}-097.00000 \mathrm{e}-02$ 5.00000e-04 5.00000e-04 5.00000e-05 1.00000e-09 1.00000e-01

$1.20569 \mathrm{e}+001.20569 \mathrm{e}+001.20569 \mathrm{e}-011.00000 \mathrm{e}-092.12000 \mathrm{e}-01$ $1.20569 \mathrm{e}+001.20569 \mathrm{e}+001.20569 \mathrm{e}-011.00000 \mathrm{e}-092.12000 \mathrm{e}-01$ $1.20569 \mathrm{e}+001.20569 \mathrm{e}+001.20569 \mathrm{e}-011.00000 \mathrm{e}-092.12000 \mathrm{e}-01$ $1.20569 \mathrm{e}+001.20569 \mathrm{e}+00$ 1.20569e-01 1.00000e-09 2.12000e-01 $1.00000 \mathrm{e}-021.00000 \mathrm{e}-02$ 1.00000e-03 1.00000e-09 1.00000e-01 $1.00000 \mathrm{e}+001.00000 \mathrm{e}+001.00000 \mathrm{e}-011.00000 \mathrm{e}-091.00000 \mathrm{e}-01$ Element: 4115 \# of layers: 7

Kx Ky Kz Ss Por

$3.01745 \mathrm{e}+013.01745 \mathrm{e}+013.01745 \mathrm{e}+00$ 1.00000e-09 7.00000e-02 $3.01745 \mathrm{e}+013.01745 \mathrm{e}+013.01745 \mathrm{e}+001.00000 \mathrm{e}-097.00000 \mathrm{e}-02$ $1.20569 \mathrm{e}+001.20569 \mathrm{e}+001.20569 \mathrm{e}-011.00000 \mathrm{e}-092.12000 \mathrm{e}-01$ $1.20569 \mathrm{e}+001.20569 \mathrm{e}+00$ 1.20569e-01 1.00000e-09 2.12000e-01 $1.20569 \mathrm{e}+001.20569 \mathrm{e}+00$ 1.20569e-01 1.00000e-09 2.12000e-01 $1.00000 \mathrm{e}-02$ 1.00000e-02 1.00000e-03 1.00000e-09 1.00000e-01 $1.00000 \mathrm{e}+001.00000 \mathrm{e}+001.00000 \mathrm{e}-011.00000 \mathrm{e}-091.00000 \mathrm{e}-01$ Element: 4116 \# of layers: 7

Kx Ky Kz Ss Por

$3.01745 \mathrm{e}+013.01745 \mathrm{e}+013.01745 \mathrm{e}+00$ 1.00000e-09 7.00000e-02 $3.01745 \mathrm{e}+013.01745 \mathrm{e}+013.01745 \mathrm{e}+001.00000 \mathrm{e}-09$ 7.00000e-02 $1.20569 \mathrm{e}+001.20569 \mathrm{e}+00$ 1.20569e-01 1.00000e-09 2.12000e-01 
$1.20569 \mathrm{e}+001.20569 \mathrm{e}+00$ 1.20569e-01 1.00000e-09 2.12000e-01 $1.20569 \mathrm{e}+001.20569 \mathrm{e}+00$ 1.20569e-01 1.00000e-09 2.12000e-01 $1.00000 \mathrm{e}-021.00000 \mathrm{e}-02$ 1.00000e-03 1.00000e-09 1.00000e-01 $1.00000 \mathrm{e}+001.00000 \mathrm{e}+001.00000 \mathrm{e}-011.00000 \mathrm{e}-091.00000 \mathrm{e}-01$ Element: 4117 \# of layers: 8

Kx Ky Kz Ss Por

$3.01745 \mathrm{e}+013.01745 \mathrm{e}+013.01745 \mathrm{e}+00$ 1.00000e-09 7.00000e-02 $3.01745 \mathrm{e}+013.01745 \mathrm{e}+013.01745 \mathrm{e}+001.00000 \mathrm{e}-097.00000 \mathrm{e}-02$ 5.00000e-04 5.00000e-04 5.00000e-05 1.00000e-09 1.00000e-01

$1.20569 \mathrm{e}+001.20569 \mathrm{e}+00$ 1.20569e-01 1.00000e-09 2.12000e-01 $1.20569 \mathrm{e}+001.20569 \mathrm{e}+001.20569 \mathrm{e}-011.00000 \mathrm{e}-092.12000 \mathrm{e}-01$ $1.20569 \mathrm{e}+001.20569 \mathrm{e}+00$ 1.20569e-01 1.00000e-09 2.12000e-01 $1.00000 \mathrm{e}-02$ 1.00000e-02 $1.00000 \mathrm{e}-031.00000 \mathrm{e}-091.00000 \mathrm{e}-01$ $1.00000 \mathrm{e}+001.00000 \mathrm{e}+001.00000 \mathrm{e}-011.00000 \mathrm{e}-091.00000 \mathrm{e}-01$ Element: 4118 \# of layers: 10

Kx Ky Kz Ss Por

$3.01745 \mathrm{e}+013.01745 \mathrm{e}+013.01745 \mathrm{e}+00$ 1.00000e-09 7.00000e-02 $3.01745 \mathrm{e}+013.01745 \mathrm{e}+013.01745 \mathrm{e}+001.00000 \mathrm{e}-097.00000 \mathrm{e}-02$ 5.00000e-04 5.00000e-04 5.00000e-05 1.00000e-09 1.00000e-01 $1.20569 \mathrm{e}+001.20569 \mathrm{e}+00$ 1.20569e-01 1.00000e-09 2.12000e-01 $1.20569 \mathrm{e}+001.20569 \mathrm{e}+001.20569 \mathrm{e}-011.00000 \mathrm{e}-092.12000 \mathrm{e}-01$ $1.20569 \mathrm{e}+001.20569 \mathrm{e}+001.20569 \mathrm{e}-011.00000 \mathrm{e}-092.12000 \mathrm{e}-01$ $1.00000 \mathrm{e}-021.00000 \mathrm{e}-02$ 1.00000e-03 1.00000e-09 1.00000e-01 $1.00000 \mathrm{e}+001.00000 \mathrm{e}+001.00000 \mathrm{e}-011.00000 \mathrm{e}-091.00000 \mathrm{e}-01$ $1.00000 \mathrm{e}-051.00000 \mathrm{e}-05$ 1.00000e-06 1.00000e-09 1.00000e-01 $1.00000 \mathrm{e}+001.00000 \mathrm{e}+001.00000 \mathrm{e}-011.00000 \mathrm{e}-091.00000 \mathrm{e}-01$ Element: 4119 \# of layers: 11

Kx Ky Kz Ss Por

$2.89482 \mathrm{e}+012.89482 \mathrm{e}+012.89482 \mathrm{e}+001.00000 \mathrm{e}-09$ 7.00000e-02 5.00000e-04 5.00000e-04 5.00000e-05 1.00000e-09 1.00000e-01 5.00000e-04 5.00000e-04 5.00000e-05 1.00000e-09 1.00000e-01 $1.15668 \mathrm{e}+001.15668 \mathrm{e}+001.15668 \mathrm{e}-011.00000 \mathrm{e}-092.12000 \mathrm{e}-01$ $1.15668 \mathrm{e}+001.15668 \mathrm{e}+001.15668 \mathrm{e}-011.00000 \mathrm{e}-092.12000 \mathrm{e}-01$ $1.15668 \mathrm{e}+001.15668 \mathrm{e}+001.15668 \mathrm{e}-011.00000 \mathrm{e}-092.12000 \mathrm{e}-01$ $1.15668 \mathrm{e}+001.15668 \mathrm{e}+001.15668 \mathrm{e}-01$ 1.00000e-09 2.12000e-01 $1.00000 \mathrm{e}-021.00000 \mathrm{e}-02$ 1.00000e-03 1.00000e-09 1.00000e-01 $1.00000 \mathrm{e}+001.00000 \mathrm{e}+001.00000 \mathrm{e}-011.00000 \mathrm{e}-091.00000 \mathrm{e}-01$ $1.00000 \mathrm{e}-05$ 1.00000e-05 1.00000e-06 1.00000e-09 1.00000e-01 $1.00000 \mathrm{e}+001.00000 \mathrm{e}+001.00000 \mathrm{e}-011.00000 \mathrm{e}-091.00000 \mathrm{e}-01$ Element: 4120 \# of layers: 11

Kx Ky Kz Ss Por

$2.89482 \mathrm{e}+012.89482 \mathrm{e}+012.89482 \mathrm{e}+00$ 1.00000e-09 7.00000e-02

$2.89482 \mathrm{e}+012.89482 \mathrm{e}+012.89482 \mathrm{e}+001.00000 \mathrm{e}-09$ 7.00000e-02

5.00000e-04 5.00000e-04 5.00000e-05 1.00000e-09 1.00000e-01 5.00000e-04 5.00000e-04 5.00000e-05 1.00000e-09 1.00000e-01 $1.15668 \mathrm{e}+001.15668 \mathrm{e}+00$ 1.15668e-01 1.00000e-09 2.12000e-01 
$1.15668 \mathrm{e}+001.15668 \mathrm{e}+00$ 1.15668e-01 1.00000e-09 2.12000e-01 $1.15668 \mathrm{e}+001.15668 \mathrm{e}+001.15668 \mathrm{e}-01$ 1.00000e-09 2.12000e-01 $1.00000 \mathrm{e}-02$ 1.00000e-02 1.00000e-03 1.00000e-09 1.00000e-01 $1.00000 \mathrm{e}+001.00000 \mathrm{e}+001.00000 \mathrm{e}-011.00000 \mathrm{e}-091.00000 \mathrm{e}-01$ $1.00000 \mathrm{e}-05$ 1.00000e-05 1.00000e-06 1.00000e-09 1.00000e-01 $1.00000 \mathrm{e}+001.00000 \mathrm{e}+001.00000 \mathrm{e}-011.00000 \mathrm{e}-091.00000 \mathrm{e}-01$ Element: 4121 \# of layers: 10

$\mathrm{Kx} \mathrm{Ky} \mathrm{Kz}$ Ss Por

$2.89482 \mathrm{e}+012.89482 \mathrm{e}+012.89482 \mathrm{e}+00$ 1.00000e-09 7.00000e-02

$2.89482 \mathrm{e}+012.89482 \mathrm{e}+012.89482 \mathrm{e}+001.00000 \mathrm{e}-09$ 7.00000e-02 5.00000e-04 5.00000e-04 5.00000e-05 1.00000e-09 1.00000e-01 5.00000e-04 5.00000e-04 5.00000e-05 1.00000e-09 1.00000e-01

$1.15668 \mathrm{e}+001.15668 \mathrm{e}+00$ 1.15668e-01 1.00000e-09 2.12000e-01 $1.15668 \mathrm{e}+001.15668 \mathrm{e}+00$ 1.15668e-01 1.00000e-09 2.12000e-01 $1.15668 \mathrm{e}+001.15668 \mathrm{e}+00$ 1.15668e-01 1.00000e-09 2.12000e-01 $1.15668 \mathrm{e}+001.15668 \mathrm{e}+001.15668 \mathrm{e}-01$ 1.00000e-09 2.12000e-01 $1.00000 \mathrm{e}-02$ 1.00000e-02 1.00000e-03 1.00000e-09 1.00000e-01 $1.00000 \mathrm{e}+001.00000 \mathrm{e}+001.00000 \mathrm{e}-01$ 1.00000e-09 1.00000e-01 Element: 4122 \# of layers: 9

$\mathrm{Kx} \mathrm{Ky} \mathrm{Kz}$ Ss Por

$2.89482 \mathrm{e}+012.89482 \mathrm{e}+012.89482 \mathrm{e}+00$ 1.00000e-09 7.00000e-02

$2.89482 \mathrm{e}+012.89482 \mathrm{e}+012.89482 \mathrm{e}+001.00000 \mathrm{e}-09$ 7.00000e-02

5.00000e-04 5.00000e-04 5.00000e-05 1.00000e-09 1.00000e-01

5.00000e-04 5.00000e-04 5.00000e-05 1.00000e-09 1.00000e-01

$1.15668 \mathrm{e}+001.15668 \mathrm{e}+001.15668 \mathrm{e}-011.00000 \mathrm{e}-092.12000 \mathrm{e}-01$

$1.15668 \mathrm{e}+001.15668 \mathrm{e}+00$ 1.15668e-01 1.00000e-09 2.12000e-01

$1.15668 \mathrm{e}+001.15668 \mathrm{e}+001.15668 \mathrm{e}-01$ 1.00000e-09 2.12000e-01 $1.00000 \mathrm{e}-02$ 1.00000e-02 1.00000e-03 1.00000e-09 1.00000e-01 $1.00000 \mathrm{e}+001.00000 \mathrm{e}+001.00000 \mathrm{e}-011.00000 \mathrm{e}-091.00000 \mathrm{e}-01$ Element: 4123 \# of layers: 10

$\mathrm{Kx} \mathrm{Ky} \mathrm{Kz}$ Ss Por

$2.89482 \mathrm{e}+012.89482 \mathrm{e}+012.89482 \mathrm{e}+00$ 1.00000e-09 7.00000e-02 $2.89482 \mathrm{e}+012.89482 \mathrm{e}+012.89482 \mathrm{e}+00$ 1.00000e-09 7.00000e-02 5.00000e-04 5.00000e-04 5.00000e-05 1.00000e-09 1.00000e-01 5.00000e-04 5.00000e-04 5.00000e-05 1.00000e-09 1.00000e-01 $1.15668 \mathrm{e}+001.15668 \mathrm{e}+00$ 1.15668e-01 1.00000e-09 2.12000e-01 $1.15668 \mathrm{e}+001.15668 \mathrm{e}+00$ 1.15668e-01 1.00000e-09 2.12000e-01 $1.15668 \mathrm{e}+001.15668 \mathrm{e}+00$ 1.15668e-01 1.00000e-09 2.12000e-01 $1.15668 \mathrm{e}+001.15668 \mathrm{e}+00$ 1.15668e-01 1.00000e-09 2.12000e-01 $1.00000 \mathrm{e}-02$ 1.00000e-02 1.00000e-03 1.00000e-09 1.00000e-01 $1.00000 \mathrm{e}+001.00000 \mathrm{e}+001.00000 \mathrm{e}-011.00000 \mathrm{e}-091.00000 \mathrm{e}-01$ Element: 4124 \# of layers: 10

$\mathrm{Kx} \mathrm{Ky} \mathrm{Kz}$ Ss Por

2.89482e+01 2.89482e+01 2.89482e+00 1.00000e-09 7.00000e-02 $2.89482 \mathrm{e}+012.89482 \mathrm{e}+012.89482 \mathrm{e}+001.00000 \mathrm{e}-09$ 7.00000e-02 $2.89482 \mathrm{e}+012.89482 \mathrm{e}+012.89482 \mathrm{e}+001.00000 \mathrm{e}-09$ 7.00000e-02 
5.00000e-04 5.00000e-04 5.00000e-05 1.00000e-09 1.00000e-01

$1.15668 \mathrm{e}+00$ 1.15668e+00 1.15668e-01 1.00000e-09 2.12000e-01

$1.15668 \mathrm{e}+001.15668 \mathrm{e}+00$ 1.15668e-01 1.00000e-09 2.12000e-01

$1.15668 \mathrm{e}+001.15668 \mathrm{e}+00$ 1.15668e-01 1.00000e-09 2.12000e-01

$1.15668 \mathrm{e}+001.15668 \mathrm{e}+001.15668 \mathrm{e}-011.00000 \mathrm{e}-092.12000 \mathrm{e}-01$

$1.00000 \mathrm{e}-02$ 1.00000e-02 1.00000e-03 1.00000e-09 1.00000e-01

$1.00000 \mathrm{e}+001.00000 \mathrm{e}+001.00000 \mathrm{e}-01$ 1.00000e-09 1.00000e-01

Element: 4125 \# of layers: 10

$\mathrm{Kx} \mathrm{Ky} \mathrm{Kz}$ Ss Por

2.89482e+01 2.89482e+01 2.89482e+00 1.00000e-09 7.00000e-02

$2.89482 \mathrm{e}+012.89482 \mathrm{e}+012.89482 \mathrm{e}+00$ 1.00000e-09 7.00000e-02

$2.89482 \mathrm{e}+012.89482 \mathrm{e}+012.89482 \mathrm{e}+001.00000 \mathrm{e}-09$ 7.00000e-02

5.00000e-04 5.00000e-04 5.00000e-05 1.00000e-09 1.00000e-01

$1.15668 \mathrm{e}+001.15668 \mathrm{e}+00$ 1.15668e-01 1.00000e-09 2.12000e-01

$1.15668 \mathrm{e}+001.15668 \mathrm{e}+00$ 1.15668e-01 1.00000e-09 2.12000e-01

$1.15668 \mathrm{e}+001.15668 \mathrm{e}+00$ 1.15668e-01 1.00000e-09 2.12000e-01

$1.15668 \mathrm{e}+001.15668 \mathrm{e}+00$ 1.15668e-01 1.00000e-09 2.12000e-01

$1.00000 \mathrm{e}-02$ 1.00000e-02 1.00000e-03 1.00000e-09 1.00000e-01

$1.00000 \mathrm{e}+001.00000 \mathrm{e}+001.00000 \mathrm{e}-011.00000 \mathrm{e}-091.00000 \mathrm{e}-01$

Element: 4126 \# of layers: 10

$\mathrm{Kx} \mathrm{Ky} \mathrm{Kz}$ Ss Por

$2.89482 \mathrm{e}+012.89482 \mathrm{e}+01$ 2.89482e+00 1.00000e-09 7.00000e-02

$2.89482 \mathrm{e}+012.89482 \mathrm{e}+012.89482 \mathrm{e}+00$ 1.00000e-09 7.00000e-02

5.00000e-04 5.00000e-04 5.00000e-05 1.00000e-09 1.00000e-01

$1.15668 \mathrm{e}+001.15668 \mathrm{e}+00$ 1.15668e-01 1.00000e-09 2.12000e-01

$1.15668 \mathrm{e}+001.15668 \mathrm{e}+00$ 1.15668e-01 1.00000e-09 2.12000e-01

$1.15668 \mathrm{e}+001.15668 \mathrm{e}+00$ 1.15668e-01 1.00000e-09 2.12000e-01

$1.00000 \mathrm{e}-02$ 1.00000e-02 1.00000e-03 1.00000e-09 1.00000e-01

$1.00000 \mathrm{e}+001.00000 \mathrm{e}+001.00000 \mathrm{e}-011.00000 \mathrm{e}-091.00000 \mathrm{e}-01$

$1.00000 \mathrm{e}-05$ 1.00000e-05 1.00000e-06 1.00000e-09 1.00000e-01

$1.00000 \mathrm{e}+001.00000 \mathrm{e}+001.00000 \mathrm{e}-011.00000 \mathrm{e}-091.00000 \mathrm{e}-01$

Element: 4127 \# of layers: 10

$\mathrm{Kx} \mathrm{Ky} \mathrm{Kz}$ Ss Por

$2.89482 \mathrm{e}+012.89482 \mathrm{e}+012.89482 \mathrm{e}+00$ 1.00000e-09 7.00000e-02

$2.89482 \mathrm{e}+012.89482 \mathrm{e}+012.89482 \mathrm{e}+001.00000 \mathrm{e}-09$ 7.00000e-02

5.00000e-04 5.00000e-04 5.00000e-05 1.00000e-09 1.00000e-01

$1.15668 \mathrm{e}+001.15668 \mathrm{e}+001.15668 \mathrm{e}-01$ 1.00000e-09 2.12000e-01

$1.15668 \mathrm{e}+001.15668 \mathrm{e}+00$ 1.15668e-01 1.00000e-09 2.12000e-01

$1.15668 \mathrm{e}+001.15668 \mathrm{e}+00$ 1.15668e-01 1.00000e-09 2.12000e-01

$1.00000 \mathrm{e}-02$ 1.00000e-02 1.00000e-03 1.00000e-09 1.00000e-01

$1.00000 \mathrm{e}+001.00000 \mathrm{e}+001.00000 \mathrm{e}-011.00000 \mathrm{e}-091.00000 \mathrm{e}-01$

$1.00000 \mathrm{e}-05$ 1.00000e-05 1.00000e-06 1.00000e-09 1.00000e-01

$1.00000 \mathrm{e}+001.00000 \mathrm{e}+001.00000 \mathrm{e}-011.00000 \mathrm{e}-091.00000 \mathrm{e}-01$

Element: 4128 \# of layers: 11

$\mathrm{Kx} \mathrm{Ky} \mathrm{Kz}$ Ss Por

2.37747e+01 2.37747e+01 2.37747e+00 1.00000e-09 7.00000e-02 
2.37747e+01 2.37747e+01 2.37747e+00 1.00000e-09 7.00000e-02 5.00000e-04 5.00000e-04 5.00000e-05 1.00000e-09 1.00000e-01 5.00000e-04 5.00000e-04 5.00000e-05 1.00000e-09 1.00000e-01 9.49948e-01 9.49948e-01 9.49948e-02 1.00000e-09 2.12000e-01 9.49948e-01 9.49948e-01 9.49948e-02 1.00000e-09 2.12000e-01 9.49948e-01 9.49948e-01 9.49948e-02 1.00000e-09 2.12000e-01 9.49948e-01 9.49948e-01 9.49948e-02 1.00000e-09 2.12000e-01 9.49948e-01 9.49948e-01 9.49948e-02 1.00000e-09 2.12000e-01 $1.00000 \mathrm{e}-02$ 1.00000e-02 1.00000e-03 1.00000e-09 1.00000e-01 $1.00000 \mathrm{e}+001.00000 \mathrm{e}+00$ 1.00000e-01 1.00000e-09 1.00000e-01 Element: 4129 \# of layers: 10

Kx Ky Kz Ss Por

2.37747e+01 2.37747e+01 2.37747e+00 1.00000e-09 7.00000e-02

$2.37747 \mathrm{e}+012.37747 \mathrm{e}+012.37747 \mathrm{e}+00$ 1.00000e-09 7.00000e-02 5.00000e-04 5.00000e-04 5.00000e-05 1.00000e-09 1.00000e-01 5.00000e-04 5.00000e-04 5.00000e-05 1.00000e-09 1.00000e-01 9.49948e-01 9.49948e-01 9.49948e-02 1.00000e-09 2.12000e-01 9.49948e-01 9.49948e-01 9.49948e-02 1.00000e-09 2.12000e-01 9.49948e-01 9.49948e-01 9.49948e-02 1.00000e-09 2.12000e-01 9.49948e-01 9.49948e-01 9.49948e-02 1.00000e-09 2.12000e-01 $1.00000 \mathrm{e}-02$ 1.00000e-02 1.00000e-03 1.00000e-09 1.00000e-01 $1.00000 \mathrm{e}+001.00000 \mathrm{e}+001.00000 \mathrm{e}-01$ 1.00000e-09 1.00000e-01 Element: 4130 \# of layers: 10

Kx Ky Kz Ss Por

2.37747e+01 2.37747e+01 2.37747e+00 1.00000e-09 7.00000e-02 $2.37747 \mathrm{e}+012.37747 \mathrm{e}+012.37747 \mathrm{e}+001.00000 \mathrm{e}-09$ 7.00000e-02 5.00000e-04 5.00000e-04 5.00000e-05 1.00000e-09 1.00000e-01 5.00000e-04 5.00000e-04 5.00000e-05 1.00000e-09 1.00000e-01 9.49948e-01 9.49948e-01 9.49948e-02 1.00000e-09 2.12000e-01 9.49948e-01 9.49948e-01 9.49948e-02 1.00000e-09 2.12000e-01 9.49948e-01 9.49948e-01 9.49948e-02 1.00000e-09 2.12000e-01 9.49948e-01 9.49948e-01 9.49948e-02 1.00000e-09 2.12000e-01 $1.00000 \mathrm{e}-02$ 1.00000e-02 1.00000e-03 1.00000e-09 1.00000e-01 $1.00000 \mathrm{e}+001.00000 \mathrm{e}+001.00000 \mathrm{e}-011.00000 \mathrm{e}-091.00000 \mathrm{e}-01$ Element: 4134 \# of layers: 10

Kx Ky Kz Ss Por

2.37747e+01 2.37747e+01 2.37747e+00 1.00000e-09 7.00000e-02

$2.37747 \mathrm{e}+012.37747 \mathrm{e}+012.37747 \mathrm{e}+001.00000 \mathrm{e}-09$ 7.00000e-02 5.00000e-04 5.00000e-04 5.00000e-05 1.00000e-09 1.00000e-01 5.00000e-04 5.00000e-04 5.00000e-05 1.00000e-09 1.00000e-01 9.49948e-01 9.49948e-01 9.49948e-02 1.00000e-09 2.12000e-01 9.49948e-01 9.49948e-01 9.49948e-02 1.00000e-09 2.12000e-01 9.49948e-01 9.49948e-01 9.49948e-02 1.00000e-09 2.12000e-01 9.49948e-01 9.49948e-01 9.49948e-02 1.00000e-09 2.12000e-01 $1.00000 \mathrm{e}-02$ 1.00000e-02 1.00000e-03 1.00000e-09 1.00000e-01 $1.00000 \mathrm{e}+001.00000 \mathrm{e}+001.00000 \mathrm{e}-011.00000 \mathrm{e}-091.00000 \mathrm{e}-01$ 
Element: 4135 \# of layers: 9

$\mathrm{Kx} \mathrm{Ky} \mathrm{Kz}$ Ss Por

2.37747e+01 2.37747e+01 2.37747e+00 1.00000e-09 7.00000e-02

$2.37747 \mathrm{e}+012.37747 \mathrm{e}+012.37747 \mathrm{e}+001.00000 \mathrm{e}-09$ 7.00000e-02

5.00000e-04 5.00000e-04 5.00000e-05 1.00000e-09 1.00000e-01

5.00000e-04 5.00000e-04 5.00000e-05 1.00000e-09 1.00000e-01

9.49948e-01 9.49948e-01 9.49948e-02 1.00000e-09 2.12000e-01

9.49948e-01 9.49948e-01 9.49948e-02 1.00000e-09 2.12000e-01

9.49948e-01 9.49948e-01 9.49948e-02 1.00000e-09 2.12000e-01

$1.00000 \mathrm{e}-02$ 1.00000e-02 1.00000e-03 1.00000e-09 1.00000e-01

$1.00000 \mathrm{e}+001.00000 \mathrm{e}+001.00000 \mathrm{e}-011.00000 \mathrm{e}-091.00000 \mathrm{e}-01$

Element: 4137 \# of layers: 11

Kx Ky Kz Ss Por

$1.91120 \mathrm{e}+011.91120 \mathrm{e}+011.91120 \mathrm{e}+001.00000 \mathrm{e}-09$ 7.00000e-02

$1.91120 \mathrm{e}+011.91120 \mathrm{e}+011.91120 \mathrm{e}+001.00000 \mathrm{e}-097.00000 \mathrm{e}-02$

$1.91120 \mathrm{e}+011.91120 \mathrm{e}+011.91120 \mathrm{e}+001.00000 \mathrm{e}-09$ 7.00000e-02

5.00000e-04 5.00000e-04 5.00000e-05 1.00000e-09 1.00000e-01

5.00000e-04 5.00000e-04 5.00000e-05 1.00000e-09 1.00000e-01

7.63644e-01 7.63644e-01 7.63644e-02 1.00000e-09 2.12000e-01

7.63644e-01 7.63644e-01 7.63644e-02 1.00000e-09 2.12000e-01

7.63644e-01 7.63644e-01 7.63644e-02 1.00000e-09 2.12000e-01

7.63644e-01 7.63644e-01 7.63644e-02 1.00000e-09 2.12000e-01

$1.00000 \mathrm{e}-02$ 1.00000e-02 1.00000e-03 1.00000e-09 1.00000e-01

$1.00000 \mathrm{e}+001.00000 \mathrm{e}+001.00000 \mathrm{e}-011.00000 \mathrm{e}-091.00000 \mathrm{e}-01$

Element: 4138 \# of layers: 11

$\mathrm{Kx} \mathrm{Ky} \mathrm{Kz}$ Ss Por

$1.91120 \mathrm{e}+011.91120 \mathrm{e}+011.91120 \mathrm{e}+001.00000 \mathrm{e}-09$ 7.00000e-02

$1.91120 \mathrm{e}+011.91120 \mathrm{e}+011.91120 \mathrm{e}+001.00000 \mathrm{e}-09$ 7.00000e-02

$1.91120 \mathrm{e}+011.91120 \mathrm{e}+011.91120 \mathrm{e}+001.00000 \mathrm{e}-097.00000 \mathrm{e}-02$

5.00000e-04 5.00000e-04 5.00000e-05 1.00000e-09 1.00000e-01

5.00000e-04 5.00000e-04 5.00000e-05 1.00000e-09 1.00000e-01

7.63644e-01 7.63644e-01 7.63644e-02 1.00000e-09 2.12000e-01

7.63644e-01 7.63644e-01 7.63644e-02 1.00000e-09 2.12000e-01

7.63644e-01 7.63644e-01 7.63644e-02 1.00000e-09 2.12000e-01

7.63644e-01 7.63644e-01 7.63644e-02 1.00000e-09 2.12000e-01

$1.00000 \mathrm{e}-02$ 1.00000e-02 1.00000e-03 1.00000e-09 1.00000e-01

$1.00000 \mathrm{e}+001.00000 \mathrm{e}+001.00000 \mathrm{e}-011.00000 \mathrm{e}-091.00000 \mathrm{e}-01$

Element: 4139 \# of layers: 10

$\mathrm{Kx} \mathrm{Ky} \mathrm{Kz}$ Ss Por

$1.91120 \mathrm{e}+011.91120 \mathrm{e}+011.91120 \mathrm{e}+001.00000 \mathrm{e}-09$ 7.00000e-02

$1.91120 \mathrm{e}+011.91120 \mathrm{e}+011.91120 \mathrm{e}+001.00000 \mathrm{e}-09$ 7.00000e-02

$1.91120 \mathrm{e}+011.91120 \mathrm{e}+011.91120 \mathrm{e}+001.00000 \mathrm{e}-09$ 7.00000e-02

5.00000e-04 5.00000e-04 5.00000e-05 1.00000e-09 1.00000e-01

5.00000e-04 5.00000e-04 5.00000e-05 1.00000e-09 1.00000e-01

7.63644e-01 7.63644e-01 7.63644e-02 1.00000e-09 2.12000e-01

7.63644e-01 7.63644e-01 7.63644e-02 1.00000e-09 2.12000e-01 
7.63644e-01 7.63644e-01 7.63644e-02 1.00000e-09 2.12000e-01 $1.00000 \mathrm{e}-021.00000 \mathrm{e}-02$ 1.00000e-03 1.00000e-09 1.00000e-01 $1.00000 \mathrm{e}+001.00000 \mathrm{e}+001.00000 \mathrm{e}-011.00000 \mathrm{e}-091.00000 \mathrm{e}-01$ Element: 4140 \# of layers: 10

Kx Ky Kz Ss Por

$2.03833 \mathrm{e}+012.03833 \mathrm{e}+012.03833 \mathrm{e}+00$ 1.00000e-09 7.00000e-02 $2.03833 \mathrm{e}+012.03833 \mathrm{e}+012.03833 \mathrm{e}+001.00000 \mathrm{e}-09$ 7.00000e-02 5.00000e-04 5.00000e-04 5.00000e-05 1.00000e-09 1.00000e-01 5.00000e-04 5.00000e-04 5.00000e-05 1.00000e-09 1.00000e-01 8.14427e-01 8.14427e-01 8.14427e-02 1.00000e-09 2.12000e-01 $8.14427 \mathrm{e}-01$ 8.14427e-01 8.14427e-02 1.00000e-09 2.12000e-01 $8.14427 \mathrm{e}-01$ 8.14427e-01 8.14427e-02 1.00000e-09 2.12000e-01 8.14427e-01 8.14427e-01 8.14427e-02 1.00000e-09 2.12000e-01 $1.00000 \mathrm{e}-02$ 1.00000e-02 1.00000e-03 1.00000e-09 1.00000e-01 $1.00000 \mathrm{e}+001.00000 \mathrm{e}+001.00000 \mathrm{e}-011.00000 \mathrm{e}-091.00000 \mathrm{e}-01$ Element: 4141 \# of layers: 10

Kx Ky Kz Ss Por $2.03833 \mathrm{e}+012.03833 \mathrm{e}+012.03833 \mathrm{e}+00$ 1.00000e-09 7.00000e-02 $2.03833 \mathrm{e}+012.03833 \mathrm{e}+012.03833 \mathrm{e}+001.00000 \mathrm{e}-09$ 7.00000e-02 5.00000e-04 5.00000e-04 5.00000e-05 1.00000e-09 1.00000e-01 5.00000e-04 5.00000e-04 5.00000e-05 1.00000e-09 1.00000e-01 8.14427e-01 8.14427e-01 8.14427e-02 1.00000e-09 2.12000e-01 8.14427e-01 8.14427e-01 8.14427e-02 1.00000e-09 2.12000e-01 $8.14427 \mathrm{e}-01$ 8.14427e-01 8.14427e-02 1.00000e-09 2.12000e-01 $8.14427 \mathrm{e}-01$ 8.14427e-01 8.14427e-02 1.00000e-09 2.12000e-01 $1.00000 \mathrm{e}-021.00000 \mathrm{e}-021.00000 \mathrm{e}-031.00000 \mathrm{e}-091.00000 \mathrm{e}-01$ $1.00000 \mathrm{e}+001.00000 \mathrm{e}+001.00000 \mathrm{e}-011.00000 \mathrm{e}-091.00000 \mathrm{e}-01$ Element: 4142 \# of layers: 9

Kx Ky Kz Ss Por $2.03833 \mathrm{e}+012.03833 \mathrm{e}+012.03833 \mathrm{e}+00$ 1.00000e-09 7.00000e-02 $2.03833 \mathrm{e}+012.03833 \mathrm{e}+012.03833 \mathrm{e}+001.00000 \mathrm{e}-09$ 7.00000e-02 5.00000e-04 5.00000e-04 5.00000e-05 1.00000e-09 1.00000e-01 5.00000e-04 5.00000e-04 5.00000e-05 1.00000e-09 1.00000e-01 $8.14427 \mathrm{e}-01$ 8.14427e-01 8.14427e-02 1.00000e-09 2.12000e-01 8.14427e-01 8.14427e-01 8.14427e-02 1.00000e-09 2.12000e-01 8.14427e-01 8.14427e-01 8.14427e-02 1.00000e-09 2.12000e-01 $1.00000 \mathrm{e}-02$ 1.00000e-02 1.00000e-03 1.00000e-09 1.00000e-01 $1.00000 \mathrm{e}+001.00000 \mathrm{e}+001.00000 \mathrm{e}-011.00000 \mathrm{e}-091.00000 \mathrm{e}-01$ Element: 4143 \# of layers: 7

Kx Ky Kz Ss Por

$7.42381 \mathrm{e}+007.42381 \mathrm{e}+00$ 7.42381e-01 1.00000e-09 2.12000e-01 $7.42381 \mathrm{e}+007.42381 \mathrm{e}+00$ 7.42381e-01 1.00000e-09 2.12000e-01 $7.42381 \mathrm{e}+007.42381 \mathrm{e}+00$ 7.42381e-01 1.00000e-09 2.12000e-01 $7.42381 \mathrm{e}+007.42381 \mathrm{e}+007.42381 \mathrm{e}-011.00000 \mathrm{e}-092.12000 \mathrm{e}-01$ $7.42381 \mathrm{e}+007.42381 \mathrm{e}+007.42381 \mathrm{e}-011.00000 \mathrm{e}-092.12000 \mathrm{e}-01$ $1.00000 \mathrm{e}-05$ 1.00000e-05 1.00000e-06 1.00000e-09 1.00000e-01 
$1.00000 \mathrm{e}+001.00000 \mathrm{e}+00$ 1.00000e-01 1.00000e-09 1.00000e-01

Element: 4144 \# of layers: 7

Kx Ky Kz Ss Por

$1.03208 \mathrm{e}+01$ 1.03208e+01 1.03208e+00 1.00000e-09 2.12000e-01

$1.03208 \mathrm{e}+011.03208 \mathrm{e}+011.03208 \mathrm{e}+001.00000 \mathrm{e}-092.12000 \mathrm{e}-01$

$1.03208 \mathrm{e}+01$ 1.03208e+01 1.03208e+00 1.00000e-09 2.12000e-01

$1.03208 \mathrm{e}+011.03208 \mathrm{e}+01$ 1.03208e+00 1.00000e-09 2.12000e-01

$1.03208 \mathrm{e}+011.03208 \mathrm{e}+01$ 1.03208e+00 1.00000e-09 2.12000e-01

$1.00000 \mathrm{e}-05$ 1.00000e-05 1.00000e-06 1.00000e-09 1.00000e-01

$1.00000 \mathrm{e}+001.00000 \mathrm{e}+001.00000 \mathrm{e}-011.00000 \mathrm{e}-091.00000 \mathrm{e}-01$

Element: 4145 \# of layers: 7

$\mathrm{Kx} \mathrm{Ky} \mathrm{Kz}$ Ss Por

$1.03208 \mathrm{e}+01$ 1.03208e+01 1.03208e+00 1.00000e-09 2.12000e-01

$1.03208 \mathrm{e}+01$ 1.03208e+01 1.03208e+00 1.00000e-09 2.12000e-01

$1.03208 \mathrm{e}+01$ 1.03208e+01 1.03208e+00 1.00000e-09 2.12000e-01

$1.03208 \mathrm{e}+011.03208 \mathrm{e}+01$ 1.03208e+00 1.00000e-09 2.12000e-01

$1.03208 \mathrm{e}+011.03208 \mathrm{e}+011.03208 \mathrm{e}+001.00000 \mathrm{e}-092.12000 \mathrm{e}-01$

$1.00000 \mathrm{e}-05$ 1.00000e-05 1.00000e-06 1.00000e-09 1.00000e-01

$1.00000 \mathrm{e}+001.00000 \mathrm{e}+001.00000 \mathrm{e}-011.00000 \mathrm{e}-091.00000 \mathrm{e}-01$

Element: 4146 \# of layers: 7

$\mathrm{Kx} \mathrm{Ky} \mathrm{Kz}$ Ss Por

$1.03208 \mathrm{e}+01$ 1.03208e+01 1.03208e+00 1.00000e-09 2.12000e-01

$1.03208 \mathrm{e}+01$ 1.03208e+01 1.03208e+00 1.00000e-09 2.12000e-01

$1.03208 \mathrm{e}+011.03208 \mathrm{e}+01 \quad 1.03208 \mathrm{e}+001.00000 \mathrm{e}-092.12000 \mathrm{e}-01$

$1.03208 \mathrm{e}+011.03208 \mathrm{e}+011.03208 \mathrm{e}+001.00000 \mathrm{e}-092.12000 \mathrm{e}-01$

$1.03208 \mathrm{e}+01$ 1.03208e+01 1.03208e+00 1.00000e-09 2.12000e-01

$1.00000 \mathrm{e}-05$ 1.00000e-05 1.00000e-06 1.00000e-09 1.00000e-01

$1.00000 \mathrm{e}+001.00000 \mathrm{e}+001.00000 \mathrm{e}-01$ 1.00000e-09 1.00000e-01

Element: 4147 \# of layers: 7

$\mathrm{Kx} \mathrm{Ky} \mathrm{Kz}$ Ss Por

$1.18141 \mathrm{e}+01$ 1.18141e+01 1.18141e+00 1.00000e-09 2.12000e-01

$1.18141 \mathrm{e}+011.18141 \mathrm{e}+01$ 1.18141e+00 1.00000e-09 2.12000e-01

$1.18141 \mathrm{e}+011.18141 \mathrm{e}+011.18141 \mathrm{e}+001.00000 \mathrm{e}-092.12000 \mathrm{e}-01$

$1.18141 \mathrm{e}+011.18141 \mathrm{e}+01$ 1.18141e+00 1.00000e-09 2.12000e-01

$1.18141 \mathrm{e}+011.18141 \mathrm{e}+011.18141 \mathrm{e}+001.00000 \mathrm{e}-092.12000 \mathrm{e}-01$

1.00000e-05 1.00000e-05 1.00000e-06 1.00000e-09 1.00000e-01

$1.00000 \mathrm{e}+001.00000 \mathrm{e}+001.00000 \mathrm{e}-011.00000 \mathrm{e}-091.00000 \mathrm{e}-01$

Element: 4148 \# of layers: 6

$\mathrm{Kx} \mathrm{Ky} \mathrm{Kz}$ Ss Por

$1.43403 \mathrm{e}+03$ 1.43403e+03 1.43403e+02 1.00000e-09 7.00000e-02

$5.72975 \mathrm{e}+015.72975 \mathrm{e}+015.72975 \mathrm{e}+001.00000 \mathrm{e}-092.12000 \mathrm{e}-01$

$5.72975 \mathrm{e}+015.72975 \mathrm{e}+015.72975 \mathrm{e}+001.00000 \mathrm{e}-092.12000 \mathrm{e}-01$

$5.72975 \mathrm{e}+01$ 5.72975e+01 5.72975e+00 1.00000e-09 2.12000e-01

$1.00000 \mathrm{e}-05$ 1.00000e-05 1.00000e-06 1.00000e-09 1.00000e-01

$1.00000 \mathrm{e}+001.00000 \mathrm{e}+001.00000 \mathrm{e}-01$ 1.00000e-09 1.00000e-01

Element: 4149 \# of layers: 7 
$\mathrm{Kx} \mathrm{Ky} \mathrm{Kz} \mathrm{Ss} \mathrm{Por}$

$1.43403 \mathrm{e}+03$ 1.43403e+03 1.43403e+02 1.00000e-09 7.00000e-02

$1.43403 \mathrm{e}+03$ 1.43403e+03 1.43403e+02 1.00000e-09 7.00000e-02

$5.72975 \mathrm{e}+015.72975 \mathrm{e}+015.72975 \mathrm{e}+001.00000 \mathrm{e}-092.12000 \mathrm{e}-01$

$5.72975 \mathrm{e}+015.72975 \mathrm{e}+015.72975 \mathrm{e}+001.00000 \mathrm{e}-092.12000 \mathrm{e}-01$

$1.00000 \mathrm{e}-05$ 1.00000e-05 1.00000e-06 1.00000e-09 1.00000e-01

$1.00000 \mathrm{e}+001.00000 \mathrm{e}+001.00000 \mathrm{e}-011.00000 \mathrm{e}-091.00000 \mathrm{e}-01$

1.00000e-06 1.00000e-06 1.00000e-06 1.00000e-09 5.00000e-02

Element: 4150 \# of layers: 5

$\mathrm{Kx} \mathrm{Ky} \mathrm{Kz}$ Ss Por

$2.63344 \mathrm{e}+03$ 2.63344e+03 2.63344e+02 1.00000e-09 7.00000e-02

$1.05221 \mathrm{e}+021.05221 \mathrm{e}+021.05221 \mathrm{e}+01$ 1.00000e-09 2.12000e-01

1.00000e-05 1.00000e-05 1.00000e-06 1.00000e-09 1.00000e-01

$1.00000 \mathrm{e}+001.00000 \mathrm{e}+001.00000 \mathrm{e}-011.00000 \mathrm{e}-091.00000 \mathrm{e}-01$

1.00000e-06 1.00000e-06 1.00000e-06 1.00000e-09 5.00000e-02

Element: 4151 \# of layers: 5

$\mathrm{Kx} \mathrm{Ky} \mathrm{Kz}$ Ss Por

$2.63344 \mathrm{e}+032.63344 \mathrm{e}+032.63344 \mathrm{e}+02$ 1.00000e-09 7.00000e-02

$1.05221 \mathrm{e}+021.05221 \mathrm{e}+021.05221 \mathrm{e}+01$ 1.00000e-09 2.12000e-01

$1.00000 \mathrm{e}-05$ 1.00000e-05 1.00000e-06 1.00000e-09 1.00000e-01

$1.00000 \mathrm{e}+001.00000 \mathrm{e}+001.00000 \mathrm{e}-011.00000 \mathrm{e}-091.00000 \mathrm{e}-01$

1.00000e-06 1.00000e-06 1.00000e-06 1.00000e-09 5.00000e-02

Element: 4152 \# of layers: 7

Kx Ky Kz Ss Por

3.41371e+03 3.41371e+03 3.41371e+02 1.00000e-09 7.00000e-02

$1.36400 \mathrm{e}+021.36400 \mathrm{e}+02$ 1.36400e+01 1.00000e-09 2.12000e-01

$1.36400 \mathrm{e}+021.36400 \mathrm{e}+021.36400 \mathrm{e}+01$ 1.00000e-09 2.12000e-01

$1.36400 \mathrm{e}+021.36400 \mathrm{e}+02 \quad 1.36400 \mathrm{e}+01$ 1.00000e-09 2.12000e-01

$1.00000 \mathrm{e}-05$ 1.00000e-05 1.00000e-06 1.00000e-09 1.00000e-01

$1.00000 \mathrm{e}+001.00000 \mathrm{e}+001.00000 \mathrm{e}-011.00000 \mathrm{e}-091.00000 \mathrm{e}-01$

1.00000e-06 1.00000e-06 1.00000e-06 1.00000e-09 5.00000e-02

Element: 4153 \# of layers: 8

Kx Ky Kz Ss Por

5.19336e+03 5.19336e+03 5.19336e+02 1.00000e-09 7.00000e-02

$2.07511 \mathrm{e}+02$ 2.07511e+02 2.07511e+01 1.00000e-09 2.12000e-01

$2.07511 \mathrm{e}+022.07511 \mathrm{e}+02$ 2.07511e+01 1.00000e-09 2.12000e-01

$2.07511 \mathrm{e}+022.07511 \mathrm{e}+022.07511 \mathrm{e}+01$ 1.00000e-09 2.12000e-01

$1.00000 \mathrm{e}-02$ 1.00000e-02 1.00000e-03 1.00000e-09 1.00000e-01

$1.00000 \mathrm{e}-05$ 1.00000e-05 1.00000e-06 1.00000e-09 1.00000e-01

$1.00000 \mathrm{e}+001.00000 \mathrm{e}+001.00000 \mathrm{e}-011.00000 \mathrm{e}-091.00000 \mathrm{e}-01$

1.00000e-06 1.00000e-06 1.00000e-06 1.00000e-09 5.00000e-02

Element: 4154 \# of layers: 8

$\mathrm{Kx} \mathrm{Ky} \mathrm{Kz}$ Ss Por

5.19336e+03 5.19336e+03 5.19336e+02 1.00000e-09 7.00000e-02

$2.07511 \mathrm{e}+022.07511 \mathrm{e}+022.07511 \mathrm{e}+01$ 1.00000e-09 2.12000e-01

$2.07511 \mathrm{e}+022.07511 \mathrm{e}+022.07511 \mathrm{e}+01$ 1.00000e-09 2.12000e-01 
$2.07511 \mathrm{e}+02$ 2.07511e+02 2.07511e+01 1.00000e-09 2.12000e-01 $1.00000 \mathrm{e}-02$ 1.00000e-02 1.00000e-03 1.00000e-09 1.00000e-01 $1.00000 \mathrm{e}-05$ 1.00000e-05 1.00000e-06 1.00000e-09 1.00000e-01 $1.00000 \mathrm{e}+001.00000 \mathrm{e}+001.00000 \mathrm{e}-011.00000 \mathrm{e}-091.00000 \mathrm{e}-01$ 1.00000e-06 1.00000e-06 1.00000e-06 1.00000e-09 5.00000e-02 Element: 4155 \# of layers: 7

$\mathrm{Kx} \mathrm{Ky} \mathrm{Kz}$ Ss Por

5.19336e+03 5.19336e+03 5.19336e+02 1.00000e-09 7.00000e-02 $5.19336 \mathrm{e}+03$ 5.19336e+03 5.19336e+02 1.00000e-09 7.00000e-02 $2.07511 \mathrm{e}+022.07511 \mathrm{e}+02$ 2.07511e+01 1.00000e-09 2.12000e-01 $2.07511 \mathrm{e}+022.07511 \mathrm{e}+022.07511 \mathrm{e}+01$ 1.00000e-09 2.12000e-01 $1.00000 \mathrm{e}-05$ 1.00000e-05 1.00000e-06 1.00000e-09 1.00000e-01 $1.00000 \mathrm{e}+001.00000 \mathrm{e}+001.00000 \mathrm{e}-011.00000 \mathrm{e}-091.00000 \mathrm{e}-01$ 1.00000e-06 1.00000e-06 1.00000e-06 1.00000e-09 5.00000e-02 Element: 4156 \# of layers: 7

Kx Ky Kz Ss Por

7.71085e+03 7.71085e+03 7.71085e+02 1.00000e-09 7.00000e-02 $7.71085 \mathrm{e}+03$ 7.71085e+03 7.71085e+02 1.00000e-09 7.00000e-02 $3.08099 \mathrm{e}+023.08099 \mathrm{e}+023.08099 \mathrm{e}+01$ 1.00000e-09 2.12000e-01 $3.08099 \mathrm{e}+02$ 3.08099e+02 3.08099e+01 1.00000e-09 2.12000e-01 $1.00000 \mathrm{e}-05$ 1.00000e-05 1.00000e-06 1.00000e-09 1.00000e-01 $1.00000 \mathrm{e}+001.00000 \mathrm{e}+001.00000 \mathrm{e}-011.00000 \mathrm{e}-091.00000 \mathrm{e}-01$ 1.00000e-06 1.00000e-06 1.00000e-06 1.00000e-09 5.00000e-02 Element: 4157 \# of layers: 6

Kx Ky Kz Ss Por

7.71085e+03 7.71085e+03 7.71085e+02 1.00000e-09 7.00000e-02 $3.08099 \mathrm{e}+023.08099 \mathrm{e}+023.08099 \mathrm{e}+01$ 1.00000e-09 2.12000e-01 $3.08099 \mathrm{e}+02$ 3.08099e+02 3.08099e+01 1.00000e-09 2.12000e-01 $1.00000 \mathrm{e}-05$ 1.00000e-05 1.00000e-06 1.00000e-09 1.00000e-01 $1.00000 \mathrm{e}+001.00000 \mathrm{e}+001.00000 \mathrm{e}-011.00000 \mathrm{e}-091.00000 \mathrm{e}-01$ 1.00000e-06 1.00000e-06 1.00000e-06 1.00000e-09 5.00000e-02 Element: 4158 \# of layers: 6

Kx Ky Kz Ss Por

5.11227e+03 5.11227e+03 5.11227e+02 1.00000e-09 7.00000e-02 $2.04266 \mathrm{e}+02$ 2.04266e+02 2.04266e+01 1.00000e-09 2.12000e-01 $2.04266 \mathrm{e}+022.04266 \mathrm{e}+022.04266 \mathrm{e}+01$ 1.00000e-09 2.12000e-01 $1.00000 \mathrm{e}-05$ 1.00000e-05 1.00000e-06 1.00000e-09 1.00000e-01 $1.00000 \mathrm{e}+001.00000 \mathrm{e}+001.00000 \mathrm{e}-011.00000 \mathrm{e}-091.00000 \mathrm{e}-01$ 1.00000e-06 1.00000e-06 1.00000e-06 1.00000e-09 5.00000e-02 Element: 4159 \# of layers: 7

$\mathrm{Kx} \mathrm{Ky} \mathrm{Kz}$ Ss Por

3.41371e+03 3.41371e+03 3.41371e+02 1.00000e-09 7.00000e-02 $3.41371 \mathrm{e}+03$ 3.41371e+03 3.41371e+02 1.00000e-09 7.00000e-02 $1.36400 \mathrm{e}+02$ 1.36400e+02 1.36400e+01 1.00000e-09 2.12000e-01 $1.36400 \mathrm{e}+02$ 1.36400e+02 1.36400e+01 1.00000e-09 2.12000e-01 $1.00000 \mathrm{e}-05$ 1.00000e-05 1.00000e-06 1.00000e-09 1.00000e-01 
$1.00000 \mathrm{e}+001.00000 \mathrm{e}+001.00000 \mathrm{e}-011.00000 \mathrm{e}-091.00000 \mathrm{e}-01$ 1.00000e-06 1.00000e-06 1.00000e-06 1.00000e-09 5.00000e-02 Element: 4160 \# of layers: 7

Kx Ky Kz Ss Por

5.19336e+03 5.19336e+03 5.19336e+02 1.00000e-09 7.00000e-02 $5.19336 \mathrm{e}+035.19336 \mathrm{e}+03$ 5.19336e+02 1.00000e-09 7.00000e-02 $2.07511 \mathrm{e}+022.07511 \mathrm{e}+02$ 2.07511e+01 1.00000e-09 2.12000e-01 $2.07511 \mathrm{e}+022.07511 \mathrm{e}+022.07511 \mathrm{e}+01$ 1.00000e-09 2.12000e-01 $1.00000 \mathrm{e}-05$ 1.00000e-05 1.00000e-06 1.00000e-09 1.00000e-01 $1.00000 \mathrm{e}+001.00000 \mathrm{e}+001.00000 \mathrm{e}-01$ 1.00000e-09 1.00000e-01 1.00000e-06 1.00000e-06 1.00000e-06 1.00000e-09 5.00000e-02 Element: 4161 \# of layers: 9

$\mathrm{Kx} \mathrm{Ky} \mathrm{Kz}$ Ss Por

3.93323e+03 3.93323e+03 3.93323e+02 1.00000e-09 7.00000e-02 $1.57157 \mathrm{e}+02$ 1.57157e+02 1.57157e+01 1.00000e-09 2.12000e-01 $1.57157 \mathrm{e}+021.57157 \mathrm{e}+02$ 1.57157e+01 1.00000e-09 2.12000e-01 $1.57157 \mathrm{e}+02$ 1.57157e+02 1.57157e+01 1.00000e-09 2.12000e-01 $1.00000 \mathrm{e}-02$ 1.00000e-02 1.00000e-03 1.00000e-09 1.00000e-01 $1.00000 \mathrm{e}+001.00000 \mathrm{e}+001.00000 \mathrm{e}-011.00000 \mathrm{e}-091.00000 \mathrm{e}-01$ $1.00000 \mathrm{e}-05$ 1.00000e-05 1.00000e-06 1.00000e-09 1.00000e-01 $1.00000 \mathrm{e}+001.00000 \mathrm{e}+001.00000 \mathrm{e}-011.00000 \mathrm{e}-091.00000 \mathrm{e}-01$ 1.00000e-06 1.00000e-06 1.00000e-06 1.00000e-09 5.00000e-02 Element: 4162 \# of layers: 9

Kx Ky Kz Ss Por

$2.55172 \mathrm{e}+03$ 2.55172e+03 2.55172e+02 1.00000e-09 7.00000e-02 $1.01959 \mathrm{e}+02$ 1.01959e+02 1.01959e+01 1.00000e-09 2.12000e-01 $1.01959 \mathrm{e}+02$ 1.01959e+02 1.01959e+01 1.00000e-09 2.12000e-01 $1.01959 \mathrm{e}+02$ 1.01959e+02 1.01959e+01 1.00000e-09 2.12000e-01 $1.00000 \mathrm{e}-02$ 1.00000e-02 1.00000e-03 1.00000e-09 1.00000e-01 $1.00000 \mathrm{e}+001.00000 \mathrm{e}+001.00000 \mathrm{e}-011.00000 \mathrm{e}-091.00000 \mathrm{e}-01$ $1.00000 \mathrm{e}-05$ 1.00000e-05 1.00000e-06 1.00000e-09 1.00000e-01 $1.00000 \mathrm{e}+001.00000 \mathrm{e}+001.00000 \mathrm{e}-011.00000 \mathrm{e}-091.00000 \mathrm{e}-01$ 1.00000e-06 1.00000e-06 1.00000e-06 1.00000e-09 5.00000e-02 Element: 4163 \# of layers: 9

$\mathrm{Kx} \mathrm{Ky} \mathrm{Kz}$ Ss Por

2.55172e+03 2.55172e+03 2.55172e+02 1.00000e-09 7.00000e-02 $1.01959 \mathrm{e}+021.01959 \mathrm{e}+02 \quad 1.01959 \mathrm{e}+01$ 1.00000e-09 2.12000e-01 $1.01959 \mathrm{e}+021.01959 \mathrm{e}+02$ 1.01959e+01 1.00000e-09 2.12000e-01 $1.01959 \mathrm{e}+02$ 1.01959e+02 1.01959e+01 1.00000e-09 2.12000e-01 $1.00000 \mathrm{e}-02$ 1.00000e-02 1.00000e-03 1.00000e-09 1.00000e-01 $1.00000 \mathrm{e}+001.00000 \mathrm{e}+001.00000 \mathrm{e}-011.00000 \mathrm{e}-091.00000 \mathrm{e}-01$ $1.00000 \mathrm{e}-05$ 1.00000e-05 1.00000e-06 1.00000e-09 1.00000e-01 $1.00000 \mathrm{e}+001.00000 \mathrm{e}+001.00000 \mathrm{e}-011.00000 \mathrm{e}-091.00000 \mathrm{e}-01$ 1.00000e-06 1.00000e-06 1.00000e-06 1.00000e-09 5.00000e-02 Element: 4164 \# of layers: 8

Kx Ky Kz Ss Por 
$2.55172 \mathrm{e}+032.55172 \mathrm{e}+032.55172 \mathrm{e}+02$ 1.00000e-09 7.00000e-02 $2.55172 \mathrm{e}+032.55172 \mathrm{e}+032.55172 \mathrm{e}+02$ 1.00000e-09 7.00000e-02 $2.55172 \mathrm{e}+032.55172 \mathrm{e}+032.55172 \mathrm{e}+021.00000 \mathrm{e}-097.00000 \mathrm{e}-02$ $1.01959 \mathrm{e}+02 \quad 1.01959 \mathrm{e}+02 \quad 1.01959 \mathrm{e}+01$ 1.00000e-09 2.12000e-01 $1.01959 \mathrm{e}+021.01959 \mathrm{e}+02 \quad 1.01959 \mathrm{e}+011.00000 \mathrm{e}-092.12000 \mathrm{e}-01$ $1.00000 \mathrm{e}-05$ 1.00000e-05 1.00000e-06 1.00000e-09 1.00000e-01 $1.00000 \mathrm{e}+001.00000 \mathrm{e}+001.00000 \mathrm{e}-011.00000 \mathrm{e}-091.00000 \mathrm{e}-01$ $1.00000 \mathrm{e}-06$ 1.00000e-06 1.00000e-06 1.00000e-09 5.00000e-02 Element: 4165 \# of layers: 8

Kx Ky Kz Ss Por

$5.73117 \mathrm{e}+03$ 5.73117e+03 5.73117e+02 1.00000e-09 7.00000e-02 $5.73117 \mathrm{e}+03$ 5.73117e+03 5.73117e+02 1.00000e-09 7.00000e-02 $5.73117 \mathrm{e}+03$ 5.73117e+03 5.73117e+02 1.00000e-09 7.00000e-02 $2.29010 \mathrm{e}+022.29010 \mathrm{e}+022.29010 \mathrm{e}+01$ 1.00000e-09 2.12000e-01 $2.29010 \mathrm{e}+02 \quad 2.29010 \mathrm{e}+02 \quad 2.29010 \mathrm{e}+01$ 1.00000e-09 2.12000e-01 $1.00000 \mathrm{e}-05$ 1.00000e-05 1.00000e-06 1.00000e-09 1.00000e-01 $1.00000 \mathrm{e}+001.00000 \mathrm{e}+001.00000 \mathrm{e}-011.00000 \mathrm{e}-091.00000 \mathrm{e}-01$ $1.00000 \mathrm{e}-06$ 1.00000e-06 1.00000e-06 1.00000e-09 5.00000e-02 Element: 4166 \# of layers: 7

Kx Ky Kz Ss Por

5.73117e+03 5.73117e+03 5.73117e+02 1.00000e-09 7.00000e-02 $5.73117 \mathrm{e}+03$ 5.73117e+03 5.73117e+02 1.00000e-09 7.00000e-02 $2.29010 \mathrm{e}+022.29010 \mathrm{e}+022.29010 \mathrm{e}+01$ 1.00000e-09 2.12000e-01 $2.29010 \mathrm{e}+022.29010 \mathrm{e}+022.29010 \mathrm{e}+01$ 1.00000e-09 2.12000e-01 $1.00000 \mathrm{e}-05$ 1.00000e-05 1.00000e-06 1.00000e-09 1.00000e-01 $1.00000 \mathrm{e}+001.00000 \mathrm{e}+001.00000 \mathrm{e}-011.00000 \mathrm{e}-091.00000 \mathrm{e}-01$ $1.00000 \mathrm{e}-061.00000 \mathrm{e}-06$ 1.00000e-06 1.00000e-09 5.00000e-02 Element: 4167 \# of layers: 7

Kx Ky Kz Ss Por

$7.95952 \mathrm{e}+03$ 7.95952e+03 7.95952e+02 1.00000e-09 7.00000e-02 $7.95952 \mathrm{e}+03$ 7.95952e+03 7.95952e+02 1.00000e-09 7.00000e-02 $3.18044 \mathrm{e}+023.18044 \mathrm{e}+023.18044 \mathrm{e}+01$ 1.00000e-09 2.12000e-01 $3.18044 \mathrm{e}+023.18044 \mathrm{e}+023.18044 \mathrm{e}+01$ 1.00000e-09 2.12000e-01 $1.00000 \mathrm{e}-05$ 1.00000e-05 1.00000e-06 1.00000e-09 1.00000e-01 $1.00000 \mathrm{e}+001.00000 \mathrm{e}+001.00000 \mathrm{e}-011.00000 \mathrm{e}-091.00000 \mathrm{e}-01$ $1.00000 \mathrm{e}-06$ 1.00000e-06 1.00000e-06 1.00000e-09 5.00000e-02 Element: 4168 \# of layers: 8

Kx Ky Kz Ss Por 3.93323e+03 3.93323e+03 3.93323e+02 1.00000e-09 7.00000e-02 $3.93323 \mathrm{e}+033.93323 \mathrm{e}+033.93323 \mathrm{e}+02$ 1.00000e-09 7.00000e-02 $3.93323 \mathrm{e}+033.93323 \mathrm{e}+033.93323 \mathrm{e}+021.00000 \mathrm{e}-09$ 7.00000e-02 $1.57157 \mathrm{e}+021.57157 \mathrm{e}+02 \quad 1.57157 \mathrm{e}+011.00000 \mathrm{e}-092.12000 \mathrm{e}-01$ $1.57157 \mathrm{e}+021.57157 \mathrm{e}+02 \quad 1.57157 \mathrm{e}+011.00000 \mathrm{e}-092.12000 \mathrm{e}-01$ $1.00000 \mathrm{e}-05$ 1.00000e-05 1.00000e-06 1.00000e-09 1.00000e-01 $1.00000 \mathrm{e}+001.00000 \mathrm{e}+001.00000 \mathrm{e}-011.00000 \mathrm{e}-091.00000 \mathrm{e}-01$ $1.00000 \mathrm{e}-06$ 1.00000e-06 1.00000e-06 1.00000e-09 5.00000e-02 
Element: 4169 \# of layers: 8

$\mathrm{Kx} \mathrm{Ky} \mathrm{Kz}$ Ss Por

2.55172e+03 2.55172e+03 2.55172e+02 1.00000e-09 7.00000e-02

$2.55172 \mathrm{e}+03$ 2.55172e+03 2.55172e+02 1.00000e-09 7.00000e-02

$2.55172 \mathrm{e}+032.55172 \mathrm{e}+032.55172 \mathrm{e}+02$ 1.00000e-09 7.00000e-02

$1.01959 \mathrm{e}+02$ 1.01959e+02 1.01959e+01 1.00000e-09 2.12000e-01

$1.01959 \mathrm{e}+02$ 1.01959e+02 1.01959e+01 1.00000e-09 2.12000e-01

$1.00000 \mathrm{e}-05$ 1.00000e-05 1.00000e-06 1.00000e-09 1.00000e-01

$1.00000 \mathrm{e}+001.00000 \mathrm{e}+001.00000 \mathrm{e}-011.00000 \mathrm{e}-091.00000 \mathrm{e}-01$

1.00000e-06 1.00000e-06 1.00000e-06 1.00000e-09 5.00000e-02

Element: 4170 \# of layers: 9

Kx Ky Kz Ss Por

1.80750e+03 1.80750e+03 1.80750e+02 1.00000e-09 7.00000e-02

$7.22220 \mathrm{e}+017.22220 \mathrm{e}+017.22220 \mathrm{e}+00$ 1.00000e-09 2.12000e-01

$7.22220 \mathrm{e}+017.22220 \mathrm{e}+01$ 7.22220e+00 1.00000e-09 2.12000e-01

$7.22220 \mathrm{e}+017.22220 \mathrm{e}+017.22220 \mathrm{e}+001.00000 \mathrm{e}-092.12000 \mathrm{e}-01$

$1.00000 \mathrm{e}-02$ 1.00000e-02 1.00000e-03 1.00000e-09 1.00000e-01

$1.00000 \mathrm{e}+001.00000 \mathrm{e}+001.00000 \mathrm{e}-011.00000 \mathrm{e}-091.00000 \mathrm{e}-01$

$1.00000 \mathrm{e}-05$ 1.00000e-05 1.00000e-06 1.00000e-09 1.00000e-01

$1.00000 \mathrm{e}+001.00000 \mathrm{e}+001.00000 \mathrm{e}-011.00000 \mathrm{e}-091.00000 \mathrm{e}-01$

1.00000e-06 1.00000e-06 1.00000e-06 1.00000e-09 5.00000e-02

Element: 4171 \# of layers: 9

$\mathrm{Kx} \mathrm{Ky} \mathrm{Kz}$ Ss Por

$1.74028 \mathrm{e}+03$ 1.74028e+03 1.74028e+02 1.00000e-09 7.00000e-02

$6.95355 \mathrm{e}+016.95355 \mathrm{e}+016.95355 \mathrm{e}+001.00000 \mathrm{e}-092.12000 \mathrm{e}-01$

$6.95355 \mathrm{e}+016.95355 \mathrm{e}+016.95355 \mathrm{e}+001.00000 \mathrm{e}-092.12000 \mathrm{e}-01$

$6.95355 \mathrm{e}+016.95355 \mathrm{e}+016.95355 \mathrm{e}+001.00000 \mathrm{e}-092.12000 \mathrm{e}-01$

$1.00000 \mathrm{e}-02$ 1.00000e-02 1.00000e-03 1.00000e-09 1.00000e-01

$1.00000 \mathrm{e}+001.00000 \mathrm{e}+001.00000 \mathrm{e}-011.00000 \mathrm{e}-091.00000 \mathrm{e}-01$

$1.00000 \mathrm{e}-05$ 1.00000e-05 1.00000e-06 1.00000e-09 1.00000e-01

$1.00000 \mathrm{e}+001.00000 \mathrm{e}+001.00000 \mathrm{e}-01$ 1.00000e-09 1.00000e-01

1.00000e-06 1.00000e-06 1.00000e-06 1.00000e-09 5.00000e-02

Element: 4172 \# of layers: 9

$\mathrm{Kx} \mathrm{Ky} \mathrm{Kz}$ Ss Por

1.74028e+03 1.74028e+03 1.74028e+02 1.00000e-09 7.00000e-02

$6.95355 \mathrm{e}+016.95355 \mathrm{e}+016.95355 \mathrm{e}+00$ 1.00000e-09 2.12000e-01

$6.95355 \mathrm{e}+016.95355 \mathrm{e}+016.95355 \mathrm{e}+001.00000 \mathrm{e}-092.12000 \mathrm{e}-01$

$6.95355 \mathrm{e}+016.95355 \mathrm{e}+016.95355 \mathrm{e}+001.00000 \mathrm{e}-092.12000 \mathrm{e}-01$

$1.00000 \mathrm{e}-02$ 1.00000e-02 1.00000e-03 1.00000e-09 1.00000e-01

$1.00000 \mathrm{e}+001.00000 \mathrm{e}+001.00000 \mathrm{e}-011.00000 \mathrm{e}-091.00000 \mathrm{e}-01$

$1.00000 \mathrm{e}-05$ 1.00000e-05 1.00000e-06 1.00000e-09 1.00000e-01

$1.00000 \mathrm{e}+001.00000 \mathrm{e}+001.00000 \mathrm{e}-011.00000 \mathrm{e}-091.00000 \mathrm{e}-01$

1.00000e-06 1.00000e-06 1.00000e-06 1.00000e-09 5.00000e-02

Element: 4173 \# of layers: 7

$\mathrm{Kx} \mathrm{Ky} \mathrm{Kz} \mathrm{Ss} \mathrm{Por}$

$1.74028 \mathrm{e}+03$ 1.74028e+03 1.74028e+02 1.00000e-09 7.00000e-02 
1.74028e+03 1.74028e+03 1.74028e+02 1.00000e-09 7.00000e-02 $1.74028 \mathrm{e}+031.74028 \mathrm{e}+03$ 1.74028e+02 1.00000e-09 7.00000e-02 $6.95355 \mathrm{e}+016.95355 \mathrm{e}+016.95355 \mathrm{e}+00$ 1.00000e-09 2.12000e-01 $1.00000 \mathrm{e}-05$ 1.00000e-05 1.00000e-06 1.00000e-09 1.00000e-01 $1.00000 \mathrm{e}+001.00000 \mathrm{e}+001.00000 \mathrm{e}-011.00000 \mathrm{e}-091.00000 \mathrm{e}-01$ 1.00000e-06 1.00000e-06 1.00000e-06 1.00000e-09 5.00000e-02 Element: 4174 \# of layers: 6

Kx Ky Kz Ss Por

$1.79560 \mathrm{e}+031.79560 \mathrm{e}+03$ 1.79560e+02 1.00000e-09 7.00000e-02 $1.79560 \mathrm{e}+031.79560 \mathrm{e}+03$ 1.79560e+02 1.00000e-09 7.00000e-02 $1.79560 \mathrm{e}+031.79560 \mathrm{e}+03$ 1.79560e+02 1.00000e-09 7.00000e-02 $1.00000 \mathrm{e}-05$ 1.00000e-05 1.00000e-06 1.00000e-09 1.00000e-01 $1.00000 \mathrm{e}+001.00000 \mathrm{e}+001.00000 \mathrm{e}-011.00000 \mathrm{e}-091.00000 \mathrm{e}-01$ 1.00000e-06 1.00000e-06 1.00000e-06 1.00000e-09 5.00000e-02 Element: 4175 \# of layers: 6

$\mathrm{Kx} \mathrm{Ky} \mathrm{Kz}$ Ss Por

$1.79560 \mathrm{e}+031.79560 \mathrm{e}+03$ 1.79560e+02 1.00000e-09 7.00000e-02 $1.79560 \mathrm{e}+031.79560 \mathrm{e}+031.79560 \mathrm{e}+021.00000 \mathrm{e}-097.00000 \mathrm{e}-02$ $1.79560 \mathrm{e}+031.79560 \mathrm{e}+031.79560 \mathrm{e}+02$ 1.00000e-09 7.00000e-02 $1.00000 \mathrm{e}-05$ 1.00000e-05 1.00000e-06 1.00000e-09 1.00000e-01 $1.00000 \mathrm{e}+001.00000 \mathrm{e}+001.00000 \mathrm{e}-011.00000 \mathrm{e}-091.00000 \mathrm{e}-01$ 1.00000e-06 1.00000e-06 1.00000e-06 1.00000e-09 5.00000e-02 Element: 4176 \# of layers: 8

Kx Ky Kz Ss Por

4.39174e+03 4.39174e+03 4.39174e+02 1.00000e-09 7.00000e-02 4.39174e+03 4.39174e+03 4.39174e+02 1.00000e-09 7.00000e-02 $4.39174 \mathrm{e}+034.39174 \mathrm{e}+03$ 4.39174e+02 1.00000e-09 7.00000e-02 $1.75479 \mathrm{e}+02$ 1.75479e+02 1.75479e+01 1.00000e-09 2.12000e-01 $1.75479 \mathrm{e}+02$ 1.75479e+02 1.75479e+01 1.00000e-09 2.12000e-01 $1.00000 \mathrm{e}-051.00000 \mathrm{e}-051.00000 \mathrm{e}-061.00000 \mathrm{e}-091.00000 \mathrm{e}-01$ $1.00000 \mathrm{e}+001.00000 \mathrm{e}+001.00000 \mathrm{e}-01$ 1.00000e-09 1.00000e-01 1.00000e-06 1.00000e-06 1.00000e-06 1.00000e-09 5.00000e-02 Element: 4177 \# of layers: 8

$\mathrm{Kx} \mathrm{Ky} \mathrm{Kz}$ Ss Por

$1.80750 \mathrm{e}+03$ 1.80750e+03 1.80750e+02 1.00000e-09 7.00000e-02 $1.80750 \mathrm{e}+031.80750 \mathrm{e}+031.80750 \mathrm{e}+02$ 1.00000e-09 7.00000e-02 $1.80750 \mathrm{e}+03$ 1.80750e+03 1.80750e+02 1.00000e-09 7.00000e-02 $7.22220 \mathrm{e}+01$ 7.22220e+01 7.22220e+00 1.00000e-09 2.12000e-01 $7.22220 \mathrm{e}+01$ 7.22220e+01 7.22220e+00 1.00000e-09 2.12000e-01 $1.00000 \mathrm{e}-05$ 1.00000e-05 1.00000e-06 1.00000e-09 1.00000e-01 $1.00000 \mathrm{e}+001.00000 \mathrm{e}+001.00000 \mathrm{e}-011.00000 \mathrm{e}-091.00000 \mathrm{e}-01$ 1.00000e-06 1.00000e-06 1.00000e-06 1.00000e-09 5.00000e-02 Element: 4178 \# of layers: 7

$\mathrm{Kx} \mathrm{Ky} \mathrm{Kz}$ Ss Por

$1.74028 \mathrm{e}+03$ 1.74028e+03 1.74028e+02 1.00000e-09 7.00000e-02 $1.74028 \mathrm{e}+03$ 1.74028e+03 1.74028e+02 1.00000e-09 7.00000e-02 
$1.74028 \mathrm{e}+03$ 1.74028e+03 1.74028e+02 1.00000e-09 7.00000e-02 $6.95355 \mathrm{e}+016.95355 \mathrm{e}+016.95355 \mathrm{e}+00$ 1.00000e-09 2.12000e-01 $1.00000 \mathrm{e}-05$ 1.00000e-05 1.00000e-06 1.00000e-09 1.00000e-01 $1.00000 \mathrm{e}+001.00000 \mathrm{e}+001.00000 \mathrm{e}-011.00000 \mathrm{e}-091.00000 \mathrm{e}-01$ $1.00000 \mathrm{e}-06$ 1.00000e-06 1.00000e-06 1.00000e-09 5.00000e-02 Element: 4179 \# of layers: 9

Kx Ky Kz Ss Por

$2.97898 \mathrm{e}+032.97898 \mathrm{e}+032.97898 \mathrm{e}+02$ 1.00000e-09 7.00000e-02 $1.19027 \mathrm{e}+021.19027 \mathrm{e}+02$ 1.19027e+01 1.00000e-09 2.12000e-01 $1.19027 \mathrm{e}+02 \quad 1.19027 \mathrm{e}+021.19027 \mathrm{e}+01$ 1.00000e-09 2.12000e-01 $1.19027 \mathrm{e}+02 \quad 1.19027 \mathrm{e}+021.19027 \mathrm{e}+01$ 1.00000e-09 2.12000e-01 $1.00000 \mathrm{e}-021.00000 \mathrm{e}-02$ 1.00000e-03 1.00000e-09 1.00000e-01 $1.00000 \mathrm{e}+001.00000 \mathrm{e}+001.00000 \mathrm{e}-011.00000 \mathrm{e}-091.00000 \mathrm{e}-01$ $1.00000 \mathrm{e}-05$ 1.00000e-05 1.00000e-06 1.00000e-09 1.00000e-01 $1.00000 \mathrm{e}+001.00000 \mathrm{e}+001.00000 \mathrm{e}-011.00000 \mathrm{e}-091.00000 \mathrm{e}-01$ $1.00000 \mathrm{e}-06$ 1.00000e-06 1.00000e-06 1.00000e-09 5.00000e-02 Element: 4180 \# of layers: 9

Kx Ky Kz Ss Por

$6.83444 \mathrm{e}+03$ 6.83444e+03 6.83444e+02 1.00000e-09 7.00000e-02 $2.73088 \mathrm{e}+022.73088 \mathrm{e}+022.73088 \mathrm{e}+01$ 1.00000e-09 2.12000e-01 $2.73088 \mathrm{e}+022.73088 \mathrm{e}+022.73088 \mathrm{e}+01$ 1.00000e-09 2.12000e-01 $2.73088 \mathrm{e}+022.73088 \mathrm{e}+022.73088 \mathrm{e}+01$ 1.00000e-09 2.12000e-01 $1.00000 \mathrm{e}-02$ 1.00000e-02 1.00000e-03 1.00000e-09 1.00000e-01 $1.00000 \mathrm{e}+001.00000 \mathrm{e}+001.00000 \mathrm{e}-011.00000 \mathrm{e}-091.00000 \mathrm{e}-01$ $1.00000 \mathrm{e}-05$ 1.00000e-05 1.00000e-06 1.00000e-09 1.00000e-01 $1.00000 \mathrm{e}+001.00000 \mathrm{e}+001.00000 \mathrm{e}-011.00000 \mathrm{e}-091.00000 \mathrm{e}-01$ $1.00000 \mathrm{e}-06$ 1.00000e-06 1.00000e-06 1.00000e-09 5.00000e-02 Element: 4181 \# of layers: 8

Kx Ky Kz Ss Por

$2.73088 \mathrm{e}+022.73088 \mathrm{e}+022.73088 \mathrm{e}+01$ 1.00000e-09 2.12000e-01 $2.73088 \mathrm{e}+022.73088 \mathrm{e}+022.73088 \mathrm{e}+01$ 1.00000e-09 2.12000e-01 $2.73088 \mathrm{e}+022.73088 \mathrm{e}+022.73088 \mathrm{e}+01$ 1.00000e-09 2.12000e-01 $1.00000 \mathrm{e}-021.00000 \mathrm{e}-02$ 1.00000e-03 1.00000e-09 1.00000e-01 $1.00000 \mathrm{e}+001.00000 \mathrm{e}+001.00000 \mathrm{e}-011.00000 \mathrm{e}-091.00000 \mathrm{e}-01$ $1.00000 \mathrm{e}-05$ 1.00000e-05 1.00000e-06 1.00000e-09 1.00000e-01 $1.00000 \mathrm{e}+001.00000 \mathrm{e}+001.00000 \mathrm{e}-011.00000 \mathrm{e}-091.00000 \mathrm{e}-01$ 1.00000e-06 1.00000e-06 1.00000e-06 1.00000e-09 5.00000e-02 Element: 4182 \# of layers: 9

Kx Ky Kz Ss Por

6.83444e+03 6.83444e+03 6.83444e+02 1.00000e-09 7.00000e-02 $6.83444 \mathrm{e}+036.83444 \mathrm{e}+036.83444 \mathrm{e}+02$ 1.00000e-09 7.00000e-02 $6.83444 \mathrm{e}+036.83444 \mathrm{e}+036.83444 \mathrm{e}+02$ 1.00000e-09 7.00000e-02 $2.73088 \mathrm{e}+022.73088 \mathrm{e}+022.73088 \mathrm{e}+01$ 1.00000e-09 2.12000e-01 $1.00000 \mathrm{e}-02$ 1.00000e-02 1.00000e-03 1.00000e-09 1.00000e-01 $1.00000 \mathrm{e}+001.00000 \mathrm{e}+001.00000 \mathrm{e}-011.00000 \mathrm{e}-091.00000 \mathrm{e}-01$ $1.00000 \mathrm{e}-05$ 1.00000e-05 1.00000e-06 1.00000e-09 1.00000e-01 
$1.00000 \mathrm{e}+001.00000 \mathrm{e}+001.00000 \mathrm{e}-011.00000 \mathrm{e}-091.00000 \mathrm{e}-01$ $1.00000 \mathrm{e}-06$ 1.00000e-06 1.00000e-06 1.00000e-09 5.00000e-02 Element: 4183 \# of layers: 7

Kx Ky Kz Ss Por

1.12958e+03 1.12958e+03 1.12958e+02 1.00000e-09 7.00000e-02 $1.12958 \mathrm{e}+031.12958 \mathrm{e}+03$ 1.12958e+02 1.00000e-09 7.00000e-02 $1.12958 \mathrm{e}+03$ 1.12958e+03 1.12958e+02 1.00000e-09 7.00000e-02 $1.00000 \mathrm{e}+001.00000 \mathrm{e}+001.00000 \mathrm{e}-011.00000 \mathrm{e}-091.00000 \mathrm{e}-01$ $1.00000 \mathrm{e}-05$ 1.00000e-05 1.00000e-06 1.00000e-09 1.00000e-01 $1.00000 \mathrm{e}+001.00000 \mathrm{e}+001.00000 \mathrm{e}-01$ 1.00000e-09 1.00000e-01 1.00000e-06 1.00000e-06 1.00000e-06 1.00000e-09 5.00000e-02 Element: 4184 \# of layers: 6

$\mathrm{Kx} \mathrm{Ky} \mathrm{Kz}$ Ss Por

$1.12958 \mathrm{e}+03$ 1.12958e+03 1.12958e+02 1.00000e-09 7.00000e-02 $1.12958 \mathrm{e}+03$ 1.12958e+03 1.12958e+02 1.00000e-09 7.00000e-02 $1.12958 \mathrm{e}+031.12958 \mathrm{e}+03$ 1.12958e+02 1.00000e-09 7.00000e-02 $1.00000 \mathrm{e}-05$ 1.00000e-05 1.00000e-06 1.00000e-09 1.00000e-01 $1.00000 \mathrm{e}+001.00000 \mathrm{e}+001.00000 \mathrm{e}-011.00000 \mathrm{e}-091.00000 \mathrm{e}-01$ 1.00000e-06 1.00000e-06 1.00000e-06 1.00000e-09 5.00000e-02 Element: 4185 \# of layers: 6

$\mathrm{Kx} \mathrm{Ky} \mathrm{Kz}$ Ss Por

$1.07066 \mathrm{e}+031.07066 \mathrm{e}+03$ 1.07066e+02 1.00000e-09 7.00000e-02 $1.07066 \mathrm{e}+031.07066 \mathrm{e}+031.07066 \mathrm{e}+021.00000 \mathrm{e}-09$ 7.00000e-02 $1.07066 \mathrm{e}+03$ 1.07066e+03 1.07066e+02 1.00000e-09 7.00000e-02 $1.00000 \mathrm{e}-05$ 1.00000e-05 1.00000e-06 1.00000e-09 1.00000e-01 $1.00000 \mathrm{e}+001.00000 \mathrm{e}+001.00000 \mathrm{e}-011.00000 \mathrm{e}-091.00000 \mathrm{e}-01$ $1.00000 \mathrm{e}-06$ 1.00000e-06 1.00000e-06 1.00000e-09 5.00000e-02 Element: 4186 \# of layers: 8

Kx Ky Kz Ss Por

2.97898e+03 2.97898e+03 2.97898e+02 1.00000e-09 7.00000e-02 $2.97898 \mathrm{e}+032.97898 \mathrm{e}+032.97898 \mathrm{e}+02$ 1.00000e-09 7.00000e-02 $2.97898 \mathrm{e}+032.97898 \mathrm{e}+032.97898 \mathrm{e}+02$ 1.00000e-09 7.00000e-02 $1.19027 \mathrm{e}+02$ 1.19027e+02 1.19027e+01 1.00000e-09 2.12000e-01 1.00000e-02 1.00000e-02 1.00000e-03 1.00000e-09 1.00000e-01 $1.00000 \mathrm{e}-05$ 1.00000e-05 1.00000e-06 1.00000e-09 1.00000e-01 $1.00000 \mathrm{e}+001.00000 \mathrm{e}+001.00000 \mathrm{e}-011.00000 \mathrm{e}-091.00000 \mathrm{e}-01$ 1.00000e-06 1.00000e-06 1.00000e-06 1.00000e-09 5.00000e-02 Element: 4187 \# of layers: 9

$\mathrm{Kx} \mathrm{Ky} \mathrm{Kz}$ Ss Por

6.83444e+03 6.83444e+03 6.83444e+02 1.00000e-09 7.00000e-02 $6.83444 \mathrm{e}+03$ 6.83444e+03 6.83444e+02 1.00000e-09 7.00000e-02 $6.83444 \mathrm{e}+03$ 6.83444e+03 6.83444e+02 1.00000e-09 7.00000e-02 $2.73088 \mathrm{e}+02$ 2.73088e+02 2.73088e+01 1.00000e-09 2.12000e-01 $1.00000 \mathrm{e}-02$ 1.00000e-02 1.00000e-03 1.00000e-09 1.00000e-01 $1.00000 \mathrm{e}+001.00000 \mathrm{e}+001.00000 \mathrm{e}-011.00000 \mathrm{e}-091.00000 \mathrm{e}-01$ $1.00000 \mathrm{e}-05$ 1.00000e-05 1.00000e-06 1.00000e-09 1.00000e-01 
$1.00000 \mathrm{e}+001.00000 \mathrm{e}+001.00000 \mathrm{e}-011.00000 \mathrm{e}-091.00000 \mathrm{e}-01$ $1.00000 \mathrm{e}-06$ 1.00000e-06 1.00000e-06 1.00000e-09 5.00000e-02 Element: 4188 \# of layers: 9

Kx Ky Kz Ss Por

$2.78778 \mathrm{e}+03$ 2.78778e+03 2.78778e+02 1.00000e-09 7.00000e-02 $1.11389 \mathrm{e}+02 \quad 1.11389 \mathrm{e}+02$ 1.11389e+01 1.00000e-09 2.12000e-01 $1.11389 \mathrm{e}+02$ 1.11389e+02 1.11389e+01 1.00000e-09 2.12000e-01 $1.11389 \mathrm{e}+02$ 1.11389e+02 1.11389e+01 1.00000e-09 2.12000e-01 $1.00000 \mathrm{e}-02$ 1.00000e-02 1.00000e-03 1.00000e-09 1.00000e-01 $1.00000 \mathrm{e}+001.00000 \mathrm{e}+001.00000 \mathrm{e}-011.00000 \mathrm{e}-091.00000 \mathrm{e}-01$ $1.00000 \mathrm{e}-05$ 1.00000e-05 1.00000e-06 1.00000e-09 1.00000e-01 $1.00000 \mathrm{e}+001.00000 \mathrm{e}+001.00000 \mathrm{e}-011.00000 \mathrm{e}-091.00000 \mathrm{e}-01$ $1.00000 \mathrm{e}-06$ 1.00000e-06 1.00000e-06 1.00000e-09 5.00000e-02 Element: 4189 \# of layers: 9

Kx Ky Kz Ss Por

$3.30766 \mathrm{e}+03$ 3.30766e +03 3.30766e+02 1.00000e-09 7.00000e-02 $1.32163 \mathrm{e}+021.32163 \mathrm{e}+021.32163 \mathrm{e}+011.00000 \mathrm{e}-092.12000 \mathrm{e}-01$ $1.32163 \mathrm{e}+021.32163 \mathrm{e}+021.32163 \mathrm{e}+01$ 1.00000e-09 2.12000e-01 $1.32163 \mathrm{e}+021.32163 \mathrm{e}+021.32163 \mathrm{e}+01$ 1.00000e-09 2.12000e-01 $1.00000 \mathrm{e}-02$ 1.00000e-02 $1.00000 \mathrm{e}-031.00000 \mathrm{e}-091.00000 \mathrm{e}-01$ $1.00000 \mathrm{e}+001.00000 \mathrm{e}+001.00000 \mathrm{e}-011.00000 \mathrm{e}-091.00000 \mathrm{e}-01$ $1.00000 \mathrm{e}-05$ 1.00000e-05 1.00000e-06 1.00000e-09 1.00000e-01 $1.00000 \mathrm{e}+001.00000 \mathrm{e}+001.00000 \mathrm{e}-011.00000 \mathrm{e}-091.00000 \mathrm{e}-01$ $1.00000 \mathrm{e}-061.00000 \mathrm{e}-06$ 1.00000e-06 1.00000e-09 5.00000e-02 Element: 4190 \# of layers: 9

Kx Ky Kz Ss Por

$3.30766 \mathrm{e}+03$ 3.30766e+03 3.30766e+02 1.00000e-09 7.00000e-02 $1.32163 \mathrm{e}+02 \quad 1.32163 \mathrm{e}+021.32163 \mathrm{e}+01$ 1.00000e-09 2.12000e-01 $1.32163 \mathrm{e}+021.32163 \mathrm{e}+021.32163 \mathrm{e}+011.00000 \mathrm{e}-092.12000 \mathrm{e}-01$ $1.32163 \mathrm{e}+02 \quad 1.32163 \mathrm{e}+021.32163 \mathrm{e}+01$ 1.00000e-09 2.12000e-01 $1.00000 \mathrm{e}-021.00000 \mathrm{e}-02$ 1.00000e-03 1.00000e-09 1.00000e-01 $1.00000 \mathrm{e}+001.00000 \mathrm{e}+001.00000 \mathrm{e}-011.00000 \mathrm{e}-091.00000 \mathrm{e}-01$ $1.00000 \mathrm{e}-05$ 1.00000e-05 1.00000e-06 1.00000e-09 1.00000e-01 $1.00000 \mathrm{e}+001.00000 \mathrm{e}+001.00000 \mathrm{e}-011.00000 \mathrm{e}-091.00000 \mathrm{e}-01$ $1.00000 \mathrm{e}-06$ 1.00000e-06 1.00000e-06 1.00000e-09 5.00000e-02 Element: 4191 \# of layers: 9

Kx Ky Kz Ss Por

$3.30766 \mathrm{e}+033.30766 \mathrm{e}+033.30766 \mathrm{e}+02$ 1.00000e-09 7.00000e-02 $3.30766 \mathrm{e}+033.30766 \mathrm{e}+033.30766 \mathrm{e}+021.00000 \mathrm{e}-09$ 7.00000e-02 $3.30766 \mathrm{e}+033.30766 \mathrm{e}+033.30766 \mathrm{e}+021.00000 \mathrm{e}-09$ 7.00000e-02 $1.32163 \mathrm{e}+02 \quad 1.32163 \mathrm{e}+021.32163 \mathrm{e}+011.00000 \mathrm{e}-092.12000 \mathrm{e}-01$ $1.00000 \mathrm{e}-021.00000 \mathrm{e}-02$ 1.00000e-03 1.00000e-09 1.00000e-01 $1.00000 \mathrm{e}+001.00000 \mathrm{e}+001.00000 \mathrm{e}-011.00000 \mathrm{e}-091.00000 \mathrm{e}-01$ $1.00000 \mathrm{e}-05$ 1.00000e-05 1.00000e-06 1.00000e-09 1.00000e-01 $1.00000 \mathrm{e}+001.00000 \mathrm{e}+001.00000 \mathrm{e}-011.00000 \mathrm{e}-091.00000 \mathrm{e}-01$ $1.00000 \mathrm{e}-06$ 1.00000e-06 1.00000e-06 1.00000e-09 5.00000e-02 
Element: 4192 \# of layers: 7

$\mathrm{Kx} \mathrm{Ky} \mathrm{Kz}$ Ss Por

3.21828e+02 3.21828e+02 3.21828e+01 1.00000e-09 7.00000e-02

$3.21828 \mathrm{e}+02$ 3.21828e+02 3.21828e+01 1.00000e-09 7.00000e-02

$3.21828 \mathrm{e}+023.21828 \mathrm{e}+023.21828 \mathrm{e}+01$ 1.00000e-09 7.00000e-02

$1.00000 \mathrm{e}+001.00000 \mathrm{e}+001.00000 \mathrm{e}-011.00000 \mathrm{e}-091.00000 \mathrm{e}-01$

1.00000e-05 1.00000e-05 1.00000e-06 1.00000e-09 1.00000e-01

$1.00000 \mathrm{e}+001.00000 \mathrm{e}+001.00000 \mathrm{e}-011.00000 \mathrm{e}-091.00000 \mathrm{e}-01$

$1.00000 \mathrm{e}-06$ 1.00000e-06 1.00000e-06 1.00000e-09 5.00000e-02

Element: 4193 \# of layers: 7

$\mathrm{Kx} \mathrm{Ky} \mathrm{Kz}$ Ss Por

3.21828e+02 3.21828e+02 3.21828e+01 1.00000e-09 7.00000e-02

$3.21828 \mathrm{e}+02$ 3.21828e+02 3.21828e+01 1.00000e-09 7.00000e-02

$3.21828 \mathrm{e}+02$ 3.21828e+02 3.21828e+01 1.00000e-09 7.00000e-02

$1.00000 \mathrm{e}+001.00000 \mathrm{e}+001.00000 \mathrm{e}-011.00000 \mathrm{e}-091.00000 \mathrm{e}-01$

$1.00000 \mathrm{e}-05$ 1.00000e-05 1.00000e-06 1.00000e-09 1.00000e-01

$1.00000 \mathrm{e}+001.00000 \mathrm{e}+001.00000 \mathrm{e}-011.00000 \mathrm{e}-091.00000 \mathrm{e}-01$

1.00000e-06 1.00000e-06 1.00000e-06 1.00000e-09 5.00000e-02

Element: 4194 \# of layers: 7

$\mathrm{Kx} \mathrm{Ky} \mathrm{Kz}$ Ss Por

6.34727e+02 6.34727e+02 6.34727e+01 1.00000e-09 7.00000e-02

6.34727e+02 6.34727e+02 6.34727e+01 1.00000e-09 7.00000e-02

6.34727e+02 6.34727e+02 6.34727e+01 1.00000e-09 7.00000e-02

$1.00000 \mathrm{e}+001.00000 \mathrm{e}+001.00000 \mathrm{e}-011.00000 \mathrm{e}-091.00000 \mathrm{e}-01$

$1.00000 \mathrm{e}-05$ 1.00000e-05 1.00000e-06 1.00000e-09 1.00000e-01

$1.00000 \mathrm{e}+001.00000 \mathrm{e}+001.00000 \mathrm{e}-011.00000 \mathrm{e}-091.00000 \mathrm{e}-01$

1.00000e-06 1.00000e-06 1.00000e-06 1.00000e-09 5.00000e-02

Element: 4195 \# of layers: 9

Kx Ky Kz Ss Por

$2.78778 \mathrm{e}+03$ 2.78778e+03 2.78778e+02 1.00000e-09 7.00000e-02

$2.78778 \mathrm{e}+032.78778 \mathrm{e}+032.78778 \mathrm{e}+02$ 1.00000e-09 7.00000e-02

$2.78778 \mathrm{e}+032.78778 \mathrm{e}+032.78778 \mathrm{e}+02$ 1.00000e-09 7.00000e-02

$1.11389 \mathrm{e}+021.11389 \mathrm{e}+02 \quad 1.11389 \mathrm{e}+01$ 1.00000e-09 2.12000e-01

$1.00000 \mathrm{e}-021.00000 \mathrm{e}-021.00000 \mathrm{e}-031.00000 \mathrm{e}-091.00000 \mathrm{e}-01$

$1.00000 \mathrm{e}+001.00000 \mathrm{e}+001.00000 \mathrm{e}-011.00000 \mathrm{e}-091.00000 \mathrm{e}-01$

$1.00000 \mathrm{e}-05$ 1.00000e-05 1.00000e-06 1.00000e-09 1.00000e-01

$1.00000 \mathrm{e}+001.00000 \mathrm{e}+001.00000 \mathrm{e}-011.00000 \mathrm{e}-091.00000 \mathrm{e}-01$

1.00000e-06 1.00000e-06 1.00000e-06 1.00000e-09 5.00000e-02

Element: 4196 \# of layers: 9

$\mathrm{Kx} \mathrm{Ky} \mathrm{Kz}$ Ss Por

3.30766e+03 3.30766e+03 3.30766e+02 1.00000e-09 7.00000e-02

$3.30766 \mathrm{e}+03$ 3.30766e+03 3.30766e+02 1.00000e-09 7.00000e-02

3.30766e+03 3.30766e+03 3.30766e+02 1.00000e-09 7.00000e-02

$1.32163 \mathrm{e}+02$ 1.32163e+02 1.32163e+01 1.00000e-09 2.12000e-01

$1.00000 \mathrm{e}-02$ 1.00000e-02 1.00000e-03 1.00000e-09 1.00000e-01

$1.00000 \mathrm{e}+001.00000 \mathrm{e}+001.00000 \mathrm{e}-011.00000 \mathrm{e}-091.00000 \mathrm{e}-01$ 
$1.00000 \mathrm{e}-05$ 1.00000e-05 1.00000e-06 1.00000e-09 1.00000e-01 $1.00000 \mathrm{e}+001.00000 \mathrm{e}+001.00000 \mathrm{e}-011.00000 \mathrm{e}-091.00000 \mathrm{e}-01$ 1.00000e-06 1.00000e-06 1.00000e-06 1.00000e-09 5.00000e-02 Element: 4197 \# of layers: 10

$\mathrm{Kx} \mathrm{Ky} \mathrm{Kz}$ Ss Por

$6.49936 \mathrm{e}+036.49936 \mathrm{e}+036.49936 \mathrm{e}+02$ 1.00000e-09 7.00000e-02 5.00000e-04 5.00000e-04 5.00000e-05 1.00000e-09 1.00000e-01

$2.59701 \mathrm{e}+022.59701 \mathrm{e}+022.59701 \mathrm{e}+01$ 1.00000e-09 2.12000e-01

$2.59701 \mathrm{e}+022.59701 \mathrm{e}+022.59701 \mathrm{e}+01$ 1.00000e-09 2.12000e-01

$2.59701 \mathrm{e}+022.59701 \mathrm{e}+022.59701 \mathrm{e}+01$ 1.00000e-09 2.12000e-01 $1.00000 \mathrm{e}-02$ 1.00000e-02 1.00000e-03 1.00000e-09 1.00000e-01 $1.00000 \mathrm{e}+001.00000 \mathrm{e}+001.00000 \mathrm{e}-011.00000 \mathrm{e}-091.00000 \mathrm{e}-01$ $1.00000 \mathrm{e}-05$ 1.00000e-05 1.00000e-06 1.00000e-09 1.00000e-01 $1.00000 \mathrm{e}+001.00000 \mathrm{e}+001.00000 \mathrm{e}-011.00000 \mathrm{e}-091.00000 \mathrm{e}-01$ 1.00000e-06 1.00000e-06 1.00000e-06 1.00000e-09 5.00000e-02 Element: 4198 \# of layers: 10

$\mathrm{Kx} \mathrm{Ky} \mathrm{Kz}$ Ss Por

$2.00310 \mathrm{e}+042.00310 \mathrm{e}+042.00310 \mathrm{e}+03$ 1.00000e-09 7.00000e-02 5.00000e-04 5.00000e-04 5.00000e-05 1.00000e-09 1.00000e-01 $8.00365 \mathrm{e}+02$ 8.00365e+02 8.00365e+01 1.00000e-09 2.12000e-01 $8.00365 \mathrm{e}+02$ 8.00365e+02 8.00365e+01 1.00000e-09 2.12000e-01 $8.00365 \mathrm{e}+02$ 8.00365e+02 8.00365e+01 1.00000e-09 2.12000e-01 $1.00000 \mathrm{e}-02$ 1.00000e-02 1.00000e-03 1.00000e-09 1.00000e-01 $1.00000 \mathrm{e}+001.00000 \mathrm{e}+001.00000 \mathrm{e}-011.00000 \mathrm{e}-091.00000 \mathrm{e}-01$ $1.00000 \mathrm{e}-05$ 1.00000e-05 1.00000e-06 1.00000e-09 1.00000e-01 $1.00000 \mathrm{e}+001.00000 \mathrm{e}+001.00000 \mathrm{e}-011.00000 \mathrm{e}-091.00000 \mathrm{e}-01$ 1.00000e-06 1.00000e-06 1.00000e-06 1.00000e-09 5.00000e-02 Element: 4199 \# of layers: 9

$\mathrm{Kx} \mathrm{Ky} \mathrm{Kz}$ Ss Por

$2.00310 \mathrm{e}+042.00310 \mathrm{e}+042.00310 \mathrm{e}+03$ 1.00000e-09 7.00000e-02 $5.00000 \mathrm{e}-04$ 5.00000e-04 5.00000e-05 1.00000e-09 1.00000e-01 $8.00365 \mathrm{e}+02$ 8.00365e+02 8.00365e+01 1.00000e-09 2.12000e-01 $8.00365 \mathrm{e}+02$ 8.00365e+02 8.00365e+01 1.00000e-09 2.12000e-01 $1.00000 \mathrm{e}-02$ 1.00000e-02 1.00000e-03 1.00000e-09 1.00000e-01 $1.00000 \mathrm{e}+001.00000 \mathrm{e}+001.00000 \mathrm{e}-011.00000 \mathrm{e}-091.00000 \mathrm{e}-01$ $1.00000 \mathrm{e}-05$ 1.00000e-05 1.00000e-06 1.00000e-09 1.00000e-01 $1.00000 \mathrm{e}+001.00000 \mathrm{e}+001.00000 \mathrm{e}-011.00000 \mathrm{e}-091.00000 \mathrm{e}-01$ 1.00000e-06 1.00000e-06 1.00000e-06 1.00000e-09 5.00000e-02 Element: 4200 \# of layers: 8

$\mathrm{Kx} \mathrm{Ky} \mathrm{Kz}$ Ss Por $2.00310 \mathrm{e}+042.00310 \mathrm{e}+042.00310 \mathrm{e}+03$ 1.00000e-09 7.00000e-02 $2.00310 \mathrm{e}+042.00310 \mathrm{e}+042.00310 \mathrm{e}+03$ 1.00000e-09 7.00000e-02 $8.00365 \mathrm{e}+028.00365 \mathrm{e}+028.00365 \mathrm{e}+01$ 1.00000e-09 2.12000e-01 $1.00000 \mathrm{e}-02$ 1.00000e-02 1.00000e-03 1.00000e-09 1.00000e-01 $1.00000 \mathrm{e}+001.00000 \mathrm{e}+001.00000 \mathrm{e}-011.00000 \mathrm{e}-091.00000 \mathrm{e}-01$ $1.00000 \mathrm{e}-05$ 1.00000e-05 1.00000e-06 1.00000e-09 1.00000e-01 
$1.00000 \mathrm{e}+001.00000 \mathrm{e}+001.00000 \mathrm{e}-011.00000 \mathrm{e}-091.00000 \mathrm{e}-01$ 1.00000e-06 1.00000e-06 1.00000e-06 1.00000e-09 5.00000e-02

Element: 4201 \# of layers: 7

Kx Ky Kz Ss Por

7.02131e+01 7.02131e+01 7.02131e+00 1.00000e-09 7.00000e-02

$7.02131 \mathrm{e}+017.02131 \mathrm{e}+017.02131 \mathrm{e}+001.00000 \mathrm{e}-09$ 7.00000e-02

$1.00000 \mathrm{e}-02$ 1.00000e-02 1.00000e-03 1.00000e-09 1.00000e-01

$1.00000 \mathrm{e}+001.00000 \mathrm{e}+001.00000 \mathrm{e}-011.00000 \mathrm{e}-091.00000 \mathrm{e}-01$

$1.00000 \mathrm{e}-05$ 1.00000e-05 1.00000e-06 1.00000e-09 1.00000e-01

$1.00000 \mathrm{e}+001.00000 \mathrm{e}+001.00000 \mathrm{e}-011.00000 \mathrm{e}-091.00000 \mathrm{e}-01$

1.00000e-06 1.00000e-06 1.00000e-06 1.00000e-09 5.00000e-02

Element: 4202 \# of layers: 6

$\mathrm{Kx} \mathrm{Ky} \mathrm{Kz}$ Ss Por

7.02131e+01 7.02131e+01 7.02131e+00 1.00000e-09 7.00000e-02

$7.02131 \mathrm{e}+017.02131 \mathrm{e}+017.02131 \mathrm{e}+001.00000 \mathrm{e}-09$ 7.00000e-02

$1.00000 \mathrm{e}+001.00000 \mathrm{e}+001.00000 \mathrm{e}-011.00000 \mathrm{e}-091.00000 \mathrm{e}-01$

$1.00000 \mathrm{e}-05$ 1.00000e-05 1.00000e-06 1.00000e-09 1.00000e-01

$1.00000 \mathrm{e}+001.00000 \mathrm{e}+001.00000 \mathrm{e}-011.00000 \mathrm{e}-091.00000 \mathrm{e}-01$

1.00000e-06 1.00000e-06 1.00000e-06 1.00000e-09 5.00000e-02

Element: 4203 \# of layers: 7

$\mathrm{Kx} \mathrm{Ky} \mathrm{Kz}$ Ss Por

5.70405e+01 5.70405e+01 5.70405e+00 1.00000e-09 7.00000e-02

$5.70405 \mathrm{e}+015.70405 \mathrm{e}+015.70405 \mathrm{e}+001.00000 \mathrm{e}-09$ 7.00000e-02

$5.70405 \mathrm{e}+015.70405 \mathrm{e}+015.70405 \mathrm{e}+001.00000 \mathrm{e}-09$ 7.00000e-02

$1.00000 \mathrm{e}+001.00000 \mathrm{e}+001.00000 \mathrm{e}-011.00000 \mathrm{e}-091.00000 \mathrm{e}-01$

$1.00000 \mathrm{e}-05$ 1.00000e-05 1.00000e-06 1.00000e-09 1.00000e-01

$1.00000 \mathrm{e}+001.00000 \mathrm{e}+001.00000 \mathrm{e}-011.00000 \mathrm{e}-091.00000 \mathrm{e}-01$

1.00000e-06 1.00000e-06 1.00000e-06 1.00000e-09 5.00000e-02

Element: 4204 \# of layers: 9

$\mathrm{Kx} \mathrm{Ky} \mathrm{Kz}$ Ss Por

$6.49936 \mathrm{e}+036.49936 \mathrm{e}+036.49936 \mathrm{e}+02$ 1.00000e-09 7.00000e-02

$6.49936 \mathrm{e}+036.49936 \mathrm{e}+036.49936 \mathrm{e}+02$ 1.00000e-09 7.00000e-02

$6.49936 \mathrm{e}+03$ 6.49936e+03 6.49936e+02 1.00000e-09 7.00000e-02

$2.59701 \mathrm{e}+022.59701 \mathrm{e}+022.59701 \mathrm{e}+01$ 1.00000e-09 2.12000e-01

$1.00000 \mathrm{e}-02$ 1.00000e-02 1.00000e-03 1.00000e-09 1.00000e-01

$1.00000 \mathrm{e}+001.00000 \mathrm{e}+001.00000 \mathrm{e}-011.00000 \mathrm{e}-091.00000 \mathrm{e}-01$

$1.00000 \mathrm{e}-051.00000 \mathrm{e}-05$ 1.00000e-06 1.00000e-09 1.00000e-01

$1.00000 \mathrm{e}+001.00000 \mathrm{e}+001.00000 \mathrm{e}-011.00000 \mathrm{e}-091.00000 \mathrm{e}-01$

1.00000e-06 1.00000e-06 1.00000e-06 1.00000e-09 5.00000e-02

Element: 4205 \# of layers: 8

$\mathrm{Kx} \mathrm{Ky} \mathrm{Kz}$ Ss Por

$2.00310 \mathrm{e}+042.00310 \mathrm{e}+042.00310 \mathrm{e}+03$ 1.00000e-09 7.00000e-02

$2.00310 \mathrm{e}+042.00310 \mathrm{e}+042.00310 \mathrm{e}+03$ 1.00000e-09 7.00000e-02

$8.00365 \mathrm{e}+02$ 8.00365e+02 8.00365e+01 1.00000e-09 2.12000e-01

$1.00000 \mathrm{e}-02$ 1.00000e-02 1.00000e-03 1.00000e-09 1.00000e-01

$1.00000 \mathrm{e}+001.00000 \mathrm{e}+001.00000 \mathrm{e}-011.00000 \mathrm{e}-091.00000 \mathrm{e}-01$ 
$1.00000 \mathrm{e}-05$ 1.00000e-05 1.00000e-06 1.00000e-09 1.00000e-01 $1.00000 \mathrm{e}+001.00000 \mathrm{e}+001.00000 \mathrm{e}-011.00000 \mathrm{e}-091.00000 \mathrm{e}-01$ 1.00000e-06 1.00000e-06 1.00000e-06 1.00000e-09 5.00000e-02 Element: 4206 \# of layers: 9

$\mathrm{Kx} \mathrm{Ky} \mathrm{Kz}$ Ss Por

$2.23088 \mathrm{e}+042.23088 \mathrm{e}+042.23088 \mathrm{e}+03$ 1.00000e-09 7.00000e-02 5.00000e-04 5.00000e-04 5.00000e-05 1.00000e-09 1.00000e-01 8.91379e+02 8.91379e+02 8.91379e+01 1.00000e-09 2.12000e-01 8.91379e+02 8.91379e+02 8.91379e+01 1.00000e-09 2.12000e-01 $1.00000 \mathrm{e}-02$ 1.00000e-02 1.00000e-03 1.00000e-09 1.00000e-01 $1.00000 \mathrm{e}+001.00000 \mathrm{e}+001.00000 \mathrm{e}-011.00000 \mathrm{e}-091.00000 \mathrm{e}-01$ $1.00000 \mathrm{e}-05$ 1.00000e-05 1.00000e-06 1.00000e-09 1.00000e-01 $1.00000 \mathrm{e}+001.00000 \mathrm{e}+001.00000 \mathrm{e}-011.00000 \mathrm{e}-091.00000 \mathrm{e}-01$ 1.00000e-06 1.00000e-06 1.00000e-06 1.00000e-09 5.00000e-02 Element: 4207 \# of layers: 9

$\mathrm{Kx} \mathrm{Ky} \mathrm{Kz}$ Ss Por

$2.30980 \mathrm{e}+042.30980 \mathrm{e}+042.30980 \mathrm{e}+03$ 1.00000e-09 7.00000e-02 5.00000e-04 5.00000e-04 5.00000e-05 1.00000e-09 1.00000e-01 9.22925e+02 9.22925e+02 9.22925e+01 1.00000e-09 2.12000e-01 $9.22925 \mathrm{e}+02$ 9.22925e+02 9.22925e+01 1.00000e-09 2.12000e-01 $1.00000 \mathrm{e}-02$ 1.00000e-02 1.00000e-03 1.00000e-09 1.00000e-01 $1.00000 \mathrm{e}+001.00000 \mathrm{e}+001.00000 \mathrm{e}-011.00000 \mathrm{e}-091.00000 \mathrm{e}-01$ $1.00000 \mathrm{e}-05$ 1.00000e-05 1.00000e-06 1.00000e-09 1.00000e-01 $1.00000 \mathrm{e}+001.00000 \mathrm{e}+001.00000 \mathrm{e}-011.00000 \mathrm{e}-091.00000 \mathrm{e}-01$ $1.00000 \mathrm{e}-06$ 1.00000e-06 1.00000e-06 1.00000e-09 5.00000e-02 Element: 4208 \# of layers: 9

$\mathrm{Kx} \mathrm{Ky} \mathrm{Kz}$ Ss Por

$2.30980 \mathrm{e}+042.30980 \mathrm{e}+042.30980 \mathrm{e}+03$ 1.00000e-09 7.00000e-02 5.00000e-04 5.00000e-04 5.00000e-05 1.00000e-09 1.00000e-01 $9.22925 \mathrm{e}+02$ 9.22925e+02 9.22925e+01 1.00000e-09 2.12000e-01 $9.22925 \mathrm{e}+02$ 9.22925e+02 9.22925e+01 1.00000e-09 2.12000e-01 $1.00000 \mathrm{e}-02$ 1.00000e-02 1.00000e-03 1.00000e-09 1.00000e-01 $1.00000 \mathrm{e}+001.00000 \mathrm{e}+001.00000 \mathrm{e}-011.00000 \mathrm{e}-091.00000 \mathrm{e}-01$ $1.00000 \mathrm{e}-05$ 1.00000e-05 1.00000e-06 1.00000e-09 1.00000e-01 $1.00000 \mathrm{e}+001.00000 \mathrm{e}+001.00000 \mathrm{e}-011.00000 \mathrm{e}-091.00000 \mathrm{e}-01$ 1.00000e-06 1.00000e-06 1.00000e-06 1.00000e-09 5.00000e-02 Element: 4209 \# of layers: 8

$\mathrm{Kx} \mathrm{Ky} \mathrm{Kz}$ Ss Por

$2.30980 \mathrm{e}+042.30980 \mathrm{e}+042.30980 \mathrm{e}+03$ 1.00000e-09 7.00000e-02 $2.30980 \mathrm{e}+042.30980 \mathrm{e}+042.30980 \mathrm{e}+03$ 1.00000e-09 7.00000e-02 9.22925e+02 9.22925e+02 9.22925e+01 1.00000e-09 2.12000e-01 $1.00000 \mathrm{e}-02$ 1.00000e-02 1.00000e-03 1.00000e-09 1.00000e-01 $1.00000 \mathrm{e}+001.00000 \mathrm{e}+001.00000 \mathrm{e}-011.00000 \mathrm{e}-091.00000 \mathrm{e}-01$ $1.00000 \mathrm{e}-05$ 1.00000e-05 1.00000e-06 1.00000e-09 1.00000e-01 $1.00000 \mathrm{e}+001.00000 \mathrm{e}+001.00000 \mathrm{e}-011.00000 \mathrm{e}-091.00000 \mathrm{e}-01$ $1.00000 \mathrm{e}-06$ 1.00000e-06 1.00000e-06 1.00000e-09 5.00000e-02 
Element: 4210 \# of layers: 7

$\mathrm{Kx} \mathrm{Ky} \mathrm{Kz}$ Ss Por

$2.18664 \mathrm{e}+022.18664 \mathrm{e}+02$ 2.18664e+01 1.00000e-09 7.00000e-02

$2.18664 \mathrm{e}+022.18664 \mathrm{e}+022.18664 \mathrm{e}+01$ 1.00000e-09 7.00000e-02

$1.00000 \mathrm{e}-02$ 1.00000e-02 1.00000e-03 1.00000e-09 1.00000e-01

$1.00000 \mathrm{e}+001.00000 \mathrm{e}+001.00000 \mathrm{e}-011.00000 \mathrm{e}-091.00000 \mathrm{e}-01$

1.00000e-05 1.00000e-05 1.00000e-06 1.00000e-09 1.00000e-01

$1.00000 \mathrm{e}+001.00000 \mathrm{e}+001.00000 \mathrm{e}-011.00000 \mathrm{e}-091.00000 \mathrm{e}-01$

1.00000e-06 1.00000e-06 1.00000e-06 1.00000e-09 5.00000e-02

Element: 4211 \# of layers: 7

$\mathrm{Kx} \mathrm{Ky} \mathrm{Kz}$ Ss Por

$2.18664 \mathrm{e}+02$ 2.18664e+02 2.18664e+01 1.00000e-09 7.00000e-02

$2.18664 \mathrm{e}+022.18664 \mathrm{e}+02$ 2.18664e+01 1.00000e-09 7.00000e-02

$1.00000 \mathrm{e}-02$ 1.00000e-02 1.00000e-03 1.00000e-09 1.00000e-01

$1.00000 \mathrm{e}+001.00000 \mathrm{e}+001.00000 \mathrm{e}-011.00000 \mathrm{e}-091.00000 \mathrm{e}-01$

$1.00000 \mathrm{e}-05$ 1.00000e-05 1.00000e-06 1.00000e-09 1.00000e-01

$1.00000 \mathrm{e}+001.00000 \mathrm{e}+001.00000 \mathrm{e}-011.00000 \mathrm{e}-091.00000 \mathrm{e}-01$

1.00000e-06 1.00000e-06 1.00000e-06 1.00000e-09 5.00000e-02

Element: 4212 \# of layers: 7

$\mathrm{Kx} \mathrm{Ky} \mathrm{Kz}$ Ss Por

9.52988e+01 9.52988e+01 9.52988e+00 1.00000e-09 7.00000e-02

9.52988e+01 9.52988e+01 9.52988e+00 1.00000e-09 7.00000e-02

$1.00000 \mathrm{e}-02$ 1.00000e-02 1.00000e-03 1.00000e-09 1.00000e-01

$1.00000 \mathrm{e}+001.00000 \mathrm{e}+001.00000 \mathrm{e}-011.00000 \mathrm{e}-091.00000 \mathrm{e}-01$

$1.00000 \mathrm{e}-05$ 1.00000e-05 1.00000e-06 1.00000e-09 1.00000e-01

$1.00000 \mathrm{e}+001.00000 \mathrm{e}+001.00000 \mathrm{e}-011.00000 \mathrm{e}-091.00000 \mathrm{e}-01$

1.00000e-06 1.00000e-06 1.00000e-06 1.00000e-09 5.00000e-02

Element: 4213 \# of layers: 8

$\mathrm{Kx} \mathrm{Ky} \mathrm{Kz}$ Ss Por

$2.23088 \mathrm{e}+042.23088 \mathrm{e}+042.23088 \mathrm{e}+03$ 1.00000e-09 7.00000e-02

$2.23088 \mathrm{e}+042.23088 \mathrm{e}+042.23088 \mathrm{e}+03$ 1.00000e-09 7.00000e-02

8.91379e+02 8.91379e+02 8.91379e+01 1.00000e-09 2.12000e-01

$1.00000 \mathrm{e}-02$ 1.00000e-02 1.00000e-03 1.00000e-09 1.00000e-01

$1.00000 \mathrm{e}+001.00000 \mathrm{e}+001.00000 \mathrm{e}-011.00000 \mathrm{e}-091.00000 \mathrm{e}-01$

$1.00000 \mathrm{e}-05$ 1.00000e-05 1.00000e-06 1.00000e-09 1.00000e-01

$1.00000 \mathrm{e}+001.00000 \mathrm{e}+001.00000 \mathrm{e}-011.00000 \mathrm{e}-091.00000 \mathrm{e}-01$

1.00000e-06 1.00000e-06 1.00000e-06 1.00000e-09 5.00000e-02

Element: 4214 \# of layers: 8

$\mathrm{Kx} \mathrm{Ky} \mathrm{Kz}$ Ss Por

$2.30980 \mathrm{e}+042.30980 \mathrm{e}+042.30980 \mathrm{e}+03$ 1.00000e-09 7.00000e-02

$2.30980 \mathrm{e}+042.30980 \mathrm{e}+042.30980 \mathrm{e}+03$ 1.00000e-09 7.00000e-02

9.22925e+02 9.22925e+02 9.22925e+01 1.00000e-09 2.12000e-01

$1.00000 \mathrm{e}-02$ 1.00000e-02 1.00000e-03 1.00000e-09 1.00000e-01

$1.00000 \mathrm{e}+001.00000 \mathrm{e}+001.00000 \mathrm{e}-011.00000 \mathrm{e}-091.00000 \mathrm{e}-01$

$1.00000 \mathrm{e}-05$ 1.00000e-05 1.00000e-06 1.00000e-09 1.00000e-01

$1.00000 \mathrm{e}+001.00000 \mathrm{e}+001.00000 \mathrm{e}-01$ 1.00000e-09 1.00000e-01 
1.00000e-06 1.00000e-06 1.00000e-06 1.00000e-09 5.00000e-02

Element: 4215 \# of layers: 8

Kx Ky Kz Ss Por

2.45234e+03 2.45234e+03 2.45234e+02 1.00000e-09 7.00000e-02

9.79873e+01 9.79873e+01 9.79873e+00 1.00000e-09 2.12000e-01

$9.79873 \mathrm{e}+01$ 9.79873e+01 9.79873e+00 1.00000e-09 2.12000e-01

$1.00000 \mathrm{e}-02$ 1.00000e-02 1.00000e-03 1.00000e-09 1.00000e-01

$1.00000 \mathrm{e}+001.00000 \mathrm{e}+001.00000 \mathrm{e}-011.00000 \mathrm{e}-091.00000 \mathrm{e}-01$

$1.00000 \mathrm{e}-05$ 1.00000e-05 1.00000e-06 1.00000e-09 1.00000e-01

$1.00000 \mathrm{e}+001.00000 \mathrm{e}+001.00000 \mathrm{e}-011.00000 \mathrm{e}-091.00000 \mathrm{e}-01$

1.00000e-06 1.00000e-06 1.00000e-06 1.00000e-09 5.00000e-02

Element: 4216 \# of layers: 9

$\mathrm{Kx} \mathrm{Ky} \mathrm{Kz}$ Ss Por

7.40144e+02 7.40144e+02 7.40144e+01 1.00000e-09 7.00000e-02

5.00000e-04 5.00000e-04 5.00000e-05 1.00000e-09 1.00000e-01

$2.95746 \mathrm{e}+012.95746 \mathrm{e}+012.95746 \mathrm{e}+001.00000 \mathrm{e}-092.12000 \mathrm{e}-01$

$2.95746 \mathrm{e}+012.95746 \mathrm{e}+012.95746 \mathrm{e}+001.00000 \mathrm{e}-092.12000 \mathrm{e}-01$

$1.00000 \mathrm{e}-02$ 1.00000e-02 1.00000e-03 1.00000e-09 1.00000e-01

$1.00000 \mathrm{e}+001.00000 \mathrm{e}+001.00000 \mathrm{e}-011.00000 \mathrm{e}-091.00000 \mathrm{e}-01$

$1.00000 \mathrm{e}-05$ 1.00000e-05 1.00000e-06 1.00000e-09 1.00000e-01

$1.00000 \mathrm{e}+001.00000 \mathrm{e}+001.00000 \mathrm{e}-011.00000 \mathrm{e}-091.00000 \mathrm{e}-01$

$1.00000 \mathrm{e}-06$ 1.00000e-06 1.00000e-06 1.00000e-09 5.00000e-02

Element: 4217 \# of layers: 10

Kx Ky Kz Ss Por

7.40144e+02 7.40144e+02 7.40144e+01 1.00000e-09 7.00000e-02

$7.40144 \mathrm{e}+02$ 7.40144e+02 7.40144e+01 1.00000e-09 7.00000e-02

5.00000e-04 5.00000e-04 5.00000e-05 1.00000e-09 1.00000e-01

$2.95746 \mathrm{e}+012.95746 \mathrm{e}+012.95746 \mathrm{e}+001.00000 \mathrm{e}-092.12000 \mathrm{e}-01$

$2.95746 \mathrm{e}+012.95746 \mathrm{e}+012.95746 \mathrm{e}+001.00000 \mathrm{e}-092.12000 \mathrm{e}-01$

$1.00000 \mathrm{e}-02$ 1.00000e-02 1.00000e-03 1.00000e-09 1.00000e-01

$1.00000 \mathrm{e}+001.00000 \mathrm{e}+001.00000 \mathrm{e}-01$ 1.00000e-09 1.00000e-01

$1.00000 \mathrm{e}-05$ 1.00000e-05 1.00000e-06 1.00000e-09 1.00000e-01

$1.00000 \mathrm{e}+001.00000 \mathrm{e}+001.00000 \mathrm{e}-011.00000 \mathrm{e}-091.00000 \mathrm{e}-01$

1.00000e-06 1.00000e-06 1.00000e-06 1.00000e-09 5.00000e-02

Element: 4218 \# of layers: 7

Kx Ky Kz Ss Por

7.40144e+02 7.40144e+02 7.40144e+01 1.00000e-09 7.00000e-02

$2.95746 \mathrm{e}+012.95746 \mathrm{e}+012.95746 \mathrm{e}+001.00000 \mathrm{e}-092.12000 \mathrm{e}-01$

$1.00000 \mathrm{e}-02$ 1.00000e-02 1.00000e-03 1.00000e-09 1.00000e-01

$1.00000 \mathrm{e}+001.00000 \mathrm{e}+001.00000 \mathrm{e}-011.00000 \mathrm{e}-091.00000 \mathrm{e}-01$

$1.00000 \mathrm{e}-05$ 1.00000e-05 1.00000e-06 1.00000e-09 1.00000e-01

$1.00000 \mathrm{e}+001.00000 \mathrm{e}+001.00000 \mathrm{e}-011.00000 \mathrm{e}-091.00000 \mathrm{e}-01$

1.00000e-06 1.00000e-06 1.00000e-06 1.00000e-09 5.00000e-02

Element: 4219 \# of layers: 6

$\mathrm{Kx} \mathrm{Ky} \mathrm{Kz}$ Ss Por

2.93798e+02 2.93798e+02 2.93798e+01 1.00000e-09 7.00000e-02 
$1.00000 \mathrm{e}-02$ 1.00000e-02 1.00000e-03 1.00000e-09 1.00000e-01 $1.00000 \mathrm{e}+001.00000 \mathrm{e}+001.00000 \mathrm{e}-011.00000 \mathrm{e}-091.00000 \mathrm{e}-01$ $1.00000 \mathrm{e}-05$ 1.00000e-05 1.00000e-06 1.00000e-09 1.00000e-01 $1.00000 \mathrm{e}+001.00000 \mathrm{e}+001.00000 \mathrm{e}-011.00000 \mathrm{e}-091.00000 \mathrm{e}-01$ 1.00000e-06 1.00000e-06 1.00000e-06 1.00000e-09 5.00000e-02 Element: 4220 \# of layers: 6

$\mathrm{Kx} \mathrm{Ky} \mathrm{Kz}$ Ss Por

2.93798e+02 2.93798e+02 2.93798e+01 1.00000e-09 7.00000e-02 $1.00000 \mathrm{e}-02$ 1.00000e-02 1.00000e-03 1.00000e-09 1.00000e-01 $1.00000 \mathrm{e}+001.00000 \mathrm{e}+001.00000 \mathrm{e}-011.00000 \mathrm{e}-091.00000 \mathrm{e}-01$ $1.00000 \mathrm{e}-05$ 1.00000e-05 1.00000e-06 1.00000e-09 1.00000e-01 $1.00000 \mathrm{e}+001.00000 \mathrm{e}+001.00000 \mathrm{e}-011.00000 \mathrm{e}-091.00000 \mathrm{e}-01$ 1.00000e-06 1.00000e-06 1.00000e-06 1.00000e-09 5.00000e-02 Element: 4221 \# of layers: 6

$\mathrm{Kx} \mathrm{Ky} \mathrm{Kz}$ Ss Por

3.75140e+02 3.75140e+02 3.75140e+01 1.00000e-09 7.00000e-02 $1.00000 \mathrm{e}-02$ 1.00000e-02 1.00000e-03 1.00000e-09 1.00000e-01 $1.00000 \mathrm{e}+001.00000 \mathrm{e}+001.00000 \mathrm{e}-011.00000 \mathrm{e}-091.00000 \mathrm{e}-01$ $1.00000 \mathrm{e}-05$ 1.00000e-05 1.00000e-06 1.00000e-09 1.00000e-01 $1.00000 \mathrm{e}+001.00000 \mathrm{e}+001.00000 \mathrm{e}-011.00000 \mathrm{e}-091.00000 \mathrm{e}-01$ 1.00000e-06 1.00000e-06 1.00000e-06 1.00000e-09 5.00000e-02 Element: 4222 \# of layers: 7

$\mathrm{Kx} \mathrm{Ky} \mathrm{Kz}$ Ss Por

$2.45234 \mathrm{e}+03$ 2.45234e+03 2.45234e+02 1.00000e-09 7.00000e-02 $9.79873 e+019.79873 e+019.79873 e+001.00000 e-092.12000 e-01$ $1.00000 \mathrm{e}-02$ 1.00000e-02 1.00000e-03 1.00000e-09 1.00000e-01 $1.00000 \mathrm{e}+001.00000 \mathrm{e}+001.00000 \mathrm{e}-011.00000 \mathrm{e}-091.00000 \mathrm{e}-01$ $1.00000 \mathrm{e}-05$ 1.00000e-05 1.00000e-06 1.00000e-09 1.00000e-01 $1.00000 \mathrm{e}+001.00000 \mathrm{e}+001.00000 \mathrm{e}-011.00000 \mathrm{e}-091.00000 \mathrm{e}-01$ 1.00000e-06 1.00000e-06 1.00000e-06 1.00000e-09 5.00000e-02 Element: 4223 \# of layers: 7

$\mathrm{Kx} \mathrm{Ky} \mathrm{Kz}$ Ss Por

7.40144e+02 7.40144e+02 7.40144e+01 1.00000e-09 7.00000e-02 $2.95746 \mathrm{e}+012.95746 \mathrm{e}+012.95746 \mathrm{e}+001.00000 \mathrm{e}-09$ 2.12000e-01 $1.00000 \mathrm{e}-02$ 1.00000e-02 1.00000e-03 1.00000e-09 1.00000e-01 $1.00000 \mathrm{e}+001.00000 \mathrm{e}+001.00000 \mathrm{e}-011.00000 \mathrm{e}-091.00000 \mathrm{e}-01$ $1.00000 \mathrm{e}-05$ 1.00000e-05 1.00000e-06 1.00000e-09 1.00000e-01 $1.00000 \mathrm{e}+001.00000 \mathrm{e}+001.00000 \mathrm{e}-011.00000 \mathrm{e}-091.00000 \mathrm{e}-01$ 1.00000e-06 1.00000e-06 1.00000e-06 1.00000e-09 5.00000e-02 Element: 4224 \# of layers: 10

$\mathrm{Kx} \mathrm{Ky} \mathrm{Kz}$ Ss Por $1.86975 \mathrm{e}+02$ 1.86975e+02 1.86975e+01 1.00000e-09 7.00000e-02 $1.86975 \mathrm{e}+02$ 1.86975e+02 1.86975e+01 1.00000e-09 7.00000e-02 5.00000e-04 5.00000e-04 5.00000e-05 1.00000e-09 1.00000e-01 $7.47084 \mathrm{e}+007.47084 \mathrm{e}+00$ 7.47084e-01 1.00000e-09 2.12000e-01 $7.47084 \mathrm{e}+007.47084 \mathrm{e}+007.47084 \mathrm{e}-01$ 1.00000e-09 2.12000e-01 
$1.00000 \mathrm{e}-02$ 1.00000e-02 1.00000e-03 1.00000e-09 1.00000e-01 $1.00000 \mathrm{e}+001.00000 \mathrm{e}+001.00000 \mathrm{e}-011.00000 \mathrm{e}-091.00000 \mathrm{e}-01$ $1.00000 \mathrm{e}-051.00000 \mathrm{e}-05$ 1.00000e-06 1.00000e-09 1.00000e-01 $1.00000 \mathrm{e}+001.00000 \mathrm{e}+001.00000 \mathrm{e}-011.00000 \mathrm{e}-091.00000 \mathrm{e}-01$ 1.00000e-06 1.00000e-06 1.00000e-06 1.00000e-09 5.00000e-02 Element: 4225 \# of layers: 10

$\mathrm{Kx} \mathrm{Ky} \mathrm{Kz}$ Ss Por

5.48988e+01 5.48988e+01 5.48988e+00 1.00000e-09 7.00000e-02

$5.48988 \mathrm{e}+015.48988 \mathrm{e}+015.48988 \mathrm{e}+001.00000 \mathrm{e}-09$ 7.00000e-02

5.00000e-04 5.00000e-04 5.00000e-05 1.00000e-09 1.00000e-01

$2.19355 \mathrm{e}+002.19355 \mathrm{e}+00$ 2.19355e-01 1.00000e-09 2.12000e-01

$2.19355 \mathrm{e}+002.19355 \mathrm{e}+002.19355 \mathrm{e}-01$ 1.00000e-09 2.12000e-01

$1.00000 \mathrm{e}-02$ 1.00000e-02 1.00000e-03 1.00000e-09 1.00000e-01

$1.00000 \mathrm{e}+001.00000 \mathrm{e}+001.00000 \mathrm{e}-011.00000 \mathrm{e}-091.00000 \mathrm{e}-01$

$1.00000 \mathrm{e}-05$ 1.00000e-05 1.00000e-06 1.00000e-09 1.00000e-01

$1.00000 \mathrm{e}+001.00000 \mathrm{e}+001.00000 \mathrm{e}-011.00000 \mathrm{e}-091.00000 \mathrm{e}-01$

1.00000e-06 1.00000e-06 1.00000e-06 1.00000e-09 5.00000e-02

Element: 4226 \# of layers: 10

$\mathrm{Kx} \mathrm{Ky} \mathrm{Kz}$ Ss Por

5.48988e+01 5.48988e+01 5.48988e+00 1.00000e-09 7.00000e-02

$5.48988 \mathrm{e}+015.48988 \mathrm{e}+015.48988 \mathrm{e}+001.00000 \mathrm{e}-09$ 7.00000e-02

5.00000e-04 5.00000e-04 5.00000e-05 1.00000e-09 1.00000e-01

$2.19355 \mathrm{e}+002.19355 \mathrm{e}+00$ 2.19355e-01 1.00000e-09 2.12000e-01

$2.19355 \mathrm{e}+002.19355 \mathrm{e}+002.19355 \mathrm{e}-01$ 1.00000e-09 2.12000e-01

$1.00000 \mathrm{e}-02$ 1.00000e-02 1.00000e-03 1.00000e-09 1.00000e-01

$1.00000 \mathrm{e}+001.00000 \mathrm{e}+001.00000 \mathrm{e}-011.00000 \mathrm{e}-091.00000 \mathrm{e}-01$

$1.00000 \mathrm{e}-05$ 1.00000e-05 1.00000e-06 1.00000e-09 1.00000e-01

$1.00000 \mathrm{e}+001.00000 \mathrm{e}+001.00000 \mathrm{e}-011.00000 \mathrm{e}-091.00000 \mathrm{e}-01$

1.00000e-06 1.00000e-06 1.00000e-06 1.00000e-09 5.00000e-02

Element: 4227 \# of layers: 8

$\mathrm{Kx} \mathrm{Ky} \mathrm{Kz}$ Ss Por

$5.48988 \mathrm{e}+015.48988 \mathrm{e}+015.48988 \mathrm{e}+00$ 1.00000e-09 7.00000e-02

5.00000e-04 5.00000e-04 5.00000e-05 1.00000e-09 1.00000e-01

$2.19355 \mathrm{e}+002.19355 \mathrm{e}+00$ 2.19355e-01 1.00000e-09 2.12000e-01

$1.00000 \mathrm{e}-02$ 1.00000e-02 1.00000e-03 1.00000e-09 1.00000e-01

$1.00000 \mathrm{e}+001.00000 \mathrm{e}+001.00000 \mathrm{e}-011.00000 \mathrm{e}-091.00000 \mathrm{e}-01$

$1.00000 \mathrm{e}-05$ 1.00000e-05 1.00000e-06 1.00000e-09 1.00000e-01

$1.00000 \mathrm{e}+001.00000 \mathrm{e}+001.00000 \mathrm{e}-011.00000 \mathrm{e}-091.00000 \mathrm{e}-01$

1.00000e-06 1.00000e-06 1.00000e-06 1.00000e-09 5.00000e-02

Element: 4228 \# of layers: 7

$\mathrm{Kx} \mathrm{Ky} \mathrm{Kz}$ Ss Por

1.40907e+02 1.40907e+02 1.40907e+01 1.00000e-09 7.00000e-02

5.63007e+00 5.63007e+00 5.63007e-01 1.00000e-09 2.12000e-01

$1.00000 \mathrm{e}-02$ 1.00000e-02 1.00000e-03 1.00000e-09 1.00000e-01

$1.00000 \mathrm{e}+001.00000 \mathrm{e}+001.00000 \mathrm{e}-011.00000 \mathrm{e}-091.00000 \mathrm{e}-01$

$1.00000 \mathrm{e}-05$ 1.00000e-05 1.00000e-06 1.00000e-09 1.00000e-01 
$1.00000 \mathrm{e}+001.00000 \mathrm{e}+001.00000 \mathrm{e}-011.00000 \mathrm{e}-091.00000 \mathrm{e}-01$ 1.00000e-06 1.00000e-06 1.00000e-06 1.00000e-09 5.00000e-02 Element: 4229 \# of layers: 7

Kx Ky Kz Ss Por

1.40907e+02 1.40907e+02 1.40907e+01 1.00000e-09 7.00000e-02

5.63007e+00 5.63007e+00 5.63007e-01 1.00000e-09 2.12000e-01

$1.00000 \mathrm{e}-02$ 1.00000e-02 1.00000e-03 1.00000e-09 1.00000e-01

$1.00000 \mathrm{e}+001.00000 \mathrm{e}+001.00000 \mathrm{e}-011.00000 \mathrm{e}-091.00000 \mathrm{e}-01$

$1.00000 \mathrm{e}-05$ 1.00000e-05 1.00000e-06 1.00000e-09 1.00000e-01

$1.00000 \mathrm{e}+001.00000 \mathrm{e}+001.00000 \mathrm{e}-011.00000 \mathrm{e}-091.00000 \mathrm{e}-01$

1.00000e-06 1.00000e-06 1.00000e-06 1.00000e-09 5.00000e-02

Element: 4230 \# of layers: 6

$\mathrm{Kx} \mathrm{Ky} \mathrm{Kz}$ Ss Por

2.52307e+02 2.52307e+02 2.52307e+01 1.00000e-09 7.00000e-02

$1.00000 \mathrm{e}-02$ 1.00000e-02 1.00000e-03 1.00000e-09 1.00000e-01

$1.00000 \mathrm{e}+001.00000 \mathrm{e}+001.00000 \mathrm{e}-011.00000 \mathrm{e}-091.00000 \mathrm{e}-01$

$1.00000 \mathrm{e}-05$ 1.00000e-05 1.00000e-06 1.00000e-09 1.00000e-01

$1.00000 \mathrm{e}+001.00000 \mathrm{e}+001.00000 \mathrm{e}-011.00000 \mathrm{e}-091.00000 \mathrm{e}-01$

1.00000e-06 1.00000e-06 1.00000e-06 1.00000e-09 5.00000e-02

Element: 4231 \# of layers: 7

$\mathrm{Kx} \mathrm{Ky} \mathrm{Kz}$ Ss Por

$1.86975 \mathrm{e}+02$ 1.86975e+02 1.86975e+01 1.00000e-09 7.00000e-02

$7.47084 \mathrm{e}+007.47084 \mathrm{e}+007.47084 \mathrm{e}-01$ 1.00000e-09 2.12000e-01

$1.00000 \mathrm{e}-02$ 1.00000e-02 1.00000e-03 1.00000e-09 1.00000e-01

$1.00000 \mathrm{e}+001.00000 \mathrm{e}+001.00000 \mathrm{e}-011.00000 \mathrm{e}-091.00000 \mathrm{e}-01$

$1.00000 \mathrm{e}-05$ 1.00000e-05 1.00000e-06 1.00000e-09 1.00000e-01

$1.00000 \mathrm{e}+001.00000 \mathrm{e}+001.00000 \mathrm{e}-011.00000 \mathrm{e}-091.00000 \mathrm{e}-01$

1.00000e-06 1.00000e-06 1.00000e-06 1.00000e-09 5.00000e-02

Element: 4232 \# of layers: 8

$\mathrm{Kx} \mathrm{Ky} \mathrm{Kz}$ Ss Por

5.48988e+01 5.48988e+01 5.48988e+00 1.00000e-09 7.00000e-02

5.00000e-04 5.00000e-04 5.00000e-05 1.00000e-09 1.00000e-01

$2.19355 \mathrm{e}+002.19355 \mathrm{e}+002.19355 \mathrm{e}-01$ 1.00000e-09 2.12000e-01

1.00000e-02 1.00000e-02 1.00000e-03 1.00000e-09 1.00000e-01

$1.00000 \mathrm{e}+001.00000 \mathrm{e}+001.00000 \mathrm{e}-011.00000 \mathrm{e}-091.00000 \mathrm{e}-01$

$1.00000 \mathrm{e}-05$ 1.00000e-05 1.00000e-06 1.00000e-09 1.00000e-01

$1.00000 \mathrm{e}+001.00000 \mathrm{e}+001.00000 \mathrm{e}-011.00000 \mathrm{e}-091.00000 \mathrm{e}-01$

1.00000e-06 1.00000e-06 1.00000e-06 1.00000e-09 5.00000e-02

Element: 4233 \# of layers: 10

$\mathrm{Kx} \mathrm{Ky} \mathrm{Kz}$ Ss Por

3.21017e+01 3.21017e+01 3.21017e+00 1.00000e-09 7.00000e-02

$3.21017 \mathrm{e}+013.21017 \mathrm{e}+013.21017 \mathrm{e}+00$ 1.00000e-09 7.00000e-02

5.00000e-04 5.00000e-04 5.00000e-05 1.00000e-09 1.00000e-01

$1.28266 \mathrm{e}+001.28266 \mathrm{e}+00$ 1.28266e-01 1.00000e-09 2.12000e-01

$1.28266 \mathrm{e}+001.28266 \mathrm{e}+001.28266 \mathrm{e}-01$ 1.00000e-09 2.12000e-01

$1.00000 \mathrm{e}-02$ 1.00000e-02 1.00000e-03 1.00000e-09 1.00000e-01 
$1.00000 \mathrm{e}+001.00000 \mathrm{e}+001.00000 \mathrm{e}-011.00000 \mathrm{e}-091.00000 \mathrm{e}-01$ $1.00000 \mathrm{e}-05$ 1.00000e-05 1.00000e-06 1.00000e-09 1.00000e-01 $1.00000 \mathrm{e}+001.00000 \mathrm{e}+001.00000 \mathrm{e}-011.00000 \mathrm{e}-091.00000 \mathrm{e}-01$ 1.00000e-06 1.00000e-06 1.00000e-06 1.00000e-09 5.00000e-02 Element: 4234 \# of layers: 11

$\mathrm{Kx} \mathrm{Ky} \mathrm{Kz}$ Ss Por

$2.19403 \mathrm{e}+012.19403 \mathrm{e}+012.19403 \mathrm{e}+00$ 1.00000e-09 7.00000e-02 $2.19403 \mathrm{e}+012.19403 \mathrm{e}+012.19403 \mathrm{e}+00$ 1.00000e-09 7.00000e-02 $2.19403 \mathrm{e}+012.19403 \mathrm{e}+012.19403 \mathrm{e}+001.00000 \mathrm{e}-09$ 7.00000e-02 5.00000e-04 5.00000e-04 5.00000e-05 1.00000e-09 1.00000e-01 8.76664e-01 8.76664e-01 8.76664e-02 1.00000e-09 2.12000e-01 8.76664e-01 8.76664e-01 8.76664e-02 1.00000e-09 2.12000e-01 $1.00000 \mathrm{e}-02$ 1.00000e-02 1.00000e-03 1.00000e-09 1.00000e-01 $1.00000 \mathrm{e}+001.00000 \mathrm{e}+001.00000 \mathrm{e}-011.00000 \mathrm{e}-091.00000 \mathrm{e}-01$ $1.00000 \mathrm{e}-05$ 1.00000e-05 1.00000e-06 1.00000e-09 1.00000e-01 $1.00000 \mathrm{e}+001.00000 \mathrm{e}+001.00000 \mathrm{e}-011.00000 \mathrm{e}-091.00000 \mathrm{e}-01$ 1.00000e-06 1.00000e-06 1.00000e-06 1.00000e-09 5.00000e-02 Element: 4235 \# of layers: 14

$\mathrm{Kx} \mathrm{Ky} \mathrm{Kz}$ Ss Por

$2.19403 e+012.19403 e+012.19403 e+001.00000 e-09$ 7.00000e-02 $2.19403 e+012.19403 e+012.19403 e+001.00000 e-09$ 7.00000e-02 $2.19403 \mathrm{e}+012.19403 \mathrm{e}+01$ 2.19403e+00 1.00000e-09 7.00000e-02 5.00000e-04 5.00000e-04 5.00000e-05 1.00000e-09 1.00000e-01 8.76664e-01 8.76664e-01 8.76664e-02 1.00000e-09 2.12000e-01 8.76664e-01 8.76664e-01 8.76664e-02 1.00000e-09 2.12000e-01 8.76664e-01 8.76664e-01 8.76664e-02 1.00000e-09 2.12000e-01 8.76664e-01 8.76664e-01 8.76664e-02 1.00000e-09 2.12000e-01 8.76664e-01 8.76664e-01 8.76664e-02 1.00000e-09 2.12000e-01 $1.00000 \mathrm{e}-02$ 1.00000e-02 1.00000e-03 1.00000e-09 1.00000e-01 $1.00000 \mathrm{e}+001.00000 \mathrm{e}+001.00000 \mathrm{e}-011.00000 \mathrm{e}-091.00000 \mathrm{e}-01$ $1.00000 \mathrm{e}-05$ 1.00000e-05 1.00000e-06 1.00000e-09 1.00000e-01 $1.00000 \mathrm{e}+001.00000 \mathrm{e}+001.00000 \mathrm{e}-011.00000 \mathrm{e}-091.00000 \mathrm{e}-01$ 1.00000e-06 1.00000e-06 1.00000e-06 1.00000e-09 5.00000e-02 Element: 4236 \# of layers: 14

$\mathrm{Kx} \mathrm{Ky} \mathrm{Kz}$ Ss Por

$2.19403 \mathrm{e}+012.19403 \mathrm{e}+012.19403 \mathrm{e}+00$ 1.00000e-09 7.00000e-02 $2.19403 \mathrm{e}+012.19403 \mathrm{e}+012.19403 \mathrm{e}+00$ 1.00000e-09 7.00000e-02 $2.19403 \mathrm{e}+012.19403 \mathrm{e}+012.19403 \mathrm{e}+00$ 1.00000e-09 7.00000e-02 5.00000e-04 5.00000e-04 5.00000e-05 1.00000e-09 1.00000e-01 8.76664e-01 8.76664e-01 8.76664e-02 1.00000e-09 2.12000e-01 8.76664e-01 8.76664e-01 8.76664e-02 1.00000e-09 2.12000e-01 8.76664e-01 8.76664e-01 8.76664e-02 1.00000e-09 2.12000e-01 8.76664e-01 8.76664e-01 8.76664e-02 1.00000e-09 2.12000e-01 8.76664e-01 8.76664e-01 8.76664e-02 1.00000e-09 2.12000e-01 $1.00000 \mathrm{e}-02$ 1.00000e-02 1.00000e-03 1.00000e-09 1.00000e-01 $1.00000 \mathrm{e}+001.00000 \mathrm{e}+001.00000 \mathrm{e}-011.00000 \mathrm{e}-091.00000 \mathrm{e}-01$ 
$1.00000 \mathrm{e}-05$ 1.00000e-05 1.00000e-06 1.00000e-09 1.00000e-01 $1.00000 \mathrm{e}+001.00000 \mathrm{e}+001.00000 \mathrm{e}-011.00000 \mathrm{e}-091.00000 \mathrm{e}-01$ 1.00000e-06 1.00000e-06 1.00000e-06 1.00000e-09 5.00000e-02

Element: 4237 \# of layers: 13

$\mathrm{Kx} \mathrm{Ky} \mathrm{Kz}$ Ss Por

$3.62085 \mathrm{e}+013.62085 \mathrm{e}+013.62085 \mathrm{e}+001.00000 \mathrm{e}-09$ 7.00000e-02 $3.62085 \mathrm{e}+013.62085 \mathrm{e}+013.62085 \mathrm{e}+00$ 1.00000e-09 7.00000e-02 5.00000e-04 5.00000e-04 5.00000e-05 1.00000e-09 1.00000e-01 $1.44678 \mathrm{e}+001.44678 \mathrm{e}+00$ 1.44678e-01 1.00000e-09 2.12000e-01 $1.44678 \mathrm{e}+001.44678 \mathrm{e}+00$ 1.44678e-01 1.00000e-09 2.12000e-01 $1.44678 \mathrm{e}+001.44678 \mathrm{e}+00$ 1.44678e-01 1.00000e-09 2.12000e-01 $1.44678 \mathrm{e}+001.44678 \mathrm{e}+00$ 1.44678e-01 1.00000e-09 2.12000e-01 $1.44678 \mathrm{e}+001.44678 \mathrm{e}+001.44678 \mathrm{e}-01$ 1.00000e-09 2.12000e-01 $1.00000 \mathrm{e}-02$ 1.00000e-02 1.00000e-03 1.00000e-09 1.00000e-01 $1.00000 \mathrm{e}+001.00000 \mathrm{e}+001.00000 \mathrm{e}-011.00000 \mathrm{e}-091.00000 \mathrm{e}-01$ $1.00000 \mathrm{e}-05$ 1.00000e-05 1.00000e-06 1.00000e-09 1.00000e-01 $1.00000 \mathrm{e}+001.00000 \mathrm{e}+001.00000 \mathrm{e}-011.00000 \mathrm{e}-091.00000 \mathrm{e}-01$ 1.00000e-06 1.00000e-06 1.00000e-06 1.00000e-09 5.00000e-02 Element: 4238 \# of layers: 7

$\mathrm{Kx} \mathrm{Ky} \mathrm{Kz}$ Ss Por

3.62085e+01 3.62085e+01 3.62085e+00 1.00000e-09 7.00000e-02 $1.44678 \mathrm{e}+001.44678 \mathrm{e}+00$ 1.44678e-01 1.00000e-09 2.12000e-01 $1.00000 \mathrm{e}-02$ 1.00000e-02 1.00000e-03 1.00000e-09 1.00000e-01 $1.00000 \mathrm{e}+001.00000 \mathrm{e}+001.00000 \mathrm{e}-011.00000 \mathrm{e}-091.00000 \mathrm{e}-01$ $1.00000 \mathrm{e}-05$ 1.00000e-05 1.00000e-06 1.00000e-09 1.00000e-01 $1.00000 \mathrm{e}+001.00000 \mathrm{e}+001.00000 \mathrm{e}-011.00000 \mathrm{e}-091.00000 \mathrm{e}-01$ 1.00000e-06 1.00000e-06 1.00000e-06 1.00000e-09 5.00000e-02 Element: 4239 \# of layers: 8

Kx Ky Kz Ss Por

5.73171e+01 5.73171e+01 5.73171e+00 1.00000e-09 7.00000e-02 $2.29010 \mathrm{e}+002.29010 \mathrm{e}+002.29010 \mathrm{e}-01$ 1.00000e-09 2.12000e-01 $2.29010 \mathrm{e}+002.29010 \mathrm{e}+00$ 2.29010e-01 1.00000e-09 2.12000e-01 $1.00000 \mathrm{e}-02$ 1.00000e-02 1.00000e-03 1.00000e-09 1.00000e-01 $1.00000 \mathrm{e}+001.00000 \mathrm{e}+001.00000 \mathrm{e}-011.00000 \mathrm{e}-091.00000 \mathrm{e}-01$ $1.00000 \mathrm{e}-05$ 1.00000e-05 1.00000e-06 1.00000e-09 1.00000e-01 $1.00000 \mathrm{e}+001.00000 \mathrm{e}+001.00000 \mathrm{e}-011.00000 \mathrm{e}-091.00000 \mathrm{e}-01$ 1.00000e-06 1.00000e-06 1.00000e-06 1.00000e-09 5.00000e-02 Element: 4240 \# of layers: 9

$\mathrm{Kx} \mathrm{Ky} \mathrm{Kz}$ Ss Por

3.21017e+01 3.21017e+01 3.21017e+00 1.00000e-09 7.00000e-02 5.00000e-04 5.00000e-04 5.00000e-05 1.00000e-09 1.00000e-01 $1.28266 \mathrm{e}+001.28266 \mathrm{e}+001.28266 \mathrm{e}-01$ 1.00000e-09 2.12000e-01 $1.28266 \mathrm{e}+001.28266 \mathrm{e}+00$ 1.28266e-01 1.00000e-09 2.12000e-01 $1.00000 \mathrm{e}-02$ 1.00000e-02 1.00000e-03 1.00000e-09 1.00000e-01 $1.00000 \mathrm{e}+001.00000 \mathrm{e}+001.00000 \mathrm{e}-011.00000 \mathrm{e}-091.00000 \mathrm{e}-01$ $1.00000 \mathrm{e}-05$ 1.00000e-05 1.00000e-06 1.00000e-09 1.00000e-01 
$1.00000 \mathrm{e}+001.00000 \mathrm{e}+001.00000 \mathrm{e}-011.00000 \mathrm{e}-091.00000 \mathrm{e}-01$ 1.00000e-06 1.00000e-06 1.00000e-06 1.00000e-09 5.00000e-02 Element: 4241 \# of layers: 8

Kx Ky Kz Ss Por

2.19403e+01 2.19403e+01 2.19403e+00 1.00000e-09 7.00000e-02

5.00000e-04 5.00000e-04 5.00000e-05 1.00000e-09 1.00000e-01

8.76664e-01 8.76664e-01 8.76664e-02 1.00000e-09 2.12000e-01

$1.00000 \mathrm{e}-021.00000 \mathrm{e}-02$ 1.00000e-03 1.00000e-09 1.00000e-01

$1.00000 \mathrm{e}+001.00000 \mathrm{e}+001.00000 \mathrm{e}-011.00000 \mathrm{e}-091.00000 \mathrm{e}-01$

$1.00000 \mathrm{e}-05$ 1.00000e-05 1.00000e-06 1.00000e-09 1.00000e-01

$1.00000 \mathrm{e}+001.00000 \mathrm{e}+001.00000 \mathrm{e}-011.00000 \mathrm{e}-091.00000 \mathrm{e}-01$

$1.00000 \mathrm{e}-06$ 1.00000e-06 1.00000e-06 1.00000e-09 5.00000e-02

Element: 4242 \# of layers: 14

$\mathrm{Kx} \mathrm{Ky} \mathrm{Kz}$ Ss Por

$1.66820 \mathrm{e}+011.66820 \mathrm{e}+011.66820 \mathrm{e}+001.00000 \mathrm{e}-09$ 7.00000e-02

$1.66820 \mathrm{e}+011.66820 \mathrm{e}+011.66820 \mathrm{e}+001.00000 \mathrm{e}-097.00000 \mathrm{e}-02$

$1.66820 \mathrm{e}+011.66820 \mathrm{e}+011.66820 \mathrm{e}+001.00000 \mathrm{e}-097.00000 \mathrm{e}-02$

5.00000e-04 5.00000e-04 5.00000e-05 1.00000e-09 1.00000e-01

6.66577e-01 6.66577e-01 6.66577e-02 1.00000e-09 2.12000e-01

6.66577e-01 6.66577e-01 6.66577e-02 1.00000e-09 2.12000e-01

6.66577e-01 6.66577e-01 6.66577e-02 1.00000e-09 2.12000e-01

6.66577e-01 6.66577e-01 6.66577e-02 1.00000e-09 2.12000e-01

6.66577e-01 6.66577e-01 6.66577e-02 1.00000e-09 2.12000e-01

$1.00000 \mathrm{e}-02$ 1.00000e-02 1.00000e-03 1.00000e-09 1.00000e-01

$1.00000 \mathrm{e}+001.00000 \mathrm{e}+001.00000 \mathrm{e}-011.00000 \mathrm{e}-091.00000 \mathrm{e}-01$

$1.00000 \mathrm{e}-05$ 1.00000e-05 1.00000e-06 1.00000e-09 1.00000e-01

$1.00000 \mathrm{e}+001.00000 \mathrm{e}+001.00000 \mathrm{e}-011.00000 \mathrm{e}-091.00000 \mathrm{e}-01$

1.00000e-06 1.00000e-06 1.00000e-06 1.00000e-09 5.00000e-02

Element: 4243 \# of layers: 13

$\mathrm{Kx} \mathrm{Ky} \mathrm{Kz}$ Ss Por

4.82990e+01 4.82990e+01 4.82990e+00 1.00000e-09 7.00000e-02

$4.82990 \mathrm{e}+014.82990 \mathrm{e}+014.82990 \mathrm{e}+001.00000 \mathrm{e}-09$ 7.00000e-02

$4.82990 \mathrm{e}+014.82990 \mathrm{e}+014.82990 \mathrm{e}+001.00000 \mathrm{e}-09$ 7.00000e-02

5.00000e-04 5.00000e-04 5.00000e-05 1.00000e-09 1.00000e-01

$1.92987 \mathrm{e}+00$ 1.92987e+00 1.92987e-01 1.00000e-09 2.12000e-01

1.92987e+00 1.92987e+00 1.92987e-01 1.00000e-09 2.12000e-01

$1.92987 \mathrm{e}+00$ 1.92987e+00 1.92987e-01 1.00000e-09 2.12000e-01

$1.92987 \mathrm{e}+00$ 1.92987e+00 1.92987e-01 1.00000e-09 2.12000e-01

$1.92987 \mathrm{e}+001.92987 \mathrm{e}+00$ 1.92987e-01 1.00000e-09 2.12000e-01

$1.00000 \mathrm{e}-02$ 1.00000e-02 1.00000e-03 1.00000e-09 1.00000e-01

$1.00000 \mathrm{e}+001.00000 \mathrm{e}+001.00000 \mathrm{e}-01$ 1.00000e-09 1.00000e-01

$1.00000 \mathrm{e}-05$ 1.00000e-05 1.00000e-06 1.00000e-09 1.00000e-01

$1.00000 \mathrm{e}+001.00000 \mathrm{e}+001.00000 \mathrm{e}-01$ 1.00000e-09 1.00000e-01

Element: 4244 \# of layers: 15

$\mathrm{Kx} \mathrm{Ky} \mathrm{Kz}$ Ss Por

4.82990e+01 4.82990e+01 4.82990e+00 1.00000e-09 7.00000e-02 
4.82990e+01 4.82990e+01 4.82990e+00 1.00000e-09 7.00000e-02 $4.82990 \mathrm{e}+014.82990 \mathrm{e}+01$ 4.82990e+00 1.00000e-09 7.00000e-02 4.82990e+01 4.82990e+01 4.82990e+00 1.00000e-09 7.00000e-02 5.00000e-04 5.00000e-04 5.00000e-05 1.00000e-09 1.00000e-01 5.00000e-04 5.00000e-04 5.00000e-05 1.00000e-09 1.00000e-01 $1.92987 \mathrm{e}+001.92987 \mathrm{e}+00$ 1.92987e-01 1.00000e-09 2.12000e-01 1.92987e+00 1.92987e+00 1.92987e-01 1.00000e-09 2.12000e-01 $1.92987 \mathrm{e}+00$ 1.92987e+00 1.92987e-01 1.00000e-09 2.12000e-01 $1.92987 \mathrm{e}+00$ 1.92987e+00 1.92987e-01 1.00000e-09 2.12000e-01 $1.92987 \mathrm{e}+00$ 1.92987e+00 1.92987e-01 1.00000e-09 2.12000e-01 $1.00000 \mathrm{e}-02$ 1.00000e-02 1.00000e-03 1.00000e-09 1.00000e-01 $1.00000 \mathrm{e}+001.00000 \mathrm{e}+001.00000 \mathrm{e}-011.00000 \mathrm{e}-091.00000 \mathrm{e}-01$ $1.00000 \mathrm{e}-05$ 1.00000e-05 1.00000e-06 1.00000e-09 1.00000e-01 $1.00000 \mathrm{e}+001.00000 \mathrm{e}+001.00000 \mathrm{e}-011.00000 \mathrm{e}-09$ 1.00000e-01 Element: 4245 \# of layers: 13

Kx Ky Kz Ss Por

4.82990e+01 4.82990e+01 4.82990e+00 1.00000e-09 7.00000e-02 $4.82990 \mathrm{e}+014.82990 \mathrm{e}+014.82990 \mathrm{e}+001.00000 \mathrm{e}-09$ 7.00000e-02 5.00000e-04 5.00000e-04 5.00000e-05 1.00000e-09 1.00000e-01 5.00000e-04 5.00000e-04 5.00000e-05 1.00000e-09 1.00000e-01 $1.92987 \mathrm{e}+001.92987 \mathrm{e}+00$ 1.92987e-01 1.00000e-09 2.12000e-01 $1.92987 \mathrm{e}+00$ 1.92987e+00 1.92987e-01 1.00000e-09 2.12000e-01 1.92987e+00 1.92987e+00 1.92987e-01 1.00000e-09 2.12000e-01 $1.92987 \mathrm{e}+00$ 1.92987e+00 1.92987e-01 1.00000e-09 2.12000e-01 $1.92987 \mathrm{e}+001.92987 \mathrm{e}+00$ 1.92987e-01 1.00000e-09 2.12000e-01 1.00000e-02 1.00000e-02 1.00000e-03 1.00000e-09 1.00000e-01 $1.00000 \mathrm{e}+001.00000 \mathrm{e}+001.00000 \mathrm{e}-011.00000 \mathrm{e}-091.00000 \mathrm{e}-01$ $1.00000 \mathrm{e}-05$ 1.00000e-05 1.00000e-06 1.00000e-09 1.00000e-01 $1.00000 \mathrm{e}+001.00000 \mathrm{e}+001.00000 \mathrm{e}-011.00000 \mathrm{e}-091.00000 \mathrm{e}-01$ Element: 4246 \# of layers: 15

$\mathrm{Kx} \mathrm{Ky} \mathrm{Kz}$ Ss Por

$1.47656 \mathrm{e}+01$ 1.47656e+01 1.47656e+00 1.00000e-09 7.00000e-02 $1.47656 \mathrm{e}+011.47656 \mathrm{e}+011.47656 \mathrm{e}+001.00000 \mathrm{e}-097.00000 \mathrm{e}-02$ $1.47656 \mathrm{e}+011.47656 \mathrm{e}+011.47656 \mathrm{e}+001.00000 \mathrm{e}-097.00000 \mathrm{e}-02$ 5.00000e-04 5.00000e-04 5.00000e-05 1.00000e-09 1.00000e-01 5.00000e-04 5.00000e-04 5.00000e-05 1.00000e-09 1.00000e-01 5.89985e-01 5.89985e-01 5.89985e-02 1.00000e-09 2.12000e-01 5.89985e-01 5.89985e-01 5.89985e-02 1.00000e-09 2.12000e-01 5.89985e-01 5.89985e-01 5.89985e-02 1.00000e-09 2.12000e-01 5.89985e-01 5.89985e-01 5.89985e-02 1.00000e-09 2.12000e-01 5.89985e-01 5.89985e-01 5.89985e-02 1.00000e-09 2.12000e-01 $1.00000 \mathrm{e}-02$ 1.00000e-02 1.00000e-03 1.00000e-09 1.00000e-01 $1.00000 \mathrm{e}+001.00000 \mathrm{e}+001.00000 \mathrm{e}-011.00000 \mathrm{e}-091.00000 \mathrm{e}-01$ $1.00000 \mathrm{e}-05$ 1.00000e-05 1.00000e-06 1.00000e-09 1.00000e-01 $1.00000 \mathrm{e}+001.00000 \mathrm{e}+001.00000 \mathrm{e}-011.00000 \mathrm{e}-091.00000 \mathrm{e}-01$ $1.00000 \mathrm{e}-06$ 1.00000e-06 1.00000e-06 1.00000e-09 5.00000e-02 
Element: 4247 \# of layers: 15

Kx Ky Kz Ss Por

$1.47656 \mathrm{e}+011.47656 \mathrm{e}+011.47656 \mathrm{e}+00$ 1.00000e-09 7.00000e-02

$1.47656 \mathrm{e}+011.47656 \mathrm{e}+011.47656 \mathrm{e}+001.00000 \mathrm{e}-097.00000 \mathrm{e}-02$

$1.47656 \mathrm{e}+011.47656 \mathrm{e}+011.47656 \mathrm{e}+001.00000 \mathrm{e}-097.00000 \mathrm{e}-02$

5.00000e-04 5.00000e-04 5.00000e-05 1.00000e-09 1.00000e-01

5.00000e-04 5.00000e-04 5.00000e-05 1.00000e-09 1.00000e-01

5.89985e-01 5.89985e-01 5.89985e-02 1.00000e-09 2.12000e-01

5.89985e-01 5.89985e-01 5.89985e-02 1.00000e-09 2.12000e-01

5.89985e-01 5.89985e-01 5.89985e-02 1.00000e-09 2.12000e-01

5.89985e-01 5.89985e-01 5.89985e-02 1.00000e-09 2.12000e-01

5.89985e-01 5.89985e-01 5.89985e-02 1.00000e-09 2.12000e-01

$1.00000 \mathrm{e}-02$ 1.00000e-02 1.00000e-03 1.00000e-09 1.00000e-01

$1.00000 \mathrm{e}+001.00000 \mathrm{e}+001.00000 \mathrm{e}-011.00000 \mathrm{e}-091.00000 \mathrm{e}-01$

$1.00000 \mathrm{e}-05$ 1.00000e-05 1.00000e-06 1.00000e-09 1.00000e-01

$1.00000 \mathrm{e}+001.00000 \mathrm{e}+001.00000 \mathrm{e}-011.00000 \mathrm{e}-091.00000 \mathrm{e}-01$

$1.00000 \mathrm{e}-06$ 1.00000e-06 1.00000e-06 1.00000e-09 5.00000e-02

Element: 4248 \# of layers: 14

Kx Ky Kz Ss Por

$2.42829 \mathrm{e}+012.42829 \mathrm{e}+012.42829 \mathrm{e}+00$ 1.00000e-09 7.00000e-02

$2.42829 \mathrm{e}+012.42829 \mathrm{e}+012.42829 \mathrm{e}+001.00000 \mathrm{e}-09$ 7.00000e-02

$2.42829 \mathrm{e}+012.42829 \mathrm{e}+012.42829 \mathrm{e}+001.00000 \mathrm{e}-09$ 7.00000e-02

5.00000e-04 5.00000e-04 5.00000e-05 1.00000e-09 1.00000e-01

9.70266e-01 9.70266e-01 9.70266e-02 1.00000e-09 2.12000e-01

9.70266e-01 9.70266e-01 9.70266e-02 1.00000e-09 2.12000e-01

9.70266e-01 9.70266e-01 9.70266e-02 1.00000e-09 2.12000e-01

9.70266e-01 9.70266e-01 9.70266e-02 1.00000e-09 2.12000e-01

9.70266e-01 9.70266e-01 9.70266e-02 1.00000e-09 2.12000e-01

$1.00000 \mathrm{e}-021.00000 \mathrm{e}-02$ 1.00000e-03 1.00000e-09 1.00000e-01

$1.00000 \mathrm{e}+001.00000 \mathrm{e}+001.00000 \mathrm{e}-011.00000 \mathrm{e}-091.00000 \mathrm{e}-01$

$1.00000 \mathrm{e}-05$ 1.00000e-05 1.00000e-06 1.00000e-09 1.00000e-01

$1.00000 \mathrm{e}+001.00000 \mathrm{e}+001.00000 \mathrm{e}-011.00000 \mathrm{e}-091.00000 \mathrm{e}-01$

$1.00000 \mathrm{e}-06$ 1.00000e-06 1.00000e-06 1.00000e-09 5.00000e-02

Element: 4249 \# of layers: 13

Kx Ky Kz Ss Por

$1.66820 \mathrm{e}+011.66820 \mathrm{e}+011.66820 \mathrm{e}+001.00000 \mathrm{e}-097.00000 \mathrm{e}-02$

$1.66820 \mathrm{e}+011.66820 \mathrm{e}+011.66820 \mathrm{e}+001.00000 \mathrm{e}-097.00000 \mathrm{e}-02$

5.00000e-04 5.00000e-04 5.00000e-05 1.00000e-09 1.00000e-01

6.66577e-01 6.66577e-01 6.66577e-02 1.00000e-09 2.12000e-01

6.66577e-01 6.66577e-01 6.66577e-02 1.00000e-09 2.12000e-01

6.66577e-01 6.66577e-01 6.66577e-02 1.00000e-09 2.12000e-01

6.66577e-01 6.66577e-01 6.66577e-02 1.00000e-09 2.12000e-01

6.66577e-01 6.66577e-01 6.66577e-02 1.00000e-09 2.12000e-01

$1.00000 \mathrm{e}-02$ 1.00000e-02 1.00000e-03 1.00000e-09 1.00000e-01

$1.00000 \mathrm{e}+001.00000 \mathrm{e}+001.00000 \mathrm{e}-011.00000 \mathrm{e}-091.00000 \mathrm{e}-01$

$1.00000 \mathrm{e}-05$ 1.00000e-05 1.00000e-06 1.00000e-09 1.00000e-01 
$1.00000 \mathrm{e}+001.00000 \mathrm{e}+001.00000 \mathrm{e}-011.00000 \mathrm{e}-091.00000 \mathrm{e}-01$ 1.00000e-06 1.00000e-06 1.00000e-06 1.00000e-09 5.00000e-02 Element: 4250 \# of layers: 14

$\mathrm{Kx} \mathrm{Ky} \mathrm{Kz} \mathrm{Ss} \mathrm{Por}$

4.82990e+01 4.82990e+01 4.82990e+00 1.00000e-09 7.00000e-02 $4.82990 \mathrm{e}+014.82990 \mathrm{e}+014.82990 \mathrm{e}+001.00000 \mathrm{e}-09$ 7.00000e-02 $5.00000 \mathrm{e}-04$ 5.00000e-04 5.00000e-05 1.00000e-09 1.00000e-01 5.00000e-04 5.00000e-04 5.00000e-05 1.00000e-09 1.00000e-01 $1.92987 \mathrm{e}+00$ 1.92987e+00 1.92987e-01 1.00000e-09 2.12000e-01 $1.92987 \mathrm{e}+00$ 1.92987e+00 1.92987e-01 1.00000e-09 2.12000e-01 1.92987e+00 1.92987e+00 1.92987e-01 1.00000e-09 2.12000e-01 $1.92987 \mathrm{e}+001.92987 \mathrm{e}+00$ 1.92987e-01 1.00000e-09 2.12000e-01 $1.92987 \mathrm{e}+001.92987 \mathrm{e}+00$ 1.92987e-01 1.00000e-09 2.12000e-01 $1.00000 \mathrm{e}-02$ 1.00000e-02 1.00000e-03 1.00000e-09 1.00000e-01 $1.00000 \mathrm{e}+001.00000 \mathrm{e}+001.00000 \mathrm{e}-011.00000 \mathrm{e}-091.00000 \mathrm{e}-01$ $1.00000 \mathrm{e}-05$ 1.00000e-05 1.00000e-06 1.00000e-09 1.00000e-01 $1.00000 \mathrm{e}+001.00000 \mathrm{e}+001.00000 \mathrm{e}-011.00000 \mathrm{e}-091.00000 \mathrm{e}-01$ 1.00000e-06 1.00000e-06 1.00000e-06 1.00000e-09 5.00000e-02 Element: 4251 \# of layers: 14

$\mathrm{Kx} \mathrm{Ky} \mathrm{Kz}$ Ss Por

2.06149e+02 2.06149e+02 2.06149e+01 1.00000e-09 7.00000e-02 $2.06149 \mathrm{e}+02$ 2.06149e+02 2.06149e+01 1.00000e-09 7.00000e-02 $2.06149 \mathrm{e}+02$ 2.06149e+02 2.06149e+01 1.00000e-09 7.00000e-02 5.00000e-04 5.00000e-04 5.00000e-05 1.00000e-09 1.00000e-01 5.00000e-04 5.00000e-04 5.00000e-05 1.00000e-09 1.00000e-01 8.23698e+00 8.23698e+00 8.23698e-01 1.00000e-09 2.12000e-01 $8.23698 \mathrm{e}+00$ 8.23698e+00 8.23698e-01 1.00000e-09 2.12000e-01 8.23698e+00 8.23698e+00 8.23698e-01 1.00000e-09 2.12000e-01 8.23698e+00 8.23698e+00 8.23698e-01 1.00000e-09 2.12000e-01 $8.23698 \mathrm{e}+00$ 8.23698e+00 8.23698e-01 1.00000e-09 2.12000e-01 $1.00000 \mathrm{e}-02$ 1.00000e-02 1.00000e-03 1.00000e-09 1.00000e-01 $1.00000 \mathrm{e}+001.00000 \mathrm{e}+001.00000 \mathrm{e}-011.00000 \mathrm{e}-091.00000 \mathrm{e}-01$ $1.00000 \mathrm{e}-05$ 1.00000e-05 1.00000e-06 1.00000e-09 1.00000e-01 $1.00000 \mathrm{e}+001.00000 \mathrm{e}+001.00000 \mathrm{e}-011.00000 \mathrm{e}-091.00000 \mathrm{e}-01$ Element: 4252 \# of layers: 14

$\mathrm{Kx} \mathrm{Ky} \mathrm{Kz}$ Ss Por

2.48099e+02 2.48099e+02 2.48099e+01 1.00000e-09 7.00000e-02 $2.48099 \mathrm{e}+022.48099 \mathrm{e}+022.48099 \mathrm{e}+01$ 1.00000e-09 7.00000e-02

$2.48099 \mathrm{e}+022.48099 \mathrm{e}+022.48099 \mathrm{e}+01$ 1.00000e-09 7.00000e-02 5.00000e-04 5.00000e-04 5.00000e-05 1.00000e-09 1.00000e-01 5.00000e-04 5.00000e-04 5.00000e-05 1.00000e-09 1.00000e-01 9.91326e+00 9.91326e+00 9.91326e-01 1.00000e-09 2.12000e-01 9.91326e+00 9.91326e+00 9.91326e-01 1.00000e-09 2.12000e-01 9.91326e+00 9.91326e+00 9.91326e-01 1.00000e-09 2.12000e-01 9.91326e+00 9.91326e+00 9.91326e-01 1.00000e-09 2.12000e-01 $9.91326 \mathrm{e}+00$ 9.91326e+00 9.91326e-01 1.00000e-09 2.12000e-01 
$1.00000 \mathrm{e}-02$ 1.00000e-02 1.00000e-03 1.00000e-09 1.00000e-01 $1.00000 \mathrm{e}+001.00000 \mathrm{e}+001.00000 \mathrm{e}-011.00000 \mathrm{e}-091.00000 \mathrm{e}-01$ $1.00000 \mathrm{e}-05$ 1.00000e-05 1.00000e-06 1.00000e-09 1.00000e-01 $1.00000 \mathrm{e}+001.00000 \mathrm{e}+001.00000 \mathrm{e}-011.00000 \mathrm{e}-091.00000 \mathrm{e}-01$ Element: 4253 \# of layers: 14

$\mathrm{Kx} \mathrm{Ky} \mathrm{Kz}$ Ss Por

$2.48099 \mathrm{e}+02$ 2.48099e+02 2.48099e+01 1.00000e-09 7.00000e-02 $2.48099 \mathrm{e}+02$ 2.48099e+02 2.48099e+01 1.00000e-09 7.00000e-02 $2.48099 \mathrm{e}+02$ 2.48099e+02 2.48099e+01 1.00000e-09 7.00000e-02 5.00000e-04 5.00000e-04 5.00000e-05 1.00000e-09 1.00000e-01 5.00000e-04 5.00000e-04 5.00000e-05 1.00000e-09 1.00000e-01 $9.91326 \mathrm{e}+00$ 9.91326e+00 9.91326e-01 1.00000e-09 2.12000e-01 9.91326e+00 9.91326e+00 9.91326e-01 1.00000e-09 2.12000e-01 9.91326e+00 9.91326e+00 9.91326e-01 1.00000e-09 2.12000e-01 9.91326e+00 9.91326e+00 9.91326e-01 1.00000e-09 2.12000e-01 $9.91326 \mathrm{e}+00$ 9.91326e+00 9.91326e-01 1.00000e-09 2.12000e-01 $1.00000 \mathrm{e}-02$ 1.00000e-02 1.00000e-03 1.00000e-09 1.00000e-01 $1.00000 \mathrm{e}+001.00000 \mathrm{e}+001.00000 \mathrm{e}-011.00000 \mathrm{e}-091.00000 \mathrm{e}-01$ $1.00000 \mathrm{e}-05$ 1.00000e-05 1.00000e-06 1.00000e-09 1.00000e-01 $1.00000 \mathrm{e}+001.00000 \mathrm{e}+001.00000 \mathrm{e}-011.00000 \mathrm{e}-091.00000 \mathrm{e}-01$ Element: 4254 \# of layers: 14

$\mathrm{Kx} \mathrm{Ky} \mathrm{Kz}$ Ss Por

2.48099e+02 2.48099e+02 2.48099e+01 1.00000e-09 7.00000e-02 $2.48099 \mathrm{e}+02$ 2.48099e+02 2.48099e+01 1.00000e-09 7.00000e-02 $2.48099 \mathrm{e}+02$ 2.48099e+02 2.48099e+01 1.00000e-09 7.00000e-02 $5.00000 \mathrm{e}-04$ 5.00000e-04 5.00000e-05 1.00000e-09 1.00000e-01 5.00000e-04 5.00000e-04 5.00000e-05 1.00000e-09 1.00000e-01 9.91326e+00 9.91326e+00 9.91326e-01 1.00000e-09 2.12000e-01 $9.91326 \mathrm{e}+00$ 9.91326e+00 9.91326e-01 1.00000e-09 2.12000e-01 9.91326e+00 9.91326e+00 9.91326e-01 1.00000e-09 2.12000e-01 9.91326e+00 9.91326e+00 9.91326e-01 1.00000e-09 2.12000e-01 $9.91326 \mathrm{e}+00$ 9.91326e+00 9.91326e-01 1.00000e-09 2.12000e-01 $1.00000 \mathrm{e}-02$ 1.00000e-02 1.00000e-03 1.00000e-09 1.00000e-01 $1.00000 \mathrm{e}+001.00000 \mathrm{e}+001.00000 \mathrm{e}-011.00000 \mathrm{e}-091.00000 \mathrm{e}-01$ $1.00000 \mathrm{e}-05$ 1.00000e-05 1.00000e-06 1.00000e-09 1.00000e-01 $1.00000 \mathrm{e}+001.00000 \mathrm{e}+001.00000 \mathrm{e}-011.00000 \mathrm{e}-091.00000 \mathrm{e}-01$ Element: 4255 \# of layers: 14

$\mathrm{Kx} \mathrm{Ky} \mathrm{Kz}$ Ss Por

1.42322e+02 1.42322e+02 1.42322e+01 1.00000e-09 7.00000e-02 $1.42322 \mathrm{e}+02$ 1.42322e+02 1.42322e+01 1.00000e-09 7.00000e-02 $1.42322 \mathrm{e}+021.42322 \mathrm{e}+021.42322 \mathrm{e}+01$ 1.00000e-09 7.00000e-02 5.00000e-04 5.00000e-04 5.00000e-05 1.00000e-09 1.00000e-01 5.00000e-04 5.00000e-04 5.00000e-05 1.00000e-09 1.00000e-01 $5.68655 \mathrm{e}+005.68655 \mathrm{e}+00$ 5.68655e-01 1.00000e-09 2.12000e-01 $5.68655 \mathrm{e}+005.68655 \mathrm{e}+00$ 5.68655e-01 1.00000e-09 2.12000e-01 $5.68655 \mathrm{e}+00$ 5.68655e+00 5.68655e-01 1.00000e-09 2.12000e-01 
$5.68655 \mathrm{e}+00$ 5.68655e+00 5.68655e-01 1.00000e-09 2.12000e-01

$5.68655 \mathrm{e}+00$ 5.68655e+00 5.68655e-01 1.00000e-09 2.12000e-01 $1.00000 \mathrm{e}-021.00000 \mathrm{e}-02$ 1.00000e-03 $1.00000 \mathrm{e}-091.00000 \mathrm{e}-01$

$1.00000 \mathrm{e}+001.00000 \mathrm{e}+001.00000 \mathrm{e}-011.00000 \mathrm{e}-091.00000 \mathrm{e}-01$ $1.00000 \mathrm{e}-05$ 1.00000e-05 1.00000e-06 1.00000e-09 1.00000e-01 $1.00000 \mathrm{e}+001.00000 \mathrm{e}+001.00000 \mathrm{e}-011.00000 \mathrm{e}-091.00000 \mathrm{e}-01$ Element: 4256 \# of layers: 14

Kx Ky Kz Ss Por

$1.42322 \mathrm{e}+021.42322 \mathrm{e}+02$ 1.42322e+01 1.00000e-09 7.00000e-02 $1.42322 \mathrm{e}+021.42322 \mathrm{e}+021.42322 \mathrm{e}+011.00000 \mathrm{e}-097.00000 \mathrm{e}-02$ $1.42322 \mathrm{e}+021.42322 \mathrm{e}+021.42322 \mathrm{e}+011.00000 \mathrm{e}-097.00000 \mathrm{e}-02$ 5.00000e-04 5.00000e-04 5.00000e-05 1.00000e-09 1.00000e-01 5.00000e-04 5.00000e-04 5.00000e-05 1.00000e-09 1.00000e-01

$5.68655 \mathrm{e}+005.68655 \mathrm{e}+00$ 5.68655e-01 1.00000e-09 2.12000e-01 $5.68655 \mathrm{e}+005.68655 \mathrm{e}+00$ 5.68655e-01 1.00000e-09 2.12000e-01 $5.68655 \mathrm{e}+005.68655 \mathrm{e}+00$ 5.68655e-01 1.00000e-09 2.12000e-01 $5.68655 \mathrm{e}+005.68655 \mathrm{e}+005.68655 \mathrm{e}-011.00000 \mathrm{e}-092.12000 \mathrm{e}-01$ $5.68655 \mathrm{e}+005.68655 \mathrm{e}+00$ 5.68655e-01 1.00000e-09 2.12000e-01 $1.00000 \mathrm{e}-021.00000 \mathrm{e}-02$ 1.00000e-03 1.00000e-09 1.00000e-01 $1.00000 \mathrm{e}+001.00000 \mathrm{e}+001.00000 \mathrm{e}-011.00000 \mathrm{e}-091.00000 \mathrm{e}-01$ $1.00000 \mathrm{e}-05$ 1.00000e-05 1.00000e-06 1.00000e-09 1.00000e-01 $1.00000 \mathrm{e}+001.00000 \mathrm{e}+001.00000 \mathrm{e}-011.00000 \mathrm{e}-091.00000 \mathrm{e}-01$ Element: 4257 \# of layers: 14

Kx Ky Kz Ss Por

$1.80587 \mathrm{e}+011.80587 \mathrm{e}+01$ 1.80587e+00 1.00000e-09 7.00000e-02 $1.80587 \mathrm{e}+011.80587 \mathrm{e}+011.80587 \mathrm{e}+001.00000 \mathrm{e}-097.00000 \mathrm{e}-02$ $1.80587 \mathrm{e}+011.80587 \mathrm{e}+011.80587 \mathrm{e}+001.00000 \mathrm{e}-09$ 7.00000e-02 5.00000e-04 5.00000e-04 5.00000e-05 1.00000e-09 1.00000e-01 5.00000e-04 5.00000e-04 5.00000e-05 1.00000e-09 1.00000e-01 7.21545e-01 7.21545e-01 7.21545e-02 1.00000e-09 2.12000e-01 7.21545e-01 7.21545e-01 7.21545e-02 1.00000e-09 2.12000e-01 7.21545e-01 7.21545e-01 7.21545e-02 1.00000e-09 2.12000e-01 7.21545e-01 7.21545e-01 7.21545e-02 1.00000e-09 2.12000e-01 7.21545e-01 7.21545e-01 7.21545e-02 1.00000e-09 2.12000e-01 $1.00000 \mathrm{e}-02$ 1.00000e-02 1.00000e-03 1.00000e-09 1.00000e-01 $1.00000 \mathrm{e}+001.00000 \mathrm{e}+001.00000 \mathrm{e}-011.00000 \mathrm{e}-091.00000 \mathrm{e}-01$ $1.00000 \mathrm{e}-05$ 1.00000e-05 1.00000e-06 1.00000e-09 1.00000e-01 $1.00000 \mathrm{e}+001.00000 \mathrm{e}+001.00000 \mathrm{e}-011.00000 \mathrm{e}-091.00000 \mathrm{e}-01$ Element: 4258 \# of layers: 14

Kx Ky Kz Ss Por $2.06149 \mathrm{e}+022.06149 \mathrm{e}+022.06149 \mathrm{e}+01$ 1.00000e-09 7.00000e-02 $2.06149 \mathrm{e}+022.06149 \mathrm{e}+022.06149 \mathrm{e}+01$ 1.00000e-09 7.00000e-02 $2.06149 \mathrm{e}+022.06149 \mathrm{e}+022.06149 \mathrm{e}+011.00000 \mathrm{e}-09$ 7.00000e-02 5.00000e-04 5.00000e-04 5.00000e-05 1.00000e-09 1.00000e-01 5.00000e-04 5.00000e-04 5.00000e-05 1.00000e-09 1.00000e-01 $8.23698 \mathrm{e}+008.23698 \mathrm{e}+00$ 8.23698e-01 1.00000e-09 2.12000e-01 
$8.23698 \mathrm{e}+008.23698 \mathrm{e}+00$ 8.23698e-01 1.00000e-09 2.12000e-01 $8.23698 \mathrm{e}+008.23698 \mathrm{e}+008.23698 \mathrm{e}-011.00000 \mathrm{e}-092.12000 \mathrm{e}-01$ $8.23698 \mathrm{e}+008.23698 \mathrm{e}+00$ 8.23698e-01 1.00000e-09 2.12000e-01 $8.23698 \mathrm{e}+008.23698 \mathrm{e}+00$ 8.23698e-01 1.00000e-09 2.12000e-01 $1.00000 \mathrm{e}-02$ 1.00000e-02 1.00000e-03 1.00000e-09 1.00000e-01 $1.00000 \mathrm{e}+001.00000 \mathrm{e}+001.00000 \mathrm{e}-011.00000 \mathrm{e}-091.00000 \mathrm{e}-01$ $1.00000 \mathrm{e}-05$ 1.00000e-05 1.00000e-06 1.00000e-09 1.00000e-01 $1.00000 \mathrm{e}+001.00000 \mathrm{e}+001.00000 \mathrm{e}-011.00000 \mathrm{e}-091.00000 \mathrm{e}-01$ Element: 4259 \# of layers: 14

Kx Ky Kz Ss Por

$2.48099 \mathrm{e}+022.48099 \mathrm{e}+022.48099 \mathrm{e}+01$ 1.00000e-09 7.00000e-02 $2.48099 \mathrm{e}+022.48099 \mathrm{e}+022.48099 \mathrm{e}+01$ 1.00000e-09 7.00000e-02 $2.48099 \mathrm{e}+022.48099 \mathrm{e}+022.48099 \mathrm{e}+01$ 1.00000e-09 7.00000e-02 5.00000e-04 5.00000e-04 5.00000e-05 1.00000e-09 1.00000e-01 5.00000e-04 5.00000e-04 5.00000e-05 1.00000e-09 1.00000e-01 $9.91326 \mathrm{e}+009.91326 \mathrm{e}+00$ 9.91326e-01 1.00000e-09 2.12000e-01 $9.91326 \mathrm{e}+009.91326 \mathrm{e}+00$ 9.91326e-01 1.00000e-09 2.12000e-01 $9.91326 \mathrm{e}+009.91326 \mathrm{e}+009.91326 \mathrm{e}-011.00000 \mathrm{e}-092.12000 \mathrm{e}-01$ $9.91326 \mathrm{e}+009.91326 \mathrm{e}+00$ 9.91326e-01 1.00000e-09 2.12000e-01 $9.91326 \mathrm{e}+00$ 9.91326e+00 9.91326e-01 1.00000e-09 2.12000e-01 $1.00000 \mathrm{e}-021.00000 \mathrm{e}-02$ 1.00000e-03 1.00000e-09 1.00000e-01 $1.00000 \mathrm{e}+001.00000 \mathrm{e}+001.00000 \mathrm{e}-011.00000 \mathrm{e}-091.00000 \mathrm{e}-01$ $1.00000 \mathrm{e}-05$ 1.00000e-05 1.00000e-06 1.00000e-09 1.00000e-01 $1.00000 \mathrm{e}+001.00000 \mathrm{e}+001.00000 \mathrm{e}-011.00000 \mathrm{e}-091.00000 \mathrm{e}-01$ Element: 4260 \# of layers: 14

Kx Ky Kz Ss Por

$2.47469 \mathrm{e}+022.47469 \mathrm{e}+022.47469 \mathrm{e}+01$ 1.00000e-09 7.00000e-02 $2.47469 \mathrm{e}+022.47469 \mathrm{e}+022.47469 \mathrm{e}+01$ 1.00000e-09 7.00000e-02 $2.47469 \mathrm{e}+022.47469 \mathrm{e}+022.47469 \mathrm{e}+01$ 1.00000e-09 7.00000e-02 5.00000e-04 5.00000e-04 5.00000e-05 1.00000e-09 1.00000e-01 5.00000e-04 5.00000e-04 5.00000e-05 1.00000e-09 1.00000e-01 $9.88784 \mathrm{e}+009.88784 \mathrm{e}+009.88784 \mathrm{e}-011.00000 \mathrm{e}-09$ 2.12000e-01 $9.88784 \mathrm{e}+009.88784 \mathrm{e}+00$ 9.88784e-01 1.00000e-09 2.12000e-01 $9.88784 \mathrm{e}+009.88784 \mathrm{e}+009.88784 \mathrm{e}-011.00000 \mathrm{e}-09$ 2.12000e-01 $9.88784 \mathrm{e}+009.88784 \mathrm{e}+00$ 9.88784e-01 1.00000e-09 2.12000e-01 $9.88784 \mathrm{e}+009.88784 \mathrm{e}+00$ 9.88784e-01 1.00000e-09 2.12000e-01 $1.00000 \mathrm{e}-02$ 1.00000e-02 1.00000e-03 1.00000e-09 1.00000e-01 $1.00000 \mathrm{e}+001.00000 \mathrm{e}+001.00000 \mathrm{e}-011.00000 \mathrm{e}-091.00000 \mathrm{e}-01$ $1.00000 \mathrm{e}-05$ 1.00000e-05 1.00000e-06 1.00000e-09 1.00000e-01 $1.00000 \mathrm{e}+001.00000 \mathrm{e}+001.00000 \mathrm{e}-011.00000 \mathrm{e}-091.00000 \mathrm{e}-01$ Element: 4261 \# of layers: 14

$\mathrm{Kx} \mathrm{Ky} \mathrm{Kz}$ Ss Por

$2.23025 \mathrm{e}+022.23025 \mathrm{e}+022.23025 \mathrm{e}+01$ 1.00000e-09 7.00000e-02 $2.23025 \mathrm{e}+022.23025 \mathrm{e}+022.23025 \mathrm{e}+011.00000 \mathrm{e}-097.00000 \mathrm{e}-02$ $2.23025 \mathrm{e}+022.23025 \mathrm{e}+022.23025 \mathrm{e}+01$ 1.00000e-09 7.00000e-02 5.00000e-04 5.00000e-04 5.00000e-05 1.00000e-09 1.00000e-01 
5.00000e-04 5.00000e-04 5.00000e-05 1.00000e-09 1.00000e-01 8.91109e+00 8.91109e+00 8.91109e-01 1.00000e-09 2.12000e-01 8.91109e+00 8.91109e+00 8.91109e-01 1.00000e-09 2.12000e-01 $8.91109 \mathrm{e}+00$ 8.91109e+00 8.91109e-01 1.00000e-09 2.12000e-01 $8.91109 \mathrm{e}+00$ 8.91109e+00 8.91109e-01 1.00000e-09 2.12000e-01 8.91109e+00 8.91109e+00 8.91109e-01 1.00000e-09 2.12000e-01 $1.00000 \mathrm{e}-02$ 1.00000e-02 1.00000e-03 1.00000e-09 1.00000e-01 $1.00000 \mathrm{e}+001.00000 \mathrm{e}+001.00000 \mathrm{e}-011.00000 \mathrm{e}-091.00000 \mathrm{e}-01$ $1.00000 \mathrm{e}-05$ 1.00000e-05 1.00000e-06 1.00000e-09 1.00000e-01 $1.00000 \mathrm{e}+001.00000 \mathrm{e}+001.00000 \mathrm{e}-011.00000 \mathrm{e}-091.00000 \mathrm{e}-01$ Element: 4262 \# of layers: 14

$\mathrm{Kx} \mathrm{Ky} \mathrm{Kz}$ Ss Por

2.23025e+02 2.23025e+02 2.23025e+01 1.00000e-09 7.00000e-02

$2.23025 \mathrm{e}+02$ 2.23025e+02 2.23025e+01 1.00000e-09 7.00000e-02

$2.23025 \mathrm{e}+022.23025 \mathrm{e}+022.23025 \mathrm{e}+01$ 1.00000e-09 7.00000e-02 5.00000e-04 5.00000e-04 5.00000e-05 1.00000e-09 1.00000e-01 5.00000e-04 5.00000e-04 5.00000e-05 1.00000e-09 1.00000e-01 8.91109e+00 8.91109e+00 8.91109e-01 1.00000e-09 2.12000e-01 8.91109e+00 8.91109e+00 8.91109e-01 1.00000e-09 2.12000e-01 $8.91109 \mathrm{e}+00$ 8.91109e+00 8.91109e-01 1.00000e-09 2.12000e-01 $8.91109 \mathrm{e}+00$ 8.91109e+00 8.91109e-01 1.00000e-09 2.12000e-01 8.91109e+00 8.91109e+00 8.91109e-01 1.00000e-09 2.12000e-01 $1.00000 \mathrm{e}-02$ 1.00000e-02 1.00000e-03 1.00000e-09 1.00000e-01 $1.00000 \mathrm{e}+001.00000 \mathrm{e}+001.00000 \mathrm{e}-011.00000 \mathrm{e}-091.00000 \mathrm{e}-01$ $1.00000 \mathrm{e}-05$ 1.00000e-05 1.00000e-06 1.00000e-09 1.00000e-01 $1.00000 \mathrm{e}+001.00000 \mathrm{e}+001.00000 \mathrm{e}-011.00000 \mathrm{e}-091.00000 \mathrm{e}-01$ Element: 4263 \# of layers: 14

$\mathrm{Kx} \mathrm{Ky} \mathrm{Kz}$ Ss Por

$2.23025 \mathrm{e}+02$ 2.23025e+02 2.23025e+01 1.00000e-09 7.00000e-02 $2.23025 \mathrm{e}+02$ 2.23025e+02 2.23025e+01 1.00000e-09 7.00000e-02 $2.23025 \mathrm{e}+022.23025 \mathrm{e}+022.23025 \mathrm{e}+01$ 1.00000e-09 7.00000e-02 5.00000e-04 5.00000e-04 5.00000e-05 1.00000e-09 1.00000e-01 5.00000e-04 5.00000e-04 5.00000e-05 1.00000e-09 1.00000e-01 8.91109e+00 8.91109e+00 8.91109e-01 1.00000e-09 2.12000e-01 8.91109e+00 8.91109e+00 8.91109e-01 1.00000e-09 2.12000e-01 $8.91109 \mathrm{e}+00$ 8.91109e+00 8.91109e-01 1.00000e-09 2.12000e-01 8.91109e+00 8.91109e+00 8.91109e-01 1.00000e-09 2.12000e-01 8.91109e+00 8.91109e+00 8.91109e-01 1.00000e-09 2.12000e-01 $1.00000 \mathrm{e}-02$ 1.00000e-02 1.00000e-03 1.00000e-09 1.00000e-01 $1.00000 \mathrm{e}+001.00000 \mathrm{e}+001.00000 \mathrm{e}-011.00000 \mathrm{e}-091.00000 \mathrm{e}-01$ $1.00000 \mathrm{e}-05$ 1.00000e-05 1.00000e-06 1.00000e-09 1.00000e-01 $1.00000 \mathrm{e}+001.00000 \mathrm{e}+001.00000 \mathrm{e}-011.00000 \mathrm{e}-091.00000 \mathrm{e}-01$ Element: 4264 \# of layers: 14

$\mathrm{Kx} \mathrm{Ky} \mathrm{Kz}$ Ss Por

$1.33060 \mathrm{e}+02$ 1.33060e+02 1.33060e+01 1.00000e-09 7.00000e-02 $1.33060 \mathrm{e}+021.33060 \mathrm{e}+021.33060 \mathrm{e}+01$ 1.00000e-09 7.00000e-02 
$1.33060 \mathrm{e}+021.33060 \mathrm{e}+02$ 1.33060e+01 1.00000e-09 7.00000e-02 5.00000e-04 5.00000e-04 5.00000e-05 1.00000e-09 1.00000e-01 5.00000e-04 5.00000e-04 5.00000e-05 1.00000e-09 1.00000e-01

$5.31641 \mathrm{e}+005.31641 \mathrm{e}+00$ 5.31641e-01 1.00000e-09 2.12000e-01 5.31641e+00 5.31641e+00 5.31641e-01 1.00000e-09 2.12000e-01 5.31641e+00 5.31641e+00 5.31641e-01 1.00000e-09 2.12000e-01 $5.31641 \mathrm{e}+005.31641 \mathrm{e}+00$ 5.31641e-01 1.00000e-09 2.12000e-01 $5.31641 \mathrm{e}+00$ 5.31641e+00 5.31641e-01 1.00000e-09 2.12000e-01 $1.00000 \mathrm{e}-02$ 1.00000e-02 1.00000e-03 1.00000e-09 1.00000e-01 $1.00000 \mathrm{e}+001.00000 \mathrm{e}+001.00000 \mathrm{e}-011.00000 \mathrm{e}-091.00000 \mathrm{e}-01$ 1.00000e-05 1.00000e-05 1.00000e-06 1.00000e-09 1.00000e-01 $1.00000 \mathrm{e}+001.00000 \mathrm{e}+001.00000 \mathrm{e}-011.00000 \mathrm{e}-091.00000 \mathrm{e}-01$ Element: 4265 \# of layers: 14

$\mathrm{Kx} \mathrm{Ky} \mathrm{Kz}$ Ss Por

1.33060e+02 1.33060e+02 1.33060e+01 1.00000e-09 7.00000e-02 $1.33060 \mathrm{e}+021.33060 \mathrm{e}+02 \quad 1.33060 \mathrm{e}+01$ 1.00000e-09 7.00000e-02 $1.33060 \mathrm{e}+021.33060 \mathrm{e}+02 \quad 1.33060 \mathrm{e}+01$ 1.00000e-09 7.00000e-02 5.00000e-04 5.00000e-04 5.00000e-05 1.00000e-09 1.00000e-01 $5.00000 \mathrm{e}-04$ 5.00000e-04 5.00000e-05 1.00000e-09 1.00000e-01 $5.31641 \mathrm{e}+005.31641 \mathrm{e}+005.31641 \mathrm{e}-011.00000 \mathrm{e}-092.12000 \mathrm{e}-01$ $5.31641 \mathrm{e}+00$ 5.31641e+00 5.31641e-01 1.00000e-09 2.12000e-01 5.31641e+00 5.31641e+00 5.31641e-01 1.00000e-09 2.12000e-01 $5.31641 \mathrm{e}+005.31641 \mathrm{e}+00$ 5.31641e-01 1.00000e-09 2.12000e-01 $5.31641 \mathrm{e}+005.31641 \mathrm{e}+00$ 5.31641e-01 1.00000e-09 2.12000e-01 $1.00000 \mathrm{e}-021.00000 \mathrm{e}-02$ 1.00000e-03 1.00000e-09 1.00000e-01 $1.00000 \mathrm{e}+001.00000 \mathrm{e}+001.00000 \mathrm{e}-011.00000 \mathrm{e}-091.00000 \mathrm{e}-01$ $1.00000 \mathrm{e}-05$ 1.00000e-05 1.00000e-06 1.00000e-09 1.00000e-01 $1.00000 \mathrm{e}+001.00000 \mathrm{e}+001.00000 \mathrm{e}-011.00000 \mathrm{e}-091.00000 \mathrm{e}-01$ Element: 4266 \# of layers: 14

$\mathrm{Kx} \mathrm{Ky} \mathrm{Kz}$ Ss Por

$2.60524 \mathrm{e}+02$ 2.60524e+02 2.60524e+01 1.00000e-09 7.00000e-02 $2.60524 \mathrm{e}+022.60524 \mathrm{e}+022.60524 \mathrm{e}+01$ 1.00000e-09 7.00000e-02 $2.60524 \mathrm{e}+022.60524 \mathrm{e}+022.60524 \mathrm{e}+01$ 1.00000e-09 7.00000e-02 5.00000e-04 5.00000e-04 5.00000e-05 1.00000e-09 1.00000e-01 5.00000e-04 5.00000e-04 5.00000e-05 1.00000e-09 1.00000e-01 $1.04094 \mathrm{e}+011.04094 \mathrm{e}+011.04094 \mathrm{e}+001.00000 \mathrm{e}-092.12000 \mathrm{e}-01$ $1.04094 \mathrm{e}+011.04094 \mathrm{e}+011.04094 \mathrm{e}+001.00000 \mathrm{e}-092.12000 \mathrm{e}-01$ $1.04094 \mathrm{e}+011.04094 \mathrm{e}+011.04094 \mathrm{e}+001.00000 \mathrm{e}-092.12000 \mathrm{e}-01$ $1.04094 \mathrm{e}+01$ 1.04094e+01 1.04094e+00 1.00000e-09 2.12000e-01 $1.04094 \mathrm{e}+011.04094 \mathrm{e}+011.04094 \mathrm{e}+001.00000 \mathrm{e}-092.12000 \mathrm{e}-01$ $1.00000 \mathrm{e}-02$ 1.00000e-02 1.00000e-03 1.00000e-09 1.00000e-01 $1.00000 \mathrm{e}+001.00000 \mathrm{e}+001.00000 \mathrm{e}-011.00000 \mathrm{e}-091.00000 \mathrm{e}-01$ $1.00000 \mathrm{e}-051.00000 \mathrm{e}-051.00000 \mathrm{e}-061.00000 \mathrm{e}-091.00000 \mathrm{e}-01$ $1.00000 \mathrm{e}+001.00000 \mathrm{e}+001.00000 \mathrm{e}-01$ 1.00000e-09 1.00000e-01 Element: 4267 \# of layers: 14

Kx Ky Kz Ss Por 
2.47469e+02 2.47469e+02 2.47469e+01 1.00000e-09 7.00000e-02 $2.47469 \mathrm{e}+02$ 2.47469e+02 2.47469e+01 1.00000e-09 7.00000e-02

$2.47469 \mathrm{e}+02$ 2.47469e+02 2.47469e+01 1.00000e-09 7.00000e-02 5.00000e-04 5.00000e-04 5.00000e-05 1.00000e-09 1.00000e-01 5.00000e-04 5.00000e-04 5.00000e-05 1.00000e-09 1.00000e-01 $9.88784 \mathrm{e}+009.88784 \mathrm{e}+00$ 9.88784e-01 1.00000e-09 2.12000e-01 9.88784e+00 9.88784e+00 9.88784e-01 1.00000e-09 2.12000e-01 $9.88784 \mathrm{e}+009.88784 \mathrm{e}+00 \quad 9.88784 \mathrm{e}-01$ 1.00000e-09 2.12000e-01 $9.88784 \mathrm{e}+009.88784 \mathrm{e}+00$ 9.88784e-01 1.00000e-09 2.12000e-01 $9.88784 \mathrm{e}+00$ 9.88784e+00 9.88784e-01 1.00000e-09 2.12000e-01 $1.00000 \mathrm{e}-02$ 1.00000e-02 1.00000e-03 1.00000e-09 1.00000e-01 $1.00000 \mathrm{e}+001.00000 \mathrm{e}+001.00000 \mathrm{e}-011.00000 \mathrm{e}-091.00000 \mathrm{e}-01$ 1.00000e-05 1.00000e-05 1.00000e-06 1.00000e-09 1.00000e-01 $1.00000 \mathrm{e}+001.00000 \mathrm{e}+001.00000 \mathrm{e}-011.00000 \mathrm{e}-091.00000 \mathrm{e}-01$ Element: 4268 \# of layers: 14

$\mathrm{Kx} \mathrm{Ky} \mathrm{Kz}$ Ss Por

$2.23025 \mathrm{e}+02$ 2.23025e+02 2.23025e+01 1.00000e-09 7.00000e-02 $2.23025 \mathrm{e}+02$ 2.23025e+02 2.23025e+01 1.00000e-09 7.00000e-02 $2.23025 \mathrm{e}+02$ 2.23025e+02 2.23025e+01 1.00000e-09 7.00000e-02 5.00000e-04 5.00000e-04 5.00000e-05 1.00000e-09 1.00000e-01 5.00000e-04 5.00000e-04 5.00000e-05 1.00000e-09 1.00000e-01 $8.91109 \mathrm{e}+00$ 8.91109e+00 8.91109e-01 1.00000e-09 2.12000e-01 8.91109e+00 8.91109e+00 8.91109e-01 1.00000e-09 2.12000e-01 $8.91109 \mathrm{e}+00$ 8.91109e+00 8.91109e-01 1.00000e-09 2.12000e-01 $8.91109 \mathrm{e}+008.91109 \mathrm{e}+00$ 8.91109e-01 1.00000e-09 2.12000e-01 $8.91109 \mathrm{e}+008.91109 \mathrm{e}+00$ 8.91109e-01 1.00000e-09 2.12000e-01 $1.00000 \mathrm{e}-02$ 1.00000e-02 1.00000e-03 1.00000e-09 1.00000e-01 $1.00000 \mathrm{e}+001.00000 \mathrm{e}+001.00000 \mathrm{e}-011.00000 \mathrm{e}-091.00000 \mathrm{e}-01$ $1.00000 \mathrm{e}-05$ 1.00000e-05 1.00000e-06 1.00000e-09 1.00000e-01 $1.00000 \mathrm{e}+001.00000 \mathrm{e}+001.00000 \mathrm{e}-011.00000 \mathrm{e}-091.00000 \mathrm{e}-01$ Element: 4269 \# of layers: 14

$\mathrm{Kx} \mathrm{Ky} \mathrm{Kz}$ Ss Por

9.34968e+01 9.34968e+01 9.34968e+00 1.00000e-09 7.00000e-02 9.34968e+01 9.34968e+01 9.34968e+00 1.00000e-09 7.00000e-02 $9.34968 \mathrm{e}+019.34968 \mathrm{e}+01$ 9.34968e+00 1.00000e-09 7.00000e-02 5.00000e-04 5.00000e-04 5.00000e-05 1.00000e-09 1.00000e-01 5.00000e-04 5.00000e-04 5.00000e-05 1.00000e-09 1.00000e-01 $3.73598 \mathrm{e}+003.73598 \mathrm{e}+00$ 3.73598e-01 1.00000e-09 2.12000e-01 $3.73598 \mathrm{e}+00$ 3.73598e+00 3.73598e-01 1.00000e-09 2.12000e-01 3.73598e+00 3.73598e+00 3.73598e-01 1.00000e-09 2.12000e-01 $3.73598 \mathrm{e}+003.73598 \mathrm{e}+00$ 3.73598e-01 1.00000e-09 2.12000e-01 3.73598e+00 3.73598e+00 3.73598e-01 1.00000e-09 2.12000e-01 $1.00000 \mathrm{e}-02$ 1.00000e-02 1.00000e-03 1.00000e-09 1.00000e-01 $1.00000 \mathrm{e}+001.00000 \mathrm{e}+001.00000 \mathrm{e}-011.00000 \mathrm{e}-091.00000 \mathrm{e}-01$ $1.00000 \mathrm{e}-05$ 1.00000e-05 1.00000e-06 1.00000e-09 1.00000e-01 $1.00000 \mathrm{e}+001.00000 \mathrm{e}+001.00000 \mathrm{e}-011.00000 \mathrm{e}-091.00000 \mathrm{e}-01$ 
Element: 4270 \# of layers: 14

$\mathrm{Kx} \mathrm{Ky} \mathrm{Kz}$ Ss Por

1.13427e+02 1.13427e+02 1.13427e+01 1.00000e-09 7.00000e-02

$1.13427 \mathrm{e}+02$ 1.13427e+02 1.13427e+01 1.00000e-09 7.00000e-02

$1.13427 \mathrm{e}+021.13427 \mathrm{e}+02$ 1.13427e+01 1.00000e-09 7.00000e-02

5.00000e-04 5.00000e-04 5.00000e-05 1.00000e-09 1.00000e-01

5.00000e-04 5.00000e-04 5.00000e-05 1.00000e-09 1.00000e-01

$4.53227 \mathrm{e}+00$ 4.53227e+00 4.53227e-01 1.00000e-09 2.12000e-01

4.53227e+00 4.53227e+00 4.53227e-01 1.00000e-09 2.12000e-01

4.53227e+00 4.53227e+00 4.53227e-01 1.00000e-09 2.12000e-01

4.53227e+00 4.53227e+00 4.53227e-01 1.00000e-09 2.12000e-01

$4.53227 \mathrm{e}+00$ 4.53227e+00 4.53227e-01 1.00000e-09 2.12000e-01

$1.00000 \mathrm{e}-02$ 1.00000e-02 1.00000e-03 1.00000e-09 1.00000e-01

$1.00000 \mathrm{e}+001.00000 \mathrm{e}+001.00000 \mathrm{e}-011.00000 \mathrm{e}-091.00000 \mathrm{e}-01$

$1.00000 \mathrm{e}-05$ 1.00000e-05 1.00000e-06 1.00000e-09 1.00000e-01

$1.00000 \mathrm{e}+001.00000 \mathrm{e}+001.00000 \mathrm{e}-011.00000 \mathrm{e}-091.00000 \mathrm{e}-01$

Element: 4271 \# of layers: 14

$\mathrm{Kx} \mathrm{Ky} \mathrm{Kz}$ Ss Por

1.13427e+02 1.13427e+02 1.13427e+01 1.00000e-09 7.00000e-02

1.13427e+02 1.13427e+02 1.13427e+01 1.00000e-09 7.00000e-02

$1.13427 \mathrm{e}+021.13427 \mathrm{e}+02$ 1.13427e+01 1.00000e-09 7.00000e-02

5.00000e-04 5.00000e-04 5.00000e-05 1.00000e-09 1.00000e-01

5.00000e-04 5.00000e-04 5.00000e-05 1.00000e-09 1.00000e-01

4.53227e+00 4.53227e+00 4.53227e-01 1.00000e-09 2.12000e-01

$4.53227 \mathrm{e}+00$ 4.53227e+00 4.53227e-01 1.00000e-09 2.12000e-01

4.53227e+00 4.53227e+00 4.53227e-01 1.00000e-09 2.12000e-01

4.53227e+00 4.53227e+00 4.53227e-01 1.00000e-09 2.12000e-01

$4.53227 \mathrm{e}+00$ 4.53227e+00 4.53227e-01 1.00000e-09 2.12000e-01

$1.00000 \mathrm{e}-02$ 1.00000e-02 1.00000e-03 1.00000e-09 1.00000e-01

$1.00000 \mathrm{e}+001.00000 \mathrm{e}+001.00000 \mathrm{e}-011.00000 \mathrm{e}-091.00000 \mathrm{e}-01$

$1.00000 \mathrm{e}-05$ 1.00000e-05 1.00000e-06 1.00000e-09 1.00000e-01

$1.00000 \mathrm{e}+001.00000 \mathrm{e}+001.00000 \mathrm{e}-011.00000 \mathrm{e}-091.00000 \mathrm{e}-01$

Element: 4272 \# of layers: 14

$\mathrm{Kx} \mathrm{Ky} \mathrm{Kz}$ Ss Por

1.13427e+02 1.13427e+02 1.13427e+01 1.00000e-09 7.00000e-02

$1.13427 \mathrm{e}+02$ 1.13427e+02 1.13427e+01 1.00000e-09 7.00000e-02

$1.13427 \mathrm{e}+021.13427 \mathrm{e}+02$ 1.13427e+01 1.00000e-09 7.00000e-02

5.00000e-04 5.00000e-04 5.00000e-05 1.00000e-09 1.00000e-01

5.00000e-04 5.00000e-04 5.00000e-05 1.00000e-09 1.00000e-01

4.53227e+00 4.53227e+00 4.53227e-01 1.00000e-09 2.12000e-01

4.53227e+00 4.53227e+00 4.53227e-01 1.00000e-09 2.12000e-01

4.53227e+00 4.53227e+00 4.53227e-01 1.00000e-09 2.12000e-01

4.53227e+00 4.53227e+00 4.53227e-01 1.00000e-09 2.12000e-01

4.53227e+00 4.53227e+00 4.53227e-01 1.00000e-09 2.12000e-01

$1.00000 \mathrm{e}-02$ 1.00000e-02 1.00000e-03 1.00000e-09 1.00000e-01

$1.00000 \mathrm{e}+001.00000 \mathrm{e}+001.00000 \mathrm{e}-011.00000 \mathrm{e}-091.00000 \mathrm{e}-01$ 
$1.00000 \mathrm{e}-05$ 1.00000e-05 1.00000e-06 1.00000e-09 1.00000e-01 $1.00000 \mathrm{e}+001.00000 \mathrm{e}+001.00000 \mathrm{e}-01$ 1.00000e-09 1.00000e-01 Element: 4273 \# of layers: 14

Kx Ky Kz Ss Por

9.73801e+01 9.73801e+01 9.73801e+00 1.00000e-09 7.00000e-02 $9.73801 \mathrm{e}+019.73801 \mathrm{e}+019.73801 \mathrm{e}+00$ 1.00000e-09 7.00000e-02 $9.73801 \mathrm{e}+019.73801 \mathrm{e}+019.73801 \mathrm{e}+001.00000 \mathrm{e}-09$ 7.00000e-02 5.00000e-04 5.00000e-04 5.00000e-05 1.00000e-09 1.00000e-01 5.00000e-04 5.00000e-04 5.00000e-05 1.00000e-09 1.00000e-01 $3.89101 \mathrm{e}+003.89101 \mathrm{e}+003.89101 \mathrm{e}-01$ 1.00000e-09 2.12000e-01 $3.89101 \mathrm{e}+003.89101 \mathrm{e}+003.89101 \mathrm{e}-01$ 1.00000e-09 2.12000e-01 $3.89101 \mathrm{e}+003.89101 \mathrm{e}+003.89101 \mathrm{e}-011.00000 \mathrm{e}-092.12000 \mathrm{e}-01$ $3.89101 \mathrm{e}+003.89101 \mathrm{e}+003.89101 \mathrm{e}-01$ 1.00000e-09 2.12000e-01 $3.89101 \mathrm{e}+003.89101 \mathrm{e}+003.89101 \mathrm{e}-01$ 1.00000e-09 2.12000e-01 $1.00000 \mathrm{e}-02$ 1.00000e-02 1.00000e-03 1.00000e-09 1.00000e-01 $1.00000 \mathrm{e}+001.00000 \mathrm{e}+001.00000 \mathrm{e}-011.00000 \mathrm{e}-091.00000 \mathrm{e}-01$ $1.00000 \mathrm{e}-05$ 1.00000e-05 1.00000e-06 1.00000e-09 1.00000e-01 $1.00000 \mathrm{e}+001.00000 \mathrm{e}+001.00000 \mathrm{e}-01$ 1.00000e-09 1.00000e-01 Element: 4274 \# of layers: 14

Kx Ky Kz Ss Por

9.73801e+01 9.73801e+01 9.73801e+00 1.00000e-09 7.00000e-02

9.73801e+01 9.73801e+01 9.73801e+00 1.00000e-09 7.00000e-02

$9.73801 \mathrm{e}+019.73801 \mathrm{e}+019.73801 \mathrm{e}+001.00000 \mathrm{e}-09$ 7.00000e-02 5.00000e-04 5.00000e-04 5.00000e-05 1.00000e-09 1.00000e-01 $5.00000 \mathrm{e}-04$ 5.00000e-04 5.00000e-05 1.00000e-09 1.00000e-01 $3.89101 \mathrm{e}+003.89101 \mathrm{e}+003.89101 \mathrm{e}-01$ 1.00000e-09 2.12000e-01 $3.89101 \mathrm{e}+003.89101 \mathrm{e}+003.89101 \mathrm{e}-01$ 1.00000e-09 2.12000e-01 $3.89101 \mathrm{e}+003.89101 \mathrm{e}+003.89101 \mathrm{e}-01$ 1.00000e-09 2.12000e-01 $3.89101 \mathrm{e}+003.89101 \mathrm{e}+003.89101 \mathrm{e}-01$ 1.00000e-09 2.12000e-01 $3.89101 \mathrm{e}+003.89101 \mathrm{e}+00$ 3.89101e-01 1.00000e-09 2.12000e-01 $1.00000 \mathrm{e}-02$ 1.00000e-02 1.00000e-03 1.00000e-09 1.00000e-01 $1.00000 \mathrm{e}+001.00000 \mathrm{e}+001.00000 \mathrm{e}-011.00000 \mathrm{e}-091.00000 \mathrm{e}-01$ $1.00000 \mathrm{e}-05$ 1.00000e-05 1.00000e-06 1.00000e-09 1.00000e-01 $1.00000 \mathrm{e}+001.00000 \mathrm{e}+001.00000 \mathrm{e}-011.00000 \mathrm{e}-091.00000 \mathrm{e}-01$ Element: 4275 \# of layers: 14

$\mathrm{Kx} \mathrm{Ky} \mathrm{Kz}$ Ss Por

9.80288e+01 9.80288e+01 9.80288e+00 1.00000e-09 7.00000e-02 $9.80288 \mathrm{e}+019.80288 \mathrm{e}+019.80288 \mathrm{e}+00$ 1.00000e-09 7.00000e-02

$9.80288 \mathrm{e}+019.80288 \mathrm{e}+01$ 9.80288e+00 1.00000e-09 7.00000e-02 5.00000e-04 5.00000e-04 5.00000e-05 1.00000e-09 1.00000e-01 5.00000e-04 5.00000e-04 5.00000e-05 1.00000e-09 1.00000e-01 $3.91711 \mathrm{e}+003.91711 \mathrm{e}+003.91711 \mathrm{e}-01$ 1.00000e-09 2.12000e-01 $3.91711 \mathrm{e}+003.91711 \mathrm{e}+003.91711 \mathrm{e}-01$ 1.00000e-09 2.12000e-01 $3.91711 \mathrm{e}+003.91711 \mathrm{e}+003.91711 \mathrm{e}-01$ 1.00000e-09 2.12000e-01 $3.91711 \mathrm{e}+003.91711 \mathrm{e}+003.91711 \mathrm{e}-01$ 1.00000e-09 2.12000e-01 $3.91711 \mathrm{e}+003.91711 \mathrm{e}+003.91711 \mathrm{e}-01$ 1.00000e-09 2.12000e-01 
$1.00000 \mathrm{e}-02$ 1.00000e-02 1.00000e-03 1.00000e-09 1.00000e-01 $1.00000 \mathrm{e}+001.00000 \mathrm{e}+001.00000 \mathrm{e}-011.00000 \mathrm{e}-091.00000 \mathrm{e}-01$ $1.00000 \mathrm{e}-051.00000 \mathrm{e}-05$ 1.00000e-06 1.00000e-09 1.00000e-01 $1.00000 \mathrm{e}+001.00000 \mathrm{e}+001.00000 \mathrm{e}-011.00000 \mathrm{e}-091.00000 \mathrm{e}-01$ Element: 4276 \# of layers: 14

Kx Ky Kz Ss Por

$9.34968 \mathrm{e}+01$ 9.34968e+01 9.34968e+00 1.00000e-09 7.00000e-02 $9.34968 \mathrm{e}+019.34968 \mathrm{e}+019.34968 \mathrm{e}+00$ 1.00000e-09 7.00000e-02 $9.34968 \mathrm{e}+01$ 9.34968e+01 9.34968e+00 1.00000e-09 7.00000e-02 5.00000e-04 5.00000e-04 5.00000e-05 1.00000e-09 1.00000e-01 5.00000e-04 5.00000e-04 5.00000e-05 1.00000e-09 1.00000e-01 $3.73598 \mathrm{e}+003.73598 \mathrm{e}+003.73598 \mathrm{e}-011.00000 \mathrm{e}-09$ 2.12000e-01 $3.73598 \mathrm{e}+003.73598 \mathrm{e}+003.73598 \mathrm{e}-01$ 1.00000e-09 2.12000e-01 $3.73598 \mathrm{e}+003.73598 \mathrm{e}+003.73598 \mathrm{e}-011.00000 \mathrm{e}-092.12000 \mathrm{e}-01$ $3.73598 \mathrm{e}+003.73598 \mathrm{e}+003.73598 \mathrm{e}-011.00000 \mathrm{e}-092.12000 \mathrm{e}-01$ $3.73598 \mathrm{e}+003.73598 \mathrm{e}+003.73598 \mathrm{e}-01$ 1.00000e-09 2.12000e-01 $1.00000 \mathrm{e}-021.00000 \mathrm{e}-02$ 1.00000e-03 1.00000e-09 1.00000e-01 $1.00000 \mathrm{e}+001.00000 \mathrm{e}+001.00000 \mathrm{e}-011.00000 \mathrm{e}-091.00000 \mathrm{e}-01$ $1.00000 \mathrm{e}-05$ 1.00000e-05 1.00000e-06 1.00000e-09 1.00000e-01 $1.00000 \mathrm{e}+001.00000 \mathrm{e}+001.00000 \mathrm{e}-011.00000 \mathrm{e}-091.00000 \mathrm{e}-01$ Element: 4277 \# of layers: 14

Kx Ky Kz Ss Por

$1.13427 \mathrm{e}+02$ 1.13427e+02 1.13427e+01 1.00000e-09 7.00000e-02 $1.13427 \mathrm{e}+021.13427 \mathrm{e}+021.13427 \mathrm{e}+01$ 1.00000e-09 7.00000e-02 $1.13427 \mathrm{e}+021.13427 \mathrm{e}+021.13427 \mathrm{e}+01$ 1.00000e-09 7.00000e-02 $5.00000 \mathrm{e}-04$ 5.00000e-04 5.00000e-05 1.00000e-09 1.00000e-01 5.00000e-04 5.00000e-04 5.00000e-05 1.00000e-09 1.00000e-01 $4.53227 \mathrm{e}+004.53227 \mathrm{e}+00$ 4.53227e-01 1.00000e-09 2.12000e-01 $4.53227 \mathrm{e}+004.53227 \mathrm{e}+00$ 4.53227e-01 1.00000e-09 2.12000e-01 $4.53227 \mathrm{e}+004.53227 \mathrm{e}+00$ 4.53227e-01 1.00000e-09 2.12000e-01 $4.53227 \mathrm{e}+004.53227 \mathrm{e}+004.53227 \mathrm{e}-011.00000 \mathrm{e}-092.12000 \mathrm{e}-01$ $4.53227 \mathrm{e}+004.53227 \mathrm{e}+00$ 4.53227e-01 1.00000e-09 2.12000e-01 $1.00000 \mathrm{e}-021.00000 \mathrm{e}-02$ 1.00000e-03 1.00000e-09 1.00000e-01 $1.00000 \mathrm{e}+001.00000 \mathrm{e}+001.00000 \mathrm{e}-011.00000 \mathrm{e}-091.00000 \mathrm{e}-01$ $1.00000 \mathrm{e}-05$ 1.00000e-05 1.00000e-06 1.00000e-09 1.00000e-01 $1.00000 \mathrm{e}+001.00000 \mathrm{e}+001.00000 \mathrm{e}-011.00000 \mathrm{e}-091.00000 \mathrm{e}-01$ Element: 4278 \# of layers: 14

Kx Ky Kz Ss Por $1.90093 \mathrm{e}+021.90093 \mathrm{e}+02$ 1.90093e+01 1.00000e-09 7.00000e-02 $1.90093 \mathrm{e}+021.90093 \mathrm{e}+021.90093 \mathrm{e}+01$ 1.00000e-09 7.00000e-02 $1.90093 \mathrm{e}+021.90093 \mathrm{e}+021.90093 \mathrm{e}+01$ 1.00000e-09 7.00000e-02 5.00000e-04 5.00000e-04 5.00000e-05 1.00000e-09 1.00000e-01 $5.00000 \mathrm{e}-04$ 5.00000e-04 5.00000e-05 1.00000e-09 1.00000e-01 $7.59526 \mathrm{e}+007.59526 \mathrm{e}+00$ 7.59526e-01 1.00000e-09 2.12000e-01 $7.59526 \mathrm{e}+007.59526 \mathrm{e}+007.59526 \mathrm{e}-011.00000 \mathrm{e}-092.12000 \mathrm{e}-01$ $7.59526 \mathrm{e}+007.59526 \mathrm{e}+00$ 7.59526e-01 1.00000e-09 2.12000e-01 
7.59526e+00 7.59526e+00 7.59526e-01 1.00000e-09 2.12000e-01 $7.59526 \mathrm{e}+00$ 7.59526e+00 7.59526e-01 1.00000e-09 2.12000e-01 $1.00000 \mathrm{e}-02$ 1.00000e-02 1.00000e-03 1.00000e-09 1.00000e-01 $1.00000 \mathrm{e}+001.00000 \mathrm{e}+001.00000 \mathrm{e}-011.00000 \mathrm{e}-091.00000 \mathrm{e}-01$ $1.00000 \mathrm{e}-05$ 1.00000e-05 1.00000e-06 1.00000e-09 1.00000e-01 $1.00000 \mathrm{e}+001.00000 \mathrm{e}+001.00000 \mathrm{e}-011.00000 \mathrm{e}-091.00000 \mathrm{e}-01$ Element: 4279 \# of layers: 14

$\mathrm{Kx} \mathrm{Ky} \mathrm{Kz} \mathrm{Ss} \mathrm{Por}$

1.78083e+02 1.78083e+02 1.78083e+01 1.00000e-09 7.00000e-02 $1.78083 \mathrm{e}+02$ 1.78083e+02 1.78083e+01 1.00000e-09 7.00000e-02 $1.78083 \mathrm{e}+02$ 1.78083e+02 1.78083e+01 1.00000e-09 7.00000e-02 5.00000e-04 5.00000e-04 5.00000e-05 1.00000e-09 1.00000e-01 5.00000e-04 5.00000e-04 5.00000e-05 1.00000e-09 1.00000e-01

7.11555e+00 7.11555e+00 7.11555e-01 1.00000e-09 2.12000e-01 7.11555e+00 7.11555e+00 7.11555e-01 1.00000e-09 2.12000e-01 $7.11555 \mathrm{e}+00$ 7.11555e+00 7.11555e-01 1.00000e-09 2.12000e-01 $7.11555 \mathrm{e}+00$ 7.11555e+00 7.11555e-01 1.00000e-09 2.12000e-01 7.11555e+00 7.11555e+00 7.11555e-01 1.00000e-09 2.12000e-01 $1.00000 \mathrm{e}-02$ 1.00000e-02 1.00000e-03 1.00000e-09 1.00000e-01 $1.00000 \mathrm{e}+001.00000 \mathrm{e}+001.00000 \mathrm{e}-011.00000 \mathrm{e}-091.00000 \mathrm{e}-01$ $1.00000 \mathrm{e}-05$ 1.00000e-05 1.00000e-06 1.00000e-09 1.00000e-01 $1.00000 \mathrm{e}+001.00000 \mathrm{e}+001.00000 \mathrm{e}-01$ 1.00000e-09 1.00000e-01 Element: 4280 \# of layers: 14

Kx Ky Kz Ss Por

$1.78083 e+02$ 1.78083e+02 1.78083e+01 1.00000e-09 7.00000e-02 $1.78083 \mathrm{e}+021.78083 \mathrm{e}+02$ 1.78083e+01 1.00000e-09 7.00000e-02 $1.78083 \mathrm{e}+021.78083 \mathrm{e}+02$ 1.78083e+01 1.00000e-09 7.00000e-02 5.00000e-04 5.00000e-04 5.00000e-05 1.00000e-09 1.00000e-01 5.00000e-04 5.00000e-04 5.00000e-05 1.00000e-09 1.00000e-01 $7.11555 \mathrm{e}+00$ 7.11555e+00 7.11555e-01 1.00000e-09 2.12000e-01 7.11555e+00 7.11555e+00 7.11555e-01 1.00000e-09 2.12000e-01 7.11555e+00 7.11555e+00 7.11555e-01 1.00000e-09 2.12000e-01 $7.11555 \mathrm{e}+00$ 7.11555e+00 7.11555e-01 1.00000e-09 2.12000e-01 $7.11555 \mathrm{e}+00$ 7.11555e+00 7.11555e-01 1.00000e-09 2.12000e-01 $1.00000 \mathrm{e}-02$ 1.00000e-02 1.00000e-03 1.00000e-09 1.00000e-01 $1.00000 \mathrm{e}+001.00000 \mathrm{e}+001.00000 \mathrm{e}-011.00000 \mathrm{e}-091.00000 \mathrm{e}-01$ $1.00000 \mathrm{e}-05$ 1.00000e-05 1.00000e-06 1.00000e-09 1.00000e-01 $1.00000 \mathrm{e}+001.00000 \mathrm{e}+001.00000 \mathrm{e}-011.00000 \mathrm{e}-091.00000 \mathrm{e}-01$ Element: 4281 \# of layers: 14

$\mathrm{Kx} \mathrm{Ky} \mathrm{Kz}$ Ss Por

$1.78083 e+02$ 1.78083e+02 1.78083e+01 1.00000e-09 7.00000e-02 $1.78083 \mathrm{e}+02$ 1.78083e+02 1.78083e+01 1.00000e-09 7.00000e-02 $1.78083 \mathrm{e}+02$ 1.78083e+02 1.78083e+01 1.00000e-09 7.00000e-02 5.00000e-04 5.00000e-04 5.00000e-05 1.00000e-09 1.00000e-01 5.00000e-04 5.00000e-04 5.00000e-05 1.00000e-09 1.00000e-01

$7.11555 \mathrm{e}+007.11555 \mathrm{e}+00$ 7.11555e-01 1.00000e-09 2.12000e-01 
$7.11555 \mathrm{e}+007.11555 \mathrm{e}+00$ 7.11555e-01 1.00000e-09 2.12000e-01 $7.11555 \mathrm{e}+00$ 7.11555e+00 7.11555e-01 1.00000e-09 2.12000e-01 $7.11555 \mathrm{e}+007.11555 \mathrm{e}+00$ 7.11555e-01 1.00000e-09 2.12000e-01 $7.11555 \mathrm{e}+007.11555 \mathrm{e}+00$ 7.11555e-01 1.00000e-09 2.12000e-01 $1.00000 \mathrm{e}-02$ 1.00000e-02 1.00000e-03 1.00000e-09 1.00000e-01 $1.00000 \mathrm{e}+001.00000 \mathrm{e}+001.00000 \mathrm{e}-011.00000 \mathrm{e}-091.00000 \mathrm{e}-01$ $1.00000 \mathrm{e}-051.00000 \mathrm{e}-05$ 1.00000e-06 1.00000e-09 1.00000e-01 $1.00000 \mathrm{e}+001.00000 \mathrm{e}+001.00000 \mathrm{e}-011.00000 \mathrm{e}-091.00000 \mathrm{e}-01$ Element: 4282 \# of layers: 14

Kx Ky Kz Ss Por

$3.68572 \mathrm{e}+013.68572 \mathrm{e}+013.68572 \mathrm{e}+00$ 1.00000e-09 7.00000e-02 $3.68572 \mathrm{e}+013.68572 \mathrm{e}+013.68572 \mathrm{e}+00$ 1.00000e-09 7.00000e-02 $3.68572 \mathrm{e}+013.68572 \mathrm{e}+013.68572 \mathrm{e}+00$ 1.00000e-09 7.00000e-02 5.00000e-04 5.00000e-04 5.00000e-05 1.00000e-09 1.00000e-01 $5.00000 \mathrm{e}-04$ 5.00000e-04 5.00000e-05 1.00000e-09 1.00000e-01 $1.47270 \mathrm{e}+001.47270 \mathrm{e}+001.47270 \mathrm{e}-011.00000 \mathrm{e}-092.12000 \mathrm{e}-01$ $1.47270 \mathrm{e}+001.47270 \mathrm{e}+001.47270 \mathrm{e}-011.00000 \mathrm{e}-092.12000 \mathrm{e}-01$ $1.47270 \mathrm{e}+001.47270 \mathrm{e}+001.47270 \mathrm{e}-011.00000 \mathrm{e}-092.12000 \mathrm{e}-01$ $1.47270 \mathrm{e}+001.47270 \mathrm{e}+001.47270 \mathrm{e}-011.00000 \mathrm{e}-092.12000 \mathrm{e}-01$ $1.47270 \mathrm{e}+001.47270 \mathrm{e}+001.47270 \mathrm{e}-011.00000 \mathrm{e}-09$ 2.12000e-01 $1.00000 \mathrm{e}-021.00000 \mathrm{e}-02$ 1.00000e-03 1.00000e-09 1.00000e-01 $1.00000 \mathrm{e}+001.00000 \mathrm{e}+001.00000 \mathrm{e}-011.00000 \mathrm{e}-091.00000 \mathrm{e}-01$ $1.00000 \mathrm{e}-05$ 1.00000e-05 1.00000e-06 1.00000e-09 1.00000e-01 $1.00000 \mathrm{e}+001.00000 \mathrm{e}+001.00000 \mathrm{e}-011.00000 \mathrm{e}-091.00000 \mathrm{e}-01$ Element: 4283 \# of layers: 14

Kx Ky Kz Ss Por

$3.68572 \mathrm{e}+013.68572 \mathrm{e}+013.68572 \mathrm{e}+00$ 1.00000e-09 7.00000e-02 $3.68572 \mathrm{e}+013.68572 \mathrm{e}+013.68572 \mathrm{e}+00$ 1.00000e-09 7.00000e-02 $3.68572 \mathrm{e}+013.68572 \mathrm{e}+013.68572 \mathrm{e}+001.00000 \mathrm{e}-09$ 7.00000e-02 $5.00000 \mathrm{e}-04$ 5.00000e-04 5.00000e-05 1.00000e-09 1.00000e-01 $5.00000 \mathrm{e}-04$ 5.00000e-04 5.00000e-05 1.00000e-09 1.00000e-01 $1.47270 \mathrm{e}+001.47270 \mathrm{e}+001.47270 \mathrm{e}-011.00000 \mathrm{e}-092.12000 \mathrm{e}-01$ $1.47270 \mathrm{e}+001.47270 \mathrm{e}+001.47270 \mathrm{e}-011.00000 \mathrm{e}-092.12000 \mathrm{e}-01$ $1.47270 \mathrm{e}+001.47270 \mathrm{e}+001.47270 \mathrm{e}-011.00000 \mathrm{e}-092.12000 \mathrm{e}-01$ $1.47270 \mathrm{e}+001.47270 \mathrm{e}+001.47270 \mathrm{e}-011.00000 \mathrm{e}-092.12000 \mathrm{e}-01$ $1.47270 \mathrm{e}+001.47270 \mathrm{e}+001.47270 \mathrm{e}-011.00000 \mathrm{e}-092.12000 \mathrm{e}-01$ $1.00000 \mathrm{e}-02$ 1.00000e-02 1.00000e-03 1.00000e-09 1.00000e-01 $1.00000 \mathrm{e}+001.00000 \mathrm{e}+001.00000 \mathrm{e}-011.00000 \mathrm{e}-091.00000 \mathrm{e}-01$ $1.00000 \mathrm{e}-05$ 1.00000e-05 1.00000e-06 1.00000e-09 1.00000e-01 $1.00000 \mathrm{e}+001.00000 \mathrm{e}+001.00000 \mathrm{e}-011.00000 \mathrm{e}-091.00000 \mathrm{e}-01$ Element: 4284 \# of layers: 14

$\mathrm{Kx} \mathrm{Ky} \mathrm{Kz}$ Ss Por

8.77781e+01 8.77781e+01 8.77781e+00 1.00000e-09 7.00000e-02 8.77781e+01 8.77781e+01 8.77781e+00 1.00000e-09 7.00000e-02 $8.77781 \mathrm{e}+018.77781 \mathrm{e}+018.77781 \mathrm{e}+001.00000 \mathrm{e}-09$ 7.00000e-02 5.00000e-04 5.00000e-04 5.00000e-05 1.00000e-09 1.00000e-01 
5.00000e-04 5.00000e-04 5.00000e-05 1.00000e-09 1.00000e-01 3.50738e+00 3.50738e+00 3.50738e-01 1.00000e-09 2.12000e-01 $3.50738 \mathrm{e}+00$ 3.50738e+00 3.50738e-01 1.00000e-09 2.12000e-01 $3.50738 \mathrm{e}+00$ 3.50738e+00 3.50738e-01 1.00000e-09 2.12000e-01 $3.50738 \mathrm{e}+003.50738 \mathrm{e}+00$ 3.50738e-01 1.00000e-09 2.12000e-01 $3.50738 \mathrm{e}+003.50738 \mathrm{e}+00$ 3.50738e-01 1.00000e-09 2.12000e-01 $1.00000 \mathrm{e}-02$ 1.00000e-02 1.00000e-03 1.00000e-09 1.00000e-01 $1.00000 \mathrm{e}+001.00000 \mathrm{e}+001.00000 \mathrm{e}-011.00000 \mathrm{e}-091.00000 \mathrm{e}-01$ $1.00000 \mathrm{e}-051.00000 \mathrm{e}-051.00000 \mathrm{e}-061.00000 \mathrm{e}-091.00000 \mathrm{e}-01$ $1.00000 \mathrm{e}+001.00000 \mathrm{e}+001.00000 \mathrm{e}-011.00000 \mathrm{e}-091.00000 \mathrm{e}-01$ Element: 4285 \# of layers: 14

$\mathrm{Kx} \mathrm{Ky} \mathrm{Kz}$ Ss Por

1.90093e+02 1.90093e+02 1.90093e+01 1.00000e-09 7.00000e-02 $1.90093 \mathrm{e}+02$ 1.90093e+02 1.90093e+01 1.00000e-09 7.00000e-02 $1.90093 \mathrm{e}+021.90093 \mathrm{e}+02$ 1.90093e+01 1.00000e-09 7.00000e-02 5.00000e-04 5.00000e-04 5.00000e-05 1.00000e-09 1.00000e-01 5.00000e-04 5.00000e-04 5.00000e-05 1.00000e-09 1.00000e-01 $7.59526 \mathrm{e}+00$ 7.59526e+00 7.59526e-01 1.00000e-09 2.12000e-01 $7.59526 \mathrm{e}+007.59526 \mathrm{e}+00$ 7.59526e-01 1.00000e-09 2.12000e-01 $7.59526 \mathrm{e}+007.59526 \mathrm{e}+007.59526 \mathrm{e}-01$ 1.00000e-09 2.12000e-01 $7.59526 \mathrm{e}+00$ 7.59526e+00 7.59526e-01 1.00000e-09 2.12000e-01 7.59526e+00 7.59526e+00 7.59526e-01 1.00000e-09 2.12000e-01 $1.00000 \mathrm{e}-02$ 1.00000e-02 1.00000e-03 1.00000e-09 1.00000e-01 $1.00000 \mathrm{e}+001.00000 \mathrm{e}+001.00000 \mathrm{e}-011.00000 \mathrm{e}-091.00000 \mathrm{e}-01$ $1.00000 \mathrm{e}-05$ 1.00000e-05 1.00000e-06 1.00000e-09 1.00000e-01 $1.00000 \mathrm{e}+001.00000 \mathrm{e}+001.00000 \mathrm{e}-011.00000 \mathrm{e}-091.00000 \mathrm{e}-01$ Element: 4286 \# of layers: 14

$\mathrm{Kx} \mathrm{Ky} \mathrm{Kz}$ Ss Por

$1.78083 e+02$ 1.78083e+02 1.78083e+01 1.00000e-09 7.00000e-02 $1.78083 \mathrm{e}+02$ 1.78083e+02 1.78083e+01 1.00000e-09 7.00000e-02

$1.78083 \mathrm{e}+021.78083 \mathrm{e}+02$ 1.78083e+01 1.00000e-09 7.00000e-02 5.00000e-04 5.00000e-04 5.00000e-05 1.00000e-09 1.00000e-01 5.00000e-04 5.00000e-04 5.00000e-05 1.00000e-09 1.00000e-01

$7.11555 \mathrm{e}+00$ 7.11555e+00 7.11555e-01 1.00000e-09 2.12000e-01 7.11555e+00 7.11555e+00 7.11555e-01 1.00000e-09 2.12000e-01 7.11555e+00 7.11555e+00 7.11555e-01 1.00000e-09 2.12000e-01 $7.11555 \mathrm{e}+00$ 7.11555e+00 7.11555e-01 1.00000e-09 2.12000e-01 7.11555e+00 7.11555e+00 7.11555e-01 1.00000e-09 2.12000e-01 $1.00000 \mathrm{e}-02$ 1.00000e-02 1.00000e-03 1.00000e-09 1.00000e-01 $1.00000 \mathrm{e}+001.00000 \mathrm{e}+001.00000 \mathrm{e}-011.00000 \mathrm{e}-091.00000 \mathrm{e}-01$ $1.00000 \mathrm{e}-05$ 1.00000e-05 1.00000e-06 1.00000e-09 1.00000e-01 $1.00000 \mathrm{e}+001.00000 \mathrm{e}+001.00000 \mathrm{e}-011.00000 \mathrm{e}-091.00000 \mathrm{e}-01$ Element: 4287 \# of layers: 14

$\mathrm{Kx} \mathrm{Ky} \mathrm{Kz}$ Ss Por $3.02718 \mathrm{e}+013.02718 \mathrm{e}+013.02718 \mathrm{e}+00$ 1.00000e-09 7.00000e-02 $3.02718 \mathrm{e}+013.02718 \mathrm{e}+013.02718 \mathrm{e}+001.00000 \mathrm{e}-09$ 7.00000e-02 
$3.02718 \mathrm{e}+013.02718 \mathrm{e}+013.02718 \mathrm{e}+001.00000 \mathrm{e}-09$ 7.00000e-02 5.00000e-04 5.00000e-04 5.00000e-05 1.00000e-09 1.00000e-01 5.00000e-04 5.00000e-04 5.00000e-05 1.00000e-09 1.00000e-01 $1.20954 \mathrm{e}+001.20954 \mathrm{e}+001.20954 \mathrm{e}-011.00000 \mathrm{e}-092.12000 \mathrm{e}-01$ $1.20954 \mathrm{e}+001.20954 \mathrm{e}+001.20954 \mathrm{e}-01$ 1.00000e-09 2.12000e-01 $1.20954 \mathrm{e}+001.20954 \mathrm{e}+001.20954 \mathrm{e}-01$ 1.00000e-09 2.12000e-01 $1.20954 \mathrm{e}+001.20954 \mathrm{e}+001.20954 \mathrm{e}-011.00000 \mathrm{e}-092.12000 \mathrm{e}-01$ $1.20954 \mathrm{e}+001.20954 \mathrm{e}+001.20954 \mathrm{e}-011.00000 \mathrm{e}-092.12000 \mathrm{e}-01$ $1.00000 \mathrm{e}-021.00000 \mathrm{e}-021.00000 \mathrm{e}-031.00000 \mathrm{e}-091.00000 \mathrm{e}-01$ $1.00000 \mathrm{e}+001.00000 \mathrm{e}+001.00000 \mathrm{e}-011.00000 \mathrm{e}-091.00000 \mathrm{e}-01$ $1.00000 \mathrm{e}-05$ 1.00000e-05 1.00000e-06 1.00000e-09 1.00000e-01 $1.00000 \mathrm{e}+001.00000 \mathrm{e}+001.00000 \mathrm{e}-011.00000 \mathrm{e}-091.00000 \mathrm{e}-01$ Element: 4288 \# of layers: 14

$\mathrm{Kx} \mathrm{Ky} \mathrm{Kz}$ Ss Por

$2.95555 \mathrm{e}+012.95555 \mathrm{e}+012.95555 \mathrm{e}+00$ 1.00000e-09 7.00000e-02 $2.95555 \mathrm{e}+012.95555 \mathrm{e}+012.95555 \mathrm{e}+001.00000 \mathrm{e}-09$ 7.00000e-02 $2.95555 \mathrm{e}+012.95555 \mathrm{e}+012.95555 \mathrm{e}+001.00000 \mathrm{e}-09$ 7.00000e-02 5.00000e-04 5.00000e-04 5.00000e-05 1.00000e-09 1.00000e-01 $5.00000 \mathrm{e}-04$ 5.00000e-04 5.00000e-05 1.00000e-09 1.00000e-01 $1.18094 \mathrm{e}+001.18094 \mathrm{e}+001.18094 \mathrm{e}-011.00000 \mathrm{e}-092.12000 \mathrm{e}-01$ $1.18094 \mathrm{e}+001.18094 \mathrm{e}+001.18094 \mathrm{e}-011.00000 \mathrm{e}-092.12000 \mathrm{e}-01$ $1.18094 \mathrm{e}+00$ 1.18094e+00 1.18094e-01 1.00000e-09 2.12000e-01 $1.18094 \mathrm{e}+001.18094 \mathrm{e}+00$ 1.18094e-01 1.00000e-09 2.12000e-01 $1.18094 \mathrm{e}+001.18094 \mathrm{e}+001.18094 \mathrm{e}-011.00000 \mathrm{e}-092.12000 \mathrm{e}-01$ $1.00000 \mathrm{e}-02$ 1.00000e-02 1.00000e-03 1.00000e-09 1.00000e-01 $1.00000 \mathrm{e}+001.00000 \mathrm{e}+001.00000 \mathrm{e}-011.00000 \mathrm{e}-091.00000 \mathrm{e}-01$ $1.00000 \mathrm{e}-05$ 1.00000e-05 1.00000e-06 1.00000e-09 1.00000e-01 $1.00000 \mathrm{e}+001.00000 \mathrm{e}+001.00000 \mathrm{e}-011.00000 \mathrm{e}-091.00000 \mathrm{e}-01$ Element: 4289 \# of layers: 15

$\mathrm{Kx} \mathrm{Ky} \mathrm{Kz}$ Ss Por

$2.95555 \mathrm{e}+012.95555 \mathrm{e}+012.95555 \mathrm{e}+00$ 1.00000e-09 7.00000e-02 $2.95555 \mathrm{e}+012.95555 \mathrm{e}+012.95555 \mathrm{e}+00$ 1.00000e-09 7.00000e-02 $2.95555 \mathrm{e}+012.95555 \mathrm{e}+012.95555 \mathrm{e}+001.00000 \mathrm{e}-09$ 7.00000e-02 $2.95555 \mathrm{e}+012.95555 \mathrm{e}+012.95555 \mathrm{e}+001.00000 \mathrm{e}-09$ 7.00000e-02 5.00000e-04 5.00000e-04 5.00000e-05 1.00000e-09 1.00000e-01 5.00000e-04 5.00000e-04 5.00000e-05 1.00000e-09 1.00000e-01 $1.18094 \mathrm{e}+001.18094 \mathrm{e}+001.18094 \mathrm{e}-011.00000 \mathrm{e}-092.12000 \mathrm{e}-01$ $1.18094 \mathrm{e}+001.18094 \mathrm{e}+001.18094 \mathrm{e}-01$ 1.00000e-09 2.12000e-01 $1.18094 \mathrm{e}+001.18094 \mathrm{e}+001.18094 \mathrm{e}-01$ 1.00000e-09 2.12000e-01 $1.18094 \mathrm{e}+001.18094 \mathrm{e}+00$ 1.18094e-01 1.00000e-09 2.12000e-01 $1.18094 \mathrm{e}+001.18094 \mathrm{e}+001.18094 \mathrm{e}-011.00000 \mathrm{e}-092.12000 \mathrm{e}-01$ $1.00000 \mathrm{e}-02$ 1.00000e-02 1.00000e-03 1.00000e-09 1.00000e-01 $1.00000 \mathrm{e}+001.00000 \mathrm{e}+001.00000 \mathrm{e}-011.00000 \mathrm{e}-091.00000 \mathrm{e}-01$ $1.00000 \mathrm{e}-05$ 1.00000e-05 1.00000e-06 1.00000e-09 1.00000e-01 $1.00000 \mathrm{e}+001.00000 \mathrm{e}+001.00000 \mathrm{e}-01$ 1.00000e-09 1.00000e-01 Element: 4290 \# of layers: 15 
$\mathrm{Kx} \mathrm{Ky} \mathrm{Kz}$ Ss Por

$2.95555 \mathrm{e}+012.95555 \mathrm{e}+012.95555 \mathrm{e}+00$ 1.00000e-09 7.00000e-02 $2.95555 \mathrm{e}+012.95555 \mathrm{e}+012.95555 \mathrm{e}+001.00000 \mathrm{e}-09$ 7.00000e-02 $2.95555 \mathrm{e}+012.95555 \mathrm{e}+012.95555 \mathrm{e}+001.00000 \mathrm{e}-09$ 7.00000e-02 $2.95555 \mathrm{e}+012.95555 \mathrm{e}+012.95555 \mathrm{e}+001.00000 \mathrm{e}-09$ 7.00000e-02 5.00000e-04 5.00000e-04 5.00000e-05 1.00000e-09 1.00000e-01 5.00000e-04 5.00000e-04 5.00000e-05 1.00000e-09 1.00000e-01 $1.18094 \mathrm{e}+001.18094 \mathrm{e}+001.18094 \mathrm{e}-011.00000 \mathrm{e}-092.12000 \mathrm{e}-01$ $1.18094 \mathrm{e}+001.18094 \mathrm{e}+00$ 1.18094e-01 1.00000e-09 2.12000e-01 $1.18094 \mathrm{e}+001.18094 \mathrm{e}+001.18094 \mathrm{e}-01$ 1.00000e-09 2.12000e-01 $1.18094 \mathrm{e}+001.18094 \mathrm{e}+001.18094 \mathrm{e}-01$ 1.00000e-09 2.12000e-01 $1.18094 \mathrm{e}+001.18094 \mathrm{e}+001.18094 \mathrm{e}-011.00000 \mathrm{e}-092.12000 \mathrm{e}-01$ $1.00000 \mathrm{e}-02$ 1.00000e-02 1.00000e-03 1.00000e-09 1.00000e-01 $1.00000 \mathrm{e}+001.00000 \mathrm{e}+001.00000 \mathrm{e}-011.00000 \mathrm{e}-091.00000 \mathrm{e}-01$ $1.00000 \mathrm{e}-05$ 1.00000e-05 1.00000e-06 1.00000e-09 1.00000e-01 $1.00000 \mathrm{e}+001.00000 \mathrm{e}+001.00000 \mathrm{e}-011.00000 \mathrm{e}-091.00000 \mathrm{e}-01$ Element: 4291 \# of layers: 15

$\mathrm{Kx} \mathrm{Ky} \mathrm{Kz}$ Ss Por

$3.09854 \mathrm{e}+013.09854 \mathrm{e}+013.09854 \mathrm{e}+001.00000 \mathrm{e}-09$ 7.00000e-02 $3.09854 \mathrm{e}+013.09854 \mathrm{e}+013.09854 \mathrm{e}+001.00000 \mathrm{e}-09$ 7.00000e-02 $3.09854 \mathrm{e}+013.09854 \mathrm{e}+013.09854 \mathrm{e}+001.00000 \mathrm{e}-097.00000 \mathrm{e}-02$ $3.09854 \mathrm{e}+013.09854 \mathrm{e}+013.09854 \mathrm{e}+001.00000 \mathrm{e}-09$ 7.00000e-02 5.00000e-04 5.00000e-04 5.00000e-05 1.00000e-09 1.00000e-01 5.00000e-04 5.00000e-04 5.00000e-05 1.00000e-09 1.00000e-01 $1.23804 \mathrm{e}+001.23804 \mathrm{e}+00 \quad 1.23804 \mathrm{e}-011.00000 \mathrm{e}-092.12000 \mathrm{e}-01$ $1.23804 \mathrm{e}+001.23804 \mathrm{e}+001.23804 \mathrm{e}-01$ 1.00000e-09 2.12000e-01 $1.23804 \mathrm{e}+001.23804 \mathrm{e}+001.23804 \mathrm{e}-011.00000 \mathrm{e}-092.12000 \mathrm{e}-01$ $1.23804 \mathrm{e}+001.23804 \mathrm{e}+001.23804 \mathrm{e}-01$ 1.00000e-09 2.12000e-01 $1.23804 \mathrm{e}+001.23804 \mathrm{e}+00 \quad 1.23804 \mathrm{e}-01 \quad 1.00000 \mathrm{e}-092.12000 \mathrm{e}-01$ $1.00000 \mathrm{e}-021.00000 \mathrm{e}-021.00000 \mathrm{e}-031.00000 \mathrm{e}-091.00000 \mathrm{e}-01$ $1.00000 \mathrm{e}+001.00000 \mathrm{e}+001.00000 \mathrm{e}-01$ 1.00000e-09 1.00000e-01 1.00000e-05 1.00000e-05 1.00000e-06 1.00000e-09 1.00000e-01 $1.00000 \mathrm{e}+001.00000 \mathrm{e}+001.00000 \mathrm{e}-011.00000 \mathrm{e}-091.00000 \mathrm{e}-01$ Element: 4292 \# of layers: 14

$\mathrm{Kx} \mathrm{Ky} \mathrm{Kz}$ Ss Por

$3.09854 \mathrm{e}+013.09854 \mathrm{e}+013.09854 \mathrm{e}+001.00000 \mathrm{e}-09$ 7.00000e-02 $3.09854 \mathrm{e}+013.09854 \mathrm{e}+013.09854 \mathrm{e}+001.00000 \mathrm{e}-09$ 7.00000e-02 $3.09854 \mathrm{e}+013.09854 \mathrm{e}+013.09854 \mathrm{e}+001.00000 \mathrm{e}-09$ 7.00000e-02 5.00000e-04 5.00000e-04 5.00000e-05 1.00000e-09 1.00000e-01 5.00000e-04 5.00000e-04 5.00000e-05 1.00000e-09 1.00000e-01 $1.23804 \mathrm{e}+001.23804 \mathrm{e}+001.23804 \mathrm{e}-01$ 1.00000e-09 2.12000e-01 $1.23804 \mathrm{e}+001.23804 \mathrm{e}+001.23804 \mathrm{e}-011.00000 \mathrm{e}-092.12000 \mathrm{e}-01$ $1.23804 \mathrm{e}+001.23804 \mathrm{e}+001.23804 \mathrm{e}-011.00000 \mathrm{e}-092.12000 \mathrm{e}-01$ $1.23804 \mathrm{e}+001.23804 \mathrm{e}+00$ 1.23804e-01 1.00000e-09 2.12000e-01 $1.23804 \mathrm{e}+001.23804 \mathrm{e}+001.23804 \mathrm{e}-011.00000 \mathrm{e}-092.12000 \mathrm{e}-01$ $1.00000 \mathrm{e}-02$ 1.00000e-02 1.00000e-03 1.00000e-09 1.00000e-01 
$1.00000 \mathrm{e}+001.00000 \mathrm{e}+001.00000 \mathrm{e}-011.00000 \mathrm{e}-091.00000 \mathrm{e}-01$ $1.00000 \mathrm{e}-05$ 1.00000e-05 1.00000e-06 1.00000e-09 1.00000e-01 $1.00000 \mathrm{e}+001.00000 \mathrm{e}+001.00000 \mathrm{e}-011.00000 \mathrm{e}-09$ 1.00000e-01 Element: 4293 \# of layers: 14

$\mathrm{Kx} \mathrm{Ky} \mathrm{Kz}$ Ss Por

$2.84617 \mathrm{e}+012.84617 \mathrm{e}+012.84617 \mathrm{e}+00$ 1.00000e-09 7.00000e-02 $2.84617 \mathrm{e}+012.84617 \mathrm{e}+012.84617 \mathrm{e}+00$ 1.00000e-09 7.00000e-02 $2.84617 \mathrm{e}+012.84617 \mathrm{e}+012.84617 \mathrm{e}+001.00000 \mathrm{e}-09$ 7.00000e-02 5.00000e-04 5.00000e-04 5.00000e-05 1.00000e-09 1.00000e-01 5.00000e-04 5.00000e-04 5.00000e-05 1.00000e-09 1.00000e-01 $1.13724 \mathrm{e}+001.13724 \mathrm{e}+001.13724 \mathrm{e}-011.00000 \mathrm{e}-092.12000 \mathrm{e}-01$ $1.13724 \mathrm{e}+001.13724 \mathrm{e}+001.13724 \mathrm{e}-011.00000 \mathrm{e}-092.12000 \mathrm{e}-01$ $1.13724 \mathrm{e}+001.13724 \mathrm{e}+001.13724 \mathrm{e}-011.00000 \mathrm{e}-092.12000 \mathrm{e}-01$ $1.13724 \mathrm{e}+001.13724 \mathrm{e}+001.13724 \mathrm{e}-01$ 1.00000e-09 2.12000e-01 $1.13724 \mathrm{e}+001.13724 \mathrm{e}+001.13724 \mathrm{e}-01$ 1.00000e-09 2.12000e-01 $1.00000 \mathrm{e}-02$ 1.00000e-02 1.00000e-03 1.00000e-09 1.00000e-01 $1.00000 \mathrm{e}+001.00000 \mathrm{e}+001.00000 \mathrm{e}-011.00000 \mathrm{e}-091.00000 \mathrm{e}-01$ $1.00000 \mathrm{e}-05$ 1.00000e-05 1.00000e-06 1.00000e-09 1.00000e-01 $1.00000 \mathrm{e}+001.00000 \mathrm{e}+001.00000 \mathrm{e}-011.00000 \mathrm{e}-091.00000 \mathrm{e}-01$ Element: 4294 \# of layers: 14

Kx Ky Kz Ss Por

3.02718e+01 3.02718e+01 3.02718e+00 1.00000e-09 7.00000e-02 $3.02718 \mathrm{e}+013.02718 \mathrm{e}+013.02718 \mathrm{e}+001.00000 \mathrm{e}-09$ 7.00000e-02 $3.02718 \mathrm{e}+013.02718 \mathrm{e}+013.02718 \mathrm{e}+001.00000 \mathrm{e}-09$ 7.00000e-02 5.00000e-04 5.00000e-04 5.00000e-05 1.00000e-09 1.00000e-01 5.00000e-04 5.00000e-04 5.00000e-05 1.00000e-09 1.00000e-01 $1.20954 \mathrm{e}+001.20954 \mathrm{e}+001.20954 \mathrm{e}-011.00000 \mathrm{e}-092.12000 \mathrm{e}-01$ $1.20954 \mathrm{e}+001.20954 \mathrm{e}+001.20954 \mathrm{e}-011.00000 \mathrm{e}-092.12000 \mathrm{e}-01$ $1.20954 \mathrm{e}+001.20954 \mathrm{e}+001.20954 \mathrm{e}-011.00000 \mathrm{e}-092.12000 \mathrm{e}-01$ $1.20954 \mathrm{e}+001.20954 \mathrm{e}+00 \quad 1.20954 \mathrm{e}-011.00000 \mathrm{e}-092.12000 \mathrm{e}-01$ $1.20954 \mathrm{e}+001.20954 \mathrm{e}+001.20954 \mathrm{e}-01$ 1.00000e-09 2.12000e-01 $1.00000 \mathrm{e}-02$ 1.00000e-02 1.00000e-03 1.00000e-09 1.00000e-01 $1.00000 \mathrm{e}+001.00000 \mathrm{e}+001.00000 \mathrm{e}-011.00000 \mathrm{e}-091.00000 \mathrm{e}-01$ 1.00000e-05 1.00000e-05 1.00000e-06 1.00000e-09 1.00000e-01 $1.00000 \mathrm{e}+001.00000 \mathrm{e}+001.00000 \mathrm{e}-01$ 1.00000e-09 1.00000e-01 Element: 4295 \# of layers: 14

Kx Ky Kz Ss Por

$2.95555 \mathrm{e}+012.95555 \mathrm{e}+012.95555 \mathrm{e}+00$ 1.00000e-09 7.00000e-02 $2.95555 \mathrm{e}+012.95555 \mathrm{e}+012.95555 \mathrm{e}+001.00000 \mathrm{e}-09$ 7.00000e-02 $2.95555 \mathrm{e}+012.95555 \mathrm{e}+012.95555 \mathrm{e}+001.00000 \mathrm{e}-09$ 7.00000e-02 5.00000e-04 5.00000e-04 5.00000e-05 1.00000e-09 1.00000e-01 5.00000e-04 5.00000e-04 5.00000e-05 1.00000e-09 1.00000e-01 $1.18094 \mathrm{e}+001.18094 \mathrm{e}+00$ 1.18094e-01 1.00000e-09 2.12000e-01 $1.18094 \mathrm{e}+001.18094 \mathrm{e}+00$ 1.18094e-01 1.00000e-09 2.12000e-01 $1.18094 \mathrm{e}+001.18094 \mathrm{e}+001.18094 \mathrm{e}-01$ 1.00000e-09 2.12000e-01 $1.18094 \mathrm{e}+001.18094 \mathrm{e}+001.18094 \mathrm{e}-01$ 1.00000e-09 2.12000e-01 
$1.18094 \mathrm{e}+00$ 1.18094e+00 1.18094e-01 1.00000e-09 2.12000e-01 $1.00000 \mathrm{e}-02$ 1.00000e-02 1.00000e-03 1.00000e-09 1.00000e-01 $1.00000 \mathrm{e}+001.00000 \mathrm{e}+001.00000 \mathrm{e}-011.00000 \mathrm{e}-091.00000 \mathrm{e}-01$ $1.00000 \mathrm{e}-05$ 1.00000e-05 1.00000e-06 1.00000e-09 1.00000e-01 $1.00000 \mathrm{e}+001.00000 \mathrm{e}+001.00000 \mathrm{e}-01$ 1.00000e-09 1.00000e-01 Element: 4296 \# of layers: 14

$\mathrm{Kx} \mathrm{Ky} \mathrm{Kz}$ Ss Por

3.15260e+01 3.15260e+01 3.15260e+00 1.00000e-09 7.00000e-02

$3.15260 \mathrm{e}+013.15260 \mathrm{e}+013.15260 \mathrm{e}+00$ 1.00000e-09 7.00000e-02

$3.15260 \mathrm{e}+013.15260 \mathrm{e}+013.15260 \mathrm{e}+001.00000 \mathrm{e}-097.00000 \mathrm{e}-02$ 5.00000e-04 5.00000e-04 5.00000e-05 1.00000e-09 1.00000e-01 5.00000e-04 5.00000e-04 5.00000e-05 1.00000e-09 1.00000e-01 $1.25967 \mathrm{e}+00$ 1.25967e+00 1.25967e-01 1.00000e-09 2.12000e-01 $1.25967 \mathrm{e}+001.25967 \mathrm{e}+00$ 1.25967e-01 1.00000e-09 2.12000e-01 $1.25967 \mathrm{e}+00$ 1.25967e+00 1.25967e-01 1.00000e-09 2.12000e-01 $1.25967 \mathrm{e}+00$ 1.25967e+00 1.25967e-01 1.00000e-09 2.12000e-01 $1.25967 \mathrm{e}+001.25967 \mathrm{e}+00$ 1.25967e-01 1.00000e-09 2.12000e-01 $1.00000 \mathrm{e}-02$ 1.00000e-02 1.00000e-03 1.00000e-09 1.00000e-01 $1.00000 \mathrm{e}+001.00000 \mathrm{e}+001.00000 \mathrm{e}-011.00000 \mathrm{e}-091.00000 \mathrm{e}-01$ $1.00000 \mathrm{e}-05$ 1.00000e-05 1.00000e-06 1.00000e-09 1.00000e-01 $1.00000 \mathrm{e}+001.00000 \mathrm{e}+001.00000 \mathrm{e}-011.00000 \mathrm{e}-091.00000 \mathrm{e}-01$ Element: 4297 \# of layers: 14

$\mathrm{Kx} \mathrm{Ky} \mathrm{Kz}$ Ss Por

3.36965e+01 3.36965e+01 3.36965e+00 1.00000e-09 7.00000e-02 $3.36965 \mathrm{e}+013.36965 \mathrm{e}+013.36965 \mathrm{e}+001.00000 \mathrm{e}-09$ 7.00000e-02 $3.36965 \mathrm{e}+013.36965 \mathrm{e}+013.36965 \mathrm{e}+001.00000 \mathrm{e}-097.00000 \mathrm{e}-02$ 5.00000e-04 5.00000e-04 5.00000e-05 1.00000e-09 1.00000e-01 5.00000e-04 5.00000e-04 5.00000e-05 1.00000e-09 1.00000e-01 $1.34638 \mathrm{e}+00$ 1.34638e+00 1.34638e-01 1.00000e-09 2.12000e-01 $1.34638 \mathrm{e}+00$ 1.34638e+00 1.34638e-01 1.00000e-09 2.12000e-01 $1.34638 \mathrm{e}+00$ 1.34638e+00 1.34638e-01 1.00000e-09 2.12000e-01 $1.34638 \mathrm{e}+00$ 1.34638e+00 1.34638e-01 1.00000e-09 2.12000e-01 $1.34638 \mathrm{e}+001.34638 \mathrm{e}+00$ 1.34638e-01 1.00000e-09 2.12000e-01 $1.00000 \mathrm{e}-02$ 1.00000e-02 1.00000e-03 1.00000e-09 1.00000e-01 $1.00000 \mathrm{e}+001.00000 \mathrm{e}+001.00000 \mathrm{e}-011.00000 \mathrm{e}-091.00000 \mathrm{e}-01$ $1.00000 \mathrm{e}-05$ 1.00000e-05 1.00000e-06 1.00000e-09 1.00000e-01 $1.00000 \mathrm{e}+001.00000 \mathrm{e}+001.00000 \mathrm{e}-011.00000 \mathrm{e}-091.00000 \mathrm{e}-01$ Element: 4298 \# of layers: 12

$\mathrm{Kx} \mathrm{Ky} \mathrm{Kz}$ Ss Por

3.36965e+01 3.36965e+01 3.36965e+00 1.00000e-09 7.00000e-02 $3.36965 \mathrm{e}+013.36965 \mathrm{e}+013.36965 \mathrm{e}+00$ 1.00000e-09 7.00000e-02 $3.36965 \mathrm{e}+013.36965 \mathrm{e}+013.36965 \mathrm{e}+001.00000 \mathrm{e}-09$ 7.00000e-02 5.00000e-04 5.00000e-04 5.00000e-05 1.00000e-09 1.00000e-01 $5.00000 \mathrm{e}-04$ 5.00000e-04 5.00000e-05 1.00000e-09 1.00000e-01 $1.34638 \mathrm{e}+001.34638 \mathrm{e}+00$ 1.34638e-01 1.00000e-09 2.12000e-01 $1.34638 \mathrm{e}+001.34638 \mathrm{e}+00$ 1.34638e-01 1.00000e-09 2.12000e-01 
$1.34638 \mathrm{e}+00$ 1.34638e+00 1.34638e-01 1.00000e-09 2.12000e-01 $1.00000 \mathrm{e}-02$ 1.00000e-02 1.00000e-03 1.00000e-09 1.00000e-01 $1.00000 \mathrm{e}+001.00000 \mathrm{e}+001.00000 \mathrm{e}-011.00000 \mathrm{e}-091.00000 \mathrm{e}-01$ $1.00000 \mathrm{e}-05$ 1.00000e-05 1.00000e-06 1.00000e-09 1.00000e-01 $1.00000 \mathrm{e}+001.00000 \mathrm{e}+001.00000 \mathrm{e}-011.00000 \mathrm{e}-091.00000 \mathrm{e}-01$ Element: 4299 \# of layers: 11

$\mathrm{Kx} \mathrm{Ky} \mathrm{Kz}$ Ss Por

3.36965e+01 3.36965e+01 3.36965e+00 1.00000e-09 7.00000e-02

$3.36965 \mathrm{e}+013.36965 \mathrm{e}+013.36965 \mathrm{e}+001.00000 \mathrm{e}-09$ 7.00000e-02

5.00000e-04 5.00000e-04 5.00000e-05 1.00000e-09 1.00000e-01

5.00000e-04 5.00000e-04 5.00000e-05 1.00000e-09 1.00000e-01

$1.34638 \mathrm{e}+001.34638 \mathrm{e}+001.34638 \mathrm{e}-01$ 1.00000e-09 2.12000e-01

$1.34638 \mathrm{e}+00$ 1.34638e+00 1.34638e-01 1.00000e-09 2.12000e-01

$1.34638 \mathrm{e}+001.34638 \mathrm{e}+00$ 1.34638e-01 1.00000e-09 2.12000e-01

$1.00000 \mathrm{e}-02$ 1.00000e-02 1.00000e-03 1.00000e-09 1.00000e-01

$1.00000 \mathrm{e}+001.00000 \mathrm{e}+001.00000 \mathrm{e}-011.00000 \mathrm{e}-091.00000 \mathrm{e}-01$

$1.00000 \mathrm{e}-05$ 1.00000e-05 1.00000e-06 1.00000e-09 1.00000e-01

$1.00000 \mathrm{e}+001.00000 \mathrm{e}+001.00000 \mathrm{e}-01$ 1.00000e-09 1.00000e-01

Element: 4300 \# of layers: 11

$\mathrm{Kx} \mathrm{Ky} \mathrm{Kz}$ Ss Por

3.21891e+01 3.21891e+01 3.21891e+00 1.00000e-09 7.00000e-02

$3.21891 \mathrm{e}+013.21891 \mathrm{e}+013.21891 \mathrm{e}+001.00000 \mathrm{e}-097.00000 \mathrm{e}-02$

5.00000e-04 5.00000e-04 5.00000e-05 1.00000e-09 1.00000e-01

5.00000e-04 5.00000e-04 5.00000e-05 1.00000e-09 1.00000e-01

$1.28617 \mathrm{e}+001.28617 \mathrm{e}+00$ 1.28617e-01 1.00000e-09 2.12000e-01

$1.28617 \mathrm{e}+001.28617 \mathrm{e}+00$ 1.28617e-01 1.00000e-09 2.12000e-01

$1.28617 \mathrm{e}+001.28617 \mathrm{e}+00$ 1.28617e-01 1.00000e-09 2.12000e-01

$1.00000 \mathrm{e}-02$ 1.00000e-02 1.00000e-03 1.00000e-09 1.00000e-01

$1.00000 \mathrm{e}+001.00000 \mathrm{e}+001.00000 \mathrm{e}-011.00000 \mathrm{e}-091.00000 \mathrm{e}-01$

$1.00000 \mathrm{e}-05$ 1.00000e-05 1.00000e-06 1.00000e-09 1.00000e-01

$1.00000 \mathrm{e}+001.00000 \mathrm{e}+001.00000 \mathrm{e}-011.00000 \mathrm{e}-091.00000 \mathrm{e}-01$

Element: 4301 \# of layers: 13

Kx Ky Kz Ss Por

3.21891e+01 3.21891e+01 3.21891e+00 1.00000e-09 7.00000e-02

$3.21891 \mathrm{e}+013.21891 \mathrm{e}+013.21891 \mathrm{e}+001.00000 \mathrm{e}-09$ 7.00000e-02

$3.21891 \mathrm{e}+013.21891 \mathrm{e}+013.21891 \mathrm{e}+001.00000 \mathrm{e}-09$ 7.00000e-02

5.00000e-04 5.00000e-04 5.00000e-05 1.00000e-09 1.00000e-01

$1.28617 \mathrm{e}+001.28617 \mathrm{e}+00$ 1.28617e-01 1.00000e-09 2.12000e-01

$1.28617 \mathrm{e}+001.28617 \mathrm{e}+00$ 1.28617e-01 1.00000e-09 2.12000e-01

$1.28617 \mathrm{e}+001.28617 \mathrm{e}+00$ 1.28617e-01 1.00000e-09 2.12000e-01

$1.28617 \mathrm{e}+001.28617 \mathrm{e}+00$ 1.28617e-01 1.00000e-09 2.12000e-01

$1.28617 \mathrm{e}+001.28617 \mathrm{e}+00$ 1.28617e-01 1.00000e-09 2.12000e-01

$1.00000 \mathrm{e}-021.00000 \mathrm{e}-021.00000 \mathrm{e}-031.00000 \mathrm{e}-091.00000 \mathrm{e}-01$

$1.00000 \mathrm{e}+001.00000 \mathrm{e}+001.00000 \mathrm{e}-011.00000 \mathrm{e}-091.00000 \mathrm{e}-01$

$1.00000 \mathrm{e}-05$ 1.00000e-05 1.00000e-06 1.00000e-09 1.00000e-01

$1.00000 \mathrm{e}+001.00000 \mathrm{e}+001.00000 \mathrm{e}-011.00000 \mathrm{e}-091.00000 \mathrm{e}-01$ 
Element: 4302 \# of layers: 14

$\mathrm{Kx} \mathrm{Ky} \mathrm{Kz}$ Ss Por

3.35965e+01 3.35965e+01 3.35965e+00 1.00000e-09 7.00000e-02

$3.35965 \mathrm{e}+013.35965 \mathrm{e}+013.35965 \mathrm{e}+001.00000 \mathrm{e}-09$ 7.00000e-02

$3.35965 \mathrm{e}+013.35965 \mathrm{e}+013.35965 \mathrm{e}+001.00000 \mathrm{e}-097.00000 \mathrm{e}-02$

5.00000e-04 5.00000e-04 5.00000e-05 1.00000e-09 1.00000e-01

5.00000e-04 5.00000e-04 5.00000e-05 1.00000e-09 1.00000e-01

$1.34240 \mathrm{e}+001.34240 \mathrm{e}+00$ 1.34240e-01 1.00000e-09 2.12000e-01

$1.34240 \mathrm{e}+001.34240 \mathrm{e}+001.34240 \mathrm{e}-01$ 1.00000e-09 2.12000e-01

$1.34240 \mathrm{e}+001.34240 \mathrm{e}+00$ 1.34240e-01 1.00000e-09 2.12000e-01

$1.34240 \mathrm{e}+001.34240 \mathrm{e}+00$ 1.34240e-01 1.00000e-09 2.12000e-01

$1.34240 \mathrm{e}+001.34240 \mathrm{e}+001.34240 \mathrm{e}-01$ 1.00000e-09 2.12000e-01

$1.00000 \mathrm{e}-02$ 1.00000e-02 1.00000e-03 1.00000e-09 1.00000e-01

$1.00000 \mathrm{e}+001.00000 \mathrm{e}+001.00000 \mathrm{e}-011.00000 \mathrm{e}-091.00000 \mathrm{e}-01$

$1.00000 \mathrm{e}-05$ 1.00000e-05 1.00000e-06 1.00000e-09 1.00000e-01

$1.00000 \mathrm{e}+001.00000 \mathrm{e}+001.00000 \mathrm{e}-011.00000 \mathrm{e}-091.00000 \mathrm{e}-01$

Element: 4303 \# of layers: 14

$\mathrm{Kx} \mathrm{Ky} \mathrm{Kz}$ Ss Por

3.15260e+01 3.15260e+01 3.15260e+00 1.00000e-09 7.00000e-02

$3.15260 \mathrm{e}+013.15260 \mathrm{e}+013.15260 \mathrm{e}+001.00000 \mathrm{e}-09$ 7.00000e-02

$3.15260 \mathrm{e}+013.15260 \mathrm{e}+013.15260 \mathrm{e}+001.00000 \mathrm{e}-097.00000 \mathrm{e}-02$

5.00000e-04 5.00000e-04 5.00000e-05 1.00000e-09 1.00000e-01

5.00000e-04 5.00000e-04 5.00000e-05 1.00000e-09 1.00000e-01

$1.25967 \mathrm{e}+00$ 1.25967e+00 1.25967e-01 1.00000e-09 2.12000e-01

$1.25967 \mathrm{e}+001.25967 \mathrm{e}+00$ 1.25967e-01 1.00000e-09 2.12000e-01

$1.25967 \mathrm{e}+001.25967 \mathrm{e}+00$ 1.25967e-01 1.00000e-09 2.12000e-01

$1.25967 \mathrm{e}+001.25967 \mathrm{e}+00$ 1.25967e-01 1.00000e-09 2.12000e-01

$1.25967 \mathrm{e}+00$ 1.25967e+00 1.25967e-01 1.00000e-09 2.12000e-01

$1.00000 \mathrm{e}-02$ 1.00000e-02 1.00000e-03 1.00000e-09 1.00000e-01

$1.00000 \mathrm{e}+001.00000 \mathrm{e}+001.00000 \mathrm{e}-011.00000 \mathrm{e}-091.00000 \mathrm{e}-01$

$1.00000 \mathrm{e}-05$ 1.00000e-05 1.00000e-06 1.00000e-09 1.00000e-01

$1.00000 \mathrm{e}+001.00000 \mathrm{e}+001.00000 \mathrm{e}-01$ 1.00000e-09 1.00000e-01

Element: 4304 \# of layers: 14

$\mathrm{Kx} \mathrm{Ky} \mathrm{Kz}$ Ss Por

3.36965e+01 3.36965e+01 3.36965e+00 1.00000e-09 7.00000e-02

$3.36965 \mathrm{e}+013.36965 \mathrm{e}+013.36965 \mathrm{e}+001.00000 \mathrm{e}-09$ 7.00000e-02

$3.36965 \mathrm{e}+013.36965 \mathrm{e}+013.36965 \mathrm{e}+001.00000 \mathrm{e}-09$ 7.00000e-02

5.00000e-04 5.00000e-04 5.00000e-05 1.00000e-09 1.00000e-01

5.00000e-04 5.00000e-04 5.00000e-05 1.00000e-09 1.00000e-01

$1.34638 \mathrm{e}+001.34638 \mathrm{e}+00$ 1.34638e-01 1.00000e-09 2.12000e-01

$1.34638 \mathrm{e}+00$ 1.34638e+00 1.34638e-01 1.00000e-09 2.12000e-01

$1.34638 \mathrm{e}+001.34638 \mathrm{e}+00$ 1.34638e-01 1.00000e-09 2.12000e-01

1.34638e+00 1.34638e+00 1.34638e-01 1.00000e-09 2.12000e-01

$1.34638 \mathrm{e}+001.34638 \mathrm{e}+00$ 1.34638e-01 1.00000e-09 2.12000e-01

$1.00000 \mathrm{e}-02$ 1.00000e-02 1.00000e-03 1.00000e-09 1.00000e-01

$1.00000 \mathrm{e}+001.00000 \mathrm{e}+001.00000 \mathrm{e}-01$ 1.00000e-09 1.00000e-01 
$1.00000 \mathrm{e}-05$ 1.00000e-05 1.00000e-06 1.00000e-09 1.00000e-01 $1.00000 \mathrm{e}+001.00000 \mathrm{e}+001.00000 \mathrm{e}-01$ 1.00000e-09 1.00000e-01 Element: 4305 \# of layers: 11

$\mathrm{Kx} \mathrm{Ky} \mathrm{Kz}$ Ss Por

$2.93492 \mathrm{e}+012.93492 \mathrm{e}+012.93492 \mathrm{e}+001.00000 \mathrm{e}-097.00000 \mathrm{e}-02$ $2.93492 \mathrm{e}+012.93492 \mathrm{e}+012.93492 \mathrm{e}+00$ 1.00000e-09 7.00000e-02 5.00000e-04 5.00000e-04 5.00000e-05 1.00000e-09 1.00000e-01 5.00000e-04 5.00000e-04 5.00000e-05 1.00000e-09 1.00000e-01 $1.17268 \mathrm{e}+001.17268 \mathrm{e}+00$ 1.17268e-01 1.00000e-09 2.12000e-01 $1.17268 \mathrm{e}+001.17268 \mathrm{e}+00$ 1.17268e-01 1.00000e-09 2.12000e-01 $1.17268 \mathrm{e}+001.17268 \mathrm{e}+001.17268 \mathrm{e}-01$ 1.00000e-09 2.12000e-01 $1.00000 \mathrm{e}-02$ 1.00000e-02 1.00000e-03 1.00000e-09 1.00000e-01 $1.00000 \mathrm{e}+001.00000 \mathrm{e}+001.00000 \mathrm{e}-011.00000 \mathrm{e}-091.00000 \mathrm{e}-01$ $1.00000 \mathrm{e}-05$ 1.00000e-05 1.00000e-06 1.00000e-09 1.00000e-01 $1.00000 \mathrm{e}+001.00000 \mathrm{e}+001.00000 \mathrm{e}-01$ 1.00000e-09 1.00000e-01 Element: 4306 \# of layers: 11

$\mathrm{Kx} \mathrm{Ky} \mathrm{Kz}$ Ss Por

$2.93492 \mathrm{e}+012.93492 \mathrm{e}+012.93492 \mathrm{e}+00$ 1.00000e-09 7.00000e-02 $2.93492 \mathrm{e}+012.93492 \mathrm{e}+012.93492 \mathrm{e}+001.00000 \mathrm{e}-09$ 7.00000e-02 5.00000e-04 5.00000e-04 5.00000e-05 1.00000e-09 1.00000e-01 5.00000e-04 5.00000e-04 5.00000e-05 1.00000e-09 1.00000e-01 $1.17268 \mathrm{e}+001.17268 \mathrm{e}+00$ 1.17268e-01 1.00000e-09 2.12000e-01 $1.17268 \mathrm{e}+001.17268 \mathrm{e}+00$ 1.17268e-01 1.00000e-09 2.12000e-01 $1.17268 \mathrm{e}+001.17268 \mathrm{e}+00$ 1.17268e-01 1.00000e-09 2.12000e-01 $1.00000 \mathrm{e}-02$ 1.00000e-02 1.00000e-03 1.00000e-09 1.00000e-01 $1.00000 \mathrm{e}+001.00000 \mathrm{e}+001.00000 \mathrm{e}-011.00000 \mathrm{e}-091.00000 \mathrm{e}-01$ $1.00000 \mathrm{e}-05$ 1.00000e-05 1.00000e-06 1.00000e-09 1.00000e-01 $1.00000 \mathrm{e}+001.00000 \mathrm{e}+001.00000 \mathrm{e}-011.00000 \mathrm{e}-091.00000 \mathrm{e}-01$ Element: 4307 \# of layers: 11

$\mathrm{Kx} \mathrm{Ky} \mathrm{Kz}$ Ss Por

2.93492e+01 2.93492e+01 2.93492e+00 1.00000e-09 7.00000e-02 $2.93492 \mathrm{e}+012.93492 \mathrm{e}+012.93492 \mathrm{e}+001.00000 \mathrm{e}-09$ 7.00000e-02 5.00000e-04 5.00000e-04 5.00000e-05 1.00000e-09 1.00000e-01 5.00000e-04 5.00000e-04 5.00000e-05 1.00000e-09 1.00000e-01 $1.17268 \mathrm{e}+001.17268 \mathrm{e}+001.17268 \mathrm{e}-01$ 1.00000e-09 2.12000e-01 $1.17268 \mathrm{e}+001.17268 \mathrm{e}+00$ 1.17268e-01 1.00000e-09 2.12000e-01 $1.17268 \mathrm{e}+001.17268 \mathrm{e}+00$ 1.17268e-01 1.00000e-09 2.12000e-01 1.00000e-01 1.00000e-01 1.00000e-02 1.00000e-09 1.00000e-01 $1.00000 \mathrm{e}+001.00000 \mathrm{e}+001.00000 \mathrm{e}-011.00000 \mathrm{e}-091.00000 \mathrm{e}-01$ $1.00000 \mathrm{e}-05$ 1.00000e-05 1.00000e-06 1.00000e-09 1.00000e-01 $1.00000 \mathrm{e}+001.00000 \mathrm{e}+001.00000 \mathrm{e}-011.00000 \mathrm{e}-091.00000 \mathrm{e}-01$ Element: 4308 \# of layers: 10

$\mathrm{Kx} \mathrm{Ky} \mathrm{Kz}$ Ss Por

3.65049e+01 3.65049e+01 3.65049e+00 1.00000e-09 7.00000e-02 $3.65049 \mathrm{e}+013.65049 \mathrm{e}+013.65049 \mathrm{e}+001.00000 \mathrm{e}-09$ 7.00000e-02 5.00000e-04 5.00000e-04 5.00000e-05 1.00000e-09 1.00000e-01 
$1.45862 \mathrm{e}+001.45862 \mathrm{e}+00$ 1.45862e-01 1.00000e-09 2.12000e-01 $1.45862 \mathrm{e}+001.45862 \mathrm{e}+00$ 1.45862e-01 1.00000e-09 2.12000e-01 $1.45862 \mathrm{e}+001.45862 \mathrm{e}+001.45862 \mathrm{e}-01$ 1.00000e-09 2.12000e-01 $1.00000 \mathrm{e}-011.00000 \mathrm{e}-01$ 1.00000e-02 1.00000e-09 1.00000e-01 $1.00000 \mathrm{e}+001.00000 \mathrm{e}+001.00000 \mathrm{e}-011.00000 \mathrm{e}-091.00000 \mathrm{e}-01$ $1.00000 \mathrm{e}-05$ 1.00000e-05 1.00000e-06 1.00000e-09 1.00000e-01 $1.00000 \mathrm{e}+001.00000 \mathrm{e}+001.00000 \mathrm{e}-01$ 1.00000e-09 1.00000e-01 Element: 4309 \# of layers: 10

$\mathrm{Kx} \mathrm{Ky} \mathrm{Kz}$ Ss Por

3.65049e+01 3.65049e+01 3.65049e+00 1.00000e-09 7.00000e-02 $3.65049 \mathrm{e}+013.65049 \mathrm{e}+013.65049 \mathrm{e}+00$ 1.00000e-09 7.00000e-02 5.00000e-04 5.00000e-04 5.00000e-05 1.00000e-09 1.00000e-01 $1.45862 \mathrm{e}+001.45862 \mathrm{e}+001.45862 \mathrm{e}-01$ 1.00000e-09 2.12000e-01 $1.45862 \mathrm{e}+001.45862 \mathrm{e}+001.45862 \mathrm{e}-01$ 1.00000e-09 2.12000e-01 $1.45862 \mathrm{e}+001.45862 \mathrm{e}+00$ 1.45862e-01 1.00000e-09 2.12000e-01 $1.00000 \mathrm{e}-01$ 1.00000e-01 1.00000e-02 1.00000e-09 1.00000e-01 $1.00000 \mathrm{e}+001.00000 \mathrm{e}+001.00000 \mathrm{e}-011.00000 \mathrm{e}-091.00000 \mathrm{e}-01$ $1.00000 \mathrm{e}-05$ 1.00000e-05 1.00000e-06 1.00000e-09 1.00000e-01 $1.00000 \mathrm{e}+001.00000 \mathrm{e}+001.00000 \mathrm{e}-011.00000 \mathrm{e}-091.00000 \mathrm{e}-01$ Element: 4310 \# of layers: 10

$\mathrm{Kx} \mathrm{Ky} \mathrm{Kz}$ Ss Por

2.93492e+01 2.93492e+01 2.93492e+00 1.00000e-09 7.00000e-02 $2.93492 \mathrm{e}+012.93492 \mathrm{e}+012.93492 \mathrm{e}+00$ 1.00000e-09 7.00000e-02 5.00000e-04 5.00000e-04 5.00000e-05 1.00000e-09 1.00000e-01

$1.17268 \mathrm{e}+001.17268 \mathrm{e}+00$ 1.17268e-01 1.00000e-09 2.12000e-01 $1.17268 \mathrm{e}+001.17268 \mathrm{e}+00$ 1.17268e-01 1.00000e-09 2.12000e-01 $1.17268 \mathrm{e}+001.17268 \mathrm{e}+00$ 1.17268e-01 1.00000e-09 2.12000e-01 1.00000e-01 1.00000e-01 1.00000e-02 1.00000e-09 1.00000e-01 $1.00000 \mathrm{e}+001.00000 \mathrm{e}+001.00000 \mathrm{e}-011.00000 \mathrm{e}-091.00000 \mathrm{e}-01$ $1.00000 \mathrm{e}-05$ 1.00000e-05 1.00000e-06 1.00000e-09 1.00000e-01 $1.00000 \mathrm{e}+001.00000 \mathrm{e}+001.00000 \mathrm{e}-01$ 1.00000e-09 1.00000e-01 Element: 4311 \# of layers: 11

Kx Ky Kz Ss Por 3.63373e+01 3.63373e+01 3.63373e+00 1.00000e-09 7.00000e-02 $3.63373 \mathrm{e}+013.63373 \mathrm{e}+013.63373 \mathrm{e}+00$ 1.00000e-09 7.00000e-02 5.00000e-04 5.00000e-04 5.00000e-05 1.00000e-09 1.00000e-01 5.00000e-04 5.00000e-04 5.00000e-05 1.00000e-09 1.00000e-01 $1.45191 \mathrm{e}+001.45191 \mathrm{e}+001.45191 \mathrm{e}-011.00000 \mathrm{e}-092.12000 \mathrm{e}-01$ $1.45191 \mathrm{e}+001.45191 \mathrm{e}+001.45191 \mathrm{e}-01$ 1.00000e-09 2.12000e-01 $1.45191 \mathrm{e}+001.45191 \mathrm{e}+001.45191 \mathrm{e}-01$ 1.00000e-09 2.12000e-01 $1.00000 \mathrm{e}-01$ 1.00000e-01 1.00000e-02 1.00000e-09 1.00000e-01 $1.00000 \mathrm{e}+001.00000 \mathrm{e}+001.00000 \mathrm{e}-011.00000 \mathrm{e}-091.00000 \mathrm{e}-01$ $1.00000 \mathrm{e}-05$ 1.00000e-05 1.00000e-06 1.00000e-09 1.00000e-01 $1.00000 \mathrm{e}+001.00000 \mathrm{e}+001.00000 \mathrm{e}-01$ 1.00000e-09 1.00000e-01 Element: 4312 \# of layers: 11

Kx Ky Kz Ss Por 
$3.22351 \mathrm{e}+013.22351 \mathrm{e}+013.22351 \mathrm{e}+00$ 1.00000e-09 7.00000e-02 $3.22351 \mathrm{e}+013.22351 \mathrm{e}+013.22351 \mathrm{e}+001.00000 \mathrm{e}-09$ 7.00000e-02 5.00000e-04 5.00000e-04 5.00000e-05 1.00000e-09 1.00000e-01 5.00000e-04 5.00000e-04 5.00000e-05 1.00000e-09 1.00000e-01 $1.28799 \mathrm{e}+001.28799 \mathrm{e}+00$ 1.28800e-01 1.00000e-09 2.12000e-01 $1.28799 \mathrm{e}+001.28799 \mathrm{e}+001.28800 \mathrm{e}-01$ 1.00000e-09 2.12000e-01 $1.28799 \mathrm{e}+001.28799 \mathrm{e}+001.28800 \mathrm{e}-01$ 1.00000e-09 2.12000e-01 $1.00000 \mathrm{e}-02$ 1.00000e-02 1.00000e-03 1.00000e-09 1.00000e-01 $1.00000 \mathrm{e}+001.00000 \mathrm{e}+001.00000 \mathrm{e}-011.00000 \mathrm{e}-091.00000 \mathrm{e}-01$ $1.00000 \mathrm{e}-05$ 1.00000e-05 1.00000e-06 1.00000e-09 1.00000e-01 $1.00000 \mathrm{e}+001.00000 \mathrm{e}+001.00000 \mathrm{e}-011.00000 \mathrm{e}-091.00000 \mathrm{e}-01$ Element: 4313 \# of layers: 11

$\mathrm{Kx} \mathrm{Ky} \mathrm{Kz}$ Ss Por

2.93492e+01 2.93492e+01 2.93492e+00 1.00000e-09 7.00000e-02 $2.93492 \mathrm{e}+012.93492 \mathrm{e}+012.93492 \mathrm{e}+001.00000 \mathrm{e}-09$ 7.00000e-02 5.00000e-04 5.00000e-04 5.00000e-05 1.00000e-09 1.00000e-01 5.00000e-04 5.00000e-04 5.00000e-05 1.00000e-09 1.00000e-01 $1.17268 \mathrm{e}+001.17268 \mathrm{e}+00$ 1.17268e-01 1.00000e-09 2.12000e-01 $1.17268 \mathrm{e}+001.17268 \mathrm{e}+00$ 1.17268e-01 1.00000e-09 2.12000e-01 $1.17268 \mathrm{e}+001.17268 \mathrm{e}+001.17268 \mathrm{e}-01$ 1.00000e-09 2.12000e-01 $1.00000 \mathrm{e}-011.00000 \mathrm{e}-01$ 1.00000e-02 1.00000e-09 1.00000e-01 $1.00000 \mathrm{e}+001.00000 \mathrm{e}+001.00000 \mathrm{e}-011.00000 \mathrm{e}-091.00000 \mathrm{e}-01$ $1.00000 \mathrm{e}-05$ 1.00000e-05 1.00000e-06 1.00000e-09 1.00000e-01 $1.00000 \mathrm{e}+001.00000 \mathrm{e}+001.00000 \mathrm{e}-011.00000 \mathrm{e}-091.00000 \mathrm{e}-01$ Element: 4314 \# of layers: 10

$\mathrm{Kx} \mathrm{Ky} \mathrm{Kz}$ Ss Por

$2.78391 \mathrm{e}+012.78391 \mathrm{e}+012.78391 \mathrm{e}+00$ 1.00000e-09 7.00000e-02

$2.78391 \mathrm{e}+012.78391 \mathrm{e}+012.78391 \mathrm{e}+001.00000 \mathrm{e}-09$ 7.00000e-02 5.00000e-04 5.00000e-04 5.00000e-05 1.00000e-09 1.00000e-01 5.00000e-04 5.00000e-04 5.00000e-05 1.00000e-09 1.00000e-01

$1.11236 \mathrm{e}+001.11236 \mathrm{e}+00$ 1.11236e-01 1.00000e-09 2.12000e-01 $1.11236 \mathrm{e}+001.11236 \mathrm{e}+001.11236 \mathrm{e}-01$ 1.00000e-09 2.12000e-01 $1.00000 \mathrm{e}-02$ 1.00000e-02 1.00000e-03 1.00000e-09 1.00000e-01 $1.00000 \mathrm{e}+001.00000 \mathrm{e}+001.00000 \mathrm{e}-011.00000 \mathrm{e}-091.00000 \mathrm{e}-01$ $1.00000 \mathrm{e}-05$ 1.00000e-05 1.00000e-06 1.00000e-09 1.00000e-01 $1.00000 \mathrm{e}+001.00000 \mathrm{e}+001.00000 \mathrm{e}-011.00000 \mathrm{e}-091.00000 \mathrm{e}-01$ Element: 4315 \# of layers: 9

$\mathrm{Kx} \mathrm{Ky} \mathrm{Kz}$ Ss Por

$2.78391 \mathrm{e}+012.78391 \mathrm{e}+012.78391 \mathrm{e}+00$ 1.00000e-09 7.00000e-02 $2.78391 \mathrm{e}+012.78391 \mathrm{e}+012.78391 \mathrm{e}+001.00000 \mathrm{e}-09$ 7.00000e-02 5.00000e-04 5.00000e-04 5.00000e-05 1.00000e-09 1.00000e-01 $1.11236 \mathrm{e}+001.11236 \mathrm{e}+00$ 1.11236e-01 1.00000e-09 2.12000e-01 $1.11236 \mathrm{e}+001.11236 \mathrm{e}+00$ 1.11236e-01 1.00000e-09 2.12000e-01 $1.00000 \mathrm{e}-02$ 1.00000e-02 1.00000e-03 1.00000e-09 1.00000e-01 $1.00000 \mathrm{e}+001.00000 \mathrm{e}+001.00000 \mathrm{e}-011.00000 \mathrm{e}-091.00000 \mathrm{e}-01$ $1.00000 \mathrm{e}-05$ 1.00000e-05 1.00000e-06 1.00000e-09 1.00000e-01 
$1.00000 \mathrm{e}+001.00000 \mathrm{e}+00$ 1.00000e-01 1.00000e-09 1.00000e-01

Element: 4316 \# of layers: 11

Kx Ky Kz Ss Por

$2.78391 \mathrm{e}+012.78391 \mathrm{e}+012.78391 \mathrm{e}+001.00000 \mathrm{e}-09$ 7.00000e-02

$2.78391 \mathrm{e}+012.78391 \mathrm{e}+012.78391 \mathrm{e}+001.00000 \mathrm{e}-09$ 7.00000e-02

$2.78391 \mathrm{e}+012.78391 \mathrm{e}+012.78391 \mathrm{e}+001.00000 \mathrm{e}-09$ 7.00000e-02

5.00000e-04 5.00000e-04 5.00000e-05 1.00000e-09 1.00000e-01

5.00000e-04 5.00000e-04 5.00000e-05 1.00000e-09 1.00000e-01

$1.11236 \mathrm{e}+001.11236 \mathrm{e}+001.11236 \mathrm{e}-011.00000 \mathrm{e}-092.12000 \mathrm{e}-01$

$1.11236 \mathrm{e}+001.11236 \mathrm{e}+001.11236 \mathrm{e}-01$ 1.00000e-09 2.12000e-01

1.00000e-02 1.00000e-02 1.00000e-03 1.00000e-09 1.00000e-01

$1.00000 \mathrm{e}+001.00000 \mathrm{e}+001.00000 \mathrm{e}-011.00000 \mathrm{e}-091.00000 \mathrm{e}-01$

$1.00000 \mathrm{e}-05$ 1.00000e-05 1.00000e-06 1.00000e-09 1.00000e-01

$1.00000 \mathrm{e}+001.00000 \mathrm{e}+001.00000 \mathrm{e}-011.00000 \mathrm{e}-09$ 1.00000e-01

Element: 4317 \# of layers: 11

Kx Ky Kz Ss Por

3.39821e+01 3.39821e+01 3.39821e+00 1.00000e-09 7.00000e-02

$3.39821 \mathrm{e}+013.39821 \mathrm{e}+013.39821 \mathrm{e}+00$ 1.00000e-09 7.00000e-02

$3.39821 \mathrm{e}+013.39821 \mathrm{e}+013.39821 \mathrm{e}+001.00000 \mathrm{e}-09$ 7.00000e-02

5.00000e-04 5.00000e-04 5.00000e-05 1.00000e-09 1.00000e-01

5.00000e-04 5.00000e-04 5.00000e-05 1.00000e-09 1.00000e-01

$1.35779 \mathrm{e}+001.35779 \mathrm{e}+00$ 1.35779e-01 1.00000e-09 2.12000e-01

$1.35779 \mathrm{e}+001.35779 \mathrm{e}+00$ 1.35779e-01 1.00000e-09 2.12000e-01

1.00000e-02 1.00000e-02 1.00000e-03 1.00000e-09 1.00000e-01

$1.00000 \mathrm{e}+001.00000 \mathrm{e}+001.00000 \mathrm{e}-011.00000 \mathrm{e}-091.00000 \mathrm{e}-01$

$1.00000 \mathrm{e}-05$ 1.00000e-05 1.00000e-06 1.00000e-09 1.00000e-01

$1.00000 \mathrm{e}+001.00000 \mathrm{e}+001.00000 \mathrm{e}-01$ 1.00000e-09 1.00000e-01

Element: 4318 \# of layers: 9

$\mathrm{Kx} \mathrm{Ky} \mathrm{Kz}$ Ss Por

3.39821e+01 3.39821e+01 3.39821e+00 1.00000e-09 7.00000e-02

$3.39821 \mathrm{e}+013.39821 \mathrm{e}+013.39821 \mathrm{e}+001.00000 \mathrm{e}-09$ 7.00000e-02

$3.39821 \mathrm{e}+013.39821 \mathrm{e}+013.39821 \mathrm{e}+001.00000 \mathrm{e}-09$ 7.00000e-02

5.00000e-04 5.00000e-04 5.00000e-05 1.00000e-09 1.00000e-01

5.00000e-04 5.00000e-04 5.00000e-05 1.00000e-09 1.00000e-01

$1.35779 \mathrm{e}+001.35779 \mathrm{e}+00$ 1.35779e-01 1.00000e-09 2.12000e-01

$1.35779 \mathrm{e}+001.35779 \mathrm{e}+00$ 1.35779e-01 1.00000e-09 2.12000e-01

$1.00000 \mathrm{e}-02$ 1.00000e-02 1.00000e-03 1.00000e-09 1.00000e-01

$1.00000 \mathrm{e}+001.00000 \mathrm{e}+001.00000 \mathrm{e}-011.00000 \mathrm{e}-091.00000 \mathrm{e}-01$

Element: 4319 \# of layers: 9

$\mathrm{Kx} \mathrm{Ky} \mathrm{Kz}$ Ss Por

2.78391e+01 2.78391e+01 2.78391e+00 1.00000e-09 7.00000e-02

$2.78391 \mathrm{e}+012.78391 \mathrm{e}+012.78391 \mathrm{e}+001.00000 \mathrm{e}-09$ 7.00000e-02

$2.78391 \mathrm{e}+012.78391 \mathrm{e}+012.78391 \mathrm{e}+001.00000 \mathrm{e}-09$ 7.00000e-02

$5.00000 \mathrm{e}-04$ 5.00000e-04 5.00000e-05 1.00000e-09 1.00000e-01

5.00000e-04 5.00000e-04 5.00000e-05 1.00000e-09 1.00000e-01

$1.11236 \mathrm{e}+001.11236 \mathrm{e}+001.11236 \mathrm{e}-011.00000 \mathrm{e}-092.12000 \mathrm{e}-01$ 
$1.11236 \mathrm{e}+001.11236 \mathrm{e}+00$ 1.11236e-01 1.00000e-09 2.12000e-01 $1.00000 \mathrm{e}-021.00000 \mathrm{e}-02$ 1.00000e-03 1.00000e-09 1.00000e-01 $1.00000 \mathrm{e}+001.00000 \mathrm{e}+001.00000 \mathrm{e}-011.00000 \mathrm{e}-091.00000 \mathrm{e}-01$ Element: 4320 \# of layers: 9

Kx Ky Kz Ss Por

$2.81436 \mathrm{e}+012.81436 \mathrm{e}+012.81436 \mathrm{e}+00$ 1.00000e-09 7.00000e-02 5.00000e-04 5.00000e-04 5.00000e-05 1.00000e-09 1.00000e-01 5.00000e-04 5.00000e-04 5.00000e-05 1.00000e-09 1.00000e-01 $1.12453 \mathrm{e}+001.12453 \mathrm{e}+00$ 1.12453e-01 1.00000e-09 2.12000e-01 $1.12453 \mathrm{e}+001.12453 \mathrm{e}+00$ 1.12453e-01 1.00000e-09 2.12000e-01 $1.00000 \mathrm{e}-011.00000 \mathrm{e}-011.00000 \mathrm{e}-021.00000 \mathrm{e}-091.00000 \mathrm{e}-01$ $1.00000 \mathrm{e}+001.00000 \mathrm{e}+001.00000 \mathrm{e}-011.00000 \mathrm{e}-091.00000 \mathrm{e}-01$ $1.00000 \mathrm{e}-05$ 1.00000e-05 1.00000e-06 1.00000e-09 1.00000e-01 $1.00000 \mathrm{e}+001.00000 \mathrm{e}+001.00000 \mathrm{e}-011.00000 \mathrm{e}-091.00000 \mathrm{e}-01$ Element: 4321 \# of layers: 9

Kx Ky Kz Ss Por

$2.81436 \mathrm{e}+012.81436 \mathrm{e}+012.81436 \mathrm{e}+001.00000 \mathrm{e}-09$ 7.00000e-02 $2.81436 \mathrm{e}+012.81436 \mathrm{e}+012.81436 \mathrm{e}+001.00000 \mathrm{e}-097.00000 \mathrm{e}-02$ 5.00000e-04 5.00000e-04 5.00000e-05 1.00000e-09 1.00000e-01 $1.12453 \mathrm{e}+001.12453 \mathrm{e}+00$ 1.12453e-01 1.00000e-09 2.12000e-01 $1.12453 \mathrm{e}+001.12453 \mathrm{e}+00$ 1.12453e-01 1.00000e-09 2.12000e-01 $1.00000 \mathrm{e}-011.00000 \mathrm{e}-011.00000 \mathrm{e}-021.00000 \mathrm{e}-091.00000 \mathrm{e}-01$ $1.00000 \mathrm{e}+001.00000 \mathrm{e}+001.00000 \mathrm{e}-011.00000 \mathrm{e}-091.00000 \mathrm{e}-01$ $1.00000 \mathrm{e}-051.00000 \mathrm{e}-05$ 1.00000e-06 1.00000e-09 1.00000e-01 $1.00000 \mathrm{e}+001.00000 \mathrm{e}+001.00000 \mathrm{e}-011.00000 \mathrm{e}-091.00000 \mathrm{e}-01$ Element: 4322 \# of layers: 11

Kx Ky Kz Ss Por

$2.78391 \mathrm{e}+012.78391 \mathrm{e}+012.78391 \mathrm{e}+001.00000 \mathrm{e}-09$ 7.00000e-02

$2.78391 \mathrm{e}+012.78391 \mathrm{e}+012.78391 \mathrm{e}+001.00000 \mathrm{e}-09$ 7.00000e-02

$2.78391 \mathrm{e}+012.78391 \mathrm{e}+012.78391 \mathrm{e}+001.00000 \mathrm{e}-09$ 7.00000e-02

5.00000e-04 5.00000e-04 5.00000e-05 1.00000e-09 1.00000e-01

5.00000e-04 5.00000e-04 5.00000e-05 1.00000e-09 1.00000e-01

$1.11236 \mathrm{e}+001.11236 \mathrm{e}+001.11236 \mathrm{e}-011.00000 \mathrm{e}-092.12000 \mathrm{e}-01$

$1.11236 \mathrm{e}+001.11236 \mathrm{e}+001.11236 \mathrm{e}-011.00000 \mathrm{e}-092.12000 \mathrm{e}-01$ $1.00000 \mathrm{e}-02$ 1.00000e-02 1.00000e-03 1.00000e-09 1.00000e-01 $1.00000 \mathrm{e}+001.00000 \mathrm{e}+001.00000 \mathrm{e}-011.00000 \mathrm{e}-091.00000 \mathrm{e}-01$ $1.00000 \mathrm{e}-05$ 1.00000e-05 1.00000e-06 1.00000e-09 1.00000e-01 $1.00000 \mathrm{e}+001.00000 \mathrm{e}+001.00000 \mathrm{e}-011.00000 \mathrm{e}-091.00000 \mathrm{e}-01$ Element: 4323 \# of layers: 11

Kx Ky Kz Ss Por

$3.06115 \mathrm{e}+013.06115 \mathrm{e}+013.06115 \mathrm{e}+00$ 1.00000e-09 7.00000e-02 $3.06115 \mathrm{e}+013.06115 \mathrm{e}+013.06115 \mathrm{e}+001.00000 \mathrm{e}-09$ 7.00000e-02 $3.06115 \mathrm{e}+013.06115 \mathrm{e}+013.06115 \mathrm{e}+001.00000 \mathrm{e}-09$ 7.00000e-02 5.00000e-04 5.00000e-04 5.00000e-05 1.00000e-09 1.00000e-01 5.00000e-04 5.00000e-04 5.00000e-05 1.00000e-09 1.00000e-01 $1.22313 \mathrm{e}+001.22313 \mathrm{e}+00$ 1.22313e-01 1.00000e-09 2.12000e-01 
$1.22313 \mathrm{e}+00$ 1.22313e+00 1.22313e-01 1.00000e-09 2.12000e-01 $1.00000 \mathrm{e}-02$ 1.00000e-02 1.00000e-03 1.00000e-09 1.00000e-01 $1.00000 \mathrm{e}+001.00000 \mathrm{e}+001.00000 \mathrm{e}-011.00000 \mathrm{e}-091.00000 \mathrm{e}-01$ $1.00000 \mathrm{e}-05$ 1.00000e-05 1.00000e-06 1.00000e-09 1.00000e-01 $1.00000 \mathrm{e}+001.00000 \mathrm{e}+001.00000 \mathrm{e}-011.00000 \mathrm{e}-091.00000 \mathrm{e}-01$ Element: 4324 \# of layers: 10

$\mathrm{Kx} \mathrm{Ky} \mathrm{Kz}$ Ss Por

3.06115e+01 3.06115e+01 3.06115e+00 1.00000e-09 7.00000e-02 $3.06115 \mathrm{e}+013.06115 \mathrm{e}+013.06115 \mathrm{e}+001.00000 \mathrm{e}-09$ 7.00000e-02 5.00000e-04 5.00000e-04 5.00000e-05 1.00000e-09 1.00000e-01 5.00000e-04 5.00000e-04 5.00000e-05 1.00000e-09 1.00000e-01 $1.22313 \mathrm{e}+001.22313 \mathrm{e}+00$ 1.22313e-01 1.00000e-09 2.12000e-01 $1.22313 \mathrm{e}+001.22313 \mathrm{e}+00$ 1.22313e-01 1.00000e-09 2.12000e-01 $1.00000 \mathrm{e}-02$ 1.00000e-02 1.00000e-03 1.00000e-09 1.00000e-01 $1.00000 \mathrm{e}+001.00000 \mathrm{e}+001.00000 \mathrm{e}-011.00000 \mathrm{e}-091.00000 \mathrm{e}-01$ $1.00000 \mathrm{e}-05$ 1.00000e-05 1.00000e-06 1.00000e-09 1.00000e-01 $1.00000 \mathrm{e}+001.00000 \mathrm{e}+001.00000 \mathrm{e}-011.00000 \mathrm{e}-091.00000 \mathrm{e}-01$ Element: 4325 \# of layers: 11

$\mathrm{Kx} \mathrm{Ky} \mathrm{Kz}$ Ss Por

3.06115e+01 3.06115e+01 3.06115e+00 1.00000e-09 7.00000e-02 $3.06115 \mathrm{e}+013.06115 \mathrm{e}+013.06115 \mathrm{e}+001.00000 \mathrm{e}-09$ 7.00000e-02 $3.06115 \mathrm{e}+013.06115 \mathrm{e}+013.06115 \mathrm{e}+001.00000 \mathrm{e}-09$ 7.00000e-02 5.00000e-04 5.00000e-04 5.00000e-05 1.00000e-09 1.00000e-01 5.00000e-04 5.00000e-04 5.00000e-05 1.00000e-09 1.00000e-01 $1.22313 \mathrm{e}+001.22313 \mathrm{e}+001.22313 \mathrm{e}-01$ 1.00000e-09 2.12000e-01 $1.22313 \mathrm{e}+001.22313 \mathrm{e}+00$ 1.22313e-01 1.00000e-09 2.12000e-01 $1.00000 \mathrm{e}-02$ 1.00000e-02 1.00000e-03 1.00000e-09 1.00000e-01 $1.00000 \mathrm{e}+001.00000 \mathrm{e}+001.00000 \mathrm{e}-01$ 1.00000e-09 1.00000e-01 $1.00000 \mathrm{e}-05$ 1.00000e-05 1.00000e-06 1.00000e-09 1.00000e-01 $1.00000 \mathrm{e}+001.00000 \mathrm{e}+001.00000 \mathrm{e}-011.00000 \mathrm{e}-091.00000 \mathrm{e}-01$ Element: 4326 \# of layers: 9

$\mathrm{Kx} \mathrm{Ky} \mathrm{Kz}$ Ss Por

$2.39098 \mathrm{e}+012.39098 \mathrm{e}+012.39098 \mathrm{e}+00$ 1.00000e-09 7.00000e-02 $2.39098 \mathrm{e}+012.39098 \mathrm{e}+012.39098 \mathrm{e}+00$ 1.00000e-09 7.00000e-02

$2.39098 \mathrm{e}+012.39098 \mathrm{e}+012.39098 \mathrm{e}+00$ 1.00000e-09 7.00000e-02

5.00000e-04 5.00000e-04 5.00000e-05 1.00000e-09 1.00000e-01 5.00000e-04 5.00000e-04 5.00000e-05 1.00000e-09 1.00000e-01 9.55370e-01 9.55370e-01 9.55370e-02 1.00000e-09 2.12000e-01 9.55370e-01 9.55370e-01 9.55370e-02 1.00000e-09 2.12000e-01 $1.00000 \mathrm{e}-02$ 1.00000e-02 1.00000e-03 1.00000e-09 1.00000e-01 $1.00000 \mathrm{e}+001.00000 \mathrm{e}+001.00000 \mathrm{e}-011.00000 \mathrm{e}-091.00000 \mathrm{e}-01$ Element: 4327 \# of layers: 5

$\mathrm{Kx} \mathrm{Ky} \mathrm{Kz}$ Ss Por

2.39098e+01 2.39098e+01 2.39098e+00 1.00000e-09 7.00000e-02 $2.39098 \mathrm{e}+012.39098 \mathrm{e}+012.39098 \mathrm{e}+00$ 1.00000e-09 7.00000e-02 $2.39098 \mathrm{e}+012.39098 \mathrm{e}+012.39098 \mathrm{e}+001.00000 \mathrm{e}-09$ 7.00000e-02 
5.00000e-04 5.00000e-04 5.00000e-05 1.00000e-09 1.00000e-01 9.55370e-01 9.55370e-01 9.55370e-02 1.00000e-09 2.12000e-01

Element: 4328 \# of layers: 7

Kx Ky Kz Ss Por

$3.06115 \mathrm{e}+013.06115 \mathrm{e}+013.06115 \mathrm{e}+001.00000 \mathrm{e}-09$ 7.00000e-02 $3.06115 \mathrm{e}+013.06115 \mathrm{e}+013.06115 \mathrm{e}+001.00000 \mathrm{e}-09$ 7.00000e-02 $3.06115 \mathrm{e}+013.06115 \mathrm{e}+013.06115 \mathrm{e}+001.00000 \mathrm{e}-09$ 7.00000e-02 5.00000e-04 5.00000e-04 5.00000e-05 1.00000e-09 1.00000e-01 5.00000e-04 5.00000e-04 5.00000e-05 1.00000e-09 1.00000e-01 $1.22313 \mathrm{e}+001.22313 \mathrm{e}+00$ 1.22313e-01 1.00000e-09 2.12000e-01 $1.00000 \mathrm{e}-02$ 1.00000e-02 1.00000e-03 1.00000e-09 1.00000e-01 Element: 4329 \# of layers: 8

Kx Ky Kz Ss Por

$3.69041 \mathrm{e}+013.69041 \mathrm{e}+013.69041 \mathrm{e}+00$ 1.00000e-09 7.00000e-02 $3.69041 \mathrm{e}+013.69041 \mathrm{e}+013.69041 \mathrm{e}+001.00000 \mathrm{e}-09$ 7.00000e-02 5.00000e-04 5.00000e-04 5.00000e-05 1.00000e-09 1.00000e-01 $5.00000 \mathrm{e}-04$ 5.00000e-04 5.00000e-05 1.00000e-09 1.00000e-01 $1.47455 \mathrm{e}+001.47455 \mathrm{e}+001.47455 \mathrm{e}-011.00000 \mathrm{e}-092.12000 \mathrm{e}-01$ $1.47455 \mathrm{e}+001.47455 \mathrm{e}+001.47455 \mathrm{e}-011.00000 \mathrm{e}-092.12000 \mathrm{e}-01$ $1.00000 \mathrm{e}-021.00000 \mathrm{e}-02$ 1.00000e-03 $1.00000 \mathrm{e}-091.00000 \mathrm{e}-01$ $1.00000 \mathrm{e}+001.00000 \mathrm{e}+001.00000 \mathrm{e}-011.00000 \mathrm{e}-091.00000 \mathrm{e}-01$ Element: 4330 \# of layers: 11

Kx Ky Kz Ss Por

$3.69041 \mathrm{e}+013.69041 \mathrm{e}+013.69041 \mathrm{e}+00$ 1.00000e-09 7.00000e-02 $3.69041 \mathrm{e}+013.69041 \mathrm{e}+013.69041 \mathrm{e}+001.00000 \mathrm{e}-09$ 7.00000e-02 $3.69041 \mathrm{e}+013.69041 \mathrm{e}+013.69041 \mathrm{e}+001.00000 \mathrm{e}-097.00000 \mathrm{e}-02$ 5.00000e-04 5.00000e-04 5.00000e-05 1.00000e-09 1.00000e-01 5.00000e-04 5.00000e-04 5.00000e-05 1.00000e-09 1.00000e-01 $1.47455 \mathrm{e}+001.47455 \mathrm{e}+001.47455 \mathrm{e}-011.00000 \mathrm{e}-092.12000 \mathrm{e}-01$ $1.47455 \mathrm{e}+001.47455 \mathrm{e}+001.47455 \mathrm{e}-011.00000 \mathrm{e}-092.12000 \mathrm{e}-01$ $1.00000 \mathrm{e}-021.00000 \mathrm{e}-02$ 1.00000e-03 1.00000e-09 1.00000e-01 $1.00000 \mathrm{e}+001.00000 \mathrm{e}+001.00000 \mathrm{e}-011.00000 \mathrm{e}-091.00000 \mathrm{e}-01$ $1.00000 \mathrm{e}-05$ 1.00000e-05 1.00000e-06 1.00000e-09 1.00000e-01 $1.00000 \mathrm{e}+001.00000 \mathrm{e}+001.00000 \mathrm{e}-011.00000 \mathrm{e}-091.00000 \mathrm{e}-01$ Element: 4331 \# of layers: 8

Kx Ky Kz Ss Por $3.06115 \mathrm{e}+013.06115 \mathrm{e}+013.06115 \mathrm{e}+00$ 1.00000e-09 7.00000e-02 $3.06115 \mathrm{e}+013.06115 \mathrm{e}+013.06115 \mathrm{e}+001.00000 \mathrm{e}-09$ 7.00000e-02 5.00000e-04 5.00000e-04 5.00000e-05 1.00000e-09 1.00000e-01 $5.00000 \mathrm{e}-04$ 5.00000e-04 5.00000e-05 1.00000e-09 1.00000e-01 $1.22313 \mathrm{e}+001.22313 \mathrm{e}+001.22313 \mathrm{e}-011.00000 \mathrm{e}-092.12000 \mathrm{e}-01$ $1.22313 \mathrm{e}+001.22313 \mathrm{e}+00$ 1.22313e-01 1.00000e-09 2.12000e-01 $1.00000 \mathrm{e}-02$ 1.00000e-02 1.00000e-03 1.00000e-09 1.00000e-01 $1.00000 \mathrm{e}+001.00000 \mathrm{e}+001.00000 \mathrm{e}-011.00000 \mathrm{e}-091.00000 \mathrm{e}-01$ Element: 4332 \# of layers: 8

Kx Ky Kz Ss Por 
$2.15871 \mathrm{e}+012.15871 \mathrm{e}+012.15871 \mathrm{e}+00$ 1.00000e-09 7.00000e-02 $2.15871 \mathrm{e}+012.15871 \mathrm{e}+012.15871 \mathrm{e}+001.00000 \mathrm{e}-09$ 7.00000e-02 $2.15871 \mathrm{e}+012.15871 \mathrm{e}+012.15871 \mathrm{e}+001.00000 \mathrm{e}-09$ 7.00000e-02 5.00000e-04 5.00000e-04 5.00000e-05 1.00000e-09 1.00000e-01 8.62533e-01 8.62533e-01 8.62533e-02 1.00000e-09 2.12000e-01 8.62533e-01 8.62533e-01 8.62533e-02 1.00000e-09 2.12000e-01 $1.00000 \mathrm{e}-021.00000 \mathrm{e}-02$ 1.00000e-03 $1.00000 \mathrm{e}-091.00000 \mathrm{e}-01$ $1.00000 \mathrm{e}+001.00000 \mathrm{e}+001.00000 \mathrm{e}-011.00000 \mathrm{e}-091.00000 \mathrm{e}-01$ Element: 4333 \# of layers: 8

Kx Ky Kz Ss Por

$2.15871 \mathrm{e}+012.15871 \mathrm{e}+012.15871 \mathrm{e}+00$ 1.00000e-09 7.00000e-02 $2.15871 \mathrm{e}+012.15871 \mathrm{e}+012.15871 \mathrm{e}+00$ 1.00000e-09 7.00000e-02 $2.15871 \mathrm{e}+012.15871 \mathrm{e}+012.15871 \mathrm{e}+001.00000 \mathrm{e}-09$ 7.00000e-02 5.00000e-04 5.00000e-04 5.00000e-05 1.00000e-09 1.00000e-01 8.62533e-01 8.62533e-01 8.62533e-02 1.00000e-09 2.12000e-01 8.62533e-01 8.62533e-01 8.62533e-02 1.00000e-09 2.12000e-01 $1.00000 \mathrm{e}-02$ 1.00000e-02 1.00000e-03 1.00000e-09 1.00000e-01 $1.00000 \mathrm{e}+001.00000 \mathrm{e}+001.00000 \mathrm{e}-011.00000 \mathrm{e}-091.00000 \mathrm{e}-01$ Element: 4334 \# of layers: 6

Kx Ky Kz Ss Por

$2.15871 \mathrm{e}+012.15871 \mathrm{e}+012.15871 \mathrm{e}+00$ 1.00000e-09 7.00000e-02

$2.15871 \mathrm{e}+012.15871 \mathrm{e}+012.15871 \mathrm{e}+001.00000 \mathrm{e}-097.00000 \mathrm{e}-02$ 5.00000e-04 5.00000e-04 5.00000e-05 1.00000e-09 1.00000e-01 8.62533e-01 8.62533e-01 8.62533e-02 1.00000e-09 2.12000e-01 8.62533e-01 8.62533e-01 8.62533e-02 1.00000e-09 2.12000e-01 $1.00000 \mathrm{e}-02$ 1.00000e-02 1.00000e-03 1.00000e-09 1.00000e-01 Element: 4335 \# of layers: 4

Kx Ky Kz Ss Por

$2.15871 \mathrm{e}+012.15871 \mathrm{e}+012.15871 \mathrm{e}+00$ 1.00000e-09 7.00000e-02 $2.15871 \mathrm{e}+012.15871 \mathrm{e}+012.15871 \mathrm{e}+001.00000 \mathrm{e}-09$ 7.00000e-02 $2.15871 \mathrm{e}+012.15871 \mathrm{e}+012.15871 \mathrm{e}+001.00000 \mathrm{e}-09$ 7.00000e-02 $1.00000 \mathrm{e}-02$ 1.00000e-02 1.00000e-03 1.00000e-09 1.00000e-01

Element: 4336 \# of layers: 6

Kx Ky Kz Ss Por

$2.15871 \mathrm{e}+012.15871 \mathrm{e}+012.15871 \mathrm{e}+00$ 1.00000e-09 7.00000e-02 $2.15871 \mathrm{e}+012.15871 \mathrm{e}+012.15871 \mathrm{e}+001.00000 \mathrm{e}-09$ 7.00000e-02 $2.15871 \mathrm{e}+012.15871 \mathrm{e}+012.15871 \mathrm{e}+001.00000 \mathrm{e}-09$ 7.00000e-02 8.62533e-01 8.62533e-01 8.62533e-02 1.00000e-09 2.12000e-01 $1.00000 \mathrm{e}-021.00000 \mathrm{e}-02$ 1.00000e-03 1.00000e-09 1.00000e-01 $1.00000 \mathrm{e}+001.00000 \mathrm{e}+001.00000 \mathrm{e}-011.00000 \mathrm{e}-091.00000 \mathrm{e}-01$ Element: 4337 \# of layers: 4

Kx Ky Kz Ss Por

$2.15871 \mathrm{e}+012.15871 \mathrm{e}+012.15871 \mathrm{e}+00$ 1.00000e-09 7.00000e-02 $2.15871 \mathrm{e}+012.15871 \mathrm{e}+012.15871 \mathrm{e}+001.00000 \mathrm{e}-09$ 7.00000e-02 $2.15871 \mathrm{e}+012.15871 \mathrm{e}+012.15871 \mathrm{e}+001.00000 \mathrm{e}-09$ 7.00000e-02 $1.00000 \mathrm{e}-021.00000 \mathrm{e}-02$ 1.00000e-03 1.00000e-09 1.00000e-01 
Element: 4338 \# of layers: 3

$\mathrm{Kx} \mathrm{Ky} \mathrm{Kz}$ Ss Por

$2.15871 \mathrm{e}+012.15871 \mathrm{e}+012.15871 \mathrm{e}+00$ 1.00000e-09 7.00000e-02

$2.15871 \mathrm{e}+012.15871 \mathrm{e}+012.15871 \mathrm{e}+001.00000 \mathrm{e}-09$ 7.00000e-02

$2.15871 \mathrm{e}+012.15871 \mathrm{e}+012.15871 \mathrm{e}+00$ 1.00000e-09 7.00000e-02

Element: 4339 \# of layers: 5

$\mathrm{Kx} \mathrm{Ky} \mathrm{Kz}$ Ss Por

$2.15871 \mathrm{e}+012.15871 \mathrm{e}+012.15871 \mathrm{e}+00$ 1.00000e-09 7.00000e-02

$2.15871 \mathrm{e}+012.15871 \mathrm{e}+012.15871 \mathrm{e}+001.00000 \mathrm{e}-09$ 7.00000e-02

$2.15871 \mathrm{e}+012.15871 \mathrm{e}+012.15871 \mathrm{e}+00$ 1.00000e-09 7.00000e-02

5.00000e-04 5.00000e-04 5.00000e-05 1.00000e-09 1.00000e-01

8.62533e-01 8.62533e-01 8.62533e-02 1.00000e-09 2.12000e-01

Element: 4340 \# of layers: 4

$\mathrm{Kx} \mathrm{Ky} \mathrm{Kz}$ Ss Por

$2.15871 \mathrm{e}+012.15871 \mathrm{e}+012.15871 \mathrm{e}+00$ 1.00000e-09 7.00000e-02

$2.15871 \mathrm{e}+012.15871 \mathrm{e}+012.15871 \mathrm{e}+00$ 1.00000e-09 7.00000e-02

$2.15871 \mathrm{e}+012.15871 \mathrm{e}+012.15871 \mathrm{e}+001.00000 \mathrm{e}-09$ 7.00000e-02

5.00000e-04 5.00000e-04 5.00000e-05 1.00000e-09 1.00000e-01

Element: 4341 \# of layers: 7

$\mathrm{Kx} \mathrm{Ky} \mathrm{Kz}$ Ss Por

$2.55794 \mathrm{e}+012.55794 \mathrm{e}+012.55794 \mathrm{e}+001.00000 \mathrm{e}-09$ 7.00000e-02

$2.55794 \mathrm{e}+012.55794 \mathrm{e}+012.55794 \mathrm{e}+001.00000 \mathrm{e}-09$ 7.00000e-02

$2.55794 \mathrm{e}+012.55794 \mathrm{e}+012.55794 \mathrm{e}+001.00000 \mathrm{e}-097.00000 \mathrm{e}-02$ 5.00000e-04 5.00000e-04 5.00000e-05 1.00000e-09 1.00000e-01

$1.02206 \mathrm{e}+001.02206 \mathrm{e}+001.02206 \mathrm{e}-011.00000 \mathrm{e}-092.12000 \mathrm{e}-01$ $1.02206 \mathrm{e}+001.02206 \mathrm{e}+001.02206 \mathrm{e}-01$ 1.00000e-09 2.12000e-01 $1.00000 \mathrm{e}-02$ 1.00000e-02 1.00000e-03 1.00000e-09 1.00000e-01

Element: 4342 \# of layers: 7

$\mathrm{Kx} \mathrm{Ky} \mathrm{Kz}$ Ss Por

$2.55794 \mathrm{e}+012.55794 \mathrm{e}+012.55794 \mathrm{e}+00$ 1.00000e-09 7.00000e-02

$2.55794 \mathrm{e}+012.55794 \mathrm{e}+012.55794 \mathrm{e}+001.00000 \mathrm{e}-097.00000 \mathrm{e}-02$

$2.55794 \mathrm{e}+012.55794 \mathrm{e}+012.55794 \mathrm{e}+001.00000 \mathrm{e}-097.00000 \mathrm{e}-02$

5.00000e-04 5.00000e-04 5.00000e-05 1.00000e-09 1.00000e-01

$1.02206 \mathrm{e}+001.02206 \mathrm{e}+00$ 1.02206e-01 1.00000e-09 2.12000e-01

$1.02206 \mathrm{e}+001.02206 \mathrm{e}+001.02206 \mathrm{e}-01$ 1.00000e-09 2.12000e-01

1.00000e-02 1.00000e-02 1.00000e-03 1.00000e-09 1.00000e-01

Element: 4343 \# of layers: 7

Kx Ky Kz Ss Por

$2.55794 \mathrm{e}+012.55794 \mathrm{e}+012.55794 \mathrm{e}+00$ 1.00000e-09 7.00000e-02

$2.55794 \mathrm{e}+012.55794 \mathrm{e}+012.55794 \mathrm{e}+001.00000 \mathrm{e}-09$ 7.00000e-02

5.00000e-04 5.00000e-04 5.00000e-05 1.00000e-09 1.00000e-01

$1.02206 \mathrm{e}+001.02206 \mathrm{e}+00$ 1.02206e-01 1.00000e-09 2.12000e-01

$1.02206 \mathrm{e}+001.02206 \mathrm{e}+001.02206 \mathrm{e}-01$ 1.00000e-09 2.12000e-01

$1.00000 \mathrm{e}-02$ 1.00000e-02 1.00000e-03 1.00000e-09 1.00000e-01

$1.00000 \mathrm{e}+001.00000 \mathrm{e}+001.00000 \mathrm{e}-01$ 1.00000e-09 1.00000e-01

Element: 4344 \# of layers: 5 
$\mathrm{Kx} \mathrm{Ky} \mathrm{Kz}$ Ss Por

$2.55794 \mathrm{e}+012.55794 \mathrm{e}+012.55794 \mathrm{e}+001.00000 \mathrm{e}-097.00000 \mathrm{e}-02$

$2.55794 \mathrm{e}+012.55794 \mathrm{e}+012.55794 \mathrm{e}+001.00000 \mathrm{e}-09$ 7.00000e-02

$1.02206 \mathrm{e}+001.02206 \mathrm{e}+00 \quad 1.02206 \mathrm{e}-011.00000 \mathrm{e}-092.12000 \mathrm{e}-01$

$1.00000 \mathrm{e}-02$ 1.00000e-02 1.00000e-03 1.00000e-09 1.00000e-01

$1.00000 \mathrm{e}+001.00000 \mathrm{e}+001.00000 \mathrm{e}-011.00000 \mathrm{e}-091.00000 \mathrm{e}-01$

Element: 4345 \# of layers: 7

$\mathrm{Kx} \mathrm{Ky} \mathrm{Kz}$ Ss Por

$2.55794 \mathrm{e}+012.55794 \mathrm{e}+012.55794 \mathrm{e}+001.00000 \mathrm{e}-09$ 7.00000e-02

$2.55794 \mathrm{e}+012.55794 \mathrm{e}+012.55794 \mathrm{e}+001.00000 \mathrm{e}-097.00000 \mathrm{e}-02$

$2.55794 \mathrm{e}+012.55794 \mathrm{e}+012.55794 \mathrm{e}+001.00000 \mathrm{e}-097.00000 \mathrm{e}-02$

$1.02206 \mathrm{e}+001.02206 \mathrm{e}+001.02206 \mathrm{e}-01$ 1.00000e-09 2.12000e-01

$1.02206 \mathrm{e}+001.02206 \mathrm{e}+00$ 1.02206e-01 1.00000e-09 2.12000e-01

$1.00000 \mathrm{e}-02$ 1.00000e-02 1.00000e-03 1.00000e-09 1.00000e-01

$1.00000 \mathrm{e}+001.00000 \mathrm{e}+001.00000 \mathrm{e}-01$ 1.00000e-09 1.00000e-01

Element: 4346 \# of layers: 7

$\mathrm{Kx} \mathrm{Ky} \mathrm{Kz}$ Ss Por

$2.55794 \mathrm{e}+012.55794 \mathrm{e}+012.55794 \mathrm{e}+00$ 1.00000e-09 7.00000e-02

$2.55794 \mathrm{e}+012.55794 \mathrm{e}+012.55794 \mathrm{e}+001.00000 \mathrm{e}-09$ 7.00000e-02

$2.55794 \mathrm{e}+012.55794 \mathrm{e}+012.55794 \mathrm{e}+001.00000 \mathrm{e}-097.00000 \mathrm{e}-02$

$1.02206 \mathrm{e}+001.02206 \mathrm{e}+001.02206 \mathrm{e}-011.00000 \mathrm{e}-092.12000 \mathrm{e}-01$

$1.02206 \mathrm{e}+00$ 1.02206e+00 1.02206e-01 1.00000e-09 2.12000e-01

$1.00000 \mathrm{e}-02$ 1.00000e-02 1.00000e-03 1.00000e-09 1.00000e-01

$1.00000 \mathrm{e}+001.00000 \mathrm{e}+001.00000 \mathrm{e}-011.00000 \mathrm{e}-091.00000 \mathrm{e}-01$

Element: 4347 \# of layers: 6

$\mathrm{Kx} \mathrm{Ky} \mathrm{Kz}$ Ss Por

$2.55794 \mathrm{e}+012.55794 \mathrm{e}+012.55794 \mathrm{e}+00$ 1.00000e-09 7.00000e-02

$2.55794 \mathrm{e}+012.55794 \mathrm{e}+012.55794 \mathrm{e}+001.00000 \mathrm{e}-097.00000 \mathrm{e}-02$

$2.55794 \mathrm{e}+012.55794 \mathrm{e}+012.55794 \mathrm{e}+001.00000 \mathrm{e}-097.00000 \mathrm{e}-02$

$1.02206 \mathrm{e}+00$ 1.02206e+00 1.02206e-01 1.00000e-09 2.12000e-01

$1.00000 \mathrm{e}-02$ 1.00000e-02 1.00000e-03 1.00000e-09 1.00000e-01

$1.00000 \mathrm{e}+001.00000 \mathrm{e}+001.00000 \mathrm{e}-011.00000 \mathrm{e}-091.00000 \mathrm{e}-01$

Element: 4348 \# of layers: 5

$\mathrm{Kx} \mathrm{Ky} \mathrm{Kz}$ Ss Por

$2.55794 \mathrm{e}+012.55794 \mathrm{e}+012.55794 \mathrm{e}+00$ 1.00000e-09 7.00000e-02

$2.55794 \mathrm{e}+012.55794 \mathrm{e}+012.55794 \mathrm{e}+001.00000 \mathrm{e}-09$ 7.00000e-02

$2.55794 \mathrm{e}+012.55794 \mathrm{e}+012.55794 \mathrm{e}+001.00000 \mathrm{e}-09$ 7.00000e-02

$1.02206 \mathrm{e}+001.02206 \mathrm{e}+001.02206 \mathrm{e}-01$ 1.00000e-09 2.12000e-01

$1.00000 \mathrm{e}-02$ 1.00000e-02 1.00000e-03 1.00000e-09 1.00000e-01

Element: 4349 \# of layers: 7

Kx Ky Kz Ss Por

$2.55794 \mathrm{e}+012.55794 \mathrm{e}+012.55794 \mathrm{e}+001.00000 \mathrm{e}-09$ 7.00000e-02

$2.55794 \mathrm{e}+012.55794 \mathrm{e}+012.55794 \mathrm{e}+001.00000 \mathrm{e}-097.00000 \mathrm{e}-02$

$2.55794 \mathrm{e}+012.55794 \mathrm{e}+012.55794 \mathrm{e}+00$ 1.00000e-09 7.00000e-02

$1.02206 \mathrm{e}+001.02206 \mathrm{e}+001.02206 \mathrm{e}-01$ 1.00000e-09 2.12000e-01

$1.02206 \mathrm{e}+001.02206 \mathrm{e}+001.02206 \mathrm{e}-01$ 1.00000e-09 2.12000e-01 
$1.00000 \mathrm{e}-02$ 1.00000e-02 1.00000e-03 1.00000e-09 1.00000e-01 $1.00000 \mathrm{e}+001.00000 \mathrm{e}+001.00000 \mathrm{e}-01$ 1.00000e-09 1.00000e-01 Element: 4350 \# of layers: 6

Kx Ky Kz Ss Por

$2.39432 \mathrm{e}+012.39432 \mathrm{e}+012.39432 \mathrm{e}+00$ 1.00000e-09 7.00000e-02

$2.39432 \mathrm{e}+012.39432 \mathrm{e}+012.39432 \mathrm{e}+00$ 1.00000e-09 7.00000e-02

$2.39432 \mathrm{e}+012.39432 \mathrm{e}+012.39432 \mathrm{e}+00$ 1.00000e-09 7.00000e-02

9.56698e-01 9.56698e-01 9.56698e-02 1.00000e-09 2.12000e-01

$1.00000 \mathrm{e}-02$ 1.00000e-02 1.00000e-03 1.00000e-09 1.00000e-01

$1.00000 \mathrm{e}+001.00000 \mathrm{e}+001.00000 \mathrm{e}-011.00000 \mathrm{e}-091.00000 \mathrm{e}-01$

Element: 4351 \# of layers: 7

$\mathrm{Kx} \mathrm{Ky} \mathrm{Kz}$ Ss Por

2.39432e+01 2.39432e+01 2.39432e+00 1.00000e-09 7.00000e-02

$2.39432 \mathrm{e}+012.39432 \mathrm{e}+012.39432 \mathrm{e}+00$ 1.00000e-09 7.00000e-02

$2.39432 \mathrm{e}+012.39432 \mathrm{e}+012.39432 \mathrm{e}+001.00000 \mathrm{e}-09$ 7.00000e-02

9.56698e-01 9.56698e-01 9.56698e-02 1.00000e-09 2.12000e-01

9.56698e-01 9.56698e-01 9.56698e-02 1.00000e-09 2.12000e-01

$1.00000 \mathrm{e}-02$ 1.00000e-02 1.00000e-03 1.00000e-09 1.00000e-01

$1.00000 \mathrm{e}+001.00000 \mathrm{e}+001.00000 \mathrm{e}-01$ 1.00000e-09 1.00000e-01

Element: 4352 \# of layers: 7

$\mathrm{Kx} \mathrm{Ky} \mathrm{Kz}$ Ss Por

2.39432e+01 2.39432e+01 2.39432e+00 1.00000e-09 7.00000e-02

$2.39432 \mathrm{e}+012.39432 \mathrm{e}+012.39432 \mathrm{e}+00$ 1.00000e-09 7.00000e-02

$2.39432 \mathrm{e}+012.39432 \mathrm{e}+012.39432 \mathrm{e}+001.00000 \mathrm{e}-09$ 7.00000e-02

9.56698e-01 9.56698e-01 9.56698e-02 1.00000e-09 2.12000e-01

9.56698e-01 9.56698e-01 9.56698e-02 1.00000e-09 2.12000e-01

$1.00000 \mathrm{e}-02$ 1.00000e-02 1.00000e-03 1.00000e-09 1.00000e-01

$1.00000 \mathrm{e}+001.00000 \mathrm{e}+001.00000 \mathrm{e}-011.00000 \mathrm{e}-091.00000 \mathrm{e}-01$

Element: 4353 \# of layers: 5

$\mathrm{Kx} \mathrm{Ky} \mathrm{Kz}$ Ss Por

2.39432e+01 2.39432e+01 2.39432e+00 1.00000e-09 7.00000e-02

$2.39432 \mathrm{e}+012.39432 \mathrm{e}+012.39432 \mathrm{e}+00$ 1.00000e-09 7.00000e-02

$2.39432 \mathrm{e}+012.39432 \mathrm{e}+012.39432 \mathrm{e}+00$ 1.00000e-09 7.00000e-02

1.00000e-02 1.00000e-02 1.00000e-03 1.00000e-09 1.00000e-01

$1.00000 \mathrm{e}+001.00000 \mathrm{e}+001.00000 \mathrm{e}-01$ 1.00000e-09 1.00000e-01

Element: 4354 \# of layers: 6

Kx Ky Kz Ss Por

2.39432e+01 2.39432e+01 2.39432e+00 1.00000e-09 7.00000e-02

$2.39432 \mathrm{e}+012.39432 \mathrm{e}+012.39432 \mathrm{e}+00$ 1.00000e-09 7.00000e-02

$2.39432 \mathrm{e}+012.39432 \mathrm{e}+012.39432 \mathrm{e}+00$ 1.00000e-09 7.00000e-02

9.56698e-01 9.56698e-01 9.56698e-02 1.00000e-09 2.12000e-01

$1.00000 \mathrm{e}-02$ 1.00000e-02 1.00000e-03 1.00000e-09 1.00000e-01

$1.00000 \mathrm{e}+001.00000 \mathrm{e}+001.00000 \mathrm{e}-01$ 1.00000e-09 1.00000e-01

Element: 4355 \# of layers: 6

$\mathrm{Kx} \mathrm{Ky} \mathrm{Kz}$ Ss Por

2.39432e+01 2.39432e+01 2.39432e+00 1.00000e-09 7.00000e-02 
2.39432e+01 2.39432e+01 2.39432e+00 1.00000e-09 7.00000e-02

$2.39432 \mathrm{e}+012.39432 \mathrm{e}+012.39432 \mathrm{e}+00$ 1.00000e-09 7.00000e-02

9.56698e-01 9.56698e-01 9.56698e-02 1.00000e-09 2.12000e-01

$1.00000 \mathrm{e}-02$ 1.00000e-02 1.00000e-03 1.00000e-09 1.00000e-01

$1.00000 \mathrm{e}+001.00000 \mathrm{e}+001.00000 \mathrm{e}-01$ 1.00000e-09 1.00000e-01

Element: 4356 \# of layers: 6

$\mathrm{Kx} \mathrm{Ky} \mathrm{Kz}$ Ss Por

$2.39432 \mathrm{e}+012.39432 \mathrm{e}+012.39432 \mathrm{e}+00$ 1.00000e-09 7.00000e-02

$2.39432 \mathrm{e}+012.39432 \mathrm{e}+012.39432 \mathrm{e}+00$ 1.00000e-09 7.00000e-02

2.39432e+01 2.39432e+01 2.39432e+00 1.00000e-09 7.00000e-02

9.56698e-01 9.56698e-01 9.56698e-02 1.00000e-09 2.12000e-01

$1.00000 \mathrm{e}-02$ 1.00000e-02 1.00000e-03 1.00000e-09 1.00000e-01

$1.00000 \mathrm{e}+001.00000 \mathrm{e}+001.00000 \mathrm{e}-01$ 1.00000e-09 1.00000e-01

Element: 4357 \# of layers: 6

$\mathrm{Kx} \mathrm{Ky} \mathrm{Kz}$ Ss Por

2.39432e+01 2.39432e+01 2.39432e+00 1.00000e-09 7.00000e-02

$2.39432 \mathrm{e}+012.39432 \mathrm{e}+012.39432 \mathrm{e}+00$ 1.00000e-09 7.00000e-02

$2.39432 \mathrm{e}+012.39432 \mathrm{e}+012.39432 \mathrm{e}+00$ 1.00000e-09 7.00000e-02

9.56698e-01 9.56698e-01 9.56698e-02 1.00000e-09 2.12000e-01

$1.00000 \mathrm{e}-02$ 1.00000e-02 1.00000e-03 1.00000e-09 1.00000e-01

$1.00000 \mathrm{e}+001.00000 \mathrm{e}+001.00000 \mathrm{e}-011.00000 \mathrm{e}-091.00000 \mathrm{e}-01$

Element: 4358 \# of layers: 6

$\mathrm{Kx} \mathrm{Ky} \mathrm{Kz}$ Ss Por

2.39432e+01 2.39432e+01 2.39432e+00 1.00000e-09 7.00000e-02

$2.39432 \mathrm{e}+012.39432 \mathrm{e}+012.39432 \mathrm{e}+00$ 1.00000e-09 7.00000e-02

$2.39432 \mathrm{e}+012.39432 \mathrm{e}+012.39432 \mathrm{e}+00$ 1.00000e-09 7.00000e-02

9.56698e-01 9.56698e-01 9.56698e-02 1.00000e-09 2.12000e-01

$1.00000 \mathrm{e}-02$ 1.00000e-02 1.00000e-03 1.00000e-09 1.00000e-01

$1.00000 \mathrm{e}+001.00000 \mathrm{e}+001.00000 \mathrm{e}-011.00000 \mathrm{e}-091.00000 \mathrm{e}-01$

Element: 4359 \# of layers: 7

$\mathrm{Kx} \mathrm{Ky} \mathrm{Kz}$ Ss Por

2.18970e+01 2.18970e+01 2.18970e+00 1.00000e-09 7.00000e-02

$2.18970 \mathrm{e}+012.18970 \mathrm{e}+012.18970 \mathrm{e}+00$ 1.00000e-09 7.00000e-02

$2.18970 \mathrm{e}+012.18970 \mathrm{e}+012.18970 \mathrm{e}+001.00000 \mathrm{e}-09$ 7.00000e-02

8.74909e-01 8.74909e-01 8.74909e-02 1.00000e-09 2.12000e-01

8.74909e-01 8.74909e-01 8.74909e-02 1.00000e-09 2.12000e-01

$1.00000 \mathrm{e}-02$ 1.00000e-02 1.00000e-03 1.00000e-09 1.00000e-01

$1.00000 \mathrm{e}+001.00000 \mathrm{e}+001.00000 \mathrm{e}-011.00000 \mathrm{e}-091.00000 \mathrm{e}-01$

Element: 4360 \# of layers: 7

$\mathrm{Kx} \mathrm{Ky} \mathrm{Kz}$ Ss Por

2.18970e+01 2.18970e+01 2.18970e+00 1.00000e-09 7.00000e-02

$2.18970 \mathrm{e}+012.18970 \mathrm{e}+012.18970 \mathrm{e}+001.00000 \mathrm{e}-09$ 7.00000e-02

$2.18970 \mathrm{e}+012.18970 \mathrm{e}+012.18970 \mathrm{e}+00$ 1.00000e-09 7.00000e-02

8.74909e-01 8.74909e-01 8.74909e-02 1.00000e-09 2.12000e-01

8.74909e-01 8.74909e-01 8.74909e-02 1.00000e-09 2.12000e-01

$1.00000 \mathrm{e}-02$ 1.00000e-02 1.00000e-03 1.00000e-09 1.00000e-01 
$1.00000 \mathrm{e}+001.00000 \mathrm{e}+00$ 1.00000e-01 1.00000e-09 1.00000e-01

Element: 4361 \# of layers: 7

Kx Ky Kz Ss Por

$2.18970 \mathrm{e}+012.18970 \mathrm{e}+012.18970 \mathrm{e}+00$ 1.00000e-09 7.00000e-02

$2.18970 \mathrm{e}+012.18970 \mathrm{e}+012.18970 \mathrm{e}+001.00000 \mathrm{e}-09$ 7.00000e-02

$2.18970 \mathrm{e}+012.18970 \mathrm{e}+012.18970 \mathrm{e}+00$ 1.00000e-09 7.00000e-02

8.74909e-01 8.74909e-01 8.74909e-02 1.00000e-09 2.12000e-01

8.74909e-01 8.74909e-01 8.74909e-02 1.00000e-09 2.12000e-01

$1.00000 \mathrm{e}-02$ 1.00000e-02 1.00000e-03 1.00000e-09 1.00000e-01

$1.00000 \mathrm{e}+001.00000 \mathrm{e}+001.00000 \mathrm{e}-01$ 1.00000e-09 1.00000e-01

Element: 4362 \# of layers: 7

Kx Ky Kz Ss Por

2.18970e+01 2.18970e+01 2.18970e+00 1.00000e-09 7.00000e-02

$2.18970 \mathrm{e}+012.18970 \mathrm{e}+012.18970 \mathrm{e}+00$ 1.00000e-09 7.00000e-02

$2.18970 \mathrm{e}+012.18970 \mathrm{e}+012.18970 \mathrm{e}+00$ 1.00000e-09 7.00000e-02

8.74909e-01 8.74909e-01 8.74909e-02 1.00000e-09 2.12000e-01

8.74909e-01 8.74909e-01 8.74909e-02 1.00000e-09 2.12000e-01

$1.00000 \mathrm{e}-02$ 1.00000e-02 1.00000e-03 1.00000e-09 1.00000e-01

$1.00000 \mathrm{e}+001.00000 \mathrm{e}+001.00000 \mathrm{e}-01$ 1.00000e-09 1.00000e-01

Element: 4363 \# of layers: 8

$\mathrm{Kx} \mathrm{Ky} \mathrm{Kz}$ Ss Por

2.18970e+01 2.18970e+01 2.18970e+00 1.00000e-09 7.00000e-02

$2.18970 \mathrm{e}+012.18970 \mathrm{e}+012.18970 \mathrm{e}+00$ 1.00000e-09 7.00000e-02

$2.18970 \mathrm{e}+012.18970 \mathrm{e}+012.18970 \mathrm{e}+00$ 1.00000e-09 7.00000e-02

5.00000e-04 5.00000e-04 5.00000e-05 1.00000e-09 1.00000e-01

8.74909e-01 8.74909e-01 8.74909e-02 1.00000e-09 2.12000e-01

8.74909e-01 8.74909e-01 8.74909e-02 1.00000e-09 2.12000e-01

$1.00000 \mathrm{e}-02$ 1.00000e-02 1.00000e-03 1.00000e-09 1.00000e-01

$1.00000 \mathrm{e}+001.00000 \mathrm{e}+001.00000 \mathrm{e}-011.00000 \mathrm{e}-091.00000 \mathrm{e}-01$

Element: 4364 \# of layers: 7

$\mathrm{Kx} \mathrm{Ky} \mathrm{Kz}$ Ss Por

2.18970e+01 2.18970e+01 2.18970e+00 1.00000e-09 7.00000e-02

$2.18970 \mathrm{e}+012.18970 \mathrm{e}+012.18970 \mathrm{e}+00$ 1.00000e-09 7.00000e-02

$2.18970 \mathrm{e}+012.18970 \mathrm{e}+012.18970 \mathrm{e}+001.00000 \mathrm{e}-09$ 7.00000e-02

5.00000e-04 5.00000e-04 5.00000e-05 1.00000e-09 1.00000e-01

8.74909e-01 8.74909e-01 8.74909e-02 1.00000e-09 2.12000e-01

$1.00000 \mathrm{e}-02$ 1.00000e-02 1.00000e-03 1.00000e-09 1.00000e-01

$1.00000 \mathrm{e}+001.00000 \mathrm{e}+001.00000 \mathrm{e}-011.00000 \mathrm{e}-091.00000 \mathrm{e}-01$

Element: 4365 \# of layers: 6

$\mathrm{Kx} \mathrm{Ky} \mathrm{Kz}$ Ss Por

2.18970e+01 2.18970e+01 2.18970e+00 1.00000e-09 7.00000e-02

$2.18970 \mathrm{e}+012.18970 \mathrm{e}+012.18970 \mathrm{e}+001.00000 \mathrm{e}-09$ 7.00000e-02

2.18970e+01 2.18970e+01 2.18970e+00 1.00000e-09 7.00000e-02

8.74909e-01 8.74909e-01 8.74909e-02 1.00000e-09 2.12000e-01

$1.00000 \mathrm{e}-02$ 1.00000e-02 1.00000e-03 1.00000e-09 1.00000e-01

$1.00000 \mathrm{e}+001.00000 \mathrm{e}+001.00000 \mathrm{e}-011.00000 \mathrm{e}-091.00000 \mathrm{e}-01$ 
Element: 4366 \# of layers: 6

$\mathrm{Kx} \mathrm{Ky} \mathrm{Kz}$ Ss Por

2.18970e+01 2.18970e+01 2.18970e+00 1.00000e-09 7.00000e-02

$2.18970 \mathrm{e}+012.18970 \mathrm{e}+012.18970 \mathrm{e}+001.00000 \mathrm{e}-09$ 7.00000e-02

$2.18970 \mathrm{e}+012.18970 \mathrm{e}+012.18970 \mathrm{e}+001.00000 \mathrm{e}-09$ 7.00000e-02

8.74909e-01 8.74909e-01 8.74909e-02 1.00000e-09 2.12000e-01

$1.00000 \mathrm{e}-02$ 1.00000e-02 1.00000e-03 1.00000e-09 1.00000e-01

$1.00000 \mathrm{e}+001.00000 \mathrm{e}+001.00000 \mathrm{e}-011.00000 \mathrm{e}-091.00000 \mathrm{e}-01$

Element: 4367 \# of layers: 7

$\mathrm{Kx} \mathrm{Ky} \mathrm{Kz}$ Ss Por

$2.18970 \mathrm{e}+012.18970 \mathrm{e}+012.18970 \mathrm{e}+00$ 1.00000e-09 7.00000e-02

$2.18970 \mathrm{e}+012.18970 \mathrm{e}+012.18970 \mathrm{e}+001.00000 \mathrm{e}-09$ 7.00000e-02

$2.18970 \mathrm{e}+012.18970 \mathrm{e}+012.18970 \mathrm{e}+00$ 1.00000e-09 7.00000e-02

8.74909e-01 8.74909e-01 8.74909e-02 1.00000e-09 2.12000e-01

8.74909e-01 8.74909e-01 8.74909e-02 1.00000e-09 2.12000e-01

$1.00000 \mathrm{e}-02$ 1.00000e-02 1.00000e-03 1.00000e-09 1.00000e-01

$1.00000 \mathrm{e}+001.00000 \mathrm{e}+001.00000 \mathrm{e}-011.00000 \mathrm{e}-091.00000 \mathrm{e}-01$

Element: 4368 \# of layers: 7

$\mathrm{Kx} \mathrm{Ky} \mathrm{Kz}$ Ss Por

$2.34269 \mathrm{e}+012.34269 \mathrm{e}+012.34269 \mathrm{e}+00$ 1.00000e-09 7.00000e-02

$2.34269 \mathrm{e}+012.34269 \mathrm{e}+012.34269 \mathrm{e}+001.00000 \mathrm{e}-09$ 7.00000e-02

2.34269e+01 2.34269e+01 2.34269e+00 1.00000e-09 7.00000e-02

9.36065e-01 9.36065e-01 9.36065e-02 1.00000e-09 2.12000e-01

9.36065e-01 9.36065e-01 9.36065e-02 1.00000e-09 2.12000e-01

$1.00000 \mathrm{e}-02$ 1.00000e-02 1.00000e-03 1.00000e-09 1.00000e-01

$1.00000 \mathrm{e}+001.00000 \mathrm{e}+001.00000 \mathrm{e}-01$ 1.00000e-09 1.00000e-01

Element: 4369 \# of layers: 7

$\mathrm{Kx} \mathrm{Ky} \mathrm{Kz}$ Ss Por

$2.34269 \mathrm{e}+012.34269 \mathrm{e}+012.34269 \mathrm{e}+00$ 1.00000e-09 7.00000e-02

$2.34269 \mathrm{e}+012.34269 \mathrm{e}+012.34269 \mathrm{e}+00$ 1.00000e-09 7.00000e-02

$2.34269 \mathrm{e}+012.34269 \mathrm{e}+012.34269 \mathrm{e}+00$ 1.00000e-09 7.00000e-02

9.36065e-01 9.36065e-01 9.36065e-02 1.00000e-09 2.12000e-01

9.36065e-01 9.36065e-01 9.36065e-02 1.00000e-09 2.12000e-01

$1.00000 \mathrm{e}-02$ 1.00000e-02 1.00000e-03 1.00000e-09 1.00000e-01

$1.00000 \mathrm{e}+001.00000 \mathrm{e}+001.00000 \mathrm{e}-011.00000 \mathrm{e}-091.00000 \mathrm{e}-01$

Element: 4370 \# of layers: 8

$\mathrm{Kx} \mathrm{Ky} \mathrm{Kz}$ Ss Por

$2.34269 \mathrm{e}+012.34269 \mathrm{e}+012.34269 \mathrm{e}+00$ 1.00000e-09 7.00000e-02

$2.34269 \mathrm{e}+012.34269 \mathrm{e}+012.34269 \mathrm{e}+00$ 1.00000e-09 7.00000e-02

$2.34269 \mathrm{e}+012.34269 \mathrm{e}+012.34269 \mathrm{e}+001.00000 \mathrm{e}-09$ 7.00000e-02

5.00000e-04 5.00000e-04 5.00000e-05 1.00000e-09 1.00000e-01

9.36065e-01 9.36065e-01 9.36065e-02 1.00000e-09 2.12000e-01

9.36065e-01 9.36065e-01 9.36065e-02 1.00000e-09 2.12000e-01

$1.00000 \mathrm{e}-02$ 1.00000e-02 1.00000e-03 1.00000e-09 1.00000e-01

$1.00000 \mathrm{e}+001.00000 \mathrm{e}+001.00000 \mathrm{e}-011.00000 \mathrm{e}-09$ 1.00000e-01

Element: 4374 \# of layers: 7 
$\mathrm{Kx} \mathrm{Ky} \mathrm{Kz}$ Ss Por

2.18970e+01 2.18970e+01 2.18970e+00 1.00000e-09 7.00000e-02

$2.18970 \mathrm{e}+012.18970 \mathrm{e}+012.18970 \mathrm{e}+00$ 1.00000e-09 7.00000e-02

$2.18970 \mathrm{e}+012.18970 \mathrm{e}+012.18970 \mathrm{e}+001.00000 \mathrm{e}-09$ 7.00000e-02

8.74909e-01 8.74909e-01 8.74909e-02 1.00000e-09 2.12000e-01

8.74909e-01 8.74909e-01 8.74909e-02 1.00000e-09 2.12000e-01

$1.00000 \mathrm{e}-02$ 1.00000e-02 1.00000e-03 1.00000e-09 1.00000e-01

$1.00000 \mathrm{e}+001.00000 \mathrm{e}+001.00000 \mathrm{e}-01$ 1.00000e-09 1.00000e-01

Element: 4375 \# of layers: 7

$\mathrm{Kx} \mathrm{Ky} \mathrm{Kz}$ Ss Por

2.18970e+01 2.18970e+01 2.18970e+00 1.00000e-09 7.00000e-02

$2.18970 \mathrm{e}+012.18970 \mathrm{e}+012.18970 \mathrm{e}+001.00000 \mathrm{e}-09$ 7.00000e-02

$2.18970 \mathrm{e}+012.18970 \mathrm{e}+012.18970 \mathrm{e}+00$ 1.00000e-09 7.00000e-02

8.74909e-01 8.74909e-01 8.74909e-02 1.00000e-09 2.12000e-01

8.74909e-01 8.74909e-01 8.74909e-02 1.00000e-09 2.12000e-01

$1.00000 \mathrm{e}-02$ 1.00000e-02 1.00000e-03 1.00000e-09 1.00000e-01

$1.00000 \mathrm{e}+001.00000 \mathrm{e}+001.00000 \mathrm{e}-011.00000 \mathrm{e}-091.00000 \mathrm{e}-01$

Element: 4377 \# of layers: 7

$\mathrm{Kx} \mathrm{Ky} \mathrm{Kz}$ Ss Por

$2.03040 \mathrm{e}+012.03040 \mathrm{e}+012.03040 \mathrm{e}+00$ 1.00000e-09 7.00000e-02

$2.03040 \mathrm{e}+012.03040 \mathrm{e}+012.03040 \mathrm{e}+001.00000 \mathrm{e}-097.00000 \mathrm{e}-02$

$2.03040 \mathrm{e}+012.03040 \mathrm{e}+012.03040 \mathrm{e}+00$ 1.00000e-09 7.00000e-02

8.11277e-01 8.11277e-01 8.11277e-02 1.00000e-09 2.12000e-01

8.11277e-01 8.11277e-01 8.11277e-02 1.00000e-09 2.12000e-01

$1.00000 \mathrm{e}-02$ 1.00000e-02 1.00000e-03 1.00000e-09 1.00000e-01

$1.00000 \mathrm{e}+001.00000 \mathrm{e}+001.00000 \mathrm{e}-01$ 1.00000e-09 1.00000e-01

Element: 4378 \# of layers: 8

$\mathrm{Kx} \mathrm{Ky} \mathrm{Kz}$ Ss Por

$2.03040 \mathrm{e}+012.03040 \mathrm{e}+012.03040 \mathrm{e}+001.00000 \mathrm{e}-097.00000 \mathrm{e}-02$

$2.03040 \mathrm{e}+012.03040 \mathrm{e}+012.03040 \mathrm{e}+001.00000 \mathrm{e}-09$ 7.00000e-02

$2.03040 \mathrm{e}+012.03040 \mathrm{e}+012.03040 \mathrm{e}+001.00000 \mathrm{e}-097.00000 \mathrm{e}-02$

5.00000e-04 5.00000e-04 5.00000e-05 1.00000e-09 1.00000e-01

8.11277e-01 8.11277e-01 8.11277e-02 1.00000e-09 2.12000e-01

8.11277e-01 8.11277e-01 8.11277e-02 1.00000e-09 2.12000e-01

$1.00000 \mathrm{e}-02$ 1.00000e-02 1.00000e-03 1.00000e-09 1.00000e-01

$1.00000 \mathrm{e}+001.00000 \mathrm{e}+001.00000 \mathrm{e}-011.00000 \mathrm{e}-091.00000 \mathrm{e}-01$

Element: 4379 \# of layers: 9

Kx Ky Kz Ss Por

$2.03040 \mathrm{e}+012.03040 \mathrm{e}+012.03040 \mathrm{e}+001.00000 \mathrm{e}-09$ 7.00000e-02

$2.03040 \mathrm{e}+012.03040 \mathrm{e}+012.03040 \mathrm{e}+001.00000 \mathrm{e}-09$ 7.00000e-02

$2.03040 \mathrm{e}+012.03040 \mathrm{e}+012.03040 \mathrm{e}+001.00000 \mathrm{e}-09$ 7.00000e-02

5.00000e-04 5.00000e-04 5.00000e-05 1.00000e-09 1.00000e-01

5.00000e-04 5.00000e-04 5.00000e-05 1.00000e-09 1.00000e-01

8.11277e-01 8.11277e-01 8.11277e-02 1.00000e-09 2.12000e-01

8.11277e-01 8.11277e-01 8.11277e-02 1.00000e-09 2.12000e-01

$1.00000 \mathrm{e}-02$ 1.00000e-02 1.00000e-03 1.00000e-09 1.00000e-01 
$1.00000 \mathrm{e}+001.00000 \mathrm{e}+00$ 1.00000e-01 1.00000e-09 1.00000e-01

Element: 4380 \# of layers: 8

$\mathrm{Kx} \mathrm{Ky} \mathrm{Kz}$ Ss Por

$2.00851 \mathrm{e}+012.00851 \mathrm{e}+012.00851 \mathrm{e}+001.00000 \mathrm{e}-09$ 7.00000e-02

$2.00851 \mathrm{e}+012.00851 \mathrm{e}+012.00851 \mathrm{e}+001.00000 \mathrm{e}-09$ 7.00000e-02

$2.00851 \mathrm{e}+012.00851 \mathrm{e}+012.00851 \mathrm{e}+001.00000 \mathrm{e}-09$ 7.00000e-02

5.00000e-04 5.00000e-04 5.00000e-05 1.00000e-09 1.00000e-01

8.02547e-01 8.02547e-01 8.02547e-02 1.00000e-09 2.12000e-01

8.02547e-01 8.02547e-01 8.02547e-02 1.00000e-09 2.12000e-01

$1.00000 \mathrm{e}-02$ 1.00000e-02 1.00000e-03 1.00000e-09 1.00000e-01

$1.00000 \mathrm{e}+001.00000 \mathrm{e}+001.00000 \mathrm{e}-011.00000 \mathrm{e}-091.00000 \mathrm{e}-01$

Element: 4381 \# of layers: 7

$\mathrm{Kx} \mathrm{Ky} \mathrm{Kz}$ Ss Por

$2.00851 \mathrm{e}+012.00851 \mathrm{e}+012.00851 \mathrm{e}+001.00000 \mathrm{e}-09$ 7.00000e-02

$2.00851 \mathrm{e}+012.00851 \mathrm{e}+012.00851 \mathrm{e}+001.00000 \mathrm{e}-09$ 7.00000e-02

$2.00851 \mathrm{e}+012.00851 \mathrm{e}+012.00851 \mathrm{e}+001.00000 \mathrm{e}-09$ 7.00000e-02

8.02547e-01 8.02547e-01 8.02547e-02 1.00000e-09 2.12000e-01

8.02547e-01 8.02547e-01 8.02547e-02 1.00000e-09 2.12000e-01

$1.00000 \mathrm{e}-02$ 1.00000e-02 1.00000e-03 1.00000e-09 1.00000e-01

$1.00000 \mathrm{e}+001.00000 \mathrm{e}+001.00000 \mathrm{e}-011.00000 \mathrm{e}-091.00000 \mathrm{e}-01$

Element: 4382 \# of layers: 7

$\mathrm{Kx} \mathrm{Ky} \mathrm{Kz}$ Ss Por

$2.00851 \mathrm{e}+012.00851 \mathrm{e}+012.00851 \mathrm{e}+00$ 1.00000e-09 7.00000e-02

$2.00851 \mathrm{e}+012.00851 \mathrm{e}+012.00851 \mathrm{e}+001.00000 \mathrm{e}-09$ 7.00000e-02

$2.00851 \mathrm{e}+012.00851 \mathrm{e}+012.00851 \mathrm{e}+001.00000 \mathrm{e}-097.00000 \mathrm{e}-02$

8.02547e-01 8.02547e-01 8.02547e-02 1.00000e-09 2.12000e-01

8.02547e-01 8.02547e-01 8.02547e-02 1.00000e-09 2.12000e-01

$1.00000 \mathrm{e}-02$ 1.00000e-02 1.00000e-03 1.00000e-09 1.00000e-01

$1.00000 \mathrm{e}+001.00000 \mathrm{e}+001.00000 \mathrm{e}-011.00000 \mathrm{e}-091.00000 \mathrm{e}-01$

Element: 4383 \# of layers: 7

$\mathrm{Kx} \mathrm{Ky} \mathrm{Kz}$ Ss Por

$1.34425 \mathrm{e}+01$ 1.34425e+01 1.34425e+00 1.00000e-09 2.12000e-01

$1.34425 \mathrm{e}+011.34425 \mathrm{e}+01$ 1.34425e+00 1.00000e-09 2.12000e-01

$1.34425 \mathrm{e}+011.34425 \mathrm{e}+01$ 1.34425e+00 1.00000e-09 2.12000e-01

$1.34425 \mathrm{e}+01$ 1.34425e+01 1.34425e+00 1.00000e-09 2.12000e-01

$1.34425 \mathrm{e}+011.34425 \mathrm{e}+011.34425 \mathrm{e}+001.00000 \mathrm{e}-092.12000 \mathrm{e}-01$

$1.00000 \mathrm{e}-05$ 1.00000e-05 1.00000e-06 1.00000e-09 1.00000e-01

$1.00000 \mathrm{e}+001.00000 \mathrm{e}+001.00000 \mathrm{e}-011.00000 \mathrm{e}-091.00000 \mathrm{e}-01$

Element: 4384 \# of layers: 7

$\mathrm{Kx} \mathrm{Ky} \mathrm{Kz}$ Ss Por

$1.34425 \mathrm{e}+01$ 1.34425e+01 1.34425e+00 1.00000e-09 2.12000e-01

$1.34425 \mathrm{e}+011.34425 \mathrm{e}+01$ 1.34425e+00 1.00000e-09 2.12000e-01

$1.34425 \mathrm{e}+01$ 1.34425e+01 1.34425e+00 1.00000e-09 2.12000e-01

$1.34425 \mathrm{e}+01$ 1.34425e+01 1.34425e+00 1.00000e-09 2.12000e-01

$1.34425 \mathrm{e}+011.34425 \mathrm{e}+01$ 1.34425e+00 1.00000e-09 2.12000e-01

$1.00000 \mathrm{e}-05$ 1.00000e-05 1.00000e-06 1.00000e-09 1.00000e-01 
$1.00000 \mathrm{e}+001.00000 \mathrm{e}+00$ 1.00000e-01 1.00000e-09 1.00000e-01

Element: 4385 \# of layers: 7

Kx Ky Kz Ss Por

$1.41330 \mathrm{e}+01$ 1.41330e+01 1.41330e+00 1.00000e-09 2.12000e-01

$1.41330 \mathrm{e}+011.41330 \mathrm{e}+011.41330 \mathrm{e}+001.00000 \mathrm{e}-092.12000 \mathrm{e}-01$

$1.41330 \mathrm{e}+01$ 1.41330e+01 1.41330e+00 1.00000e-09 2.12000e-01

$1.41330 \mathrm{e}+011.41330 \mathrm{e}+011.41330 \mathrm{e}+001.00000 \mathrm{e}-092.12000 \mathrm{e}-01$

$1.41330 \mathrm{e}+011.41330 \mathrm{e}+011.41330 \mathrm{e}+001.00000 \mathrm{e}-092.12000 \mathrm{e}-01$

$1.00000 \mathrm{e}-05$ 1.00000e-05 1.00000e-06 1.00000e-09 1.00000e-01

$1.00000 \mathrm{e}+001.00000 \mathrm{e}+001.00000 \mathrm{e}-011.00000 \mathrm{e}-091.00000 \mathrm{e}-01$

Element: 4386 \# of layers: 7

$\mathrm{Kx} \mathrm{Ky} \mathrm{Kz}$ Ss Por

7.60764e+00 7.60764e+00 7.60764e-01 1.00000e-09 2.12000e-01

$7.60764 \mathrm{e}+007.60764 \mathrm{e}+007.60764 \mathrm{e}-01$ 1.00000e-09 2.12000e-01

$7.60764 \mathrm{e}+007.60764 \mathrm{e}+007.60764 \mathrm{e}-01$ 1.00000e-09 2.12000e-01

$7.60764 \mathrm{e}+007.60764 \mathrm{e}+007.60764 \mathrm{e}-01$ 1.00000e-09 2.12000e-01

$7.60764 \mathrm{e}+00$ 7.60764e+00 7.60764e-01 1.00000e-09 2.12000e-01

$1.00000 \mathrm{e}-051.00000 \mathrm{e}-051.00000 \mathrm{e}-061.00000 \mathrm{e}-091.00000 \mathrm{e}-01$

$1.00000 \mathrm{e}+001.00000 \mathrm{e}+001.00000 \mathrm{e}-011.00000 \mathrm{e}-091.00000 \mathrm{e}-01$

Element: 4387 \# of layers: 5

$\mathrm{Kx} \mathrm{Ky} \mathrm{Kz}$ Ss Por

8.59095e+03 8.59095e+03 8.59095e+02 1.00000e-09 7.00000e-02

3.43267e+02 3.43267e+02 3.43267e+01 1.00000e-09 2.12000e-01

$1.00000 \mathrm{e}-05$ 1.00000e-05 1.00000e-06 1.00000e-09 1.00000e-01

$1.00000 \mathrm{e}+001.00000 \mathrm{e}+001.00000 \mathrm{e}-011.00000 \mathrm{e}-091.00000 \mathrm{e}-01$

1.00000e-06 1.00000e-06 1.00000e-06 1.00000e-09 5.00000e-02

Element: 4388 \# of layers: 5

$\mathrm{Kx} \mathrm{Ky} \mathrm{Kz}$ Ss Por

8.59095e+03 8.59095e+03 8.59095e+02 1.00000e-09 7.00000e-02

3.43267e+02 3.43267e+02 3.43267e+01 1.00000e-09 2.12000e-01

$1.00000 \mathrm{e}-05$ 1.00000e-05 1.00000e-06 1.00000e-09 1.00000e-01

$1.00000 \mathrm{e}+001.00000 \mathrm{e}+001.00000 \mathrm{e}-011.00000 \mathrm{e}-091.00000 \mathrm{e}-01$

1.00000e-06 1.00000e-06 1.00000e-06 1.00000e-09 5.00000e-02

Element: 4389 \# of layers: 5

$\mathrm{Kx} \mathrm{Ky} \mathrm{Kz}$ Ss Por

8.59095e+03 8.59095e+03 8.59095e+02 1.00000e-09 7.00000e-02

$3.43267 \mathrm{e}+02$ 3.43267e+02 3.43267e+01 1.00000e-09 2.12000e-01

$1.00000 \mathrm{e}-051.00000 \mathrm{e}-051.00000 \mathrm{e}-061.00000 \mathrm{e}-091.00000 \mathrm{e}-01$

$1.00000 \mathrm{e}+001.00000 \mathrm{e}+001.00000 \mathrm{e}-011.00000 \mathrm{e}-091.00000 \mathrm{e}-01$

1.00000e-06 1.00000e-06 1.00000e-06 1.00000e-09 5.00000e-02

Element: 4390 \# of layers: 5

$\mathrm{Kx} \mathrm{Ky} \mathrm{Kz}$ Ss Por

$1.63477 \mathrm{e}+04$ 1.63477e+04 1.63477e+03 1.00000e-09 7.00000e-02

6.53189e+02 6.53189e+02 6.53189e+01 1.00000e-09 2.12000e-01

$1.00000 \mathrm{e}-05$ 1.00000e-05 1.00000e-06 1.00000e-09 1.00000e-01

$1.00000 \mathrm{e}+001.00000 \mathrm{e}+001.00000 \mathrm{e}-011.00000 \mathrm{e}-091.00000 \mathrm{e}-01$ 
1.00000e-06 1.00000e-06 1.00000e-06 1.00000e-09 5.00000e-02

Element: 4391 \# of layers: 5

$\mathrm{Kx} \mathrm{Ky} \mathrm{Kz}$ Ss Por

1.63477e+04 1.63477e+04 1.63477e+03 1.00000e-09 7.00000e-02

$6.53189 \mathrm{e}+02$ 6.53189e+02 6.53189e+01 1.00000e-09 2.12000e-01

$1.00000 \mathrm{e}-05$ 1.00000e-05 1.00000e-06 1.00000e-09 1.00000e-01

$1.00000 \mathrm{e}+001.00000 \mathrm{e}+001.00000 \mathrm{e}-011.00000 \mathrm{e}-091.00000 \mathrm{e}-01$

1.00000e-06 1.00000e-06 1.00000e-06 1.00000e-09 5.00000e-02

Element: 4392 \# of layers: 5

$\mathrm{Kx} \mathrm{Ky} \mathrm{Kz}$ Ss Por

5.30175e+03 5.30175e+03 5.30175e+02 1.00000e-09 7.00000e-02

$2.11840 \mathrm{e}+02$ 2.11840e+02 2.11840e+01 1.00000e-09 2.12000e-01

$1.00000 \mathrm{e}-051.00000 \mathrm{e}-051.00000 \mathrm{e}-061.00000 \mathrm{e}-091.00000 \mathrm{e}-01$

$1.00000 \mathrm{e}+001.00000 \mathrm{e}+001.00000 \mathrm{e}-011.00000 \mathrm{e}-091.00000 \mathrm{e}-01$

1.00000e-06 1.00000e-06 1.00000e-06 1.00000e-09 5.00000e-02

Element: 4393 \# of layers: 5

$\mathrm{Kx} \mathrm{Ky} \mathrm{Kz}$ Ss Por

$1.04516 \mathrm{e}+041.04516 \mathrm{e}+041.04516 \mathrm{e}+03$ 1.00000e-09 7.00000e-02

4.17631e+02 4.17631e+02 4.17631e+01 1.00000e-09 2.12000e-01

$1.00000 \mathrm{e}-05$ 1.00000e-05 1.00000e-06 1.00000e-09 1.00000e-01

$1.00000 \mathrm{e}+001.00000 \mathrm{e}+001.00000 \mathrm{e}-011.00000 \mathrm{e}-091.00000 \mathrm{e}-01$

$1.00000 \mathrm{e}-06$ 1.00000e-06 1.00000e-06 1.00000e-09 5.00000e-02

Element: 4394 \# of layers: 5

Kx Ky Kz Ss Por

8.59095e+03 8.59095e+03 8.59095e+02 1.00000e-09 7.00000e-02

$3.43267 \mathrm{e}+02$ 3.43267e+02 3.43267e+01 1.00000e-09 2.12000e-01

$1.00000 \mathrm{e}-05$ 1.00000e-05 1.00000e-06 1.00000e-09 1.00000e-01

$1.00000 \mathrm{e}+001.00000 \mathrm{e}+001.00000 \mathrm{e}-011.00000 \mathrm{e}-091.00000 \mathrm{e}-01$

1.00000e-06 1.00000e-06 1.00000e-06 1.00000e-09 5.00000e-02

Element: 4395 \# of layers: 5

$\mathrm{Kx} \mathrm{Ky} \mathrm{Kz}$ Ss Por

6.97095e+03 6.97095e+03 6.97095e+02 1.00000e-09 7.00000e-02

$2.78533 \mathrm{e}+02$ 2.78533e+02 2.78533e+01 1.00000e-09 2.12000e-01

$1.00000 \mathrm{e}-05$ 1.00000e-05 1.00000e-06 1.00000e-09 1.00000e-01

$1.00000 \mathrm{e}+001.00000 \mathrm{e}+001.00000 \mathrm{e}-011.00000 \mathrm{e}-091.00000 \mathrm{e}-01$

1.00000e-06 1.00000e-06 1.00000e-06 1.00000e-09 5.00000e-02

Element: 4396 \# of layers: 5

Kx Ky Kz Ss Por

4.88576e+03 4.88576e+03 4.88576e+02 1.00000e-09 7.00000e-02

$1.95216 \mathrm{e}+021.95216 \mathrm{e}+021.95216 \mathrm{e}+01$ 1.00000e-09 2.12000e-01

$1.00000 \mathrm{e}-05$ 1.00000e-05 1.00000e-06 1.00000e-09 1.00000e-01

$1.00000 \mathrm{e}+001.00000 \mathrm{e}+001.00000 \mathrm{e}-011.00000 \mathrm{e}-091.00000 \mathrm{e}-01$

1.00000e-06 1.00000e-06 1.00000e-06 1.00000e-09 5.00000e-02

Element: 4397 \# of layers: 7

$\mathrm{Kx} \mathrm{Ky} \mathrm{Kz}$ Ss Por

4.88576e+03 4.88576e+03 4.88576e+02 1.00000e-09 7.00000e-02 
4.88576e+03 4.88576e+03 4.88576e+02 1.00000e-09 7.00000e-02 4.88576e+03 4.88576e+03 4.88576e+02 1.00000e-09 7.00000e-02 $1.95216 \mathrm{e}+021.95216 \mathrm{e}+02$ 1.95216e+01 1.00000e-09 2.12000e-01 $1.00000 \mathrm{e}-05$ 1.00000e-05 1.00000e-06 1.00000e-09 1.00000e-01 $1.00000 \mathrm{e}+001.00000 \mathrm{e}+001.00000 \mathrm{e}-011.00000 \mathrm{e}-091.00000 \mathrm{e}-01$ 1.00000e-06 1.00000e-06 1.00000e-06 1.00000e-09 5.00000e-02 Element: 4398 \# of layers: 5

$\mathrm{Kx} \mathrm{Ky} \mathrm{Kz}$ Ss Por

4.88576e+03 4.88576e+03 4.88576e+02 1.00000e-09 7.00000e-02 $4.88576 \mathrm{e}+034.88576 \mathrm{e}+03$ 4.88576e+02 1.00000e-09 7.00000e-02 $1.95216 \mathrm{e}+021.95216 \mathrm{e}+02 \quad 1.95216 \mathrm{e}+01$ 1.00000e-09 2.12000e-01 $1.00000 \mathrm{e}+001.00000 \mathrm{e}+001.00000 \mathrm{e}-011.00000 \mathrm{e}-091.00000 \mathrm{e}-01$ 1.00000e-06 1.00000e-06 1.00000e-06 1.00000e-09 5.00000e-02 Element: 4399 \# of layers: 5

$\mathrm{Kx} \mathrm{Ky} \mathrm{Kz}$ Ss Por

6.35989e+03 6.35989e+03 6.35989e+02 1.00000e-09 7.00000e-02 $6.35989 \mathrm{e}+03$ 6.35989e+03 6.35989e+02 1.00000e-09 7.00000e-02 $2.54120 \mathrm{e}+022.54120 \mathrm{e}+02$ 2.54120e+01 1.00000e-09 2.12000e-01 $1.00000 \mathrm{e}+001.00000 \mathrm{e}+001.00000 \mathrm{e}-011.00000 \mathrm{e}-091.00000 \mathrm{e}-01$ 1.00000e-06 1.00000e-06 1.00000e-06 1.00000e-09 5.00000e-02

Element: 4400 \# of layers: 5

$\mathrm{Kx} \mathrm{Ky} \mathrm{Kz}$ Ss Por

6.35989e+03 6.35989e+03 6.35989e+02 1.00000e-09 7.00000e-02 $2.54120 \mathrm{e}+022.54120 \mathrm{e}+02 \quad 2.54120 \mathrm{e}+01$ 1.00000e-09 2.12000e-01 $2.54120 \mathrm{e}+02$ 2.54120e+02 2.54120e+01 1.00000e-09 2.12000e-01 $1.00000 \mathrm{e}+001.00000 \mathrm{e}+001.00000 \mathrm{e}-011.00000 \mathrm{e}-091.00000 \mathrm{e}-01$ 1.00000e-06 1.00000e-06 1.00000e-06 1.00000e-09 5.00000e-02 Element: 4401 \# of layers: 5

Kx Ky Kz Ss Por

$1.21581 \mathrm{e}+041.21581 \mathrm{e}+041.21581 \mathrm{e}+03$ 1.00000e-09 7.00000e-02 $4.85785 \mathrm{e}+02$ 4.85785e+02 4.85785e+01 1.00000e-09 2.12000e-01 $4.85785 \mathrm{e}+02$ 4.85785e+02 4.85785e+01 1.00000e-09 2.12000e-01 $1.00000 \mathrm{e}+001.00000 \mathrm{e}+001.00000 \mathrm{e}-011.00000 \mathrm{e}-091.00000 \mathrm{e}-01$ 1.00000e-06 1.00000e-06 1.00000e-06 1.00000e-09 5.00000e-02 Element: 4402 \# of layers: 5

$\mathrm{Kx} \mathrm{Ky} \mathrm{Kz}$ Ss Por

6.97095e+03 6.97095e+03 6.97095e+02 1.00000e-09 7.00000e-02 $2.78533 \mathrm{e}+02$ 2.78533e+02 2.78533e+01 1.00000e-09 2.12000e-01 $1.00000 \mathrm{e}-05$ 1.00000e-05 1.00000e-06 1.00000e-09 1.00000e-01 $1.00000 \mathrm{e}+001.00000 \mathrm{e}+001.00000 \mathrm{e}-011.00000 \mathrm{e}-091.00000 \mathrm{e}-01$ 1.00000e-06 1.00000e-06 1.00000e-06 1.00000e-09 5.00000e-02 Element: 4403 \# of layers: 5

$\mathrm{Kx} \mathrm{Ky} \mathrm{Kz}$ Ss Por

4.88576e+03 4.88576e+03 4.88576e+02 1.00000e-09 7.00000e-02 $1.95216 \mathrm{e}+021.95216 \mathrm{e}+02 \quad 1.95216 \mathrm{e}+01$ 1.00000e-09 2.12000e-01 $1.00000 \mathrm{e}-05$ 1.00000e-05 1.00000e-06 1.00000e-09 1.00000e-01 
$1.00000 \mathrm{e}+001.00000 \mathrm{e}+001.00000 \mathrm{e}-011.00000 \mathrm{e}-091.00000 \mathrm{e}-01$ $1.00000 \mathrm{e}-06$ 1.00000e-06 1.00000e-06 1.00000e-09 5.00000e-02

Element: 4404 \# of layers: 8

Kx Ky Kz Ss Por

4.57402e+03 4.57402e+03 4.57402e+02 1.00000e-09 7.00000e-02

4.57402e+03 4.57402e+03 4.57402e+02 1.00000e-09 7.00000e-02

$4.57402 \mathrm{e}+034.57402 \mathrm{e}+03$ 4.57402e+02 1.00000e-09 7.00000e-02

$1.82762 \mathrm{e}+021.82762 \mathrm{e}+02 \quad 1.82762 \mathrm{e}+01$ 1.00000e-09 2.12000e-01

$1.82762 \mathrm{e}+02$ 1.82762e+02 1.82762e+01 1.00000e-09 2.12000e-01

$1.00000 \mathrm{e}-05$ 1.00000e-05 1.00000e-06 1.00000e-09 1.00000e-01

$1.00000 \mathrm{e}+001.00000 \mathrm{e}+001.00000 \mathrm{e}-011.00000 \mathrm{e}-091.00000 \mathrm{e}-01$

1.00000e-06 1.00000e-06 1.00000e-06 1.00000e-09 5.00000e-02

Element: 4405 \# of layers: 8

$\mathrm{Kx} \mathrm{Ky} \mathrm{Kz}$ Ss Por

5.52709e+03 5.52709e+03 5.52709e+02 1.00000e-09 7.00000e-02

$5.52709 \mathrm{e}+035.52709 \mathrm{e}+03$ 5.52709e+02 1.00000e-09 7.00000e-02

$5.52709 \mathrm{e}+03$ 5.52709e+03 5.52709e+02 1.00000e-09 7.00000e-02

$2.20844 \mathrm{e}+02$ 2.20844e+02 2.20845e+01 1.00000e-09 2.12000e-01

$2.20844 \mathrm{e}+02$ 2.20844e+02 2.20845e+01 1.00000e-09 2.12000e-01

$1.00000 \mathrm{e}-05$ 1.00000e-05 1.00000e-06 1.00000e-09 1.00000e-01

$1.00000 \mathrm{e}+001.00000 \mathrm{e}+001.00000 \mathrm{e}-011.00000 \mathrm{e}-091.00000 \mathrm{e}-01$

1.00000e-06 1.00000e-06 1.00000e-06 1.00000e-09 5.00000e-02

Element: 4406 \# of layers: 8

Kx Ky Kz Ss Por

5.52709e+03 5.52709e+03 5.52709e+02 1.00000e-09 7.00000e-02

$5.52709 \mathrm{e}+03$ 5.52709e+03 5.52709e+02 1.00000e-09 7.00000e-02

$5.52709 \mathrm{e}+03$ 5.52709e+03 5.52709e+02 1.00000e-09 7.00000e-02

$2.20844 \mathrm{e}+02$ 2.20844e+02 2.20845e+01 1.00000e-09 2.12000e-01

$2.20844 \mathrm{e}+02$ 2.20844e+02 2.20845e+01 1.00000e-09 2.12000e-01

$1.00000 \mathrm{e}-05$ 1.00000e-05 1.00000e-06 1.00000e-09 1.00000e-01

$1.00000 \mathrm{e}+001.00000 \mathrm{e}+001.00000 \mathrm{e}-01$ 1.00000e-09 1.00000e-01

1.00000e-06 1.00000e-06 1.00000e-06 1.00000e-09 5.00000e-02

Element: 4407 \# of layers: 4

$\mathrm{Kx} \mathrm{Ky} \mathrm{Kz}$ Ss Por

5.52709e+03 5.52709e+03 5.52709e+02 1.00000e-09 7.00000e-02

$5.52709 \mathrm{e}+03$ 5.52709e+03 5.52709e+02 1.00000e-09 7.00000e-02

$1.00000 \mathrm{e}+001.00000 \mathrm{e}+001.00000 \mathrm{e}-011.00000 \mathrm{e}-091.00000 \mathrm{e}-01$

1.00000e-06 1.00000e-06 1.00000e-06 1.00000e-09 5.00000e-02

Element: 4408 \# of layers: 4

$\mathrm{Kx} \mathrm{Ky} \mathrm{Kz}$ Ss Por

6.84454e+03 6.84454e+03 6.84454e+02 1.00000e-09 7.00000e-02

$6.84454 \mathrm{e}+036.84454 \mathrm{e}+036.84454 \mathrm{e}+02$ 1.00000e-09 7.00000e-02

$1.00000 \mathrm{e}+001.00000 \mathrm{e}+001.00000 \mathrm{e}-011.00000 \mathrm{e}-091.00000 \mathrm{e}-01$

1.00000e-06 1.00000e-06 1.00000e-06 1.00000e-09 5.00000e-02

Element: 4409 \# of layers: 4

Kx Ky Kz Ss Por 
$6.84454 \mathrm{e}+036.84454 \mathrm{e}+036.84454 \mathrm{e}+02$ 1.00000e-09 7.00000e-02 $6.84454 \mathrm{e}+036.84454 \mathrm{e}+036.84454 \mathrm{e}+021.00000 \mathrm{e}-097.00000 \mathrm{e}-02$ $1.00000 \mathrm{e}+001.00000 \mathrm{e}+001.00000 \mathrm{e}-011.00000 \mathrm{e}-091.00000 \mathrm{e}-01$ $1.00000 \mathrm{e}-06$ 1.00000e-06 1.00000e-06 1.00000e-09 5.00000e-02 Element: 4410 \# of layers: 5

Kx Ky Kz Ss Por

$4.74782 \mathrm{e}+03$ 4.74782e+03 4.74782e+02 1.00000e-09 7.00000e-02 $4.74782 \mathrm{e}+03$ 4.74782e+03 4.74782e+02 1.00000e-09 7.00000e-02 $2.54120 \mathrm{e}+022.54120 \mathrm{e}+022.54120 \mathrm{e}+011.00000 \mathrm{e}-092.12000 \mathrm{e}-01$ $1.00000 \mathrm{e}+001.00000 \mathrm{e}+001.00000 \mathrm{e}-011.00000 \mathrm{e}-091.00000 \mathrm{e}-01$ $1.00000 \mathrm{e}-06$ 1.00000e-06 1.00000e-06 1.00000e-09 5.00000e-02

Element: 4411 \# of layers: 5

Kx Ky Kz Ss Por

$4.57402 \mathrm{e}+03$ 4.57402e+03 4.57402e+02 1.00000e-09 7.00000e-02 $4.57402 \mathrm{e}+034.57402 \mathrm{e}+034.57402 \mathrm{e}+021.00000 \mathrm{e}-097.00000 \mathrm{e}-02$ $1.82762 \mathrm{e}+021.82762 \mathrm{e}+021.82762 \mathrm{e}+01$ 1.00000e-09 2.12000e-01 $1.00000 \mathrm{e}+001.00000 \mathrm{e}+001.00000 \mathrm{e}-011.00000 \mathrm{e}-091.00000 \mathrm{e}-01$ $1.00000 \mathrm{e}-06$ 1.00000e-06 1.00000e-06 1.00000e-09 5.00000e-02

Element: 4412 \# of layers: 4

Kx Ky Kz Ss Por

$5.52709 \mathrm{e}+03$ 5.52709e+03 5.52709e+02 1.00000e-09 7.00000e-02

$5.52709 \mathrm{e}+03$ 5.52709e+03 5.52709e+02 1.00000e-09 7.00000e-02 $1.00000 \mathrm{e}+001.00000 \mathrm{e}+001.00000 \mathrm{e}-011.00000 \mathrm{e}-091.00000 \mathrm{e}-01$ 1.00000e-06 1.00000e-06 1.00000e-06 1.00000e-09 5.00000e-02

Element: 4413 \# of layers: 6

Kx Ky Kz Ss Por

$5.28635 \mathrm{e}+03$ 5.28635e+03 5.28635e+02 1.00000e-09 7.00000e-02 $5.28635 \mathrm{e}+03$ 5.28635e+03 5.28635e+02 1.00000e-09 7.00000e-02 $5.28635 \mathrm{e}+03$ 5.28635e+03 5.28635e+02 1.00000e-09 7.00000e-02 $1.00000 \mathrm{e}-05$ 1.00000e-05 1.00000e-06 1.00000e-09 1.00000e-01 $1.00000 \mathrm{e}+001.00000 \mathrm{e}+001.00000 \mathrm{e}-011.00000 \mathrm{e}-091.00000 \mathrm{e}-01$ 1.00000e-06 1.00000e-06 1.00000e-06 1.00000e-09 5.00000e-02 Element: 4414 \# of layers: 5

Kx Ky Kz Ss Por

$3.13728 \mathrm{e}+033.13728 \mathrm{e}+033.13728 \mathrm{e}+02$ 1.00000e-09 7.00000e-02 $3.13728 \mathrm{e}+033.13728 \mathrm{e}+033.13728 \mathrm{e}+02$ 1.00000e-09 7.00000e-02 $3.13728 \mathrm{e}+033.13728 \mathrm{e}+033.13728 \mathrm{e}+02$ 1.00000e-09 7.00000e-02 $1.00000 \mathrm{e}+001.00000 \mathrm{e}+001.00000 \mathrm{e}-011.00000 \mathrm{e}-091.00000 \mathrm{e}-01$ $1.00000 \mathrm{e}-06$ 1.00000e-06 1.00000e-06 1.00000e-09 5.00000e-02 Element: 4415 \# of layers: 5

Kx Ky Kz Ss Por

$3.13728 \mathrm{e}+033.13728 \mathrm{e}+03$ 3.13728e+02 1.00000e-09 7.00000e-02 $3.13728 \mathrm{e}+033.13728 \mathrm{e}+033.13728 \mathrm{e}+02$ 1.00000e-09 7.00000e-02 $3.13728 \mathrm{e}+033.13728 \mathrm{e}+033.13728 \mathrm{e}+02$ 1.00000e-09 7.00000e-02 $1.00000 \mathrm{e}+001.00000 \mathrm{e}+001.00000 \mathrm{e}-011.00000 \mathrm{e}-091.00000 \mathrm{e}-01$ $1.00000 \mathrm{e}-06$ 1.00000e-06 1.00000e-06 1.00000e-09 5.00000e-02 
Element: 4416 \# of layers: 4

$\mathrm{Kx} \mathrm{Ky} \mathrm{Kz}$ Ss Por

3.13728e+03 3.13728e+03 3.13728e+02 1.00000e-09 7.00000e-02

$3.13728 \mathrm{e}+03$ 3.13728e+03 3.13728e+02 1.00000e-09 7.00000e-02

$1.00000 \mathrm{e}+001.00000 \mathrm{e}+001.00000 \mathrm{e}-011.00000 \mathrm{e}-091.00000 \mathrm{e}-01$

1.00000e-06 1.00000e-06 1.00000e-06 1.00000e-09 5.00000e-02

Element: 4417 \# of layers: 3

Kx Ky Kz Ss Por

9.19471e+03 9.19471e+03 9.19471e+02 1.00000e-09 7.00000e-02

$1.00000 \mathrm{e}+001.00000 \mathrm{e}+001.00000 \mathrm{e}-011.00000 \mathrm{e}-091.00000 \mathrm{e}-01$

1.00000e-06 1.00000e-06 1.00000e-06 1.00000e-09 5.00000e-02

Element: 4418 \# of layers: 3

$\mathrm{Kx} \mathrm{Ky} \mathrm{Kz}$ Ss Por

9.19471e+03 9.19471e+03 9.19471e+02 1.00000e-09 7.00000e-02

$1.00000 \mathrm{e}+001.00000 \mathrm{e}+001.00000 \mathrm{e}-011.00000 \mathrm{e}-091.00000 \mathrm{e}-01$

1.00000e-06 1.00000e-06 1.00000e-06 1.00000e-09 5.00000e-02

Element: 4419 \# of layers: 4

$\mathrm{Kx} \mathrm{Ky} \mathrm{Kz}$ Ss Por

$1.23572 \mathrm{e}+041.23572 \mathrm{e}+04$ 1.23572e+03 1.00000e-09 7.00000e-02

$1.23572 \mathrm{e}+041.23572 \mathrm{e}+04$ 1.23572e+03 1.00000e-09 7.00000e-02

$1.00000 \mathrm{e}+001.00000 \mathrm{e}+001.00000 \mathrm{e}-011.00000 \mathrm{e}-091.00000 \mathrm{e}-01$

$1.00000 \mathrm{e}-06$ 1.00000e-06 1.00000e-06 1.00000e-09 5.00000e-02

Element: 4420 \# of layers: 4

$\mathrm{Kx} \mathrm{Ky} \mathrm{Kz}$ Ss Por

5.28635e+03 5.28635e+03 5.28635e+02 1.00000e-09 7.00000e-02

$5.28635 \mathrm{e}+03$ 5.28635e+03 5.28635e+02 1.00000e-09 7.00000e-02

$1.00000 \mathrm{e}+001.00000 \mathrm{e}+001.00000 \mathrm{e}-011.00000 \mathrm{e}-091.00000 \mathrm{e}-01$

1.00000e-06 1.00000e-06 1.00000e-06 1.00000e-09 5.00000e-02

Element: 4421 \# of layers: 4

$\mathrm{Kx} \mathrm{Ky} \mathrm{Kz}$ Ss Por

3.13728e+03 3.13728e+03 3.13728e+02 1.00000e-09 7.00000e-02

$3.13728 \mathrm{e}+03$ 3.13728e+03 3.13728e+02 1.00000e-09 7.00000e-02

$1.00000 \mathrm{e}+001.00000 \mathrm{e}+001.00000 \mathrm{e}-011.00000 \mathrm{e}-091.00000 \mathrm{e}-01$

$1.00000 \mathrm{e}-06$ 1.00000e-06 1.00000e-06 1.00000e-09 5.00000e-02

Element: 4422 \# of layers: 5

$\mathrm{Kx} \mathrm{Ky} \mathrm{Kz}$ Ss Por

4.14235e+02 4.14235e+02 4.14235e+01 1.00000e-09 7.00000e-02

4.14235e+02 4.14235e+02 4.14235e+01 1.00000e-09 7.00000e-02

4.14235e+02 4.14235e+02 4.14235e+01 1.00000e-09 7.00000e-02 $1.00000 \mathrm{e}+001.00000 \mathrm{e}+001.00000 \mathrm{e}-011.00000 \mathrm{e}-091.00000 \mathrm{e}-01$

$1.00000 \mathrm{e}-06$ 1.00000e-06 1.00000e-06 1.00000e-09 5.00000e-02

Element: 4423 \# of layers: 6

$\mathrm{Kx} \mathrm{Ky} \mathrm{Kz}$ Ss Por

$1.90174 \mathrm{e}+02$ 1.90174e+02 1.90174e+01 1.00000e-09 7.00000e-02

$1.90174 \mathrm{e}+02$ 1.90174e+02 1.90174e+01 1.00000e-09 7.00000e-02

$1.90174 \mathrm{e}+021.90174 \mathrm{e}+02 \quad 1.90174 \mathrm{e}+011.00000 \mathrm{e}-097.00000 \mathrm{e}-02$ 
$1.00000 \mathrm{e}-05$ 1.00000e-05 1.00000e-06 1.00000e-09 1.00000e-01 $1.00000 \mathrm{e}+001.00000 \mathrm{e}+001.00000 \mathrm{e}-011.00000 \mathrm{e}-091.00000 \mathrm{e}-01$ 1.00000e-06 1.00000e-06 1.00000e-06 1.00000e-09 5.00000e-02

Element: 4424 \# of layers: 6

$\mathrm{Kx} \mathrm{Ky} \mathrm{Kz}$ Ss Por

$1.90174 \mathrm{e}+02$ 1.90174e+02 1.90174e+01 1.00000e-09 7.00000e-02 $1.90174 \mathrm{e}+021.90174 \mathrm{e}+02 \quad 1.90174 \mathrm{e}+01$ 1.00000e-09 7.00000e-02 $1.90174 \mathrm{e}+02 \quad 1.90174 \mathrm{e}+02 \quad 1.90174 \mathrm{e}+01 \quad 1.00000 \mathrm{e}-097.00000 \mathrm{e}-02$ $1.00000 \mathrm{e}-05$ 1.00000e-05 1.00000e-06 1.00000e-09 1.00000e-01 $1.00000 \mathrm{e}+001.00000 \mathrm{e}+001.00000 \mathrm{e}-01$ 1.00000e-09 1.00000e-01 1.00000e-06 1.00000e-06 1.00000e-06 1.00000e-09 5.00000e-02

Element: 4425 \# of layers: 4

$\mathrm{Kx} \mathrm{Ky} \mathrm{Kz}$ Ss Por

$1.90174 \mathrm{e}+021.90174 \mathrm{e}+02$ 1.90174e+01 1.00000e-09 7.00000e-02 $1.90174 \mathrm{e}+021.90174 \mathrm{e}+02 \quad 1.90174 \mathrm{e}+01$ 1.00000e-09 7.00000e-02 $1.00000 \mathrm{e}+001.00000 \mathrm{e}+001.00000 \mathrm{e}-011.00000 \mathrm{e}-091.00000 \mathrm{e}-01$ 1.00000e-06 1.00000e-06 1.00000e-06 1.00000e-09 5.00000e-02

Element: 4426 \# of layers: 4

$\mathrm{Kx} \mathrm{Ky} \mathrm{Kz}$ Ss Por

4.47482e+02 4.47482e+02 4.47482e+01 1.00000e-09 7.00000e-02 4.47482e+02 4.47482e+02 4.47482e+01 1.00000e-09 7.00000e-02 $1.00000 \mathrm{e}+001.00000 \mathrm{e}+001.00000 \mathrm{e}-011.00000 \mathrm{e}-091.00000 \mathrm{e}-01$ 1.00000e-06 1.00000e-06 1.00000e-06 1.00000e-09 5.00000e-02 Element: 4427 \# of layers: 4

Kx Ky Kz Ss Por 4.47482e+02 4.47482e+02 4.47482e+01 1.00000e-09 7.00000e-02 4.47482e+02 4.47482e+02 4.47482e+01 1.00000e-09 7.00000e-02 $1.00000 \mathrm{e}+001.00000 \mathrm{e}+001.00000 \mathrm{e}-011.00000 \mathrm{e}-091.00000 \mathrm{e}-01$ 1.00000e-06 1.00000e-06 1.00000e-06 1.00000e-09 5.00000e-02 Element: 4428 \# of layers: 3

$\mathrm{Kx} \mathrm{Ky} \mathrm{Kz}$ Ss Por

$4.96514 \mathrm{e}+024.96514 \mathrm{e}+024.96514 \mathrm{e}+01$ 1.00000e-09 7.00000e-02 $1.00000 \mathrm{e}+001.00000 \mathrm{e}+001.00000 \mathrm{e}-011.00000 \mathrm{e}-091.00000 \mathrm{e}-01$ 1.00000e-06 1.00000e-06 1.00000e-06 1.00000e-09 5.00000e-02

Element: 4429 \# of layers: 4

$\mathrm{Kx} \mathrm{Ky} \mathrm{Kz}$ Ss Por

4.14235e+02 4.14235e+02 4.14235e+01 1.00000e-09 7.00000e-02 4.14235e+02 4.14235e+02 4.14235e+01 1.00000e-09 7.00000e-02 $1.00000 \mathrm{e}+001.00000 \mathrm{e}+001.00000 \mathrm{e}-011.00000 \mathrm{e}-091.00000 \mathrm{e}-01$ 1.00000e-06 1.00000e-06 1.00000e-06 1.00000e-09 5.00000e-02 Element: 4430 \# of layers: 4

$\mathrm{Kx} \mathrm{Ky} \mathrm{Kz}$ Ss Por

$1.90174 \mathrm{e}+02$ 1.90174e+02 1.90174e+01 1.00000e-09 7.00000e-02 $1.90174 \mathrm{e}+021.90174 \mathrm{e}+02$ 1.90174e+01 1.00000e-09 7.00000e-02 $1.00000 \mathrm{e}+001.00000 \mathrm{e}+001.00000 \mathrm{e}-011.00000 \mathrm{e}-091.00000 \mathrm{e}-01$ $1.00000 \mathrm{e}-06$ 1.00000e-06 1.00000e-06 1.00000e-09 5.00000e-02 
Element: 4431 \# of layers: 6

$\mathrm{Kx} \mathrm{Ky} \mathrm{Kz}$ Ss Por

$1.65928 \mathrm{e}+02$ 1.65928e+02 1.65928e+01 1.00000e-09 7.00000e-02

$1.65928 \mathrm{e}+02$ 1.65928e+02 1.65928e+01 1.00000e-09 7.00000e-02

$1.65928 \mathrm{e}+021.65928 \mathrm{e}+021.65928 \mathrm{e}+01$ 1.00000e-09 7.00000e-02

$1.00000 \mathrm{e}-05$ 1.00000e-05 1.00000e-06 1.00000e-09 1.00000e-01

$1.00000 \mathrm{e}+001.00000 \mathrm{e}+001.00000 \mathrm{e}-011.00000 \mathrm{e}-091.00000 \mathrm{e}-01$

1.00000e-06 1.00000e-06 1.00000e-06 1.00000e-09 5.00000e-02

Element: 4432 \# of layers: 6

$\mathrm{Kx} \mathrm{Ky} \mathrm{Kz}$ Ss Por

$1.69784 \mathrm{e}+02$ 1.69784e+02 1.69784e+01 1.00000e-09 7.00000e-02

$1.69784 \mathrm{e}+021.69784 \mathrm{e}+02 \quad 1.69784 \mathrm{e}+01$ 1.00000e-09 7.00000e-02

$1.69784 \mathrm{e}+02$ 1.69784e+02 1.69784e+01 1.00000e-09 7.00000e-02

$1.00000 \mathrm{e}-051.00000 \mathrm{e}-05$ 1.00000e-06 1.00000e-09 1.00000e-01

$1.00000 \mathrm{e}+001.00000 \mathrm{e}+001.00000 \mathrm{e}-011.00000 \mathrm{e}-091.00000 \mathrm{e}-01$

1.00000e-06 1.00000e-06 1.00000e-06 1.00000e-09 5.00000e-02

Element: 4433 \# of layers: 6

$\mathrm{Kx} \mathrm{Ky} \mathrm{Kz}$ Ss Por

$1.69784 \mathrm{e}+02$ 1.69784e+02 1.69784e+01 1.00000e-09 7.00000e-02

$1.69784 \mathrm{e}+021.69784 \mathrm{e}+02$ 1.69784e+01 1.00000e-09 7.00000e-02

$1.69784 \mathrm{e}+021.69784 \mathrm{e}+021.69784 \mathrm{e}+01$ 1.00000e-09 7.00000e-02

$1.00000 \mathrm{e}-05$ 1.00000e-05 1.00000e-06 1.00000e-09 1.00000e-01

$1.00000 \mathrm{e}+001.00000 \mathrm{e}+001.00000 \mathrm{e}-011.00000 \mathrm{e}-091.00000 \mathrm{e}-01$

1.00000e-06 1.00000e-06 1.00000e-06 1.00000e-09 5.00000e-02

Element: 4434 \# of layers: 4

$\mathrm{Kx} \mathrm{Ky} \mathrm{Kz}$ Ss Por

$1.69784 \mathrm{e}+02$ 1.69784e+02 1.69784e+01 1.00000e-09 7.00000e-02

$1.69784 \mathrm{e}+021.69784 \mathrm{e}+021.69784 \mathrm{e}+01$ 1.00000e-09 7.00000e-02

$1.00000 \mathrm{e}+001.00000 \mathrm{e}+001.00000 \mathrm{e}-011.00000 \mathrm{e}-091.00000 \mathrm{e}-01$

1.00000e-06 1.00000e-06 1.00000e-06 1.00000e-09 5.00000e-02

Element: 4435 \# of layers: 4

$\mathrm{Kx} \mathrm{Ky} \mathrm{Kz}$ Ss Por

3.88818e+02 3.88818e+02 3.88818e+01 1.00000e-09 7.00000e-02

$3.88818 \mathrm{e}+023.88818 \mathrm{e}+023.88818 \mathrm{e}+01$ 1.00000e-09 7.00000e-02

$1.00000 \mathrm{e}+001.00000 \mathrm{e}+001.00000 \mathrm{e}-011.00000 \mathrm{e}-091.00000 \mathrm{e}-01$

1.00000e-06 1.00000e-06 1.00000e-06 1.00000e-09 5.00000e-02

Element: 4436 \# of layers: 4

Kx Ky Kz Ss Por

3.88818e+02 3.88818e+02 3.88818e+01 1.00000e-09 7.00000e-02

$3.88818 \mathrm{e}+023.88818 \mathrm{e}+02$ 3.88818e+01 1.00000e-09 7.00000e-02

$1.00000 \mathrm{e}+001.00000 \mathrm{e}+001.00000 \mathrm{e}-011.00000 \mathrm{e}-091.00000 \mathrm{e}-01$

1.00000e-06 1.00000e-06 1.00000e-06 1.00000e-09 5.00000e-02

Element: 4437 \# of layers: 4

$\mathrm{Kx} \mathrm{Ky} \mathrm{Kz}$ Ss Por

3.97819e+02 3.97819e+02 3.97819e+01 1.00000e-09 7.00000e-02

$3.97819 \mathrm{e}+02$ 3.97819e+02 3.97819e+01 1.00000e-09 7.00000e-02 
$1.00000 \mathrm{e}+001.00000 \mathrm{e}+001.00000 \mathrm{e}-011.00000 \mathrm{e}-091.00000 \mathrm{e}-01$ 1.00000e-06 1.00000e-06 1.00000e-06 1.00000e-09 5.00000e-02

Element: 4438 \# of layers: 4

Kx Ky Kz Ss Por

$1.65928 \mathrm{e}+02$ 1.65928e+02 1.65928e+01 1.00000e-09 7.00000e-02

$1.65928 \mathrm{e}+021.65928 \mathrm{e}+02 \quad 1.65928 \mathrm{e}+01$ 1.00000e-09 7.00000e-02

$1.00000 \mathrm{e}+001.00000 \mathrm{e}+001.00000 \mathrm{e}-011.00000 \mathrm{e}-091.00000 \mathrm{e}-01$

$1.00000 \mathrm{e}-06$ 1.00000e-06 1.00000e-06 1.00000e-09 5.00000e-02

Element: 4439 \# of layers: 4

$\mathrm{Kx} \mathrm{Ky} \mathrm{Kz}$ Ss Por

$1.69784 \mathrm{e}+021.69784 \mathrm{e}+02$ 1.69784e+01 1.00000e-09 7.00000e-02

$1.69784 \mathrm{e}+02 \quad 1.69784 \mathrm{e}+02 \quad 1.69784 \mathrm{e}+011.00000 \mathrm{e}-097.00000 \mathrm{e}-02$

$1.00000 \mathrm{e}+001.00000 \mathrm{e}+001.00000 \mathrm{e}-011.00000 \mathrm{e}-091.00000 \mathrm{e}-01$

1.00000e-06 1.00000e-06 1.00000e-06 1.00000e-09 5.00000e-02

Element: 4440 \# of layers: 6

Kx Ky Kz Ss Por

8.43723e+01 8.43723e+01 8.43723e+00 1.00000e-09 7.00000e-02

8.43723e+01 8.43723e+01 8.43723e+00 1.00000e-09 7.00000e-02

8.43723e+01 8.43723e+01 8.43723e+00 1.00000e-09 7.00000e-02

$1.00000 \mathrm{e}-05$ 1.00000e-05 1.00000e-06 1.00000e-09 1.00000e-01

$1.00000 \mathrm{e}+001.00000 \mathrm{e}+001.00000 \mathrm{e}-011.00000 \mathrm{e}-091.00000 \mathrm{e}-01$

$1.00000 \mathrm{e}-06$ 1.00000e-06 1.00000e-06 1.00000e-09 5.00000e-02

Element: 4441 \# of layers: 5

Kx Ky Kz Ss Por

7.05925e+01 7.05925e+01 7.05925e+00 1.00000e-09 7.00000e-02

$7.05925 \mathrm{e}+017.05925 \mathrm{e}+017.05925 \mathrm{e}+001.00000 \mathrm{e}-097.00000 \mathrm{e}-02$

$1.00000 \mathrm{e}-05$ 1.00000e-05 1.00000e-06 1.00000e-09 1.00000e-01

$1.00000 \mathrm{e}+001.00000 \mathrm{e}+001.00000 \mathrm{e}-011.00000 \mathrm{e}-091.00000 \mathrm{e}-01$

1.00000e-06 1.00000e-06 1.00000e-06 1.00000e-09 5.00000e-02

Element: 4442 \# of layers: 6

$\mathrm{Kx} \mathrm{Ky} \mathrm{Kz}$ Ss Por

7.05925e+01 7.05925e+01 7.05925e+00 1.00000e-09 7.00000e-02

$7.05925 \mathrm{e}+017.05925 \mathrm{e}+017.05925 \mathrm{e}+001.00000 \mathrm{e}-09$ 7.00000e-02

$1.00000 \mathrm{e}+001.00000 \mathrm{e}+001.00000 \mathrm{e}-011.00000 \mathrm{e}-091.00000 \mathrm{e}-01$

$1.00000 \mathrm{e}-05$ 1.00000e-05 1.00000e-06 1.00000e-09 1.00000e-01

$1.00000 \mathrm{e}+001.00000 \mathrm{e}+001.00000 \mathrm{e}-011.00000 \mathrm{e}-091.00000 \mathrm{e}-01$

1.00000e-06 1.00000e-06 1.00000e-06 1.00000e-09 5.00000e-02

Element: 4443 \# of layers: 5

$\mathrm{Kx} \mathrm{Ky} \mathrm{Kz}$ Ss Por

7.05925e+01 7.05925e+01 7.05925e+00 1.00000e-09 7.00000e-02

$7.05925 \mathrm{e}+017.05925 \mathrm{e}+01$ 7.05925e+00 1.00000e-09 7.00000e-02

$1.00000 \mathrm{e}-05$ 1.00000e-05 1.00000e-06 1.00000e-09 1.00000e-01

$1.00000 \mathrm{e}+001.00000 \mathrm{e}+001.00000 \mathrm{e}-011.00000 \mathrm{e}-091.00000 \mathrm{e}-01$

1.00000e-06 1.00000e-06 1.00000e-06 1.00000e-09 5.00000e-02

Element: 4444 \# of layers: 4

Kx Ky Kz Ss Por 
4.58402e+02 4.58402e+02 4.58402e+01 1.00000e-09 7.00000e-02 $1.00000 \mathrm{e}-05$ 1.00000e-05 1.00000e-06 1.00000e-09 1.00000e-01

$1.00000 \mathrm{e}+001.00000 \mathrm{e}+001.00000 \mathrm{e}-011.00000 \mathrm{e}-091.00000 \mathrm{e}-01$

1.00000e-06 1.00000e-06 1.00000e-06 1.00000e-09 5.00000e-02

Element: 4445 \# of layers: 5

$\mathrm{Kx} \mathrm{Ky} \mathrm{Kz}$ Ss Por

4.58402e+02 4.58402e+02 4.58402e+01 1.00000e-09 7.00000e-02

$4.58402 \mathrm{e}+02$ 4.58402e+02 4.58402e+01 1.00000e-09 7.00000e-02

$1.00000 \mathrm{e}-05$ 1.00000e-05 1.00000e-06 1.00000e-09 1.00000e-01

$1.00000 \mathrm{e}+001.00000 \mathrm{e}+001.00000 \mathrm{e}-011.00000 \mathrm{e}-091.00000 \mathrm{e}-01$

1.00000e-06 1.00000e-06 1.00000e-06 1.00000e-09 5.00000e-02

Element: 4446 \# of layers: 4

$\mathrm{Kx} \mathrm{Ky} \mathrm{Kz}$ Ss Por

4.60555e+02 4.60555e+02 4.60555e+01 1.00000e-09 7.00000e-02

$4.60555 \mathrm{e}+02$ 4.60555e+02 4.60555e+01 1.00000e-09 7.00000e-02

$1.00000 \mathrm{e}+001.00000 \mathrm{e}+001.00000 \mathrm{e}-011.00000 \mathrm{e}-091.00000 \mathrm{e}-01$

1.00000e-06 1.00000e-06 1.00000e-06 1.00000e-09 5.00000e-02

Element: 4447 \# of layers: 5

$\mathrm{Kx} \mathrm{Ky} \mathrm{Kz}$ Ss Por

8.43723e+01 8.43723e+01 8.43723e+00 1.00000e-09 7.00000e-02

$8.43723 \mathrm{e}+018.43723 \mathrm{e}+018.43723 \mathrm{e}+001.00000 \mathrm{e}-09$ 7.00000e-02

$1.00000 \mathrm{e}-051.00000 \mathrm{e}-051.00000 \mathrm{e}-061.00000 \mathrm{e}-091.00000 \mathrm{e}-01$

$1.00000 \mathrm{e}+001.00000 \mathrm{e}+001.00000 \mathrm{e}-011.00000 \mathrm{e}-091.00000 \mathrm{e}-01$

1.00000e-06 1.00000e-06 1.00000e-06 1.00000e-09 5.00000e-02

Element: 4448 \# of layers: 5

$\mathrm{Kx} \mathrm{Ky} \mathrm{Kz}$ Ss Por

7.05925e+01 7.05925e+01 7.05925e+00 1.00000e-09 7.00000e-02

$7.05925 \mathrm{e}+017.05925 \mathrm{e}+01$ 7.05925e+00 1.00000e-09 7.00000e-02

$1.00000 \mathrm{e}-05$ 1.00000e-05 1.00000e-06 1.00000e-09 1.00000e-01

$1.00000 \mathrm{e}+001.00000 \mathrm{e}+001.00000 \mathrm{e}-011.00000 \mathrm{e}-091.00000 \mathrm{e}-01$

1.00000e-06 1.00000e-06 1.00000e-06 1.00000e-09 5.00000e-02

Element: 4449 \# of layers: 6

Kx Ky Kz Ss Por

7.51470e+01 7.51470e+01 7.51470e+00 1.00000e-09 7.00000e-02

$7.51470 \mathrm{e}+017.51470 \mathrm{e}+017.51470 \mathrm{e}+001.00000 \mathrm{e}-09$ 7.00000e-02

$1.00000 \mathrm{e}+001.00000 \mathrm{e}+001.00000 \mathrm{e}-011.00000 \mathrm{e}-091.00000 \mathrm{e}-01$

$1.00000 \mathrm{e}-05$ 1.00000e-05 1.00000e-06 1.00000e-09 1.00000e-01

$1.00000 \mathrm{e}+001.00000 \mathrm{e}+001.00000 \mathrm{e}-011.00000 \mathrm{e}-091.00000 \mathrm{e}-01$

1.00000e-06 1.00000e-06 1.00000e-06 1.00000e-09 5.00000e-02

Element: 4450 \# of layers: 7

$\mathrm{Kx} \mathrm{Ky} \mathrm{Kz}$ Ss Por

$1.32456 \mathrm{e}+02$ 1.32456e+02 1.32456e+01 1.00000e-09 7.00000e-02

$1.32456 \mathrm{e}+021.32456 \mathrm{e}+02$ 1.32456e+01 1.00000e-09 7.00000e-02

$1.00000 \mathrm{e}-02$ 1.00000e-02 1.00000e-03 1.00000e-09 1.00000e-01

$1.00000 \mathrm{e}+001.00000 \mathrm{e}+001.00000 \mathrm{e}-011.00000 \mathrm{e}-091.00000 \mathrm{e}-01$

$1.00000 \mathrm{e}-05$ 1.00000e-05 1.00000e-06 1.00000e-09 1.00000e-01 
$1.00000 \mathrm{e}+001.00000 \mathrm{e}+001.00000 \mathrm{e}-011.00000 \mathrm{e}-091.00000 \mathrm{e}-01$ 1.00000e-06 1.00000e-06 1.00000e-06 1.00000e-09 5.00000e-02

Element: 4451 \# of layers: 7

Kx Ky Kz Ss Por

1.32456e+02 1.32456e+02 1.32456e+01 1.00000e-09 7.00000e-02 $1.32456 \mathrm{e}+021.32456 \mathrm{e}+02 \quad 1.32456 \mathrm{e}+01$ 1.00000e-09 7.00000e-02 $1.00000 \mathrm{e}-02$ 1.00000e-02 1.00000e-03 1.00000e-09 1.00000e-01 $1.00000 \mathrm{e}+001.00000 \mathrm{e}+001.00000 \mathrm{e}-011.00000 \mathrm{e}-091.00000 \mathrm{e}-01$ $1.00000 \mathrm{e}-05$ 1.00000e-05 1.00000e-06 1.00000e-09 1.00000e-01 $1.00000 \mathrm{e}+001.00000 \mathrm{e}+001.00000 \mathrm{e}-01$ 1.00000e-09 1.00000e-01 1.00000e-06 1.00000e-06 1.00000e-06 1.00000e-09 5.00000e-02 Element: 4452 \# of layers: 7

$\mathrm{Kx} \mathrm{Ky} \mathrm{Kz}$ Ss Por

$1.32456 \mathrm{e}+02$ 1.32456e+02 1.32456e+01 1.00000e-09 7.00000e-02 $1.32456 \mathrm{e}+021.32456 \mathrm{e}+021.32456 \mathrm{e}+01$ 1.00000e-09 7.00000e-02 $1.00000 \mathrm{e}-021.00000 \mathrm{e}-02$ 1.00000e-03 1.00000e-09 1.00000e-01 $1.00000 \mathrm{e}+001.00000 \mathrm{e}+001.00000 \mathrm{e}-011.00000 \mathrm{e}-091.00000 \mathrm{e}-01$ $1.00000 \mathrm{e}-05$ 1.00000e-05 1.00000e-06 1.00000e-09 1.00000e-01 $1.00000 \mathrm{e}+001.00000 \mathrm{e}+001.00000 \mathrm{e}-011.00000 \mathrm{e}-091.00000 \mathrm{e}-01$ $1.00000 \mathrm{e}-06$ 1.00000e-06 1.00000e-06 1.00000e-09 5.00000e-02 Element: 4453 \# of layers: 6

$\mathrm{Kx} \mathrm{Ky} \mathrm{Kz}$ Ss Por

1.11391e+02 1.11391e+02 1.11391e+01 1.00000e-09 7.00000e-02 $1.00000 \mathrm{e}-02$ 1.00000e-02 1.00000e-03 1.00000e-09 1.00000e-01 $1.00000 \mathrm{e}+001.00000 \mathrm{e}+001.00000 \mathrm{e}-011.00000 \mathrm{e}-091.00000 \mathrm{e}-01$ $1.00000 \mathrm{e}-05$ 1.00000e-05 1.00000e-06 1.00000e-09 1.00000e-01 $1.00000 \mathrm{e}+001.00000 \mathrm{e}+001.00000 \mathrm{e}-011.00000 \mathrm{e}-091.00000 \mathrm{e}-01$ 1.00000e-06 1.00000e-06 1.00000e-06 1.00000e-09 5.00000e-02

Element: 4454 \# of layers: 4

$\mathrm{Kx} \mathrm{Ky} \mathrm{Kz}$ Ss Por

$1.11391 \mathrm{e}+021.11391 \mathrm{e}+02$ 1.11391e+01 1.00000e-09 7.00000e-02 $1.00000 \mathrm{e}-05$ 1.00000e-05 1.00000e-06 1.00000e-09 1.00000e-01 $1.00000 \mathrm{e}+001.00000 \mathrm{e}+001.00000 \mathrm{e}-011.00000 \mathrm{e}-091.00000 \mathrm{e}-01$ 1.00000e-06 1.00000e-06 1.00000e-06 1.00000e-09 5.00000e-02 Element: 4455 \# of layers: 5

$\mathrm{Kx} \mathrm{Ky} \mathrm{Kz}$ Ss Por

1.51827e+02 1.51827e+02 1.51828e+01 1.00000e-09 7.00000e-02 $1.51827 \mathrm{e}+02$ 1.51827e+02 1.51828e+01 1.00000e-09 7.00000e-02 $1.00000 \mathrm{e}-05$ 1.00000e-05 1.00000e-06 1.00000e-09 1.00000e-01 $1.00000 \mathrm{e}+001.00000 \mathrm{e}+001.00000 \mathrm{e}-011.00000 \mathrm{e}-091.00000 \mathrm{e}-01$ $1.00000 \mathrm{e}-06$ 1.00000e-06 1.00000e-06 1.00000e-09 5.00000e-02 Element: 4456 \# of layers: 5

$\mathrm{Kx} \mathrm{Ky} \mathrm{Kz}$ Ss Por

7.51470e+01 7.51470e+01 7.51470e+00 1.00000e-09 7.00000e-02 $7.51470 \mathrm{e}+017.51470 \mathrm{e}+017.51470 \mathrm{e}+001.00000 \mathrm{e}-09$ 7.00000e-02 $1.00000 \mathrm{e}-05$ 1.00000e-05 1.00000e-06 1.00000e-09 1.00000e-01 
$1.00000 \mathrm{e}+001.00000 \mathrm{e}+001.00000 \mathrm{e}-011.00000 \mathrm{e}-091.00000 \mathrm{e}-01$ 1.00000e-06 1.00000e-06 1.00000e-06 1.00000e-09 5.00000e-02

Element: 4457 \# of layers: 6

$\mathrm{Kx} \mathrm{Ky} \mathrm{Kz}$ Ss Por

1.32456e+02 1.32456e+02 1.32456e+01 1.00000e-09 7.00000e-02 $1.32456 \mathrm{e}+021.32456 \mathrm{e}+02$ 1.32456e+01 1.00000e-09 7.00000e-02 $1.00000 \mathrm{e}+001.00000 \mathrm{e}+001.00000 \mathrm{e}-011.00000 \mathrm{e}-091.00000 \mathrm{e}-01$ $1.00000 \mathrm{e}-05$ 1.00000e-05 1.00000e-06 1.00000e-09 1.00000e-01 $1.00000 \mathrm{e}+001.00000 \mathrm{e}+001.00000 \mathrm{e}-011.00000 \mathrm{e}-091.00000 \mathrm{e}-01$ 1.00000e-06 1.00000e-06 1.00000e-06 1.00000e-09 5.00000e-02 Element: 4458 \# of layers: 6

$\mathrm{Kx} \mathrm{Ky} \mathrm{Kz}$ Ss Por

2.37242e+02 2.37242e+02 2.37242e+01 1.00000e-09 7.00000e-02 $1.00000 \mathrm{e}-02$ 1.00000e-02 1.00000e-03 1.00000e-09 1.00000e-01 $1.00000 \mathrm{e}+001.00000 \mathrm{e}+001.00000 \mathrm{e}-011.00000 \mathrm{e}-091.00000 \mathrm{e}-01$ $1.00000 \mathrm{e}-05$ 1.00000e-05 1.00000e-06 1.00000e-09 1.00000e-01 $1.00000 \mathrm{e}+001.00000 \mathrm{e}+001.00000 \mathrm{e}-011.00000 \mathrm{e}-091.00000 \mathrm{e}-01$ 1.00000e-06 1.00000e-06 1.00000e-06 1.00000e-09 5.00000e-02 Element: 4459 \# of layers: 5

$\mathrm{Kx} \mathrm{Ky} \mathrm{Kz}$ Ss Por

1.00000e-02 1.00000e-02 1.00000e-03 1.00000e-09 1.00000e-01 $1.00000 \mathrm{e}+001.00000 \mathrm{e}+001.00000 \mathrm{e}-011.00000 \mathrm{e}-091.00000 \mathrm{e}-01$ $1.00000 \mathrm{e}-05$ 1.00000e-05 1.00000e-06 1.00000e-09 1.00000e-01 $1.00000 \mathrm{e}+001.00000 \mathrm{e}+001.00000 \mathrm{e}-011.00000 \mathrm{e}-091.00000 \mathrm{e}-01$ 1.00000e-06 1.00000e-06 1.00000e-06 1.00000e-09 5.00000e-02 Element: 4460 \# of layers: 5

$\mathrm{Kx} \mathrm{Ky} \mathrm{Kz}$ Ss Por $1.00000 \mathrm{e}-02$ 1.00000e-02 1.00000e-03 1.00000e-09 1.00000e-01 $1.00000 \mathrm{e}+001.00000 \mathrm{e}+001.00000 \mathrm{e}-011.00000 \mathrm{e}-091.00000 \mathrm{e}-01$ $1.00000 \mathrm{e}-05$ 1.00000e-05 1.00000e-06 1.00000e-09 1.00000e-01 $1.00000 \mathrm{e}+001.00000 \mathrm{e}+001.00000 \mathrm{e}-011.00000 \mathrm{e}-091.00000 \mathrm{e}-01$ 1.00000e-06 1.00000e-06 1.00000e-06 1.00000e-09 5.00000e-02 Element: 4461 \# of layers: 5

$\mathrm{Kx} \mathrm{Ky} \mathrm{Kz}$ Ss Por $1.00000 \mathrm{e}-02$ 1.00000e-02 1.00000e-03 1.00000e-09 1.00000e-01 $1.00000 \mathrm{e}+001.00000 \mathrm{e}+001.00000 \mathrm{e}-011.00000 \mathrm{e}-091.00000 \mathrm{e}-01$ $1.00000 \mathrm{e}-05$ 1.00000e-05 1.00000e-06 1.00000e-09 1.00000e-01 $1.00000 \mathrm{e}+001.00000 \mathrm{e}+001.00000 \mathrm{e}-011.00000 \mathrm{e}-091.00000 \mathrm{e}-01$ 1.00000e-06 1.00000e-06 1.00000e-06 1.00000e-09 5.00000e-02 Element: 4462 \# of layers: 6

$\mathrm{Kx} \mathrm{Ky} \mathrm{Kz}$ Ss Por 1.51392e+02 1.51392e+02 1.51392e+01 1.00000e-09 2.12000e-01 $1.00000 \mathrm{e}-02$ 1.00000e-02 1.00000e-03 1.00000e-09 1.00000e-01 $1.00000 \mathrm{e}+001.00000 \mathrm{e}+001.00000 \mathrm{e}-011.00000 \mathrm{e}-091.00000 \mathrm{e}-01$ $1.00000 \mathrm{e}-05$ 1.00000e-05 1.00000e-06 1.00000e-09 1.00000e-01 $1.00000 \mathrm{e}+001.00000 \mathrm{e}+001.00000 \mathrm{e}-011.00000 \mathrm{e}-091.00000 \mathrm{e}-01$ 
1.00000e-06 1.00000e-06 1.00000e-06 1.00000e-09 5.00000e-02

Element: 4463 \# of layers: 6

Kx Ky Kz Ss Por

$1.51392 \mathrm{e}+02$ 1.51392e+02 1.51392e+01 1.00000e-09 2.12000e-01

$1.00000 \mathrm{e}-02$ 1.00000e-02 1.00000e-03 1.00000e-09 1.00000e-01

$1.00000 \mathrm{e}+001.00000 \mathrm{e}+001.00000 \mathrm{e}-011.00000 \mathrm{e}-091.00000 \mathrm{e}-01$

$1.00000 \mathrm{e}-05$ 1.00000e-05 1.00000e-06 1.00000e-09 1.00000e-01

$1.00000 \mathrm{e}+001.00000 \mathrm{e}+001.00000 \mathrm{e}-011.00000 \mathrm{e}-091.00000 \mathrm{e}-01$

1.00000e-06 1.00000e-06 1.00000e-06 1.00000e-09 5.00000e-02

Element: 4464 \# of layers: 7

$\mathrm{Kx} \mathrm{Ky} \mathrm{Kz}$ Ss Por

7.67544e+01 7.67544e+01 7.67544e+00 1.00000e-09 7.00000e-02

$3.06682 \mathrm{e}+003.06682 \mathrm{e}+00$ 3.06682e-01 1.00000e-09 2.12000e-01

$1.00000 \mathrm{e}-02$ 1.00000e-02 1.00000e-03 1.00000e-09 1.00000e-01

$1.00000 \mathrm{e}+001.00000 \mathrm{e}+001.00000 \mathrm{e}-011.00000 \mathrm{e}-091.00000 \mathrm{e}-01$

$1.00000 \mathrm{e}-05$ 1.00000e-05 1.00000e-06 1.00000e-09 1.00000e-01

$1.00000 \mathrm{e}+001.00000 \mathrm{e}+001.00000 \mathrm{e}-011.00000 \mathrm{e}-091.00000 \mathrm{e}-01$

1.00000e-06 1.00000e-06 1.00000e-06 1.00000e-09 5.00000e-02

Element: 4465 \# of layers: 7

$\mathrm{Kx} \mathrm{Ky} \mathrm{Kz}$ Ss Por

2.37242e+02 2.37242e+02 2.37242e+01 1.00000e-09 7.00000e-02

2.37242e+02 2.37242e+02 2.37242e+01 1.00000e-09 7.00000e-02

$1.00000 \mathrm{e}-02$ 1.00000e-02 1.00000e-03 1.00000e-09 1.00000e-01

$1.00000 \mathrm{e}+001.00000 \mathrm{e}+001.00000 \mathrm{e}-011.00000 \mathrm{e}-091.00000 \mathrm{e}-01$

$1.00000 \mathrm{e}-05$ 1.00000e-05 1.00000e-06 1.00000e-09 1.00000e-01

$1.00000 \mathrm{e}+001.00000 \mathrm{e}+001.00000 \mathrm{e}-011.00000 \mathrm{e}-091.00000 \mathrm{e}-01$

1.00000e-06 1.00000e-06 1.00000e-06 1.00000e-09 5.00000e-02

Element: 4466 \# of layers: 5

$\mathrm{Kx} \mathrm{Ky} \mathrm{Kz}$ Ss Por

1.00000e-02 1.00000e-02 1.00000e-03 1.00000e-09 1.00000e-01

$1.00000 \mathrm{e}+001.00000 \mathrm{e}+001.00000 \mathrm{e}-011.00000 \mathrm{e}-091.00000 \mathrm{e}-01$

$1.00000 \mathrm{e}-05$ 1.00000e-05 1.00000e-06 1.00000e-09 1.00000e-01

$1.00000 \mathrm{e}+001.00000 \mathrm{e}+001.00000 \mathrm{e}-011.00000 \mathrm{e}-091.00000 \mathrm{e}-01$

1.00000e-06 1.00000e-06 1.00000e-06 1.00000e-09 5.00000e-02

Element: 4467 \# of layers: 5

$\mathrm{Kx} \mathrm{Ky} \mathrm{Kz}$ Ss Por

1.00000e-02 1.00000e-02 1.00000e-03 1.00000e-09 1.00000e-01

$1.00000 \mathrm{e}+001.00000 \mathrm{e}+001.00000 \mathrm{e}-011.00000 \mathrm{e}-091.00000 \mathrm{e}-01$

$1.00000 \mathrm{e}-05$ 1.00000e-05 1.00000e-06 1.00000e-09 1.00000e-01

$1.00000 \mathrm{e}+001.00000 \mathrm{e}+001.00000 \mathrm{e}-011.00000 \mathrm{e}-091.00000 \mathrm{e}-01$

1.00000e-06 1.00000e-06 1.00000e-06 1.00000e-09 5.00000e-02

Element: 4468 \# of layers: 6

$\mathrm{Kx} \mathrm{Ky} \mathrm{Kz}$ Ss Por

2.52298e+01 2.52298e+01 2.52298e+00 1.00000e-09 2.12000e-01

$1.00000 \mathrm{e}-02$ 1.00000e-02 1.00000e-03 1.00000e-09 1.00000e-01

$1.00000 \mathrm{e}+001.00000 \mathrm{e}+001.00000 \mathrm{e}-011.00000 \mathrm{e}-091.00000 \mathrm{e}-01$ 
$1.00000 \mathrm{e}-05$ 1.00000e-05 1.00000e-06 1.00000e-09 1.00000e-01 $1.00000 \mathrm{e}+001.00000 \mathrm{e}+001.00000 \mathrm{e}-011.00000 \mathrm{e}-091.00000 \mathrm{e}-01$ 1.00000e-06 1.00000e-06 1.00000e-06 1.00000e-09 5.00000e-02 Element: 4469 \# of layers: 7

$\mathrm{Kx} \mathrm{Ky} \mathrm{Kz}$ Ss Por

6.31412e+02 6.31412e+02 6.31412e+01 1.00000e-09 7.00000e-02

$2.52298 \mathrm{e}+012.52298 \mathrm{e}+012.52298 \mathrm{e}+00$ 1.00000e-09 2.12000e-01

$1.00000 \mathrm{e}-02$ 1.00000e-02 1.00000e-03 1.00000e-09 1.00000e-01

$1.00000 \mathrm{e}+001.00000 \mathrm{e}+001.00000 \mathrm{e}-011.00000 \mathrm{e}-091.00000 \mathrm{e}-01$

$1.00000 \mathrm{e}-05$ 1.00000e-05 1.00000e-06 1.00000e-09 1.00000e-01

$1.00000 \mathrm{e}+001.00000 \mathrm{e}+001.00000 \mathrm{e}-011.00000 \mathrm{e}-091.00000 \mathrm{e}-01$

$1.00000 \mathrm{e}-06$ 1.00000e-06 1.00000e-06 1.00000e-09 5.00000e-02

Element: 4470 \# of layers: 6

$\mathrm{Kx} \mathrm{Ky} \mathrm{Kz}$ Ss Por

$2.52298 \mathrm{e}+012.52298 \mathrm{e}+012.52298 \mathrm{e}+00$ 1.00000e-09 2.12000e-01 $1.00000 \mathrm{e}-02$ 1.00000e-02 1.00000e-03 1.00000e-09 1.00000e-01

$1.00000 \mathrm{e}+001.00000 \mathrm{e}+001.00000 \mathrm{e}-011.00000 \mathrm{e}-091.00000 \mathrm{e}-01$ $1.00000 \mathrm{e}-05$ 1.00000e-05 1.00000e-06 1.00000e-09 1.00000e-01

$1.00000 \mathrm{e}+001.00000 \mathrm{e}+001.00000 \mathrm{e}-011.00000 \mathrm{e}-091.00000 \mathrm{e}-01$ 1.00000e-06 1.00000e-06 1.00000e-06 1.00000e-09 5.00000e-02

Element: 4471 \# of layers: 7

$\mathrm{Kx} \mathrm{Ky} \mathrm{Kz}$ Ss Por

1.72785e+02 1.72785e+02 1.72785e+01 1.00000e-09 7.00000e-02 $6.90382 \mathrm{e}+006.90382 \mathrm{e}+006.90382 \mathrm{e}-01$ 1.00000e-09 2.12000e-01 $1.00000 \mathrm{e}-021.00000 \mathrm{e}-02$ 1.00000e-03 1.00000e-09 1.00000e-01 $1.00000 \mathrm{e}+001.00000 \mathrm{e}+001.00000 \mathrm{e}-011.00000 \mathrm{e}-091.00000 \mathrm{e}-01$ $1.00000 \mathrm{e}-05$ 1.00000e-05 1.00000e-06 1.00000e-09 1.00000e-01 $1.00000 \mathrm{e}+001.00000 \mathrm{e}+001.00000 \mathrm{e}-01$ 1.00000e-09 1.00000e-01 1.00000e-06 1.00000e-06 1.00000e-06 1.00000e-09 5.00000e-02 Element: 4472 \# of layers: 7

$\mathrm{Kx} \mathrm{Ky} \mathrm{Kz}$ Ss Por

1.72785e+02 1.72785e+02 1.72785e+01 1.00000e-09 7.00000e-02 $6.90382 \mathrm{e}+006.90382 \mathrm{e}+006.90382 \mathrm{e}-01$ 1.00000e-09 2.12000e-01 $1.00000 \mathrm{e}-021.00000 \mathrm{e}-021.00000 \mathrm{e}-031.00000 \mathrm{e}-091.00000 \mathrm{e}-01$ $1.00000 \mathrm{e}+001.00000 \mathrm{e}+001.00000 \mathrm{e}-011.00000 \mathrm{e}-091.00000 \mathrm{e}-01$ $1.00000 \mathrm{e}-05$ 1.00000e-05 1.00000e-06 1.00000e-09 1.00000e-01 $1.00000 \mathrm{e}+001.00000 \mathrm{e}+001.00000 \mathrm{e}-011.00000 \mathrm{e}-091.00000 \mathrm{e}-01$ 1.00000e-06 1.00000e-06 1.00000e-06 1.00000e-09 5.00000e-02 Element: 4473 \# of layers: 6

$\mathrm{Kx} \mathrm{Ky} \mathrm{Kz}$ Ss Por

$3.58208 \mathrm{e}+013.58208 \mathrm{e}+01$ 3.58208e+00 1.00000e-09 2.12000e-01 $1.00000 \mathrm{e}-02$ 1.00000e-02 1.00000e-03 1.00000e-09 1.00000e-01 $1.00000 \mathrm{e}+001.00000 \mathrm{e}+001.00000 \mathrm{e}-011.00000 \mathrm{e}-091.00000 \mathrm{e}-01$ $1.00000 \mathrm{e}-05$ 1.00000e-05 1.00000e-06 1.00000e-09 1.00000e-01 $1.00000 \mathrm{e}+001.00000 \mathrm{e}+001.00000 \mathrm{e}-011.00000 \mathrm{e}-091.00000 \mathrm{e}-01$ $1.00000 \mathrm{e}-06$ 1.00000e-06 1.00000e-06 1.00000e-09 5.00000e-02 
Element: 4474 \# of layers: 5

$\mathrm{Kx} \mathrm{Ky} \mathrm{Kz}$ Ss Por

1.00000e-02 1.00000e-02 1.00000e-03 1.00000e-09 1.00000e-01

$1.00000 \mathrm{e}+001.00000 \mathrm{e}+001.00000 \mathrm{e}-011.00000 \mathrm{e}-091.00000 \mathrm{e}-01$

$1.00000 \mathrm{e}-05$ 1.00000e-05 1.00000e-06 1.00000e-09 1.00000e-01

$1.00000 \mathrm{e}+001.00000 \mathrm{e}+001.00000 \mathrm{e}-011.00000 \mathrm{e}-091.00000 \mathrm{e}-01$

1.00000e-06 1.00000e-06 1.00000e-06 1.00000e-09 5.00000e-02

Element: 4475 \# of layers: 6

$\mathrm{Kx} \mathrm{Ky} \mathrm{Kz}$ Ss Por

$2.52298 \mathrm{e}+012.52298 \mathrm{e}+012.52298 \mathrm{e}+00$ 1.00000e-09 2.12000e-01

$1.00000 \mathrm{e}-02$ 1.00000e-02 1.00000e-03 1.00000e-09 1.00000e-01

$1.00000 \mathrm{e}+001.00000 \mathrm{e}+001.00000 \mathrm{e}-011.00000 \mathrm{e}-091.00000 \mathrm{e}-01$

$1.00000 \mathrm{e}-05$ 1.00000e-05 1.00000e-06 1.00000e-09 1.00000e-01

$1.00000 \mathrm{e}+001.00000 \mathrm{e}+001.00000 \mathrm{e}-011.00000 \mathrm{e}-091.00000 \mathrm{e}-01$

1.00000e-06 1.00000e-06 1.00000e-06 1.00000e-09 5.00000e-02

Element: 4476 \# of layers: 8

$\mathrm{Kx} \mathrm{Ky} \mathrm{Kz}$ Ss Por

1.48007e+02 1.48007e+02 1.48007e+01 1.00000e-09 7.00000e-02

5.91380e+00 5.91380e+00 5.91380e-01 1.00000e-09 2.12000e-01

$5.91380 \mathrm{e}+00$ 5.91380e+00 5.91380e-01 1.00000e-09 2.12000e-01

$1.00000 \mathrm{e}-02$ 1.00000e-02 1.00000e-03 1.00000e-09 1.00000e-01

$1.00000 \mathrm{e}+001.00000 \mathrm{e}+001.00000 \mathrm{e}-011.00000 \mathrm{e}-091.00000 \mathrm{e}-01$

$1.00000 \mathrm{e}-05$ 1.00000e-05 1.00000e-06 1.00000e-09 1.00000e-01

$1.00000 \mathrm{e}+001.00000 \mathrm{e}+001.00000 \mathrm{e}-011.00000 \mathrm{e}-091.00000 \mathrm{e}-01$

1.00000e-06 1.00000e-06 1.00000e-06 1.00000e-09 5.00000e-02

Element: 4477 \# of layers: 7

$\mathrm{Kx} \mathrm{Ky} \mathrm{Kz}$ Ss Por

7.46659e+01 7.46659e+01 7.46659e+00 1.00000e-09 7.00000e-02

$2.98334 \mathrm{e}+002.98334 \mathrm{e}+002.98334 \mathrm{e}-01$ 1.00000e-09 2.12000e-01

$1.00000 \mathrm{e}-02$ 1.00000e-02 1.00000e-03 1.00000e-09 1.00000e-01

$1.00000 \mathrm{e}+001.00000 \mathrm{e}+001.00000 \mathrm{e}-011.00000 \mathrm{e}-091.00000 \mathrm{e}-01$

$1.00000 \mathrm{e}-05$ 1.00000e-05 1.00000e-06 1.00000e-09 1.00000e-01

$1.00000 \mathrm{e}+001.00000 \mathrm{e}+001.00000 \mathrm{e}-011.00000 \mathrm{e}-091.00000 \mathrm{e}-01$

1.00000e-06 1.00000e-06 1.00000e-06 1.00000e-09 5.00000e-02

Element: 4478 \# of layers: 9

$\mathrm{Kx} \mathrm{Ky} \mathrm{Kz}$ Ss Por

7.46659e+01 7.46659e+01 7.46659e+00 1.00000e-09 7.00000e-02

7.46659e+01 7.46659e+01 7.46659e+00 1.00000e-09 7.00000e-02

$2.98334 \mathrm{e}+002.98334 \mathrm{e}+002.98334 \mathrm{e}-01$ 1.00000e-09 2.12000e-01

$2.98334 \mathrm{e}+002.98334 \mathrm{e}+002.98334 \mathrm{e}-01$ 1.00000e-09 2.12000e-01

$1.00000 \mathrm{e}-02$ 1.00000e-02 1.00000e-03 1.00000e-09 1.00000e-01

$1.00000 \mathrm{e}+001.00000 \mathrm{e}+001.00000 \mathrm{e}-011.00000 \mathrm{e}-091.00000 \mathrm{e}-01$

$1.00000 \mathrm{e}-051.00000 \mathrm{e}-051.00000 \mathrm{e}-061.00000 \mathrm{e}-091.00000 \mathrm{e}-01$

$1.00000 \mathrm{e}+001.00000 \mathrm{e}+001.00000 \mathrm{e}-011.00000 \mathrm{e}-091.00000 \mathrm{e}-01$

1.00000e-06 1.00000e-06 1.00000e-06 1.00000e-09 5.00000e-02

Element: 4479 \# of layers: 9 
$\mathrm{Kx} \mathrm{Ky} \mathrm{Kz} \mathrm{Ss} \mathrm{Por}$

7.46659e+01 7.46659e+01 7.46659e+00 1.00000e-09 7.00000e-02

7.46659e+01 7.46659e+01 7.46659e+00 1.00000e-09 7.00000e-02

$2.98334 \mathrm{e}+002.98334 \mathrm{e}+002.98334 \mathrm{e}-01$ 1.00000e-09 2.12000e-01

$2.98334 \mathrm{e}+002.98334 \mathrm{e}+002.98334 \mathrm{e}-01$ 1.00000e-09 2.12000e-01

$1.00000 \mathrm{e}-02$ 1.00000e-02 1.00000e-03 1.00000e-09 1.00000e-01

$1.00000 \mathrm{e}+001.00000 \mathrm{e}+001.00000 \mathrm{e}-011.00000 \mathrm{e}-091.00000 \mathrm{e}-01$

$1.00000 \mathrm{e}-05$ 1.00000e-05 1.00000e-06 1.00000e-09 1.00000e-01

$1.00000 \mathrm{e}+001.00000 \mathrm{e}+001.00000 \mathrm{e}-011.00000 \mathrm{e}-091.00000 \mathrm{e}-01$

$1.00000 \mathrm{e}-06$ 1.00000e-06 1.00000e-06 1.00000e-09 5.00000e-02

Element: 4480 \# of layers: 9

Kx Ky Kz Ss Por

5.31437e+01 5.31437e+01 5.31437e+00 1.00000e-09 7.00000e-02

5.31437e+01 5.31437e+01 5.31437e+00 1.00000e-09 7.00000e-02

$2.12341 \mathrm{e}+002.12341 \mathrm{e}+00$ 2.12342e-01 1.00000e-09 2.12000e-01

$2.12341 \mathrm{e}+002.12341 \mathrm{e}+00$ 2.12342e-01 1.00000e-09 2.12000e-01

$1.00000 \mathrm{e}-02$ 1.00000e-02 1.00000e-03 1.00000e-09 1.00000e-01

$1.00000 \mathrm{e}+001.00000 \mathrm{e}+001.00000 \mathrm{e}-011.00000 \mathrm{e}-091.00000 \mathrm{e}-01$

$1.00000 \mathrm{e}-05$ 1.00000e-05 1.00000e-06 1.00000e-09 1.00000e-01

$1.00000 \mathrm{e}+001.00000 \mathrm{e}+001.00000 \mathrm{e}-011.00000 \mathrm{e}-091.00000 \mathrm{e}-01$

1.00000e-06 1.00000e-06 1.00000e-06 1.00000e-09 5.00000e-02

Element: 4481 \# of layers: 7

$\mathrm{Kx} \mathrm{Ky} \mathrm{Kz}$ Ss Por

5.31437e+01 5.31437e+01 5.31437e+00 1.00000e-09 7.00000e-02

$2.12341 \mathrm{e}+002.12341 \mathrm{e}+002.12342 \mathrm{e}-01$ 1.00000e-09 2.12000e-01

$1.00000 \mathrm{e}-02$ 1.00000e-02 1.00000e-03 1.00000e-09 1.00000e-01

$1.00000 \mathrm{e}+001.00000 \mathrm{e}+001.00000 \mathrm{e}-011.00000 \mathrm{e}-091.00000 \mathrm{e}-01$

$1.00000 \mathrm{e}-05$ 1.00000e-05 1.00000e-06 1.00000e-09 1.00000e-01

$1.00000 \mathrm{e}+001.00000 \mathrm{e}+001.00000 \mathrm{e}-011.00000 \mathrm{e}-091.00000 \mathrm{e}-01$

1.00000e-06 1.00000e-06 1.00000e-06 1.00000e-09 5.00000e-02

Element: 4482 \# of layers: 8

Kx Ky Kz Ss Por

9.45599e+01 9.45599e+01 9.45599e+00 1.00000e-09 7.00000e-02

$3.77828 \mathrm{e}+003.77828 \mathrm{e}+00$ 3.77828e-01 1.00000e-09 2.12000e-01

$3.77828 \mathrm{e}+003.77828 \mathrm{e}+00$ 3.77828e-01 1.00000e-09 2.12000e-01

$1.00000 \mathrm{e}-02$ 1.00000e-02 1.00000e-03 1.00000e-09 1.00000e-01

$1.00000 \mathrm{e}+001.00000 \mathrm{e}+001.00000 \mathrm{e}-011.00000 \mathrm{e}-091.00000 \mathrm{e}-01$

$1.00000 \mathrm{e}-05$ 1.00000e-05 1.00000e-06 1.00000e-09 1.00000e-01

$1.00000 \mathrm{e}+001.00000 \mathrm{e}+001.00000 \mathrm{e}-011.00000 \mathrm{e}-091.00000 \mathrm{e}-01$

1.00000e-06 1.00000e-06 1.00000e-06 1.00000e-09 5.00000e-02

Element: 4483 \# of layers: 8

$\mathrm{Kx} \mathrm{Ky} \mathrm{Kz}$ Ss Por

1.48007e+02 1.48007e+02 1.48007e+01 1.00000e-09 7.00000e-02

$5.91380 \mathrm{e}+005.91380 \mathrm{e}+00$ 5.91380e-01 1.00000e-09 2.12000e-01

$5.91380 \mathrm{e}+005.91380 \mathrm{e}+00$ 5.91380e-01 1.00000e-09 2.12000e-01

$1.00000 \mathrm{e}-02$ 1.00000e-02 1.00000e-03 1.00000e-09 1.00000e-01 
$1.00000 \mathrm{e}+001.00000 \mathrm{e}+001.00000 \mathrm{e}-011.00000 \mathrm{e}-091.00000 \mathrm{e}-01$ $1.00000 \mathrm{e}-05$ 1.00000e-05 1.00000e-06 1.00000e-09 1.00000e-01 $1.00000 \mathrm{e}+001.00000 \mathrm{e}+001.00000 \mathrm{e}-011.00000 \mathrm{e}-091.00000 \mathrm{e}-01$ 1.00000e-06 1.00000e-06 1.00000e-06 1.00000e-09 5.00000e-02 Element: 4484 \# of layers: 7

$\mathrm{Kx} \mathrm{Ky} \mathrm{Kz}$ Ss Por

7.46659e+01 7.46659e+01 7.46659e+00 1.00000e-09 7.00000e-02 $2.98334 \mathrm{e}+002.98334 \mathrm{e}+002.98334 \mathrm{e}-01$ 1.00000e-09 2.12000e-01 $1.00000 \mathrm{e}-02$ 1.00000e-02 1.00000e-03 1.00000e-09 1.00000e-01 $1.00000 \mathrm{e}+001.00000 \mathrm{e}+001.00000 \mathrm{e}-011.00000 \mathrm{e}-091.00000 \mathrm{e}-01$ $1.00000 \mathrm{e}-05$ 1.00000e-05 1.00000e-06 1.00000e-09 1.00000e-01 $1.00000 \mathrm{e}+001.00000 \mathrm{e}+001.00000 \mathrm{e}-011.00000 \mathrm{e}-091.00000 \mathrm{e}-01$ 1.00000e-06 1.00000e-06 1.00000e-06 1.00000e-09 5.00000e-02 Element: 4485 \# of layers: 13

$\mathrm{Kx} \mathrm{Ky} \mathrm{Kz}$ Ss Por 3.09872e+01 3.09872e+01 3.09872e+00 1.00000e-09 7.00000e-02 $3.09872 \mathrm{e}+013.09872 \mathrm{e}+013.09872 \mathrm{e}+00$ 1.00000e-09 7.00000e-02 5.00000e-04 5.00000e-04 5.00000e-05 1.00000e-09 1.00000e-01 $1.23813 \mathrm{e}+001.23813 \mathrm{e}+00$ 1.23813e-01 1.00000e-09 2.12000e-01 $1.23813 \mathrm{e}+00$ 1.23813e+00 1.23813e-01 1.00000e-09 2.12000e-01 $1.23813 \mathrm{e}+001.23813 \mathrm{e}+00$ 1.23813e-01 1.00000e-09 2.12000e-01 $1.23813 \mathrm{e}+00$ 1.23813e+00 1.23813e-01 1.00000e-09 2.12000e-01 $1.23813 \mathrm{e}+001.23813 \mathrm{e}+00$ 1.23813e-01 1.00000e-09 2.12000e-01 $1.00000 \mathrm{e}-02$ 1.00000e-02 1.00000e-03 1.00000e-09 1.00000e-01 $1.00000 \mathrm{e}+001.00000 \mathrm{e}+001.00000 \mathrm{e}-011.00000 \mathrm{e}-091.00000 \mathrm{e}-01$ $1.00000 \mathrm{e}-051.00000 \mathrm{e}-05$ 1.00000e-06 1.00000e-09 1.00000e-01 $1.00000 \mathrm{e}+001.00000 \mathrm{e}+001.00000 \mathrm{e}-011.00000 \mathrm{e}-091.00000 \mathrm{e}-01$ 1.00000e-06 1.00000e-06 1.00000e-06 1.00000e-09 5.00000e-02 Element: 4486 \# of layers: 13

$\mathrm{Kx} \mathrm{Ky} \mathrm{Kz}$ Ss Por

$2.01851 \mathrm{e}+012.01851 \mathrm{e}+012.01851 \mathrm{e}+001.00000 \mathrm{e}-09$ 7.00000e-02 $2.01851 \mathrm{e}+012.01851 \mathrm{e}+012.01851 \mathrm{e}+001.00000 \mathrm{e}-09$ 7.00000e-02 5.00000e-04 5.00000e-04 5.00000e-05 1.00000e-09 1.00000e-01 8.06507e-01 8.06507e-01 8.06507e-02 1.00000e-09 2.12000e-01 8.06507e-01 8.06507e-01 8.06507e-02 1.00000e-09 2.12000e-01 8.06507e-01 8.06507e-01 8.06507e-02 1.00000e-09 2.12000e-01 8.06507e-01 8.06507e-01 8.06507e-02 1.00000e-09 2.12000e-01 8.06507e-01 8.06507e-01 8.06507e-02 1.00000e-09 2.12000e-01 $1.00000 \mathrm{e}-02$ 1.00000e-02 1.00000e-03 1.00000e-09 1.00000e-01 $1.00000 \mathrm{e}+001.00000 \mathrm{e}+001.00000 \mathrm{e}-011.00000 \mathrm{e}-091.00000 \mathrm{e}-01$ $1.00000 \mathrm{e}-05$ 1.00000e-05 1.00000e-06 1.00000e-09 1.00000e-01 $1.00000 \mathrm{e}+001.00000 \mathrm{e}+001.00000 \mathrm{e}-011.00000 \mathrm{e}-091.00000 \mathrm{e}-01$ 1.00000e-06 1.00000e-06 1.00000e-06 1.00000e-09 5.00000e-02 Element: 4487 \# of layers: 15

$\mathrm{Kx} \mathrm{Ky} \mathrm{Kz}$ Ss Por $2.01851 \mathrm{e}+012.01851 \mathrm{e}+012.01851 \mathrm{e}+00$ 1.00000e-09 7.00000e-02 
$2.01851 \mathrm{e}+012.01851 \mathrm{e}+012.01851 \mathrm{e}+001.00000 \mathrm{e}-09$ 7.00000e-02 $2.01851 \mathrm{e}+012.01851 \mathrm{e}+012.01851 \mathrm{e}+001.00000 \mathrm{e}-09$ 7.00000e-02 5.00000e-04 5.00000e-04 5.00000e-05 1.00000e-09 1.00000e-01 5.00000e-04 5.00000e-04 5.00000e-05 1.00000e-09 1.00000e-01 8.06507e-01 8.06507e-01 8.06507e-02 1.00000e-09 2.12000e-01 8.06507e-01 8.06507e-01 8.06507e-02 1.00000e-09 2.12000e-01 8.06507e-01 8.06507e-01 8.06507e-02 1.00000e-09 2.12000e-01 8.06507e-01 8.06507e-01 8.06507e-02 1.00000e-09 2.12000e-01 8.06507e-01 8.06507e-01 8.06507e-02 1.00000e-09 2.12000e-01 $1.00000 \mathrm{e}-02$ 1.00000e-02 1.00000e-03 1.00000e-09 1.00000e-01 $1.00000 \mathrm{e}+001.00000 \mathrm{e}+001.00000 \mathrm{e}-011.00000 \mathrm{e}-091.00000 \mathrm{e}-01$ $1.00000 \mathrm{e}-05$ 1.00000e-05 1.00000e-06 1.00000e-09 1.00000e-01 $1.00000 \mathrm{e}+001.00000 \mathrm{e}+001.00000 \mathrm{e}-011.00000 \mathrm{e}-091.00000 \mathrm{e}-01$ 1.00000e-06 1.00000e-06 1.00000e-06 1.00000e-09 5.00000e-02 Element: 4488 \# of layers: 13

Kx Ky Kz Ss Por

$2.01851 \mathrm{e}+012.01851 \mathrm{e}+012.01851 \mathrm{e}+001.00000 \mathrm{e}-09$ 7.00000e-02 5.00000e-04 5.00000e-04 5.00000e-05 1.00000e-09 1.00000e-01 $5.00000 \mathrm{e}-04$ 5.00000e-04 5.00000e-05 1.00000e-09 1.00000e-01 8.06507e-01 8.06507e-01 8.06507e-02 1.00000e-09 2.12000e-01 8.06507e-01 8.06507e-01 8.06507e-02 1.00000e-09 2.12000e-01 8.06507e-01 8.06507e-01 8.06507e-02 1.00000e-09 2.12000e-01 8.06507e-01 8.06507e-01 8.06507e-02 1.00000e-09 2.12000e-01 8.06507e-01 8.06507e-01 8.06507e-02 1.00000e-09 2.12000e-01 $1.00000 \mathrm{e}-02$ 1.00000e-02 1.00000e-03 1.00000e-09 1.00000e-01 $1.00000 \mathrm{e}+001.00000 \mathrm{e}+001.00000 \mathrm{e}-011.00000 \mathrm{e}-091.00000 \mathrm{e}-01$ $1.00000 \mathrm{e}-05$ 1.00000e-05 1.00000e-06 1.00000e-09 1.00000e-01 $1.00000 \mathrm{e}+001.00000 \mathrm{e}+001.00000 \mathrm{e}-011.00000 \mathrm{e}-091.00000 \mathrm{e}-01$ 1.00000e-06 1.00000e-06 1.00000e-06 1.00000e-09 5.00000e-02 Element: 4489 \# of layers: 14

$\mathrm{Kx} \mathrm{Ky} \mathrm{Kz}$ Ss Por

$1.68478 \mathrm{e}+01$ 1.68478e+01 1.68478e+00 1.00000e-09 7.00000e-02 $1.68478 \mathrm{e}+011.68478 \mathrm{e}+011.68478 \mathrm{e}+001.00000 \mathrm{e}-09$ 7.00000e-02 5.00000e-04 5.00000e-04 5.00000e-05 1.00000e-09 1.00000e-01 5.00000e-04 5.00000e-04 5.00000e-05 1.00000e-09 1.00000e-01 6.73169e-01 6.73169e-01 6.73169e-02 1.00000e-09 2.12000e-01 6.73169e-01 6.73169e-01 6.73169e-02 1.00000e-09 2.12000e-01 6.73169e-01 6.73169e-01 6.73169e-02 1.00000e-09 2.12000e-01 6.73169e-01 6.73169e-01 6.73169e-02 1.00000e-09 2.12000e-01 6.73169e-01 6.73169e-01 6.73169e-02 1.00000e-09 2.12000e-01 $1.00000 \mathrm{e}-02$ 1.00000e-02 1.00000e-03 1.00000e-09 1.00000e-01 $1.00000 \mathrm{e}+001.00000 \mathrm{e}+001.00000 \mathrm{e}-011.00000 \mathrm{e}-091.00000 \mathrm{e}-01$ $1.00000 \mathrm{e}-05$ 1.00000e-05 1.00000e-06 1.00000e-09 1.00000e-01 $1.00000 \mathrm{e}+001.00000 \mathrm{e}+001.00000 \mathrm{e}-011.00000 \mathrm{e}-091.00000 \mathrm{e}-01$ 1.00000e-06 1.00000e-06 1.00000e-06 1.00000e-09 5.00000e-02 Element: 4490 \# of layers: 12 
$\mathrm{Kx} \mathrm{Ky} \mathrm{Kz} \mathrm{Ss} \mathrm{Por}$

$1.68478 \mathrm{e}+01$ 1.68478e+01 1.68478e+00 1.00000e-09 7.00000e-02

5.00000e-04 5.00000e-04 5.00000e-05 1.00000e-09 1.00000e-01

6.73169e-01 6.73169e-01 6.73169e-02 1.00000e-09 2.12000e-01

6.73169e-01 6.73169e-01 6.73169e-02 1.00000e-09 2.12000e-01

6.73169e-01 6.73169e-01 6.73169e-02 1.00000e-09 2.12000e-01

6.73169e-01 6.73169e-01 6.73169e-02 1.00000e-09 2.12000e-01

6.73169e-01 6.73169e-01 6.73169e-02 1.00000e-09 2.12000e-01

$1.00000 \mathrm{e}-02$ 1.00000e-02 1.00000e-03 1.00000e-09 1.00000e-01

$1.00000 \mathrm{e}+001.00000 \mathrm{e}+001.00000 \mathrm{e}-011.00000 \mathrm{e}-091.00000 \mathrm{e}-01$

1.00000e-05 1.00000e-05 1.00000e-06 1.00000e-09 1.00000e-01

$1.00000 \mathrm{e}+001.00000 \mathrm{e}+001.00000 \mathrm{e}-011.00000 \mathrm{e}-091.00000 \mathrm{e}-01$

1.00000e-06 1.00000e-06 1.00000e-06 1.00000e-09 5.00000e-02

Element: 4491 \# of layers: 12

$\mathrm{Kx} \mathrm{Ky} \mathrm{Kz}$ Ss Por

$1.54215 \mathrm{e}+011.54215 \mathrm{e}+011.54215 \mathrm{e}+00$ 1.00000e-09 7.00000e-02

5.00000e-04 5.00000e-04 5.00000e-05 1.00000e-09 1.00000e-01

6.16198e-01 6.16198e-01 6.16198e-02 1.00000e-09 2.12000e-01

6.16198e-01 6.16198e-01 6.16198e-02 1.00000e-09 2.12000e-01

6.16198e-01 6.16198e-01 6.16198e-02 1.00000e-09 2.12000e-01

6.16198e-01 6.16198e-01 6.16198e-02 1.00000e-09 2.12000e-01

6.16198e-01 6.16198e-01 6.16198e-02 1.00000e-09 2.12000e-01

$1.00000 \mathrm{e}-02$ 1.00000e-02 1.00000e-03 1.00000e-09 1.00000e-01

$1.00000 \mathrm{e}+001.00000 \mathrm{e}+001.00000 \mathrm{e}-011.00000 \mathrm{e}-091.00000 \mathrm{e}-01$

$1.00000 \mathrm{e}-05$ 1.00000e-05 1.00000e-06 1.00000e-09 1.00000e-01

$1.00000 \mathrm{e}+001.00000 \mathrm{e}+001.00000 \mathrm{e}-011.00000 \mathrm{e}-091.00000 \mathrm{e}-01$

1.00000e-06 1.00000e-06 1.00000e-06 1.00000e-09 5.00000e-02

Element: 4492 \# of layers: 12

$\mathrm{Kx} \mathrm{Ky} \mathrm{Kz}$ Ss Por

3.09872e+01 3.09872e+01 3.09872e+00 1.00000e-09 7.00000e-02

5.00000e-04 5.00000e-04 5.00000e-05 1.00000e-09 1.00000e-01

$1.23813 \mathrm{e}+001.23813 \mathrm{e}+00$ 1.23813e-01 1.00000e-09 2.12000e-01

$1.23813 \mathrm{e}+001.23813 \mathrm{e}+00$ 1.23813e-01 1.00000e-09 2.12000e-01

$1.23813 \mathrm{e}+00$ 1.23813e+00 1.23813e-01 1.00000e-09 2.12000e-01

$1.23813 \mathrm{e}+001.23813 \mathrm{e}+00$ 1.23813e-01 1.00000e-09 2.12000e-01

$1.23813 \mathrm{e}+001.23813 \mathrm{e}+00$ 1.23813e-01 1.00000e-09 2.12000e-01

$1.00000 \mathrm{e}-02$ 1.00000e-02 1.00000e-03 1.00000e-09 1.00000e-01

$1.00000 \mathrm{e}+001.00000 \mathrm{e}+001.00000 \mathrm{e}-011.00000 \mathrm{e}-091.00000 \mathrm{e}-01$

$1.00000 \mathrm{e}-05$ 1.00000e-05 1.00000e-06 1.00000e-09 1.00000e-01

$1.00000 \mathrm{e}+001.00000 \mathrm{e}+001.00000 \mathrm{e}-011.00000 \mathrm{e}-091.00000 \mathrm{e}-01$

1.00000e-06 1.00000e-06 1.00000e-06 1.00000e-09 5.00000e-02

Element: 4493 \# of layers: 12

$\mathrm{Kx} \mathrm{Ky} \mathrm{Kz}$ Ss Por

2.01851e+01 2.01851e+01 2.01851e+00 1.00000e-09 7.00000e-02

5.00000e-04 5.00000e-04 5.00000e-05 1.00000e-09 1.00000e-01

8.06507e-01 8.06507e-01 8.06507e-02 1.00000e-09 2.12000e-01 
8.06507e-01 8.06507e-01 8.06507e-02 1.00000e-09 2.12000e-01 8.06507e-01 8.06507e-01 8.06507e-02 1.00000e-09 2.12000e-01 8.06507e-01 8.06507e-01 8.06507e-02 1.00000e-09 2.12000e-01 8.06507e-01 8.06507e-01 8.06507e-02 1.00000e-09 2.12000e-01 $1.00000 \mathrm{e}-02$ 1.00000e-02 1.00000e-03 1.00000e-09 1.00000e-01 $1.00000 \mathrm{e}+001.00000 \mathrm{e}+001.00000 \mathrm{e}-011.00000 \mathrm{e}-091.00000 \mathrm{e}-01$ $1.00000 \mathrm{e}-05$ 1.00000e-05 1.00000e-06 1.00000e-09 1.00000e-01 $1.00000 \mathrm{e}+001.00000 \mathrm{e}+001.00000 \mathrm{e}-011.00000 \mathrm{e}-091.00000 \mathrm{e}-01$ 1.00000e-06 1.00000e-06 1.00000e-06 1.00000e-09 5.00000e-02 Element: 4494 \# of layers: 15

$\mathrm{Kx} \mathrm{Ky} \mathrm{Kz}$ Ss Por

$1.40898 \mathrm{e}+01$ 1.40898e+01 1.40898e+00 1.00000e-09 7.00000e-02 $1.40898 \mathrm{e}+011.40898 \mathrm{e}+01$ 1.40898e+00 1.00000e-09 7.00000e-02 $1.40898 \mathrm{e}+011.40898 \mathrm{e}+011.40898 \mathrm{e}+001.00000 \mathrm{e}-09$ 7.00000e-02 5.00000e-04 5.00000e-04 5.00000e-05 1.00000e-09 1.00000e-01 5.00000e-04 5.00000e-04 5.00000e-05 1.00000e-09 1.00000e-01 5.62985e-01 5.62985e-01 5.62985e-02 1.00000e-09 2.12000e-01 5.62985e-01 5.62985e-01 5.62985e-02 1.00000e-09 2.12000e-01 5.62985e-01 5.62985e-01 5.62985e-02 1.00000e-09 2.12000e-01 5.62985e-01 5.62985e-01 5.62985e-02 1.00000e-09 2.12000e-01 5.62985e-01 5.62985e-01 5.62985e-02 1.00000e-09 2.12000e-01 $1.00000 \mathrm{e}-02$ 1.00000e-02 1.00000e-03 1.00000e-09 1.00000e-01 $1.00000 \mathrm{e}+001.00000 \mathrm{e}+001.00000 \mathrm{e}-011.00000 \mathrm{e}-091.00000 \mathrm{e}-01$ $1.00000 \mathrm{e}-05$ 1.00000e-05 1.00000e-06 1.00000e-09 1.00000e-01 $1.00000 \mathrm{e}+001.00000 \mathrm{e}+001.00000 \mathrm{e}-011.00000 \mathrm{e}-091.00000 \mathrm{e}-01$ 1.00000e-06 1.00000e-06 1.00000e-06 1.00000e-09 5.00000e-02 Element: 4495 \# of layers: 14

$\mathrm{Kx} \mathrm{Ky} \mathrm{Kz}$ Ss Por

$1.11084 \mathrm{e}+011.11084 \mathrm{e}+011.11084 \mathrm{e}+001.00000 \mathrm{e}-09$ 7.00000e-02 $1.11084 \mathrm{e}+011.11084 \mathrm{e}+011.11084 \mathrm{e}+001.00000 \mathrm{e}-09$ 7.00000e-02 $1.11084 \mathrm{e}+011.11084 \mathrm{e}+011.11084 \mathrm{e}+001.00000 \mathrm{e}-097.00000 \mathrm{e}-02$ 5.00000e-04 5.00000e-04 5.00000e-05 1.00000e-09 1.00000e-01 5.00000e-04 5.00000e-04 5.00000e-05 1.00000e-09 1.00000e-01 4.43867e-01 4.43867e-01 4.43867e-02 1.00000e-09 2.12000e-01 4.43867e-01 4.43867e-01 4.43867e-02 1.00000e-09 2.12000e-01 4.43867e-01 4.43867e-01 4.43867e-02 1.00000e-09 2.12000e-01 4.43867e-01 4.43867e-01 4.43867e-02 1.00000e-09 2.12000e-01 4.43867e-01 4.43867e-01 4.43867e-02 1.00000e-09 2.12000e-01 $1.00000 \mathrm{e}-02$ 1.00000e-02 1.00000e-03 1.00000e-09 1.00000e-01 $1.00000 \mathrm{e}+001.00000 \mathrm{e}+001.00000 \mathrm{e}-011.00000 \mathrm{e}-091.00000 \mathrm{e}-01$ $1.00000 \mathrm{e}-05$ 1.00000e-05 1.00000e-06 1.00000e-09 1.00000e-01 $1.00000 \mathrm{e}+001.00000 \mathrm{e}+001.00000 \mathrm{e}-011.00000 \mathrm{e}-091.00000 \mathrm{e}-01$ Element: 4496 \# of layers: 13

$\mathrm{Kx} \mathrm{Ky} \mathrm{Kz}$ Ss Por

$1.11084 \mathrm{e}+011.11084 \mathrm{e}+011.11084 \mathrm{e}+001.00000 \mathrm{e}-09$ 7.00000e-02 $1.11084 \mathrm{e}+011.11084 \mathrm{e}+011.11084 \mathrm{e}+001.00000 \mathrm{e}-097.00000 \mathrm{e}-02$ 
$1.11084 \mathrm{e}+011.11084 \mathrm{e}+011.11084 \mathrm{e}+001.00000 \mathrm{e}-09$ 7.00000e-02 5.00000e-04 5.00000e-04 5.00000e-05 1.00000e-09 1.00000e-01 4.43867e-01 4.43867e-01 4.43867e-02 1.00000e-09 2.12000e-01 4.43867e-01 4.43867e-01 4.43867e-02 1.00000e-09 2.12000e-01 4.43867e-01 4.43867e-01 4.43867e-02 1.00000e-09 2.12000e-01 4.43867e-01 4.43867e-01 4.43867e-02 1.00000e-09 2.12000e-01 4.43867e-01 4.43867e-01 4.43867e-02 1.00000e-09 2.12000e-01 $1.00000 \mathrm{e}-02$ 1.00000e-02 1.00000e-03 1.00000e-09 1.00000e-01 $1.00000 \mathrm{e}+001.00000 \mathrm{e}+001.00000 \mathrm{e}-011.00000 \mathrm{e}-091.00000 \mathrm{e}-01$ $1.00000 \mathrm{e}-05$ 1.00000e-05 1.00000e-06 1.00000e-09 1.00000e-01 $1.00000 \mathrm{e}+001.00000 \mathrm{e}+001.00000 \mathrm{e}-01$ 1.00000e-09 1.00000e-01 Element: 4497 \# of layers: 14

$\mathrm{Kx} \mathrm{Ky} \mathrm{Kz}$ Ss Por

$1.11084 \mathrm{e}+011.11084 \mathrm{e}+011.11084 \mathrm{e}+001.00000 \mathrm{e}-09$ 7.00000e-02 $1.11084 \mathrm{e}+011.11084 \mathrm{e}+011.11084 \mathrm{e}+001.00000 \mathrm{e}-097.00000 \mathrm{e}-02$ $1.11084 \mathrm{e}+011.11084 \mathrm{e}+011.11084 \mathrm{e}+001.00000 \mathrm{e}-09$ 7.00000e-02 5.00000e-04 5.00000e-04 5.00000e-05 1.00000e-09 1.00000e-01 4.43867e-01 4.43867e-01 4.43867e-02 1.00000e-09 2.12000e-01 4.43867e-01 4.43867e-01 4.43867e-02 1.00000e-09 2.12000e-01 4.43867e-01 4.43867e-01 4.43867e-02 1.00000e-09 2.12000e-01 4.43867e-01 4.43867e-01 4.43867e-02 1.00000e-09 2.12000e-01 4.43867e-01 4.43867e-01 4.43867e-02 1.00000e-09 2.12000e-01 $1.00000 \mathrm{e}-02$ 1.00000e-02 1.00000e-03 1.00000e-09 1.00000e-01 $1.00000 \mathrm{e}+001.00000 \mathrm{e}+001.00000 \mathrm{e}-011.00000 \mathrm{e}-091.00000 \mathrm{e}-01$ $1.00000 \mathrm{e}-05$ 1.00000e-05 1.00000e-06 1.00000e-09 1.00000e-01 $1.00000 \mathrm{e}+001.00000 \mathrm{e}+001.00000 \mathrm{e}-011.00000 \mathrm{e}-091.00000 \mathrm{e}-01$ 1.00000e-06 1.00000e-06 1.00000e-06 1.00000e-09 5.00000e-02 Element: 4498 \# of layers: 15

$\mathrm{Kx} \mathrm{Ky} \mathrm{Kz}$ Ss Por

$1.25302 \mathrm{e}+01$ 1.25302e+01 1.25302e+00 1.00000e-09 7.00000e-02 $1.25302 \mathrm{e}+01$ 1.25302e+01 1.25302e+00 1.00000e-09 7.00000e-02 $1.25302 \mathrm{e}+011.25302 \mathrm{e}+011.25302 \mathrm{e}+001.00000 \mathrm{e}-09$ 7.00000e-02 5.00000e-04 5.00000e-04 5.00000e-05 1.00000e-09 1.00000e-01 5.00000e-04 5.00000e-04 5.00000e-05 1.00000e-09 1.00000e-01 5.00681e-01 5.00681e-01 5.00681e-02 1.00000e-09 2.12000e-01 5.00681e-01 5.00681e-01 5.00681e-02 1.00000e-09 2.12000e-01 5.00681e-01 5.00681e-01 5.00681e-02 1.00000e-09 2.12000e-01 5.00681e-01 5.00681e-01 5.00681e-02 1.00000e-09 2.12000e-01 5.00681e-01 5.00681e-01 5.00681e-02 1.00000e-09 2.12000e-01 $1.00000 \mathrm{e}-02$ 1.00000e-02 1.00000e-03 1.00000e-09 1.00000e-01 $1.00000 \mathrm{e}+001.00000 \mathrm{e}+001.00000 \mathrm{e}-01$ 1.00000e-09 1.00000e-01 $1.00000 \mathrm{e}-05$ 1.00000e-05 1.00000e-06 1.00000e-09 1.00000e-01 $1.00000 \mathrm{e}+001.00000 \mathrm{e}+001.00000 \mathrm{e}-011.00000 \mathrm{e}-091.00000 \mathrm{e}-01$ 1.00000e-06 1.00000e-06 1.00000e-06 1.00000e-09 5.00000e-02 Element: 4499 \# of layers: 13

Kx Ky Kz Ss Por 
1.25302e+01 1.25302e+01 1.25302e+00 1.00000e-09 7.00000e-02 $1.25302 \mathrm{e}+011.25302 \mathrm{e}+011.25302 \mathrm{e}+001.00000 \mathrm{e}-09$ 7.00000e-02 5.00000e-04 5.00000e-04 5.00000e-05 1.00000e-09 1.00000e-01 5.00681e-01 5.00681e-01 5.00681e-02 1.00000e-09 2.12000e-01 5.00681e-01 5.00681e-01 5.00681e-02 1.00000e-09 2.12000e-01 5.00681e-01 5.00681e-01 5.00681e-02 1.00000e-09 2.12000e-01 5.00681e-01 5.00681e-01 5.00681e-02 1.00000e-09 2.12000e-01 5.00681e-01 5.00681e-01 5.00681e-02 1.00000e-09 2.12000e-01 $1.00000 \mathrm{e}-02$ 1.00000e-02 1.00000e-03 1.00000e-09 1.00000e-01 $1.00000 \mathrm{e}+001.00000 \mathrm{e}+001.00000 \mathrm{e}-011.00000 \mathrm{e}-091.00000 \mathrm{e}-01$ $1.00000 \mathrm{e}-05$ 1.00000e-05 1.00000e-06 1.00000e-09 1.00000e-01 $1.00000 \mathrm{e}+001.00000 \mathrm{e}+001.00000 \mathrm{e}-011.00000 \mathrm{e}-091.00000 \mathrm{e}-01$ 1.00000e-06 1.00000e-06 1.00000e-06 1.00000e-09 5.00000e-02 Element: 4500 \# of layers: 14

$\mathrm{Kx} \mathrm{Ky} \mathrm{Kz}$ Ss Por

$1.58729 \mathrm{e}+01$ 1.58729e+01 1.58729e+00 1.00000e-09 7.00000e-02 $1.58729 \mathrm{e}+011.58729 \mathrm{e}+011.58729 \mathrm{e}+001.00000 \mathrm{e}-09$ 7.00000e-02 5.00000e-04 5.00000e-04 5.00000e-05 1.00000e-09 1.00000e-01 5.00000e-04 5.00000e-04 5.00000e-05 1.00000e-09 1.00000e-01 6.34221e-01 6.34221e-01 6.34221e-02 1.00000e-09 2.12000e-01 6.34221e-01 6.34221e-01 6.34221e-02 1.00000e-09 2.12000e-01 6.34221e-01 6.34221e-01 6.34221e-02 1.00000e-09 2.12000e-01 6.34221e-01 6.34221e-01 6.34221e-02 1.00000e-09 2.12000e-01 6.34221e-01 6.34221e-01 6.34221e-02 1.00000e-09 2.12000e-01 $1.00000 \mathrm{e}-021.00000 \mathrm{e}-02$ 1.00000e-03 1.00000e-09 1.00000e-01 $1.00000 \mathrm{e}+001.00000 \mathrm{e}+001.00000 \mathrm{e}-011.00000 \mathrm{e}-091.00000 \mathrm{e}-01$ $1.00000 \mathrm{e}-05$ 1.00000e-05 1.00000e-06 1.00000e-09 1.00000e-01 $1.00000 \mathrm{e}+001.00000 \mathrm{e}+001.00000 \mathrm{e}-011.00000 \mathrm{e}-091.00000 \mathrm{e}-01$ 1.00000e-06 1.00000e-06 1.00000e-06 1.00000e-09 5.00000e-02 Element: 4501 \# of layers: 14

$\mathrm{Kx} \mathrm{Ky} \mathrm{Kz}$ Ss Por

1.40898e+01 1.40898e+01 1.40898e+00 1.00000e-09 7.00000e-02 $1.40898 \mathrm{e}+011.40898 \mathrm{e}+011.40898 \mathrm{e}+001.00000 \mathrm{e}-09$ 7.00000e-02 5.00000e-04 5.00000e-04 5.00000e-05 1.00000e-09 1.00000e-01 5.00000e-04 5.00000e-04 5.00000e-05 1.00000e-09 1.00000e-01 5.62985e-01 5.62985e-01 5.62985e-02 1.00000e-09 2.12000e-01 5.62985e-01 5.62985e-01 5.62985e-02 1.00000e-09 2.12000e-01 5.62985e-01 5.62985e-01 5.62985e-02 1.00000e-09 2.12000e-01 5.62985e-01 5.62985e-01 5.62985e-02 1.00000e-09 2.12000e-01 5.62985e-01 5.62985e-01 5.62985e-02 1.00000e-09 2.12000e-01 $1.00000 \mathrm{e}-02$ 1.00000e-02 1.00000e-03 1.00000e-09 1.00000e-01 $1.00000 \mathrm{e}+001.00000 \mathrm{e}+001.00000 \mathrm{e}-011.00000 \mathrm{e}-091.00000 \mathrm{e}-01$ $1.00000 \mathrm{e}-05$ 1.00000e-05 1.00000e-06 1.00000e-09 1.00000e-01 $1.00000 \mathrm{e}+001.00000 \mathrm{e}+001.00000 \mathrm{e}-011.00000 \mathrm{e}-091.00000 \mathrm{e}-01$ 1.00000e-06 1.00000e-06 1.00000e-06 1.00000e-09 5.00000e-02 Element: 4502 \# of layers: 13 
$\mathrm{Kx} \mathrm{Ky} \mathrm{Kz}$ Ss Por

$1.11084 \mathrm{e}+011.11084 \mathrm{e}+01$ 1.11084e+00 1.00000e-09 7.00000e-02

$1.11084 \mathrm{e}+011.11084 \mathrm{e}+011.11084 \mathrm{e}+001.00000 \mathrm{e}-09$ 7.00000e-02

5.00000e-04 5.00000e-04 5.00000e-05 1.00000e-09 1.00000e-01

4.43867e-01 4.43867e-01 4.43867e-02 1.00000e-09 2.12000e-01

4.43867e-01 4.43867e-01 4.43867e-02 1.00000e-09 2.12000e-01

4.43867e-01 4.43867e-01 4.43867e-02 1.00000e-09 2.12000e-01

4.43867e-01 4.43867e-01 4.43867e-02 1.00000e-09 2.12000e-01

4.43867e-01 4.43867e-01 4.43867e-02 1.00000e-09 2.12000e-01

$1.00000 \mathrm{e}-02$ 1.00000e-02 1.00000e-03 1.00000e-09 1.00000e-01

$1.00000 \mathrm{e}+001.00000 \mathrm{e}+001.00000 \mathrm{e}-011.00000 \mathrm{e}-091.00000 \mathrm{e}-01$

$1.00000 \mathrm{e}-05$ 1.00000e-05 1.00000e-06 1.00000e-09 1.00000e-01

$1.00000 \mathrm{e}+001.00000 \mathrm{e}+001.00000 \mathrm{e}-011.00000 \mathrm{e}-091.00000 \mathrm{e}-01$

1.00000e-06 1.00000e-06 1.00000e-06 1.00000e-09 5.00000e-02

Element: 4503 \# of layers: 14

Kx Ky Kz Ss Por

5.91011e+01 5.91011e+01 5.91011e+00 1.00000e-09 7.00000e-02

$5.91011 \mathrm{e}+015.91011 \mathrm{e}+015.91011 \mathrm{e}+001.00000 \mathrm{e}-09$ 7.00000e-02

$5.91011 \mathrm{e}+015.91011 \mathrm{e}+015.91011 \mathrm{e}+001.00000 \mathrm{e}-09$ 7.00000e-02

5.00000e-04 5.00000e-04 5.00000e-05 1.00000e-09 1.00000e-01

5.00000e-04 5.00000e-04 5.00000e-05 1.00000e-09 1.00000e-01

2.36142e+00 2.36142e+00 2.36142e-01 1.00000e-09 2.12000e-01

2.36142e+00 2.36142e+00 2.36142e-01 1.00000e-09 2.12000e-01

2.36142e+00 2.36142e+00 2.36142e-01 1.00000e-09 2.12000e-01

$2.36142 \mathrm{e}+002.36142 \mathrm{e}+00$ 2.36142e-01 1.00000e-09 2.12000e-01

2.36142e+00 2.36142e+00 2.36142e-01 1.00000e-09 2.12000e-01

$1.00000 \mathrm{e}-02$ 1.00000e-02 1.00000e-03 1.00000e-09 1.00000e-01

$1.00000 \mathrm{e}+001.00000 \mathrm{e}+001.00000 \mathrm{e}-01$ 1.00000e-09 1.00000e-01

$1.00000 \mathrm{e}-05$ 1.00000e-05 1.00000e-06 1.00000e-09 1.00000e-01

$1.00000 \mathrm{e}+001.00000 \mathrm{e}+001.00000 \mathrm{e}-011.00000 \mathrm{e}-091.00000 \mathrm{e}-01$

Element: 4504 \# of layers: 14

$\mathrm{Kx} \mathrm{Ky} \mathrm{Kz}$ Ss Por

$1.00732 \mathrm{e}+02$ 1.00732e+02 1.00732e+01 1.00000e-09 7.00000e-02 $1.00732 \mathrm{e}+02$ 1.00732e+02 1.00732e+01 1.00000e-09 7.00000e-02 $1.00732 \mathrm{e}+021.00732 \mathrm{e}+02$ 1.00732e+01 1.00000e-09 7.00000e-02 5.00000e-04 5.00000e-04 5.00000e-05 1.00000e-09 1.00000e-01 5.00000e-04 5.00000e-04 5.00000e-05 1.00000e-09 1.00000e-01 $4.02489 \mathrm{e}+00$ 4.02489e+00 4.02489e-01 1.00000e-09 2.12000e-01 $4.02489 \mathrm{e}+00$ 4.02489e+00 4.02489e-01 1.00000e-09 2.12000e-01 4.02489e+00 4.02489e+00 4.02489e-01 1.00000e-09 2.12000e-01 $4.02489 \mathrm{e}+004.02489 \mathrm{e}+00$ 4.02489e-01 1.00000e-09 2.12000e-01 $4.02489 \mathrm{e}+004.02489 \mathrm{e}+004.02489 \mathrm{e}-01$ 1.00000e-09 2.12000e-01 $1.00000 \mathrm{e}-02$ 1.00000e-02 1.00000e-03 1.00000e-09 1.00000e-01 $1.00000 \mathrm{e}+001.00000 \mathrm{e}+001.00000 \mathrm{e}-011.00000 \mathrm{e}-091.00000 \mathrm{e}-01$ $1.00000 \mathrm{e}-05$ 1.00000e-05 1.00000e-06 1.00000e-09 1.00000e-01 $1.00000 \mathrm{e}+001.00000 \mathrm{e}+001.00000 \mathrm{e}-011.00000 \mathrm{e}-091.00000 \mathrm{e}-01$ 
Element: 4505 \# of layers: 14

$\mathrm{Kx} \mathrm{Ky} \mathrm{Kz}$ Ss Por

$1.00732 \mathrm{e}+02$ 1.00732e+02 1.00732e+01 1.00000e-09 7.00000e-02

$1.00732 \mathrm{e}+02$ 1.00732e+02 1.00732e+01 1.00000e-09 7.00000e-02

$1.00732 \mathrm{e}+021.00732 \mathrm{e}+021.00732 \mathrm{e}+01$ 1.00000e-09 7.00000e-02

5.00000e-04 5.00000e-04 5.00000e-05 1.00000e-09 1.00000e-01

5.00000e-04 5.00000e-04 5.00000e-05 1.00000e-09 1.00000e-01

$4.02489 \mathrm{e}+00$ 4.02489e+00 4.02489e-01 1.00000e-09 2.12000e-01

$4.02489 \mathrm{e}+004.02489 \mathrm{e}+00$ 4.02489e-01 1.00000e-09 2.12000e-01

4.02489e+00 4.02489e+00 4.02489e-01 1.00000e-09 2.12000e-01

$4.02489 \mathrm{e}+00$ 4.02489e+00 4.02489e-01 1.00000e-09 2.12000e-01

$4.02489 \mathrm{e}+00$ 4.02489e+00 4.02489e-01 1.00000e-09 2.12000e-01

$1.00000 \mathrm{e}-02$ 1.00000e-02 1.00000e-03 1.00000e-09 1.00000e-01

$1.00000 \mathrm{e}+001.00000 \mathrm{e}+001.00000 \mathrm{e}-011.00000 \mathrm{e}-091.00000 \mathrm{e}-01$

$1.00000 \mathrm{e}-05$ 1.00000e-05 1.00000e-06 1.00000e-09 1.00000e-01

$1.00000 \mathrm{e}+001.00000 \mathrm{e}+001.00000 \mathrm{e}-011.00000 \mathrm{e}-091.00000 \mathrm{e}-01$

Element: 4506 \# of layers: 13

$\mathrm{Kx} \mathrm{Ky} \mathrm{Kz}$ Ss Por

1.00732e+02 1.00732e+02 1.00732e+01 1.00000e-09 7.00000e-02

$1.00732 \mathrm{e}+021.00732 \mathrm{e}+02$ 1.00732e+01 1.00000e-09 7.00000e-02

5.00000e-04 5.00000e-04 5.00000e-05 1.00000e-09 1.00000e-01

5.00000e-04 5.00000e-04 5.00000e-05 1.00000e-09 1.00000e-01

$4.02489 \mathrm{e}+004.02489 \mathrm{e}+00$ 4.02489e-01 1.00000e-09 2.12000e-01

$4.02489 \mathrm{e}+00$ 4.02489e+00 4.02489e-01 1.00000e-09 2.12000e-01

$4.02489 \mathrm{e}+004.02489 \mathrm{e}+00$ 4.02489e-01 1.00000e-09 2.12000e-01

$4.02489 \mathrm{e}+00$ 4.02489e+00 4.02489e-01 1.00000e-09 2.12000e-01

$4.02489 \mathrm{e}+004.02489 \mathrm{e}+00$ 4.02489e-01 1.00000e-09 2.12000e-01

$1.00000 \mathrm{e}-02$ 1.00000e-02 1.00000e-03 1.00000e-09 1.00000e-01

$1.00000 \mathrm{e}+001.00000 \mathrm{e}+001.00000 \mathrm{e}-011.00000 \mathrm{e}-091.00000 \mathrm{e}-01$

$1.00000 \mathrm{e}-05$ 1.00000e-05 1.00000e-06 1.00000e-09 1.00000e-01

$1.00000 \mathrm{e}+001.00000 \mathrm{e}+001.00000 \mathrm{e}-011.00000 \mathrm{e}-091.00000 \mathrm{e}-01$

Element: 4507 \# of layers: 13

Kx Ky Kz Ss Por

7.95484e+01 7.95484e+01 7.95484e+00 1.00000e-09 7.00000e-02

$7.95484 \mathrm{e}+017.95484 \mathrm{e}+017.95484 \mathrm{e}+001.00000 \mathrm{e}-097.00000 \mathrm{e}-02$

5.00000e-04 5.00000e-04 5.00000e-05 1.00000e-09 1.00000e-01

5.00000e-04 5.00000e-04 5.00000e-05 1.00000e-09 1.00000e-01

$3.17842 \mathrm{e}+003.17842 \mathrm{e}+00$ 3.17842e-01 1.00000e-09 2.12000e-01

3.17842e+00 3.17842e+00 3.17842e-01 1.00000e-09 2.12000e-01

3.17842e+00 3.17842e+00 3.17842e-01 1.00000e-09 2.12000e-01

3.17842e+00 3.17842e+00 3.17842e-01 1.00000e-09 2.12000e-01

3.17842e+00 3.17842e+00 3.17842e-01 1.00000e-09 2.12000e-01

$1.00000 \mathrm{e}-02$ 1.00000e-02 1.00000e-03 1.00000e-09 1.00000e-01

$1.00000 \mathrm{e}+001.00000 \mathrm{e}+001.00000 \mathrm{e}-011.00000 \mathrm{e}-091.00000 \mathrm{e}-01$

$1.00000 \mathrm{e}-05$ 1.00000e-05 1.00000e-06 1.00000e-09 1.00000e-01

$1.00000 \mathrm{e}+001.00000 \mathrm{e}+001.00000 \mathrm{e}-011.00000 \mathrm{e}-091.00000 \mathrm{e}-01$ 
Element: 4508 \# of layers: 13

$\mathrm{Kx} \mathrm{Ky} \mathrm{Kz}$ Ss Por

7.95484e+01 7.95484e+01 7.95484e+00 1.00000e-09 7.00000e-02

$7.95484 \mathrm{e}+017.95484 \mathrm{e}+017.95484 \mathrm{e}+001.00000 \mathrm{e}-097.00000 \mathrm{e}-02$

5.00000e-04 5.00000e-04 5.00000e-05 1.00000e-09 1.00000e-01

5.00000e-04 5.00000e-04 5.00000e-05 1.00000e-09 1.00000e-01

$3.17842 \mathrm{e}+003.17842 \mathrm{e}+00$ 3.17842e-01 1.00000e-09 2.12000e-01

$3.17842 \mathrm{e}+003.17842 \mathrm{e}+00$ 3.17842e-01 1.00000e-09 2.12000e-01

3.17842e+00 3.17842e+00 3.17842e-01 1.00000e-09 2.12000e-01

$3.17842 \mathrm{e}+003.17842 \mathrm{e}+00$ 3.17842e-01 1.00000e-09 2.12000e-01

3.17842e+00 3.17842e+00 3.17842e-01 1.00000e-09 2.12000e-01

$1.00000 \mathrm{e}-02$ 1.00000e-02 1.00000e-03 1.00000e-09 1.00000e-01

$1.00000 \mathrm{e}+001.00000 \mathrm{e}+001.00000 \mathrm{e}-011.00000 \mathrm{e}-091.00000 \mathrm{e}-01$

$1.00000 \mathrm{e}-05$ 1.00000e-05 1.00000e-06 1.00000e-09 1.00000e-01

$1.00000 \mathrm{e}+001.00000 \mathrm{e}+001.00000 \mathrm{e}-01$ 1.00000e-09 1.00000e-01

Element: 4509 \# of layers: 14

$\mathrm{Kx} \mathrm{Ky} \mathrm{Kz}$ Ss Por

$1.10706 \mathrm{e}+011.10706 \mathrm{e}+011.10706 \mathrm{e}+00$ 1.00000e-09 7.00000e-02

$1.10706 \mathrm{e}+01$ 1.10706e+01 1.10706e+00 1.00000e-09 7.00000e-02

$1.10706 \mathrm{e}+011.10706 \mathrm{e}+01$ 1.10706e+00 1.00000e-09 7.00000e-02

5.00000e-04 5.00000e-04 5.00000e-05 1.00000e-09 1.00000e-01

5.00000e-04 5.00000e-04 5.00000e-05 1.00000e-09 1.00000e-01

4.42337e-01 4.42337e-01 4.42337e-02 1.00000e-09 2.12000e-01

4.42337e-01 4.42337e-01 4.42337e-02 1.00000e-09 2.12000e-01

4.42337e-01 4.42337e-01 4.42337e-02 1.00000e-09 2.12000e-01

4.42337e-01 4.42337e-01 4.42337e-02 1.00000e-09 2.12000e-01

4.42337e-01 4.42337e-01 4.42337e-02 1.00000e-09 2.12000e-01

$1.00000 \mathrm{e}-02$ 1.00000e-02 1.00000e-03 1.00000e-09 1.00000e-01

$1.00000 \mathrm{e}+001.00000 \mathrm{e}+001.00000 \mathrm{e}-011.00000 \mathrm{e}-091.00000 \mathrm{e}-01$

$1.00000 \mathrm{e}-05$ 1.00000e-05 1.00000e-06 1.00000e-09 1.00000e-01

$1.00000 \mathrm{e}+001.00000 \mathrm{e}+001.00000 \mathrm{e}-011.00000 \mathrm{e}-091.00000 \mathrm{e}-01$

Element: 4510 \# of layers: 14

Kx Ky Kz Ss Por

$5.91011 \mathrm{e}+015.91011 \mathrm{e}+015.91011 \mathrm{e}+001.00000 \mathrm{e}-09$ 7.00000e-02

$5.91011 \mathrm{e}+015.91011 \mathrm{e}+015.91011 \mathrm{e}+001.00000 \mathrm{e}-09$ 7.00000e-02

$5.91011 \mathrm{e}+015.91011 \mathrm{e}+015.91011 \mathrm{e}+001.00000 \mathrm{e}-09$ 7.00000e-02

5.00000e-04 5.00000e-04 5.00000e-05 1.00000e-09 1.00000e-01

5.00000e-04 5.00000e-04 5.00000e-05 1.00000e-09 1.00000e-01

2.36142e+00 2.36142e+00 2.36142e-01 1.00000e-09 2.12000e-01

2.36142e+00 2.36142e+00 2.36142e-01 1.00000e-09 2.12000e-01

$2.36142 \mathrm{e}+002.36142 \mathrm{e}+00$ 2.36142e-01 1.00000e-09 2.12000e-01

$2.36142 \mathrm{e}+002.36142 \mathrm{e}+00$ 2.36142e-01 1.00000e-09 2.12000e-01

2.36142e+00 2.36142e+00 2.36142e-01 1.00000e-09 2.12000e-01

$1.00000 \mathrm{e}-02$ 1.00000e-02 1.00000e-03 1.00000e-09 1.00000e-01

$1.00000 \mathrm{e}+001.00000 \mathrm{e}+001.00000 \mathrm{e}-011.00000 \mathrm{e}-091.00000 \mathrm{e}-01$

$1.00000 \mathrm{e}-05$ 1.00000e-05 1.00000e-06 1.00000e-09 1.00000e-01 
$1.00000 \mathrm{e}+001.00000 \mathrm{e}+001.00000 \mathrm{e}-01$ 1.00000e-09 1.00000e-01

Element: 4511 \# of layers: 14

Kx Ky Kz Ss Por

$1.00732 \mathrm{e}+02$ 1.00732e+02 1.00732e+01 1.00000e-09 7.00000e-02

$1.00732 \mathrm{e}+02$ 1.00732e+02 1.00732e+01 1.00000e-09 7.00000e-02

$1.00732 \mathrm{e}+021.00732 \mathrm{e}+021.00732 \mathrm{e}+01$ 1.00000e-09 7.00000e-02

5.00000e-04 5.00000e-04 5.00000e-05 1.00000e-09 1.00000e-01

5.00000e-04 5.00000e-04 5.00000e-05 1.00000e-09 1.00000e-01

$4.02489 \mathrm{e}+00$ 4.02489e+00 4.02489e-01 1.00000e-09 2.12000e-01

$4.02489 \mathrm{e}+00$ 4.02489e+00 4.02489e-01 1.00000e-09 2.12000e-01

$4.02489 \mathrm{e}+00$ 4.02489e+00 4.02489e-01 1.00000e-09 2.12000e-01

$4.02489 \mathrm{e}+004.02489 \mathrm{e}+00$ 4.02489e-01 1.00000e-09 2.12000e-01

4.02489e+00 4.02489e+00 4.02489e-01 1.00000e-09 2.12000e-01

$1.00000 \mathrm{e}-02$ 1.00000e-02 1.00000e-03 1.00000e-09 1.00000e-01

$1.00000 \mathrm{e}+001.00000 \mathrm{e}+001.00000 \mathrm{e}-011.00000 \mathrm{e}-091.00000 \mathrm{e}-01$

$1.00000 \mathrm{e}-05$ 1.00000e-05 1.00000e-06 1.00000e-09 1.00000e-01

$1.00000 \mathrm{e}+001.00000 \mathrm{e}+001.00000 \mathrm{e}-01$ 1.00000e-09 1.00000e-01

Element: 4512 \# of layers: 13

$\mathrm{Kx} \mathrm{Ky} \mathrm{Kz}$ Ss Por

1.06138e+02 1.06138e+02 1.06138e+01 1.00000e-09 7.00000e-02 $1.06138 \mathrm{e}+021.06138 \mathrm{e}+02$ 1.06138e+01 1.00000e-09 7.00000e-02 5.00000e-04 5.00000e-04 5.00000e-05 1.00000e-09 1.00000e-01 5.00000e-04 5.00000e-04 5.00000e-05 1.00000e-09 1.00000e-01 4.24089e+00 4.24089e+00 4.24089e-01 1.00000e-09 2.12000e-01 $4.24089 \mathrm{e}+004.24089 \mathrm{e}+00$ 4.24089e-01 1.00000e-09 2.12000e-01 $4.24089 \mathrm{e}+004.24089 \mathrm{e}+00$ 4.24089e-01 1.00000e-09 2.12000e-01 $4.24089 \mathrm{e}+00$ 4.24089e+00 4.24089e-01 1.00000e-09 2.12000e-01 $4.24089 \mathrm{e}+00$ 4.24089e+00 4.24089e-01 1.00000e-09 2.12000e-01 $1.00000 \mathrm{e}-02$ 1.00000e-02 1.00000e-03 1.00000e-09 1.00000e-01 $1.00000 \mathrm{e}+001.00000 \mathrm{e}+001.00000 \mathrm{e}-011.00000 \mathrm{e}-091.00000 \mathrm{e}-01$ $1.00000 \mathrm{e}-05$ 1.00000e-05 1.00000e-06 1.00000e-09 1.00000e-01 $1.00000 \mathrm{e}+001.00000 \mathrm{e}+001.00000 \mathrm{e}-011.00000 \mathrm{e}-091.00000 \mathrm{e}-01$ Element: 4513 \# of layers: 13

$\mathrm{Kx} \mathrm{Ky} \mathrm{Kz}$ Ss Por

$1.05615 \mathrm{e}+02$ 1.05615e+02 1.05615e+01 1.00000e-09 7.00000e-02 $1.05615 \mathrm{e}+021.05615 \mathrm{e}+021.05615 \mathrm{e}+01$ 1.00000e-09 7.00000e-02 5.00000e-04 5.00000e-04 5.00000e-05 1.00000e-09 1.00000e-01 5.00000e-04 5.00000e-04 5.00000e-05 1.00000e-09 1.00000e-01 4.21996e+00 4.21996e+00 4.21997e-01 1.00000e-09 2.12000e-01 4.21996e+00 4.21996e+00 4.21997e-01 1.00000e-09 2.12000e-01 4.21996e+00 4.21996e+00 4.21997e-01 1.00000e-09 2.12000e-01 4.21996e+00 4.21996e+00 4.21997e-01 1.00000e-09 2.12000e-01 4.21996e+00 4.21996e+00 4.21997e-01 1.00000e-09 2.12000e-01 $1.00000 \mathrm{e}-021.00000 \mathrm{e}-021.00000 \mathrm{e}-031.00000 \mathrm{e}-091.00000 \mathrm{e}-01$ $1.00000 \mathrm{e}+001.00000 \mathrm{e}+001.00000 \mathrm{e}-011.00000 \mathrm{e}-091.00000 \mathrm{e}-01$ $1.00000 \mathrm{e}-05$ 1.00000e-05 1.00000e-06 1.00000e-09 1.00000e-01 
$1.00000 \mathrm{e}+001.00000 \mathrm{e}+001.00000 \mathrm{e}-01$ 1.00000e-09 1.00000e-01

Element: 4514 \# of layers: 14

Kx Ky Kz Ss Por

$1.05615 \mathrm{e}+02$ 1.05615e+02 1.05615e+01 1.00000e-09 7.00000e-02

$1.05615 \mathrm{e}+021.05615 \mathrm{e}+021.05615 \mathrm{e}+01$ 1.00000e-09 7.00000e-02

$1.05615 \mathrm{e}+021.05615 \mathrm{e}+021.05615 \mathrm{e}+01$ 1.00000e-09 7.00000e-02

5.00000e-04 5.00000e-04 5.00000e-05 1.00000e-09 1.00000e-01

5.00000e-04 5.00000e-04 5.00000e-05 1.00000e-09 1.00000e-01

$4.21996 \mathrm{e}+004.21996 \mathrm{e}+00$ 4.21997e-01 1.00000e-09 2.12000e-01

$4.21996 \mathrm{e}+004.21996 \mathrm{e}+00$ 4.21997e-01 1.00000e-09 2.12000e-01

4.21996e+00 4.21996e+00 4.21997e-01 1.00000e-09 2.12000e-01

$4.21996 \mathrm{e}+00$ 4.21996e+00 4.21997e-01 1.00000e-09 2.12000e-01

4.21996e+00 4.21996e+00 4.21997e-01 1.00000e-09 2.12000e-01

$1.00000 \mathrm{e}-02$ 1.00000e-02 1.00000e-03 1.00000e-09 1.00000e-01

$1.00000 \mathrm{e}+001.00000 \mathrm{e}+001.00000 \mathrm{e}-011.00000 \mathrm{e}-091.00000 \mathrm{e}-01$

$1.00000 \mathrm{e}-05$ 1.00000e-05 1.00000e-06 1.00000e-09 1.00000e-01

$1.00000 \mathrm{e}+001.00000 \mathrm{e}+001.00000 \mathrm{e}-01$ 1.00000e-09 1.00000e-01

Element: 4515 \# of layers: 13

$\mathrm{Kx} \mathrm{Ky} \mathrm{Kz}$ Ss Por

$1.05615 \mathrm{e}+02$ 1.05615e+02 1.05615e+01 1.00000e-09 7.00000e-02

$1.05615 \mathrm{e}+021.05615 \mathrm{e}+021.05615 \mathrm{e}+01$ 1.00000e-09 7.00000e-02

5.00000e-04 5.00000e-04 5.00000e-05 1.00000e-09 1.00000e-01

5.00000e-04 5.00000e-04 5.00000e-05 1.00000e-09 1.00000e-01

4.21996e+00 4.21996e+00 4.21997e-01 1.00000e-09 2.12000e-01

$4.21996 \mathrm{e}+004.21996 \mathrm{e}+00$ 4.21997e-01 1.00000e-09 2.12000e-01

4.21996e+00 4.21996e+00 4.21997e-01 1.00000e-09 2.12000e-01

4.21996e+00 4.21996e+00 4.21997e-01 1.00000e-09 2.12000e-01

4.21996e+00 4.21996e+00 4.21997e-01 1.00000e-09 2.12000e-01

$1.00000 \mathrm{e}-02$ 1.00000e-02 1.00000e-03 1.00000e-09 1.00000e-01

$1.00000 \mathrm{e}+001.00000 \mathrm{e}+001.00000 \mathrm{e}-011.00000 \mathrm{e}-091.00000 \mathrm{e}-01$

$1.00000 \mathrm{e}-05$ 1.00000e-05 1.00000e-06 1.00000e-09 1.00000e-01

$1.00000 \mathrm{e}+001.00000 \mathrm{e}+001.00000 \mathrm{e}-011.00000 \mathrm{e}-091.00000 \mathrm{e}-01$

Element: 4516 \# of layers: 13

$\mathrm{Kx} \mathrm{Ky} \mathrm{Kz}$ Ss Por

7.57561e+01 7.57561e+01 7.57561e+00 1.00000e-09 7.00000e-02

$7.57561 \mathrm{e}+017.57561 \mathrm{e}+017.57561 \mathrm{e}+001.00000 \mathrm{e}-09$ 7.00000e-02

5.00000e-04 5.00000e-04 5.00000e-05 1.00000e-09 1.00000e-01

5.00000e-04 5.00000e-04 5.00000e-05 1.00000e-09 1.00000e-01

$3.02699 \mathrm{e}+003.02699 \mathrm{e}+00$ 3.02699e-01 1.00000e-09 2.12000e-01

$3.02699 \mathrm{e}+003.02699 \mathrm{e}+003.02699 \mathrm{e}-01$ 1.00000e-09 2.12000e-01

$3.02699 \mathrm{e}+003.02699 \mathrm{e}+00$ 3.02699e-01 1.00000e-09 2.12000e-01

$3.02699 \mathrm{e}+003.02699 \mathrm{e}+00$ 3.02699e-01 1.00000e-09 2.12000e-01

$3.02699 \mathrm{e}+00$ 3.02699e+00 3.02699e-01 1.00000e-09 2.12000e-01

$1.00000 \mathrm{e}-02$ 1.00000e-02 1.00000e-03 1.00000e-09 1.00000e-01

$1.00000 \mathrm{e}+001.00000 \mathrm{e}+001.00000 \mathrm{e}-011.00000 \mathrm{e}-091.00000 \mathrm{e}-01$

$1.00000 \mathrm{e}-05$ 1.00000e-05 1.00000e-06 1.00000e-09 1.00000e-01 
$1.00000 \mathrm{e}+001.00000 \mathrm{e}+00$ 1.00000e-01 1.00000e-09 1.00000e-01 Element: 4517 \# of layers: 13

Kx Ky Kz Ss Por

7.57561e+01 7.57561e+01 7.57561e+00 1.00000e-09 7.00000e-02

$7.57561 \mathrm{e}+017.57561 \mathrm{e}+017.57561 \mathrm{e}+001.00000 \mathrm{e}-09$ 7.00000e-02

5.00000e-04 5.00000e-04 5.00000e-05 1.00000e-09 1.00000e-01

5.00000e-04 5.00000e-04 5.00000e-05 1.00000e-09 1.00000e-01

$3.02699 \mathrm{e}+003.02699 \mathrm{e}+00$ 3.02699e-01 1.00000e-09 2.12000e-01

$3.02699 \mathrm{e}+003.02699 \mathrm{e}+003.02699 \mathrm{e}-01$ 1.00000e-09 2.12000e-01

$3.02699 \mathrm{e}+003.02699 \mathrm{e}+00$ 3.02699e-01 1.00000e-09 2.12000e-01

$3.02699 \mathrm{e}+003.02699 \mathrm{e}+00$ 3.02699e-01 1.00000e-09 2.12000e-01

$3.02699 \mathrm{e}+003.02699 \mathrm{e}+00$ 3.02699e-01 1.00000e-09 2.12000e-01

$1.00000 \mathrm{e}-02$ 1.00000e-02 1.00000e-03 1.00000e-09 1.00000e-01

$1.00000 \mathrm{e}+001.00000 \mathrm{e}+001.00000 \mathrm{e}-011.00000 \mathrm{e}-091.00000 \mathrm{e}-01$

$1.00000 \mathrm{e}-05$ 1.00000e-05 1.00000e-06 1.00000e-09 1.00000e-01

$1.00000 \mathrm{e}+001.00000 \mathrm{e}+001.00000 \mathrm{e}-011.00000 \mathrm{e}-091.00000 \mathrm{e}-01$

Element: 4518 \# of layers: 13

$\mathrm{Kx} \mathrm{Ky} \mathrm{Kz}$ Ss Por

1.18779e+02 1.18779e+02 1.18779e+01 1.00000e-09 7.00000e-02

$1.18779 \mathrm{e}+02$ 1.18779e+02 1.18779e+01 1.00000e-09 7.00000e-02

5.00000e-04 5.00000e-04 5.00000e-05 1.00000e-09 1.00000e-01

5.00000e-04 5.00000e-04 5.00000e-05 1.00000e-09 1.00000e-01

$4.74625 \mathrm{e}+004.74625 \mathrm{e}+00$ 4.74625e-01 1.00000e-09 2.12000e-01

$4.74625 \mathrm{e}+004.74625 \mathrm{e}+00$ 4.74625e-01 1.00000e-09 2.12000e-01

$4.74625 \mathrm{e}+004.74625 \mathrm{e}+00$ 4.74625e-01 1.00000e-09 2.12000e-01

$4.74625 \mathrm{e}+00$ 4.74625e+00 4.74625e-01 1.00000e-09 2.12000e-01

$4.74625 \mathrm{e}+004.74625 \mathrm{e}+00$ 4.74625e-01 1.00000e-09 2.12000e-01

$1.00000 \mathrm{e}-02$ 1.00000e-02 1.00000e-03 1.00000e-09 1.00000e-01

$1.00000 \mathrm{e}+001.00000 \mathrm{e}+001.00000 \mathrm{e}-011.00000 \mathrm{e}-091.00000 \mathrm{e}-01$

$1.00000 \mathrm{e}-05$ 1.00000e-05 1.00000e-06 1.00000e-09 1.00000e-01

$1.00000 \mathrm{e}+001.00000 \mathrm{e}+001.00000 \mathrm{e}-011.00000 \mathrm{e}-091.00000 \mathrm{e}-01$

Element: 4519 \# of layers: 13

Kx Ky Kz Ss Por

$1.06138 \mathrm{e}+021.06138 \mathrm{e}+02$ 1.06138e+01 1.00000e-09 7.00000e-02

$1.06138 \mathrm{e}+021.06138 \mathrm{e}+02 \quad 1.06138 \mathrm{e}+01$ 1.00000e-09 7.00000e-02

5.00000e-04 5.00000e-04 5.00000e-05 1.00000e-09 1.00000e-01

5.00000e-04 5.00000e-04 5.00000e-05 1.00000e-09 1.00000e-01

$4.24089 \mathrm{e}+004.24089 \mathrm{e}+00$ 4.24089e-01 1.00000e-09 2.12000e-01

$4.24089 \mathrm{e}+00$ 4.24089e+00 4.24089e-01 1.00000e-09 2.12000e-01

4.24089e+00 4.24089e+00 4.24089e-01 1.00000e-09 2.12000e-01

$4.24089 \mathrm{e}+00$ 4.24089e+00 4.24089e-01 1.00000e-09 2.12000e-01

$4.24089 \mathrm{e}+004.24089 \mathrm{e}+00$ 4.24089e-01 1.00000e-09 2.12000e-01

$1.00000 \mathrm{e}-021.00000 \mathrm{e}-021.00000 \mathrm{e}-031.00000 \mathrm{e}-091.00000 \mathrm{e}-01$

$1.00000 \mathrm{e}+001.00000 \mathrm{e}+001.00000 \mathrm{e}-011.00000 \mathrm{e}-091.00000 \mathrm{e}-01$ $1.00000 \mathrm{e}-05$ 1.00000e-05 1.00000e-06 1.00000e-09 1.00000e-01

$1.00000 \mathrm{e}+001.00000 \mathrm{e}+001.00000 \mathrm{e}-011.00000 \mathrm{e}-091.00000 \mathrm{e}-01$ 
Element: 4520 \# of layers: 13

Kx Ky Kz Ss Por

$1.05615 \mathrm{e}+021.05615 \mathrm{e}+021.05615 \mathrm{e}+011.00000 \mathrm{e}-09$ 7.00000e-02

$1.05615 \mathrm{e}+021.05615 \mathrm{e}+021.05615 \mathrm{e}+011.00000 \mathrm{e}-097.00000 \mathrm{e}-02$

$5.00000 \mathrm{e}-04$ 5.00000e-04 5.00000e-05 1.00000e-09 1.00000e-01

5.00000e-04 5.00000e-04 5.00000e-05 1.00000e-09 1.00000e-01

$4.21996 \mathrm{e}+00$ 4.21996e+00 4.21997e-01 1.00000e-09 2.12000e-01

$4.21996 \mathrm{e}+004.21996 \mathrm{e}+00$ 4.21997e-01 1.00000e-09 2.12000e-01

$4.21996 \mathrm{e}+004.21996 \mathrm{e}+00$ 4.21997e-01 1.00000e-09 2.12000e-01

$4.21996 \mathrm{e}+004.21996 \mathrm{e}+00$ 4.21997e-01 1.00000e-09 2.12000e-01

$4.21996 \mathrm{e}+004.21996 \mathrm{e}+00$ 4.21997e-01 1.00000e-09 2.12000e-01

$1.00000 \mathrm{e}-021.00000 \mathrm{e}-02$ 1.00000e-03 1.00000e-09 1.00000e-01

$1.00000 \mathrm{e}+001.00000 \mathrm{e}+001.00000 \mathrm{e}-011.00000 \mathrm{e}-091.00000 \mathrm{e}-01$

$1.00000 \mathrm{e}-05$ 1.00000e-05 1.00000e-06 1.00000e-09 1.00000e-01

$1.00000 \mathrm{e}+001.00000 \mathrm{e}+001.00000 \mathrm{e}-011.00000 \mathrm{e}-091.00000 \mathrm{e}-01$

Element: 4521 \# of layers: 14

Kx Ky Kz Ss Por

$4.58807 \mathrm{e}+014.58807 \mathrm{e}+014.58807 \mathrm{e}+00$ 1.00000e-09 7.00000e-02

$4.58807 \mathrm{e}+014.58807 \mathrm{e}+014.58807 \mathrm{e}+001.00000 \mathrm{e}-09$ 7.00000e-02

$4.58807 \mathrm{e}+014.58807 \mathrm{e}+014.58807 \mathrm{e}+001.00000 \mathrm{e}-09$ 7.00000e-02

$5.00000 \mathrm{e}-04$ 5.00000e-04 5.00000e-05 1.00000e-09 1.00000e-01

$5.00000 \mathrm{e}-04$ 5.00000e-04 5.00000e-05 1.00000e-09 1.00000e-01

$1.83325 \mathrm{e}+001.83325 \mathrm{e}+001.83325 \mathrm{e}-011.00000 \mathrm{e}-092.12000 \mathrm{e}-01$

$1.83325 \mathrm{e}+001.83325 \mathrm{e}+001.83325 \mathrm{e}-011.00000 \mathrm{e}-092.12000 \mathrm{e}-01$

$1.83325 \mathrm{e}+001.83325 \mathrm{e}+001.83325 \mathrm{e}-011.00000 \mathrm{e}-092.12000 \mathrm{e}-01$

$1.83325 \mathrm{e}+001.83325 \mathrm{e}+001.83325 \mathrm{e}-011.00000 \mathrm{e}-092.12000 \mathrm{e}-01$

$1.83325 \mathrm{e}+001.83325 \mathrm{e}+001.83325 \mathrm{e}-011.00000 \mathrm{e}-092.12000 \mathrm{e}-01$

$1.00000 \mathrm{e}-021.00000 \mathrm{e}-021.00000 \mathrm{e}-031.00000 \mathrm{e}-091.00000 \mathrm{e}-01$

$1.00000 \mathrm{e}+001.00000 \mathrm{e}+001.00000 \mathrm{e}-011.00000 \mathrm{e}-091.00000 \mathrm{e}-01$

$1.00000 \mathrm{e}-05$ 1.00000e-05 1.00000e-06 1.00000e-09 1.00000e-01

$1.00000 \mathrm{e}+001.00000 \mathrm{e}+001.00000 \mathrm{e}-011.00000 \mathrm{e}-091.00000 \mathrm{e}-01$

Element: 4522 \# of layers: 13

Kx Ky Kz Ss Por

$2.13771 \mathrm{e}+012.13771 \mathrm{e}+012.13771 \mathrm{e}+00$ 1.00000e-09 7.00000e-02

$2.13771 \mathrm{e}+012.13771 \mathrm{e}+012.13771 \mathrm{e}+001.00000 \mathrm{e}-09$ 7.00000e-02

$2.13771 \mathrm{e}+012.13771 \mathrm{e}+012.13771 \mathrm{e}+001.00000 \mathrm{e}-09$ 7.00000e-02

5.00000e-04 5.00000e-04 5.00000e-05 1.00000e-09 1.00000e-01

8.54141e-01 8.54141e-01 8.54141e-02 1.00000e-09 2.12000e-01

8.54141e-01 8.54141e-01 8.54141e-02 1.00000e-09 2.12000e-01

8.54141e-01 8.54141e-01 8.54141e-02 1.00000e-09 2.12000e-01

$8.54141 \mathrm{e}-01$ 8.54141e-01 8.54141e-02 1.00000e-09 2.12000e-01

$8.54141 \mathrm{e}-01$ 8.54141e-01 8.54141e-02 1.00000e-09 2.12000e-01

$1.00000 \mathrm{e}-021.00000 \mathrm{e}-021.00000 \mathrm{e}-031.00000 \mathrm{e}-091.00000 \mathrm{e}-01$

$1.00000 \mathrm{e}+001.00000 \mathrm{e}+001.00000 \mathrm{e}-011.00000 \mathrm{e}-091.00000 \mathrm{e}-01$ $1.00000 \mathrm{e}-05$ 1.00000e-05 1.00000e-06 1.00000e-09 1.00000e-01

$1.00000 \mathrm{e}+001.00000 \mathrm{e}+001.00000 \mathrm{e}-011.00000 \mathrm{e}-091.00000 \mathrm{e}-01$ 
Element: 4523 \# of layers: 14

$\mathrm{Kx} \mathrm{Ky} \mathrm{Kz}$ Ss Por

2.13771e+01 2.13771e+01 2.13771e+00 1.00000e-09 7.00000e-02

$2.13771 \mathrm{e}+012.13771 \mathrm{e}+012.13771 \mathrm{e}+001.00000 \mathrm{e}-09$ 7.00000e-02

$2.13771 \mathrm{e}+012.13771 \mathrm{e}+012.13771 \mathrm{e}+001.00000 \mathrm{e}-097.00000 \mathrm{e}-02$

5.00000e-04 5.00000e-04 5.00000e-05 1.00000e-09 1.00000e-01

5.00000e-04 5.00000e-04 5.00000e-05 1.00000e-09 1.00000e-01

8.54141e-01 8.54141e-01 8.54141e-02 1.00000e-09 2.12000e-01

8.54141e-01 8.54141e-01 8.54141e-02 1.00000e-09 2.12000e-01

8.54141e-01 8.54141e-01 8.54141e-02 1.00000e-09 2.12000e-01

8.54141e-01 8.54141e-01 8.54141e-02 1.00000e-09 2.12000e-01

8.54141e-01 8.54141e-01 8.54141e-02 1.00000e-09 2.12000e-01

$1.00000 \mathrm{e}-02$ 1.00000e-02 1.00000e-03 1.00000e-09 1.00000e-01

$1.00000 \mathrm{e}+001.00000 \mathrm{e}+001.00000 \mathrm{e}-011.00000 \mathrm{e}-091.00000 \mathrm{e}-01$

$1.00000 \mathrm{e}-05$ 1.00000e-05 1.00000e-06 1.00000e-09 1.00000e-01

$1.00000 \mathrm{e}+001.00000 \mathrm{e}+001.00000 \mathrm{e}-011.00000 \mathrm{e}-091.00000 \mathrm{e}-01$

Element: 4524 \# of layers: 14

$\mathrm{Kx} \mathrm{Ky} \mathrm{Kz}$ Ss Por

2.13771e+01 2.13771e+01 2.13771e+00 1.00000e-09 7.00000e-02

$2.13771 \mathrm{e}+012.13771 \mathrm{e}+012.13771 \mathrm{e}+001.00000 \mathrm{e}-09$ 7.00000e-02

$2.13771 \mathrm{e}+012.13771 \mathrm{e}+012.13771 \mathrm{e}+001.00000 \mathrm{e}-09$ 7.00000e-02

$2.13771 \mathrm{e}+012.13771 \mathrm{e}+012.13771 \mathrm{e}+00$ 1.00000e-09 7.00000e-02

5.00000e-04 5.00000e-04 5.00000e-05 1.00000e-09 1.00000e-01

8.54141e-01 8.54141e-01 8.54141e-02 1.00000e-09 2.12000e-01

8.54141e-01 8.54141e-01 8.54141e-02 1.00000e-09 2.12000e-01

8.54141e-01 8.54141e-01 8.54141e-02 1.00000e-09 2.12000e-01

8.54141e-01 8.54141e-01 8.54141e-02 1.00000e-09 2.12000e-01

8.54141e-01 8.54141e-01 8.54141e-02 1.00000e-09 2.12000e-01

$1.00000 \mathrm{e}-02$ 1.00000e-02 1.00000e-03 1.00000e-09 1.00000e-01

$1.00000 \mathrm{e}+001.00000 \mathrm{e}+001.00000 \mathrm{e}-011.00000 \mathrm{e}-091.00000 \mathrm{e}-01$

$1.00000 \mathrm{e}-05$ 1.00000e-05 1.00000e-06 1.00000e-09 1.00000e-01

$1.00000 \mathrm{e}+001.00000 \mathrm{e}+001.00000 \mathrm{e}-01$ 1.00000e-09 1.00000e-01

Element: 4525 \# of layers: 13

$\mathrm{Kx} \mathrm{Ky} \mathrm{Kz}$ Ss Por

$2.42504 \mathrm{e}+012.42504 \mathrm{e}+012.42504 \mathrm{e}+001.00000 \mathrm{e}-09$ 7.00000e-02

$2.42504 \mathrm{e}+012.42504 \mathrm{e}+012.42504 \mathrm{e}+001.00000 \mathrm{e}-097.00000 \mathrm{e}-02$

$2.42504 \mathrm{e}+012.42504 \mathrm{e}+012.42504 \mathrm{e}+001.00000 \mathrm{e}-09$ 7.00000e-02

5.00000e-04 5.00000e-04 5.00000e-05 1.00000e-09 1.00000e-01

9.68961e-01 9.68961e-01 9.68961e-02 1.00000e-09 2.12000e-01

9.68961e-01 9.68961e-01 9.68961e-02 1.00000e-09 2.12000e-01

9.68961e-01 9.68961e-01 9.68961e-02 1.00000e-09 2.12000e-01

9.68961e-01 9.68961e-01 9.68961e-02 1.00000e-09 2.12000e-01

9.68961e-01 9.68961e-01 9.68961e-02 1.00000e-09 2.12000e-01

$1.00000 \mathrm{e}-02$ 1.00000e-02 1.00000e-03 1.00000e-09 1.00000e-01

$1.00000 \mathrm{e}+001.00000 \mathrm{e}+001.00000 \mathrm{e}-011.00000 \mathrm{e}-091.00000 \mathrm{e}-01$

$1.00000 \mathrm{e}-05$ 1.00000e-05 1.00000e-06 1.00000e-09 1.00000e-01 
$1.00000 \mathrm{e}+001.00000 \mathrm{e}+00$ 1.00000e-01 1.00000e-09 1.00000e-01 Element: 4526 \# of layers: 13

$\mathrm{Kx} \mathrm{Ky} \mathrm{Kz}$ Ss Por

$2.42504 \mathrm{e}+012.42504 \mathrm{e}+012.42504 \mathrm{e}+001.00000 \mathrm{e}-09$ 7.00000e-02

$2.42504 \mathrm{e}+012.42504 \mathrm{e}+012.42504 \mathrm{e}+001.00000 \mathrm{e}-09$ 7.00000e-02

5.00000e-04 5.00000e-04 5.00000e-05 1.00000e-09 1.00000e-01

5.00000e-04 5.00000e-04 5.00000e-05 1.00000e-09 1.00000e-01

9.68961e-01 9.68961e-01 9.68961e-02 1.00000e-09 2.12000e-01

9.68961e-01 9.68961e-01 9.68961e-02 1.00000e-09 2.12000e-01

9.68961e-01 9.68961e-01 9.68961e-02 1.00000e-09 2.12000e-01

9.68961e-01 9.68961e-01 9.68961e-02 1.00000e-09 2.12000e-01

9.68961e-01 9.68961e-01 9.68961e-02 1.00000e-09 2.12000e-01

$1.00000 \mathrm{e}-02$ 1.00000e-02 1.00000e-03 1.00000e-09 1.00000e-01

$1.00000 \mathrm{e}+001.00000 \mathrm{e}+001.00000 \mathrm{e}-011.00000 \mathrm{e}-091.00000 \mathrm{e}-01$

$1.00000 \mathrm{e}-05$ 1.00000e-05 1.00000e-06 1.00000e-09 1.00000e-01

$1.00000 \mathrm{e}+001.00000 \mathrm{e}+001.00000 \mathrm{e}-011.00000 \mathrm{e}-091.00000 \mathrm{e}-01$

Element: 4527 \# of layers: 13

$\mathrm{Kx} \mathrm{Ky} \mathrm{Kz}$ Ss Por

$2.65074 \mathrm{e}+012.65074 \mathrm{e}+012.65074 \mathrm{e}+00$ 1.00000e-09 7.00000e-02

$2.65074 \mathrm{e}+012.65074 \mathrm{e}+012.65074 \mathrm{e}+001.00000 \mathrm{e}-09$ 7.00000e-02

5.00000e-04 5.00000e-04 5.00000e-05 1.00000e-09 1.00000e-01

5.00000e-04 5.00000e-04 5.00000e-05 1.00000e-09 1.00000e-01

$1.05912 \mathrm{e}+001.05912 \mathrm{e}+00$ 1.05912e-01 1.00000e-09 2.12000e-01

$1.05912 \mathrm{e}+001.05912 \mathrm{e}+001.05912 \mathrm{e}-01$ 1.00000e-09 2.12000e-01

$1.05912 \mathrm{e}+001.05912 \mathrm{e}+001.05912 \mathrm{e}-011.00000 \mathrm{e}-092.12000 \mathrm{e}-01$

$1.05912 \mathrm{e}+001.05912 \mathrm{e}+00$ 1.05912e-01 1.00000e-09 2.12000e-01

$1.05912 \mathrm{e}+001.05912 \mathrm{e}+001.05912 \mathrm{e}-01$ 1.00000e-09 2.12000e-01

$1.00000 \mathrm{e}-02$ 1.00000e-02 1.00000e-03 1.00000e-09 1.00000e-01

$1.00000 \mathrm{e}+001.00000 \mathrm{e}+001.00000 \mathrm{e}-011.00000 \mathrm{e}-091.00000 \mathrm{e}-01$

$1.00000 \mathrm{e}-05$ 1.00000e-05 1.00000e-06 1.00000e-09 1.00000e-01

$1.00000 \mathrm{e}+001.00000 \mathrm{e}+001.00000 \mathrm{e}-011.00000 \mathrm{e}-091.00000 \mathrm{e}-01$

Element: 4528 \# of layers: 14

Kx Ky Kz Ss Por

4.58807e+01 4.58807e+01 4.58807e+00 1.00000e-09 7.00000e-02

4.58807e+01 4.58807e+01 4.58807e+00 1.00000e-09 7.00000e-02

$4.58807 \mathrm{e}+014.58807 \mathrm{e}+014.58807 \mathrm{e}+001.00000 \mathrm{e}-09$ 7.00000e-02

5.00000e-04 5.00000e-04 5.00000e-05 1.00000e-09 1.00000e-01

5.00000e-04 5.00000e-04 5.00000e-05 1.00000e-09 1.00000e-01

$1.83325 \mathrm{e}+001.83325 \mathrm{e}+001.83325 \mathrm{e}-01$ 1.00000e-09 2.12000e-01

$1.83325 \mathrm{e}+001.83325 \mathrm{e}+00$ 1.83325e-01 1.00000e-09 2.12000e-01

$1.83325 \mathrm{e}+001.83325 \mathrm{e}+00$ 1.83325e-01 1.00000e-09 2.12000e-01

$1.83325 \mathrm{e}+001.83325 \mathrm{e}+001.83325 \mathrm{e}-01 \quad 1.00000 \mathrm{e}-092.12000 \mathrm{e}-01$

$1.83325 \mathrm{e}+001.83325 \mathrm{e}+00$ 1.83325e-01 1.00000e-09 2.12000e-01

$1.00000 \mathrm{e}-02$ 1.00000e-02 1.00000e-03 1.00000e-09 1.00000e-01

$1.00000 \mathrm{e}+001.00000 \mathrm{e}+001.00000 \mathrm{e}-011.00000 \mathrm{e}-091.00000 \mathrm{e}-01$

$1.00000 \mathrm{e}-05$ 1.00000e-05 1.00000e-06 1.00000e-09 1.00000e-01 
$1.00000 \mathrm{e}+001.00000 \mathrm{e}+00$ 1.00000e-01 1.00000e-09 1.00000e-01 Element: 4529 \# of layers: 14

Kx Ky Kz Ss Por

$2.13771 \mathrm{e}+012.13771 \mathrm{e}+012.13771 \mathrm{e}+00$ 1.00000e-09 7.00000e-02

$2.13771 \mathrm{e}+012.13771 \mathrm{e}+012.13771 \mathrm{e}+001.00000 \mathrm{e}-09$ 7.00000e-02

$2.13771 \mathrm{e}+012.13771 \mathrm{e}+012.13771 \mathrm{e}+001.00000 \mathrm{e}-097.00000 \mathrm{e}-02$

5.00000e-04 5.00000e-04 5.00000e-05 1.00000e-09 1.00000e-01

5.00000e-04 5.00000e-04 5.00000e-05 1.00000e-09 1.00000e-01

8.54141e-01 8.54141e-01 8.54141e-02 1.00000e-09 2.12000e-01

8.54141e-01 8.54141e-01 8.54141e-02 1.00000e-09 2.12000e-01

8.54141e-01 8.54141e-01 8.54141e-02 1.00000e-09 2.12000e-01

8.54141e-01 8.54141e-01 8.54141e-02 1.00000e-09 2.12000e-01

8.54141e-01 8.54141e-01 8.54141e-02 1.00000e-09 2.12000e-01

$1.00000 \mathrm{e}-02$ 1.00000e-02 1.00000e-03 1.00000e-09 1.00000e-01

$1.00000 \mathrm{e}+001.00000 \mathrm{e}+001.00000 \mathrm{e}-011.00000 \mathrm{e}-091.00000 \mathrm{e}-01$

$1.00000 \mathrm{e}-05$ 1.00000e-05 1.00000e-06 1.00000e-09 1.00000e-01

$1.00000 \mathrm{e}+001.00000 \mathrm{e}+001.00000 \mathrm{e}-01$ 1.00000e-09 1.00000e-01

Element: 4530 \# of layers: 14

$\mathrm{Kx} \mathrm{Ky} \mathrm{Kz}$ Ss Por

$2.05870 \mathrm{e}+012.05870 \mathrm{e}+012.05870 \mathrm{e}+00$ 1.00000e-09 7.00000e-02

$2.05870 \mathrm{e}+012.05870 \mathrm{e}+012.05870 \mathrm{e}+001.00000 \mathrm{e}-09$ 7.00000e-02

$2.05870 \mathrm{e}+012.05870 \mathrm{e}+012.05870 \mathrm{e}+001.00000 \mathrm{e}-09$ 7.00000e-02

5.00000e-04 5.00000e-04 5.00000e-05 1.00000e-09 1.00000e-01

5.00000e-04 5.00000e-04 5.00000e-05 1.00000e-09 1.00000e-01

8.22595e-01 8.22595e-01 8.22595e-02 1.00000e-09 2.12000e-01

8.22595e-01 8.22595e-01 8.22595e-02 1.00000e-09 2.12000e-01

8.22595e-01 8.22595e-01 8.22595e-02 1.00000e-09 2.12000e-01

8.22595e-01 8.22595e-01 8.22595e-02 1.00000e-09 2.12000e-01

8.22595e-01 8.22595e-01 8.22595e-02 1.00000e-09 2.12000e-01

$1.00000 \mathrm{e}-02$ 1.00000e-02 1.00000e-03 1.00000e-09 1.00000e-01

$1.00000 \mathrm{e}+001.00000 \mathrm{e}+001.00000 \mathrm{e}-011.00000 \mathrm{e}-091.00000 \mathrm{e}-01$

1.00000e-05 1.00000e-05 1.00000e-06 1.00000e-09 1.00000e-01

$1.00000 \mathrm{e}+001.00000 \mathrm{e}+001.00000 \mathrm{e}-011.00000 \mathrm{e}-091.00000 \mathrm{e}-01$

Element: 4531 \# of layers: 14

Kx Ky Kz Ss Por

$2.53613 \mathrm{e}+012.53613 \mathrm{e}+012.53613 \mathrm{e}+00$ 1.00000e-09 7.00000e-02

$2.53613 \mathrm{e}+012.53613 \mathrm{e}+012.53613 \mathrm{e}+001.00000 \mathrm{e}-09$ 7.00000e-02

$2.53613 \mathrm{e}+012.53613 \mathrm{e}+012.53613 \mathrm{e}+001.00000 \mathrm{e}-09$ 7.00000e-02

5.00000e-04 5.00000e-04 5.00000e-05 1.00000e-09 1.00000e-01

5.00000e-04 5.00000e-04 5.00000e-05 1.00000e-09 1.00000e-01

$1.01335 \mathrm{e}+001.01335 \mathrm{e}+001.01335 \mathrm{e}-011.00000 \mathrm{e}-092.12000 \mathrm{e}-01$

$1.01335 \mathrm{e}+001.01335 \mathrm{e}+00$ 1.01335e-01 1.00000e-09 2.12000e-01

$1.01335 \mathrm{e}+001.01335 \mathrm{e}+00$ 1.01335e-01 1.00000e-09 2.12000e-01

$1.01335 \mathrm{e}+001.01335 \mathrm{e}+00$ 1.01335e-01 1.00000e-09 2.12000e-01

$1.01335 \mathrm{e}+001.01335 \mathrm{e}+001.01335 \mathrm{e}-011.00000 \mathrm{e}-092.12000 \mathrm{e}-01$

$1.00000 \mathrm{e}-02$ 1.00000e-02 1.00000e-03 1.00000e-09 1.00000e-01 
$1.00000 \mathrm{e}+001.00000 \mathrm{e}+001.00000 \mathrm{e}-011.00000 \mathrm{e}-091.00000 \mathrm{e}-01$ $1.00000 \mathrm{e}-05$ 1.00000e-05 1.00000e-06 1.00000e-09 1.00000e-01 $1.00000 \mathrm{e}+001.00000 \mathrm{e}+001.00000 \mathrm{e}-011.00000 \mathrm{e}-09$ 1.00000e-01 Element: 4532 \# of layers: 15

$\mathrm{Kx} \mathrm{Ky} \mathrm{Kz}$ Ss Por

$2.53613 \mathrm{e}+012.53613 \mathrm{e}+012.53613 \mathrm{e}+00$ 1.00000e-09 7.00000e-02 $2.53613 \mathrm{e}+012.53613 \mathrm{e}+012.53613 \mathrm{e}+001.00000 \mathrm{e}-09$ 7.00000e-02 $2.53613 \mathrm{e}+012.53613 \mathrm{e}+012.53613 \mathrm{e}+001.00000 \mathrm{e}-09$ 7.00000e-02 $2.53613 \mathrm{e}+012.53613 \mathrm{e}+012.53613 \mathrm{e}+001.00000 \mathrm{e}-09$ 7.00000e-02 5.00000e-04 5.00000e-04 5.00000e-05 1.00000e-09 1.00000e-01 5.00000e-04 5.00000e-04 5.00000e-05 1.00000e-09 1.00000e-01 $1.01335 \mathrm{e}+001.01335 \mathrm{e}+00$ 1.01335e-01 1.00000e-09 2.12000e-01 $1.01335 \mathrm{e}+001.01335 \mathrm{e}+00$ 1.01335e-01 1.00000e-09 2.12000e-01 $1.01335 \mathrm{e}+001.01335 \mathrm{e}+00$ 1.01335e-01 1.00000e-09 2.12000e-01 $1.01335 \mathrm{e}+001.01335 \mathrm{e}+00$ 1.01335e-01 1.00000e-09 2.12000e-01 $1.01335 \mathrm{e}+001.01335 \mathrm{e}+001.01335 \mathrm{e}-011.00000 \mathrm{e}-092.12000 \mathrm{e}-01$ $1.00000 \mathrm{e}-02$ 1.00000e-02 1.00000e-03 1.00000e-09 1.00000e-01 $1.00000 \mathrm{e}+001.00000 \mathrm{e}+001.00000 \mathrm{e}-011.00000 \mathrm{e}-091.00000 \mathrm{e}-01$ $1.00000 \mathrm{e}-05$ 1.00000e-05 1.00000e-06 1.00000e-09 1.00000e-01 $1.00000 \mathrm{e}+001.00000 \mathrm{e}+001.00000 \mathrm{e}-011.00000 \mathrm{e}-091.00000 \mathrm{e}-01$ Element: 4533 \# of layers: 14

$\mathrm{Kx} \mathrm{Ky} \mathrm{Kz}$ Ss Por

$2.53613 \mathrm{e}+012.53613 \mathrm{e}+012.53613 \mathrm{e}+00$ 1.00000e-09 7.00000e-02 $2.53613 \mathrm{e}+012.53613 \mathrm{e}+012.53613 \mathrm{e}+001.00000 \mathrm{e}-09$ 7.00000e-02 $2.53613 \mathrm{e}+012.53613 \mathrm{e}+012.53613 \mathrm{e}+001.00000 \mathrm{e}-09$ 7.00000e-02 $2.53613 \mathrm{e}+012.53613 \mathrm{e}+012.53613 \mathrm{e}+001.00000 \mathrm{e}-09$ 7.00000e-02 5.00000e-04 5.00000e-04 5.00000e-05 1.00000e-09 1.00000e-01 5.00000e-04 5.00000e-04 5.00000e-05 1.00000e-09 1.00000e-01 $1.01335 \mathrm{e}+001.01335 \mathrm{e}+001.01335 \mathrm{e}-011.00000 \mathrm{e}-092.12000 \mathrm{e}-01$ $1.01335 \mathrm{e}+001.01335 \mathrm{e}+001.01335 \mathrm{e}-011.00000 \mathrm{e}-092.12000 \mathrm{e}-01$ $1.01335 \mathrm{e}+001.01335 \mathrm{e}+001.01335 \mathrm{e}-01$ 1.00000e-09 2.12000e-01 $1.01335 \mathrm{e}+001.01335 \mathrm{e}+00$ 1.01335e-01 1.00000e-09 2.12000e-01 $1.00000 \mathrm{e}-02$ 1.00000e-02 1.00000e-03 1.00000e-09 1.00000e-01 $1.00000 \mathrm{e}+001.00000 \mathrm{e}+001.00000 \mathrm{e}-011.00000 \mathrm{e}-091.00000 \mathrm{e}-01$ $1.00000 \mathrm{e}-05$ 1.00000e-05 1.00000e-06 1.00000e-09 1.00000e-01 $1.00000 \mathrm{e}+001.00000 \mathrm{e}+001.00000 \mathrm{e}-01$ 1.00000e-09 1.00000e-01 Element: 4534 \# of layers: 12

$\mathrm{Kx} \mathrm{Ky} \mathrm{Kz}$ Ss Por $2.08825 \mathrm{e}+012.08825 \mathrm{e}+012.08825 \mathrm{e}+00$ 1.00000e-09 7.00000e-02 $2.08825 \mathrm{e}+012.08825 \mathrm{e}+012.08825 \mathrm{e}+001.00000 \mathrm{e}-09$ 7.00000e-02 $2.08825 \mathrm{e}+012.08825 \mathrm{e}+012.08825 \mathrm{e}+001.00000 \mathrm{e}-09$ 7.00000e-02 5.00000e-04 5.00000e-04 5.00000e-05 1.00000e-09 1.00000e-01 8.34385e-01 8.34385e-01 8.34385e-02 1.00000e-09 2.12000e-01 8.34385e-01 8.34385e-01 8.34385e-02 1.00000e-09 2.12000e-01 8.34385e-01 8.34385e-01 8.34385e-02 1.00000e-09 2.12000e-01 8.34385e-01 8.34385e-01 8.34385e-02 1.00000e-09 2.12000e-01 
$1.00000 \mathrm{e}-02$ 1.00000e-02 1.00000e-03 1.00000e-09 1.00000e-01 $1.00000 \mathrm{e}+001.00000 \mathrm{e}+001.00000 \mathrm{e}-011.00000 \mathrm{e}-091.00000 \mathrm{e}-01$ $1.00000 \mathrm{e}-05$ 1.00000e-05 1.00000e-06 1.00000e-09 1.00000e-01 $1.00000 \mathrm{e}+001.00000 \mathrm{e}+001.00000 \mathrm{e}-011.00000 \mathrm{e}-091.00000 \mathrm{e}-01$ Element: 4535 \# of layers: 13

$\mathrm{Kx} \mathrm{Ky} \mathrm{Kz}$ Ss Por

$2.08825 \mathrm{e}+012.08825 \mathrm{e}+012.08825 \mathrm{e}+00$ 1.00000e-09 7.00000e-02 $2.08825 \mathrm{e}+012.08825 \mathrm{e}+012.08825 \mathrm{e}+001.00000 \mathrm{e}-09$ 7.00000e-02 $2.08825 \mathrm{e}+012.08825 \mathrm{e}+012.08825 \mathrm{e}+001.00000 \mathrm{e}-09$ 7.00000e-02 5.00000e-04 5.00000e-04 5.00000e-05 1.00000e-09 1.00000e-01 8.34385e-01 8.34385e-01 8.34385e-02 1.00000e-09 2.12000e-01 8.34385e-01 8.34385e-01 8.34385e-02 1.00000e-09 2.12000e-01 8.34385e-01 8.34385e-01 8.34385e-02 1.00000e-09 2.12000e-01 8.34385e-01 8.34385e-01 8.34385e-02 1.00000e-09 2.12000e-01 8.34385e-01 8.34385e-01 8.34385e-02 1.00000e-09 2.12000e-01 $1.00000 \mathrm{e}-02$ 1.00000e-02 1.00000e-03 1.00000e-09 1.00000e-01 $1.00000 \mathrm{e}+001.00000 \mathrm{e}+001.00000 \mathrm{e}-011.00000 \mathrm{e}-091.00000 \mathrm{e}-01$ $1.00000 \mathrm{e}-05$ 1.00000e-05 1.00000e-06 1.00000e-09 1.00000e-01 $1.00000 \mathrm{e}+001.00000 \mathrm{e}+001.00000 \mathrm{e}-011.00000 \mathrm{e}-091.00000 \mathrm{e}-01$ Element: 4536 \# of layers: 13

$\mathrm{Kx} \mathrm{Ky} \mathrm{Kz}$ Ss Por

2.20952e+01 2.20952e+01 2.20952e+00 1.00000e-09 7.00000e-02 $2.20952 \mathrm{e}+012.20952 \mathrm{e}+012.20952 \mathrm{e}+00$ 1.00000e-09 7.00000e-02 $2.20952 \mathrm{e}+012.20952 \mathrm{e}+012.20952 \mathrm{e}+001.00000 \mathrm{e}-09$ 7.00000e-02 5.00000e-04 5.00000e-04 5.00000e-05 1.00000e-09 1.00000e-01 8.82851e-01 8.82851e-01 8.82851e-02 1.00000e-09 2.12000e-01 8.82851e-01 8.82851e-01 8.82851e-02 1.00000e-09 2.12000e-01 8.82851e-01 8.82851e-01 8.82851e-02 1.00000e-09 2.12000e-01 8.82851e-01 8.82851e-01 8.82851e-02 1.00000e-09 2.12000e-01 8.82851e-01 8.82851e-01 8.82851e-02 1.00000e-09 2.12000e-01 $1.00000 \mathrm{e}-02$ 1.00000e-02 1.00000e-03 1.00000e-09 1.00000e-01 $1.00000 \mathrm{e}+001.00000 \mathrm{e}+001.00000 \mathrm{e}-011.00000 \mathrm{e}-091.00000 \mathrm{e}-01$ $1.00000 \mathrm{e}-05$ 1.00000e-05 1.00000e-06 1.00000e-09 1.00000e-01 $1.00000 \mathrm{e}+001.00000 \mathrm{e}+001.00000 \mathrm{e}-011.00000 \mathrm{e}-091.00000 \mathrm{e}-01$ Element: 4537 \# of layers: 15

$\mathrm{Kx} \mathrm{Ky} \mathrm{Kz}$ Ss Por $2.05870 \mathrm{e}+012.05870 \mathrm{e}+012.05870 \mathrm{e}+00$ 1.00000e-09 7.00000e-02 $2.05870 \mathrm{e}+012.05870 \mathrm{e}+012.05870 \mathrm{e}+001.00000 \mathrm{e}-09$ 7.00000e-02 $2.05870 \mathrm{e}+012.05870 \mathrm{e}+012.05870 \mathrm{e}+001.00000 \mathrm{e}-09$ 7.00000e-02 $2.05870 \mathrm{e}+012.05870 \mathrm{e}+012.05870 \mathrm{e}+001.00000 \mathrm{e}-097.00000 \mathrm{e}-02$ 5.00000e-04 5.00000e-04 5.00000e-05 1.00000e-09 1.00000e-01 5.00000e-04 5.00000e-04 5.00000e-05 1.00000e-09 1.00000e-01 8.22595e-01 8.22595e-01 8.22595e-02 1.00000e-09 2.12000e-01 8.22595e-01 8.22595e-01 8.22595e-02 1.00000e-09 2.12000e-01 8.22595e-01 8.22595e-01 8.22595e-02 1.00000e-09 2.12000e-01 8.22595e-01 8.22595e-01 8.22595e-02 1.00000e-09 2.12000e-01 
8.22595e-01 8.22595e-01 8.22595e-02 1.00000e-09 2.12000e-01 $1.00000 \mathrm{e}-02$ 1.00000e-02 1.00000e-03 1.00000e-09 1.00000e-01 $1.00000 \mathrm{e}+001.00000 \mathrm{e}+001.00000 \mathrm{e}-011.00000 \mathrm{e}-091.00000 \mathrm{e}-01$ $1.00000 \mathrm{e}-05$ 1.00000e-05 1.00000e-06 1.00000e-09 1.00000e-01 $1.00000 \mathrm{e}+001.00000 \mathrm{e}+001.00000 \mathrm{e}-011.00000 \mathrm{e}-091.00000 \mathrm{e}-01$ Element: 4538 \# of layers: 15

$\mathrm{Kx} \mathrm{Ky} \mathrm{Kz}$ Ss Por

$2.53613 e+012.53613 e+012.53613 e+001.00000 e-09$ 7.00000e-02 $2.53613 \mathrm{e}+012.53613 \mathrm{e}+012.53613 \mathrm{e}+001.00000 \mathrm{e}-09$ 7.00000e-02 $2.53613 \mathrm{e}+012.53613 \mathrm{e}+012.53613 \mathrm{e}+001.00000 \mathrm{e}-09$ 7.00000e-02 $2.53613 \mathrm{e}+012.53613 \mathrm{e}+012.53613 \mathrm{e}+001.00000 \mathrm{e}-09$ 7.00000e-02 5.00000e-04 5.00000e-04 5.00000e-05 1.00000e-09 1.00000e-01 5.00000e-04 5.00000e-04 5.00000e-05 1.00000e-09 1.00000e-01 $1.01335 \mathrm{e}+001.01335 \mathrm{e}+00$ 1.01335e-01 1.00000e-09 2.12000e-01 $1.01335 \mathrm{e}+001.01335 \mathrm{e}+00$ 1.01335e-01 1.00000e-09 2.12000e-01 $1.01335 \mathrm{e}+001.01335 \mathrm{e}+00$ 1.01335e-01 1.00000e-09 2.12000e-01 $1.01335 \mathrm{e}+001.01335 \mathrm{e}+00$ 1.01335e-01 1.00000e-09 2.12000e-01 $1.01335 \mathrm{e}+001.01335 \mathrm{e}+00$ 1.01335e-01 1.00000e-09 2.12000e-01 $1.00000 \mathrm{e}-02$ 1.00000e-02 1.00000e-03 1.00000e-09 1.00000e-01 $1.00000 \mathrm{e}+001.00000 \mathrm{e}+001.00000 \mathrm{e}-011.00000 \mathrm{e}-091.00000 \mathrm{e}-01$ $1.00000 \mathrm{e}-05$ 1.00000e-05 1.00000e-06 1.00000e-09 1.00000e-01 $1.00000 \mathrm{e}+001.00000 \mathrm{e}+001.00000 \mathrm{e}-011.00000 \mathrm{e}-091.00000 \mathrm{e}-01$ Element: 4539 \# of layers: 14

Kx Ky Kz Ss Por

$2.95519 \mathrm{e}+012.95519 \mathrm{e}+012.95519 \mathrm{e}+001.00000 \mathrm{e}-09$ 7.00000e-02 $2.95519 \mathrm{e}+012.95519 \mathrm{e}+012.95519 \mathrm{e}+001.00000 \mathrm{e}-09$ 7.00000e-02 $2.95519 \mathrm{e}+012.95519 \mathrm{e}+012.95519 \mathrm{e}+001.00000 \mathrm{e}-09$ 7.00000e-02 5.00000e-04 5.00000e-04 5.00000e-05 1.00000e-09 1.00000e-01 5.00000e-04 5.00000e-04 5.00000e-05 1.00000e-09 1.00000e-01 $1.18080 \mathrm{e}+001.18080 \mathrm{e}+001.18080 \mathrm{e}-01$ 1.00000e-09 2.12000e-01 $1.18080 \mathrm{e}+001.18080 \mathrm{e}+00$ 1.18080e-01 1.00000e-09 2.12000e-01 $1.18080 \mathrm{e}+001.18080 \mathrm{e}+00$ 1.18080e-01 1.00000e-09 2.12000e-01 $1.18080 \mathrm{e}+001.18080 \mathrm{e}+001.18080 \mathrm{e}-011.00000 \mathrm{e}-092.12000 \mathrm{e}-01$ $1.18080 \mathrm{e}+001.18080 \mathrm{e}+001.18080 \mathrm{e}-01$ 1.00000e-09 2.12000e-01 $1.00000 \mathrm{e}-02$ 1.00000e-02 1.00000e-03 1.00000e-09 1.00000e-01 $1.00000 \mathrm{e}+001.00000 \mathrm{e}+001.00000 \mathrm{e}-011.00000 \mathrm{e}-091.00000 \mathrm{e}-01$ $1.00000 \mathrm{e}-05$ 1.00000e-05 1.00000e-06 1.00000e-09 1.00000e-01 $1.00000 \mathrm{e}+001.00000 \mathrm{e}+001.00000 \mathrm{e}-011.00000 \mathrm{e}-091.00000 \mathrm{e}-01$ Element: 4540 \# of layers: 12

$\mathrm{Kx} \mathrm{Ky} \mathrm{Kz}$ Ss Por

3.18449e+01 3.18449e+01 3.18450e+00 1.00000e-09 7.00000e-02 $3.18449 \mathrm{e}+013.18449 \mathrm{e}+013.18450 \mathrm{e}+00$ 1.00000e-09 7.00000e-02 5.00000e-04 5.00000e-04 5.00000e-05 1.00000e-09 1.00000e-01 $1.27240 \mathrm{e}+001.27240 \mathrm{e}+001.27240 \mathrm{e}-01$ 1.00000e-09 2.12000e-01 $1.27240 \mathrm{e}+001.27240 \mathrm{e}+001.27240 \mathrm{e}-01$ 1.00000e-09 2.12000e-01 $1.27240 \mathrm{e}+001.27240 \mathrm{e}+001.27240 \mathrm{e}-011.00000 \mathrm{e}-092.12000 \mathrm{e}-01$ 
$1.27240 \mathrm{e}+001.27240 \mathrm{e}+001.27240 \mathrm{e}-01$ 1.00000e-09 2.12000e-01 $1.27240 \mathrm{e}+001.27240 \mathrm{e}+001.27240 \mathrm{e}-01$ 1.00000e-09 2.12000e-01 $1.00000 \mathrm{e}-02$ 1.00000e-02 1.00000e-03 1.00000e-09 1.00000e-01 $1.00000 \mathrm{e}+001.00000 \mathrm{e}+001.00000 \mathrm{e}-011.00000 \mathrm{e}-091.00000 \mathrm{e}-01$ $1.00000 \mathrm{e}-05$ 1.00000e-05 1.00000e-06 1.00000e-09 1.00000e-01 $1.00000 \mathrm{e}+001.00000 \mathrm{e}+001.00000 \mathrm{e}-011.00000 \mathrm{e}-091.00000 \mathrm{e}-01$ Element: 4541 \# of layers: 11

$\mathrm{Kx} \mathrm{Ky} \mathrm{Kz}$ Ss Por

3.18449e+01 3.18449e+01 3.18450e+00 1.00000e-09 7.00000e-02 $3.18449 \mathrm{e}+013.18449 \mathrm{e}+013.18450 \mathrm{e}+00$ 1.00000e-09 7.00000e-02 5.00000e-04 5.00000e-04 5.00000e-05 1.00000e-09 1.00000e-01 5.00000e-04 5.00000e-04 5.00000e-05 1.00000e-09 1.00000e-01 $1.27240 \mathrm{e}+001.27240 \mathrm{e}+001.27240 \mathrm{e}-01$ 1.00000e-09 2.12000e-01 $1.27240 \mathrm{e}+001.27240 \mathrm{e}+001.27240 \mathrm{e}-01$ 1.00000e-09 2.12000e-01 $1.27240 \mathrm{e}+001.27240 \mathrm{e}+001.27240 \mathrm{e}-01$ 1.00000e-09 2.12000e-01 $1.00000 \mathrm{e}-02$ 1.00000e-02 1.00000e-03 1.00000e-09 1.00000e-01 $1.00000 \mathrm{e}+001.00000 \mathrm{e}+001.00000 \mathrm{e}-011.00000 \mathrm{e}-091.00000 \mathrm{e}-01$ $1.00000 \mathrm{e}-05$ 1.00000e-05 1.00000e-06 1.00000e-09 1.00000e-01 $1.00000 \mathrm{e}+001.00000 \mathrm{e}+001.00000 \mathrm{e}-011.00000 \mathrm{e}-091.00000 \mathrm{e}-01$ Element: 4542 \# of layers: 11

$\mathrm{Kx} \mathrm{Ky} \mathrm{Kz}$ Ss Por

3.18449e+01 3.18449e+01 3.18450e+00 1.00000e-09 7.00000e-02 $3.18449 \mathrm{e}+013.18449 \mathrm{e}+013.18450 \mathrm{e}+00$ 1.00000e-09 7.00000e-02 $5.00000 \mathrm{e}-04$ 5.00000e-04 5.00000e-05 1.00000e-09 1.00000e-01 5.00000e-04 5.00000e-04 5.00000e-05 1.00000e-09 1.00000e-01 $1.27240 \mathrm{e}+001.27240 \mathrm{e}+001.27240 \mathrm{e}-011.00000 \mathrm{e}-092.12000 \mathrm{e}-01$ $1.27240 \mathrm{e}+001.27240 \mathrm{e}+001.27240 \mathrm{e}-01$ 1.00000e-09 2.12000e-01 $1.27240 \mathrm{e}+001.27240 \mathrm{e}+001.27240 \mathrm{e}-01$ 1.00000e-09 2.12000e-01 $1.00000 \mathrm{e}-02$ 1.00000e-02 1.00000e-03 1.00000e-09 1.00000e-01 $1.00000 \mathrm{e}+001.00000 \mathrm{e}+001.00000 \mathrm{e}-011.00000 \mathrm{e}-091.00000 \mathrm{e}-01$ $1.00000 \mathrm{e}-05$ 1.00000e-05 1.00000e-06 1.00000e-09 1.00000e-01 $1.00000 \mathrm{e}+001.00000 \mathrm{e}+001.00000 \mathrm{e}-01$ 1.00000e-09 1.00000e-01 Element: 4543 \# of layers: 9

$\mathrm{Kx} \mathrm{Ky} \mathrm{Kz}$ Ss Por

3.16044e+01 3.16044e+01 3.16044e+00 1.00000e-09 7.00000e-02 $3.16044 \mathrm{e}+013.16044 \mathrm{e}+013.16044 \mathrm{e}+001.00000 \mathrm{e}-09$ 7.00000e-02 $3.16044 \mathrm{e}+013.16044 \mathrm{e}+013.16044 \mathrm{e}+001.00000 \mathrm{e}-09$ 7.00000e-02 5.00000e-04 5.00000e-04 5.00000e-05 1.00000e-09 1.00000e-01 5.00000e-04 5.00000e-04 5.00000e-05 1.00000e-09 1.00000e-01 $1.26282 \mathrm{e}+001.26282 \mathrm{e}+00$ 1.26282e-01 1.00000e-09 2.12000e-01 $1.26282 \mathrm{e}+00$ 1.26282e+00 1.26282e-01 1.00000e-09 2.12000e-01 $1.00000 \mathrm{e}-02$ 1.00000e-02 1.00000e-03 1.00000e-09 1.00000e-01 $1.00000 \mathrm{e}+001.00000 \mathrm{e}+001.00000 \mathrm{e}-01$ 1.00000e-09 1.00000e-01 Element: 4544 \# of layers: 11

$\mathrm{Kx} \mathrm{Ky} \mathrm{Kz}$ Ss Por

3.16044e+01 3.16044e+01 3.16044e+00 1.00000e-09 7.00000e-02 
$3.16044 \mathrm{e}+013.16044 \mathrm{e}+013.16044 \mathrm{e}+001.00000 \mathrm{e}-09$ 7.00000e-02 5.00000e-04 5.00000e-04 5.00000e-05 1.00000e-09 1.00000e-01 $1.26282 \mathrm{e}+001.26282 \mathrm{e}+00$ 1.26282e-01 1.00000e-09 2.12000e-01 $1.26282 \mathrm{e}+001.26282 \mathrm{e}+00$ 1.26282e-01 1.00000e-09 2.12000e-01 $1.26282 \mathrm{e}+00$ 1.26282e+00 1.26282e-01 1.00000e-09 2.12000e-01 $1.26282 \mathrm{e}+001.26282 \mathrm{e}+00$ 1.26282e-01 1.00000e-09 2.12000e-01 $1.00000 \mathrm{e}-02$ 1.00000e-02 1.00000e-03 1.00000e-09 1.00000e-01 $1.00000 \mathrm{e}+001.00000 \mathrm{e}+001.00000 \mathrm{e}-011.00000 \mathrm{e}-091.00000 \mathrm{e}-01$ $1.00000 \mathrm{e}-051.00000 \mathrm{e}-051.00000 \mathrm{e}-061.00000 \mathrm{e}-091.00000 \mathrm{e}-01$ $1.00000 \mathrm{e}+001.00000 \mathrm{e}+001.00000 \mathrm{e}-011.00000 \mathrm{e}-091.00000 \mathrm{e}-01$ Element: 4545 \# of layers: 12

$\mathrm{Kx} \mathrm{Ky} \mathrm{Kz}$ Ss Por

$2.42234 \mathrm{e}+012.42234 \mathrm{e}+012.42234 \mathrm{e}+00$ 1.00000e-09 7.00000e-02 $2.42234 \mathrm{e}+012.42234 \mathrm{e}+012.42234 \mathrm{e}+001.00000 \mathrm{e}-09$ 7.00000e-02 $2.42234 \mathrm{e}+012.42234 \mathrm{e}+012.42234 \mathrm{e}+001.00000 \mathrm{e}-09$ 7.00000e-02 5.00000e-04 5.00000e-04 5.00000e-05 1.00000e-09 1.00000e-01 9.67881e-01 9.67881e-01 9.67881e-02 1.00000e-09 2.12000e-01 9.67881e-01 9.67881e-01 9.67881e-02 1.00000e-09 2.12000e-01 9.67881e-01 9.67881e-01 9.67881e-02 1.00000e-09 2.12000e-01 9.67881e-01 9.67881e-01 9.67881e-02 1.00000e-09 2.12000e-01 $1.00000 \mathrm{e}-02$ 1.00000e-02 1.00000e-03 1.00000e-09 1.00000e-01 $1.00000 \mathrm{e}+001.00000 \mathrm{e}+001.00000 \mathrm{e}-011.00000 \mathrm{e}-091.00000 \mathrm{e}-01$ $1.00000 \mathrm{e}-05$ 1.00000e-05 1.00000e-06 1.00000e-09 1.00000e-01 $1.00000 \mathrm{e}+001.00000 \mathrm{e}+001.00000 \mathrm{e}-011.00000 \mathrm{e}-09$ 1.00000e-01 Element: 4546 \# of layers: 13

$\mathrm{Kx} \mathrm{Ky} \mathrm{Kz}$ Ss Por

$2.95519 \mathrm{e}+012.95519 \mathrm{e}+012.95519 \mathrm{e}+00$ 1.00000e-09 7.00000e-02 $2.95519 \mathrm{e}+012.95519 \mathrm{e}+012.95519 \mathrm{e}+00$ 1.00000e-09 7.00000e-02 $2.95519 \mathrm{e}+012.95519 \mathrm{e}+012.95519 \mathrm{e}+001.00000 \mathrm{e}-09$ 7.00000e-02 5.00000e-04 5.00000e-04 5.00000e-05 1.00000e-09 1.00000e-01 $5.00000 \mathrm{e}-04$ 5.00000e-04 5.00000e-05 1.00000e-09 1.00000e-01 $1.18080 \mathrm{e}+001.18080 \mathrm{e}+001.18080 \mathrm{e}-01$ 1.00000e-09 2.12000e-01 $1.18080 \mathrm{e}+001.18080 \mathrm{e}+001.18080 \mathrm{e}-011.00000 \mathrm{e}-092.12000 \mathrm{e}-01$ $1.18080 \mathrm{e}+001.18080 \mathrm{e}+001.18080 \mathrm{e}-011.00000 \mathrm{e}-092.12000 \mathrm{e}-01$ $1.18080 \mathrm{e}+001.18080 \mathrm{e}+001.18080 \mathrm{e}-01$ 1.00000e-09 2.12000e-01 1.00000e-02 1.00000e-02 1.00000e-03 1.00000e-09 1.00000e-01 $1.00000 \mathrm{e}+001.00000 \mathrm{e}+001.00000 \mathrm{e}-011.00000 \mathrm{e}-091.00000 \mathrm{e}-01$ $1.00000 \mathrm{e}-05$ 1.00000e-05 1.00000e-06 1.00000e-09 1.00000e-01 $1.00000 \mathrm{e}+001.00000 \mathrm{e}+001.00000 \mathrm{e}-01$ 1.00000e-09 1.00000e-01 Element: 4547 \# of layers: 11

$\mathrm{Kx} \mathrm{Ky} \mathrm{Kz}$ Ss Por

3.18449e+01 3.18449e+01 3.18450e+00 1.00000e-09 7.00000e-02 $3.18449 \mathrm{e}+013.18449 \mathrm{e}+013.18450 \mathrm{e}+001.00000 \mathrm{e}-09$ 7.00000e-02 5.00000e-04 5.00000e-04 5.00000e-05 1.00000e-09 1.00000e-01 $1.27240 \mathrm{e}+001.27240 \mathrm{e}+001.27240 \mathrm{e}-01$ 1.00000e-09 2.12000e-01 $1.27240 \mathrm{e}+001.27240 \mathrm{e}+001.27240 \mathrm{e}-011.00000 \mathrm{e}-092.12000 \mathrm{e}-01$ 
$1.27240 \mathrm{e}+001.27240 \mathrm{e}+001.27240 \mathrm{e}-01$ 1.00000e-09 2.12000e-01 $1.27240 \mathrm{e}+001.27240 \mathrm{e}+001.27240 \mathrm{e}-01$ 1.00000e-09 2.12000e-01 $1.00000 \mathrm{e}-02$ 1.00000e-02 1.00000e-03 1.00000e-09 1.00000e-01 $1.00000 \mathrm{e}+001.00000 \mathrm{e}+001.00000 \mathrm{e}-011.00000 \mathrm{e}-091.00000 \mathrm{e}-01$ $1.00000 \mathrm{e}-05$ 1.00000e-05 1.00000e-06 1.00000e-09 1.00000e-01 $1.00000 \mathrm{e}+001.00000 \mathrm{e}+001.00000 \mathrm{e}-011.00000 \mathrm{e}-091.00000 \mathrm{e}-01$ Element: 4548 \# of layers: 11

$\mathrm{Kx} \mathrm{Ky} \mathrm{Kz}$ Ss Por

$3.57904 \mathrm{e}+013.57904 \mathrm{e}+013.57904 \mathrm{e}+00$ 1.00000e-09 7.00000e-02

$3.57904 \mathrm{e}+013.57904 \mathrm{e}+013.57904 \mathrm{e}+001.00000 \mathrm{e}-097.00000 \mathrm{e}-02$ 5.00000e-04 5.00000e-04 5.00000e-05 1.00000e-09 1.00000e-01 5.00000e-04 5.00000e-04 5.00000e-05 1.00000e-09 1.00000e-01 $1.43004 \mathrm{e}+001.43004 \mathrm{e}+001.43004 \mathrm{e}-01$ 1.00000e-09 2.12000e-01 $1.43004 \mathrm{e}+001.43004 \mathrm{e}+001.43004 \mathrm{e}-01$ 1.00000e-09 2.12000e-01 $1.43004 \mathrm{e}+001.43004 \mathrm{e}+001.43004 \mathrm{e}-01$ 1.00000e-09 2.12000e-01 $1.00000 \mathrm{e}-02$ 1.00000e-02 1.00000e-03 1.00000e-09 1.00000e-01 $1.00000 \mathrm{e}+001.00000 \mathrm{e}+001.00000 \mathrm{e}-011.00000 \mathrm{e}-091.00000 \mathrm{e}-01$ $1.00000 \mathrm{e}-05$ 1.00000e-05 1.00000e-06 1.00000e-09 1.00000e-01 $1.00000 \mathrm{e}+001.00000 \mathrm{e}+001.00000 \mathrm{e}-011.00000 \mathrm{e}-091.00000 \mathrm{e}-01$ Element: 4549 \# of layers: 11

$\mathrm{Kx} \mathrm{Ky} \mathrm{Kz}$ Ss Por

3.77699e+01 3.77699e+01 3.77699e+00 1.00000e-09 7.00000e-02 $3.77699 \mathrm{e}+013.77699 \mathrm{e}+013.77699 \mathrm{e}+00$ 1.00000e-09 7.00000e-02 $5.00000 \mathrm{e}-04$ 5.00000e-04 5.00000e-05 1.00000e-09 1.00000e-01 5.00000e-04 5.00000e-04 5.00000e-05 1.00000e-09 1.00000e-01 $1.50913 \mathrm{e}+00$ 1.50913e+00 1.50913e-01 1.00000e-09 2.12000e-01 $1.50913 \mathrm{e}+001.50913 \mathrm{e}+00$ 1.50913e-01 1.00000e-09 2.12000e-01 $1.50913 \mathrm{e}+001.50913 \mathrm{e}+00$ 1.50913e-01 1.00000e-09 2.12000e-01 $1.00000 \mathrm{e}-01$ 1.00000e-01 1.00000e-02 1.00000e-09 1.00000e-01 $1.00000 \mathrm{e}+001.00000 \mathrm{e}+001.00000 \mathrm{e}-011.00000 \mathrm{e}-091.00000 \mathrm{e}-01$ $1.00000 \mathrm{e}-05$ 1.00000e-05 1.00000e-06 1.00000e-09 1.00000e-01 $1.00000 \mathrm{e}+001.00000 \mathrm{e}+001.00000 \mathrm{e}-01$ 1.00000e-09 1.00000e-01 Element: 4550 \# of layers: 9

$\mathrm{Kx} \mathrm{Ky} \mathrm{Kz}$ Ss Por

3.77699e+01 3.77699e+01 3.77699e+00 1.00000e-09 7.00000e-02 $3.77699 \mathrm{e}+013.77699 \mathrm{e}+013.77699 \mathrm{e}+001.00000 \mathrm{e}-09$ 7.00000e-02 5.00000e-04 5.00000e-04 5.00000e-05 1.00000e-09 1.00000e-01 5.00000e-04 5.00000e-04 5.00000e-05 1.00000e-09 1.00000e-01 $1.50913 \mathrm{e}+001.50913 \mathrm{e}+00$ 1.50913e-01 1.00000e-09 2.12000e-01 $1.50913 \mathrm{e}+001.50913 \mathrm{e}+00$ 1.50913e-01 1.00000e-09 2.12000e-01 $1.50913 \mathrm{e}+001.50913 \mathrm{e}+00$ 1.50913e-01 1.00000e-09 2.12000e-01 $1.00000 \mathrm{e}-01$ 1.00000e-01 1.00000e-02 1.00000e-09 1.00000e-01 $1.00000 \mathrm{e}+001.00000 \mathrm{e}+001.00000 \mathrm{e}-01$ 1.00000e-09 1.00000e-01 Element: 4551 \# of layers: 8

$\mathrm{Kx} \mathrm{Ky} \mathrm{Kz}$ Ss Por

3.77699e+01 3.77699e+01 3.77699e+00 1.00000e-09 7.00000e-02 
$3.77699 \mathrm{e}+013.77699 \mathrm{e}+013.77699 \mathrm{e}+00$ 1.00000e-09 7.00000e-02 5.00000e-04 5.00000e-04 5.00000e-05 1.00000e-09 1.00000e-01 5.00000e-04 5.00000e-04 5.00000e-05 1.00000e-09 1.00000e-01 $1.50913 \mathrm{e}+001.50913 \mathrm{e}+00$ 1.50913e-01 1.00000e-09 2.12000e-01 $1.50913 \mathrm{e}+001.50913 \mathrm{e}+00$ 1.50913e-01 1.00000e-09 2.12000e-01 $1.00000 \mathrm{e}-021.00000 \mathrm{e}-02$ 1.00000e-03 1.00000e-09 1.00000e-01 $1.00000 \mathrm{e}+001.00000 \mathrm{e}+001.00000 \mathrm{e}-011.00000 \mathrm{e}-091.00000 \mathrm{e}-01$ Element: 4552 \# of layers: 9

Kx Ky Kz Ss Por

$2.07131 \mathrm{e}+012.07131 \mathrm{e}+012.07131 \mathrm{e}+001.00000 \mathrm{e}-097.00000 \mathrm{e}-02$ $2.07131 \mathrm{e}+012.07131 \mathrm{e}+012.07131 \mathrm{e}+001.00000 \mathrm{e}-097.00000 \mathrm{e}-02$ $2.07131 \mathrm{e}+012.07131 \mathrm{e}+012.07131 \mathrm{e}+001.00000 \mathrm{e}-097.00000 \mathrm{e}-02$ 5.00000e-04 5.00000e-04 5.00000e-05 1.00000e-09 1.00000e-01 5.00000e-04 5.00000e-04 5.00000e-05 1.00000e-09 1.00000e-01 8.27613e-01 8.27613e-01 8.27613e-02 1.00000e-09 2.12000e-01 8.27613e-01 8.27613e-01 8.27613e-02 1.00000e-09 2.12000e-01 $1.00000 \mathrm{e}-02$ 1.00000e-02 1.00000e-03 1.00000e-09 1.00000e-01 $1.00000 \mathrm{e}+001.00000 \mathrm{e}+001.00000 \mathrm{e}-011.00000 \mathrm{e}-091.00000 \mathrm{e}-01$ Element: 4553 \# of layers: 8

Kx Ky Kz Ss Por

$2.07131 \mathrm{e}+012.07131 \mathrm{e}+012.07131 \mathrm{e}+00$ 1.00000e-09 7.00000e-02 $2.07131 \mathrm{e}+012.07131 \mathrm{e}+012.07131 \mathrm{e}+001.00000 \mathrm{e}-097.00000 \mathrm{e}-02$ $2.07131 \mathrm{e}+012.07131 \mathrm{e}+012.07131 \mathrm{e}+001.00000 \mathrm{e}-097.00000 \mathrm{e}-02$ 5.00000e-04 5.00000e-04 5.00000e-05 1.00000e-09 1.00000e-01 5.00000e-04 5.00000e-04 5.00000e-05 1.00000e-09 1.00000e-01 8.27613e-01 8.27613e-01 8.27613e-02 1.00000e-09 2.12000e-01 $1.00000 \mathrm{e}-02$ 1.00000e-02 1.00000e-03 1.00000e-09 1.00000e-01 $1.00000 \mathrm{e}+001.00000 \mathrm{e}+001.00000 \mathrm{e}-011.00000 \mathrm{e}-091.00000 \mathrm{e}-01$ Element: 4554 \# of layers: 8

Kx Ky Kz Ss Por

$2.88951 \mathrm{e}+012.88951 \mathrm{e}+012.88951 \mathrm{e}+00$ 1.00000e-09 7.00000e-02 $2.88951 \mathrm{e}+012.88951 \mathrm{e}+012.88951 \mathrm{e}+001.00000 \mathrm{e}-097.00000 \mathrm{e}-02$ $2.88951 \mathrm{e}+012.88951 \mathrm{e}+012.88951 \mathrm{e}+001.00000 \mathrm{e}-09$ 7.00000e-02 5.00000e-04 5.00000e-04 5.00000e-05 1.00000e-09 1.00000e-01 5.00000e-04 5.00000e-04 5.00000e-05 1.00000e-09 1.00000e-01 $1.15454 \mathrm{e}+001.15454 \mathrm{e}+001.15454 \mathrm{e}-011.00000 \mathrm{e}-09$ 2.12000e-01 $1.00000 \mathrm{e}-021.00000 \mathrm{e}-02$ 1.00000e-03 1.00000e-09 1.00000e-01 $1.00000 \mathrm{e}+001.00000 \mathrm{e}+001.00000 \mathrm{e}-011.00000 \mathrm{e}-091.00000 \mathrm{e}-01$ Element: 4555 \# of layers: 9

Kx Ky Kz Ss Por

$3.57904 \mathrm{e}+013.57904 \mathrm{e}+013.57904 \mathrm{e}+00$ 1.00000e-09 7.00000e-02 $3.57904 \mathrm{e}+013.57904 \mathrm{e}+013.57904 \mathrm{e}+001.00000 \mathrm{e}-097.00000 \mathrm{e}-02$ $5.00000 \mathrm{e}-04$ 5.00000e-04 5.00000e-05 1.00000e-09 1.00000e-01 5.00000e-04 5.00000e-04 5.00000e-05 1.00000e-09 1.00000e-01 $1.43004 \mathrm{e}+001.43004 \mathrm{e}+001.43004 \mathrm{e}-011.00000 \mathrm{e}-092.12000 \mathrm{e}-01$ $1.43004 \mathrm{e}+001.43004 \mathrm{e}+001.43004 \mathrm{e}-011.00000 \mathrm{e}-092.12000 \mathrm{e}-01$ 
$1.43004 \mathrm{e}+001.43004 \mathrm{e}+00$ 1.43004e-01 1.00000e-09 2.12000e-01 $1.00000 \mathrm{e}-02$ 1.00000e-02 1.00000e-03 1.00000e-09 1.00000e-01 $1.00000 \mathrm{e}+001.00000 \mathrm{e}+001.00000 \mathrm{e}-011.00000 \mathrm{e}-091.00000 \mathrm{e}-01$ Element: 4556 \# of layers: 8

$\mathrm{Kx} \mathrm{Ky} \mathrm{Kz}$ Ss Por

3.77699e+01 3.77699e+01 3.77699e+00 1.00000e-09 7.00000e-02 $3.77699 \mathrm{e}+013.77699 \mathrm{e}+013.77699 \mathrm{e}+00$ 1.00000e-09 7.00000e-02 5.00000e-04 5.00000e-04 5.00000e-05 1.00000e-09 1.00000e-01 5.00000e-04 5.00000e-04 5.00000e-05 1.00000e-09 1.00000e-01 $1.50913 \mathrm{e}+001.50913 \mathrm{e}+00$ 1.50913e-01 1.00000e-09 2.12000e-01 $1.50913 \mathrm{e}+001.50913 \mathrm{e}+00$ 1.50913e-01 1.00000e-09 2.12000e-01 $1.00000 \mathrm{e}-02$ 1.00000e-02 1.00000e-03 1.00000e-09 1.00000e-01 $1.00000 \mathrm{e}+001.00000 \mathrm{e}+001.00000 \mathrm{e}-01$ 1.00000e-09 1.00000e-01 Element: 4557 \# of layers: 8

$\mathrm{Kx} \mathrm{Ky} \mathrm{Kz}$ Ss Por

3.34298e+01 3.34298e+01 3.34298e+00 1.00000e-09 7.00000e-02 $3.34298 \mathrm{e}+013.34298 \mathrm{e}+013.34298 \mathrm{e}+00$ 1.00000e-09 7.00000e-02 5.00000e-04 5.00000e-04 5.00000e-05 1.00000e-09 1.00000e-01 5.00000e-04 5.00000e-04 5.00000e-05 1.00000e-09 1.00000e-01 $1.33574 \mathrm{e}+001.33574 \mathrm{e}+001.33574 \mathrm{e}-011.00000 \mathrm{e}-092.12000 \mathrm{e}-01$ $1.33574 \mathrm{e}+001.33574 \mathrm{e}+00 \quad 1.33574 \mathrm{e}-011.00000 \mathrm{e}-092.12000 \mathrm{e}-01$ $1.00000 \mathrm{e}-021.00000 \mathrm{e}-021.00000 \mathrm{e}-031.00000 \mathrm{e}-091.00000 \mathrm{e}-01$ $1.00000 \mathrm{e}+001.00000 \mathrm{e}+001.00000 \mathrm{e}-011.00000 \mathrm{e}-091.00000 \mathrm{e}-01$ Element: 4558 \# of layers: 8

Kx Ky Kz Ss Por

3.44227e+01 3.44227e+01 3.44227e+00 1.00000e-09 7.00000e-02 $3.44227 \mathrm{e}+013.44227 \mathrm{e}+013.44227 \mathrm{e}+001.00000 \mathrm{e}-09$ 7.00000e-02 5.00000e-04 5.00000e-04 5.00000e-05 1.00000e-09 1.00000e-01 5.00000e-04 5.00000e-04 5.00000e-05 1.00000e-09 1.00000e-01 $1.37543 \mathrm{e}+001.37543 \mathrm{e}+00$ 1.37543e-01 1.00000e-09 2.12000e-01 $1.37543 \mathrm{e}+00$ 1.37543e+00 1.37543e-01 1.00000e-09 2.12000e-01 $1.00000 \mathrm{e}-02$ 1.00000e-02 1.00000e-03 1.00000e-09 1.00000e-01 $1.00000 \mathrm{e}+001.00000 \mathrm{e}+001.00000 \mathrm{e}-011.00000 \mathrm{e}-091.00000 \mathrm{e}-01$ Element: 4559 \# of layers: 8

$\mathrm{Kx} \mathrm{Ky} \mathrm{Kz}$ Ss Por

3.44227e+01 3.44227e+01 3.44227e+00 1.00000e-09 7.00000e-02 $3.44227 \mathrm{e}+013.44227 \mathrm{e}+013.44227 \mathrm{e}+001.00000 \mathrm{e}-09$ 7.00000e-02 5.00000e-04 5.00000e-04 5.00000e-05 1.00000e-09 1.00000e-01 5.00000e-04 5.00000e-04 5.00000e-05 1.00000e-09 1.00000e-01 $1.37543 \mathrm{e}+00$ 1.37543e+00 1.37543e-01 1.00000e-09 2.12000e-01 $1.37543 \mathrm{e}+001.37543 \mathrm{e}+00$ 1.37543e-01 1.00000e-09 2.12000e-01 $1.00000 \mathrm{e}-02$ 1.00000e-02 1.00000e-03 1.00000e-09 1.00000e-01 $1.00000 \mathrm{e}+001.00000 \mathrm{e}+001.00000 \mathrm{e}-011.00000 \mathrm{e}-091.00000 \mathrm{e}-01$ Element: 4560 \# of layers: 8

$\mathrm{Kx} \mathrm{Ky} \mathrm{Kz}$ Ss Por

3.44227e+01 3.44227e+01 3.44227e+00 1.00000e-09 7.00000e-02 
3.44227e+01 3.44227e+01 3.44227e+00 1.00000e-09 7.00000e-02 5.00000e-04 5.00000e-04 5.00000e-05 1.00000e-09 1.00000e-01 5.00000e-04 5.00000e-04 5.00000e-05 1.00000e-09 1.00000e-01 $1.37543 \mathrm{e}+001.37543 \mathrm{e}+00$ 1.37543e-01 1.00000e-09 2.12000e-01 $1.37543 \mathrm{e}+00$ 1.37543e+00 1.37543e-01 1.00000e-09 2.12000e-01 $1.00000 \mathrm{e}-02$ 1.00000e-02 1.00000e-03 1.00000e-09 1.00000e-01 $1.00000 \mathrm{e}+001.00000 \mathrm{e}+001.00000 \mathrm{e}-011.00000 \mathrm{e}-091.00000 \mathrm{e}-01$ Element: 4561 \# of layers: 5

$\mathrm{Kx} \mathrm{Ky} \mathrm{Kz}$ Ss Por

5.78397e+01 5.78397e+01 5.78397e+00 1.00000e-09 7.00000e-02 5.78397e+01 5.78397e+01 5.78397e+00 1.00000e-09 7.00000e-02 5.78397e+01 5.78397e+01 5.78397e+00 1.00000e-09 7.00000e-02 5.00000e-04 5.00000e-04 5.00000e-05 1.00000e-09 1.00000e-01 5.00000e-04 5.00000e-04 5.00000e-05 1.00000e-09 1.00000e-01 Element: 4562 \# of layers: 7

$\mathrm{Kx} \mathrm{Ky} \mathrm{Kz}$ Ss Por

5.78397e+01 5.78397e+01 5.78397e+00 1.00000e-09 7.00000e-02 5.78397e+01 5.78397e+01 5.78397e+00 1.00000e-09 7.00000e-02 $5.78397 \mathrm{e}+015.78397 \mathrm{e}+015.78397 \mathrm{e}+001.00000 \mathrm{e}-09$ 7.00000e-02 5.00000e-04 5.00000e-04 5.00000e-05 1.00000e-09 1.00000e-01 5.00000e-04 5.00000e-04 5.00000e-05 1.00000e-09 1.00000e-01 2.31102e+00 2.31102e+00 2.31102e-01 1.00000e-09 2.12000e-01 $1.00000 \mathrm{e}-02$ 1.00000e-02 1.00000e-03 1.00000e-09 1.00000e-01 Element: 4563 \# of layers: 9

$\mathrm{Kx} \mathrm{Ky} \mathrm{Kz}$ Ss Por

$2.11059 \mathrm{e}+012.11059 \mathrm{e}+012.11059 \mathrm{e}+00$ 1.00000e-09 7.00000e-02 $2.11059 \mathrm{e}+012.11059 \mathrm{e}+012.11059 \mathrm{e}+00$ 1.00000e-09 7.00000e-02 $2.11059 \mathrm{e}+012.11059 \mathrm{e}+012.11059 \mathrm{e}+00$ 1.00000e-09 7.00000e-02 5.00000e-04 5.00000e-04 5.00000e-05 1.00000e-09 1.00000e-01 5.00000e-04 5.00000e-04 5.00000e-05 1.00000e-09 1.00000e-01 8.43318e-01 8.43318e-01 8.43318e-02 1.00000e-09 2.12000e-01 8.43318e-01 8.43318e-01 8.43318e-02 1.00000e-09 2.12000e-01 $1.00000 \mathrm{e}-02$ 1.00000e-02 1.00000e-03 1.00000e-09 1.00000e-01 $1.00000 \mathrm{e}+001.00000 \mathrm{e}+001.00000 \mathrm{e}-011.00000 \mathrm{e}-091.00000 \mathrm{e}-01$ Element: 4564 \# of layers: 9

$\mathrm{Kx} \mathrm{Ky} \mathrm{Kz}$ Ss Por

3.34298e+01 3.34298e+01 3.34298e+00 1.00000e-09 7.00000e-02 $3.34298 \mathrm{e}+013.34298 \mathrm{e}+013.34298 \mathrm{e}+00$ 1.00000e-09 7.00000e-02 $3.34298 \mathrm{e}+013.34298 \mathrm{e}+013.34298 \mathrm{e}+00$ 1.00000e-09 7.00000e-02 5.00000e-04 5.00000e-04 5.00000e-05 1.00000e-09 1.00000e-01 5.00000e-04 5.00000e-04 5.00000e-05 1.00000e-09 1.00000e-01 $1.33574 \mathrm{e}+001.33574 \mathrm{e}+001.33574 \mathrm{e}-011.00000 \mathrm{e}-092.12000 \mathrm{e}-01$ $1.33574 \mathrm{e}+001.33574 \mathrm{e}+001.33574 \mathrm{e}-01$ 1.00000e-09 2.12000e-01 $1.00000 \mathrm{e}-02$ 1.00000e-02 1.00000e-03 1.00000e-09 1.00000e-01 $1.00000 \mathrm{e}+001.00000 \mathrm{e}+001.00000 \mathrm{e}-011.00000 \mathrm{e}-09$ 1.00000e-01 Element: 4565 \# of layers: 9 
$\mathrm{Kx} \mathrm{Ky} \mathrm{Kz}$ Ss Por

3.44227e+01 3.44227e+01 3.44227e+00 1.00000e-09 7.00000e-02

$3.44227 \mathrm{e}+013.44227 \mathrm{e}+013.44227 \mathrm{e}+00$ 1.00000e-09 7.00000e-02

$3.44227 \mathrm{e}+01$ 3.44227e+01 3.44227e+00 1.00000e-09 7.00000e-02

5.00000e-04 5.00000e-04 5.00000e-05 1.00000e-09 1.00000e-01

5.00000e-04 5.00000e-04 5.00000e-05 1.00000e-09 1.00000e-01

$1.37543 \mathrm{e}+00$ 1.37543e+00 1.37543e-01 1.00000e-09 2.12000e-01

$1.37543 \mathrm{e}+001.37543 \mathrm{e}+00$ 1.37543e-01 1.00000e-09 2.12000e-01

$1.00000 \mathrm{e}-021.00000 \mathrm{e}-021.00000 \mathrm{e}-031.00000 \mathrm{e}-091.00000 \mathrm{e}-01$

$1.00000 \mathrm{e}+001.00000 \mathrm{e}+001.00000 \mathrm{e}-011.00000 \mathrm{e}-091.00000 \mathrm{e}-01$

Element: 4566 \# of layers: 8

$\mathrm{Kx} \mathrm{Ky} \mathrm{Kz}$ Ss Por

$2.92906 \mathrm{e}+012.92906 \mathrm{e}+012.92906 \mathrm{e}+00$ 1.00000e-09 7.00000e-02

$2.92906 \mathrm{e}+012.92906 \mathrm{e}+012.92906 \mathrm{e}+001.00000 \mathrm{e}-09$ 7.00000e-02

$2.92906 \mathrm{e}+012.92906 \mathrm{e}+012.92906 \mathrm{e}+001.00000 \mathrm{e}-09$ 7.00000e-02

5.00000e-04 5.00000e-04 5.00000e-05 1.00000e-09 1.00000e-01

5.00000e-04 5.00000e-04 5.00000e-05 1.00000e-09 1.00000e-01

$1.17036 \mathrm{e}+001.17036 \mathrm{e}+001.17036 \mathrm{e}-01$ 1.00000e-09 2.12000e-01

$1.17036 \mathrm{e}+001.17036 \mathrm{e}+001.17036 \mathrm{e}-01$ 1.00000e-09 2.12000e-01

1.00000e-02 1.00000e-02 1.00000e-03 1.00000e-09 1.00000e-01

Element: 4567 \# of layers: 5

$\mathrm{Kx} \mathrm{Ky} \mathrm{Kz}$ Ss Por

$2.16871 \mathrm{e}+012.16871 \mathrm{e}+012.16871 \mathrm{e}+00$ 1.00000e-09 7.00000e-02

$2.16871 \mathrm{e}+012.16871 \mathrm{e}+012.16871 \mathrm{e}+001.00000 \mathrm{e}-09$ 7.00000e-02

$2.16871 \mathrm{e}+012.16871 \mathrm{e}+012.16871 \mathrm{e}+001.00000 \mathrm{e}-097.00000 \mathrm{e}-02$

5.00000e-04 5.00000e-04 5.00000e-05 1.00000e-09 1.00000e-01

5.00000e-04 5.00000e-04 5.00000e-05 1.00000e-09 1.00000e-01

Element: 4568 \# of layers: 3

$\mathrm{Kx} \mathrm{Ky} \mathrm{Kz}$ Ss Por

$2.16871 \mathrm{e}+012.16871 \mathrm{e}+012.16871 \mathrm{e}+00$ 1.00000e-09 7.00000e-02

$2.16871 \mathrm{e}+012.16871 \mathrm{e}+012.16871 \mathrm{e}+001.00000 \mathrm{e}-09$ 7.00000e-02

$2.16871 \mathrm{e}+012.16871 \mathrm{e}+012.16871 \mathrm{e}+00$ 1.00000e-09 7.00000e-02

Element: 4569 \# of layers: 6

$\mathrm{Kx} \mathrm{Ky} \mathrm{Kz}$ Ss Por

$2.16871 \mathrm{e}+012.16871 \mathrm{e}+012.16871 \mathrm{e}+00$ 1.00000e-09 7.00000e-02

$2.16871 \mathrm{e}+012.16871 \mathrm{e}+012.16871 \mathrm{e}+001.00000 \mathrm{e}-09$ 7.00000e-02

$2.16871 \mathrm{e}+012.16871 \mathrm{e}+012.16871 \mathrm{e}+00$ 1.00000e-09 7.00000e-02

7.30118e-01 7.30118e-01 7.30118e-02 1.00000e-09 2.12000e-01

$1.00000 \mathrm{e}-021.00000 \mathrm{e}-021.00000 \mathrm{e}-031.00000 \mathrm{e}-091.00000 \mathrm{e}-01$

$1.00000 \mathrm{e}+001.00000 \mathrm{e}+001.00000 \mathrm{e}-01$ 1.00000e-09 1.00000e-01

Element: 4570 \# of layers: 6

$\mathrm{Kx} \mathrm{Ky} \mathrm{Kz}$ Ss Por

$1.82732 \mathrm{e}+01$ 1.82732e+01 1.82732e+00 1.00000e-09 7.00000e-02

$1.82732 \mathrm{e}+01$ 1.82732e+01 1.82732e+00 1.00000e-09 7.00000e-02

$1.82732 \mathrm{e}+011.82732 \mathrm{e}+01$ 1.82732e+00 1.00000e-09 7.00000e-02

7.30118e-01 7.30118e-01 7.30118e-02 1.00000e-09 2.12000e-01 
$1.00000 \mathrm{e}-02$ 1.00000e-02 1.00000e-03 1.00000e-09 1.00000e-01 $1.00000 \mathrm{e}+001.00000 \mathrm{e}+001.00000 \mathrm{e}-01$ 1.00000e-09 1.00000e-01 Element: 4571 \# of layers: 5

Kx Ky Kz Ss Por

$1.82732 \mathrm{e}+011.82732 \mathrm{e}+011.82732 \mathrm{e}+001.00000 \mathrm{e}-097.00000 \mathrm{e}-02$ $1.82732 \mathrm{e}+01$ 1.82732e+01 1.82732e+00 1.00000e-09 7.00000e-02 $1.82732 \mathrm{e}+01$ 1.82732e+01 1.82732e+00 1.00000e-09 7.00000e-02 7.30118e-01 7.30118e-01 7.30118e-02 1.00000e-09 2.12000e-01 1.00000e-02 1.00000e-02 1.00000e-03 1.00000e-09 1.00000e-01 Element: 4572 \# of layers: 4

$\mathrm{Kx} \mathrm{Ky} \mathrm{Kz}$ Ss Por

$2.35620 \mathrm{e}+012.35620 \mathrm{e}+012.35621 \mathrm{e}+00$ 1.00000e-09 7.00000e-02 $2.35620 \mathrm{e}+012.35620 \mathrm{e}+012.35621 \mathrm{e}+001.00000 \mathrm{e}-09$ 7.00000e-02

$2.35620 \mathrm{e}+012.35620 \mathrm{e}+012.35621 \mathrm{e}+001.00000 \mathrm{e}-09$ 7.00000e-02 5.00000e-04 5.00000e-04 5.00000e-05 1.00000e-09 1.00000e-01

Element: 4573 \# of layers: 4

$\mathrm{Kx} \mathrm{Ky} \mathrm{Kz}$ Ss Por

$2.92906 \mathrm{e}+012.92906 \mathrm{e}+012.92906 \mathrm{e}+00$ 1.00000e-09 7.00000e-02 $2.92906 \mathrm{e}+012.92906 \mathrm{e}+012.92906 \mathrm{e}+00$ 1.00000e-09 7.00000e-02 $2.92906 \mathrm{e}+012.92906 \mathrm{e}+012.92906 \mathrm{e}+001.00000 \mathrm{e}-097.00000 \mathrm{e}-02$ 5.00000e-04 5.00000e-04 5.00000e-05 1.00000e-09 1.00000e-01

Element: 4574 \# of layers: 3

$\mathrm{Kx} \mathrm{Ky} \mathrm{Kz}$ Ss Por

$2.16871 \mathrm{e}+012.16871 \mathrm{e}+012.16871 \mathrm{e}+00$ 1.00000e-09 7.00000e-02

$2.16871 \mathrm{e}+012.16871 \mathrm{e}+012.16871 \mathrm{e}+001.00000 \mathrm{e}-09$ 7.00000e-02

$2.16871 \mathrm{e}+012.16871 \mathrm{e}+012.16871 \mathrm{e}+00$ 1.00000e-09 7.00000e-02

Element: 4575 \# of layers: 5

$\mathrm{Kx} \mathrm{Ky} \mathrm{Kz}$ Ss Por

$1.83750 \mathrm{e}+011.83750 \mathrm{e}+011.83750 \mathrm{e}+001.00000 \mathrm{e}-09$ 7.00000e-02

$1.83750 \mathrm{e}+011.83750 \mathrm{e}+011.83750 \mathrm{e}+001.00000 \mathrm{e}-09$ 7.00000e-02

$1.83750 \mathrm{e}+011.83750 \mathrm{e}+01 \quad 1.83750 \mathrm{e}+001.00000 \mathrm{e}-097.00000 \mathrm{e}-02$

8.62533e-01 8.62533e-01 8.62533e-02 1.00000e-09 2.12000e-01

1.00000e-02 1.00000e-02 1.00000e-03 1.00000e-09 1.00000e-01

Element: 4576 \# of layers: 6

$\mathrm{Kx} \mathrm{Ky} \mathrm{Kz}$ Ss Por

$1.83750 \mathrm{e}+011.83750 \mathrm{e}+011.83750 \mathrm{e}+001.00000 \mathrm{e}-09$ 7.00000e-02 $1.83750 \mathrm{e}+011.83750 \mathrm{e}+011.83750 \mathrm{e}+001.00000 \mathrm{e}-097.00000 \mathrm{e}-02$ $1.83750 \mathrm{e}+011.83750 \mathrm{e}+011.83750 \mathrm{e}+001.00000 \mathrm{e}-09$ 7.00000e-02 8.11457e-01 8.11457e-01 8.11457e-02 1.00000e-09 2.12000e-01 $1.00000 \mathrm{e}-02$ 1.00000e-02 1.00000e-03 1.00000e-09 1.00000e-01 $1.00000 \mathrm{e}+001.00000 \mathrm{e}+001.00000 \mathrm{e}-011.00000 \mathrm{e}-091.00000 \mathrm{e}-01$ Element: 4577 \# of layers: 6

$\mathrm{Kx} \mathrm{Ky} \mathrm{Kz}$ Ss Por $2.03085 \mathrm{e}+012.03085 \mathrm{e}+012.03085 \mathrm{e}+00$ 1.00000e-09 7.00000e-02 $2.03085 \mathrm{e}+012.03085 \mathrm{e}+012.03085 \mathrm{e}+001.00000 \mathrm{e}-09$ 7.00000e-02 $2.03085 \mathrm{e}+012.03085 \mathrm{e}+012.03085 \mathrm{e}+001.00000 \mathrm{e}-097.00000 \mathrm{e}-02$ 
8.11457e-01 8.11457e-01 8.11457e-02 1.00000e-09 2.12000e-01 $1.00000 \mathrm{e}-021.00000 \mathrm{e}-02$ 1.00000e-03 1.00000e-09 1.00000e-01 $1.00000 \mathrm{e}+001.00000 \mathrm{e}+001.00000 \mathrm{e}-011.00000 \mathrm{e}-091.00000 \mathrm{e}-01$ Element: 4578 \# of layers: 8

Kx Ky Kz Ss Por

$2.03085 \mathrm{e}+012.03085 \mathrm{e}+012.03085 \mathrm{e}+00$ 1.00000e-09 7.00000e-02

$2.03085 \mathrm{e}+012.03085 \mathrm{e}+012.03085 \mathrm{e}+001.00000 \mathrm{e}-09$ 7.00000e-02

$2.03085 \mathrm{e}+012.03085 \mathrm{e}+012.03085 \mathrm{e}+001.00000 \mathrm{e}-09$ 7.00000e-02

5.00000e-04 5.00000e-04 5.00000e-05 1.00000e-09 1.00000e-01

8.11457e-01 8.11457e-01 8.11457e-02 1.00000e-09 2.12000e-01

8.11457e-01 8.11457e-01 8.11457e-02 1.00000e-09 2.12000e-01

$1.00000 \mathrm{e}-021.00000 \mathrm{e}-02$ 1.00000e-03 1.00000e-09 1.00000e-01

$1.00000 \mathrm{e}+001.00000 \mathrm{e}+001.00000 \mathrm{e}-011.00000 \mathrm{e}-091.00000 \mathrm{e}-01$

Element: 4579 \# of layers: 9

Kx Ky Kz Ss Por

$2.03085 \mathrm{e}+012.03085 \mathrm{e}+012.03085 \mathrm{e}+00$ 1.00000e-09 7.00000e-02

$2.03085 \mathrm{e}+012.03085 \mathrm{e}+012.03085 \mathrm{e}+001.00000 \mathrm{e}-09$ 7.00000e-02

$2.03085 \mathrm{e}+012.03085 \mathrm{e}+012.03085 \mathrm{e}+001.00000 \mathrm{e}-09$ 7.00000e-02

5.00000e-04 5.00000e-04 5.00000e-05 1.00000e-09 1.00000e-01

5.00000e-04 5.00000e-04 5.00000e-05 1.00000e-09 1.00000e-01

8.11457e-01 8.11457e-01 8.11457e-02 1.00000e-09 2.12000e-01

8.11457e-01 8.11457e-01 8.11457e-02 1.00000e-09 2.12000e-01

$1.00000 \mathrm{e}-02$ 1.00000e-02 $1.00000 \mathrm{e}-031.00000 \mathrm{e}-091.00000 \mathrm{e}-01$

$1.00000 \mathrm{e}+001.00000 \mathrm{e}+001.00000 \mathrm{e}-011.00000 \mathrm{e}-091.00000 \mathrm{e}-01$

Element: 4580 \# of layers: 8

Kx Ky Kz Ss Por

$1.82525 \mathrm{e}+011.82525 \mathrm{e}+011.82525 \mathrm{e}+00$ 1.00000e-09 7.00000e-02

$1.82525 \mathrm{e}+011.82525 \mathrm{e}+011.82525 \mathrm{e}+001.00000 \mathrm{e}-09$ 7.00000e-02

$1.82525 \mathrm{e}+011.82525 \mathrm{e}+011.82525 \mathrm{e}+001.00000 \mathrm{e}-097.00000 \mathrm{e}-02$

$5.00000 \mathrm{e}-04$ 5.00000e-04 5.00000e-05 1.00000e-09 1.00000e-01

5.00000e-04 5.00000e-04 5.00000e-05 1.00000e-09 1.00000e-01

7.29285e-01 7.29285e-01 7.29285e-02 1.00000e-09 2.12000e-01

$1.00000 \mathrm{e}-021.00000 \mathrm{e}-02$ 1.00000e-03 1.00000e-09 1.00000e-01

$1.00000 \mathrm{e}+001.00000 \mathrm{e}+001.00000 \mathrm{e}-011.00000 \mathrm{e}-091.00000 \mathrm{e}-01$

Element: 4581 \# of layers: 7

Kx Ky Kz Ss Por

$1.82525 \mathrm{e}+011.82525 \mathrm{e}+011.82525 \mathrm{e}+00$ 1.00000e-09 7.00000e-02

$1.82525 \mathrm{e}+011.82525 \mathrm{e}+011.82525 \mathrm{e}+001.00000 \mathrm{e}-097.00000 \mathrm{e}-02$

$1.82525 \mathrm{e}+011.82525 \mathrm{e}+011.82525 \mathrm{e}+001.00000 \mathrm{e}-097.00000 \mathrm{e}-02$

5.00000e-04 5.00000e-04 5.00000e-05 1.00000e-09 1.00000e-01

7.29285e-01 7.29285e-01 7.29285e-02 1.00000e-09 2.12000e-01

$1.00000 \mathrm{e}-02$ 1.00000e-02 1.00000e-03 1.00000e-09 1.00000e-01

$1.00000 \mathrm{e}+001.00000 \mathrm{e}+001.00000 \mathrm{e}-011.00000 \mathrm{e}-091.00000 \mathrm{e}-01$

Element: 4582 \# of layers: 6

Kx Ky Kz Ss Por

$2.03085 \mathrm{e}+012.03085 \mathrm{e}+012.03085 \mathrm{e}+00$ 1.00000e-09 7.00000e-02 
$2.03085 \mathrm{e}+012.03085 \mathrm{e}+012.03085 \mathrm{e}+001.00000 \mathrm{e}-09$ 7.00000e-02 $2.03085 \mathrm{e}+012.03085 \mathrm{e}+012.03085 \mathrm{e}+00$ 1.00000e-09 7.00000e-02 8.11457e-01 8.11457e-01 8.11457e-02 1.00000e-09 2.12000e-01 $1.00000 \mathrm{e}-02$ 1.00000e-02 1.00000e-03 1.00000e-09 1.00000e-01 $1.00000 \mathrm{e}+001.00000 \mathrm{e}+001.00000 \mathrm{e}-01$ 1.00000e-09 1.00000e-01 Element: 4583 \# of layers: 6

$\mathrm{Kx} \mathrm{Ky} \mathrm{Kz}$ Ss Por

$2.03085 \mathrm{e}+012.03085 \mathrm{e}+012.03085 \mathrm{e}+00$ 1.00000e-09 7.00000e-02 $2.03085 \mathrm{e}+012.03085 \mathrm{e}+012.03085 \mathrm{e}+001.00000 \mathrm{e}-09$ 7.00000e-02 $2.03085 \mathrm{e}+012.03085 \mathrm{e}+012.03085 \mathrm{e}+001.00000 \mathrm{e}-09$ 7.00000e-02 8.11457e-01 8.11457e-01 8.11457e-02 1.00000e-09 2.12000e-01 $1.00000 \mathrm{e}-02$ 1.00000e-02 1.00000e-03 1.00000e-09 1.00000e-01 $1.00000 \mathrm{e}+001.00000 \mathrm{e}+001.00000 \mathrm{e}-011.00000 \mathrm{e}-091.00000 \mathrm{e}-01$ Element: 4584 \# of layers: 6

$\mathrm{Kx} \mathrm{Ky} \mathrm{Kz}$ Ss Por

$2.90500 \mathrm{e}+012.90500 \mathrm{e}+012.90500 \mathrm{e}+00$ 1.00000e-09 7.00000e-02 $2.90500 \mathrm{e}+012.90500 \mathrm{e}+012.90500 \mathrm{e}+001.00000 \mathrm{e}-09$ 7.00000e-02

$2.90500 \mathrm{e}+012.90500 \mathrm{e}+012.90500 \mathrm{e}+001.00000 \mathrm{e}-09$ 7.00000e-02 $1.16073 \mathrm{e}+00$ 1.16073e+00 1.16073e-01 1.00000e-09 2.12000e-01 $1.00000 \mathrm{e}-02$ 1.00000e-02 1.00000e-03 1.00000e-09 1.00000e-01 $1.00000 \mathrm{e}+001.00000 \mathrm{e}+001.00000 \mathrm{e}-011.00000 \mathrm{e}-091.00000 \mathrm{e}-01$ Element: 4585 \# of layers: 7

$\mathrm{Kx} \mathrm{Ky} \mathrm{Kz}$ Ss Por

$2.90500 \mathrm{e}+012.90500 \mathrm{e}+012.90500 \mathrm{e}+00$ 1.00000e-09 7.00000e-02 $2.90500 \mathrm{e}+012.90500 \mathrm{e}+012.90500 \mathrm{e}+001.00000 \mathrm{e}-09$ 7.00000e-02 $2.90500 \mathrm{e}+012.90500 \mathrm{e}+012.90500 \mathrm{e}+001.00000 \mathrm{e}-09$ 7.00000e-02 $1.16073 \mathrm{e}+00$ 1.16073e+00 1.16073e-01 1.00000e-09 2.12000e-01 $1.16073 \mathrm{e}+00$ 1.16073e+00 1.16073e-01 1.00000e-09 2.12000e-01 $1.00000 \mathrm{e}-02$ 1.00000e-02 1.00000e-03 1.00000e-09 1.00000e-01 $1.00000 \mathrm{e}+001.00000 \mathrm{e}+001.00000 \mathrm{e}-01$ 1.00000e-09 1.00000e-01 Element: 4586 \# of layers: 7

$\mathrm{Kx} \mathrm{Ky} \mathrm{Kz}$ Ss Por

$2.90500 \mathrm{e}+012.90500 \mathrm{e}+012.90500 \mathrm{e}+00$ 1.00000e-09 7.00000e-02 $2.90500 \mathrm{e}+012.90500 \mathrm{e}+012.90500 \mathrm{e}+001.00000 \mathrm{e}-09$ 7.00000e-02 $2.90500 \mathrm{e}+012.90500 \mathrm{e}+012.90500 \mathrm{e}+001.00000 \mathrm{e}-09$ 7.00000e-02 $1.16073 \mathrm{e}+00$ 1.16073e+00 1.16073e-01 1.00000e-09 2.12000e-01 $1.16073 \mathrm{e}+001.16073 \mathrm{e}+00$ 1.16073e-01 1.00000e-09 2.12000e-01 $1.00000 \mathrm{e}-021.00000 \mathrm{e}-02$ 1.00000e-03 1.00000e-09 1.00000e-01 $1.00000 \mathrm{e}+001.00000 \mathrm{e}+001.00000 \mathrm{e}-011.00000 \mathrm{e}-091.00000 \mathrm{e}-01$ Element: 4587 \# of layers: 9

$\mathrm{Kx} \mathrm{Ky} \mathrm{Kz}$ Ss Por

$2.90500 \mathrm{e}+012.90500 \mathrm{e}+012.90500 \mathrm{e}+001.00000 \mathrm{e}-09$ 7.00000e-02 $2.90500 \mathrm{e}+012.90500 \mathrm{e}+012.90500 \mathrm{e}+001.00000 \mathrm{e}-09$ 7.00000e-02 $2.90500 \mathrm{e}+012.90500 \mathrm{e}+012.90500 \mathrm{e}+001.00000 \mathrm{e}-09$ 7.00000e-02 5.00000e-04 5.00000e-04 5.00000e-05 1.00000e-09 1.00000e-01 5.00000e-04 5.00000e-04 5.00000e-05 1.00000e-09 1.00000e-01 
$1.16073 \mathrm{e}+00$ 1.16073e+00 1.16073e-01 1.00000e-09 2.12000e-01 $1.16073 \mathrm{e}+001.16073 \mathrm{e}+00$ 1.16073e-01 1.00000e-09 2.12000e-01 $1.00000 \mathrm{e}-021.00000 \mathrm{e}-02$ 1.00000e-03 1.00000e-09 1.00000e-01 $1.00000 \mathrm{e}+001.00000 \mathrm{e}+001.00000 \mathrm{e}-011.00000 \mathrm{e}-091.00000 \mathrm{e}-01$ Element: 4588 \# of layers: 6

Kx Ky Kz Ss Por

$2.90500 \mathrm{e}+012.90500 \mathrm{e}+012.90500 \mathrm{e}+001.00000 \mathrm{e}-097.00000 \mathrm{e}-02$ 5.00000e-04 5.00000e-04 5.00000e-05 1.00000e-09 1.00000e-01 5.00000e-04 5.00000e-04 5.00000e-05 1.00000e-09 1.00000e-01 $1.16073 \mathrm{e}+001.16073 \mathrm{e}+00$ 1.16073e-01 1.00000e-09 2.12000e-01 $1.00000 \mathrm{e}-021.00000 \mathrm{e}-02$ 1.00000e-03 1.00000e-09 1.00000e-01 $1.00000 \mathrm{e}+001.00000 \mathrm{e}+001.00000 \mathrm{e}-011.00000 \mathrm{e}-091.00000 \mathrm{e}-01$ Element: 4589 \# of layers: 9

Kx Ky Kz Ss Por $2.90500 \mathrm{e}+012.90500 \mathrm{e}+012.90500 \mathrm{e}+001.00000 \mathrm{e}-097.00000 \mathrm{e}-02$ $2.90500 \mathrm{e}+012.90500 \mathrm{e}+012.90500 \mathrm{e}+001.00000 \mathrm{e}-097.00000 \mathrm{e}-02$ $2.90500 \mathrm{e}+012.90500 \mathrm{e}+012.90500 \mathrm{e}+001.00000 \mathrm{e}-097.00000 \mathrm{e}-02$ 5.00000e-04 5.00000e-04 5.00000e-05 1.00000e-09 1.00000e-01 5.00000e-04 5.00000e-04 5.00000e-05 1.00000e-09 1.00000e-01 $1.16073 \mathrm{e}+001.16073 \mathrm{e}+00$ 1.16073e-01 1.00000e-09 2.12000e-01 $1.16073 \mathrm{e}+001.16073 \mathrm{e}+00$ 1.16073e-01 1.00000e-09 2.12000e-01 $1.00000 \mathrm{e}-02$ 1.00000e-02 1.00000e-03 1.00000e-09 1.00000e-01 $1.00000 \mathrm{e}+001.00000 \mathrm{e}+001.00000 \mathrm{e}-011.00000 \mathrm{e}-091.00000 \mathrm{e}-01$ Element: 4590 \# of layers: 9

Kx Ky Kz Ss Por

$2.90500 \mathrm{e}+012.90500 \mathrm{e}+012.90500 \mathrm{e}+001.00000 \mathrm{e}-097.00000 \mathrm{e}-02$ $2.90500 \mathrm{e}+012.90500 \mathrm{e}+012.90500 \mathrm{e}+001.00000 \mathrm{e}-09$ 7.00000e-02 $2.90500 \mathrm{e}+012.90500 \mathrm{e}+012.90500 \mathrm{e}+001.00000 \mathrm{e}-097.00000 \mathrm{e}-02$ 5.00000e-04 5.00000e-04 5.00000e-05 1.00000e-09 1.00000e-01 $5.00000 \mathrm{e}-04$ 5.00000e-04 5.00000e-05 1.00000e-09 1.00000e-01 $1.16073 \mathrm{e}+001.16073 \mathrm{e}+00$ 1.16073e-01 1.00000e-09 2.12000e-01 $1.16073 \mathrm{e}+001.16073 \mathrm{e}+00$ 1.16073e-01 1.00000e-09 2.12000e-01 $1.00000 \mathrm{e}-021.00000 \mathrm{e}-02$ 1.00000e-03 1.00000e-09 1.00000e-01 $1.00000 \mathrm{e}+001.00000 \mathrm{e}+001.00000 \mathrm{e}-011.00000 \mathrm{e}-091.00000 \mathrm{e}-01$ Element: 4591 \# of layers: 9

Kx Ky Kz Ss Por $2.90500 \mathrm{e}+012.90500 \mathrm{e}+012.90500 \mathrm{e}+001.00000 \mathrm{e}-097.00000 \mathrm{e}-02$ $2.90500 \mathrm{e}+012.90500 \mathrm{e}+012.90500 \mathrm{e}+001.00000 \mathrm{e}-097.00000 \mathrm{e}-02$ $2.90500 \mathrm{e}+012.90500 \mathrm{e}+012.90500 \mathrm{e}+001.00000 \mathrm{e}-097.00000 \mathrm{e}-02$ 5.00000e-04 5.00000e-04 5.00000e-05 1.00000e-09 1.00000e-01 5.00000e-04 5.00000e-04 5.00000e-05 1.00000e-09 1.00000e-01 $1.16073 \mathrm{e}+001.16073 \mathrm{e}+00$ 1.16073e-01 1.00000e-09 2.12000e-01 $1.16073 \mathrm{e}+001.16073 \mathrm{e}+00$ 1.16073e-01 1.00000e-09 2.12000e-01 $1.00000 \mathrm{e}-021.00000 \mathrm{e}-02$ 1.00000e-03 1.00000e-09 1.00000e-01 $1.00000 \mathrm{e}+001.00000 \mathrm{e}+001.00000 \mathrm{e}-011.00000 \mathrm{e}-091.00000 \mathrm{e}-01$ Element: 4592 \# of layers: 9 
$\mathrm{Kx} \mathrm{Ky} \mathrm{Kz}$ Ss Por

$2.90500 \mathrm{e}+012.90500 \mathrm{e}+012.90500 \mathrm{e}+00$ 1.00000e-09 7.00000e-02

$2.90500 \mathrm{e}+012.90500 \mathrm{e}+012.90500 \mathrm{e}+001.00000 \mathrm{e}-09$ 7.00000e-02

$2.90500 \mathrm{e}+012.90500 \mathrm{e}+012.90500 \mathrm{e}+001.00000 \mathrm{e}-097.00000 \mathrm{e}-02$

5.00000e-04 5.00000e-04 5.00000e-05 1.00000e-09 1.00000e-01

5.00000e-04 5.00000e-04 5.00000e-05 1.00000e-09 1.00000e-01

$1.16073 \mathrm{e}+00$ 1.16073e+00 1.16073e-01 1.00000e-09 2.12000e-01

$1.16073 \mathrm{e}+001.16073 \mathrm{e}+00$ 1.16073e-01 1.00000e-09 2.12000e-01

$1.00000 \mathrm{e}-02$ 1.00000e-02 1.00000e-03 1.00000e-09 1.00000e-01

$1.00000 \mathrm{e}+001.00000 \mathrm{e}+001.00000 \mathrm{e}-011.00000 \mathrm{e}-091.00000 \mathrm{e}-01$

Element: 4593 \# of layers: 8

$\mathrm{Kx} \mathrm{Ky} \mathrm{Kz}$ Ss Por

3.04412e+01 3.04412e+01 3.04412e+00 1.00000e-09 7.00000e-02

$3.04412 \mathrm{e}+013.04412 \mathrm{e}+013.04412 \mathrm{e}+001.00000 \mathrm{e}-09$ 7.00000e-02

$3.04412 \mathrm{e}+013.04412 \mathrm{e}+013.04412 \mathrm{e}+001.00000 \mathrm{e}-09$ 7.00000e-02

5.00000e-04 5.00000e-04 5.00000e-05 1.00000e-09 1.00000e-01

5.00000e-04 5.00000e-04 5.00000e-05 1.00000e-09 1.00000e-01

$1.21633 \mathrm{e}+00$ 1.21633e+00 1.21633e-01 1.00000e-09 2.12000e-01

$1.00000 \mathrm{e}-02$ 1.00000e-02 1.00000e-03 1.00000e-09 1.00000e-01

$1.00000 \mathrm{e}+001.00000 \mathrm{e}+001.00000 \mathrm{e}-011.00000 \mathrm{e}-091.00000 \mathrm{e}-01$

Element: 4594 \# of layers: 8

$\mathrm{Kx} \mathrm{Ky} \mathrm{Kz}$ Ss Por

3.04412e+01 3.04412e+01 3.04412e+00 1.00000e-09 7.00000e-02 $3.04412 \mathrm{e}+013.04412 \mathrm{e}+013.04412 \mathrm{e}+001.00000 \mathrm{e}-09$ 7.00000e-02

$3.04412 \mathrm{e}+013.04412 \mathrm{e}+013.04412 \mathrm{e}+001.00000 \mathrm{e}-09$ 7.00000e-02

5.00000e-04 5.00000e-04 5.00000e-05 1.00000e-09 1.00000e-01

5.00000e-04 5.00000e-04 5.00000e-05 1.00000e-09 1.00000e-01

$1.21633 \mathrm{e}+001.21633 \mathrm{e}+00$ 1.21633e-01 1.00000e-09 2.12000e-01

$1.00000 \mathrm{e}-02$ 1.00000e-02 1.00000e-03 1.00000e-09 1.00000e-01

$1.00000 \mathrm{e}+001.00000 \mathrm{e}+001.00000 \mathrm{e}-011.00000 \mathrm{e}-091.00000 \mathrm{e}-01$

Element: 4595 \# of layers: 7

$\mathrm{Kx} \mathrm{Ky} \mathrm{Kz}$ Ss Por

3.04412e+01 3.04412e+01 3.04412e+00 1.00000e-09 7.00000e-02

$3.04412 \mathrm{e}+013.04412 \mathrm{e}+013.04412 \mathrm{e}+001.00000 \mathrm{e}-09$ 7.00000e-02

$3.04412 \mathrm{e}+013.04412 \mathrm{e}+013.04412 \mathrm{e}+001.00000 \mathrm{e}-09$ 7.00000e-02

5.00000e-04 5.00000e-04 5.00000e-05 1.00000e-09 1.00000e-01

$1.21633 \mathrm{e}+001.21633 \mathrm{e}+00$ 1.21633e-01 1.00000e-09 2.12000e-01

$1.00000 \mathrm{e}-02$ 1.00000e-02 1.00000e-03 1.00000e-09 1.00000e-01

$1.00000 \mathrm{e}+001.00000 \mathrm{e}+001.00000 \mathrm{e}-011.00000 \mathrm{e}-091.00000 \mathrm{e}-01$

Element: 4596 \# of layers: 8

$\mathrm{Kx} \mathrm{Ky} \mathrm{Kz}$ Ss Por

3.04412e+01 3.04412e+01 3.04412e+00 1.00000e-09 7.00000e-02

$3.04412 \mathrm{e}+013.04412 \mathrm{e}+013.04412 \mathrm{e}+001.00000 \mathrm{e}-097.00000 \mathrm{e}-02$

3.04412e+01 3.04412e+01 3.04412e+00 1.00000e-09 7.00000e-02

$5.00000 \mathrm{e}-04$ 5.00000e-04 5.00000e-05 1.00000e-09 1.00000e-01

5.00000e-04 5.00000e-04 5.00000e-05 1.00000e-09 1.00000e-01 
$1.21633 \mathrm{e}+001.21633 \mathrm{e}+00$ 1.21633e-01 1.00000e-09 2.12000e-01 $1.00000 \mathrm{e}-021.00000 \mathrm{e}-02$ 1.00000e-03 1.00000e-09 1.00000e-01 $1.00000 \mathrm{e}+001.00000 \mathrm{e}+001.00000 \mathrm{e}-011.00000 \mathrm{e}-091.00000 \mathrm{e}-01$ Element: 4597 \# of layers: 8

Kx Ky Kz Ss Por

3.04412e+01 3.04412e+01 3.04412e+00 1.00000e-09 7.00000e-02 $3.04412 \mathrm{e}+013.04412 \mathrm{e}+013.04412 \mathrm{e}+001.00000 \mathrm{e}-097.00000 \mathrm{e}-02$ 5.00000e-04 5.00000e-04 5.00000e-05 1.00000e-09 1.00000e-01 5.00000e-04 5.00000e-04 5.00000e-05 1.00000e-09 1.00000e-01 $1.21633 \mathrm{e}+001.21633 \mathrm{e}+00$ 1.21633e-01 1.00000e-09 2.12000e-01 $1.21633 \mathrm{e}+001.21633 \mathrm{e}+00$ 1.21633e-01 1.00000e-09 2.12000e-01 $1.00000 \mathrm{e}-021.00000 \mathrm{e}-02$ 1.00000e-03 1.00000e-09 1.00000e-01 $1.00000 \mathrm{e}+001.00000 \mathrm{e}+001.00000 \mathrm{e}-011.00000 \mathrm{e}-091.00000 \mathrm{e}-01$ Element: 4598 \# of layers: 7

Kx Ky Kz Ss Por $3.04412 \mathrm{e}+013.04412 \mathrm{e}+013.04412 \mathrm{e}+00$ 1.00000e-09 7.00000e-02 5.00000e-04 5.00000e-04 5.00000e-05 1.00000e-09 1.00000e-01 5.00000e-04 5.00000e-04 5.00000e-05 1.00000e-09 1.00000e-01 $1.21633 \mathrm{e}+001.21633 \mathrm{e}+00$ 1.21633e-01 1.00000e-09 2.12000e-01 $1.21633 \mathrm{e}+001.21633 \mathrm{e}+001.21633 \mathrm{e}-011.00000 \mathrm{e}-092.12000 \mathrm{e}-01$ $1.00000 \mathrm{e}-021.00000 \mathrm{e}-02$ 1.00000e-03 1.00000e-09 1.00000e-01 $1.00000 \mathrm{e}+001.00000 \mathrm{e}+001.00000 \mathrm{e}-011.00000 \mathrm{e}-091.00000 \mathrm{e}-01$ Element: 4599 \# of layers: 7

Kx Ky Kz Ss Por

$3.04412 \mathrm{e}+013.04412 \mathrm{e}+013.04412 \mathrm{e}+00$ 1.00000e-09 7.00000e-02 $5.00000 \mathrm{e}-04$ 5.00000e-04 5.00000e-05 1.00000e-09 1.00000e-01 5.00000e-04 5.00000e-04 5.00000e-05 1.00000e-09 1.00000e-01 $1.21633 \mathrm{e}+001.21633 \mathrm{e}+001.21633 \mathrm{e}-011.00000 \mathrm{e}-092.12000 \mathrm{e}-01$ $1.21633 \mathrm{e}+001.21633 \mathrm{e}+001.21633 \mathrm{e}-011.00000 \mathrm{e}-092.12000 \mathrm{e}-01$ $1.00000 \mathrm{e}-02$ 1.00000e-02 1.00000e-03 1.00000e-09 1.00000e-01 $1.00000 \mathrm{e}+001.00000 \mathrm{e}+001.00000 \mathrm{e}-011.00000 \mathrm{e}-091.00000 \mathrm{e}-01$ Element: 4600 \# of layers: 8

Kx Ky Kz Ss Por $3.04412 \mathrm{e}+013.04412 \mathrm{e}+013.04412 \mathrm{e}+00$ 1.00000e-09 7.00000e-02 $3.04412 \mathrm{e}+013.04412 \mathrm{e}+013.04412 \mathrm{e}+00$ 1.00000e-09 7.00000e-02 $3.04412 \mathrm{e}+013.04412 \mathrm{e}+013.04412 \mathrm{e}+00$ 1.00000e-09 7.00000e-02 5.00000e-04 5.00000e-04 5.00000e-05 1.00000e-09 1.00000e-01 5.00000e-04 5.00000e-04 5.00000e-05 1.00000e-09 1.00000e-01 $1.21633 \mathrm{e}+001.21633 \mathrm{e}+00$ 1.21633e-01 1.00000e-09 2.12000e-01 $1.00000 \mathrm{e}-02$ 1.00000e-02 1.00000e-03 1.00000e-09 1.00000e-01 $1.00000 \mathrm{e}+001.00000 \mathrm{e}+001.00000 \mathrm{e}-011.00000 \mathrm{e}-091.00000 \mathrm{e}-01$ Element: 4601 \# of layers: 7

Kx Ky Kz Ss Por $3.04412 \mathrm{e}+013.04412 \mathrm{e}+013.04412 \mathrm{e}+00$ 1.00000e-09 7.00000e-02 $3.04412 \mathrm{e}+013.04412 \mathrm{e}+013.04412 \mathrm{e}+001.00000 \mathrm{e}-09$ 7.00000e-02 5.00000e-04 5.00000e-04 5.00000e-05 1.00000e-09 1.00000e-01 
5.00000e-04 5.00000e-04 5.00000e-05 1.00000e-09 1.00000e-01 $1.21633 \mathrm{e}+00$ 1.21633e+00 1.21633e-01 1.00000e-09 2.12000e-01 $1.00000 \mathrm{e}-02$ 1.00000e-02 1.00000e-03 1.00000e-09 1.00000e-01 $1.00000 \mathrm{e}+001.00000 \mathrm{e}+001.00000 \mathrm{e}-011.00000 \mathrm{e}-091.00000 \mathrm{e}-01$ Element: 4602 \# of layers: 7

$\mathrm{Kx} \mathrm{Ky} \mathrm{Kz}$ Ss Por

$2.34756 \mathrm{e}+012.34756 \mathrm{e}+012.34756 \mathrm{e}+00$ 1.00000e-09 7.00000e-02 $2.34756 \mathrm{e}+012.34756 \mathrm{e}+012.34756 \mathrm{e}+00$ 1.00000e-09 7.00000e-02 $2.34756 \mathrm{e}+012.34756 \mathrm{e}+012.34756 \mathrm{e}+001.00000 \mathrm{e}-09$ 7.00000e-02 5.00000e-04 5.00000e-04 5.00000e-05 1.00000e-09 1.00000e-01 9.38022e-01 9.38022e-01 9.38023e-02 1.00000e-09 2.12000e-01 $1.00000 \mathrm{e}-02$ 1.00000e-02 1.00000e-03 1.00000e-09 1.00000e-01 $1.00000 \mathrm{e}+001.00000 \mathrm{e}+001.00000 \mathrm{e}-011.00000 \mathrm{e}-091.00000 \mathrm{e}-01$ Element: 4603 \# of layers: 8

$\mathrm{Kx} \mathrm{Ky} \mathrm{Kz}$ Ss Por

$2.34756 \mathrm{e}+012.34756 \mathrm{e}+012.34756 \mathrm{e}+00$ 1.00000e-09 7.00000e-02 $2.34756 \mathrm{e}+012.34756 \mathrm{e}+012.34756 \mathrm{e}+00$ 1.00000e-09 7.00000e-02

$2.34756 \mathrm{e}+012.34756 \mathrm{e}+012.34756 \mathrm{e}+001.00000 \mathrm{e}-09$ 7.00000e-02 5.00000e-04 5.00000e-04 5.00000e-05 1.00000e-09 1.00000e-01 5.00000e-04 5.00000e-04 5.00000e-05 1.00000e-09 1.00000e-01 9.38022e-01 9.38022e-01 9.38023e-02 1.00000e-09 2.12000e-01 $1.00000 \mathrm{e}-02$ 1.00000e-02 1.00000e-03 1.00000e-09 1.00000e-01 $1.00000 \mathrm{e}+001.00000 \mathrm{e}+001.00000 \mathrm{e}-011.00000 \mathrm{e}-091.00000 \mathrm{e}-01$ Element: 4604 \# of layers: 9

$\mathrm{Kx} \mathrm{Ky} \mathrm{Kz}$ Ss Por

$2.34756 \mathrm{e}+012.34756 \mathrm{e}+012.34756 \mathrm{e}+001.00000 \mathrm{e}-09$ 7.00000e-02 $2.34756 \mathrm{e}+012.34756 \mathrm{e}+012.34756 \mathrm{e}+001.00000 \mathrm{e}-09$ 7.00000e-02 $2.34756 \mathrm{e}+012.34756 \mathrm{e}+012.34756 \mathrm{e}+001.00000 \mathrm{e}-09$ 7.00000e-02 5.00000e-04 5.00000e-04 5.00000e-05 1.00000e-09 1.00000e-01 5.00000e-04 5.00000e-04 5.00000e-05 1.00000e-09 1.00000e-01 9.38022e-01 9.38022e-01 9.38023e-02 1.00000e-09 2.12000e-01 9.38022e-01 9.38022e-01 9.38023e-02 1.00000e-09 2.12000e-01 $1.00000 \mathrm{e}-02$ 1.00000e-02 1.00000e-03 1.00000e-09 1.00000e-01 $1.00000 \mathrm{e}+001.00000 \mathrm{e}+001.00000 \mathrm{e}-011.00000 \mathrm{e}-091.00000 \mathrm{e}-01$ Element: 4608 \# of layers: 9

Kx Ky Kz Ss Por

$2.34756 \mathrm{e}+012.34756 \mathrm{e}+012.34756 \mathrm{e}+00$ 1.00000e-09 7.00000e-02 $2.34756 \mathrm{e}+012.34756 \mathrm{e}+012.34756 \mathrm{e}+001.00000 \mathrm{e}-09$ 7.00000e-02

$2.34756 \mathrm{e}+012.34756 \mathrm{e}+012.34756 \mathrm{e}+001.00000 \mathrm{e}-09$ 7.00000e-02 5.00000e-04 5.00000e-04 5.00000e-05 1.00000e-09 1.00000e-01 5.00000e-04 5.00000e-04 5.00000e-05 1.00000e-09 1.00000e-01 9.38022e-01 9.38022e-01 9.38023e-02 1.00000e-09 2.12000e-01 9.38022e-01 9.38022e-01 9.38023e-02 1.00000e-09 2.12000e-01 $1.00000 \mathrm{e}-02$ 1.00000e-02 1.00000e-03 1.00000e-09 1.00000e-01 $1.00000 \mathrm{e}+001.00000 \mathrm{e}+001.00000 \mathrm{e}-011.00000 \mathrm{e}-091.00000 \mathrm{e}-01$ Element: 4609 \# of layers: 8 
Kx Ky Kz Ss Por

$2.34756 \mathrm{e}+012.34756 \mathrm{e}+012.34756 \mathrm{e}+001.00000 \mathrm{e}-09$ 7.00000e-02

$2.34756 \mathrm{e}+012.34756 \mathrm{e}+012.34756 \mathrm{e}+001.00000 \mathrm{e}-09$ 7.00000e-02

$2.34756 \mathrm{e}+012.34756 \mathrm{e}+012.34756 \mathrm{e}+001.00000 \mathrm{e}-09$ 7.00000e-02

5.00000e-04 5.00000e-04 5.00000e-05 1.00000e-09 1.00000e-01

5.00000e-04 5.00000e-04 5.00000e-05 1.00000e-09 1.00000e-01

9.38022e-01 9.38022e-01 9.38023e-02 1.00000e-09 2.12000e-01

$1.00000 \mathrm{e}-02$ 1.00000e-02 1.00000e-03 1.00000e-09 1.00000e-01

$1.00000 \mathrm{e}+001.00000 \mathrm{e}+001.00000 \mathrm{e}-011.00000 \mathrm{e}-09$ 1.00000e-01

Element: 4611 \# of layers: 7

Kx Ky Kz Ss Por

3.27108e+01 3.27108e+01 3.27108e+00 1.00000e-09 7.00000e-02

$3.27108 \mathrm{e}+013.27108 \mathrm{e}+013.27108 \mathrm{e}+001.00000 \mathrm{e}-09$ 7.00000e-02

5.00000e-04 5.00000e-04 5.00000e-05 1.00000e-09 1.00000e-01

5.00000e-04 5.00000e-04 5.00000e-05 1.00000e-09 1.00000e-01

$1.30701 \mathrm{e}+001.30701 \mathrm{e}+001.30701 \mathrm{e}-01$ 1.00000e-09 2.12000e-01

$1.00000 \mathrm{e}-02$ 1.00000e-02 1.00000e-03 1.00000e-09 1.00000e-01

$1.00000 \mathrm{e}+001.00000 \mathrm{e}+001.00000 \mathrm{e}-01$ 1.00000e-09 1.00000e-01

Element: 4612 \# of layers: 7

$\mathrm{Kx} \mathrm{Ky} \mathrm{Kz}$ Ss Por

3.27108e+01 3.27108e+01 3.27108e+00 1.00000e-09 7.00000e-02

$3.27108 \mathrm{e}+013.27108 \mathrm{e}+013.27108 \mathrm{e}+001.00000 \mathrm{e}-09$ 7.00000e-02

5.00000e-04 5.00000e-04 5.00000e-05 1.00000e-09 1.00000e-01

5.00000e-04 5.00000e-04 5.00000e-05 1.00000e-09 1.00000e-01

$1.30701 \mathrm{e}+001.30701 \mathrm{e}+001.30701 \mathrm{e}-011.00000 \mathrm{e}-092.12000 \mathrm{e}-01$

$1.00000 \mathrm{e}-02$ 1.00000e-02 1.00000e-03 1.00000e-09 1.00000e-01

$1.00000 \mathrm{e}+001.00000 \mathrm{e}+001.00000 \mathrm{e}-011.00000 \mathrm{e}-091.00000 \mathrm{e}-01$

Element: 4613 \# of layers: 8

$\mathrm{Kx} \mathrm{Ky} \mathrm{Kz}$ Ss Por

$3.27108 \mathrm{e}+013.27108 \mathrm{e}+013.27108 \mathrm{e}+00$ 1.00000e-09 7.00000e-02

$3.27108 \mathrm{e}+013.27108 \mathrm{e}+013.27108 \mathrm{e}+001.00000 \mathrm{e}-09$ 7.00000e-02

5.00000e-04 5.00000e-04 5.00000e-05 1.00000e-09 1.00000e-01

5.00000e-04 5.00000e-04 5.00000e-05 1.00000e-09 1.00000e-01

$1.30701 \mathrm{e}+001.30701 \mathrm{e}+001.30701 \mathrm{e}-011.00000 \mathrm{e}-092.12000 \mathrm{e}-01$

$1.30701 \mathrm{e}+001.30701 \mathrm{e}+001.30701 \mathrm{e}-01$ 1.00000e-09 2.12000e-01

1.00000e-02 1.00000e-02 1.00000e-03 1.00000e-09 1.00000e-01

$1.00000 \mathrm{e}+001.00000 \mathrm{e}+001.00000 \mathrm{e}-011.00000 \mathrm{e}-091.00000 \mathrm{e}-01$

Element: 4614 \# of layers: 9

$\mathrm{Kx} \mathrm{Ky} \mathrm{Kz}$ Ss Por

$2.47424 \mathrm{e}+012.47424 \mathrm{e}+012.47424 \mathrm{e}+00$ 1.00000e-09 7.00000e-02

$2.47424 \mathrm{e}+012.47424 \mathrm{e}+012.47424 \mathrm{e}+001.00000 \mathrm{e}-097.00000 \mathrm{e}-02$

$2.47424 \mathrm{e}+012.47424 \mathrm{e}+012.47424 \mathrm{e}+001.00000 \mathrm{e}-097.00000 \mathrm{e}-02$

5.00000e-04 5.00000e-04 5.00000e-05 1.00000e-09 1.00000e-01

5.00000e-04 5.00000e-04 5.00000e-05 1.00000e-09 1.00000e-01

9.88626e-01 9.88626e-01 9.88626e-02 1.00000e-09 2.12000e-01

9.88626e-01 9.88626e-01 9.88626e-02 1.00000e-09 2.12000e-01 
$1.00000 \mathrm{e}-02$ 1.00000e-02 1.00000e-03 1.00000e-09 1.00000e-01 $1.00000 \mathrm{e}+001.00000 \mathrm{e}+001.00000 \mathrm{e}-01$ 1.00000e-09 1.00000e-01 Element: 4615 \# of layers: 9

Kx Ky Kz Ss Por

$2.47424 \mathrm{e}+012.47424 \mathrm{e}+012.47424 \mathrm{e}+001.00000 \mathrm{e}-097.00000 \mathrm{e}-02$

$2.47424 \mathrm{e}+012.47424 \mathrm{e}+012.47424 \mathrm{e}+001.00000 \mathrm{e}-097.00000 \mathrm{e}-02$

$2.47424 \mathrm{e}+012.47424 \mathrm{e}+012.47424 \mathrm{e}+001.00000 \mathrm{e}-097.00000 \mathrm{e}-02$

5.00000e-04 5.00000e-04 5.00000e-05 1.00000e-09 1.00000e-01

5.00000e-04 5.00000e-04 5.00000e-05 1.00000e-09 1.00000e-01

9.88626e-01 9.88626e-01 9.88626e-02 1.00000e-09 2.12000e-01

9.88626e-01 9.88626e-01 9.88626e-02 1.00000e-09 2.12000e-01

$1.00000 \mathrm{e}-02$ 1.00000e-02 1.00000e-03 1.00000e-09 1.00000e-01

$1.00000 \mathrm{e}+001.00000 \mathrm{e}+001.00000 \mathrm{e}-011.00000 \mathrm{e}-091.00000 \mathrm{e}-01$

Element: 4616 \# of layers: 8

$\mathrm{Kx} \mathrm{Ky} \mathrm{Kz}$ Ss Por

$2.47424 \mathrm{e}+012.47424 \mathrm{e}+012.47424 \mathrm{e}+00$ 1.00000e-09 7.00000e-02

$2.47424 \mathrm{e}+012.47424 \mathrm{e}+012.47424 \mathrm{e}+001.00000 \mathrm{e}-09$ 7.00000e-02

$2.47424 \mathrm{e}+012.47424 \mathrm{e}+012.47424 \mathrm{e}+001.00000 \mathrm{e}-09$ 7.00000e-02

5.00000e-04 5.00000e-04 5.00000e-05 1.00000e-09 1.00000e-01

5.00000e-04 5.00000e-04 5.00000e-05 1.00000e-09 1.00000e-01

9.88626e-01 9.88626e-01 9.88626e-02 1.00000e-09 2.12000e-01

$1.00000 \mathrm{e}-02$ 1.00000e-02 1.00000e-03 1.00000e-09 1.00000e-01

$1.00000 \mathrm{e}+001.00000 \mathrm{e}+001.00000 \mathrm{e}-01$ 1.00000e-09 1.00000e-01

Element: 4617 \# of layers: 7

Kx Ky Kz Ss Por

9.01864e+00 9.01864e+00 9.01864e-01 1.00000e-09 2.12000e-01

$9.01864 \mathrm{e}+009.01864 \mathrm{e}+00$ 9.01864e-01 1.00000e-09 2.12000e-01

$9.01864 \mathrm{e}+00$ 9.01864e+00 9.01864e-01 1.00000e-09 2.12000e-01

$9.01864 \mathrm{e}+009.01864 \mathrm{e}+00 \quad 9.01864 \mathrm{e}-01$ 1.00000e-09 2.12000e-01

$9.01864 \mathrm{e}+009.01864 \mathrm{e}+00$ 9.01864e-01 1.00000e-09 2.12000e-01

$1.00000 \mathrm{e}-05$ 1.00000e-05 1.00000e-06 1.00000e-09 1.00000e-01

$1.00000 \mathrm{e}+001.00000 \mathrm{e}+001.00000 \mathrm{e}-01$ 1.00000e-09 1.00000e-01

Element: 4618 \# of layers: 7

$\mathrm{Kx} \mathrm{Ky} \mathrm{Kz}$ Ss Por

9.01864e+00 9.01864e+00 9.01864e-01 1.00000e-09 2.12000e-01

$9.01864 \mathrm{e}+009.01864 \mathrm{e}+00$ 9.01864e-01 1.00000e-09 2.12000e-01

$9.01864 \mathrm{e}+009.01864 \mathrm{e}+00$ 9.01864e-01 1.00000e-09 2.12000e-01

$9.01864 \mathrm{e}+009.01864 \mathrm{e}+00$ 9.01864e-01 1.00000e-09 2.12000e-01

$9.01864 \mathrm{e}+009.01864 \mathrm{e}+00$ 9.01864e-01 1.00000e-09 2.12000e-01

$1.00000 \mathrm{e}-05$ 1.00000e-05 1.00000e-06 1.00000e-09 1.00000e-01

$1.00000 \mathrm{e}+001.00000 \mathrm{e}+001.00000 \mathrm{e}-011.00000 \mathrm{e}-091.00000 \mathrm{e}-01$

Element: 4619 \# of layers: 7

$\mathrm{Kx} \mathrm{Ky} \mathrm{Kz}$ Ss Por

7.68751e+00 7.68751e+00 7.68751e-01 1.00000e-09 2.12000e-01

$7.68751 \mathrm{e}+00$ 7.68751e+00 7.68751e-01 1.00000e-09 2.12000e-01

$7.68751 \mathrm{e}+007.68751 \mathrm{e}+00$ 7.68751e-01 1.00000e-09 2.12000e-01 
$7.68751 \mathrm{e}+007.68751 \mathrm{e}+00$ 7.68751e-01 1.00000e-09 2.12000e-01 $7.68751 \mathrm{e}+007.68751 \mathrm{e}+00$ 7.68751e-01 1.00000e-09 2.12000e-01 $1.00000 \mathrm{e}-05$ 1.00000e-05 1.00000e-06 1.00000e-09 1.00000e-01 $1.00000 \mathrm{e}+001.00000 \mathrm{e}+001.00000 \mathrm{e}-011.00000 \mathrm{e}-091.00000 \mathrm{e}-01$ Element: 4620 \# of layers: 7

Kx Ky Kz Ss Por

$7.66344 \mathrm{e}+007.66344 \mathrm{e}+00$ 7.66344e-01 1.00000e-09 2.12000e-01

$7.66344 \mathrm{e}+007.66344 \mathrm{e}+007.66344 \mathrm{e}-011.00000 \mathrm{e}-092.12000 \mathrm{e}-01$

$7.66344 \mathrm{e}+007.66344 \mathrm{e}+007.66344 \mathrm{e}-011.00000 \mathrm{e}-092.12000 \mathrm{e}-01$

$7.66344 \mathrm{e}+007.66344 \mathrm{e}+007.66344 \mathrm{e}-011.00000 \mathrm{e}-092.12000 \mathrm{e}-01$

$7.66344 \mathrm{e}+00$ 7.66344e+00 7.66344e-01 1.00000e-09 2.12000e-01

$1.00000 \mathrm{e}-05$ 1.00000e-05 1.00000e-06 1.00000e-09 1.00000e-01

$1.00000 \mathrm{e}+001.00000 \mathrm{e}+001.00000 \mathrm{e}-011.00000 \mathrm{e}-091.00000 \mathrm{e}-01$

Element: 4621 \# of layers: 5

Kx Ky Kz Ss Por

$1.64324 \mathrm{e}+031.64324 \mathrm{e}+031.64324 \mathrm{e}+021.00000 \mathrm{e}-09$ 7.00000e-02

$6.56587 \mathrm{e}+016.56587 \mathrm{e}+016.56587 \mathrm{e}+001.00000 \mathrm{e}-092.12000 \mathrm{e}-01$

$1.00000 \mathrm{e}-05$ 1.00000e-05 1.00000e-06 1.00000e-09 1.00000e-01

$1.00000 \mathrm{e}+001.00000 \mathrm{e}+001.00000 \mathrm{e}-011.00000 \mathrm{e}-091.00000 \mathrm{e}-01$

$1.00000 \mathrm{e}-061.00000 \mathrm{e}-06$ 1.00000e-06 1.00000e-09 5.00000e-02

Element: 4622 \# of layers: 5

Kx Ky Kz Ss Por

$1.64324 \mathrm{e}+031.64324 \mathrm{e}+031.64324 \mathrm{e}+021.00000 \mathrm{e}-097.00000 \mathrm{e}-02$

$6.56587 \mathrm{e}+016.56587 \mathrm{e}+016.56587 \mathrm{e}+001.00000 \mathrm{e}-092.12000 \mathrm{e}-01$

$1.00000 \mathrm{e}-05$ 1.00000e-05 1.00000e-06 1.00000e-09 1.00000e-01

$1.00000 \mathrm{e}+001.00000 \mathrm{e}+001.00000 \mathrm{e}-011.00000 \mathrm{e}-091.00000 \mathrm{e}-01$

$1.00000 \mathrm{e}-06$ 1.00000e-06 1.00000e-06 1.00000e-09 5.00000e-02

Element: 4623 \# of layers: 6

Kx Ky Kz Ss Por

$1.87408 \mathrm{e}+03$ 1.87408e+03 1.87408e+02 1.00000e-09 7.00000e-02

$1.87408 \mathrm{e}+031.87408 \mathrm{e}+031.87408 \mathrm{e}+021.00000 \mathrm{e}-097.00000 \mathrm{e}-02$

$7.48816 \mathrm{e}+01$ 7.48816e+01 7.48816e+00 1.00000e-09 2.12000e-01

$1.00000 \mathrm{e}-05$ 1.00000e-05 1.00000e-06 1.00000e-09 1.00000e-01

$1.00000 \mathrm{e}+001.00000 \mathrm{e}+001.00000 \mathrm{e}-011.00000 \mathrm{e}-091.00000 \mathrm{e}-01$

$1.00000 \mathrm{e}-06$ 1.00000e-06 1.00000e-06 1.00000e-09 5.00000e-02

Element: 4624 \# of layers: 5

Kx Ky Kz Ss Por

$1.87408 \mathrm{e}+03$ 1.87408e+03 1.87408e+02 1.00000e-09 7.00000e-02

$7.48816 \mathrm{e}+01$ 7.48816e+01 7.48816e+00 1.00000e-09 2.12000e-01

$1.00000 \mathrm{e}-05$ 1.00000e-05 1.00000e-06 1.00000e-09 1.00000e-01

$1.00000 \mathrm{e}+001.00000 \mathrm{e}+001.00000 \mathrm{e}-011.00000 \mathrm{e}-091.00000 \mathrm{e}-01$

$1.00000 \mathrm{e}-06$ 1.00000e-06 1.00000e-06 1.00000e-09 5.00000e-02

Element: 4625 \# of layers: 5

Kx Ky Kz Ss Por

$1.64324 \mathrm{e}+031.64324 \mathrm{e}+031.64324 \mathrm{e}+021.00000 \mathrm{e}-097.00000 \mathrm{e}-02$

$6.56587 \mathrm{e}+016.56587 \mathrm{e}+016.56587 \mathrm{e}+001.00000 \mathrm{e}-092.12000 \mathrm{e}-01$ 
$1.00000 \mathrm{e}-05$ 1.00000e-05 1.00000e-06 1.00000e-09 1.00000e-01 $1.00000 \mathrm{e}+001.00000 \mathrm{e}+001.00000 \mathrm{e}-01$ 1.00000e-09 1.00000e-01 1.00000e-06 1.00000e-06 1.00000e-06 1.00000e-09 5.00000e-02

Element: 4626 \# of layers: 5

$\mathrm{Kx} \mathrm{Ky} \mathrm{Kz}$ Ss Por

$1.50296 \mathrm{e}+031.50296 \mathrm{e}+03$ 1.50296e+02 1.00000e-09 7.00000e-02 $6.00515 \mathrm{e}+016.00515 \mathrm{e}+016.00515 \mathrm{e}+00$ 1.00000e-09 2.12000e-01 $1.00000 \mathrm{e}-05$ 1.00000e-05 1.00000e-06 1.00000e-09 1.00000e-01 $1.00000 \mathrm{e}+001.00000 \mathrm{e}+001.00000 \mathrm{e}-011.00000 \mathrm{e}-091.00000 \mathrm{e}-01$ 1.00000e-06 1.00000e-06 1.00000e-06 1.00000e-09 5.00000e-02 Element: 4627 \# of layers: 5

Kx Ky Kz Ss Por

$1.08598 \mathrm{e}+04$ 1.08598e+04 1.08598e+03 1.00000e-09 7.00000e-02 4.33922e+02 4.33922e+02 4.33922e+01 1.00000e-09 2.12000e-01 $1.00000 \mathrm{e}-05$ 1.00000e-05 1.00000e-06 1.00000e-09 1.00000e-01 $1.00000 \mathrm{e}+001.00000 \mathrm{e}+001.00000 \mathrm{e}-011.00000 \mathrm{e}-091.00000 \mathrm{e}-01$ 1.00000e-06 1.00000e-06 1.00000e-06 1.00000e-09 5.00000e-02 Element: 4628 \# of layers: 5

$\mathrm{Kx} \mathrm{Ky} \mathrm{Kz}$ Ss Por 1.08598e+04 1.08598e+04 1.08598e+03 1.00000e-09 7.00000e-02 $4.33922 \mathrm{e}+02$ 4.33922e+02 4.33922e+01 1.00000e-09 2.12000e-01 $1.00000 \mathrm{e}-05$ 1.00000e-05 1.00000e-06 1.00000e-09 1.00000e-01 $1.00000 \mathrm{e}+001.00000 \mathrm{e}+001.00000 \mathrm{e}-011.00000 \mathrm{e}-091.00000 \mathrm{e}-01$ 1.00000e-06 1.00000e-06 1.00000e-06 1.00000e-09 5.00000e-02

Element: 4629 \# of layers: 5

$\mathrm{Kx} \mathrm{Ky} \mathrm{Kz}$ Ss Por

$1.08598 \mathrm{e}+041.08598 \mathrm{e}+041.08598 \mathrm{e}+03$ 1.00000e-09 7.00000e-02 $1.08598 \mathrm{e}+04$ 1.08598e+04 1.08598e+03 1.00000e-09 7.00000e-02 $4.33922 \mathrm{e}+02$ 4.33922e+02 4.33922e+01 1.00000e-09 2.12000e-01 $1.00000 \mathrm{e}+001.00000 \mathrm{e}+001.00000 \mathrm{e}-011.00000 \mathrm{e}-091.00000 \mathrm{e}-01$ 1.00000e-06 1.00000e-06 1.00000e-06 1.00000e-09 5.00000e-02 Element: 4630 \# of layers: 4

$\mathrm{Kx} \mathrm{Ky} \mathrm{Kz}$ Ss Por

6.94302e+03 6.94302e+03 6.94302e+02 1.00000e-09 7.00000e-02 $6.94302 \mathrm{e}+036.94302 \mathrm{e}+03$ 6.94302e+02 1.00000e-09 7.00000e-02 $1.00000 \mathrm{e}+001.00000 \mathrm{e}+001.00000 \mathrm{e}-011.00000 \mathrm{e}-091.00000 \mathrm{e}-01$ 1.00000e-06 1.00000e-06 1.00000e-06 1.00000e-09 5.00000e-02

Element: 4631 \# of layers: 5

$\mathrm{Kx} \mathrm{Ky} \mathrm{Kz}$ Ss Por

6.94302e+03 6.94302e+03 6.94302e+02 1.00000e-09 7.00000e-02 $6.94302 \mathrm{e}+036.94302 \mathrm{e}+03$ 6.94302e+02 1.00000e-09 7.00000e-02 $2.77408 \mathrm{e}+02$ 2.77408e+02 2.77408e+01 1.00000e-09 2.12000e-01 $1.00000 \mathrm{e}+001.00000 \mathrm{e}+001.00000 \mathrm{e}-011.00000 \mathrm{e}-091.00000 \mathrm{e}-01$ 1.00000e-06 1.00000e-06 1.00000e-06 1.00000e-09 5.00000e-02 Element: 4632 \# of layers: 7

Kx Ky Kz Ss Por 
3.69410e+03 3.69410e+03 3.69410e+02 1.00000e-09 7.00000e-02 $3.69410 \mathrm{e}+03$ 3.69410e+03 3.69410e+02 1.00000e-09 7.00000e-02 $1.47603 \mathrm{e}+02$ 1.47603e+02 1.47603e+01 1.00000e-09 2.12000e-01 $1.47603 \mathrm{e}+02$ 1.47603e+02 1.47603e+01 1.00000e-09 2.12000e-01 $1.00000 \mathrm{e}-05$ 1.00000e-05 1.00000e-06 1.00000e-09 1.00000e-01 $1.00000 \mathrm{e}+001.00000 \mathrm{e}+001.00000 \mathrm{e}-011.00000 \mathrm{e}-091.00000 \mathrm{e}-01$ 1.00000e-06 1.00000e-06 1.00000e-06 1.00000e-09 5.00000e-02 Element: 4633 \# of layers: 7

$\mathrm{Kx} \mathrm{Ky} \mathrm{Kz}$ Ss Por

$1.50296 \mathrm{e}+031.50296 \mathrm{e}+03$ 1.50296e+02 1.00000e-09 7.00000e-02 $1.50296 \mathrm{e}+031.50296 \mathrm{e}+03$ 1.50296e+02 1.00000e-09 7.00000e-02 $6.00515 \mathrm{e}+016.00515 \mathrm{e}+016.00515 \mathrm{e}+00$ 1.00000e-09 2.12000e-01 $6.00515 \mathrm{e}+016.00515 \mathrm{e}+016.00515 \mathrm{e}+00$ 1.00000e-09 2.12000e-01 $1.00000 \mathrm{e}-05$ 1.00000e-05 1.00000e-06 1.00000e-09 1.00000e-01 $1.00000 \mathrm{e}+001.00000 \mathrm{e}+001.00000 \mathrm{e}-011.00000 \mathrm{e}-091.00000 \mathrm{e}-01$ 1.00000e-06 1.00000e-06 1.00000e-06 1.00000e-09 5.00000e-02

Element: 4634 \# of layers: 7

$\mathrm{Kx} \mathrm{Ky} \mathrm{Kz}$ Ss Por

$1.08598 \mathrm{e}+041.08598 \mathrm{e}+04$ 1.08598e+03 1.00000e-09 7.00000e-02 $1.08598 \mathrm{e}+04$ 1.08598e+04 1.08598e+03 1.00000e-09 7.00000e-02 $4.33922 \mathrm{e}+02$ 4.33922e+02 4.33922e+01 1.00000e-09 2.12000e-01 4.33922e+02 4.33922e+02 4.33922e+01 1.00000e-09 2.12000e-01 $1.00000 \mathrm{e}-051.00000 \mathrm{e}-051.00000 \mathrm{e}-061.00000 \mathrm{e}-091.00000 \mathrm{e}-01$ $1.00000 \mathrm{e}+001.00000 \mathrm{e}+001.00000 \mathrm{e}-011.00000 \mathrm{e}-091.00000 \mathrm{e}-01$ 1.00000e-06 1.00000e-06 1.00000e-06 1.00000e-09 5.00000e-02 Element: 4635 \# of layers: 5

$\mathrm{Kx} \mathrm{Ky} \mathrm{Kz}$ Ss Por

3.38704e+04 3.38704e+04 3.38704e+03 1.00000e-09 7.00000e-02 $1.35334 \mathrm{e}+03$ 1.35334e+03 1.35334e+02 1.00000e-09 2.12000e-01 $1.35334 \mathrm{e}+03$ 1.35334e+03 1.35334e+02 1.00000e-09 2.12000e-01 $1.00000 \mathrm{e}+001.00000 \mathrm{e}+001.00000 \mathrm{e}-011.00000 \mathrm{e}-091.00000 \mathrm{e}-01$ 1.00000e-06 1.00000e-06 1.00000e-06 1.00000e-09 5.00000e-02 Element: 4636 \# of layers: 5

$\mathrm{Kx} \mathrm{Ky} \mathrm{Kz}$ Ss Por

$1.40646 \mathrm{e}+041.40646 \mathrm{e}+041.40646 \mathrm{e}+03$ 1.00000e-09 7.00000e-02 $1.35334 \mathrm{e}+031.35334 \mathrm{e}+03$ 1.35334e+02 1.00000e-09 2.12000e-01 $1.35334 \mathrm{e}+031.35334 \mathrm{e}+031.35334 \mathrm{e}+021.00000 \mathrm{e}-092.12000 \mathrm{e}-01$ $1.00000 \mathrm{e}+001.00000 \mathrm{e}+001.00000 \mathrm{e}-011.00000 \mathrm{e}-091.00000 \mathrm{e}-01$ 1.00000e-06 1.00000e-06 1.00000e-06 1.00000e-09 5.00000e-02 Element: 4637 \# of layers: 4

$\mathrm{Kx} \mathrm{Ky} \mathrm{Kz}$ Ss Por

$1.40646 \mathrm{e}+041.40646 \mathrm{e}+04$ 1.40646e+03 1.00000e-09 7.00000e-02 $1.40646 \mathrm{e}+041.40646 \mathrm{e}+041.40646 \mathrm{e}+031.00000 \mathrm{e}-09$ 7.00000e-02 $1.00000 \mathrm{e}+001.00000 \mathrm{e}+001.00000 \mathrm{e}-011.00000 \mathrm{e}-091.00000 \mathrm{e}-01$ 1.00000e-06 1.00000e-06 1.00000e-06 1.00000e-09 5.00000e-02 Element: 4638 \# of layers: 4 
$\mathrm{Kx} \mathrm{Ky} \mathrm{Kz} \mathrm{Ss} \mathrm{Por}$

1.40646e+04 1.40646e+04 1.40646e+03 1.00000e-09 7.00000e-02

$1.40646 \mathrm{e}+041.40646 \mathrm{e}+041.40646 \mathrm{e}+03$ 1.00000e-09 7.00000e-02

$1.00000 \mathrm{e}+001.00000 \mathrm{e}+001.00000 \mathrm{e}-011.00000 \mathrm{e}-091.00000 \mathrm{e}-01$

1.00000e-06 1.00000e-06 1.00000e-06 1.00000e-09 5.00000e-02

Element: 4639 \# of layers: 4

$\mathrm{Kx} \mathrm{Ky} \mathrm{Kz}$ Ss Por

1.17923e+04 1.17923e+04 1.17923e+03 1.00000e-09 7.00000e-02

$1.17923 \mathrm{e}+041.17923 \mathrm{e}+04$ 1.17923e+03 1.00000e-09 7.00000e-02

$1.00000 \mathrm{e}+001.00000 \mathrm{e}+001.00000 \mathrm{e}-011.00000 \mathrm{e}-091.00000 \mathrm{e}-01$

1.00000e-06 1.00000e-06 1.00000e-06 1.00000e-09 5.00000e-02

Element: 4640 \# of layers: 3

$\mathrm{Kx} \mathrm{Ky} \mathrm{Kz}$ Ss Por

$1.17923 \mathrm{e}+04$ 1.17923e+04 1.17923e+03 1.00000e-09 7.00000e-02

$1.00000 \mathrm{e}+001.00000 \mathrm{e}+001.00000 \mathrm{e}-011.00000 \mathrm{e}-091.00000 \mathrm{e}-01$

1.00000e-06 1.00000e-06 1.00000e-06 1.00000e-09 5.00000e-02

Element: 4641 \# of layers: 4

$\mathrm{Kx} \mathrm{Ky} \mathrm{Kz}$ Ss Por

1.17238e+04 1.17238e+04 1.17238e+03 1.00000e-09 7.00000e-02

$1.17238 \mathrm{e}+041.17238 \mathrm{e}+041.17238 \mathrm{e}+03$ 1.00000e-09 7.00000e-02

$1.00000 \mathrm{e}+001.00000 \mathrm{e}+001.00000 \mathrm{e}-011.00000 \mathrm{e}-091.00000 \mathrm{e}-01$

1.00000e-06 1.00000e-06 1.00000e-06 1.00000e-09 5.00000e-02

Element: 4642 \# of layers: 4

Kx Ky Kz Ss Por

3.38704e+04 3.38704e+04 3.38704e+03 1.00000e-09 7.00000e-02

$3.38704 \mathrm{e}+043.38704 \mathrm{e}+043.38704 \mathrm{e}+03$ 1.00000e-09 7.00000e-02

$1.00000 \mathrm{e}+001.00000 \mathrm{e}+001.00000 \mathrm{e}-011.00000 \mathrm{e}-091.00000 \mathrm{e}-01$

1.00000e-06 1.00000e-06 1.00000e-06 1.00000e-09 5.00000e-02

Element: 4643 \# of layers: 3

$\mathrm{Kx} \mathrm{Ky} \mathrm{Kz}$ Ss Por

$1.40646 \mathrm{e}+041.40646 \mathrm{e}+041.40646 \mathrm{e}+03$ 1.00000e-09 7.00000e-02

$1.00000 \mathrm{e}+001.00000 \mathrm{e}+001.00000 \mathrm{e}-011.00000 \mathrm{e}-091.00000 \mathrm{e}-01$

1.00000e-06 1.00000e-06 1.00000e-06 1.00000e-09 5.00000e-02

Element: 4644 \# of layers: 4

$\mathrm{Kx} \mathrm{Ky} \mathrm{Kz}$ Ss Por

9.82270e+03 9.82270e+03 9.82270e+02 1.00000e-09 7.00000e-02

$9.82270 \mathrm{e}+03$ 9.82270e+03 9.82270e+02 1.00000e-09 7.00000e-02

$1.00000 \mathrm{e}+001.00000 \mathrm{e}+001.00000 \mathrm{e}-011.00000 \mathrm{e}-091.00000 \mathrm{e}-01$

1.00000e-06 1.00000e-06 1.00000e-06 1.00000e-09 5.00000e-02

Element: 4645 \# of layers: 4

$\mathrm{Kx} \mathrm{Ky} \mathrm{Kz}$ Ss Por

$1.35024 \mathrm{e}+041.35024 \mathrm{e}+041.35024 \mathrm{e}+03$ 1.00000e-09 7.00000e-02

$1.35024 \mathrm{e}+041.35024 \mathrm{e}+041.35024 \mathrm{e}+031.00000 \mathrm{e}-097.00000 \mathrm{e}-02$

$1.00000 \mathrm{e}+001.00000 \mathrm{e}+001.00000 \mathrm{e}-011.00000 \mathrm{e}-091.00000 \mathrm{e}-01$

1.00000e-06 1.00000e-06 1.00000e-06 1.00000e-09 5.00000e-02

Element: 4646 \# of layers: 4 
$\mathrm{Kx} \mathrm{Ky} \mathrm{Kz}$ Ss Por

$1.35024 \mathrm{e}+041.35024 \mathrm{e}+04$ 1.35024e+03 1.00000e-09 7.00000e-02

$1.35024 \mathrm{e}+041.35024 \mathrm{e}+041.35024 \mathrm{e}+031.00000 \mathrm{e}-097.00000 \mathrm{e}-02$

$1.00000 \mathrm{e}+001.00000 \mathrm{e}+001.00000 \mathrm{e}-011.00000 \mathrm{e}-091.00000 \mathrm{e}-01$

1.00000e-06 1.00000e-06 1.00000e-06 1.00000e-09 5.00000e-02

Element: 4647 \# of layers: 4

$\mathrm{Kx} \mathrm{Ky} \mathrm{Kz}$ Ss Por

9.33706e+03 9.33706e+03 9.33706e+02 1.00000e-09 7.00000e-02

$9.33706 \mathrm{e}+03$ 9.33706e+03 9.33706e+02 1.00000e-09 7.00000e-02

$1.00000 \mathrm{e}+001.00000 \mathrm{e}+001.00000 \mathrm{e}-011.00000 \mathrm{e}-091.00000 \mathrm{e}-01$

1.00000e-06 1.00000e-06 1.00000e-06 1.00000e-09 5.00000e-02

Element: 4648 \# of layers: 4

$\mathrm{Kx} \mathrm{Ky} \mathrm{Kz}$ Ss Por

9.33706e+03 9.33706e+03 9.33706e+02 1.00000e-09 7.00000e-02

9.33706e+03 9.33706e+03 9.33706e+02 1.00000e-09 7.00000e-02

$1.00000 \mathrm{e}+001.00000 \mathrm{e}+001.00000 \mathrm{e}-011.00000 \mathrm{e}-091.00000 \mathrm{e}-01$

1.00000e-06 1.00000e-06 1.00000e-06 1.00000e-09 5.00000e-02

Element: 4649 \# of layers: 3

$\mathrm{Kx} \mathrm{Ky} \mathrm{Kz}$ Ss Por

9.33706e+03 9.33706e+03 9.33706e+02 1.00000e-09 7.00000e-02

$1.00000 \mathrm{e}+001.00000 \mathrm{e}+001.00000 \mathrm{e}-011.00000 \mathrm{e}-091.00000 \mathrm{e}-01$

1.00000e-06 1.00000e-06 1.00000e-06 1.00000e-09 5.00000e-02

Element: 4650 \# of layers: 4

Kx Ky Kz Ss Por

8.15027e+03 8.15027e+03 8.15027e+02 1.00000e-09 7.00000e-02

8.15027e+03 8.15027e+03 8.15027e+02 1.00000e-09 7.00000e-02

$1.00000 \mathrm{e}+001.00000 \mathrm{e}+001.00000 \mathrm{e}-011.00000 \mathrm{e}-091.00000 \mathrm{e}-01$

1.00000e-06 1.00000e-06 1.00000e-06 1.00000e-09 5.00000e-02

Element: 4651 \# of layers: 4

$\mathrm{Kx} \mathrm{Ky} \mathrm{Kz}$ Ss Por

8.15027e+03 8.15027e+03 8.15027e+02 1.00000e-09 7.00000e-02

8.15027e+03 8.15027e+03 8.15027e+02 1.00000e-09 7.00000e-02

$1.00000 \mathrm{e}+001.00000 \mathrm{e}+001.00000 \mathrm{e}-011.00000 \mathrm{e}-091.00000 \mathrm{e}-01$

1.00000e-06 1.00000e-06 1.00000e-06 1.00000e-09 5.00000e-02

Element: 4652 \# of layers: 3

$\mathrm{Kx} \mathrm{Ky} \mathrm{Kz}$ Ss Por

$1.35024 \mathrm{e}+041.35024 \mathrm{e}+041.35024 \mathrm{e}+03$ 1.00000e-09 7.00000e-02

$1.00000 \mathrm{e}+001.00000 \mathrm{e}+001.00000 \mathrm{e}-011.00000 \mathrm{e}-091.00000 \mathrm{e}-01$

1.00000e-06 1.00000e-06 1.00000e-06 1.00000e-09 5.00000e-02

Element: 4653 \# of layers: 4

$\mathrm{Kx} \mathrm{Ky} \mathrm{Kz}$ Ss Por

$2.43576 \mathrm{e}+042.43576 \mathrm{e}+042.43576 \mathrm{e}+03$ 1.00000e-09 7.00000e-02

$2.43576 \mathrm{e}+042.43576 \mathrm{e}+042.43576 \mathrm{e}+03$ 1.00000e-09 7.00000e-02

$1.00000 \mathrm{e}+001.00000 \mathrm{e}+001.00000 \mathrm{e}-011.00000 \mathrm{e}-091.00000 \mathrm{e}-01$

1.00000e-06 1.00000e-06 1.00000e-06 1.00000e-09 5.00000e-02

Element: 4654 \# of layers: 3 
$\mathrm{Kx} \mathrm{Ky} \mathrm{Kz}$ Ss Por

$2.40513 \mathrm{e}+042.40513 \mathrm{e}+042.40513 \mathrm{e}+03$ 1.00000e-09 7.00000e-02

$1.00000 \mathrm{e}+001.00000 \mathrm{e}+001.00000 \mathrm{e}-011.00000 \mathrm{e}-091.00000 \mathrm{e}-01$

$1.00000 \mathrm{e}-06$ 1.00000e-06 1.00000e-06 1.00000e-09 5.00000e-02

Element: 4655 \# of layers: 3

$\mathrm{Kx} \mathrm{Ky} \mathrm{Kz}$ Ss Por

2.40513e+04 2.40513e+04 2.40513e+03 1.00000e-09 7.00000e-02

$1.00000 \mathrm{e}+001.00000 \mathrm{e}+001.00000 \mathrm{e}-011.00000 \mathrm{e}-091.00000 \mathrm{e}-01$

1.00000e-06 1.00000e-06 1.00000e-06 1.00000e-09 5.00000e-02

Element: 4656 \# of layers: 3

$\mathrm{Kx} \mathrm{Ky} \mathrm{Kz}$ Ss Por

$2.40513 \mathrm{e}+042.40513 \mathrm{e}+042.40513 \mathrm{e}+03$ 1.00000e-09 7.00000e-02

$1.00000 \mathrm{e}+001.00000 \mathrm{e}+001.00000 \mathrm{e}-011.00000 \mathrm{e}-091.00000 \mathrm{e}-01$

1.00000e-06 1.00000e-06 1.00000e-06 1.00000e-09 5.00000e-02

Element: 4657 \# of layers: 3

Kx Ky Kz Ss Por

$1.13148 \mathrm{e}+041.13148 \mathrm{e}+04$ 1.13148e+03 1.00000e-09 7.00000e-02 $1.00000 \mathrm{e}+001.00000 \mathrm{e}+001.00000 \mathrm{e}-011.00000 \mathrm{e}-091.00000 \mathrm{e}-01$

1.00000e-06 1.00000e-06 1.00000e-06 1.00000e-09 5.00000e-02

Element: 4658 \# of layers: 3

$\mathrm{Kx} \mathrm{Ky} \mathrm{Kz}$ Ss Por

$1.13148 \mathrm{e}+04$ 1.13148e+04 1.13148e+03 1.00000e-09 7.00000e-02

$1.00000 \mathrm{e}+001.00000 \mathrm{e}+001.00000 \mathrm{e}-011.00000 \mathrm{e}-091.00000 \mathrm{e}-01$

1.00000e-06 1.00000e-06 1.00000e-06 1.00000e-09 5.00000e-02

Element: 4659 \# of layers: 4

$\mathrm{Kx} \mathrm{Ky} \mathrm{Kz}$ Ss Por

$1.28510 \mathrm{e}+041.28510 \mathrm{e}+041.28510 \mathrm{e}+03$ 1.00000e-09 7.00000e-02

$1.28510 \mathrm{e}+041.28510 \mathrm{e}+041.28510 \mathrm{e}+03$ 1.00000e-09 7.00000e-02

$1.00000 \mathrm{e}+001.00000 \mathrm{e}+001.00000 \mathrm{e}-011.00000 \mathrm{e}-091.00000 \mathrm{e}-01$

1.00000e-06 1.00000e-06 1.00000e-06 1.00000e-09 5.00000e-02

Element: 4660 \# of layers: 4

$\mathrm{Kx} \mathrm{Ky} \mathrm{Kz}$ Ss Por

$1.28510 \mathrm{e}+041.28510 \mathrm{e}+041.28510 \mathrm{e}+03$ 1.00000e-09 7.00000e-02

$1.28510 \mathrm{e}+041.28510 \mathrm{e}+041.28510 \mathrm{e}+03$ 1.00000e-09 7.00000e-02

$1.00000 \mathrm{e}+001.00000 \mathrm{e}+001.00000 \mathrm{e}-011.00000 \mathrm{e}-091.00000 \mathrm{e}-01$

1.00000e-06 1.00000e-06 1.00000e-06 1.00000e-09 5.00000e-02

Element: 4661 \# of layers: 3

Kx Ky Kz Ss Por

$2.40513 \mathrm{e}+042.40513 \mathrm{e}+042.40513 \mathrm{e}+03$ 1.00000e-09 7.00000e-02 $1.00000 \mathrm{e}+001.00000 \mathrm{e}+001.00000 \mathrm{e}-011.00000 \mathrm{e}-091.00000 \mathrm{e}-01$

1.00000e-06 1.00000e-06 1.00000e-06 1.00000e-09 5.00000e-02

Element: 4662 \# of layers: 3

$\mathrm{Kx} \mathrm{Ky} \mathrm{Kz}$ Ss Por

2.26791e+03 2.26791e+03 2.26791e+02 1.00000e-09 7.00000e-02 $1.00000 \mathrm{e}+001.00000 \mathrm{e}+001.00000 \mathrm{e}-011.00000 \mathrm{e}-091.00000 \mathrm{e}-01$ $1.00000 \mathrm{e}-06$ 1.00000e-06 1.00000e-06 1.00000e-09 5.00000e-02 
Element: 4663 \# of layers: 4

$\mathrm{Kx} \mathrm{Ky} \mathrm{Kz}$ Ss Por

$1.53594 \mathrm{e}+03$ 1.53594e+03 1.53594e+02 1.00000e-09 7.00000e-02

$1.53594 \mathrm{e}+031.53594 \mathrm{e}+03$ 1.53594e+02 1.00000e-09 7.00000e-02

$1.00000 \mathrm{e}+001.00000 \mathrm{e}+001.00000 \mathrm{e}-011.00000 \mathrm{e}-091.00000 \mathrm{e}-01$

1.00000e-06 1.00000e-06 1.00000e-06 1.00000e-09 5.00000e-02

Element: 4664 \# of layers: 4

$\mathrm{Kx} \mathrm{Ky} \mathrm{Kz}$ Ss Por

$1.53594 \mathrm{e}+031.53594 \mathrm{e}+03$ 1.53594e+02 1.00000e-09 7.00000e-02

$1.53594 \mathrm{e}+031.53594 \mathrm{e}+031.53594 \mathrm{e}+021.00000 \mathrm{e}-097.00000 \mathrm{e}-02$

$1.00000 \mathrm{e}+001.00000 \mathrm{e}+001.00000 \mathrm{e}-011.00000 \mathrm{e}-091.00000 \mathrm{e}-01$

1.00000e-06 1.00000e-06 1.00000e-06 1.00000e-09 5.00000e-02

Element: 4665 \# of layers: 4

$\mathrm{Kx} \mathrm{Ky} \mathrm{Kz}$ Ss Por

8.95684e+02 8.95684e+02 8.95684e+01 1.00000e-09 7.00000e-02

$8.95684 \mathrm{e}+028.95684 \mathrm{e}+028.95684 \mathrm{e}+01$ 1.00000e-09 7.00000e-02

$1.00000 \mathrm{e}+001.00000 \mathrm{e}+001.00000 \mathrm{e}-011.00000 \mathrm{e}-091.00000 \mathrm{e}-01$

1.00000e-06 1.00000e-06 1.00000e-06 1.00000e-09 5.00000e-02

Element: 4666 \# of layers: 4

$\mathrm{Kx} \mathrm{Ky} \mathrm{Kz}$ Ss Por

8.95684e+02 8.95684e+02 8.95684e+01 1.00000e-09 7.00000e-02

$8.95684 \mathrm{e}+02$ 8.95684e+02 8.95684e+01 1.00000e-09 7.00000e-02

$1.00000 \mathrm{e}+001.00000 \mathrm{e}+001.00000 \mathrm{e}-011.00000 \mathrm{e}-091.00000 \mathrm{e}-01$

1.00000e-06 1.00000e-06 1.00000e-06 1.00000e-09 5.00000e-02

Element: 4667 \# of layers: 3

$\mathrm{Kx} \mathrm{Ky} \mathrm{Kz}$ Ss Por

8.95684e+02 8.95684e+02 8.95684e+01 1.00000e-09 7.00000e-02

$1.00000 \mathrm{e}+001.00000 \mathrm{e}+001.00000 \mathrm{e}-011.00000 \mathrm{e}-091.00000 \mathrm{e}-01$

1.00000e-06 1.00000e-06 1.00000e-06 1.00000e-09 5.00000e-02

Element: 4668 \# of layers: 3

$\mathrm{Kx} \mathrm{Ky} \mathrm{Kz}$ Ss Por

1.19067e+03 1.19067e+03 1.19067e+02 1.00000e-09 7.00000e-02

$1.00000 \mathrm{e}+001.00000 \mathrm{e}+001.00000 \mathrm{e}-011.00000 \mathrm{e}-091.00000 \mathrm{e}-01$

1.00000e-06 1.00000e-06 1.00000e-06 1.00000e-09 5.00000e-02

Element: 4669 \# of layers: 3

$\mathrm{Kx} \mathrm{Ky} \mathrm{Kz}$ Ss Por

2.26791e+03 2.26791e+03 2.26791e+02 1.00000e-09 7.00000e-02

$1.00000 \mathrm{e}+001.00000 \mathrm{e}+001.00000 \mathrm{e}-011.00000 \mathrm{e}-091.00000 \mathrm{e}-01$

1.00000e-06 1.00000e-06 1.00000e-06 1.00000e-09 5.00000e-02

Element: 4670 \# of layers: 3

$\mathrm{Kx} \mathrm{Ky} \mathrm{Kz}$ Ss Por

$1.53594 \mathrm{e}+031.53594 \mathrm{e}+03$ 1.53594e+02 1.00000e-09 7.00000e-02 $1.00000 \mathrm{e}+001.00000 \mathrm{e}+001.00000 \mathrm{e}-011.00000 \mathrm{e}-091.00000 \mathrm{e}-01$ 1.00000e-06 1.00000e-06 1.00000e-06 1.00000e-09 5.00000e-02

Element: 4671 \# of layers: 4

Kx Ky Kz Ss Por 
$8.97288 \mathrm{e}+028.97288 \mathrm{e}+028.97288 \mathrm{e}+01$ 1.00000e-09 7.00000e-02 $8.97288 \mathrm{e}+028.97288 \mathrm{e}+028.97288 \mathrm{e}+01$ 1.00000e-09 7.00000e-02 $1.00000 \mathrm{e}+001.00000 \mathrm{e}+001.00000 \mathrm{e}-011.00000 \mathrm{e}-091.00000 \mathrm{e}-01$ $1.00000 \mathrm{e}-06$ 1.00000e-06 1.00000e-06 1.00000e-09 5.00000e-02 Element: 4672 \# of layers: 4

Kx Ky Kz Ss Por

$7.64634 \mathrm{e}+02$ 7.64634e+02 7.64634e+01 1.00000e-09 7.00000e-02

$7.64634 \mathrm{e}+02$ 7.64634e+02 7.64634e+01 1.00000e-09 7.00000e-02 $1.00000 \mathrm{e}+001.00000 \mathrm{e}+001.00000 \mathrm{e}-011.00000 \mathrm{e}-091.00000 \mathrm{e}-01$ $1.00000 \mathrm{e}-06$ 1.00000e-06 1.00000e-06 1.00000e-09 5.00000e-02 Element: 4673 \# of layers: 4

Kx Ky Kz Ss Por

$7.64634 \mathrm{e}+02$ 7.64634e+02 7.64634e+01 1.00000e-09 7.00000e-02

$7.64634 \mathrm{e}+02$ 7.64634e+02 7.64634e+01 1.00000e-09 7.00000e-02 $1.00000 \mathrm{e}+001.00000 \mathrm{e}+001.00000 \mathrm{e}-011.00000 \mathrm{e}-091.00000 \mathrm{e}-01$ $1.00000 \mathrm{e}-06$ 1.00000e-06 1.00000e-06 1.00000e-09 5.00000e-02 Element: 4674 \# of layers: 4

Kx Ky Kz Ss Por

7.64634e+02 7.64634e+02 7.64634e+01 1.00000e-09 7.00000e-02 $1.00000 \mathrm{e}-05$ 1.00000e-05 1.00000e-06 1.00000e-09 1.00000e-01 $1.00000 \mathrm{e}+001.00000 \mathrm{e}+001.00000 \mathrm{e}-011.00000 \mathrm{e}-091.00000 \mathrm{e}-01$ $1.00000 \mathrm{e}-06$ 1.00000e-06 1.00000e-06 1.00000e-09 5.00000e-02

Element: 4675 \# of layers: 4

Kx Ky Kz Ss Por

5.99742e+02 5.99742e+02 5.99742e+01 1.00000e-09 7.00000e-02 $1.00000 \mathrm{e}-05$ 1.00000e-05 1.00000e-06 1.00000e-09 1.00000e-01

$1.00000 \mathrm{e}+001.00000 \mathrm{e}+001.00000 \mathrm{e}-011.00000 \mathrm{e}-091.00000 \mathrm{e}-01$ $1.00000 \mathrm{e}-06$ 1.00000e-06 1.00000e-06 1.00000e-09 5.00000e-02

Element: 4676 \# of layers: 4

$\mathrm{Kx} \mathrm{Ky} \mathrm{Kz}$ Ss Por

5.99742e+02 5.99742e+02 5.99742e+01 1.00000e-09 7.00000e-02 $1.00000 \mathrm{e}-05$ 1.00000e-05 1.00000e-06 1.00000e-09 1.00000e-01 $1.00000 \mathrm{e}+001.00000 \mathrm{e}+001.00000 \mathrm{e}-011.00000 \mathrm{e}-091.00000 \mathrm{e}-01$ $1.00000 \mathrm{e}-06$ 1.00000e-06 1.00000e-06 1.00000e-09 5.00000e-02 Element: 4677 \# of layers: 4

Kx Ky Kz Ss Por

$6.79516 \mathrm{e}+02$ 6.79516e+02 6.79516e+01 1.00000e-09 7.00000e-02

$6.79516 \mathrm{e}+026.79516 \mathrm{e}+026.79516 \mathrm{e}+011.00000 \mathrm{e}-09$ 7.00000e-02 $1.00000 \mathrm{e}+001.00000 \mathrm{e}+001.00000 \mathrm{e}-011.00000 \mathrm{e}-091.00000 \mathrm{e}-01$ $1.00000 \mathrm{e}-06$ 1.00000e-06 1.00000e-06 1.00000e-09 5.00000e-02 Element: 4678 \# of layers: 4

Kx Ky Kz Ss Por

$6.79516 \mathrm{e}+026.79516 \mathrm{e}+026.79516 \mathrm{e}+01$ 1.00000e-09 7.00000e-02 $6.79516 \mathrm{e}+026.79516 \mathrm{e}+026.79516 \mathrm{e}+011.00000 \mathrm{e}-09$ 7.00000e-02 $1.00000 \mathrm{e}+001.00000 \mathrm{e}+001.00000 \mathrm{e}-011.00000 \mathrm{e}-091.00000 \mathrm{e}-01$ $1.00000 \mathrm{e}-06$ 1.00000e-06 1.00000e-06 1.00000e-09 5.00000e-02 
Element: 4679 \# of layers: 4

$\mathrm{Kx} \mathrm{Ky} \mathrm{Kz}$ Ss Por

7.64634e+02 7.64634e+02 7.64634e+01 1.00000e-09 7.00000e-02

$1.00000 \mathrm{e}-05$ 1.00000e-05 1.00000e-06 1.00000e-09 1.00000e-01

$1.00000 \mathrm{e}+001.00000 \mathrm{e}+001.00000 \mathrm{e}-011.00000 \mathrm{e}-091.00000 \mathrm{e}-01$

1.00000e-06 1.00000e-06 1.00000e-06 1.00000e-09 5.00000e-02

Element: 4680 \# of layers: 5

$\mathrm{Kx} \mathrm{Ky} \mathrm{Kz}$ Ss Por

6.79805e+02 6.79805e+02 6.79805e+01 1.00000e-09 7.00000e-02

6.79805e+02 6.79805e+02 6.79805e+01 1.00000e-09 7.00000e-02

$1.00000 \mathrm{e}-05$ 1.00000e-05 1.00000e-06 1.00000e-09 1.00000e-01

$1.00000 \mathrm{e}+001.00000 \mathrm{e}+001.00000 \mathrm{e}-011.00000 \mathrm{e}-091.00000 \mathrm{e}-01$

1.00000e-06 1.00000e-06 1.00000e-06 1.00000e-09 5.00000e-02

Element: 4681 \# of layers: 4

$\mathrm{Kx} \mathrm{Ky} \mathrm{Kz}$ Ss Por

3.08863e+02 3.08863e+02 3.08863e+01 1.00000e-09 7.00000e-02

$1.00000 \mathrm{e}-05$ 1.00000e-05 1.00000e-06 1.00000e-09 1.00000e-01

$1.00000 \mathrm{e}+001.00000 \mathrm{e}+001.00000 \mathrm{e}-011.00000 \mathrm{e}-091.00000 \mathrm{e}-01$

$1.00000 \mathrm{e}-06$ 1.00000e-06 1.00000e-06 1.00000e-09 5.00000e-02

Element: 4682 \# of layers: 4

$\mathrm{Kx} \mathrm{Ky} \mathrm{Kz}$ Ss Por

3.08863e+02 3.08863e+02 3.08863e+01 1.00000e-09 7.00000e-02

$1.00000 \mathrm{e}-05$ 1.00000e-05 1.00000e-06 1.00000e-09 1.00000e-01

$1.00000 \mathrm{e}+001.00000 \mathrm{e}+001.00000 \mathrm{e}-011.00000 \mathrm{e}-091.00000 \mathrm{e}-01$

1.00000e-06 1.00000e-06 1.00000e-06 1.00000e-09 5.00000e-02

Element: 4683 \# of layers: 4

$\mathrm{Kx} \mathrm{Ky} \mathrm{Kz}$ Ss Por

1.99842e+02 1.99842e+02 1.99842e+01 1.00000e-09 7.00000e-02

$1.00000 \mathrm{e}-05$ 1.00000e-05 1.00000e-06 1.00000e-09 1.00000e-01

$1.00000 \mathrm{e}+001.00000 \mathrm{e}+001.00000 \mathrm{e}-011.00000 \mathrm{e}-091.00000 \mathrm{e}-01$

1.00000e-06 1.00000e-06 1.00000e-06 1.00000e-09 5.00000e-02

Element: 4684 \# of layers: 4

$\mathrm{Kx} \mathrm{Ky} \mathrm{Kz}$ Ss Por

$1.99842 \mathrm{e}+021.99842 \mathrm{e}+02$ 1.99842e+01 1.00000e-09 7.00000e-02

$1.00000 \mathrm{e}-05$ 1.00000e-05 1.00000e-06 1.00000e-09 1.00000e-01

$1.00000 \mathrm{e}+001.00000 \mathrm{e}+001.00000 \mathrm{e}-011.00000 \mathrm{e}-091.00000 \mathrm{e}-01$

1.00000e-06 1.00000e-06 1.00000e-06 1.00000e-09 5.00000e-02

Element: 4685 \# of layers: 4

$\mathrm{Kx} \mathrm{Ky} \mathrm{Kz}$ Ss Por

1.99842e+02 1.99842e+02 1.99842e+01 1.00000e-09 7.00000e-02

$1.00000 \mathrm{e}-05$ 1.00000e-05 1.00000e-06 1.00000e-09 1.00000e-01

$1.00000 \mathrm{e}+001.00000 \mathrm{e}+001.00000 \mathrm{e}-011.00000 \mathrm{e}-091.00000 \mathrm{e}-01$

1.00000e-06 1.00000e-06 1.00000e-06 1.00000e-09 5.00000e-02

Element: 4686 \# of layers: 4

$\mathrm{Kx} \mathrm{Ky} \mathrm{Kz}$ Ss Por

4.26434e+02 4.26434e+02 4.26434e+01 1.00000e-09 7.00000e-02 
$1.00000 \mathrm{e}-05$ 1.00000e-05 1.00000e-06 1.00000e-09 1.00000e-01 $1.00000 \mathrm{e}+001.00000 \mathrm{e}+001.00000 \mathrm{e}-011.00000 \mathrm{e}-091.00000 \mathrm{e}-01$ 1.00000e-06 1.00000e-06 1.00000e-06 1.00000e-09 5.00000e-02

Element: 4687 \# of layers: 4

$\mathrm{Kx} \mathrm{Ky} \mathrm{Kz}$ Ss Por

4.26434e+02 4.26434e+02 4.26434e+01 1.00000e-09 7.00000e-02 $1.00000 \mathrm{e}-05$ 1.00000e-05 1.00000e-06 1.00000e-09 1.00000e-01

$1.00000 \mathrm{e}+001.00000 \mathrm{e}+001.00000 \mathrm{e}-011.00000 \mathrm{e}-091.00000 \mathrm{e}-01$ 1.00000e-06 1.00000e-06 1.00000e-06 1.00000e-09 5.00000e-02

Element: 4688 \# of layers: 4

$\mathrm{Kx} \mathrm{Ky} \mathrm{Kz}$ Ss Por

1.99842e+02 1.99842e+02 1.99842e+01 1.00000e-09 7.00000e-02 $1.00000 \mathrm{e}-051.00000 \mathrm{e}-051.00000 \mathrm{e}-061.00000 \mathrm{e}-091.00000 \mathrm{e}-01$ $1.00000 \mathrm{e}+001.00000 \mathrm{e}+001.00000 \mathrm{e}-011.00000 \mathrm{e}-091.00000 \mathrm{e}-01$ 1.00000e-06 1.00000e-06 1.00000e-06 1.00000e-09 5.00000e-02 Element: 4689 \# of layers: 5

$\mathrm{Kx} \mathrm{Ky} \mathrm{Kz}$ Ss Por

2.35981e+02 2.35981e+02 2.35981e+01 1.00000e-09 7.00000e-02 $2.35981 \mathrm{e}+02$ 2.35981e+02 2.35981e+01 1.00000e-09 7.00000e-02 $1.00000 \mathrm{e}-05$ 1.00000e-05 1.00000e-06 1.00000e-09 1.00000e-01 $1.00000 \mathrm{e}+001.00000 \mathrm{e}+001.00000 \mathrm{e}-011.00000 \mathrm{e}-091.00000 \mathrm{e}-01$ 1.00000e-06 1.00000e-06 1.00000e-06 1.00000e-09 5.00000e-02

Element: 4690 \# of layers: 5

Kx Ky Kz Ss Por

$1.09940 \mathrm{e}+02$ 1.09940e+02 1.09940e+01 1.00000e-09 7.00000e-02 $1.09940 \mathrm{e}+021.09940 \mathrm{e}+021.09940 \mathrm{e}+01$ 1.00000e-09 7.00000e-02 $1.00000 \mathrm{e}-05$ 1.00000e-05 1.00000e-06 1.00000e-09 1.00000e-01 $1.00000 \mathrm{e}+001.00000 \mathrm{e}+001.00000 \mathrm{e}-011.00000 \mathrm{e}-091.00000 \mathrm{e}-01$ 1.00000e-06 1.00000e-06 1.00000e-06 1.00000e-09 5.00000e-02 Element: 4691 \# of layers: 4

$\mathrm{Kx} \mathrm{Ky} \mathrm{Kz}$ Ss Por

$1.09940 \mathrm{e}+02$ 1.09940e+02 1.09940e+01 1.00000e-09 7.00000e-02 $1.00000 \mathrm{e}-05$ 1.00000e-05 1.00000e-06 1.00000e-09 1.00000e-01 $1.00000 \mathrm{e}+001.00000 \mathrm{e}+001.00000 \mathrm{e}-011.00000 \mathrm{e}-091.00000 \mathrm{e}-01$ 1.00000e-06 1.00000e-06 1.00000e-06 1.00000e-09 5.00000e-02 Element: 4692 \# of layers: 4

Kx Ky Kz Ss Por $1.09940 \mathrm{e}+02$ 1.09940e+02 1.09940e+01 1.00000e-09 7.00000e-02 $1.00000 \mathrm{e}-05$ 1.00000e-05 1.00000e-06 1.00000e-09 1.00000e-01 $1.00000 \mathrm{e}+001.00000 \mathrm{e}+001.00000 \mathrm{e}-011.00000 \mathrm{e}-091.00000 \mathrm{e}-01$ 1.00000e-06 1.00000e-06 1.00000e-06 1.00000e-09 5.00000e-02 Element: 4693 \# of layers: 4

$\mathrm{Kx} \mathrm{Ky} \mathrm{Kz}$ Ss Por

8.02377e+01 8.02377e+01 8.02377e+00 1.00000e-09 7.00000e-02 $1.00000 \mathrm{e}-051.00000 \mathrm{e}-051.00000 \mathrm{e}-061.00000 \mathrm{e}-091.00000 \mathrm{e}-01$ $1.00000 \mathrm{e}+001.00000 \mathrm{e}+001.00000 \mathrm{e}-011.00000 \mathrm{e}-091.00000 \mathrm{e}-01$ 
1.00000e-06 1.00000e-06 1.00000e-06 1.00000e-09 5.00000e-02

Element: 4694 \# of layers: 5

$\mathrm{Kx} \mathrm{Ky} \mathrm{Kz}$ Ss Por

1.39655e+02 1.39655e+02 1.39655e+01 1.00000e-09 7.00000e-02

$1.39655 \mathrm{e}+021.39655 \mathrm{e}+021.39655 \mathrm{e}+01$ 1.00000e-09 7.00000e-02

$1.00000 \mathrm{e}-05$ 1.00000e-05 1.00000e-06 1.00000e-09 1.00000e-01

$1.00000 \mathrm{e}+001.00000 \mathrm{e}+001.00000 \mathrm{e}-011.00000 \mathrm{e}-091.00000 \mathrm{e}-01$

1.00000e-06 1.00000e-06 1.00000e-06 1.00000e-09 5.00000e-02

Element: 4695 \# of layers: 5

$\mathrm{Kx} \mathrm{Ky} \mathrm{Kz}$ Ss Por

1.39655e+02 1.39655e+02 1.39655e+01 1.00000e-09 7.00000e-02

$1.39655 \mathrm{e}+02$ 1.39655e+02 1.39655e+01 1.00000e-09 7.00000e-02

$1.00000 \mathrm{e}-051.00000 \mathrm{e}-051.00000 \mathrm{e}-061.00000 \mathrm{e}-091.00000 \mathrm{e}-01$

$1.00000 \mathrm{e}+001.00000 \mathrm{e}+001.00000 \mathrm{e}-011.00000 \mathrm{e}-091.00000 \mathrm{e}-01$

1.00000e-06 1.00000e-06 1.00000e-06 1.00000e-09 5.00000e-02

Element: 4696 \# of layers: 5

$\mathrm{Kx} \mathrm{Ky} \mathrm{Kz}$ Ss Por

$2.35981 \mathrm{e}+02$ 2.35981e+02 2.35981e+01 1.00000e-09 7.00000e-02

$2.35981 \mathrm{e}+02$ 2.35981e+02 2.35981e+01 1.00000e-09 7.00000e-02

$1.00000 \mathrm{e}-05$ 1.00000e-05 1.00000e-06 1.00000e-09 1.00000e-01

$1.00000 \mathrm{e}+001.00000 \mathrm{e}+001.00000 \mathrm{e}-011.00000 \mathrm{e}-091.00000 \mathrm{e}-01$

1.00000e-06 1.00000e-06 1.00000e-06 1.00000e-09 5.00000e-02

Element: 4697 \# of layers: 5

Kx Ky Kz Ss Por

$1.09940 \mathrm{e}+02$ 1.09940e+02 1.09940e+01 1.00000e-09 7.00000e-02

$1.09940 \mathrm{e}+021.09940 \mathrm{e}+021.09940 \mathrm{e}+01$ 1.00000e-09 7.00000e-02

$1.00000 \mathrm{e}-05$ 1.00000e-05 1.00000e-06 1.00000e-09 1.00000e-01

$1.00000 \mathrm{e}+001.00000 \mathrm{e}+001.00000 \mathrm{e}-011.00000 \mathrm{e}-091.00000 \mathrm{e}-01$

1.00000e-06 1.00000e-06 1.00000e-06 1.00000e-09 5.00000e-02

Element: 4698 \# of layers: 7

$\mathrm{Kx} \mathrm{Ky} \mathrm{Kz}$ Ss Por

$3.74140 \mathrm{e}+013.74140 \mathrm{e}+013.74140 \mathrm{e}+00$ 1.00000e-09 7.00000e-02

$3.74140 \mathrm{e}+013.74140 \mathrm{e}+013.74140 \mathrm{e}+001.00000 \mathrm{e}-09$ 7.00000e-02

$1.49493 \mathrm{e}+00$ 1.49493e+00 1.49493e-01 1.00000e-09 2.12000e-01

$1.00000 \mathrm{e}-02$ 1.00000e-02 1.00000e-03 1.00000e-09 1.00000e-01

$1.00000 \mathrm{e}-05$ 1.00000e-05 1.00000e-06 1.00000e-09 1.00000e-01

$1.00000 \mathrm{e}+001.00000 \mathrm{e}+001.00000 \mathrm{e}-011.00000 \mathrm{e}-091.00000 \mathrm{e}-01$

1.00000e-06 1.00000e-06 1.00000e-06 1.00000e-09 5.00000e-02

Element: 4699 \# of layers: 8

$\mathrm{Kx} \mathrm{Ky} \mathrm{Kz}$ Ss Por

8.25911e+01 8.25911e+01 8.25911e+00 1.00000e-09 7.00000e-02

$8.25911 \mathrm{e}+018.25911 \mathrm{e}+018.25911 \mathrm{e}+00$ 1.00000e-09 7.00000e-02

$3.30014 \mathrm{e}+003.30014 \mathrm{e}+003.30014 \mathrm{e}-01$ 1.00000e-09 2.12000e-01

$1.00000 \mathrm{e}-02$ 1.00000e-02 1.00000e-03 1.00000e-09 1.00000e-01

$1.00000 \mathrm{e}+001.00000 \mathrm{e}+001.00000 \mathrm{e}-011.00000 \mathrm{e}-091.00000 \mathrm{e}-01$

$1.00000 \mathrm{e}-05$ 1.00000e-05 1.00000e-06 1.00000e-09 1.00000e-01 
$1.00000 \mathrm{e}+001.00000 \mathrm{e}+001.00000 \mathrm{e}-011.00000 \mathrm{e}-091.00000 \mathrm{e}-01$ 1.00000e-06 1.00000e-06 1.00000e-06 1.00000e-09 5.00000e-02

Element: 4700 \# of layers: 7

$\mathrm{Kx} \mathrm{Ky} \mathrm{Kz}$ Ss Por

8.25911e+01 8.25911e+01 8.25911e+00 1.00000e-09 7.00000e-02

$3.30014 \mathrm{e}+003.30014 \mathrm{e}+003.30014 \mathrm{e}-01$ 1.00000e-09 2.12000e-01

$1.00000 \mathrm{e}-02$ 1.00000e-02 1.00000e-03 1.00000e-09 1.00000e-01

$1.00000 \mathrm{e}+001.00000 \mathrm{e}+001.00000 \mathrm{e}-011.00000 \mathrm{e}-091.00000 \mathrm{e}-01$

$1.00000 \mathrm{e}-051.00000 \mathrm{e}-051.00000 \mathrm{e}-061.00000 \mathrm{e}-091.00000 \mathrm{e}-01$

$1.00000 \mathrm{e}+001.00000 \mathrm{e}+001.00000 \mathrm{e}-011.00000 \mathrm{e}-091.00000 \mathrm{e}-01$

1.00000e-06 1.00000e-06 1.00000e-06 1.00000e-09 5.00000e-02

Element: 4701 \# of layers: 7

$\mathrm{Kx} \mathrm{Ky} \mathrm{Kz}$ Ss Por

8.25911e+01 8.25911e+01 8.25911e+00 1.00000e-09 7.00000e-02

$8.25911 \mathrm{e}+018.25911 \mathrm{e}+018.25911 \mathrm{e}+00$ 1.00000e-09 7.00000e-02

$3.30014 \mathrm{e}+003.30014 \mathrm{e}+003.30014 \mathrm{e}-01$ 1.00000e-09 2.12000e-01

1.00000e-02 1.00000e-02 1.00000e-03 1.00000e-09 1.00000e-01

$1.00000 \mathrm{e}-05$ 1.00000e-05 1.00000e-06 1.00000e-09 1.00000e-01

$1.00000 \mathrm{e}+001.00000 \mathrm{e}+001.00000 \mathrm{e}-011.00000 \mathrm{e}-091.00000 \mathrm{e}-01$

$1.00000 \mathrm{e}-06$ 1.00000e-06 1.00000e-06 1.00000e-09 5.00000e-02

Element: 4702 \# of layers: 4

$\mathrm{Kx} \mathrm{Ky} \mathrm{Kz}$ Ss Por

4.87027e+01 4.87027e+01 4.87027e+00 1.00000e-09 7.00000e-02

$1.00000 \mathrm{e}-05$ 1.00000e-05 1.00000e-06 1.00000e-09 1.00000e-01

$1.00000 \mathrm{e}+001.00000 \mathrm{e}+001.00000 \mathrm{e}-011.00000 \mathrm{e}-091.00000 \mathrm{e}-01$

1.00000e-06 1.00000e-06 1.00000e-06 1.00000e-09 5.00000e-02

Element: 4703 \# of layers: 4

$\mathrm{Kx} \mathrm{Ky} \mathrm{Kz}$ Ss Por

3.72771e+01 3.72771e+01 3.72771e+00 1.00000e-09 7.00000e-02

$1.00000 \mathrm{e}-051.00000 \mathrm{e}-051.00000 \mathrm{e}-061.00000 \mathrm{e}-091.00000 \mathrm{e}-01$

$1.00000 \mathrm{e}+001.00000 \mathrm{e}+001.00000 \mathrm{e}-011.00000 \mathrm{e}-091.00000 \mathrm{e}-01$

1.00000e-06 1.00000e-06 1.00000e-06 1.00000e-09 5.00000e-02

Element: 4704 \# of layers: 4

$\mathrm{Kx} \mathrm{Ky} \mathrm{Kz}$ Ss Por

3.72771e+01 3.72771e+01 3.72771e+00 1.00000e-09 7.00000e-02

$1.00000 \mathrm{e}-05$ 1.00000e-05 1.00000e-06 1.00000e-09 1.00000e-01

$1.00000 \mathrm{e}+001.00000 \mathrm{e}+001.00000 \mathrm{e}-011.00000 \mathrm{e}-091.00000 \mathrm{e}-01$

1.00000e-06 1.00000e-06 1.00000e-06 1.00000e-09 5.00000e-02

Element: 4705 \# of layers: 5

$\mathrm{Kx} \mathrm{Ky} \mathrm{Kz}$ Ss Por

3.74140e+01 3.74140e+01 3.74140e+00 1.00000e-09 7.00000e-02

$3.74140 \mathrm{e}+013.74140 \mathrm{e}+013.74140 \mathrm{e}+001.00000 \mathrm{e}-09$ 7.00000e-02

$1.00000 \mathrm{e}-051.00000 \mathrm{e}-051.00000 \mathrm{e}-061.00000 \mathrm{e}-091.00000 \mathrm{e}-01$

$1.00000 \mathrm{e}+001.00000 \mathrm{e}+001.00000 \mathrm{e}-011.00000 \mathrm{e}-091.00000 \mathrm{e}-01$

$1.00000 \mathrm{e}-06$ 1.00000e-06 1.00000e-06 1.00000e-09 5.00000e-02

Element: 4706 \# of layers: 6 
$\mathrm{Kx} \mathrm{Ky} \mathrm{Kz}$ Ss Por

8.25911e+01 8.25911e+01 8.25911e+00 1.00000e-09 7.00000e-02

$8.25911 \mathrm{e}+018.25911 \mathrm{e}+018.25911 \mathrm{e}+001.00000 \mathrm{e}-09$ 7.00000e-02

$3.30014 \mathrm{e}+003.30014 \mathrm{e}+003.30014 \mathrm{e}-01$ 1.00000e-09 2.12000e-01

$1.00000 \mathrm{e}-05$ 1.00000e-05 1.00000e-06 1.00000e-09 1.00000e-01

$1.00000 \mathrm{e}+001.00000 \mathrm{e}+001.00000 \mathrm{e}-011.00000 \mathrm{e}-091.00000 \mathrm{e}-01$

1.00000e-06 1.00000e-06 1.00000e-06 1.00000e-09 5.00000e-02

Element: 4707 \# of layers: 7

$\mathrm{Kx} \mathrm{Ky} \mathrm{Kz}$ Ss Por

$1.00903 \mathrm{e}+02$ 1.00903e+02 1.00903e+01 1.00000e-09 7.00000e-02

$4.03186 \mathrm{e}+00$ 4.03186e+00 4.03186e-01 1.00000e-09 2.12000e-01

$1.00000 \mathrm{e}-02$ 1.00000e-02 1.00000e-03 1.00000e-09 1.00000e-01

$1.00000 \mathrm{e}+001.00000 \mathrm{e}+001.00000 \mathrm{e}-011.00000 \mathrm{e}-091.00000 \mathrm{e}-01$

$1.00000 \mathrm{e}-05$ 1.00000e-05 1.00000e-06 1.00000e-09 1.00000e-01

$1.00000 \mathrm{e}+001.00000 \mathrm{e}+001.00000 \mathrm{e}-011.00000 \mathrm{e}-091.00000 \mathrm{e}-01$

1.00000e-06 1.00000e-06 1.00000e-06 1.00000e-09 5.00000e-02

Element: 4708 \# of layers: 8

$\mathrm{Kx} \mathrm{Ky} \mathrm{Kz}$ Ss Por

4.95874e+01 4.95874e+01 4.95874e+00 1.00000e-09 7.00000e-02 $4.95874 \mathrm{e}+014.95874 \mathrm{e}+014.95874 \mathrm{e}+001.00000 \mathrm{e}-09$ 7.00000e-02 $1.98133 \mathrm{e}+00$ 1.98133e+00 1.98133e-01 1.00000e-09 2.12000e-01 $1.00000 \mathrm{e}-02$ 1.00000e-02 1.00000e-03 1.00000e-09 1.00000e-01

$1.00000 \mathrm{e}+001.00000 \mathrm{e}+001.00000 \mathrm{e}-011.00000 \mathrm{e}-091.00000 \mathrm{e}-01$ $1.00000 \mathrm{e}-05$ 1.00000e-05 1.00000e-06 1.00000e-09 1.00000e-01

$1.00000 \mathrm{e}+001.00000 \mathrm{e}+001.00000 \mathrm{e}-011.00000 \mathrm{e}-091.00000 \mathrm{e}-01$ 1.00000e-06 1.00000e-06 1.00000e-06 1.00000e-09 5.00000e-02

Element: 4709 \# of layers: 8

$\mathrm{Kx} \mathrm{Ky} \mathrm{Kz}$ Ss Por

4.95874e+01 4.95874e+01 4.95874e+00 1.00000e-09 7.00000e-02

$4.95874 \mathrm{e}+014.95874 \mathrm{e}+014.95874 \mathrm{e}+001.00000 \mathrm{e}-09$ 7.00000e-02

$1.98133 \mathrm{e}+001.98133 \mathrm{e}+00$ 1.98133e-01 1.00000e-09 2.12000e-01

$1.00000 \mathrm{e}-02$ 1.00000e-02 1.00000e-03 1.00000e-09 1.00000e-01

$1.00000 \mathrm{e}+001.00000 \mathrm{e}+001.00000 \mathrm{e}-011.00000 \mathrm{e}-091.00000 \mathrm{e}-01$

$1.00000 \mathrm{e}-05$ 1.00000e-05 1.00000e-06 1.00000e-09 1.00000e-01

$1.00000 \mathrm{e}+001.00000 \mathrm{e}+001.00000 \mathrm{e}-011.00000 \mathrm{e}-091.00000 \mathrm{e}-01$

1.00000e-06 1.00000e-06 1.00000e-06 1.00000e-09 5.00000e-02

Element: 4710 \# of layers: 8

$\mathrm{Kx} \mathrm{Ky} \mathrm{Kz}$ Ss Por

$5.25184 \mathrm{e}+01$ 5.25184e+01 5.25184e+00 1.00000e-09 7.00000e-02

$5.25184 \mathrm{e}+015.25184 \mathrm{e}+015.25184 \mathrm{e}+001.00000 \mathrm{e}-09$ 7.00000e-02

$2.09844 \mathrm{e}+002.09844 \mathrm{e}+002.09844 \mathrm{e}-01$ 1.00000e-09 2.12000e-01

$1.00000 \mathrm{e}-02$ 1.00000e-02 1.00000e-03 1.00000e-09 1.00000e-01

$1.00000 \mathrm{e}+001.00000 \mathrm{e}+001.00000 \mathrm{e}-011.00000 \mathrm{e}-091.00000 \mathrm{e}-01$

$1.00000 \mathrm{e}-05$ 1.00000e-05 1.00000e-06 1.00000e-09 1.00000e-01

$1.00000 \mathrm{e}+001.00000 \mathrm{e}+001.00000 \mathrm{e}-011.00000 \mathrm{e}-091.00000 \mathrm{e}-01$

$1.00000 \mathrm{e}-06$ 1.00000e-06 1.00000e-06 1.00000e-09 5.00000e-02 
Element: 4711 \# of layers: 6

$\mathrm{Kx} \mathrm{Ky} \mathrm{Kz}$ Ss Por

$5.25184 \mathrm{e}+015.25184 \mathrm{e}+015.25184 \mathrm{e}+00$ 1.00000e-09 7.00000e-02

$2.09844 \mathrm{e}+002.09844 \mathrm{e}+002.09844 \mathrm{e}-01$ 1.00000e-09 2.12000e-01

$1.00000 \mathrm{e}-02$ 1.00000e-02 1.00000e-03 1.00000e-09 1.00000e-01

$1.00000 \mathrm{e}-05$ 1.00000e-05 1.00000e-06 1.00000e-09 1.00000e-01

$1.00000 \mathrm{e}+001.00000 \mathrm{e}+001.00000 \mathrm{e}-011.00000 \mathrm{e}-091.00000 \mathrm{e}-01$

1.00000e-06 1.00000e-06 1.00000e-06 1.00000e-09 5.00000e-02

Element: 4712 \# of layers: 5

$\mathrm{Kx} \mathrm{Ky} \mathrm{Kz} \mathrm{Ss} \mathrm{Por}$

7.25512e+01 7.25512e+01 7.25512e+00 1.00000e-09 7.00000e-02

$2.89896 \mathrm{e}+002.89896 \mathrm{e}+002.89896 \mathrm{e}-01$ 1.00000e-09 2.12000e-01

$1.00000 \mathrm{e}-05$ 1.00000e-05 1.00000e-06 1.00000e-09 1.00000e-01

$1.00000 \mathrm{e}+001.00000 \mathrm{e}+001.00000 \mathrm{e}-011.00000 \mathrm{e}-091.00000 \mathrm{e}-01$

1.00000e-06 1.00000e-06 1.00000e-06 1.00000e-09 5.00000e-02

Element: 4713 \# of layers: 5

$\mathrm{Kx} \mathrm{Ky} \mathrm{Kz}$ Ss Por

7.25512e+01 7.25512e+01 7.25512e+00 1.00000e-09 7.00000e-02

$2.89896 \mathrm{e}+002.89896 \mathrm{e}+00$ 2.89896e-01 1.00000e-09 2.12000e-01

$1.00000 \mathrm{e}-05$ 1.00000e-05 1.00000e-06 1.00000e-09 1.00000e-01

$1.00000 \mathrm{e}+001.00000 \mathrm{e}+001.00000 \mathrm{e}-011.00000 \mathrm{e}-091.00000 \mathrm{e}-01$

1.00000e-06 1.00000e-06 1.00000e-06 1.00000e-09 5.00000e-02

Element: 4714 \# of layers: 7

Kx Ky Kz Ss Por

$7.25512 \mathrm{e}+017.25512 \mathrm{e}+017.25512 \mathrm{e}+001.00000 \mathrm{e}-09$ 7.00000e-02

7.25512e+01 7.25512e+01 7.25512e+00 1.00000e-09 7.00000e-02

$2.89896 \mathrm{e}+002.89896 \mathrm{e}+00$ 2.89896e-01 1.00000e-09 2.12000e-01

$1.00000 \mathrm{e}-02$ 1.00000e-02 1.00000e-03 1.00000e-09 1.00000e-01

$1.00000 \mathrm{e}-05$ 1.00000e-05 1.00000e-06 1.00000e-09 1.00000e-01

$1.00000 \mathrm{e}+001.00000 \mathrm{e}+001.00000 \mathrm{e}-011.00000 \mathrm{e}-091.00000 \mathrm{e}-01$

1.00000e-06 1.00000e-06 1.00000e-06 1.00000e-09 5.00000e-02

Element: 4715 \# of layers: 7

$\mathrm{Kx} \mathrm{Ky} \mathrm{Kz}$ Ss Por

$1.00903 \mathrm{e}+02$ 1.00903e+02 1.00903e+01 1.00000e-09 7.00000e-02

$1.00903 \mathrm{e}+02$ 1.00903e+02 1.00903e+01 1.00000e-09 7.00000e-02

4.03186e+00 4.03186e+00 4.03186e-01 1.00000e-09 2.12000e-01

$1.00000 \mathrm{e}-02$ 1.00000e-02 1.00000e-03 1.00000e-09 1.00000e-01

$1.00000 \mathrm{e}-05$ 1.00000e-05 1.00000e-06 1.00000e-09 1.00000e-01

$1.00000 \mathrm{e}+001.00000 \mathrm{e}+001.00000 \mathrm{e}-011.00000 \mathrm{e}-091.00000 \mathrm{e}-01$

1.00000e-06 1.00000e-06 1.00000e-06 1.00000e-09 5.00000e-02

Element: 4716 \# of layers: 9

$\mathrm{Kx} \mathrm{Ky} \mathrm{Kz}$ Ss Por

$2.86149 \mathrm{e}+012.86149 \mathrm{e}+012.86149 \mathrm{e}+00$ 1.00000e-09 7.00000e-02

$2.86149 \mathrm{e}+012.86149 \mathrm{e}+012.86149 \mathrm{e}+00$ 1.00000e-09 7.00000e-02

$1.14334 \mathrm{e}+001.14334 \mathrm{e}+001.14334 \mathrm{e}-011.00000 \mathrm{e}-092.12000 \mathrm{e}-01$

$1.14334 \mathrm{e}+001.14334 \mathrm{e}+001.14334 \mathrm{e}-011.00000 \mathrm{e}-092.12000 \mathrm{e}-01$ 
$1.00000 \mathrm{e}-02$ 1.00000e-02 1.00000e-03 1.00000e-09 1.00000e-01 $1.00000 \mathrm{e}+001.00000 \mathrm{e}+001.00000 \mathrm{e}-011.00000 \mathrm{e}-091.00000 \mathrm{e}-01$ $1.00000 \mathrm{e}-05$ 1.00000e-05 1.00000e-06 1.00000e-09 1.00000e-01 $1.00000 \mathrm{e}+001.00000 \mathrm{e}+001.00000 \mathrm{e}-011.00000 \mathrm{e}-091.00000 \mathrm{e}-01$ 1.00000e-06 1.00000e-06 1.00000e-06 1.00000e-09 5.00000e-02 Element: 4717 \# of layers: 9

$\mathrm{Kx} \mathrm{Ky} \mathrm{Kz}$ Ss Por

$1.45025 \mathrm{e}+011.45025 \mathrm{e}+01$ 1.45025e+00 1.00000e-09 7.00000e-02 $1.45025 \mathrm{e}+011.45025 \mathrm{e}+011.45025 \mathrm{e}+001.00000 \mathrm{e}-09$ 7.00000e-02 5.79477e-01 5.79477e-01 5.79477e-02 1.00000e-09 2.12000e-01 5.79477e-01 5.79477e-01 5.79477e-02 1.00000e-09 2.12000e-01 $1.00000 \mathrm{e}-02$ 1.00000e-02 1.00000e-03 1.00000e-09 1.00000e-01 $1.00000 \mathrm{e}+001.00000 \mathrm{e}+001.00000 \mathrm{e}-011.00000 \mathrm{e}-091.00000 \mathrm{e}-01$ $1.00000 \mathrm{e}-05$ 1.00000e-05 1.00000e-06 1.00000e-09 1.00000e-01 $1.00000 \mathrm{e}+001.00000 \mathrm{e}+001.00000 \mathrm{e}-011.00000 \mathrm{e}-091.00000 \mathrm{e}-01$ 1.00000e-06 1.00000e-06 1.00000e-06 1.00000e-09 5.00000e-02 Element: 4718 \# of layers: 9

$\mathrm{Kx} \mathrm{Ky} \mathrm{Kz}$ Ss Por

$1.45025 \mathrm{e}+01$ 1.45025e+01 1.45025e+00 1.00000e-09 7.00000e-02 $1.45025 \mathrm{e}+011.45025 \mathrm{e}+011.45025 \mathrm{e}+001.00000 \mathrm{e}-09$ 7.00000e-02 5.79477e-01 5.79477e-01 5.79477e-02 1.00000e-09 2.12000e-01 5.79477e-01 5.79477e-01 5.79477e-02 1.00000e-09 2.12000e-01 $1.00000 \mathrm{e}-02$ 1.00000e-02 1.00000e-03 1.00000e-09 1.00000e-01 $1.00000 \mathrm{e}+001.00000 \mathrm{e}+001.00000 \mathrm{e}-011.00000 \mathrm{e}-091.00000 \mathrm{e}-01$ $1.00000 \mathrm{e}-05$ 1.00000e-05 1.00000e-06 1.00000e-09 1.00000e-01 $1.00000 \mathrm{e}+001.00000 \mathrm{e}+001.00000 \mathrm{e}-011.00000 \mathrm{e}-091.00000 \mathrm{e}-01$ 1.00000e-06 1.00000e-06 1.00000e-06 1.00000e-09 5.00000e-02 Element: 4719 \# of layers: 9

$\mathrm{Kx} \mathrm{Ky} \mathrm{Kz}$ Ss Por

9.30282e+00 9.30282e+00 9.30283e-01 1.00000e-09 7.00000e-02 9.30282e+00 9.30282e+00 9.30283e-01 1.00000e-09 7.00000e-02 3.71708e-01 3.71708e-01 3.71708e-02 1.00000e-09 2.12000e-01 3.71708e-01 3.71708e-01 3.71708e-02 1.00000e-09 2.12000e-01 $1.00000 \mathrm{e}-02$ 1.00000e-02 1.00000e-03 1.00000e-09 1.00000e-01 $1.00000 \mathrm{e}+001.00000 \mathrm{e}+001.00000 \mathrm{e}-011.00000 \mathrm{e}-091.00000 \mathrm{e}-01$ $1.00000 \mathrm{e}-05$ 1.00000e-05 1.00000e-06 1.00000e-09 1.00000e-01 $1.00000 \mathrm{e}+001.00000 \mathrm{e}+001.00000 \mathrm{e}-011.00000 \mathrm{e}-091.00000 \mathrm{e}-01$ 1.00000e-06 1.00000e-06 1.00000e-06 1.00000e-09 5.00000e-02 Element: 4720 \# of layers: 9

$\mathrm{Kx} \mathrm{Ky} \mathrm{Kz}$ Ss Por

9.30282e+00 9.30282e+00 9.30283e-01 1.00000e-09 7.00000e-02 9.30282e+00 9.30282e+00 9.30283e-01 1.00000e-09 7.00000e-02 3.71708e-01 3.71708e-01 3.71708e-02 1.00000e-09 2.12000e-01 3.71708e-01 3.71708e-01 3.71708e-02 1.00000e-09 2.12000e-01 $1.00000 \mathrm{e}-02$ 1.00000e-02 1.00000e-03 1.00000e-09 1.00000e-01 $1.00000 \mathrm{e}+001.00000 \mathrm{e}+001.00000 \mathrm{e}-011.00000 \mathrm{e}-091.00000 \mathrm{e}-01$ 
$1.00000 \mathrm{e}-05$ 1.00000e-05 1.00000e-06 1.00000e-09 1.00000e-01 $1.00000 \mathrm{e}+001.00000 \mathrm{e}+001.00000 \mathrm{e}-011.00000 \mathrm{e}-091.00000 \mathrm{e}-01$ 1.00000e-06 1.00000e-06 1.00000e-06 1.00000e-09 5.00000e-02 Element: 4721 \# of layers: 9

$\mathrm{Kx} \mathrm{Ky} \mathrm{Kz}$ Ss Por

1.44872e+01 1.44872e+01 1.44872e+00 1.00000e-09 7.00000e-02 $1.44872 \mathrm{e}+01$ 1.44872e+01 1.44872e+00 1.00000e-09 7.00000e-02 5.78847e-01 5.78847e-01 5.78847e-02 1.00000e-09 2.12000e-01 5.78847e-01 5.78847e-01 5.78847e-02 1.00000e-09 2.12000e-01 $1.00000 \mathrm{e}-02$ 1.00000e-02 1.00000e-03 1.00000e-09 1.00000e-01 $1.00000 \mathrm{e}+001.00000 \mathrm{e}+001.00000 \mathrm{e}-011.00000 \mathrm{e}-091.00000 \mathrm{e}-01$ $1.00000 \mathrm{e}-05$ 1.00000e-05 1.00000e-06 1.00000e-09 1.00000e-01 $1.00000 \mathrm{e}+001.00000 \mathrm{e}+001.00000 \mathrm{e}-011.00000 \mathrm{e}-091.00000 \mathrm{e}-01$ 1.00000e-06 1.00000e-06 1.00000e-06 1.00000e-09 5.00000e-02 Element: 4722 \# of layers: 9

$\mathrm{Kx} \mathrm{Ky} \mathrm{Kz}$ Ss Por

1.44872e+01 1.44872e+01 1.44872e+00 1.00000e-09 7.00000e-02 $1.44872 \mathrm{e}+01$ 1.44872e+01 1.44872e+00 1.00000e-09 7.00000e-02 5.78847e-01 5.78847e-01 5.78847e-02 1.00000e-09 2.12000e-01 5.78847e-01 5.78847e-01 5.78847e-02 1.00000e-09 2.12000e-01 $1.00000 \mathrm{e}-02$ 1.00000e-02 1.00000e-03 1.00000e-09 1.00000e-01 $1.00000 \mathrm{e}+001.00000 \mathrm{e}+001.00000 \mathrm{e}-011.00000 \mathrm{e}-091.00000 \mathrm{e}-01$ $1.00000 \mathrm{e}-05$ 1.00000e-05 1.00000e-06 1.00000e-09 1.00000e-01 $1.00000 \mathrm{e}+001.00000 \mathrm{e}+001.00000 \mathrm{e}-011.00000 \mathrm{e}-091.00000 \mathrm{e}-01$ 1.00000e-06 1.00000e-06 1.00000e-06 1.00000e-09 5.00000e-02 Element: 4723 \# of layers: 9

$\mathrm{Kx} \mathrm{Ky} \mathrm{Kz}$ Ss Por

1.44872e+01 1.44872e+01 1.44872e+00 1.00000e-09 7.00000e-02 $1.44872 \mathrm{e}+01$ 1.44872e+01 1.44872e+00 1.00000e-09 7.00000e-02 5.78847e-01 5.78847e-01 5.78847e-02 1.00000e-09 2.12000e-01 5.78847e-01 5.78847e-01 5.78847e-02 1.00000e-09 2.12000e-01 $1.00000 \mathrm{e}-02$ 1.00000e-02 1.00000e-03 1.00000e-09 1.00000e-01 $1.00000 \mathrm{e}+001.00000 \mathrm{e}+001.00000 \mathrm{e}-011.00000 \mathrm{e}-091.00000 \mathrm{e}-01$ $1.00000 \mathrm{e}-05$ 1.00000e-05 1.00000e-06 1.00000e-09 1.00000e-01 $1.00000 \mathrm{e}+001.00000 \mathrm{e}+001.00000 \mathrm{e}-011.00000 \mathrm{e}-091.00000 \mathrm{e}-01$ 1.00000e-06 1.00000e-06 1.00000e-06 1.00000e-09 5.00000e-02 Element: 4724 \# of layers: 9

$\mathrm{Kx} \mathrm{Ky} \mathrm{Kz}$ Ss Por

$2.86149 \mathrm{e}+012.86149 \mathrm{e}+012.86149 \mathrm{e}+001.00000 \mathrm{e}-09$ 7.00000e-02 $2.86149 \mathrm{e}+012.86149 \mathrm{e}+012.86149 \mathrm{e}+001.00000 \mathrm{e}-09$ 7.00000e-02 $1.14334 \mathrm{e}+001.14334 \mathrm{e}+001.14334 \mathrm{e}-011.00000 \mathrm{e}-092.12000 \mathrm{e}-01$ $1.14334 \mathrm{e}+001.14334 \mathrm{e}+001.14334 \mathrm{e}-011.00000 \mathrm{e}-092.12000 \mathrm{e}-01$ $1.00000 \mathrm{e}-021.00000 \mathrm{e}-021.00000 \mathrm{e}-031.00000 \mathrm{e}-091.00000 \mathrm{e}-01$ $1.00000 \mathrm{e}+001.00000 \mathrm{e}+001.00000 \mathrm{e}-011.00000 \mathrm{e}-091.00000 \mathrm{e}-01$ $1.00000 \mathrm{e}-05$ 1.00000e-05 1.00000e-06 1.00000e-09 1.00000e-01 $1.00000 \mathrm{e}+001.00000 \mathrm{e}+001.00000 \mathrm{e}-011.00000 \mathrm{e}-091.00000 \mathrm{e}-01$ 
1.00000e-06 1.00000e-06 1.00000e-06 1.00000e-09 5.00000e-02 Element: 4725 \# of layers: 13

Kx Ky Kz Ss Por

9.47311e+00 9.47311e+00 9.47311e-01 1.00000e-09 7.00000e-02

$9.47311 \mathrm{e}+009.47311 \mathrm{e}+009.47311 \mathrm{e}-011.00000 \mathrm{e}-09$ 7.00000e-02

5.00000e-04 5.00000e-04 5.00000e-05 1.00000e-09 1.00000e-01

3.78503e-01 3.78503e-01 3.78503e-02 1.00000e-09 2.12000e-01

3.78503e-01 3.78503e-01 3.78503e-02 1.00000e-09 2.12000e-01

3.78503e-01 3.78503e-01 3.78503e-02 1.00000e-09 2.12000e-01

3.78503e-01 3.78503e-01 3.78503e-02 1.00000e-09 2.12000e-01

3.78503e-01 3.78503e-01 3.78503e-02 1.00000e-09 2.12000e-01

$1.00000 \mathrm{e}-02$ 1.00000e-02 1.00000e-03 1.00000e-09 1.00000e-01

$1.00000 \mathrm{e}+001.00000 \mathrm{e}+001.00000 \mathrm{e}-011.00000 \mathrm{e}-091.00000 \mathrm{e}-01$

$1.00000 \mathrm{e}-05$ 1.00000e-05 1.00000e-06 1.00000e-09 1.00000e-01

$1.00000 \mathrm{e}+001.00000 \mathrm{e}+001.00000 \mathrm{e}-011.00000 \mathrm{e}-091.00000 \mathrm{e}-01$

1.00000e-06 1.00000e-06 1.00000e-06 1.00000e-09 5.00000e-02

Element: 4726 \# of layers: 14

$\mathrm{Kx} \mathrm{Ky} \mathrm{Kz}$ Ss Por

7.55966e+00 7.55966e+00 7.55966e-01 1.00000e-09 7.00000e-02

$7.55966 \mathrm{e}+00$ 7.55966e+00 7.55966e-01 1.00000e-09 7.00000e-02

$7.55966 \mathrm{e}+00$ 7.55966e+00 7.55966e-01 1.00000e-09 7.00000e-02

5.00000e-04 5.00000e-04 5.00000e-05 1.00000e-09 1.00000e-01

3.02046e-01 3.02046e-01 3.02046e-02 1.00000e-09 2.12000e-01

3.02046e-01 3.02046e-01 3.02046e-02 1.00000e-09 2.12000e-01

3.02046e-01 3.02046e-01 3.02046e-02 1.00000e-09 2.12000e-01

3.02046e-01 3.02046e-01 3.02046e-02 1.00000e-09 2.12000e-01

3.02046e-01 3.02046e-01 3.02046e-02 1.00000e-09 2.12000e-01

$1.00000 \mathrm{e}-02$ 1.00000e-02 1.00000e-03 1.00000e-09 1.00000e-01

$1.00000 \mathrm{e}+001.00000 \mathrm{e}+001.00000 \mathrm{e}-011.00000 \mathrm{e}-091.00000 \mathrm{e}-01$

$1.00000 \mathrm{e}-05$ 1.00000e-05 1.00000e-06 1.00000e-09 1.00000e-01

$1.00000 \mathrm{e}+001.00000 \mathrm{e}+001.00000 \mathrm{e}-011.00000 \mathrm{e}-091.00000 \mathrm{e}-01$

1.00000e-06 1.00000e-06 1.00000e-06 1.00000e-09 5.00000e-02

Element: 4727 \# of layers: 14

$\mathrm{Kx} \mathrm{Ky} \mathrm{Kz}$ Ss Por

7.55966e+00 7.55966e+00 7.55966e-01 1.00000e-09 7.00000e-02

$7.55966 \mathrm{e}+007.55966 \mathrm{e}+007.55966 \mathrm{e}-01$ 1.00000e-09 7.00000e-02

5.00000e-04 5.00000e-04 5.00000e-05 1.00000e-09 1.00000e-01

5.00000e-04 5.00000e-04 5.00000e-05 1.00000e-09 1.00000e-01

3.02046e-01 3.02046e-01 3.02046e-02 1.00000e-09 2.12000e-01

3.02046e-01 3.02046e-01 3.02046e-02 1.00000e-09 2.12000e-01

3.02046e-01 3.02046e-01 3.02046e-02 1.00000e-09 2.12000e-01

3.02046e-01 3.02046e-01 3.02046e-02 1.00000e-09 2.12000e-01

3.02046e-01 3.02046e-01 3.02046e-02 1.00000e-09 2.12000e-01

$1.00000 \mathrm{e}-02$ 1.00000e-02 1.00000e-03 1.00000e-09 1.00000e-01

$1.00000 \mathrm{e}+001.00000 \mathrm{e}+001.00000 \mathrm{e}-011.00000 \mathrm{e}-091.00000 \mathrm{e}-01$

$1.00000 \mathrm{e}-05$ 1.00000e-05 1.00000e-06 1.00000e-09 1.00000e-01 
$1.00000 \mathrm{e}+001.00000 \mathrm{e}+001.00000 \mathrm{e}-011.00000 \mathrm{e}-091.00000 \mathrm{e}-01$ $1.00000 \mathrm{e}-06$ 1.00000e-06 1.00000e-06 1.00000e-09 5.00000e-02 Element: 4728 \# of layers: 14

Kx Ky Kz Ss Por

7.55966e+00 7.55966e+00 7.55966e-01 1.00000e-09 7.00000e-02

$7.55966 \mathrm{e}+007.55966 \mathrm{e}+00$ 7.55966e-01 1.00000e-09 7.00000e-02 5.00000e-04 5.00000e-04 5.00000e-05 1.00000e-09 1.00000e-01 5.00000e-04 5.00000e-04 5.00000e-05 1.00000e-09 1.00000e-01 3.02046e-01 3.02046e-01 3.02046e-02 1.00000e-09 2.12000e-01 3.02046e-01 3.02046e-01 3.02046e-02 1.00000e-09 2.12000e-01 3.02046e-01 3.02046e-01 3.02046e-02 1.00000e-09 2.12000e-01 3.02046e-01 3.02046e-01 3.02046e-02 1.00000e-09 2.12000e-01 3.02046e-01 3.02046e-01 3.02046e-02 1.00000e-09 2.12000e-01 $1.00000 \mathrm{e}-02$ 1.00000e-02 1.00000e-03 1.00000e-09 1.00000e-01 $1.00000 \mathrm{e}+001.00000 \mathrm{e}+001.00000 \mathrm{e}-011.00000 \mathrm{e}-091.00000 \mathrm{e}-01$ $1.00000 \mathrm{e}-05$ 1.00000e-05 1.00000e-06 1.00000e-09 1.00000e-01 $1.00000 \mathrm{e}+001.00000 \mathrm{e}+001.00000 \mathrm{e}-011.00000 \mathrm{e}-091.00000 \mathrm{e}-01$ 1.00000e-06 1.00000e-06 1.00000e-06 1.00000e-09 5.00000e-02 Element: 4729 \# of layers: 14

$\mathrm{Kx} \mathrm{Ky} \mathrm{Kz}$ Ss Por

5.68783e+00 5.68783e+00 5.68783e-01 1.00000e-09 7.00000e-02

5.68783e+00 5.68783e+00 5.68783e-01 1.00000e-09 7.00000e-02 5.00000e-04 5.00000e-04 5.00000e-05 1.00000e-09 1.00000e-01 5.00000e-04 5.00000e-04 5.00000e-05 1.00000e-09 1.00000e-01 2.27255e-01 2.27255e-01 2.27255e-02 1.00000e-09 2.12000e-01 2.27255e-01 2.27255e-01 2.27255e-02 1.00000e-09 2.12000e-01 2.27255e-01 2.27255e-01 2.27255e-02 1.00000e-09 2.12000e-01 2.27255e-01 2.27255e-01 2.27255e-02 1.00000e-09 2.12000e-01 2.27255e-01 2.27255e-01 2.27255e-02 1.00000e-09 2.12000e-01 $1.00000 \mathrm{e}-02$ 1.00000e-02 1.00000e-03 1.00000e-09 1.00000e-01 $1.00000 \mathrm{e}+001.00000 \mathrm{e}+001.00000 \mathrm{e}-011.00000 \mathrm{e}-091.00000 \mathrm{e}-01$ $1.00000 \mathrm{e}-05$ 1.00000e-05 1.00000e-06 1.00000e-09 1.00000e-01 $1.00000 \mathrm{e}+001.00000 \mathrm{e}+001.00000 \mathrm{e}-011.00000 \mathrm{e}-091.00000 \mathrm{e}-01$ 1.00000e-06 1.00000e-06 1.00000e-06 1.00000e-09 5.00000e-02 Element: 4730 \# of layers: 13

$\mathrm{Kx} \mathrm{Ky} \mathrm{Kz}$ Ss Por

5.68783e+00 5.68783e+00 5.68783e-01 1.00000e-09 7.00000e-02 5.68783e+00 5.68783e+00 5.68783e-01 1.00000e-09 7.00000e-02 5.00000e-04 5.00000e-04 5.00000e-05 1.00000e-09 1.00000e-01 2.27255e-01 2.27255e-01 2.27255e-02 1.00000e-09 2.12000e-01 2.27255e-01 2.27255e-01 2.27255e-02 1.00000e-09 2.12000e-01 2.27255e-01 2.27255e-01 2.27255e-02 1.00000e-09 2.12000e-01 2.27255e-01 2.27255e-01 2.27255e-02 1.00000e-09 2.12000e-01 2.27255e-01 2.27255e-01 2.27255e-02 1.00000e-09 2.12000e-01 $1.00000 \mathrm{e}-021.00000 \mathrm{e}-021.00000 \mathrm{e}-031.00000 \mathrm{e}-091.00000 \mathrm{e}-01$ $1.00000 \mathrm{e}+001.00000 \mathrm{e}+001.00000 \mathrm{e}-011.00000 \mathrm{e}-091.00000 \mathrm{e}-01$ 
$1.00000 \mathrm{e}-05$ 1.00000e-05 1.00000e-06 1.00000e-09 1.00000e-01 $1.00000 \mathrm{e}+001.00000 \mathrm{e}+001.00000 \mathrm{e}-011.00000 \mathrm{e}-091.00000 \mathrm{e}-01$ 1.00000e-06 1.00000e-06 1.00000e-06 1.00000e-09 5.00000e-02 Element: 4731 \# of layers: 14

$\mathrm{Kx} \mathrm{Ky} \mathrm{Kz}$ Ss Por

6.91067e+00 6.91067e+00 6.91067e-01 1.00000e-09 7.00000e-02 $6.91067 \mathrm{e}+006.91067 \mathrm{e}+00$ 6.91067e-01 1.00000e-09 7.00000e-02 6.91067e+00 6.91067e+00 6.91067e-01 1.00000e-09 7.00000e-02 5.00000e-04 5.00000e-04 5.00000e-05 1.00000e-09 1.00000e-01 2.76126e-01 2.76126e-01 2.76126e-02 1.00000e-09 2.12000e-01 2.76126e-01 2.76126e-01 2.76126e-02 1.00000e-09 2.12000e-01 2.76126e-01 2.76126e-01 2.76126e-02 1.00000e-09 2.12000e-01 2.76126e-01 2.76126e-01 2.76126e-02 1.00000e-09 2.12000e-01 2.76126e-01 2.76126e-01 2.76126e-02 1.00000e-09 2.12000e-01 $1.00000 \mathrm{e}-02$ 1.00000e-02 1.00000e-03 1.00000e-09 1.00000e-01 $1.00000 \mathrm{e}+001.00000 \mathrm{e}+001.00000 \mathrm{e}-011.00000 \mathrm{e}-091.00000 \mathrm{e}-01$ $1.00000 \mathrm{e}-05$ 1.00000e-05 1.00000e-06 1.00000e-09 1.00000e-01 $1.00000 \mathrm{e}+001.00000 \mathrm{e}+001.00000 \mathrm{e}-011.00000 \mathrm{e}-091.00000 \mathrm{e}-01$ 1.00000e-06 1.00000e-06 1.00000e-06 1.00000e-09 5.00000e-02 Element: 4732 \# of layers: 14

$\mathrm{Kx} \mathrm{Ky} \mathrm{Kz}$ Ss Por

9.47311e+00 9.47311e+00 9.47311e-01 1.00000e-09 7.00000e-02 9.47311e+00 9.47311e+00 9.47311e-01 1.00000e-09 7.00000e-02 9.47311e+00 9.47311e+00 9.47311e-01 1.00000e-09 7.00000e-02 5.00000e-04 5.00000e-04 5.00000e-05 1.00000e-09 1.00000e-01 3.78503e-01 3.78503e-01 3.78503e-02 1.00000e-09 2.12000e-01 3.78503e-01 3.78503e-01 3.78503e-02 1.00000e-09 2.12000e-01 3.78503e-01 3.78503e-01 3.78503e-02 1.00000e-09 2.12000e-01 3.78503e-01 3.78503e-01 3.78503e-02 1.00000e-09 2.12000e-01 3.78503e-01 3.78503e-01 3.78503e-02 1.00000e-09 2.12000e-01 $1.00000 \mathrm{e}-02$ 1.00000e-02 1.00000e-03 1.00000e-09 1.00000e-01 $1.00000 \mathrm{e}+001.00000 \mathrm{e}+001.00000 \mathrm{e}-011.00000 \mathrm{e}-091.00000 \mathrm{e}-01$ 1.00000e-05 1.00000e-05 1.00000e-06 1.00000e-09 1.00000e-01 $1.00000 \mathrm{e}+001.00000 \mathrm{e}+001.00000 \mathrm{e}-011.00000 \mathrm{e}-091.00000 \mathrm{e}-01$ 1.00000e-06 1.00000e-06 1.00000e-06 1.00000e-09 5.00000e-02 Element: 4733 \# of layers: 14

Kx Ky Kz Ss Por

7.55966e+00 7.55966e+00 7.55966e-01 1.00000e-09 7.00000e-02 $7.55966 \mathrm{e}+00$ 7.55966e+00 7.55966e-01 1.00000e-09 7.00000e-02 $7.55966 \mathrm{e}+007.55966 \mathrm{e}+007.55966 \mathrm{e}-01$ 1.00000e-09 7.00000e-02 5.00000e-04 5.00000e-04 5.00000e-05 1.00000e-09 1.00000e-01 3.02046e-01 3.02046e-01 3.02046e-02 1.00000e-09 2.12000e-01 3.02046e-01 3.02046e-01 3.02046e-02 1.00000e-09 2.12000e-01 3.02046e-01 3.02046e-01 3.02046e-02 1.00000e-09 2.12000e-01 3.02046e-01 3.02046e-01 3.02046e-02 1.00000e-09 2.12000e-01 3.02046e-01 3.02046e-01 3.02046e-02 1.00000e-09 2.12000e-01 
$1.00000 \mathrm{e}-02$ 1.00000e-02 1.00000e-03 1.00000e-09 1.00000e-01 $1.00000 \mathrm{e}+001.00000 \mathrm{e}+001.00000 \mathrm{e}-011.00000 \mathrm{e}-091.00000 \mathrm{e}-01$ $1.00000 \mathrm{e}-051.00000 \mathrm{e}-05$ 1.00000e-06 1.00000e-09 1.00000e-01 $1.00000 \mathrm{e}+001.00000 \mathrm{e}+001.00000 \mathrm{e}-011.00000 \mathrm{e}-091.00000 \mathrm{e}-01$ 1.00000e-06 1.00000e-06 1.00000e-06 1.00000e-09 5.00000e-02 Element: 4734 \# of layers: 14

$\mathrm{Kx} \mathrm{Ky} \mathrm{Kz}$ Ss Por

$1.26744 \mathrm{e}+011.26744 \mathrm{e}+011.26744 \mathrm{e}+001.00000 \mathrm{e}-09$ 7.00000e-02 $1.26744 \mathrm{e}+011.26744 \mathrm{e}+011.26744 \mathrm{e}+001.00000 \mathrm{e}-09$ 7.00000e-02 5.00000e-04 5.00000e-04 5.00000e-05 1.00000e-09 1.00000e-01 5.00000e-04 5.00000e-04 5.00000e-05 1.00000e-09 1.00000e-01 5.06418e-01 5.06418e-01 5.06418e-02 1.00000e-09 2.12000e-01 5.06418e-01 5.06418e-01 5.06418e-02 1.00000e-09 2.12000e-01 5.06418e-01 5.06418e-01 5.06418e-02 1.00000e-09 2.12000e-01 5.06418e-01 5.06418e-01 5.06418e-02 1.00000e-09 2.12000e-01 5.06418e-01 5.06418e-01 5.06418e-02 1.00000e-09 2.12000e-01 $1.00000 \mathrm{e}-02$ 1.00000e-02 1.00000e-03 1.00000e-09 1.00000e-01 $1.00000 \mathrm{e}+001.00000 \mathrm{e}+001.00000 \mathrm{e}-011.00000 \mathrm{e}-091.00000 \mathrm{e}-01$ $1.00000 \mathrm{e}-05$ 1.00000e-05 1.00000e-06 1.00000e-09 1.00000e-01 $1.00000 \mathrm{e}+001.00000 \mathrm{e}+001.00000 \mathrm{e}-011.00000 \mathrm{e}-091.00000 \mathrm{e}-01$ 1.00000e-06 1.00000e-06 1.00000e-06 1.00000e-09 5.00000e-02 Element: 4735 \# of layers: 13

$\mathrm{Kx} \mathrm{Ky} \mathrm{Kz}$ Ss Por

1.35637e+01 1.35637e+01 1.35637e+00 1.00000e-09 7.00000e-02 $1.35637 \mathrm{e}+011.35637 \mathrm{e}+011.35637 \mathrm{e}+001.00000 \mathrm{e}-09$ 7.00000e-02 5.00000e-04 5.00000e-04 5.00000e-05 1.00000e-09 1.00000e-01 5.41969e-01 5.41969e-01 5.41969e-02 1.00000e-09 2.12000e-01 5.41969e-01 5.41969e-01 5.41969e-02 1.00000e-09 2.12000e-01 5.41969e-01 5.41969e-01 5.41969e-02 1.00000e-09 2.12000e-01 5.41969e-01 5.41969e-01 5.41969e-02 1.00000e-09 2.12000e-01 5.41969e-01 5.41969e-01 5.41969e-02 1.00000e-09 2.12000e-01 $1.00000 \mathrm{e}-02$ 1.00000e-02 1.00000e-03 1.00000e-09 1.00000e-01 $1.00000 \mathrm{e}+001.00000 \mathrm{e}+001.00000 \mathrm{e}-011.00000 \mathrm{e}-091.00000 \mathrm{e}-01$ $1.00000 \mathrm{e}-05$ 1.00000e-05 1.00000e-06 1.00000e-09 1.00000e-01 $1.00000 \mathrm{e}+001.00000 \mathrm{e}+001.00000 \mathrm{e}-011.00000 \mathrm{e}-091.00000 \mathrm{e}-01$ 1.00000e-06 1.00000e-06 1.00000e-06 1.00000e-09 5.00000e-02 Element: 4736 \# of layers: 15

$\mathrm{Kx} \mathrm{Ky} \mathrm{Kz}$ Ss Por

$1.35637 \mathrm{e}+01$ 1.35637e+01 1.35637e+00 1.00000e-09 7.00000e-02 $1.35637 \mathrm{e}+01$ 1.35637e+01 1.35637e+00 1.00000e-09 7.00000e-02 $1.35637 \mathrm{e}+01$ 1.35637e+01 1.35637e+00 1.00000e-09 7.00000e-02 5.00000e-04 5.00000e-04 5.00000e-05 1.00000e-09 1.00000e-01 5.00000e-04 5.00000e-04 5.00000e-05 1.00000e-09 1.00000e-01 5.41969e-01 5.41969e-01 5.41969e-02 1.00000e-09 2.12000e-01 5.41969e-01 5.41969e-01 5.41969e-02 1.00000e-09 2.12000e-01 5.41969e-01 5.41969e-01 5.41969e-02 1.00000e-09 2.12000e-01 
5.41969e-01 5.41969e-01 5.41969e-02 1.00000e-09 2.12000e-01 5.41969e-01 5.41969e-01 5.41969e-02 1.00000e-09 2.12000e-01 $1.00000 \mathrm{e}-021.00000 \mathrm{e}-02$ 1.00000e-03 1.00000e-09 1.00000e-01 $1.00000 \mathrm{e}+001.00000 \mathrm{e}+001.00000 \mathrm{e}-011.00000 \mathrm{e}-091.00000 \mathrm{e}-01$ $1.00000 \mathrm{e}-05$ 1.00000e-05 1.00000e-06 1.00000e-09 1.00000e-01 $1.00000 \mathrm{e}+001.00000 \mathrm{e}+001.00000 \mathrm{e}-011.00000 \mathrm{e}-091.00000 \mathrm{e}-01$ $1.00000 \mathrm{e}-06$ 1.00000e-06 1.00000e-06 1.00000e-09 5.00000e-02 Element: 4737 \# of layers: 15

$\mathrm{Kx} \mathrm{Ky} \mathrm{Kz}$ Ss Por

1.35637e+01 1.35637e+01 1.35637e+00 1.00000e-09 7.00000e-02 $1.35637 \mathrm{e}+01$ 1.35637e+01 1.35637e+00 1.00000e-09 7.00000e-02 $1.35637 \mathrm{e}+01$ 1.35637e+01 1.35637e+00 1.00000e-09 7.00000e-02 5.00000e-04 5.00000e-04 5.00000e-05 1.00000e-09 1.00000e-01 5.00000e-04 5.00000e-04 5.00000e-05 1.00000e-09 1.00000e-01 5.41969e-01 5.41969e-01 5.41969e-02 1.00000e-09 2.12000e-01 5.41969e-01 5.41969e-01 5.41969e-02 1.00000e-09 2.12000e-01 5.41969e-01 5.41969e-01 5.41969e-02 1.00000e-09 2.12000e-01 5.41969e-01 5.41969e-01 5.41969e-02 1.00000e-09 2.12000e-01 5.41969e-01 5.41969e-01 5.41969e-02 1.00000e-09 2.12000e-01 $1.00000 \mathrm{e}-021.00000 \mathrm{e}-02$ 1.00000e-03 $1.00000 \mathrm{e}-091.00000 \mathrm{e}-01$ $1.00000 \mathrm{e}+001.00000 \mathrm{e}+001.00000 \mathrm{e}-011.00000 \mathrm{e}-091.00000 \mathrm{e}-01$ $1.00000 \mathrm{e}-05$ 1.00000e-05 1.00000e-06 1.00000e-09 1.00000e-01 $1.00000 \mathrm{e}+001.00000 \mathrm{e}+001.00000 \mathrm{e}-011.00000 \mathrm{e}-091.00000 \mathrm{e}-01$ $1.00000 \mathrm{e}-061.00000 \mathrm{e}-06$ 1.00000e-06 1.00000e-09 5.00000e-02 Element: 4738 \# of layers: 15

Kx Ky Kz Ss Por

$1.29753 \mathrm{e}+011.29753 \mathrm{e}+011.29753 \mathrm{e}+00$ 1.00000e-09 7.00000e-02 $1.29753 \mathrm{e}+011.29753 \mathrm{e}+011.29753 \mathrm{e}+001.00000 \mathrm{e}-09$ 7.00000e-02 $1.29753 \mathrm{e}+011.29753 \mathrm{e}+011.29753 \mathrm{e}+001.00000 \mathrm{e}-09$ 7.00000e-02 5.00000e-04 5.00000e-04 5.00000e-05 1.00000e-09 1.00000e-01 5.00000e-04 5.00000e-04 5.00000e-05 1.00000e-09 1.00000e-01 5.18456e-01 5.18456e-01 5.18456e-02 1.00000e-09 2.12000e-01 5.18456e-01 5.18456e-01 5.18456e-02 1.00000e-09 2.12000e-01 5.18456e-01 5.18456e-01 5.18456e-02 1.00000e-09 2.12000e-01 5.18456e-01 5.18456e-01 5.18456e-02 1.00000e-09 2.12000e-01 5.18456e-01 5.18456e-01 5.18456e-02 1.00000e-09 2.12000e-01 $1.00000 \mathrm{e}-021.00000 \mathrm{e}-02$ 1.00000e-03 1.00000e-09 1.00000e-01 $1.00000 \mathrm{e}+001.00000 \mathrm{e}+001.00000 \mathrm{e}-011.00000 \mathrm{e}-091.00000 \mathrm{e}-01$ $1.00000 \mathrm{e}-05$ 1.00000e-05 1.00000e-06 1.00000e-09 1.00000e-01 $1.00000 \mathrm{e}+001.00000 \mathrm{e}+001.00000 \mathrm{e}-011.00000 \mathrm{e}-091.00000 \mathrm{e}-01$ $1.00000 \mathrm{e}-06$ 1.00000e-06 1.00000e-06 1.00000e-09 5.00000e-02 Element: 4739 \# of layers: 14

Kx Ky Kz Ss Por $1.29753 \mathrm{e}+011.29753 \mathrm{e}+011.29753 \mathrm{e}+00$ 1.00000e-09 7.00000e-02 $1.29753 \mathrm{e}+011.29753 \mathrm{e}+011.29753 \mathrm{e}+001.00000 \mathrm{e}-097.00000 \mathrm{e}-02$ 5.00000e-04 5.00000e-04 5.00000e-05 1.00000e-09 1.00000e-01 
5.00000e-04 5.00000e-04 5.00000e-05 1.00000e-09 1.00000e-01 5.18456e-01 5.18456e-01 5.18456e-02 1.00000e-09 2.12000e-01 5.18456e-01 5.18456e-01 5.18456e-02 1.00000e-09 2.12000e-01 5.18456e-01 5.18456e-01 5.18456e-02 1.00000e-09 2.12000e-01 5.18456e-01 5.18456e-01 5.18456e-02 1.00000e-09 2.12000e-01 5.18456e-01 5.18456e-01 5.18456e-02 1.00000e-09 2.12000e-01 $1.00000 \mathrm{e}-02$ 1.00000e-02 1.00000e-03 1.00000e-09 1.00000e-01 $1.00000 \mathrm{e}+001.00000 \mathrm{e}+001.00000 \mathrm{e}-011.00000 \mathrm{e}-091.00000 \mathrm{e}-01$ $1.00000 \mathrm{e}-05$ 1.00000e-05 1.00000e-06 1.00000e-09 1.00000e-01 $1.00000 \mathrm{e}+001.00000 \mathrm{e}+001.00000 \mathrm{e}-011.00000 \mathrm{e}-091.00000 \mathrm{e}-01$ 1.00000e-06 1.00000e-06 1.00000e-06 1.00000e-09 5.00000e-02 Element: 4740 \# of layers: 14

$\mathrm{Kx} \mathrm{Ky} \mathrm{Kz}$ Ss Por

4.19551e+00 4.19551e+00 4.19551e-01 1.00000e-09 7.00000e-02 4.19551e+00 4.19551e+00 4.19551e-01 1.00000e-09 7.00000e-02 5.00000e-04 5.00000e-04 5.00000e-05 1.00000e-09 1.00000e-01 5.00000e-04 5.00000e-04 5.00000e-05 1.00000e-09 1.00000e-01 1.67640e-01 1.67640e-01 1.67640e-02 1.00000e-09 2.12000e-01 1.67640e-01 1.67640e-01 1.67640e-02 1.00000e-09 2.12000e-01 1.67640e-01 1.67640e-01 1.67640e-02 1.00000e-09 2.12000e-01 1.67640e-01 1.67640e-01 1.67640e-02 1.00000e-09 2.12000e-01 1.67640e-01 1.67640e-01 1.67640e-02 1.00000e-09 2.12000e-01 $1.00000 \mathrm{e}-02$ 1.00000e-02 1.00000e-03 1.00000e-09 1.00000e-01 $1.00000 \mathrm{e}+001.00000 \mathrm{e}+001.00000 \mathrm{e}-011.00000 \mathrm{e}-091.00000 \mathrm{e}-01$ $1.00000 \mathrm{e}-05$ 1.00000e-05 1.00000e-06 1.00000e-09 1.00000e-01 $1.00000 \mathrm{e}+001.00000 \mathrm{e}+001.00000 \mathrm{e}-011.00000 \mathrm{e}-091.00000 \mathrm{e}-01$ 1.00000e-06 1.00000e-06 1.00000e-06 1.00000e-09 5.00000e-02 Element: 4741 \# of layers: 14

Kx Ky Kz Ss Por

$1.26744 \mathrm{e}+011.26744 \mathrm{e}+011.26744 \mathrm{e}+001.00000 \mathrm{e}-097.00000 \mathrm{e}-02$ $1.26744 \mathrm{e}+011.26744 \mathrm{e}+011.26744 \mathrm{e}+001.00000 \mathrm{e}-097.00000 \mathrm{e}-02$ 5.00000e-04 5.00000e-04 5.00000e-05 1.00000e-09 1.00000e-01 5.00000e-04 5.00000e-04 5.00000e-05 1.00000e-09 1.00000e-01 5.06418e-01 5.06418e-01 5.06418e-02 1.00000e-09 2.12000e-01 5.06418e-01 5.06418e-01 5.06418e-02 1.00000e-09 2.12000e-01 5.06418e-01 5.06418e-01 5.06418e-02 1.00000e-09 2.12000e-01 5.06418e-01 5.06418e-01 5.06418e-02 1.00000e-09 2.12000e-01 5.06418e-01 5.06418e-01 5.06418e-02 1.00000e-09 2.12000e-01 $1.00000 \mathrm{e}-02$ 1.00000e-02 1.00000e-03 1.00000e-09 1.00000e-01 $1.00000 \mathrm{e}+001.00000 \mathrm{e}+001.00000 \mathrm{e}-011.00000 \mathrm{e}-091.00000 \mathrm{e}-01$ $1.00000 \mathrm{e}-05$ 1.00000e-05 1.00000e-06 1.00000e-09 1.00000e-01 $1.00000 \mathrm{e}+001.00000 \mathrm{e}+001.00000 \mathrm{e}-011.00000 \mathrm{e}-091.00000 \mathrm{e}-01$ 1.00000e-06 1.00000e-06 1.00000e-06 1.00000e-09 5.00000e-02 Element: 4742 \# of layers: 14

$\mathrm{Kx} \mathrm{Ky} \mathrm{Kz}$ Ss Por

1.35637e+01 1.35637e+01 1.35637e+00 1.00000e-09 7.00000e-02 
1.35637e+01 1.35637e+01 1.35637e+00 1.00000e-09 7.00000e-02 5.00000e-04 5.00000e-04 5.00000e-05 1.00000e-09 1.00000e-01 5.00000e-04 5.00000e-04 5.00000e-05 1.00000e-09 1.00000e-01 5.41969e-01 5.41969e-01 5.41969e-02 1.00000e-09 2.12000e-01 5.41969e-01 5.41969e-01 5.41969e-02 1.00000e-09 2.12000e-01 5.41969e-01 5.41969e-01 5.41969e-02 1.00000e-09 2.12000e-01 5.41969e-01 5.41969e-01 5.41969e-02 1.00000e-09 2.12000e-01 5.41969e-01 5.41969e-01 5.41969e-02 1.00000e-09 2.12000e-01 $1.00000 \mathrm{e}-02$ 1.00000e-02 1.00000e-03 1.00000e-09 1.00000e-01 $1.00000 \mathrm{e}+001.00000 \mathrm{e}+001.00000 \mathrm{e}-011.00000 \mathrm{e}-091.00000 \mathrm{e}-01$ $1.00000 \mathrm{e}-05$ 1.00000e-05 1.00000e-06 1.00000e-09 1.00000e-01 $1.00000 \mathrm{e}+001.00000 \mathrm{e}+001.00000 \mathrm{e}-011.00000 \mathrm{e}-091.00000 \mathrm{e}-01$ 1.00000e-06 1.00000e-06 1.00000e-06 1.00000e-09 5.00000e-02 Element: 4743 \# of layers: 15

$\mathrm{Kx} \mathrm{Ky} \mathrm{Kz}$ Ss Por $1.20833 \mathrm{e}+01$ 1.20833e+01 1.20833e+00 1.00000e-09 7.00000e-02 $1.20833 \mathrm{e}+011.20833 \mathrm{e}+011.20833 \mathrm{e}+001.00000 \mathrm{e}-09$ 7.00000e-02 $1.20833 \mathrm{e}+01$ 1.20833e+01 1.20833e+00 1.00000e-09 7.00000e-02 5.00000e-04 5.00000e-04 5.00000e-05 1.00000e-09 1.00000e-01 5.00000e-04 5.00000e-04 5.00000e-05 1.00000e-09 1.00000e-01 4.82815e-01 4.82815e-01 4.82815e-02 1.00000e-09 2.12000e-01 4.82815e-01 4.82815e-01 4.82815e-02 1.00000e-09 2.12000e-01 4.82815e-01 4.82815e-01 4.82815e-02 1.00000e-09 2.12000e-01 4.82815e-01 4.82815e-01 4.82815e-02 1.00000e-09 2.12000e-01 4.82815e-01 4.82815e-01 4.82815e-02 1.00000e-09 2.12000e-01 $1.00000 \mathrm{e}-02$ 1.00000e-02 1.00000e-03 1.00000e-09 1.00000e-01 $1.00000 \mathrm{e}+001.00000 \mathrm{e}+001.00000 \mathrm{e}-011.00000 \mathrm{e}-091.00000 \mathrm{e}-01$ $1.00000 \mathrm{e}-05$ 1.00000e-05 1.00000e-06 1.00000e-09 1.00000e-01 $1.00000 \mathrm{e}+001.00000 \mathrm{e}+001.00000 \mathrm{e}-011.00000 \mathrm{e}-091.00000 \mathrm{e}-01$ 1.00000e-06 1.00000e-06 1.00000e-06 1.00000e-09 5.00000e-02 Element: 4744 \# of layers: 15

$\mathrm{Kx} \mathrm{Ky} \mathrm{Kz}$ Ss Por

3.57310e+01 3.57310e+01 3.57310e+00 1.00000e-09 7.00000e-02 $3.57310 \mathrm{e}+013.57310 \mathrm{e}+013.57310 \mathrm{e}+001.00000 \mathrm{e}-097.00000 \mathrm{e}-02$ $3.57310 \mathrm{e}+013.57310 \mathrm{e}+013.57310 \mathrm{e}+001.00000 \mathrm{e}-09$ 7.00000e-02 5.00000e-04 5.00000e-04 5.00000e-05 1.00000e-09 1.00000e-01 5.00000e-04 5.00000e-04 5.00000e-05 1.00000e-09 1.00000e-01 $1.42768 \mathrm{e}+001.42768 \mathrm{e}+001.42768 \mathrm{e}-01$ 1.00000e-09 2.12000e-01 $1.42768 \mathrm{e}+001.42768 \mathrm{e}+00$ 1.42768e-01 1.00000e-09 2.12000e-01 $1.42768 \mathrm{e}+001.42768 \mathrm{e}+00$ 1.42768e-01 1.00000e-09 2.12000e-01 $1.42768 \mathrm{e}+001.42768 \mathrm{e}+00$ 1.42768e-01 1.00000e-09 2.12000e-01 $1.42768 \mathrm{e}+001.42768 \mathrm{e}+00 \quad 1.42768 \mathrm{e}-01$ 1.00000e-09 2.12000e-01 $1.00000 \mathrm{e}-021.00000 \mathrm{e}-021.00000 \mathrm{e}-031.00000 \mathrm{e}-091.00000 \mathrm{e}-01$ $1.00000 \mathrm{e}+001.00000 \mathrm{e}+001.00000 \mathrm{e}-011.00000 \mathrm{e}-091.00000 \mathrm{e}-01$ $1.00000 \mathrm{e}-05$ 1.00000e-05 1.00000e-06 1.00000e-09 1.00000e-01 $1.00000 \mathrm{e}+001.00000 \mathrm{e}+001.00000 \mathrm{e}-011.00000 \mathrm{e}-091.00000 \mathrm{e}-01$ 
1.00000e-06 1.00000e-06 1.00000e-06 1.00000e-09 5.00000e-02

Element: 4745 \# of layers: 15

Kx Ky Kz Ss Por

3.57310e+01 3.57310e+01 3.57310e+00 1.00000e-09 7.00000e-02

$3.57310 \mathrm{e}+013.57310 \mathrm{e}+013.57310 \mathrm{e}+001.00000 \mathrm{e}-09$ 7.00000e-02

$3.57310 \mathrm{e}+013.57310 \mathrm{e}+013.57310 \mathrm{e}+001.00000 \mathrm{e}-097.00000 \mathrm{e}-02$

5.00000e-04 5.00000e-04 5.00000e-05 1.00000e-09 1.00000e-01

5.00000e-04 5.00000e-04 5.00000e-05 1.00000e-09 1.00000e-01

$1.42768 \mathrm{e}+001.42768 \mathrm{e}+00$ 1.42768e-01 1.00000e-09 2.12000e-01

$1.42768 \mathrm{e}+001.42768 \mathrm{e}+00$ 1.42768e-01 1.00000e-09 2.12000e-01

$1.42768 \mathrm{e}+001.42768 \mathrm{e}+00$ 1.42768e-01 1.00000e-09 2.12000e-01

$1.42768 \mathrm{e}+001.42768 \mathrm{e}+001.42768 \mathrm{e}-011.00000 \mathrm{e}-092.12000 \mathrm{e}-01$

$1.42768 \mathrm{e}+001.42768 \mathrm{e}+001.42768 \mathrm{e}-01$ 1.00000e-09 2.12000e-01

$1.00000 \mathrm{e}-02$ 1.00000e-02 1.00000e-03 1.00000e-09 1.00000e-01

$1.00000 \mathrm{e}+001.00000 \mathrm{e}+001.00000 \mathrm{e}-011.00000 \mathrm{e}-091.00000 \mathrm{e}-01$

1.00000e-05 1.00000e-05 1.00000e-06 1.00000e-09 1.00000e-01

$1.00000 \mathrm{e}+001.00000 \mathrm{e}+001.00000 \mathrm{e}-011.00000 \mathrm{e}-091.00000 \mathrm{e}-01$

1.00000e-06 1.00000e-06 1.00000e-06 1.00000e-09 5.00000e-02

Element: 4746 \# of layers: 13

$\mathrm{Kx} \mathrm{Ky} \mathrm{Kz}$ Ss Por

3.57310e+01 3.57310e+01 3.57310e+00 1.00000e-09 7.00000e-02

$3.57310 \mathrm{e}+013.57310 \mathrm{e}+013.57310 \mathrm{e}+001.00000 \mathrm{e}-09$ 7.00000e-02

5.00000e-04 5.00000e-04 5.00000e-05 1.00000e-09 1.00000e-01

$1.42768 \mathrm{e}+001.42768 \mathrm{e}+00$ 1.42768e-01 1.00000e-09 2.12000e-01

$1.42768 \mathrm{e}+001.42768 \mathrm{e}+001.42768 \mathrm{e}-01$ 1.00000e-09 2.12000e-01

$1.42768 \mathrm{e}+001.42768 \mathrm{e}+00$ 1.42768e-01 1.00000e-09 2.12000e-01

$1.42768 \mathrm{e}+001.42768 \mathrm{e}+00$ 1.42768e-01 1.00000e-09 2.12000e-01

$1.42768 \mathrm{e}+001.42768 \mathrm{e}+001.42768 \mathrm{e}-01$ 1.00000e-09 2.12000e-01

$1.00000 \mathrm{e}-02$ 1.00000e-02 1.00000e-03 1.00000e-09 1.00000e-01

$1.00000 \mathrm{e}+001.00000 \mathrm{e}+001.00000 \mathrm{e}-011.00000 \mathrm{e}-091.00000 \mathrm{e}-01$

$1.00000 \mathrm{e}-05$ 1.00000e-05 1.00000e-06 1.00000e-09 1.00000e-01

$1.00000 \mathrm{e}+001.00000 \mathrm{e}+001.00000 \mathrm{e}-011.00000 \mathrm{e}-091.00000 \mathrm{e}-01$

1.00000e-06 1.00000e-06 1.00000e-06 1.00000e-09 5.00000e-02

Element: 4747 \# of layers: 14

Kx Ky Kz Ss Por

$1.21536 \mathrm{e}+011.21536 \mathrm{e}+011.21536 \mathrm{e}+001.00000 \mathrm{e}-09$ 7.00000e-02

$1.21536 \mathrm{e}+011.21536 \mathrm{e}+011.21536 \mathrm{e}+001.00000 \mathrm{e}-097.00000 \mathrm{e}-02$

5.00000e-04 5.00000e-04 5.00000e-05 1.00000e-09 1.00000e-01

5.00000e-04 5.00000e-04 5.00000e-05 1.00000e-09 1.00000e-01

4.85628e-01 4.85628e-01 4.85628e-02 1.00000e-09 2.12000e-01

4.85628e-01 4.85628e-01 4.85628e-02 1.00000e-09 2.12000e-01

4.85628e-01 4.85628e-01 4.85628e-02 1.00000e-09 2.12000e-01

4.85628e-01 4.85628e-01 4.85628e-02 1.00000e-09 2.12000e-01

4.85628e-01 4.85628e-01 4.85628e-02 1.00000e-09 2.12000e-01

$1.00000 \mathrm{e}-02$ 1.00000e-02 1.00000e-03 1.00000e-09 1.00000e-01

$1.00000 \mathrm{e}+001.00000 \mathrm{e}+001.00000 \mathrm{e}-011.00000 \mathrm{e}-091.00000 \mathrm{e}-01$ 
$1.00000 \mathrm{e}-05$ 1.00000e-05 1.00000e-06 1.00000e-09 1.00000e-01 $1.00000 \mathrm{e}+001.00000 \mathrm{e}+001.00000 \mathrm{e}-011.00000 \mathrm{e}-091.00000 \mathrm{e}-01$ 1.00000e-06 1.00000e-06 1.00000e-06 1.00000e-09 5.00000e-02 Element: 4748 \# of layers: 14

$\mathrm{Kx} \mathrm{Ky} \mathrm{Kz}$ Ss Por

$1.21536 \mathrm{e}+011.21536 \mathrm{e}+011.21536 \mathrm{e}+001.00000 \mathrm{e}-09$ 7.00000e-02 $1.21536 \mathrm{e}+011.21536 \mathrm{e}+011.21536 \mathrm{e}+001.00000 \mathrm{e}-09$ 7.00000e-02 5.00000e-04 5.00000e-04 5.00000e-05 1.00000e-09 1.00000e-01 5.00000e-04 5.00000e-04 5.00000e-05 1.00000e-09 1.00000e-01 4.85628e-01 4.85628e-01 4.85628e-02 1.00000e-09 2.12000e-01 4.85628e-01 4.85628e-01 4.85628e-02 1.00000e-09 2.12000e-01 4.85628e-01 4.85628e-01 4.85628e-02 1.00000e-09 2.12000e-01 4.85628e-01 4.85628e-01 4.85628e-02 1.00000e-09 2.12000e-01 4.85628e-01 4.85628e-01 4.85628e-02 1.00000e-09 2.12000e-01 $1.00000 \mathrm{e}-02$ 1.00000e-02 1.00000e-03 1.00000e-09 1.00000e-01 $1.00000 \mathrm{e}+001.00000 \mathrm{e}+001.00000 \mathrm{e}-011.00000 \mathrm{e}-091.00000 \mathrm{e}-01$ $1.00000 \mathrm{e}-05$ 1.00000e-05 1.00000e-06 1.00000e-09 1.00000e-01 $1.00000 \mathrm{e}+001.00000 \mathrm{e}+001.00000 \mathrm{e}-011.00000 \mathrm{e}-091.00000 \mathrm{e}-01$ $1.00000 \mathrm{e}-06$ 1.00000e-06 1.00000e-06 1.00000e-09 5.00000e-02 Element: 4749 \# of layers: 14

Kx Ky Kz Ss Por

$1.38556 \mathrm{e}+01$ 1.38556e+01 1.38556e+00 1.00000e-09 7.00000e-02 $1.38556 \mathrm{e}+011.38556 \mathrm{e}+01$ 1.38556e+00 1.00000e-09 7.00000e-02 5.00000e-04 5.00000e-04 5.00000e-05 1.00000e-09 1.00000e-01 $5.00000 \mathrm{e}-04$ 5.00000e-04 5.00000e-05 1.00000e-09 1.00000e-01 5.53624e-01 5.53624e-01 5.53624e-02 1.00000e-09 2.12000e-01 5.53624e-01 5.53624e-01 5.53624e-02 1.00000e-09 2.12000e-01 $5.53624 \mathrm{e}-015.53624 \mathrm{e}-015.53624 \mathrm{e}-02$ 1.00000e-09 2.12000e-01 5.53624e-01 5.53624e-01 5.53624e-02 1.00000e-09 2.12000e-01 $5.53624 \mathrm{e}-015.53624 \mathrm{e}-015.53624 \mathrm{e}-02$ 1.00000e-09 2.12000e-01 $1.00000 \mathrm{e}-02$ 1.00000e-02 1.00000e-03 1.00000e-09 1.00000e-01 $1.00000 \mathrm{e}+001.00000 \mathrm{e}+001.00000 \mathrm{e}-011.00000 \mathrm{e}-091.00000 \mathrm{e}-01$ $1.00000 \mathrm{e}-05$ 1.00000e-05 1.00000e-06 1.00000e-09 1.00000e-01 $1.00000 \mathrm{e}+001.00000 \mathrm{e}+001.00000 \mathrm{e}-011.00000 \mathrm{e}-091.00000 \mathrm{e}-01$ 1.00000e-06 1.00000e-06 1.00000e-06 1.00000e-09 5.00000e-02 Element: 4750 \# of layers: 15

Kx Ky Kz Ss Por $1.20833 \mathrm{e}+01$ 1.20833e+01 1.20833e+00 1.00000e-09 7.00000e-02 $1.20833 \mathrm{e}+01$ 1.20833e+01 1.20833e+00 1.00000e-09 7.00000e-02 $1.20833 \mathrm{e}+01$ 1.20833e+01 1.20833e+00 1.00000e-09 7.00000e-02 5.00000e-04 5.00000e-04 5.00000e-05 1.00000e-09 1.00000e-01 5.00000e-04 5.00000e-04 5.00000e-05 1.00000e-09 1.00000e-01 4.82815e-01 4.82815e-01 4.82815e-02 1.00000e-09 2.12000e-01 4.82815e-01 4.82815e-01 4.82815e-02 1.00000e-09 2.12000e-01 4.82815e-01 4.82815e-01 4.82815e-02 1.00000e-09 2.12000e-01 4.82815e-01 4.82815e-01 4.82815e-02 1.00000e-09 2.12000e-01 
4.82815e-01 4.82815e-01 4.82815e-02 1.00000e-09 2.12000e-01 $1.00000 \mathrm{e}-02$ 1.00000e-02 1.00000e-03 1.00000e-09 1.00000e-01 $1.00000 \mathrm{e}+001.00000 \mathrm{e}+001.00000 \mathrm{e}-011.00000 \mathrm{e}-091.00000 \mathrm{e}-01$ $1.00000 \mathrm{e}-05$ 1.00000e-05 1.00000e-06 1.00000e-09 1.00000e-01 $1.00000 \mathrm{e}+001.00000 \mathrm{e}+001.00000 \mathrm{e}-011.00000 \mathrm{e}-091.00000 \mathrm{e}-01$ 1.00000e-06 1.00000e-06 1.00000e-06 1.00000e-09 5.00000e-02 Element: 4751 \# of layers: 14

Kx Ky Kz Ss Por

3.57310e+01 3.57310e+01 3.57310e+00 1.00000e-09 7.00000e-02

$3.57310 \mathrm{e}+013.57310 \mathrm{e}+013.57310 \mathrm{e}+001.00000 \mathrm{e}-097.00000 \mathrm{e}-02$ 5.00000e-04 5.00000e-04 5.00000e-05 1.00000e-09 1.00000e-01 5.00000e-04 5.00000e-04 5.00000e-05 1.00000e-09 1.00000e-01 $1.42768 \mathrm{e}+001.42768 \mathrm{e}+00$ 1.42768e-01 1.00000e-09 2.12000e-01 $1.42768 \mathrm{e}+001.42768 \mathrm{e}+00$ 1.42768e-01 1.00000e-09 2.12000e-01 $1.42768 \mathrm{e}+001.42768 \mathrm{e}+00$ 1.42768e-01 1.00000e-09 2.12000e-01 $1.42768 \mathrm{e}+001.42768 \mathrm{e}+00$ 1.42768e-01 1.00000e-09 2.12000e-01 $1.42768 \mathrm{e}+001.42768 \mathrm{e}+00 \quad 1.42768 \mathrm{e}-01$ 1.00000e-09 2.12000e-01 $1.00000 \mathrm{e}-02$ 1.00000e-02 1.00000e-03 1.00000e-09 1.00000e-01 $1.00000 \mathrm{e}+001.00000 \mathrm{e}+001.00000 \mathrm{e}-011.00000 \mathrm{e}-091.00000 \mathrm{e}-01$ $1.00000 \mathrm{e}-05$ 1.00000e-05 1.00000e-06 1.00000e-09 1.00000e-01 $1.00000 \mathrm{e}+001.00000 \mathrm{e}+001.00000 \mathrm{e}-01$ 1.00000e-09 1.00000e-01 1.00000e-06 1.00000e-06 1.00000e-06 1.00000e-09 5.00000e-02 Element: 4752 \# of layers: 15

$\mathrm{Kx} \mathrm{Ky} \mathrm{Kz}$ Ss Por

1.10021e+02 1.10021e+02 1.10021e+01 1.00000e-09 7.00000e-02 $1.10021 \mathrm{e}+021.10021 \mathrm{e}+021.10021 \mathrm{e}+01$ 1.00000e-09 7.00000e-02 $1.10021 \mathrm{e}+021.10021 \mathrm{e}+021.10021 \mathrm{e}+01$ 1.00000e-09 7.00000e-02 5.00000e-04 5.00000e-04 5.00000e-05 1.00000e-09 1.00000e-01 5.00000e-04 5.00000e-04 5.00000e-05 1.00000e-09 1.00000e-01 $4.39614 \mathrm{e}+004.39614 \mathrm{e}+004.39614 \mathrm{e}-01$ 1.00000e-09 2.12000e-01 $4.39614 \mathrm{e}+004.39614 \mathrm{e}+004.39614 \mathrm{e}-01$ 1.00000e-09 2.12000e-01 $4.39614 \mathrm{e}+004.39614 \mathrm{e}+00$ 4.39614e-01 1.00000e-09 2.12000e-01 $4.39614 \mathrm{e}+004.39614 \mathrm{e}+004.39614 \mathrm{e}-01$ 1.00000e-09 2.12000e-01 $4.39614 \mathrm{e}+004.39614 \mathrm{e}+00 \quad 4.39614 \mathrm{e}-01$ 1.00000e-09 2.12000e-01 $1.00000 \mathrm{e}-02$ 1.00000e-02 1.00000e-03 1.00000e-09 1.00000e-01 $1.00000 \mathrm{e}+001.00000 \mathrm{e}+001.00000 \mathrm{e}-011.00000 \mathrm{e}-091.00000 \mathrm{e}-01$ $1.00000 \mathrm{e}-05$ 1.00000e-05 1.00000e-06 1.00000e-09 1.00000e-01 $1.00000 \mathrm{e}+001.00000 \mathrm{e}+001.00000 \mathrm{e}-011.00000 \mathrm{e}-091.00000 \mathrm{e}-01$ 1.00000e-06 1.00000e-06 1.00000e-06 1.00000e-09 5.00000e-02 Element: 4753 \# of layers: 15

$\mathrm{Kx} \mathrm{Ky} \mathrm{Kz}$ Ss Por

3.72627e+01 3.72627e+01 3.72627e+00 1.00000e-09 7.00000e-02 $3.72627 \mathrm{e}+013.72627 \mathrm{e}+013.72627 \mathrm{e}+00$ 1.00000e-09 7.00000e-02 3.72627e+01 3.72627e+01 3.72627e+00 1.00000e-09 7.00000e-02 $5.00000 \mathrm{e}-04$ 5.00000e-04 5.00000e-05 1.00000e-09 1.00000e-01 5.00000e-04 5.00000e-04 5.00000e-05 1.00000e-09 1.00000e-01 
$1.48890 \mathrm{e}+001.48890 \mathrm{e}+00$ 1.48890e-01 1.00000e-09 2.12000e-01 $1.48890 \mathrm{e}+001.48890 \mathrm{e}+001.48890 \mathrm{e}-01$ 1.00000e-09 2.12000e-01 $1.48890 \mathrm{e}+001.48890 \mathrm{e}+001.48890 \mathrm{e}-01$ 1.00000e-09 2.12000e-01 $1.48890 \mathrm{e}+001.48890 \mathrm{e}+001.48890 \mathrm{e}-011.00000 \mathrm{e}-092.12000 \mathrm{e}-01$ $1.48890 \mathrm{e}+001.48890 \mathrm{e}+001.48890 \mathrm{e}-011.00000 \mathrm{e}-092.12000 \mathrm{e}-01$ $1.00000 \mathrm{e}-02$ 1.00000e-02 1.00000e-03 1.00000e-09 1.00000e-01 $1.00000 \mathrm{e}+001.00000 \mathrm{e}+001.00000 \mathrm{e}-011.00000 \mathrm{e}-091.00000 \mathrm{e}-01$ $1.00000 \mathrm{e}-05$ 1.00000e-05 1.00000e-06 1.00000e-09 1.00000e-01 $1.00000 \mathrm{e}+001.00000 \mathrm{e}+001.00000 \mathrm{e}-011.00000 \mathrm{e}-091.00000 \mathrm{e}-01$ 1.00000e-06 1.00000e-06 1.00000e-06 1.00000e-09 5.00000e-02 Element: 4754 \# of layers: 15

Kx Ky Kz Ss Por

3.72627e+01 3.72627e+01 3.72627e+00 1.00000e-09 7.00000e-02 $3.72627 \mathrm{e}+013.72627 \mathrm{e}+013.72627 \mathrm{e}+00$ 1.00000e-09 7.00000e-02 $3.72627 \mathrm{e}+013.72627 \mathrm{e}+013.72627 \mathrm{e}+001.00000 \mathrm{e}-09$ 7.00000e-02 5.00000e-04 5.00000e-04 5.00000e-05 1.00000e-09 1.00000e-01 5.00000e-04 5.00000e-04 5.00000e-05 1.00000e-09 1.00000e-01 $1.48890 \mathrm{e}+001.48890 \mathrm{e}+001.48890 \mathrm{e}-01$ 1.00000e-09 2.12000e-01 $1.48890 \mathrm{e}+001.48890 \mathrm{e}+001.48890 \mathrm{e}-01$ 1.00000e-09 2.12000e-01 $1.48890 \mathrm{e}+001.48890 \mathrm{e}+001.48890 \mathrm{e}-01$ 1.00000e-09 2.12000e-01 $1.48890 \mathrm{e}+001.48890 \mathrm{e}+001.48890 \mathrm{e}-01$ 1.00000e-09 2.12000e-01 $1.48890 \mathrm{e}+001.48890 \mathrm{e}+00$ 1.48890e-01 1.00000e-09 2.12000e-01 $1.00000 \mathrm{e}-02$ 1.00000e-02 1.00000e-03 1.00000e-09 1.00000e-01 $1.00000 \mathrm{e}+001.00000 \mathrm{e}+001.00000 \mathrm{e}-011.00000 \mathrm{e}-091.00000 \mathrm{e}-01$ $1.00000 \mathrm{e}-05$ 1.00000e-05 1.00000e-06 1.00000e-09 1.00000e-01 $1.00000 \mathrm{e}+001.00000 \mathrm{e}+001.00000 \mathrm{e}-011.00000 \mathrm{e}-091.00000 \mathrm{e}-01$ 1.00000e-06 1.00000e-06 1.00000e-06 1.00000e-09 5.00000e-02 Element: 4755 \# of layers: 14

$\mathrm{Kx} \mathrm{Ky} \mathrm{Kz}$ Ss Por

3.72627e+01 3.72627e+01 3.72627e+00 1.00000e-09 7.00000e-02 $3.72627 \mathrm{e}+013.72627 \mathrm{e}+013.72627 \mathrm{e}+00$ 1.00000e-09 7.00000e-02 5.00000e-04 5.00000e-04 5.00000e-05 1.00000e-09 1.00000e-01 5.00000e-04 5.00000e-04 5.00000e-05 1.00000e-09 1.00000e-01 $1.48890 \mathrm{e}+001.48890 \mathrm{e}+001.48890 \mathrm{e}-011.00000 \mathrm{e}-092.12000 \mathrm{e}-01$ $1.48890 \mathrm{e}+001.48890 \mathrm{e}+00$ 1.48890e-01 1.00000e-09 2.12000e-01 $1.48890 \mathrm{e}+001.48890 \mathrm{e}+001.48890 \mathrm{e}-01$ 1.00000e-09 2.12000e-01 $1.48890 \mathrm{e}+001.48890 \mathrm{e}+001.48890 \mathrm{e}-01$ 1.00000e-09 2.12000e-01 $1.48890 \mathrm{e}+001.48890 \mathrm{e}+001.48890 \mathrm{e}-011.00000 \mathrm{e}-092.12000 \mathrm{e}-01$ $1.00000 \mathrm{e}-02$ 1.00000e-02 1.00000e-03 1.00000e-09 1.00000e-01 $1.00000 \mathrm{e}+001.00000 \mathrm{e}+001.00000 \mathrm{e}-011.00000 \mathrm{e}-091.00000 \mathrm{e}-01$ $1.00000 \mathrm{e}-05$ 1.00000e-05 1.00000e-06 1.00000e-09 1.00000e-01 $1.00000 \mathrm{e}+001.00000 \mathrm{e}+001.00000 \mathrm{e}-011.00000 \mathrm{e}-091.00000 \mathrm{e}-01$ 1.00000e-06 1.00000e-06 1.00000e-06 1.00000e-09 5.00000e-02 Element: 4756 \# of layers: 14

$\mathrm{Kx} \mathrm{Ky} \mathrm{Kz}$ Ss Por 6.06625e+01 6.06625e+01 6.06625e+00 1.00000e-09 7.00000e-02 
6.06625e+01 6.06625e+01 6.06625e+00 1.00000e-09 7.00000e-02 5.00000e-04 5.00000e-04 5.00000e-05 1.00000e-09 1.00000e-01 5.00000e-04 5.00000e-04 5.00000e-05 1.00000e-09 1.00000e-01

$2.42398 \mathrm{e}+002.42398 \mathrm{e}+00$ 2.42398e-01 1.00000e-09 2.12000e-01 $2.42398 \mathrm{e}+002.42398 \mathrm{e}+00$ 2.42398e-01 1.00000e-09 2.12000e-01 $2.42398 \mathrm{e}+002.42398 \mathrm{e}+00$ 2.42398e-01 1.00000e-09 2.12000e-01 $2.42398 \mathrm{e}+002.42398 \mathrm{e}+00$ 2.42398e-01 1.00000e-09 2.12000e-01 $2.42398 \mathrm{e}+002.42398 \mathrm{e}+002.42398 \mathrm{e}-01$ 1.00000e-09 2.12000e-01 $1.00000 \mathrm{e}-02$ 1.00000e-02 1.00000e-03 1.00000e-09 1.00000e-01 $1.00000 \mathrm{e}+001.00000 \mathrm{e}+001.00000 \mathrm{e}-011.00000 \mathrm{e}-091.00000 \mathrm{e}-01$ $1.00000 \mathrm{e}-05$ 1.00000e-05 1.00000e-06 1.00000e-09 1.00000e-01 $1.00000 \mathrm{e}+001.00000 \mathrm{e}+001.00000 \mathrm{e}-011.00000 \mathrm{e}-091.00000 \mathrm{e}-01$ 1.00000e-06 1.00000e-06 1.00000e-06 1.00000e-09 5.00000e-02 Element: 4757 \# of layers: 14

$\mathrm{Kx} \mathrm{Ky} \mathrm{Kz}$ Ss Por

6.06625e+01 6.06625e+01 6.06625e+00 1.00000e-09 7.00000e-02 $6.06625 \mathrm{e}+016.06625 \mathrm{e}+016.06625 \mathrm{e}+001.00000 \mathrm{e}-09$ 7.00000e-02 5.00000e-04 5.00000e-04 5.00000e-05 1.00000e-09 1.00000e-01 5.00000e-04 5.00000e-04 5.00000e-05 1.00000e-09 1.00000e-01 $2.42398 \mathrm{e}+002.42398 \mathrm{e}+002.42398 \mathrm{e}-01$ 1.00000e-09 2.12000e-01 $2.42398 \mathrm{e}+002.42398 \mathrm{e}+00$ 2.42398e-01 1.00000e-09 2.12000e-01 $2.42398 \mathrm{e}+002.42398 \mathrm{e}+002.42398 \mathrm{e}-01$ 1.00000e-09 2.12000e-01 2.42398e+00 2.42398e+00 2.42398e-01 1.00000e-09 2.12000e-01 $2.42398 \mathrm{e}+002.42398 \mathrm{e}+002.42398 \mathrm{e}-01$ 1.00000e-09 2.12000e-01 $1.00000 \mathrm{e}-02$ 1.00000e-02 1.00000e-03 1.00000e-09 1.00000e-01 $1.00000 \mathrm{e}+001.00000 \mathrm{e}+001.00000 \mathrm{e}-011.00000 \mathrm{e}-091.00000 \mathrm{e}-01$ $1.00000 \mathrm{e}-05$ 1.00000e-05 1.00000e-06 1.00000e-09 1.00000e-01 $1.00000 \mathrm{e}+001.00000 \mathrm{e}+001.00000 \mathrm{e}-011.00000 \mathrm{e}-091.00000 \mathrm{e}-01$ 1.00000e-06 1.00000e-06 1.00000e-06 1.00000e-09 5.00000e-02 Element: 4758 \# of layers: 14

$\mathrm{Kx} \mathrm{Ky} \mathrm{Kz}$ Ss Por

$2.71111 \mathrm{e}+012.71111 \mathrm{e}+012.71111 \mathrm{e}+00$ 1.00000e-09 7.00000e-02 $2.71111 \mathrm{e}+012.71111 \mathrm{e}+012.71111 \mathrm{e}+001.00000 \mathrm{e}-09$ 7.00000e-02 5.00000e-04 5.00000e-04 5.00000e-05 1.00000e-09 1.00000e-01 5.00000e-04 5.00000e-04 5.00000e-05 1.00000e-09 1.00000e-01 $1.08326 \mathrm{e}+001.08326 \mathrm{e}+001.08326 \mathrm{e}-01$ 1.00000e-09 2.12000e-01 $1.08326 \mathrm{e}+001.08326 \mathrm{e}+001.08326 \mathrm{e}-011.00000 \mathrm{e}-092.12000 \mathrm{e}-01$ $1.08326 \mathrm{e}+001.08326 \mathrm{e}+001.08326 \mathrm{e}-01$ 1.00000e-09 2.12000e-01 $1.08326 \mathrm{e}+001.08326 \mathrm{e}+00$ 1.08326e-01 1.00000e-09 2.12000e-01 $1.08326 \mathrm{e}+001.08326 \mathrm{e}+001.08326 \mathrm{e}-01$ 1.00000e-09 2.12000e-01 $1.00000 \mathrm{e}-02$ 1.00000e-02 1.00000e-03 1.00000e-09 1.00000e-01 $1.00000 \mathrm{e}+001.00000 \mathrm{e}+001.00000 \mathrm{e}-011.00000 \mathrm{e}-091.00000 \mathrm{e}-01$ $1.00000 \mathrm{e}-05$ 1.00000e-05 1.00000e-06 1.00000e-09 1.00000e-01 $1.00000 \mathrm{e}+001.00000 \mathrm{e}+001.00000 \mathrm{e}-011.00000 \mathrm{e}-091.00000 \mathrm{e}-01$ 1.00000e-06 1.00000e-06 1.00000e-06 1.00000e-09 5.00000e-02 Element: 4759 \# of layers: 14 
$\mathrm{Kx} \mathrm{Ky} \mathrm{Kz} \mathrm{Ss} \mathrm{Por}$

1.10021e+02 1.10021e+02 1.10021e+01 1.00000e-09 7.00000e-02

$1.10021 \mathrm{e}+021.10021 \mathrm{e}+02$ 1.10021e+01 1.00000e-09 7.00000e-02

5.00000e-04 5.00000e-04 5.00000e-05 1.00000e-09 1.00000e-01

5.00000e-04 5.00000e-04 5.00000e-05 1.00000e-09 1.00000e-01

$4.39614 \mathrm{e}+004.39614 \mathrm{e}+00$ 4.39614e-01 1.00000e-09 2.12000e-01

$4.39614 \mathrm{e}+004.39614 \mathrm{e}+00$ 4.39614e-01 1.00000e-09 2.12000e-01

$4.39614 \mathrm{e}+004.39614 \mathrm{e}+004.39614 \mathrm{e}-01$ 1.00000e-09 2.12000e-01

$4.39614 \mathrm{e}+004.39614 \mathrm{e}+004.39614 \mathrm{e}-01$ 1.00000e-09 2.12000e-01

$4.39614 \mathrm{e}+004.39614 \mathrm{e}+004.39614 \mathrm{e}-01$ 1.00000e-09 2.12000e-01

$1.00000 \mathrm{e}-02$ 1.00000e-02 1.00000e-03 1.00000e-09 1.00000e-01

$1.00000 \mathrm{e}+001.00000 \mathrm{e}+001.00000 \mathrm{e}-011.00000 \mathrm{e}-091.00000 \mathrm{e}-01$

$1.00000 \mathrm{e}-05$ 1.00000e-05 1.00000e-06 1.00000e-09 1.00000e-01

$1.00000 \mathrm{e}+001.00000 \mathrm{e}+001.00000 \mathrm{e}-011.00000 \mathrm{e}-091.00000 \mathrm{e}-01$

1.00000e-06 1.00000e-06 1.00000e-06 1.00000e-09 5.00000e-02

Element: 4760 \# of layers: 14

$\mathrm{Kx} \mathrm{Ky} \mathrm{Kz}$ Ss Por

3.72627e+01 3.72627e+01 3.72627e+00 1.00000e-09 7.00000e-02

$3.72627 \mathrm{e}+013.72627 \mathrm{e}+013.72627 \mathrm{e}+001.00000 \mathrm{e}-09$ 7.00000e-02

5.00000e-04 5.00000e-04 5.00000e-05 1.00000e-09 1.00000e-01

5.00000e-04 5.00000e-04 5.00000e-05 1.00000e-09 1.00000e-01

$1.48890 \mathrm{e}+001.48890 \mathrm{e}+00$ 1.48890e-01 1.00000e-09 2.12000e-01

$1.48890 \mathrm{e}+001.48890 \mathrm{e}+00$ 1.48890e-01 1.00000e-09 2.12000e-01

$1.48890 \mathrm{e}+001.48890 \mathrm{e}+001.48890 \mathrm{e}-01$ 1.00000e-09 2.12000e-01

$1.48890 \mathrm{e}+001.48890 \mathrm{e}+001.48890 \mathrm{e}-011.00000 \mathrm{e}-092.12000 \mathrm{e}-01$

$1.48890 \mathrm{e}+001.48890 \mathrm{e}+001.48890 \mathrm{e}-01$ 1.00000e-09 2.12000e-01

$1.00000 \mathrm{e}-02$ 1.00000e-02 1.00000e-03 1.00000e-09 1.00000e-01

$1.00000 \mathrm{e}+001.00000 \mathrm{e}+001.00000 \mathrm{e}-01$ 1.00000e-09 1.00000e-01

$1.00000 \mathrm{e}-05$ 1.00000e-05 1.00000e-06 1.00000e-09 1.00000e-01

$1.00000 \mathrm{e}+001.00000 \mathrm{e}+001.00000 \mathrm{e}-011.00000 \mathrm{e}-091.00000 \mathrm{e}-01$

1.00000e-06 1.00000e-06 1.00000e-06 1.00000e-09 5.00000e-02

Element: 4761 \# of layers: 15

Kx Ky Kz Ss Por

3.81538e+01 3.81538e+01 3.81538e+00 1.00000e-09 7.00000e-02

$3.81538 \mathrm{e}+013.81538 \mathrm{e}+013.81538 \mathrm{e}+001.00000 \mathrm{e}-09$ 7.00000e-02

$3.81538 \mathrm{e}+013.81538 \mathrm{e}+013.81538 \mathrm{e}+001.00000 \mathrm{e}-09$ 7.00000e-02

5.00000e-04 5.00000e-04 5.00000e-05 1.00000e-09 1.00000e-01

5.00000e-04 5.00000e-04 5.00000e-05 1.00000e-09 1.00000e-01

$1.52447 \mathrm{e}+001.52447 \mathrm{e}+00$ 1.52448e-01 1.00000e-09 2.12000e-01

$1.52447 \mathrm{e}+001.52447 \mathrm{e}+00$ 1.52448e-01 1.00000e-09 2.12000e-01

$1.52447 \mathrm{e}+001.52447 \mathrm{e}+00$ 1.52448e-01 1.00000e-09 2.12000e-01

$1.52447 \mathrm{e}+001.52447 \mathrm{e}+00$ 1.52448e-01 1.00000e-09 2.12000e-01

$1.52447 \mathrm{e}+00$ 1.52447e+00 1.52448e-01 1.00000e-09 2.12000e-01

$1.00000 \mathrm{e}-02$ 1.00000e-02 1.00000e-03 1.00000e-09 1.00000e-01

$1.00000 \mathrm{e}+001.00000 \mathrm{e}+001.00000 \mathrm{e}-011.00000 \mathrm{e}-091.00000 \mathrm{e}-01$

$1.00000 \mathrm{e}-05$ 1.00000e-05 1.00000e-06 1.00000e-09 1.00000e-01 
$1.00000 \mathrm{e}+001.00000 \mathrm{e}+001.00000 \mathrm{e}-011.00000 \mathrm{e}-091.00000 \mathrm{e}-01$ $1.00000 \mathrm{e}-06$ 1.00000e-06 1.00000e-06 1.00000e-09 5.00000e-02 Element: 4762 \# of layers: 14

$\mathrm{Kx} \mathrm{Ky} \mathrm{Kz}$ Ss Por

$3.81538 \mathrm{e}+013.81538 \mathrm{e}+013.81538 \mathrm{e}+001.00000 \mathrm{e}-09$ 7.00000e-02 $3.81538 \mathrm{e}+013.81538 \mathrm{e}+013.81538 \mathrm{e}+001.00000 \mathrm{e}-09$ 7.00000e-02 5.00000e-04 5.00000e-04 5.00000e-05 1.00000e-09 1.00000e-01 5.00000e-04 5.00000e-04 5.00000e-05 1.00000e-09 1.00000e-01 $1.52447 \mathrm{e}+001.52447 \mathrm{e}+00$ 1.52448e-01 1.00000e-09 2.12000e-01 $1.52447 \mathrm{e}+00$ 1.52447e+00 1.52448e-01 1.00000e-09 2.12000e-01 $1.52447 \mathrm{e}+001.52447 \mathrm{e}+00$ 1.52448e-01 1.00000e-09 2.12000e-01 $1.52447 \mathrm{e}+001.52447 \mathrm{e}+001.52448 \mathrm{e}-01$ 1.00000e-09 2.12000e-01 $1.52447 \mathrm{e}+001.52447 \mathrm{e}+00$ 1.52448e-01 1.00000e-09 2.12000e-01 $1.00000 \mathrm{e}-02$ 1.00000e-02 1.00000e-03 1.00000e-09 1.00000e-01 $1.00000 \mathrm{e}+001.00000 \mathrm{e}+001.00000 \mathrm{e}-011.00000 \mathrm{e}-091.00000 \mathrm{e}-01$ $1.00000 \mathrm{e}-05$ 1.00000e-05 1.00000e-06 1.00000e-09 1.00000e-01 $1.00000 \mathrm{e}+001.00000 \mathrm{e}+001.00000 \mathrm{e}-011.00000 \mathrm{e}-091.00000 \mathrm{e}-01$ 1.00000e-06 1.00000e-06 1.00000e-06 1.00000e-09 5.00000e-02 Element: 4763 \# of layers: 14

$\mathrm{Kx} \mathrm{Ky} \mathrm{Kz}$ Ss Por

3.42092e+01 3.42092e+01 3.42092e+00 1.00000e-09 7.00000e-02 3.42092e+01 3.42092e+01 3.42092e+00 1.00000e-09 7.00000e-02 3.42092e+01 3.42092e+01 3.42092e+00 1.00000e-09 7.00000e-02 5.00000e-04 5.00000e-04 5.00000e-05 1.00000e-09 1.00000e-01

$1.36686 \mathrm{e}+001.36686 \mathrm{e}+001.36686 \mathrm{e}-011.00000 \mathrm{e}-092.12000 \mathrm{e}-01$ $1.36686 \mathrm{e}+001.36686 \mathrm{e}+00$ 1.36686e-01 1.00000e-09 2.12000e-01 $1.36686 \mathrm{e}+001.36686 \mathrm{e}+001.36686 \mathrm{e}-01$ 1.00000e-09 2.12000e-01 $1.36686 \mathrm{e}+001.36686 \mathrm{e}+001.36686 \mathrm{e}-01$ 1.00000e-09 2.12000e-01 $1.36686 \mathrm{e}+001.36686 \mathrm{e}+001.36686 \mathrm{e}-01 \quad 1.00000 \mathrm{e}-092.12000 \mathrm{e}-01$ $1.00000 \mathrm{e}-02$ 1.00000e-02 1.00000e-03 1.00000e-09 1.00000e-01 $1.00000 \mathrm{e}+001.00000 \mathrm{e}+001.00000 \mathrm{e}-011.00000 \mathrm{e}-091.00000 \mathrm{e}-01$ $1.00000 \mathrm{e}-05$ 1.00000e-05 1.00000e-06 1.00000e-09 1.00000e-01 $1.00000 \mathrm{e}+001.00000 \mathrm{e}+001.00000 \mathrm{e}-011.00000 \mathrm{e}-091.00000 \mathrm{e}-01$ 1.00000e-06 1.00000e-06 1.00000e-06 1.00000e-09 5.00000e-02 Element: 4764 \# of layers: 14

$\mathrm{Kx} \mathrm{Ky} \mathrm{Kz}$ Ss Por

3.42092e+01 3.42092e+01 3.42092e+00 1.00000e-09 7.00000e-02 $3.42092 \mathrm{e}+013.42092 \mathrm{e}+013.42092 \mathrm{e}+00$ 1.00000e-09 7.00000e-02 5.00000e-04 5.00000e-04 5.00000e-05 1.00000e-09 1.00000e-01 5.00000e-04 5.00000e-04 5.00000e-05 1.00000e-09 1.00000e-01 $1.36686 \mathrm{e}+001.36686 \mathrm{e}+00$ 1.36686e-01 1.00000e-09 2.12000e-01 $1.36686 \mathrm{e}+001.36686 \mathrm{e}+00$ 1.36686e-01 1.00000e-09 2.12000e-01 $1.36686 \mathrm{e}+00$ 1.36686e+00 1.36686e-01 1.00000e-09 2.12000e-01 $1.36686 \mathrm{e}+00$ 1.36686e+00 1.36686e-01 1.00000e-09 2.12000e-01 $1.36686 \mathrm{e}+001.36686 \mathrm{e}+00$ 1.36686e-01 1.00000e-09 2.12000e-01 $1.00000 \mathrm{e}-02$ 1.00000e-02 1.00000e-03 1.00000e-09 1.00000e-01 
$1.00000 \mathrm{e}+001.00000 \mathrm{e}+001.00000 \mathrm{e}-011.00000 \mathrm{e}-091.00000 \mathrm{e}-01$ $1.00000 \mathrm{e}-05$ 1.00000e-05 1.00000e-06 1.00000e-09 1.00000e-01 $1.00000 \mathrm{e}+001.00000 \mathrm{e}+001.00000 \mathrm{e}-011.00000 \mathrm{e}-091.00000 \mathrm{e}-01$ 1.00000e-06 1.00000e-06 1.00000e-06 1.00000e-09 5.00000e-02 Element: 4765 \# of layers: 14

$\mathrm{Kx} \mathrm{Ky} \mathrm{Kz}$ Ss Por

7.89294e+01 7.89294e+01 7.89294e+00 1.00000e-09 7.00000e-02 $7.89294 \mathrm{e}+017.89294 \mathrm{e}+017.89294 \mathrm{e}+001.00000 \mathrm{e}-097.00000 \mathrm{e}-02$ 5.00000e-04 5.00000e-04 5.00000e-05 1.00000e-09 1.00000e-01 5.00000e-04 5.00000e-04 5.00000e-05 1.00000e-09 1.00000e-01 $3.15367 \mathrm{e}+003.15367 \mathrm{e}+00$ 3.15367e-01 1.00000e-09 2.12000e-01 $3.15367 \mathrm{e}+003.15367 \mathrm{e}+003.15367 \mathrm{e}-01$ 1.00000e-09 2.12000e-01 3.15367e+00 3.15367e+00 3.15367e-01 1.00000e-09 2.12000e-01 3.15367e+00 3.15367e+00 3.15367e-01 1.00000e-09 2.12000e-01 3.15367e+00 3.15367e+00 3.15367e-01 1.00000e-09 2.12000e-01 $1.00000 \mathrm{e}-02$ 1.00000e-02 1.00000e-03 1.00000e-09 1.00000e-01 $1.00000 \mathrm{e}+001.00000 \mathrm{e}+001.00000 \mathrm{e}-011.00000 \mathrm{e}-091.00000 \mathrm{e}-01$ $1.00000 \mathrm{e}-05$ 1.00000e-05 1.00000e-06 1.00000e-09 1.00000e-01 $1.00000 \mathrm{e}+001.00000 \mathrm{e}+001.00000 \mathrm{e}-011.00000 \mathrm{e}-091.00000 \mathrm{e}-01$ 1.00000e-06 1.00000e-06 1.00000e-06 1.00000e-09 5.00000e-02 Element: 4766 \# of layers: 13

$\mathrm{Kx} \mathrm{Ky} \mathrm{Kz}$ Ss Por

7.89294e+01 7.89294e+01 7.89294e+00 1.00000e-09 7.00000e-02 5.00000e-04 5.00000e-04 5.00000e-05 1.00000e-09 1.00000e-01 5.00000e-04 5.00000e-04 5.00000e-05 1.00000e-09 1.00000e-01 $3.15367 \mathrm{e}+003.15367 \mathrm{e}+00$ 3.15367e-01 1.00000e-09 2.12000e-01 3.15367e+00 3.15367e+00 3.15367e-01 1.00000e-09 2.12000e-01 3.15367e+00 3.15367e+00 3.15367e-01 1.00000e-09 2.12000e-01 3.15367e+00 3.15367e+00 3.15367e-01 1.00000e-09 2.12000e-01 3.15367e+00 3.15367e+00 3.15367e-01 1.00000e-09 2.12000e-01 $1.00000 \mathrm{e}-02$ 1.00000e-02 1.00000e-03 1.00000e-09 1.00000e-01 $1.00000 \mathrm{e}+001.00000 \mathrm{e}+001.00000 \mathrm{e}-011.00000 \mathrm{e}-091.00000 \mathrm{e}-01$ $1.00000 \mathrm{e}-05$ 1.00000e-05 1.00000e-06 1.00000e-09 1.00000e-01 $1.00000 \mathrm{e}+001.00000 \mathrm{e}+001.00000 \mathrm{e}-011.00000 \mathrm{e}-091.00000 \mathrm{e}-01$ 1.00000e-06 1.00000e-06 1.00000e-06 1.00000e-09 5.00000e-02 Element: 4767 \# of layers: 14

Kx Ky Kz Ss Por

8.74240e+01 8.74240e+01 8.74240e+00 1.00000e-09 7.00000e-02 $8.74240 \mathrm{e}+018.74240 \mathrm{e}+018.74240 \mathrm{e}+001.00000 \mathrm{e}-097.00000 \mathrm{e}-02$ 5.00000e-04 5.00000e-04 5.00000e-05 1.00000e-09 1.00000e-01 5.00000e-04 5.00000e-04 5.00000e-05 1.00000e-09 1.00000e-01 $3.49320 \mathrm{e}+003.49320 \mathrm{e}+003.49320 \mathrm{e}-01$ 1.00000e-09 2.12000e-01 $3.49320 \mathrm{e}+003.49320 \mathrm{e}+003.49320 \mathrm{e}-01$ 1.00000e-09 2.12000e-01 $3.49320 \mathrm{e}+003.49320 \mathrm{e}+00$ 3.49320e-01 1.00000e-09 2.12000e-01 $3.49320 \mathrm{e}+003.49320 \mathrm{e}+003.49320 \mathrm{e}-01$ 1.00000e-09 2.12000e-01 $3.49320 \mathrm{e}+003.49320 \mathrm{e}+003.49320 \mathrm{e}-01$ 1.00000e-09 2.12000e-01 
$1.00000 \mathrm{e}-02$ 1.00000e-02 1.00000e-03 1.00000e-09 1.00000e-01 $1.00000 \mathrm{e}+001.00000 \mathrm{e}+001.00000 \mathrm{e}-011.00000 \mathrm{e}-091.00000 \mathrm{e}-01$ $1.00000 \mathrm{e}-051.00000 \mathrm{e}-05$ 1.00000e-06 1.00000e-09 1.00000e-01 $1.00000 \mathrm{e}+001.00000 \mathrm{e}+001.00000 \mathrm{e}-011.00000 \mathrm{e}-091.00000 \mathrm{e}-01$ 1.00000e-06 1.00000e-06 1.00000e-06 1.00000e-09 5.00000e-02 Element: 4768 \# of layers: 14

$\mathrm{Kx} \mathrm{Ky} \mathrm{Kz}$ Ss Por

8.74240e+01 8.74240e+01 8.74240e+00 1.00000e-09 7.00000e-02

$8.74240 \mathrm{e}+018.74240 \mathrm{e}+018.74240 \mathrm{e}+001.00000 \mathrm{e}-09$ 7.00000e-02

$5.00000 \mathrm{e}-045.00000 \mathrm{e}-045.00000 \mathrm{e}-051.00000 \mathrm{e}-091.00000 \mathrm{e}-01$

5.00000e-04 5.00000e-04 5.00000e-05 1.00000e-09 1.00000e-01

$3.49320 \mathrm{e}+003.49320 \mathrm{e}+003.49320 \mathrm{e}-01$ 1.00000e-09 2.12000e-01

$3.49320 \mathrm{e}+003.49320 \mathrm{e}+003.49320 \mathrm{e}-01$ 1.00000e-09 2.12000e-01

$3.49320 \mathrm{e}+003.49320 \mathrm{e}+003.49320 \mathrm{e}-01$ 1.00000e-09 2.12000e-01

$3.49320 \mathrm{e}+003.49320 \mathrm{e}+00$ 3.49320e-01 1.00000e-09 2.12000e-01

$3.49320 \mathrm{e}+003.49320 \mathrm{e}+003.49320 \mathrm{e}-01$ 1.00000e-09 2.12000e-01

$1.00000 \mathrm{e}-02$ 1.00000e-02 1.00000e-03 1.00000e-09 1.00000e-01

$1.00000 \mathrm{e}+001.00000 \mathrm{e}+001.00000 \mathrm{e}-011.00000 \mathrm{e}-091.00000 \mathrm{e}-01$

$1.00000 \mathrm{e}-05$ 1.00000e-05 1.00000e-06 1.00000e-09 1.00000e-01

$1.00000 \mathrm{e}+001.00000 \mathrm{e}+001.00000 \mathrm{e}-011.00000 \mathrm{e}-091.00000 \mathrm{e}-01$

$1.00000 \mathrm{e}-06$ 1.00000e-06 1.00000e-06 1.00000e-09 5.00000e-02

Element: 4769 \# of layers: 13

$\mathrm{Kx} \mathrm{Ky} \mathrm{Kz}$ Ss Por

3.42092e+01 3.42092e+01 3.42092e+00 1.00000e-09 7.00000e-02

$5.00000 \mathrm{e}-04$ 5.00000e-04 5.00000e-05 1.00000e-09 1.00000e-01

5.00000e-04 5.00000e-04 5.00000e-05 1.00000e-09 1.00000e-01

$1.36686 \mathrm{e}+001.36686 \mathrm{e}+00$ 1.36686e-01 1.00000e-09 2.12000e-01

$1.36686 \mathrm{e}+001.36686 \mathrm{e}+001.36686 \mathrm{e}-01$ 1.00000e-09 2.12000e-01

$1.36686 \mathrm{e}+001.36686 \mathrm{e}+001.36686 \mathrm{e}-011.00000 \mathrm{e}-092.12000 \mathrm{e}-01$

$1.36686 \mathrm{e}+00$ 1.36686e+00 1.36686e-01 1.00000e-09 2.12000e-01

$1.36686 \mathrm{e}+001.36686 \mathrm{e}+00$ 1.36686e-01 1.00000e-09 2.12000e-01

$1.00000 \mathrm{e}-02$ 1.00000e-02 1.00000e-03 1.00000e-09 1.00000e-01

$1.00000 \mathrm{e}+001.00000 \mathrm{e}+001.00000 \mathrm{e}-011.00000 \mathrm{e}-091.00000 \mathrm{e}-01$

$1.00000 \mathrm{e}-05$ 1.00000e-05 1.00000e-06 1.00000e-09 1.00000e-01

$1.00000 \mathrm{e}+001.00000 \mathrm{e}+001.00000 \mathrm{e}-011.00000 \mathrm{e}-091.00000 \mathrm{e}-01$

1.00000e-06 1.00000e-06 1.00000e-06 1.00000e-09 5.00000e-02

Element: 4770 \# of layers: 14

Kx Ky Kz Ss Por

$2.37197 \mathrm{e}+012.37197 \mathrm{e}+01$ 2.37197e+00 1.00000e-09 7.00000e-02

$2.37197 \mathrm{e}+012.37197 \mathrm{e}+012.37197 \mathrm{e}+00$ 1.00000e-09 7.00000e-02

2.37197e+01 2.37197e+01 2.37197e+00 1.00000e-09 7.00000e-02

5.00000e-04 5.00000e-04 5.00000e-05 1.00000e-09 1.00000e-01

9.47765e-01 9.47765e-01 9.47765e-02 1.00000e-09 2.12000e-01

9.47765e-01 9.47765e-01 9.47765e-02 1.00000e-09 2.12000e-01

9.47765e-01 9.47765e-01 9.47765e-02 1.00000e-09 2.12000e-01

9.47765e-01 9.47765e-01 9.47765e-02 1.00000e-09 2.12000e-01 
9.47765e-01 9.47765e-01 9.47765e-02 1.00000e-09 2.12000e-01 $1.00000 \mathrm{e}-02$ 1.00000e-02 1.00000e-03 1.00000e-09 1.00000e-01 $1.00000 \mathrm{e}+001.00000 \mathrm{e}+001.00000 \mathrm{e}-011.00000 \mathrm{e}-091.00000 \mathrm{e}-01$ $1.00000 \mathrm{e}-05$ 1.00000e-05 1.00000e-06 1.00000e-09 1.00000e-01 $1.00000 \mathrm{e}+001.00000 \mathrm{e}+001.00000 \mathrm{e}-011.00000 \mathrm{e}-091.00000 \mathrm{e}-01$ 1.00000e-06 1.00000e-06 1.00000e-06 1.00000e-09 5.00000e-02 Element: 4771 \# of layers: 15

Kx Ky Kz Ss Por

2.37197e+01 2.37197e+01 2.37197e+00 1.00000e-09 7.00000e-02

$2.37197 \mathrm{e}+012.37197 \mathrm{e}+012.37197 \mathrm{e}+00$ 1.00000e-09 7.00000e-02

$2.37197 \mathrm{e}+012.37197 \mathrm{e}+012.37197 \mathrm{e}+00$ 1.00000e-09 7.00000e-02 5.00000e-04 5.00000e-04 5.00000e-05 1.00000e-09 1.00000e-01 5.00000e-04 5.00000e-04 5.00000e-05 1.00000e-09 1.00000e-01 9.47765e-01 9.47765e-01 9.47765e-02 1.00000e-09 2.12000e-01 9.47765e-01 9.47765e-01 9.47765e-02 1.00000e-09 2.12000e-01 9.47765e-01 9.47765e-01 9.47765e-02 1.00000e-09 2.12000e-01 9.47765e-01 9.47765e-01 9.47765e-02 1.00000e-09 2.12000e-01 9.47765e-01 9.47765e-01 9.47765e-02 1.00000e-09 2.12000e-01 $1.00000 \mathrm{e}-02$ 1.00000e-02 1.00000e-03 1.00000e-09 1.00000e-01 $1.00000 \mathrm{e}+001.00000 \mathrm{e}+001.00000 \mathrm{e}-011.00000 \mathrm{e}-091.00000 \mathrm{e}-01$ $1.00000 \mathrm{e}-05$ 1.00000e-05 1.00000e-06 1.00000e-09 1.00000e-01 $1.00000 \mathrm{e}+001.00000 \mathrm{e}+001.00000 \mathrm{e}-011.00000 \mathrm{e}-091.00000 \mathrm{e}-01$ 1.00000e-06 1.00000e-06 1.00000e-06 1.00000e-09 5.00000e-02 Element: 4772 \# of layers: 13

$\mathrm{Kx} \mathrm{Ky} \mathrm{Kz}$ Ss Por $2.02878 \mathrm{e}+012.02878 \mathrm{e}+012.02878 \mathrm{e}+00$ 1.00000e-09 7.00000e-02 $2.02878 \mathrm{e}+012.02878 \mathrm{e}+012.02878 \mathrm{e}+001.00000 \mathrm{e}-09$ 7.00000e-02 $2.02878 \mathrm{e}+012.02878 \mathrm{e}+012.02878 \mathrm{e}+001.00000 \mathrm{e}-09$ 7.00000e-02 5.00000e-04 5.00000e-04 5.00000e-05 1.00000e-09 1.00000e-01 5.00000e-04 5.00000e-04 5.00000e-05 1.00000e-09 1.00000e-01 8.10625e-01 8.10625e-01 8.10625e-02 1.00000e-09 2.12000e-01 8.10625e-01 8.10625e-01 8.10625e-02 1.00000e-09 2.12000e-01 8.10625e-01 8.10625e-01 8.10625e-02 1.00000e-09 2.12000e-01 8.10625e-01 8.10625e-01 8.10625e-02 1.00000e-09 2.12000e-01 $1.00000 \mathrm{e}-02$ 1.00000e-02 1.00000e-03 1.00000e-09 1.00000e-01 $1.00000 \mathrm{e}+001.00000 \mathrm{e}+001.00000 \mathrm{e}-011.00000 \mathrm{e}-091.00000 \mathrm{e}-01$ $1.00000 \mathrm{e}-051.00000 \mathrm{e}-05$ 1.00000e-06 1.00000e-09 1.00000e-01 $1.00000 \mathrm{e}+001.00000 \mathrm{e}+001.00000 \mathrm{e}-01$ 1.00000e-09 1.00000e-01 Element: 4773 \# of layers: 14

$\mathrm{Kx} \mathrm{Ky} \mathrm{Kz}$ Ss Por 3.09313e+01 3.09313e+01 3.09313e+00 1.00000e-09 7.00000e-02 $3.09313 \mathrm{e}+013.09313 \mathrm{e}+013.09313 \mathrm{e}+001.00000 \mathrm{e}-09$ 7.00000e-02 $3.09313 \mathrm{e}+013.09313 \mathrm{e}+013.09313 \mathrm{e}+001.00000 \mathrm{e}-09$ 7.00000e-02 5.00000e-04 5.00000e-04 5.00000e-05 1.00000e-09 1.00000e-01 5.00000e-04 5.00000e-04 5.00000e-05 1.00000e-09 1.00000e-01 $1.23593 \mathrm{e}+001.23593 \mathrm{e}+00$ 1.23593e-01 1.00000e-09 2.12000e-01 
$1.23593 \mathrm{e}+00$ 1.23593e+00 1.23593e-01 1.00000e-09 2.12000e-01 $1.23593 \mathrm{e}+00$ 1.23593e+00 1.23593e-01 1.00000e-09 2.12000e-01 $1.23593 \mathrm{e}+001.23593 \mathrm{e}+00$ 1.23593e-01 1.00000e-09 2.12000e-01 $1.00000 \mathrm{e}-02$ 1.00000e-02 1.00000e-03 1.00000e-09 1.00000e-01 $1.00000 \mathrm{e}+001.00000 \mathrm{e}+001.00000 \mathrm{e}-011.00000 \mathrm{e}-091.00000 \mathrm{e}-01$ $1.00000 \mathrm{e}-05$ 1.00000e-05 1.00000e-06 1.00000e-09 1.00000e-01 $1.00000 \mathrm{e}+001.00000 \mathrm{e}+001.00000 \mathrm{e}-011.00000 \mathrm{e}-091.00000 \mathrm{e}-01$ 1.00000e-06 1.00000e-06 1.00000e-06 1.00000e-09 5.00000e-02 Element: 4774 \# of layers: 9

$\mathrm{Kx} \mathrm{Ky} \mathrm{Kz}$ Ss Por

3.09313e+01 3.09313e+01 3.09313e+00 1.00000e-09 7.00000e-02 $3.09313 \mathrm{e}+013.09313 \mathrm{e}+013.09313 \mathrm{e}+001.00000 \mathrm{e}-09$ 7.00000e-02 5.00000e-04 5.00000e-04 5.00000e-05 1.00000e-09 1.00000e-01

$1.23593 \mathrm{e}+001.23593 \mathrm{e}+00$ 1.23593e-01 1.00000e-09 2.12000e-01 $1.23593 \mathrm{e}+001.23593 \mathrm{e}+00$ 1.23593e-01 1.00000e-09 2.12000e-01 $1.23593 \mathrm{e}+001.23593 \mathrm{e}+00$ 1.23593e-01 1.00000e-09 2.12000e-01 $1.23593 \mathrm{e}+001.23593 \mathrm{e}+00$ 1.23593e-01 1.00000e-09 2.12000e-01 $1.00000 \mathrm{e}+001.00000 \mathrm{e}+001.00000 \mathrm{e}-011.00000 \mathrm{e}-091.00000 \mathrm{e}-01$ 1.00000e-06 1.00000e-06 1.00000e-06 1.00000e-09 5.00000e-02 Element: 4775 \# of layers: 10

$\mathrm{Kx} \mathrm{Ky} \mathrm{Kz}$ Ss Por

4.41211e+01 4.41211e+01 4.41211e+00 1.00000e-09 7.00000e-02 $4.41211 \mathrm{e}+014.41211 \mathrm{e}+014.41211 \mathrm{e}+001.00000 \mathrm{e}-09$ 7.00000e-02 5.00000e-04 5.00000e-04 5.00000e-05 1.00000e-09 1.00000e-01

$1.76294 \mathrm{e}+001.76294 \mathrm{e}+001.76294 \mathrm{e}-011.00000 \mathrm{e}-092.12000 \mathrm{e}-01$ $1.76294 \mathrm{e}+001.76294 \mathrm{e}+00$ 1.76294e-01 1.00000e-09 2.12000e-01 $1.76294 \mathrm{e}+001.76294 \mathrm{e}+001.76294 \mathrm{e}-01$ 1.00000e-09 2.12000e-01 $1.76294 \mathrm{e}+001.76294 \mathrm{e}+001.76294 \mathrm{e}-01$ 1.00000e-09 2.12000e-01 $1.00000 \mathrm{e}-02$ 1.00000e-02 1.00000e-03 1.00000e-09 1.00000e-01 $1.00000 \mathrm{e}+001.00000 \mathrm{e}+001.00000 \mathrm{e}-011.00000 \mathrm{e}-091.00000 \mathrm{e}-01$ 1.00000e-06 1.00000e-06 1.00000e-06 1.00000e-09 5.00000e-02 Element: 4776 \# of layers: 12

Kx Ky Kz Ss Por

4.41211e+01 4.41211e+01 4.41211e+00 1.00000e-09 7.00000e-02 $4.41211 \mathrm{e}+014.41211 \mathrm{e}+014.41211 \mathrm{e}+001.00000 \mathrm{e}-09$ 7.00000e-02 5.00000e-04 5.00000e-04 5.00000e-05 1.00000e-09 1.00000e-01 5.00000e-04 5.00000e-04 5.00000e-05 1.00000e-09 1.00000e-01

$1.76294 \mathrm{e}+001.76294 \mathrm{e}+00$ 1.76294e-01 1.00000e-09 2.12000e-01 $1.76294 \mathrm{e}+001.76294 \mathrm{e}+00$ 1.76294e-01 1.00000e-09 2.12000e-01 $1.76294 \mathrm{e}+001.76294 \mathrm{e}+001.76294 \mathrm{e}-01$ 1.00000e-09 2.12000e-01 $1.76294 \mathrm{e}+001.76294 \mathrm{e}+001.76294 \mathrm{e}-01$ 1.00000e-09 2.12000e-01 $1.76294 \mathrm{e}+001.76294 \mathrm{e}+00 \quad 1.76294 \mathrm{e}-011.00000 \mathrm{e}-092.12000 \mathrm{e}-01$ $1.00000 \mathrm{e}-021.00000 \mathrm{e}-021.00000 \mathrm{e}-031.00000 \mathrm{e}-091.00000 \mathrm{e}-01$ $1.00000 \mathrm{e}+001.00000 \mathrm{e}+001.00000 \mathrm{e}-011.00000 \mathrm{e}-091.00000 \mathrm{e}-01$ $1.00000 \mathrm{e}-06$ 1.00000e-06 1.00000e-06 1.00000e-09 5.00000e-02 Element: 4777 \# of layers: 14 
$\mathrm{Kx} \mathrm{Ky} \mathrm{Kz}$ Ss Por

2.37197e+01 2.37197e+01 2.37197e+00 1.00000e-09 7.00000e-02

$2.37197 \mathrm{e}+012.37197 \mathrm{e}+012.37197 \mathrm{e}+001.00000 \mathrm{e}-09$ 7.00000e-02

5.00000e-04 5.00000e-04 5.00000e-05 1.00000e-09 1.00000e-01

5.00000e-04 5.00000e-04 5.00000e-05 1.00000e-09 1.00000e-01

9.47765e-01 9.47765e-01 9.47765e-02 1.00000e-09 2.12000e-01

9.47765e-01 9.47765e-01 9.47765e-02 1.00000e-09 2.12000e-01

9.47765e-01 9.47765e-01 9.47765e-02 1.00000e-09 2.12000e-01

9.47765e-01 9.47765e-01 9.47765e-02 1.00000e-09 2.12000e-01

9.47765e-01 9.47765e-01 9.47765e-02 1.00000e-09 2.12000e-01

$1.00000 \mathrm{e}-02$ 1.00000e-02 1.00000e-03 1.00000e-09 1.00000e-01

$1.00000 \mathrm{e}+001.00000 \mathrm{e}+001.00000 \mathrm{e}-011.00000 \mathrm{e}-091.00000 \mathrm{e}-01$

$1.00000 \mathrm{e}-05$ 1.00000e-05 1.00000e-06 1.00000e-09 1.00000e-01

$1.00000 \mathrm{e}+001.00000 \mathrm{e}+001.00000 \mathrm{e}-011.00000 \mathrm{e}-091.00000 \mathrm{e}-01$

1.00000e-06 1.00000e-06 1.00000e-06 1.00000e-09 5.00000e-02

Element: 4778 \# of layers: 14

$\mathrm{Kx} \mathrm{Ky} \mathrm{Kz}$ Ss Por

$2.02878 \mathrm{e}+012.02878 \mathrm{e}+012.02878 \mathrm{e}+00$ 1.00000e-09 7.00000e-02

$2.02878 \mathrm{e}+012.02878 \mathrm{e}+012.02878 \mathrm{e}+00$ 1.00000e-09 7.00000e-02

$2.02878 \mathrm{e}+012.02878 \mathrm{e}+012.02878 \mathrm{e}+00$ 1.00000e-09 7.00000e-02

5.00000e-04 5.00000e-04 5.00000e-05 1.00000e-09 1.00000e-01

5.00000e-04 5.00000e-04 5.00000e-05 1.00000e-09 1.00000e-01

8.10625e-01 8.10625e-01 8.10625e-02 1.00000e-09 2.12000e-01

8.10625e-01 8.10625e-01 8.10625e-02 1.00000e-09 2.12000e-01

8.10625e-01 8.10625e-01 8.10625e-02 1.00000e-09 2.12000e-01

8.10625e-01 8.10625e-01 8.10625e-02 1.00000e-09 2.12000e-01

$1.00000 \mathrm{e}-02$ 1.00000e-02 1.00000e-03 1.00000e-09 1.00000e-01

$1.00000 \mathrm{e}+001.00000 \mathrm{e}+001.00000 \mathrm{e}-011.00000 \mathrm{e}-091.00000 \mathrm{e}-01$

$1.00000 \mathrm{e}-05$ 1.00000e-05 1.00000e-06 1.00000e-09 1.00000e-01

$1.00000 \mathrm{e}+001.00000 \mathrm{e}+001.00000 \mathrm{e}-011.00000 \mathrm{e}-091.00000 \mathrm{e}-01$

1.00000e-06 1.00000e-06 1.00000e-06 1.00000e-09 5.00000e-02

Element: 4779 \# of layers: 13

Kx Ky Kz Ss Por

$2.68489 \mathrm{e}+012.68489 \mathrm{e}+012.68489 \mathrm{e}+00$ 1.00000e-09 7.00000e-02

$2.68489 \mathrm{e}+012.68489 \mathrm{e}+012.68489 \mathrm{e}+00$ 1.00000e-09 7.00000e-02

$2.68489 \mathrm{e}+012.68489 \mathrm{e}+012.68489 \mathrm{e}+001.00000 \mathrm{e}-09$ 7.00000e-02

5.00000e-04 5.00000e-04 5.00000e-05 1.00000e-09 1.00000e-01

$1.07278 \mathrm{e}+001.07278 \mathrm{e}+00$ 1.07278e-01 1.00000e-09 2.12000e-01

$1.07278 \mathrm{e}+001.07278 \mathrm{e}+00$ 1.07278e-01 1.00000e-09 2.12000e-01

$1.07278 \mathrm{e}+001.07278 \mathrm{e}+00$ 1.07278e-01 1.00000e-09 2.12000e-01

$1.07278 \mathrm{e}+00$ 1.07278e+00 1.07278e-01 1.00000e-09 2.12000e-01

$1.00000 \mathrm{e}-02$ 1.00000e-02 1.00000e-03 1.00000e-09 1.00000e-01

$1.00000 \mathrm{e}+001.00000 \mathrm{e}+001.00000 \mathrm{e}-011.00000 \mathrm{e}-091.00000 \mathrm{e}-01$

$1.00000 \mathrm{e}-05$ 1.00000e-05 1.00000e-06 1.00000e-09 1.00000e-01

$1.00000 \mathrm{e}+001.00000 \mathrm{e}+001.00000 \mathrm{e}-011.00000 \mathrm{e}-091.00000 \mathrm{e}-01$

$1.00000 \mathrm{e}-06$ 1.00000e-06 1.00000e-06 1.00000e-09 5.00000e-02 
Element: 4780 \# of layers: 12

$\mathrm{Kx} \mathrm{Ky} \mathrm{Kz}$ Ss Por

3.48173e+01 3.48173e+01 3.48173e+00 1.00000e-09 7.00000e-02

$3.48173 \mathrm{e}+013.48173 \mathrm{e}+013.48173 \mathrm{e}+001.00000 \mathrm{e}-09$ 7.00000e-02

5.00000e-04 5.00000e-04 5.00000e-05 1.00000e-09 1.00000e-01

$1.39118 \mathrm{e}+001.39118 \mathrm{e}+00$ 1.39118e-01 1.00000e-09 2.12000e-01

$1.39118 \mathrm{e}+001.39118 \mathrm{e}+00$ 1.39118e-01 1.00000e-09 2.12000e-01

$1.39118 \mathrm{e}+001.39118 \mathrm{e}+00$ 1.39118e-01 1.00000e-09 2.12000e-01

$1.39118 \mathrm{e}+001.39118 \mathrm{e}+00$ 1.39118e-01 1.00000e-09 2.12000e-01

$1.00000 \mathrm{e}-02$ 1.00000e-02 1.00000e-03 1.00000e-09 1.00000e-01

$1.00000 \mathrm{e}+001.00000 \mathrm{e}+001.00000 \mathrm{e}-011.00000 \mathrm{e}-091.00000 \mathrm{e}-01$

$1.00000 \mathrm{e}-05$ 1.00000e-05 1.00000e-06 1.00000e-09 1.00000e-01

$1.00000 \mathrm{e}+001.00000 \mathrm{e}+001.00000 \mathrm{e}-011.00000 \mathrm{e}-091.00000 \mathrm{e}-01$

1.00000e-06 1.00000e-06 1.00000e-06 1.00000e-09 5.00000e-02

Element: 4781 \# of layers: 11

Kx Ky Kz Ss Por

3.48173e+01 3.48173e+01 3.48173e+00 1.00000e-09 7.00000e-02

$3.48173 \mathrm{e}+013.48173 \mathrm{e}+013.48173 \mathrm{e}+001.00000 \mathrm{e}-09$ 7.00000e-02

$3.48173 \mathrm{e}+013.48173 \mathrm{e}+013.48173 \mathrm{e}+001.00000 \mathrm{e}-09$ 7.00000e-02

5.00000e-04 5.00000e-04 5.00000e-05 1.00000e-09 1.00000e-01

5.00000e-04 5.00000e-04 5.00000e-05 1.00000e-09 1.00000e-01

$1.39118 \mathrm{e}+00$ 1.39118e+00 1.39118e-01 1.00000e-09 2.12000e-01

$1.39118 \mathrm{e}+001.39118 \mathrm{e}+00$ 1.39118e-01 1.00000e-09 2.12000e-01

$1.39118 \mathrm{e}+001.39118 \mathrm{e}+00$ 1.39118e-01 1.00000e-09 2.12000e-01

$1.00000 \mathrm{e}-02$ 1.00000e-02 1.00000e-03 1.00000e-09 1.00000e-01

$1.00000 \mathrm{e}+001.00000 \mathrm{e}+001.00000 \mathrm{e}-011.00000 \mathrm{e}-091.00000 \mathrm{e}-01$

1.00000e-06 1.00000e-06 1.00000e-06 1.00000e-09 5.00000e-02

Element: 4782 \# of layers: 9

Kx Ky Kz Ss Por

3.48173e+01 3.48173e+01 3.48173e+00 1.00000e-09 7.00000e-02

$3.48173 \mathrm{e}+013.48173 \mathrm{e}+013.48173 \mathrm{e}+001.00000 \mathrm{e}-09$ 7.00000e-02

$3.48173 \mathrm{e}+013.48173 \mathrm{e}+013.48173 \mathrm{e}+00$ 1.00000e-09 7.00000e-02

5.00000e-04 5.00000e-04 5.00000e-05 1.00000e-09 1.00000e-01

5.00000e-04 5.00000e-04 5.00000e-05 1.00000e-09 1.00000e-01

$1.39118 \mathrm{e}+001.39118 \mathrm{e}+00$ 1.39118e-01 1.00000e-09 2.12000e-01

$1.39118 \mathrm{e}+001.39118 \mathrm{e}+00$ 1.39118e-01 1.00000e-09 2.12000e-01

$1.00000 \mathrm{e}-02$ 1.00000e-02 1.00000e-03 1.00000e-09 1.00000e-01

1.00000e-06 1.00000e-06 1.00000e-06 1.00000e-09 5.00000e-02

Element: 4783 \# of layers: 7

$\mathrm{Kx} \mathrm{Ky} \mathrm{Kz}$ Ss Por

4.52861e+01 4.52861e+01 4.52861e+00 1.00000e-09 7.00000e-02

$4.52861 \mathrm{e}+014.52861 \mathrm{e}+014.52861 \mathrm{e}+001.00000 \mathrm{e}-09$ 7.00000e-02

$4.52861 \mathrm{e}+014.52861 \mathrm{e}+014.52861 \mathrm{e}+001.00000 \mathrm{e}-09$ 7.00000e-02

$5.00000 \mathrm{e}-04$ 5.00000e-04 5.00000e-05 1.00000e-09 1.00000e-01

5.00000e-04 5.00000e-04 5.00000e-05 1.00000e-09 1.00000e-01

$1.80947 \mathrm{e}+001.80947 \mathrm{e}+00$ 1.80947e-01 1.00000e-09 2.12000e-01 
1.00000e-06 1.00000e-06 1.00000e-06 1.00000e-09 5.00000e-02

Element: 4784 \# of layers: 9

Kx Ky Kz Ss Por

4.44076e+01 4.44076e+01 4.44076e+00 1.00000e-09 7.00000e-02

$4.44076 \mathrm{e}+014.44076 \mathrm{e}+014.44076 \mathrm{e}+001.00000 \mathrm{e}-09$ 7.00000e-02

5.00000e-04 5.00000e-04 5.00000e-05 1.00000e-09 1.00000e-01

5.00000e-04 5.00000e-04 5.00000e-05 1.00000e-09 1.00000e-01

$1.77436 \mathrm{e}+001.77436 \mathrm{e}+001.77436 \mathrm{e}-011.00000 \mathrm{e}-092.12000 \mathrm{e}-01$

$1.77436 \mathrm{e}+001.77436 \mathrm{e}+00$ 1.77436e-01 1.00000e-09 2.12000e-01

$1.77436 \mathrm{e}+001.77436 \mathrm{e}+001.77436 \mathrm{e}-01$ 1.00000e-09 2.12000e-01

1.00000e-02 1.00000e-02 1.00000e-03 1.00000e-09 1.00000e-01

1.00000e-06 1.00000e-06 1.00000e-06 1.00000e-09 5.00000e-02

Element: 4785 \# of layers: 10

$\mathrm{Kx} \mathrm{Ky} \mathrm{Kz}$ Ss Por

4.44076e+01 4.44076e+01 4.44076e+00 1.00000e-09 7.00000e-02

$4.44076 \mathrm{e}+014.44076 \mathrm{e}+014.44076 \mathrm{e}+001.00000 \mathrm{e}-09$ 7.00000e-02

5.00000e-04 5.00000e-04 5.00000e-05 1.00000e-09 1.00000e-01

$1.77436 \mathrm{e}+001.77436 \mathrm{e}+00$ 1.77436e-01 1.00000e-09 2.12000e-01

$1.77436 \mathrm{e}+001.77436 \mathrm{e}+001.77436 \mathrm{e}-01$ 1.00000e-09 2.12000e-01

$1.77436 \mathrm{e}+001.77436 \mathrm{e}+00$ 1.77436e-01 1.00000e-09 2.12000e-01

$1.77436 \mathrm{e}+001.77436 \mathrm{e}+00 \quad 1.77436 \mathrm{e}-01$ 1.00000e-09 2.12000e-01

$1.00000 \mathrm{e}-021.00000 \mathrm{e}-021.00000 \mathrm{e}-031.00000 \mathrm{e}-091.00000 \mathrm{e}-01$

$1.00000 \mathrm{e}+001.00000 \mathrm{e}+001.00000 \mathrm{e}-011.00000 \mathrm{e}-091.00000 \mathrm{e}-01$

1.00000e-06 1.00000e-06 1.00000e-06 1.00000e-09 5.00000e-02

Element: 4786 \# of layers: 13

$\mathrm{Kx} \mathrm{Ky} \mathrm{Kz}$ Ss Por

4.44076e+01 4.44076e+01 4.44076e+00 1.00000e-09 7.00000e-02

4.44076e+01 4.44076e+01 4.44076e+00 1.00000e-09 7.00000e-02

$4.44076 \mathrm{e}+014.44076 \mathrm{e}+014.44076 \mathrm{e}+001.00000 \mathrm{e}-097.00000 \mathrm{e}-02$

5.00000e-04 5.00000e-04 5.00000e-05 1.00000e-09 1.00000e-01

$1.77436 \mathrm{e}+001.77436 \mathrm{e}+00$ 1.77436e-01 1.00000e-09 2.12000e-01

$1.77436 \mathrm{e}+001.77436 \mathrm{e}+00$ 1.77436e-01 1.00000e-09 2.12000e-01

$1.77436 \mathrm{e}+001.77436 \mathrm{e}+001.77436 \mathrm{e}-01$ 1.00000e-09 2.12000e-01

$1.77436 \mathrm{e}+00$ 1.77436e+00 1.77436e-01 1.00000e-09 2.12000e-01

$1.00000 \mathrm{e}-02$ 1.00000e-02 1.00000e-03 1.00000e-09 1.00000e-01

$1.00000 \mathrm{e}+001.00000 \mathrm{e}+001.00000 \mathrm{e}-011.00000 \mathrm{e}-091.00000 \mathrm{e}-01$

$1.00000 \mathrm{e}-05$ 1.00000e-05 1.00000e-06 1.00000e-09 1.00000e-01

$1.00000 \mathrm{e}+001.00000 \mathrm{e}+001.00000 \mathrm{e}-011.00000 \mathrm{e}-091.00000 \mathrm{e}-01$

1.00000e-06 1.00000e-06 1.00000e-06 1.00000e-09 5.00000e-02

Element: 4787 \# of layers: 12

$\mathrm{Kx} \mathrm{Ky} \mathrm{Kz}$ Ss Por

4.44076e+01 4.44076e+01 4.44076e+00 1.00000e-09 7.00000e-02

4.44076e+01 4.44076e+01 4.44076e+00 1.00000e-09 7.00000e-02

4.44076e+01 4.44076e+01 4.44076e+00 1.00000e-09 7.00000e-02

5.00000e-04 5.00000e-04 5.00000e-05 1.00000e-09 1.00000e-01

5.00000e-04 5.00000e-04 5.00000e-05 1.00000e-09 1.00000e-01 
$1.77436 \mathrm{e}+001.77436 \mathrm{e}+00$ 1.77436e-01 1.00000e-09 2.12000e-01 $1.77436 \mathrm{e}+00$ 1.77436e+00 1.77436e-01 1.00000e-09 2.12000e-01 $1.77436 \mathrm{e}+001.77436 \mathrm{e}+001.77436 \mathrm{e}-011.00000 \mathrm{e}-092.12000 \mathrm{e}-01$ $1.77436 \mathrm{e}+001.77436 \mathrm{e}+00 \quad 1.77436 \mathrm{e}-011.00000 \mathrm{e}-092.12000 \mathrm{e}-01$ $1.00000 \mathrm{e}-02$ 1.00000e-02 1.00000e-03 1.00000e-09 1.00000e-01 $1.00000 \mathrm{e}+001.00000 \mathrm{e}+001.00000 \mathrm{e}-011.00000 \mathrm{e}-091.00000 \mathrm{e}-01$ 1.00000e-06 1.00000e-06 1.00000e-06 1.00000e-09 5.00000e-02 Element: 4788 \# of layers: 9

$\mathrm{Kx} \mathrm{Ky} \mathrm{Kz}$ Ss Por

2.18402e+01 2.18402e+01 2.18402e+00 1.00000e-09 7.00000e-02 $2.18402 \mathrm{e}+012.18402 \mathrm{e}+012.18402 \mathrm{e}+00$ 1.00000e-09 7.00000e-02 $2.18402 \mathrm{e}+012.18402 \mathrm{e}+012.18402 \mathrm{e}+001.00000 \mathrm{e}-09$ 7.00000e-02 5.00000e-04 5.00000e-04 5.00000e-05 1.00000e-09 1.00000e-01 5.00000e-04 5.00000e-04 5.00000e-05 1.00000e-09 1.00000e-01 8.72659e-01 8.72659e-01 8.72659e-02 1.00000e-09 2.12000e-01 8.72659e-01 8.72659e-01 8.72659e-02 1.00000e-09 2.12000e-01 $1.00000 \mathrm{e}-02$ 1.00000e-02 1.00000e-03 1.00000e-09 1.00000e-01 $1.00000 \mathrm{e}+001.00000 \mathrm{e}+001.00000 \mathrm{e}-011.00000 \mathrm{e}-091.00000 \mathrm{e}-01$ Element: 4789 \# of layers: 8

$\mathrm{Kx} \mathrm{Ky} \mathrm{Kz}$ Ss Por

$2.18402 \mathrm{e}+012.18402 \mathrm{e}+012.18402 \mathrm{e}+00$ 1.00000e-09 7.00000e-02

$2.18402 \mathrm{e}+012.18402 \mathrm{e}+012.18402 \mathrm{e}+00$ 1.00000e-09 7.00000e-02

$2.18402 \mathrm{e}+012.18402 \mathrm{e}+012.18402 \mathrm{e}+00$ 1.00000e-09 7.00000e-02 5.00000e-04 5.00000e-04 5.00000e-05 1.00000e-09 1.00000e-01 5.00000e-04 5.00000e-04 5.00000e-05 1.00000e-09 1.00000e-01 8.72659e-01 8.72659e-01 8.72659e-02 1.00000e-09 2.12000e-01 $1.00000 \mathrm{e}-02$ 1.00000e-02 1.00000e-03 1.00000e-09 1.00000e-01 $1.00000 \mathrm{e}+001.00000 \mathrm{e}+001.00000 \mathrm{e}-011.00000 \mathrm{e}-091.00000 \mathrm{e}-01$ Element: 4790 \# of layers: 8

$\mathrm{Kx} \mathrm{Ky} \mathrm{Kz}$ Ss Por

$1.43944 \mathrm{e}+01$ 1.43944e+01 1.43944e+00 1.00000e-09 7.00000e-02 $1.43944 \mathrm{e}+011.43944 \mathrm{e}+011.43944 \mathrm{e}+001.00000 \mathrm{e}-09$ 7.00000e-02 $1.43944 \mathrm{e}+011.43944 \mathrm{e}+011.43944 \mathrm{e}+001.00000 \mathrm{e}-097.00000 \mathrm{e}-02$ 5.00000e-04 5.00000e-04 5.00000e-05 1.00000e-09 1.00000e-01 5.00000e-04 5.00000e-04 5.00000e-05 1.00000e-09 1.00000e-01 5.75157e-01 5.75157e-01 5.75157e-02 1.00000e-09 2.12000e-01 $1.00000 \mathrm{e}-02$ 1.00000e-02 1.00000e-03 1.00000e-09 1.00000e-01 $1.00000 \mathrm{e}+001.00000 \mathrm{e}+001.00000 \mathrm{e}-011.00000 \mathrm{e}-091.00000 \mathrm{e}-01$ Element: 4791 \# of layers: 5

$\mathrm{Kx} \mathrm{Ky} \mathrm{Kz}$ Ss Por

4.56969e+01 4.56969e+01 4.56969e+00 1.00000e-09 7.00000e-02 4.56969e+01 4.56969e+01 4.56969e+00 1.00000e-09 7.00000e-02

$4.56969 \mathrm{e}+014.56969 \mathrm{e}+01$ 4.56969e+00 1.00000e-09 7.00000e-02 5.00000e-04 5.00000e-04 5.00000e-05 1.00000e-09 1.00000e-01 1.00000e-06 1.00000e-06 1.00000e-06 1.00000e-09 5.00000e-02 Element: 4792 \# of layers: 4 
$\mathrm{Kx} \mathrm{Ky} \mathrm{Kz}$ Ss Por

4.56969e+01 4.56969e+01 4.56969e+00 1.00000e-09 7.00000e-02

$4.56969 \mathrm{e}+014.56969 \mathrm{e}+014.56969 \mathrm{e}+00$ 1.00000e-09 7.00000e-02

$4.56969 \mathrm{e}+014.56969 \mathrm{e}+014.56969 \mathrm{e}+001.00000 \mathrm{e}-09$ 7.00000e-02

1.00000e-06 1.00000e-06 1.00000e-06 1.00000e-09 5.00000e-02

Element: 4793 \# of layers: 4

$\mathrm{Kx} \mathrm{Ky} \mathrm{Kz}$ Ss Por

3.44092e+01 3.44092e+01 3.44092e+00 1.00000e-09 7.00000e-02

3.44092e+01 3.44092e+01 3.44092e+00 1.00000e-09 7.00000e-02

$3.44092 \mathrm{e}+013.44092 \mathrm{e}+013.44092 \mathrm{e}+001.00000 \mathrm{e}-09$ 7.00000e-02

1.00000e-06 1.00000e-06 1.00000e-06 1.00000e-09 5.00000e-02

Element: 4794 \# of layers: 4

$\mathrm{Kx} \mathrm{Ky} \mathrm{Kz}$ Ss Por

3.44092e+01 3.44092e+01 3.44092e+00 1.00000e-09 7.00000e-02

$3.44092 \mathrm{e}+013.44092 \mathrm{e}+013.44092 \mathrm{e}+001.00000 \mathrm{e}-09$ 7.00000e-02

$3.44092 \mathrm{e}+013.44092 \mathrm{e}+013.44092 \mathrm{e}+00$ 1.00000e-09 7.00000e-02

1.00000e-06 1.00000e-06 1.00000e-06 1.00000e-09 5.00000e-02

Element: 4795 \# of layers: 8

$\mathrm{Kx} \mathrm{Ky} \mathrm{Kz}$ Ss Por

2.18402e+01 2.18402e+01 2.18402e+00 1.00000e-09 7.00000e-02

$2.18402 \mathrm{e}+012.18402 \mathrm{e}+012.18402 \mathrm{e}+001.00000 \mathrm{e}-09$ 7.00000e-02

$2.18402 \mathrm{e}+012.18402 \mathrm{e}+012.18402 \mathrm{e}+00$ 1.00000e-09 7.00000e-02

5.00000e-04 5.00000e-04 5.00000e-05 1.00000e-09 1.00000e-01

5.00000e-04 5.00000e-04 5.00000e-05 1.00000e-09 1.00000e-01

8.72659e-01 8.72659e-01 8.72659e-02 1.00000e-09 2.12000e-01

8.72659e-01 8.72659e-01 8.72659e-02 1.00000e-09 2.12000e-01

1.00000e-06 1.00000e-06 1.00000e-06 1.00000e-09 5.00000e-02

Element: 4796 \# of layers: 7

$\mathrm{Kx} \mathrm{Ky} \mathrm{Kz}$ Ss Por

3.44092e+01 3.44092e+01 3.44092e+00 1.00000e-09 7.00000e-02

$3.44092 \mathrm{e}+013.44092 \mathrm{e}+013.44092 \mathrm{e}+001.00000 \mathrm{e}-09$ 7.00000e-02

$3.44092 \mathrm{e}+013.44092 \mathrm{e}+013.44092 \mathrm{e}+001.00000 \mathrm{e}-09$ 7.00000e-02

5.00000e-04 5.00000e-04 5.00000e-05 1.00000e-09 1.00000e-01

5.00000e-04 5.00000e-04 5.00000e-05 1.00000e-09 1.00000e-01

$1.37485 \mathrm{e}+001.37485 \mathrm{e}+00$ 1.37485e-01 1.00000e-09 2.12000e-01

1.00000e-06 1.00000e-06 1.00000e-06 1.00000e-09 5.00000e-02

Element: 4797 \# of layers: 7

Kx Ky Kz Ss Por

4.31417e+01 4.31417e+01 4.31417e+00 1.00000e-09 7.00000e-02

4.31417e+01 4.31417e+01 4.31417e+00 1.00000e-09 7.00000e-02

4.31417e+01 4.31417e+01 4.31417e+00 1.00000e-09 7.00000e-02

5.00000e-04 5.00000e-04 5.00000e-05 1.00000e-09 1.00000e-01

5.00000e-04 5.00000e-04 5.00000e-05 1.00000e-09 1.00000e-01

5.75157e-01 5.75157e-01 5.75157e-02 1.00000e-09 2.12000e-01

1.00000e-02 1.00000e-02 1.00000e-03 1.00000e-09 1.00000e-01

Element: 4798 \# of layers: 5 
Kx Ky Kz Ss Por

6.14734e+01 6.14734e+01 6.14734e+00 1.00000e-09 7.00000e-02

$6.14734 \mathrm{e}+016.14734 \mathrm{e}+016.14734 \mathrm{e}+00$ 1.00000e-09 7.00000e-02

$6.14734 \mathrm{e}+016.14734 \mathrm{e}+016.14734 \mathrm{e}+001.00000 \mathrm{e}-09$ 7.00000e-02

5.00000e-04 5.00000e-04 5.00000e-05 1.00000e-09 1.00000e-01

5.00000e-04 5.00000e-04 5.00000e-05 1.00000e-09 1.00000e-01

Element: 4799 \# of layers: 3

Kx Ky Kz Ss Por

6.14734e+01 6.14734e+01 6.14734e+00 1.00000e-09 7.00000e-02

$6.14734 \mathrm{e}+016.14734 \mathrm{e}+016.14734 \mathrm{e}+00$ 1.00000e-09 7.00000e-02

6.14734e+01 6.14734e+01 6.14734e+00 1.00000e-09 7.00000e-02

Element: 4800 \# of layers: 8

Kx Ky Kz Ss Por

6.14734e+01 6.14734e+01 6.14734e+00 1.00000e-09 7.00000e-02

$6.14734 \mathrm{e}+016.14734 \mathrm{e}+016.14734 \mathrm{e}+001.00000 \mathrm{e}-09$ 7.00000e-02

$6.14734 \mathrm{e}+016.14734 \mathrm{e}+016.14734 \mathrm{e}+00$ 1.00000e-09 7.00000e-02

5.00000e-04 5.00000e-04 5.00000e-05 1.00000e-09 1.00000e-01

5.00000e-04 5.00000e-04 5.00000e-05 1.00000e-09 1.00000e-01

$1.87539 \mathrm{e}+001.87539 \mathrm{e}+00$ 1.87539e-01 1.00000e-09 2.12000e-01

1.00000e-02 1.00000e-02 1.00000e-03 1.00000e-09 1.00000e-01

$1.00000 \mathrm{e}+001.00000 \mathrm{e}+001.00000 \mathrm{e}-011.00000 \mathrm{e}-091.00000 \mathrm{e}-01$

Element: 4801 \# of layers: 9

$\mathrm{Kx} \mathrm{Ky} \mathrm{Kz}$ Ss Por

4.69358e+01 4.69358e+01 4.69358e+00 1.00000e-09 7.00000e-02

$4.69358 \mathrm{e}+014.69358 \mathrm{e}+014.69358 \mathrm{e}+001.00000 \mathrm{e}-09$ 7.00000e-02

$4.69358 \mathrm{e}+014.69358 \mathrm{e}+014.69358 \mathrm{e}+001.00000 \mathrm{e}-09$ 7.00000e-02

$4.69358 \mathrm{e}+014.69358 \mathrm{e}+014.69358 \mathrm{e}+001.00000 \mathrm{e}-09$ 7.00000e-02

5.00000e-04 5.00000e-04 5.00000e-05 1.00000e-09 1.00000e-01

5.00000e-04 5.00000e-04 5.00000e-05 1.00000e-09 1.00000e-01

$1.87539 \mathrm{e}+001.87539 \mathrm{e}+00$ 1.87539e-01 1.00000e-09 2.12000e-01

$1.00000 \mathrm{e}-02$ 1.00000e-02 1.00000e-03 1.00000e-09 1.00000e-01

$1.00000 \mathrm{e}+001.00000 \mathrm{e}+001.00000 \mathrm{e}-011.00000 \mathrm{e}-091.00000 \mathrm{e}-01$

Element: 4802 \# of layers: 7

$\mathrm{Kx} \mathrm{Ky} \mathrm{Kz}$ Ss Por

4.69358e+01 4.69358e+01 4.69358e+00 1.00000e-09 7.00000e-02

4.69358e+01 4.69358e+01 4.69358e+00 1.00000e-09 7.00000e-02

$4.69358 \mathrm{e}+014.69358 \mathrm{e}+014.69358 \mathrm{e}+00$ 1.00000e-09 7.00000e-02

$4.69358 \mathrm{e}+014.69358 \mathrm{e}+014.69358 \mathrm{e}+001.00000 \mathrm{e}-09$ 7.00000e-02

5.00000e-04 5.00000e-04 5.00000e-05 1.00000e-09 1.00000e-01

5.00000e-04 5.00000e-04 5.00000e-05 1.00000e-09 1.00000e-01

$1.87539 \mathrm{e}+001.87539 \mathrm{e}+00$ 1.87539e-01 1.00000e-09 2.12000e-01

Element: 4803 \# of layers: 6

$\mathrm{Kx} \mathrm{Ky} \mathrm{Kz}$ Ss Por

4.57014e+01 4.57014e+01 4.57014e+00 1.00000e-09 7.00000e-02

$4.57014 \mathrm{e}+014.57014 \mathrm{e}+014.57014 \mathrm{e}+001.00000 \mathrm{e}-097.00000 \mathrm{e}-02$

$4.57014 \mathrm{e}+014.57014 \mathrm{e}+014.57014 \mathrm{e}+001.00000 \mathrm{e}-097.00000 \mathrm{e}-02$ 
$4.57014 \mathrm{e}+014.57014 \mathrm{e}+014.57014 \mathrm{e}+001.00000 \mathrm{e}-097.00000 \mathrm{e}-02$ 5.00000e-04 5.00000e-04 5.00000e-05 1.00000e-09 1.00000e-01 $2.32903 \mathrm{e}+00$ 2.32903e+00 2.32903e-01 1.00000e-09 2.12000e-01

Element: 4804 \# of layers: 3

$\mathrm{Kx} \mathrm{Ky} \mathrm{Kz}$ Ss Por

4.31417e+01 4.31417e+01 4.31417e+00 1.00000e-09 7.00000e-02 4.31417e+01 4.31417e+01 4.31417e+00 1.00000e-09 7.00000e-02 4.31417e+01 4.31417e+01 4.31417e+00 1.00000e-09 7.00000e-02 Element: 4805 \# of layers: 3

$\mathrm{Kx} \mathrm{Ky} \mathrm{Kz}$ Ss Por

6.14734e+01 6.14734e+01 6.14734e+00 1.00000e-09 7.00000e-02 $6.14734 \mathrm{e}+016.14734 \mathrm{e}+016.14734 \mathrm{e}+001.00000 \mathrm{e}-09$ 7.00000e-02 6.14734e+01 6.14734e+01 6.14734e+00 1.00000e-09 7.00000e-02 Element: 4806 \# of layers: 4

$\mathrm{Kx} \mathrm{Ky} \mathrm{Kz}$ Ss Por

4.91360e+01 4.91360e+01 4.91360e+00 1.00000e-09 7.00000e-02 $4.91360 \mathrm{e}+014.91360 \mathrm{e}+014.91360 \mathrm{e}+001.00000 \mathrm{e}-09$ 7.00000e-02 $4.91360 \mathrm{e}+014.91360 \mathrm{e}+014.91360 \mathrm{e}+001.00000 \mathrm{e}-09$ 7.00000e-02 $1.96330 \mathrm{e}+001.96330 \mathrm{e}+00$ 1.96330e-01 1.00000e-09 2.12000e-01

Element: 4807 \# of layers: 6

$\mathrm{Kx} \mathrm{Ky} \mathrm{Kz}$ Ss Por

$2.00698 \mathrm{e}+012.00698 \mathrm{e}+012.00698 \mathrm{e}+00$ 1.00000e-09 7.00000e-02 $2.00698 \mathrm{e}+012.00698 \mathrm{e}+012.00698 \mathrm{e}+00$ 1.00000e-09 7.00000e-02 $2.00698 \mathrm{e}+012.00698 \mathrm{e}+012.00698 \mathrm{e}+00$ 1.00000e-09 7.00000e-02 8.01917e-01 8.01917e-01 8.01917e-02 1.00000e-09 2.12000e-01 $1.00000 \mathrm{e}-02$ 1.00000e-02 1.00000e-03 1.00000e-09 1.00000e-01 $1.00000 \mathrm{e}+001.00000 \mathrm{e}+001.00000 \mathrm{e}-011.00000 \mathrm{e}-091.00000 \mathrm{e}-01$ Element: 4808 \# of layers: 8

$\mathrm{Kx} \mathrm{Ky} \mathrm{Kz}$ Ss Por $2.00698 \mathrm{e}+012.00698 \mathrm{e}+012.00698 \mathrm{e}+00$ 1.00000e-09 7.00000e-02 $2.00698 \mathrm{e}+012.00698 \mathrm{e}+012.00698 \mathrm{e}+001.00000 \mathrm{e}-09$ 7.00000e-02 $2.00698 \mathrm{e}+012.00698 \mathrm{e}+012.00698 \mathrm{e}+00$ 1.00000e-09 7.00000e-02 5.00000e-04 5.00000e-04 5.00000e-05 1.00000e-09 1.00000e-01 5.00000e-04 5.00000e-04 5.00000e-05 1.00000e-09 1.00000e-01 8.01917e-01 8.01917e-01 8.01917e-02 1.00000e-09 2.12000e-01 $1.00000 \mathrm{e}-02$ 1.00000e-02 1.00000e-03 1.00000e-09 1.00000e-01 $1.00000 \mathrm{e}+001.00000 \mathrm{e}+001.00000 \mathrm{e}-011.00000 \mathrm{e}-091.00000 \mathrm{e}-01$ Element: 4809 \# of layers: 9

$\mathrm{Kx} \mathrm{Ky} \mathrm{Kz}$ Ss Por

$2.00698 \mathrm{e}+012.00698 \mathrm{e}+012.00698 \mathrm{e}+00$ 1.00000e-09 7.00000e-02 $2.00698 \mathrm{e}+012.00698 \mathrm{e}+012.00698 \mathrm{e}+001.00000 \mathrm{e}-09$ 7.00000e-02 $2.00698 \mathrm{e}+012.00698 \mathrm{e}+012.00698 \mathrm{e}+001.00000 \mathrm{e}-09$ 7.00000e-02 5.00000e-04 5.00000e-04 5.00000e-05 1.00000e-09 1.00000e-01 5.00000e-04 5.00000e-04 5.00000e-05 1.00000e-09 1.00000e-01 8.01917e-01 8.01917e-01 8.01917e-02 1.00000e-09 2.12000e-01 8.01917e-01 8.01917e-01 8.01917e-02 1.00000e-09 2.12000e-01 
$1.00000 \mathrm{e}-02$ 1.00000e-02 1.00000e-03 1.00000e-09 1.00000e-01 $1.00000 \mathrm{e}+001.00000 \mathrm{e}+001.00000 \mathrm{e}-01$ 1.00000e-09 1.00000e-01 Element: 4810 \# of layers: 9

Kx Ky Kz Ss Por

8.79124e+01 8.79124e+01 8.79124e+00 1.00000e-09 7.00000e-02 $8.79124 \mathrm{e}+018.79124 \mathrm{e}+018.79124 \mathrm{e}+001.00000 \mathrm{e}-097.00000 \mathrm{e}-02$ $8.79124 \mathrm{e}+018.79124 \mathrm{e}+018.79124 \mathrm{e}+001.00000 \mathrm{e}-097.00000 \mathrm{e}-02$ 5.00000e-04 5.00000e-04 5.00000e-05 1.00000e-09 1.00000e-01 5.00000e-04 5.00000e-04 5.00000e-05 1.00000e-09 1.00000e-01 $3.51277 \mathrm{e}+003.51277 \mathrm{e}+00$ 3.51277e-01 1.00000e-09 2.12000e-01 $3.51277 \mathrm{e}+003.51277 \mathrm{e}+00$ 3.51277e-01 1.00000e-09 2.12000e-01 $1.00000 \mathrm{e}-02$ 1.00000e-02 1.00000e-03 1.00000e-09 1.00000e-01 $1.00000 \mathrm{e}+001.00000 \mathrm{e}+001.00000 \mathrm{e}-01$ 1.00000e-09 1.00000e-01 Element: 4811 \# of layers: 9

$\mathrm{Kx} \mathrm{Ky} \mathrm{Kz}$ Ss Por

8.79124e+01 8.79124e+01 8.79124e+00 1.00000e-09 7.00000e-02 $8.79124 \mathrm{e}+018.79124 \mathrm{e}+018.79124 \mathrm{e}+001.00000 \mathrm{e}-09$ 7.00000e-02 $8.79124 \mathrm{e}+018.79124 \mathrm{e}+018.79124 \mathrm{e}+001.00000 \mathrm{e}-097.00000 \mathrm{e}-02$ $5.00000 \mathrm{e}-04$ 5.00000e-04 5.00000e-05 1.00000e-09 1.00000e-01 5.00000e-04 5.00000e-04 5.00000e-05 1.00000e-09 1.00000e-01

$3.51277 \mathrm{e}+003.51277 \mathrm{e}+00$ 3.51277e-01 1.00000e-09 2.12000e-01 3.51277e+00 3.51277e+00 3.51277e-01 1.00000e-09 2.12000e-01 $1.00000 \mathrm{e}-02$ 1.00000e-02 1.00000e-03 1.00000e-09 1.00000e-01 $1.00000 \mathrm{e}+001.00000 \mathrm{e}+001.00000 \mathrm{e}-011.00000 \mathrm{e}-091.00000 \mathrm{e}-01$ Element: 4812 \# of layers: 10

$\mathrm{Kx} \mathrm{Ky} \mathrm{Kz}$ Ss Por

6.23879e+01 6.23879e+01 6.23879e+00 1.00000e-09 7.00000e-02 6.23879e+01 6.23879e+01 6.23879e+00 1.00000e-09 7.00000e-02 $6.23879 \mathrm{e}+016.23879 \mathrm{e}+016.23879 \mathrm{e}+001.00000 \mathrm{e}-09$ 7.00000e-02 $6.23879 \mathrm{e}+016.23879 \mathrm{e}+016.23879 \mathrm{e}+001.00000 \mathrm{e}-09$ 7.00000e-02 5.00000e-04 5.00000e-04 5.00000e-05 1.00000e-09 1.00000e-01 5.00000e-04 5.00000e-04 5.00000e-05 1.00000e-09 1.00000e-01 $2.49283 e+002.49283 e+002.49283 e-01$ 1.00000e-09 2.12000e-01 $2.49283 \mathrm{e}+002.49283 \mathrm{e}+002.49283 \mathrm{e}-01$ 1.00000e-09 2.12000e-01 $1.00000 \mathrm{e}-02$ 1.00000e-02 1.00000e-03 1.00000e-09 1.00000e-01 $1.00000 \mathrm{e}+001.00000 \mathrm{e}+001.00000 \mathrm{e}-011.00000 \mathrm{e}-091.00000 \mathrm{e}-01$ Element: 4813 \# of layers: 9

Kx Ky Kz Ss Por

4.91360e+01 4.91360e+01 4.91360e+00 1.00000e-09 7.00000e-02 $4.91360 \mathrm{e}+014.91360 \mathrm{e}+014.91360 \mathrm{e}+001.00000 \mathrm{e}-09$ 7.00000e-02 $4.91360 \mathrm{e}+014.91360 \mathrm{e}+014.91360 \mathrm{e}+001.00000 \mathrm{e}-09$ 7.00000e-02 5.00000e-04 5.00000e-04 5.00000e-05 1.00000e-09 1.00000e-01 5.00000e-04 5.00000e-04 5.00000e-05 1.00000e-09 1.00000e-01 $1.96330 \mathrm{e}+001.96330 \mathrm{e}+001.96330 \mathrm{e}-01$ 1.00000e-09 2.12000e-01 $1.96330 \mathrm{e}+001.96330 \mathrm{e}+001.96330 \mathrm{e}-011.00000 \mathrm{e}-092.12000 \mathrm{e}-01$ $1.00000 \mathrm{e}-02$ 1.00000e-02 1.00000e-03 1.00000e-09 1.00000e-01 
$1.00000 \mathrm{e}+001.00000 \mathrm{e}+00$ 1.00000e-01 1.00000e-09 1.00000e-01

Element: 4814 \# of layers: 9

Kx Ky Kz Ss Por

$2.00698 \mathrm{e}+012.00698 \mathrm{e}+012.00698 \mathrm{e}+00$ 1.00000e-09 7.00000e-02

$2.00698 \mathrm{e}+012.00698 \mathrm{e}+012.00698 \mathrm{e}+001.00000 \mathrm{e}-09$ 7.00000e-02

$2.00698 \mathrm{e}+012.00698 \mathrm{e}+012.00698 \mathrm{e}+001.00000 \mathrm{e}-09$ 7.00000e-02

5.00000e-04 5.00000e-04 5.00000e-05 1.00000e-09 1.00000e-01

5.00000e-04 5.00000e-04 5.00000e-05 1.00000e-09 1.00000e-01

8.01917e-01 8.01917e-01 8.01917e-02 1.00000e-09 2.12000e-01

8.01917e-01 8.01917e-01 8.01917e-02 1.00000e-09 2.12000e-01

$1.00000 \mathrm{e}-02$ 1.00000e-02 1.00000e-03 1.00000e-09 1.00000e-01

$1.00000 \mathrm{e}+001.00000 \mathrm{e}+001.00000 \mathrm{e}-011.00000 \mathrm{e}-091.00000 \mathrm{e}-01$

Element: 4815 \# of layers: 8

$\mathrm{Kx} \mathrm{Ky} \mathrm{Kz}$ Ss Por

$2.25574 \mathrm{e}+012.25574 \mathrm{e}+012.25574 \mathrm{e}+001.00000 \mathrm{e}-09$ 7.00000e-02

$2.25574 \mathrm{e}+012.25574 \mathrm{e}+012.25574 \mathrm{e}+001.00000 \mathrm{e}-097.00000 \mathrm{e}-02$

$2.25574 \mathrm{e}+012.25574 \mathrm{e}+012.25574 \mathrm{e}+001.00000 \mathrm{e}-097.00000 \mathrm{e}-02$

5.00000e-04 5.00000e-04 5.00000e-05 1.00000e-09 1.00000e-01

5.00000e-04 5.00000e-04 5.00000e-05 1.00000e-09 1.00000e-01

9.01302e-01 9.01302e-01 9.01302e-02 1.00000e-09 2.12000e-01

$1.00000 \mathrm{e}-02$ 1.00000e-02 1.00000e-03 1.00000e-09 1.00000e-01

$1.00000 \mathrm{e}+001.00000 \mathrm{e}+001.00000 \mathrm{e}-011.00000 \mathrm{e}-091.00000 \mathrm{e}-01$

Element: 4816 \# of layers: 8

$\mathrm{Kx} \mathrm{Ky} \mathrm{Kz}$ Ss Por

$2.25574 \mathrm{e}+012.25574 \mathrm{e}+012.25574 \mathrm{e}+001.00000 \mathrm{e}-09$ 7.00000e-02

$2.25574 \mathrm{e}+012.25574 \mathrm{e}+012.25574 \mathrm{e}+001.00000 \mathrm{e}-09$ 7.00000e-02

$2.25574 \mathrm{e}+012.25574 \mathrm{e}+012.25574 \mathrm{e}+001.00000 \mathrm{e}-097.00000 \mathrm{e}-02$

5.00000e-04 5.00000e-04 5.00000e-05 1.00000e-09 1.00000e-01

5.00000e-04 5.00000e-04 5.00000e-05 1.00000e-09 1.00000e-01

9.01302e-01 9.01302e-01 9.01302e-02 1.00000e-09 2.12000e-01

$1.00000 \mathrm{e}-02$ 1.00000e-02 1.00000e-03 1.00000e-09 1.00000e-01

$1.00000 \mathrm{e}+001.00000 \mathrm{e}+001.00000 \mathrm{e}-011.00000 \mathrm{e}-091.00000 \mathrm{e}-01$

Element: 4817 \# of layers: 8

$\mathrm{Kx} \mathrm{Ky} \mathrm{Kz}$ Ss Por

3.27288e+01 3.27288e+01 3.27288e+00 1.00000e-09 7.00000e-02

$3.27288 \mathrm{e}+013.27288 \mathrm{e}+013.27288 \mathrm{e}+00$ 1.00000e-09 7.00000e-02

$3.27288 \mathrm{e}+013.27288 \mathrm{e}+013.27288 \mathrm{e}+00$ 1.00000e-09 7.00000e-02

5.00000e-04 5.00000e-04 5.00000e-05 1.00000e-09 1.00000e-01

5.00000e-04 5.00000e-04 5.00000e-05 1.00000e-09 1.00000e-01

$1.30775 \mathrm{e}+001.30775 \mathrm{e}+00$ 1.30775e-01 1.00000e-09 2.12000e-01

$1.00000 \mathrm{e}-02$ 1.00000e-02 1.00000e-03 1.00000e-09 1.00000e-01

$1.00000 \mathrm{e}+001.00000 \mathrm{e}+001.00000 \mathrm{e}-011.00000 \mathrm{e}-091.00000 \mathrm{e}-01$

Element: 4818 \# of layers: 8

$\mathrm{Kx} \mathrm{Ky} \mathrm{Kz}$ Ss Por

$3.27288 \mathrm{e}+013.27288 \mathrm{e}+013.27288 \mathrm{e}+00$ 1.00000e-09 7.00000e-02

$3.27288 \mathrm{e}+013.27288 \mathrm{e}+013.27288 \mathrm{e}+00$ 1.00000e-09 7.00000e-02 
5.00000e-04 5.00000e-04 5.00000e-05 1.00000e-09 1.00000e-01 5.00000e-04 5.00000e-04 5.00000e-05 1.00000e-09 1.00000e-01 $1.30775 \mathrm{e}+001.30775 \mathrm{e}+001.30775 \mathrm{e}-01$ 1.00000e-09 2.12000e-01 $1.30775 \mathrm{e}+001.30775 \mathrm{e}+001.30775 \mathrm{e}-01$ 1.00000e-09 2.12000e-01 $1.00000 \mathrm{e}-021.00000 \mathrm{e}-02$ 1.00000e-03 1.00000e-09 1.00000e-01 $1.00000 \mathrm{e}+001.00000 \mathrm{e}+001.00000 \mathrm{e}-011.00000 \mathrm{e}-091.00000 \mathrm{e}-01$ Element: 4819 \# of layers: 8

$\mathrm{Kx} \mathrm{Ky} \mathrm{Kz}$ Ss Por

3.27288e+01 3.27288e+01 3.27288e+00 1.00000e-09 7.00000e-02

$3.27288 \mathrm{e}+013.27288 \mathrm{e}+013.27288 \mathrm{e}+00$ 1.00000e-09 7.00000e-02 5.00000e-04 5.00000e-04 5.00000e-05 1.00000e-09 1.00000e-01 5.00000e-04 5.00000e-04 5.00000e-05 1.00000e-09 1.00000e-01

$1.30775 \mathrm{e}+001.30775 \mathrm{e}+00$ 1.30775e-01 1.00000e-09 2.12000e-01 $1.30775 \mathrm{e}+001.30775 \mathrm{e}+001.30775 \mathrm{e}-01$ 1.00000e-09 2.12000e-01 $1.00000 \mathrm{e}-02$ 1.00000e-02 1.00000e-03 1.00000e-09 1.00000e-01 $1.00000 \mathrm{e}+001.00000 \mathrm{e}+001.00000 \mathrm{e}-011.00000 \mathrm{e}-091.00000 \mathrm{e}-01$ Element: 4820 \# of layers: 8

$\mathrm{Kx} \mathrm{Ky} \mathrm{Kz}$ Ss Por

5.96102e+01 5.96102e+01 5.96102e+00 1.00000e-09 7.00000e-02 $5.96102 \mathrm{e}+015.96102 \mathrm{e}+015.96102 \mathrm{e}+001.00000 \mathrm{e}-097.00000 \mathrm{e}-02$ 5.00000e-04 5.00000e-04 5.00000e-05 1.00000e-09 1.00000e-01 5.00000e-04 5.00000e-04 5.00000e-05 1.00000e-09 1.00000e-01 $2.38190 \mathrm{e}+002.38190 \mathrm{e}+00$ 2.38190e-01 1.00000e-09 2.12000e-01 $2.38190 \mathrm{e}+002.38190 \mathrm{e}+00$ 2.38190e-01 1.00000e-09 2.12000e-01 $1.00000 \mathrm{e}-02$ 1.00000e-02 1.00000e-03 1.00000e-09 1.00000e-01 $1.00000 \mathrm{e}+001.00000 \mathrm{e}+001.00000 \mathrm{e}-01$ 1.00000e-09 1.00000e-01 Element: 4821 \# of layers: 7

$\mathrm{Kx} \mathrm{Ky} \mathrm{Kz}$ Ss Por

5.96102e+01 5.96102e+01 5.96102e+00 1.00000e-09 7.00000e-02 5.96102e+01 5.96102e+01 5.96102e+00 1.00000e-09 7.00000e-02 5.00000e-04 5.00000e-04 5.00000e-05 1.00000e-09 1.00000e-01 5.00000e-04 5.00000e-04 5.00000e-05 1.00000e-09 1.00000e-01 $2.38190 \mathrm{e}+002.38190 \mathrm{e}+002.38190 \mathrm{e}-01$ 1.00000e-09 2.12000e-01 $1.00000 \mathrm{e}-02$ 1.00000e-02 1.00000e-03 1.00000e-09 1.00000e-01 $1.00000 \mathrm{e}+001.00000 \mathrm{e}+001.00000 \mathrm{e}-011.00000 \mathrm{e}-091.00000 \mathrm{e}-01$ Element: 4822 \# of layers: 8

Kx Ky Kz Ss Por

$3.27288 \mathrm{e}+013.27288 \mathrm{e}+013.27288 \mathrm{e}+00$ 1.00000e-09 7.00000e-02 $3.27288 \mathrm{e}+013.27288 \mathrm{e}+013.27288 \mathrm{e}+00$ 1.00000e-09 7.00000e-02 $3.27288 \mathrm{e}+013.27288 \mathrm{e}+013.27288 \mathrm{e}+001.00000 \mathrm{e}-09$ 7.00000e-02 5.00000e-04 5.00000e-04 5.00000e-05 1.00000e-09 1.00000e-01 5.00000e-04 5.00000e-04 5.00000e-05 1.00000e-09 1.00000e-01 $1.30775 \mathrm{e}+001.30775 \mathrm{e}+00$ 1.30775e-01 1.00000e-09 2.12000e-01 $1.00000 \mathrm{e}-02$ 1.00000e-02 1.00000e-03 1.00000e-09 1.00000e-01 $1.00000 \mathrm{e}+001.00000 \mathrm{e}+001.00000 \mathrm{e}-01$ 1.00000e-09 1.00000e-01 Element: 4823 \# of layers: 8 
$\mathrm{Kx} \mathrm{Ky} \mathrm{Kz}$ Ss Por

3.27288e+01 3.27288e+01 3.27288e+00 1.00000e-09 7.00000e-02

$3.27288 \mathrm{e}+013.27288 \mathrm{e}+013.27288 \mathrm{e}+00$ 1.00000e-09 7.00000e-02

$3.27288 \mathrm{e}+013.27288 \mathrm{e}+013.27288 \mathrm{e}+001.00000 \mathrm{e}-09$ 7.00000e-02

$5.00000 \mathrm{e}-04$ 5.00000e-04 5.00000e-05 1.00000e-09 1.00000e-01

5.00000e-04 5.00000e-04 5.00000e-05 1.00000e-09 1.00000e-01

$1.30775 \mathrm{e}+001.30775 \mathrm{e}+001.30775 \mathrm{e}-01$ 1.00000e-09 2.12000e-01

$1.00000 \mathrm{e}-02$ 1.00000e-02 1.00000e-03 1.00000e-09 1.00000e-01

$1.00000 \mathrm{e}+001.00000 \mathrm{e}+001.00000 \mathrm{e}-011.00000 \mathrm{e}-091.00000 \mathrm{e}-01$

Element: 4824 \# of layers: 9

Kx Ky Kz Ss Por

3.58148e+01 3.58148e+01 3.58148e+00 1.00000e-09 7.00000e-02

$3.58148 \mathrm{e}+013.58148 \mathrm{e}+013.58148 \mathrm{e}+001.00000 \mathrm{e}-09$ 7.00000e-02

$3.58148 \mathrm{e}+013.58148 \mathrm{e}+013.58148 \mathrm{e}+001.00000 \mathrm{e}-09$ 7.00000e-02

5.00000e-04 5.00000e-04 5.00000e-05 1.00000e-09 1.00000e-01

5.00000e-04 5.00000e-04 5.00000e-05 1.00000e-09 1.00000e-01

$1.43103 \mathrm{e}+001.43103 \mathrm{e}+00$ 1.43103e-01 1.00000e-09 2.12000e-01

$1.43103 \mathrm{e}+00$ 1.43103e+00 1.43103e-01 1.00000e-09 2.12000e-01

$1.00000 \mathrm{e}-021.00000 \mathrm{e}-021.00000 \mathrm{e}-031.00000 \mathrm{e}-091.00000 \mathrm{e}-01$

$1.00000 \mathrm{e}+001.00000 \mathrm{e}+001.00000 \mathrm{e}-011.00000 \mathrm{e}-091.00000 \mathrm{e}-01$

Element: 4825 \# of layers: 8

$\mathrm{Kx} \mathrm{Ky} \mathrm{Kz}$ Ss Por

3.58148e+01 3.58148e+01 3.58148e+00 1.00000e-09 7.00000e-02

$3.58148 \mathrm{e}+013.58148 \mathrm{e}+013.58148 \mathrm{e}+00$ 1.00000e-09 7.00000e-02

5.00000e-04 5.00000e-04 5.00000e-05 1.00000e-09 1.00000e-01

5.00000e-04 5.00000e-04 5.00000e-05 1.00000e-09 1.00000e-01

$1.43103 \mathrm{e}+001.43103 \mathrm{e}+00$ 1.43103e-01 1.00000e-09 2.12000e-01

$1.43103 \mathrm{e}+001.43103 \mathrm{e}+00$ 1.43103e-01 1.00000e-09 2.12000e-01

$1.00000 \mathrm{e}-02$ 1.00000e-02 1.00000e-03 1.00000e-09 1.00000e-01

$1.00000 \mathrm{e}+001.00000 \mathrm{e}+001.00000 \mathrm{e}-01$ 1.00000e-09 1.00000e-01

Element: 4826 \# of layers: 7

Kx Ky Kz Ss Por

3.58148e+01 3.58148e+01 3.58148e+00 1.00000e-09 7.00000e-02

5.00000e-04 5.00000e-04 5.00000e-05 1.00000e-09 1.00000e-01

5.00000e-04 5.00000e-04 5.00000e-05 1.00000e-09 1.00000e-01

$1.43103 \mathrm{e}+001.43103 \mathrm{e}+00$ 1.43103e-01 1.00000e-09 2.12000e-01

$1.43103 \mathrm{e}+001.43103 \mathrm{e}+00$ 1.43103e-01 1.00000e-09 2.12000e-01

$1.00000 \mathrm{e}-021.00000 \mathrm{e}-02$ 1.00000e-03 1.00000e-09 1.00000e-01

$1.00000 \mathrm{e}+001.00000 \mathrm{e}+001.00000 \mathrm{e}-011.00000 \mathrm{e}-09$ 1.00000e-01

Element: 4827 \# of layers: 8

$\mathrm{Kx} \mathrm{Ky} \mathrm{Kz}$ Ss Por

3.58148e+01 3.58148e+01 3.58148e+00 1.00000e-09 7.00000e-02

5.00000e-04 5.00000e-04 5.00000e-05 1.00000e-09 1.00000e-01

$5.00000 \mathrm{e}-04$ 5.00000e-04 5.00000e-05 1.00000e-09 1.00000e-01

$1.43103 \mathrm{e}+001.43103 \mathrm{e}+001.43103 \mathrm{e}-01$ 1.00000e-09 2.12000e-01

$1.43103 e+001.43103 e+001.43103 e-01$ 1.00000e-09 2.12000e-01 
$1.43103 \mathrm{e}+001.43103 \mathrm{e}+00$ 1.43103e-01 1.00000e-09 2.12000e-01 $1.00000 \mathrm{e}-021.00000 \mathrm{e}-02$ 1.00000e-03 1.00000e-09 1.00000e-01 $1.00000 \mathrm{e}+001.00000 \mathrm{e}+001.00000 \mathrm{e}-011.00000 \mathrm{e}-091.00000 \mathrm{e}-01$ Element: 4828 \# of layers: 9

Kx Ky Kz Ss Por

$3.58148 \mathrm{e}+013.58148 \mathrm{e}+013.58148 \mathrm{e}+00$ 1.00000e-09 7.00000e-02 $3.58148 \mathrm{e}+013.58148 \mathrm{e}+013.58148 \mathrm{e}+001.00000 \mathrm{e}-09$ 7.00000e-02 $3.58148 \mathrm{e}+013.58148 \mathrm{e}+013.58148 \mathrm{e}+001.00000 \mathrm{e}-097.00000 \mathrm{e}-02$ 5.00000e-04 5.00000e-04 5.00000e-05 1.00000e-09 1.00000e-01 5.00000e-04 5.00000e-04 5.00000e-05 1.00000e-09 1.00000e-01 $1.43103 \mathrm{e}+001.43103 \mathrm{e}+00$ 1.43103e-01 1.00000e-09 2.12000e-01 $1.43103 \mathrm{e}+001.43103 \mathrm{e}+00$ 1.43103e-01 1.00000e-09 2.12000e-01 $1.00000 \mathrm{e}-02$ 1.00000e-02 1.00000e-03 1.00000e-09 1.00000e-01 $1.00000 \mathrm{e}+001.00000 \mathrm{e}+001.00000 \mathrm{e}-011.00000 \mathrm{e}-091.00000 \mathrm{e}-01$ Element: 4829 \# of layers: 8

Kx Ky Kz Ss Por

$3.58148 \mathrm{e}+013.58148 \mathrm{e}+013.58148 \mathrm{e}+00$ 1.00000e-09 7.00000e-02

$3.58148 \mathrm{e}+013.58148 \mathrm{e}+013.58148 \mathrm{e}+001.00000 \mathrm{e}-09$ 7.00000e-02 5.00000e-04 5.00000e-04 5.00000e-05 1.00000e-09 1.00000e-01 5.00000e-04 5.00000e-04 5.00000e-05 1.00000e-09 1.00000e-01 $1.43103 \mathrm{e}+001.43103 \mathrm{e}+001.43103 \mathrm{e}-011.00000 \mathrm{e}-092.12000 \mathrm{e}-01$ $1.43103 \mathrm{e}+001.43103 \mathrm{e}+001.43103 \mathrm{e}-011.00000 \mathrm{e}-092.12000 \mathrm{e}-01$ $1.00000 \mathrm{e}-021.00000 \mathrm{e}-02$ 1.00000e-03 1.00000e-09 1.00000e-01 $1.00000 \mathrm{e}+001.00000 \mathrm{e}+001.00000 \mathrm{e}-011.00000 \mathrm{e}-091.00000 \mathrm{e}-01$ Element: 4830 \# of layers: 8

Kx Ky Kz Ss Por

$3.58148 \mathrm{e}+013.58148 \mathrm{e}+013.58148 \mathrm{e}+00$ 1.00000e-09 7.00000e-02 $3.58148 \mathrm{e}+013.58148 \mathrm{e}+013.58148 \mathrm{e}+001.00000 \mathrm{e}-09$ 7.00000e-02 5.00000e-04 5.00000e-04 5.00000e-05 1.00000e-09 1.00000e-01 5.00000e-04 5.00000e-04 5.00000e-05 1.00000e-09 1.00000e-01 $1.43103 \mathrm{e}+001.43103 \mathrm{e}+001.43103 \mathrm{e}-011.00000 \mathrm{e}-09$ 2.12000e-01 $1.43103 \mathrm{e}+001.43103 \mathrm{e}+00$ 1.43103e-01 1.00000e-09 2.12000e-01 $1.00000 \mathrm{e}-021.00000 \mathrm{e}-02$ 1.00000e-03 1.00000e-09 1.00000e-01 $1.00000 \mathrm{e}+001.00000 \mathrm{e}+001.00000 \mathrm{e}-011.00000 \mathrm{e}-091.00000 \mathrm{e}-01$ Element: 4831 \# of layers: 9

Kx Ky Kz Ss Por

$3.58148 \mathrm{e}+013.58148 \mathrm{e}+013.58148 \mathrm{e}+00$ 1.00000e-09 7.00000e-02

$3.58148 \mathrm{e}+013.58148 \mathrm{e}+013.58148 \mathrm{e}+001.00000 \mathrm{e}-09$ 7.00000e-02

5.00000e-04 5.00000e-04 5.00000e-05 1.00000e-09 1.00000e-01

5.00000e-04 5.00000e-04 5.00000e-05 1.00000e-09 1.00000e-01

$1.43103 \mathrm{e}+001.43103 \mathrm{e}+001.43103 \mathrm{e}-011.00000 \mathrm{e}-092.12000 \mathrm{e}-01$ $1.43103 \mathrm{e}+001.43103 \mathrm{e}+001.43103 \mathrm{e}-011.00000 \mathrm{e}-092.12000 \mathrm{e}-01$ $1.43103 \mathrm{e}+001.43103 \mathrm{e}+001.43103 \mathrm{e}-011.00000 \mathrm{e}-092.12000 \mathrm{e}-01$ $1.00000 \mathrm{e}-021.00000 \mathrm{e}-02$ 1.00000e-03 1.00000e-09 1.00000e-01 $1.00000 \mathrm{e}+001.00000 \mathrm{e}+001.00000 \mathrm{e}-011.00000 \mathrm{e}-091.00000 \mathrm{e}-01$ Element: 4832 \# of layers: 8 
$\mathrm{Kx} \mathrm{Ky} \mathrm{Kz}$ Ss Por

$3.58148 \mathrm{e}+013.58148 \mathrm{e}+013.58148 \mathrm{e}+00$ 1.00000e-09 7.00000e-02 5.00000e-04 5.00000e-04 5.00000e-05 1.00000e-09 1.00000e-01 5.00000e-04 5.00000e-04 5.00000e-05 1.00000e-09 1.00000e-01 $1.43103 \mathrm{e}+001.43103 \mathrm{e}+00$ 1.43103e-01 1.00000e-09 2.12000e-01 $1.43103 \mathrm{e}+001.43103 \mathrm{e}+00$ 1.43103e-01 1.00000e-09 2.12000e-01 $1.43103 \mathrm{e}+00$ 1.43103e+00 1.43103e-01 1.00000e-09 2.12000e-01 $1.00000 \mathrm{e}-02$ 1.00000e-02 1.00000e-03 1.00000e-09 1.00000e-01 $1.00000 \mathrm{e}+001.00000 \mathrm{e}+001.00000 \mathrm{e}-011.00000 \mathrm{e}-091.00000 \mathrm{e}-01$ Element: 4833 \# of layers: 7

$\mathrm{Kx} \mathrm{Ky} \mathrm{Kz}$ Ss Por

3.73609e+01 3.73609e+01 3.73609e+00 1.00000e-09 7.00000e-02 5.00000e-04 5.00000e-04 5.00000e-05 1.00000e-09 1.00000e-01 5.00000e-04 5.00000e-04 5.00000e-05 1.00000e-09 1.00000e-01 $1.49279 \mathrm{e}+001.49279 \mathrm{e}+00$ 1.49279e-01 1.00000e-09 2.12000e-01 $1.49279 \mathrm{e}+001.49279 \mathrm{e}+001.49279 \mathrm{e}-01$ 1.00000e-09 2.12000e-01 $1.00000 \mathrm{e}-02$ 1.00000e-02 1.00000e-03 1.00000e-09 1.00000e-01 $1.00000 \mathrm{e}+001.00000 \mathrm{e}+001.00000 \mathrm{e}-01$ 1.00000e-09 1.00000e-01 Element: 4834 \# of layers: 8

$\mathrm{Kx} \mathrm{Ky} \mathrm{Kz}$ Ss Por

3.73609e+01 3.73609e+01 3.73609e+00 1.00000e-09 7.00000e-02

$3.73609 \mathrm{e}+013.73609 \mathrm{e}+013.73609 \mathrm{e}+001.00000 \mathrm{e}-09$ 7.00000e-02 5.00000e-04 5.00000e-04 5.00000e-05 1.00000e-09 1.00000e-01 5.00000e-04 5.00000e-04 5.00000e-05 1.00000e-09 1.00000e-01 $1.49279 \mathrm{e}+001.49279 \mathrm{e}+001.49279 \mathrm{e}-01$ 1.00000e-09 2.12000e-01 $1.49279 \mathrm{e}+001.49279 \mathrm{e}+00$ 1.49279e-01 1.00000e-09 2.12000e-01 $1.00000 \mathrm{e}-02$ 1.00000e-02 1.00000e-03 1.00000e-09 1.00000e-01 $1.00000 \mathrm{e}+001.00000 \mathrm{e}+001.00000 \mathrm{e}-011.00000 \mathrm{e}-091.00000 \mathrm{e}-01$ Element: 4835 \# of layers: 9

$\mathrm{Kx} \mathrm{Ky} \mathrm{Kz}$ Ss Por

3.73609e+01 3.73609e+01 3.73609e+00 1.00000e-09 7.00000e-02 $3.73609 \mathrm{e}+013.73609 \mathrm{e}+013.73609 \mathrm{e}+001.00000 \mathrm{e}-09$ 7.00000e-02 $3.73609 \mathrm{e}+013.73609 \mathrm{e}+013.73609 \mathrm{e}+00$ 1.00000e-09 7.00000e-02 $5.00000 \mathrm{e}-045.00000 \mathrm{e}-045.00000 \mathrm{e}-051.00000 \mathrm{e}-091.00000 \mathrm{e}-01$ 5.00000e-04 5.00000e-04 5.00000e-05 1.00000e-09 1.00000e-01 $1.49279 \mathrm{e}+001.49279 \mathrm{e}+00$ 1.49279e-01 1.00000e-09 2.12000e-01 $1.49279 \mathrm{e}+001.49279 \mathrm{e}+001.49279 \mathrm{e}-01$ 1.00000e-09 2.12000e-01 $1.00000 \mathrm{e}-02$ 1.00000e-02 1.00000e-03 1.00000e-09 1.00000e-01 $1.00000 \mathrm{e}+001.00000 \mathrm{e}+001.00000 \mathrm{e}-011.00000 \mathrm{e}-09$ 1.00000e-01 Element: 4839 \# of layers: 8

$\mathrm{Kx} \mathrm{Ky} \mathrm{Kz}$ Ss Por

3.73609e+01 3.73609e+01 3.73609e+00 1.00000e-09 7.00000e-02 $3.73609 \mathrm{e}+013.73609 \mathrm{e}+013.73609 \mathrm{e}+001.00000 \mathrm{e}-09$ 7.00000e-02 5.00000e-04 5.00000e-04 5.00000e-05 1.00000e-09 1.00000e-01 5.00000e-04 5.00000e-04 5.00000e-05 1.00000e-09 1.00000e-01 $1.49279 \mathrm{e}+001.49279 \mathrm{e}+00$ 1.49279e-01 1.00000e-09 2.12000e-01 
$1.49279 \mathrm{e}+001.49279 \mathrm{e}+00$ 1.49279e-01 1.00000e-09 2.12000e-01 $1.00000 \mathrm{e}-021.00000 \mathrm{e}-02$ 1.00000e-03 1.00000e-09 1.00000e-01 $1.00000 \mathrm{e}+001.00000 \mathrm{e}+001.00000 \mathrm{e}-011.00000 \mathrm{e}-091.00000 \mathrm{e}-01$ Element: 4840 \# of layers: 9

Kx Ky Kz Ss Por

$3.73609 \mathrm{e}+013.73609 \mathrm{e}+013.73609 \mathrm{e}+00$ 1.00000e-09 7.00000e-02 $3.73609 \mathrm{e}+013.73609 \mathrm{e}+013.73609 \mathrm{e}+001.00000 \mathrm{e}-09$ 7.00000e-02 5.00000e-04 5.00000e-04 5.00000e-05 1.00000e-09 1.00000e-01 5.00000e-04 5.00000e-04 5.00000e-05 1.00000e-09 1.00000e-01 $1.49279 \mathrm{e}+001.49279 \mathrm{e}+001.49279 \mathrm{e}-011.00000 \mathrm{e}-09$ 2.12000e-01 $1.49279 \mathrm{e}+001.49279 \mathrm{e}+00$ 1.49279e-01 1.00000e-09 2.12000e-01 $1.49279 \mathrm{e}+001.49279 \mathrm{e}+00$ 1.49279e-01 1.00000e-09 2.12000e-01 $1.00000 \mathrm{e}-02$ 1.00000e-02 1.00000e-03 1.00000e-09 1.00000e-01 $1.00000 \mathrm{e}+001.00000 \mathrm{e}+001.00000 \mathrm{e}-011.00000 \mathrm{e}-091.00000 \mathrm{e}-01$ Element: 4842 \# of layers: 8

Kx Ky Kz Ss Por

$2.86707 \mathrm{e}+012.86707 \mathrm{e}+012.86707 \mathrm{e}+00$ 1.00000e-09 7.00000e-02

$2.86707 \mathrm{e}+012.86707 \mathrm{e}+012.86707 \mathrm{e}+001.00000 \mathrm{e}-09$ 7.00000e-02 5.00000e-04 5.00000e-04 5.00000e-05 1.00000e-09 1.00000e-01 5.00000e-04 5.00000e-04 5.00000e-05 1.00000e-09 1.00000e-01 $1.14557 \mathrm{e}+001.14557 \mathrm{e}+001.14557 \mathrm{e}-011.00000 \mathrm{e}-092.12000 \mathrm{e}-01$ $1.14557 \mathrm{e}+001.14557 \mathrm{e}+001.14557 \mathrm{e}-011.00000 \mathrm{e}-092.12000 \mathrm{e}-01$ $1.00000 \mathrm{e}-021.00000 \mathrm{e}-02$ 1.00000e-03 1.00000e-09 1.00000e-01 $1.00000 \mathrm{e}+001.00000 \mathrm{e}+001.00000 \mathrm{e}-011.00000 \mathrm{e}-091.00000 \mathrm{e}-01$ Element: 4843 \# of layers: 8

Kx Ky Kz Ss Por

$2.86707 \mathrm{e}+012.86707 \mathrm{e}+012.86707 \mathrm{e}+00$ 1.00000e-09 7.00000e-02 $2.86707 \mathrm{e}+012.86707 \mathrm{e}+012.86707 \mathrm{e}+001.00000 \mathrm{e}-09$ 7.00000e-02 5.00000e-04 5.00000e-04 5.00000e-05 1.00000e-09 1.00000e-01 $5.00000 \mathrm{e}-04$ 5.00000e-04 5.00000e-05 1.00000e-09 1.00000e-01 $1.14557 \mathrm{e}+001.14557 \mathrm{e}+001.14557 \mathrm{e}-011.00000 \mathrm{e}-092.12000 \mathrm{e}-01$ $1.14557 \mathrm{e}+001.14557 \mathrm{e}+00$ 1.14557e-01 1.00000e-09 2.12000e-01 $1.00000 \mathrm{e}-021.00000 \mathrm{e}-02$ 1.00000e-03 1.00000e-09 1.00000e-01 $1.00000 \mathrm{e}+001.00000 \mathrm{e}+001.00000 \mathrm{e}-011.00000 \mathrm{e}-091.00000 \mathrm{e}-01$ Element: 4844 \# of layers: 8

Kx Ky Kz Ss Por $2.86707 \mathrm{e}+012.86707 \mathrm{e}+012.86707 \mathrm{e}+001.00000 \mathrm{e}-09$ 7.00000e-02 $2.86707 \mathrm{e}+012.86707 \mathrm{e}+012.86707 \mathrm{e}+001.00000 \mathrm{e}-09$ 7.00000e-02 5.00000e-04 5.00000e-04 5.00000e-05 1.00000e-09 1.00000e-01 5.00000e-04 5.00000e-04 5.00000e-05 1.00000e-09 1.00000e-01 $1.14557 \mathrm{e}+001.14557 \mathrm{e}+001.14557 \mathrm{e}-011.00000 \mathrm{e}-092.12000 \mathrm{e}-01$ $1.14557 \mathrm{e}+001.14557 \mathrm{e}+001.14557 \mathrm{e}-011.00000 \mathrm{e}-092.12000 \mathrm{e}-01$ $1.00000 \mathrm{e}-02$ 1.00000e-02 1.00000e-03 1.00000e-09 1.00000e-01 $1.00000 \mathrm{e}+001.00000 \mathrm{e}+001.00000 \mathrm{e}-011.00000 \mathrm{e}-091.00000 \mathrm{e}-01$ Element: 4845 \# of layers: 8

Kx Ky Kz Ss Por 
3.22927e+01 3.22927e+01 3.22927e+00 1.00000e-09 7.00000e-02 $3.22927 \mathrm{e}+013.22927 \mathrm{e}+013.22927 \mathrm{e}+00$ 1.00000e-09 7.00000e-02 5.00000e-04 5.00000e-04 5.00000e-05 1.00000e-09 1.00000e-01 5.00000e-04 5.00000e-04 5.00000e-05 1.00000e-09 1.00000e-01 $1.29029 \mathrm{e}+00$ 1.29029e+00 1.29029e-01 1.00000e-09 2.12000e-01 $1.29029 \mathrm{e}+001.29029 \mathrm{e}+00 \quad 1.29029 \mathrm{e}-01$ 1.00000e-09 2.12000e-01 $1.00000 \mathrm{e}-02$ 1.00000e-02 1.00000e-03 1.00000e-09 1.00000e-01 $1.00000 \mathrm{e}+001.00000 \mathrm{e}+001.00000 \mathrm{e}-011.00000 \mathrm{e}-091.00000 \mathrm{e}-01$ Element: 4846 \# of layers: 9

$\mathrm{Kx} \mathrm{Ky} \mathrm{Kz}$ Ss Por

3.22927e+01 3.22927e+01 3.22927e+00 1.00000e-09 7.00000e-02 $3.22927 \mathrm{e}+013.22927 \mathrm{e}+013.22927 \mathrm{e}+00$ 1.00000e-09 7.00000e-02 5.00000e-04 5.00000e-04 5.00000e-05 1.00000e-09 1.00000e-01 5.00000e-04 5.00000e-04 5.00000e-05 1.00000e-09 1.00000e-01 $1.29029 \mathrm{e}+001.29029 \mathrm{e}+00$ 1.29029e-01 1.00000e-09 2.12000e-01 $1.29029 \mathrm{e}+001.29029 \mathrm{e}+00$ 1.29029e-01 1.00000e-09 2.12000e-01 $1.29029 \mathrm{e}+001.29029 \mathrm{e}+00$ 1.29029e-01 1.00000e-09 2.12000e-01 $1.00000 \mathrm{e}-02$ 1.00000e-02 1.00000e-03 1.00000e-09 1.00000e-01 $1.00000 \mathrm{e}+001.00000 \mathrm{e}+001.00000 \mathrm{e}-011.00000 \mathrm{e}-091.00000 \mathrm{e}-01$ Element: 4847 \# of layers: 8

$\mathrm{Kx} \mathrm{Ky} \mathrm{Kz}$ Ss Por

3.22927e+01 3.22927e+01 3.22927e+00 1.00000e-09 7.00000e-02 $3.22927 \mathrm{e}+013.22927 \mathrm{e}+013.22927 \mathrm{e}+00$ 1.00000e-09 7.00000e-02 5.00000e-04 5.00000e-04 5.00000e-05 1.00000e-09 1.00000e-01 5.00000e-04 5.00000e-04 5.00000e-05 1.00000e-09 1.00000e-01 $1.29029 \mathrm{e}+001.29029 \mathrm{e}+00$ 1.29029e-01 1.00000e-09 2.12000e-01 $1.29029 \mathrm{e}+001.29029 \mathrm{e}+001.29029 \mathrm{e}-01$ 1.00000e-09 2.12000e-01 $1.00000 \mathrm{e}-02$ 1.00000e-02 1.00000e-03 1.00000e-09 1.00000e-01 $1.00000 \mathrm{e}+001.00000 \mathrm{e}+001.00000 \mathrm{e}-011.00000 \mathrm{e}-091.00000 \mathrm{e}-01$ Element: 4848 \# of layers: 7

$\mathrm{Kx} \mathrm{Ky} \mathrm{Kz}$ Ss Por

8.07790e+00 8.07790e+00 8.07790e-01 1.00000e-09 2.12000e-01 $8.07790 \mathrm{e}+008.07790 \mathrm{e}+008.07790 \mathrm{e}-01$ 1.00000e-09 2.12000e-01 $8.07790 \mathrm{e}+00$ 8.07790e+00 8.07790e-01 1.00000e-09 2.12000e-01 8.07790e+00 8.07790e+00 8.07790e-01 1.00000e-09 2.12000e-01 8.07790e+00 8.07790e+00 8.07790e-01 1.00000e-09 2.12000e-01 $1.00000 \mathrm{e}-05$ 1.00000e-05 1.00000e-06 1.00000e-09 1.00000e-01 $1.00000 \mathrm{e}+001.00000 \mathrm{e}+001.00000 \mathrm{e}-01$ 1.00000e-09 1.00000e-01 Element: 4849 \# of layers: 7

$\mathrm{Kx} \mathrm{Ky} \mathrm{Kz}$ Ss Por

8.07790e+00 8.07790e+00 8.07790e-01 1.00000e-09 2.12000e-01 $8.07790 \mathrm{e}+008.07790 \mathrm{e}+00$ 8.07790e-01 1.00000e-09 2.12000e-01 $8.07790 \mathrm{e}+00$ 8.07790e+00 8.07790e-01 1.00000e-09 2.12000e-01 8.07790e+00 8.07790e+00 8.07790e-01 1.00000e-09 2.12000e-01 $8.07790 \mathrm{e}+008.07790 \mathrm{e}+00$ 8.07790e-01 1.00000e-09 2.12000e-01 $1.00000 \mathrm{e}-05$ 1.00000e-05 1.00000e-06 1.00000e-09 1.00000e-01 
$1.00000 \mathrm{e}+001.00000 \mathrm{e}+001.00000 \mathrm{e}-01$ 1.00000e-09 1.00000e-01

Element: 4850 \# of layers: 7

$\mathrm{Kx} \mathrm{Ky} \mathrm{Kz}$ Ss Por

5.85012e+00 5.85012e+00 5.85012e-01 1.00000e-09 2.12000e-01

$5.85012 \mathrm{e}+00$ 5.85012e+00 5.85012e-01 1.00000e-09 2.12000e-01

$5.85012 \mathrm{e}+005.85012 \mathrm{e}+005.85012 \mathrm{e}-01$ 1.00000e-09 2.12000e-01

5.85012e+00 5.85012e+00 5.85012e-01 1.00000e-09 2.12000e-01

$5.85012 \mathrm{e}+005.85012 \mathrm{e}+00$ 5.85012e-01 1.00000e-09 2.12000e-01

$1.00000 \mathrm{e}-05$ 1.00000e-05 1.00000e-06 1.00000e-09 1.00000e-01

$1.00000 \mathrm{e}+001.00000 \mathrm{e}+001.00000 \mathrm{e}-01$ 1.00000e-09 1.00000e-01

Element: 4851 \# of layers: 7

Kx Ky Kz Ss Por

8.14135e+00 8.14135e+00 8.14135e-01 1.00000e-09 2.12000e-01

8.14135e+00 8.14135e+00 8.14135e-01 1.00000e-09 2.12000e-01

8.14135e+00 8.14135e+00 8.14135e-01 1.00000e-09 2.12000e-01

$8.14135 \mathrm{e}+00$ 8.14135e+00 8.14135e-01 1.00000e-09 2.12000e-01

$8.14135 \mathrm{e}+00$ 8.14135e+00 8.14135e-01 1.00000e-09 2.12000e-01

$1.00000 \mathrm{e}-05$ 1.00000e-05 1.00000e-06 1.00000e-09 1.00000e-01

$1.00000 \mathrm{e}+001.00000 \mathrm{e}+001.00000 \mathrm{e}-011.00000 \mathrm{e}-091.00000 \mathrm{e}-01$

Element: 4852 \# of layers: 3

$\mathrm{Kx} \mathrm{Ky} \mathrm{Kz}$ Ss Por

2.51240e+03 2.51240e+03 2.51240e+02 1.00000e-09 2.12000e-01

$2.51240 \mathrm{e}+032.51240 \mathrm{e}+032.51240 \mathrm{e}+02$ 1.00000e-09 2.12000e-01

1.00000e-06 1.00000e-06 1.00000e-06 1.00000e-09 5.00000e-02

Element: 4853 \# of layers: 3

$\mathrm{Kx} \mathrm{Ky} \mathrm{Kz}$ Ss Por

$1.08641 \mathrm{e}+041.08641 \mathrm{e}+041.08641 \mathrm{e}+03$ 1.00000e-09 2.12000e-01

$1.08641 \mathrm{e}+041.08641 \mathrm{e}+041.08641 \mathrm{e}+03$ 1.00000e-09 2.12000e-01

1.00000e-06 1.00000e-06 1.00000e-06 1.00000e-09 5.00000e-02

Element: 4854 \# of layers: 6

$\mathrm{Kx} \mathrm{Ky} \mathrm{Kz}$ Ss Por

2.07843e+04 2.07843e+04 2.07843e+03 1.00000e-09 7.00000e-02

$8.30470 \mathrm{e}+02$ 8.30470e+02 8.30470e+01 1.00000e-09 2.12000e-01

$8.30470 \mathrm{e}+02$ 8.30470e+02 8.30470e+01 1.00000e-09 2.12000e-01

$1.00000 \mathrm{e}-05$ 1.00000e-05 1.00000e-06 1.00000e-09 1.00000e-01

$1.00000 \mathrm{e}+001.00000 \mathrm{e}+001.00000 \mathrm{e}-011.00000 \mathrm{e}-091.00000 \mathrm{e}-01$

1.00000e-06 1.00000e-06 1.00000e-06 1.00000e-09 5.00000e-02

Element: 4855 \# of layers: 5

$\mathrm{Kx} \mathrm{Ky} \mathrm{Kz}$ Ss Por

8.50868e+03 8.50868e+03 8.50868e+02 1.00000e-09 7.00000e-02

$3.39982 \mathrm{e}+02$ 3.39982e+02 3.39982e+01 1.00000e-09 2.12000e-01

$1.00000 \mathrm{e}-05$ 1.00000e-05 1.00000e-06 1.00000e-09 1.00000e-01

$1.00000 \mathrm{e}+001.00000 \mathrm{e}+001.00000 \mathrm{e}-011.00000 \mathrm{e}-091.00000 \mathrm{e}-01$

1.00000e-06 1.00000e-06 1.00000e-06 1.00000e-09 5.00000e-02

Element: 4856 \# of layers: 6

Kx Ky Kz Ss Por 
8.50868e+03 8.50868e+03 8.50868e+02 1.00000e-09 7.00000e-02 $8.50868 \mathrm{e}+03$ 8.50868e+03 8.50868e+02 1.00000e-09 7.00000e-02 $3.39982 \mathrm{e}+02$ 3.39982e+02 3.39982e+01 1.00000e-09 2.12000e-01 $1.00000 \mathrm{e}-05$ 1.00000e-05 1.00000e-06 1.00000e-09 1.00000e-01 $1.00000 \mathrm{e}+001.00000 \mathrm{e}+001.00000 \mathrm{e}-011.00000 \mathrm{e}-091.00000 \mathrm{e}-01$ 1.00000e-06 1.00000e-06 1.00000e-06 1.00000e-09 5.00000e-02 Element: 4857 \# of layers: 4

$\mathrm{Kx} \mathrm{Ky} \mathrm{Kz}$ Ss Por

8.50868e+03 8.50868e+03 8.50868e+02 1.00000e-09 7.00000e-02

$8.50868 \mathrm{e}+03$ 8.50868e+03 8.50868e+02 1.00000e-09 7.00000e-02 $3.39982 \mathrm{e}+02$ 3.39982e+02 3.39982e+01 1.00000e-09 2.12000e-01 1.00000e-06 1.00000e-06 1.00000e-06 1.00000e-09 5.00000e-02

Element: 4858 \# of layers: 3

$\mathrm{Kx} \mathrm{Ky} \mathrm{Kz}$ Ss Por

$1.15634 \mathrm{e}+041.15634 \mathrm{e}+041.15634 \mathrm{e}+03$ 1.00000e-09 7.00000e-02 $4.62025 \mathrm{e}+024.62025 \mathrm{e}+02$ 4.62025e+01 1.00000e-09 2.12000e-01 1.00000e-06 1.00000e-06 1.00000e-06 1.00000e-09 5.00000e-02

Element: 4859 \# of layers: 4

$\mathrm{Kx} \mathrm{Ky} \mathrm{Kz}$ Ss Por

$1.15634 \mathrm{e}+041.15634 \mathrm{e}+04$ 1.15634e+03 1.00000e-09 7.00000e-02 $4.62025 \mathrm{e}+02$ 4.62025e+02 4.62025e+01 1.00000e-09 2.12000e-01 $4.62025 \mathrm{e}+02$ 4.62025e+02 4.62025e+01 1.00000e-09 2.12000e-01 1.00000e-06 1.00000e-06 1.00000e-06 1.00000e-09 5.00000e-02 Element: 4860 \# of layers: 3

Kx Ky Kz Ss Por

$1.73922 \mathrm{e}+03$ 1.73922e+03 1.73922e+02 1.00000e-09 2.12000e-01 $1.73922 \mathrm{e}+03$ 1.73922e+03 1.73922e+02 1.00000e-09 2.12000e-01 1.00000e-06 1.00000e-06 1.00000e-06 1.00000e-09 5.00000e-02

Element: 4861 \# of layers: 4

$\mathrm{Kx} \mathrm{Ky} \mathrm{Kz}$ Ss Por

2.07843e+04 2.07843e+04 2.07843e+03 1.00000e-09 7.00000e-02 8.30470e+02 8.30470e+02 8.30470e+01 1.00000e-09 2.12000e-01 $8.30470 \mathrm{e}+028.30470 \mathrm{e}+028.30470 \mathrm{e}+01$ 1.00000e-09 2.12000e-01 1.00000e-06 1.00000e-06 1.00000e-06 1.00000e-09 5.00000e-02

Element: 4862 \# of layers: 4

$\mathrm{Kx} \mathrm{Ky} \mathrm{Kz}$ Ss Por

8.50868e+03 8.50868e+03 8.50868e+02 1.00000e-09 7.00000e-02 $3.39982 \mathrm{e}+02$ 3.39982e+02 3.39982e+01 1.00000e-09 2.12000e-01 $3.39982 \mathrm{e}+02$ 3.39982e+02 3.39982e+01 1.00000e-09 2.12000e-01 1.00000e-06 1.00000e-06 1.00000e-06 1.00000e-09 5.00000e-02 Element: 4863 \# of layers: 4

$\mathrm{Kx} \mathrm{Ky} \mathrm{Kz}$ Ss Por

4.90288e+03 4.90288e+03 4.90288e+02 1.00000e-09 7.00000e-02 4.90288e+03 4.90288e+03 4.90288e+02 1.00000e-09 7.00000e-02 $1.95903 \mathrm{e}+02$ 1.95903e+02 1.95903e+01 1.00000e-09 2.12000e-01 $1.00000 \mathrm{e}-06$ 1.00000e-06 1.00000e-06 1.00000e-09 5.00000e-02 
Element: 4864 \# of layers: 3

$\mathrm{Kx} \mathrm{Ky} \mathrm{Kz}$ Ss Por

4.90288e+03 4.90288e+03 4.90288e+02 1.00000e-09 7.00000e-02

$4.90288 \mathrm{e}+03$ 4.90288e+03 4.90288e+02 1.00000e-09 7.00000e-02

1.00000e-06 1.00000e-06 1.00000e-06 1.00000e-09 5.00000e-02

Element: 4865 \# of layers: 4

$\mathrm{Kx} \mathrm{Ky} \mathrm{Kz}$ Ss Por

5.09768e+03 5.09768e+03 5.09768e+02 1.00000e-09 7.00000e-02

$5.09768 \mathrm{e}+03$ 5.09768e+03 5.09768e+02 1.00000e-09 7.00000e-02

$1.00000 \mathrm{e}+001.00000 \mathrm{e}+00$ 1.00000e-01 1.00000e-09 1.00000e-01

1.00000e-06 1.00000e-06 1.00000e-06 1.00000e-09 5.00000e-02

Element: 4866 \# of layers: 2

$\mathrm{Kx} \mathrm{Ky} \mathrm{Kz}$ Ss Por

5.09768e+03 5.09768e+03 5.09768e+02 1.00000e-09 7.00000e-02

1.00000e-06 1.00000e-06 1.00000e-06 1.00000e-09 5.00000e-02

Element: 4867 \# of layers: 2

$\mathrm{Kx} \mathrm{Ky} \mathrm{Kz}$ Ss Por

9.60826e+03 9.60826e+03 9.60826e+02 1.00000e-09 7.00000e-02

$1.00000 \mathrm{e}-06$ 1.00000e-06 1.00000e-06 1.00000e-09 5.00000e-02

Element: 4868 \# of layers: 2

$\mathrm{Kx} \mathrm{Ky} \mathrm{Kz}$ Ss Por

8.17360e+03 8.17360e+03 8.17360e+02 1.00000e-09 7.00000e-02 $1.00000 \mathrm{e}-06$ 1.00000e-06 1.00000e-06 1.00000e-09 5.00000e-02

Element: 4869 \# of layers: 3

Kx Ky Kz Ss Por

8.17360e+03 8.17360e+03 8.17360e+02 1.00000e-09 7.00000e-02

$4.62025 \mathrm{e}+02$ 4.62025e+02 4.62025e+01 1.00000e-09 2.12000e-01

1.00000e-06 1.00000e-06 1.00000e-06 1.00000e-09 5.00000e-02

Element: 4870 \# of layers: 4

$\mathrm{Kx} \mathrm{Ky} \mathrm{Kz}$ Ss Por

4.90288e+03 4.90288e+03 4.90288e+02 1.00000e-09 7.00000e-02

$4.90288 \mathrm{e}+03$ 4.90288e+03 4.90288e+02 1.00000e-09 7.00000e-02

$1.95903 \mathrm{e}+021.95903 \mathrm{e}+02$ 1.95903e+01 1.00000e-09 2.12000e-01

1.00000e-06 1.00000e-06 1.00000e-06 1.00000e-09 5.00000e-02

Element: 4871 \# of layers: 3

$\mathrm{Kx} \mathrm{Ky} \mathrm{Kz}$ Ss Por

5.09768e+03 5.09768e+03 5.09768e+02 1.00000e-09 7.00000e-02

$5.09768 \mathrm{e}+03$ 5.09768e+03 5.09768e+02 1.00000e-09 7.00000e-02

1.00000e-06 1.00000e-06 1.00000e-06 1.00000e-09 5.00000e-02

Element: 4872 \# of layers: 3

$\mathrm{Kx} \mathrm{Ky} \mathrm{Kz}$ Ss Por

7.50371e+03 7.50371e+03 7.50371e+02 1.00000e-09 7.00000e-02 $1.00000 \mathrm{e}+001.00000 \mathrm{e}+001.00000 \mathrm{e}-011.00000 \mathrm{e}-091.00000 \mathrm{e}-01$ 1.00000e-06 1.00000e-06 1.00000e-06 1.00000e-09 5.00000e-02

Element: 4873 \# of layers: 3

Kx Ky Kz Ss Por 
8.40507e+03 8.40507e+03 8.40507e+02 1.00000e-09 7.00000e-02 $1.00000 \mathrm{e}+001.00000 \mathrm{e}+001.00000 \mathrm{e}-011.00000 \mathrm{e}-091.00000 \mathrm{e}-01$ 1.00000e-06 1.00000e-06 1.00000e-06 1.00000e-09 5.00000e-02

Element: 4874 \# of layers: 2

$\mathrm{Kx} \mathrm{Ky} \mathrm{Kz}$ Ss Por

8.40507e+03 8.40507e+03 8.40507e+02 1.00000e-09 7.00000e-02 1.00000e-06 1.00000e-06 1.00000e-06 1.00000e-09 5.00000e-02

Element: 4875 \# of layers: 2

$\mathrm{Kx} \mathrm{Ky} \mathrm{Kz}$ Ss Por

8.40507e+03 8.40507e+03 8.40507e+02 1.00000e-09 7.00000e-02 1.00000e-06 1.00000e-06 1.00000e-06 1.00000e-09 5.00000e-02

Element: 4876 \# of layers: 2

$\mathrm{Kx} \mathrm{Ky} \mathrm{Kz}$ Ss Por

$1.59558 \mathrm{e}+041.59558 \mathrm{e}+041.59558 \mathrm{e}+03$ 1.00000e-09 7.00000e-02 1.00000e-06 1.00000e-06 1.00000e-06 1.00000e-09 5.00000e-02

Element: 4877 \# of layers: 2

$\mathrm{Kx} \mathrm{Ky} \mathrm{Kz}$ Ss Por

$1.27771 \mathrm{e}+041.27771 \mathrm{e}+041.27771 \mathrm{e}+03$ 1.00000e-09 7.00000e-02 1.00000e-06 1.00000e-06 1.00000e-06 1.00000e-09 5.00000e-02

Element: 4878 \# of layers: 2

$\mathrm{Kx} \mathrm{Ky} \mathrm{Kz}$ Ss Por

$1.27771 \mathrm{e}+041.27771 \mathrm{e}+041.27771 \mathrm{e}+03$ 1.00000e-09 7.00000e-02 1.00000e-06 1.00000e-06 1.00000e-06 1.00000e-09 5.00000e-02

Element: 4879 \# of layers: 2

$\mathrm{Kx} \mathrm{Ky} \mathrm{Kz}$ Ss Por

7.50371e+03 7.50371e+03 7.50371e+02 1.00000e-09 7.00000e-02 1.00000e-06 1.00000e-06 1.00000e-06 1.00000e-09 5.00000e-02

Element: 4880 \# of layers: 2

$\mathrm{Kx} \mathrm{Ky} \mathrm{Kz}$ Ss Por

7.50371e+03 7.50371e+03 7.50371e+02 1.00000e-09 7.00000e-02 $1.00000 \mathrm{e}-061.00000 \mathrm{e}-06$ 1.00000e-06 1.00000e-09 5.00000e-02

Element: 4881 \# of layers: 2

$\mathrm{Kx} \mathrm{Ky} \mathrm{Kz}$ Ss Por

$7.00050 \mathrm{e}+03$ 7.00050e+03 7.00050e+02 1.00000e-09 7.00000e-02 1.00000e-06 1.00000e-06 1.00000e-06 1.00000e-09 5.00000e-02

Element: 4882 \# of layers: 2

Kx Ky Kz Ss Por

7.06699e+03 7.06699e+03 7.06699e+02 1.00000e-09 7.00000e-02 1.00000e-06 1.00000e-06 1.00000e-06 1.00000e-09 5.00000e-02

Element: 4883 \# of layers: 2

$\mathrm{Kx} \mathrm{Ky} \mathrm{Kz}$ Ss Por

7.06699e+03 7.06699e+03 7.06699e+02 1.00000e-09 7.00000e-02 1.00000e-06 1.00000e-06 1.00000e-06 1.00000e-09 5.00000e-02

Element: 4884 \# of layers: 2

$\mathrm{Kx} \mathrm{Ky} \mathrm{Kz}$ Ss Por

9.72449e+03 9.72449e+03 9.72449e+02 1.00000e-09 7.00000e-02 
1.00000e-06 1.00000e-06 1.00000e-06 1.00000e-09 5.00000e-02

Element: 4885 \# of layers: 3

$\mathrm{Kx} \mathrm{Ky} \mathrm{Kz}$ Ss Por

9.72449e+03 9.72449e+03 9.72449e+02 1.00000e-09 7.00000e-02

9.72449e+03 9.72449e+03 9.72449e+02 1.00000e-09 7.00000e-02

1.00000e-06 1.00000e-06 1.00000e-06 1.00000e-09 5.00000e-02

Element: 4886 \# of layers: 3

$\mathrm{Kx} \mathrm{Ky} \mathrm{Kz}$ Ss Por

9.72449e+03 9.72449e+03 9.72449e+02 1.00000e-09 7.00000e-02

9.72449e+03 9.72449e+03 9.72449e+02 1.00000e-09 7.00000e-02

1.00000e-06 1.00000e-06 1.00000e-06 1.00000e-09 5.00000e-02

Element: 4887 \# of layers: 2

$\mathrm{Kx} \mathrm{Ky} \mathrm{Kz}$ Ss Por

$1.52215 \mathrm{e}+041.52215 \mathrm{e}+041.52215 \mathrm{e}+03$ 1.00000e-09 7.00000e-02 1.00000e-06 1.00000e-06 1.00000e-06 1.00000e-09 5.00000e-02

Element: 4888 \# of layers: 2

$\mathrm{Kx} \mathrm{Ky} \mathrm{Kz}$ Ss Por

$1.52215 \mathrm{e}+041.52215 \mathrm{e}+041.52215 \mathrm{e}+03$ 1.00000e-09 7.00000e-02 1.00000e-06 1.00000e-06 1.00000e-06 1.00000e-09 5.00000e-02

Element: 4889 \# of layers: 2

$\mathrm{Kx} \mathrm{Ky} \mathrm{Kz}$ Ss Por

9.72449e+03 9.72449e+03 9.72449e+02 1.00000e-09 7.00000e-02 1.00000e-06 1.00000e-06 1.00000e-06 1.00000e-09 5.00000e-02

Element: 4890 \# of layers: 2

$\mathrm{Kx} \mathrm{Ky} \mathrm{Kz}$ Ss Por

6.07328e+03 6.07328e+03 6.07328e+02 1.00000e-09 7.00000e-02

1.00000e-06 1.00000e-06 1.00000e-06 1.00000e-09 5.00000e-02

Element: 4891 \# of layers: 3

$\mathrm{Kx} \mathrm{Ky} \mathrm{Kz}$ Ss Por

6.02634e+03 6.02634e+03 6.02634e+02 1.00000e-09 7.00000e-02 $1.00000 \mathrm{e}+001.00000 \mathrm{e}+001.00000 \mathrm{e}-011.00000 \mathrm{e}-091.00000 \mathrm{e}-01$

1.00000e-06 1.00000e-06 1.00000e-06 1.00000e-09 5.00000e-02

Element: 4892 \# of layers: 3

$\mathrm{Kx} \mathrm{Ky} \mathrm{Kz}$ Ss Por

6.02634e+03 6.02634e+03 6.02634e+02 1.00000e-09 7.00000e-02

$1.00000 \mathrm{e}+001.00000 \mathrm{e}+001.00000 \mathrm{e}-011.00000 \mathrm{e}-091.00000 \mathrm{e}-01$

1.00000e-06 1.00000e-06 1.00000e-06 1.00000e-09 5.00000e-02

Element: 4893 \# of layers: 2

$\mathrm{Kx} \mathrm{Ky} \mathrm{Kz}$ Ss Por

9.62088e+03 9.62088e+03 9.62088e+02 1.00000e-09 7.00000e-02

1.00000e-06 1.00000e-06 1.00000e-06 1.00000e-09 5.00000e-02

Element: 4894 \# of layers: 2

$\mathrm{Kx} \mathrm{Ky} \mathrm{Kz}$ Ss Por

9.62088e+03 9.62088e+03 9.62088e+02 1.00000e-09 7.00000e-02

1.00000e-06 1.00000e-06 1.00000e-06 1.00000e-09 5.00000e-02

Element: 4895 \# of layers: 2 
$\mathrm{Kx} \mathrm{Ky} \mathrm{Kz} \mathrm{Ss} \mathrm{Por}$

8.03962e+03 8.03962e+03 8.03962e+02 1.00000e-09 7.00000e-02

1.00000e-06 1.00000e-06 1.00000e-06 1.00000e-09 5.00000e-02

Element: 4896 \# of layers: 2

$\mathrm{Kx} \mathrm{Ky} \mathrm{Kz}$ Ss Por

8.03962e+03 8.03962e+03 8.03962e+02 1.00000e-09 7.00000e-02

1.00000e-06 1.00000e-06 1.00000e-06 1.00000e-09 5.00000e-02

Element: 4897 \# of layers: 2

$\mathrm{Kx} \mathrm{Ky} \mathrm{Kz}$ Ss Por

8.03962e+03 8.03962e+03 8.03962e+02 1.00000e-09 7.00000e-02

1.00000e-06 1.00000e-06 1.00000e-06 1.00000e-09 5.00000e-02

Element: 4898 \# of layers: 2

$\mathrm{Kx} \mathrm{Ky} \mathrm{Kz}$ Ss Por

6.07328e+03 6.07328e+03 6.07328e+02 1.00000e-09 7.00000e-02

1.00000e-06 1.00000e-06 1.00000e-06 1.00000e-09 5.00000e-02

Element: 4899 \# of layers: 3

$\mathrm{Kx} \mathrm{Ky} \mathrm{Kz}$ Ss Por

7.43685e+02 7.43685e+02 7.43685e+01 1.00000e-09 7.00000e-02

$1.00000 \mathrm{e}+001.00000 \mathrm{e}+001.00000 \mathrm{e}-011.00000 \mathrm{e}-091.00000 \mathrm{e}-01$

1.00000e-06 1.00000e-06 1.00000e-06 1.00000e-09 5.00000e-02

Element: 4900 \# of layers: 3

$\mathrm{Kx} \mathrm{Ky} \mathrm{Kz}$ Ss Por

7.43685e+02 7.43685e+02 7.43685e+01 1.00000e-09 7.00000e-02

$1.00000 \mathrm{e}+001.00000 \mathrm{e}+001.00000 \mathrm{e}-011.00000 \mathrm{e}-091.00000 \mathrm{e}-01$

1.00000e-06 1.00000e-06 1.00000e-06 1.00000e-09 5.00000e-02

Element: 4901 \# of layers: 2

$\mathrm{Kx} \mathrm{Ky} \mathrm{Kz}$ Ss Por

7.01573e+02 7.01573e+02 7.01573e+01 1.00000e-09 7.00000e-02

1.00000e-06 1.00000e-06 1.00000e-06 1.00000e-09 5.00000e-02

Element: 4902 \# of layers: 2

$\mathrm{Kx} \mathrm{Ky} \mathrm{Kz}$ Ss Por

$1.21167 \mathrm{e}+03$ 1.21167e+03 1.21167e+02 1.00000e-09 7.00000e-02

1.00000e-06 1.00000e-06 1.00000e-06 1.00000e-09 5.00000e-02

Element: 4903 \# of layers: 2

$\mathrm{Kx} \mathrm{Ky} \mathrm{Kz}$ Ss Por

$1.21167 \mathrm{e}+03$ 1.21167e+03 1.21167e+02 1.00000e-09 7.00000e-02

1.00000e-06 1.00000e-06 1.00000e-06 1.00000e-09 5.00000e-02

Element: 4904 \# of layers: 2

$\mathrm{Kx} \mathrm{Ky} \mathrm{Kz}$ Ss Por

$1.21167 \mathrm{e}+03$ 1.21167e+03 1.21167e+02 1.00000e-09 7.00000e-02

1.00000e-06 1.00000e-06 1.00000e-06 1.00000e-09 5.00000e-02

Element: 4905 \# of layers: 2

$\mathrm{Kx} \mathrm{Ky} \mathrm{Kz}$ Ss Por

1.11724e+03 1.11724e+03 1.11724e+02 1.00000e-09 7.00000e-02

1.00000e-06 1.00000e-06 1.00000e-06 1.00000e-09 5.00000e-02

Element: 4906 \# of layers: 2 
Kx Ky Kz Ss Por

$7.43685 \mathrm{e}+02$ 7.43685e+02 7.43685e+01 1.00000e-09 7.00000e-02

$1.00000 \mathrm{e}-06$ 1.00000e-06 1.00000e-06 1.00000e-09 5.00000e-02

Element: 4907 \# of layers: 2

Kx Ky Kz Ss Por

$7.43685 \mathrm{e}+02$ 7.43685e+02 7.43685e+01 1.00000e-09 7.00000e-02

$1.00000 \mathrm{e}-06$ 1.00000e-06 1.00000e-06 1.00000e-09 5.00000e-02

Element: 4908 \# of layers: 2

Kx Ky Kz Ss Por

6.11347e+02 6.11347e+02 6.11347e+01 1.00000e-09 7.00000e-02

$1.00000 \mathrm{e}-06$ 1.00000e-06 1.00000e-06 1.00000e-09 5.00000e-02

Element: 4909 \# of layers: 2

Kx Ky Kz Ss Por

$3.62941 \mathrm{e}+023.62941 \mathrm{e}+023.62941 \mathrm{e}+01$ 1.00000e-09 7.00000e-02

$1.00000 \mathrm{e}-06$ 1.00000e-06 1.00000e-06 1.00000e-09 5.00000e-02

Element: 4910 \# of layers: 2

Kx Ky Kz Ss Por

$3.62941 \mathrm{e}+023.62941 \mathrm{e}+023.62941 \mathrm{e}+01$ 1.00000e-09 7.00000e-02 $1.00000 \mathrm{e}-06$ 1.00000e-06 1.00000e-06 1.00000e-09 5.00000e-02

Element: 4911 \# of layers: 2

Kx Ky Kz Ss Por

$3.62941 \mathrm{e}+023.62941 \mathrm{e}+023.62941 \mathrm{e}+01$ 1.00000e-09 7.00000e-02 1.00000e-06 1.00000e-06 1.00000e-06 1.00000e-09 5.00000e-02

Element: 4912 \# of layers: 2

Kx Ky Kz Ss Por

$1.75974 \mathrm{e}+021.75974 \mathrm{e}+021.75974 \mathrm{e}+01$ 1.00000e-09 7.00000e-02

$1.00000 \mathrm{e}-06$ 1.00000e-06 1.00000e-06 1.00000e-09 5.00000e-02

Element: 4913 \# of layers: 2

Kx Ky Kz Ss Por

$9.98218 \mathrm{e}+02$ 9.98218e+02 9.98218e+01 1.00000e-09 7.00000e-02 $1.00000 \mathrm{e}-06$ 1.00000e-06 1.00000e-06 1.00000e-09 5.00000e-02

Element: 4914 \# of layers: 2

Kx Ky Kz Ss Por

$9.98218 \mathrm{e}+02$ 9.98218e+02 9.98218e+01 1.00000e-09 7.00000e-02 $1.00000 \mathrm{e}-06$ 1.00000e-06 1.00000e-06 1.00000e-09 5.00000e-02

Element: 4915 \# of layers: 2

Kx Ky Kz Ss Por

$6.11347 \mathrm{e}+02$ 6.11347e+02 6.11347e+01 1.00000e-09 7.00000e-02 $1.00000 \mathrm{e}-06$ 1.00000e-06 1.00000e-06 1.00000e-09 5.00000e-02

Element: 4916 \# of layers: 2

Kx Ky Kz Ss Por

$3.62941 \mathrm{e}+023.62941 \mathrm{e}+023.62941 \mathrm{e}+01$ 1.00000e-09 7.00000e-02 $1.00000 \mathrm{e}-06$ 1.00000e-06 1.00000e-06 1.00000e-09 5.00000e-02

Element: 4917 \# of layers: 2

Kx Ky Kz Ss Por

$1.87147 \mathrm{e}+02$ 1.87147e+02 1.87147e+01 1.00000e-09 7.00000e-02 
1.00000e-06 1.00000e-06 1.00000e-06 1.00000e-09 5.00000e-02

Element: 4918 \# of layers: 2

Kx Ky Kz Ss Por

1.87147e+02 1.87147e+02 1.87147e+01 1.00000e-09 7.00000e-02

1.00000e-06 1.00000e-06 1.00000e-06 1.00000e-09 5.00000e-02

Element: 4919 \# of layers: 2

$\mathrm{Kx} \mathrm{Ky} \mathrm{Kz}$ Ss Por

8.12134e+01 8.12134e+01 8.12134e+00 1.00000e-09 7.00000e-02

1.00000e-06 1.00000e-06 1.00000e-06 1.00000e-09 5.00000e-02

Element: 4920 \# of layers: 2

$\mathrm{Kx} \mathrm{Ky} \mathrm{Kz}$ Ss Por

8.12134e+01 8.12134e+01 8.12134e+00 1.00000e-09 7.00000e-02

1.00000e-06 1.00000e-06 1.00000e-06 1.00000e-09 5.00000e-02

Element: 4921 \# of layers: 2

Kx Ky Kz Ss Por

$5.82614 \mathrm{e}+015.82614 \mathrm{e}+015.82614 \mathrm{e}+00$ 1.00000e-09 7.00000e-02

1.00000e-06 1.00000e-06 1.00000e-06 1.00000e-09 5.00000e-02

Element: 4922 \# of layers: 2

$\mathrm{Kx} \mathrm{Ky} \mathrm{Kz}$ Ss Por

5.82614e+01 5.82614e+01 5.82614e+00 1.00000e-09 7.00000e-02

1.00000e-06 1.00000e-06 1.00000e-06 1.00000e-09 5.00000e-02

Element: 4923 \# of layers: 2

$\mathrm{Kx} \mathrm{Ky} \mathrm{Kz}$ Ss Por

6.28475e+01 6.28475e+01 6.28475e+00 1.00000e-09 7.00000e-02

1.00000e-06 1.00000e-06 1.00000e-06 1.00000e-09 5.00000e-02

Element: 4924 \# of layers: 2

$\mathrm{Kx} \mathrm{Ky} \mathrm{Kz}$ Ss Por

6.28475e+01 6.28475e+01 6.28475e+00 1.00000e-09 7.00000e-02

$1.00000 \mathrm{e}-06$ 1.00000e-06 1.00000e-06 1.00000e-09 5.00000e-02

Element: 4925 \# of layers: 2

$\mathrm{Kx} \mathrm{Ky} \mathrm{Kz}$ Ss Por

$5.82614 \mathrm{e}+015.82614 \mathrm{e}+015.82614 \mathrm{e}+001.00000 \mathrm{e}-097.00000 \mathrm{e}-02$

1.00000e-06 1.00000e-06 1.00000e-06 1.00000e-09 5.00000e-02

Element: 4926 \# of layers: 4

$\mathrm{Kx} \mathrm{Ky} \mathrm{Kz}$ Ss Por

4.26371e+01 4.26371e+01 4.26371e+00 1.00000e-09 7.00000e-02

$1.00000 \mathrm{e}-05$ 1.00000e-05 1.00000e-06 1.00000e-09 1.00000e-01

$1.00000 \mathrm{e}+001.00000 \mathrm{e}+001.00000 \mathrm{e}-011.00000 \mathrm{e}-091.00000 \mathrm{e}-01$

1.00000e-06 1.00000e-06 1.00000e-06 1.00000e-09 5.00000e-02

Element: 4927 \# of layers: 4

$\mathrm{Kx} \mathrm{Ky} \mathrm{Kz}$ Ss Por

4.26371e+01 4.26371e+01 4.26371e+00 1.00000e-09 7.00000e-02

$1.00000 \mathrm{e}-051.00000 \mathrm{e}-051.00000 \mathrm{e}-061.00000 \mathrm{e}-091.00000 \mathrm{e}-01$

$1.00000 \mathrm{e}+001.00000 \mathrm{e}+001.00000 \mathrm{e}-011.00000 \mathrm{e}-091.00000 \mathrm{e}-01$

1.00000e-06 1.00000e-06 1.00000e-06 1.00000e-09 5.00000e-02

Element: 4928 \# of layers: 4 
$\mathrm{Kx} \mathrm{Ky} \mathrm{Kz} \mathrm{Ss} \mathrm{Por}$

5.14255e+01 5.14255e+01 5.14255e+00 1.00000e-09 7.00000e-02

$1.00000 \mathrm{e}-05$ 1.00000e-05 1.00000e-06 1.00000e-09 1.00000e-01

$1.00000 \mathrm{e}+001.00000 \mathrm{e}+001.00000 \mathrm{e}-011.00000 \mathrm{e}-091.00000 \mathrm{e}-01$

1.00000e-06 1.00000e-06 1.00000e-06 1.00000e-09 5.00000e-02

Element: 4929 \# of layers: 4

$\mathrm{Kx} \mathrm{Ky} \mathrm{Kz}$ Ss Por

5.14255e+01 5.14255e+01 5.14255e+00 1.00000e-09 7.00000e-02

$1.00000 \mathrm{e}-05$ 1.00000e-05 1.00000e-06 1.00000e-09 1.00000e-01

$1.00000 \mathrm{e}+001.00000 \mathrm{e}+001.00000 \mathrm{e}-011.00000 \mathrm{e}-091.00000 \mathrm{e}-01$

1.00000e-06 1.00000e-06 1.00000e-06 1.00000e-09 5.00000e-02

Element: 4930 \# of layers: 5

$\mathrm{Kx} \mathrm{Ky} \mathrm{Kz}$ Ss Por

7.73896e+01 7.73896e+01 7.73896e+00 1.00000e-09 7.00000e-02

7.73896e+01 7.73896e+01 7.73896e+00 1.00000e-09 7.00000e-02

1.00000e-05 1.00000e-05 1.00000e-06 1.00000e-09 1.00000e-01

$1.00000 \mathrm{e}+001.00000 \mathrm{e}+001.00000 \mathrm{e}-011.00000 \mathrm{e}-091.00000 \mathrm{e}-01$

1.00000e-06 1.00000e-06 1.00000e-06 1.00000e-09 5.00000e-02

Element: 4931 \# of layers: 5

$\mathrm{Kx} \mathrm{Ky} \mathrm{Kz}$ Ss Por

7.73896e+01 7.73896e+01 7.73896e+00 1.00000e-09 7.00000e-02

7.73896e+01 7.73896e+01 7.73896e+00 1.00000e-09 7.00000e-02

$1.00000 \mathrm{e}-05$ 1.00000e-05 1.00000e-06 1.00000e-09 1.00000e-01

$1.00000 \mathrm{e}+001.00000 \mathrm{e}+001.00000 \mathrm{e}-011.00000 \mathrm{e}-091.00000 \mathrm{e}-01$

1.00000e-06 1.00000e-06 1.00000e-06 1.00000e-09 5.00000e-02

Element: 4932 \# of layers: 3

$\mathrm{Kx} \mathrm{Ky} \mathrm{Kz}$ Ss Por

6.46107e+01 6.46107e+01 6.46107e+00 1.00000e-09 7.00000e-02

$6.46107 \mathrm{e}+016.46107 \mathrm{e}+016.46107 \mathrm{e}+00$ 1.00000e-09 7.00000e-02

1.00000e-06 1.00000e-06 1.00000e-06 1.00000e-09 5.00000e-02

Element: 4933 \# of layers: 2

$\mathrm{Kx} \mathrm{Ky} \mathrm{Kz}$ Ss Por

4.26371e+01 4.26371e+01 4.26371e+00 1.00000e-09 7.00000e-02

1.00000e-06 1.00000e-06 1.00000e-06 1.00000e-09 5.00000e-02

Element: 4934 \# of layers: 4

Kx Ky Kz Ss Por

5.14255e+01 5.14255e+01 5.14255e+00 1.00000e-09 7.00000e-02

$1.00000 \mathrm{e}-05$ 1.00000e-05 1.00000e-06 1.00000e-09 1.00000e-01

$1.00000 \mathrm{e}+001.00000 \mathrm{e}+001.00000 \mathrm{e}-011.00000 \mathrm{e}-091.00000 \mathrm{e}-01$

1.00000e-06 1.00000e-06 1.00000e-06 1.00000e-09 5.00000e-02

Element: 4935 \# of layers: 4

$\mathrm{Kx} \mathrm{Ky} \mathrm{Kz}$ Ss Por

5.06957e+01 5.06957e+01 5.06957e+00 1.00000e-09 7.00000e-02

$1.00000 \mathrm{e}-05$ 1.00000e-05 1.00000e-06 1.00000e-09 1.00000e-01

$1.00000 \mathrm{e}+001.00000 \mathrm{e}+001.00000 \mathrm{e}-011.00000 \mathrm{e}-091.00000 \mathrm{e}-01$

1.00000e-06 1.00000e-06 1.00000e-06 1.00000e-09 5.00000e-02 
Element: 4936 \# of layers: 4

$\mathrm{Kx} \mathrm{Ky} \mathrm{Kz}$ Ss Por

5.06957e+01 5.06957e+01 5.06957e+00 1.00000e-09 7.00000e-02

$1.00000 \mathrm{e}-05$ 1.00000e-05 1.00000e-06 1.00000e-09 1.00000e-01

$1.00000 \mathrm{e}+001.00000 \mathrm{e}+001.00000 \mathrm{e}-011.00000 \mathrm{e}-091.00000 \mathrm{e}-01$

1.00000e-06 1.00000e-06 1.00000e-06 1.00000e-09 5.00000e-02

Element: 4937 \# of layers: 5

$\mathrm{Kx} \mathrm{Ky} \mathrm{Kz}$ Ss Por

6.44936e+01 6.44936e+01 6.44936e+00 1.00000e-09 7.00000e-02

$6.44936 \mathrm{e}+016.44936 \mathrm{e}+016.44936 \mathrm{e}+00$ 1.00000e-09 7.00000e-02

$1.00000 \mathrm{e}-05$ 1.00000e-05 1.00000e-06 1.00000e-09 1.00000e-01

$1.00000 \mathrm{e}+001.00000 \mathrm{e}+001.00000 \mathrm{e}-011.00000 \mathrm{e}-091.00000 \mathrm{e}-01$

1.00000e-06 1.00000e-06 1.00000e-06 1.00000e-09 5.00000e-02

Element: 4938 \# of layers: 5

$\mathrm{Kx} \mathrm{Ky} \mathrm{Kz}$ Ss Por

6.44936e+01 6.44936e+01 6.44936e+00 1.00000e-09 7.00000e-02

$6.44936 \mathrm{e}+016.44936 \mathrm{e}+016.44936 \mathrm{e}+001.00000 \mathrm{e}-09$ 7.00000e-02

$1.00000 \mathrm{e}-051.00000 \mathrm{e}-051.00000 \mathrm{e}-061.00000 \mathrm{e}-091.00000 \mathrm{e}-01$

$1.00000 \mathrm{e}+001.00000 \mathrm{e}+001.00000 \mathrm{e}-011.00000 \mathrm{e}-091.00000 \mathrm{e}-01$

1.00000e-06 1.00000e-06 1.00000e-06 1.00000e-09 5.00000e-02

Element: 4939 \# of layers: 5

$\mathrm{Kx} \mathrm{Ky} \mathrm{Kz}$ Ss Por

3.76429e+01 3.76429e+01 3.76429e+00 1.00000e-09 7.00000e-02

$3.76429 \mathrm{e}+013.76429 \mathrm{e}+013.76429 \mathrm{e}+001.00000 \mathrm{e}-09$ 7.00000e-02

$1.00000 \mathrm{e}-05$ 1.00000e-05 1.00000e-06 1.00000e-09 1.00000e-01

$1.00000 \mathrm{e}+001.00000 \mathrm{e}+001.00000 \mathrm{e}-011.00000 \mathrm{e}-091.00000 \mathrm{e}-01$

1.00000e-06 1.00000e-06 1.00000e-06 1.00000e-09 5.00000e-02

Element: 4940 \# of layers: 5

Kx Ky Kz Ss Por

5.03317e+01 5.03317e+01 5.03317e+00 1.00000e-09 7.00000e-02

$5.03317 \mathrm{e}+015.03317 \mathrm{e}+015.03317 \mathrm{e}+001.00000 \mathrm{e}-09$ 7.00000e-02

$1.00000 \mathrm{e}-05$ 1.00000e-05 1.00000e-06 1.00000e-09 1.00000e-01

$1.00000 \mathrm{e}+001.00000 \mathrm{e}+001.00000 \mathrm{e}-011.00000 \mathrm{e}-091.00000 \mathrm{e}-01$

1.00000e-06 1.00000e-06 1.00000e-06 1.00000e-09 5.00000e-02

Element: 4941 \# of layers: 5

Kx Ky Kz Ss Por

5.03317e+01 5.03317e+01 5.03317e+00 1.00000e-09 7.00000e-02

$5.03317 \mathrm{e}+015.03317 \mathrm{e}+015.03317 \mathrm{e}+001.00000 \mathrm{e}-09$ 7.00000e-02

$1.00000 \mathrm{e}-05$ 1.00000e-05 1.00000e-06 1.00000e-09 1.00000e-01

$1.00000 \mathrm{e}+001.00000 \mathrm{e}+001.00000 \mathrm{e}-011.00000 \mathrm{e}-091.00000 \mathrm{e}-01$

1.00000e-06 1.00000e-06 1.00000e-06 1.00000e-09 5.00000e-02

Element: 4942 \# of layers: 4

$\mathrm{Kx} \mathrm{Ky} \mathrm{Kz}$ Ss Por

5.06957e+01 5.06957e+01 5.06957e+00 1.00000e-09 7.00000e-02

$1.00000 \mathrm{e}-05$ 1.00000e-05 1.00000e-06 1.00000e-09 1.00000e-01

$1.00000 \mathrm{e}+001.00000 \mathrm{e}+001.00000 \mathrm{e}-011.00000 \mathrm{e}-091.00000 \mathrm{e}-01$ 
1.00000e-06 1.00000e-06 1.00000e-06 1.00000e-09 5.00000e-02

Element: 4943 \# of layers: 4

$\mathrm{Kx} \mathrm{Ky} \mathrm{Kz}$ Ss Por

6.44936e+01 6.44936e+01 6.44936e+00 1.00000e-09 7.00000e-02

$1.00000 \mathrm{e}-05$ 1.00000e-05 1.00000e-06 1.00000e-09 1.00000e-01

$1.00000 \mathrm{e}+001.00000 \mathrm{e}+001.00000 \mathrm{e}-011.00000 \mathrm{e}-091.00000 \mathrm{e}-01$

1.00000e-06 1.00000e-06 1.00000e-06 1.00000e-09 5.00000e-02

Element: 4944 \# of layers: 5

$\mathrm{Kx} \mathrm{Ky} \mathrm{Kz}$ Ss Por

$1.12211 \mathrm{e}+021.12211 \mathrm{e}+02$ 1.12211e+01 1.00000e-09 7.00000e-02

$1.12211 \mathrm{e}+021.12211 \mathrm{e}+021.12211 \mathrm{e}+01$ 1.00000e-09 7.00000e-02

$1.00000 \mathrm{e}-05$ 1.00000e-05 1.00000e-06 1.00000e-09 1.00000e-01

$1.00000 \mathrm{e}+001.00000 \mathrm{e}+001.00000 \mathrm{e}-011.00000 \mathrm{e}-091.00000 \mathrm{e}-01$

1.00000e-06 1.00000e-06 1.00000e-06 1.00000e-09 5.00000e-02

Element: 4945 \# of layers: 6

Kx Ky Kz Ss Por

$1.12211 \mathrm{e}+021.12211 \mathrm{e}+02$ 1.12211e+01 1.00000e-09 7.00000e-02

$1.12211 \mathrm{e}+021.12211 \mathrm{e}+021.12211 \mathrm{e}+01$ 1.00000e-09 7.00000e-02

4.48367e+00 4.48367e+00 4.48367e-01 1.00000e-09 2.12000e-01

$1.00000 \mathrm{e}-05$ 1.00000e-05 1.00000e-06 1.00000e-09 1.00000e-01

$1.00000 \mathrm{e}+001.00000 \mathrm{e}+001.00000 \mathrm{e}-011.00000 \mathrm{e}-091.00000 \mathrm{e}-01$

$1.00000 \mathrm{e}-06$ 1.00000e-06 1.00000e-06 1.00000e-09 5.00000e-02

Element: 4946 \# of layers: 7

Kx Ky Kz Ss Por

6.37277e+01 6.37277e+01 6.37277e+00 1.00000e-09 7.00000e-02

6.37277e+01 6.37277e+01 6.37277e+00 1.00000e-09 7.00000e-02

$2.54638 \mathrm{e}+002.54638 \mathrm{e}+002.54638 \mathrm{e}-01$ 1.00000e-09 2.12000e-01

$1.00000 \mathrm{e}-02$ 1.00000e-02 1.00000e-03 1.00000e-09 1.00000e-01

$1.00000 \mathrm{e}-05$ 1.00000e-05 1.00000e-06 1.00000e-09 1.00000e-01

$1.00000 \mathrm{e}+001.00000 \mathrm{e}+001.00000 \mathrm{e}-011.00000 \mathrm{e}-091.00000 \mathrm{e}-01$

$1.00000 \mathrm{e}-06$ 1.00000e-06 1.00000e-06 1.00000e-09 5.00000e-02

Element: 4947 \# of layers: 6

Kx Ky Kz Ss Por

6.37277e+01 6.37277e+01 6.37277e+00 1.00000e-09 7.00000e-02

6.37277e+01 6.37277e+01 6.37277e+00 1.00000e-09 7.00000e-02

$2.54638 \mathrm{e}+002.54638 \mathrm{e}+00$ 2.54638e-01 1.00000e-09 2.12000e-01

$1.00000 \mathrm{e}-05$ 1.00000e-05 1.00000e-06 1.00000e-09 1.00000e-01

$1.00000 \mathrm{e}+001.00000 \mathrm{e}+001.00000 \mathrm{e}-011.00000 \mathrm{e}-091.00000 \mathrm{e}-01$

1.00000e-06 1.00000e-06 1.00000e-06 1.00000e-09 5.00000e-02

Element: 4948 \# of layers: 6

$\mathrm{Kx} \mathrm{Ky} \mathrm{Kz}$ Ss Por

8.65960e+01 8.65960e+01 8.65960e+00 1.00000e-09 7.00000e-02

$8.65960 \mathrm{e}+018.65960 \mathrm{e}+018.65960 \mathrm{e}+001.00000 \mathrm{e}-09$ 7.00000e-02

$3.46012 \mathrm{e}+003.46012 \mathrm{e}+003.46012 \mathrm{e}-01$ 1.00000e-09 2.12000e-01

$1.00000 \mathrm{e}-05$ 1.00000e-05 1.00000e-06 1.00000e-09 1.00000e-01

$1.00000 \mathrm{e}+001.00000 \mathrm{e}+001.00000 \mathrm{e}-011.00000 \mathrm{e}-091.00000 \mathrm{e}-01$ 
1.00000e-06 1.00000e-06 1.00000e-06 1.00000e-09 5.00000e-02

Element: 4949 \# of layers: 3

Kx Ky Kz Ss Por

1.00000e-05 1.00000e-05 1.00000e-06 1.00000e-09 1.00000e-01

$1.00000 \mathrm{e}+001.00000 \mathrm{e}+001.00000 \mathrm{e}-011.00000 \mathrm{e}-091.00000 \mathrm{e}-01$

1.00000e-06 1.00000e-06 1.00000e-06 1.00000e-09 5.00000e-02

Element: 4950 \# of layers: 4

$\mathrm{Kx} \mathrm{Ky} \mathrm{Kz}$ Ss Por

8.45589e+01 8.45589e+01 8.45589e+00 1.00000e-09 7.00000e-02

$8.45589 \mathrm{e}+018.45589 \mathrm{e}+018.45589 \mathrm{e}+001.00000 \mathrm{e}-09$ 7.00000e-02

$1.00000 \mathrm{e}+001.00000 \mathrm{e}+001.00000 \mathrm{e}-011.00000 \mathrm{e}-091.00000 \mathrm{e}-01$

1.00000e-06 1.00000e-06 1.00000e-06 1.00000e-09 5.00000e-02

Element: 4951 \# of layers: 5

$\mathrm{Kx} \mathrm{Ky} \mathrm{Kz}$ Ss Por

$1.12211 \mathrm{e}+02$ 1.12211e+02 1.12211e+01 1.00000e-09 7.00000e-02

$1.12211 \mathrm{e}+021.12211 \mathrm{e}+021.12211 \mathrm{e}+01$ 1.00000e-09 7.00000e-02

$1.00000 \mathrm{e}-05$ 1.00000e-05 1.00000e-06 1.00000e-09 1.00000e-01

$1.00000 \mathrm{e}+001.00000 \mathrm{e}+001.00000 \mathrm{e}-011.00000 \mathrm{e}-091.00000 \mathrm{e}-01$

$1.00000 \mathrm{e}-06$ 1.00000e-06 1.00000e-06 1.00000e-09 5.00000e-02

Element: 4952 \# of layers: 4

$\mathrm{Kx} \mathrm{Ky} \mathrm{Kz}$ Ss Por

6.37277e+01 6.37277e+01 6.37277e+00 1.00000e-09 7.00000e-02

$1.00000 \mathrm{e}-05$ 1.00000e-05 1.00000e-06 1.00000e-09 1.00000e-01

$1.00000 \mathrm{e}+001.00000 \mathrm{e}+001.00000 \mathrm{e}-011.00000 \mathrm{e}-091.00000 \mathrm{e}-01$

1.00000e-06 1.00000e-06 1.00000e-06 1.00000e-09 5.00000e-02

Element: 4953 \# of layers: 7

$\mathrm{Kx} \mathrm{Ky} \mathrm{Kz}$ Ss Por

1.35772e+01 1.35772e+01 1.35772e+00 1.00000e-09 7.00000e-02

5.42509e-01 5.42509e-01 5.42509e-02 1.00000e-09 2.12000e-01

5.42509e-01 5.42509e-01 5.42509e-02 1.00000e-09 2.12000e-01

1.00000e-02 1.00000e-02 1.00000e-03 1.00000e-09 1.00000e-01

$1.00000 \mathrm{e}-05$ 1.00000e-05 1.00000e-06 1.00000e-09 1.00000e-01

$1.00000 \mathrm{e}+001.00000 \mathrm{e}+001.00000 \mathrm{e}-011.00000 \mathrm{e}-091.00000 \mathrm{e}-01$

1.00000e-06 1.00000e-06 1.00000e-06 1.00000e-09 5.00000e-02

Element: 4954 \# of layers: 8

Kx Ky Kz Ss Por

1.35772e+01 1.35772e+01 1.35772e+00 1.00000e-09 7.00000e-02

$1.35772 \mathrm{e}+01$ 1.35772e+01 1.35772e+00 1.00000e-09 7.00000e-02

5.42509e-01 5.42509e-01 5.42509e-02 1.00000e-09 2.12000e-01

$1.00000 \mathrm{e}-02$ 1.00000e-02 1.00000e-03 1.00000e-09 1.00000e-01

$1.00000 \mathrm{e}+001.00000 \mathrm{e}+001.00000 \mathrm{e}-011.00000 \mathrm{e}-091.00000 \mathrm{e}-01$

$1.00000 \mathrm{e}-05$ 1.00000e-05 1.00000e-06 1.00000e-09 1.00000e-01

$1.00000 \mathrm{e}+001.00000 \mathrm{e}+001.00000 \mathrm{e}-011.00000 \mathrm{e}-091.00000 \mathrm{e}-01$

1.00000e-06 1.00000e-06 1.00000e-06 1.00000e-09 5.00000e-02

Element: 4955 \# of layers: 9

Kx Ky Kz Ss Por 
1.04327e+01 1.04327e+01 1.04327e+00 1.00000e-09 7.00000e-02 $1.04327 \mathrm{e}+01$ 1.04327e+01 1.04327e+00 1.00000e-09 7.00000e-02 4.16844e-01 4.16844e-01 4.16844e-02 1.00000e-09 2.12000e-01 4.16844e-01 4.16844e-01 4.16844e-02 1.00000e-09 2.12000e-01 $1.00000 \mathrm{e}-02$ 1.00000e-02 1.00000e-03 1.00000e-09 1.00000e-01 $1.00000 \mathrm{e}+001.00000 \mathrm{e}+001.00000 \mathrm{e}-011.00000 \mathrm{e}-091.00000 \mathrm{e}-01$ $1.00000 \mathrm{e}-05$ 1.00000e-05 1.00000e-06 1.00000e-09 1.00000e-01 $1.00000 \mathrm{e}+001.00000 \mathrm{e}+001.00000 \mathrm{e}-011.00000 \mathrm{e}-091.00000 \mathrm{e}-01$ 1.00000e-06 1.00000e-06 1.00000e-06 1.00000e-09 5.00000e-02

Element: 4956 \# of layers: 6

$\mathrm{Kx} \mathrm{Ky} \mathrm{Kz}$ Ss Por

$1.04327 \mathrm{e}+01$ 1.04327e+01 1.04327e+00 1.00000e-09 7.00000e-02 $1.04327 \mathrm{e}+01$ 1.04327e+01 1.04327e+00 1.00000e-09 7.00000e-02 4.16844e-01 4.16844e-01 4.16844e-02 1.00000e-09 2.12000e-01 $1.00000 \mathrm{e}-02$ 1.00000e-02 1.00000e-03 1.00000e-09 1.00000e-01 $1.00000 \mathrm{e}+001.00000 \mathrm{e}+001.00000 \mathrm{e}-011.00000 \mathrm{e}-091.00000 \mathrm{e}-01$ 1.00000e-06 1.00000e-06 1.00000e-06 1.00000e-09 5.00000e-02 Element: 4957 \# of layers: 5

$\mathrm{Kx} \mathrm{Ky} \mathrm{Kz}$ Ss Por

$1.86309 \mathrm{e}+01$ 1.86309e+01 1.86309e+00 1.00000e-09 7.00000e-02 $1.86309 \mathrm{e}+011.86309 \mathrm{e}+011.86309 \mathrm{e}+001.00000 \mathrm{e}-09$ 7.00000e-02 $1.00000 \mathrm{e}-02$ 1.00000e-02 1.00000e-03 1.00000e-09 1.00000e-01 $1.00000 \mathrm{e}+001.00000 \mathrm{e}+001.00000 \mathrm{e}-011.00000 \mathrm{e}-091.00000 \mathrm{e}-01$ 1.00000e-06 1.00000e-06 1.00000e-06 1.00000e-09 5.00000e-02

Element: 4958 \# of layers: 7

$\mathrm{Kx} \mathrm{Ky} \mathrm{Kz}$ Ss Por

$1.86309 \mathrm{e}+01$ 1.86309e+01 1.86309e+00 1.00000e-09 7.00000e-02 $1.86309 \mathrm{e}+011.86309 \mathrm{e}+01$ 1.86309e+00 1.00000e-09 7.00000e-02 $1.00000 \mathrm{e}-02$ 1.00000e-02 1.00000e-03 1.00000e-09 1.00000e-01 $1.00000 \mathrm{e}+001.00000 \mathrm{e}+001.00000 \mathrm{e}-011.00000 \mathrm{e}-091.00000 \mathrm{e}-01$ $1.00000 \mathrm{e}-05$ 1.00000e-05 1.00000e-06 1.00000e-09 1.00000e-01 $1.00000 \mathrm{e}+001.00000 \mathrm{e}+001.00000 \mathrm{e}-011.00000 \mathrm{e}-091.00000 \mathrm{e}-01$ 1.00000e-06 1.00000e-06 1.00000e-06 1.00000e-09 5.00000e-02 Element: 4959 \# of layers: 6

$\mathrm{Kx} \mathrm{Ky} \mathrm{Kz}$ Ss Por

$2.41639 \mathrm{e}+012.41639 \mathrm{e}+012.41639 \mathrm{e}+00$ 1.00000e-09 7.00000e-02 $2.41639 \mathrm{e}+012.41639 \mathrm{e}+012.41639 \mathrm{e}+001.00000 \mathrm{e}-09$ 7.00000e-02 9.65518e-01 9.65518e-01 9.65518e-02 1.00000e-09 2.12000e-01 $1.00000 \mathrm{e}-05$ 1.00000e-05 1.00000e-06 1.00000e-09 1.00000e-01 $1.00000 \mathrm{e}+001.00000 \mathrm{e}+001.00000 \mathrm{e}-011.00000 \mathrm{e}-091.00000 \mathrm{e}-01$ 1.00000e-06 1.00000e-06 1.00000e-06 1.00000e-09 5.00000e-02 Element: 4960 \# of layers: 7

$\mathrm{Kx} \mathrm{Ky} \mathrm{Kz}$ Ss Por

1.35772e+01 1.35772e+01 1.35772e+00 1.00000e-09 7.00000e-02 5.42509e-01 5.42509e-01 5.42509e-02 1.00000e-09 2.12000e-01 5.42509e-01 5.42509e-01 5.42509e-02 1.00000e-09 2.12000e-01 
1.00000e-02 1.00000e-02 1.00000e-03 1.00000e-09 1.00000e-01 $1.00000 \mathrm{e}-05$ 1.00000e-05 1.00000e-06 1.00000e-09 1.00000e-01 $1.00000 \mathrm{e}+001.00000 \mathrm{e}+001.00000 \mathrm{e}-011.00000 \mathrm{e}-091.00000 \mathrm{e}-01$ 1.00000e-06 1.00000e-06 1.00000e-06 1.00000e-09 5.00000e-02 Element: 4961 \# of layers: 8

$\mathrm{Kx} \mathrm{Ky} \mathrm{Kz}$ Ss Por

$1.04327 \mathrm{e}+01$ 1.04327e+01 1.04327e+00 1.00000e-09 7.00000e-02 $1.04327 \mathrm{e}+01$ 1.04327e+01 1.04327e+00 1.00000e-09 7.00000e-02 4.16844e-01 4.16844e-01 4.16844e-02 1.00000e-09 2.12000e-01 $1.00000 \mathrm{e}-02$ 1.00000e-02 1.00000e-03 1.00000e-09 1.00000e-01 $1.00000 \mathrm{e}+001.00000 \mathrm{e}+001.00000 \mathrm{e}-011.00000 \mathrm{e}-091.00000 \mathrm{e}-01$ $1.00000 \mathrm{e}-05$ 1.00000e-05 1.00000e-06 1.00000e-09 1.00000e-01 $1.00000 \mathrm{e}+001.00000 \mathrm{e}+001.00000 \mathrm{e}-011.00000 \mathrm{e}-091.00000 \mathrm{e}-01$ 1.00000e-06 1.00000e-06 1.00000e-06 1.00000e-09 5.00000e-02 Element: 4962 \# of layers: 14

Kx Ky Kz Ss Por

6.47927e+00 6.47927e+00 6.47927e-01 1.00000e-09 7.00000e-02 6.47927e+00 6.47927e+00 6.47927e-01 1.00000e-09 7.00000e-02 6.47927e+00 6.47927e+00 6.47927e-01 1.00000e-09 7.00000e-02 5.00000e-04 5.00000e-04 5.00000e-05 1.00000e-09 1.00000e-01 2.58891e-01 2.58891e-01 2.58891e-02 1.00000e-09 2.12000e-01

2.58891e-01 2.58891e-01 2.58891e-02 1.00000e-09 2.12000e-01 2.58891e-01 2.58891e-01 2.58891e-02 1.00000e-09 2.12000e-01 2.58891e-01 2.58891e-01 2.58891e-02 1.00000e-09 2.12000e-01 2.58891e-01 2.58891e-01 2.58891e-02 1.00000e-09 2.12000e-01 $1.00000 \mathrm{e}-02$ 1.00000e-02 1.00000e-03 1.00000e-09 1.00000e-01 $1.00000 \mathrm{e}+001.00000 \mathrm{e}+001.00000 \mathrm{e}-011.00000 \mathrm{e}-091.00000 \mathrm{e}-01$ $1.00000 \mathrm{e}-05$ 1.00000e-05 1.00000e-06 1.00000e-09 1.00000e-01 $1.00000 \mathrm{e}+001.00000 \mathrm{e}+001.00000 \mathrm{e}-011.00000 \mathrm{e}-091.00000 \mathrm{e}-01$ 1.00000e-06 1.00000e-06 1.00000e-06 1.00000e-09 5.00000e-02 Element: 4963 \# of layers: 14

$\mathrm{Kx} \mathrm{Ky} \mathrm{Kz}$ Ss Por

2.62227e+00 2.62227e+00 2.62227e-01 1.00000e-09 7.00000e-02 $2.62227 \mathrm{e}+00$ 2.62227e+00 2.62227e-01 1.00000e-09 7.00000e-02 5.00000e-04 5.00000e-04 5.00000e-05 1.00000e-09 1.00000e-01 5.00000e-04 5.00000e-04 5.00000e-05 1.00000e-09 1.00000e-01 1.04776e-01 1.04776e-01 1.04776e-02 1.00000e-09 2.12000e-01 1.04776e-01 1.04776e-01 1.04776e-02 1.00000e-09 2.12000e-01 1.04776e-01 1.04776e-01 1.04776e-02 1.00000e-09 2.12000e-01 1.04776e-01 1.04776e-01 1.04776e-02 1.00000e-09 2.12000e-01 1.04776e-01 1.04776e-01 1.04776e-02 1.00000e-09 2.12000e-01 $1.00000 \mathrm{e}-02$ 1.00000e-02 1.00000e-03 1.00000e-09 1.00000e-01 $1.00000 \mathrm{e}+001.00000 \mathrm{e}+001.00000 \mathrm{e}-011.00000 \mathrm{e}-091.00000 \mathrm{e}-01$ $1.00000 \mathrm{e}-05$ 1.00000e-05 1.00000e-06 1.00000e-09 1.00000e-01 $1.00000 \mathrm{e}+001.00000 \mathrm{e}+001.00000 \mathrm{e}-011.00000 \mathrm{e}-091.00000 \mathrm{e}-01$ $1.00000 \mathrm{e}-06$ 1.00000e-06 1.00000e-06 1.00000e-09 5.00000e-02 
Element: 4964 \# of layers: 14

$\mathrm{Kx} \mathrm{Ky} \mathrm{Kz}$ Ss Por

2.62227e+00 2.62227e+00 2.62227e-01 1.00000e-09 7.00000e-02

$2.62227 \mathrm{e}+002.62227 \mathrm{e}+00$ 2.62227e-01 1.00000e-09 7.00000e-02

$5.00000 \mathrm{e}-04$ 5.00000e-04 5.00000e-05 1.00000e-09 1.00000e-01

5.00000e-04 5.00000e-04 5.00000e-05 1.00000e-09 1.00000e-01

1.04776e-01 1.04776e-01 1.04776e-02 1.00000e-09 2.12000e-01

1.04776e-01 1.04776e-01 1.04776e-02 1.00000e-09 2.12000e-01

1.04776e-01 1.04776e-01 1.04776e-02 1.00000e-09 2.12000e-01

$1.04776 \mathrm{e}-01$ 1.04776e-01 1.04776e-02 1.00000e-09 2.12000e-01

1.04776e-01 1.04776e-01 1.04776e-02 1.00000e-09 2.12000e-01

$1.00000 \mathrm{e}-02$ 1.00000e-02 1.00000e-03 1.00000e-09 1.00000e-01

$1.00000 \mathrm{e}+001.00000 \mathrm{e}+001.00000 \mathrm{e}-011.00000 \mathrm{e}-091.00000 \mathrm{e}-01$

$1.00000 \mathrm{e}-05$ 1.00000e-05 1.00000e-06 1.00000e-09 1.00000e-01

$1.00000 \mathrm{e}+001.00000 \mathrm{e}+001.00000 \mathrm{e}-011.00000 \mathrm{e}-091.00000 \mathrm{e}-01$

1.00000e-06 1.00000e-06 1.00000e-06 1.00000e-09 5.00000e-02

Element: 4965 \# of layers: 14

$\mathrm{Kx} \mathrm{Ky} \mathrm{Kz}$ Ss Por

2.62227e+00 2.62227e+00 2.62227e-01 1.00000e-09 7.00000e-02

$2.62227 \mathrm{e}+002.62227 \mathrm{e}+00$ 2.62227e-01 1.00000e-09 7.00000e-02

5.00000e-04 5.00000e-04 5.00000e-05 1.00000e-09 1.00000e-01

5.00000e-04 5.00000e-04 5.00000e-05 1.00000e-09 1.00000e-01

1.04776e-01 1.04776e-01 1.04776e-02 1.00000e-09 2.12000e-01

1.04776e-01 1.04776e-01 1.04776e-02 1.00000e-09 2.12000e-01

1.04776e-01 1.04776e-01 1.04776e-02 1.00000e-09 2.12000e-01

1.04776e-01 1.04776e-01 1.04776e-02 1.00000e-09 2.12000e-01

1.04776e-01 1.04776e-01 1.04776e-02 1.00000e-09 2.12000e-01

$1.00000 \mathrm{e}-02$ 1.00000e-02 1.00000e-03 1.00000e-09 1.00000e-01

$1.00000 \mathrm{e}+001.00000 \mathrm{e}+001.00000 \mathrm{e}-011.00000 \mathrm{e}-091.00000 \mathrm{e}-01$

$1.00000 \mathrm{e}-05$ 1.00000e-05 1.00000e-06 1.00000e-09 1.00000e-01

$1.00000 \mathrm{e}+001.00000 \mathrm{e}+001.00000 \mathrm{e}-011.00000 \mathrm{e}-091.00000 \mathrm{e}-01$

1.00000e-06 1.00000e-06 1.00000e-06 1.00000e-09 5.00000e-02

Element: 4966 \# of layers: 15

$\mathrm{Kx} \mathrm{Ky} \mathrm{Kz}$ Ss Por

2.93077e+00 2.93077e+00 2.93077e-01 1.00000e-09 7.00000e-02

$2.93077 \mathrm{e}+00$ 2.93077e+00 2.93077e-01 1.00000e-09 7.00000e-02

2.93077e+00 2.93077e+00 2.93077e-01 1.00000e-09 7.00000e-02

5.00000e-04 5.00000e-04 5.00000e-05 1.00000e-09 1.00000e-01

5.00000e-04 5.00000e-04 5.00000e-05 1.00000e-09 1.00000e-01

1.17106e-01 1.17106e-01 1.17106e-02 1.00000e-09 2.12000e-01

1.17106e-01 1.17106e-01 1.17106e-02 1.00000e-09 2.12000e-01

1.17106e-01 1.17106e-01 1.17106e-02 1.00000e-09 2.12000e-01

1.17106e-01 1.17106e-01 1.17106e-02 1.00000e-09 2.12000e-01

1.17106e-01 1.17106e-01 1.17106e-02 1.00000e-09 2.12000e-01

$1.00000 \mathrm{e}-02$ 1.00000e-02 1.00000e-03 1.00000e-09 1.00000e-01

$1.00000 \mathrm{e}+001.00000 \mathrm{e}+001.00000 \mathrm{e}-011.00000 \mathrm{e}-091.00000 \mathrm{e}-01$ 
$1.00000 \mathrm{e}-05$ 1.00000e-05 1.00000e-06 1.00000e-09 1.00000e-01 $1.00000 \mathrm{e}+001.00000 \mathrm{e}+001.00000 \mathrm{e}-011.00000 \mathrm{e}-091.00000 \mathrm{e}-01$ 1.00000e-06 1.00000e-06 1.00000e-06 1.00000e-09 5.00000e-02 Element: 4967 \# of layers: 15

$\mathrm{Kx} \mathrm{Ky} \mathrm{Kz}$ Ss Por

6.02481e+00 6.02481e+00 6.02481e-01 1.00000e-09 7.00000e-02 $6.02481 \mathrm{e}+006.02481 \mathrm{e}+00$ 6.02481e-01 1.00000e-09 7.00000e-02 $6.02481 \mathrm{e}+006.02481 \mathrm{e}+00$ 6.02481e-01 1.00000e-09 7.00000e-02 5.00000e-04 5.00000e-04 5.00000e-05 1.00000e-09 1.00000e-01 5.00000e-04 5.00000e-04 5.00000e-05 1.00000e-09 1.00000e-01 2.40733e-01 2.40733e-01 2.40733e-02 1.00000e-09 2.12000e-01 2.40733e-01 2.40733e-01 2.40733e-02 1.00000e-09 2.12000e-01 2.40733e-01 2.40733e-01 2.40733e-02 1.00000e-09 2.12000e-01 2.40733e-01 2.40733e-01 2.40733e-02 1.00000e-09 2.12000e-01 2.40733e-01 2.40733e-01 2.40733e-02 1.00000e-09 2.12000e-01 $1.00000 \mathrm{e}-02$ 1.00000e-02 1.00000e-03 1.00000e-09 1.00000e-01 $1.00000 \mathrm{e}+001.00000 \mathrm{e}+001.00000 \mathrm{e}-011.00000 \mathrm{e}-091.00000 \mathrm{e}-01$ $1.00000 \mathrm{e}-05$ 1.00000e-05 1.00000e-06 1.00000e-09 1.00000e-01 $1.00000 \mathrm{e}+001.00000 \mathrm{e}+001.00000 \mathrm{e}-011.00000 \mathrm{e}-091.00000 \mathrm{e}-01$ 1.00000e-06 1.00000e-06 1.00000e-06 1.00000e-09 5.00000e-02 Element: 4968 \# of layers: 13

$\mathrm{Kx} \mathrm{Ky} \mathrm{Kz}$ Ss Por 6.02481e+00 6.02481e+00 6.02481e-01 1.00000e-09 7.00000e-02 $6.02481 \mathrm{e}+006.02481 \mathrm{e}+00$ 6.02481e-01 1.00000e-09 7.00000e-02 $6.02481 \mathrm{e}+006.02481 \mathrm{e}+00$ 6.02481e-01 1.00000e-09 7.00000e-02 2.40733e-01 2.40733e-01 2.40733e-02 1.00000e-09 2.12000e-01 2.40733e-01 2.40733e-01 2.40733e-02 1.00000e-09 2.12000e-01 2.40733e-01 2.40733e-01 2.40733e-02 1.00000e-09 2.12000e-01 2.40733e-01 2.40733e-01 2.40733e-02 1.00000e-09 2.12000e-01 2.40733e-01 2.40733e-01 2.40733e-02 1.00000e-09 2.12000e-01 $1.00000 \mathrm{e}-02$ 1.00000e-02 1.00000e-03 1.00000e-09 1.00000e-01 $1.00000 \mathrm{e}+001.00000 \mathrm{e}+001.00000 \mathrm{e}-011.00000 \mathrm{e}-091.00000 \mathrm{e}-01$ $1.00000 \mathrm{e}-05$ 1.00000e-05 1.00000e-06 1.00000e-09 1.00000e-01 $1.00000 \mathrm{e}+001.00000 \mathrm{e}+001.00000 \mathrm{e}-011.00000 \mathrm{e}-091.00000 \mathrm{e}-01$ 1.00000e-06 1.00000e-06 1.00000e-06 1.00000e-09 5.00000e-02 Element: 4969 \# of layers: 12

Kx Ky Kz Ss Por

6.47927e+00 6.47927e+00 6.47927e-01 1.00000e-09 7.00000e-02 6.47927e+00 6.47927e+00 6.47927e-01 1.00000e-09 7.00000e-02 2.58891e-01 2.58891e-01 2.58891e-02 1.00000e-09 2.12000e-01 2.58891e-01 2.58891e-01 2.58891e-02 1.00000e-09 2.12000e-01 2.58891e-01 2.58891e-01 2.58891e-02 1.00000e-09 2.12000e-01 2.58891e-01 2.58891e-01 2.58891e-02 1.00000e-09 2.12000e-01 2.58891e-01 2.58891e-01 2.58891e-02 1.00000e-09 2.12000e-01 $1.00000 \mathrm{e}-02$ 1.00000e-02 1.00000e-03 1.00000e-09 1.00000e-01 $1.00000 \mathrm{e}+001.00000 \mathrm{e}+001.00000 \mathrm{e}-011.00000 \mathrm{e}-091.00000 \mathrm{e}-01$ 
$1.00000 \mathrm{e}-05$ 1.00000e-05 1.00000e-06 1.00000e-09 1.00000e-01 $1.00000 \mathrm{e}+001.00000 \mathrm{e}+001.00000 \mathrm{e}-011.00000 \mathrm{e}-091.00000 \mathrm{e}-01$ 1.00000e-06 1.00000e-06 1.00000e-06 1.00000e-09 5.00000e-02 Element: 4970 \# of layers: 14

$\mathrm{Kx} \mathrm{Ky} \mathrm{Kz}$ Ss Por

2.62227e+00 2.62227e+00 2.62227e-01 1.00000e-09 7.00000e-02

$2.62227 \mathrm{e}+002.62227 \mathrm{e}+00$ 2.62227e-01 1.00000e-09 7.00000e-02 5.00000e-04 5.00000e-04 5.00000e-05 1.00000e-09 1.00000e-01 5.00000e-04 5.00000e-04 5.00000e-05 1.00000e-09 1.00000e-01 1.04776e-01 1.04776e-01 1.04776e-02 1.00000e-09 2.12000e-01 1.04776e-01 1.04776e-01 1.04776e-02 1.00000e-09 2.12000e-01 1.04776e-01 1.04776e-01 1.04776e-02 1.00000e-09 2.12000e-01 1.04776e-01 1.04776e-01 1.04776e-02 1.00000e-09 2.12000e-01 1.04776e-01 1.04776e-01 1.04776e-02 1.00000e-09 2.12000e-01 $1.00000 \mathrm{e}-02$ 1.00000e-02 1.00000e-03 1.00000e-09 1.00000e-01 $1.00000 \mathrm{e}+001.00000 \mathrm{e}+001.00000 \mathrm{e}-011.00000 \mathrm{e}-091.00000 \mathrm{e}-01$ $1.00000 \mathrm{e}-05$ 1.00000e-05 1.00000e-06 1.00000e-09 1.00000e-01 $1.00000 \mathrm{e}+001.00000 \mathrm{e}+001.00000 \mathrm{e}-011.00000 \mathrm{e}-091.00000 \mathrm{e}-01$ 1.00000e-06 1.00000e-06 1.00000e-06 1.00000e-09 5.00000e-02 Element: 4971 \# of layers: 14

$\mathrm{Kx} \mathrm{Ky} \mathrm{Kz}$ Ss Por

$2.40225 \mathrm{e}+002.40225 \mathrm{e}+00$ 2.40225e-01 1.00000e-09 7.00000e-02 $2.40225 \mathrm{e}+002.40225 \mathrm{e}+002.40225 \mathrm{e}-01$ 1.00000e-09 7.00000e-02 5.00000e-04 5.00000e-04 5.00000e-05 1.00000e-09 1.00000e-01 5.00000e-04 5.00000e-04 5.00000e-05 1.00000e-09 1.00000e-01 9.59848e-02 9.59848e-02 9.59848e-03 1.00000e-09 2.12000e-01 9.59848e-02 9.59848e-02 9.59848e-03 1.00000e-09 2.12000e-01 9.59848e-02 9.59848e-02 9.59848e-03 1.00000e-09 2.12000e-01 9.59848e-02 9.59848e-02 9.59848e-03 1.00000e-09 2.12000e-01 9.59848e-02 9.59848e-02 9.59848e-03 1.00000e-09 2.12000e-01 $1.00000 \mathrm{e}-02$ 1.00000e-02 1.00000e-03 1.00000e-09 1.00000e-01 $1.00000 \mathrm{e}+001.00000 \mathrm{e}+001.00000 \mathrm{e}-011.00000 \mathrm{e}-091.00000 \mathrm{e}-01$ $1.00000 \mathrm{e}-05$ 1.00000e-05 1.00000e-06 1.00000e-09 1.00000e-01 $1.00000 \mathrm{e}+001.00000 \mathrm{e}+001.00000 \mathrm{e}-011.00000 \mathrm{e}-091.00000 \mathrm{e}-01$ 1.00000e-06 1.00000e-06 1.00000e-06 1.00000e-09 5.00000e-02 Element: 4972 \# of layers: 14

Kx Ky Kz Ss Por

6.85481e+00 6.85481e+00 6.85481e-01 1.00000e-09 7.00000e-02 $6.85481 \mathrm{e}+006.85481 \mathrm{e}+006.85481 \mathrm{e}-01$ 1.00000e-09 7.00000e-02 5.00000e-04 5.00000e-04 5.00000e-05 1.00000e-09 1.00000e-01 5.00000e-04 5.00000e-04 5.00000e-05 1.00000e-09 1.00000e-01 2.73898e-01 2.73898e-01 2.73898e-02 1.00000e-09 2.12000e-01 2.73898e-01 2.73898e-01 2.73898e-02 1.00000e-09 2.12000e-01 2.73898e-01 2.73898e-01 2.73898e-02 1.00000e-09 2.12000e-01 2.73898e-01 2.73898e-01 2.73898e-02 1.00000e-09 2.12000e-01 2.73898e-01 2.73898e-01 2.73898e-02 1.00000e-09 2.12000e-01 
$1.00000 \mathrm{e}-02$ 1.00000e-02 1.00000e-03 1.00000e-09 1.00000e-01 $1.00000 \mathrm{e}+001.00000 \mathrm{e}+001.00000 \mathrm{e}-011.00000 \mathrm{e}-091.00000 \mathrm{e}-01$ $1.00000 \mathrm{e}-05$ 1.00000e-05 1.00000e-06 1.00000e-09 1.00000e-01 $1.00000 \mathrm{e}+001.00000 \mathrm{e}+001.00000 \mathrm{e}-011.00000 \mathrm{e}-091.00000 \mathrm{e}-01$ 1.00000e-06 1.00000e-06 1.00000e-06 1.00000e-09 5.00000e-02 Element: 4973 \# of layers: 14

$\mathrm{Kx} \mathrm{Ky} \mathrm{Kz}$ Ss Por

6.85481e+00 6.85481e+00 6.85481e-01 1.00000e-09 7.00000e-02 $6.85481 \mathrm{e}+006.85481 \mathrm{e}+006.85481 \mathrm{e}-01$ 1.00000e-09 7.00000e-02 $6.85481 \mathrm{e}+006.85481 \mathrm{e}+00$ 6.85481e-01 1.00000e-09 7.00000e-02 5.00000e-04 5.00000e-04 5.00000e-05 1.00000e-09 1.00000e-01 2.73898e-01 2.73898e-01 2.73898e-02 1.00000e-09 2.12000e-01 2.73898e-01 2.73898e-01 2.73898e-02 1.00000e-09 2.12000e-01 2.73898e-01 2.73898e-01 2.73898e-02 1.00000e-09 2.12000e-01 2.73898e-01 2.73898e-01 2.73898e-02 1.00000e-09 2.12000e-01 2.73898e-01 2.73898e-01 2.73898e-02 1.00000e-09 2.12000e-01 $1.00000 \mathrm{e}-02$ 1.00000e-02 1.00000e-03 1.00000e-09 1.00000e-01 $1.00000 \mathrm{e}+001.00000 \mathrm{e}+001.00000 \mathrm{e}-011.00000 \mathrm{e}-091.00000 \mathrm{e}-01$ $1.00000 \mathrm{e}-05$ 1.00000e-05 1.00000e-06 1.00000e-09 1.00000e-01 $1.00000 \mathrm{e}+001.00000 \mathrm{e}+001.00000 \mathrm{e}-011.00000 \mathrm{e}-091.00000 \mathrm{e}-01$ 1.00000e-06 1.00000e-06 1.00000e-06 1.00000e-09 5.00000e-02 Element: 4974 \# of layers: 15

$\mathrm{Kx} \mathrm{Ky} \mathrm{Kz}$ Ss Por

6.85481e+00 6.85481e+00 6.85481e-01 1.00000e-09 7.00000e-02 $6.85481 \mathrm{e}+006.85481 \mathrm{e}+006.85481 \mathrm{e}-01$ 1.00000e-09 7.00000e-02 6.85481e+00 6.85481e+00 6.85481e-01 1.00000e-09 7.00000e-02 5.00000e-04 5.00000e-04 5.00000e-05 1.00000e-09 1.00000e-01 5.00000e-04 5.00000e-04 5.00000e-05 1.00000e-09 1.00000e-01 2.73898e-01 2.73898e-01 2.73898e-02 1.00000e-09 2.12000e-01 2.73898e-01 2.73898e-01 2.73898e-02 1.00000e-09 2.12000e-01 2.73898e-01 2.73898e-01 2.73898e-02 1.00000e-09 2.12000e-01 2.73898e-01 2.73898e-01 2.73898e-02 1.00000e-09 2.12000e-01 2.73898e-01 2.73898e-01 2.73898e-02 1.00000e-09 2.12000e-01 $1.00000 \mathrm{e}-02$ 1.00000e-02 1.00000e-03 1.00000e-09 1.00000e-01 $1.00000 \mathrm{e}+001.00000 \mathrm{e}+001.00000 \mathrm{e}-011.00000 \mathrm{e}-091.00000 \mathrm{e}-01$ $1.00000 \mathrm{e}-05$ 1.00000e-05 1.00000e-06 1.00000e-09 1.00000e-01 $1.00000 \mathrm{e}+001.00000 \mathrm{e}+001.00000 \mathrm{e}-011.00000 \mathrm{e}-091.00000 \mathrm{e}-01$ 1.00000e-06 1.00000e-06 1.00000e-06 1.00000e-09 5.00000e-02 Element: 4975 \# of layers: 15

$\mathrm{Kx} \mathrm{Ky} \mathrm{Kz}$ Ss Por

3.80862e+00 3.80862e+00 3.80862e-01 1.00000e-09 7.00000e-02 $3.80862 \mathrm{e}+003.80862 \mathrm{e}+003.80862 \mathrm{e}-01$ 1.00000e-09 7.00000e-02 $3.80862 \mathrm{e}+00$ 3.80862e+00 3.80862e-01 1.00000e-09 7.00000e-02 $5.00000 \mathrm{e}-04$ 5.00000e-04 5.00000e-05 1.00000e-09 1.00000e-01 5.00000e-04 5.00000e-04 5.00000e-05 1.00000e-09 1.00000e-01 1.52180e-01 1.52180e-01 1.52180e-02 1.00000e-09 2.12000e-01 
1.52180e-01 1.52180e-01 1.52180e-02 1.00000e-09 2.12000e-01 1.52180e-01 1.52180e-01 1.52180e-02 1.00000e-09 2.12000e-01 $1.52180 \mathrm{e}-01$ 1.52180e-01 1.52180e-02 1.00000e-09 2.12000e-01 $1.52180 \mathrm{e}-01$ 1.52180e-01 1.52180e-02 1.00000e-09 2.12000e-01 $1.00000 \mathrm{e}-02$ 1.00000e-02 1.00000e-03 1.00000e-09 1.00000e-01 $1.00000 \mathrm{e}+001.00000 \mathrm{e}+001.00000 \mathrm{e}-011.00000 \mathrm{e}-091.00000 \mathrm{e}-01$ $1.00000 \mathrm{e}-05$ 1.00000e-05 1.00000e-06 1.00000e-09 1.00000e-01 $1.00000 \mathrm{e}+001.00000 \mathrm{e}+001.00000 \mathrm{e}-011.00000 \mathrm{e}-091.00000 \mathrm{e}-01$ 1.00000e-06 1.00000e-06 1.00000e-06 1.00000e-09 5.00000e-02 Element: 4976 \# of layers: 14

$\mathrm{Kx} \mathrm{Ky} \mathrm{Kz}$ Ss Por

3.80862e+00 3.80862e+00 3.80862e-01 1.00000e-09 7.00000e-02 $3.80862 \mathrm{e}+003.80862 \mathrm{e}+003.80862 \mathrm{e}-01$ 1.00000e-09 7.00000e-02 5.00000e-04 5.00000e-04 5.00000e-05 1.00000e-09 1.00000e-01 5.00000e-04 5.00000e-04 5.00000e-05 1.00000e-09 1.00000e-01 $1.52180 \mathrm{e}-01$ 1.52180e-01 1.52180e-02 1.00000e-09 2.12000e-01 1.52180e-01 1.52180e-01 1.52180e-02 1.00000e-09 2.12000e-01 1.52180e-01 1.52180e-01 1.52180e-02 1.00000e-09 2.12000e-01 1.52180e-01 1.52180e-01 1.52180e-02 1.00000e-09 2.12000e-01 1.52180e-01 1.52180e-01 1.52180e-02 1.00000e-09 2.12000e-01 $1.00000 \mathrm{e}-02$ 1.00000e-02 1.00000e-03 1.00000e-09 1.00000e-01 $1.00000 \mathrm{e}+001.00000 \mathrm{e}+001.00000 \mathrm{e}-011.00000 \mathrm{e}-091.00000 \mathrm{e}-01$ $1.00000 \mathrm{e}-051.00000 \mathrm{e}-051.00000 \mathrm{e}-061.00000 \mathrm{e}-091.00000 \mathrm{e}-01$ $1.00000 \mathrm{e}+001.00000 \mathrm{e}+001.00000 \mathrm{e}-011.00000 \mathrm{e}-091.00000 \mathrm{e}-01$ 1.00000e-06 1.00000e-06 1.00000e-06 1.00000e-09 5.00000e-02 Element: 4977 \# of layers: 14

$\mathrm{Kx} \mathrm{Ky} \mathrm{Kz}$ Ss Por

2.54731e+00 2.54731e+00 2.54731e-01 1.00000e-09 7.00000e-02 $2.54731 \mathrm{e}+002.54731 \mathrm{e}+002.54731 \mathrm{e}-011.00000 \mathrm{e}-097.00000 \mathrm{e}-02$ $5.00000 \mathrm{e}-04$ 5.00000e-04 5.00000e-05 1.00000e-09 1.00000e-01 5.00000e-04 5.00000e-04 5.00000e-05 1.00000e-09 1.00000e-01 1.01783e-01 1.01783e-01 1.01783e-02 1.00000e-09 2.12000e-01 1.01783e-01 1.01783e-01 1.01783e-02 1.00000e-09 2.12000e-01 1.01783e-01 1.01783e-01 1.01783e-02 1.00000e-09 2.12000e-01 1.01783e-01 1.01783e-01 1.01783e-02 1.00000e-09 2.12000e-01 1.01783e-01 1.01783e-01 1.01783e-02 1.00000e-09 2.12000e-01 $1.00000 \mathrm{e}-02$ 1.00000e-02 1.00000e-03 1.00000e-09 1.00000e-01 $1.00000 \mathrm{e}+001.00000 \mathrm{e}+001.00000 \mathrm{e}-011.00000 \mathrm{e}-091.00000 \mathrm{e}-01$ $1.00000 \mathrm{e}-05$ 1.00000e-05 1.00000e-06 1.00000e-09 1.00000e-01 $1.00000 \mathrm{e}+001.00000 \mathrm{e}+001.00000 \mathrm{e}-011.00000 \mathrm{e}-091.00000 \mathrm{e}-01$ 1.00000e-06 1.00000e-06 1.00000e-06 1.00000e-09 5.00000e-02 Element: 4978 \# of layers: 14

$\mathrm{Kx} \mathrm{Ky} \mathrm{Kz}$ Ss Por

$2.40225 \mathrm{e}+002.40225 \mathrm{e}+002.40225 \mathrm{e}-01$ 1.00000e-09 7.00000e-02 $2.40225 \mathrm{e}+002.40225 \mathrm{e}+002.40225 \mathrm{e}-01$ 1.00000e-09 7.00000e-02 5.00000e-04 5.00000e-04 5.00000e-05 1.00000e-09 1.00000e-01 
5.00000e-04 5.00000e-04 5.00000e-05 1.00000e-09 1.00000e-01 9.59848e-02 9.59848e-02 9.59848e-03 1.00000e-09 2.12000e-01 9.59848e-02 9.59848e-02 9.59848e-03 1.00000e-09 2.12000e-01 9.59848e-02 9.59848e-02 9.59848e-03 1.00000e-09 2.12000e-01 9.59848e-02 9.59848e-02 9.59848e-03 1.00000e-09 2.12000e-01 9.59848e-02 9.59848e-02 9.59848e-03 1.00000e-09 2.12000e-01 $1.00000 \mathrm{e}-02$ 1.00000e-02 1.00000e-03 1.00000e-09 1.00000e-01 $1.00000 \mathrm{e}+001.00000 \mathrm{e}+001.00000 \mathrm{e}-011.00000 \mathrm{e}-091.00000 \mathrm{e}-01$ $1.00000 \mathrm{e}-05$ 1.00000e-05 1.00000e-06 1.00000e-09 1.00000e-01 $1.00000 \mathrm{e}+001.00000 \mathrm{e}+001.00000 \mathrm{e}-011.00000 \mathrm{e}-091.00000 \mathrm{e}-01$ 1.00000e-06 1.00000e-06 1.00000e-06 1.00000e-09 5.00000e-02 Element: 4979 \# of layers: 14

$\mathrm{Kx} \mathrm{Ky} \mathrm{Kz}$ Ss Por

6.85481e+00 6.85481e+00 6.85481e-01 1.00000e-09 7.00000e-02 $6.85481 \mathrm{e}+006.85481 \mathrm{e}+006.85481 \mathrm{e}-01$ 1.00000e-09 7.00000e-02 5.00000e-04 5.00000e-04 5.00000e-05 1.00000e-09 1.00000e-01 5.00000e-04 5.00000e-04 5.00000e-05 1.00000e-09 1.00000e-01 2.73898e-01 2.73898e-01 2.73898e-02 1.00000e-09 2.12000e-01 2.73898e-01 2.73898e-01 2.73898e-02 1.00000e-09 2.12000e-01 2.73898e-01 2.73898e-01 2.73898e-02 1.00000e-09 2.12000e-01 2.73898e-01 2.73898e-01 2.73898e-02 1.00000e-09 2.12000e-01 2.73898e-01 2.73898e-01 2.73898e-02 1.00000e-09 2.12000e-01 $1.00000 \mathrm{e}-02$ 1.00000e-02 1.00000e-03 1.00000e-09 1.00000e-01 $1.00000 \mathrm{e}+001.00000 \mathrm{e}+001.00000 \mathrm{e}-011.00000 \mathrm{e}-091.00000 \mathrm{e}-01$ $1.00000 \mathrm{e}-05$ 1.00000e-05 1.00000e-06 1.00000e-09 1.00000e-01 $1.00000 \mathrm{e}+001.00000 \mathrm{e}+001.00000 \mathrm{e}-011.00000 \mathrm{e}-091.00000 \mathrm{e}-01$ 1.00000e-06 1.00000e-06 1.00000e-06 1.00000e-09 5.00000e-02 Element: 4980 \# of layers: 13

Kx Ky Kz Ss Por

$1.33483 \mathrm{e}+01$ 1.33483e+01 1.33483e+00 1.00000e-09 7.00000e-02 $1.33483 \mathrm{e}+01$ 1.33483e+01 1.33483e+00 1.00000e-09 7.00000e-02 5.00000e-04 5.00000e-04 5.00000e-05 1.00000e-09 1.00000e-01 5.33329e-01 5.33329e-01 5.33329e-02 1.00000e-09 2.12000e-01 5.33329e-01 5.33329e-01 5.33329e-02 1.00000e-09 2.12000e-01 5.33329e-01 5.33329e-01 5.33329e-02 1.00000e-09 2.12000e-01 5.33329e-01 5.33329e-01 5.33329e-02 1.00000e-09 2.12000e-01 5.33329e-01 5.33329e-01 5.33329e-02 1.00000e-09 2.12000e-01 $1.00000 \mathrm{e}-02$ 1.00000e-02 1.00000e-03 1.00000e-09 1.00000e-01 $1.00000 \mathrm{e}+001.00000 \mathrm{e}+001.00000 \mathrm{e}-011.00000 \mathrm{e}-091.00000 \mathrm{e}-01$ $1.00000 \mathrm{e}-05$ 1.00000e-05 1.00000e-06 1.00000e-09 1.00000e-01 $1.00000 \mathrm{e}+001.00000 \mathrm{e}+001.00000 \mathrm{e}-011.00000 \mathrm{e}-091.00000 \mathrm{e}-01$ 1.00000e-06 1.00000e-06 1.00000e-06 1.00000e-09 5.00000e-02 Element: 4981 \# of layers: 14

$\mathrm{Kx} \mathrm{Ky} \mathrm{Kz}$ Ss Por

5.39240e+00 5.39240e+00 5.39240e-01 1.00000e-09 7.00000e-02 $5.39240 \mathrm{e}+00$ 5.39240e+00 5.39240e-01 1.00000e-09 7.00000e-02 
5.00000e-04 5.00000e-04 5.00000e-05 1.00000e-09 1.00000e-01 5.00000e-04 5.00000e-04 5.00000e-05 1.00000e-09 1.00000e-01 2.15462e-01 2.15462e-01 2.15462e-02 1.00000e-09 2.12000e-01 2.15462e-01 2.15462e-01 2.15462e-02 1.00000e-09 2.12000e-01 2.15462e-01 2.15462e-01 2.15462e-02 1.00000e-09 2.12000e-01 2.15462e-01 2.15462e-01 2.15462e-02 1.00000e-09 2.12000e-01 2.15462e-01 2.15462e-01 2.15462e-02 1.00000e-09 2.12000e-01 $1.00000 \mathrm{e}-02$ 1.00000e-02 1.00000e-03 1.00000e-09 1.00000e-01 $1.00000 \mathrm{e}+001.00000 \mathrm{e}+001.00000 \mathrm{e}-011.00000 \mathrm{e}-091.00000 \mathrm{e}-01$ $1.00000 \mathrm{e}-05$ 1.00000e-05 1.00000e-06 1.00000e-09 1.00000e-01 $1.00000 \mathrm{e}+001.00000 \mathrm{e}+001.00000 \mathrm{e}-011.00000 \mathrm{e}-091.00000 \mathrm{e}-01$ 1.00000e-06 1.00000e-06 1.00000e-06 1.00000e-09 5.00000e-02 Element: 4982 \# of layers: 14

$\mathrm{Kx} \mathrm{Ky} \mathrm{Kz}$ Ss Por

5.39240e+00 5.39240e+00 5.39240e-01 1.00000e-09 7.00000e-02 $5.39240 \mathrm{e}+005.39240 \mathrm{e}+00$ 5.39240e-01 1.00000e-09 7.00000e-02 5.00000e-04 5.00000e-04 5.00000e-05 1.00000e-09 1.00000e-01 5.00000e-04 5.00000e-04 5.00000e-05 1.00000e-09 1.00000e-01 2.15462e-01 2.15462e-01 2.15462e-02 1.00000e-09 2.12000e-01 2.15462e-01 2.15462e-01 2.15462e-02 1.00000e-09 2.12000e-01 2.15462e-01 2.15462e-01 2.15462e-02 1.00000e-09 2.12000e-01 2.15462e-01 2.15462e-01 2.15462e-02 1.00000e-09 2.12000e-01 2.15462e-01 2.15462e-01 2.15462e-02 1.00000e-09 2.12000e-01 $1.00000 \mathrm{e}-02$ 1.00000e-02 1.00000e-03 1.00000e-09 1.00000e-01 $1.00000 \mathrm{e}+001.00000 \mathrm{e}+001.00000 \mathrm{e}-011.00000 \mathrm{e}-091.00000 \mathrm{e}-01$ $1.00000 \mathrm{e}-05$ 1.00000e-05 1.00000e-06 1.00000e-09 1.00000e-01 $1.00000 \mathrm{e}+001.00000 \mathrm{e}+001.00000 \mathrm{e}-011.00000 \mathrm{e}-091.00000 \mathrm{e}-01$ 1.00000e-06 1.00000e-06 1.00000e-06 1.00000e-09 5.00000e-02 Element: 4983 \# of layers: 13

$\mathrm{Kx} \mathrm{Ky} \mathrm{Kz}$ Ss Por

5.39240e+00 5.39240e+00 5.39240e-01 1.00000e-09 7.00000e-02 5.00000e-04 5.00000e-04 5.00000e-05 1.00000e-09 1.00000e-01 5.00000e-04 5.00000e-04 5.00000e-05 1.00000e-09 1.00000e-01 2.15462e-01 2.15462e-01 2.15462e-02 1.00000e-09 2.12000e-01 2.15462e-01 2.15462e-01 2.15462e-02 1.00000e-09 2.12000e-01 2.15462e-01 2.15462e-01 2.15462e-02 1.00000e-09 2.12000e-01 2.15462e-01 2.15462e-01 2.15462e-02 1.00000e-09 2.12000e-01 2.15462e-01 2.15462e-01 2.15462e-02 1.00000e-09 2.12000e-01 $1.00000 \mathrm{e}-021.00000 \mathrm{e}-021.00000 \mathrm{e}-031.00000 \mathrm{e}-091.00000 \mathrm{e}-01$ $1.00000 \mathrm{e}+001.00000 \mathrm{e}+001.00000 \mathrm{e}-011.00000 \mathrm{e}-091.00000 \mathrm{e}-01$ $1.00000 \mathrm{e}-05$ 1.00000e-05 1.00000e-06 1.00000e-09 1.00000e-01 $1.00000 \mathrm{e}+001.00000 \mathrm{e}+001.00000 \mathrm{e}-011.00000 \mathrm{e}-091.00000 \mathrm{e}-01$ 1.00000e-06 1.00000e-06 1.00000e-06 1.00000e-09 5.00000e-02 Element: 4984 \# of layers: 13

$\mathrm{Kx} \mathrm{Ky} \mathrm{Kz} \mathrm{Ss} \mathrm{Por}$

5.77622e+00 5.77622e+00 5.77622e-01 1.00000e-09 7.00000e-02 
5.00000e-04 5.00000e-04 5.00000e-05 1.00000e-09 1.00000e-01 5.00000e-04 5.00000e-04 5.00000e-05 1.00000e-09 1.00000e-01 2.30787e-01 2.30787e-01 2.30787e-02 1.00000e-09 2.12000e-01 2.30787e-01 2.30787e-01 2.30787e-02 1.00000e-09 2.12000e-01 2.30787e-01 2.30787e-01 2.30787e-02 1.00000e-09 2.12000e-01 2.30787e-01 2.30787e-01 2.30787e-02 1.00000e-09 2.12000e-01 2.30787e-01 2.30787e-01 2.30787e-02 1.00000e-09 2.12000e-01 1.00000e-02 1.00000e-02 1.00000e-03 1.00000e-09 1.00000e-01 $1.00000 \mathrm{e}+001.00000 \mathrm{e}+001.00000 \mathrm{e}-01$ 1.00000e-09 1.00000e-01 $1.00000 \mathrm{e}-05$ 1.00000e-05 1.00000e-06 1.00000e-09 1.00000e-01 $1.00000 \mathrm{e}+001.00000 \mathrm{e}+001.00000 \mathrm{e}-011.00000 \mathrm{e}-091.00000 \mathrm{e}-01$ 1.00000e-06 1.00000e-06 1.00000e-06 1.00000e-09 5.00000e-02 Element: 4985 \# of layers: 13

$\mathrm{Kx} \mathrm{Ky} \mathrm{Kz}$ Ss Por

5.77622e+00 5.77622e+00 5.77622e-01 1.00000e-09 7.00000e-02 5.00000e-04 5.00000e-04 5.00000e-05 1.00000e-09 1.00000e-01 5.00000e-04 5.00000e-04 5.00000e-05 1.00000e-09 1.00000e-01 2.30787e-01 2.30787e-01 2.30787e-02 1.00000e-09 2.12000e-01 2.30787e-01 2.30787e-01 2.30787e-02 1.00000e-09 2.12000e-01 2.30787e-01 2.30787e-01 2.30787e-02 1.00000e-09 2.12000e-01 2.30787e-01 2.30787e-01 2.30787e-02 1.00000e-09 2.12000e-01 2.30787e-01 2.30787e-01 2.30787e-02 1.00000e-09 2.12000e-01 $1.00000 \mathrm{e}-02$ 1.00000e-02 1.00000e-03 1.00000e-09 1.00000e-01 $1.00000 \mathrm{e}+001.00000 \mathrm{e}+001.00000 \mathrm{e}-011.00000 \mathrm{e}-091.00000 \mathrm{e}-01$ $1.00000 \mathrm{e}-05$ 1.00000e-05 1.00000e-06 1.00000e-09 1.00000e-01 $1.00000 \mathrm{e}+001.00000 \mathrm{e}+001.00000 \mathrm{e}-011.00000 \mathrm{e}-091.00000 \mathrm{e}-01$ 1.00000e-06 1.00000e-06 1.00000e-06 1.00000e-09 5.00000e-02 Element: 4986 \# of layers: 14

$\mathrm{Kx} \mathrm{Ky} \mathrm{Kz}$ Ss Por

5.12128e+00 5.12128e+00 5.12128e-01 1.00000e-09 7.00000e-02 5.12128e+00 5.12128e+00 5.12128e-01 1.00000e-09 7.00000e-02 5.00000e-04 5.00000e-04 5.00000e-05 1.00000e-09 1.00000e-01 5.00000e-04 5.00000e-04 5.00000e-05 1.00000e-09 1.00000e-01 2.04626e-01 2.04626e-01 2.04626e-02 1.00000e-09 2.12000e-01 2.04626e-01 2.04626e-01 2.04626e-02 1.00000e-09 2.12000e-01 2.04626e-01 2.04626e-01 2.04626e-02 1.00000e-09 2.12000e-01 2.04626e-01 2.04626e-01 2.04626e-02 1.00000e-09 2.12000e-01 2.04626e-01 2.04626e-01 2.04626e-02 1.00000e-09 2.12000e-01 $1.00000 \mathrm{e}-02$ 1.00000e-02 1.00000e-03 1.00000e-09 1.00000e-01 $1.00000 \mathrm{e}+001.00000 \mathrm{e}+001.00000 \mathrm{e}-011.00000 \mathrm{e}-091.00000 \mathrm{e}-01$ $1.00000 \mathrm{e}-05$ 1.00000e-05 1.00000e-06 1.00000e-09 1.00000e-01 $1.00000 \mathrm{e}+001.00000 \mathrm{e}+001.00000 \mathrm{e}-011.00000 \mathrm{e}-091.00000 \mathrm{e}-01$ 1.00000e-06 1.00000e-06 1.00000e-06 1.00000e-09 5.00000e-02 Element: 4987 \# of layers: 14

$\mathrm{Kx} \mathrm{Ky} \mathrm{Kz}$ Ss Por

$1.33483 e+01$ 1.33483e+01 1.33483e+00 1.00000e-09 7.00000e-02 
1.33483e+01 1.33483e+01 1.33483e+00 1.00000e-09 7.00000e-02 5.00000e-04 5.00000e-04 5.00000e-05 1.00000e-09 1.00000e-01 5.00000e-04 5.00000e-04 5.00000e-05 1.00000e-09 1.00000e-01 5.33329e-01 5.33329e-01 5.33329e-02 1.00000e-09 2.12000e-01 5.33329e-01 5.33329e-01 5.33329e-02 1.00000e-09 2.12000e-01 5.33329e-01 5.33329e-01 5.33329e-02 1.00000e-09 2.12000e-01 5.33329e-01 5.33329e-01 5.33329e-02 1.00000e-09 2.12000e-01 5.33329e-01 5.33329e-01 5.33329e-02 1.00000e-09 2.12000e-01 $1.00000 \mathrm{e}-02$ 1.00000e-02 1.00000e-03 1.00000e-09 1.00000e-01 $1.00000 \mathrm{e}+001.00000 \mathrm{e}+001.00000 \mathrm{e}-011.00000 \mathrm{e}-091.00000 \mathrm{e}-01$ $1.00000 \mathrm{e}-05$ 1.00000e-05 1.00000e-06 1.00000e-09 1.00000e-01 $1.00000 \mathrm{e}+001.00000 \mathrm{e}+001.00000 \mathrm{e}-011.00000 \mathrm{e}-091.00000 \mathrm{e}-01$ 1.00000e-06 1.00000e-06 1.00000e-06 1.00000e-09 5.00000e-02 Element: 4988 \# of layers: 12

$\mathrm{Kx} \mathrm{Ky} \mathrm{Kz}$ Ss Por

$5.39240 \mathrm{e}+005.39240 \mathrm{e}+005.39240 \mathrm{e}-01$ 1.00000e-09 7.00000e-02 5.00000e-04 5.00000e-04 5.00000e-05 1.00000e-09 1.00000e-01 2.15462e-01 2.15462e-01 2.15462e-02 1.00000e-09 2.12000e-01 2.15462e-01 2.15462e-01 2.15462e-02 1.00000e-09 2.12000e-01 2.15462e-01 2.15462e-01 2.15462e-02 1.00000e-09 2.12000e-01 2.15462e-01 2.15462e-01 2.15462e-02 1.00000e-09 2.12000e-01 2.15462e-01 2.15462e-01 2.15462e-02 1.00000e-09 2.12000e-01 $1.00000 \mathrm{e}-02$ 1.00000e-02 1.00000e-03 1.00000e-09 1.00000e-01 $1.00000 \mathrm{e}+001.00000 \mathrm{e}+001.00000 \mathrm{e}-011.00000 \mathrm{e}-091.00000 \mathrm{e}-01$ $1.00000 \mathrm{e}-05$ 1.00000e-05 1.00000e-06 1.00000e-09 1.00000e-01 $1.00000 \mathrm{e}+001.00000 \mathrm{e}+001.00000 \mathrm{e}-011.00000 \mathrm{e}-091.00000 \mathrm{e}-01$ 1.00000e-06 1.00000e-06 1.00000e-06 1.00000e-09 5.00000e-02 Element: 4989 \# of layers: 14

$\mathrm{Kx} \mathrm{Ky} \mathrm{Kz}$ Ss Por

7.67616e+00 7.67616e+00 7.67616e-01 1.00000e-09 7.00000e-02 $7.67616 \mathrm{e}+007.67616 \mathrm{e}+00$ 7.67616e-01 1.00000e-09 7.00000e-02 5.00000e-04 5.00000e-04 5.00000e-05 1.00000e-09 1.00000e-01 5.00000e-04 5.00000e-04 5.00000e-05 1.00000e-09 1.00000e-01 3.06704e-01 3.06704e-01 3.06704e-02 1.00000e-09 2.12000e-01 3.06704e-01 3.06704e-01 3.06704e-02 1.00000e-09 2.12000e-01 3.06704e-01 3.06704e-01 3.06704e-02 1.00000e-09 2.12000e-01 3.06704e-01 3.06704e-01 3.06704e-02 1.00000e-09 2.12000e-01 3.06704e-01 3.06704e-01 3.06704e-02 1.00000e-09 2.12000e-01 $1.00000 \mathrm{e}-02$ 1.00000e-02 1.00000e-03 1.00000e-09 1.00000e-01 $1.00000 \mathrm{e}+001.00000 \mathrm{e}+001.00000 \mathrm{e}-011.00000 \mathrm{e}-091.00000 \mathrm{e}-01$ $1.00000 \mathrm{e}-05$ 1.00000e-05 1.00000e-06 1.00000e-09 1.00000e-01 $1.00000 \mathrm{e}+001.00000 \mathrm{e}+001.00000 \mathrm{e}-011.00000 \mathrm{e}-091.00000 \mathrm{e}-01$ 1.00000e-06 1.00000e-06 1.00000e-06 1.00000e-09 5.00000e-02 Element: 4990 \# of layers: 14

$\mathrm{Kx} \mathrm{Ky} \mathrm{Kz}$ Ss Por

1.13310e+02 1.13310e+02 1.13310e+01 1.00000e-09 7.00000e-02 
$1.13310 \mathrm{e}+021.13310 \mathrm{e}+021.13310 \mathrm{e}+01$ 1.00000e-09 7.00000e-02 5.00000e-04 5.00000e-04 5.00000e-05 1.00000e-09 1.00000e-01 5.00000e-04 5.00000e-04 5.00000e-05 1.00000e-09 1.00000e-01 $4.52755 \mathrm{e}+004.52755 \mathrm{e}+00$ 4.52755e-01 1.00000e-09 2.12000e-01 $4.52755 \mathrm{e}+004.52755 \mathrm{e}+00$ 4.52755e-01 1.00000e-09 2.12000e-01 $4.52755 \mathrm{e}+004.52755 \mathrm{e}+00$ 4.52755e-01 1.00000e-09 2.12000e-01 $4.52755 \mathrm{e}+00$ 4.52755e+00 4.52755e-01 1.00000e-09 2.12000e-01 $4.52755 \mathrm{e}+00$ 4.52755e+00 4.52755e-01 1.00000e-09 2.12000e-01 $1.00000 \mathrm{e}-02$ 1.00000e-02 1.00000e-03 1.00000e-09 1.00000e-01 $1.00000 \mathrm{e}+001.00000 \mathrm{e}+001.00000 \mathrm{e}-011.00000 \mathrm{e}-091.00000 \mathrm{e}-01$ $1.00000 \mathrm{e}-05$ 1.00000e-05 1.00000e-06 1.00000e-09 1.00000e-01 $1.00000 \mathrm{e}+001.00000 \mathrm{e}+001.00000 \mathrm{e}-011.00000 \mathrm{e}-091.00000 \mathrm{e}-01$ 1.00000e-06 1.00000e-06 1.00000e-06 1.00000e-09 5.00000e-02 Element: 4991 \# of layers: 12

$\mathrm{Kx} \mathrm{Ky} \mathrm{Kz}$ Ss Por

$1.13310 \mathrm{e}+02$ 1.13310e+02 1.13310e+01 1.00000e-09 7.00000e-02 5.00000e-04 5.00000e-04 5.00000e-05 1.00000e-09 1.00000e-01

$4.52755 \mathrm{e}+004.52755 \mathrm{e}+00$ 4.52755e-01 1.00000e-09 2.12000e-01 4.52755e+00 4.52755e+00 4.52755e-01 1.00000e-09 2.12000e-01 $4.52755 \mathrm{e}+004.52755 \mathrm{e}+00$ 4.52755e-01 1.00000e-09 2.12000e-01 $4.52755 \mathrm{e}+00$ 4.52755e+00 4.52755e-01 1.00000e-09 2.12000e-01 $4.52755 \mathrm{e}+004.52755 \mathrm{e}+004.52755 \mathrm{e}-01$ 1.00000e-09 2.12000e-01 $1.00000 \mathrm{e}-02$ 1.00000e-02 1.00000e-03 1.00000e-09 1.00000e-01 $1.00000 \mathrm{e}+001.00000 \mathrm{e}+001.00000 \mathrm{e}-011.00000 \mathrm{e}-091.00000 \mathrm{e}-01$ $1.00000 \mathrm{e}-05$ 1.00000e-05 1.00000e-06 1.00000e-09 1.00000e-01 $1.00000 \mathrm{e}+001.00000 \mathrm{e}+001.00000 \mathrm{e}-011.00000 \mathrm{e}-091.00000 \mathrm{e}-01$ 1.00000e-06 1.00000e-06 1.00000e-06 1.00000e-09 5.00000e-02 Element: 4992 \# of layers: 11

$\mathrm{Kx} \mathrm{Ky} \mathrm{Kz}$ Ss Por 5.00000e-04 5.00000e-04 5.00000e-05 1.00000e-09 1.00000e-01 $4.52755 \mathrm{e}+004.52755 \mathrm{e}+00$ 4.52755e-01 1.00000e-09 2.12000e-01 $4.52755 \mathrm{e}+004.52755 \mathrm{e}+00$ 4.52755e-01 1.00000e-09 2.12000e-01 $4.52755 \mathrm{e}+004.52755 \mathrm{e}+004.52755 \mathrm{e}-01$ 1.00000e-09 2.12000e-01 $4.52755 \mathrm{e}+004.52755 \mathrm{e}+00$ 4.52755e-01 1.00000e-09 2.12000e-01 $4.52755 \mathrm{e}+00$ 4.52755e+00 4.52755e-01 1.00000e-09 2.12000e-01 $1.00000 \mathrm{e}-02$ 1.00000e-02 1.00000e-03 1.00000e-09 1.00000e-01 $1.00000 \mathrm{e}+001.00000 \mathrm{e}+001.00000 \mathrm{e}-011.00000 \mathrm{e}-091.00000 \mathrm{e}-01$ $1.00000 \mathrm{e}-05$ 1.00000e-05 1.00000e-06 1.00000e-09 1.00000e-01 $1.00000 \mathrm{e}+001.00000 \mathrm{e}+001.00000 \mathrm{e}-011.00000 \mathrm{e}-091.00000 \mathrm{e}-01$ 1.00000e-06 1.00000e-06 1.00000e-06 1.00000e-09 5.00000e-02 Element: 4993 \# of layers: 10

$\mathrm{Kx} \mathrm{Ky} \mathrm{Kz}$ Ss Por $5.64684 \mathrm{e}+015.64684 \mathrm{e}+015.64684 \mathrm{e}+001.00000 \mathrm{e}-09$ 7.00000e-02 5.00000e-04 5.00000e-04 5.00000e-05 1.00000e-09 1.00000e-01 $2.25635 \mathrm{e}+002.25635 \mathrm{e}+002.25635 \mathrm{e}-01$ 1.00000e-09 2.12000e-01 $2.25635 \mathrm{e}+002.25635 \mathrm{e}+002.25635 \mathrm{e}-01$ 1.00000e-09 2.12000e-01 
$2.25635 \mathrm{e}+00$ 2.25635e+00 2.25635e-01 1.00000e-09 2.12000e-01 $2.25635 \mathrm{e}+002.25635 \mathrm{e}+00$ 2.25635e-01 1.00000e-09 2.12000e-01 $2.25635 \mathrm{e}+002.25635 \mathrm{e}+002.25635 \mathrm{e}-01$ 1.00000e-09 2.12000e-01 $1.00000 \mathrm{e}-02$ 1.00000e-02 1.00000e-03 1.00000e-09 1.00000e-01 $1.00000 \mathrm{e}+001.00000 \mathrm{e}+001.00000 \mathrm{e}-011.00000 \mathrm{e}-091.00000 \mathrm{e}-01$ 1.00000e-06 1.00000e-06 1.00000e-06 1.00000e-09 5.00000e-02 Element: 4994 \# of layers: 13

$\mathrm{Kx} \mathrm{Ky} \mathrm{Kz}$ Ss Por

$5.64684 \mathrm{e}+015.64684 \mathrm{e}+015.64684 \mathrm{e}+001.00000 \mathrm{e}-097.00000 \mathrm{e}-02$

$5.64684 \mathrm{e}+015.64684 \mathrm{e}+015.64684 \mathrm{e}+001.00000 \mathrm{e}-097.00000 \mathrm{e}-02$ 5.00000e-04 5.00000e-04 5.00000e-05 1.00000e-09 1.00000e-01 $2.25635 \mathrm{e}+002.25635 \mathrm{e}+002.25635 \mathrm{e}-01$ 1.00000e-09 2.12000e-01 $2.25635 \mathrm{e}+002.25635 \mathrm{e}+00$ 2.25635e-01 1.00000e-09 2.12000e-01

$2.25635 \mathrm{e}+002.25635 \mathrm{e}+00$ 2.25635e-01 1.00000e-09 2.12000e-01 $2.25635 \mathrm{e}+002.25635 \mathrm{e}+002.25635 \mathrm{e}-01$ 1.00000e-09 2.12000e-01 $2.25635 \mathrm{e}+002.25635 \mathrm{e}+002.25635 \mathrm{e}-01$ 1.00000e-09 2.12000e-01 $1.00000 \mathrm{e}-02$ 1.00000e-02 1.00000e-03 1.00000e-09 1.00000e-01 $1.00000 \mathrm{e}+001.00000 \mathrm{e}+001.00000 \mathrm{e}-011.00000 \mathrm{e}-091.00000 \mathrm{e}-01$ $1.00000 \mathrm{e}-05$ 1.00000e-05 1.00000e-06 1.00000e-09 1.00000e-01 $1.00000 \mathrm{e}+001.00000 \mathrm{e}+001.00000 \mathrm{e}-011.00000 \mathrm{e}-091.00000 \mathrm{e}-01$ 1.00000e-06 1.00000e-06 1.00000e-06 1.00000e-09 5.00000e-02 Element: 4995 \# of layers: 14

$\mathrm{Kx} \mathrm{Ky} \mathrm{Kz}$ Ss Por

9.46771e+00 9.46771e+00 9.46771e-01 1.00000e-09 7.00000e-02 $9.46771 \mathrm{e}+009.46771 \mathrm{e}+009.46771 \mathrm{e}-01$ 1.00000e-09 7.00000e-02 $5.00000 \mathrm{e}-04$ 5.00000e-04 5.00000e-05 1.00000e-09 1.00000e-01 5.00000e-04 5.00000e-04 5.00000e-05 1.00000e-09 1.00000e-01 3.78278e-01 3.78278e-01 3.78278e-02 1.00000e-09 2.12000e-01 3.78278e-01 3.78278e-01 3.78278e-02 1.00000e-09 2.12000e-01 3.78278e-01 3.78278e-01 3.78278e-02 1.00000e-09 2.12000e-01 3.78278e-01 3.78278e-01 3.78278e-02 1.00000e-09 2.12000e-01 3.78278e-01 3.78278e-01 3.78278e-02 1.00000e-09 2.12000e-01 $1.00000 \mathrm{e}-02$ 1.00000e-02 1.00000e-03 1.00000e-09 1.00000e-01 $1.00000 \mathrm{e}+001.00000 \mathrm{e}+001.00000 \mathrm{e}-011.00000 \mathrm{e}-091.00000 \mathrm{e}-01$ $1.00000 \mathrm{e}-05$ 1.00000e-05 1.00000e-06 1.00000e-09 1.00000e-01 $1.00000 \mathrm{e}+001.00000 \mathrm{e}+001.00000 \mathrm{e}-011.00000 \mathrm{e}-091.00000 \mathrm{e}-01$ 1.00000e-06 1.00000e-06 1.00000e-06 1.00000e-09 5.00000e-02 Element: 4996 \# of layers: 13

$\mathrm{Kx} \mathrm{Ky} \mathrm{Kz}$ Ss Por

7.67616e+00 7.67616e+00 7.67616e-01 1.00000e-09 7.00000e-02 5.00000e-04 5.00000e-04 5.00000e-05 1.00000e-09 1.00000e-01 5.00000e-04 5.00000e-04 5.00000e-05 1.00000e-09 1.00000e-01 3.06704e-01 3.06704e-01 3.06704e-02 1.00000e-09 2.12000e-01 3.06704e-01 3.06704e-01 3.06704e-02 1.00000e-09 2.12000e-01 3.06704e-01 3.06704e-01 3.06704e-02 1.00000e-09 2.12000e-01 3.06704e-01 3.06704e-01 3.06704e-02 1.00000e-09 2.12000e-01 
3.06704e-01 3.06704e-01 3.06704e-02 1.00000e-09 2.12000e-01 $1.00000 \mathrm{e}-02$ 1.00000e-02 1.00000e-03 1.00000e-09 1.00000e-01 $1.00000 \mathrm{e}+001.00000 \mathrm{e}+001.00000 \mathrm{e}-011.00000 \mathrm{e}-091.00000 \mathrm{e}-01$ $1.00000 \mathrm{e}-05$ 1.00000e-05 1.00000e-06 1.00000e-09 1.00000e-01 $1.00000 \mathrm{e}+001.00000 \mathrm{e}+001.00000 \mathrm{e}-011.00000 \mathrm{e}-091.00000 \mathrm{e}-01$ $1.00000 \mathrm{e}-06$ 1.00000e-06 1.00000e-06 1.00000e-09 5.00000e-02 Element: 4997 \# of layers: 12

$\mathrm{Kx} \mathrm{Ky} \mathrm{Kz}$ Ss Por

$1.13310 \mathrm{e}+021.13310 \mathrm{e}+02$ 1.13310e+01 1.00000e-09 7.00000e-02 5.00000e-04 5.00000e-04 5.00000e-05 1.00000e-09 1.00000e-01 $4.52755 \mathrm{e}+004.52755 \mathrm{e}+00$ 4.52755e-01 1.00000e-09 2.12000e-01 $4.52755 \mathrm{e}+004.52755 \mathrm{e}+00$ 4.52755e-01 1.00000e-09 2.12000e-01 $4.52755 \mathrm{e}+00$ 4.52755e+00 4.52755e-01 1.00000e-09 2.12000e-01 $4.52755 \mathrm{e}+00$ 4.52755e+00 4.52755e-01 1.00000e-09 2.12000e-01 $4.52755 \mathrm{e}+004.52755 \mathrm{e}+00$ 4.52755e-01 1.00000e-09 2.12000e-01 $1.00000 \mathrm{e}-02$ 1.00000e-02 1.00000e-03 1.00000e-09 1.00000e-01 $1.00000 \mathrm{e}+001.00000 \mathrm{e}+001.00000 \mathrm{e}-011.00000 \mathrm{e}-091.00000 \mathrm{e}-01$ $1.00000 \mathrm{e}-05$ 1.00000e-05 1.00000e-06 1.00000e-09 1.00000e-01 $1.00000 \mathrm{e}+001.00000 \mathrm{e}+001.00000 \mathrm{e}-011.00000 \mathrm{e}-091.00000 \mathrm{e}-01$ $1.00000 \mathrm{e}-06$ 1.00000e-06 1.00000e-06 1.00000e-09 5.00000e-02 Element: 4998 \# of layers: 12

$\mathrm{Kx} \mathrm{Ky} \mathrm{Kz}$ Ss Por

3.04268e+02 3.04268e+02 3.04268e+01 1.00000e-09 7.00000e-02 5.00000e-04 5.00000e-04 5.00000e-05 1.00000e-09 1.00000e-01

$1.21577 \mathrm{e}+01$ 1.21577e+01 1.21577e+00 1.00000e-09 2.12000e-01 $1.21577 \mathrm{e}+01$ 1.21577e+01 1.21577e+00 1.00000e-09 2.12000e-01 $1.21577 \mathrm{e}+01$ 1.21577e+01 1.21577e+00 1.00000e-09 2.12000e-01 $1.21577 \mathrm{e}+01$ 1.21577e+01 1.21577e+00 1.00000e-09 2.12000e-01 $1.21577 \mathrm{e}+01$ 1.21577e+01 1.21577e+00 1.00000e-09 2.12000e-01 $1.00000 \mathrm{e}-02$ 1.00000e-02 1.00000e-03 1.00000e-09 1.00000e-01 $1.00000 \mathrm{e}+001.00000 \mathrm{e}+001.00000 \mathrm{e}-01$ 1.00000e-09 1.00000e-01 $1.00000 \mathrm{e}-05$ 1.00000e-05 1.00000e-06 1.00000e-09 1.00000e-01 $1.00000 \mathrm{e}+001.00000 \mathrm{e}+001.00000 \mathrm{e}-011.00000 \mathrm{e}-091.00000 \mathrm{e}-01$ 1.00000e-06 1.00000e-06 1.00000e-06 1.00000e-09 5.00000e-02 Element: 4999 \# of layers: 11

$\mathrm{Kx} \mathrm{Ky} \mathrm{Kz}$ Ss Por 5.00000e-04 5.00000e-04 5.00000e-05 1.00000e-09 1.00000e-01 $1.21577 \mathrm{e}+011.21577 \mathrm{e}+01$ 1.21577e+00 1.00000e-09 2.12000e-01 $1.21577 \mathrm{e}+01$ 1.21577e+01 1.21577e+00 1.00000e-09 2.12000e-01 $1.21577 \mathrm{e}+01$ 1.21577e+01 1.21577e+00 1.00000e-09 2.12000e-01 $1.21577 \mathrm{e}+01$ 1.21577e+01 1.21577e+00 1.00000e-09 2.12000e-01 $1.21577 \mathrm{e}+01$ 1.21577e+01 1.21577e+00 1.00000e-09 2.12000e-01 $1.00000 \mathrm{e}-021.00000 \mathrm{e}-021.00000 \mathrm{e}-031.00000 \mathrm{e}-091.00000 \mathrm{e}-01$ $1.00000 \mathrm{e}+001.00000 \mathrm{e}+001.00000 \mathrm{e}-011.00000 \mathrm{e}-091.00000 \mathrm{e}-01$ $1.00000 \mathrm{e}-05$ 1.00000e-05 1.00000e-06 1.00000e-09 1.00000e-01 $1.00000 \mathrm{e}+001.00000 \mathrm{e}+001.00000 \mathrm{e}-011.00000 \mathrm{e}-091.00000 \mathrm{e}-01$ 
1.00000e-06 1.00000e-06 1.00000e-06 1.00000e-09 5.00000e-02

Element: 5000 \# of layers: 10

$\mathrm{Kx} \mathrm{Ky} \mathrm{Kz}$ Ss Por

3.37812e+02 3.37812e+02 3.37812e+01 1.00000e-09 7.00000e-02

$3.37812 \mathrm{e}+023.37812 \mathrm{e}+023.37812 \mathrm{e}+01$ 1.00000e-09 7.00000e-02

5.00000e-04 5.00000e-04 5.00000e-05 1.00000e-09 1.00000e-01

$1.34978 \mathrm{e}+01$ 1.34978e+01 1.34978e+00 1.00000e-09 2.12000e-01

$1.34978 \mathrm{e}+01$ 1.34978e+01 1.34978e+00 1.00000e-09 2.12000e-01

$1.34978 \mathrm{e}+01$ 1.34978e+01 1.34978e+00 1.00000e-09 2.12000e-01

$1.34978 \mathrm{e}+01$ 1.34978e+01 1.34978e+00 1.00000e-09 2.12000e-01

$1.34978 \mathrm{e}+01$ 1.34978e+01 1.34978e+00 1.00000e-09 2.12000e-01

$1.00000 \mathrm{e}+001.00000 \mathrm{e}+001.00000 \mathrm{e}-011.00000 \mathrm{e}-091.00000 \mathrm{e}-01$

1.00000e-06 1.00000e-06 1.00000e-06 1.00000e-09 5.00000e-02

Element: 5001 \# of layers: 7

$\mathrm{Kx} \mathrm{Ky} \mathrm{Kz}$ Ss Por

3.37812e+02 3.37812e+02 3.37812e+01 1.00000e-09 7.00000e-02

$1.34978 \mathrm{e}+01$ 1.34978e+01 1.34978e+00 1.00000e-09 2.12000e-01

$1.34978 \mathrm{e}+01$ 1.34978e+01 1.34978e+00 1.00000e-09 2.12000e-01

$1.34978 \mathrm{e}+01$ 1.34978e+01 1.34978e+00 1.00000e-09 2.12000e-01

$1.34978 \mathrm{e}+01$ 1.34978e+01 1.34978e+00 1.00000e-09 2.12000e-01

$1.34978 \mathrm{e}+01$ 1.34978e+01 1.34978e+00 1.00000e-09 2.12000e-01

1.00000e-06 1.00000e-06 1.00000e-06 1.00000e-09 5.00000e-02

Element: 5002 \# of layers: 8

$\mathrm{Kx} \mathrm{Ky} \mathrm{Kz}$ Ss Por

$6.89292 \mathrm{e}+016.89292 \mathrm{e}+016.89292 \mathrm{e}+00$ 1.00000e-09 7.00000e-02

6.89292e+01 6.89292e+01 6.89292e+00 1.00000e-09 7.00000e-02

$2.75406 \mathrm{e}+002.75406 \mathrm{e}+00$ 2.75406e-01 1.00000e-09 2.12000e-01

$2.75406 \mathrm{e}+002.75406 \mathrm{e}+002.75406 \mathrm{e}-01$ 1.00000e-09 2.12000e-01

$2.75406 \mathrm{e}+002.75406 \mathrm{e}+002.75406 \mathrm{e}-01$ 1.00000e-09 2.12000e-01

$2.75406 \mathrm{e}+002.75406 \mathrm{e}+00$ 2.75406e-01 1.00000e-09 2.12000e-01

$2.75406 \mathrm{e}+002.75406 \mathrm{e}+002.75406 \mathrm{e}-01$ 1.00000e-09 2.12000e-01

1.00000e-06 1.00000e-06 1.00000e-06 1.00000e-09 5.00000e-02

Element: 5003 \# of layers: 9

$\mathrm{Kx} \mathrm{Ky} \mathrm{Kz}$ Ss Por

$1.05390 \mathrm{e}+02$ 1.05390e+02 1.05390e+01 1.00000e-09 7.00000e-02

4.21097e+00 4.21097e+00 4.21097e-01 1.00000e-09 2.12000e-01

4.21097e+00 4.21097e+00 4.21097e-01 1.00000e-09 2.12000e-01

4.21097e+00 4.21097e+00 4.21097e-01 1.00000e-09 2.12000e-01

4.21097e+00 4.21097e+00 4.21097e-01 1.00000e-09 2.12000e-01

4.21097e+00 4.21097e+00 4.21097e-01 1.00000e-09 2.12000e-01

$1.00000 \mathrm{e}-02$ 1.00000e-02 1.00000e-03 1.00000e-09 1.00000e-01

$1.00000 \mathrm{e}+001.00000 \mathrm{e}+001.00000 \mathrm{e}-011.00000 \mathrm{e}-091.00000 \mathrm{e}-01$

1.00000e-06 1.00000e-06 1.00000e-06 1.00000e-09 5.00000e-02

Element: 5004 \# of layers: 8

$\mathrm{Kx} \mathrm{Ky} \mathrm{Kz}$ Ss Por

4.21097e+00 4.21097e+00 4.21097e-01 1.00000e-09 2.12000e-01 
4.21097e+00 4.21097e+00 4.21097e-01 1.00000e-09 2.12000e-01 $4.21097 \mathrm{e}+004.21097 \mathrm{e}+00$ 4.21097e-01 1.00000e-09 2.12000e-01 $4.21097 \mathrm{e}+004.21097 \mathrm{e}+00$ 4.21097e-01 1.00000e-09 2.12000e-01 $4.21097 \mathrm{e}+004.21097 \mathrm{e}+00$ 4.21097e-01 1.00000e-09 2.12000e-01 $1.00000 \mathrm{e}-02$ 1.00000e-02 1.00000e-03 1.00000e-09 1.00000e-01 $1.00000 \mathrm{e}+001.00000 \mathrm{e}+001.00000 \mathrm{e}-011.00000 \mathrm{e}-091.00000 \mathrm{e}-01$ $1.00000 \mathrm{e}-06$ 1.00000e-06 1.00000e-06 1.00000e-09 5.00000e-02 Element: 5005 \# of layers: 10

$\mathrm{Kx} \mathrm{Ky} \mathrm{Kz}$ Ss Por

1.21577e+01 1.21577e+01 1.21577e+00 1.00000e-09 2.12000e-01 $1.21577 \mathrm{e}+01$ 1.21577e+01 1.21577e+00 1.00000e-09 2.12000e-01 $1.21577 \mathrm{e}+01$ 1.21577e+01 1.21577e+00 1.00000e-09 2.12000e-01 $1.21577 \mathrm{e}+011.21577 \mathrm{e}+01$ 1.21577e+00 1.00000e-09 2.12000e-01 $1.21577 \mathrm{e}+011.21577 \mathrm{e}+01$ 1.21577e+00 1.00000e-09 2.12000e-01 $1.00000 \mathrm{e}-02$ 1.00000e-02 1.00000e-03 1.00000e-09 1.00000e-01 $1.00000 \mathrm{e}+001.00000 \mathrm{e}+001.00000 \mathrm{e}-011.00000 \mathrm{e}-091.00000 \mathrm{e}-01$ $1.00000 \mathrm{e}-05$ 1.00000e-05 1.00000e-06 1.00000e-09 1.00000e-01 $1.00000 \mathrm{e}+001.00000 \mathrm{e}+001.00000 \mathrm{e}-011.00000 \mathrm{e}-091.00000 \mathrm{e}-01$ 1.00000e-06 1.00000e-06 1.00000e-06 1.00000e-09 5.00000e-02 Element: 5006 \# of layers: 8

$\mathrm{Kx} \mathrm{Ky} \mathrm{Kz}$ Ss Por

1.21577e+01 1.21577e+01 1.21577e+00 1.00000e-09 2.12000e-01 $1.21577 \mathrm{e}+01$ 1.21577e+01 1.21577e+00 1.00000e-09 2.12000e-01 $1.21577 \mathrm{e}+011.21577 \mathrm{e}+01$ 1.21577e+00 1.00000e-09 2.12000e-01 $1.21577 \mathrm{e}+01$ 1.21577e+01 1.21577e+00 1.00000e-09 2.12000e-01 $1.21577 \mathrm{e}+011.21577 \mathrm{e}+01$ 1.21577e+00 1.00000e-09 2.12000e-01 $1.00000 \mathrm{e}-02$ 1.00000e-02 1.00000e-03 1.00000e-09 1.00000e-01 $1.00000 \mathrm{e}+001.00000 \mathrm{e}+001.00000 \mathrm{e}-011.00000 \mathrm{e}-091.00000 \mathrm{e}-01$ 1.00000e-06 1.00000e-06 1.00000e-06 1.00000e-09 5.00000e-02 Element: 5007 \# of layers: 4

$\mathrm{Kx} \mathrm{Ky} \mathrm{Kz}$ Ss Por

9.65692e+01 9.65692e+01 9.65692e+00 1.00000e-09 7.00000e-02 $9.65692 \mathrm{e}+019.65692 \mathrm{e}+019.65692 \mathrm{e}+00$ 1.00000e-09 7.00000e-02 $9.65692 \mathrm{e}+019.65692 \mathrm{e}+019.65692 \mathrm{e}+001.00000 \mathrm{e}-09$ 7.00000e-02 1.00000e-06 1.00000e-06 1.00000e-06 1.00000e-09 5.00000e-02 Element: 5008 \# of layers: 5

Kx Ky Kz Ss Por

9.65692e+01 9.65692e+01 9.65692e+00 1.00000e-09 7.00000e-02 $9.65692 \mathrm{e}+019.65692 \mathrm{e}+01$ 9.65692e+00 1.00000e-09 7.00000e-02 $9.65692 \mathrm{e}+019.65692 \mathrm{e}+019.65692 \mathrm{e}+001.00000 \mathrm{e}-09$ 7.00000e-02 5.00000e-04 5.00000e-04 5.00000e-05 1.00000e-09 1.00000e-01 1.00000e-06 1.00000e-06 1.00000e-06 1.00000e-09 5.00000e-02 Element: 5009 \# of layers: 6

$\mathrm{Kx} \mathrm{Ky} \mathrm{Kz}$ Ss Por 5.82875e+01 5.82875e+01 5.82875e+00 1.00000e-09 7.00000e-02 $5.82875 \mathrm{e}+015.82875 \mathrm{e}+015.82875 \mathrm{e}+001.00000 \mathrm{e}-09$ 7.00000e-02 
5.82875e+01 5.82875e+01 5.82875e+00 1.00000e-09 7.00000e-02 5.00000e-04 5.00000e-04 5.00000e-05 1.00000e-09 1.00000e-01 $1.00000 \mathrm{e}+001.00000 \mathrm{e}+001.00000 \mathrm{e}-011.00000 \mathrm{e}-091.00000 \mathrm{e}-01$ 1.00000e-06 1.00000e-06 1.00000e-06 1.00000e-09 5.00000e-02 Element: 5010 \# of layers: 9

$\mathrm{Kx} \mathrm{Ky} \mathrm{Kz}$ Ss Por

6.84183e+01 6.84183e+01 6.84183e+00 1.00000e-09 7.00000e-02 $6.84183 \mathrm{e}+016.84183 \mathrm{e}+016.84183 \mathrm{e}+00$ 1.00000e-09 7.00000e-02 $6.84183 \mathrm{e}+016.84183 \mathrm{e}+016.84183 \mathrm{e}+001.00000 \mathrm{e}-09$ 7.00000e-02 5.00000e-04 5.00000e-04 5.00000e-05 1.00000e-09 1.00000e-01 5.00000e-04 5.00000e-04 5.00000e-05 1.00000e-09 1.00000e-01 $2.73381 \mathrm{e}+002.73381 \mathrm{e}+002.73381 \mathrm{e}-01$ 1.00000e-09 2.12000e-01 $1.00000 \mathrm{e}-02$ 1.00000e-02 1.00000e-03 1.00000e-09 1.00000e-01 $1.00000 \mathrm{e}+001.00000 \mathrm{e}+001.00000 \mathrm{e}-011.00000 \mathrm{e}-091.00000 \mathrm{e}-01$ 1.00000e-06 1.00000e-06 1.00000e-06 1.00000e-09 5.00000e-02 Element: 5011 \# of layers: 9

$\mathrm{Kx} \mathrm{Ky} \mathrm{Kz}$ Ss Por

6.84183e+01 6.84183e+01 6.84183e+00 1.00000e-09 7.00000e-02 $6.84183 \mathrm{e}+016.84183 \mathrm{e}+01$ 6.84183e+00 1.00000e-09 7.00000e-02 $6.84183 \mathrm{e}+016.84183 \mathrm{e}+016.84183 \mathrm{e}+00$ 1.00000e-09 7.00000e-02 5.00000e-04 5.00000e-04 5.00000e-05 1.00000e-09 1.00000e-01 5.00000e-04 5.00000e-04 5.00000e-05 1.00000e-09 1.00000e-01 $2.73381 \mathrm{e}+002.73381 \mathrm{e}+00$ 2.73381e-01 1.00000e-09 2.12000e-01 $1.00000 \mathrm{e}-02$ 1.00000e-02 1.00000e-03 1.00000e-09 1.00000e-01 $1.00000 \mathrm{e}+001.00000 \mathrm{e}+001.00000 \mathrm{e}-011.00000 \mathrm{e}-091.00000 \mathrm{e}-01$ 1.00000e-06 1.00000e-06 1.00000e-06 1.00000e-09 5.00000e-02 Element: 5012 \# of layers: 9

$\mathrm{Kx} \mathrm{Ky} \mathrm{Kz}$ Ss Por

6.84183e+01 6.84183e+01 6.84183e+00 1.00000e-09 7.00000e-02 6.84183e+01 6.84183e+01 6.84183e+00 1.00000e-09 7.00000e-02 $6.84183 \mathrm{e}+016.84183 \mathrm{e}+016.84183 \mathrm{e}+00$ 1.00000e-09 7.00000e-02 5.00000e-04 5.00000e-04 5.00000e-05 1.00000e-09 1.00000e-01 5.00000e-04 5.00000e-04 5.00000e-05 1.00000e-09 1.00000e-01 $2.73381 \mathrm{e}+002.73381 \mathrm{e}+002.73381 \mathrm{e}-01$ 1.00000e-09 2.12000e-01 $1.00000 \mathrm{e}-021.00000 \mathrm{e}-02$ 1.00000e-03 1.00000e-09 1.00000e-01 $1.00000 \mathrm{e}+001.00000 \mathrm{e}+001.00000 \mathrm{e}-011.00000 \mathrm{e}-091.00000 \mathrm{e}-01$ 1.00000e-06 1.00000e-06 1.00000e-06 1.00000e-09 5.00000e-02 Element: 5013 \# of layers: 6

$\mathrm{Kx} \mathrm{Ky} \mathrm{Kz}$ Ss Por

1.30312e+02 1.30312e+02 1.30312e+01 1.00000e-09 7.00000e-02 $1.30312 \mathrm{e}+02$ 1.30312e+02 1.30312e+01 1.00000e-09 7.00000e-02 5.00000e-04 5.00000e-04 5.00000e-05 1.00000e-09 1.00000e-01 5.00000e-04 5.00000e-04 5.00000e-05 1.00000e-09 1.00000e-01 $5.20661 \mathrm{e}+005.20661 \mathrm{e}+00$ 5.20661e-01 1.00000e-09 2.12000e-01 1.00000e-06 1.00000e-06 1.00000e-06 1.00000e-09 5.00000e-02 Element: 5014 \# of layers: 5 
$\mathrm{Kx} \mathrm{Ky} \mathrm{Kz}$ Ss Por

1.30312e+02 1.30312e+02 1.30312e+01 1.00000e-09 7.00000e-02

$1.30312 \mathrm{e}+02$ 1.30312e+02 1.30312e+01 1.00000e-09 7.00000e-02

$1.30312 \mathrm{e}+02$ 1.30312e+02 1.30312e+01 1.00000e-09 7.00000e-02

5.00000e-04 5.00000e-04 5.00000e-05 1.00000e-09 1.00000e-01

1.00000e-06 1.00000e-06 1.00000e-06 1.00000e-09 5.00000e-02

Element: 5015 \# of layers: 7

$\mathrm{Kx} \mathrm{Ky} \mathrm{Kz}$ Ss Por

1.30312e+02 1.30312e+02 1.30312e+01 1.00000e-09 7.00000e-02

$1.30312 \mathrm{e}+02$ 1.30312e+02 1.30312e+01 1.00000e-09 7.00000e-02

$1.30312 \mathrm{e}+021.30312 \mathrm{e}+02$ 1.30312e+01 1.00000e-09 7.00000e-02

5.00000e-04 5.00000e-04 5.00000e-05 1.00000e-09 1.00000e-01

5.00000e-04 5.00000e-04 5.00000e-05 1.00000e-09 1.00000e-01

$5.20661 \mathrm{e}+005.20661 \mathrm{e}+00$ 5.20661e-01 1.00000e-09 2.12000e-01

1.00000e-06 1.00000e-06 1.00000e-06 1.00000e-09 5.00000e-02

Element: 5016 \# of layers: 8

$\mathrm{Kx} \mathrm{Ky} \mathrm{Kz}$ Ss Por

4.64240e+01 4.64240e+01 4.64240e+00 1.00000e-09 7.00000e-02

$4.64240 \mathrm{e}+014.64240 \mathrm{e}+014.64240 \mathrm{e}+001.00000 \mathrm{e}-09$ 7.00000e-02

$4.64240 \mathrm{e}+014.64240 \mathrm{e}+014.64240 \mathrm{e}+001.00000 \mathrm{e}-09$ 7.00000e-02

$4.64240 \mathrm{e}+014.64240 \mathrm{e}+014.64240 \mathrm{e}+001.00000 \mathrm{e}-09$ 7.00000e-02

5.00000e-04 5.00000e-04 5.00000e-05 1.00000e-09 1.00000e-01

5.00000e-04 5.00000e-04 5.00000e-05 1.00000e-09 1.00000e-01

$1.85496 \mathrm{e}+001.85496 \mathrm{e}+001.85496 \mathrm{e}-011.00000 \mathrm{e}-092.12000 \mathrm{e}-01$

$1.00000 \mathrm{e}+001.00000 \mathrm{e}+001.00000 \mathrm{e}-011.00000 \mathrm{e}-091.00000 \mathrm{e}-01$

Element: 5017 \# of layers: 9

$\mathrm{Kx} \mathrm{Ky} \mathrm{Kz}$ Ss Por

4.85765e+01 4.85765e+01 4.85765e+00 1.00000e-09 7.00000e-02

$4.85765 \mathrm{e}+014.85765 \mathrm{e}+014.85765 \mathrm{e}+001.00000 \mathrm{e}-09$ 7.00000e-02

4.85765e+01 4.85765e+01 4.85765e+00 1.00000e-09 7.00000e-02

$4.85765 \mathrm{e}+014.85765 \mathrm{e}+014.85765 \mathrm{e}+001.00000 \mathrm{e}-09$ 7.00000e-02

5.00000e-04 5.00000e-04 5.00000e-05 1.00000e-09 1.00000e-01

5.00000e-04 5.00000e-04 5.00000e-05 1.00000e-09 1.00000e-01

$1.94094 \mathrm{e}+001.94094 \mathrm{e}+001.94094 \mathrm{e}-011.00000 \mathrm{e}-092.12000 \mathrm{e}-01$

$1.00000 \mathrm{e}-02$ 1.00000e-02 1.00000e-03 1.00000e-09 1.00000e-01

$1.00000 \mathrm{e}+001.00000 \mathrm{e}+001.00000 \mathrm{e}-011.00000 \mathrm{e}-091.00000 \mathrm{e}-01$

Element: 5018 \# of layers: 9

Kx Ky Kz Ss Por

4.85765e+01 4.85765e+01 4.85765e+00 1.00000e-09 7.00000e-02

$4.85765 \mathrm{e}+014.85765 \mathrm{e}+014.85765 \mathrm{e}+00$ 1.00000e-09 7.00000e-02

4.85765e+01 4.85765e+01 4.85765e+00 1.00000e-09 7.00000e-02

$4.85765 \mathrm{e}+014.85765 \mathrm{e}+014.85765 \mathrm{e}+001.00000 \mathrm{e}-09$ 7.00000e-02

5.00000e-04 5.00000e-04 5.00000e-05 1.00000e-09 1.00000e-01

5.00000e-04 5.00000e-04 5.00000e-05 1.00000e-09 1.00000e-01

$1.94094 \mathrm{e}+001.94094 \mathrm{e}+001.94094 \mathrm{e}-01$ 1.00000e-09 2.12000e-01

$1.00000 \mathrm{e}-02$ 1.00000e-02 1.00000e-03 1.00000e-09 1.00000e-01 
$1.00000 \mathrm{e}+001.00000 \mathrm{e}+00$ 1.00000e-01 1.00000e-09 1.00000e-01

Element: 5019 \# of layers: 9

Kx Ky Kz Ss Por

4.85765e+01 4.85765e+01 4.85765e+00 1.00000e-09 7.00000e-02

$4.85765 \mathrm{e}+014.85765 \mathrm{e}+014.85765 \mathrm{e}+001.00000 \mathrm{e}-09$ 7.00000e-02

$4.85765 \mathrm{e}+014.85765 \mathrm{e}+014.85765 \mathrm{e}+00$ 1.00000e-09 7.00000e-02

$4.85765 \mathrm{e}+014.85765 \mathrm{e}+014.85765 \mathrm{e}+00$ 1.00000e-09 7.00000e-02

5.00000e-04 5.00000e-04 5.00000e-05 1.00000e-09 1.00000e-01

5.00000e-04 5.00000e-04 5.00000e-05 1.00000e-09 1.00000e-01

$1.94094 \mathrm{e}+001.94094 \mathrm{e}+001.94094 \mathrm{e}-01$ 1.00000e-09 2.12000e-01

$1.00000 \mathrm{e}-02$ 1.00000e-02 1.00000e-03 1.00000e-09 1.00000e-01

$1.00000 \mathrm{e}+001.00000 \mathrm{e}+001.00000 \mathrm{e}-011.00000 \mathrm{e}-091.00000 \mathrm{e}-01$

Element: 5020 \# of layers: 9

$\mathrm{Kx} \mathrm{Ky} \mathrm{Kz}$ Ss Por

5.88849e+01 5.88849e+01 5.88849e+00 1.00000e-09 7.00000e-02

$5.88849 \mathrm{e}+015.88849 \mathrm{e}+015.88849 \mathrm{e}+00$ 1.00000e-09 7.00000e-02

$5.88849 \mathrm{e}+015.88849 \mathrm{e}+015.88849 \mathrm{e}+001.00000 \mathrm{e}-09$ 7.00000e-02

$5.88849 \mathrm{e}+015.88849 \mathrm{e}+015.88849 \mathrm{e}+001.00000 \mathrm{e}-09$ 7.00000e-02

5.00000e-04 5.00000e-04 5.00000e-05 1.00000e-09 1.00000e-01

5.00000e-04 5.00000e-04 5.00000e-05 1.00000e-09 1.00000e-01

$2.35287 \mathrm{e}+002.35287 \mathrm{e}+00$ 2.35288e-01 1.00000e-09 2.12000e-01

$1.00000 \mathrm{e}-02$ 1.00000e-02 1.00000e-03 1.00000e-09 1.00000e-01

$1.00000 \mathrm{e}+001.00000 \mathrm{e}+001.00000 \mathrm{e}-01$ 1.00000e-09 1.00000e-01

Element: 5021 \# of layers: 9

Kx Ky Kz Ss Por

$5.88849 \mathrm{e}+015.88849 \mathrm{e}+015.88849 \mathrm{e}+001.00000 \mathrm{e}-09$ 7.00000e-02

$5.88849 \mathrm{e}+015.88849 \mathrm{e}+015.88849 \mathrm{e}+001.00000 \mathrm{e}-09$ 7.00000e-02

$5.88849 \mathrm{e}+015.88849 \mathrm{e}+015.88849 \mathrm{e}+001.00000 \mathrm{e}-09$ 7.00000e-02

$5.88849 \mathrm{e}+015.88849 \mathrm{e}+015.88849 \mathrm{e}+00$ 1.00000e-09 7.00000e-02

5.00000e-04 5.00000e-04 5.00000e-05 1.00000e-09 1.00000e-01

5.00000e-04 5.00000e-04 5.00000e-05 1.00000e-09 1.00000e-01

$2.35287 \mathrm{e}+00$ 2.35287e+00 2.35288e-01 1.00000e-09 2.12000e-01

1.00000e-02 1.00000e-02 1.00000e-03 1.00000e-09 1.00000e-01

$1.00000 \mathrm{e}+001.00000 \mathrm{e}+001.00000 \mathrm{e}-011.00000 \mathrm{e}-091.00000 \mathrm{e}-01$

Element: 5022 \# of layers: 9

$\mathrm{Kx} \mathrm{Ky} \mathrm{Kz}$ Ss Por

5.65936e+01 5.65936e+01 5.65936e+00 1.00000e-09 7.00000e-02

$5.65936 \mathrm{e}+015.65936 \mathrm{e}+015.65936 \mathrm{e}+001.00000 \mathrm{e}-097.00000 \mathrm{e}-02$

$5.65936 \mathrm{e}+015.65936 \mathrm{e}+015.65936 \mathrm{e}+001.00000 \mathrm{e}-09$ 7.00000e-02

$5.65936 \mathrm{e}+015.65936 \mathrm{e}+015.65936 \mathrm{e}+001.00000 \mathrm{e}-097.00000 \mathrm{e}-02$

5.00000e-04 5.00000e-04 5.00000e-05 1.00000e-09 1.00000e-01

5.00000e-04 5.00000e-04 5.00000e-05 1.00000e-09 1.00000e-01

$2.26130 \mathrm{e}+002.26130 \mathrm{e}+002.26130 \mathrm{e}-01$ 1.00000e-09 2.12000e-01

$1.00000 \mathrm{e}-02$ 1.00000e-02 1.00000e-03 1.00000e-09 1.00000e-01

$1.00000 \mathrm{e}+001.00000 \mathrm{e}+001.00000 \mathrm{e}-01$ 1.00000e-09 1.00000e-01

Element: 5023 \# of layers: 9 
$\mathrm{Kx} \mathrm{Ky} \mathrm{Kz}$ Ss Por

4.64240e+01 4.64240e+01 4.64240e+00 1.00000e-09 7.00000e-02

4.64240e+01 4.64240e+01 4.64240e+00 1.00000e-09 7.00000e-02

$4.64240 \mathrm{e}+014.64240 \mathrm{e}+014.64240 \mathrm{e}+001.00000 \mathrm{e}-09$ 7.00000e-02

$4.64240 \mathrm{e}+014.64240 \mathrm{e}+014.64240 \mathrm{e}+001.00000 \mathrm{e}-09$ 7.00000e-02

5.00000e-04 5.00000e-04 5.00000e-05 1.00000e-09 1.00000e-01

5.00000e-04 5.00000e-04 5.00000e-05 1.00000e-09 1.00000e-01

$1.85496 \mathrm{e}+001.85496 \mathrm{e}+001.85496 \mathrm{e}-01$ 1.00000e-09 2.12000e-01

$1.00000 \mathrm{e}-02$ 1.00000e-02 1.00000e-03 1.00000e-09 1.00000e-01

$1.00000 \mathrm{e}+001.00000 \mathrm{e}+001.00000 \mathrm{e}-011.00000 \mathrm{e}-091.00000 \mathrm{e}-01$

Element: 5024 \# of layers: 9

Kx Ky Kz Ss Por

4.85765e+01 4.85765e+01 4.85765e+00 1.00000e-09 7.00000e-02

$4.85765 \mathrm{e}+014.85765 \mathrm{e}+014.85765 \mathrm{e}+00$ 1.00000e-09 7.00000e-02

$4.85765 \mathrm{e}+014.85765 \mathrm{e}+014.85765 \mathrm{e}+001.00000 \mathrm{e}-09$ 7.00000e-02

$4.85765 \mathrm{e}+014.85765 \mathrm{e}+014.85765 \mathrm{e}+001.00000 \mathrm{e}-09$ 7.00000e-02

5.00000e-04 5.00000e-04 5.00000e-05 1.00000e-09 1.00000e-01

5.00000e-04 5.00000e-04 5.00000e-05 1.00000e-09 1.00000e-01

$1.94094 \mathrm{e}+001.94094 \mathrm{e}+001.94094 \mathrm{e}-01$ 1.00000e-09 2.12000e-01

$1.00000 \mathrm{e}-02$ 1.00000e-02 1.00000e-03 1.00000e-09 1.00000e-01

$1.00000 \mathrm{e}+001.00000 \mathrm{e}+001.00000 \mathrm{e}-011.00000 \mathrm{e}-091.00000 \mathrm{e}-01$

Element: 5025 \# of layers: 9

$\mathrm{Kx} \mathrm{Ky} \mathrm{Kz}$ Ss Por

7.33873e+01 7.33873e+01 7.33873e+00 1.00000e-09 7.00000e-02

$7.33873 e+017.33873 e+017.33873 e+001.00000 e-09$ 7.00000e-02

7.33873e+01 7.33873e+01 7.33873e+00 1.00000e-09 7.00000e-02

7.33873e+01 7.33873e+01 7.33873e+00 1.00000e-09 7.00000e-02

5.00000e-04 5.00000e-04 5.00000e-05 1.00000e-09 1.00000e-01

5.00000e-04 5.00000e-04 5.00000e-05 1.00000e-09 1.00000e-01

$2.93226 \mathrm{e}+002.93226 \mathrm{e}+002.93226 \mathrm{e}-01$ 1.00000e-09 2.12000e-01

$1.00000 \mathrm{e}-02$ 1.00000e-02 1.00000e-03 1.00000e-09 1.00000e-01

$1.00000 \mathrm{e}+001.00000 \mathrm{e}+001.00000 \mathrm{e}-011.00000 \mathrm{e}-091.00000 \mathrm{e}-01$

Element: 5026 \# of layers: 8

$\mathrm{Kx} \mathrm{Ky} \mathrm{Kz}$ Ss Por

$1.49323 \mathrm{e}+02$ 1.49323e+02 1.49323e+01 1.00000e-09 7.00000e-02

$1.49323 \mathrm{e}+02$ 1.49323e+02 1.49323e+01 1.00000e-09 7.00000e-02

$1.49323 \mathrm{e}+021.49323 \mathrm{e}+02$ 1.49323e+01 1.00000e-09 7.00000e-02

5.00000e-04 5.00000e-04 5.00000e-05 1.00000e-09 1.00000e-01

5.00000e-04 5.00000e-04 5.00000e-05 1.00000e-09 1.00000e-01

5.96623e+00 5.96623e+00 5.96623e-01 1.00000e-09 2.12000e-01

$1.00000 \mathrm{e}-02$ 1.00000e-02 1.00000e-03 1.00000e-09 1.00000e-01

$1.00000 \mathrm{e}+001.00000 \mathrm{e}+001.00000 \mathrm{e}-011.00000 \mathrm{e}-091.00000 \mathrm{e}-01$

Element: 5027 \# of layers: 8

$\mathrm{Kx} \mathrm{Ky} \mathrm{Kz}$ Ss Por

$1.49323 \mathrm{e}+02$ 1.49323e+02 1.49323e+01 1.00000e-09 7.00000e-02

$1.49323 \mathrm{e}+02$ 1.49323e+02 1.49323e+01 1.00000e-09 7.00000e-02 
1.49323e+02 1.49323e+02 1.49323e+01 1.00000e-09 7.00000e-02 5.00000e-04 5.00000e-04 5.00000e-05 1.00000e-09 1.00000e-01 5.00000e-04 5.00000e-04 5.00000e-05 1.00000e-09 1.00000e-01 $5.96623 \mathrm{e}+00$ 5.96623e+00 5.96623e-01 1.00000e-09 2.12000e-01 $1.00000 \mathrm{e}-02$ 1.00000e-02 1.00000e-03 1.00000e-09 1.00000e-01 $1.00000 \mathrm{e}+001.00000 \mathrm{e}+001.00000 \mathrm{e}-011.00000 \mathrm{e}-091.00000 \mathrm{e}-01$ Element: 5028 \# of layers: 8

$\mathrm{Kx} \mathrm{Ky} \mathrm{Kz}$ Ss Por

1.49323e+02 1.49323e+02 1.49323e+01 1.00000e-09 7.00000e-02 $1.49323 \mathrm{e}+021.49323 \mathrm{e}+021.49323 \mathrm{e}+01$ 1.00000e-09 7.00000e-02 5.00000e-04 5.00000e-04 5.00000e-05 1.00000e-09 1.00000e-01 $5.00000 \mathrm{e}-04$ 5.00000e-04 5.00000e-05 1.00000e-09 1.00000e-01 5.96623e+00 5.96623e+00 5.96623e-01 1.00000e-09 2.12000e-01 5.96623e+00 5.96623e+00 5.96623e-01 1.00000e-09 2.12000e-01 $1.00000 \mathrm{e}-021.00000 \mathrm{e}-021.00000 \mathrm{e}-031.00000 \mathrm{e}-091.00000 \mathrm{e}-01$ $1.00000 \mathrm{e}+001.00000 \mathrm{e}+001.00000 \mathrm{e}-011.00000 \mathrm{e}-091.00000 \mathrm{e}-01$ Element: 5029 \# of layers: 8

$\mathrm{Kx} \mathrm{Ky} \mathrm{Kz}$ Ss Por

1.24698e+02 1.24698e+02 1.24698e+01 1.00000e-09 7.00000e-02 $1.24698 \mathrm{e}+02 \quad 1.24698 \mathrm{e}+02 \quad 1.24698 \mathrm{e}+01$ 1.00000e-09 7.00000e-02 5.00000e-04 5.00000e-04 5.00000e-05 1.00000e-09 1.00000e-01 5.00000e-04 5.00000e-04 5.00000e-05 1.00000e-09 1.00000e-01 4.98273e+00 4.98273e+00 4.98273e-01 1.00000e-09 2.12000e-01 $4.98273 \mathrm{e}+004.98273 \mathrm{e}+00$ 4.98273e-01 1.00000e-09 2.12000e-01 $1.00000 \mathrm{e}-021.00000 \mathrm{e}-02$ 1.00000e-03 1.00000e-09 1.00000e-01 $1.00000 \mathrm{e}+001.00000 \mathrm{e}+001.00000 \mathrm{e}-011.00000 \mathrm{e}-091.00000 \mathrm{e}-01$ Element: 5030 \# of layers: 9

$\mathrm{Kx} \mathrm{Ky} \mathrm{Kz}$ Ss Por

1.24698e+02 1.24698e+02 1.24698e+01 1.00000e-09 7.00000e-02 $1.24698 \mathrm{e}+02$ 1.24698e+02 1.24698e+01 1.00000e-09 7.00000e-02 $1.24698 \mathrm{e}+02 \quad 1.24698 \mathrm{e}+02 \quad 1.24698 \mathrm{e}+01$ 1.00000e-09 7.00000e-02 5.00000e-04 5.00000e-04 5.00000e-05 1.00000e-09 1.00000e-01 5.00000e-04 5.00000e-04 5.00000e-05 1.00000e-09 1.00000e-01 4.98273e+00 4.98273e+00 4.98273e-01 1.00000e-09 2.12000e-01 4.98273e+00 4.98273e+00 4.98273e-01 1.00000e-09 2.12000e-01 1.00000e-02 1.00000e-02 1.00000e-03 1.00000e-09 1.00000e-01 $1.00000 \mathrm{e}+001.00000 \mathrm{e}+001.00000 \mathrm{e}-011.00000 \mathrm{e}-091.00000 \mathrm{e}-01$ Element: 5031 \# of layers: 10

$\mathrm{Kx} \mathrm{Ky} \mathrm{Kz}$ Ss Por

7.87807e+01 7.87807e+01 7.87807e+00 1.00000e-09 7.00000e-02 7.87807e+01 7.87807e+01 7.87807e+00 1.00000e-09 7.00000e-02 7.87807e+01 7.87807e+01 7.87807e+00 1.00000e-09 7.00000e-02 7.87807e+01 7.87807e+01 7.87807e+00 1.00000e-09 7.00000e-02 5.00000e-04 5.00000e-04 5.00000e-05 1.00000e-09 1.00000e-01 5.00000e-04 5.00000e-04 5.00000e-05 1.00000e-09 1.00000e-01 $3.14782 \mathrm{e}+003.14782 \mathrm{e}+003.14782 \mathrm{e}-01$ 1.00000e-09 2.12000e-01 
3.14782e+00 3.14782e+00 3.14782e-01 1.00000e-09 2.12000e-01 $1.00000 \mathrm{e}-02$ 1.00000e-02 1.00000e-03 1.00000e-09 1.00000e-01 $1.00000 \mathrm{e}+001.00000 \mathrm{e}+001.00000 \mathrm{e}-011.00000 \mathrm{e}-091.00000 \mathrm{e}-01$ Element: 5032 \# of layers: 8

Kx Ky Kz Ss Por

7.33873e+01 7.33873e+01 7.33873e+00 1.00000e-09 7.00000e-02 $7.33873 \mathrm{e}+01$ 7.33873e+01 7.33873e+00 1.00000e-09 7.00000e-02 $7.33873 \mathrm{e}+01$ 7.33873e+01 7.33873e+00 1.00000e-09 7.00000e-02 5.00000e-04 5.00000e-04 5.00000e-05 1.00000e-09 1.00000e-01 $5.00000 \mathrm{e}-04$ 5.00000e-04 5.00000e-05 1.00000e-09 1.00000e-01 $2.93226 \mathrm{e}+002.93226 \mathrm{e}+002.93226 \mathrm{e}-011.00000 \mathrm{e}-092.12000 \mathrm{e}-01$ $1.00000 \mathrm{e}-021.00000 \mathrm{e}-02$ 1.00000e-03 1.00000e-09 1.00000e-01 $1.00000 \mathrm{e}+001.00000 \mathrm{e}+001.00000 \mathrm{e}-011.00000 \mathrm{e}-091.00000 \mathrm{e}-01$ Element: 5033 \# of layers: 8

Kx Ky Kz Ss Por

7.87807e+01 7.87807e+01 7.87807e+00 1.00000e-09 7.00000e-02 $7.87807 \mathrm{e}+01$ 7.87807e+01 7.87807e+00 1.00000e-09 7.00000e-02 5.00000e-04 5.00000e-04 5.00000e-05 1.00000e-09 1.00000e-01 5.00000e-04 5.00000e-04 5.00000e-05 1.00000e-09 1.00000e-01 $3.14782 \mathrm{e}+003.14782 \mathrm{e}+003.14782 \mathrm{e}-011.00000 \mathrm{e}-092.12000 \mathrm{e}-01$ $3.14782 \mathrm{e}+003.14782 \mathrm{e}+003.14782 \mathrm{e}-01$ 1.00000e-09 2.12000e-01 $1.00000 \mathrm{e}-02$ 1.00000e-02 1.00000e-03 1.00000e-09 1.00000e-01 $1.00000 \mathrm{e}+001.00000 \mathrm{e}+001.00000 \mathrm{e}-011.00000 \mathrm{e}-091.00000 \mathrm{e}-01$ Element: 5034 \# of layers: 7

Kx Ky Kz Ss Por

$1.56774 \mathrm{e}+021.56774 \mathrm{e}+021.56774 \mathrm{e}+011.00000 \mathrm{e}-097.00000 \mathrm{e}-02$ 5.00000e-04 5.00000e-04 5.00000e-05 1.00000e-09 1.00000e-01 5.00000e-04 5.00000e-04 5.00000e-05 1.00000e-09 1.00000e-01 $6.26436 \mathrm{e}+006.26436 \mathrm{e}+006.26436 \mathrm{e}-011.00000 \mathrm{e}-09$ 2.12000e-01 $6.26436 \mathrm{e}+006.26436 \mathrm{e}+006.26436 \mathrm{e}-011.00000 \mathrm{e}-09$ 2.12000e-01 $1.00000 \mathrm{e}-021.00000 \mathrm{e}-02$ 1.00000e-03 1.00000e-09 1.00000e-01 $1.00000 \mathrm{e}+001.00000 \mathrm{e}+001.00000 \mathrm{e}-011.00000 \mathrm{e}-091.00000 \mathrm{e}-01$ Element: 5035 \# of layers: 7

Kx Ky Kz Ss Por

$1.56774 \mathrm{e}+021.56774 \mathrm{e}+021.56774 \mathrm{e}+011.00000 \mathrm{e}-097.00000 \mathrm{e}-02$ 5.00000e-04 5.00000e-04 5.00000e-05 1.00000e-09 1.00000e-01 5.00000e-04 5.00000e-04 5.00000e-05 1.00000e-09 1.00000e-01 $6.26436 \mathrm{e}+006.26436 \mathrm{e}+006.26436 \mathrm{e}-011.00000 \mathrm{e}-09$ 2.12000e-01 $6.26436 \mathrm{e}+006.26436 \mathrm{e}+00$ 6.26436e-01 1.00000e-09 2.12000e-01 $1.00000 \mathrm{e}-02$ 1.00000e-02 1.00000e-03 1.00000e-09 1.00000e-01 $1.00000 \mathrm{e}+001.00000 \mathrm{e}+001.00000 \mathrm{e}-011.00000 \mathrm{e}-091.00000 \mathrm{e}-01$ Element: 5036 \# of layers: 7

Kx Ky Kz Ss Por

$1.62297 \mathrm{e}+02$ 1.62297e+02 1.62297e+01 1.00000e-09 7.00000e-02 5.00000e-04 5.00000e-04 5.00000e-05 1.00000e-09 1.00000e-01 5.00000e-04 5.00000e-04 5.00000e-05 1.00000e-09 1.00000e-01 
$6.48464 \mathrm{e}+006.48464 \mathrm{e}+006.48464 \mathrm{e}-011.00000 \mathrm{e}-092.12000 \mathrm{e}-01$ $6.48464 \mathrm{e}+006.48464 \mathrm{e}+00$ 6.48464e-01 1.00000e-09 2.12000e-01 $1.00000 \mathrm{e}-02$ 1.00000e-02 $1.00000 \mathrm{e}-031.00000 \mathrm{e}-091.00000 \mathrm{e}-01$ $1.00000 \mathrm{e}+001.00000 \mathrm{e}+001.00000 \mathrm{e}-011.00000 \mathrm{e}-091.00000 \mathrm{e}-01$ Element: 5037 \# of layers: 7

Kx Ky Kz Ss Por

$1.62297 \mathrm{e}+02$ 1.62297e+02 1.62297e+01 1.00000e-09 7.00000e-02 5.00000e-04 5.00000e-04 5.00000e-05 1.00000e-09 1.00000e-01 $5.00000 \mathrm{e}-04$ 5.00000e-04 5.00000e-05 1.00000e-09 1.00000e-01 $6.48464 \mathrm{e}+006.48464 \mathrm{e}+006.48464 \mathrm{e}-011.00000 \mathrm{e}-092.12000 \mathrm{e}-01$ $6.48464 \mathrm{e}+006.48464 \mathrm{e}+006.48464 \mathrm{e}-01$ 1.00000e-09 2.12000e-01 $1.00000 \mathrm{e}-021.00000 \mathrm{e}-02$ 1.00000e-03 1.00000e-09 1.00000e-01 $1.00000 \mathrm{e}+001.00000 \mathrm{e}+001.00000 \mathrm{e}-011.00000 \mathrm{e}-091.00000 \mathrm{e}-01$ Element: 5038 \# of layers: 7

Kx Ky Kz Ss Por $1.62297 \mathrm{e}+02$ 1.62297e+02 1.62297e+01 1.00000e-09 7.00000e-02 $5.00000 \mathrm{e}-04$ 5.00000e-04 5.00000e-05 1.00000e-09 1.00000e-01 $5.00000 \mathrm{e}-04$ 5.00000e-04 5.00000e-05 1.00000e-09 1.00000e-01 $6.48464 \mathrm{e}+006.48464 \mathrm{e}+006.48464 \mathrm{e}-011.00000 \mathrm{e}-092.12000 \mathrm{e}-01$ $6.48464 \mathrm{e}+006.48464 \mathrm{e}+006.48464 \mathrm{e}-01$ 1.00000e-09 2.12000e-01 $1.00000 \mathrm{e}-021.00000 \mathrm{e}-02$ 1.00000e-03 1.00000e-09 1.00000e-01 $1.00000 \mathrm{e}+001.00000 \mathrm{e}+001.00000 \mathrm{e}-011.00000 \mathrm{e}-091.00000 \mathrm{e}-01$ Element: 5039 \# of layers: 7

Kx Ky Kz Ss Por $1.71010 \mathrm{e}+021.71010 \mathrm{e}+021.71010 \mathrm{e}+01$ 1.00000e-09 7.00000e-02 $5.00000 \mathrm{e}-04$ 5.00000e-04 5.00000e-05 1.00000e-09 1.00000e-01 $5.00000 \mathrm{e}-04$ 5.00000e-04 5.00000e-05 1.00000e-09 1.00000e-01 $6.83294 \mathrm{e}+006.83294 \mathrm{e}+006.83294 \mathrm{e}-011.00000 \mathrm{e}-092.12000 \mathrm{e}-01$ $6.83294 \mathrm{e}+006.83294 \mathrm{e}+00 \quad 6.83294 \mathrm{e}-011.00000 \mathrm{e}-092.12000 \mathrm{e}-01$ $1.00000 \mathrm{e}-02$ 1.00000e-02 1.00000e-03 1.00000e-09 1.00000e-01 $1.00000 \mathrm{e}+001.00000 \mathrm{e}+001.00000 \mathrm{e}-011.00000 \mathrm{e}-091.00000 \mathrm{e}-01$ Element: 5040 \# of layers: 8

Kx Ky Kz Ss Por

$1.71010 \mathrm{e}+021.71010 \mathrm{e}+021.71010 \mathrm{e}+011.00000 \mathrm{e}-09$ 7.00000e-02 $1.71010 \mathrm{e}+021.71010 \mathrm{e}+021.71010 \mathrm{e}+011.00000 \mathrm{e}-097.00000 \mathrm{e}-02$ 5.00000e-04 5.00000e-04 5.00000e-05 1.00000e-09 1.00000e-01 5.00000e-04 5.00000e-04 5.00000e-05 1.00000e-09 1.00000e-01 $6.83294 \mathrm{e}+006.83294 \mathrm{e}+00$ 6.83294e-01 1.00000e-09 2.12000e-01 $6.83294 \mathrm{e}+006.83294 \mathrm{e}+00$ 6.83294e-01 1.00000e-09 2.12000e-01 $1.00000 \mathrm{e}-02$ 1.00000e-02 1.00000e-03 1.00000e-09 1.00000e-01 $1.00000 \mathrm{e}+001.00000 \mathrm{e}+001.00000 \mathrm{e}-011.00000 \mathrm{e}-091.00000 \mathrm{e}-01$ Element: 5041 \# of layers: 7

Kx Ky Kz Ss Por

$1.62297 \mathrm{e}+02$ 1.62297e+02 1.62297e+01 1.00000e-09 7.00000e-02 5.00000e-04 5.00000e-04 5.00000e-05 1.00000e-09 1.00000e-01 5.00000e-04 5.00000e-04 5.00000e-05 1.00000e-09 1.00000e-01 
$6.48464 \mathrm{e}+006.48464 \mathrm{e}+006.48464 \mathrm{e}-011.00000 \mathrm{e}-092.12000 \mathrm{e}-01$ $6.48464 \mathrm{e}+006.48464 \mathrm{e}+00$ 6.48464e-01 1.00000e-09 2.12000e-01 $1.00000 \mathrm{e}-02$ 1.00000e-02 $1.00000 \mathrm{e}-031.00000 \mathrm{e}-091.00000 \mathrm{e}-01$ $1.00000 \mathrm{e}+001.00000 \mathrm{e}+001.00000 \mathrm{e}-011.00000 \mathrm{e}-091.00000 \mathrm{e}-01$ Element: 5042 \# of layers: 7

Kx Ky Kz Ss Por

$1.62297 \mathrm{e}+02$ 1.62297e+02 1.62297e+01 1.00000e-09 7.00000e-02 5.00000e-04 5.00000e-04 5.00000e-05 1.00000e-09 1.00000e-01 $5.00000 \mathrm{e}-04$ 5.00000e-04 5.00000e-05 1.00000e-09 1.00000e-01 $6.48464 \mathrm{e}+006.48464 \mathrm{e}+006.48464 \mathrm{e}-011.00000 \mathrm{e}-092.12000 \mathrm{e}-01$ $6.48464 \mathrm{e}+006.48464 \mathrm{e}+006.48464 \mathrm{e}-01$ 1.00000e-09 2.12000e-01 $1.00000 \mathrm{e}-021.00000 \mathrm{e}-02$ 1.00000e-03 1.00000e-09 1.00000e-01 $1.00000 \mathrm{e}+001.00000 \mathrm{e}+001.00000 \mathrm{e}-011.00000 \mathrm{e}-091.00000 \mathrm{e}-01$ Element: 5043 \# of layers: 7

Kx Ky Kz Ss Por $4.25885 \mathrm{e}+014.25885 \mathrm{e}+014.25885 \mathrm{e}+00$ 1.00000e-09 7.00000e-02 $5.00000 \mathrm{e}-04$ 5.00000e-04 5.00000e-05 1.00000e-09 1.00000e-01 5.00000e-04 5.00000e-04 5.00000e-05 1.00000e-09 1.00000e-01 $1.70169 \mathrm{e}+001.70169 \mathrm{e}+001.70169 \mathrm{e}-011.00000 \mathrm{e}-092.12000 \mathrm{e}-01$ $1.70169 \mathrm{e}+001.70169 \mathrm{e}+00$ 1.70169e-01 1.00000e-09 2.12000e-01 $1.00000 \mathrm{e}-021.00000 \mathrm{e}-02$ 1.00000e-03 1.00000e-09 1.00000e-01 $1.00000 \mathrm{e}+001.00000 \mathrm{e}+001.00000 \mathrm{e}-011.00000 \mathrm{e}-091.00000 \mathrm{e}-01$ Element: 5044 \# of layers: 9

Kx Ky Kz Ss Por

$4.25885 \mathrm{e}+014.25885 \mathrm{e}+014.25885 \mathrm{e}+001.00000 \mathrm{e}-09$ 7.00000e-02 $4.25885 \mathrm{e}+014.25885 \mathrm{e}+014.25885 \mathrm{e}+001.00000 \mathrm{e}-09$ 7.00000e-02 $4.25885 \mathrm{e}+014.25885 \mathrm{e}+014.25885 \mathrm{e}+001.00000 \mathrm{e}-097.00000 \mathrm{e}-02$ 5.00000e-04 5.00000e-04 5.00000e-05 1.00000e-09 1.00000e-01 5.00000e-04 5.00000e-04 5.00000e-05 1.00000e-09 1.00000e-01 $1.70169 \mathrm{e}+001.70169 \mathrm{e}+00$ 1.70169e-01 1.00000e-09 2.12000e-01 $1.70169 \mathrm{e}+001.70169 \mathrm{e}+001.70169 \mathrm{e}-011.00000 \mathrm{e}-092.12000 \mathrm{e}-01$ $1.00000 \mathrm{e}-02$ 1.00000e-02 1.00000e-03 1.00000e-09 1.00000e-01 $1.00000 \mathrm{e}+001.00000 \mathrm{e}+001.00000 \mathrm{e}-011.00000 \mathrm{e}-091.00000 \mathrm{e}-01$ Element: 5045 \# of layers: 9

Kx Ky Kz Ss Por

$4.25885 \mathrm{e}+014.25885 \mathrm{e}+014.25885 \mathrm{e}+00$ 1.00000e-09 7.00000e-02 $4.25885 \mathrm{e}+014.25885 \mathrm{e}+014.25885 \mathrm{e}+001.00000 \mathrm{e}-09$ 7.00000e-02 $4.25885 \mathrm{e}+014.25885 \mathrm{e}+014.25885 \mathrm{e}+001.00000 \mathrm{e}-09$ 7.00000e-02 $5.00000 \mathrm{e}-04$ 5.00000e-04 5.00000e-05 1.00000e-09 1.00000e-01 5.00000e-04 5.00000e-04 5.00000e-05 1.00000e-09 1.00000e-01 $1.70169 \mathrm{e}+001.70169 \mathrm{e}+001.70169 \mathrm{e}-011.00000 \mathrm{e}-092.12000 \mathrm{e}-01$ $1.70169 \mathrm{e}+001.70169 \mathrm{e}+00$ 1.70169e-01 1.00000e-09 2.12000e-01 $1.00000 \mathrm{e}-02$ 1.00000e-02 1.00000e-03 1.00000e-09 1.00000e-01 $1.00000 \mathrm{e}+001.00000 \mathrm{e}+001.00000 \mathrm{e}-011.00000 \mathrm{e}-091.00000 \mathrm{e}-01$ Element: 5049 \# of layers: 7

Kx Ky Kz Ss Por 
4.25885e+01 4.25885e+01 4.25885e+00 1.00000e-09 7.00000e-02 5.00000e-04 5.00000e-04 5.00000e-05 1.00000e-09 1.00000e-01 5.00000e-04 5.00000e-04 5.00000e-05 1.00000e-09 1.00000e-01

$1.70169 \mathrm{e}+001.70169 \mathrm{e}+00$ 1.70169e-01 1.00000e-09 2.12000e-01 $1.70169 \mathrm{e}+001.70169 \mathrm{e}+00$ 1.70169e-01 1.00000e-09 2.12000e-01 $1.00000 \mathrm{e}-02$ 1.00000e-02 1.00000e-03 1.00000e-09 1.00000e-01 $1.00000 \mathrm{e}+001.00000 \mathrm{e}+001.00000 \mathrm{e}-011.00000 \mathrm{e}-091.00000 \mathrm{e}-01$ Element: 5050 \# of layers: 7

$\mathrm{Kx} \mathrm{Ky} \mathrm{Kz}$ Ss Por

4.25885e+01 4.25885e+01 4.25885e+00 1.00000e-09 7.00000e-02 5.00000e-04 5.00000e-04 5.00000e-05 1.00000e-09 1.00000e-01 5.00000e-04 5.00000e-04 5.00000e-05 1.00000e-09 1.00000e-01

$1.70169 \mathrm{e}+001.70169 \mathrm{e}+00$ 1.70169e-01 1.00000e-09 2.12000e-01 $1.70169 \mathrm{e}+00$ 1.70169e+00 1.70169e-01 1.00000e-09 2.12000e-01 $1.00000 \mathrm{e}-02$ 1.00000e-02 1.00000e-03 1.00000e-09 1.00000e-01 $1.00000 \mathrm{e}+001.00000 \mathrm{e}+001.00000 \mathrm{e}-011.00000 \mathrm{e}-091.00000 \mathrm{e}-01$ Element: 5052 \# of layers: 8

$\mathrm{Kx} \mathrm{Ky} \mathrm{Kz}$ Ss Por

7.55074e+01 7.55074e+01 7.55074e+00 1.00000e-09 7.00000e-02 $7.55074 \mathrm{e}+017.55074 \mathrm{e}+017.55074 \mathrm{e}+001.00000 \mathrm{e}-097.00000 \mathrm{e}-02$ 5.00000e-04 5.00000e-04 5.00000e-05 1.00000e-09 1.00000e-01 5.00000e-04 5.00000e-04 5.00000e-05 1.00000e-09 1.00000e-01 $3.01709 \mathrm{e}+003.01709 \mathrm{e}+00$ 3.01709e-01 1.00000e-09 2.12000e-01 $3.01709 \mathrm{e}+003.01709 \mathrm{e}+00$ 3.01709e-01 1.00000e-09 2.12000e-01 $1.00000 \mathrm{e}-02$ 1.00000e-02 1.00000e-03 1.00000e-09 1.00000e-01 $1.00000 \mathrm{e}+001.00000 \mathrm{e}+001.00000 \mathrm{e}-01$ 1.00000e-09 1.00000e-01 Element: 5053 \# of layers: 8

$\mathrm{Kx} \mathrm{Ky} \mathrm{Kz}$ Ss Por

$7.55074 \mathrm{e}+01$ 7.55074e+01 7.55074e+00 1.00000e-09 7.00000e-02 $7.55074 \mathrm{e}+017.55074 \mathrm{e}+01$ 7.55074e+00 1.00000e-09 7.00000e-02 5.00000e-04 5.00000e-04 5.00000e-05 1.00000e-09 1.00000e-01 5.00000e-04 5.00000e-04 5.00000e-05 1.00000e-09 1.00000e-01 $3.01709 \mathrm{e}+003.01709 \mathrm{e}+003.01709 \mathrm{e}-01$ 1.00000e-09 2.12000e-01 3.01709e+00 3.01709e+00 3.01709e-01 1.00000e-09 2.12000e-01 $1.00000 \mathrm{e}-02$ 1.00000e-02 1.00000e-03 1.00000e-09 1.00000e-01 $1.00000 \mathrm{e}+001.00000 \mathrm{e}+001.00000 \mathrm{e}-01$ 1.00000e-09 1.00000e-01 Element: 5054 \# of layers: 8

$\mathrm{Kx} \mathrm{Ky} \mathrm{Kz}$ Ss Por

7.55074e+01 7.55074e+01 7.55074e+00 1.00000e-09 7.00000e-02 $7.55074 \mathrm{e}+017.55074 \mathrm{e}+017.55074 \mathrm{e}+001.00000 \mathrm{e}-097.00000 \mathrm{e}-02$ 5.00000e-04 5.00000e-04 5.00000e-05 1.00000e-09 1.00000e-01 5.00000e-04 5.00000e-04 5.00000e-05 1.00000e-09 1.00000e-01 $3.01709 \mathrm{e}+003.01709 \mathrm{e}+00$ 3.01709e-01 1.00000e-09 2.12000e-01 3.01709e+00 3.01709e+00 3.01709e-01 1.00000e-09 2.12000e-01 $1.00000 \mathrm{e}-02$ 1.00000e-02 1.00000e-03 1.00000e-09 1.00000e-01 $1.00000 \mathrm{e}+001.00000 \mathrm{e}+001.00000 \mathrm{e}-011.00000 \mathrm{e}-091.00000 \mathrm{e}-01$ 
Element: 5055 \# of layers: 8

$\mathrm{Kx} \mathrm{Ky} \mathrm{Kz}$ Ss Por

3.00105e+01 3.00105e+01 3.00105e+00 1.00000e-09 7.00000e-02

$3.00105 \mathrm{e}+013.00105 \mathrm{e}+013.00105 \mathrm{e}+00$ 1.00000e-09 7.00000e-02

5.00000e-04 5.00000e-04 5.00000e-05 1.00000e-09 1.00000e-01

5.00000e-04 5.00000e-04 5.00000e-05 1.00000e-09 1.00000e-01

$1.19912 \mathrm{e}+001.19912 \mathrm{e}+00$ 1.19912e-01 1.00000e-09 2.12000e-01

$1.19912 \mathrm{e}+001.19912 \mathrm{e}+001.19912 \mathrm{e}-01$ 1.00000e-09 2.12000e-01

$1.00000 \mathrm{e}-021.00000 \mathrm{e}-021.00000 \mathrm{e}-031.00000 \mathrm{e}-091.00000 \mathrm{e}-01$

$1.00000 \mathrm{e}+001.00000 \mathrm{e}+001.00000 \mathrm{e}-011.00000 \mathrm{e}-091.00000 \mathrm{e}-01$

Element: 5056 \# of layers: 8

Kx Ky Kz Ss Por

3.00105e+01 3.00105e+01 3.00105e+00 1.00000e-09 7.00000e-02

$3.00105 \mathrm{e}+013.00105 \mathrm{e}+013.00105 \mathrm{e}+001.00000 \mathrm{e}-09$ 7.00000e-02

5.00000e-04 5.00000e-04 5.00000e-05 1.00000e-09 1.00000e-01

5.00000e-04 5.00000e-04 5.00000e-05 1.00000e-09 1.00000e-01

$1.19912 \mathrm{e}+001.19912 \mathrm{e}+00$ 1.19912e-01 1.00000e-09 2.12000e-01

$1.19912 \mathrm{e}+001.19912 \mathrm{e}+00$ 1.19912e-01 1.00000e-09 2.12000e-01

$1.00000 \mathrm{e}-02$ 1.00000e-02 1.00000e-03 1.00000e-09 1.00000e-01

$1.00000 \mathrm{e}+001.00000 \mathrm{e}+001.00000 \mathrm{e}-011.00000 \mathrm{e}-091.00000 \mathrm{e}-01$

Element: 5057 \# of layers: 8

$\mathrm{Kx} \mathrm{Ky} \mathrm{Kz}$ Ss Por

3.00105e+01 3.00105e+01 3.00105e+00 1.00000e-09 7.00000e-02

$3.00105 \mathrm{e}+013.00105 \mathrm{e}+013.00105 \mathrm{e}+001.00000 \mathrm{e}-09$ 7.00000e-02

5.00000e-04 5.00000e-04 5.00000e-05 1.00000e-09 1.00000e-01

5.00000e-04 5.00000e-04 5.00000e-05 1.00000e-09 1.00000e-01

$1.19912 \mathrm{e}+001.19912 \mathrm{e}+001.19912 \mathrm{e}-01$ 1.00000e-09 2.12000e-01

$1.19912 \mathrm{e}+001.19912 \mathrm{e}+001.19912 \mathrm{e}-01$ 1.00000e-09 2.12000e-01

$1.00000 \mathrm{e}-02$ 1.00000e-02 1.00000e-03 1.00000e-09 1.00000e-01

$1.00000 \mathrm{e}+001.00000 \mathrm{e}+001.00000 \mathrm{e}-011.00000 \mathrm{e}-091.00000 \mathrm{e}-01$

Element: 5058 \# of layers: 7

$\mathrm{Kx} \mathrm{Ky} \mathrm{Kz}$ Ss Por

$2.66946 \mathrm{e}+002.66946 \mathrm{e}+00$ 2.66946e-01 1.00000e-09 2.12000e-01

$2.66946 \mathrm{e}+00$ 2.66946e+00 2.66946e-01 1.00000e-09 2.12000e-01

$2.66946 \mathrm{e}+00$ 2.66946e+00 2.66946e-01 1.00000e-09 2.12000e-01

$2.66946 \mathrm{e}+002.66946 \mathrm{e}+002.66946 \mathrm{e}-01$ 1.00000e-09 2.12000e-01

$2.66946 \mathrm{e}+002.66946 \mathrm{e}+002.66946 \mathrm{e}-01$ 1.00000e-09 2.12000e-01

$1.00000 \mathrm{e}-05$ 1.00000e-05 1.00000e-06 1.00000e-09 1.00000e-01

$1.00000 \mathrm{e}+001.00000 \mathrm{e}+001.00000 \mathrm{e}-01$ 1.00000e-09 1.00000e-01

Element: 5059 \# of layers: 7

$\mathrm{Kx} \mathrm{Ky} \mathrm{Kz}$ Ss Por

$2.66946 \mathrm{e}+002.66946 \mathrm{e}+00$ 2.66946e-01 1.00000e-09 2.12000e-01

$2.66946 \mathrm{e}+00$ 2.66946e+00 2.66946e-01 1.00000e-09 2.12000e-01

$2.66946 \mathrm{e}+002.66946 \mathrm{e}+00$ 2.66946e-01 1.00000e-09 2.12000e-01

$2.66946 \mathrm{e}+002.66946 \mathrm{e}+00$ 2.66946e-01 1.00000e-09 2.12000e-01

$2.66946 \mathrm{e}+002.66946 \mathrm{e}+00$ 2.66946e-01 1.00000e-09 2.12000e-01 
$1.00000 \mathrm{e}-05$ 1.00000e-05 1.00000e-06 1.00000e-09 1.00000e-01 $1.00000 \mathrm{e}+001.00000 \mathrm{e}+001.00000 \mathrm{e}-01$ 1.00000e-09 1.00000e-01 Element: 5060 \# of layers: 7

Kx Ky Kz Ss Por

2.73381e+00 2.73381e+00 2.73381e-01 1.00000e-09 2.12000e-01

$2.73381 \mathrm{e}+002.73381 \mathrm{e}+00$ 2.73381e-01 1.00000e-09 2.12000e-01

$2.73381 \mathrm{e}+002.73381 \mathrm{e}+00$ 2.73381e-01 1.00000e-09 2.12000e-01

$2.73381 \mathrm{e}+002.73381 \mathrm{e}+00$ 2.73381e-01 1.00000e-09 2.12000e-01

$2.73381 \mathrm{e}+002.73381 \mathrm{e}+00$ 2.73381e-01 1.00000e-09 2.12000e-01

$1.00000 \mathrm{e}-05$ 1.00000e-05 1.00000e-06 1.00000e-09 1.00000e-01

$1.00000 \mathrm{e}+001.00000 \mathrm{e}+001.00000 \mathrm{e}-011.00000 \mathrm{e}-091.00000 \mathrm{e}-01$

Element: 5061 \# of layers: 7

$\mathrm{Kx} \mathrm{Ky} \mathrm{Kz}$ Ss Por

$2.91066 \mathrm{e}+002.91066 \mathrm{e}+00$ 2.91066e-01 1.00000e-09 2.12000e-01

$2.91066 \mathrm{e}+002.91066 \mathrm{e}+00$ 2.91066e-01 1.00000e-09 2.12000e-01

$2.91066 \mathrm{e}+002.91066 \mathrm{e}+002.91066 \mathrm{e}-01$ 1.00000e-09 2.12000e-01

$2.91066 \mathrm{e}+002.91066 \mathrm{e}+002.91066 \mathrm{e}-01$ 1.00000e-09 2.12000e-01

$2.91066 \mathrm{e}+002.91066 \mathrm{e}+00$ 2.91066e-01 1.00000e-09 2.12000e-01

$1.00000 \mathrm{e}-05$ 1.00000e-05 1.00000e-06 1.00000e-09 1.00000e-01

$1.00000 \mathrm{e}+001.00000 \mathrm{e}+001.00000 \mathrm{e}-011.00000 \mathrm{e}-091.00000 \mathrm{e}-01$

Element: 5062 \# of layers: 3

$\mathrm{Kx} \mathrm{Ky} \mathrm{Kz}$ Ss Por

3.80573e+01 3.80573e+01 3.80573e+00 1.00000e-09 2.12000e-01

$3.80573 \mathrm{e}+013.80573 \mathrm{e}+013.80573 \mathrm{e}+00$ 1.00000e-09 2.12000e-01

1.00000e-06 1.00000e-06 1.00000e-06 1.00000e-09 5.00000e-02

Element: 5063 \# of layers: 3

$\mathrm{Kx} \mathrm{Ky} \mathrm{Kz}$ Ss Por

7.26113e+01 7.26113e+01 7.26113e+00 1.00000e-09 2.12000e-01

$7.26113 \mathrm{e}+01$ 7.26113e+01 7.26113e+00 1.00000e-09 2.12000e-01

1.00000e-06 1.00000e-06 1.00000e-06 1.00000e-09 5.00000e-02

Element: 5064 \# of layers: 3

$\mathrm{Kx} \mathrm{Ky} \mathrm{Kz}$ Ss Por

7.26113e+01 7.26113e+01 7.26113e+00 1.00000e-09 2.12000e-01

$7.26113 \mathrm{e}+01$ 7.26113e+01 7.26113e+00 1.00000e-09 2.12000e-01

1.00000e-06 1.00000e-06 1.00000e-06 1.00000e-09 5.00000e-02

Element: 5065 \# of layers: 2

Kx Ky Kz Ss Por

7.26113e+01 7.26113e+01 7.26113e+00 1.00000e-09 2.12000e-01

1.00000e-06 1.00000e-06 1.00000e-06 1.00000e-09 5.00000e-02

Element: 5066 \# of layers: 4

$\mathrm{Kx} \mathrm{Ky} \mathrm{Kz}$ Ss Por

$1.75344 \mathrm{e}+02$ 1.75344e+02 1.75344e+01 1.00000e-09 7.00000e-02

$1.75344 \mathrm{e}+021.75344 \mathrm{e}+02$ 1.75344e+01 1.00000e-09 7.00000e-02

7.00597e+00 7.00597e+00 7.00597e-01 1.00000e-09 2.12000e-01

1.00000e-06 1.00000e-06 1.00000e-06 1.00000e-09 5.00000e-02

Element: 5067 \# of layers: 3 
$\mathrm{Kx} \mathrm{Ky} \mathrm{Kz}$ Ss Por

$1.75344 \mathrm{e}+02$ 1.75344e+02 1.75344e+01 1.00000e-09 7.00000e-02

7.00597e+00 7.00597e+00 7.00597e-01 1.00000e-09 2.12000e-01

$1.00000 \mathrm{e}-06$ 1.00000e-06 1.00000e-06 1.00000e-09 5.00000e-02

Element: 5068 \# of layers: 3

$\mathrm{Kx} \mathrm{Ky} \mathrm{Kz}$ Ss Por

7.84907e+01 7.84907e+01 7.84907e+00 1.00000e-09 2.12000e-01

$7.84907 \mathrm{e}+01$ 7.84907e+01 7.84907e+00 1.00000e-09 2.12000e-01

1.00000e-06 1.00000e-06 1.00000e-06 1.00000e-09 5.00000e-02

Element: 5069 \# of layers: 3

$\mathrm{Kx} \mathrm{Ky} \mathrm{Kz}$ Ss Por

$1.28905 \mathrm{e}+02$ 1.28905e+02 1.28905e+01 1.00000e-09 2.12000e-01

$1.28905 \mathrm{e}+02$ 1.28905e+02 1.28905e+01 1.00000e-09 2.12000e-01

1.00000e-06 1.00000e-06 1.00000e-06 1.00000e-09 5.00000e-02

Element: 5070 \# of layers: 2

Kx Ky Kz Ss Por

7.26113e+01 7.26113e+01 7.26113e+00 1.00000e-09 2.12000e-01

1.00000e-06 1.00000e-06 1.00000e-06 1.00000e-09 5.00000e-02

Element: 5071 \# of layers: 4

$\mathrm{Kx} \mathrm{Ky} \mathrm{Kz}$ Ss Por

1.16148e+04 1.16148e+04 1.16148e+03 1.00000e-09 7.00000e-02

4.64095e+02 4.64095e+02 4.64095e+01 1.00000e-09 2.12000e-01

4.64095e+02 4.64095e+02 4.64095e+01 1.00000e-09 2.12000e-01

1.00000e-06 1.00000e-06 1.00000e-06 1.00000e-09 5.00000e-02

Element: 5072 \# of layers: 3

$\mathrm{Kx} \mathrm{Ky} \mathrm{Kz}$ Ss Por

$1.40925 \mathrm{e}+041.40925 \mathrm{e}+041.40925 \mathrm{e}+03$ 1.00000e-09 7.00000e-02

$5.63097 \mathrm{e}+02$ 5.63097e+02 5.63097e+01 1.00000e-09 2.12000e-01

1.00000e-06 1.00000e-06 1.00000e-06 1.00000e-09 5.00000e-02

Element: 5073 \# of layers: 3

$\mathrm{Kx} \mathrm{Ky} \mathrm{Kz}$ Ss Por

$1.40925 \mathrm{e}+04$ 1.40925e+04 1.40925e+03 1.00000e-09 7.00000e-02

$5.63097 \mathrm{e}+02$ 5.63097e+02 5.63097e+01 1.00000e-09 2.12000e-01

1.00000e-06 1.00000e-06 1.00000e-06 1.00000e-09 5.00000e-02

Element: 5074 \# of layers: 2

Kx Ky Kz Ss Por

$1.40925 \mathrm{e}+041.40925 \mathrm{e}+041.40925 \mathrm{e}+03$ 1.00000e-09 7.00000e-02

1.00000e-06 1.00000e-06 1.00000e-06 1.00000e-09 5.00000e-02

Element: 5075 \# of layers: 2

$\mathrm{Kx} \mathrm{Ky} \mathrm{Kz}$ Ss Por

1.35952e+04 1.35952e+04 1.35952e+03 1.00000e-09 7.00000e-02

1.00000e-06 1.00000e-06 1.00000e-06 1.00000e-09 5.00000e-02

Element: 5076 \# of layers: 2

$\mathrm{Kx} \mathrm{Ky} \mathrm{Kz}$ Ss Por

1.35952e+04 1.35952e+04 1.35952e+03 1.00000e-09 7.00000e-02

1.00000e-06 1.00000e-06 1.00000e-06 1.00000e-09 5.00000e-02 
Element: 5077 \# of layers: 3

$\mathrm{Kx} \mathrm{Ky} \mathrm{Kz}$ Ss Por

1.00696e+04 1.00696e+04 1.00696e+03 1.00000e-09 7.00000e-02

$4.02354 \mathrm{e}+02$ 4.02354e+02 4.02354e+01 1.00000e-09 2.12000e-01

1.00000e-06 1.00000e-06 1.00000e-06 1.00000e-09 5.00000e-02

Element: 5078 \# of layers: 3

Kx Ky Kz Ss Por

$1.16148 \mathrm{e}+04$ 1.16148e+04 1.16148e+03 1.00000e-09 7.00000e-02

4.64095e+02 4.64095e+02 4.64095e+01 1.00000e-09 2.12000e-01

1.00000e-06 1.00000e-06 1.00000e-06 1.00000e-09 5.00000e-02

Element: 5079 \# of layers: 3

Kx Ky Kz Ss Por

$1.40925 \mathrm{e}+04$ 1.40925e+04 1.40925e+03 1.00000e-09 7.00000e-02

$5.63097 \mathrm{e}+02$ 5.63097e+02 5.63097e+01 1.00000e-09 2.12000e-01

1.00000e-06 1.00000e-06 1.00000e-06 1.00000e-09 5.00000e-02

Element: 5080 \# of layers: 2

$\mathrm{Kx} \mathrm{Ky} \mathrm{Kz}$ Ss Por

$1.25906 \mathrm{e}+041.25906 \mathrm{e}+041.25906 \mathrm{e}+03$ 1.00000e-09 7.00000e-02 1.00000e-06 1.00000e-06 1.00000e-06 1.00000e-09 5.00000e-02

Element: 5081 \# of layers: 2

$\mathrm{Kx} \mathrm{Ky} \mathrm{Kz}$ Ss Por

$1.25906 \mathrm{e}+041.25906 \mathrm{e}+041.25906 \mathrm{e}+03$ 1.00000e-09 7.00000e-02

1.00000e-06 1.00000e-06 1.00000e-06 1.00000e-09 5.00000e-02

Element: 5082 \# of layers: 2

$\mathrm{Kx} \mathrm{Ky} \mathrm{Kz}$ Ss Por

$1.53485 \mathrm{e}+041.53485 \mathrm{e}+041.53485 \mathrm{e}+03$ 1.00000e-09 7.00000e-02

1.00000e-06 1.00000e-06 1.00000e-06 1.00000e-09 5.00000e-02

Element: 5083 \# of layers: 2

Kx Ky Kz Ss Por

$1.53485 \mathrm{e}+04$ 1.53485e+04 1.53485e+03 1.00000e-09 7.00000e-02

1.00000e-06 1.00000e-06 1.00000e-06 1.00000e-09 5.00000e-02

Element: 5084 \# of layers: 2

Kx Ky Kz Ss Por

$1.81903 \mathrm{e}+04$ 1.81903e+04 1.81903e+03 1.00000e-09 7.00000e-02

$1.00000 \mathrm{e}-06$ 1.00000e-06 1.00000e-06 1.00000e-09 5.00000e-02

Element: 5085 \# of layers: 2

Kx Ky Kz Ss Por

$1.81903 \mathrm{e}+041.81903 \mathrm{e}+04$ 1.81903e+03 1.00000e-09 7.00000e-02 1.00000e-06 1.00000e-06 1.00000e-06 1.00000e-09 5.00000e-02

Element: 5086 \# of layers: 2

$\mathrm{Kx} \mathrm{Ky} \mathrm{Kz}$ Ss Por

$1.47034 \mathrm{e}+041.47034 \mathrm{e}+041.47034 \mathrm{e}+03$ 1.00000e-09 7.00000e-02 1.00000e-06 1.00000e-06 1.00000e-06 1.00000e-09 5.00000e-02

Element: 5087 \# of layers: 2

$\mathrm{Kx} \mathrm{Ky} \mathrm{Kz}$ Ss Por

$1.25906 \mathrm{e}+041.25906 \mathrm{e}+041.25906 \mathrm{e}+03$ 1.00000e-09 7.00000e-02 
1.00000e-06 1.00000e-06 1.00000e-06 1.00000e-09 5.00000e-02

Element: 5088 \# of layers: 2

Kx Ky Kz Ss Por

$1.53485 \mathrm{e}+041.53485 \mathrm{e}+041.53485 \mathrm{e}+03$ 1.00000e-09 7.00000e-02

1.00000e-06 1.00000e-06 1.00000e-06 1.00000e-09 5.00000e-02

Element: 5089 \# of layers: 2

$\mathrm{Kx} \mathrm{Ky} \mathrm{Kz}$ Ss Por

$2.40945 \mathrm{e}+042.40945 \mathrm{e}+04$ 2.40945e+03 1.00000e-09 7.00000e-02

1.00000e-06 1.00000e-06 1.00000e-06 1.00000e-09 5.00000e-02

Element: 5090 \# of layers: 2

$\mathrm{Kx} \mathrm{Ky} \mathrm{Kz}$ Ss Por

$2.40945 \mathrm{e}+042.40945 \mathrm{e}+042.40945 \mathrm{e}+03$ 1.00000e-09 7.00000e-02

1.00000e-06 1.00000e-06 1.00000e-06 1.00000e-09 5.00000e-02

Element: 5091 \# of layers: 2

$\mathrm{Kx} \mathrm{Ky} \mathrm{Kz}$ Ss Por

3.18431e+04 3.18431e+04 3.18431e+03 1.00000e-09 7.00000e-02

1.00000e-06 1.00000e-06 1.00000e-06 1.00000e-09 5.00000e-02

Element: 5092 \# of layers: 2

$\mathrm{Kx} \mathrm{Ky} \mathrm{Kz}$ Ss Por

7.94114e+04 7.94114e+04 7.94114e+03 1.00000e-09 7.00000e-02

1.00000e-06 1.00000e-06 1.00000e-06 1.00000e-09 5.00000e-02

Element: 5093 \# of layers: 2

$\mathrm{Kx} \mathrm{Ky} \mathrm{Kz}$ Ss Por

7.94114e+04 7.94114e+04 7.94114e+03 1.00000e-09 7.00000e-02

1.00000e-06 1.00000e-06 1.00000e-06 1.00000e-09 5.00000e-02

Element: 5094 \# of layers: 2

$\mathrm{Kx} \mathrm{Ky} \mathrm{Kz}$ Ss Por

7.94114e+04 7.94114e+04 7.94114e+03 1.00000e-09 7.00000e-02

1.00000e-06 1.00000e-06 1.00000e-06 1.00000e-09 5.00000e-02

Element: 5095 \# of layers: 2

$\mathrm{Kx} \mathrm{Ky} \mathrm{Kz}$ Ss Por

3.65689e+04 3.65689e+04 3.65689e+03 1.00000e-09 7.00000e-02

1.00000e-06 1.00000e-06 1.00000e-06 1.00000e-09 5.00000e-02

Element: 5096 \# of layers: 2

$\mathrm{Kx} \mathrm{Ky} \mathrm{Kz}$ Ss Por

$2.40945 \mathrm{e}+042.40945 \mathrm{e}+042.40945 \mathrm{e}+03$ 1.00000e-09 7.00000e-02

1.00000e-06 1.00000e-06 1.00000e-06 1.00000e-09 5.00000e-02

Element: 5097 \# of layers: 2

$\mathrm{Kx} \mathrm{Ky} \mathrm{Kz}$ Ss Por

7.94114e+04 7.94114e+04 7.94114e+03 1.00000e-09 7.00000e-02

1.00000e-06 1.00000e-06 1.00000e-06 1.00000e-09 5.00000e-02

Element: 5098 \# of layers: 2

$\mathrm{Kx} \mathrm{Ky} \mathrm{Kz}$ Ss Por

$1.75100 \mathrm{e}+021.75100 \mathrm{e}+02$ 1.75100e+01 1.00000e-09 7.00000e-02

1.00000e-06 1.00000e-06 1.00000e-06 1.00000e-09 5.00000e-02

Element: 5099 \# of layers: 2 
$\mathrm{Kx} \mathrm{Ky} \mathrm{Kz}$ Ss Por

$1.75100 \mathrm{e}+02$ 1.75100e+02 1.75100e+01 1.00000e-09 7.00000e-02

1.00000e-06 1.00000e-06 1.00000e-06 1.00000e-09 5.00000e-02

Element: 5100 \# of layers: 3

$\mathrm{Kx} \mathrm{Ky} \mathrm{Kz}$ Ss Por

$1.70830 \mathrm{e}+02$ 1.70830e+02 1.70830e+01 1.00000e-09 7.00000e-02

$1.70830 \mathrm{e}+021.70830 \mathrm{e}+02$ 1.70830e+01 1.00000e-09 7.00000e-02

1.00000e-06 1.00000e-06 1.00000e-06 1.00000e-09 5.00000e-02

Element: 5101 \# of layers: 4

$\mathrm{Kx} \mathrm{Ky} \mathrm{Kz}$ Ss Por

2.50172e+02 2.50172e+02 2.50172e+01 1.00000e-09 7.00000e-02

$2.50172 \mathrm{e}+02$ 2.50172e+02 2.50172e+01 1.00000e-09 7.00000e-02

$1.00000 \mathrm{e}+001.00000 \mathrm{e}+001.00000 \mathrm{e}-01$ 1.00000e-09 1.00000e-01

1.00000e-06 1.00000e-06 1.00000e-06 1.00000e-09 5.00000e-02

Element: 5102 \# of layers: 3

Kx Ky Kz Ss Por

2.50172e+02 2.50172e+02 2.50172e+01 1.00000e-09 7.00000e-02 $1.00000 \mathrm{e}+001.00000 \mathrm{e}+001.00000 \mathrm{e}-011.00000 \mathrm{e}-091.00000 \mathrm{e}-01$

1.00000e-06 1.00000e-06 1.00000e-06 1.00000e-09 5.00000e-02

Element: 5103 \# of layers: 3

$\mathrm{Kx} \mathrm{Ky} \mathrm{Kz}$ Ss Por

$2.32008 \mathrm{e}+02$ 2.32008e+02 2.32008e+01 1.00000e-09 7.00000e-02

$1.00000 \mathrm{e}+001.00000 \mathrm{e}+001.00000 \mathrm{e}-011.00000 \mathrm{e}-091.00000 \mathrm{e}-01$

1.00000e-06 1.00000e-06 1.00000e-06 1.00000e-09 5.00000e-02

Element: 5104 \# of layers: 3

$\mathrm{Kx} \mathrm{Ky} \mathrm{Kz}$ Ss Por

$2.32008 \mathrm{e}+02$ 2.32008e+02 2.32008e+01 1.00000e-09 7.00000e-02

$1.00000 \mathrm{e}+001.00000 \mathrm{e}+001.00000 \mathrm{e}-011.00000 \mathrm{e}-091.00000 \mathrm{e}-01$

1.00000e-06 1.00000e-06 1.00000e-06 1.00000e-09 5.00000e-02

Element: 5105 \# of layers: 2

$\mathrm{Kx} \mathrm{Ky} \mathrm{Kz}$ Ss Por

$1.75100 \mathrm{e}+02$ 1.75100e+02 1.75100e+01 1.00000e-09 7.00000e-02

1.00000e-06 1.00000e-06 1.00000e-06 1.00000e-09 5.00000e-02

Element: 5106 \# of layers: 3

$\mathrm{Kx} \mathrm{Ky} \mathrm{Kz}$ Ss Por

2.50172e+02 2.50172e+02 2.50172e+01 1.00000e-09 7.00000e-02

$1.00000 \mathrm{e}+001.00000 \mathrm{e}+001.00000 \mathrm{e}-011.00000 \mathrm{e}-091.00000 \mathrm{e}-01$

1.00000e-06 1.00000e-06 1.00000e-06 1.00000e-09 5.00000e-02

Element: 5107 \# of layers: 4

$\mathrm{Kx} \mathrm{Ky} \mathrm{Kz}$ Ss Por

$2.65065 \mathrm{e}+02$ 2.65065e+02 2.65065e+01 1.00000e-09 7.00000e-02

$2.65065 \mathrm{e}+022.65065 \mathrm{e}+02$ 2.65065e+01 1.00000e-09 7.00000e-02

$1.00000 \mathrm{e}+001.00000 \mathrm{e}+001.00000 \mathrm{e}-011.00000 \mathrm{e}-091.00000 \mathrm{e}-01$

1.00000e-06 1.00000e-06 1.00000e-06 1.00000e-09 5.00000e-02

Element: 5108 \# of layers: 3

Kx Ky Kz Ss Por 
$1.93445 \mathrm{e}+02$ 1.93445e+02 1.93445e+01 1.00000e-09 7.00000e-02 $1.00000 \mathrm{e}+001.00000 \mathrm{e}+001.00000 \mathrm{e}-011.00000 \mathrm{e}-091.00000 \mathrm{e}-01$ 1.00000e-06 1.00000e-06 1.00000e-06 1.00000e-09 5.00000e-02

Element: 5109 \# of layers: 4

$\mathrm{Kx} \mathrm{Ky} \mathrm{Kz}$ Ss Por

$1.93445 \mathrm{e}+02$ 1.93445e+02 1.93445e+01 1.00000e-09 7.00000e-02 $1.00000 \mathrm{e}-05$ 1.00000e-05 1.00000e-06 1.00000e-09 1.00000e-01

$1.00000 \mathrm{e}+001.00000 \mathrm{e}+001.00000 \mathrm{e}-011.00000 \mathrm{e}-091.00000 \mathrm{e}-01$ 1.00000e-06 1.00000e-06 1.00000e-06 1.00000e-09 5.00000e-02

Element: 5110 \# of layers: 2

$\mathrm{Kx} \mathrm{Ky} \mathrm{Kz}$ Ss Por

$1.00000 \mathrm{e}+001.00000 \mathrm{e}+001.00000 \mathrm{e}-011.00000 \mathrm{e}-091.00000 \mathrm{e}-01$ 1.00000e-06 1.00000e-06 1.00000e-06 1.00000e-09 5.00000e-02

Element: 5111 \# of layers: 2

$\mathrm{Kx} \mathrm{Ky} \mathrm{Kz}$ Ss Por

$1.00000 \mathrm{e}+001.00000 \mathrm{e}+001.00000 \mathrm{e}-01$ 1.00000e-09 1.00000e-01

1.00000e-06 1.00000e-06 1.00000e-06 1.00000e-09 5.00000e-02

Element: 5112 \# of layers: 4

$\mathrm{Kx} \mathrm{Ky} \mathrm{Kz}$ Ss Por

6.46062e+02 6.46062e+02 6.46062e+01 1.00000e-09 7.00000e-02

$1.00000 \mathrm{e}-05$ 1.00000e-05 1.00000e-06 1.00000e-09 1.00000e-01

$1.00000 \mathrm{e}+001.00000 \mathrm{e}+001.00000 \mathrm{e}-011.00000 \mathrm{e}-091.00000 \mathrm{e}-01$

1.00000e-06 1.00000e-06 1.00000e-06 1.00000e-09 5.00000e-02

Element: 5113 \# of layers: 5

$\mathrm{Kx} \mathrm{Ky} \mathrm{Kz}$ Ss Por

6.46062e+02 6.46062e+02 6.46062e+01 1.00000e-09 7.00000e-02

$6.46062 \mathrm{e}+026.46062 \mathrm{e}+02$ 6.46062e+01 1.00000e-09 7.00000e-02

$1.00000 \mathrm{e}-05$ 1.00000e-05 1.00000e-06 1.00000e-09 1.00000e-01

$1.00000 \mathrm{e}+001.00000 \mathrm{e}+001.00000 \mathrm{e}-011.00000 \mathrm{e}-091.00000 \mathrm{e}-01$

1.00000e-06 1.00000e-06 1.00000e-06 1.00000e-09 5.00000e-02

Element: 5114 \# of layers: 3

$\mathrm{Kx} \mathrm{Ky} \mathrm{Kz}$ Ss Por

6.46062e+02 6.46062e+02 6.46062e+01 1.00000e-09 7.00000e-02

$1.00000 \mathrm{e}+001.00000 \mathrm{e}+001.00000 \mathrm{e}-011.00000 \mathrm{e}-091.00000 \mathrm{e}-01$

1.00000e-06 1.00000e-06 1.00000e-06 1.00000e-09 5.00000e-02

Element: 5115 \# of layers: 2

$\mathrm{Kx} \mathrm{Ky} \mathrm{Kz}$ Ss Por

$1.00000 \mathrm{e}+001.00000 \mathrm{e}+001.00000 \mathrm{e}-01$ 1.00000e-09 1.00000e-01

1.00000e-06 1.00000e-06 1.00000e-06 1.00000e-09 5.00000e-02

Element: 5116 \# of layers: 4

$\mathrm{Kx} \mathrm{Ky} \mathrm{Kz}$ Ss Por

6.96329e+01 6.96329e+01 6.96329e+00 1.00000e-09 7.00000e-02

$1.00000 \mathrm{e}-051.00000 \mathrm{e}-051.00000 \mathrm{e}-061.00000 \mathrm{e}-091.00000 \mathrm{e}-01$

$1.00000 \mathrm{e}+001.00000 \mathrm{e}+001.00000 \mathrm{e}-011.00000 \mathrm{e}-091.00000 \mathrm{e}-01$

1.00000e-06 1.00000e-06 1.00000e-06 1.00000e-09 5.00000e-02

Element: 5117 \# of layers: 4 
Kx Ky Kz Ss Por

$2.63615 \mathrm{e}+012.63615 \mathrm{e}+012.63615 \mathrm{e}+00$ 1.00000e-09 7.00000e-02

$1.00000 \mathrm{e}-05$ 1.00000e-05 1.00000e-06 1.00000e-09 1.00000e-01

$1.00000 \mathrm{e}+001.00000 \mathrm{e}+001.00000 \mathrm{e}-011.00000 \mathrm{e}-091.00000 \mathrm{e}-01$

1.00000e-06 1.00000e-06 1.00000e-06 1.00000e-09 5.00000e-02

Element: 5118 \# of layers: 4

$\mathrm{Kx} \mathrm{Ky} \mathrm{Kz}$ Ss Por

$2.63615 \mathrm{e}+012.63615 \mathrm{e}+012.63615 \mathrm{e}+001.00000 \mathrm{e}-09$ 7.00000e-02

$1.00000 \mathrm{e}-05$ 1.00000e-05 1.00000e-06 1.00000e-09 1.00000e-01

$1.00000 \mathrm{e}+001.00000 \mathrm{e}+001.00000 \mathrm{e}-01$ 1.00000e-09 1.00000e-01

1.00000e-06 1.00000e-06 1.00000e-06 1.00000e-09 5.00000e-02

Element: 5119 \# of layers: 4

$\mathrm{Kx} \mathrm{Ky} \mathrm{Kz}$ Ss Por

$2.63615 \mathrm{e}+012.63615 \mathrm{e}+012.63615 \mathrm{e}+00$ 1.00000e-09 7.00000e-02

$1.00000 \mathrm{e}-05$ 1.00000e-05 1.00000e-06 1.00000e-09 1.00000e-01

$1.00000 \mathrm{e}+001.00000 \mathrm{e}+001.00000 \mathrm{e}-011.00000 \mathrm{e}-091.00000 \mathrm{e}-01$

1.00000e-06 1.00000e-06 1.00000e-06 1.00000e-09 5.00000e-02

Element: 5120 \# of layers: 3

$\mathrm{Kx} \mathrm{Ky} \mathrm{Kz}$ Ss Por

3.96755e+01 3.96755e+01 3.96755e+00 1.00000e-09 7.00000e-02

$1.00000 \mathrm{e}+001.00000 \mathrm{e}+001.00000 \mathrm{e}-011.00000 \mathrm{e}-091.00000 \mathrm{e}-01$

1.00000e-06 1.00000e-06 1.00000e-06 1.00000e-09 5.00000e-02

Element: 5121 \# of layers: 3

Kx Ky Kz Ss Por

3.86160e+02 3.86160e+02 3.86160e+01 1.00000e-09 7.00000e-02

$1.00000 \mathrm{e}+001.00000 \mathrm{e}+001.00000 \mathrm{e}-011.00000 \mathrm{e}-091.00000 \mathrm{e}-01$

1.00000e-06 1.00000e-06 1.00000e-06 1.00000e-09 5.00000e-02

Element: 5122 \# of layers: 2

$\mathrm{Kx} \mathrm{Ky} \mathrm{Kz}$ Ss Por

$1.00000 \mathrm{e}+001.00000 \mathrm{e}+001.00000 \mathrm{e}-01$ 1.00000e-09 1.00000e-01

1.00000e-06 1.00000e-06 1.00000e-06 1.00000e-09 5.00000e-02

Element: 5123 \# of layers: 4

Kx Ky Kz Ss Por

6.96329e+01 6.96329e+01 6.96329e+00 1.00000e-09 7.00000e-02

$1.00000 \mathrm{e}-05$ 1.00000e-05 1.00000e-06 1.00000e-09 1.00000e-01

$1.00000 \mathrm{e}+001.00000 \mathrm{e}+001.00000 \mathrm{e}-011.00000 \mathrm{e}-091.00000 \mathrm{e}-01$

1.00000e-06 1.00000e-06 1.00000e-06 1.00000e-09 5.00000e-02

Element: 5124 \# of layers: 4

$\mathrm{Kx} \mathrm{Ky} \mathrm{Kz}$ Ss Por

6.96329e+01 6.96329e+01 6.96329e+00 1.00000e-09 7.00000e-02

$1.00000 \mathrm{e}-051.00000 \mathrm{e}-05$ 1.00000e-06 1.00000e-09 1.00000e-01

$1.00000 \mathrm{e}+001.00000 \mathrm{e}+001.00000 \mathrm{e}-011.00000 \mathrm{e}-091.00000 \mathrm{e}-01$

1.00000e-06 1.00000e-06 1.00000e-06 1.00000e-09 5.00000e-02

Element: 5125 \# of layers: 12

$\mathrm{Kx} \mathrm{Ky} \mathrm{Kz}$ Ss Por

5.96120e+00 5.96120e+00 5.96120e-01 1.00000e-09 7.00000e-02 
5.96120e+00 5.96120e+00 5.96120e-01 1.00000e-09 7.00000e-02 2.38190e-01 2.38190e-01 2.38190e-02 1.00000e-09 2.12000e-01 2.38190e-01 2.38190e-01 2.38190e-02 1.00000e-09 2.12000e-01 2.38190e-01 2.38190e-01 2.38190e-02 1.00000e-09 2.12000e-01 2.38190e-01 2.38190e-01 2.38190e-02 1.00000e-09 2.12000e-01 2.38190e-01 2.38190e-01 2.38190e-02 1.00000e-09 2.12000e-01 $1.00000 \mathrm{e}-02$ 1.00000e-02 1.00000e-03 1.00000e-09 1.00000e-01 $1.00000 \mathrm{e}+001.00000 \mathrm{e}+001.00000 \mathrm{e}-011.00000 \mathrm{e}-091.00000 \mathrm{e}-01$ $1.00000 \mathrm{e}-051.00000 \mathrm{e}-051.00000 \mathrm{e}-061.00000 \mathrm{e}-091.00000 \mathrm{e}-01$ $1.00000 \mathrm{e}+001.00000 \mathrm{e}+001.00000 \mathrm{e}-011.00000 \mathrm{e}-091.00000 \mathrm{e}-01$ 1.00000e-06 1.00000e-06 1.00000e-06 1.00000e-09 5.00000e-02 Element: 5126 \# of layers: 14

$\mathrm{Kx} \mathrm{Ky} \mathrm{Kz}$ Ss Por

5.96120e+00 5.96120e+00 5.96120e-01 1.00000e-09 7.00000e-02 $5.96120 \mathrm{e}+005.96120 \mathrm{e}+005.96120 \mathrm{e}-01$ 1.00000e-09 7.00000e-02 5.00000e-04 5.00000e-04 5.00000e-05 1.00000e-09 1.00000e-01 5.00000e-04 5.00000e-04 5.00000e-05 1.00000e-09 1.00000e-01 2.38190e-01 2.38190e-01 2.38190e-02 1.00000e-09 2.12000e-01 2.38190e-01 2.38190e-01 2.38190e-02 1.00000e-09 2.12000e-01 2.38190e-01 2.38190e-01 2.38190e-02 1.00000e-09 2.12000e-01 2.38190e-01 2.38190e-01 2.38190e-02 1.00000e-09 2.12000e-01 2.38190e-01 2.38190e-01 2.38190e-02 1.00000e-09 2.12000e-01 $1.00000 \mathrm{e}-02$ 1.00000e-02 1.00000e-03 1.00000e-09 1.00000e-01 $1.00000 \mathrm{e}+001.00000 \mathrm{e}+001.00000 \mathrm{e}-011.00000 \mathrm{e}-091.00000 \mathrm{e}-01$ $1.00000 \mathrm{e}-05$ 1.00000e-05 1.00000e-06 1.00000e-09 1.00000e-01 $1.00000 \mathrm{e}+001.00000 \mathrm{e}+001.00000 \mathrm{e}-011.00000 \mathrm{e}-091.00000 \mathrm{e}-01$ 1.00000e-06 1.00000e-06 1.00000e-06 1.00000e-09 5.00000e-02 Element: 5127 \# of layers: 15

$\mathrm{Kx} \mathrm{Ky} \mathrm{Kz}$ Ss Por

3.76645e+00 3.76645e+00 3.76645e-01 1.00000e-09 7.00000e-02 $3.76645 \mathrm{e}+003.76645 \mathrm{e}+00$ 3.76645e-01 1.00000e-09 7.00000e-02 $3.76645 \mathrm{e}+003.76645 \mathrm{e}+003.76645 \mathrm{e}-01$ 1.00000e-09 7.00000e-02 5.00000e-04 5.00000e-04 5.00000e-05 1.00000e-09 1.00000e-01 5.00000e-04 5.00000e-04 5.00000e-05 1.00000e-09 1.00000e-01 1.50495e-01 1.50495e-01 1.50495e-02 1.00000e-09 2.12000e-01 1.50495e-01 1.50495e-01 1.50495e-02 1.00000e-09 2.12000e-01 1.50495e-01 1.50495e-01 1.50495e-02 1.00000e-09 2.12000e-01 1.50495e-01 1.50495e-01 1.50495e-02 1.00000e-09 2.12000e-01 1.50495e-01 1.50495e-01 1.50495e-02 1.00000e-09 2.12000e-01 $1.00000 \mathrm{e}-02$ 1.00000e-02 1.00000e-03 1.00000e-09 1.00000e-01 $1.00000 \mathrm{e}+001.00000 \mathrm{e}+001.00000 \mathrm{e}-011.00000 \mathrm{e}-091.00000 \mathrm{e}-01$ $1.00000 \mathrm{e}-05$ 1.00000e-05 1.00000e-06 1.00000e-09 1.00000e-01 $1.00000 \mathrm{e}+001.00000 \mathrm{e}+001.00000 \mathrm{e}-011.00000 \mathrm{e}-091.00000 \mathrm{e}-01$ 1.00000e-06 1.00000e-06 1.00000e-06 1.00000e-09 5.00000e-02 Element: 5128 \# of layers: 15

Kx Ky Kz Ss Por 
$3.76645 \mathrm{e}+003.76645 \mathrm{e}+003.76645 \mathrm{e}-01$ 1.00000e-09 7.00000e-02 $3.76645 \mathrm{e}+003.76645 \mathrm{e}+003.76645 \mathrm{e}-011.00000 \mathrm{e}-09$ 7.00000e-02 $3.76645 \mathrm{e}+003.76645 \mathrm{e}+003.76645 \mathrm{e}-01$ 1.00000e-09 7.00000e-02 5.00000e-04 5.00000e-04 5.00000e-05 1.00000e-09 1.00000e-01 $5.00000 \mathrm{e}-04$ 5.00000e-04 5.00000e-05 1.00000e-09 1.00000e-01 $1.50495 \mathrm{e}-01$ 1.50495e-01 1.50495e-02 1.00000e-09 2.12000e-01 $1.50495 \mathrm{e}-01$ 1.50495e-01 1.50495e-02 1.00000e-09 2.12000e-01 $1.50495 \mathrm{e}-01$ 1.50495e-01 1.50495e-02 1.00000e-09 2.12000e-01 $1.50495 \mathrm{e}-01$ 1.50495e-01 1.50495e-02 1.00000e-09 2.12000e-01 $1.50495 \mathrm{e}-01$ 1.50495e-01 1.50495e-02 1.00000e-09 2.12000e-01 $1.00000 \mathrm{e}-021.00000 \mathrm{e}-02$ 1.00000e-03 1.00000e-09 1.00000e-01 $1.00000 \mathrm{e}+001.00000 \mathrm{e}+001.00000 \mathrm{e}-011.00000 \mathrm{e}-091.00000 \mathrm{e}-01$ $1.00000 \mathrm{e}-05$ 1.00000e-05 1.00000e-06 1.00000e-09 1.00000e-01 $1.00000 \mathrm{e}+001.00000 \mathrm{e}+001.00000 \mathrm{e}-011.00000 \mathrm{e}-091.00000 \mathrm{e}-01$ $1.00000 \mathrm{e}-06$ 1.00000e-06 1.00000e-06 1.00000e-09 5.00000e-02 Element: 5129 \# of layers: 15

Kx Ky Kz Ss Por

4.18641e+00 4.18641e+00 4.18641e-01 1.00000e-09 7.00000e-02 $4.18641 \mathrm{e}+004.18641 \mathrm{e}+004.18641 \mathrm{e}-011.00000 \mathrm{e}-09$ 7.00000e-02 $4.18641 \mathrm{e}+004.18641 \mathrm{e}+004.18641 \mathrm{e}-011.00000 \mathrm{e}-09$ 7.00000e-02 5.00000e-04 5.00000e-04 5.00000e-05 1.00000e-09 1.00000e-01 $5.00000 \mathrm{e}-04$ 5.00000e-04 5.00000e-05 1.00000e-09 1.00000e-01 1.67273e-01 1.67273e-01 1.67273e-02 1.00000e-09 2.12000e-01 $1.67273 \mathrm{e}-01$ 1.67273e-01 1.67273e-02 1.00000e-09 2.12000e-01 1.67273e-01 1.67273e-01 1.67273e-02 1.00000e-09 2.12000e-01 1.67273e-01 1.67273e-01 1.67273e-02 1.00000e-09 2.12000e-01 $1.67273 \mathrm{e}-01$ 1.67273e-01 1.67273e-02 1.00000e-09 2.12000e-01 $1.00000 \mathrm{e}-021.00000 \mathrm{e}-02$ 1.00000e-03 1.00000e-09 1.00000e-01 $1.00000 \mathrm{e}+001.00000 \mathrm{e}+001.00000 \mathrm{e}-011.00000 \mathrm{e}-091.00000 \mathrm{e}-01$ $1.00000 \mathrm{e}-05$ 1.00000e-05 1.00000e-06 1.00000e-09 1.00000e-01 $1.00000 \mathrm{e}+001.00000 \mathrm{e}+001.00000 \mathrm{e}-011.00000 \mathrm{e}-091.00000 \mathrm{e}-01$ 1.00000e-06 1.00000e-06 1.00000e-06 1.00000e-09 5.00000e-02 Element: 5130 \# of layers: 13

Kx Ky Kz Ss Por

4.69349e+00 4.69349e+00 4.69349e-01 1.00000e-09 7.00000e-02 $4.69349 \mathrm{e}+004.69349 \mathrm{e}+00$ 4.69349e-01 1.00000e-09 7.00000e-02 4.69349e+00 4.69349e+00 4.69349e-01 1.00000e-09 7.00000e-02 $1.87535 \mathrm{e}-011.87535 \mathrm{e}-011.87535 \mathrm{e}-021.00000 \mathrm{e}-092.12000 \mathrm{e}-01$ $1.87535 \mathrm{e}-01$ 1.87535e-01 1.87535e-02 1.00000e-09 2.12000e-01 $1.87535 \mathrm{e}-01$ 1.87535e-01 1.87535e-02 1.00000e-09 2.12000e-01 $1.87535 \mathrm{e}-011.87535 \mathrm{e}-011.87535 \mathrm{e}-021.00000 \mathrm{e}-092.12000 \mathrm{e}-01$ $1.87535 \mathrm{e}-01$ 1.87535e-01 1.87535e-02 1.00000e-09 2.12000e-01 $1.00000 \mathrm{e}-02$ 1.00000e-02 1.00000e-03 1.00000e-09 1.00000e-01 $1.00000 \mathrm{e}+001.00000 \mathrm{e}+001.00000 \mathrm{e}-011.00000 \mathrm{e}-091.00000 \mathrm{e}-01$ $1.00000 \mathrm{e}-05$ 1.00000e-05 1.00000e-06 1.00000e-09 1.00000e-01 $1.00000 \mathrm{e}+001.00000 \mathrm{e}+001.00000 \mathrm{e}-011.00000 \mathrm{e}-091.00000 \mathrm{e}-01$ 
1.00000e-06 1.00000e-06 1.00000e-06 1.00000e-09 5.00000e-02

Element: 5131 \# of layers: 13

Kx Ky Kz Ss Por

4.69349e+00 4.69349e+00 4.69349e-01 1.00000e-09 7.00000e-02 $4.69349 \mathrm{e}+00$ 4.69349e+00 4.69349e-01 1.00000e-09 7.00000e-02

4.69349e+00 4.69349e+00 4.69349e-01 1.00000e-09 7.00000e-02

$1.87535 \mathrm{e}-01$ 1.87535e-01 1.87535e-02 1.00000e-09 2.12000e-01

$1.87535 \mathrm{e}-011.87535 \mathrm{e}-01$ 1.87535e-02 1.00000e-09 2.12000e-01

$1.87535 \mathrm{e}-01$ 1.87535e-01 1.87535e-02 1.00000e-09 2.12000e-01

1.87535e-01 1.87535e-01 1.87535e-02 1.00000e-09 2.12000e-01

$1.87535 \mathrm{e}-01$ 1.87535e-01 1.87535e-02 1.00000e-09 2.12000e-01

$1.00000 \mathrm{e}-02$ 1.00000e-02 1.00000e-03 1.00000e-09 1.00000e-01

$1.00000 \mathrm{e}+001.00000 \mathrm{e}+001.00000 \mathrm{e}-011.00000 \mathrm{e}-091.00000 \mathrm{e}-01$

$1.00000 \mathrm{e}-05$ 1.00000e-05 1.00000e-06 1.00000e-09 1.00000e-01

$1.00000 \mathrm{e}+001.00000 \mathrm{e}+001.00000 \mathrm{e}-011.00000 \mathrm{e}-091.00000 \mathrm{e}-01$ 1.00000e-06 1.00000e-06 1.00000e-06 1.00000e-09 5.00000e-02

Element: 5132 \# of layers: 13

$\mathrm{Kx} \mathrm{Ky} \mathrm{Kz}$ Ss Por

4.69349e+00 4.69349e+00 4.69349e-01 1.00000e-09 7.00000e-02

$4.69349 \mathrm{e}+00$ 4.69349e+00 4.69349e-01 1.00000e-09 7.00000e-02

$4.69349 \mathrm{e}+004.69349 \mathrm{e}+00$ 4.69349e-01 1.00000e-09 7.00000e-02

1.87535e-01 1.87535e-01 1.87535e-02 1.00000e-09 2.12000e-01

$1.87535 \mathrm{e}-01$ 1.87535e-01 1.87535e-02 1.00000e-09 2.12000e-01

1.87535e-01 1.87535e-01 1.87535e-02 1.00000e-09 2.12000e-01

$1.87535 \mathrm{e}-01$ 1.87535e-01 1.87535e-02 1.00000e-09 2.12000e-01

$1.87535 \mathrm{e}-01$ 1.87535e-01 1.87535e-02 1.00000e-09 2.12000e-01

$1.00000 \mathrm{e}-02$ 1.00000e-02 1.00000e-03 1.00000e-09 1.00000e-01

$1.00000 \mathrm{e}+001.00000 \mathrm{e}+001.00000 \mathrm{e}-01$ 1.00000e-09 1.00000e-01

$1.00000 \mathrm{e}-05$ 1.00000e-05 1.00000e-06 1.00000e-09 1.00000e-01

$1.00000 \mathrm{e}+001.00000 \mathrm{e}+001.00000 \mathrm{e}-011.00000 \mathrm{e}-091.00000 \mathrm{e}-01$

1.00000e-06 1.00000e-06 1.00000e-06 1.00000e-09 5.00000e-02

Element: 5133 \# of layers: 14

Kx Ky Kz Ss Por

$5.96120 \mathrm{e}+005.96120 \mathrm{e}+005.96120 \mathrm{e}-011.00000 \mathrm{e}-097.00000 \mathrm{e}-02$

$5.96120 \mathrm{e}+005.96120 \mathrm{e}+00$ 5.96120e-01 1.00000e-09 7.00000e-02

$5.96120 \mathrm{e}+005.96120 \mathrm{e}+00$ 5.96120e-01 1.00000e-09 7.00000e-02

5.00000e-04 5.00000e-04 5.00000e-05 1.00000e-09 1.00000e-01

2.38190e-01 2.38190e-01 2.38190e-02 1.00000e-09 2.12000e-01

2.38190e-01 2.38190e-01 2.38190e-02 1.00000e-09 2.12000e-01

2.38190e-01 2.38190e-01 2.38190e-02 1.00000e-09 2.12000e-01

2.38190e-01 2.38190e-01 2.38190e-02 1.00000e-09 2.12000e-01

2.38190e-01 2.38190e-01 2.38190e-02 1.00000e-09 2.12000e-01

$1.00000 \mathrm{e}-021.00000 \mathrm{e}-021.00000 \mathrm{e}-031.00000 \mathrm{e}-091.00000 \mathrm{e}-01$

$1.00000 \mathrm{e}+001.00000 \mathrm{e}+001.00000 \mathrm{e}-011.00000 \mathrm{e}-091.00000 \mathrm{e}-01$ $1.00000 \mathrm{e}-05$ 1.00000e-05 1.00000e-06 1.00000e-09 1.00000e-01

$1.00000 \mathrm{e}+001.00000 \mathrm{e}+001.00000 \mathrm{e}-011.00000 \mathrm{e}-091.00000 \mathrm{e}-01$ 
1.00000e-06 1.00000e-06 1.00000e-06 1.00000e-09 5.00000e-02

Element: 5134 \# of layers: 14

Kx Ky Kz Ss Por

4.24975e+00 4.24975e+00 4.24975e-01 1.00000e-09 7.00000e-02 $4.24975 \mathrm{e}+00$ 4.24975e+00 4.24975e-01 1.00000e-09 7.00000e-02

5.00000e-04 5.00000e-04 5.00000e-05 1.00000e-09 1.00000e-01

5.00000e-04 5.00000e-04 5.00000e-05 1.00000e-09 1.00000e-01

1.69807e-01 1.69807e-01 1.69807e-02 1.00000e-09 2.12000e-01

1.69807e-01 1.69807e-01 1.69807e-02 1.00000e-09 2.12000e-01

1.69807e-01 1.69807e-01 1.69807e-02 1.00000e-09 2.12000e-01

1.69807e-01 1.69807e-01 1.69807e-02 1.00000e-09 2.12000e-01

1.69807e-01 1.69807e-01 1.69807e-02 1.00000e-09 2.12000e-01

$1.00000 \mathrm{e}-02$ 1.00000e-02 1.00000e-03 1.00000e-09 1.00000e-01

$1.00000 \mathrm{e}+001.00000 \mathrm{e}+001.00000 \mathrm{e}-011.00000 \mathrm{e}-091.00000 \mathrm{e}-01$

$1.00000 \mathrm{e}-05$ 1.00000e-05 1.00000e-06 1.00000e-09 1.00000e-01

$1.00000 \mathrm{e}+001.00000 \mathrm{e}+001.00000 \mathrm{e}-011.00000 \mathrm{e}-091.00000 \mathrm{e}-01$

1.00000e-06 1.00000e-06 1.00000e-06 1.00000e-09 5.00000e-02

Element: 5135 \# of layers: 14

$\mathrm{Kx} \mathrm{Ky} \mathrm{Kz}$ Ss Por

5.20760e+00 5.20760e+00 5.20760e-01 1.00000e-09 7.00000e-02

$5.20760 \mathrm{e}+005.20760 \mathrm{e}+00$ 5.20760e-01 1.00000e-09 7.00000e-02

5.00000e-04 5.00000e-04 5.00000e-05 1.00000e-09 1.00000e-01

5.00000e-04 5.00000e-04 5.00000e-05 1.00000e-09 1.00000e-01

2.08075e-01 2.08075e-01 2.08075e-02 1.00000e-09 2.12000e-01

2.08075e-01 2.08075e-01 2.08075e-02 1.00000e-09 2.12000e-01

2.08075e-01 2.08075e-01 2.08075e-02 1.00000e-09 2.12000e-01

2.08075e-01 2.08075e-01 2.08075e-02 1.00000e-09 2.12000e-01

2.08075e-01 2.08075e-01 2.08075e-02 1.00000e-09 2.12000e-01

$1.00000 \mathrm{e}-02$ 1.00000e-02 1.00000e-03 1.00000e-09 1.00000e-01

$1.00000 \mathrm{e}+001.00000 \mathrm{e}+001.00000 \mathrm{e}-011.00000 \mathrm{e}-091.00000 \mathrm{e}-01$

$1.00000 \mathrm{e}-05$ 1.00000e-05 1.00000e-06 1.00000e-09 1.00000e-01

$1.00000 \mathrm{e}+001.00000 \mathrm{e}+001.00000 \mathrm{e}-011.00000 \mathrm{e}-091.00000 \mathrm{e}-01$

1.00000e-06 1.00000e-06 1.00000e-06 1.00000e-09 5.00000e-02

Element: 5136 \# of layers: 13

$\mathrm{Kx} \mathrm{Ky} \mathrm{Kz}$ Ss Por

5.20760e+00 5.20760e+00 5.20760e-01 1.00000e-09 7.00000e-02

$5.20760 \mathrm{e}+005.20760 \mathrm{e}+00$ 5.20760e-01 1.00000e-09 7.00000e-02

5.00000e-04 5.00000e-04 5.00000e-05 1.00000e-09 1.00000e-01

2.08075e-01 2.08075e-01 2.08075e-02 1.00000e-09 2.12000e-01

2.08075e-01 2.08075e-01 2.08075e-02 1.00000e-09 2.12000e-01

2.08075e-01 2.08075e-01 2.08075e-02 1.00000e-09 2.12000e-01

2.08075e-01 2.08075e-01 2.08075e-02 1.00000e-09 2.12000e-01

2.08075e-01 2.08075e-01 2.08075e-02 1.00000e-09 2.12000e-01

$1.00000 \mathrm{e}-02$ 1.00000e-02 1.00000e-03 1.00000e-09 1.00000e-01

$1.00000 \mathrm{e}+001.00000 \mathrm{e}+001.00000 \mathrm{e}-011.00000 \mathrm{e}-091.00000 \mathrm{e}-01$

$1.00000 \mathrm{e}-05$ 1.00000e-05 1.00000e-06 1.00000e-09 1.00000e-01 
$1.00000 \mathrm{e}+001.00000 \mathrm{e}+001.00000 \mathrm{e}-011.00000 \mathrm{e}-091.00000 \mathrm{e}-01$ 1.00000e-06 1.00000e-06 1.00000e-06 1.00000e-09 5.00000e-02 Element: 5137 \# of layers: 14

$\mathrm{Kx} \mathrm{Ky} \mathrm{Kz}$ Ss Por

5.20760e+00 5.20760e+00 5.20760e-01 1.00000e-09 7.00000e-02

$5.20760 \mathrm{e}+005.20760 \mathrm{e}+005.20760 \mathrm{e}-01$ 1.00000e-09 7.00000e-02

5.00000e-04 5.00000e-04 5.00000e-05 1.00000e-09 1.00000e-01

5.00000e-04 5.00000e-04 5.00000e-05 1.00000e-09 1.00000e-01

2.08075e-01 2.08075e-01 2.08075e-02 1.00000e-09 2.12000e-01

2.08075e-01 2.08075e-01 2.08075e-02 1.00000e-09 2.12000e-01

2.08075e-01 2.08075e-01 2.08075e-02 1.00000e-09 2.12000e-01

2.08075e-01 2.08075e-01 2.08075e-02 1.00000e-09 2.12000e-01

2.08075e-01 2.08075e-01 2.08075e-02 1.00000e-09 2.12000e-01

$1.00000 \mathrm{e}-02$ 1.00000e-02 1.00000e-03 1.00000e-09 1.00000e-01

$1.00000 \mathrm{e}+001.00000 \mathrm{e}+001.00000 \mathrm{e}-011.00000 \mathrm{e}-091.00000 \mathrm{e}-01$ $1.00000 \mathrm{e}-05$ 1.00000e-05 1.00000e-06 1.00000e-09 1.00000e-01

$1.00000 \mathrm{e}+001.00000 \mathrm{e}+001.00000 \mathrm{e}-011.00000 \mathrm{e}-091.00000 \mathrm{e}-01$ 1.00000e-06 1.00000e-06 1.00000e-06 1.00000e-09 5.00000e-02

Element: 5138 \# of layers: 12

$\mathrm{Kx} \mathrm{Ky} \mathrm{Kz}$ Ss Por

4.63015e+00 4.63015e+00 4.63015e-01 1.00000e-09 7.00000e-02 $4.63015 \mathrm{e}+00$ 4.63015e+00 4.63015e-01 1.00000e-09 7.00000e-02 $4.63015 \mathrm{e}+00$ 4.63015e+00 4.63015e-01 1.00000e-09 7.00000e-02 5.00000e-04 5.00000e-04 5.00000e-05 1.00000e-09 1.00000e-01 5.00000e-04 5.00000e-04 5.00000e-05 1.00000e-09 1.00000e-01 $1.85003 \mathrm{e}-01$ 1.85003e-01 1.85003e-02 1.00000e-09 2.12000e-01 1.85003e-01 1.85003e-01 1.85003e-02 1.00000e-09 2.12000e-01 1.85003e-01 1.85003e-01 1.85003e-02 1.00000e-09 2.12000e-01 1.85003e-01 1.85003e-01 1.85003e-02 1.00000e-09 2.12000e-01 1.85003e-01 1.85003e-01 1.85003e-02 1.00000e-09 2.12000e-01 $1.00000 \mathrm{e}-02$ 1.00000e-02 1.00000e-03 1.00000e-09 1.00000e-01 1.00000e-06 1.00000e-06 1.00000e-06 1.00000e-09 5.00000e-02 Element: 5139 \# of layers: 11

$\mathrm{Kx} \mathrm{Ky} \mathrm{Kz}$ Ss Por

4.63015e+00 4.63015e+00 4.63015e-01 1.00000e-09 7.00000e-02 $4.63015 \mathrm{e}+004.63015 \mathrm{e}+00$ 4.63015e-01 1.00000e-09 7.00000e-02 $4.63015 \mathrm{e}+004.63015 \mathrm{e}+004.63015 \mathrm{e}-01$ 1.00000e-09 7.00000e-02 5.00000e-04 5.00000e-04 5.00000e-05 1.00000e-09 1.00000e-01 1.85003e-01 1.85003e-01 1.85003e-02 1.00000e-09 2.12000e-01 1.85003e-01 1.85003e-01 1.85003e-02 1.00000e-09 2.12000e-01 1.85003e-01 1.85003e-01 1.85003e-02 1.00000e-09 2.12000e-01 1.85003e-01 1.85003e-01 1.85003e-02 1.00000e-09 2.12000e-01 1.85003e-01 1.85003e-01 1.85003e-02 1.00000e-09 2.12000e-01 $1.00000 \mathrm{e}-02$ 1.00000e-02 1.00000e-03 1.00000e-09 1.00000e-01 $1.00000 \mathrm{e}-06$ 1.00000e-06 1.00000e-06 1.00000e-09 5.00000e-02 Element: 5140 \# of layers: 13 
Kx Ky Kz Ss Por

4.06144e+00 4.06144e+00 4.06144e-01 1.00000e-09 7.00000e-02 $4.06144 \mathrm{e}+004.06144 \mathrm{e}+004.06144 \mathrm{e}-01$ 1.00000e-09 7.00000e-02 $4.06144 \mathrm{e}+004.06144 \mathrm{e}+004.06144 \mathrm{e}-01$ 1.00000e-09 7.00000e-02 5.00000e-04 5.00000e-04 5.00000e-05 1.00000e-09 1.00000e-01 5.00000e-04 5.00000e-04 5.00000e-05 1.00000e-09 1.00000e-01 1.62280e-01 1.62280e-01 1.62280e-02 1.00000e-09 2.12000e-01 $1.62280 \mathrm{e}-01$ 1.62280e-01 1.62280e-02 1.00000e-09 2.12000e-01 $1.62280 \mathrm{e}-01$ 1.62280e-01 1.62280e-02 1.00000e-09 2.12000e-01 $1.62280 \mathrm{e}-01$ 1.62280e-01 1.62280e-02 1.00000e-09 2.12000e-01 $1.62280 \mathrm{e}-01$ 1.62280e-01 1.62280e-02 1.00000e-09 2.12000e-01 $1.00000 \mathrm{e}-02$ 1.00000e-02 1.00000e-03 1.00000e-09 1.00000e-01 $1.00000 \mathrm{e}+001.00000 \mathrm{e}+001.00000 \mathrm{e}-011.00000 \mathrm{e}-091.00000 \mathrm{e}-01$ 1.00000e-06 1.00000e-06 1.00000e-06 1.00000e-09 5.00000e-02 Element: 5141 \# of layers: 14

Kx Ky Kz Ss Por

4.24975e+00 4.24975e+00 4.24975e-01 1.00000e-09 7.00000e-02 4.24975e+00 4.24975e+00 4.24975e-01 1.00000e-09 7.00000e-02 5.00000e-04 5.00000e-04 5.00000e-05 1.00000e-09 1.00000e-01 5.00000e-04 5.00000e-04 5.00000e-05 1.00000e-09 1.00000e-01 1.69807e-01 1.69807e-01 1.69807e-02 1.00000e-09 2.12000e-01 1.69807e-01 1.69807e-01 1.69807e-02 1.00000e-09 2.12000e-01 1.69807e-01 1.69807e-01 1.69807e-02 1.00000e-09 2.12000e-01 1.69807e-01 1.69807e-01 1.69807e-02 1.00000e-09 2.12000e-01 1.69807e-01 1.69807e-01 1.69807e-02 1.00000e-09 2.12000e-01 $1.00000 \mathrm{e}-02$ 1.00000e-02 1.00000e-03 1.00000e-09 1.00000e-01 $1.00000 \mathrm{e}+001.00000 \mathrm{e}+001.00000 \mathrm{e}-011.00000 \mathrm{e}-091.00000 \mathrm{e}-01$ $1.00000 \mathrm{e}-05$ 1.00000e-05 1.00000e-06 1.00000e-09 1.00000e-01 $1.00000 \mathrm{e}+001.00000 \mathrm{e}+001.00000 \mathrm{e}-011.00000 \mathrm{e}-091.00000 \mathrm{e}-01$ 1.00000e-06 1.00000e-06 1.00000e-06 1.00000e-09 5.00000e-02 Element: 5142 \# of layers: 13

$\mathrm{Kx} \mathrm{Ky} \mathrm{Kz}$ Ss Por

5.20760e+00 5.20760e+00 5.20760e-01 1.00000e-09 7.00000e-02 $5.20760 \mathrm{e}+005.20760 \mathrm{e}+00$ 5.20760e-01 1.00000e-09 7.00000e-02 5.00000e-04 5.00000e-04 5.00000e-05 1.00000e-09 1.00000e-01 2.08075e-01 2.08075e-01 2.08075e-02 1.00000e-09 2.12000e-01 2.08075e-01 2.08075e-01 2.08075e-02 1.00000e-09 2.12000e-01 2.08075e-01 2.08075e-01 2.08075e-02 1.00000e-09 2.12000e-01 2.08075e-01 2.08075e-01 2.08075e-02 1.00000e-09 2.12000e-01 2.08075e-01 2.08075e-01 2.08075e-02 1.00000e-09 2.12000e-01 $1.00000 \mathrm{e}-021.00000 \mathrm{e}-02$ 1.00000e-03 1.00000e-09 1.00000e-01 $1.00000 \mathrm{e}+001.00000 \mathrm{e}+001.00000 \mathrm{e}-011.00000 \mathrm{e}-091.00000 \mathrm{e}-01$ $1.00000 \mathrm{e}-05$ 1.00000e-05 1.00000e-06 1.00000e-09 1.00000e-01 $1.00000 \mathrm{e}+001.00000 \mathrm{e}+001.00000 \mathrm{e}-011.00000 \mathrm{e}-091.00000 \mathrm{e}-01$ 1.00000e-06 1.00000e-06 1.00000e-06 1.00000e-09 5.00000e-02 Element: 5143 \# of layers: 12 
Kx Ky Kz Ss Por

6.22122e+00 6.22122e+00 6.22122e-01 1.00000e-09 7.00000e-02 5.00000e-04 5.00000e-04 5.00000e-05 1.00000e-09 1.00000e-01 2.48585e-01 2.48585e-01 2.48585e-02 1.00000e-09 2.12000e-01 2.48585e-01 2.48585e-01 2.48585e-02 1.00000e-09 2.12000e-01

2.48585e-01 2.48585e-01 2.48585e-02 1.00000e-09 2.12000e-01 2.48585e-01 2.48585e-01 2.48585e-02 1.00000e-09 2.12000e-01 2.48585e-01 2.48585e-01 2.48585e-02 1.00000e-09 2.12000e-01 $1.00000 \mathrm{e}-02$ 1.00000e-02 1.00000e-03 1.00000e-09 1.00000e-01 $1.00000 \mathrm{e}+001.00000 \mathrm{e}+001.00000 \mathrm{e}-011.00000 \mathrm{e}-091.00000 \mathrm{e}-01$ $1.00000 \mathrm{e}-05$ 1.00000e-05 1.00000e-06 1.00000e-09 1.00000e-01 $1.00000 \mathrm{e}+001.00000 \mathrm{e}+001.00000 \mathrm{e}-011.00000 \mathrm{e}-091.00000 \mathrm{e}-01$ 1.00000e-06 1.00000e-06 1.00000e-06 1.00000e-09 5.00000e-02 Element: 5144 \# of layers: 13

$\mathrm{Kx} \mathrm{Ky} \mathrm{Kz}$ Ss Por

5.33104e+00 5.33104e+00 5.33104e-01 1.00000e-09 7.00000e-02 5.00000e-04 5.00000e-04 5.00000e-05 1.00000e-09 1.00000e-01 5.00000e-04 5.00000e-04 5.00000e-05 1.00000e-09 1.00000e-01 2.13010e-01 2.13010e-01 2.13010e-02 1.00000e-09 2.12000e-01 2.13010e-01 2.13010e-01 2.13010e-02 1.00000e-09 2.12000e-01 2.13010e-01 2.13010e-01 2.13010e-02 1.00000e-09 2.12000e-01 2.13010e-01 2.13010e-01 2.13010e-02 1.00000e-09 2.12000e-01 2.13010e-01 2.13010e-01 2.13010e-02 1.00000e-09 2.12000e-01 $1.00000 \mathrm{e}-02$ 1.00000e-02 1.00000e-03 1.00000e-09 1.00000e-01 $1.00000 \mathrm{e}+001.00000 \mathrm{e}+001.00000 \mathrm{e}-011.00000 \mathrm{e}-091.00000 \mathrm{e}-01$ $1.00000 \mathrm{e}-05$ 1.00000e-05 1.00000e-06 1.00000e-09 1.00000e-01 $1.00000 \mathrm{e}+001.00000 \mathrm{e}+001.00000 \mathrm{e}-011.00000 \mathrm{e}-091.00000 \mathrm{e}-01$ 1.00000e-06 1.00000e-06 1.00000e-06 1.00000e-09 5.00000e-02 Element: 5145 \# of layers: 13

$\mathrm{Kx} \mathrm{Ky} \mathrm{Kz}$ Ss Por

5.33104e+00 5.33104e+00 5.33104e-01 1.00000e-09 7.00000e-02 5.00000e-04 5.00000e-04 5.00000e-05 1.00000e-09 1.00000e-01 5.00000e-04 5.00000e-04 5.00000e-05 1.00000e-09 1.00000e-01 2.13010e-01 2.13010e-01 2.13010e-02 1.00000e-09 2.12000e-01 2.13010e-01 2.13010e-01 2.13010e-02 1.00000e-09 2.12000e-01 2.13010e-01 2.13010e-01 2.13010e-02 1.00000e-09 2.12000e-01 2.13010e-01 2.13010e-01 2.13010e-02 1.00000e-09 2.12000e-01 2.13010e-01 2.13010e-01 2.13010e-02 1.00000e-09 2.12000e-01 $1.00000 \mathrm{e}-021.00000 \mathrm{e}-02$ 1.00000e-03 1.00000e-09 1.00000e-01 $1.00000 \mathrm{e}+001.00000 \mathrm{e}+001.00000 \mathrm{e}-011.00000 \mathrm{e}-091.00000 \mathrm{e}-01$ $1.00000 \mathrm{e}-05$ 1.00000e-05 1.00000e-06 1.00000e-09 1.00000e-01 $1.00000 \mathrm{e}+001.00000 \mathrm{e}+001.00000 \mathrm{e}-011.00000 \mathrm{e}-091.00000 \mathrm{e}-01$ 1.00000e-06 1.00000e-06 1.00000e-06 1.00000e-09 5.00000e-02 Element: 5146 \# of layers: 12

$\mathrm{Kx} \mathrm{Ky} \mathrm{Kz}$ Ss Por

5.33104e+00 5.33104e+00 5.33104e-01 1.00000e-09 7.00000e-02 
5.33104e+00 5.33104e+00 5.33104e-01 1.00000e-09 7.00000e-02 5.00000e-04 5.00000e-04 5.00000e-05 1.00000e-09 1.00000e-01 5.00000e-04 5.00000e-04 5.00000e-05 1.00000e-09 1.00000e-01 2.13010e-01 2.13010e-01 2.13010e-02 1.00000e-09 2.12000e-01 2.13010e-01 2.13010e-01 2.13010e-02 1.00000e-09 2.12000e-01 2.13010e-01 2.13010e-01 2.13010e-02 1.00000e-09 2.12000e-01 2.13010e-01 2.13010e-01 2.13010e-02 1.00000e-09 2.12000e-01 2.13010e-01 2.13010e-01 2.13010e-02 1.00000e-09 2.12000e-01 $1.00000 \mathrm{e}-02$ 1.00000e-02 1.00000e-03 1.00000e-09 1.00000e-01 $1.00000 \mathrm{e}+001.00000 \mathrm{e}+001.00000 \mathrm{e}-011.00000 \mathrm{e}-091.00000 \mathrm{e}-01$ 1.00000e-06 1.00000e-06 1.00000e-06 1.00000e-09 5.00000e-02 Element: 5147 \# of layers: 10

$\mathrm{Kx} \mathrm{Ky} \mathrm{Kz}$ Ss Por

4.49815e+00 4.49815e+00 4.49815e-01 1.00000e-09 7.00000e-02 4.49815e+00 4.49815e+00 4.49815e-01 1.00000e-09 7.00000e-02 5.00000e-04 5.00000e-04 5.00000e-05 1.00000e-09 1.00000e-01 5.00000e-04 5.00000e-04 5.00000e-05 1.00000e-09 1.00000e-01 1.79732e-01 1.79732e-01 1.79732e-02 1.00000e-09 2.12000e-01 1.79732e-01 1.79732e-01 1.79732e-02 1.00000e-09 2.12000e-01 1.79732e-01 1.79732e-01 1.79732e-02 1.00000e-09 2.12000e-01 1.79732e-01 1.79732e-01 1.79732e-02 1.00000e-09 2.12000e-01 1.79732e-01 1.79732e-01 1.79732e-02 1.00000e-09 2.12000e-01 $1.00000 \mathrm{e}-06$ 1.00000e-06 1.00000e-06 1.00000e-09 5.00000e-02 Element: 5148 \# of layers: 10

$\mathrm{Kx} \mathrm{Ky} \mathrm{Kz}$ Ss Por 4.49815e+00 4.49815e+00 4.49815e-01 1.00000e-09 7.00000e-02 $4.49815 \mathrm{e}+004.49815 \mathrm{e}+00$ 4.49815e-01 1.00000e-09 7.00000e-02 5.00000e-04 5.00000e-04 5.00000e-05 1.00000e-09 1.00000e-01 5.00000e-04 5.00000e-04 5.00000e-05 1.00000e-09 1.00000e-01 1.79732e-01 1.79732e-01 1.79732e-02 1.00000e-09 2.12000e-01 1.79732e-01 1.79732e-01 1.79732e-02 1.00000e-09 2.12000e-01 1.79732e-01 1.79732e-01 1.79732e-02 1.00000e-09 2.12000e-01 1.79732e-01 1.79732e-01 1.79732e-02 1.00000e-09 2.12000e-01 1.79732e-01 1.79732e-01 1.79732e-02 1.00000e-09 2.12000e-01 1.00000e-06 1.00000e-06 1.00000e-06 1.00000e-09 5.00000e-02 Element: 5149 \# of layers: 11

Kx Ky Kz Ss Por

6.07085e+00 6.07085e+00 6.07085e-01 1.00000e-09 7.00000e-02 $6.07085 \mathrm{e}+006.07085 \mathrm{e}+00$ 6.07085e-01 1.00000e-09 7.00000e-02 5.00000e-04 5.00000e-04 5.00000e-05 1.00000e-09 1.00000e-01 5.00000e-04 5.00000e-04 5.00000e-05 1.00000e-09 1.00000e-01 2.42578e-01 2.42578e-01 2.42578e-02 1.00000e-09 2.12000e-01 2.42578e-01 2.42578e-01 2.42578e-02 1.00000e-09 2.12000e-01 2.42578e-01 2.42578e-01 2.42578e-02 1.00000e-09 2.12000e-01 2.42578e-01 2.42578e-01 2.42578e-02 1.00000e-09 2.12000e-01 2.42578e-01 2.42578e-01 2.42578e-02 1.00000e-09 2.12000e-01 
1.00000e-02 1.00000e-02 1.00000e-03 1.00000e-09 1.00000e-01 $1.00000 \mathrm{e}-06$ 1.00000e-06 1.00000e-06 1.00000e-09 5.00000e-02 Element: 5150 \# of layers: 13

Kx Ky Kz Ss Por

$6.22122 \mathrm{e}+006.22122 \mathrm{e}+00$ 6.22122e-01 1.00000e-09 7.00000e-02

$5.00000 \mathrm{e}-04$ 5.00000e-04 5.00000e-05 1.00000e-09 1.00000e-01

5.00000e-04 5.00000e-04 5.00000e-05 1.00000e-09 1.00000e-01

2.48585e-01 2.48585e-01 2.48585e-02 1.00000e-09 2.12000e-01

2.48585e-01 2.48585e-01 2.48585e-02 1.00000e-09 2.12000e-01

$2.48585 \mathrm{e}-012.48585 \mathrm{e}-012.48585 \mathrm{e}-021.00000 \mathrm{e}-092.12000 \mathrm{e}-01$

2.48585e-01 2.48585e-01 2.48585e-02 1.00000e-09 2.12000e-01

2.48585e-01 2.48585e-01 2.48585e-02 1.00000e-09 2.12000e-01

$1.00000 \mathrm{e}-02$ 1.00000e-02 1.00000e-03 1.00000e-09 1.00000e-01

$1.00000 \mathrm{e}+001.00000 \mathrm{e}+001.00000 \mathrm{e}-011.00000 \mathrm{e}-091.00000 \mathrm{e}-01$

$1.00000 \mathrm{e}-05$ 1.00000e-05 1.00000e-06 1.00000e-09 1.00000e-01

$1.00000 \mathrm{e}+001.00000 \mathrm{e}+001.00000 \mathrm{e}-011.00000 \mathrm{e}-091.00000 \mathrm{e}-01$

$1.00000 \mathrm{e}-06$ 1.00000e-06 1.00000e-06 1.00000e-09 5.00000e-02

Element: 5151 \# of layers: 11

Kx Ky Kz Ss Por

6.22122e+00 6.22122e+00 6.22122e-01 1.00000e-09 7.00000e-02

5.00000e-04 5.00000e-04 5.00000e-05 1.00000e-09 1.00000e-01

5.00000e-04 5.00000e-04 5.00000e-05 1.00000e-09 1.00000e-01

2.48585e-01 2.48585e-01 2.48585e-02 1.00000e-09 2.12000e-01

2.48585e-01 2.48585e-01 2.48585e-02 1.00000e-09 2.12000e-01

2.48585e-01 2.48585e-01 2.48585e-02 1.00000e-09 2.12000e-01

2.48585e-01 2.48585e-01 2.48585e-02 1.00000e-09 2.12000e-01

$2.48585 \mathrm{e}-012.48585 \mathrm{e}-012.48585 \mathrm{e}-021.00000 \mathrm{e}-092.12000 \mathrm{e}-01$

$1.00000 \mathrm{e}-021.00000 \mathrm{e}-02$ 1.00000e-03 $1.00000 \mathrm{e}-091.00000 \mathrm{e}-01$

$1.00000 \mathrm{e}+001.00000 \mathrm{e}+001.00000 \mathrm{e}-011.00000 \mathrm{e}-091.00000 \mathrm{e}-01$

$1.00000 \mathrm{e}-06$ 1.00000e-06 1.00000e-06 1.00000e-09 5.00000e-02

Element: 5152 \# of layers: 14

Kx Ky Kz Ss Por

5.91353e+00 5.91353e+00 5.91353e-01 1.00000e-09 7.00000e-02

$5.91353 \mathrm{e}+00$ 5.91353e+00 5.91353e-01 1.00000e-09 7.00000e-02

5.00000e-04 5.00000e-04 5.00000e-05 1.00000e-09 1.00000e-01

5.00000e-04 5.00000e-04 5.00000e-05 1.00000e-09 1.00000e-01

2.36278e-01 2.36278e-01 2.36278e-02 1.00000e-09 2.12000e-01

2.36278e-01 2.36278e-01 2.36278e-02 1.00000e-09 2.12000e-01

2.36278e-01 2.36278e-01 2.36278e-02 1.00000e-09 2.12000e-01

2.36278e-01 2.36278e-01 2.36278e-02 1.00000e-09 2.12000e-01

2.36278e-01 2.36278e-01 2.36278e-02 1.00000e-09 2.12000e-01

$1.00000 \mathrm{e}-021.00000 \mathrm{e}-02$ 1.00000e-03 $1.00000 \mathrm{e}-091.00000 \mathrm{e}-01$

$1.00000 \mathrm{e}+001.00000 \mathrm{e}+001.00000 \mathrm{e}-011.00000 \mathrm{e}-091.00000 \mathrm{e}-01$

$1.00000 \mathrm{e}-05$ 1.00000e-05 1.00000e-06 1.00000e-09 1.00000e-01

$1.00000 \mathrm{e}+001.00000 \mathrm{e}+001.00000 \mathrm{e}-011.00000 \mathrm{e}-091.00000 \mathrm{e}-01$

$1.00000 \mathrm{e}-06$ 1.00000e-06 1.00000e-06 1.00000e-09 5.00000e-02 
Element: 5153 \# of layers: 11

$\mathrm{Kx} \mathrm{Ky} \mathrm{Kz}$ Ss Por

4.22362e+01 4.22362e+01 4.22362e+00 1.00000e-09 7.00000e-02

$4.22362 \mathrm{e}+014.22362 \mathrm{e}+014.22362 \mathrm{e}+00$ 1.00000e-09 7.00000e-02

5.00000e-04 5.00000e-04 5.00000e-05 1.00000e-09 1.00000e-01

$1.68763 \mathrm{e}+001.68763 \mathrm{e}+00$ 1.68763e-01 1.00000e-09 2.12000e-01

$1.68763 \mathrm{e}+001.68763 \mathrm{e}+00$ 1.68763e-01 1.00000e-09 2.12000e-01

$1.68763 \mathrm{e}+001.68763 \mathrm{e}+00$ 1.68763e-01 1.00000e-09 2.12000e-01

$1.68763 \mathrm{e}+001.68763 \mathrm{e}+00$ 1.68763e-01 1.00000e-09 2.12000e-01

$1.68763 \mathrm{e}+001.68763 \mathrm{e}+00$ 1.68763e-01 1.00000e-09 2.12000e-01

$1.00000 \mathrm{e}-02$ 1.00000e-02 1.00000e-03 1.00000e-09 1.00000e-01

$1.00000 \mathrm{e}+001.00000 \mathrm{e}+001.00000 \mathrm{e}-011.00000 \mathrm{e}-091.00000 \mathrm{e}-01$

1.00000e-06 1.00000e-06 1.00000e-06 1.00000e-09 5.00000e-02

Element: 5154 \# of layers: 11

$\mathrm{Kx} \mathrm{Ky} \mathrm{Kz}$ Ss Por

4.22362e+01 4.22362e+01 4.22362e+00 1.00000e-09 7.00000e-02

4.22362e+01 4.22362e+01 4.22362e+00 1.00000e-09 7.00000e-02

5.00000e-04 5.00000e-04 5.00000e-05 1.00000e-09 1.00000e-01

$1.68763 \mathrm{e}+001.68763 \mathrm{e}+00$ 1.68763e-01 1.00000e-09 2.12000e-01

$1.68763 \mathrm{e}+001.68763 \mathrm{e}+00$ 1.68763e-01 1.00000e-09 2.12000e-01

$1.68763 \mathrm{e}+001.68763 \mathrm{e}+00$ 1.68763e-01 1.00000e-09 2.12000e-01

$1.68763 \mathrm{e}+00$ 1.68763e+00 1.68763e-01 1.00000e-09 2.12000e-01

$1.68763 \mathrm{e}+001.68763 \mathrm{e}+00$ 1.68763e-01 1.00000e-09 2.12000e-01

$1.00000 \mathrm{e}-021.00000 \mathrm{e}-02$ 1.00000e-03 1.00000e-09 1.00000e-01

$1.00000 \mathrm{e}+001.00000 \mathrm{e}+001.00000 \mathrm{e}-011.00000 \mathrm{e}-091.00000 \mathrm{e}-01$

1.00000e-06 1.00000e-06 1.00000e-06 1.00000e-09 5.00000e-02

Element: 5155 \# of layers: 9

$\mathrm{Kx} \mathrm{Ky} \mathrm{Kz}$ Ss Por

4.22362e+01 4.22362e+01 4.22362e+00 1.00000e-09 7.00000e-02

4.22362e+01 4.22362e+01 4.22362e+00 1.00000e-09 7.00000e-02

$1.68763 \mathrm{e}+001.68763 \mathrm{e}+00$ 1.68763e-01 1.00000e-09 2.12000e-01

$1.68763 \mathrm{e}+001.68763 \mathrm{e}+00$ 1.68763e-01 1.00000e-09 2.12000e-01

$1.68763 \mathrm{e}+001.68763 \mathrm{e}+00$ 1.68763e-01 1.00000e-09 2.12000e-01

$1.68763 \mathrm{e}+001.68763 \mathrm{e}+00$ 1.68763e-01 1.00000e-09 2.12000e-01

$1.68763 \mathrm{e}+001.68763 \mathrm{e}+001.68763 \mathrm{e}-01$ 1.00000e-09 2.12000e-01

$1.00000 \mathrm{e}+001.00000 \mathrm{e}+001.00000 \mathrm{e}-011.00000 \mathrm{e}-091.00000 \mathrm{e}-01$

1.00000e-06 1.00000e-06 1.00000e-06 1.00000e-09 5.00000e-02

Element: 5156 \# of layers: 8

$\mathrm{Kx} \mathrm{Ky} \mathrm{Kz}$ Ss Por

4.02540e+01 4.02540e+01 4.02540e+00 1.00000e-09 7.00000e-02 $4.02540 \mathrm{e}+014.02540 \mathrm{e}+014.02540 \mathrm{e}+001.00000 \mathrm{e}-09$ 7.00000e-02 $1.60842 \mathrm{e}+001.60842 \mathrm{e}+00$ 1.60842e-01 1.00000e-09 2.12000e-01 $1.60842 \mathrm{e}+00$ 1.60842e+00 1.60842e-01 1.00000e-09 2.12000e-01 $1.60842 \mathrm{e}+001.60842 \mathrm{e}+00$ 1.60842e-01 1.00000e-09 2.12000e-01 $1.60842 \mathrm{e}+001.60842 \mathrm{e}+00$ 1.60842e-01 1.00000e-09 2.12000e-01 $1.60842 \mathrm{e}+001.60842 \mathrm{e}+00$ 1.60842e-01 1.00000e-09 2.12000e-01 
1.00000e-06 1.00000e-06 1.00000e-06 1.00000e-09 5.00000e-02

Element: 5157 \# of layers: 8

Kx Ky Kz Ss Por

4.02540e+01 4.02540e+01 4.02540e+00 1.00000e-09 7.00000e-02 $1.60842 \mathrm{e}+001.60842 \mathrm{e}+00$ 1.60842e-01 1.00000e-09 2.12000e-01 $1.60842 \mathrm{e}+001.60842 \mathrm{e}+00$ 1.60842e-01 1.00000e-09 2.12000e-01 $1.60842 \mathrm{e}+001.60842 \mathrm{e}+00$ 1.60842e-01 1.00000e-09 2.12000e-01 $1.60842 \mathrm{e}+001.60842 \mathrm{e}+00$ 1.60842e-01 1.00000e-09 2.12000e-01 $1.60842 \mathrm{e}+00$ 1.60842e+00 1.60842e-01 1.00000e-09 2.12000e-01 $1.00000 \mathrm{e}+001.00000 \mathrm{e}+001.00000 \mathrm{e}-011.00000 \mathrm{e}-091.00000 \mathrm{e}-01$ 1.00000e-06 1.00000e-06 1.00000e-06 1.00000e-09 5.00000e-02

Element: 5158 \# of layers: 9

$\mathrm{Kx} \mathrm{Ky} \mathrm{Kz}$ Ss Por

$1.26951 \mathrm{e}+01$ 1.26951e+01 1.26951e+00 1.00000e-09 7.00000e-02 $1.26951 \mathrm{e}+011.26951 \mathrm{e}+011.26951 \mathrm{e}+001.00000 \mathrm{e}-09$ 7.00000e-02 5.07251e-01 5.07251e-01 5.07251e-02 1.00000e-09 2.12000e-01 5.07251e-01 5.07251e-01 5.07251e-02 1.00000e-09 2.12000e-01 5.07251e-01 5.07251e-01 5.07251e-02 1.00000e-09 2.12000e-01 5.07251e-01 5.07251e-01 5.07251e-02 1.00000e-09 2.12000e-01 5.07251e-01 5.07251e-01 5.07251e-02 1.00000e-09 2.12000e-01 $1.00000 \mathrm{e}+001.00000 \mathrm{e}+001.00000 \mathrm{e}-011.00000 \mathrm{e}-091.00000 \mathrm{e}-01$ 1.00000e-06 1.00000e-06 1.00000e-06 1.00000e-09 5.00000e-02 Element: 5159 \# of layers: 9

Kx Ky Kz Ss Por

$1.26951 \mathrm{e}+011.26951 \mathrm{e}+011.26951 \mathrm{e}+001.00000 \mathrm{e}-09$ 7.00000e-02 $1.26951 \mathrm{e}+011.26951 \mathrm{e}+011.26951 \mathrm{e}+001.00000 \mathrm{e}-097.00000 \mathrm{e}-02$ 5.07251e-01 5.07251e-01 5.07251e-02 1.00000e-09 2.12000e-01 5.07251e-01 5.07251e-01 5.07251e-02 1.00000e-09 2.12000e-01 5.07251e-01 5.07251e-01 5.07251e-02 1.00000e-09 2.12000e-01 5.07251e-01 5.07251e-01 5.07251e-02 1.00000e-09 2.12000e-01 5.07251e-01 5.07251e-01 5.07251e-02 1.00000e-09 2.12000e-01 $1.00000 \mathrm{e}+001.00000 \mathrm{e}+001.00000 \mathrm{e}-011.00000 \mathrm{e}-091.00000 \mathrm{e}-01$ 1.00000e-06 1.00000e-06 1.00000e-06 1.00000e-09 5.00000e-02 Element: 5160 \# of layers: 8

$\mathrm{Kx} \mathrm{Ky} \mathrm{Kz}$ Ss Por

5.91353e+00 5.91353e+00 5.91353e-01 1.00000e-09 7.00000e-02 2.36278e-01 2.36278e-01 2.36278e-02 1.00000e-09 2.12000e-01 2.36278e-01 2.36278e-01 2.36278e-02 1.00000e-09 2.12000e-01 2.36278e-01 2.36278e-01 2.36278e-02 1.00000e-09 2.12000e-01 2.36278e-01 2.36278e-01 2.36278e-02 1.00000e-09 2.12000e-01 2.36278e-01 2.36278e-01 2.36278e-02 1.00000e-09 2.12000e-01 $1.00000 \mathrm{e}+001.00000 \mathrm{e}+001.00000 \mathrm{e}-011.00000 \mathrm{e}-091.00000 \mathrm{e}-01$ 1.00000e-06 1.00000e-06 1.00000e-06 1.00000e-09 5.00000e-02 Element: 5161 \# of layers: 8

$\mathrm{Kx} \mathrm{Ky} \mathrm{Kz}$ Ss Por

4.19695e+01 4.19695e+01 4.19695e+00 1.00000e-09 7.00000e-02 
$1.67694 \mathrm{e}+001.67694 \mathrm{e}+001.67694 \mathrm{e}-01$ 1.00000e-09 2.12000e-01 $1.67694 \mathrm{e}+001.67694 \mathrm{e}+00$ 1.67694e-01 1.00000e-09 2.12000e-01 $1.67694 \mathrm{e}+001.67694 \mathrm{e}+001.67694 \mathrm{e}-011.00000 \mathrm{e}-092.12000 \mathrm{e}-01$ $1.67694 \mathrm{e}+001.67694 \mathrm{e}+001.67694 \mathrm{e}-011.00000 \mathrm{e}-092.12000 \mathrm{e}-01$ $1.67694 \mathrm{e}+001.67694 \mathrm{e}+001.67694 \mathrm{e}-01$ 1.00000e-09 2.12000e-01 $1.00000 \mathrm{e}+001.00000 \mathrm{e}+001.00000 \mathrm{e}-011.00000 \mathrm{e}-091.00000 \mathrm{e}-01$ 1.00000e-06 1.00000e-06 1.00000e-06 1.00000e-09 5.00000e-02

Element: 5162 \# of layers: 9

$\mathrm{Kx} \mathrm{Ky} \mathrm{Kz}$ Ss Por

$1.05390 \mathrm{e}+021.05390 \mathrm{e}+02$ 1.05390e+01 1.00000e-09 7.00000e-02 $1.05390 \mathrm{e}+02$ 1.05390e+02 1.05390e+01 1.00000e-09 7.00000e-02 4.21097e+00 4.21097e+00 4.21097e-01 1.00000e-09 2.12000e-01 4.21097e+00 4.21097e+00 4.21097e-01 1.00000e-09 2.12000e-01 4.21097e+00 4.21097e+00 4.21097e-01 1.00000e-09 2.12000e-01 4.21097e+00 4.21097e+00 4.21097e-01 1.00000e-09 2.12000e-01 4.21097e+00 4.21097e+00 4.21097e-01 1.00000e-09 2.12000e-01 $1.00000 \mathrm{e}+001.00000 \mathrm{e}+001.00000 \mathrm{e}-011.00000 \mathrm{e}-091.00000 \mathrm{e}-01$ 1.00000e-06 1.00000e-06 1.00000e-06 1.00000e-09 5.00000e-02 Element: 5163 \# of layers: 8

$\mathrm{Kx} \mathrm{Ky} \mathrm{Kz}$ Ss Por

6.89292e+01 6.89292e+01 6.89292e+00 1.00000e-09 7.00000e-02 $6.89292 \mathrm{e}+016.89292 \mathrm{e}+016.89292 \mathrm{e}+00$ 1.00000e-09 7.00000e-02 $2.75406 \mathrm{e}+002.75406 \mathrm{e}+00$ 2.75406e-01 1.00000e-09 2.12000e-01 $2.75406 \mathrm{e}+002.75406 \mathrm{e}+00$ 2.75406e-01 1.00000e-09 2.12000e-01 $2.75406 \mathrm{e}+002.75406 \mathrm{e}+00$ 2.75406e-01 1.00000e-09 2.12000e-01 $2.75406 \mathrm{e}+002.75406 \mathrm{e}+00$ 2.75406e-01 1.00000e-09 2.12000e-01 $2.75406 \mathrm{e}+002.75406 \mathrm{e}+002.75406 \mathrm{e}-01$ 1.00000e-09 2.12000e-01 1.00000e-06 1.00000e-06 1.00000e-06 1.00000e-09 5.00000e-02 Element: 5167 \# of layers: 8

$\mathrm{Kx} \mathrm{Ky} \mathrm{Kz}$ Ss Por

3.28901e+01 3.28901e+01 3.28901e+00 1.00000e-09 7.00000e-02 $3.28901 \mathrm{e}+013.28901 \mathrm{e}+013.28901 \mathrm{e}+00$ 1.00000e-09 7.00000e-02 $1.31419 \mathrm{e}+00$ 1.31419e+00 1.31419e-01 1.00000e-09 2.12000e-01 $1.31419 \mathrm{e}+00$ 1.31419e+00 1.31419e-01 1.00000e-09 2.12000e-01 $1.31419 \mathrm{e}+00$ 1.31419e+00 1.31419e-01 1.00000e-09 2.12000e-01 $1.31419 \mathrm{e}+00$ 1.31419e+00 1.31419e-01 1.00000e-09 2.12000e-01 $1.31419 \mathrm{e}+00$ 1.31419e+00 1.31419e-01 1.00000e-09 2.12000e-01 1.00000e-06 1.00000e-06 1.00000e-06 1.00000e-09 5.00000e-02 Element: 5168 \# of layers: 9

$\mathrm{Kx} \mathrm{Ky} \mathrm{Kz}$ Ss Por 4.19695e+01 4.19695e+01 4.19695e+00 1.00000e-09 7.00000e-02 4.19695e+01 4.19695e+01 4.19695e+00 1.00000e-09 7.00000e-02 $1.67694 \mathrm{e}+001.67694 \mathrm{e}+00$ 1.67694e-01 1.00000e-09 2.12000e-01 $1.67694 \mathrm{e}+001.67694 \mathrm{e}+00$ 1.67694e-01 1.00000e-09 2.12000e-01 $1.67694 \mathrm{e}+001.67694 \mathrm{e}+001.67694 \mathrm{e}-011.00000 \mathrm{e}-092.12000 \mathrm{e}-01$ $1.67694 \mathrm{e}+001.67694 \mathrm{e}+001.67694 \mathrm{e}-011.00000 \mathrm{e}-092.12000 \mathrm{e}-01$ 
$1.67694 \mathrm{e}+001.67694 \mathrm{e}+001.67694 \mathrm{e}-011.00000 \mathrm{e}-092.12000 \mathrm{e}-01$ $1.00000 \mathrm{e}+001.00000 \mathrm{e}+001.00000 \mathrm{e}-01$ 1.00000e-09 1.00000e-01 1.00000e-06 1.00000e-06 1.00000e-06 1.00000e-09 5.00000e-02

Element: 5173 \# of layers: 6

$\mathrm{Kx} \mathrm{Ky} \mathrm{Kz}$ Ss Por

5.00000e-04 5.00000e-04 5.00000e-05 1.00000e-09 1.00000e-01

5.00000e-04 5.00000e-04 5.00000e-05 1.00000e-09 1.00000e-01

$4.86033 \mathrm{e}+02$ 4.86033e+02 4.86033e+01 1.00000e-09 2.12000e-01

$1.00000 \mathrm{e}-021.00000 \mathrm{e}-021.00000 \mathrm{e}-031.00000 \mathrm{e}-091.00000 \mathrm{e}-01$

$1.00000 \mathrm{e}+001.00000 \mathrm{e}+001.00000 \mathrm{e}-011.00000 \mathrm{e}-091.00000 \mathrm{e}-01$

1.00000e-06 1.00000e-06 1.00000e-06 1.00000e-09 5.00000e-02

Element: 5174 \# of layers: 8

$\mathrm{Kx} \mathrm{Ky} \mathrm{Kz}$ Ss Por

9.31814e+02 9.31814e+02 9.31814e+01 1.00000e-09 7.00000e-02

$9.31814 \mathrm{e}+02$ 9.31814e+02 9.31814e+01 1.00000e-09 7.00000e-02

5.00000e-04 5.00000e-04 5.00000e-05 1.00000e-09 1.00000e-01

5.00000e-04 5.00000e-04 5.00000e-05 1.00000e-09 1.00000e-01

$3.72315 \mathrm{e}+013.72315 \mathrm{e}+013.72315 \mathrm{e}+00$ 1.00000e-09 2.12000e-01

$1.00000 \mathrm{e}-02$ 1.00000e-02 1.00000e-03 1.00000e-09 1.00000e-01

$1.00000 \mathrm{e}+001.00000 \mathrm{e}+001.00000 \mathrm{e}-011.00000 \mathrm{e}-091.00000 \mathrm{e}-01$

1.00000e-06 1.00000e-06 1.00000e-06 1.00000e-09 5.00000e-02

Element: 5179 \# of layers: 3

$\mathrm{Kx} \mathrm{Ky} \mathrm{Kz}$ Ss Por

5.00000e-04 5.00000e-04 5.00000e-05 1.00000e-09 1.00000e-01

$5.00000 \mathrm{e}-04$ 5.00000e-04 5.00000e-05 1.00000e-09 1.00000e-01

1.00000e-06 1.00000e-06 1.00000e-06 1.00000e-09 5.00000e-02

Element: 5180 \# of layers: 3

$\mathrm{Kx} \mathrm{Ky} \mathrm{Kz}$ Ss Por

5.00000e-04 5.00000e-04 5.00000e-05 1.00000e-09 1.00000e-01

5.00000e-04 5.00000e-04 5.00000e-05 1.00000e-09 1.00000e-01

1.00000e-06 1.00000e-06 1.00000e-06 1.00000e-09 5.00000e-02

Element: 5181 \# of layers: 7

Kx Ky Kz Ss Por

$1.71686 \mathrm{e}+02$ 1.71686e+02 1.71686e+01 1.00000e-09 7.00000e-02

$1.71686 \mathrm{e}+021.71686 \mathrm{e}+02 \quad 1.71686 \mathrm{e}+01$ 1.00000e-09 7.00000e-02

5.00000e-04 5.00000e-04 5.00000e-05 1.00000e-09 1.00000e-01

5.00000e-04 5.00000e-04 5.00000e-05 1.00000e-09 1.00000e-01

6.85972e+00 6.85972e+00 6.85972e-01 1.00000e-09 2.12000e-01

$1.00000 \mathrm{e}+001.00000 \mathrm{e}+001.00000 \mathrm{e}-011.00000 \mathrm{e}-091.00000 \mathrm{e}-01$

1.00000e-06 1.00000e-06 1.00000e-06 1.00000e-09 5.00000e-02

Element: 5182 \# of layers: 7

$\mathrm{Kx} \mathrm{Ky} \mathrm{Kz}$ Ss Por

$5.84560 \mathrm{e}+025.84560 \mathrm{e}+025.84560 \mathrm{e}+01$ 1.00000e-09 7.00000e-02

5.00000e-04 5.00000e-04 5.00000e-05 1.00000e-09 1.00000e-01

5.00000e-04 5.00000e-04 5.00000e-05 1.00000e-09 1.00000e-01

$2.33577 \mathrm{e}+012.33577 \mathrm{e}+012.33578 \mathrm{e}+001.00000 \mathrm{e}-092.12000 \mathrm{e}-01$ 
$1.00000 \mathrm{e}-02$ 1.00000e-02 1.00000e-03 1.00000e-09 1.00000e-01 $1.00000 \mathrm{e}+001.00000 \mathrm{e}+001.00000 \mathrm{e}-011.00000 \mathrm{e}-091.00000 \mathrm{e}-01$ 1.00000e-06 1.00000e-06 1.00000e-06 1.00000e-09 5.00000e-02 Element: 5183 \# of layers: 7

$\mathrm{Kx} \mathrm{Ky} \mathrm{Kz}$ Ss Por

$5.84560 \mathrm{e}+025.84560 \mathrm{e}+025.84560 \mathrm{e}+01$ 1.00000e-09 7.00000e-02 $5.00000 \mathrm{e}-04$ 5.00000e-04 5.00000e-05 1.00000e-09 1.00000e-01 5.00000e-04 5.00000e-04 5.00000e-05 1.00000e-09 1.00000e-01 $2.33577 \mathrm{e}+012.33577 \mathrm{e}+012.33578 \mathrm{e}+00$ 1.00000e-09 2.12000e-01 $1.00000 \mathrm{e}-02$ 1.00000e-02 1.00000e-03 1.00000e-09 1.00000e-01 $1.00000 \mathrm{e}+001.00000 \mathrm{e}+001.00000 \mathrm{e}-011.00000 \mathrm{e}-091.00000 \mathrm{e}-01$ 1.00000e-06 1.00000e-06 1.00000e-06 1.00000e-09 5.00000e-02 Element: 5184 \# of layers: 7

$\mathrm{Kx} \mathrm{Ky} \mathrm{Kz}$ Ss Por

$5.84560 \mathrm{e}+025.84560 \mathrm{e}+025.84560 \mathrm{e}+01$ 1.00000e-09 7.00000e-02 5.00000e-04 5.00000e-04 5.00000e-05 1.00000e-09 1.00000e-01 5.00000e-04 5.00000e-04 5.00000e-05 1.00000e-09 1.00000e-01 $2.33577 \mathrm{e}+012.33577 \mathrm{e}+012.33578 \mathrm{e}+00$ 1.00000e-09 2.12000e-01 $1.00000 \mathrm{e}-02$ 1.00000e-02 1.00000e-03 1.00000e-09 1.00000e-01 $1.00000 \mathrm{e}+001.00000 \mathrm{e}+001.00000 \mathrm{e}-011.00000 \mathrm{e}-091.00000 \mathrm{e}-01$ 1.00000e-06 1.00000e-06 1.00000e-06 1.00000e-09 5.00000e-02 Element: 5185 \# of layers: 7

$\mathrm{Kx} \mathrm{Ky} \mathrm{Kz}$ Ss Por

3.94188e+03 3.94188e+03 3.94188e+02 1.00000e-09 7.00000e-02 5.00000e-04 5.00000e-04 5.00000e-05 1.00000e-09 1.00000e-01 5.00000e-04 5.00000e-04 5.00000e-05 1.00000e-09 1.00000e-01 $1.57501 \mathrm{e}+021.57501 \mathrm{e}+021.57501 \mathrm{e}+01$ 1.00000e-09 2.12000e-01 1.00000e-02 1.00000e-02 1.00000e-03 1.00000e-09 1.00000e-01 $1.00000 \mathrm{e}+001.00000 \mathrm{e}+001.00000 \mathrm{e}-011.00000 \mathrm{e}-091.00000 \mathrm{e}-01$ 1.00000e-06 1.00000e-06 1.00000e-06 1.00000e-09 5.00000e-02 Element: 5186 \# of layers: 6

$\mathrm{Kx} \mathrm{Ky} \mathrm{Kz}$ Ss Por

5.00000e-04 5.00000e-04 5.00000e-05 1.00000e-09 1.00000e-01 5.00000e-04 5.00000e-04 5.00000e-05 1.00000e-09 1.00000e-01 $1.57501 \mathrm{e}+021.57501 \mathrm{e}+02$ 1.57501e+01 1.00000e-09 2.12000e-01 1.00000e-02 1.00000e-02 1.00000e-03 1.00000e-09 1.00000e-01 $1.00000 \mathrm{e}+001.00000 \mathrm{e}+001.00000 \mathrm{e}-011.00000 \mathrm{e}-091.00000 \mathrm{e}-01$ 1.00000e-06 1.00000e-06 1.00000e-06 1.00000e-09 5.00000e-02 Element: 5187 \# of layers: 6

$\mathrm{Kx} \mathrm{Ky} \mathrm{Kz}$ Ss Por 5.00000e-04 5.00000e-04 5.00000e-05 1.00000e-09 1.00000e-01 5.00000e-04 5.00000e-04 5.00000e-05 1.00000e-09 1.00000e-01 $1.57501 \mathrm{e}+021.57501 \mathrm{e}+021.57501 \mathrm{e}+01$ 1.00000e-09 2.12000e-01 $1.00000 \mathrm{e}-02$ 1.00000e-02 1.00000e-03 1.00000e-09 1.00000e-01 $1.00000 \mathrm{e}+001.00000 \mathrm{e}+001.00000 \mathrm{e}-011.00000 \mathrm{e}-091.00000 \mathrm{e}-01$ $1.00000 \mathrm{e}-06$ 1.00000e-06 1.00000e-06 1.00000e-09 5.00000e-02 
Element: 5188 \# of layers: 9

$\mathrm{Kx} \mathrm{Ky} \mathrm{Kz}$ Ss Por

1.71686e+02 1.71686e+02 1.71686e+01 1.00000e-09 7.00000e-02

$1.71686 \mathrm{e}+02$ 1.71686e+02 1.71686e+01 1.00000e-09 7.00000e-02

$1.71686 \mathrm{e}+021.71686 \mathrm{e}+021.71686 \mathrm{e}+01$ 1.00000e-09 7.00000e-02

5.00000e-04 5.00000e-04 5.00000e-05 1.00000e-09 1.00000e-01

5.00000e-04 5.00000e-04 5.00000e-05 1.00000e-09 1.00000e-01

6.85972e+00 6.85972e+00 6.85972e-01 1.00000e-09 2.12000e-01

$1.00000 \mathrm{e}-02$ 1.00000e-02 1.00000e-03 1.00000e-09 1.00000e-01

$1.00000 \mathrm{e}+001.00000 \mathrm{e}+001.00000 \mathrm{e}-011.00000 \mathrm{e}-091.00000 \mathrm{e}-01$

1.00000e-06 1.00000e-06 1.00000e-06 1.00000e-09 5.00000e-02

Element: 5189 \# of layers: 9

$\mathrm{Kx} \mathrm{Ky} \mathrm{Kz}$ Ss Por

$1.71686 \mathrm{e}+02$ 1.71686e+02 1.71686e+01 1.00000e-09 7.00000e-02

$1.71686 \mathrm{e}+02$ 1.71686e+02 1.71686e+01 1.00000e-09 7.00000e-02

$1.71686 \mathrm{e}+021.71686 \mathrm{e}+021.71686 \mathrm{e}+01$ 1.00000e-09 7.00000e-02

5.00000e-04 5.00000e-04 5.00000e-05 1.00000e-09 1.00000e-01

5.00000e-04 5.00000e-04 5.00000e-05 1.00000e-09 1.00000e-01

6.85972e+00 6.85972e+00 6.85972e-01 1.00000e-09 2.12000e-01

$1.00000 \mathrm{e}-02$ 1.00000e-02 1.00000e-03 1.00000e-09 1.00000e-01

$1.00000 \mathrm{e}+001.00000 \mathrm{e}+001.00000 \mathrm{e}-011.00000 \mathrm{e}-091.00000 \mathrm{e}-01$

$1.00000 \mathrm{e}-06$ 1.00000e-06 1.00000e-06 1.00000e-09 5.00000e-02

Element: 5190 \# of layers: 9

Kx Ky Kz Ss Por

9.27309e+01 9.27309e+01 9.27309e+00 1.00000e-09 7.00000e-02

9.27309e+01 9.27309e+01 9.27309e+00 1.00000e-09 7.00000e-02

9.27309e+01 9.27309e+01 9.27309e+00 1.00000e-09 7.00000e-02

5.00000e-04 5.00000e-04 5.00000e-05 1.00000e-09 1.00000e-01

5.00000e-04 5.00000e-04 5.00000e-05 1.00000e-09 1.00000e-01

$3.70515 \mathrm{e}+003.70515 \mathrm{e}+003.70515 \mathrm{e}-01$ 1.00000e-09 2.12000e-01

$1.00000 \mathrm{e}-02$ 1.00000e-02 1.00000e-03 1.00000e-09 1.00000e-01

$1.00000 \mathrm{e}+001.00000 \mathrm{e}+001.00000 \mathrm{e}-011.00000 \mathrm{e}-091.00000 \mathrm{e}-01$

1.00000e-06 1.00000e-06 1.00000e-06 1.00000e-09 5.00000e-02

Element: 5191 \# of layers: 9

$\mathrm{Kx} \mathrm{Ky} \mathrm{Kz}$ Ss Por

$1.07615 \mathrm{e}+02$ 1.07615e+02 1.07615e+01 1.00000e-09 7.00000e-02

$1.07615 \mathrm{e}+021.07615 \mathrm{e}+02$ 1.07615e+01 1.00000e-09 7.00000e-02

$1.07615 \mathrm{e}+021.07615 \mathrm{e}+021.07615 \mathrm{e}+01$ 1.00000e-09 7.00000e-02

5.00000e-04 5.00000e-04 5.00000e-05 1.00000e-09 1.00000e-01

5.00000e-04 5.00000e-04 5.00000e-05 1.00000e-09 1.00000e-01

$4.29984 \mathrm{e}+004.29984 \mathrm{e}+00 \quad 4.29984 \mathrm{e}-01$ 1.00000e-09 2.12000e-01

$1.00000 \mathrm{e}-02$ 1.00000e-02 1.00000e-03 1.00000e-09 1.00000e-01

$1.00000 \mathrm{e}+001.00000 \mathrm{e}+001.00000 \mathrm{e}-011.00000 \mathrm{e}-091.00000 \mathrm{e}-01$

1.00000e-06 1.00000e-06 1.00000e-06 1.00000e-09 5.00000e-02

Element: 5192 \# of layers: 8

Kx Ky Kz Ss Por 
$1.07615 \mathrm{e}+02$ 1.07615e+02 1.07615e+01 1.00000e-09 7.00000e-02 $1.07615 \mathrm{e}+021.07615 \mathrm{e}+02$ 1.07615e+01 1.00000e-09 7.00000e-02 5.00000e-04 5.00000e-04 5.00000e-05 1.00000e-09 1.00000e-01 5.00000e-04 5.00000e-04 5.00000e-05 1.00000e-09 1.00000e-01 $4.29984 \mathrm{e}+004.29984 \mathrm{e}+00$ 4.29984e-01 1.00000e-09 2.12000e-01 $1.00000 \mathrm{e}-02$ 1.00000e-02 1.00000e-03 1.00000e-09 1.00000e-01 $1.00000 \mathrm{e}+001.00000 \mathrm{e}+001.00000 \mathrm{e}-011.00000 \mathrm{e}-091.00000 \mathrm{e}-01$ 1.00000e-06 1.00000e-06 1.00000e-06 1.00000e-09 5.00000e-02 Element: 5193 \# of layers: 8

$\mathrm{Kx} \mathrm{Ky} \mathrm{Kz}$ Ss Por

$1.07615 \mathrm{e}+02$ 1.07615e+02 1.07615e+01 1.00000e-09 7.00000e-02 $1.07615 \mathrm{e}+021.07615 \mathrm{e}+02 \quad 1.07615 \mathrm{e}+01$ 1.00000e-09 7.00000e-02 5.00000e-04 5.00000e-04 5.00000e-05 1.00000e-09 1.00000e-01 5.00000e-04 5.00000e-04 5.00000e-05 1.00000e-09 1.00000e-01 $4.29984 \mathrm{e}+004.29984 \mathrm{e}+00$ 4.29984e-01 1.00000e-09 2.12000e-01 $1.00000 \mathrm{e}-02$ 1.00000e-02 1.00000e-03 1.00000e-09 1.00000e-01 $1.00000 \mathrm{e}+001.00000 \mathrm{e}+001.00000 \mathrm{e}-011.00000 \mathrm{e}-091.00000 \mathrm{e}-01$ 1.00000e-06 1.00000e-06 1.00000e-06 1.00000e-09 5.00000e-02 Element: 5194 \# of layers: 9

$\mathrm{Kx} \mathrm{Ky} \mathrm{Kz}$ Ss Por

$1.98770 \mathrm{e}+02$ 1.98770e+02 1.98770e+01 1.00000e-09 7.00000e-02 $1.98770 \mathrm{e}+02$ 1.98770e+02 1.98770e+01 1.00000e-09 7.00000e-02 $1.98770 \mathrm{e}+021.98770 \mathrm{e}+021.98770 \mathrm{e}+01$ 1.00000e-09 7.00000e-02 5.00000e-04 5.00000e-04 5.00000e-05 1.00000e-09 1.00000e-01 5.00000e-04 5.00000e-04 5.00000e-05 1.00000e-09 1.00000e-01 7.94222e+00 7.94222e+00 7.94222e-01 1.00000e-09 2.12000e-01 $1.00000 \mathrm{e}-02$ 1.00000e-02 1.00000e-03 1.00000e-09 1.00000e-01 $1.00000 \mathrm{e}+001.00000 \mathrm{e}+001.00000 \mathrm{e}-011.00000 \mathrm{e}-091.00000 \mathrm{e}-01$ 1.00000e-06 1.00000e-06 1.00000e-06 1.00000e-09 5.00000e-02 Element: 5195 \# of layers: 8

$\mathrm{Kx} \mathrm{Ky} \mathrm{Kz}$ Ss Por

$1.98770 \mathrm{e}+02$ 1.98770e+02 1.98770e+01 1.00000e-09 7.00000e-02 $1.98770 \mathrm{e}+021.98770 \mathrm{e}+02 \quad 1.98770 \mathrm{e}+01$ 1.00000e-09 7.00000e-02 5.00000e-04 5.00000e-04 5.00000e-05 1.00000e-09 1.00000e-01 5.00000e-04 5.00000e-04 5.00000e-05 1.00000e-09 1.00000e-01 $7.94222 \mathrm{e}+00$ 7.94222e+00 7.94222e-01 1.00000e-09 2.12000e-01 $1.00000 \mathrm{e}-02$ 1.00000e-02 1.00000e-03 1.00000e-09 1.00000e-01 $1.00000 \mathrm{e}+001.00000 \mathrm{e}+001.00000 \mathrm{e}-011.00000 \mathrm{e}-091.00000 \mathrm{e}-01$ 1.00000e-06 1.00000e-06 1.00000e-06 1.00000e-09 5.00000e-02 Element: 5196 \# of layers: 8

$\mathrm{Kx} \mathrm{Ky} \mathrm{Kz}$ Ss Por

9.27309e+01 9.27309e+01 9.27309e+00 1.00000e-09 7.00000e-02

9.27309e+01 9.27309e+01 9.27309e+00 1.00000e-09 7.00000e-02

5.00000e-04 5.00000e-04 5.00000e-05 1.00000e-09 1.00000e-01 5.00000e-04 5.00000e-04 5.00000e-05 1.00000e-09 1.00000e-01

$3.70515 \mathrm{e}+003.70515 \mathrm{e}+003.70515 \mathrm{e}-01$ 1.00000e-09 2.12000e-01 
$1.00000 \mathrm{e}-02$ 1.00000e-02 1.00000e-03 1.00000e-09 1.00000e-01 $1.00000 \mathrm{e}+001.00000 \mathrm{e}+001.00000 \mathrm{e}-011.00000 \mathrm{e}-091.00000 \mathrm{e}-01$ $1.00000 \mathrm{e}-06$ 1.00000e-06 1.00000e-06 1.00000e-09 5.00000e-02 Element: 5197 \# of layers: 9

Kx Ky Kz Ss Por

$7.26008 \mathrm{e}+01$ 7.26008e+01 7.26008e+00 1.00000e-09 7.00000e-02 $7.26008 \mathrm{e}+01$ 7.26008e+01 7.26008e+00 1.00000e-09 7.00000e-02 $7.26008 \mathrm{e}+01$ 7.26008e+01 7.26008e+00 1.00000e-09 7.00000e-02 $7.26008 \mathrm{e}+017.26008 \mathrm{e}+01$ 7.26008e+00 1.00000e-09 7.00000e-02 $5.00000 \mathrm{e}-04$ 5.00000e-04 5.00000e-05 1.00000e-09 1.00000e-01 5.00000e-04 5.00000e-04 5.00000e-05 1.00000e-09 1.00000e-01 $2.90076 \mathrm{e}+002.90076 \mathrm{e}+002.90076 \mathrm{e}-011.00000 \mathrm{e}-092.12000 \mathrm{e}-01$ $1.00000 \mathrm{e}-021.00000 \mathrm{e}-02$ 1.00000e-03 1.00000e-09 1.00000e-01 $1.00000 \mathrm{e}+001.00000 \mathrm{e}+001.00000 \mathrm{e}-011.00000 \mathrm{e}-091.00000 \mathrm{e}-01$ Element: 5198 \# of layers: 9

Kx Ky Kz Ss Por $6.93923 \mathrm{e}+016.93923 \mathrm{e}+016.93923 \mathrm{e}+00$ 1.00000e-09 7.00000e-02 $6.93923 \mathrm{e}+016.93923 \mathrm{e}+016.93923 \mathrm{e}+00$ 1.00000e-09 7.00000e-02 $6.93923 \mathrm{e}+016.93923 \mathrm{e}+016.93923 \mathrm{e}+001.00000 \mathrm{e}-09$ 7.00000e-02 5.00000e-04 5.00000e-04 5.00000e-05 1.00000e-09 1.00000e-01 5.00000e-04 5.00000e-04 5.00000e-05 1.00000e-09 1.00000e-01

$2.77273 \mathrm{e}+002.77273 \mathrm{e}+002.77273 \mathrm{e}-01$ 1.00000e-09 2.12000e-01 $2.77273 \mathrm{e}+002.77273 \mathrm{e}+00$ 2.77273e-01 1.00000e-09 2.12000e-01 $1.00000 \mathrm{e}-021.00000 \mathrm{e}-02$ 1.00000e-03 1.00000e-09 1.00000e-01 $1.00000 \mathrm{e}+001.00000 \mathrm{e}+001.00000 \mathrm{e}-011.00000 \mathrm{e}-091.00000 \mathrm{e}-01$ Element: 5199 \# of layers: 10

Kx Ky Kz Ss Por

$6.93923 \mathrm{e}+016.93923 \mathrm{e}+016.93923 \mathrm{e}+00$ 1.00000e-09 7.00000e-02 $6.93923 \mathrm{e}+016.93923 \mathrm{e}+016.93923 \mathrm{e}+001.00000 \mathrm{e}-09$ 7.00000e-02 $6.93923 \mathrm{e}+016.93923 \mathrm{e}+016.93923 \mathrm{e}+001.00000 \mathrm{e}-09$ 7.00000e-02 5.00000e-04 5.00000e-04 5.00000e-05 1.00000e-09 1.00000e-01 5.00000e-04 5.00000e-04 5.00000e-05 1.00000e-09 1.00000e-01 $2.77273 \mathrm{e}+002.77273 \mathrm{e}+002.77273 \mathrm{e}-01$ 1.00000e-09 2.12000e-01 $2.77273 \mathrm{e}+002.77273 \mathrm{e}+002.77273 \mathrm{e}-01$ 1.00000e-09 2.12000e-01 $2.77273 \mathrm{e}+002.77273 \mathrm{e}+002.77273 \mathrm{e}-01$ 1.00000e-09 2.12000e-01 $1.00000 \mathrm{e}-021.00000 \mathrm{e}-02$ 1.00000e-03 1.00000e-09 1.00000e-01 $1.00000 \mathrm{e}+001.00000 \mathrm{e}+001.00000 \mathrm{e}-011.00000 \mathrm{e}-091.00000 \mathrm{e}-01$ Element: 5200 \# of layers: 10

Kx Ky Kz Ss Por

7.16358e+01 7.16358e+01 7.16358e+00 1.00000e-09 7.00000e-02 $7.16358 \mathrm{e}+01$ 7.16358e+01 7.16358e+00 1.00000e-09 7.00000e-02 $7.16358 \mathrm{e}+01$ 7.16358e+01 7.16358e+00 1.00000e-09 7.00000e-02 5.00000e-04 5.00000e-04 5.00000e-05 1.00000e-09 1.00000e-01 5.00000e-04 5.00000e-04 5.00000e-05 1.00000e-09 1.00000e-01 $2.86229 \mathrm{e}+002.86229 \mathrm{e}+002.86229 \mathrm{e}-011.00000 \mathrm{e}-092.12000 \mathrm{e}-01$ $2.86229 \mathrm{e}+002.86229 \mathrm{e}+002.86229 \mathrm{e}-01$ 1.00000e-09 2.12000e-01 
$2.86229 \mathrm{e}+002.86229 \mathrm{e}+00$ 2.86229e-01 1.00000e-09 2.12000e-01 $1.00000 \mathrm{e}-021.00000 \mathrm{e}-02$ 1.00000e-03 1.00000e-09 1.00000e-01 $1.00000 \mathrm{e}+001.00000 \mathrm{e}+001.00000 \mathrm{e}-011.00000 \mathrm{e}-091.00000 \mathrm{e}-01$ Element: 5201 \# of layers: 9

Kx Ky Kz Ss Por

7.16358e +01 7.16358e +01 7.16358e+00 1.00000e-09 7.00000e-02 $7.16358 \mathrm{e}+01$ 7.16358e+01 7.16358e+00 1.00000e-09 7.00000e-02 $7.16358 \mathrm{e}+01$ 7.16358e+01 7.16358e+00 1.00000e-09 7.00000e-02 5.00000e-04 5.00000e-04 5.00000e-05 1.00000e-09 1.00000e-01 5.00000e-04 5.00000e-04 5.00000e-05 1.00000e-09 1.00000e-01 $2.86229 \mathrm{e}+002.86229 \mathrm{e}+002.86229 \mathrm{e}-011.00000 \mathrm{e}-092.12000 \mathrm{e}-01$ $2.86229 \mathrm{e}+002.86229 \mathrm{e}+002.86229 \mathrm{e}-01$ 1.00000e-09 2.12000e-01 $1.00000 \mathrm{e}-02$ 1.00000e-02 1.00000e-03 1.00000e-09 1.00000e-01 $1.00000 \mathrm{e}+001.00000 \mathrm{e}+001.00000 \mathrm{e}-011.00000 \mathrm{e}-091.00000 \mathrm{e}-01$ Element: 5202 \# of layers: 9

Kx Ky Kz Ss Por

7.16358e+01 7.16358e+01 7.16358e+00 1.00000e-09 7.00000e-02 $7.16358 \mathrm{e}+017.16358 \mathrm{e}+01$ 7.16358e+00 1.00000e-09 7.00000e-02 $7.16358 \mathrm{e}+01$ 7.16358e+01 7.16358e+00 1.00000e-09 7.00000e-02 5.00000e-04 5.00000e-04 5.00000e-05 1.00000e-09 1.00000e-01 5.00000e-04 5.00000e-04 5.00000e-05 1.00000e-09 1.00000e-01 $2.86229 \mathrm{e}+002.86229 \mathrm{e}+002.86229 \mathrm{e}-01$ 1.00000e-09 2.12000e-01 $2.86229 \mathrm{e}+002.86229 \mathrm{e}+002.86229 \mathrm{e}-01$ 1.00000e-09 2.12000e-01 $1.00000 \mathrm{e}-021.00000 \mathrm{e}-02$ 1.00000e-03 1.00000e-09 1.00000e-01 $1.00000 \mathrm{e}+001.00000 \mathrm{e}+001.00000 \mathrm{e}-011.00000 \mathrm{e}-091.00000 \mathrm{e}-01$ Element: 5203 \# of layers: 9

Kx Ky Kz Ss Por

$7.89781 \mathrm{e}+01$ 7.89781e+01 7.89781e+00 1.00000e-09 7.00000e-02 $7.89781 \mathrm{e}+017.89781 \mathrm{e}+017.89781 \mathrm{e}+001.00000 \mathrm{e}-097.00000 \mathrm{e}-02$ $7.89781 \mathrm{e}+017.89781 \mathrm{e}+017.89781 \mathrm{e}+001.00000 \mathrm{e}-097.00000 \mathrm{e}-02$ 5.00000e-04 5.00000e-04 5.00000e-05 1.00000e-09 1.00000e-01 5.00000e-04 5.00000e-04 5.00000e-05 1.00000e-09 1.00000e-01 $3.15569 \mathrm{e}+003.15569 \mathrm{e}+00$ 3.15569e-01 1.00000e-09 2.12000e-01 $3.15569 \mathrm{e}+003.15569 \mathrm{e}+00$ 3.15569e-01 1.00000e-09 2.12000e-01 $1.00000 \mathrm{e}-02$ 1.00000e-02 1.00000e-03 1.00000e-09 1.00000e-01 $1.00000 \mathrm{e}+001.00000 \mathrm{e}+001.00000 \mathrm{e}-011.00000 \mathrm{e}-091.00000 \mathrm{e}-01$ Element: 5204 \# of layers: 10

Kx Ky Kz Ss Por

$7.26008 \mathrm{e}+017.26008 \mathrm{e}+01$ 7.26008e+00 1.00000e-09 7.00000e-02 $7.26008 \mathrm{e}+017.26008 \mathrm{e}+01$ 7.26008e+00 1.00000e-09 7.00000e-02 $7.26008 \mathrm{e}+017.26008 \mathrm{e}+017.26008 \mathrm{e}+001.00000 \mathrm{e}-097.00000 \mathrm{e}-02$ $7.26008 \mathrm{e}+017.26008 \mathrm{e}+017.26008 \mathrm{e}+001.00000 \mathrm{e}-097.00000 \mathrm{e}-02$ 5.00000e-04 5.00000e-04 5.00000e-05 1.00000e-09 1.00000e-01 5.00000e-04 5.00000e-04 5.00000e-05 1.00000e-09 1.00000e-01 $2.90076 \mathrm{e}+002.90076 \mathrm{e}+002.90076 \mathrm{e}-011.00000 \mathrm{e}-092.12000 \mathrm{e}-01$ $2.90076 \mathrm{e}+002.90076 \mathrm{e}+002.90076 \mathrm{e}-011.00000 \mathrm{e}-092.12000 \mathrm{e}-01$ 
$1.00000 \mathrm{e}-02$ 1.00000e-02 1.00000e-03 1.00000e-09 1.00000e-01 $1.00000 \mathrm{e}+001.00000 \mathrm{e}+001.00000 \mathrm{e}-01$ 1.00000e-09 1.00000e-01 Element: 5205 \# of layers: 10

Kx Ky Kz Ss Por

6.93923e+01 6.93923e+01 6.93923e+00 1.00000e-09 7.00000e-02 $6.93923 \mathrm{e}+016.93923 \mathrm{e}+016.93923 \mathrm{e}+00$ 1.00000e-09 7.00000e-02 $6.93923 \mathrm{e}+016.93923 \mathrm{e}+016.93923 \mathrm{e}+00$ 1.00000e-09 7.00000e-02 5.00000e-04 5.00000e-04 5.00000e-05 1.00000e-09 1.00000e-01 5.00000e-04 5.00000e-04 5.00000e-05 1.00000e-09 1.00000e-01 $2.77273 \mathrm{e}+002.77273 \mathrm{e}+00$ 2.77273e-01 1.00000e-09 2.12000e-01 $2.77273 e+002.77273 e+00$ 2.77273e-01 1.00000e-09 2.12000e-01 $2.77273 \mathrm{e}+00$ 2.77273e+00 2.77273e-01 1.00000e-09 2.12000e-01 $1.00000 \mathrm{e}-02$ 1.00000e-02 1.00000e-03 1.00000e-09 1.00000e-01 $1.00000 \mathrm{e}+001.00000 \mathrm{e}+001.00000 \mathrm{e}-011.00000 \mathrm{e}-091.00000 \mathrm{e}-01$ Element: 5206 \# of layers: 10

Kx Ky Kz Ss Por

7.49767e+01 7.49767e+01 7.49767e+00 1.00000e-09 7.00000e-02 7.49767e+01 7.49767e+01 7.49767e+00 1.00000e-09 7.00000e-02 7.49767e+01 7.49767e+01 7.49767e+00 1.00000e-09 7.00000e-02 7.49767e+01 7.49767e+01 7.49767e+00 1.00000e-09 7.00000e-02 5.00000e-04 5.00000e-04 5.00000e-05 1.00000e-09 1.00000e-01 5.00000e-04 5.00000e-04 5.00000e-05 1.00000e-09 1.00000e-01 $2.99571 \mathrm{e}+002.99571 \mathrm{e}+002.99571 \mathrm{e}-01$ 1.00000e-09 2.12000e-01 $2.99571 \mathrm{e}+002.99571 \mathrm{e}+002.99571 \mathrm{e}-01$ 1.00000e-09 2.12000e-01 $1.00000 \mathrm{e}-02$ 1.00000e-02 1.00000e-03 1.00000e-09 1.00000e-01 $1.00000 \mathrm{e}+001.00000 \mathrm{e}+001.00000 \mathrm{e}-01$ 1.00000e-09 1.00000e-01 Element: 5207 \# of layers: 9

$\mathrm{Kx} \mathrm{Ky} \mathrm{Kz}$ Ss Por

7.66138e+01 7.66138e+01 7.66138e+00 1.00000e-09 7.00000e-02 $7.66138 \mathrm{e}+01$ 7.66138e+01 7.66138e+00 1.00000e-09 7.00000e-02

$7.66138 \mathrm{e}+017.66138 \mathrm{e}+017.66138 \mathrm{e}+001.00000 \mathrm{e}-09$ 7.00000e-02 5.00000e-04 5.00000e-04 5.00000e-05 1.00000e-09 1.00000e-01 5.00000e-04 5.00000e-04 5.00000e-05 1.00000e-09 1.00000e-01 $3.06119 \mathrm{e}+003.06119 \mathrm{e}+003.06119 \mathrm{e}-01$ 1.00000e-09 2.12000e-01 $3.06119 \mathrm{e}+003.06119 \mathrm{e}+003.06119 \mathrm{e}-01$ 1.00000e-09 2.12000e-01 1.00000e-02 1.00000e-02 1.00000e-03 1.00000e-09 1.00000e-01 $1.00000 \mathrm{e}+001.00000 \mathrm{e}+001.00000 \mathrm{e}-011.00000 \mathrm{e}-091.00000 \mathrm{e}-01$ Element: 5208 \# of layers: 8

$\mathrm{Kx} \mathrm{Ky} \mathrm{Kz}$ Ss Por

8.90188e+01 8.90188e+01 8.90188e+00 1.00000e-09 7.00000e-02 $8.90188 \mathrm{e}+018.90188 \mathrm{e}+018.90188 \mathrm{e}+00$ 1.00000e-09 7.00000e-02 5.00000e-04 5.00000e-04 5.00000e-05 1.00000e-09 1.00000e-01 5.00000e-04 5.00000e-04 5.00000e-05 1.00000e-09 1.00000e-01 $3.55688 \mathrm{e}+003.55688 \mathrm{e}+003.55688 \mathrm{e}-01$ 1.00000e-09 2.12000e-01 $3.55688 \mathrm{e}+003.55688 \mathrm{e}+003.55688 \mathrm{e}-01$ 1.00000e-09 2.12000e-01 $1.00000 \mathrm{e}-02$ 1.00000e-02 1.00000e-03 1.00000e-09 1.00000e-01 
$1.00000 \mathrm{e}+001.00000 \mathrm{e}+00$ 1.00000e-01 1.00000e-09 1.00000e-01

Element: 5212 \# of layers: 10

Kx Ky Kz Ss Por

7.66138e+01 7.66138e+01 7.66138e+00 1.00000e-09 7.00000e-02

$7.66138 \mathrm{e}+017.66138 \mathrm{e}+01$ 7.66138e+00 1.00000e-09 7.00000e-02

$7.66138 \mathrm{e}+017.66138 \mathrm{e}+017.66138 \mathrm{e}+00$ 1.00000e-09 7.00000e-02

$7.66138 \mathrm{e}+01$ 7.66138e+01 7.66138e+00 1.00000e-09 7.00000e-02

5.00000e-04 5.00000e-04 5.00000e-05 1.00000e-09 1.00000e-01

5.00000e-04 5.00000e-04 5.00000e-05 1.00000e-09 1.00000e-01

$3.06119 \mathrm{e}+003.06119 \mathrm{e}+00$ 3.06119e-01 1.00000e-09 2.12000e-01

$3.06119 \mathrm{e}+003.06119 \mathrm{e}+00$ 3.06119e-01 1.00000e-09 2.12000e-01

$1.00000 \mathrm{e}-02$ 1.00000e-02 1.00000e-03 1.00000e-09 1.00000e-01

$1.00000 \mathrm{e}+001.00000 \mathrm{e}+001.00000 \mathrm{e}-011.00000 \mathrm{e}-091.00000 \mathrm{e}-01$

Element: 5213 \# of layers: 10

Kx Ky Kz Ss Por

7.66138e+01 7.66138e+01 7.66138e+00 1.00000e-09 7.00000e-02

$7.66138 \mathrm{e}+01$ 7.66138e+01 7.66138e+00 1.00000e-09 7.00000e-02

$7.66138 \mathrm{e}+017.66138 \mathrm{e}+01$ 7.66138e+00 1.00000e-09 7.00000e-02

$7.66138 \mathrm{e}+017.66138 \mathrm{e}+01$ 7.66138e+00 1.00000e-09 7.00000e-02

5.00000e-04 5.00000e-04 5.00000e-05 1.00000e-09 1.00000e-01

5.00000e-04 5.00000e-04 5.00000e-05 1.00000e-09 1.00000e-01

$3.06119 \mathrm{e}+003.06119 \mathrm{e}+00$ 3.06119e-01 1.00000e-09 2.12000e-01

3.06119e+00 3.06119e+00 3.06119e-01 1.00000e-09 2.12000e-01

$1.00000 \mathrm{e}-02$ 1.00000e-02 1.00000e-03 1.00000e-09 1.00000e-01

$1.00000 \mathrm{e}+001.00000 \mathrm{e}+001.00000 \mathrm{e}-011.00000 \mathrm{e}-091.00000 \mathrm{e}-01$

Element: 5215 \# of layers: 9

$\mathrm{Kx} \mathrm{Ky} \mathrm{Kz}$ Ss Por

7.60462e+01 7.60462e+01 7.60462e+00 1.00000e-09 7.00000e-02

$7.60462 \mathrm{e}+01$ 7.60462e+01 7.60462e+00 1.00000e-09 7.00000e-02

7.60462e+01 7.60462e+01 7.60462e+00 1.00000e-09 7.00000e-02

$5.00000 \mathrm{e}-04$ 5.00000e-04 5.00000e-05 1.00000e-09 1.00000e-01

5.00000e-04 5.00000e-04 5.00000e-05 1.00000e-09 1.00000e-01

$3.03847 \mathrm{e}+003.03847 \mathrm{e}+003.03847 \mathrm{e}-01$ 1.00000e-09 2.12000e-01

$3.03847 \mathrm{e}+003.03847 \mathrm{e}+00$ 3.03847e-01 1.00000e-09 2.12000e-01

$1.00000 \mathrm{e}-02$ 1.00000e-02 1.00000e-03 1.00000e-09 1.00000e-01

$1.00000 \mathrm{e}+001.00000 \mathrm{e}+001.00000 \mathrm{e}-011.00000 \mathrm{e}-091.00000 \mathrm{e}-01$

Element: 5216 \# of layers: 7

$\mathrm{Kx} \mathrm{Ky} \mathrm{Kz}$ Ss Por

7.60462e+01 7.60462e+01 7.60462e+00 1.00000e-09 7.00000e-02

$7.60462 \mathrm{e}+017.60462 \mathrm{e}+01$ 7.60462e+00 1.00000e-09 7.00000e-02

$7.60462 \mathrm{e}+017.60462 \mathrm{e}+01$ 7.60462e+00 1.00000e-09 7.00000e-02

$3.03847 \mathrm{e}+003.03847 \mathrm{e}+00$ 3.03847e-01 1.00000e-09 2.12000e-01

$3.03847 \mathrm{e}+00$ 3.03847e+00 3.03847e-01 1.00000e-09 2.12000e-01

$1.00000 \mathrm{e}-02$ 1.00000e-02 1.00000e-03 1.00000e-09 1.00000e-01

$1.00000 \mathrm{e}+001.00000 \mathrm{e}+001.00000 \mathrm{e}-01$ 1.00000e-09 1.00000e-01

Element: 5217 \# of layers: 8 
$\mathrm{Kx} \mathrm{Ky} \mathrm{Kz}$ Ss Por

7.60462e+01 7.60462e+01 7.60462e+00 1.00000e-09 7.00000e-02

$7.60462 \mathrm{e}+01$ 7.60462e+01 7.60462e+00 1.00000e-09 7.00000e-02

$7.60462 \mathrm{e}+01$ 7.60462e+01 7.60462e+00 1.00000e-09 7.00000e-02

7.60462e+01 7.60462e+01 7.60462e+00 1.00000e-09 7.00000e-02

$3.03847 \mathrm{e}+003.03847 \mathrm{e}+00$ 3.03847e-01 1.00000e-09 2.12000e-01

$3.03847 \mathrm{e}+00$ 3.03847e+00 3.03847e-01 1.00000e-09 2.12000e-01

$1.00000 \mathrm{e}-02$ 1.00000e-02 1.00000e-03 1.00000e-09 1.00000e-01

$1.00000 \mathrm{e}+001.00000 \mathrm{e}+001.00000 \mathrm{e}-011.00000 \mathrm{e}-091.00000 \mathrm{e}-01$

Element: 5218 \# of layers: 9

$\mathrm{Kx} \mathrm{Ky} \mathrm{Kz}$ Ss Por

$1.08688 \mathrm{e}+021.08688 \mathrm{e}+02$ 1.08688e+01 1.00000e-09 7.00000e-02

$1.08688 \mathrm{e}+02$ 1.08688 +02 1.08688e+01 1.00000e-09 7.00000e-02

$1.08688 \mathrm{e}+021.08688 \mathrm{e}+02$ 1.08688e+01 1.00000e-09 7.00000e-02

5.00000e-04 5.00000e-04 5.00000e-05 1.00000e-09 1.00000e-01

5.00000e-04 5.00000e-04 5.00000e-05 1.00000e-09 1.00000e-01

4.34259e+00 4.34259e+00 4.34259e-01 1.00000e-09 2.12000e-01

$4.34259 \mathrm{e}+00$ 4.34259e+00 4.34259e-01 1.00000e-09 2.12000e-01

$1.00000 \mathrm{e}-02$ 1.00000e-02 1.00000e-03 1.00000e-09 1.00000e-01

$1.00000 \mathrm{e}+001.00000 \mathrm{e}+001.00000 \mathrm{e}-011.00000 \mathrm{e}-091.00000 \mathrm{e}-01$

Element: 5219 \# of layers: 9

$\mathrm{Kx} \mathrm{Ky} \mathrm{Kz}$ Ss Por

$1.08688 \mathrm{e}+02$ 1.08688e+02 1.08688e+01 1.00000e-09 7.00000e-02

$1.08688 \mathrm{e}+021.08688 \mathrm{e}+02$ 1.08688e+01 1.00000e-09 7.00000e-02

$1.08688 \mathrm{e}+021.08688 \mathrm{e}+02$ 1.08688e+01 1.00000e-09 7.00000e-02

5.00000e-04 5.00000e-04 5.00000e-05 1.00000e-09 1.00000e-01

5.00000e-04 5.00000e-04 5.00000e-05 1.00000e-09 1.00000e-01

$4.34259 \mathrm{e}+00$ 4.34259e+00 4.34259e-01 1.00000e-09 2.12000e-01

$4.34259 \mathrm{e}+00$ 4.34259e+00 4.34259e-01 1.00000e-09 2.12000e-01

$1.00000 \mathrm{e}-02$ 1.00000e-02 1.00000e-03 1.00000e-09 1.00000e-01

$1.00000 \mathrm{e}+001.00000 \mathrm{e}+001.00000 \mathrm{e}-011.00000 \mathrm{e}-091.00000 \mathrm{e}-01$

Element: 5220 \# of layers: 9

$\mathrm{Kx} \mathrm{Ky} \mathrm{Kz}$ Ss Por

$1.08688 \mathrm{e}+02$ 1.08688e+02 1.08688e+01 1.00000e-09 7.00000e-02

$1.08688 \mathrm{e}+021.08688 \mathrm{e}+02$ 1.08688e+01 1.00000e-09 7.00000e-02

$1.08688 \mathrm{e}+021.08688 \mathrm{e}+02$ 1.08688e+01 1.00000e-09 7.00000e-02

5.00000e-04 5.00000e-04 5.00000e-05 1.00000e-09 1.00000e-01

5.00000e-04 5.00000e-04 5.00000e-05 1.00000e-09 1.00000e-01

4.34259e+00 4.34259e+00 4.34259e-01 1.00000e-09 2.12000e-01

$4.34259 \mathrm{e}+00$ 4.34259e+00 4.34259e-01 1.00000e-09 2.12000e-01

$1.00000 \mathrm{e}-02$ 1.00000e-02 1.00000e-03 1.00000e-09 1.00000e-01

$1.00000 \mathrm{e}+001.00000 \mathrm{e}+001.00000 \mathrm{e}-011.00000 \mathrm{e}-091.00000 \mathrm{e}-01$

Element: 5221 \# of layers: 8

$\mathrm{Kx} \mathrm{Ky} \mathrm{Kz}$ Ss Por

2.27295e+02 2.27295e+02 2.27295e+01 1.00000e-09 7.00000e-02

$2.27295 \mathrm{e}+02$ 2.27295e+02 2.27295e+01 1.00000e-09 7.00000e-02 
5.00000e-04 5.00000e-04 5.00000e-05 1.00000e-09 1.00000e-01 5.00000e-04 5.00000e-04 5.00000e-05 1.00000e-09 1.00000e-01 $9.08187 \mathrm{e}+00$ 9.08187e+00 9.08187e-01 1.00000e-09 2.12000e-01 $9.08187 \mathrm{e}+00$ 9.08187e+00 9.08187e-01 1.00000e-09 2.12000e-01 $1.00000 \mathrm{e}-02$ 1.00000e-02 1.00000e-03 1.00000e-09 1.00000e-01 $1.00000 \mathrm{e}+001.00000 \mathrm{e}+001.00000 \mathrm{e}-011.00000 \mathrm{e}-091.00000 \mathrm{e}-01$ Element: 5222 \# of layers: 8

$\mathrm{Kx} \mathrm{Ky} \mathrm{Kz}$ Ss Por

2.27295e+02 2.27295e+02 2.27295e+01 1.00000e-09 7.00000e-02

$2.27295 \mathrm{e}+02$ 2.27295e+02 2.27295e+01 1.00000e-09 7.00000e-02 5.00000e-04 5.00000e-04 5.00000e-05 1.00000e-09 1.00000e-01 5.00000e-04 5.00000e-04 5.00000e-05 1.00000e-09 1.00000e-01

9.08187e+00 9.08187e+00 9.08187e-01 1.00000e-09 2.12000e-01 9.08187e+00 9.08187e+00 9.08187e-01 1.00000e-09 2.12000e-01 $1.00000 \mathrm{e}-02$ 1.00000e-02 1.00000e-03 1.00000e-09 1.00000e-01 $1.00000 \mathrm{e}+001.00000 \mathrm{e}+001.00000 \mathrm{e}-011.00000 \mathrm{e}-091.00000 \mathrm{e}-01$ Element: 5223 \# of layers: 8

$\mathrm{Kx} \mathrm{Ky} \mathrm{Kz}$ Ss Por

2.27295e+02 2.27295e+02 2.27295e+01 1.00000e-09 7.00000e-02 $2.27295 \mathrm{e}+022.27295 \mathrm{e}+02 \quad 2.27295 \mathrm{e}+01$ 1.00000e-09 7.00000e-02 5.00000e-04 5.00000e-04 5.00000e-05 1.00000e-09 1.00000e-01 5.00000e-04 5.00000e-04 5.00000e-05 1.00000e-09 1.00000e-01 $9.08187 \mathrm{e}+00$ 9.08187e+00 9.08187e-01 1.00000e-09 2.12000e-01 9.08187e+00 9.08187e+00 9.08187e-01 1.00000e-09 2.12000e-01 $1.00000 \mathrm{e}-021.00000 \mathrm{e}-02$ 1.00000e-03 1.00000e-09 1.00000e-01 $1.00000 \mathrm{e}+001.00000 \mathrm{e}+001.00000 \mathrm{e}-011.00000 \mathrm{e}-091.00000 \mathrm{e}-01$ Element: 5224 \# of layers: 7

$\mathrm{Kx} \mathrm{Ky} \mathrm{Kz}$ Ss Por

3.00449e+00 3.00449e+00 3.00449e-01 1.00000e-09 2.12000e-01 $3.00449 \mathrm{e}+00$ 3.00449e+00 3.00449e-01 1.00000e-09 2.12000e-01 $3.00449 \mathrm{e}+003.00449 \mathrm{e}+003.00449 \mathrm{e}-01$ 1.00000e-09 2.12000e-01 3.00449e+00 3.00449e+00 3.00449e-01 1.00000e-09 2.12000e-01 $3.00449 \mathrm{e}+00$ 3.00449e+00 3.00449e-01 1.00000e-09 2.12000e-01 $1.00000 \mathrm{e}-05$ 1.00000e-05 1.00000e-06 1.00000e-09 1.00000e-01 $1.00000 \mathrm{e}+001.00000 \mathrm{e}+001.00000 \mathrm{e}-011.00000 \mathrm{e}-091.00000 \mathrm{e}-01$ Element: 5225 \# of layers: 7

Kx Ky Kz Ss Por

3.00449e+00 3.00449e+00 3.00449e-01 1.00000e-09 2.12000e-01 $3.00449 \mathrm{e}+003.00449 \mathrm{e}+003.00449 \mathrm{e}-01$ 1.00000e-09 2.12000e-01 $3.00449 \mathrm{e}+003.00449 \mathrm{e}+00$ 3.00449e-01 1.00000e-09 2.12000e-01 $3.00449 \mathrm{e}+003.00449 \mathrm{e}+00$ 3.00449e-01 1.00000e-09 2.12000e-01 $3.00449 \mathrm{e}+003.00449 \mathrm{e}+003.00449 \mathrm{e}-01$ 1.00000e-09 2.12000e-01 $1.00000 \mathrm{e}-051.00000 \mathrm{e}-051.00000 \mathrm{e}-061.00000 \mathrm{e}-091.00000 \mathrm{e}-01$ $1.00000 \mathrm{e}+001.00000 \mathrm{e}+001.00000 \mathrm{e}-01$ 1.00000e-09 1.00000e-01 Element: 5226 \# of layers: 7

Kx Ky Kz Ss Por 
$3.36247 \mathrm{e}+003.36247 \mathrm{e}+00$ 3.36247e-01 1.00000e-09 2.12000e-01 $3.36247 \mathrm{e}+003.36247 \mathrm{e}+003.36247 \mathrm{e}-011.00000 \mathrm{e}-092.12000 \mathrm{e}-01$ $3.36247 \mathrm{e}+003.36247 \mathrm{e}+003.36247 \mathrm{e}-01$ 1.00000e-09 2.12000e-01 $3.36247 \mathrm{e}+003.36247 \mathrm{e}+003.36247 \mathrm{e}-011.00000 \mathrm{e}-092.12000 \mathrm{e}-01$ $3.36247 \mathrm{e}+003.36247 \mathrm{e}+003.36247 \mathrm{e}-01$ 1.00000e-09 2.12000e-01 $1.00000 \mathrm{e}-05$ 1.00000e-05 1.00000e-06 1.00000e-09 1.00000e-01 $1.00000 \mathrm{e}+001.00000 \mathrm{e}+001.00000 \mathrm{e}-011.00000 \mathrm{e}-091.00000 \mathrm{e}-01$ Element: 5227 \# of layers: 7

$\mathrm{Kx} \mathrm{Ky} \mathrm{Kz}$ Ss Por

3.36247e+00 3.36247e+00 3.36247e-01 1.00000e-09 2.12000e-01 $3.36247 \mathrm{e}+003.36247 \mathrm{e}+003.36247 \mathrm{e}-011.00000 \mathrm{e}-092.12000 \mathrm{e}-01$ $3.36247 \mathrm{e}+003.36247 \mathrm{e}+003.36247 \mathrm{e}-011.00000 \mathrm{e}-092.12000 \mathrm{e}-01$ $3.36247 \mathrm{e}+003.36247 \mathrm{e}+003.36247 \mathrm{e}-011.00000 \mathrm{e}-092.12000 \mathrm{e}-01$ $3.36247 \mathrm{e}+003.36247 \mathrm{e}+003.36247 \mathrm{e}-01$ 1.00000e-09 2.12000e-01 $1.00000 \mathrm{e}-05$ 1.00000e-05 1.00000e-06 1.00000e-09 1.00000e-01 $1.00000 \mathrm{e}+001.00000 \mathrm{e}+001.00000 \mathrm{e}-011.00000 \mathrm{e}-091.00000 \mathrm{e}-01$ Element: 5228 \# of layers: 7

Kx Ky Kz Ss Por

3.27292e+00 3.27292e+00 3.27292e-01 1.00000e-09 2.12000e-01 $3.27292 \mathrm{e}+003.27292 \mathrm{e}+003.27292 \mathrm{e}-01$ 1.00000e-09 2.12000e-01 $3.27292 \mathrm{e}+003.27292 \mathrm{e}+003.27292 \mathrm{e}-01$ 1.00000e-09 2.12000e-01 $3.27292 \mathrm{e}+003.27292 \mathrm{e}+003.27292 \mathrm{e}-01$ 1.00000e-09 2.12000e-01 $3.27292 \mathrm{e}+003.27292 \mathrm{e}+003.27292 \mathrm{e}-01$ 1.00000e-09 2.12000e-01 $1.00000 \mathrm{e}-05$ 1.00000e-05 1.00000e-06 1.00000e-09 1.00000e-01 $1.00000 \mathrm{e}+001.00000 \mathrm{e}+001.00000 \mathrm{e}-011.00000 \mathrm{e}-091.00000 \mathrm{e}-01$ Element: 5229 \# of layers: 7

Kx Ky Kz Ss Por

3.15817e+00 3.15817e+00 3.15817e-01 1.00000e-09 2.12000e-01 $3.15817 \mathrm{e}+003.15817 \mathrm{e}+003.15817 \mathrm{e}-011.00000 \mathrm{e}-092.12000 \mathrm{e}-01$ $3.15817 \mathrm{e}+003.15817 \mathrm{e}+003.15817 \mathrm{e}-011.00000 \mathrm{e}-092.12000 \mathrm{e}-01$ $3.15817 \mathrm{e}+003.15817 \mathrm{e}+003.15817 \mathrm{e}-01$ 1.00000e-09 2.12000e-01 $3.15817 \mathrm{e}+003.15817 \mathrm{e}+003.15817 \mathrm{e}-01$ 1.00000e-09 2.12000e-01 $1.00000 \mathrm{e}-05$ 1.00000e-05 1.00000e-06 1.00000e-09 1.00000e-01 $1.00000 \mathrm{e}+001.00000 \mathrm{e}+001.00000 \mathrm{e}-011.00000 \mathrm{e}-091.00000 \mathrm{e}-01$ Element: 5230 \# of layers: 7

Kx Ky Kz Ss Por

$3.33862 \mathrm{e}+003.33862 \mathrm{e}+00$ 3.33862e-01 1.00000e-09 2.12000e-01 $3.33862 \mathrm{e}+003.33862 \mathrm{e}+003.33862 \mathrm{e}-01$ 1.00000e-09 2.12000e-01 $3.33862 \mathrm{e}+003.33862 \mathrm{e}+003.33862 \mathrm{e}-01$ 1.00000e-09 2.12000e-01 $3.33862 \mathrm{e}+003.33862 \mathrm{e}+003.33862 \mathrm{e}-01$ 1.00000e-09 2.12000e-01 $3.33862 \mathrm{e}+003.33862 \mathrm{e}+003.33862 \mathrm{e}-01$ 1.00000e-09 2.12000e-01 $1.00000 \mathrm{e}-05$ 1.00000e-05 1.00000e-06 1.00000e-09 1.00000e-01 $1.00000 \mathrm{e}+001.00000 \mathrm{e}+001.00000 \mathrm{e}-011.00000 \mathrm{e}-091.00000 \mathrm{e}-01$ Element: 5231 \# of layers: 7

Kx Ky Kz Ss Por 3.33862e+00 3.33862e+00 3.33862e-01 1.00000e-09 2.12000e-01 
$3.33862 \mathrm{e}+003.33862 \mathrm{e}+00$ 3.33862e-01 1.00000e-09 2.12000e-01 $3.33862 \mathrm{e}+003.33862 \mathrm{e}+003.33862 \mathrm{e}-01$ 1.00000e-09 2.12000e-01 $3.33862 \mathrm{e}+003.33862 \mathrm{e}+003.33862 \mathrm{e}-01$ 1.00000e-09 2.12000e-01 $3.33862 \mathrm{e}+003.33862 \mathrm{e}+003.33862 \mathrm{e}-01$ 1.00000e-09 2.12000e-01 $1.00000 \mathrm{e}-05$ 1.00000e-05 1.00000e-06 1.00000e-09 1.00000e-01 $1.00000 \mathrm{e}+001.00000 \mathrm{e}+001.00000 \mathrm{e}-011.00000 \mathrm{e}-091.00000 \mathrm{e}-01$ Element: 5232 \# of layers: 7

Kx Ky Kz Ss Por

$3.33862 \mathrm{e}+003.33862 \mathrm{e}+003.33862 \mathrm{e}-01$ 1.00000e-09 2.12000e-01 $3.33862 \mathrm{e}+003.33862 \mathrm{e}+003.33862 \mathrm{e}-01$ 1.00000e-09 2.12000e-01 $3.33862 \mathrm{e}+003.33862 \mathrm{e}+003.33862 \mathrm{e}-01$ 1.00000e-09 2.12000e-01 $3.33862 \mathrm{e}+003.33862 \mathrm{e}+003.33862 \mathrm{e}-01$ 1.00000e-09 2.12000e-01 $3.33862 \mathrm{e}+003.33862 \mathrm{e}+003.33862 \mathrm{e}-01$ 1.00000e-09 2.12000e-01 $1.00000 \mathrm{e}-05$ 1.00000e-05 1.00000e-06 1.00000e-09 1.00000e-01 $1.00000 \mathrm{e}+001.00000 \mathrm{e}+001.00000 \mathrm{e}-011.00000 \mathrm{e}-091.00000 \mathrm{e}-01$ Element: 5233 \# of layers: 7

Kx Ky Kz Ss Por

$4.11264 \mathrm{e}+004.11264 \mathrm{e}+00$ 4.11264e-01 1.00000e-09 2.12000e-01 $4.11264 \mathrm{e}+004.11264 \mathrm{e}+004.11264 \mathrm{e}-011.00000 \mathrm{e}-092.12000 \mathrm{e}-01$ $4.11264 \mathrm{e}+004.11264 \mathrm{e}+004.11264 \mathrm{e}-011.00000 \mathrm{e}-092.12000 \mathrm{e}-01$ $4.11264 \mathrm{e}+004.11264 \mathrm{e}+004.11264 \mathrm{e}-011.00000 \mathrm{e}-092.12000 \mathrm{e}-01$ $4.11264 \mathrm{e}+004.11264 \mathrm{e}+004.11264 \mathrm{e}-011.00000 \mathrm{e}-09$ 2.12000e-01 $1.00000 \mathrm{e}-05$ 1.00000e-05 1.00000e-06 1.00000e-09 1.00000e-01 $1.00000 \mathrm{e}+001.00000 \mathrm{e}+001.00000 \mathrm{e}-011.00000 \mathrm{e}-091.00000 \mathrm{e}-01$ Element: 5234 \# of layers: 7

Kx Ky Kz Ss Por

4.11264e+00 4.11264e+00 4.11264e-01 1.00000e-09 2.12000e-01 $4.11264 \mathrm{e}+004.11264 \mathrm{e}+004.11264 \mathrm{e}-011.00000 \mathrm{e}-092.12000 \mathrm{e}-01$ $4.11264 \mathrm{e}+004.11264 \mathrm{e}+004.11264 \mathrm{e}-011.00000 \mathrm{e}-092.12000 \mathrm{e}-01$ $4.11264 \mathrm{e}+004.11264 \mathrm{e}+004.11264 \mathrm{e}-011.00000 \mathrm{e}-092.12000 \mathrm{e}-01$ $4.11264 \mathrm{e}+004.11264 \mathrm{e}+004.11264 \mathrm{e}-011.00000 \mathrm{e}-09$ 2.12000e-01 $1.00000 \mathrm{e}-05$ 1.00000e-05 1.00000e-06 1.00000e-09 1.00000e-01 $1.00000 \mathrm{e}+001.00000 \mathrm{e}+00$ 1.00000e-01 1.00000e-09 1.00000e-01 Element: 5235 \# of layers: 7

Kx Ky Kz Ss Por

$3.57600 \mathrm{e}+003.57600 \mathrm{e}+00$ 3.57600e-01 1.00000e-09 2.12000e-01

$3.57600 \mathrm{e}+003.57600 \mathrm{e}+003.57600 \mathrm{e}-011.00000 \mathrm{e}-092.12000 \mathrm{e}-01$

$3.57600 \mathrm{e}+003.57600 \mathrm{e}+003.57600 \mathrm{e}-011.00000 \mathrm{e}-092.12000 \mathrm{e}-01$

$3.57600 \mathrm{e}+003.57600 \mathrm{e}+003.57600 \mathrm{e}-011.00000 \mathrm{e}-092.12000 \mathrm{e}-01$

$3.57600 \mathrm{e}+003.57600 \mathrm{e}+003.57600 \mathrm{e}-011.00000 \mathrm{e}-092.12000 \mathrm{e}-01$ $1.00000 \mathrm{e}-05$ 1.00000e-05 1.00000e-06 1.00000e-09 1.00000e-01 $1.00000 \mathrm{e}+001.00000 \mathrm{e}+001.00000 \mathrm{e}-011.00000 \mathrm{e}-091.00000 \mathrm{e}-01$ Element: 5236 \# of layers: 7

Kx Ky Kz Ss Por

3.15817e+00 3.15817e+00 3.15817e-01 1.00000e-09 2.12000e-01 $3.15817 \mathrm{e}+003.15817 \mathrm{e}+00$ 3.15817e-01 1.00000e-09 2.12000e-01 
$3.15817 \mathrm{e}+003.15817 \mathrm{e}+00$ 3.15817e-01 1.00000e-09 2.12000e-01 $3.15817 \mathrm{e}+003.15817 \mathrm{e}+00$ 3.15817e-01 1.00000e-09 2.12000e-01 $3.15817 \mathrm{e}+003.15817 \mathrm{e}+003.15817 \mathrm{e}-011.00000 \mathrm{e}-092.12000 \mathrm{e}-01$ $1.00000 \mathrm{e}-05$ 1.00000e-05 1.00000e-06 1.00000e-09 1.00000e-01 $1.00000 \mathrm{e}+001.00000 \mathrm{e}+001.00000 \mathrm{e}-011.00000 \mathrm{e}-091.00000 \mathrm{e}-01$ Element: 5237 \# of layers: 7

Kx Ky Kz Ss Por

3.33862e+00 3.33862e+00 3.33862e-01 1.00000e-09 2.12000e-01 $3.33862 \mathrm{e}+003.33862 \mathrm{e}+003.33862 \mathrm{e}-01$ 1.00000e-09 2.12000e-01 $3.33862 \mathrm{e}+003.33862 \mathrm{e}+003.33862 \mathrm{e}-01$ 1.00000e-09 2.12000e-01 $3.33862 \mathrm{e}+003.33862 \mathrm{e}+003.33862 \mathrm{e}-01$ 1.00000e-09 2.12000e-01 $3.33862 \mathrm{e}+003.33862 \mathrm{e}+003.33862 \mathrm{e}-01$ 1.00000e-09 2.12000e-01 $1.00000 \mathrm{e}-05$ 1.00000e-05 1.00000e-06 1.00000e-09 1.00000e-01 $1.00000 \mathrm{e}+001.00000 \mathrm{e}+001.00000 \mathrm{e}-011.00000 \mathrm{e}-091.00000 \mathrm{e}-01$ Element: 5238 \# of layers: 7

Kx Ky Kz Ss Por

$5.46537 \mathrm{e}+00$ 5.46537e+00 5.46537e-01 1.00000e-09 2.12000e-01

$5.46537 \mathrm{e}+005.46537 \mathrm{e}+005.46537 \mathrm{e}-011.00000 \mathrm{e}-092.12000 \mathrm{e}-01$ $5.46537 \mathrm{e}+005.46537 \mathrm{e}+005.46537 \mathrm{e}-011.00000 \mathrm{e}-092.12000 \mathrm{e}-01$ $5.46537 \mathrm{e}+005.46537 \mathrm{e}+00$ 5.46537e-01 1.00000e-09 2.12000e-01 $5.46537 \mathrm{e}+005.46537 \mathrm{e}+00$ 5.46537e-01 1.00000e-09 2.12000e-01 $1.00000 \mathrm{e}-05$ 1.00000e-05 1.00000e-06 1.00000e-09 1.00000e-01 $1.00000 \mathrm{e}+001.00000 \mathrm{e}+001.00000 \mathrm{e}-011.00000 \mathrm{e}-091.00000 \mathrm{e}-01$ Element: 5239 \# of layers: 7

Kx Ky Kz Ss Por

$6.51096 \mathrm{e}+006.51096 \mathrm{e}+00$ 6.51096e-01 1.00000e-09 2.12000e-01 $6.51096 \mathrm{e}+006.51096 \mathrm{e}+006.51096 \mathrm{e}-011.00000 \mathrm{e}-092.12000 \mathrm{e}-01$ $6.51096 \mathrm{e}+006.51096 \mathrm{e}+006.51096 \mathrm{e}-011.00000 \mathrm{e}-092.12000 \mathrm{e}-01$ $6.51096 \mathrm{e}+006.51096 \mathrm{e}+00$ 6.51096e-01 1.00000e-09 2.12000e-01 $6.51096 \mathrm{e}+006.51096 \mathrm{e}+00$ 6.51096e-01 1.00000e-09 2.12000e-01 $1.00000 \mathrm{e}-05$ 1.00000e-05 1.00000e-06 1.00000e-09 1.00000e-01 $1.00000 \mathrm{e}+001.00000 \mathrm{e}+001.00000 \mathrm{e}-011.00000 \mathrm{e}-091.00000 \mathrm{e}-01$ Element: 5240 \# of layers: 7

Kx Ky Kz Ss Por

6.51096e+00 6.51096e+00 6.51096e-01 1.00000e-09 2.12000e-01 $6.51096 \mathrm{e}+006.51096 \mathrm{e}+006.51096 \mathrm{e}-011.00000 \mathrm{e}-092.12000 \mathrm{e}-01$ $6.51096 \mathrm{e}+006.51096 \mathrm{e}+006.51096 \mathrm{e}-011.00000 \mathrm{e}-092.12000 \mathrm{e}-01$ $6.51096 \mathrm{e}+006.51096 \mathrm{e}+00$ 6.51096e-01 1.00000e-09 2.12000e-01 $6.51096 \mathrm{e}+006.51096 \mathrm{e}+00$ 6.51096e-01 1.00000e-09 2.12000e-01 $1.00000 \mathrm{e}-05$ 1.00000e-05 1.00000e-06 1.00000e-09 1.00000e-01 $1.00000 \mathrm{e}+001.00000 \mathrm{e}+001.00000 \mathrm{e}-011.00000 \mathrm{e}-091.00000 \mathrm{e}-01$ Element: 5241 \# of layers: 7

Kx Ky Kz Ss Por $6.51096 \mathrm{e}+006.51096 \mathrm{e}+00$ 6.51096e-01 1.00000e-09 2.12000e-01 $6.51096 \mathrm{e}+006.51096 \mathrm{e}+00$ 6.51096e-01 1.00000e-09 2.12000e-01 $6.51096 \mathrm{e}+006.51096 \mathrm{e}+00$ 6.51096e-01 1.00000e-09 2.12000e-01 
$6.51096 \mathrm{e}+006.51096 \mathrm{e}+00$ 6.51096e-01 1.00000e-09 2.12000e-01 $6.51096 \mathrm{e}+006.51096 \mathrm{e}+00$ 6.51096e-01 1.00000e-09 2.12000e-01 $1.00000 \mathrm{e}-05$ 1.00000e-05 1.00000e-06 1.00000e-09 1.00000e-01 $1.00000 \mathrm{e}+001.00000 \mathrm{e}+001.00000 \mathrm{e}-011.00000 \mathrm{e}-091.00000 \mathrm{e}-01$ Element: 5242 \# of layers: 7

Kx Ky Kz Ss Por

$4.91636 \mathrm{e}+004.91636 \mathrm{e}+00$ 4.91636e-01 1.00000e-09 2.12000e-01 $4.91636 \mathrm{e}+004.91636 \mathrm{e}+004.91636 \mathrm{e}-011.00000 \mathrm{e}-092.12000 \mathrm{e}-01$ $4.91636 \mathrm{e}+004.91636 \mathrm{e}+004.91636 \mathrm{e}-011.00000 \mathrm{e}-092.12000 \mathrm{e}-01$ $4.91636 \mathrm{e}+004.91636 \mathrm{e}+004.91636 \mathrm{e}-011.00000 \mathrm{e}-092.12000 \mathrm{e}-01$ $4.91636 \mathrm{e}+004.91636 \mathrm{e}+004.91636 \mathrm{e}-011.00000 \mathrm{e}-09$ 2.12000e-01 $1.00000 \mathrm{e}-05$ 1.00000e-05 1.00000e-06 1.00000e-09 1.00000e-01 $1.00000 \mathrm{e}+001.00000 \mathrm{e}+001.00000 \mathrm{e}-011.00000 \mathrm{e}-091.00000 \mathrm{e}-01$ Element: 5243 \# of layers: 7

Kx Ky Kz Ss Por

$4.91636 \mathrm{e}+004.91636 \mathrm{e}+004.91636 \mathrm{e}-011.00000 \mathrm{e}-092.12000 \mathrm{e}-01$ $4.91636 \mathrm{e}+004.91636 \mathrm{e}+004.91636 \mathrm{e}-011.00000 \mathrm{e}-092.12000 \mathrm{e}-01$ $4.91636 \mathrm{e}+004.91636 \mathrm{e}+004.91636 \mathrm{e}-011.00000 \mathrm{e}-09$ 2.12000e-01 $4.91636 \mathrm{e}+004.91636 \mathrm{e}+004.91636 \mathrm{e}-011.00000 \mathrm{e}-092.12000 \mathrm{e}-01$ $4.91636 \mathrm{e}+004.91636 \mathrm{e}+004.91636 \mathrm{e}-011.00000 \mathrm{e}-092.12000 \mathrm{e}-01$ $1.00000 \mathrm{e}-05$ 1.00000e-05 1.00000e-06 1.00000e-09 1.00000e-01 $1.00000 \mathrm{e}+001.00000 \mathrm{e}+001.00000 \mathrm{e}-011.00000 \mathrm{e}-091.00000 \mathrm{e}-01$ Element: 5244 \# of layers: 7

Kx Ky Kz Ss Por

$4.91951 \mathrm{e}+004.91951 \mathrm{e}+004.91951 \mathrm{e}-011.00000 \mathrm{e}-092.12000 \mathrm{e}-01$ $4.91951 \mathrm{e}+004.91951 \mathrm{e}+004.91951 \mathrm{e}-011.00000 \mathrm{e}-092.12000 \mathrm{e}-01$ $4.91951 \mathrm{e}+004.91951 \mathrm{e}+004.91951 \mathrm{e}-01$ 1.00000e-09 2.12000e-01 $4.91951 \mathrm{e}+004.91951 \mathrm{e}+004.91951 \mathrm{e}-01$ 1.00000e-09 2.12000e-01 $4.91951 \mathrm{e}+004.91951 \mathrm{e}+004.91951 \mathrm{e}-011.00000 \mathrm{e}-09$ 2.12000e-01 $1.00000 \mathrm{e}-05$ 1.00000e-05 1.00000e-06 1.00000e-09 1.00000e-01 $1.00000 \mathrm{e}+001.00000 \mathrm{e}+001.00000 \mathrm{e}-011.00000 \mathrm{e}-091.00000 \mathrm{e}-01$ Element: 5245 \# of layers: 7

Kx Ky Kz Ss Por

$5.46537 \mathrm{e}+00$ 5.46537e+00 5.46537e-01 1.00000e-09 2.12000e-01

$5.46537 \mathrm{e}+005.46537 \mathrm{e}+00$ 5.46537e-01 1.00000e-09 2.12000e-01 $5.46537 \mathrm{e}+005.46537 \mathrm{e}+005.46537 \mathrm{e}-011.00000 \mathrm{e}-092.12000 \mathrm{e}-01$ $5.46537 \mathrm{e}+005.46537 \mathrm{e}+00$ 5.46537e-01 1.00000e-09 2.12000e-01 $5.46537 \mathrm{e}+005.46537 \mathrm{e}+00$ 5.46537e-01 1.00000e-09 2.12000e-01 $1.00000 \mathrm{e}-05$ 1.00000e-05 1.00000e-06 1.00000e-09 1.00000e-01 $1.00000 \mathrm{e}+001.00000 \mathrm{e}+001.00000 \mathrm{e}-011.00000 \mathrm{e}-091.00000 \mathrm{e}-01$ Element: 5246 \# of layers: 7

Kx Ky Kz Ss Por

$6.51096 \mathrm{e}+006.51096 \mathrm{e}+00$ 6.51096e-01 1.00000e-09 2.12000e-01 $6.51096 \mathrm{e}+006.51096 \mathrm{e}+00$ 6.51096e-01 1.00000e-09 2.12000e-01 $6.51096 \mathrm{e}+006.51096 \mathrm{e}+006.51096 \mathrm{e}-011.00000 \mathrm{e}-092.12000 \mathrm{e}-01$ $6.51096 \mathrm{e}+006.51096 \mathrm{e}+00$ 6.51096e-01 1.00000e-09 2.12000e-01 
$6.51096 \mathrm{e}+00$ 6.51096e+00 6.51096e-01 1.00000e-09 2.12000e-01 $1.00000 \mathrm{e}-05$ 1.00000e-05 1.00000e-06 1.00000e-09 1.00000e-01 $1.00000 \mathrm{e}+001.00000 \mathrm{e}+001.00000 \mathrm{e}-01$ 1.00000e-09 1.00000e-01 Element: 5247 \# of layers: 7

$\mathrm{Kx} \mathrm{Ky} \mathrm{Kz}$ Ss Por

4.97216e+00 4.97216e+00 4.97216e-01 1.00000e-09 2.12000e-01 $4.97216 \mathrm{e}+004.97216 \mathrm{e}+00$ 4.97216e-01 1.00000e-09 2.12000e-01 $4.97216 \mathrm{e}+004.97216 \mathrm{e}+00$ 4.97216e-01 1.00000e-09 2.12000e-01 $4.97216 \mathrm{e}+004.97216 \mathrm{e}+00$ 4.97216e-01 1.00000e-09 2.12000e-01 $4.97216 \mathrm{e}+004.97216 \mathrm{e}+00$ 4.97216e-01 1.00000e-09 2.12000e-01 $1.00000 \mathrm{e}-05$ 1.00000e-05 1.00000e-06 1.00000e-09 1.00000e-01 $1.00000 \mathrm{e}+001.00000 \mathrm{e}+001.00000 \mathrm{e}-011.00000 \mathrm{e}-091.00000 \mathrm{e}-01$ Element: 5248 \# of layers: 6

$\mathrm{Kx} \mathrm{Ky} \mathrm{Kz}$ Ss Por

4.95978e+00 4.95978e+00 4.95978e-01 1.00000e-09 2.12000e-01 $4.95978 \mathrm{e}+004.95978 \mathrm{e}+00$ 4.95978e-01 1.00000e-09 2.12000e-01 4.95978e+00 4.95978e+00 4.95978e-01 1.00000e-09 2.12000e-01 4.95978e+00 4.95978e+00 4.95978e-01 1.00000e-09 2.12000e-01 4.95978e+00 4.95978e+00 4.95978e-01 1.00000e-09 2.12000e-01 $1.00000 \mathrm{e}+001.00000 \mathrm{e}+001.00000 \mathrm{e}-01$ 1.00000e-09 1.00000e-01 Element: 5249 \# of layers: 6

$\mathrm{Kx} \mathrm{Ky} \mathrm{Kz}$ Ss Por

4.95978e+00 4.95978e+00 4.95978e-01 1.00000e-09 2.12000e-01 $4.95978 \mathrm{e}+00$ 4.95978e+00 4.95978e-01 1.00000e-09 2.12000e-01 4.95978e+00 4.95978e+00 4.95978e-01 1.00000e-09 2.12000e-01 4.95978e+00 4.95978e+00 4.95978e-01 1.00000e-09 2.12000e-01 $4.95978 \mathrm{e}+00$ 4.95978e+00 4.95978e-01 1.00000e-09 2.12000e-01 $1.00000 \mathrm{e}+001.00000 \mathrm{e}+001.00000 \mathrm{e}-011.00000 \mathrm{e}-091.00000 \mathrm{e}-01$ Element: 5250 \# of layers: 6

$\mathrm{Kx} \mathrm{Ky} \mathrm{Kz}$ Ss Por

4.95978e+00 4.95978e+00 4.95978e-01 1.00000e-09 2.12000e-01 4.95978e+00 4.95978e+00 4.95978e-01 1.00000e-09 2.12000e-01 $4.95978 \mathrm{e}+004.95978 \mathrm{e}+00$ 4.95978e-01 1.00000e-09 2.12000e-01 4.95978e+00 4.95978e+00 4.95978e-01 1.00000e-09 2.12000e-01 $4.95978 \mathrm{e}+00$ 4.95978e+00 4.95978e-01 1.00000e-09 2.12000e-01 $1.00000 \mathrm{e}+001.00000 \mathrm{e}+001.00000 \mathrm{e}-011.00000 \mathrm{e}-091.00000 \mathrm{e}-01$ Element: 5251 \# of layers: 6

$\mathrm{Kx} \mathrm{Ky} \mathrm{Kz}$ Ss Por

4.72645e+00 4.72645e+00 4.72645e-01 1.00000e-09 2.12000e-01 $4.72645 \mathrm{e}+004.72645 \mathrm{e}+00$ 4.72645e-01 1.00000e-09 2.12000e-01 $4.72645 \mathrm{e}+004.72645 \mathrm{e}+00$ 4.72645e-01 1.00000e-09 2.12000e-01 $4.72645 \mathrm{e}+004.72645 \mathrm{e}+00$ 4.72645e-01 1.00000e-09 2.12000e-01 $4.72645 \mathrm{e}+00$ 4.72645e+00 4.72645e-01 1.00000e-09 2.12000e-01 $1.00000 \mathrm{e}+001.00000 \mathrm{e}+001.00000 \mathrm{e}-01$ 1.00000e-09 1.00000e-01 Element: 5252 \# of layers: 6

Kx Ky Kz Ss Por 
4.72645e+00 4.72645e+00 4.72645e-01 1.00000e-09 2.12000e-01 4.72645e+00 4.72645e+00 4.72645e-01 1.00000e-09 2.12000e-01 $4.72645 \mathrm{e}+004.72645 \mathrm{e}+00$ 4.72645e-01 1.00000e-09 2.12000e-01 $4.72645 \mathrm{e}+004.72645 \mathrm{e}+00$ 4.72645e-01 1.00000e-09 2.12000e-01 $4.72645 \mathrm{e}+004.72645 \mathrm{e}+00$ 4.72645e-01 1.00000e-09 2.12000e-01 $1.00000 \mathrm{e}+001.00000 \mathrm{e}+001.00000 \mathrm{e}-011.00000 \mathrm{e}-091.00000 \mathrm{e}-01$ Element: 5253 \# of layers: 6

$\mathrm{Kx} \mathrm{Ky} \mathrm{Kz}$ Ss Por

4.82095e+00 4.82095e+00 4.82095e-01 1.00000e-09 2.12000e-01 $4.82095 \mathrm{e}+004.82095 \mathrm{e}+00$ 4.82095e-01 1.00000e-09 2.12000e-01 4.82095e+00 4.82095e+00 4.82095e-01 1.00000e-09 2.12000e-01 $4.82095 \mathrm{e}+00$ 4.82095e+00 4.82095e-01 1.00000e-09 2.12000e-01 $4.82095 \mathrm{e}+00$ 4.82095e+00 4.82095e-01 1.00000e-09 2.12000e-01 $1.00000 \mathrm{e}+001.00000 \mathrm{e}+001.00000 \mathrm{e}-01$ 1.00000e-09 1.00000e-01 Element: 5254 \# of layers: 6

Kx Ky Kz Ss Por

4.97216e+00 4.97216e+00 4.97216e-01 1.00000e-09 2.12000e-01 $4.97216 \mathrm{e}+004.97216 \mathrm{e}+00$ 4.97216e-01 1.00000e-09 2.12000e-01 $4.97216 \mathrm{e}+004.97216 \mathrm{e}+00$ 4.97216e-01 1.00000e-09 2.12000e-01 $4.97216 \mathrm{e}+004.97216 \mathrm{e}+004.97216 \mathrm{e}-01$ 1.00000e-09 2.12000e-01 $4.97216 \mathrm{e}+004.97216 \mathrm{e}+004.97216 \mathrm{e}-01$ 1.00000e-09 2.12000e-01 $1.00000 \mathrm{e}+001.00000 \mathrm{e}+001.00000 \mathrm{e}-01$ 1.00000e-09 1.00000e-01 Element: 5255 \# of layers: 6

Kx Ky Kz Ss Por

4.95978e+00 4.95978e+00 4.95978e-01 1.00000e-09 2.12000e-01 4.95978e+00 4.95978e+00 4.95978e-01 1.00000e-09 2.12000e-01 4.95978e+00 4.95978e+00 4.95978e-01 1.00000e-09 2.12000e-01 4.95978e+00 4.95978e+00 4.95978e-01 1.00000e-09 2.12000e-01 $4.95978 \mathrm{e}+004.95978 \mathrm{e}+00$ 4.95978e-01 1.00000e-09 2.12000e-01 $1.00000 \mathrm{e}+001.00000 \mathrm{e}+001.00000 \mathrm{e}-011.00000 \mathrm{e}-091.00000 \mathrm{e}-01$ Element: 5256 \# of layers: 6

$\mathrm{Kx} \mathrm{Ky} \mathrm{Kz}$ Ss Por

5.06261e+00 5.06261e+00 5.06261e-01 1.00000e-09 2.12000e-01 5.06261e+00 5.06261e+00 5.06261e-01 1.00000e-09 2.12000e-01 $5.06261 \mathrm{e}+005.06261 \mathrm{e}+00$ 5.06261e-01 1.00000e-09 2.12000e-01 $5.06261 \mathrm{e}+005.06261 \mathrm{e}+00$ 5.06261e-01 1.00000e-09 2.12000e-01 $5.06261 \mathrm{e}+005.06261 \mathrm{e}+00$ 5.06261e-01 1.00000e-09 2.12000e-01 $1.00000 \mathrm{e}+001.00000 \mathrm{e}+001.00000 \mathrm{e}-01$ 1.00000e-09 1.00000e-01 Element: 5257 \# of layers: 6

$\mathrm{Kx} \mathrm{Ky} \mathrm{Kz}$ Ss Por 5.03966e+00 5.03966e+00 5.03966e-01 1.00000e-09 2.12000e-01 $5.03966 \mathrm{e}+005.03966 \mathrm{e}+00$ 5.03966e-01 1.00000e-09 2.12000e-01 5.03966e+00 5.03966e+00 5.03966e-01 1.00000e-09 2.12000e-01 5.03966e +00 5.03966e+00 5.03966e-01 1.00000e-09 2.12000e-01 $5.03966 \mathrm{e}+00$ 5.03966e+00 5.03966e-01 1.00000e-09 2.12000e-01 $1.00000 \mathrm{e}+001.00000 \mathrm{e}+001.00000 \mathrm{e}-011.00000 \mathrm{e}-091.00000 \mathrm{e}-01$ 
Element: 5258 \# of layers: 6

$\mathrm{Kx} \mathrm{Ky} \mathrm{Kz}$ Ss Por

5.03966e+00 5.03966e+00 5.03966e-01 1.00000e-09 2.12000e-01

$5.03966 \mathrm{e}+005.03966 \mathrm{e}+00$ 5.03966e-01 1.00000e-09 2.12000e-01

5.03966e+00 5.03966e+00 5.03966e-01 1.00000e-09 2.12000e-01

$5.03966 \mathrm{e}+005.03966 \mathrm{e}+005.03966 \mathrm{e}-011.00000 \mathrm{e}-092.12000 \mathrm{e}-01$

$5.03966 \mathrm{e}+00$ 5.03966e+00 5.03966e-01 1.00000e-09 2.12000e-01

$1.00000 \mathrm{e}+001.00000 \mathrm{e}+001.00000 \mathrm{e}-01$ 1.00000e-09 1.00000e-01

Element: 5259 \# of layers: 5

$\mathrm{Kx} \mathrm{Ky} \mathrm{Kz}$ Ss Por

5.03966e+00 5.03966e+00 5.03966e-01 1.00000e-09 2.12000e-01

$5.03966 \mathrm{e}+005.03966 \mathrm{e}+00$ 5.03966e-01 1.00000e-09 2.12000e-01

$5.03966 \mathrm{e}+00$ 5.03966e+00 5.03966e-01 1.00000e-09 2.12000e-01

$5.03966 \mathrm{e}+005.03966 \mathrm{e}+00$ 5.03966e-01 1.00000e-09 2.12000e-01

5.03966e+00 5.03966e+00 5.03966e-01 1.00000e-09 2.12000e-01

Element: 5260 \# of layers: 5

$\mathrm{Kx} \mathrm{Ky} \mathrm{Kz}$ Ss Por

5.08061e+00 5.08061e+00 5.08061e-01 1.00000e-09 2.12000e-01

$5.08061 \mathrm{e}+005.08061 \mathrm{e}+00$ 5.08061e-01 1.00000e-09 2.12000e-01

$5.08061 \mathrm{e}+005.08061 \mathrm{e}+005.08061 \mathrm{e}-011.00000 \mathrm{e}-092.12000 \mathrm{e}-01$

$5.08061 \mathrm{e}+005.08061 \mathrm{e}+005.08061 \mathrm{e}-01$ 1.00000e-09 2.12000e-01

5.08061e+00 5.08061e+00 5.08061e-01 1.00000e-09 2.12000e-01

Element: 5261 \# of layers: 5

Kx Ky Kz Ss Por

5.08061e+00 5.08061e+00 5.08061e-01 1.00000e-09 2.12000e-01

$5.08061 \mathrm{e}+005.08061 \mathrm{e}+00$ 5.08061e-01 1.00000e-09 2.12000e-01

$5.08061 \mathrm{e}+005.08061 \mathrm{e}+00$ 5.08061e-01 1.00000e-09 2.12000e-01

$5.08061 \mathrm{e}+005.08061 \mathrm{e}+00$ 5.08061e-01 1.00000e-09 2.12000e-01

$5.08061 \mathrm{e}+00$ 5.08061e+00 5.08061e-01 1.00000e-09 2.12000e-01

Element: 5262 \# of layers: 5

$\mathrm{Kx} \mathrm{Ky} \mathrm{Kz}$ Ss Por

4.71903e+00 4.71903e+00 4.71903e-01 1.00000e-09 2.12000e-01

$4.71903 e+004.71903 e+00$ 4.71903e-01 1.00000e-09 2.12000e-01

4.71903e+00 4.71903e+00 4.71903e-01 1.00000e-09 2.12000e-01

4.71903e+00 4.71903e+00 4.71903e-01 1.00000e-09 2.12000e-01

4.71903e+00 4.71903e+00 4.71903e-01 1.00000e-09 2.12000e-01

Element: 5263 \# of layers: 6

$\mathrm{Kx} \mathrm{Ky} \mathrm{Kz}$ Ss Por

5.06261e+00 5.06261e+00 5.06261e-01 1.00000e-09 2.12000e-01

$5.06261 \mathrm{e}+005.06261 \mathrm{e}+00$ 5.06261e-01 1.00000e-09 2.12000e-01

$5.06261 \mathrm{e}+005.06261 \mathrm{e}+00$ 5.06261e-01 1.00000e-09 2.12000e-01

$5.06261 \mathrm{e}+005.06261 \mathrm{e}+00$ 5.06261e-01 1.00000e-09 2.12000e-01

$5.06261 \mathrm{e}+005.06261 \mathrm{e}+00$ 5.06261e-01 1.00000e-09 2.12000e-01

$1.00000 \mathrm{e}+001.00000 \mathrm{e}+001.00000 \mathrm{e}-01$ 1.00000e-09 1.00000e-01

Element: 5264 \# of layers: 6

Kx Ky Kz Ss Por 
$5.03966 \mathrm{e}+005.03966 \mathrm{e}+00$ 5.03966e-01 1.00000e-09 2.12000e-01 $5.03966 \mathrm{e}+005.03966 \mathrm{e}+00$ 5.03966e-01 1.00000e-09 2.12000e-01 $5.03966 \mathrm{e}+005.03966 \mathrm{e}+00$ 5.03966e-01 1.00000e-09 2.12000e-01 $5.03966 \mathrm{e}+005.03966 \mathrm{e}+00$ 5.03966e-01 1.00000e-09 2.12000e-01 $5.03966 \mathrm{e}+005.03966 \mathrm{e}+00$ 5.03966e-01 1.00000e-09 2.12000e-01 $1.00000 \mathrm{e}+001.00000 \mathrm{e}+001.00000 \mathrm{e}-011.00000 \mathrm{e}-091.00000 \mathrm{e}-01$ Element: 5265 \# of layers: 6

Kx Ky Kz Ss Por

5.12763e+00 5.12763e+00 5.12763e-01 1.00000e-09 2.12000e-01 $5.12763 \mathrm{e}+00$ 5.12763e+00 5.12763e-01 1.00000e-09 2.12000e-01 $5.12763 \mathrm{e}+00$ 5.12763e+00 5.12763e-01 1.00000e-09 2.12000e-01 $5.12763 \mathrm{e}+00$ 5.12763e+00 5.12763e-01 1.00000e-09 2.12000e-01 $5.12763 \mathrm{e}+00$ 5.12763e+00 5.12763e-01 1.00000e-09 2.12000e-01 $1.00000 \mathrm{e}+001.00000 \mathrm{e}+00$ 1.00000e-01 1.00000e-09 1.00000e-01 Element: 5266 \# of layers: 6

Kx Ky Kz Ss Por

$5.62557 \mathrm{e}+00$ 5.62557e+00 5.62557e-01 1.00000e-09 2.12000e-01 $5.62557 \mathrm{e}+005.62557 \mathrm{e}+005.62557 \mathrm{e}-011.00000 \mathrm{e}-092.12000 \mathrm{e}-01$ $5.62557 \mathrm{e}+005.62557 \mathrm{e}+005.62557 \mathrm{e}-011.00000 \mathrm{e}-092.12000 \mathrm{e}-01$ $5.62557 \mathrm{e}+005.62557 \mathrm{e}+00$ 5.62557e-01 1.00000e-09 2.12000e-01 $5.62557 \mathrm{e}+00$ 5.62557e+00 5.62557e-01 1.00000e-09 2.12000e-01 $1.00000 \mathrm{e}+001.00000 \mathrm{e}+001.00000 \mathrm{e}-011.00000 \mathrm{e}-091.00000 \mathrm{e}-01$ Element: 5267 \# of layers: 5

Kx Ky Kz Ss Por

$5.62557 \mathrm{e}+00$ 5.62557e+00 5.62557e-01 1.00000e-09 2.12000e-01 $5.62557 \mathrm{e}+005.62557 \mathrm{e}+005.62557 \mathrm{e}-011.00000 \mathrm{e}-092.12000 \mathrm{e}-01$ $5.62557 \mathrm{e}+005.62557 \mathrm{e}+005.62557 \mathrm{e}-011.00000 \mathrm{e}-092.12000 \mathrm{e}-01$ $5.62557 \mathrm{e}+005.62557 \mathrm{e}+00$ 5.62557e-01 1.00000e-09 2.12000e-01 $5.62557 \mathrm{e}+00$ 5.62557e+00 5.62557e-01 1.00000e-09 2.12000e-01 Element: 5268 \# of layers: 6

Kx Ky Kz Ss Por

$5.62557 \mathrm{e}+00$ 5.62557e+00 5.62557e-01 1.00000e-09 2.12000e-01

$5.62557 \mathrm{e}+005.62557 \mathrm{e}+005.62557 \mathrm{e}-011.00000 \mathrm{e}-092.12000 \mathrm{e}-01$

$5.62557 \mathrm{e}+005.62557 \mathrm{e}+005.62557 \mathrm{e}-011.00000 \mathrm{e}-092.12000 \mathrm{e}-01$

$5.62557 \mathrm{e}+005.62557 \mathrm{e}+005.62557 \mathrm{e}-011.00000 \mathrm{e}-092.12000 \mathrm{e}-01$

$5.62557 \mathrm{e}+00$ 5.62557e+00 5.62557e-01 1.00000e-09 2.12000e-01 $1.00000 \mathrm{e}-06$ 1.00000e-06 1.00000e-06 1.00000e-09 5.00000e-02

Element: 5269 \# of layers: 6

Kx Ky Kz Ss Por

$6.55911 \mathrm{e}+006.55911 \mathrm{e}+00$ 6.55912e-01 1.00000e-09 2.12000e-01 $6.55911 \mathrm{e}+006.55911 \mathrm{e}+006.55912 \mathrm{e}-011.00000 \mathrm{e}-092.12000 \mathrm{e}-01$ $6.55911 \mathrm{e}+006.55911 \mathrm{e}+006.55912 \mathrm{e}-011.00000 \mathrm{e}-092.12000 \mathrm{e}-01$ $6.55911 \mathrm{e}+006.55911 \mathrm{e}+006.55912 \mathrm{e}-011.00000 \mathrm{e}-092.12000 \mathrm{e}-01$ $6.55911 \mathrm{e}+006.55911 \mathrm{e}+00$ 6.55912e-01 1.00000e-09 2.12000e-01 $1.00000 \mathrm{e}-06$ 1.00000e-06 1.00000e-06 1.00000e-09 5.00000e-02 Element: 5270 \# of layers: 5 
$\mathrm{Kx} \mathrm{Ky} \mathrm{Kz}$ Ss Por

6.55911e+00 6.55911e+00 6.55912e-01 1.00000e-09 2.12000e-01

$6.55911 \mathrm{e}+006.55911 \mathrm{e}+00$ 6.55912e-01 1.00000e-09 2.12000e-01

$6.55911 \mathrm{e}+006.55911 \mathrm{e}+006.55912 \mathrm{e}-01$ 1.00000e-09 2.12000e-01

$6.55911 \mathrm{e}+006.55911 \mathrm{e}+00$ 6.55912e-01 1.00000e-09 2.12000e-01

6.55911e+00 6.55911e+00 6.55912e-01 1.00000e-09 2.12000e-01

Element: 5271 \# of layers: 5

$\mathrm{Kx} \mathrm{Ky} \mathrm{Kz}$ Ss Por

6.01595e+00 6.01595e+00 6.01595e-01 1.00000e-09 2.12000e-01 $6.01595 \mathrm{e}+00$ 6.01595e+00 6.01595e-01 1.00000e-09 2.12000e-01 $6.01595 \mathrm{e}+00$ 6.01595e+00 6.01595e-01 1.00000e-09 2.12000e-01 $6.01595 \mathrm{e}+00$ 6.01595e+00 6.01595e-01 1.00000e-09 2.12000e-01 6.01595e+00 6.01595e+00 6.01595e-01 1.00000e-09 2.12000e-01 Element: 5272 \# of layers: 5

$\mathrm{Kx} \mathrm{Ky} \mathrm{Kz}$ Ss Por

5.12763e+00 5.12763e+00 5.12763e-01 1.00000e-09 2.12000e-01

5.12763e+00 5.12763e+00 5.12763e-01 1.00000e-09 2.12000e-01

5.12763e+00 5.12763e+00 5.12763e-01 1.00000e-09 2.12000e-01

5.12763e+00 5.12763e+00 5.12763e-01 1.00000e-09 2.12000e-01

5.12763e+00 5.12763e+00 5.12763e-01 1.00000e-09 2.12000e-01

Element: 5273 \# of layers: 5

$\mathrm{Kx} \mathrm{Ky} \mathrm{Kz}$ Ss Por

5.62557e+00 5.62557e+00 5.62557e-01 1.00000e-09 2.12000e-01

5.62557e+00 5.62557e+00 5.62557e-01 1.00000e-09 2.12000e-01

$5.62557 \mathrm{e}+00$ 5.62557e+00 5.62557e-01 1.00000e-09 2.12000e-01

5.62557e+00 5.62557e+00 5.62557e-01 1.00000e-09 2.12000e-01

5.62557e+00 5.62557e+00 5.62557e-01 1.00000e-09 2.12000e-01

Element: 5274 \# of layers: 5

$\mathrm{Kx} \mathrm{Ky} \mathrm{Kz}$ Ss Por

4.96046e+00 4.96046e+00 4.96046e-01 1.00000e-09 2.12000e-01

$4.96046 \mathrm{e}+004.96046 \mathrm{e}+00$ 4.96046e-01 1.00000e-09 2.12000e-01

$4.96046 \mathrm{e}+00$ 4.96046e+00 4.96046e-01 1.00000e-09 2.12000e-01

$4.96046 \mathrm{e}+004.96046 \mathrm{e}+004.96046 \mathrm{e}-01$ 1.00000e-09 2.12000e-01

4.96046e+00 4.96046e+00 4.96046e-01 1.00000e-09 2.12000e-01

Element: 5275 \# of layers: 6

$\mathrm{Kx} \mathrm{Ky} \mathrm{Kz}$ Ss Por

2.20932e+00 2.20932e+00 2.20932e-01 1.00000e-09 2.12000e-01

$2.20932 \mathrm{e}+00$ 2.20932e+00 2.20932e-01 1.00000e-09 2.12000e-01

$2.20932 \mathrm{e}+00$ 2.20932e+00 2.20932e-01 1.00000e-09 2.12000e-01

$2.20932 \mathrm{e}+002.20932 \mathrm{e}+00$ 2.20932e-01 1.00000e-09 2.12000e-01

$2.20932 \mathrm{e}+002.20932 \mathrm{e}+002.20932 \mathrm{e}-01$ 1.00000e-09 2.12000e-01

1.00000e-06 1.00000e-06 1.00000e-06 1.00000e-09 5.00000e-02

Element: 5276 \# of layers: 6

$\mathrm{Kx} \mathrm{Ky} \mathrm{Kz}$ Ss Por

2.20932e+00 2.20932e+00 2.20932e-01 1.00000e-09 2.12000e-01

$2.20932 \mathrm{e}+00$ 2.20932e+00 2.20932e-01 1.00000e-09 2.12000e-01 
$2.20932 \mathrm{e}+002.20932 \mathrm{e}+00$ 2.20932e-01 1.00000e-09 2.12000e-01 $2.20932 \mathrm{e}+002.20932 \mathrm{e}+002.20932 \mathrm{e}-01$ 1.00000e-09 2.12000e-01 $2.20932 \mathrm{e}+002.20932 \mathrm{e}+002.20932 \mathrm{e}-011.00000 \mathrm{e}-092.12000 \mathrm{e}-01$ $1.00000 \mathrm{e}-06$ 1.00000e-06 1.00000e-06 1.00000e-09 5.00000e-02 Element: 5277 \# of layers: 6

Kx Ky Kz Ss Por

$2.20932 \mathrm{e}+002.20932 \mathrm{e}+00$ 2.20932e-01 1.00000e-09 2.12000e-01 $2.20932 \mathrm{e}+002.20932 \mathrm{e}+002.20932 \mathrm{e}-01$ 1.00000e-09 2.12000e-01 $2.20932 \mathrm{e}+002.20932 \mathrm{e}+002.20932 \mathrm{e}-011.00000 \mathrm{e}-092.12000 \mathrm{e}-01$ $2.20932 \mathrm{e}+002.20932 \mathrm{e}+002.20932 \mathrm{e}-01$ 1.00000e-09 2.12000e-01 $2.20932 \mathrm{e}+002.20932 \mathrm{e}+002.20932 \mathrm{e}-01$ 1.00000e-09 2.12000e-01 $1.00000 \mathrm{e}-06$ 1.00000e-06 1.00000e-06 1.00000e-09 5.00000e-02 Element: 5278 \# of layers: 6

Kx Ky Kz Ss Por $2.82989 \mathrm{e}+002.82989 \mathrm{e}+00$ 2.82989e-01 1.00000e-09 2.12000e-01 $2.82989 \mathrm{e}+002.82989 \mathrm{e}+002.82989 \mathrm{e}-01$ 1.00000e-09 2.12000e-01 $2.82989 \mathrm{e}+002.82989 \mathrm{e}+002.82989 \mathrm{e}-011.00000 \mathrm{e}-092.12000 \mathrm{e}-01$ $2.82989 \mathrm{e}+002.82989 \mathrm{e}+002.82989 \mathrm{e}-01$ 1.00000e-09 2.12000e-01 $2.82989 \mathrm{e}+002.82989 \mathrm{e}+002.82989 \mathrm{e}-01$ 1.00000e-09 2.12000e-01 1.00000e-06 1.00000e-06 1.00000e-06 1.00000e-09 5.00000e-02 Element: 5279 \# of layers: 5

Kx Ky Kz Ss Por

$2.82989 \mathrm{e}+002.82989 \mathrm{e}+00$ 2.82989e-01 1.00000e-09 2.12000e-01 $2.82989 \mathrm{e}+002.82989 \mathrm{e}+002.82989 \mathrm{e}-011.00000 \mathrm{e}-092.12000 \mathrm{e}-01$ $2.82989 \mathrm{e}+002.82989 \mathrm{e}+002.82989 \mathrm{e}-011.00000 \mathrm{e}-092.12000 \mathrm{e}-01$ $2.82989 \mathrm{e}+002.82989 \mathrm{e}+002.82989 \mathrm{e}-011.00000 \mathrm{e}-092.12000 \mathrm{e}-01$ $1.00000 \mathrm{e}-06$ 1.00000e-06 1.00000e-06 1.00000e-09 5.00000e-02 Element: 5280 \# of layers: 6

Kx Ky Kz Ss Por

2.97636e+00 2.97636e+00 2.97636e-01 1.00000e-09 2.12000e-01 $2.97636 \mathrm{e}+002.97636 \mathrm{e}+002.97636 \mathrm{e}-011.00000 \mathrm{e}-092.12000 \mathrm{e}-01$ $2.97636 \mathrm{e}+002.97636 \mathrm{e}+002.97636 \mathrm{e}-011.00000 \mathrm{e}-092.12000 \mathrm{e}-01$ $2.97636 \mathrm{e}+002.97636 \mathrm{e}+002.97636 \mathrm{e}-011.00000 \mathrm{e}-092.12000 \mathrm{e}-01$ $2.97636 \mathrm{e}+002.97636 \mathrm{e}+002.97636 \mathrm{e}-011.00000 \mathrm{e}-092.12000 \mathrm{e}-01$ $1.00000 \mathrm{e}-06$ 1.00000e-06 1.00000e-06 1.00000e-09 5.00000e-02 Element: 5281 \# of layers: 6

Kx Ky Kz Ss Por

$4.96046 \mathrm{e}+004.96046 \mathrm{e}+00$ 4.96046e-01 1.00000e-09 2.12000e-01 $4.96046 \mathrm{e}+004.96046 \mathrm{e}+004.96046 \mathrm{e}-011.00000 \mathrm{e}-092.12000 \mathrm{e}-01$ $4.96046 \mathrm{e}+004.96046 \mathrm{e}+004.96046 \mathrm{e}-011.00000 \mathrm{e}-092.12000 \mathrm{e}-01$ $4.96046 \mathrm{e}+004.96046 \mathrm{e}+004.96046 \mathrm{e}-011.00000 \mathrm{e}-092.12000 \mathrm{e}-01$ $4.96046 \mathrm{e}+004.96046 \mathrm{e}+004.96046 \mathrm{e}-011.00000 \mathrm{e}-092.12000 \mathrm{e}-01$ $1.00000 \mathrm{e}-06$ 1.00000e-06 1.00000e-06 1.00000e-09 5.00000e-02 Element: 5282 \# of layers: 6

Kx Ky Kz Ss Por 2.20932e+00 2.20932e+00 2.20932e-01 1.00000e-09 2.12000e-01 
$2.20932 \mathrm{e}+002.20932 \mathrm{e}+00$ 2.20932e-01 1.00000e-09 2.12000e-01 $2.20932 \mathrm{e}+002.20932 \mathrm{e}+002.20932 \mathrm{e}-011.00000 \mathrm{e}-092.12000 \mathrm{e}-01$ $2.20932 \mathrm{e}+002.20932 \mathrm{e}+002.20932 \mathrm{e}-01$ 1.00000e-09 2.12000e-01 $2.20932 \mathrm{e}+002.20932 \mathrm{e}+002.20932 \mathrm{e}-011.00000 \mathrm{e}-092.12000 \mathrm{e}-01$ $1.00000 \mathrm{e}-06$ 1.00000e-06 1.00000e-06 1.00000e-09 5.00000e-02 Element: 5283 \# of layers: 6

Kx Ky Kz Ss Por

$2.65843 \mathrm{e}+002.65843 \mathrm{e}+002.65843 \mathrm{e}-01$ 1.00000e-09 2.12000e-01 $2.65843 \mathrm{e}+002.65843 \mathrm{e}+002.65843 \mathrm{e}-011.00000 \mathrm{e}-092.12000 \mathrm{e}-01$ $2.65843 \mathrm{e}+002.65843 \mathrm{e}+002.65843 \mathrm{e}-011.00000 \mathrm{e}-092.12000 \mathrm{e}-01$ $2.65843 \mathrm{e}+002.65843 \mathrm{e}+002.65843 \mathrm{e}-011.00000 \mathrm{e}-092.12000 \mathrm{e}-01$ $2.65843 \mathrm{e}+002.65843 \mathrm{e}+002.65843 \mathrm{e}-01$ 1.00000e-09 2.12000e-01 $1.00000 \mathrm{e}-06$ 1.00000e-06 1.00000e-06 1.00000e-09 5.00000e-02 Element: 5284 \# of layers: 6

Kx Ky Kz Ss Por

3.25807e+00 3.25807e+00 3.25807e-01 1.00000e-09 2.12000e-01 $3.25807 \mathrm{e}+003.25807 \mathrm{e}+003.25807 \mathrm{e}-011.00000 \mathrm{e}-092.12000 \mathrm{e}-01$ $3.25807 \mathrm{e}+003.25807 \mathrm{e}+003.25807 \mathrm{e}-011.00000 \mathrm{e}-092.12000 \mathrm{e}-01$ $3.25807 \mathrm{e}+003.25807 \mathrm{e}+003.25807 \mathrm{e}-011.00000 \mathrm{e}-092.12000 \mathrm{e}-01$ $3.25807 \mathrm{e}+003.25807 \mathrm{e}+003.25807 \mathrm{e}-01$ 1.00000e-09 2.12000e-01 $1.00000 \mathrm{e}-06$ 1.00000e-06 1.00000e-06 1.00000e-09 5.00000e-02 Element: 5285 \# of layers: 5

Kx Ky Kz Ss Por

$3.25807 \mathrm{e}+003.25807 \mathrm{e}+00$ 3.25807e-01 1.00000e-09 2.12000e-01 $3.25807 \mathrm{e}+003.25807 \mathrm{e}+003.25807 \mathrm{e}-011.00000 \mathrm{e}-092.12000 \mathrm{e}-01$ $3.25807 \mathrm{e}+003.25807 \mathrm{e}+003.25807 \mathrm{e}-011.00000 \mathrm{e}-092.12000 \mathrm{e}-01$ $3.25807 \mathrm{e}+003.25807 \mathrm{e}+00$ 3.25807e-01 1.00000e-09 2.12000e-01 $1.00000 \mathrm{e}-06$ 1.00000e-06 1.00000e-06 1.00000e-09 5.00000e-02

Element: 5286 \# of layers: 5

$\mathrm{Kx} \mathrm{Ky} \mathrm{Kz}$ Ss Por

$3.25807 \mathrm{e}+003.25807 \mathrm{e}+00$ 3.25807e-01 1.00000e-09 2.12000e-01 $3.25807 \mathrm{e}+003.25807 \mathrm{e}+00$ 3.25807e-01 1.00000e-09 2.12000e-01 $3.25807 \mathrm{e}+003.25807 \mathrm{e}+003.25807 \mathrm{e}-01$ 1.00000e-09 2.12000e-01 $3.25807 \mathrm{e}+003.25807 \mathrm{e}+003.25807 \mathrm{e}-011.00000 \mathrm{e}-092.12000 \mathrm{e}-01$ $1.00000 \mathrm{e}-06$ 1.00000e-06 1.00000e-06 1.00000e-09 5.00000e-02 Element: 5287 \# of layers: 4

Kx Ky Kz Ss Por

$4.39524 \mathrm{e}+004.39524 \mathrm{e}+004.39524 \mathrm{e}-01$ 1.00000e-09 2.12000e-01 $4.39524 \mathrm{e}+004.39524 \mathrm{e}+004.39524 \mathrm{e}-011.00000 \mathrm{e}-092.12000 \mathrm{e}-01$ $4.39524 \mathrm{e}+004.39524 \mathrm{e}+00 \quad 4.39524 \mathrm{e}-01$ 1.00000e-09 2.12000e-01 $1.00000 \mathrm{e}-06$ 1.00000e-06 1.00000e-06 1.00000e-09 5.00000e-02 Element: 5288 \# of layers: 5

Kx Ky Kz Ss Por

$4.39524 \mathrm{e}+004.39524 \mathrm{e}+00$ 4.39524e-01 1.00000e-09 2.12000e-01 $4.39524 \mathrm{e}+004.39524 \mathrm{e}+004.39524 \mathrm{e}-011.00000 \mathrm{e}-092.12000 \mathrm{e}-01$ $4.39524 \mathrm{e}+004.39524 \mathrm{e}+004.39524 \mathrm{e}-01$ 1.00000e-09 2.12000e-01 
4.39524e+00 4.39524e+00 4.39524e-01 1.00000e-09 2.12000e-01 1.00000e-06 1.00000e-06 1.00000e-06 1.00000e-09 5.00000e-02

Element: 5289 \# of layers: 5

Kx Ky Kz Ss Por

3.29970e+00 3.29970e+00 3.29970e-01 1.00000e-09 2.12000e-01

$3.29970 \mathrm{e}+003.29970 \mathrm{e}+00$ 3.29970e-01 1.00000e-09 2.12000e-01

$3.29970 \mathrm{e}+003.29970 \mathrm{e}+00$ 3.29970e-01 1.00000e-09 2.12000e-01

3.29970e+00 3.29970e+00 3.29970e-01 1.00000e-09 2.12000e-01

1.00000e-06 1.00000e-06 1.00000e-06 1.00000e-09 5.00000e-02

Element: 5290 \# of layers: 5

$\mathrm{Kx} \mathrm{Ky} \mathrm{Kz}$ Ss Por

2.65843e+00 2.65843e+00 2.65843e-01 1.00000e-09 2.12000e-01

$2.65843 \mathrm{e}+00$ 2.65843e+00 2.65843e-01 1.00000e-09 2.12000e-01

$2.65843 \mathrm{e}+002.65843 \mathrm{e}+00$ 2.65843e-01 1.00000e-09 2.12000e-01

$2.65843 \mathrm{e}+00$ 2.65843e+00 2.65843e-01 1.00000e-09 2.12000e-01

1.00000e-06 1.00000e-06 1.00000e-06 1.00000e-09 5.00000e-02

Element: 5291 \# of layers: 4

$\mathrm{Kx} \mathrm{Ky} \mathrm{Kz}$ Ss Por

3.25807e+00 3.25807e+00 3.25807e-01 1.00000e-09 2.12000e-01

$3.25807 \mathrm{e}+003.25807 \mathrm{e}+00$ 3.25807e-01 1.00000e-09 2.12000e-01

$3.25807 \mathrm{e}+003.25807 \mathrm{e}+00$ 3.25807e-01 1.00000e-09 2.12000e-01

1.00000e-06 1.00000e-06 1.00000e-06 1.00000e-09 5.00000e-02

Element: 5292 \# of layers: 5

Kx Ky Kz Ss Por

5.55582e+00 5.55582e+00 5.55582e-01 1.00000e-09 2.12000e-01

$5.55582 \mathrm{e}+005.55582 \mathrm{e}+00$ 5.55582e-01 1.00000e-09 2.12000e-01

5.55582e+00 5.55582e+00 5.55582e-01 1.00000e-09 2.12000e-01

5.55582e+00 5.55582e+00 5.55582e-01 1.00000e-09 2.12000e-01

1.00000e-06 1.00000e-06 1.00000e-06 1.00000e-09 5.00000e-02

Element: 5293 \# of layers: 4

$\mathrm{Kx} \mathrm{Ky} \mathrm{Kz}$ Ss Por

7.73207e+00 7.73207e+00 7.73207e-01 1.00000e-09 2.12000e-01

$7.73207 \mathrm{e}+00$ 7.73207e+00 7.73207e-01 1.00000e-09 2.12000e-01

7.73207e+00 7.73207e+00 7.73207e-01 1.00000e-09 2.12000e-01

1.00000e-06 1.00000e-06 1.00000e-06 1.00000e-09 5.00000e-02

Element: 5294 \# of layers: 4

Kx Ky Kz Ss Por

7.73207e+00 7.73207e+00 7.73207e-01 1.00000e-09 2.12000e-01

7.73207e+00 7.73207e+00 7.73207e-01 1.00000e-09 2.12000e-01

7.73207e+00 7.73207e+00 7.73207e-01 1.00000e-09 2.12000e-01

1.00000e-06 1.00000e-06 1.00000e-06 1.00000e-09 5.00000e-02

Element: 5295 \# of layers: 4

$\mathrm{Kx} \mathrm{Ky} \mathrm{Kz}$ Ss Por

$1.21026 \mathrm{e}+01$ 1.21026e+01 1.21026e+00 1.00000e-09 2.12000e-01

$1.21026 \mathrm{e}+011.21026 \mathrm{e}+011.21026 \mathrm{e}+001.00000 \mathrm{e}-092.12000 \mathrm{e}-01$

$1.21026 \mathrm{e}+011.21026 \mathrm{e}+011.21026 \mathrm{e}+001.00000 \mathrm{e}-092.12000 \mathrm{e}-01$ 
1.00000e-06 1.00000e-06 1.00000e-06 1.00000e-09 5.00000e-02

Element: 5296 \# of layers: 3

$\mathrm{Kx} \mathrm{Ky} \mathrm{Kz}$ Ss Por

$1.21026 \mathrm{e}+011.21026 \mathrm{e}+011.21026 \mathrm{e}+001.00000 \mathrm{e}-092.12000 \mathrm{e}-01$

$1.21026 \mathrm{e}+011.21026 \mathrm{e}+011.21026 \mathrm{e}+001.00000 \mathrm{e}-092.12000 \mathrm{e}-01$

1.00000e-06 1.00000e-06 1.00000e-06 1.00000e-09 5.00000e-02

Element: 5297 \# of layers: 3

$\mathrm{Kx} \mathrm{Ky} \mathrm{Kz}$ Ss Por

7.06538e+00 7.06538e+00 7.06538e-01 1.00000e-09 2.12000e-01

$7.06538 \mathrm{e}+00$ 7.06538e+00 7.06538e-01 1.00000e-09 2.12000e-01

1.00000e-06 1.00000e-06 1.00000e-06 1.00000e-09 5.00000e-02

Element: 5298 \# of layers: 3

$\mathrm{Kx} \mathrm{Ky} \mathrm{Kz}$ Ss Por

7.06538e+00 7.06538e+00 7.06538e-01 1.00000e-09 2.12000e-01

$7.06538 \mathrm{e}+00$ 7.06538e+00 7.06538e-01 1.00000e-09 2.12000e-01

1.00000e-06 1.00000e-06 1.00000e-06 1.00000e-09 5.00000e-02

Element: 5299 \# of layers: 4

$\mathrm{Kx} \mathrm{Ky} \mathrm{Kz}$ Ss Por

7.06538e+00 7.06538e+00 7.06538e-01 1.00000e-09 2.12000e-01

$7.06538 \mathrm{e}+00$ 7.06538e+00 7.06538e-01 1.00000e-09 2.12000e-01

$7.06538 \mathrm{e}+00$ 7.06538e+00 7.06538e-01 1.00000e-09 2.12000e-01

1.00000e-06 1.00000e-06 1.00000e-06 1.00000e-09 5.00000e-02

Element: 5300 \# of layers: 3

Kx Ky Kz Ss Por

7.06538e+00 7.06538e+00 7.06538e-01 1.00000e-09 2.12000e-01

$7.06538 \mathrm{e}+00$ 7.06538e+00 7.06538e-01 1.00000e-09 2.12000e-01

1.00000e-06 1.00000e-06 1.00000e-06 1.00000e-09 5.00000e-02

Element: 5301 \# of layers: 4

$\mathrm{Kx} \mathrm{Ky} \mathrm{Kz}$ Ss Por

$3.00629 \mathrm{e}+013.00629 \mathrm{e}+013.00629 \mathrm{e}+001.00000 \mathrm{e}-092.12000 \mathrm{e}-01$

$3.00629 \mathrm{e}+013.00629 \mathrm{e}+013.00629 \mathrm{e}+001.00000 \mathrm{e}-092.12000 \mathrm{e}-01$

$3.00629 \mathrm{e}+013.00629 \mathrm{e}+013.00629 \mathrm{e}+00$ 1.00000e-09 2.12000e-01

1.00000e-06 1.00000e-06 1.00000e-06 1.00000e-09 5.00000e-02

Element: 5302 \# of layers: 3

$\mathrm{Kx} \mathrm{Ky} \mathrm{Kz}$ Ss Por

$3.00629 \mathrm{e}+013.00629 \mathrm{e}+013.00629 \mathrm{e}+00$ 1.00000e-09 2.12000e-01

$3.00629 \mathrm{e}+013.00629 \mathrm{e}+013.00629 \mathrm{e}+001.00000 \mathrm{e}-092.12000 \mathrm{e}-01$

1.00000e-06 1.00000e-06 1.00000e-06 1.00000e-09 5.00000e-02

Element: 5303 \# of layers: 2

$\mathrm{Kx} \mathrm{Ky} \mathrm{Kz}$ Ss Por

$1.64051 \mathrm{e}+01$ 1.64051e+01 1.64051e+00 1.00000e-09 2.12000e-01

1.00000e-06 1.00000e-06 1.00000e-06 1.00000e-09 5.00000e-02

Element: 5304 \# of layers: 3

$\mathrm{Kx} \mathrm{Ky} \mathrm{Kz}$ Ss Por

2.73012e+02 2.73012e+02 2.73012e+01 1.00000e-09 7.00000e-02

$1.09087 \mathrm{e}+01$ 1.09087e+01 1.09087e+00 1.00000e-09 2.12000e-01 
1.00000e-06 1.00000e-06 1.00000e-06 1.00000e-09 5.00000e-02

Element: 5305 \# of layers: 3

Kx Ky Kz Ss Por

2.73012e+02 2.73012e+02 2.73012e+01 1.00000e-09 7.00000e-02

$1.09087 \mathrm{e}+01$ 1.09087e+01 1.09087e+00 1.00000e-09 2.12000e-01

1.00000e-06 1.00000e-06 1.00000e-06 1.00000e-09 5.00000e-02

Element: 5306 \# of layers: 4

$\mathrm{Kx} \mathrm{Ky} \mathrm{Kz}$ Ss Por

$2.64831 \mathrm{e}+02$ 2.64831e+02 2.64831e+01 1.00000e-09 7.00000e-02

$2.64831 \mathrm{e}+022.64831 \mathrm{e}+02$ 2.64831e+01 1.00000e-09 7.00000e-02

$1.05817 \mathrm{e}+011.05817 \mathrm{e}+011.05818 \mathrm{e}+001.00000 \mathrm{e}-092.12000 \mathrm{e}-01$

1.00000e-06 1.00000e-06 1.00000e-06 1.00000e-09 5.00000e-02

Element: 5307 \# of layers: 3

$\mathrm{Kx} \mathrm{Ky} \mathrm{Kz}$ Ss Por

$2.64831 \mathrm{e}+02$ 2.64831e+02 2.64831e+01 1.00000e-09 7.00000e-02

$1.05817 \mathrm{e}+011.05817 \mathrm{e}+011.05818 \mathrm{e}+001.00000 \mathrm{e}-092.12000 \mathrm{e}-01$

1.00000e-06 1.00000e-06 1.00000e-06 1.00000e-09 5.00000e-02

Element: 5308 \# of layers: 3

$\mathrm{Kx} \mathrm{Ky} \mathrm{Kz}$ Ss Por

$1.05817 \mathrm{e}+01$ 1.05817e+01 1.05818e+00 1.00000e-09 2.12000e-01

$1.05817 \mathrm{e}+01$ 1.05817e+01 1.05818e+00 1.00000e-09 2.12000e-01

1.00000e-06 1.00000e-06 1.00000e-06 1.00000e-09 5.00000e-02

Element: 5309 \# of layers: 2

Kx Ky Kz Ss Por

$1.09087 \mathrm{e}+01$ 1.09087e+01 1.09087e+00 1.00000e-09 2.12000e-01

1.00000e-06 1.00000e-06 1.00000e-06 1.00000e-09 5.00000e-02

Element: 5310 \# of layers: 3

$\mathrm{Kx} \mathrm{Ky} \mathrm{Kz}$ Ss Por

1.38799e+02 1.38799e+02 1.38799e+01 1.00000e-09 7.00000e-02

$5.54569 \mathrm{e}+00$ 5.54569e+00 5.54569e-01 1.00000e-09 2.12000e-01

1.00000e-06 1.00000e-06 1.00000e-06 1.00000e-09 5.00000e-02

Element: 5311 \# of layers: 4

Kx Ky Kz Ss Por

6.87805e+01 6.87805e+01 6.87805e+00 1.00000e-09 7.00000e-02

$6.87805 \mathrm{e}+016.87805 \mathrm{e}+016.87805 \mathrm{e}+00$ 1.00000e-09 7.00000e-02

$2.74821 \mathrm{e}+002.74821 \mathrm{e}+00$ 2.74821e-01 1.00000e-09 2.12000e-01

1.00000e-06 1.00000e-06 1.00000e-06 1.00000e-09 5.00000e-02

Element: 5312 \# of layers: 3

$\mathrm{Kx} \mathrm{Ky} \mathrm{Kz}$ Ss Por

6.87805e+01 6.87805e+01 6.87805e+00 1.00000e-09 7.00000e-02

$6.87805 \mathrm{e}+016.87805 \mathrm{e}+016.87805 \mathrm{e}+00$ 1.00000e-09 7.00000e-02

1.00000e-06 1.00000e-06 1.00000e-06 1.00000e-09 5.00000e-02

Element: 5313 \# of layers: 2

$\mathrm{Kx} \mathrm{Ky} \mathrm{Kz}$ Ss Por

$3.25811 \mathrm{e}+03$ 3.25811e+03 3.25811e+02 1.00000e-09 7.00000e-02

1.00000e-06 1.00000e-06 1.00000e-06 1.00000e-09 5.00000e-02 
Element: 5314 \# of layers: 2

$\mathrm{Kx} \mathrm{Ky} \mathrm{Kz}$ Ss Por

3.25811e+03 3.25811e+03 3.25811e+02 1.00000e-09 7.00000e-02

1.00000e-06 1.00000e-06 1.00000e-06 1.00000e-09 5.00000e-02

Element: 5315 \# of layers: 2

$\mathrm{Kx} \mathrm{Ky} \mathrm{Kz}$ Ss Por

3.25811e+03 3.25811e+03 3.25811e+02 1.00000e-09 7.00000e-02

1.00000e-06 1.00000e-06 1.00000e-06 1.00000e-09 5.00000e-02

Element: 5316 \# of layers: 2

$\mathrm{Kx} \mathrm{Ky} \mathrm{Kz}$ Ss Por

$1.61531 \mathrm{e}+021.61531 \mathrm{e}+02$ 1.61531e+01 1.00000e-09 7.00000e-02

1.00000e-06 1.00000e-06 1.00000e-06 1.00000e-09 5.00000e-02

Element: 5317 \# of layers: 3

$\mathrm{Kx} \mathrm{Ky} \mathrm{Kz}$ Ss Por

$1.61531 \mathrm{e}+02$ 1.61531e+02 1.61531e+01 1.00000e-09 7.00000e-02

$1.61531 \mathrm{e}+021.61531 \mathrm{e}+021.61531 \mathrm{e}+01$ 1.00000e-09 7.00000e-02

1.00000e-06 1.00000e-06 1.00000e-06 1.00000e-09 5.00000e-02

Element: 5318 \# of layers: 3

$\mathrm{Kx} \mathrm{Ky} \mathrm{Kz}$ Ss Por

$1.61531 \mathrm{e}+021.61531 \mathrm{e}+02$ 1.61531e+01 1.00000e-09 7.00000e-02

$1.61531 \mathrm{e}+021.61531 \mathrm{e}+021.61531 \mathrm{e}+01$ 1.00000e-09 7.00000e-02

$1.00000 \mathrm{e}-06$ 1.00000e-06 1.00000e-06 1.00000e-09 5.00000e-02

Element: 5319 \# of layers: 2

Kx Ky Kz Ss Por

$1.15184 \mathrm{e}+041.15184 \mathrm{e}+041.15184 \mathrm{e}+03$ 1.00000e-09 7.00000e-02 1.00000e-06 1.00000e-06 1.00000e-06 1.00000e-09 5.00000e-02

Element: 5320 \# of layers: 2

$\mathrm{Kx} \mathrm{Ky} \mathrm{Kz}$ Ss Por

$1.11346 \mathrm{e}+04$ 1.11346e+04 1.11346e+03 1.00000e-09 7.00000e-02 1.00000e-06 1.00000e-06 1.00000e-06 1.00000e-09 5.00000e-02

Element: 5321 \# of layers: 2

Kx Ky Kz Ss Por

$1.11346 \mathrm{e}+041.11346 \mathrm{e}+041.11346 \mathrm{e}+03$ 1.00000e-09 7.00000e-02

1.00000e-06 1.00000e-06 1.00000e-06 1.00000e-09 5.00000e-02

Element: 5322 \# of layers: 3

Kx Ky Kz Ss Por

$1.11346 \mathrm{e}+041.11346 \mathrm{e}+041.11346 \mathrm{e}+03$ 1.00000e-09 7.00000e-02

$1.11346 \mathrm{e}+041.11346 \mathrm{e}+041.11346 \mathrm{e}+03$ 1.00000e-09 7.00000e-02

1.00000e-06 1.00000e-06 1.00000e-06 1.00000e-09 5.00000e-02

Element: 5323 \# of layers: 3

$\mathrm{Kx} \mathrm{Ky} \mathrm{Kz}$ Ss Por

8.68393e+03 8.68393e+03 8.68393e+02 1.00000e-09 7.00000e-02

$8.68393 \mathrm{e}+03$ 8.68393e+03 8.68393e+02 1.00000e-09 7.00000e-02

$1.00000 \mathrm{e}-06$ 1.00000e-06 1.00000e-06 1.00000e-09 5.00000e-02

Element: 5324 \# of layers: 2

Kx Ky Kz Ss Por 
8.68393e+03 8.68393e+03 8.68393e+02 1.00000e-09 7.00000e-02 1.00000e-06 1.00000e-06 1.00000e-06 1.00000e-09 5.00000e-02

Element: 5325 \# of layers: 2

$\mathrm{Kx} \mathrm{Ky} \mathrm{Kz}$ Ss Por

$1.26618 \mathrm{e}+041.26618 \mathrm{e}+041.26618 \mathrm{e}+03$ 1.00000e-09 7.00000e-02 1.00000e-06 1.00000e-06 1.00000e-06 1.00000e-09 5.00000e-02

Element: 5326 \# of layers: 2

Kx Ky Kz Ss Por

$1.15184 \mathrm{e}+041.15184 \mathrm{e}+041.15184 \mathrm{e}+031.00000 \mathrm{e}-097.00000 \mathrm{e}-02$ 1.00000e-06 1.00000e-06 1.00000e-06 1.00000e-09 5.00000e-02

Element: 5327 \# of layers: 2

$\mathrm{Kx} \mathrm{Ky} \mathrm{Kz}$ Ss Por

$1.11346 \mathrm{e}+04$ 1.11346e+04 1.11346e+03 1.00000e-09 7.00000e-02 1.00000e-06 1.00000e-06 1.00000e-06 1.00000e-09 5.00000e-02

Element: 5328 \# of layers: 3

Kx Ky Kz Ss Por

9.16317e+03 9.16317e+03 9.16317e+02 1.00000e-09 7.00000e-02

9.16317e+03 9.16317e+03 9.16317e+02 1.00000e-09 7.00000e-02 1.00000e-06 1.00000e-06 1.00000e-06 1.00000e-09 5.00000e-02

Element: 5329 \# of layers: 3

$\mathrm{Kx} \mathrm{Ky} \mathrm{Kz}$ Ss Por

$1.42790 \mathrm{e}+041.42790 \mathrm{e}+041.42791 \mathrm{e}+03$ 1.00000e-09 7.00000e-02

$1.42790 \mathrm{e}+041.42790 \mathrm{e}+041.42791 \mathrm{e}+03$ 1.00000e-09 7.00000e-02

1.00000e-06 1.00000e-06 1.00000e-06 1.00000e-09 5.00000e-02

Element: 5330 \# of layers: 3

$\mathrm{Kx} \mathrm{Ky} \mathrm{Kz}$ Ss Por

$1.42790 \mathrm{e}+041.42790 \mathrm{e}+041.42791 \mathrm{e}+03$ 1.00000e-09 7.00000e-02

$1.42790 \mathrm{e}+041.42790 \mathrm{e}+041.42791 \mathrm{e}+03$ 1.00000e-09 7.00000e-02

1.00000e-06 1.00000e-06 1.00000e-06 1.00000e-09 5.00000e-02

Element: 5331 \# of layers: 4

$\mathrm{Kx} \mathrm{Ky} \mathrm{Kz}$ Ss Por

$1.42790 \mathrm{e}+041.42790 \mathrm{e}+041.42791 \mathrm{e}+03$ 1.00000e-09 7.00000e-02

$1.42790 \mathrm{e}+041.42790 \mathrm{e}+041.42791 \mathrm{e}+03$ 1.00000e-09 7.00000e-02

$1.42790 \mathrm{e}+041.42790 \mathrm{e}+041.42791 \mathrm{e}+03$ 1.00000e-09 7.00000e-02

1.00000e-06 1.00000e-06 1.00000e-06 1.00000e-09 5.00000e-02

Element: 5332 \# of layers: 4

Kx Ky Kz Ss Por

5.61819e+03 5.61819e+03 5.61819e+02 1.00000e-09 7.00000e-02

$5.61819 \mathrm{e}+03$ 5.61819e+03 5.61819e+02 1.00000e-09 7.00000e-02

$5.61819 \mathrm{e}+03$ 5.61819e+03 5.61819e+02 1.00000e-09 7.00000e-02

1.00000e-06 1.00000e-06 1.00000e-06 1.00000e-09 5.00000e-02

Element: 5333 \# of layers: 4

$\mathrm{Kx} \mathrm{Ky} \mathrm{Kz}$ Ss Por

5.61819e+03 5.61819e+03 5.61819e+02 1.00000e-09 7.00000e-02

$5.61819 \mathrm{e}+03$ 5.61819e+03 5.61819e+02 1.00000e-09 7.00000e-02

$5.61819 \mathrm{e}+035.61819 \mathrm{e}+03$ 5.61819e+02 1.00000e-09 7.00000e-02 
1.00000e-06 1.00000e-06 1.00000e-06 1.00000e-09 5.00000e-02

Element: 5334 \# of layers: 3

$\mathrm{Kx} \mathrm{Ky} \mathrm{Kz}$ Ss Por

5.45168e+03 5.45168e+03 5.45168e+02 1.00000e-09 7.00000e-02

$5.45168 \mathrm{e}+035.45168 \mathrm{e}+03$ 5.45168e+02 1.00000e-09 7.00000e-02

1.00000e-06 1.00000e-06 1.00000e-06 1.00000e-09 5.00000e-02

Element: 5335 \# of layers: 4

Kx Ky Kz Ss Por

9.16317e+03 9.16317e+03 9.16317e+02 1.00000e-09 7.00000e-02

9.16317e+03 9.16317e+03 9.16317e+02 1.00000e-09 7.00000e-02

9.16317e+03 9.16317e+03 9.16317e+02 1.00000e-09 7.00000e-02

1.00000e-06 1.00000e-06 1.00000e-06 1.00000e-09 5.00000e-02

Element: 5336 \# of layers: 4

$\mathrm{Kx} \mathrm{Ky} \mathrm{Kz}$ Ss Por

$1.42790 \mathrm{e}+041.42790 \mathrm{e}+041.42791 \mathrm{e}+03$ 1.00000e-09 7.00000e-02

$1.42790 \mathrm{e}+041.42790 \mathrm{e}+041.42791 \mathrm{e}+03$ 1.00000e-09 7.00000e-02

$1.42790 \mathrm{e}+041.42790 \mathrm{e}+041.42791 \mathrm{e}+03$ 1.00000e-09 7.00000e-02

1.00000e-06 1.00000e-06 1.00000e-06 1.00000e-09 5.00000e-02

Element: 5337 \# of layers: 2

$\mathrm{Kx} \mathrm{Ky} \mathrm{Kz}$ Ss Por

3.46723e+04 3.46723e+04 3.46723e+03 1.00000e-09 7.00000e-02

$1.00000 \mathrm{e}-06$ 1.00000e-06 1.00000e-06 1.00000e-09 5.00000e-02

Element: 5338 \# of layers: 2

Kx Ky Kz Ss Por

9.02081e+04 9.02081e+04 9.02081e+03 1.00000e-09 7.00000e-02

1.00000e-06 1.00000e-06 1.00000e-06 1.00000e-09 5.00000e-02

Element: 5339 \# of layers: 2

$\mathrm{Kx} \mathrm{Ky} \mathrm{Kz}$ Ss Por

9.02081e+04 9.02081e+04 9.02081e+03 1.00000e-09 7.00000e-02

1.00000e-06 1.00000e-06 1.00000e-06 1.00000e-09 5.00000e-02

Element: 5340 \# of layers: 3

$\mathrm{Kx} \mathrm{Ky} \mathrm{Kz}$ Ss Por

1.16499e+04 1.16499e+04 1.16499e+03 1.00000e-09 7.00000e-02

$1.16499 \mathrm{e}+041.16499 \mathrm{e}+041.16499 \mathrm{e}+03$ 1.00000e-09 7.00000e-02

1.00000e-06 1.00000e-06 1.00000e-06 1.00000e-09 5.00000e-02

Element: 5341 \# of layers: 4

Kx Ky Kz Ss Por

$1.16499 \mathrm{e}+04$ 1.16499e+04 1.16499e+03 1.00000e-09 7.00000e-02

$1.16499 \mathrm{e}+041.16499 \mathrm{e}+041.16499 \mathrm{e}+03$ 1.00000e-09 7.00000e-02

$1.16499 \mathrm{e}+041.16499 \mathrm{e}+041.16499 \mathrm{e}+03$ 1.00000e-09 7.00000e-02

1.00000e-06 1.00000e-06 1.00000e-06 1.00000e-09 5.00000e-02

Element: 5342 \# of layers: 4

$\mathrm{Kx} \mathrm{Ky} \mathrm{Kz}$ Ss Por

7.23854e+03 7.23854e+03 7.23854e+02 1.00000e-09 7.00000e-02

$7.23854 \mathrm{e}+03$ 7.23854e+03 7.23854e+02 1.00000e-09 7.00000e-02

$7.23854 \mathrm{e}+03$ 7.23854e+03 7.23854e+02 1.00000e-09 7.00000e-02 
1.00000e-06 1.00000e-06 1.00000e-06 1.00000e-09 5.00000e-02

Element: 5343 \# of layers: 4

$\mathrm{Kx} \mathrm{Ky} \mathrm{Kz}$ Ss Por

7.23854e+03 7.23854e+03 7.23854e+02 1.00000e-09 7.00000e-02

$7.23854 \mathrm{e}+03$ 7.23854e+03 7.23854e+02 1.00000e-09 7.00000e-02

$7.23854 \mathrm{e}+03$ 7.23854e+03 7.23854e+02 1.00000e-09 7.00000e-02

1.00000e-06 1.00000e-06 1.00000e-06 1.00000e-09 5.00000e-02

Element: 5344 \# of layers: 4

$\mathrm{Kx} \mathrm{Ky} \mathrm{Kz}$ Ss Por

3.46723e+04 3.46723e+04 3.46723e+03 1.00000e-09 7.00000e-02

$3.46723 \mathrm{e}+043.46723 \mathrm{e}+04$ 3.46723e+03 1.00000e-09 7.00000e-02

$3.46723 \mathrm{e}+04$ 3.46723e+04 3.46723e+03 1.00000e-09 7.00000e-02

1.00000e-06 1.00000e-06 1.00000e-06 1.00000e-09 5.00000e-02

Element: 5345 \# of layers: 3

$\mathrm{Kx} \mathrm{Ky} \mathrm{Kz}$ Ss Por

7.23854e+03 7.23854e+03 7.23854e+02 1.00000e-09 7.00000e-02

$7.23854 \mathrm{e}+03$ 7.23854e+03 7.23854e+02 1.00000e-09 7.00000e-02

1.00000e-06 1.00000e-06 1.00000e-06 1.00000e-09 5.00000e-02

Element: 5346 \# of layers: 3

$\mathrm{Kx} \mathrm{Ky} \mathrm{Kz}$ Ss Por

$3.36893 e+04$ 3.36893e+04 3.36893e+03 1.00000e-09 7.00000e-02

$1.00000 \mathrm{e}+001.00000 \mathrm{e}+001.00000 \mathrm{e}-011.00000 \mathrm{e}-091.00000 \mathrm{e}-01$

$1.00000 \mathrm{e}-06$ 1.00000e-06 1.00000e-06 1.00000e-09 5.00000e-02

Element: 5347 \# of layers: 2

$\mathrm{Kx} \mathrm{Ky} \mathrm{Kz}$ Ss Por

3.36893e+04 3.36893e+04 3.36893e+03 1.00000e-09 7.00000e-02

1.00000e-06 1.00000e-06 1.00000e-06 1.00000e-09 5.00000e-02

Element: 5348 \# of layers: 3

Kx Ky Kz Ss Por

9.76954e+03 9.76954e+03 9.76954e+02 1.00000e-09 7.00000e-02

$9.76954 \mathrm{e}+03$ 9.76954e+03 9.76954e+02 1.00000e-09 7.00000e-02

1.00000e-06 1.00000e-06 1.00000e-06 1.00000e-09 5.00000e-02

Element: 5349 \# of layers: 4

$\mathrm{Kx} \mathrm{Ky} \mathrm{Kz}$ Ss Por

2.72525e+03 2.72525e+03 2.72525e+02 1.00000e-09 7.00000e-02

$2.72525 \mathrm{e}+032.72525 \mathrm{e}+032.72525 \mathrm{e}+02$ 1.00000e-09 7.00000e-02

$2.72525 \mathrm{e}+032.72525 \mathrm{e}+032.72525 \mathrm{e}+02$ 1.00000e-09 7.00000e-02

1.00000e-06 1.00000e-06 1.00000e-06 1.00000e-09 5.00000e-02

Element: 5350 \# of layers: 4

$\mathrm{Kx} \mathrm{Ky} \mathrm{Kz}$ Ss Por

$2.72525 \mathrm{e}+03$ 2.72525e+03 2.72525e+02 1.00000e-09 7.00000e-02

$2.72525 \mathrm{e}+032.72525 \mathrm{e}+032.72525 \mathrm{e}+02$ 1.00000e-09 7.00000e-02

$2.72525 \mathrm{e}+03$ 2.72525e+03 2.72525e+02 1.00000e-09 7.00000e-02

1.00000e-06 1.00000e-06 1.00000e-06 1.00000e-09 5.00000e-02

Element: 5351 \# of layers: 4

Kx Ky Kz Ss Por 
8.11846e+03 8.11846e+03 8.11846e+02 1.00000e-09 7.00000e-02 8.11846e+03 8.11846e+03 8.11846e+02 1.00000e-09 7.00000e-02

8.11846e+03 8.11846e+03 8.11846e+02 1.00000e-09 7.00000e-02 $1.00000 \mathrm{e}-06$ 1.00000e-06 1.00000e-06 1.00000e-09 5.00000e-02

Element: 5352 \# of layers: 5

$\mathrm{Kx} \mathrm{Ky} \mathrm{Kz}$ Ss Por

8.11846e+03 8.11846e+03 8.11846e+02 1.00000e-09 7.00000e-02

8.11846e+03 8.11846e+03 8.11846e+02 1.00000e-09 7.00000e-02

$8.11846 \mathrm{e}+03$ 8.11846e+03 8.11846e+02 1.00000e-09 7.00000e-02 $1.00000 \mathrm{e}+001.00000 \mathrm{e}+001.00000 \mathrm{e}-011.00000 \mathrm{e}-091.00000 \mathrm{e}-01$ 1.00000e-06 1.00000e-06 1.00000e-06 1.00000e-09 5.00000e-02

Element: 5353 \# of layers: 3

$\mathrm{Kx} \mathrm{Ky} \mathrm{Kz}$ Ss Por

8.11846e+03 8.11846e+03 8.11846e+02 1.00000e-09 7.00000e-02 $1.00000 \mathrm{e}+001.00000 \mathrm{e}+001.00000 \mathrm{e}-011.00000 \mathrm{e}-091.00000 \mathrm{e}-01$ 1.00000e-06 1.00000e-06 1.00000e-06 1.00000e-09 5.00000e-02

Element: 5354 \# of layers: 4

$\mathrm{Kx} \mathrm{Ky} \mathrm{Kz}$ Ss Por

3.36893e+04 3.36893e+04 3.36893e+03 1.00000e-09 7.00000e-02

$3.36893 \mathrm{e}+04$ 3.36893e+04 3.36893e+03 1.00000e-09 7.00000e-02

$3.36893 e+043.36893 e+043.36893 e+03$ 1.00000e-09 7.00000e-02

1.00000e-06 1.00000e-06 1.00000e-06 1.00000e-09 5.00000e-02

Element: 5355 \# of layers: 4

Kx Ky Kz Ss Por

$1.31095 \mathrm{e}+04$ 1.31095e+04 1.31096e+03 1.00000e-09 7.00000e-02

$1.31095 \mathrm{e}+041.31095 \mathrm{e}+041.31096 \mathrm{e}+03$ 1.00000e-09 7.00000e-02

$1.00000 \mathrm{e}+001.00000 \mathrm{e}+001.00000 \mathrm{e}-011.00000 \mathrm{e}-091.00000 \mathrm{e}-01$

1.00000e-06 1.00000e-06 1.00000e-06 1.00000e-09 5.00000e-02

Element: 5356 \# of layers: 4

$\mathrm{Kx} \mathrm{Ky} \mathrm{Kz}$ Ss Por

1.15355e+03 1.15355e+03 1.15355e+02 1.00000e-09 7.00000e-02

$1.15355 \mathrm{e}+031.15355 \mathrm{e}+03$ 1.15355e+02 1.00000e-09 7.00000e-02

$1.00000 \mathrm{e}+001.00000 \mathrm{e}+001.00000 \mathrm{e}-011.00000 \mathrm{e}-091.00000 \mathrm{e}-01$

1.00000e-06 1.00000e-06 1.00000e-06 1.00000e-09 5.00000e-02

Element: 5357 \# of layers: 4

Kx Ky Kz Ss Por

$1.15355 \mathrm{e}+03$ 1.15355e+03 1.15355e+02 1.00000e-09 7.00000e-02

$1.15355 \mathrm{e}+031.15355 \mathrm{e}+031.15355 \mathrm{e}+02$ 1.00000e-09 7.00000e-02 $1.00000 \mathrm{e}+001.00000 \mathrm{e}+001.00000 \mathrm{e}-011.00000 \mathrm{e}-091.00000 \mathrm{e}-01$ 1.00000e-06 1.00000e-06 1.00000e-06 1.00000e-09 5.00000e-02

Element: 5358 \# of layers: 5

$\mathrm{Kx} \mathrm{Ky} \mathrm{Kz}$ Ss Por

2.23917e+03 2.23917e+03 2.23917e+02 1.00000e-09 7.00000e-02 2.23917e+03 2.23917e+03 2.23917e+02 1.00000e-09 7.00000e-02 $2.23917 \mathrm{e}+03$ 2.23917e+03 2.23917e+02 1.00000e-09 7.00000e-02 $1.00000 \mathrm{e}+001.00000 \mathrm{e}+001.00000 \mathrm{e}-011.00000 \mathrm{e}-091.00000 \mathrm{e}-01$ 
1.00000e-06 1.00000e-06 1.00000e-06 1.00000e-09 5.00000e-02

Element: 5359 \# of layers: 4

$\mathrm{Kx} \mathrm{Ky} \mathrm{Kz}$ Ss Por

2.23917e+03 2.23917e+03 2.23917e+02 1.00000e-09 7.00000e-02

$2.23917 \mathrm{e}+03$ 2.23917e+03 2.23917e+02 1.00000e-09 7.00000e-02

$2.23917 \mathrm{e}+03$ 2.23917e+03 2.23917e+02 1.00000e-09 7.00000e-02

1.00000e-06 1.00000e-06 1.00000e-06 1.00000e-09 5.00000e-02

Element: 5360 \# of layers: 4

$\mathrm{Kx} \mathrm{Ky} \mathrm{Kz}$ Ss Por

2.23917e+03 2.23917e+03 2.23917e+02 1.00000e-09 7.00000e-02

$2.23917 \mathrm{e}+03$ 2.23917e+03 2.23917e+02 1.00000e-09 7.00000e-02

$2.23917 \mathrm{e}+032.23917 \mathrm{e}+03$ 2.23917e+02 1.00000e-09 7.00000e-02

1.00000e-06 1.00000e-06 1.00000e-06 1.00000e-09 5.00000e-02

Element: 5361 \# of layers: 4

$\mathrm{Kx} \mathrm{Ky} \mathrm{Kz}$ Ss Por

3.29442e+03 3.29442e+03 3.29442e+02 1.00000e-09 7.00000e-02

3.29442e+03 3.29442e+03 3.29442e+02 1.00000e-09 7.00000e-02

3.29442e+03 3.29442e+03 3.29442e+02 1.00000e-09 7.00000e-02

1.00000e-06 1.00000e-06 1.00000e-06 1.00000e-09 5.00000e-02

Element: 5362 \# of layers: 4

$\mathrm{Kx} \mathrm{Ky} \mathrm{Kz}$ Ss Por

9.76954e+03 9.76954e+03 9.76954e+02 1.00000e-09 7.00000e-02

9.76954e+03 9.76954e+03 9.76954e+02 1.00000e-09 7.00000e-02

9.76954e+03 9.76954e+03 9.76954e+02 1.00000e-09 7.00000e-02

1.00000e-06 1.00000e-06 1.00000e-06 1.00000e-09 5.00000e-02

Element: 5363 \# of layers: 4

$\mathrm{Kx} \mathrm{Ky} \mathrm{Kz}$ Ss Por

$1.31095 \mathrm{e}+04$ 1.31095e+04 1.31096e+03 1.00000e-09 7.00000e-02

$1.31095 \mathrm{e}+041.31095 \mathrm{e}+041.31096 \mathrm{e}+03$ 1.00000e-09 7.00000e-02

$1.31095 \mathrm{e}+041.31095 \mathrm{e}+041.31096 \mathrm{e}+03$ 1.00000e-09 7.00000e-02

$1.00000 \mathrm{e}-06$ 1.00000e-06 1.00000e-06 1.00000e-09 5.00000e-02

Element: 5364 \# of layers: 3

$\mathrm{Kx} \mathrm{Ky} \mathrm{Kz}$ Ss Por

$1.23446 \mathrm{e}+02$ 1.23446e+02 1.23446e+01 1.00000e-09 7.00000e-02 $1.00000 \mathrm{e}+001.00000 \mathrm{e}+001.00000 \mathrm{e}-011.00000 \mathrm{e}-091.00000 \mathrm{e}-01$

1.00000e-06 1.00000e-06 1.00000e-06 1.00000e-09 5.00000e-02

Element: 5365 \# of layers: 3

Kx Ky Kz Ss Por

$1.01398 \mathrm{e}+02$ 1.01398e+02 1.01399e+01 1.00000e-09 7.00000e-02 $1.00000 \mathrm{e}+001.00000 \mathrm{e}+001.00000 \mathrm{e}-011.00000 \mathrm{e}-091.00000 \mathrm{e}-01$ 1.00000e-06 1.00000e-06 1.00000e-06 1.00000e-09 5.00000e-02

Element: 5366 \# of layers: 4

$\mathrm{Kx} \mathrm{Ky} \mathrm{Kz}$ Ss Por

1.01398e+02 1.01398e+02 1.01399e+01 1.00000e-09 7.00000e-02 $1.00000 \mathrm{e}-05$ 1.00000e-05 1.00000e-06 1.00000e-09 1.00000e-01

$1.00000 \mathrm{e}+001.00000 \mathrm{e}+001.00000 \mathrm{e}-011.00000 \mathrm{e}-091.00000 \mathrm{e}-01$ 
1.00000e-06 1.00000e-06 1.00000e-06 1.00000e-09 5.00000e-02

Element: 5367 \# of layers: 4

$\mathrm{Kx} \mathrm{Ky} \mathrm{Kz}$ Ss Por

$1.01398 \mathrm{e}+02$ 1.01398e+02 1.01399e+01 1.00000e-09 7.00000e-02

$1.00000 \mathrm{e}-051.00000 \mathrm{e}-051.00000 \mathrm{e}-061.00000 \mathrm{e}-091.00000 \mathrm{e}-01$

$1.00000 \mathrm{e}+001.00000 \mathrm{e}+001.00000 \mathrm{e}-011.00000 \mathrm{e}-091.00000 \mathrm{e}-01$

1.00000e-06 1.00000e-06 1.00000e-06 1.00000e-09 5.00000e-02

Element: 5368 \# of layers: 3

$\mathrm{Kx} \mathrm{Ky} \mathrm{Kz}$ Ss Por

$6.05580 \mathrm{e}+016.05580 \mathrm{e}+016.05580 \mathrm{e}+001.00000 \mathrm{e}-09$ 7.00000e-02

$6.05580 \mathrm{e}+016.05580 \mathrm{e}+016.05580 \mathrm{e}+00$ 1.00000e-09 7.00000e-02

1.00000e-06 1.00000e-06 1.00000e-06 1.00000e-09 5.00000e-02

Element: 5369 \# of layers: 4

$\mathrm{Kx} \mathrm{Ky} \mathrm{Kz}$ Ss Por

$6.05580 \mathrm{e}+016.05580 \mathrm{e}+016.05580 \mathrm{e}+00$ 1.00000e-09 7.00000e-02

$6.05580 \mathrm{e}+016.05580 \mathrm{e}+016.05580 \mathrm{e}+001.00000 \mathrm{e}-09$ 7.00000e-02

$6.05580 \mathrm{e}+016.05580 \mathrm{e}+016.05580 \mathrm{e}+001.00000 \mathrm{e}-09$ 7.00000e-02

1.00000e-06 1.00000e-06 1.00000e-06 1.00000e-09 5.00000e-02

Element: 5370 \# of layers: 4

$\mathrm{Kx} \mathrm{Ky} \mathrm{Kz}$ Ss Por

4.45427e+01 4.45427e+01 4.45427e+00 1.00000e-09 7.00000e-02

4.45427e+01 4.45427e+01 4.45427e+00 1.00000e-09 7.00000e-02

4.45427e+01 4.45427e+01 4.45427e+00 1.00000e-09 7.00000e-02

1.00000e-06 1.00000e-06 1.00000e-06 1.00000e-09 5.00000e-02

Element: 5371 \# of layers: 5

$\mathrm{Kx} \mathrm{Ky} \mathrm{Kz}$ Ss Por

4.45427e+01 4.45427e+01 4.45427e+00 1.00000e-09 7.00000e-02

4.45427e+01 4.45427e+01 4.45427e+00 1.00000e-09 7.00000e-02

$4.45427 \mathrm{e}+014.45427 \mathrm{e}+014.45427 \mathrm{e}+001.00000 \mathrm{e}-09$ 7.00000e-02

$1.00000 \mathrm{e}+001.00000 \mathrm{e}+001.00000 \mathrm{e}-011.00000 \mathrm{e}-091.00000 \mathrm{e}-01$

1.00000e-06 1.00000e-06 1.00000e-06 1.00000e-09 5.00000e-02

Element: 5372 \# of layers: 4

Kx Ky Kz Ss Por

6.05580e+01 6.05580e+01 6.05580e+00 1.00000e-09 7.00000e-02

$6.05580 \mathrm{e}+016.05580 \mathrm{e}+016.05580 \mathrm{e}+00$ 1.00000e-09 7.00000e-02

$1.00000 \mathrm{e}+001.00000 \mathrm{e}+001.00000 \mathrm{e}-011.00000 \mathrm{e}-091.00000 \mathrm{e}-01$

1.00000e-06 1.00000e-06 1.00000e-06 1.00000e-09 5.00000e-02

Element: 5373 \# of layers: 5

$\mathrm{Kx} \mathrm{Ky} \mathrm{Kz}$ Ss Por

9.12082e+01 9.12082e+01 9.12082e+00 1.00000e-09 7.00000e-02

9.12082e+01 9.12082e+01 9.12082e+00 1.00000e-09 7.00000e-02

$1.00000 \mathrm{e}-05$ 1.00000e-05 1.00000e-06 1.00000e-09 1.00000e-01

$1.00000 \mathrm{e}+001.00000 \mathrm{e}+001.00000 \mathrm{e}-011.00000 \mathrm{e}-091.00000 \mathrm{e}-01$

$1.00000 \mathrm{e}-06$ 1.00000e-06 1.00000e-06 1.00000e-09 5.00000e-02

Element: 5374 \# of layers: 5

Kx Ky Kz Ss Por 
9.12082e+01 9.12082e+01 9.12082e+00 1.00000e-09 7.00000e-02 $9.12082 \mathrm{e}+01$ 9.12082e+01 9.12082e+00 1.00000e-09 7.00000e-02 $1.00000 \mathrm{e}-05$ 1.00000e-05 1.00000e-06 1.00000e-09 1.00000e-01 $1.00000 \mathrm{e}+001.00000 \mathrm{e}+001.00000 \mathrm{e}-011.00000 \mathrm{e}-091.00000 \mathrm{e}-01$ $1.00000 \mathrm{e}-06$ 1.00000e-06 1.00000e-06 1.00000e-09 5.00000e-02

Element: 5375 \# of layers: 2

Kx Ky Kz Ss Por

$1.95373 \mathrm{e}+02$ 1.95373e+02 1.95373e+01 1.00000e-09 7.00000e-02 $1.00000 \mathrm{e}-06$ 1.00000e-06 1.00000e-06 1.00000e-09 5.00000e-02

Element: 5376 \# of layers: 2

Kx Ky Kz Ss Por

$1.95373 \mathrm{e}+02$ 1.95373e+02 1.95373e+01 1.00000e-09 7.00000e-02 $1.00000 \mathrm{e}-06$ 1.00000e-06 1.00000e-06 1.00000e-09 5.00000e-02

Element: 5377 \# of layers: 4

Kx Ky Kz Ss Por

$3.76141 \mathrm{e}+013.76141 \mathrm{e}+013.76141 \mathrm{e}+00$ 1.00000e-09 7.00000e-02

$3.76141 \mathrm{e}+013.76141 \mathrm{e}+013.76141 \mathrm{e}+001.00000 \mathrm{e}-09$ 7.00000e-02

$3.76141 \mathrm{e}+013.76141 \mathrm{e}+013.76141 \mathrm{e}+001.00000 \mathrm{e}-09$ 7.00000e-02 $1.00000 \mathrm{e}-06$ 1.00000e-06 1.00000e-06 1.00000e-09 5.00000e-02

Element: 5378 \# of layers: 3

Kx Ky Kz Ss Por

$3.76141 \mathrm{e}+013.76141 \mathrm{e}+013.76141 \mathrm{e}+00$ 1.00000e-09 7.00000e-02

$3.76141 \mathrm{e}+013.76141 \mathrm{e}+013.76141 \mathrm{e}+001.00000 \mathrm{e}-09$ 7.00000e-02

$1.00000 \mathrm{e}-06$ 1.00000e-06 1.00000e-06 1.00000e-09 5.00000e-02

Element: 5379 \# of layers: 3

Kx Ky Kz Ss Por

3.35722e+01 3.35722e+01 3.35722e+00 1.00000e-09 7.00000e-02

$3.35722 \mathrm{e}+013.35722 \mathrm{e}+013.35722 \mathrm{e}+001.00000 \mathrm{e}-09$ 7.00000e-02

$1.00000 \mathrm{e}-06$ 1.00000e-06 1.00000e-06 1.00000e-09 5.00000e-02

Element: 5380 \# of layers: 4

Kx Ky Kz Ss Por

$3.35722 \mathrm{e}+013.35722 \mathrm{e}+013.35722 \mathrm{e}+00$ 1.00000e-09 7.00000e-02 $1.00000 \mathrm{e}-05$ 1.00000e-05 1.00000e-06 1.00000e-09 1.00000e-01

$1.00000 \mathrm{e}+001.00000 \mathrm{e}+001.00000 \mathrm{e}-011.00000 \mathrm{e}-091.00000 \mathrm{e}-01$ $1.00000 \mathrm{e}-06$ 1.00000e-06 1.00000e-06 1.00000e-09 5.00000e-02

Element: 5381 \# of layers: 2

Kx Ky Kz Ss Por

$1.95373 \mathrm{e}+02$ 1.95373e+02 1.95373e+01 1.00000e-09 7.00000e-02 $1.00000 \mathrm{e}-06$ 1.00000e-06 1.00000e-06 1.00000e-09 5.00000e-02

Element: 5382 \# of layers: 5

Kx Ky Kz Ss Por

$5.25715 \mathrm{e}+00$ 5.25715e+00 5.25715e-01 1.00000e-09 7.00000e-02

$5.25715 \mathrm{e}+005.25715 \mathrm{e}+00$ 5.25715e-01 1.00000e-09 7.00000e-02

$5.25715 \mathrm{e}+005.25715 \mathrm{e}+00$ 5.25715e-01 1.00000e-09 7.00000e-02

2.10058e-01 2.10058e-01 2.10058e-02 1.00000e-09 2.12000e-01

$1.00000 \mathrm{e}-06$ 1.00000e-06 1.00000e-06 1.00000e-09 5.00000e-02 
Element: 5383 \# of layers: 6

$\mathrm{Kx} \mathrm{Ky} \mathrm{Kz}$ Ss Por

4.62348e+00 4.62348e+00 4.62348e-01 1.00000e-09 7.00000e-02

$4.62348 \mathrm{e}+00$ 4.62348e+00 4.62348e-01 1.00000e-09 7.00000e-02

4.62348e+00 4.62348e+00 4.62348e-01 1.00000e-09 7.00000e-02

1.84738e-01 1.84738e-01 1.84738e-02 1.00000e-09 2.12000e-01

1.84738e-01 1.84738e-01 1.84738e-02 1.00000e-09 2.12000e-01

1.00000e-06 1.00000e-06 1.00000e-06 1.00000e-09 5.00000e-02

Element: 5384 \# of layers: 10

$\mathrm{Kx} \mathrm{Ky} \mathrm{Kz}$ Ss Por

4.62348e+00 4.62348e+00 4.62348e-01 1.00000e-09 7.00000e-02

$4.62348 \mathrm{e}+00$ 4.62348e+00 4.62348e-01 1.00000e-09 7.00000e-02

4.62348e+00 4.62348e+00 4.62348e-01 1.00000e-09 7.00000e-02

1.84738e-01 1.84738e-01 1.84738e-02 1.00000e-09 2.12000e-01

1.84738e-01 1.84738e-01 1.84738e-02 1.00000e-09 2.12000e-01

1.84738e-01 1.84738e-01 1.84738e-02 1.00000e-09 2.12000e-01

1.84738e-01 1.84738e-01 1.84738e-02 1.00000e-09 2.12000e-01

1.84738e-01 1.84738e-01 1.84738e-02 1.00000e-09 2.12000e-01

$1.00000 \mathrm{e}-02$ 1.00000e-02 1.00000e-03 1.00000e-09 1.00000e-01

1.00000e-06 1.00000e-06 1.00000e-06 1.00000e-09 5.00000e-02

Element: 5385 \# of layers: 9

$\mathrm{Kx} \mathrm{Ky} \mathrm{Kz}$ Ss Por

3.15999e+00 3.15999e+00 3.15999e-01 1.00000e-09 7.00000e-02

$3.15999 \mathrm{e}+003.15999 \mathrm{e}+00$ 3.15999e-01 1.00000e-09 7.00000e-02

$3.15999 \mathrm{e}+003.15999 \mathrm{e}+00$ 3.15999e-01 1.00000e-09 7.00000e-02

1.26261e-01 1.26261e-01 1.26261e-02 1.00000e-09 2.12000e-01

$1.26261 \mathrm{e}-01$ 1.26261e-01 1.26261e-02 1.00000e-09 2.12000e-01

$1.26261 \mathrm{e}-01$ 1.26261e-01 1.26261e-02 1.00000e-09 2.12000e-01

$1.26261 \mathrm{e}-01$ 1.26261e-01 1.26261e-02 1.00000e-09 2.12000e-01

$1.26261 \mathrm{e}-01$ 1.26261e-01 1.26261e-02 1.00000e-09 2.12000e-01

1.00000e-06 1.00000e-06 1.00000e-06 1.00000e-09 5.00000e-02

Element: 5386 \# of layers: 6

$\mathrm{Kx} \mathrm{Ky} \mathrm{Kz}$ Ss Por

3.15999e+00 3.15999e+00 3.15999e-01 1.00000e-09 7.00000e-02

$3.15999 \mathrm{e}+003.15999 \mathrm{e}+00$ 3.15999e-01 1.00000e-09 7.00000e-02

3.15999e+00 3.15999e+00 3.15999e-01 1.00000e-09 7.00000e-02

1.26261e-01 1.26261e-01 1.26261e-02 1.00000e-09 2.12000e-01

$1.26261 \mathrm{e}-01$ 1.26261e-01 1.26261e-02 1.00000e-09 2.12000e-01

1.00000e-06 1.00000e-06 1.00000e-06 1.00000e-09 5.00000e-02

Element: 5387 \# of layers: 4

$\mathrm{Kx} \mathrm{Ky} \mathrm{Kz}$ Ss Por

3.15999e+00 3.15999e+00 3.15999e-01 1.00000e-09 7.00000e-02

3.15999e+00 3.15999e+00 3.15999e-01 1.00000e-09 7.00000e-02

3.15999e+00 3.15999e+00 3.15999e-01 1.00000e-09 7.00000e-02

1.00000e-06 1.00000e-06 1.00000e-06 1.00000e-09 5.00000e-02

Element: 5388 \# of layers: 4 
$\mathrm{Kx} \mathrm{Ky} \mathrm{Kz}$ Ss Por

4.21263e+00 4.21263e+00 4.21263e-01 1.00000e-09 7.00000e-02

4.21263e+00 4.21263e+00 4.21263e-01 1.00000e-09 7.00000e-02

$4.21263 \mathrm{e}+004.21263 \mathrm{e}+00$ 4.21263e-01 1.00000e-09 7.00000e-02

1.00000e-06 1.00000e-06 1.00000e-06 1.00000e-09 5.00000e-02

Element: 5389 \# of layers: 4

$\mathrm{Kx} \mathrm{Ky} \mathrm{Kz}$ Ss Por

4.21263e+00 4.21263e+00 4.21263e-01 1.00000e-09 7.00000e-02 4.21263e+00 4.21263e+00 4.21263e-01 1.00000e-09 7.00000e-02

4.21263e+00 4.21263e+00 4.21263e-01 1.00000e-09 7.00000e-02 1.00000e-06 1.00000e-06 1.00000e-06 1.00000e-09 5.00000e-02

Element: 5390 \# of layers: 5

$\mathrm{Kx} \mathrm{Ky} \mathrm{Kz}$ Ss Por

3.15999e+00 3.15999e+00 3.15999e-01 1.00000e-09 7.00000e-02

3.15999e+00 3.15999e+00 3.15999e-01 1.00000e-09 7.00000e-02

3.15999e+00 3.15999e+00 3.15999e-01 1.00000e-09 7.00000e-02

1.26261e-01 1.26261e-01 1.26261e-02 1.00000e-09 2.12000e-01

1.00000e-06 1.00000e-06 1.00000e-06 1.00000e-09 5.00000e-02

Element: 5391 \# of layers: 10

$\mathrm{Kx} \mathrm{Ky} \mathrm{Kz}$ Ss Por

3.27351e+00 3.27351e+00 3.27351e-01 1.00000e-09 7.00000e-02

3.27351e+00 3.27351e+00 3.27351e-01 1.00000e-09 7.00000e-02

3.27351e+00 3.27351e+00 3.27351e-01 1.00000e-09 7.00000e-02

1.30798e-01 1.30798e-01 1.30798e-02 1.00000e-09 2.12000e-01

1.30798e-01 1.30798e-01 1.30798e-02 1.00000e-09 2.12000e-01

1.30798e-01 1.30798e-01 1.30798e-02 1.00000e-09 2.12000e-01

1.30798e-01 1.30798e-01 1.30798e-02 1.00000e-09 2.12000e-01

1.30798e-01 1.30798e-01 1.30798e-02 1.00000e-09 2.12000e-01

$1.00000 \mathrm{e}-02$ 1.00000e-02 1.00000e-03 1.00000e-09 1.00000e-01

$1.00000 \mathrm{e}-06$ 1.00000e-06 1.00000e-06 1.00000e-09 5.00000e-02

Element: 5392 \# of layers: 10

$\mathrm{Kx} \mathrm{Ky} \mathrm{Kz}$ Ss Por

3.27351e+00 3.27351e+00 3.27351e-01 1.00000e-09 7.00000e-02

3.27351e+00 3.27351e+00 3.27351e-01 1.00000e-09 7.00000e-02

$3.27351 \mathrm{e}+003.27351 \mathrm{e}+003.27351 \mathrm{e}-01$ 1.00000e-09 7.00000e-02

1.30798e-01 1.30798e-01 1.30798e-02 1.00000e-09 2.12000e-01

1.30798e-01 1.30798e-01 1.30798e-02 1.00000e-09 2.12000e-01

1.30798e-01 1.30798e-01 1.30798e-02 1.00000e-09 2.12000e-01

1.30798e-01 1.30798e-01 1.30798e-02 1.00000e-09 2.12000e-01

1.30798e-01 1.30798e-01 1.30798e-02 1.00000e-09 2.12000e-01

$1.00000 \mathrm{e}-02$ 1.00000e-02 1.00000e-03 1.00000e-09 1.00000e-01

1.00000e-06 1.00000e-06 1.00000e-06 1.00000e-09 5.00000e-02

Element: 5393 \# of layers: 11

$\mathrm{Kx} \mathrm{Ky} \mathrm{Kz}$ Ss Por

$2.83896 \mathrm{e}+002.83896 \mathrm{e}+00$ 2.83896e-01 1.00000e-09 7.00000e-02

$2.83896 \mathrm{e}+002.83896 \mathrm{e}+00$ 2.83896e-01 1.00000e-09 7.00000e-02 
2.83896e+00 2.83896e+00 2.83896e-01 1.00000e-09 7.00000e-02 5.00000e-04 5.00000e-04 5.00000e-05 1.00000e-09 1.00000e-01 1.13436e-01 1.13436e-01 1.13436e-02 1.00000e-09 2.12000e-01 1.13436e-01 1.13436e-01 1.13436e-02 1.00000e-09 2.12000e-01 1.13436e-01 1.13436e-01 1.13436e-02 1.00000e-09 2.12000e-01 1.13436e-01 1.13436e-01 1.13436e-02 1.00000e-09 2.12000e-01 1.13436e-01 1.13436e-01 1.13436e-02 1.00000e-09 2.12000e-01 $1.00000 \mathrm{e}-02$ 1.00000e-02 1.00000e-03 1.00000e-09 1.00000e-01 1.00000e-06 1.00000e-06 1.00000e-06 1.00000e-09 5.00000e-02 Element: 5394 \# of layers: 10

$\mathrm{Kx} \mathrm{Ky} \mathrm{Kz}$ Ss Por

2.21763e+00 2.21763e+00 2.21763e-01 1.00000e-09 7.00000e-02 $2.21763 \mathrm{e}+002.21763 \mathrm{e}+002.21763 \mathrm{e}-01$ 1.00000e-09 7.00000e-02 $2.21763 \mathrm{e}+002.21763 \mathrm{e}+002.21763 \mathrm{e}-01$ 1.00000e-09 7.00000e-02 8.86091e-02 8.86091e-02 8.86091e-03 1.00000e-09 2.12000e-01 8.86091e-02 8.86091e-02 8.86091e-03 1.00000e-09 2.12000e-01 8.86091e-02 8.86091e-02 8.86091e-03 1.00000e-09 2.12000e-01 8.86091e-02 8.86091e-02 8.86091e-03 1.00000e-09 2.12000e-01 8.86091e-02 8.86091e-02 8.86091e-03 1.00000e-09 2.12000e-01 $1.00000 \mathrm{e}-02$ 1.00000e-02 1.00000e-03 1.00000e-09 1.00000e-01 1.00000e-06 1.00000e-06 1.00000e-06 1.00000e-09 5.00000e-02 Element: 5395 \# of layers: 7

$\mathrm{Kx} \mathrm{Ky} \mathrm{Kz}$ Ss Por

$2.21763 \mathrm{e}+00$ 2.21763e+00 2.21763e-01 1.00000e-09 7.00000e-02 $2.21763 \mathrm{e}+002.21763 \mathrm{e}+00$ 2.21763e-01 1.00000e-09 7.00000e-02 $2.21763 \mathrm{e}+002.21763 \mathrm{e}+002.21763 \mathrm{e}-01$ 1.00000e-09 7.00000e-02 8.86091e-02 8.86091e-02 8.86091e-03 1.00000e-09 2.12000e-01 8.86091e-02 8.86091e-02 8.86091e-03 1.00000e-09 2.12000e-01 8.86091e-02 8.86091e-02 8.86091e-03 1.00000e-09 2.12000e-01 1.00000e-06 1.00000e-06 1.00000e-06 1.00000e-09 5.00000e-02 Element: 5396 \# of layers: 8

$\mathrm{Kx} \mathrm{Ky} \mathrm{Kz}$ Ss Por

2.21763e+00 2.21763e+00 2.21763e-01 1.00000e-09 7.00000e-02 2.21763e+00 2.21763e+00 2.21763e-01 1.00000e-09 7.00000e-02 $2.21763 \mathrm{e}+002.21763 \mathrm{e}+002.21763 \mathrm{e}-01$ 1.00000e-09 7.00000e-02 8.86091e-02 8.86091e-02 8.86091e-03 1.00000e-09 2.12000e-01 8.86091e-02 8.86091e-02 8.86091e-03 1.00000e-09 2.12000e-01 8.86091e-02 8.86091e-02 8.86091e-03 1.00000e-09 2.12000e-01 8.86091e-02 8.86091e-02 8.86091e-03 1.00000e-09 2.12000e-01 1.00000e-06 1.00000e-06 1.00000e-06 1.00000e-09 5.00000e-02 Element: 5397 \# of layers: 7

$\mathrm{Kx} \mathrm{Ky} \mathrm{Kz}$ Ss Por

$2.28620 \mathrm{e}+002.28620 \mathrm{e}+00$ 2.28620e-01 1.00000e-09 7.00000e-02 $2.28620 \mathrm{e}+002.28620 \mathrm{e}+00$ 2.28620e-01 1.00000e-09 7.00000e-02 $2.28620 \mathrm{e}+002.28620 \mathrm{e}+002.28620 \mathrm{e}-01$ 1.00000e-09 7.00000e-02 9.13474e-02 9.13474e-02 9.13474e-03 1.00000e-09 2.12000e-01 
9.13474e-02 9.13474e-02 9.13474e-03 1.00000e-09 2.12000e-01 9.13474e-02 9.13474e-02 9.13474e-03 1.00000e-09 2.12000e-01 $1.00000 \mathrm{e}-06$ 1.00000e-06 1.00000e-06 1.00000e-09 5.00000e-02 Element: 5398 \# of layers: 9

Kx Ky Kz Ss Por

$3.27351 \mathrm{e}+003.27351 \mathrm{e}+003.27351 \mathrm{e}-011.00000 \mathrm{e}-09$ 7.00000e-02 $3.27351 \mathrm{e}+003.27351 \mathrm{e}+003.27351 \mathrm{e}-011.00000 \mathrm{e}-09$ 7.00000e-02 $3.27351 \mathrm{e}+003.27351 \mathrm{e}+003.27351 \mathrm{e}-01$ 1.00000e-09 7.00000e-02 1.30798e-01 1.30798e-01 1.30798e-02 1.00000e-09 2.12000e-01 1.30798e-01 1.30798e-01 1.30798e-02 1.00000e-09 2.12000e-01 1.30798e-01 1.30798e-01 1.30798e-02 1.00000e-09 2.12000e-01 1.30798e-01 1.30798e-01 1.30798e-02 1.00000e-09 2.12000e-01 $1.00000 \mathrm{e}-02$ 1.00000e-02 1.00000e-03 1.00000e-09 1.00000e-01 $1.00000 \mathrm{e}-06$ 1.00000e-06 1.00000e-06 1.00000e-09 5.00000e-02 Element: 5399 \# of layers: 10

Kx Ky Kz Ss Por

$2.21763 \mathrm{e}+002.21763 \mathrm{e}+00$ 2.21763e-01 1.00000e-09 7.00000e-02 $2.21763 \mathrm{e}+002.21763 \mathrm{e}+002.21763 \mathrm{e}-011.00000 \mathrm{e}-09$ 7.00000e-02 $2.21763 \mathrm{e}+002.21763 \mathrm{e}+00$ 2.21763e-01 1.00000e-09 7.00000e-02 8.86091e-02 8.86091e-02 8.86091e-03 1.00000e-09 2.12000e-01 8.86091e-02 8.86091e-02 8.86091e-03 1.00000e-09 2.12000e-01 8.86091e-02 8.86091e-02 8.86091e-03 1.00000e-09 2.12000e-01 8.86091e-02 8.86091e-02 8.86091e-03 1.00000e-09 2.12000e-01 8.86091e-02 8.86091e-02 8.86091e-03 1.00000e-09 2.12000e-01 $1.00000 \mathrm{e}-021.00000 \mathrm{e}-02$ 1.00000e-03 1.00000e-09 1.00000e-01 $1.00000 \mathrm{e}-06$ 1.00000e-06 1.00000e-06 1.00000e-09 5.00000e-02 Element: 5400 \# of layers: 10

Kx Ky Kz Ss Por

$3.07457 \mathrm{e}+003.07457 \mathrm{e}+00$ 3.07457e-01 1.00000e-09 7.00000e-02 $3.07457 \mathrm{e}+003.07457 \mathrm{e}+003.07457 \mathrm{e}-011.00000 \mathrm{e}-09$ 7.00000e-02 $3.07457 \mathrm{e}+003.07457 \mathrm{e}+003.07457 \mathrm{e}-011.00000 \mathrm{e}-09$ 7.00000e-02 5.00000e-04 5.00000e-04 5.00000e-05 1.00000e-09 1.00000e-01 $1.22848 \mathrm{e}-01$ 1.22848e-01 1.22848e-02 1.00000e-09 2.12000e-01 $1.22848 \mathrm{e}-01$ 1.22848e-01 1.22848e-02 1.00000e-09 2.12000e-01 $1.22848 \mathrm{e}-011.22848 \mathrm{e}-011.22848 \mathrm{e}-021.00000 \mathrm{e}-092.12000 \mathrm{e}-01$ $1.22848 \mathrm{e}-01$ 1.22848e-01 1.22848e-02 1.00000e-09 2.12000e-01 $1.00000 \mathrm{e}-02$ 1.00000e-02 1.00000e-03 1.00000e-09 1.00000e-01 $1.00000 \mathrm{e}-06$ 1.00000e-06 1.00000e-06 1.00000e-09 5.00000e-02 Element: 5401 \# of layers: 9

Kx Ky Kz Ss Por

$3.72924 \mathrm{e}+003.72924 \mathrm{e}+003.72924 \mathrm{e}-011.00000 \mathrm{e}-09$ 7.00000e-02 $3.72924 \mathrm{e}+003.72924 \mathrm{e}+003.72924 \mathrm{e}-011.00000 \mathrm{e}-09$ 7.00000e-02 $3.72924 \mathrm{e}+003.72924 \mathrm{e}+003.72924 \mathrm{e}-011.00000 \mathrm{e}-09$ 7.00000e-02 $1.49005 \mathrm{e}-01$ 1.49005e-01 1.49005e-02 1.00000e-09 2.12000e-01 $1.49005 \mathrm{e}-01$ 1.49005e-01 1.49005e-02 1.00000e-09 2.12000e-01 $1.49005 \mathrm{e}-01$ 1.49005e-01 1.49005e-02 1.00000e-09 2.12000e-01 
1.49005e-01 1.49005e-01 1.49005e-02 1.00000e-09 2.12000e-01 $1.00000 \mathrm{e}-02$ 1.00000e-02 1.00000e-03 1.00000e-09 1.00000e-01 $1.00000 \mathrm{e}-06$ 1.00000e-06 1.00000e-06 1.00000e-09 5.00000e-02 Element: 5402 \# of layers: 11

Kx Ky Kz Ss Por

$3.72924 \mathrm{e}+003.72924 \mathrm{e}+00$ 3.72924e-01 1.00000e-09 7.00000e-02 $3.72924 \mathrm{e}+003.72924 \mathrm{e}+003.72924 \mathrm{e}-011.00000 \mathrm{e}-09$ 7.00000e-02 $3.72924 \mathrm{e}+003.72924 \mathrm{e}+003.72924 \mathrm{e}-011.00000 \mathrm{e}-09$ 7.00000e-02 5.00000e-04 5.00000e-04 5.00000e-05 1.00000e-09 1.00000e-01 $1.49005 \mathrm{e}-011.49005 \mathrm{e}-011.49005 \mathrm{e}-021.00000 \mathrm{e}-092.12000 \mathrm{e}-01$ $1.49005 \mathrm{e}-01$ 1.49005e-01 1.49005e-02 1.00000e-09 2.12000e-01 $1.49005 \mathrm{e}-01$ 1.49005e-01 1.49005e-02 1.00000e-09 2.12000e-01 $1.49005 \mathrm{e}-011.49005 \mathrm{e}-011.49005 \mathrm{e}-021.00000 \mathrm{e}-092.12000 \mathrm{e}-01$ $1.49005 \mathrm{e}-01$ 1.49005e-01 1.49005e-02 1.00000e-09 2.12000e-01 $1.00000 \mathrm{e}-02$ 1.00000e-02 1.00000e-03 1.00000e-09 1.00000e-01 $1.00000 \mathrm{e}-06$ 1.00000e-06 1.00000e-06 1.00000e-09 5.00000e-02 Element: 5403 \# of layers: 10

Kx Ky Kz Ss Por

$3.72924 \mathrm{e}+003.72924 \mathrm{e}+00$ 3.72924e-01 1.00000e-09 7.00000e-02

$3.72924 \mathrm{e}+003.72924 \mathrm{e}+003.72924 \mathrm{e}-011.00000 \mathrm{e}-09$ 7.00000e-02 $3.72924 \mathrm{e}+003.72924 \mathrm{e}+003.72924 \mathrm{e}-011.00000 \mathrm{e}-09$ 7.00000e-02 5.00000e-04 5.00000e-04 5.00000e-05 1.00000e-09 1.00000e-01 5.00000e-04 5.00000e-04 5.00000e-05 1.00000e-09 1.00000e-01 $1.49005 \mathrm{e}-01$ 1.49005e-01 1.49005e-02 1.00000e-09 2.12000e-01 $1.49005 \mathrm{e}-01$ 1.49005e-01 1.49005e-02 1.00000e-09 2.12000e-01 $1.49005 \mathrm{e}-011.49005 \mathrm{e}-011.49005 \mathrm{e}-021.00000 \mathrm{e}-092.12000 \mathrm{e}-01$ $1.49005 \mathrm{e}-01$ 1.49005e-01 1.49005e-02 1.00000e-09 2.12000e-01 $1.00000 \mathrm{e}-06$ 1.00000e-06 1.00000e-06 1.00000e-09 5.00000e-02 Element: 5404 \# of layers: 8

Kx Ky Kz Ss Por

$3.34568 \mathrm{e}+003.34568 \mathrm{e}+00$ 3.34568e-01 1.00000e-09 7.00000e-02 $3.34568 \mathrm{e}+003.34568 \mathrm{e}+003.34568 \mathrm{e}-011.00000 \mathrm{e}-09$ 7.00000e-02 $3.34568 \mathrm{e}+003.34568 \mathrm{e}+003.34568 \mathrm{e}-01$ 1.00000e-09 7.00000e-02 5.00000e-04 5.00000e-04 5.00000e-05 1.00000e-09 1.00000e-01 1.33682e-01 1.33682e-01 1.33682e-02 1.00000e-09 2.12000e-01 1.33682e-01 1.33682e-01 1.33682e-02 1.00000e-09 2.12000e-01 $1.33682 \mathrm{e}-01$ 1.33682e-01 1.33682e-02 1.00000e-09 2.12000e-01 1.00000e-06 1.00000e-06 1.00000e-06 1.00000e-09 5.00000e-02 Element: 5405 \# of layers: 7

Kx Ky Kz Ss Por

$3.34568 \mathrm{e}+003.34568 \mathrm{e}+00$ 3.34568e-01 1.00000e-09 7.00000e-02 $3.34568 \mathrm{e}+003.34568 \mathrm{e}+003.34568 \mathrm{e}-011.00000 \mathrm{e}-09$ 7.00000e-02 $3.34568 \mathrm{e}+003.34568 \mathrm{e}+00$ 3.34568e-01 1.00000e-09 7.00000e-02 $1.33682 \mathrm{e}-01$ 1.33682e-01 1.33682e-02 1.00000e-09 2.12000e-01 $1.33682 \mathrm{e}-011.33682 \mathrm{e}-011.33682 \mathrm{e}-021.00000 \mathrm{e}-092.12000 \mathrm{e}-01$ $1.33682 \mathrm{e}-01$ 1.33682e-01 1.33682e-02 1.00000e-09 2.12000e-01 
1.00000e-06 1.00000e-06 1.00000e-06 1.00000e-09 5.00000e-02 Element: 5406 \# of layers: 7

Kx Ky Kz Ss Por

2.65047e+00 2.65047e+00 2.65047e-01 1.00000e-09 7.00000e-02

$2.65047 \mathrm{e}+002.65047 \mathrm{e}+00$ 2.65047e-01 1.00000e-09 7.00000e-02

$2.65047 \mathrm{e}+002.65047 \mathrm{e}+00$ 2.65047e-01 1.00000e-09 7.00000e-02

1.05903e-01 1.05903e-01 1.05903e-02 1.00000e-09 2.12000e-01

1.05903e-01 1.05903e-01 1.05903e-02 1.00000e-09 2.12000e-01

1.05903e-01 1.05903e-01 1.05903e-02 1.00000e-09 2.12000e-01

1.00000e-06 1.00000e-06 1.00000e-06 1.00000e-09 5.00000e-02

Element: 5407 \# of layers: 9

Kx Ky Kz Ss Por

3.07457e+00 3.07457e+00 3.07457e-01 1.00000e-09 7.00000e-02

$3.07457 \mathrm{e}+003.07457 \mathrm{e}+003.07457 \mathrm{e}-01$ 1.00000e-09 7.00000e-02

3.07457e+00 3.07457e+00 3.07457e-01 1.00000e-09 7.00000e-02

1.22848e-01 1.22848e-01 1.22848e-02 1.00000e-09 2.12000e-01

1.22848e-01 1.22848e-01 1.22848e-02 1.00000e-09 2.12000e-01

1.22848e-01 1.22848e-01 1.22848e-02 1.00000e-09 2.12000e-01

1.22848e-01 1.22848e-01 1.22848e-02 1.00000e-09 2.12000e-01

1.22848e-01 1.22848e-01 1.22848e-02 1.00000e-09 2.12000e-01

$1.00000 \mathrm{e}-06$ 1.00000e-06 1.00000e-06 1.00000e-09 5.00000e-02

Element: 5408 \# of layers: 9

$\mathrm{Kx} \mathrm{Ky} \mathrm{Kz}$ Ss Por

3.34568e+00 3.34568e+00 3.34568e-01 1.00000e-09 7.00000e-02

$3.34568 \mathrm{e}+003.34568 \mathrm{e}+00$ 3.34568e-01 1.00000e-09 7.00000e-02

3.34568e+00 3.34568e+00 3.34568e-01 1.00000e-09 7.00000e-02

1.33682e-01 1.33682e-01 1.33682e-02 1.00000e-09 2.12000e-01

1.33682e-01 1.33682e-01 1.33682e-02 1.00000e-09 2.12000e-01

1.33682e-01 1.33682e-01 1.33682e-02 1.00000e-09 2.12000e-01

1.33682e-01 1.33682e-01 1.33682e-02 1.00000e-09 2.12000e-01

1.33682e-01 1.33682e-01 1.33682e-02 1.00000e-09 2.12000e-01

1.00000e-06 1.00000e-06 1.00000e-06 1.00000e-09 5.00000e-02

Element: 5409 \# of layers: 9

$\mathrm{Kx} \mathrm{Ky} \mathrm{Kz}$ Ss Por

5.17805e+00 5.17805e+00 5.17805e-01 1.00000e-09 7.00000e-02

$5.17805 \mathrm{e}+005.17805 \mathrm{e}+00$ 5.17805e-01 1.00000e-09 7.00000e-02

5.00000e-04 5.00000e-04 5.00000e-05 1.00000e-09 1.00000e-01

2.06894e-01 2.06894e-01 2.06894e-02 1.00000e-09 2.12000e-01

2.06894e-01 2.06894e-01 2.06894e-02 1.00000e-09 2.12000e-01

2.06894e-01 2.06894e-01 2.06894e-02 1.00000e-09 2.12000e-01

2.06894e-01 2.06894e-01 2.06894e-02 1.00000e-09 2.12000e-01

2.06894e-01 2.06894e-01 2.06894e-02 1.00000e-09 2.12000e-01

$1.00000 \mathrm{e}-06$ 1.00000e-06 1.00000e-06 1.00000e-09 5.00000e-02

Element: 5410 \# of layers: 8

$\mathrm{Kx} \mathrm{Ky} \mathrm{Kz}$ Ss Por

5.17805e+00 5.17805e+00 5.17805e-01 1.00000e-09 7.00000e-02 
5.17805e+00 5.17805e+00 5.17805e-01 1.00000e-09 7.00000e-02 2.06894e-01 2.06894e-01 2.06894e-02 1.00000e-09 2.12000e-01 2.06894e-01 2.06894e-01 2.06894e-02 1.00000e-09 2.12000e-01 2.06894e-01 2.06894e-01 2.06894e-02 1.00000e-09 2.12000e-01 2.06894e-01 2.06894e-01 2.06894e-02 1.00000e-09 2.12000e-01 2.06894e-01 2.06894e-01 2.06894e-02 1.00000e-09 2.12000e-01 $1.00000 \mathrm{e}-06$ 1.00000e-06 1.00000e-06 1.00000e-09 5.00000e-02 Element: 5411 \# of layers: 8

Kx Ky Kz Ss Por

$4.48608 \mathrm{e}+004.48608 \mathrm{e}+00$ 4.48608e-01 1.00000e-09 7.00000e-02 $4.48608 \mathrm{e}+004.48608 \mathrm{e}+004.48608 \mathrm{e}-01$ 1.00000e-09 7.00000e-02 $1.79248 \mathrm{e}-01$ 1.79248e-01 1.79248e-02 1.00000e-09 2.12000e-01 1.79248e-01 1.79248e-01 1.79248e-02 1.00000e-09 2.12000e-01 $1.79248 \mathrm{e}-01$ 1.79248e-01 1.79248e-02 1.00000e-09 2.12000e-01 $1.79248 \mathrm{e}-01$ 1.79248e-01 1.79248e-02 1.00000e-09 2.12000e-01 $1.79248 \mathrm{e}-01$ 1.79248e-01 1.79248e-02 1.00000e-09 2.12000e-01 1.00000e-06 1.00000e-06 1.00000e-06 1.00000e-09 5.00000e-02 Element: 5412 \# of layers: 6

Kx Ky Kz Ss Por

$4.48608 \mathrm{e}+004.48608 \mathrm{e}+004.48608 \mathrm{e}-01$ 1.00000e-09 7.00000e-02 $4.48608 \mathrm{e}+004.48608 \mathrm{e}+004.48608 \mathrm{e}-01$ 1.00000e-09 7.00000e-02 $1.79248 \mathrm{e}-01$ 1.79248e-01 1.79248e-02 1.00000e-09 2.12000e-01 $1.79248 \mathrm{e}-01$ 1.79248e-01 1.79248e-02 1.00000e-09 2.12000e-01 $1.79248 \mathrm{e}-011.79248 \mathrm{e}-011.79248 \mathrm{e}-021.00000 \mathrm{e}-092.12000 \mathrm{e}-01$ $1.00000 \mathrm{e}-06$ 1.00000e-06 1.00000e-06 1.00000e-09 5.00000e-02 Element: 5413 \# of layers: 5

Kx Ky Kz Ss Por

5.20616e+00 5.20616e+00 5.20616e-01 1.00000e-09 7.00000e-02 $5.20616 \mathrm{e}+005.20616 \mathrm{e}+00$ 5.20616e-01 1.00000e-09 7.00000e-02 2.08021e-01 2.08021e-01 2.08021e-02 1.00000e-09 2.12000e-01 2.08021e-01 2.08021e-01 2.08021e-02 1.00000e-09 2.12000e-01 $1.00000 \mathrm{e}-06$ 1.00000e-06 1.00000e-06 1.00000e-09 5.00000e-02 Element: 5414 \# of layers: 5

Kx Ky Kz Ss Por

5.20616e+00 5.20616e+00 5.20616e-01 1.00000e-09 7.00000e-02 $5.20616 \mathrm{e}+005.20616 \mathrm{e}+00$ 5.20616e-01 1.00000e-09 7.00000e-02 $2.08021 \mathrm{e}-012.08021 \mathrm{e}-012.08021 \mathrm{e}-021.00000 \mathrm{e}-092.12000 \mathrm{e}-01$ 2.08021e-01 2.08021e-01 2.08021e-02 1.00000e-09 2.12000e-01 $1.00000 \mathrm{e}-06$ 1.00000e-06 1.00000e-06 1.00000e-09 5.00000e-02 Element: 5415 \# of layers: 7

Kx Ky Kz Ss Por

$4.75160 \mathrm{e}+004.75160 \mathrm{e}+004.75160 \mathrm{e}-011.00000 \mathrm{e}-09$ 7.00000e-02 $4.75160 \mathrm{e}+004.75160 \mathrm{e}+004.75160 \mathrm{e}-011.00000 \mathrm{e}-09$ 7.00000e-02 5.00000e-04 5.00000e-04 5.00000e-05 1.00000e-09 1.00000e-01 $1.89857 \mathrm{e}-01$ 1.89857e-01 1.89857e-02 1.00000e-09 2.12000e-01 $1.89857 \mathrm{e}-01$ 1.89857e-01 1.89857e-02 1.00000e-09 2.12000e-01 
1.89857e-01 1.89857e-01 1.89857e-02 1.00000e-09 2.12000e-01 $1.00000 \mathrm{e}-06$ 1.00000e-06 1.00000e-06 1.00000e-09 5.00000e-02 Element: 5416 \# of layers: 9

Kx Ky Kz Ss Por

$4.75160 \mathrm{e}+004.75160 \mathrm{e}+00$ 4.75160e-01 1.00000e-09 7.00000e-02

$4.75160 \mathrm{e}+004.75160 \mathrm{e}+004.75160 \mathrm{e}-011.00000 \mathrm{e}-09$ 7.00000e-02

$5.00000 \mathrm{e}-04$ 5.00000e-04 5.00000e-05 1.00000e-09 1.00000e-01

5.00000e-04 5.00000e-04 5.00000e-05 1.00000e-09 1.00000e-01

$1.89857 \mathrm{e}-01$ 1.89857e-01 1.89857e-02 1.00000e-09 2.12000e-01

$1.89857 \mathrm{e}-01$ 1.89857e-01 1.89857e-02 1.00000e-09 2.12000e-01

$1.89857 \mathrm{e}-01$ 1.89857e-01 1.89857e-02 1.00000e-09 2.12000e-01

$1.89857 \mathrm{e}-01$ 1.89857e-01 1.89857e-02 1.00000e-09 2.12000e-01

$1.00000 \mathrm{e}-06$ 1.00000e-06 1.00000e-06 1.00000e-09 5.00000e-02

Element: 5417 \# of layers: 7

Kx Ky Kz Ss Por

$5.20616 \mathrm{e}+005.20616 \mathrm{e}+00$ 5.20616e-01 1.00000e-09 7.00000e-02

$5.20616 \mathrm{e}+005.20616 \mathrm{e}+00$ 5.20616e-01 1.00000e-09 7.00000e-02

$2.08021 \mathrm{e}-01$ 2.08021e-01 2.08021e-02 1.00000e-09 2.12000e-01

$2.08021 \mathrm{e}-012.08021 \mathrm{e}-012.08021 \mathrm{e}-021.00000 \mathrm{e}-092.12000 \mathrm{e}-01$

$2.08021 \mathrm{e}-012.08021 \mathrm{e}-012.08021 \mathrm{e}-021.00000 \mathrm{e}-092.12000 \mathrm{e}-01$

$2.08021 \mathrm{e}-012.08021 \mathrm{e}-012.08021 \mathrm{e}-021.00000 \mathrm{e}-092.12000 \mathrm{e}-01$

$1.00000 \mathrm{e}-06$ 1.00000e-06 1.00000e-06 1.00000e-09 5.00000e-02

Element: 5422 \# of layers: 10

Kx Ky Kz Ss Por

$4.06901 \mathrm{e}+024.06901 \mathrm{e}+024.06901 \mathrm{e}+01$ 1.00000e-09 7.00000e-02

$4.06901 \mathrm{e}+024.06901 \mathrm{e}+024.06901 \mathrm{e}+011.00000 \mathrm{e}-097.00000 \mathrm{e}-02$

$4.06901 \mathrm{e}+02 \quad 4.06901 \mathrm{e}+024.06901 \mathrm{e}+011.00000 \mathrm{e}-097.00000 \mathrm{e}-02$

5.00000e-04 5.00000e-04 5.00000e-05 1.00000e-09 1.00000e-01

5.00000e-04 5.00000e-04 5.00000e-05 1.00000e-09 1.00000e-01

$1.62584 \mathrm{e}+011.62584 \mathrm{e}+011.62584 \mathrm{e}+001.00000 \mathrm{e}-092.12000 \mathrm{e}-01$

$1.62584 \mathrm{e}+011.62584 \mathrm{e}+011.62584 \mathrm{e}+001.00000 \mathrm{e}-092.12000 \mathrm{e}-01$

$1.00000 \mathrm{e}-021.00000 \mathrm{e}-02$ 1.00000e-03 1.00000e-09 1.00000e-01

$1.00000 \mathrm{e}+001.00000 \mathrm{e}+001.00000 \mathrm{e}-011.00000 \mathrm{e}-091.00000 \mathrm{e}-01$

$1.00000 \mathrm{e}-06$ 1.00000e-06 1.00000e-06 1.00000e-09 5.00000e-02

Element: 5423 \# of layers: 9

Kx Ky Kz Ss Por

$5.43853 \mathrm{e}+02$ 5.43853e+02 5.43853e+01 1.00000e-09 7.00000e-02

$5.43853 \mathrm{e}+025.43853 \mathrm{e}+025.43853 \mathrm{e}+01$ 1.00000e-09 7.00000e-02

$5.43853 \mathrm{e}+02$ 5.43853e+02 5.43853e+01 1.00000e-09 7.00000e-02

5.00000e-04 5.00000e-04 5.00000e-05 1.00000e-09 1.00000e-01

5.00000e-04 5.00000e-04 5.00000e-05 1.00000e-09 1.00000e-01

$2.17305 \mathrm{e}+012.17305 \mathrm{e}+012.17305 \mathrm{e}+001.00000 \mathrm{e}-092.12000 \mathrm{e}-01$

$1.00000 \mathrm{e}-02$ 1.00000e-02 1.00000e-03 1.00000e-09 1.00000e-01

$1.00000 \mathrm{e}+001.00000 \mathrm{e}+001.00000 \mathrm{e}-011.00000 \mathrm{e}-091.00000 \mathrm{e}-01$

$1.00000 \mathrm{e}-06$ 1.00000e-06 1.00000e-06 1.00000e-09 5.00000e-02

Element: 5428 \# of layers: 8 
$\mathrm{Kx} \mathrm{Ky} \mathrm{Kz}$ Ss Por

9.31814e+02 9.31814e+02 9.31814e+01 1.00000e-09 7.00000e-02

9.31814e+02 9.31814e+02 9.31814e+01 1.00000e-09 7.00000e-02

5.00000e-04 5.00000e-04 5.00000e-05 1.00000e-09 1.00000e-01

5.00000e-04 5.00000e-04 5.00000e-05 1.00000e-09 1.00000e-01

$3.72315 \mathrm{e}+013.72315 \mathrm{e}+013.72315 \mathrm{e}+00$ 1.00000e-09 2.12000e-01

$1.00000 \mathrm{e}-02$ 1.00000e-02 1.00000e-03 1.00000e-09 1.00000e-01

$1.00000 \mathrm{e}+001.00000 \mathrm{e}+001.00000 \mathrm{e}-011.00000 \mathrm{e}-091.00000 \mathrm{e}-01$

$1.00000 \mathrm{e}-06$ 1.00000e-06 1.00000e-06 1.00000e-09 5.00000e-02

Element: 5429 \# of layers: 8

$\mathrm{Kx} \mathrm{Ky} \mathrm{Kz}$ Ss Por

9.31814e+02 9.31814e+02 9.31814e+01 1.00000e-09 7.00000e-02

$9.31814 \mathrm{e}+02$ 9.31814e+02 9.31814e+01 1.00000e-09 7.00000e-02

5.00000e-04 5.00000e-04 5.00000e-05 1.00000e-09 1.00000e-01

5.00000e-04 5.00000e-04 5.00000e-05 1.00000e-09 1.00000e-01

$3.72315 \mathrm{e}+013.72315 \mathrm{e}+013.72315 \mathrm{e}+001.00000 \mathrm{e}-092.12000 \mathrm{e}-01$

$1.00000 \mathrm{e}-02$ 1.00000e-02 1.00000e-03 1.00000e-09 1.00000e-01

$1.00000 \mathrm{e}+001.00000 \mathrm{e}+001.00000 \mathrm{e}-011.00000 \mathrm{e}-091.00000 \mathrm{e}-01$

1.00000e-06 1.00000e-06 1.00000e-06 1.00000e-09 5.00000e-02

Element: 5430 \# of layers: 9

$\mathrm{Kx} \mathrm{Ky} \mathrm{Kz}$ Ss Por

3.35325e+02 3.35325e+02 3.35325e+01 1.00000e-09 7.00000e-02

3.35325e+02 3.35325e+02 3.35325e+01 1.00000e-09 7.00000e-02

$3.35325 \mathrm{e}+02$ 3.35325e+02 3.35325e+01 1.00000e-09 7.00000e-02

$5.00000 \mathrm{e}-04$ 5.00000e-04 5.00000e-05 1.00000e-09 1.00000e-01

5.00000e-04 5.00000e-04 5.00000e-05 1.00000e-09 1.00000e-01

$1.33984 \mathrm{e}+011.33984 \mathrm{e}+01$ 1.33984e+00 1.00000e-09 2.12000e-01

$1.00000 \mathrm{e}-02$ 1.00000e-02 1.00000e-03 1.00000e-09 1.00000e-01

$1.00000 \mathrm{e}+001.00000 \mathrm{e}+001.00000 \mathrm{e}-011.00000 \mathrm{e}-091.00000 \mathrm{e}-01$

1.00000e-06 1.00000e-06 1.00000e-06 1.00000e-09 5.00000e-02

Element: 5431 \# of layers: 8

$\mathrm{Kx} \mathrm{Ky} \mathrm{Kz}$ Ss Por

3.35325e+02 3.35325e+02 3.35325e+01 1.00000e-09 7.00000e-02

$3.35325 \mathrm{e}+02$ 3.35325e+02 3.35325e+01 1.00000e-09 7.00000e-02

5.00000e-04 5.00000e-04 5.00000e-05 1.00000e-09 1.00000e-01

5.00000e-04 5.00000e-04 5.00000e-05 1.00000e-09 1.00000e-01

$1.33984 \mathrm{e}+011.33984 \mathrm{e}+011.33984 \mathrm{e}+001.00000 \mathrm{e}-092.12000 \mathrm{e}-01$

$1.00000 \mathrm{e}-02$ 1.00000e-02 1.00000e-03 1.00000e-09 1.00000e-01

$1.00000 \mathrm{e}+001.00000 \mathrm{e}+001.00000 \mathrm{e}-011.00000 \mathrm{e}-091.00000 \mathrm{e}-01$

1.00000e-06 1.00000e-06 1.00000e-06 1.00000e-09 5.00000e-02

Element: 5432 \# of layers: 8

$\mathrm{Kx} \mathrm{Ky} \mathrm{Kz}$ Ss Por

3.35325e+02 3.35325e+02 3.35325e+01 1.00000e-09 7.00000e-02

3.35325e+02 3.35325e+02 3.35325e+01 1.00000e-09 7.00000e-02

5.00000e-04 5.00000e-04 5.00000e-05 1.00000e-09 1.00000e-01

5.00000e-04 5.00000e-04 5.00000e-05 1.00000e-09 1.00000e-01 
$1.33984 \mathrm{e}+011.33984 \mathrm{e}+01$ 1.33984e+00 1.00000e-09 2.12000e-01 $1.00000 \mathrm{e}-02$ 1.00000e-02 1.00000e-03 1.00000e-09 1.00000e-01 $1.00000 \mathrm{e}+001.00000 \mathrm{e}+001.00000 \mathrm{e}-011.00000 \mathrm{e}-091.00000 \mathrm{e}-01$ 1.00000e-06 1.00000e-06 1.00000e-06 1.00000e-09 5.00000e-02 Element: 5433 \# of layers: 10

$\mathrm{Kx} \mathrm{Ky} \mathrm{Kz}$ Ss Por

4.06901e+02 4.06901e+02 4.06901e+01 1.00000e-09 7.00000e-02 $4.06901 \mathrm{e}+02$ 4.06901e+02 4.06901e+01 1.00000e-09 7.00000e-02 4.06901e+02 4.06901e+02 4.06901e+01 1.00000e-09 7.00000e-02 $5.00000 \mathrm{e}-045.00000 \mathrm{e}-045.00000 \mathrm{e}-051.00000 \mathrm{e}-091.00000 \mathrm{e}-01$ 5.00000e-04 5.00000e-04 5.00000e-05 1.00000e-09 1.00000e-01 $1.62584 \mathrm{e}+011.62584 \mathrm{e}+011.62584 \mathrm{e}+001.00000 \mathrm{e}-092.12000 \mathrm{e}-01$ $1.62584 \mathrm{e}+011.62584 \mathrm{e}+011.62584 \mathrm{e}+001.00000 \mathrm{e}-092.12000 \mathrm{e}-01$ $1.00000 \mathrm{e}-02$ 1.00000e-02 1.00000e-03 1.00000e-09 1.00000e-01 $1.00000 \mathrm{e}+001.00000 \mathrm{e}+001.00000 \mathrm{e}-011.00000 \mathrm{e}-091.00000 \mathrm{e}-01$ 1.00000e-06 1.00000e-06 1.00000e-06 1.00000e-09 5.00000e-02 Element: 5434 \# of layers: 9

$\mathrm{Kx} \mathrm{Ky} \mathrm{Kz}$ Ss Por

4.06901e+02 4.06901e+02 4.06901e+01 1.00000e-09 7.00000e-02 $4.06901 \mathrm{e}+02$ 4.06901e+02 4.06901e+01 1.00000e-09 7.00000e-02 4.06901e+02 4.06901e+02 4.06901e+01 1.00000e-09 7.00000e-02 5.00000e-04 5.00000e-04 5.00000e-05 1.00000e-09 1.00000e-01 5.00000e-04 5.00000e-04 5.00000e-05 1.00000e-09 1.00000e-01 $1.62584 \mathrm{e}+011.62584 \mathrm{e}+011.62584 \mathrm{e}+001.00000 \mathrm{e}-092.12000 \mathrm{e}-01$ $1.00000 \mathrm{e}-021.00000 \mathrm{e}-02$ 1.00000e-03 1.00000e-09 1.00000e-01 $1.00000 \mathrm{e}+001.00000 \mathrm{e}+001.00000 \mathrm{e}-011.00000 \mathrm{e}-091.00000 \mathrm{e}-01$ 1.00000e-06 1.00000e-06 1.00000e-06 1.00000e-09 5.00000e-02 Element: 5435 \# of layers: 9

$\mathrm{Kx} \mathrm{Ky} \mathrm{Kz}$ Ss Por

9.31814e+02 9.31814e+02 9.31814e+01 1.00000e-09 7.00000e-02 $9.31814 \mathrm{e}+02$ 9.31814e+02 9.31814e+01 1.00000e-09 7.00000e-02 9.31814e+02 9.31814e+02 9.31814e+01 1.00000e-09 7.00000e-02 5.00000e-04 5.00000e-04 5.00000e-05 1.00000e-09 1.00000e-01 5.00000e-04 5.00000e-04 5.00000e-05 1.00000e-09 1.00000e-01 $3.72315 \mathrm{e}+013.72315 \mathrm{e}+013.72315 \mathrm{e}+00$ 1.00000e-09 2.12000e-01 $1.00000 \mathrm{e}-02$ 1.00000e-02 1.00000e-03 1.00000e-09 1.00000e-01 $1.00000 \mathrm{e}+001.00000 \mathrm{e}+001.00000 \mathrm{e}-011.00000 \mathrm{e}-091.00000 \mathrm{e}-01$ 1.00000e-06 1.00000e-06 1.00000e-06 1.00000e-09 5.00000e-02 Element: 5436 \# of layers: 8

$\mathrm{Kx} \mathrm{Ky} \mathrm{Kz}$ Ss Por 6.60496e+02 6.60496e+02 6.60496e+01 1.00000e-09 7.00000e-02 $6.60496 \mathrm{e}+026.60496 \mathrm{e}+02$ 6.60496e+01 1.00000e-09 7.00000e-02 5.00000e-04 5.00000e-04 5.00000e-05 1.00000e-09 1.00000e-01 $5.00000 \mathrm{e}-04$ 5.00000e-04 5.00000e-05 1.00000e-09 1.00000e-01 $2.63908 \mathrm{e}+012.63908 \mathrm{e}+012.63908 \mathrm{e}+001.00000 \mathrm{e}-092.12000 \mathrm{e}-01$ $1.00000 \mathrm{e}-02$ 1.00000e-02 1.00000e-03 1.00000e-09 1.00000e-01 
$1.00000 \mathrm{e}+001.00000 \mathrm{e}+001.00000 \mathrm{e}-011.00000 \mathrm{e}-091.00000 \mathrm{e}-01$ 1.00000e-06 1.00000e-06 1.00000e-06 1.00000e-09 5.00000e-02 Element: 5437 \# of layers: 8

$\mathrm{Kx} \mathrm{Ky} \mathrm{Kz}$ Ss Por

2.37441e+02 2.37441e+02 2.37441e+01 1.00000e-09 7.00000e-02

$2.37441 \mathrm{e}+02$ 2.37441e+02 2.37441e+01 1.00000e-09 7.00000e-02

5.00000e-04 5.00000e-04 5.00000e-05 1.00000e-09 1.00000e-01

5.00000e-04 5.00000e-04 5.00000e-05 1.00000e-09 1.00000e-01

$9.48733 \mathrm{e}+00$ 9.48733e+00 9.48733e-01 1.00000e-09 2.12000e-01

$1.00000 \mathrm{e}-02$ 1.00000e-02 1.00000e-03 1.00000e-09 1.00000e-01

$1.00000 \mathrm{e}+001.00000 \mathrm{e}+001.00000 \mathrm{e}-011.00000 \mathrm{e}-091.00000 \mathrm{e}-01$

1.00000e-06 1.00000e-06 1.00000e-06 1.00000e-09 5.00000e-02

Element: 5438 \# of layers: 8

$\mathrm{Kx} \mathrm{Ky} \mathrm{Kz}$ Ss Por

$2.37441 \mathrm{e}+02$ 2.37441e+02 2.37441e+01 1.00000e-09 7.00000e-02

$2.37441 \mathrm{e}+022.37441 \mathrm{e}+02$ 2.37441e+01 1.00000e-09 7.00000e-02

5.00000e-04 5.00000e-04 5.00000e-05 1.00000e-09 1.00000e-01

5.00000e-04 5.00000e-04 5.00000e-05 1.00000e-09 1.00000e-01

9.48733e+00 9.48733e+00 9.48733e-01 1.00000e-09 2.12000e-01

$1.00000 \mathrm{e}-02$ 1.00000e-02 1.00000e-03 1.00000e-09 1.00000e-01

$1.00000 \mathrm{e}+001.00000 \mathrm{e}+001.00000 \mathrm{e}-011.00000 \mathrm{e}-091.00000 \mathrm{e}-01$

1.00000e-06 1.00000e-06 1.00000e-06 1.00000e-09 5.00000e-02

Element: 5439 \# of layers: 9

Kx Ky Kz Ss Por

2.37441e+02 2.37441e+02 2.37441e+01 1.00000e-09 7.00000e-02

$2.37441 \mathrm{e}+02$ 2.37441e+02 2.37441e+01 1.00000e-09 7.00000e-02

$2.37441 \mathrm{e}+02$ 2.37441e+02 2.37441e+01 1.00000e-09 7.00000e-02

5.00000e-04 5.00000e-04 5.00000e-05 1.00000e-09 1.00000e-01

5.00000e-04 5.00000e-04 5.00000e-05 1.00000e-09 1.00000e-01

$9.48733 \mathrm{e}+00$ 9.48733e+00 9.48733e-01 1.00000e-09 2.12000e-01

$1.00000 \mathrm{e}-02$ 1.00000e-02 1.00000e-03 1.00000e-09 1.00000e-01

$1.00000 \mathrm{e}+001.00000 \mathrm{e}+001.00000 \mathrm{e}-011.00000 \mathrm{e}-091.00000 \mathrm{e}-01$

1.00000e-06 1.00000e-06 1.00000e-06 1.00000e-09 5.00000e-02

Element: 5440 \# of layers: 9

$\mathrm{Kx} \mathrm{Ky} \mathrm{Kz}$ Ss Por

2.25439e+02 2.25439e+02 2.25439e+01 1.00000e-09 7.00000e-02

$2.25439 \mathrm{e}+02$ 2.25439e+02 2.25439e+01 1.00000e-09 7.00000e-02

$2.25439 \mathrm{e}+02$ 2.25439e+02 2.25439e+01 1.00000e-09 7.00000e-02

5.00000e-04 5.00000e-04 5.00000e-05 1.00000e-09 1.00000e-01

5.00000e-04 5.00000e-04 5.00000e-05 1.00000e-09 1.00000e-01

$9.00784 \mathrm{e}+009.00784 \mathrm{e}+009.00784 \mathrm{e}-01$ 1.00000e-09 2.12000e-01

$1.00000 \mathrm{e}-02$ 1.00000e-02 1.00000e-03 1.00000e-09 1.00000e-01

$1.00000 \mathrm{e}+001.00000 \mathrm{e}+001.00000 \mathrm{e}-011.00000 \mathrm{e}-091.00000 \mathrm{e}-01$

1.00000e-06 1.00000e-06 1.00000e-06 1.00000e-09 5.00000e-02

Element: 5441 \# of layers: 9

Kx Ky Kz Ss Por 
2.25439e+02 2.25439e+02 2.25439e+01 1.00000e-09 7.00000e-02 $2.25439 \mathrm{e}+02$ 2.25439e+02 2.25439e+01 1.00000e-09 7.00000e-02

$2.25439 \mathrm{e}+02$ 2.25439e+02 2.25439e+01 1.00000e-09 7.00000e-02 5.00000e-04 5.00000e-04 5.00000e-05 1.00000e-09 1.00000e-01 $5.00000 \mathrm{e}-04$ 5.00000e-04 5.00000e-05 1.00000e-09 1.00000e-01 $9.00784 \mathrm{e}+009.00784 \mathrm{e}+00$ 9.00784e-01 1.00000e-09 2.12000e-01 1.00000e-02 1.00000e-02 1.00000e-03 1.00000e-09 1.00000e-01 $1.00000 \mathrm{e}+001.00000 \mathrm{e}+001.00000 \mathrm{e}-011.00000 \mathrm{e}-091.00000 \mathrm{e}-01$ $1.00000 \mathrm{e}-06$ 1.00000e-06 1.00000e-06 1.00000e-09 5.00000e-02 Element: 5442 \# of layers: 8

$\mathrm{Kx} \mathrm{Ky} \mathrm{Kz}$ Ss Por

$2.94366 \mathrm{e}+02$ 2.94366e+02 2.94366e+01 1.00000e-09 7.00000e-02 $2.94366 \mathrm{e}+02$ 2.94366e+02 2.94366e+01 1.00000e-09 7.00000e-02 5.00000e-04 5.00000e-04 5.00000e-05 1.00000e-09 1.00000e-01 5.00000e-04 5.00000e-04 5.00000e-05 1.00000e-09 1.00000e-01 $1.17617 \mathrm{e}+011.17617 \mathrm{e}+011.17617 \mathrm{e}+001.00000 \mathrm{e}-092.12000 \mathrm{e}-01$ $1.00000 \mathrm{e}-02$ 1.00000e-02 1.00000e-03 1.00000e-09 1.00000e-01 $1.00000 \mathrm{e}+001.00000 \mathrm{e}+001.00000 \mathrm{e}-011.00000 \mathrm{e}-091.00000 \mathrm{e}-01$ 1.00000e-06 1.00000e-06 1.00000e-06 1.00000e-09 5.00000e-02 Element: 5443 \# of layers: 8

$\mathrm{Kx} \mathrm{Ky} \mathrm{Kz}$ Ss Por 6.60496e+02 6.60496e+02 6.60496e+01 1.00000e-09 7.00000e-02 $6.60496 \mathrm{e}+026.60496 \mathrm{e}+02$ 6.60496e+01 1.00000e-09 7.00000e-02 5.00000e-04 5.00000e-04 5.00000e-05 1.00000e-09 1.00000e-01 5.00000e-04 5.00000e-04 5.00000e-05 1.00000e-09 1.00000e-01 $2.63908 \mathrm{e}+012.63908 \mathrm{e}+012.63908 \mathrm{e}+001.00000 \mathrm{e}-092.12000 \mathrm{e}-01$ $1.00000 \mathrm{e}-02$ 1.00000e-02 1.00000e-03 1.00000e-09 1.00000e-01 $1.00000 \mathrm{e}+001.00000 \mathrm{e}+001.00000 \mathrm{e}-011.00000 \mathrm{e}-091.00000 \mathrm{e}-01$ 1.00000e-06 1.00000e-06 1.00000e-06 1.00000e-09 5.00000e-02 Element: 5444 \# of layers: 8

$\mathrm{Kx} \mathrm{Ky} \mathrm{Kz}$ Ss Por

2.37441e+02 2.37441e+02 2.37441e+01 1.00000e-09 7.00000e-02 $2.37441 \mathrm{e}+02$ 2.37441e+02 2.37441e+01 1.00000e-09 7.00000e-02 $5.00000 \mathrm{e}-04$ 5.00000e-04 5.00000e-05 1.00000e-09 1.00000e-01 5.00000e-04 5.00000e-04 5.00000e-05 1.00000e-09 1.00000e-01 9.48733e+00 9.48733e+00 9.48733e-01 1.00000e-09 2.12000e-01 $1.00000 \mathrm{e}-02$ 1.00000e-02 1.00000e-03 1.00000e-09 1.00000e-01 $1.00000 \mathrm{e}+001.00000 \mathrm{e}+001.00000 \mathrm{e}-011.00000 \mathrm{e}-091.00000 \mathrm{e}-01$ 1.00000e-06 1.00000e-06 1.00000e-06 1.00000e-09 5.00000e-02 Element: 5445 \# of layers: 9

$\mathrm{Kx} \mathrm{Ky} \mathrm{Kz}$ Ss Por 1.30041e+02 1.30041e+02 1.30041e+01 1.00000e-09 7.00000e-02 $1.30041 \mathrm{e}+02$ 1.30041e+02 1.30041e+01 1.00000e-09 7.00000e-02 $1.30041 \mathrm{e}+021.30041 \mathrm{e}+02$ 1.30041e+01 1.00000e-09 7.00000e-02 5.00000e-04 5.00000e-04 5.00000e-05 1.00000e-09 1.00000e-01 5.00000e-04 5.00000e-04 5.00000e-05 1.00000e-09 1.00000e-01 
$5.19581 \mathrm{e}+00$ 5.19581e+00 5.19581e-01 1.00000e-09 2.12000e-01 $1.00000 \mathrm{e}-02$ 1.00000e-02 1.00000e-03 1.00000e-09 1.00000e-01 $1.00000 \mathrm{e}+001.00000 \mathrm{e}+001.00000 \mathrm{e}-011.00000 \mathrm{e}-091.00000 \mathrm{e}-01$ $1.00000 \mathrm{e}-06$ 1.00000e-06 1.00000e-06 1.00000e-09 5.00000e-02 Element: 5446 \# of layers: 9

Kx Ky Kz Ss Por

$8.12396 \mathrm{e}+018.12396 \mathrm{e}+018.12396 \mathrm{e}+00$ 1.00000e-09 7.00000e-02 $8.12396 \mathrm{e}+018.12396 \mathrm{e}+018.12396 \mathrm{e}+00$ 1.00000e-09 7.00000e-02 $8.12396 \mathrm{e}+018.12396 \mathrm{e}+018.12396 \mathrm{e}+001.00000 \mathrm{e}-09$ 7.00000e-02 5.00000e-04 5.00000e-04 5.00000e-05 1.00000e-09 1.00000e-01 5.00000e-04 5.00000e-04 5.00000e-05 1.00000e-09 1.00000e-01 $3.24614 \mathrm{e}+003.24614 \mathrm{e}+003.24614 \mathrm{e}-011.00000 \mathrm{e}-092.12000 \mathrm{e}-01$ $1.00000 \mathrm{e}-02$ 1.00000e-02 1.00000e-03 1.00000e-09 1.00000e-01 $1.00000 \mathrm{e}+001.00000 \mathrm{e}+001.00000 \mathrm{e}-011.00000 \mathrm{e}-091.00000 \mathrm{e}-01$ $1.00000 \mathrm{e}-06$ 1.00000e-06 1.00000e-06 1.00000e-09 5.00000e-02 Element: 5447 \# of layers: 9

Kx Ky Kz Ss Por

$8.12396 \mathrm{e}+018.12396 \mathrm{e}+018.12396 \mathrm{e}+00$ 1.00000e-09 7.00000e-02 $8.12396 \mathrm{e}+018.12396 \mathrm{e}+018.12396 \mathrm{e}+001.00000 \mathrm{e}-09$ 7.00000e-02 $8.12396 \mathrm{e}+018.12396 \mathrm{e}+018.12396 \mathrm{e}+001.00000 \mathrm{e}-09$ 7.00000e-02 $8.12396 \mathrm{e}+018.12396 \mathrm{e}+018.12396 \mathrm{e}+001.00000 \mathrm{e}-09$ 7.00000e-02 5.00000e-04 5.00000e-04 5.00000e-05 1.00000e-09 1.00000e-01 5.00000e-04 5.00000e-04 5.00000e-05 1.00000e-09 1.00000e-01 $3.24614 \mathrm{e}+003.24614 \mathrm{e}+003.24614 \mathrm{e}-011.00000 \mathrm{e}-092.12000 \mathrm{e}-01$ $1.00000 \mathrm{e}-021.00000 \mathrm{e}-02$ 1.00000e-03 1.00000e-09 1.00000e-01 $1.00000 \mathrm{e}+001.00000 \mathrm{e}+001.00000 \mathrm{e}-011.00000 \mathrm{e}-091.00000 \mathrm{e}-01$ Element: 5448 \# of layers: 9

Kx Ky Kz Ss Por

$8.12396 \mathrm{e}+018.12396 \mathrm{e}+018.12396 \mathrm{e}+00$ 1.00000e-09 7.00000e-02 $8.12396 \mathrm{e}+018.12396 \mathrm{e}+018.12396 \mathrm{e}+001.00000 \mathrm{e}-09$ 7.00000e-02 $8.12396 \mathrm{e}+018.12396 \mathrm{e}+018.12396 \mathrm{e}+001.00000 \mathrm{e}-09$ 7.00000e-02 $8.12396 \mathrm{e}+018.12396 \mathrm{e}+018.12396 \mathrm{e}+001.00000 \mathrm{e}-09$ 7.00000e-02 5.00000e-04 5.00000e-04 5.00000e-05 1.00000e-09 1.00000e-01 5.00000e-04 5.00000e-04 5.00000e-05 1.00000e-09 1.00000e-01 $3.24614 \mathrm{e}+003.24614 \mathrm{e}+003.24614 \mathrm{e}-01$ 1.00000e-09 2.12000e-01 $1.00000 \mathrm{e}-021.00000 \mathrm{e}-02$ 1.00000e-03 1.00000e-09 1.00000e-01 $1.00000 \mathrm{e}+001.00000 \mathrm{e}+001.00000 \mathrm{e}-011.00000 \mathrm{e}-091.00000 \mathrm{e}-01$ Element: 5449 \# of layers: 10

Kx Ky Kz Ss Por $6.01255 \mathrm{e}+016.01255 \mathrm{e}+016.01255 \mathrm{e}+00$ 1.00000e-09 7.00000e-02 $6.01255 \mathrm{e}+016.01255 \mathrm{e}+016.01255 \mathrm{e}+001.00000 \mathrm{e}-097.00000 \mathrm{e}-02$ $6.01255 \mathrm{e}+016.01255 \mathrm{e}+016.01255 \mathrm{e}+001.00000 \mathrm{e}-09$ 7.00000e-02 $6.01255 \mathrm{e}+016.01255 \mathrm{e}+016.01255 \mathrm{e}+001.00000 \mathrm{e}-097.00000 \mathrm{e}-02$ 5.00000e-04 5.00000e-04 5.00000e-05 1.00000e-09 1.00000e-01 $2.40238 \mathrm{e}+002.40238 \mathrm{e}+002.40238 \mathrm{e}-011.00000 \mathrm{e}-092.12000 \mathrm{e}-01$ $2.40238 \mathrm{e}+002.40238 \mathrm{e}+002.40238 \mathrm{e}-01$ 1.00000e-09 2.12000e-01 
$1.00000 \mathrm{e}-02$ 1.00000e-02 1.00000e-03 1.00000e-09 1.00000e-01 $1.00000 \mathrm{e}+001.00000 \mathrm{e}+001.00000 \mathrm{e}-011.00000 \mathrm{e}-091.00000 \mathrm{e}-01$ 1.00000e-06 1.00000e-06 1.00000e-06 1.00000e-09 5.00000e-02

Element: 5450 \# of layers: 10

$\mathrm{Kx} \mathrm{Ky} \mathrm{Kz}$ Ss Por

6.01255e+01 6.01255e+01 6.01255e+00 1.00000e-09 7.00000e-02 $6.01255 \mathrm{e}+016.01255 \mathrm{e}+016.01255 \mathrm{e}+00$ 1.00000e-09 7.00000e-02 $6.01255 \mathrm{e}+016.01255 \mathrm{e}+016.01255 \mathrm{e}+001.00000 \mathrm{e}-09$ 7.00000e-02 $6.01255 \mathrm{e}+016.01255 \mathrm{e}+016.01255 \mathrm{e}+001.00000 \mathrm{e}-09$ 7.00000e-02 $5.00000 \mathrm{e}-045.00000 \mathrm{e}-045.00000 \mathrm{e}-051.00000 \mathrm{e}-091.00000 \mathrm{e}-01$ 5.00000e-04 5.00000e-04 5.00000e-05 1.00000e-09 1.00000e-01

$2.40238 \mathrm{e}+002.40238 \mathrm{e}+002.40238 \mathrm{e}-01$ 1.00000e-09 2.12000e-01 $1.00000 \mathrm{e}-02$ 1.00000e-02 1.00000e-03 1.00000e-09 1.00000e-01 $1.00000 \mathrm{e}+001.00000 \mathrm{e}+001.00000 \mathrm{e}-011.00000 \mathrm{e}-091.00000 \mathrm{e}-01$ 1.00000e-06 1.00000e-06 1.00000e-06 1.00000e-09 5.00000e-02 Element: 5451 \# of layers: 10

$\mathrm{Kx} \mathrm{Ky} \mathrm{Kz}$ Ss Por

8.41651e+01 8.41651e+01 8.41651e+00 1.00000e-09 7.00000e-02 8.41651e+01 8.41651e+01 8.41651e+00 1.00000e-09 7.00000e-02 $8.41651 \mathrm{e}+018.41651 \mathrm{e}+018.41651 \mathrm{e}+001.00000 \mathrm{e}-09$ 7.00000e-02 $8.41651 \mathrm{e}+018.41651 \mathrm{e}+018.41651 \mathrm{e}+001.00000 \mathrm{e}-097.00000 \mathrm{e}-02$ $5.00000 \mathrm{e}-04$ 5.00000e-04 5.00000e-05 1.00000e-09 1.00000e-01 5.00000e-04 5.00000e-04 5.00000e-05 1.00000e-09 1.00000e-01 $3.36292 \mathrm{e}+00$ 3.36292e+00 3.36292e-01 1.00000e-09 2.12000e-01 $1.00000 \mathrm{e}-021.00000 \mathrm{e}-02$ 1.00000e-03 1.00000e-09 1.00000e-01 $1.00000 \mathrm{e}+001.00000 \mathrm{e}+001.00000 \mathrm{e}-011.00000 \mathrm{e}-091.00000 \mathrm{e}-01$ 1.00000e-06 1.00000e-06 1.00000e-06 1.00000e-09 5.00000e-02 Element: 5452 \# of layers: 10

$\mathrm{Kx} \mathrm{Ky} \mathrm{Kz}$ Ss Por

$1.30041 \mathrm{e}+02$ 1.30041e+02 1.30041e+01 1.00000e-09 7.00000e-02 $1.30041 \mathrm{e}+021.30041 \mathrm{e}+02$ 1.30041e+01 1.00000e-09 7.00000e-02 $1.30041 \mathrm{e}+021.30041 \mathrm{e}+02$ 1.30041e+01 1.00000e-09 7.00000e-02 $1.30041 \mathrm{e}+021.30041 \mathrm{e}+021.30041 \mathrm{e}+01$ 1.00000e-09 7.00000e-02 $5.00000 \mathrm{e}-04$ 5.00000e-04 5.00000e-05 1.00000e-09 1.00000e-01 5.00000e-04 5.00000e-04 5.00000e-05 1.00000e-09 1.00000e-01 $5.19581 \mathrm{e}+00$ 5.19581e+00 5.19581e-01 1.00000e-09 2.12000e-01 1.00000e-02 1.00000e-02 1.00000e-03 1.00000e-09 1.00000e-01 $1.00000 \mathrm{e}+001.00000 \mathrm{e}+001.00000 \mathrm{e}-011.00000 \mathrm{e}-091.00000 \mathrm{e}-01$ 1.00000e-06 1.00000e-06 1.00000e-06 1.00000e-09 5.00000e-02 Element: 5453 \# of layers: 9

$\mathrm{Kx} \mathrm{Ky} \mathrm{Kz}$ Ss Por

8.12396e+01 8.12396e+01 8.12396e+00 1.00000e-09 7.00000e-02 8.12396e+01 8.12396e+01 8.12396e+00 1.00000e-09 7.00000e-02 $8.12396 \mathrm{e}+018.12396 \mathrm{e}+018.12396 \mathrm{e}+00$ 1.00000e-09 7.00000e-02 $8.12396 \mathrm{e}+018.12396 \mathrm{e}+018.12396 \mathrm{e}+001.00000 \mathrm{e}-09$ 7.00000e-02 5.00000e-04 5.00000e-04 5.00000e-05 1.00000e-09 1.00000e-01 
5.00000e-04 5.00000e-04 5.00000e-05 1.00000e-09 1.00000e-01 $3.24614 \mathrm{e}+003.24614 \mathrm{e}+003.24614 \mathrm{e}-01$ 1.00000e-09 2.12000e-01 $1.00000 \mathrm{e}-02$ 1.00000e-02 1.00000e-03 1.00000e-09 1.00000e-01 $1.00000 \mathrm{e}+001.00000 \mathrm{e}+001.00000 \mathrm{e}-011.00000 \mathrm{e}-091.00000 \mathrm{e}-01$ Element: 5454 \# of layers: 10

$\mathrm{Kx} \mathrm{Ky} \mathrm{Kz}$ Ss Por

7.21872e+01 7.21872e+01 7.21872e+00 1.00000e-09 7.00000e-02 7.21872e+01 7.21872e+01 7.21872e+00 1.00000e-09 7.00000e-02 7.21872e+01 7.21872e+01 7.21872e+00 1.00000e-09 7.00000e-02 $7.21872 \mathrm{e}+017.21872 \mathrm{e}+017.21872 \mathrm{e}+00$ 1.00000e-09 7.00000e-02 5.00000e-04 5.00000e-04 5.00000e-05 1.00000e-09 1.00000e-01 5.00000e-04 5.00000e-04 5.00000e-05 1.00000e-09 1.00000e-01

$2.88434 \mathrm{e}+002.88434 \mathrm{e}+002.88434 \mathrm{e}-01$ 1.00000e-09 2.12000e-01

$2.88434 \mathrm{e}+002.88434 \mathrm{e}+002.88434 \mathrm{e}-01$ 1.00000e-09 2.12000e-01 $1.00000 \mathrm{e}-02$ 1.00000e-02 1.00000e-03 1.00000e-09 1.00000e-01 $1.00000 \mathrm{e}+001.00000 \mathrm{e}+001.00000 \mathrm{e}-011.00000 \mathrm{e}-091.00000 \mathrm{e}-01$ Element: 5455 \# of layers: 10

$\mathrm{Kx} \mathrm{Ky} \mathrm{Kz}$ Ss Por

5.95462e+01 5.95462e+01 5.95462e+00 1.00000e-09 7.00000e-02 $5.95462 \mathrm{e}+015.95462 \mathrm{e}+015.95462 \mathrm{e}+001.00000 \mathrm{e}-09$ 7.00000e-02 $5.95462 \mathrm{e}+015.95462 \mathrm{e}+015.95462 \mathrm{e}+001.00000 \mathrm{e}-09$ 7.00000e-02 5.95462e+01 5.95462e+01 5.95462e+00 1.00000e-09 7.00000e-02 5.00000e-04 5.00000e-04 5.00000e-05 1.00000e-09 1.00000e-01 5.00000e-04 5.00000e-04 5.00000e-05 1.00000e-09 1.00000e-01

$2.37920 \mathrm{e}+002.37920 \mathrm{e}+00$ 2.37920e-01 1.00000e-09 2.12000e-01 $2.37920 \mathrm{e}+002.37920 \mathrm{e}+00$ 2.37920e-01 1.00000e-09 2.12000e-01 $1.00000 \mathrm{e}-02$ 1.00000e-02 1.00000e-03 1.00000e-09 1.00000e-01 $1.00000 \mathrm{e}+001.00000 \mathrm{e}+001.00000 \mathrm{e}-01$ 1.00000e-09 1.00000e-01 Element: 5456 \# of layers: 7

$\mathrm{Kx} \mathrm{Ky} \mathrm{Kz}$ Ss Por

6.86931e+01 6.86931e+01 6.86931e+00 1.00000e-09 7.00000e-02 $6.86931 \mathrm{e}+016.86931 \mathrm{e}+016.86931 \mathrm{e}+00$ 1.00000e-09 7.00000e-02 $6.86931 \mathrm{e}+016.86931 \mathrm{e}+016.86931 \mathrm{e}+001.00000 \mathrm{e}-09$ 7.00000e-02 $2.74483 \mathrm{e}+00$ 2.74483e+00 2.74483e-01 1.00000e-09 2.12000e-01 $2.74483 \mathrm{e}+002.74483 \mathrm{e}+002.74483 \mathrm{e}-01$ 1.00000e-09 2.12000e-01 $1.00000 \mathrm{e}-02$ 1.00000e-02 1.00000e-03 1.00000e-09 1.00000e-01 $1.00000 \mathrm{e}+001.00000 \mathrm{e}+001.00000 \mathrm{e}-011.00000 \mathrm{e}-091.00000 \mathrm{e}-01$ Element: 5460 \# of layers: 9

$\mathrm{Kx} \mathrm{Ky} \mathrm{Kz}$ Ss Por

6.30141e+01 6.30141e+01 6.30141e+00 1.00000e-09 7.00000e-02 $6.30141 \mathrm{e}+016.30141 \mathrm{e}+016.30141 \mathrm{e}+00$ 1.00000e-09 7.00000e-02 $6.30141 \mathrm{e}+016.30141 \mathrm{e}+016.30141 \mathrm{e}+001.00000 \mathrm{e}-09$ 7.00000e-02 6.30141e+01 6.30141e+01 6.30141e+00 1.00000e-09 7.00000e-02 $2.51780 \mathrm{e}+002.51780 \mathrm{e}+00$ 2.51780e-01 1.00000e-09 2.12000e-01 $2.51780 \mathrm{e}+002.51780 \mathrm{e}+002.51780 \mathrm{e}-01$ 1.00000e-09 2.12000e-01 $2.51780 \mathrm{e}+002.51780 \mathrm{e}+002.51780 \mathrm{e}-01$ 1.00000e-09 2.12000e-01 
$1.00000 \mathrm{e}-02$ 1.00000e-02 1.00000e-03 1.00000e-09 1.00000e-01 $1.00000 \mathrm{e}+001.00000 \mathrm{e}+001.00000 \mathrm{e}-01$ 1.00000e-09 1.00000e-01 Element: 5461 \# of layers: 9

Kx Ky Kz Ss Por

5.95462e+01 5.95462e+01 5.95462e+00 1.00000e-09 7.00000e-02 $5.95462 \mathrm{e}+015.95462 \mathrm{e}+015.95462 \mathrm{e}+001.00000 \mathrm{e}-09$ 7.00000e-02 $5.95462 \mathrm{e}+015.95462 \mathrm{e}+015.95462 \mathrm{e}+001.00000 \mathrm{e}-09$ 7.00000e-02 $5.95462 \mathrm{e}+015.95462 \mathrm{e}+015.95462 \mathrm{e}+001.00000 \mathrm{e}-09$ 7.00000e-02 5.00000e-04 5.00000e-04 5.00000e-05 1.00000e-09 1.00000e-01 $2.37920 \mathrm{e}+002.37920 \mathrm{e}+00$ 2.37920e-01 1.00000e-09 2.12000e-01 $2.37920 \mathrm{e}+002.37920 \mathrm{e}+00$ 2.37920e-01 1.00000e-09 2.12000e-01 $1.00000 \mathrm{e}-02$ 1.00000e-02 1.00000e-03 1.00000e-09 1.00000e-01 $1.00000 \mathrm{e}+001.00000 \mathrm{e}+001.00000 \mathrm{e}-011.00000 \mathrm{e}-091.00000 \mathrm{e}-01$ Element: 5463 \# of layers: 7

$\mathrm{Kx} \mathrm{Ky} \mathrm{Kz}$ Ss Por

6.59469e+01 6.59469e+01 6.59469e+00 1.00000e-09 7.00000e-02 $6.59469 \mathrm{e}+016.59469 \mathrm{e}+016.59469 \mathrm{e}+00$ 1.00000e-09 7.00000e-02 $6.59469 \mathrm{e}+016.59469 \mathrm{e}+016.59469 \mathrm{e}+00$ 1.00000e-09 7.00000e-02 $2.63503 \mathrm{e}+002.63503 \mathrm{e}+00$ 2.63503e-01 1.00000e-09 2.12000e-01 $2.63503 \mathrm{e}+002.63503 \mathrm{e}+002.63503 \mathrm{e}-01$ 1.00000e-09 2.12000e-01 $1.00000 \mathrm{e}-02$ 1.00000e-02 1.00000e-03 1.00000e-09 1.00000e-01 $1.00000 \mathrm{e}+001.00000 \mathrm{e}+001.00000 \mathrm{e}-011.00000 \mathrm{e}-091.00000 \mathrm{e}-01$ Element: 5464 \# of layers: 7

$\mathrm{Kx} \mathrm{Ky} \mathrm{Kz}$ Ss Por

$6.59469 \mathrm{e}+016.59469 \mathrm{e}+016.59469 \mathrm{e}+00$ 1.00000e-09 7.00000e-02 $6.59469 \mathrm{e}+016.59469 \mathrm{e}+016.59469 \mathrm{e}+001.00000 \mathrm{e}-09$ 7.00000e-02 $6.59469 \mathrm{e}+016.59469 \mathrm{e}+016.59469 \mathrm{e}+00$ 1.00000e-09 7.00000e-02 $2.63503 \mathrm{e}+002.63503 \mathrm{e}+00$ 2.63503e-01 1.00000e-09 2.12000e-01 $2.63503 \mathrm{e}+002.63503 \mathrm{e}+002.63503 \mathrm{e}-01$ 1.00000e-09 2.12000e-01 $1.00000 \mathrm{e}-02$ 1.00000e-02 1.00000e-03 1.00000e-09 1.00000e-01 $1.00000 \mathrm{e}+001.00000 \mathrm{e}+001.00000 \mathrm{e}-011.00000 \mathrm{e}-091.00000 \mathrm{e}-01$ Element: 5465 \# of layers: 8

$\mathrm{Kx} \mathrm{Ky} \mathrm{Kz}$ Ss Por

6.59469e+01 6.59469e+01 6.59469e+00 1.00000e-09 7.00000e-02 $6.59469 \mathrm{e}+016.59469 \mathrm{e}+016.59469 \mathrm{e}+00$ 1.00000e-09 7.00000e-02 $6.59469 \mathrm{e}+016.59469 \mathrm{e}+016.59469 \mathrm{e}+00$ 1.00000e-09 7.00000e-02 $2.63503 \mathrm{e}+002.63503 \mathrm{e}+00$ 2.63503e-01 1.00000e-09 2.12000e-01 $2.63503 \mathrm{e}+002.63503 \mathrm{e}+00$ 2.63503e-01 1.00000e-09 2.12000e-01 $2.63503 \mathrm{e}+002.63503 \mathrm{e}+002.63503 \mathrm{e}-01$ 1.00000e-09 2.12000e-01 1.00000e-02 1.00000e-02 1.00000e-03 1.00000e-09 1.00000e-01 $1.00000 \mathrm{e}+001.00000 \mathrm{e}+001.00000 \mathrm{e}-011.00000 \mathrm{e}-091.00000 \mathrm{e}-01$ Element: 5466 \# of layers: 8

$\mathrm{Kx} \mathrm{Ky} \mathrm{Kz}$ Ss Por

7.21746e+01 7.21746e+01 7.21746e+00 1.00000e-09 7.00000e-02 $7.21746 \mathrm{e}+01$ 7.21746e+01 7.21746e+00 1.00000e-09 7.00000e-02 $7.21746 \mathrm{e}+017.21746 \mathrm{e}+017.21746 \mathrm{e}+001.00000 \mathrm{e}-09$ 7.00000e-02 
7.21746e+01 7.21746e+01 7.21746e+00 1.00000e-09 7.00000e-02 $2.88389 \mathrm{e}+00$ 2.88389e+00 2.88389e-01 1.00000e-09 2.12000e-01 $2.88389 \mathrm{e}+002.88389 \mathrm{e}+00$ 2.88389e-01 1.00000e-09 2.12000e-01 $1.00000 \mathrm{e}-02$ 1.00000e-02 1.00000e-03 1.00000e-09 1.00000e-01 $1.00000 \mathrm{e}+001.00000 \mathrm{e}+001.00000 \mathrm{e}-011.00000 \mathrm{e}-091.00000 \mathrm{e}-01$ Element: 5467 \# of layers: 7

$\mathrm{Kx} \mathrm{Ky} \mathrm{Kz}$ Ss Por

7.21746e+01 7.21746e+01 7.21746e+00 1.00000e-09 7.00000e-02 $7.21746 \mathrm{e}+017.21746 \mathrm{e}+01$ 7.21746e+00 1.00000e-09 7.00000e-02 7.21746e+01 7.21746e+01 7.21746e+00 1.00000e-09 7.00000e-02 $2.88389 \mathrm{e}+002.88389 \mathrm{e}+00$ 2.88389e-01 1.00000e-09 2.12000e-01 $2.88389 \mathrm{e}+002.88389 \mathrm{e}+002.88389 \mathrm{e}-01$ 1.00000e-09 2.12000e-01 $1.00000 \mathrm{e}-02$ 1.00000e-02 1.00000e-03 1.00000e-09 1.00000e-01 $1.00000 \mathrm{e}+001.00000 \mathrm{e}+001.00000 \mathrm{e}-01$ 1.00000e-09 1.00000e-01 Element: 5468 \# of layers: 7

Kx Ky Kz Ss Por

7.21746e+01 7.21746e+01 7.21746e+00 1.00000e-09 7.00000e-02 $7.21746 \mathrm{e}+017.21746 \mathrm{e}+017.21746 \mathrm{e}+001.00000 \mathrm{e}-09$ 7.00000e-02 7.21746e+01 7.21746e+01 7.21746e+00 1.00000e-09 7.00000e-02 $2.88389 \mathrm{e}+002.88389 \mathrm{e}+002.88389 \mathrm{e}-01$ 1.00000e-09 2.12000e-01 $2.88389 \mathrm{e}+002.88389 \mathrm{e}+00$ 2.88389e-01 1.00000e-09 2.12000e-01 $1.00000 \mathrm{e}-02$ 1.00000e-02 1.00000e-03 1.00000e-09 1.00000e-01 $1.00000 \mathrm{e}+001.00000 \mathrm{e}+001.00000 \mathrm{e}-011.00000 \mathrm{e}-091.00000 \mathrm{e}-01$ Element: 5469 \# of layers: 7

Kx Ky Kz Ss Por

3.77131e+00 3.77131e+00 3.77131e-01 1.00000e-09 2.12000e-01 $3.77131 \mathrm{e}+003.77131 \mathrm{e}+003.77131 \mathrm{e}-01$ 1.00000e-09 2.12000e-01 $3.77131 \mathrm{e}+003.77131 \mathrm{e}+00$ 3.77131e-01 1.00000e-09 2.12000e-01 $3.77131 \mathrm{e}+003.77131 \mathrm{e}+003.77131 \mathrm{e}-01$ 1.00000e-09 2.12000e-01 $3.77131 \mathrm{e}+003.77131 \mathrm{e}+00$ 3.77131e-01 1.00000e-09 2.12000e-01 $1.00000 \mathrm{e}-05$ 1.00000e-05 1.00000e-06 1.00000e-09 1.00000e-01 $1.00000 \mathrm{e}+001.00000 \mathrm{e}+001.00000 \mathrm{e}-01$ 1.00000e-09 1.00000e-01 Element: 5470 \# of layers: 7

$\mathrm{Kx} \mathrm{Ky} \mathrm{Kz}$ Ss Por

4.75053e+00 4.75053e+00 4.75053e-01 1.00000e-09 2.12000e-01 4.75053e+00 4.75053e+00 4.75053e-01 1.00000e-09 2.12000e-01 $4.75053 \mathrm{e}+004.75053 \mathrm{e}+00$ 4.75053e-01 1.00000e-09 2.12000e-01 4.75053e+00 4.75053e+00 4.75053e-01 1.00000e-09 2.12000e-01 4.75053e+00 4.75053e+00 4.75053e-01 1.00000e-09 2.12000e-01 $1.00000 \mathrm{e}-05$ 1.00000e-05 1.00000e-06 1.00000e-09 1.00000e-01 $1.00000 \mathrm{e}+001.00000 \mathrm{e}+001.00000 \mathrm{e}-011.00000 \mathrm{e}-09$ 1.00000e-01 Element: 5471 \# of layers: 7

$\mathrm{Kx} \mathrm{Ky} \mathrm{Kz}$ Ss Por

4.29939e+00 4.29939e+00 4.29939e-01 1.00000e-09 2.12000e-01 4.29939e+00 4.29939e+00 4.29939e-01 1.00000e-09 2.12000e-01 $4.29939 \mathrm{e}+00$ 4.29939e+00 4.29939e-01 1.00000e-09 2.12000e-01 
$4.29939 \mathrm{e}+004.29939 \mathrm{e}+00$ 4.29939e-01 1.00000e-09 2.12000e-01 $4.29939 \mathrm{e}+004.29939 \mathrm{e}+00$ 4.29939e-01 1.00000e-09 2.12000e-01 $1.00000 \mathrm{e}-05$ 1.00000e-05 1.00000e-06 1.00000e-09 1.00000e-01 $1.00000 \mathrm{e}+001.00000 \mathrm{e}+001.00000 \mathrm{e}-011.00000 \mathrm{e}-091.00000 \mathrm{e}-01$ Element: 5472 \# of layers: 7

Kx Ky Kz Ss Por

4.75053e+00 4.75053e+00 4.75053e-01 1.00000e-09 2.12000e-01

$4.75053 \mathrm{e}+004.75053 \mathrm{e}+00$ 4.75053e-01 1.00000e-09 2.12000e-01

$4.75053 \mathrm{e}+004.75053 \mathrm{e}+00$ 4.75053e-01 1.00000e-09 2.12000e-01

$4.75053 \mathrm{e}+004.75053 \mathrm{e}+00$ 4.75053e-01 1.00000e-09 2.12000e-01

$4.75053 \mathrm{e}+004.75053 \mathrm{e}+00$ 4.75053e-01 1.00000e-09 2.12000e-01 $1.00000 \mathrm{e}-05$ 1.00000e-05 1.00000e-06 1.00000e-09 1.00000e-01 $1.00000 \mathrm{e}+001.00000 \mathrm{e}+001.00000 \mathrm{e}-011.00000 \mathrm{e}-091.00000 \mathrm{e}-01$ Element: 5473 \# of layers: 3

Kx Ky Kz Ss Por

4.75053e+00 4.75053e+00 4.75053e-01 1.00000e-09 2.12000e-01 $1.00000 \mathrm{e}-05$ 1.00000e-05 1.00000e-06 1.00000e-09 1.00000e-01 $1.00000 \mathrm{e}+001.00000 \mathrm{e}+001.00000 \mathrm{e}-011.00000 \mathrm{e}-091.00000 \mathrm{e}-01$ Element: 5474 \# of layers: 3

Kx Ky Kz Ss Por

6.17368e+00 6.17368e+00 6.17368e-01 1.00000e-09 2.12000e-01 $1.00000 \mathrm{e}-05$ 1.00000e-05 1.00000e-06 1.00000e-09 1.00000e-01 $1.00000 \mathrm{e}+001.00000 \mathrm{e}+001.00000 \mathrm{e}-011.00000 \mathrm{e}-091.00000 \mathrm{e}-01$ Element: 5475 \# of layers: 7

Kx Ky Kz Ss Por

$4.65782 \mathrm{e}+004.65782 \mathrm{e}+00$ 4.65783e-01 1.00000e-09 2.12000e-01 $4.65782 \mathrm{e}+004.65782 \mathrm{e}+004.65783 \mathrm{e}-011.00000 \mathrm{e}-092.12000 \mathrm{e}-01$ $4.65782 \mathrm{e}+004.65782 \mathrm{e}+004.65783 \mathrm{e}-011.00000 \mathrm{e}-092.12000 \mathrm{e}-01$ $4.65782 \mathrm{e}+004.65782 \mathrm{e}+004.65783 \mathrm{e}-011.00000 \mathrm{e}-092.12000 \mathrm{e}-01$ 4.65782e+00 4.65782e+00 4.65783e-01 1.00000e-09 2.12000e-01 $1.00000 \mathrm{e}-05$ 1.00000e-05 1.00000e-06 1.00000e-09 1.00000e-01 $1.00000 \mathrm{e}+001.00000 \mathrm{e}+001.00000 \mathrm{e}-011.00000 \mathrm{e}-091.00000 \mathrm{e}-01$ Element: 5476 \# of layers: 7

Kx Ky Kz Ss Por

4.65782e+00 4.65782e+00 4.65783e-01 1.00000e-09 2.12000e-01 $4.65782 \mathrm{e}+004.65782 \mathrm{e}+004.65783 \mathrm{e}-011.00000 \mathrm{e}-092.12000 \mathrm{e}-01$ $4.65782 \mathrm{e}+004.65782 \mathrm{e}+004.65783 \mathrm{e}-011.00000 \mathrm{e}-092.12000 \mathrm{e}-01$ $4.65782 \mathrm{e}+004.65782 \mathrm{e}+00$ 4.65783e-01 1.00000e-09 2.12000e-01 4.65782e+00 4.65782e+00 4.65783e-01 1.00000e-09 2.12000e-01 $1.00000 \mathrm{e}-05$ 1.00000e-05 1.00000e-06 1.00000e-09 1.00000e-01 $1.00000 \mathrm{e}+001.00000 \mathrm{e}+001.00000 \mathrm{e}-011.00000 \mathrm{e}-091.00000 \mathrm{e}-01$ Element: 5477 \# of layers: 7

Kx Ky Kz Ss Por

$6.17368 \mathrm{e}+00$ 6.17368e+00 6.17368e-01 1.00000e-09 2.12000e-01

$6.17368 \mathrm{e}+006.17368 \mathrm{e}+00$ 6.17368e-01 1.00000e-09 2.12000e-01

$6.17368 \mathrm{e}+006.17368 \mathrm{e}+00$ 6.17368e-01 1.00000e-09 2.12000e-01 
$6.17368 \mathrm{e}+006.17368 \mathrm{e}+00$ 6.17368e-01 1.00000e-09 2.12000e-01 $6.17368 \mathrm{e}+006.17368 \mathrm{e}+00$ 6.17368e-01 1.00000e-09 2.12000e-01 $1.00000 \mathrm{e}-05$ 1.00000e-05 1.00000e-06 1.00000e-09 1.00000e-01 $1.00000 \mathrm{e}+001.00000 \mathrm{e}+001.00000 \mathrm{e}-011.00000 \mathrm{e}-091.00000 \mathrm{e}-01$ Element: 5478 \# of layers: 7

Kx Ky Kz Ss Por

$5.47864 \mathrm{e}+005.47864 \mathrm{e}+00$ 5.47864e-01 1.00000e-09 2.12000e-01

$5.47864 \mathrm{e}+005.47864 \mathrm{e}+005.47864 \mathrm{e}-011.00000 \mathrm{e}-092.12000 \mathrm{e}-01$

$5.47864 \mathrm{e}+005.47864 \mathrm{e}+005.47864 \mathrm{e}-011.00000 \mathrm{e}-092.12000 \mathrm{e}-01$

$5.47864 \mathrm{e}+005.47864 \mathrm{e}+005.47864 \mathrm{e}-011.00000 \mathrm{e}-092.12000 \mathrm{e}-01$

$5.47864 \mathrm{e}+005.47864 \mathrm{e}+005.47864 \mathrm{e}-011.00000 \mathrm{e}-092.12000 \mathrm{e}-01$ $1.00000 \mathrm{e}-05$ 1.00000e-05 1.00000e-06 1.00000e-09 1.00000e-01 $1.00000 \mathrm{e}+001.00000 \mathrm{e}+001.00000 \mathrm{e}-011.00000 \mathrm{e}-091.00000 \mathrm{e}-01$ Element: 5479 \# of layers: 7

Kx Ky Kz Ss Por

$5.51082 \mathrm{e}+00$ 5.51082e+00 5.51082e-01 1.00000e-09 2.12000e-01 $5.51082 \mathrm{e}+005.51082 \mathrm{e}+005.51082 \mathrm{e}-011.00000 \mathrm{e}-092.12000 \mathrm{e}-01$ $5.51082 \mathrm{e}+005.51082 \mathrm{e}+005.51082 \mathrm{e}-011.00000 \mathrm{e}-092.12000 \mathrm{e}-01$ $5.51082 \mathrm{e}+005.51082 \mathrm{e}+005.51082 \mathrm{e}-011.00000 \mathrm{e}-092.12000 \mathrm{e}-01$ $5.51082 \mathrm{e}+005.51082 \mathrm{e}+00$ 5.51082e-01 1.00000e-09 2.12000e-01 $1.00000 \mathrm{e}-05$ 1.00000e-05 1.00000e-06 1.00000e-09 1.00000e-01 $1.00000 \mathrm{e}+001.00000 \mathrm{e}+001.00000 \mathrm{e}-011.00000 \mathrm{e}-091.00000 \mathrm{e}-01$ Element: 5480 \# of layers: 7

Kx Ky Kz Ss Por

$5.01468 \mathrm{e}+00$ 5.01468e+00 5.01468e-01 1.00000e-09 2.12000e-01 $5.01468 \mathrm{e}+005.01468 \mathrm{e}+00$ 5.01468e-01 1.00000e-09 2.12000e-01 $5.01468 \mathrm{e}+005.01468 \mathrm{e}+005.01468 \mathrm{e}-011.00000 \mathrm{e}-092.12000 \mathrm{e}-01$ $5.01468 \mathrm{e}+005.01468 \mathrm{e}+00$ 5.01468e-01 1.00000e-09 2.12000e-01 $5.01468 \mathrm{e}+00$ 5.01468e+00 5.01468e-01 1.00000e-09 2.12000e-01 $1.00000 \mathrm{e}-05$ 1.00000e-05 1.00000e-06 1.00000e-09 1.00000e-01 $1.00000 \mathrm{e}+001.00000 \mathrm{e}+001.00000 \mathrm{e}-011.00000 \mathrm{e}-091.00000 \mathrm{e}-01$ Element: 5481 \# of layers: 7

Kx Ky Kz Ss Por

$4.52462 \mathrm{e}+004.52462 \mathrm{e}+00$ 4.52462e-01 1.00000e-09 2.12000e-01 $4.52462 \mathrm{e}+004.52462 \mathrm{e}+004.52462 \mathrm{e}-011.00000 \mathrm{e}-092.12000 \mathrm{e}-01$ $4.52462 \mathrm{e}+004.52462 \mathrm{e}+004.52462 \mathrm{e}-011.00000 \mathrm{e}-092.12000 \mathrm{e}-01$ $4.52462 \mathrm{e}+004.52462 \mathrm{e}+004.52462 \mathrm{e}-011.00000 \mathrm{e}-092.12000 \mathrm{e}-01$ $4.52462 \mathrm{e}+004.52462 \mathrm{e}+00$ 4.52462e-01 1.00000e-09 2.12000e-01 $1.00000 \mathrm{e}-05$ 1.00000e-05 1.00000e-06 1.00000e-09 1.00000e-01 $1.00000 \mathrm{e}+001.00000 \mathrm{e}+001.00000 \mathrm{e}-011.00000 \mathrm{e}-091.00000 \mathrm{e}-01$ Element: 5482 \# of layers: 7

Kx Ky Kz Ss Por

$5.01468 \mathrm{e}+00$ 5.01468e+00 5.01468e-01 1.00000e-09 2.12000e-01 $5.01468 \mathrm{e}+005.01468 \mathrm{e}+00$ 5.01468e-01 1.00000e-09 2.12000e-01 $5.01468 \mathrm{e}+005.01468 \mathrm{e}+005.01468 \mathrm{e}-011.00000 \mathrm{e}-092.12000 \mathrm{e}-01$ $5.01468 \mathrm{e}+005.01468 \mathrm{e}+00$ 5.01468e-01 1.00000e-09 2.12000e-01 
5.01468e+00 5.01468e+00 5.01468e-01 1.00000e-09 2.12000e-01 $1.00000 \mathrm{e}-05$ 1.00000e-05 1.00000e-06 1.00000e-09 1.00000e-01

$1.00000 \mathrm{e}+001.00000 \mathrm{e}+001.00000 \mathrm{e}-011.00000 \mathrm{e}-091.00000 \mathrm{e}-01$

Element: 5483 \# of layers: 6

$\mathrm{Kx} \mathrm{Ky} \mathrm{Kz}$ Ss Por

4.32932e+00 4.32932e+00 4.32932e-01 1.00000e-09 2.12000e-01

4.32932e+00 4.32932e+00 4.32932e-01 1.00000e-09 2.12000e-01

$4.32932 \mathrm{e}+00$ 4.32932e+00 4.32932e-01 1.00000e-09 2.12000e-01

4.32932e+00 4.32932e+00 4.32932e-01 1.00000e-09 2.12000e-01

$4.32932 \mathrm{e}+00$ 4.32932e+00 4.32932e-01 1.00000e-09 2.12000e-01

$1.00000 \mathrm{e}+001.00000 \mathrm{e}+001.00000 \mathrm{e}-01$ 1.00000e-09 1.00000e-01

Element: 5484 \# of layers: 6

$\mathrm{Kx} \mathrm{Ky} \mathrm{Kz}$ Ss Por

4.70215e+00 4.70215e+00 4.70215e-01 1.00000e-09 2.12000e-01

$4.70215 \mathrm{e}+00$ 4.70215e+00 4.70215e-01 1.00000e-09 2.12000e-01

$4.70215 \mathrm{e}+004.70215 \mathrm{e}+004.70215 \mathrm{e}-01$ 1.00000e-09 2.12000e-01

$4.70215 \mathrm{e}+00$ 4.70215e+00 4.70215e-01 1.00000e-09 2.12000e-01

$4.70215 \mathrm{e}+00$ 4.70215e+00 4.70215e-01 1.00000e-09 2.12000e-01

$1.00000 \mathrm{e}+001.00000 \mathrm{e}+001.00000 \mathrm{e}-01$ 1.00000e-09 1.00000e-01

Element: 5485 \# of layers: 5

$\mathrm{Kx} \mathrm{Ky} \mathrm{Kz}$ Ss Por

4.70215e+00 4.70215e+00 4.70215e-01 1.00000e-09 2.12000e-01

4.70215e+00 4.70215e+00 4.70215e-01 1.00000e-09 2.12000e-01

$4.70215 \mathrm{e}+004.70215 \mathrm{e}+00$ 4.70215e-01 1.00000e-09 2.12000e-01

$4.70215 \mathrm{e}+004.70215 \mathrm{e}+00$ 4.70215e-01 1.00000e-09 2.12000e-01

4.70215e+00 4.70215e+00 4.70215e-01 1.00000e-09 2.12000e-01

Element: 5486 \# of layers: 5

$\mathrm{Kx} \mathrm{Ky} \mathrm{Kz} \mathrm{Ss} \mathrm{Por}$

5.07836e+00 5.07836e+00 5.07836e-01 1.00000e-09 2.12000e-01

5.07836e+00 5.07836e+00 5.07836e-01 1.00000e-09 2.12000e-01

$5.07836 \mathrm{e}+00$ 5.07836e+00 5.07836e-01 1.00000e-09 2.12000e-01

$5.07836 \mathrm{e}+00$ 5.07836e+00 5.07836e-01 1.00000e-09 2.12000e-01

$5.07836 \mathrm{e}+00$ 5.07836e+00 5.07836e-01 1.00000e-09 2.12000e-01

Element: 5487 \# of layers: 5

$\mathrm{Kx} \mathrm{Ky} \mathrm{Kz}$ Ss Por

5.43589e+00 5.43589e+00 5.43589e-01 1.00000e-09 2.12000e-01

$5.43589 \mathrm{e}+005.43589 \mathrm{e}+00$ 5.43589e-01 1.00000e-09 2.12000e-01

$5.43589 \mathrm{e}+005.43589 \mathrm{e}+00$ 5.43589e-01 1.00000e-09 2.12000e-01

$5.43589 \mathrm{e}+00$ 5.43589e+00 5.43589e-01 1.00000e-09 2.12000e-01

5.43589e+00 5.43589e+00 5.43589e-01 1.00000e-09 2.12000e-01

Element: 5488 \# of layers: 5

$\mathrm{Kx} \mathrm{Ky} \mathrm{Kz}$ Ss Por

6.26728e+00 6.26728e+00 6.26728e-01 1.00000e-09 2.12000e-01

$6.26728 \mathrm{e}+006.26728 \mathrm{e}+00$ 6.26728e-01 1.00000e-09 2.12000e-01

$6.26728 \mathrm{e}+00$ 6.26728e+00 6.26728e-01 1.00000e-09 2.12000e-01

$6.26728 \mathrm{e}+00$ 6.26728e+00 6.26728e-01 1.00000e-09 2.12000e-01 
6.26728e+00 6.26728e+00 6.26728e-01 1.00000e-09 2.12000e-01

Element: 5489 \# of layers: 5

$\mathrm{Kx} \mathrm{Ky} \mathrm{Kz}$ Ss Por

6.26728e+00 6.26728e+00 6.26728e-01 1.00000e-09 2.12000e-01

$6.26728 \mathrm{e}+00$ 6.26728e+00 6.26728e-01 1.00000e-09 2.12000e-01

$6.26728 \mathrm{e}+006.26728 \mathrm{e}+00$ 6.26728e-01 1.00000e-09 2.12000e-01

6.26728e+00 6.26728e+00 6.26728e-01 1.00000e-09 2.12000e-01

6.26728e+00 6.26728e+00 6.26728e-01 1.00000e-09 2.12000e-01

Element: 5490 \# of layers: 5

$\mathrm{Kx} \mathrm{Ky} \mathrm{Kz}$ Ss Por

4.33044e+00 4.33044e+00 4.33044e-01 1.00000e-09 2.12000e-01

$4.33044 \mathrm{e}+004.33044 \mathrm{e}+004.33044 \mathrm{e}-01$ 1.00000e-09 2.12000e-01

$4.33044 \mathrm{e}+004.33044 \mathrm{e}+00$ 4.33044e-01 1.00000e-09 2.12000e-01

$4.33044 \mathrm{e}+004.33044 \mathrm{e}+00$ 4.33044e-01 1.00000e-09 2.12000e-01

4.33044e+00 4.33044e+00 4.33044e-01 1.00000e-09 2.12000e-01

Element: 5491 \# of layers: 5

$\mathrm{Kx} \mathrm{Ky} \mathrm{Kz}$ Ss Por

7.05232e+00 7.05232e+00 7.05232e-01 1.00000e-09 2.12000e-01

7.05232e+00 7.05232e+00 7.05232e-01 1.00000e-09 2.12000e-01

$7.05232 \mathrm{e}+00$ 7.05232e+00 7.05232e-01 1.00000e-09 2.12000e-01

$7.05232 \mathrm{e}+00$ 7.05232e+00 7.05232e-01 1.00000e-09 2.12000e-01

7.05232e+00 7.05232e+00 7.05232e-01 1.00000e-09 2.12000e-01

Element: 5492 \# of layers: 6

Kx Ky Kz Ss Por

$4.60990 \mathrm{e}+00$ 4.60990e+00 4.60990e-01 1.00000e-09 2.12000e-01

$4.60990 \mathrm{e}+004.60990 \mathrm{e}+00$ 4.60990e-01 1.00000e-09 2.12000e-01

$4.60990 \mathrm{e}+004.60990 \mathrm{e}+004.60990 \mathrm{e}-01$ 1.00000e-09 2.12000e-01

$4.60990 \mathrm{e}+004.60990 \mathrm{e}+00$ 4.60990e-01 1.00000e-09 2.12000e-01

$4.60990 \mathrm{e}+004.60990 \mathrm{e}+004.60990 \mathrm{e}-01$ 1.00000e-09 2.12000e-01

1.00000e-06 1.00000e-06 1.00000e-06 1.00000e-09 5.00000e-02

Element: 5493 \# of layers: 7

$\mathrm{Kx} \mathrm{Ky} \mathrm{Kz}$ Ss Por

5.84560e+00 5.84560e+00 5.84560e-01 1.00000e-09 7.00000e-02

$4.60990 \mathrm{e}+004.60990 \mathrm{e}+00$ 4.60990e-01 1.00000e-09 2.12000e-01

$4.60990 \mathrm{e}+004.60990 \mathrm{e}+00$ 4.60990e-01 1.00000e-09 2.12000e-01

$4.60990 \mathrm{e}+004.60990 \mathrm{e}+00$ 4.60990e-01 1.00000e-09 2.12000e-01

$4.60990 \mathrm{e}+004.60990 \mathrm{e}+00$ 4.60990e-01 1.00000e-09 2.12000e-01

$4.60990 \mathrm{e}+004.60990 \mathrm{e}+004.60990 \mathrm{e}-01$ 1.00000e-09 2.12000e-01

1.00000e-06 1.00000e-06 1.00000e-06 1.00000e-09 5.00000e-02

Element: 5494 \# of layers: 7

$\mathrm{Kx} \mathrm{Ky} \mathrm{Kz}$ Ss Por

5.84560e+00 5.84560e+00 5.84560e-01 1.00000e-09 7.00000e-02

2.33578e-01 2.33578e-01 2.33578e-02 1.00000e-09 2.12000e-01

2.33578e-01 2.33578e-01 2.33578e-02 1.00000e-09 2.12000e-01

2.33578e-01 2.33578e-01 2.33578e-02 1.00000e-09 2.12000e-01

2.33578e-01 2.33578e-01 2.33578e-02 1.00000e-09 2.12000e-01 
2.33578e-01 2.33578e-01 2.33578e-02 1.00000e-09 2.12000e-01 $1.00000 \mathrm{e}-06$ 1.00000e-06 1.00000e-06 1.00000e-09 5.00000e-02 Element: 5495 \# of layers: 7

Kx Ky Kz Ss Por

$2.81490 \mathrm{e}+002.81490 \mathrm{e}+002.81490 \mathrm{e}-011.00000 \mathrm{e}-09$ 7.00000e-02 $2.73921 \mathrm{e}+002.73921 \mathrm{e}+002.73921 \mathrm{e}-011.00000 \mathrm{e}-092.12000 \mathrm{e}-01$ $2.73921 \mathrm{e}+002.73921 \mathrm{e}+002.73921 \mathrm{e}-011.00000 \mathrm{e}-092.12000 \mathrm{e}-01$ $2.73921 \mathrm{e}+002.73921 \mathrm{e}+002.73921 \mathrm{e}-011.00000 \mathrm{e}-092.12000 \mathrm{e}-01$ $2.73921 \mathrm{e}+002.73921 \mathrm{e}+002.73921 \mathrm{e}-011.00000 \mathrm{e}-092.12000 \mathrm{e}-01$ $2.73921 \mathrm{e}+002.73921 \mathrm{e}+002.73921 \mathrm{e}-011.00000 \mathrm{e}-092.12000 \mathrm{e}-01$ 1.00000e-06 1.00000e-06 1.00000e-06 1.00000e-09 5.00000e-02 Element: 5496 \# of layers: 5

Kx Ky Kz Ss Por

3.09449e+00 3.09449e+00 3.09449e-01 1.00000e-09 2.12000e-01 $3.09449 \mathrm{e}+003.09449 \mathrm{e}+00$ 3.09449e-01 1.00000e-09 2.12000e-01 $3.09449 \mathrm{e}+003.09449 \mathrm{e}+00$ 3.09449e-01 1.00000e-09 2.12000e-01 $3.09449 \mathrm{e}+003.09449 \mathrm{e}+00$ 3.09449e-01 1.00000e-09 2.12000e-01 $1.00000 \mathrm{e}-06$ 1.00000e-06 1.00000e-06 1.00000e-09 5.00000e-02 Element: 5497 \# of layers: 6

Kx Ky Kz Ss Por

$3.02727 \mathrm{e}+003.02727 \mathrm{e}+00$ 3.02727e-01 1.00000e-09 7.00000e-02 $3.09449 \mathrm{e}+003.09449 \mathrm{e}+003.09449 \mathrm{e}-011.00000 \mathrm{e}-092.12000 \mathrm{e}-01$ $3.09449 \mathrm{e}+003.09449 \mathrm{e}+00$ 3.09449e-01 1.00000e-09 2.12000e-01 $3.09449 \mathrm{e}+003.09449 \mathrm{e}+003.09449 \mathrm{e}-01$ 1.00000e-09 2.12000e-01 $3.09449 \mathrm{e}+003.09449 \mathrm{e}+00$ 3.09449e-01 1.00000e-09 2.12000e-01 $1.00000 \mathrm{e}-06$ 1.00000e-06 1.00000e-06 1.00000e-09 5.00000e-02

Element: 5498 \# of layers: 6

Kx Ky Kz Ss Por

$2.81490 \mathrm{e}+002.81490 \mathrm{e}+002.81490 \mathrm{e}-01$ 1.00000e-09 7.00000e-02 $1.12471 \mathrm{e}-011.12471 \mathrm{e}-011.12471 \mathrm{e}-021.00000 \mathrm{e}-09$ 2.12000e-01 $1.12471 \mathrm{e}-011.12471 \mathrm{e}-011.12471 \mathrm{e}-021.00000 \mathrm{e}-092.12000 \mathrm{e}-01$ $1.12471 \mathrm{e}-01$ 1.12471e-01 1.12471e-02 1.00000e-09 2.12000e-01 $1.12471 \mathrm{e}-011.12471 \mathrm{e}-011.12471 \mathrm{e}-02$ 1.00000e-09 2.12000e-01 $1.00000 \mathrm{e}-06$ 1.00000e-06 1.00000e-06 1.00000e-09 5.00000e-02 Element: 5499 \# of layers: 5

Kx Ky Kz Ss Por

4.35859e+00 4.35859e+00 4.35859e-01 1.00000e-09 7.00000e-02 $3.65070 \mathrm{e}+003.65070 \mathrm{e}+003.65070 \mathrm{e}-011.00000 \mathrm{e}-092.12000 \mathrm{e}-01$ $3.65070 \mathrm{e}+003.65070 \mathrm{e}+003.65070 \mathrm{e}-01$ 1.00000e-09 2.12000e-01 $3.65070 \mathrm{e}+003.65070 \mathrm{e}+003.65070 \mathrm{e}-011.00000 \mathrm{e}-092.12000 \mathrm{e}-01$ $1.00000 \mathrm{e}-06$ 1.00000e-06 1.00000e-06 1.00000e-09 5.00000e-02 Element: 5500 \# of layers: 4

Kx Ky Kz Ss Por

$3.65070 \mathrm{e}+003.65070 \mathrm{e}+00$ 3.65070e-01 1.00000e-09 2.12000e-01 $3.65070 \mathrm{e}+003.65070 \mathrm{e}+003.65070 \mathrm{e}-011.00000 \mathrm{e}-092.12000 \mathrm{e}-01$ $3.65070 \mathrm{e}+003.65070 \mathrm{e}+003.65070 \mathrm{e}-01$ 1.00000e-09 2.12000e-01 
1.00000e-06 1.00000e-06 1.00000e-06 1.00000e-09 5.00000e-02

Element: 5501 \# of layers: 3

Kx Ky Kz Ss Por

3.07559e+00 3.07559e+00 3.07559e-01 1.00000e-09 2.12000e-01

$3.07559 \mathrm{e}+00$ 3.07559e+00 3.07559e-01 1.00000e-09 2.12000e-01

1.00000e-06 1.00000e-06 1.00000e-06 1.00000e-09 5.00000e-02

Element: 5502 \# of layers: 4

$\mathrm{Kx} \mathrm{Ky} \mathrm{Kz}$ Ss Por

6.96275e+00 6.96275e+00 6.96275e-01 1.00000e-09 7.00000e-02

2.78196e-01 2.78196e-01 2.78196e-02 1.00000e-09 2.12000e-01

2.78196e-01 2.78196e-01 2.78196e-02 1.00000e-09 2.12000e-01

1.00000e-06 1.00000e-06 1.00000e-06 1.00000e-09 5.00000e-02

Element: 5503 \# of layers: 2

$\mathrm{Kx} \mathrm{Ky} \mathrm{Kz}$ Ss Por

6.96275e+00 6.96275e+00 6.96275e-01 1.00000e-09 7.00000e-02

1.00000e-06 1.00000e-06 1.00000e-06 1.00000e-09 5.00000e-02

Element: 5504 \# of layers: 4

$\mathrm{Kx} \mathrm{Ky} \mathrm{Kz}$ Ss Por

2.10167e+01 2.10167e+01 2.10167e+00 1.00000e-09 7.00000e-02

8.39763e-01 8.39763e-01 8.39763e-02 1.00000e-09 2.12000e-01

8.39763e-01 8.39763e-01 8.39763e-02 1.00000e-09 2.12000e-01

1.00000e-06 1.00000e-06 1.00000e-06 1.00000e-09 5.00000e-02

Element: 5505 \# of layers: 4

Kx Ky Kz Ss Por

3.75321e+01 3.75321e+01 3.75321e+00 1.00000e-09 7.00000e-02

$1.49966 \mathrm{e}+001.49966 \mathrm{e}+001.49966 \mathrm{e}-01$ 1.00000e-09 2.12000e-01

$1.49966 \mathrm{e}+001.49966 \mathrm{e}+001.49966 \mathrm{e}-01$ 1.00000e-09 2.12000e-01

1.00000e-06 1.00000e-06 1.00000e-06 1.00000e-09 5.00000e-02

Element: 5506 \# of layers: 3

$\mathrm{Kx} \mathrm{Ky} \mathrm{Kz}$ Ss Por

3.75321e+01 3.75321e+01 3.75321e+00 1.00000e-09 7.00000e-02

$1.49966 \mathrm{e}+001.49966 \mathrm{e}+001.49966 \mathrm{e}-01$ 1.00000e-09 2.12000e-01

1.00000e-06 1.00000e-06 1.00000e-06 1.00000e-09 5.00000e-02

Element: 5507 \# of layers: 3

$\mathrm{Kx} \mathrm{Ky} \mathrm{Kz}$ Ss Por

$1.32690 \mathrm{e}+02$ 1.32690e+02 1.32690e+01 1.00000e-09 7.00000e-02

$1.32690 \mathrm{e}+021.32690 \mathrm{e}+021.32690 \mathrm{e}+01$ 1.00000e-09 7.00000e-02

1.00000e-06 1.00000e-06 1.00000e-06 1.00000e-09 5.00000e-02

Element: 5508 \# of layers: 3

$\mathrm{Kx} \mathrm{Ky} \mathrm{Kz}$ Ss Por

1.32690e+02 1.32690e+02 1.32690e+01 1.00000e-09 7.00000e-02

$1.32690 \mathrm{e}+021.32690 \mathrm{e}+021.32690 \mathrm{e}+01$ 1.00000e-09 7.00000e-02

1.00000e-06 1.00000e-06 1.00000e-06 1.00000e-09 5.00000e-02

Element: 5509 \# of layers: 2

$\mathrm{Kx} \mathrm{Ky} \mathrm{Kz}$ Ss Por

1.32690e+02 1.32690e+02 1.32690e+01 1.00000e-09 7.00000e-02 
1.00000e-06 1.00000e-06 1.00000e-06 1.00000e-09 5.00000e-02

Element: 5510 \# of layers: 2

Kx Ky Kz Ss Por

$1.02705 \mathrm{e}+01$ 1.02705e+01 1.02705e+00 1.00000e-09 7.00000e-02

1.00000e-06 1.00000e-06 1.00000e-06 1.00000e-09 5.00000e-02

Element: 5511 \# of layers: 4

$\mathrm{Kx} \mathrm{Ky} \mathrm{Kz}$ Ss Por

2.10167e+01 2.10167e+01 2.10167e+00 1.00000e-09 7.00000e-02

8.39763e-01 8.39763e-01 8.39763e-02 1.00000e-09 2.12000e-01

8.39763e-01 8.39763e-01 8.39763e-02 1.00000e-09 2.12000e-01

1.00000e-06 1.00000e-06 1.00000e-06 1.00000e-09 5.00000e-02

Element: 5512 \# of layers: 2

$\mathrm{Kx} \mathrm{Ky} \mathrm{Kz}$ Ss Por

$1.32690 \mathrm{e}+021.32690 \mathrm{e}+021.32690 \mathrm{e}+01$ 1.00000e-09 7.00000e-02

1.00000e-06 1.00000e-06 1.00000e-06 1.00000e-09 5.00000e-02

Element: 5513 \# of layers: 3

$\mathrm{Kx} \mathrm{Ky} \mathrm{Kz}$ Ss Por

2.07383e+02 2.07383e+02 2.07383e+01 1.00000e-09 7.00000e-02

$2.07383 \mathrm{e}+02$ 2.07383e+02 2.07383e+01 1.00000e-09 7.00000e-02

1.00000e-06 1.00000e-06 1.00000e-06 1.00000e-09 5.00000e-02

Element: 5514 \# of layers: 3

$\mathrm{Kx} \mathrm{Ky} \mathrm{Kz}$ Ss Por

2.07383e+02 2.07383e+02 2.07383e+01 1.00000e-09 7.00000e-02

$2.07383 \mathrm{e}+02$ 2.07383e+02 2.07383e+01 1.00000e-09 7.00000e-02

$1.00000 \mathrm{e}-06$ 1.00000e-06 1.00000e-06 1.00000e-09 5.00000e-02

Element: 5515 \# of layers: 2

$\mathrm{Kx} \mathrm{Ky} \mathrm{Kz}$ Ss Por

$1.80065 \mathrm{e}+02$ 1.80065e+02 1.80065e+01 1.00000e-09 7.00000e-02

1.00000e-06 1.00000e-06 1.00000e-06 1.00000e-09 5.00000e-02

Element: 5516 \# of layers: 2

$\mathrm{Kx} \mathrm{Ky} \mathrm{Kz}$ Ss Por

5.03767e+02 5.03767e+02 5.03767e+01 1.00000e-09 7.00000e-02

1.00000e-06 1.00000e-06 1.00000e-06 1.00000e-09 5.00000e-02

Element: 5517 \# of layers: 4

$\mathrm{Kx} \mathrm{Ky} \mathrm{Kz}$ Ss Por

5.03767e+02 5.03767e+02 5.03767e+01 1.00000e-09 7.00000e-02

$5.03767 \mathrm{e}+025.03767 \mathrm{e}+02$ 5.03767e+01 1.00000e-09 7.00000e-02

$5.03767 \mathrm{e}+02$ 5.03767e+02 5.03767e+01 1.00000e-09 7.00000e-02

1.00000e-06 1.00000e-06 1.00000e-06 1.00000e-09 5.00000e-02

Element: 5518 \# of layers: 2

$\mathrm{Kx} \mathrm{Ky} \mathrm{Kz}$ Ss Por

5.03767e+02 5.03767e+02 5.03767e+01 1.00000e-09 7.00000e-02

1.00000e-06 1.00000e-06 1.00000e-06 1.00000e-09 5.00000e-02

Element: 5519 \# of layers: 2

$\mathrm{Kx} \mathrm{Ky} \mathrm{Kz}$ Ss Por

$1.86165 \mathrm{e}+02$ 1.86165e+02 1.86165e+01 1.00000e-09 7.00000e-02 
1.00000e-06 1.00000e-06 1.00000e-06 1.00000e-09 5.00000e-02

Element: 5520 \# of layers: 3

$\mathrm{Kx} \mathrm{Ky} \mathrm{Kz}$ Ss Por

$1.86165 \mathrm{e}+02$ 1.86165e+02 1.86165e+01 1.00000e-09 7.00000e-02

$1.86165 \mathrm{e}+021.86165 \mathrm{e}+021.86165 \mathrm{e}+01$ 1.00000e-09 7.00000e-02

1.00000e-06 1.00000e-06 1.00000e-06 1.00000e-09 5.00000e-02

Element: 5521 \# of layers: 2

$\mathrm{Kx} \mathrm{Ky} \mathrm{Kz}$ Ss Por

$1.80065 \mathrm{e}+021.80065 \mathrm{e}+02$ 1.80065e+01 1.00000e-09 7.00000e-02

$1.00000 \mathrm{e}-06$ 1.00000e-06 1.00000e-06 1.00000e-09 5.00000e-02

Element: 5522 \# of layers: 2

$\mathrm{Kx} \mathrm{Ky} \mathrm{Kz}$ Ss Por

3.89016e+02 3.89016e+02 3.89016e+01 1.00000e-09 7.00000e-02

1.00000e-06 1.00000e-06 1.00000e-06 1.00000e-09 5.00000e-02

Element: 5523 \# of layers: 2

Kx Ky Kz Ss Por

8.05530e+03 8.05530e+03 8.05530e+02 1.00000e-09 7.00000e-02 1.00000e-06 1.00000e-06 1.00000e-06 1.00000e-09 5.00000e-02

Element: 5524 \# of layers: 2

$\mathrm{Kx} \mathrm{Ky} \mathrm{Kz}$ Ss Por

8.05530e+03 8.05530e+03 8.05530e+02 1.00000e-09 7.00000e-02 $1.00000 \mathrm{e}-06$ 1.00000e-06 1.00000e-06 1.00000e-09 5.00000e-02

Element: 5525 \# of layers: 3

Kx Ky Kz Ss Por

5.32770e+03 5.32770e+03 5.32770e+02 1.00000e-09 7.00000e-02

$5.32770 \mathrm{e}+035.32770 \mathrm{e}+035.32770 \mathrm{e}+02$ 1.00000e-09 7.00000e-02

1.00000e-06 1.00000e-06 1.00000e-06 1.00000e-09 5.00000e-02

Element: 5526 \# of layers: 4

Kx Ky Kz Ss Por

5.32770e+03 5.32770e+03 5.32770e+02 1.00000e-09 7.00000e-02

$5.32770 \mathrm{e}+035.32770 \mathrm{e}+03$ 5.32770e+02 1.00000e-09 7.00000e-02

$5.32770 \mathrm{e}+035.32770 \mathrm{e}+03$ 5.32770e+02 1.00000e-09 7.00000e-02

1.00000e-06 1.00000e-06 1.00000e-06 1.00000e-09 5.00000e-02

Element: 5527 \# of layers: 4

$\mathrm{Kx} \mathrm{Ky} \mathrm{Kz}$ Ss Por

5.32770e+03 5.32770e+03 5.32770e+02 1.00000e-09 7.00000e-02

$5.32770 \mathrm{e}+035.32770 \mathrm{e}+035.32770 \mathrm{e}+02$ 1.00000e-09 7.00000e-02

$5.32770 \mathrm{e}+035.32770 \mathrm{e}+035.32770 \mathrm{e}+02$ 1.00000e-09 7.00000e-02

1.00000e-06 1.00000e-06 1.00000e-06 1.00000e-09 5.00000e-02

Element: 5528 \# of layers: 4

$\mathrm{Kx} \mathrm{Ky} \mathrm{Kz}$ Ss Por

4.85053e+03 4.85053e+03 4.85053e+02 1.00000e-09 7.00000e-02

4.85053e+03 4.85053e+03 4.85053e+02 1.00000e-09 7.00000e-02

4.85053e+03 4.85053e+03 4.85053e+02 1.00000e-09 7.00000e-02

1.00000e-06 1.00000e-06 1.00000e-06 1.00000e-09 5.00000e-02

Element: 5529 \# of layers: 2 
Kx Ky Kz Ss Por

$3.89016 \mathrm{e}+02$ 3.89016e+02 3.89016e+01 1.00000e-09 7.00000e-02

1.00000e-06 1.00000e-06 1.00000e-06 1.00000e-09 5.00000e-02

Element: 5530 \# of layers: 3

$\mathrm{Kx} \mathrm{Ky} \mathrm{Kz}$ Ss Por

3.89016e+02 3.89016e+02 3.89016e+01 1.00000e-09 7.00000e-02

$3.89016 \mathrm{e}+023.89016 \mathrm{e}+023.89016 \mathrm{e}+01$ 1.00000e-09 7.00000e-02

1.00000e-06 1.00000e-06 1.00000e-06 1.00000e-09 5.00000e-02

Element: 5531 \# of layers: 2

$\mathrm{Kx} \mathrm{Ky} \mathrm{Kz}$ Ss Por

9.65331e+03 9.65331e+03 9.65331e+02 1.00000e-09 7.00000e-02

1.00000e-06 1.00000e-06 1.00000e-06 1.00000e-09 5.00000e-02

Element: 5532 \# of layers: 2

$\mathrm{Kx} \mathrm{Ky} \mathrm{Kz}$ Ss Por

8.05278e+03 8.05278e+03 8.05278e+02 1.00000e-09 7.00000e-02

1.00000e-06 1.00000e-06 1.00000e-06 1.00000e-09 5.00000e-02

Element: 5533 \# of layers: 4

$\mathrm{Kx} \mathrm{Ky} \mathrm{Kz}$ Ss Por

8.05278e+03 8.05278e+03 8.05278e+02 1.00000e-09 7.00000e-02

$8.05278 \mathrm{e}+03$ 8.05278e+03 8.05278e+02 1.00000e-09 7.00000e-02

$8.05278 \mathrm{e}+038.05278 \mathrm{e}+03$ 8.05278e+02 1.00000e-09 7.00000e-02

1.00000e-06 1.00000e-06 1.00000e-06 1.00000e-09 5.00000e-02

Element: 5534 \# of layers: 4

$\mathrm{Kx} \mathrm{Ky} \mathrm{Kz}$ Ss Por

8.05278e+03 8.05278e+03 8.05278e+02 1.00000e-09 7.00000e-02

8.05278e+03 8.05278e+03 8.05278e+02 1.00000e-09 7.00000e-02

$8.05278 \mathrm{e}+038.05278 \mathrm{e}+03$ 8.05278e+02 1.00000e-09 7.00000e-02

1.00000e-06 1.00000e-06 1.00000e-06 1.00000e-09 5.00000e-02

Element: 5535 \# of layers: 3

$\mathrm{Kx} \mathrm{Ky} \mathrm{Kz}$ Ss Por

7.68598e+03 7.68598e+03 7.68598e+02 1.00000e-09 7.00000e-02

$7.68598 \mathrm{e}+03$ 7.68598e+03 7.68598e+02 1.00000e-09 7.00000e-02

1.00000e-06 1.00000e-06 1.00000e-06 1.00000e-09 5.00000e-02

Element: 5536 \# of layers: 4

$\mathrm{Kx} \mathrm{Ky} \mathrm{Kz}$ Ss Por

7.68598e+03 7.68598e+03 7.68598e+02 1.00000e-09 7.00000e-02

$7.68598 \mathrm{e}+03$ 7.68598e+03 7.68598e+02 1.00000e-09 7.00000e-02

$7.68598 \mathrm{e}+03$ 7.68598e+03 7.68598e+02 1.00000e-09 7.00000e-02

1.00000e-06 1.00000e-06 1.00000e-06 1.00000e-09 5.00000e-02

Element: 5537 \# of layers: 4

$\mathrm{Kx} \mathrm{Ky} \mathrm{Kz}$ Ss Por

5.59575e+03 5.59575e+03 5.59575e+02 1.00000e-09 7.00000e-02

$5.59575 \mathrm{e}+03$ 5.59575e+03 5.59575e+02 1.00000e-09 7.00000e-02

$5.59575 \mathrm{e}+03$ 5.59575e+03 5.59575e+02 1.00000e-09 7.00000e-02

1.00000e-06 1.00000e-06 1.00000e-06 1.00000e-09 5.00000e-02

Element: 5538 \# of layers: 4 
Kx Ky Kz Ss Por

9.65331e+03 9.65331e+03 9.65331e+02 1.00000e-09 7.00000e-02

$9.65331 \mathrm{e}+03$ 9.65331e+03 9.65331e+02 1.00000e-09 7.00000e-02

$9.65331 \mathrm{e}+03$ 9.65331e+03 9.65331e+02 1.00000e-09 7.00000e-02

1.00000e-06 1.00000e-06 1.00000e-06 1.00000e-09 5.00000e-02

Element: 5539 \# of layers: 4

$\mathrm{Kx} \mathrm{Ky} \mathrm{Kz}$ Ss Por

8.05278e+03 8.05278e+03 8.05278e+02 1.00000e-09 7.00000e-02

8.05278e+03 8.05278e+03 8.05278e+02 1.00000e-09 7.00000e-02

8.05278e+03 8.05278e+03 8.05278e+02 1.00000e-09 7.00000e-02

1.00000e-06 1.00000e-06 1.00000e-06 1.00000e-09 5.00000e-02

Element: 5540 \# of layers: 4

$\mathrm{Kx} \mathrm{Ky} \mathrm{Kz}$ Ss Por

4.28425e+03 4.28425e+03 4.28425e+02 1.00000e-09 7.00000e-02

$4.28425 \mathrm{e}+03$ 4.28425e+03 4.28425e+02 1.00000e-09 7.00000e-02

$4.28425 \mathrm{e}+034.28425 \mathrm{e}+03$ 4.28425e+02 1.00000e-09 7.00000e-02

1.00000e-06 1.00000e-06 1.00000e-06 1.00000e-09 5.00000e-02

Element: 5541 \# of layers: 4

$\mathrm{Kx} \mathrm{Ky} \mathrm{Kz}$ Ss Por

2.43495e+03 2.43495e+03 2.43495e+02 1.00000e-09 7.00000e-02

$2.43495 \mathrm{e}+032.43495 \mathrm{e}+032.43495 \mathrm{e}+02$ 1.00000e-09 7.00000e-02

$2.43495 \mathrm{e}+03$ 2.43495e+03 2.43495e+02 1.00000e-09 7.00000e-02

1.00000e-06 1.00000e-06 1.00000e-06 1.00000e-09 5.00000e-02

Element: 5542 \# of layers: 4

$\mathrm{Kx} \mathrm{Ky} \mathrm{Kz}$ Ss Por

$2.43495 \mathrm{e}+032.43495 \mathrm{e}+03$ 2.43495e+02 1.00000e-09 7.00000e-02

$2.43495 \mathrm{e}+032.43495 \mathrm{e}+032.43495 \mathrm{e}+02$ 1.00000e-09 7.00000e-02

$2.43495 \mathrm{e}+03$ 2.43495e+03 2.43495e+02 1.00000e-09 7.00000e-02

1.00000e-06 1.00000e-06 1.00000e-06 1.00000e-09 5.00000e-02

Element: 5543 \# of layers: 4

$\mathrm{Kx} \mathrm{Ky} \mathrm{Kz}$ Ss Por

2.43495e+03 2.43495e+03 2.43495e+02 1.00000e-09 7.00000e-02

$2.43495 \mathrm{e}+032.43495 \mathrm{e}+032.43495 \mathrm{e}+02$ 1.00000e-09 7.00000e-02

$2.43495 \mathrm{e}+032.43495 \mathrm{e}+032.43495 \mathrm{e}+02$ 1.00000e-09 7.00000e-02

1.00000e-06 1.00000e-06 1.00000e-06 1.00000e-09 5.00000e-02

Element: 5544 \# of layers: 4

Kx Ky Kz Ss Por

$2.58407 \mathrm{e}+03$ 2.58407e+03 2.58407e+02 1.00000e-09 7.00000e-02

$2.58407 \mathrm{e}+032.58407 \mathrm{e}+03$ 2.58407e+02 1.00000e-09 7.00000e-02

$2.58407 \mathrm{e}+032.58407 \mathrm{e}+032.58407 \mathrm{e}+02$ 1.00000e-09 7.00000e-02

1.00000e-06 1.00000e-06 1.00000e-06 1.00000e-09 5.00000e-02

Element: 5545 \# of layers: 4

$\mathrm{Kx} \mathrm{Ky} \mathrm{Kz}$ Ss Por

2.58407e+03 2.58407e+03 2.58407e+02 1.00000e-09 7.00000e-02

$2.58407 \mathrm{e}+03$ 2.58407e+03 2.58407e+02 1.00000e-09 7.00000e-02

$2.58407 \mathrm{e}+032.58407 \mathrm{e}+032.58407 \mathrm{e}+02$ 1.00000e-09 7.00000e-02 
1.00000e-06 1.00000e-06 1.00000e-06 1.00000e-09 5.00000e-02

Element: 5546 \# of layers: 3

Kx Ky Kz Ss Por

5.62386e+03 5.62386e+03 5.62386e+02 1.00000e-09 7.00000e-02

$5.62386 \mathrm{e}+035.62386 \mathrm{e}+035.62386 \mathrm{e}+021.00000 \mathrm{e}-097.00000 \mathrm{e}-02$

1.00000e-06 1.00000e-06 1.00000e-06 1.00000e-09 5.00000e-02

Element: 5547 \# of layers: 4

$\mathrm{Kx} \mathrm{Ky} \mathrm{Kz}$ Ss Por

4.28425e+03 4.28425e+03 4.28425e+02 1.00000e-09 7.00000e-02

$4.28425 \mathrm{e}+03$ 4.28425e+03 4.28425e+02 1.00000e-09 7.00000e-02

$4.28425 \mathrm{e}+03$ 4.28425e+03 4.28425e+02 1.00000e-09 7.00000e-02

1.00000e-06 1.00000e-06 1.00000e-06 1.00000e-09 5.00000e-02

Element: 5548 \# of layers: 4

$\mathrm{Kx} \mathrm{Ky} \mathrm{Kz}$ Ss Por

$2.43495 \mathrm{e}+03$ 2.43495e+03 2.43495e+02 1.00000e-09 7.00000e-02

$2.43495 \mathrm{e}+032.43495 \mathrm{e}+032.43495 \mathrm{e}+02$ 1.00000e-09 7.00000e-02

$2.43495 \mathrm{e}+03$ 2.43495e+03 2.43495e+02 1.00000e-09 7.00000e-02

1.00000e-06 1.00000e-06 1.00000e-06 1.00000e-09 5.00000e-02

Element: 5549 \# of layers: 4

$\mathrm{Kx} \mathrm{Ky} \mathrm{Kz}$ Ss Por

2.76445e+03 2.76445e+03 2.76445e+02 1.00000e-09 7.00000e-02

$2.76445 \mathrm{e}+032.76445 \mathrm{e}+032.76445 \mathrm{e}+02$ 1.00000e-09 7.00000e-02

$2.76445 \mathrm{e}+032.76445 \mathrm{e}+032.76445 \mathrm{e}+02$ 1.00000e-09 7.00000e-02

1.00000e-06 1.00000e-06 1.00000e-06 1.00000e-09 5.00000e-02

Element: 5550 \# of layers: 4

$\mathrm{Kx} \mathrm{Ky} \mathrm{Kz}$ Ss Por

$2.76445 \mathrm{e}+03$ 2.76445e+03 2.76445e+02 1.00000e-09 7.00000e-02

$2.76445 \mathrm{e}+032.76445 \mathrm{e}+032.76445 \mathrm{e}+02$ 1.00000e-09 7.00000e-02

$2.76445 \mathrm{e}+032.76445 \mathrm{e}+032.76445 \mathrm{e}+021.00000 \mathrm{e}-09$ 7.00000e-02

1.00000e-06 1.00000e-06 1.00000e-06 1.00000e-09 5.00000e-02

Element: 5551 \# of layers: 4

Kx Ky Kz Ss Por

6.01048e+03 6.01048e+03 6.01048e+02 1.00000e-09 7.00000e-02

6.01048e+03 6.01048e+03 6.01048e+02 1.00000e-09 7.00000e-02

$6.01048 \mathrm{e}+036.01048 \mathrm{e}+03$ 6.01048e+02 1.00000e-09 7.00000e-02

1.00000e-06 1.00000e-06 1.00000e-06 1.00000e-09 5.00000e-02

Element: 5552 \# of layers: 4

$\mathrm{Kx} \mathrm{Ky} \mathrm{Kz}$ Ss Por

6.01048e+03 6.01048e+03 6.01048e+02 1.00000e-09 7.00000e-02

$6.01048 \mathrm{e}+036.01048 \mathrm{e}+03$ 6.01048e+02 1.00000e-09 7.00000e-02

$6.01048 \mathrm{e}+036.01048 \mathrm{e}+03$ 6.01048e+02 1.00000e-09 7.00000e-02

1.00000e-06 1.00000e-06 1.00000e-06 1.00000e-09 5.00000e-02

Element: 5553 \# of layers: 4

$\mathrm{Kx} \mathrm{Ky} \mathrm{Kz}$ Ss Por

5.22787e+03 5.22787e+03 5.22787e+02 1.00000e-09 7.00000e-02

$5.22787 \mathrm{e}+03$ 5.22787e+03 5.22787e+02 1.00000e-09 7.00000e-02 
$5.22787 \mathrm{e}+03$ 5.22787e+03 5.22787e+02 1.00000e-09 7.00000e-02 $1.00000 \mathrm{e}-06$ 1.00000e-06 1.00000e-06 1.00000e-09 5.00000e-02

Element: 5554 \# of layers: 4

Kx Ky Kz Ss Por

$5.22787 \mathrm{e}+03$ 5.22787e+03 5.22787e+02 1.00000e-09 7.00000e-02

$5.22787 \mathrm{e}+035.22787 \mathrm{e}+035.22787 \mathrm{e}+02$ 1.00000e-09 7.00000e-02

$5.22787 \mathrm{e}+03$ 5.22787e+03 5.22787e+02 1.00000e-09 7.00000e-02

$1.00000 \mathrm{e}-06$ 1.00000e-06 1.00000e-06 1.00000e-09 5.00000e-02

Element: 5555 \# of layers: 4

Kx Ky Kz Ss Por

$2.33539 \mathrm{e}+032.33539 \mathrm{e}+032.33539 \mathrm{e}+02$ 1.00000e-09 7.00000e-02

$2.33539 \mathrm{e}+032.33539 \mathrm{e}+032.33539 \mathrm{e}+02$ 1.00000e-09 7.00000e-02

$2.33539 \mathrm{e}+032.33539 \mathrm{e}+032.33539 \mathrm{e}+02$ 1.00000e-09 7.00000e-02

1.00000e-06 1.00000e-06 1.00000e-06 1.00000e-09 5.00000e-02

Element: 5556 \# of layers: 4

Kx Ky Kz Ss Por

$2.76445 \mathrm{e}+032.76445 \mathrm{e}+032.76445 \mathrm{e}+02$ 1.00000e-09 7.00000e-02

$2.76445 \mathrm{e}+032.76445 \mathrm{e}+032.76445 \mathrm{e}+02$ 1.00000e-09 7.00000e-02

$2.76445 \mathrm{e}+032.76445 \mathrm{e}+032.76445 \mathrm{e}+02$ 1.00000e-09 7.00000e-02

$1.00000 \mathrm{e}-06$ 1.00000e-06 1.00000e-06 1.00000e-09 5.00000e-02

Element: 5557 \# of layers: 4

Kx Ky Kz Ss Por

$6.01048 \mathrm{e}+03$ 6.01048e +03 6.01048e +02 1.00000e-09 7.00000e-02

$6.01048 \mathrm{e}+036.01048 \mathrm{e}+036.01048 \mathrm{e}+02$ 1.00000e-09 7.00000e-02

$6.01048 \mathrm{e}+036.01048 \mathrm{e}+036.01048 \mathrm{e}+02$ 1.00000e-09 7.00000e-02

$1.00000 \mathrm{e}-06$ 1.00000e-06 1.00000e-06 1.00000e-09 5.00000e-02

Element: 5558 \# of layers: 3

Kx Ky Kz Ss Por

$1.72758 \mathrm{e}+04$ 1.72758e+04 1.72758e+03 1.00000e-09 7.00000e-02

$1.72758 \mathrm{e}+041.72758 \mathrm{e}+041.72758 \mathrm{e}+03$ 1.00000e-09 7.00000e-02

$1.00000 \mathrm{e}-06$ 1.00000e-06 1.00000e-06 1.00000e-09 5.00000e-02

Element: 5559 \# of layers: 2

Kx Ky Kz Ss Por

$1.72758 \mathrm{e}+04$ 1.72758e+04 1.72758e+03 1.00000e-09 7.00000e-02 $1.00000 \mathrm{e}-06$ 1.00000e-06 1.00000e-06 1.00000e-09 5.00000e-02

Element: 5560 \# of layers: 4

Kx Ky Kz Ss Por

$2.64903 \mathrm{e}+042.64903 \mathrm{e}+042.64903 \mathrm{e}+03$ 1.00000e-09 7.00000e-02

$2.64903 \mathrm{e}+042.64903 \mathrm{e}+042.64903 \mathrm{e}+03$ 1.00000e-09 7.00000e-02

$1.00000 \mathrm{e}+001.00000 \mathrm{e}+001.00000 \mathrm{e}-011.00000 \mathrm{e}-091.00000 \mathrm{e}-01$

$1.00000 \mathrm{e}-061.00000 \mathrm{e}-06$ 1.00000e-06 1.00000e-09 5.00000e-02

Element: 5561 \# of layers: 4

Kx Ky Kz Ss Por

$2.64903 \mathrm{e}+042.64903 \mathrm{e}+042.64903 \mathrm{e}+03$ 1.00000e-09 7.00000e-02

$2.64903 \mathrm{e}+042.64903 \mathrm{e}+042.64903 \mathrm{e}+03$ 1.00000e-09 7.00000e-02

$1.00000 \mathrm{e}+001.00000 \mathrm{e}+001.00000 \mathrm{e}-011.00000 \mathrm{e}-091.00000 \mathrm{e}-01$ 
1.00000e-06 1.00000e-06 1.00000e-06 1.00000e-09 5.00000e-02

Element: 5562 \# of layers: 4

Kx Ky Kz Ss Por

$1.67694 \mathrm{e}+04$ 1.67694e+04 1.67694e+03 1.00000e-09 7.00000e-02

$1.67694 \mathrm{e}+041.67694 \mathrm{e}+041.67694 \mathrm{e}+031.00000 \mathrm{e}-097.00000 \mathrm{e}-02$

$1.00000 \mathrm{e}+001.00000 \mathrm{e}+001.00000 \mathrm{e}-011.00000 \mathrm{e}-091.00000 \mathrm{e}-01$

1.00000e-06 1.00000e-06 1.00000e-06 1.00000e-09 5.00000e-02

Element: 5563 \# of layers: 4

$\mathrm{Kx} \mathrm{Ky} \mathrm{Kz}$ Ss Por

$1.67694 \mathrm{e}+041.67694 \mathrm{e}+041.67694 \mathrm{e}+03$ 1.00000e-09 7.00000e-02

$1.67694 \mathrm{e}+041.67694 \mathrm{e}+041.67694 \mathrm{e}+03$ 1.00000e-09 7.00000e-02

$1.67694 \mathrm{e}+041.67694 \mathrm{e}+041.67694 \mathrm{e}+031.00000 \mathrm{e}-097.00000 \mathrm{e}-02$

1.00000e-06 1.00000e-06 1.00000e-06 1.00000e-09 5.00000e-02

Element: 5564 \# of layers: 4

$\mathrm{Kx} \mathrm{Ky} \mathrm{Kz}$ Ss Por

$1.13445 \mathrm{e}+041.13445 \mathrm{e}+041.13445 \mathrm{e}+03$ 1.00000e-09 7.00000e-02

$1.13445 \mathrm{e}+041.13445 \mathrm{e}+041.13445 \mathrm{e}+03$ 1.00000e-09 7.00000e-02

$1.13445 \mathrm{e}+041.13445 \mathrm{e}+041.13445 \mathrm{e}+03$ 1.00000e-09 7.00000e-02

1.00000e-06 1.00000e-06 1.00000e-06 1.00000e-09 5.00000e-02

Element: 5565 \# of layers: 3

$\mathrm{Kx} \mathrm{Ky} \mathrm{Kz}$ Ss Por

$1.72758 \mathrm{e}+041.72758 \mathrm{e}+04$ 1.72758e+03 1.00000e-09 7.00000e-02

$1.72758 \mathrm{e}+041.72758 \mathrm{e}+041.72758 \mathrm{e}+03$ 1.00000e-09 7.00000e-02

1.00000e-06 1.00000e-06 1.00000e-06 1.00000e-09 5.00000e-02

Element: 5566 \# of layers: 3

$\mathrm{Kx} \mathrm{Ky} \mathrm{Kz}$ Ss Por

$1.67694 \mathrm{e}+041.67694 \mathrm{e}+041.67694 \mathrm{e}+03$ 1.00000e-09 7.00000e-02

$1.67694 \mathrm{e}+041.67694 \mathrm{e}+041.67694 \mathrm{e}+031.00000 \mathrm{e}-097.00000 \mathrm{e}-02$

1.00000e-06 1.00000e-06 1.00000e-06 1.00000e-09 5.00000e-02

Element: 5567 \# of layers: 4

$\mathrm{Kx} \mathrm{Ky} \mathrm{Kz}$ Ss Por

$2.91582 \mathrm{e}+042.91582 \mathrm{e}+042.91582 \mathrm{e}+03$ 1.00000e-09 7.00000e-02

$2.91582 \mathrm{e}+042.91582 \mathrm{e}+042.91582 \mathrm{e}+03$ 1.00000e-09 7.00000e-02

$1.00000 \mathrm{e}+001.00000 \mathrm{e}+001.00000 \mathrm{e}-011.00000 \mathrm{e}-091.00000 \mathrm{e}-01$

1.00000e-06 1.00000e-06 1.00000e-06 1.00000e-09 5.00000e-02

Element: 5568 \# of layers: 4

Kx Ky Kz Ss Por

3.87935e+04 3.87935e+04 3.87935e+03 1.00000e-09 7.00000e-02

$3.87935 \mathrm{e}+043.87935 \mathrm{e}+043.87935 \mathrm{e}+03$ 1.00000e-09 7.00000e-02

$1.00000 \mathrm{e}+001.00000 \mathrm{e}+001.00000 \mathrm{e}-011.00000 \mathrm{e}-091.00000 \mathrm{e}-01$

1.00000e-06 1.00000e-06 1.00000e-06 1.00000e-09 5.00000e-02

Element: 5569 \# of layers: 3

$\mathrm{Kx} \mathrm{Ky} \mathrm{Kz}$ Ss Por

3.87935e+04 3.87935e+04 3.87935e+03 1.00000e-09 7.00000e-02

$1.00000 \mathrm{e}+001.00000 \mathrm{e}+001.00000 \mathrm{e}-011.00000 \mathrm{e}-091.00000 \mathrm{e}-01$

$1.00000 \mathrm{e}-06$ 1.00000e-06 1.00000e-06 1.00000e-09 5.00000e-02 
Element: 5570 \# of layers: 5

$\mathrm{Kx} \mathrm{Ky} \mathrm{Kz}$ Ss Por

4.89702e+03 4.89702e+03 4.89702e+02 1.00000e-09 7.00000e-02

$4.89702 \mathrm{e}+03$ 4.89702e+03 4.89702e+02 1.00000e-09 7.00000e-02

4.89702e+03 4.89702e+03 4.89702e+02 1.00000e-09 7.00000e-02

$1.00000 \mathrm{e}+001.00000 \mathrm{e}+001.00000 \mathrm{e}-011.00000 \mathrm{e}-091.00000 \mathrm{e}-01$

1.00000e-06 1.00000e-06 1.00000e-06 1.00000e-09 5.00000e-02

Element: 5571 \# of layers: 4

$\mathrm{Kx} \mathrm{Ky} \mathrm{Kz}$ Ss Por

4.89702e+03 4.89702e+03 4.89702e+02 1.00000e-09 7.00000e-02

4.89702e+03 4.89702e+03 4.89702e+02 1.00000e-09 7.00000e-02

$4.89702 \mathrm{e}+03$ 4.89702e+03 4.89702e+02 1.00000e-09 7.00000e-02

1.00000e-06 1.00000e-06 1.00000e-06 1.00000e-09 5.00000e-02

Element: 5572 \# of layers: 5

$\mathrm{Kx} \mathrm{Ky} \mathrm{Kz}$ Ss Por

4.89702e+03 4.89702e+03 4.89702e+02 1.00000e-09 7.00000e-02

$4.89702 \mathrm{e}+03$ 4.89702e+03 4.89702e+02 1.00000e-09 7.00000e-02

4.89702e+03 4.89702e+03 4.89702e+02 1.00000e-09 7.00000e-02

$1.00000 \mathrm{e}+001.00000 \mathrm{e}+001.00000 \mathrm{e}-011.00000 \mathrm{e}-091.00000 \mathrm{e}-01$

1.00000e-06 1.00000e-06 1.00000e-06 1.00000e-09 5.00000e-02

Element: 5573 \# of layers: 5

$\mathrm{Kx} \mathrm{Ky} \mathrm{Kz}$ Ss Por

1.52017e+04 1.52017e+04 1.52017e+03 1.00000e-09 7.00000e-02

$1.52017 \mathrm{e}+041.52017 \mathrm{e}+04$ 1.52017e+03 1.00000e-09 7.00000e-02

$1.52017 \mathrm{e}+041.52017 \mathrm{e}+04$ 1.52017e+03 1.00000e-09 7.00000e-02

$1.00000 \mathrm{e}+001.00000 \mathrm{e}+001.00000 \mathrm{e}-011.00000 \mathrm{e}-091.00000 \mathrm{e}-01$

1.00000e-06 1.00000e-06 1.00000e-06 1.00000e-09 5.00000e-02

Element: 5574 \# of layers: 4

$\mathrm{Kx} \mathrm{Ky} \mathrm{Kz}$ Ss Por

$2.91582 \mathrm{e}+042.91582 \mathrm{e}+042.91582 \mathrm{e}+03$ 1.00000e-09 7.00000e-02

$2.91582 \mathrm{e}+042.91582 \mathrm{e}+042.91582 \mathrm{e}+03$ 1.00000e-09 7.00000e-02

$1.00000 \mathrm{e}+001.00000 \mathrm{e}+001.00000 \mathrm{e}-011.00000 \mathrm{e}-091.00000 \mathrm{e}-01$

1.00000e-06 1.00000e-06 1.00000e-06 1.00000e-09 5.00000e-02

Element: 5575 \# of layers: 5

$\mathrm{Kx} \mathrm{Ky} \mathrm{Kz}$ Ss Por

3.87935e+04 3.87935e+04 3.87935e+03 1.00000e-09 7.00000e-02

$3.87935 \mathrm{e}+043.87935 \mathrm{e}+043.87935 \mathrm{e}+03$ 1.00000e-09 7.00000e-02

$3.87935 \mathrm{e}+04$ 3.87935e+04 3.87935e+03 1.00000e-09 7.00000e-02

$1.00000 \mathrm{e}+001.00000 \mathrm{e}+001.00000 \mathrm{e}-011.00000 \mathrm{e}-091.00000 \mathrm{e}-01$

1.00000e-06 1.00000e-06 1.00000e-06 1.00000e-09 5.00000e-02

Element: 5576 \# of layers: 4

$\mathrm{Kx} \mathrm{Ky} \mathrm{Kz}$ Ss Por

8.11846e+03 8.11846e+03 8.11846e+02 1.00000e-09 7.00000e-02

8.11846e+03 8.11846e+03 8.11846e+02 1.00000e-09 7.00000e-02

8.11846e+03 8.11846e+03 8.11846e+02 1.00000e-09 7.00000e-02

$1.00000 \mathrm{e}-06$ 1.00000e-06 1.00000e-06 1.00000e-09 5.00000e-02 
Element: 5577 \# of layers: 4

$\mathrm{Kx} \mathrm{Ky} \mathrm{Kz}$ Ss Por

$1.90859 \mathrm{e}+03$ 1.90859e+03 1.90859e+02 1.00000e-09 7.00000e-02

$1.90859 \mathrm{e}+03$ 1.90859e+03 1.90859e+02 1.00000e-09 7.00000e-02

$1.90859 \mathrm{e}+03$ 1.90859e+03 1.90859e+02 1.00000e-09 7.00000e-02

1.00000e-06 1.00000e-06 1.00000e-06 1.00000e-09 5.00000e-02

Element: 5578 \# of layers: 4

$\mathrm{Kx} \mathrm{Ky} \mathrm{Kz}$ Ss Por

$2.72525 \mathrm{e}+032.72525 \mathrm{e}+03$ 2.72525e+02 1.00000e-09 7.00000e-02

$2.72525 \mathrm{e}+032.72525 \mathrm{e}+032.72525 \mathrm{e}+02$ 1.00000e-09 7.00000e-02

$2.72525 \mathrm{e}+032.72525 \mathrm{e}+032.72525 \mathrm{e}+02$ 1.00000e-09 7.00000e-02

1.00000e-06 1.00000e-06 1.00000e-06 1.00000e-09 5.00000e-02

Element: 5579 \# of layers: 4

$\mathrm{Kx} \mathrm{Ky} \mathrm{Kz}$ Ss Por

$1.90859 \mathrm{e}+03$ 1.90859e+03 1.90859e+02 1.00000e-09 7.00000e-02

$1.90859 \mathrm{e}+031.90859 \mathrm{e}+03$ 1.90859e+02 1.00000e-09 7.00000e-02

$1.90859 \mathrm{e}+03$ 1.90859e+03 1.90859e+02 1.00000e-09 7.00000e-02

1.00000e-06 1.00000e-06 1.00000e-06 1.00000e-09 5.00000e-02

Element: 5580 \# of layers: 4

$\mathrm{Kx} \mathrm{Ky} \mathrm{Kz}$ Ss Por

$1.55179 \mathrm{e}+03$ 1.55179e+03 1.55179e+02 1.00000e-09 7.00000e-02

$1.55179 \mathrm{e}+031.55179 \mathrm{e}+03$ 1.55179e+02 1.00000e-09 7.00000e-02

$1.55179 \mathrm{e}+031.55179 \mathrm{e}+03$ 1.55179e+02 1.00000e-09 7.00000e-02

1.00000e-06 1.00000e-06 1.00000e-06 1.00000e-09 5.00000e-02

Element: 5581 \# of layers: 4

$\mathrm{Kx} \mathrm{Ky} \mathrm{Kz}$ Ss Por

$1.55179 \mathrm{e}+03$ 1.55179e+03 1.55179e+02 1.00000e-09 7.00000e-02

$1.55179 \mathrm{e}+03$ 1.55179e+03 1.55179e+02 1.00000e-09 7.00000e-02

$1.55179 \mathrm{e}+03$ 1.55179e+03 1.55179e+02 1.00000e-09 7.00000e-02

1.00000e-06 1.00000e-06 1.00000e-06 1.00000e-09 5.00000e-02

Element: 5582 \# of layers: 4

$\mathrm{Kx} \mathrm{Ky} \mathrm{Kz}$ Ss Por

$2.26016 \mathrm{e}+03$ 2.26016e+03 2.26016e+02 1.00000e-09 7.00000e-02

$2.26016 \mathrm{e}+03$ 2.26016e+03 2.26016e+02 1.00000e-09 7.00000e-02

$2.26016 \mathrm{e}+032.26016 \mathrm{e}+032.26016 \mathrm{e}+02$ 1.00000e-09 7.00000e-02

1.00000e-06 1.00000e-06 1.00000e-06 1.00000e-09 5.00000e-02

Element: 5583 \# of layers: 4

$\mathrm{Kx} \mathrm{Ky} \mathrm{Kz}$ Ss Por

3.93124e+03 3.93124e+03 3.93124e+02 1.00000e-09 7.00000e-02 $3.93124 \mathrm{e}+033.93124 \mathrm{e}+033.93124 \mathrm{e}+02$ 1.00000e-09 7.00000e-02

$3.93124 \mathrm{e}+033.93124 \mathrm{e}+03 \quad 3.93124 \mathrm{e}+02$ 1.00000e-09 7.00000e-02

1.00000e-06 1.00000e-06 1.00000e-06 1.00000e-09 5.00000e-02

Element: 5584 \# of layers: 4

$\mathrm{Kx} \mathrm{Ky} \mathrm{Kz}$ Ss Por

$1.55179 \mathrm{e}+03$ 1.55179e+03 1.55179e+02 1.00000e-09 7.00000e-02

$1.55179 \mathrm{e}+03$ 1.55179e+03 1.55179e+02 1.00000e-09 7.00000e-02 
$1.55179 \mathrm{e}+03$ 1.55179e+03 1.55179e+02 1.00000e-09 7.00000e-02 1.00000e-06 1.00000e-06 1.00000e-06 1.00000e-09 5.00000e-02

Element: 5585 \# of layers: 4

Kx Ky Kz Ss Por

$1.92814 \mathrm{e}+031.92814 \mathrm{e}+031.92814 \mathrm{e}+021.00000 \mathrm{e}-097.00000 \mathrm{e}-02$ $1.92814 \mathrm{e}+031.92814 \mathrm{e}+031.92814 \mathrm{e}+02$ 1.00000e-09 7.00000e-02 $1.92814 \mathrm{e}+031.92814 \mathrm{e}+03 \quad 1.92814 \mathrm{e}+02 \quad 1.00000 \mathrm{e}-097.00000 \mathrm{e}-02$ $1.00000 \mathrm{e}-06$ 1.00000e-06 1.00000e-06 1.00000e-09 5.00000e-02

Element: 5586 \# of layers: 4

$\mathrm{Kx} \mathrm{Ky} \mathrm{Kz}$ Ss Por

$1.69343 \mathrm{e}+03$ 1.69343e+03 1.69343e+02 1.00000e-09 7.00000e-02

$1.69343 \mathrm{e}+031.69343 \mathrm{e}+03 \quad 1.69343 \mathrm{e}+02$ 1.00000e-09 7.00000e-02

$1.69343 \mathrm{e}+03$ 1.69343e+03 1.69343e+02 1.00000e-09 7.00000e-02 1.00000e-06 1.00000e-06 1.00000e-06 1.00000e-09 5.00000e-02

Element: 5587 \# of layers: 4

Kx Ky Kz Ss Por

$1.69343 \mathrm{e}+03$ 1.69343e+03 1.69343e+02 1.00000e-09 7.00000e-02 $1.69343 \mathrm{e}+031.69343 \mathrm{e}+03$ 1.69343e+02 1.00000e-09 7.00000e-02 $1.69343 \mathrm{e}+03$ 1.69343e+03 1.69343e+02 1.00000e-09 7.00000e-02 1.00000e-06 1.00000e-06 1.00000e-06 1.00000e-09 5.00000e-02

Element: 5588 \# of layers: 4

$\mathrm{Kx} \mathrm{Ky} \mathrm{Kz}$ Ss Por

$1.69343 \mathrm{e}+03$ 1.69343e+03 1.69343e+02 1.00000e-09 7.00000e-02 $1.69343 \mathrm{e}+03$ 1.69343e+03 1.69343e+02 1.00000e-09 7.00000e-02 $1.69343 \mathrm{e}+03$ 1.69343e+03 1.69343e+02 1.00000e-09 7.00000e-02 1.00000e-06 1.00000e-06 1.00000e-06 1.00000e-09 5.00000e-02

Element: 5589 \# of layers: 4

$\mathrm{Kx} \mathrm{Ky} \mathrm{Kz}$ Ss Por

$1.35483 e+03$ 1.35483e+03 1.35483e+02 1.00000e-09 7.00000e-02 $1.35483 \mathrm{e}+03$ 1.35483e+03 1.35483e+02 1.00000e-09 7.00000e-02 $1.35483 \mathrm{e}+03$ 1.35483e+03 1.35483e+02 1.00000e-09 7.00000e-02 1.00000e-06 1.00000e-06 1.00000e-06 1.00000e-09 5.00000e-02

Element: 5590 \# of layers: 4

$\mathrm{Kx} \mathrm{Ky} \mathrm{Kz}$ Ss Por

1.35483e+03 1.35483e+03 1.35483e+02 1.00000e-09 7.00000e-02 $1.35483 \mathrm{e}+03$ 1.35483e+03 1.35483e+02 1.00000e-09 7.00000e-02 $1.35483 \mathrm{e}+03$ 1.35483e+03 1.35483e+02 1.00000e-09 7.00000e-02 1.00000e-06 1.00000e-06 1.00000e-06 1.00000e-09 5.00000e-02

Element: 5591 \# of layers: 4

$\mathrm{Kx} \mathrm{Ky} \mathrm{Kz}$ Ss Por

$1.62955 \mathrm{e}+03$ 1.62955e+03 1.62955e+02 1.00000e-09 7.00000e-02 $1.62955 \mathrm{e}+03$ 1.62955e+03 1.62955e+02 1.00000e-09 7.00000e-02 $1.62955 \mathrm{e}+031.62955 \mathrm{e}+03$ 1.62955e+02 1.00000e-09 7.00000e-02 1.00000e-06 1.00000e-06 1.00000e-06 1.00000e-09 5.00000e-02 Element: 5592 \# of layers: 4

Kx Ky Kz Ss Por 
$1.62955 \mathrm{e}+03$ 1.62955e+03 1.62955e+02 1.00000e-09 7.00000e-02 $1.62955 \mathrm{e}+031.62955 \mathrm{e}+03$ 1.62955e+02 1.00000e-09 7.00000e-02 $1.62955 \mathrm{e}+03$ 1.62955e+03 1.62955e+02 1.00000e-09 7.00000e-02 1.00000e-06 1.00000e-06 1.00000e-06 1.00000e-09 5.00000e-02

Element: 5593 \# of layers: 4

$\mathrm{Kx} \mathrm{Ky} \mathrm{Kz}$ Ss Por

$1.69343 \mathrm{e}+03$ 1.69343e+03 1.69343e+02 1.00000e-09 7.00000e-02

$1.69343 \mathrm{e}+031.69343 \mathrm{e}+03$ 1.69343e+02 1.00000e-09 7.00000e-02

$1.69343 \mathrm{e}+03$ 1.69343e+03 1.69343e+02 1.00000e-09 7.00000e-02 1.00000e-06 1.00000e-06 1.00000e-06 1.00000e-09 5.00000e-02

Element: 5594 \# of layers: 4

Kx Ky Kz Ss Por

$2.45117 \mathrm{e}+012.45117 \mathrm{e}+012.45117 \mathrm{e}+00$ 1.00000e-09 7.00000e-02

$2.45117 \mathrm{e}+012.45117 \mathrm{e}+012.45117 \mathrm{e}+001.00000 \mathrm{e}-09$ 7.00000e-02

$2.45117 \mathrm{e}+012.45117 \mathrm{e}+012.45117 \mathrm{e}+00$ 1.00000e-09 7.00000e-02 1.00000e-06 1.00000e-06 1.00000e-06 1.00000e-09 5.00000e-02

Element: 5595 \# of layers: 4

$\mathrm{Kx} \mathrm{Ky} \mathrm{Kz}$ Ss Por

$2.45117 \mathrm{e}+012.45117 \mathrm{e}+012.45117 \mathrm{e}+00$ 1.00000e-09 7.00000e-02

$2.45117 \mathrm{e}+012.45117 \mathrm{e}+012.45117 \mathrm{e}+00$ 1.00000e-09 7.00000e-02

$2.45117 \mathrm{e}+012.45117 \mathrm{e}+012.45117 \mathrm{e}+001.00000 \mathrm{e}-09$ 7.00000e-02

1.00000e-06 1.00000e-06 1.00000e-06 1.00000e-09 5.00000e-02

Element: 5596 \# of layers: 3

Kx Ky Kz Ss Por

3.70113e+01 3.70113e+01 3.70113e+00 1.00000e-09 7.00000e-02

$3.70113 \mathrm{e}+013.70113 \mathrm{e}+013.70113 \mathrm{e}+001.00000 \mathrm{e}-09$ 7.00000e-02

1.00000e-06 1.00000e-06 1.00000e-06 1.00000e-09 5.00000e-02

Element: 5597 \# of layers: 4

Kx Ky Kz Ss Por

3.70113e+01 3.70113e+01 3.70113e+00 1.00000e-09 7.00000e-02

$3.70113 \mathrm{e}+013.70113 \mathrm{e}+013.70113 \mathrm{e}+001.00000 \mathrm{e}-09$ 7.00000e-02

$3.70113 \mathrm{e}+013.70113 \mathrm{e}+013.70113 \mathrm{e}+00$ 1.00000e-09 7.00000e-02

1.00000e-06 1.00000e-06 1.00000e-06 1.00000e-09 5.00000e-02

Element: 5598 \# of layers: 4

$\mathrm{Kx} \mathrm{Ky} \mathrm{Kz}$ Ss Por

$2.52839 \mathrm{e}+012.52839 \mathrm{e}+012.52839 \mathrm{e}+00$ 1.00000e-09 7.00000e-02

$2.52839 \mathrm{e}+012.52839 \mathrm{e}+012.52839 \mathrm{e}+001.00000 \mathrm{e}-09$ 7.00000e-02

$2.52839 \mathrm{e}+012.52839 \mathrm{e}+012.52839 \mathrm{e}+00$ 1.00000e-09 7.00000e-02

1.00000e-06 1.00000e-06 1.00000e-06 1.00000e-09 5.00000e-02

Element: 5599 \# of layers: 4

$\mathrm{Kx} \mathrm{Ky} \mathrm{Kz}$ Ss Por

$2.52839 \mathrm{e}+012.52839 \mathrm{e}+012.52839 \mathrm{e}+00$ 1.00000e-09 7.00000e-02

$2.52839 \mathrm{e}+012.52839 \mathrm{e}+012.52839 \mathrm{e}+001.00000 \mathrm{e}-09$ 7.00000e-02

$2.52839 \mathrm{e}+012.52839 \mathrm{e}+012.52839 \mathrm{e}+00$ 1.00000e-09 7.00000e-02

1.00000e-06 1.00000e-06 1.00000e-06 1.00000e-09 5.00000e-02

Element: 5600 \# of layers: 4 
Kx Ky Kz Ss Por

$1.76677 \mathrm{e}+01$ 1.76677e+01 1.76677e+00 1.00000e-09 7.00000e-02

$1.76677 \mathrm{e}+011.76677 \mathrm{e}+01$ 1.76677e+00 1.00000e-09 7.00000e-02

$1.76677 \mathrm{e}+01$ 1.76677e+01 1.76677e+00 1.00000e-09 7.00000e-02

1.00000e-06 1.00000e-06 1.00000e-06 1.00000e-09 5.00000e-02

Element: 5601 \# of layers: 4

Kx Ky Kz Ss Por

2.45117e+01 2.45117e+01 2.45117e+00 1.00000e-09 7.00000e-02

$2.45117 \mathrm{e}+012.45117 \mathrm{e}+012.45117 \mathrm{e}+00$ 1.00000e-09 7.00000e-02

$2.45117 \mathrm{e}+012.45117 \mathrm{e}+012.45117 \mathrm{e}+001.00000 \mathrm{e}-09$ 7.00000e-02

1.00000e-06 1.00000e-06 1.00000e-06 1.00000e-09 5.00000e-02

Element: 5602 \# of layers: 4

Kx Ky Kz Ss Por

$2.45117 \mathrm{e}+012.45117 \mathrm{e}+012.45117 \mathrm{e}+001.00000 \mathrm{e}-09$ 7.00000e-02

$2.45117 \mathrm{e}+012.45117 \mathrm{e}+012.45117 \mathrm{e}+001.00000 \mathrm{e}-09$ 7.00000e-02

$2.45117 \mathrm{e}+012.45117 \mathrm{e}+012.45117 \mathrm{e}+00$ 1.00000e-09 7.00000e-02

1.00000e-06 1.00000e-06 1.00000e-06 1.00000e-09 5.00000e-02

Element: 5603 \# of layers: 3

$\mathrm{Kx} \mathrm{Ky} \mathrm{Kz}$ Ss Por

$2.59299 \mathrm{e}+012.59299 \mathrm{e}+012.59299 \mathrm{e}+00$ 1.00000e-09 7.00000e-02

$2.59299 \mathrm{e}+012.59299 \mathrm{e}+012.59299 \mathrm{e}+00$ 1.00000e-09 7.00000e-02

1.00000e-06 1.00000e-06 1.00000e-06 1.00000e-09 5.00000e-02

Element: 5604 \# of layers: 3

$\mathrm{Kx} \mathrm{Ky} \mathrm{Kz}$ Ss Por

$2.22295 \mathrm{e}+012.22295 \mathrm{e}+012.22295 \mathrm{e}+001.00000 \mathrm{e}-09$ 7.00000e-02

$2.22295 \mathrm{e}+012.22295 \mathrm{e}+012.22295 \mathrm{e}+00$ 1.00000e-09 7.00000e-02

1.00000e-06 1.00000e-06 1.00000e-06 1.00000e-09 5.00000e-02

Element: 5605 \# of layers: 4

$\mathrm{Kx} \mathrm{Ky} \mathrm{Kz}$ Ss Por

$2.22295 \mathrm{e}+01$ 2.22295e+01 2.22295e+00 1.00000e-09 7.00000e-02

$2.22295 \mathrm{e}+012.22295 \mathrm{e}+012.22295 \mathrm{e}+001.00000 \mathrm{e}-09$ 7.00000e-02

$2.22295 \mathrm{e}+012.22295 \mathrm{e}+012.22295 \mathrm{e}+00$ 1.00000e-09 7.00000e-02

1.00000e-06 1.00000e-06 1.00000e-06 1.00000e-09 5.00000e-02

Element: 5606 \# of layers: 3

$\mathrm{Kx} \mathrm{Ky} \mathrm{Kz}$ Ss Por

$2.22295 \mathrm{e}+012.22295 \mathrm{e}+012.22295 \mathrm{e}+00$ 1.00000e-09 7.00000e-02

$2.22295 \mathrm{e}+012.22295 \mathrm{e}+012.22295 \mathrm{e}+001.00000 \mathrm{e}-09$ 7.00000e-02

1.00000e-06 1.00000e-06 1.00000e-06 1.00000e-09 5.00000e-02

Element: 5607 \# of layers: 4

$\mathrm{Kx} \mathrm{Ky} \mathrm{Kz}$ Ss Por

$1.92174 \mathrm{e}+01$ 1.92174e+01 1.92174e+00 1.00000e-09 7.00000e-02

$1.92174 \mathrm{e}+011.92174 \mathrm{e}+011.92174 \mathrm{e}+001.00000 \mathrm{e}-097.00000 \mathrm{e}-02$

$1.92174 \mathrm{e}+011.92174 \mathrm{e}+011.92174 \mathrm{e}+001.00000 \mathrm{e}-097.00000 \mathrm{e}-02$

1.00000e-06 1.00000e-06 1.00000e-06 1.00000e-09 5.00000e-02

Element: 5608 \# of layers: 4

Kx Ky Kz Ss Por 
1.91453e+01 1.91453e+01 1.91453e+00 1.00000e-09 7.00000e-02 $1.91453 \mathrm{e}+01$ 1.91453e+01 1.91453e+00 1.00000e-09 7.00000e-02 $1.91453 \mathrm{e}+011.91453 \mathrm{e}+01$ 1.91453e+00 1.00000e-09 7.00000e-02 1.00000e-06 1.00000e-06 1.00000e-06 1.00000e-09 5.00000e-02

Element: 5609 \# of layers: 4

$\mathrm{Kx} \mathrm{Ky} \mathrm{Kz}$ Ss Por

$1.91453 \mathrm{e}+01$ 1.91453e+01 1.91453e+00 1.00000e-09 7.00000e-02 $1.91453 \mathrm{e}+011.91453 \mathrm{e}+01$ 1.91453e+00 1.00000e-09 7.00000e-02 $1.91453 \mathrm{e}+01$ 1.91453e+01 1.91453e+00 1.00000e-09 7.00000e-02 1.00000e-06 1.00000e-06 1.00000e-06 1.00000e-09 5.00000e-02

Element: 5610 \# of layers: 3

$\mathrm{Kx} \mathrm{Ky} \mathrm{Kz}$ Ss Por

$2.59299 \mathrm{e}+012.59299 \mathrm{e}+012.59299 \mathrm{e}+00$ 1.00000e-09 7.00000e-02

$2.59299 \mathrm{e}+012.59299 \mathrm{e}+012.59299 \mathrm{e}+001.00000 \mathrm{e}-09$ 7.00000e-02 1.00000e-06 1.00000e-06 1.00000e-06 1.00000e-09 5.00000e-02

Element: 5611 \# of layers: 3

$\mathrm{Kx} \mathrm{Ky} \mathrm{Kz}$ Ss Por

$2.22295 \mathrm{e}+012.22295 \mathrm{e}+012.22295 \mathrm{e}+00$ 1.00000e-09 7.00000e-02 $2.22295 \mathrm{e}+012.22295 \mathrm{e}+012.22295 \mathrm{e}+00$ 1.00000e-09 7.00000e-02 1.00000e-06 1.00000e-06 1.00000e-06 1.00000e-09 5.00000e-02

Element: 5612 \# of layers: 3

$\mathrm{Kx} \mathrm{Ky} \mathrm{Kz}$ Ss Por

$1.09075 \mathrm{e}+02$ 1.09075e+02 1.09075e+01 1.00000e-09 7.00000e-02 $1.09075 \mathrm{e}+02$ 1.09075e+02 1.09075e+01 1.00000e-09 7.00000e-02 1.00000e-06 1.00000e-06 1.00000e-06 1.00000e-09 5.00000e-02

Element: 5613 \# of layers: 2

$\mathrm{Kx} \mathrm{Ky} \mathrm{Kz}$ Ss Por

1.77686e+02 1.77686e+02 1.77686e+01 1.00000e-09 7.00000e-02 1.00000e-06 1.00000e-06 1.00000e-06 1.00000e-09 5.00000e-02

Element: 5614 \# of layers: 3

$\mathrm{Kx} \mathrm{Ky} \mathrm{Kz}$ Ss Por

$1.77686 \mathrm{e}+02$ 1.77686e+02 1.77686e+01 1.00000e-09 7.00000e-02

$1.77686 \mathrm{e}+021.77686 \mathrm{e}+02 \quad 1.77686 \mathrm{e}+01$ 1.00000e-09 7.00000e-02 1.00000e-06 1.00000e-06 1.00000e-06 1.00000e-09 5.00000e-02

Element: 5615 \# of layers: 4

Kx Ky Kz Ss Por

$1.15256 \mathrm{e}+02$ 1.15256e+02 1.15256e+01 1.00000e-09 7.00000e-02 $1.15256 \mathrm{e}+021.15256 \mathrm{e}+021.15256 \mathrm{e}+01$ 1.00000e-09 7.00000e-02 $1.15256 \mathrm{e}+021.15256 \mathrm{e}+021.15256 \mathrm{e}+01$ 1.00000e-09 7.00000e-02 1.00000e-06 1.00000e-06 1.00000e-06 1.00000e-09 5.00000e-02

Element: 5616 \# of layers: 4

$\mathrm{Kx} \mathrm{Ky} \mathrm{Kz}$ Ss Por

$1.15256 \mathrm{e}+02$ 1.15256e+02 1.15256e+01 1.00000e-09 7.00000e-02 $1.15256 \mathrm{e}+02$ 1.15256e+02 1.15256e+01 1.00000e-09 7.00000e-02 $1.15256 \mathrm{e}+021.15256 \mathrm{e}+02 \quad 1.15256 \mathrm{e}+01$ 1.00000e-09 7.00000e-02 $1.00000 \mathrm{e}-06$ 1.00000e-06 1.00000e-06 1.00000e-09 5.00000e-02 
Element: 5617 \# of layers: 4

$\mathrm{Kx} \mathrm{Ky} \mathrm{Kz}$ Ss Por

6.68074e+01 6.68074e+01 6.68074e+00 1.00000e-09 7.00000e-02

$6.68074 \mathrm{e}+016.68074 \mathrm{e}+016.68074 \mathrm{e}+001.00000 \mathrm{e}-09$ 7.00000e-02

$6.68074 \mathrm{e}+016.68074 \mathrm{e}+016.68074 \mathrm{e}+001.00000 \mathrm{e}-097.00000 \mathrm{e}-02$

1.00000e-06 1.00000e-06 1.00000e-06 1.00000e-09 5.00000e-02

Element: 5618 \# of layers: 3

$\mathrm{Kx} \mathrm{Ky} \mathrm{Kz}$ Ss Por

6.68074e+01 6.68074e+01 6.68074e+00 1.00000e-09 7.00000e-02

$6.68074 \mathrm{e}+016.68074 \mathrm{e}+016.68074 \mathrm{e}+00$ 1.00000e-09 7.00000e-02

1.00000e-06 1.00000e-06 1.00000e-06 1.00000e-09 5.00000e-02

Element: 5619 \# of layers: 3

$\mathrm{Kx} \mathrm{Ky} \mathrm{Kz}$ Ss Por

$1.09075 \mathrm{e}+02$ 1.09075e+02 1.09075e+01 1.00000e-09 7.00000e-02 $1.09075 \mathrm{e}+021.09075 \mathrm{e}+02$ 1.09075e+01 1.00000e-09 7.00000e-02 1.00000e-06 1.00000e-06 1.00000e-06 1.00000e-09 5.00000e-02

Element: 5620 \# of layers: 3

$\mathrm{Kx} \mathrm{Ky} \mathrm{Kz}$ Ss Por

1.77686e+02 1.77686e+02 1.77686e+01 1.00000e-09 7.00000e-02

$1.77686 \mathrm{e}+02 \quad 1.77686 \mathrm{e}+02 \quad 1.77686 \mathrm{e}+01$ 1.00000e-09 7.00000e-02

1.00000e-06 1.00000e-06 1.00000e-06 1.00000e-09 5.00000e-02

Element: 5621 \# of layers: 2

$\mathrm{Kx} \mathrm{Ky} \mathrm{Kz}$ Ss Por

8.51670e+01 8.51670e+01 8.51670e+00 1.00000e-09 7.00000e-02

$1.00000 \mathrm{e}-06$ 1.00000e-06 1.00000e-06 1.00000e-09 5.00000e-02

Element: 5622 \# of layers: 2

$\mathrm{Kx} \mathrm{Ky} \mathrm{Kz}$ Ss Por

$1.75109 \mathrm{e}+01$ 1.75109e+01 1.75109e+00 1.00000e-09 7.00000e-02

1.00000e-06 1.00000e-06 1.00000e-06 1.00000e-09 5.00000e-02

Element: 5623 \# of layers: 3

$\mathrm{Kx} \mathrm{Ky} \mathrm{Kz}$ Ss Por

$1.75109 \mathrm{e}+01$ 1.75109e+01 1.75109e+00 1.00000e-09 7.00000e-02

$1.75109 \mathrm{e}+011.75109 \mathrm{e}+011.75109 \mathrm{e}+001.00000 \mathrm{e}-09$ 7.00000e-02

1.00000e-06 1.00000e-06 1.00000e-06 1.00000e-09 5.00000e-02

Element: 5624 \# of layers: 3

$\mathrm{Kx} \mathrm{Ky} \mathrm{Kz}$ Ss Por

3.40443e+01 3.40443e+01 3.40443e+00 1.00000e-09 7.00000e-02

$3.40443 \mathrm{e}+013.40443 \mathrm{e}+013.40443 \mathrm{e}+00$ 1.00000e-09 7.00000e-02

$1.00000 \mathrm{e}-06$ 1.00000e-06 1.00000e-06 1.00000e-09 5.00000e-02

Element: 5625 \# of layers: 4

$\mathrm{Kx} \mathrm{Ky} \mathrm{Kz}$ Ss Por

3.40443e+01 3.40443e+01 3.40443e+00 1.00000e-09 7.00000e-02

$3.40443 \mathrm{e}+013.40443 \mathrm{e}+013.40443 \mathrm{e}+001.00000 \mathrm{e}-09$ 7.00000e-02

3.40443e+01 3.40443e+01 3.40443e+00 1.00000e-09 7.00000e-02

1.00000e-06 1.00000e-06 1.00000e-06 1.00000e-09 5.00000e-02

Element: 5626 \# of layers: 3 
$\mathrm{Kx} \mathrm{Ky} \mathrm{Kz}$ Ss Por

7.86276e+01 7.86276e+01 7.86276e+00 1.00000e-09 7.00000e-02

$7.86276 \mathrm{e}+017.86276 \mathrm{e}+01$ 7.86276e+00 1.00000e-09 7.00000e-02

$1.00000 \mathrm{e}-06$ 1.00000e-06 1.00000e-06 1.00000e-09 5.00000e-02

Element: 5627 \# of layers: 3

$\mathrm{Kx} \mathrm{Ky} \mathrm{Kz}$ Ss Por

7.86276e+01 7.86276e+01 7.86276e+00 1.00000e-09 7.00000e-02

$7.86276 \mathrm{e}+01$ 7.86276e+01 7.86276e+00 1.00000e-09 7.00000e-02

1.00000e-06 1.00000e-06 1.00000e-06 1.00000e-09 5.00000e-02

Element: 5628 \# of layers: 3

Kx Ky Kz Ss Por

7.86276e+01 7.86276e+01 7.86276e+00 1.00000e-09 7.00000e-02

$7.86276 \mathrm{e}+01$ 7.86276e+01 7.86276e+00 1.00000e-09 7.00000e-02

1.00000e-06 1.00000e-06 1.00000e-06 1.00000e-09 5.00000e-02

Element: 5629 \# of layers: 3

Kx Ky Kz Ss Por

3.40443e+01 3.40443e+01 3.40443e+00 1.00000e-09 7.00000e-02

$3.40443 \mathrm{e}+013.40443 \mathrm{e}+013.40443 \mathrm{e}+00$ 1.00000e-09 7.00000e-02

1.00000e-06 1.00000e-06 1.00000e-06 1.00000e-09 5.00000e-02

Element: 5630 \# of layers: 4

$\mathrm{Kx} \mathrm{Ky} \mathrm{Kz}$ Ss Por

4.01396e+00 4.01396e+00 4.01396e-01 1.00000e-09 7.00000e-02

4.01396e+00 4.01396e+00 4.01396e-01 1.00000e-09 7.00000e-02

$4.01396 \mathrm{e}+004.01396 \mathrm{e}+004.01396 \mathrm{e}-01$ 1.00000e-09 7.00000e-02

1.00000e-06 1.00000e-06 1.00000e-06 1.00000e-09 5.00000e-02

Element: 5631 \# of layers: 4

$\mathrm{Kx} \mathrm{Ky} \mathrm{Kz}$ Ss Por

3.06628e+00 3.06628e+00 3.06628e-01 1.00000e-09 7.00000e-02

$3.06628 \mathrm{e}+003.06628 \mathrm{e}+00$ 3.06628e-01 1.00000e-09 7.00000e-02

$3.06628 \mathrm{e}+00$ 3.06628e+00 3.06628e-01 1.00000e-09 7.00000e-02

1.00000e-06 1.00000e-06 1.00000e-06 1.00000e-09 5.00000e-02

Element: 5632 \# of layers: 4

$\mathrm{Kx} \mathrm{Ky} \mathrm{Kz}$ Ss Por

3.06628e+00 3.06628e+00 3.06628e-01 1.00000e-09 7.00000e-02

$3.06628 \mathrm{e}+003.06628 \mathrm{e}+003.06628 \mathrm{e}-01$ 1.00000e-09 7.00000e-02

$3.06628 \mathrm{e}+003.06628 \mathrm{e}+00$ 3.06628e-01 1.00000e-09 7.00000e-02

1.00000e-06 1.00000e-06 1.00000e-06 1.00000e-09 5.00000e-02

Element: 5633 \# of layers: 4

$\mathrm{Kx} \mathrm{Ky} \mathrm{Kz}$ Ss Por

4.18298e+00 4.18298e+00 4.18298e-01 1.00000e-09 7.00000e-02

4.18298e+00 4.18298e+00 4.18298e-01 1.00000e-09 7.00000e-02

4.18298e+00 4.18298e+00 4.18298e-01 1.00000e-09 7.00000e-02

1.00000e-06 1.00000e-06 1.00000e-06 1.00000e-09 5.00000e-02

Element: 5634 \# of layers: 4

$\mathrm{Kx} \mathrm{Ky} \mathrm{Kz}$ Ss Por

4.18298e+00 4.18298e+00 4.18298e-01 1.00000e-09 7.00000e-02 
4.18298e+00 4.18298e+00 4.18298e-01 1.00000e-09 7.00000e-02 $4.18298 \mathrm{e}+004.18298 \mathrm{e}+00$ 4.18298e-01 1.00000e-09 7.00000e-02 $1.00000 \mathrm{e}-06$ 1.00000e-06 1.00000e-06 1.00000e-09 5.00000e-02 Element: 5635 \# of layers: 4

Kx Ky Kz Ss Por

4.18298e+00 4.18298e+00 4.18298e-01 1.00000e-09 7.00000e-02

$4.18298 \mathrm{e}+004.18298 \mathrm{e}+004.18298 \mathrm{e}-011.00000 \mathrm{e}-09$ 7.00000e-02

$4.18298 \mathrm{e}+004.18298 \mathrm{e}+00$ 4.18298e-01 1.00000e-09 7.00000e-02 1.00000e-06 1.00000e-06 1.00000e-06 1.00000e-09 5.00000e-02

Element: 5636 \# of layers: 4

Kx Ky Kz Ss Por

$4.94658 \mathrm{e}+004.94658 \mathrm{e}+004.94658 \mathrm{e}-01$ 1.00000e-09 7.00000e-02 $4.94658 \mathrm{e}+004.94658 \mathrm{e}+004.94658 \mathrm{e}-011.00000 \mathrm{e}-09$ 7.00000e-02 $4.94658 \mathrm{e}+004.94658 \mathrm{e}+004.94658 \mathrm{e}-011.00000 \mathrm{e}-09$ 7.00000e-02 $1.00000 \mathrm{e}-06$ 1.00000e-06 1.00000e-06 1.00000e-09 5.00000e-02

Element: 5637 \# of layers: 4

Kx Ky Kz Ss Por

$4.94658 \mathrm{e}+004.94658 \mathrm{e}+00$ 4.94658e-01 1.00000e-09 7.00000e-02 $4.94658 \mathrm{e}+004.94658 \mathrm{e}+004.94658 \mathrm{e}-011.00000 \mathrm{e}-09$ 7.00000e-02 $4.94658 \mathrm{e}+004.94658 \mathrm{e}+004.94658 \mathrm{e}-011.00000 \mathrm{e}-09$ 7.00000e-02 $1.00000 \mathrm{e}-06$ 1.00000e-06 1.00000e-06 1.00000e-09 5.00000e-02

Element: 5638 \# of layers: 4

Kx Ky Kz Ss Por

$3.06628 \mathrm{e}+003.06628 \mathrm{e}+00$ 3.06628e-01 1.00000e-09 7.00000e-02 $3.06628 \mathrm{e}+003.06628 \mathrm{e}+003.06628 \mathrm{e}-011.00000 \mathrm{e}-09$ 7.00000e-02 $3.06628 \mathrm{e}+003.06628 \mathrm{e}+003.06628 \mathrm{e}-01$ 1.00000e-09 7.00000e-02 $1.00000 \mathrm{e}-06$ 1.00000e-06 1.00000e-06 1.00000e-09 5.00000e-02 Element: 5639 \# of layers: 5

Kx Ky Kz Ss Por

$2.29187 \mathrm{e}+002.29187 \mathrm{e}+00$ 2.29187e-01 1.00000e-09 7.00000e-02 $2.29187 \mathrm{e}+002.29187 \mathrm{e}+002.29187 \mathrm{e}-011.00000 \mathrm{e}-09$ 7.00000e-02 $2.29187 \mathrm{e}+002.29187 \mathrm{e}+002.29187 \mathrm{e}-01$ 1.00000e-09 7.00000e-02 9.13474e-02 9.13474e-02 9.13474e-03 1.00000e-09 2.12000e-01 $1.00000 \mathrm{e}-06$ 1.00000e-06 1.00000e-06 1.00000e-09 5.00000e-02 Element: 5640 \# of layers: 5

Kx Ky Kz Ss Por

$2.29187 \mathrm{e}+002.29187 \mathrm{e}+002.29187 \mathrm{e}-01$ 1.00000e-09 7.00000e-02 $2.29187 \mathrm{e}+002.29187 \mathrm{e}+002.29187 \mathrm{e}-011.00000 \mathrm{e}-09$ 7.00000e-02 $2.29187 \mathrm{e}+002.29187 \mathrm{e}+00$ 2.29187e-01 1.00000e-09 7.00000e-02 9.13474e-02 9.13474e-02 9.13474e-03 1.00000e-09 2.12000e-01 $1.00000 \mathrm{e}-06$ 1.00000e-06 1.00000e-06 1.00000e-09 5.00000e-02 Element: 5641 \# of layers: 5

Kx Ky Kz Ss Por

$2.33845 \mathrm{e}+002.33845 \mathrm{e}+002.33845 \mathrm{e}-01$ 1.00000e-09 7.00000e-02 $2.33845 \mathrm{e}+002.33845 \mathrm{e}+002.33845 \mathrm{e}-011.00000 \mathrm{e}-09$ 7.00000e-02 $2.33845 \mathrm{e}+002.33845 \mathrm{e}+002.33845 \mathrm{e}-01$ 1.00000e-09 7.00000e-02 
8.86091e-02 8.86091e-02 8.86091e-03 1.00000e-09 2.12000e-01 $1.00000 \mathrm{e}-06$ 1.00000e-06 1.00000e-06 1.00000e-09 5.00000e-02 Element: 5642 \# of layers: 4

Kx Ky Kz Ss Por

3.15089e+00 3.15089e+00 3.15089e-01 1.00000e-09 7.00000e-02

$3.15089 \mathrm{e}+003.15089 \mathrm{e}+003.15089 \mathrm{e}-011.00000 \mathrm{e}-09$ 7.00000e-02

$3.15089 \mathrm{e}+003.15089 \mathrm{e}+003.15089 \mathrm{e}-01$ 1.00000e-09 7.00000e-02

$1.00000 \mathrm{e}-06$ 1.00000e-06 1.00000e-06 1.00000e-09 5.00000e-02

Element: 5643 \# of layers: 4

Kx Ky Kz Ss Por

$3.15089 \mathrm{e}+003.15089 \mathrm{e}+00$ 3.15089e-01 1.00000e-09 7.00000e-02

$3.15089 \mathrm{e}+003.15089 \mathrm{e}+003.15089 \mathrm{e}-01$ 1.00000e-09 7.00000e-02

$3.15089 \mathrm{e}+003.15089 \mathrm{e}+003.15089 \mathrm{e}-01$ 1.00000e-09 7.00000e-02

$1.00000 \mathrm{e}-06$ 1.00000e-06 1.00000e-06 1.00000e-09 5.00000e-02

Element: 5644 \# of layers: 4

Kx Ky Kz Ss Por

3.15089e+00 3.15089e+00 3.15089e-01 1.00000e-09 7.00000e-02

$3.15089 \mathrm{e}+003.15089 \mathrm{e}+003.15089 \mathrm{e}-011.00000 \mathrm{e}-09$ 7.00000e-02

$3.15089 \mathrm{e}+003.15089 \mathrm{e}+00$ 3.15089e-01 1.00000e-09 7.00000e-02

$1.00000 \mathrm{e}-06$ 1.00000e-06 1.00000e-06 1.00000e-09 5.00000e-02

Element: 5645 \# of layers: 4

Kx Ky Kz Ss Por

$3.28901 \mathrm{e}+003.28901 \mathrm{e}+003.28901 \mathrm{e}-011.00000 \mathrm{e}-09$ 7.00000e-02

$3.28901 \mathrm{e}+003.28901 \mathrm{e}+003.28901 \mathrm{e}-011.00000 \mathrm{e}-09$ 7.00000e-02

$3.28901 \mathrm{e}+003.28901 \mathrm{e}+003.28901 \mathrm{e}-011.00000 \mathrm{e}-09$ 7.00000e-02

$1.00000 \mathrm{e}-06$ 1.00000e-06 1.00000e-06 1.00000e-09 5.00000e-02

Element: 5646 \# of layers: 4

Kx Ky Kz Ss Por

$2.29187 \mathrm{e}+002.29187 \mathrm{e}+00$ 2.29187e-01 1.00000e-09 7.00000e-02

$2.29187 \mathrm{e}+002.29187 \mathrm{e}+002.29187 \mathrm{e}-01$ 1.00000e-09 7.00000e-02

$2.29187 \mathrm{e}+002.29187 \mathrm{e}+002.29187 \mathrm{e}-01$ 1.00000e-09 7.00000e-02

1.00000e-06 1.00000e-06 1.00000e-06 1.00000e-09 5.00000e-02

Element: 5647 \# of layers: 4

Kx Ky Kz Ss Por

$2.33845 \mathrm{e}+002.33845 \mathrm{e}+002.33845 \mathrm{e}-01$ 1.00000e-09 7.00000e-02

$2.33845 \mathrm{e}+002.33845 \mathrm{e}+002.33845 \mathrm{e}-011.00000 \mathrm{e}-09$ 7.00000e-02

$2.33845 \mathrm{e}+002.33845 \mathrm{e}+002.33845 \mathrm{e}-011.00000 \mathrm{e}-09$ 7.00000e-02

$1.00000 \mathrm{e}-06$ 1.00000e-06 1.00000e-06 1.00000e-09 5.00000e-02

Element: 5648 \# of layers: 9

Kx Ky Kz Ss Por

$3.75014 \mathrm{e}+023.75014 \mathrm{e}+023.75014 \mathrm{e}+01$ 1.00000e-09 7.00000e-02

$3.75014 \mathrm{e}+023.75014 \mathrm{e}+023.75014 \mathrm{e}+01$ 1.00000e-09 7.00000e-02

$3.75014 \mathrm{e}+023.75014 \mathrm{e}+023.75014 \mathrm{e}+011.00000 \mathrm{e}-097.00000 \mathrm{e}-02$

$5.00000 \mathrm{e}-04$ 5.00000e-04 5.00000e-05 1.00000e-09 1.00000e-01

5.00000e-04 5.00000e-04 5.00000e-05 1.00000e-09 1.00000e-01

$1.49842 \mathrm{e}+011.49842 \mathrm{e}+011.49842 \mathrm{e}+001.00000 \mathrm{e}-092.12000 \mathrm{e}-01$ 
$1.00000 \mathrm{e}-02$ 1.00000e-02 1.00000e-03 1.00000e-09 1.00000e-01 $1.00000 \mathrm{e}+001.00000 \mathrm{e}+001.00000 \mathrm{e}-011.00000 \mathrm{e}-091.00000 \mathrm{e}-01$ 1.00000e-06 1.00000e-06 1.00000e-06 1.00000e-09 5.00000e-02 Element: 5649 \# of layers: 9

$\mathrm{Kx} \mathrm{Ky} \mathrm{Kz}$ Ss Por

3.75014e+02 3.75014e+02 3.75014e+01 1.00000e-09 7.00000e-02 $3.75014 \mathrm{e}+023.75014 \mathrm{e}+023.75014 \mathrm{e}+01$ 1.00000e-09 7.00000e-02 $3.75014 \mathrm{e}+02 \quad 3.75014 \mathrm{e}+023.75014 \mathrm{e}+01$ 1.00000e-09 7.00000e-02 5.00000e-04 5.00000e-04 5.00000e-05 1.00000e-09 1.00000e-01 5.00000e-04 5.00000e-04 5.00000e-05 1.00000e-09 1.00000e-01 $1.49842 \mathrm{e}+01$ 1.49842e+01 1.49842e+00 1.00000e-09 2.12000e-01 $1.00000 \mathrm{e}-02$ 1.00000e-02 1.00000e-03 1.00000e-09 1.00000e-01 $1.00000 \mathrm{e}+001.00000 \mathrm{e}+001.00000 \mathrm{e}-011.00000 \mathrm{e}-091.00000 \mathrm{e}-01$ 1.00000e-06 1.00000e-06 1.00000e-06 1.00000e-09 5.00000e-02 Element: 5650 \# of layers: 9

$\mathrm{Kx} \mathrm{Ky} \mathrm{Kz}$ Ss Por

2.99871e+02 2.99871e+02 2.99871e+01 1.00000e-09 7.00000e-02 $2.99871 \mathrm{e}+022.99871 \mathrm{e}+022.99871 \mathrm{e}+01$ 1.00000e-09 7.00000e-02 5.00000e-04 5.00000e-04 5.00000e-05 1.00000e-09 1.00000e-01 5.00000e-04 5.00000e-04 5.00000e-05 1.00000e-09 1.00000e-01

$1.19820 \mathrm{e}+011.19820 \mathrm{e}+011.19820 \mathrm{e}+001.00000 \mathrm{e}-092.12000 \mathrm{e}-01$ $1.19820 \mathrm{e}+011.19820 \mathrm{e}+011.19820 \mathrm{e}+001.00000 \mathrm{e}-092.12000 \mathrm{e}-01$ $1.00000 \mathrm{e}-02$ 1.00000e-02 1.00000e-03 1.00000e-09 1.00000e-01 $1.00000 \mathrm{e}+001.00000 \mathrm{e}+001.00000 \mathrm{e}-011.00000 \mathrm{e}-091.00000 \mathrm{e}-01$ 1.00000e-06 1.00000e-06 1.00000e-06 1.00000e-09 5.00000e-02 Element: 5651 \# of layers: 10

$\mathrm{Kx} \mathrm{Ky} \mathrm{Kz}$ Ss Por

$2.08600 \mathrm{e}+02$ 2.08600e+02 2.08600e+01 1.00000e-09 7.00000e-02 $2.08600 \mathrm{e}+022.08600 \mathrm{e}+022.08600 \mathrm{e}+01$ 1.00000e-09 7.00000e-02 $2.08600 \mathrm{e}+022.08600 \mathrm{e}+022.08600 \mathrm{e}+01$ 1.00000e-09 7.00000e-02 5.00000e-04 5.00000e-04 5.00000e-05 1.00000e-09 1.00000e-01 5.00000e-04 5.00000e-04 5.00000e-05 1.00000e-09 1.00000e-01 8.33485e+00 8.33485e+00 8.33485e-01 1.00000e-09 2.12000e-01 $8.33485 \mathrm{e}+00$ 8.33485e+00 8.33485e-01 1.00000e-09 2.12000e-01 $1.00000 \mathrm{e}-02$ 1.00000e-02 1.00000e-03 1.00000e-09 1.00000e-01 $1.00000 \mathrm{e}+001.00000 \mathrm{e}+001.00000 \mathrm{e}-011.00000 \mathrm{e}-091.00000 \mathrm{e}-01$ 1.00000e-06 1.00000e-06 1.00000e-06 1.00000e-09 5.00000e-02 Element: 5652 \# of layers: 11

$\mathrm{Kx} \mathrm{Ky} \mathrm{Kz}$ Ss Por

$2.08600 \mathrm{e}+02$ 2.08600e+02 2.08600e+01 1.00000e-09 7.00000e-02 $2.08600 \mathrm{e}+022.08600 \mathrm{e}+022.08600 \mathrm{e}+01$ 1.00000e-09 7.00000e-02 $2.08600 \mathrm{e}+022.08600 \mathrm{e}+022.08600 \mathrm{e}+01$ 1.00000e-09 7.00000e-02 $2.08600 \mathrm{e}+022.08600 \mathrm{e}+022.08600 \mathrm{e}+01$ 1.00000e-09 7.00000e-02 5.00000e-04 5.00000e-04 5.00000e-05 1.00000e-09 1.00000e-01 5.00000e-04 5.00000e-04 5.00000e-05 1.00000e-09 1.00000e-01 8.33485e+00 8.33485e+00 8.33485e-01 1.00000e-09 2.12000e-01 
8.33485e+00 8.33485e+00 8.33485e-01 1.00000e-09 2.12000e-01 $1.00000 \mathrm{e}-02$ 1.00000e-02 1.00000e-03 1.00000e-09 1.00000e-01 $1.00000 \mathrm{e}+001.00000 \mathrm{e}+001.00000 \mathrm{e}-011.00000 \mathrm{e}-091.00000 \mathrm{e}-01$ 1.00000e-06 1.00000e-06 1.00000e-06 1.00000e-09 5.00000e-02 Element: 5653 \# of layers: 10

$\mathrm{Kx} \mathrm{Ky} \mathrm{Kz}$ Ss Por

$2.08600 \mathrm{e}+02$ 2.08600e+02 2.08600e+01 1.00000e-09 7.00000e-02 $2.08600 \mathrm{e}+022.08600 \mathrm{e}+022.08600 \mathrm{e}+01$ 1.00000e-09 7.00000e-02 $2.08600 \mathrm{e}+022.08600 \mathrm{e}+022.08600 \mathrm{e}+01$ 1.00000e-09 7.00000e-02 5.00000e-04 5.00000e-04 5.00000e-05 1.00000e-09 1.00000e-01 5.00000e-04 5.00000e-04 5.00000e-05 1.00000e-09 1.00000e-01 8.33485e+00 8.33485e+00 8.33485e-01 1.00000e-09 2.12000e-01 8.33485e+00 8.33485e+00 8.33485e-01 1.00000e-09 2.12000e-01 $1.00000 \mathrm{e}-02$ 1.00000e-02 1.00000e-03 1.00000e-09 1.00000e-01 $1.00000 \mathrm{e}+001.00000 \mathrm{e}+001.00000 \mathrm{e}-011.00000 \mathrm{e}-091.00000 \mathrm{e}-01$ 1.00000e-06 1.00000e-06 1.00000e-06 1.00000e-09 5.00000e-02 Element: 5654 \# of layers: 9

$\mathrm{Kx} \mathrm{Ky} \mathrm{Kz}$ Ss Por

1.84975e+02 1.84975e+02 1.84975e+01 1.00000e-09 7.00000e-02 $1.84975 \mathrm{e}+02$ 1.84975e+02 1.84975e+01 1.00000e-09 7.00000e-02 $1.84975 \mathrm{e}+021.84975 \mathrm{e}+02 \quad 1.84975 \mathrm{e}+01$ 1.00000e-09 7.00000e-02 5.00000e-04 5.00000e-04 5.00000e-05 1.00000e-09 1.00000e-01 5.00000e-04 5.00000e-04 5.00000e-05 1.00000e-09 1.00000e-01 $7.39118 \mathrm{e}+00$ 7.39118e+00 7.39118e-01 1.00000e-09 2.12000e-01 $1.00000 \mathrm{e}-021.00000 \mathrm{e}-02$ 1.00000e-03 1.00000e-09 1.00000e-01 $1.00000 \mathrm{e}+001.00000 \mathrm{e}+001.00000 \mathrm{e}-011.00000 \mathrm{e}-091.00000 \mathrm{e}-01$ 1.00000e-06 1.00000e-06 1.00000e-06 1.00000e-09 5.00000e-02 Element: 5655 \# of layers: 10

$\mathrm{Kx} \mathrm{Ky} \mathrm{Kz}$ Ss Por $1.84975 \mathrm{e}+02$ 1.84975e+02 1.84975e+01 1.00000e-09 7.00000e-02 $1.84975 \mathrm{e}+02$ 1.84975e+02 1.84975e+01 1.00000e-09 7.00000e-02 $1.84975 \mathrm{e}+02$ 1.84975e+02 1.84975e+01 1.00000e-09 7.00000e-02 5.00000e-04 5.00000e-04 5.00000e-05 1.00000e-09 1.00000e-01 5.00000e-04 5.00000e-04 5.00000e-05 1.00000e-09 1.00000e-01 7.39118e+00 7.39118e+00 7.39118e-01 1.00000e-09 2.12000e-01 7.39118e+00 7.39118e+00 7.39118e-01 1.00000e-09 2.12000e-01 $1.00000 \mathrm{e}-02$ 1.00000e-02 1.00000e-03 1.00000e-09 1.00000e-01 $1.00000 \mathrm{e}+001.00000 \mathrm{e}+001.00000 \mathrm{e}-011.00000 \mathrm{e}-091.00000 \mathrm{e}-01$ 1.00000e-06 1.00000e-06 1.00000e-06 1.00000e-09 5.00000e-02 Element: 5656 \# of layers: 9

$\mathrm{Kx} \mathrm{Ky} \mathrm{Kz}$ Ss Por $1.84975 \mathrm{e}+02$ 1.84975e+02 1.84975e+01 1.00000e-09 7.00000e-02 $1.84975 \mathrm{e}+021.84975 \mathrm{e}+02$ 1.84975e+01 1.00000e-09 7.00000e-02 5.00000e-04 5.00000e-04 5.00000e-05 1.00000e-09 1.00000e-01 5.00000e-04 5.00000e-04 5.00000e-05 1.00000e-09 1.00000e-01 $7.39118 \mathrm{e}+00$ 7.39118e+00 7.39118e-01 1.00000e-09 2.12000e-01 
7.39118e+00 7.39118e+00 7.39118e-01 1.00000e-09 2.12000e-01 $1.00000 \mathrm{e}-02$ 1.00000e-02 1.00000e-03 1.00000e-09 1.00000e-01 $1.00000 \mathrm{e}+001.00000 \mathrm{e}+001.00000 \mathrm{e}-011.00000 \mathrm{e}-091.00000 \mathrm{e}-01$ $1.00000 \mathrm{e}-06$ 1.00000e-06 1.00000e-06 1.00000e-09 5.00000e-02 Element: 5657 \# of layers: 10

Kx Ky Kz Ss Por

$2.37558 \mathrm{e}+022.37558 \mathrm{e}+022.37558 \mathrm{e}+01$ 1.00000e-09 7.00000e-02 $2.37558 \mathrm{e}+022.37558 \mathrm{e}+022.37558 \mathrm{e}+01$ 1.00000e-09 7.00000e-02 $2.37558 \mathrm{e}+022.37558 \mathrm{e}+022.37558 \mathrm{e}+011.00000 \mathrm{e}-097.00000 \mathrm{e}-02$ 5.00000e-04 5.00000e-04 5.00000e-05 1.00000e-09 1.00000e-01 5.00000e-04 5.00000e-04 5.00000e-05 1.00000e-09 1.00000e-01 $9.49183 \mathrm{e}+00$ 9.49183e+00 9.49183e-01 1.00000e-09 2.12000e-01 $9.49183 \mathrm{e}+00$ 9.49183e+00 9.49183e-01 1.00000e-09 2.12000e-01 $1.00000 \mathrm{e}-02$ 1.00000e-02 1.00000e-03 1.00000e-09 1.00000e-01 $1.00000 \mathrm{e}+001.00000 \mathrm{e}+001.00000 \mathrm{e}-011.00000 \mathrm{e}-091.00000 \mathrm{e}-01$ $1.00000 \mathrm{e}-06$ 1.00000e-06 1.00000e-06 1.00000e-09 5.00000e-02 Element: 5658 \# of layers: 10

Kx Ky Kz Ss Por

$2.10825 \mathrm{e}+022.10825 \mathrm{e}+022.10825 \mathrm{e}+01$ 1.00000e-09 7.00000e-02 $2.10825 \mathrm{e}+022.10825 \mathrm{e}+022.10825 \mathrm{e}+01$ 1.00000e-09 7.00000e-02 $2.10825 \mathrm{e}+022.10825 \mathrm{e}+022.10825 \mathrm{e}+01$ 1.00000e-09 7.00000e-02 5.00000e-04 5.00000e-04 5.00000e-05 1.00000e-09 1.00000e-01 5.00000e-04 5.00000e-04 5.00000e-05 1.00000e-09 1.00000e-01 $8.42395 \mathrm{e}+008.42395 \mathrm{e}+008.42396 \mathrm{e}-011.00000 \mathrm{e}-092.12000 \mathrm{e}-01$ $8.42395 \mathrm{e}+008.42395 \mathrm{e}+00$ 8.42396e-01 1.00000e-09 2.12000e-01 $1.00000 \mathrm{e}-02$ 1.00000e-02 1.00000e-03 1.00000e-09 1.00000e-01 $1.00000 \mathrm{e}+001.00000 \mathrm{e}+001.00000 \mathrm{e}-011.00000 \mathrm{e}-091.00000 \mathrm{e}-01$ $1.00000 \mathrm{e}-06$ 1.00000e-06 1.00000e-06 1.00000e-09 5.00000e-02 Element: 5659 \# of layers: 10

Kx Ky Kz Ss Por

$2.10825 \mathrm{e}+022.10825 \mathrm{e}+022.10825 \mathrm{e}+01$ 1.00000e-09 7.00000e-02 $2.10825 \mathrm{e}+022.10825 \mathrm{e}+022.10825 \mathrm{e}+01$ 1.00000e-09 7.00000e-02 $2.10825 \mathrm{e}+022.10825 \mathrm{e}+022.10825 \mathrm{e}+01$ 1.00000e-09 7.00000e-02 5.00000e-04 5.00000e-04 5.00000e-05 1.00000e-09 1.00000e-01 5.00000e-04 5.00000e-04 5.00000e-05 1.00000e-09 1.00000e-01 $8.42395 \mathrm{e}+008.42395 \mathrm{e}+00$ 8.42396e-01 1.00000e-09 2.12000e-01 $8.42395 \mathrm{e}+008.42395 \mathrm{e}+00$ 8.42396e-01 1.00000e-09 2.12000e-01 $1.00000 \mathrm{e}-021.00000 \mathrm{e}-02$ 1.00000e-03 1.00000e-09 1.00000e-01 $1.00000 \mathrm{e}+001.00000 \mathrm{e}+001.00000 \mathrm{e}-011.00000 \mathrm{e}-091.00000 \mathrm{e}-01$ 1.00000e-06 1.00000e-06 1.00000e-06 1.00000e-09 5.00000e-02 Element: 5660 \# of layers: 10

Kx Ky Kz Ss Por

$1.77848 \mathrm{e}+021.77848 \mathrm{e}+021.77848 \mathrm{e}+01$ 1.00000e-09 7.00000e-02 $1.77848 \mathrm{e}+021.77848 \mathrm{e}+021.77848 \mathrm{e}+01$ 1.00000e-09 7.00000e-02 $1.77848 \mathrm{e}+021.77848 \mathrm{e}+021.77848 \mathrm{e}+011.00000 \mathrm{e}-097.00000 \mathrm{e}-02$ 5.00000e-04 5.00000e-04 5.00000e-05 1.00000e-09 1.00000e-01 
5.00000e-04 5.00000e-04 5.00000e-05 1.00000e-09 1.00000e-01

7.10633e+00 7.10633e+00 7.10633e-01 1.00000e-09 2.12000e-01

$7.10633 \mathrm{e}+00$ 7.10633e+00 7.10633e-01 1.00000e-09 2.12000e-01

$1.00000 \mathrm{e}-02$ 1.00000e-02 1.00000e-03 1.00000e-09 1.00000e-01

$1.00000 \mathrm{e}+001.00000 \mathrm{e}+001.00000 \mathrm{e}-011.00000 \mathrm{e}-091.00000 \mathrm{e}-01$

1.00000e-06 1.00000e-06 1.00000e-06 1.00000e-09 5.00000e-02

Element: 5661 \# of layers: 11

$\mathrm{Kx} \mathrm{Ky} \mathrm{Kz}$ Ss Por

$1.77848 \mathrm{e}+02$ 1.77848e+02 1.77848e+01 1.00000e-09 7.00000e-02

$1.77848 \mathrm{e}+02$ 1.77848e+02 1.77848e+01 1.00000e-09 7.00000e-02

$1.77848 \mathrm{e}+02$ 1.77848e+02 1.77848e+01 1.00000e-09 7.00000e-02

$1.77848 \mathrm{e}+02$ 1.77848e+02 1.77848e+01 1.00000e-09 7.00000e-02

5.00000e-04 5.00000e-04 5.00000e-05 1.00000e-09 1.00000e-01

5.00000e-04 5.00000e-04 5.00000e-05 1.00000e-09 1.00000e-01

7.10633e+00 7.10633e+00 7.10633e-01 1.00000e-09 2.12000e-01

7.10633e+00 7.10633e+00 7.10633e-01 1.00000e-09 2.12000e-01

1.00000e-02 1.00000e-02 1.00000e-03 1.00000e-09 1.00000e-01

$1.00000 \mathrm{e}+001.00000 \mathrm{e}+001.00000 \mathrm{e}-011.00000 \mathrm{e}-091.00000 \mathrm{e}-01$

$1.00000 \mathrm{e}-06$ 1.00000e-06 1.00000e-06 1.00000e-09 5.00000e-02

Element: 5662 \# of layers: 11

$\mathrm{Kx} \mathrm{Ky} \mathrm{Kz}$ Ss Por

$1.82101 \mathrm{e}+021.82101 \mathrm{e}+02$ 1.82101e+01 1.00000e-09 7.00000e-02

$1.82101 \mathrm{e}+021.82101 \mathrm{e}+021.82101 \mathrm{e}+01$ 1.00000e-09 7.00000e-02

$1.82101 \mathrm{e}+021.82101 \mathrm{e}+02$ 1.82101e+01 1.00000e-09 7.00000e-02

$1.82101 \mathrm{e}+021.82101 \mathrm{e}+021.82101 \mathrm{e}+011.00000 \mathrm{e}-097.00000 \mathrm{e}-02$

5.00000e-04 5.00000e-04 5.00000e-05 1.00000e-09 1.00000e-01

5.00000e-04 5.00000e-04 5.00000e-05 1.00000e-09 1.00000e-01

$7.27621 \mathrm{e}+007.27621 \mathrm{e}+00$ 7.27621e-01 1.00000e-09 2.12000e-01

$7.27621 \mathrm{e}+007.27621 \mathrm{e}+007.27621 \mathrm{e}-01$ 1.00000e-09 2.12000e-01

$1.00000 \mathrm{e}-02$ 1.00000e-02 1.00000e-03 1.00000e-09 1.00000e-01

$1.00000 \mathrm{e}+001.00000 \mathrm{e}+001.00000 \mathrm{e}-011.00000 \mathrm{e}-091.00000 \mathrm{e}-01$

1.00000e-06 1.00000e-06 1.00000e-06 1.00000e-09 5.00000e-02

Element: 5663 \# of layers: 11

$\mathrm{Kx} \mathrm{Ky} \mathrm{Kz}$ Ss Por

$1.82101 \mathrm{e}+021.82101 \mathrm{e}+02$ 1.82101e+01 1.00000e-09 7.00000e-02

$1.82101 \mathrm{e}+021.82101 \mathrm{e}+021.82101 \mathrm{e}+01$ 1.00000e-09 7.00000e-02

$1.82101 \mathrm{e}+021.82101 \mathrm{e}+021.82101 \mathrm{e}+01$ 1.00000e-09 7.00000e-02

$1.82101 \mathrm{e}+021.82101 \mathrm{e}+021.82101 \mathrm{e}+01$ 1.00000e-09 7.00000e-02

5.00000e-04 5.00000e-04 5.00000e-05 1.00000e-09 1.00000e-01

5.00000e-04 5.00000e-04 5.00000e-05 1.00000e-09 1.00000e-01

$7.27621 \mathrm{e}+007.27621 \mathrm{e}+00$ 7.27621e-01 1.00000e-09 2.12000e-01

$7.27621 \mathrm{e}+007.27621 \mathrm{e}+00$ 7.27621e-01 1.00000e-09 2.12000e-01

$1.00000 \mathrm{e}-021.00000 \mathrm{e}-021.00000 \mathrm{e}-031.00000 \mathrm{e}-091.00000 \mathrm{e}-01$

$1.00000 \mathrm{e}+001.00000 \mathrm{e}+001.00000 \mathrm{e}-011.00000 \mathrm{e}-091.00000 \mathrm{e}-01$

$1.00000 \mathrm{e}-06$ 1.00000e-06 1.00000e-06 1.00000e-09 5.00000e-02

Element: 5664 \# of layers: 10 
$\mathrm{Kx} \mathrm{Ky} \mathrm{Kz}$ Ss Por

2.37558e+02 2.37558e+02 2.37558e+01 1.00000e-09 7.00000e-02

$2.37558 \mathrm{e}+02$ 2.37558e+02 2.37558e+01 1.00000e-09 7.00000e-02

$2.37558 \mathrm{e}+02$ 2.37558e+02 2.37558e+01 1.00000e-09 7.00000e-02

5.00000e-04 5.00000e-04 5.00000e-05 1.00000e-09 1.00000e-01

5.00000e-04 5.00000e-04 5.00000e-05 1.00000e-09 1.00000e-01

9.49183e+00 9.49183e+00 9.49183e-01 1.00000e-09 2.12000e-01

$9.49183 \mathrm{e}+00$ 9.49183e+00 9.49183e-01 1.00000e-09 2.12000e-01

$1.00000 \mathrm{e}-02$ 1.00000e-02 1.00000e-03 1.00000e-09 1.00000e-01

$1.00000 \mathrm{e}+001.00000 \mathrm{e}+001.00000 \mathrm{e}-011.00000 \mathrm{e}-091.00000 \mathrm{e}-01$

1.00000e-06 1.00000e-06 1.00000e-06 1.00000e-09 5.00000e-02

Element: 5665 \# of layers: 10

$\mathrm{Kx} \mathrm{Ky} \mathrm{Kz}$ Ss Por

$1.77848 \mathrm{e}+02$ 1.77848e+02 1.77848e+01 1.00000e-09 7.00000e-02

1.77848e+02 1.77848e+02 1.77848e+01 1.00000e-09 7.00000e-02

$1.77848 \mathrm{e}+021.77848 \mathrm{e}+02$ 1.77848e+01 1.00000e-09 7.00000e-02

5.00000e-04 5.00000e-04 5.00000e-05 1.00000e-09 1.00000e-01

5.00000e-04 5.00000e-04 5.00000e-05 1.00000e-09 1.00000e-01

7.10633e+00 7.10633e+00 7.10633e-01 1.00000e-09 2.12000e-01

7.10633e+00 7.10633e+00 7.10633e-01 1.00000e-09 2.12000e-01

$1.00000 \mathrm{e}-02$ 1.00000e-02 1.00000e-03 1.00000e-09 1.00000e-01

$1.00000 \mathrm{e}+001.00000 \mathrm{e}+001.00000 \mathrm{e}-011.00000 \mathrm{e}-091.00000 \mathrm{e}-01$

$1.00000 \mathrm{e}-06$ 1.00000e-06 1.00000e-06 1.00000e-09 5.00000e-02

Element: 5666 \# of layers: 10

$\mathrm{Kx} \mathrm{Ky} \mathrm{Kz}$ Ss Por

$1.93255 \mathrm{e}+02$ 1.93255e+02 1.93255e+01 1.00000e-09 7.00000e-02

$1.93255 \mathrm{e}+021.93255 \mathrm{e}+02$ 1.93255e+01 1.00000e-09 7.00000e-02

$1.93255 \mathrm{e}+02$ 1.93255e+02 1.93255e+01 1.00000e-09 7.00000e-02

5.00000e-04 5.00000e-04 5.00000e-05 1.00000e-09 1.00000e-01

5.00000e-04 5.00000e-04 5.00000e-05 1.00000e-09 1.00000e-01

$7.72194 \mathrm{e}+007.72194 \mathrm{e}+00$ 7.72194e-01 1.00000e-09 2.12000e-01

$7.72194 \mathrm{e}+00$ 7.72194e+00 7.72194e-01 1.00000e-09 2.12000e-01

1.00000e-02 1.00000e-02 1.00000e-03 1.00000e-09 1.00000e-01

$1.00000 \mathrm{e}+001.00000 \mathrm{e}+001.00000 \mathrm{e}-011.00000 \mathrm{e}-091.00000 \mathrm{e}-01$

1.00000e-06 1.00000e-06 1.00000e-06 1.00000e-09 5.00000e-02

Element: 5667 \# of layers: 10

Kx Ky Kz Ss Por

$1.67117 \mathrm{e}+02$ 1.67117e+02 1.67117e+01 1.00000e-09 7.00000e-02

$1.67117 \mathrm{e}+02$ 1.67117e+02 1.67117e+01 1.00000e-09 7.00000e-02

$1.67117 \mathrm{e}+021.67117 \mathrm{e}+02$ 1.67117e+01 1.00000e-09 7.00000e-02

5.00000e-04 5.00000e-04 5.00000e-05 1.00000e-09 1.00000e-01

5.00000e-04 5.00000e-04 5.00000e-05 1.00000e-09 1.00000e-01

6.67747e+00 6.67747e+00 6.67747e-01 1.00000e-09 2.12000e-01

6.67747e+00 6.67747e+00 6.67747e-01 1.00000e-09 2.12000e-01

$1.00000 \mathrm{e}-02$ 1.00000e-02 1.00000e-03 1.00000e-09 1.00000e-01

$1.00000 \mathrm{e}+001.00000 \mathrm{e}+001.00000 \mathrm{e}-011.00000 \mathrm{e}-091.00000 \mathrm{e}-01$ 
1.00000e-06 1.00000e-06 1.00000e-06 1.00000e-09 5.00000e-02

Element: 5668 \# of layers: 9

Kx Ky Kz Ss Por

1.67117e+02 1.67117e+02 1.67117e+01 1.00000e-09 7.00000e-02

$1.67117 \mathrm{e}+02$ 1.67117e+02 1.67117e+01 1.00000e-09 7.00000e-02

$1.67117 \mathrm{e}+021.67117 \mathrm{e}+02$ 1.67117e+01 1.00000e-09 7.00000e-02

5.00000e-04 5.00000e-04 5.00000e-05 1.00000e-09 1.00000e-01

5.00000e-04 5.00000e-04 5.00000e-05 1.00000e-09 1.00000e-01

6.67747e+00 6.67747e+00 6.67747e-01 1.00000e-09 2.12000e-01

$1.00000 \mathrm{e}-02$ 1.00000e-02 1.00000e-03 1.00000e-09 1.00000e-01

$1.00000 \mathrm{e}+001.00000 \mathrm{e}+001.00000 \mathrm{e}-011.00000 \mathrm{e}-091.00000 \mathrm{e}-01$

1.00000e-06 1.00000e-06 1.00000e-06 1.00000e-09 5.00000e-02

Element: 5669 \# of layers: 8

$\mathrm{Kx} \mathrm{Ky} \mathrm{Kz}$ Ss Por

1.67117e+02 1.67117e+02 1.67117e+01 1.00000e-09 7.00000e-02

$1.67117 \mathrm{e}+02$ 1.67117e+02 1.67117e+01 1.00000e-09 7.00000e-02

$1.67117 \mathrm{e}+02$ 1.67117e+02 1.67117e+01 1.00000e-09 7.00000e-02

6.67747e+00 6.67747e+00 6.67747e-01 1.00000e-09 2.12000e-01

6.67747e+00 6.67747e+00 6.67747e-01 1.00000e-09 2.12000e-01

$1.00000 \mathrm{e}-02$ 1.00000e-02 1.00000e-03 1.00000e-09 1.00000e-01

$1.00000 \mathrm{e}+001.00000 \mathrm{e}+001.00000 \mathrm{e}-011.00000 \mathrm{e}-091.00000 \mathrm{e}-01$

1.00000e-06 1.00000e-06 1.00000e-06 1.00000e-09 5.00000e-02

Element: 5670 \# of layers: 9

Kx Ky Kz Ss Por

$1.65865 \mathrm{e}+02$ 1.65865e+02 1.65865e+01 1.00000e-09 7.00000e-02

$1.65865 \mathrm{e}+021.65865 \mathrm{e}+02$ 1.65865e+01 1.00000e-09 7.00000e-02

$1.65865 \mathrm{e}+021.65865 \mathrm{e}+021.65865 \mathrm{e}+01$ 1.00000e-09 7.00000e-02

$1.65865 \mathrm{e}+02$ 1.65865e+02 1.65865e+01 1.00000e-09 7.00000e-02

$6.62729 \mathrm{e}+00$ 6.62729e+00 6.62729e-01 1.00000e-09 2.12000e-01

$6.62729 \mathrm{e}+00$ 6.62729e+00 6.62729e-01 1.00000e-09 2.12000e-01

$1.00000 \mathrm{e}-02$ 1.00000e-02 1.00000e-03 1.00000e-09 1.00000e-01

$1.00000 \mathrm{e}+001.00000 \mathrm{e}+001.00000 \mathrm{e}-011.00000 \mathrm{e}-091.00000 \mathrm{e}-01$

1.00000e-06 1.00000e-06 1.00000e-06 1.00000e-09 5.00000e-02

Element: 5671 \# of layers: 9

$\mathrm{Kx} \mathrm{Ky} \mathrm{Kz}$ Ss Por

1.72199e+02 1.72199e+02 1.72199e+01 1.00000e-09 7.00000e-02

$1.72199 \mathrm{e}+021.72199 \mathrm{e}+02$ 1.72199e+01 1.00000e-09 7.00000e-02

$1.72199 \mathrm{e}+021.72199 \mathrm{e}+02$ 1.72199e+01 1.00000e-09 7.00000e-02

$1.72199 \mathrm{e}+02$ 1.72199e+02 1.72199e+01 1.00000e-09 7.00000e-02

6.88042e+00 6.88042e+00 6.88042e-01 1.00000e-09 2.12000e-01

$6.88042 \mathrm{e}+006.88042 \mathrm{e}+00$ 6.88042e-01 1.00000e-09 2.12000e-01

$1.00000 \mathrm{e}-02$ 1.00000e-02 1.00000e-03 1.00000e-09 1.00000e-01

$1.00000 \mathrm{e}+001.00000 \mathrm{e}+001.00000 \mathrm{e}-011.00000 \mathrm{e}-091.00000 \mathrm{e}-01$

1.00000e-06 1.00000e-06 1.00000e-06 1.00000e-09 5.00000e-02

Element: 5672 \# of layers: 9

Kx Ky Kz Ss Por 
1.72199e+02 1.72199e+02 1.72199e+01 1.00000e-09 7.00000e-02 $1.72199 \mathrm{e}+02$ 1.72199e+02 1.72199e+01 1.00000e-09 7.00000e-02 $1.72199 \mathrm{e}+02$ 1.72199e+02 1.72199e+01 1.00000e-09 7.00000e-02 $1.72199 \mathrm{e}+02$ 1.72199e+02 1.72199e+01 1.00000e-09 7.00000e-02 $6.88042 \mathrm{e}+006.88042 \mathrm{e}+00$ 6.88042e-01 1.00000e-09 2.12000e-01 $6.88042 \mathrm{e}+006.88042 \mathrm{e}+00$ 6.88042e-01 1.00000e-09 2.12000e-01 $1.00000 \mathrm{e}-02$ 1.00000e-02 1.00000e-03 1.00000e-09 1.00000e-01 $1.00000 \mathrm{e}+001.00000 \mathrm{e}+001.00000 \mathrm{e}-011.00000 \mathrm{e}-091.00000 \mathrm{e}-01$ $1.00000 \mathrm{e}-06$ 1.00000e-06 1.00000e-06 1.00000e-09 5.00000e-02 Element: 5673 \# of layers: 10

$\mathrm{Kx} \mathrm{Ky} \mathrm{Kz}$ Ss Por

$1.93255 \mathrm{e}+02$ 1.93255e+02 1.93255e+01 1.00000e-09 7.00000e-02 $1.93255 \mathrm{e}+02$ 1.93255e+02 1.93255e+01 1.00000e-09 7.00000e-02 $1.93255 \mathrm{e}+021.93255 \mathrm{e}+021.93255 \mathrm{e}+01$ 1.00000e-09 7.00000e-02 5.00000e-04 5.00000e-04 5.00000e-05 1.00000e-09 1.00000e-01 5.00000e-04 5.00000e-04 5.00000e-05 1.00000e-09 1.00000e-01

$7.72194 \mathrm{e}+00$ 7.72194e+00 7.72194e-01 1.00000e-09 2.12000e-01 $7.72194 \mathrm{e}+00$ 7.72194e+00 7.72194e-01 1.00000e-09 2.12000e-01 $1.00000 \mathrm{e}-02$ 1.00000e-02 1.00000e-03 1.00000e-09 1.00000e-01 $1.00000 \mathrm{e}+001.00000 \mathrm{e}+001.00000 \mathrm{e}-011.00000 \mathrm{e}-091.00000 \mathrm{e}-01$ 1.00000e-06 1.00000e-06 1.00000e-06 1.00000e-09 5.00000e-02 Element: 5674 \# of layers: 8

$\mathrm{Kx} \mathrm{Ky} \mathrm{Kz}$ Ss Por

$1.93255 \mathrm{e}+02$ 1.93255e+02 1.93255e+01 1.00000e-09 7.00000e-02 $1.93255 \mathrm{e}+02$ 1.93255e+02 1.93255e+01 1.00000e-09 7.00000e-02 $1.93255 \mathrm{e}+02$ 1.93255e+02 1.93255e+01 1.00000e-09 7.00000e-02 $7.72194 \mathrm{e}+007.72194 \mathrm{e}+007.72194 \mathrm{e}-01$ 1.00000e-09 2.12000e-01 $7.72194 \mathrm{e}+00$ 7.72194e+00 7.72194e-01 1.00000e-09 2.12000e-01 $1.00000 \mathrm{e}-02$ 1.00000e-02 1.00000e-03 1.00000e-09 1.00000e-01 $1.00000 \mathrm{e}+001.00000 \mathrm{e}+001.00000 \mathrm{e}-011.00000 \mathrm{e}-091.00000 \mathrm{e}-01$ 1.00000e-06 1.00000e-06 1.00000e-06 1.00000e-09 5.00000e-02 Element: 5675 \# of layers: 9

$\mathrm{Kx} \mathrm{Ky} \mathrm{Kz}$ Ss Por

1.24203e+02 1.24203e+02 1.24203e+01 1.00000e-09 7.00000e-02 $1.24203 \mathrm{e}+02$ 1.24203e+02 1.24203e+01 1.00000e-09 7.00000e-02 $1.24203 \mathrm{e}+02$ 1.24203e+02 1.24203e+01 1.00000e-09 7.00000e-02 $1.24203 \mathrm{e}+021.24203 \mathrm{e}+02$ 1.24203e+01 1.00000e-09 7.00000e-02 5.00000e-04 5.00000e-04 5.00000e-05 1.00000e-09 1.00000e-01 4.96248e+00 4.96248e+00 4.96248e-01 1.00000e-09 2.12000e-01 $1.00000 \mathrm{e}-02$ 1.00000e-02 1.00000e-03 1.00000e-09 1.00000e-01 $1.00000 \mathrm{e}+001.00000 \mathrm{e}+001.00000 \mathrm{e}-011.00000 \mathrm{e}-091.00000 \mathrm{e}-01$ 1.00000e-06 1.00000e-06 1.00000e-06 1.00000e-09 5.00000e-02 Element: 5676 \# of layers: 8

$\mathrm{Kx} \mathrm{Ky} \mathrm{Kz}$ Ss Por

$1.41115 \mathrm{e}+02$ 1.41115e+02 1.41115e+01 1.00000e-09 7.00000e-02 $1.41115 \mathrm{e}+02$ 1.41115e+02 1.41115e+01 1.00000e-09 7.00000e-02 
1.41115e+02 1.41115e+02 1.41115e+01 1.00000e-09 7.00000e-02 $1.41115 \mathrm{e}+02$ 1.41115e+02 1.41115e+01 1.00000e-09 7.00000e-02 $5.63839 \mathrm{e}+00$ 5.63839e+00 5.63839e-01 1.00000e-09 2.12000e-01 $1.00000 \mathrm{e}-02$ 1.00000e-02 1.00000e-03 1.00000e-09 1.00000e-01 $1.00000 \mathrm{e}+001.00000 \mathrm{e}+001.00000 \mathrm{e}-011.00000 \mathrm{e}-091.00000 \mathrm{e}-01$ 1.00000e-06 1.00000e-06 1.00000e-06 1.00000e-09 5.00000e-02 Element: 5677 \# of layers: 9

Kx Ky Kz Ss Por

$5.84794 \mathrm{e}+015.84794 \mathrm{e}+015.84794 \mathrm{e}+001.00000 \mathrm{e}-09$ 7.00000e-02 $5.84794 \mathrm{e}+015.84794 \mathrm{e}+015.84794 \mathrm{e}+001.00000 \mathrm{e}-097.00000 \mathrm{e}-02$ $5.84794 \mathrm{e}+015.84794 \mathrm{e}+015.84794 \mathrm{e}+001.00000 \mathrm{e}-09$ 7.00000e-02 $5.84794 \mathrm{e}+015.84794 \mathrm{e}+015.84794 \mathrm{e}+001.00000 \mathrm{e}-09$ 7.00000e-02 $2.33667 \mathrm{e}+002.33667 \mathrm{e}+00$ 2.33667e-01 1.00000e-09 2.12000e-01 2.33667e+00 2.33667e+00 2.33667e-01 1.00000e-09 2.12000e-01 $1.00000 \mathrm{e}-02$ 1.00000e-02 1.00000e-03 1.00000e-09 1.00000e-01 $1.00000 \mathrm{e}+001.00000 \mathrm{e}+001.00000 \mathrm{e}-011.00000 \mathrm{e}-091.00000 \mathrm{e}-01$ 1.00000e-06 1.00000e-06 1.00000e-06 1.00000e-09 5.00000e-02 Element: 5681 \# of layers: 9

$\mathrm{Kx} \mathrm{Ky} \mathrm{Kz}$ Ss Por

1.33213e+02 1.33213e+02 1.33213e+01 1.00000e-09 7.00000e-02 $1.33213 \mathrm{e}+02$ 1.33213e+02 1.33213e+01 1.00000e-09 7.00000e-02 1.33213e+02 1.33213e+02 1.33213e+01 1.00000e-09 7.00000e-02 1.33213e+02 1.33213e+02 1.33213e+01 1.00000e-09 7.00000e-02 $5.32271 \mathrm{e}+00$ 5.32271e+00 5.32271e-01 1.00000e-09 2.12000e-01 $5.32271 \mathrm{e}+00$ 5.32271e+00 5.32271e-01 1.00000e-09 2.12000e-01 $1.00000 \mathrm{e}-021.00000 \mathrm{e}-021.00000 \mathrm{e}-031.00000 \mathrm{e}-091.00000 \mathrm{e}-01$ $1.00000 \mathrm{e}+001.00000 \mathrm{e}+001.00000 \mathrm{e}-011.00000 \mathrm{e}-091.00000 \mathrm{e}-01$ 1.00000e-06 1.00000e-06 1.00000e-06 1.00000e-09 5.00000e-02 Element: 5682 \# of layers: 7

$\mathrm{Kx} \mathrm{Ky} \mathrm{Kz}$ Ss Por

$1.41115 \mathrm{e}+02$ 1.41115e+02 1.41115e+01 1.00000e-09 7.00000e-02 $1.41115 \mathrm{e}+02$ 1.41115e+02 1.41115e+01 1.00000e-09 7.00000e-02 $1.41115 \mathrm{e}+021.41115 \mathrm{e}+02$ 1.41115e+01 1.00000e-09 7.00000e-02 5.63839e+00 5.63839e+00 5.63839e-01 1.00000e-09 2.12000e-01 $1.00000 \mathrm{e}-02$ 1.00000e-02 1.00000e-03 1.00000e-09 1.00000e-01 $1.00000 \mathrm{e}+001.00000 \mathrm{e}+001.00000 \mathrm{e}-011.00000 \mathrm{e}-091.00000 \mathrm{e}-01$ 1.00000e-06 1.00000e-06 1.00000e-06 1.00000e-09 5.00000e-02 Element: 5684 \# of layers: 8

$\mathrm{Kx} \mathrm{Ky} \mathrm{Kz}$ Ss Por

$1.64171 \mathrm{e}+02$ 1.64171e+02 1.64171e+01 1.00000e-09 7.00000e-02 $1.64171 \mathrm{e}+021.64171 \mathrm{e}+021.64171 \mathrm{e}+01$ 1.00000e-09 7.00000e-02 $1.64171 \mathrm{e}+021.64171 \mathrm{e}+02$ 1.64171e+01 1.00000e-09 7.00000e-02 $1.64171 \mathrm{e}+021.64171 \mathrm{e}+02$ 1.64171e+01 1.00000e-09 7.00000e-02 6.55979e+00 6.55979e+00 6.55979e-01 1.00000e-09 2.12000e-01 $1.00000 \mathrm{e}-02$ 1.00000e-02 1.00000e-03 1.00000e-09 1.00000e-01 $1.00000 \mathrm{e}+001.00000 \mathrm{e}+001.00000 \mathrm{e}-011.00000 \mathrm{e}-091.00000 \mathrm{e}-01$ 
1.00000e-06 1.00000e-06 1.00000e-06 1.00000e-09 5.00000e-02

Element: 5685 \# of layers: 8

Kx Ky Kz Ss Por

$1.64171 \mathrm{e}+02$ 1.64171e+02 1.64171e+01 1.00000e-09 7.00000e-02

$1.64171 \mathrm{e}+021.64171 \mathrm{e}+021.64171 \mathrm{e}+01$ 1.00000e-09 7.00000e-02

$1.64171 \mathrm{e}+021.64171 \mathrm{e}+02$ 1.64171e+01 1.00000e-09 7.00000e-02

$1.64171 \mathrm{e}+02$ 1.64171e+02 1.64171e+01 1.00000e-09 7.00000e-02

$6.55979 \mathrm{e}+00$ 6.55979e+00 6.55979e-01 1.00000e-09 2.12000e-01

$1.00000 \mathrm{e}-02$ 1.00000e-02 1.00000e-03 1.00000e-09 1.00000e-01

$1.00000 \mathrm{e}+001.00000 \mathrm{e}+001.00000 \mathrm{e}-011.00000 \mathrm{e}-091.00000 \mathrm{e}-01$

1.00000e-06 1.00000e-06 1.00000e-06 1.00000e-09 5.00000e-02

Element: 5686 \# of layers: 9

$\mathrm{Kx} \mathrm{Ky} \mathrm{Kz}$ Ss Por

$1.64171 \mathrm{e}+02$ 1.64171e+02 1.64171e+01 1.00000e-09 7.00000e-02

$1.64171 \mathrm{e}+021.64171 \mathrm{e}+02$ 1.64171e+01 1.00000e-09 7.00000e-02

$1.64171 \mathrm{e}+021.64171 \mathrm{e}+021.64171 \mathrm{e}+01$ 1.00000e-09 7.00000e-02

$1.64171 \mathrm{e}+02$ 1.64171e+02 1.64171e+01 1.00000e-09 7.00000e-02

$6.55979 \mathrm{e}+00$ 6.55979e+00 6.55979e-01 1.00000e-09 2.12000e-01

6.55979e+00 6.55979e+00 6.55979e-01 1.00000e-09 2.12000e-01

1.00000e-02 1.00000e-02 1.00000e-03 1.00000e-09 1.00000e-01

$1.00000 \mathrm{e}+001.00000 \mathrm{e}+001.00000 \mathrm{e}-011.00000 \mathrm{e}-091.00000 \mathrm{e}-01$

1.00000e-06 1.00000e-06 1.00000e-06 1.00000e-09 5.00000e-02

Element: 5687 \# of layers: 7

Kx Ky Kz Ss Por

$6.36493 e+016.36493 e+016.36493 e+001.00000 e-09$ 7.00000e-02

$6.36493 \mathrm{e}+016.36493 \mathrm{e}+01$ 6.36493e+00 1.00000e-09 7.00000e-02

$6.36493 \mathrm{e}+016.36493 \mathrm{e}+01$ 6.36493e+00 1.00000e-09 7.00000e-02

$2.54323 \mathrm{e}+00$ 2.54323e+00 2.54323e-01 1.00000e-09 2.12000e-01

$2.54323 \mathrm{e}+002.54323 \mathrm{e}+00$ 2.54323e-01 1.00000e-09 2.12000e-01

$1.00000 \mathrm{e}-02$ 1.00000e-02 1.00000e-03 1.00000e-09 1.00000e-01

$1.00000 \mathrm{e}+001.00000 \mathrm{e}+001.00000 \mathrm{e}-011.00000 \mathrm{e}-091.00000 \mathrm{e}-01$

Element: 5688 \# of layers: 7

$\mathrm{Kx} \mathrm{Ky} \mathrm{Kz}$ Ss Por

6.36493e+01 6.36493e+01 6.36493e+00 1.00000e-09 7.00000e-02

$6.36493 \mathrm{e}+016.36493 \mathrm{e}+016.36493 \mathrm{e}+00$ 1.00000e-09 7.00000e-02

$6.36493 \mathrm{e}+016.36493 \mathrm{e}+016.36493 \mathrm{e}+00$ 1.00000e-09 7.00000e-02

$2.54323 \mathrm{e}+002.54323 \mathrm{e}+00$ 2.54323e-01 1.00000e-09 2.12000e-01

$1.00000 \mathrm{e}-02$ 1.00000e-02 1.00000e-03 1.00000e-09 1.00000e-01

$1.00000 \mathrm{e}+001.00000 \mathrm{e}+001.00000 \mathrm{e}-011.00000 \mathrm{e}-091.00000 \mathrm{e}-01$

1.00000e-06 1.00000e-06 1.00000e-06 1.00000e-09 5.00000e-02

Element: 5689 \# of layers: 7

$\mathrm{Kx} \mathrm{Ky} \mathrm{Kz}$ Ss Por

6.36493e+01 6.36493e+01 6.36493e+00 1.00000e-09 7.00000e-02

6.36493e+01 6.36493e+01 6.36493e+00 1.00000e-09 7.00000e-02

$6.36493 \mathrm{e}+016.36493 \mathrm{e}+016.36493 \mathrm{e}+00$ 1.00000e-09 7.00000e-02

$2.54323 \mathrm{e}+002.54323 \mathrm{e}+00$ 2.54323e-01 1.00000e-09 2.12000e-01 
$1.00000 \mathrm{e}-02$ 1.00000e-02 1.00000e-03 1.00000e-09 1.00000e-01 $1.00000 \mathrm{e}+001.00000 \mathrm{e}+001.00000 \mathrm{e}-011.00000 \mathrm{e}-091.00000 \mathrm{e}-01$ $1.00000 \mathrm{e}-06$ 1.00000e-06 1.00000e-06 1.00000e-09 5.00000e-02

Element: 5690 \# of layers: 2

$\mathrm{Kx} \mathrm{Ky} \mathrm{Kz}$ Ss Por

3.77555e+02 3.77555e+02 3.77555e+01 1.00000e-09 7.00000e-02 $1.00000 \mathrm{e}-06$ 1.00000e-06 1.00000e-06 1.00000e-09 5.00000e-02

Element: 5691 \# of layers: 3

$\mathrm{Kx} \mathrm{Ky} \mathrm{Kz}$ Ss Por

3.85583e+03 3.85583e+03 3.85583e+02 1.00000e-09 7.00000e-02

$3.85583 \mathrm{e}+03$ 3.85583e+03 3.85583e+02 1.00000e-09 7.00000e-02

1.00000e-06 1.00000e-06 1.00000e-06 1.00000e-09 5.00000e-02

Element: 5692 \# of layers: 4

$\mathrm{Kx} \mathrm{Ky} \mathrm{Kz}$ Ss Por

3.85583e+03 3.85583e+03 3.85583e+02 1.00000e-09 7.00000e-02

$3.85583 \mathrm{e}+03$ 3.85583e+03 3.85583e+02 1.00000e-09 7.00000e-02

$3.85583 \mathrm{e}+03$ 3.85583e+03 3.85583e+02 1.00000e-09 7.00000e-02

1.00000e-06 1.00000e-06 1.00000e-06 1.00000e-09 5.00000e-02

Element: 5693 \# of layers: 4

$\mathrm{Kx} \mathrm{Ky} \mathrm{Kz}$ Ss Por

3.53102e+03 3.53102e+03 3.53102e+02 1.00000e-09 7.00000e-02

$3.53102 \mathrm{e}+033.53102 \mathrm{e}+033.53102 \mathrm{e}+02$ 1.00000e-09 7.00000e-02

$3.53102 \mathrm{e}+033.53102 \mathrm{e}+03$ 3.53102e+02 1.00000e-09 7.00000e-02

1.00000e-06 1.00000e-06 1.00000e-06 1.00000e-09 5.00000e-02

Element: 5694 \# of layers: 5

$\mathrm{Kx} \mathrm{Ky} \mathrm{Kz}$ Ss Por

3.53102e+03 3.53102e+03 3.53102e+02 1.00000e-09 7.00000e-02

$3.53102 \mathrm{e}+03$ 3.53102e+03 3.53102e+02 1.00000e-09 7.00000e-02

$3.53102 \mathrm{e}+03$ 3.53102e+03 3.53102e+02 1.00000e-09 7.00000e-02

$3.53102 \mathrm{e}+03$ 3.53102e+03 3.53102e+02 1.00000e-09 7.00000e-02

$1.00000 \mathrm{e}-06$ 1.00000e-06 1.00000e-06 1.00000e-09 5.00000e-02

Element: 5695 \# of layers: 4

Kx Ky Kz Ss Por

$1.82434 \mathrm{e}+031.82434 \mathrm{e}+03$ 1.82434e+02 1.00000e-09 7.00000e-02

$1.82434 \mathrm{e}+031.82434 \mathrm{e}+03 \quad 1.82434 \mathrm{e}+02$ 1.00000e-09 7.00000e-02

$1.82434 \mathrm{e}+031.82434 \mathrm{e}+031.82434 \mathrm{e}+02$ 1.00000e-09 7.00000e-02

1.00000e-06 1.00000e-06 1.00000e-06 1.00000e-09 5.00000e-02

Element: 5696 \# of layers: 4

$\mathrm{Kx} \mathrm{Ky} \mathrm{Kz}$ Ss Por

$1.82434 \mathrm{e}+03$ 1.82434e+03 1.82434e+02 1.00000e-09 7.00000e-02

$1.82434 \mathrm{e}+031.82434 \mathrm{e}+031.82434 \mathrm{e}+021.00000 \mathrm{e}-097.00000 \mathrm{e}-02$

$1.82434 \mathrm{e}+031.82434 \mathrm{e}+031.82434 \mathrm{e}+02$ 1.00000e-09 7.00000e-02

1.00000e-06 1.00000e-06 1.00000e-06 1.00000e-09 5.00000e-02

Element: 5697 \# of layers: 3

$\mathrm{Kx} \mathrm{Ky} \mathrm{Kz}$ Ss Por

$1.82434 \mathrm{e}+03$ 1.82434e+03 1.82434e+02 1.00000e-09 7.00000e-02 
$1.82434 \mathrm{e}+03$ 1.82434e+03 1.82434e+02 1.00000e-09 7.00000e-02 1.00000e-06 1.00000e-06 1.00000e-06 1.00000e-09 5.00000e-02

Element: 5698 \# of layers: 4

Kx Ky Kz Ss Por

3.85583e+03 3.85583e+03 3.85583e+02 1.00000e-09 7.00000e-02

$3.85583 \mathrm{e}+03$ 3.85583e+03 3.85583e+02 1.00000e-09 7.00000e-02

$3.85583 \mathrm{e}+033.85583 \mathrm{e}+03$ 3.85583e+02 1.00000e-09 7.00000e-02

$1.00000 \mathrm{e}-06$ 1.00000e-06 1.00000e-06 1.00000e-09 5.00000e-02

Element: 5699 \# of layers: 4

$\mathrm{Kx} \mathrm{Ky} \mathrm{Kz}$ Ss Por

3.40542e+03 3.40542e+03 3.40542e+02 1.00000e-09 7.00000e-02

$3.40542 \mathrm{e}+03$ 3.40542e+03 3.40542e+02 1.00000e-09 7.00000e-02

$3.40542 \mathrm{e}+03$ 3.40542e+03 3.40542e+02 1.00000e-09 7.00000e-02

1.00000e-06 1.00000e-06 1.00000e-06 1.00000e-09 5.00000e-02

Element: 5700 \# of layers: 4

Kx Ky Kz Ss Por

$2.75589 \mathrm{e}+03$ 2.75589e+03 2.75589e+02 1.00000e-09 7.00000e-02

$2.75589 \mathrm{e}+032.75589 \mathrm{e}+032.75589 \mathrm{e}+02$ 1.00000e-09 7.00000e-02

$2.75589 \mathrm{e}+032.75589 \mathrm{e}+032.75589 \mathrm{e}+02$ 1.00000e-09 7.00000e-02

1.00000e-06 1.00000e-06 1.00000e-06 1.00000e-09 5.00000e-02

Element: 5701 \# of layers: 4

$\mathrm{Kx} \mathrm{Ky} \mathrm{Kz}$ Ss Por

2.75589e+03 2.75589e+03 2.75589e+02 1.00000e-09 7.00000e-02

$2.75589 \mathrm{e}+032.75589 \mathrm{e}+03$ 2.75589e+02 1.00000e-09 7.00000e-02

$2.75589 \mathrm{e}+032.75589 \mathrm{e}+032.75589 \mathrm{e}+02$ 1.00000e-09 7.00000e-02

1.00000e-06 1.00000e-06 1.00000e-06 1.00000e-09 5.00000e-02

Element: 5702 \# of layers: 4

$\mathrm{Kx} \mathrm{Ky} \mathrm{Kz}$ Ss Por

$1.96842 \mathrm{e}+03$ 1.96842e+03 1.96842e+02 1.00000e-09 7.00000e-02

$1.96842 \mathrm{e}+03$ 1.96842e+03 1.96842e+02 1.00000e-09 7.00000e-02

$1.96842 \mathrm{e}+03$ 1.96842e+03 1.96842e+02 1.00000e-09 7.00000e-02

1.00000e-06 1.00000e-06 1.00000e-06 1.00000e-09 5.00000e-02

Element: 5703 \# of layers: 5

$\mathrm{Kx} \mathrm{Ky} \mathrm{Kz}$ Ss Por

1.96842e+03 1.96842e+03 1.96842e+02 1.00000e-09 7.00000e-02

$1.96842 \mathrm{e}+03$ 1.96842e+03 1.96842e+02 1.00000e-09 7.00000e-02

$1.96842 \mathrm{e}+03$ 1.96842e+03 1.96842e+02 1.00000e-09 7.00000e-02

$1.96842 \mathrm{e}+03$ 1.96842e+03 1.96842e+02 1.00000e-09 7.00000e-02

1.00000e-06 1.00000e-06 1.00000e-06 1.00000e-09 5.00000e-02

Element: 5704 \# of layers: 5

$\mathrm{Kx} \mathrm{Ky} \mathrm{Kz}$ Ss Por

1.96842e+03 1.96842e+03 1.96842e+02 1.00000e-09 7.00000e-02

$1.96842 \mathrm{e}+03$ 1.96842e+03 1.96842e+02 1.00000e-09 7.00000e-02

$1.96842 \mathrm{e}+03$ 1.96842e+03 1.96842e+02 1.00000e-09 7.00000e-02

$1.96842 \mathrm{e}+03$ 1.96842e+03 1.96842e+02 1.00000e-09 7.00000e-02

$1.00000 \mathrm{e}-06$ 1.00000e-06 1.00000e-06 1.00000e-09 5.00000e-02 
Element: 5705 \# of layers: 5

$\mathrm{Kx} \mathrm{Ky} \mathrm{Kz}$ Ss Por

2.33368e+03 2.33368e+03 2.33368e+02 1.00000e-09 7.00000e-02

$2.33368 \mathrm{e}+03$ 2.33368e+03 2.33368e+02 1.00000e-09 7.00000e-02

$2.33368 \mathrm{e}+032.33368 \mathrm{e}+03$ 2.33368e+02 1.00000e-09 7.00000e-02

$2.33368 \mathrm{e}+032.33368 \mathrm{e}+03$ 2.33368e+02 1.00000e-09 7.00000e-02

1.00000e-06 1.00000e-06 1.00000e-06 1.00000e-09 5.00000e-02

Element: 5706 \# of layers: 4

$\mathrm{Kx} \mathrm{Ky} \mathrm{Kz}$ Ss Por

3.40542e+03 3.40542e+03 3.40542e+02 1.00000e-09 7.00000e-02

$3.40542 \mathrm{e}+03$ 3.40542e+03 3.40542e+02 1.00000e-09 7.00000e-02

$3.40542 \mathrm{e}+03$ 3.40542e+03 3.40542e+02 1.00000e-09 7.00000e-02

1.00000e-06 1.00000e-06 1.00000e-06 1.00000e-09 5.00000e-02

Element: 5707 \# of layers: 4

$\mathrm{Kx} \mathrm{Ky} \mathrm{Kz}$ Ss Por

1.96842e+03 1.96842e+03 1.96842e+02 1.00000e-09 7.00000e-02

$1.96842 \mathrm{e}+03$ 1.96842e+03 1.96842e+02 1.00000e-09 7.00000e-02

$1.96842 \mathrm{e}+03$ 1.96842e+03 1.96842e+02 1.00000e-09 7.00000e-02

1.00000e-06 1.00000e-06 1.00000e-06 1.00000e-09 5.00000e-02

Element: 5708 \# of layers: 4

$\mathrm{Kx} \mathrm{Ky} \mathrm{Kz}$ Ss Por

3.01294e+03 3.01294e+03 3.01294e+02 1.00000e-09 7.00000e-02 $3.01294 \mathrm{e}+033.01294 \mathrm{e}+03$ 3.01294e+02 1.00000e-09 7.00000e-02

$3.01294 \mathrm{e}+033.01294 \mathrm{e}+03$ 3.01294e+02 1.00000e-09 7.00000e-02

$1.00000 \mathrm{e}-06$ 1.00000e-06 1.00000e-06 1.00000e-09 5.00000e-02

Element: 5709 \# of layers: 4

$\mathrm{Kx} \mathrm{Ky} \mathrm{Kz}$ Ss Por

4.86594e+03 4.86594e+03 4.86594e+02 1.00000e-09 7.00000e-02

$4.86594 \mathrm{e}+03$ 4.86594e+03 4.86594e+02 1.00000e-09 7.00000e-02

$4.86594 \mathrm{e}+03$ 4.86594e+03 4.86594e+02 1.00000e-09 7.00000e-02

$1.00000 \mathrm{e}-06$ 1.00000e-06 1.00000e-06 1.00000e-09 5.00000e-02

Element: 5710 \# of layers: 4

Kx Ky Kz Ss Por

$4.86594 \mathrm{e}+03$ 4.86594e+03 4.86594e+02 1.00000e-09 7.00000e-02

$4.86594 \mathrm{e}+034.86594 \mathrm{e}+03$ 4.86594e+02 1.00000e-09 7.00000e-02

$4.86594 \mathrm{e}+03$ 4.86594e+03 4.86594e+02 1.00000e-09 7.00000e-02

1.00000e-06 1.00000e-06 1.00000e-06 1.00000e-09 5.00000e-02

Element: 5711 \# of layers: 4

$\mathrm{Kx} \mathrm{Ky} \mathrm{Kz}$ Ss Por

4.86594e+03 4.86594e+03 4.86594e+02 1.00000e-09 7.00000e-02

$4.86594 \mathrm{e}+034.86594 \mathrm{e}+03$ 4.86594e+02 1.00000e-09 7.00000e-02

$4.86594 \mathrm{e}+034.86594 \mathrm{e}+03$ 4.86594e+02 1.00000e-09 7.00000e-02

$1.00000 \mathrm{e}-06$ 1.00000e-06 1.00000e-06 1.00000e-09 5.00000e-02

Element: 5712 \# of layers: 5

$\mathrm{Kx} \mathrm{Ky} \mathrm{Kz}$ Ss Por

2.79526e+03 2.79526e+03 2.79526e+02 1.00000e-09 7.00000e-02 
$2.79526 \mathrm{e}+032.79526 \mathrm{e}+032.79526 \mathrm{e}+02$ 1.00000e-09 7.00000e-02 $2.79526 \mathrm{e}+032.79526 \mathrm{e}+032.79526 \mathrm{e}+021.00000 \mathrm{e}-09$ 7.00000e-02

$2.79526 \mathrm{e}+032.79526 \mathrm{e}+032.79526 \mathrm{e}+021.00000 \mathrm{e}-097.00000 \mathrm{e}-02$ $1.00000 \mathrm{e}-06$ 1.00000e-06 1.00000e-06 1.00000e-09 5.00000e-02 Element: 5713 \# of layers: 5

Kx Ky Kz Ss Por

$2.79526 \mathrm{e}+032.79526 \mathrm{e}+032.79526 \mathrm{e}+02$ 1.00000e-09 7.00000e-02 $2.79526 \mathrm{e}+032.79526 \mathrm{e}+032.79526 \mathrm{e}+02$ 1.00000e-09 7.00000e-02 $2.79526 \mathrm{e}+032.79526 \mathrm{e}+032.79526 \mathrm{e}+02$ 1.00000e-09 7.00000e-02 $2.79526 \mathrm{e}+032.79526 \mathrm{e}+032.79526 \mathrm{e}+021.00000 \mathrm{e}-097.00000 \mathrm{e}-02$ $1.00000 \mathrm{e}-06$ 1.00000e-06 1.00000e-06 1.00000e-09 5.00000e-02

Element: 5714 \# of layers: 5

Kx Ky Kz Ss Por

$2.13970 \mathrm{e}+032.13970 \mathrm{e}+032.13970 \mathrm{e}+02$ 1.00000e-09 7.00000e-02 $2.13970 \mathrm{e}+032.13970 \mathrm{e}+032.13970 \mathrm{e}+02$ 1.00000e-09 7.00000e-02 $2.13970 \mathrm{e}+032.13970 \mathrm{e}+032.13970 \mathrm{e}+02$ 1.00000e-09 7.00000e-02 $2.13970 \mathrm{e}+032.13970 \mathrm{e}+032.13970 \mathrm{e}+02$ 1.00000e-09 7.00000e-02 $1.00000 \mathrm{e}-06$ 1.00000e-06 1.00000e-06 1.00000e-09 5.00000e-02

Element: 5715 \# of layers: 4

Kx Ky Kz Ss Por

$3.01294 \mathrm{e}+033.01294 \mathrm{e}+033.01294 \mathrm{e}+02$ 1.00000e-09 7.00000e-02 $3.01294 \mathrm{e}+033.01294 \mathrm{e}+033.01294 \mathrm{e}+021.00000 \mathrm{e}-097.00000 \mathrm{e}-02$ $3.01294 \mathrm{e}+033.01294 \mathrm{e}+033.01294 \mathrm{e}+021.00000 \mathrm{e}-097.00000 \mathrm{e}-02$ $1.00000 \mathrm{e}-06$ 1.00000e-06 1.00000e-06 1.00000e-09 5.00000e-02

Element: 5716 \# of layers: 4

Kx Ky Kz Ss Por

$4.86594 \mathrm{e}+03$ 4.86594e+03 4.86594e+02 1.00000e-09 7.00000e-02 $4.86594 \mathrm{e}+034.86594 \mathrm{e}+034.86594 \mathrm{e}+02$ 1.00000e-09 7.00000e-02 $4.86594 \mathrm{e}+03$ 4.86594e+03 4.86594e+02 1.00000e-09 7.00000e-02 $1.00000 \mathrm{e}-06$ 1.00000e-06 1.00000e-06 1.00000e-09 5.00000e-02

Element: 5717 \# of layers: 3

Kx Ky Kz Ss Por

$6.25276 \mathrm{e}+03$ 6.25276e+03 6.25276e+02 1.00000e-09 7.00000e-02 $6.25276 \mathrm{e}+036.25276 \mathrm{e}+036.25276 \mathrm{e}+02$ 1.00000e-09 7.00000e-02 $1.00000 \mathrm{e}-06$ 1.00000e-06 1.00000e-06 1.00000e-09 5.00000e-02

Element: 5718 \# of layers: 4

Kx Ky Kz Ss Por

$3.91277 \mathrm{e}+03$ 3.91277e+03 3.91277e+02 1.00000e-09 7.00000e-02 $3.91277 \mathrm{e}+033.91277 \mathrm{e}+033.91277 \mathrm{e}+02$ 1.00000e-09 7.00000e-02 $3.91277 \mathrm{e}+033.91277 \mathrm{e}+033.91277 \mathrm{e}+02$ 1.00000e-09 7.00000e-02 $1.00000 \mathrm{e}-06$ 1.00000e-06 1.00000e-06 1.00000e-09 5.00000e-02

Element: 5719 \# of layers: 4

Kx Ky Kz Ss Por

$3.91277 \mathrm{e}+03$ 3.91277e+03 3.91277e+02 1.00000e-09 7.00000e-02 $3.91277 \mathrm{e}+033.91277 \mathrm{e}+033.91277 \mathrm{e}+02$ 1.00000e-09 7.00000e-02 $3.91277 \mathrm{e}+03$ 3.91277e+03 3.91277e+02 1.00000e-09 7.00000e-02 
1.00000e-06 1.00000e-06 1.00000e-06 1.00000e-09 5.00000e-02

Element: 5720 \# of layers: 4

Kx Ky Kz Ss Por

3.91277e+03 3.91277e+03 3.91277e+02 1.00000e-09 7.00000e-02

$3.91277 \mathrm{e}+03$ 3.91277e+03 3.91277e+02 1.00000e-09 7.00000e-02

$3.91277 \mathrm{e}+03$ 3.91277e+03 3.91277e+02 1.00000e-09 7.00000e-02

1.00000e-06 1.00000e-06 1.00000e-06 1.00000e-09 5.00000e-02

Element: 5721 \# of layers: 5

$\mathrm{Kx} \mathrm{Ky} \mathrm{Kz}$ Ss Por

3.53868e+03 3.53868e+03 3.53868e+02 1.00000e-09 7.00000e-02

$3.53868 \mathrm{e}+03$ 3.53868e+03 3.53868e+02 1.00000e-09 7.00000e-02

$3.53868 \mathrm{e}+03$ 3.53868e+03 3.53868e+02 1.00000e-09 7.00000e-02

$3.53868 \mathrm{e}+03$ 3.53868e+03 3.53868e+02 1.00000e-09 7.00000e-02

1.00000e-06 1.00000e-06 1.00000e-06 1.00000e-09 5.00000e-02

Element: 5722 \# of layers: 5

Kx Ky Kz Ss Por

3.53868e+03 3.53868e+03 3.53868e+02 1.00000e-09 7.00000e-02

$3.53868 \mathrm{e}+033.53868 \mathrm{e}+03$ 3.53868e+02 1.00000e-09 7.00000e-02

$3.53868 \mathrm{e}+033.53868 \mathrm{e}+03$ 3.53868e+02 1.00000e-09 7.00000e-02

$3.53868 \mathrm{e}+03$ 3.53868e+03 3.53868e+02 1.00000e-09 7.00000e-02

1.00000e-06 1.00000e-06 1.00000e-06 1.00000e-09 5.00000e-02

Element: 5723 \# of layers: 5

$\mathrm{Kx} \mathrm{Ky} \mathrm{Kz}$ Ss Por

3.53084e+03 3.53084e+03 3.53084e+02 1.00000e-09 7.00000e-02

$3.53084 \mathrm{e}+033.53084 \mathrm{e}+033.53084 \mathrm{e}+021.00000 \mathrm{e}-097.00000 \mathrm{e}-02$

$3.53084 \mathrm{e}+033.53084 \mathrm{e}+033.53084 \mathrm{e}+02$ 1.00000e-09 7.00000e-02

$3.53084 \mathrm{e}+033.53084 \mathrm{e}+033.53084 \mathrm{e}+021.00000 \mathrm{e}-097.00000 \mathrm{e}-02$

1.00000e-06 1.00000e-06 1.00000e-06 1.00000e-09 5.00000e-02

Element: 5724 \# of layers: 4

$\mathrm{Kx} \mathrm{Ky} \mathrm{Kz}$ Ss Por

6.25276e+03 6.25276e+03 6.25276e+02 1.00000e-09 7.00000e-02

$6.25276 \mathrm{e}+036.25276 \mathrm{e}+03$ 6.25276e+02 1.00000e-09 7.00000e-02

$6.25276 \mathrm{e}+036.25276 \mathrm{e}+036.25276 \mathrm{e}+02$ 1.00000e-09 7.00000e-02

1.00000e-06 1.00000e-06 1.00000e-06 1.00000e-09 5.00000e-02

Element: 5725 \# of layers: 4

$\mathrm{Kx} \mathrm{Ky} \mathrm{Kz}$ Ss Por

3.91277e+03 3.91277e+03 3.91277e+02 1.00000e-09 7.00000e-02

3.91277e+03 3.91277e+03 3.91277e+02 1.00000e-09 7.00000e-02

$3.91277 \mathrm{e}+03$ 3.91277e+03 3.91277e+02 1.00000e-09 7.00000e-02

1.00000e-06 1.00000e-06 1.00000e-06 1.00000e-09 5.00000e-02

Element: 5726 \# of layers: 4

$\mathrm{Kx} \mathrm{Ky} \mathrm{Kz}$ Ss Por

3.58634e+03 3.58634e+03 3.58634e+02 1.00000e-09 7.00000e-02

$3.58634 \mathrm{e}+03$ 3.58634e+03 3.58634e+02 1.00000e-09 7.00000e-02

$3.58634 \mathrm{e}+033.58634 \mathrm{e}+03$ 3.58634e+02 1.00000e-09 7.00000e-02

$1.00000 \mathrm{e}-06$ 1.00000e-06 1.00000e-06 1.00000e-09 5.00000e-02 
Element: 5727 \# of layers: 4

$\mathrm{Kx} \mathrm{Ky} \mathrm{Kz}$ Ss Por

4.59699e+03 4.59699e+03 4.59699e+02 1.00000e-09 7.00000e-02

$4.59699 \mathrm{e}+03$ 4.59699e+03 4.59699e+02 1.00000e-09 7.00000e-02

$4.59699 \mathrm{e}+03$ 4.59699e+03 4.59699e+02 1.00000e-09 7.00000e-02

1.00000e-06 1.00000e-06 1.00000e-06 1.00000e-09 5.00000e-02

Element: 5728 \# of layers: 4

$\mathrm{Kx} \mathrm{Ky} \mathrm{Kz}$ Ss Por

4.59699e+03 4.59699e+03 4.59699e+02 1.00000e-09 7.00000e-02

4.59699e+03 4.59699e+03 4.59699e+02 1.00000e-09 7.00000e-02

$4.59699 \mathrm{e}+03$ 4.59699e+03 4.59699e+02 1.00000e-09 7.00000e-02

1.00000e-06 1.00000e-06 1.00000e-06 1.00000e-09 5.00000e-02

Element: 5729 \# of layers: 4

$\mathrm{Kx} \mathrm{Ky} \mathrm{Kz}$ Ss Por

3.43795e+03 3.43795e+03 3.43795e+02 1.00000e-09 7.00000e-02

$3.43795 \mathrm{e}+033.43795 \mathrm{e}+03$ 3.43795e+02 1.00000e-09 7.00000e-02

$3.43795 \mathrm{e}+03$ 3.43795e+03 3.43795e+02 1.00000e-09 7.00000e-02

1.00000e-06 1.00000e-06 1.00000e-06 1.00000e-09 5.00000e-02

Element: 5730 \# of layers: 5

$\mathrm{Kx} \mathrm{Ky} \mathrm{Kz}$ Ss Por

3.43795e+03 3.43795e+03 3.43795e+02 1.00000e-09 7.00000e-02

$3.43795 \mathrm{e}+033.43795 \mathrm{e}+03$ 3.43795e+02 1.00000e-09 7.00000e-02

$3.43795 \mathrm{e}+03$ 3.43795e+03 3.43795e+02 1.00000e-09 7.00000e-02

$3.43795 \mathrm{e}+03$ 3.43795e+03 3.43795e+02 1.00000e-09 7.00000e-02

1.00000e-06 1.00000e-06 1.00000e-06 1.00000e-09 5.00000e-02

Element: 5731 \# of layers: 5

$\mathrm{Kx} \mathrm{Ky} \mathrm{Kz}$ Ss Por

3.43795e+03 3.43795e+03 3.43795e+02 1.00000e-09 7.00000e-02

$3.43795 \mathrm{e}+03$ 3.43795e+03 3.43795e+02 1.00000e-09 7.00000e-02

$3.43795 \mathrm{e}+03$ 3.43795e+03 3.43795e+02 1.00000e-09 7.00000e-02

$3.43795 \mathrm{e}+033.43795 \mathrm{e}+03$ 3.43795e+02 1.00000e-09 7.00000e-02

1.00000e-06 1.00000e-06 1.00000e-06 1.00000e-09 5.00000e-02

Element: 5732 \# of layers: 5

$\mathrm{Kx} \mathrm{Ky} \mathrm{Kz}$ Ss Por

3.47552e+03 3.47552e+03 3.47552e+02 1.00000e-09 7.00000e-02

3.47552e+03 3.47552e+03 3.47552e+02 1.00000e-09 7.00000e-02

$3.47552 \mathrm{e}+03$ 3.47552e+03 3.47552e+02 1.00000e-09 7.00000e-02

$3.47552 \mathrm{e}+03$ 3.47552e+03 3.47552e+02 1.00000e-09 7.00000e-02

1.00000e-06 1.00000e-06 1.00000e-06 1.00000e-09 5.00000e-02

Element: 5733 \# of layers: 4

$\mathrm{Kx} \mathrm{Ky} \mathrm{Kz}$ Ss Por

$3.58634 \mathrm{e}+03$ 3.58634e+03 3.58634e+02 1.00000e-09 7.00000e-02

$3.58634 \mathrm{e}+033.58634 \mathrm{e}+033.58634 \mathrm{e}+021.00000 \mathrm{e}-097.00000 \mathrm{e}-02$

$3.58634 \mathrm{e}+033.58634 \mathrm{e}+033.58634 \mathrm{e}+02$ 1.00000e-09 7.00000e-02

1.00000e-06 1.00000e-06 1.00000e-06 1.00000e-09 5.00000e-02

Element: 5734 \# of layers: 4 
$\mathrm{Kx} \mathrm{Ky} \mathrm{Kz}$ Ss Por

3.43795e+03 3.43795e+03 3.43795e+02 1.00000e-09 7.00000e-02

$3.43795 \mathrm{e}+03$ 3.43795e+03 3.43795e+02 1.00000e-09 7.00000e-02

$3.43795 \mathrm{e}+03$ 3.43795e+03 3.43795e+02 1.00000e-09 7.00000e-02

1.00000e-06 1.00000e-06 1.00000e-06 1.00000e-09 5.00000e-02

Element: 5735 \# of layers: 4

$\mathrm{Kx} \mathrm{Ky} \mathrm{Kz}$ Ss Por

5.53737e+03 5.53737e+03 5.53737e+02 1.00000e-09 7.00000e-02

$5.53737 \mathrm{e}+03$ 5.53737e+03 5.53737e+02 1.00000e-09 7.00000e-02

5.53737e+03 5.53737e+03 5.53737e+02 1.00000e-09 7.00000e-02

1.00000e-06 1.00000e-06 1.00000e-06 1.00000e-09 5.00000e-02

Element: 5736 \# of layers: 5

Kx Ky Kz Ss Por

4.27335e+03 4.27335e+03 4.27335e+02 1.00000e-09 7.00000e-02

4.27335e+03 4.27335e+03 4.27335e+02 1.00000e-09 7.00000e-02

$4.27335 \mathrm{e}+034.27335 \mathrm{e}+03$ 4.27335e+02 1.00000e-09 7.00000e-02

$1.00000 \mathrm{e}+001.00000 \mathrm{e}+001.00000 \mathrm{e}-011.00000 \mathrm{e}-091.00000 \mathrm{e}-01$

1.00000e-06 1.00000e-06 1.00000e-06 1.00000e-09 5.00000e-02

Element: 5737 \# of layers: 5

$\mathrm{Kx} \mathrm{Ky} \mathrm{Kz}$ Ss Por

4.27335e+03 4.27335e+03 4.27335e+02 1.00000e-09 7.00000e-02

4.27335e+03 4.27335e+03 4.27335e+02 1.00000e-09 7.00000e-02

$4.27335 \mathrm{e}+03$ 4.27335e+03 4.27335e+02 1.00000e-09 7.00000e-02

$1.00000 \mathrm{e}+001.00000 \mathrm{e}+001.00000 \mathrm{e}-011.00000 \mathrm{e}-091.00000 \mathrm{e}-01$

1.00000e-06 1.00000e-06 1.00000e-06 1.00000e-09 5.00000e-02

Element: 5738 \# of layers: 5

$\mathrm{Kx} \mathrm{Ky} \mathrm{Kz}$ Ss Por

4.27335e+03 4.27335e+03 4.27335e+02 1.00000e-09 7.00000e-02

$4.27335 \mathrm{e}+03$ 4.27335e+03 4.27335e+02 1.00000e-09 7.00000e-02

$4.27335 \mathrm{e}+03$ 4.27335e+03 4.27335e+02 1.00000e-09 7.00000e-02

$1.00000 \mathrm{e}+001.00000 \mathrm{e}+001.00000 \mathrm{e}-011.00000 \mathrm{e}-091.00000 \mathrm{e}-01$

1.00000e-06 1.00000e-06 1.00000e-06 1.00000e-09 5.00000e-02

Element: 5739 \# of layers: 4

$\mathrm{Kx} \mathrm{Ky} \mathrm{Kz}$ Ss Por

2.12285e+03 2.12285e+03 2.12285e+02 1.00000e-09 7.00000e-02

$2.12285 \mathrm{e}+03$ 2.12285e+03 2.12285e+02 1.00000e-09 7.00000e-02

$2.12285 \mathrm{e}+032.12285 \mathrm{e}+032.12285 \mathrm{e}+02$ 1.00000e-09 7.00000e-02

1.00000e-06 1.00000e-06 1.00000e-06 1.00000e-09 5.00000e-02

Element: 5740 \# of layers: 4

$\mathrm{Kx} \mathrm{Ky} \mathrm{Kz}$ Ss Por

2.12285e+03 2.12285e+03 2.12285e+02 1.00000e-09 7.00000e-02

$2.12285 \mathrm{e}+032.12285 \mathrm{e}+032.12285 \mathrm{e}+02$ 1.00000e-09 7.00000e-02

$2.12285 \mathrm{e}+03$ 2.12285e+03 2.12285e+02 1.00000e-09 7.00000e-02

1.00000e-06 1.00000e-06 1.00000e-06 1.00000e-09 5.00000e-02

Element: 5741 \# of layers: 5

Kx Ky Kz Ss Por 
$2.67813 \mathrm{e}+032.67813 \mathrm{e}+032.67813 \mathrm{e}+02$ 1.00000e-09 7.00000e-02 $2.67813 \mathrm{e}+032.67813 \mathrm{e}+032.67813 \mathrm{e}+02$ 1.00000e-09 7.00000e-02 $2.67813 \mathrm{e}+032.67813 \mathrm{e}+032.67813 \mathrm{e}+02$ 1.00000e-09 7.00000e-02 $2.67813 \mathrm{e}+032.67813 \mathrm{e}+032.67813 \mathrm{e}+021.00000 \mathrm{e}-09$ 7.00000e-02 1.00000e-06 1.00000e-06 1.00000e-06 1.00000e-09 5.00000e-02

Element: 5742 \# of layers: 4

$\mathrm{Kx} \mathrm{Ky} \mathrm{Kz}$ Ss Por

5.53737e+03 5.53737e+03 5.53737e+02 1.00000e-09 7.00000e-02

5.53737e+03 5.53737e+03 5.53737e+02 1.00000e-09 7.00000e-02

$5.53737 \mathrm{e}+035.53737 \mathrm{e}+03$ 5.53737e+02 1.00000e-09 7.00000e-02 1.00000e-06 1.00000e-06 1.00000e-06 1.00000e-09 5.00000e-02

Element: 5743 \# of layers: 5

$\mathrm{Kx} \mathrm{Ky} \mathrm{Kz}$ Ss Por

4.27335e+03 4.27335e+03 4.27335e+02 1.00000e-09 7.00000e-02 4.27335e+03 4.27335e+03 4.27335e+02 1.00000e-09 7.00000e-02 $4.27335 \mathrm{e}+034.27335 \mathrm{e}+03$ 4.27335e+02 1.00000e-09 7.00000e-02 $1.00000 \mathrm{e}+001.00000 \mathrm{e}+001.00000 \mathrm{e}-011.00000 \mathrm{e}-091.00000 \mathrm{e}-01$ 1.00000e-06 1.00000e-06 1.00000e-06 1.00000e-09 5.00000e-02

Element: 5744 \# of layers: 5

$\mathrm{Kx} \mathrm{Ky} \mathrm{Kz}$ Ss Por

3.07250e+03 3.07250e+03 3.07250e+02 1.00000e-09 7.00000e-02 $3.07250 \mathrm{e}+033.07250 \mathrm{e}+033.07250 \mathrm{e}+021.00000 \mathrm{e}-097.00000 \mathrm{e}-02$ $3.07250 \mathrm{e}+033.07250 \mathrm{e}+033.07250 \mathrm{e}+02$ 1.00000e-09 7.00000e-02 $1.00000 \mathrm{e}+001.00000 \mathrm{e}+001.00000 \mathrm{e}-011.00000 \mathrm{e}-091.00000 \mathrm{e}-01$ $1.00000 \mathrm{e}-06$ 1.00000e-06 1.00000e-06 1.00000e-09 5.00000e-02 Element: 5745 \# of layers: 5

$\mathrm{Kx} \mathrm{Ky} \mathrm{Kz}$ Ss Por

$1.97634 \mathrm{e}+03$ 1.97634e+03 1.97634e+02 1.00000e-09 7.00000e-02 $1.97634 \mathrm{e}+031.97634 \mathrm{e}+03 \quad 1.97634 \mathrm{e}+021.00000 \mathrm{e}-097.00000 \mathrm{e}-02$ $1.97634 \mathrm{e}+031.97634 \mathrm{e}+03$ 1.97634e+02 1.00000e-09 7.00000e-02 $1.00000 \mathrm{e}+001.00000 \mathrm{e}+001.00000 \mathrm{e}-011.00000 \mathrm{e}-091.00000 \mathrm{e}-01$ 1.00000e-06 1.00000e-06 1.00000e-06 1.00000e-09 5.00000e-02

Element: 5746 \# of layers: 4

$\mathrm{Kx} \mathrm{Ky} \mathrm{Kz}$ Ss Por

$1.97634 \mathrm{e}+03$ 1.97634e+03 1.97634e+02 1.00000e-09 7.00000e-02 $1.97634 \mathrm{e}+031.97634 \mathrm{e}+031.97634 \mathrm{e}+02$ 1.00000e-09 7.00000e-02 $1.97634 \mathrm{e}+031.97634 \mathrm{e}+031.97634 \mathrm{e}+02$ 1.00000e-09 7.00000e-02 1.00000e-06 1.00000e-06 1.00000e-06 1.00000e-09 5.00000e-02

Element: 5747 \# of layers: 4

$\mathrm{Kx} \mathrm{Ky} \mathrm{Kz}$ Ss Por

$1.41484 \mathrm{e}+031.41484 \mathrm{e}+03$ 1.41484e+02 1.00000e-09 7.00000e-02 $1.41484 \mathrm{e}+031.41484 \mathrm{e}+03$ 1.41484e+02 1.00000e-09 7.00000e-02 $1.41484 \mathrm{e}+031.41484 \mathrm{e}+03$ 1.41484e+02 1.00000e-09 7.00000e-02 1.00000e-06 1.00000e-06 1.00000e-06 1.00000e-09 5.00000e-02 Element: 5748 \# of layers: 4

Kx Ky Kz Ss Por 
$1.41484 \mathrm{e}+031.41484 \mathrm{e}+03$ 1.41484e+02 1.00000e-09 7.00000e-02 $1.41484 \mathrm{e}+031.41484 \mathrm{e}+03$ 1.41484e+02 1.00000e-09 7.00000e-02 $1.41484 \mathrm{e}+031.41484 \mathrm{e}+03$ 1.41484e+02 1.00000e-09 7.00000e-02 1.00000e-06 1.00000e-06 1.00000e-06 1.00000e-09 5.00000e-02

Element: 5749 \# of layers: 4

$\mathrm{Kx} \mathrm{Ky} \mathrm{Kz}$ Ss Por

$1.41484 \mathrm{e}+03$ 1.41484e+03 1.41484e+02 1.00000e-09 7.00000e-02 $1.41484 \mathrm{e}+03$ 1.41484e+03 1.41484e+02 1.00000e-09 7.00000e-02 $1.41484 \mathrm{e}+03$ 1.41484e+03 1.41484e+02 1.00000e-09 7.00000e-02 1.00000e-06 1.00000e-06 1.00000e-06 1.00000e-09 5.00000e-02

Element: 5750 \# of layers: 4

Kx Ky Kz Ss Por

$1.66361 \mathrm{e}+03$ 1.66361e+03 1.66361e+02 1.00000e-09 7.00000e-02 $1.66361 \mathrm{e}+031.66361 \mathrm{e}+031.66361 \mathrm{e}+02$ 1.00000e-09 7.00000e-02 $1.66361 \mathrm{e}+031.66361 \mathrm{e}+031.66361 \mathrm{e}+02$ 1.00000e-09 7.00000e-02 1.00000e-06 1.00000e-06 1.00000e-06 1.00000e-09 5.00000e-02

Element: 5751 \# of layers: 4

$\mathrm{Kx} \mathrm{Ky} \mathrm{Kz}$ Ss Por

3.07250e+03 3.07250e+03 3.07250e+02 1.00000e-09 7.00000e-02 $3.07250 \mathrm{e}+033.07250 \mathrm{e}+033.07250 \mathrm{e}+02$ 1.00000e-09 7.00000e-02 $3.07250 \mathrm{e}+033.07250 \mathrm{e}+033.07250 \mathrm{e}+02$ 1.00000e-09 7.00000e-02 1.00000e-06 1.00000e-06 1.00000e-06 1.00000e-09 5.00000e-02

Element: 5752 \# of layers: 4

Kx Ky Kz Ss Por

$1.97634 \mathrm{e}+03$ 1.97634e+03 1.97634e+02 1.00000e-09 7.00000e-02 $1.97634 \mathrm{e}+03$ 1.97634e+03 1.97634e+02 1.00000e-09 7.00000e-02 $1.97634 \mathrm{e}+03$ 1.97634e+03 1.97634e+02 1.00000e-09 7.00000e-02 1.00000e-06 1.00000e-06 1.00000e-06 1.00000e-09 5.00000e-02

Element: 5753 \# of layers: 4

$\mathrm{Kx} \mathrm{Ky} \mathrm{Kz}$ Ss Por

$1.53918 \mathrm{e}+03$ 1.53918e+03 1.53918e+02 1.00000e-09 7.00000e-02 $1.53918 \mathrm{e}+03$ 1.53918e+03 1.53918e+02 1.00000e-09 7.00000e-02 $1.53918 \mathrm{e}+031.53918 \mathrm{e}+03$ 1.53918e+02 1.00000e-09 7.00000e-02 1.00000e-06 1.00000e-06 1.00000e-06 1.00000e-09 5.00000e-02

Element: 5754 \# of layers: 4

$\mathrm{Kx} \mathrm{Ky} \mathrm{Kz}$ Ss Por

$1.35060 \mathrm{e}+031.35060 \mathrm{e}+03$ 1.35060e+02 1.00000e-09 7.00000e-02 $1.35060 \mathrm{e}+031.35060 \mathrm{e}+031.35060 \mathrm{e}+021.00000 \mathrm{e}-097.00000 \mathrm{e}-02$ $1.35060 \mathrm{e}+031.35060 \mathrm{e}+031.35060 \mathrm{e}+021.00000 \mathrm{e}-097.00000 \mathrm{e}-02$ 1.00000e-06 1.00000e-06 1.00000e-06 1.00000e-09 5.00000e-02

Element: 5755 \# of layers: 4

$\mathrm{Kx} \mathrm{Ky} \mathrm{Kz}$ Ss Por

$1.35060 \mathrm{e}+03$ 1.35060e+03 1.35060e+02 1.00000e-09 7.00000e-02 $1.35060 \mathrm{e}+03$ 1.35060e+03 1.35060e+02 1.00000e-09 7.00000e-02 $1.35060 \mathrm{e}+031.35060 \mathrm{e}+031.35060 \mathrm{e}+021.00000 \mathrm{e}-097.00000 \mathrm{e}-02$ $1.00000 \mathrm{e}-06$ 1.00000e-06 1.00000e-06 1.00000e-09 5.00000e-02 
Element: 5756 \# of layers: 4

$\mathrm{Kx} \mathrm{Ky} \mathrm{Kz}$ Ss Por

$1.35060 \mathrm{e}+03$ 1.35060e+03 1.35060e+02 1.00000e-09 7.00000e-02

$1.35060 \mathrm{e}+03$ 1.35060e+03 1.35060e+02 1.00000e-09 7.00000e-02

$1.35060 \mathrm{e}+031.35060 \mathrm{e}+031.35060 \mathrm{e}+021.00000 \mathrm{e}-097.00000 \mathrm{e}-02$

1.00000e-06 1.00000e-06 1.00000e-06 1.00000e-09 5.00000e-02

Element: 5757 \# of layers: 4

$\mathrm{Kx} \mathrm{Ky} \mathrm{Kz}$ Ss Por

$1.25599 \mathrm{e}+03$ 1.25599e+03 1.25599e+02 1.00000e-09 7.00000e-02

$1.25599 \mathrm{e}+03$ 1.25599e+03 1.25599e+02 1.00000e-09 7.00000e-02

$1.25599 \mathrm{e}+031.25599 \mathrm{e}+03$ 1.25599e+02 1.00000e-09 7.00000e-02

1.00000e-06 1.00000e-06 1.00000e-06 1.00000e-09 5.00000e-02

Element: 5758 \# of layers: 4

$\mathrm{Kx} \mathrm{Ky} \mathrm{Kz}$ Ss Por

$1.25599 \mathrm{e}+03$ 1.25599e+03 1.25599e+02 1.00000e-09 7.00000e-02

$1.25599 \mathrm{e}+031.25599 \mathrm{e}+03$ 1.25599e+02 1.00000e-09 7.00000e-02

$1.25599 \mathrm{e}+031.25599 \mathrm{e}+03 \quad 1.25599 \mathrm{e}+02$ 1.00000e-09 7.00000e-02

1.00000e-06 1.00000e-06 1.00000e-06 1.00000e-09 5.00000e-02

Element: 5759 \# of layers: 4

$\mathrm{Kx} \mathrm{Ky} \mathrm{Kz}$ Ss Por

$1.31699 \mathrm{e}+03$ 1.31699e+03 1.31699e+02 1.00000e-09 7.00000e-02

$1.31699 \mathrm{e}+03$ 1.31699e+03 1.31699e+02 1.00000e-09 7.00000e-02

$1.31699 \mathrm{e}+031.31699 \mathrm{e}+03$ 1.31699e+02 1.00000e-09 7.00000e-02

1.00000e-06 1.00000e-06 1.00000e-06 1.00000e-09 5.00000e-02

Element: 5760 \# of layers: 4

$\mathrm{Kx} \mathrm{Ky} \mathrm{Kz}$ Ss Por

1.31699e+03 1.31699e+03 1.31699e+02 1.00000e-09 7.00000e-02

$1.31699 \mathrm{e}+03$ 1.31699e+03 1.31699e+02 1.00000e-09 7.00000e-02

$1.31699 \mathrm{e}+03$ 1.31699e+03 1.31699e+02 1.00000e-09 7.00000e-02

1.00000e-06 1.00000e-06 1.00000e-06 1.00000e-09 5.00000e-02

Element: 5761 \# of layers: 4

$\mathrm{Kx} \mathrm{Ky} \mathrm{Kz}$ Ss Por

1.25599e+03 1.25599e+03 1.25599e+02 1.00000e-09 7.00000e-02

$1.25599 \mathrm{e}+03$ 1.25599e+03 1.25599e+02 1.00000e-09 7.00000e-02

$1.25599 \mathrm{e}+031.25599 \mathrm{e}+03$ 1.25599e+02 1.00000e-09 7.00000e-02

1.00000e-06 1.00000e-06 1.00000e-06 1.00000e-09 5.00000e-02

Element: 5762 \# of layers: 4

$\mathrm{Kx} \mathrm{Ky} \mathrm{Kz}$ Ss Por

$1.45791 \mathrm{e}+03$ 1.45791e+03 1.45791e+02 1.00000e-09 7.00000e-02

$1.45791 \mathrm{e}+031.45791 \mathrm{e}+03$ 1.45791e+02 1.00000e-09 7.00000e-02

$1.45791 \mathrm{e}+031.45791 \mathrm{e}+03$ 1.45791e+02 1.00000e-09 7.00000e-02

1.00000e-06 1.00000e-06 1.00000e-06 1.00000e-09 5.00000e-02

Element: 5763 \# of layers: 4

$\mathrm{Kx} \mathrm{Ky} \mathrm{Kz}$ Ss Por

$1.21581 \mathrm{e}+03$ 1.21581e+03 1.21581e+02 1.00000e-09 7.00000e-02

$1.21581 \mathrm{e}+031.21581 \mathrm{e}+031.21581 \mathrm{e}+021.00000 \mathrm{e}-097.00000 \mathrm{e}-02$ 
$1.21581 \mathrm{e}+03$ 1.21581e+03 1.21581e+02 1.00000e-09 7.00000e-02 1.00000e-06 1.00000e-06 1.00000e-06 1.00000e-09 5.00000e-02

Element: 5764 \# of layers: 4

Kx Ky Kz Ss Por

$1.21581 \mathrm{e}+031.21581 \mathrm{e}+03$ 1.21581e+02 1.00000e-09 7.00000e-02

$1.21581 \mathrm{e}+031.21581 \mathrm{e}+03$ 1.21581e+02 1.00000e-09 7.00000e-02

$1.21581 \mathrm{e}+031.21581 \mathrm{e}+031.21581 \mathrm{e}+02$ 1.00000e-09 7.00000e-02

1.00000e-06 1.00000e-06 1.00000e-06 1.00000e-09 5.00000e-02

Element: 5765 \# of layers: 4

$\mathrm{Kx} \mathrm{Ky} \mathrm{Kz}$ Ss Por

$1.38394 \mathrm{e}+03$ 1.38394e+03 1.38394e+02 1.00000e-09 7.00000e-02

$1.38394 \mathrm{e}+03$ 1.38394e+03 1.38394e+02 1.00000e-09 7.00000e-02

$1.38394 \mathrm{e}+03$ 1.38394e+03 1.38394e+02 1.00000e-09 7.00000e-02

1.00000e-06 1.00000e-06 1.00000e-06 1.00000e-09 5.00000e-02

Element: 5766 \# of layers: 4

Kx Ky Kz Ss Por

$1.38394 \mathrm{e}+03$ 1.38394e+03 1.38394e+02 1.00000e-09 7.00000e-02

$1.38394 \mathrm{e}+031.38394 \mathrm{e}+03$ 1.38394e+02 1.00000e-09 7.00000e-02

$1.38394 \mathrm{e}+031.38394 \mathrm{e}+03$ 1.38394e+02 1.00000e-09 7.00000e-02

1.00000e-06 1.00000e-06 1.00000e-06 1.00000e-09 5.00000e-02

Element: 5767 \# of layers: 4

$\mathrm{Kx} \mathrm{Ky} \mathrm{Kz}$ Ss Por

$1.38394 \mathrm{e}+03$ 1.38394e+03 1.38394e+02 1.00000e-09 7.00000e-02

$1.38394 \mathrm{e}+03$ 1.38394e+03 1.38394e+02 1.00000e-09 7.00000e-02

$1.38394 \mathrm{e}+031.38394 \mathrm{e}+031.38394 \mathrm{e}+02 \quad 1.00000 \mathrm{e}-097.00000 \mathrm{e}-02$

1.00000e-06 1.00000e-06 1.00000e-06 1.00000e-09 5.00000e-02

Element: 5768 \# of layers: 4

$\mathrm{Kx} \mathrm{Ky} \mathrm{Kz}$ Ss Por

$1.38961 \mathrm{e}+03$ 1.38961e+03 1.38961e+02 1.00000e-09 7.00000e-02

$1.38961 \mathrm{e}+03$ 1.38961e+03 1.38961e+02 1.00000e-09 7.00000e-02

$1.38961 \mathrm{e}+031.38961 \mathrm{e}+03$ 1.38961e+02 1.00000e-09 7.00000e-02

1.00000e-06 1.00000e-06 1.00000e-06 1.00000e-09 5.00000e-02

Element: 5769 \# of layers: 4

$\mathrm{Kx} \mathrm{Ky} \mathrm{Kz}$ Ss Por

1.38961e+03 1.38961e+03 1.38961e+02 1.00000e-09 7.00000e-02

$1.38961 \mathrm{e}+031.38961 \mathrm{e}+03$ 1.38961e+02 1.00000e-09 7.00000e-02

$1.38961 \mathrm{e}+031.38961 \mathrm{e}+031.38961 \mathrm{e}+02$ 1.00000e-09 7.00000e-02

1.00000e-06 1.00000e-06 1.00000e-06 1.00000e-09 5.00000e-02

Element: 5770 \# of layers: 4

$\mathrm{Kx} \mathrm{Ky} \mathrm{Kz}$ Ss Por

$1.21581 \mathrm{e}+03$ 1.21581e+03 1.21581e+02 1.00000e-09 7.00000e-02

$1.21581 \mathrm{e}+03$ 1.21581e+03 1.21581e+02 1.00000e-09 7.00000e-02

$1.21581 \mathrm{e}+031.21581 \mathrm{e}+031.21581 \mathrm{e}+021.00000 \mathrm{e}-097.00000 \mathrm{e}-02$

1.00000e-06 1.00000e-06 1.00000e-06 1.00000e-09 5.00000e-02

Element: 5771 \# of layers: 4

Kx Ky Kz Ss Por 
$1.45575 \mathrm{e}+011.45575 \mathrm{e}+01$ 1.45575e+00 1.00000e-09 7.00000e-02 $1.45575 \mathrm{e}+011.45575 \mathrm{e}+01$ 1.45575e+00 1.00000e-09 7.00000e-02 $1.45575 \mathrm{e}+011.45575 \mathrm{e}+011.45575 \mathrm{e}+001.00000 \mathrm{e}-09$ 7.00000e-02 1.00000e-06 1.00000e-06 1.00000e-06 1.00000e-09 5.00000e-02

Element: 5772 \# of layers: 4

$\mathrm{Kx} \mathrm{Ky} \mathrm{Kz}$ Ss Por

$1.94661 \mathrm{e}+011.94661 \mathrm{e}+01$ 1.94661e+00 1.00000e-09 7.00000e-02 $1.94661 \mathrm{e}+011.94661 \mathrm{e}+011.94661 \mathrm{e}+001.00000 \mathrm{e}-097.00000 \mathrm{e}-02$ $1.94661 \mathrm{e}+011.94661 \mathrm{e}+011.94661 \mathrm{e}+001.00000 \mathrm{e}-09$ 7.00000e-02 1.00000e-06 1.00000e-06 1.00000e-06 1.00000e-09 5.00000e-02

Element: 5773 \# of layers: 4

Kx Ky Kz Ss Por

$1.94661 \mathrm{e}+011.94661 \mathrm{e}+011.94661 \mathrm{e}+001.00000 \mathrm{e}-09$ 7.00000e-02 $1.94661 \mathrm{e}+011.94661 \mathrm{e}+011.94661 \mathrm{e}+001.00000 \mathrm{e}-09$ 7.00000e-02 $1.94661 \mathrm{e}+011.94661 \mathrm{e}+011.94661 \mathrm{e}+001.00000 \mathrm{e}-09$ 7.00000e-02 1.00000e-06 1.00000e-06 1.00000e-06 1.00000e-09 5.00000e-02

Element: 5774 \# of layers: 4

$\mathrm{Kx} \mathrm{Ky} \mathrm{Kz}$ Ss Por

$1.94661 \mathrm{e}+01$ 1.94661e+01 1.94661e+00 1.00000e-09 7.00000e-02 $1.94661 \mathrm{e}+011.94661 \mathrm{e}+011.94661 \mathrm{e}+001.00000 \mathrm{e}-09$ 7.00000e-02 $1.94661 \mathrm{e}+011.94661 \mathrm{e}+011.94661 \mathrm{e}+001.00000 \mathrm{e}-09$ 7.00000e-02 1.00000e-06 1.00000e-06 1.00000e-06 1.00000e-09 5.00000e-02

Element: 5775 \# of layers: 4

Kx Ky Kz Ss Por

$1.99761 \mathrm{e}+011.99761 \mathrm{e}+011.99761 \mathrm{e}+001.00000 \mathrm{e}-09$ 7.00000e-02 $1.99761 \mathrm{e}+011.99761 \mathrm{e}+011.99761 \mathrm{e}+001.00000 \mathrm{e}-097.00000 \mathrm{e}-02$ $1.99761 \mathrm{e}+011.99761 \mathrm{e}+011.99761 \mathrm{e}+001.00000 \mathrm{e}-09$ 7.00000e-02 1.00000e-06 1.00000e-06 1.00000e-06 1.00000e-09 5.00000e-02

Element: 5776 \# of layers: 4

$\mathrm{Kx} \mathrm{Ky} \mathrm{Kz}$ Ss Por

$1.99761 \mathrm{e}+011.99761 \mathrm{e}+011.99761 \mathrm{e}+00$ 1.00000e-09 7.00000e-02 $1.99761 \mathrm{e}+011.99761 \mathrm{e}+011.99761 \mathrm{e}+001.00000 \mathrm{e}-09$ 7.00000e-02 $1.99761 \mathrm{e}+011.99761 \mathrm{e}+011.99761 \mathrm{e}+001.00000 \mathrm{e}-09$ 7.00000e-02 1.00000e-06 1.00000e-06 1.00000e-06 1.00000e-09 5.00000e-02

Element: 5777 \# of layers: 4

$\mathrm{Kx} \mathrm{Ky} \mathrm{Kz}$ Ss Por

$1.70325 \mathrm{e}+01$ 1.70325e+01 1.70325e+00 1.00000e-09 7.00000e-02 $1.70325 \mathrm{e}+011.70325 \mathrm{e}+011.70325 \mathrm{e}+001.00000 \mathrm{e}-09$ 7.00000e-02 $1.70325 \mathrm{e}+011.70325 \mathrm{e}+011.70325 \mathrm{e}+001.00000 \mathrm{e}-09$ 7.00000e-02 1.00000e-06 1.00000e-06 1.00000e-06 1.00000e-09 5.00000e-02

Element: 5778 \# of layers: 4

$\mathrm{Kx} \mathrm{Ky} \mathrm{Kz}$ Ss Por

$1.45575 \mathrm{e}+011.45575 \mathrm{e}+011.45575 \mathrm{e}+001.00000 \mathrm{e}-09$ 7.00000e-02 $1.45575 \mathrm{e}+011.45575 \mathrm{e}+01$ 1.45575e+00 1.00000e-09 7.00000e-02 $1.45575 \mathrm{e}+011.45575 \mathrm{e}+011.45575 \mathrm{e}+001.00000 \mathrm{e}-09$ 7.00000e-02 $1.00000 \mathrm{e}-06$ 1.00000e-06 1.00000e-06 1.00000e-09 5.00000e-02 
Element: 5779 \# of layers: 4

$\mathrm{Kx} \mathrm{Ky} \mathrm{Kz}$ Ss Por

$1.99761 \mathrm{e}+011.99761 \mathrm{e}+011.99761 \mathrm{e}+001.00000 \mathrm{e}-09$ 7.00000e-02

$1.99761 \mathrm{e}+011.99761 \mathrm{e}+011.99761 \mathrm{e}+001.00000 \mathrm{e}-097.00000 \mathrm{e}-02$

$1.99761 \mathrm{e}+011.99761 \mathrm{e}+011.99761 \mathrm{e}+001.00000 \mathrm{e}-097.00000 \mathrm{e}-02$

1.00000e-06 1.00000e-06 1.00000e-06 1.00000e-09 5.00000e-02

Element: 5780 \# of layers: 4

$\mathrm{Kx} \mathrm{Ky} \mathrm{Kz}$ Ss Por

$1.71208 \mathrm{e}+01$ 1.71208e+01 1.71208e+00 1.00000e-09 7.00000e-02

$1.71208 \mathrm{e}+011.71208 \mathrm{e}+01$ 1.71208e+00 1.00000e-09 7.00000e-02

$1.71208 \mathrm{e}+011.71208 \mathrm{e}+01$ 1.71208e+00 1.00000e-09 7.00000e-02

1.00000e-06 1.00000e-06 1.00000e-06 1.00000e-09 5.00000e-02

Element: 5781 \# of layers: 4

$\mathrm{Kx} \mathrm{Ky} \mathrm{Kz}$ Ss Por

$1.74839 \mathrm{e}+01$ 1.74839e+01 1.74839e+00 1.00000e-09 7.00000e-02

$1.74839 \mathrm{e}+011.74839 \mathrm{e}+011.74839 \mathrm{e}+001.00000 \mathrm{e}-09$ 7.00000e-02

$1.74839 \mathrm{e}+011.74839 \mathrm{e}+01$ 1.74839e+00 1.00000e-09 7.00000e-02

1.00000e-06 1.00000e-06 1.00000e-06 1.00000e-09 5.00000e-02

Element: 5782 \# of layers: 4

$\mathrm{Kx} \mathrm{Ky} \mathrm{Kz}$ Ss Por

$1.74839 \mathrm{e}+01$ 1.74839e+01 1.74839e+00 1.00000e-09 7.00000e-02

$1.74839 \mathrm{e}+01$ 1.74839e+01 1.74839e+00 1.00000e-09 7.00000e-02

$1.74839 \mathrm{e}+01$ 1.74839e+01 1.74839e+00 1.00000e-09 7.00000e-02

1.00000e-06 1.00000e-06 1.00000e-06 1.00000e-09 5.00000e-02

Element: 5783 \# of layers: 3

$\mathrm{Kx} \mathrm{Ky} \mathrm{Kz}$ Ss Por

$2.12483 \mathrm{e}+012.12483 \mathrm{e}+012.12483 \mathrm{e}+00$ 1.00000e-09 7.00000e-02

$2.12483 \mathrm{e}+012.12483 \mathrm{e}+012.12483 \mathrm{e}+00$ 1.00000e-09 7.00000e-02

$1.00000 \mathrm{e}-06$ 1.00000e-06 1.00000e-06 1.00000e-09 5.00000e-02

Element: 5784 \# of layers: 4

$\mathrm{Kx} \mathrm{Ky} \mathrm{Kz}$ Ss Por

$2.12483 \mathrm{e}+012.12483 \mathrm{e}+012.12483 \mathrm{e}+00$ 1.00000e-09 7.00000e-02

$2.12483 \mathrm{e}+012.12483 \mathrm{e}+012.12483 \mathrm{e}+00$ 1.00000e-09 7.00000e-02

$2.12483 \mathrm{e}+012.12483 \mathrm{e}+012.12483 \mathrm{e}+001.00000 \mathrm{e}-09$ 7.00000e-02

1.00000e-06 1.00000e-06 1.00000e-06 1.00000e-09 5.00000e-02

Element: 5785 \# of layers: 4

Kx Ky Kz Ss Por

$2.12483 e+012.12483 e+012.12483 e+001.00000 e-09$ 7.00000e-02

$2.12483 \mathrm{e}+012.12483 \mathrm{e}+012.12483 \mathrm{e}+00$ 1.00000e-09 7.00000e-02

$2.12483 \mathrm{e}+012.12483 \mathrm{e}+012.12483 \mathrm{e}+00$ 1.00000e-09 7.00000e-02

1.00000e-06 1.00000e-06 1.00000e-06 1.00000e-09 5.00000e-02

Element: 5786 \# of layers: 4

$\mathrm{Kx} \mathrm{Ky} \mathrm{Kz}$ Ss Por

$2.33476 \mathrm{e}+012.33476 \mathrm{e}+012.33476 \mathrm{e}+00$ 1.00000e-09 7.00000e-02

$2.33476 \mathrm{e}+012.33476 \mathrm{e}+012.33476 \mathrm{e}+001.00000 \mathrm{e}-09$ 7.00000e-02

$2.33476 \mathrm{e}+012.33476 \mathrm{e}+012.33476 \mathrm{e}+001.00000 \mathrm{e}-09$ 7.00000e-02 
1.00000e-06 1.00000e-06 1.00000e-06 1.00000e-09 5.00000e-02

Element: 5787 \# of layers: 4

Kx Ky Kz Ss Por

$1.71208 \mathrm{e}+01$ 1.71208e+01 1.71208e+00 1.00000e-09 7.00000e-02

$1.71208 \mathrm{e}+011.71208 \mathrm{e}+01$ 1.71208e+00 1.00000e-09 7.00000e-02

$1.71208 \mathrm{e}+011.71208 \mathrm{e}+01$ 1.71208e+00 1.00000e-09 7.00000e-02

1.00000e-06 1.00000e-06 1.00000e-06 1.00000e-09 5.00000e-02

Element: 5788 \# of layers: 4

$\mathrm{Kx} \mathrm{Ky} \mathrm{Kz}$ Ss Por

2.12483e+01 2.12483e+01 2.12483e+00 1.00000e-09 7.00000e-02

$2.12483 \mathrm{e}+012.12483 \mathrm{e}+012.12483 \mathrm{e}+00$ 1.00000e-09 7.00000e-02

$2.12483 \mathrm{e}+012.12483 \mathrm{e}+012.12483 \mathrm{e}+001.00000 \mathrm{e}-09$ 7.00000e-02

1.00000e-06 1.00000e-06 1.00000e-06 1.00000e-09 5.00000e-02

Element: 5789 \# of layers: 4

$\mathrm{Kx} \mathrm{Ky} \mathrm{Kz}$ Ss Por

4.74277e+01 4.74277e+01 4.74277e+00 1.00000e-09 7.00000e-02

4.74277e+01 4.74277e+01 4.74277e+00 1.00000e-09 7.00000e-02

4.74277e+01 4.74277e+01 4.74277e+00 1.00000e-09 7.00000e-02 1.00000e-06 1.00000e-06 1.00000e-06 1.00000e-09 5.00000e-02

Element: 5790 \# of layers: 4

$\mathrm{Kx} \mathrm{Ky} \mathrm{Kz}$ Ss Por

4.74277e+01 4.74277e+01 4.74277e+00 1.00000e-09 7.00000e-02

4.74277e+01 4.74277e+01 4.74277e+00 1.00000e-09 7.00000e-02

4.74277e+01 4.74277e+01 4.74277e+00 1.00000e-09 7.00000e-02

1.00000e-06 1.00000e-06 1.00000e-06 1.00000e-09 5.00000e-02

Element: 5791 \# of layers: 3

$\mathrm{Kx} \mathrm{Ky} \mathrm{Kz}$ Ss Por

9.04784e+01 9.04784e+01 9.04784e+00 1.00000e-09 7.00000e-02

$9.04784 \mathrm{e}+019.04784 \mathrm{e}+019.04784 \mathrm{e}+001.00000 \mathrm{e}-09$ 7.00000e-02

1.00000e-06 1.00000e-06 1.00000e-06 1.00000e-09 5.00000e-02

Element: 5792 \# of layers: 3

Kx Ky Kz Ss Por

1.11580e+02 1.11580e+02 1.11580e+01 1.00000e-09 7.00000e-02

$1.11580 \mathrm{e}+021.11580 \mathrm{e}+021.11580 \mathrm{e}+01$ 1.00000e-09 7.00000e-02

1.00000e-06 1.00000e-06 1.00000e-06 1.00000e-09 5.00000e-02

Element: 5793 \# of layers: 4

Kx Ky Kz Ss Por

$1.11580 \mathrm{e}+02$ 1.11580e+02 1.11580e+01 1.00000e-09 7.00000e-02

$1.11580 \mathrm{e}+021.11580 \mathrm{e}+021.11580 \mathrm{e}+01$ 1.00000e-09 7.00000e-02

$1.11580 \mathrm{e}+021.11580 \mathrm{e}+021.11580 \mathrm{e}+01$ 1.00000e-09 7.00000e-02

1.00000e-06 1.00000e-06 1.00000e-06 1.00000e-09 5.00000e-02

Element: 5794 \# of layers: 4

$\mathrm{Kx} \mathrm{Ky} \mathrm{Kz}$ Ss Por

1.11580e+02 1.11580e+02 1.11580e+01 1.00000e-09 7.00000e-02

$1.11580 \mathrm{e}+02$ 1.11580e+02 1.11580e+01 1.00000e-09 7.00000e-02

$1.11580 \mathrm{e}+021.11580 \mathrm{e}+021.11580 \mathrm{e}+01$ 1.00000e-09 7.00000e-02 
1.00000e-06 1.00000e-06 1.00000e-06 1.00000e-09 5.00000e-02

Element: 5795 \# of layers: 4

Kx Ky Kz Ss Por

4.32867e+01 4.32867e+01 4.32867e+00 1.00000e-09 7.00000e-02

4.32867e+01 4.32867e+01 4.32867e+00 1.00000e-09 7.00000e-02

$4.32867 \mathrm{e}+014.32867 \mathrm{e}+014.32867 \mathrm{e}+00$ 1.00000e-09 7.00000e-02

1.00000e-06 1.00000e-06 1.00000e-06 1.00000e-09 5.00000e-02

Element: 5796 \# of layers: 4

$\mathrm{Kx} \mathrm{Ky} \mathrm{Kz}$ Ss Por

4.74277e+01 4.74277e+01 4.74277e+00 1.00000e-09 7.00000e-02 4.74277e+01 4.74277e+01 4.74277e+00 1.00000e-09 7.00000e-02

4.74277e+01 4.74277e+01 4.74277e+00 1.00000e-09 7.00000e-02

1.00000e-06 1.00000e-06 1.00000e-06 1.00000e-09 5.00000e-02

Element: 5797 \# of layers: 4

Kx Ky Kz Ss Por

$1.11580 \mathrm{e}+02$ 1.11580e+02 1.11580e+01 1.00000e-09 7.00000e-02

$1.11580 \mathrm{e}+021.11580 \mathrm{e}+02$ 1.11580e+01 1.00000e-09 7.00000e-02

$1.11580 \mathrm{e}+021.11580 \mathrm{e}+021.11580 \mathrm{e}+01$ 1.00000e-09 7.00000e-02

1.00000e-06 1.00000e-06 1.00000e-06 1.00000e-09 5.00000e-02

Element: 5798 \# of layers: 3

$\mathrm{Kx} \mathrm{Ky} \mathrm{Kz}$ Ss Por

8.34605e+01 8.34605e+01 8.34605e+00 1.00000e-09 7.00000e-02

8.34605e+01 8.34605e+01 8.34605e+00 1.00000e-09 7.00000e-02

1.00000e-06 1.00000e-06 1.00000e-06 1.00000e-09 5.00000e-02

Element: 5799 \# of layers: 3

$\mathrm{Kx} \mathrm{Ky} \mathrm{Kz}$ Ss Por

8.34605e+01 8.34605e+01 8.34605e+00 1.00000e-09 7.00000e-02

$8.34605 \mathrm{e}+018.34605 \mathrm{e}+018.34605 \mathrm{e}+001.00000 \mathrm{e}-09$ 7.00000e-02

1.00000e-06 1.00000e-06 1.00000e-06 1.00000e-09 5.00000e-02

Element: 5800 \# of layers: 4

$\mathrm{Kx} \mathrm{Ky} \mathrm{Kz}$ Ss Por

3.40443e+01 3.40443e+01 3.40443e+00 1.00000e-09 7.00000e-02

$3.40443 \mathrm{e}+013.40443 \mathrm{e}+013.40443 \mathrm{e}+00$ 1.00000e-09 7.00000e-02

$3.40443 \mathrm{e}+013.40443 \mathrm{e}+013.40443 \mathrm{e}+00$ 1.00000e-09 7.00000e-02

1.00000e-06 1.00000e-06 1.00000e-06 1.00000e-09 5.00000e-02

Element: 5801 \# of layers: 4

Kx Ky Kz Ss Por

7.64075e+01 7.64075e+01 7.64075e+00 1.00000e-09 7.00000e-02

$7.64075 \mathrm{e}+01$ 7.64075e+01 7.64075e+00 1.00000e-09 7.00000e-02

$7.64075 \mathrm{e}+017.64075 \mathrm{e}+01$ 7.64075e+00 1.00000e-09 7.00000e-02

1.00000e-06 1.00000e-06 1.00000e-06 1.00000e-09 5.00000e-02

Element: 5802 \# of layers: 4

$\mathrm{Kx} \mathrm{Ky} \mathrm{Kz}$ Ss Por

1.26392e+02 1.26392e+02 1.26392e+01 1.00000e-09 7.00000e-02

$1.26392 \mathrm{e}+02$ 1.26392e+02 1.26392e+01 1.00000e-09 7.00000e-02

$1.26392 \mathrm{e}+02$ 1.26392e+02 1.26392e+01 1.00000e-09 7.00000e-02 
1.00000e-06 1.00000e-06 1.00000e-06 1.00000e-09 5.00000e-02

Element: 5803 \# of layers: 4

Kx Ky Kz Ss Por

$1.03390 \mathrm{e}+02$ 1.03390e+02 1.03390e+01 1.00000e-09 7.00000e-02

$1.03390 \mathrm{e}+021.03390 \mathrm{e}+021.03390 \mathrm{e}+01$ 1.00000e-09 7.00000e-02

$1.03390 \mathrm{e}+021.03390 \mathrm{e}+021.03390 \mathrm{e}+01$ 1.00000e-09 7.00000e-02

1.00000e-06 1.00000e-06 1.00000e-06 1.00000e-09 5.00000e-02

Element: 5804 \# of layers: 4

$\mathrm{Kx} \mathrm{Ky} \mathrm{Kz}$ Ss Por

$1.03390 \mathrm{e}+02$ 1.03390e+02 1.03390e+01 1.00000e-09 7.00000e-02

$1.03390 \mathrm{e}+02$ 1.03390e+02 1.03390e+01 1.00000e-09 7.00000e-02

$1.03390 \mathrm{e}+02$ 1.03390e+02 1.03390e+01 1.00000e-09 7.00000e-02

1.00000e-06 1.00000e-06 1.00000e-06 1.00000e-09 5.00000e-02

Element: 5805 \# of layers: 3

$\mathrm{Kx} \mathrm{Ky} \mathrm{Kz}$ Ss Por

$1.03390 \mathrm{e}+02$ 1.03390e+02 1.03390e+01 1.00000e-09 7.00000e-02

$1.03390 \mathrm{e}+021.03390 \mathrm{e}+02$ 1.03390e+01 1.00000e-09 7.00000e-02

1.00000e-06 1.00000e-06 1.00000e-06 1.00000e-09 5.00000e-02

Element: 5806 \# of layers: 3

$\mathrm{Kx} \mathrm{Ky} \mathrm{Kz}$ Ss Por

$1.03390 \mathrm{e}+02$ 1.03390e+02 1.03390e+01 1.00000e-09 7.00000e-02

$1.03390 \mathrm{e}+021.03390 \mathrm{e}+02$ 1.03390e+01 1.00000e-09 7.00000e-02

1.00000e-06 1.00000e-06 1.00000e-06 1.00000e-09 5.00000e-02

Element: 5807 \# of layers: 7

$\mathrm{Kx} \mathrm{Ky} \mathrm{Kz}$ Ss Por

$1.15436 \mathrm{e}+02$ 1.15436e+02 1.15436e+01 1.00000e-09 7.00000e-02

$1.15436 \mathrm{e}+021.15436 \mathrm{e}+02$ 1.15436e+01 1.00000e-09 7.00000e-02

$1.15436 \mathrm{e}+02$ 1.15436e+02 1.15436e+01 1.00000e-09 7.00000e-02

$1.15436 \mathrm{e}+02$ 1.15436e+02 1.15436e+01 1.00000e-09 7.00000e-02

$1.15436 \mathrm{e}+02$ 1.15436e+02 1.15436e+01 1.00000e-09 7.00000e-02

5.00000e-04 5.00000e-04 5.00000e-05 1.00000e-09 1.00000e-01

5.00000e-04 5.00000e-04 5.00000e-05 1.00000e-09 1.00000e-01

Element: 5808 \# of layers: 9

$\mathrm{Kx} \mathrm{Ky} \mathrm{Kz}$ Ss Por

1.12283e+02 1.12283e+02 1.12283e+01 1.00000e-09 7.00000e-02

$1.12283 \mathrm{e}+02$ 1.12283e+02 1.12283e+01 1.00000e-09 7.00000e-02

$1.12283 \mathrm{e}+021.12283 \mathrm{e}+02$ 1.12283e+01 1.00000e-09 7.00000e-02

$1.12283 \mathrm{e}+021.12283 \mathrm{e}+021.12283 \mathrm{e}+01$ 1.00000e-09 7.00000e-02

5.00000e-04 5.00000e-04 5.00000e-05 1.00000e-09 1.00000e-01

5.00000e-04 5.00000e-04 5.00000e-05 1.00000e-09 1.00000e-01

$1.00000 \mathrm{e}-02$ 1.00000e-02 1.00000e-03 1.00000e-09 1.00000e-01

$1.00000 \mathrm{e}+001.00000 \mathrm{e}+001.00000 \mathrm{e}-011.00000 \mathrm{e}-091.00000 \mathrm{e}-01$

1.00000e-06 1.00000e-06 1.00000e-06 1.00000e-09 5.00000e-02

Element: 5809 \# of layers: 10

$\mathrm{Kx} \mathrm{Ky} \mathrm{Kz}$ Ss Por

$1.12283 e+02$ 1.12283e+02 1.12283e+01 1.00000e-09 7.00000e-02 
1.12283e+02 1.12283e+02 1.12283e+01 1.00000e-09 7.00000e-02 $1.12283 \mathrm{e}+02$ 1.12283e+02 1.12283e+01 1.00000e-09 7.00000e-02

$1.12283 \mathrm{e}+02$ 1.12283e+02 1.12283e+01 1.00000e-09 7.00000e-02 5.00000e-04 5.00000e-04 5.00000e-05 1.00000e-09 1.00000e-01 5.00000e-04 5.00000e-04 5.00000e-05 1.00000e-09 1.00000e-01 $4.88418 \mathrm{e}+004.88418 \mathrm{e}+00$ 4.88418e-01 1.00000e-09 2.12000e-01 $1.00000 \mathrm{e}-02$ 1.00000e-02 1.00000e-03 1.00000e-09 1.00000e-01 $1.00000 \mathrm{e}+001.00000 \mathrm{e}+001.00000 \mathrm{e}-011.00000 \mathrm{e}-091.00000 \mathrm{e}-01$ $1.00000 \mathrm{e}-06$ 1.00000e-06 1.00000e-06 1.00000e-09 5.00000e-02 Element: 5810 \# of layers: 10

$\mathrm{Kx} \mathrm{Ky} \mathrm{Kz}$ Ss Por

1.15436e+02 1.15436e+02 1.15436e+01 1.00000e-09 7.00000e-02 $1.15436 \mathrm{e}+02$ 1.15436e+02 1.15436e+01 1.00000e-09 7.00000e-02 $1.15436 \mathrm{e}+021.15436 \mathrm{e}+02$ 1.15436e+01 1.00000e-09 7.00000e-02 $1.15436 \mathrm{e}+021.15436 \mathrm{e}+021.15436 \mathrm{e}+01$ 1.00000e-09 7.00000e-02 5.00000e-04 5.00000e-04 5.00000e-05 1.00000e-09 1.00000e-01 5.00000e-04 5.00000e-04 5.00000e-05 1.00000e-09 1.00000e-01 $4.65153 \mathrm{e}+00$ 4.65153e+00 4.65153e-01 1.00000e-09 2.12000e-01 $1.00000 \mathrm{e}-02$ 1.00000e-02 1.00000e-03 1.00000e-09 1.00000e-01 $1.00000 \mathrm{e}+001.00000 \mathrm{e}+001.00000 \mathrm{e}-011.00000 \mathrm{e}-091.00000 \mathrm{e}-01$ 1.00000e-06 1.00000e-06 1.00000e-06 1.00000e-09 5.00000e-02 Element: 5811 \# of layers: 11

$\mathrm{Kx} \mathrm{Ky} \mathrm{Kz}$ Ss Por

1.16418e+02 1.16418e+02 1.16418e+01 1.00000e-09 7.00000e-02 $1.16418 \mathrm{e}+02$ 1.16418e+02 1.16418e+01 1.00000e-09 7.00000e-02 $1.16418 \mathrm{e}+02$ 1.16418e+02 1.16418e+01 1.00000e-09 7.00000e-02 $1.16418 \mathrm{e}+021.16418 \mathrm{e}+02$ 1.16418e+01 1.00000e-09 7.00000e-02 5.00000e-04 5.00000e-04 5.00000e-05 1.00000e-09 1.00000e-01 5.00000e-04 5.00000e-04 5.00000e-05 1.00000e-09 1.00000e-01 $4.65153 \mathrm{e}+00$ 4.65153e+00 4.65153e-01 1.00000e-09 2.12000e-01 $4.65153 \mathrm{e}+004.65153 \mathrm{e}+00$ 4.65153e-01 1.00000e-09 2.12000e-01 $1.00000 \mathrm{e}-02$ 1.00000e-02 1.00000e-03 1.00000e-09 1.00000e-01 $1.00000 \mathrm{e}+001.00000 \mathrm{e}+001.00000 \mathrm{e}-011.00000 \mathrm{e}-091.00000 \mathrm{e}-01$ $1.00000 \mathrm{e}-061.00000 \mathrm{e}-06$ 1.00000e-06 1.00000e-09 5.00000e-02 Element: 5812 \# of layers: 8

$\mathrm{Kx} \mathrm{Ky} \mathrm{Kz}$ Ss Por

1.16418e+02 1.16418e+02 1.16418e+01 1.00000e-09 7.00000e-02 $1.16418 \mathrm{e}+021.16418 \mathrm{e}+02$ 1.16418e+01 1.00000e-09 7.00000e-02 $1.16418 \mathrm{e}+021.16418 \mathrm{e}+02$ 1.16418e+01 1.00000e-09 7.00000e-02 5.00000e-04 5.00000e-04 5.00000e-05 1.00000e-09 1.00000e-01 5.00000e-04 5.00000e-04 5.00000e-05 1.00000e-09 1.00000e-01 4.65153e+00 4.65153e+00 4.65153e-01 1.00000e-09 2.12000e-01 $1.00000 \mathrm{e}-02$ 1.00000e-02 1.00000e-03 1.00000e-09 1.00000e-01 $1.00000 \mathrm{e}+001.00000 \mathrm{e}+001.00000 \mathrm{e}-01$ 1.00000e-09 1.00000e-01 Element: 5813 \# of layers: 9

Kx Ky Kz Ss Por 
1.16418e+02 1.16418e+02 1.16418e+01 1.00000e-09 7.00000e-02 $1.16418 \mathrm{e}+02$ 1.16418e+02 1.16418e+01 1.00000e-09 7.00000e-02 $1.16418 \mathrm{e}+02$ 1.16418e+02 1.16418e+01 1.00000e-09 7.00000e-02 $1.16418 \mathrm{e}+02$ 1.16418e+02 1.16418e+01 1.00000e-09 7.00000e-02 5.00000e-04 5.00000e-04 5.00000e-05 1.00000e-09 1.00000e-01 5.00000e-04 5.00000e-04 5.00000e-05 1.00000e-09 1.00000e-01 $4.65153 \mathrm{e}+004.65153 \mathrm{e}+00$ 4.65153e-01 1.00000e-09 2.12000e-01 $1.00000 \mathrm{e}-02$ 1.00000e-02 1.00000e-03 1.00000e-09 1.00000e-01 $1.00000 \mathrm{e}+001.00000 \mathrm{e}+001.00000 \mathrm{e}-011.00000 \mathrm{e}-091.00000 \mathrm{e}-01$ Element: 5814 \# of layers: 8

Kx Ky Kz Ss Por

$1.15436 \mathrm{e}+02$ 1.15436e+02 1.15436e+01 1.00000e-09 7.00000e-02 $1.15436 \mathrm{e}+02$ 1.15436e+02 1.15436e+01 1.00000e-09 7.00000e-02 $1.15436 \mathrm{e}+02$ 1.15436e+02 1.15436e+01 1.00000e-09 7.00000e-02 $1.15436 \mathrm{e}+021.15436 \mathrm{e}+021.15436 \mathrm{e}+01$ 1.00000e-09 7.00000e-02 5.00000e-04 5.00000e-04 5.00000e-05 1.00000e-09 1.00000e-01 5.00000e-04 5.00000e-04 5.00000e-05 1.00000e-09 1.00000e-01 $1.00000 \mathrm{e}-02$ 1.00000e-02 1.00000e-03 1.00000e-09 1.00000e-01 $1.00000 \mathrm{e}+001.00000 \mathrm{e}+001.00000 \mathrm{e}-01$ 1.00000e-09 1.00000e-01 Element: 5815 \# of layers: 10

$\mathrm{Kx} \mathrm{Ky} \mathrm{Kz}$ Ss Por

1.15436e+02 1.15436e+02 1.15436e+01 1.00000e-09 7.00000e-02 $1.15436 \mathrm{e}+02$ 1.15436e+02 1.15436e+01 1.00000e-09 7.00000e-02 $1.15436 \mathrm{e}+021.15436 \mathrm{e}+02$ 1.15436e+01 1.00000e-09 7.00000e-02 $1.15436 \mathrm{e}+021.15436 \mathrm{e}+021.15436 \mathrm{e}+01$ 1.00000e-09 7.00000e-02 5.00000e-04 5.00000e-04 5.00000e-05 1.00000e-09 1.00000e-01 5.00000e-04 5.00000e-04 5.00000e-05 1.00000e-09 1.00000e-01 $4.65153 \mathrm{e}+00$ 4.65153e+00 4.65153e-01 1.00000e-09 2.12000e-01 $1.00000 \mathrm{e}-02$ 1.00000e-02 1.00000e-03 1.00000e-09 1.00000e-01 $1.00000 \mathrm{e}+001.00000 \mathrm{e}+001.00000 \mathrm{e}-011.00000 \mathrm{e}-091.00000 \mathrm{e}-01$ 1.00000e-06 1.00000e-06 1.00000e-06 1.00000e-09 5.00000e-02 Element: 5816 \# of layers: 10

$\mathrm{Kx} \mathrm{Ky} \mathrm{Kz}$ Ss Por

$1.22239 \mathrm{e}+02$ 1.22239e+02 1.22239e+01 1.00000e-09 7.00000e-02 $1.22239 \mathrm{e}+02$ 1.22239e+02 1.22239e+01 1.00000e-09 7.00000e-02 $1.22239 \mathrm{e}+02$ 1.22239e+02 1.22239e+01 1.00000e-09 7.00000e-02 $1.22239 \mathrm{e}+021.22239 \mathrm{e}+021.22239 \mathrm{e}+01$ 1.00000e-09 7.00000e-02 5.00000e-04 5.00000e-04 5.00000e-05 1.00000e-09 1.00000e-01 5.00000e-04 5.00000e-04 5.00000e-05 1.00000e-09 1.00000e-01 $4.88418 \mathrm{e}+004.88418 \mathrm{e}+00$ 4.88418e-01 1.00000e-09 2.12000e-01 $1.00000 \mathrm{e}-02$ 1.00000e-02 1.00000e-03 1.00000e-09 1.00000e-01 $1.00000 \mathrm{e}+001.00000 \mathrm{e}+001.00000 \mathrm{e}-011.00000 \mathrm{e}-091.00000 \mathrm{e}-01$ 1.00000e-06 1.00000e-06 1.00000e-06 1.00000e-09 5.00000e-02 Element: 5817 \# of layers: 11

$\mathrm{Kx} \mathrm{Ky} \mathrm{Kz}$ Ss Por

1.22239e+02 1.22239e+02 1.22239e+01 1.00000e-09 7.00000e-02 
$1.22239 \mathrm{e}+02$ 1.22239e+02 1.22239e+01 1.00000e-09 7.00000e-02 $1.22239 \mathrm{e}+02$ 1.22239e+02 1.22239e+01 1.00000e-09 7.00000e-02 $1.22239 \mathrm{e}+02$ 1.22239e+02 1.22239e+01 1.00000e-09 7.00000e-02 5.00000e-04 5.00000e-04 5.00000e-05 1.00000e-09 1.00000e-01 5.00000e-04 5.00000e-04 5.00000e-05 1.00000e-09 1.00000e-01 $4.88418 \mathrm{e}+004.88418 \mathrm{e}+00$ 4.88418e-01 1.00000e-09 2.12000e-01 $4.88418 \mathrm{e}+004.88418 \mathrm{e}+00$ 4.88418e-01 1.00000e-09 2.12000e-01 $1.00000 \mathrm{e}-02$ 1.00000e-02 1.00000e-03 1.00000e-09 1.00000e-01 $1.00000 \mathrm{e}+001.00000 \mathrm{e}+001.00000 \mathrm{e}-011.00000 \mathrm{e}-091.00000 \mathrm{e}-01$ 1.00000e-06 1.00000e-06 1.00000e-06 1.00000e-09 5.00000e-02 Element: 5818 \# of layers: 11

$\mathrm{Kx} \mathrm{Ky} \mathrm{Kz}$ Ss Por

$1.44998 \mathrm{e}+02$ 1.44998e+02 1.44998e+01 1.00000e-09 7.00000e-02 $1.44998 \mathrm{e}+02$ 1.44998e+02 1.44998e+01 1.00000e-09 7.00000e-02 $1.44998 \mathrm{e}+021.44998 \mathrm{e}+02$ 1.44998e+01 1.00000e-09 7.00000e-02 $1.44998 \mathrm{e}+021.44998 \mathrm{e}+02$ 1.44998e+01 1.00000e-09 7.00000e-02 5.00000e-04 5.00000e-04 5.00000e-05 1.00000e-09 1.00000e-01 5.00000e-04 5.00000e-04 5.00000e-05 1.00000e-09 1.00000e-01 $5.79365 \mathrm{e}+005.79365 \mathrm{e}+00$ 5.79365e-01 1.00000e-09 2.12000e-01 $5.79365 \mathrm{e}+00$ 5.79365e+00 5.79365e-01 1.00000e-09 2.12000e-01 $1.00000 \mathrm{e}-02$ 1.00000e-02 1.00000e-03 1.00000e-09 1.00000e-01 $1.00000 \mathrm{e}+001.00000 \mathrm{e}+001.00000 \mathrm{e}-011.00000 \mathrm{e}-091.00000 \mathrm{e}-01$ 1.00000e-06 1.00000e-06 1.00000e-06 1.00000e-09 5.00000e-02 Element: 5819 \# of layers: 11

$\mathrm{Kx} \mathrm{Ky} \mathrm{Kz}$ Ss Por $1.42061 \mathrm{e}+02$ 1.42061e+02 1.42061e+01 1.00000e-09 7.00000e-02 $1.42061 \mathrm{e}+021.42061 \mathrm{e}+021.42061 \mathrm{e}+01$ 1.00000e-09 7.00000e-02 $1.42061 \mathrm{e}+02$ 1.42061e+02 1.42061e+01 1.00000e-09 7.00000e-02 $1.42061 \mathrm{e}+021.42061 \mathrm{e}+021.42061 \mathrm{e}+011.00000 \mathrm{e}-097.00000 \mathrm{e}-02$ 5.00000e-04 5.00000e-04 5.00000e-05 1.00000e-09 1.00000e-01 5.00000e-04 5.00000e-04 5.00000e-05 1.00000e-09 1.00000e-01 $5.67597 \mathrm{e}+00$ 5.67597e+00 5.67597e-01 1.00000e-09 2.12000e-01 5.67597e+00 5.67597e+00 5.67597e-01 1.00000e-09 2.12000e-01 $1.00000 \mathrm{e}-02$ 1.00000e-02 1.00000e-03 1.00000e-09 1.00000e-01 $1.00000 \mathrm{e}+001.00000 \mathrm{e}+001.00000 \mathrm{e}-011.00000 \mathrm{e}-091.00000 \mathrm{e}-01$ 1.00000e-06 1.00000e-06 1.00000e-06 1.00000e-09 5.00000e-02 Element: 5820 \# of layers: 11

$\mathrm{Kx} \mathrm{Ky} \mathrm{Kz}$ Ss Por 1.42061e+02 1.42061e+02 1.42061e+01 1.00000e-09 7.00000e-02 $1.42061 \mathrm{e}+021.42061 \mathrm{e}+02$ 1.42061e+01 1.00000e-09 7.00000e-02 $1.42061 \mathrm{e}+021.42061 \mathrm{e}+021.42061 \mathrm{e}+01$ 1.00000e-09 7.00000e-02 $1.42061 \mathrm{e}+021.42061 \mathrm{e}+021.42061 \mathrm{e}+01$ 1.00000e-09 7.00000e-02 $5.00000 \mathrm{e}-04$ 5.00000e-04 5.00000e-05 1.00000e-09 1.00000e-01 5.00000e-04 5.00000e-04 5.00000e-05 1.00000e-09 1.00000e-01 5.67597e+00 5.67597e+00 5.67597e-01 1.00000e-09 2.12000e-01 $5.67597 \mathrm{e}+00$ 5.67597e+00 5.67597e-01 1.00000e-09 2.12000e-01 
$1.00000 \mathrm{e}-02$ 1.00000e-02 1.00000e-03 1.00000e-09 1.00000e-01 $1.00000 \mathrm{e}+001.00000 \mathrm{e}+001.00000 \mathrm{e}-011.00000 \mathrm{e}-091.00000 \mathrm{e}-01$ $1.00000 \mathrm{e}-06$ 1.00000e-06 1.00000e-06 1.00000e-09 5.00000e-02

Element: 5821 \# of layers: 11

Kx Ky Kz Ss Por

$1.42061 \mathrm{e}+021.42061 \mathrm{e}+021.42061 \mathrm{e}+01$ 1.00000e-09 7.00000e-02 $1.42061 \mathrm{e}+021.42061 \mathrm{e}+021.42061 \mathrm{e}+011.00000 \mathrm{e}-097.00000 \mathrm{e}-02$ $1.42061 \mathrm{e}+021.42061 \mathrm{e}+021.42061 \mathrm{e}+011.00000 \mathrm{e}-097.00000 \mathrm{e}-02$ $1.42061 \mathrm{e}+021.42061 \mathrm{e}+021.42061 \mathrm{e}+011.00000 \mathrm{e}-097.00000 \mathrm{e}-02$ $5.00000 \mathrm{e}-04$ 5.00000e-04 5.00000e-05 1.00000e-09 1.00000e-01 $5.00000 \mathrm{e}-04$ 5.00000e-04 5.00000e-05 1.00000e-09 1.00000e-01 $5.67597 \mathrm{e}+005.67597 \mathrm{e}+00$ 5.67597e-01 1.00000e-09 2.12000e-01 $5.67597 \mathrm{e}+005.67597 \mathrm{e}+00$ 5.67597e-01 1.00000e-09 2.12000e-01 $1.00000 \mathrm{e}-021.00000 \mathrm{e}-02$ 1.00000e-03 1.00000e-09 1.00000e-01 $1.00000 \mathrm{e}+001.00000 \mathrm{e}+001.00000 \mathrm{e}-011.00000 \mathrm{e}-091.00000 \mathrm{e}-01$ $1.00000 \mathrm{e}-06$ 1.00000e-06 1.00000e-06 1.00000e-09 5.00000e-02 Element: 5822 \# of layers: 11

Kx Ky Kz Ss Por

$1.22347 \mathrm{e}+021.22347 \mathrm{e}+02$ 1.22347e+01 1.00000e-09 7.00000e-02 $1.22347 \mathrm{e}+02 \quad 1.22347 \mathrm{e}+021.22347 \mathrm{e}+011.00000 \mathrm{e}-097.00000 \mathrm{e}-02$ $1.22347 \mathrm{e}+021.22347 \mathrm{e}+02 \quad 1.22347 \mathrm{e}+011.00000 \mathrm{e}-09$ 7.00000e-02 $1.22347 \mathrm{e}+021.22347 \mathrm{e}+021.22347 \mathrm{e}+011.00000 \mathrm{e}-097.00000 \mathrm{e}-02$ 5.00000e-04 5.00000e-04 5.00000e-05 1.00000e-09 1.00000e-01 5.00000e-04 5.00000e-04 5.00000e-05 1.00000e-09 1.00000e-01

$4.88845 \mathrm{e}+004.88845 \mathrm{e}+004.88845 \mathrm{e}-011.00000 \mathrm{e}-092.12000 \mathrm{e}-01$ $4.88845 \mathrm{e}+004.88845 \mathrm{e}+00$ 4.88845e-01 1.00000e-09 2.12000e-01 $1.00000 \mathrm{e}-021.00000 \mathrm{e}-02$ 1.00000e-03 1.00000e-09 1.00000e-01 $1.00000 \mathrm{e}+001.00000 \mathrm{e}+001.00000 \mathrm{e}-011.00000 \mathrm{e}-091.00000 \mathrm{e}-01$ $1.00000 \mathrm{e}-06$ 1.00000e-06 1.00000e-06 1.00000e-09 5.00000e-02 Element: 5823 \# of layers: 10

Kx Ky Kz Ss Por

$1.22347 \mathrm{e}+02$ 1.22347e+02 1.22347e+01 1.00000e-09 7.00000e-02 $1.22347 \mathrm{e}+021.22347 \mathrm{e}+02 \quad 1.22347 \mathrm{e}+011.00000 \mathrm{e}-09$ 7.00000e-02 $1.22347 \mathrm{e}+02 \quad 1.22347 \mathrm{e}+021.22347 \mathrm{e}+011.00000 \mathrm{e}-097.00000 \mathrm{e}-02$ $1.22347 \mathrm{e}+02 \quad 1.22347 \mathrm{e}+021.22347 \mathrm{e}+011.00000 \mathrm{e}-097.00000 \mathrm{e}-02$ 5.00000e-04 5.00000e-04 5.00000e-05 1.00000e-09 1.00000e-01 5.00000e-04 5.00000e-04 5.00000e-05 1.00000e-09 1.00000e-01 $4.88845 \mathrm{e}+004.88845 \mathrm{e}+004.88845 \mathrm{e}-011.00000 \mathrm{e}-09$ 2.12000e-01 $1.00000 \mathrm{e}-02$ 1.00000e-02 1.00000e-03 1.00000e-09 1.00000e-01 $1.00000 \mathrm{e}+001.00000 \mathrm{e}+001.00000 \mathrm{e}-011.00000 \mathrm{e}-091.00000 \mathrm{e}-01$ $1.00000 \mathrm{e}-06$ 1.00000e-06 1.00000e-06 1.00000e-09 5.00000e-02 Element: 5824 \# of layers: 11

Kx Ky Kz Ss Por

$1.42061 \mathrm{e}+021.42061 \mathrm{e}+021.42061 \mathrm{e}+01$ 1.00000e-09 7.00000e-02 $1.42061 \mathrm{e}+021.42061 \mathrm{e}+021.42061 \mathrm{e}+011.00000 \mathrm{e}-097.00000 \mathrm{e}-02$ $1.42061 \mathrm{e}+021.42061 \mathrm{e}+021.42061 \mathrm{e}+011.00000 \mathrm{e}-09$ 7.00000e-02 
$1.42061 \mathrm{e}+021.42061 \mathrm{e}+02$ 1.42061e+01 1.00000e-09 7.00000e-02 5.00000e-04 5.00000e-04 5.00000e-05 1.00000e-09 1.00000e-01 5.00000e-04 5.00000e-04 5.00000e-05 1.00000e-09 1.00000e-01

5.67597e+00 5.67597e+00 5.67597e-01 1.00000e-09 2.12000e-01 5.67597e+00 5.67597e+00 5.67597e-01 1.00000e-09 2.12000e-01 $1.00000 \mathrm{e}-02$ 1.00000e-02 1.00000e-03 1.00000e-09 1.00000e-01 $1.00000 \mathrm{e}+001.00000 \mathrm{e}+001.00000 \mathrm{e}-011.00000 \mathrm{e}-091.00000 \mathrm{e}-01$ 1.00000e-06 1.00000e-06 1.00000e-06 1.00000e-09 5.00000e-02 Element: 5825 \# of layers: 11

$\mathrm{Kx} \mathrm{Ky} \mathrm{Kz}$ Ss Por

$1.52206 \mathrm{e}+02$ 1.52206e+02 1.52206e+01 1.00000e-09 7.00000e-02 $1.52206 \mathrm{e}+02 \quad 1.52206 \mathrm{e}+02 \quad 1.52206 \mathrm{e}+01$ 1.00000e-09 7.00000e-02 $1.52206 \mathrm{e}+02$ 1.52206e+02 1.52206e+01 1.00000e-09 7.00000e-02 $1.52206 \mathrm{e}+021.52206 \mathrm{e}+021.52206 \mathrm{e}+01$ 1.00000e-09 7.00000e-02 5.00000e-04 5.00000e-04 5.00000e-05 1.00000e-09 1.00000e-01 5.00000e-04 5.00000e-04 5.00000e-05 1.00000e-09 1.00000e-01 $6.08166 \mathrm{e}+006.08166 \mathrm{e}+006.08166 \mathrm{e}-01$ 1.00000e-09 2.12000e-01 $6.08166 \mathrm{e}+006.08166 \mathrm{e}+006.08166 \mathrm{e}-01$ 1.00000e-09 2.12000e-01 $1.00000 \mathrm{e}-02$ 1.00000e-02 1.00000e-03 1.00000e-09 1.00000e-01 $1.00000 \mathrm{e}+001.00000 \mathrm{e}+001.00000 \mathrm{e}-011.00000 \mathrm{e}-091.00000 \mathrm{e}-01$ 1.00000e-06 1.00000e-06 1.00000e-06 1.00000e-09 5.00000e-02 Element: 5826 \# of layers: 10

$\mathrm{Kx} \mathrm{Ky} \mathrm{Kz}$ Ss Por

$1.65973 \mathrm{e}+02$ 1.65973e+02 1.65973e+01 1.00000e-09 7.00000e-02 $1.65973 \mathrm{e}+02$ 1.65973e+02 1.65973e+01 1.00000e-09 7.00000e-02 $1.65973 \mathrm{e}+02$ 1.65973e+02 1.65973e+01 1.00000e-09 7.00000e-02 $1.65973 \mathrm{e}+021.65973 \mathrm{e}+02$ 1.65973e+01 1.00000e-09 7.00000e-02 5.00000e-04 5.00000e-04 5.00000e-05 1.00000e-09 1.00000e-01 6.63179e+00 6.63179e+00 6.63179e-01 1.00000e-09 2.12000e-01 $6.63179 \mathrm{e}+006.63179 \mathrm{e}+00$ 6.63179e-01 1.00000e-09 2.12000e-01 $1.00000 \mathrm{e}-02$ 1.00000e-02 1.00000e-03 1.00000e-09 1.00000e-01 $1.00000 \mathrm{e}+001.00000 \mathrm{e}+001.00000 \mathrm{e}-011.00000 \mathrm{e}-091.00000 \mathrm{e}-01$ $1.00000 \mathrm{e}-06$ 1.00000e-06 1.00000e-06 1.00000e-09 5.00000e-02 Element: 5827 \# of layers: 8

$\mathrm{Kx} \mathrm{Ky} \mathrm{Kz}$ Ss Por

1.65973e+02 1.65973e+02 1.65973e+01 1.00000e-09 7.00000e-02 $1.65973 \mathrm{e}+02$ 1.65973e+02 1.65973e+01 1.00000e-09 7.00000e-02 $1.65973 \mathrm{e}+02$ 1.65973e+02 1.65973e+01 1.00000e-09 7.00000e-02 6.63179e+00 6.63179e+00 6.63179e-01 1.00000e-09 2.12000e-01 6.63179e+00 6.63179e+00 6.63179e-01 1.00000e-09 2.12000e-01 $1.00000 \mathrm{e}-02$ 1.00000e-02 1.00000e-03 1.00000e-09 1.00000e-01 $1.00000 \mathrm{e}+001.00000 \mathrm{e}+001.00000 \mathrm{e}-011.00000 \mathrm{e}-091.00000 \mathrm{e}-01$ 1.00000e-06 1.00000e-06 1.00000e-06 1.00000e-09 5.00000e-02 Element: 5828 \# of layers: 8

$\mathrm{Kx} \mathrm{Ky} \mathrm{Kz}$ Ss Por

1.76326e+02 1.76326e+02 1.76326e+01 1.00000e-09 7.00000e-02 
1.76326e+02 1.76326e+02 1.76326e+01 1.00000e-09 7.00000e-02 $1.76326 \mathrm{e}+02$ 1.76326e+02 1.76326e+01 1.00000e-09 7.00000e-02 $7.04535 \mathrm{e}+00$ 7.04535e+00 7.04535e-01 1.00000e-09 2.12000e-01 $7.04535 \mathrm{e}+007.04535 \mathrm{e}+00$ 7.04535e-01 1.00000e-09 2.12000e-01 $1.00000 \mathrm{e}-02$ 1.00000e-02 1.00000e-03 1.00000e-09 1.00000e-01 $1.00000 \mathrm{e}+001.00000 \mathrm{e}+001.00000 \mathrm{e}-011.00000 \mathrm{e}-091.00000 \mathrm{e}-01$ 1.00000e-06 1.00000e-06 1.00000e-06 1.00000e-09 5.00000e-02 Element: 5829 \# of layers: 8

$\mathrm{Kx} \mathrm{Ky} \mathrm{Kz}$ Ss Por

$1.76326 \mathrm{e}+02$ 1.76326e+02 1.76326e+01 1.00000e-09 7.00000e-02 $1.76326 \mathrm{e}+02$ 1.76326e+02 1.76326e+01 1.00000e-09 7.00000e-02 $1.76326 \mathrm{e}+02 \quad 1.76326 \mathrm{e}+02 \quad 1.76326 \mathrm{e}+01$ 1.00000e-09 7.00000e-02 7.04535e+00 7.04535e+00 7.04535e-01 1.00000e-09 2.12000e-01 $7.04535 \mathrm{e}+00$ 7.04535e+00 7.04535e-01 1.00000e-09 2.12000e-01 $1.00000 \mathrm{e}-02$ 1.00000e-02 1.00000e-03 1.00000e-09 1.00000e-01 $1.00000 \mathrm{e}+001.00000 \mathrm{e}+001.00000 \mathrm{e}-011.00000 \mathrm{e}-091.00000 \mathrm{e}-01$ 1.00000e-06 1.00000e-06 1.00000e-06 1.00000e-09 5.00000e-02 Element: 5830 \# of layers: 8

$\mathrm{Kx} \mathrm{Ky} \mathrm{Kz}$ Ss Por

$1.52954 \mathrm{e}+02$ 1.52954e+02 1.52954e+01 1.00000e-09 7.00000e-02 $1.52954 \mathrm{e}+021.52954 \mathrm{e}+02 \quad 1.52954 \mathrm{e}+01$ 1.00000e-09 7.00000e-02 $1.52954 \mathrm{e}+02$ 1.52954e+02 1.52954e+01 1.00000e-09 7.00000e-02 6.11135e+00 6.11135e+00 6.11135e-01 1.00000e-09 2.12000e-01 $6.11135 \mathrm{e}+006.11135 \mathrm{e}+00$ 6.11135e-01 1.00000e-09 2.12000e-01 $1.00000 \mathrm{e}-02$ 1.00000e-02 1.00000e-03 1.00000e-09 1.00000e-01 $1.00000 \mathrm{e}+001.00000 \mathrm{e}+001.00000 \mathrm{e}-011.00000 \mathrm{e}-091.00000 \mathrm{e}-01$ 1.00000e-06 1.00000e-06 1.00000e-06 1.00000e-09 5.00000e-02 Element: 5831 \# of layers: 9

Kx Ky Kz Ss Por

$1.52954 \mathrm{e}+02$ 1.52954e+02 1.52954e+01 1.00000e-09 7.00000e-02 $1.52954 \mathrm{e}+021.52954 \mathrm{e}+02 \quad 1.52954 \mathrm{e}+01$ 1.00000e-09 7.00000e-02 $1.52954 \mathrm{e}+021.52954 \mathrm{e}+02 \quad 1.52954 \mathrm{e}+01$ 1.00000e-09 7.00000e-02 $1.52954 \mathrm{e}+021.52954 \mathrm{e}+02 \quad 1.52954 \mathrm{e}+01$ 1.00000e-09 7.00000e-02 $6.11135 \mathrm{e}+006.11135 \mathrm{e}+00$ 6.11135e-01 1.00000e-09 2.12000e-01 6.11135e+00 6.11135e+00 6.11135e-01 1.00000e-09 2.12000e-01 1.00000e-02 1.00000e-02 1.00000e-03 1.00000e-09 1.00000e-01 $1.00000 \mathrm{e}+001.00000 \mathrm{e}+001.00000 \mathrm{e}-011.00000 \mathrm{e}-091.00000 \mathrm{e}-01$ 1.00000e-06 1.00000e-06 1.00000e-06 1.00000e-09 5.00000e-02 Element: 5832 \# of layers: 10

$\mathrm{Kx} \mathrm{Ky} \mathrm{Kz}$ Ss Por

$1.52206 \mathrm{e}+02$ 1.52206e+02 1.52206e+01 1.00000e-09 7.00000e-02 $1.52206 \mathrm{e}+02 \quad 1.52206 \mathrm{e}+02 \quad 1.52206 \mathrm{e}+01$ 1.00000e-09 7.00000e-02 $1.52206 \mathrm{e}+021.52206 \mathrm{e}+02$ 1.52206e+01 1.00000e-09 7.00000e-02 $1.52206 \mathrm{e}+02$ 1.52206e+02 1.52206e+01 1.00000e-09 7.00000e-02 5.00000e-04 5.00000e-04 5.00000e-05 1.00000e-09 1.00000e-01

$6.08166 \mathrm{e}+006.08166 \mathrm{e}+00$ 6.08166e-01 1.00000e-09 2.12000e-01 
$6.08166 \mathrm{e}+006.08166 \mathrm{e}+00$ 6.08166e-01 1.00000e-09 2.12000e-01 $1.00000 \mathrm{e}-02$ 1.00000e-02 1.00000e-03 1.00000e-09 1.00000e-01 $1.00000 \mathrm{e}+001.00000 \mathrm{e}+001.00000 \mathrm{e}-011.00000 \mathrm{e}-091.00000 \mathrm{e}-01$ $1.00000 \mathrm{e}-06$ 1.00000e-06 1.00000e-06 1.00000e-09 5.00000e-02 Element: 5833 \# of layers: 9

Kx Ky Kz Ss Por

$1.76326 \mathrm{e}+021.76326 \mathrm{e}+021.76326 \mathrm{e}+01$ 1.00000e-09 7.00000e-02 $1.76326 \mathrm{e}+021.76326 \mathrm{e}+021.76326 \mathrm{e}+011.00000 \mathrm{e}-097.00000 \mathrm{e}-02$ $1.76326 \mathrm{e}+021.76326 \mathrm{e}+021.76326 \mathrm{e}+011.00000 \mathrm{e}-097.00000 \mathrm{e}-02$ $1.76326 \mathrm{e}+021.76326 \mathrm{e}+021.76326 \mathrm{e}+011.00000 \mathrm{e}-097.00000 \mathrm{e}-02$ $7.04535 \mathrm{e}+007.04535 \mathrm{e}+00$ 7.04535e-01 1.00000e-09 2.12000e-01 $7.04535 \mathrm{e}+007.04535 \mathrm{e}+00$ 7.04535e-01 1.00000e-09 2.12000e-01 $1.00000 \mathrm{e}-02$ 1.00000e-02 $1.00000 \mathrm{e}-031.00000 \mathrm{e}-091.00000 \mathrm{e}-01$ $1.00000 \mathrm{e}+001.00000 \mathrm{e}+001.00000 \mathrm{e}-011.00000 \mathrm{e}-091.00000 \mathrm{e}-01$ $1.00000 \mathrm{e}-06$ 1.00000e-06 1.00000e-06 1.00000e-09 5.00000e-02 Element: 5834 \# of layers: 8

Kx Ky Kz Ss Por

$1.75596 \mathrm{e}+021.75596 \mathrm{e}+021.75596 \mathrm{e}+01$ 1.00000e-09 7.00000e-02 $1.75596 \mathrm{e}+021.75596 \mathrm{e}+021.75596 \mathrm{e}+011.00000 \mathrm{e}-09$ 7.00000e-02 $1.75596 \mathrm{e}+021.75596 \mathrm{e}+021.75596 \mathrm{e}+011.00000 \mathrm{e}-097.00000 \mathrm{e}-02$ $7.01632 \mathrm{e}+00$ 7.01632e+00 7.01633e-01 1.00000e-09 2.12000e-01 $7.01632 \mathrm{e}+00$ 7.01632e+00 7.01633e-01 1.00000e-09 2.12000e-01 $1.00000 \mathrm{e}-021.00000 \mathrm{e}-02$ 1.00000e-03 1.00000e-09 1.00000e-01 $1.00000 \mathrm{e}+001.00000 \mathrm{e}+001.00000 \mathrm{e}-011.00000 \mathrm{e}-091.00000 \mathrm{e}-01$ $1.00000 \mathrm{e}-06$ 1.00000e-06 1.00000e-06 1.00000e-09 5.00000e-02 Element: 5835 \# of layers: 8

Kx Ky Kz Ss Por

$1.97770 \mathrm{e}+021.97770 \mathrm{e}+021.97770 \mathrm{e}+01$ 1.00000e-09 7.00000e-02 $1.97770 \mathrm{e}+021.97770 \mathrm{e}+021.97770 \mathrm{e}+011.00000 \mathrm{e}-097.00000 \mathrm{e}-02$ $1.97770 \mathrm{e}+021.97770 \mathrm{e}+021.97770 \mathrm{e}+011.00000 \mathrm{e}-09$ 7.00000e-02 $7.90217 \mathrm{e}+00$ 7.90217e+00 7.90217e-01 1.00000e-09 2.12000e-01 $7.90217 \mathrm{e}+00$ 7.90217e+00 7.90217e-01 1.00000e-09 2.12000e-01 $1.00000 \mathrm{e}-02$ 1.00000e-02 1.00000e-03 1.00000e-09 1.00000e-01 $1.00000 \mathrm{e}+001.00000 \mathrm{e}+001.00000 \mathrm{e}-011.00000 \mathrm{e}-091.00000 \mathrm{e}-01$ $1.00000 \mathrm{e}-06$ 1.00000e-06 1.00000e-06 1.00000e-09 5.00000e-02 Element: 5836 \# of layers: 8

Kx Ky Kz Ss Por

$1.91219 \mathrm{e}+02$ 1.91219e+02 1.91219e+01 1.00000e-09 7.00000e-02 $1.91219 \mathrm{e}+021.91219 \mathrm{e}+021.91219 \mathrm{e}+011.00000 \mathrm{e}-097.00000 \mathrm{e}-02$ $1.91219 \mathrm{e}+021.91219 \mathrm{e}+021.91219 \mathrm{e}+011.00000 \mathrm{e}-097.00000 \mathrm{e}-02$ $7.64049 \mathrm{e}+00$ 7.64049e+00 7.64049e-01 1.00000e-09 2.12000e-01 $7.64049 \mathrm{e}+00$ 7.64049e+00 7.64049e-01 1.00000e-09 2.12000e-01 $1.00000 \mathrm{e}-02$ 1.00000e-02 1.00000e-03 1.00000e-09 1.00000e-01 $1.00000 \mathrm{e}+001.00000 \mathrm{e}+001.00000 \mathrm{e}-011.00000 \mathrm{e}-091.00000 \mathrm{e}-01$ $1.00000 \mathrm{e}-06$ 1.00000e-06 1.00000e-06 1.00000e-09 5.00000e-02 Element: 5840 \# of layers: 8 
Kx Ky Kz Ss Por

1.97770e+02 1.97770e+02 1.97770e+01 1.00000e-09 7.00000e-02

$1.97770 \mathrm{e}+02$ 1.97770e+02 1.97770e+01 1.00000e-09 7.00000e-02

$1.97770 \mathrm{e}+02$ 1.97770e+02 1.97770e+01 1.00000e-09 7.00000e-02

7.90217e+00 7.90217e+00 7.90217e-01 1.00000e-09 2.12000e-01

$7.90217 \mathrm{e}+00$ 7.90217e+00 7.90217e-01 1.00000e-09 2.12000e-01

$1.00000 \mathrm{e}-02$ 1.00000e-02 1.00000e-03 1.00000e-09 1.00000e-01

$1.00000 \mathrm{e}+001.00000 \mathrm{e}+001.00000 \mathrm{e}-011.00000 \mathrm{e}-091.00000 \mathrm{e}-01$

$1.00000 \mathrm{e}-06$ 1.00000e-06 1.00000e-06 1.00000e-09 5.00000e-02

Element: 5841 \# of layers: 8

$\mathrm{Kx} \mathrm{Ky} \mathrm{Kz}$ Ss Por

$1.75596 \mathrm{e}+02$ 1.75596e+02 1.75596e+01 1.00000e-09 7.00000e-02

$1.75596 \mathrm{e}+02$ 1.75596e+02 1.75596e+01 1.00000e-09 7.00000e-02

$1.75596 \mathrm{e}+021.75596 \mathrm{e}+02 \quad 1.75596 \mathrm{e}+01$ 1.00000e-09 7.00000e-02

7.01632e+00 7.01632e+00 7.01633e-01 1.00000e-09 2.12000e-01

$7.01632 \mathrm{e}+00$ 7.01632e+00 7.01633e-01 1.00000e-09 2.12000e-01

$1.00000 \mathrm{e}-02$ 1.00000e-02 1.00000e-03 1.00000e-09 1.00000e-01

$1.00000 \mathrm{e}+001.00000 \mathrm{e}+001.00000 \mathrm{e}-011.00000 \mathrm{e}-091.00000 \mathrm{e}-01$

1.00000e-06 1.00000e-06 1.00000e-06 1.00000e-09 5.00000e-02

Element: 5843 \# of layers: 7

$\mathrm{Kx} \mathrm{Ky} \mathrm{Kz}$ Ss Por

2.27773e+02 2.27773e+02 2.27773e+01 1.00000e-09 7.00000e-02

2.27773e+02 2.27773e+02 2.27773e+01 1.00000e-09 7.00000e-02

$2.27773 \mathrm{e}+02$ 2.27773e+02 2.27773e+01 1.00000e-09 7.00000e-02

$9.10099 \mathrm{e}+00$ 9.10099e+00 9.10099e-01 1.00000e-09 2.12000e-01

$1.00000 \mathrm{e}-02$ 1.00000e-02 1.00000e-03 1.00000e-09 1.00000e-01

$1.00000 \mathrm{e}+001.00000 \mathrm{e}+001.00000 \mathrm{e}-011.00000 \mathrm{e}-091.00000 \mathrm{e}-01$

1.00000e-06 1.00000e-06 1.00000e-06 1.00000e-09 5.00000e-02

Element: 5844 \# of layers: 7

$\mathrm{Kx} \mathrm{Ky} \mathrm{Kz}$ Ss Por

2.27773e+02 2.27773e+02 2.27773e+01 1.00000e-09 7.00000e-02

$2.27773 \mathrm{e}+02$ 2.27773e+02 2.27773e+01 1.00000e-09 7.00000e-02

$2.27773 \mathrm{e}+02$ 2.27773e+02 2.27773e+01 1.00000e-09 7.00000e-02

9.10099e+00 9.10099e+00 9.10099e-01 1.00000e-09 2.12000e-01

$1.00000 \mathrm{e}-02$ 1.00000e-02 1.00000e-03 1.00000e-09 1.00000e-01

$1.00000 \mathrm{e}+001.00000 \mathrm{e}+001.00000 \mathrm{e}-011.00000 \mathrm{e}-091.00000 \mathrm{e}-01$

1.00000e-06 1.00000e-06 1.00000e-06 1.00000e-09 5.00000e-02

Element: 5845 \# of layers: 6

$\mathrm{Kx} \mathrm{Ky} \mathrm{Kz}$ Ss Por

2.27773e+02 2.27773e+02 2.27773e+01 1.00000e-09 7.00000e-02

$2.27773 \mathrm{e}+02$ 2.27773e+02 2.27773e+01 1.00000e-09 7.00000e-02

2.27773e+02 2.27773e+02 2.27773e+01 1.00000e-09 7.00000e-02

9.10099e+00 9.10099e+00 9.10099e-01 1.00000e-09 2.12000e-01

$1.00000 \mathrm{e}-02$ 1.00000e-02 1.00000e-03 1.00000e-09 1.00000e-01

$1.00000 \mathrm{e}+001.00000 \mathrm{e}+001.00000 \mathrm{e}-011.00000 \mathrm{e}-091.00000 \mathrm{e}-01$

Element: 5846 \# of layers: 8 
$\mathrm{Kx} \mathrm{Ky} \mathrm{Kz}$ Ss Por

$2.01752 \mathrm{e}+02$ 2.01752e+02 2.01752e+01 1.00000e-09 7.00000e-02

$2.01752 \mathrm{e}+02$ 2.01752e+02 2.01752e+01 1.00000e-09 7.00000e-02

$2.01752 \mathrm{e}+02$ 2.01752e+02 2.01752e+01 1.00000e-09 7.00000e-02

8.06102e+00 8.06102e+00 8.06102e-01 1.00000e-09 2.12000e-01

8.06102e+00 8.06102e+00 8.06102e-01 1.00000e-09 2.12000e-01

$1.00000 \mathrm{e}-02$ 1.00000e-02 1.00000e-03 1.00000e-09 1.00000e-01

$1.00000 \mathrm{e}+001.00000 \mathrm{e}+001.00000 \mathrm{e}-011.00000 \mathrm{e}-091.00000 \mathrm{e}-01$

1.00000e-06 1.00000e-06 1.00000e-06 1.00000e-09 5.00000e-02

Element: 5847 \# of layers: 8

$\mathrm{Kx} \mathrm{Ky} \mathrm{Kz}$ Ss Por

2.01752e+02 2.01752e+02 2.01752e+01 1.00000e-09 7.00000e-02

$2.01752 \mathrm{e}+02$ 2.01752e+02 2.01752e+01 1.00000e-09 7.00000e-02

$2.01752 \mathrm{e}+022.01752 \mathrm{e}+02$ 2.01752e+01 1.00000e-09 7.00000e-02

8.06102e+00 8.06102e+00 8.06102e-01 1.00000e-09 2.12000e-01

$8.06102 \mathrm{e}+00$ 8.06102e+00 8.06102e-01 1.00000e-09 2.12000e-01

$1.00000 \mathrm{e}-02$ 1.00000e-02 1.00000e-03 1.00000e-09 1.00000e-01

$1.00000 \mathrm{e}+001.00000 \mathrm{e}+001.00000 \mathrm{e}-011.00000 \mathrm{e}-091.00000 \mathrm{e}-01$

1.00000e-06 1.00000e-06 1.00000e-06 1.00000e-09 5.00000e-02

Element: 5848 \# of layers: 7

$\mathrm{Kx} \mathrm{Ky} \mathrm{Kz}$ Ss Por

$2.01752 \mathrm{e}+02$ 2.01752e+02 2.01752e+01 1.00000e-09 7.00000e-02

$2.01752 \mathrm{e}+02$ 2.01752e+02 2.01752e+01 1.00000e-09 7.00000e-02

$2.01752 \mathrm{e}+022.01752 \mathrm{e}+02$ 2.01752e+01 1.00000e-09 7.00000e-02

$8.06102 \mathrm{e}+008.06102 \mathrm{e}+00$ 8.06102e-01 1.00000e-09 2.12000e-01

$1.00000 \mathrm{e}-021.00000 \mathrm{e}-021.00000 \mathrm{e}-031.00000 \mathrm{e}-091.00000 \mathrm{e}-01$

$1.00000 \mathrm{e}+001.00000 \mathrm{e}+001.00000 \mathrm{e}-011.00000 \mathrm{e}-091.00000 \mathrm{e}-01$

1.00000e-06 1.00000e-06 1.00000e-06 1.00000e-09 5.00000e-02

Element: 5849 \# of layers: 4

$\mathrm{Kx} \mathrm{Ky} \mathrm{Kz}$ Ss Por

6.41701e+02 6.41701e+02 6.41701e+01 1.00000e-09 7.00000e-02

6.41701e+02 6.41701e+02 6.41701e+01 1.00000e-09 7.00000e-02

$6.41701 \mathrm{e}+026.41701 \mathrm{e}+026.41701 \mathrm{e}+01$ 1.00000e-09 7.00000e-02

$1.00000 \mathrm{e}-06$ 1.00000e-06 1.00000e-06 1.00000e-09 5.00000e-02

Element: 5850 \# of layers: 4

$\mathrm{Kx} \mathrm{Ky} \mathrm{Kz}$ Ss Por

6.41701e+02 6.41701e+02 6.41701e+01 1.00000e-09 7.00000e-02

6.41701e+02 6.41701e+02 6.41701e+01 1.00000e-09 7.00000e-02

6.41701e+02 6.41701e+02 6.41701e+01 1.00000e-09 7.00000e-02

1.00000e-06 1.00000e-06 1.00000e-06 1.00000e-09 5.00000e-02

Element: 5851 \# of layers: 5

$\mathrm{Kx} \mathrm{Ky} \mathrm{Kz}$ Ss Por

2.57713e+03 2.57713e+03 2.57713e+02 1.00000e-09 7.00000e-02

2.57713e+03 2.57713e+03 2.57713e+02 1.00000e-09 7.00000e-02

$2.57713 \mathrm{e}+032.57713 \mathrm{e}+032.57713 \mathrm{e}+02$ 1.00000e-09 7.00000e-02

$2.57713 \mathrm{e}+032.57713 \mathrm{e}+032.57713 \mathrm{e}+02$ 1.00000e-09 7.00000e-02 
1.00000e-06 1.00000e-06 1.00000e-06 1.00000e-09 5.00000e-02

Element: 5852 \# of layers: 5

$\mathrm{Kx} \mathrm{Ky} \mathrm{Kz}$ Ss Por

$1.06742 \mathrm{e}+03$ 1.06742e+03 1.06742e+02 1.00000e-09 7.00000e-02

$1.06742 \mathrm{e}+031.06742 \mathrm{e}+03$ 1.06742e+02 1.00000e-09 7.00000e-02

$1.06742 \mathrm{e}+03$ 1.06742e+03 1.06742e+02 1.00000e-09 7.00000e-02

$1.06742 \mathrm{e}+031.06742 \mathrm{e}+03$ 1.06742e+02 1.00000e-09 7.00000e-02

1.00000e-06 1.00000e-06 1.00000e-06 1.00000e-09 5.00000e-02

Element: 5853 \# of layers: 5

$\mathrm{Kx} \mathrm{Ky} \mathrm{Kz}$ Ss Por

$1.06742 \mathrm{e}+03$ 1.06742e+03 1.06742e+02 1.00000e-09 7.00000e-02

$1.06742 \mathrm{e}+031.06742 \mathrm{e}+03$ 1.06742e+02 1.00000e-09 7.00000e-02

$1.06742 \mathrm{e}+031.06742 \mathrm{e}+03$ 1.06742e+02 1.00000e-09 7.00000e-02

$1.06742 \mathrm{e}+031.06742 \mathrm{e}+03$ 1.06742e+02 1.00000e-09 7.00000e-02

1.00000e-06 1.00000e-06 1.00000e-06 1.00000e-09 5.00000e-02

Element: 5854 \# of layers: 5

$\mathrm{Kx} \mathrm{Ky} \mathrm{Kz}$ Ss Por

$1.06742 \mathrm{e}+03$ 1.06742e+03 1.06742e+02 1.00000e-09 7.00000e-02 $1.06742 \mathrm{e}+031.06742 \mathrm{e}+03$ 1.06742e+02 1.00000e-09 7.00000e-02

$1.06742 \mathrm{e}+031.06742 \mathrm{e}+03$ 1.06742e+02 1.00000e-09 7.00000e-02

$1.06742 \mathrm{e}+03$ 1.06742e+03 1.06742e+02 1.00000e-09 7.00000e-02

1.00000e-06 1.00000e-06 1.00000e-06 1.00000e-09 5.00000e-02

Element: 5855 \# of layers: 5

Kx Ky Kz Ss Por

8.15045e+02 8.15045e+02 8.15045e+01 1.00000e-09 7.00000e-02

8.15045e+02 8.15045e+02 8.15045e+01 1.00000e-09 7.00000e-02

$8.15045 \mathrm{e}+028.15045 \mathrm{e}+028.15045 \mathrm{e}+01$ 1.00000e-09 7.00000e-02

8.15045e+02 8.15045e+02 8.15045e+01 1.00000e-09 7.00000e-02

1.00000e-06 1.00000e-06 1.00000e-06 1.00000e-09 5.00000e-02

Element: 5856 \# of layers: 4

$\mathrm{Kx} \mathrm{Ky} \mathrm{Kz}$ Ss Por

6.41701e+02 6.41701e+02 6.41701e+01 1.00000e-09 7.00000e-02

$6.41701 \mathrm{e}+026.41701 \mathrm{e}+026.41701 \mathrm{e}+01$ 1.00000e-09 7.00000e-02

6.41701e+02 6.41701e+02 6.41701e+01 1.00000e-09 7.00000e-02

1.00000e-06 1.00000e-06 1.00000e-06 1.00000e-09 5.00000e-02

Element: 5857 \# of layers: 5

Kx Ky Kz Ss Por

1.06742e+03 1.06742e+03 1.06742e+02 1.00000e-09 7.00000e-02 $1.06742 \mathrm{e}+031.06742 \mathrm{e}+03$ 1.06742e+02 1.00000e-09 7.00000e-02 $1.06742 \mathrm{e}+031.06742 \mathrm{e}+03$ 1.06742e+02 1.00000e-09 7.00000e-02 $1.06742 \mathrm{e}+031.06742 \mathrm{e}+03$ 1.06742e+02 1.00000e-09 7.00000e-02 1.00000e-06 1.00000e-06 1.00000e-06 1.00000e-09 5.00000e-02

Element: 5858 \# of layers: 5

$\mathrm{Kx} \mathrm{Ky} \mathrm{Kz}$ Ss Por

$2.23304 \mathrm{e}+03$ 2.23304e+03 2.23304e+02 1.00000e-09 7.00000e-02

$2.23304 \mathrm{e}+032.23304 \mathrm{e}+032.23304 \mathrm{e}+021.00000 \mathrm{e}-097.00000 \mathrm{e}-02$ 
$2.23304 \mathrm{e}+032.23304 \mathrm{e}+032.23304 \mathrm{e}+02$ 1.00000e-09 7.00000e-02 $2.23304 \mathrm{e}+032.23304 \mathrm{e}+032.23304 \mathrm{e}+021.00000 \mathrm{e}-097.00000 \mathrm{e}-02$ $1.00000 \mathrm{e}-06$ 1.00000e-06 1.00000e-06 1.00000e-09 5.00000e-02

Element: 5859 \# of layers: 5

Kx Ky Kz Ss Por

$2.23304 \mathrm{e}+032.23304 \mathrm{e}+032.23304 \mathrm{e}+02$ 1.00000e-09 7.00000e-02

$2.23304 \mathrm{e}+032.23304 \mathrm{e}+032.23304 \mathrm{e}+02$ 1.00000e-09 7.00000e-02

$2.23304 \mathrm{e}+032.23304 \mathrm{e}+032.23304 \mathrm{e}+02$ 1.00000e-09 7.00000e-02

$2.23304 \mathrm{e}+032.23304 \mathrm{e}+032.23304 \mathrm{e}+021.00000 \mathrm{e}-097.00000 \mathrm{e}-02$

$1.00000 \mathrm{e}-06$ 1.00000e-06 1.00000e-06 1.00000e-09 5.00000e-02

Element: 5860 \# of layers: 5

Kx Ky Kz Ss Por

$1.89643 \mathrm{e}+03$ 1.89643e+03 1.89643e+02 1.00000e-09 7.00000e-02

$1.89643 \mathrm{e}+031.89643 \mathrm{e}+031.89643 \mathrm{e}+021.00000 \mathrm{e}-09$ 7.00000e-02

$1.89643 \mathrm{e}+031.89643 \mathrm{e}+03$ 1.89643e+02 1.00000e-09 7.00000e-02

$1.89643 \mathrm{e}+03$ 1.89643e+03 1.89643e+02 1.00000e-09 7.00000e-02

$1.00000 \mathrm{e}-06$ 1.00000e-06 1.00000e-06 1.00000e-09 5.00000e-02

Element: 5861 \# of layers: 5

Kx Ky Kz Ss Por

$2.16853 \mathrm{e}+032.16853 \mathrm{e}+032.16853 \mathrm{e}+02$ 1.00000e-09 7.00000e-02

$2.16853 \mathrm{e}+032.16853 \mathrm{e}+032.16853 \mathrm{e}+02$ 1.00000e-09 7.00000e-02

$2.16853 \mathrm{e}+032.16853 \mathrm{e}+032.16853 \mathrm{e}+02$ 1.00000e-09 7.00000e-02

$2.16853 \mathrm{e}+032.16853 \mathrm{e}+032.16853 \mathrm{e}+02$ 1.00000e-09 7.00000e-02

$1.00000 \mathrm{e}-06$ 1.00000e-06 1.00000e-06 1.00000e-09 5.00000e-02

Element: 5862 \# of layers: 5

Kx Ky Kz Ss Por

$2.16853 \mathrm{e}+032.16853 \mathrm{e}+032.16853 \mathrm{e}+02$ 1.00000e-09 7.00000e-02

$2.16853 \mathrm{e}+032.16853 \mathrm{e}+032.16853 \mathrm{e}+02$ 1.00000e-09 7.00000e-02

$2.16853 \mathrm{e}+032.16853 \mathrm{e}+032.16853 \mathrm{e}+02$ 1.00000e-09 7.00000e-02

$2.16853 \mathrm{e}+032.16853 \mathrm{e}+032.16853 \mathrm{e}+02$ 1.00000e-09 7.00000e-02

$1.00000 \mathrm{e}-06$ 1.00000e-06 1.00000e-06 1.00000e-09 5.00000e-02

Element: 5863 \# of layers: 5

Kx Ky Kz Ss Por

$2.22718 \mathrm{e}+032.22718 \mathrm{e}+032.22718 \mathrm{e}+02$ 1.00000e-09 7.00000e-02

$2.22718 \mathrm{e}+032.22718 \mathrm{e}+032.22718 \mathrm{e}+02$ 1.00000e-09 7.00000e-02

$2.22718 \mathrm{e}+032.22718 \mathrm{e}+032.22718 \mathrm{e}+021.00000 \mathrm{e}-09$ 7.00000e-02

$2.22718 \mathrm{e}+032.22718 \mathrm{e}+032.22718 \mathrm{e}+021.00000 \mathrm{e}-097.00000 \mathrm{e}-02$

1.00000e-06 1.00000e-06 1.00000e-06 1.00000e-09 5.00000e-02

Element: 5864 \# of layers: 5

Kx Ky Kz Ss Por

$2.22718 \mathrm{e}+032.22718 \mathrm{e}+032.22718 \mathrm{e}+02$ 1.00000e-09 7.00000e-02

$2.22718 \mathrm{e}+032.22718 \mathrm{e}+032.22718 \mathrm{e}+02$ 1.00000e-09 7.00000e-02

$2.22718 \mathrm{e}+032.22718 \mathrm{e}+032.22718 \mathrm{e}+02$ 1.00000e-09 7.00000e-02

$2.22718 \mathrm{e}+032.22718 \mathrm{e}+032.22718 \mathrm{e}+021.00000 \mathrm{e}-097.00000 \mathrm{e}-02$

$1.00000 \mathrm{e}-06$ 1.00000e-06 1.00000e-06 1.00000e-09 5.00000e-02

Element: 5865 \# of layers: 5 
$\mathrm{Kx} \mathrm{Ky} \mathrm{Kz}$ Ss Por

$2.23304 \mathrm{e}+03$ 2.23304e+03 2.23304e+02 1.00000e-09 7.00000e-02

$2.23304 \mathrm{e}+032.23304 \mathrm{e}+032.23304 \mathrm{e}+02$ 1.00000e-09 7.00000e-02

$2.23304 \mathrm{e}+032.23304 \mathrm{e}+032.23304 \mathrm{e}+02 \quad 1.00000 \mathrm{e}-09$ 7.00000e-02

$2.23304 \mathrm{e}+032.23304 \mathrm{e}+032.23304 \mathrm{e}+02$ 1.00000e-09 7.00000e-02

1.00000e-06 1.00000e-06 1.00000e-06 1.00000e-09 5.00000e-02

Element: 5866 \# of layers: 5

$\mathrm{Kx} \mathrm{Ky} \mathrm{Kz}$ Ss Por

1.89643e+03 1.89643e+03 1.89643e+02 1.00000e-09 7.00000e-02

$1.89643 \mathrm{e}+03$ 1.89643e+03 1.89643e+02 1.00000e-09 7.00000e-02

$1.89643 \mathrm{e}+03$ 1.89643e+03 1.89643e+02 1.00000e-09 7.00000e-02

$1.89643 \mathrm{e}+03$ 1.89643e+03 1.89643e+02 1.00000e-09 7.00000e-02

1.00000e-06 1.00000e-06 1.00000e-06 1.00000e-09 5.00000e-02

Element: 5867 \# of layers: 5

$\mathrm{Kx} \mathrm{Ky} \mathrm{Kz}$ Ss Por

$1.94634 \mathrm{e}+03$ 1.94634e+03 1.94634e+02 1.00000e-09 7.00000e-02

$1.94634 \mathrm{e}+03$ 1.94634e+03 1.94634e+02 1.00000e-09 7.00000e-02

$1.94634 \mathrm{e}+03$ 1.94634e+03 1.94634e+02 1.00000e-09 7.00000e-02

$1.94634 \mathrm{e}+031.94634 \mathrm{e}+03$ 1.94634e+02 1.00000e-09 7.00000e-02

1.00000e-06 1.00000e-06 1.00000e-06 1.00000e-09 5.00000e-02

Element: 5868 \# of layers: 5

$\mathrm{Kx} \mathrm{Ky} \mathrm{Kz}$ Ss Por

2.19114e+03 2.19114e+03 2.19114e+02 1.00000e-09 7.00000e-02

$2.19114 \mathrm{e}+032.19114 \mathrm{e}+032.19114 \mathrm{e}+02$ 1.00000e-09 7.00000e-02

$2.19114 \mathrm{e}+032.19114 \mathrm{e}+032.19114 \mathrm{e}+021.00000 \mathrm{e}-097.00000 \mathrm{e}-02$

$2.19114 \mathrm{e}+032.19114 \mathrm{e}+032.19114 \mathrm{e}+02$ 1.00000e-09 7.00000e-02

1.00000e-06 1.00000e-06 1.00000e-06 1.00000e-09 5.00000e-02

Element: 5869 \# of layers: 5

Kx Ky Kz Ss Por

$2.19114 \mathrm{e}+032.19114 \mathrm{e}+03$ 2.19114e+02 1.00000e-09 7.00000e-02

$2.19114 \mathrm{e}+032.19114 \mathrm{e}+032.19114 \mathrm{e}+02$ 1.00000e-09 7.00000e-02

$2.19114 \mathrm{e}+032.19114 \mathrm{e}+032.19114 \mathrm{e}+02$ 1.00000e-09 7.00000e-02

$2.19114 \mathrm{e}+032.19114 \mathrm{e}+032.19114 \mathrm{e}+02$ 1.00000e-09 7.00000e-02

1.00000e-06 1.00000e-06 1.00000e-06 1.00000e-09 5.00000e-02

Element: 5870 \# of layers: 5

$\mathrm{Kx} \mathrm{Ky} \mathrm{Kz}$ Ss Por

$2.52803 \mathrm{e}+032.52803 \mathrm{e}+032.52803 \mathrm{e}+02$ 1.00000e-09 7.00000e-02

$2.52803 \mathrm{e}+032.52803 \mathrm{e}+032.52803 \mathrm{e}+02$ 1.00000e-09 7.00000e-02

$2.52803 \mathrm{e}+032.52803 \mathrm{e}+032.52803 \mathrm{e}+02$ 1.00000e-09 7.00000e-02

$2.52803 \mathrm{e}+032.52803 \mathrm{e}+032.52803 \mathrm{e}+02$ 1.00000e-09 7.00000e-02

1.00000e-06 1.00000e-06 1.00000e-06 1.00000e-09 5.00000e-02

Element: 5871 \# of layers: 5

$\mathrm{Kx} \mathrm{Ky} \mathrm{Kz}$ Ss Por

2.52803e+03 2.52803e+03 2.52803e+02 1.00000e-09 7.00000e-02

$2.52803 \mathrm{e}+032.52803 \mathrm{e}+032.52803 \mathrm{e}+02$ 1.00000e-09 7.00000e-02

$2.52803 e+032.52803 e+032.52803 e+021.00000 e-09$ 7.00000e-02 
$2.52803 \mathrm{e}+032.52803 \mathrm{e}+032.52803 \mathrm{e}+02$ 1.00000e-09 7.00000e-02 1.00000e-06 1.00000e-06 1.00000e-06 1.00000e-09 5.00000e-02

Element: 5872 \# of layers: 5

Kx Ky Kz Ss Por

$2.43315 \mathrm{e}+032.43315 \mathrm{e}+03$ 2.43315e+02 1.00000e-09 7.00000e-02

$2.43315 \mathrm{e}+032.43315 \mathrm{e}+03$ 2.43315e+02 1.00000e-09 7.00000e-02

$2.43315 \mathrm{e}+03$ 2.43315e+03 2.43315e+02 1.00000e-09 7.00000e-02

$2.43315 \mathrm{e}+032.43315 \mathrm{e}+032.43315 \mathrm{e}+021.00000 \mathrm{e}-09$ 7.00000e-02

1.00000e-06 1.00000e-06 1.00000e-06 1.00000e-09 5.00000e-02

Element: 5873 \# of layers: 5

$\mathrm{Kx} \mathrm{Ky} \mathrm{Kz}$ Ss Por

$2.43315 e+03$ 2.43315e+03 2.43315e+02 1.00000e-09 7.00000e-02

$2.43315 \mathrm{e}+03$ 2.43315e+03 2.43315e+02 1.00000e-09 7.00000e-02

$2.43315 \mathrm{e}+032.43315 \mathrm{e}+032.43315 \mathrm{e}+02$ 1.00000e-09 7.00000e-02

$2.43315 \mathrm{e}+032.43315 \mathrm{e}+032.43315 \mathrm{e}+02$ 1.00000e-09 7.00000e-02

1.00000e-06 1.00000e-06 1.00000e-06 1.00000e-09 5.00000e-02

Element: 5874 \# of layers: 5

$\mathrm{Kx} \mathrm{Ky} \mathrm{Kz}$ Ss Por

2.43315e+03 2.43315e+03 2.43315e+02 1.00000e-09 7.00000e-02

$2.43315 \mathrm{e}+032.43315 \mathrm{e}+032.43315 \mathrm{e}+02$ 1.00000e-09 7.00000e-02

$2.43315 \mathrm{e}+032.43315 \mathrm{e}+032.43315 \mathrm{e}+02$ 1.00000e-09 7.00000e-02

$2.43315 \mathrm{e}+032.43315 \mathrm{e}+032.43315 \mathrm{e}+02$ 1.00000e-09 7.00000e-02

1.00000e-06 1.00000e-06 1.00000e-06 1.00000e-09 5.00000e-02

Element: 5875 \# of layers: 5

$\mathrm{Kx} \mathrm{Ky} \mathrm{Kz}$ Ss Por

$2.43315 \mathrm{e}+032.43315 \mathrm{e}+03$ 2.43315e+02 1.00000e-09 7.00000e-02

$2.43315 \mathrm{e}+032.43315 \mathrm{e}+032.43315 \mathrm{e}+02$ 1.00000e-09 7.00000e-02

$2.43315 \mathrm{e}+03$ 2.43315e+03 2.43315e+02 1.00000e-09 7.00000e-02

$2.43315 \mathrm{e}+032.43315 \mathrm{e}+032.43315 \mathrm{e}+02$ 1.00000e-09 7.00000e-02

1.00000e-06 1.00000e-06 1.00000e-06 1.00000e-09 5.00000e-02

Element: 5876 \# of layers: 5

$\mathrm{Kx} \mathrm{Ky} \mathrm{Kz}$ Ss Por

$2.48090 \mathrm{e}+032.48090 \mathrm{e}+032.48090 \mathrm{e}+02$ 1.00000e-09 7.00000e-02

$2.48090 \mathrm{e}+032.48090 \mathrm{e}+032.48090 \mathrm{e}+02$ 1.00000e-09 7.00000e-02

$2.48090 \mathrm{e}+032.48090 \mathrm{e}+032.48090 \mathrm{e}+02$ 1.00000e-09 7.00000e-02

$2.48090 \mathrm{e}+032.48090 \mathrm{e}+032.48090 \mathrm{e}+02$ 1.00000e-09 7.00000e-02

1.00000e-06 1.00000e-06 1.00000e-06 1.00000e-09 5.00000e-02

Element: 5877 \# of layers: 5

$\mathrm{Kx} \mathrm{Ky} \mathrm{Kz}$ Ss Por

2.43405e+03 2.43405e+03 2.43405e+02 1.00000e-09 7.00000e-02

$2.43405 \mathrm{e}+032.43405 \mathrm{e}+032.43405 \mathrm{e}+02$ 1.00000e-09 7.00000e-02

$2.43405 \mathrm{e}+032.43405 \mathrm{e}+032.43405 \mathrm{e}+02$ 1.00000e-09 7.00000e-02

$2.43405 \mathrm{e}+032.43405 \mathrm{e}+03$ 2.43405e+02 1.00000e-09 7.00000e-02

$1.00000 \mathrm{e}-061.00000 \mathrm{e}-06$ 1.00000e-06 1.00000e-09 5.00000e-02

Element: 5878 \# of layers: 5

Kx Ky Kz Ss Por 
2.43405e+03 2.43405e+03 2.43405e+02 1.00000e-09 7.00000e-02 $2.43405 \mathrm{e}+032.43405 \mathrm{e}+03$ 2.43405e+02 1.00000e-09 7.00000e-02 $2.43405 \mathrm{e}+032.43405 \mathrm{e}+03$ 2.43405e+02 1.00000e-09 7.00000e-02 $2.43405 \mathrm{e}+03$ 2.43405e+03 2.43405e+02 1.00000e-09 7.00000e-02 1.00000e-06 1.00000e-06 1.00000e-06 1.00000e-09 5.00000e-02

Element: 5879 \# of layers: 5

$\mathrm{Kx} \mathrm{Ky} \mathrm{Kz}$ Ss Por

$2.43405 \mathrm{e}+03$ 2.43405e+03 2.43405e+02 1.00000e-09 7.00000e-02 $2.43405 \mathrm{e}+032.43405 \mathrm{e}+032.43405 \mathrm{e}+02$ 1.00000e-09 7.00000e-02

$2.43405 \mathrm{e}+03$ 2.43405e+03 2.43405e+02 1.00000e-09 7.00000e-02 $2.43405 \mathrm{e}+032.43405 \mathrm{e}+032.43405 \mathrm{e}+02$ 1.00000e-09 7.00000e-02 1.00000e-06 1.00000e-06 1.00000e-06 1.00000e-09 5.00000e-02

Element: 5880 \# of layers: 5

$\mathrm{Kx} \mathrm{Ky} \mathrm{Kz}$ Ss Por

2.45027e+03 2.45027e+03 2.45027e+02 1.00000e-09 7.00000e-02 $2.45027 \mathrm{e}+032.45027 \mathrm{e}+03$ 2.45027e+02 1.00000e-09 7.00000e-02 $2.45027 \mathrm{e}+03$ 2.45027e+03 2.45027e+02 1.00000e-09 7.00000e-02 $2.45027 \mathrm{e}+032.45027 \mathrm{e}+03$ 2.45027e+02 1.00000e-09 7.00000e-02 1.00000e-06 1.00000e-06 1.00000e-06 1.00000e-09 5.00000e-02

Element: 5881 \# of layers: 5

$\mathrm{Kx} \mathrm{Ky} \mathrm{Kz}$ Ss Por

2.52812e+03 2.52812e+03 2.52812e+02 1.00000e-09 7.00000e-02 $2.52812 \mathrm{e}+032.52812 \mathrm{e}+032.52812 \mathrm{e}+02$ 1.00000e-09 7.00000e-02 $2.52812 \mathrm{e}+032.52812 \mathrm{e}+032.52812 \mathrm{e}+02$ 1.00000e-09 7.00000e-02 $2.52812 \mathrm{e}+032.52812 \mathrm{e}+032.52812 \mathrm{e}+02$ 1.00000e-09 7.00000e-02 1.00000e-06 1.00000e-06 1.00000e-06 1.00000e-09 5.00000e-02

Element: 5882 \# of layers: 5

$\mathrm{Kx} \mathrm{Ky} \mathrm{Kz}$ Ss Por

$2.52812 \mathrm{e}+03$ 2.52812e+03 2.52812e+02 1.00000e-09 7.00000e-02

$2.52812 \mathrm{e}+03$ 2.52812e+03 2.52812e+02 1.00000e-09 7.00000e-02

$2.52812 \mathrm{e}+032.52812 \mathrm{e}+032.52812 \mathrm{e}+02$ 1.00000e-09 7.00000e-02

$2.52812 \mathrm{e}+032.52812 \mathrm{e}+032.52812 \mathrm{e}+02$ 1.00000e-09 7.00000e-02 1.00000e-06 1.00000e-06 1.00000e-06 1.00000e-09 5.00000e-02

Element: 5883 \# of layers: 5

$\mathrm{Kx} \mathrm{Ky} \mathrm{Kz}$ Ss Por

$2.48090 \mathrm{e}+032.48090 \mathrm{e}+032.48090 \mathrm{e}+02$ 1.00000e-09 7.00000e-02 $2.48090 \mathrm{e}+032.48090 \mathrm{e}+032.48090 \mathrm{e}+02$ 1.00000e-09 7.00000e-02 $2.48090 \mathrm{e}+032.48090 \mathrm{e}+032.48090 \mathrm{e}+02$ 1.00000e-09 7.00000e-02

$2.48090 \mathrm{e}+032.48090 \mathrm{e}+032.48090 \mathrm{e}+021.00000 \mathrm{e}-09$ 7.00000e-02 1.00000e-06 1.00000e-06 1.00000e-06 1.00000e-09 5.00000e-02

Element: 5884 \# of layers: 5

$\mathrm{Kx} \mathrm{Ky} \mathrm{Kz}$ Ss Por

$2.52812 \mathrm{e}+032.52812 \mathrm{e}+03$ 2.52812e+02 1.00000e-09 7.00000e-02 $2.52812 \mathrm{e}+03$ 2.52812e+03 2.52812e+02 1.00000e-09 7.00000e-02 $2.52812 \mathrm{e}+032.52812 \mathrm{e}+032.52812 \mathrm{e}+02$ 1.00000e-09 7.00000e-02 $2.52812 \mathrm{e}+032.52812 \mathrm{e}+032.52812 \mathrm{e}+021.00000 \mathrm{e}-09$ 7.00000e-02 
1.00000e-06 1.00000e-06 1.00000e-06 1.00000e-09 5.00000e-02

Element: 5885 \# of layers: 5

$\mathrm{Kx} \mathrm{Ky} \mathrm{Kz}$ Ss Por

$2.37071 \mathrm{e}+03$ 2.37071e+03 2.37071e+02 1.00000e-09 7.00000e-02

$2.37071 \mathrm{e}+032.37071 \mathrm{e}+03$ 2.37071e+02 1.00000e-09 7.00000e-02

$2.37071 \mathrm{e}+032.37071 \mathrm{e}+032.37071 \mathrm{e}+02$ 1.00000e-09 7.00000e-02

$2.37071 \mathrm{e}+032.37071 \mathrm{e}+032.37071 \mathrm{e}+02$ 1.00000e-09 7.00000e-02

1.00000e-06 1.00000e-06 1.00000e-06 1.00000e-09 5.00000e-02

Element: 5886 \# of layers: 5

$\mathrm{Kx} \mathrm{Ky} \mathrm{Kz}$ Ss Por

2.76337e+03 2.76337e+03 2.76337e+02 1.00000e-09 7.00000e-02

$2.76337 \mathrm{e}+03$ 2.76337e+03 2.76337e+02 1.00000e-09 7.00000e-02

2.76337e+03 2.76337e+03 2.76337e+02 1.00000e-09 7.00000e-02

2.76337e+03 2.76337e+03 2.76337e+02 1.00000e-09 7.00000e-02

1.00000e-06 1.00000e-06 1.00000e-06 1.00000e-09 5.00000e-02

Element: 5887 \# of layers: 5

$\mathrm{Kx} \mathrm{Ky} \mathrm{Kz}$ Ss Por

2.76337e+03 2.76337e+03 2.76337e+02 1.00000e-09 7.00000e-02

2.76337e+03 2.76337e+03 2.76337e+02 1.00000e-09 7.00000e-02

$2.76337 \mathrm{e}+032.76337 \mathrm{e}+03$ 2.76337e+02 1.00000e-09 7.00000e-02

$2.76337 \mathrm{e}+03$ 2.76337e+03 2.76337e+02 1.00000e-09 7.00000e-02

1.00000e-06 1.00000e-06 1.00000e-06 1.00000e-09 5.00000e-02

Element: 5888 \# of layers: 5

Kx Ky Kz Ss Por

2.76337e+03 2.76337e+03 2.76337e+02 1.00000e-09 7.00000e-02

2.76337e+03 2.76337e+03 2.76337e+02 1.00000e-09 7.00000e-02

$2.76337 \mathrm{e}+03$ 2.76337e+03 2.76337e+02 1.00000e-09 7.00000e-02

$2.76337 \mathrm{e}+03$ 2.76337e+03 2.76337e+02 1.00000e-09 7.00000e-02

1.00000e-06 1.00000e-06 1.00000e-06 1.00000e-09 5.00000e-02

Element: 5889 \# of layers: 5

$\mathrm{Kx} \mathrm{Ky} \mathrm{Kz}$ Ss Por

3.13116e+03 3.13116e+03 3.13116e+02 1.00000e-09 7.00000e-02

$3.13116 \mathrm{e}+033.13116 \mathrm{e}+03$ 3.13116e+02 1.00000e-09 7.00000e-02

3.13116e+03 3.13116e+03 3.13116e+02 1.00000e-09 7.00000e-02

$3.13116 \mathrm{e}+033.13116 \mathrm{e}+03$ 3.13116e+02 1.00000e-09 7.00000e-02

1.00000e-06 1.00000e-06 1.00000e-06 1.00000e-09 5.00000e-02

Element: 5890 \# of layers: 5

Kx Ky Kz Ss Por

2.38783e+03 2.38783e+03 2.38783e+02 1.00000e-09 7.00000e-02

$2.38783 \mathrm{e}+032.38783 \mathrm{e}+03$ 2.38783e+02 1.00000e-09 7.00000e-02

$2.38783 \mathrm{e}+032.38783 \mathrm{e}+032.38783 \mathrm{e}+02$ 1.00000e-09 7.00000e-02

$2.38783 \mathrm{e}+032.38783 \mathrm{e}+032.38783 \mathrm{e}+02$ 1.00000e-09 7.00000e-02

$1.00000 \mathrm{e}-06$ 1.00000e-06 1.00000e-06 1.00000e-09 5.00000e-02

Element: 5891 \# of layers: 5

$\mathrm{Kx} \mathrm{Ky} \mathrm{Kz}$ Ss Por

$2.38783 e+032.38783 e+032.38783 e+02$ 1.00000e-09 7.00000e-02 
2.38783e+03 2.38783e+03 2.38783e+02 1.00000e-09 7.00000e-02 $2.38783 \mathrm{e}+032.38783 \mathrm{e}+03$ 2.38783e+02 1.00000e-09 7.00000e-02 $2.38783 e+032.38783 e+032.38783 e+02$ 1.00000e-09 7.00000e-02 $1.00000 \mathrm{e}-06$ 1.00000e-06 1.00000e-06 1.00000e-09 5.00000e-02 Element: 5892 \# of layers: 5

$\mathrm{Kx} \mathrm{Ky} \mathrm{Kz}$ Ss Por

$2.38783 e+03$ 2.38783e+03 2.38783e+02 1.00000e-09 7.00000e-02 $2.38783 e+032.38783 e+032.38783 e+02$ 1.00000e-09 7.00000e-02 $2.38783 \mathrm{e}+032.38783 \mathrm{e}+032.38783 \mathrm{e}+02$ 1.00000e-09 7.00000e-02 $2.38783 \mathrm{e}+032.38783 \mathrm{e}+032.38783 \mathrm{e}+02$ 1.00000e-09 7.00000e-02 1.00000e-06 1.00000e-06 1.00000e-06 1.00000e-09 5.00000e-02

Element: 5893 \# of layers: 5

$\mathrm{Kx} \mathrm{Ky} \mathrm{Kz}$ Ss Por

3.13116e+03 3.13116e+03 3.13116e+02 1.00000e-09 7.00000e-02 $3.13116 \mathrm{e}+033.13116 \mathrm{e}+033.13116 \mathrm{e}+02$ 1.00000e-09 7.00000e-02 $3.13116 \mathrm{e}+033.13116 \mathrm{e}+033.13116 \mathrm{e}+02$ 1.00000e-09 7.00000e-02 $3.13116 \mathrm{e}+033.13116 \mathrm{e}+033.13116 \mathrm{e}+02$ 1.00000e-09 7.00000e-02 1.00000e-06 1.00000e-06 1.00000e-06 1.00000e-09 5.00000e-02

Element: 5894 \# of layers: 5

$\mathrm{Kx} \mathrm{Ky} \mathrm{Kz}$ Ss Por

2.32332e+03 2.32332e+03 2.32332e+02 1.00000e-09 7.00000e-02

2.32332e+03 2.32332e+03 2.32332e+02 1.00000e-09 7.00000e-02

2.32332e+03 2.32332e+03 2.32332e+02 1.00000e-09 7.00000e-02

2.32332e+03 2.32332e+03 2.32332e+02 1.00000e-09 7.00000e-02 1.00000e-06 1.00000e-06 1.00000e-06 1.00000e-09 5.00000e-02

Element: 5895 \# of layers: 4

$\mathrm{Kx} \mathrm{Ky} \mathrm{Kz}$ Ss Por

$1.71839 \mathrm{e}+03$ 1.71839e+03 1.71839e+02 1.00000e-09 7.00000e-02

$1.71839 \mathrm{e}+03$ 1.71839e+03 1.71839e+02 1.00000e-09 7.00000e-02

$1.71839 \mathrm{e}+03$ 1.71839e+03 1.71839e+02 1.00000e-09 7.00000e-02 1.00000e-06 1.00000e-06 1.00000e-06 1.00000e-09 5.00000e-02

Element: 5896 \# of layers: 4

Kx Ky Kz Ss Por

$1.71839 \mathrm{e}+03$ 1.71839e+03 1.71839e+02 1.00000e-09 7.00000e-02 $1.71839 \mathrm{e}+03$ 1.71839e+03 1.71839e+02 1.00000e-09 7.00000e-02 $1.71839 \mathrm{e}+03$ 1.71839e+03 1.71839e+02 1.00000e-09 7.00000e-02 1.00000e-06 1.00000e-06 1.00000e-06 1.00000e-09 5.00000e-02

Element: 5897 \# of layers: 4

$\mathrm{Kx} \mathrm{Ky} \mathrm{Kz}$ Ss Por

$1.93346 \mathrm{e}+03$ 1.93346e+03 1.93346e+02 1.00000e-09 7.00000e-02 $1.93346 \mathrm{e}+031.93346 \mathrm{e}+03$ 1.93346e+02 1.00000e-09 7.00000e-02 $1.93346 \mathrm{e}+031.93346 \mathrm{e}+03$ 1.93346e+02 1.00000e-09 7.00000e-02 1.00000e-06 1.00000e-06 1.00000e-06 1.00000e-09 5.00000e-02

Element: 5898 \# of layers: 4

$\mathrm{Kx} \mathrm{Ky} \mathrm{Kz}$ Ss Por

$1.93346 \mathrm{e}+03$ 1.93346e+03 1.93346e+02 1.00000e-09 7.00000e-02 
1.93346e+03 1.93346e+03 1.93346e+02 1.00000e-09 7.00000e-02 $1.93346 \mathrm{e}+03$ 1.93346e+03 1.93346e+02 1.00000e-09 7.00000e-02 1.00000e-06 1.00000e-06 1.00000e-06 1.00000e-09 5.00000e-02

Element: 5899 \# of layers: 4

$\mathrm{Kx} \mathrm{Ky} \mathrm{Kz}$ Ss Por

$2.91726 \mathrm{e}+03$ 2.91726e+03 2.91726e+02 1.00000e-09 7.00000e-02 $2.91726 \mathrm{e}+032.91726 \mathrm{e}+032.91726 \mathrm{e}+02$ 1.00000e-09 7.00000e-02 $2.91726 \mathrm{e}+032.91726 \mathrm{e}+032.91726 \mathrm{e}+021.00000 \mathrm{e}-097.00000 \mathrm{e}-02$ 1.00000e-06 1.00000e-06 1.00000e-06 1.00000e-09 5.00000e-02

Element: 5900 \# of layers: 5

$\mathrm{Kx} \mathrm{Ky} \mathrm{Kz}$ Ss Por

$2.91726 \mathrm{e}+032.91726 \mathrm{e}+032.91726 \mathrm{e}+02$ 1.00000e-09 7.00000e-02 $2.91726 \mathrm{e}+032.91726 \mathrm{e}+032.91726 \mathrm{e}+02$ 1.00000e-09 7.00000e-02 $2.91726 \mathrm{e}+032.91726 \mathrm{e}+032.91726 \mathrm{e}+02$ 1.00000e-09 7.00000e-02 $2.91726 \mathrm{e}+032.91726 \mathrm{e}+032.91726 \mathrm{e}+02$ 1.00000e-09 7.00000e-02 1.00000e-06 1.00000e-06 1.00000e-06 1.00000e-09 5.00000e-02

Element: 5901 \# of layers: 5

$\mathrm{Kx} \mathrm{Ky} \mathrm{Kz}$ Ss Por

2.91726e+03 2.91726e+03 2.91726e+02 1.00000e-09 7.00000e-02 $2.91726 \mathrm{e}+032.91726 \mathrm{e}+032.91726 \mathrm{e}+02$ 1.00000e-09 7.00000e-02 $2.91726 \mathrm{e}+032.91726 \mathrm{e}+032.91726 \mathrm{e}+02$ 1.00000e-09 7.00000e-02 $2.91726 \mathrm{e}+032.91726 \mathrm{e}+032.91726 \mathrm{e}+02$ 1.00000e-09 7.00000e-02 1.00000e-06 1.00000e-06 1.00000e-06 1.00000e-09 5.00000e-02

Element: 5902 \# of layers: 4

Kx Ky Kz Ss Por

$1.71839 \mathrm{e}+03$ 1.71839e+03 1.71839e+02 1.00000e-09 7.00000e-02 $1.71839 \mathrm{e}+03$ 1.71839e+03 1.71839e+02 1.00000e-09 7.00000e-02 $1.71839 \mathrm{e}+03$ 1.71839e+03 1.71839e+02 1.00000e-09 7.00000e-02 1.00000e-06 1.00000e-06 1.00000e-06 1.00000e-09 5.00000e-02

Element: 5903 \# of layers: 4

$\mathrm{Kx} \mathrm{Ky} \mathrm{Kz}$ Ss Por

$1.46665 \mathrm{e}+03$ 1.46665e+03 1.46665e+02 1.00000e-09 7.00000e-02 $1.46665 \mathrm{e}+031.46665 \mathrm{e}+031.46665 \mathrm{e}+02$ 1.00000e-09 7.00000e-02 $1.46665 \mathrm{e}+03$ 1.46665e+03 1.46665e+02 1.00000e-09 7.00000e-02 1.00000e-06 1.00000e-06 1.00000e-06 1.00000e-09 5.00000e-02

Element: 5904 \# of layers: 4

Kx Ky Kz Ss Por

$1.35474 \mathrm{e}+031.35474 \mathrm{e}+03$ 1.35474e+02 1.00000e-09 7.00000e-02 $1.35474 \mathrm{e}+031.35474 \mathrm{e}+03$ 1.35474e+02 1.00000e-09 7.00000e-02 $1.35474 \mathrm{e}+03$ 1.35474e+03 1.35474e+02 1.00000e-09 7.00000e-02 1.00000e-06 1.00000e-06 1.00000e-06 1.00000e-09 5.00000e-02

Element: 5905 \# of layers: 4

$\mathrm{Kx} \mathrm{Ky} \mathrm{Kz}$ Ss Por

1.35474e+03 1.35474e+03 1.35474e+02 1.00000e-09 7.00000e-02 $1.35474 \mathrm{e}+031.35474 \mathrm{e}+031.35474 \mathrm{e}+021.00000 \mathrm{e}-097.00000 \mathrm{e}-02$ $1.35474 \mathrm{e}+031.35474 \mathrm{e}+031.35474 \mathrm{e}+021.00000 \mathrm{e}-097.00000 \mathrm{e}-02$ 
1.00000e-06 1.00000e-06 1.00000e-06 1.00000e-09 5.00000e-02

Element: 5906 \# of layers: 4

Kx Ky Kz Ss Por

$1.35474 \mathrm{e}+03$ 1.35474e+03 1.35474e+02 1.00000e-09 7.00000e-02

$1.35474 \mathrm{e}+031.35474 \mathrm{e}+03$ 1.35474e+02 1.00000e-09 7.00000e-02

$1.35474 \mathrm{e}+031.35474 \mathrm{e}+031.35474 \mathrm{e}+021.00000 \mathrm{e}-097.00000 \mathrm{e}-02$

1.00000e-06 1.00000e-06 1.00000e-06 1.00000e-09 5.00000e-02

Element: 5907 \# of layers: 4

$\mathrm{Kx} \mathrm{Ky} \mathrm{Kz}$ Ss Por

$1.59008 \mathrm{e}+03$ 1.59008e+03 1.59008e+02 1.00000e-09 7.00000e-02

$1.59008 \mathrm{e}+031.59008 \mathrm{e}+03$ 1.59008e+02 1.00000e-09 7.00000e-02

$1.59008 \mathrm{e}+031.59008 \mathrm{e}+03 \quad 1.59008 \mathrm{e}+021.00000 \mathrm{e}-097.00000 \mathrm{e}-02$

1.00000e-06 1.00000e-06 1.00000e-06 1.00000e-09 5.00000e-02

Element: 5908 \# of layers: 4

$\mathrm{Kx} \mathrm{Ky} \mathrm{Kz}$ Ss Por

$1.59008 \mathrm{e}+03$ 1.59008e+03 1.59008e+02 1.00000e-09 7.00000e-02

$1.59008 \mathrm{e}+03$ 1.59008e+03 1.59008e+02 1.00000e-09 7.00000e-02

$1.59008 \mathrm{e}+03$ 1.59008e+03 1.59008e+02 1.00000e-09 7.00000e-02

1.00000e-06 1.00000e-06 1.00000e-06 1.00000e-09 5.00000e-02

Element: 5909 \# of layers: 4

$\mathrm{Kx} \mathrm{Ky} \mathrm{Kz}$ Ss Por

$1.72415 \mathrm{e}+03$ 1.72415e+03 1.72415e+02 1.00000e-09 7.00000e-02

$1.72415 \mathrm{e}+031.72415 \mathrm{e}+03$ 1.72415e+02 1.00000e-09 7.00000e-02

$1.72415 \mathrm{e}+03$ 1.72415e+03 1.72415e+02 1.00000e-09 7.00000e-02

1.00000e-06 1.00000e-06 1.00000e-06 1.00000e-09 5.00000e-02

Element: 5910 \# of layers: 4

$\mathrm{Kx} \mathrm{Ky} \mathrm{Kz}$ Ss Por

$1.46665 \mathrm{e}+03$ 1.46665e+03 1.46665e+02 1.00000e-09 7.00000e-02

$1.46665 \mathrm{e}+03$ 1.46665e+03 1.46665e+02 1.00000e-09 7.00000e-02

$1.46665 \mathrm{e}+03$ 1.46665e+03 1.46665e+02 1.00000e-09 7.00000e-02

1.00000e-06 1.00000e-06 1.00000e-06 1.00000e-09 5.00000e-02

Element: 5911 \# of layers: 4

Kx Ky Kz Ss Por

$1.59008 \mathrm{e}+03$ 1.59008e+03 1.59008e+02 1.00000e-09 7.00000e-02

$1.59008 \mathrm{e}+031.59008 \mathrm{e}+03$ 1.59008e+02 1.00000e-09 7.00000e-02

$1.59008 \mathrm{e}+031.59008 \mathrm{e}+03$ 1.59008e+02 1.00000e-09 7.00000e-02

1.00000e-06 1.00000e-06 1.00000e-06 1.00000e-09 5.00000e-02

Element: 5912 \# of layers: 4

$\mathrm{Kx} \mathrm{Ky} \mathrm{Kz}$ Ss Por

$1.28429 \mathrm{e}+03$ 1.28429e+03 1.28429e+02 1.00000e-09 7.00000e-02

$1.28429 \mathrm{e}+031.28429 \mathrm{e}+03$ 1.28429e+02 1.00000e-09 7.00000e-02

$1.28429 \mathrm{e}+031.28429 \mathrm{e}+03$ 1.28429e+02 1.00000e-09 7.00000e-02

$1.00000 \mathrm{e}-06$ 1.00000e-06 1.00000e-06 1.00000e-09 5.00000e-02

Element: 5913 \# of layers: 4

$\mathrm{Kx} \mathrm{Ky} \mathrm{Kz} \mathrm{Ss} \mathrm{Por}$

$1.26581 \mathrm{e}+03$ 1.26581e+03 1.26581e+02 1.00000e-09 7.00000e-02 
$1.26581 \mathrm{e}+03$ 1.26581e+03 1.26581e+02 1.00000e-09 7.00000e-02 $1.26581 \mathrm{e}+031.26581 \mathrm{e}+031.26581 \mathrm{e}+02$ 1.00000e-09 7.00000e-02 1.00000e-06 1.00000e-06 1.00000e-06 1.00000e-09 5.00000e-02

Element: 5914 \# of layers: 4

$\mathrm{Kx} \mathrm{Ky} \mathrm{Kz}$ Ss Por

$1.26581 \mathrm{e}+03$ 1.26581e+03 1.26581e+02 1.00000e-09 7.00000e-02 $1.26581 \mathrm{e}+031.26581 \mathrm{e}+03$ 1.26581e+02 1.00000e-09 7.00000e-02 $1.26581 \mathrm{e}+031.26581 \mathrm{e}+031.26581 \mathrm{e}+021.00000 \mathrm{e}-097.00000 \mathrm{e}-02$ 1.00000e-06 1.00000e-06 1.00000e-06 1.00000e-09 5.00000e-02

Element: 5915 \# of layers: 4

$\mathrm{Kx} \mathrm{Ky} \mathrm{Kz}$ Ss Por

$1.26581 \mathrm{e}+03$ 1.26581e+03 1.26581e+02 1.00000e-09 7.00000e-02 $1.26581 \mathrm{e}+03$ 1.26581e+03 1.26581e+02 1.00000e-09 7.00000e-02

$1.26581 \mathrm{e}+031.26581 \mathrm{e}+03$ 1.26581e+02 1.00000e-09 7.00000e-02 1.00000e-06 1.00000e-06 1.00000e-06 1.00000e-09 5.00000e-02

Element: 5916 \# of layers: 4

$\mathrm{Kx} \mathrm{Ky} \mathrm{Kz}$ Ss Por

1.44412e+03 1.44412e+03 1.44412e+02 1.00000e-09 7.00000e-02 $1.44412 \mathrm{e}+031.44412 \mathrm{e}+03$ 1.44412e+02 1.00000e-09 7.00000e-02 $1.44412 \mathrm{e}+03$ 1.44412e+03 1.44412e+02 1.00000e-09 7.00000e-02 1.00000e-06 1.00000e-06 1.00000e-06 1.00000e-09 5.00000e-02

Element: 5917 \# of layers: 4

$\mathrm{Kx} \mathrm{Ky} \mathrm{Kz}$ Ss Por

1.44412e+03 1.44412e+03 1.44412e+02 1.00000e-09 7.00000e-02 $1.44412 \mathrm{e}+03$ 1.44412e+03 1.44412e+02 1.00000e-09 7.00000e-02 $1.44412 \mathrm{e}+03$ 1.44412e+03 1.44412e+02 1.00000e-09 7.00000e-02 1.00000e-06 1.00000e-06 1.00000e-06 1.00000e-09 5.00000e-02

Element: 5918 \# of layers: 4

Kx Ky Kz Ss Por

1.43583e+03 1.43583e+03 1.43583e+02 1.00000e-09 7.00000e-02 $1.43583 \mathrm{e}+03$ 1.43583e+03 1.43583e+02 1.00000e-09 7.00000e-02 $1.43583 \mathrm{e}+03$ 1.43583e+03 1.43583e+02 1.00000e-09 7.00000e-02 1.00000e-06 1.00000e-06 1.00000e-06 1.00000e-09 5.00000e-02

Element: 5919 \# of layers: 4

$\mathrm{Kx} \mathrm{Ky} \mathrm{Kz}$ Ss Por

$1.43583 e+03$ 1.43583e+03 1.43583e+02 1.00000e-09 7.00000e-02 $1.43583 \mathrm{e}+031.43583 \mathrm{e}+03$ 1.43583e+02 1.00000e-09 7.00000e-02 $1.43583 \mathrm{e}+031.43583 \mathrm{e}+03$ 1.43583e+02 1.00000e-09 7.00000e-02 1.00000e-06 1.00000e-06 1.00000e-06 1.00000e-09 5.00000e-02

Element: 5920 \# of layers: 4

Kx Ky Kz Ss Por

1.44412e+03 1.44412e+03 1.44412e+02 1.00000e-09 7.00000e-02 $1.44412 \mathrm{e}+031.44412 \mathrm{e}+03$ 1.44412e+02 1.00000e-09 7.00000e-02 1.44412e+03 1.44412e+03 1.44412e+02 1.00000e-09 7.00000e-02 1.00000e-06 1.00000e-06 1.00000e-06 1.00000e-09 5.00000e-02

Element: 5921 \# of layers: 4 
$\mathrm{Kx} \mathrm{Ky} \mathrm{Kz}$ Ss Por

$1.38961 \mathrm{e}+03$ 1.38961e+03 1.38961e+02 1.00000e-09 7.00000e-02

$1.38961 \mathrm{e}+03$ 1.38961e+03 1.38961e+02 1.00000e-09 7.00000e-02

$1.38961 \mathrm{e}+031.38961 \mathrm{e}+03$ 1.38961e+02 1.00000e-09 7.00000e-02

1.00000e-06 1.00000e-06 1.00000e-06 1.00000e-09 5.00000e-02

Element: 5922 \# of layers: 4

$\mathrm{Kx} \mathrm{Ky} \mathrm{Kz}$ Ss Por

1.43439e+03 1.43439e+03 1.43439e+02 1.00000e-09 7.00000e-02

$1.43439 \mathrm{e}+03$ 1.43439e+03 1.43439e+02 1.00000e-09 7.00000e-02

$1.43439 \mathrm{e}+03$ 1.43439e+03 1.43439e+02 1.00000e-09 7.00000e-02

1.00000e-06 1.00000e-06 1.00000e-06 1.00000e-09 5.00000e-02

Element: 5923 \# of layers: 4

$\mathrm{Kx} \mathrm{Ky} \mathrm{Kz}$ Ss Por

2.13528e+03 2.13528e+03 2.13528e+02 1.00000e-09 7.00000e-02

2.13528e+03 2.13528e+03 2.13528e+02 1.00000e-09 7.00000e-02

$2.13528 \mathrm{e}+032.13528 \mathrm{e}+032.13528 \mathrm{e}+02$ 1.00000e-09 7.00000e-02

1.00000e-06 1.00000e-06 1.00000e-06 1.00000e-09 5.00000e-02

Element: 5924 \# of layers: 4

$\mathrm{Kx} \mathrm{Ky} \mathrm{Kz}$ Ss Por

3.34676e+03 3.34676e+03 3.34676e+02 1.00000e-09 7.00000e-02

3.34676e+03 3.34676e+03 3.34676e+02 1.00000e-09 7.00000e-02

$3.34676 \mathrm{e}+03$ 3.34676e+03 3.34676e+02 1.00000e-09 7.00000e-02

1.00000e-06 1.00000e-06 1.00000e-06 1.00000e-09 5.00000e-02

Element: 5925 \# of layers: 4

$\mathrm{Kx} \mathrm{Ky} \mathrm{Kz}$ Ss Por

3.34676e+03 3.34676e+03 3.34676e+02 1.00000e-09 7.00000e-02

$3.34676 \mathrm{e}+03$ 3.34676e+03 3.34676e+02 1.00000e-09 7.00000e-02

$3.34676 \mathrm{e}+03$ 3.34676e+03 3.34676e+02 1.00000e-09 7.00000e-02

1.00000e-06 1.00000e-06 1.00000e-06 1.00000e-09 5.00000e-02

Element: 5926 \# of layers: 4

$\mathrm{Kx} \mathrm{Ky} \mathrm{Kz}$ Ss Por

$1.84660 \mathrm{e}+03$ 1.84660e+03 1.84660e+02 1.00000e-09 7.00000e-02

$1.84660 \mathrm{e}+031.84660 \mathrm{e}+031.84660 \mathrm{e}+02$ 1.00000e-09 7.00000e-02

$1.84660 \mathrm{e}+03$ 1.84660e+03 1.84660e+02 1.00000e-09 7.00000e-02

1.00000e-06 1.00000e-06 1.00000e-06 1.00000e-09 5.00000e-02

Element: 5927 \# of layers: 4

Kx Ky Kz Ss Por

$1.84660 \mathrm{e}+03$ 1.84660e+03 1.84660e+02 1.00000e-09 7.00000e-02

$1.84660 \mathrm{e}+031.84660 \mathrm{e}+031.84660 \mathrm{e}+021.00000 \mathrm{e}-097.00000 \mathrm{e}-02$

$1.84660 \mathrm{e}+031.84660 \mathrm{e}+031.84660 \mathrm{e}+021.00000 \mathrm{e}-09$ 7.00000e-02

1.00000e-06 1.00000e-06 1.00000e-06 1.00000e-09 5.00000e-02

Element: 5928 \# of layers: 4

$\mathrm{Kx} \mathrm{Ky} \mathrm{Kz}$ Ss Por

1.43439e+03 1.43439e+03 1.43439e+02 1.00000e-09 7.00000e-02

$1.43439 \mathrm{e}+03$ 1.43439e+03 1.43439e+02 1.00000e-09 7.00000e-02

$1.43439 \mathrm{e}+03$ 1.43439e+03 1.43439e+02 1.00000e-09 7.00000e-02 
1.00000e-06 1.00000e-06 1.00000e-06 1.00000e-09 5.00000e-02

Element: 5929 \# of layers: 4

$\mathrm{Kx} \mathrm{Ky} \mathrm{Kz}$ Ss Por

$1.43439 \mathrm{e}+03$ 1.43439e+03 1.43439e+02 1.00000e-09 7.00000e-02

$1.43439 \mathrm{e}+031.43439 \mathrm{e}+03$ 1.43439e+02 1.00000e-09 7.00000e-02

$1.43439 \mathrm{e}+03$ 1.43439e+03 1.43439e+02 1.00000e-09 7.00000e-02

1.00000e-06 1.00000e-06 1.00000e-06 1.00000e-09 5.00000e-02

Element: 5930 \# of layers: 7

$\mathrm{Kx} \mathrm{Ky} \mathrm{Kz}$ Ss Por

$1.25356 \mathrm{e}+02$ 1.25356e+02 1.25356e+01 1.00000e-09 7.00000e-02

$1.25356 \mathrm{e}+021.25356 \mathrm{e}+02 \quad 1.25356 \mathrm{e}+01$ 1.00000e-09 7.00000e-02

$1.25356 \mathrm{e}+02 \quad 1.25356 \mathrm{e}+02 \quad 1.25356 \mathrm{e}+01$ 1.00000e-09 7.00000e-02

$1.25356 \mathrm{e}+02$ 1.25356e+02 1.25356e+01 1.00000e-09 7.00000e-02

$1.25356 \mathrm{e}+021.25356 \mathrm{e}+021.25356 \mathrm{e}+01$ 1.00000e-09 7.00000e-02

5.00000e-04 5.00000e-04 5.00000e-05 1.00000e-09 1.00000e-01

$1.00000 \mathrm{e}-02$ 1.00000e-02 1.00000e-03 1.00000e-09 1.00000e-01

Element: 5931 \# of layers: 9

$\mathrm{Kx} \mathrm{Ky} \mathrm{Kz}$ Ss Por

$1.25356 \mathrm{e}+02$ 1.25356e+02 1.25356e+01 1.00000e-09 7.00000e-02

$1.25356 \mathrm{e}+02 \quad 1.25356 \mathrm{e}+02 \quad 1.25356 \mathrm{e}+01$ 1.00000e-09 7.00000e-02

$1.25356 \mathrm{e}+02 \quad 1.25356 \mathrm{e}+02 \quad 1.25356 \mathrm{e}+01$ 1.00000e-09 7.00000e-02

$1.25356 \mathrm{e}+02$ 1.25356e+02 1.25356e+01 1.00000e-09 7.00000e-02

$1.25356 \mathrm{e}+021.25356 \mathrm{e}+021.25356 \mathrm{e}+01$ 1.00000e-09 7.00000e-02

5.00000e-04 5.00000e-04 5.00000e-05 1.00000e-09 1.00000e-01

$5.00000 \mathrm{e}-04$ 5.00000e-04 5.00000e-05 1.00000e-09 1.00000e-01

$1.00000 \mathrm{e}-02$ 1.00000e-02 1.00000e-03 1.00000e-09 1.00000e-01

$1.00000 \mathrm{e}+001.00000 \mathrm{e}+001.00000 \mathrm{e}-01$ 1.00000e-09 1.00000e-01

Element: 5932 \# of layers: 9

$\mathrm{Kx} \mathrm{Ky} \mathrm{Kz}$ Ss Por

1.25356e+02 1.25356e+02 1.25356e+01 1.00000e-09 7.00000e-02

$1.25356 \mathrm{e}+021.25356 \mathrm{e}+02 \quad 1.25356 \mathrm{e}+01$ 1.00000e-09 7.00000e-02

$1.25356 \mathrm{e}+021.25356 \mathrm{e}+02 \quad 1.25356 \mathrm{e}+01$ 1.00000e-09 7.00000e-02

$1.25356 \mathrm{e}+021.25356 \mathrm{e}+02 \quad 1.25356 \mathrm{e}+01$ 1.00000e-09 7.00000e-02

$1.25356 \mathrm{e}+02 \quad 1.25356 \mathrm{e}+021.25356 \mathrm{e}+011.00000 \mathrm{e}-097.00000 \mathrm{e}-02$

5.00000e-04 5.00000e-04 5.00000e-05 1.00000e-09 1.00000e-01

5.00000e-04 5.00000e-04 5.00000e-05 1.00000e-09 1.00000e-01

$1.00000 \mathrm{e}-02$ 1.00000e-02 1.00000e-03 1.00000e-09 1.00000e-01

$1.00000 \mathrm{e}+001.00000 \mathrm{e}+001.00000 \mathrm{e}-011.00000 \mathrm{e}-091.00000 \mathrm{e}-01$

Element: 5933 \# of layers: 10

$\mathrm{Kx} \mathrm{Ky} \mathrm{Kz}$ Ss Por

$1.25356 \mathrm{e}+02$ 1.25356e+02 1.25356e+01 1.00000e-09 7.00000e-02

$1.25356 \mathrm{e}+021.25356 \mathrm{e}+021.25356 \mathrm{e}+01$ 1.00000e-09 7.00000e-02

$1.25356 \mathrm{e}+021.25356 \mathrm{e}+02$ 1.25356e+01 1.00000e-09 7.00000e-02

$1.25356 \mathrm{e}+02$ 1.25356e+02 1.25356e+01 1.00000e-09 7.00000e-02

5.00000e-04 5.00000e-04 5.00000e-05 1.00000e-09 1.00000e-01

5.00000e-04 5.00000e-04 5.00000e-05 1.00000e-09 1.00000e-01 
$5.00861 \mathrm{e}+005.00861 \mathrm{e}+00$ 5.00861e-01 1.00000e-09 2.12000e-01 $5.00861 \mathrm{e}+005.00861 \mathrm{e}+00$ 5.00861e-01 1.00000e-09 2.12000e-01 $1.00000 \mathrm{e}-02$ 1.00000e-02 1.00000e-03 1.00000e-09 1.00000e-01 $1.00000 \mathrm{e}+001.00000 \mathrm{e}+001.00000 \mathrm{e}-011.00000 \mathrm{e}-091.00000 \mathrm{e}-01$ Element: 5934 \# of layers: 10

Kx Ky Kz Ss Por

$1.25356 \mathrm{e}+021.25356 \mathrm{e}+021.25356 \mathrm{e}+01$ 1.00000e-09 7.00000e-02 $1.25356 \mathrm{e}+02 \quad 1.25356 \mathrm{e}+02 \quad 1.25356 \mathrm{e}+011.00000 \mathrm{e}-097.00000 \mathrm{e}-02$ $1.25356 \mathrm{e}+021.25356 \mathrm{e}+021.25356 \mathrm{e}+011.00000 \mathrm{e}-097.00000 \mathrm{e}-02$ $1.25356 \mathrm{e}+021.25356 \mathrm{e}+021.25356 \mathrm{e}+011.00000 \mathrm{e}-097.00000 \mathrm{e}-02$ 5.00000e-04 5.00000e-04 5.00000e-05 1.00000e-09 1.00000e-01 $5.00000 \mathrm{e}-04$ 5.00000e-04 5.00000e-05 1.00000e-09 1.00000e-01 $5.00861 \mathrm{e}+005.00861 \mathrm{e}+00$ 5.00861e-01 1.00000e-09 2.12000e-01 $5.00861 \mathrm{e}+005.00861 \mathrm{e}+00$ 5.00861e-01 1.00000e-09 2.12000e-01 $1.00000 \mathrm{e}-02$ 1.00000e-02 1.00000e-03 1.00000e-09 1.00000e-01 $1.00000 \mathrm{e}+001.00000 \mathrm{e}+001.00000 \mathrm{e}-011.00000 \mathrm{e}-091.00000 \mathrm{e}-01$ Element: 5935 \# of layers: 9

Kx Ky Kz Ss Por

$1.25356 \mathrm{e}+021.25356 \mathrm{e}+021.25356 \mathrm{e}+011.00000 \mathrm{e}-097.00000 \mathrm{e}-02$ $1.25356 \mathrm{e}+021.25356 \mathrm{e}+021.25356 \mathrm{e}+011.00000 \mathrm{e}-097.00000 \mathrm{e}-02$ $1.25356 \mathrm{e}+021.25356 \mathrm{e}+02 \quad 1.25356 \mathrm{e}+011.00000 \mathrm{e}-097.00000 \mathrm{e}-02$ $1.25356 \mathrm{e}+021.25356 \mathrm{e}+021.25356 \mathrm{e}+011.00000 \mathrm{e}-097.00000 \mathrm{e}-02$ 5.00000e-04 5.00000e-04 5.00000e-05 1.00000e-09 1.00000e-01 5.00000e-04 5.00000e-04 5.00000e-05 1.00000e-09 1.00000e-01 $5.00861 \mathrm{e}+005.00861 \mathrm{e}+00$ 5.00861e-01 1.00000e-09 2.12000e-01 $1.00000 \mathrm{e}-02$ 1.00000e-02 1.00000e-03 1.00000e-09 1.00000e-01 $1.00000 \mathrm{e}+001.00000 \mathrm{e}+00$ 1.00000e-01 1.00000e-09 1.00000e-01 Element: 5936 \# of layers: 8

$\mathrm{Kx} \mathrm{Ky} \mathrm{Kz}$ Ss Por

1.25356e+02 1.25356e+02 1.25356e+01 1.00000e-09 7.00000e-02 $1.25356 \mathrm{e}+021.25356 \mathrm{e}+02 \quad 1.25356 \mathrm{e}+01$ 1.00000e-09 7.00000e-02 $1.25356 \mathrm{e}+021.25356 \mathrm{e}+021.25356 \mathrm{e}+01$ 1.00000e-09 7.00000e-02 $1.25356 \mathrm{e}+021.25356 \mathrm{e}+021.25356 \mathrm{e}+01$ 1.00000e-09 7.00000e-02 5.00000e-04 5.00000e-04 5.00000e-05 1.00000e-09 1.00000e-01 $5.00861 \mathrm{e}+005.00861 \mathrm{e}+005.00861 \mathrm{e}-01$ 1.00000e-09 2.12000e-01 1.00000e-02 1.00000e-02 1.00000e-03 1.00000e-09 1.00000e-01 $1.00000 \mathrm{e}+001.00000 \mathrm{e}+001.00000 \mathrm{e}-011.00000 \mathrm{e}-091.00000 \mathrm{e}-01$ Element: 5937 \# of layers: 8

$\mathrm{Kx} \mathrm{Ky} \mathrm{Kz}$ Ss Por

$1.25356 \mathrm{e}+02$ 1.25356e+02 1.25356e+01 1.00000e-09 7.00000e-02 $1.25356 \mathrm{e}+021.25356 \mathrm{e}+021.25356 \mathrm{e}+01$ 1.00000e-09 7.00000e-02 $1.25356 \mathrm{e}+021.25356 \mathrm{e}+02 \quad 1.25356 \mathrm{e}+01$ 1.00000e-09 7.00000e-02 $1.25356 \mathrm{e}+021.25356 \mathrm{e}+02 \quad 1.25356 \mathrm{e}+01$ 1.00000e-09 7.00000e-02 $1.25356 \mathrm{e}+02$ 1.25356e+02 1.25356e+01 1.00000e-09 7.00000e-02 5.00000e-04 5.00000e-04 5.00000e-05 1.00000e-09 1.00000e-01 $1.00000 \mathrm{e}-02$ 1.00000e-02 1.00000e-03 1.00000e-09 1.00000e-01 
$1.00000 \mathrm{e}+001.00000 \mathrm{e}+00$ 1.00000e-01 1.00000e-09 1.00000e-01

Element: 5938 \# of layers: 10

$\mathrm{Kx} \mathrm{Ky} \mathrm{Kz}$ Ss Por

$1.25356 \mathrm{e}+02$ 1.25356e+02 1.25356e+01 1.00000e-09 7.00000e-02

$1.25356 \mathrm{e}+021.25356 \mathrm{e}+021.25356 \mathrm{e}+01$ 1.00000e-09 7.00000e-02

$1.25356 \mathrm{e}+02$ 1.25356e+02 1.25356e+01 1.00000e-09 7.00000e-02

$1.25356 \mathrm{e}+021.25356 \mathrm{e}+02$ 1.25356e+01 1.00000e-09 7.00000e-02

$1.25356 \mathrm{e}+021.25356 \mathrm{e}+02 \quad 1.25356 \mathrm{e}+01$ 1.00000e-09 7.00000e-02

5.00000e-04 5.00000e-04 5.00000e-05 1.00000e-09 1.00000e-01

5.00000e-04 5.00000e-04 5.00000e-05 1.00000e-09 1.00000e-01

$5.00861 \mathrm{e}+005.00861 \mathrm{e}+00$ 5.00861e-01 1.00000e-09 2.12000e-01

$1.00000 \mathrm{e}-02$ 1.00000e-02 1.00000e-03 1.00000e-09 1.00000e-01

$1.00000 \mathrm{e}+001.00000 \mathrm{e}+001.00000 \mathrm{e}-011.00000 \mathrm{e}-091.00000 \mathrm{e}-01$

Element: 5939 \# of layers: 10

$\mathrm{Kx} \mathrm{Ky} \mathrm{Kz}$ Ss Por

1.33952e+02 1.33952e+02 1.33952e+01 1.00000e-09 7.00000e-02

1.33952e+02 1.33952e+02 1.33952e+01 1.00000e-09 7.00000e-02

1.33952e+02 1.33952e+02 1.33952e+01 1.00000e-09 7.00000e-02

1.33952e+02 1.33952e+02 1.33952e+01 1.00000e-09 7.00000e-02

1.33952e+02 1.33952e+02 1.33952e+01 1.00000e-09 7.00000e-02

5.00000e-04 5.00000e-04 5.00000e-05 1.00000e-09 1.00000e-01

5.00000e-04 5.00000e-04 5.00000e-05 1.00000e-09 1.00000e-01

$5.35219 \mathrm{e}+00$ 5.35219e+00 5.35219e-01 1.00000e-09 2.12000e-01

$1.00000 \mathrm{e}-02$ 1.00000e-02 1.00000e-03 1.00000e-09 1.00000e-01

$1.00000 \mathrm{e}+001.00000 \mathrm{e}+001.00000 \mathrm{e}-011.00000 \mathrm{e}-091.00000 \mathrm{e}-01$

Element: 5940 \# of layers: 9

$\mathrm{Kx} \mathrm{Ky} \mathrm{Kz}$ Ss Por

1.33952e+02 1.33952e+02 1.33952e+01 1.00000e-09 7.00000e-02

$1.33952 \mathrm{e}+02$ 1.33952e+02 1.33952e+01 1.00000e-09 7.00000e-02

1.33952e+02 1.33952e+02 1.33952e+01 1.00000e-09 7.00000e-02

1.33952e+02 1.33952e+02 1.33952e+01 1.00000e-09 7.00000e-02

5.00000e-04 5.00000e-04 5.00000e-05 1.00000e-09 1.00000e-01

5.00000e-04 5.00000e-04 5.00000e-05 1.00000e-09 1.00000e-01

$5.35219 \mathrm{e}+00$ 5.35219e+00 5.35219e-01 1.00000e-09 2.12000e-01

$1.00000 \mathrm{e}-02$ 1.00000e-02 1.00000e-03 1.00000e-09 1.00000e-01

$1.00000 \mathrm{e}+001.00000 \mathrm{e}+001.00000 \mathrm{e}-011.00000 \mathrm{e}-091.00000 \mathrm{e}-01$

Element: 5941 \# of layers: 9

Kx Ky Kz Ss Por

1.33952e+02 1.33952e+02 1.33952e+01 1.00000e-09 7.00000e-02

$1.33952 \mathrm{e}+02$ 1.33952e+02 1.33952e+01 1.00000e-09 7.00000e-02

1.33952e+02 1.33952e+02 1.33952e+01 1.00000e-09 7.00000e-02

1.33952e+02 1.33952e+02 1.33952e+01 1.00000e-09 7.00000e-02

$5.00000 \mathrm{e}-04$ 5.00000e-04 5.00000e-05 1.00000e-09 1.00000e-01

5.00000e-04 5.00000e-04 5.00000e-05 1.00000e-09 1.00000e-01

$5.35219 \mathrm{e}+00$ 5.35219e+00 5.35219e-01 1.00000e-09 2.12000e-01

$1.00000 \mathrm{e}-02$ 1.00000e-02 1.00000e-03 1.00000e-09 1.00000e-01 
$1.00000 \mathrm{e}+001.00000 \mathrm{e}+00$ 1.00000e-01 1.00000e-09 1.00000e-01

Element: 5942 \# of layers: 9

Kx Ky Kz Ss Por

1.33952e+02 1.33952e+02 1.33952e+01 1.00000e-09 7.00000e-02

1.33952e+02 1.33952e+02 1.33952e+01 1.00000e-09 7.00000e-02

$1.33952 \mathrm{e}+021.33952 \mathrm{e}+02$ 1.33952e+01 1.00000e-09 7.00000e-02

5.00000e-04 5.00000e-04 5.00000e-05 1.00000e-09 1.00000e-01

5.00000e-04 5.00000e-04 5.00000e-05 1.00000e-09 1.00000e-01

$5.35219 \mathrm{e}+00$ 5.35219e+00 5.35219e-01 1.00000e-09 2.12000e-01

5.35219e+00 5.35219e+00 5.35219e-01 1.00000e-09 2.12000e-01

1.00000e-02 1.00000e-02 1.00000e-03 1.00000e-09 1.00000e-01

$1.00000 \mathrm{e}+001.00000 \mathrm{e}+001.00000 \mathrm{e}-011.00000 \mathrm{e}-091.00000 \mathrm{e}-01$

Element: 5943 \# of layers: 9

$\mathrm{Kx} \mathrm{Ky} \mathrm{Kz}$ Ss Por

1.33952e+02 1.33952e+02 1.33952e+01 1.00000e-09 7.00000e-02

$1.33952 \mathrm{e}+02$ 1.33952e+02 1.33952e+01 1.00000e-09 7.00000e-02

$1.33952 \mathrm{e}+02$ 1.33952e+02 1.33952e+01 1.00000e-09 7.00000e-02

5.00000e-04 5.00000e-04 5.00000e-05 1.00000e-09 1.00000e-01

5.00000e-04 5.00000e-04 5.00000e-05 1.00000e-09 1.00000e-01

$5.35219 \mathrm{e}+00$ 5.35219e+00 5.35219e-01 1.00000e-09 2.12000e-01

$5.35219 \mathrm{e}+00$ 5.35219e+00 5.35219e-01 1.00000e-09 2.12000e-01

$1.00000 \mathrm{e}-02$ 1.00000e-02 1.00000e-03 1.00000e-09 1.00000e-01

$1.00000 \mathrm{e}+001.00000 \mathrm{e}+001.00000 \mathrm{e}-01$ 1.00000e-09 1.00000e-01

Element: 5944 \# of layers: 10

$\mathrm{Kx} \mathrm{Ky} \mathrm{Kz}$ Ss Por

1.33952e+02 1.33952e+02 1.33952e+01 1.00000e-09 7.00000e-02

1.33952e+02 1.33952e+02 1.33952e+01 1.00000e-09 7.00000e-02

1.33952e+02 1.33952e+02 1.33952e+01 1.00000e-09 7.00000e-02

$1.33952 \mathrm{e}+02$ 1.33952 $+021.33952 \mathrm{e}+01$ 1.00000e-09 7.00000e-02

5.00000e-04 5.00000e-04 5.00000e-05 1.00000e-09 1.00000e-01

5.00000e-04 5.00000e-04 5.00000e-05 1.00000e-09 1.00000e-01

$5.35219 \mathrm{e}+00$ 5.35219e+00 5.35219e-01 1.00000e-09 2.12000e-01

$5.35219 \mathrm{e}+00$ 5.35219e+00 5.35219e-01 1.00000e-09 2.12000e-01

$1.00000 \mathrm{e}-02$ 1.00000e-02 1.00000e-03 1.00000e-09 1.00000e-01

$1.00000 \mathrm{e}+001.00000 \mathrm{e}+001.00000 \mathrm{e}-011.00000 \mathrm{e}-091.00000 \mathrm{e}-01$

Element: 5945 \# of layers: 10

Kx Ky Kz Ss Por

1.33952e+02 1.33952e+02 1.33952e+01 1.00000e-09 7.00000e-02

$1.33952 \mathrm{e}+02$ 1.33952e+02 1.33952e+01 1.00000e-09 7.00000e-02

1.33952e+02 1.33952e+02 1.33952e+01 1.00000e-09 7.00000e-02

1.33952e+02 1.33952e+02 1.33952e+01 1.00000e-09 7.00000e-02

5.00000e-04 5.00000e-04 5.00000e-05 1.00000e-09 1.00000e-01

5.00000e-04 5.00000e-04 5.00000e-05 1.00000e-09 1.00000e-01

5.35219e+00 5.35219e+00 5.35219e-01 1.00000e-09 2.12000e-01

$5.35219 \mathrm{e}+00$ 5.35219e+00 5.35219e-01 1.00000e-09 2.12000e-01

$1.00000 \mathrm{e}-02$ 1.00000e-02 1.00000e-03 1.00000e-09 1.00000e-01 
$1.00000 \mathrm{e}+001.00000 \mathrm{e}+00$ 1.00000e-01 1.00000e-09 1.00000e-01

Element: 5946 \# of layers: 10

$\mathrm{Kx} \mathrm{Ky} \mathrm{Kz}$ Ss Por

1.33952e+02 1.33952e+02 1.33952e+01 1.00000e-09 7.00000e-02

1.33952e+02 1.33952e+02 1.33952e+01 1.00000e-09 7.00000e-02

1.33952e+02 1.33952e+02 1.33952e+01 1.00000e-09 7.00000e-02

$1.33952 \mathrm{e}+02$ 1.33952e+02 1.33952e+01 1.00000e-09 7.00000e-02

5.00000e-04 5.00000e-04 5.00000e-05 1.00000e-09 1.00000e-01

5.00000e-04 5.00000e-04 5.00000e-05 1.00000e-09 1.00000e-01

$5.35219 \mathrm{e}+005.35219 \mathrm{e}+00$ 5.35219e-01 1.00000e-09 2.12000e-01

$5.35219 \mathrm{e}+00$ 5.35219e+00 5.35219e-01 1.00000e-09 2.12000e-01

$1.00000 \mathrm{e}-02$ 1.00000e-02 1.00000e-03 1.00000e-09 1.00000e-01

$1.00000 \mathrm{e}+001.00000 \mathrm{e}+001.00000 \mathrm{e}-011.00000 \mathrm{e}-091.00000 \mathrm{e}-01$

Element: 5947 \# of layers: 8

$\mathrm{Kx} \mathrm{Ky} \mathrm{Kz}$ Ss Por

1.33952e+02 1.33952e+02 1.33952e+01 1.00000e-09 7.00000e-02

1.33952e+02 1.33952e+02 1.33952e+01 1.00000e-09 7.00000e-02

1.33952e+02 1.33952e+02 1.33952e+01 1.00000e-09 7.00000e-02

5.00000e-04 5.00000e-04 5.00000e-05 1.00000e-09 1.00000e-01

5.00000e-04 5.00000e-04 5.00000e-05 1.00000e-09 1.00000e-01

$5.35219 \mathrm{e}+00$ 5.35219e+00 5.35219e-01 1.00000e-09 2.12000e-01

$1.00000 \mathrm{e}-02$ 1.00000e-02 1.00000e-03 1.00000e-09 1.00000e-01

$1.00000 \mathrm{e}+001.00000 \mathrm{e}+001.00000 \mathrm{e}-01$ 1.00000e-09 1.00000e-01

Element: 5948 \# of layers: 9

Kx Ky Kz Ss Por

1.44926e+02 1.44926e+02 1.44926e+01 1.00000e-09 7.00000e-02

$1.44926 \mathrm{e}+02$ 1.44926e+02 1.44926e+01 1.00000e-09 7.00000e-02

$1.44926 \mathrm{e}+021.44926 \mathrm{e}+02$ 1.44926e+01 1.00000e-09 7.00000e-02

$1.44926 \mathrm{e}+02 \quad 1.44926 \mathrm{e}+02 \quad 1.44926 \mathrm{e}+01 \quad 1.00000 \mathrm{e}-097.00000 \mathrm{e}-02$

5.00000e-04 5.00000e-04 5.00000e-05 1.00000e-09 1.00000e-01

5.00000e-04 5.00000e-04 5.00000e-05 1.00000e-09 1.00000e-01

$5.79072 \mathrm{e}+00$ 5.79072e+00 5.79072e-01 1.00000e-09 2.12000e-01

$1.00000 \mathrm{e}-02$ 1.00000e-02 1.00000e-03 1.00000e-09 1.00000e-01

$1.00000 \mathrm{e}+001.00000 \mathrm{e}+001.00000 \mathrm{e}-011.00000 \mathrm{e}-091.00000 \mathrm{e}-01$

Element: 5949 \# of layers: 9

$\mathrm{Kx} \mathrm{Ky} \mathrm{Kz}$ Ss Por

$1.44926 \mathrm{e}+021.44926 \mathrm{e}+02$ 1.44926e+01 1.00000e-09 7.00000e-02

$1.44926 \mathrm{e}+021.44926 \mathrm{e}+021.44926 \mathrm{e}+01$ 1.00000e-09 7.00000e-02

$1.44926 \mathrm{e}+021.44926 \mathrm{e}+021.44926 \mathrm{e}+01$ 1.00000e-09 7.00000e-02

5.00000e-04 5.00000e-04 5.00000e-05 1.00000e-09 1.00000e-01

5.00000e-04 5.00000e-04 5.00000e-05 1.00000e-09 1.00000e-01

$5.79072 \mathrm{e}+00$ 5.79072e+00 5.79072e-01 1.00000e-09 2.12000e-01

5.79072e+00 5.79072e+00 5.79072e-01 1.00000e-09 2.12000e-01

$1.00000 \mathrm{e}-02$ 1.00000e-02 1.00000e-03 1.00000e-09 1.00000e-01

$1.00000 \mathrm{e}+001.00000 \mathrm{e}+001.00000 \mathrm{e}-01$ 1.00000e-09 1.00000e-01

Element: 5950 \# of layers: 10 
$\mathrm{Kx} \mathrm{Ky} \mathrm{Kz}$ Ss Por

1.44926e+02 1.44926e+02 1.44926e+01 1.00000e-09 7.00000e-02

$1.44926 \mathrm{e}+02$ 1.44926e+02 1.44926e+01 1.00000e-09 7.00000e-02

$1.44926 \mathrm{e}+02 \quad 1.44926 \mathrm{e}+02 \quad 1.44926 \mathrm{e}+01 \quad 1.00000 \mathrm{e}-09$ 7.00000e-02

$1.44926 \mathrm{e}+021.44926 \mathrm{e}+021.44926 \mathrm{e}+01$ 1.00000e-09 7.00000e-02

5.00000e-04 5.00000e-04 5.00000e-05 1.00000e-09 1.00000e-01

5.00000e-04 5.00000e-04 5.00000e-05 1.00000e-09 1.00000e-01

$5.79072 \mathrm{e}+00$ 5.79072e+00 5.79072e-01 1.00000e-09 2.12000e-01

5.79072e+00 5.79072e+00 5.79072e-01 1.00000e-09 2.12000e-01

$1.00000 \mathrm{e}-02$ 1.00000e-02 1.00000e-03 1.00000e-09 1.00000e-01

$1.00000 \mathrm{e}+001.00000 \mathrm{e}+001.00000 \mathrm{e}-011.00000 \mathrm{e}-091.00000 \mathrm{e}-01$

Element: 5951 \# of layers: 7

$\mathrm{Kx} \mathrm{Ky} \mathrm{Kz}$ Ss Por

$1.44926 \mathrm{e}+02$ 1.44926e+02 1.44926e+01 1.00000e-09 7.00000e-02 $1.44926 \mathrm{e}+021.44926 \mathrm{e}+021.44926 \mathrm{e}+01$ 1.00000e-09 7.00000e-02

$1.44926 \mathrm{e}+021.44926 \mathrm{e}+02 \quad 1.44926 \mathrm{e}+01$ 1.00000e-09 7.00000e-02

5.79072e+00 5.79072e+00 5.79072e-01 1.00000e-09 2.12000e-01

5.79072e+00 5.79072e+00 5.79072e-01 1.00000e-09 2.12000e-01

$1.00000 \mathrm{e}-02$ 1.00000e-02 1.00000e-03 1.00000e-09 1.00000e-01

$1.00000 \mathrm{e}+001.00000 \mathrm{e}+001.00000 \mathrm{e}-011.00000 \mathrm{e}-091.00000 \mathrm{e}-01$

Element: 5952 \# of layers: 7

$\mathrm{Kx} \mathrm{Ky} \mathrm{Kz}$ Ss Por

1.44926e+02 1.44926e+02 1.44926e+01 1.00000e-09 7.00000e-02

$1.44926 \mathrm{e}+02$ 1.44926e+02 1.44926e+01 1.00000e-09 7.00000e-02

$1.44926 \mathrm{e}+02$ 1.44926e+02 1.44926e+01 1.00000e-09 7.00000e-02

5.79072e+00 5.79072e+00 5.79072e-01 1.00000e-09 2.12000e-01

$5.79072 \mathrm{e}+00$ 5.79072e+00 5.79072e-01 1.00000e-09 2.12000e-01

$1.00000 \mathrm{e}-02$ 1.00000e-02 1.00000e-03 1.00000e-09 1.00000e-01

$1.00000 \mathrm{e}+001.00000 \mathrm{e}+001.00000 \mathrm{e}-011.00000 \mathrm{e}-091.00000 \mathrm{e}-01$

Element: 5953 \# of layers: 8

$\mathrm{Kx} \mathrm{Ky} \mathrm{Kz}$ Ss Por

$1.44926 \mathrm{e}+02$ 1.44926e+02 1.44926e+01 1.00000e-09 7.00000e-02

$1.44926 \mathrm{e}+021.44926 \mathrm{e}+02 \quad 1.44926 \mathrm{e}+01$ 1.00000e-09 7.00000e-02

$1.44926 \mathrm{e}+02 \quad 1.44926 \mathrm{e}+02 \quad 1.44926 \mathrm{e}+01$ 1.00000e-09 7.00000e-02

5.00000e-04 5.00000e-04 5.00000e-05 1.00000e-09 1.00000e-01

5.79072e+00 5.79072e+00 5.79072e-01 1.00000e-09 2.12000e-01

$5.79072 \mathrm{e}+00$ 5.79072e+00 5.79072e-01 1.00000e-09 2.12000e-01

$1.00000 \mathrm{e}-02$ 1.00000e-02 1.00000e-03 1.00000e-09 1.00000e-01

$1.00000 \mathrm{e}+001.00000 \mathrm{e}+001.00000 \mathrm{e}-011.00000 \mathrm{e}-091.00000 \mathrm{e}-01$

Element: 5954 \# of layers: 9

$\mathrm{Kx} \mathrm{Ky} \mathrm{Kz}$ Ss Por

$1.44926 \mathrm{e}+02$ 1.44926e+02 1.44926e+01 1.00000e-09 7.00000e-02

$1.44926 \mathrm{e}+02$ 1.44926e+02 1.44926e+01 1.00000e-09 7.00000e-02

$1.44926 \mathrm{e}+02$ 1.44926e+02 1.44926e+01 1.00000e-09 7.00000e-02

$5.00000 \mathrm{e}-04$ 5.00000e-04 5.00000e-05 1.00000e-09 1.00000e-01

5.00000e-04 5.00000e-04 5.00000e-05 1.00000e-09 1.00000e-01 
$5.79072 \mathrm{e}+00$ 5.79072e+00 5.79072e-01 1.00000e-09 2.12000e-01 $5.79072 \mathrm{e}+005.79072 \mathrm{e}+00$ 5.79072e-01 1.00000e-09 2.12000e-01 $1.00000 \mathrm{e}-02$ 1.00000e-02 1.00000e-03 1.00000e-09 1.00000e-01 $1.00000 \mathrm{e}+001.00000 \mathrm{e}+001.00000 \mathrm{e}-011.00000 \mathrm{e}-091.00000 \mathrm{e}-01$ Element: 5955 \# of layers: 9

Kx Ky Kz Ss Por

$1.44926 \mathrm{e}+021.44926 \mathrm{e}+021.44926 \mathrm{e}+01$ 1.00000e-09 7.00000e-02 $1.44926 \mathrm{e}+021.44926 \mathrm{e}+021.44926 \mathrm{e}+011.00000 \mathrm{e}-097.00000 \mathrm{e}-02$ $1.44926 \mathrm{e}+021.44926 \mathrm{e}+021.44926 \mathrm{e}+011.00000 \mathrm{e}-097.00000 \mathrm{e}-02$ $5.00000 \mathrm{e}-04$ 5.00000e-04 5.00000e-05 1.00000e-09 1.00000e-01 5.00000e-04 5.00000e-04 5.00000e-05 1.00000e-09 1.00000e-01 $5.79072 \mathrm{e}+005.79072 \mathrm{e}+00$ 5.79072e-01 1.00000e-09 2.12000e-01 $5.79072 \mathrm{e}+005.79072 \mathrm{e}+00$ 5.79072e-01 1.00000e-09 2.12000e-01 $1.00000 \mathrm{e}-02$ 1.00000e-02 1.00000e-03 1.00000e-09 1.00000e-01 $1.00000 \mathrm{e}+001.00000 \mathrm{e}+001.00000 \mathrm{e}-011.00000 \mathrm{e}-091.00000 \mathrm{e}-01$ Element: 5956 \# of layers: 9

Kx Ky Kz Ss Por

$1.44926 \mathrm{e}+021.44926 \mathrm{e}+021.44926 \mathrm{e}+01$ 1.00000e-09 7.00000e-02 $1.44926 \mathrm{e}+021.44926 \mathrm{e}+021.44926 \mathrm{e}+011.00000 \mathrm{e}-097.00000 \mathrm{e}-02$ $1.44926 \mathrm{e}+021.44926 \mathrm{e}+021.44926 \mathrm{e}+011.00000 \mathrm{e}-097.00000 \mathrm{e}-02$ 5.00000e-04 5.00000e-04 5.00000e-05 1.00000e-09 1.00000e-01 5.00000e-04 5.00000e-04 5.00000e-05 1.00000e-09 1.00000e-01 $5.79072 \mathrm{e}+005.79072 \mathrm{e}+00$ 5.79072e-01 1.00000e-09 2.12000e-01 $5.79072 \mathrm{e}+00$ 5.79072e+00 5.79072e-01 1.00000e-09 2.12000e-01 $1.00000 \mathrm{e}-021.00000 \mathrm{e}-02$ 1.00000e-03 1.00000e-09 1.00000e-01 $1.00000 \mathrm{e}+001.00000 \mathrm{e}+001.00000 \mathrm{e}-011.00000 \mathrm{e}-091.00000 \mathrm{e}-01$ Element: 5957 \# of layers: 10

Kx Ky Kz Ss Por

$1.49881 \mathrm{e}+021.49881 \mathrm{e}+021.49881 \mathrm{e}+01$ 1.00000e-09 7.00000e-02 $1.49881 \mathrm{e}+021.49881 \mathrm{e}+021.49881 \mathrm{e}+011.00000 \mathrm{e}-097.00000 \mathrm{e}-02$ $1.49881 \mathrm{e}+021.49881 \mathrm{e}+021.49881 \mathrm{e}+011.00000 \mathrm{e}-097.00000 \mathrm{e}-02$ $1.49881 \mathrm{e}+021.49881 \mathrm{e}+021.49881 \mathrm{e}+011.00000 \mathrm{e}-097.00000 \mathrm{e}-02$ 5.00000e-04 5.00000e-04 5.00000e-05 1.00000e-09 1.00000e-01 $5.00000 \mathrm{e}-04$ 5.00000e-04 5.00000e-05 1.00000e-09 1.00000e-01 $5.98873 \mathrm{e}+005.98873 \mathrm{e}+00$ 5.98873e-01 1.00000e-09 2.12000e-01 $5.98873 \mathrm{e}+00$ 5.98873e+00 5.98873e-01 1.00000e-09 2.12000e-01 $1.00000 \mathrm{e}-02$ 1.00000e-02 1.00000e-03 1.00000e-09 1.00000e-01 $1.00000 \mathrm{e}+001.00000 \mathrm{e}+001.00000 \mathrm{e}-011.00000 \mathrm{e}-091.00000 \mathrm{e}-01$ Element: 5958 \# of layers: 8

Kx Ky Kz Ss Por $1.98058 \mathrm{e}+021.98058 \mathrm{e}+021.98058 \mathrm{e}+01$ 1.00000e-09 7.00000e-02 $1.98058 \mathrm{e}+021.98058 \mathrm{e}+021.98058 \mathrm{e}+011.00000 \mathrm{e}-09$ 7.00000e-02 $1.98058 \mathrm{e}+021.98058 \mathrm{e}+021.98058 \mathrm{e}+011.00000 \mathrm{e}-097.00000 \mathrm{e}-02$ $1.98058 \mathrm{e}+021.98058 \mathrm{e}+021.98058 \mathrm{e}+01$ 1.00000e-09 7.00000e-02 $7.91342 \mathrm{e}+007.91342 \mathrm{e}+00$ 7.91342e-01 1.00000e-09 2.12000e-01 $7.91342 \mathrm{e}+007.91342 \mathrm{e}+00$ 7.91342e-01 1.00000e-09 2.12000e-01 
$1.00000 \mathrm{e}-02$ 1.00000e-02 1.00000e-03 1.00000e-09 1.00000e-01 $1.00000 \mathrm{e}+001.00000 \mathrm{e}+001.00000 \mathrm{e}-011.00000 \mathrm{e}-091.00000 \mathrm{e}-01$ Element: 5959 \# of layers: 8

Kx Ky Kz Ss Por

$1.95382 \mathrm{e}+02$ 1.95382e+02 1.95382e+01 1.00000e-09 7.00000e-02 $1.95382 \mathrm{e}+02$ 1.95382e+02 1.95382e+01 1.00000e-09 7.00000e-02 $1.95382 \mathrm{e}+02$ 1.95382e+02 1.95382e+01 1.00000e-09 7.00000e-02 $1.95382 \mathrm{e}+02$ 1.95382e+02 1.95382e+01 1.00000e-09 7.00000e-02 7.80677e+00 7.80677e+00 7.80677e-01 1.00000e-09 2.12000e-01 $7.80677 \mathrm{e}+00$ 7.80677e+00 7.80677e-01 1.00000e-09 2.12000e-01 $1.00000 \mathrm{e}-02$ 1.00000e-02 1.00000e-03 1.00000e-09 1.00000e-01 $1.00000 \mathrm{e}+001.00000 \mathrm{e}+001.00000 \mathrm{e}-011.00000 \mathrm{e}-091.00000 \mathrm{e}-01$ Element: 5960 \# of layers: 6

$\mathrm{Kx} \mathrm{Ky} \mathrm{Kz}$ Ss Por

1.95382e+02 1.95382e+02 1.95382e+01 1.00000e-09 7.00000e-02 $1.95382 \mathrm{e}+02$ 1.95382e+02 1.95382e+01 1.00000e-09 7.00000e-02 $1.95382 \mathrm{e}+02$ 1.95382e+02 1.95382e+01 1.00000e-09 7.00000e-02 7.80677e+00 7.80677e+00 7.80677e-01 1.00000e-09 2.12000e-01 $1.00000 \mathrm{e}-02$ 1.00000e-02 1.00000e-03 1.00000e-09 1.00000e-01 $1.00000 \mathrm{e}+001.00000 \mathrm{e}+001.00000 \mathrm{e}-011.00000 \mathrm{e}-091.00000 \mathrm{e}-01$ Element: 5961 \# of layers: 8

$\mathrm{Kx} \mathrm{Ky} \mathrm{Kz}$ Ss Por

1.95382e+02 1.95382e+02 1.95382e+01 1.00000e-09 7.00000e-02 $1.95382 \mathrm{e}+02$ 1.95382e+02 1.95382e+01 1.00000e-09 7.00000e-02 $1.95382 \mathrm{e}+02$ 1.95382e+02 1.95382e+01 1.00000e-09 7.00000e-02 1.95382e+02 1.95382e+02 1.95382e+01 1.00000e-09 7.00000e-02 7.80677e+00 7.80677e+00 7.80677e-01 1.00000e-09 2.12000e-01 $7.80677 \mathrm{e}+00$ 7.80677e+00 7.80677e-01 1.00000e-09 2.12000e-01 $1.00000 \mathrm{e}-02$ 1.00000e-02 1.00000e-03 1.00000e-09 1.00000e-01 $1.00000 \mathrm{e}+001.00000 \mathrm{e}+001.00000 \mathrm{e}-011.00000 \mathrm{e}-091.00000 \mathrm{e}-01$ Element: 5962 \# of layers: 8

$\mathrm{Kx} \mathrm{Ky} \mathrm{Kz}$ Ss Por

$1.98058 \mathrm{e}+02$ 1.98058e+02 1.98058e+01 1.00000e-09 7.00000e-02 $1.98058 \mathrm{e}+02$ 1.98058e+02 1.98058e+01 1.00000e-09 7.00000e-02 $1.98058 \mathrm{e}+02$ 1.98058e+02 1.98058e+01 1.00000e-09 7.00000e-02 $1.98058 \mathrm{e}+02$ 1.98058e+02 1.98058e+01 1.00000e-09 7.00000e-02 $7.91342 \mathrm{e}+00$ 7.91342e+00 7.91342e-01 1.00000e-09 2.12000e-01 $7.91342 \mathrm{e}+00$ 7.91342e+00 7.91342e-01 1.00000e-09 2.12000e-01 $1.00000 \mathrm{e}-02$ 1.00000e-02 1.00000e-03 1.00000e-09 1.00000e-01 $1.00000 \mathrm{e}+001.00000 \mathrm{e}+001.00000 \mathrm{e}-01$ 1.00000e-09 1.00000e-01 Element: 5963 \# of layers: 8

$\mathrm{Kx} \mathrm{Ky} \mathrm{Kz}$ Ss Por

$1.98058 \mathrm{e}+02$ 1.98058e+02 1.98058e+01 1.00000e-09 7.00000e-02 $1.98058 \mathrm{e}+02$ 1.98058e+02 1.98058e+01 1.00000e-09 7.00000e-02 $1.98058 \mathrm{e}+02$ 1.98058e+02 1.98058e+01 1.00000e-09 7.00000e-02 $1.98058 \mathrm{e}+02$ 1.98058e+02 1.98058e+01 1.00000e-09 7.00000e-02 
7.91342e+00 7.91342e+00 7.91342e-01 1.00000e-09 2.12000e-01 7.91342e+00 7.91342e+00 7.91342e-01 1.00000e-09 2.12000e-01 $1.00000 \mathrm{e}-021.00000 \mathrm{e}-02$ 1.00000e-03 1.00000e-09 1.00000e-01 $1.00000 \mathrm{e}+001.00000 \mathrm{e}+001.00000 \mathrm{e}-011.00000 \mathrm{e}-091.00000 \mathrm{e}-01$ Element: 5964 \# of layers: 6

Kx Ky Kz Ss Por

$1.49881 \mathrm{e}+021.49881 \mathrm{e}+021.49881 \mathrm{e}+01$ 1.00000e-09 7.00000e-02 $1.49881 \mathrm{e}+021.49881 \mathrm{e}+021.49881 \mathrm{e}+011.00000 \mathrm{e}-097.00000 \mathrm{e}-02$ $1.49881 \mathrm{e}+021.49881 \mathrm{e}+021.49881 \mathrm{e}+011.00000 \mathrm{e}-097.00000 \mathrm{e}-02$ $5.98873 \mathrm{e}+00$ 5.98873e+00 5.98873e-01 1.00000e-09 2.12000e-01 $1.00000 \mathrm{e}-02$ 1.00000e-02 1.00000e-03 1.00000e-09 1.00000e-01 $1.00000 \mathrm{e}+001.00000 \mathrm{e}+001.00000 \mathrm{e}-011.00000 \mathrm{e}-091.00000 \mathrm{e}-01$ Element: 5965 \# of layers: 6

Kx Ky Kz Ss Por

$1.98058 \mathrm{e}+021.98058 \mathrm{e}+021.98058 \mathrm{e}+01$ 1.00000e-09 7.00000e-02 $1.98058 \mathrm{e}+021.98058 \mathrm{e}+021.98058 \mathrm{e}+01$ 1.00000e-09 7.00000e-02 $1.98058 \mathrm{e}+021.98058 \mathrm{e}+02 \quad 1.98058 \mathrm{e}+011.00000 \mathrm{e}-09$ 7.00000e-02 7.91342e+00 7.91342e+00 7.91342e-01 1.00000e-09 2.12000e-01 $1.00000 \mathrm{e}-021.00000 \mathrm{e}-02$ 1.00000e-03 1.00000e-09 1.00000e-01 $1.00000 \mathrm{e}+001.00000 \mathrm{e}+001.00000 \mathrm{e}-011.00000 \mathrm{e}-091.00000 \mathrm{e}-01$ Element: 5966 \# of layers: 8

Kx Ky Kz Ss Por

$1.83182 \mathrm{e}+021.83182 \mathrm{e}+021.83182 \mathrm{e}+01$ 1.00000e-09 7.00000e-02 $1.83182 \mathrm{e}+021.83182 \mathrm{e}+021.83182 \mathrm{e}+011.00000 \mathrm{e}-097.00000 \mathrm{e}-02$ $1.83182 \mathrm{e}+021.83182 \mathrm{e}+021.83182 \mathrm{e}+011.00000 \mathrm{e}-09$ 7.00000e-02 $7.31941 \mathrm{e}+00$ 7.31941e+00 7.31941e-01 1.00000e-09 2.12000e-01 $7.31941 \mathrm{e}+00$ 7.31941e+00 7.31941e-01 1.00000e-09 2.12000e-01 $1.00000 \mathrm{e}-021.00000 \mathrm{e}-02$ 1.00000e-03 1.00000e-09 1.00000e-01 $1.00000 \mathrm{e}+001.00000 \mathrm{e}+001.00000 \mathrm{e}-011.00000 \mathrm{e}-091.00000 \mathrm{e}-01$ $1.00000 \mathrm{e}-06$ 1.00000e-06 1.00000e-06 1.00000e-09 5.00000e-02 Element: 5967 \# of layers: 8

Kx Ky Kz Ss Por

$2.49568 \mathrm{e}+022.49568 \mathrm{e}+022.49568 \mathrm{e}+01$ 1.00000e-09 7.00000e-02 $2.49568 \mathrm{e}+022.49568 \mathrm{e}+022.49568 \mathrm{e}+01$ 1.00000e-09 7.00000e-02 $2.49568 \mathrm{e}+022.49568 \mathrm{e}+022.49568 \mathrm{e}+01$ 1.00000e-09 7.00000e-02 $9.97176 \mathrm{e}+009.97176 \mathrm{e}+00$ 9.97176e-01 1.00000e-09 2.12000e-01 $9.97176 \mathrm{e}+009.97176 \mathrm{e}+00$ 9.97176e-01 1.00000e-09 2.12000e-01 $1.00000 \mathrm{e}-021.00000 \mathrm{e}-02$ 1.00000e-03 1.00000e-09 1.00000e-01 $1.00000 \mathrm{e}+001.00000 \mathrm{e}+001.00000 \mathrm{e}-011.00000 \mathrm{e}-091.00000 \mathrm{e}-01$ $1.00000 \mathrm{e}-06$ 1.00000e-06 1.00000e-06 1.00000e-09 5.00000e-02 Element: 5968 \# of layers: 6

Kx Ky Kz Ss Por $2.24313 \mathrm{e}+022.24313 \mathrm{e}+022.24313 \mathrm{e}+01$ 1.00000e-09 7.00000e-02 $2.24313 \mathrm{e}+022.24313 \mathrm{e}+022.24313 \mathrm{e}+01$ 1.00000e-09 7.00000e-02 $2.24313 \mathrm{e}+022.24313 \mathrm{e}+022.24313 \mathrm{e}+01$ 1.00000e-09 7.00000e-02 $8.96262 \mathrm{e}+008.96262 \mathrm{e}+00$ 8.96262e-01 1.00000e-09 2.12000e-01 
$1.00000 \mathrm{e}-02$ 1.00000e-02 1.00000e-03 1.00000e-09 1.00000e-01 $1.00000 \mathrm{e}+001.00000 \mathrm{e}+001.00000 \mathrm{e}-01$ 1.00000e-09 1.00000e-01 Element: 5972 \# of layers: 7

Kx Ky Kz Ss Por

$2.49568 \mathrm{e}+02$ 2.49568e+02 2.49568e+01 1.00000e-09 7.00000e-02

$2.49568 \mathrm{e}+02$ 2.49568e+02 2.49568e+01 1.00000e-09 7.00000e-02

$2.49568 \mathrm{e}+02$ 2.49568e+02 2.49568e+01 1.00000e-09 7.00000e-02

$9.97176 \mathrm{e}+00$ 9.97176e+00 9.97176e-01 1.00000e-09 2.12000e-01

9.97176e+00 9.97176e+00 9.97176e-01 1.00000e-09 2.12000e-01

$1.00000 \mathrm{e}-02$ 1.00000e-02 1.00000e-03 1.00000e-09 1.00000e-01

$1.00000 \mathrm{e}+001.00000 \mathrm{e}+001.00000 \mathrm{e}-01$ 1.00000e-09 1.00000e-01

Element: 5973 \# of layers: 7

Kx Ky Kz Ss Por

1.83182e+02 1.83182e+02 1.83182e+01 1.00000e-09 7.00000e-02 $1.83182 \mathrm{e}+02$ 1.83182e+02 1.83182e+01 1.00000e-09 7.00000e-02 $1.83182 \mathrm{e}+021.83182 \mathrm{e}+02$ 1.83182e+01 1.00000e-09 7.00000e-02 7.31941e+00 7.31941e+00 7.31941e-01 1.00000e-09 2.12000e-01 7.31941e+00 7.31941e+00 7.31941e-01 1.00000e-09 2.12000e-01 $1.00000 \mathrm{e}-02$ 1.00000e-02 1.00000e-03 1.00000e-09 1.00000e-01 $1.00000 \mathrm{e}+001.00000 \mathrm{e}+001.00000 \mathrm{e}-011.00000 \mathrm{e}-091.00000 \mathrm{e}-01$ Element: 5975 \# of layers: 6

$\mathrm{Kx} \mathrm{Ky} \mathrm{Kz}$ Ss Por

3.67473e+02 3.67473e+02 3.67473e+01 1.00000e-09 7.00000e-02 $3.67473 \mathrm{e}+02$ 3.67473e+02 3.67473e+01 1.00000e-09 7.00000e-02 $1.46829 \mathrm{e}+011.46829 \mathrm{e}+011.46829 \mathrm{e}+001.00000 \mathrm{e}-092.12000 \mathrm{e}-01$ $1.46829 \mathrm{e}+011.46829 \mathrm{e}+01$ 1.46829e+00 1.00000e-09 2.12000e-01 $1.00000 \mathrm{e}-02$ 1.00000e-02 1.00000e-03 1.00000e-09 1.00000e-01 $1.00000 \mathrm{e}+001.00000 \mathrm{e}+001.00000 \mathrm{e}-011.00000 \mathrm{e}-091.00000 \mathrm{e}-01$ Element: 5976 \# of layers: 6

$\mathrm{Kx} \mathrm{Ky} \mathrm{Kz}$ Ss Por

3.67473e+02 3.67473e+02 3.67473e+01 1.00000e-09 7.00000e-02 $3.67473 \mathrm{e}+02$ 3.67473e+02 3.67473e+01 1.00000e-09 7.00000e-02 3.67473e+02 3.67473e+02 3.67473e+01 1.00000e-09 7.00000e-02 $1.46829 \mathrm{e}+01$ 1.46829e+01 1.46829e+00 1.00000e-09 2.12000e-01 $1.00000 \mathrm{e}-02$ 1.00000e-02 1.00000e-03 1.00000e-09 1.00000e-01 $1.00000 \mathrm{e}+001.00000 \mathrm{e}+001.00000 \mathrm{e}-011.00000 \mathrm{e}-091.00000 \mathrm{e}-01$ Element: 5977 \# of layers: 6

Kx Ky Kz Ss Por

3.67473e+02 3.67473e+02 3.67473e+01 1.00000e-09 7.00000e-02 $3.67473 \mathrm{e}+02$ 3.67473e+02 3.67473e+01 1.00000e-09 7.00000e-02 $3.67473 \mathrm{e}+02$ 3.67473e+02 3.67473e+01 1.00000e-09 7.00000e-02 $1.46829 \mathrm{e}+01$ 1.46829e+01 1.46829e+00 1.00000e-09 2.12000e-01 $1.00000 \mathrm{e}-02$ 1.00000e-02 1.00000e-03 1.00000e-09 1.00000e-01 $1.00000 \mathrm{e}+001.00000 \mathrm{e}+001.00000 \mathrm{e}-01$ 1.00000e-09 1.00000e-01 Element: 5978 \# of layers: 6

Kx Ky Kz Ss Por 
$2.76481 \mathrm{e}+022.76481 \mathrm{e}+022.76481 \mathrm{e}+01$ 1.00000e-09 7.00000e-02 $2.76481 \mathrm{e}+022.76481 \mathrm{e}+022.76481 \mathrm{e}+011.00000 \mathrm{e}-09$ 7.00000e-02 $2.76481 \mathrm{e}+022.76481 \mathrm{e}+022.76481 \mathrm{e}+01$ 1.00000e-09 7.00000e-02 $1.10473 \mathrm{e}+011.10473 \mathrm{e}+011.10473 \mathrm{e}+001.00000 \mathrm{e}-092.12000 \mathrm{e}-01$ $1.00000 \mathrm{e}-021.00000 \mathrm{e}-021.00000 \mathrm{e}-031.00000 \mathrm{e}-091.00000 \mathrm{e}-01$ $1.00000 \mathrm{e}+001.00000 \mathrm{e}+001.00000 \mathrm{e}-011.00000 \mathrm{e}-091.00000 \mathrm{e}-01$ Element: 5979 \# of layers: 5

Kx Ky Kz Ss Por

$2.76481 \mathrm{e}+022.76481 \mathrm{e}+022.76481 \mathrm{e}+01$ 1.00000e-09 7.00000e-02

$2.76481 \mathrm{e}+022.76481 \mathrm{e}+022.76481 \mathrm{e}+01$ 1.00000e-09 7.00000e-02

$1.10473 \mathrm{e}+011.10473 \mathrm{e}+011.10473 \mathrm{e}+001.00000 \mathrm{e}-092.12000 \mathrm{e}-01$ $1.00000 \mathrm{e}-021.00000 \mathrm{e}-02$ 1.00000e-03 1.00000e-09 1.00000e-01 $1.00000 \mathrm{e}+001.00000 \mathrm{e}+001.00000 \mathrm{e}-011.00000 \mathrm{e}-091.00000 \mathrm{e}-01$ Element: 5980 \# of layers: 5

Kx Ky Kz Ss Por

$2.76481 \mathrm{e}+022.76481 \mathrm{e}+022.76481 \mathrm{e}+01$ 1.00000e-09 7.00000e-02

$2.76481 \mathrm{e}+022.76481 \mathrm{e}+022.76481 \mathrm{e}+01$ 1.00000e-09 7.00000e-02 $1.10473 \mathrm{e}+011.10473 \mathrm{e}+011.10473 \mathrm{e}+00$ 1.00000e-09 2.12000e-01 $1.00000 \mathrm{e}-021.00000 \mathrm{e}-02$ 1.00000e-03 1.00000e-09 1.00000e-01 $1.00000 \mathrm{e}+001.00000 \mathrm{e}+001.00000 \mathrm{e}-011.00000 \mathrm{e}-091.00000 \mathrm{e}-01$ Element: 5981 \# of layers: 5

Kx Ky Kz Ss Por

$8.44651 \mathrm{e}+028.44651 \mathrm{e}+028.44652 \mathrm{e}+01$ 1.00000e-09 7.00000e-02 $8.44651 \mathrm{e}+028.44651 \mathrm{e}+028.44652 \mathrm{e}+01$ 1.00000e-09 7.00000e-02 $8.44651 \mathrm{e}+028.44651 \mathrm{e}+028.44652 \mathrm{e}+01$ 1.00000e-09 7.00000e-02 $3.37485 \mathrm{e}+013.37485 \mathrm{e}+013.37485 \mathrm{e}+00$ 1.00000e-09 2.12000e-01 $1.00000 \mathrm{e}-06$ 1.00000e-06 1.00000e-06 1.00000e-09 5.00000e-02 Element: 5982 \# of layers: 6

Kx Ky Kz Ss Por

$8.44651 \mathrm{e}+028.44651 \mathrm{e}+028.44652 \mathrm{e}+01$ 1.00000e-09 7.00000e-02 $8.44651 \mathrm{e}+028.44651 \mathrm{e}+028.44652 \mathrm{e}+01$ 1.00000e-09 7.00000e-02 $8.44651 \mathrm{e}+028.44651 \mathrm{e}+028.44652 \mathrm{e}+01$ 1.00000e-09 7.00000e-02 $8.44651 \mathrm{e}+028.44651 \mathrm{e}+028.44652 \mathrm{e}+01$ 1.00000e-09 7.00000e-02 $3.37485 \mathrm{e}+013.37485 \mathrm{e}+013.37485 \mathrm{e}+001.00000 \mathrm{e}-092.12000 \mathrm{e}-01$ $1.00000 \mathrm{e}-06$ 1.00000e-06 1.00000e-06 1.00000e-09 5.00000e-02

Element: 5983 \# of layers: 6

Kx Ky Kz Ss Por

$7.24656 \mathrm{e}+02$ 7.24656e+02 7.24656e+01 1.00000e-09 7.00000e-02 $7.24656 \mathrm{e}+02$ 7.24656e+02 7.24656e+01 1.00000e-09 7.00000e-02 $7.24656 \mathrm{e}+02$ 7.24656e+02 7.24656e+01 1.00000e-09 7.00000e-02 $7.24656 \mathrm{e}+02$ 7.24656e+02 7.24656e+01 1.00000e-09 7.00000e-02 $2.89559 \mathrm{e}+012.89559 \mathrm{e}+012.89559 \mathrm{e}+001.00000 \mathrm{e}-092.12000 \mathrm{e}-01$ $1.00000 \mathrm{e}-06$ 1.00000e-06 1.00000e-06 1.00000e-09 5.00000e-02 Element: 5984 \# of layers: 6

Kx Ky Kz Ss Por

7.24656e+02 7.24656e+02 7.24656e+01 1.00000e-09 7.00000e-02 
$7.24656 \mathrm{e}+02$ 7.24656e +02 7.24656e+01 1.00000e-09 7.00000e-02 $7.24656 \mathrm{e}+02$ 7.24656e+02 7.24656e+01 1.00000e-09 7.00000e-02 $7.24656 \mathrm{e}+02$ 7.24656e+02 7.24656e+01 1.00000e-09 7.00000e-02 $2.89559 \mathrm{e}+012.89559 \mathrm{e}+012.89559 \mathrm{e}+001.00000 \mathrm{e}-092.12000 \mathrm{e}-01$ $1.00000 \mathrm{e}-06$ 1.00000e-06 1.00000e-06 1.00000e-09 5.00000e-02

Element: 5985 \# of layers: 7

Kx Ky Kz Ss Por

$7.00032 \mathrm{e}+02$ 7.00032e+02 7.00032e+01 1.00000e-09 7.00000e-02 $7.00032 \mathrm{e}+02$ 7.00032e+02 7.00032e+01 1.00000e-09 7.00000e-02 $7.00032 \mathrm{e}+02$ 7.00032e+02 7.00032e+01 1.00000e-09 7.00000e-02 $7.00032 \mathrm{e}+02$ 7.00032e+02 7.00032e+01 1.00000e-09 7.00000e-02 $2.79704 \mathrm{e}+012.79704 \mathrm{e}+012.79704 \mathrm{e}+001.00000 \mathrm{e}-092.12000 \mathrm{e}-01$ $1.00000 \mathrm{e}-02$ 1.00000e-02 1.00000e-03 1.00000e-09 1.00000e-01 1.00000e-06 1.00000e-06 1.00000e-06 1.00000e-09 5.00000e-02 Element: 5986 \# of layers: 6

Kx Ky Kz Ss Por

$8.28001 \mathrm{e}+028.28001 \mathrm{e}+028.28001 \mathrm{e}+01$ 1.00000e-09 7.00000e-02

$8.28001 \mathrm{e}+028.28001 \mathrm{e}+028.28001 \mathrm{e}+011.00000 \mathrm{e}-09$ 7.00000e-02 $8.28001 \mathrm{e}+028.28001 \mathrm{e}+028.28001 \mathrm{e}+011.00000 \mathrm{e}-09$ 7.00000e-02 $3.30847 \mathrm{e}+013.30847 \mathrm{e}+013.30847 \mathrm{e}+00$ 1.00000e-09 2.12000e-01 $1.00000 \mathrm{e}-02$ 1.00000e-02 1.00000e-03 1.00000e-09 1.00000e-01 $1.00000 \mathrm{e}-06$ 1.00000e-06 1.00000e-06 1.00000e-09 5.00000e-02 Element: 5987 \# of layers: 6

Kx Ky Kz Ss Por $8.28001 \mathrm{e}+028.28001 \mathrm{e}+028.28001 \mathrm{e}+01$ 1.00000e-09 7.00000e-02 $8.28001 \mathrm{e}+028.28001 \mathrm{e}+028.28001 \mathrm{e}+011.00000 \mathrm{e}-097.00000 \mathrm{e}-02$ $8.28001 \mathrm{e}+028.28001 \mathrm{e}+028.28001 \mathrm{e}+01$ 1.00000e-09 7.00000e-02 $3.30847 \mathrm{e}+013.30847 \mathrm{e}+013.30847 \mathrm{e}+00$ 1.00000e-09 2.12000e-01 $1.00000 \mathrm{e}-021.00000 \mathrm{e}-02$ 1.00000e-03 1.00000e-09 1.00000e-01 $1.00000 \mathrm{e}-06$ 1.00000e-06 1.00000e-06 1.00000e-09 5.00000e-02 Element: 5988 \# of layers: 6

$\mathrm{Kx}$ Ky Kz Ss Por $8.28001 \mathrm{e}+028.28001 \mathrm{e}+028.28001 \mathrm{e}+01$ 1.00000e-09 7.00000e-02 $8.28001 \mathrm{e}+028.28001 \mathrm{e}+028.28001 \mathrm{e}+011.00000 \mathrm{e}-097.00000 \mathrm{e}-02$ $8.28001 \mathrm{e}+028.28001 \mathrm{e}+028.28001 \mathrm{e}+01$ 1.00000e-09 7.00000e-02 $3.30847 \mathrm{e}+013.30847 \mathrm{e}+013.30847 \mathrm{e}+00$ 1.00000e-09 2.12000e-01 $1.00000 \mathrm{e}-02$ 1.00000e-02 1.00000e-03 1.00000e-09 1.00000e-01 $1.00000 \mathrm{e}-06$ 1.00000e-06 1.00000e-06 1.00000e-09 5.00000e-02 Element: 5989 \# of layers: 7

Kx Ky Kz Ss Por

$8.44651 \mathrm{e}+028.44651 \mathrm{e}+028.44652 \mathrm{e}+01$ 1.00000e-09 7.00000e-02 $8.44651 \mathrm{e}+028.44651 \mathrm{e}+028.44652 \mathrm{e}+01$ 1.00000e-09 7.00000e-02 $8.44651 \mathrm{e}+028.44651 \mathrm{e}+028.44652 \mathrm{e}+011.00000 \mathrm{e}-09$ 7.00000e-02 $8.44651 \mathrm{e}+028.44651 \mathrm{e}+028.44652 \mathrm{e}+011.00000 \mathrm{e}-09$ 7.00000e-02 $3.37485 \mathrm{e}+013.37485 \mathrm{e}+013.37485 \mathrm{e}+001.00000 \mathrm{e}-092.12000 \mathrm{e}-01$ $1.00000 \mathrm{e}-021.00000 \mathrm{e}-02$ 1.00000e-03 1.00000e-09 1.00000e-01 
1.00000e-06 1.00000e-06 1.00000e-06 1.00000e-09 5.00000e-02

Element: 5990 \# of layers: 5

Kx Ky Kz Ss Por

5.79730e+02 5.79730e+02 5.79730e+01 1.00000e-09 7.00000e-02

$5.79730 \mathrm{e}+025.79730 \mathrm{e}+025.79730 \mathrm{e}+01$ 1.00000e-09 7.00000e-02

$5.79730 \mathrm{e}+025.79730 \mathrm{e}+025.79730 \mathrm{e}+01$ 1.00000e-09 7.00000e-02

$5.79730 \mathrm{e}+025.79730 \mathrm{e}+025.79730 \mathrm{e}+01$ 1.00000e-09 7.00000e-02

1.00000e-06 1.00000e-06 1.00000e-06 1.00000e-09 5.00000e-02

Element: 5991 \# of layers: 5

$\mathrm{Kx} \mathrm{Ky} \mathrm{Kz}$ Ss Por

6.35331e+02 6.35331e+02 6.35331e+01 1.00000e-09 7.00000e-02

$6.35331 \mathrm{e}+026.35331 \mathrm{e}+02$ 6.35331e+01 1.00000e-09 7.00000e-02

6.35331e+02 6.35331e+02 6.35331e+01 1.00000e-09 7.00000e-02

$6.35331 \mathrm{e}+026.35331 \mathrm{e}+026.35331 \mathrm{e}+01$ 1.00000e-09 7.00000e-02

1.00000e-06 1.00000e-06 1.00000e-06 1.00000e-09 5.00000e-02

Element: 5992 \# of layers: 5

$\mathrm{Kx} \mathrm{Ky} \mathrm{Kz}$ Ss Por

6.35331e+02 6.35331e+02 6.35331e+01 1.00000e-09 7.00000e-02

6.35331e+02 6.35331e+02 6.35331e+01 1.00000e-09 7.00000e-02

$6.35331 \mathrm{e}+02$ 6.35331e+02 6.35331e+01 1.00000e-09 7.00000e-02

$6.35331 \mathrm{e}+02$ 6.35331e+02 6.35331e+01 1.00000e-09 7.00000e-02

1.00000e-06 1.00000e-06 1.00000e-06 1.00000e-09 5.00000e-02

Element: 5993 \# of layers: 6

Kx Ky Kz Ss Por

6.35331e+02 6.35331e+02 6.35331e+01 1.00000e-09 7.00000e-02

6.35331e+02 6.35331e+02 6.35331e+01 1.00000e-09 7.00000e-02

6.35331e+02 6.35331e+02 6.35331e+01 1.00000e-09 7.00000e-02

6.35331e+02 6.35331e+02 6.35331e+01 1.00000e-09 7.00000e-02

$2.53850 \mathrm{e}+012.53850 \mathrm{e}+012.53850 \mathrm{e}+001.00000 \mathrm{e}-092.12000 \mathrm{e}-01$

1.00000e-06 1.00000e-06 1.00000e-06 1.00000e-09 5.00000e-02

Element: 5994 \# of layers: 6

Kx Ky Kz Ss Por

2.16844e+03 2.16844e+03 2.16844e+02 1.00000e-09 7.00000e-02

$2.16844 \mathrm{e}+032.16844 \mathrm{e}+032.16844 \mathrm{e}+02 \quad 1.00000 \mathrm{e}-09$ 7.00000e-02

$2.16844 \mathrm{e}+032.16844 \mathrm{e}+032.16844 \mathrm{e}+02$ 1.00000e-09 7.00000e-02

$2.16844 \mathrm{e}+032.16844 \mathrm{e}+032.16844 \mathrm{e}+02$ 1.00000e-09 7.00000e-02

$8.66426 \mathrm{e}+018.66426 \mathrm{e}+018.66426 \mathrm{e}+001.00000 \mathrm{e}-092.12000 \mathrm{e}-01$

1.00000e-06 1.00000e-06 1.00000e-06 1.00000e-09 5.00000e-02

Element: 5995 \# of layers: 6

$\mathrm{Kx} \mathrm{Ky} \mathrm{Kz}$ Ss Por

1.11319e+03 1.11319e+03 1.11319e+02 1.00000e-09 7.00000e-02

$1.11319 \mathrm{e}+03$ 1.11319e+03 1.11319e+02 1.00000e-09 7.00000e-02

$1.11319 \mathrm{e}+03$ 1.11319e+03 1.11319e+02 1.00000e-09 7.00000e-02

1.11319e+03 1.11319e+03 1.11319e+02 1.00000e-09 7.00000e-02

4.44790e+01 4.44790e+01 4.44790e+00 1.00000e-09 2.12000e-01

1.00000e-06 1.00000e-06 1.00000e-06 1.00000e-09 5.00000e-02 
Element: 5996 \# of layers: 6

$\mathrm{Kx} \mathrm{Ky} \mathrm{Kz}$ Ss Por

$1.11319 \mathrm{e}+03$ 1.11319e+03 1.11319e+02 1.00000e-09 7.00000e-02

$1.11319 \mathrm{e}+03$ 1.11319e+03 1.11319e+02 1.00000e-09 7.00000e-02

$1.11319 \mathrm{e}+03$ 1.11319e+03 1.11319e+02 1.00000e-09 7.00000e-02

$1.11319 \mathrm{e}+03$ 1.11319e+03 1.11319e+02 1.00000e-09 7.00000e-02

$4.44790 \mathrm{e}+014.44790 \mathrm{e}+014.44790 \mathrm{e}+00$ 1.00000e-09 2.12000e-01

1.00000e-06 1.00000e-06 1.00000e-06 1.00000e-09 5.00000e-02

Element: 5997 \# of layers: 6

$\mathrm{Kx} \mathrm{Ky} \mathrm{Kz}$ Ss Por

5.79730e+02 5.79730e+02 5.79730e+01 1.00000e-09 7.00000e-02

$5.79730 \mathrm{e}+025.79730 \mathrm{e}+025.79730 \mathrm{e}+01$ 1.00000e-09 7.00000e-02

$5.79730 \mathrm{e}+025.79730 \mathrm{e}+025.79730 \mathrm{e}+01$ 1.00000e-09 7.00000e-02

$5.79730 \mathrm{e}+02$ 5.79730e+02 5.79730e+01 1.00000e-09 7.00000e-02

$2.31642 \mathrm{e}+012.31642 \mathrm{e}+012.31642 \mathrm{e}+00$ 1.00000e-09 2.12000e-01

1.00000e-06 1.00000e-06 1.00000e-06 1.00000e-09 5.00000e-02

Element: 5998 \# of layers: 6

$\mathrm{Kx} \mathrm{Ky} \mathrm{Kz}$ Ss Por

5.79730e+02 5.79730e+02 5.79730e+01 1.00000e-09 7.00000e-02

$5.79730 \mathrm{e}+025.79730 \mathrm{e}+025.79730 \mathrm{e}+01$ 1.00000e-09 7.00000e-02

$5.79730 \mathrm{e}+025.79730 \mathrm{e}+025.79730 \mathrm{e}+01$ 1.00000e-09 7.00000e-02

$5.79730 \mathrm{e}+02$ 5.79730e+02 5.79730e+01 1.00000e-09 7.00000e-02

$2.31642 \mathrm{e}+012.31642 \mathrm{e}+012.31642 \mathrm{e}+00$ 1.00000e-09 2.12000e-01

1.00000e-06 1.00000e-06 1.00000e-06 1.00000e-09 5.00000e-02

Element: 5999 \# of layers: 5

$\mathrm{Kx} \mathrm{Ky} \mathrm{Kz}$ Ss Por

2.38567e+03 2.38567e+03 2.38567e+02 1.00000e-09 7.00000e-02

$2.38567 \mathrm{e}+03$ 2.38567e+03 2.38567e+02 1.00000e-09 7.00000e-02

$2.38567 \mathrm{e}+032.38567 \mathrm{e}+032.38567 \mathrm{e}+02$ 1.00000e-09 7.00000e-02

2.38567e+03 2.38567e+03 2.38567e+02 1.00000e-09 7.00000e-02

1.00000e-06 1.00000e-06 1.00000e-06 1.00000e-09 5.00000e-02

Element: 6000 \# of layers: 5

$\mathrm{Kx} \mathrm{Ky} \mathrm{Kz}$ Ss Por

3.23315e+03 3.23315e+03 3.23315e+02 1.00000e-09 7.00000e-02

$3.23315 \mathrm{e}+03$ 3.23315e+03 3.23315e+02 1.00000e-09 7.00000e-02

$3.23315 \mathrm{e}+033.23315 \mathrm{e}+03$ 3.23315e+02 1.00000e-09 7.00000e-02

$3.23315 \mathrm{e}+033.23315 \mathrm{e}+03$ 3.23315e+02 1.00000e-09 7.00000e-02

1.00000e-06 1.00000e-06 1.00000e-06 1.00000e-09 5.00000e-02

Element: 6001 \# of layers: 5

$\mathrm{Kx} \mathrm{Ky} \mathrm{Kz}$ Ss Por

3.23315e+03 3.23315e+03 3.23315e+02 1.00000e-09 7.00000e-02

$3.23315 \mathrm{e}+033.23315 \mathrm{e}+03$ 3.23315e+02 1.00000e-09 7.00000e-02

$3.23315 \mathrm{e}+033.23315 \mathrm{e}+03$ 3.23315e+02 1.00000e-09 7.00000e-02

3.23315e+03 3.23315e+03 3.23315e+02 1.00000e-09 7.00000e-02

1.00000e-06 1.00000e-06 1.00000e-06 1.00000e-09 5.00000e-02

Element: 6002 \# of layers: 3 
$\mathrm{Kx} \mathrm{Ky} \mathrm{Kz}$ Ss Por

5.85947e+03 5.85947e+03 5.85947e+02 1.00000e-09 7.00000e-02

$5.85947 \mathrm{e}+03$ 5.85947e+03 5.85947e+02 1.00000e-09 7.00000e-02

1.00000e-06 1.00000e-06 1.00000e-06 1.00000e-09 5.00000e-02

Element: 6003 \# of layers: 3

$\mathrm{Kx} \mathrm{Ky} \mathrm{Kz}$ Ss Por

5.85947e+03 5.85947e+03 5.85947e+02 1.00000e-09 7.00000e-02

$5.85947 \mathrm{e}+03$ 5.85947e+03 5.85947e+02 1.00000e-09 7.00000e-02

1.00000e-06 1.00000e-06 1.00000e-06 1.00000e-09 5.00000e-02

Element: 6004 \# of layers: 6

Kx Ky Kz Ss Por

5.85947e+03 5.85947e+03 5.85947e+02 1.00000e-09 7.00000e-02

$5.85947 \mathrm{e}+03$ 5.85947e+03 5.85947e+02 1.00000e-09 7.00000e-02

$5.85947 \mathrm{e}+03$ 5.85947e+03 5.85947e+02 1.00000e-09 7.00000e-02

5.85947e+03 5.85947e+03 5.85947e+02 1.00000e-09 7.00000e-02

$2.34117 \mathrm{e}+02$ 2.34117e+02 2.34117e+01 1.00000e-09 2.12000e-01

1.00000e-06 1.00000e-06 1.00000e-06 1.00000e-09 5.00000e-02

Element: 6005 \# of layers: 6

$\mathrm{Kx} \mathrm{Ky} \mathrm{Kz}$ Ss Por

3.33938e+03 3.33938e+03 3.33938e+02 1.00000e-09 7.00000e-02

$3.33938 \mathrm{e}+03$ 3.33938e+03 3.33938e+02 1.00000e-09 7.00000e-02

$3.33938 \mathrm{e}+03$ 3.33938e+03 3.33938e+02 1.00000e-09 7.00000e-02

3.33938e+03 3.33938e+03 3.33938e+02 1.00000e-09 7.00000e-02

$1.33428 \mathrm{e}+02$ 1.33428e+02 1.33428e+01 1.00000e-09 2.12000e-01

1.00000e-06 1.00000e-06 1.00000e-06 1.00000e-09 5.00000e-02

Element: 6006 \# of layers: 6

$\mathrm{Kx} \mathrm{Ky} \mathrm{Kz}$ Ss Por

2.38567e+03 2.38567e+03 2.38567e+02 1.00000e-09 7.00000e-02

$2.38567 \mathrm{e}+032.38567 \mathrm{e}+032.38567 \mathrm{e}+02$ 1.00000e-09 7.00000e-02

$2.38567 \mathrm{e}+03$ 2.38567e+03 2.38567e+02 1.00000e-09 7.00000e-02

$2.38567 \mathrm{e}+03$ 2.38567e+03 2.38567e+02 1.00000e-09 7.00000e-02

$1.33428 \mathrm{e}+02$ 1.33428e+02 1.33428e+01 1.00000e-09 2.12000e-01

1.00000e-06 1.00000e-06 1.00000e-06 1.00000e-09 5.00000e-02

Element: 6007 \# of layers: 6

$\mathrm{Kx} \mathrm{Ky} \mathrm{Kz}$ Ss Por

3.23315e+03 3.23315e+03 3.23315e+02 1.00000e-09 7.00000e-02

$3.23315 \mathrm{e}+033.23315 \mathrm{e}+03$ 3.23315e+02 1.00000e-09 7.00000e-02

$3.23315 \mathrm{e}+033.23315 \mathrm{e}+03$ 3.23315e+02 1.00000e-09 7.00000e-02

$3.23315 \mathrm{e}+03$ 3.23315e+03 3.23315e+02 1.00000e-09 7.00000e-02

$2.34117 \mathrm{e}+02$ 2.34117e+02 2.34117e+01 1.00000e-09 2.12000e-01

1.00000e-06 1.00000e-06 1.00000e-06 1.00000e-09 5.00000e-02

Element: 6008 \# of layers: 5

$\mathrm{Kx} \mathrm{Ky} \mathrm{Kz}$ Ss Por

4.07639e+03 4.07639e+03 4.07639e+02 1.00000e-09 7.00000e-02

$4.07639 \mathrm{e}+03$ 4.07639e+03 4.07639e+02 1.00000e-09 7.00000e-02

$4.07639 \mathrm{e}+03$ 4.07639e+03 4.07639e+02 1.00000e-09 7.00000e-02 
4.07639e+03 4.07639e+03 4.07639e+02 1.00000e-09 7.00000e-02 1.00000e-06 1.00000e-06 1.00000e-06 1.00000e-09 5.00000e-02

Element: 6009 \# of layers: 5

$\mathrm{Kx} \mathrm{Ky} \mathrm{Kz}$ Ss Por

4.07639e+03 4.07639e+03 4.07639e+02 1.00000e-09 7.00000e-02 $4.07639 \mathrm{e}+03$ 4.07639e+03 4.07639e+02 1.00000e-09 7.00000e-02 $4.07639 \mathrm{e}+03$ 4.07639e+03 4.07639e+02 1.00000e-09 7.00000e-02 4.07639e+03 4.07639e+03 4.07639e+02 1.00000e-09 7.00000e-02 1.00000e-06 1.00000e-06 1.00000e-06 1.00000e-09 5.00000e-02

Element: 6010 \# of layers: 5

$\mathrm{Kx} \mathrm{Ky} \mathrm{Kz}$ Ss Por

4.09477e+03 4.09477e+03 4.09477e+02 1.00000e-09 7.00000e-02 $4.09477 \mathrm{e}+03$ 4.09477e+03 4.09477e+02 1.00000e-09 7.00000e-02 4.09477e+03 4.09477e+03 4.09477e+02 1.00000e-09 7.00000e-02 4.09477e+03 4.09477e+03 4.09477e+02 1.00000e-09 7.00000e-02 1.00000e-06 1.00000e-06 1.00000e-06 1.00000e-09 5.00000e-02

Element: 6011 \# of layers: 3

$\mathrm{Kx} \mathrm{Ky} \mathrm{Kz}$ Ss Por

4.09477e+03 4.09477e+03 4.09477e+02 1.00000e-09 7.00000e-02 $4.09477 \mathrm{e}+03$ 4.09477e+03 4.09477e+02 1.00000e-09 7.00000e-02 1.00000e-06 1.00000e-06 1.00000e-06 1.00000e-09 5.00000e-02

Element: 6012 \# of layers: 3

$\mathrm{Kx} \mathrm{Ky} \mathrm{Kz}$ Ss Por

5.56241e+03 5.56241e+03 5.56241e+02 1.00000e-09 7.00000e-02

$5.56241 \mathrm{e}+035.56241 \mathrm{e}+035.56241 \mathrm{e}+02$ 1.00000e-09 7.00000e-02 1.00000e-06 1.00000e-06 1.00000e-06 1.00000e-09 5.00000e-02

Element: 6013 \# of layers: 3

$\mathrm{Kx} \mathrm{Ky} \mathrm{Kz}$ Ss Por

5.56241e+03 5.56241e+03 5.56241e+02 1.00000e-09 7.00000e-02

5.56241e+03 5.56241e+03 5.56241e+02 1.00000e-09 7.00000e-02 1.00000e-06 1.00000e-06 1.00000e-06 1.00000e-09 5.00000e-02

Element: 6014 \# of layers: 2

Kx Ky Kz Ss Por

7.51921e+03 7.51921e+03 7.51921e+02 1.00000e-09 7.00000e-02 1.00000e-06 1.00000e-06 1.00000e-06 1.00000e-09 5.00000e-02

Element: 6015 \# of layers: 3

Kx Ky Kz Ss Por

7.51921e+03 7.51921e+03 7.51921e+02 1.00000e-09 7.00000e-02

$7.51921 \mathrm{e}+03$ 7.51921e+03 7.51921e+02 1.00000e-09 7.00000e-02 1.00000e-06 1.00000e-06 1.00000e-06 1.00000e-09 5.00000e-02

Element: 6016 \# of layers: 3

$\mathrm{Kx} \mathrm{Ky} \mathrm{Kz}$ Ss Por

4.07639e+03 4.07639e+03 4.07639e+02 1.00000e-09 7.00000e-02 4.07639e+03 4.07639e+03 4.07639e+02 1.00000e-09 7.00000e-02 1.00000e-06 1.00000e-06 1.00000e-06 1.00000e-09 5.00000e-02 Element: 6017 \# of layers: 3 
Kx Ky Kz Ss Por

4.80116e+01 4.80116e+01 4.80116e+00 1.00000e-09 7.00000e-02

$4.80116 \mathrm{e}+014.80116 \mathrm{e}+014.80116 \mathrm{e}+001.00000 \mathrm{e}-09$ 7.00000e-02

$1.00000 \mathrm{e}-02$ 1.00000e-02 1.00000e-03 1.00000e-09 1.00000e-01

Element: 6018 \# of layers: 4

$\mathrm{Kx} \mathrm{Ky} \mathrm{Kz}$ Ss Por

4.80116e+01 4.80116e+01 4.80116e+00 1.00000e-09 7.00000e-02

$4.80116 \mathrm{e}+014.80116 \mathrm{e}+014.80116 \mathrm{e}+001.00000 \mathrm{e}-09$ 7.00000e-02

$1.00000 \mathrm{e}-02$ 1.00000e-02 1.00000e-03 1.00000e-09 1.00000e-01

$1.00000 \mathrm{e}+001.00000 \mathrm{e}+001.00000 \mathrm{e}-011.00000 \mathrm{e}-091.00000 \mathrm{e}-01$

Element: 6019 \# of layers: 4

Kx Ky Kz Ss Por

4.80116e+01 4.80116e+01 4.80116e+00 1.00000e-09 7.00000e-02

$4.80116 \mathrm{e}+014.80116 \mathrm{e}+014.80116 \mathrm{e}+001.00000 \mathrm{e}-09$ 7.00000e-02

$1.00000 \mathrm{e}-02$ 1.00000e-02 1.00000e-03 1.00000e-09 1.00000e-01

$1.00000 \mathrm{e}+001.00000 \mathrm{e}+001.00000 \mathrm{e}-011.00000 \mathrm{e}-091.00000 \mathrm{e}-01$

Element: 6020 \# of layers: 6

$\mathrm{Kx} \mathrm{Ky} \mathrm{Kz}$ Ss Por

4.80116e+01 4.80116e+01 4.80116e+00 1.00000e-09 7.00000e-02

$4.80116 \mathrm{e}+014.80116 \mathrm{e}+014.80116 \mathrm{e}+001.00000 \mathrm{e}-09$ 7.00000e-02

4.80116e+01 4.80116e+01 4.80116e+00 1.00000e-09 7.00000e-02

$1.91839 \mathrm{e}+00$ 1.91839e+00 1.91839e-01 1.00000e-09 2.12000e-01

$1.00000 \mathrm{e}-021.00000 \mathrm{e}-021.00000 \mathrm{e}-031.00000 \mathrm{e}-091.00000 \mathrm{e}-01$

$1.00000 \mathrm{e}+001.00000 \mathrm{e}+001.00000 \mathrm{e}-011.00000 \mathrm{e}-091.00000 \mathrm{e}-01$

Element: 6021 \# of layers: 6

$\mathrm{Kx} \mathrm{Ky} \mathrm{Kz}$ Ss Por

4.80116e+01 4.80116e+01 4.80116e+00 1.00000e-09 7.00000e-02

$4.80116 \mathrm{e}+014.80116 \mathrm{e}+014.80116 \mathrm{e}+001.00000 \mathrm{e}-09$ 7.00000e-02

$4.80116 \mathrm{e}+014.80116 \mathrm{e}+014.80116 \mathrm{e}+001.00000 \mathrm{e}-09$ 7.00000e-02

$1.91839 \mathrm{e}+00$ 1.91839e+00 1.91839e-01 1.00000e-09 2.12000e-01

$1.00000 \mathrm{e}-02$ 1.00000e-02 1.00000e-03 1.00000e-09 1.00000e-01

$1.00000 \mathrm{e}+001.00000 \mathrm{e}+001.00000 \mathrm{e}-011.00000 \mathrm{e}-091.00000 \mathrm{e}-01$

Element: 6022 \# of layers: 6

$\mathrm{Kx} \mathrm{Ky} \mathrm{Kz}$ Ss Por

4.80116e+01 4.80116e+01 4.80116e+00 1.00000e-09 7.00000e-02

$4.80116 \mathrm{e}+014.80116 \mathrm{e}+014.80116 \mathrm{e}+001.00000 \mathrm{e}-09$ 7.00000e-02

$4.80116 \mathrm{e}+014.80116 \mathrm{e}+014.80116 \mathrm{e}+001.00000 \mathrm{e}-09$ 7.00000e-02

$1.91839 \mathrm{e}+001.91839 \mathrm{e}+00$ 1.91839e-01 1.00000e-09 2.12000e-01

$1.00000 \mathrm{e}-02$ 1.00000e-02 1.00000e-03 1.00000e-09 1.00000e-01

$1.00000 \mathrm{e}+001.00000 \mathrm{e}+001.00000 \mathrm{e}-01$ 1.00000e-09 1.00000e-01

Element: 6023 \# of layers: 6

$\mathrm{Kx} \mathrm{Ky} \mathrm{Kz}$ Ss Por

4.80116e+01 4.80116e+01 4.80116e+00 1.00000e-09 7.00000e-02

4.80116e+01 4.80116e+01 4.80116e+00 1.00000e-09 7.00000e-02

4.80116e+01 4.80116e+01 4.80116e+00 1.00000e-09 7.00000e-02

$1.91839 \mathrm{e}+001.91839 \mathrm{e}+00$ 1.91839e-01 1.00000e-09 2.12000e-01 
$1.00000 \mathrm{e}-02$ 1.00000e-02 1.00000e-03 1.00000e-09 1.00000e-01 $1.00000 \mathrm{e}+001.00000 \mathrm{e}+001.00000 \mathrm{e}-01$ 1.00000e-09 1.00000e-01 Element: 6024 \# of layers: 3

Kx Ky Kz Ss Por

4.80116e+01 4.80116e+01 4.80116e+00 1.00000e-09 7.00000e-02 $4.80116 \mathrm{e}+014.80116 \mathrm{e}+014.80116 \mathrm{e}+00$ 1.00000e-09 7.00000e-02 1.00000e-02 1.00000e-02 1.00000e-03 1.00000e-09 1.00000e-01

Element: 6025 \# of layers: 5

$\mathrm{Kx} \mathrm{Ky} \mathrm{Kz}$ Ss Por

4.80116e+01 4.80116e+01 4.80116e+00 1.00000e-09 7.00000e-02 $4.80116 \mathrm{e}+014.80116 \mathrm{e}+014.80116 \mathrm{e}+00$ 1.00000e-09 7.00000e-02 $1.91839 \mathrm{e}+00$ 1.91839e+00 1.91839e-01 1.00000e-09 2.12000e-01 $1.00000 \mathrm{e}-02$ 1.00000e-02 1.00000e-03 1.00000e-09 1.00000e-01 $1.00000 \mathrm{e}+001.00000 \mathrm{e}+001.00000 \mathrm{e}-011.00000 \mathrm{e}-091.00000 \mathrm{e}-01$ Element: 6026 \# of layers: 4

Kx Ky Kz Ss Por

8.24334e+01 8.24334e+01 8.24334e+00 1.00000e-09 7.00000e-02

8.24334e+01 8.24334e+01 8.24334e+00 1.00000e-09 7.00000e-02 $1.00000 \mathrm{e}-02$ 1.00000e-02 1.00000e-03 1.00000e-09 1.00000e-01 $1.00000 \mathrm{e}+001.00000 \mathrm{e}+001.00000 \mathrm{e}-011.00000 \mathrm{e}-091.00000 \mathrm{e}-01$ Element: 6027 \# of layers: 4

$\mathrm{Kx} \mathrm{Ky} \mathrm{Kz}$ Ss Por

8.24334e+01 8.24334e+01 8.24334e+00 1.00000e-09 7.00000e-02 $3.29362 \mathrm{e}+003.29362 \mathrm{e}+003.29362 \mathrm{e}-01$ 1.00000e-09 2.12000e-01 $1.00000 \mathrm{e}-021.00000 \mathrm{e}-02$ 1.00000e-03 1.00000e-09 1.00000e-01 $1.00000 \mathrm{e}+001.00000 \mathrm{e}+001.00000 \mathrm{e}-011.00000 \mathrm{e}-09$ 1.00000e-01 Element: 6028 \# of layers: 4

$\mathrm{Kx} \mathrm{Ky} \mathrm{Kz}$ Ss Por

8.24334e+01 8.24334e+01 8.24334e+00 1.00000e-09 7.00000e-02 $3.29362 \mathrm{e}+00$ 3.29362e+00 3.29362e-01 1.00000e-09 2.12000e-01 $1.00000 \mathrm{e}-02$ 1.00000e-02 1.00000e-03 1.00000e-09 1.00000e-01 $1.00000 \mathrm{e}+001.00000 \mathrm{e}+001.00000 \mathrm{e}-011.00000 \mathrm{e}-091.00000 \mathrm{e}-01$ Element: 6029 \# of layers: 5

$\mathrm{Kx} \mathrm{Ky} \mathrm{Kz}$ Ss Por

8.24334e+01 8.24334e+01 8.24334e+00 1.00000e-09 7.00000e-02 $8.24334 \mathrm{e}+018.24334 \mathrm{e}+018.24334 \mathrm{e}+00$ 1.00000e-09 7.00000e-02 $3.29362 \mathrm{e}+00$ 3.29362e+00 3.29362e-01 1.00000e-09 2.12000e-01 $1.00000 \mathrm{e}-02$ 1.00000e-02 1.00000e-03 1.00000e-09 1.00000e-01 $1.00000 \mathrm{e}+001.00000 \mathrm{e}+001.00000 \mathrm{e}-011.00000 \mathrm{e}-091.00000 \mathrm{e}-01$ Element: 6030 \# of layers: 4

$\mathrm{Kx} \mathrm{Ky} \mathrm{Kz}$ Ss Por

8.24334e+01 8.24334e+01 8.24334e+00 1.00000e-09 7.00000e-02 3.29362e+00 3.29362e+00 3.29362e-01 1.00000e-09 2.12000e-01 $1.00000 \mathrm{e}-02$ 1.00000e-02 1.00000e-03 1.00000e-09 1.00000e-01 $1.00000 \mathrm{e}+001.00000 \mathrm{e}+001.00000 \mathrm{e}-011.00000 \mathrm{e}-091.00000 \mathrm{e}-01$ Element: 6031 \# of layers: 5 
$\mathrm{Kx} \mathrm{Ky} \mathrm{Kz}$ Ss Por

8.24334e+01 8.24334e+01 8.24334e+00 1.00000e-09 7.00000e-02

$8.24334 \mathrm{e}+018.24334 \mathrm{e}+018.24334 \mathrm{e}+00$ 1.00000e-09 7.00000e-02

$3.29362 \mathrm{e}+003.29362 \mathrm{e}+00$ 3.29362e-01 1.00000e-09 2.12000e-01

$1.00000 \mathrm{e}-02$ 1.00000e-02 1.00000e-03 1.00000e-09 1.00000e-01

$1.00000 \mathrm{e}+001.00000 \mathrm{e}+001.00000 \mathrm{e}-011.00000 \mathrm{e}-091.00000 \mathrm{e}-01$

Element: 6032 \# of layers: 5

$\mathrm{Kx} \mathrm{Ky} \mathrm{Kz}$ Ss Por

8.24334e+01 8.24334e+01 8.24334e+00 1.00000e-09 7.00000e-02

$8.24334 \mathrm{e}+018.24334 \mathrm{e}+018.24334 \mathrm{e}+00$ 1.00000e-09 7.00000e-02

$3.29362 \mathrm{e}+003.29362 \mathrm{e}+00$ 3.29362e-01 1.00000e-09 2.12000e-01

$1.00000 \mathrm{e}-02$ 1.00000e-02 1.00000e-03 1.00000e-09 1.00000e-01

$1.00000 \mathrm{e}+001.00000 \mathrm{e}+001.00000 \mathrm{e}-011.00000 \mathrm{e}-091.00000 \mathrm{e}-01$

Element: 6033 \# of layers: 6

$\mathrm{Kx} \mathrm{Ky} \mathrm{Kz}$ Ss Por

8.24334e+01 8.24334e+01 8.24334e+00 1.00000e-09 7.00000e-02

$8.24334 \mathrm{e}+018.24334 \mathrm{e}+018.24334 \mathrm{e}+00$ 1.00000e-09 7.00000e-02

8.24334e+01 8.24334e+01 8.24334e+00 1.00000e-09 7.00000e-02

$3.29362 \mathrm{e}+003.29362 \mathrm{e}+00$ 3.29362e-01 1.00000e-09 2.12000e-01

$1.00000 \mathrm{e}-02$ 1.00000e-02 1.00000e-03 1.00000e-09 1.00000e-01

$1.00000 \mathrm{e}+001.00000 \mathrm{e}+001.00000 \mathrm{e}-011.00000 \mathrm{e}-091.00000 \mathrm{e}-01$

Element: 6034 \# of layers: 5

$\mathrm{Kx} \mathrm{Ky} \mathrm{Kz}$ Ss Por

8.24334e+01 8.24334e+01 8.24334e+00 1.00000e-09 7.00000e-02

$8.24334 \mathrm{e}+018.24334 \mathrm{e}+018.24334 \mathrm{e}+001.00000 \mathrm{e}-09$ 7.00000e-02

$3.29362 \mathrm{e}+003.29362 \mathrm{e}+00$ 3.29362e-01 1.00000e-09 2.12000e-01

$1.00000 \mathrm{e}-02$ 1.00000e-02 1.00000e-03 1.00000e-09 1.00000e-01

$1.00000 \mathrm{e}+001.00000 \mathrm{e}+001.00000 \mathrm{e}-011.00000 \mathrm{e}-091.00000 \mathrm{e}-01$

Element: 6035 \# of layers: 4

$\mathrm{Kx} \mathrm{Ky} \mathrm{Kz}$ Ss Por

$1.63144 \mathrm{e}+021.63144 \mathrm{e}+02$ 1.63144e+01 1.00000e-09 7.00000e-02

$6.51861 \mathrm{e}+006.51861 \mathrm{e}+006.51861 \mathrm{e}-01$ 1.00000e-09 2.12000e-01

$1.00000 \mathrm{e}-02$ 1.00000e-02 1.00000e-03 1.00000e-09 1.00000e-01

$1.00000 \mathrm{e}+001.00000 \mathrm{e}+001.00000 \mathrm{e}-011.00000 \mathrm{e}-091.00000 \mathrm{e}-01$

Element: 6036 \# of layers: 4

$\mathrm{Kx} \mathrm{Ky} \mathrm{Kz}$ Ss Por

$1.63144 \mathrm{e}+021.63144 \mathrm{e}+02$ 1.63144e+01 1.00000e-09 7.00000e-02

$1.63144 \mathrm{e}+021.63144 \mathrm{e}+021.63144 \mathrm{e}+01$ 1.00000e-09 7.00000e-02

$1.00000 \mathrm{e}-02$ 1.00000e-02 1.00000e-03 1.00000e-09 1.00000e-01

$1.00000 \mathrm{e}+001.00000 \mathrm{e}+001.00000 \mathrm{e}-01$ 1.00000e-09 1.00000e-01

Element: 6037 \# of layers: 4

$\mathrm{Kx} \mathrm{Ky} \mathrm{Kz}$ Ss Por

$1.63144 \mathrm{e}+02$ 1.63144e+02 1.63144e+01 1.00000e-09 7.00000e-02

$1.63144 \mathrm{e}+02$ 1.63144e+02 1.63144e+01 1.00000e-09 7.00000e-02

$1.00000 \mathrm{e}-02$ 1.00000e-02 1.00000e-03 1.00000e-09 1.00000e-01

$1.00000 \mathrm{e}+001.00000 \mathrm{e}+001.00000 \mathrm{e}-011.00000 \mathrm{e}-091.00000 \mathrm{e}-01$ 
Element: 6038 \# of layers: 4

$\mathrm{Kx} \mathrm{Ky} \mathrm{Kz}$ Ss Por

$1.63144 \mathrm{e}+02$ 1.63144e+02 1.63144e+01 1.00000e-09 7.00000e-02

$1.63144 \mathrm{e}+021.63144 \mathrm{e}+021.63144 \mathrm{e}+011.00000 \mathrm{e}-097.00000 \mathrm{e}-02$

$1.00000 \mathrm{e}-021.00000 \mathrm{e}-021.00000 \mathrm{e}-031.00000 \mathrm{e}-091.00000 \mathrm{e}-01$

$1.00000 \mathrm{e}+001.00000 \mathrm{e}+001.00000 \mathrm{e}-011.00000 \mathrm{e}-091.00000 \mathrm{e}-01$

Element: 6039 \# of layers: 4

$\mathrm{Kx} \mathrm{Ky} \mathrm{Kz}$ Ss Por

$1.63144 \mathrm{e}+02$ 1.63144e+02 1.63144e+01 1.00000e-09 7.00000e-02

6.51861e+00 6.51861e+00 6.51861e-01 1.00000e-09 2.12000e-01

$1.00000 \mathrm{e}-02$ 1.00000e-02 1.00000e-03 1.00000e-09 1.00000e-01

$1.00000 \mathrm{e}+001.00000 \mathrm{e}+001.00000 \mathrm{e}-011.00000 \mathrm{e}-091.00000 \mathrm{e}-01$

Element: 6040 \# of layers: 4

$\mathrm{Kx} \mathrm{Ky} \mathrm{Kz}$ Ss Por

$1.63144 \mathrm{e}+021.63144 \mathrm{e}+02$ 1.63144e+01 1.00000e-09 7.00000e-02

$6.51861 \mathrm{e}+006.51861 \mathrm{e}+00$ 6.51861e-01 1.00000e-09 2.12000e-01

$1.00000 \mathrm{e}-02$ 1.00000e-02 1.00000e-03 1.00000e-09 1.00000e-01

$1.00000 \mathrm{e}+001.00000 \mathrm{e}+001.00000 \mathrm{e}-011.00000 \mathrm{e}-091.00000 \mathrm{e}-01$

Element: 6041 \# of layers: 5

$\mathrm{Kx} \mathrm{Ky} \mathrm{Kz}$ Ss Por

$1.63144 \mathrm{e}+02$ 1.63144e+02 1.63144e+01 1.00000e-09 7.00000e-02

$1.63144 \mathrm{e}+021.63144 \mathrm{e}+02$ 1.63144e+01 1.00000e-09 7.00000e-02

$6.51861 \mathrm{e}+006.51861 \mathrm{e}+006.51861 \mathrm{e}-01$ 1.00000e-09 2.12000e-01

$1.00000 \mathrm{e}-02$ 1.00000e-02 1.00000e-03 1.00000e-09 1.00000e-01

$1.00000 \mathrm{e}+001.00000 \mathrm{e}+001.00000 \mathrm{e}-011.00000 \mathrm{e}-091.00000 \mathrm{e}-01$

Element: 6042 \# of layers: 5

$\mathrm{Kx} \mathrm{Ky} \mathrm{Kz}$ Ss Por

$1.63144 \mathrm{e}+02$ 1.63144e+02 1.63144e+01 1.00000e-09 7.00000e-02

$1.63144 \mathrm{e}+021.63144 \mathrm{e}+021.63144 \mathrm{e}+011.00000 \mathrm{e}-097.00000 \mathrm{e}-02$

6.51861e+00 6.51861e+00 6.51861e-01 1.00000e-09 2.12000e-01

$1.00000 \mathrm{e}-02$ 1.00000e-02 1.00000e-03 1.00000e-09 1.00000e-01

$1.00000 \mathrm{e}+001.00000 \mathrm{e}+001.00000 \mathrm{e}-011.00000 \mathrm{e}-091.00000 \mathrm{e}-01$

Element: 6043 \# of layers: 5

$\mathrm{Kx} \mathrm{Ky} \mathrm{Kz}$ Ss Por

$1.63144 \mathrm{e}+021.63144 \mathrm{e}+02$ 1.63144e+01 1.00000e-09 7.00000e-02

$1.63144 \mathrm{e}+021.63144 \mathrm{e}+02 \quad 1.63144 \mathrm{e}+01$ 1.00000e-09 7.00000e-02

$6.51861 \mathrm{e}+006.51861 \mathrm{e}+00$ 6.51861e-01 1.00000e-09 2.12000e-01

1.00000e-02 1.00000e-02 1.00000e-03 1.00000e-09 1.00000e-01

$1.00000 \mathrm{e}+001.00000 \mathrm{e}+001.00000 \mathrm{e}-011.00000 \mathrm{e}-091.00000 \mathrm{e}-01$

Element: 6044 \# of layers: 4

$\mathrm{Kx} \mathrm{Ky} \mathrm{Kz}$ Ss Por

7.17493e+02 7.17493e+02 7.17493e+01 1.00000e-09 7.00000e-02

7.17493e+02 7.17493e+02 7.17493e+01 1.00000e-09 7.00000e-02

1.00000e-02 1.00000e-02 1.00000e-03 1.00000e-09 1.00000e-01

$1.00000 \mathrm{e}+001.00000 \mathrm{e}+001.00000 \mathrm{e}-01$ 1.00000e-09 1.00000e-01

Element: 6045 \# of layers: 4 
Kx Ky Kz Ss Por

7.17493e+02 7.17493e+02 7.17493e+01 1.00000e-09 7.00000e-02

7.17493e+02 7.17493e+02 7.17493e+01 1.00000e-09 7.00000e-02

$1.00000 \mathrm{e}-02$ 1.00000e-02 1.00000e-03 1.00000e-09 1.00000e-01

$1.00000 \mathrm{e}+001.00000 \mathrm{e}+001.00000 \mathrm{e}-01$ 1.00000e-09 1.00000e-01

Element: 6046 \# of layers: 4

$\mathrm{Kx} \mathrm{Ky} \mathrm{Kz}$ Ss Por

7.17493e+02 7.17493e+02 7.17493e+01 1.00000e-09 7.00000e-02

$7.17493 \mathrm{e}+02$ 7.17493e+02 7.17493e+01 1.00000e-09 7.00000e-02

$1.00000 \mathrm{e}-02$ 1.00000e-02 1.00000e-03 1.00000e-09 1.00000e-01

$1.00000 \mathrm{e}+001.00000 \mathrm{e}+001.00000 \mathrm{e}-011.00000 \mathrm{e}-091.00000 \mathrm{e}-01$

Element: 6047 \# of layers: 4

$\mathrm{Kx} \mathrm{Ky} \mathrm{Kz}$ Ss Por

7.17493e+02 7.17493e+02 7.17493e+01 1.00000e-09 7.00000e-02

$7.17493 \mathrm{e}+02$ 7.17493e+02 7.17493e+01 1.00000e-09 7.00000e-02

$1.00000 \mathrm{e}-02$ 1.00000e-02 1.00000e-03 1.00000e-09 1.00000e-01

$1.00000 \mathrm{e}+001.00000 \mathrm{e}+001.00000 \mathrm{e}-01$ 1.00000e-09 1.00000e-01

Element: 6048 \# of layers: 5

$\mathrm{Kx} \mathrm{Ky} \mathrm{Kz}$ Ss Por

7.17493e+02 7.17493e+02 7.17493e+01 1.00000e-09 7.00000e-02

7.17493e+02 7.17493e+02 7.17493e+01 1.00000e-09 7.00000e-02

$2.86679 \mathrm{e}+012.86679 \mathrm{e}+012.86679 \mathrm{e}+00$ 1.00000e-09 2.12000e-01

$1.00000 \mathrm{e}-021.00000 \mathrm{e}-021.00000 \mathrm{e}-031.00000 \mathrm{e}-091.00000 \mathrm{e}-01$

$1.00000 \mathrm{e}+001.00000 \mathrm{e}+001.00000 \mathrm{e}-011.00000 \mathrm{e}-091.00000 \mathrm{e}-01$

Element: 6049 \# of layers: 4

$\mathrm{Kx} \mathrm{Ky} \mathrm{Kz}$ Ss Por

7.17493e+02 7.17493e+02 7.17493e+01 1.00000e-09 7.00000e-02

$2.86679 \mathrm{e}+012.86679 \mathrm{e}+012.86679 \mathrm{e}+00$ 1.00000e-09 2.12000e-01

$1.00000 \mathrm{e}-02$ 1.00000e-02 1.00000e-03 1.00000e-09 1.00000e-01

$1.00000 \mathrm{e}+001.00000 \mathrm{e}+001.00000 \mathrm{e}-011.00000 \mathrm{e}-091.00000 \mathrm{e}-01$

Element: 6050 \# of layers: 3

Kx Ky Kz Ss Por

7.17493e+02 7.17493e+02 7.17493e+01 1.00000e-09 7.00000e-02

$1.00000 \mathrm{e}-021.00000 \mathrm{e}-021.00000 \mathrm{e}-031.00000 \mathrm{e}-091.00000 \mathrm{e}-01$

$1.00000 \mathrm{e}+001.00000 \mathrm{e}+001.00000 \mathrm{e}-011.00000 \mathrm{e}-091.00000 \mathrm{e}-01$

Element: 6051 \# of layers: 4

Kx Ky Kz Ss Por

7.17493e+02 7.17493e+02 7.17493e+01 1.00000e-09 7.00000e-02

7.17493e+02 7.17493e+02 7.17493e+01 1.00000e-09 7.00000e-02

$1.00000 \mathrm{e}-021.00000 \mathrm{e}-021.00000 \mathrm{e}-031.00000 \mathrm{e}-091.00000 \mathrm{e}-01$

$1.00000 \mathrm{e}+001.00000 \mathrm{e}+001.00000 \mathrm{e}-011.00000 \mathrm{e}-091.00000 \mathrm{e}-01$

Element: 6052 \# of layers: 4

$\mathrm{Kx} \mathrm{Ky} \mathrm{Kz}$ Ss Por

7.17493e+02 7.17493e+02 7.17493e+01 1.00000e-09 7.00000e-02

7.17493e+02 7.17493e+02 7.17493e+01 1.00000e-09 7.00000e-02

$1.00000 \mathrm{e}-02$ 1.00000e-02 1.00000e-03 1.00000e-09 1.00000e-01 
$1.00000 \mathrm{e}+001.00000 \mathrm{e}+00$ 1.00000e-01 1.00000e-09 1.00000e-01

Element: 6053 \# of layers: 5

$\mathrm{Kx} \mathrm{Ky} \mathrm{Kz}$ Ss Por

3.65869e+02 3.65869e+02 3.65869e+01 1.00000e-09 7.00000e-02

$3.65869 \mathrm{e}+02$ 3.65869e+02 3.65869e+01 1.00000e-09 7.00000e-02

$3.65869 \mathrm{e}+02$ 3.65869e+02 3.65869e+01 1.00000e-09 7.00000e-02

$1.00000 \mathrm{e}-02$ 1.00000e-02 1.00000e-03 1.00000e-09 1.00000e-01

$1.00000 \mathrm{e}+001.00000 \mathrm{e}+001.00000 \mathrm{e}-011.00000 \mathrm{e}-091.00000 \mathrm{e}-01$

Element: 6054 \# of layers: 5

$\mathrm{Kx} \mathrm{Ky} \mathrm{Kz}$ Ss Por

$3.65869 \mathrm{e}+02$ 3.65869e+02 3.65869e+01 1.00000e-09 7.00000e-02

$3.65869 \mathrm{e}+02$ 3.65869e+02 3.65869e+01 1.00000e-09 7.00000e-02

$3.65869 \mathrm{e}+023.65869 \mathrm{e}+023.65869 \mathrm{e}+01$ 1.00000e-09 7.00000e-02

1.00000e-02 1.00000e-02 1.00000e-03 1.00000e-09 1.00000e-01

$1.00000 \mathrm{e}+001.00000 \mathrm{e}+001.00000 \mathrm{e}-01$ 1.00000e-09 1.00000e-01

Element: 6055 \# of layers: 7

$\mathrm{Kx} \mathrm{Ky} \mathrm{Kz}$ Ss Por

3.65869e+02 3.65869e+02 3.65869e+01 1.00000e-09 7.00000e-02

$3.65869 \mathrm{e}+023.65869 \mathrm{e}+023.65869 \mathrm{e}+01$ 1.00000e-09 7.00000e-02

$3.65869 \mathrm{e}+023.65869 \mathrm{e}+023.65869 \mathrm{e}+01$ 1.00000e-09 7.00000e-02

$3.65869 \mathrm{e}+02$ 3.65869e+02 3.65869e+01 1.00000e-09 7.00000e-02

$1.46188 \mathrm{e}+011.46188 \mathrm{e}+011.46188 \mathrm{e}+001.00000 \mathrm{e}-092.12000 \mathrm{e}-01$

$1.00000 \mathrm{e}-021.00000 \mathrm{e}-021.00000 \mathrm{e}-031.00000 \mathrm{e}-091.00000 \mathrm{e}-01$

$1.00000 \mathrm{e}+001.00000 \mathrm{e}+001.00000 \mathrm{e}-011.00000 \mathrm{e}-09$ 1.00000e-01

Element: 6056 \# of layers: 7

$\mathrm{Kx} \mathrm{Ky} \mathrm{Kz}$ Ss Por

3.65869e+02 3.65869e+02 3.65869e+01 1.00000e-09 7.00000e-02

$3.65869 \mathrm{e}+02$ 3.65869e+02 3.65869e+01 1.00000e-09 7.00000e-02

$3.65869 \mathrm{e}+02$ 3.65869e+02 3.65869e+01 1.00000e-09 7.00000e-02

$1.46188 \mathrm{e}+01$ 1.46188e+01 1.46188e+00 1.00000e-09 2.12000e-01

$1.46188 \mathrm{e}+01$ 1.46188e+01 1.46188e+00 1.00000e-09 2.12000e-01

1.00000e-02 1.00000e-02 1.00000e-03 1.00000e-09 1.00000e-01

$1.00000 \mathrm{e}+001.00000 \mathrm{e}+001.00000 \mathrm{e}-011.00000 \mathrm{e}-091.00000 \mathrm{e}-01$

Element: 6057 \# of layers: 7

$\mathrm{Kx} \mathrm{Ky} \mathrm{Kz}$ Ss Por

$3.65869 \mathrm{e}+02$ 3.65869e+02 3.65869e+01 1.00000e-09 7.00000e-02

$3.65869 \mathrm{e}+023.65869 \mathrm{e}+023.65869 \mathrm{e}+01$ 1.00000e-09 7.00000e-02

$3.65869 \mathrm{e}+02$ 3.65869e+02 3.65869e+01 1.00000e-09 7.00000e-02

$1.46188 \mathrm{e}+01$ 1.46188e+01 1.46188e+00 1.00000e-09 2.12000e-01

$1.46188 \mathrm{e}+01$ 1.46188e+01 1.46188e+00 1.00000e-09 2.12000e-01

$1.00000 \mathrm{e}-02$ 1.00000e-02 1.00000e-03 1.00000e-09 1.00000e-01

$1.00000 \mathrm{e}+001.00000 \mathrm{e}+001.00000 \mathrm{e}-011.00000 \mathrm{e}-091.00000 \mathrm{e}-01$

Element: 6058 \# of layers: 6

$\mathrm{Kx} \mathrm{Ky} \mathrm{Kz}$ Ss Por

3.65869e+02 3.65869e+02 3.65869e+01 1.00000e-09 7.00000e-02

$3.65869 \mathrm{e}+02$ 3.65869e+02 3.65869e+01 1.00000e-09 7.00000e-02 
3.65869e+02 3.65869e+02 3.65869e+01 1.00000e-09 7.00000e-02 $1.46188 \mathrm{e}+01$ 1.46188e+01 1.46188e+00 1.00000e-09 2.12000e-01 $1.00000 \mathrm{e}-02$ 1.00000e-02 1.00000e-03 1.00000e-09 1.00000e-01 $1.00000 \mathrm{e}+001.00000 \mathrm{e}+001.00000 \mathrm{e}-011.00000 \mathrm{e}-091.00000 \mathrm{e}-01$ Element: 6059 \# of layers: 5

$\mathrm{Kx} \mathrm{Ky} \mathrm{Kz}$ Ss Por

3.65869e+02 3.65869e+02 3.65869e+01 1.00000e-09 7.00000e-02 $3.65869 \mathrm{e}+02$ 3.65869e+02 3.65869e+01 1.00000e-09 7.00000e-02 $1.46188 \mathrm{e}+01$ 1.46188e+01 1.46188e+00 1.00000e-09 2.12000e-01 $1.00000 \mathrm{e}-02$ 1.00000e-02 1.00000e-03 1.00000e-09 1.00000e-01 $1.00000 \mathrm{e}+001.00000 \mathrm{e}+001.00000 \mathrm{e}-011.00000 \mathrm{e}-091.00000 \mathrm{e}-01$ Element: 6060 \# of layers: 5

$\mathrm{Kx} \mathrm{Ky} \mathrm{Kz}$ Ss Por

3.65869e+02 3.65869e+02 3.65869e+01 1.00000e-09 7.00000e-02 $3.65869 \mathrm{e}+02$ 3.65869e+02 3.65869e+01 1.00000e-09 7.00000e-02 $1.46188 \mathrm{e}+011.46188 \mathrm{e}+01$ 1.46188e+00 1.00000e-09 2.12000e-01 $1.00000 \mathrm{e}-02$ 1.00000e-02 1.00000e-03 1.00000e-09 1.00000e-01 $1.00000 \mathrm{e}+001.00000 \mathrm{e}+001.00000 \mathrm{e}-01$ 1.00000e-09 1.00000e-01 Element: 6061 \# of layers: 5

$\mathrm{Kx} \mathrm{Ky} \mathrm{Kz}$ Ss Por

3.65869e+02 3.65869e+02 3.65869e+01 1.00000e-09 7.00000e-02

$3.65869 \mathrm{e}+02$ 3.65869e+02 3.65869e+01 1.00000e-09 7.00000e-02

$1.46188 \mathrm{e}+01$ 1.46188e+01 1.46188e+00 1.00000e-09 2.12000e-01 $1.00000 \mathrm{e}-02$ 1.00000e-02 1.00000e-03 1.00000e-09 1.00000e-01

$1.00000 \mathrm{e}+001.00000 \mathrm{e}+001.00000 \mathrm{e}-011.00000 \mathrm{e}-091.00000 \mathrm{e}-01$ Element: 6062 \# of layers: 7

$\mathrm{Kx} \mathrm{Ky} \mathrm{Kz}$ Ss Por

$1.40313 \mathrm{e}+02$ 1.40313e+02 1.40313e+01 1.00000e-09 7.00000e-02 $1.40313 \mathrm{e}+02$ 1.40313e+02 1.40313e+01 1.00000e-09 7.00000e-02 $1.40313 \mathrm{e}+02$ 1.40313e+02 1.40313e+01 1.00000e-09 7.00000e-02

$5.60644 \mathrm{e}+005.60644 \mathrm{e}+005.60644 \mathrm{e}-011.00000 \mathrm{e}-092.12000 \mathrm{e}-01$

$5.60644 \mathrm{e}+005.60644 \mathrm{e}+005.60644 \mathrm{e}-01$ 1.00000e-09 2.12000e-01 1.00000e-02 1.00000e-02 1.00000e-03 1.00000e-09 1.00000e-01 $1.00000 \mathrm{e}+001.00000 \mathrm{e}+001.00000 \mathrm{e}-01$ 1.00000e-09 1.00000e-01 Element: 6063 \# of layers: 8

$\mathrm{Kx} \mathrm{Ky} \mathrm{Kz}$ Ss Por

1.40313e+02 1.40313e+02 1.40313e+01 1.00000e-09 7.00000e-02 $1.40313 \mathrm{e}+021.40313 \mathrm{e}+021.40313 \mathrm{e}+01$ 1.00000e-09 7.00000e-02 $1.40313 \mathrm{e}+02$ 1.40313e+02 1.40313e+01 1.00000e-09 7.00000e-02 5.00000e-04 5.00000e-04 5.00000e-05 1.00000e-09 1.00000e-01 5.00000e-04 5.00000e-04 5.00000e-05 1.00000e-09 1.00000e-01

$5.60644 \mathrm{e}+005.60644 \mathrm{e}+005.60644 \mathrm{e}-011.00000 \mathrm{e}-092.12000 \mathrm{e}-01$ $1.00000 \mathrm{e}-02$ 1.00000e-02 1.00000e-03 1.00000e-09 1.00000e-01 $1.00000 \mathrm{e}+001.00000 \mathrm{e}+001.00000 \mathrm{e}-011.00000 \mathrm{e}-091.00000 \mathrm{e}-01$ Element: 6064 \# of layers: 9

Kx Ky Kz Ss Por 
1.40313e+02 1.40313e+02 1.40313e+01 1.00000e-09 7.00000e-02 $1.40313 \mathrm{e}+02$ 1.40313e+02 1.40313e+01 1.00000e-09 7.00000e-02 $1.40313 \mathrm{e}+021.40313 \mathrm{e}+02$ 1.40313e+01 1.00000e-09 7.00000e-02 5.00000e-04 5.00000e-04 5.00000e-05 1.00000e-09 1.00000e-01 $5.00000 \mathrm{e}-04$ 5.00000e-04 5.00000e-05 1.00000e-09 1.00000e-01

$5.60644 \mathrm{e}+005.60644 \mathrm{e}+005.60644 \mathrm{e}-01$ 1.00000e-09 2.12000e-01 $5.60644 \mathrm{e}+005.60644 \mathrm{e}+00$ 5.60644e-01 1.00000e-09 2.12000e-01 $1.00000 \mathrm{e}-02$ 1.00000e-02 1.00000e-03 1.00000e-09 1.00000e-01 $1.00000 \mathrm{e}+001.00000 \mathrm{e}+001.00000 \mathrm{e}-011.00000 \mathrm{e}-091.00000 \mathrm{e}-01$ Element: 6065 \# of layers: 8

$\mathrm{Kx} \mathrm{Ky} \mathrm{Kz}$ Ss Por

$1.40313 \mathrm{e}+02$ 1.40313e+02 1.40313e+01 1.00000e-09 7.00000e-02 $1.40313 \mathrm{e}+02$ 1.40313e+02 1.40313e+01 1.00000e-09 7.00000e-02 $1.40313 \mathrm{e}+021.40313 \mathrm{e}+02$ 1.40313e+01 1.00000e-09 7.00000e-02 5.00000e-04 5.00000e-04 5.00000e-05 1.00000e-09 1.00000e-01 5.00000e-04 5.00000e-04 5.00000e-05 1.00000e-09 1.00000e-01 $5.60644 \mathrm{e}+005.60644 \mathrm{e}+00$ 5.60644e-01 1.00000e-09 2.12000e-01 $1.00000 \mathrm{e}-02$ 1.00000e-02 1.00000e-03 1.00000e-09 1.00000e-01 $1.00000 \mathrm{e}+001.00000 \mathrm{e}+001.00000 \mathrm{e}-011.00000 \mathrm{e}-091.00000 \mathrm{e}-01$ Element: 6066 \# of layers: 6

$\mathrm{Kx} \mathrm{Ky} \mathrm{Kz}$ Ss Por

1.40313e+02 1.40313e+02 1.40313e+01 1.00000e-09 7.00000e-02 $1.40313 \mathrm{e}+02$ 1.40313e+02 1.40313e+01 1.00000e-09 7.00000e-02 $1.40313 \mathrm{e}+02$ 1.40313e+02 1.40313e+01 1.00000e-09 7.00000e-02 $5.60644 \mathrm{e}+005.60644 \mathrm{e}+00$ 5.60644e-01 1.00000e-09 2.12000e-01 $1.00000 \mathrm{e}-02$ 1.00000e-02 1.00000e-03 1.00000e-09 1.00000e-01 $1.00000 \mathrm{e}+001.00000 \mathrm{e}+001.00000 \mathrm{e}-01$ 1.00000e-09 1.00000e-01 Element: 6067 \# of layers: 6

$\mathrm{Kx} \mathrm{Ky} \mathrm{Kz}$ Ss Por

1.40313e+02 1.40313e+02 1.40313e+01 1.00000e-09 7.00000e-02 $1.40313 \mathrm{e}+021.40313 \mathrm{e}+02$ 1.40313e+01 1.00000e-09 7.00000e-02 $1.40313 \mathrm{e}+021.40313 \mathrm{e}+02$ 1.40313e+01 1.00000e-09 7.00000e-02 $5.60644 \mathrm{e}+005.60644 \mathrm{e}+005.60644 \mathrm{e}-01$ 1.00000e-09 2.12000e-01 $1.00000 \mathrm{e}-02$ 1.00000e-02 1.00000e-03 1.00000e-09 1.00000e-01 $1.00000 \mathrm{e}+001.00000 \mathrm{e}+001.00000 \mathrm{e}-011.00000 \mathrm{e}-091.00000 \mathrm{e}-01$ Element: 6068 \# of layers: 7

Kx Ky Kz Ss Por $1.40313 \mathrm{e}+02$ 1.40313e+02 1.40313e+01 1.00000e-09 7.00000e-02 $1.40313 \mathrm{e}+02$ 1.40313e+02 1.40313e+01 1.00000e-09 7.00000e-02 $1.40313 \mathrm{e}+021.40313 \mathrm{e}+02$ 1.40313e+01 1.00000e-09 7.00000e-02 $5.60644 \mathrm{e}+005.60644 \mathrm{e}+005.60644 \mathrm{e}-011.00000 \mathrm{e}-092.12000 \mathrm{e}-01$ $5.60644 \mathrm{e}+005.60644 \mathrm{e}+00$ 5.60644e-01 1.00000e-09 2.12000e-01 $1.00000 \mathrm{e}-02$ 1.00000e-02 1.00000e-03 1.00000e-09 1.00000e-01 $1.00000 \mathrm{e}+001.00000 \mathrm{e}+001.00000 \mathrm{e}-01$ 1.00000e-09 1.00000e-01 Element: 6069 \# of layers: 7

Kx Ky Kz Ss Por 
1.40313e+02 1.40313e+02 1.40313e+01 1.00000e-09 7.00000e-02 $1.40313 \mathrm{e}+02$ 1.40313e+02 1.40313e+01 1.00000e-09 7.00000e-02 $1.40313 \mathrm{e}+021.40313 \mathrm{e}+02$ 1.40313e+01 1.00000e-09 7.00000e-02 $5.60644 \mathrm{e}+005.60644 \mathrm{e}+005.60644 \mathrm{e}-011.00000 \mathrm{e}-092.12000 \mathrm{e}-01$ $5.60644 \mathrm{e}+005.60644 \mathrm{e}+00$ 5.60644e-01 1.00000e-09 2.12000e-01 $1.00000 \mathrm{e}-02$ 1.00000e-02 1.00000e-03 1.00000e-09 1.00000e-01 $1.00000 \mathrm{e}+001.00000 \mathrm{e}+001.00000 \mathrm{e}-011.00000 \mathrm{e}-091.00000 \mathrm{e}-01$ Element: 6070 \# of layers: 7

$\mathrm{Kx} \mathrm{Ky} \mathrm{Kz}$ Ss Por

$1.40313 \mathrm{e}+02$ 1.40313e+02 1.40313e+01 1.00000e-09 7.00000e-02 $1.40313 \mathrm{e}+02$ 1.40313e+02 1.40313e+01 1.00000e-09 7.00000e-02 $1.40313 \mathrm{e}+02$ 1.40313e+02 1.40313e+01 1.00000e-09 7.00000e-02 5.00000e-04 5.00000e-04 5.00000e-05 1.00000e-09 1.00000e-01

$5.60644 \mathrm{e}+005.60644 \mathrm{e}+005.60644 \mathrm{e}-01$ 1.00000e-09 2.12000e-01 $1.00000 \mathrm{e}-02$ 1.00000e-02 1.00000e-03 1.00000e-09 1.00000e-01 $1.00000 \mathrm{e}+001.00000 \mathrm{e}+001.00000 \mathrm{e}-011.00000 \mathrm{e}-091.00000 \mathrm{e}-01$ Element: 6071 \# of layers: 10

$\mathrm{Kx} \mathrm{Ky} \mathrm{Kz}$ Ss Por

1.14905e+02 1.14905e+02 1.14905e+01 1.00000e-09 7.00000e-02 $1.14905 \mathrm{e}+02$ 1.14905e+02 1.14905e+01 1.00000e-09 7.00000e-02 $1.14905 \mathrm{e}+02$ 1.14905e+02 1.14905e+01 1.00000e-09 7.00000e-02 $1.14905 \mathrm{e}+021.14905 \mathrm{e}+02$ 1.14905e+01 1.00000e-09 7.00000e-02 5.00000e-04 5.00000e-04 5.00000e-05 1.00000e-09 1.00000e-01 5.00000e-04 5.00000e-04 5.00000e-05 1.00000e-09 1.00000e-01

$4.59100 \mathrm{e}+00$ 4.59100e+00 4.59100e-01 1.00000e-09 2.12000e-01 $4.59100 \mathrm{e}+004.59100 \mathrm{e}+004.59100 \mathrm{e}-01$ 1.00000e-09 2.12000e-01 $1.00000 \mathrm{e}-02$ 1.00000e-02 1.00000e-03 1.00000e-09 1.00000e-01 $1.00000 \mathrm{e}+001.00000 \mathrm{e}+001.00000 \mathrm{e}-011.00000 \mathrm{e}-091.00000 \mathrm{e}-01$ Element: 6072 \# of layers: 9

$\mathrm{Kx} \mathrm{Ky} \mathrm{Kz}$ Ss Por

1.14905e+02 1.14905e+02 1.14905e+01 1.00000e-09 7.00000e-02 $1.14905 \mathrm{e}+02$ 1.14905e+02 1.14905e+01 1.00000e-09 7.00000e-02 $1.14905 \mathrm{e}+02$ 1.14905e+02 1.14905e+01 1.00000e-09 7.00000e-02 $1.14905 \mathrm{e}+021.14905 \mathrm{e}+021.14905 \mathrm{e}+01$ 1.00000e-09 7.00000e-02 5.00000e-04 5.00000e-04 5.00000e-05 1.00000e-09 1.00000e-01 $4.59100 \mathrm{e}+004.59100 \mathrm{e}+00$ 4.59100e-01 1.00000e-09 2.12000e-01 $4.59100 \mathrm{e}+004.59100 \mathrm{e}+004.59100 \mathrm{e}-01$ 1.00000e-09 2.12000e-01 $1.00000 \mathrm{e}-02$ 1.00000e-02 1.00000e-03 1.00000e-09 1.00000e-01 $1.00000 \mathrm{e}+001.00000 \mathrm{e}+001.00000 \mathrm{e}-011.00000 \mathrm{e}-091.00000 \mathrm{e}-01$ Element: 6073 \# of layers: 7

$\mathrm{Kx} \mathrm{Ky} \mathrm{Kz}$ Ss Por 1.14905e+02 1.14905e+02 1.14905e+01 1.00000e-09 7.00000e-02 $1.14905 \mathrm{e}+02$ 1.14905e+02 1.14905e+01 1.00000e-09 7.00000e-02 $1.14905 \mathrm{e}+02$ 1.14905e+02 1.14905e+01 1.00000e-09 7.00000e-02 5.00000e-04 5.00000e-04 5.00000e-05 1.00000e-09 1.00000e-01 $4.59100 \mathrm{e}+004.59100 \mathrm{e}+004.59100 \mathrm{e}-01$ 1.00000e-09 2.12000e-01 
$1.00000 \mathrm{e}-02$ 1.00000e-02 1.00000e-03 1.00000e-09 1.00000e-01 $1.00000 \mathrm{e}+001.00000 \mathrm{e}+001.00000 \mathrm{e}-01$ 1.00000e-09 1.00000e-01 Element: 6074 \# of layers: 6

Kx Ky Kz Ss Por

$1.14905 \mathrm{e}+02$ 1.14905e+02 1.14905e+01 1.00000e-09 7.00000e-02 $1.14905 \mathrm{e}+02$ 1.14905e+02 1.14905e+01 1.00000e-09 7.00000e-02 $1.14905 \mathrm{e}+02$ 1.14905e+02 1.14905e+01 1.00000e-09 7.00000e-02 $4.59100 \mathrm{e}+00$ 4.59100e+00 4.59100e-01 1.00000e-09 2.12000e-01 $1.00000 \mathrm{e}-02$ 1.00000e-02 1.00000e-03 1.00000e-09 1.00000e-01 $1.00000 \mathrm{e}+001.00000 \mathrm{e}+001.00000 \mathrm{e}-011.00000 \mathrm{e}-091.00000 \mathrm{e}-01$ Element: 6075 \# of layers: 5

$\mathrm{Kx} \mathrm{Ky} \mathrm{Kz}$ Ss Por

1.14905e+02 1.14905e+02 1.14905e+01 1.00000e-09 7.00000e-02 $1.14905 \mathrm{e}+02$ 1.14905e+02 1.14905e+01 1.00000e-09 7.00000e-02 $4.59100 \mathrm{e}+004.59100 \mathrm{e}+00$ 4.59100e-01 1.00000e-09 2.12000e-01 $1.00000 \mathrm{e}-02$ 1.00000e-02 1.00000e-03 1.00000e-09 1.00000e-01 $1.00000 \mathrm{e}+001.00000 \mathrm{e}+001.00000 \mathrm{e}-011.00000 \mathrm{e}-091.00000 \mathrm{e}-01$ Element: 6076 \# of layers: 5

$\mathrm{Kx} \mathrm{Ky} \mathrm{Kz}$ Ss Por

1.14905e+02 1.14905e+02 1.14905e+01 1.00000e-09 7.00000e-02 $1.14905 \mathrm{e}+02$ 1.14905e+02 1.14905e+01 1.00000e-09 7.00000e-02 4.59100e+00 4.59100e+00 4.59100e-01 1.00000e-09 2.12000e-01 $1.00000 \mathrm{e}-02$ 1.00000e-02 1.00000e-03 1.00000e-09 1.00000e-01 $1.00000 \mathrm{e}+001.00000 \mathrm{e}+001.00000 \mathrm{e}-011.00000 \mathrm{e}-091.00000 \mathrm{e}-01$

Element: 6077 \# of layers: 6

$\mathrm{Kx} \mathrm{Ky} \mathrm{Kz}$ Ss Por

$1.14905 \mathrm{e}+02$ 1.14905e+02 1.14905e+01 1.00000e-09 7.00000e-02 $1.14905 \mathrm{e}+02$ 1.14905e+02 1.14905e+01 1.00000e-09 7.00000e-02 $1.14905 \mathrm{e}+02$ 1.14905e+02 1.14905e+01 1.00000e-09 7.00000e-02 $4.59100 \mathrm{e}+004.59100 \mathrm{e}+00$ 4.59100e-01 1.00000e-09 2.12000e-01 $1.00000 \mathrm{e}-02$ 1.00000e-02 1.00000e-03 1.00000e-09 1.00000e-01 $1.00000 \mathrm{e}+001.00000 \mathrm{e}+001.00000 \mathrm{e}-011.00000 \mathrm{e}-091.00000 \mathrm{e}-01$ Element: 6078 \# of layers: 8

$\mathrm{Kx} \mathrm{Ky} \mathrm{Kz}$ Ss Por

1.14905e+02 1.14905e+02 1.14905e+01 1.00000e-09 7.00000e-02 $1.14905 \mathrm{e}+02$ 1.14905e+02 1.14905e+01 1.00000e-09 7.00000e-02 $1.14905 \mathrm{e}+021.14905 \mathrm{e}+021.14905 \mathrm{e}+01$ 1.00000e-09 7.00000e-02 5.00000e-04 5.00000e-04 5.00000e-05 1.00000e-09 1.00000e-01

$4.59100 \mathrm{e}+004.59100 \mathrm{e}+004.59100 \mathrm{e}-01$ 1.00000e-09 2.12000e-01 $4.59100 \mathrm{e}+004.59100 \mathrm{e}+00$ 4.59100e-01 1.00000e-09 2.12000e-01 $1.00000 \mathrm{e}-02$ 1.00000e-02 1.00000e-03 1.00000e-09 1.00000e-01 $1.00000 \mathrm{e}+001.00000 \mathrm{e}+001.00000 \mathrm{e}-011.00000 \mathrm{e}-091.00000 \mathrm{e}-01$ Element: 6079 \# of layers: 7

$\mathrm{Kx} \mathrm{Ky} \mathrm{Kz}$ Ss Por $1.14905 \mathrm{e}+02$ 1.14905e+02 1.14905e+01 1.00000e-09 7.00000e-02 $1.14905 \mathrm{e}+02$ 1.14905e+02 1.14905e+01 1.00000e-09 7.00000e-02 
$1.14905 \mathrm{e}+02$ 1.14905e+02 1.14905e+01 1.00000e-09 7.00000e-02 $4.59100 \mathrm{e}+004.59100 \mathrm{e}+00$ 4.59100e-01 1.00000e-09 2.12000e-01 4.59100e+00 4.59100e+00 4.59100e-01 1.00000e-09 2.12000e-01 $1.00000 \mathrm{e}-02$ 1.00000e-02 1.00000e-03 1.00000e-09 1.00000e-01 $1.00000 \mathrm{e}+001.00000 \mathrm{e}+001.00000 \mathrm{e}-01$ 1.00000e-09 1.00000e-01 Element: 6080 \# of layers: 6

$\mathrm{Kx} \mathrm{Ky} \mathrm{Kz}$ Ss Por

2.55542e+02 2.55542e+02 2.55542e+01 1.00000e-09 7.00000e-02 $2.55542 \mathrm{e}+02$ 2.55542e+02 2.55542e+01 1.00000e-09 7.00000e-02 2.55542e+02 2.55542e+02 2.55542e+01 1.00000e-09 7.00000e-02 $1.02105 \mathrm{e}+011.02105 \mathrm{e}+01$ 1.02105e+00 1.00000e-09 2.12000e-01 $1.00000 \mathrm{e}-02$ 1.00000e-02 1.00000e-03 1.00000e-09 1.00000e-01 $1.00000 \mathrm{e}+001.00000 \mathrm{e}+001.00000 \mathrm{e}-011.00000 \mathrm{e}-091.00000 \mathrm{e}-01$ Element: 6081 \# of layers: 7

$\mathrm{Kx} \mathrm{Ky} \mathrm{Kz}$ Ss Por

2.55542e+02 2.55542e+02 2.55542e+01 1.00000e-09 7.00000e-02 $2.55542 \mathrm{e}+02$ 2.55542e+02 2.55542e+01 1.00000e-09 7.00000e-02 $2.55542 \mathrm{e}+02$ 2.55542e+02 2.55542e+01 1.00000e-09 7.00000e-02 $1.02105 \mathrm{e}+01$ 1.02105e+01 1.02105e+00 1.00000e-09 2.12000e-01 $1.02105 \mathrm{e}+011.02105 \mathrm{e}+011.02105 \mathrm{e}+001.00000 \mathrm{e}-092.12000 \mathrm{e}-01$ $1.00000 \mathrm{e}-02$ 1.00000e-02 1.00000e-03 1.00000e-09 1.00000e-01 $1.00000 \mathrm{e}+001.00000 \mathrm{e}+001.00000 \mathrm{e}-011.00000 \mathrm{e}-091.00000 \mathrm{e}-01$ Element: 6082 \# of layers: 6

$\mathrm{Kx} \mathrm{Ky} \mathrm{Kz}$ Ss Por

$2.55542 \mathrm{e}+02$ 2.55542e+02 2.55542e+01 1.00000e-09 7.00000e-02

$2.55542 \mathrm{e}+02$ 2.55542e+02 2.55542e+01 1.00000e-09 7.00000e-02

$2.55542 \mathrm{e}+02$ 2.55542e+02 2.55542e+01 1.00000e-09 7.00000e-02

$1.02105 \mathrm{e}+01$ 1.02105e+01 1.02105e+00 1.00000e-09 2.12000e-01 $1.00000 \mathrm{e}-02$ 1.00000e-02 1.00000e-03 1.00000e-09 1.00000e-01 $1.00000 \mathrm{e}+001.00000 \mathrm{e}+001.00000 \mathrm{e}-011.00000 \mathrm{e}-091.00000 \mathrm{e}-01$ Element: 6083 \# of layers: 5

$\mathrm{Kx} \mathrm{Ky} \mathrm{Kz}$ Ss Por

2.55542e+02 2.55542e+02 2.55542e+01 1.00000e-09 7.00000e-02

$2.55542 \mathrm{e}+02$ 2.55542e+02 2.55542e+01 1.00000e-09 7.00000e-02 $1.02105 \mathrm{e}+011.02105 \mathrm{e}+01 \quad 1.02105 \mathrm{e}+001.00000 \mathrm{e}-092.12000 \mathrm{e}-01$ $1.00000 \mathrm{e}-02$ 1.00000e-02 1.00000e-03 1.00000e-09 1.00000e-01 $1.00000 \mathrm{e}+001.00000 \mathrm{e}+001.00000 \mathrm{e}-011.00000 \mathrm{e}-091.00000 \mathrm{e}-01$ Element: 6084 \# of layers: 5

$\mathrm{Kx} \mathrm{Ky} \mathrm{Kz}$ Ss Por

2.55542e+02 2.55542e+02 2.55542e+01 1.00000e-09 7.00000e-02 $2.55542 \mathrm{e}+02$ 2.55542e+02 2.55542e+01 1.00000e-09 7.00000e-02 $1.02105 \mathrm{e}+01$ 1.02105e+01 1.02105e+00 1.00000e-09 2.12000e-01 $1.00000 \mathrm{e}-02$ 1.00000e-02 1.00000e-03 1.00000e-09 1.00000e-01 $1.00000 \mathrm{e}+001.00000 \mathrm{e}+001.00000 \mathrm{e}-01$ 1.00000e-09 1.00000e-01 Element: 6085 \# of layers: 5

Kx Ky Kz Ss Por 
$2.55542 \mathrm{e}+022.55542 \mathrm{e}+022.55542 \mathrm{e}+01$ 1.00000e-09 7.00000e-02 $2.55542 \mathrm{e}+022.55542 \mathrm{e}+022.55542 \mathrm{e}+011.00000 \mathrm{e}-097.00000 \mathrm{e}-02$ $1.02105 \mathrm{e}+011.02105 \mathrm{e}+011.02105 \mathrm{e}+001.00000 \mathrm{e}-092.12000 \mathrm{e}-01$ $1.00000 \mathrm{e}-021.00000 \mathrm{e}-02$ 1.00000e-03 1.00000e-09 1.00000e-01 $1.00000 \mathrm{e}+001.00000 \mathrm{e}+001.00000 \mathrm{e}-011.00000 \mathrm{e}-091.00000 \mathrm{e}-01$ Element: 6086 \# of layers: 5

Kx Ky Kz Ss Por

$2.55542 \mathrm{e}+022.55542 \mathrm{e}+022.55542 \mathrm{e}+01$ 1.00000e-09 7.00000e-02

$2.55542 \mathrm{e}+022.55542 \mathrm{e}+022.55542 \mathrm{e}+011.00000 \mathrm{e}-097.00000 \mathrm{e}-02$ $1.02105 \mathrm{e}+011.02105 \mathrm{e}+011.02105 \mathrm{e}+001.00000 \mathrm{e}-092.12000 \mathrm{e}-01$ $1.00000 \mathrm{e}-021.00000 \mathrm{e}-02$ 1.00000e-03 1.00000e-09 1.00000e-01 $1.00000 \mathrm{e}+001.00000 \mathrm{e}+00$ 1.00000e-01 1.00000e-09 1.00000e-01 Element: 6087 \# of layers: 5

Kx Ky Kz Ss Por

$2.55542 \mathrm{e}+022.55542 \mathrm{e}+022.55542 \mathrm{e}+01$ 1.00000e-09 7.00000e-02 $2.55542 \mathrm{e}+022.55542 \mathrm{e}+022.55542 \mathrm{e}+01$ 1.00000e-09 7.00000e-02 $1.02105 \mathrm{e}+011.02105 \mathrm{e}+011.02105 \mathrm{e}+001.00000 \mathrm{e}-092.12000 \mathrm{e}-01$ $1.00000 \mathrm{e}-02$ 1.00000e-02 1.00000e-03 1.00000e-09 1.00000e-01 $1.00000 \mathrm{e}+001.00000 \mathrm{e}+001.00000 \mathrm{e}-011.00000 \mathrm{e}-091.00000 \mathrm{e}-01$ Element: 6088 \# of layers: 5

Kx Ky Kz Ss Por

$2.55542 \mathrm{e}+022.55542 \mathrm{e}+022.55542 \mathrm{e}+01$ 1.00000e-09 7.00000e-02 $2.55542 \mathrm{e}+022.55542 \mathrm{e}+022.55542 \mathrm{e}+011.00000 \mathrm{e}-097.00000 \mathrm{e}-02$ $1.02105 \mathrm{e}+011.02105 \mathrm{e}+011.02105 \mathrm{e}+001.00000 \mathrm{e}-092.12000 \mathrm{e}-01$ $1.00000 \mathrm{e}-021.00000 \mathrm{e}-02$ 1.00000e-03 1.00000e-09 1.00000e-01 $1.00000 \mathrm{e}+001.00000 \mathrm{e}+001.00000 \mathrm{e}-011.00000 \mathrm{e}-091.00000 \mathrm{e}-01$ Element: 6089 \# of layers: 8

Kx Ky Kz Ss Por

$3.04105 \mathrm{e}+023.04105 \mathrm{e}+023.04106 \mathrm{e}+01$ 1.00000e-09 7.00000e-02 $3.04105 \mathrm{e}+023.04105 \mathrm{e}+023.04106 \mathrm{e}+011.00000 \mathrm{e}-097.00000 \mathrm{e}-02$ $3.04105 \mathrm{e}+023.04105 \mathrm{e}+023.04106 \mathrm{e}+011.00000 \mathrm{e}-09$ 7.00000e-02 $3.04105 \mathrm{e}+023.04105 \mathrm{e}+023.04106 \mathrm{e}+011.00000 \mathrm{e}-09$ 7.00000e-02 $1.21512 \mathrm{e}+011.21512 \mathrm{e}+011.21512 \mathrm{e}+001.00000 \mathrm{e}-092.12000 \mathrm{e}-01$ $1.21512 \mathrm{e}+011.21512 \mathrm{e}+011.21512 \mathrm{e}+00$ 1.00000e-09 2.12000e-01 $1.00000 \mathrm{e}-021.00000 \mathrm{e}-02$ 1.00000e-03 1.00000e-09 1.00000e-01 $1.00000 \mathrm{e}+001.00000 \mathrm{e}+001.00000 \mathrm{e}-011.00000 \mathrm{e}-091.00000 \mathrm{e}-01$ Element: 6090 \# of layers: 7

Kx Ky Kz Ss Por

$3.04105 \mathrm{e}+023.04105 \mathrm{e}+023.04106 \mathrm{e}+01$ 1.00000e-09 7.00000e-02 $3.04105 \mathrm{e}+023.04105 \mathrm{e}+023.04106 \mathrm{e}+01$ 1.00000e-09 7.00000e-02 $3.04105 \mathrm{e}+023.04105 \mathrm{e}+023.04106 \mathrm{e}+01$ 1.00000e-09 7.00000e-02 $1.21512 \mathrm{e}+011.21512 \mathrm{e}+011.21512 \mathrm{e}+001.00000 \mathrm{e}-092.12000 \mathrm{e}-01$ $1.21512 \mathrm{e}+011.21512 \mathrm{e}+011.21512 \mathrm{e}+00$ 1.00000e-09 2.12000e-01 $1.00000 \mathrm{e}-02$ 1.00000e-02 1.00000e-03 1.00000e-09 1.00000e-01 $1.00000 \mathrm{e}+001.00000 \mathrm{e}+00$ 1.00000e-01 1.00000e-09 1.00000e-01 Element: 6091 \# of layers: 7 
$\mathrm{Kx} \mathrm{Ky} \mathrm{Kz}$ Ss Por

3.04105e+02 3.04105e+02 3.04106e+01 1.00000e-09 7.00000e-02

$3.04105 \mathrm{e}+02$ 3.04105e+02 3.04106e+01 1.00000e-09 7.00000e-02

$3.04105 \mathrm{e}+02$ 3.04105e+02 3.04106e+01 1.00000e-09 7.00000e-02

$1.21512 \mathrm{e}+011.21512 \mathrm{e}+011.21512 \mathrm{e}+001.00000 \mathrm{e}-092.12000 \mathrm{e}-01$

$1.21512 \mathrm{e}+011.21512 \mathrm{e}+011.21512 \mathrm{e}+001.00000 \mathrm{e}-092.12000 \mathrm{e}-01$

$1.00000 \mathrm{e}-02$ 1.00000e-02 1.00000e-03 1.00000e-09 1.00000e-01

$1.00000 \mathrm{e}+001.00000 \mathrm{e}+001.00000 \mathrm{e}-01$ 1.00000e-09 1.00000e-01

Element: 6092 \# of layers: 6

$\mathrm{Kx} \mathrm{Ky} \mathrm{Kz}$ Ss Por

3.04105e+02 3.04105e+02 3.04106e+01 1.00000e-09 7.00000e-02

$3.04105 \mathrm{e}+023.04105 \mathrm{e}+023.04106 \mathrm{e}+01$ 1.00000e-09 7.00000e-02

3.04105e+02 3.04105e+02 3.04106e+01 1.00000e-09 7.00000e-02

$1.21512 \mathrm{e}+011.21512 \mathrm{e}+011.21512 \mathrm{e}+001.00000 \mathrm{e}-092.12000 \mathrm{e}-01$

$1.00000 \mathrm{e}-02$ 1.00000e-02 1.00000e-03 1.00000e-09 1.00000e-01

$1.00000 \mathrm{e}+001.00000 \mathrm{e}+001.00000 \mathrm{e}-011.00000 \mathrm{e}-091.00000 \mathrm{e}-01$

Element: 6093 \# of layers: 5

$\mathrm{Kx} \mathrm{Ky} \mathrm{Kz}$ Ss Por

3.04105e+02 3.04105e+02 3.04106e+01 1.00000e-09 7.00000e-02

$3.04105 \mathrm{e}+023.04105 \mathrm{e}+023.04106 \mathrm{e}+01$ 1.00000e-09 7.00000e-02

$3.04105 \mathrm{e}+02$ 3.04105e+02 3.04106e+01 1.00000e-09 7.00000e-02

$1.00000 \mathrm{e}-02$ 1.00000e-02 1.00000e-03 1.00000e-09 1.00000e-01

$1.00000 \mathrm{e}+001.00000 \mathrm{e}+001.00000 \mathrm{e}-01$ 1.00000e-09 1.00000e-01

Element: 6094 \# of layers: 4

$\mathrm{Kx} \mathrm{Ky} \mathrm{Kz}$ Ss Por

3.04105e+02 3.04105e+02 3.04106e+01 1.00000e-09 7.00000e-02

$3.04105 \mathrm{e}+023.04105 \mathrm{e}+02$ 3.04106e+01 1.00000e-09 7.00000e-02

$1.00000 \mathrm{e}-02$ 1.00000e-02 1.00000e-03 1.00000e-09 1.00000e-01

$1.00000 \mathrm{e}+001.00000 \mathrm{e}+001.00000 \mathrm{e}-011.00000 \mathrm{e}-091.00000 \mathrm{e}-01$

Element: 6095 \# of layers: 4

$\mathrm{Kx} \mathrm{Ky} \mathrm{Kz}$ Ss Por

3.04105e+02 3.04105e+02 3.04106e+01 1.00000e-09 7.00000e-02

$3.04105 \mathrm{e}+02$ 3.04105e+02 3.04106e+01 1.00000e-09 7.00000e-02

$1.00000 \mathrm{e}-02$ 1.00000e-02 1.00000e-03 1.00000e-09 1.00000e-01

$1.00000 \mathrm{e}+001.00000 \mathrm{e}+001.00000 \mathrm{e}-011.00000 \mathrm{e}-091.00000 \mathrm{e}-01$

Element: 6096 \# of layers: 5

$\mathrm{Kx} \mathrm{Ky} \mathrm{Kz}$ Ss Por

3.04105e+02 3.04105e+02 3.04106e+01 1.00000e-09 7.00000e-02

$3.04105 \mathrm{e}+02$ 3.04105e+02 3.04106e+01 1.00000e-09 7.00000e-02

$1.21512 \mathrm{e}+011.21512 \mathrm{e}+011.21512 \mathrm{e}+001.00000 \mathrm{e}-092.12000 \mathrm{e}-01$

$1.00000 \mathrm{e}-02$ 1.00000e-02 1.00000e-03 1.00000e-09 1.00000e-01

$1.00000 \mathrm{e}+001.00000 \mathrm{e}+001.00000 \mathrm{e}-011.00000 \mathrm{e}-091.00000 \mathrm{e}-01$

Element: 6097 \# of layers: 5

$\mathrm{Kx} \mathrm{Ky} \mathrm{Kz}$ Ss Por

3.04105e+02 3.04105e+02 3.04106e+01 1.00000e-09 7.00000e-02

$3.04105 \mathrm{e}+02$ 3.04105e+02 3.04106e+01 1.00000e-09 7.00000e-02 
$1.21512 \mathrm{e}+011.21512 \mathrm{e}+011.21512 \mathrm{e}+00$ 1.00000e-09 2.12000e-01 $1.00000 \mathrm{e}-021.00000 \mathrm{e}-02$ 1.00000e-03 1.00000e-09 1.00000e-01 $1.00000 \mathrm{e}+001.00000 \mathrm{e}+001.00000 \mathrm{e}-011.00000 \mathrm{e}-091.00000 \mathrm{e}-01$ Element: 6098 \# of layers: 7

Kx Ky Kz Ss Por

$4.72529 \mathrm{e}+02$ 4.72529e $+024.72529 \mathrm{e}+01$ 1.00000e-09 7.00000e-02 $4.72529 \mathrm{e}+02 \quad 4.72529 \mathrm{e}+024.72529 \mathrm{e}+01$ 1.00000e-09 7.00000e-02 $4.72529 \mathrm{e}+024.72529 \mathrm{e}+024.72529 \mathrm{e}+01$ 1.00000e-09 7.00000e-02 $1.88804 \mathrm{e}+011.88804 \mathrm{e}+011.88804 \mathrm{e}+001.00000 \mathrm{e}-092.12000 \mathrm{e}-01$ $1.88804 \mathrm{e}+011.88804 \mathrm{e}+011.88804 \mathrm{e}+001.00000 \mathrm{e}-092.12000 \mathrm{e}-01$ $1.00000 \mathrm{e}-021.00000 \mathrm{e}-02$ 1.00000e-03 1.00000e-09 1.00000e-01 $1.00000 \mathrm{e}+001.00000 \mathrm{e}+001.00000 \mathrm{e}-011.00000 \mathrm{e}-091.00000 \mathrm{e}-01$ Element: 6099 \# of layers: 6

Kx Ky Kz Ss Por

$4.72529 \mathrm{e}+02$ 4.72529e+02 4.72529e+01 1.00000e-09 7.00000e-02 $4.72529 \mathrm{e}+024.72529 \mathrm{e}+024.72529 \mathrm{e}+01$ 1.00000e-09 7.00000e-02 $4.72529 \mathrm{e}+024.72529 \mathrm{e}+024.72529 \mathrm{e}+01$ 1.00000e-09 7.00000e-02 $1.88804 \mathrm{e}+011.88804 \mathrm{e}+011.88804 \mathrm{e}+001.00000 \mathrm{e}-092.12000 \mathrm{e}-01$ $1.00000 \mathrm{e}-02$ 1.00000e-02 1.00000e-03 1.00000e-09 1.00000e-01 $1.00000 \mathrm{e}+001.00000 \mathrm{e}+001.00000 \mathrm{e}-011.00000 \mathrm{e}-091.00000 \mathrm{e}-01$ Element: 6100 \# of layers: 4

Kx Ky Kz Ss Por

$4.72529 \mathrm{e}+02$ 4.72529e $+024.72529 \mathrm{e}+01$ 1.00000e-09 7.00000e-02 $4.72529 \mathrm{e}+024.72529 \mathrm{e}+024.72529 \mathrm{e}+01$ 1.00000e-09 7.00000e-02 $1.00000 \mathrm{e}-021.00000 \mathrm{e}-02$ 1.00000e-03 1.00000e-09 1.00000e-01 $1.00000 \mathrm{e}+001.00000 \mathrm{e}+001.00000 \mathrm{e}-011.00000 \mathrm{e}-091.00000 \mathrm{e}-01$

Element: 6101 \# of layers: 7

Kx Ky Kz Ss Por

$7.51245 \mathrm{e}+027.51245 \mathrm{e}+027.51245 \mathrm{e}+01$ 1.00000e-09 7.00000e-02 $7.51245 \mathrm{e}+027.51245 \mathrm{e}+027.51245 \mathrm{e}+011.00000 \mathrm{e}-097.00000 \mathrm{e}-02$ $7.51245 \mathrm{e}+02$ 7.51245e+02 7.51245e+01 1.00000e-09 7.00000e-02 $7.51245 \mathrm{e}+027.51245 \mathrm{e}+027.51245 \mathrm{e}+011.00000 \mathrm{e}-097.00000 \mathrm{e}-02$ $7.51245 \mathrm{e}+027.51245 \mathrm{e}+027.51245 \mathrm{e}+01$ 1.00000e-09 7.00000e-02 $3.00179 \mathrm{e}+013.00179 \mathrm{e}+013.00179 \mathrm{e}+001.00000 \mathrm{e}-092.12000 \mathrm{e}-01$ $1.00000 \mathrm{e}-02$ 1.00000e-02 1.00000e-03 1.00000e-09 1.00000e-01

Element: 6102 \# of layers: 6

Kx Ky Kz Ss Por

$7.51245 \mathrm{e}+02$ 7.51245e+02 7.51245e+01 1.00000e-09 7.00000e-02 $7.51245 \mathrm{e}+02$ 7.51245e+02 7.51245e+01 1.00000e-09 7.00000e-02 $7.51245 \mathrm{e}+02$ 7.51245e+02 7.51245e+01 1.00000e-09 7.00000e-02 $7.51245 \mathrm{e}+027.51245 \mathrm{e}+027.51245 \mathrm{e}+01$ 1.00000e-09 7.00000e-02 $3.00179 \mathrm{e}+013.00179 \mathrm{e}+013.00179 \mathrm{e}+001.00000 \mathrm{e}-092.12000 \mathrm{e}-01$ $1.00000 \mathrm{e}-02$ 1.00000e-02 1.00000e-03 1.00000e-09 1.00000e-01

Element: 6103 \# of layers: 6

Kx Ky Kz Ss Por

7.51245e+02 7.51245e+02 7.51245e+01 1.00000e-09 7.00000e-02 
$7.51245 \mathrm{e}+027.51245 \mathrm{e}+02$ 7.51245e+01 1.00000e-09 7.00000e-02 $7.51245 \mathrm{e}+027.51245 \mathrm{e}+027.51245 \mathrm{e}+011.00000 \mathrm{e}-097.00000 \mathrm{e}-02$ $7.51245 \mathrm{e}+027.51245 \mathrm{e}+027.51245 \mathrm{e}+01$ 1.00000e-09 7.00000e-02 $3.00179 \mathrm{e}+013.00179 \mathrm{e}+013.00179 \mathrm{e}+001.00000 \mathrm{e}-092.12000 \mathrm{e}-01$ $1.00000 \mathrm{e}-02$ 1.00000e-02 1.00000e-03 1.00000e-09 1.00000e-01

Element: 6104 \# of layers: 6

Kx Ky Kz Ss Por

$7.51245 \mathrm{e}+02$ 7.51245e+02 7.51245e+01 1.00000e-09 7.00000e-02 $7.51245 \mathrm{e}+027.51245 \mathrm{e}+027.51245 \mathrm{e}+011.00000 \mathrm{e}-097.00000 \mathrm{e}-02$ $7.51245 \mathrm{e}+02$ 7.51245e+02 7.51245e+01 1.00000e-09 7.00000e-02 $7.51245 \mathrm{e}+027.51245 \mathrm{e}+02$ 7.51245e+01 1.00000e-09 7.00000e-02 $3.00179 \mathrm{e}+013.00179 \mathrm{e}+013.00179 \mathrm{e}+001.00000 \mathrm{e}-092.12000 \mathrm{e}-01$ $1.00000 \mathrm{e}-02$ 1.00000e-02 1.00000e-03 1.00000e-09 1.00000e-01

Element: 6105 \# of layers: 7

Kx Ky Kz Ss Por

$7.51245 \mathrm{e}+02$ 7.51245e+02 7.51245e+01 1.00000e-09 7.00000e-02 $7.51245 \mathrm{e}+02$ 7.51245e+02 7.51245e+01 1.00000e-09 7.00000e-02 $7.51245 \mathrm{e}+02$ 7.51245e+02 7.51245e+01 1.00000e-09 7.00000e-02 $7.51245 \mathrm{e}+027.51245 \mathrm{e}+02$ 7.51245e+01 1.00000e-09 7.00000e-02 $3.00179 \mathrm{e}+013.00179 \mathrm{e}+013.00179 \mathrm{e}+00$ 1.00000e-09 2.12000e-01 $1.00000 \mathrm{e}-02$ 1.00000e-02 1.00000e-03 1.00000e-09 1.00000e-01 $1.00000 \mathrm{e}+001.00000 \mathrm{e}+001.00000 \mathrm{e}-011.00000 \mathrm{e}-091.00000 \mathrm{e}-01$ Element: 6106 \# of layers: 6

Kx Ky Kz Ss Por

$7.51245 \mathrm{e}+02$ 7.51245e+02 7.51245e+01 1.00000e-09 7.00000e-02 $7.51245 \mathrm{e}+027.51245 \mathrm{e}+027.51245 \mathrm{e}+011.00000 \mathrm{e}-097.00000 \mathrm{e}-02$ $7.51245 \mathrm{e}+02$ 7.51245e+02 7.51245e+01 1.00000e-09 7.00000e-02 $7.51245 \mathrm{e}+027.51245 \mathrm{e}+02$ 7.51245e+01 1.00000e-09 7.00000e-02 $3.00179 \mathrm{e}+013.00179 \mathrm{e}+013.00179 \mathrm{e}+001.00000 \mathrm{e}-092.12000 \mathrm{e}-01$ $1.00000 \mathrm{e}-02$ 1.00000e-02 1.00000e-03 1.00000e-09 1.00000e-01

Element: 6107 \# of layers: 5

Kx Ky Kz Ss Por

$7.51245 \mathrm{e}+02$ 7.51245e+02 7.51245e+01 1.00000e-09 7.00000e-02

$7.51245 \mathrm{e}+027.51245 \mathrm{e}+027.51245 \mathrm{e}+011.00000 \mathrm{e}-097.00000 \mathrm{e}-02$

$7.51245 \mathrm{e}+027.51245 \mathrm{e}+027.51245 \mathrm{e}+011.00000 \mathrm{e}-097.00000 \mathrm{e}-02$ $3.00179 \mathrm{e}+013.00179 \mathrm{e}+013.00179 \mathrm{e}+00$ 1.00000e-09 2.12000e-01 $1.00000 \mathrm{e}-02$ 1.00000e-02 1.00000e-03 1.00000e-09 1.00000e-01

Element: 6108 \# of layers: 5

Kx Ky Kz Ss Por

$7.51245 \mathrm{e}+02$ 7.51245e+02 7.51245e+01 1.00000e-09 7.00000e-02 $7.51245 \mathrm{e}+027.51245 \mathrm{e}+027.51245 \mathrm{e}+011.00000 \mathrm{e}-097.00000 \mathrm{e}-02$ $7.51245 \mathrm{e}+02$ 7.51245e+02 7.51245e+01 1.00000e-09 7.00000e-02 $3.00179 \mathrm{e}+013.00179 \mathrm{e}+013.00179 \mathrm{e}+00$ 1.00000e-09 2.12000e-01 $1.00000 \mathrm{e}-02$ 1.00000e-02 1.00000e-03 1.00000e-09 1.00000e-01 Element: 6109 \# of layers: 6

Kx Ky Kz Ss Por 
7.51245e+02 7.51245e+02 7.51245e+01 1.00000e-09 7.00000e-02 7.51245e+02 7.51245e+02 7.51245e+01 1.00000e-09 7.00000e-02 7.51245e+02 7.51245e+02 7.51245e+01 1.00000e-09 7.00000e-02 $7.51245 \mathrm{e}+02$ 7.51245e+02 7.51245e+01 1.00000e-09 7.00000e-02 $3.00179 \mathrm{e}+013.00179 \mathrm{e}+013.00179 \mathrm{e}+001.00000 \mathrm{e}-092.12000 \mathrm{e}-01$ 1.00000e-02 1.00000e-02 1.00000e-03 1.00000e-09 1.00000e-01

Element: 6110 \# of layers: 8

$\mathrm{Kx} \mathrm{Ky} \mathrm{Kz}$ Ss Por

6.88643e+02 6.88643e+02 6.88643e+01 1.00000e-09 7.00000e-02

$6.88643 \mathrm{e}+02$ 6.88643e+02 6.88643e+01 1.00000e-09 7.00000e-02

$6.88643 \mathrm{e}+02$ 6.88643e+02 6.88643e+01 1.00000e-09 7.00000e-02

$6.88643 \mathrm{e}+02$ 6.88643e+02 6.88643e+01 1.00000e-09 7.00000e-02

6.88643e+02 6.88643e+02 6.88643e+01 1.00000e-09 7.00000e-02

$2.75158 \mathrm{e}+012.75158 \mathrm{e}+012.75158 \mathrm{e}+00$ 1.00000e-09 2.12000e-01

$2.75158 \mathrm{e}+012.75158 \mathrm{e}+012.75158 \mathrm{e}+00$ 1.00000e-09 2.12000e-01

1.00000e-02 1.00000e-02 1.00000e-03 1.00000e-09 1.00000e-01

Element: 6111 \# of layers: 7

$\mathrm{Kx} \mathrm{Ky} \mathrm{Kz}$ Ss Por

6.98194e+02 6.98194e+02 6.98194e+01 1.00000e-09 7.00000e-02

$6.98194 \mathrm{e}+02$ 6.98194e+02 6.98194e+01 1.00000e-09 7.00000e-02

$6.98194 \mathrm{e}+026.98194 \mathrm{e}+026.98194 \mathrm{e}+01$ 1.00000e-09 7.00000e-02

6.98194e+02 6.98194e+02 6.98194e+01 1.00000e-09 7.00000e-02

$2.78983 \mathrm{e}+012.78983 \mathrm{e}+012.78984 \mathrm{e}+00$ 1.00000e-09 2.12000e-01

$1.00000 \mathrm{e}-02$ 1.00000e-02 1.00000e-03 1.00000e-09 1.00000e-01

$1.00000 \mathrm{e}-06$ 1.00000e-06 1.00000e-06 1.00000e-09 5.00000e-02

Element: 6112 \# of layers: 6

$\mathrm{Kx} \mathrm{Ky} \mathrm{Kz}$ Ss Por

6.98194e+02 6.98194e+02 6.98194e+01 1.00000e-09 7.00000e-02

$6.98194 \mathrm{e}+02$ 6.98194e+02 6.98194e+01 1.00000e-09 7.00000e-02

6.98194e+02 6.98194e+02 6.98194e+01 1.00000e-09 7.00000e-02

$2.78983 \mathrm{e}+012.78983 \mathrm{e}+012.78984 \mathrm{e}+00$ 1.00000e-09 2.12000e-01

1.00000e-02 1.00000e-02 1.00000e-03 1.00000e-09 1.00000e-01

1.00000e-06 1.00000e-06 1.00000e-06 1.00000e-09 5.00000e-02

Element: 6113 \# of layers: 7

$\mathrm{Kx} \mathrm{Ky} \mathrm{Kz}$ Ss Por

6.88643e+02 6.88643e+02 6.88643e+01 1.00000e-09 7.00000e-02

$6.88643 \mathrm{e}+026.88643 \mathrm{e}+02$ 6.88643e+01 1.00000e-09 7.00000e-02

$6.88643 \mathrm{e}+026.88643 \mathrm{e}+02$ 6.88643e+01 1.00000e-09 7.00000e-02

6.88643e+02 6.88643e+02 6.88643e+01 1.00000e-09 7.00000e-02

$2.75158 \mathrm{e}+012.75158 \mathrm{e}+012.75158 \mathrm{e}+00$ 1.00000e-09 2.12000e-01

1.00000e-02 1.00000e-02 1.00000e-03 1.00000e-09 1.00000e-01

$1.00000 \mathrm{e}-06$ 1.00000e-06 1.00000e-06 1.00000e-09 5.00000e-02

Element: 6114 \# of layers: 8

$\mathrm{Kx} \mathrm{Ky} \mathrm{Kz}$ Ss Por

7.32648e+02 7.32648e+02 7.32648e+01 1.00000e-09 7.00000e-02

$7.32648 \mathrm{e}+02$ 7.32648e+02 7.32648e+01 1.00000e-09 7.00000e-02 
7.32648e+02 7.32648e+02 7.32648e+01 1.00000e-09 7.00000e-02 7.32648e+02 7.32648e+02 7.32648e+01 1.00000e-09 7.00000e-02 $2.92731 \mathrm{e}+012.92731 \mathrm{e}+012.92731 \mathrm{e}+001.00000 \mathrm{e}-092.12000 \mathrm{e}-01$ $1.00000 \mathrm{e}-02$ 1.00000e-02 1.00000e-03 1.00000e-09 1.00000e-01 $1.00000 \mathrm{e}+001.00000 \mathrm{e}+001.00000 \mathrm{e}-011.00000 \mathrm{e}-091.00000 \mathrm{e}-01$ 1.00000e-06 1.00000e-06 1.00000e-06 1.00000e-09 5.00000e-02 Element: 6115 \# of layers: 8

$\mathrm{Kx} \mathrm{Ky} \mathrm{Kz}$ Ss Por

7.32648e+02 7.32648e+02 7.32648e+01 1.00000e-09 7.00000e-02 7.32648e+02 7.32648e+02 7.32648e+01 1.00000e-09 7.00000e-02 7.32648e+02 7.32648e+02 7.32648e+01 1.00000e-09 7.00000e-02 $7.32648 \mathrm{e}+02$ 7.32648e+02 7.32648e+01 1.00000e-09 7.00000e-02 $2.92731 \mathrm{e}+012.92731 \mathrm{e}+012.92731 \mathrm{e}+001.00000 \mathrm{e}-092.12000 \mathrm{e}-01$ $1.00000 \mathrm{e}-02$ 1.00000e-02 1.00000e-03 1.00000e-09 1.00000e-01 $1.00000 \mathrm{e}+001.00000 \mathrm{e}+001.00000 \mathrm{e}-011.00000 \mathrm{e}-091.00000 \mathrm{e}-01$ 1.00000e-06 1.00000e-06 1.00000e-06 1.00000e-09 5.00000e-02 Element: 6116 \# of layers: 10

$\mathrm{Kx} \mathrm{Ky} \mathrm{Kz}$ Ss Por

6.88643e+02 6.88643e+02 6.88643e+01 1.00000e-09 7.00000e-02 $6.88643 \mathrm{e}+02$ 6.88643e+02 6.88643e+01 1.00000e-09 7.00000e-02 $6.88643 \mathrm{e}+02$ 6.88643e+02 6.88643e+01 1.00000e-09 7.00000e-02 6.88643e+02 6.88643e+02 6.88643e+01 1.00000e-09 7.00000e-02 6.88643e+02 6.88643e+02 6.88643e+01 1.00000e-09 7.00000e-02 $2.75158 \mathrm{e}+012.75158 \mathrm{e}+012.75158 \mathrm{e}+00$ 1.00000e-09 2.12000e-01 $2.75158 \mathrm{e}+012.75158 \mathrm{e}+012.75158 \mathrm{e}+001.00000 \mathrm{e}-092.12000 \mathrm{e}-01$ $1.00000 \mathrm{e}-02$ 1.00000e-02 1.00000e-03 1.00000e-09 1.00000e-01 $1.00000 \mathrm{e}+001.00000 \mathrm{e}+001.00000 \mathrm{e}-011.00000 \mathrm{e}-091.00000 \mathrm{e}-01$ 1.00000e-06 1.00000e-06 1.00000e-06 1.00000e-09 5.00000e-02 Element: 6117 \# of layers: 8

$\mathrm{Kx} \mathrm{Ky} \mathrm{Kz}$ Ss Por 6.88643e+02 6.88643e+02 6.88643e+01 1.00000e-09 7.00000e-02 $6.88643 \mathrm{e}+02$ 6.88643e+02 6.88643e+01 1.00000e-09 7.00000e-02 $6.88643 \mathrm{e}+026.88643 \mathrm{e}+02$ 6.88643e+01 1.00000e-09 7.00000e-02 6.88643e+02 6.88643e+02 6.88643e+01 1.00000e-09 7.00000e-02 6.88643e+02 6.88643e+02 6.88643e+01 1.00000e-09 7.00000e-02 $2.75158 \mathrm{e}+012.75158 \mathrm{e}+012.75158 \mathrm{e}+00$ 1.00000e-09 2.12000e-01 $2.75158 \mathrm{e}+012.75158 \mathrm{e}+012.75158 \mathrm{e}+001.00000 \mathrm{e}-092.12000 \mathrm{e}-01$ 1.00000e-02 1.00000e-02 1.00000e-03 1.00000e-09 1.00000e-01 Element: 6118 \# of layers: 7

$\mathrm{Kx} \mathrm{Ky} \mathrm{Kz}$ Ss Por 6.88643e+02 6.88643e+02 6.88643e+01 1.00000e-09 7.00000e-02 $6.88643 \mathrm{e}+02$ 6.88643e+02 6.88643e+01 1.00000e-09 7.00000e-02 6.88643e+02 6.88643e+02 6.88643e+01 1.00000e-09 7.00000e-02 6.88643e+02 6.88643e+02 6.88643e+01 1.00000e-09 7.00000e-02 $2.75158 \mathrm{e}+012.75158 \mathrm{e}+012.75158 \mathrm{e}+001.00000 \mathrm{e}-092.12000 \mathrm{e}-01$ $1.00000 \mathrm{e}-02$ 1.00000e-02 1.00000e-03 1.00000e-09 1.00000e-01 
1.00000e-06 1.00000e-06 1.00000e-06 1.00000e-09 5.00000e-02

Element: 6119 \# of layers: 6

Kx Ky Kz Ss Por

8.41453e+02 8.41453e+02 8.41453e+01 1.00000e-09 7.00000e-02

8.41453e+02 8.41453e+02 8.41453e+01 1.00000e-09 7.00000e-02

8.41453e+02 8.41453e+02 8.41453e+01 1.00000e-09 7.00000e-02

$3.36225 \mathrm{e}+013.36225 \mathrm{e}+013.36225 \mathrm{e}+00$ 1.00000e-09 2.12000e-01

$1.00000 \mathrm{e}-02$ 1.00000e-02 1.00000e-03 1.00000e-09 1.00000e-01

$1.00000 \mathrm{e}-06$ 1.00000e-06 1.00000e-06 1.00000e-09 5.00000e-02

Element: 6120 \# of layers: 6

$\mathrm{Kx} \mathrm{Ky} \mathrm{Kz}$ Ss Por

$2.22439 \mathrm{e}+03$ 2.22439e+03 2.22439e+02 1.00000e-09 7.00000e-02

$2.22439 \mathrm{e}+03$ 2.22439e+03 2.22439e+02 1.00000e-09 7.00000e-02

$2.22439 \mathrm{e}+03$ 2.22439e+03 2.22439e+02 1.00000e-09 7.00000e-02

$8.88769 \mathrm{e}+018.88769 \mathrm{e}+018.88769 \mathrm{e}+00$ 1.00000e-09 2.12000e-01

$1.00000 \mathrm{e}-02$ 1.00000e-02 1.00000e-03 1.00000e-09 1.00000e-01

1.00000e-06 1.00000e-06 1.00000e-06 1.00000e-09 5.00000e-02

Element: 6121 \# of layers: 6

$\mathrm{Kx} \mathrm{Ky} \mathrm{Kz}$ Ss Por

2.22439e+03 2.22439e+03 2.22439e+02 1.00000e-09 7.00000e-02

$2.22439 \mathrm{e}+032.22439 \mathrm{e}+03$ 2.22439e+02 1.00000e-09 7.00000e-02

$2.22439 \mathrm{e}+03$ 2.22439e+03 2.22439e+02 1.00000e-09 7.00000e-02

$8.88769 \mathrm{e}+018.88769 \mathrm{e}+018.88769 \mathrm{e}+00$ 1.00000e-09 2.12000e-01

$1.00000 \mathrm{e}-02$ 1.00000e-02 1.00000e-03 1.00000e-09 1.00000e-01

1.00000e-06 1.00000e-06 1.00000e-06 1.00000e-09 5.00000e-02

Element: 6122 \# of layers: 6

$\mathrm{Kx} \mathrm{Ky} \mathrm{Kz}$ Ss Por

3.37271e+03 3.37271e+03 3.37271e+02 1.00000e-09 7.00000e-02

$3.37271 \mathrm{e}+033.37271 \mathrm{e}+03$ 3.37271e+02 1.00000e-09 7.00000e-02

3.37271e+03 3.37271e+03 3.37271e+02 1.00000e-09 7.00000e-02

$1.34762 \mathrm{e}+02 \quad 1.34762 \mathrm{e}+02 \quad 1.34762 \mathrm{e}+01$ 1.00000e-09 2.12000e-01

$1.00000 \mathrm{e}-02$ 1.00000e-02 1.00000e-03 1.00000e-09 1.00000e-01

1.00000e-06 1.00000e-06 1.00000e-06 1.00000e-09 5.00000e-02

Element: 6123 \# of layers: 7

$\mathrm{Kx} \mathrm{Ky} \mathrm{Kz}$ Ss Por

3.37271e+03 3.37271e+03 3.37271e+02 1.00000e-09 7.00000e-02

3.37271e+03 3.37271e+03 3.37271e+02 1.00000e-09 7.00000e-02

3.37271e+03 3.37271e+03 3.37271e+02 1.00000e-09 7.00000e-02

$1.34762 \mathrm{e}+02$ 1.34762e+02 1.34762e+01 1.00000e-09 2.12000e-01

$1.00000 \mathrm{e}-02$ 1.00000e-02 1.00000e-03 1.00000e-09 1.00000e-01

$1.00000 \mathrm{e}+001.00000 \mathrm{e}+001.00000 \mathrm{e}-011.00000 \mathrm{e}-091.00000 \mathrm{e}-01$

1.00000e-06 1.00000e-06 1.00000e-06 1.00000e-09 5.00000e-02

Element: 6124 \# of layers: 7

$\mathrm{Kx} \mathrm{Ky} \mathrm{Kz}$ Ss Por

3.37271e+03 3.37271e+03 3.37271e+02 1.00000e-09 7.00000e-02

$3.37271 \mathrm{e}+033.37271 \mathrm{e}+033.37271 \mathrm{e}+02$ 1.00000e-09 7.00000e-02 
3.37271e+03 3.37271e+03 3.37271e+02 1.00000e-09 7.00000e-02 $1.34762 \mathrm{e}+02$ 1.34762e+02 1.34762e+01 1.00000e-09 2.12000e-01 $1.00000 \mathrm{e}-02$ 1.00000e-02 1.00000e-03 1.00000e-09 1.00000e-01

$1.00000 \mathrm{e}+001.00000 \mathrm{e}+001.00000 \mathrm{e}-011.00000 \mathrm{e}-091.00000 \mathrm{e}-01$ 1.00000e-06 1.00000e-06 1.00000e-06 1.00000e-09 5.00000e-02

Element: 6125 \# of layers: 7

$\mathrm{Kx} \mathrm{Ky} \mathrm{Kz}$ Ss Por

$1.91291 \mathrm{e}+03$ 1.91291e+03 1.91291e+02 1.00000e-09 7.00000e-02 $1.91291 \mathrm{e}+03$ 1.91291e+03 1.91291e+02 1.00000e-09 7.00000e-02 $1.91291 \mathrm{e}+03$ 1.91291e+03 1.91291e+02 1.00000e-09 7.00000e-02 $7.64341 \mathrm{e}+017.64341 \mathrm{e}+01$ 7.64341e+00 1.00000e-09 2.12000e-01 $1.00000 \mathrm{e}-02$ 1.00000e-02 1.00000e-03 1.00000e-09 1.00000e-01 $1.00000 \mathrm{e}+001.00000 \mathrm{e}+001.00000 \mathrm{e}-011.00000 \mathrm{e}-091.00000 \mathrm{e}-01$ 1.00000e-06 1.00000e-06 1.00000e-06 1.00000e-09 5.00000e-02 Element: 6126 \# of layers: 6

Kx Ky Kz Ss Por

$1.91291 \mathrm{e}+03$ 1.91291e+03 1.91291e+02 1.00000e-09 7.00000e-02 $1.91291 \mathrm{e}+03$ 1.91291e+03 1.91291e+02 1.00000e-09 7.00000e-02 $1.91291 \mathrm{e}+03$ 1.91291e+03 1.91291e+02 1.00000e-09 7.00000e-02 $7.64341 \mathrm{e}+017.64341 \mathrm{e}+01$ 7.64341e+00 1.00000e-09 2.12000e-01 $1.00000 \mathrm{e}-02$ 1.00000e-02 1.00000e-03 1.00000e-09 1.00000e-01 1.00000e-06 1.00000e-06 1.00000e-06 1.00000e-09 5.00000e-02 Element: 6127 \# of layers: 6

$\mathrm{Kx} \mathrm{Ky} \mathrm{Kz}$ Ss Por

3.37271e+03 3.37271e+03 3.37271e+02 1.00000e-09 7.00000e-02 $3.37271 \mathrm{e}+033.37271 \mathrm{e}+03$ 3.37271e+02 1.00000e-09 7.00000e-02 3.37271e+03 3.37271e+03 3.37271e+02 1.00000e-09 7.00000e-02 $1.34762 \mathrm{e}+02$ 1.34762e+02 1.34762e+01 1.00000e-09 2.12000e-01 $1.00000 \mathrm{e}-02$ 1.00000e-02 1.00000e-03 1.00000e-09 1.00000e-01 1.00000e-06 1.00000e-06 1.00000e-06 1.00000e-09 5.00000e-02 Element: 6128 \# of layers: 6

$\mathrm{Kx} \mathrm{Ky} \mathrm{Kz}$ Ss Por

2.95762e+03 2.95762e+03 2.95762e+02 1.00000e-09 7.00000e-02 $2.95762 \mathrm{e}+03$ 2.95762e+03 2.95762e+02 1.00000e-09 7.00000e-02 2.95762e+03 2.95762e+03 2.95762e+02 1.00000e-09 7.00000e-02 $1.18175 \mathrm{e}+02$ 1.18175e+02 1.18175e+01 1.00000e-09 2.12000e-01 $1.00000 \mathrm{e}-02$ 1.00000e-02 1.00000e-03 1.00000e-09 1.00000e-01 1.00000e-06 1.00000e-06 1.00000e-06 1.00000e-09 5.00000e-02 Element: 6129 \# of layers: 7

$\mathrm{Kx} \mathrm{Ky} \mathrm{Kz}$ Ss Por

3.14188e+03 3.14188e+03 3.14188e+02 1.00000e-09 7.00000e-02 $3.14188 \mathrm{e}+03$ 3.14188e+03 3.14188e+02 1.00000e-09 7.00000e-02 $3.14188 \mathrm{e}+03$ 3.14188e+03 3.14188e+02 1.00000e-09 7.00000e-02 $3.14188 \mathrm{e}+03$ 3.14188e+03 3.14188e+02 1.00000e-09 7.00000e-02 $1.25539 \mathrm{e}+021.25539 \mathrm{e}+021.25539 \mathrm{e}+01$ 1.00000e-09 2.12000e-01 $1.00000 \mathrm{e}-02$ 1.00000e-02 1.00000e-03 1.00000e-09 1.00000e-01 
1.00000e-06 1.00000e-06 1.00000e-06 1.00000e-09 5.00000e-02

Element: 6130 \# of layers: 6

$\mathrm{Kx} \mathrm{Ky} \mathrm{Kz}$ Ss Por

3.14188e+03 3.14188e+03 3.14188e+02 1.00000e-09 7.00000e-02

$3.14188 \mathrm{e}+03$ 3.14188e+03 3.14188e+02 1.00000e-09 7.00000e-02

$3.14188 \mathrm{e}+03$ 3.14188e+03 3.14188e+02 1.00000e-09 7.00000e-02

3.14188e+03 3.14188e+03 3.14188e+02 1.00000e-09 7.00000e-02

$1.25539 \mathrm{e}+02$ 1.25539e+02 1.25539e+01 1.00000e-09 2.12000e-01

1.00000e-06 1.00000e-06 1.00000e-06 1.00000e-09 5.00000e-02

Element: 6131 \# of layers: 6

$\mathrm{Kx} \mathrm{Ky} \mathrm{Kz}$ Ss Por

3.14188e+03 3.14188e+03 3.14188e+02 1.00000e-09 7.00000e-02

$3.14188 \mathrm{e}+03$ 3.14188e+03 3.14188e+02 1.00000e-09 7.00000e-02

$3.14188 \mathrm{e}+03$ 3.14188e+03 3.14188e+02 1.00000e-09 7.00000e-02

$1.25539 \mathrm{e}+021.25539 \mathrm{e}+02$ 1.25539e+01 1.00000e-09 2.12000e-01

$1.00000 \mathrm{e}-02$ 1.00000e-02 1.00000e-03 1.00000e-09 1.00000e-01

1.00000e-06 1.00000e-06 1.00000e-06 1.00000e-09 5.00000e-02

Element: 6132 \# of layers: 8

$\mathrm{Kx} \mathrm{Ky} \mathrm{Kz}$ Ss Por

3.67122e+03 3.67122e+03 3.67122e+02 1.00000e-09 7.00000e-02

$3.67122 \mathrm{e}+033.67122 \mathrm{e}+033.67122 \mathrm{e}+02$ 1.00000e-09 7.00000e-02

$3.67122 \mathrm{e}+03$ 3.67122e+03 3.67122e+02 1.00000e-09 7.00000e-02

$3.67122 \mathrm{e}+033.67122 \mathrm{e}+03$ 3.67122e+02 1.00000e-09 7.00000e-02

$1.46690 \mathrm{e}+02$ 1.46690e+02 1.46690e+01 1.00000e-09 2.12000e-01

$1.00000 \mathrm{e}-02$ 1.00000e-02 1.00000e-03 1.00000e-09 1.00000e-01

$1.00000 \mathrm{e}+001.00000 \mathrm{e}+001.00000 \mathrm{e}-011.00000 \mathrm{e}-091.00000 \mathrm{e}-01$

1.00000e-06 1.00000e-06 1.00000e-06 1.00000e-09 5.00000e-02

Element: 6133 \# of layers: 8

$\mathrm{Kx} \mathrm{Ky} \mathrm{Kz}$ Ss Por

$3.67122 \mathrm{e}+03$ 3.67122e+03 3.67122e+02 1.00000e-09 7.00000e-02

$3.67122 \mathrm{e}+033.67122 \mathrm{e}+03$ 3.67122e+02 1.00000e-09 7.00000e-02

$3.67122 \mathrm{e}+033.67122 \mathrm{e}+03$ 3.67122e+02 1.00000e-09 7.00000e-02

$3.67122 \mathrm{e}+03$ 3.67122e+03 3.67122e+02 1.00000e-09 7.00000e-02

$1.46690 \mathrm{e}+02$ 1.46690e+02 1.46690e+01 1.00000e-09 2.12000e-01

$1.00000 \mathrm{e}-02$ 1.00000e-02 1.00000e-03 1.00000e-09 1.00000e-01

$1.00000 \mathrm{e}+001.00000 \mathrm{e}+001.00000 \mathrm{e}-011.00000 \mathrm{e}-091.00000 \mathrm{e}-01$

1.00000e-06 1.00000e-06 1.00000e-06 1.00000e-09 5.00000e-02

Element: 6134 \# of layers: 7

$\mathrm{Kx} \mathrm{Ky} \mathrm{Kz}$ Ss Por

3.42542e+03 3.42542e+03 3.42542e+02 1.00000e-09 7.00000e-02

$3.42542 \mathrm{e}+03$ 3.42542e+03 3.42542e+02 1.00000e-09 7.00000e-02

3.42542e+03 3.42542e+03 3.42542e+02 1.00000e-09 7.00000e-02

$1.36868 \mathrm{e}+02$ 1.36868e+02 1.36868e+01 1.00000e-09 2.12000e-01

$1.00000 \mathrm{e}-02$ 1.00000e-02 1.00000e-03 1.00000e-09 1.00000e-01

$1.00000 \mathrm{e}+001.00000 \mathrm{e}+001.00000 \mathrm{e}-011.00000 \mathrm{e}-091.00000 \mathrm{e}-01$

$1.00000 \mathrm{e}-06$ 1.00000e-06 1.00000e-06 1.00000e-09 5.00000e-02 
Element: 6135 \# of layers: 6

$\mathrm{Kx} \mathrm{Ky} \mathrm{Kz}$ Ss Por

3.42542e+03 3.42542e+03 3.42542e+02 1.00000e-09 7.00000e-02

$3.42542 \mathrm{e}+03$ 3.42542e+03 3.42542e+02 1.00000e-09 7.00000e-02

$3.42542 \mathrm{e}+033.42542 \mathrm{e}+03$ 3.42542e+02 1.00000e-09 7.00000e-02

$1.36868 \mathrm{e}+02$ 1.36868e+02 1.36868e+01 1.00000e-09 2.12000e-01

1.00000e-02 1.00000e-02 1.00000e-03 1.00000e-09 1.00000e-01

1.00000e-06 1.00000e-06 1.00000e-06 1.00000e-09 5.00000e-02

Element: 6136 \# of layers: 6

$\mathrm{Kx} \mathrm{Ky} \mathrm{Kz}$ Ss Por

3.14188e+03 3.14188e+03 3.14188e+02 1.00000e-09 7.00000e-02

$3.14188 \mathrm{e}+03$ 3.14188e+03 3.14188e+02 1.00000e-09 7.00000e-02

3.14188e+03 3.14188e+03 3.14188e+02 1.00000e-09 7.00000e-02

$1.25539 \mathrm{e}+021.25539 \mathrm{e}+02$ 1.25539e+01 1.00000e-09 2.12000e-01

$1.00000 \mathrm{e}-02$ 1.00000e-02 1.00000e-03 1.00000e-09 1.00000e-01

1.00000e-06 1.00000e-06 1.00000e-06 1.00000e-09 5.00000e-02

Element: 6137 \# of layers: 6

$\mathrm{Kx} \mathrm{Ky} \mathrm{Kz}$ Ss Por

4.39931e+03 4.39931e+03 4.39931e+02 1.00000e-09 7.00000e-02

4.39931e+03 4.39931e+03 4.39931e+02 1.00000e-09 7.00000e-02

$4.39931 \mathrm{e}+03$ 4.39931e+03 4.39931e+02 1.00000e-09 7.00000e-02

4.39931e+03 4.39931e+03 4.39931e+02 1.00000e-09 7.00000e-02

$1.75781 \mathrm{e}+021.75781 \mathrm{e}+02$ 1.75781e+01 1.00000e-09 2.12000e-01

1.00000e-06 1.00000e-06 1.00000e-06 1.00000e-09 5.00000e-02

Element: 6138 \# of layers: 5

$\mathrm{Kx} \mathrm{Ky} \mathrm{Kz}$ Ss Por

6.67830e+03 6.67830e+03 6.67830e+02 1.00000e-09 7.00000e-02

$6.67830 \mathrm{e}+036.67830 \mathrm{e}+03$ 6.67830e+02 1.00000e-09 7.00000e-02

$6.67830 \mathrm{e}+03$ 6.67830e+03 6.67830e+02 1.00000e-09 7.00000e-02

$2.66833 \mathrm{e}+02$ 2.66833e+02 2.66833e+01 1.00000e-09 2.12000e-01

1.00000e-06 1.00000e-06 1.00000e-06 1.00000e-09 5.00000e-02

Element: 6139 \# of layers: 4

Kx Ky Kz Ss Por

6.67830e+03 6.67830e+03 6.67830e+02 1.00000e-09 7.00000e-02

$6.67830 \mathrm{e}+036.67830 \mathrm{e}+03$ 6.67830e+02 1.00000e-09 7.00000e-02

$2.66833 \mathrm{e}+02$ 2.66833e+02 2.66833e+01 1.00000e-09 2.12000e-01

1.00000e-06 1.00000e-06 1.00000e-06 1.00000e-09 5.00000e-02

Element: 6140 \# of layers: 5

$\mathrm{Kx} \mathrm{Ky} \mathrm{Kz}$ Ss Por

6.67830e+03 6.67830e+03 6.67830e+02 1.00000e-09 7.00000e-02

6.67830e+03 6.67830e+03 6.67830e+02 1.00000e-09 7.00000e-02

$2.66833 \mathrm{e}+02$ 2.66833e+02 2.66833e+01 1.00000e-09 2.12000e-01

$1.00000 \mathrm{e}-021.00000 \mathrm{e}-021.00000 \mathrm{e}-031.00000 \mathrm{e}-091.00000 \mathrm{e}-01$

1.00000e-06 1.00000e-06 1.00000e-06 1.00000e-09 5.00000e-02

Element: 6141 \# of layers: 6

Kx Ky Kz Ss Por 
5.45916e+03 5.45916e+03 5.45916e+02 1.00000e-09 7.00000e-02 5.45916e+03 5.45916e+03 5.45916e+02 1.00000e-09 7.00000e-02 $2.18129 \mathrm{e}+02$ 2.18129e+02 2.18129e+01 1.00000e-09 2.12000e-01 $1.00000 \mathrm{e}-02$ 1.00000e-02 1.00000e-03 1.00000e-09 1.00000e-01 $1.00000 \mathrm{e}+001.00000 \mathrm{e}+001.00000 \mathrm{e}-011.00000 \mathrm{e}-091.00000 \mathrm{e}-01$ 1.00000e-06 1.00000e-06 1.00000e-06 1.00000e-09 5.00000e-02 Element: 6142 \# of layers: 7

Kx Ky Kz Ss Por

5.45916e+03 5.45916e+03 5.45916e+02 1.00000e-09 7.00000e-02

$5.45916 \mathrm{e}+035.45916 \mathrm{e}+035.45916 \mathrm{e}+02$ 1.00000e-09 7.00000e-02

$5.45916 \mathrm{e}+035.45916 \mathrm{e}+03$ 5.45916e+02 1.00000e-09 7.00000e-02

$2.18129 \mathrm{e}+02$ 2.18129e+02 2.18129e+01 1.00000e-09 2.12000e-01

$1.00000 \mathrm{e}-02$ 1.00000e-02 1.00000e-03 1.00000e-09 1.00000e-01

$1.00000 \mathrm{e}+001.00000 \mathrm{e}+001.00000 \mathrm{e}-011.00000 \mathrm{e}-091.00000 \mathrm{e}-01$

1.00000e-06 1.00000e-06 1.00000e-06 1.00000e-09 5.00000e-02

Element: 6143 \# of layers: 7

$\mathrm{Kx} \mathrm{Ky} \mathrm{Kz}$ Ss Por

4.26029e+03 4.26029e+03 4.26029e+02 1.00000e-09 7.00000e-02 4.26029e+03 4.26029e+03 4.26029e+02 1.00000e-09 7.00000e-02

4.26029e+03 4.26029e+03 4.26029e+02 1.00000e-09 7.00000e-02

$1.70225 \mathrm{e}+02 \quad 1.70225 \mathrm{e}+02 \quad 1.70225 \mathrm{e}+01$ 1.00000e-09 2.12000e-01

$1.00000 \mathrm{e}-02$ 1.00000e-02 1.00000e-03 1.00000e-09 1.00000e-01

$1.00000 \mathrm{e}+001.00000 \mathrm{e}+001.00000 \mathrm{e}-011.00000 \mathrm{e}-091.00000 \mathrm{e}-01$

1.00000e-06 1.00000e-06 1.00000e-06 1.00000e-09 5.00000e-02

Element: 6144 \# of layers: 6

$\mathrm{Kx} \mathrm{Ky} \mathrm{Kz}$ Ss Por

4.39931e+03 4.39931e+03 4.39931e+02 1.00000e-09 7.00000e-02

$4.39931 \mathrm{e}+03$ 4.39931e+03 4.39931e+02 1.00000e-09 7.00000e-02

$4.39931 \mathrm{e}+03$ 4.39931e+03 4.39931e+02 1.00000e-09 7.00000e-02

$1.75781 \mathrm{e}+02$ 1.75781e+02 1.75781e+01 1.00000e-09 2.12000e-01

$1.00000 \mathrm{e}-02$ 1.00000e-02 1.00000e-03 1.00000e-09 1.00000e-01

1.00000e-06 1.00000e-06 1.00000e-06 1.00000e-09 5.00000e-02

Element: 6145 \# of layers: 6

$\mathrm{Kx} \mathrm{Ky} \mathrm{Kz}$ Ss Por

6.67830e+03 6.67830e+03 6.67830e+02 1.00000e-09 7.00000e-02

6.67830e+03 6.67830e+03 6.67830e+02 1.00000e-09 7.00000e-02

$6.67830 \mathrm{e}+036.67830 \mathrm{e}+036.67830 \mathrm{e}+02$ 1.00000e-09 7.00000e-02

$2.66833 \mathrm{e}+022.66833 \mathrm{e}+02$ 2.66833e+01 1.00000e-09 2.12000e-01

$1.00000 \mathrm{e}-02$ 1.00000e-02 1.00000e-03 1.00000e-09 1.00000e-01

1.00000e-06 1.00000e-06 1.00000e-06 1.00000e-09 5.00000e-02

Element: 6146 \# of layers: 4

$\mathrm{Kx} \mathrm{Ky} \mathrm{Kz}$ Ss Por

8.31749e+03 8.31749e+03 8.31749e+02 1.00000e-09 7.00000e-02

8.31749e+03 8.31749e+03 8.31749e+02 1.00000e-09 7.00000e-02

$3.32332 \mathrm{e}+02$ 3.32332e+02 3.32332e+01 1.00000e-09 2.12000e-01

$1.00000 \mathrm{e}-06$ 1.00000e-06 1.00000e-06 1.00000e-09 5.00000e-02 
Element: 6147 \# of layers: 4

$\mathrm{Kx} \mathrm{Ky} \mathrm{Kz}$ Ss Por

$1.14409 \mathrm{e}+04$ 1.14409e+04 1.14409e+03 1.00000e-09 7.00000e-02

$1.14409 \mathrm{e}+041.14409 \mathrm{e}+041.14409 \mathrm{e}+03$ 1.00000e-09 7.00000e-02

4.57142e+02 4.57142e+02 4.57142e+01 1.00000e-09 2.12000e-01

1.00000e-06 1.00000e-06 1.00000e-06 1.00000e-09 5.00000e-02

Element: 6148 \# of layers: 3

$\mathrm{Kx} \mathrm{Ky} \mathrm{Kz}$ Ss Por

$1.14409 \mathrm{e}+04$ 1.14409e+04 1.14409e+03 1.00000e-09 7.00000e-02

$4.57142 \mathrm{e}+024.57142 \mathrm{e}+02$ 4.57142e+01 1.00000e-09 2.12000e-01

1.00000e-06 1.00000e-06 1.00000e-06 1.00000e-09 5.00000e-02

Element: 6149 \# of layers: 4

$\mathrm{Kx} \mathrm{Ky} \mathrm{Kz}$ Ss Por

$1.30041 \mathrm{e}+041.30041 \mathrm{e}+041.30041 \mathrm{e}+03$ 1.00000e-09 7.00000e-02

$5.19604 \mathrm{e}+025.19604 \mathrm{e}+025.19604 \mathrm{e}+01$ 1.00000e-09 2.12000e-01

$1.00000 \mathrm{e}-02$ 1.00000e-02 1.00000e-03 1.00000e-09 1.00000e-01

$1.00000 \mathrm{e}-06$ 1.00000e-06 1.00000e-06 1.00000e-09 5.00000e-02

Element: 6150 \# of layers: 6

$\mathrm{Kx} \mathrm{Ky} \mathrm{Kz}$ Ss Por

$1.30041 \mathrm{e}+041.30041 \mathrm{e}+041.30041 \mathrm{e}+03$ 1.00000e-09 7.00000e-02

$1.30041 \mathrm{e}+041.30041 \mathrm{e}+041.30041 \mathrm{e}+03$ 1.00000e-09 7.00000e-02

$5.19604 \mathrm{e}+025.19604 \mathrm{e}+025.19604 \mathrm{e}+01$ 1.00000e-09 2.12000e-01

$1.00000 \mathrm{e}-02$ 1.00000e-02 1.00000e-03 1.00000e-09 1.00000e-01

$1.00000 \mathrm{e}+001.00000 \mathrm{e}+001.00000 \mathrm{e}-011.00000 \mathrm{e}-091.00000 \mathrm{e}-01$

$1.00000 \mathrm{e}-06$ 1.00000e-06 1.00000e-06 1.00000e-09 5.00000e-02

Element: 6151 \# of layers: 6

$\mathrm{Kx} \mathrm{Ky} \mathrm{Kz}$ Ss Por

$1.30041 \mathrm{e}+041.30041 \mathrm{e}+04$ 1.30041e+03 1.00000e-09 7.00000e-02

$1.30041 \mathrm{e}+041.30041 \mathrm{e}+041.30041 \mathrm{e}+03$ 1.00000e-09 7.00000e-02

$5.19604 \mathrm{e}+025.19604 \mathrm{e}+025.19604 \mathrm{e}+01$ 1.00000e-09 2.12000e-01

$1.00000 \mathrm{e}-02$ 1.00000e-02 1.00000e-03 1.00000e-09 1.00000e-01

$1.00000 \mathrm{e}+001.00000 \mathrm{e}+001.00000 \mathrm{e}-011.00000 \mathrm{e}-091.00000 \mathrm{e}-01$

1.00000e-06 1.00000e-06 1.00000e-06 1.00000e-09 5.00000e-02

Element: 6152 \# of layers: 6

$\mathrm{Kx} \mathrm{Ky} \mathrm{Kz}$ Ss Por

7.47262e+03 7.47262e+03 7.47262e+02 1.00000e-09 7.00000e-02

$7.47262 \mathrm{e}+03$ 7.47262e+03 7.47262e+02 1.00000e-09 7.00000e-02

$2.98581 \mathrm{e}+022.98581 \mathrm{e}+022.98581 \mathrm{e}+01$ 1.00000e-09 2.12000e-01

$1.00000 \mathrm{e}-02$ 1.00000e-02 1.00000e-03 1.00000e-09 1.00000e-01

$1.00000 \mathrm{e}+001.00000 \mathrm{e}+001.00000 \mathrm{e}-011.00000 \mathrm{e}-091.00000 \mathrm{e}-01$

1.00000e-06 1.00000e-06 1.00000e-06 1.00000e-09 5.00000e-02

Element: 6153 \# of layers: 5

$\mathrm{Kx} \mathrm{Ky} \mathrm{Kz}$ Ss Por

7.47262e+03 7.47262e+03 7.47262e+02 1.00000e-09 7.00000e-02

7.47262e+03 7.47262e+03 7.47262e+02 1.00000e-09 7.00000e-02

$2.98581 \mathrm{e}+022.98581 \mathrm{e}+022.98581 \mathrm{e}+01$ 1.00000e-09 2.12000e-01 
1.00000e-02 1.00000e-02 1.00000e-03 1.00000e-09 1.00000e-01 $1.00000 \mathrm{e}-06$ 1.00000e-06 1.00000e-06 1.00000e-09 5.00000e-02 Element: 6154 \# of layers: 5

Kx Ky Kz Ss Por

$1.30041 \mathrm{e}+041.30041 \mathrm{e}+041.30041 \mathrm{e}+03$ 1.00000e-09 7.00000e-02

$1.30041 \mathrm{e}+041.30041 \mathrm{e}+041.30041 \mathrm{e}+03$ 1.00000e-09 7.00000e-02

$5.19604 \mathrm{e}+025.19604 \mathrm{e}+025.19604 \mathrm{e}+01$ 1.00000e-09 2.12000e-01

1.00000e-02 1.00000e-02 1.00000e-03 1.00000e-09 1.00000e-01

1.00000e-06 1.00000e-06 1.00000e-06 1.00000e-09 5.00000e-02

Element: 6155 \# of layers: 2

$\mathrm{Kx} \mathrm{Ky} \mathrm{Kz}$ Ss Por

$2.25475 \mathrm{e}+042.25475 \mathrm{e}+042.25475 \mathrm{e}+03$ 1.00000e-09 7.00000e-02

1.00000e-06 1.00000e-06 1.00000e-06 1.00000e-09 5.00000e-02

Element: 6156 \# of layers: 4

$\mathrm{Kx} \mathrm{Ky} \mathrm{Kz}$ Ss Por

9.98128e+03 9.98128e+03 9.98128e+02 1.00000e-09 7.00000e-02

9.98128e+03 9.98128e+03 9.98128e+02 1.00000e-09 7.00000e-02

$1.00000 \mathrm{e}-02$ 1.00000e-02 1.00000e-03 1.00000e-09 1.00000e-01

1.00000e-06 1.00000e-06 1.00000e-06 1.00000e-09 5.00000e-02

Element: 6157 \# of layers: 6

$\mathrm{Kx} \mathrm{Ky} \mathrm{Kz}$ Ss Por

9.98128e+03 9.98128e+03 9.98128e+02 1.00000e-09 7.00000e-02

9.98128e+03 9.98128e+03 9.98128e+02 1.00000e-09 7.00000e-02

$3.98821 \mathrm{e}+02$ 3.98821e+02 3.98821e+01 1.00000e-09 2.12000e-01

$1.00000 \mathrm{e}-021.00000 \mathrm{e}-02$ 1.00000e-03 1.00000e-09 1.00000e-01

$1.00000 \mathrm{e}+001.00000 \mathrm{e}+001.00000 \mathrm{e}-011.00000 \mathrm{e}-091.00000 \mathrm{e}-01$

1.00000e-06 1.00000e-06 1.00000e-06 1.00000e-09 5.00000e-02

Element: 6158 \# of layers: 6

$\mathrm{Kx} \mathrm{Ky} \mathrm{Kz}$ Ss Por

9.98128e+03 9.98128e+03 9.98128e+02 1.00000e-09 7.00000e-02

$9.98128 \mathrm{e}+03$ 9.98128e+03 9.98128e+02 1.00000e-09 7.00000e-02

$3.98821 \mathrm{e}+02$ 3.98821e+02 3.98821e+01 1.00000e-09 2.12000e-01

1.00000e-02 1.00000e-02 1.00000e-03 1.00000e-09 1.00000e-01

$1.00000 \mathrm{e}+001.00000 \mathrm{e}+001.00000 \mathrm{e}-011.00000 \mathrm{e}-091.00000 \mathrm{e}-01$

1.00000e-06 1.00000e-06 1.00000e-06 1.00000e-09 5.00000e-02

Element: 6159 \# of layers: 6

Kx Ky Kz Ss Por

7.54146e+03 7.54146e+03 7.54146e+02 1.00000e-09 7.00000e-02

$7.54146 \mathrm{e}+03$ 7.54146e+03 7.54146e+02 1.00000e-09 7.00000e-02

$3.01326 \mathrm{e}+023.01326 \mathrm{e}+023.01326 \mathrm{e}+01$ 1.00000e-09 2.12000e-01

$1.00000 \mathrm{e}-02$ 1.00000e-02 1.00000e-03 1.00000e-09 1.00000e-01

$1.00000 \mathrm{e}+001.00000 \mathrm{e}+001.00000 \mathrm{e}-011.00000 \mathrm{e}-091.00000 \mathrm{e}-01$

1.00000e-06 1.00000e-06 1.00000e-06 1.00000e-09 5.00000e-02

Element: 6160 \# of layers: 6

$\mathrm{Kx} \mathrm{Ky} \mathrm{Kz}$ Ss Por

7.54146e+03 7.54146e+03 7.54146e+02 1.00000e-09 7.00000e-02 
7.54146e +03 7.54146e +03 7.54146e+02 1.00000e-09 7.00000e-02 $3.01326 \mathrm{e}+023.01326 \mathrm{e}+023.01326 \mathrm{e}+01$ 1.00000e-09 2.12000e-01 $1.00000 \mathrm{e}-02$ 1.00000e-02 1.00000e-03 1.00000e-09 1.00000e-01 $1.00000 \mathrm{e}+001.00000 \mathrm{e}+001.00000 \mathrm{e}-011.00000 \mathrm{e}-091.00000 \mathrm{e}-01$ $1.00000 \mathrm{e}-06$ 1.00000e-06 1.00000e-06 1.00000e-09 5.00000e-02

Element: 6161 \# of layers: 6

Kx Ky Kz Ss Por

$1.37186 \mathrm{e}+041.37186 \mathrm{e}+041.37186 \mathrm{e}+03$ 1.00000e-09 7.00000e-02 $1.37186 \mathrm{e}+041.37186 \mathrm{e}+041.37186 \mathrm{e}+031.00000 \mathrm{e}-097.00000 \mathrm{e}-02$ $5.48157 \mathrm{e}+025.48157 \mathrm{e}+025.48157 \mathrm{e}+01$ 1.00000e-09 2.12000e-01 $1.00000 \mathrm{e}-021.00000 \mathrm{e}-02$ 1.00000e-03 1.00000e-09 1.00000e-01 $1.00000 \mathrm{e}+001.00000 \mathrm{e}+001.00000 \mathrm{e}-011.00000 \mathrm{e}-091.00000 \mathrm{e}-01$ $1.00000 \mathrm{e}-06$ 1.00000e-06 1.00000e-06 1.00000e-09 5.00000e-02 Element: 6162 \# of layers: 5

Kx Ky Kz Ss Por

$1.37186 \mathrm{e}+041.37186 \mathrm{e}+041.37186 \mathrm{e}+03$ 1.00000e-09 7.00000e-02 $5.48157 \mathrm{e}+02$ 5.48157e+02 5.48157e+01 1.00000e-09 2.12000e-01 $1.00000 \mathrm{e}-02$ 1.00000e-02 1.00000e-03 1.00000e-09 1.00000e-01 $1.00000 \mathrm{e}+001.00000 \mathrm{e}+001.00000 \mathrm{e}-011.00000 \mathrm{e}-091.00000 \mathrm{e}-01$ $1.00000 \mathrm{e}-06$ 1.00000e-06 1.00000e-06 1.00000e-09 5.00000e-02 Element: 6163 \# of layers: 5

Kx Ky Kz Ss Por

$9.98128 \mathrm{e}+03$ 9.98128e+03 9.98128e+02 1.00000e-09 7.00000e-02 $3.98821 \mathrm{e}+023.98821 \mathrm{e}+023.98821 \mathrm{e}+01$ 1.00000e-09 2.12000e-01 $1.00000 \mathrm{e}-021.00000 \mathrm{e}-02$ 1.00000e-03 1.00000e-09 1.00000e-01 $1.00000 \mathrm{e}+001.00000 \mathrm{e}+001.00000 \mathrm{e}-011.00000 \mathrm{e}-091.00000 \mathrm{e}-01$ $1.00000 \mathrm{e}-06$ 1.00000e-06 1.00000e-06 1.00000e-09 5.00000e-02 Element: 6164 \# of layers: 6

Kx Ky Kz Ss Por

$8.25586 \mathrm{e}+03$ 8.25586e+03 8.25586e+02 1.00000e-09 7.00000e-02 $8.25586 \mathrm{e}+03$ 8.25586e+03 8.25586e+02 1.00000e-09 7.00000e-02 $3.29879 \mathrm{e}+023.29879 \mathrm{e}+023.29879 \mathrm{e}+01$ 1.00000e-09 2.12000e-01 $1.00000 \mathrm{e}-02$ 1.00000e-02 1.00000e-03 1.00000e-09 1.00000e-01 $1.00000 \mathrm{e}+001.00000 \mathrm{e}+001.00000 \mathrm{e}-011.00000 \mathrm{e}-091.00000 \mathrm{e}-01$ $1.00000 \mathrm{e}-06$ 1.00000e-06 1.00000e-06 1.00000e-09 5.00000e-02 Element: 6165 \# of layers: 7

Kx Ky Kz Ss Por $5.26454 \mathrm{e}+03$ 5.26454e+03 5.26454e+02 1.00000e-09 7.00000e-02 $5.26454 \mathrm{e}+03$ 5.26454e+03 5.26454e+02 1.00000e-09 7.00000e-02 $2.10350 \mathrm{e}+022.10350 \mathrm{e}+022.10350 \mathrm{e}+01$ 1.00000e-09 2.12000e-01 $2.10350 \mathrm{e}+02 \quad 2.10350 \mathrm{e}+02 \quad 2.10350 \mathrm{e}+01$ 1.00000e-09 2.12000e-01 $1.00000 \mathrm{e}-02$ 1.00000e-02 1.00000e-03 1.00000e-09 1.00000e-01 $1.00000 \mathrm{e}+001.00000 \mathrm{e}+001.00000 \mathrm{e}-011.00000 \mathrm{e}-091.00000 \mathrm{e}-01$ $1.00000 \mathrm{e}-06$ 1.00000e-06 1.00000e-06 1.00000e-09 5.00000e-02 Element: 6166 \# of layers: 5

Kx Ky Kz Ss Por 
$5.26454 \mathrm{e}+03$ 5.26454e+03 5.26454e+02 1.00000e-09 7.00000e-02 $2.10350 \mathrm{e}+022.10350 \mathrm{e}+022.10350 \mathrm{e}+01$ 1.00000e-09 2.12000e-01 $1.00000 \mathrm{e}-02$ 1.00000e-02 1.00000e-03 1.00000e-09 1.00000e-01 $1.00000 \mathrm{e}+001.00000 \mathrm{e}+001.00000 \mathrm{e}-011.00000 \mathrm{e}-091.00000 \mathrm{e}-01$ $1.00000 \mathrm{e}-06$ 1.00000e-06 1.00000e-06 1.00000e-09 5.00000e-02 Element: 6167 \# of layers: 6

Kx Ky Kz Ss Por

$5.26454 \mathrm{e}+03$ 5.26454e+03 5.26454e+02 1.00000e-09 7.00000e-02 $5.26454 \mathrm{e}+03$ 5.26454e+03 5.26454e+02 1.00000e-09 7.00000e-02 $2.10350 \mathrm{e}+022.10350 \mathrm{e}+022.10350 \mathrm{e}+01$ 1.00000e-09 2.12000e-01 $1.00000 \mathrm{e}-02$ 1.00000e-02 1.00000e-03 1.00000e-09 1.00000e-01 $1.00000 \mathrm{e}+001.00000 \mathrm{e}+001.00000 \mathrm{e}-011.00000 \mathrm{e}-091.00000 \mathrm{e}-01$ $1.00000 \mathrm{e}-06$ 1.00000e-06 1.00000e-06 1.00000e-09 5.00000e-02 Element: 6168 \# of layers: 5

Kx Ky Kz Ss Por

$5.26454 \mathrm{e}+03$ 5.26454e+03 5.26454e+02 1.00000e-09 7.00000e-02 $2.10350 \mathrm{e}+022.10350 \mathrm{e}+022.10350 \mathrm{e}+01$ 1.00000e-09 2.12000e-01 $1.00000 \mathrm{e}-02$ 1.00000e-02 1.00000e-03 1.00000e-09 1.00000e-01 $1.00000 \mathrm{e}+001.00000 \mathrm{e}+001.00000 \mathrm{e}-011.00000 \mathrm{e}-091.00000 \mathrm{e}-01$ $1.00000 \mathrm{e}-06$ 1.00000e-06 1.00000e-06 1.00000e-09 5.00000e-02 Element: 6169 \# of layers: 7

Kx Ky Kz Ss Por

$3.90953 \mathrm{e}+03$ 3.90953e+03 3.90953e+02 1.00000e-09 7.00000e-02 $3.90953 \mathrm{e}+03$ 3.90953e+03 3.90953e+02 1.00000e-09 7.00000e-02 $1.56212 \mathrm{e}+021.56212 \mathrm{e}+021.56212 \mathrm{e}+011.00000 \mathrm{e}-092.12000 \mathrm{e}-01$ $1.56212 \mathrm{e}+021.56212 \mathrm{e}+021.56212 \mathrm{e}+011.00000 \mathrm{e}-092.12000 \mathrm{e}-01$ $1.00000 \mathrm{e}-02$ 1.00000e-02 1.00000e-03 1.00000e-09 1.00000e-01 $1.00000 \mathrm{e}+001.00000 \mathrm{e}+001.00000 \mathrm{e}-011.00000 \mathrm{e}-091.00000 \mathrm{e}-01$ $1.00000 \mathrm{e}-06$ 1.00000e-06 1.00000e-06 1.00000e-09 5.00000e-02 Element: 6170 \# of layers: 5

Kx Ky Kz Ss Por

$3.90953 \mathrm{e}+03$ 3.90953e+03 3.90953e+02 1.00000e-09 7.00000e-02 $1.56212 \mathrm{e}+021.56212 \mathrm{e}+021.56212 \mathrm{e}+01$ 1.00000e-09 2.12000e-01 $1.00000 \mathrm{e}-02$ 1.00000e-02 1.00000e-03 1.00000e-09 1.00000e-01 $1.00000 \mathrm{e}+001.00000 \mathrm{e}+001.00000 \mathrm{e}-011.00000 \mathrm{e}-091.00000 \mathrm{e}-01$ 1.00000e-06 1.00000e-06 1.00000e-06 1.00000e-09 5.00000e-02 Element: 6171 \# of layers: 6

Kx Ky Kz Ss Por

$5.26454 \mathrm{e}+03$ 5.26454e+03 5.26454e+02 1.00000e-09 7.00000e-02 $5.26454 \mathrm{e}+03$ 5.26454e+03 5.26454e+02 1.00000e-09 7.00000e-02 $2.10350 \mathrm{e}+022.10350 \mathrm{e}+02 \quad 2.10350 \mathrm{e}+01$ 1.00000e-09 2.12000e-01 $1.00000 \mathrm{e}-02$ 1.00000e-02 1.00000e-03 1.00000e-09 1.00000e-01 $1.00000 \mathrm{e}+001.00000 \mathrm{e}+001.00000 \mathrm{e}-011.00000 \mathrm{e}-091.00000 \mathrm{e}-01$ $1.00000 \mathrm{e}-06$ 1.00000e-06 1.00000e-06 1.00000e-09 5.00000e-02 Element: 6172 \# of layers: 7

Kx Ky Kz Ss Por 
5.26454e+03 5.26454e+03 5.26454e+02 1.00000e-09 7.00000e-02 $5.26454 \mathrm{e}+03$ 5.26454e+03 5.26454e+02 1.00000e-09 7.00000e-02 $2.10350 \mathrm{e}+02$ 2.10350e+02 2.10350e+01 1.00000e-09 2.12000e-01 $2.10350 \mathrm{e}+02$ 2.10350e+02 2.10350e+01 1.00000e-09 2.12000e-01 $1.00000 \mathrm{e}-021.00000 \mathrm{e}-02$ 1.00000e-03 1.00000e-09 1.00000e-01 $1.00000 \mathrm{e}+001.00000 \mathrm{e}+001.00000 \mathrm{e}-011.00000 \mathrm{e}-091.00000 \mathrm{e}-01$ 1.00000e-06 1.00000e-06 1.00000e-06 1.00000e-09 5.00000e-02

Element: 6173 \# of layers: 4

$\mathrm{Kx} \mathrm{Ky} \mathrm{Kz}$ Ss Por

$1.75657 \mathrm{e}+02$ 1.75657e+02 1.75657e+01 1.00000e-09 2.12000e-01 $1.00000 \mathrm{e}-02$ 1.00000e-02 1.00000e-03 1.00000e-09 1.00000e-01 $1.00000 \mathrm{e}+001.00000 \mathrm{e}+001.00000 \mathrm{e}-011.00000 \mathrm{e}-091.00000 \mathrm{e}-01$ 1.00000e-06 1.00000e-06 1.00000e-06 1.00000e-09 5.00000e-02 Element: 6174 \# of layers: 5

$\mathrm{Kx} \mathrm{Ky} \mathrm{Kz}$ Ss Por

4.39625e+03 4.39625e+03 4.39625e+02 1.00000e-09 7.00000e-02 $1.75657 \mathrm{e}+02$ 1.75657e+02 1.75657e+01 1.00000e-09 2.12000e-01 $1.75657 \mathrm{e}+02$ 1.75657e+02 1.75657e+01 1.00000e-09 2.12000e-01 $1.00000 \mathrm{e}-02$ 1.00000e-02 1.00000e-03 1.00000e-09 1.00000e-01 $1.00000 \mathrm{e}+001.00000 \mathrm{e}+001.00000 \mathrm{e}-01$ 1.00000e-09 1.00000e-01 Element: 6175 \# of layers: 5

$\mathrm{Kx} \mathrm{Ky} \mathrm{Kz}$ Ss Por

4.39625e+03 4.39625e+03 4.39625e+02 1.00000e-09 7.00000e-02 $1.75657 \mathrm{e}+02$ 1.75657e+02 1.75657e+01 1.00000e-09 2.12000e-01 $1.75657 \mathrm{e}+02$ 1.75657e+02 1.75657e+01 1.00000e-09 2.12000e-01 $1.00000 \mathrm{e}-021.00000 \mathrm{e}-02$ 1.00000e-03 1.00000e-09 1.00000e-01 $1.00000 \mathrm{e}+001.00000 \mathrm{e}+001.00000 \mathrm{e}-011.00000 \mathrm{e}-091.00000 \mathrm{e}-01$ Element: 6176 \# of layers: 6

$\mathrm{Kx} \mathrm{Ky} \mathrm{Kz}$ Ss Por

4.39625e+03 4.39625e+03 4.39625e+02 1.00000e-09 7.00000e-02 4.39625e+03 4.39625e+03 4.39625e+02 1.00000e-09 7.00000e-02 $1.75657 \mathrm{e}+02$ 1.75657e+02 1.75657e+01 1.00000e-09 2.12000e-01 $1.75657 \mathrm{e}+021.75657 \mathrm{e}+02$ 1.75657e+01 1.00000e-09 2.12000e-01 $1.00000 \mathrm{e}-021.00000 \mathrm{e}-021.00000 \mathrm{e}-031.00000 \mathrm{e}-091.00000 \mathrm{e}-01$ $1.00000 \mathrm{e}+001.00000 \mathrm{e}+001.00000 \mathrm{e}-01$ 1.00000e-09 1.00000e-01 Element: 6177 \# of layers: 6

$\mathrm{Kx} \mathrm{Ky} \mathrm{Kz}$ Ss Por

4.39625e+03 4.39625e+03 4.39625e+02 1.00000e-09 7.00000e-02 $4.39625 \mathrm{e}+03$ 4.39625e+03 4.39625e+02 1.00000e-09 7.00000e-02 $1.75657 \mathrm{e}+02$ 1.75657e+02 1.75657e+01 1.00000e-09 2.12000e-01 $1.75657 \mathrm{e}+02$ 1.75657e+02 1.75657e+01 1.00000e-09 2.12000e-01 $1.00000 \mathrm{e}-02$ 1.00000e-02 1.00000e-03 1.00000e-09 1.00000e-01 $1.00000 \mathrm{e}+001.00000 \mathrm{e}+001.00000 \mathrm{e}-01$ 1.00000e-09 1.00000e-01 Element: 6178 \# of layers: 4

$\mathrm{Kx} \mathrm{Ky} \mathrm{Kz}$ Ss Por

4.39625e+03 4.39625e+03 4.39625e+02 1.00000e-09 7.00000e-02 
$1.75657 \mathrm{e}+02$ 1.75657e+02 1.75657e+01 1.00000e-09 2.12000e-01 $1.00000 \mathrm{e}-021.00000 \mathrm{e}-02$ 1.00000e-03 1.00000e-09 1.00000e-01 $1.00000 \mathrm{e}+001.00000 \mathrm{e}+001.00000 \mathrm{e}-011.00000 \mathrm{e}-091.00000 \mathrm{e}-01$

Element: 6179 \# of layers: 5

Kx Ky Kz Ss Por

$4.39625 \mathrm{e}+03$ 4.39625e+03 4.39625e+02 1.00000e-09 7.00000e-02

$1.75657 \mathrm{e}+02 \quad 1.75657 \mathrm{e}+02 \quad 1.75657 \mathrm{e}+01$ 1.00000e-09 2.12000e-01

$1.00000 \mathrm{e}-021.00000 \mathrm{e}-02$ 1.00000e-03 1.00000e-09 1.00000e-01

$1.00000 \mathrm{e}+001.00000 \mathrm{e}+001.00000 \mathrm{e}-011.00000 \mathrm{e}-091.00000 \mathrm{e}-01$

$1.00000 \mathrm{e}-06$ 1.00000e-06 1.00000e-06 1.00000e-09 5.00000e-02

Element: 6180 \# of layers: 4

Kx Ky Kz Ss Por

$1.75657 \mathrm{e}+02$ 1.75657e+02 1.75657e+01 1.00000e-09 2.12000e-01 $1.00000 \mathrm{e}-021.00000 \mathrm{e}-02$ 1.00000e-03 1.00000e-09 1.00000e-01

$1.00000 \mathrm{e}+001.00000 \mathrm{e}+001.00000 \mathrm{e}-011.00000 \mathrm{e}-091.00000 \mathrm{e}-01$

$1.00000 \mathrm{e}-06$ 1.00000e-06 1.00000e-06 1.00000e-09 5.00000e-02

Element: 6181 \# of layers: 5

Kx Ky Kz Ss Por

$4.39625 \mathrm{e}+03$ 4.39625e+03 4.39625e+02 1.00000e-09 7.00000e-02

$1.75657 \mathrm{e}+02 \quad 1.75657 \mathrm{e}+02 \quad 1.75657 \mathrm{e}+011.00000 \mathrm{e}-092.12000 \mathrm{e}-01$

$1.75657 \mathrm{e}+02 \quad 1.75657 \mathrm{e}+021.75657 \mathrm{e}+011.00000 \mathrm{e}-092.12000 \mathrm{e}-01$

$1.00000 \mathrm{e}-02$ 1.00000e-02 1.00000e-03 1.00000e-09 1.00000e-01

$1.00000 \mathrm{e}+001.00000 \mathrm{e}+001.00000 \mathrm{e}-011.00000 \mathrm{e}-091.00000 \mathrm{e}-01$

Element: 6182 \# of layers: 4

Kx Ky Kz Ss Por

$8.66870 \mathrm{e}+028.66870 \mathrm{e}+028.66870 \mathrm{e}+01$ 1.00000e-09 7.00000e-02

$3.46372 \mathrm{e}+013.46372 \mathrm{e}+013.46372 \mathrm{e}+001.00000 \mathrm{e}-09$ 2.12000e-01

$1.00000 \mathrm{e}-021.00000 \mathrm{e}-02$ 1.00000e-03 1.00000e-09 1.00000e-01

$1.00000 \mathrm{e}+001.00000 \mathrm{e}+001.00000 \mathrm{e}-011.00000 \mathrm{e}-091.00000 \mathrm{e}-01$

Element: 6183 \# of layers: 5

Kx Ky Kz Ss Por

$8.66870 \mathrm{e}+028.66870 \mathrm{e}+028.66870 \mathrm{e}+01$ 1.00000e-09 7.00000e-02

$3.46372 \mathrm{e}+013.46372 \mathrm{e}+013.46372 \mathrm{e}+001.00000 \mathrm{e}-092.12000 \mathrm{e}-01$

$3.46372 \mathrm{e}+013.46372 \mathrm{e}+013.46372 \mathrm{e}+001.00000 \mathrm{e}-092.12000 \mathrm{e}-01$

$1.00000 \mathrm{e}-021.00000 \mathrm{e}-02$ 1.00000e-03 1.00000e-09 1.00000e-01

$1.00000 \mathrm{e}+001.00000 \mathrm{e}+001.00000 \mathrm{e}-011.00000 \mathrm{e}-091.00000 \mathrm{e}-01$

Element: 6184 \# of layers: 5

Kx Ky Kz Ss Por

8.66870e+02 8.66870e+02 8.66870e+01 1.00000e-09 7.00000e-02

$3.46372 \mathrm{e}+013.46372 \mathrm{e}+013.46372 \mathrm{e}+001.00000 \mathrm{e}-092.12000 \mathrm{e}-01$

$3.46372 \mathrm{e}+013.46372 \mathrm{e}+013.46372 \mathrm{e}+001.00000 \mathrm{e}-092.12000 \mathrm{e}-01$

$1.00000 \mathrm{e}-021.00000 \mathrm{e}-02$ 1.00000e-03 1.00000e-09 1.00000e-01

$1.00000 \mathrm{e}+001.00000 \mathrm{e}+001.00000 \mathrm{e}-011.00000 \mathrm{e}-091.00000 \mathrm{e}-01$

Element: 6185 \# of layers: 5

Kx Ky Kz Ss Por

8.66870e+02 8.66870e+02 8.66870e+01 1.00000e-09 7.00000e-02 
3.46372e $+013.46372 \mathrm{e}+013.46372 \mathrm{e}+00$ 1.00000e-09 2.12000e-01 $3.46372 \mathrm{e}+013.46372 \mathrm{e}+013.46372 \mathrm{e}+00$ 1.00000e-09 2.12000e-01 $1.00000 \mathrm{e}-021.00000 \mathrm{e}-02$ 1.00000e-03 1.00000e-09 1.00000e-01 $1.00000 \mathrm{e}+001.00000 \mathrm{e}+001.00000 \mathrm{e}-011.00000 \mathrm{e}-091.00000 \mathrm{e}-01$ Element: 6186 \# of layers: 4

Kx Ky Kz Ss Por

8.66870e+02 8.66870e+02 8.66870e+01 1.00000e-09 7.00000e-02 $3.46372 \mathrm{e}+013.46372 \mathrm{e}+013.46372 \mathrm{e}+001.00000 \mathrm{e}-092.12000 \mathrm{e}-01$ $1.00000 \mathrm{e}-021.00000 \mathrm{e}-02$ 1.00000e-03 1.00000e-09 1.00000e-01 $1.00000 \mathrm{e}+001.00000 \mathrm{e}+001.00000 \mathrm{e}-011.00000 \mathrm{e}-091.00000 \mathrm{e}-01$ Element: 6187 \# of layers: 5

Kx Ky Kz Ss Por $8.66870 \mathrm{e}+028.66870 \mathrm{e}+028.66870 \mathrm{e}+01$ 1.00000e-09 7.00000e-02 $8.66870 \mathrm{e}+028.66870 \mathrm{e}+028.66870 \mathrm{e}+01$ 1.00000e-09 7.00000e-02 $3.46372 \mathrm{e}+013.46372 \mathrm{e}+013.46372 \mathrm{e}+00$ 1.00000e-09 2.12000e-01 $1.00000 \mathrm{e}-021.00000 \mathrm{e}-02$ 1.00000e-03 1.00000e-09 1.00000e-01 $1.00000 \mathrm{e}+001.00000 \mathrm{e}+001.00000 \mathrm{e}-011.00000 \mathrm{e}-091.00000 \mathrm{e}-01$ Element: 6188 \# of layers: 7

Kx Ky Kz Ss Por

$8.66870 \mathrm{e}+02$ 8.66870e+02 8.66870e+01 1.00000e-09 7.00000e-02 $8.66870 \mathrm{e}+028.66870 \mathrm{e}+028.66870 \mathrm{e}+01$ 1.00000e-09 7.00000e-02 $8.66870 \mathrm{e}+028.66870 \mathrm{e}+028.66870 \mathrm{e}+01$ 1.00000e-09 7.00000e-02 $3.46372 \mathrm{e}+013.46372 \mathrm{e}+013.46372 \mathrm{e}+00$ 1.00000e-09 2.12000e-01 $3.46372 \mathrm{e}+013.46372 \mathrm{e}+013.46372 \mathrm{e}+00$ 1.00000e-09 2.12000e-01 $1.00000 \mathrm{e}-021.00000 \mathrm{e}-02$ 1.00000e-03 1.00000e-09 1.00000e-01 $1.00000 \mathrm{e}+001.00000 \mathrm{e}+001.00000 \mathrm{e}-011.00000 \mathrm{e}-091.00000 \mathrm{e}-01$ Element: 6189 \# of layers: 6

Kx Ky Kz Ss Por

$8.66870 \mathrm{e}+028.66870 \mathrm{e}+028.66870 \mathrm{e}+01$ 1.00000e-09 7.00000e-02 $8.66870 \mathrm{e}+028.66870 \mathrm{e}+028.66870 \mathrm{e}+01$ 1.00000e-09 7.00000e-02 $3.46372 \mathrm{e}+013.46372 \mathrm{e}+013.46372 \mathrm{e}+00$ 1.00000e-09 2.12000e-01 $3.46372 \mathrm{e}+013.46372 \mathrm{e}+013.46372 \mathrm{e}+00$ 1.00000e-09 2.12000e-01 $1.00000 \mathrm{e}-021.00000 \mathrm{e}-021.00000 \mathrm{e}-031.00000 \mathrm{e}-091.00000 \mathrm{e}-01$ $1.00000 \mathrm{e}+001.00000 \mathrm{e}+00$ 1.00000e-01 1.00000e-09 1.00000e-01 Element: 6190 \# of layers: 5

Kx Ky Kz Ss Por 8.66870e+02 8.66870e+02 8.66870e+01 1.00000e-09 7.00000e-02 $3.46372 \mathrm{e}+013.46372 \mathrm{e}+013.46372 \mathrm{e}+00$ 1.00000e-09 2.12000e-01 $3.46372 \mathrm{e}+013.46372 \mathrm{e}+013.46372 \mathrm{e}+00$ 1.00000e-09 2.12000e-01 $1.00000 \mathrm{e}-02$ 1.00000e-02 1.00000e-03 1.00000e-09 1.00000e-01 $1.00000 \mathrm{e}+001.00000 \mathrm{e}+001.00000 \mathrm{e}-011.00000 \mathrm{e}-091.00000 \mathrm{e}-01$ Element: 6191 \# of layers: 5

Kx Ky Kz Ss Por

$8.17847 \mathrm{e}+01$ 8.17847e+01 8.17847e+00 1.00000e-09 7.00000e-02 $8.17847 \mathrm{e}+018.17847 \mathrm{e}+018.17847 \mathrm{e}+001.00000 \mathrm{e}-09$ 7.00000e-02 $3.26775 \mathrm{e}+003.26775 \mathrm{e}+003.26775 \mathrm{e}-01$ 1.00000e-09 2.12000e-01 
$1.00000 \mathrm{e}-02$ 1.00000e-02 1.00000e-03 1.00000e-09 1.00000e-01 $1.00000 \mathrm{e}+001.00000 \mathrm{e}+001.00000 \mathrm{e}-01$ 1.00000e-09 1.00000e-01 Element: 6192 \# of layers: 5

Kx Ky Kz Ss Por

8.17847e+01 8.17847e+01 8.17847e+00 1.00000e-09 7.00000e-02

8.17847e+01 8.17847e+01 8.17847e+00 1.00000e-09 7.00000e-02

$3.26775 \mathrm{e}+003.26775 \mathrm{e}+00$ 3.26775e-01 1.00000e-09 2.12000e-01

$1.00000 \mathrm{e}-02$ 1.00000e-02 1.00000e-03 1.00000e-09 1.00000e-01

$1.00000 \mathrm{e}+001.00000 \mathrm{e}+001.00000 \mathrm{e}-011.00000 \mathrm{e}-091.00000 \mathrm{e}-01$

Element: 6193 \# of layers: 6

$\mathrm{Kx} \mathrm{Ky} \mathrm{Kz}$ Ss Por

8.17847e+01 8.17847e+01 8.17847e+00 1.00000e-09 7.00000e-02

8.17847e+01 8.17847e+01 8.17847e+00 1.00000e-09 7.00000e-02

8.17847e+01 8.17847e+01 8.17847e+00 1.00000e-09 7.00000e-02

$3.26775 \mathrm{e}+003.26775 \mathrm{e}+00$ 3.26775e-01 1.00000e-09 2.12000e-01

$1.00000 \mathrm{e}-02$ 1.00000e-02 1.00000e-03 1.00000e-09 1.00000e-01

$1.00000 \mathrm{e}+001.00000 \mathrm{e}+001.00000 \mathrm{e}-011.00000 \mathrm{e}-091.00000 \mathrm{e}-01$

Element: 6194 \# of layers: 6

$\mathrm{Kx} \mathrm{Ky} \mathrm{Kz}$ Ss Por

8.17847e+01 8.17847e+01 8.17847e+00 1.00000e-09 7.00000e-02

8.17847e+01 8.17847e+01 8.17847e+00 1.00000e-09 7.00000e-02

8.17847e+01 8.17847e+01 8.17847e+00 1.00000e-09 7.00000e-02

$3.26775 \mathrm{e}+003.26775 \mathrm{e}+00$ 3.26775e-01 1.00000e-09 2.12000e-01

$1.00000 \mathrm{e}-02$ 1.00000e-02 1.00000e-03 1.00000e-09 1.00000e-01

$1.00000 \mathrm{e}+001.00000 \mathrm{e}+001.00000 \mathrm{e}-011.00000 \mathrm{e}-091.00000 \mathrm{e}-01$

Element: 6195 \# of layers: 5

Kx Ky Kz Ss Por

8.17847e+01 8.17847e+01 8.17847e+00 1.00000e-09 7.00000e-02

8.17847e+01 8.17847e+01 8.17847e+00 1.00000e-09 7.00000e-02

$3.26775 \mathrm{e}+00$ 3.26775e+00 3.26775e-01 1.00000e-09 2.12000e-01

$1.00000 \mathrm{e}-02$ 1.00000e-02 1.00000e-03 1.00000e-09 1.00000e-01

$1.00000 \mathrm{e}+001.00000 \mathrm{e}+001.00000 \mathrm{e}-011.00000 \mathrm{e}-091.00000 \mathrm{e}-01$

Element: 6196 \# of layers: 5

$\mathrm{Kx} \mathrm{Ky} \mathrm{Kz}$ Ss Por

8.17847e+01 8.17847e+01 8.17847e+00 1.00000e-09 7.00000e-02

8.17847e+01 8.17847e+01 8.17847e+00 1.00000e-09 7.00000e-02

$3.26775 \mathrm{e}+003.26775 \mathrm{e}+003.26775 \mathrm{e}-01$ 1.00000e-09 2.12000e-01

$1.00000 \mathrm{e}-02$ 1.00000e-02 1.00000e-03 1.00000e-09 1.00000e-01

$1.00000 \mathrm{e}+001.00000 \mathrm{e}+001.00000 \mathrm{e}-011.00000 \mathrm{e}-091.00000 \mathrm{e}-01$

Element: 6197 \# of layers: 5

Kx Ky Kz Ss Por

8.17847e+01 8.17847e+01 8.17847e+00 1.00000e-09 7.00000e-02

8.17847e+01 8.17847e+01 8.17847e+00 1.00000e-09 7.00000e-02

$3.26775 \mathrm{e}+003.26775 \mathrm{e}+003.26775 \mathrm{e}-01$ 1.00000e-09 2.12000e-01

$1.00000 \mathrm{e}-02$ 1.00000e-02 1.00000e-03 1.00000e-09 1.00000e-01

$1.00000 \mathrm{e}+001.00000 \mathrm{e}+001.00000 \mathrm{e}-011.00000 \mathrm{e}-091.00000 \mathrm{e}-01$ 
Element: 6198 \# of layers: 5

$\mathrm{Kx} \mathrm{Ky} \mathrm{Kz}$ Ss Por

8.17847e+01 8.17847e+01 8.17847e+00 1.00000e-09 7.00000e-02

8.17847e+01 8.17847e+01 8.17847e+00 1.00000e-09 7.00000e-02

$3.26775 \mathrm{e}+003.26775 \mathrm{e}+00$ 3.26775e-01 1.00000e-09 2.12000e-01

$1.00000 \mathrm{e}-02$ 1.00000e-02 1.00000e-03 1.00000e-09 1.00000e-01

$1.00000 \mathrm{e}+001.00000 \mathrm{e}+001.00000 \mathrm{e}-011.00000 \mathrm{e}-091.00000 \mathrm{e}-01$

Element: 6199 \# of layers: 5

$\mathrm{Kx} \mathrm{Ky} \mathrm{Kz}$ Ss Por

8.17847e+01 8.17847e+01 8.17847e+00 1.00000e-09 7.00000e-02

8.17847e+01 8.17847e+01 8.17847e+00 1.00000e-09 7.00000e-02

$3.26775 \mathrm{e}+003.26775 \mathrm{e}+003.26775 \mathrm{e}-01$ 1.00000e-09 2.12000e-01

$1.00000 \mathrm{e}-02$ 1.00000e-02 1.00000e-03 1.00000e-09 1.00000e-01

$1.00000 \mathrm{e}+001.00000 \mathrm{e}+001.00000 \mathrm{e}-01$ 1.00000e-09 1.00000e-01

Element: 6200 \# of layers: 6

Kx Ky Kz Ss Por

8.40327e+01 8.40327e+01 8.40327e+00 1.00000e-09 7.00000e-02

8.40327e+01 8.40327e+01 8.40327e+00 1.00000e-09 7.00000e-02

8.40327e+01 8.40327e+01 8.40327e+00 1.00000e-09 7.00000e-02

$3.35775 \mathrm{e}+003.35775 \mathrm{e}+003.35775 \mathrm{e}-01$ 1.00000e-09 2.12000e-01

$1.00000 \mathrm{e}-02$ 1.00000e-02 1.00000e-03 1.00000e-09 1.00000e-01

$1.00000 \mathrm{e}+001.00000 \mathrm{e}+001.00000 \mathrm{e}-01$ 1.00000e-09 1.00000e-01

Element: 6201 \# of layers: 4

Kx Ky Kz Ss Por

8.40327e+01 8.40327e+01 8.40327e+00 1.00000e-09 7.00000e-02

$3.35775 \mathrm{e}+003.35775 \mathrm{e}+00$ 3.35775e-01 1.00000e-09 2.12000e-01

$1.00000 \mathrm{e}-02$ 1.00000e-02 1.00000e-03 1.00000e-09 1.00000e-01

$1.00000 \mathrm{e}+001.00000 \mathrm{e}+001.00000 \mathrm{e}-011.00000 \mathrm{e}-091.00000 \mathrm{e}-01$

Element: 6202 \# of layers: 5

$\mathrm{Kx} \mathrm{Ky} \mathrm{Kz}$ Ss Por

8.40327e+01 8.40327e+01 8.40327e+00 1.00000e-09 7.00000e-02

8.40327e+01 8.40327e+01 8.40327e+00 1.00000e-09 7.00000e-02

$3.35775 \mathrm{e}+003.35775 \mathrm{e}+003.35775 \mathrm{e}-01$ 1.00000e-09 2.12000e-01

1.00000e-02 1.00000e-02 1.00000e-03 1.00000e-09 1.00000e-01

$1.00000 \mathrm{e}+001.00000 \mathrm{e}+001.00000 \mathrm{e}-01$ 1.00000e-09 1.00000e-01

Element: 6203 \# of layers: 4

Kx Ky Kz Ss Por

8.40327e+01 8.40327e+01 8.40327e+00 1.00000e-09 7.00000e-02

$3.35775 \mathrm{e}+003.35775 \mathrm{e}+003.35775 \mathrm{e}-01$ 1.00000e-09 2.12000e-01

$1.00000 \mathrm{e}-02$ 1.00000e-02 1.00000e-03 1.00000e-09 1.00000e-01

$1.00000 \mathrm{e}+001.00000 \mathrm{e}+001.00000 \mathrm{e}-011.00000 \mathrm{e}-091.00000 \mathrm{e}-01$

Element: 6204 \# of layers: 6

$\mathrm{Kx} \mathrm{Ky} \mathrm{Kz}$ Ss Por

8.40327e+01 8.40327e+01 8.40327e+00 1.00000e-09 7.00000e-02

8.40327e+01 8.40327e+01 8.40327e+00 1.00000e-09 7.00000e-02

$3.35775 \mathrm{e}+003.35775 \mathrm{e}+003.35775 \mathrm{e}-01$ 1.00000e-09 2.12000e-01 
3.35775e+00 3.35775e+00 3.35775e-01 1.00000e-09 2.12000e-01 $1.00000 \mathrm{e}-02$ 1.00000e-02 1.00000e-03 1.00000e-09 1.00000e-01 $1.00000 \mathrm{e}+001.00000 \mathrm{e}+001.00000 \mathrm{e}-01$ 1.00000e-09 1.00000e-01 Element: 6205 \# of layers: 5

$\mathrm{Kx} \mathrm{Ky} \mathrm{Kz}$ Ss Por

8.40327e+01 8.40327e+01 8.40327e+00 1.00000e-09 7.00000e-02 8.40327e+01 8.40327e+01 8.40327e+00 1.00000e-09 7.00000e-02 $3.35775 \mathrm{e}+003.35775 \mathrm{e}+00$ 3.35775e-01 1.00000e-09 2.12000e-01 $1.00000 \mathrm{e}-02$ 1.00000e-02 1.00000e-03 1.00000e-09 1.00000e-01 $1.00000 \mathrm{e}+001.00000 \mathrm{e}+00$ 1.00000e-01 1.00000e-09 1.00000e-01 Element: 6206 \# of layers: 5

$\mathrm{Kx} \mathrm{Ky} \mathrm{Kz}$ Ss Por 8.40327e+01 8.40327e+01 8.40327e+00 1.00000e-09 7.00000e-02 8.40327e+01 8.40327e+01 8.40327e+00 1.00000e-09 7.00000e-02 $3.35775 \mathrm{e}+003.35775 \mathrm{e}+00$ 3.35775e-01 1.00000e-09 2.12000e-01 1.00000e-02 1.00000e-02 1.00000e-03 1.00000e-09 1.00000e-01 $1.00000 \mathrm{e}+001.00000 \mathrm{e}+001.00000 \mathrm{e}-011.00000 \mathrm{e}-091.00000 \mathrm{e}-01$ Element: 6207 \# of layers: 5

$\mathrm{Kx} \mathrm{Ky} \mathrm{Kz}$ Ss Por

8.40327e+01 8.40327e+01 8.40327e+00 1.00000e-09 7.00000e-02 8.40327e+01 8.40327e+01 8.40327e+00 1.00000e-09 7.00000e-02 3.35775e+00 3.35775e+00 3.35775e-01 1.00000e-09 2.12000e-01 $1.00000 \mathrm{e}-02$ 1.00000e-02 1.00000e-03 1.00000e-09 1.00000e-01 $1.00000 \mathrm{e}+001.00000 \mathrm{e}+001.00000 \mathrm{e}-011.00000 \mathrm{e}-091.00000 \mathrm{e}-01$

Element: 6208 \# of layers: 4

$\mathrm{Kx} \mathrm{Ky} \mathrm{Kz}$ Ss Por

8.40327e+01 8.40327e+01 8.40327e+00 1.00000e-09 7.00000e-02 $3.35775 \mathrm{e}+003.35775 \mathrm{e}+00$ 3.35775e-01 1.00000e-09 2.12000e-01 $1.00000 \mathrm{e}-02$ 1.00000e-02 1.00000e-03 1.00000e-09 1.00000e-01 $1.00000 \mathrm{e}+001.00000 \mathrm{e}+001.00000 \mathrm{e}-011.00000 \mathrm{e}-091.00000 \mathrm{e}-01$ Element: 6209 \# of layers: 6

$\mathrm{Kx} \mathrm{Ky} \mathrm{Kz}$ Ss Por

7.92853e+01 7.92853e+01 7.92853e+00 1.00000e-09 7.00000e-02 $7.92853 \mathrm{e}+01$ 7.92853e+01 7.92853e+00 1.00000e-09 7.00000e-02 7.92853e+01 7.92853e+01 7.92853e+00 1.00000e-09 7.00000e-02 $3.16807 \mathrm{e}+003.16807 \mathrm{e}+00$ 3.16807e-01 1.00000e-09 2.12000e-01 $1.00000 \mathrm{e}-02$ 1.00000e-02 1.00000e-03 1.00000e-09 1.00000e-01 $1.00000 \mathrm{e}+001.00000 \mathrm{e}+001.00000 \mathrm{e}-011.00000 \mathrm{e}-091.00000 \mathrm{e}-01$ Element: 6210 \# of layers: 5

$\mathrm{Kx} \mathrm{Ky} \mathrm{Kz}$ Ss Por

7.92853e+01 7.92853e+01 7.92853e+00 1.00000e-09 7.00000e-02 7.92853e+01 7.92853e+01 7.92853e+00 1.00000e-09 7.00000e-02 3.16807e+00 3.16807e+00 3.16807e-01 1.00000e-09 2.12000e-01 $1.00000 \mathrm{e}-02$ 1.00000e-02 1.00000e-03 1.00000e-09 1.00000e-01 $1.00000 \mathrm{e}+001.00000 \mathrm{e}+001.00000 \mathrm{e}-011.00000 \mathrm{e}-091.00000 \mathrm{e}-01$ Element: 6211 \# of layers: 5 
$\mathrm{Kx} \mathrm{Ky} \mathrm{Kz}$ Ss Por

7.92853e+01 7.92853e+01 7.92853e+00 1.00000e-09 7.00000e-02

7.92853e+01 7.92853e+01 7.92853e+00 1.00000e-09 7.00000e-02

$3.16807 \mathrm{e}+00$ 3.16807e+00 3.16807e-01 1.00000e-09 2.12000e-01

$1.00000 \mathrm{e}-02$ 1.00000e-02 1.00000e-03 1.00000e-09 1.00000e-01

$1.00000 \mathrm{e}+001.00000 \mathrm{e}+001.00000 \mathrm{e}-011.00000 \mathrm{e}-091.00000 \mathrm{e}-01$

Element: 6212 \# of layers: 4

$\mathrm{Kx} \mathrm{Ky} \mathrm{Kz}$ Ss Por

7.92853e+01 7.92853e+01 7.92853e+00 1.00000e-09 7.00000e-02

$3.16807 \mathrm{e}+003.16807 \mathrm{e}+00$ 3.16807e-01 1.00000e-09 2.12000e-01

$1.00000 \mathrm{e}-02$ 1.00000e-02 1.00000e-03 1.00000e-09 1.00000e-01

$1.00000 \mathrm{e}+001.00000 \mathrm{e}+001.00000 \mathrm{e}-011.00000 \mathrm{e}-091.00000 \mathrm{e}-01$

Element: 6213 \# of layers: 6

$\mathrm{Kx} \mathrm{Ky} \mathrm{Kz}$ Ss Por

7.92853e+01 7.92853e+01 7.92853e+00 1.00000e-09 7.00000e-02

$7.92853 \mathrm{e}+017.92853 \mathrm{e}+01$ 7.92853e+00 1.00000e-09 7.00000e-02

$3.16807 \mathrm{e}+00$ 3.16807e+00 3.16807e-01 1.00000e-09 2.12000e-01

3.16807e+00 3.16807e+00 3.16807e-01 1.00000e-09 2.12000e-01

$1.00000 \mathrm{e}-02$ 1.00000e-02 1.00000e-03 1.00000e-09 1.00000e-01

$1.00000 \mathrm{e}+001.00000 \mathrm{e}+001.00000 \mathrm{e}-011.00000 \mathrm{e}-091.00000 \mathrm{e}-01$

Element: 6214 \# of layers: 6

$\mathrm{Kx} \mathrm{Ky} \mathrm{Kz}$ Ss Por

7.92853e+01 7.92853e+01 7.92853e+00 1.00000e-09 7.00000e-02

7.92853e+01 7.92853e+01 7.92853e+00 1.00000e-09 7.00000e-02

$3.16807 \mathrm{e}+00$ 3.16807e+00 3.16807e-01 1.00000e-09 2.12000e-01

3.16807e+00 3.16807e+00 3.16807e-01 1.00000e-09 2.12000e-01

$1.00000 \mathrm{e}-02$ 1.00000e-02 1.00000e-03 1.00000e-09 1.00000e-01

$1.00000 \mathrm{e}+001.00000 \mathrm{e}+001.00000 \mathrm{e}-011.00000 \mathrm{e}-09$ 1.00000e-01

Element: 6215 \# of layers: 6

$\mathrm{Kx} \mathrm{Ky} \mathrm{Kz}$ Ss Por

7.92853e+01 7.92853e+01 7.92853e+00 1.00000e-09 7.00000e-02

7.92853e+01 7.92853e+01 7.92853e+00 1.00000e-09 7.00000e-02

3.16807e+00 3.16807e+00 3.16807e-01 1.00000e-09 2.12000e-01

3.16807e+00 3.16807e+00 3.16807e-01 1.00000e-09 2.12000e-01

$1.00000 \mathrm{e}-02$ 1.00000e-02 1.00000e-03 1.00000e-09 1.00000e-01

$1.00000 \mathrm{e}+001.00000 \mathrm{e}+001.00000 \mathrm{e}-011.00000 \mathrm{e}-091.00000 \mathrm{e}-01$

Element: 6216 \# of layers: 4

Kx Ky Kz Ss Por

7.92853e+01 7.92853e+01 7.92853e+00 1.00000e-09 7.00000e-02

3.16807e+00 3.16807e+00 3.16807e-01 1.00000e-09 2.12000e-01

1.00000e-02 1.00000e-02 1.00000e-03 1.00000e-09 1.00000e-01

$1.00000 \mathrm{e}+001.00000 \mathrm{e}+001.00000 \mathrm{e}-011.00000 \mathrm{e}-091.00000 \mathrm{e}-01$

Element: 6217 \# of layers: 4

$\mathrm{Kx} \mathrm{Ky} \mathrm{Kz}$ Ss Por

7.92853e+01 7.92853e+01 7.92853e+00 1.00000e-09 7.00000e-02

$3.16807 \mathrm{e}+003.16807 \mathrm{e}+00$ 3.16807e-01 1.00000e-09 2.12000e-01 
$1.00000 \mathrm{e}-02$ 1.00000e-02 1.00000e-03 1.00000e-09 1.00000e-01 $1.00000 \mathrm{e}+001.00000 \mathrm{e}+001.00000 \mathrm{e}-01$ 1.00000e-09 1.00000e-01 Element: 6218 \# of layers: 6

Kx Ky Kz Ss Por

9.01541e+01 9.01541e+01 9.01541e+00 1.00000e-09 7.00000e-02 $9.01541 \mathrm{e}+019.01541 \mathrm{e}+019.01541 \mathrm{e}+001.00000 \mathrm{e}-09$ 7.00000e-02 $9.01541 \mathrm{e}+019.01541 \mathrm{e}+019.01541 \mathrm{e}+00$ 1.00000e-09 7.00000e-02 $3.60233 \mathrm{e}+00$ 3.60233e+00 3.60233e-01 1.00000e-09 2.12000e-01 $1.00000 \mathrm{e}-021.00000 \mathrm{e}-021.00000 \mathrm{e}-031.00000 \mathrm{e}-091.00000 \mathrm{e}-01$ $1.00000 \mathrm{e}+001.00000 \mathrm{e}+001.00000 \mathrm{e}-011.00000 \mathrm{e}-091.00000 \mathrm{e}-01$ Element: 6219 \# of layers: 5

Kx Ky Kz Ss Por

9.01541e+01 9.01541e+01 9.01541e+00 1.00000e-09 7.00000e-02 $9.01541 \mathrm{e}+019.01541 \mathrm{e}+019.01541 \mathrm{e}+001.00000 \mathrm{e}-09$ 7.00000e-02 3.60233e+00 3.60233e+00 3.60233e-01 1.00000e-09 2.12000e-01 $1.00000 \mathrm{e}-02$ 1.00000e-02 1.00000e-03 1.00000e-09 1.00000e-01 $1.00000 \mathrm{e}+001.00000 \mathrm{e}+001.00000 \mathrm{e}-011.00000 \mathrm{e}-091.00000 \mathrm{e}-01$ Element: 6220 \# of layers: 5

$\mathrm{Kx} \mathrm{Ky} \mathrm{Kz}$ Ss Por 9.01541e+01 9.01541e+01 9.01541e+00 1.00000e-09 7.00000e-02 9.01541e+01 9.01541e+01 9.01541e+00 1.00000e-09 7.00000e-02 3.60233e+00 3.60233e+00 3.60233e-01 1.00000e-09 2.12000e-01 $1.00000 \mathrm{e}-02$ 1.00000e-02 1.00000e-03 1.00000e-09 1.00000e-01 $1.00000 \mathrm{e}+001.00000 \mathrm{e}+001.00000 \mathrm{e}-011.00000 \mathrm{e}-091.00000 \mathrm{e}-01$ Element: 6221 \# of layers: 5

$\mathrm{Kx} \mathrm{Ky} \mathrm{Kz}$ Ss Por

9.01541e+01 9.01541e+01 9.01541e+00 1.00000e-09 7.00000e-02 $3.60233 \mathrm{e}+003.60233 \mathrm{e}+00$ 3.60233e-01 1.00000e-09 2.12000e-01 $3.60233 \mathrm{e}+003.60233 \mathrm{e}+00$ 3.60233e-01 1.00000e-09 2.12000e-01 $1.00000 \mathrm{e}-02$ 1.00000e-02 1.00000e-03 1.00000e-09 1.00000e-01 $1.00000 \mathrm{e}+001.00000 \mathrm{e}+001.00000 \mathrm{e}-011.00000 \mathrm{e}-091.00000 \mathrm{e}-01$ Element: 6222 \# of layers: 6

Kx Ky Kz Ss Por

9.01541e+01 9.01541e+01 9.01541e+00 1.00000e-09 7.00000e-02 $3.60233 \mathrm{e}+003.60233 \mathrm{e}+00$ 3.60233e-01 1.00000e-09 2.12000e-01 $3.60233 \mathrm{e}+003.60233 \mathrm{e}+00$ 3.60233e-01 1.00000e-09 2.12000e-01 $3.60233 \mathrm{e}+003.60233 \mathrm{e}+00$ 3.60233e-01 1.00000e-09 2.12000e-01 $1.00000 \mathrm{e}-02$ 1.00000e-02 1.00000e-03 1.00000e-09 1.00000e-01 $1.00000 \mathrm{e}+001.00000 \mathrm{e}+001.00000 \mathrm{e}-011.00000 \mathrm{e}-091.00000 \mathrm{e}-01$ Element: 6223 \# of layers: 7

Kx Ky Kz Ss Por

9.01541e+01 9.01541e+01 9.01541e+00 1.00000e-09 7.00000e-02 $9.01541 \mathrm{e}+019.01541 \mathrm{e}+019.01541 \mathrm{e}+001.00000 \mathrm{e}-09$ 7.00000e-02 3.60233e+00 3.60233e+00 3.60233e-01 1.00000e-09 2.12000e-01 $3.60233 \mathrm{e}+003.60233 \mathrm{e}+00$ 3.60233e-01 1.00000e-09 2.12000e-01 $3.60233 \mathrm{e}+003.60233 \mathrm{e}+00$ 3.60233e-01 1.00000e-09 2.12000e-01 
$1.00000 \mathrm{e}-02$ 1.00000e-02 1.00000e-03 1.00000e-09 1.00000e-01 $1.00000 \mathrm{e}+001.00000 \mathrm{e}+001.00000 \mathrm{e}-01$ 1.00000e-09 1.00000e-01 Element: 6224 \# of layers: 6

Kx Ky Kz Ss Por

9.01541e+01 9.01541e+01 9.01541e+00 1.00000e-09 7.00000e-02 $9.01541 \mathrm{e}+019.01541 \mathrm{e}+019.01541 \mathrm{e}+001.00000 \mathrm{e}-09$ 7.00000e-02 $3.60233 \mathrm{e}+003.60233 \mathrm{e}+00$ 3.60233e-01 1.00000e-09 2.12000e-01 $3.60233 \mathrm{e}+003.60233 \mathrm{e}+00$ 3.60233e-01 1.00000e-09 2.12000e-01 $1.00000 \mathrm{e}-02$ 1.00000e-02 1.00000e-03 1.00000e-09 1.00000e-01 $1.00000 \mathrm{e}+001.00000 \mathrm{e}+001.00000 \mathrm{e}-011.00000 \mathrm{e}-091.00000 \mathrm{e}-01$ Element: 6225 \# of layers: 5

$\mathrm{Kx} \mathrm{Ky} \mathrm{Kz}$ Ss Por

9.01541e+01 9.01541e+01 9.01541e+00 1.00000e-09 7.00000e-02 $3.60233 \mathrm{e}+003.60233 \mathrm{e}+00$ 3.60233e-01 1.00000e-09 2.12000e-01 3.60233e+00 3.60233e+00 3.60233e-01 1.00000e-09 2.12000e-01 $1.00000 \mathrm{e}-02$ 1.00000e-02 1.00000e-03 1.00000e-09 1.00000e-01 $1.00000 \mathrm{e}+001.00000 \mathrm{e}+001.00000 \mathrm{e}-011.00000 \mathrm{e}-091.00000 \mathrm{e}-01$ Element: 6226 \# of layers: 6

$\mathrm{Kx} \mathrm{Ky} \mathrm{Kz}$ Ss Por 9.01541e+01 9.01541e+01 9.01541e+00 1.00000e-09 7.00000e-02 9.01541e+01 9.01541e+01 9.01541e+00 1.00000e-09 7.00000e-02 3.60233e+00 3.60233e+00 3.60233e-01 1.00000e-09 2.12000e-01 $3.60233 \mathrm{e}+003.60233 \mathrm{e}+00$ 3.60233e-01 1.00000e-09 2.12000e-01 $1.00000 \mathrm{e}-02$ 1.00000e-02 1.00000e-03 1.00000e-09 1.00000e-01 $1.00000 \mathrm{e}+001.00000 \mathrm{e}+001.00000 \mathrm{e}-011.00000 \mathrm{e}-091.00000 \mathrm{e}-01$ Element: 6227 \# of layers: 5

$\mathrm{Kx} \mathrm{Ky} \mathrm{Kz}$ Ss Por

$2.09906 \mathrm{e}+02$ 2.09906e+02 2.09906e+01 1.00000e-09 7.00000e-02 $2.09906 \mathrm{e}+022.09906 \mathrm{e}+022.09906 \mathrm{e}+01$ 1.00000e-09 7.00000e-02 $8.38728 \mathrm{e}+00$ 8.38728e+00 8.38728e-01 1.00000e-09 2.12000e-01 $1.00000 \mathrm{e}-02$ 1.00000e-02 1.00000e-03 1.00000e-09 1.00000e-01 $1.00000 \mathrm{e}+001.00000 \mathrm{e}+001.00000 \mathrm{e}-011.00000 \mathrm{e}-091.00000 \mathrm{e}-01$ Element: 6228 \# of layers: 4

$\mathrm{Kx} \mathrm{Ky} \mathrm{Kz}$ Ss Por

2.09906e+02 2.09906e+02 2.09906e+01 1.00000e-09 7.00000e-02 8.38728e+00 8.38728e+00 8.38728e-01 1.00000e-09 2.12000e-01 $1.00000 \mathrm{e}-02$ 1.00000e-02 1.00000e-03 1.00000e-09 1.00000e-01 $1.00000 \mathrm{e}+001.00000 \mathrm{e}+001.00000 \mathrm{e}-011.00000 \mathrm{e}-091.00000 \mathrm{e}-01$ Element: 6229 \# of layers: 4

$\mathrm{Kx} \mathrm{Ky} \mathrm{Kz}$ Ss Por $2.09906 \mathrm{e}+02$ 2.09906e+02 2.09906e+01 1.00000e-09 7.00000e-02 8.38728e+00 8.38728e+00 8.38728e-01 1.00000e-09 2.12000e-01 $1.00000 \mathrm{e}-021.00000 \mathrm{e}-021.00000 \mathrm{e}-031.00000 \mathrm{e}-091.00000 \mathrm{e}-01$ $1.00000 \mathrm{e}+001.00000 \mathrm{e}+001.00000 \mathrm{e}-011.00000 \mathrm{e}-091.00000 \mathrm{e}-01$ Element: 6230 \# of layers: 3

Kx Ky Kz Ss Por 
8.38728e+00 8.38728e+00 8.38728e-01 1.00000e-09 2.12000e-01 $1.00000 \mathrm{e}-02$ 1.00000e-02 1.00000e-03 1.00000e-09 1.00000e-01 $1.00000 \mathrm{e}+001.00000 \mathrm{e}+001.00000 \mathrm{e}-01$ 1.00000e-09 1.00000e-01 Element: 6231 \# of layers: 3

$\mathrm{Kx} \mathrm{Ky} \mathrm{Kz}$ Ss Por

8.38728e+00 8.38728e+00 8.38728e-01 1.00000e-09 2.12000e-01 $1.00000 \mathrm{e}-02$ 1.00000e-02 1.00000e-03 1.00000e-09 1.00000e-01 $1.00000 \mathrm{e}+001.00000 \mathrm{e}+001.00000 \mathrm{e}-011.00000 \mathrm{e}-091.00000 \mathrm{e}-01$ Element: 6232 \# of layers: 3

$\mathrm{Kx} \mathrm{Ky} \mathrm{Kz}$ Ss Por

8.38728e+00 8.38728e+00 8.38728e-01 1.00000e-09 2.12000e-01 $1.00000 \mathrm{e}-02$ 1.00000e-02 1.00000e-03 1.00000e-09 1.00000e-01 $1.00000 \mathrm{e}+001.00000 \mathrm{e}+001.00000 \mathrm{e}-01$ 1.00000e-09 1.00000e-01 Element: 6233 \# of layers: 4

$\mathrm{Kx} \mathrm{Ky} \mathrm{Kz}$ Ss Por $2.09906 \mathrm{e}+02$ 2.09906e+02 2.09906e+01 1.00000e-09 7.00000e-02 8.38728e+00 8.38728e+00 8.38728e-01 1.00000e-09 2.12000e-01 $1.00000 \mathrm{e}-02$ 1.00000e-02 1.00000e-03 1.00000e-09 1.00000e-01 $1.00000 \mathrm{e}+001.00000 \mathrm{e}+001.00000 \mathrm{e}-01$ 1.00000e-09 1.00000e-01 Element: 6234 \# of layers: 4

$\mathrm{Kx} \mathrm{Ky} \mathrm{Kz}$ Ss Por $2.09906 \mathrm{e}+02$ 2.09906e+02 2.09906e+01 1.00000e-09 7.00000e-02 8.38728e+00 8.38728e+00 8.38728e-01 1.00000e-09 2.12000e-01 $1.00000 \mathrm{e}-02$ 1.00000e-02 1.00000e-03 1.00000e-09 1.00000e-01 $1.00000 \mathrm{e}+001.00000 \mathrm{e}+001.00000 \mathrm{e}-011.00000 \mathrm{e}-091.00000 \mathrm{e}-01$ Element: 6235 \# of layers: 4

$\mathrm{Kx} \mathrm{Ky} \mathrm{Kz}$ Ss Por $2.09906 \mathrm{e}+02$ 2.09906e+02 2.09906e+01 1.00000e-09 7.00000e-02 $8.38728 \mathrm{e}+00$ 8.38728e+00 8.38728e-01 1.00000e-09 2.12000e-01 $1.00000 \mathrm{e}-02$ 1.00000e-02 1.00000e-03 1.00000e-09 1.00000e-01 $1.00000 \mathrm{e}+001.00000 \mathrm{e}+001.00000 \mathrm{e}-01$ 1.00000e-09 1.00000e-01 Element: 6236 \# of layers: 5

Kx Ky Kz Ss Por

3.33974e+02 3.33974e+02 3.33974e+01 1.00000e-09 7.00000e-02 $3.33974 \mathrm{e}+02$ 3.33974e+02 3.33974e+01 1.00000e-09 7.00000e-02 $1.33444 \mathrm{e}+011.33444 \mathrm{e}+011.33444 \mathrm{e}+001.00000 \mathrm{e}-092.12000 \mathrm{e}-01$ $1.00000 \mathrm{e}-02$ 1.00000e-02 1.00000e-03 1.00000e-09 1.00000e-01 $1.00000 \mathrm{e}+001.00000 \mathrm{e}+001.00000 \mathrm{e}-011.00000 \mathrm{e}-091.00000 \mathrm{e}-01$ Element: 6237 \# of layers: 5

$\mathrm{Kx} \mathrm{Ky} \mathrm{Kz}$ Ss Por 3.33974e+02 3.33974e+02 3.33974e+01 1.00000e-09 7.00000e-02 $3.33974 \mathrm{e}+02$ 3.33974e+02 3.33974e+01 1.00000e-09 7.00000e-02 $1.33444 \mathrm{e}+011.33444 \mathrm{e}+011.33444 \mathrm{e}+001.00000 \mathrm{e}-092.12000 \mathrm{e}-01$ $1.00000 \mathrm{e}-02$ 1.00000e-02 1.00000e-03 1.00000e-09 1.00000e-01 $1.00000 \mathrm{e}+001.00000 \mathrm{e}+001.00000 \mathrm{e}-011.00000 \mathrm{e}-091.00000 \mathrm{e}-01$ Element: 6238 \# of layers: 5 
$\mathrm{Kx} \mathrm{Ky} \mathrm{Kz}$ Ss Por

3.33974e+02 3.33974e+02 3.33974e+01 1.00000e-09 7.00000e-02

$3.33974 \mathrm{e}+02$ 3.33974e+02 3.33974e+01 1.00000e-09 7.00000e-02

$1.33444 \mathrm{e}+011.33444 \mathrm{e}+011.33444 \mathrm{e}+001.00000 \mathrm{e}-092.12000 \mathrm{e}-01$

$1.00000 \mathrm{e}-02$ 1.00000e-02 1.00000e-03 1.00000e-09 1.00000e-01

$1.00000 \mathrm{e}+001.00000 \mathrm{e}+001.00000 \mathrm{e}-011.00000 \mathrm{e}-09$ 1.00000e-01

Element: 6239 \# of layers: 5

$\mathrm{Kx} \mathrm{Ky} \mathrm{Kz}$ Ss Por

3.33974e+02 3.33974e+02 3.33974e+01 1.00000e-09 7.00000e-02

$3.33974 \mathrm{e}+023.33974 \mathrm{e}+02$ 3.33974e+01 1.00000e-09 7.00000e-02

$1.33444 \mathrm{e}+011.33444 \mathrm{e}+011.33444 \mathrm{e}+001.00000 \mathrm{e}-092.12000 \mathrm{e}-01$

$1.00000 \mathrm{e}-02$ 1.00000e-02 1.00000e-03 1.00000e-09 1.00000e-01

$1.00000 \mathrm{e}+001.00000 \mathrm{e}+001.00000 \mathrm{e}-011.00000 \mathrm{e}-091.00000 \mathrm{e}-01$

Element: 6240 \# of layers: 4

$\mathrm{Kx} \mathrm{Ky} \mathrm{Kz}$ Ss Por

3.33974e+02 3.33974e+02 3.33974e+01 1.00000e-09 7.00000e-02

$1.33444 \mathrm{e}+011.33444 \mathrm{e}+011.33444 \mathrm{e}+001.00000 \mathrm{e}-092.12000 \mathrm{e}-01$

$1.00000 \mathrm{e}-02$ 1.00000e-02 1.00000e-03 1.00000e-09 1.00000e-01

$1.00000 \mathrm{e}+001.00000 \mathrm{e}+001.00000 \mathrm{e}-01$ 1.00000e-09 1.00000e-01

Element: 6241 \# of layers: 4

$\mathrm{Kx} \mathrm{Ky} \mathrm{Kz}$ Ss Por

3.33974e+02 3.33974e+02 3.33974e+01 1.00000e-09 7.00000e-02

$1.33444 \mathrm{e}+011.33444 \mathrm{e}+01$ 1.33444e+00 1.00000e-09 2.12000e-01

$1.00000 \mathrm{e}-02$ 1.00000e-02 1.00000e-03 1.00000e-09 1.00000e-01

$1.00000 \mathrm{e}+001.00000 \mathrm{e}+001.00000 \mathrm{e}-011.00000 \mathrm{e}-091.00000 \mathrm{e}-01$

Element: 6242 \# of layers: 3

$\mathrm{Kx} \mathrm{Ky} \mathrm{Kz}$ Ss Por

$1.33444 \mathrm{e}+01$ 1.33444e+01 1.33444e+00 1.00000e-09 2.12000e-01

$1.00000 \mathrm{e}-02$ 1.00000e-02 1.00000e-03 1.00000e-09 1.00000e-01

$1.00000 \mathrm{e}+001.00000 \mathrm{e}+001.00000 \mathrm{e}-011.00000 \mathrm{e}-091.00000 \mathrm{e}-01$

Element: 6243 \# of layers: 4

Kx Ky Kz Ss Por

3.33974e+02 3.33974e+02 3.33974e+01 1.00000e-09 7.00000e-02

$1.33444 \mathrm{e}+011.33444 \mathrm{e}+011.33444 \mathrm{e}+001.00000 \mathrm{e}-092.12000 \mathrm{e}-01$

$1.00000 \mathrm{e}-02$ 1.00000e-02 1.00000e-03 1.00000e-09 1.00000e-01

$1.00000 \mathrm{e}+001.00000 \mathrm{e}+001.00000 \mathrm{e}-011.00000 \mathrm{e}-091.00000 \mathrm{e}-01$

Element: 6244 \# of layers: 4

$\mathrm{Kx} \mathrm{Ky} \mathrm{Kz}$ Ss Por

3.33974e+02 3.33974e+02 3.33974e+01 1.00000e-09 7.00000e-02

$1.33444 \mathrm{e}+011.33444 \mathrm{e}+011.33444 \mathrm{e}+001.00000 \mathrm{e}-092.12000 \mathrm{e}-01$

$1.00000 \mathrm{e}-02$ 1.00000e-02 1.00000e-03 1.00000e-09 1.00000e-01

$1.00000 \mathrm{e}+001.00000 \mathrm{e}+001.00000 \mathrm{e}-011.00000 \mathrm{e}-091.00000 \mathrm{e}-01$

Element: 6245 \# of layers: 4

$\mathrm{Kx} \mathrm{Ky} \mathrm{Kz}$ Ss Por

8.26893e+02 8.26893e+02 8.26893e+01 1.00000e-09 7.00000e-02

$3.30397 \mathrm{e}+013.30397 \mathrm{e}+01$ 3.30397e+00 1.00000e-09 2.12000e-01 
$1.00000 \mathrm{e}-02$ 1.00000e-02 1.00000e-03 1.00000e-09 1.00000e-01 $1.00000 \mathrm{e}+001.00000 \mathrm{e}+001.00000 \mathrm{e}-01$ 1.00000e-09 1.00000e-01 Element: 6246 \# of layers: 4

$\mathrm{Kx} \mathrm{Ky} \mathrm{Kz}$ Ss Por

8.26893e+02 8.26893e+02 8.26893e+01 1.00000e-09 7.00000e-02

$3.30397 \mathrm{e}+013.30397 \mathrm{e}+013.30397 \mathrm{e}+00$ 1.00000e-09 2.12000e-01

$1.00000 \mathrm{e}-02$ 1.00000e-02 1.00000e-03 1.00000e-09 1.00000e-01

$1.00000 \mathrm{e}+001.00000 \mathrm{e}+001.00000 \mathrm{e}-01$ 1.00000e-09 1.00000e-01

Element: 6247 \# of layers: 4

$\mathrm{Kx} \mathrm{Ky} \mathrm{Kz}$ Ss Por

8.26893e+02 8.26893e+02 8.26893e+01 1.00000e-09 7.00000e-02

$3.30397 \mathrm{e}+01$ 3.30397e+01 3.30397e+00 1.00000e-09 2.12000e-01

$1.00000 \mathrm{e}-02$ 1.00000e-02 1.00000e-03 1.00000e-09 1.00000e-01

$1.00000 \mathrm{e}+001.00000 \mathrm{e}+001.00000 \mathrm{e}-011.00000 \mathrm{e}-091.00000 \mathrm{e}-01$

Element: 6248 \# of layers: 5

$\mathrm{Kx} \mathrm{Ky} \mathrm{Kz}$ Ss Por

8.26893e+02 8.26893e+02 8.26893e+01 1.00000e-09 7.00000e-02

8.26893e+02 8.26893e+02 8.26893e+01 1.00000e-09 7.00000e-02

$3.30397 \mathrm{e}+013.30397 \mathrm{e}+01$ 3.30397e+00 1.00000e-09 2.12000e-01

$1.00000 \mathrm{e}-02$ 1.00000e-02 1.00000e-03 1.00000e-09 1.00000e-01

$1.00000 \mathrm{e}+001.00000 \mathrm{e}+001.00000 \mathrm{e}-011.00000 \mathrm{e}-091.00000 \mathrm{e}-01$

Element: 6249 \# of layers: 4

$\mathrm{Kx} \mathrm{Ky} \mathrm{Kz}$ Ss Por

8.26893e+02 8.26893e+02 8.26893e+01 1.00000e-09 7.00000e-02

$3.30397 \mathrm{e}+01$ 3.30397e+01 3.30397e+00 1.00000e-09 2.12000e-01

$1.00000 \mathrm{e}-02$ 1.00000e-02 1.00000e-03 1.00000e-09 1.00000e-01

$1.00000 \mathrm{e}+001.00000 \mathrm{e}+001.00000 \mathrm{e}-011.00000 \mathrm{e}-091.00000 \mathrm{e}-01$

Element: 6250 \# of layers: 4

$\mathrm{Kx} \mathrm{Ky} \mathrm{Kz}$ Ss Por

8.26893e+02 8.26893e+02 8.26893e+01 1.00000e-09 7.00000e-02

$3.30397 \mathrm{e}+013.30397 \mathrm{e}+013.30397 \mathrm{e}+00$ 1.00000e-09 2.12000e-01

$1.00000 \mathrm{e}-02$ 1.00000e-02 1.00000e-03 1.00000e-09 1.00000e-01

$1.00000 \mathrm{e}+001.00000 \mathrm{e}+001.00000 \mathrm{e}-011.00000 \mathrm{e}-091.00000 \mathrm{e}-01$

Element: 6251 \# of layers: 4

$\mathrm{Kx} \mathrm{Ky} \mathrm{Kz}$ Ss Por

8.26893e+02 8.26893e+02 8.26893e+01 1.00000e-09 7.00000e-02

$3.30397 \mathrm{e}+013.30397 \mathrm{e}+013.30397 \mathrm{e}+00$ 1.00000e-09 2.12000e-01

$1.00000 \mathrm{e}-02$ 1.00000e-02 1.00000e-03 1.00000e-09 1.00000e-01

$1.00000 \mathrm{e}+001.00000 \mathrm{e}+001.00000 \mathrm{e}-011.00000 \mathrm{e}-091.00000 \mathrm{e}-01$

Element: 6252 \# of layers: 5

$\mathrm{Kx} \mathrm{Ky} \mathrm{Kz}$ Ss Por

8.26893e+02 8.26893e+02 8.26893e+01 1.00000e-09 7.00000e-02

8.26893e+02 8.26893e+02 8.26893e+01 1.00000e-09 7.00000e-02

3.30397e+01 3.30397e+01 3.30397e+00 1.00000e-09 2.12000e-01

$1.00000 \mathrm{e}-02$ 1.00000e-02 1.00000e-03 1.00000e-09 1.00000e-01

$1.00000 \mathrm{e}+001.00000 \mathrm{e}+001.00000 \mathrm{e}-011.00000 \mathrm{e}-091.00000 \mathrm{e}-01$ 
Element: 6253 \# of layers: 5

Kx Ky Kz Ss Por

$8.26893 \mathrm{e}+028.26893 \mathrm{e}+028.26893 \mathrm{e}+01$ 1.00000e-09 7.00000e-02

$8.26893 \mathrm{e}+028.26893 \mathrm{e}+028.26893 \mathrm{e}+01$ 1.00000e-09 7.00000e-02

$3.30397 \mathrm{e}+013.30397 \mathrm{e}+013.30397 \mathrm{e}+00$ 1.00000e-09 2.12000e-01

$1.00000 \mathrm{e}-021.00000 \mathrm{e}-02$ 1.00000e-03 1.00000e-09 1.00000e-01

$1.00000 \mathrm{e}+001.00000 \mathrm{e}+001.00000 \mathrm{e}-011.00000 \mathrm{e}-091.00000 \mathrm{e}-01$

Element: 6254 \# of layers: 4

Kx Ky Kz Ss Por

$3.02006 \mathrm{e}+023.02006 \mathrm{e}+023.02006 \mathrm{e}+01$ 1.00000e-09 7.00000e-02

$1.20672 \mathrm{e}+011.20672 \mathrm{e}+011.20672 \mathrm{e}+001.00000 \mathrm{e}-092.12000 \mathrm{e}-01$

$1.00000 \mathrm{e}-021.00000 \mathrm{e}-02$ 1.00000e-03 1.00000e-09 1.00000e-01

$1.00000 \mathrm{e}+001.00000 \mathrm{e}+001.00000 \mathrm{e}-011.00000 \mathrm{e}-091.00000 \mathrm{e}-01$

Element: 6255 \# of layers: 5

Kx Ky Kz Ss Por

$3.02006 \mathrm{e}+023.02006 \mathrm{e}+023.02006 \mathrm{e}+01$ 1.00000e-09 7.00000e-02

$3.02006 \mathrm{e}+023.02006 \mathrm{e}+023.02006 \mathrm{e}+01$ 1.00000e-09 7.00000e-02

$1.20672 \mathrm{e}+011.20672 \mathrm{e}+011.20672 \mathrm{e}+00$ 1.00000e-09 2.12000e-01

$1.00000 \mathrm{e}-02$ 1.00000e-02 1.00000e-03 1.00000e-09 1.00000e-01

$1.00000 \mathrm{e}+001.00000 \mathrm{e}+001.00000 \mathrm{e}-011.00000 \mathrm{e}-091.00000 \mathrm{e}-01$

Element: 6256 \# of layers: 7

Kx Ky Kz Ss Por

$3.02006 \mathrm{e}+023.02006 \mathrm{e}+023.02006 \mathrm{e}+01$ 1.00000e-09 7.00000e-02

$3.02006 \mathrm{e}+023.02006 \mathrm{e}+023.02006 \mathrm{e}+01$ 1.00000e-09 7.00000e-02

$3.02006 \mathrm{e}+023.02006 \mathrm{e}+023.02006 \mathrm{e}+01$ 1.00000e-09 7.00000e-02

$1.20672 \mathrm{e}+011.20672 \mathrm{e}+011.20672 \mathrm{e}+001.00000 \mathrm{e}-092.12000 \mathrm{e}-01$

$1.20672 \mathrm{e}+011.20672 \mathrm{e}+011.20672 \mathrm{e}+001.00000 \mathrm{e}-092.12000 \mathrm{e}-01$

$1.00000 \mathrm{e}-021.00000 \mathrm{e}-02$ 1.00000e-03 1.00000e-09 1.00000e-01

$1.00000 \mathrm{e}+001.00000 \mathrm{e}+001.00000 \mathrm{e}-011.00000 \mathrm{e}-091.00000 \mathrm{e}-01$

Element: 6257 \# of layers: 5

Kx Ky Kz Ss Por

$3.02006 \mathrm{e}+023.02006 \mathrm{e}+023.02006 \mathrm{e}+01$ 1.00000e-09 7.00000e-02

$3.02006 \mathrm{e}+023.02006 \mathrm{e}+023.02006 \mathrm{e}+01$ 1.00000e-09 7.00000e-02

$1.20672 \mathrm{e}+011.20672 \mathrm{e}+011.20672 \mathrm{e}+001.00000 \mathrm{e}-092.12000 \mathrm{e}-01$

$1.00000 \mathrm{e}-021.00000 \mathrm{e}-02$ 1.00000e-03 1.00000e-09 1.00000e-01

$1.00000 \mathrm{e}+001.00000 \mathrm{e}+001.00000 \mathrm{e}-011.00000 \mathrm{e}-091.00000 \mathrm{e}-01$

Element: 6258 \# of layers: 4

Kx Ky Kz Ss Por

3.02006e+02 3.02006e+02 3.02006e+01 1.00000e-09 7.00000e-02

$1.20672 \mathrm{e}+011.20672 \mathrm{e}+011.20672 \mathrm{e}+001.00000 \mathrm{e}-092.12000 \mathrm{e}-01$

$1.00000 \mathrm{e}-021.00000 \mathrm{e}-02$ 1.00000e-03 1.00000e-09 1.00000e-01

$1.00000 \mathrm{e}+001.00000 \mathrm{e}+001.00000 \mathrm{e}-011.00000 \mathrm{e}-091.00000 \mathrm{e}-01$

Element: 6259 \# of layers: 4

Kx Ky Kz Ss Por

$3.02006 \mathrm{e}+023.02006 \mathrm{e}+023.02006 \mathrm{e}+01$ 1.00000e-09 7.00000e-02

$1.20672 \mathrm{e}+011.20672 \mathrm{e}+011.20672 \mathrm{e}+00$ 1.00000e-09 2.12000e-01 
$1.00000 \mathrm{e}-02$ 1.00000e-02 1.00000e-03 1.00000e-09 1.00000e-01 $1.00000 \mathrm{e}+001.00000 \mathrm{e}+001.00000 \mathrm{e}-01$ 1.00000e-09 1.00000e-01 Element: 6260 \# of layers: 5

$\mathrm{Kx} \mathrm{Ky} \mathrm{Kz}$ Ss Por

$3.02006 \mathrm{e}+02$ 3.02006e+02 3.02006e+01 1.00000e-09 7.00000e-02 $3.02006 \mathrm{e}+023.02006 \mathrm{e}+023.02006 \mathrm{e}+01$ 1.00000e-09 7.00000e-02 $1.20672 \mathrm{e}+01$ 1.20672e+01 1.20672e+00 1.00000e-09 2.12000e-01 $1.00000 \mathrm{e}-02$ 1.00000e-02 1.00000e-03 1.00000e-09 1.00000e-01 $1.00000 \mathrm{e}+001.00000 \mathrm{e}+001.00000 \mathrm{e}-011.00000 \mathrm{e}-09$ 1.00000e-01 Element: 6261 \# of layers: 5

$\mathrm{Kx} \mathrm{Ky} \mathrm{Kz}$ Ss Por

3.02006e+02 3.02006e+02 3.02006e+01 1.00000e-09 7.00000e-02 $3.02006 \mathrm{e}+02$ 3.02006e+02 3.02006e+01 1.00000e-09 7.00000e-02 $1.20672 \mathrm{e}+01$ 1.20672e+01 1.20672e+00 1.00000e-09 2.12000e-01 $1.00000 \mathrm{e}-02$ 1.00000e-02 1.00000e-03 1.00000e-09 1.00000e-01 $1.00000 \mathrm{e}+001.00000 \mathrm{e}+001.00000 \mathrm{e}-011.00000 \mathrm{e}-091.00000 \mathrm{e}-01$ Element: 6262 \# of layers: 4

$\mathrm{Kx} \mathrm{Ky} \mathrm{Kz}$ Ss Por

3.02006e+02 3.02006e+02 3.02006e+01 1.00000e-09 7.00000e-02 $1.20672 \mathrm{e}+01$ 1.20672e+01 1.20672e+00 1.00000e-09 2.12000e-01 $1.00000 \mathrm{e}-02$ 1.00000e-02 1.00000e-03 1.00000e-09 1.00000e-01 $1.00000 \mathrm{e}+001.00000 \mathrm{e}+001.00000 \mathrm{e}-011.00000 \mathrm{e}-091.00000 \mathrm{e}-01$ Element: 6263 \# of layers: 7

Kx Ky Kz Ss Por

9.49384e+01 9.49384e+01 9.49384e+00 1.00000e-09 7.00000e-02 $9.49384 \mathrm{e}+019.49384 \mathrm{e}+019.49384 \mathrm{e}+001.00000 \mathrm{e}-09$ 7.00000e-02

9.49384e+01 9.49384e+01 9.49384e+00 1.00000e-09 7.00000e-02 $3.79358 \mathrm{e}+00$ 3.79358e+00 3.79358e-01 1.00000e-09 2.12000e-01 $3.79358 \mathrm{e}+003.79358 \mathrm{e}+00$ 3.79358e-01 1.00000e-09 2.12000e-01 $1.00000 \mathrm{e}-02$ 1.00000e-02 1.00000e-03 1.00000e-09 1.00000e-01 $1.00000 \mathrm{e}+001.00000 \mathrm{e}+001.00000 \mathrm{e}-011.00000 \mathrm{e}-091.00000 \mathrm{e}-01$ Element: 6264 \# of layers: 5

Kx Ky Kz Ss Por

9.49384e+01 9.49384e+01 9.49384e+00 1.00000e-09 7.00000e-02

9.49384e+01 9.49384e+01 9.49384e+00 1.00000e-09 7.00000e-02

$3.79358 \mathrm{e}+003.79358 \mathrm{e}+003.79358 \mathrm{e}-01$ 1.00000e-09 2.12000e-01 1.00000e-02 1.00000e-02 1.00000e-03 1.00000e-09 1.00000e-01 $1.00000 \mathrm{e}+001.00000 \mathrm{e}+001.00000 \mathrm{e}-011.00000 \mathrm{e}-091.00000 \mathrm{e}-01$ Element: 6265 \# of layers: 5

$\mathrm{Kx} \mathrm{Ky} \mathrm{Kz}$ Ss Por

9.49384e+01 9.49384e+01 9.49384e+00 1.00000e-09 7.00000e-02 $9.49384 \mathrm{e}+019.49384 \mathrm{e}+019.49384 \mathrm{e}+001.00000 \mathrm{e}-09$ 7.00000e-02 $3.79358 \mathrm{e}+003.79358 \mathrm{e}+00$ 3.79358e-01 1.00000e-09 2.12000e-01 $1.00000 \mathrm{e}-02$ 1.00000e-02 1.00000e-03 1.00000e-09 1.00000e-01 $1.00000 \mathrm{e}+001.00000 \mathrm{e}+001.00000 \mathrm{e}-01$ 1.00000e-09 1.00000e-01 Element: 6266 \# of layers: 5 
Kx Ky Kz Ss Por

9.49384e+01 9.49384e+01 9.49384e+00 1.00000e-09 7.00000e-02

$9.49384 \mathrm{e}+019.49384 \mathrm{e}+019.49384 \mathrm{e}+001.00000 \mathrm{e}-09$ 7.00000e-02

$3.79358 \mathrm{e}+003.79358 \mathrm{e}+00$ 3.79358e-01 1.00000e-09 2.12000e-01

$1.00000 \mathrm{e}-02$ 1.00000e-02 1.00000e-03 1.00000e-09 1.00000e-01

$1.00000 \mathrm{e}+001.00000 \mathrm{e}+001.00000 \mathrm{e}-011.00000 \mathrm{e}-091.00000 \mathrm{e}-01$

Element: 6267 \# of layers: 5

$\mathrm{Kx} \mathrm{Ky} \mathrm{Kz}$ Ss Por

9.49384e+01 9.49384e+01 9.49384e+00 1.00000e-09 7.00000e-02

9.49384e+01 9.49384e+01 9.49384e+00 1.00000e-09 7.00000e-02

$3.79358 \mathrm{e}+003.79358 \mathrm{e}+00$ 3.79358e-01 1.00000e-09 2.12000e-01

$1.00000 \mathrm{e}-02$ 1.00000e-02 1.00000e-03 1.00000e-09 1.00000e-01

$1.00000 \mathrm{e}+001.00000 \mathrm{e}+001.00000 \mathrm{e}-011.00000 \mathrm{e}-091.00000 \mathrm{e}-01$

Element: 6268 \# of layers: 5

$\mathrm{Kx} \mathrm{Ky} \mathrm{Kz}$ Ss Por

9.49384e+01 9.49384e+01 9.49384e+00 1.00000e-09 7.00000e-02

$9.49384 \mathrm{e}+019.49384 \mathrm{e}+019.49384 \mathrm{e}+001.00000 \mathrm{e}-09$ 7.00000e-02

$3.79358 \mathrm{e}+003.79358 \mathrm{e}+00$ 3.79358e-01 1.00000e-09 2.12000e-01

$1.00000 \mathrm{e}-02$ 1.00000e-02 1.00000e-03 1.00000e-09 1.00000e-01

$1.00000 \mathrm{e}+001.00000 \mathrm{e}+001.00000 \mathrm{e}-011.00000 \mathrm{e}-091.00000 \mathrm{e}-01$

Element: 6269 \# of layers: 5

$\mathrm{Kx} \mathrm{Ky} \mathrm{Kz}$ Ss Por

9.49384e+01 9.49384e+01 9.49384e+00 1.00000e-09 7.00000e-02

$9.49384 \mathrm{e}+019.49384 \mathrm{e}+019.49384 \mathrm{e}+001.00000 \mathrm{e}-09$ 7.00000e-02

$3.79358 \mathrm{e}+003.79358 \mathrm{e}+00$ 3.79358e-01 1.00000e-09 2.12000e-01

1.00000e-02 1.00000e-02 1.00000e-03 1.00000e-09 1.00000e-01

$1.00000 \mathrm{e}+001.00000 \mathrm{e}+001.00000 \mathrm{e}-011.00000 \mathrm{e}-091.00000 \mathrm{e}-01$

Element: 6270 \# of layers: 5

$\mathrm{Kx} \mathrm{Ky} \mathrm{Kz}$ Ss Por

9.49384e+01 9.49384e+01 9.49384e+00 1.00000e-09 7.00000e-02

$9.49384 \mathrm{e}+019.49384 \mathrm{e}+019.49384 \mathrm{e}+001.00000 \mathrm{e}-09$ 7.00000e-02

$3.79358 \mathrm{e}+00$ 3.79358e+00 3.79358e-01 1.00000e-09 2.12000e-01

$1.00000 \mathrm{e}-02$ 1.00000e-02 1.00000e-03 1.00000e-09 1.00000e-01

$1.00000 \mathrm{e}+001.00000 \mathrm{e}+001.00000 \mathrm{e}-011.00000 \mathrm{e}-091.00000 \mathrm{e}-01$

Element: 6271 \# of layers: 5

Kx Ky Kz Ss Por

9.49384e+01 9.49384e+01 9.49384e+00 1.00000e-09 7.00000e-02

$9.49384 \mathrm{e}+019.49384 \mathrm{e}+019.49384 \mathrm{e}+001.00000 \mathrm{e}-09$ 7.00000e-02

$3.79358 \mathrm{e}+003.79358 \mathrm{e}+00$ 3.79358e-01 1.00000e-09 2.12000e-01

$1.00000 \mathrm{e}-02$ 1.00000e-02 1.00000e-03 1.00000e-09 1.00000e-01

$1.00000 \mathrm{e}+001.00000 \mathrm{e}+001.00000 \mathrm{e}-011.00000 \mathrm{e}-091.00000 \mathrm{e}-01$

Element: 6272 \# of layers: 5

$\mathrm{Kx} \mathrm{Ky} \mathrm{Kz}$ Ss Por

6.97383e+01 6.97383e+01 6.97383e+00 1.00000e-09 7.00000e-02

$6.97383 \mathrm{e}+016.97383 \mathrm{e}+016.97383 \mathrm{e}+00$ 1.00000e-09 7.00000e-02

$2.78646 \mathrm{e}+00$ 2.78646e+00 2.78646e-01 1.00000e-09 2.12000e-01 
$1.00000 \mathrm{e}-02$ 1.00000e-02 1.00000e-03 1.00000e-09 1.00000e-01 $1.00000 \mathrm{e}+001.00000 \mathrm{e}+001.00000 \mathrm{e}-01$ 1.00000e-09 1.00000e-01 Element: 6273 \# of layers: 5

Kx Ky Kz Ss Por

6.97383e+01 6.97383e+01 6.97383e+00 1.00000e-09 7.00000e-02 $6.97383 \mathrm{e}+016.97383 \mathrm{e}+016.97383 \mathrm{e}+00$ 1.00000e-09 7.00000e-02 $2.78646 \mathrm{e}+002.78646 \mathrm{e}+00$ 2.78646e-01 1.00000e-09 2.12000e-01 $1.00000 \mathrm{e}-02$ 1.00000e-02 1.00000e-03 1.00000e-09 1.00000e-01 $1.00000 \mathrm{e}+001.00000 \mathrm{e}+001.00000 \mathrm{e}-011.00000 \mathrm{e}-091.00000 \mathrm{e}-01$ Element: 6274 \# of layers: 5

$\mathrm{Kx} \mathrm{Ky} \mathrm{Kz}$ Ss Por

6.97383e+01 6.97383e+01 6.97383e+00 1.00000e-09 7.00000e-02 $6.97383 \mathrm{e}+016.97383 \mathrm{e}+016.97383 \mathrm{e}+001.00000 \mathrm{e}-09$ 7.00000e-02 $2.78646 \mathrm{e}+002.78646 \mathrm{e}+00$ 2.78646e-01 1.00000e-09 2.12000e-01 $1.00000 \mathrm{e}-02$ 1.00000e-02 1.00000e-03 1.00000e-09 1.00000e-01 $1.00000 \mathrm{e}+001.00000 \mathrm{e}+001.00000 \mathrm{e}-011.00000 \mathrm{e}-091.00000 \mathrm{e}-01$ Element: 6275 \# of layers: 5

$\mathrm{Kx} \mathrm{Ky} \mathrm{Kz}$ Ss Por

6.97383e+01 6.97383e+01 6.97383e+00 1.00000e-09 7.00000e-02 $6.97383 \mathrm{e}+016.97383 \mathrm{e}+016.97383 \mathrm{e}+00$ 1.00000e-09 7.00000e-02 $2.78646 \mathrm{e}+002.78646 \mathrm{e}+00 \quad 2.78646 \mathrm{e}-01$ 1.00000e-09 2.12000e-01 $1.00000 \mathrm{e}-021.00000 \mathrm{e}-021.00000 \mathrm{e}-031.00000 \mathrm{e}-091.00000 \mathrm{e}-01$ $1.00000 \mathrm{e}+001.00000 \mathrm{e}+001.00000 \mathrm{e}-01$ 1.00000e-09 1.00000e-01 Element: 6276 \# of layers: 5

$\mathrm{Kx} \mathrm{Ky} \mathrm{Kz}$ Ss Por 6.97383e+01 6.97383e+01 6.97383e+00 1.00000e-09 7.00000e-02 $6.97383 \mathrm{e}+016.97383 \mathrm{e}+01$ 6.97383e+00 1.00000e-09 7.00000e-02 $2.78646 \mathrm{e}+00$ 2.78646e+00 2.78646e-01 1.00000e-09 2.12000e-01 $1.00000 \mathrm{e}-02$ 1.00000e-02 1.00000e-03 1.00000e-09 1.00000e-01 $1.00000 \mathrm{e}+001.00000 \mathrm{e}+001.00000 \mathrm{e}-011.00000 \mathrm{e}-091.00000 \mathrm{e}-01$ Element: 6277 \# of layers: 5

Kx Ky Kz Ss Por

6.97383e+01 6.97383e+01 6.97383e+00 1.00000e-09 7.00000e-02 $6.97383 \mathrm{e}+016.97383 \mathrm{e}+016.97383 \mathrm{e}+001.00000 \mathrm{e}-09$ 7.00000e-02 $2.78646 \mathrm{e}+002.78646 \mathrm{e}+002.78646 \mathrm{e}-01$ 1.00000e-09 2.12000e-01 $1.00000 \mathrm{e}-02$ 1.00000e-02 1.00000e-03 1.00000e-09 1.00000e-01 $1.00000 \mathrm{e}+001.00000 \mathrm{e}+001.00000 \mathrm{e}-011.00000 \mathrm{e}-091.00000 \mathrm{e}-01$ Element: 6278 \# of layers: 5

$\mathrm{Kx} \mathrm{Ky} \mathrm{Kz}$ Ss Por

6.97383e+01 6.97383e+01 6.97383e+00 1.00000e-09 7.00000e-02 $6.97383 \mathrm{e}+016.97383 \mathrm{e}+016.97383 \mathrm{e}+00$ 1.00000e-09 7.00000e-02 $2.78646 \mathrm{e}+002.78646 \mathrm{e}+00$ 2.78646e-01 1.00000e-09 2.12000e-01 $1.00000 \mathrm{e}-02$ 1.00000e-02 1.00000e-03 1.00000e-09 1.00000e-01 $1.00000 \mathrm{e}+001.00000 \mathrm{e}+001.00000 \mathrm{e}-01$ 1.00000e-09 1.00000e-01 Element: 6279 \# of layers: 5

Kx Ky Kz Ss Por 
6.97383e+01 6.97383e+01 6.97383e+00 1.00000e-09 7.00000e-02 $6.97383 \mathrm{e}+016.97383 \mathrm{e}+01$ 6.97383e+00 1.00000e-09 7.00000e-02 $2.78646 \mathrm{e}+002.78646 \mathrm{e}+00$ 2.78646e-01 1.00000e-09 2.12000e-01 $1.00000 \mathrm{e}-02$ 1.00000e-02 1.00000e-03 1.00000e-09 1.00000e-01 $1.00000 \mathrm{e}+001.00000 \mathrm{e}+001.00000 \mathrm{e}-01$ 1.00000e-09 1.00000e-01 Element: 6280 \# of layers: 5

$\mathrm{Kx} \mathrm{Ky} \mathrm{Kz}$ Ss Por

6.97383e+01 6.97383e+01 6.97383e+00 1.00000e-09 7.00000e-02

$6.97383 \mathrm{e}+016.97383 \mathrm{e}+016.97383 \mathrm{e}+001.00000 \mathrm{e}-09$ 7.00000e-02

$2.78646 \mathrm{e}+002.78646 \mathrm{e}+00$ 2.78646e-01 1.00000e-09 2.12000e-01

$1.00000 \mathrm{e}-02$ 1.00000e-02 1.00000e-03 1.00000e-09 1.00000e-01

$1.00000 \mathrm{e}+001.00000 \mathrm{e}+001.00000 \mathrm{e}-011.00000 \mathrm{e}-091.00000 \mathrm{e}-01$

Element: 6281 \# of layers: 5

$\mathrm{Kx} \mathrm{Ky} \mathrm{Kz}$ Ss Por

3.02177e+02 3.02177e+02 3.02177e+01 1.00000e-09 7.00000e-02 $3.02177 \mathrm{e}+02$ 3.02177e+02 3.02177e+01 1.00000e-09 7.00000e-02 $1.20738 \mathrm{e}+01$ 1.20738e+01 1.20738e+00 1.00000e-09 2.12000e-01 $1.00000 \mathrm{e}-02$ 1.00000e-02 1.00000e-03 1.00000e-09 1.00000e-01

$1.00000 \mathrm{e}+001.00000 \mathrm{e}+001.00000 \mathrm{e}-011.00000 \mathrm{e}-091.00000 \mathrm{e}-01$

Element: 6282 \# of layers: 5

$\mathrm{Kx} \mathrm{Ky} \mathrm{Kz}$ Ss Por

3.02177e+02 3.02177e+02 3.02177e+01 1.00000e-09 7.00000e-02 3.02177e+02 3.02177e+02 3.02177e+01 1.00000e-09 7.00000e-02 $1.20738 \mathrm{e}+01$ 1.20738e+01 1.20738e+00 1.00000e-09 2.12000e-01 $1.00000 \mathrm{e}-021.00000 \mathrm{e}-02$ 1.00000e-03 1.00000e-09 1.00000e-01 $1.00000 \mathrm{e}+001.00000 \mathrm{e}+001.00000 \mathrm{e}-011.00000 \mathrm{e}-091.00000 \mathrm{e}-01$ Element: 6283 \# of layers: 5

$\mathrm{Kx} \mathrm{Ky} \mathrm{Kz} \mathrm{Ss} \mathrm{Por}$

3.02177e+02 3.02177e+02 3.02177e+01 1.00000e-09 7.00000e-02 3.02177e+02 3.02177e+02 3.02177e+01 1.00000e-09 7.00000e-02 $1.20738 \mathrm{e}+01$ 1.20738e+01 1.20738e+00 1.00000e-09 2.12000e-01 $1.00000 \mathrm{e}-02$ 1.00000e-02 1.00000e-03 1.00000e-09 1.00000e-01 $1.00000 \mathrm{e}+001.00000 \mathrm{e}+001.00000 \mathrm{e}-011.00000 \mathrm{e}-091.00000 \mathrm{e}-01$ Element: 6284 \# of layers: 5

$\mathrm{Kx} \mathrm{Ky} \mathrm{Kz}$ Ss Por

3.02177e+02 3.02177e+02 3.02177e+01 1.00000e-09 7.00000e-02 3.02177e+02 3.02177e+02 3.02177e+01 1.00000e-09 7.00000e-02 $1.20738 \mathrm{e}+01$ 1.20738e+01 1.20738e+00 1.00000e-09 2.12000e-01 $1.00000 \mathrm{e}-02$ 1.00000e-02 1.00000e-03 1.00000e-09 1.00000e-01 $1.00000 \mathrm{e}+001.00000 \mathrm{e}+001.00000 \mathrm{e}-01$ 1.00000e-09 1.00000e-01 Element: 6285 \# of layers: 3

$\mathrm{Kx} \mathrm{Ky} \mathrm{Kz}$ Ss Por

3.02177e+02 3.02177e+02 3.02177e+01 1.00000e-09 7.00000e-02 $1.00000 \mathrm{e}-02$ 1.00000e-02 1.00000e-03 1.00000e-09 1.00000e-01 $1.00000 \mathrm{e}+001.00000 \mathrm{e}+001.00000 \mathrm{e}-011.00000 \mathrm{e}-091.00000 \mathrm{e}-01$ Element: 6286 \# of layers: 5 
$\mathrm{Kx} \mathrm{Ky} \mathrm{Kz}$ Ss Por

3.02177e+02 3.02177e+02 3.02177e+01 1.00000e-09 7.00000e-02 3.02177e+02 3.02177e+02 3.02177e+01 1.00000e-09 7.00000e-02

$1.20738 \mathrm{e}+01$ 1.20738e+01 1.20738e+00 1.00000e-09 2.12000e-01 $1.00000 \mathrm{e}-02$ 1.00000e-02 1.00000e-03 1.00000e-09 1.00000e-01 $1.00000 \mathrm{e}+001.00000 \mathrm{e}+001.00000 \mathrm{e}-011.00000 \mathrm{e}-091.00000 \mathrm{e}-01$ Element: 6287 \# of layers: 5

$\mathrm{Kx} \mathrm{Ky} \mathrm{Kz}$ Ss Por

3.02177e+02 3.02177e+02 3.02177e+01 1.00000e-09 7.00000e-02 3.02177e+02 3.02177e+02 3.02177e+01 1.00000e-09 7.00000e-02 $1.20738 \mathrm{e}+01$ 1.20738e+01 1.20738e+00 1.00000e-09 2.12000e-01 $1.00000 \mathrm{e}-02$ 1.00000e-02 1.00000e-03 1.00000e-09 1.00000e-01 $1.00000 \mathrm{e}+001.00000 \mathrm{e}+001.00000 \mathrm{e}-011.00000 \mathrm{e}-091.00000 \mathrm{e}-01$ Element: 6288 \# of layers: 5

Kx Ky Kz Ss Por

3.02177e+02 3.02177e+02 3.02177e+01 1.00000e-09 7.00000e-02 3.02177e+02 3.02177e+02 3.02177e+01 1.00000e-09 7.00000e-02 $1.20738 \mathrm{e}+01$ 1.20738e+01 1.20738e+00 1.00000e-09 2.12000e-01 $1.00000 \mathrm{e}-02$ 1.00000e-02 1.00000e-03 1.00000e-09 1.00000e-01 $1.00000 \mathrm{e}+001.00000 \mathrm{e}+001.00000 \mathrm{e}-011.00000 \mathrm{e}-091.00000 \mathrm{e}-01$ Element: 6289 \# of layers: 5

$\mathrm{Kx} \mathrm{Ky} \mathrm{Kz}$ Ss Por

3.02177e+02 3.02177e+02 3.02177e+01 1.00000e-09 7.00000e-02 $3.02177 \mathrm{e}+02$ 3.02177e+02 3.02177e+01 1.00000e-09 7.00000e-02 $1.20738 \mathrm{e}+01$ 1.20738e+01 1.20738e+00 1.00000e-09 2.12000e-01 $1.00000 \mathrm{e}-02$ 1.00000e-02 1.00000e-03 1.00000e-09 1.00000e-01 $1.00000 \mathrm{e}+001.00000 \mathrm{e}+001.00000 \mathrm{e}-011.00000 \mathrm{e}-091.00000 \mathrm{e}-01$ Element: 6290 \# of layers: 5

$\mathrm{Kx} \mathrm{Ky} \mathrm{Kz}$ Ss Por

4.93721e+02 4.93721e+02 4.93721e+01 1.00000e-09 7.00000e-02 4.93721e+02 4.93721e+02 4.93721e+01 1.00000e-09 7.00000e-02 4.93721e+02 4.93721e+02 4.93721e+01 1.00000e-09 7.00000e-02 $1.00000 \mathrm{e}-02$ 1.00000e-02 1.00000e-03 1.00000e-09 1.00000e-01 $1.00000 \mathrm{e}+001.00000 \mathrm{e}+001.00000 \mathrm{e}-011.00000 \mathrm{e}-091.00000 \mathrm{e}-01$ Element: 6291 \# of layers: 5

Kx Ky Kz Ss Por

3.04105e+02 3.04105e+02 3.04106e+01 1.00000e-09 7.00000e-02 $3.04105 \mathrm{e}+023.04105 \mathrm{e}+023.04106 \mathrm{e}+01$ 1.00000e-09 7.00000e-02 $3.04105 \mathrm{e}+02$ 3.04105e+02 3.04106e+01 1.00000e-09 7.00000e-02 $1.00000 \mathrm{e}-02$ 1.00000e-02 1.00000e-03 1.00000e-09 1.00000e-01 $1.00000 \mathrm{e}+001.00000 \mathrm{e}+001.00000 \mathrm{e}-011.00000 \mathrm{e}-091.00000 \mathrm{e}-01$ Element: 6292 \# of layers: 4

$\mathrm{Kx} \mathrm{Ky} \mathrm{Kz}$ Ss Por

4.93721e+02 4.93721e+02 4.93721e+01 1.00000e-09 7.00000e-02 $4.93721 \mathrm{e}+02$ 4.93721e+02 4.93721e+01 1.00000e-09 7.00000e-02 1.00000e-02 1.00000e-02 1.00000e-03 1.00000e-09 1.00000e-01 
$1.00000 \mathrm{e}+001.00000 \mathrm{e}+00$ 1.00000e-01 1.00000e-09 1.00000e-01

Element: 6296 \# of layers: 3

$\mathrm{Kx} \mathrm{Ky} \mathrm{Kz}$ Ss Por

4.93721e+02 4.93721e+02 4.93721e+01 1.00000e-09 7.00000e-02

$1.00000 \mathrm{e}-021.00000 \mathrm{e}-021.00000 \mathrm{e}-031.00000 \mathrm{e}-091.00000 \mathrm{e}-01$

$1.00000 \mathrm{e}+001.00000 \mathrm{e}+001.00000 \mathrm{e}-011.00000 \mathrm{e}-091.00000 \mathrm{e}-01$

Element: 6297 \# of layers: 5

$\mathrm{Kx} \mathrm{Ky} \mathrm{Kz}$ Ss Por

3.02177e+02 3.02177e+02 3.02177e+01 1.00000e-09 7.00000e-02

3.02177e+02 3.02177e+02 3.02177e+01 1.00000e-09 7.00000e-02

$3.02177 \mathrm{e}+02$ 3.02177e+02 3.02177e+01 1.00000e-09 7.00000e-02

$1.00000 \mathrm{e}-02$ 1.00000e-02 1.00000e-03 1.00000e-09 1.00000e-01

$1.00000 \mathrm{e}+001.00000 \mathrm{e}+001.00000 \mathrm{e}-011.00000 \mathrm{e}-091.00000 \mathrm{e}-01$

Element: 6299 \# of layers: 3

$\mathrm{Kx} \mathrm{Ky} \mathrm{Kz}$ Ss Por

7.63886e+02 7.63886e+02 7.63886e+01 1.00000e-09 7.00000e-02

$1.00000 \mathrm{e}-02$ 1.00000e-02 1.00000e-03 1.00000e-09 1.00000e-01

$1.00000 \mathrm{e}+001.00000 \mathrm{e}+001.00000 \mathrm{e}-01$ 1.00000e-09 1.00000e-01

Element: 6300 \# of layers: 3

$\mathrm{Kx} \mathrm{Ky} \mathrm{Kz}$ Ss Por

7.63886e+02 7.63886e+02 7.63886e+01 1.00000e-09 7.00000e-02

$1.00000 \mathrm{e}-02$ 1.00000e-02 1.00000e-03 1.00000e-09 1.00000e-01

$1.00000 \mathrm{e}+001.00000 \mathrm{e}+001.00000 \mathrm{e}-01$ 1.00000e-09 1.00000e-01

Element: 6301 \# of layers: 3

$\mathrm{Kx} \mathrm{Ky} \mathrm{Kz}$ Ss Por

7.63886e+02 7.63886e+02 7.63886e+01 1.00000e-09 7.00000e-02

$1.00000 \mathrm{e}-021.00000 \mathrm{e}-021.00000 \mathrm{e}-031.00000 \mathrm{e}-091.00000 \mathrm{e}-01$

$1.00000 \mathrm{e}+001.00000 \mathrm{e}+001.00000 \mathrm{e}-011.00000 \mathrm{e}-09$ 1.00000e-01

Element: 6302 \# of layers: 3

$\mathrm{Kx} \mathrm{Ky} \mathrm{Kz}$ Ss Por

6.17852e+02 6.17852e+02 6.17852e+01 1.00000e-09 7.00000e-02

$1.00000 \mathrm{e}-02$ 1.00000e-02 1.00000e-03 1.00000e-09 1.00000e-01

$1.00000 \mathrm{e}+001.00000 \mathrm{e}+001.00000 \mathrm{e}-011.00000 \mathrm{e}-091.00000 \mathrm{e}-01$

Element: 6303 \# of layers: 3

$\mathrm{Kx} \mathrm{Ky} \mathrm{Kz}$ Ss Por

6.17852e+02 6.17852e+02 6.17852e+01 1.00000e-09 7.00000e-02

$1.00000 \mathrm{e}-02$ 1.00000e-02 1.00000e-03 1.00000e-09 1.00000e-01

$1.00000 \mathrm{e}+001.00000 \mathrm{e}+001.00000 \mathrm{e}-011.00000 \mathrm{e}-091.00000 \mathrm{e}-01$

Element: 6304 \# of layers: 3

$\mathrm{Kx} \mathrm{Ky} \mathrm{Kz}$ Ss Por

6.17852e+02 6.17852e+02 6.17852e+01 1.00000e-09 7.00000e-02

$1.00000 \mathrm{e}-02$ 1.00000e-02 1.00000e-03 1.00000e-09 1.00000e-01

$1.00000 \mathrm{e}+001.00000 \mathrm{e}+001.00000 \mathrm{e}-011.00000 \mathrm{e}-091.00000 \mathrm{e}-01$

Element: 6305 \# of layers: 6

$\mathrm{Kx} \mathrm{Ky} \mathrm{Kz}$ Ss Por

4.70565e+02 4.70565e+02 4.70565e+01 1.00000e-09 7.00000e-02 
$4.70565 \mathrm{e}+024.70565 \mathrm{e}+024.70565 \mathrm{e}+01$ 1.00000e-09 7.00000e-02 $1.88023 \mathrm{e}+011.88023 \mathrm{e}+011.88023 \mathrm{e}+001.00000 \mathrm{e}-092.12000 \mathrm{e}-01$ $1.88023 \mathrm{e}+011.88023 \mathrm{e}+011.88023 \mathrm{e}+001.00000 \mathrm{e}-092.12000 \mathrm{e}-01$ $1.88023 \mathrm{e}+011.88023 \mathrm{e}+011.88023 \mathrm{e}+001.00000 \mathrm{e}-092.12000 \mathrm{e}-01$ $1.00000 \mathrm{e}-02$ 1.00000e-02 1.00000e-03 1.00000e-09 1.00000e-01

Element: 6306 \# of layers: 8

Kx Ky Kz Ss Por

$4.70565 \mathrm{e}+02$ 4.70565e+02 4.70565e+01 1.00000e-09 7.00000e-02

$4.70565 \mathrm{e}+024.70565 \mathrm{e}+024.70565 \mathrm{e}+011.00000 \mathrm{e}-09$ 7.00000e-02

$4.70565 \mathrm{e}+024.70565 \mathrm{e}+024.70565 \mathrm{e}+01$ 1.00000e-09 7.00000e-02

$1.88023 \mathrm{e}+011.88023 \mathrm{e}+011.88023 \mathrm{e}+001.00000 \mathrm{e}-092.12000 \mathrm{e}-01$

$1.88023 \mathrm{e}+011.88023 \mathrm{e}+011.88023 \mathrm{e}+001.00000 \mathrm{e}-092.12000 \mathrm{e}-01$

$1.88023 \mathrm{e}+011.88023 \mathrm{e}+011.88023 \mathrm{e}+00$ 1.00000e-09 2.12000e-01

$1.88023 \mathrm{e}+011.88023 \mathrm{e}+011.88023 \mathrm{e}+001.00000 \mathrm{e}-092.12000 \mathrm{e}-01$

$1.00000 \mathrm{e}-02$ 1.00000e-02 1.00000e-03 1.00000e-09 1.00000e-01

Element: 6307 \# of layers: 7

Kx Ky Kz Ss Por

$4.70565 \mathrm{e}+02$ 4.70565e+02 4.70565e+01 1.00000e-09 7.00000e-02

$4.70565 \mathrm{e}+024.70565 \mathrm{e}+024.70565 \mathrm{e}+011.00000 \mathrm{e}-09$ 7.00000e-02

$1.88023 \mathrm{e}+011.88023 \mathrm{e}+011.88023 \mathrm{e}+001.00000 \mathrm{e}-092.12000 \mathrm{e}-01$

$1.88023 \mathrm{e}+011.88023 \mathrm{e}+011.88023 \mathrm{e}+001.00000 \mathrm{e}-092.12000 \mathrm{e}-01$

$1.88023 \mathrm{e}+011.88023 \mathrm{e}+011.88023 \mathrm{e}+00$ 1.00000e-09 2.12000e-01

$1.00000 \mathrm{e}-021.00000 \mathrm{e}-02$ 1.00000e-03 1.00000e-09 1.00000e-01

$1.00000 \mathrm{e}+001.00000 \mathrm{e}+001.00000 \mathrm{e}-011.00000 \mathrm{e}-091.00000 \mathrm{e}-01$

Element: 6308 \# of layers: 8

Kx Ky Kz Ss Por

$4.70565 \mathrm{e}+02$ 4.70565e+02 4.70565e+01 1.00000e-09 7.00000e-02

$4.70565 \mathrm{e}+024.70565 \mathrm{e}+024.70565 \mathrm{e}+01$ 1.00000e-09 7.00000e-02

$4.70565 \mathrm{e}+024.70565 \mathrm{e}+024.70565 \mathrm{e}+01$ 1.00000e-09 7.00000e-02

$1.88023 \mathrm{e}+011.88023 \mathrm{e}+011.88023 \mathrm{e}+001.00000 \mathrm{e}-092.12000 \mathrm{e}-01$

$1.88023 \mathrm{e}+011.88023 \mathrm{e}+011.88023 \mathrm{e}+001.00000 \mathrm{e}-092.12000 \mathrm{e}-01$

$1.88023 \mathrm{e}+011.88023 \mathrm{e}+011.88023 \mathrm{e}+001.00000 \mathrm{e}-092.12000 \mathrm{e}-01$

$1.00000 \mathrm{e}-021.00000 \mathrm{e}-02$ 1.00000e-03 1.00000e-09 1.00000e-01

$1.00000 \mathrm{e}-06$ 1.00000e-06 1.00000e-06 1.00000e-09 5.00000e-02

Element: 6309 \# of layers: 7

Kx Ky Kz Ss Por

$4.70565 \mathrm{e}+02$ 4.70565e+02 4.70565e+01 1.00000e-09 7.00000e-02

$4.70565 \mathrm{e}+024.70565 \mathrm{e}+024.70565 \mathrm{e}+01$ 1.00000e-09 7.00000e-02

$4.70565 \mathrm{e}+024.70565 \mathrm{e}+024.70565 \mathrm{e}+01$ 1.00000e-09 7.00000e-02

$1.88023 \mathrm{e}+011.88023 \mathrm{e}+011.88023 \mathrm{e}+001.00000 \mathrm{e}-092.12000 \mathrm{e}-01$

$1.88023 \mathrm{e}+011.88023 \mathrm{e}+011.88023 \mathrm{e}+001.00000 \mathrm{e}-092.12000 \mathrm{e}-01$

$1.00000 \mathrm{e}-021.00000 \mathrm{e}-02$ 1.00000e-03 1.00000e-09 1.00000e-01

$1.00000 \mathrm{e}-06$ 1.00000e-06 1.00000e-06 1.00000e-09 5.00000e-02

Element: 6310 \# of layers: 7

Kx Ky Kz Ss Por

4.70565e+02 4.70565e+02 4.70565e+01 1.00000e-09 7.00000e-02 
$4.70565 \mathrm{e}+024.70565 \mathrm{e}+024.70565 \mathrm{e}+01$ 1.00000e-09 7.00000e-02 $4.70565 \mathrm{e}+024.70565 \mathrm{e}+024.70565 \mathrm{e}+011.00000 \mathrm{e}-09$ 7.00000e-02 $1.88023 \mathrm{e}+011.88023 \mathrm{e}+011.88023 \mathrm{e}+001.00000 \mathrm{e}-092.12000 \mathrm{e}-01$ $1.88023 \mathrm{e}+011.88023 \mathrm{e}+011.88023 \mathrm{e}+001.00000 \mathrm{e}-092.12000 \mathrm{e}-01$ $1.00000 \mathrm{e}-021.00000 \mathrm{e}-021.00000 \mathrm{e}-031.00000 \mathrm{e}-091.00000 \mathrm{e}-01$ $1.00000 \mathrm{e}-06$ 1.00000e-06 1.00000e-06 1.00000e-09 5.00000e-02 Element: 6311 \# of layers: 6

Kx Ky Kz Ss Por

$4.70565 \mathrm{e}+02$ 4.70565e+02 4.70565e+01 1.00000e-09 7.00000e-02 $4.70565 \mathrm{e}+024.70565 \mathrm{e}+024.70565 \mathrm{e}+01$ 1.00000e-09 7.00000e-02 $1.88023 \mathrm{e}+011.88023 \mathrm{e}+011.88023 \mathrm{e}+001.00000 \mathrm{e}-092.12000 \mathrm{e}-01$ $1.88023 \mathrm{e}+011.88023 \mathrm{e}+011.88023 \mathrm{e}+001.00000 \mathrm{e}-092.12000 \mathrm{e}-01$ $1.00000 \mathrm{e}-02$ 1.00000e-02 1.00000e-03 1.00000e-09 1.00000e-01 1.00000e-06 1.00000e-06 1.00000e-06 1.00000e-09 5.00000e-02 Element: 6312 \# of layers: 7

Kx Ky Kz Ss Por

$4.70565 \mathrm{e}+02$ 4.70565e $+024.70565 \mathrm{e}+01$ 1.00000e-09 7.00000e-02 $4.70565 \mathrm{e}+024.70565 \mathrm{e}+024.70565 \mathrm{e}+01$ 1.00000e-09 7.00000e-02 $4.70565 \mathrm{e}+024.70565 \mathrm{e}+024.70565 \mathrm{e}+01$ 1.00000e-09 7.00000e-02 $1.88023 \mathrm{e}+011.88023 \mathrm{e}+011.88023 \mathrm{e}+001.00000 \mathrm{e}-092.12000 \mathrm{e}-01$ $1.88023 \mathrm{e}+011.88023 \mathrm{e}+011.88023 \mathrm{e}+001.00000 \mathrm{e}-092.12000 \mathrm{e}-01$ $1.88023 \mathrm{e}+011.88023 \mathrm{e}+011.88023 \mathrm{e}+00$ 1.00000e-09 2.12000e-01 $1.00000 \mathrm{e}-021.00000 \mathrm{e}-02$ 1.00000e-03 1.00000e-09 1.00000e-01 Element: 6313 \# of layers: 7

Kx Ky Kz Ss Por

$7.67274 \mathrm{e}+02$ 7.67274e+02 7.67274e+01 1.00000e-09 7.00000e-02 $7.67274 \mathrm{e}+02$ 7.67274e+02 7.67274e+01 1.00000e-09 7.00000e-02 $7.67274 \mathrm{e}+02$ 7.67274e+02 7.67274e+01 1.00000e-09 7.00000e-02 $3.06569 \mathrm{e}+013.06569 \mathrm{e}+013.06569 \mathrm{e}+001.00000 \mathrm{e}-092.12000 \mathrm{e}-01$ $3.06569 \mathrm{e}+013.06569 \mathrm{e}+013.06569 \mathrm{e}+001.00000 \mathrm{e}-092.12000 \mathrm{e}-01$ $3.06569 \mathrm{e}+013.06569 \mathrm{e}+013.06569 \mathrm{e}+001.00000 \mathrm{e}-092.12000 \mathrm{e}-01$ $1.00000 \mathrm{e}-021.00000 \mathrm{e}-02$ 1.00000e-03 1.00000e-09 1.00000e-01

Element: 6314 \# of layers: 8

Kx Ky Kz Ss Por

$7.67274 \mathrm{e}+02$ 7.67274e+02 7.67274e+01 1.00000e-09 7.00000e-02 $7.67274 \mathrm{e}+02$ 7.67274e+02 7.67274e+01 1.00000e-09 7.00000e-02 $7.67274 \mathrm{e}+02$ 7.67274e+02 7.67274e+01 1.00000e-09 7.00000e-02 $3.06569 \mathrm{e}+013.06569 \mathrm{e}+013.06569 \mathrm{e}+001.00000 \mathrm{e}-092.12000 \mathrm{e}-01$ $3.06569 \mathrm{e}+013.06569 \mathrm{e}+013.06569 \mathrm{e}+001.00000 \mathrm{e}-092.12000 \mathrm{e}-01$ $3.06569 \mathrm{e}+013.06569 \mathrm{e}+013.06569 \mathrm{e}+001.00000 \mathrm{e}-092.12000 \mathrm{e}-01$ $3.06569 \mathrm{e}+013.06569 \mathrm{e}+013.06569 \mathrm{e}+001.00000 \mathrm{e}-092.12000 \mathrm{e}-01$ $1.00000 \mathrm{e}-021.00000 \mathrm{e}-02$ 1.00000e-03 1.00000e-09 1.00000e-01 Element: 6315 \# of layers: 7

Kx Ky Kz Ss Por

$7.67274 \mathrm{e}+02$ 7.67274e+02 7.67274e+01 1.00000e-09 7.00000e-02

$7.67274 \mathrm{e}+02$ 7.67274e+02 7.67274e+01 1.00000e-09 7.00000e-02 
$3.06569 \mathrm{e}+013.06569 \mathrm{e}+013.06569 \mathrm{e}+00$ 1.00000e-09 2.12000e-01 $3.06569 \mathrm{e}+013.06569 \mathrm{e}+013.06569 \mathrm{e}+001.00000 \mathrm{e}-092.12000 \mathrm{e}-01$ $3.06569 \mathrm{e}+013.06569 \mathrm{e}+013.06569 \mathrm{e}+001.00000 \mathrm{e}-092.12000 \mathrm{e}-01$ $3.06569 \mathrm{e}+013.06569 \mathrm{e}+013.06569 \mathrm{e}+001.00000 \mathrm{e}-092.12000 \mathrm{e}-01$ 1.00000e-02 1.00000e-02 1.00000e-03 1.00000e-09 1.00000e-01

Element: 6316 \# of layers: 8

$\mathrm{Kx} \mathrm{Ky} \mathrm{Kz}$ Ss Por

7.67274e+02 7.67274e+02 7.67274e+01 1.00000e-09 7.00000e-02

$7.67274 \mathrm{e}+02$ 7.67274e+02 7.67274e+01 1.00000e-09 7.00000e-02

$3.06569 \mathrm{e}+013.06569 \mathrm{e}+013.06569 \mathrm{e}+001.00000 \mathrm{e}-09$ 2.12000e-01

$3.06569 \mathrm{e}+013.06569 \mathrm{e}+013.06569 \mathrm{e}+00$ 1.00000e-09 2.12000e-01

$3.06569 \mathrm{e}+013.06569 \mathrm{e}+013.06569 \mathrm{e}+001.00000 \mathrm{e}-092.12000 \mathrm{e}-01$

$3.06569 \mathrm{e}+013.06569 \mathrm{e}+013.06569 \mathrm{e}+00$ 1.00000e-09 2.12000e-01

$1.00000 \mathrm{e}-02$ 1.00000e-02 1.00000e-03 1.00000e-09 1.00000e-01

$1.00000 \mathrm{e}+001.00000 \mathrm{e}+001.00000 \mathrm{e}-01$ 1.00000e-09 1.00000e-01

Element: 6317 \# of layers: 8

$\mathrm{Kx} \mathrm{Ky} \mathrm{Kz}$ Ss Por

7.67274e+02 7.67274e+02 7.67274e+01 1.00000e-09 7.00000e-02

$7.67274 \mathrm{e}+02$ 7.67274e+02 7.67274e+01 1.00000e-09 7.00000e-02

$3.06569 \mathrm{e}+013.06569 \mathrm{e}+013.06569 \mathrm{e}+001.00000 \mathrm{e}-092.12000 \mathrm{e}-01$

$3.06569 \mathrm{e}+013.06569 \mathrm{e}+013.06569 \mathrm{e}+001.00000 \mathrm{e}-092.12000 \mathrm{e}-01$

$3.06569 \mathrm{e}+013.06569 \mathrm{e}+013.06569 \mathrm{e}+001.00000 \mathrm{e}-092.12000 \mathrm{e}-01$

$3.06569 \mathrm{e}+013.06569 \mathrm{e}+013.06569 \mathrm{e}+00$ 1.00000e-09 2.12000e-01

$1.00000 \mathrm{e}-02$ 1.00000e-02 1.00000e-03 1.00000e-09 1.00000e-01

$1.00000 \mathrm{e}+001.00000 \mathrm{e}+001.00000 \mathrm{e}-011.00000 \mathrm{e}-091.00000 \mathrm{e}-01$

Element: 6318 \# of layers: 8

$\mathrm{Kx} \mathrm{Ky} \mathrm{Kz}$ Ss Por

7.67274e+02 7.67274e+02 7.67274e+01 1.00000e-09 7.00000e-02

$7.67274 \mathrm{e}+02$ 7.67274e+02 7.67274e+01 1.00000e-09 7.00000e-02

$3.06569 \mathrm{e}+013.06569 \mathrm{e}+013.06569 \mathrm{e}+001.00000 \mathrm{e}-092.12000 \mathrm{e}-01$

$3.06569 \mathrm{e}+013.06569 \mathrm{e}+013.06569 \mathrm{e}+001.00000 \mathrm{e}-092.12000 \mathrm{e}-01$

$3.06569 \mathrm{e}+013.06569 \mathrm{e}+013.06569 \mathrm{e}+00$ 1.00000e-09 2.12000e-01

$3.06569 \mathrm{e}+013.06569 \mathrm{e}+013.06569 \mathrm{e}+001.00000 \mathrm{e}-092.12000 \mathrm{e}-01$

$1.00000 \mathrm{e}-02$ 1.00000e-02 1.00000e-03 1.00000e-09 1.00000e-01

$1.00000 \mathrm{e}+001.00000 \mathrm{e}+001.00000 \mathrm{e}-011.00000 \mathrm{e}-091.00000 \mathrm{e}-01$

Element: 6319 \# of layers: 8

Kx Ky Kz Ss Por

7.67274e+02 7.67274e+02 7.67274e+01 1.00000e-09 7.00000e-02

$7.67274 \mathrm{e}+02$ 7.67274e+02 7.67274e+01 1.00000e-09 7.00000e-02

$3.06569 \mathrm{e}+013.06569 \mathrm{e}+013.06569 \mathrm{e}+001.00000 \mathrm{e}-092.12000 \mathrm{e}-01$

$3.06569 \mathrm{e}+013.06569 \mathrm{e}+01$ 3.06569e+00 1.00000e-09 2.12000e-01

$3.06569 \mathrm{e}+013.06569 \mathrm{e}+013.06569 \mathrm{e}+001.00000 \mathrm{e}-09$ 2.12000e-01

$3.06569 \mathrm{e}+013.06569 \mathrm{e}+013.06569 \mathrm{e}+00$ 1.00000e-09 2.12000e-01

$1.00000 \mathrm{e}-02$ 1.00000e-02 1.00000e-03 1.00000e-09 1.00000e-01

$1.00000 \mathrm{e}+001.00000 \mathrm{e}+001.00000 \mathrm{e}-011.00000 \mathrm{e}-09$ 1.00000e-01

Element: 6320 \# of layers: 7 
$\mathrm{Kx} \mathrm{Ky} \mathrm{Kz} \mathrm{Ss} \mathrm{Por}$

7.67274e+02 7.67274e+02 7.67274e+01 1.00000e-09 7.00000e-02

$7.67274 \mathrm{e}+02$ 7.67274e+02 7.67274e+01 1.00000e-09 7.00000e-02

$3.06569 \mathrm{e}+013.06569 \mathrm{e}+013.06569 \mathrm{e}+001.00000 \mathrm{e}-092.12000 \mathrm{e}-01$

$3.06569 \mathrm{e}+013.06569 \mathrm{e}+013.06569 \mathrm{e}+001.00000 \mathrm{e}-092.12000 \mathrm{e}-01$

$3.06569 \mathrm{e}+013.06569 \mathrm{e}+013.06569 \mathrm{e}+001.00000 \mathrm{e}-092.12000 \mathrm{e}-01$

$3.06569 \mathrm{e}+013.06569 \mathrm{e}+013.06569 \mathrm{e}+001.00000 \mathrm{e}-09$ 2.12000e-01

1.00000e-02 1.00000e-02 1.00000e-03 1.00000e-09 1.00000e-01

Element: 6321 \# of layers: 7

$\mathrm{Kx} \mathrm{Ky} \mathrm{Kz}$ Ss Por

7.67274e+02 7.67274e+02 7.67274e+01 1.00000e-09 7.00000e-02

$7.67274 \mathrm{e}+027.67274 \mathrm{e}+027.67274 \mathrm{e}+01$ 1.00000e-09 7.00000e-02

$3.06569 \mathrm{e}+013.06569 \mathrm{e}+013.06569 \mathrm{e}+001.00000 \mathrm{e}-092.12000 \mathrm{e}-01$

$3.06569 \mathrm{e}+013.06569 \mathrm{e}+013.06569 \mathrm{e}+001.00000 \mathrm{e}-092.12000 \mathrm{e}-01$

$3.06569 \mathrm{e}+013.06569 \mathrm{e}+013.06569 \mathrm{e}+001.00000 \mathrm{e}-092.12000 \mathrm{e}-01$

$3.06569 \mathrm{e}+013.06569 \mathrm{e}+013.06569 \mathrm{e}+00$ 1.00000e-09 2.12000e-01

$1.00000 \mathrm{e}-02$ 1.00000e-02 1.00000e-03 1.00000e-09 1.00000e-01

Element: 6322 \# of layers: 7

$\mathrm{Kx} \mathrm{Ky} \mathrm{Kz}$ Ss Por

7.93357e+02 7.93357e+02 7.93357e+01 1.00000e-09 7.00000e-02 7.93357e+02 7.93357e+02 7.93357e+01 1.00000e-09 7.00000e-02

7.93357e+02 7.93357e+02 7.93357e+01 1.00000e-09 7.00000e-02

$3.16987 \mathrm{e}+013.16987 \mathrm{e}+01$ 3.16987e+00 1.00000e-09 2.12000e-01

$3.16987 \mathrm{e}+013.16987 \mathrm{e}+013.16987 \mathrm{e}+00$ 1.00000e-09 2.12000e-01

$3.16987 \mathrm{e}+013.16987 \mathrm{e}+013.16987 \mathrm{e}+00$ 1.00000e-09 2.12000e-01

1.00000e-02 1.00000e-02 1.00000e-03 1.00000e-09 1.00000e-01

Element: 6323 \# of layers: 8

$\mathrm{Kx} \mathrm{Ky} \mathrm{Kz} \mathrm{Ss} \mathrm{Por}$

7.93357e+02 7.93357e+02 7.93357e+01 1.00000e-09 7.00000e-02

7.93357e+02 7.93357e+02 7.93357e+01 1.00000e-09 7.00000e-02

7.93357e+02 7.93357e+02 7.93357e+01 1.00000e-09 7.00000e-02

$3.16987 \mathrm{e}+01$ 3.16987e+01 3.16987e+00 1.00000e-09 2.12000e-01

$3.16987 \mathrm{e}+013.16987 \mathrm{e}+013.16987 \mathrm{e}+00$ 1.00000e-09 2.12000e-01

$3.16987 \mathrm{e}+01$ 3.16987e+01 3.16987e+00 1.00000e-09 2.12000e-01

$3.16987 \mathrm{e}+013.16987 \mathrm{e}+01$ 3.16987e+00 1.00000e-09 2.12000e-01

1.00000e-01 1.00000e-01 1.00000e-02 1.00000e-09 1.00000e-01

Element: 6324 \# of layers: 8

Kx Ky Kz Ss Por

7.93357e+02 7.93357e+02 7.93357e+01 1.00000e-09 7.00000e-02 7.93357e+02 7.93357e+02 7.93357e+01 1.00000e-09 7.00000e-02 7.93357e+02 7.93357e+02 7.93357e+01 1.00000e-09 7.00000e-02 7.93357e+02 7.93357e+02 7.93357e+01 1.00000e-09 7.00000e-02 3.16987e+01 3.16987e+01 3.16987e+00 1.00000e-09 2.12000e-01 3.16987e+01 3.16987e+01 3.16987e+00 1.00000e-09 2.12000e-01 $3.16987 \mathrm{e}+013.16987 \mathrm{e}+01$ 3.16987e+00 1.00000e-09 2.12000e-01 $1.00000 \mathrm{e}-01$ 1.00000e-01 1.00000e-02 1.00000e-09 1.00000e-01 
Element: 6325 \# of layers: 8

$\mathrm{Kx} \mathrm{Ky} \mathrm{Kz}$ Ss Por

7.93357e+02 7.93357e+02 7.93357e+01 1.00000e-09 7.00000e-02

7.93357e+02 7.93357e+02 7.93357e+01 1.00000e-09 7.00000e-02

7.93357e+02 7.93357e+02 7.93357e+01 1.00000e-09 7.00000e-02

$3.16987 \mathrm{e}+013.16987 \mathrm{e}+01$ 3.16987e+00 1.00000e-09 2.12000e-01

$3.16987 \mathrm{e}+013.16987 \mathrm{e}+01$ 3.16987e+00 1.00000e-09 2.12000e-01

$3.16987 \mathrm{e}+01$ 3.16987e+01 3.16987e+00 1.00000e-09 2.12000e-01

$1.00000 \mathrm{e}-01$ 1.00000e-01 1.00000e-02 1.00000e-09 1.00000e-01

$1.00000 \mathrm{e}+001.00000 \mathrm{e}+001.00000 \mathrm{e}-011.00000 \mathrm{e}-091.00000 \mathrm{e}-01$

Element: 6326 \# of layers: 10

$\mathrm{Kx} \mathrm{Ky} \mathrm{Kz}$ Ss Por

7.93357e+02 7.93357e+02 7.93357e+01 1.00000e-09 7.00000e-02

7.93357e+02 7.93357e+02 7.93357e+01 1.00000e-09 7.00000e-02

7.93357e+02 7.93357e+02 7.93357e+01 1.00000e-09 7.00000e-02

$3.16987 \mathrm{e}+013.16987 \mathrm{e}+013.16987 \mathrm{e}+00$ 1.00000e-09 2.12000e-01

$3.16987 \mathrm{e}+013.16987 \mathrm{e}+013.16987 \mathrm{e}+00$ 1.00000e-09 2.12000e-01

$3.16987 \mathrm{e}+013.16987 \mathrm{e}+01$ 3.16987e+00 1.00000e-09 2.12000e-01

3.16987e+01 3.16987e+01 3.16987e+00 1.00000e-09 2.12000e-01

$3.16987 \mathrm{e}+013.16987 \mathrm{e}+01$ 3.16987e+00 1.00000e-09 2.12000e-01

$1.00000 \mathrm{e}-011.00000 \mathrm{e}-01$ 1.00000e-02 1.00000e-09 1.00000e-01

$1.00000 \mathrm{e}+001.00000 \mathrm{e}+001.00000 \mathrm{e}-01$ 1.00000e-09 1.00000e-01

Element: 6327 \# of layers: 9

Kx Ky Kz Ss Por

7.93357e+02 7.93357e+02 7.93357e+01 1.00000e-09 7.00000e-02

7.93357e+02 7.93357e+02 7.93357e+01 1.00000e-09 7.00000e-02

$3.16987 \mathrm{e}+013.16987 \mathrm{e}+01$ 3.16987e+00 1.00000e-09 2.12000e-01

$3.16987 \mathrm{e}+013.16987 \mathrm{e}+01$ 3.16987e+00 1.00000e-09 2.12000e-01

$3.16987 \mathrm{e}+01$ 3.16987e+01 3.16987e+00 1.00000e-09 2.12000e-01

3.16987e+01 3.16987e+01 3.16987e+00 1.00000e-09 2.12000e-01

$3.16987 \mathrm{e}+013.16987 \mathrm{e}+013.16987 \mathrm{e}+00$ 1.00000e-09 2.12000e-01

$1.00000 \mathrm{e}-01$ 1.00000e-01 1.00000e-02 1.00000e-09 1.00000e-01

$1.00000 \mathrm{e}+001.00000 \mathrm{e}+001.00000 \mathrm{e}-011.00000 \mathrm{e}-091.00000 \mathrm{e}-01$

Element: 6328 \# of layers: 8

$\mathrm{Kx} \mathrm{Ky} \mathrm{Kz}$ Ss Por

7.93357e+02 7.93357e+02 7.93357e+01 1.00000e-09 7.00000e-02

7.93357e+02 7.93357e+02 7.93357e+01 1.00000e-09 7.00000e-02

$3.16987 \mathrm{e}+013.16987 \mathrm{e}+01$ 3.16987e+00 1.00000e-09 2.12000e-01

3.16987e+01 3.16987e+01 3.16987e+00 1.00000e-09 2.12000e-01

$3.16987 \mathrm{e}+013.16987 \mathrm{e}+01$ 3.16987e+00 1.00000e-09 2.12000e-01

$3.16987 \mathrm{e}+013.16987 \mathrm{e}+013.16987 \mathrm{e}+00$ 1.00000e-09 2.12000e-01

$1.00000 \mathrm{e}-021.00000 \mathrm{e}-02$ 1.00000e-03 1.00000e-09 1.00000e-01

$1.00000 \mathrm{e}+001.00000 \mathrm{e}+001.00000 \mathrm{e}-011.00000 \mathrm{e}-091.00000 \mathrm{e}-01$

Element: 6329 \# of layers: 8

$\mathrm{Kx} \mathrm{Ky} \mathrm{Kz}$ Ss Por

7.93357e+02 7.93357e+02 7.93357e+01 1.00000e-09 7.00000e-02 
7.93357e+02 7.93357e+02 7.93357e+01 1.00000e-09 7.00000e-02 $3.16987 \mathrm{e}+013.16987 \mathrm{e}+01$ 3.16987e+00 1.00000e-09 2.12000e-01 $3.16987 \mathrm{e}+013.16987 \mathrm{e}+01$ 3.16987e+00 1.00000e-09 2.12000e-01 $3.16987 \mathrm{e}+01$ 3.16987e+01 3.16987e+00 1.00000e-09 2.12000e-01 $3.16987 \mathrm{e}+013.16987 \mathrm{e}+01$ 3.16987e+00 1.00000e-09 2.12000e-01 $1.00000 \mathrm{e}-02$ 1.00000e-02 1.00000e-03 1.00000e-09 1.00000e-01 $1.00000 \mathrm{e}+001.00000 \mathrm{e}+001.00000 \mathrm{e}-011.00000 \mathrm{e}-091.00000 \mathrm{e}-01$

Element: 6330 \# of layers: 10

$\mathrm{Kx} \mathrm{Ky} \mathrm{Kz}$ Ss Por

7.93357e+02 7.93357e+02 7.93357e+01 1.00000e-09 7.00000e-02 7.93357e+02 7.93357e+02 7.93357e+01 1.00000e-09 7.00000e-02 7.93357e+02 7.93357e+02 7.93357e+01 1.00000e-09 7.00000e-02 $3.16987 \mathrm{e}+013.16987 \mathrm{e}+01$ 3.16987e+00 1.00000e-09 2.12000e-01 $3.16987 \mathrm{e}+013.16987 \mathrm{e}+01$ 3.16987e+00 1.00000e-09 2.12000e-01 $3.16987 \mathrm{e}+013.16987 \mathrm{e}+01$ 3.16987e+00 1.00000e-09 2.12000e-01 $3.16987 \mathrm{e}+013.16987 \mathrm{e}+013.16987 \mathrm{e}+00$ 1.00000e-09 2.12000e-01 3.16987e+01 3.16987e+01 3.16987e+00 1.00000e-09 2.12000e-01 $1.00000 \mathrm{e}-01$ 1.00000e-01 1.00000e-02 1.00000e-09 1.00000e-01 $1.00000 \mathrm{e}+001.00000 \mathrm{e}+001.00000 \mathrm{e}-011.00000 \mathrm{e}-091.00000 \mathrm{e}-01$ Element: 6331 \# of layers: 7

$\mathrm{Kx} \mathrm{Ky} \mathrm{Kz}$ Ss Por $1.02588 \mathrm{e}+031.02588 \mathrm{e}+03$ 1.02588e+02 1.00000e-09 7.00000e-02 $1.02588 \mathrm{e}+031.02588 \mathrm{e}+03$ 1.02588e+02 1.00000e-09 7.00000e-02 $1.02588 \mathrm{e}+03$ 1.02588e+03 1.02588e+02 1.00000e-09 7.00000e-02 $4.09891 \mathrm{e}+014.09891 \mathrm{e}+014.09891 \mathrm{e}+001.00000 \mathrm{e}-092.12000 \mathrm{e}-01$ $4.09891 \mathrm{e}+014.09891 \mathrm{e}+014.09891 \mathrm{e}+001.00000 \mathrm{e}-092.12000 \mathrm{e}-01$ $1.00000 \mathrm{e}-01$ 1.00000e-01 1.00000e-02 1.00000e-09 1.00000e-01 $1.00000 \mathrm{e}+001.00000 \mathrm{e}+001.00000 \mathrm{e}-011.00000 \mathrm{e}-091.00000 \mathrm{e}-01$ Element: 6332 \# of layers: 8

$\mathrm{Kx} \mathrm{Ky} \mathrm{Kz}$ Ss Por

$1.02588 \mathrm{e}+03$ 1.02588e+03 1.02588e+02 1.00000e-09 7.00000e-02 $1.02588 \mathrm{e}+031.02588 \mathrm{e}+03$ 1.02588e+02 1.00000e-09 7.00000e-02 $1.02588 \mathrm{e}+031.02588 \mathrm{e}+03$ 1.02588e+02 1.00000e-09 7.00000e-02 $1.02588 \mathrm{e}+031.02588 \mathrm{e}+03$ 1.02588e+02 1.00000e-09 7.00000e-02 $4.09891 \mathrm{e}+014.09891 \mathrm{e}+014.09891 \mathrm{e}+00$ 1.00000e-09 2.12000e-01 $4.09891 \mathrm{e}+014.09891 \mathrm{e}+014.09891 \mathrm{e}+00$ 1.00000e-09 2.12000e-01 $1.00000 \mathrm{e}-011.00000 \mathrm{e}-01$ 1.00000e-02 1.00000e-09 1.00000e-01 $1.00000 \mathrm{e}+001.00000 \mathrm{e}+001.00000 \mathrm{e}-011.00000 \mathrm{e}-091.00000 \mathrm{e}-01$ Element: 6333 \# of layers: 7

$\mathrm{Kx} \mathrm{Ky} \mathrm{Kz}$ Ss Por $1.02588 \mathrm{e}+03$ 1.02588e+03 1.02588e+02 1.00000e-09 7.00000e-02 $1.02588 \mathrm{e}+03$ 1.02588e+03 1.02588e+02 1.00000e-09 7.00000e-02 $1.02588 \mathrm{e}+031.02588 \mathrm{e}+03$ 1.02588e+02 1.00000e-09 7.00000e-02 $1.02588 \mathrm{e}+03$ 1.02588e+03 1.02588e+02 1.00000e-09 7.00000e-02 $4.09891 \mathrm{e}+014.09891 \mathrm{e}+014.09891 \mathrm{e}+001.00000 \mathrm{e}-092.12000 \mathrm{e}-01$ $1.00000 \mathrm{e}-01$ 1.00000e-01 1.00000e-02 1.00000e-09 1.00000e-01 
$1.00000 \mathrm{e}+001.00000 \mathrm{e}+00$ 1.00000e-01 1.00000e-09 1.00000e-01

Element: 6334 \# of layers: 6

Kx Ky Kz Ss Por

$1.02588 \mathrm{e}+03$ 1.02588e+03 1.02588e+02 1.00000e-09 7.00000e-02

$1.02588 \mathrm{e}+031.02588 \mathrm{e}+03$ 1.02588e+02 1.00000e-09 7.00000e-02

$1.02588 \mathrm{e}+031.02588 \mathrm{e}+03$ 1.02588e+02 1.00000e-09 7.00000e-02

$4.09891 \mathrm{e}+014.09891 \mathrm{e}+014.09891 \mathrm{e}+001.00000 \mathrm{e}-09$ 2.12000e-01

$1.00000 \mathrm{e}-011.00000 \mathrm{e}-01$ 1.00000e-02 1.00000e-09 1.00000e-01

$1.00000 \mathrm{e}+001.00000 \mathrm{e}+001.00000 \mathrm{e}-011.00000 \mathrm{e}-091.00000 \mathrm{e}-01$

Element: 6335 \# of layers: 7

$\mathrm{Kx} \mathrm{Ky} \mathrm{Kz}$ Ss Por

$1.02588 \mathrm{e}+03$ 1.02588e+03 1.02588e+02 1.00000e-09 7.00000e-02

$1.02588 \mathrm{e}+03$ 1.02588e+03 1.02588e+02 1.00000e-09 7.00000e-02

$1.02588 \mathrm{e}+03$ 1.02588e+03 1.02588e+02 1.00000e-09 7.00000e-02

$4.09891 \mathrm{e}+014.09891 \mathrm{e}+014.09891 \mathrm{e}+001.00000 \mathrm{e}-092.12000 \mathrm{e}-01$

$4.09891 \mathrm{e}+014.09891 \mathrm{e}+014.09891 \mathrm{e}+001.00000 \mathrm{e}-092.12000 \mathrm{e}-01$

$1.00000 \mathrm{e}-01$ 1.00000e-01 1.00000e-02 1.00000e-09 1.00000e-01

$1.00000 \mathrm{e}+001.00000 \mathrm{e}+001.00000 \mathrm{e}-01$ 1.00000e-09 1.00000e-01

Element: 6336 \# of layers: 7

$\mathrm{Kx} \mathrm{Ky} \mathrm{Kz}$ Ss Por

$1.02588 \mathrm{e}+03$ 1.02588e+03 1.02588e+02 1.00000e-09 7.00000e-02 $1.02588 \mathrm{e}+03$ 1.02588e+03 1.02588e+02 1.00000e-09 7.00000e-02 $4.09891 \mathrm{e}+014.09891 \mathrm{e}+014.09891 \mathrm{e}+001.00000 \mathrm{e}-092.12000 \mathrm{e}-01$ $4.09891 \mathrm{e}+014.09891 \mathrm{e}+014.09891 \mathrm{e}+001.00000 \mathrm{e}-092.12000 \mathrm{e}-01$ $4.09891 \mathrm{e}+014.09891 \mathrm{e}+014.09891 \mathrm{e}+001.00000 \mathrm{e}-092.12000 \mathrm{e}-01$ $1.00000 \mathrm{e}-01$ 1.00000e-01 1.00000e-02 1.00000e-09 1.00000e-01

$1.00000 \mathrm{e}+001.00000 \mathrm{e}+001.00000 \mathrm{e}-011.00000 \mathrm{e}-091.00000 \mathrm{e}-01$

Element: 6337 \# of layers: 9

$\mathrm{Kx} \mathrm{Ky} \mathrm{Kz}$ Ss Por

$1.02588 \mathrm{e}+031.02588 \mathrm{e}+03$ 1.02588e+02 1.00000e-09 7.00000e-02 $1.02588 \mathrm{e}+031.02588 \mathrm{e}+03$ 1.02588e+02 1.00000e-09 7.00000e-02 $1.02588 \mathrm{e}+03$ 1.02588e+03 1.02588e+02 1.00000e-09 7.00000e-02 $4.09891 \mathrm{e}+014.09891 \mathrm{e}+014.09891 \mathrm{e}+001.00000 \mathrm{e}-092.12000 \mathrm{e}-01$ $4.09891 \mathrm{e}+014.09891 \mathrm{e}+014.09891 \mathrm{e}+001.00000 \mathrm{e}-092.12000 \mathrm{e}-01$ $4.09891 \mathrm{e}+014.09891 \mathrm{e}+014.09891 \mathrm{e}+001.00000 \mathrm{e}-09$ 2.12000e-01 $4.09891 \mathrm{e}+014.09891 \mathrm{e}+014.09891 \mathrm{e}+001.00000 \mathrm{e}-092.12000 \mathrm{e}-01$ $1.00000 \mathrm{e}-01$ 1.00000e-01 1.00000e-02 1.00000e-09 1.00000e-01 $1.00000 \mathrm{e}+001.00000 \mathrm{e}+001.00000 \mathrm{e}-011.00000 \mathrm{e}-091.00000 \mathrm{e}-01$ Element: 6338 \# of layers: 9

$\mathrm{Kx} \mathrm{Ky} \mathrm{Kz}$ Ss Por

$1.02588 \mathrm{e}+03$ 1.02588e+03 1.02588e+02 1.00000e-09 7.00000e-02 $1.02588 \mathrm{e}+031.02588 \mathrm{e}+03$ 1.02588e+02 1.00000e-09 7.00000e-02 $1.02588 \mathrm{e}+03$ 1.02588e+03 1.02588e+02 1.00000e-09 7.00000e-02 $1.02588 \mathrm{e}+03$ 1.02588e+03 1.02588e+02 1.00000e-09 7.00000e-02 $4.09891 \mathrm{e}+014.09891 \mathrm{e}+014.09891 \mathrm{e}+001.00000 \mathrm{e}-092.12000 \mathrm{e}-01$ $4.09891 \mathrm{e}+014.09891 \mathrm{e}+014.09891 \mathrm{e}+00$ 1.00000e-09 2.12000e-01 
4.09891e+01 4.09891e+01 4.09891e+00 1.00000e-09 2.12000e-01 $1.00000 \mathrm{e}-01$ 1.00000e-01 1.00000e-02 1.00000e-09 1.00000e-01 $1.00000 \mathrm{e}+001.00000 \mathrm{e}+001.00000 \mathrm{e}-011.00000 \mathrm{e}-09$ 1.00000e-01

Element: 6339 \# of layers: 7

$\mathrm{Kx} \mathrm{Ky} \mathrm{Kz}$ Ss Por

$1.02588 \mathrm{e}+03$ 1.02588e+03 1.02588e+02 1.00000e-09 7.00000e-02

$1.02588 \mathrm{e}+03$ 1.02588e+03 1.02588e+02 1.00000e-09 7.00000e-02

$1.02588 \mathrm{e}+031.02588 \mathrm{e}+03$ 1.02588e+02 1.00000e-09 7.00000e-02

$4.09891 \mathrm{e}+014.09891 \mathrm{e}+014.09891 \mathrm{e}+001.00000 \mathrm{e}-092.12000 \mathrm{e}-01$

$4.09891 \mathrm{e}+014.09891 \mathrm{e}+014.09891 \mathrm{e}+001.00000 \mathrm{e}-092.12000 \mathrm{e}-01$

$1.00000 \mathrm{e}-01$ 1.00000e-01 1.00000e-02 1.00000e-09 1.00000e-01

$1.00000 \mathrm{e}+001.00000 \mathrm{e}+001.00000 \mathrm{e}-011.00000 \mathrm{e}-091.00000 \mathrm{e}-01$

Element: 6340 \# of layers: 7

$\mathrm{Kx} \mathrm{Ky} \mathrm{Kz}$ Ss Por

9.17038e+02 9.17038e+02 9.17038e+01 1.00000e-09 7.00000e-02

$9.17038 \mathrm{e}+02$ 9.17038e+02 9.17038e+01 1.00000e-09 7.00000e-02

9.17038e+02 9.17038e+02 9.17038e+01 1.00000e-09 7.00000e-02

9.17038e+02 9.17038e+02 9.17038e+01 1.00000e-09 7.00000e-02

$3.66420 \mathrm{e}+013.66420 \mathrm{e}+013.66420 \mathrm{e}+001.00000 \mathrm{e}-092.12000 \mathrm{e}-01$

$1.00000 \mathrm{e}-01$ 1.00000e-01 1.00000e-02 1.00000e-09 1.00000e-01

$1.00000 \mathrm{e}+001.00000 \mathrm{e}+001.00000 \mathrm{e}-011.00000 \mathrm{e}-091.00000 \mathrm{e}-01$

Element: 6341 \# of layers: 6

$\mathrm{Kx} \mathrm{Ky} \mathrm{Kz}$ Ss Por

9.17038e+02 9.17038e+02 9.17038e+01 1.00000e-09 7.00000e-02

9.17038e+02 9.17038e+02 9.17038e+01 1.00000e-09 7.00000e-02

$9.17038 \mathrm{e}+02$ 9.17038e+02 9.17038e+01 1.00000e-09 7.00000e-02

$3.66420 \mathrm{e}+013.66420 \mathrm{e}+013.66420 \mathrm{e}+001.00000 \mathrm{e}-092.12000 \mathrm{e}-01$

$1.00000 \mathrm{e}-01$ 1.00000e-01 1.00000e-02 1.00000e-09 1.00000e-01

$1.00000 \mathrm{e}+001.00000 \mathrm{e}+001.00000 \mathrm{e}-011.00000 \mathrm{e}-091.00000 \mathrm{e}-01$

Element: 6342 \# of layers: 6

$\mathrm{Kx} \mathrm{Ky} \mathrm{Kz}$ Ss Por

9.17038e+02 9.17038e+02 9.17038e+01 1.00000e-09 7.00000e-02

9.17038e+02 9.17038e+02 9.17038e+01 1.00000e-09 7.00000e-02

$9.17038 \mathrm{e}+02$ 9.17038e+02 9.17038e+01 1.00000e-09 7.00000e-02

$3.66420 \mathrm{e}+013.66420 \mathrm{e}+013.66420 \mathrm{e}+001.00000 \mathrm{e}-092.12000 \mathrm{e}-01$

1.00000e-01 1.00000e-01 1.00000e-02 1.00000e-09 1.00000e-01

$1.00000 \mathrm{e}+001.00000 \mathrm{e}+001.00000 \mathrm{e}-011.00000 \mathrm{e}-091.00000 \mathrm{e}-01$

Element: 6343 \# of layers: 6

$\mathrm{Kx} \mathrm{Ky} \mathrm{Kz}$ Ss Por

9.17038e+02 9.17038e+02 9.17038e+01 1.00000e-09 7.00000e-02

9.17038e+02 9.17038e+02 9.17038e+01 1.00000e-09 7.00000e-02

$9.17038 \mathrm{e}+02$ 9.17038e+02 9.17038e+01 1.00000e-09 7.00000e-02

$3.66420 \mathrm{e}+013.66420 \mathrm{e}+013.66420 \mathrm{e}+00$ 1.00000e-09 2.12000e-01

$1.00000 \mathrm{e}-011.00000 \mathrm{e}-011.00000 \mathrm{e}-021.00000 \mathrm{e}-091.00000 \mathrm{e}-01$

$1.00000 \mathrm{e}+001.00000 \mathrm{e}+001.00000 \mathrm{e}-011.00000 \mathrm{e}-091.00000 \mathrm{e}-01$

Element: 6344 \# of layers: 6 
$\mathrm{Kx} \mathrm{Ky} \mathrm{Kz}$ Ss Por

9.17038e+02 9.17038e+02 9.17038e+01 1.00000e-09 7.00000e-02

9.17038e+02 9.17038e+02 9.17038e+01 1.00000e-09 7.00000e-02

9.17038e+02 9.17038e+02 9.17038e+01 1.00000e-09 7.00000e-02

$3.66420 \mathrm{e}+013.66420 \mathrm{e}+013.66420 \mathrm{e}+001.00000 \mathrm{e}-092.12000 \mathrm{e}-01$

$1.00000 \mathrm{e}-011.00000 \mathrm{e}-01$ 1.00000e-02 1.00000e-09 1.00000e-01

$1.00000 \mathrm{e}+001.00000 \mathrm{e}+001.00000 \mathrm{e}-01$ 1.00000e-09 1.00000e-01

Element: 6345 \# of layers: 6

$\mathrm{Kx} \mathrm{Ky} \mathrm{Kz}$ Ss Por

9.17038e+02 9.17038e+02 9.17038e+01 1.00000e-09 7.00000e-02

9.17038e+02 9.17038e+02 9.17038e+01 1.00000e-09 7.00000e-02

9.17038e+02 9.17038e+02 9.17038e+01 1.00000e-09 7.00000e-02

$3.66420 \mathrm{e}+013.66420 \mathrm{e}+013.66420 \mathrm{e}+001.00000 \mathrm{e}-092.12000 \mathrm{e}-01$

$1.00000 \mathrm{e}-01$ 1.00000e-01 1.00000e-02 1.00000e-09 1.00000e-01

$1.00000 \mathrm{e}+001.00000 \mathrm{e}+001.00000 \mathrm{e}-01$ 1.00000e-09 1.00000e-01

Element: 6346 \# of layers: 7

$\mathrm{Kx} \mathrm{Ky} \mathrm{Kz}$ Ss Por

9.17038e+02 9.17038e+02 9.17038e+01 1.00000e-09 7.00000e-02

9.17038e+02 9.17038e+02 9.17038e+01 1.00000e-09 7.00000e-02

9.17038e+02 9.17038e+02 9.17038e+01 1.00000e-09 7.00000e-02

$3.66420 \mathrm{e}+013.66420 \mathrm{e}+013.66420 \mathrm{e}+001.00000 \mathrm{e}-092.12000 \mathrm{e}-01$

$3.66420 \mathrm{e}+013.66420 \mathrm{e}+013.66420 \mathrm{e}+001.00000 \mathrm{e}-092.12000 \mathrm{e}-01$

$1.00000 \mathrm{e}-011.00000 \mathrm{e}-011.00000 \mathrm{e}-021.00000 \mathrm{e}-091.00000 \mathrm{e}-01$

$1.00000 \mathrm{e}+001.00000 \mathrm{e}+001.00000 \mathrm{e}-011.00000 \mathrm{e}-091.00000 \mathrm{e}-01$

Element: 6347 \# of layers: 6

$\mathrm{Kx} \mathrm{Ky} \mathrm{Kz}$ Ss Por

9.17038e+02 9.17038e+02 9.17038e+01 1.00000e-09 7.00000e-02

9.17038e+02 9.17038e+02 9.17038e+01 1.00000e-09 7.00000e-02

9.17038e+02 9.17038e+02 9.17038e+01 1.00000e-09 7.00000e-02

$3.66420 \mathrm{e}+013.66420 \mathrm{e}+013.66420 \mathrm{e}+00$ 1.00000e-09 2.12000e-01

$1.00000 \mathrm{e}-011.00000 \mathrm{e}-01$ 1.00000e-02 1.00000e-09 1.00000e-01

$1.00000 \mathrm{e}+001.00000 \mathrm{e}+001.00000 \mathrm{e}-01$ 1.00000e-09 1.00000e-01

Element: 6348 \# of layers: 6

$\mathrm{Kx} \mathrm{Ky} \mathrm{Kz}$ Ss Por

9.17038e+02 9.17038e+02 9.17038e+01 1.00000e-09 7.00000e-02

9.17038e+02 9.17038e+02 9.17038e+01 1.00000e-09 7.00000e-02

9.17038e+02 9.17038e+02 9.17038e+01 1.00000e-09 7.00000e-02

$3.66420 \mathrm{e}+013.66420 \mathrm{e}+013.66420 \mathrm{e}+001.00000 \mathrm{e}-092.12000 \mathrm{e}-01$

$1.00000 \mathrm{e}-01$ 1.00000e-01 1.00000e-02 1.00000e-09 1.00000e-01

$1.00000 \mathrm{e}+001.00000 \mathrm{e}+001.00000 \mathrm{e}-01$ 1.00000e-09 1.00000e-01

Element: 6349 \# of layers: 7

$\mathrm{Kx} \mathrm{Ky} \mathrm{Kz}$ Ss Por

7.76707e+02 7.76707e+02 7.76707e+01 1.00000e-09 7.00000e-02

7.76707e+02 7.76707e+02 7.76707e+01 1.00000e-09 7.00000e-02

7.76707e+02 7.76707e+02 7.76707e+01 1.00000e-09 7.00000e-02

$3.10349 e+013.10349 e+013.10349 e+00$ 1.00000e-09 2.12000e-01 
$3.10349 \mathrm{e}+013.10349 \mathrm{e}+013.10349 \mathrm{e}+00$ 1.00000e-09 2.12000e-01 $1.00000 \mathrm{e}-02$ 1.00000e-02 1.00000e-03 1.00000e-09 1.00000e-01 $1.00000 \mathrm{e}+001.00000 \mathrm{e}+001.00000 \mathrm{e}-011.00000 \mathrm{e}-091.00000 \mathrm{e}-01$

Element: 6350 \# of layers: 8

$\mathrm{Kx} \mathrm{Ky} \mathrm{Kz}$ Ss Por

7.76707e+02 7.76707e+02 7.76707e+01 1.00000e-09 7.00000e-02 7.76707e+02 7.76707e+02 7.76707e+01 1.00000e-09 7.00000e-02 7.76707e+02 7.76707e+02 7.76707e+01 1.00000e-09 7.00000e-02 7.76707e+02 7.76707e+02 7.76707e+01 1.00000e-09 7.00000e-02 $3.10349 \mathrm{e}+013.10349 \mathrm{e}+013.10349 \mathrm{e}+00$ 1.00000e-09 2.12000e-01 $3.10349 \mathrm{e}+013.10349 \mathrm{e}+013.10349 \mathrm{e}+00$ 1.00000e-09 2.12000e-01 $1.00000 \mathrm{e}-02$ 1.00000e-02 1.00000e-03 1.00000e-09 1.00000e-01 $1.00000 \mathrm{e}+001.00000 \mathrm{e}+001.00000 \mathrm{e}-011.00000 \mathrm{e}-09$ 1.00000e-01 Element: 6351 \# of layers: 7

$\mathrm{Kx} \mathrm{Ky} \mathrm{Kz}$ Ss Por

7.76707e+02 7.76707e+02 7.76707e+01 1.00000e-09 7.00000e-02 7.76707e+02 7.76707e+02 7.76707e+01 1.00000e-09 7.00000e-02 7.76707e+02 7.76707e+02 7.76707e+01 1.00000e-09 7.00000e-02 7.76707e+02 7.76707e+02 7.76707e+01 1.00000e-09 7.00000e-02 $3.10349 \mathrm{e}+013.10349 \mathrm{e}+01$ 3.10349e+00 1.00000e-09 2.12000e-01 $1.00000 \mathrm{e}-02$ 1.00000e-02 1.00000e-03 1.00000e-09 1.00000e-01 $1.00000 \mathrm{e}+001.00000 \mathrm{e}+001.00000 \mathrm{e}-01$ 1.00000e-09 1.00000e-01 Element: 6352 \# of layers: 7

Kx Ky Kz Ss Por

7.76707e+02 7.76707e+02 7.76707e+01 1.00000e-09 7.00000e-02 7.76707e+02 7.76707e+02 7.76707e+01 1.00000e-09 7.00000e-02 7.76707e+02 7.76707e+02 7.76707e+01 1.00000e-09 7.00000e-02 7.76707e+02 7.76707e+02 7.76707e+01 1.00000e-09 7.00000e-02 $3.10349 \mathrm{e}+01$ 3.10349e+01 3.10349e+00 1.00000e-09 2.12000e-01 $1.00000 \mathrm{e}-02$ 1.00000e-02 1.00000e-03 1.00000e-09 1.00000e-01 $1.00000 \mathrm{e}+001.00000 \mathrm{e}+001.00000 \mathrm{e}-011.00000 \mathrm{e}-091.00000 \mathrm{e}-01$ Element: 6353 \# of layers: 7

Kx Ky Kz Ss Por

7.76707e+02 7.76707e+02 7.76707e+01 1.00000e-09 7.00000e-02 7.76707e+02 7.76707e+02 7.76707e+01 1.00000e-09 7.00000e-02 7.76707e+02 7.76707e+02 7.76707e+01 1.00000e-09 7.00000e-02 7.76707e+02 7.76707e+02 7.76707e+01 1.00000e-09 7.00000e-02 $3.10349 \mathrm{e}+013.10349 \mathrm{e}+013.10349 \mathrm{e}+00$ 1.00000e-09 2.12000e-01 $1.00000 \mathrm{e}-02$ 1.00000e-02 1.00000e-03 1.00000e-09 1.00000e-01 $1.00000 \mathrm{e}+001.00000 \mathrm{e}+001.00000 \mathrm{e}-01$ 1.00000e-09 1.00000e-01 Element: 6354 \# of layers: 7

$\mathrm{Kx} \mathrm{Ky} \mathrm{Kz}$ Ss Por

7.76707e+02 7.76707e+02 7.76707e+01 1.00000e-09 7.00000e-02 7.76707e+02 7.76707e+02 7.76707e+01 1.00000e-09 7.00000e-02 7.76707e+02 7.76707e+02 7.76707e+01 1.00000e-09 7.00000e-02 $7.76707 \mathrm{e}+02$ 7.76707e+02 7.76707e+01 1.00000e-09 7.00000e-02 
$3.10349 \mathrm{e}+013.10349 \mathrm{e}+013.10349 \mathrm{e}+00$ 1.00000e-09 2.12000e-01 $1.00000 \mathrm{e}-02$ 1.00000e-02 1.00000e-03 1.00000e-09 1.00000e-01 $1.00000 \mathrm{e}+001.00000 \mathrm{e}+001.00000 \mathrm{e}-011.00000 \mathrm{e}-091.00000 \mathrm{e}-01$

Element: 6355 \# of layers: 6

$\mathrm{Kx} \mathrm{Ky} \mathrm{Kz}$ Ss Por

7.76707e+02 7.76707e+02 7.76707e+01 1.00000e-09 7.00000e-02 $7.76707 \mathrm{e}+02$ 7.76707e+02 7.76707e+01 1.00000e-09 7.00000e-02

$7.76707 \mathrm{e}+02$ 7.76707e+02 7.76707e+01 1.00000e-09 7.00000e-02 $3.10349 \mathrm{e}+013.10349 \mathrm{e}+013.10349 \mathrm{e}+00$ 1.00000e-09 2.12000e-01 $1.00000 \mathrm{e}-011.00000 \mathrm{e}-011.00000 \mathrm{e}-021.00000 \mathrm{e}-091.00000 \mathrm{e}-01$ $1.00000 \mathrm{e}+001.00000 \mathrm{e}+001.00000 \mathrm{e}-011.00000 \mathrm{e}-091.00000 \mathrm{e}-01$ Element: 6356 \# of layers: 7

Kx Ky Kz Ss Por

7.76707e+02 7.76707e+02 7.76707e+01 1.00000e-09 7.00000e-02 $7.76707 \mathrm{e}+02$ 7.76707e+02 7.76707e+01 1.00000e-09 7.00000e-02 $7.76707 \mathrm{e}+02$ 7.76707e+02 7.76707e+01 1.00000e-09 7.00000e-02 $3.10349 \mathrm{e}+013.10349 \mathrm{e}+013.10349 \mathrm{e}+00$ 1.00000e-09 2.12000e-01 $3.10349 \mathrm{e}+013.10349 \mathrm{e}+013.10349 \mathrm{e}+00$ 1.00000e-09 2.12000e-01 $1.00000 \mathrm{e}-02$ 1.00000e-02 1.00000e-03 1.00000e-09 1.00000e-01 $1.00000 \mathrm{e}+001.00000 \mathrm{e}+001.00000 \mathrm{e}-011.00000 \mathrm{e}-091.00000 \mathrm{e}-01$ Element: 6357 \# of layers: 8

Kx Ky Kz Ss Por

7.76707e+02 7.76707e+02 7.76707e+01 1.00000e-09 7.00000e-02 $7.76707 \mathrm{e}+02$ 7.76707e+02 7.76707e+01 1.00000e-09 7.00000e-02 $7.76707 \mathrm{e}+02$ 7.76707e+02 7.76707e+01 1.00000e-09 7.00000e-02 $7.76707 \mathrm{e}+02$ 7.76707e+02 7.76707e+01 1.00000e-09 7.00000e-02 $3.10349 \mathrm{e}+013.10349 \mathrm{e}+013.10349 \mathrm{e}+00$ 1.00000e-09 2.12000e-01 $3.10349 \mathrm{e}+013.10349 \mathrm{e}+013.10349 \mathrm{e}+00$ 1.00000e-09 2.12000e-01 $1.00000 \mathrm{e}-021.00000 \mathrm{e}-02$ 1.00000e-03 1.00000e-09 1.00000e-01 $1.00000 \mathrm{e}+001.00000 \mathrm{e}+001.00000 \mathrm{e}-011.00000 \mathrm{e}-091.00000 \mathrm{e}-01$ Element: 6358 \# of layers: 10

Kx Ky Kz Ss Por

$8.04115 \mathrm{e}+028.04115 \mathrm{e}+028.04115 \mathrm{e}+01$ 1.00000e-09 7.00000e-02 $8.04115 \mathrm{e}+028.04115 \mathrm{e}+028.04115 \mathrm{e}+011.00000 \mathrm{e}-09$ 7.00000e-02 $8.04115 \mathrm{e}+028.04115 \mathrm{e}+028.04115 \mathrm{e}+01$ 1.00000e-09 7.00000e-02 $8.04115 \mathrm{e}+028.04115 \mathrm{e}+028.04115 \mathrm{e}+01$ 1.00000e-09 7.00000e-02 $8.04115 \mathrm{e}+028.04115 \mathrm{e}+028.04115 \mathrm{e}+01$ 1.00000e-09 7.00000e-02 $3.21307 \mathrm{e}+013.21307 \mathrm{e}+013.21307 \mathrm{e}+00$ 1.00000e-09 2.12000e-01 $3.21307 \mathrm{e}+013.21307 \mathrm{e}+013.21307 \mathrm{e}+00$ 1.00000e-09 2.12000e-01 $1.00000 \mathrm{e}-02$ 1.00000e-02 1.00000e-03 1.00000e-09 1.00000e-01 $1.00000 \mathrm{e}+001.00000 \mathrm{e}+001.00000 \mathrm{e}-011.00000 \mathrm{e}-091.00000 \mathrm{e}-01$ $1.00000 \mathrm{e}-06$ 1.00000e-06 1.00000e-06 1.00000e-09 5.00000e-02 Element: 6359 \# of layers: 7

Kx Ky Kz Ss Por $8.04115 \mathrm{e}+028.04115 \mathrm{e}+028.04115 \mathrm{e}+01$ 1.00000e-09 7.00000e-02 $8.04115 \mathrm{e}+028.04115 \mathrm{e}+028.04115 \mathrm{e}+01$ 1.00000e-09 7.00000e-02 
8.04115e+02 8.04115e+02 8.04115e+01 1.00000e-09 7.00000e-02 $3.21307 \mathrm{e}+013.21307 \mathrm{e}+013.21307 \mathrm{e}+00$ 1.00000e-09 2.12000e-01 $1.00000 \mathrm{e}-02$ 1.00000e-02 1.00000e-03 1.00000e-09 1.00000e-01

$1.00000 \mathrm{e}+001.00000 \mathrm{e}+001.00000 \mathrm{e}-011.00000 \mathrm{e}-091.00000 \mathrm{e}-01$ 1.00000e-06 1.00000e-06 1.00000e-06 1.00000e-09 5.00000e-02

Element: 6360 \# of layers: 5

$\mathrm{Kx} \mathrm{Ky} \mathrm{Kz}$ Ss Por

8.04115e+02 8.04115e+02 8.04115e+01 1.00000e-09 7.00000e-02

8.04115e+02 8.04115e+02 8.04115e+01 1.00000e-09 7.00000e-02

$3.21307 \mathrm{e}+013.21307 \mathrm{e}+013.21307 \mathrm{e}+00$ 1.00000e-09 2.12000e-01

$1.00000 \mathrm{e}-02$ 1.00000e-02 1.00000e-03 1.00000e-09 1.00000e-01

$1.00000 \mathrm{e}+001.00000 \mathrm{e}+001.00000 \mathrm{e}-011.00000 \mathrm{e}-091.00000 \mathrm{e}-01$

Element: 6361 \# of layers: 7

$\mathrm{Kx} \mathrm{Ky} \mathrm{Kz}$ Ss Por

8.04115e+02 8.04115e+02 8.04115e+01 1.00000e-09 7.00000e-02 $8.04115 \mathrm{e}+02$ 8.04115e+02 8.04115e+01 1.00000e-09 7.00000e-02 8.04115e+02 8.04115e+02 8.04115e+01 1.00000e-09 7.00000e-02 3.21307e+01 3.21307e+01 3.21307e+00 1.00000e-09 2.12000e-01 $3.21307 \mathrm{e}+013.21307 \mathrm{e}+013.21307 \mathrm{e}+00$ 1.00000e-09 2.12000e-01 $1.00000 \mathrm{e}-02$ 1.00000e-02 1.00000e-03 1.00000e-09 1.00000e-01 $1.00000 \mathrm{e}+001.00000 \mathrm{e}+001.00000 \mathrm{e}-011.00000 \mathrm{e}-091.00000 \mathrm{e}-01$ Element: 6362 \# of layers: 6

$\mathrm{Kx} \mathrm{Ky} \mathrm{Kz}$ Ss Por

8.04115e+02 8.04115e+02 8.04115e+01 1.00000e-09 7.00000e-02 8.04115e+02 8.04115e+02 8.04115e+01 1.00000e-09 7.00000e-02 8.04115e+02 8.04115e+02 8.04115e+01 1.00000e-09 7.00000e-02 $3.21307 \mathrm{e}+013.21307 \mathrm{e}+01$ 3.21307e+00 1.00000e-09 2.12000e-01 $1.00000 \mathrm{e}-02$ 1.00000e-02 1.00000e-03 1.00000e-09 1.00000e-01 $1.00000 \mathrm{e}+001.00000 \mathrm{e}+001.00000 \mathrm{e}-011.00000 \mathrm{e}-091.00000 \mathrm{e}-01$ Element: 6363 \# of layers: 6

$\mathrm{Kx} \mathrm{Ky} \mathrm{Kz}$ Ss Por

8.04115e+02 8.04115e+02 8.04115e+01 1.00000e-09 7.00000e-02 $8.04115 \mathrm{e}+02$ 8.04115e+02 8.04115e+01 1.00000e-09 7.00000e-02 8.04115e+02 8.04115e+02 8.04115e+01 1.00000e-09 7.00000e-02 $3.21307 \mathrm{e}+013.21307 \mathrm{e}+01$ 3.21307e+00 1.00000e-09 2.12000e-01 $1.00000 \mathrm{e}-02$ 1.00000e-02 1.00000e-03 1.00000e-09 1.00000e-01 $1.00000 \mathrm{e}+001.00000 \mathrm{e}+001.00000 \mathrm{e}-011.00000 \mathrm{e}-091.00000 \mathrm{e}-01$ Element: 6364 \# of layers: 7

$\mathrm{Kx} \mathrm{Ky} \mathrm{Kz}$ Ss Por

8.04115e+02 8.04115e+02 8.04115e+01 1.00000e-09 7.00000e-02 8.04115e+02 8.04115e+02 8.04115e+01 1.00000e-09 7.00000e-02 8.04115e+02 8.04115e+02 8.04115e+01 1.00000e-09 7.00000e-02 8.04115e+02 8.04115e+02 8.04115e+01 1.00000e-09 7.00000e-02 3.21307e+01 3.21307e+01 3.21307e+00 1.00000e-09 2.12000e-01 $1.00000 \mathrm{e}-02$ 1.00000e-02 1.00000e-03 1.00000e-09 1.00000e-01 $1.00000 \mathrm{e}+001.00000 \mathrm{e}+001.00000 \mathrm{e}-011.00000 \mathrm{e}-091.00000 \mathrm{e}-01$ 
Element: 6365 \# of layers: 9

$\mathrm{Kx} \mathrm{Ky} \mathrm{Kz}$ Ss Por

8.04115e+02 8.04115e+02 8.04115e+01 1.00000e-09 7.00000e-02

8.04115e+02 8.04115e+02 8.04115e+01 1.00000e-09 7.00000e-02

8.04115e+02 8.04115e+02 8.04115e+01 1.00000e-09 7.00000e-02

8.04115e+02 8.04115e+02 8.04115e+01 1.00000e-09 7.00000e-02

8.04115e+02 8.04115e+02 8.04115e+01 1.00000e-09 7.00000e-02

$3.21307 \mathrm{e}+013.21307 \mathrm{e}+013.21307 \mathrm{e}+00$ 1.00000e-09 2.12000e-01

$3.21307 \mathrm{e}+013.21307 \mathrm{e}+01$ 3.21307e+00 1.00000e-09 2.12000e-01

$1.00000 \mathrm{e}-02$ 1.00000e-02 1.00000e-03 1.00000e-09 1.00000e-01

$1.00000 \mathrm{e}+001.00000 \mathrm{e}+001.00000 \mathrm{e}-011.00000 \mathrm{e}-091.00000 \mathrm{e}-01$

Element: 6366 \# of layers: 8

$\mathrm{Kx} \mathrm{Ky} \mathrm{Kz}$ Ss Por

8.04115e+02 8.04115e+02 8.04115e+01 1.00000e-09 7.00000e-02

8.04115e+02 8.04115e+02 8.04115e+01 1.00000e-09 7.00000e-02

$8.04115 \mathrm{e}+02$ 8.04115e+02 8.04115e+01 1.00000e-09 7.00000e-02

8.04115e+02 8.04115e+02 8.04115e+01 1.00000e-09 7.00000e-02

$3.21307 \mathrm{e}+013.21307 \mathrm{e}+013.21307 \mathrm{e}+00$ 1.00000e-09 2.12000e-01

$3.21307 \mathrm{e}+013.21307 \mathrm{e}+013.21307 \mathrm{e}+00$ 1.00000e-09 2.12000e-01

$1.00000 \mathrm{e}-02$ 1.00000e-02 1.00000e-03 1.00000e-09 1.00000e-01

$1.00000 \mathrm{e}+001.00000 \mathrm{e}+001.00000 \mathrm{e}-011.00000 \mathrm{e}-091.00000 \mathrm{e}-01$

Element: 6367 \# of layers: 6

$\mathrm{Kx} \mathrm{Ky} \mathrm{Kz}$ Ss Por

8.81052e+02 8.81052e+02 8.81052e+01 1.00000e-09 7.00000e-02

$8.81052 \mathrm{e}+02$ 8.81052e+02 8.81052e+01 1.00000e-09 7.00000e-02

$3.52043 \mathrm{e}+013.52043 \mathrm{e}+013.52043 \mathrm{e}+00$ 1.00000e-09 2.12000e-01

$1.00000 \mathrm{e}-02$ 1.00000e-02 1.00000e-03 1.00000e-09 1.00000e-01

$1.00000 \mathrm{e}+001.00000 \mathrm{e}+001.00000 \mathrm{e}-011.00000 \mathrm{e}-091.00000 \mathrm{e}-01$

1.00000e-06 1.00000e-06 1.00000e-06 1.00000e-09 5.00000e-02

Element: 6368 \# of layers: 6

$\mathrm{Kx} \mathrm{Ky} \mathrm{Kz}$ Ss Por

$1.71974 \mathrm{e}+03$ 1.71974e+03 1.71974e+02 1.00000e-09 7.00000e-02

$1.71974 \mathrm{e}+031.71974 \mathrm{e}+031.71974 \mathrm{e}+02$ 1.00000e-09 7.00000e-02

6.87165e+01 6.87165e+01 6.87165e+00 1.00000e-09 2.12000e-01

$1.00000 \mathrm{e}-02$ 1.00000e-02 1.00000e-03 1.00000e-09 1.00000e-01

$1.00000 \mathrm{e}+001.00000 \mathrm{e}+001.00000 \mathrm{e}-011.00000 \mathrm{e}-091.00000 \mathrm{e}-01$

1.00000e-06 1.00000e-06 1.00000e-06 1.00000e-09 5.00000e-02

Element: 6369 \# of layers: 5

$\mathrm{Kx} \mathrm{Ky} \mathrm{Kz}$ Ss Por

$1.70424 \mathrm{e}+03$ 1.70424e+03 1.70424e+02 1.00000e-09 7.00000e-02

$1.70424 \mathrm{e}+031.70424 \mathrm{e}+031.70424 \mathrm{e}+02$ 1.00000e-09 7.00000e-02

$6.80955 \mathrm{e}+016.80955 \mathrm{e}+016.80955 \mathrm{e}+00$ 1.00000e-09 2.12000e-01

$1.00000 \mathrm{e}-02$ 1.00000e-02 1.00000e-03 1.00000e-09 1.00000e-01

$1.00000 \mathrm{e}+001.00000 \mathrm{e}+001.00000 \mathrm{e}-01$ 1.00000e-09 1.00000e-01

Element: 6370 \# of layers: 8

Kx Ky Kz Ss Por 
$1.70424 \mathrm{e}+031.70424 \mathrm{e}+03$ 1.70424e+02 1.00000e-09 7.00000e-02 $1.70424 \mathrm{e}+031.70424 \mathrm{e}+031.70424 \mathrm{e}+02$ 1.00000e-09 7.00000e-02 $1.70424 \mathrm{e}+031.70424 \mathrm{e}+03 \quad 1.70424 \mathrm{e}+02$ 1.00000e-09 7.00000e-02 $6.80955 \mathrm{e}+016.80955 \mathrm{e}+016.80955 \mathrm{e}+001.00000 \mathrm{e}-092.12000 \mathrm{e}-01$ $6.80955 \mathrm{e}+016.80955 \mathrm{e}+016.80955 \mathrm{e}+001.00000 \mathrm{e}-092.12000 \mathrm{e}-01$ $6.80955 \mathrm{e}+016.80955 \mathrm{e}+016.80955 \mathrm{e}+00$ 1.00000e-09 2.12000e-01 $1.00000 \mathrm{e}-02$ 1.00000e-02 1.00000e-03 1.00000e-09 1.00000e-01 $1.00000 \mathrm{e}+001.00000 \mathrm{e}+001.00000 \mathrm{e}-011.00000 \mathrm{e}-091.00000 \mathrm{e}-01$ Element: 6371 \# of layers: 7

$\mathrm{Kx} \mathrm{Ky} \mathrm{Kz}$ Ss Por

$1.71974 \mathrm{e}+03$ 1.71974e+03 1.71974e+02 1.00000e-09 7.00000e-02 $1.71974 \mathrm{e}+03$ 1.71974e+03 1.71974e+02 1.00000e-09 7.00000e-02 $1.71974 \mathrm{e}+03$ 1.71974e+03 1.71974e+02 1.00000e-09 7.00000e-02 $6.87165 \mathrm{e}+016.87165 \mathrm{e}+016.87165 \mathrm{e}+00$ 1.00000e-09 2.12000e-01 $6.87165 \mathrm{e}+016.87165 \mathrm{e}+016.87165 \mathrm{e}+001.00000 \mathrm{e}-092.12000 \mathrm{e}-01$ $1.00000 \mathrm{e}-02$ 1.00000e-02 1.00000e-03 1.00000e-09 1.00000e-01 $1.00000 \mathrm{e}+001.00000 \mathrm{e}+001.00000 \mathrm{e}-011.00000 \mathrm{e}-091.00000 \mathrm{e}-01$ Element: 6372 \# of layers: 7

$\mathrm{Kx} \mathrm{Ky} \mathrm{Kz}$ Ss Por

1.71974e+03 1.71974e+03 1.71974e+02 1.00000e-09 7.00000e-02 $1.71974 \mathrm{e}+031.71974 \mathrm{e}+031.71974 \mathrm{e}+02$ 1.00000e-09 7.00000e-02 $1.71974 \mathrm{e}+031.71974 \mathrm{e}+03$ 1.71974e+02 1.00000e-09 7.00000e-02 $6.87165 \mathrm{e}+016.87165 \mathrm{e}+016.87165 \mathrm{e}+00$ 1.00000e-09 2.12000e-01 $6.87165 \mathrm{e}+016.87165 \mathrm{e}+016.87165 \mathrm{e}+00$ 1.00000e-09 2.12000e-01 $1.00000 \mathrm{e}-021.00000 \mathrm{e}-02$ 1.00000e-03 1.00000e-09 1.00000e-01 $1.00000 \mathrm{e}+001.00000 \mathrm{e}+001.00000 \mathrm{e}-01$ 1.00000e-09 1.00000e-01 Element: 6373 \# of layers: 7

$\mathrm{Kx} \mathrm{Ky} \mathrm{Kz}$ Ss Por

$1.71974 \mathrm{e}+03$ 1.71974e+03 1.71974e+02 1.00000e-09 7.00000e-02 $1.71974 \mathrm{e}+03$ 1.71974e+03 1.71974e+02 1.00000e-09 7.00000e-02 $1.71974 \mathrm{e}+031.71974 \mathrm{e}+031.71974 \mathrm{e}+021.00000 \mathrm{e}-09$ 7.00000e-02 6.87165e+01 6.87165e+01 6.87165e+00 1.00000e-09 2.12000e-01 $6.87165 \mathrm{e}+016.87165 \mathrm{e}+016.87165 \mathrm{e}+00$ 1.00000e-09 2.12000e-01 $1.00000 \mathrm{e}-02$ 1.00000e-02 1.00000e-03 1.00000e-09 1.00000e-01 $1.00000 \mathrm{e}+001.00000 \mathrm{e}+001.00000 \mathrm{e}-011.00000 \mathrm{e}-091.00000 \mathrm{e}-01$ Element: 6374 \# of layers: 7

$\mathrm{Kx} \mathrm{Ky} \mathrm{Kz}$ Ss Por 8.81052e+02 8.81052e+02 8.81052e+01 1.00000e-09 7.00000e-02 8.81052e+02 8.81052e+02 8.81052e+01 1.00000e-09 7.00000e-02 8.81052e+02 8.81052e+02 8.81052e+01 1.00000e-09 7.00000e-02 $3.52043 \mathrm{e}+013.52043 \mathrm{e}+013.52043 \mathrm{e}+00$ 1.00000e-09 2.12000e-01 $3.52043 \mathrm{e}+013.52043 \mathrm{e}+013.52043 \mathrm{e}+00$ 1.00000e-09 2.12000e-01 $1.00000 \mathrm{e}-02$ 1.00000e-02 1.00000e-03 1.00000e-09 1.00000e-01 $1.00000 \mathrm{e}+001.00000 \mathrm{e}+001.00000 \mathrm{e}-01$ 1.00000e-09 1.00000e-01 Element: 6375 \# of layers: 8

Kx Ky Kz Ss Por 
1.71974e+03 1.71974e+03 1.71974e+02 1.00000e-09 7.00000e-02 $1.71974 \mathrm{e}+031.71974 \mathrm{e}+031.71974 \mathrm{e}+02$ 1.00000e-09 7.00000e-02 $1.71974 \mathrm{e}+03$ 1.71974e+03 1.71974e+02 1.00000e-09 7.00000e-02 $6.87165 \mathrm{e}+016.87165 \mathrm{e}+016.87165 \mathrm{e}+001.00000 \mathrm{e}-092.12000 \mathrm{e}-01$ $6.87165 \mathrm{e}+016.87165 \mathrm{e}+016.87165 \mathrm{e}+001.00000 \mathrm{e}-092.12000 \mathrm{e}-01$ $6.87165 \mathrm{e}+016.87165 \mathrm{e}+016.87165 \mathrm{e}+00$ 1.00000e-09 2.12000e-01 $1.00000 \mathrm{e}-02$ 1.00000e-02 1.00000e-03 1.00000e-09 1.00000e-01 $1.00000 \mathrm{e}+001.00000 \mathrm{e}+001.00000 \mathrm{e}-011.00000 \mathrm{e}-091.00000 \mathrm{e}-01$ Element: 6376 \# of layers: 5

$\mathrm{Kx} \mathrm{Ky} \mathrm{Kz}$ Ss Por

$2.44450 \mathrm{e}+032.44450 \mathrm{e}+03$ 2.44450e+02 1.00000e-09 7.00000e-02 $2.44450 \mathrm{e}+032.44450 \mathrm{e}+032.44450 \mathrm{e}+02$ 1.00000e-09 7.00000e-02 9.76746e+01 9.76746e+01 9.76746e+00 1.00000e-09 2.12000e-01 $1.00000 \mathrm{e}-02$ 1.00000e-02 1.00000e-03 1.00000e-09 1.00000e-01 $1.00000 \mathrm{e}+001.00000 \mathrm{e}+001.00000 \mathrm{e}-01$ 1.00000e-09 1.00000e-01 Element: 6377 \# of layers: 6

$\mathrm{Kx} \mathrm{Ky} \mathrm{Kz}$ Ss Por

3.71960e+03 3.71960e+03 3.71960e+02 1.00000e-09 7.00000e-02 $3.71960 \mathrm{e}+033.71960 \mathrm{e}+033.71960 \mathrm{e}+02$ 1.00000e-09 7.00000e-02 $3.71960 \mathrm{e}+03$ 3.71960e+03 3.71960e+02 1.00000e-09 7.00000e-02 $1.48622 \mathrm{e}+02$ 1.48622e+02 1.48622e+01 1.00000e-09 2.12000e-01 $1.00000 \mathrm{e}-02$ 1.00000e-02 1.00000e-03 1.00000e-09 1.00000e-01 $1.00000 \mathrm{e}+001.00000 \mathrm{e}+001.00000 \mathrm{e}-01$ 1.00000e-09 1.00000e-01 Element: 6378 \# of layers: 6

Kx Ky Kz Ss Por

4.23380e+03 4.23380e+03 4.23380e+02 1.00000e-09 7.00000e-02 $4.23380 \mathrm{e}+034.23380 \mathrm{e}+034.23380 \mathrm{e}+02$ 1.00000e-09 7.00000e-02 $1.69168 \mathrm{e}+021.69168 \mathrm{e}+02$ 1.69168e+01 1.00000e-09 2.12000e-01 $1.00000 \mathrm{e}-02$ 1.00000e-02 1.00000e-03 1.00000e-09 1.00000e-01 $1.00000 \mathrm{e}+001.00000 \mathrm{e}+001.00000 \mathrm{e}-011.00000 \mathrm{e}-091.00000 \mathrm{e}-01$ 1.00000e-06 1.00000e-06 1.00000e-06 1.00000e-09 5.00000e-02 Element: 6379 \# of layers: 7

$\mathrm{Kx} \mathrm{Ky} \mathrm{Kz}$ Ss Por

4.23380e+03 4.23380e+03 4.23380e+02 1.00000e-09 7.00000e-02 4.23380e+03 4.23380e+03 4.23380e+02 1.00000e-09 7.00000e-02 $1.69168 \mathrm{e}+021.69168 \mathrm{e}+02$ 1.69168e+01 1.00000e-09 2.12000e-01 $1.69168 \mathrm{e}+021.69168 \mathrm{e}+02$ 1.69168e+01 1.00000e-09 2.12000e-01 $1.69168 \mathrm{e}+021.69168 \mathrm{e}+02$ 1.69168e+01 1.00000e-09 2.12000e-01 $1.00000 \mathrm{e}-02$ 1.00000e-02 1.00000e-03 1.00000e-09 1.00000e-01 $1.00000 \mathrm{e}+001.00000 \mathrm{e}+001.00000 \mathrm{e}-01$ 1.00000e-09 1.00000e-01 Element: 6380 \# of layers: 6

$\mathrm{Kx} \mathrm{Ky} \mathrm{Kz}$ Ss Por

3.71960e+03 3.71960e+03 3.71960e+02 1.00000e-09 7.00000e-02 $3.71960 \mathrm{e}+03$ 3.71960e+03 3.71960e+02 1.00000e-09 7.00000e-02 $1.48622 \mathrm{e}+02$ 1.48622e+02 1.48622e+01 1.00000e-09 2.12000e-01 $1.48622 \mathrm{e}+02$ 1.48622e+02 1.48622e+01 1.00000e-09 2.12000e-01 
$1.00000 \mathrm{e}-02$ 1.00000e-02 1.00000e-03 1.00000e-09 1.00000e-01 $1.00000 \mathrm{e}+001.00000 \mathrm{e}+001.00000 \mathrm{e}-01$ 1.00000e-09 1.00000e-01 Element: 6381 \# of layers: 6

Kx Ky Kz Ss Por

$3.71960 \mathrm{e}+03$ 3.71960e+03 3.71960e+02 1.00000e-09 7.00000e-02 $3.71960 \mathrm{e}+03$ 3.71960e+03 3.71960e+02 1.00000e-09 7.00000e-02 $1.48622 \mathrm{e}+02$ 1.48622e+02 1.48622e+01 1.00000e-09 2.12000e-01 $1.48622 \mathrm{e}+02$ 1.48622e+02 1.48622e+01 1.00000e-09 2.12000e-01 $1.00000 \mathrm{e}-021.00000 \mathrm{e}-021.00000 \mathrm{e}-031.00000 \mathrm{e}-091.00000 \mathrm{e}-01$ $1.00000 \mathrm{e}+001.00000 \mathrm{e}+001.00000 \mathrm{e}-011.00000 \mathrm{e}-091.00000 \mathrm{e}-01$ Element: 6382 \# of layers: 6

Kx Ky Kz Ss Por

3.71960e+03 3.71960e+03 3.71960e+02 1.00000e-09 7.00000e-02 $3.71960 \mathrm{e}+03$ 3.71960e+03 3.71960e+02 1.00000e-09 7.00000e-02 $1.48622 \mathrm{e}+02$ 1.48622e+02 1.48622e+01 1.00000e-09 2.12000e-01 $1.48622 \mathrm{e}+021.48622 \mathrm{e}+021.48622 \mathrm{e}+01$ 1.00000e-09 2.12000e-01 $1.00000 \mathrm{e}-02$ 1.00000e-02 1.00000e-03 1.00000e-09 1.00000e-01 $1.00000 \mathrm{e}+001.00000 \mathrm{e}+001.00000 \mathrm{e}-01$ 1.00000e-09 1.00000e-01 Element: 6383 \# of layers: 8

$\mathrm{Kx} \mathrm{Ky} \mathrm{Kz}$ Ss Por

$2.44450 \mathrm{e}+032.44450 \mathrm{e}+032.44450 \mathrm{e}+02$ 1.00000e-09 7.00000e-02 $2.44450 \mathrm{e}+032.44450 \mathrm{e}+032.44450 \mathrm{e}+02$ 1.00000e-09 7.00000e-02 $2.44450 \mathrm{e}+032.44450 \mathrm{e}+032.44450 \mathrm{e}+02$ 1.00000e-09 7.00000e-02 9.76746e+01 9.76746e+01 9.76746e+00 1.00000e-09 2.12000e-01 $9.76746 \mathrm{e}+019.76746 \mathrm{e}+019.76746 \mathrm{e}+001.00000 \mathrm{e}-092.12000 \mathrm{e}-01$ 9.76746e+01 9.76746e+01 9.76746e+00 1.00000e-09 2.12000e-01 $1.00000 \mathrm{e}-02$ 1.00000e-02 1.00000e-03 1.00000e-09 1.00000e-01 $1.00000 \mathrm{e}+001.00000 \mathrm{e}+001.00000 \mathrm{e}-011.00000 \mathrm{e}-09$ 1.00000e-01 Element: 6384 \# of layers: 7

$\mathrm{Kx} \mathrm{Ky} \mathrm{Kz}$ Ss Por

$3.71960 \mathrm{e}+03$ 3.71960e+03 3.71960e+02 1.00000e-09 7.00000e-02 $3.71960 \mathrm{e}+033.71960 \mathrm{e}+03$ 3.71960e+02 1.00000e-09 7.00000e-02 $1.48622 \mathrm{e}+021.48622 \mathrm{e}+021.48622 \mathrm{e}+01$ 1.00000e-09 2.12000e-01 $1.48622 \mathrm{e}+02$ 1.48622e+02 1.48622e+01 1.00000e-09 2.12000e-01 $1.48622 \mathrm{e}+02$ 1.48622e+02 1.48622e+01 1.00000e-09 2.12000e-01 $1.00000 \mathrm{e}-02$ 1.00000e-02 1.00000e-03 1.00000e-09 1.00000e-01 $1.00000 \mathrm{e}+001.00000 \mathrm{e}+001.00000 \mathrm{e}-011.00000 \mathrm{e}-091.00000 \mathrm{e}-01$ Element: 6385 \# of layers: 5

$\mathrm{Kx} \mathrm{Ky} \mathrm{Kz}$ Ss Por

4.24236e+03 4.24236e+03 4.24236e+02 1.00000e-09 7.00000e-02 $1.69510 \mathrm{e}+021.69510 \mathrm{e}+021.69510 \mathrm{e}+01$ 1.00000e-09 2.12000e-01 $1.00000 \mathrm{e}-02$ 1.00000e-02 1.00000e-03 1.00000e-09 1.00000e-01 $1.00000 \mathrm{e}+001.00000 \mathrm{e}+001.00000 \mathrm{e}-011.00000 \mathrm{e}-091.00000 \mathrm{e}-01$ 1.00000e-06 1.00000e-06 1.00000e-06 1.00000e-09 5.00000e-02 Element: 6386 \# of layers: 6

Kx Ky Kz Ss Por 
5.28202e+03 5.28202e+03 5.28202e+02 1.00000e-09 7.00000e-02 $5.28202 \mathrm{e}+03$ 5.28202e+03 5.28202e+02 1.00000e-09 7.00000e-02 $2.11052 \mathrm{e}+02$ 2.11052e+02 2.11052e+01 1.00000e-09 2.12000e-01 $1.00000 \mathrm{e}-02$ 1.00000e-02 1.00000e-03 1.00000e-09 1.00000e-01 $1.00000 \mathrm{e}+001.00000 \mathrm{e}+001.00000 \mathrm{e}-011.00000 \mathrm{e}-091.00000 \mathrm{e}-01$ 1.00000e-06 1.00000e-06 1.00000e-06 1.00000e-09 5.00000e-02 Element: 6387 \# of layers: 5

$\mathrm{Kx} \mathrm{Ky} \mathrm{Kz}$ Ss Por

6.03463e+03 6.03463e+03 6.03463e+02 1.00000e-09 7.00000e-02 $2.41115 \mathrm{e}+02$ 2.41115e+02 2.41115e+01 1.00000e-09 2.12000e-01 $1.00000 \mathrm{e}-02$ 1.00000e-02 1.00000e-03 1.00000e-09 1.00000e-01 $1.00000 \mathrm{e}+001.00000 \mathrm{e}+001.00000 \mathrm{e}-011.00000 \mathrm{e}-091.00000 \mathrm{e}-01$ 1.00000e-06 1.00000e-06 1.00000e-06 1.00000e-09 5.00000e-02 Element: 6388 \# of layers: 8

$\mathrm{Kx} \mathrm{Ky} \mathrm{Kz}$ Ss Por 6.03463e+03 6.03463e+03 6.03463e+02 1.00000e-09 7.00000e-02 6.03463e+03 6.03463e+03 6.03463e+02 1.00000e-09 7.00000e-02 6.03463e+03 6.03463e+03 6.03463e+02 1.00000e-09 7.00000e-02 $2.41115 \mathrm{e}+02$ 2.41115e+02 2.41115e+01 1.00000e-09 2.12000e-01 $2.41115 \mathrm{e}+02$ 2.41115e+02 2.41115e+01 1.00000e-09 2.12000e-01 $2.41115 \mathrm{e}+02$ 2.41115e+02 2.41115e+01 1.00000e-09 2.12000e-01 $1.00000 \mathrm{e}-02$ 1.00000e-02 1.00000e-03 1.00000e-09 1.00000e-01 $1.00000 \mathrm{e}+001.00000 \mathrm{e}+001.00000 \mathrm{e}-01$ 1.00000e-09 1.00000e-01 Element: 6389 \# of layers: 6

$\mathrm{Kx} \mathrm{Ky} \mathrm{Kz}$ Ss Por

5.28202e+03 5.28202e+03 5.28202e+02 1.00000e-09 7.00000e-02 $5.28202 \mathrm{e}+03$ 5.28202e+03 5.28202e+02 1.00000e-09 7.00000e-02 2.11052e+02 2.11052e+02 2.11052e+01 1.00000e-09 2.12000e-01 $2.11052 \mathrm{e}+02$ 2.11052e+02 2.11052e+01 1.00000e-09 2.12000e-01 $1.00000 \mathrm{e}-02$ 1.00000e-02 1.00000e-03 1.00000e-09 1.00000e-01 $1.00000 \mathrm{e}+001.00000 \mathrm{e}+001.00000 \mathrm{e}-011.00000 \mathrm{e}-091.00000 \mathrm{e}-01$ Element: 6390 \# of layers: 6

$\mathrm{Kx} \mathrm{Ky} \mathrm{Kz}$ Ss Por

5.28202e+03 5.28202e+03 5.28202e+02 1.00000e-09 7.00000e-02 $5.28202 \mathrm{e}+03$ 5.28202e+03 5.28202e+02 1.00000e-09 7.00000e-02 $2.11052 \mathrm{e}+02$ 2.11052e+02 2.11052e+01 1.00000e-09 2.12000e-01 $2.11052 \mathrm{e}+02$ 2.11052e+02 2.11052e+01 1.00000e-09 2.12000e-01 $1.00000 \mathrm{e}-02$ 1.00000e-02 1.00000e-03 1.00000e-09 1.00000e-01 $1.00000 \mathrm{e}+001.00000 \mathrm{e}+001.00000 \mathrm{e}-011.00000 \mathrm{e}-091.00000 \mathrm{e}-01$ Element: 6391 \# of layers: 6

$\mathrm{Kx} \mathrm{Ky} \mathrm{Kz}$ Ss Por 5.28202e+03 5.28202e+03 5.28202e+02 1.00000e-09 7.00000e-02 $5.28202 \mathrm{e}+03$ 5.28202e+03 5.28202e+02 1.00000e-09 7.00000e-02 2.11052e+02 2.11052e+02 2.11052e+01 1.00000e-09 2.12000e-01 $2.11052 \mathrm{e}+02$ 2.11052e+02 2.11052e+01 1.00000e-09 2.12000e-01 $1.00000 \mathrm{e}-02$ 1.00000e-02 1.00000e-03 1.00000e-09 1.00000e-01 
$1.00000 \mathrm{e}+001.00000 \mathrm{e}+00$ 1.00000e-01 1.00000e-09 1.00000e-01

Element: 6392 \# of layers: 7

$\mathrm{Kx} \mathrm{Ky} \mathrm{Kz}$ Ss Por

4.24236e+03 4.24236e+03 4.24236e+02 1.00000e-09 7.00000e-02

$4.24236 \mathrm{e}+03$ 4.24236e+03 4.24236e+02 1.00000e-09 7.00000e-02

$1.69510 \mathrm{e}+021.69510 \mathrm{e}+021.69510 \mathrm{e}+01$ 1.00000e-09 2.12000e-01

$1.69510 \mathrm{e}+021.69510 \mathrm{e}+02$ 1.69510e+01 1.00000e-09 2.12000e-01

$1.69510 \mathrm{e}+021.69510 \mathrm{e}+02 \quad 1.69510 \mathrm{e}+01$ 1.00000e-09 2.12000e-01

$1.00000 \mathrm{e}-02$ 1.00000e-02 1.00000e-03 1.00000e-09 1.00000e-01

$1.00000 \mathrm{e}+001.00000 \mathrm{e}+001.00000 \mathrm{e}-011.00000 \mathrm{e}-091.00000 \mathrm{e}-01$

Element: 6393 \# of layers: 8

$\mathrm{Kx} \mathrm{Ky} \mathrm{Kz}$ Ss Por

5.28202e+03 5.28202e+03 5.28202e+02 1.00000e-09 7.00000e-02

$5.28202 \mathrm{e}+03$ 5.28202e+03 5.28202e+02 1.00000e-09 7.00000e-02

$5.28202 \mathrm{e}+03$ 5.28202e+03 5.28202e+02 1.00000e-09 7.00000e-02

$2.11052 \mathrm{e}+02$ 2.11052e+02 2.11052e+01 1.00000e-09 2.12000e-01

2.11052e+02 2.11052e+02 2.11052e+01 1.00000e-09 2.12000e-01

$2.11052 \mathrm{e}+02$ 2.11052e+02 2.11052e+01 1.00000e-09 2.12000e-01

$1.00000 \mathrm{e}-02$ 1.00000e-02 1.00000e-03 1.00000e-09 1.00000e-01

$1.00000 \mathrm{e}+001.00000 \mathrm{e}+001.00000 \mathrm{e}-011.00000 \mathrm{e}-091.00000 \mathrm{e}-01$

Element: 6394 \# of layers: 5

$\mathrm{Kx} \mathrm{Ky} \mathrm{Kz}$ Ss Por

6.53883e+03 6.53883e+03 6.53883e+02 1.00000e-09 7.00000e-02

$2.61276 \mathrm{e}+022.61276 \mathrm{e}+02$ 2.61276e+01 1.00000e-09 2.12000e-01

$1.00000 \mathrm{e}-02$ 1.00000e-02 1.00000e-03 1.00000e-09 1.00000e-01

$1.00000 \mathrm{e}+001.00000 \mathrm{e}+001.00000 \mathrm{e}-011.00000 \mathrm{e}-091.00000 \mathrm{e}-01$

1.00000e-06 1.00000e-06 1.00000e-06 1.00000e-09 5.00000e-02

Element: 6395 \# of layers: 5

Kx Ky Kz Ss Por

7.14457e+03 7.14457e+03 7.14457e+02 1.00000e-09 7.00000e-02

$2.85464 \mathrm{e}+022.85464 \mathrm{e}+022.85464 \mathrm{e}+01$ 1.00000e-09 2.12000e-01

$1.00000 \mathrm{e}-02$ 1.00000e-02 1.00000e-03 1.00000e-09 1.00000e-01

$1.00000 \mathrm{e}+001.00000 \mathrm{e}+001.00000 \mathrm{e}-011.00000 \mathrm{e}-091.00000 \mathrm{e}-01$

1.00000e-06 1.00000e-06 1.00000e-06 1.00000e-09 5.00000e-02

Element: 6396 \# of layers: 5

$\mathrm{Kx} \mathrm{Ky} \mathrm{Kz}$ Ss Por

8.29803e+03 8.29803e+03 8.29803e+02 1.00000e-09 7.00000e-02

$3.31567 \mathrm{e}+02$ 3.31567e+02 3.31567e+01 1.00000e-09 2.12000e-01

$1.00000 \mathrm{e}-02$ 1.00000e-02 1.00000e-03 1.00000e-09 1.00000e-01

$1.00000 \mathrm{e}+001.00000 \mathrm{e}+001.00000 \mathrm{e}-011.00000 \mathrm{e}-091.00000 \mathrm{e}-01$

1.00000e-06 1.00000e-06 1.00000e-06 1.00000e-09 5.00000e-02

Element: 6397 \# of layers: 6

$\mathrm{Kx} \mathrm{Ky} \mathrm{Kz}$ Ss Por

8.29803e+03 8.29803e+03 8.29803e+02 1.00000e-09 7.00000e-02

8.29803e+03 8.29803e+03 8.29803e+02 1.00000e-09 7.00000e-02

$3.31567 \mathrm{e}+02$ 3.31567e+02 3.31567e+01 1.00000e-09 2.12000e-01 
$3.31567 \mathrm{e}+02$ 3.31567e+02 3.31567e+01 1.00000e-09 2.12000e-01 $1.00000 \mathrm{e}-02$ 1.00000e-02 1.00000e-03 1.00000e-09 1.00000e-01 $1.00000 \mathrm{e}+001.00000 \mathrm{e}+001.00000 \mathrm{e}-011.00000 \mathrm{e}-091.00000 \mathrm{e}-01$

Element: 6398 \# of layers: 4

Kx Ky Kz Ss Por

7.14457e+03 7.14457e+03 7.14457e+02 1.00000e-09 7.00000e-02

$2.85464 \mathrm{e}+022.85464 \mathrm{e}+022.85464 \mathrm{e}+01$ 1.00000e-09 2.12000e-01

$1.00000 \mathrm{e}-021.00000 \mathrm{e}-02$ 1.00000e-03 1.00000e-09 1.00000e-01

$1.00000 \mathrm{e}+001.00000 \mathrm{e}+001.00000 \mathrm{e}-011.00000 \mathrm{e}-091.00000 \mathrm{e}-01$

Element: 6399 \# of layers: 4

Kx Ky Kz Ss Por

7.14457e+03 7.14457e+03 7.14457e+02 1.00000e-09 7.00000e-02

$2.85464 \mathrm{e}+022.85464 \mathrm{e}+022.85464 \mathrm{e}+01$ 1.00000e-09 2.12000e-01

$1.00000 \mathrm{e}-021.00000 \mathrm{e}-02$ 1.00000e-03 1.00000e-09 1.00000e-01

$1.00000 \mathrm{e}+001.00000 \mathrm{e}+001.00000 \mathrm{e}-011.00000 \mathrm{e}-091.00000 \mathrm{e}-01$

Element: 6400 \# of layers: 6

Kx Ky Kz Ss Por

7.14457e+03 7.14457e+03 7.14457e+02 1.00000e-09 7.00000e-02 $7.14457 \mathrm{e}+03$ 7.14457e+03 7.14457e+02 1.00000e-09 7.00000e-02 $2.85464 \mathrm{e}+022.85464 \mathrm{e}+022.85464 \mathrm{e}+01$ 1.00000e-09 2.12000e-01 $2.85464 \mathrm{e}+022.85464 \mathrm{e}+022.85464 \mathrm{e}+01 \quad 1.00000 \mathrm{e}-092.12000 \mathrm{e}-01$ $1.00000 \mathrm{e}-021.00000 \mathrm{e}-02$ 1.00000e-03 1.00000e-09 1.00000e-01

$1.00000 \mathrm{e}+001.00000 \mathrm{e}+001.00000 \mathrm{e}-011.00000 \mathrm{e}-091.00000 \mathrm{e}-01$ Element: 6401 \# of layers: 7

Kx Ky Kz Ss Por

$6.53883 \mathrm{e}+03$ 6.53883e+03 6.53883e+02 1.00000e-09 7.00000e-02 $6.53883 \mathrm{e}+036.53883 \mathrm{e}+036.53883 \mathrm{e}+02$ 1.00000e-09 7.00000e-02 $6.53883 \mathrm{e}+036.53883 \mathrm{e}+036.53883 \mathrm{e}+02$ 1.00000e-09 7.00000e-02 $2.61276 \mathrm{e}+022.61276 \mathrm{e}+022.61276 \mathrm{e}+011.00000 \mathrm{e}-092.12000 \mathrm{e}-01$ $2.61276 \mathrm{e}+022.61276 \mathrm{e}+022.61276 \mathrm{e}+011.00000 \mathrm{e}-092.12000 \mathrm{e}-01$ $1.00000 \mathrm{e}-021.00000 \mathrm{e}-02$ 1.00000e-03 1.00000e-09 1.00000e-01 $1.00000 \mathrm{e}+001.00000 \mathrm{e}+001.00000 \mathrm{e}-011.00000 \mathrm{e}-091.00000 \mathrm{e}-01$ Element: 6402 \# of layers: 6

Kx Ky Kz Ss Por

7.14457e+03 7.14457e+03 7.14457e+02 1.00000e-09 7.00000e-02 $7.14457 \mathrm{e}+03$ 7.14457e+03 7.14457e+02 1.00000e-09 7.00000e-02 $2.85464 \mathrm{e}+022.85464 \mathrm{e}+022.85464 \mathrm{e}+01$ 1.00000e-09 2.12000e-01 $2.85464 \mathrm{e}+022.85464 \mathrm{e}+022.85464 \mathrm{e}+01$ 1.00000e-09 2.12000e-01 $1.00000 \mathrm{e}-02$ 1.00000e-02 1.00000e-03 1.00000e-09 1.00000e-01 $1.00000 \mathrm{e}+001.00000 \mathrm{e}+001.00000 \mathrm{e}-011.00000 \mathrm{e}-091.00000 \mathrm{e}-01$ Element: 6403 \# of layers: 5

Kx Ky Kz Ss Por

$9.19380 \mathrm{e}+03$ 9.19380e+03 9.19380e+02 1.00000e-09 7.00000e-02 $3.67365 \mathrm{e}+023.67365 \mathrm{e}+023.67365 \mathrm{e}+01$ 1.00000e-09 2.12000e-01 $1.00000 \mathrm{e}-02$ 1.00000e-02 1.00000e-03 1.00000e-09 1.00000e-01 $1.00000 \mathrm{e}+001.00000 \mathrm{e}+001.00000 \mathrm{e}-011.00000 \mathrm{e}-091.00000 \mathrm{e}-01$ 
1.00000e-06 1.00000e-06 1.00000e-06 1.00000e-09 5.00000e-02

Element: 6404 \# of layers: 5

$\mathrm{Kx} \mathrm{Ky} \mathrm{Kz}$ Ss Por

7.91240e+03 7.91240e+03 7.91240e+02 1.00000e-09 7.00000e-02

$3.16154 \mathrm{e}+023.16154 \mathrm{e}+023.16154 \mathrm{e}+01$ 1.00000e-09 2.12000e-01

$1.00000 \mathrm{e}-02$ 1.00000e-02 1.00000e-03 1.00000e-09 1.00000e-01

$1.00000 \mathrm{e}+001.00000 \mathrm{e}+001.00000 \mathrm{e}-011.00000 \mathrm{e}-091.00000 \mathrm{e}-01$

1.00000e-06 1.00000e-06 1.00000e-06 1.00000e-09 5.00000e-02

Element: 6405 \# of layers: 5

$\mathrm{Kx} \mathrm{Ky} \mathrm{Kz}$ Ss Por

7.18926e+03 7.18926e+03 7.18926e+02 1.00000e-09 7.00000e-02

$2.87264 \mathrm{e}+022.87264 \mathrm{e}+02 \quad 2.87264 \mathrm{e}+01$ 1.00000e-09 2.12000e-01

$1.00000 \mathrm{e}-021.00000 \mathrm{e}-021.00000 \mathrm{e}-031.00000 \mathrm{e}-091.00000 \mathrm{e}-01$

$1.00000 \mathrm{e}+001.00000 \mathrm{e}+001.00000 \mathrm{e}-011.00000 \mathrm{e}-091.00000 \mathrm{e}-01$

1.00000e-06 1.00000e-06 1.00000e-06 1.00000e-09 5.00000e-02

Element: 6406 \# of layers: 6

$\mathrm{Kx} \mathrm{Ky} \mathrm{Kz}$ Ss Por

7.18926e+03 7.18926e+03 7.18926e+02 1.00000e-09 7.00000e-02

7.18926e+03 7.18926e+03 7.18926e+02 1.00000e-09 7.00000e-02

$2.87264 \mathrm{e}+022.87264 \mathrm{e}+02 \quad 2.87264 \mathrm{e}+01$ 1.00000e-09 2.12000e-01

$2.87264 \mathrm{e}+02 \quad 2.87264 \mathrm{e}+02 \quad 2.87264 \mathrm{e}+01 \quad 1.00000 \mathrm{e}-092.12000 \mathrm{e}-01$

$1.00000 \mathrm{e}-02$ 1.00000e-02 1.00000e-03 1.00000e-09 1.00000e-01

$1.00000 \mathrm{e}+001.00000 \mathrm{e}+001.00000 \mathrm{e}-01$ 1.00000e-09 1.00000e-01

Element: 6407 \# of layers: 4

$\mathrm{Kx} \mathrm{Ky} \mathrm{Kz}$ Ss Por

7.91240e+03 7.91240e+03 7.91240e+02 1.00000e-09 7.00000e-02

$3.16154 \mathrm{e}+023.16154 \mathrm{e}+023.16154 \mathrm{e}+01$ 1.00000e-09 2.12000e-01

$1.00000 \mathrm{e}-02$ 1.00000e-02 1.00000e-03 1.00000e-09 1.00000e-01

$1.00000 \mathrm{e}+001.00000 \mathrm{e}+001.00000 \mathrm{e}-011.00000 \mathrm{e}-091.00000 \mathrm{e}-01$

Element: 6408 \# of layers: 4

$\mathrm{Kx} \mathrm{Ky} \mathrm{Kz}$ Ss Por

7.91240e+03 7.91240e+03 7.91240e+02 1.00000e-09 7.00000e-02

$3.16154 \mathrm{e}+023.16154 \mathrm{e}+023.16154 \mathrm{e}+01$ 1.00000e-09 2.12000e-01

$1.00000 \mathrm{e}-02$ 1.00000e-02 1.00000e-03 1.00000e-09 1.00000e-01

$1.00000 \mathrm{e}+001.00000 \mathrm{e}+001.00000 \mathrm{e}-011.00000 \mathrm{e}-091.00000 \mathrm{e}-01$

Element: 6409 \# of layers: 4

Kx Ky Kz Ss Por

7.91240e+03 7.91240e+03 7.91240e+02 1.00000e-09 7.00000e-02

$3.16154 \mathrm{e}+023.16154 \mathrm{e}+02$ 3.16154e+01 1.00000e-09 2.12000e-01

$1.00000 \mathrm{e}-02$ 1.00000e-02 1.00000e-03 1.00000e-09 1.00000e-01

$1.00000 \mathrm{e}+001.00000 \mathrm{e}+001.00000 \mathrm{e}-011.00000 \mathrm{e}-091.00000 \mathrm{e}-01$

Element: 6410 \# of layers: 6

$\mathrm{Kx} \mathrm{Ky} \mathrm{Kz}$ Ss Por

9.19380e+03 9.19380e+03 9.19380e+02 1.00000e-09 7.00000e-02

9.19380e+03 9.19380e+03 9.19380e+02 1.00000e-09 7.00000e-02

$3.67365 \mathrm{e}+02$ 3.67365e+02 3.67365e+01 1.00000e-09 2.12000e-01 
3.67365e+02 3.67365e+02 3.67365e+01 1.00000e-09 2.12000e-01 $1.00000 \mathrm{e}-02$ 1.00000e-02 1.00000e-03 1.00000e-09 1.00000e-01

$1.00000 \mathrm{e}+001.00000 \mathrm{e}+001.00000 \mathrm{e}-011.00000 \mathrm{e}-091.00000 \mathrm{e}-01$

Element: 6411 \# of layers: 6

$\mathrm{Kx} \mathrm{Ky} \mathrm{Kz}$ Ss Por

7.91240e+03 7.91240e+03 7.91240e+02 1.00000e-09 7.00000e-02

7.91240e+03 7.91240e+03 7.91240e+02 1.00000e-09 7.00000e-02

$3.16154 \mathrm{e}+02$ 3.16154e+02 3.16154e+01 1.00000e-09 2.12000e-01

$3.16154 \mathrm{e}+02$ 3.16154e+02 3.16154e+01 1.00000e-09 2.12000e-01

$1.00000 \mathrm{e}-02$ 1.00000e-02 1.00000e-03 1.00000e-09 1.00000e-01

$1.00000 \mathrm{e}+001.00000 \mathrm{e}+001.00000 \mathrm{e}-011.00000 \mathrm{e}-091.00000 \mathrm{e}-01$

Element: 6412 \# of layers: 5

$\mathrm{Kx} \mathrm{Ky} \mathrm{Kz}$ Ss Por

2.06752e+03 2.06752e+03 2.06752e+02 1.00000e-09 7.00000e-02

$8.26105 \mathrm{e}+018.26105 \mathrm{e}+018.26105 \mathrm{e}+001.00000 \mathrm{e}-092.12000 \mathrm{e}-01$

$1.00000 \mathrm{e}-02$ 1.00000e-02 1.00000e-03 1.00000e-09 1.00000e-01

$1.00000 \mathrm{e}+001.00000 \mathrm{e}+001.00000 \mathrm{e}-011.00000 \mathrm{e}-091.00000 \mathrm{e}-01$

1.00000e-06 1.00000e-06 1.00000e-06 1.00000e-09 5.00000e-02

Element: 6413 \# of layers: 7

$\mathrm{Kx} \mathrm{Ky} \mathrm{Kz}$ Ss Por

$2.06752 \mathrm{e}+03$ 2.06752e+03 2.06752e+02 1.00000e-09 7.00000e-02

$2.06752 \mathrm{e}+032.06752 \mathrm{e}+03$ 2.06752e+02 1.00000e-09 7.00000e-02

8.26105e+01 8.26105e+01 8.26105e+00 1.00000e-09 2.12000e-01

$8.26105 \mathrm{e}+018.26105 \mathrm{e}+018.26105 \mathrm{e}+00$ 1.00000e-09 2.12000e-01

$1.00000 \mathrm{e}-021.00000 \mathrm{e}-02$ 1.00000e-03 1.00000e-09 1.00000e-01

$1.00000 \mathrm{e}+001.00000 \mathrm{e}+001.00000 \mathrm{e}-011.00000 \mathrm{e}-091.00000 \mathrm{e}-01$

$1.00000 \mathrm{e}-06$ 1.00000e-06 1.00000e-06 1.00000e-09 5.00000e-02

Element: 6414 \# of layers: 4

$\mathrm{Kx} \mathrm{Ky} \mathrm{Kz}$ Ss Por

$2.06752 \mathrm{e}+032.06752 \mathrm{e}+03$ 2.06752e+02 1.00000e-09 7.00000e-02

$8.26105 \mathrm{e}+018.26105 \mathrm{e}+018.26105 \mathrm{e}+00$ 1.00000e-09 2.12000e-01

$1.00000 \mathrm{e}-02$ 1.00000e-02 1.00000e-03 1.00000e-09 1.00000e-01

$1.00000 \mathrm{e}+001.00000 \mathrm{e}+001.00000 \mathrm{e}-011.00000 \mathrm{e}-091.00000 \mathrm{e}-01$

Element: 6415 \# of layers: 4

$\mathrm{Kx} \mathrm{Ky} \mathrm{Kz}$ Ss Por

2.06752e+03 2.06752e+03 2.06752e+02 1.00000e-09 7.00000e-02

$8.26105 \mathrm{e}+018.26105 \mathrm{e}+018.26105 \mathrm{e}+00$ 1.00000e-09 2.12000e-01

$1.00000 \mathrm{e}-02$ 1.00000e-02 1.00000e-03 1.00000e-09 1.00000e-01

$1.00000 \mathrm{e}+001.00000 \mathrm{e}+001.00000 \mathrm{e}-011.00000 \mathrm{e}-091.00000 \mathrm{e}-01$

Element: 6416 \# of layers: 4

$\mathrm{Kx} \mathrm{Ky} \mathrm{Kz}$ Ss Por

2.06752e+03 2.06752e+03 2.06752e+02 1.00000e-09 7.00000e-02

$8.26105 \mathrm{e}+01$ 8.26105e+01 8.26105e+00 1.00000e-09 2.12000e-01

$1.00000 \mathrm{e}-02$ 1.00000e-02 1.00000e-03 1.00000e-09 1.00000e-01

$1.00000 \mathrm{e}+001.00000 \mathrm{e}+001.00000 \mathrm{e}-011.00000 \mathrm{e}-091.00000 \mathrm{e}-01$

Element: 6417 \# of layers: 4 
Kx Ky Kz Ss Por

2.06752e+03 2.06752e+03 2.06752e+02 1.00000e-09 7.00000e-02

$8.26105 \mathrm{e}+018.26105 \mathrm{e}+018.26105 \mathrm{e}+00$ 1.00000e-09 2.12000e-01

$1.00000 \mathrm{e}-02$ 1.00000e-02 1.00000e-03 1.00000e-09 1.00000e-01

$1.00000 \mathrm{e}+001.00000 \mathrm{e}+001.00000 \mathrm{e}-01$ 1.00000e-09 1.00000e-01

Element: 6418 \# of layers: 4

$\mathrm{Kx} \mathrm{Ky} \mathrm{Kz}$ Ss Por

2.06752e+03 2.06752e+03 2.06752e+02 1.00000e-09 7.00000e-02

$8.26105 \mathrm{e}+018.26105 \mathrm{e}+018.26105 \mathrm{e}+00$ 1.00000e-09 2.12000e-01

$1.00000 \mathrm{e}-02$ 1.00000e-02 1.00000e-03 1.00000e-09 1.00000e-01

$1.00000 \mathrm{e}+001.00000 \mathrm{e}+001.00000 \mathrm{e}-011.00000 \mathrm{e}-091.00000 \mathrm{e}-01$

Element: 6419 \# of layers: 6

$\mathrm{Kx} \mathrm{Ky} \mathrm{Kz}$ Ss Por

$2.06752 \mathrm{e}+03$ 2.06752e+03 2.06752e+02 1.00000e-09 7.00000e-02

$2.06752 \mathrm{e}+032.06752 \mathrm{e}+03$ 2.06752e+02 1.00000e-09 7.00000e-02

$8.26105 \mathrm{e}+018.26105 \mathrm{e}+018.26105 \mathrm{e}+00$ 1.00000e-09 2.12000e-01

8.26105e+01 8.26105e+01 8.26105e+00 1.00000e-09 2.12000e-01

$1.00000 \mathrm{e}-02$ 1.00000e-02 1.00000e-03 1.00000e-09 1.00000e-01

$1.00000 \mathrm{e}+001.00000 \mathrm{e}+001.00000 \mathrm{e}-011.00000 \mathrm{e}-091.00000 \mathrm{e}-01$

Element: 6420 \# of layers: 6

$\mathrm{Kx} \mathrm{Ky} \mathrm{Kz}$ Ss Por

$2.06752 \mathrm{e}+032.06752 \mathrm{e}+03$ 2.06752e+02 1.00000e-09 7.00000e-02

$2.06752 \mathrm{e}+03$ 2.06752e+03 2.06752e+02 1.00000e-09 7.00000e-02

$8.26105 \mathrm{e}+018.26105 \mathrm{e}+018.26105 \mathrm{e}+00$ 1.00000e-09 2.12000e-01

$8.26105 \mathrm{e}+018.26105 \mathrm{e}+018.26105 \mathrm{e}+00$ 1.00000e-09 2.12000e-01

$1.00000 \mathrm{e}-021.00000 \mathrm{e}-02$ 1.00000e-03 1.00000e-09 1.00000e-01

$1.00000 \mathrm{e}+001.00000 \mathrm{e}+001.00000 \mathrm{e}-01$ 1.00000e-09 1.00000e-01

Element: 6421 \# of layers: 4

$\mathrm{Kx} \mathrm{Ky} \mathrm{Kz}$ Ss Por

$1.49683 \mathrm{e}+03$ 1.49683e+03 1.49683e+02 1.00000e-09 7.00000e-02

$5.98085 \mathrm{e}+015.98085 \mathrm{e}+015.98085 \mathrm{e}+001.00000 \mathrm{e}-092.12000 \mathrm{e}-01$

$1.00000 \mathrm{e}-02$ 1.00000e-02 1.00000e-03 1.00000e-09 1.00000e-01

$1.00000 \mathrm{e}+001.00000 \mathrm{e}+001.00000 \mathrm{e}-011.00000 \mathrm{e}-091.00000 \mathrm{e}-01$

Element: 6422 \# of layers: 4

$\mathrm{Kx} \mathrm{Ky} \mathrm{Kz}$ Ss Por

$1.49683 \mathrm{e}+03$ 1.49683e+03 1.49683e+02 1.00000e-09 7.00000e-02

$5.98085 \mathrm{e}+015.98085 \mathrm{e}+015.98085 \mathrm{e}+001.00000 \mathrm{e}-092.12000 \mathrm{e}-01$

$1.00000 \mathrm{e}-02$ 1.00000e-02 1.00000e-03 1.00000e-09 1.00000e-01

$1.00000 \mathrm{e}+001.00000 \mathrm{e}+001.00000 \mathrm{e}-011.00000 \mathrm{e}-09$ 1.00000e-01

Element: 6423 \# of layers: 5

$\mathrm{Kx} \mathrm{Ky} \mathrm{Kz}$ Ss Por

$1.49683 \mathrm{e}+03$ 1.49683e+03 1.49683e+02 1.00000e-09 7.00000e-02

$1.49683 \mathrm{e}+03$ 1.49683e+03 1.49683e+02 1.00000e-09 7.00000e-02

$5.98085 \mathrm{e}+015.98085 \mathrm{e}+01$ 5.98085e+00 1.00000e-09 2.12000e-01

$1.00000 \mathrm{e}-02$ 1.00000e-02 1.00000e-03 1.00000e-09 1.00000e-01

$1.00000 \mathrm{e}+001.00000 \mathrm{e}+001.00000 \mathrm{e}-011.00000 \mathrm{e}-091.00000 \mathrm{e}-01$ 
Element: 6424 \# of layers: 5

$\mathrm{Kx} \mathrm{Ky} \mathrm{Kz}$ Ss Por

1.49683e+03 1.49683e+03 1.49683e+02 1.00000e-09 7.00000e-02

$1.49683 \mathrm{e}+03$ 1.49683e+03 1.49683e+02 1.00000e-09 7.00000e-02

$5.98085 \mathrm{e}+015.98085 \mathrm{e}+015.98085 \mathrm{e}+001.00000 \mathrm{e}-092.12000 \mathrm{e}-01$

$1.00000 \mathrm{e}-02$ 1.00000e-02 1.00000e-03 1.00000e-09 1.00000e-01

$1.00000 \mathrm{e}+001.00000 \mathrm{e}+001.00000 \mathrm{e}-01$ 1.00000e-09 1.00000e-01

Element: 6425 \# of layers: 5

$\mathrm{Kx} \mathrm{Ky} \mathrm{Kz}$ Ss Por

1.49683e+03 1.49683e+03 1.49683e+02 1.00000e-09 7.00000e-02 $1.49683 \mathrm{e}+03$ 1.49683e+03 1.49683e+02 1.00000e-09 7.00000e-02

$5.98085 \mathrm{e}+015.98085 \mathrm{e}+015.98085 \mathrm{e}+001.00000 \mathrm{e}-092.12000 \mathrm{e}-01$

$1.00000 \mathrm{e}-02$ 1.00000e-02 1.00000e-03 1.00000e-09 1.00000e-01

$1.00000 \mathrm{e}+001.00000 \mathrm{e}+001.00000 \mathrm{e}-01$ 1.00000e-09 1.00000e-01

Element: 6426 \# of layers: 4

Kx Ky Kz Ss Por

$1.49683 \mathrm{e}+03$ 1.49683e+03 1.49683e+02 1.00000e-09 7.00000e-02

$5.98085 \mathrm{e}+015.98085 \mathrm{e}+015.98085 \mathrm{e}+001.00000 \mathrm{e}-092.12000 \mathrm{e}-01$

$1.00000 \mathrm{e}-02$ 1.00000e-02 1.00000e-03 1.00000e-09 1.00000e-01

$1.00000 \mathrm{e}+001.00000 \mathrm{e}+001.00000 \mathrm{e}-01$ 1.00000e-09 1.00000e-01

Element: 6427 \# of layers: 4

$\mathrm{Kx} \mathrm{Ky} \mathrm{Kz}$ Ss Por

$1.49683 \mathrm{e}+03$ 1.49683e+03 1.49683e+02 1.00000e-09 7.00000e-02

$5.98085 \mathrm{e}+015.98085 \mathrm{e}+015.98085 \mathrm{e}+001.00000 \mathrm{e}-092.12000 \mathrm{e}-01$

$1.00000 \mathrm{e}-02$ 1.00000e-02 1.00000e-03 1.00000e-09 1.00000e-01

$1.00000 \mathrm{e}+001.00000 \mathrm{e}+001.00000 \mathrm{e}-011.00000 \mathrm{e}-091.00000 \mathrm{e}-01$

Element: 6428 \# of layers: 4

$\mathrm{Kx} \mathrm{Ky} \mathrm{Kz}$ Ss Por

$1.49683 \mathrm{e}+03$ 1.49683e+03 1.49683e+02 1.00000e-09 7.00000e-02

$5.98085 \mathrm{e}+01$ 5.98085e+01 5.98085e+00 1.00000e-09 2.12000e-01

$1.00000 \mathrm{e}-02$ 1.00000e-02 1.00000e-03 1.00000e-09 1.00000e-01

$1.00000 \mathrm{e}+001.00000 \mathrm{e}+001.00000 \mathrm{e}-01$ 1.00000e-09 1.00000e-01

Element: 6429 \# of layers: 4

$\mathrm{Kx} \mathrm{Ky} \mathrm{Kz}$ Ss Por

$1.49683 \mathrm{e}+03$ 1.49683e+03 1.49683e+02 1.00000e-09 7.00000e-02

$5.98085 \mathrm{e}+015.98085 \mathrm{e}+015.98085 \mathrm{e}+001.00000 \mathrm{e}-092.12000 \mathrm{e}-01$

$1.00000 \mathrm{e}-02$ 1.00000e-02 1.00000e-03 1.00000e-09 1.00000e-01

$1.00000 \mathrm{e}+001.00000 \mathrm{e}+001.00000 \mathrm{e}-011.00000 \mathrm{e}-091.00000 \mathrm{e}-01$

Element: 6430 \# of layers: 5

$\mathrm{Kx} \mathrm{Ky} \mathrm{Kz}$ Ss Por

1.04102e+03 1.04102e+03 1.04102e+02 1.00000e-09 7.00000e-02

$1.04102 \mathrm{e}+03$ 1.04102e+03 1.04102e+02 1.00000e-09 7.00000e-02

4.15944e+01 4.15944e+01 4.15944e+00 1.00000e-09 2.12000e-01

$1.00000 \mathrm{e}-02$ 1.00000e-02 1.00000e-03 1.00000e-09 1.00000e-01

$1.00000 \mathrm{e}+001.00000 \mathrm{e}+001.00000 \mathrm{e}-01$ 1.00000e-09 1.00000e-01

Element: 6431 \# of layers: 5 
$\mathrm{Kx} \mathrm{Ky} \mathrm{Kz}$ Ss Por

$1.04102 \mathrm{e}+031.04102 \mathrm{e}+03$ 1.04102e+02 1.00000e-09 7.00000e-02

$1.04102 \mathrm{e}+03$ 1.04102e+03 1.04102e+02 1.00000e-09 7.00000e-02

$4.15944 \mathrm{e}+014.15944 \mathrm{e}+014.15944 \mathrm{e}+001.00000 \mathrm{e}-092.12000 \mathrm{e}-01$

$1.00000 \mathrm{e}-02$ 1.00000e-02 1.00000e-03 1.00000e-09 1.00000e-01

$1.00000 \mathrm{e}+001.00000 \mathrm{e}+001.00000 \mathrm{e}-011.00000 \mathrm{e}-091.00000 \mathrm{e}-01$

Element: 6432 \# of layers: 5

$\mathrm{Kx} \mathrm{Ky} \mathrm{Kz}$ Ss Por

$1.04102 \mathrm{e}+031.04102 \mathrm{e}+03$ 1.04102e+02 1.00000e-09 7.00000e-02

$1.04102 \mathrm{e}+03$ 1.04102e+03 1.04102e+02 1.00000e-09 7.00000e-02

$4.15944 \mathrm{e}+014.15944 \mathrm{e}+014.15944 \mathrm{e}+00$ 1.00000e-09 2.12000e-01

$1.00000 \mathrm{e}-02$ 1.00000e-02 1.00000e-03 1.00000e-09 1.00000e-01

$1.00000 \mathrm{e}+001.00000 \mathrm{e}+001.00000 \mathrm{e}-011.00000 \mathrm{e}-091.00000 \mathrm{e}-01$

Element: 6433 \# of layers: 5

$\mathrm{Kx} \mathrm{Ky} \mathrm{Kz}$ Ss Por

1.04102e+03 1.04102e+03 1.04102e+02 1.00000e-09 7.00000e-02

$1.04102 \mathrm{e}+03$ 1.04102e+03 1.04102e+02 1.00000e-09 7.00000e-02

$4.15944 \mathrm{e}+014.15944 \mathrm{e}+014.15944 \mathrm{e}+001.00000 \mathrm{e}-09$ 2.12000e-01

$1.00000 \mathrm{e}-02$ 1.00000e-02 1.00000e-03 1.00000e-09 1.00000e-01

$1.00000 \mathrm{e}+001.00000 \mathrm{e}+001.00000 \mathrm{e}-011.00000 \mathrm{e}-091.00000 \mathrm{e}-01$

Element: 6434 \# of layers: 5

$\mathrm{Kx} \mathrm{Ky} \mathrm{Kz}$ Ss Por

1.04102e+03 1.04102e+03 1.04102e+02 1.00000e-09 7.00000e-02

$4.15944 \mathrm{e}+014.15944 \mathrm{e}+014.15944 \mathrm{e}+001.00000 \mathrm{e}-09$ 2.12000e-01

$4.15944 \mathrm{e}+014.15944 \mathrm{e}+014.15944 \mathrm{e}+001.00000 \mathrm{e}-092.12000 \mathrm{e}-01$

$1.00000 \mathrm{e}-02$ 1.00000e-02 1.00000e-03 1.00000e-09 1.00000e-01

$1.00000 \mathrm{e}+001.00000 \mathrm{e}+001.00000 \mathrm{e}-011.00000 \mathrm{e}-091.00000 \mathrm{e}-01$

Element: 6435 \# of layers: 5

$\mathrm{Kx} \mathrm{Ky} \mathrm{Kz}$ Ss Por

$1.04102 \mathrm{e}+031.04102 \mathrm{e}+03$ 1.04102e+02 1.00000e-09 7.00000e-02

$1.04102 \mathrm{e}+03$ 1.04102e+03 1.04102e+02 1.00000e-09 7.00000e-02

$4.15944 \mathrm{e}+014.15944 \mathrm{e}+014.15944 \mathrm{e}+00$ 1.00000e-09 2.12000e-01

$1.00000 \mathrm{e}-02$ 1.00000e-02 1.00000e-03 1.00000e-09 1.00000e-01

$1.00000 \mathrm{e}+001.00000 \mathrm{e}+001.00000 \mathrm{e}-011.00000 \mathrm{e}-091.00000 \mathrm{e}-01$

Element: 6436 \# of layers: 5

$\mathrm{Kx} \mathrm{Ky} \mathrm{Kz}$ Ss Por

1.04102e+03 1.04102e+03 1.04102e+02 1.00000e-09 7.00000e-02

$1.04102 \mathrm{e}+03$ 1.04102e+03 1.04102e+02 1.00000e-09 7.00000e-02

$4.15944 \mathrm{e}+014.15944 \mathrm{e}+014.15944 \mathrm{e}+001.00000 \mathrm{e}-09$ 2.12000e-01

$1.00000 \mathrm{e}-02$ 1.00000e-02 1.00000e-03 1.00000e-09 1.00000e-01

$1.00000 \mathrm{e}+001.00000 \mathrm{e}+001.00000 \mathrm{e}-011.00000 \mathrm{e}-091.00000 \mathrm{e}-01$

Element: 6437 \# of layers: 5

$\mathrm{Kx} \mathrm{Ky} \mathrm{Kz}$ Ss Por

1.04102e+03 1.04102e+03 1.04102e+02 1.00000e-09 7.00000e-02

$1.04102 \mathrm{e}+03$ 1.04102e+03 1.04102e+02 1.00000e-09 7.00000e-02

$4.15944 \mathrm{e}+014.15944 \mathrm{e}+014.15944 \mathrm{e}+001.00000 \mathrm{e}-092.12000 \mathrm{e}-01$ 
$1.00000 \mathrm{e}-02$ 1.00000e-02 1.00000e-03 1.00000e-09 1.00000e-01 $1.00000 \mathrm{e}+001.00000 \mathrm{e}+001.00000 \mathrm{e}-01$ 1.00000e-09 1.00000e-01 Element: 6438 \# of layers: 5

Kx Ky Kz Ss Por

$1.04102 \mathrm{e}+031.04102 \mathrm{e}+03$ 1.04102e+02 1.00000e-09 7.00000e-02 $1.04102 \mathrm{e}+03$ 1.04102e+03 1.04102e+02 1.00000e-09 7.00000e-02

$4.15944 \mathrm{e}+014.15944 \mathrm{e}+014.15944 \mathrm{e}+001.00000 \mathrm{e}-092.12000 \mathrm{e}-01$ $1.00000 \mathrm{e}-02$ 1.00000e-02 1.00000e-03 1.00000e-09 1.00000e-01 $1.00000 \mathrm{e}+001.00000 \mathrm{e}+001.00000 \mathrm{e}-011.00000 \mathrm{e}-091.00000 \mathrm{e}-01$ Element: 6439 \# of layers: 4

$\mathrm{Kx} \mathrm{Ky} \mathrm{Kz}$ Ss Por

2.16492e+02 2.16492e+02 2.16492e+01 1.00000e-09 7.00000e-02

$8.65031 \mathrm{e}+008.65031 \mathrm{e}+00$ 8.65031e-01 1.00000e-09 2.12000e-01 $1.00000 \mathrm{e}-02$ 1.00000e-02 1.00000e-03 1.00000e-09 1.00000e-01 $1.00000 \mathrm{e}+001.00000 \mathrm{e}+001.00000 \mathrm{e}-011.00000 \mathrm{e}-091.00000 \mathrm{e}-01$ Element: 6440 \# of layers: 4

$\mathrm{Kx} \mathrm{Ky} \mathrm{Kz}$ Ss Por

2.16492e+02 2.16492e+02 2.16492e+01 1.00000e-09 7.00000e-02 $8.65031 \mathrm{e}+008.65031 \mathrm{e}+00$ 8.65031e-01 1.00000e-09 2.12000e-01 1.00000e-02 1.00000e-02 1.00000e-03 1.00000e-09 1.00000e-01 $1.00000 \mathrm{e}+001.00000 \mathrm{e}+001.00000 \mathrm{e}-011.00000 \mathrm{e}-091.00000 \mathrm{e}-01$ Element: 6441 \# of layers: 5

$\mathrm{Kx} \mathrm{Ky} \mathrm{Kz}$ Ss Por

2.16492e+02 2.16492e+02 2.16492e+01 1.00000e-09 7.00000e-02 $8.65031 \mathrm{e}+008.65031 \mathrm{e}+008.65031 \mathrm{e}-011.00000 \mathrm{e}-092.12000 \mathrm{e}-01$ 8.65031e+00 8.65031e+00 8.65031e-01 1.00000e-09 2.12000e-01 $1.00000 \mathrm{e}-021.00000 \mathrm{e}-02$ 1.00000e-03 1.00000e-09 1.00000e-01 $1.00000 \mathrm{e}+001.00000 \mathrm{e}+001.00000 \mathrm{e}-011.00000 \mathrm{e}-091.00000 \mathrm{e}-01$ Element: 6442 \# of layers: 5

$\mathrm{Kx} \mathrm{Ky} \mathrm{Kz}$ Ss Por

2.16492e+02 2.16492e+02 2.16492e+01 1.00000e-09 7.00000e-02 8.65031e+00 8.65031e+00 8.65031e-01 1.00000e-09 2.12000e-01 $8.65031 \mathrm{e}+008.65031 \mathrm{e}+008.65031 \mathrm{e}-01$ 1.00000e-09 2.12000e-01 $1.00000 \mathrm{e}-02$ 1.00000e-02 1.00000e-03 1.00000e-09 1.00000e-01 $1.00000 \mathrm{e}+001.00000 \mathrm{e}+001.00000 \mathrm{e}-011.00000 \mathrm{e}-091.00000 \mathrm{e}-01$ Element: 6443 \# of layers: 5

$\mathrm{Kx} \mathrm{Ky} \mathrm{Kz}$ Ss Por

2.16492e+02 2.16492e+02 2.16492e+01 1.00000e-09 7.00000e-02 $8.65031 \mathrm{e}+008.65031 \mathrm{e}+00$ 8.65031e-01 1.00000e-09 2.12000e-01 8.65031e+00 8.65031e+00 8.65031e-01 1.00000e-09 2.12000e-01 $1.00000 \mathrm{e}-02$ 1.00000e-02 1.00000e-03 1.00000e-09 1.00000e-01 $1.00000 \mathrm{e}+001.00000 \mathrm{e}+001.00000 \mathrm{e}-011.00000 \mathrm{e}-091.00000 \mathrm{e}-01$ Element: 6444 \# of layers: 5

$\mathrm{Kx} \mathrm{Ky} \mathrm{Kz}$ Ss Por

2.16492e+02 2.16492e+02 2.16492e+01 1.00000e-09 7.00000e-02 $8.65031 \mathrm{e}+008.65031 \mathrm{e}+008.65031 \mathrm{e}-01$ 1.00000e-09 2.12000e-01 
8.65031e+00 8.65031e+00 8.65031e-01 1.00000e-09 2.12000e-01 $1.00000 \mathrm{e}-02$ 1.00000e-02 1.00000e-03 1.00000e-09 1.00000e-01 $1.00000 \mathrm{e}+001.00000 \mathrm{e}+001.00000 \mathrm{e}-011.00000 \mathrm{e}-09$ 1.00000e-01 Element: 6445 \# of layers: 5

$\mathrm{Kx} \mathrm{Ky} \mathrm{Kz}$ Ss Por

2.16492e+02 2.16492e+02 2.16492e+01 1.00000e-09 7.00000e-02 $8.65031 \mathrm{e}+008.65031 \mathrm{e}+00$ 8.65031e-01 1.00000e-09 2.12000e-01 $8.65031 \mathrm{e}+008.65031 \mathrm{e}+008.65031 \mathrm{e}-01$ 1.00000e-09 2.12000e-01 $1.00000 \mathrm{e}-02$ 1.00000e-02 1.00000e-03 1.00000e-09 1.00000e-01 $1.00000 \mathrm{e}+001.00000 \mathrm{e}+001.00000 \mathrm{e}-011.00000 \mathrm{e}-091.00000 \mathrm{e}-01$ Element: 6446 \# of layers: 5

$\mathrm{Kx} \mathrm{Ky} \mathrm{Kz}$ Ss Por

2.16492e+02 2.16492e+02 2.16492e+01 1.00000e-09 7.00000e-02 $8.65031 \mathrm{e}+008.65031 \mathrm{e}+00$ 8.65031e-01 1.00000e-09 2.12000e-01 8.65031e+00 8.65031e+00 8.65031e-01 1.00000e-09 2.12000e-01 $1.00000 \mathrm{e}-021.00000 \mathrm{e}-02$ 1.00000e-03 1.00000e-09 1.00000e-01 $1.00000 \mathrm{e}+001.00000 \mathrm{e}+001.00000 \mathrm{e}-011.00000 \mathrm{e}-091.00000 \mathrm{e}-01$ Element: 6447 \# of layers: 5

$\mathrm{Kx} \mathrm{Ky} \mathrm{Kz}$ Ss Por

2.16492e+02 2.16492e+02 2.16492e+01 1.00000e-09 7.00000e-02 $8.65031 \mathrm{e}+008.65031 \mathrm{e}+008.65031 \mathrm{e}-01$ 1.00000e-09 2.12000e-01 $8.65031 \mathrm{e}+008.65031 \mathrm{e}+00$ 8.65031e-01 1.00000e-09 2.12000e-01 1.00000e-02 1.00000e-02 1.00000e-03 1.00000e-09 1.00000e-01 $1.00000 \mathrm{e}+001.00000 \mathrm{e}+001.00000 \mathrm{e}-011.00000 \mathrm{e}-091.00000 \mathrm{e}-01$ Element: 6448 \# of layers: 6

$\mathrm{Kx} \mathrm{Ky} \mathrm{Kz}$ Ss Por

2.12312e+02 2.12312e+02 2.12312e+01 1.00000e-09 7.00000e-02 $2.12312 \mathrm{e}+02$ 2.12312e+02 2.12312e+01 1.00000e-09 7.00000e-02 8.48313e+00 8.48313e+00 8.48313e-01 1.00000e-09 2.12000e-01 $8.48313 \mathrm{e}+00$ 8.48313e+00 8.48313e-01 1.00000e-09 2.12000e-01 $1.00000 \mathrm{e}-02$ 1.00000e-02 1.00000e-03 1.00000e-09 1.00000e-01 $1.00000 \mathrm{e}+001.00000 \mathrm{e}+001.00000 \mathrm{e}-01$ 1.00000e-09 1.00000e-01 Element: 6449 \# of layers: 6

$\mathrm{Kx} \mathrm{Ky} \mathrm{Kz}$ Ss Por

2.12312e+02 2.12312e+02 2.12312e+01 1.00000e-09 7.00000e-02 $2.12312 \mathrm{e}+02$ 2.12312e+02 2.12312e+01 1.00000e-09 7.00000e-02 8.48313e+00 8.48313e+00 8.48313e-01 1.00000e-09 2.12000e-01 $8.48313 \mathrm{e}+00$ 8.48313e+00 8.48313e-01 1.00000e-09 2.12000e-01 $1.00000 \mathrm{e}-02$ 1.00000e-02 1.00000e-03 1.00000e-09 1.00000e-01 $1.00000 \mathrm{e}+001.00000 \mathrm{e}+001.00000 \mathrm{e}-01$ 1.00000e-09 1.00000e-01 Element: 6450 \# of layers: 6

$\mathrm{Kx} \mathrm{Ky} \mathrm{Kz}$ Ss Por

2.12312e+02 2.12312e+02 2.12312e+01 1.00000e-09 7.00000e-02 $2.12312 \mathrm{e}+02$ 2.12312e+02 2.12312e+01 1.00000e-09 7.00000e-02 $8.48313 \mathrm{e}+00$ 8.48313e+00 8.48313e-01 1.00000e-09 2.12000e-01 $8.48313 \mathrm{e}+008.48313 \mathrm{e}+00$ 8.48313e-01 1.00000e-09 2.12000e-01 
$1.00000 \mathrm{e}-02$ 1.00000e-02 1.00000e-03 1.00000e-09 1.00000e-01 $1.00000 \mathrm{e}+001.00000 \mathrm{e}+001.00000 \mathrm{e}-01$ 1.00000e-09 1.00000e-01 Element: 6451 \# of layers: 5

Kx Ky Kz Ss Por

2.12312e+02 2.12312e+02 2.12312e+01 1.00000e-09 7.00000e-02

8.48313e+00 8.48313e+00 8.48313e-01 1.00000e-09 2.12000e-01

8.48313e+00 8.48313e+00 8.48313e-01 1.00000e-09 2.12000e-01

$1.00000 \mathrm{e}-021.00000 \mathrm{e}-02$ 1.00000e-03 1.00000e-09 1.00000e-01

$1.00000 \mathrm{e}+001.00000 \mathrm{e}+001.00000 \mathrm{e}-011.00000 \mathrm{e}-091.00000 \mathrm{e}-01$

Element: 6452 \# of layers: 4

$\mathrm{Kx} \mathrm{Ky} \mathrm{Kz}$ Ss Por

8.48313e+00 8.48313e+00 8.48313e-01 1.00000e-09 2.12000e-01

$8.48313 \mathrm{e}+00$ 8.48313e+00 8.48313e-01 1.00000e-09 2.12000e-01

$1.00000 \mathrm{e}-02$ 1.00000e-02 1.00000e-03 1.00000e-09 1.00000e-01

$1.00000 \mathrm{e}+001.00000 \mathrm{e}+001.00000 \mathrm{e}-01$ 1.00000e-09 1.00000e-01

Element: 6453 \# of layers: 5

$\mathrm{Kx} \mathrm{Ky} \mathrm{Kz}$ Ss Por

2.12312e+02 2.12312e+02 2.12312e+01 1.00000e-09 7.00000e-02

8.48313e+00 8.48313e+00 8.48313e-01 1.00000e-09 2.12000e-01

$8.48313 \mathrm{e}+00$ 8.48313e+00 8.48313e-01 1.00000e-09 2.12000e-01

$1.00000 \mathrm{e}-02$ 1.00000e-02 1.00000e-03 1.00000e-09 1.00000e-01

$1.00000 \mathrm{e}+001.00000 \mathrm{e}+001.00000 \mathrm{e}-011.00000 \mathrm{e}-091.00000 \mathrm{e}-01$

Element: 6454 \# of layers: 6

$\mathrm{Kx} \mathrm{Ky} \mathrm{Kz}$ Ss Por

$2.12312 \mathrm{e}+02$ 2.12312e+02 2.12312e+01 1.00000e-09 7.00000e-02

2.12312e+02 2.12312e+02 2.12312e+01 1.00000e-09 7.00000e-02

8.48313e+00 8.48313e+00 8.48313e-01 1.00000e-09 2.12000e-01

$8.48313 \mathrm{e}+00$ 8.48313e+00 8.48313e-01 1.00000e-09 2.12000e-01

$1.00000 \mathrm{e}-02$ 1.00000e-02 1.00000e-03 1.00000e-09 1.00000e-01

$1.00000 \mathrm{e}+001.00000 \mathrm{e}+001.00000 \mathrm{e}-011.00000 \mathrm{e}-091.00000 \mathrm{e}-01$

Element: 6455 \# of layers: 6

$\mathrm{Kx} \mathrm{Ky} \mathrm{Kz}$ Ss Por

2.12312e+02 2.12312e+02 2.12312e+01 1.00000e-09 7.00000e-02

$2.12312 \mathrm{e}+02$ 2.12312e+02 2.12312e+01 1.00000e-09 7.00000e-02

8.48313e+00 8.48313e+00 8.48313e-01 1.00000e-09 2.12000e-01

8.48313e+00 8.48313e+00 8.48313e-01 1.00000e-09 2.12000e-01

$1.00000 \mathrm{e}-02$ 1.00000e-02 1.00000e-03 1.00000e-09 1.00000e-01

$1.00000 \mathrm{e}+001.00000 \mathrm{e}+001.00000 \mathrm{e}-011.00000 \mathrm{e}-091.00000 \mathrm{e}-01$

Element: 6456 \# of layers: 6

$\mathrm{Kx} \mathrm{Ky} \mathrm{Kz}$ Ss Por

2.12312e+02 2.12312e+02 2.12312e+01 1.00000e-09 7.00000e-02

$2.12312 \mathrm{e}+02$ 2.12312e+02 2.12312e+01 1.00000e-09 7.00000e-02

8.48313e+00 8.48313e+00 8.48313e-01 1.00000e-09 2.12000e-01

$8.48313 \mathrm{e}+00$ 8.48313e+00 8.48313e-01 1.00000e-09 2.12000e-01

$1.00000 \mathrm{e}-02$ 1.00000e-02 1.00000e-03 1.00000e-09 1.00000e-01

$1.00000 \mathrm{e}+001.00000 \mathrm{e}+001.00000 \mathrm{e}-011.00000 \mathrm{e}-091.00000 \mathrm{e}-01$ 
Element: 6457 \# of layers: 6

$\mathrm{Kx} \mathrm{Ky} \mathrm{Kz}$ Ss Por

$2.73868 \mathrm{e}+02$ 2.73868e+02 2.73868e+01 1.00000e-09 7.00000e-02

$2.73868 \mathrm{e}+022.73868 \mathrm{e}+02$ 2.73868e+01 1.00000e-09 7.00000e-02

$1.09427 \mathrm{e}+011.09427 \mathrm{e}+01$ 1.09427e+00 1.00000e-09 2.12000e-01

$1.09427 \mathrm{e}+01$ 1.09427e+01 1.09427e+00 1.00000e-09 2.12000e-01

1.00000e-02 1.00000e-02 1.00000e-03 1.00000e-09 1.00000e-01

$1.00000 \mathrm{e}+001.00000 \mathrm{e}+001.00000 \mathrm{e}-011.00000 \mathrm{e}-091.00000 \mathrm{e}-01$

Element: 6458 \# of layers: 6

$\mathrm{Kx} \mathrm{Ky} \mathrm{Kz}$ Ss Por

$2.73868 \mathrm{e}+02$ 2.73868e+02 2.73868e+01 1.00000e-09 7.00000e-02

$2.73868 \mathrm{e}+02$ 2.73868e+02 2.73868e+01 1.00000e-09 7.00000e-02

$1.09427 \mathrm{e}+01$ 1.09427e+01 1.09427e+00 1.00000e-09 2.12000e-01

$1.09427 \mathrm{e}+01$ 1.09427e+01 1.09427e+00 1.00000e-09 2.12000e-01

$1.00000 \mathrm{e}-02$ 1.00000e-02 1.00000e-03 1.00000e-09 1.00000e-01

$1.00000 \mathrm{e}+001.00000 \mathrm{e}+001.00000 \mathrm{e}-011.00000 \mathrm{e}-091.00000 \mathrm{e}-01$

Element: 6459 \# of layers: 6

$\mathrm{Kx} \mathrm{Ky} \mathrm{Kz}$ Ss Por

2.73868e+02 2.73868e+02 2.73868e+01 1.00000e-09 7.00000e-02

$2.73868 \mathrm{e}+022.73868 \mathrm{e}+02 \quad 2.73868 \mathrm{e}+01$ 1.00000e-09 7.00000e-02

$1.09427 \mathrm{e}+011.09427 \mathrm{e}+01$ 1.09427e+00 1.00000e-09 2.12000e-01

$1.09427 \mathrm{e}+01$ 1.09427e+01 1.09427e+00 1.00000e-09 2.12000e-01

$1.00000 \mathrm{e}-02$ 1.00000e-02 1.00000e-03 1.00000e-09 1.00000e-01

$1.00000 \mathrm{e}+001.00000 \mathrm{e}+001.00000 \mathrm{e}-011.00000 \mathrm{e}-091.00000 \mathrm{e}-01$

Element: 6460 \# of layers: 5

$\mathrm{Kx} \mathrm{Ky} \mathrm{Kz}$ Ss Por

2.73868e+02 2.73868e+02 2.73868e+01 1.00000e-09 7.00000e-02 $1.09427 \mathrm{e}+011.09427 \mathrm{e}+01$ 1.09427e+00 1.00000e-09 2.12000e-01

$1.09427 \mathrm{e}+01$ 1.09427e+01 1.09427e+00 1.00000e-09 2.12000e-01 $1.00000 \mathrm{e}-021.00000 \mathrm{e}-021.00000 \mathrm{e}-031.00000 \mathrm{e}-091.00000 \mathrm{e}-01$

$1.00000 \mathrm{e}+001.00000 \mathrm{e}+001.00000 \mathrm{e}-01$ 1.00000e-09 1.00000e-01

Element: 6461 \# of layers: 4

Kx Ky Kz Ss Por

$1.09427 \mathrm{e}+01$ 1.09427e+01 1.09427e+00 1.00000e-09 2.12000e-01 $1.09427 \mathrm{e}+01$ 1.09427e+01 1.09427e+00 1.00000e-09 2.12000e-01 $1.00000 \mathrm{e}-02$ 1.00000e-02 1.00000e-03 1.00000e-09 1.00000e-01

$1.00000 \mathrm{e}+001.00000 \mathrm{e}+001.00000 \mathrm{e}-011.00000 \mathrm{e}-091.00000 \mathrm{e}-01$

Element: 6462 \# of layers: 4

$\mathrm{Kx} \mathrm{Ky} \mathrm{Kz}$ Ss Por

$1.09427 \mathrm{e}+01$ 1.09427e+01 1.09427e+00 1.00000e-09 2.12000e-01 $1.09427 \mathrm{e}+01$ 1.09427e+01 1.09427e+00 1.00000e-09 2.12000e-01 $1.00000 \mathrm{e}-02$ 1.00000e-02 1.00000e-03 1.00000e-09 1.00000e-01 $1.00000 \mathrm{e}+001.00000 \mathrm{e}+001.00000 \mathrm{e}-01$ 1.00000e-09 1.00000e-01

Element: 6463 \# of layers: 4

$\mathrm{Kx} \mathrm{Ky} \mathrm{Kz}$ Ss Por

1.09427e+01 1.09427e+01 1.09427e+00 1.00000e-09 2.12000e-01 
$1.09427 \mathrm{e}+01$ 1.09427e+01 1.09427e+00 1.00000e-09 2.12000e-01 $1.00000 \mathrm{e}-02$ 1.00000e-02 1.00000e-03 1.00000e-09 1.00000e-01

$1.00000 \mathrm{e}+001.00000 \mathrm{e}+001.00000 \mathrm{e}-011.00000 \mathrm{e}-091.00000 \mathrm{e}-01$

Element: 6464 \# of layers: 5

$\mathrm{Kx} \mathrm{Ky} \mathrm{Kz}$ Ss Por

$2.73868 \mathrm{e}+02$ 2.73868e+02 2.73868e+01 1.00000e-09 7.00000e-02

$1.09427 \mathrm{e}+011.09427 \mathrm{e}+01$ 1.09427e+00 1.00000e-09 2.12000e-01

$1.09427 \mathrm{e}+011.09427 \mathrm{e}+01$ 1.09427e+00 1.00000e-09 2.12000e-01

$1.00000 \mathrm{e}-021.00000 \mathrm{e}-02$ 1.00000e-03 1.00000e-09 1.00000e-01

$1.00000 \mathrm{e}+001.00000 \mathrm{e}+001.00000 \mathrm{e}-011.00000 \mathrm{e}-091.00000 \mathrm{e}-01$

Element: 6465 \# of layers: 5

$\mathrm{Kx} \mathrm{Ky} \mathrm{Kz}$ Ss Por

2.73868e+02 2.73868e+02 2.73868e+01 1.00000e-09 7.00000e-02 $1.09427 \mathrm{e}+01$ 1.09427e+01 1.09427e+00 1.00000e-09 2.12000e-01 $1.09427 \mathrm{e}+01$ 1.09427e+01 1.09427e+00 1.00000e-09 2.12000e-01 $1.00000 \mathrm{e}-02$ 1.00000e-02 1.00000e-03 1.00000e-09 1.00000e-01

$1.00000 \mathrm{e}+001.00000 \mathrm{e}+001.00000 \mathrm{e}-011.00000 \mathrm{e}-091.00000 \mathrm{e}-01$

Element: 6466 \# of layers: 5

$\mathrm{Kx} \mathrm{Ky} \mathrm{Kz}$ Ss Por

4.24425e+02 4.24425e+02 4.24425e+01 1.00000e-09 7.00000e-02

$1.69584 \mathrm{e}+011.69584 \mathrm{e}+011.69584 \mathrm{e}+001.00000 \mathrm{e}-092.12000 \mathrm{e}-01$

$1.69584 \mathrm{e}+011.69584 \mathrm{e}+011.69584 \mathrm{e}+001.00000 \mathrm{e}-092.12000 \mathrm{e}-01$

$1.00000 \mathrm{e}-02$ 1.00000e-02 1.00000e-03 1.00000e-09 1.00000e-01

$1.00000 \mathrm{e}+001.00000 \mathrm{e}+001.00000 \mathrm{e}-011.00000 \mathrm{e}-091.00000 \mathrm{e}-01$

Element: 6467 \# of layers: 6

$\mathrm{Kx} \mathrm{Ky} \mathrm{Kz}$ Ss Por

4.24425e+02 4.24425e+02 4.24425e+01 1.00000e-09 7.00000e-02

$1.69584 \mathrm{e}+011.69584 \mathrm{e}+011.69584 \mathrm{e}+001.00000 \mathrm{e}-092.12000 \mathrm{e}-01$

$1.69584 \mathrm{e}+011.69584 \mathrm{e}+011.69584 \mathrm{e}+001.00000 \mathrm{e}-092.12000 \mathrm{e}-01$

$1.69584 \mathrm{e}+011.69584 \mathrm{e}+011.69584 \mathrm{e}+001.00000 \mathrm{e}-092.12000 \mathrm{e}-01$

$1.00000 \mathrm{e}-02$ 1.00000e-02 1.00000e-03 1.00000e-09 1.00000e-01

$1.00000 \mathrm{e}+001.00000 \mathrm{e}+001.00000 \mathrm{e}-011.00000 \mathrm{e}-091.00000 \mathrm{e}-01$

Element: 6468 \# of layers: 5

$\mathrm{Kx} \mathrm{Ky} \mathrm{Kz}$ Ss Por

4.24425e+02 4.24425e+02 4.24425e+01 1.00000e-09 7.00000e-02 $1.69584 \mathrm{e}+011.69584 \mathrm{e}+011.69584 \mathrm{e}+001.00000 \mathrm{e}-092.12000 \mathrm{e}-01$

$1.69584 \mathrm{e}+011.69584 \mathrm{e}+011.69584 \mathrm{e}+001.00000 \mathrm{e}-092.12000 \mathrm{e}-01$

$1.00000 \mathrm{e}-02$ 1.00000e-02 1.00000e-03 1.00000e-09 1.00000e-01

$1.00000 \mathrm{e}+001.00000 \mathrm{e}+001.00000 \mathrm{e}-011.00000 \mathrm{e}-091.00000 \mathrm{e}-01$

Element: 6469 \# of layers: 3

$\mathrm{Kx} \mathrm{Ky} \mathrm{Kz}$ Ss Por

$1.69584 \mathrm{e}+011.69584 \mathrm{e}+011.69584 \mathrm{e}+001.00000 \mathrm{e}-092.12000 \mathrm{e}-01$ $1.00000 \mathrm{e}-02$ 1.00000e-02 1.00000e-03 1.00000e-09 1.00000e-01

$1.00000 \mathrm{e}+001.00000 \mathrm{e}+001.00000 \mathrm{e}-01$ 1.00000e-09 1.00000e-01

Element: 6470 \# of layers: 3

Kx Ky Kz Ss Por 
$1.69584 \mathrm{e}+011.69584 \mathrm{e}+011.69584 \mathrm{e}+001.00000 \mathrm{e}-092.12000 \mathrm{e}-01$ $1.00000 \mathrm{e}-02$ 1.00000e-02 1.00000e-03 1.00000e-09 1.00000e-01

$1.00000 \mathrm{e}+001.00000 \mathrm{e}+001.00000 \mathrm{e}-011.00000 \mathrm{e}-091.00000 \mathrm{e}-01$

Element: 6471 \# of layers: 3

$\mathrm{Kx} \mathrm{Ky} \mathrm{Kz}$ Ss Por

$1.69584 \mathrm{e}+011.69584 \mathrm{e}+011.69584 \mathrm{e}+001.00000 \mathrm{e}-092.12000 \mathrm{e}-01$ 1.00000e-02 1.00000e-02 1.00000e-03 1.00000e-09 1.00000e-01

$1.00000 \mathrm{e}+001.00000 \mathrm{e}+001.00000 \mathrm{e}-011.00000 \mathrm{e}-091.00000 \mathrm{e}-01$

Element: 6472 \# of layers: 3

$\mathrm{Kx} \mathrm{Ky} \mathrm{Kz}$ Ss Por

$1.69584 \mathrm{e}+011.69584 \mathrm{e}+011.69584 \mathrm{e}+001.00000 \mathrm{e}-092.12000 \mathrm{e}-01$

$1.00000 \mathrm{e}-02$ 1.00000e-02 1.00000e-03 1.00000e-09 1.00000e-01

$1.00000 \mathrm{e}+001.00000 \mathrm{e}+001.00000 \mathrm{e}-011.00000 \mathrm{e}-091.00000 \mathrm{e}-01$

Element: 6473 \# of layers: 4

$\mathrm{Kx} \mathrm{Ky} \mathrm{Kz}$ Ss Por

$1.69584 \mathrm{e}+011.69584 \mathrm{e}+011.69584 \mathrm{e}+001.00000 \mathrm{e}-092.12000 \mathrm{e}-01$

$1.69584 \mathrm{e}+011.69584 \mathrm{e}+011.69584 \mathrm{e}+001.00000 \mathrm{e}-092.12000 \mathrm{e}-01$

$1.00000 \mathrm{e}-02$ 1.00000e-02 1.00000e-03 1.00000e-09 1.00000e-01

$1.00000 \mathrm{e}+001.00000 \mathrm{e}+001.00000 \mathrm{e}-01$ 1.00000e-09 1.00000e-01

Element: 6474 \# of layers: 3

$\mathrm{Kx} \mathrm{Ky} \mathrm{Kz}$ Ss Por

$1.69584 \mathrm{e}+011.69584 \mathrm{e}+01$ 1.69584e+00 1.00000e-09 2.12000e-01

$1.00000 \mathrm{e}-021.00000 \mathrm{e}-021.00000 \mathrm{e}-031.00000 \mathrm{e}-091.00000 \mathrm{e}-01$

$1.00000 \mathrm{e}+001.00000 \mathrm{e}+001.00000 \mathrm{e}-011.00000 \mathrm{e}-091.00000 \mathrm{e}-01$

Element: 6475 \# of layers: 4

$\mathrm{Kx} \mathrm{Ky} \mathrm{Kz}$ Ss Por

$1.47124 \mathrm{e}+031.47124 \mathrm{e}+03$ 1.47124e+02 1.00000e-09 7.00000e-02

$5.87848 \mathrm{e}+015.87848 \mathrm{e}+015.87848 \mathrm{e}+00$ 1.00000e-09 2.12000e-01

$1.00000 \mathrm{e}-02$ 1.00000e-02 1.00000e-03 1.00000e-09 1.00000e-01

$1.00000 \mathrm{e}+001.00000 \mathrm{e}+001.00000 \mathrm{e}-011.00000 \mathrm{e}-091.00000 \mathrm{e}-01$

Element: 6476 \# of layers: 3

Kx Ky Kz Ss Por

5.87848e+01 5.87848e+01 5.87848e+00 1.00000e-09 2.12000e-01

$1.00000 \mathrm{e}-021.00000 \mathrm{e}-021.00000 \mathrm{e}-031.00000 \mathrm{e}-091.00000 \mathrm{e}-01$

$1.00000 \mathrm{e}+001.00000 \mathrm{e}+001.00000 \mathrm{e}-011.00000 \mathrm{e}-091.00000 \mathrm{e}-01$

Element: 6477 \# of layers: 3

Kx Ky Kz Ss Por

5.87848e+01 5.87848e+01 5.87848e+00 1.00000e-09 2.12000e-01

$1.00000 \mathrm{e}-021.00000 \mathrm{e}-021.00000 \mathrm{e}-031.00000 \mathrm{e}-091.00000 \mathrm{e}-01$

$1.00000 \mathrm{e}+001.00000 \mathrm{e}+001.00000 \mathrm{e}-011.00000 \mathrm{e}-091.00000 \mathrm{e}-01$

Element: 6478 \# of layers: 3

$\mathrm{Kx} \mathrm{Ky} \mathrm{Kz}$ Ss Por

5.87848e+01 5.87848e+01 5.87848e+00 1.00000e-09 2.12000e-01

$1.00000 \mathrm{e}-02$ 1.00000e-02 1.00000e-03 1.00000e-09 1.00000e-01

$1.00000 \mathrm{e}+001.00000 \mathrm{e}+001.00000 \mathrm{e}-01$ 1.00000e-09 1.00000e-01

Element: 6479 \# of layers: 3 


\section{Kx Ky Kz Ss Por}

5.87848e+01 5.87848e+01 5.87848e+00 1.00000e-09 2.12000e-01

$1.00000 \mathrm{e}-02$ 1.00000e-02 1.00000e-03 1.00000e-09 1.00000e-01

$1.00000 \mathrm{e}+001.00000 \mathrm{e}+001.00000 \mathrm{e}-011.00000 \mathrm{e}-091.00000 \mathrm{e}-01$

Element: 6480 \# of layers: 3

$\mathrm{Kx} \mathrm{Ky} \mathrm{Kz}$ Ss Por

5.87848e+01 5.87848e+01 5.87848e+00 1.00000e-09 2.12000e-01

$1.00000 \mathrm{e}-02$ 1.00000e-02 1.00000e-03 1.00000e-09 1.00000e-01

$1.00000 \mathrm{e}+001.00000 \mathrm{e}+001.00000 \mathrm{e}-011.00000 \mathrm{e}-09$ 1.00000e-01

Element: 6481 \# of layers: 3

Kx Ky Kz Ss Por

5.87848e+01 5.87848e+01 5.87848e+00 1.00000e-09 2.12000e-01

$1.00000 \mathrm{e}-02$ 1.00000e-02 1.00000e-03 1.00000e-09 1.00000e-01

$1.00000 \mathrm{e}+001.00000 \mathrm{e}+001.00000 \mathrm{e}-011.00000 \mathrm{e}-09$ 1.00000e-01

Element: 6482 \# of layers: 3

$\mathrm{Kx} \mathrm{Ky} \mathrm{Kz}$ Ss Por

5.87848e+01 5.87848e+01 5.87848e+00 1.00000e-09 2.12000e-01

$1.00000 \mathrm{e}-02$ 1.00000e-02 1.00000e-03 1.00000e-09 1.00000e-01

$1.00000 \mathrm{e}+001.00000 \mathrm{e}+001.00000 \mathrm{e}-011.00000 \mathrm{e}-091.00000 \mathrm{e}-01$

Element: 6483 \# of layers: 3

$\mathrm{Kx} \mathrm{Ky} \mathrm{Kz}$ Ss Por

5.87848e+01 5.87848e+01 5.87848e+00 1.00000e-09 2.12000e-01

$1.00000 \mathrm{e}-021.00000 \mathrm{e}-021.00000 \mathrm{e}-031.00000 \mathrm{e}-091.00000 \mathrm{e}-01$

$1.00000 \mathrm{e}+001.00000 \mathrm{e}+001.00000 \mathrm{e}-011.00000 \mathrm{e}-091.00000 \mathrm{e}-01$

Element: 6484 \# of layers: 3

$\mathrm{Kx} \mathrm{Ky} \mathrm{Kz}$ Ss Por

$2.90526 \mathrm{e}+02$ 2.90526e+02 2.90526e+01 1.00000e-09 2.12000e-01

$1.00000 \mathrm{e}-02$ 1.00000e-02 1.00000e-03 1.00000e-09 1.00000e-01

$1.00000 \mathrm{e}+001.00000 \mathrm{e}+001.00000 \mathrm{e}-011.00000 \mathrm{e}-091.00000 \mathrm{e}-01$

Element: 6485 \# of layers: 3

$\mathrm{Kx} \mathrm{Ky} \mathrm{Kz}$ Ss Por

$2.90526 \mathrm{e}+02$ 2.90526e+02 2.90526e+01 1.00000e-09 2.12000e-01

$1.00000 \mathrm{e}-02$ 1.00000e-02 1.00000e-03 1.00000e-09 1.00000e-01

$1.00000 \mathrm{e}+001.00000 \mathrm{e}+001.00000 \mathrm{e}-011.00000 \mathrm{e}-091.00000 \mathrm{e}-01$

Element: 6486 \# of layers: 4

$\mathrm{Kx} \mathrm{Ky} \mathrm{Kz}$ Ss Por

$2.90526 \mathrm{e}+02$ 2.90526e+02 2.90526e+01 1.00000e-09 2.12000e-01

$2.90526 \mathrm{e}+022.90526 \mathrm{e}+022.90526 \mathrm{e}+01$ 1.00000e-09 2.12000e-01

$1.00000 \mathrm{e}-02$ 1.00000e-02 1.00000e-03 1.00000e-09 1.00000e-01

$1.00000 \mathrm{e}+001.00000 \mathrm{e}+001.00000 \mathrm{e}-01$ 1.00000e-09 1.00000e-01

Element: 6487 \# of layers: 4

$\mathrm{Kx} \mathrm{Ky} \mathrm{Kz}$ Ss Por

$2.90526 \mathrm{e}+02$ 2.90526e+02 2.90526e+01 1.00000e-09 2.12000e-01

2.90526e+02 2.90526e+02 2.90526e+01 1.00000e-09 2.12000e-01

$1.00000 \mathrm{e}-02$ 1.00000e-02 1.00000e-03 1.00000e-09 1.00000e-01

$1.00000 \mathrm{e}+001.00000 \mathrm{e}+001.00000 \mathrm{e}-011.00000 \mathrm{e}-091.00000 \mathrm{e}-01$ 
Element: 6488 \# of layers: 3

$\mathrm{Kx} \mathrm{Ky} \mathrm{Kz}$ Ss Por

$2.90526 \mathrm{e}+02$ 2.90526e+02 2.90526e+01 1.00000e-09 2.12000e-01

$1.00000 \mathrm{e}-02$ 1.00000e-02 1.00000e-03 1.00000e-09 1.00000e-01

$1.00000 \mathrm{e}+001.00000 \mathrm{e}+001.00000 \mathrm{e}-01$ 1.00000e-09 1.00000e-01

Element: 6489 \# of layers: 3

$\mathrm{Kx} \mathrm{Ky} \mathrm{Kz}$ Ss Por

$2.90526 \mathrm{e}+02$ 2.90526e+02 2.90526e+01 1.00000e-09 2.12000e-01

$1.00000 \mathrm{e}-02$ 1.00000e-02 1.00000e-03 1.00000e-09 1.00000e-01

$1.00000 \mathrm{e}+001.00000 \mathrm{e}+001.00000 \mathrm{e}-01$ 1.00000e-09 1.00000e-01

Element: 6490 \# of layers: 4

$\mathrm{Kx} \mathrm{Ky} \mathrm{Kz}$ Ss Por

2.90526e+02 2.90526e+02 2.90526e+01 1.00000e-09 2.12000e-01

$2.90526 \mathrm{e}+022.90526 \mathrm{e}+022.90526 \mathrm{e}+01$ 1.00000e-09 2.12000e-01

$1.00000 \mathrm{e}-02$ 1.00000e-02 1.00000e-03 1.00000e-09 1.00000e-01

$1.00000 \mathrm{e}+001.00000 \mathrm{e}+001.00000 \mathrm{e}-011.00000 \mathrm{e}-091.00000 \mathrm{e}-01$

Element: 6491 \# of layers: 4

$\mathrm{Kx} \mathrm{Ky} \mathrm{Kz}$ Ss Por

$2.90526 \mathrm{e}+02$ 2.90526e+02 2.90526e+01 1.00000e-09 2.12000e-01

$2.90526 \mathrm{e}+02$ 2.90526e+02 2.90526e+01 1.00000e-09 2.12000e-01

$1.00000 \mathrm{e}-02$ 1.00000e-02 1.00000e-03 1.00000e-09 1.00000e-01

$1.00000 \mathrm{e}+001.00000 \mathrm{e}+001.00000 \mathrm{e}-01$ 1.00000e-09 1.00000e-01

Element: 6492 \# of layers: 4

$\mathrm{Kx} \mathrm{Ky} \mathrm{Kz}$ Ss Por

$2.90526 \mathrm{e}+02$ 2.90526e+02 2.90526e+01 1.00000e-09 2.12000e-01

$2.90526 \mathrm{e}+02$ 2.90526e+02 2.90526e+01 1.00000e-09 2.12000e-01

$1.00000 \mathrm{e}-02$ 1.00000e-02 1.00000e-03 1.00000e-09 1.00000e-01

$1.00000 \mathrm{e}+001.00000 \mathrm{e}+001.00000 \mathrm{e}-011.00000 \mathrm{e}-09$ 1.00000e-01

Element: 6493 \# of layers: 4

$\mathrm{Kx} \mathrm{Ky} \mathrm{Kz}$ Ss Por

$1.50265 \mathrm{e}+02$ 1.50265e+02 1.50265e+01 1.00000e-09 2.12000e-01

$1.50265 \mathrm{e}+02$ 1.50265e+02 1.50265e+01 1.00000e-09 2.12000e-01

$1.00000 \mathrm{e}-02$ 1.00000e-02 1.00000e-03 1.00000e-09 1.00000e-01

$1.00000 \mathrm{e}+001.00000 \mathrm{e}+001.00000 \mathrm{e}-011.00000 \mathrm{e}-091.00000 \mathrm{e}-01$

Element: 6494 \# of layers: 4

Kx Ky Kz Ss Por

$1.50265 \mathrm{e}+021.50265 \mathrm{e}+02$ 1.50265e+01 1.00000e-09 2.12000e-01

$1.50265 \mathrm{e}+021.50265 \mathrm{e}+021.50265 \mathrm{e}+01$ 1.00000e-09 2.12000e-01

$1.00000 \mathrm{e}-02$ 1.00000e-02 1.00000e-03 1.00000e-09 1.00000e-01

$1.00000 \mathrm{e}+001.00000 \mathrm{e}+001.00000 \mathrm{e}-01$ 1.00000e-09 1.00000e-01

Element: 6495 \# of layers: 4

$\mathrm{Kx} \mathrm{Ky} \mathrm{Kz}$ Ss Por

3.76068e+03 3.76068e+03 3.76068e+02 1.00000e-09 7.00000e-02

$1.50265 \mathrm{e}+02$ 1.50265e+02 1.50265e+01 1.00000e-09 2.12000e-01

$1.00000 \mathrm{e}-02$ 1.00000e-02 1.00000e-03 1.00000e-09 1.00000e-01

$1.00000 \mathrm{e}+001.00000 \mathrm{e}+001.00000 \mathrm{e}-011.00000 \mathrm{e}-091.00000 \mathrm{e}-01$ 
Element: 6496 \# of layers: 4

$\mathrm{Kx} \mathrm{Ky} \mathrm{Kz}$ Ss Por

$1.50265 \mathrm{e}+02$ 1.50265e+02 1.50265e+01 1.00000e-09 2.12000e-01

$1.50265 \mathrm{e}+021.50265 \mathrm{e}+02$ 1.50265e+01 1.00000e-09 2.12000e-01

$1.00000 \mathrm{e}-02$ 1.00000e-02 1.00000e-03 1.00000e-09 1.00000e-01

$1.00000 \mathrm{e}+001.00000 \mathrm{e}+001.00000 \mathrm{e}-011.00000 \mathrm{e}-091.00000 \mathrm{e}-01$

Element: 6497 \# of layers: 4

$\mathrm{Kx} \mathrm{Ky} \mathrm{Kz}$ Ss Por

$1.50265 \mathrm{e}+02$ 1.50265e+02 1.50265e+01 1.00000e-09 2.12000e-01

$1.50265 \mathrm{e}+021.50265 \mathrm{e}+02 \quad 1.50265 \mathrm{e}+01$ 1.00000e-09 2.12000e-01

$1.00000 \mathrm{e}-02$ 1.00000e-02 1.00000e-03 1.00000e-09 1.00000e-01

$1.00000 \mathrm{e}+001.00000 \mathrm{e}+001.00000 \mathrm{e}-011.00000 \mathrm{e}-091.00000 \mathrm{e}-01$

Element: 6498 \# of layers: 3

$\mathrm{Kx} \mathrm{Ky} \mathrm{Kz}$ Ss Por

$1.50265 \mathrm{e}+021.50265 \mathrm{e}+02$ 1.50265e+01 1.00000e-09 2.12000e-01

$1.00000 \mathrm{e}-02$ 1.00000e-02 1.00000e-03 1.00000e-09 1.00000e-01

$1.00000 \mathrm{e}+001.00000 \mathrm{e}+001.00000 \mathrm{e}-011.00000 \mathrm{e}-091.00000 \mathrm{e}-01$

Element: 6499 \# of layers: 3

$\mathrm{Kx} \mathrm{Ky} \mathrm{Kz}$ Ss Por

$1.50265 \mathrm{e}+02$ 1.50265e+02 1.50265e+01 1.00000e-09 2.12000e-01

$1.00000 \mathrm{e}-02$ 1.00000e-02 1.00000e-03 1.00000e-09 1.00000e-01

$1.00000 \mathrm{e}+001.00000 \mathrm{e}+001.00000 \mathrm{e}-01$ 1.00000e-09 1.00000e-01

Element: 6500 \# of layers: 3

$\mathrm{Kx} \mathrm{Ky} \mathrm{Kz}$ Ss Por

$1.50265 \mathrm{e}+02$ 1.50265e+02 1.50265e+01 1.00000e-09 2.12000e-01

$1.00000 \mathrm{e}-02$ 1.00000e-02 1.00000e-03 1.00000e-09 1.00000e-01

$1.00000 \mathrm{e}+001.00000 \mathrm{e}+001.00000 \mathrm{e}-01$ 1.00000e-09 1.00000e-01

Element: 6501 \# of layers: 4

$\mathrm{Kx} \mathrm{Ky} \mathrm{Kz}$ Ss Por

$1.50265 \mathrm{e}+021.50265 \mathrm{e}+02$ 1.50265e+01 1.00000e-09 2.12000e-01

$1.50265 \mathrm{e}+021.50265 \mathrm{e}+02 \quad 1.50265 \mathrm{e}+01$ 1.00000e-09 2.12000e-01

$1.00000 \mathrm{e}-02$ 1.00000e-02 1.00000e-03 1.00000e-09 1.00000e-01

$1.00000 \mathrm{e}+001.00000 \mathrm{e}+001.00000 \mathrm{e}-011.00000 \mathrm{e}-091.00000 \mathrm{e}-01$

Element: 6502 \# of layers: 5

$\mathrm{Kx} \mathrm{Ky} \mathrm{Kz}$ Ss Por

5.16669e+02 5.16669e+02 5.16669e+01 1.00000e-09 7.00000e-02

$5.16669 \mathrm{e}+025.16669 \mathrm{e}+025.16669 \mathrm{e}+01$ 1.00000e-09 7.00000e-02

$2.06442 \mathrm{e}+012.06442 \mathrm{e}+012.06442 \mathrm{e}+00$ 1.00000e-09 2.12000e-01

$1.00000 \mathrm{e}-021.00000 \mathrm{e}-021.00000 \mathrm{e}-031.00000 \mathrm{e}-091.00000 \mathrm{e}-01$

$1.00000 \mathrm{e}+001.00000 \mathrm{e}+001.00000 \mathrm{e}-01$ 1.00000e-09 1.00000e-01

Element: 6503 \# of layers: 4

$\mathrm{Kx} \mathrm{Ky} \mathrm{Kz}$ Ss Por

5.16669e+02 5.16669e+02 5.16669e+01 1.00000e-09 7.00000e-02

$2.06442 \mathrm{e}+012.06442 \mathrm{e}+012.06442 \mathrm{e}+00$ 1.00000e-09 2.12000e-01

$1.00000 \mathrm{e}-02$ 1.00000e-02 1.00000e-03 1.00000e-09 1.00000e-01

$1.00000 \mathrm{e}+001.00000 \mathrm{e}+001.00000 \mathrm{e}-01$ 1.00000e-09 1.00000e-01 
Element: 6504 \# of layers: 3

$\mathrm{Kx} \mathrm{Ky} \mathrm{Kz}$ Ss Por

5.16669e+02 5.16669e+02 5.16669e+01 1.00000e-09 7.00000e-02

$1.00000 \mathrm{e}-02$ 1.00000e-02 1.00000e-03 1.00000e-09 1.00000e-01

$1.00000 \mathrm{e}+001.00000 \mathrm{e}+001.00000 \mathrm{e}-011.00000 \mathrm{e}-091.00000 \mathrm{e}-01$

Element: 6505 \# of layers: 3

$\mathrm{Kx} \mathrm{Ky} \mathrm{Kz}$ Ss Por

5.16669e+02 5.16669e+02 5.16669e+01 1.00000e-09 7.00000e-02

$1.00000 \mathrm{e}-021.00000 \mathrm{e}-02$ 1.00000e-03 1.00000e-09 1.00000e-01

$1.00000 \mathrm{e}+001.00000 \mathrm{e}+001.00000 \mathrm{e}-011.00000 \mathrm{e}-091.00000 \mathrm{e}-01$

Element: 6506 \# of layers: 3

$\mathrm{Kx} \mathrm{Ky} \mathrm{Kz}$ Ss Por

5.16669e+02 5.16669e+02 5.16669e+01 1.00000e-09 7.00000e-02

$1.00000 \mathrm{e}-02$ 1.00000e-02 1.00000e-03 1.00000e-09 1.00000e-01

$1.00000 \mathrm{e}+001.00000 \mathrm{e}+001.00000 \mathrm{e}-01$ 1.00000e-09 1.00000e-01

Element: 6507 \# of layers: 4

$\mathrm{Kx} \mathrm{Ky} \mathrm{Kz}$ Ss Por

5.16669e+02 5.16669e+02 5.16669e+01 1.00000e-09 7.00000e-02

$2.06442 \mathrm{e}+012.06442 \mathrm{e}+012.06442 \mathrm{e}+00$ 1.00000e-09 2.12000e-01

$1.00000 \mathrm{e}-02$ 1.00000e-02 1.00000e-03 1.00000e-09 1.00000e-01

$1.00000 \mathrm{e}+001.00000 \mathrm{e}+001.00000 \mathrm{e}-011.00000 \mathrm{e}-091.00000 \mathrm{e}-01$

Element: 6508 \# of layers: 5

$\mathrm{Kx} \mathrm{Ky} \mathrm{Kz}$ Ss Por

5.16669e+02 5.16669e+02 5.16669e+01 1.00000e-09 7.00000e-02

$2.06442 \mathrm{e}+012.06442 \mathrm{e}+012.06442 \mathrm{e}+001.00000 \mathrm{e}-092.12000 \mathrm{e}-01$

$2.06442 \mathrm{e}+012.06442 \mathrm{e}+012.06442 \mathrm{e}+00$ 1.00000e-09 2.12000e-01

$1.00000 \mathrm{e}-02$ 1.00000e-02 1.00000e-03 1.00000e-09 1.00000e-01

$1.00000 \mathrm{e}+001.00000 \mathrm{e}+001.00000 \mathrm{e}-011.00000 \mathrm{e}-09$ 1.00000e-01

Element: 6509 \# of layers: 4

$\mathrm{Kx} \mathrm{Ky} \mathrm{Kz}$ Ss Por

5.16669e+02 5.16669e+02 5.16669e+01 1.00000e-09 7.00000e-02

$2.06442 \mathrm{e}+012.06442 \mathrm{e}+012.06442 \mathrm{e}+00$ 1.00000e-09 2.12000e-01

$1.00000 \mathrm{e}-021.00000 \mathrm{e}-02$ 1.00000e-03 1.00000e-09 1.00000e-01

$1.00000 \mathrm{e}+001.00000 \mathrm{e}+001.00000 \mathrm{e}-011.00000 \mathrm{e}-091.00000 \mathrm{e}-01$

Element: 6510 \# of layers: 4

Kx Ky Kz Ss Por

5.16669e+02 5.16669e+02 5.16669e+01 1.00000e-09 7.00000e-02

$2.06442 \mathrm{e}+012.06442 \mathrm{e}+012.06442 \mathrm{e}+00$ 1.00000e-09 2.12000e-01

$1.00000 \mathrm{e}-02$ 1.00000e-02 1.00000e-03 1.00000e-09 1.00000e-01

$1.00000 \mathrm{e}+001.00000 \mathrm{e}+001.00000 \mathrm{e}-01$ 1.00000e-09 1.00000e-01

Element: 6511 \# of layers: 4

$\mathrm{Kx} \mathrm{Ky} \mathrm{Kz}$ Ss Por

$1.98986 \mathrm{e}+02$ 1.98986e+02 1.98986e+01 1.00000e-09 7.00000e-02

7.95099e+00 7.95099e+00 7.95099e-01 1.00000e-09 2.12000e-01

$1.00000 \mathrm{e}-02$ 1.00000e-02 1.00000e-03 1.00000e-09 1.00000e-01

$1.00000 \mathrm{e}+001.00000 \mathrm{e}+001.00000 \mathrm{e}-011.00000 \mathrm{e}-091.00000 \mathrm{e}-01$ 
Element: 6512 \# of layers: 4

$\mathrm{Kx} \mathrm{Ky} \mathrm{Kz}$ Ss Por

1.98986e+02 1.98986e+02 1.98986e+01 1.00000e-09 7.00000e-02

$7.95099 \mathrm{e}+00$ 7.95099e+00 7.95099e-01 1.00000e-09 2.12000e-01

$1.00000 \mathrm{e}-02$ 1.00000e-02 1.00000e-03 1.00000e-09 1.00000e-01

$1.00000 \mathrm{e}+001.00000 \mathrm{e}+001.00000 \mathrm{e}-01$ 1.00000e-09 1.00000e-01

Element: 6513 \# of layers: 4

$\mathrm{Kx} \mathrm{Ky} \mathrm{Kz}$ Ss Por

$1.98986 \mathrm{e}+02$ 1.98986e+02 1.98986e+01 1.00000e-09 7.00000e-02

7.95099e+00 7.95099e+00 7.95099e-01 1.00000e-09 2.12000e-01

1.00000e-02 1.00000e-02 1.00000e-03 1.00000e-09 1.00000e-01

$1.00000 \mathrm{e}+001.00000 \mathrm{e}+001.00000 \mathrm{e}-011.00000 \mathrm{e}-091.00000 \mathrm{e}-01$

Element: 6514 \# of layers: 4

$\mathrm{Kx} \mathrm{Ky} \mathrm{Kz}$ Ss Por

$1.98986 \mathrm{e}+02$ 1.98986e+02 1.98986e+01 1.00000e-09 7.00000e-02

$7.95099 \mathrm{e}+00$ 7.95099e+00 7.95099e-01 1.00000e-09 2.12000e-01

$1.00000 \mathrm{e}-02$ 1.00000e-02 1.00000e-03 1.00000e-09 1.00000e-01

$1.00000 \mathrm{e}+001.00000 \mathrm{e}+001.00000 \mathrm{e}-01$ 1.00000e-09 1.00000e-01

Element: 6515 \# of layers: 4

$\mathrm{Kx} \mathrm{Ky} \mathrm{Kz}$ Ss Por

$1.98986 \mathrm{e}+02$ 1.98986e+02 1.98986e+01 1.00000e-09 7.00000e-02

7.95099e+00 7.95099e+00 7.95099e-01 1.00000e-09 2.12000e-01

$1.00000 \mathrm{e}-02$ 1.00000e-02 1.00000e-03 1.00000e-09 1.00000e-01

$1.00000 \mathrm{e}+001.00000 \mathrm{e}+001.00000 \mathrm{e}-011.00000 \mathrm{e}-091.00000 \mathrm{e}-01$

Element: 6516 \# of layers: 4

$\mathrm{Kx} \mathrm{Ky} \mathrm{Kz}$ Ss Por

$1.98986 \mathrm{e}+02$ 1.98986e+02 1.98986e+01 1.00000e-09 7.00000e-02

7.95099e+00 7.95099e+00 7.95099e-01 1.00000e-09 2.12000e-01

$1.00000 \mathrm{e}-02$ 1.00000e-02 1.00000e-03 1.00000e-09 1.00000e-01

$1.00000 \mathrm{e}+001.00000 \mathrm{e}+001.00000 \mathrm{e}-011.00000 \mathrm{e}-091.00000 \mathrm{e}-01$

Element: 6517 \# of layers: 4

$\mathrm{Kx} \mathrm{Ky} \mathrm{Kz}$ Ss Por

1.98986e+02 1.98986e+02 1.98986e+01 1.00000e-09 7.00000e-02

7.95099e+00 7.95099e+00 7.95099e-01 1.00000e-09 2.12000e-01

$1.00000 \mathrm{e}-02$ 1.00000e-02 1.00000e-03 1.00000e-09 1.00000e-01

$1.00000 \mathrm{e}+001.00000 \mathrm{e}+001.00000 \mathrm{e}-011.00000 \mathrm{e}-091.00000 \mathrm{e}-01$

Element: 6518 \# of layers: 4

$\mathrm{Kx} \mathrm{Ky} \mathrm{Kz}$ Ss Por

$1.98986 \mathrm{e}+02$ 1.98986e+02 1.98986e+01 1.00000e-09 7.00000e-02

7.95099e+00 7.95099e+00 7.95099e-01 1.00000e-09 2.12000e-01

$1.00000 \mathrm{e}-02$ 1.00000e-02 1.00000e-03 1.00000e-09 1.00000e-01

$1.00000 \mathrm{e}+001.00000 \mathrm{e}+001.00000 \mathrm{e}-011.00000 \mathrm{e}-091.00000 \mathrm{e}-01$

Element: 6519 \# of layers: 4

$\mathrm{Kx} \mathrm{Ky} \mathrm{Kz}$ Ss Por

$1.98986 \mathrm{e}+02$ 1.98986e+02 1.98986e+01 1.00000e-09 7.00000e-02

$7.95099 \mathrm{e}+00$ 7.95099e+00 7.95099e-01 1.00000e-09 2.12000e-01 
$1.00000 \mathrm{e}-02$ 1.00000e-02 1.00000e-03 1.00000e-09 1.00000e-01 $1.00000 \mathrm{e}+001.00000 \mathrm{e}+001.00000 \mathrm{e}-01$ 1.00000e-09 1.00000e-01 Element: 6520 \# of layers: 4

Kx Ky Kz Ss Por

$1.25131 \mathrm{e}+021.25131 \mathrm{e}+02$ 1.25131e+01 1.00000e-09 7.00000e-02 $4.99961 \mathrm{e}+004.99961 \mathrm{e}+00$ 4.99961e-01 1.00000e-09 2.12000e-01 $1.00000 \mathrm{e}-02$ 1.00000e-02 1.00000e-03 1.00000e-09 1.00000e-01 $1.00000 \mathrm{e}+001.00000 \mathrm{e}+001.00000 \mathrm{e}-011.00000 \mathrm{e}-091.00000 \mathrm{e}-01$ Element: 6521 \# of layers: 4

$\mathrm{Kx} \mathrm{Ky} \mathrm{Kz}$ Ss Por

1.25131e+02 1.25131e+02 1.25131e+01 1.00000e-09 7.00000e-02 $4.99961 \mathrm{e}+004.99961 \mathrm{e}+00$ 4.99961e-01 1.00000e-09 2.12000e-01 $1.00000 \mathrm{e}-02$ 1.00000e-02 1.00000e-03 1.00000e-09 1.00000e-01 $1.00000 \mathrm{e}+001.00000 \mathrm{e}+001.00000 \mathrm{e}-011.00000 \mathrm{e}-091.00000 \mathrm{e}-01$ Element: 6522 \# of layers: 4

Kx Ky Kz Ss Por

$1.25131 \mathrm{e}+02$ 1.25131e+02 1.25131e+01 1.00000e-09 7.00000e-02 4.99961e+00 4.99961e+00 4.99961e-01 1.00000e-09 2.12000e-01 $1.00000 \mathrm{e}-02$ 1.00000e-02 1.00000e-03 1.00000e-09 1.00000e-01 $1.00000 \mathrm{e}+001.00000 \mathrm{e}+001.00000 \mathrm{e}-011.00000 \mathrm{e}-091.00000 \mathrm{e}-01$ Element: 6523 \# of layers: 3

$\mathrm{Kx} \mathrm{Ky} \mathrm{Kz}$ Ss Por

1.25131e+02 1.25131e+02 1.25131e+01 1.00000e-09 7.00000e-02 $1.00000 \mathrm{e}-02$ 1.00000e-02 1.00000e-03 1.00000e-09 1.00000e-01 $1.00000 \mathrm{e}+001.00000 \mathrm{e}+001.00000 \mathrm{e}-011.00000 \mathrm{e}-091.00000 \mathrm{e}-01$ Element: 6524 \# of layers: 3

$\mathrm{Kx} \mathrm{Ky} \mathrm{Kz}$ Ss Por

$1.25131 \mathrm{e}+02$ 1.25131e+02 1.25131e+01 1.00000e-09 7.00000e-02 $1.00000 \mathrm{e}-02$ 1.00000e-02 1.00000e-03 1.00000e-09 1.00000e-01 $1.00000 \mathrm{e}+001.00000 \mathrm{e}+001.00000 \mathrm{e}-011.00000 \mathrm{e}-091.00000 \mathrm{e}-01$ Element: 6525 \# of layers: 4

$\mathrm{Kx} \mathrm{Ky} \mathrm{Kz}$ Ss Por

1.25131e+02 1.25131e+02 1.25131e+01 1.00000e-09 7.00000e-02 4.99961e+00 4.99961e+00 4.99961e-01 1.00000e-09 2.12000e-01 $1.00000 \mathrm{e}-02$ 1.00000e-02 1.00000e-03 1.00000e-09 1.00000e-01 $1.00000 \mathrm{e}+001.00000 \mathrm{e}+001.00000 \mathrm{e}-011.00000 \mathrm{e}-091.00000 \mathrm{e}-01$ Element: 6526 \# of layers: 4

$\mathrm{Kx} \mathrm{Ky} \mathrm{Kz}$ Ss Por

1.25131e+02 1.25131e+02 1.25131e+01 1.00000e-09 7.00000e-02 $4.99961 \mathrm{e}+004.99961 \mathrm{e}+00$ 4.99961e-01 1.00000e-09 2.12000e-01 1.00000e-02 1.00000e-02 1.00000e-03 1.00000e-09 1.00000e-01 $1.00000 \mathrm{e}+001.00000 \mathrm{e}+001.00000 \mathrm{e}-011.00000 \mathrm{e}-091.00000 \mathrm{e}-01$ Element: 6527 \# of layers: 4

$\mathrm{Kx} \mathrm{Ky} \mathrm{Kz}$ Ss Por 1.25131e+02 1.25131e+02 1.25131e+01 1.00000e-09 7.00000e-02 $4.99961 \mathrm{e}+004.99961 \mathrm{e}+004.99961 \mathrm{e}-01$ 1.00000e-09 2.12000e-01 
$1.00000 \mathrm{e}-02$ 1.00000e-02 1.00000e-03 1.00000e-09 1.00000e-01 $1.00000 \mathrm{e}+001.00000 \mathrm{e}+001.00000 \mathrm{e}-01$ 1.00000e-09 1.00000e-01 Element: 6528 \# of layers: 4

Kx Ky Kz Ss Por

$1.25131 \mathrm{e}+021.25131 \mathrm{e}+02$ 1.25131e+01 1.00000e-09 7.00000e-02 $4.99961 \mathrm{e}+004.99961 \mathrm{e}+00$ 4.99961e-01 1.00000e-09 2.12000e-01 1.00000e-02 1.00000e-02 1.00000e-03 1.00000e-09 1.00000e-01 $1.00000 \mathrm{e}+001.00000 \mathrm{e}+001.00000 \mathrm{e}-011.00000 \mathrm{e}-091.00000 \mathrm{e}-01$ Element: 6529 \# of layers: 3

$\mathrm{Kx} \mathrm{Ky} \mathrm{Kz}$ Ss Por

$1.48836 \mathrm{e}+02$ 1.48836e+02 1.48836e+01 1.00000e-09 7.00000e-02 $1.00000 \mathrm{e}-02$ 1.00000e-02 1.00000e-03 1.00000e-09 1.00000e-01 $1.00000 \mathrm{e}+001.00000 \mathrm{e}+001.00000 \mathrm{e}-01$ 1.00000e-09 1.00000e-01 Element: 6530 \# of layers: 3

$\mathrm{Kx} \mathrm{Ky} \mathrm{Kz}$ Ss Por $1.48836 \mathrm{e}+02$ 1.48836e+02 1.48836e+01 1.00000e-09 7.00000e-02 $1.00000 \mathrm{e}-02$ 1.00000e-02 1.00000e-03 1.00000e-09 1.00000e-01 $1.00000 \mathrm{e}+001.00000 \mathrm{e}+001.00000 \mathrm{e}-01$ 1.00000e-09 1.00000e-01 Element: 6531 \# of layers: 3

$\mathrm{Kx} \mathrm{Ky} \mathrm{Kz}$ Ss Por

$1.48836 \mathrm{e}+02$ 1.48836e+02 1.48836e+01 1.00000e-09 7.00000e-02 $1.00000 \mathrm{e}-021.00000 \mathrm{e}-021.00000 \mathrm{e}-031.00000 \mathrm{e}-091.00000 \mathrm{e}-01$

$1.00000 \mathrm{e}+001.00000 \mathrm{e}+001.00000 \mathrm{e}-01$ 1.00000e-09 1.00000e-01 Element: 6532 \# of layers: 3

$\mathrm{Kx} \mathrm{Ky} \mathrm{Kz}$ Ss Por $1.48836 \mathrm{e}+021.48836 \mathrm{e}+02$ 1.48836e+01 1.00000e-09 7.00000e-02 $1.00000 \mathrm{e}-02$ 1.00000e-02 1.00000e-03 1.00000e-09 1.00000e-01 $1.00000 \mathrm{e}+001.00000 \mathrm{e}+001.00000 \mathrm{e}-011.00000 \mathrm{e}-091.00000 \mathrm{e}-01$

Element: 6533 \# of layers: 3

$\mathrm{Kx} \mathrm{Ky} \mathrm{Kz}$ Ss Por

1.48836e+02 1.48836e+02 1.48836e+01 1.00000e-09 7.00000e-02 1.00000e-02 1.00000e-02 1.00000e-03 1.00000e-09 1.00000e-01 $1.00000 \mathrm{e}+001.00000 \mathrm{e}+001.00000 \mathrm{e}-011.00000 \mathrm{e}-091.00000 \mathrm{e}-01$

Element: 6534 \# of layers: 3

$\mathrm{Kx} \mathrm{Ky} \mathrm{Kz}$ Ss Por

$1.48836 \mathrm{e}+02$ 1.48836e+02 1.48836e+01 1.00000e-09 7.00000e-02 $1.00000 \mathrm{e}-021.00000 \mathrm{e}-02$ 1.00000e-03 1.00000e-09 1.00000e-01 $1.00000 \mathrm{e}+001.00000 \mathrm{e}+001.00000 \mathrm{e}-011.00000 \mathrm{e}-091.00000 \mathrm{e}-01$ Element: 6535 \# of layers: 3

$\mathrm{Kx} \mathrm{Ky} \mathrm{Kz}$ Ss Por $1.48836 \mathrm{e}+02$ 1.48836e+02 1.48836e+01 1.00000e-09 7.00000e-02 $1.00000 \mathrm{e}-02$ 1.00000e-02 1.00000e-03 1.00000e-09 1.00000e-01 $1.00000 \mathrm{e}+001.00000 \mathrm{e}+001.00000 \mathrm{e}-01$ 1.00000e-09 1.00000e-01 Element: 6536 \# of layers: 3

$\mathrm{Kx} \mathrm{Ky} \mathrm{Kz}$ Ss Por

$1.48836 \mathrm{e}+021.48836 \mathrm{e}+02$ 1.48836e+01 1.00000e-09 7.00000e-02 
$1.00000 \mathrm{e}-02$ 1.00000e-02 1.00000e-03 1.00000e-09 1.00000e-01 $1.00000 \mathrm{e}+001.00000 \mathrm{e}+001.00000 \mathrm{e}-01$ 1.00000e-09 1.00000e-01 Element: 6537 \# of layers: 3

Kx Ky Kz Ss Por

$1.48836 \mathrm{e}+021.48836 \mathrm{e}+021.48836 \mathrm{e}+01$ 1.00000e-09 7.00000e-02 $1.00000 \mathrm{e}-02$ 1.00000e-02 1.00000e-03 1.00000e-09 1.00000e-01 $1.00000 \mathrm{e}+001.00000 \mathrm{e}+001.00000 \mathrm{e}-011.00000 \mathrm{e}-091.00000 \mathrm{e}-01$

Element: 6538 \# of layers: 3

$\mathrm{Kx} \mathrm{Ky} \mathrm{Kz}$ Ss Por

3.35118e+02 3.35118e+02 3.35118e+01 1.00000e-09 7.00000e-02 $1.00000 \mathrm{e}-02$ 1.00000e-02 1.00000e-03 1.00000e-09 1.00000e-01 $1.00000 \mathrm{e}+001.00000 \mathrm{e}+001.00000 \mathrm{e}-011.00000 \mathrm{e}-091.00000 \mathrm{e}-01$ Element: 6539 \# of layers: 3

$\mathrm{Kx} \mathrm{Ky} \mathrm{Kz}$ Ss Por

3.35118e+02 3.35118e+02 3.35118e+01 1.00000e-09 7.00000e-02 $1.00000 \mathrm{e}-02$ 1.00000e-02 1.00000e-03 1.00000e-09 1.00000e-01 $1.00000 \mathrm{e}+001.00000 \mathrm{e}+001.00000 \mathrm{e}-011.00000 \mathrm{e}-091.00000 \mathrm{e}-01$ Element: 6540 \# of layers: 3

$\mathrm{Kx} \mathrm{Ky} \mathrm{Kz}$ Ss Por

3.35118e+02 3.35118e+02 3.35118e+01 1.00000e-09 7.00000e-02 $1.00000 \mathrm{e}-02$ 1.00000e-02 1.00000e-03 1.00000e-09 1.00000e-01 $1.00000 \mathrm{e}+001.00000 \mathrm{e}+001.00000 \mathrm{e}-01$ 1.00000e-09 1.00000e-01 Element: 6541 \# of layers: 10

$\mathrm{Kx} \mathrm{Ky} \mathrm{Kz}$ Ss Por

3.84421e+02 3.84421e+02 3.84421e+01 1.00000e-09 7.00000e-02 $3.84421 \mathrm{e}+023.84421 \mathrm{e}+023.84421 \mathrm{e}+01$ 1.00000e-09 7.00000e-02 $3.84421 \mathrm{e}+02$ 3.84421e+02 3.84421e+01 1.00000e-09 7.00000e-02 $1.53600 \mathrm{e}+011.53600 \mathrm{e}+011.53600 \mathrm{e}+001.00000 \mathrm{e}-092.12000 \mathrm{e}-01$ $1.53600 \mathrm{e}+011.53600 \mathrm{e}+011.53600 \mathrm{e}+001.00000 \mathrm{e}-092.12000 \mathrm{e}-01$ $1.53600 \mathrm{e}+011.53600 \mathrm{e}+011.53600 \mathrm{e}+001.00000 \mathrm{e}-092.12000 \mathrm{e}-01$ $1.53600 \mathrm{e}+011.53600 \mathrm{e}+011.53600 \mathrm{e}+001.00000 \mathrm{e}-092.12000 \mathrm{e}-01$ $1.00000 \mathrm{e}-02$ 1.00000e-02 1.00000e-03 1.00000e-09 1.00000e-01 $1.00000 \mathrm{e}+001.00000 \mathrm{e}+001.00000 \mathrm{e}-011.00000 \mathrm{e}-091.00000 \mathrm{e}-01$ 1.00000e-06 1.00000e-06 1.00000e-06 1.00000e-09 5.00000e-02 Element: 6542 \# of layers: 9

$\mathrm{Kx} \mathrm{Ky} \mathrm{Kz}$ Ss Por

3.84421e+02 3.84421e+02 3.84421e+01 1.00000e-09 7.00000e-02 $3.84421 \mathrm{e}+02$ 3.84421e+02 3.84421e+01 1.00000e-09 7.00000e-02 $1.53600 \mathrm{e}+011.53600 \mathrm{e}+011.53600 \mathrm{e}+001.00000 \mathrm{e}-092.12000 \mathrm{e}-01$ $1.53600 \mathrm{e}+011.53600 \mathrm{e}+011.53600 \mathrm{e}+001.00000 \mathrm{e}-092.12000 \mathrm{e}-01$ $1.53600 \mathrm{e}+011.53600 \mathrm{e}+011.53600 \mathrm{e}+001.00000 \mathrm{e}-092.12000 \mathrm{e}-01$ $1.53600 \mathrm{e}+011.53600 \mathrm{e}+011.53600 \mathrm{e}+001.00000 \mathrm{e}-092.12000 \mathrm{e}-01$ $1.53600 \mathrm{e}+011.53600 \mathrm{e}+011.53600 \mathrm{e}+001.00000 \mathrm{e}-092.12000 \mathrm{e}-01$ $1.00000 \mathrm{e}-02$ 1.00000e-02 1.00000e-03 1.00000e-09 1.00000e-01 $1.00000 \mathrm{e}+001.00000 \mathrm{e}+001.00000 \mathrm{e}-011.00000 \mathrm{e}-091.00000 \mathrm{e}-01$ Element: 6543 \# of layers: 8 
$\mathrm{Kx} \mathrm{Ky} \mathrm{Kz}$ Ss Por

3.84421e+02 3.84421e+02 3.84421e+01 1.00000e-09 7.00000e-02

$3.84421 \mathrm{e}+023.84421 \mathrm{e}+023.84421 \mathrm{e}+01$ 1.00000e-09 7.00000e-02

$1.53600 \mathrm{e}+011.53600 \mathrm{e}+011.53600 \mathrm{e}+001.00000 \mathrm{e}-092.12000 \mathrm{e}-01$

$1.53600 \mathrm{e}+011.53600 \mathrm{e}+011.53600 \mathrm{e}+001.00000 \mathrm{e}-092.12000 \mathrm{e}-01$

$1.53600 \mathrm{e}+011.53600 \mathrm{e}+011.53600 \mathrm{e}+001.00000 \mathrm{e}-092.12000 \mathrm{e}-01$

$1.53600 \mathrm{e}+011.53600 \mathrm{e}+011.53600 \mathrm{e}+001.00000 \mathrm{e}-092.12000 \mathrm{e}-01$

$1.00000 \mathrm{e}-02$ 1.00000e-02 1.00000e-03 1.00000e-09 1.00000e-01

$1.00000 \mathrm{e}+001.00000 \mathrm{e}+001.00000 \mathrm{e}-011.00000 \mathrm{e}-091.00000 \mathrm{e}-01$

Element: 6544 \# of layers: 10

$\mathrm{Kx} \mathrm{Ky} \mathrm{Kz}$ Ss Por

3.84421e+02 3.84421e+02 3.84421e+01 1.00000e-09 7.00000e-02

$3.84421 \mathrm{e}+023.84421 \mathrm{e}+02$ 3.84421e+01 1.00000e-09 7.00000e-02

3.84421e+02 3.84421e+02 3.84421e+01 1.00000e-09 7.00000e-02

$1.53600 \mathrm{e}+011.53600 \mathrm{e}+011.53600 \mathrm{e}+001.00000 \mathrm{e}-092.12000 \mathrm{e}-01$

$1.53600 \mathrm{e}+011.53600 \mathrm{e}+011.53600 \mathrm{e}+001.00000 \mathrm{e}-092.12000 \mathrm{e}-01$

$1.53600 \mathrm{e}+011.53600 \mathrm{e}+011.53600 \mathrm{e}+001.00000 \mathrm{e}-092.12000 \mathrm{e}-01$

$1.53600 \mathrm{e}+011.53600 \mathrm{e}+011.53600 \mathrm{e}+001.00000 \mathrm{e}-092.12000 \mathrm{e}-01$

$1.53600 \mathrm{e}+011.53600 \mathrm{e}+011.53600 \mathrm{e}+001.00000 \mathrm{e}-092.12000 \mathrm{e}-01$

$1.00000 \mathrm{e}-02$ 1.00000e-02 1.00000e-03 1.00000e-09 1.00000e-01

$1.00000 \mathrm{e}+001.00000 \mathrm{e}+001.00000 \mathrm{e}-011.00000 \mathrm{e}-091.00000 \mathrm{e}-01$

Element: 6545 \# of layers: 10

$\mathrm{Kx} \mathrm{Ky} \mathrm{Kz}$ Ss Por

3.84421e+02 3.84421e+02 3.84421e+01 1.00000e-09 7.00000e-02

$3.84421 \mathrm{e}+02$ 3.84421e+02 3.84421e+01 1.00000e-09 7.00000e-02

$3.84421 \mathrm{e}+023.84421 \mathrm{e}+023.84421 \mathrm{e}+01$ 1.00000e-09 7.00000e-02

$1.53600 \mathrm{e}+011.53600 \mathrm{e}+011.53600 \mathrm{e}+001.00000 \mathrm{e}-092.12000 \mathrm{e}-01$

$1.53600 \mathrm{e}+011.53600 \mathrm{e}+011.53600 \mathrm{e}+001.00000 \mathrm{e}-092.12000 \mathrm{e}-01$

$1.53600 \mathrm{e}+011.53600 \mathrm{e}+011.53600 \mathrm{e}+001.00000 \mathrm{e}-092.12000 \mathrm{e}-01$

$1.53600 \mathrm{e}+011.53600 \mathrm{e}+011.53600 \mathrm{e}+001.00000 \mathrm{e}-092.12000 \mathrm{e}-01$

$1.00000 \mathrm{e}-02$ 1.00000e-02 1.00000e-03 1.00000e-09 1.00000e-01

$1.00000 \mathrm{e}+001.00000 \mathrm{e}+001.00000 \mathrm{e}-011.00000 \mathrm{e}-091.00000 \mathrm{e}-01$

1.00000e-06 1.00000e-06 1.00000e-06 1.00000e-09 5.00000e-02

Element: 6546 \# of layers: 9

$\mathrm{Kx} \mathrm{Ky} \mathrm{Kz}$ Ss Por

7.82681e+02 7.82681e+02 7.82681e+01 1.00000e-09 7.00000e-02

$7.82681 \mathrm{e}+02$ 7.82681e+02 7.82681e+01 1.00000e-09 7.00000e-02

7.82681e+02 7.82681e+02 7.82681e+01 1.00000e-09 7.00000e-02

$3.12734 \mathrm{e}+013.12734 \mathrm{e}+013.12734 \mathrm{e}+001.00000 \mathrm{e}-092.12000 \mathrm{e}-01$

$3.12734 \mathrm{e}+013.12734 \mathrm{e}+013.12734 \mathrm{e}+001.00000 \mathrm{e}-092.12000 \mathrm{e}-01$

$3.12734 \mathrm{e}+013.12734 \mathrm{e}+013.12734 \mathrm{e}+001.00000 \mathrm{e}-092.12000 \mathrm{e}-01$

$1.00000 \mathrm{e}-02$ 1.00000e-02 1.00000e-03 1.00000e-09 1.00000e-01

$1.00000 \mathrm{e}+001.00000 \mathrm{e}+001.00000 \mathrm{e}-011.00000 \mathrm{e}-091.00000 \mathrm{e}-01$

$1.00000 \mathrm{e}-061.00000 \mathrm{e}-06$ 1.00000e-06 1.00000e-09 5.00000e-02

Element: 6547 \# of layers: 9

Kx Ky Kz Ss Por 
7.82681e+02 7.82681e+02 7.82681e+01 1.00000e-09 7.00000e-02 7.82681e+02 7.82681e+02 7.82681e+01 1.00000e-09 7.00000e-02 $3.12734 \mathrm{e}+013.12734 \mathrm{e}+013.12734 \mathrm{e}+001.00000 \mathrm{e}-092.12000 \mathrm{e}-01$ $3.12734 \mathrm{e}+013.12734 \mathrm{e}+013.12734 \mathrm{e}+001.00000 \mathrm{e}-092.12000 \mathrm{e}-01$ $3.12734 \mathrm{e}+013.12734 \mathrm{e}+013.12734 \mathrm{e}+001.00000 \mathrm{e}-092.12000 \mathrm{e}-01$ $3.12734 \mathrm{e}+013.12734 \mathrm{e}+013.12734 \mathrm{e}+001.00000 \mathrm{e}-092.12000 \mathrm{e}-01$ $1.00000 \mathrm{e}-02$ 1.00000e-02 1.00000e-03 1.00000e-09 1.00000e-01 $1.00000 \mathrm{e}+001.00000 \mathrm{e}+001.00000 \mathrm{e}-011.00000 \mathrm{e}-091.00000 \mathrm{e}-01$ $1.00000 \mathrm{e}-06$ 1.00000e-06 1.00000e-06 1.00000e-09 5.00000e-02 Element: 6548 \# of layers: 8

$\mathrm{Kx} \mathrm{Ky} \mathrm{Kz}$ Ss Por

7.82681e+02 7.82681e+02 7.82681e+01 1.00000e-09 7.00000e-02 $3.12734 \mathrm{e}+013.12734 \mathrm{e}+013.12734 \mathrm{e}+001.00000 \mathrm{e}-092.12000 \mathrm{e}-01$ $3.12734 \mathrm{e}+013.12734 \mathrm{e}+013.12734 \mathrm{e}+00$ 1.00000e-09 2.12000e-01 $3.12734 \mathrm{e}+013.12734 \mathrm{e}+013.12734 \mathrm{e}+001.00000 \mathrm{e}-092.12000 \mathrm{e}-01$ $3.12734 \mathrm{e}+013.12734 \mathrm{e}+013.12734 \mathrm{e}+001.00000 \mathrm{e}-092.12000 \mathrm{e}-01$ $3.12734 \mathrm{e}+013.12734 \mathrm{e}+013.12734 \mathrm{e}+001.00000 \mathrm{e}-092.12000 \mathrm{e}-01$ $1.00000 \mathrm{e}-02$ 1.00000e-02 1.00000e-03 1.00000e-09 1.00000e-01 $1.00000 \mathrm{e}+001.00000 \mathrm{e}+001.00000 \mathrm{e}-011.00000 \mathrm{e}-091.00000 \mathrm{e}-01$ Element: 6549 \# of layers: 8

$\mathrm{Kx} \mathrm{Ky} \mathrm{Kz}$ Ss Por

7.82681e+02 7.82681e+02 7.82681e+01 1.00000e-09 7.00000e-02 $3.12734 \mathrm{e}+013.12734 \mathrm{e}+013.12734 \mathrm{e}+001.00000 \mathrm{e}-092.12000 \mathrm{e}-01$ $3.12734 \mathrm{e}+013.12734 \mathrm{e}+013.12734 \mathrm{e}+00$ 1.00000e-09 2.12000e-01 $3.12734 \mathrm{e}+013.12734 \mathrm{e}+013.12734 \mathrm{e}+001.00000 \mathrm{e}-092.12000 \mathrm{e}-01$ $3.12734 \mathrm{e}+013.12734 \mathrm{e}+013.12734 \mathrm{e}+001.00000 \mathrm{e}-092.12000 \mathrm{e}-01$ $3.12734 \mathrm{e}+013.12734 \mathrm{e}+013.12734 \mathrm{e}+00$ 1.00000e-09 2.12000e-01 $1.00000 \mathrm{e}-02$ 1.00000e-02 1.00000e-03 1.00000e-09 1.00000e-01 $1.00000 \mathrm{e}+001.00000 \mathrm{e}+001.00000 \mathrm{e}-011.00000 \mathrm{e}-091.00000 \mathrm{e}-01$ Element: 6550 \# of layers: 7

$\mathrm{Kx} \mathrm{Ky} \mathrm{Kz}$ Ss Por

7.82681e+02 7.82681e+02 7.82681e+01 1.00000e-09 7.00000e-02 $3.12734 \mathrm{e}+013.12734 \mathrm{e}+013.12734 \mathrm{e}+001.00000 \mathrm{e}-092.12000 \mathrm{e}-01$ $3.12734 \mathrm{e}+013.12734 \mathrm{e}+013.12734 \mathrm{e}+001.00000 \mathrm{e}-092.12000 \mathrm{e}-01$ $3.12734 \mathrm{e}+013.12734 \mathrm{e}+013.12734 \mathrm{e}+001.00000 \mathrm{e}-092.12000 \mathrm{e}-01$ $3.12734 \mathrm{e}+013.12734 \mathrm{e}+013.12734 \mathrm{e}+00$ 1.00000e-09 2.12000e-01 $1.00000 \mathrm{e}-02$ 1.00000e-02 1.00000e-03 1.00000e-09 1.00000e-01 $1.00000 \mathrm{e}+001.00000 \mathrm{e}+001.00000 \mathrm{e}-011.00000 \mathrm{e}-09$ 1.00000e-01 Element: 6551 \# of layers: 7

$\mathrm{Kx} \mathrm{Ky} \mathrm{Kz}$ Ss Por

7.82681e+02 7.82681e+02 7.82681e+01 1.00000e-09 7.00000e-02 $3.12734 \mathrm{e}+013.12734 \mathrm{e}+013.12734 \mathrm{e}+001.00000 \mathrm{e}-092.12000 \mathrm{e}-01$ $3.12734 \mathrm{e}+013.12734 \mathrm{e}+013.12734 \mathrm{e}+00$ 1.00000e-09 2.12000e-01 3.12734e+01 3.12734e+01 3.12734e+00 1.00000e-09 2.12000e-01 $3.12734 \mathrm{e}+013.12734 \mathrm{e}+013.12734 \mathrm{e}+001.00000 \mathrm{e}-092.12000 \mathrm{e}-01$ $1.00000 \mathrm{e}-02$ 1.00000e-02 1.00000e-03 1.00000e-09 1.00000e-01 
$1.00000 \mathrm{e}+001.00000 \mathrm{e}+00$ 1.00000e-01 1.00000e-09 1.00000e-01

Element: 6552 \# of layers: 7

$\mathrm{Kx} \mathrm{Ky} \mathrm{Kz}$ Ss Por

7.82681e+02 7.82681e+02 7.82681e+01 1.00000e-09 7.00000e-02

$3.12734 \mathrm{e}+013.12734 \mathrm{e}+013.12734 \mathrm{e}+001.00000 \mathrm{e}-092.12000 \mathrm{e}-01$

$3.12734 \mathrm{e}+013.12734 \mathrm{e}+013.12734 \mathrm{e}+00$ 1.00000e-09 2.12000e-01

$3.12734 \mathrm{e}+013.12734 \mathrm{e}+013.12734 \mathrm{e}+001.00000 \mathrm{e}-092.12000 \mathrm{e}-01$

$3.12734 \mathrm{e}+013.12734 \mathrm{e}+013.12734 \mathrm{e}+00$ 1.00000e-09 2.12000e-01

$1.00000 \mathrm{e}-02$ 1.00000e-02 1.00000e-03 1.00000e-09 1.00000e-01

$1.00000 \mathrm{e}+001.00000 \mathrm{e}+001.00000 \mathrm{e}-01$ 1.00000e-09 1.00000e-01

Element: 6553 \# of layers: 7

$\mathrm{Kx} \mathrm{Ky} \mathrm{Kz}$ Ss Por

7.82681e+02 7.82681e+02 7.82681e+01 1.00000e-09 7.00000e-02

$3.12734 \mathrm{e}+013.12734 \mathrm{e}+013.12734 \mathrm{e}+001.00000 \mathrm{e}-092.12000 \mathrm{e}-01$

$3.12734 \mathrm{e}+013.12734 \mathrm{e}+013.12734 \mathrm{e}+001.00000 \mathrm{e}-092.12000 \mathrm{e}-01$

$3.12734 \mathrm{e}+013.12734 \mathrm{e}+013.12734 \mathrm{e}+00$ 1.00000e-09 2.12000e-01

$3.12734 \mathrm{e}+013.12734 \mathrm{e}+013.12734 \mathrm{e}+00$ 1.00000e-09 2.12000e-01

$1.00000 \mathrm{e}-02$ 1.00000e-02 1.00000e-03 1.00000e-09 1.00000e-01

$1.00000 \mathrm{e}+001.00000 \mathrm{e}+001.00000 \mathrm{e}-011.00000 \mathrm{e}-091.00000 \mathrm{e}-01$

Element: 6554 \# of layers: 8

$\mathrm{Kx} \mathrm{Ky} \mathrm{Kz}$ Ss Por

7.82681e+02 7.82681e+02 7.82681e+01 1.00000e-09 7.00000e-02

$3.12734 \mathrm{e}+013.12734 \mathrm{e}+013.12734 \mathrm{e}+001.00000 \mathrm{e}-092.12000 \mathrm{e}-01$

$3.12734 \mathrm{e}+013.12734 \mathrm{e}+013.12734 \mathrm{e}+00$ 1.00000e-09 2.12000e-01

$3.12734 \mathrm{e}+013.12734 \mathrm{e}+013.12734 \mathrm{e}+001.00000 \mathrm{e}-092.12000 \mathrm{e}-01$

$3.12734 \mathrm{e}+013.12734 \mathrm{e}+013.12734 \mathrm{e}+001.00000 \mathrm{e}-092.12000 \mathrm{e}-01$

$3.12734 \mathrm{e}+013.12734 \mathrm{e}+013.12734 \mathrm{e}+00$ 1.00000e-09 2.12000e-01

1.00000e-02 1.00000e-02 1.00000e-03 1.00000e-09 1.00000e-01

$1.00000 \mathrm{e}+001.00000 \mathrm{e}+001.00000 \mathrm{e}-011.00000 \mathrm{e}-091.00000 \mathrm{e}-01$

Element: 6555 \# of layers: 8

$\mathrm{Kx} \mathrm{Ky} \mathrm{Kz}$ Ss Por

$1.63739 \mathrm{e}+03$ 1.63739e+03 1.63739e+02 1.00000e-09 7.00000e-02

$1.63739 \mathrm{e}+031.63739 \mathrm{e}+03$ 1.63739e+02 1.00000e-09 7.00000e-02

$6.54224 \mathrm{e}+016.54224 \mathrm{e}+016.54224 \mathrm{e}+001.00000 \mathrm{e}-092.12000 \mathrm{e}-01$

$6.54224 \mathrm{e}+016.54224 \mathrm{e}+016.54224 \mathrm{e}+001.00000 \mathrm{e}-092.12000 \mathrm{e}-01$

$6.54224 \mathrm{e}+016.54224 \mathrm{e}+016.54224 \mathrm{e}+001.00000 \mathrm{e}-092.12000 \mathrm{e}-01$

$6.54224 \mathrm{e}+016.54224 \mathrm{e}+016.54224 \mathrm{e}+001.00000 \mathrm{e}-092.12000 \mathrm{e}-01$

$1.00000 \mathrm{e}-02$ 1.00000e-02 1.00000e-03 1.00000e-09 1.00000e-01

$1.00000 \mathrm{e}+001.00000 \mathrm{e}+001.00000 \mathrm{e}-011.00000 \mathrm{e}-091.00000 \mathrm{e}-01$

Element: 6556 \# of layers: 8

$\mathrm{Kx} \mathrm{Ky} \mathrm{Kz}$ Ss Por

$1.63739 \mathrm{e}+03$ 1.63739e+03 1.63739e+02 1.00000e-09 7.00000e-02

$1.63739 \mathrm{e}+031.63739 \mathrm{e}+03$ 1.63739e+02 1.00000e-09 7.00000e-02

$6.54224 \mathrm{e}+016.54224 \mathrm{e}+016.54224 \mathrm{e}+00$ 1.00000e-09 2.12000e-01

$6.54224 \mathrm{e}+016.54224 \mathrm{e}+016.54224 \mathrm{e}+001.00000 \mathrm{e}-092.12000 \mathrm{e}-01$

$6.54224 \mathrm{e}+016.54224 \mathrm{e}+016.54224 \mathrm{e}+001.00000 \mathrm{e}-092.12000 \mathrm{e}-01$ 
$6.54224 \mathrm{e}+016.54224 \mathrm{e}+016.54224 \mathrm{e}+001.00000 \mathrm{e}-092.12000 \mathrm{e}-01$ $1.00000 \mathrm{e}-02$ 1.00000e-02 1.00000e-03 1.00000e-09 1.00000e-01 $1.00000 \mathrm{e}+001.00000 \mathrm{e}+001.00000 \mathrm{e}-01$ 1.00000e-09 1.00000e-01

Element: 6557 \# of layers: 6

$\mathrm{Kx} \mathrm{Ky} \mathrm{Kz}$ Ss Por

$6.54224 \mathrm{e}+016.54224 \mathrm{e}+016.54224 \mathrm{e}+00$ 1.00000e-09 2.12000e-01

$6.54224 \mathrm{e}+016.54224 \mathrm{e}+016.54224 \mathrm{e}+001.00000 \mathrm{e}-092.12000 \mathrm{e}-01$

$6.54224 \mathrm{e}+016.54224 \mathrm{e}+016.54224 \mathrm{e}+001.00000 \mathrm{e}-092.12000 \mathrm{e}-01$

$6.54224 \mathrm{e}+016.54224 \mathrm{e}+016.54224 \mathrm{e}+001.00000 \mathrm{e}-092.12000 \mathrm{e}-01$

$1.00000 \mathrm{e}-02$ 1.00000e-02 1.00000e-03 1.00000e-09 1.00000e-01

$1.00000 \mathrm{e}+001.00000 \mathrm{e}+001.00000 \mathrm{e}-011.00000 \mathrm{e}-091.00000 \mathrm{e}-01$

Element: 6558 \# of layers: 7

Kx Ky Kz Ss Por

$1.63739 \mathrm{e}+03$ 1.63739e+03 1.63739e+02 1.00000e-09 7.00000e-02

$6.54224 \mathrm{e}+016.54224 \mathrm{e}+016.54224 \mathrm{e}+001.00000 \mathrm{e}-092.12000 \mathrm{e}-01$

$6.54224 \mathrm{e}+016.54224 \mathrm{e}+016.54224 \mathrm{e}+001.00000 \mathrm{e}-092.12000 \mathrm{e}-01$

$6.54224 \mathrm{e}+016.54224 \mathrm{e}+016.54224 \mathrm{e}+001.00000 \mathrm{e}-092.12000 \mathrm{e}-01$

$6.54224 \mathrm{e}+016.54224 \mathrm{e}+016.54224 \mathrm{e}+001.00000 \mathrm{e}-092.12000 \mathrm{e}-01$

$1.00000 \mathrm{e}-02$ 1.00000e-02 1.00000e-03 1.00000e-09 1.00000e-01

$1.00000 \mathrm{e}+001.00000 \mathrm{e}+001.00000 \mathrm{e}-011.00000 \mathrm{e}-091.00000 \mathrm{e}-01$

Element: 6559 \# of layers: 7

$\mathrm{Kx} \mathrm{Ky} \mathrm{Kz}$ Ss Por

$1.63739 \mathrm{e}+03$ 1.63739e+03 1.63739e+02 1.00000e-09 7.00000e-02

$6.54224 \mathrm{e}+016.54224 \mathrm{e}+016.54224 \mathrm{e}+00$ 1.00000e-09 2.12000e-01

$6.54224 \mathrm{e}+016.54224 \mathrm{e}+016.54224 \mathrm{e}+001.00000 \mathrm{e}-092.12000 \mathrm{e}-01$

$6.54224 \mathrm{e}+016.54224 \mathrm{e}+016.54224 \mathrm{e}+001.00000 \mathrm{e}-092.12000 \mathrm{e}-01$

$6.54224 \mathrm{e}+016.54224 \mathrm{e}+016.54224 \mathrm{e}+001.00000 \mathrm{e}-092.12000 \mathrm{e}-01$

$1.00000 \mathrm{e}-02$ 1.00000e-02 1.00000e-03 1.00000e-09 1.00000e-01

$1.00000 \mathrm{e}+001.00000 \mathrm{e}+001.00000 \mathrm{e}-011.00000 \mathrm{e}-091.00000 \mathrm{e}-01$

Element: 6560 \# of layers: 7

$\mathrm{Kx} \mathrm{Ky} \mathrm{Kz}$ Ss Por

$1.63739 \mathrm{e}+03$ 1.63739e+03 1.63739e+02 1.00000e-09 7.00000e-02

$6.54224 \mathrm{e}+016.54224 \mathrm{e}+016.54224 \mathrm{e}+001.00000 \mathrm{e}-092.12000 \mathrm{e}-01$

$6.54224 \mathrm{e}+016.54224 \mathrm{e}+016.54224 \mathrm{e}+001.00000 \mathrm{e}-092.12000 \mathrm{e}-01$

$6.54224 \mathrm{e}+016.54224 \mathrm{e}+016.54224 \mathrm{e}+001.00000 \mathrm{e}-092.12000 \mathrm{e}-01$

$6.54224 \mathrm{e}+016.54224 \mathrm{e}+016.54224 \mathrm{e}+001.00000 \mathrm{e}-092.12000 \mathrm{e}-01$

$1.00000 \mathrm{e}-02$ 1.00000e-02 1.00000e-03 1.00000e-09 1.00000e-01

$1.00000 \mathrm{e}+001.00000 \mathrm{e}+001.00000 \mathrm{e}-011.00000 \mathrm{e}-091.00000 \mathrm{e}-01$

Element: 6561 \# of layers: 7

$\mathrm{Kx} \mathrm{Ky} \mathrm{Kz}$ Ss Por

$1.63739 \mathrm{e}+03$ 1.63739e+03 1.63739e+02 1.00000e-09 7.00000e-02

$6.54224 \mathrm{e}+016.54224 \mathrm{e}+016.54224 \mathrm{e}+00$ 1.00000e-09 2.12000e-01

$6.54224 \mathrm{e}+016.54224 \mathrm{e}+016.54224 \mathrm{e}+001.00000 \mathrm{e}-092.12000 \mathrm{e}-01$

$6.54224 \mathrm{e}+016.54224 \mathrm{e}+016.54224 \mathrm{e}+00$ 1.00000e-09 2.12000e-01

$6.54224 \mathrm{e}+016.54224 \mathrm{e}+016.54224 \mathrm{e}+001.00000 \mathrm{e}-092.12000 \mathrm{e}-01$

$1.00000 \mathrm{e}-02$ 1.00000e-02 1.00000e-03 1.00000e-09 1.00000e-01 
$1.00000 \mathrm{e}+001.00000 \mathrm{e}+00$ 1.00000e-01 1.00000e-09 1.00000e-01

Element: 6562 \# of layers: 8

Kx Ky Kz Ss Por

$1.63739 \mathrm{e}+03$ 1.63739e+03 1.63739e+02 1.00000e-09 7.00000e-02

$1.63739 \mathrm{e}+031.63739 \mathrm{e}+03$ 1.63739e+02 1.00000e-09 7.00000e-02

$6.54224 \mathrm{e}+016.54224 \mathrm{e}+016.54224 \mathrm{e}+001.00000 \mathrm{e}-092.12000 \mathrm{e}-01$

$6.54224 \mathrm{e}+016.54224 \mathrm{e}+016.54224 \mathrm{e}+001.00000 \mathrm{e}-092.12000 \mathrm{e}-01$

$6.54224 \mathrm{e}+016.54224 \mathrm{e}+016.54224 \mathrm{e}+001.00000 \mathrm{e}-092.12000 \mathrm{e}-01$

$6.54224 \mathrm{e}+016.54224 \mathrm{e}+016.54224 \mathrm{e}+001.00000 \mathrm{e}-092.12000 \mathrm{e}-01$

$1.00000 \mathrm{e}-02$ 1.00000e-02 1.00000e-03 1.00000e-09 1.00000e-01

$1.00000 \mathrm{e}+001.00000 \mathrm{e}+001.00000 \mathrm{e}-011.00000 \mathrm{e}-091.00000 \mathrm{e}-01$

Element: 6563 \# of layers: 8

$\mathrm{Kx} \mathrm{Ky} \mathrm{Kz}$ Ss Por

$1.63739 \mathrm{e}+03$ 1.63739e+03 1.63739e+02 1.00000e-09 7.00000e-02

$1.63739 \mathrm{e}+03$ 1.63739e+03 1.63739e+02 1.00000e-09 7.00000e-02

$6.54224 \mathrm{e}+016.54224 \mathrm{e}+016.54224 \mathrm{e}+001.00000 \mathrm{e}-092.12000 \mathrm{e}-01$

$6.54224 \mathrm{e}+016.54224 \mathrm{e}+016.54224 \mathrm{e}+001.00000 \mathrm{e}-092.12000 \mathrm{e}-01$

$6.54224 \mathrm{e}+016.54224 \mathrm{e}+016.54224 \mathrm{e}+001.00000 \mathrm{e}-092.12000 \mathrm{e}-01$

$6.54224 \mathrm{e}+016.54224 \mathrm{e}+016.54224 \mathrm{e}+00$ 1.00000e-09 2.12000e-01

$1.00000 \mathrm{e}-02$ 1.00000e-02 1.00000e-03 1.00000e-09 1.00000e-01

$1.00000 \mathrm{e}+001.00000 \mathrm{e}+001.00000 \mathrm{e}-011.00000 \mathrm{e}-091.00000 \mathrm{e}-01$

Element: 6564 \# of layers: 7

$\mathrm{Kx} \mathrm{Ky} \mathrm{Kz}$ Ss Por

1.25726e+03 1.25726e+03 1.25726e+02 1.00000e-09 7.00000e-02

$5.02346 \mathrm{e}+015.02346 \mathrm{e}+015.02346 \mathrm{e}+001.00000 \mathrm{e}-092.12000 \mathrm{e}-01$

$5.02346 \mathrm{e}+015.02346 \mathrm{e}+015.02346 \mathrm{e}+001.00000 \mathrm{e}-092.12000 \mathrm{e}-01$

$5.02346 \mathrm{e}+015.02346 \mathrm{e}+015.02346 \mathrm{e}+001.00000 \mathrm{e}-092.12000 \mathrm{e}-01$

$5.02346 \mathrm{e}+015.02346 \mathrm{e}+015.02346 \mathrm{e}+001.00000 \mathrm{e}-092.12000 \mathrm{e}-01$

$1.00000 \mathrm{e}-02$ 1.00000e-02 1.00000e-03 1.00000e-09 1.00000e-01

$1.00000 \mathrm{e}+001.00000 \mathrm{e}+001.00000 \mathrm{e}-011.00000 \mathrm{e}-091.00000 \mathrm{e}-01$

Element: 6565 \# of layers: 8

$\mathrm{Kx} \mathrm{Ky} \mathrm{Kz}$ Ss Por

$1.25726 \mathrm{e}+03$ 1.25726e+03 1.25726e+02 1.00000e-09 7.00000e-02

$1.25726 \mathrm{e}+031.25726 \mathrm{e}+031.25726 \mathrm{e}+02$ 1.00000e-09 7.00000e-02

$5.02346 \mathrm{e}+015.02346 \mathrm{e}+015.02346 \mathrm{e}+00$ 1.00000e-09 2.12000e-01

$5.02346 \mathrm{e}+015.02346 \mathrm{e}+015.02346 \mathrm{e}+001.00000 \mathrm{e}-092.12000 \mathrm{e}-01$

$5.02346 \mathrm{e}+015.02346 \mathrm{e}+015.02346 \mathrm{e}+001.00000 \mathrm{e}-092.12000 \mathrm{e}-01$

$5.02346 \mathrm{e}+015.02346 \mathrm{e}+015.02346 \mathrm{e}+001.00000 \mathrm{e}-092.12000 \mathrm{e}-01$

$1.00000 \mathrm{e}-011.00000 \mathrm{e}-011.00000 \mathrm{e}-021.00000 \mathrm{e}-091.00000 \mathrm{e}-01$

$1.00000 \mathrm{e}+001.00000 \mathrm{e}+001.00000 \mathrm{e}-01$ 1.00000e-09 1.00000e-01

Element: 6566 \# of layers: 8

$\mathrm{Kx} \mathrm{Ky} \mathrm{Kz}$ Ss Por

$1.25726 \mathrm{e}+031.25726 \mathrm{e}+03$ 1.25726e+02 1.00000e-09 7.00000e-02

$1.25726 \mathrm{e}+031.25726 \mathrm{e}+03$ 1.25726e+02 1.00000e-09 7.00000e-02

$5.02346 \mathrm{e}+015.02346 \mathrm{e}+015.02346 \mathrm{e}+001.00000 \mathrm{e}-092.12000 \mathrm{e}-01$

$5.02346 \mathrm{e}+015.02346 \mathrm{e}+015.02346 \mathrm{e}+001.00000 \mathrm{e}-092.12000 \mathrm{e}-01$ 
$5.02346 \mathrm{e}+015.02346 \mathrm{e}+015.02346 \mathrm{e}+001.00000 \mathrm{e}-092.12000 \mathrm{e}-01$ $5.02346 \mathrm{e}+015.02346 \mathrm{e}+015.02346 \mathrm{e}+00$ 1.00000e-09 2.12000e-01 $1.00000 \mathrm{e}-01$ 1.00000e-01 1.00000e-02 1.00000e-09 1.00000e-01 $1.00000 \mathrm{e}+001.00000 \mathrm{e}+001.00000 \mathrm{e}-011.00000 \mathrm{e}-091.00000 \mathrm{e}-01$ Element: 6567 \# of layers: 8

$\mathrm{Kx} \mathrm{Ky} \mathrm{Kz}$ Ss Por

$1.25726 \mathrm{e}+03$ 1.25726e+03 1.25726e+02 1.00000e-09 7.00000e-02 $1.25726 \mathrm{e}+031.25726 \mathrm{e}+031.25726 \mathrm{e}+02$ 1.00000e-09 7.00000e-02 $5.02346 \mathrm{e}+015.02346 \mathrm{e}+015.02346 \mathrm{e}+001.00000 \mathrm{e}-092.12000 \mathrm{e}-01$ $5.02346 \mathrm{e}+015.02346 \mathrm{e}+015.02346 \mathrm{e}+001.00000 \mathrm{e}-092.12000 \mathrm{e}-01$ $5.02346 \mathrm{e}+015.02346 \mathrm{e}+015.02346 \mathrm{e}+001.00000 \mathrm{e}-092.12000 \mathrm{e}-01$ $5.02346 \mathrm{e}+015.02346 \mathrm{e}+015.02346 \mathrm{e}+001.00000 \mathrm{e}-092.12000 \mathrm{e}-01$ $1.00000 \mathrm{e}-01$ 1.00000e-01 1.00000e-02 1.00000e-09 1.00000e-01 $1.00000 \mathrm{e}+001.00000 \mathrm{e}+001.00000 \mathrm{e}-011.00000 \mathrm{e}-09$ 1.00000e-01 Element: 6568 \# of layers: 8

$\mathrm{Kx} \mathrm{Ky} \mathrm{Kz}$ Ss Por

$1.25726 \mathrm{e}+03$ 1.25726e+03 1.25726e+02 1.00000e-09 7.00000e-02 $1.25726 \mathrm{e}+031.25726 \mathrm{e}+031.25726 \mathrm{e}+021.00000 \mathrm{e}-097.00000 \mathrm{e}-02$ $5.02346 \mathrm{e}+015.02346 \mathrm{e}+015.02346 \mathrm{e}+001.00000 \mathrm{e}-092.12000 \mathrm{e}-01$ $5.02346 \mathrm{e}+015.02346 \mathrm{e}+015.02346 \mathrm{e}+001.00000 \mathrm{e}-092.12000 \mathrm{e}-01$ $5.02346 \mathrm{e}+015.02346 \mathrm{e}+015.02346 \mathrm{e}+001.00000 \mathrm{e}-092.12000 \mathrm{e}-01$ $5.02346 \mathrm{e}+01$ 5.02346e+01 5.02346e+00 1.00000e-09 2.12000e-01 $1.00000 \mathrm{e}-011.00000 \mathrm{e}-011.00000 \mathrm{e}-021.00000 \mathrm{e}-091.00000 \mathrm{e}-01$ $1.00000 \mathrm{e}+001.00000 \mathrm{e}+001.00000 \mathrm{e}-011.00000 \mathrm{e}-091.00000 \mathrm{e}-01$

Element: 6569 \# of layers: 8

$\mathrm{Kx} \mathrm{Ky} \mathrm{Kz}$ Ss Por

$1.25726 \mathrm{e}+03$ 1.25726e+03 1.25726e+02 1.00000e-09 7.00000e-02 $1.25726 \mathrm{e}+031.25726 \mathrm{e}+03 \quad 1.25726 \mathrm{e}+02$ 1.00000e-09 7.00000e-02 $5.02346 \mathrm{e}+015.02346 \mathrm{e}+015.02346 \mathrm{e}+001.00000 \mathrm{e}-092.12000 \mathrm{e}-01$ $5.02346 \mathrm{e}+015.02346 \mathrm{e}+015.02346 \mathrm{e}+001.00000 \mathrm{e}-092.12000 \mathrm{e}-01$ $5.02346 \mathrm{e}+015.02346 \mathrm{e}+015.02346 \mathrm{e}+001.00000 \mathrm{e}-092.12000 \mathrm{e}-01$ $5.02346 \mathrm{e}+015.02346 \mathrm{e}+015.02346 \mathrm{e}+00$ 1.00000e-09 2.12000e-01 1.00000e-02 1.00000e-02 1.00000e-03 1.00000e-09 1.00000e-01 $1.00000 \mathrm{e}+001.00000 \mathrm{e}+001.00000 \mathrm{e}-011.00000 \mathrm{e}-091.00000 \mathrm{e}-01$ Element: 6570 \# of layers: 8

$\mathrm{Kx} \mathrm{Ky} \mathrm{Kz}$ Ss Por

$1.25726 \mathrm{e}+031.25726 \mathrm{e}+03$ 1.25726e+02 1.00000e-09 7.00000e-02 $1.25726 \mathrm{e}+031.25726 \mathrm{e}+031.25726 \mathrm{e}+021.00000 \mathrm{e}-097.00000 \mathrm{e}-02$ $5.02346 \mathrm{e}+015.02346 \mathrm{e}+015.02346 \mathrm{e}+001.00000 \mathrm{e}-092.12000 \mathrm{e}-01$ $5.02346 \mathrm{e}+015.02346 \mathrm{e}+015.02346 \mathrm{e}+001.00000 \mathrm{e}-092.12000 \mathrm{e}-01$ $5.02346 \mathrm{e}+015.02346 \mathrm{e}+015.02346 \mathrm{e}+001.00000 \mathrm{e}-092.12000 \mathrm{e}-01$ $5.02346 \mathrm{e}+015.02346 \mathrm{e}+015.02346 \mathrm{e}+001.00000 \mathrm{e}-092.12000 \mathrm{e}-01$ $1.00000 \mathrm{e}-02$ 1.00000e-02 1.00000e-03 1.00000e-09 1.00000e-01 $1.00000 \mathrm{e}+001.00000 \mathrm{e}+001.00000 \mathrm{e}-01$ 1.00000e-09 1.00000e-01 Element: 6571 \# of layers: 8

Kx Ky Kz Ss Por 
1.25726e+03 1.25726e+03 1.25726e+02 1.00000e-09 7.00000e-02 $1.25726 \mathrm{e}+031.25726 \mathrm{e}+031.25726 \mathrm{e}+021.00000 \mathrm{e}-097.00000 \mathrm{e}-02$ $5.02346 \mathrm{e}+015.02346 \mathrm{e}+015.02346 \mathrm{e}+001.00000 \mathrm{e}-092.12000 \mathrm{e}-01$ $5.02346 \mathrm{e}+015.02346 \mathrm{e}+015.02346 \mathrm{e}+001.00000 \mathrm{e}-092.12000 \mathrm{e}-01$ $5.02346 \mathrm{e}+015.02346 \mathrm{e}+015.02346 \mathrm{e}+001.00000 \mathrm{e}-092.12000 \mathrm{e}-01$ $5.02346 \mathrm{e}+015.02346 \mathrm{e}+015.02346 \mathrm{e}+001.00000 \mathrm{e}-092.12000 \mathrm{e}-01$ $1.00000 \mathrm{e}-02$ 1.00000e-02 1.00000e-03 1.00000e-09 1.00000e-01 $1.00000 \mathrm{e}+001.00000 \mathrm{e}+001.00000 \mathrm{e}-011.00000 \mathrm{e}-091.00000 \mathrm{e}-01$ Element: 6572 \# of layers: 7

$\mathrm{Kx} \mathrm{Ky} \mathrm{Kz}$ Ss Por

$1.25726 \mathrm{e}+03$ 1.25726e+03 1.25726e+02 1.00000e-09 7.00000e-02 $5.02346 \mathrm{e}+015.02346 \mathrm{e}+015.02346 \mathrm{e}+001.00000 \mathrm{e}-092.12000 \mathrm{e}-01$ $5.02346 \mathrm{e}+015.02346 \mathrm{e}+015.02346 \mathrm{e}+001.00000 \mathrm{e}-092.12000 \mathrm{e}-01$ $5.02346 \mathrm{e}+015.02346 \mathrm{e}+015.02346 \mathrm{e}+001.00000 \mathrm{e}-092.12000 \mathrm{e}-01$ $5.02346 \mathrm{e}+015.02346 \mathrm{e}+015.02346 \mathrm{e}+001.00000 \mathrm{e}-092.12000 \mathrm{e}-01$ $1.00000 \mathrm{e}-01$ 1.00000e-01 1.00000e-02 1.00000e-09 1.00000e-01 $1.00000 \mathrm{e}+001.00000 \mathrm{e}+001.00000 \mathrm{e}-011.00000 \mathrm{e}-091.00000 \mathrm{e}-01$ Element: 6573 \# of layers: 9

$\mathrm{Kx} \mathrm{Ky} \mathrm{Kz}$ Ss Por

3.72437e+02 3.72437e+02 3.72437e+01 1.00000e-09 7.00000e-02 3.72437e+02 3.72437e+02 3.72437e+01 1.00000e-09 7.00000e-02 3.72437e+02 3.72437e+02 3.72437e+01 1.00000e-09 7.00000e-02 $1.48811 \mathrm{e}+011.48811 \mathrm{e}+011.48811 \mathrm{e}+001.00000 \mathrm{e}-092.12000 \mathrm{e}-01$ $1.48811 \mathrm{e}+011.48811 \mathrm{e}+011.48811 \mathrm{e}+001.00000 \mathrm{e}-092.12000 \mathrm{e}-01$ $1.48811 \mathrm{e}+011.48811 \mathrm{e}+011.48811 \mathrm{e}+001.00000 \mathrm{e}-092.12000 \mathrm{e}-01$ $1.48811 \mathrm{e}+011.48811 \mathrm{e}+011.48811 \mathrm{e}+001.00000 \mathrm{e}-092.12000 \mathrm{e}-01$ $1.00000 \mathrm{e}-011.00000 \mathrm{e}-011.00000 \mathrm{e}-021.00000 \mathrm{e}-091.00000 \mathrm{e}-01$ $1.00000 \mathrm{e}+001.00000 \mathrm{e}+001.00000 \mathrm{e}-011.00000 \mathrm{e}-091.00000 \mathrm{e}-01$ Element: 6574 \# of layers: 8

$\mathrm{Kx} \mathrm{Ky} \mathrm{Kz}$ Ss Por

3.72437e+02 3.72437e+02 3.72437e+01 1.00000e-09 7.00000e-02 3.72437e+02 3.72437e+02 3.72437e+01 1.00000e-09 7.00000e-02 $1.48811 \mathrm{e}+011.48811 \mathrm{e}+011.48811 \mathrm{e}+001.00000 \mathrm{e}-092.12000 \mathrm{e}-01$ $1.48811 \mathrm{e}+011.48811 \mathrm{e}+011.48811 \mathrm{e}+001.00000 \mathrm{e}-092.12000 \mathrm{e}-01$ $1.48811 \mathrm{e}+011.48811 \mathrm{e}+011.48811 \mathrm{e}+001.00000 \mathrm{e}-092.12000 \mathrm{e}-01$ $1.48811 \mathrm{e}+011.48811 \mathrm{e}+011.48811 \mathrm{e}+001.00000 \mathrm{e}-092.12000 \mathrm{e}-01$ $1.00000 \mathrm{e}-01$ 1.00000e-01 1.00000e-02 1.00000e-09 1.00000e-01 $1.00000 \mathrm{e}+001.00000 \mathrm{e}+001.00000 \mathrm{e}-011.00000 \mathrm{e}-091.00000 \mathrm{e}-01$ Element: 6575 \# of layers: 7

$\mathrm{Kx} \mathrm{Ky} \mathrm{Kz}$ Ss Por

3.72437e+02 3.72437e+02 3.72437e+01 1.00000e-09 7.00000e-02 $3.72437 \mathrm{e}+023.72437 \mathrm{e}+02$ 3.72437e+01 1.00000e-09 7.00000e-02 $1.48811 \mathrm{e}+011.48811 \mathrm{e}+011.48811 \mathrm{e}+001.00000 \mathrm{e}-092.12000 \mathrm{e}-01$ $1.48811 \mathrm{e}+011.48811 \mathrm{e}+01$ 1.48811e+00 1.00000e-09 2.12000e-01 $1.48811 \mathrm{e}+011.48811 \mathrm{e}+011.48811 \mathrm{e}+001.00000 \mathrm{e}-092.12000 \mathrm{e}-01$ $1.00000 \mathrm{e}-01$ 1.00000e-01 1.00000e-02 1.00000e-09 1.00000e-01 
$1.00000 \mathrm{e}+001.00000 \mathrm{e}+00$ 1.00000e-01 1.00000e-09 1.00000e-01

Element: 6576 \# of layers: 8

$\mathrm{Kx} \mathrm{Ky} \mathrm{Kz}$ Ss Por

3.72437e+02 3.72437e+02 3.72437e+01 1.00000e-09 7.00000e-02

3.72437e+02 3.72437e+02 3.72437e+01 1.00000e-09 7.00000e-02

$1.48811 \mathrm{e}+011.48811 \mathrm{e}+011.48811 \mathrm{e}+001.00000 \mathrm{e}-092.12000 \mathrm{e}-01$

$1.48811 \mathrm{e}+011.48811 \mathrm{e}+011.48811 \mathrm{e}+001.00000 \mathrm{e}-092.12000 \mathrm{e}-01$

$1.48811 \mathrm{e}+011.48811 \mathrm{e}+011.48811 \mathrm{e}+001.00000 \mathrm{e}-092.12000 \mathrm{e}-01$

$1.48811 \mathrm{e}+011.48811 \mathrm{e}+011.48811 \mathrm{e}+001.00000 \mathrm{e}-092.12000 \mathrm{e}-01$

$1.00000 \mathrm{e}-011.00000 \mathrm{e}-01$ 1.00000e-02 1.00000e-09 1.00000e-01

$1.00000 \mathrm{e}+001.00000 \mathrm{e}+001.00000 \mathrm{e}-011.00000 \mathrm{e}-091.00000 \mathrm{e}-01$

Element: 6577 \# of layers: 7

$\mathrm{Kx} \mathrm{Ky} \mathrm{Kz}$ Ss Por

3.72437e+02 3.72437e+02 3.72437e+01 1.00000e-09 7.00000e-02 3.72437e+02 3.72437e+02 3.72437e+01 1.00000e-09 7.00000e-02

$1.48811 \mathrm{e}+011.48811 \mathrm{e}+011.48811 \mathrm{e}+001.00000 \mathrm{e}-092.12000 \mathrm{e}-01$

$1.48811 \mathrm{e}+011.48811 \mathrm{e}+011.48811 \mathrm{e}+001.00000 \mathrm{e}-092.12000 \mathrm{e}-01$

$1.48811 \mathrm{e}+011.48811 \mathrm{e}+011.48811 \mathrm{e}+001.00000 \mathrm{e}-092.12000 \mathrm{e}-01$

$1.00000 \mathrm{e}-011.00000 \mathrm{e}-011.00000 \mathrm{e}-021.00000 \mathrm{e}-091.00000 \mathrm{e}-01$

$1.00000 \mathrm{e}+001.00000 \mathrm{e}+001.00000 \mathrm{e}-011.00000 \mathrm{e}-091.00000 \mathrm{e}-01$

Element: 6578 \# of layers: 8

$\mathrm{Kx} \mathrm{Ky} \mathrm{Kz}$ Ss Por

3.72437e+02 3.72437e+02 3.72437e+01 1.00000e-09 7.00000e-02

$3.72437 \mathrm{e}+02$ 3.72437e+02 3.72437e+01 1.00000e-09 7.00000e-02

$1.48811 \mathrm{e}+011.48811 \mathrm{e}+011.48811 \mathrm{e}+001.00000 \mathrm{e}-092.12000 \mathrm{e}-01$

$1.48811 \mathrm{e}+011.48811 \mathrm{e}+011.48811 \mathrm{e}+001.00000 \mathrm{e}-092.12000 \mathrm{e}-01$

$1.48811 \mathrm{e}+011.48811 \mathrm{e}+011.48811 \mathrm{e}+001.00000 \mathrm{e}-092.12000 \mathrm{e}-01$

$1.48811 \mathrm{e}+011.48811 \mathrm{e}+011.48811 \mathrm{e}+001.00000 \mathrm{e}-092.12000 \mathrm{e}-01$

$1.00000 \mathrm{e}-011.00000 \mathrm{e}-01$ 1.00000e-02 1.00000e-09 1.00000e-01

$1.00000 \mathrm{e}+001.00000 \mathrm{e}+001.00000 \mathrm{e}-011.00000 \mathrm{e}-091.00000 \mathrm{e}-01$

Element: 6579 \# of layers: 7

$\mathrm{Kx} \mathrm{Ky} \mathrm{Kz}$ Ss Por

3.72437e+02 3.72437e+02 3.72437e+01 1.00000e-09 7.00000e-02

$1.48811 \mathrm{e}+011.48811 \mathrm{e}+011.48811 \mathrm{e}+001.00000 \mathrm{e}-092.12000 \mathrm{e}-01$

$1.48811 \mathrm{e}+011.48811 \mathrm{e}+011.48811 \mathrm{e}+001.00000 \mathrm{e}-092.12000 \mathrm{e}-01$

$1.48811 \mathrm{e}+011.48811 \mathrm{e}+011.48811 \mathrm{e}+001.00000 \mathrm{e}-092.12000 \mathrm{e}-01$

$1.48811 \mathrm{e}+011.48811 \mathrm{e}+011.48811 \mathrm{e}+001.00000 \mathrm{e}-092.12000 \mathrm{e}-01$

$1.00000 \mathrm{e}-01$ 1.00000e-01 1.00000e-02 1.00000e-09 1.00000e-01

$1.00000 \mathrm{e}+001.00000 \mathrm{e}+001.00000 \mathrm{e}-011.00000 \mathrm{e}-091.00000 \mathrm{e}-01$

Element: 6580 \# of layers: 8

$\mathrm{Kx} \mathrm{Ky} \mathrm{Kz}$ Ss Por

3.72437e+02 3.72437e+02 3.72437e+01 1.00000e-09 7.00000e-02

3.72437e+02 3.72437e+02 3.72437e+01 1.00000e-09 7.00000e-02

$1.48811 \mathrm{e}+011.48811 \mathrm{e}+011.48811 \mathrm{e}+001.00000 \mathrm{e}-092.12000 \mathrm{e}-01$

$1.48811 \mathrm{e}+011.48811 \mathrm{e}+011.48811 \mathrm{e}+001.00000 \mathrm{e}-092.12000 \mathrm{e}-01$

$1.48811 \mathrm{e}+011.48811 \mathrm{e}+011.48811 \mathrm{e}+001.00000 \mathrm{e}-092.12000 \mathrm{e}-01$ 
$1.48811 \mathrm{e}+011.48811 \mathrm{e}+011.48811 \mathrm{e}+001.00000 \mathrm{e}-092.12000 \mathrm{e}-01$ $1.00000 \mathrm{e}-011.00000 \mathrm{e}-01$ 1.00000e-02 1.00000e-09 1.00000e-01 $1.00000 \mathrm{e}+001.00000 \mathrm{e}+001.00000 \mathrm{e}-011.00000 \mathrm{e}-091.00000 \mathrm{e}-01$

Element: 6581 \# of layers: 8

$\mathrm{Kx} \mathrm{Ky} \mathrm{Kz}$ Ss Por

3.72437e+02 3.72437e+02 3.72437e+01 1.00000e-09 7.00000e-02

3.72437e+02 3.72437e+02 3.72437e+01 1.00000e-09 7.00000e-02

$1.48811 \mathrm{e}+011.48811 \mathrm{e}+011.48811 \mathrm{e}+001.00000 \mathrm{e}-092.12000 \mathrm{e}-01$

$1.48811 \mathrm{e}+011.48811 \mathrm{e}+011.48811 \mathrm{e}+001.00000 \mathrm{e}-092.12000 \mathrm{e}-01$

$1.48811 \mathrm{e}+011.48811 \mathrm{e}+011.48811 \mathrm{e}+001.00000 \mathrm{e}-092.12000 \mathrm{e}-01$

$1.48811 \mathrm{e}+011.48811 \mathrm{e}+011.48811 \mathrm{e}+001.00000 \mathrm{e}-092.12000 \mathrm{e}-01$

$1.00000 \mathrm{e}-01$ 1.00000e-01 1.00000e-02 1.00000e-09 1.00000e-01

$1.00000 \mathrm{e}+001.00000 \mathrm{e}+001.00000 \mathrm{e}-011.00000 \mathrm{e}-091.00000 \mathrm{e}-01$

Element: 6582 \# of layers: 8

$\mathrm{Kx} \mathrm{Ky} \mathrm{Kz}$ Ss Por

4.52563e+02 4.52563e+02 4.52563e+01 1.00000e-09 7.00000e-02

$4.52563 \mathrm{e}+02$ 4.52563e+02 4.52563e+01 1.00000e-09 7.00000e-02

4.52563e+02 4.52563e+02 4.52563e+01 1.00000e-09 7.00000e-02

$1.80827 \mathrm{e}+01$ 1.80827e+01 1.80827e+00 1.00000e-09 2.12000e-01

$1.80827 \mathrm{e}+01$ 1.80827e+01 1.80827e+00 1.00000e-09 2.12000e-01

$1.80827 \mathrm{e}+011.80827 \mathrm{e}+01$ 1.80827e+00 1.00000e-09 2.12000e-01

$1.00000 \mathrm{e}-011.00000 \mathrm{e}-011.00000 \mathrm{e}-021.00000 \mathrm{e}-091.00000 \mathrm{e}-01$

$1.00000 \mathrm{e}+001.00000 \mathrm{e}+001.00000 \mathrm{e}-01$ 1.00000e-09 1.00000e-01

Element: 6583 \# of layers: 8

$\mathrm{Kx} \mathrm{Ky} \mathrm{Kz}$ Ss Por

4.52563e+02 4.52563e+02 4.52563e+01 1.00000e-09 7.00000e-02

$4.52563 \mathrm{e}+02$ 4.52563e+02 4.52563e+01 1.00000e-09 7.00000e-02

4.52563e+02 4.52563e+02 4.52563e+01 1.00000e-09 7.00000e-02

$4.52563 \mathrm{e}+02$ 4.52563e+02 4.52563e+01 1.00000e-09 7.00000e-02

$1.80827 \mathrm{e}+01$ 1.80827e+01 1.80827e+00 1.00000e-09 2.12000e-01

$1.80827 \mathrm{e}+01$ 1.80827e+01 1.80827e+00 1.00000e-09 2.12000e-01

$1.00000 \mathrm{e}-01$ 1.00000e-01 1.00000e-02 1.00000e-09 1.00000e-01

$1.00000 \mathrm{e}+001.00000 \mathrm{e}+001.00000 \mathrm{e}-011.00000 \mathrm{e}-091.00000 \mathrm{e}-01$

Element: 6584 \# of layers: 7

$\mathrm{Kx} \mathrm{Ky} \mathrm{Kz}$ Ss Por

4.52563e+02 4.52563e+02 4.52563e+01 1.00000e-09 7.00000e-02

$4.52563 \mathrm{e}+02$ 4.52563e+02 4.52563e+01 1.00000e-09 7.00000e-02

$4.52563 \mathrm{e}+02$ 4.52563e+02 4.52563e+01 1.00000e-09 7.00000e-02

4.52563e+02 4.52563e+02 4.52563e+01 1.00000e-09 7.00000e-02

$1.80827 \mathrm{e}+01$ 1.80827e+01 1.80827e+00 1.00000e-09 2.12000e-01

$1.00000 \mathrm{e}-01$ 1.00000e-01 1.00000e-02 1.00000e-09 1.00000e-01

$1.00000 \mathrm{e}+001.00000 \mathrm{e}+001.00000 \mathrm{e}-011.00000 \mathrm{e}-091.00000 \mathrm{e}-01$

Element: 6585 \# of layers: 8

$\mathrm{Kx} \mathrm{Ky} \mathrm{Kz}$ Ss Por

4.52563e+02 4.52563e+02 4.52563e+01 1.00000e-09 7.00000e-02

$4.52563 \mathrm{e}+024.52563 \mathrm{e}+024.52563 \mathrm{e}+01$ 1.00000e-09 7.00000e-02 
4.52563e+02 4.52563e+02 4.52563e+01 1.00000e-09 7.00000e-02 4.52563e+02 4.52563e+02 4.52563e+01 1.00000e-09 7.00000e-02 $1.80827 \mathrm{e}+011.80827 \mathrm{e}+01$ 1.80827e+00 1.00000e-09 2.12000e-01 $1.80827 \mathrm{e}+01$ 1.80827e+01 1.80827e+00 1.00000e-09 2.12000e-01 1.00000e-01 1.00000e-01 1.00000e-02 1.00000e-09 1.00000e-01 $1.00000 \mathrm{e}+001.00000 \mathrm{e}+001.00000 \mathrm{e}-011.00000 \mathrm{e}-091.00000 \mathrm{e}-01$ Element: 6586 \# of layers: 6

$\mathrm{Kx} \mathrm{Ky} \mathrm{Kz}$ Ss Por

4.52563e+02 4.52563e+02 4.52563e+01 1.00000e-09 7.00000e-02 $4.52563 \mathrm{e}+02$ 4.52563e+02 4.52563e+01 1.00000e-09 7.00000e-02 $1.80827 \mathrm{e}+01$ 1.80827e+01 1.80827e+00 1.00000e-09 2.12000e-01 $1.80827 \mathrm{e}+01$ 1.80827e+01 1.80827e+00 1.00000e-09 2.12000e-01 $1.00000 \mathrm{e}-01$ 1.00000e-01 1.00000e-02 1.00000e-09 1.00000e-01 $1.00000 \mathrm{e}+001.00000 \mathrm{e}+001.00000 \mathrm{e}-011.00000 \mathrm{e}-091.00000 \mathrm{e}-01$ Element: 6587 \# of layers: 7

Kx Ky Kz Ss Por

4.52563e+02 4.52563e+02 4.52563e+01 1.00000e-09 7.00000e-02 4.52563e+02 4.52563e+02 4.52563e+01 1.00000e-09 7.00000e-02 $1.80827 \mathrm{e}+01$ 1.80827e+01 1.80827e+00 1.00000e-09 2.12000e-01 $1.80827 \mathrm{e}+01$ 1.80827e+01 1.80827e+00 1.00000e-09 2.12000e-01 $1.80827 \mathrm{e}+01$ 1.80827e+01 1.80827e+00 1.00000e-09 2.12000e-01 $1.00000 \mathrm{e}-011.00000 \mathrm{e}-011.00000 \mathrm{e}-021.00000 \mathrm{e}-091.00000 \mathrm{e}-01$ $1.00000 \mathrm{e}+001.00000 \mathrm{e}+001.00000 \mathrm{e}-01$ 1.00000e-09 1.00000e-01 Element: 6588 \# of layers: 7

$\mathrm{Kx} \mathrm{Ky} \mathrm{Kz}$ Ss Por

4.52563e+02 4.52563e+02 4.52563e+01 1.00000e-09 7.00000e-02 4.52563e+02 4.52563e+02 4.52563e+01 1.00000e-09 7.00000e-02 $1.80827 \mathrm{e}+01$ 1.80827e+01 1.80827e+00 1.00000e-09 2.12000e-01 $1.80827 \mathrm{e}+01$ 1.80827e+01 1.80827e+00 1.00000e-09 2.12000e-01 $1.80827 \mathrm{e}+01$ 1.80827e+01 1.80827e+00 1.00000e-09 2.12000e-01 $1.00000 \mathrm{e}-01$ 1.00000e-01 1.00000e-02 1.00000e-09 1.00000e-01 $1.00000 \mathrm{e}+001.00000 \mathrm{e}+001.00000 \mathrm{e}-011.00000 \mathrm{e}-091.00000 \mathrm{e}-01$ Element: 6589 \# of layers: 7

$\mathrm{Kx} \mathrm{Ky} \mathrm{Kz}$ Ss Por

4.52563e+02 4.52563e+02 4.52563e+01 1.00000e-09 7.00000e-02 4.52563e+02 4.52563e+02 4.52563e+01 1.00000e-09 7.00000e-02 $1.80827 \mathrm{e}+011.80827 \mathrm{e}+011.80827 \mathrm{e}+001.00000 \mathrm{e}-092.12000 \mathrm{e}-01$ $1.80827 \mathrm{e}+011.80827 \mathrm{e}+01$ 1.80827e+00 1.00000e-09 2.12000e-01 $1.80827 \mathrm{e}+011.80827 \mathrm{e}+01$ 1.80827e+00 1.00000e-09 2.12000e-01 $1.00000 \mathrm{e}-01$ 1.00000e-01 1.00000e-02 1.00000e-09 1.00000e-01 $1.00000 \mathrm{e}+001.00000 \mathrm{e}+001.00000 \mathrm{e}-011.00000 \mathrm{e}-091.00000 \mathrm{e}-01$ Element: 6590 \# of layers: 8

$\mathrm{Kx} \mathrm{Ky} \mathrm{Kz}$ Ss Por

4.52563e+02 4.52563e+02 4.52563e+01 1.00000e-09 7.00000e-02 4.52563e+02 4.52563e+02 4.52563e+01 1.00000e-09 7.00000e-02 $4.52563 \mathrm{e}+02$ 4.52563e+02 4.52563e+01 1.00000e-09 7.00000e-02 
$1.80827 \mathrm{e}+01$ 1.80827e+01 1.80827e+00 1.00000e-09 2.12000e-01 $1.80827 \mathrm{e}+01$ 1.80827e+01 1.80827e+00 1.00000e-09 2.12000e-01 $1.80827 \mathrm{e}+011.80827 \mathrm{e}+01$ 1.80827e+00 1.00000e-09 2.12000e-01 $1.00000 \mathrm{e}-011.00000 \mathrm{e}-01$ 1.00000e-02 1.00000e-09 1.00000e-01 $1.00000 \mathrm{e}+001.00000 \mathrm{e}+001.00000 \mathrm{e}-01$ 1.00000e-09 1.00000e-01 Element: 6591 \# of layers: 6

$\mathrm{Kx} \mathrm{Ky} \mathrm{Kz}$ Ss Por

$1.18581 \mathrm{e}+03$ 1.18581e+03 1.18581e+02 1.00000e-09 7.00000e-02 $1.18581 \mathrm{e}+03$ 1.18581e+03 1.18581e+02 1.00000e-09 7.00000e-02 $1.18581 \mathrm{e}+031.18581 \mathrm{e}+03$ 1.18581e+02 1.00000e-09 7.00000e-02 $4.73815 \mathrm{e}+014.73815 \mathrm{e}+014.73815 \mathrm{e}+00$ 1.00000e-09 2.12000e-01 $1.00000 \mathrm{e}-01$ 1.00000e-01 1.00000e-02 1.00000e-09 1.00000e-01 $1.00000 \mathrm{e}+001.00000 \mathrm{e}+001.00000 \mathrm{e}-011.00000 \mathrm{e}-091.00000 \mathrm{e}-01$ Element: 6592 \# of layers: 6

$\mathrm{Kx} \mathrm{Ky} \mathrm{Kz}$ Ss Por

1.18581e+03 1.18581e+03 1.18581e+02 1.00000e-09 7.00000e-02 $1.18581 \mathrm{e}+03$ 1.18581e+03 1.18581e+02 1.00000e-09 7.00000e-02 $1.18581 \mathrm{e}+03$ 1.18581e+03 1.18581e+02 1.00000e-09 7.00000e-02 $4.73815 \mathrm{e}+014.73815 \mathrm{e}+01$ 4.73815e+00 1.00000e-09 2.12000e-01 $1.00000 \mathrm{e}-021.00000 \mathrm{e}-021.00000 \mathrm{e}-031.00000 \mathrm{e}-091.00000 \mathrm{e}-01$ $1.00000 \mathrm{e}+001.00000 \mathrm{e}+001.00000 \mathrm{e}-011.00000 \mathrm{e}-091.00000 \mathrm{e}-01$ Element: 6593 \# of layers: 6

$\mathrm{Kx} \mathrm{Ky} \mathrm{Kz}$ Ss Por

1.18581e+03 1.18581e+03 1.18581e+02 1.00000e-09 7.00000e-02 $1.18581 \mathrm{e}+03$ 1.18581e+03 1.18581e+02 1.00000e-09 7.00000e-02 $1.18581 \mathrm{e}+03$ 1.18581e+03 1.18581e+02 1.00000e-09 7.00000e-02 4.73815e+01 4.73815e+01 4.73815e+00 1.00000e-09 2.12000e-01 $1.00000 \mathrm{e}-02$ 1.00000e-02 1.00000e-03 1.00000e-09 1.00000e-01 $1.00000 \mathrm{e}+001.00000 \mathrm{e}+001.00000 \mathrm{e}-011.00000 \mathrm{e}-091.00000 \mathrm{e}-01$ Element: 6594 \# of layers: 7

$\mathrm{Kx} \mathrm{Ky} \mathrm{Kz}$ Ss Por

$1.18581 \mathrm{e}+031.18581 \mathrm{e}+03$ 1.18581e+02 1.00000e-09 7.00000e-02 $1.18581 \mathrm{e}+031.18581 \mathrm{e}+031.18581 \mathrm{e}+02$ 1.00000e-09 7.00000e-02 $1.18581 \mathrm{e}+03$ 1.18581e+03 1.18581e+02 1.00000e-09 7.00000e-02 4.73815e+01 4.73815e+01 4.73815e+00 1.00000e-09 2.12000e-01 $4.73815 \mathrm{e}+014.73815 \mathrm{e}+014.73815 \mathrm{e}+00$ 1.00000e-09 2.12000e-01 1.00000e-02 1.00000e-02 1.00000e-03 1.00000e-09 1.00000e-01 $1.00000 \mathrm{e}+001.00000 \mathrm{e}+001.00000 \mathrm{e}-011.00000 \mathrm{e}-091.00000 \mathrm{e}-01$ Element: 6595 \# of layers: 6

$\mathrm{Kx} \mathrm{Ky} \mathrm{Kz}$ Ss Por

1.18581e+03 1.18581e+03 1.18581e+02 1.00000e-09 7.00000e-02 $1.18581 \mathrm{e}+031.18581 \mathrm{e}+03$ 1.18581e+02 1.00000e-09 7.00000e-02 $4.73815 \mathrm{e}+014.73815 \mathrm{e}+014.73815 \mathrm{e}+00$ 1.00000e-09 2.12000e-01 4.73815e+01 4.73815e+01 4.73815e+00 1.00000e-09 2.12000e-01 $1.00000 \mathrm{e}-021.00000 \mathrm{e}-021.00000 \mathrm{e}-031.00000 \mathrm{e}-091.00000 \mathrm{e}-01$ $1.00000 \mathrm{e}+001.00000 \mathrm{e}+001.00000 \mathrm{e}-011.00000 \mathrm{e}-091.00000 \mathrm{e}-01$ 
Element: 6596 \# of layers: 6

$\mathrm{Kx} \mathrm{Ky} \mathrm{Kz}$ Ss Por

$1.18581 \mathrm{e}+03$ 1.18581e+03 1.18581e+02 1.00000e-09 7.00000e-02

$1.18581 \mathrm{e}+03$ 1.18581e+03 1.18581e+02 1.00000e-09 7.00000e-02

4.73815e+01 4.73815e+01 4.73815e+00 1.00000e-09 2.12000e-01

$4.73815 \mathrm{e}+014.73815 \mathrm{e}+014.73815 \mathrm{e}+00$ 1.00000e-09 2.12000e-01

$1.00000 \mathrm{e}-011.00000 \mathrm{e}-01$ 1.00000e-02 1.00000e-09 1.00000e-01

$1.00000 \mathrm{e}+001.00000 \mathrm{e}+001.00000 \mathrm{e}-011.00000 \mathrm{e}-091.00000 \mathrm{e}-01$

Element: 6597 \# of layers: 6

$\mathrm{Kx} \mathrm{Ky} \mathrm{Kz}$ Ss Por

1.18581e+03 1.18581e+03 1.18581e+02 1.00000e-09 7.00000e-02

$1.18581 \mathrm{e}+03$ 1.18581e+03 1.18581e+02 1.00000e-09 7.00000e-02

$4.73815 \mathrm{e}+014.73815 \mathrm{e}+014.73815 \mathrm{e}+00$ 1.00000e-09 2.12000e-01

$4.73815 \mathrm{e}+014.73815 \mathrm{e}+014.73815 \mathrm{e}+00$ 1.00000e-09 2.12000e-01

$1.00000 \mathrm{e}-011.00000 \mathrm{e}-011.00000 \mathrm{e}-021.00000 \mathrm{e}-091.00000 \mathrm{e}-01$

$1.00000 \mathrm{e}+001.00000 \mathrm{e}+001.00000 \mathrm{e}-011.00000 \mathrm{e}-091.00000 \mathrm{e}-01$

Element: 6598 \# of layers: 7

$\mathrm{Kx} \mathrm{Ky} \mathrm{Kz}$ Ss Por

1.18581e+03 1.18581e+03 1.18581e+02 1.00000e-09 7.00000e-02

$1.18581 \mathrm{e}+03$ 1.18581e+03 1.18581e+02 1.00000e-09 7.00000e-02

$1.18581 \mathrm{e}+03$ 1.18581e+03 1.18581e+02 1.00000e-09 7.00000e-02

4.73815e+01 4.73815e+01 4.73815e+00 1.00000e-09 2.12000e-01

4.73815e+01 4.73815e+01 4.73815e+00 1.00000e-09 2.12000e-01

$1.00000 \mathrm{e}-011.00000 \mathrm{e}-01$ 1.00000e-02 1.00000e-09 1.00000e-01

$1.00000 \mathrm{e}+001.00000 \mathrm{e}+001.00000 \mathrm{e}-011.00000 \mathrm{e}-091.00000 \mathrm{e}-01$

Element: 6599 \# of layers: 7

$\mathrm{Kx} \mathrm{Ky} \mathrm{Kz}$ Ss Por

$1.18581 \mathrm{e}+03$ 1.18581e+03 1.18581e+02 1.00000e-09 7.00000e-02

$1.18581 \mathrm{e}+031.18581 \mathrm{e}+03$ 1.18581e+02 1.00000e-09 7.00000e-02

$1.18581 \mathrm{e}+03$ 1.18581e+03 1.18581e+02 1.00000e-09 7.00000e-02

$4.73815 \mathrm{e}+014.73815 \mathrm{e}+014.73815 \mathrm{e}+00$ 1.00000e-09 2.12000e-01

$4.73815 \mathrm{e}+014.73815 \mathrm{e}+014.73815 \mathrm{e}+00$ 1.00000e-09 2.12000e-01

$1.00000 \mathrm{e}-011.00000 \mathrm{e}-01$ 1.00000e-02 1.00000e-09 1.00000e-01

$1.00000 \mathrm{e}+001.00000 \mathrm{e}+001.00000 \mathrm{e}-011.00000 \mathrm{e}-091.00000 \mathrm{e}-01$

Element: 6600 \# of layers: 6

$\mathrm{Kx} \mathrm{Ky} \mathrm{Kz}$ Ss Por

$2.86365 \mathrm{e}+032.86365 \mathrm{e}+032.86365 \mathrm{e}+02$ 1.00000e-09 7.00000e-02

$2.86365 \mathrm{e}+032.86365 \mathrm{e}+032.86365 \mathrm{e}+02$ 1.00000e-09 7.00000e-02

$2.86365 \mathrm{e}+032.86365 \mathrm{e}+032.86365 \mathrm{e}+02$ 1.00000e-09 7.00000e-02

$1.14419 \mathrm{e}+02$ 1.14419e+02 1.14419e+01 1.00000e-09 2.12000e-01 $1.00000 \mathrm{e}-02$ 1.00000e-02 1.00000e-03 1.00000e-09 1.00000e-01

$1.00000 \mathrm{e}+001.00000 \mathrm{e}+001.00000 \mathrm{e}-011.00000 \mathrm{e}-091.00000 \mathrm{e}-01$

Element: 6601 \# of layers: 7

$\mathrm{Kx} \mathrm{Ky} \mathrm{Kz}$ Ss Por

$2.86365 \mathrm{e}+03$ 2.86365e+03 2.86365e+02 1.00000e-09 7.00000e-02

$2.86365 \mathrm{e}+032.86365 \mathrm{e}+032.86365 \mathrm{e}+02$ 1.00000e-09 7.00000e-02 
$2.86365 \mathrm{e}+032.86365 \mathrm{e}+03$ 2.86365e+02 1.00000e-09 7.00000e-02 $1.14419 \mathrm{e}+02$ 1.14419e+02 1.14419e+01 1.00000e-09 2.12000e-01 $1.14419 \mathrm{e}+02$ 1.14419e+02 1.14419e+01 1.00000e-09 2.12000e-01 $1.00000 \mathrm{e}-02$ 1.00000e-02 1.00000e-03 1.00000e-09 1.00000e-01 $1.00000 \mathrm{e}+001.00000 \mathrm{e}+001.00000 \mathrm{e}-01$ 1.00000e-09 1.00000e-01 Element: 6602 \# of layers: 8

$\mathrm{Kx} \mathrm{Ky} \mathrm{Kz}$ Ss Por

$2.86365 \mathrm{e}+03$ 2.86365e+03 2.86365e+02 1.00000e-09 7.00000e-02 $2.86365 \mathrm{e}+032.86365 \mathrm{e}+032.86365 \mathrm{e}+02$ 1.00000e-09 7.00000e-02 $2.86365 \mathrm{e}+032.86365 \mathrm{e}+032.86365 \mathrm{e}+02$ 1.00000e-09 7.00000e-02 $1.14419 \mathrm{e}+02$ 1.14419e+02 1.14419e+01 1.00000e-09 2.12000e-01 $1.14419 \mathrm{e}+02$ 1.14419e+02 1.14419e+01 1.00000e-09 2.12000e-01 $1.14419 \mathrm{e}+02$ 1.14419e+02 1.14419e+01 1.00000e-09 2.12000e-01 $1.00000 \mathrm{e}-02$ 1.00000e-02 1.00000e-03 1.00000e-09 1.00000e-01 $1.00000 \mathrm{e}+001.00000 \mathrm{e}+001.00000 \mathrm{e}-01$ 1.00000e-09 1.00000e-01 Element: 6603 \# of layers: 8

$\mathrm{Kx} \mathrm{Ky} \mathrm{Kz}$ Ss Por

$2.86365 \mathrm{e}+032.86365 \mathrm{e}+032.86365 \mathrm{e}+02$ 1.00000e-09 7.00000e-02 $2.86365 \mathrm{e}+032.86365 \mathrm{e}+032.86365 \mathrm{e}+02$ 1.00000e-09 7.00000e-02 $2.86365 \mathrm{e}+032.86365 \mathrm{e}+032.86365 \mathrm{e}+02$ 1.00000e-09 7.00000e-02 $1.14419 \mathrm{e}+021.14419 \mathrm{e}+02 \quad 1.14419 \mathrm{e}+01$ 1.00000e-09 2.12000e-01 $1.14419 \mathrm{e}+02$ 1.14419e+02 1.14419e+01 1.00000e-09 2.12000e-01 $1.14419 \mathrm{e}+02$ 1.14419e+02 1.14419e+01 1.00000e-09 2.12000e-01 $1.00000 \mathrm{e}-02$ 1.00000e-02 1.00000e-03 1.00000e-09 1.00000e-01 $1.00000 \mathrm{e}+001.00000 \mathrm{e}+001.00000 \mathrm{e}-011.00000 \mathrm{e}-091.00000 \mathrm{e}-01$ Element: 6604 \# of layers: 6

$\mathrm{Kx} \mathrm{Ky} \mathrm{Kz}$ Ss Por

$2.86365 \mathrm{e}+03$ 2.86365e+03 2.86365e+02 1.00000e-09 7.00000e-02 $2.86365 \mathrm{e}+032.86365 \mathrm{e}+032.86365 \mathrm{e}+02$ 1.00000e-09 7.00000e-02 $1.14419 \mathrm{e}+02$ 1.14419e+02 1.14419e+01 1.00000e-09 2.12000e-01 $1.14419 \mathrm{e}+02$ 1.14419e+02 1.14419e+01 1.00000e-09 2.12000e-01 1.00000e-02 1.00000e-02 1.00000e-03 1.00000e-09 1.00000e-01 $1.00000 \mathrm{e}+001.00000 \mathrm{e}+001.00000 \mathrm{e}-011.00000 \mathrm{e}-091.00000 \mathrm{e}-01$ Element: 6605 \# of layers: 7

$\mathrm{Kx} \mathrm{Ky} \mathrm{Kz}$ Ss Por

$2.86365 \mathrm{e}+03$ 2.86365e+03 2.86365e+02 1.00000e-09 7.00000e-02 $2.86365 \mathrm{e}+032.86365 \mathrm{e}+032.86365 \mathrm{e}+02$ 1.00000e-09 7.00000e-02 $2.86365 \mathrm{e}+032.86365 \mathrm{e}+032.86365 \mathrm{e}+02$ 1.00000e-09 7.00000e-02 $1.14419 \mathrm{e}+02$ 1.14419e+02 1.14419e+01 1.00000e-09 2.12000e-01 $1.14419 \mathrm{e}+02$ 1.14419e+02 1.14419e+01 1.00000e-09 2.12000e-01 $1.00000 \mathrm{e}-02$ 1.00000e-02 1.00000e-03 1.00000e-09 1.00000e-01 $1.00000 \mathrm{e}+001.00000 \mathrm{e}+001.00000 \mathrm{e}-011.00000 \mathrm{e}-091.00000 \mathrm{e}-01$ Element: 6606 \# of layers: 7

$\mathrm{Kx} \mathrm{Ky} \mathrm{Kz}$ Ss Por

$2.86365 \mathrm{e}+03$ 2.86365e+03 2.86365e+02 1.00000e-09 7.00000e-02 $2.86365 \mathrm{e}+032.86365 \mathrm{e}+032.86365 \mathrm{e}+02$ 1.00000e-09 7.00000e-02 
$2.86365 \mathrm{e}+032.86365 \mathrm{e}+03$ 2.86365e+02 1.00000e-09 7.00000e-02 $1.14419 \mathrm{e}+02$ 1.14419e+02 1.14419e+01 1.00000e-09 2.12000e-01 $1.14419 \mathrm{e}+02$ 1.14419e+02 1.14419e+01 1.00000e-09 2.12000e-01 $1.00000 \mathrm{e}-02$ 1.00000e-02 1.00000e-03 1.00000e-09 1.00000e-01 $1.00000 \mathrm{e}+001.00000 \mathrm{e}+001.00000 \mathrm{e}-01$ 1.00000e-09 1.00000e-01 Element: 6607 \# of layers: 7

$\mathrm{Kx} \mathrm{Ky} \mathrm{Kz}$ Ss Por

$2.86365 \mathrm{e}+03$ 2.86365e+03 2.86365e+02 1.00000e-09 7.00000e-02 $2.86365 \mathrm{e}+032.86365 \mathrm{e}+032.86365 \mathrm{e}+02$ 1.00000e-09 7.00000e-02 $2.86365 \mathrm{e}+032.86365 \mathrm{e}+032.86365 \mathrm{e}+02$ 1.00000e-09 7.00000e-02 $1.14419 \mathrm{e}+02$ 1.14419e+02 1.14419e+01 1.00000e-09 2.12000e-01 $1.14419 \mathrm{e}+021.14419 \mathrm{e}+02 \quad 1.14419 \mathrm{e}+01$ 1.00000e-09 2.12000e-01 $1.00000 \mathrm{e}-02$ 1.00000e-02 1.00000e-03 1.00000e-09 1.00000e-01 $1.00000 \mathrm{e}+001.00000 \mathrm{e}+001.00000 \mathrm{e}-01$ 1.00000e-09 1.00000e-01 Element: 6608 \# of layers: 8

Kx Ky Kz Ss Por

$2.86365 \mathrm{e}+03$ 2.86365e+03 2.86365e+02 1.00000e-09 7.00000e-02

$2.86365 \mathrm{e}+032.86365 \mathrm{e}+032.86365 \mathrm{e}+02$ 1.00000e-09 7.00000e-02

$2.86365 \mathrm{e}+032.86365 \mathrm{e}+03$ 2.86365e+02 1.00000e-09 7.00000e-02

$1.14419 \mathrm{e}+021.14419 \mathrm{e}+02$ 1.14419e+01 1.00000e-09 2.12000e-01 $1.14419 \mathrm{e}+02$ 1.14419e+02 1.14419e+01 1.00000e-09 2.12000e-01 $1.14419 \mathrm{e}+02$ 1.14419e+02 1.14419e+01 1.00000e-09 2.12000e-01 $1.00000 \mathrm{e}-02$ 1.00000e-02 1.00000e-03 1.00000e-09 1.00000e-01 $1.00000 \mathrm{e}+001.00000 \mathrm{e}+001.00000 \mathrm{e}-011.00000 \mathrm{e}-091.00000 \mathrm{e}-01$

Element: 6609 \# of layers: 7

$\mathrm{Kx} \mathrm{Ky} \mathrm{Kz}$ Ss Por

4.01504e+03 4.01504e+03 4.01504e+02 1.00000e-09 7.00000e-02 $4.01504 \mathrm{e}+034.01504 \mathrm{e}+034.01504 \mathrm{e}+021.00000 \mathrm{e}-097.00000 \mathrm{e}-02$ $4.01504 \mathrm{e}+03$ 4.01504e+03 4.01504e+02 1.00000e-09 7.00000e-02 $1.60428 \mathrm{e}+02$ 1.60428e+02 1.60428e+01 1.00000e-09 2.12000e-01 $1.60428 \mathrm{e}+02$ 1.60428e+02 1.60428e+01 1.00000e-09 2.12000e-01 $1.00000 \mathrm{e}-02$ 1.00000e-02 1.00000e-03 1.00000e-09 1.00000e-01 $1.00000 \mathrm{e}+001.00000 \mathrm{e}+001.00000 \mathrm{e}-011.00000 \mathrm{e}-091.00000 \mathrm{e}-01$ Element: 6610 \# of layers: 7

$\mathrm{Kx} \mathrm{Ky} \mathrm{Kz}$ Ss Por

4.01504e+03 4.01504e+03 4.01504e+02 1.00000e-09 7.00000e-02 $4.01504 \mathrm{e}+034.01504 \mathrm{e}+034.01504 \mathrm{e}+02$ 1.00000e-09 7.00000e-02 $4.01504 \mathrm{e}+034.01504 \mathrm{e}+034.01504 \mathrm{e}+02$ 1.00000e-09 7.00000e-02 $1.60428 \mathrm{e}+021.60428 \mathrm{e}+02$ 1.60428e+01 1.00000e-09 2.12000e-01 $1.60428 \mathrm{e}+021.60428 \mathrm{e}+02$ 1.60428e+01 1.00000e-09 2.12000e-01 $1.00000 \mathrm{e}-02$ 1.00000e-02 1.00000e-03 1.00000e-09 1.00000e-01 $1.00000 \mathrm{e}+001.00000 \mathrm{e}+001.00000 \mathrm{e}-011.00000 \mathrm{e}-091.00000 \mathrm{e}-01$ Element: 6611 \# of layers: 6

$\mathrm{Kx} \mathrm{Ky} \mathrm{Kz}$ Ss Por $4.01504 \mathrm{e}+03$ 4.01504e+03 4.01504e+02 1.00000e-09 7.00000e-02 $4.01504 \mathrm{e}+034.01504 \mathrm{e}+034.01504 \mathrm{e}+02$ 1.00000e-09 7.00000e-02 
$1.60428 \mathrm{e}+02$ 1.60428e+02 1.60428e+01 1.00000e-09 2.12000e-01 $1.60428 \mathrm{e}+02$ 1.60428e+02 1.60428e+01 1.00000e-09 2.12000e-01 $1.00000 \mathrm{e}-02$ 1.00000e-02 1.00000e-03 1.00000e-09 1.00000e-01

$1.00000 \mathrm{e}+001.00000 \mathrm{e}+001.00000 \mathrm{e}-011.00000 \mathrm{e}-091.00000 \mathrm{e}-01$

Element: 6612 \# of layers: 6

$\mathrm{Kx} \mathrm{Ky} \mathrm{Kz}$ Ss Por

4.01504e+03 4.01504e+03 4.01504e+02 1.00000e-09 7.00000e-02 $4.01504 \mathrm{e}+034.01504 \mathrm{e}+034.01504 \mathrm{e}+02$ 1.00000e-09 7.00000e-02 $1.60428 \mathrm{e}+02$ 1.60428e+02 1.60428e+01 1.00000e-09 2.12000e-01 $1.60428 \mathrm{e}+02$ 1.60428e+02 1.60428e+01 1.00000e-09 2.12000e-01 1.00000e-02 1.00000e-02 1.00000e-03 1.00000e-09 1.00000e-01 $1.00000 \mathrm{e}+001.00000 \mathrm{e}+001.00000 \mathrm{e}-011.00000 \mathrm{e}-091.00000 \mathrm{e}-01$ Element: 6613 \# of layers: 6

$\mathrm{Kx} \mathrm{Ky} \mathrm{Kz}$ Ss Por

4.01504e+03 4.01504e+03 4.01504e+02 1.00000e-09 7.00000e-02 $4.01504 \mathrm{e}+034.01504 \mathrm{e}+034.01504 \mathrm{e}+02$ 1.00000e-09 7.00000e-02 $1.60428 \mathrm{e}+02$ 1.60428e+02 1.60428e+01 1.00000e-09 2.12000e-01 $1.60428 \mathrm{e}+02$ 1.60428e+02 1.60428e+01 1.00000e-09 2.12000e-01 $1.00000 \mathrm{e}-02$ 1.00000e-02 1.00000e-03 1.00000e-09 1.00000e-01 $1.00000 \mathrm{e}+001.00000 \mathrm{e}+001.00000 \mathrm{e}-011.00000 \mathrm{e}-091.00000 \mathrm{e}-01$ Element: 6614 \# of layers: 6

$\mathrm{Kx} \mathrm{Ky} \mathrm{Kz}$ Ss Por

4.01504e+03 4.01504e+03 4.01504e+02 1.00000e-09 7.00000e-02 $4.01504 \mathrm{e}+034.01504 \mathrm{e}+034.01504 \mathrm{e}+02$ 1.00000e-09 7.00000e-02 $1.60428 \mathrm{e}+021.60428 \mathrm{e}+02$ 1.60428e+01 1.00000e-09 2.12000e-01 $1.60428 \mathrm{e}+021.60428 \mathrm{e}+02$ 1.60428e+01 1.00000e-09 2.12000e-01 $1.00000 \mathrm{e}-02$ 1.00000e-02 1.00000e-03 1.00000e-09 1.00000e-01 $1.00000 \mathrm{e}+001.00000 \mathrm{e}+001.00000 \mathrm{e}-011.00000 \mathrm{e}-09$ 1.00000e-01

Element: 6615 \# of layers: 6

$\mathrm{Kx} \mathrm{Ky} \mathrm{Kz}$ Ss Por

4.01504e+03 4.01504e+03 4.01504e+02 1.00000e-09 7.00000e-02 $4.01504 \mathrm{e}+034.01504 \mathrm{e}+034.01504 \mathrm{e}+02$ 1.00000e-09 7.00000e-02 $1.60428 \mathrm{e}+021.60428 \mathrm{e}+02$ 1.60428e+01 1.00000e-09 2.12000e-01 $1.60428 \mathrm{e}+021.60428 \mathrm{e}+02$ 1.60428e+01 1.00000e-09 2.12000e-01 $1.00000 \mathrm{e}-02$ 1.00000e-02 1.00000e-03 1.00000e-09 1.00000e-01 $1.00000 \mathrm{e}+001.00000 \mathrm{e}+001.00000 \mathrm{e}-011.00000 \mathrm{e}-091.00000 \mathrm{e}-01$ Element: 6616 \# of layers: 7

$\mathrm{Kx} \mathrm{Ky} \mathrm{Kz}$ Ss Por

4.01504e+03 4.01504e+03 4.01504e+02 1.00000e-09 7.00000e-02 $4.01504 \mathrm{e}+034.01504 \mathrm{e}+03$ 4.01504e+02 1.00000e-09 7.00000e-02 $4.01504 \mathrm{e}+034.01504 \mathrm{e}+034.01504 \mathrm{e}+02$ 1.00000e-09 7.00000e-02 $1.60428 \mathrm{e}+021.60428 \mathrm{e}+02$ 1.60428e+01 1.00000e-09 2.12000e-01 $1.60428 \mathrm{e}+02$ 1.60428e+02 1.60428e+01 1.00000e-09 2.12000e-01 $1.00000 \mathrm{e}-02$ 1.00000e-02 1.00000e-03 1.00000e-09 1.00000e-01 $1.00000 \mathrm{e}+001.00000 \mathrm{e}+001.00000 \mathrm{e}-01$ 1.00000e-09 1.00000e-01 Element: 6617 \# of layers: 6 
$\mathrm{Kx} \mathrm{Ky} \mathrm{Kz}$ Ss Por

4.01504e+03 4.01504e+03 4.01504e+02 1.00000e-09 7.00000e-02

$4.01504 \mathrm{e}+03$ 4.01504e+03 4.01504e+02 1.00000e-09 7.00000e-02

$1.60428 \mathrm{e}+02$ 1.60428e+02 1.60428e+01 1.00000e-09 2.12000e-01

$1.60428 \mathrm{e}+021.60428 \mathrm{e}+02$ 1.60428e+01 1.00000e-09 2.12000e-01

$1.00000 \mathrm{e}-02$ 1.00000e-02 1.00000e-03 1.00000e-09 1.00000e-01

$1.00000 \mathrm{e}+001.00000 \mathrm{e}+001.00000 \mathrm{e}-011.00000 \mathrm{e}-091.00000 \mathrm{e}-01$

Element: 6618 \# of layers: 6

$\mathrm{Kx} \mathrm{Ky} \mathrm{Kz}$ Ss Por

5.10029e+03 5.10029e+03 5.10029e+02 1.00000e-09 7.00000e-02

$5.10029 \mathrm{e}+03$ 5.10029e+03 5.10029e+02 1.00000e-09 7.00000e-02

$2.03789 \mathrm{e}+02$ 2.03789e+02 2.03789e+01 1.00000e-09 2.12000e-01

$2.03789 \mathrm{e}+02$ 2.03789e+02 2.03789e+01 1.00000e-09 2.12000e-01

$1.00000 \mathrm{e}-02$ 1.00000e-02 1.00000e-03 1.00000e-09 1.00000e-01

$1.00000 \mathrm{e}+001.00000 \mathrm{e}+001.00000 \mathrm{e}-01$ 1.00000e-09 1.00000e-01

Element: 6619 \# of layers: 6

$\mathrm{Kx} \mathrm{Ky} \mathrm{Kz}$ Ss Por

5.10029e+03 5.10029e+03 5.10029e+02 1.00000e-09 7.00000e-02

$5.10029 \mathrm{e}+03$ 5.10029e+03 5.10029e+02 1.00000e-09 7.00000e-02

$2.03789 \mathrm{e}+02$ 2.03789e+02 2.03789e+01 1.00000e-09 2.12000e-01

$2.03789 \mathrm{e}+02$ 2.03789e+02 2.03789e+01 1.00000e-09 2.12000e-01

$1.00000 \mathrm{e}-02$ 1.00000e-02 1.00000e-03 1.00000e-09 1.00000e-01

$1.00000 \mathrm{e}+001.00000 \mathrm{e}+001.00000 \mathrm{e}-01$ 1.00000e-09 1.00000e-01

Element: 6620 \# of layers: 6

$\mathrm{Kx} \mathrm{Ky} \mathrm{Kz}$ Ss Por

5.10029e+03 5.10029e+03 5.10029e+02 1.00000e-09 7.00000e-02

$5.10029 \mathrm{e}+035.10029 \mathrm{e}+03$ 5.10029e+02 1.00000e-09 7.00000e-02

$2.03789 \mathrm{e}+02$ 2.03789e+02 2.03789e+01 1.00000e-09 2.12000e-01

$2.03789 \mathrm{e}+02$ 2.03789e+02 2.03789e+01 1.00000e-09 2.12000e-01

$1.00000 \mathrm{e}-02$ 1.00000e-02 1.00000e-03 1.00000e-09 1.00000e-01

$1.00000 \mathrm{e}+001.00000 \mathrm{e}+001.00000 \mathrm{e}-011.00000 \mathrm{e}-091.00000 \mathrm{e}-01$

Element: 6621 \# of layers: 6

Kx Ky Kz Ss Por

5.10029e+03 5.10029e+03 5.10029e+02 1.00000e-09 7.00000e-02

$5.10029 \mathrm{e}+03$ 5.10029e+03 5.10029e+02 1.00000e-09 7.00000e-02

$2.03789 \mathrm{e}+02$ 2.03789e+02 2.03789e+01 1.00000e-09 2.12000e-01

$2.03789 \mathrm{e}+02$ 2.03789e+02 2.03789e+01 1.00000e-09 2.12000e-01

$1.00000 \mathrm{e}-02$ 1.00000e-02 1.00000e-03 1.00000e-09 1.00000e-01

$1.00000 \mathrm{e}+001.00000 \mathrm{e}+001.00000 \mathrm{e}-011.00000 \mathrm{e}-091.00000 \mathrm{e}-01$

Element: 6622 \# of layers: 6

$\mathrm{Kx} \mathrm{Ky} \mathrm{Kz}$ Ss Por

5.10029e+03 5.10029e+03 5.10029e+02 1.00000e-09 7.00000e-02

$5.10029 \mathrm{e}+035.10029 \mathrm{e}+03$ 5.10029e+02 1.00000e-09 7.00000e-02

$2.03789 \mathrm{e}+02$ 2.03789e+02 2.03789e+01 1.00000e-09 2.12000e-01

$2.03789 \mathrm{e}+02$ 2.03789e+02 2.03789e+01 1.00000e-09 2.12000e-01

$1.00000 \mathrm{e}-02$ 1.00000e-02 1.00000e-03 1.00000e-09 1.00000e-01 
$1.00000 \mathrm{e}+001.00000 \mathrm{e}+00$ 1.00000e-01 1.00000e-09 1.00000e-01

Element: 6623 \# of layers: 6

$\mathrm{Kx} \mathrm{Ky} \mathrm{Kz}$ Ss Por

5.10029e+03 5.10029e+03 5.10029e+02 1.00000e-09 7.00000e-02

$5.10029 \mathrm{e}+03$ 5.10029e+03 5.10029e+02 1.00000e-09 7.00000e-02

$2.03789 \mathrm{e}+02$ 2.03789e+02 2.03789e+01 1.00000e-09 2.12000e-01

$2.03789 \mathrm{e}+02$ 2.03789e+02 2.03789e+01 1.00000e-09 2.12000e-01

$1.00000 \mathrm{e}-02$ 1.00000e-02 1.00000e-03 1.00000e-09 1.00000e-01

$1.00000 \mathrm{e}+001.00000 \mathrm{e}+001.00000 \mathrm{e}-011.00000 \mathrm{e}-091.00000 \mathrm{e}-01$

Element: 6624 \# of layers: 6

$\mathrm{Kx} \mathrm{Ky} \mathrm{Kz}$ Ss Por

5.10029e+03 5.10029e+03 5.10029e+02 1.00000e-09 7.00000e-02

5.10029e+03 5.10029e+03 5.10029e+02 1.00000e-09 7.00000e-02

$2.03789 \mathrm{e}+02$ 2.03789e+02 2.03789e+01 1.00000e-09 2.12000e-01

$2.03789 \mathrm{e}+02$ 2.03789e+02 2.03789e+01 1.00000e-09 2.12000e-01

$1.00000 \mathrm{e}-02$ 1.00000e-02 1.00000e-03 1.00000e-09 1.00000e-01

$1.00000 \mathrm{e}+001.00000 \mathrm{e}+001.00000 \mathrm{e}-01$ 1.00000e-09 1.00000e-01

Element: 6625 \# of layers: 6

$\mathrm{Kx} \mathrm{Ky} \mathrm{Kz}$ Ss Por

5.10029e+03 5.10029e+03 5.10029e+02 1.00000e-09 7.00000e-02

$5.10029 \mathrm{e}+035.10029 \mathrm{e}+03$ 5.10029e+02 1.00000e-09 7.00000e-02

$2.03789 \mathrm{e}+02$ 2.03789e+02 2.03789e+01 1.00000e-09 2.12000e-01

$2.03789 \mathrm{e}+02$ 2.03789e+02 2.03789e+01 1.00000e-09 2.12000e-01

$1.00000 \mathrm{e}-02$ 1.00000e-02 1.00000e-03 1.00000e-09 1.00000e-01

$1.00000 \mathrm{e}+001.00000 \mathrm{e}+001.00000 \mathrm{e}-011.00000 \mathrm{e}-091.00000 \mathrm{e}-01$

Element: 6626 \# of layers: 6

$\mathrm{Kx} \mathrm{Ky} \mathrm{Kz}$ Ss Por

5.10029e+03 5.10029e+03 5.10029e+02 1.00000e-09 7.00000e-02

5.10029e+03 5.10029e+03 5.10029e+02 1.00000e-09 7.00000e-02

$2.03789 \mathrm{e}+02$ 2.03789e+02 2.03789e+01 1.00000e-09 2.12000e-01

$2.03789 \mathrm{e}+02$ 2.03789e+02 2.03789e+01 1.00000e-09 2.12000e-01

$1.00000 \mathrm{e}-02$ 1.00000e-02 1.00000e-03 1.00000e-09 1.00000e-01

$1.00000 \mathrm{e}+001.00000 \mathrm{e}+001.00000 \mathrm{e}-011.00000 \mathrm{e}-091.00000 \mathrm{e}-01$

Element: 6627 \# of layers: 6

$\mathrm{Kx} \mathrm{Ky} \mathrm{Kz}$ Ss Por

6.63010e+03 6.63010e+03 6.63010e+02 1.00000e-09 7.00000e-02

$6.63010 \mathrm{e}+036.63010 \mathrm{e}+036.63010 \mathrm{e}+02$ 1.00000e-09 7.00000e-02

$2.64921 \mathrm{e}+022.64921 \mathrm{e}+022.64921 \mathrm{e}+01$ 1.00000e-09 2.12000e-01

$2.64921 \mathrm{e}+02$ 2.64921e+02 2.64921e+01 1.00000e-09 2.12000e-01

$1.00000 \mathrm{e}-02$ 1.00000e-02 1.00000e-03 1.00000e-09 1.00000e-01

$1.00000 \mathrm{e}+001.00000 \mathrm{e}+001.00000 \mathrm{e}-011.00000 \mathrm{e}-091.00000 \mathrm{e}-01$

Element: 6628 \# of layers: 6

$\mathrm{Kx} \mathrm{Ky} \mathrm{Kz}$ Ss Por

6.63010e+03 6.63010e+03 6.63010e+02 1.00000e-09 7.00000e-02

$6.63010 \mathrm{e}+036.63010 \mathrm{e}+036.63010 \mathrm{e}+02$ 1.00000e-09 7.00000e-02

$2.64921 \mathrm{e}+022.64921 \mathrm{e}+022.64921 \mathrm{e}+01$ 1.00000e-09 2.12000e-01 
$2.64921 \mathrm{e}+02$ 2.64921e+02 2.64921e+01 1.00000e-09 2.12000e-01 $1.00000 \mathrm{e}-02$ 1.00000e-02 1.00000e-03 1.00000e-09 1.00000e-01 $1.00000 \mathrm{e}+001.00000 \mathrm{e}+001.00000 \mathrm{e}-011.00000 \mathrm{e}-091.00000 \mathrm{e}-01$

Element: 6629 \# of layers: 6

$\mathrm{Kx} \mathrm{Ky} \mathrm{Kz}$ Ss Por

6.63010e+03 6.63010e+03 6.63010e+02 1.00000e-09 7.00000e-02

6.63010e+03 6.63010e+03 6.63010e+02 1.00000e-09 7.00000e-02

$2.64921 \mathrm{e}+02$ 2.64921e+02 2.64921e+01 1.00000e-09 2.12000e-01

$2.64921 \mathrm{e}+022.64921 \mathrm{e}+022.64921 \mathrm{e}+01$ 1.00000e-09 2.12000e-01

$1.00000 \mathrm{e}-02$ 1.00000e-02 1.00000e-03 1.00000e-09 1.00000e-01

$1.00000 \mathrm{e}+001.00000 \mathrm{e}+001.00000 \mathrm{e}-011.00000 \mathrm{e}-091.00000 \mathrm{e}-01$

Element: 6630 \# of layers: 5

$\mathrm{Kx} \mathrm{Ky} \mathrm{Kz}$ Ss Por

6.63010e+03 6.63010e+03 6.63010e+02 1.00000e-09 7.00000e-02 $2.64921 \mathrm{e}+022.64921 \mathrm{e}+02$ 2.64921e+01 1.00000e-09 2.12000e-01

$2.64921 \mathrm{e}+022.64921 \mathrm{e}+022.64921 \mathrm{e}+01$ 1.00000e-09 2.12000e-01

$1.00000 \mathrm{e}-02$ 1.00000e-02 1.00000e-03 1.00000e-09 1.00000e-01

$1.00000 \mathrm{e}+001.00000 \mathrm{e}+001.00000 \mathrm{e}-01$ 1.00000e-09 1.00000e-01

Element: 6631 \# of layers: 5

$\mathrm{Kx} \mathrm{Ky} \mathrm{Kz}$ Ss Por

6.63010e+03 6.63010e+03 6.63010e+02 1.00000e-09 7.00000e-02

$2.64921 \mathrm{e}+02$ 2.64921e+02 2.64921e+01 1.00000e-09 2.12000e-01

$2.64921 \mathrm{e}+02$ 2.64921e+02 2.64921e+01 1.00000e-09 2.12000e-01

$1.00000 \mathrm{e}-02$ 1.00000e-02 1.00000e-03 1.00000e-09 1.00000e-01

$1.00000 \mathrm{e}+001.00000 \mathrm{e}+001.00000 \mathrm{e}-011.00000 \mathrm{e}-091.00000 \mathrm{e}-01$

Element: 6632 \# of layers: 5

$\mathrm{Kx} \mathrm{Ky} \mathrm{Kz}$ Ss Por

6.63010e+03 6.63010e+03 6.63010e+02 1.00000e-09 7.00000e-02

$2.64921 \mathrm{e}+022.64921 \mathrm{e}+022.64921 \mathrm{e}+01$ 1.00000e-09 2.12000e-01

$2.64921 \mathrm{e}+022.64921 \mathrm{e}+022.64921 \mathrm{e}+01$ 1.00000e-09 2.12000e-01

$1.00000 \mathrm{e}-02$ 1.00000e-02 1.00000e-03 1.00000e-09 1.00000e-01

$1.00000 \mathrm{e}+001.00000 \mathrm{e}+001.00000 \mathrm{e}-011.00000 \mathrm{e}-091.00000 \mathrm{e}-01$

Element: 6633 \# of layers: 6

$\mathrm{Kx} \mathrm{Ky} \mathrm{Kz}$ Ss Por

6.63010e+03 6.63010e+03 6.63010e+02 1.00000e-09 7.00000e-02

6.63010e+03 6.63010e+03 6.63010e+02 1.00000e-09 7.00000e-02

$2.64921 \mathrm{e}+022.64921 \mathrm{e}+022.64921 \mathrm{e}+01$ 1.00000e-09 2.12000e-01

$2.64921 \mathrm{e}+022.64921 \mathrm{e}+022.64921 \mathrm{e}+01$ 1.00000e-09 2.12000e-01

$1.00000 \mathrm{e}-02$ 1.00000e-02 1.00000e-03 1.00000e-09 1.00000e-01

$1.00000 \mathrm{e}+001.00000 \mathrm{e}+001.00000 \mathrm{e}-01$ 1.00000e-09 1.00000e-01

Element: 6634 \# of layers: 6

$\mathrm{Kx} \mathrm{Ky} \mathrm{Kz}$ Ss Por

6.63010e+03 6.63010e+03 6.63010e+02 1.00000e-09 7.00000e-02

$6.63010 \mathrm{e}+036.63010 \mathrm{e}+03$ 6.63010e+02 1.00000e-09 7.00000e-02

$2.64921 \mathrm{e}+022.64921 \mathrm{e}+02$ 2.64921e+01 1.00000e-09 2.12000e-01

$2.64921 \mathrm{e}+022.64921 \mathrm{e}+022.64921 \mathrm{e}+01$ 1.00000e-09 2.12000e-01 
$1.00000 \mathrm{e}-02$ 1.00000e-02 1.00000e-03 1.00000e-09 1.00000e-01 $1.00000 \mathrm{e}+001.00000 \mathrm{e}+001.00000 \mathrm{e}-01$ 1.00000e-09 1.00000e-01

Element: 6635 \# of layers: 6

Kx Ky Kz Ss Por

6.63010e+03 6.63010e+03 6.63010e+02 1.00000e-09 7.00000e-02

$6.63010 \mathrm{e}+036.63010 \mathrm{e}+03$ 6.63010e+02 1.00000e-09 7.00000e-02

$2.64921 \mathrm{e}+02$ 2.64921e+02 2.64921e+01 1.00000e-09 2.12000e-01

$2.64921 \mathrm{e}+022.64921 \mathrm{e}+022.64921 \mathrm{e}+01$ 1.00000e-09 2.12000e-01

$1.00000 \mathrm{e}-02$ 1.00000e-02 1.00000e-03 1.00000e-09 1.00000e-01

$1.00000 \mathrm{e}+001.00000 \mathrm{e}+001.00000 \mathrm{e}-011.00000 \mathrm{e}-091.00000 \mathrm{e}-01$

Element: 6636 \# of layers: 5

$\mathrm{Kx} \mathrm{Ky} \mathrm{Kz}$ Ss Por

8.28461e+03 8.28461e+03 8.28461e+02 1.00000e-09 7.00000e-02

$3.31027 \mathrm{e}+02$ 3.31027e+02 3.31027e+01 1.00000e-09 2.12000e-01

$3.31027 \mathrm{e}+02$ 3.31027e+02 3.31027e+01 1.00000e-09 2.12000e-01

1.00000e-02 1.00000e-02 1.00000e-03 1.00000e-09 1.00000e-01

$1.00000 \mathrm{e}+001.00000 \mathrm{e}+001.00000 \mathrm{e}-011.00000 \mathrm{e}-091.00000 \mathrm{e}-01$

Element: 6637 \# of layers: 4

$\mathrm{Kx} \mathrm{Ky} \mathrm{Kz}$ Ss Por

8.28461e+03 8.28461e+03 8.28461e+02 1.00000e-09 7.00000e-02

$3.31027 \mathrm{e}+023.31027 \mathrm{e}+02$ 3.31027e+01 1.00000e-09 2.12000e-01

$1.00000 \mathrm{e}-02$ 1.00000e-02 1.00000e-03 1.00000e-09 1.00000e-01

$1.00000 \mathrm{e}+001.00000 \mathrm{e}+001.00000 \mathrm{e}-01$ 1.00000e-09 1.00000e-01

Element: 6638 \# of layers: 4

$\mathrm{Kx} \mathrm{Ky} \mathrm{Kz}$ Ss Por

8.28461e+03 8.28461e+03 8.28461e+02 1.00000e-09 7.00000e-02

$3.31027 \mathrm{e}+02$ 3.31027e+02 3.31027e+01 1.00000e-09 2.12000e-01

$1.00000 \mathrm{e}-02$ 1.00000e-02 1.00000e-03 1.00000e-09 1.00000e-01

$1.00000 \mathrm{e}+001.00000 \mathrm{e}+001.00000 \mathrm{e}-011.00000 \mathrm{e}-091.00000 \mathrm{e}-01$

Element: 6639 \# of layers: 4

$\mathrm{Kx} \mathrm{Ky} \mathrm{Kz}$ Ss Por

8.28461e+03 8.28461e+03 8.28461e+02 1.00000e-09 7.00000e-02

$3.31027 \mathrm{e}+02$ 3.31027e+02 3.31027e+01 1.00000e-09 2.12000e-01

$1.00000 \mathrm{e}-02$ 1.00000e-02 1.00000e-03 1.00000e-09 1.00000e-01

$1.00000 \mathrm{e}+001.00000 \mathrm{e}+001.00000 \mathrm{e}-011.00000 \mathrm{e}-091.00000 \mathrm{e}-01$

Element: 6640 \# of layers: 4

$\mathrm{Kx} \mathrm{Ky} \mathrm{Kz}$ Ss Por

8.28461e+03 8.28461e+03 8.28461e+02 1.00000e-09 7.00000e-02

$3.31027 \mathrm{e}+02$ 3.31027e+02 3.31027e+01 1.00000e-09 2.12000e-01

$1.00000 \mathrm{e}-02$ 1.00000e-02 1.00000e-03 1.00000e-09 1.00000e-01

$1.00000 \mathrm{e}+001.00000 \mathrm{e}+001.00000 \mathrm{e}-011.00000 \mathrm{e}-091.00000 \mathrm{e}-01$

Element: 6641 \# of layers: 5

$\mathrm{Kx} \mathrm{Ky} \mathrm{Kz}$ Ss Por

8.28461e+03 8.28461e+03 8.28461e+02 1.00000e-09 7.00000e-02

$3.31027 \mathrm{e}+02$ 3.31027e+02 3.31027e+01 1.00000e-09 2.12000e-01

$3.31027 \mathrm{e}+02$ 3.31027e+02 3.31027e+01 1.00000e-09 2.12000e-01 
$1.00000 \mathrm{e}-02$ 1.00000e-02 1.00000e-03 1.00000e-09 1.00000e-01 $1.00000 \mathrm{e}+001.00000 \mathrm{e}+001.00000 \mathrm{e}-01$ 1.00000e-09 1.00000e-01 Element: 6642 \# of layers: 5

$\mathrm{Kx} \mathrm{Ky} \mathrm{Kz}$ Ss Por

8.28461e+03 8.28461e+03 8.28461e+02 1.00000e-09 7.00000e-02 $3.31027 \mathrm{e}+02$ 3.31027e+02 3.31027e+01 1.00000e-09 2.12000e-01 $3.31027 \mathrm{e}+02$ 3.31027e+02 3.31027e+01 1.00000e-09 2.12000e-01 $1.00000 \mathrm{e}-02$ 1.00000e-02 1.00000e-03 1.00000e-09 1.00000e-01 $1.00000 \mathrm{e}+001.00000 \mathrm{e}+001.00000 \mathrm{e}-011.00000 \mathrm{e}-091.00000 \mathrm{e}-01$ Element: 6643 \# of layers: 5

$\mathrm{Kx} \mathrm{Ky} \mathrm{Kz}$ Ss Por

8.28461e+03 8.28461e+03 8.28461e+02 1.00000e-09 7.00000e-02 $3.31027 \mathrm{e}+02$ 3.31027e+02 3.31027e+01 1.00000e-09 2.12000e-01 $3.31027 \mathrm{e}+02$ 3.31027e+02 3.31027e+01 1.00000e-09 2.12000e-01 $1.00000 \mathrm{e}-02$ 1.00000e-02 1.00000e-03 1.00000e-09 1.00000e-01 $1.00000 \mathrm{e}+001.00000 \mathrm{e}+001.00000 \mathrm{e}-011.00000 \mathrm{e}-091.00000 \mathrm{e}-01$ Element: 6644 \# of layers: 4

$\mathrm{Kx} \mathrm{Ky} \mathrm{Kz}$ Ss Por

8.28461e+03 8.28461e+03 8.28461e+02 1.00000e-09 7.00000e-02 $3.31027 \mathrm{e}+02$ 3.31027e+02 3.31027e+01 1.00000e-09 2.12000e-01 $1.00000 \mathrm{e}-02$ 1.00000e-02 1.00000e-03 1.00000e-09 1.00000e-01 $1.00000 \mathrm{e}+001.00000 \mathrm{e}+001.00000 \mathrm{e}-011.00000 \mathrm{e}-091.00000 \mathrm{e}-01$ Element: 6645 \# of layers: 4

Kx Ky Kz Ss Por

9.77225e+03 9.77225e+03 9.77225e+02 1.00000e-09 7.00000e-02 $3.90473 \mathrm{e}+02$ 3.90473e+02 3.90473e+01 1.00000e-09 2.12000e-01 $1.00000 \mathrm{e}-02$ 1.00000e-02 1.00000e-03 1.00000e-09 1.00000e-01 $1.00000 \mathrm{e}+001.00000 \mathrm{e}+001.00000 \mathrm{e}-01$ 1.00000e-09 1.00000e-01

Element: 6646 \# of layers: 4

$\mathrm{Kx} \mathrm{Ky} \mathrm{Kz}$ Ss Por

9.77225e+03 9.77225e+03 9.77225e+02 1.00000e-09 7.00000e-02 $3.90473 \mathrm{e}+02$ 3.90473e+02 3.90473e+01 1.00000e-09 2.12000e-01 1.00000e-02 1.00000e-02 1.00000e-03 1.00000e-09 1.00000e-01 $1.00000 \mathrm{e}+001.00000 \mathrm{e}+001.00000 \mathrm{e}-011.00000 \mathrm{e}-091.00000 \mathrm{e}-01$ Element: 6647 \# of layers: 4

$\mathrm{Kx} \mathrm{Ky} \mathrm{Kz}$ Ss Por

9.77225e+03 9.77225e+03 9.77225e+02 1.00000e-09 7.00000e-02 3.90473e+02 3.90473e+02 3.90473e+01 1.00000e-09 2.12000e-01 $1.00000 \mathrm{e}-02$ 1.00000e-02 1.00000e-03 1.00000e-09 1.00000e-01 $1.00000 \mathrm{e}+001.00000 \mathrm{e}+001.00000 \mathrm{e}-01$ 1.00000e-09 1.00000e-01 Element: 6648 \# of layers: 4

$\mathrm{Kx} \mathrm{Ky} \mathrm{Kz}$ Ss Por

9.77225e+03 9.77225e+03 9.77225e+02 1.00000e-09 7.00000e-02 3.90473e+02 3.90473e+02 3.90473e+01 1.00000e-09 2.12000e-01 $1.00000 \mathrm{e}-02$ 1.00000e-02 1.00000e-03 1.00000e-09 1.00000e-01 $1.00000 \mathrm{e}+001.00000 \mathrm{e}+001.00000 \mathrm{e}-011.00000 \mathrm{e}-091.00000 \mathrm{e}-01$ 
Element: 6649 \# of layers: 4

$\mathrm{Kx} \mathrm{Ky} \mathrm{Kz}$ Ss Por

9.77225e+03 9.77225e+03 9.77225e+02 1.00000e-09 7.00000e-02

$3.90473 \mathrm{e}+02$ 3.90473e+02 3.90473e+01 1.00000e-09 2.12000e-01

$1.00000 \mathrm{e}-02$ 1.00000e-02 1.00000e-03 1.00000e-09 1.00000e-01

$1.00000 \mathrm{e}+001.00000 \mathrm{e}+001.00000 \mathrm{e}-01$ 1.00000e-09 1.00000e-01

Element: 6650 \# of layers: 4

$\mathrm{Kx} \mathrm{Ky} \mathrm{Kz}$ Ss Por

9.77225e+03 9.77225e+03 9.77225e+02 1.00000e-09 7.00000e-02

3.90473e+02 3.90473e+02 3.90473e+01 1.00000e-09 2.12000e-01

$1.00000 \mathrm{e}-02$ 1.00000e-02 1.00000e-03 1.00000e-09 1.00000e-01

$1.00000 \mathrm{e}+001.00000 \mathrm{e}+001.00000 \mathrm{e}-011.00000 \mathrm{e}-091.00000 \mathrm{e}-01$

Element: 6651 \# of layers: 4

$\mathrm{Kx} \mathrm{Ky} \mathrm{Kz}$ Ss Por

9.77225e+03 9.77225e+03 9.77225e+02 1.00000e-09 7.00000e-02

3.90473e+02 3.90473e+02 3.90473e+01 1.00000e-09 2.12000e-01

$1.00000 \mathrm{e}-02$ 1.00000e-02 1.00000e-03 1.00000e-09 1.00000e-01

$1.00000 \mathrm{e}+001.00000 \mathrm{e}+001.00000 \mathrm{e}-01$ 1.00000e-09 1.00000e-01

Element: 6652 \# of layers: 4

$\mathrm{Kx} \mathrm{Ky} \mathrm{Kz}$ Ss Por

9.77225e+03 9.77225e+03 9.77225e+02 1.00000e-09 7.00000e-02

3.90473e+02 3.90473e+02 3.90473e+01 1.00000e-09 2.12000e-01

$1.00000 \mathrm{e}-02$ 1.00000e-02 1.00000e-03 1.00000e-09 1.00000e-01

$1.00000 \mathrm{e}+001.00000 \mathrm{e}+001.00000 \mathrm{e}-011.00000 \mathrm{e}-091.00000 \mathrm{e}-01$

Element: 6653 \# of layers: 4

$\mathrm{Kx} \mathrm{Ky} \mathrm{Kz}$ Ss Por

9.77225e+03 9.77225e+03 9.77225e+02 1.00000e-09 7.00000e-02

3.90473e+02 3.90473e+02 3.90473e+01 1.00000e-09 2.12000e-01

$1.00000 \mathrm{e}-02$ 1.00000e-02 1.00000e-03 1.00000e-09 1.00000e-01

$1.00000 \mathrm{e}+001.00000 \mathrm{e}+001.00000 \mathrm{e}-011.00000 \mathrm{e}-091.00000 \mathrm{e}-01$

Element: 6654 \# of layers: 4

$\mathrm{Kx} \mathrm{Ky} \mathrm{Kz}$ Ss Por

6.54775e+03 6.54775e+03 6.54775e+02 1.00000e-09 7.00000e-02

$2.61636 \mathrm{e}+02$ 2.61636e+02 2.61636e+01 1.00000e-09 2.12000e-01

$1.00000 \mathrm{e}-02$ 1.00000e-02 1.00000e-03 1.00000e-09 1.00000e-01

$1.00000 \mathrm{e}+001.00000 \mathrm{e}+001.00000 \mathrm{e}-011.00000 \mathrm{e}-091.00000 \mathrm{e}-01$

Element: 6655 \# of layers: 4

Kx Ky Kz Ss Por

6.54775e+03 6.54775e+03 6.54775e+02 1.00000e-09 7.00000e-02

$2.61636 \mathrm{e}+022.61636 \mathrm{e}+02$ 2.61636e+01 1.00000e-09 2.12000e-01

$1.00000 \mathrm{e}-02$ 1.00000e-02 1.00000e-03 1.00000e-09 1.00000e-01

$1.00000 \mathrm{e}+001.00000 \mathrm{e}+001.00000 \mathrm{e}-011.00000 \mathrm{e}-091.00000 \mathrm{e}-01$

Element: 6656 \# of layers: 4

$\mathrm{Kx} \mathrm{Ky} \mathrm{Kz}$ Ss Por

6.54775e+03 6.54775e+03 6.54775e+02 1.00000e-09 7.00000e-02

$2.61636 \mathrm{e}+022.61636 \mathrm{e}+022.61636 \mathrm{e}+01$ 1.00000e-09 2.12000e-01 
$1.00000 \mathrm{e}-02$ 1.00000e-02 1.00000e-03 1.00000e-09 1.00000e-01 $1.00000 \mathrm{e}+001.00000 \mathrm{e}+001.00000 \mathrm{e}-01$ 1.00000e-09 1.00000e-01 Element: 6657 \# of layers: 4

Kx Ky Kz Ss Por

6.54775e+03 6.54775e+03 6.54775e+02 1.00000e-09 7.00000e-02 $2.61636 \mathrm{e}+022.61636 \mathrm{e}+022.61636 \mathrm{e}+01$ 1.00000e-09 2.12000e-01 $1.00000 \mathrm{e}-02$ 1.00000e-02 1.00000e-03 1.00000e-09 1.00000e-01 $1.00000 \mathrm{e}+001.00000 \mathrm{e}+001.00000 \mathrm{e}-011.00000 \mathrm{e}-091.00000 \mathrm{e}-01$ Element: 6658 \# of layers: 4

$\mathrm{Kx} \mathrm{Ky} \mathrm{Kz}$ Ss Por

6.54775e+03 6.54775e+03 6.54775e+02 1.00000e-09 7.00000e-02 $2.61636 \mathrm{e}+022.61636 \mathrm{e}+022.61636 \mathrm{e}+01$ 1.00000e-09 2.12000e-01 $1.00000 \mathrm{e}-02$ 1.00000e-02 1.00000e-03 1.00000e-09 1.00000e-01 $1.00000 \mathrm{e}+001.00000 \mathrm{e}+001.00000 \mathrm{e}-011.00000 \mathrm{e}-091.00000 \mathrm{e}-01$ Element: 6659 \# of layers: 4

Kx Ky Kz Ss Por

6.54775e+03 6.54775e+03 6.54775e+02 1.00000e-09 7.00000e-02 $2.61636 \mathrm{e}+022.61636 \mathrm{e}+02$ 2.61636e+01 1.00000e-09 2.12000e-01 $1.00000 \mathrm{e}-02$ 1.00000e-02 1.00000e-03 1.00000e-09 1.00000e-01 $1.00000 \mathrm{e}+001.00000 \mathrm{e}+001.00000 \mathrm{e}-011.00000 \mathrm{e}-091.00000 \mathrm{e}-01$

Element: 6660 \# of layers: 4

$\mathrm{Kx} \mathrm{Ky} \mathrm{Kz}$ Ss Por

6.54775e+03 6.54775e+03 6.54775e+02 1.00000e-09 7.00000e-02 $2.61636 \mathrm{e}+022.61636 \mathrm{e}+02$ 2.61636e+01 1.00000e-09 2.12000e-01 $1.00000 \mathrm{e}-02$ 1.00000e-02 1.00000e-03 1.00000e-09 1.00000e-01 $1.00000 \mathrm{e}+001.00000 \mathrm{e}+001.00000 \mathrm{e}-01$ 1.00000e-09 1.00000e-01

Element: 6661 \# of layers: 4

$\mathrm{Kx} \mathrm{Ky} \mathrm{Kz}$ Ss Por

6.54775e+03 6.54775e+03 6.54775e+02 1.00000e-09 7.00000e-02 $2.61636 \mathrm{e}+02$ 2.61636e+02 2.61636e+01 1.00000e-09 2.12000e-01 $1.00000 \mathrm{e}-02$ 1.00000e-02 1.00000e-03 1.00000e-09 1.00000e-01 $1.00000 \mathrm{e}+001.00000 \mathrm{e}+001.00000 \mathrm{e}-011.00000 \mathrm{e}-091.00000 \mathrm{e}-01$

Element: 6662 \# of layers: 4

$\mathrm{Kx} \mathrm{Ky} \mathrm{Kz}$ Ss Por

6.54775e+03 6.54775e+03 6.54775e+02 1.00000e-09 7.00000e-02 $2.61636 \mathrm{e}+022.61636 \mathrm{e}+022.61636 \mathrm{e}+01$ 1.00000e-09 2.12000e-01 1.00000e-02 1.00000e-02 1.00000e-03 1.00000e-09 1.00000e-01 $1.00000 \mathrm{e}+001.00000 \mathrm{e}+001.00000 \mathrm{e}-011.00000 \mathrm{e}-091.00000 \mathrm{e}-01$ Element: 6663 \# of layers: 4

$\mathrm{Kx} \mathrm{Ky} \mathrm{Kz}$ Ss Por

1.46512e+03 1.46512e+03 1.46512e+02 1.00000e-09 7.00000e-02 $5.85418 \mathrm{e}+015.85418 \mathrm{e}+015.85418 \mathrm{e}+00$ 1.00000e-09 2.12000e-01 $1.00000 \mathrm{e}-02$ 1.00000e-02 1.00000e-03 1.00000e-09 1.00000e-01 $1.00000 \mathrm{e}+001.00000 \mathrm{e}+001.00000 \mathrm{e}-01$ 1.00000e-09 1.00000e-01 Element: 6664 \# of layers: 4

Kx Ky Kz Ss Por 
$1.46512 \mathrm{e}+03$ 1.46512e+03 1.46512e+02 1.00000e-09 7.00000e-02 $5.85418 \mathrm{e}+015.85418 \mathrm{e}+015.85418 \mathrm{e}+00$ 1.00000e-09 2.12000e-01 $1.00000 \mathrm{e}-02$ 1.00000e-02 1.00000e-03 1.00000e-09 1.00000e-01

$1.00000 \mathrm{e}+001.00000 \mathrm{e}+001.00000 \mathrm{e}-011.00000 \mathrm{e}-091.00000 \mathrm{e}-01$

Element: 6665 \# of layers: 4

$\mathrm{Kx} \mathrm{Ky} \mathrm{Kz}$ Ss Por

$1.46512 \mathrm{e}+03$ 1.46512e+03 1.46512e+02 1.00000e-09 7.00000e-02

$5.85418 \mathrm{e}+015.85418 \mathrm{e}+015.85418 \mathrm{e}+00$ 1.00000e-09 2.12000e-01

$1.00000 \mathrm{e}-02$ 1.00000e-02 1.00000e-03 1.00000e-09 1.00000e-01

$1.00000 \mathrm{e}+001.00000 \mathrm{e}+001.00000 \mathrm{e}-011.00000 \mathrm{e}-091.00000 \mathrm{e}-01$

Element: 6666 \# of layers: 4

Kx Ky Kz Ss Por

$1.46512 \mathrm{e}+03$ 1.46512e+03 1.46512e+02 1.00000e-09 7.00000e-02

$5.85418 \mathrm{e}+015.85418 \mathrm{e}+015.85418 \mathrm{e}+00$ 1.00000e-09 2.12000e-01

$1.00000 \mathrm{e}-02$ 1.00000e-02 1.00000e-03 1.00000e-09 1.00000e-01

$1.00000 \mathrm{e}+001.00000 \mathrm{e}+001.00000 \mathrm{e}-011.00000 \mathrm{e}-091.00000 \mathrm{e}-01$

Element: 6667 \# of layers: 4

$\mathrm{Kx} \mathrm{Ky} \mathrm{Kz}$ Ss Por

$1.46512 \mathrm{e}+03$ 1.46512e+03 1.46512e+02 1.00000e-09 7.00000e-02

$5.85418 \mathrm{e}+015.85418 \mathrm{e}+015.85418 \mathrm{e}+00$ 1.00000e-09 2.12000e-01

$1.00000 \mathrm{e}-02$ 1.00000e-02 1.00000e-03 1.00000e-09 1.00000e-01

$1.00000 \mathrm{e}+001.00000 \mathrm{e}+001.00000 \mathrm{e}-011.00000 \mathrm{e}-091.00000 \mathrm{e}-01$

Element: 6668 \# of layers: 4

Kx Ky Kz Ss Por

1.46512e+03 1.46512e+03 1.46512e+02 1.00000e-09 7.00000e-02

$5.85418 \mathrm{e}+015.85418 \mathrm{e}+015.85418 \mathrm{e}+00$ 1.00000e-09 2.12000e-01

$1.00000 \mathrm{e}-02$ 1.00000e-02 1.00000e-03 1.00000e-09 1.00000e-01

$1.00000 \mathrm{e}+001.00000 \mathrm{e}+001.00000 \mathrm{e}-011.00000 \mathrm{e}-091.00000 \mathrm{e}-01$

Element: 6669 \# of layers: 4

$\mathrm{Kx} \mathrm{Ky} \mathrm{Kz}$ Ss Por

$1.46512 \mathrm{e}+03$ 1.46512e+03 1.46512e+02 1.00000e-09 7.00000e-02

$5.85418 \mathrm{e}+015.85418 \mathrm{e}+015.85418 \mathrm{e}+00$ 1.00000e-09 2.12000e-01

$1.00000 \mathrm{e}-02$ 1.00000e-02 1.00000e-03 1.00000e-09 1.00000e-01

$1.00000 \mathrm{e}+001.00000 \mathrm{e}+001.00000 \mathrm{e}-011.00000 \mathrm{e}-091.00000 \mathrm{e}-01$

Element: 6670 \# of layers: 4

Kx Ky Kz Ss Por

1.46512e+03 1.46512e+03 1.46512e+02 1.00000e-09 7.00000e-02

$5.85418 \mathrm{e}+015.85418 \mathrm{e}+015.85418 \mathrm{e}+001.00000 \mathrm{e}-092.12000 \mathrm{e}-01$

$1.00000 \mathrm{e}-02$ 1.00000e-02 1.00000e-03 1.00000e-09 1.00000e-01

$1.00000 \mathrm{e}+001.00000 \mathrm{e}+001.00000 \mathrm{e}-01$ 1.00000e-09 1.00000e-01

Element: 6671 \# of layers: 4

$\mathrm{Kx} \mathrm{Ky} \mathrm{Kz}$ Ss Por

$1.46512 \mathrm{e}+03$ 1.46512e+03 1.46512e+02 1.00000e-09 7.00000e-02

$5.85418 \mathrm{e}+015.85418 \mathrm{e}+015.85418 \mathrm{e}+00$ 1.00000e-09 2.12000e-01

$1.00000 \mathrm{e}-02$ 1.00000e-02 1.00000e-03 1.00000e-09 1.00000e-01

$1.00000 \mathrm{e}+001.00000 \mathrm{e}+001.00000 \mathrm{e}-011.00000 \mathrm{e}-091.00000 \mathrm{e}-01$ 
Element: 6672 \# of layers: 4

$\mathrm{Kx} \mathrm{Ky} \mathrm{Kz}$ Ss Por

$1.47728 \mathrm{e}+03$ 1.47728e+03 1.47728e+02 1.00000e-09 7.00000e-02

$5.90278 \mathrm{e}+015.90278 \mathrm{e}+015.90278 \mathrm{e}+001.00000 \mathrm{e}-092.12000 \mathrm{e}-01$

$1.00000 \mathrm{e}-02$ 1.00000e-02 1.00000e-03 1.00000e-09 1.00000e-01

$1.00000 \mathrm{e}+001.00000 \mathrm{e}+001.00000 \mathrm{e}-011.00000 \mathrm{e}-091.00000 \mathrm{e}-01$

Element: 6673 \# of layers: 4

$\mathrm{Kx} \mathrm{Ky} \mathrm{Kz}$ Ss Por

$1.47728 \mathrm{e}+03$ 1.47728e+03 1.47728e+02 1.00000e-09 7.00000e-02

$5.90278 \mathrm{e}+015.90278 \mathrm{e}+015.90278 \mathrm{e}+00$ 1.00000e-09 2.12000e-01

$1.00000 \mathrm{e}-02$ 1.00000e-02 1.00000e-03 1.00000e-09 1.00000e-01

$1.00000 \mathrm{e}+001.00000 \mathrm{e}+001.00000 \mathrm{e}-011.00000 \mathrm{e}-091.00000 \mathrm{e}-01$

Element: 6674 \# of layers: 5

$\mathrm{Kx} \mathrm{Ky} \mathrm{Kz}$ Ss Por

$1.47728 \mathrm{e}+03$ 1.47728e+03 1.47728e+02 1.00000e-09 7.00000e-02

$5.90278 \mathrm{e}+015.90278 \mathrm{e}+015.90278 \mathrm{e}+00$ 1.00000e-09 2.12000e-01

$5.90278 \mathrm{e}+015.90278 \mathrm{e}+015.90278 \mathrm{e}+00$ 1.00000e-09 2.12000e-01

$1.00000 \mathrm{e}-02$ 1.00000e-02 1.00000e-03 1.00000e-09 1.00000e-01

$1.00000 \mathrm{e}+001.00000 \mathrm{e}+001.00000 \mathrm{e}-01$ 1.00000e-09 1.00000e-01

Element: 6675 \# of layers: 5

$\mathrm{Kx} \mathrm{Ky} \mathrm{Kz}$ Ss Por

$1.47728 \mathrm{e}+03$ 1.47728e+03 1.47728e+02 1.00000e-09 7.00000e-02

$5.90278 \mathrm{e}+015.90278 \mathrm{e}+015.90278 \mathrm{e}+00$ 1.00000e-09 2.12000e-01

$5.90278 \mathrm{e}+015.90278 \mathrm{e}+015.90278 \mathrm{e}+00$ 1.00000e-09 2.12000e-01

$1.00000 \mathrm{e}-021.00000 \mathrm{e}-02$ 1.00000e-03 1.00000e-09 1.00000e-01

$1.00000 \mathrm{e}+001.00000 \mathrm{e}+001.00000 \mathrm{e}-01$ 1.00000e-09 1.00000e-01

Element: 6676 \# of layers: 5

$\mathrm{Kx} \mathrm{Ky} \mathrm{Kz}$ Ss Por

$1.47728 \mathrm{e}+03$ 1.47728e+03 1.47728e+02 1.00000e-09 7.00000e-02

$5.90278 \mathrm{e}+015.90278 \mathrm{e}+01$ 5.90278e+00 1.00000e-09 2.12000e-01

$5.90278 \mathrm{e}+015.90278 \mathrm{e}+015.90278 \mathrm{e}+001.00000 \mathrm{e}-092.12000 \mathrm{e}-01$

$1.00000 \mathrm{e}-02$ 1.00000e-02 1.00000e-03 1.00000e-09 1.00000e-01

$1.00000 \mathrm{e}+001.00000 \mathrm{e}+001.00000 \mathrm{e}-011.00000 \mathrm{e}-091.00000 \mathrm{e}-01$

Element: 6677 \# of layers: 5

$\mathrm{Kx} \mathrm{Ky} \mathrm{Kz}$ Ss Por

1.47728e+03 1.47728e+03 1.47728e+02 1.00000e-09 7.00000e-02

$5.90278 \mathrm{e}+015.90278 \mathrm{e}+015.90278 \mathrm{e}+001.00000 \mathrm{e}-092.12000 \mathrm{e}-01$

$5.90278 \mathrm{e}+015.90278 \mathrm{e}+015.90278 \mathrm{e}+00$ 1.00000e-09 2.12000e-01

$1.00000 \mathrm{e}-02$ 1.00000e-02 1.00000e-03 1.00000e-09 1.00000e-01

$1.00000 \mathrm{e}+001.00000 \mathrm{e}+001.00000 \mathrm{e}-01$ 1.00000e-09 1.00000e-01

Element: 6678 \# of layers: 4

$\mathrm{Kx} \mathrm{Ky} \mathrm{Kz}$ Ss Por

1.47728e+03 1.47728e+03 1.47728e+02 1.00000e-09 7.00000e-02

5.90278e+01 5.90278e+01 5.90278e+00 1.00000e-09 2.12000e-01

$1.00000 \mathrm{e}-02$ 1.00000e-02 1.00000e-03 1.00000e-09 1.00000e-01

$1.00000 \mathrm{e}+001.00000 \mathrm{e}+001.00000 \mathrm{e}-011.00000 \mathrm{e}-091.00000 \mathrm{e}-01$ 
Element: 6679 \# of layers: 4

$\mathrm{Kx} \mathrm{Ky} \mathrm{Kz}$ Ss Por

$1.47728 \mathrm{e}+03$ 1.47728e+03 1.47728e+02 1.00000e-09 7.00000e-02

$5.90278 \mathrm{e}+015.90278 \mathrm{e}+015.90278 \mathrm{e}+001.00000 \mathrm{e}-092.12000 \mathrm{e}-01$

$1.00000 \mathrm{e}-02$ 1.00000e-02 1.00000e-03 1.00000e-09 1.00000e-01

$1.00000 \mathrm{e}+001.00000 \mathrm{e}+001.00000 \mathrm{e}-01$ 1.00000e-09 1.00000e-01

Element: 6680 \# of layers: 4

Kx Ky Kz Ss Por

$1.47728 \mathrm{e}+031.47728 \mathrm{e}+03$ 1.47728e+02 1.00000e-09 7.00000e-02

$5.90278 \mathrm{e}+015.90278 \mathrm{e}+015.90278 \mathrm{e}+00$ 1.00000e-09 2.12000e-01

1.00000e-02 1.00000e-02 1.00000e-03 1.00000e-09 1.00000e-01

$1.00000 \mathrm{e}+001.00000 \mathrm{e}+001.00000 \mathrm{e}-011.00000 \mathrm{e}-091.00000 \mathrm{e}-01$

Element: 6681 \# of layers: 5

$\mathrm{Kx} \mathrm{Ky} \mathrm{Kz}$ Ss Por

1.42673e+03 1.42673e+03 1.42673e+02 1.00000e-09 7.00000e-02

$5.70050 \mathrm{e}+015.70050 \mathrm{e}+015.70050 \mathrm{e}+001.00000 \mathrm{e}-092.12000 \mathrm{e}-01$

$5.70050 \mathrm{e}+01$ 5.70050e+01 5.70050e+00 1.00000e-09 2.12000e-01

1.00000e-02 1.00000e-02 1.00000e-03 1.00000e-09 1.00000e-01

$1.00000 \mathrm{e}+001.00000 \mathrm{e}+001.00000 \mathrm{e}-011.00000 \mathrm{e}-091.00000 \mathrm{e}-01$

Element: 6682 \# of layers: 5

$\mathrm{Kx} \mathrm{Ky} \mathrm{Kz}$ Ss Por

1.42673e+03 1.42673e+03 1.42673e+02 1.00000e-09 7.00000e-02

$5.70050 \mathrm{e}+015.70050 \mathrm{e}+015.70050 \mathrm{e}+001.00000 \mathrm{e}-092.12000 \mathrm{e}-01$

$5.70050 \mathrm{e}+015.70050 \mathrm{e}+015.70050 \mathrm{e}+001.00000 \mathrm{e}-092.12000 \mathrm{e}-01$

$1.00000 \mathrm{e}-02$ 1.00000e-02 1.00000e-03 1.00000e-09 1.00000e-01

$1.00000 \mathrm{e}+001.00000 \mathrm{e}+001.00000 \mathrm{e}-011.00000 \mathrm{e}-091.00000 \mathrm{e}-01$

Element: 6683 \# of layers: 5

$\mathrm{Kx} \mathrm{Ky} \mathrm{Kz}$ Ss Por

1.42673e+03 1.42673e+03 1.42673e+02 1.00000e-09 7.00000e-02

$5.70050 \mathrm{e}+015.70050 \mathrm{e}+015.70050 \mathrm{e}+001.00000 \mathrm{e}-092.12000 \mathrm{e}-01$

$5.70050 \mathrm{e}+015.70050 \mathrm{e}+015.70050 \mathrm{e}+001.00000 \mathrm{e}-092.12000 \mathrm{e}-01$

$1.00000 \mathrm{e}-02$ 1.00000e-02 1.00000e-03 1.00000e-09 1.00000e-01

$1.00000 \mathrm{e}+001.00000 \mathrm{e}+001.00000 \mathrm{e}-011.00000 \mathrm{e}-091.00000 \mathrm{e}-01$

Element: 6684 \# of layers: 5

$\mathrm{Kx} \mathrm{Ky} \mathrm{Kz}$ Ss Por

$1.42673 \mathrm{e}+03$ 1.42673e+03 1.42673e+02 1.00000e-09 7.00000e-02

$5.70050 \mathrm{e}+015.70050 \mathrm{e}+015.70050 \mathrm{e}+001.00000 \mathrm{e}-092.12000 \mathrm{e}-01$

$5.70050 \mathrm{e}+015.70050 \mathrm{e}+015.70050 \mathrm{e}+001.00000 \mathrm{e}-092.12000 \mathrm{e}-01$

$1.00000 \mathrm{e}-02$ 1.00000e-02 1.00000e-03 1.00000e-09 1.00000e-01

$1.00000 \mathrm{e}+001.00000 \mathrm{e}+001.00000 \mathrm{e}-011.00000 \mathrm{e}-091.00000 \mathrm{e}-01$

Element: 6685 \# of layers: 5

$\mathrm{Kx} \mathrm{Ky} \mathrm{Kz}$ Ss Por

$1.42673 \mathrm{e}+03$ 1.42673e+03 1.42673e+02 1.00000e-09 7.00000e-02

$5.70050 \mathrm{e}+015.70050 \mathrm{e}+015.70050 \mathrm{e}+001.00000 \mathrm{e}-092.12000 \mathrm{e}-01$

$5.70050 \mathrm{e}+015.70050 \mathrm{e}+015.70050 \mathrm{e}+001.00000 \mathrm{e}-092.12000 \mathrm{e}-01$

$1.00000 \mathrm{e}-02$ 1.00000e-02 1.00000e-03 1.00000e-09 1.00000e-01 
$1.00000 \mathrm{e}+001.00000 \mathrm{e}+00$ 1.00000e-01 1.00000e-09 1.00000e-01

Element: 6686 \# of layers: 5

Kx Ky Kz Ss Por

$1.42673 \mathrm{e}+03$ 1.42673e+03 1.42673e+02 1.00000e-09 7.00000e-02

$5.70050 \mathrm{e}+015.70050 \mathrm{e}+015.70050 \mathrm{e}+001.00000 \mathrm{e}-092.12000 \mathrm{e}-01$

$5.70050 \mathrm{e}+015.70050 \mathrm{e}+015.70050 \mathrm{e}+001.00000 \mathrm{e}-092.12000 \mathrm{e}-01$

$1.00000 \mathrm{e}-02$ 1.00000e-02 1.00000e-03 1.00000e-09 1.00000e-01

$1.00000 \mathrm{e}+001.00000 \mathrm{e}+001.00000 \mathrm{e}-01$ 1.00000e-09 1.00000e-01

Element: 6687 \# of layers: 5

$\mathrm{Kx} \mathrm{Ky} \mathrm{Kz}$ Ss Por

1.42673e+03 1.42673e+03 1.42673e+02 1.00000e-09 7.00000e-02

$5.70050 \mathrm{e}+015.70050 \mathrm{e}+015.70050 \mathrm{e}+001.00000 \mathrm{e}-092.12000 \mathrm{e}-01$

$5.70050 \mathrm{e}+01$ 5.70050e+01 5.70050e+00 1.00000e-09 2.12000e-01

$1.00000 \mathrm{e}-02$ 1.00000e-02 1.00000e-03 1.00000e-09 1.00000e-01

$1.00000 \mathrm{e}+001.00000 \mathrm{e}+001.00000 \mathrm{e}-01$ 1.00000e-09 1.00000e-01

Element: 6688 \# of layers: 5

$\mathrm{Kx} \mathrm{Ky} \mathrm{Kz}$ Ss Por

1.42673e+03 1.42673e+03 1.42673e+02 1.00000e-09 7.00000e-02

$5.70050 \mathrm{e}+015.70050 \mathrm{e}+015.70050 \mathrm{e}+001.00000 \mathrm{e}-092.12000 \mathrm{e}-01$

$5.70050 \mathrm{e}+015.70050 \mathrm{e}+015.70050 \mathrm{e}+001.00000 \mathrm{e}-092.12000 \mathrm{e}-01$

$1.00000 \mathrm{e}-02$ 1.00000e-02 1.00000e-03 1.00000e-09 1.00000e-01

$1.00000 \mathrm{e}+001.00000 \mathrm{e}+001.00000 \mathrm{e}-011.00000 \mathrm{e}-091.00000 \mathrm{e}-01$

Element: 6689 \# of layers: 5

Kx Ky Kz Ss Por

$1.42673 e+03$ 1.42673e+03 1.42673e+02 1.00000e-09 7.00000e-02

$5.70050 \mathrm{e}+015.70050 \mathrm{e}+015.70050 \mathrm{e}+001.00000 \mathrm{e}-092.12000 \mathrm{e}-01$

$5.70050 \mathrm{e}+015.70050 \mathrm{e}+015.70050 \mathrm{e}+001.00000 \mathrm{e}-09$ 2.12000e-01

$1.00000 \mathrm{e}-02$ 1.00000e-02 1.00000e-03 1.00000e-09 1.00000e-01

$1.00000 \mathrm{e}+001.00000 \mathrm{e}+001.00000 \mathrm{e}-011.00000 \mathrm{e}-091.00000 \mathrm{e}-01$

Element: 6690 \# of layers: 5

$\mathrm{Kx} \mathrm{Ky} \mathrm{Kz}$ Ss Por

5.82965e+02 5.82965e+02 5.82965e+01 1.00000e-09 7.00000e-02

$2.32925 \mathrm{e}+012.32925 \mathrm{e}+012.32925 \mathrm{e}+00$ 1.00000e-09 2.12000e-01

$2.32925 \mathrm{e}+012.32925 \mathrm{e}+012.32925 \mathrm{e}+001.00000 \mathrm{e}-092.12000 \mathrm{e}-01$

$1.00000 \mathrm{e}-02$ 1.00000e-02 1.00000e-03 1.00000e-09 1.00000e-01

$1.00000 \mathrm{e}+001.00000 \mathrm{e}+001.00000 \mathrm{e}-011.00000 \mathrm{e}-091.00000 \mathrm{e}-01$

Element: 6691 \# of layers: 4

Kx Ky Kz Ss Por

$2.32925 \mathrm{e}+012.32925 \mathrm{e}+01$ 2.32925e+00 1.00000e-09 2.12000e-01

$2.32925 \mathrm{e}+012.32925 \mathrm{e}+012.32925 \mathrm{e}+00$ 1.00000e-09 2.12000e-01

1.00000e-02 1.00000e-02 1.00000e-03 1.00000e-09 1.00000e-01

$1.00000 \mathrm{e}+001.00000 \mathrm{e}+001.00000 \mathrm{e}-011.00000 \mathrm{e}-091.00000 \mathrm{e}-01$

Element: 6692 \# of layers: 4

$\mathrm{Kx} \mathrm{Ky} \mathrm{Kz}$ Ss Por

$2.32925 \mathrm{e}+012.32925 \mathrm{e}+012.32925 \mathrm{e}+00$ 1.00000e-09 2.12000e-01

$2.32925 \mathrm{e}+012.32925 \mathrm{e}+012.32925 \mathrm{e}+001.00000 \mathrm{e}-092.12000 \mathrm{e}-01$ 
$1.00000 \mathrm{e}-02$ 1.00000e-02 1.00000e-03 1.00000e-09 1.00000e-01 $1.00000 \mathrm{e}+001.00000 \mathrm{e}+001.00000 \mathrm{e}-01$ 1.00000e-09 1.00000e-01 Element: 6693 \# of layers: 4

$\mathrm{Kx} \mathrm{Ky} \mathrm{Kz}$ Ss Por

$2.32925 \mathrm{e}+012.32925 \mathrm{e}+012.32925 \mathrm{e}+00$ 1.00000e-09 2.12000e-01 $2.32925 \mathrm{e}+012.32925 \mathrm{e}+012.32925 \mathrm{e}+00$ 1.00000e-09 2.12000e-01 1.00000e-02 1.00000e-02 1.00000e-03 1.00000e-09 1.00000e-01 $1.00000 \mathrm{e}+001.00000 \mathrm{e}+001.00000 \mathrm{e}-011.00000 \mathrm{e}-091.00000 \mathrm{e}-01$ Element: 6694 \# of layers: 6

$\mathrm{Kx} \mathrm{Ky} \mathrm{Kz}$ Ss Por

5.82965e+02 5.82965e+02 5.82965e+01 1.00000e-09 7.00000e-02 $5.82965 \mathrm{e}+02$ 5.82965e+02 5.82965e+01 1.00000e-09 7.00000e-02 $2.32925 \mathrm{e}+012.32925 \mathrm{e}+012.32925 \mathrm{e}+00$ 1.00000e-09 2.12000e-01 $2.32925 \mathrm{e}+012.32925 \mathrm{e}+012.32925 \mathrm{e}+00$ 1.00000e-09 2.12000e-01 $1.00000 \mathrm{e}-02$ 1.00000e-02 1.00000e-03 1.00000e-09 1.00000e-01 $1.00000 \mathrm{e}+001.00000 \mathrm{e}+001.00000 \mathrm{e}-011.00000 \mathrm{e}-091.00000 \mathrm{e}-01$ Element: 6695 \# of layers: 5

$\mathrm{Kx} \mathrm{Ky} \mathrm{Kz}$ Ss Por

5.82965e+02 5.82965e+02 5.82965e+01 1.00000e-09 7.00000e-02 $2.32925 \mathrm{e}+012.32925 \mathrm{e}+012.32925 \mathrm{e}+00$ 1.00000e-09 2.12000e-01 $2.32925 \mathrm{e}+012.32925 \mathrm{e}+012.32925 \mathrm{e}+001.00000 \mathrm{e}-092.12000 \mathrm{e}-01$ $1.00000 \mathrm{e}-02$ 1.00000e-02 1.00000e-03 1.00000e-09 1.00000e-01 $1.00000 \mathrm{e}+001.00000 \mathrm{e}+001.00000 \mathrm{e}-01$ 1.00000e-09 1.00000e-01 Element: 6696 \# of layers: 5

$\mathrm{Kx} \mathrm{Ky} \mathrm{Kz}$ Ss Por

5.82965e+02 5.82965e+02 5.82965e+01 1.00000e-09 7.00000e-02 $2.32925 \mathrm{e}+012.32925 \mathrm{e}+012.32925 \mathrm{e}+001.00000 \mathrm{e}-092.12000 \mathrm{e}-01$ $2.32925 \mathrm{e}+012.32925 \mathrm{e}+012.32925 \mathrm{e}+001.00000 \mathrm{e}-092.12000 \mathrm{e}-01$ $1.00000 \mathrm{e}-02$ 1.00000e-02 1.00000e-03 1.00000e-09 1.00000e-01 $1.00000 \mathrm{e}+001.00000 \mathrm{e}+001.00000 \mathrm{e}-011.00000 \mathrm{e}-091.00000 \mathrm{e}-01$ Element: 6697 \# of layers: 5

$\mathrm{Kx} \mathrm{Ky} \mathrm{Kz}$ Ss Por

5.82965e+02 5.82965e+02 5.82965e+01 1.00000e-09 7.00000e-02 $2.32925 \mathrm{e}+012.32925 \mathrm{e}+012.32925 \mathrm{e}+00$ 1.00000e-09 2.12000e-01 $2.32925 \mathrm{e}+012.32925 \mathrm{e}+012.32925 \mathrm{e}+001.00000 \mathrm{e}-092.12000 \mathrm{e}-01$ $1.00000 \mathrm{e}-02$ 1.00000e-02 1.00000e-03 1.00000e-09 1.00000e-01 $1.00000 \mathrm{e}+001.00000 \mathrm{e}+001.00000 \mathrm{e}-011.00000 \mathrm{e}-091.00000 \mathrm{e}-01$ Element: 6698 \# of layers: 4

$\mathrm{Kx} \mathrm{Ky} \mathrm{Kz}$ Ss Por

$2.32925 \mathrm{e}+012.32925 \mathrm{e}+012.32925 \mathrm{e}+00$ 1.00000e-09 2.12000e-01 $2.32925 \mathrm{e}+012.32925 \mathrm{e}+012.32925 \mathrm{e}+00$ 1.00000e-09 2.12000e-01 $1.00000 \mathrm{e}-02$ 1.00000e-02 1.00000e-03 1.00000e-09 1.00000e-01 $1.00000 \mathrm{e}+001.00000 \mathrm{e}+001.00000 \mathrm{e}-011.00000 \mathrm{e}-091.00000 \mathrm{e}-01$ Element: 6699 \# of layers: 4

$\mathrm{Kx} \mathrm{Ky} \mathrm{Kz}$ Ss Por $2.23160 \mathrm{e}+012.23160 \mathrm{e}+012.23160 \mathrm{e}+001.00000 \mathrm{e}-092.12000 \mathrm{e}-01$ 
$2.23160 \mathrm{e}+012.23160 \mathrm{e}+012.23160 \mathrm{e}+00$ 1.00000e-09 2.12000e-01 $1.00000 \mathrm{e}-021.00000 \mathrm{e}-02$ 1.00000e-03 1.00000e-09 1.00000e-01 $1.00000 \mathrm{e}+001.00000 \mathrm{e}+001.00000 \mathrm{e}-011.00000 \mathrm{e}-091.00000 \mathrm{e}-01$

Element: 6700 \# of layers: 4

Kx Ky Kz Ss Por

$2.23160 \mathrm{e}+012.23160 \mathrm{e}+012.23160 \mathrm{e}+00$ 1.00000e-09 2.12000e-01

$2.23160 \mathrm{e}+012.23160 \mathrm{e}+012.23160 \mathrm{e}+001.00000 \mathrm{e}-092.12000 \mathrm{e}-01$ $1.00000 \mathrm{e}-021.00000 \mathrm{e}-02$ 1.00000e-03 1.00000e-09 1.00000e-01 $1.00000 \mathrm{e}+001.00000 \mathrm{e}+001.00000 \mathrm{e}-011.00000 \mathrm{e}-091.00000 \mathrm{e}-01$ Element: 6701 \# of layers: 4

Kx Ky Kz Ss Por

$2.23160 \mathrm{e}+012.23160 \mathrm{e}+012.23160 \mathrm{e}+00$ 1.00000e-09 2.12000e-01 $2.23160 \mathrm{e}+012.23160 \mathrm{e}+012.23160 \mathrm{e}+001.00000 \mathrm{e}-092.12000 \mathrm{e}-01$ $1.00000 \mathrm{e}-021.00000 \mathrm{e}-02$ 1.00000e-03 1.00000e-09 1.00000e-01 $1.00000 \mathrm{e}+001.00000 \mathrm{e}+001.00000 \mathrm{e}-011.00000 \mathrm{e}-091.00000 \mathrm{e}-01$ Element: 6702 \# of layers: 5

Kx Ky Kz Ss Por

5.58512e+02 5.58512e+02 5.58512e+01 1.00000e-09 7.00000e-02 $2.23160 \mathrm{e}+012.23160 \mathrm{e}+012.23160 \mathrm{e}+001.00000 \mathrm{e}-092.12000 \mathrm{e}-01$ $2.23160 \mathrm{e}+012.23160 \mathrm{e}+012.23160 \mathrm{e}+001.00000 \mathrm{e}-092.12000 \mathrm{e}-01$ $1.00000 \mathrm{e}-02$ 1.00000e-02 1.00000e-03 1.00000e-09 1.00000e-01 $1.00000 \mathrm{e}+001.00000 \mathrm{e}+001.00000 \mathrm{e}-011.00000 \mathrm{e}-091.00000 \mathrm{e}-01$ Element: 6703 \# of layers: 5

Kx Ky Kz Ss Por

$5.58512 \mathrm{e}+025.58512 \mathrm{e}+025.58512 \mathrm{e}+01$ 1.00000e-09 7.00000e-02 $2.23160 \mathrm{e}+012.23160 \mathrm{e}+012.23160 \mathrm{e}+001.00000 \mathrm{e}-092.12000 \mathrm{e}-01$ $2.23160 \mathrm{e}+012.23160 \mathrm{e}+012.23160 \mathrm{e}+001.00000 \mathrm{e}-092.12000 \mathrm{e}-01$ $1.00000 \mathrm{e}-021.00000 \mathrm{e}-02$ 1.00000e-03 1.00000e-09 1.00000e-01 $1.00000 \mathrm{e}+001.00000 \mathrm{e}+001.00000 \mathrm{e}-011.00000 \mathrm{e}-091.00000 \mathrm{e}-01$ Element: 6704 \# of layers: 5

Kx Ky Kz Ss Por

$5.58512 \mathrm{e}+025.58512 \mathrm{e}+025.58512 \mathrm{e}+01$ 1.00000e-09 7.00000e-02 $2.23160 \mathrm{e}+012.23160 \mathrm{e}+012.23160 \mathrm{e}+001.00000 \mathrm{e}-092.12000 \mathrm{e}-01$ $2.23160 \mathrm{e}+012.23160 \mathrm{e}+012.23160 \mathrm{e}+001.00000 \mathrm{e}-092.12000 \mathrm{e}-01$ $1.00000 \mathrm{e}-021.00000 \mathrm{e}-02$ 1.00000e-03 1.00000e-09 1.00000e-01 $1.00000 \mathrm{e}+001.00000 \mathrm{e}+001.00000 \mathrm{e}-011.00000 \mathrm{e}-091.00000 \mathrm{e}-01$ Element: 6705 \# of layers: 5

Kx Ky Kz Ss Por

5.58512e+02 5.58512e+02 5.58512e+01 1.00000e-09 7.00000e-02 $2.23160 \mathrm{e}+012.23160 \mathrm{e}+012.23160 \mathrm{e}+001.00000 \mathrm{e}-092.12000 \mathrm{e}-01$ $2.23160 \mathrm{e}+012.23160 \mathrm{e}+012.23160 \mathrm{e}+001.00000 \mathrm{e}-092.12000 \mathrm{e}-01$ $1.00000 \mathrm{e}-021.00000 \mathrm{e}-02$ 1.00000e-03 1.00000e-09 1.00000e-01 $1.00000 \mathrm{e}+001.00000 \mathrm{e}+001.00000 \mathrm{e}-011.00000 \mathrm{e}-091.00000 \mathrm{e}-01$ Element: 6706 \# of layers: 4

Kx Ky Kz Ss Por

$2.23160 \mathrm{e}+012.23160 \mathrm{e}+012.23160 \mathrm{e}+00$ 1.00000e-09 2.12000e-01 
$2.23160 \mathrm{e}+012.23160 \mathrm{e}+012.23160 \mathrm{e}+001.00000 \mathrm{e}-092.12000 \mathrm{e}-01$ $1.00000 \mathrm{e}-02$ 1.00000e-02 1.00000e-03 1.00000e-09 1.00000e-01

$1.00000 \mathrm{e}+001.00000 \mathrm{e}+001.00000 \mathrm{e}-01$ 1.00000e-09 1.00000e-01

Element: 6707 \# of layers: 5

$\mathrm{Kx} \mathrm{Ky} \mathrm{Kz}$ Ss Por

5.58512e+02 5.58512e+02 5.58512e+01 1.00000e-09 7.00000e-02

$2.23160 \mathrm{e}+012.23160 \mathrm{e}+012.23160 \mathrm{e}+00$ 1.00000e-09 2.12000e-01

$2.23160 \mathrm{e}+012.23160 \mathrm{e}+012.23160 \mathrm{e}+001.00000 \mathrm{e}-092.12000 \mathrm{e}-01$

$1.00000 \mathrm{e}-02$ 1.00000e-02 1.00000e-03 1.00000e-09 1.00000e-01

$1.00000 \mathrm{e}+001.00000 \mathrm{e}+001.00000 \mathrm{e}-011.00000 \mathrm{e}-091.00000 \mathrm{e}-01$

Element: 6708 \# of layers: 3

$\mathrm{Kx} \mathrm{Ky} \mathrm{Kz}$ Ss Por

2.02617e+01 2.02617e+01 2.02617e+00 1.00000e-09 2.12000e-01 $1.00000 \mathrm{e}-02$ 1.00000e-02 1.00000e-03 1.00000e-09 1.00000e-01

$1.00000 \mathrm{e}+001.00000 \mathrm{e}+001.00000 \mathrm{e}-01$ 1.00000e-09 1.00000e-01

Element: 6709 \# of layers: 4

$\mathrm{Kx} \mathrm{Ky} \mathrm{Kz}$ Ss Por

5.07092e+02 5.07092e+02 5.07092e+01 1.00000e-09 7.00000e-02 $2.02617 \mathrm{e}+012.02617 \mathrm{e}+012.02617 \mathrm{e}+00$ 1.00000e-09 2.12000e-01 $1.00000 \mathrm{e}-02$ 1.00000e-02 1.00000e-03 1.00000e-09 1.00000e-01

$1.00000 \mathrm{e}+001.00000 \mathrm{e}+001.00000 \mathrm{e}-011.00000 \mathrm{e}-091.00000 \mathrm{e}-01$

Element: 6710 \# of layers: 4

$\mathrm{Kx} \mathrm{Ky} \mathrm{Kz}$ Ss Por

5.07092e+02 5.07092e+02 5.07092e+01 1.00000e-09 7.00000e-02

$2.02617 \mathrm{e}+012.02617 \mathrm{e}+012.02617 \mathrm{e}+001.00000 \mathrm{e}-092.12000 \mathrm{e}-01$

$1.00000 \mathrm{e}-02$ 1.00000e-02 1.00000e-03 1.00000e-09 1.00000e-01

$1.00000 \mathrm{e}+001.00000 \mathrm{e}+001.00000 \mathrm{e}-01$ 1.00000e-09 1.00000e-01

Element: 6711 \# of layers: 4

$\mathrm{Kx} \mathrm{Ky} \mathrm{Kz}$ Ss Por

5.07092e+02 5.07092e+02 5.07092e+01 1.00000e-09 7.00000e-02

$2.02617 \mathrm{e}+012.02617 \mathrm{e}+012.02617 \mathrm{e}+00$ 1.00000e-09 2.12000e-01

$1.00000 \mathrm{e}-02$ 1.00000e-02 1.00000e-03 1.00000e-09 1.00000e-01

$1.00000 \mathrm{e}+001.00000 \mathrm{e}+001.00000 \mathrm{e}-011.00000 \mathrm{e}-091.00000 \mathrm{e}-01$

Element: 6712 \# of layers: 4

$\mathrm{Kx} \mathrm{Ky} \mathrm{Kz}$ Ss Por

5.07092e+02 5.07092e+02 5.07092e+01 1.00000e-09 7.00000e-02

$2.02617 \mathrm{e}+012.02617 \mathrm{e}+012.02617 \mathrm{e}+001.00000 \mathrm{e}-092.12000 \mathrm{e}-01$

$1.00000 \mathrm{e}-02$ 1.00000e-02 1.00000e-03 1.00000e-09 1.00000e-01

$1.00000 \mathrm{e}+001.00000 \mathrm{e}+001.00000 \mathrm{e}-011.00000 \mathrm{e}-091.00000 \mathrm{e}-01$

Element: 6713 \# of layers: 4

$\mathrm{Kx} \mathrm{Ky} \mathrm{Kz}$ Ss Por

5.07092e+02 5.07092e+02 5.07092e+01 1.00000e-09 7.00000e-02

$2.02617 \mathrm{e}+012.02617 \mathrm{e}+012.02617 \mathrm{e}+00$ 1.00000e-09 2.12000e-01

$1.00000 \mathrm{e}-021.00000 \mathrm{e}-021.00000 \mathrm{e}-031.00000 \mathrm{e}-091.00000 \mathrm{e}-01$

$1.00000 \mathrm{e}+001.00000 \mathrm{e}+001.00000 \mathrm{e}-011.00000 \mathrm{e}-091.00000 \mathrm{e}-01$

Element: 6714 \# of layers: 4 
$\mathrm{Kx} \mathrm{Ky} \mathrm{Kz} \mathrm{Ss} \mathrm{Por}$

5.07092e+02 5.07092e+02 5.07092e+01 1.00000e-09 7.00000e-02

$2.02617 \mathrm{e}+012.02617 \mathrm{e}+012.02617 \mathrm{e}+00$ 1.00000e-09 2.12000e-01

$1.00000 \mathrm{e}-02$ 1.00000e-02 1.00000e-03 1.00000e-09 1.00000e-01

$1.00000 \mathrm{e}+001.00000 \mathrm{e}+001.00000 \mathrm{e}-01$ 1.00000e-09 1.00000e-01

Element: 6715 \# of layers: 4

Kx Ky Kz Ss Por

5.07092e+02 5.07092e+02 5.07092e+01 1.00000e-09 7.00000e-02

$2.02617 \mathrm{e}+012.02617 \mathrm{e}+012.02617 \mathrm{e}+00$ 1.00000e-09 2.12000e-01

$1.00000 \mathrm{e}-02$ 1.00000e-02 1.00000e-03 1.00000e-09 1.00000e-01

$1.00000 \mathrm{e}+001.00000 \mathrm{e}+001.00000 \mathrm{e}-011.00000 \mathrm{e}-091.00000 \mathrm{e}-01$

Element: 6716 \# of layers: 4

$\mathrm{Kx} \mathrm{Ky} \mathrm{Kz}$ Ss Por

5.07092e+02 5.07092e+02 5.07092e+01 1.00000e-09 7.00000e-02

$2.02617 \mathrm{e}+012.02617 \mathrm{e}+012.02617 \mathrm{e}+001.00000 \mathrm{e}-092.12000 \mathrm{e}-01$

$1.00000 \mathrm{e}-02$ 1.00000e-02 1.00000e-03 1.00000e-09 1.00000e-01

$1.00000 \mathrm{e}+001.00000 \mathrm{e}+001.00000 \mathrm{e}-01$ 1.00000e-09 1.00000e-01

Element: 6717 \# of layers: 4

$\mathrm{Kx} \mathrm{Ky} \mathrm{Kz}$ Ss Por

7.46073e+02 7.46073e+02 7.46073e+01 1.00000e-09 7.00000e-02

$2.98109 \mathrm{e}+012.98109 \mathrm{e}+012.98109 \mathrm{e}+00$ 1.00000e-09 2.12000e-01

$1.00000 \mathrm{e}-02$ 1.00000e-02 1.00000e-03 1.00000e-09 1.00000e-01

$1.00000 \mathrm{e}+001.00000 \mathrm{e}+001.00000 \mathrm{e}-01$ 1.00000e-09 1.00000e-01

Element: 6718 \# of layers: 3

$\mathrm{Kx} \mathrm{Ky} \mathrm{Kz}$ Ss Por

$2.98109 \mathrm{e}+012.98109 \mathrm{e}+012.98109 \mathrm{e}+00$ 1.00000e-09 2.12000e-01

$1.00000 \mathrm{e}-02$ 1.00000e-02 1.00000e-03 1.00000e-09 1.00000e-01

$1.00000 \mathrm{e}+001.00000 \mathrm{e}+001.00000 \mathrm{e}-01$ 1.00000e-09 1.00000e-01

Element: 6719 \# of layers: 3

$\mathrm{Kx} \mathrm{Ky} \mathrm{Kz}$ Ss Por

$2.98109 \mathrm{e}+012.98109 \mathrm{e}+012.98109 \mathrm{e}+00$ 1.00000e-09 2.12000e-01

$1.00000 \mathrm{e}-02$ 1.00000e-02 1.00000e-03 1.00000e-09 1.00000e-01

$1.00000 \mathrm{e}+001.00000 \mathrm{e}+001.00000 \mathrm{e}-011.00000 \mathrm{e}-091.00000 \mathrm{e}-01$

Element: 6720 \# of layers: 3

$\mathrm{Kx} \mathrm{Ky} \mathrm{Kz}$ Ss Por

$2.98109 \mathrm{e}+012.98109 \mathrm{e}+012.98109 \mathrm{e}+00$ 1.00000e-09 2.12000e-01

$1.00000 \mathrm{e}-02$ 1.00000e-02 1.00000e-03 1.00000e-09 1.00000e-01

$1.00000 \mathrm{e}+001.00000 \mathrm{e}+001.00000 \mathrm{e}-011.00000 \mathrm{e}-091.00000 \mathrm{e}-01$

Element: 6721 \# of layers: 4

$\mathrm{Kx} \mathrm{Ky} \mathrm{Kz}$ Ss Por

7.46073e+02 7.46073e+02 7.46073e+01 1.00000e-09 7.00000e-02

$2.98109 \mathrm{e}+012.98109 \mathrm{e}+012.98109 \mathrm{e}+001.00000 \mathrm{e}-092.12000 \mathrm{e}-01$

$1.00000 \mathrm{e}-02$ 1.00000e-02 1.00000e-03 1.00000e-09 1.00000e-01

$1.00000 \mathrm{e}+001.00000 \mathrm{e}+001.00000 \mathrm{e}-01$ 1.00000e-09 1.00000e-01

Element: 6722 \# of layers: 4

Kx Ky Kz Ss Por 
7.46073e+02 7.46073e+02 7.46073e+01 1.00000e-09 7.00000e-02 $2.98109 \mathrm{e}+012.98109 \mathrm{e}+012.98109 \mathrm{e}+001.00000 \mathrm{e}-092.12000 \mathrm{e}-01$ $1.00000 \mathrm{e}-02$ 1.00000e-02 1.00000e-03 1.00000e-09 1.00000e-01 $1.00000 \mathrm{e}+001.00000 \mathrm{e}+001.00000 \mathrm{e}-011.00000 \mathrm{e}-091.00000 \mathrm{e}-01$ Element: 6723 \# of layers: 4

Kx Ky Kz Ss Por

7.46073e+02 7.46073e+02 7.46073e+01 1.00000e-09 7.00000e-02

$2.98109 \mathrm{e}+012.98109 \mathrm{e}+012.98109 \mathrm{e}+001.00000 \mathrm{e}-092.12000 \mathrm{e}-01$

$1.00000 \mathrm{e}-02$ 1.00000e-02 1.00000e-03 1.00000e-09 1.00000e-01

$1.00000 \mathrm{e}+001.00000 \mathrm{e}+001.00000 \mathrm{e}-011.00000 \mathrm{e}-091.00000 \mathrm{e}-01$

Element: 6724 \# of layers: 4

Kx Ky Kz Ss Por

7.46073e+02 7.46073e+02 7.46073e+01 1.00000e-09 7.00000e-02

$2.98109 \mathrm{e}+012.98109 \mathrm{e}+012.98109 \mathrm{e}+001.00000 \mathrm{e}-092.12000 \mathrm{e}-01$

$1.00000 \mathrm{e}-02$ 1.00000e-02 1.00000e-03 1.00000e-09 1.00000e-01

$1.00000 \mathrm{e}+001.00000 \mathrm{e}+001.00000 \mathrm{e}-011.00000 \mathrm{e}-091.00000 \mathrm{e}-01$

Element: 6725 \# of layers: 4

Kx Ky Kz Ss Por

7.46073e+02 7.46073e+02 7.46073e+01 1.00000e-09 7.00000e-02

$2.98109 \mathrm{e}+012.98109 \mathrm{e}+012.98109 \mathrm{e}+00$ 1.00000e-09 2.12000e-01

$1.00000 \mathrm{e}-021.00000 \mathrm{e}-02$ 1.00000e-03 1.00000e-09 1.00000e-01

$1.00000 \mathrm{e}+001.00000 \mathrm{e}+001.00000 \mathrm{e}-011.00000 \mathrm{e}-091.00000 \mathrm{e}-01$

Element: 6726 \# of layers: 4

Kx Ky Kz Ss Por

$8.10670 \mathrm{e}+018.10670 \mathrm{e}+018.10670 \mathrm{e}+00$ 1.00000e-09 2.12000e-01

$8.10670 \mathrm{e}+018.10670 \mathrm{e}+018.10670 \mathrm{e}+00$ 1.00000e-09 2.12000e-01

$1.00000 \mathrm{e}-021.00000 \mathrm{e}-02$ 1.00000e-03 1.00000e-09 1.00000e-01

$1.00000 \mathrm{e}+001.00000 \mathrm{e}+001.00000 \mathrm{e}-011.00000 \mathrm{e}-091.00000 \mathrm{e}-01$

Element: 6727 \# of layers: 3

Kx Ky Kz Ss Por

$8.10670 \mathrm{e}+018.10670 \mathrm{e}+018.10670 \mathrm{e}+00$ 1.00000e-09 2.12000e-01

$1.00000 \mathrm{e}-021.00000 \mathrm{e}-02$ 1.00000e-03 1.00000e-09 1.00000e-01

$1.00000 \mathrm{e}+001.00000 \mathrm{e}+00$ 1.00000e-01 1.00000e-09 1.00000e-01

Element: 6728 \# of layers: 3

Kx Ky Kz Ss Por

8.10670e+01 8.10670e+01 8.10670e+00 1.00000e-09 2.12000e-01

$1.00000 \mathrm{e}-02$ 1.00000e-02 1.00000e-03 1.00000e-09 1.00000e-01

$1.00000 \mathrm{e}+001.00000 \mathrm{e}+001.00000 \mathrm{e}-011.00000 \mathrm{e}-091.00000 \mathrm{e}-01$

Element: 6729 \# of layers: 3

Kx Ky Kz Ss Por

8.10670e+01 8.10670e+01 8.10670e+00 1.00000e-09 2.12000e-01

$1.00000 \mathrm{e}-02$ 1.00000e-02 1.00000e-03 1.00000e-09 1.00000e-01

$1.00000 \mathrm{e}+001.00000 \mathrm{e}+001.00000 \mathrm{e}-011.00000 \mathrm{e}-091.00000 \mathrm{e}-01$

Element: 6730 \# of layers: 4

Kx Ky Kz Ss Por

8.10670e+01 8.10670e+01 8.10670e+00 1.00000e-09 2.12000e-01 
8.10670e+01 8.10670e+01 8.10670e+00 1.00000e-09 2.12000e-01 $1.00000 \mathrm{e}-02$ 1.00000e-02 1.00000e-03 1.00000e-09 1.00000e-01

$1.00000 \mathrm{e}+001.00000 \mathrm{e}+001.00000 \mathrm{e}-01$ 1.00000e-09 1.00000e-01

Element: 6731 \# of layers: 5

$\mathrm{Kx} \mathrm{Ky} \mathrm{Kz}$ Ss Por

2.02887e+03 2.02887e+03 2.02887e+02 1.00000e-09 7.00000e-02

$8.10670 \mathrm{e}+018.10670 \mathrm{e}+018.10670 \mathrm{e}+00$ 1.00000e-09 2.12000e-01

$8.10670 \mathrm{e}+018.10670 \mathrm{e}+018.10670 \mathrm{e}+001.00000 \mathrm{e}-092.12000 \mathrm{e}-01$

$1.00000 \mathrm{e}-021.00000 \mathrm{e}-021.00000 \mathrm{e}-031.00000 \mathrm{e}-091.00000 \mathrm{e}-01$

$1.00000 \mathrm{e}+001.00000 \mathrm{e}+001.00000 \mathrm{e}-011.00000 \mathrm{e}-091.00000 \mathrm{e}-01$

Element: 6732 \# of layers: 4

$\mathrm{Kx} \mathrm{Ky} \mathrm{Kz}$ Ss Por

2.02887e+03 2.02887e+03 2.02887e+02 1.00000e-09 7.00000e-02

$8.10670 \mathrm{e}+018.10670 \mathrm{e}+018.10670 \mathrm{e}+00$ 1.00000e-09 2.12000e-01

$1.00000 \mathrm{e}-02$ 1.00000e-02 1.00000e-03 1.00000e-09 1.00000e-01

$1.00000 \mathrm{e}+001.00000 \mathrm{e}+001.00000 \mathrm{e}-011.00000 \mathrm{e}-091.00000 \mathrm{e}-01$

Element: 6733 \# of layers: 4

$\mathrm{Kx} \mathrm{Ky} \mathrm{Kz}$ Ss Por

8.10670e+01 8.10670e+01 8.10670e+00 1.00000e-09 2.12000e-01

$8.10670 \mathrm{e}+018.10670 \mathrm{e}+018.10670 \mathrm{e}+001.00000 \mathrm{e}-092.12000 \mathrm{e}-01$

$1.00000 \mathrm{e}-02$ 1.00000e-02 1.00000e-03 1.00000e-09 1.00000e-01

$1.00000 \mathrm{e}+001.00000 \mathrm{e}+001.00000 \mathrm{e}-01$ 1.00000e-09 1.00000e-01

Element: 6734 \# of layers: 4

Kx Ky Kz Ss Por

8.10670e+01 8.10670e+01 8.10670e+00 1.00000e-09 2.12000e-01

$8.10670 \mathrm{e}+018.10670 \mathrm{e}+018.10670 \mathrm{e}+001.00000 \mathrm{e}-092.12000 \mathrm{e}-01$

$1.00000 \mathrm{e}-02$ 1.00000e-02 1.00000e-03 1.00000e-09 1.00000e-01

$1.00000 \mathrm{e}+001.00000 \mathrm{e}+001.00000 \mathrm{e}-011.00000 \mathrm{e}-09$ 1.00000e-01

Element: 6735 \# of layers: 3

$\mathrm{Kx} \mathrm{Ky} \mathrm{Kz}$ Ss Por

8.94304e+01 8.94304e+01 8.94304e+00 1.00000e-09 2.12000e-01

$1.00000 \mathrm{e}-02$ 1.00000e-02 1.00000e-03 1.00000e-09 1.00000e-01

$1.00000 \mathrm{e}+001.00000 \mathrm{e}+001.00000 \mathrm{e}-011.00000 \mathrm{e}-091.00000 \mathrm{e}-01$

Element: 6736 \# of layers: 3

$\mathrm{Kx} \mathrm{Ky} \mathrm{Kz}$ Ss Por

8.94304e+01 8.94304e+01 8.94304e+00 1.00000e-09 2.12000e-01

$1.00000 \mathrm{e}-02$ 1.00000e-02 1.00000e-03 1.00000e-09 1.00000e-01

$1.00000 \mathrm{e}+001.00000 \mathrm{e}+001.00000 \mathrm{e}-011.00000 \mathrm{e}-09$ 1.00000e-01

Element: 6737 \# of layers: 3

$\mathrm{Kx} \mathrm{Ky} \mathrm{Kz}$ Ss Por

8.94304e+01 8.94304e+01 8.94304e+00 1.00000e-09 2.12000e-01

$1.00000 \mathrm{e}-02$ 1.00000e-02 1.00000e-03 1.00000e-09 1.00000e-01

$1.00000 \mathrm{e}+001.00000 \mathrm{e}+001.00000 \mathrm{e}-01$ 1.00000e-09 1.00000e-01

Element: 6738 \# of layers: 3

$\mathrm{Kx} \mathrm{Ky} \mathrm{Kz}$ Ss Por

8.94304e+01 8.94304e+01 8.94304e+00 1.00000e-09 2.12000e-01 
$1.00000 \mathrm{e}-02$ 1.00000e-02 1.00000e-03 1.00000e-09 1.00000e-01 $1.00000 \mathrm{e}+001.00000 \mathrm{e}+001.00000 \mathrm{e}-01$ 1.00000e-09 1.00000e-01 Element: 6739 \# of layers: 5

$\mathrm{Kx} \mathrm{Ky} \mathrm{Kz}$ Ss Por

2.23817e+03 2.23817e+03 2.23817e+02 1.00000e-09 7.00000e-02 $8.94304 \mathrm{e}+018.94304 \mathrm{e}+018.94304 \mathrm{e}+00$ 1.00000e-09 2.12000e-01 $8.94304 \mathrm{e}+018.94304 \mathrm{e}+018.94304 \mathrm{e}+001.00000 \mathrm{e}-092.12000 \mathrm{e}-01$ $1.00000 \mathrm{e}-021.00000 \mathrm{e}-02$ 1.00000e-03 1.00000e-09 1.00000e-01 $1.00000 \mathrm{e}+001.00000 \mathrm{e}+001.00000 \mathrm{e}-011.00000 \mathrm{e}-091.00000 \mathrm{e}-01$ Element: 6740 \# of layers: 5

$\mathrm{Kx} \mathrm{Ky} \mathrm{Kz}$ Ss Por

2.23817e+03 2.23817e+03 2.23817e+02 1.00000e-09 7.00000e-02

$8.94304 \mathrm{e}+018.94304 \mathrm{e}+018.94304 \mathrm{e}+001.00000 \mathrm{e}-092.12000 \mathrm{e}-01$

$8.94304 \mathrm{e}+018.94304 \mathrm{e}+018.94304 \mathrm{e}+001.00000 \mathrm{e}-092.12000 \mathrm{e}-01$ $1.00000 \mathrm{e}-02$ 1.00000e-02 1.00000e-03 1.00000e-09 1.00000e-01

$1.00000 \mathrm{e}+001.00000 \mathrm{e}+001.00000 \mathrm{e}-011.00000 \mathrm{e}-091.00000 \mathrm{e}-01$

Element: 6741 \# of layers: 4

$\mathrm{Kx} \mathrm{Ky} \mathrm{Kz}$ Ss Por

$8.94304 \mathrm{e}+018.94304 \mathrm{e}+018.94304 \mathrm{e}+00$ 1.00000e-09 2.12000e-01 $8.94304 \mathrm{e}+018.94304 \mathrm{e}+018.94304 \mathrm{e}+001.00000 \mathrm{e}-092.12000 \mathrm{e}-01$ $1.00000 \mathrm{e}-02$ 1.00000e-02 1.00000e-03 1.00000e-09 1.00000e-01 $1.00000 \mathrm{e}+001.00000 \mathrm{e}+001.00000 \mathrm{e}-011.00000 \mathrm{e}-091.00000 \mathrm{e}-01$ Element: 6742 \# of layers: 3

Kx Ky Kz Ss Por

8.94304e+01 8.94304e+01 8.94304e+00 1.00000e-09 2.12000e-01 $1.00000 \mathrm{e}-02$ 1.00000e-02 1.00000e-03 1.00000e-09 1.00000e-01

$1.00000 \mathrm{e}+001.00000 \mathrm{e}+001.00000 \mathrm{e}-011.00000 \mathrm{e}-091.00000 \mathrm{e}-01$ Element: 6743 \# of layers: 3

$\mathrm{Kx} \mathrm{Ky} \mathrm{Kz}$ Ss Por

8.94304e+01 8.94304e+01 8.94304e+00 1.00000e-09 2.12000e-01 $1.00000 \mathrm{e}-02$ 1.00000e-02 1.00000e-03 1.00000e-09 1.00000e-01 $1.00000 \mathrm{e}+001.00000 \mathrm{e}+001.00000 \mathrm{e}-011.00000 \mathrm{e}-091.00000 \mathrm{e}-01$ Element: 6744 \# of layers: 6

$\mathrm{Kx} \mathrm{Ky} \mathrm{Kz}$ Ss Por

7.77878e+02 7.77878e+02 7.77878e+01 1.00000e-09 7.00000e-02 7.77878e+02 7.77878e+02 7.77878e+01 1.00000e-09 7.00000e-02 $3.10822 \mathrm{e}+013.10822 \mathrm{e}+013.10822 \mathrm{e}+00$ 1.00000e-09 2.12000e-01 $3.10822 \mathrm{e}+013.10822 \mathrm{e}+013.10822 \mathrm{e}+00$ 1.00000e-09 2.12000e-01 $1.00000 \mathrm{e}-02$ 1.00000e-02 1.00000e-03 1.00000e-09 1.00000e-01 $1.00000 \mathrm{e}+001.00000 \mathrm{e}+001.00000 \mathrm{e}-01$ 1.00000e-09 1.00000e-01 Element: 6745 \# of layers: 5

$\mathrm{Kx} \mathrm{Ky} \mathrm{Kz}$ Ss Por

7.77878e+02 7.77878e+02 7.77878e+01 1.00000e-09 7.00000e-02 7.77878e+02 7.77878e+02 7.77878e+01 1.00000e-09 7.00000e-02 $3.10822 \mathrm{e}+013.10822 \mathrm{e}+013.10822 \mathrm{e}+00$ 1.00000e-09 2.12000e-01 $1.00000 \mathrm{e}-02$ 1.00000e-02 1.00000e-03 1.00000e-09 1.00000e-01 
$1.00000 \mathrm{e}+001.00000 \mathrm{e}+00$ 1.00000e-01 1.00000e-09 1.00000e-01

Element: 6746 \# of layers: 3

Kx Ky Kz Ss Por

7.77878e+02 7.77878e+02 7.77878e+01 1.00000e-09 7.00000e-02

$1.00000 \mathrm{e}-021.00000 \mathrm{e}-021.00000 \mathrm{e}-031.00000 \mathrm{e}-091.00000 \mathrm{e}-01$

$1.00000 \mathrm{e}+001.00000 \mathrm{e}+001.00000 \mathrm{e}-011.00000 \mathrm{e}-091.00000 \mathrm{e}-01$

Element: 6747 \# of layers: 4

$\mathrm{Kx} \mathrm{Ky} \mathrm{Kz}$ Ss Por

7.77878e+02 7.77878e+02 7.77878e+01 1.00000e-09 7.00000e-02

$3.10822 \mathrm{e}+013.10822 \mathrm{e}+013.10822 \mathrm{e}+00$ 1.00000e-09 2.12000e-01

$1.00000 \mathrm{e}-02$ 1.00000e-02 1.00000e-03 1.00000e-09 1.00000e-01

$1.00000 \mathrm{e}+001.00000 \mathrm{e}+001.00000 \mathrm{e}-011.00000 \mathrm{e}-091.00000 \mathrm{e}-01$

Element: 6748 \# of layers: 4

$\mathrm{Kx} \mathrm{Ky} \mathrm{Kz}$ Ss Por

7.77878e+02 7.77878e+02 7.77878e+01 1.00000e-09 7.00000e-02

$3.10822 \mathrm{e}+013.10822 \mathrm{e}+013.10822 \mathrm{e}+00$ 1.00000e-09 2.12000e-01

$1.00000 \mathrm{e}-02$ 1.00000e-02 1.00000e-03 1.00000e-09 1.00000e-01

$1.00000 \mathrm{e}+001.00000 \mathrm{e}+001.00000 \mathrm{e}-011.00000 \mathrm{e}-09$ 1.00000e-01

Element: 6749 \# of layers: 5

$\mathrm{Kx} \mathrm{Ky} \mathrm{Kz}$ Ss Por

7.77878e+02 7.77878e+02 7.77878e+01 1.00000e-09 7.00000e-02

7.77878e+02 7.77878e+02 7.77878e+01 1.00000e-09 7.00000e-02

$3.10822 \mathrm{e}+013.10822 \mathrm{e}+013.10822 \mathrm{e}+00$ 1.00000e-09 2.12000e-01

$1.00000 \mathrm{e}-02$ 1.00000e-02 1.00000e-03 1.00000e-09 1.00000e-01

$1.00000 \mathrm{e}+001.00000 \mathrm{e}+001.00000 \mathrm{e}-011.00000 \mathrm{e}-091.00000 \mathrm{e}-01$

Element: 6750 \# of layers: 6

$\mathrm{Kx} \mathrm{Ky} \mathrm{Kz}$ Ss Por

7.77878e+02 7.77878e+02 7.77878e+01 1.00000e-09 7.00000e-02

$7.77878 \mathrm{e}+02$ 7.77878e+02 7.77878e+01 1.00000e-09 7.00000e-02

$3.10822 \mathrm{e}+013.10822 \mathrm{e}+01$ 3.10822e+00 1.00000e-09 2.12000e-01

$3.10822 \mathrm{e}+013.10822 \mathrm{e}+013.10822 \mathrm{e}+00$ 1.00000e-09 2.12000e-01

$1.00000 \mathrm{e}-02$ 1.00000e-02 1.00000e-03 1.00000e-09 1.00000e-01

$1.00000 \mathrm{e}+001.00000 \mathrm{e}+001.00000 \mathrm{e}-011.00000 \mathrm{e}-091.00000 \mathrm{e}-01$

Element: 6751 \# of layers: 5

$\mathrm{Kx} \mathrm{Ky} \mathrm{Kz}$ Ss Por

7.77878e+02 7.77878e+02 7.77878e+01 1.00000e-09 7.00000e-02

$3.10822 \mathrm{e}+013.10822 \mathrm{e}+013.10822 \mathrm{e}+00$ 1.00000e-09 2.12000e-01

$3.10822 \mathrm{e}+013.10822 \mathrm{e}+013.10822 \mathrm{e}+00$ 1.00000e-09 2.12000e-01 $1.00000 \mathrm{e}-02$ 1.00000e-02 1.00000e-03 1.00000e-09 1.00000e-01

$1.00000 \mathrm{e}+001.00000 \mathrm{e}+001.00000 \mathrm{e}-01$ 1.00000e-09 1.00000e-01

Element: 6752 \# of layers: 5

$\mathrm{Kx} \mathrm{Ky} \mathrm{Kz}$ Ss Por

7.77878e+02 7.77878e+02 7.77878e+01 1.00000e-09 7.00000e-02

7.77878e+02 7.77878e+02 7.77878e+01 1.00000e-09 7.00000e-02

$3.10822 \mathrm{e}+013.10822 \mathrm{e}+013.10822 \mathrm{e}+001.00000 \mathrm{e}-092.12000 \mathrm{e}-01$

$1.00000 \mathrm{e}-02$ 1.00000e-02 1.00000e-03 1.00000e-09 1.00000e-01 
$1.00000 \mathrm{e}+001.00000 \mathrm{e}+00$ 1.00000e-01 1.00000e-09 1.00000e-01

Element: 6753 \# of layers: 3

$\mathrm{Kx} \mathrm{Ky} \mathrm{Kz}$ Ss Por

3.53210e+02 3.53210e+02 3.53210e+01 1.00000e-09 7.00000e-02

$1.00000 \mathrm{e}-02$ 1.00000e-02 1.00000e-03 1.00000e-09 1.00000e-01

$1.00000 \mathrm{e}+001.00000 \mathrm{e}+001.00000 \mathrm{e}-011.00000 \mathrm{e}-091.00000 \mathrm{e}-01$

Element: 6754 \# of layers: 3

$\mathrm{Kx} \mathrm{Ky} \mathrm{Kz}$ Ss Por

$3.53210 \mathrm{e}+023.53210 \mathrm{e}+023.53210 \mathrm{e}+01$ 1.00000e-09 7.00000e-02

$1.00000 \mathrm{e}-02$ 1.00000e-02 1.00000e-03 1.00000e-09 1.00000e-01

$1.00000 \mathrm{e}+001.00000 \mathrm{e}+001.00000 \mathrm{e}-011.00000 \mathrm{e}-091.00000 \mathrm{e}-01$

Element: 6755 \# of layers: 3

$\mathrm{Kx} \mathrm{Ky} \mathrm{Kz}$ Ss Por

3.53210e+02 3.53210e+02 3.53210e+01 1.00000e-09 7.00000e-02

$1.00000 \mathrm{e}-02$ 1.00000e-02 1.00000e-03 1.00000e-09 1.00000e-01

$1.00000 \mathrm{e}+001.00000 \mathrm{e}+001.00000 \mathrm{e}-011.00000 \mathrm{e}-091.00000 \mathrm{e}-01$

Element: 6756 \# of layers: 3

$\mathrm{Kx} \mathrm{Ky} \mathrm{Kz}$ Ss Por

3.53210e+02 3.53210e+02 3.53210e+01 1.00000e-09 7.00000e-02

$1.00000 \mathrm{e}-02$ 1.00000e-02 1.00000e-03 1.00000e-09 1.00000e-01

$1.00000 \mathrm{e}+001.00000 \mathrm{e}+001.00000 \mathrm{e}-011.00000 \mathrm{e}-091.00000 \mathrm{e}-01$

Element: 6757 \# of layers: 3

$\mathrm{Kx} \mathrm{Ky} \mathrm{Kz}$ Ss Por

3.53210e+02 3.53210e+02 3.53210e+01 1.00000e-09 7.00000e-02

$1.00000 \mathrm{e}-02$ 1.00000e-02 1.00000e-03 1.00000e-09 1.00000e-01

$1.00000 \mathrm{e}+001.00000 \mathrm{e}+001.00000 \mathrm{e}-01$ 1.00000e-09 1.00000e-01

Element: 6758 \# of layers: 3

$\mathrm{Kx} \mathrm{Ky} \mathrm{Kz}$ Ss Por

3.53210e+02 3.53210e+02 3.53210e+01 1.00000e-09 7.00000e-02

$1.00000 \mathrm{e}-02$ 1.00000e-02 1.00000e-03 1.00000e-09 1.00000e-01

$1.00000 \mathrm{e}+001.00000 \mathrm{e}+001.00000 \mathrm{e}-011.00000 \mathrm{e}-091.00000 \mathrm{e}-01$

Element: 6759 \# of layers: 3

$\mathrm{Kx} \mathrm{Ky} \mathrm{Kz}$ Ss Por

3.53210e+02 3.53210e+02 3.53210e+01 1.00000e-09 7.00000e-02

$1.00000 \mathrm{e}-02$ 1.00000e-02 1.00000e-03 1.00000e-09 1.00000e-01

$1.00000 \mathrm{e}+001.00000 \mathrm{e}+001.00000 \mathrm{e}-011.00000 \mathrm{e}-091.00000 \mathrm{e}-01$

Element: 6760 \# of layers: 3

Kx Ky Kz Ss Por

3.53210e+02 3.53210e+02 3.53210e+01 1.00000e-09 7.00000e-02

$1.00000 \mathrm{e}-02$ 1.00000e-02 1.00000e-03 1.00000e-09 1.00000e-01

$1.00000 \mathrm{e}+001.00000 \mathrm{e}+001.00000 \mathrm{e}-011.00000 \mathrm{e}-091.00000 \mathrm{e}-01$

Element: 6761 \# of layers: 3

$\mathrm{Kx} \mathrm{Ky} \mathrm{Kz}$ Ss Por

3.53210e+02 3.53210e+02 3.53210e+01 1.00000e-09 7.00000e-02

$1.00000 \mathrm{e}-02$ 1.00000e-02 1.00000e-03 1.00000e-09 1.00000e-01

$1.00000 \mathrm{e}+001.00000 \mathrm{e}+001.00000 \mathrm{e}-011.00000 \mathrm{e}-091.00000 \mathrm{e}-01$ 
Element: 6762 \# of layers: 3

$\mathrm{Kx} \mathrm{Ky} \mathrm{Kz}$ Ss Por

2.30494e+02 2.30494e+02 2.30494e+01 1.00000e-09 7.00000e-02

$1.00000 \mathrm{e}-02$ 1.00000e-02 1.00000e-03 1.00000e-09 1.00000e-01

$1.00000 \mathrm{e}+001.00000 \mathrm{e}+001.00000 \mathrm{e}-01$ 1.00000e-09 1.00000e-01

Element: 6763 \# of layers: 3

$\mathrm{Kx} \mathrm{Ky} \mathrm{Kz}$ Ss Por

$2.30494 \mathrm{e}+02$ 2.30494e+02 2.30494e+01 1.00000e-09 7.00000e-02

$1.00000 \mathrm{e}-02$ 1.00000e-02 1.00000e-03 1.00000e-09 1.00000e-01

$1.00000 \mathrm{e}+001.00000 \mathrm{e}+001.00000 \mathrm{e}-011.00000 \mathrm{e}-091.00000 \mathrm{e}-01$

Element: 6764 \# of layers: 3

$\mathrm{Kx} \mathrm{Ky} \mathrm{Kz}$ Ss Por

2.30494e+02 2.30494e+02 2.30494e+01 1.00000e-09 7.00000e-02

1.00000e-02 1.00000e-02 1.00000e-03 1.00000e-09 1.00000e-01

$1.00000 \mathrm{e}+001.00000 \mathrm{e}+001.00000 \mathrm{e}-01$ 1.00000e-09 1.00000e-01

Element: 6765 \# of layers: 3

$\mathrm{Kx} \mathrm{Ky} \mathrm{Kz}$ Ss Por

$2.30494 \mathrm{e}+02$ 2.30494e+02 2.30494e+01 1.00000e-09 7.00000e-02

$1.00000 \mathrm{e}-02$ 1.00000e-02 1.00000e-03 1.00000e-09 1.00000e-01

$1.00000 \mathrm{e}+001.00000 \mathrm{e}+001.00000 \mathrm{e}-011.00000 \mathrm{e}-091.00000 \mathrm{e}-01$

Element: 6766 \# of layers: 3

$\mathrm{Kx} \mathrm{Ky} \mathrm{Kz}$ Ss Por

2.30494e+02 2.30494e+02 2.30494e+01 1.00000e-09 7.00000e-02

$1.00000 \mathrm{e}-02$ 1.00000e-02 1.00000e-03 1.00000e-09 1.00000e-01

$1.00000 \mathrm{e}+001.00000 \mathrm{e}+001.00000 \mathrm{e}-011.00000 \mathrm{e}-091.00000 \mathrm{e}-01$

Element: 6767 \# of layers: 3

$\mathrm{Kx} \mathrm{Ky} \mathrm{Kz}$ Ss Por

2.30494e+02 2.30494e+02 2.30494e+01 1.00000e-09 7.00000e-02

$1.00000 \mathrm{e}-02$ 1.00000e-02 1.00000e-03 1.00000e-09 1.00000e-01

$1.00000 \mathrm{e}+001.00000 \mathrm{e}+001.00000 \mathrm{e}-011.00000 \mathrm{e}-091.00000 \mathrm{e}-01$

Element: 6768 \# of layers: 3

$\mathrm{Kx} \mathrm{Ky} \mathrm{Kz}$ Ss Por

2.30494e+02 2.30494e+02 2.30494e+01 1.00000e-09 7.00000e-02

$1.00000 \mathrm{e}-021.00000 \mathrm{e}-021.00000 \mathrm{e}-031.00000 \mathrm{e}-091.00000 \mathrm{e}-01$

$1.00000 \mathrm{e}+001.00000 \mathrm{e}+001.00000 \mathrm{e}-011.00000 \mathrm{e}-091.00000 \mathrm{e}-01$

Element: 6769 \# of layers: 3

$\mathrm{Kx} \mathrm{Ky} \mathrm{Kz}$ Ss Por

2.30494e+02 2.30494e+02 2.30494e+01 1.00000e-09 7.00000e-02

$1.00000 \mathrm{e}-021.00000 \mathrm{e}-02$ 1.00000e-03 1.00000e-09 1.00000e-01

$1.00000 \mathrm{e}+001.00000 \mathrm{e}+001.00000 \mathrm{e}-011.00000 \mathrm{e}-091.00000 \mathrm{e}-01$

Element: 6770 \# of layers: 3

$\mathrm{Kx} \mathrm{Ky} \mathrm{Kz}$ Ss Por

2.30494e+02 2.30494e+02 2.30494e+01 1.00000e-09 7.00000e-02

$1.00000 \mathrm{e}-02$ 1.00000e-02 1.00000e-03 1.00000e-09 1.00000e-01

$1.00000 \mathrm{e}+001.00000 \mathrm{e}+001.00000 \mathrm{e}-01$ 1.00000e-09 1.00000e-01

Element: 6771 \# of layers: 3 
Kx Ky Kz Ss Por

$2.30494 \mathrm{e}+022.30494 \mathrm{e}+022.30494 \mathrm{e}+01$ 1.00000e-09 7.00000e-02

$1.00000 \mathrm{e}-02$ 1.00000e-02 1.00000e-03 1.00000e-09 1.00000e-01

$1.00000 \mathrm{e}+001.00000 \mathrm{e}+001.00000 \mathrm{e}-011.00000 \mathrm{e}-091.00000 \mathrm{e}-01$

Element: 6772 \# of layers: 3

Kx Ky Kz Ss Por

$2.55866 \mathrm{e}+022.55866 \mathrm{e}+022.55866 \mathrm{e}+01$ 1.00000e-09 7.00000e-02

$1.00000 \mathrm{e}-021.00000 \mathrm{e}-02$ 1.00000e-03 1.00000e-09 1.00000e-01

$1.00000 \mathrm{e}+001.00000 \mathrm{e}+001.00000 \mathrm{e}-011.00000 \mathrm{e}-091.00000 \mathrm{e}-01$

Element: 6773 \# of layers: 3

Kx Ky Kz Ss Por

$2.55866 \mathrm{e}+022.55866 \mathrm{e}+022.55866 \mathrm{e}+01$ 1.00000e-09 7.00000e-02

$1.00000 \mathrm{e}-02$ 1.00000e-02 1.00000e-03 1.00000e-09 1.00000e-01

$1.00000 \mathrm{e}+001.00000 \mathrm{e}+001.00000 \mathrm{e}-011.00000 \mathrm{e}-091.00000 \mathrm{e}-01$

Element: 6777 \# of layers: 3

Kx Ky Kz Ss Por

$2.30494 \mathrm{e}+022.30494 \mathrm{e}+022.30494 \mathrm{e}+01$ 1.00000e-09 7.00000e-02

$1.00000 \mathrm{e}-02$ 1.00000e-02 1.00000e-03 1.00000e-09 1.00000e-01

$1.00000 \mathrm{e}+001.00000 \mathrm{e}+001.00000 \mathrm{e}-011.00000 \mathrm{e}-091.00000 \mathrm{e}-01$

Element: 6778 \# of layers: 3

Kx Ky Kz Ss Por

$2.30494 \mathrm{e}+022.30494 \mathrm{e}+022.30494 \mathrm{e}+01$ 1.00000e-09 7.00000e-02

$1.00000 \mathrm{e}-02$ 1.00000e-02 1.00000e-03 1.00000e-09 1.00000e-01

$1.00000 \mathrm{e}+001.00000 \mathrm{e}+001.00000 \mathrm{e}-011.00000 \mathrm{e}-091.00000 \mathrm{e}-01$

Element: 6780 \# of layers: 3

Kx Ky Kz Ss Por

$2.59650 \mathrm{e}+022.59650 \mathrm{e}+022.59650 \mathrm{e}+01$ 1.00000e-09 7.00000e-02

$1.00000 \mathrm{e}-02$ 1.00000e-02 1.00000e-03 1.00000e-09 1.00000e-01

$1.00000 \mathrm{e}+001.00000 \mathrm{e}+001.00000 \mathrm{e}-011.00000 \mathrm{e}-091.00000 \mathrm{e}-01$

Element: 6781 \# of layers: 3

Kx Ky Kz Ss Por

$2.59650 \mathrm{e}+022.59650 \mathrm{e}+022.59650 \mathrm{e}+01$ 1.00000e-09 7.00000e-02

$1.00000 \mathrm{e}-02$ 1.00000e-02 1.00000e-03 1.00000e-09 1.00000e-01

$1.00000 \mathrm{e}+001.00000 \mathrm{e}+001.00000 \mathrm{e}-011.00000 \mathrm{e}-091.00000 \mathrm{e}-01$

Element: 6782 \# of layers: 3

Kx Ky Kz Ss Por

$2.59650 \mathrm{e}+022.59650 \mathrm{e}+022.59650 \mathrm{e}+01$ 1.00000e-09 7.00000e-02

$1.00000 \mathrm{e}-021.00000 \mathrm{e}-021.00000 \mathrm{e}-031.00000 \mathrm{e}-091.00000 \mathrm{e}-01$

$1.00000 \mathrm{e}+001.00000 \mathrm{e}+001.00000 \mathrm{e}-011.00000 \mathrm{e}-091.00000 \mathrm{e}-01$

Element: 6783 \# of layers: 3

Kx Ky Kz Ss Por

$2.85230 \mathrm{e}+022.85230 \mathrm{e}+022.85230 \mathrm{e}+01$ 1.00000e-09 7.00000e-02

$1.00000 \mathrm{e}-02$ 1.00000e-02 1.00000e-03 1.00000e-09 1.00000e-01

$1.00000 \mathrm{e}+001.00000 \mathrm{e}+001.00000 \mathrm{e}-011.00000 \mathrm{e}-091.00000 \mathrm{e}-01$

Element: 6784 \# of layers: 3

Kx Ky Kz Ss Por 
$2.85230 \mathrm{e}+022.85230 \mathrm{e}+02$ 2.85230e+01 1.00000e-09 7.00000e-02 $1.00000 \mathrm{e}-02$ 1.00000e-02 1.00000e-03 1.00000e-09 1.00000e-01 $1.00000 \mathrm{e}+001.00000 \mathrm{e}+001.00000 \mathrm{e}-011.00000 \mathrm{e}-091.00000 \mathrm{e}-01$

Element: 6785 \# of layers: 3

$\mathrm{Kx} \mathrm{Ky} \mathrm{Kz}$ Ss Por

$2.85230 \mathrm{e}+02$ 2.85230e+02 2.85230e+01 1.00000e-09 7.00000e-02 1.00000e-02 1.00000e-02 1.00000e-03 1.00000e-09 1.00000e-01

$1.00000 \mathrm{e}+001.00000 \mathrm{e}+001.00000 \mathrm{e}-011.00000 \mathrm{e}-091.00000 \mathrm{e}-01$

Element: 6786 \# of layers: 8

$\mathrm{Kx} \mathrm{Ky} \mathrm{Kz}$ Ss Por

$2.90708 \mathrm{e}+02$ 2.90708e+02 2.90708e+01 1.00000e-09 7.00000e-02 $2.90708 \mathrm{e}+022.90708 \mathrm{e}+02$ 2.90708e+01 1.00000e-09 7.00000e-02 $1.16157 \mathrm{e}+01$ 1.16157e+01 1.16157e+00 1.00000e-09 2.12000e-01 $1.16157 \mathrm{e}+01$ 1.16157e+01 1.16157e+00 1.00000e-09 2.12000e-01 $1.16157 \mathrm{e}+01$ 1.16157e+01 1.16157e+00 1.00000e-09 2.12000e-01 $1.16157 \mathrm{e}+011.16157 \mathrm{e}+01$ 1.16157e+00 1.00000e-09 2.12000e-01 $1.00000 \mathrm{e}-02$ 1.00000e-02 1.00000e-03 1.00000e-09 1.00000e-01 $1.00000 \mathrm{e}+001.00000 \mathrm{e}+001.00000 \mathrm{e}-011.00000 \mathrm{e}-091.00000 \mathrm{e}-01$ Element: 6787 \# of layers: 8

$\mathrm{Kx} \mathrm{Ky} \mathrm{Kz}$ Ss Por

$2.90708 \mathrm{e}+02$ 2.90708e+02 2.90708e+01 1.00000e-09 7.00000e-02 $2.90708 \mathrm{e}+02$ 2.90708e+02 2.90708e+01 1.00000e-09 7.00000e-02 $1.16157 \mathrm{e}+01$ 1.16157e+01 1.16157e+00 1.00000e-09 2.12000e-01 $1.16157 \mathrm{e}+01$ 1.16157e+01 1.16157e+00 1.00000e-09 2.12000e-01 $1.16157 \mathrm{e}+011.16157 \mathrm{e}+011.16157 \mathrm{e}+001.00000 \mathrm{e}-092.12000 \mathrm{e}-01$ $1.16157 \mathrm{e}+01$ 1.16157e+01 1.16157e+00 1.00000e-09 2.12000e-01 $1.00000 \mathrm{e}-02$ 1.00000e-02 1.00000e-03 1.00000e-09 1.00000e-01 $1.00000 \mathrm{e}+001.00000 \mathrm{e}+001.00000 \mathrm{e}-011.00000 \mathrm{e}-09$ 1.00000e-01

Element: 6788 \# of layers: 9

$\mathrm{Kx} \mathrm{Ky} \mathrm{Kz}$ Ss Por

$2.90708 \mathrm{e}+02$ 2.90708e+02 2.90708e+01 1.00000e-09 7.00000e-02 $2.90708 \mathrm{e}+02$ 2.90708e+02 2.90708e+01 1.00000e-09 7.00000e-02 $1.16157 \mathrm{e}+011.16157 \mathrm{e}+01$ 1.16157e+00 1.00000e-09 2.12000e-01 $1.16157 \mathrm{e}+01$ 1.16157e+01 1.16157e+00 1.00000e-09 2.12000e-01 $1.16157 \mathrm{e}+01$ 1.16157e+01 1.16157e+00 1.00000e-09 2.12000e-01 $1.16157 \mathrm{e}+011.16157 \mathrm{e}+01$ 1.16157e+00 1.00000e-09 2.12000e-01 $1.16157 \mathrm{e}+011.16157 \mathrm{e}+011.16157 \mathrm{e}+001.00000 \mathrm{e}-092.12000 \mathrm{e}-01$ $1.00000 \mathrm{e}-02$ 1.00000e-02 1.00000e-03 1.00000e-09 1.00000e-01 $1.00000 \mathrm{e}+001.00000 \mathrm{e}+001.00000 \mathrm{e}-011.00000 \mathrm{e}-091.00000 \mathrm{e}-01$ Element: 6789 \# of layers: 9

$\mathrm{Kx} \mathrm{Ky} \mathrm{Kz}$ Ss Por

$2.90708 \mathrm{e}+02$ 2.90708e+02 2.90708e+01 1.00000e-09 7.00000e-02 $2.90708 \mathrm{e}+02$ 2.90708e+02 2.90708e+01 1.00000e-09 7.00000e-02 1.16157e+01 1.16157e+01 1.16157e+00 1.00000e-09 2.12000e-01 $1.16157 \mathrm{e}+01$ 1.16157e+01 1.16157e+00 1.00000e-09 2.12000e-01 $1.16157 \mathrm{e}+01$ 1.16157e+01 1.16157e+00 1.00000e-09 2.12000e-01 
$1.16157 \mathrm{e}+01$ 1.16157e+01 1.16157e+00 1.00000e-09 2.12000e-01 $1.16157 \mathrm{e}+01$ 1.16157e+01 1.16157e+00 1.00000e-09 2.12000e-01 $1.00000 \mathrm{e}-021.00000 \mathrm{e}-02$ 1.00000e-03 1.00000e-09 1.00000e-01 $1.00000 \mathrm{e}+001.00000 \mathrm{e}+001.00000 \mathrm{e}-011.00000 \mathrm{e}-091.00000 \mathrm{e}-01$ Element: 6790 \# of layers: 9

$\mathrm{Kx} \mathrm{Ky} \mathrm{Kz}$ Ss Por

$2.90708 \mathrm{e}+02$ 2.90708e+02 2.90708e+01 1.00000e-09 7.00000e-02 $2.90708 \mathrm{e}+022.90708 \mathrm{e}+02$ 2.90708e+01 1.00000e-09 7.00000e-02 $1.16157 \mathrm{e}+01$ 1.16157e+01 1.16157e+00 1.00000e-09 2.12000e-01 $1.16157 \mathrm{e}+01$ 1.16157e+01 1.16157e+00 1.00000e-09 2.12000e-01 $1.16157 \mathrm{e}+01$ 1.16157e+01 1.16157e+00 1.00000e-09 2.12000e-01 $1.16157 \mathrm{e}+01$ 1.16157e+01 1.16157e+00 1.00000e-09 2.12000e-01 $1.16157 \mathrm{e}+01$ 1.16157e+01 1.16157e+00 1.00000e-09 2.12000e-01 $1.00000 \mathrm{e}-02$ 1.00000e-02 1.00000e-03 1.00000e-09 1.00000e-01 $1.00000 \mathrm{e}+001.00000 \mathrm{e}+001.00000 \mathrm{e}-01$ 1.00000e-09 1.00000e-01 Element: 6791 \# of layers: 10

$\mathrm{Kx} \mathrm{Ky} \mathrm{Kz}$ Ss Por

$2.90708 \mathrm{e}+02$ 2.90708e+02 2.90708e+01 1.00000e-09 7.00000e-02 $2.90708 \mathrm{e}+02$ 2.90708e+02 2.90708e+01 1.00000e-09 7.00000e-02 $2.90708 \mathrm{e}+022.90708 \mathrm{e}+02$ 2.90708e+01 1.00000e-09 7.00000e-02 $1.16157 \mathrm{e}+01$ 1.16157e+01 1.16157e+00 1.00000e-09 2.12000e-01 $1.16157 \mathrm{e}+01$ 1.16157e+01 1.16157e+00 1.00000e-09 2.12000e-01 $1.16157 \mathrm{e}+01$ 1.16157e+01 1.16157e+00 1.00000e-09 2.12000e-01 $1.16157 \mathrm{e}+011.16157 \mathrm{e}+01$ 1.16157e+00 1.00000e-09 2.12000e-01 $1.16157 \mathrm{e}+01$ 1.16157e+01 1.16157e+00 1.00000e-09 2.12000e-01 $1.00000 \mathrm{e}-02$ 1.00000e-02 1.00000e-03 1.00000e-09 1.00000e-01 $1.00000 \mathrm{e}+001.00000 \mathrm{e}+001.00000 \mathrm{e}-011.00000 \mathrm{e}-091.00000 \mathrm{e}-01$ Element: 6792 \# of layers: 9

$\mathrm{Kx} \mathrm{Ky} \mathrm{Kz}$ Ss Por

$2.90708 \mathrm{e}+02$ 2.90708e+02 2.90708e+01 1.00000e-09 7.00000e-02 $2.90708 \mathrm{e}+02$ 2.90708e+02 2.90708e+01 1.00000e-09 7.00000e-02 $2.90708 \mathrm{e}+022.90708 \mathrm{e}+02$ 2.90708e+01 1.00000e-09 7.00000e-02 $1.16157 \mathrm{e}+011.16157 \mathrm{e}+011.16157 \mathrm{e}+001.00000 \mathrm{e}-092.12000 \mathrm{e}-01$ $1.16157 \mathrm{e}+01$ 1.16157e+01 1.16157e+00 1.00000e-09 2.12000e-01 $1.16157 \mathrm{e}+011.16157 \mathrm{e}+01$ 1.16157e+00 1.00000e-09 2.12000e-01 $1.16157 \mathrm{e}+011.16157 \mathrm{e}+01$ 1.16157e+00 1.00000e-09 2.12000e-01 1.00000e-02 1.00000e-02 1.00000e-03 1.00000e-09 1.00000e-01 $1.00000 \mathrm{e}+001.00000 \mathrm{e}+001.00000 \mathrm{e}-011.00000 \mathrm{e}-091.00000 \mathrm{e}-01$ Element: 6793 \# of layers: 8

$\mathrm{Kx} \mathrm{Ky} \mathrm{Kz}$ Ss Por

$2.90708 \mathrm{e}+02$ 2.90708e+02 2.90708e+01 1.00000e-09 7.00000e-02 $2.90708 \mathrm{e}+02$ 2.90708e+02 2.90708e+01 1.00000e-09 7.00000e-02 $1.16157 \mathrm{e}+011.16157 \mathrm{e}+01$ 1.16157e+00 1.00000e-09 2.12000e-01 1.16157e+01 1.16157e+01 1.16157e+00 1.00000e-09 2.12000e-01 $1.16157 \mathrm{e}+011.16157 \mathrm{e}+01$ 1.16157e+00 1.00000e-09 2.12000e-01 $1.16157 \mathrm{e}+01$ 1.16157e+01 1.16157e+00 1.00000e-09 2.12000e-01 
$1.00000 \mathrm{e}-02$ 1.00000e-02 1.00000e-03 1.00000e-09 1.00000e-01 $1.00000 \mathrm{e}+001.00000 \mathrm{e}+001.00000 \mathrm{e}-01$ 1.00000e-09 1.00000e-01 Element: 6794 \# of layers: 8

$\mathrm{Kx} \mathrm{Ky} \mathrm{Kz}$ Ss Por

5.29220e+02 5.29220e+02 5.29220e+01 1.00000e-09 7.00000e-02 $2.11457 \mathrm{e}+012.11457 \mathrm{e}+012.11457 \mathrm{e}+00$ 1.00000e-09 2.12000e-01 $2.11457 \mathrm{e}+012.11457 \mathrm{e}+012.11457 \mathrm{e}+00$ 1.00000e-09 2.12000e-01 $2.11457 \mathrm{e}+012.11457 \mathrm{e}+012.11457 \mathrm{e}+00$ 1.00000e-09 2.12000e-01 $2.11457 \mathrm{e}+012.11457 \mathrm{e}+012.11457 \mathrm{e}+00$ 1.00000e-09 2.12000e-01 $2.11457 \mathrm{e}+012.11457 \mathrm{e}+012.11457 \mathrm{e}+00$ 1.00000e-09 2.12000e-01 $1.00000 \mathrm{e}-02$ 1.00000e-02 1.00000e-03 1.00000e-09 1.00000e-01 $1.00000 \mathrm{e}+001.00000 \mathrm{e}+001.00000 \mathrm{e}-011.00000 \mathrm{e}-091.00000 \mathrm{e}-01$ Element: 6795 \# of layers: 8

$\mathrm{Kx} \mathrm{Ky} \mathrm{Kz}$ Ss Por

5.29220e+02 5.29220e+02 5.29220e+01 1.00000e-09 7.00000e-02 $2.11457 \mathrm{e}+012.11457 \mathrm{e}+012.11457 \mathrm{e}+00$ 1.00000e-09 2.12000e-01 $2.11457 \mathrm{e}+012.11457 \mathrm{e}+012.11457 \mathrm{e}+00$ 1.00000e-09 2.12000e-01 $2.11457 \mathrm{e}+012.11457 \mathrm{e}+012.11457 \mathrm{e}+00$ 1.00000e-09 2.12000e-01 $2.11457 \mathrm{e}+012.11457 \mathrm{e}+012.11457 \mathrm{e}+00$ 1.00000e-09 2.12000e-01 $2.11457 \mathrm{e}+012.11457 \mathrm{e}+012.11457 \mathrm{e}+00$ 1.00000e-09 2.12000e-01 $1.00000 \mathrm{e}-02$ 1.00000e-02 1.00000e-03 1.00000e-09 1.00000e-01 $1.00000 \mathrm{e}+001.00000 \mathrm{e}+001.00000 \mathrm{e}-011.00000 \mathrm{e}-091.00000 \mathrm{e}-01$ Element: 6796 \# of layers: 8

$\mathrm{Kx} \mathrm{Ky} \mathrm{Kz}$ Ss Por

5.29220e+02 5.29220e+02 5.29220e+01 1.00000e-09 7.00000e-02 $2.11457 \mathrm{e}+012.11457 \mathrm{e}+012.11457 \mathrm{e}+00$ 1.00000e-09 2.12000e-01 $2.11457 \mathrm{e}+012.11457 \mathrm{e}+012.11457 \mathrm{e}+00$ 1.00000e-09 2.12000e-01 $2.11457 \mathrm{e}+012.11457 \mathrm{e}+012.11457 \mathrm{e}+00$ 1.00000e-09 2.12000e-01 $2.11457 \mathrm{e}+012.11457 \mathrm{e}+012.11457 \mathrm{e}+00$ 1.00000e-09 2.12000e-01 $2.11457 \mathrm{e}+012.11457 \mathrm{e}+012.11457 \mathrm{e}+00$ 1.00000e-09 2.12000e-01 $1.00000 \mathrm{e}-02$ 1.00000e-02 1.00000e-03 1.00000e-09 1.00000e-01 $1.00000 \mathrm{e}+001.00000 \mathrm{e}+001.00000 \mathrm{e}-011.00000 \mathrm{e}-091.00000 \mathrm{e}-01$ Element: 6797 \# of layers: 8

$\mathrm{Kx} \mathrm{Ky} \mathrm{Kz}$ Ss Por

5.29220e+02 5.29220e+02 5.29220e+01 1.00000e-09 7.00000e-02 $2.11457 \mathrm{e}+012.11457 \mathrm{e}+012.11457 \mathrm{e}+00$ 1.00000e-09 2.12000e-01 $2.11457 \mathrm{e}+012.11457 \mathrm{e}+012.11457 \mathrm{e}+00$ 1.00000e-09 2.12000e-01 $2.11457 \mathrm{e}+012.11457 \mathrm{e}+012.11457 \mathrm{e}+00$ 1.00000e-09 2.12000e-01 $2.11457 \mathrm{e}+012.11457 \mathrm{e}+012.11457 \mathrm{e}+00$ 1.00000e-09 2.12000e-01 $2.11457 \mathrm{e}+012.11457 \mathrm{e}+012.11457 \mathrm{e}+00$ 1.00000e-09 2.12000e-01 1.00000e-02 1.00000e-02 1.00000e-03 1.00000e-09 1.00000e-01 $1.00000 \mathrm{e}+001.00000 \mathrm{e}+001.00000 \mathrm{e}-011.00000 \mathrm{e}-091.00000 \mathrm{e}-01$ Element: 6798 \# of layers: 8

$\mathrm{Kx} \mathrm{Ky} \mathrm{Kz}$ Ss Por

5.29220e+02 5.29220e+02 5.29220e+01 1.00000e-09 7.00000e-02 $2.11457 \mathrm{e}+012.11457 \mathrm{e}+012.11457 \mathrm{e}+001.00000 \mathrm{e}-092.12000 \mathrm{e}-01$ 
$2.11457 \mathrm{e}+012.11457 \mathrm{e}+012.11457 \mathrm{e}+00$ 1.00000e-09 2.12000e-01 $2.11457 \mathrm{e}+012.11457 \mathrm{e}+012.11457 \mathrm{e}+00$ 1.00000e-09 2.12000e-01 $2.11457 \mathrm{e}+012.11457 \mathrm{e}+012.11457 \mathrm{e}+00$ 1.00000e-09 2.12000e-01 $2.11457 \mathrm{e}+012.11457 \mathrm{e}+012.11457 \mathrm{e}+001.00000 \mathrm{e}-092.12000 \mathrm{e}-01$ $1.00000 \mathrm{e}-021.00000 \mathrm{e}-021.00000 \mathrm{e}-031.00000 \mathrm{e}-091.00000 \mathrm{e}-01$ $1.00000 \mathrm{e}+001.00000 \mathrm{e}+001.00000 \mathrm{e}-011.00000 \mathrm{e}-091.00000 \mathrm{e}-01$ Element: 6799 \# of layers: 8

Kx Ky Kz Ss Por

$5.29220 \mathrm{e}+025.29220 \mathrm{e}+025.29220 \mathrm{e}+01$ 1.00000e-09 7.00000e-02 $2.11457 \mathrm{e}+012.11457 \mathrm{e}+012.11457 \mathrm{e}+001.00000 \mathrm{e}-092.12000 \mathrm{e}-01$ $2.11457 \mathrm{e}+012.11457 \mathrm{e}+012.11457 \mathrm{e}+001.00000 \mathrm{e}-092.12000 \mathrm{e}-01$ $2.11457 \mathrm{e}+012.11457 \mathrm{e}+012.11457 \mathrm{e}+001.00000 \mathrm{e}-092.12000 \mathrm{e}-01$ $2.11457 \mathrm{e}+012.11457 \mathrm{e}+012.11457 \mathrm{e}+00$ 1.00000e-09 2.12000e-01 $2.11457 \mathrm{e}+012.11457 \mathrm{e}+012.11457 \mathrm{e}+001.00000 \mathrm{e}-092.12000 \mathrm{e}-01$ $1.00000 \mathrm{e}-02$ 1.00000e-02 1.00000e-03 1.00000e-09 1.00000e-01 $1.00000 \mathrm{e}+001.00000 \mathrm{e}+001.00000 \mathrm{e}-011.00000 \mathrm{e}-091.00000 \mathrm{e}-01$ Element: 6800 \# of layers: 8

Kx Ky Kz Ss Por

$5.29220 \mathrm{e}+02$ 5.29220e+02 5.29220e+01 1.00000e-09 7.00000e-02 $2.11457 \mathrm{e}+012.11457 \mathrm{e}+012.11457 \mathrm{e}+001.00000 \mathrm{e}-092.12000 \mathrm{e}-01$ $2.11457 \mathrm{e}+012.11457 \mathrm{e}+012.11457 \mathrm{e}+001.00000 \mathrm{e}-092.12000 \mathrm{e}-01$ $2.11457 \mathrm{e}+012.11457 \mathrm{e}+012.11457 \mathrm{e}+00$ 1.00000e-09 2.12000e-01 $2.11457 \mathrm{e}+012.11457 \mathrm{e}+012.11457 \mathrm{e}+00$ 1.00000e-09 2.12000e-01 $2.11457 \mathrm{e}+012.11457 \mathrm{e}+012.11457 \mathrm{e}+00$ 1.00000e-09 2.12000e-01 $1.00000 \mathrm{e}-021.00000 \mathrm{e}-02$ 1.00000e-03 1.00000e-09 1.00000e-01 $1.00000 \mathrm{e}+001.00000 \mathrm{e}+001.00000 \mathrm{e}-011.00000 \mathrm{e}-091.00000 \mathrm{e}-01$ Element: 6801 \# of layers: 8

Kx Ky Kz Ss Por

$5.29220 \mathrm{e}+02$ 5.29220e+02 5.29220e+01 1.00000e-09 7.00000e-02 $2.11457 \mathrm{e}+012.11457 \mathrm{e}+012.11457 \mathrm{e}+00$ 1.00000e-09 2.12000e-01 $2.11457 \mathrm{e}+012.11457 \mathrm{e}+012.11457 \mathrm{e}+001.00000 \mathrm{e}-092.12000 \mathrm{e}-01$ $2.11457 \mathrm{e}+012.11457 \mathrm{e}+012.11457 \mathrm{e}+001.00000 \mathrm{e}-092.12000 \mathrm{e}-01$ $2.11457 \mathrm{e}+012.11457 \mathrm{e}+012.11457 \mathrm{e}+00$ 1.00000e-09 2.12000e-01 $2.11457 \mathrm{e}+012.11457 \mathrm{e}+012.11457 \mathrm{e}+00$ 1.00000e-09 2.12000e-01 $1.00000 \mathrm{e}-021.00000 \mathrm{e}-02$ 1.00000e-03 1.00000e-09 1.00000e-01 $1.00000 \mathrm{e}+001.00000 \mathrm{e}+001.00000 \mathrm{e}-011.00000 \mathrm{e}-091.00000 \mathrm{e}-01$ Element: 6802 \# of layers: 8

Kx Ky Kz Ss Por

$5.29220 \mathrm{e}+02$ 5.29220e+02 5.29220e+01 1.00000e-09 7.00000e-02 $2.11457 \mathrm{e}+012.11457 \mathrm{e}+012.11457 \mathrm{e}+001.00000 \mathrm{e}-092.12000 \mathrm{e}-01$ $2.11457 \mathrm{e}+012.11457 \mathrm{e}+012.11457 \mathrm{e}+001.00000 \mathrm{e}-092.12000 \mathrm{e}-01$ $2.11457 \mathrm{e}+012.11457 \mathrm{e}+012.11457 \mathrm{e}+001.00000 \mathrm{e}-092.12000 \mathrm{e}-01$ $2.11457 \mathrm{e}+012.11457 \mathrm{e}+012.11457 \mathrm{e}+00$ 1.00000e-09 2.12000e-01 $2.11457 \mathrm{e}+012.11457 \mathrm{e}+012.11457 \mathrm{e}+00$ 1.00000e-09 2.12000e-01 $1.00000 \mathrm{e}-02$ 1.00000e-02 1.00000e-03 1.00000e-09 1.00000e-01 $1.00000 \mathrm{e}+001.00000 \mathrm{e}+001.00000 \mathrm{e}-011.00000 \mathrm{e}-091.00000 \mathrm{e}-01$ 
Element: 6803 \# of layers: 8

Kx Ky Kz Ss Por

$6.83589 \mathrm{e}+02$ 6.83589e+02 6.83589e+01 1.00000e-09 7.00000e-02

$2.73133 \mathrm{e}+012.73133 \mathrm{e}+012.73133 \mathrm{e}+001.00000 \mathrm{e}-092.12000 \mathrm{e}-01$

$2.73133 \mathrm{e}+012.73133 \mathrm{e}+012.73133 \mathrm{e}+001.00000 \mathrm{e}-092.12000 \mathrm{e}-01$

$2.73133 \mathrm{e}+012.73133 \mathrm{e}+012.73133 \mathrm{e}+001.00000 \mathrm{e}-092.12000 \mathrm{e}-01$

$2.73133 \mathrm{e}+012.73133 \mathrm{e}+012.73133 \mathrm{e}+001.00000 \mathrm{e}-092.12000 \mathrm{e}-01$

$2.73133 \mathrm{e}+012.73133 \mathrm{e}+012.73133 \mathrm{e}+001.00000 \mathrm{e}-092.12000 \mathrm{e}-01$

$1.00000 \mathrm{e}-02$ 1.00000e-02 1.00000e-03 1.00000e-09 1.00000e-01

$1.00000 \mathrm{e}+001.00000 \mathrm{e}+001.00000 \mathrm{e}-011.00000 \mathrm{e}-091.00000 \mathrm{e}-01$

Element: 6804 \# of layers: 8

Kx Ky Kz Ss Por

$6.83589 \mathrm{e}+026.83589 \mathrm{e}+026.83589 \mathrm{e}+01$ 1.00000e-09 7.00000e-02

$2.73133 \mathrm{e}+012.73133 \mathrm{e}+012.73133 \mathrm{e}+00$ 1.00000e-09 2.12000e-01

$2.73133 \mathrm{e}+012.73133 \mathrm{e}+012.73133 \mathrm{e}+00$ 1.00000e-09 2.12000e-01

$2.73133 \mathrm{e}+012.73133 \mathrm{e}+012.73133 \mathrm{e}+001.00000 \mathrm{e}-092.12000 \mathrm{e}-01$

$2.73133 \mathrm{e}+012.73133 \mathrm{e}+012.73133 \mathrm{e}+00$ 1.00000e-09 2.12000e-01

$2.73133 \mathrm{e}+012.73133 \mathrm{e}+012.73133 \mathrm{e}+00$ 1.00000e-09 2.12000e-01

$1.00000 \mathrm{e}-02$ 1.00000e-02 1.00000e-03 1.00000e-09 1.00000e-01

$1.00000 \mathrm{e}+001.00000 \mathrm{e}+001.00000 \mathrm{e}-011.00000 \mathrm{e}-091.00000 \mathrm{e}-01$

Element: 6805 \# of layers: 8

Kx Ky Kz Ss Por

$6.83589 \mathrm{e}+02$ 6.83589e+02 6.83589e+01 1.00000e-09 7.00000e-02

$2.73133 \mathrm{e}+012.73133 \mathrm{e}+012.73133 \mathrm{e}+00$ 1.00000e-09 2.12000e-01

$2.73133 \mathrm{e}+012.73133 \mathrm{e}+012.73133 \mathrm{e}+001.00000 \mathrm{e}-092.12000 \mathrm{e}-01$

$2.73133 \mathrm{e}+012.73133 \mathrm{e}+012.73133 \mathrm{e}+001.00000 \mathrm{e}-092.12000 \mathrm{e}-01$

$2.73133 \mathrm{e}+012.73133 \mathrm{e}+012.73133 \mathrm{e}+001.00000 \mathrm{e}-092.12000 \mathrm{e}-01$

$2.73133 \mathrm{e}+012.73133 \mathrm{e}+012.73133 \mathrm{e}+001.00000 \mathrm{e}-092.12000 \mathrm{e}-01$

$1.00000 \mathrm{e}-021.00000 \mathrm{e}-02$ 1.00000e-03 1.00000e-09 1.00000e-01

$1.00000 \mathrm{e}+001.00000 \mathrm{e}+001.00000 \mathrm{e}-011.00000 \mathrm{e}-091.00000 \mathrm{e}-01$

Element: 6806 \# of layers: 8

Kx Ky Kz Ss Por

$6.83589 \mathrm{e}+026.83589 \mathrm{e}+026.83589 \mathrm{e}+01$ 1.00000e-09 7.00000e-02

$2.73133 \mathrm{e}+012.73133 \mathrm{e}+012.73133 \mathrm{e}+00$ 1.00000e-09 2.12000e-01

$2.73133 \mathrm{e}+012.73133 \mathrm{e}+012.73133 \mathrm{e}+00$ 1.00000e-09 2.12000e-01

$2.73133 \mathrm{e}+012.73133 \mathrm{e}+012.73133 \mathrm{e}+00$ 1.00000e-09 2.12000e-01

$2.73133 \mathrm{e}+012.73133 \mathrm{e}+012.73133 \mathrm{e}+00$ 1.00000e-09 2.12000e-01

$2.73133 \mathrm{e}+012.73133 \mathrm{e}+012.73133 \mathrm{e}+00$ 1.00000e-09 2.12000e-01

$1.00000 \mathrm{e}-02$ 1.00000e-02 1.00000e-03 1.00000e-09 1.00000e-01

$1.00000 \mathrm{e}+001.00000 \mathrm{e}+001.00000 \mathrm{e}-011.00000 \mathrm{e}-091.00000 \mathrm{e}-01$

Element: 6807 \# of layers: 8

Kx Ky Kz Ss Por

$6.83589 \mathrm{e}+026.83589 \mathrm{e}+026.83589 \mathrm{e}+01$ 1.00000e-09 7.00000e-02

$2.73133 \mathrm{e}+012.73133 \mathrm{e}+012.73133 \mathrm{e}+00$ 1.00000e-09 2.12000e-01

$2.73133 \mathrm{e}+012.73133 \mathrm{e}+012.73133 \mathrm{e}+001.00000 \mathrm{e}-092.12000 \mathrm{e}-01$

$2.73133 \mathrm{e}+012.73133 \mathrm{e}+012.73133 \mathrm{e}+00$ 1.00000e-09 2.12000e-01 
$2.73133 \mathrm{e}+012.73133 \mathrm{e}+012.73133 \mathrm{e}+00$ 1.00000e-09 2.12000e-01 $2.73133 \mathrm{e}+012.73133 \mathrm{e}+012.73133 \mathrm{e}+00$ 1.00000e-09 2.12000e-01 $1.00000 \mathrm{e}-021.00000 \mathrm{e}-02$ 1.00000e-03 1.00000e-09 1.00000e-01 $1.00000 \mathrm{e}+001.00000 \mathrm{e}+001.00000 \mathrm{e}-011.00000 \mathrm{e}-091.00000 \mathrm{e}-01$ Element: 6808 \# of layers: 8

Kx Ky Kz Ss Por

$6.83589 \mathrm{e}+026.83589 \mathrm{e}+026.83589 \mathrm{e}+01$ 1.00000e-09 7.00000e-02 $2.73133 \mathrm{e}+012.73133 \mathrm{e}+012.73133 \mathrm{e}+00$ 1.00000e-09 2.12000e-01 $2.73133 \mathrm{e}+012.73133 \mathrm{e}+012.73133 \mathrm{e}+00$ 1.00000e-09 2.12000e-01 $2.73133 \mathrm{e}+012.73133 \mathrm{e}+012.73133 \mathrm{e}+00$ 1.00000e-09 2.12000e-01 $2.73133 \mathrm{e}+012.73133 \mathrm{e}+012.73133 \mathrm{e}+00$ 1.00000e-09 2.12000e-01 $2.73133 \mathrm{e}+012.73133 \mathrm{e}+012.73133 \mathrm{e}+00$ 1.00000e-09 2.12000e-01 $1.00000 \mathrm{e}-021.00000 \mathrm{e}-02$ 1.00000e-03 1.00000e-09 1.00000e-01 $1.00000 \mathrm{e}+001.00000 \mathrm{e}+001.00000 \mathrm{e}-011.00000 \mathrm{e}-091.00000 \mathrm{e}-01$ Element: 6809 \# of layers: 8

Kx Ky Kz Ss Por

$6.83589 \mathrm{e}+02$ 6.83589e+02 6.83589e+01 1.00000e-09 7.00000e-02 $2.73133 \mathrm{e}+012.73133 \mathrm{e}+012.73133 \mathrm{e}+00$ 1.00000e-09 2.12000e-01 $2.73133 \mathrm{e}+012.73133 \mathrm{e}+012.73133 \mathrm{e}+00$ 1.00000e-09 2.12000e-01 $2.73133 \mathrm{e}+012.73133 \mathrm{e}+012.73133 \mathrm{e}+00$ 1.00000e-09 2.12000e-01 $2.73133 \mathrm{e}+012.73133 \mathrm{e}+012.73133 \mathrm{e}+00$ 1.00000e-09 2.12000e-01 $2.73133 \mathrm{e}+012.73133 \mathrm{e}+012.73133 \mathrm{e}+00$ 1.00000e-09 2.12000e-01 $1.00000 \mathrm{e}-02$ 1.00000e-02 1.00000e-03 1.00000e-09 1.00000e-01 $1.00000 \mathrm{e}+001.00000 \mathrm{e}+00$ 1.00000e-01 1.00000e-09 1.00000e-01 Element: 6810 \# of layers: 8

Kx Ky Kz Ss Por

6.83589e+02 6.83589e+02 6.83589e+01 1.00000e-09 7.00000e-02 $2.73133 \mathrm{e}+012.73133 \mathrm{e}+012.73133 \mathrm{e}+001.00000 \mathrm{e}-092.12000 \mathrm{e}-01$ $2.73133 \mathrm{e}+012.73133 \mathrm{e}+012.73133 \mathrm{e}+001.00000 \mathrm{e}-092.12000 \mathrm{e}-01$ $2.73133 \mathrm{e}+012.73133 \mathrm{e}+012.73133 \mathrm{e}+00$ 1.00000e-09 2.12000e-01 $2.73133 \mathrm{e}+012.73133 \mathrm{e}+012.73133 \mathrm{e}+001.00000 \mathrm{e}-092.12000 \mathrm{e}-01$ $2.73133 \mathrm{e}+012.73133 \mathrm{e}+012.73133 \mathrm{e}+00$ 1.00000e-09 2.12000e-01 $1.00000 \mathrm{e}-021.00000 \mathrm{e}-02$ 1.00000e-03 1.00000e-09 1.00000e-01 $1.00000 \mathrm{e}+001.00000 \mathrm{e}+001.00000 \mathrm{e}-011.00000 \mathrm{e}-091.00000 \mathrm{e}-01$ Element: 6811 \# of layers: 8

Kx Ky Kz Ss Por

$6.83589 \mathrm{e}+02$ 6.83589e+02 6.83589e+01 1.00000e-09 7.00000e-02 $2.73133 \mathrm{e}+012.73133 \mathrm{e}+012.73133 \mathrm{e}+00$ 1.00000e-09 2.12000e-01 $2.73133 \mathrm{e}+012.73133 \mathrm{e}+012.73133 \mathrm{e}+00$ 1.00000e-09 2.12000e-01 $2.73133 \mathrm{e}+012.73133 \mathrm{e}+012.73133 \mathrm{e}+00$ 1.00000e-09 2.12000e-01 $2.73133 \mathrm{e}+012.73133 \mathrm{e}+012.73133 \mathrm{e}+00$ 1.00000e-09 2.12000e-01 $2.73133 \mathrm{e}+012.73133 \mathrm{e}+012.73133 \mathrm{e}+001.00000 \mathrm{e}-092.12000 \mathrm{e}-01$ $1.00000 \mathrm{e}-02$ 1.00000e-02 1.00000e-03 1.00000e-09 1.00000e-01 $1.00000 \mathrm{e}+001.00000 \mathrm{e}+001.00000 \mathrm{e}-011.00000 \mathrm{e}-091.00000 \mathrm{e}-01$ Element: 6812 \# of layers: 7

Kx Ky Kz Ss Por 
9.76954e+02 9.76954e+02 9.76954e+01 1.00000e-09 7.00000e-02 $3.90361 \mathrm{e}+013.90361 \mathrm{e}+013.90361 \mathrm{e}+001.00000 \mathrm{e}-092.12000 \mathrm{e}-01$ $3.90361 \mathrm{e}+013.90361 \mathrm{e}+013.90361 \mathrm{e}+001.00000 \mathrm{e}-092.12000 \mathrm{e}-01$ $3.90361 \mathrm{e}+013.90361 \mathrm{e}+013.90361 \mathrm{e}+001.00000 \mathrm{e}-092.12000 \mathrm{e}-01$ $3.90361 \mathrm{e}+013.90361 \mathrm{e}+013.90361 \mathrm{e}+001.00000 \mathrm{e}-092.12000 \mathrm{e}-01$ $1.00000 \mathrm{e}-02$ 1.00000e-02 1.00000e-03 1.00000e-09 1.00000e-01 $1.00000 \mathrm{e}+001.00000 \mathrm{e}+001.00000 \mathrm{e}-011.00000 \mathrm{e}-091.00000 \mathrm{e}-01$ Element: 6813 \# of layers: 7

$\mathrm{Kx} \mathrm{Ky} \mathrm{Kz}$ Ss Por

9.76954e+02 9.76954e+02 9.76954e+01 1.00000e-09 7.00000e-02 $3.90361 \mathrm{e}+013.90361 \mathrm{e}+013.90361 \mathrm{e}+00$ 1.00000e-09 2.12000e-01 $3.90361 \mathrm{e}+013.90361 \mathrm{e}+013.90361 \mathrm{e}+001.00000 \mathrm{e}-092.12000 \mathrm{e}-01$ $3.90361 \mathrm{e}+013.90361 \mathrm{e}+013.90361 \mathrm{e}+001.00000 \mathrm{e}-092.12000 \mathrm{e}-01$ $3.90361 \mathrm{e}+013.90361 \mathrm{e}+013.90361 \mathrm{e}+001.00000 \mathrm{e}-092.12000 \mathrm{e}-01$ $1.00000 \mathrm{e}-021.00000 \mathrm{e}-02$ 1.00000e-03 1.00000e-09 1.00000e-01 $1.00000 \mathrm{e}+001.00000 \mathrm{e}+001.00000 \mathrm{e}-011.00000 \mathrm{e}-091.00000 \mathrm{e}-01$ Element: 6814 \# of layers: 7

$\mathrm{Kx} \mathrm{Ky} \mathrm{Kz}$ Ss Por

9.76954e+02 9.76954e+02 9.76954e+01 1.00000e-09 7.00000e-02 $3.90361 \mathrm{e}+013.90361 \mathrm{e}+013.90361 \mathrm{e}+001.00000 \mathrm{e}-092.12000 \mathrm{e}-01$ $3.90361 \mathrm{e}+013.90361 \mathrm{e}+013.90361 \mathrm{e}+001.00000 \mathrm{e}-092.12000 \mathrm{e}-01$ $3.90361 \mathrm{e}+013.90361 \mathrm{e}+013.90361 \mathrm{e}+001.00000 \mathrm{e}-092.12000 \mathrm{e}-01$ $3.90361 \mathrm{e}+013.90361 \mathrm{e}+013.90361 \mathrm{e}+001.00000 \mathrm{e}-092.12000 \mathrm{e}-01$ $1.00000 \mathrm{e}-02$ 1.00000e-02 1.00000e-03 1.00000e-09 1.00000e-01 $1.00000 \mathrm{e}+001.00000 \mathrm{e}+001.00000 \mathrm{e}-011.00000 \mathrm{e}-091.00000 \mathrm{e}-01$ Element: 6815 \# of layers: 7

$\mathrm{Kx} \mathrm{Ky} \mathrm{Kz}$ Ss Por

9.76954e+02 9.76954e+02 9.76954e+01 1.00000e-09 7.00000e-02 $3.90361 \mathrm{e}+013.90361 \mathrm{e}+013.90361 \mathrm{e}+001.00000 \mathrm{e}-092.12000 \mathrm{e}-01$ $3.90361 \mathrm{e}+013.90361 \mathrm{e}+013.90361 \mathrm{e}+001.00000 \mathrm{e}-092.12000 \mathrm{e}-01$ $3.90361 \mathrm{e}+013.90361 \mathrm{e}+013.90361 \mathrm{e}+001.00000 \mathrm{e}-092.12000 \mathrm{e}-01$ $3.90361 \mathrm{e}+013.90361 \mathrm{e}+013.90361 \mathrm{e}+00$ 1.00000e-09 2.12000e-01 1.00000e-02 1.00000e-02 1.00000e-03 1.00000e-09 1.00000e-01 $1.00000 \mathrm{e}+001.00000 \mathrm{e}+001.00000 \mathrm{e}-011.00000 \mathrm{e}-091.00000 \mathrm{e}-01$ Element: 6816 \# of layers: 8

Kx Ky Kz Ss Por

9.76954e+02 9.76954e+02 9.76954e+01 1.00000e-09 7.00000e-02

$9.76954 \mathrm{e}+02$ 9.76954e+02 9.76954e+01 1.00000e-09 7.00000e-02

$3.90361 \mathrm{e}+013.90361 \mathrm{e}+013.90361 \mathrm{e}+001.00000 \mathrm{e}-092.12000 \mathrm{e}-01$ $3.90361 \mathrm{e}+013.90361 \mathrm{e}+013.90361 \mathrm{e}+001.00000 \mathrm{e}-092.12000 \mathrm{e}-01$ $3.90361 \mathrm{e}+013.90361 \mathrm{e}+013.90361 \mathrm{e}+001.00000 \mathrm{e}-092.12000 \mathrm{e}-01$ $3.90361 \mathrm{e}+013.90361 \mathrm{e}+013.90361 \mathrm{e}+001.00000 \mathrm{e}-092.12000 \mathrm{e}-01$ $1.00000 \mathrm{e}-02$ 1.00000e-02 1.00000e-03 1.00000e-09 1.00000e-01 $1.00000 \mathrm{e}+001.00000 \mathrm{e}+001.00000 \mathrm{e}-01$ 1.00000e-09 1.00000e-01 Element: 6817 \# of layers: 8

Kx Ky Kz Ss Por 
9.76954e+02 9.76954e+02 9.76954e+01 1.00000e-09 7.00000e-02 9.76954e+02 9.76954e+02 9.76954e+01 1.00000e-09 7.00000e-02 $3.90361 \mathrm{e}+013.90361 \mathrm{e}+013.90361 \mathrm{e}+001.00000 \mathrm{e}-092.12000 \mathrm{e}-01$ $3.90361 \mathrm{e}+013.90361 \mathrm{e}+013.90361 \mathrm{e}+001.00000 \mathrm{e}-092.12000 \mathrm{e}-01$ $3.90361 \mathrm{e}+013.90361 \mathrm{e}+013.90361 \mathrm{e}+001.00000 \mathrm{e}-092.12000 \mathrm{e}-01$ $3.90361 \mathrm{e}+013.90361 \mathrm{e}+013.90361 \mathrm{e}+001.00000 \mathrm{e}-092.12000 \mathrm{e}-01$ $1.00000 \mathrm{e}-02$ 1.00000e-02 1.00000e-03 1.00000e-09 1.00000e-01 $1.00000 \mathrm{e}+001.00000 \mathrm{e}+001.00000 \mathrm{e}-011.00000 \mathrm{e}-091.00000 \mathrm{e}-01$ Element: 6818 \# of layers: 8

$\mathrm{Kx} \mathrm{Ky} \mathrm{Kz}$ Ss Por

9.76954e+02 9.76954e+02 9.76954e+01 1.00000e-09 7.00000e-02 $9.76954 \mathrm{e}+02$ 9.76954e+02 9.76954e+01 1.00000e-09 7.00000e-02 $3.90361 \mathrm{e}+013.90361 \mathrm{e}+013.90361 \mathrm{e}+001.00000 \mathrm{e}-092.12000 \mathrm{e}-01$ $3.90361 \mathrm{e}+013.90361 \mathrm{e}+013.90361 \mathrm{e}+001.00000 \mathrm{e}-092.12000 \mathrm{e}-01$ $3.90361 \mathrm{e}+013.90361 \mathrm{e}+013.90361 \mathrm{e}+001.00000 \mathrm{e}-092.12000 \mathrm{e}-01$ $3.90361 \mathrm{e}+013.90361 \mathrm{e}+013.90361 \mathrm{e}+001.00000 \mathrm{e}-092.12000 \mathrm{e}-01$ $1.00000 \mathrm{e}-02$ 1.00000e-02 1.00000e-03 1.00000e-09 1.00000e-01 $1.00000 \mathrm{e}+001.00000 \mathrm{e}+001.00000 \mathrm{e}-011.00000 \mathrm{e}-091.00000 \mathrm{e}-01$ Element: 6819 \# of layers: 7

$\mathrm{Kx} \mathrm{Ky} \mathrm{Kz}$ Ss Por

9.76954e+02 9.76954e+02 9.76954e+01 1.00000e-09 7.00000e-02 $3.90361 \mathrm{e}+013.90361 \mathrm{e}+013.90361 \mathrm{e}+00$ 1.00000e-09 2.12000e-01 $3.90361 \mathrm{e}+013.90361 \mathrm{e}+013.90361 \mathrm{e}+001.00000 \mathrm{e}-092.12000 \mathrm{e}-01$ $3.90361 \mathrm{e}+013.90361 \mathrm{e}+013.90361 \mathrm{e}+001.00000 \mathrm{e}-092.12000 \mathrm{e}-01$ $3.90361 \mathrm{e}+013.90361 \mathrm{e}+013.90361 \mathrm{e}+001.00000 \mathrm{e}-092.12000 \mathrm{e}-01$ $1.00000 \mathrm{e}-02$ 1.00000e-02 1.00000e-03 1.00000e-09 1.00000e-01 $1.00000 \mathrm{e}+001.00000 \mathrm{e}+001.00000 \mathrm{e}-011.00000 \mathrm{e}-091.00000 \mathrm{e}-01$ Element: 6820 \# of layers: 7

$\mathrm{Kx} \mathrm{Ky} \mathrm{Kz}$ Ss Por

9.76954e+02 9.76954e+02 9.76954e+01 1.00000e-09 7.00000e-02 $3.90361 \mathrm{e}+013.90361 \mathrm{e}+013.90361 \mathrm{e}+001.00000 \mathrm{e}-092.12000 \mathrm{e}-01$ $3.90361 \mathrm{e}+013.90361 \mathrm{e}+013.90361 \mathrm{e}+001.00000 \mathrm{e}-092.12000 \mathrm{e}-01$ $3.90361 \mathrm{e}+013.90361 \mathrm{e}+013.90361 \mathrm{e}+001.00000 \mathrm{e}-092.12000 \mathrm{e}-01$ $3.90361 \mathrm{e}+013.90361 \mathrm{e}+013.90361 \mathrm{e}+001.00000 \mathrm{e}-092.12000 \mathrm{e}-01$ $1.00000 \mathrm{e}-02$ 1.00000e-02 1.00000e-03 1.00000e-09 1.00000e-01 $1.00000 \mathrm{e}+001.00000 \mathrm{e}+001.00000 \mathrm{e}-011.00000 \mathrm{e}-091.00000 \mathrm{e}-01$ Element: 6821 \# of layers: 7

Kx Ky Kz Ss Por

4.65105e+02 4.65105e+02 4.65105e+01 1.00000e-09 7.00000e-02 $1.85838 \mathrm{e}+01$ 1.85838e+01 1.85838e+00 1.00000e-09 2.12000e-01 $1.85838 \mathrm{e}+01$ 1.85838e+01 1.85838e+00 1.00000e-09 2.12000e-01 $1.85838 \mathrm{e}+011.85838 \mathrm{e}+011.85838 \mathrm{e}+001.00000 \mathrm{e}-092.12000 \mathrm{e}-01$ $1.85838 \mathrm{e}+01$ 1.85838e+01 1.85838e+00 1.00000e-09 2.12000e-01 $1.00000 \mathrm{e}-011.00000 \mathrm{e}-011.00000 \mathrm{e}-021.00000 \mathrm{e}-091.00000 \mathrm{e}-01$ $1.00000 \mathrm{e}+001.00000 \mathrm{e}+001.00000 \mathrm{e}-011.00000 \mathrm{e}-091.00000 \mathrm{e}-01$ Element: 6822 \# of layers: 8 
$\mathrm{Kx} \mathrm{Ky} \mathrm{Kz}$ Ss Por

4.65105e+02 4.65105e+02 4.65105e+01 1.00000e-09 7.00000e-02

$1.85838 \mathrm{e}+011.85838 \mathrm{e}+01$ 1.85838e+00 1.00000e-09 2.12000e-01

$1.85838 \mathrm{e}+01$ 1.85838e+01 1.85838e+00 1.00000e-09 2.12000e-01

$1.85838 \mathrm{e}+011.85838 \mathrm{e}+01$ 1.85838e+00 1.00000e-09 2.12000e-01

$1.85838 \mathrm{e}+01$ 1.85838e+01 1.85838e+00 1.00000e-09 2.12000e-01

$1.85838 \mathrm{e}+011.85838 \mathrm{e}+01$ 1.85838e+00 1.00000e-09 2.12000e-01

$1.00000 \mathrm{e}-011.00000 \mathrm{e}-01$ 1.00000e-02 1.00000e-09 1.00000e-01

$1.00000 \mathrm{e}+001.00000 \mathrm{e}+001.00000 \mathrm{e}-011.00000 \mathrm{e}-091.00000 \mathrm{e}-01$

Element: 6823 \# of layers: 7

$\mathrm{Kx} \mathrm{Ky} \mathrm{Kz}$ Ss Por

4.65105e+02 4.65105e+02 4.65105e+01 1.00000e-09 7.00000e-02 $1.85838 \mathrm{e}+01$ 1.85838e+01 1.85838e+00 1.00000e-09 2.12000e-01

$1.85838 \mathrm{e}+011.85838 \mathrm{e}+011.85838 \mathrm{e}+001.00000 \mathrm{e}-092.12000 \mathrm{e}-01$

$1.85838 \mathrm{e}+01$ 1.85838e+01 1.85838e+00 1.00000e-09 2.12000e-01

$1.85838 \mathrm{e}+011.85838 \mathrm{e}+01$ 1.85838e+00 1.00000e-09 2.12000e-01

$1.00000 \mathrm{e}-01$ 1.00000e-01 1.00000e-02 1.00000e-09 1.00000e-01

$1.00000 \mathrm{e}+001.00000 \mathrm{e}+001.00000 \mathrm{e}-01$ 1.00000e-09 1.00000e-01

Element: 6824 \# of layers: 8

$\mathrm{Kx} \mathrm{Ky} \mathrm{Kz}$ Ss Por

4.65105e+02 4.65105e+02 4.65105e+01 1.00000e-09 7.00000e-02 $1.85838 \mathrm{e}+01$ 1.85838e+01 1.85838e+00 1.00000e-09 2.12000e-01

$1.85838 \mathrm{e}+01$ 1.85838e+01 1.85838e+00 1.00000e-09 2.12000e-01

$1.85838 \mathrm{e}+01$ 1.85838e+01 1.85838e+00 1.00000e-09 2.12000e-01

$1.85838 \mathrm{e}+011.85838 \mathrm{e}+011.85838 \mathrm{e}+001.00000 \mathrm{e}-092.12000 \mathrm{e}-01$

$1.85838 \mathrm{e}+01$ 1.85838e+01 1.85838e+00 1.00000e-09 2.12000e-01

$1.00000 \mathrm{e}-011.00000 \mathrm{e}-011.00000 \mathrm{e}-021.00000 \mathrm{e}-091.00000 \mathrm{e}-01$

$1.00000 \mathrm{e}+001.00000 \mathrm{e}+001.00000 \mathrm{e}-011.00000 \mathrm{e}-09$ 1.00000e-01

Element: 6825 \# of layers: 8

$\mathrm{Kx} \mathrm{Ky} \mathrm{Kz}$ Ss Por

4.65105e+02 4.65105e+02 4.65105e+01 1.00000e-09 7.00000e-02

4.65105e+02 4.65105e+02 4.65105e+01 1.00000e-09 7.00000e-02

$1.85838 \mathrm{e}+011.85838 \mathrm{e}+01$ 1.85838e+00 1.00000e-09 2.12000e-01

$1.85838 \mathrm{e}+01$ 1.85838e+01 1.85838e+00 1.00000e-09 2.12000e-01

$1.85838 \mathrm{e}+01$ 1.85838e+01 1.85838e+00 1.00000e-09 2.12000e-01

$1.85838 \mathrm{e}+01$ 1.85838e+01 1.85838e+00 1.00000e-09 2.12000e-01

$1.00000 \mathrm{e}-011.00000 \mathrm{e}-01$ 1.00000e-02 1.00000e-09 1.00000e-01

$1.00000 \mathrm{e}+001.00000 \mathrm{e}+001.00000 \mathrm{e}-011.00000 \mathrm{e}-091.00000 \mathrm{e}-01$

Element: 6826 \# of layers: 8

$\mathrm{Kx} \mathrm{Ky} \mathrm{Kz}$ Ss Por

4.65105e+02 4.65105e+02 4.65105e+01 1.00000e-09 7.00000e-02

4.65105e+02 4.65105e+02 4.65105e+01 1.00000e-09 7.00000e-02

$1.85838 \mathrm{e}+01$ 1.85838e+01 1.85838e+00 1.00000e-09 2.12000e-01

$1.85838 \mathrm{e}+01$ 1.85838e+01 1.85838e+00 1.00000e-09 2.12000e-01

$1.85838 \mathrm{e}+01$ 1.85838e+01 1.85838e+00 1.00000e-09 2.12000e-01

$1.85838 \mathrm{e}+011.85838 \mathrm{e}+011.85838 \mathrm{e}+001.00000 \mathrm{e}-092.12000 \mathrm{e}-01$ 
$1.00000 \mathrm{e}-01$ 1.00000e-01 1.00000e-02 1.00000e-09 1.00000e-01 $1.00000 \mathrm{e}+001.00000 \mathrm{e}+001.00000 \mathrm{e}-01$ 1.00000e-09 1.00000e-01 Element: 6827 \# of layers: 8

Kx Ky Kz Ss Por

4.65105e+02 4.65105e+02 4.65105e+01 1.00000e-09 7.00000e-02 $4.65105 \mathrm{e}+02$ 4.65105e+02 4.65105e+01 1.00000e-09 7.00000e-02 $1.85838 \mathrm{e}+01$ 1.85838e+01 1.85838e+00 1.00000e-09 2.12000e-01 $1.85838 \mathrm{e}+011.85838 \mathrm{e}+011.85838 \mathrm{e}+001.00000 \mathrm{e}-092.12000 \mathrm{e}-01$ $1.85838 \mathrm{e}+01$ 1.85838e+01 1.85838e+00 1.00000e-09 2.12000e-01 $1.85838 \mathrm{e}+01$ 1.85838e+01 1.85838e+00 1.00000e-09 2.12000e-01 $1.00000 \mathrm{e}-02$ 1.00000e-02 1.00000e-03 1.00000e-09 1.00000e-01 $1.00000 \mathrm{e}+001.00000 \mathrm{e}+001.00000 \mathrm{e}-011.00000 \mathrm{e}-091.00000 \mathrm{e}-01$ Element: 6828 \# of layers: 7

$\mathrm{Kx} \mathrm{Ky} \mathrm{Kz}$ Ss Por

4.65105e+02 4.65105e+02 4.65105e+01 1.00000e-09 7.00000e-02 $1.85838 \mathrm{e}+01$ 1.85838e+01 1.85838e+00 1.00000e-09 2.12000e-01 $1.85838 \mathrm{e}+011.85838 \mathrm{e}+011.85838 \mathrm{e}+001.00000 \mathrm{e}-092.12000 \mathrm{e}-01$ $1.85838 \mathrm{e}+01$ 1.85838e+01 1.85838e+00 1.00000e-09 2.12000e-01 $1.85838 \mathrm{e}+01$ 1.85838e+01 1.85838e+00 1.00000e-09 2.12000e-01 $1.00000 \mathrm{e}-01$ 1.00000e-01 1.00000e-02 1.00000e-09 1.00000e-01 $1.00000 \mathrm{e}+001.00000 \mathrm{e}+001.00000 \mathrm{e}-011.00000 \mathrm{e}-091.00000 \mathrm{e}-01$ Element: 6829 \# of layers: 8

$\mathrm{Kx} \mathrm{Ky} \mathrm{Kz}$ Ss Por

4.65105e+02 4.65105e+02 4.65105e+01 1.00000e-09 7.00000e-02 $1.85838 \mathrm{e}+011.85838 \mathrm{e}+01$ 1.85838e+00 1.00000e-09 2.12000e-01 $1.85838 \mathrm{e}+01$ 1.85838e+01 1.85838e+00 1.00000e-09 2.12000e-01 $1.85838 \mathrm{e}+01$ 1.85838e+01 1.85838e+00 1.00000e-09 2.12000e-01 $1.85838 \mathrm{e}+01$ 1.85838e+01 1.85838e+00 1.00000e-09 2.12000e-01 $1.85838 \mathrm{e}+01$ 1.85838e+01 1.85838e+00 1.00000e-09 2.12000e-01 $1.00000 \mathrm{e}-01$ 1.00000e-01 1.00000e-02 1.00000e-09 1.00000e-01 $1.00000 \mathrm{e}+001.00000 \mathrm{e}+001.00000 \mathrm{e}-011.00000 \mathrm{e}-091.00000 \mathrm{e}-01$ Element: 6830 \# of layers: 7

Kx Ky Kz Ss Por

1.99707e+02 1.99707e+02 1.99707e+01 1.00000e-09 7.00000e-02 1.99707e+02 1.99707e+02 1.99707e+01 1.00000e-09 7.00000e-02 7.97957e+00 7.97957e+00 7.97957e-01 1.00000e-09 2.12000e-01 7.97957e+00 7.97957e+00 7.97957e-01 1.00000e-09 2.12000e-01 7.97957e+00 7.97957e+00 7.97957e-01 1.00000e-09 2.12000e-01 $1.00000 \mathrm{e}-011.00000 \mathrm{e}-011.00000 \mathrm{e}-021.00000 \mathrm{e}-091.00000 \mathrm{e}-01$ $1.00000 \mathrm{e}+001.00000 \mathrm{e}+001.00000 \mathrm{e}-01$ 1.00000e-09 1.00000e-01 Element: 6831 \# of layers: 7

$\mathrm{Kx} \mathrm{Ky} \mathrm{Kz}$ Ss Por

1.99707e+02 1.99707e+02 1.99707e+01 1.00000e-09 7.00000e-02 1.99707e+02 1.99707e+02 1.99707e+01 1.00000e-09 7.00000e-02 7.97957e+00 7.97957e+00 7.97957e-01 1.00000e-09 2.12000e-01 7.97957e+00 7.97957e+00 7.97957e-01 1.00000e-09 2.12000e-01 
7.97957e+00 7.97957e+00 7.97957e-01 1.00000e-09 2.12000e-01 $1.00000 \mathrm{e}-01$ 1.00000e-01 1.00000e-02 1.00000e-09 1.00000e-01 $1.00000 \mathrm{e}+001.00000 \mathrm{e}+001.00000 \mathrm{e}-011.00000 \mathrm{e}-091.00000 \mathrm{e}-01$ Element: 6832 \# of layers: 7

Kx Ky Kz Ss Por

$1.99707 \mathrm{e}+02$ 1.99707e+02 1.99707e+01 1.00000e-09 7.00000e-02 $1.99707 \mathrm{e}+021.99707 \mathrm{e}+021.99707 \mathrm{e}+01$ 1.00000e-09 7.00000e-02 $7.97957 \mathrm{e}+00$ 7.97957e+00 7.97957e-01 1.00000e-09 2.12000e-01 $7.97957 \mathrm{e}+007.97957 \mathrm{e}+00$ 7.97957e-01 1.00000e-09 2.12000e-01 $7.97957 \mathrm{e}+007.97957 \mathrm{e}+007.97957 \mathrm{e}-01$ 1.00000e-09 2.12000e-01 $1.00000 \mathrm{e}-01$ 1.00000e-01 1.00000e-02 1.00000e-09 1.00000e-01 $1.00000 \mathrm{e}+001.00000 \mathrm{e}+001.00000 \mathrm{e}-011.00000 \mathrm{e}-091.00000 \mathrm{e}-01$ Element: 6833 \# of layers: 6

Kx Ky Kz Ss Por

$1.99707 \mathrm{e}+02$ 1.99707e+02 1.99707e+01 1.00000e-09 7.00000e-02 $7.97957 \mathrm{e}+00$ 7.97957e+00 7.97957e-01 1.00000e-09 2.12000e-01 $7.97957 \mathrm{e}+007.97957 \mathrm{e}+00$ 7.97957e-01 1.00000e-09 2.12000e-01 7.97957e+00 7.97957e+00 7.97957e-01 1.00000e-09 2.12000e-01 $1.00000 \mathrm{e}-011.00000 \mathrm{e}-011.00000 \mathrm{e}-021.00000 \mathrm{e}-091.00000 \mathrm{e}-01$ $1.00000 \mathrm{e}+001.00000 \mathrm{e}+001.00000 \mathrm{e}-011.00000 \mathrm{e}-091.00000 \mathrm{e}-01$ Element: 6834 \# of layers: 7

Kx Ky Kz Ss Por

$1.99707 \mathrm{e}+02$ 1.99707e+02 1.99707e+01 1.00000e-09 7.00000e-02 $1.99707 \mathrm{e}+021.99707 \mathrm{e}+021.99707 \mathrm{e}+01$ 1.00000e-09 7.00000e-02 $7.97957 \mathrm{e}+007.97957 \mathrm{e}+00$ 7.97957e-01 1.00000e-09 2.12000e-01 $7.97957 \mathrm{e}+00$ 7.97957e+00 7.97957e-01 1.00000e-09 2.12000e-01 $7.97957 \mathrm{e}+00$ 7.97957e+00 7.97957e-01 1.00000e-09 2.12000e-01 $1.00000 \mathrm{e}-011.00000 \mathrm{e}-011.00000 \mathrm{e}-021.00000 \mathrm{e}-091.00000 \mathrm{e}-01$ $1.00000 \mathrm{e}+001.00000 \mathrm{e}+001.00000 \mathrm{e}-011.00000 \mathrm{e}-091.00000 \mathrm{e}-01$ Element: 6835 \# of layers: 8

Kx Ky Kz Ss Por

$1.99707 \mathrm{e}+02$ 1.99707e+02 1.99707e+01 1.00000e-09 7.00000e-02 $1.99707 \mathrm{e}+02 \quad 1.99707 \mathrm{e}+02 \quad 1.99707 \mathrm{e}+01$ 1.00000e-09 7.00000e-02 $7.97957 \mathrm{e}+00$ 7.97957e+00 7.97957e-01 1.00000e-09 2.12000e-01 $7.97957 \mathrm{e}+007.97957 \mathrm{e}+00$ 7.97957e-01 1.00000e-09 2.12000e-01 $7.97957 \mathrm{e}+007.97957 \mathrm{e}+00$ 7.97957e-01 1.00000e-09 2.12000e-01 $7.97957 \mathrm{e}+007.97957 \mathrm{e}+00$ 7.97957e-01 1.00000e-09 2.12000e-01 $1.00000 \mathrm{e}-011.00000 \mathrm{e}-011.00000 \mathrm{e}-021.00000 \mathrm{e}-091.00000 \mathrm{e}-01$ $1.00000 \mathrm{e}+001.00000 \mathrm{e}+001.00000 \mathrm{e}-011.00000 \mathrm{e}-091.00000 \mathrm{e}-01$ Element: 6836 \# of layers: 8

Kx Ky Kz Ss Por $1.99707 \mathrm{e}+02$ 1.99707e+02 1.99707e+01 1.00000e-09 7.00000e-02 $1.99707 \mathrm{e}+021.99707 \mathrm{e}+021.99707 \mathrm{e}+011.00000 \mathrm{e}-097.00000 \mathrm{e}-02$ 7.97957e+00 7.97957e+00 7.97957e-01 1.00000e-09 2.12000e-01 $7.97957 \mathrm{e}+007.97957 \mathrm{e}+007.97957 \mathrm{e}-011.00000 \mathrm{e}-092.12000 \mathrm{e}-01$ $7.97957 \mathrm{e}+007.97957 \mathrm{e}+00$ 7.97957e-01 1.00000e-09 2.12000e-01 
7.97957e+00 7.97957e+00 7.97957e-01 1.00000e-09 2.12000e-01 $1.00000 \mathrm{e}-01$ 1.00000e-01 1.00000e-02 1.00000e-09 1.00000e-01 $1.00000 \mathrm{e}+001.00000 \mathrm{e}+001.00000 \mathrm{e}-011.00000 \mathrm{e}-091.00000 \mathrm{e}-01$ Element: 6837 \# of layers: 7

Kx Ky Kz Ss Por

$1.99707 \mathrm{e}+02$ 1.99707e+02 1.99707e+01 1.00000e-09 7.00000e-02 $7.97957 \mathrm{e}+007.97957 \mathrm{e}+00$ 7.97957e-01 1.00000e-09 2.12000e-01 $7.97957 \mathrm{e}+007.97957 \mathrm{e}+00$ 7.97957e-01 1.00000e-09 2.12000e-01 $7.97957 \mathrm{e}+007.97957 \mathrm{e}+00$ 7.97957e-01 1.00000e-09 2.12000e-01 $7.97957 \mathrm{e}+00$ 7.97957e+00 7.97957e-01 1.00000e-09 2.12000e-01 $1.00000 \mathrm{e}-011.00000 \mathrm{e}-011.00000 \mathrm{e}-021.00000 \mathrm{e}-09$ 1.00000e-01 $1.00000 \mathrm{e}+001.00000 \mathrm{e}+001.00000 \mathrm{e}-011.00000 \mathrm{e}-091.00000 \mathrm{e}-01$ Element: 6838 \# of layers: 6

Kx Ky Kz Ss Por

$1.99707 \mathrm{e}+02$ 1.99707e+02 1.99707e+01 1.00000e-09 7.00000e-02 $7.97957 \mathrm{e}+00$ 7.97957e+00 7.97957e-01 1.00000e-09 2.12000e-01 $7.97957 \mathrm{e}+007.97957 \mathrm{e}+00$ 7.97957e-01 1.00000e-09 2.12000e-01 7.97957e+00 7.97957e+00 7.97957e-01 1.00000e-09 2.12000e-01 $1.00000 \mathrm{e}-011.00000 \mathrm{e}-011.00000 \mathrm{e}-021.00000 \mathrm{e}-091.00000 \mathrm{e}-01$ $1.00000 \mathrm{e}+001.00000 \mathrm{e}+001.00000 \mathrm{e}-011.00000 \mathrm{e}-091.00000 \mathrm{e}-01$ Element: 6839 \# of layers: 8

Kx Ky Kz Ss Por

$1.73542 \mathrm{e}+02$ 1.73542e+02 1.73542e+01 1.00000e-09 7.00000e-02 $1.73542 \mathrm{e}+021.73542 \mathrm{e}+021.73542 \mathrm{e}+011.00000 \mathrm{e}-097.00000 \mathrm{e}-02$ $6.93420 \mathrm{e}+006.93420 \mathrm{e}+006.93420 \mathrm{e}-011.00000 \mathrm{e}-092.12000 \mathrm{e}-01$ $6.93420 \mathrm{e}+006.93420 \mathrm{e}+00$ 6.93420e-01 1.00000e-09 2.12000e-01 $6.93420 \mathrm{e}+006.93420 \mathrm{e}+00$ 6.93420e-01 1.00000e-09 2.12000e-01 $6.93420 \mathrm{e}+006.93420 \mathrm{e}+006.93420 \mathrm{e}-011.00000 \mathrm{e}-092.12000 \mathrm{e}-01$ $1.00000 \mathrm{e}-011.00000 \mathrm{e}-011.00000 \mathrm{e}-021.00000 \mathrm{e}-091.00000 \mathrm{e}-01$ $1.00000 \mathrm{e}+001.00000 \mathrm{e}+001.00000 \mathrm{e}-011.00000 \mathrm{e}-091.00000 \mathrm{e}-01$ Element: 6840 \# of layers: 8

Kx Ky Kz Ss Por

$1.73542 \mathrm{e}+02$ 1.73542e+02 1.73542e+01 1.00000e-09 7.00000e-02 $1.73542 \mathrm{e}+021.73542 \mathrm{e}+021.73542 \mathrm{e}+011.00000 \mathrm{e}-097.00000 \mathrm{e}-02$ $1.73542 \mathrm{e}+02 \quad 1.73542 \mathrm{e}+021.73542 \mathrm{e}+011.00000 \mathrm{e}-097.00000 \mathrm{e}-02$ $6.93420 \mathrm{e}+006.93420 \mathrm{e}+00$ 6.93420e-01 1.00000e-09 2.12000e-01 $6.93420 \mathrm{e}+006.93420 \mathrm{e}+006.93420 \mathrm{e}-011.00000 \mathrm{e}-092.12000 \mathrm{e}-01$ $6.93420 \mathrm{e}+006.93420 \mathrm{e}+00$ 6.93420e-01 1.00000e-09 2.12000e-01 $1.00000 \mathrm{e}-011.00000 \mathrm{e}-011.00000 \mathrm{e}-021.00000 \mathrm{e}-091.00000 \mathrm{e}-01$ $1.00000 \mathrm{e}+001.00000 \mathrm{e}+001.00000 \mathrm{e}-011.00000 \mathrm{e}-091.00000 \mathrm{e}-01$ Element: 6841 \# of layers: 8

Kx Ky Kz Ss Por

$1.73542 \mathrm{e}+021.73542 \mathrm{e}+02$ 1.73542e+01 1.00000e-09 7.00000e-02 $1.73542 \mathrm{e}+021.73542 \mathrm{e}+021.73542 \mathrm{e}+011.00000 \mathrm{e}-097.00000 \mathrm{e}-02$ $1.73542 \mathrm{e}+021.73542 \mathrm{e}+021.73542 \mathrm{e}+01$ 1.00000e-09 7.00000e-02 $6.93420 \mathrm{e}+006.93420 \mathrm{e}+006.93420 \mathrm{e}-011.00000 \mathrm{e}-092.12000 \mathrm{e}-01$ 
$6.93420 \mathrm{e}+006.93420 \mathrm{e}+006.93420 \mathrm{e}-011.00000 \mathrm{e}-092.12000 \mathrm{e}-01$ $6.93420 \mathrm{e}+006.93420 \mathrm{e}+006.93420 \mathrm{e}-011.00000 \mathrm{e}-09$ 2.12000e-01 $1.00000 \mathrm{e}-02$ 1.00000e-02 1.00000e-03 1.00000e-09 1.00000e-01 $1.00000 \mathrm{e}+001.00000 \mathrm{e}+001.00000 \mathrm{e}-011.00000 \mathrm{e}-091.00000 \mathrm{e}-01$ Element: 6842 \# of layers: 8

Kx Ky Kz Ss Por

$1.73542 \mathrm{e}+02$ 1.73542e+02 1.73542e+01 1.00000e-09 7.00000e-02 $1.73542 \mathrm{e}+021.73542 \mathrm{e}+021.73542 \mathrm{e}+01$ 1.00000e-09 7.00000e-02 $6.93420 \mathrm{e}+006.93420 \mathrm{e}+006.93420 \mathrm{e}-011.00000 \mathrm{e}-092.12000 \mathrm{e}-01$ $6.93420 \mathrm{e}+006.93420 \mathrm{e}+006.93420 \mathrm{e}-011.00000 \mathrm{e}-092.12000 \mathrm{e}-01$ $6.93420 \mathrm{e}+006.93420 \mathrm{e}+006.93420 \mathrm{e}-011.00000 \mathrm{e}-09$ 2.12000e-01 $6.93420 \mathrm{e}+006.93420 \mathrm{e}+006.93420 \mathrm{e}-011.00000 \mathrm{e}-09$ 2.12000e-01 $1.00000 \mathrm{e}-02$ 1.00000e-02 1.00000e-03 1.00000e-09 1.00000e-01 $1.00000 \mathrm{e}+001.00000 \mathrm{e}+001.00000 \mathrm{e}-011.00000 \mathrm{e}-091.00000 \mathrm{e}-01$ Element: 6843 \# of layers: 8

Kx Ky Kz Ss Por

$1.73542 \mathrm{e}+02$ 1.73542e+02 1.73542e+01 1.00000e-09 7.00000e-02 $1.73542 \mathrm{e}+021.73542 \mathrm{e}+021.73542 \mathrm{e}+011.00000 \mathrm{e}-097.00000 \mathrm{e}-02$ $6.93420 \mathrm{e}+006.93420 \mathrm{e}+006.93420 \mathrm{e}-011.00000 \mathrm{e}-092.12000 \mathrm{e}-01$ $6.93420 \mathrm{e}+006.93420 \mathrm{e}+006.93420 \mathrm{e}-011.00000 \mathrm{e}-092.12000 \mathrm{e}-01$ $6.93420 \mathrm{e}+006.93420 \mathrm{e}+006.93420 \mathrm{e}-011.00000 \mathrm{e}-092.12000 \mathrm{e}-01$ $6.93420 \mathrm{e}+006.93420 \mathrm{e}+006.93420 \mathrm{e}-011.00000 \mathrm{e}-092.12000 \mathrm{e}-01$ $1.00000 \mathrm{e}-021.00000 \mathrm{e}-02$ 1.00000e-03 1.00000e-09 1.00000e-01 $1.00000 \mathrm{e}+001.00000 \mathrm{e}+001.00000 \mathrm{e}-011.00000 \mathrm{e}-091.00000 \mathrm{e}-01$ Element: 6844 \# of layers: 7

Kx Ky Kz Ss Por

$1.73542 \mathrm{e}+02$ 1.73542e+02 1.73542e+01 1.00000e-09 7.00000e-02 $6.93420 \mathrm{e}+006.93420 \mathrm{e}+006.93420 \mathrm{e}-011.00000 \mathrm{e}-092.12000 \mathrm{e}-01$ $6.93420 \mathrm{e}+006.93420 \mathrm{e}+006.93420 \mathrm{e}-011.00000 \mathrm{e}-092.12000 \mathrm{e}-01$ $6.93420 \mathrm{e}+006.93420 \mathrm{e}+006.93420 \mathrm{e}-011.00000 \mathrm{e}-092.12000 \mathrm{e}-01$ $6.93420 \mathrm{e}+006.93420 \mathrm{e}+006.93420 \mathrm{e}-011.00000 \mathrm{e}-09$ 2.12000e-01 $1.00000 \mathrm{e}-021.00000 \mathrm{e}-02$ 1.00000e-03 1.00000e-09 1.00000e-01 $1.00000 \mathrm{e}+001.00000 \mathrm{e}+001.00000 \mathrm{e}-011.00000 \mathrm{e}-091.00000 \mathrm{e}-01$ Element: 6845 \# of layers: 7

Kx Ky Kz Ss Por

$1.73542 \mathrm{e}+021.73542 \mathrm{e}+02$ 1.73542e+01 1.00000e-09 7.00000e-02 $1.73542 \mathrm{e}+021.73542 \mathrm{e}+021.73542 \mathrm{e}+011.00000 \mathrm{e}-097.00000 \mathrm{e}-02$ $6.93420 \mathrm{e}+006.93420 \mathrm{e}+00$ 6.93420e-01 1.00000e-09 2.12000e-01 $6.93420 \mathrm{e}+006.93420 \mathrm{e}+006.93420 \mathrm{e}-011.00000 \mathrm{e}-092.12000 \mathrm{e}-01$ $6.93420 \mathrm{e}+006.93420 \mathrm{e}+00$ 6.93420e-01 1.00000e-09 2.12000e-01 $1.00000 \mathrm{e}-011.00000 \mathrm{e}-011.00000 \mathrm{e}-021.00000 \mathrm{e}-091.00000 \mathrm{e}-01$ $1.00000 \mathrm{e}+001.00000 \mathrm{e}+001.00000 \mathrm{e}-011.00000 \mathrm{e}-091.00000 \mathrm{e}-01$ Element: 6846 \# of layers: 7

Kx Ky Kz Ss Por $1.73542 \mathrm{e}+02$ 1.73542e+02 1.73542e+01 1.00000e-09 7.00000e-02 $6.93420 \mathrm{e}+006.93420 \mathrm{e}+006.93420 \mathrm{e}-011.00000 \mathrm{e}-092.12000 \mathrm{e}-01$ 
$6.93420 \mathrm{e}+006.93420 \mathrm{e}+006.93420 \mathrm{e}-011.00000 \mathrm{e}-092.12000 \mathrm{e}-01$ $6.93420 \mathrm{e}+006.93420 \mathrm{e}+006.93420 \mathrm{e}-011.00000 \mathrm{e}-092.12000 \mathrm{e}-01$ $6.93420 \mathrm{e}+006.93420 \mathrm{e}+00$ 6.93420e-01 1.00000e-09 2.12000e-01 $1.00000 \mathrm{e}-011.00000 \mathrm{e}-011.00000 \mathrm{e}-021.00000 \mathrm{e}-091.00000 \mathrm{e}-01$ $1.00000 \mathrm{e}+001.00000 \mathrm{e}+001.00000 \mathrm{e}-011.00000 \mathrm{e}-091.00000 \mathrm{e}-01$ Element: 6847 \# of layers: 8

Kx Ky Kz Ss Por

$1.73542 \mathrm{e}+02$ 1.73542e+02 1.73542e+01 1.00000e-09 7.00000e-02 $1.73542 \mathrm{e}+021.73542 \mathrm{e}+021.73542 \mathrm{e}+011.00000 \mathrm{e}-097.00000 \mathrm{e}-02$ $6.93420 \mathrm{e}+006.93420 \mathrm{e}+00$ 6.93420e-01 1.00000e-09 2.12000e-01 $6.93420 \mathrm{e}+006.93420 \mathrm{e}+006.93420 \mathrm{e}-011.00000 \mathrm{e}-09$ 2.12000e-01 $6.93420 \mathrm{e}+006.93420 \mathrm{e}+006.93420 \mathrm{e}-011.00000 \mathrm{e}-09$ 2.12000e-01 $6.93420 \mathrm{e}+006.93420 \mathrm{e}+00$ 6.93420e-01 1.00000e-09 2.12000e-01 $1.00000 \mathrm{e}-02$ 1.00000e-02 1.00000e-03 1.00000e-09 1.00000e-01 $1.00000 \mathrm{e}+001.00000 \mathrm{e}+001.00000 \mathrm{e}-011.00000 \mathrm{e}-091.00000 \mathrm{e}-01$ Element: 6848 \# of layers: 8

Kx Ky Kz Ss Por $1.82633 \mathrm{e}+03$ 1.82633e+03 1.82633e+02 1.00000e-09 7.00000e-02 $1.82633 \mathrm{e}+03$ 1.82633e+03 1.82633e+02 1.00000e-09 7.00000e-02 $1.82633 \mathrm{e}+031.82633 \mathrm{e}+03$ 1.82633e+02 1.00000e-09 7.00000e-02 $7.29713 \mathrm{e}+01$ 7.29713e+01 7.29713e+00 1.00000e-09 2.12000e-01 $7.29713 \mathrm{e}+01$ 7.29713e+01 7.29713e+00 1.00000e-09 2.12000e-01 $7.29713 \mathrm{e}+01$ 7.29713e+01 7.29713e+00 1.00000e-09 2.12000e-01 $1.00000 \mathrm{e}-02$ 1.00000e-02 1.00000e-03 1.00000e-09 1.00000e-01 $1.00000 \mathrm{e}+001.00000 \mathrm{e}+001.00000 \mathrm{e}-011.00000 \mathrm{e}-091.00000 \mathrm{e}-01$ Element: 6849 \# of layers: 9

Kx Ky Kz Ss Por

$1.82633 \mathrm{e}+03$ 1.82633e+03 1.82633e+02 1.00000e-09 7.00000e-02 $1.82633 \mathrm{e}+031.82633 \mathrm{e}+03$ 1.82633e+02 1.00000e-09 7.00000e-02 $1.82633 \mathrm{e}+031.82633 \mathrm{e}+03$ 1.82633e+02 1.00000e-09 7.00000e-02 $7.29713 \mathrm{e}+01$ 7.29713e+01 7.29713e+00 1.00000e-09 2.12000e-01 $7.29713 \mathrm{e}+01$ 7.29713e+01 7.29713e+00 1.00000e-09 2.12000e-01 $7.29713 \mathrm{e}+01$ 7.29713e+01 7.29713e+00 1.00000e-09 2.12000e-01 $7.29713 \mathrm{e}+01$ 7.29713e+01 7.29713e+00 1.00000e-09 2.12000e-01 $1.00000 \mathrm{e}-021.00000 \mathrm{e}-02$ 1.00000e-03 1.00000e-09 1.00000e-01 $1.00000 \mathrm{e}+001.00000 \mathrm{e}+001.00000 \mathrm{e}-011.00000 \mathrm{e}-091.00000 \mathrm{e}-01$ Element: 6850 \# of layers: 8

Kx Ky Kz Ss Por $1.82633 \mathrm{e}+03$ 1.82633e+03 1.82633e+02 1.00000e-09 7.00000e-02 $1.82633 \mathrm{e}+03$ 1.82633e+03 1.82633e+02 1.00000e-09 7.00000e-02 $1.82633 \mathrm{e}+03$ 1.82633e+03 1.82633e+02 1.00000e-09 7.00000e-02 $7.29713 \mathrm{e}+01$ 7.29713e+01 7.29713e+00 1.00000e-09 2.12000e-01 $7.29713 \mathrm{e}+01$ 7.29713e+01 7.29713e+00 1.00000e-09 2.12000e-01 $7.29713 \mathrm{e}+01$ 7.29713e+01 7.29713e+00 1.00000e-09 2.12000e-01 $1.00000 \mathrm{e}-021.00000 \mathrm{e}-02$ 1.00000e-03 1.00000e-09 1.00000e-01 $1.00000 \mathrm{e}+001.00000 \mathrm{e}+001.00000 \mathrm{e}-011.00000 \mathrm{e}-091.00000 \mathrm{e}-01$ 
Element: 6851 \# of layers: 7

Kx Ky Kz Ss Por

$1.82633 \mathrm{e}+03$ 1.82633e+03 1.82633e+02 1.00000e-09 7.00000e-02

$1.82633 \mathrm{e}+031.82633 \mathrm{e}+031.82633 \mathrm{e}+02$ 1.00000e-09 7.00000e-02

$7.29713 \mathrm{e}+01$ 7.29713e+01 7.29713e+00 1.00000e-09 2.12000e-01

$7.29713 \mathrm{e}+01$ 7.29713e+01 7.29713e+00 1.00000e-09 2.12000e-01

$7.29713 \mathrm{e}+01$ 7.29713e+01 7.29713e+00 1.00000e-09 2.12000e-01

$1.00000 \mathrm{e}-021.00000 \mathrm{e}-02$ 1.00000e-03 1.00000e-09 1.00000e-01

$1.00000 \mathrm{e}+001.00000 \mathrm{e}+001.00000 \mathrm{e}-011.00000 \mathrm{e}-091.00000 \mathrm{e}-01$

Element: 6852 \# of layers: 7

Kx Ky Kz Ss Por

$1.82633 \mathrm{e}+03$ 1.82633e+03 1.82633e+02 1.00000e-09 7.00000e-02

$7.29713 \mathrm{e}+01$ 7.29713e+01 7.29713e+00 1.00000e-09 2.12000e-01

$7.29713 \mathrm{e}+01$ 7.29713e+01 7.29713e+00 1.00000e-09 2.12000e-01

$7.29713 \mathrm{e}+01$ 7.29713e+01 7.29713e+00 1.00000e-09 2.12000e-01

$7.29713 \mathrm{e}+01$ 7.29713e+01 7.29713e+00 1.00000e-09 2.12000e-01

$1.00000 \mathrm{e}-021.00000 \mathrm{e}-02$ 1.00000e-03 1.00000e-09 1.00000e-01

$1.00000 \mathrm{e}+001.00000 \mathrm{e}+001.00000 \mathrm{e}-011.00000 \mathrm{e}-091.00000 \mathrm{e}-01$

Element: 6853 \# of layers: 7

Kx Ky Kz Ss Por

$1.82633 \mathrm{e}+03$ 1.82633e+03 1.82633e+02 1.00000e-09 7.00000e-02

7.29713e+01 7.29713e+01 7.29713e+00 1.00000e-09 2.12000e-01

$7.29713 \mathrm{e}+01$ 7.29713e+01 7.29713e+00 1.00000e-09 2.12000e-01

$7.29713 \mathrm{e}+01$ 7.29713e+01 7.29713e+00 1.00000e-09 2.12000e-01

$7.29713 \mathrm{e}+01$ 7.29713e+01 7.29713e+00 1.00000e-09 2.12000e-01

$1.00000 \mathrm{e}-02$ 1.00000e-02 1.00000e-03 1.00000e-09 1.00000e-01

$1.00000 \mathrm{e}+001.00000 \mathrm{e}+001.00000 \mathrm{e}-011.00000 \mathrm{e}-091.00000 \mathrm{e}-01$

Element: 6854 \# of layers: 8

Kx Ky Kz Ss Por

$1.82633 \mathrm{e}+03$ 1.82633e+03 1.82633e+02 1.00000e-09 7.00000e-02

$1.82633 \mathrm{e}+031.82633 \mathrm{e}+031.82633 \mathrm{e}+021.00000 \mathrm{e}-09$ 7.00000e-02

$7.29713 \mathrm{e}+01$ 7.29713e+01 7.29713e+00 1.00000e-09 2.12000e-01

$7.29713 \mathrm{e}+01$ 7.29713e+01 7.29713e+00 1.00000e-09 2.12000e-01

$7.29713 \mathrm{e}+01$ 7.29713e+01 7.29713e+00 1.00000e-09 2.12000e-01

$7.29713 \mathrm{e}+01$ 7.29713e+01 7.29713e+00 1.00000e-09 2.12000e-01

$1.00000 \mathrm{e}-02$ 1.00000e-02 1.00000e-03 1.00000e-09 1.00000e-01

$1.00000 \mathrm{e}+001.00000 \mathrm{e}+001.00000 \mathrm{e}-011.00000 \mathrm{e}-091.00000 \mathrm{e}-01$

Element: 6855 \# of layers: 8

Kx Ky Kz Ss Por

$1.82633 \mathrm{e}+03$ 1.82633e+03 1.82633e+02 1.00000e-09 7.00000e-02

$1.82633 \mathrm{e}+031.82633 \mathrm{e}+031.82633 \mathrm{e}+02$ 1.00000e-09 7.00000e-02

$7.29713 \mathrm{e}+01$ 7.29713e+01 7.29713e+00 1.00000e-09 2.12000e-01

$7.29713 \mathrm{e}+01$ 7.29713e+01 7.29713e+00 1.00000e-09 2.12000e-01

$7.29713 \mathrm{e}+01$ 7.29713e+01 7.29713e+00 1.00000e-09 2.12000e-01

$7.29713 \mathrm{e}+01$ 7.29713e+01 7.29713e+00 1.00000e-09 2.12000e-01

$1.00000 \mathrm{e}-021.00000 \mathrm{e}-02$ 1.00000e-03 1.00000e-09 1.00000e-01 
$1.00000 \mathrm{e}+001.00000 \mathrm{e}+00$ 1.00000e-01 1.00000e-09 1.00000e-01

Element: 6856 \# of layers: 8

$\mathrm{Kx} \mathrm{Ky} \mathrm{Kz}$ Ss Por

$1.82633 \mathrm{e}+03$ 1.82633e+03 1.82633e+02 1.00000e-09 7.00000e-02

$1.82633 \mathrm{e}+031.82633 \mathrm{e}+03$ 1.82633e+02 1.00000e-09 7.00000e-02

7.29713e+01 7.29713e+01 7.29713e+00 1.00000e-09 2.12000e-01

7.29713e+01 7.29713e+01 7.29713e+00 1.00000e-09 2.12000e-01

$7.29713 \mathrm{e}+01$ 7.29713e+01 7.29713e+00 1.00000e-09 2.12000e-01

7.29713e+01 7.29713e+01 7.29713e+00 1.00000e-09 2.12000e-01

$1.00000 \mathrm{e}-02$ 1.00000e-02 1.00000e-03 1.00000e-09 1.00000e-01

$1.00000 \mathrm{e}+001.00000 \mathrm{e}+001.00000 \mathrm{e}-011.00000 \mathrm{e}-091.00000 \mathrm{e}-01$

Element: 6857 \# of layers: 8

$\mathrm{Kx} \mathrm{Ky} \mathrm{Kz}$ Ss Por

$5.59305 \mathrm{e}+03$ 5.59305e+03 5.59305e+02 1.00000e-09 7.00000e-02 $5.59305 \mathrm{e}+03$ 5.59305e+03 5.59305e+02 1.00000e-09 7.00000e-02 $5.59305 \mathrm{e}+035.59305 \mathrm{e}+03$ 5.59305e+02 1.00000e-09 7.00000e-02 2.23477e+02 2.23477e+02 2.23477e+01 1.00000e-09 2.12000e-01

$2.23477 \mathrm{e}+02$ 2.23477e+02 2.23477e+01 1.00000e-09 2.12000e-01 $2.23477 \mathrm{e}+02$ 2.23477e+02 2.23477e+01 1.00000e-09 2.12000e-01 $1.00000 \mathrm{e}-02$ 1.00000e-02 1.00000e-03 1.00000e-09 1.00000e-01 $1.00000 \mathrm{e}+001.00000 \mathrm{e}+001.00000 \mathrm{e}-011.00000 \mathrm{e}-091.00000 \mathrm{e}-01$ Element: 6858 \# of layers: 8

$\mathrm{Kx} \mathrm{Ky} \mathrm{Kz}$ Ss Por

5.59305e+03 5.59305e+03 5.59305e+02 1.00000e-09 7.00000e-02 $5.59305 \mathrm{e}+03$ 5.59305e+03 5.59305e+02 1.00000e-09 7.00000e-02 $5.59305 \mathrm{e}+03$ 5.59305e+03 5.59305e+02 1.00000e-09 7.00000e-02 $2.23477 \mathrm{e}+02$ 2.23477e+02 2.23477e+01 1.00000e-09 2.12000e-01 2.23477e+02 2.23477e+02 2.23477e+01 1.00000e-09 2.12000e-01 $2.23477 \mathrm{e}+02$ 2.23477e+02 2.23477e+01 1.00000e-09 2.12000e-01 $1.00000 \mathrm{e}-02$ 1.00000e-02 1.00000e-03 1.00000e-09 1.00000e-01 $1.00000 \mathrm{e}+001.00000 \mathrm{e}+001.00000 \mathrm{e}-011.00000 \mathrm{e}-091.00000 \mathrm{e}-01$ Element: 6859 \# of layers: 7

Kx Ky Kz Ss Por

5.59305e+03 5.59305e+03 5.59305e+02 1.00000e-09 7.00000e-02 $5.59305 \mathrm{e}+03$ 5.59305e+03 5.59305e+02 1.00000e-09 7.00000e-02 $2.23477 \mathrm{e}+02$ 2.23477e+02 2.23477e+01 1.00000e-09 2.12000e-01 $2.23477 \mathrm{e}+02$ 2.23477e+02 2.23477e+01 1.00000e-09 2.12000e-01 $2.23477 \mathrm{e}+02$ 2.23477e+02 2.23477e+01 1.00000e-09 2.12000e-01 $1.00000 \mathrm{e}-02$ 1.00000e-02 1.00000e-03 1.00000e-09 1.00000e-01 $1.00000 \mathrm{e}+001.00000 \mathrm{e}+001.00000 \mathrm{e}-01$ 1.00000e-09 1.00000e-01 Element: 6860 \# of layers: 6

$\mathrm{Kx} \mathrm{Ky} \mathrm{Kz}$ Ss Por

5.59305e+03 5.59305e+03 5.59305e+02 1.00000e-09 7.00000e-02 2.23477e+02 2.23477e+02 2.23477e+01 1.00000e-09 2.12000e-01 $2.23477 \mathrm{e}+02$ 2.23477e+02 2.23477e+01 1.00000e-09 2.12000e-01 $2.23477 \mathrm{e}+02$ 2.23477e+02 2.23477e+01 1.00000e-09 2.12000e-01 
$1.00000 \mathrm{e}-02$ 1.00000e-02 1.00000e-03 1.00000e-09 1.00000e-01 $1.00000 \mathrm{e}+001.00000 \mathrm{e}+001.00000 \mathrm{e}-01$ 1.00000e-09 1.00000e-01

Element: 6861 \# of layers: 6

$\mathrm{Kx} \mathrm{Ky} \mathrm{Kz}$ Ss Por

5.59305e+03 5.59305e+03 5.59305e+02 1.00000e-09 7.00000e-02 $2.23477 \mathrm{e}+02$ 2.23477e+02 2.23477e+01 1.00000e-09 2.12000e-01

$2.23477 \mathrm{e}+02$ 2.23477e+02 2.23477e+01 1.00000e-09 2.12000e-01

$2.23477 \mathrm{e}+02$ 2.23477e+02 2.23477e+01 1.00000e-09 2.12000e-01

$1.00000 \mathrm{e}-021.00000 \mathrm{e}-021.00000 \mathrm{e}-031.00000 \mathrm{e}-091.00000 \mathrm{e}-01$

$1.00000 \mathrm{e}+001.00000 \mathrm{e}+001.00000 \mathrm{e}-011.00000 \mathrm{e}-091.00000 \mathrm{e}-01$

Element: 6862 \# of layers: 6

$\mathrm{Kx} \mathrm{Ky} \mathrm{Kz}$ Ss Por

5.59305e+03 5.59305e+03 5.59305e+02 1.00000e-09 7.00000e-02

$2.23477 \mathrm{e}+02$ 2.23477e+02 2.23477e+01 1.00000e-09 2.12000e-01

$2.23477 \mathrm{e}+02$ 2.23477e+02 2.23477e+01 1.00000e-09 2.12000e-01

$2.23477 \mathrm{e}+02$ 2.23477e+02 2.23477e+01 1.00000e-09 2.12000e-01

1.00000e-02 1.00000e-02 1.00000e-03 1.00000e-09 1.00000e-01

$1.00000 \mathrm{e}+001.00000 \mathrm{e}+001.00000 \mathrm{e}-01$ 1.00000e-09 1.00000e-01

Element: 6863 \# of layers: 6

$\mathrm{Kx} \mathrm{Ky} \mathrm{Kz}$ Ss Por

$5.59305 e+03$ 5.59305e+03 5.59305e+02 1.00000e-09 7.00000e-02

$2.23477 \mathrm{e}+02$ 2.23477e+02 2.23477e+01 1.00000e-09 2.12000e-01

2.23477e+02 2.23477e+02 2.23477e+01 1.00000e-09 2.12000e-01

$2.23477 \mathrm{e}+02$ 2.23477e+02 2.23477e+01 1.00000e-09 2.12000e-01

$1.00000 \mathrm{e}-02$ 1.00000e-02 1.00000e-03 1.00000e-09 1.00000e-01

$1.00000 \mathrm{e}+001.00000 \mathrm{e}+001.00000 \mathrm{e}-01$ 1.00000e-09 1.00000e-01

Element: 6864 \# of layers: 7

$\mathrm{Kx} \mathrm{Ky} \mathrm{Kz}$ Ss Por

5.59305e+03 5.59305e+03 5.59305e+02 1.00000e-09 7.00000e-02

5.59305e+03 5.59305e+03 5.59305e+02 1.00000e-09 7.00000e-02

$2.23477 \mathrm{e}+02$ 2.23477e+02 2.23477e+01 1.00000e-09 2.12000e-01

$2.23477 \mathrm{e}+02$ 2.23477e+02 2.23477e+01 1.00000e-09 2.12000e-01

$2.23477 \mathrm{e}+02$ 2.23477e+02 2.23477e+01 1.00000e-09 2.12000e-01

$1.00000 \mathrm{e}-02$ 1.00000e-02 1.00000e-03 1.00000e-09 1.00000e-01

$1.00000 \mathrm{e}+001.00000 \mathrm{e}+001.00000 \mathrm{e}-01$ 1.00000e-09 1.00000e-01

Element: 6865 \# of layers: 7

Kx Ky Kz Ss Por

5.59305e+03 5.59305e+03 5.59305e+02 1.00000e-09 7.00000e-02

$5.59305 \mathrm{e}+03$ 5.59305e+03 5.59305e+02 1.00000e-09 7.00000e-02

$2.23477 \mathrm{e}+02$ 2.23477e+02 2.23477e+01 1.00000e-09 2.12000e-01

$2.23477 \mathrm{e}+02$ 2.23477e+02 2.23477e+01 1.00000e-09 2.12000e-01

$2.23477 \mathrm{e}+02$ 2.23477e+02 2.23477e+01 1.00000e-09 2.12000e-01

$1.00000 \mathrm{e}-021.00000 \mathrm{e}-021.00000 \mathrm{e}-031.00000 \mathrm{e}-091.00000 \mathrm{e}-01$

$1.00000 \mathrm{e}+001.00000 \mathrm{e}+001.00000 \mathrm{e}-01$ 1.00000e-09 1.00000e-01

Element: 6866 \# of layers: 7

Kx Ky Kz Ss Por 
8.44733e+03 8.44733e+03 8.44733e+02 1.00000e-09 7.00000e-02 8.44733e+03 8.44733e+03 8.44733e+02 1.00000e-09 7.00000e-02 $3.37530 \mathrm{e}+02$ 3.37530e+02 3.37530e+01 1.00000e-09 2.12000e-01 $3.37530 \mathrm{e}+02$ 3.37530e+02 3.37530e+01 1.00000e-09 2.12000e-01 $3.37530 \mathrm{e}+023.37530 \mathrm{e}+023.37530 \mathrm{e}+01$ 1.00000e-09 2.12000e-01 $1.00000 \mathrm{e}-02$ 1.00000e-02 1.00000e-03 1.00000e-09 1.00000e-01 $1.00000 \mathrm{e}+001.00000 \mathrm{e}+001.00000 \mathrm{e}-01$ 1.00000e-09 1.00000e-01

Element: 6867 \# of layers: 6

$\mathrm{Kx} \mathrm{Ky} \mathrm{Kz}$ Ss Por

8.44733e+03 8.44733e+03 8.44733e+02 1.00000e-09 7.00000e-02 8.44733e+03 8.44733e+03 8.44733e+02 1.00000e-09 7.00000e-02 $3.37530 \mathrm{e}+02$ 3.37530e+02 3.37530e+01 1.00000e-09 2.12000e-01 $3.37530 \mathrm{e}+023.37530 \mathrm{e}+023.37530 \mathrm{e}+01$ 1.00000e-09 2.12000e-01 $1.00000 \mathrm{e}-02$ 1.00000e-02 1.00000e-03 1.00000e-09 1.00000e-01 $1.00000 \mathrm{e}+001.00000 \mathrm{e}+001.00000 \mathrm{e}-01$ 1.00000e-09 1.00000e-01 Element: 6868 \# of layers: 5

$\mathrm{Kx} \mathrm{Ky} \mathrm{Kz}$ Ss Por

8.44733e+03 8.44733e+03 8.44733e+02 1.00000e-09 7.00000e-02 $3.37530 \mathrm{e}+023.37530 \mathrm{e}+023.37530 \mathrm{e}+01$ 1.00000e-09 2.12000e-01 $3.37530 \mathrm{e}+02$ 3.37530e+02 3.37530e+01 1.00000e-09 2.12000e-01 $1.00000 \mathrm{e}-02$ 1.00000e-02 1.00000e-03 1.00000e-09 1.00000e-01 $1.00000 \mathrm{e}+001.00000 \mathrm{e}+001.00000 \mathrm{e}-01$ 1.00000e-09 1.00000e-01 Element: 6869 \# of layers: 5

Kx Ky Kz Ss Por

8.44733e+03 8.44733e+03 8.44733e+02 1.00000e-09 7.00000e-02 $3.37530 \mathrm{e}+023.37530 \mathrm{e}+02$ 3.37530e+01 1.00000e-09 2.12000e-01 $3.37530 \mathrm{e}+023.37530 \mathrm{e}+023.37530 \mathrm{e}+01$ 1.00000e-09 2.12000e-01 $1.00000 \mathrm{e}-02$ 1.00000e-02 1.00000e-03 1.00000e-09 1.00000e-01 $1.00000 \mathrm{e}+001.00000 \mathrm{e}+001.00000 \mathrm{e}-011.00000 \mathrm{e}-091.00000 \mathrm{e}-01$ Element: 6870 \# of layers: 6

$\mathrm{Kx} \mathrm{Ky} \mathrm{Kz}$ Ss Por

8.44733e+03 8.44733e+03 8.44733e+02 1.00000e-09 7.00000e-02 $3.37530 \mathrm{e}+023.37530 \mathrm{e}+02$ 3.37530e+01 1.00000e-09 2.12000e-01 $3.37530 \mathrm{e}+02$ 3.37530e+02 3.37530e+01 1.00000e-09 2.12000e-01 $3.37530 \mathrm{e}+02$ 3.37530e+02 3.37530e+01 1.00000e-09 2.12000e-01 $1.00000 \mathrm{e}-02$ 1.00000e-02 1.00000e-03 1.00000e-09 1.00000e-01 $1.00000 \mathrm{e}+001.00000 \mathrm{e}+001.00000 \mathrm{e}-011.00000 \mathrm{e}-091.00000 \mathrm{e}-01$ Element: 6871 \# of layers: 6

$\mathrm{Kx} \mathrm{Ky} \mathrm{Kz}$ Ss Por

8.44733e+03 8.44733e+03 8.44733e+02 1.00000e-09 7.00000e-02 $3.37530 \mathrm{e}+023.37530 \mathrm{e}+023.37530 \mathrm{e}+01$ 1.00000e-09 2.12000e-01 $3.37530 \mathrm{e}+023.37530 \mathrm{e}+023.37530 \mathrm{e}+01$ 1.00000e-09 2.12000e-01 $3.37530 \mathrm{e}+02$ 3.37530e+02 3.37530e+01 1.00000e-09 2.12000e-01 $1.00000 \mathrm{e}-02$ 1.00000e-02 1.00000e-03 1.00000e-09 1.00000e-01 $1.00000 \mathrm{e}+001.00000 \mathrm{e}+001.00000 \mathrm{e}-01$ 1.00000e-09 1.00000e-01 Element: 6872 \# of layers: 6 
Kx Ky Kz Ss Por

8.44733e+03 8.44733e+03 8.44733e+02 1.00000e-09 7.00000e-02

$3.37530 \mathrm{e}+02$ 3.37530e+02 3.37530e+01 1.00000e-09 2.12000e-01

$3.37530 \mathrm{e}+02$ 3.37530e+02 3.37530e+01 1.00000e-09 2.12000e-01

$3.37530 \mathrm{e}+023.37530 \mathrm{e}+02$ 3.37530e+01 1.00000e-09 2.12000e-01

$1.00000 \mathrm{e}-02$ 1.00000e-02 1.00000e-03 1.00000e-09 1.00000e-01

$1.00000 \mathrm{e}+001.00000 \mathrm{e}+001.00000 \mathrm{e}-01$ 1.00000e-09 1.00000e-01

Element: 6873 \# of layers: 6

$\mathrm{Kx} \mathrm{Ky} \mathrm{Kz}$ Ss Por

8.44733e+03 8.44733e+03 8.44733e+02 1.00000e-09 7.00000e-02

$3.37530 \mathrm{e}+02$ 3.37530e+02 3.37530e+01 1.00000e-09 2.12000e-01

$3.37530 \mathrm{e}+023.37530 \mathrm{e}+023.37530 \mathrm{e}+01$ 1.00000e-09 2.12000e-01

$3.37530 \mathrm{e}+02$ 3.37530e+02 3.37530e+01 1.00000e-09 2.12000e-01

$1.00000 \mathrm{e}-02$ 1.00000e-02 1.00000e-03 1.00000e-09 1.00000e-01

$1.00000 \mathrm{e}+001.00000 \mathrm{e}+001.00000 \mathrm{e}-01$ 1.00000e-09 1.00000e-01

Element: 6874 \# of layers: 6

$\mathrm{Kx} \mathrm{Ky} \mathrm{Kz}$ Ss Por

8.44733e+03 8.44733e+03 8.44733e+02 1.00000e-09 7.00000e-02

$3.37530 \mathrm{e}+023.37530 \mathrm{e}+023.37530 \mathrm{e}+01$ 1.00000e-09 2.12000e-01

$3.37530 \mathrm{e}+02$ 3.37530e+02 3.37530e+01 1.00000e-09 2.12000e-01

$3.37530 \mathrm{e}+023.37530 \mathrm{e}+02$ 3.37530e+01 1.00000e-09 2.12000e-01

$1.00000 \mathrm{e}-02$ 1.00000e-02 1.00000e-03 1.00000e-09 1.00000e-01

$1.00000 \mathrm{e}+001.00000 \mathrm{e}+001.00000 \mathrm{e}-01$ 1.00000e-09 1.00000e-01

Element: 6875 \# of layers: 5

$\mathrm{Kx} \mathrm{Ky} \mathrm{Kz}$ Ss Por

9.19290e+03 9.19290e+03 9.19290e+02 1.00000e-09 7.00000e-02

$3.67298 \mathrm{e}+02$ 3.67298e+02 3.67298e+01 1.00000e-09 2.12000e-01

$3.67298 \mathrm{e}+02$ 3.67298e+02 3.67298e+01 1.00000e-09 2.12000e-01

$1.00000 \mathrm{e}-02$ 1.00000e-02 1.00000e-03 1.00000e-09 1.00000e-01

$1.00000 \mathrm{e}+001.00000 \mathrm{e}+001.00000 \mathrm{e}-011.00000 \mathrm{e}-091.00000 \mathrm{e}-01$

Element: 6876 \# of layers: 5

$\mathrm{Kx} \mathrm{Ky} \mathrm{Kz}$ Ss Por

9.19290e+03 9.19290e+03 9.19290e+02 1.00000e-09 7.00000e-02

$3.67298 \mathrm{e}+02$ 3.67298e+02 3.67298e+01 1.00000e-09 2.12000e-01

$3.67298 \mathrm{e}+02$ 3.67298e+02 3.67298e+01 1.00000e-09 2.12000e-01

$1.00000 \mathrm{e}-02$ 1.00000e-02 1.00000e-03 1.00000e-09 1.00000e-01

$1.00000 \mathrm{e}+001.00000 \mathrm{e}+001.00000 \mathrm{e}-011.00000 \mathrm{e}-091.00000 \mathrm{e}-01$

Element: 6877 \# of layers: 5

$\mathrm{Kx} \mathrm{Ky} \mathrm{Kz}$ Ss Por

9.19290e+03 9.19290e+03 9.19290e+02 1.00000e-09 7.00000e-02

$3.67298 \mathrm{e}+023.67298 \mathrm{e}+02$ 3.67298e+01 1.00000e-09 2.12000e-01

$3.67298 \mathrm{e}+02$ 3.67298e+02 3.67298e+01 1.00000e-09 2.12000e-01

$1.00000 \mathrm{e}-02$ 1.00000e-02 1.00000e-03 1.00000e-09 1.00000e-01

$1.00000 \mathrm{e}+001.00000 \mathrm{e}+001.00000 \mathrm{e}-01$ 1.00000e-09 1.00000e-01

Element: 6878 \# of layers: 5

Kx Ky Kz Ss Por 
9.19290e+03 9.19290e+03 9.19290e+02 1.00000e-09 7.00000e-02 $3.67298 \mathrm{e}+02$ 3.67298e+02 3.67298e+01 1.00000e-09 2.12000e-01

$3.67298 \mathrm{e}+02$ 3.67298e+02 3.67298e+01 1.00000e-09 2.12000e-01

$1.00000 \mathrm{e}-02$ 1.00000e-02 1.00000e-03 1.00000e-09 1.00000e-01

$1.00000 \mathrm{e}+001.00000 \mathrm{e}+001.00000 \mathrm{e}-01$ 1.00000e-09 1.00000e-01

Element: 6879 \# of layers: 5

$\mathrm{Kx} \mathrm{Ky} \mathrm{Kz}$ Ss Por

9.19290e+03 9.19290e+03 9.19290e+02 1.00000e-09 7.00000e-02

$3.67298 \mathrm{e}+02$ 3.67298e+02 3.67298e+01 1.00000e-09 2.12000e-01

$3.67298 \mathrm{e}+02$ 3.67298e+02 3.67298e+01 1.00000e-09 2.12000e-01

$1.00000 \mathrm{e}-02$ 1.00000e-02 1.00000e-03 1.00000e-09 1.00000e-01

$1.00000 \mathrm{e}+001.00000 \mathrm{e}+001.00000 \mathrm{e}-011.00000 \mathrm{e}-091.00000 \mathrm{e}-01$

Element: 6880 \# of layers: 5

$\mathrm{Kx} \mathrm{Ky} \mathrm{Kz}$ Ss Por

9.19290e+03 9.19290e+03 9.19290e+02 1.00000e-09 7.00000e-02

$3.67298 \mathrm{e}+023.67298 \mathrm{e}+02$ 3.67298e+01 1.00000e-09 2.12000e-01

$3.67298 \mathrm{e}+023.67298 \mathrm{e}+02$ 3.67298e+01 1.00000e-09 2.12000e-01

$1.00000 \mathrm{e}-02$ 1.00000e-02 1.00000e-03 1.00000e-09 1.00000e-01

$1.00000 \mathrm{e}+001.00000 \mathrm{e}+001.00000 \mathrm{e}-011.00000 \mathrm{e}-091.00000 \mathrm{e}-01$

Element: 6881 \# of layers: 6

$\mathrm{Kx} \mathrm{Ky} \mathrm{Kz}$ Ss Por

9.19290e+03 9.19290e+03 9.19290e+02 1.00000e-09 7.00000e-02

$3.67298 \mathrm{e}+02$ 3.67298e+02 3.67298e+01 1.00000e-09 2.12000e-01

$3.67298 \mathrm{e}+02$ 3.67298e+02 3.67298e+01 1.00000e-09 2.12000e-01

$3.67298 \mathrm{e}+02$ 3.67298e+02 3.67298e+01 1.00000e-09 2.12000e-01

$1.00000 \mathrm{e}-02$ 1.00000e-02 1.00000e-03 1.00000e-09 1.00000e-01

$1.00000 \mathrm{e}+001.00000 \mathrm{e}+001.00000 \mathrm{e}-01$ 1.00000e-09 1.00000e-01

Element: 6882 \# of layers: 5

$\mathrm{Kx} \mathrm{Ky} \mathrm{Kz}$ Ss Por

9.19290e+03 9.19290e+03 9.19290e+02 1.00000e-09 7.00000e-02

$3.67298 \mathrm{e}+02$ 3.67298e+02 3.67298e+01 1.00000e-09 2.12000e-01

$3.67298 \mathrm{e}+02$ 3.67298e+02 3.67298e+01 1.00000e-09 2.12000e-01

$1.00000 \mathrm{e}-02$ 1.00000e-02 1.00000e-03 1.00000e-09 1.00000e-01

$1.00000 \mathrm{e}+001.00000 \mathrm{e}+001.00000 \mathrm{e}-011.00000 \mathrm{e}-091.00000 \mathrm{e}-01$

Element: 6883 \# of layers: 5

Kx Ky Kz Ss Por

9.19290e+03 9.19290e+03 9.19290e+02 1.00000e-09 7.00000e-02

$3.67298 \mathrm{e}+023.67298 \mathrm{e}+023.67298 \mathrm{e}+01$ 1.00000e-09 2.12000e-01

$3.67298 \mathrm{e}+02$ 3.67298e+02 3.67298e+01 1.00000e-09 2.12000e-01

$1.00000 \mathrm{e}-02$ 1.00000e-02 1.00000e-03 1.00000e-09 1.00000e-01

$1.00000 \mathrm{e}+001.00000 \mathrm{e}+001.00000 \mathrm{e}-011.00000 \mathrm{e}-091.00000 \mathrm{e}-01$

Element: 6884 \# of layers: 5

$\mathrm{Kx} \mathrm{Ky} \mathrm{Kz}$ Ss Por

1.05633e+04 1.05633e+04 1.05633e+03 1.00000e-09 7.00000e-02

4.22086e+02 4.22086e+02 4.22086e+01 1.00000e-09 2.12000e-01

$4.22086 \mathrm{e}+02$ 4.22086e+02 4.22086e+01 1.00000e-09 2.12000e-01 
$1.00000 \mathrm{e}-02$ 1.00000e-02 1.00000e-03 1.00000e-09 1.00000e-01 $1.00000 \mathrm{e}+001.00000 \mathrm{e}+001.00000 \mathrm{e}-01$ 1.00000e-09 1.00000e-01 Element: 6885 \# of layers: 5

Kx Ky Kz Ss Por

$1.05633 \mathrm{e}+041.05633 \mathrm{e}+04$ 1.05633e+03 1.00000e-09 7.00000e-02 $4.22086 \mathrm{e}+024.22086 \mathrm{e}+02$ 4.22086e+01 1.00000e-09 2.12000e-01

$4.22086 \mathrm{e}+02$ 4.22086e+02 4.22086e+01 1.00000e-09 2.12000e-01 $1.00000 \mathrm{e}-021.00000 \mathrm{e}-02$ 1.00000e-03 1.00000e-09 1.00000e-01 $1.00000 \mathrm{e}+001.00000 \mathrm{e}+001.00000 \mathrm{e}-011.00000 \mathrm{e}-091.00000 \mathrm{e}-01$ Element: 6886 \# of layers: 5

$\mathrm{Kx} \mathrm{Ky} \mathrm{Kz}$ Ss Por

$1.05633 \mathrm{e}+04$ 1.05633e+04 1.05633e+03 1.00000e-09 7.00000e-02 4.22086e+02 4.22086e+02 4.22086e+01 1.00000e-09 2.12000e-01 4.22086e+02 4.22086e+02 4.22086e+01 1.00000e-09 2.12000e-01 $1.00000 \mathrm{e}-02$ 1.00000e-02 1.00000e-03 1.00000e-09 1.00000e-01 $1.00000 \mathrm{e}+001.00000 \mathrm{e}+001.00000 \mathrm{e}-011.00000 \mathrm{e}-091.00000 \mathrm{e}-01$ Element: 6887 \# of layers: 5

$\mathrm{Kx} \mathrm{Ky} \mathrm{Kz}$ Ss Por

$1.05633 \mathrm{e}+04$ 1.05633e+04 1.05633e+03 1.00000e-09 7.00000e-02 $4.22086 \mathrm{e}+02$ 4.22086e+02 4.22086e+01 1.00000e-09 2.12000e-01 $4.22086 \mathrm{e}+02$ 4.22086e+02 4.22086e+01 1.00000e-09 2.12000e-01 $1.00000 \mathrm{e}-021.00000 \mathrm{e}-021.00000 \mathrm{e}-031.00000 \mathrm{e}-091.00000 \mathrm{e}-01$ $1.00000 \mathrm{e}+001.00000 \mathrm{e}+001.00000 \mathrm{e}-01$ 1.00000e-09 1.00000e-01 Element: 6888 \# of layers: 5

Kx Ky Kz Ss Por $1.05633 \mathrm{e}+041.05633 \mathrm{e}+04$ 1.05633e+03 1.00000e-09 7.00000e-02 $4.22086 \mathrm{e}+02$ 4.22086e+02 4.22086e+01 1.00000e-09 2.12000e-01 $4.22086 \mathrm{e}+024.22086 \mathrm{e}+024.22086 \mathrm{e}+01$ 1.00000e-09 2.12000e-01 $1.00000 \mathrm{e}-02$ 1.00000e-02 1.00000e-03 1.00000e-09 1.00000e-01 $1.00000 \mathrm{e}+001.00000 \mathrm{e}+001.00000 \mathrm{e}-011.00000 \mathrm{e}-091.00000 \mathrm{e}-01$ Element: 6889 \# of layers: 5

Kx Ky Kz Ss Por

$1.05633 \mathrm{e}+04$ 1.05633e+04 1.05633e+03 1.00000e-09 7.00000e-02 $4.22086 \mathrm{e}+02$ 4.22086e+02 4.22086e+01 1.00000e-09 2.12000e-01 $4.22086 \mathrm{e}+02$ 4.22086e+02 4.22086e+01 1.00000e-09 2.12000e-01 $1.00000 \mathrm{e}-02$ 1.00000e-02 1.00000e-03 1.00000e-09 1.00000e-01 $1.00000 \mathrm{e}+001.00000 \mathrm{e}+001.00000 \mathrm{e}-011.00000 \mathrm{e}-091.00000 \mathrm{e}-01$ Element: 6890 \# of layers: 5

$\mathrm{Kx} \mathrm{Ky} \mathrm{Kz}$ Ss Por

$1.05633 \mathrm{e}+04$ 1.05633e+04 1.05633e+03 1.00000e-09 7.00000e-02 $4.22086 \mathrm{e}+024.22086 \mathrm{e}+024.22086 \mathrm{e}+01$ 1.00000e-09 2.12000e-01 $4.22086 \mathrm{e}+024.22086 \mathrm{e}+024.22086 \mathrm{e}+01$ 1.00000e-09 2.12000e-01 $1.00000 \mathrm{e}-02$ 1.00000e-02 1.00000e-03 1.00000e-09 1.00000e-01 $1.00000 \mathrm{e}+001.00000 \mathrm{e}+001.00000 \mathrm{e}-01$ 1.00000e-09 1.00000e-01 Element: 6891 \# of layers: 5

Kx Ky Kz Ss Por 
$1.05633 \mathrm{e}+04$ 1.05633e+04 1.05633e+03 1.00000e-09 7.00000e-02 4.22086e+02 4.22086e+02 4.22086e+01 1.00000e-09 2.12000e-01

4.22086e+02 4.22086e+02 4.22086e+01 1.00000e-09 2.12000e-01 $1.00000 \mathrm{e}-02$ 1.00000e-02 1.00000e-03 1.00000e-09 1.00000e-01 $1.00000 \mathrm{e}+001.00000 \mathrm{e}+001.00000 \mathrm{e}-01$ 1.00000e-09 1.00000e-01 Element: 6892 \# of layers: 5

$\mathrm{Kx} \mathrm{Ky} \mathrm{Kz}$ Ss Por

$1.05633 \mathrm{e}+04$ 1.05633e+04 1.05633e+03 1.00000e-09 7.00000e-02 $4.22086 \mathrm{e}+02$ 4.22086e+02 4.22086e+01 1.00000e-09 2.12000e-01 $4.22086 \mathrm{e}+02$ 4.22086e+02 4.22086e+01 1.00000e-09 2.12000e-01 $1.00000 \mathrm{e}-02$ 1.00000e-02 1.00000e-03 1.00000e-09 1.00000e-01 $1.00000 \mathrm{e}+001.00000 \mathrm{e}+001.00000 \mathrm{e}-011.00000 \mathrm{e}-091.00000 \mathrm{e}-01$ Element: 6893 \# of layers: 4

$\mathrm{Kx} \mathrm{Ky} \mathrm{Kz}$ Ss Por

1.17959e+04 1.17959e+04 1.17959e+03 1.00000e-09 7.00000e-02 $4.71318 \mathrm{e}+02$ 4.71318e+02 4.71318e+01 1.00000e-09 2.12000e-01 $1.00000 \mathrm{e}-02$ 1.00000e-02 1.00000e-03 1.00000e-09 1.00000e-01 $1.00000 \mathrm{e}+001.00000 \mathrm{e}+001.00000 \mathrm{e}-01$ 1.00000e-09 1.00000e-01 Element: 6894 \# of layers: 4

$\mathrm{Kx} \mathrm{Ky} \mathrm{Kz}$ Ss Por

1.17959e+04 1.17959e+04 1.17959e+03 1.00000e-09 7.00000e-02 4.71318e+02 4.71318e+02 4.71318e+01 1.00000e-09 2.12000e-01 $1.00000 \mathrm{e}-02$ 1.00000e-02 1.00000e-03 1.00000e-09 1.00000e-01 $1.00000 \mathrm{e}+001.00000 \mathrm{e}+001.00000 \mathrm{e}-011.00000 \mathrm{e}-091.00000 \mathrm{e}-01$

Element: 6895 \# of layers: 4

$\mathrm{Kx} \mathrm{Ky} \mathrm{Kz}$ Ss Por

1.17959e+04 1.17959e+04 1.17959e+03 1.00000e-09 7.00000e-02 4.71318e+02 4.71318e+02 4.71318e+01 1.00000e-09 2.12000e-01 $1.00000 \mathrm{e}-02$ 1.00000e-02 1.00000e-03 1.00000e-09 1.00000e-01 $1.00000 \mathrm{e}+001.00000 \mathrm{e}+001.00000 \mathrm{e}-011.00000 \mathrm{e}-091.00000 \mathrm{e}-01$ Element: 6896 \# of layers: 4

Kx Ky Kz Ss Por

1.17959e+04 1.17959e+04 1.17959e+03 1.00000e-09 7.00000e-02 4.71318e+02 4.71318e+02 4.71318e+01 1.00000e-09 2.12000e-01 $1.00000 \mathrm{e}-02$ 1.00000e-02 1.00000e-03 1.00000e-09 1.00000e-01 $1.00000 \mathrm{e}+001.00000 \mathrm{e}+001.00000 \mathrm{e}-011.00000 \mathrm{e}-091.00000 \mathrm{e}-01$ Element: 6897 \# of layers: 4

$\mathrm{Kx} \mathrm{Ky} \mathrm{Kz}$ Ss Por

1.17959e+04 1.17959e+04 1.17959e+03 1.00000e-09 7.00000e-02 $4.71318 \mathrm{e}+02$ 4.71318e+02 4.71318e+01 1.00000e-09 2.12000e-01 $1.00000 \mathrm{e}-02$ 1.00000e-02 1.00000e-03 1.00000e-09 1.00000e-01 $1.00000 \mathrm{e}+001.00000 \mathrm{e}+001.00000 \mathrm{e}-011.00000 \mathrm{e}-091.00000 \mathrm{e}-01$ Element: 6898 \# of layers: 5

$\mathrm{Kx} \mathrm{Ky} \mathrm{Kz}$ Ss Por

$1.17959 \mathrm{e}+04$ 1.17959e+04 1.17959e+03 1.00000e-09 7.00000e-02 4.71318e+02 4.71318e+02 4.71318e+01 1.00000e-09 2.12000e-01 
$4.71318 \mathrm{e}+02$ 4.71318e +02 4.71318e+01 1.00000e-09 2.12000e-01 $1.00000 \mathrm{e}-02$ 1.00000e-02 1.00000e-03 1.00000e-09 1.00000e-01 $1.00000 \mathrm{e}+001.00000 \mathrm{e}+001.00000 \mathrm{e}-011.00000 \mathrm{e}-091.00000 \mathrm{e}-01$

Element: 6899 \# of layers: 5

$\mathrm{Kx} \mathrm{Ky} \mathrm{Kz}$ Ss Por

1.17959e+04 1.17959e+04 1.17959e+03 1.00000e-09 7.00000e-02

4.71318e+02 4.71318e+02 4.71318e+01 1.00000e-09 2.12000e-01

$4.71318 \mathrm{e}+02$ 4.71318e+02 4.71318e+01 1.00000e-09 2.12000e-01

$1.00000 \mathrm{e}-02$ 1.00000e-02 1.00000e-03 1.00000e-09 1.00000e-01

$1.00000 \mathrm{e}+001.00000 \mathrm{e}+001.00000 \mathrm{e}-011.00000 \mathrm{e}-091.00000 \mathrm{e}-01$

Element: 6900 \# of layers: 5

Kx Ky Kz Ss Por

1.17959e+04 1.17959e+04 1.17959e+03 1.00000e-09 7.00000e-02

4.71318e+02 4.71318e+02 4.71318e+01 1.00000e-09 2.12000e-01

4.71318e+02 4.71318e+02 4.71318e+01 1.00000e-09 2.12000e-01

$1.00000 \mathrm{e}-02$ 1.00000e-02 1.00000e-03 1.00000e-09 1.00000e-01

$1.00000 \mathrm{e}+001.00000 \mathrm{e}+001.00000 \mathrm{e}-011.00000 \mathrm{e}-091.00000 \mathrm{e}-01$

Element: 6901 \# of layers: 4

$\mathrm{Kx} \mathrm{Ky} \mathrm{Kz}$ Ss Por

1.17959e+04 1.17959e+04 1.17959e+03 1.00000e-09 7.00000e-02

4.71318e+02 4.71318e+02 4.71318e+01 1.00000e-09 2.12000e-01

$1.00000 \mathrm{e}-021.00000 \mathrm{e}-021.00000 \mathrm{e}-031.00000 \mathrm{e}-091.00000 \mathrm{e}-01$

$1.00000 \mathrm{e}+001.00000 \mathrm{e}+001.00000 \mathrm{e}-01$ 1.00000e-09 1.00000e-01

Element: 6902 \# of layers: 4

Kx Ky Kz Ss Por

$1.70073 \mathrm{e}+04$ 1.70073e+04 1.70073e+03 1.00000e-09 7.00000e-02

6.79559e+02 6.79559e+02 6.79559e+01 1.00000e-09 2.12000e-01

$1.00000 \mathrm{e}-02$ 1.00000e-02 1.00000e-03 1.00000e-09 1.00000e-01

$1.00000 \mathrm{e}+001.00000 \mathrm{e}+001.00000 \mathrm{e}-011.00000 \mathrm{e}-091.00000 \mathrm{e}-01$

Element: 6903 \# of layers: 4

$\mathrm{Kx} \mathrm{Ky} \mathrm{Kz}$ Ss Por

$1.70073 \mathrm{e}+04$ 1.70073e+04 1.70073e+03 1.00000e-09 7.00000e-02

6.79559e+02 6.79559e+02 6.79559e+01 1.00000e-09 2.12000e-01

$1.00000 \mathrm{e}-021.00000 \mathrm{e}-021.00000 \mathrm{e}-031.00000 \mathrm{e}-091.00000 \mathrm{e}-01$

$1.00000 \mathrm{e}+001.00000 \mathrm{e}+001.00000 \mathrm{e}-01$ 1.00000e-09 1.00000e-01

Element: 6904 \# of layers: 4

Kx Ky Kz Ss Por

$1.70073 \mathrm{e}+04$ 1.70073e+04 1.70073e+03 1.00000e-09 7.00000e-02

6.79559e+02 6.79559e+02 6.79559e+01 1.00000e-09 2.12000e-01

$1.00000 \mathrm{e}-02$ 1.00000e-02 1.00000e-03 1.00000e-09 1.00000e-01

$1.00000 \mathrm{e}+001.00000 \mathrm{e}+001.00000 \mathrm{e}-011.00000 \mathrm{e}-091.00000 \mathrm{e}-01$

Element: 6905 \# of layers: 4

$\mathrm{Kx} \mathrm{Ky} \mathrm{Kz}$ Ss Por

1.70073e+04 1.70073e+04 1.70073e+03 1.00000e-09 7.00000e-02

6.79559e+02 6.79559e+02 6.79559e+01 1.00000e-09 2.12000e-01

$1.00000 \mathrm{e}-02$ 1.00000e-02 1.00000e-03 1.00000e-09 1.00000e-01 
$1.00000 \mathrm{e}+001.00000 \mathrm{e}+00$ 1.00000e-01 1.00000e-09 1.00000e-01

Element: 6906 \# of layers: 4

Kx Ky Kz Ss Por

$1.70073 e+04$ 1.70073e+04 1.70073e+03 1.00000e-09 7.00000e-02

6.79559e+02 6.79559e+02 6.79559e+01 1.00000e-09 2.12000e-01

$1.00000 \mathrm{e}-02$ 1.00000e-02 1.00000e-03 1.00000e-09 1.00000e-01

$1.00000 \mathrm{e}+001.00000 \mathrm{e}+001.00000 \mathrm{e}-01$ 1.00000e-09 1.00000e-01

Element: 6907 \# of layers: 4

$\mathrm{Kx} \mathrm{Ky} \mathrm{Kz}$ Ss Por

1.70073e+04 1.70073e+04 1.70073e+03 1.00000e-09 7.00000e-02

6.79559e+02 6.79559e+02 6.79559e+01 1.00000e-09 2.12000e-01

$1.00000 \mathrm{e}-02$ 1.00000e-02 1.00000e-03 1.00000e-09 1.00000e-01

$1.00000 \mathrm{e}+001.00000 \mathrm{e}+001.00000 \mathrm{e}-011.00000 \mathrm{e}-091.00000 \mathrm{e}-01$

Element: 6908 \# of layers: 4

$\mathrm{Kx} \mathrm{Ky} \mathrm{Kz}$ Ss Por

1.70073e+04 1.70073e+04 1.70073e+03 1.00000e-09 7.00000e-02

6.79559e+02 6.79559e+02 6.79559e+01 1.00000e-09 2.12000e-01

1.00000e-02 1.00000e-02 1.00000e-03 1.00000e-09 1.00000e-01

$1.00000 \mathrm{e}+001.00000 \mathrm{e}+001.00000 \mathrm{e}-011.00000 \mathrm{e}-091.00000 \mathrm{e}-01$

Element: 6909 \# of layers: 4

$\mathrm{Kx} \mathrm{Ky} \mathrm{Kz}$ Ss Por

1.70073e+04 1.70073e+04 1.70073e+03 1.00000e-09 7.00000e-02

6.79559e+02 6.79559e+02 6.79559e+01 1.00000e-09 2.12000e-01

$1.00000 \mathrm{e}-02$ 1.00000e-02 1.00000e-03 1.00000e-09 1.00000e-01

$1.00000 \mathrm{e}+001.00000 \mathrm{e}+001.00000 \mathrm{e}-011.00000 \mathrm{e}-091.00000 \mathrm{e}-01$

Element: 6910 \# of layers: 4

$\mathrm{Kx} \mathrm{Ky} \mathrm{Kz}$ Ss Por

1.70073e+04 1.70073e+04 1.70073e+03 1.00000e-09 7.00000e-02

$6.79559 \mathrm{e}+02$ 6.79559e+02 6.79559e+01 1.00000e-09 2.12000e-01

$1.00000 \mathrm{e}-02$ 1.00000e-02 1.00000e-03 1.00000e-09 1.00000e-01

$1.00000 \mathrm{e}+001.00000 \mathrm{e}+001.00000 \mathrm{e}-011.00000 \mathrm{e}-091.00000 \mathrm{e}-01$

Element: 6911 \# of layers: 4

Kx Ky Kz Ss Por

4.30192e+03 4.30192e+03 4.30192e+02 1.00000e-09 7.00000e-02

$1.71888 \mathrm{e}+02$ 1.71888e+02 1.71888e+01 1.00000e-09 2.12000e-01

$1.00000 \mathrm{e}-02$ 1.00000e-02 1.00000e-03 1.00000e-09 1.00000e-01

$1.00000 \mathrm{e}+001.00000 \mathrm{e}+001.00000 \mathrm{e}-011.00000 \mathrm{e}-091.00000 \mathrm{e}-01$

Element: 6912 \# of layers: 4

$\mathrm{Kx} \mathrm{Ky} \mathrm{Kz}$ Ss Por

4.30192e+03 4.30192e+03 4.30192e+02 1.00000e-09 7.00000e-02

$1.71888 \mathrm{e}+021.71888 \mathrm{e}+02$ 1.71888e+01 1.00000e-09 2.12000e-01

$1.00000 \mathrm{e}-02$ 1.00000e-02 1.00000e-03 1.00000e-09 1.00000e-01

$1.00000 \mathrm{e}+001.00000 \mathrm{e}+001.00000 \mathrm{e}-01$ 1.00000e-09 1.00000e-01

Element: 6913 \# of layers: 4

$\mathrm{Kx} \mathrm{Ky} \mathrm{Kz}$ Ss Por

4.30192e+03 4.30192e+03 4.30192e+02 1.00000e-09 7.00000e-02 
$1.71888 \mathrm{e}+021.71888 \mathrm{e}+02$ 1.71888e+01 1.00000e-09 2.12000e-01 $1.00000 \mathrm{e}-021.00000 \mathrm{e}-02$ 1.00000e-03 1.00000e-09 1.00000e-01

$1.00000 \mathrm{e}+001.00000 \mathrm{e}+001.00000 \mathrm{e}-011.00000 \mathrm{e}-091.00000 \mathrm{e}-01$

Element: 6914 \# of layers: 4

Kx Ky Kz Ss Por

4.30192e+03 4.30192e+03 4.30192e+02 1.00000e-09 7.00000e-02

$1.71888 \mathrm{e}+02$ 1.71888e+02 1.71888e+01 1.00000e-09 2.12000e-01

$1.00000 \mathrm{e}-021.00000 \mathrm{e}-02$ 1.00000e-03 1.00000e-09 1.00000e-01

$1.00000 \mathrm{e}+001.00000 \mathrm{e}+001.00000 \mathrm{e}-011.00000 \mathrm{e}-091.00000 \mathrm{e}-01$

Element: 6915 \# of layers: 4

Kx Ky Kz Ss Por

$4.30192 \mathrm{e}+03$ 4.30192e+03 4.30192e+02 1.00000e-09 7.00000e-02

$1.71888 \mathrm{e}+02 \quad 1.71888 \mathrm{e}+02 \quad 1.71888 \mathrm{e}+01$ 1.00000e-09 2.12000e-01

$1.00000 \mathrm{e}-021.00000 \mathrm{e}-02$ 1.00000e-03 1.00000e-09 1.00000e-01

$1.00000 \mathrm{e}+001.00000 \mathrm{e}+001.00000 \mathrm{e}-011.00000 \mathrm{e}-091.00000 \mathrm{e}-01$

Element: 6916 \# of layers: 4

Kx Ky Kz Ss Por

4.30192e+03 4.30192e+03 4.30192e+02 1.00000e-09 7.00000e-02

$1.71888 \mathrm{e}+02$ 1.71888e+02 1.71888e+01 1.00000e-09 2.12000e-01

$1.00000 \mathrm{e}-021.00000 \mathrm{e}-02$ 1.00000e-03 1.00000e-09 1.00000e-01

$1.00000 \mathrm{e}+001.00000 \mathrm{e}+001.00000 \mathrm{e}-011.00000 \mathrm{e}-091.00000 \mathrm{e}-01$

Element: 6917 \# of layers: 4

Kx Ky Kz Ss Por

4.30192e+03 4.30192e+03 4.30192e+02 1.00000e-09 7.00000e-02

$1.71888 \mathrm{e}+02$ 1.71888e+02 1.71888e+01 1.00000e-09 2.12000e-01

$1.00000 \mathrm{e}-021.00000 \mathrm{e}-021.00000 \mathrm{e}-031.00000 \mathrm{e}-091.00000 \mathrm{e}-01$

$1.00000 \mathrm{e}+001.00000 \mathrm{e}+001.00000 \mathrm{e}-011.00000 \mathrm{e}-091.00000 \mathrm{e}-01$

Element: 6918 \# of layers: 4

Kx Ky Kz Ss Por

4.30192e+03 4.30192e+03 4.30192e+02 1.00000e-09 7.00000e-02

$1.71888 \mathrm{e}+02 \quad 1.71888 \mathrm{e}+021.71888 \mathrm{e}+01$ 1.00000e-09 2.12000e-01

$1.00000 \mathrm{e}-02$ 1.00000e-02 1.00000e-03 1.00000e-09 1.00000e-01

$1.00000 \mathrm{e}+001.00000 \mathrm{e}+00$ 1.00000e-01 1.00000e-09 1.00000e-01

Element: 6919 \# of layers: 4

Kx Ky Kz Ss Por

4.30192e+03 4.30192e+03 4.30192e+02 1.00000e-09 7.00000e-02

$1.71888 \mathrm{e}+02$ 1.71888e+02 1.71888e+01 1.00000e-09 2.12000e-01

$1.00000 \mathrm{e}-021.00000 \mathrm{e}-02$ 1.00000e-03 1.00000e-09 1.00000e-01

$1.00000 \mathrm{e}+001.00000 \mathrm{e}+001.00000 \mathrm{e}-011.00000 \mathrm{e}-091.00000 \mathrm{e}-01$

Element: 6920 \# of layers: 4

Kx Ky Kz Ss Por

$8.77223 \mathrm{e}+02$ 8.77223e+02 8.77223e+01 1.00000e-09 7.00000e-02

$3.50513 \mathrm{e}+013.50513 \mathrm{e}+013.50513 \mathrm{e}+00$ 1.00000e-09 2.12000e-01

$1.00000 \mathrm{e}-021.00000 \mathrm{e}-02$ 1.00000e-03 1.00000e-09 1.00000e-01

$1.00000 \mathrm{e}+001.00000 \mathrm{e}+001.00000 \mathrm{e}-011.00000 \mathrm{e}-091.00000 \mathrm{e}-01$

Element: 6921 \# of layers: 5 
Kx Ky Kz Ss Por

8.77223e+02 8.77223e+02 8.77223e+01 1.00000e-09 7.00000e-02

$3.50513 \mathrm{e}+013.50513 \mathrm{e}+013.50513 \mathrm{e}+00$ 1.00000e-09 2.12000e-01

$3.50513 \mathrm{e}+013.50513 \mathrm{e}+013.50513 \mathrm{e}+001.00000 \mathrm{e}-092.12000 \mathrm{e}-01$

$1.00000 \mathrm{e}-02$ 1.00000e-02 1.00000e-03 1.00000e-09 1.00000e-01

$1.00000 \mathrm{e}+001.00000 \mathrm{e}+001.00000 \mathrm{e}-011.00000 \mathrm{e}-091.00000 \mathrm{e}-01$

Element: 6922 \# of layers: 5

$\mathrm{Kx} \mathrm{Ky} \mathrm{Kz}$ Ss Por

8.77223e+02 8.77223e+02 8.77223e+01 1.00000e-09 7.00000e-02

$3.50513 \mathrm{e}+013.50513 \mathrm{e}+013.50513 \mathrm{e}+001.00000 \mathrm{e}-092.12000 \mathrm{e}-01$

$3.50513 \mathrm{e}+013.50513 \mathrm{e}+013.50513 \mathrm{e}+00$ 1.00000e-09 2.12000e-01

$1.00000 \mathrm{e}-02$ 1.00000e-02 1.00000e-03 1.00000e-09 1.00000e-01

$1.00000 \mathrm{e}+001.00000 \mathrm{e}+001.00000 \mathrm{e}-011.00000 \mathrm{e}-091.00000 \mathrm{e}-01$

Element: 6923 \# of layers: 5

$\mathrm{Kx} \mathrm{Ky} \mathrm{Kz}$ Ss Por

8.77223e+02 8.77223e+02 8.77223e+01 1.00000e-09 7.00000e-02

$3.50513 \mathrm{e}+013.50513 \mathrm{e}+013.50513 \mathrm{e}+00$ 1.00000e-09 2.12000e-01

$3.50513 \mathrm{e}+013.50513 \mathrm{e}+013.50513 \mathrm{e}+00$ 1.00000e-09 2.12000e-01

$1.00000 \mathrm{e}-02$ 1.00000e-02 1.00000e-03 1.00000e-09 1.00000e-01

$1.00000 \mathrm{e}+001.00000 \mathrm{e}+001.00000 \mathrm{e}-011.00000 \mathrm{e}-091.00000 \mathrm{e}-01$

Element: 6924 \# of layers: 4

$\mathrm{Kx} \mathrm{Ky} \mathrm{Kz}$ Ss Por

8.77223e+02 8.77223e+02 8.77223e+01 1.00000e-09 7.00000e-02

$3.50513 \mathrm{e}+013.50513 \mathrm{e}+013.50513 \mathrm{e}+001.00000 \mathrm{e}-092.12000 \mathrm{e}-01$

$1.00000 \mathrm{e}-02$ 1.00000e-02 1.00000e-03 1.00000e-09 1.00000e-01

$1.00000 \mathrm{e}+001.00000 \mathrm{e}+001.00000 \mathrm{e}-01$ 1.00000e-09 1.00000e-01

Element: 6925 \# of layers: 4

$\mathrm{Kx} \mathrm{Ky} \mathrm{Kz} \mathrm{Ss} \mathrm{Por}$

8.77223e+02 8.77223e+02 8.77223e+01 1.00000e-09 7.00000e-02

$3.50513 \mathrm{e}+013.50513 \mathrm{e}+013.50513 \mathrm{e}+00$ 1.00000e-09 2.12000e-01

$1.00000 \mathrm{e}-02$ 1.00000e-02 1.00000e-03 1.00000e-09 1.00000e-01

$1.00000 \mathrm{e}+001.00000 \mathrm{e}+001.00000 \mathrm{e}-011.00000 \mathrm{e}-091.00000 \mathrm{e}-01$

Element: 6926 \# of layers: 4

$\mathrm{Kx} \mathrm{Ky} \mathrm{Kz}$ Ss Por

8.77223e+02 8.77223e+02 8.77223e+01 1.00000e-09 7.00000e-02

$3.50513 \mathrm{e}+013.50513 \mathrm{e}+013.50513 \mathrm{e}+001.00000 \mathrm{e}-092.12000 \mathrm{e}-01$

$1.00000 \mathrm{e}-02$ 1.00000e-02 1.00000e-03 1.00000e-09 1.00000e-01

$1.00000 \mathrm{e}+001.00000 \mathrm{e}+001.00000 \mathrm{e}-011.00000 \mathrm{e}-091.00000 \mathrm{e}-01$

Element: 6927 \# of layers: 4

$\mathrm{Kx} \mathrm{Ky} \mathrm{Kz}$ Ss Por

8.77223e+02 8.77223e+02 8.77223e+01 1.00000e-09 7.00000e-02

$3.50513 \mathrm{e}+013.50513 \mathrm{e}+013.50513 \mathrm{e}+00$ 1.00000e-09 2.12000e-01

$1.00000 \mathrm{e}-02$ 1.00000e-02 1.00000e-03 1.00000e-09 1.00000e-01

$1.00000 \mathrm{e}+001.00000 \mathrm{e}+001.00000 \mathrm{e}-01$ 1.00000e-09 1.00000e-01

Element: 6928 \# of layers: 4

Kx Ky Kz Ss Por 
8.77223e+02 8.77223e+02 8.77223e+01 1.00000e-09 7.00000e-02 $3.50513 \mathrm{e}+013.50513 \mathrm{e}+013.50513 \mathrm{e}+00$ 1.00000e-09 2.12000e-01 $1.00000 \mathrm{e}-02$ 1.00000e-02 1.00000e-03 1.00000e-09 1.00000e-01 $1.00000 \mathrm{e}+001.00000 \mathrm{e}+001.00000 \mathrm{e}-011.00000 \mathrm{e}-091.00000 \mathrm{e}-01$ Element: 6929 \# of layers: 5

$\mathrm{Kx} \mathrm{Ky} \mathrm{Kz}$ Ss Por

$1.82714 \mathrm{e}+021.82714 \mathrm{e}+02$ 1.82714e+01 1.00000e-09 7.00000e-02

7.30073e+00 7.30073e+00 7.30073e-01 1.00000e-09 2.12000e-01

7.30073e+00 7.30073e+00 7.30073e-01 1.00000e-09 2.12000e-01

$1.00000 \mathrm{e}-02$ 1.00000e-02 1.00000e-03 1.00000e-09 1.00000e-01

$1.00000 \mathrm{e}+001.00000 \mathrm{e}+001.00000 \mathrm{e}-011.00000 \mathrm{e}-091.00000 \mathrm{e}-01$

Element: 6930 \# of layers: 5

Kx Ky Kz Ss Por

$1.82714 \mathrm{e}+021.82714 \mathrm{e}+02 \quad 1.82714 \mathrm{e}+01$ 1.00000e-09 7.00000e-02 7.30073e+00 7.30073e+00 7.30073e-01 1.00000e-09 2.12000e-01

7.30073e+00 7.30073e+00 7.30073e-01 1.00000e-09 2.12000e-01 $1.00000 \mathrm{e}-02$ 1.00000e-02 1.00000e-03 1.00000e-09 1.00000e-01 $1.00000 \mathrm{e}+001.00000 \mathrm{e}+001.00000 \mathrm{e}-011.00000 \mathrm{e}-091.00000 \mathrm{e}-01$ Element: 6931 \# of layers: 5

$\mathrm{Kx} \mathrm{Ky} \mathrm{Kz}$ Ss Por

$1.82714 \mathrm{e}+02$ 1.82714e+02 1.82714e+01 1.00000e-09 7.00000e-02 7.30073e+00 7.30073e+00 7.30073e-01 1.00000e-09 2.12000e-01 7.30073e+00 7.30073e+00 7.30073e-01 1.00000e-09 2.12000e-01 $1.00000 \mathrm{e}-02$ 1.00000e-02 1.00000e-03 1.00000e-09 1.00000e-01 $1.00000 \mathrm{e}+001.00000 \mathrm{e}+001.00000 \mathrm{e}-011.00000 \mathrm{e}-091.00000 \mathrm{e}-01$ Element: 6932 \# of layers: 5

$\mathrm{Kx} \mathrm{Ky} \mathrm{Kz}$ Ss Por

$1.82714 \mathrm{e}+02$ 1.82714e+02 1.82714e+01 1.00000e-09 7.00000e-02

7.30073e+00 7.30073e+00 7.30073e-01 1.00000e-09 2.12000e-01

7.30073e+00 7.30073e+00 7.30073e-01 1.00000e-09 2.12000e-01

$1.00000 \mathrm{e}-02$ 1.00000e-02 1.00000e-03 1.00000e-09 1.00000e-01

$1.00000 \mathrm{e}+001.00000 \mathrm{e}+001.00000 \mathrm{e}-011.00000 \mathrm{e}-091.00000 \mathrm{e}-01$

Element: 6933 \# of layers: 5

$\mathrm{Kx} \mathrm{Ky} \mathrm{Kz}$ Ss Por

$1.82714 \mathrm{e}+021.82714 \mathrm{e}+02 \quad 1.82714 \mathrm{e}+01$ 1.00000e-09 7.00000e-02 7.30073e+00 7.30073e+00 7.30073e-01 1.00000e-09 2.12000e-01 7.30073e+00 7.30073e+00 7.30073e-01 1.00000e-09 2.12000e-01 $1.00000 \mathrm{e}-02$ 1.00000e-02 1.00000e-03 1.00000e-09 1.00000e-01 $1.00000 \mathrm{e}+001.00000 \mathrm{e}+001.00000 \mathrm{e}-011.00000 \mathrm{e}-091.00000 \mathrm{e}-01$ Element: 6934 \# of layers: 5

$\mathrm{Kx} \mathrm{Ky} \mathrm{Kz}$ Ss Por

$1.82714 \mathrm{e}+02 \quad 1.82714 \mathrm{e}+02 \quad 1.82714 \mathrm{e}+01$ 1.00000e-09 7.00000e-02 7.30073e+00 7.30073e+00 7.30073e-01 1.00000e-09 2.12000e-01 7.30073e+00 7.30073e+00 7.30073e-01 1.00000e-09 2.12000e-01 1.00000e-02 1.00000e-02 1.00000e-03 1.00000e-09 1.00000e-01 $1.00000 \mathrm{e}+001.00000 \mathrm{e}+001.00000 \mathrm{e}-011.00000 \mathrm{e}-091.00000 \mathrm{e}-01$ 
Element: 6935 \# of layers: 4

$\mathrm{Kx} \mathrm{Ky} \mathrm{Kz}$ Ss Por

$1.82714 \mathrm{e}+02$ 1.82714e+02 1.82714e+01 1.00000e-09 7.00000e-02

7.30073e+00 7.30073e+00 7.30073e-01 1.00000e-09 2.12000e-01

$1.00000 \mathrm{e}-021.00000 \mathrm{e}-021.00000 \mathrm{e}-031.00000 \mathrm{e}-091.00000 \mathrm{e}-01$

$1.00000 \mathrm{e}+001.00000 \mathrm{e}+001.00000 \mathrm{e}-011.00000 \mathrm{e}-091.00000 \mathrm{e}-01$

Element: 6936 \# of layers: 5

$\mathrm{Kx} \mathrm{Ky} \mathrm{Kz}$ Ss Por

$1.82714 \mathrm{e}+021.82714 \mathrm{e}+02$ 1.82714e+01 1.00000e-09 7.00000e-02

7.30073e+00 7.30073e+00 7.30073e-01 1.00000e-09 2.12000e-01

7.30073e+00 7.30073e+00 7.30073e-01 1.00000e-09 2.12000e-01

$1.00000 \mathrm{e}-02$ 1.00000e-02 1.00000e-03 1.00000e-09 1.00000e-01

$1.00000 \mathrm{e}+001.00000 \mathrm{e}+001.00000 \mathrm{e}-01$ 1.00000e-09 1.00000e-01

Element: 6937 \# of layers: 5

$\mathrm{Kx} \mathrm{Ky} \mathrm{Kz}$ Ss Por

$1.82714 \mathrm{e}+021.82714 \mathrm{e}+02 \quad 1.82714 \mathrm{e}+01$ 1.00000e-09 7.00000e-02

7.30073e+00 7.30073e+00 7.30073e-01 1.00000e-09 2.12000e-01

7.30073e+00 7.30073e+00 7.30073e-01 1.00000e-09 2.12000e-01

$1.00000 \mathrm{e}-02$ 1.00000e-02 1.00000e-03 1.00000e-09 1.00000e-01

$1.00000 \mathrm{e}+001.00000 \mathrm{e}+001.00000 \mathrm{e}-011.00000 \mathrm{e}-091.00000 \mathrm{e}-01$

Element: 6938 \# of layers: 5

$\mathrm{Kx} \mathrm{Ky} \mathrm{Kz}$ Ss Por

1.75668e+02 1.75668e+02 1.75668e+01 1.00000e-09 7.00000e-02

7.01902e+00 7.01902e+00 7.01902e-01 1.00000e-09 2.12000e-01

$7.01902 \mathrm{e}+007.01902 \mathrm{e}+00$ 7.01902e-01 1.00000e-09 2.12000e-01

$1.00000 \mathrm{e}-021.00000 \mathrm{e}-021.00000 \mathrm{e}-031.00000 \mathrm{e}-091.00000 \mathrm{e}-01$

$1.00000 \mathrm{e}+001.00000 \mathrm{e}+001.00000 \mathrm{e}-011.00000 \mathrm{e}-091.00000 \mathrm{e}-01$

Element: 6939 \# of layers: 5

$\mathrm{Kx} \mathrm{Ky} \mathrm{Kz}$ Ss Por

$1.75668 \mathrm{e}+02$ 1.75668e+02 1.75668e+01 1.00000e-09 7.00000e-02

7.01902e+00 7.01902e+00 7.01902e-01 1.00000e-09 2.12000e-01

$7.01902 \mathrm{e}+00$ 7.01902e+00 7.01902e-01 1.00000e-09 2.12000e-01

$1.00000 \mathrm{e}-02$ 1.00000e-02 1.00000e-03 1.00000e-09 1.00000e-01

$1.00000 \mathrm{e}+001.00000 \mathrm{e}+001.00000 \mathrm{e}-011.00000 \mathrm{e}-091.00000 \mathrm{e}-01$

Element: 6940 \# of layers: 6

$\mathrm{Kx} \mathrm{Ky} \mathrm{Kz}$ Ss Por

1.75668e+02 1.75668e+02 1.75668e+01 1.00000e-09 7.00000e-02

$1.75668 \mathrm{e}+02$ 1.75668e+02 1.75668e+01 1.00000e-09 7.00000e-02

7.01902e+00 7.01902e+00 7.01902e-01 1.00000e-09 2.12000e-01

7.01902e+00 7.01902e+00 7.01902e-01 1.00000e-09 2.12000e-01

$1.00000 \mathrm{e}-02$ 1.00000e-02 1.00000e-03 1.00000e-09 1.00000e-01

$1.00000 \mathrm{e}+001.00000 \mathrm{e}+001.00000 \mathrm{e}-011.00000 \mathrm{e}-091.00000 \mathrm{e}-01$

Element: 6941 \# of layers: 5

$\mathrm{Kx} \mathrm{Ky} \mathrm{Kz}$ Ss Por

$1.75668 \mathrm{e}+02$ 1.75668e+02 1.75668e+01 1.00000e-09 7.00000e-02

$7.01902 \mathrm{e}+00$ 7.01902e+00 7.01902e-01 1.00000e-09 2.12000e-01 
$7.01902 \mathrm{e}+00$ 7.01902e+00 7.01902e-01 1.00000e-09 2.12000e-01 $1.00000 \mathrm{e}-02$ 1.00000e-02 1.00000e-03 1.00000e-09 1.00000e-01 $1.00000 \mathrm{e}+001.00000 \mathrm{e}+001.00000 \mathrm{e}-011.00000 \mathrm{e}-091.00000 \mathrm{e}-01$ Element: 6942 \# of layers: 4

Kx Ky Kz Ss Por

$1.75668 \mathrm{e}+02$ 1.75668e +02 1.75668e+01 1.00000e-09 7.00000e-02 $7.01902 \mathrm{e}+007.01902 \mathrm{e}+00$ 7.01902e-01 1.00000e-09 2.12000e-01 $1.00000 \mathrm{e}-021.00000 \mathrm{e}-02$ 1.00000e-03 1.00000e-09 1.00000e-01 $1.00000 \mathrm{e}+001.00000 \mathrm{e}+001.00000 \mathrm{e}-011.00000 \mathrm{e}-091.00000 \mathrm{e}-01$ Element: 6943 \# of layers: 4

Kx Ky Kz Ss Por

$1.75668 \mathrm{e}+02$ 1.75668e+02 1.75668e+01 1.00000e-09 7.00000e-02 $7.01902 \mathrm{e}+00$ 7.01902e+00 7.01902e-01 1.00000e-09 2.12000e-01 $1.00000 \mathrm{e}-02$ 1.00000e-02 1.00000e-03 1.00000e-09 1.00000e-01 $1.00000 \mathrm{e}+001.00000 \mathrm{e}+001.00000 \mathrm{e}-011.00000 \mathrm{e}-091.00000 \mathrm{e}-01$ Element: 6944 \# of layers: 4

Kx Ky Kz Ss Por

$1.75668 \mathrm{e}+021.75668 \mathrm{e}+021.75668 \mathrm{e}+01$ 1.00000e-09 7.00000e-02 $7.01902 \mathrm{e}+00$ 7.01902e+00 7.01902e-01 1.00000e-09 2.12000e-01 $1.00000 \mathrm{e}-021.00000 \mathrm{e}-02$ 1.00000e-03 $1.00000 \mathrm{e}-091.00000 \mathrm{e}-01$ $1.00000 \mathrm{e}+001.00000 \mathrm{e}+001.00000 \mathrm{e}-011.00000 \mathrm{e}-091.00000 \mathrm{e}-01$ Element: 6945 \# of layers: 5

Kx Ky Kz Ss Por

$1.75668 \mathrm{e}+02$ 1.75668e+02 1.75668e+01 1.00000e-09 7.00000e-02 $7.01902 \mathrm{e}+007.01902 \mathrm{e}+007.01902 \mathrm{e}-011.00000 \mathrm{e}-092.12000 \mathrm{e}-01$ $7.01902 \mathrm{e}+00$ 7.01902e+00 7.01902e-01 1.00000e-09 2.12000e-01 $1.00000 \mathrm{e}-021.00000 \mathrm{e}-02$ 1.00000e-03 1.00000e-09 1.00000e-01 $1.00000 \mathrm{e}+001.00000 \mathrm{e}+001.00000 \mathrm{e}-011.00000 \mathrm{e}-091.00000 \mathrm{e}-01$ Element: 6946 \# of layers: 5

Kx Ky Kz Ss Por

$1.75668 \mathrm{e}+02$ 1.75668e +02 1.75668e+01 1.00000e-09 7.00000e-02 $7.01902 \mathrm{e}+007.01902 \mathrm{e}+00$ 7.01902e-01 1.00000e-09 2.12000e-01 $7.01902 \mathrm{e}+007.01902 \mathrm{e}+00$ 7.01902e-01 1.00000e-09 2.12000e-01 $1.00000 \mathrm{e}-02$ 1.00000e-02 1.00000e-03 1.00000e-09 1.00000e-01 $1.00000 \mathrm{e}+001.00000 \mathrm{e}+001.00000 \mathrm{e}-011.00000 \mathrm{e}-091.00000 \mathrm{e}-01$ Element: 6947 \# of layers: 7

Kx Ky Kz Ss Por

$1.66171 \mathrm{e}+021.66171 \mathrm{e}+021.66171 \mathrm{e}+01$ 1.00000e-09 7.00000e-02 $1.66171 \mathrm{e}+021.66171 \mathrm{e}+021.66171 \mathrm{e}+011.00000 \mathrm{e}-097.00000 \mathrm{e}-02$ $6.63967 \mathrm{e}+006.63967 \mathrm{e}+00$ 6.63967e-01 1.00000e-09 2.12000e-01 $6.63967 \mathrm{e}+006.63967 \mathrm{e}+00$ 6.63967e-01 1.00000e-09 2.12000e-01 $6.63967 \mathrm{e}+006.63967 \mathrm{e}+00$ 6.63967e-01 1.00000e-09 2.12000e-01 $1.00000 \mathrm{e}-02$ 1.00000e-02 1.00000e-03 1.00000e-09 1.00000e-01 $1.00000 \mathrm{e}+001.00000 \mathrm{e}+001.00000 \mathrm{e}-011.00000 \mathrm{e}-091.00000 \mathrm{e}-01$ Element: 6948 \# of layers: 7

Kx Ky Kz Ss Por 
1.66171e+02 1.66171e+02 1.66171e+01 1.00000e-09 7.00000e-02 $1.66171 \mathrm{e}+021.66171 \mathrm{e}+02$ 1.66171e+01 1.00000e-09 7.00000e-02 6.63967e+00 6.63967e+00 6.63967e-01 1.00000e-09 2.12000e-01 $6.63967 \mathrm{e}+00$ 6.63967e+00 6.63967e-01 1.00000e-09 2.12000e-01 6.63967e+00 6.63967e+00 6.63967e-01 1.00000e-09 2.12000e-01 $1.00000 \mathrm{e}-02$ 1.00000e-02 1.00000e-03 1.00000e-09 1.00000e-01 $1.00000 \mathrm{e}+001.00000 \mathrm{e}+001.00000 \mathrm{e}-011.00000 \mathrm{e}-091.00000 \mathrm{e}-01$

Element: 6949 \# of layers: 5

$\mathrm{Kx} \mathrm{Ky} \mathrm{Kz}$ Ss Por

$1.66171 \mathrm{e}+021.66171 \mathrm{e}+02$ 1.66171e+01 1.00000e-09 7.00000e-02 $1.66171 \mathrm{e}+021.66171 \mathrm{e}+02$ 1.66171e+01 1.00000e-09 7.00000e-02 6.63967e+00 6.63967e+00 6.63967e-01 1.00000e-09 2.12000e-01 $1.00000 \mathrm{e}-02$ 1.00000e-02 1.00000e-03 1.00000e-09 1.00000e-01 $1.00000 \mathrm{e}+001.00000 \mathrm{e}+001.00000 \mathrm{e}-011.00000 \mathrm{e}-091.00000 \mathrm{e}-01$ Element: 6950 \# of layers: 5

Kx Ky Kz Ss Por

$1.66171 \mathrm{e}+02$ 1.66171e+02 1.66171e+01 1.00000e-09 7.00000e-02 $1.66171 \mathrm{e}+021.66171 \mathrm{e}+02$ 1.66171e+01 1.00000e-09 7.00000e-02 6.63967e+00 6.63967e+00 6.63967e-01 1.00000e-09 2.12000e-01 $1.00000 \mathrm{e}-02$ 1.00000e-02 1.00000e-03 1.00000e-09 1.00000e-01 $1.00000 \mathrm{e}+001.00000 \mathrm{e}+001.00000 \mathrm{e}-011.00000 \mathrm{e}-091.00000 \mathrm{e}-01$ Element: 6951 \# of layers: 4

$\mathrm{Kx} \mathrm{Ky} \mathrm{Kz}$ Ss Por

$1.66171 \mathrm{e}+02$ 1.66171e+02 1.66171e+01 1.00000e-09 7.00000e-02 6.63967e+00 6.63967e+00 6.63967e-01 1.00000e-09 2.12000e-01 $1.00000 \mathrm{e}-02$ 1.00000e-02 1.00000e-03 1.00000e-09 1.00000e-01 $1.00000 \mathrm{e}+001.00000 \mathrm{e}+001.00000 \mathrm{e}-011.00000 \mathrm{e}-091.00000 \mathrm{e}-01$ Element: 6952 \# of layers: 4

Kx Ky Kz Ss Por

$1.66171 \mathrm{e}+02$ 1.66171e+02 1.66171e+01 1.00000e-09 7.00000e-02 6.63967e+00 6.63967e+00 6.63967e-01 1.00000e-09 2.12000e-01 1.00000e-02 1.00000e-02 1.00000e-03 1.00000e-09 1.00000e-01 $1.00000 \mathrm{e}+001.00000 \mathrm{e}+001.00000 \mathrm{e}-011.00000 \mathrm{e}-091.00000 \mathrm{e}-01$ Element: 6953 \# of layers: 4

$\mathrm{Kx} \mathrm{Ky} \mathrm{Kz}$ Ss Por

$1.66171 \mathrm{e}+021.66171 \mathrm{e}+02$ 1.66171e+01 1.00000e-09 7.00000e-02 $6.63967 \mathrm{e}+00$ 6.63967e+00 6.63967e-01 1.00000e-09 2.12000e-01 $1.00000 \mathrm{e}-02$ 1.00000e-02 1.00000e-03 1.00000e-09 1.00000e-01 $1.00000 \mathrm{e}+001.00000 \mathrm{e}+001.00000 \mathrm{e}-011.00000 \mathrm{e}-091.00000 \mathrm{e}-01$ Element: 6954 \# of layers: 6

$\mathrm{Kx} \mathrm{Ky} \mathrm{Kz}$ Ss Por

$1.66171 \mathrm{e}+02$ 1.66171e+02 1.66171e+01 1.00000e-09 7.00000e-02 6.63967e+00 6.63967e+00 6.63967e-01 1.00000e-09 2.12000e-01 6.63967e+00 6.63967e+00 6.63967e-01 1.00000e-09 2.12000e-01 6.63967e+00 6.63967e+00 6.63967e-01 1.00000e-09 2.12000e-01 $1.00000 \mathrm{e}-02$ 1.00000e-02 1.00000e-03 1.00000e-09 1.00000e-01 
$1.00000 \mathrm{e}+001.00000 \mathrm{e}+00$ 1.00000e-01 1.00000e-09 1.00000e-01

Element: 6955 \# of layers: 5

Kx Ky Kz Ss Por

$1.66171 \mathrm{e}+02$ 1.66171e+02 1.66171e+01 1.00000e-09 7.00000e-02

6.63967e+00 6.63967e+00 6.63967e-01 1.00000e-09 2.12000e-01

$6.63967 \mathrm{e}+006.63967 \mathrm{e}+00$ 6.63967e-01 1.00000e-09 2.12000e-01

1.00000e-02 1.00000e-02 1.00000e-03 1.00000e-09 1.00000e-01

$1.00000 \mathrm{e}+001.00000 \mathrm{e}+001.00000 \mathrm{e}-01$ 1.00000e-09 1.00000e-01

Element: 6956 \# of layers: 4

$\mathrm{Kx} \mathrm{Ky} \mathrm{Kz}$ Ss Por

1.00497e+02 1.00497e+02 1.00497e+01 1.00000e-09 7.00000e-02

$4.01566 \mathrm{e}+004.01566 \mathrm{e}+004.01566 \mathrm{e}-01$ 1.00000e-09 2.12000e-01

$1.00000 \mathrm{e}-021.00000 \mathrm{e}-021.00000 \mathrm{e}-031.00000 \mathrm{e}-091.00000 \mathrm{e}-01$

$1.00000 \mathrm{e}+001.00000 \mathrm{e}+001.00000 \mathrm{e}-011.00000 \mathrm{e}-09$ 1.00000e-01

Element: 6957 \# of layers: 4

Kx Ky Kz Ss Por

1.00497e+02 1.00497e+02 1.00497e+01 1.00000e-09 7.00000e-02

$4.01566 \mathrm{e}+004.01566 \mathrm{e}+00$ 4.01566e-01 1.00000e-09 2.12000e-01

$1.00000 \mathrm{e}-02$ 1.00000e-02 1.00000e-03 1.00000e-09 1.00000e-01

$1.00000 \mathrm{e}+001.00000 \mathrm{e}+001.00000 \mathrm{e}-011.00000 \mathrm{e}-091.00000 \mathrm{e}-01$

Element: 6958 \# of layers: 4

$\mathrm{Kx} \mathrm{Ky} \mathrm{Kz}$ Ss Por

1.00497e+02 1.00497e+02 1.00497e+01 1.00000e-09 7.00000e-02

$4.01566 \mathrm{e}+004.01566 \mathrm{e}+004.01566 \mathrm{e}-01$ 1.00000e-09 2.12000e-01

$1.00000 \mathrm{e}-02$ 1.00000e-02 1.00000e-03 1.00000e-09 1.00000e-01

$1.00000 \mathrm{e}+001.00000 \mathrm{e}+001.00000 \mathrm{e}-01$ 1.00000e-09 1.00000e-01

Element: 6959 \# of layers: 5

$\mathrm{Kx} \mathrm{Ky} \mathrm{Kz}$ Ss Por

1.00497e+02 1.00497e+02 1.00497e+01 1.00000e-09 7.00000e-02

$1.00497 \mathrm{e}+02$ 1.00497e+02 1.00497e+01 1.00000e-09 7.00000e-02

$4.01566 \mathrm{e}+004.01566 \mathrm{e}+004.01566 \mathrm{e}-01$ 1.00000e-09 2.12000e-01

$1.00000 \mathrm{e}-02$ 1.00000e-02 1.00000e-03 1.00000e-09 1.00000e-01

$1.00000 \mathrm{e}+001.00000 \mathrm{e}+001.00000 \mathrm{e}-011.00000 \mathrm{e}-091.00000 \mathrm{e}-01$

Element: 6960 \# of layers: 4

$\mathrm{Kx} \mathrm{Ky} \mathrm{Kz}$ Ss Por

1.00497e+02 1.00497e+02 1.00497e+01 1.00000e-09 7.00000e-02

$4.01566 \mathrm{e}+004.01566 \mathrm{e}+004.01566 \mathrm{e}-01$ 1.00000e-09 2.12000e-01

$1.00000 \mathrm{e}-02$ 1.00000e-02 1.00000e-03 1.00000e-09 1.00000e-01

$1.00000 \mathrm{e}+001.00000 \mathrm{e}+001.00000 \mathrm{e}-011.00000 \mathrm{e}-09$ 1.00000e-01

Element: 6961 \# of layers: 4

$\mathrm{Kx} \mathrm{Ky} \mathrm{Kz}$ Ss Por

1.00497e+02 1.00497e+02 1.00497e+01 1.00000e-09 7.00000e-02

$4.01566 \mathrm{e}+00$ 4.01566e+00 4.01566e-01 1.00000e-09 2.12000e-01

$1.00000 \mathrm{e}-02$ 1.00000e-02 1.00000e-03 1.00000e-09 1.00000e-01

$1.00000 \mathrm{e}+001.00000 \mathrm{e}+001.00000 \mathrm{e}-011.00000 \mathrm{e}-091.00000 \mathrm{e}-01$

Element: 6962 \# of layers: 4 
$\mathrm{Kx} \mathrm{Ky} \mathrm{Kz}$ Ss Por

1.00497e+02 1.00497e+02 1.00497e+01 1.00000e-09 7.00000e-02

$4.01566 \mathrm{e}+004.01566 \mathrm{e}+00$ 4.01566e-01 1.00000e-09 2.12000e-01

$1.00000 \mathrm{e}-02$ 1.00000e-02 1.00000e-03 1.00000e-09 1.00000e-01

$1.00000 \mathrm{e}+001.00000 \mathrm{e}+001.00000 \mathrm{e}-01$ 1.00000e-09 1.00000e-01

Element: 6963 \# of layers: 5

$\mathrm{Kx} \mathrm{Ky} \mathrm{Kz}$ Ss Por

$1.00497 \mathrm{e}+02$ 1.00497e+02 1.00497e+01 1.00000e-09 7.00000e-02

$1.00497 \mathrm{e}+02$ 1.00497e+02 1.00497e+01 1.00000e-09 7.00000e-02

$4.01566 \mathrm{e}+004.01566 \mathrm{e}+004.01566 \mathrm{e}-01$ 1.00000e-09 2.12000e-01

$1.00000 \mathrm{e}-02$ 1.00000e-02 1.00000e-03 1.00000e-09 1.00000e-01

$1.00000 \mathrm{e}+001.00000 \mathrm{e}+001.00000 \mathrm{e}-011.00000 \mathrm{e}-091.00000 \mathrm{e}-01$

Element: 6964 \# of layers: 5

$\mathrm{Kx} \mathrm{Ky} \mathrm{Kz}$ Ss Por

1.00497e+02 1.00497e+02 1.00497e+01 1.00000e-09 7.00000e-02

$1.00497 \mathrm{e}+02$ 1.00497e+02 1.00497e+01 1.00000e-09 7.00000e-02

$4.01566 \mathrm{e}+00$ 4.01566e+00 4.01566e-01 1.00000e-09 2.12000e-01

$1.00000 \mathrm{e}-021.00000 \mathrm{e}-02$ 1.00000e-03 1.00000e-09 1.00000e-01

$1.00000 \mathrm{e}+001.00000 \mathrm{e}+001.00000 \mathrm{e}-01$ 1.00000e-09 1.00000e-01

Element: 6965 \# of layers: 4

$\mathrm{Kx} \mathrm{Ky} \mathrm{Kz}$ Ss Por

$4.86414 \mathrm{e}+014.86414 \mathrm{e}+014.86414 \mathrm{e}+001.00000 \mathrm{e}-097.00000 \mathrm{e}-02$

$1.94355 \mathrm{e}+001.94355 \mathrm{e}+00$ 1.94355e-01 1.00000e-09 2.12000e-01

$1.00000 \mathrm{e}-02$ 1.00000e-02 1.00000e-03 1.00000e-09 1.00000e-01

$1.00000 \mathrm{e}+001.00000 \mathrm{e}+001.00000 \mathrm{e}-011.00000 \mathrm{e}-091.00000 \mathrm{e}-01$

Element: 6966 \# of layers: 4

$\mathrm{Kx} \mathrm{Ky} \mathrm{Kz}$ Ss Por

4.86414e+01 4.86414e+01 4.86414e+00 1.00000e-09 7.00000e-02

$1.94355 \mathrm{e}+001.94355 \mathrm{e}+00 \quad 1.94355 \mathrm{e}-011.00000 \mathrm{e}-092.12000 \mathrm{e}-01$

$1.00000 \mathrm{e}-02$ 1.00000e-02 1.00000e-03 1.00000e-09 1.00000e-01

$1.00000 \mathrm{e}+001.00000 \mathrm{e}+001.00000 \mathrm{e}-011.00000 \mathrm{e}-091.00000 \mathrm{e}-01$

Element: 6967 \# of layers: 4

Kx Ky Kz Ss Por

4.86414e+01 4.86414e+01 4.86414e+00 1.00000e-09 7.00000e-02

$1.94355 \mathrm{e}+001.94355 \mathrm{e}+00$ 1.94355e-01 1.00000e-09 2.12000e-01

$1.00000 \mathrm{e}-02$ 1.00000e-02 1.00000e-03 1.00000e-09 1.00000e-01

$1.00000 \mathrm{e}+001.00000 \mathrm{e}+001.00000 \mathrm{e}-011.00000 \mathrm{e}-091.00000 \mathrm{e}-01$

Element: 6968 \# of layers: 5

$\mathrm{Kx} \mathrm{Ky} \mathrm{Kz}$ Ss Por

4.86414e+01 4.86414e+01 4.86414e+00 1.00000e-09 7.00000e-02

$4.86414 \mathrm{e}+014.86414 \mathrm{e}+014.86414 \mathrm{e}+001.00000 \mathrm{e}-09$ 7.00000e-02

$1.94355 \mathrm{e}+001.94355 \mathrm{e}+00$ 1.94355e-01 1.00000e-09 2.12000e-01

$1.00000 \mathrm{e}-02$ 1.00000e-02 1.00000e-03 1.00000e-09 1.00000e-01

$1.00000 \mathrm{e}+001.00000 \mathrm{e}+001.00000 \mathrm{e}-01$ 1.00000e-09 1.00000e-01

Element: 6969 \# of layers: 4

Kx Ky Kz Ss Por 
4.86414e+01 4.86414e+01 4.86414e+00 1.00000e-09 7.00000e-02 $1.94355 \mathrm{e}+001.94355 \mathrm{e}+00$ 1.94355e-01 1.00000e-09 2.12000e-01 $1.00000 \mathrm{e}-02$ 1.00000e-02 1.00000e-03 1.00000e-09 1.00000e-01

$1.00000 \mathrm{e}+001.00000 \mathrm{e}+001.00000 \mathrm{e}-011.00000 \mathrm{e}-091.00000 \mathrm{e}-01$

Element: 6970 \# of layers: 4

$\mathrm{Kx} \mathrm{Ky} \mathrm{Kz}$ Ss Por

4.86414e+01 4.86414e+01 4.86414e+00 1.00000e-09 7.00000e-02

$1.94355 \mathrm{e}+001.94355 \mathrm{e}+001.94355 \mathrm{e}-011.00000 \mathrm{e}-092.12000 \mathrm{e}-01$

$1.00000 \mathrm{e}-02$ 1.00000e-02 1.00000e-03 1.00000e-09 1.00000e-01

$1.00000 \mathrm{e}+001.00000 \mathrm{e}+001.00000 \mathrm{e}-011.00000 \mathrm{e}-09$ 1.00000e-01

Element: 6971 \# of layers: 4

Kx Ky Kz Ss Por

4.86414e+01 4.86414e+01 4.86414e+00 1.00000e-09 7.00000e-02

$1.94355 \mathrm{e}+001.94355 \mathrm{e}+00$ 1.94355e-01 1.00000e-09 2.12000e-01

$1.00000 \mathrm{e}-02$ 1.00000e-02 1.00000e-03 1.00000e-09 1.00000e-01

$1.00000 \mathrm{e}+001.00000 \mathrm{e}+001.00000 \mathrm{e}-011.00000 \mathrm{e}-091.00000 \mathrm{e}-01$

Element: 6972 \# of layers: 5

$\mathrm{Kx} \mathrm{Ky} \mathrm{Kz}$ Ss Por

4.86414e+01 4.86414e+01 4.86414e+00 1.00000e-09 7.00000e-02

$4.86414 \mathrm{e}+014.86414 \mathrm{e}+014.86414 \mathrm{e}+001.00000 \mathrm{e}-09$ 7.00000e-02

$1.94355 \mathrm{e}+001.94355 \mathrm{e}+001.94355 \mathrm{e}-011.00000 \mathrm{e}-092.12000 \mathrm{e}-01$

$1.00000 \mathrm{e}-02$ 1.00000e-02 1.00000e-03 1.00000e-09 1.00000e-01

$1.00000 \mathrm{e}+001.00000 \mathrm{e}+001.00000 \mathrm{e}-01$ 1.00000e-09 1.00000e-01

Element: 6973 \# of layers: 5

Kx Ky Kz Ss Por

4.86414e+01 4.86414e+01 4.86414e+00 1.00000e-09 7.00000e-02

$4.86414 \mathrm{e}+014.86414 \mathrm{e}+014.86414 \mathrm{e}+001.00000 \mathrm{e}-09$ 7.00000e-02

$1.94355 \mathrm{e}+001.94355 \mathrm{e}+00$ 1.94355e-01 1.00000e-09 2.12000e-01

$1.00000 \mathrm{e}-02$ 1.00000e-02 1.00000e-03 1.00000e-09 1.00000e-01

$1.00000 \mathrm{e}+001.00000 \mathrm{e}+001.00000 \mathrm{e}-011.00000 \mathrm{e}-091.00000 \mathrm{e}-01$

Element: 6974 \# of layers: 4

Kx Ky Kz Ss Por

7.12430e+01 7.12430e+01 7.12430e+00 1.00000e-09 7.00000e-02

$2.84654 \mathrm{e}+002.84654 \mathrm{e}+002.84654 \mathrm{e}-01$ 1.00000e-09 2.12000e-01

$1.00000 \mathrm{e}-02$ 1.00000e-02 1.00000e-03 1.00000e-09 1.00000e-01

$1.00000 \mathrm{e}+001.00000 \mathrm{e}+001.00000 \mathrm{e}-011.00000 \mathrm{e}-091.00000 \mathrm{e}-01$

Element: 6975 \# of layers: 4

Kx Ky Kz Ss Por

7.12430e+01 7.12430e+01 7.12430e+00 1.00000e-09 7.00000e-02

$2.84654 \mathrm{e}+002.84654 \mathrm{e}+00$ 2.84654e-01 1.00000e-09 2.12000e-01

$1.00000 \mathrm{e}-02$ 1.00000e-02 1.00000e-03 1.00000e-09 1.00000e-01

$1.00000 \mathrm{e}+001.00000 \mathrm{e}+001.00000 \mathrm{e}-011.00000 \mathrm{e}-091.00000 \mathrm{e}-01$

Element: 6976 \# of layers: 4

$\mathrm{Kx} \mathrm{Ky} \mathrm{Kz}$ Ss Por

7.12430e+01 7.12430e+01 7.12430e+00 1.00000e-09 7.00000e-02

$2.84654 \mathrm{e}+002.84654 \mathrm{e}+002.84654 \mathrm{e}-01$ 1.00000e-09 2.12000e-01 
$1.00000 \mathrm{e}-02$ 1.00000e-02 1.00000e-03 1.00000e-09 1.00000e-01 $1.00000 \mathrm{e}+001.00000 \mathrm{e}+001.00000 \mathrm{e}-01$ 1.00000e-09 1.00000e-01 Element: 6977 \# of layers: 5

Kx Ky Kz Ss Por

7.12430e+01 7.12430e+01 7.12430e+00 1.00000e-09 7.00000e-02

$7.12430 \mathrm{e}+017.12430 \mathrm{e}+017.12430 \mathrm{e}+001.00000 \mathrm{e}-09$ 7.00000e-02

$2.84654 \mathrm{e}+002.84654 \mathrm{e}+002.84654 \mathrm{e}-01$ 1.00000e-09 2.12000e-01

$1.00000 \mathrm{e}-02$ 1.00000e-02 1.00000e-03 1.00000e-09 1.00000e-01

$1.00000 \mathrm{e}+001.00000 \mathrm{e}+001.00000 \mathrm{e}-011.00000 \mathrm{e}-091.00000 \mathrm{e}-01$

Element: 6978 \# of layers: 4

$\mathrm{Kx} \mathrm{Ky} \mathrm{Kz}$ Ss Por

7.12430e+01 7.12430e+01 7.12430e+00 1.00000e-09 7.00000e-02

$2.84654 \mathrm{e}+002.84654 \mathrm{e}+002.84654 \mathrm{e}-01$ 1.00000e-09 2.12000e-01

$1.00000 \mathrm{e}-02$ 1.00000e-02 1.00000e-03 1.00000e-09 1.00000e-01

$1.00000 \mathrm{e}+001.00000 \mathrm{e}+001.00000 \mathrm{e}-01$ 1.00000e-09 1.00000e-01

Element: 6979 \# of layers: 4

$\mathrm{Kx} \mathrm{Ky} \mathrm{Kz}$ Ss Por

7.12430e+01 7.12430e+01 7.12430e+00 1.00000e-09 7.00000e-02

$2.84654 \mathrm{e}+002.84654 \mathrm{e}+002.84654 \mathrm{e}-01$ 1.00000e-09 2.12000e-01

1.00000e-02 1.00000e-02 1.00000e-03 1.00000e-09 1.00000e-01

$1.00000 \mathrm{e}+001.00000 \mathrm{e}+001.00000 \mathrm{e}-011.00000 \mathrm{e}-091.00000 \mathrm{e}-01$

Element: 6980 \# of layers: 4

$\mathrm{Kx} \mathrm{Ky} \mathrm{Kz}$ Ss Por

7.12430e+01 7.12430e+01 7.12430e+00 1.00000e-09 7.00000e-02

$2.84654 \mathrm{e}+002.84654 \mathrm{e}+00 \quad 2.84654 \mathrm{e}-011.00000 \mathrm{e}-092.12000 \mathrm{e}-01$

$1.00000 \mathrm{e}-02$ 1.00000e-02 1.00000e-03 1.00000e-09 1.00000e-01

$1.00000 \mathrm{e}+001.00000 \mathrm{e}+001.00000 \mathrm{e}-011.00000 \mathrm{e}-091.00000 \mathrm{e}-01$

Element: 6981 \# of layers: 5

$\mathrm{Kx} \mathrm{Ky} \mathrm{Kz}$ Ss Por

7.12430e+01 7.12430e+01 7.12430e+00 1.00000e-09 7.00000e-02

$7.12430 \mathrm{e}+017.12430 \mathrm{e}+017.12430 \mathrm{e}+001.00000 \mathrm{e}-09$ 7.00000e-02

$2.84654 \mathrm{e}+002.84654 \mathrm{e}+002.84654 \mathrm{e}-01$ 1.00000e-09 2.12000e-01

$1.00000 \mathrm{e}-02$ 1.00000e-02 1.00000e-03 1.00000e-09 1.00000e-01

$1.00000 \mathrm{e}+001.00000 \mathrm{e}+001.00000 \mathrm{e}-011.00000 \mathrm{e}-091.00000 \mathrm{e}-01$

Element: 6982 \# of layers: 5

$\mathrm{Kx} \mathrm{Ky} \mathrm{Kz}$ Ss Por

7.12430e+01 7.12430e+01 7.12430e+00 1.00000e-09 7.00000e-02

$7.12430 \mathrm{e}+017.12430 \mathrm{e}+017.12430 \mathrm{e}+001.00000 \mathrm{e}-09$ 7.00000e-02

$2.84654 \mathrm{e}+002.84654 \mathrm{e}+002.84654 \mathrm{e}-01$ 1.00000e-09 2.12000e-01

$1.00000 \mathrm{e}-02$ 1.00000e-02 1.00000e-03 1.00000e-09 1.00000e-01

$1.00000 \mathrm{e}+001.00000 \mathrm{e}+001.00000 \mathrm{e}-011.00000 \mathrm{e}-091.00000 \mathrm{e}-01$

Element: 6983 \# of layers: 4

$\mathrm{Kx} \mathrm{Ky} \mathrm{Kz}$ Ss Por

8.82241e+01 8.82241e+01 8.82241e+00 1.00000e-09 7.00000e-02

$3.52515 \mathrm{e}+003.52515 \mathrm{e}+003.52515 \mathrm{e}-01$ 1.00000e-09 2.12000e-01

$1.00000 \mathrm{e}-02$ 1.00000e-02 1.00000e-03 1.00000e-09 1.00000e-01 
$1.00000 \mathrm{e}+001.00000 \mathrm{e}+00$ 1.00000e-01 1.00000e-09 1.00000e-01

Element: 6984 \# of layers: 4

$\mathrm{Kx} \mathrm{Ky} \mathrm{Kz}$ Ss Por

8.82241e+01 8.82241e+01 8.82241e+00 1.00000e-09 7.00000e-02

$3.52515 \mathrm{e}+003.52515 \mathrm{e}+003.52515 \mathrm{e}-01$ 1.00000e-09 2.12000e-01

$1.00000 \mathrm{e}-02$ 1.00000e-02 1.00000e-03 1.00000e-09 1.00000e-01

$1.00000 \mathrm{e}+001.00000 \mathrm{e}+001.00000 \mathrm{e}-01$ 1.00000e-09 1.00000e-01

Element: 6985 \# of layers: 4

$\mathrm{Kx} \mathrm{Ky} \mathrm{Kz}$ Ss Por

8.82241e+01 8.82241e+01 8.82241e+00 1.00000e-09 7.00000e-02

$3.52515 \mathrm{e}+003.52515 \mathrm{e}+003.52515 \mathrm{e}-01$ 1.00000e-09 2.12000e-01

$1.00000 \mathrm{e}-02$ 1.00000e-02 1.00000e-03 1.00000e-09 1.00000e-01

$1.00000 \mathrm{e}+001.00000 \mathrm{e}+001.00000 \mathrm{e}-011.00000 \mathrm{e}-091.00000 \mathrm{e}-01$

Element: 6986 \# of layers: 5

$\mathrm{Kx} \mathrm{Ky} \mathrm{Kz}$ Ss Por

8.82241e+01 8.82241e+01 8.82241e+00 1.00000e-09 7.00000e-02

$8.82241 \mathrm{e}+018.82241 \mathrm{e}+018.82241 \mathrm{e}+00$ 1.00000e-09 7.00000e-02

$3.52515 \mathrm{e}+003.52515 \mathrm{e}+00$ 3.52515e-01 1.00000e-09 2.12000e-01

$1.00000 \mathrm{e}-02$ 1.00000e-02 1.00000e-03 1.00000e-09 1.00000e-01

$1.00000 \mathrm{e}+001.00000 \mathrm{e}+001.00000 \mathrm{e}-011.00000 \mathrm{e}-091.00000 \mathrm{e}-01$

Element: 6987 \# of layers: 4

$\mathrm{Kx} \mathrm{Ky} \mathrm{Kz}$ Ss Por

8.82241e+01 8.82241e+01 8.82241e+00 1.00000e-09 7.00000e-02

$3.52515 \mathrm{e}+003.52515 \mathrm{e}+003.52515 \mathrm{e}-01$ 1.00000e-09 2.12000e-01

$1.00000 \mathrm{e}-02$ 1.00000e-02 1.00000e-03 1.00000e-09 1.00000e-01

$1.00000 \mathrm{e}+001.00000 \mathrm{e}+001.00000 \mathrm{e}-01$ 1.00000e-09 1.00000e-01

Element: 6988 \# of layers: 4

$\mathrm{Kx} \mathrm{Ky} \mathrm{Kz}$ Ss Por

8.82241e+01 8.82241e+01 8.82241e+00 1.00000e-09 7.00000e-02

$3.52515 \mathrm{e}+003.52515 \mathrm{e}+00$ 3.52515e-01 1.00000e-09 2.12000e-01

$1.00000 \mathrm{e}-02$ 1.00000e-02 1.00000e-03 1.00000e-09 1.00000e-01

$1.00000 \mathrm{e}+001.00000 \mathrm{e}+001.00000 \mathrm{e}-01$ 1.00000e-09 1.00000e-01

Element: 6989 \# of layers: 4

$\mathrm{Kx} \mathrm{Ky} \mathrm{Kz}$ Ss Por

8.82241e+01 8.82241e+01 8.82241e+00 1.00000e-09 7.00000e-02

$3.52515 \mathrm{e}+003.52515 \mathrm{e}+003.52515 \mathrm{e}-01$ 1.00000e-09 2.12000e-01

$1.00000 \mathrm{e}-02$ 1.00000e-02 1.00000e-03 1.00000e-09 1.00000e-01

$1.00000 \mathrm{e}+001.00000 \mathrm{e}+001.00000 \mathrm{e}-011.00000 \mathrm{e}-091.00000 \mathrm{e}-01$

Element: 6990 \# of layers: 5

$\mathrm{Kx} \mathrm{Ky} \mathrm{Kz}$ Ss Por

8.82241e+01 8.82241e+01 8.82241e+00 1.00000e-09 7.00000e-02

8.82241e+01 8.82241e+01 8.82241e+00 1.00000e-09 7.00000e-02

$3.52515 \mathrm{e}+003.52515 \mathrm{e}+00$ 3.52515e-01 1.00000e-09 2.12000e-01

$1.00000 \mathrm{e}-02$ 1.00000e-02 1.00000e-03 1.00000e-09 1.00000e-01

$1.00000 \mathrm{e}+001.00000 \mathrm{e}+001.00000 \mathrm{e}-01$ 1.00000e-09 1.00000e-01

Element: 6991 \# of layers: 5 
$\mathrm{Kx} \mathrm{Ky} \mathrm{Kz}$ Ss Por

8.82241e+01 8.82241e+01 8.82241e+00 1.00000e-09 7.00000e-02

$8.82241 \mathrm{e}+018.82241 \mathrm{e}+018.82241 \mathrm{e}+00$ 1.00000e-09 7.00000e-02

$3.52515 \mathrm{e}+003.52515 \mathrm{e}+003.52515 \mathrm{e}-01$ 1.00000e-09 2.12000e-01

$1.00000 \mathrm{e}-02$ 1.00000e-02 1.00000e-03 1.00000e-09 1.00000e-01

$1.00000 \mathrm{e}+001.00000 \mathrm{e}+001.00000 \mathrm{e}-01$ 1.00000e-09 1.00000e-01

Element: 6992 \# of layers: 5

$\mathrm{Kx} \mathrm{Ky} \mathrm{Kz}$ Ss Por

$1.97815 \mathrm{e}+02$ 1.97815e+02 1.97815e+01 1.00000e-09 7.00000e-02

$1.97815 \mathrm{e}+02$ 1.97815e+02 1.97815e+01 1.00000e-09 7.00000e-02

7.90397e+00 7.90397e+00 7.90397e-01 1.00000e-09 2.12000e-01

$1.00000 \mathrm{e}-02$ 1.00000e-02 1.00000e-03 1.00000e-09 1.00000e-01

$1.00000 \mathrm{e}+001.00000 \mathrm{e}+001.00000 \mathrm{e}-011.00000 \mathrm{e}-091.00000 \mathrm{e}-01$

Element: 6993 \# of layers: 4

$\mathrm{Kx} \mathrm{Ky} \mathrm{Kz}$ Ss Por

1.97815e+02 1.97815e+02 1.97815e+01 1.00000e-09 7.00000e-02

7.90397e+00 7.90397e+00 7.90397e-01 1.00000e-09 2.12000e-01

$1.00000 \mathrm{e}-02$ 1.00000e-02 1.00000e-03 1.00000e-09 1.00000e-01

$1.00000 \mathrm{e}+001.00000 \mathrm{e}+001.00000 \mathrm{e}-01$ 1.00000e-09 1.00000e-01

Element: 6994 \# of layers: 3

$\mathrm{Kx} \mathrm{Ky} \mathrm{Kz}$ Ss Por

$1.97815 \mathrm{e}+02$ 1.97815e+02 1.97815e+01 1.00000e-09 7.00000e-02

$1.00000 \mathrm{e}-02$ 1.00000e-02 1.00000e-03 1.00000e-09 1.00000e-01

$1.00000 \mathrm{e}+001.00000 \mathrm{e}+001.00000 \mathrm{e}-011.00000 \mathrm{e}-09$ 1.00000e-01

Element: 6995 \# of layers: 3

$\mathrm{Kx} \mathrm{Ky} \mathrm{Kz}$ Ss Por

$1.97815 \mathrm{e}+02$ 1.97815e+02 1.97815e+01 1.00000e-09 7.00000e-02

$1.00000 \mathrm{e}-02$ 1.00000e-02 1.00000e-03 1.00000e-09 1.00000e-01

$1.00000 \mathrm{e}+001.00000 \mathrm{e}+001.00000 \mathrm{e}-011.00000 \mathrm{e}-091.00000 \mathrm{e}-01$

Element: 6996 \# of layers: 3

$\mathrm{Kx} \mathrm{Ky} \mathrm{Kz}$ Ss Por

$1.97815 \mathrm{e}+02$ 1.97815e+02 1.97815e+01 1.00000e-09 7.00000e-02

$1.00000 \mathrm{e}-02$ 1.00000e-02 1.00000e-03 1.00000e-09 1.00000e-01

$1.00000 \mathrm{e}+001.00000 \mathrm{e}+001.00000 \mathrm{e}-011.00000 \mathrm{e}-091.00000 \mathrm{e}-01$

Element: 6997 \# of layers: 3

Kx Ky Kz Ss Por

$1.97815 \mathrm{e}+02$ 1.97815e+02 1.97815e+01 1.00000e-09 7.00000e-02

$1.00000 \mathrm{e}-02$ 1.00000e-02 1.00000e-03 1.00000e-09 1.00000e-01

$1.00000 \mathrm{e}+001.00000 \mathrm{e}+001.00000 \mathrm{e}-011.00000 \mathrm{e}-091.00000 \mathrm{e}-01$

Element: 6998 \# of layers: 4

$\mathrm{Kx} \mathrm{Ky} \mathrm{Kz}$ Ss Por

1.97815e+02 1.97815e+02 1.97815e+01 1.00000e-09 7.00000e-02

7.90397e+00 7.90397e+00 7.90397e-01 1.00000e-09 2.12000e-01

$1.00000 \mathrm{e}-02$ 1.00000e-02 1.00000e-03 1.00000e-09 1.00000e-01

$1.00000 \mathrm{e}+001.00000 \mathrm{e}+001.00000 \mathrm{e}-011.00000 \mathrm{e}-091.00000 \mathrm{e}-01$

Element: 6999 \# of layers: 5 
Kx Ky Kz Ss Por

$1.97815 \mathrm{e}+02$ 1.97815e+02 1.97815e+01 1.00000e-09 7.00000e-02

$1.97815 \mathrm{e}+02$ 1.97815e+02 1.97815e+01 1.00000e-09 7.00000e-02

7.90397e+00 7.90397e+00 7.90397e-01 1.00000e-09 2.12000e-01

$1.00000 \mathrm{e}-021.00000 \mathrm{e}-02$ 1.00000e-03 1.00000e-09 1.00000e-01

$1.00000 \mathrm{e}+001.00000 \mathrm{e}+001.00000 \mathrm{e}-011.00000 \mathrm{e}-091.00000 \mathrm{e}-01$

Element: 7000 \# of layers: 3

$\mathrm{Kx} \mathrm{Ky} \mathrm{Kz}$ Ss Por

$1.97815 \mathrm{e}+02$ 1.97815e+02 1.97815e+01 1.00000e-09 7.00000e-02

$1.00000 \mathrm{e}-02$ 1.00000e-02 1.00000e-03 1.00000e-09 1.00000e-01

$1.00000 \mathrm{e}+001.00000 \mathrm{e}+001.00000 \mathrm{e}-011.00000 \mathrm{e}-091.00000 \mathrm{e}-01$

Element: 7001 \# of layers: 3

$\mathrm{Kx} \mathrm{Ky} \mathrm{Kz}$ Ss Por

$2.59443 \mathrm{e}+02$ 2.59443e+02 2.59443e+01 1.00000e-09 7.00000e-02 $1.00000 \mathrm{e}-02$ 1.00000e-02 1.00000e-03 1.00000e-09 1.00000e-01

$1.00000 \mathrm{e}+001.00000 \mathrm{e}+001.00000 \mathrm{e}-011.00000 \mathrm{e}-091.00000 \mathrm{e}-01$

Element: 7002 \# of layers: 3

$\mathrm{Kx} \mathrm{Ky} \mathrm{Kz}$ Ss Por

2.59443e+02 2.59443e+02 2.59443e+01 1.00000e-09 7.00000e-02

$1.00000 \mathrm{e}-02$ 1.00000e-02 1.00000e-03 1.00000e-09 1.00000e-01

$1.00000 \mathrm{e}+001.00000 \mathrm{e}+001.00000 \mathrm{e}-011.00000 \mathrm{e}-091.00000 \mathrm{e}-01$

Element: 7003 \# of layers: 3

$\mathrm{Kx} \mathrm{Ky} \mathrm{Kz}$ Ss Por

$2.59443 \mathrm{e}+02$ 2.59443e+02 2.59443e+01 1.00000e-09 7.00000e-02

$1.00000 \mathrm{e}-02$ 1.00000e-02 1.00000e-03 1.00000e-09 1.00000e-01

$1.00000 \mathrm{e}+001.00000 \mathrm{e}+001.00000 \mathrm{e}-01$ 1.00000e-09 1.00000e-01

Element: 7004 \# of layers: 3

$\mathrm{Kx} \mathrm{Ky} \mathrm{Kz}$ Ss Por

$2.59443 \mathrm{e}+02$ 2.59443e+02 2.59443e+01 1.00000e-09 7.00000e-02

$1.00000 \mathrm{e}-02$ 1.00000e-02 1.00000e-03 1.00000e-09 1.00000e-01

$1.00000 \mathrm{e}+001.00000 \mathrm{e}+001.00000 \mathrm{e}-011.00000 \mathrm{e}-091.00000 \mathrm{e}-01$

Element: 7005 \# of layers: 3

$\mathrm{Kx} \mathrm{Ky} \mathrm{Kz}$ Ss Por

2.59443e+02 2.59443e+02 2.59443e+01 1.00000e-09 7.00000e-02

$1.00000 \mathrm{e}-02$ 1.00000e-02 1.00000e-03 1.00000e-09 1.00000e-01

$1.00000 \mathrm{e}+001.00000 \mathrm{e}+001.00000 \mathrm{e}-011.00000 \mathrm{e}-091.00000 \mathrm{e}-01$

Element: 7006 \# of layers: 3

$\mathrm{Kx} \mathrm{Ky} \mathrm{Kz}$ Ss Por

2.59443e+02 2.59443e+02 2.59443e+01 1.00000e-09 7.00000e-02 $1.00000 \mathrm{e}-02$ 1.00000e-02 1.00000e-03 1.00000e-09 1.00000e-01

$1.00000 \mathrm{e}+001.00000 \mathrm{e}+001.00000 \mathrm{e}-011.00000 \mathrm{e}-091.00000 \mathrm{e}-01$

Element: 7007 \# of layers: 3

$\mathrm{Kx} \mathrm{Ky} \mathrm{Kz}$ Ss Por

2.59443e+02 2.59443e+02 2.59443e+01 1.00000e-09 7.00000e-02 $1.00000 \mathrm{e}-02$ 1.00000e-02 1.00000e-03 1.00000e-09 1.00000e-01

$1.00000 \mathrm{e}+001.00000 \mathrm{e}+001.00000 \mathrm{e}-011.00000 \mathrm{e}-091.00000 \mathrm{e}-01$ 
Element: 7008 \# of layers: 3

$\mathrm{Kx} \mathrm{Ky} \mathrm{Kz}$ Ss Por

$2.59443 e+02$ 2.59443e+02 2.59443e+01 1.00000e-09 7.00000e-02

$1.00000 \mathrm{e}-02$ 1.00000e-02 1.00000e-03 1.00000e-09 1.00000e-01

$1.00000 \mathrm{e}+001.00000 \mathrm{e}+001.00000 \mathrm{e}-011.00000 \mathrm{e}-091.00000 \mathrm{e}-01$

Element: 7009 \# of layers: 3

$\mathrm{Kx} \mathrm{Ky} \mathrm{Kz}$ Ss Por

$2.59443 \mathrm{e}+02$ 2.59443e+02 2.59443e+01 1.00000e-09 7.00000e-02

$1.00000 \mathrm{e}-02$ 1.00000e-02 1.00000e-03 1.00000e-09 1.00000e-01

$1.00000 \mathrm{e}+001.00000 \mathrm{e}+001.00000 \mathrm{e}-01$ 1.00000e-09 1.00000e-01

Element: 7010 \# of layers: 3

$\mathrm{Kx} \mathrm{Ky} \mathrm{Kz}$ Ss Por

2.42693e+02 2.42693e+02 2.42693e+01 1.00000e-09 7.00000e-02

1.00000e-02 1.00000e-02 1.00000e-03 1.00000e-09 1.00000e-01

$1.00000 \mathrm{e}+001.00000 \mathrm{e}+001.00000 \mathrm{e}-01$ 1.00000e-09 1.00000e-01

Element: 7011 \# of layers: 3

$\mathrm{Kx} \mathrm{Ky} \mathrm{Kz}$ Ss Por

2.42693e+02 2.42693e+02 2.42693e+01 1.00000e-09 7.00000e-02

$1.00000 \mathrm{e}-02$ 1.00000e-02 1.00000e-03 1.00000e-09 1.00000e-01

$1.00000 \mathrm{e}+001.00000 \mathrm{e}+001.00000 \mathrm{e}-011.00000 \mathrm{e}-091.00000 \mathrm{e}-01$

Element: 7012 \# of layers: 3

$\mathrm{Kx} \mathrm{Ky} \mathrm{Kz}$ Ss Por

2.42693e+02 2.42693e+02 2.42693e+01 1.00000e-09 7.00000e-02

$1.00000 \mathrm{e}-02$ 1.00000e-02 1.00000e-03 1.00000e-09 1.00000e-01

$1.00000 \mathrm{e}+001.00000 \mathrm{e}+001.00000 \mathrm{e}-011.00000 \mathrm{e}-091.00000 \mathrm{e}-01$

Element: 7013 \# of layers: 3

$\mathrm{Kx} \mathrm{Ky} \mathrm{Kz}$ Ss Por

$2.42693 \mathrm{e}+02$ 2.42693e+02 2.42693e+01 1.00000e-09 7.00000e-02

$1.00000 \mathrm{e}-02$ 1.00000e-02 1.00000e-03 1.00000e-09 1.00000e-01

$1.00000 \mathrm{e}+001.00000 \mathrm{e}+001.00000 \mathrm{e}-011.00000 \mathrm{e}-091.00000 \mathrm{e}-01$

Element: 7014 \# of layers: 3

$\mathrm{Kx} \mathrm{Ky} \mathrm{Kz}$ Ss Por

2.42693e+02 2.42693e+02 2.42693e+01 1.00000e-09 7.00000e-02

$1.00000 \mathrm{e}-021.00000 \mathrm{e}-021.00000 \mathrm{e}-031.00000 \mathrm{e}-091.00000 \mathrm{e}-01$

$1.00000 \mathrm{e}+001.00000 \mathrm{e}+001.00000 \mathrm{e}-011.00000 \mathrm{e}-091.00000 \mathrm{e}-01$

Element: 7015 \# of layers: 3

$\mathrm{Kx} \mathrm{Ky} \mathrm{Kz}$ Ss Por

2.42693e+02 2.42693e+02 2.42693e+01 1.00000e-09 7.00000e-02

$1.00000 \mathrm{e}-021.00000 \mathrm{e}-021.00000 \mathrm{e}-031.00000 \mathrm{e}-091.00000 \mathrm{e}-01$

$1.00000 \mathrm{e}+001.00000 \mathrm{e}+001.00000 \mathrm{e}-01$ 1.00000e-09 1.00000e-01

Element: 7016 \# of layers: 3

$\mathrm{Kx} \mathrm{Ky} \mathrm{Kz}$ Ss Por

2.42693e+02 2.42693e+02 2.42693e+01 1.00000e-09 7.00000e-02

$1.00000 \mathrm{e}-02$ 1.00000e-02 1.00000e-03 1.00000e-09 1.00000e-01

$1.00000 \mathrm{e}+001.00000 \mathrm{e}+001.00000 \mathrm{e}-01$ 1.00000e-09 1.00000e-01

Element: 7017 \# of layers: 3 
Kx Ky Kz Ss Por

$2.42693 \mathrm{e}+02$ 2.42693e+02 2.42693e+01 1.00000e-09 7.00000e-02

$1.00000 \mathrm{e}-02$ 1.00000e-02 1.00000e-03 1.00000e-09 1.00000e-01

$1.00000 \mathrm{e}+001.00000 \mathrm{e}+001.00000 \mathrm{e}-011.00000 \mathrm{e}-091.00000 \mathrm{e}-01$

Element: 7018 \# of layers: 3

Kx Ky Kz Ss Por

$2.42693 \mathrm{e}+022.42693 \mathrm{e}+022.42693 \mathrm{e}+01$ 1.00000e-09 7.00000e-02

$1.00000 \mathrm{e}-021.00000 \mathrm{e}-02$ 1.00000e-03 1.00000e-09 1.00000e-01

$1.00000 \mathrm{e}+001.00000 \mathrm{e}+001.00000 \mathrm{e}-011.00000 \mathrm{e}-091.00000 \mathrm{e}-01$

Element: 7019 \# of layers: 3

Kx Ky Kz Ss Por

$1.89309 \mathrm{e}+02$ 1.89309e+02 1.89309e+01 1.00000e-09 7.00000e-02

$1.00000 \mathrm{e}-02$ 1.00000e-02 1.00000e-03 1.00000e-09 1.00000e-01

$1.00000 \mathrm{e}+001.00000 \mathrm{e}+001.00000 \mathrm{e}-011.00000 \mathrm{e}-091.00000 \mathrm{e}-01$

Element: 7020 \# of layers: 3

Kx Ky Kz Ss Por

$1.89309 \mathrm{e}+02$ 1.89309e+02 1.89309e+01 1.00000e-09 7.00000e-02 $1.00000 \mathrm{e}-02$ 1.00000e-02 1.00000e-03 1.00000e-09 1.00000e-01

$1.00000 \mathrm{e}+001.00000 \mathrm{e}+001.00000 \mathrm{e}-011.00000 \mathrm{e}-091.00000 \mathrm{e}-01$

Element: 7021 \# of layers: 3

Kx Ky Kz Ss Por

$1.89309 \mathrm{e}+021.89309 \mathrm{e}+021.89309 \mathrm{e}+01$ 1.00000e-09 7.00000e-02

$1.00000 \mathrm{e}-02$ 1.00000e-02 1.00000e-03 1.00000e-09 1.00000e-01

$1.00000 \mathrm{e}+001.00000 \mathrm{e}+001.00000 \mathrm{e}-011.00000 \mathrm{e}-091.00000 \mathrm{e}-01$

Element: 7022 \# of layers: 7

Kx Ky Kz Ss Por

$1.56891 \mathrm{e}+031.56891 \mathrm{e}+03$ 1.56891e+02 1.00000e-09 7.00000e-02

$6.26886 \mathrm{e}+016.26886 \mathrm{e}+016.26886 \mathrm{e}+001.00000 \mathrm{e}-092.12000 \mathrm{e}-01$

$6.26886 \mathrm{e}+016.26886 \mathrm{e}+016.26886 \mathrm{e}+001.00000 \mathrm{e}-092.12000 \mathrm{e}-01$

$6.26886 \mathrm{e}+016.26886 \mathrm{e}+016.26886 \mathrm{e}+001.00000 \mathrm{e}-092.12000 \mathrm{e}-01$

$6.26886 \mathrm{e}+016.26886 \mathrm{e}+016.26886 \mathrm{e}+001.00000 \mathrm{e}-092.12000 \mathrm{e}-01$

$1.00000 \mathrm{e}-021.00000 \mathrm{e}-02$ 1.00000e-03 1.00000e-09 1.00000e-01

$1.00000 \mathrm{e}+001.00000 \mathrm{e}+001.00000 \mathrm{e}-011.00000 \mathrm{e}-091.00000 \mathrm{e}-01$

Element: 7023 \# of layers: 8

Kx Ky Kz Ss Por

$4.65105 \mathrm{e}+024.65105 \mathrm{e}+024.65105 \mathrm{e}+01$ 1.00000e-09 7.00000e-02

$4.65105 \mathrm{e}+024.65105 \mathrm{e}+024.65105 \mathrm{e}+01$ 1.00000e-09 7.00000e-02

$1.85838 \mathrm{e}+011.85838 \mathrm{e}+011.85838 \mathrm{e}+001.00000 \mathrm{e}-092.12000 \mathrm{e}-01$

$1.85838 \mathrm{e}+011.85838 \mathrm{e}+011.85838 \mathrm{e}+001.00000 \mathrm{e}-092.12000 \mathrm{e}-01$

$1.85838 \mathrm{e}+011.85838 \mathrm{e}+011.85838 \mathrm{e}+001.00000 \mathrm{e}-092.12000 \mathrm{e}-01$

$1.85838 \mathrm{e}+011.85838 \mathrm{e}+011.85838 \mathrm{e}+001.00000 \mathrm{e}-092.12000 \mathrm{e}-01$

$1.00000 \mathrm{e}-011.00000 \mathrm{e}-011.00000 \mathrm{e}-021.00000 \mathrm{e}-091.00000 \mathrm{e}-01$

$1.00000 \mathrm{e}+001.00000 \mathrm{e}+001.00000 \mathrm{e}-011.00000 \mathrm{e}-091.00000 \mathrm{e}-01$

Element: 7024 \# of layers: 8

Kx Ky Kz Ss Por

$1.56891 \mathrm{e}+03$ 1.56891e+03 1.56891e+02 1.00000e-09 7.00000e-02 
$1.56891 \mathrm{e}+031.56891 \mathrm{e}+03$ 1.56891e+02 1.00000e-09 7.00000e-02 6.26886e+01 6.26886e+01 6.26886e+00 1.00000e-09 2.12000e-01 $6.26886 \mathrm{e}+016.26886 \mathrm{e}+016.26886 \mathrm{e}+00$ 1.00000e-09 2.12000e-01 $6.26886 \mathrm{e}+016.26886 \mathrm{e}+016.26886 \mathrm{e}+001.00000 \mathrm{e}-092.12000 \mathrm{e}-01$ $6.26886 \mathrm{e}+016.26886 \mathrm{e}+016.26886 \mathrm{e}+001.00000 \mathrm{e}-092.12000 \mathrm{e}-01$ $1.00000 \mathrm{e}-011.00000 \mathrm{e}-01$ 1.00000e-02 1.00000e-09 1.00000e-01 $1.00000 \mathrm{e}+001.00000 \mathrm{e}+001.00000 \mathrm{e}-011.00000 \mathrm{e}-091.00000 \mathrm{e}-01$ Element: 7025 \# of layers: 6

$\mathrm{Kx} \mathrm{Ky} \mathrm{Kz} \mathrm{Ss} \mathrm{Por}$

6.26886e+01 6.26886e+01 6.26886e+00 1.00000e-09 2.12000e-01 $6.26886 \mathrm{e}+016.26886 \mathrm{e}+016.26886 \mathrm{e}+00$ 1.00000e-09 2.12000e-01 $6.26886 \mathrm{e}+016.26886 \mathrm{e}+016.26886 \mathrm{e}+001.00000 \mathrm{e}-092.12000 \mathrm{e}-01$ $6.26886 \mathrm{e}+016.26886 \mathrm{e}+016.26886 \mathrm{e}+001.00000 \mathrm{e}-09$ 2.12000e-01 $1.00000 \mathrm{e}-02$ 1.00000e-02 1.00000e-03 1.00000e-09 1.00000e-01 $1.00000 \mathrm{e}+001.00000 \mathrm{e}+001.00000 \mathrm{e}-01$ 1.00000e-09 1.00000e-01 Element: 7026 \# of layers: 6

$\mathrm{Kx} \mathrm{Ky} \mathrm{Kz}$ Ss Por 6.26886e+01 6.26886e+01 6.26886e+00 1.00000e-09 2.12000e-01 $6.26886 \mathrm{e}+016.26886 \mathrm{e}+01$ 6.26886e+00 1.00000e-09 2.12000e-01 $6.26886 \mathrm{e}+016.26886 \mathrm{e}+016.26886 \mathrm{e}+00$ 1.00000e-09 2.12000e-01 $6.26886 \mathrm{e}+016.26886 \mathrm{e}+016.26886 \mathrm{e}+001.00000 \mathrm{e}-092.12000 \mathrm{e}-01$ $1.00000 \mathrm{e}-02$ 1.00000e-02 1.00000e-03 1.00000e-09 1.00000e-01 $1.00000 \mathrm{e}+001.00000 \mathrm{e}+001.00000 \mathrm{e}-01$ 1.00000e-09 1.00000e-01 Element: 7031 \# of layers: 7

$\mathrm{Kx} \mathrm{Ky} \mathrm{Kz}$ Ss Por $1.22302 \mathrm{e}+031.22302 \mathrm{e}+03$ 1.22302e+02 1.00000e-09 7.00000e-02 $4.88688 \mathrm{e}+014.88688 \mathrm{e}+014.88688 \mathrm{e}+00$ 1.00000e-09 2.12000e-01 $4.88688 \mathrm{e}+014.88688 \mathrm{e}+014.88688 \mathrm{e}+00$ 1.00000e-09 2.12000e-01 $4.88688 \mathrm{e}+014.88688 \mathrm{e}+014.88688 \mathrm{e}+00$ 1.00000e-09 2.12000e-01 $4.88688 \mathrm{e}+014.88688 \mathrm{e}+014.88688 \mathrm{e}+00$ 1.00000e-09 2.12000e-01 $1.00000 \mathrm{e}-011.00000 \mathrm{e}-01$ 1.00000e-02 1.00000e-09 1.00000e-01 $1.00000 \mathrm{e}+001.00000 \mathrm{e}+001.00000 \mathrm{e}-011.00000 \mathrm{e}-091.00000 \mathrm{e}-01$ Element: 7032 \# of layers: 7

$\mathrm{Kx} \mathrm{Ky} \mathrm{Kz}$ Ss Por

1.22302e+03 1.22302e+03 1.22302e+02 1.00000e-09 7.00000e-02 $4.88688 \mathrm{e}+014.88688 \mathrm{e}+014.88688 \mathrm{e}+00$ 1.00000e-09 2.12000e-01 $4.88688 \mathrm{e}+014.88688 \mathrm{e}+014.88688 \mathrm{e}+00$ 1.00000e-09 2.12000e-01 $4.88688 \mathrm{e}+014.88688 \mathrm{e}+014.88688 \mathrm{e}+00$ 1.00000e-09 2.12000e-01 $4.88688 \mathrm{e}+014.88688 \mathrm{e}+014.88688 \mathrm{e}+00$ 1.00000e-09 2.12000e-01 $1.00000 \mathrm{e}-01$ 1.00000e-01 1.00000e-02 1.00000e-09 1.00000e-01 $1.00000 \mathrm{e}+001.00000 \mathrm{e}+001.00000 \mathrm{e}-011.00000 \mathrm{e}-09$ 1.00000e-01 Element: 7033 \# of layers: 7

$\mathrm{Kx} \mathrm{Ky} \mathrm{Kz}$ Ss Por

1.22302e+03 1.22302e+03 1.22302e+02 1.00000e-09 7.00000e-02 $4.88688 \mathrm{e}+014.88688 \mathrm{e}+014.88688 \mathrm{e}+00$ 1.00000e-09 2.12000e-01 $4.88688 \mathrm{e}+014.88688 \mathrm{e}+014.88688 \mathrm{e}+00$ 1.00000e-09 2.12000e-01 
$4.88688 \mathrm{e}+014.88688 \mathrm{e}+014.88688 \mathrm{e}+00$ 1.00000e-09 2.12000e-01 $4.88688 \mathrm{e}+014.88688 \mathrm{e}+014.88688 \mathrm{e}+00$ 1.00000e-09 2.12000e-01 1.00000e-01 1.00000e-01 1.00000e-02 1.00000e-09 1.00000e-01 $1.00000 \mathrm{e}+001.00000 \mathrm{e}+001.00000 \mathrm{e}-011.00000 \mathrm{e}-091.00000 \mathrm{e}-01$ Element: 7034 \# of layers: 6

$\mathrm{Kx} \mathrm{Ky} \mathrm{Kz}$ Ss Por

4.88688e+01 4.88688e+01 4.88688e+00 1.00000e-09 2.12000e-01 $4.88688 \mathrm{e}+014.88688 \mathrm{e}+014.88688 \mathrm{e}+00$ 1.00000e-09 2.12000e-01 $4.88688 \mathrm{e}+014.88688 \mathrm{e}+014.88688 \mathrm{e}+001.00000 \mathrm{e}-092.12000 \mathrm{e}-01$ $4.88688 \mathrm{e}+014.88688 \mathrm{e}+014.88688 \mathrm{e}+00$ 1.00000e-09 2.12000e-01 $1.00000 \mathrm{e}-02$ 1.00000e-02 1.00000e-03 1.00000e-09 1.00000e-01 $1.00000 \mathrm{e}+001.00000 \mathrm{e}+001.00000 \mathrm{e}-011.00000 \mathrm{e}-091.00000 \mathrm{e}-01$ Element: 7035 \# of layers: 6

$\mathrm{Kx} \mathrm{Ky} \mathrm{Kz}$ Ss Por

4.88688e+01 4.88688e+01 4.88688e+00 1.00000e-09 2.12000e-01 $4.88688 \mathrm{e}+014.88688 \mathrm{e}+014.88688 \mathrm{e}+00$ 1.00000e-09 2.12000e-01 $4.88688 \mathrm{e}+014.88688 \mathrm{e}+014.88688 \mathrm{e}+00$ 1.00000e-09 2.12000e-01 $4.88688 \mathrm{e}+014.88688 \mathrm{e}+014.88688 \mathrm{e}+00$ 1.00000e-09 2.12000e-01 $1.00000 \mathrm{e}-02$ 1.00000e-02 1.00000e-03 1.00000e-09 1.00000e-01 $1.00000 \mathrm{e}+001.00000 \mathrm{e}+001.00000 \mathrm{e}-011.00000 \mathrm{e}-091.00000 \mathrm{e}-01$ Element: 7036 \# of layers: 6

$\mathrm{Kx} \mathrm{Ky} \mathrm{Kz}$ Ss Por

4.88688e+01 4.88688e+01 4.88688e+00 1.00000e-09 2.12000e-01 $4.88688 \mathrm{e}+014.88688 \mathrm{e}+014.88688 \mathrm{e}+00$ 1.00000e-09 2.12000e-01 $4.88688 \mathrm{e}+014.88688 \mathrm{e}+014.88688 \mathrm{e}+001.00000 \mathrm{e}-092.12000 \mathrm{e}-01$ $4.88688 \mathrm{e}+014.88688 \mathrm{e}+014.88688 \mathrm{e}+00$ 1.00000e-09 2.12000e-01 $1.00000 \mathrm{e}-02$ 1.00000e-02 1.00000e-03 1.00000e-09 1.00000e-01 $1.00000 \mathrm{e}+001.00000 \mathrm{e}+001.00000 \mathrm{e}-011.00000 \mathrm{e}-09$ 1.00000e-01 Element: 7037 \# of layers: 6

$\mathrm{Kx} \mathrm{Ky} \mathrm{Kz}$ Ss Por

$4.88688 \mathrm{e}+014.88688 \mathrm{e}+014.88688 \mathrm{e}+00$ 1.00000e-09 2.12000e-01 $4.88688 \mathrm{e}+014.88688 \mathrm{e}+014.88688 \mathrm{e}+00$ 1.00000e-09 2.12000e-01 $4.88688 \mathrm{e}+014.88688 \mathrm{e}+014.88688 \mathrm{e}+00$ 1.00000e-09 2.12000e-01 $4.88688 \mathrm{e}+014.88688 \mathrm{e}+014.88688 \mathrm{e}+001.00000 \mathrm{e}-092.12000 \mathrm{e}-01$ $1.00000 \mathrm{e}-02$ 1.00000e-02 1.00000e-03 1.00000e-09 1.00000e-01 $1.00000 \mathrm{e}+001.00000 \mathrm{e}+001.00000 \mathrm{e}-01$ 1.00000e-09 1.00000e-01 Element: 7038 \# of layers: 6

Kx Ky Kz Ss Por 4.88688e+01 4.88688e+01 4.88688e+00 1.00000e-09 2.12000e-01 $4.88688 \mathrm{e}+014.88688 \mathrm{e}+014.88688 \mathrm{e}+00$ 1.00000e-09 2.12000e-01 $4.88688 \mathrm{e}+014.88688 \mathrm{e}+014.88688 \mathrm{e}+00$ 1.00000e-09 2.12000e-01 $4.88688 \mathrm{e}+014.88688 \mathrm{e}+014.88688 \mathrm{e}+00$ 1.00000e-09 2.12000e-01 $1.00000 \mathrm{e}-01$ 1.00000e-01 1.00000e-02 1.00000e-09 1.00000e-01 $1.00000 \mathrm{e}+001.00000 \mathrm{e}+001.00000 \mathrm{e}-01$ 1.00000e-09 1.00000e-01 Element: 7039 \# of layers: 6

Kx Ky Kz Ss Por 
$4.88688 \mathrm{e}+014.88688 \mathrm{e}+014.88688 \mathrm{e}+00$ 1.00000e-09 2.12000e-01 $4.88688 \mathrm{e}+014.88688 \mathrm{e}+01$ 4.88688e+00 1.00000e-09 2.12000e-01 $4.88688 \mathrm{e}+014.88688 \mathrm{e}+014.88688 \mathrm{e}+00$ 1.00000e-09 2.12000e-01 $4.88688 \mathrm{e}+014.88688 \mathrm{e}+014.88688 \mathrm{e}+001.00000 \mathrm{e}-092.12000 \mathrm{e}-01$ $1.00000 \mathrm{e}-011.00000 \mathrm{e}-011.00000 \mathrm{e}-021.00000 \mathrm{e}-091.00000 \mathrm{e}-01$ $1.00000 \mathrm{e}+001.00000 \mathrm{e}+001.00000 \mathrm{e}-011.00000 \mathrm{e}-091.00000 \mathrm{e}-01$ Element: 7040 \# of layers: 8

Kx Ky Kz Ss Por

$1.17590 \mathrm{e}+031.17590 \mathrm{e}+03$ 1.17590e+02 1.00000e-09 7.00000e-02 $1.17590 \mathrm{e}+031.17590 \mathrm{e}+03$ 1.17590e+02 1.00000e-09 7.00000e-02 $4.69832 \mathrm{e}+014.69832 \mathrm{e}+01$ 4.69833e+00 1.00000e-09 2.12000e-01 $4.69832 \mathrm{e}+01$ 4.69832e+01 4.69833e+00 1.00000e-09 2.12000e-01 4.69832e+01 4.69832e+01 4.69833e+00 1.00000e-09 2.12000e-01 $4.69832 \mathrm{e}+014.69832 \mathrm{e}+014.69833 \mathrm{e}+00$ 1.00000e-09 2.12000e-01 $1.00000 \mathrm{e}-02$ 1.00000e-02 1.00000e-03 1.00000e-09 1.00000e-01 $1.00000 \mathrm{e}+001.00000 \mathrm{e}+001.00000 \mathrm{e}-011.00000 \mathrm{e}-091.00000 \mathrm{e}-01$ Element: 7041 \# of layers: 7

$\mathrm{Kx} \mathrm{Ky} \mathrm{Kz}$ Ss Por

1.17590e+03 1.17590e+03 1.17590e+02 1.00000e-09 7.00000e-02 $4.69832 \mathrm{e}+014.69832 \mathrm{e}+014.69833 \mathrm{e}+00$ 1.00000e-09 2.12000e-01 $4.69832 \mathrm{e}+014.69832 \mathrm{e}+014.69833 \mathrm{e}+001.00000 \mathrm{e}-092.12000 \mathrm{e}-01$ $4.69832 \mathrm{e}+014.69832 \mathrm{e}+01$ 4.69833e+00 1.00000e-09 2.12000e-01 4.69832e+01 4.69832e+01 4.69833e+00 1.00000e-09 2.12000e-01 $1.00000 \mathrm{e}-02$ 1.00000e-02 1.00000e-03 1.00000e-09 1.00000e-01 $1.00000 \mathrm{e}+001.00000 \mathrm{e}+001.00000 \mathrm{e}-011.00000 \mathrm{e}-091.00000 \mathrm{e}-01$ Element: 7042 \# of layers: 8

Kx Ky Kz Ss Por

$1.17590 \mathrm{e}+03$ 1.17590e+03 1.17590e+02 1.00000e-09 7.00000e-02 $1.17590 \mathrm{e}+03$ 1.17590e+03 1.17590e+02 1.00000e-09 7.00000e-02 4.69832e+01 4.69832e+01 4.69833e+00 1.00000e-09 2.12000e-01 $4.69832 \mathrm{e}+014.69832 \mathrm{e}+014.69833 \mathrm{e}+00$ 1.00000e-09 2.12000e-01 $4.69832 \mathrm{e}+014.69832 \mathrm{e}+01$ 4.69833e+00 1.00000e-09 2.12000e-01 $4.69832 \mathrm{e}+014.69832 \mathrm{e}+014.69833 \mathrm{e}+00$ 1.00000e-09 2.12000e-01 $1.00000 \mathrm{e}-02$ 1.00000e-02 1.00000e-03 1.00000e-09 1.00000e-01 $1.00000 \mathrm{e}+001.00000 \mathrm{e}+001.00000 \mathrm{e}-011.00000 \mathrm{e}-091.00000 \mathrm{e}-01$ Element: 7043 \# of layers: 6

Kx Ky Kz Ss Por 4.69832e+01 4.69832e+01 4.69833e+00 1.00000e-09 2.12000e-01 4.69832e+01 4.69832e+01 4.69833e+00 1.00000e-09 2.12000e-01 $4.69832 \mathrm{e}+014.69832 \mathrm{e}+01$ 4.69833e+00 1.00000e-09 2.12000e-01 $4.69832 \mathrm{e}+014.69832 \mathrm{e}+01$ 4.69833e+00 1.00000e-09 2.12000e-01 $1.00000 \mathrm{e}-02$ 1.00000e-02 1.00000e-03 1.00000e-09 1.00000e-01 $1.00000 \mathrm{e}+001.00000 \mathrm{e}+001.00000 \mathrm{e}-01$ 1.00000e-09 1.00000e-01 Element: 7044 \# of layers: 6

$\mathrm{Kx} \mathrm{Ky} \mathrm{Kz} \mathrm{Ss} \mathrm{Por}$ 4.69832e+01 4.69832e+01 4.69833e+00 1.00000e-09 2.12000e-01 
4.69832e+01 4.69832e+01 4.69833e+00 1.00000e-09 2.12000e-01 $4.69832 \mathrm{e}+014.69832 \mathrm{e}+01$ 4.69833e+00 1.00000e-09 2.12000e-01 4.69832e+01 4.69832e+01 4.69833e+00 1.00000e-09 2.12000e-01 $1.00000 \mathrm{e}-02$ 1.00000e-02 1.00000e-03 1.00000e-09 1.00000e-01 $1.00000 \mathrm{e}+001.00000 \mathrm{e}+001.00000 \mathrm{e}-01$ 1.00000e-09 1.00000e-01 Element: 7045 \# of layers: 6

$\mathrm{Kx} \mathrm{Ky} \mathrm{Kz}$ Ss Por

4.69832e+01 4.69832e+01 4.69833e+00 1.00000e-09 2.12000e-01 4.69832e+01 4.69832e+01 4.69833e+00 1.00000e-09 2.12000e-01 4.69832e+01 4.69832e+01 4.69833e+00 1.00000e-09 2.12000e-01 $4.69832 \mathrm{e}+014.69832 \mathrm{e}+014.69833 \mathrm{e}+00$ 1.00000e-09 2.12000e-01 $1.00000 \mathrm{e}-02$ 1.00000e-02 1.00000e-03 1.00000e-09 1.00000e-01 $1.00000 \mathrm{e}+001.00000 \mathrm{e}+001.00000 \mathrm{e}-011.00000 \mathrm{e}-091.00000 \mathrm{e}-01$ Element: 7046 \# of layers: 6

$\mathrm{Kx} \mathrm{Ky} \mathrm{Kz}$ Ss Por 4.69832e+01 4.69832e+01 4.69833e+00 1.00000e-09 2.12000e-01 4.69832e+01 4.69832e+01 4.69833e+00 1.00000e-09 2.12000e-01 4.69832e+01 4.69832e+01 4.69833e+00 1.00000e-09 2.12000e-01 4.69832e+01 4.69832e+01 4.69833e+00 1.00000e-09 2.12000e-01 $1.00000 \mathrm{e}-02$ 1.00000e-02 1.00000e-03 1.00000e-09 1.00000e-01 $1.00000 \mathrm{e}+001.00000 \mathrm{e}+001.00000 \mathrm{e}-011.00000 \mathrm{e}-091.00000 \mathrm{e}-01$ Element: 7047 \# of layers: 6

$\mathrm{Kx} \mathrm{Ky} \mathrm{Kz}$ Ss Por 4.69832e+01 4.69832e+01 4.69833e+00 1.00000e-09 2.12000e-01 $4.69832 \mathrm{e}+014.69832 \mathrm{e}+01$ 4.69833e+00 1.00000e-09 2.12000e-01 $4.69832 \mathrm{e}+014.69832 \mathrm{e}+014.69833 \mathrm{e}+001.00000 \mathrm{e}-092.12000 \mathrm{e}-01$ $4.69832 \mathrm{e}+014.69832 \mathrm{e}+01$ 4.69833e+00 1.00000e-09 2.12000e-01 $1.00000 \mathrm{e}-021.00000 \mathrm{e}-021.00000 \mathrm{e}-031.00000 \mathrm{e}-091.00000 \mathrm{e}-01$ $1.00000 \mathrm{e}+001.00000 \mathrm{e}+001.00000 \mathrm{e}-011.00000 \mathrm{e}-091.00000 \mathrm{e}-01$ Element: 7048 \# of layers: 6

$\mathrm{Kx} \mathrm{Ky} \mathrm{Kz}$ Ss Por

4.69832e+01 4.69832e+01 4.69833e+00 1.00000e-09 2.12000e-01 $4.69832 \mathrm{e}+014.69832 \mathrm{e}+014.69833 \mathrm{e}+00$ 1.00000e-09 2.12000e-01 4.69832e+01 4.69832e+01 4.69833e+00 1.00000e-09 2.12000e-01 4.69832e+01 4.69832e+01 4.69833e+00 1.00000e-09 2.12000e-01 $1.00000 \mathrm{e}-02$ 1.00000e-02 1.00000e-03 1.00000e-09 1.00000e-01 $1.00000 \mathrm{e}+001.00000 \mathrm{e}+001.00000 \mathrm{e}-011.00000 \mathrm{e}-091.00000 \mathrm{e}-01$ Element: 7049 \# of layers: 8

$\mathrm{Kx} \mathrm{Ky} \mathrm{Kz}$ Ss Por

7.52416e+02 7.52416e+02 7.52416e+01 1.00000e-09 7.00000e-02 $7.52416 \mathrm{e}+02$ 7.52416e+02 7.52416e+01 1.00000e-09 7.00000e-02 $3.00629 \mathrm{e}+013.00629 \mathrm{e}+013.00629 \mathrm{e}+001.00000 \mathrm{e}-092.12000 \mathrm{e}-01$ $3.00629 \mathrm{e}+013.00629 \mathrm{e}+013.00629 \mathrm{e}+001.00000 \mathrm{e}-092.12000 \mathrm{e}-01$ $3.00629 \mathrm{e}+013.00629 \mathrm{e}+013.00629 \mathrm{e}+001.00000 \mathrm{e}-092.12000 \mathrm{e}-01$ $3.00629 \mathrm{e}+013.00629 \mathrm{e}+013.00629 \mathrm{e}+001.00000 \mathrm{e}-092.12000 \mathrm{e}-01$ $1.00000 \mathrm{e}-02$ 1.00000e-02 1.00000e-03 1.00000e-09 1.00000e-01 
$1.00000 \mathrm{e}+001.00000 \mathrm{e}+00$ 1.00000e-01 1.00000e-09 1.00000e-01

Element: 7050 \# of layers: 7

$\mathrm{Kx} \mathrm{Ky} \mathrm{Kz}$ Ss Por

7.52416e+02 7.52416e+02 7.52416e+01 1.00000e-09 7.00000e-02

$3.00629 \mathrm{e}+013.00629 \mathrm{e}+013.00629 \mathrm{e}+001.00000 \mathrm{e}-092.12000 \mathrm{e}-01$

$3.00629 \mathrm{e}+013.00629 \mathrm{e}+013.00629 \mathrm{e}+001.00000 \mathrm{e}-092.12000 \mathrm{e}-01$

$3.00629 \mathrm{e}+013.00629 \mathrm{e}+013.00629 \mathrm{e}+001.00000 \mathrm{e}-092.12000 \mathrm{e}-01$

$3.00629 \mathrm{e}+013.00629 \mathrm{e}+013.00629 \mathrm{e}+001.00000 \mathrm{e}-092.12000 \mathrm{e}-01$

$1.00000 \mathrm{e}-02$ 1.00000e-02 1.00000e-03 1.00000e-09 1.00000e-01

$1.00000 \mathrm{e}+001.00000 \mathrm{e}+001.00000 \mathrm{e}-011.00000 \mathrm{e}-091.00000 \mathrm{e}-01$

Element: 7051 \# of layers: 7

Kx Ky Kz Ss Por

7.52416e+02 7.52416e+02 7.52416e+01 1.00000e-09 7.00000e-02

$3.00629 \mathrm{e}+013.00629 \mathrm{e}+013.00629 \mathrm{e}+001.00000 \mathrm{e}-092.12000 \mathrm{e}-01$

$3.00629 \mathrm{e}+013.00629 \mathrm{e}+013.00629 \mathrm{e}+001.00000 \mathrm{e}-092.12000 \mathrm{e}-01$

$3.00629 \mathrm{e}+013.00629 \mathrm{e}+013.00629 \mathrm{e}+001.00000 \mathrm{e}-092.12000 \mathrm{e}-01$

$3.00629 \mathrm{e}+013.00629 \mathrm{e}+013.00629 \mathrm{e}+001.00000 \mathrm{e}-092.12000 \mathrm{e}-01$

$1.00000 \mathrm{e}-021.00000 \mathrm{e}-021.00000 \mathrm{e}-031.00000 \mathrm{e}-091.00000 \mathrm{e}-01$

$1.00000 \mathrm{e}+001.00000 \mathrm{e}+001.00000 \mathrm{e}-011.00000 \mathrm{e}-091.00000 \mathrm{e}-01$

Element: 7052 \# of layers: 6

$\mathrm{Kx} \mathrm{Ky} \mathrm{Kz}$ Ss Por

$3.00629 \mathrm{e}+013.00629 \mathrm{e}+013.00629 \mathrm{e}+00$ 1.00000e-09 2.12000e-01

$3.00629 \mathrm{e}+013.00629 \mathrm{e}+013.00629 \mathrm{e}+001.00000 \mathrm{e}-092.12000 \mathrm{e}-01$

$3.00629 \mathrm{e}+013.00629 \mathrm{e}+013.00629 \mathrm{e}+001.00000 \mathrm{e}-092.12000 \mathrm{e}-01$

$3.00629 \mathrm{e}+013.00629 \mathrm{e}+013.00629 \mathrm{e}+001.00000 \mathrm{e}-092.12000 \mathrm{e}-01$

$1.00000 \mathrm{e}-02$ 1.00000e-02 1.00000e-03 1.00000e-09 1.00000e-01

$1.00000 \mathrm{e}+001.00000 \mathrm{e}+001.00000 \mathrm{e}-011.00000 \mathrm{e}-09$ 1.00000e-01

Element: 7053 \# of layers: 6

$\mathrm{Kx} \mathrm{Ky} \mathrm{Kz}$ Ss Por

$3.00629 \mathrm{e}+013.00629 \mathrm{e}+013.00629 \mathrm{e}+001.00000 \mathrm{e}-092.12000 \mathrm{e}-01$

$3.00629 \mathrm{e}+013.00629 \mathrm{e}+013.00629 \mathrm{e}+00$ 1.00000e-09 2.12000e-01

$3.00629 \mathrm{e}+013.00629 \mathrm{e}+013.00629 \mathrm{e}+00$ 1.00000e-09 2.12000e-01

$3.00629 \mathrm{e}+013.00629 \mathrm{e}+013.00629 \mathrm{e}+00$ 1.00000e-09 2.12000e-01

$1.00000 \mathrm{e}-02$ 1.00000e-02 1.00000e-03 1.00000e-09 1.00000e-01

$1.00000 \mathrm{e}+001.00000 \mathrm{e}+001.00000 \mathrm{e}-01$ 1.00000e-09 1.00000e-01

Element: 7054 \# of layers: 6

$\mathrm{Kx} \mathrm{Ky} \mathrm{Kz}$ Ss Por

$3.00629 \mathrm{e}+013.00629 \mathrm{e}+013.00629 \mathrm{e}+001.00000 \mathrm{e}-092.12000 \mathrm{e}-01$

$3.00629 \mathrm{e}+013.00629 \mathrm{e}+013.00629 \mathrm{e}+001.00000 \mathrm{e}-092.12000 \mathrm{e}-01$

$3.00629 \mathrm{e}+013.00629 \mathrm{e}+013.00629 \mathrm{e}+001.00000 \mathrm{e}-092.12000 \mathrm{e}-01$

$3.00629 \mathrm{e}+013.00629 \mathrm{e}+013.00629 \mathrm{e}+00$ 1.00000e-09 2.12000e-01

$1.00000 \mathrm{e}-02$ 1.00000e-02 1.00000e-03 1.00000e-09 1.00000e-01

$1.00000 \mathrm{e}+001.00000 \mathrm{e}+001.00000 \mathrm{e}-01$ 1.00000e-09 1.00000e-01

Element: 7055 \# of layers: 6

$\mathrm{Kx} \mathrm{Ky} \mathrm{Kz} \mathrm{Ss} \mathrm{Por}$

3.00629e+01 3.00629e+01 3.00629e+00 1.00000e-09 2.12000e-01 
3.00629e+01 3.00629e+01 3.00629e+00 1.00000e-09 2.12000e-01 $3.00629 \mathrm{e}+013.00629 \mathrm{e}+013.00629 \mathrm{e}+001.00000 \mathrm{e}-092.12000 \mathrm{e}-01$ $3.00629 \mathrm{e}+013.00629 \mathrm{e}+013.00629 \mathrm{e}+00$ 1.00000e-09 2.12000e-01 $1.00000 \mathrm{e}-02$ 1.00000e-02 1.00000e-03 1.00000e-09 1.00000e-01 $1.00000 \mathrm{e}+001.00000 \mathrm{e}+001.00000 \mathrm{e}-01$ 1.00000e-09 1.00000e-01 Element: 7056 \# of layers: 6

$\mathrm{Kx} \mathrm{Ky} \mathrm{Kz}$ Ss Por

3.00629e+01 3.00629e+01 3.00629e+00 1.00000e-09 2.12000e-01 $3.00629 \mathrm{e}+013.00629 \mathrm{e}+013.00629 \mathrm{e}+001.00000 \mathrm{e}-092.12000 \mathrm{e}-01$ $3.00629 \mathrm{e}+013.00629 \mathrm{e}+013.00629 \mathrm{e}+001.00000 \mathrm{e}-092.12000 \mathrm{e}-01$ $3.00629 \mathrm{e}+013.00629 \mathrm{e}+013.00629 \mathrm{e}+00$ 1.00000e-09 2.12000e-01 $1.00000 \mathrm{e}-02$ 1.00000e-02 1.00000e-03 1.00000e-09 1.00000e-01 $1.00000 \mathrm{e}+001.00000 \mathrm{e}+001.00000 \mathrm{e}-011.00000 \mathrm{e}-091.00000 \mathrm{e}-01$ Element: 7057 \# of layers: 6

$\mathrm{Kx} \mathrm{Ky} \mathrm{Kz}$ Ss Por

$3.00629 \mathrm{e}+013.00629 \mathrm{e}+013.00629 \mathrm{e}+00$ 1.00000e-09 2.12000e-01 $3.00629 \mathrm{e}+013.00629 \mathrm{e}+013.00629 \mathrm{e}+001.00000 \mathrm{e}-092.12000 \mathrm{e}-01$ $3.00629 \mathrm{e}+013.00629 \mathrm{e}+013.00629 \mathrm{e}+001.00000 \mathrm{e}-092.12000 \mathrm{e}-01$ $3.00629 \mathrm{e}+013.00629 \mathrm{e}+013.00629 \mathrm{e}+001.00000 \mathrm{e}-092.12000 \mathrm{e}-01$ $1.00000 \mathrm{e}-02$ 1.00000e-02 1.00000e-03 1.00000e-09 1.00000e-01 $1.00000 \mathrm{e}+001.00000 \mathrm{e}+001.00000 \mathrm{e}-011.00000 \mathrm{e}-091.00000 \mathrm{e}-01$ Element: 7058 \# of layers: 7

$\mathrm{Kx} \mathrm{Ky} \mathrm{Kz}$ Ss Por

5.13489e+02 5.13489e+02 5.13489e+01 1.00000e-09 7.00000e-02 $2.05173 \mathrm{e}+012.05173 \mathrm{e}+012.05173 \mathrm{e}+001.00000 \mathrm{e}-092.12000 \mathrm{e}-01$ $2.05173 \mathrm{e}+012.05173 \mathrm{e}+012.05173 \mathrm{e}+001.00000 \mathrm{e}-092.12000 \mathrm{e}-01$ $2.05173 \mathrm{e}+012.05173 \mathrm{e}+012.05173 \mathrm{e}+00$ 1.00000e-09 2.12000e-01 $2.05173 \mathrm{e}+012.05173 \mathrm{e}+012.05173 \mathrm{e}+00$ 1.00000e-09 2.12000e-01 $1.00000 \mathrm{e}-02$ 1.00000e-02 1.00000e-03 1.00000e-09 1.00000e-01 $1.00000 \mathrm{e}+001.00000 \mathrm{e}+001.00000 \mathrm{e}-011.00000 \mathrm{e}-091.00000 \mathrm{e}-01$ Element: 7059 \# of layers: 7

Kx Ky Kz Ss Por

5.13489e+02 5.13489e+02 5.13489e+01 1.00000e-09 7.00000e-02 $2.05173 \mathrm{e}+012.05173 \mathrm{e}+012.05173 \mathrm{e}+00$ 1.00000e-09 2.12000e-01 $2.05173 \mathrm{e}+012.05173 \mathrm{e}+012.05173 \mathrm{e}+00$ 1.00000e-09 2.12000e-01 $2.05173 \mathrm{e}+012.05173 \mathrm{e}+01$ 2.05173e+00 1.00000e-09 2.12000e-01 $2.05173 \mathrm{e}+012.05173 \mathrm{e}+012.05173 \mathrm{e}+001.00000 \mathrm{e}-092.12000 \mathrm{e}-01$ $1.00000 \mathrm{e}-02$ 1.00000e-02 1.00000e-03 1.00000e-09 1.00000e-01 $1.00000 \mathrm{e}+001.00000 \mathrm{e}+001.00000 \mathrm{e}-011.00000 \mathrm{e}-09$ 1.00000e-01 Element: 7060 \# of layers: 6

$\mathrm{Kx} \mathrm{Ky} \mathrm{Kz}$ Ss Por

5.13489e+02 5.13489e+02 5.13489e+01 1.00000e-09 7.00000e-02 $2.05173 \mathrm{e}+012.05173 \mathrm{e}+01$ 2.05173e+00 1.00000e-09 2.12000e-01 2.05173e+01 2.05173e+01 2.05173e+00 1.00000e-09 2.12000e-01 $2.05173 \mathrm{e}+012.05173 \mathrm{e}+012.05173 \mathrm{e}+00$ 1.00000e-09 2.12000e-01 $1.00000 \mathrm{e}-02$ 1.00000e-02 1.00000e-03 1.00000e-09 1.00000e-01 
$1.00000 \mathrm{e}+001.00000 \mathrm{e}+00$ 1.00000e-01 1.00000e-09 1.00000e-01

Element: 7061 \# of layers: 7

$\mathrm{Kx} \mathrm{Ky} \mathrm{Kz}$ Ss Por

5.13489e+02 5.13489e+02 5.13489e+01 1.00000e-09 7.00000e-02

$2.05173 \mathrm{e}+012.05173 \mathrm{e}+012.05173 \mathrm{e}+001.00000 \mathrm{e}-092.12000 \mathrm{e}-01$

$2.05173 \mathrm{e}+012.05173 \mathrm{e}+012.05173 \mathrm{e}+00$ 1.00000e-09 2.12000e-01

$2.05173 \mathrm{e}+012.05173 \mathrm{e}+012.05173 \mathrm{e}+00$ 1.00000e-09 2.12000e-01

$2.05173 \mathrm{e}+012.05173 \mathrm{e}+012.05173 \mathrm{e}+00$ 1.00000e-09 2.12000e-01

$1.00000 \mathrm{e}-02$ 1.00000e-02 1.00000e-03 1.00000e-09 1.00000e-01

$1.00000 \mathrm{e}+001.00000 \mathrm{e}+001.00000 \mathrm{e}-011.00000 \mathrm{e}-091.00000 \mathrm{e}-01$

Element: 7062 \# of layers: 6

Kx Ky Kz Ss Por

2.05173e+01 2.05173e+01 2.05173e+00 1.00000e-09 2.12000e-01

$2.05173 \mathrm{e}+012.05173 \mathrm{e}+012.05173 \mathrm{e}+00$ 1.00000e-09 2.12000e-01

$2.05173 \mathrm{e}+012.05173 \mathrm{e}+012.05173 \mathrm{e}+00$ 1.00000e-09 2.12000e-01

$2.05173 \mathrm{e}+012.05173 \mathrm{e}+012.05173 \mathrm{e}+00$ 1.00000e-09 2.12000e-01

1.00000e-02 1.00000e-02 1.00000e-03 1.00000e-09 1.00000e-01

$1.00000 \mathrm{e}+001.00000 \mathrm{e}+001.00000 \mathrm{e}-01$ 1.00000e-09 1.00000e-01

Element: 7063 \# of layers: 6

$\mathrm{Kx} \mathrm{Ky} \mathrm{Kz}$ Ss Por

$2.05173 \mathrm{e}+012.05173 \mathrm{e}+012.05173 \mathrm{e}+001.00000 \mathrm{e}-092.12000 \mathrm{e}-01$

$2.05173 \mathrm{e}+012.05173 \mathrm{e}+012.05173 \mathrm{e}+00$ 1.00000e-09 2.12000e-01

$2.05173 \mathrm{e}+012.05173 \mathrm{e}+012.05173 \mathrm{e}+00$ 1.00000e-09 2.12000e-01

$2.05173 \mathrm{e}+012.05173 \mathrm{e}+012.05173 \mathrm{e}+001.00000 \mathrm{e}-092.12000 \mathrm{e}-01$

$1.00000 \mathrm{e}-02$ 1.00000e-02 1.00000e-03 1.00000e-09 1.00000e-01

$1.00000 \mathrm{e}+001.00000 \mathrm{e}+001.00000 \mathrm{e}-01$ 1.00000e-09 1.00000e-01

Element: 7064 \# of layers: 6

$\mathrm{Kx} \mathrm{Ky} \mathrm{Kz} \mathrm{Ss} \mathrm{Por}$

$2.05173 e+012.05173 e+012.05173 e+001.00000 e-092.12000 e-01$

$2.05173 \mathrm{e}+012.05173 \mathrm{e}+012.05173 \mathrm{e}+00$ 1.00000e-09 2.12000e-01

$2.05173 \mathrm{e}+012.05173 \mathrm{e}+012.05173 \mathrm{e}+001.00000 \mathrm{e}-092.12000 \mathrm{e}-01$

$2.05173 \mathrm{e}+012.05173 \mathrm{e}+012.05173 \mathrm{e}+00$ 1.00000e-09 2.12000e-01

$1.00000 \mathrm{e}-02$ 1.00000e-02 1.00000e-03 1.00000e-09 1.00000e-01

$1.00000 \mathrm{e}+001.00000 \mathrm{e}+001.00000 \mathrm{e}-011.00000 \mathrm{e}-091.00000 \mathrm{e}-01$

Element: 7065 \# of layers: 6

Kx Ky Kz Ss Por

2.05173e+01 2.05173e+01 2.05173e+00 1.00000e-09 2.12000e-01

$2.05173 \mathrm{e}+012.05173 \mathrm{e}+012.05173 \mathrm{e}+00$ 1.00000e-09 2.12000e-01

$2.05173 \mathrm{e}+012.05173 \mathrm{e}+012.05173 \mathrm{e}+00$ 1.00000e-09 2.12000e-01

$2.05173 \mathrm{e}+012.05173 \mathrm{e}+012.05173 \mathrm{e}+00$ 1.00000e-09 2.12000e-01

$1.00000 \mathrm{e}-02$ 1.00000e-02 1.00000e-03 1.00000e-09 1.00000e-01

$1.00000 \mathrm{e}+001.00000 \mathrm{e}+001.00000 \mathrm{e}-011.00000 \mathrm{e}-091.00000 \mathrm{e}-01$

Element: 7066 \# of layers: 7

$\mathrm{Kx} \mathrm{Ky} \mathrm{Kz}$ Ss Por

5.13489e+02 5.13489e+02 5.13489e+01 1.00000e-09 7.00000e-02

$2.05173 e+012.05173 e+012.05173 e+001.00000 e-092.12000 e-01$ 
2.05173e+01 2.05173e+01 2.05173e+00 1.00000e-09 2.12000e-01 $2.05173 \mathrm{e}+012.05173 \mathrm{e}+012.05173 \mathrm{e}+00$ 1.00000e-09 2.12000e-01 $2.05173 \mathrm{e}+012.05173 \mathrm{e}+012.05173 \mathrm{e}+00$ 1.00000e-09 2.12000e-01 $1.00000 \mathrm{e}-02$ 1.00000e-02 1.00000e-03 1.00000e-09 1.00000e-01 $1.00000 \mathrm{e}+001.00000 \mathrm{e}+001.00000 \mathrm{e}-01$ 1.00000e-09 1.00000e-01 Element: 7067 \# of layers: 6

$\mathrm{Kx} \mathrm{Ky} \mathrm{Kz}$ Ss Por

8.28199e+03 8.28199e+03 8.28199e+02 1.00000e-09 7.00000e-02 $3.30915 \mathrm{e}+02$ 3.30915e+02 3.30915e+01 1.00000e-09 2.12000e-01 $3.30915 \mathrm{e}+02$ 3.30915e+02 3.30915e+01 1.00000e-09 2.12000e-01 $3.30915 \mathrm{e}+02$ 3.30915e+02 3.30915e+01 1.00000e-09 2.12000e-01 $1.00000 \mathrm{e}-02$ 1.00000e-02 1.00000e-03 1.00000e-09 1.00000e-01 $1.00000 \mathrm{e}+001.00000 \mathrm{e}+001.00000 \mathrm{e}-011.00000 \mathrm{e}-091.00000 \mathrm{e}-01$ Element: 7068 \# of layers: 6

$\mathrm{Kx} \mathrm{Ky} \mathrm{Kz}$ Ss Por

8.28199e+03 8.28199e+03 8.28199e+02 1.00000e-09 7.00000e-02 $3.30915 \mathrm{e}+02$ 3.30915e+02 3.30915e+01 1.00000e-09 2.12000e-01 $3.30915 \mathrm{e}+02$ 3.30915e+02 3.30915e+01 1.00000e-09 2.12000e-01 $3.30915 \mathrm{e}+02$ 3.30915e+02 3.30915e+01 1.00000e-09 2.12000e-01 $1.00000 \mathrm{e}-02$ 1.00000e-02 1.00000e-03 1.00000e-09 1.00000e-01 $1.00000 \mathrm{e}+001.00000 \mathrm{e}+001.00000 \mathrm{e}-011.00000 \mathrm{e}-091.00000 \mathrm{e}-01$ Element: 7069 \# of layers: 6

$\mathrm{Kx} \mathrm{Ky} \mathrm{Kz}$ Ss Por

8.28199e+03 8.28199e+03 8.28199e+02 1.00000e-09 7.00000e-02 $3.30915 \mathrm{e}+02$ 3.30915e+02 3.30915e+01 1.00000e-09 2.12000e-01 $3.30915 \mathrm{e}+02$ 3.30915e+02 3.30915e+01 1.00000e-09 2.12000e-01 $3.30915 \mathrm{e}+02$ 3.30915e+02 3.30915e+01 1.00000e-09 2.12000e-01 $1.00000 \mathrm{e}-02$ 1.00000e-02 1.00000e-03 1.00000e-09 1.00000e-01 $1.00000 \mathrm{e}+001.00000 \mathrm{e}+001.00000 \mathrm{e}-011.00000 \mathrm{e}-091.00000 \mathrm{e}-01$ Element: 7070 \# of layers: 6

$\mathrm{Kx} \mathrm{Ky} \mathrm{Kz}$ Ss Por

8.28199e+03 8.28199e+03 8.28199e+02 1.00000e-09 7.00000e-02 $3.30915 \mathrm{e}+023.30915 \mathrm{e}+023.30915 \mathrm{e}+01$ 1.00000e-09 2.12000e-01 $3.30915 \mathrm{e}+02$ 3.30915e+02 3.30915e+01 1.00000e-09 2.12000e-01 $3.30915 \mathrm{e}+02$ 3.30915e+02 3.30915e+01 1.00000e-09 2.12000e-01 $1.00000 \mathrm{e}-02$ 1.00000e-02 1.00000e-03 1.00000e-09 1.00000e-01 $1.00000 \mathrm{e}+001.00000 \mathrm{e}+001.00000 \mathrm{e}-011.00000 \mathrm{e}-091.00000 \mathrm{e}-01$ Element: 7071 \# of layers: 6

$\mathrm{Kx} \mathrm{Ky} \mathrm{Kz}$ Ss Por

8.28199e+03 8.28199e+03 8.28199e+02 1.00000e-09 7.00000e-02 $3.30915 \mathrm{e}+023.30915 \mathrm{e}+023.30915 \mathrm{e}+01$ 1.00000e-09 2.12000e-01 $3.30915 \mathrm{e}+02$ 3.30915e+02 3.30915e+01 1.00000e-09 2.12000e-01 3.30915e+02 3.30915e+02 3.30915e+01 1.00000e-09 2.12000e-01 $1.00000 \mathrm{e}-02$ 1.00000e-02 1.00000e-03 1.00000e-09 1.00000e-01 $1.00000 \mathrm{e}+001.00000 \mathrm{e}+001.00000 \mathrm{e}-01$ 1.00000e-09 1.00000e-01 Element: 7072 \# of layers: 6 
$\mathrm{Kx} \mathrm{Ky} \mathrm{Kz}$ Ss Por

8.28199e+03 8.28199e+03 8.28199e+02 1.00000e-09 7.00000e-02

$3.30915 \mathrm{e}+02$ 3.30915e+02 3.30915e+01 1.00000e-09 2.12000e-01

$3.30915 \mathrm{e}+02$ 3.30915e+02 3.30915e+01 1.00000e-09 2.12000e-01

$3.30915 \mathrm{e}+02$ 3.30915e+02 3.30915e+01 1.00000e-09 2.12000e-01

$1.00000 \mathrm{e}-02$ 1.00000e-02 1.00000e-03 1.00000e-09 1.00000e-01

$1.00000 \mathrm{e}+001.00000 \mathrm{e}+001.00000 \mathrm{e}-011.00000 \mathrm{e}-091.00000 \mathrm{e}-01$

Element: 7073 \# of layers: 7

$\mathrm{Kx} \mathrm{Ky} \mathrm{Kz}$ Ss Por

8.28199e+03 8.28199e+03 8.28199e+02 1.00000e-09 7.00000e-02

$3.30915 \mathrm{e}+02$ 3.30915e+02 3.30915e+01 1.00000e-09 2.12000e-01

$3.30915 \mathrm{e}+02$ 3.30915e+02 3.30915e+01 1.00000e-09 2.12000e-01

$3.30915 \mathrm{e}+02$ 3.30915e+02 3.30915e+01 1.00000e-09 2.12000e-01

$3.30915 \mathrm{e}+02$ 3.30915e+02 3.30915e+01 1.00000e-09 2.12000e-01

$1.00000 \mathrm{e}-02$ 1.00000e-02 1.00000e-03 1.00000e-09 1.00000e-01

$1.00000 \mathrm{e}+001.00000 \mathrm{e}+001.00000 \mathrm{e}-011.00000 \mathrm{e}-091.00000 \mathrm{e}-01$

Element: 7074 \# of layers: 6

$\mathrm{Kx} \mathrm{Ky} \mathrm{Kz}$ Ss Por

8.28199e+03 8.28199e+03 8.28199e+02 1.00000e-09 7.00000e-02

$3.30915 \mathrm{e}+023.30915 \mathrm{e}+023.30915 \mathrm{e}+01$ 1.00000e-09 2.12000e-01

$3.30915 \mathrm{e}+02$ 3.30915e+02 3.30915e+01 1.00000e-09 2.12000e-01

$3.30915 \mathrm{e}+02$ 3.30915e+02 3.30915e+01 1.00000e-09 2.12000e-01

$1.00000 \mathrm{e}-02$ 1.00000e-02 1.00000e-03 1.00000e-09 1.00000e-01

$1.00000 \mathrm{e}+001.00000 \mathrm{e}+001.00000 \mathrm{e}-011.00000 \mathrm{e}-091.00000 \mathrm{e}-01$

Element: 7075 \# of layers: 6

$\mathrm{Kx} \mathrm{Ky} \mathrm{Kz}$ Ss Por

8.28199e+03 8.28199e+03 8.28199e+02 1.00000e-09 7.00000e-02

$3.30915 \mathrm{e}+02$ 3.30915e+02 3.30915e+01 1.00000e-09 2.12000e-01

$3.30915 \mathrm{e}+02$ 3.30915e+02 3.30915e+01 1.00000e-09 2.12000e-01

$3.30915 \mathrm{e}+02$ 3.30915e+02 3.30915e+01 1.00000e-09 2.12000e-01

$1.00000 \mathrm{e}-02$ 1.00000e-02 1.00000e-03 1.00000e-09 1.00000e-01

$1.00000 \mathrm{e}+001.00000 \mathrm{e}+001.00000 \mathrm{e}-01$ 1.00000e-09 1.00000e-01

Element: 7076 \# of layers: 6

$\mathrm{Kx} \mathrm{Ky} \mathrm{Kz}$ Ss Por

1.36339e+04 1.36339e+04 1.36339e+03 1.00000e-09 7.00000e-02 $5.44782 \mathrm{e}+025.44782 \mathrm{e}+02$ 5.44782e+01 1.00000e-09 2.12000e-01 $5.44782 \mathrm{e}+025.44782 \mathrm{e}+025.44782 \mathrm{e}+01$ 1.00000e-09 2.12000e-01 $5.44782 \mathrm{e}+025.44782 \mathrm{e}+02$ 5.44782e+01 1.00000e-09 2.12000e-01 $1.00000 \mathrm{e}-02$ 1.00000e-02 1.00000e-03 1.00000e-09 1.00000e-01

$1.00000 \mathrm{e}+001.00000 \mathrm{e}+001.00000 \mathrm{e}-01$ 1.00000e-09 1.00000e-01

Element: 7077 \# of layers: 5

Kx Ky Kz Ss Por

$1.36339 \mathrm{e}+04$ 1.36339e+04 1.36339e+03 1.00000e-09 7.00000e-02 5.44782e+02 5.44782e+02 5.44782e+01 1.00000e-09 2.12000e-01 5.44782e+02 5.44782e+02 5.44782e+01 1.00000e-09 2.12000e-01 $1.00000 \mathrm{e}-02$ 1.00000e-02 1.00000e-03 1.00000e-09 1.00000e-01 
$1.00000 \mathrm{e}+001.00000 \mathrm{e}+00$ 1.00000e-01 1.00000e-09 1.00000e-01

Element: 7078 \# of layers: 5

Kx Ky Kz Ss Por

1.36339e+04 1.36339e+04 1.36339e+03 1.00000e-09 7.00000e-02

$5.44782 \mathrm{e}+025.44782 \mathrm{e}+025.44782 \mathrm{e}+01$ 1.00000e-09 2.12000e-01

5.44782e+02 5.44782e+02 5.44782e+01 1.00000e-09 2.12000e-01

$1.00000 \mathrm{e}-02$ 1.00000e-02 1.00000e-03 1.00000e-09 1.00000e-01

$1.00000 \mathrm{e}+001.00000 \mathrm{e}+001.00000 \mathrm{e}-01$ 1.00000e-09 1.00000e-01

Element: 7079 \# of layers: 5

$\mathrm{Kx} \mathrm{Ky} \mathrm{Kz}$ Ss Por

1.36339e+04 1.36339e+04 1.36339e+03 1.00000e-09 7.00000e-02

$5.44782 \mathrm{e}+02$ 5.44782e+02 5.44782e+01 1.00000e-09 2.12000e-01

5.44782e+02 5.44782e+02 5.44782e+01 1.00000e-09 2.12000e-01

$1.00000 \mathrm{e}-02$ 1.00000e-02 1.00000e-03 1.00000e-09 1.00000e-01

$1.00000 \mathrm{e}+001.00000 \mathrm{e}+001.00000 \mathrm{e}-011.00000 \mathrm{e}-091.00000 \mathrm{e}-01$

Element: 7080 \# of layers: 5

$\mathrm{Kx} \mathrm{Ky} \mathrm{Kz}$ Ss Por

$1.36339 \mathrm{e}+04$ 1.36339e+04 1.36339e+03 1.00000e-09 7.00000e-02

$5.44782 \mathrm{e}+025.44782 \mathrm{e}+02$ 5.44782e+01 1.00000e-09 2.12000e-01

$5.44782 \mathrm{e}+02$ 5.44782e+02 5.44782e+01 1.00000e-09 2.12000e-01

$1.00000 \mathrm{e}-02$ 1.00000e-02 1.00000e-03 1.00000e-09 1.00000e-01

$1.00000 \mathrm{e}+001.00000 \mathrm{e}+001.00000 \mathrm{e}-011.00000 \mathrm{e}-09$ 1.00000e-01

Element: 7081 \# of layers: 6

Kx Ky Kz Ss Por

$1.36339 \mathrm{e}+04$ 1.36339e+04 1.36339e+03 1.00000e-09 7.00000e-02

5.44782e+02 5.44782e+02 5.44782e+01 1.00000e-09 2.12000e-01

$5.44782 \mathrm{e}+025.44782 \mathrm{e}+025.44782 \mathrm{e}+01$ 1.00000e-09 2.12000e-01

$5.44782 \mathrm{e}+025.44782 \mathrm{e}+025.44782 \mathrm{e}+01$ 1.00000e-09 2.12000e-01

$1.00000 \mathrm{e}-02$ 1.00000e-02 1.00000e-03 1.00000e-09 1.00000e-01

$1.00000 \mathrm{e}+001.00000 \mathrm{e}+001.00000 \mathrm{e}-011.00000 \mathrm{e}-091.00000 \mathrm{e}-01$

Element: 7082 \# of layers: 6

$\mathrm{Kx} \mathrm{Ky} \mathrm{Kz}$ Ss Por

1.36339e+04 1.36339e+04 1.36339e+03 1.00000e-09 7.00000e-02

5.44782e+02 5.44782e+02 5.44782e+01 1.00000e-09 2.12000e-01

$5.44782 \mathrm{e}+025.44782 \mathrm{e}+02$ 5.44782e+01 1.00000e-09 2.12000e-01

$5.44782 \mathrm{e}+025.44782 \mathrm{e}+02$ 5.44782e+01 1.00000e-09 2.12000e-01

$1.00000 \mathrm{e}-02$ 1.00000e-02 1.00000e-03 1.00000e-09 1.00000e-01

$1.00000 \mathrm{e}+001.00000 \mathrm{e}+001.00000 \mathrm{e}-011.00000 \mathrm{e}-091.00000 \mathrm{e}-01$

Element: 7083 \# of layers: 6

$\mathrm{Kx} \mathrm{Ky} \mathrm{Kz}$ Ss Por

1.36339e+04 1.36339e+04 1.36339e+03 1.00000e-09 7.00000e-02

$5.44782 \mathrm{e}+025.44782 \mathrm{e}+02$ 5.44782e+01 1.00000e-09 2.12000e-01

5.44782e+02 5.44782e+02 5.44782e+01 1.00000e-09 2.12000e-01

$5.44782 \mathrm{e}+02$ 5.44782e+02 5.44782e+01 1.00000e-09 2.12000e-01

$1.00000 \mathrm{e}-02$ 1.00000e-02 1.00000e-03 1.00000e-09 1.00000e-01

$1.00000 \mathrm{e}+001.00000 \mathrm{e}+001.00000 \mathrm{e}-011.00000 \mathrm{e}-091.00000 \mathrm{e}-01$ 
Element: 7084 \# of layers: 5

$\mathrm{Kx} \mathrm{Ky} \mathrm{Kz}$ Ss Por

1.36339e+04 1.36339e+04 1.36339e+03 1.00000e-09 7.00000e-02

5.44782e+02 5.44782e+02 5.44782e+01 1.00000e-09 2.12000e-01

$5.44782 \mathrm{e}+02$ 5.44782e+02 5.44782e+01 1.00000e-09 2.12000e-01

$1.00000 \mathrm{e}-02$ 1.00000e-02 1.00000e-03 1.00000e-09 1.00000e-01

$1.00000 \mathrm{e}+001.00000 \mathrm{e}+001.00000 \mathrm{e}-01$ 1.00000e-09 1.00000e-01

Element: 7085 \# of layers: 5

$\mathrm{Kx} \mathrm{Ky} \mathrm{Kz}$ Ss Por

5.74793e+03 5.74793e+03 5.74793e+02 1.00000e-09 7.00000e-02

$2.29662 \mathrm{e}+02$ 2.29662e+02 2.29662e+01 1.00000e-09 2.12000e-01

$2.29662 \mathrm{e}+02$ 2.29662e+02 2.29662e+01 1.00000e-09 2.12000e-01

$1.00000 \mathrm{e}-02$ 1.00000e-02 1.00000e-03 1.00000e-09 1.00000e-01

$1.00000 \mathrm{e}+001.00000 \mathrm{e}+001.00000 \mathrm{e}-011.00000 \mathrm{e}-09$ 1.00000e-01

Element: 7086 \# of layers: 5

Kx Ky Kz Ss Por

5.74793e+03 5.74793e+03 5.74793e+02 1.00000e-09 7.00000e-02

$2.29662 \mathrm{e}+02$ 2.29662e+02 2.29662e+01 1.00000e-09 2.12000e-01

$2.29662 \mathrm{e}+02$ 2.29662e+02 2.29662e+01 1.00000e-09 2.12000e-01

$1.00000 \mathrm{e}-02$ 1.00000e-02 1.00000e-03 1.00000e-09 1.00000e-01

$1.00000 \mathrm{e}+001.00000 \mathrm{e}+001.00000 \mathrm{e}-011.00000 \mathrm{e}-091.00000 \mathrm{e}-01$

Element: 7087 \# of layers: 5

$\mathrm{Kx} \mathrm{Ky} \mathrm{Kz}$ Ss Por

5.74793e+03 5.74793e+03 5.74793e+02 1.00000e-09 7.00000e-02

$2.29662 \mathrm{e}+02$ 2.29662e+02 2.29662e+01 1.00000e-09 2.12000e-01

$2.29662 \mathrm{e}+022.29662 \mathrm{e}+02$ 2.29662e+01 1.00000e-09 2.12000e-01

$1.00000 \mathrm{e}-02$ 1.00000e-02 1.00000e-03 1.00000e-09 1.00000e-01

$1.00000 \mathrm{e}+001.00000 \mathrm{e}+001.00000 \mathrm{e}-011.00000 \mathrm{e}-09$ 1.00000e-01

Element: 7088 \# of layers: 5

$\mathrm{Kx} \mathrm{Ky} \mathrm{Kz}$ Ss Por

5.74793e+03 5.74793e+03 5.74793e+02 1.00000e-09 7.00000e-02

$2.29662 \mathrm{e}+02$ 2.29662e+02 2.29662e+01 1.00000e-09 2.12000e-01

$2.29662 \mathrm{e}+02$ 2.29662e+02 2.29662e+01 1.00000e-09 2.12000e-01

$1.00000 \mathrm{e}-02$ 1.00000e-02 1.00000e-03 1.00000e-09 1.00000e-01

$1.00000 \mathrm{e}+001.00000 \mathrm{e}+001.00000 \mathrm{e}-011.00000 \mathrm{e}-091.00000 \mathrm{e}-01$

Element: 7089 \# of layers: 5

Kx Ky Kz Ss Por

5.74793e+03 5.74793e+03 5.74793e+02 1.00000e-09 7.00000e-02

$2.29662 \mathrm{e}+02$ 2.29662e+02 2.29662e+01 1.00000e-09 2.12000e-01

$2.29662 \mathrm{e}+02$ 2.29662e+02 2.29662e+01 1.00000e-09 2.12000e-01

$1.00000 \mathrm{e}-02$ 1.00000e-02 1.00000e-03 1.00000e-09 1.00000e-01

$1.00000 \mathrm{e}+001.00000 \mathrm{e}+001.00000 \mathrm{e}-011.00000 \mathrm{e}-091.00000 \mathrm{e}-01$

Element: 7090 \# of layers: 5

$\mathrm{Kx} \mathrm{Ky} \mathrm{Kz}$ Ss Por

5.74793e+03 5.74793e+03 5.74793e+02 1.00000e-09 7.00000e-02

$2.29662 \mathrm{e}+02$ 2.29662e+02 2.29662e+01 1.00000e-09 2.12000e-01 
$2.29662 \mathrm{e}+02$ 2.29662e+02 2.29662e+01 1.00000e-09 2.12000e-01 $1.00000 \mathrm{e}-02$ 1.00000e-02 1.00000e-03 1.00000e-09 1.00000e-01 $1.00000 \mathrm{e}+001.00000 \mathrm{e}+001.00000 \mathrm{e}-011.00000 \mathrm{e}-091.00000 \mathrm{e}-01$

Element: 7091 \# of layers: 5

$\mathrm{Kx} \mathrm{Ky} \mathrm{Kz}$ Ss Por

5.74793e+03 5.74793e+03 5.74793e+02 1.00000e-09 7.00000e-02 $2.29662 \mathrm{e}+02$ 2.29662e+02 2.29662e+01 1.00000e-09 2.12000e-01 $2.29662 \mathrm{e}+02$ 2.29662e+02 2.29662e+01 1.00000e-09 2.12000e-01 $1.00000 \mathrm{e}-02$ 1.00000e-02 1.00000e-03 1.00000e-09 1.00000e-01 $1.00000 \mathrm{e}+001.00000 \mathrm{e}+001.00000 \mathrm{e}-01$ 1.00000e-09 1.00000e-01 Element: 7092 \# of layers: 5

Kx Ky Kz Ss Por

5.74793e+03 5.74793e+03 5.74793e+02 1.00000e-09 7.00000e-02 $2.29662 \mathrm{e}+02$ 2.29662e+02 2.29662e+01 1.00000e-09 2.12000e-01 $2.29662 \mathrm{e}+02$ 2.29662e+02 2.29662e+01 1.00000e-09 2.12000e-01 $1.00000 \mathrm{e}-02$ 1.00000e-02 1.00000e-03 1.00000e-09 1.00000e-01 $1.00000 \mathrm{e}+001.00000 \mathrm{e}+001.00000 \mathrm{e}-01$ 1.00000e-09 1.00000e-01 Element: 7093 \# of layers: 5

$\mathrm{Kx} \mathrm{Ky} \mathrm{Kz}$ Ss Por

5.74793e+03 5.74793e+03 5.74793e+02 1.00000e-09 7.00000e-02 $2.29662 \mathrm{e}+02$ 2.29662e+02 2.29662e+01 1.00000e-09 2.12000e-01

2.29662e+02 2.29662e+02 2.29662e+01 1.00000e-09 2.12000e-01 $1.00000 \mathrm{e}-02$ 1.00000e-02 1.00000e-03 1.00000e-09 1.00000e-01 $1.00000 \mathrm{e}+001.00000 \mathrm{e}+001.00000 \mathrm{e}-011.00000 \mathrm{e}-091.00000 \mathrm{e}-01$

Element: 7094 \# of layers: 5

$\mathrm{Kx} \mathrm{Ky} \mathrm{Kz}$ Ss Por

5.93975e+02 5.93975e+02 5.93975e+01 1.00000e-09 7.00000e-02 $2.37335 \mathrm{e}+012.37335 \mathrm{e}+012.37335 \mathrm{e}+00$ 1.00000e-09 2.12000e-01 $2.37335 \mathrm{e}+012.37335 \mathrm{e}+012.37335 \mathrm{e}+001.00000 \mathrm{e}-092.12000 \mathrm{e}-01$ $1.00000 \mathrm{e}-02$ 1.00000e-02 1.00000e-03 1.00000e-09 1.00000e-01 $1.00000 \mathrm{e}+001.00000 \mathrm{e}+001.00000 \mathrm{e}-011.00000 \mathrm{e}-091.00000 \mathrm{e}-01$ Element: 7095 \# of layers: 5

Kx Ky Kz Ss Por

5.93975e+02 5.93975e+02 5.93975e+01 1.00000e-09 7.00000e-02 $2.37335 \mathrm{e}+012.37335 \mathrm{e}+012.37335 \mathrm{e}+00$ 1.00000e-09 2.12000e-01 $2.37335 \mathrm{e}+012.37335 \mathrm{e}+012.37335 \mathrm{e}+00$ 1.00000e-09 2.12000e-01 $1.00000 \mathrm{e}-02$ 1.00000e-02 1.00000e-03 1.00000e-09 1.00000e-01 $1.00000 \mathrm{e}+001.00000 \mathrm{e}+001.00000 \mathrm{e}-011.00000 \mathrm{e}-091.00000 \mathrm{e}-01$ Element: 7096 \# of layers: 4

$\mathrm{Kx} \mathrm{Ky} \mathrm{Kz}$ Ss Por 5.93975e+02 5.93975e+02 5.93975e+01 1.00000e-09 7.00000e-02 $2.37335 \mathrm{e}+012.37335 \mathrm{e}+012.37335 \mathrm{e}+00$ 1.00000e-09 2.12000e-01 $1.00000 \mathrm{e}-02$ 1.00000e-02 1.00000e-03 1.00000e-09 1.00000e-01 $1.00000 \mathrm{e}+001.00000 \mathrm{e}+001.00000 \mathrm{e}-01$ 1.00000e-09 1.00000e-01 Element: 7097 \# of layers: 5

Kx Ky Kz Ss Por 
5.93975e+02 5.93975e+02 5.93975e+01 1.00000e-09 7.00000e-02 $2.37335 \mathrm{e}+012.37335 \mathrm{e}+012.37335 \mathrm{e}+00$ 1.00000e-09 2.12000e-01

$2.37335 \mathrm{e}+012.37335 \mathrm{e}+012.37335 \mathrm{e}+00$ 1.00000e-09 2.12000e-01 $1.00000 \mathrm{e}-02$ 1.00000e-02 1.00000e-03 1.00000e-09 1.00000e-01 $1.00000 \mathrm{e}+001.00000 \mathrm{e}+001.00000 \mathrm{e}-01$ 1.00000e-09 1.00000e-01 Element: 7098 \# of layers: 5

$\mathrm{Kx} \mathrm{Ky} \mathrm{Kz}$ Ss Por

5.93975e+02 5.93975e+02 5.93975e+01 1.00000e-09 7.00000e-02 $2.37335 \mathrm{e}+012.37335 \mathrm{e}+012.37335 \mathrm{e}+00$ 1.00000e-09 2.12000e-01

$2.37335 \mathrm{e}+012.37335 \mathrm{e}+012.37335 \mathrm{e}+00$ 1.00000e-09 2.12000e-01 $1.00000 \mathrm{e}-02$ 1.00000e-02 1.00000e-03 1.00000e-09 1.00000e-01 $1.00000 \mathrm{e}+001.00000 \mathrm{e}+001.00000 \mathrm{e}-011.00000 \mathrm{e}-091.00000 \mathrm{e}-01$ Element: 7099 \# of layers: 5

$\mathrm{Kx} \mathrm{Ky} \mathrm{Kz}$ Ss Por

5.93975e+02 5.93975e+02 5.93975e+01 1.00000e-09 7.00000e-02 $2.37335 \mathrm{e}+012.37335 \mathrm{e}+012.37335 \mathrm{e}+00$ 1.00000e-09 2.12000e-01 $2.37335 \mathrm{e}+012.37335 \mathrm{e}+012.37335 \mathrm{e}+00$ 1.00000e-09 2.12000e-01 $1.00000 \mathrm{e}-02$ 1.00000e-02 1.00000e-03 1.00000e-09 1.00000e-01 $1.00000 \mathrm{e}+001.00000 \mathrm{e}+001.00000 \mathrm{e}-011.00000 \mathrm{e}-091.00000 \mathrm{e}-01$ Element: 7100 \# of layers: 5

Kx Ky Kz Ss Por

5.93975e+02 5.93975e+02 5.93975e+01 1.00000e-09 7.00000e-02 $2.37335 \mathrm{e}+012.37335 \mathrm{e}+012.37335 \mathrm{e}+00$ 1.00000e-09 2.12000e-01 $2.37335 \mathrm{e}+012.37335 \mathrm{e}+012.37335 \mathrm{e}+00$ 1.00000e-09 2.12000e-01 $1.00000 \mathrm{e}-02$ 1.00000e-02 1.00000e-03 1.00000e-09 1.00000e-01 $1.00000 \mathrm{e}+001.00000 \mathrm{e}+001.00000 \mathrm{e}-011.00000 \mathrm{e}-091.00000 \mathrm{e}-01$ Element: 7101 \# of layers: 5

$\mathrm{Kx} \mathrm{Ky} \mathrm{Kz}$ Ss Por

5.93975e+02 5.93975e+02 5.93975e+01 1.00000e-09 7.00000e-02 $2.37335 \mathrm{e}+012.37335 \mathrm{e}+012.37335 \mathrm{e}+00$ 1.00000e-09 2.12000e-01

$2.37335 \mathrm{e}+012.37335 \mathrm{e}+012.37335 \mathrm{e}+00$ 1.00000e-09 2.12000e-01 $1.00000 \mathrm{e}-02$ 1.00000e-02 1.00000e-03 1.00000e-09 1.00000e-01 $1.00000 \mathrm{e}+001.00000 \mathrm{e}+001.00000 \mathrm{e}-011.00000 \mathrm{e}-091.00000 \mathrm{e}-01$ Element: 7102 \# of layers: 5

$\mathrm{Kx} \mathrm{Ky} \mathrm{Kz}$ Ss Por

5.93975e+02 5.93975e+02 5.93975e+01 1.00000e-09 7.00000e-02 $2.37335 \mathrm{e}+012.37335 \mathrm{e}+012.37335 \mathrm{e}+00$ 1.00000e-09 2.12000e-01 $2.37335 \mathrm{e}+012.37335 \mathrm{e}+012.37335 \mathrm{e}+00$ 1.00000e-09 2.12000e-01 $1.00000 \mathrm{e}-02$ 1.00000e-02 1.00000e-03 1.00000e-09 1.00000e-01 $1.00000 \mathrm{e}+001.00000 \mathrm{e}+001.00000 \mathrm{e}-01$ 1.00000e-09 1.00000e-01 Element: 7103 \# of layers: 4

$\mathrm{Kx} \mathrm{Ky} \mathrm{Kz}$ Ss Por

9.30733e+03 9.30733e+03 9.30733e+02 1.00000e-09 7.00000e-02 3.71888e+02 3.71888e+02 3.71888e+01 1.00000e-09 2.12000e-01 $1.00000 \mathrm{e}-02$ 1.00000e-02 1.00000e-03 1.00000e-09 1.00000e-01 $1.00000 \mathrm{e}+001.00000 \mathrm{e}+001.00000 \mathrm{e}-011.00000 \mathrm{e}-091.00000 \mathrm{e}-01$ 
Element: 7104 \# of layers: 4

$\mathrm{Kx} \mathrm{Ky} \mathrm{Kz}$ Ss Por

9.30733e+03 9.30733e+03 9.30733e+02 1.00000e-09 7.00000e-02

$3.71888 \mathrm{e}+02$ 3.71888e+02 3.71888e+01 1.00000e-09 2.12000e-01

$1.00000 \mathrm{e}-021.00000 \mathrm{e}-02$ 1.00000e-03 1.00000e-09 1.00000e-01

$1.00000 \mathrm{e}+001.00000 \mathrm{e}+001.00000 \mathrm{e}-011.00000 \mathrm{e}-091.00000 \mathrm{e}-01$

Element: 7105 \# of layers: 4

Kx Ky Kz Ss Por

9.30733e+03 9.30733e+03 9.30733e+02 1.00000e-09 7.00000e-02

$3.71888 \mathrm{e}+02$ 3.71888e+02 3.71888e+01 1.00000e-09 2.12000e-01

$1.00000 \mathrm{e}-02$ 1.00000e-02 1.00000e-03 1.00000e-09 1.00000e-01

$1.00000 \mathrm{e}+001.00000 \mathrm{e}+001.00000 \mathrm{e}-011.00000 \mathrm{e}-091.00000 \mathrm{e}-01$

Element: 7106 \# of layers: 4

$\mathrm{Kx} \mathrm{Ky} \mathrm{Kz}$ Ss Por

9.30733e+03 9.30733e+03 9.30733e+02 1.00000e-09 7.00000e-02

$3.71888 \mathrm{e}+02$ 3.71888e+02 3.71888e+01 1.00000e-09 2.12000e-01

$1.00000 \mathrm{e}-02$ 1.00000e-02 1.00000e-03 1.00000e-09 1.00000e-01

$1.00000 \mathrm{e}+001.00000 \mathrm{e}+001.00000 \mathrm{e}-01$ 1.00000e-09 1.00000e-01

Element: 7107 \# of layers: 4

$\mathrm{Kx} \mathrm{Ky} \mathrm{Kz}$ Ss Por

9.30733e+03 9.30733e+03 9.30733e+02 1.00000e-09 7.00000e-02

$3.71888 \mathrm{e}+02$ 3.71888e+02 3.71888e+01 1.00000e-09 2.12000e-01

$1.00000 \mathrm{e}-02$ 1.00000e-02 1.00000e-03 1.00000e-09 1.00000e-01

$1.00000 \mathrm{e}+001.00000 \mathrm{e}+001.00000 \mathrm{e}-011.00000 \mathrm{e}-091.00000 \mathrm{e}-01$

Element: 7108 \# of layers: 4

$\mathrm{Kx} \mathrm{Ky} \mathrm{Kz}$ Ss Por

9.30733e+03 9.30733e+03 9.30733e+02 1.00000e-09 7.00000e-02

$3.71888 \mathrm{e}+02$ 3.71888e+02 3.71888e+01 1.00000e-09 2.12000e-01

$1.00000 \mathrm{e}-02$ 1.00000e-02 1.00000e-03 1.00000e-09 1.00000e-01

$1.00000 \mathrm{e}+001.00000 \mathrm{e}+001.00000 \mathrm{e}-011.00000 \mathrm{e}-091.00000 \mathrm{e}-01$

Element: 7109 \# of layers: 5

$\mathrm{Kx} \mathrm{Ky} \mathrm{Kz}$ Ss Por

9.30733e+03 9.30733e+03 9.30733e+02 1.00000e-09 7.00000e-02

$3.71888 \mathrm{e}+02$ 3.71888e+02 3.71888e+01 1.00000e-09 2.12000e-01

$3.71888 \mathrm{e}+02$ 3.71888e+02 3.71888e+01 1.00000e-09 2.12000e-01

$1.00000 \mathrm{e}-02$ 1.00000e-02 1.00000e-03 1.00000e-09 1.00000e-01

$1.00000 \mathrm{e}+001.00000 \mathrm{e}+001.00000 \mathrm{e}-011.00000 \mathrm{e}-091.00000 \mathrm{e}-01$

Element: 7110 \# of layers: 4

$\mathrm{Kx} \mathrm{Ky} \mathrm{Kz}$ Ss Por

9.30733e+03 9.30733e+03 9.30733e+02 1.00000e-09 7.00000e-02

$3.71888 \mathrm{e}+02$ 3.71888e+02 3.71888e+01 1.00000e-09 2.12000e-01

$1.00000 \mathrm{e}-02$ 1.00000e-02 1.00000e-03 1.00000e-09 1.00000e-01

$1.00000 \mathrm{e}+001.00000 \mathrm{e}+001.00000 \mathrm{e}-01$ 1.00000e-09 1.00000e-01

Element: 7111 \# of layers: 4

$\mathrm{Kx} \mathrm{Ky} \mathrm{Kz}$ Ss Por

9.30733e+03 9.30733e+03 9.30733e+02 1.00000e-09 7.00000e-02 
$3.71888 \mathrm{e}+02$ 3.71888e+02 3.71888e+01 1.00000e-09 2.12000e-01 $1.00000 \mathrm{e}-02$ 1.00000e-02 1.00000e-03 1.00000e-09 1.00000e-01 $1.00000 \mathrm{e}+001.00000 \mathrm{e}+001.00000 \mathrm{e}-011.00000 \mathrm{e}-091.00000 \mathrm{e}-01$

Element: 7112 \# of layers: 4

Kx Ky Kz Ss Por

$9.32805 \mathrm{e}+03$ 9.32805e+03 9.32805e+02 1.00000e-09 7.00000e-02

$3.72743 \mathrm{e}+023.72743 \mathrm{e}+023.72743 \mathrm{e}+01$ 1.00000e-09 2.12000e-01

$1.00000 \mathrm{e}-021.00000 \mathrm{e}-02$ 1.00000e-03 1.00000e-09 1.00000e-01

$1.00000 \mathrm{e}+001.00000 \mathrm{e}+00$ 1.00000e-01 1.00000e-09 1.00000e-01

Element: 7113 \# of layers: 4

Kx Ky Kz Ss Por

$9.32805 \mathrm{e}+03$ 9.32805e+03 9.32805e+02 1.00000e-09 7.00000e-02

$3.72743 \mathrm{e}+02 \quad 3.72743 \mathrm{e}+023.72743 \mathrm{e}+01$ 1.00000e-09 2.12000e-01

$1.00000 \mathrm{e}-02$ 1.00000e-02 1.00000e-03 1.00000e-09 1.00000e-01

$1.00000 \mathrm{e}+001.00000 \mathrm{e}+001.00000 \mathrm{e}-011.00000 \mathrm{e}-091.00000 \mathrm{e}-01$

Element: 7114 \# of layers: 4

Kx Ky Kz Ss Por

9.32805e+03 9.32805e+03 9.32805e+02 1.00000e-09 7.00000e-02

$3.72743 \mathrm{e}+023.72743 \mathrm{e}+023.72743 \mathrm{e}+01$ 1.00000e-09 2.12000e-01

$1.00000 \mathrm{e}-021.00000 \mathrm{e}-02$ 1.00000e-03 1.00000e-09 1.00000e-01

$1.00000 \mathrm{e}+001.00000 \mathrm{e}+001.00000 \mathrm{e}-011.00000 \mathrm{e}-091.00000 \mathrm{e}-01$

Element: 7115 \# of layers: 4

Kx Ky Kz Ss Por

$9.32805 \mathrm{e}+03$ 9.32805e+03 9.32805e+02 1.00000e-09 7.00000e-02

$3.72743 \mathrm{e}+02$ 3.72743e+02 3.72743e+01 1.00000e-09 2.12000e-01

$1.00000 \mathrm{e}-02$ 1.00000e-02 1.00000e-03 1.00000e-09 1.00000e-01

$1.00000 \mathrm{e}+001.00000 \mathrm{e}+001.00000 \mathrm{e}-011.00000 \mathrm{e}-091.00000 \mathrm{e}-01$

Element: 7116 \# of layers: 4

Kx Ky Kz Ss Por

$9.32805 \mathrm{e}+03$ 9.32805e+03 9.32805e+02 1.00000e-09 7.00000e-02

$3.72743 \mathrm{e}+023.72743 \mathrm{e}+023.72743 \mathrm{e}+01$ 1.00000e-09 2.12000e-01

$1.00000 \mathrm{e}-021.00000 \mathrm{e}-02$ 1.00000e-03 1.00000e-09 1.00000e-01

$1.00000 \mathrm{e}+001.00000 \mathrm{e}+00$ 1.00000e-01 1.00000e-09 1.00000e-01

Element: 7117 \# of layers: 4

Kx Ky Kz Ss Por

$9.32805 \mathrm{e}+03$ 9.32805e+03 9.32805e+02 1.00000e-09 7.00000e-02

$3.72743 \mathrm{e}+02$ 3.72743e+02 3.72743e+01 1.00000e-09 2.12000e-01

$1.00000 \mathrm{e}-021.00000 \mathrm{e}-02$ 1.00000e-03 1.00000e-09 1.00000e-01

$1.00000 \mathrm{e}+001.00000 \mathrm{e}+001.00000 \mathrm{e}-011.00000 \mathrm{e}-091.00000 \mathrm{e}-01$

Element: 7118 \# of layers: 4

Kx Ky Kz Ss Por

$9.32805 \mathrm{e}+03$ 9.32805e+03 9.32805e+02 1.00000e-09 7.00000e-02

$3.72743 \mathrm{e}+023.72743 \mathrm{e}+023.72743 \mathrm{e}+01$ 1.00000e-09 2.12000e-01

$1.00000 \mathrm{e}-02$ 1.00000e-02 1.00000e-03 1.00000e-09 1.00000e-01

$1.00000 \mathrm{e}+001.00000 \mathrm{e}+001.00000 \mathrm{e}-011.00000 \mathrm{e}-091.00000 \mathrm{e}-01$

Element: 7119 \# of layers: 4 
$\mathrm{Kx} \mathrm{Ky} \mathrm{Kz}$ Ss Por

9.32805e+03 9.32805e+03 9.32805e+02 1.00000e-09 7.00000e-02

$3.72743 \mathrm{e}+02$ 3.72743e+02 3.72743e+01 1.00000e-09 2.12000e-01

$1.00000 \mathrm{e}-02$ 1.00000e-02 1.00000e-03 1.00000e-09 1.00000e-01

$1.00000 \mathrm{e}+001.00000 \mathrm{e}+001.00000 \mathrm{e}-011.00000 \mathrm{e}-091.00000 \mathrm{e}-01$

Element: 7120 \# of layers: 4

$\mathrm{Kx} \mathrm{Ky} \mathrm{Kz}$ Ss Por

9.32805e+03 9.32805e+03 9.32805e+02 1.00000e-09 7.00000e-02

$3.72743 \mathrm{e}+02$ 3.72743e+02 3.72743e+01 1.00000e-09 2.12000e-01

$1.00000 \mathrm{e}-02$ 1.00000e-02 1.00000e-03 1.00000e-09 1.00000e-01

$1.00000 \mathrm{e}+001.00000 \mathrm{e}+001.00000 \mathrm{e}-011.00000 \mathrm{e}-091.00000 \mathrm{e}-01$

Element: 7121 \# of layers: 4

$\mathrm{Kx} \mathrm{Ky} \mathrm{Kz}$ Ss Por

1.49602e+02 1.49602e+02 1.49602e+01 1.00000e-09 7.00000e-02

5.97748e+00 5.97748e+00 5.97748e-01 1.00000e-09 2.12000e-01

$1.00000 \mathrm{e}-02$ 1.00000e-02 1.00000e-03 1.00000e-09 1.00000e-01

$1.00000 \mathrm{e}+001.00000 \mathrm{e}+001.00000 \mathrm{e}-011.00000 \mathrm{e}-09$ 1.00000e-01

Element: 7122 \# of layers: 4

$\mathrm{Kx} \mathrm{Ky} \mathrm{Kz}$ Ss Por

1.49602e+02 1.49602e+02 1.49602e+01 1.00000e-09 7.00000e-02

5.97748e+00 5.97748e+00 5.97748e-01 1.00000e-09 2.12000e-01

$1.00000 \mathrm{e}-02$ 1.00000e-02 1.00000e-03 1.00000e-09 1.00000e-01

$1.00000 \mathrm{e}+001.00000 \mathrm{e}+001.00000 \mathrm{e}-01$ 1.00000e-09 1.00000e-01

Element: 7123 \# of layers: 4

$\mathrm{Kx} \mathrm{Ky} \mathrm{Kz}$ Ss Por

$1.49602 \mathrm{e}+02$ 1.49602e+02 1.49602e+01 1.00000e-09 7.00000e-02

5.97748e+00 5.97748e+00 5.97748e-01 1.00000e-09 2.12000e-01

$1.00000 \mathrm{e}-02$ 1.00000e-02 1.00000e-03 1.00000e-09 1.00000e-01

$1.00000 \mathrm{e}+001.00000 \mathrm{e}+001.00000 \mathrm{e}-011.00000 \mathrm{e}-091.00000 \mathrm{e}-01$

Element: 7124 \# of layers: 4

$\mathrm{Kx} \mathrm{Ky} \mathrm{Kz}$ Ss Por

1.49602e+02 1.49602e+02 1.49602e+01 1.00000e-09 7.00000e-02

$5.97748 \mathrm{e}+00$ 5.97748e+00 5.97748e-01 1.00000e-09 2.12000e-01

$1.00000 \mathrm{e}-02$ 1.00000e-02 1.00000e-03 1.00000e-09 1.00000e-01

$1.00000 \mathrm{e}+001.00000 \mathrm{e}+001.00000 \mathrm{e}-011.00000 \mathrm{e}-091.00000 \mathrm{e}-01$

Element: 7125 \# of layers: 4

Kx Ky Kz Ss Por

$1.49602 \mathrm{e}+02$ 1.49602e+02 1.49602e+01 1.00000e-09 7.00000e-02

5.97748e+00 5.97748e+00 5.97748e-01 1.00000e-09 2.12000e-01

$1.00000 \mathrm{e}-02$ 1.00000e-02 1.00000e-03 1.00000e-09 1.00000e-01

$1.00000 \mathrm{e}+001.00000 \mathrm{e}+001.00000 \mathrm{e}-011.00000 \mathrm{e}-091.00000 \mathrm{e}-01$

Element: 7126 \# of layers: 4

$\mathrm{Kx} \mathrm{Ky} \mathrm{Kz}$ Ss Por

1.49602e+02 1.49602e+02 1.49602e+01 1.00000e-09 7.00000e-02

$5.97748 \mathrm{e}+00$ 5.97748e+00 5.97748e-01 1.00000e-09 2.12000e-01

$1.00000 \mathrm{e}-02$ 1.00000e-02 1.00000e-03 1.00000e-09 1.00000e-01 
$1.00000 \mathrm{e}+001.00000 \mathrm{e}+00$ 1.00000e-01 1.00000e-09 1.00000e-01

Element: 7127 \# of layers: 4

$\mathrm{Kx} \mathrm{Ky} \mathrm{Kz}$ Ss Por

1.49602e+02 1.49602e+02 1.49602e+01 1.00000e-09 7.00000e-02

5.97748e+00 5.97748e+00 5.97748e-01 1.00000e-09 2.12000e-01

$1.00000 \mathrm{e}-02$ 1.00000e-02 1.00000e-03 1.00000e-09 1.00000e-01

$1.00000 \mathrm{e}+001.00000 \mathrm{e}+001.00000 \mathrm{e}-01$ 1.00000e-09 1.00000e-01

Element: 7128 \# of layers: 4

$\mathrm{Kx} \mathrm{Ky} \mathrm{Kz}$ Ss Por

1.49602e+02 1.49602e+02 1.49602e+01 1.00000e-09 7.00000e-02

5.97748e+00 5.97748e+00 5.97748e-01 1.00000e-09 2.12000e-01

$1.00000 \mathrm{e}-02$ 1.00000e-02 1.00000e-03 1.00000e-09 1.00000e-01

$1.00000 \mathrm{e}+001.00000 \mathrm{e}+001.00000 \mathrm{e}-011.00000 \mathrm{e}-091.00000 \mathrm{e}-01$

Element: 7129 \# of layers: 4

$\mathrm{Kx} \mathrm{Ky} \mathrm{Kz}$ Ss Por

1.49602e+02 1.49602e+02 1.49602e+01 1.00000e-09 7.00000e-02

5.97748e+00 5.97748e+00 5.97748e-01 1.00000e-09 2.12000e-01

$1.00000 \mathrm{e}-02$ 1.00000e-02 1.00000e-03 1.00000e-09 1.00000e-01

$1.00000 \mathrm{e}+001.00000 \mathrm{e}+001.00000 \mathrm{e}-01$ 1.00000e-09 1.00000e-01

Element: 7130 \# of layers: 4

$\mathrm{Kx} \mathrm{Ky} \mathrm{Kz}$ Ss Por

1.07399e+02 1.07399e+02 1.07399e+01 1.00000e-09 7.00000e-02

4.29129e+00 4.29129e+00 4.29129e-01 1.00000e-09 2.12000e-01

$1.00000 \mathrm{e}-02$ 1.00000e-02 1.00000e-03 1.00000e-09 1.00000e-01

$1.00000 \mathrm{e}+001.00000 \mathrm{e}+001.00000 \mathrm{e}-011.00000 \mathrm{e}-091.00000 \mathrm{e}-01$

Element: 7131 \# of layers: 4

$\mathrm{Kx} \mathrm{Ky} \mathrm{Kz}$ Ss Por

1.07399e+02 1.07399e+02 1.07399e+01 1.00000e-09 7.00000e-02

$4.29129 \mathrm{e}+004.29129 \mathrm{e}+004.29129 \mathrm{e}-01$ 1.00000e-09 2.12000e-01

$1.00000 \mathrm{e}-02$ 1.00000e-02 1.00000e-03 1.00000e-09 1.00000e-01

$1.00000 \mathrm{e}+001.00000 \mathrm{e}+001.00000 \mathrm{e}-011.00000 \mathrm{e}-091.00000 \mathrm{e}-01$

Element: 7132 \# of layers: 4

Kx Ky Kz Ss Por

$1.07399 \mathrm{e}+02$ 1.07399e+02 1.07399e+01 1.00000e-09 7.00000e-02

4.29129e+00 4.29129e+00 4.29129e-01 1.00000e-09 2.12000e-01

1.00000e-02 1.00000e-02 1.00000e-03 1.00000e-09 1.00000e-01

$1.00000 \mathrm{e}+001.00000 \mathrm{e}+001.00000 \mathrm{e}-011.00000 \mathrm{e}-091.00000 \mathrm{e}-01$

Element: 7133 \# of layers: 4

$\mathrm{Kx} \mathrm{Ky} \mathrm{Kz}$ Ss Por

$1.07399 \mathrm{e}+02$ 1.07399e+02 1.07399e+01 1.00000e-09 7.00000e-02

$4.29129 \mathrm{e}+004.29129 \mathrm{e}+00$ 4.29129e-01 1.00000e-09 2.12000e-01

$1.00000 \mathrm{e}-02$ 1.00000e-02 1.00000e-03 1.00000e-09 1.00000e-01

$1.00000 \mathrm{e}+001.00000 \mathrm{e}+001.00000 \mathrm{e}-01$ 1.00000e-09 1.00000e-01

Element: 7134 \# of layers: 4

$\mathrm{Kx} \mathrm{Ky} \mathrm{Kz}$ Ss Por

1.07399e+02 1.07399e+02 1.07399e+01 1.00000e-09 7.00000e-02 
$4.29129 \mathrm{e}+00$ 4.29129e+00 4.29129e-01 1.00000e-09 2.12000e-01 $1.00000 \mathrm{e}-02$ 1.00000e-02 1.00000e-03 1.00000e-09 1.00000e-01 $1.00000 \mathrm{e}+001.00000 \mathrm{e}+001.00000 \mathrm{e}-011.00000 \mathrm{e}-09$ 1.00000e-01 Element: 7135 \# of layers: 4

$\mathrm{Kx} \mathrm{Ky} \mathrm{Kz}$ Ss Por

1.07399e+02 1.07399e+02 1.07399e+01 1.00000e-09 7.00000e-02 $4.29129 \mathrm{e}+00$ 4.29129e+00 4.29129e-01 1.00000e-09 2.12000e-01 1.00000e-02 1.00000e-02 1.00000e-03 1.00000e-09 1.00000e-01 $1.00000 \mathrm{e}+001.00000 \mathrm{e}+001.00000 \mathrm{e}-011.00000 \mathrm{e}-091.00000 \mathrm{e}-01$ Element: 7136 \# of layers: 4

$\mathrm{Kx} \mathrm{Ky} \mathrm{Kz}$ Ss Por

1.07399e+02 1.07399e+02 1.07399e+01 1.00000e-09 7.00000e-02 $4.29129 \mathrm{e}+00$ 4.29129e+00 4.29129e-01 1.00000e-09 2.12000e-01 $1.00000 \mathrm{e}-02$ 1.00000e-02 1.00000e-03 1.00000e-09 1.00000e-01 $1.00000 \mathrm{e}+001.00000 \mathrm{e}+001.00000 \mathrm{e}-01$ 1.00000e-09 1.00000e-01 Element: 7137 \# of layers: 4

$\mathrm{Kx} \mathrm{Ky} \mathrm{Kz}$ Ss Por

1.07399e+02 1.07399e+02 1.07399e+01 1.00000e-09 7.00000e-02 $4.29129 \mathrm{e}+004.29129 \mathrm{e}+00$ 4.29129e-01 1.00000e-09 2.12000e-01 $1.00000 \mathrm{e}-02$ 1.00000e-02 1.00000e-03 1.00000e-09 1.00000e-01 $1.00000 \mathrm{e}+001.00000 \mathrm{e}+001.00000 \mathrm{e}-011.00000 \mathrm{e}-091.00000 \mathrm{e}-01$ Element: 7138 \# of layers: 4

$\mathrm{Kx} \mathrm{Ky} \mathrm{Kz}$ Ss Por

1.07399e+02 1.07399e+02 1.07399e+01 1.00000e-09 7.00000e-02 $4.29129 \mathrm{e}+004.29129 \mathrm{e}+00 \quad 4.29129 \mathrm{e}-01$ 1.00000e-09 2.12000e-01 $1.00000 \mathrm{e}-02$ 1.00000e-02 1.00000e-03 1.00000e-09 1.00000e-01 $1.00000 \mathrm{e}+001.00000 \mathrm{e}+001.00000 \mathrm{e}-011.00000 \mathrm{e}-091.00000 \mathrm{e}-01$ Element: 7139 \# of layers: 4

Kx Ky Kz Ss Por

9.55511e+01 9.55511e+01 9.55511e+00 1.00000e-09 7.00000e-02 $3.81788 \mathrm{e}+003.81788 \mathrm{e}+003.81788 \mathrm{e}-01$ 1.00000e-09 2.12000e-01 $1.00000 \mathrm{e}-02$ 1.00000e-02 1.00000e-03 1.00000e-09 1.00000e-01 $1.00000 \mathrm{e}+001.00000 \mathrm{e}+001.00000 \mathrm{e}-011.00000 \mathrm{e}-091.00000 \mathrm{e}-01$ Element: 7140 \# of layers: 4

$\mathrm{Kx} \mathrm{Ky} \mathrm{Kz}$ Ss Por

9.55511e+01 9.55511e+01 9.55511e+00 1.00000e-09 7.00000e-02 3.81788e+00 3.81788e+00 3.81788e-01 1.00000e-09 2.12000e-01 $1.00000 \mathrm{e}-02$ 1.00000e-02 1.00000e-03 1.00000e-09 1.00000e-01 $1.00000 \mathrm{e}+001.00000 \mathrm{e}+001.00000 \mathrm{e}-011.00000 \mathrm{e}-091.00000 \mathrm{e}-01$ Element: 7141 \# of layers: 4

Kx Ky Kz Ss Por

9.55511e+01 9.55511e+01 9.55511e+00 1.00000e-09 7.00000e-02 3.81788e+00 3.81788e+00 3.81788e-01 1.00000e-09 2.12000e-01 $1.00000 \mathrm{e}-02$ 1.00000e-02 1.00000e-03 1.00000e-09 1.00000e-01 $1.00000 \mathrm{e}+001.00000 \mathrm{e}+001.00000 \mathrm{e}-011.00000 \mathrm{e}-09$ 1.00000e-01 Element: 7142 \# of layers: 4 
Kx Ky Kz Ss Por

9.55511e+01 9.55511e+01 9.55511e+00 1.00000e-09 7.00000e-02

$3.81788 \mathrm{e}+003.81788 \mathrm{e}+00$ 3.81788e-01 1.00000e-09 2.12000e-01

$1.00000 \mathrm{e}-02$ 1.00000e-02 1.00000e-03 1.00000e-09 1.00000e-01

$1.00000 \mathrm{e}+001.00000 \mathrm{e}+001.00000 \mathrm{e}-01$ 1.00000e-09 1.00000e-01

Element: 7143 \# of layers: 3

Kx Ky Kz Ss Por

9.55511e+01 9.55511e+01 9.55511e+00 1.00000e-09 7.00000e-02

$1.00000 \mathrm{e}-02$ 1.00000e-02 1.00000e-03 1.00000e-09 1.00000e-01

$1.00000 \mathrm{e}+001.00000 \mathrm{e}+001.00000 \mathrm{e}-01$ 1.00000e-09 1.00000e-01

Element: 7144 \# of layers: 3

Kx Ky Kz Ss Por

9.55511e+01 9.55511e+01 9.55511e+00 1.00000e-09 7.00000e-02 1.00000e-02 1.00000e-02 1.00000e-03 1.00000e-09 1.00000e-01

$1.00000 \mathrm{e}+001.00000 \mathrm{e}+001.00000 \mathrm{e}-011.00000 \mathrm{e}-091.00000 \mathrm{e}-01$

Element: 7145 \# of layers: 4

$\mathrm{Kx} \mathrm{Ky} \mathrm{Kz}$ Ss Por

9.55511e+01 9.55511e+01 9.55511e+00 1.00000e-09 7.00000e-02

3.81788e+00 3.81788e+00 3.81788e-01 1.00000e-09 2.12000e-01

$1.00000 \mathrm{e}-02$ 1.00000e-02 1.00000e-03 1.00000e-09 1.00000e-01

$1.00000 \mathrm{e}+001.00000 \mathrm{e}+001.00000 \mathrm{e}-011.00000 \mathrm{e}-091.00000 \mathrm{e}-01$

Element: 7146 \# of layers: 4

$\mathrm{Kx} \mathrm{Ky} \mathrm{Kz}$ Ss Por

9.55511e+01 9.55511e+01 9.55511e+00 1.00000e-09 7.00000e-02

$3.81788 \mathrm{e}+003.81788 \mathrm{e}+00$ 3.81788e-01 1.00000e-09 2.12000e-01

$1.00000 \mathrm{e}-021.00000 \mathrm{e}-021.00000 \mathrm{e}-031.00000 \mathrm{e}-091.00000 \mathrm{e}-01$

$1.00000 \mathrm{e}+001.00000 \mathrm{e}+001.00000 \mathrm{e}-011.00000 \mathrm{e}-091.00000 \mathrm{e}-01$

Element: 7147 \# of layers: 4

Kx Ky Kz Ss Por

9.55511e+01 9.55511e+01 9.55511e+00 1.00000e-09 7.00000e-02

$3.81788 \mathrm{e}+003.81788 \mathrm{e}+00$ 3.81788e-01 1.00000e-09 2.12000e-01

$1.00000 \mathrm{e}-02$ 1.00000e-02 1.00000e-03 1.00000e-09 1.00000e-01

$1.00000 \mathrm{e}+001.00000 \mathrm{e}+001.00000 \mathrm{e}-011.00000 \mathrm{e}-091.00000 \mathrm{e}-01$

Element: 7148 \# of layers: 4

$\mathrm{Kx} \mathrm{Ky} \mathrm{Kz}$ Ss Por

$1.00984 \mathrm{e}+02$ 1.00984e+02 1.00984e+01 1.00000e-09 7.00000e-02

$4.03479 \mathrm{e}+004.03479 \mathrm{e}+00$ 4.03479e-01 1.00000e-09 2.12000e-01

$1.00000 \mathrm{e}-02$ 1.00000e-02 1.00000e-03 1.00000e-09 1.00000e-01

$1.00000 \mathrm{e}+001.00000 \mathrm{e}+001.00000 \mathrm{e}-011.00000 \mathrm{e}-091.00000 \mathrm{e}-01$

Element: 7149 \# of layers: 4

$\mathrm{Kx} \mathrm{Ky} \mathrm{Kz}$ Ss Por

$1.00984 \mathrm{e}+021.00984 \mathrm{e}+02 \quad 1.00984 \mathrm{e}+01$ 1.00000e-09 7.00000e-02

4.03479e+00 4.03479e+00 4.03479e-01 1.00000e-09 2.12000e-01

$1.00000 \mathrm{e}-02$ 1.00000e-02 1.00000e-03 1.00000e-09 1.00000e-01

$1.00000 \mathrm{e}+001.00000 \mathrm{e}+001.00000 \mathrm{e}-01$ 1.00000e-09 1.00000e-01

Element: 7150 \# of layers: 5 
$\mathrm{Kx} \mathrm{Ky} \mathrm{Kz}$ Ss Por

$1.00984 \mathrm{e}+021.00984 \mathrm{e}+02$ 1.00984e+01 1.00000e-09 7.00000e-02

$4.03479 \mathrm{e}+00$ 4.03479e+00 4.03479e-01 1.00000e-09 2.12000e-01

$4.03479 \mathrm{e}+004.03479 \mathrm{e}+00$ 4.03479e-01 1.00000e-09 2.12000e-01

$1.00000 \mathrm{e}-02$ 1.00000e-02 1.00000e-03 1.00000e-09 1.00000e-01

$1.00000 \mathrm{e}+001.00000 \mathrm{e}+001.00000 \mathrm{e}-011.00000 \mathrm{e}-091.00000 \mathrm{e}-01$

Element: 7151 \# of layers: 5

$\mathrm{Kx} \mathrm{Ky} \mathrm{Kz}$ Ss Por

$1.00984 \mathrm{e}+021.00984 \mathrm{e}+02$ 1.00984e+01 1.00000e-09 7.00000e-02

4.03479e+00 4.03479e+00 4.03479e-01 1.00000e-09 2.12000e-01

4.03479e+00 4.03479e+00 4.03479e-01 1.00000e-09 2.12000e-01

$1.00000 \mathrm{e}-02$ 1.00000e-02 1.00000e-03 1.00000e-09 1.00000e-01

$1.00000 \mathrm{e}+001.00000 \mathrm{e}+001.00000 \mathrm{e}-011.00000 \mathrm{e}-091.00000 \mathrm{e}-01$

Element: 7152 \# of layers: 3

$\mathrm{Kx} \mathrm{Ky} \mathrm{Kz}$ Ss Por

$1.00984 \mathrm{e}+02$ 1.00984e+02 1.00984e+01 1.00000e-09 7.00000e-02

$1.00000 \mathrm{e}-02$ 1.00000e-02 1.00000e-03 1.00000e-09 1.00000e-01

$1.00000 \mathrm{e}+001.00000 \mathrm{e}+001.00000 \mathrm{e}-01$ 1.00000e-09 1.00000e-01

Element: 7153 \# of layers: 3

$\mathrm{Kx} \mathrm{Ky} \mathrm{Kz}$ Ss Por

$1.00984 \mathrm{e}+021.00984 \mathrm{e}+02 \quad 1.00984 \mathrm{e}+01$ 1.00000e-09 7.00000e-02

$1.00000 \mathrm{e}-021.00000 \mathrm{e}-021.00000 \mathrm{e}-031.00000 \mathrm{e}-091.00000 \mathrm{e}-01$

$1.00000 \mathrm{e}+001.00000 \mathrm{e}+001.00000 \mathrm{e}-01$ 1.00000e-09 1.00000e-01

Element: 7154 \# of layers: 3

$\mathrm{Kx} \mathrm{Ky} \mathrm{Kz}$ Ss Por

$1.00984 \mathrm{e}+021.00984 \mathrm{e}+02$ 1.00984e+01 1.00000e-09 7.00000e-02

$1.00000 \mathrm{e}-02$ 1.00000e-02 1.00000e-03 1.00000e-09 1.00000e-01

$1.00000 \mathrm{e}+001.00000 \mathrm{e}+001.00000 \mathrm{e}-011.00000 \mathrm{e}-09$ 1.00000e-01

Element: 7155 \# of layers: 4

$\mathrm{Kx} \mathrm{Ky} \mathrm{Kz}$ Ss Por

$1.00984 \mathrm{e}+02$ 1.00984e+02 1.00984e+01 1.00000e-09 7.00000e-02

4.03479e+00 4.03479e+00 4.03479e-01 1.00000e-09 2.12000e-01

$1.00000 \mathrm{e}-02$ 1.00000e-02 1.00000e-03 1.00000e-09 1.00000e-01

$1.00000 \mathrm{e}+001.00000 \mathrm{e}+001.00000 \mathrm{e}-011.00000 \mathrm{e}-091.00000 \mathrm{e}-01$

Element: 7156 \# of layers: 4

$\mathrm{Kx} \mathrm{Ky} \mathrm{Kz}$ Ss Por

$1.00984 \mathrm{e}+02$ 1.00984e+02 1.00984e+01 1.00000e-09 7.00000e-02

4.03479e+00 4.03479e+00 4.03479e-01 1.00000e-09 2.12000e-01

$1.00000 \mathrm{e}-02$ 1.00000e-02 1.00000e-03 1.00000e-09 1.00000e-01

$1.00000 \mathrm{e}+001.00000 \mathrm{e}+001.00000 \mathrm{e}-01$ 1.00000e-09 1.00000e-01

Element: 7157 \# of layers: 5

$\mathrm{Kx} \mathrm{Ky} \mathrm{Kz}$ Ss Por

$1.04120 \mathrm{e}+021.04120 \mathrm{e}+02$ 1.04120e+01 1.00000e-09 7.00000e-02

$4.16034 \mathrm{e}+004.16034 \mathrm{e}+004.16034 \mathrm{e}-01$ 1.00000e-09 2.12000e-01

$4.16034 \mathrm{e}+004.16034 \mathrm{e}+004.16034 \mathrm{e}-01$ 1.00000e-09 2.12000e-01

$1.00000 \mathrm{e}-02$ 1.00000e-02 1.00000e-03 1.00000e-09 1.00000e-01 
$1.00000 \mathrm{e}+001.00000 \mathrm{e}+00$ 1.00000e-01 1.00000e-09 1.00000e-01

Element: 7158 \# of layers: 4

Kx Ky Kz Ss Por

$1.04120 \mathrm{e}+02$ 1.04120e+02 1.04120e+01 1.00000e-09 7.00000e-02

$4.16034 \mathrm{e}+004.16034 \mathrm{e}+00$ 4.16034e-01 1.00000e-09 2.12000e-01

$1.00000 \mathrm{e}-02$ 1.00000e-02 1.00000e-03 1.00000e-09 1.00000e-01

$1.00000 \mathrm{e}+001.00000 \mathrm{e}+001.00000 \mathrm{e}-01$ 1.00000e-09 1.00000e-01

Element: 7159 \# of layers: 4

$\mathrm{Kx} \mathrm{Ky} \mathrm{Kz}$ Ss Por

$1.04120 \mathrm{e}+02$ 1.04120e+02 1.04120e+01 1.00000e-09 7.00000e-02

$4.16034 \mathrm{e}+004.16034 \mathrm{e}+004.16034 \mathrm{e}-01$ 1.00000e-09 2.12000e-01

$1.00000 \mathrm{e}-02$ 1.00000e-02 1.00000e-03 1.00000e-09 1.00000e-01

$1.00000 \mathrm{e}+001.00000 \mathrm{e}+001.00000 \mathrm{e}-011.00000 \mathrm{e}-09$ 1.00000e-01

Element: 7160 \# of layers: 3

$\mathrm{Kx} \mathrm{Ky} \mathrm{Kz}$ Ss Por

$1.04120 \mathrm{e}+021.04120 \mathrm{e}+02$ 1.04120e+01 1.00000e-09 7.00000e-02

$1.00000 \mathrm{e}-02$ 1.00000e-02 1.00000e-03 1.00000e-09 1.00000e-01

$1.00000 \mathrm{e}+001.00000 \mathrm{e}+001.00000 \mathrm{e}-01$ 1.00000e-09 1.00000e-01

Element: 7161 \# of layers: 3

$\mathrm{Kx} \mathrm{Ky} \mathrm{Kz}$ Ss Por

$1.04120 \mathrm{e}+021.04120 \mathrm{e}+02$ 1.04120e+01 1.00000e-09 7.00000e-02 $1.00000 \mathrm{e}-021.00000 \mathrm{e}-02$ 1.00000e-03 1.00000e-09 1.00000e-01

$1.00000 \mathrm{e}+001.00000 \mathrm{e}+001.00000 \mathrm{e}-01$ 1.00000e-09 1.00000e-01

Element: 7162 \# of layers: 3

Kx Ky Kz Ss Por

$1.04120 \mathrm{e}+021.04120 \mathrm{e}+021.04120 \mathrm{e}+011.00000 \mathrm{e}-097.00000 \mathrm{e}-02$

$1.00000 \mathrm{e}-021.00000 \mathrm{e}-021.00000 \mathrm{e}-031.00000 \mathrm{e}-091.00000 \mathrm{e}-01$

$1.00000 \mathrm{e}+001.00000 \mathrm{e}+001.00000 \mathrm{e}-011.00000 \mathrm{e}-091.00000 \mathrm{e}-01$

Element: 7163 \# of layers: 3

$\mathrm{Kx} \mathrm{Ky} \mathrm{Kz}$ Ss Por

$1.04120 \mathrm{e}+021.04120 \mathrm{e}+021.04120 \mathrm{e}+01$ 1.00000e-09 7.00000e-02

$1.00000 \mathrm{e}-02$ 1.00000e-02 1.00000e-03 1.00000e-09 1.00000e-01

$1.00000 \mathrm{e}+001.00000 \mathrm{e}+001.00000 \mathrm{e}-011.00000 \mathrm{e}-091.00000 \mathrm{e}-01$

Element: 7164 \# of layers: 5

$\mathrm{Kx} \mathrm{Ky} \mathrm{Kz}$ Ss Por

$1.04120 \mathrm{e}+02$ 1.04120e+02 1.04120e+01 1.00000e-09 7.00000e-02

$4.16034 \mathrm{e}+004.16034 \mathrm{e}+004.16034 \mathrm{e}-01$ 1.00000e-09 2.12000e-01

$4.16034 \mathrm{e}+004.16034 \mathrm{e}+004.16034 \mathrm{e}-01$ 1.00000e-09 2.12000e-01

$1.00000 \mathrm{e}-021.00000 \mathrm{e}-021.00000 \mathrm{e}-031.00000 \mathrm{e}-091.00000 \mathrm{e}-01$

$1.00000 \mathrm{e}+001.00000 \mathrm{e}+001.00000 \mathrm{e}-01$ 1.00000e-09 1.00000e-01

Element: 7165 \# of layers: 4

$\mathrm{Kx} \mathrm{Ky} \mathrm{Kz}$ Ss Por

$1.04120 \mathrm{e}+021.04120 \mathrm{e}+02$ 1.04120e+01 1.00000e-09 7.00000e-02

4.16034e+00 4.16034e+00 4.16034e-01 1.00000e-09 2.12000e-01

$1.00000 \mathrm{e}-02$ 1.00000e-02 1.00000e-03 1.00000e-09 1.00000e-01

$1.00000 \mathrm{e}+001.00000 \mathrm{e}+001.00000 \mathrm{e}-011.00000 \mathrm{e}-091.00000 \mathrm{e}-01$ 
Element: 7166 \# of layers: 4

$\mathrm{Kx} \mathrm{Ky} \mathrm{Kz}$ Ss Por

8.57518e+01 8.57518e+01 8.57518e+00 1.00000e-09 7.00000e-02

$3.42637 \mathrm{e}+00$ 3.42637e+00 3.42637e-01 1.00000e-09 2.12000e-01

$1.00000 \mathrm{e}-02$ 1.00000e-02 1.00000e-03 1.00000e-09 1.00000e-01

$1.00000 \mathrm{e}+001.00000 \mathrm{e}+001.00000 \mathrm{e}-011.00000 \mathrm{e}-091.00000 \mathrm{e}-01$

Element: 7167 \# of layers: 4

$\mathrm{Kx} \mathrm{Ky} \mathrm{Kz}$ Ss Por

8.57518e+01 8.57518e+01 8.57518e+00 1.00000e-09 7.00000e-02

$3.42637 \mathrm{e}+003.42637 \mathrm{e}+00$ 3.42637e-01 1.00000e-09 2.12000e-01

$1.00000 \mathrm{e}-02$ 1.00000e-02 1.00000e-03 1.00000e-09 1.00000e-01

$1.00000 \mathrm{e}+001.00000 \mathrm{e}+001.00000 \mathrm{e}-011.00000 \mathrm{e}-091.00000 \mathrm{e}-01$

Element: 7168 \# of layers: 4

$\mathrm{Kx} \mathrm{Ky} \mathrm{Kz}$ Ss Por

8.57518e+01 8.57518e+01 8.57518e+00 1.00000e-09 7.00000e-02

$3.42637 \mathrm{e}+003.42637 \mathrm{e}+00$ 3.42637e-01 1.00000e-09 2.12000e-01

$1.00000 \mathrm{e}-02$ 1.00000e-02 1.00000e-03 1.00000e-09 1.00000e-01

$1.00000 \mathrm{e}+001.00000 \mathrm{e}+001.00000 \mathrm{e}-01$ 1.00000e-09 1.00000e-01

Element: 7169 \# of layers: 3

$\mathrm{Kx} \mathrm{Ky} \mathrm{Kz}$ Ss Por

8.57518e+01 8.57518e+01 8.57518e+00 1.00000e-09 7.00000e-02

$1.00000 \mathrm{e}-02$ 1.00000e-02 1.00000e-03 1.00000e-09 1.00000e-01

$1.00000 \mathrm{e}+001.00000 \mathrm{e}+001.00000 \mathrm{e}-01$ 1.00000e-09 1.00000e-01

Element: 7170 \# of layers: 3

Kx Ky Kz Ss Por

8.57518e+01 8.57518e+01 8.57518e+00 1.00000e-09 7.00000e-02

$1.00000 \mathrm{e}-02$ 1.00000e-02 1.00000e-03 1.00000e-09 1.00000e-01

$1.00000 \mathrm{e}+001.00000 \mathrm{e}+001.00000 \mathrm{e}-011.00000 \mathrm{e}-091.00000 \mathrm{e}-01$

Element: 7171 \# of layers: 3

$\mathrm{Kx} \mathrm{Ky} \mathrm{Kz}$ Ss Por

8.57518e+01 8.57518e+01 8.57518e+00 1.00000e-09 7.00000e-02

$1.00000 \mathrm{e}-02$ 1.00000e-02 1.00000e-03 1.00000e-09 1.00000e-01

$1.00000 \mathrm{e}+001.00000 \mathrm{e}+001.00000 \mathrm{e}-011.00000 \mathrm{e}-091.00000 \mathrm{e}-01$

Element: 7172 \# of layers: 3

$\mathrm{Kx} \mathrm{Ky} \mathrm{Kz}$ Ss Por

8.57518e+01 8.57518e+01 8.57518e+00 1.00000e-09 7.00000e-02

$1.00000 \mathrm{e}-02$ 1.00000e-02 1.00000e-03 1.00000e-09 1.00000e-01

$1.00000 \mathrm{e}+001.00000 \mathrm{e}+001.00000 \mathrm{e}-011.00000 \mathrm{e}-09$ 1.00000e-01

Element: 7173 \# of layers: 3

$\mathrm{Kx} \mathrm{Ky} \mathrm{Kz}$ Ss Por

8.57518e+01 8.57518e+01 8.57518e+00 1.00000e-09 7.00000e-02

$1.00000 \mathrm{e}-02$ 1.00000e-02 1.00000e-03 1.00000e-09 1.00000e-01

$1.00000 \mathrm{e}+001.00000 \mathrm{e}+001.00000 \mathrm{e}-01$ 1.00000e-09 1.00000e-01

Element: 7174 \# of layers: 3

Kx Ky Kz Ss Por

8.57518e+01 8.57518e+01 8.57518e+00 1.00000e-09 7.00000e-02 
$1.00000 \mathrm{e}-02$ 1.00000e-02 1.00000e-03 1.00000e-09 1.00000e-01 $1.00000 \mathrm{e}+001.00000 \mathrm{e}+001.00000 \mathrm{e}-01$ 1.00000e-09 1.00000e-01 Element: 7175 \# of layers: 4

Kx Ky Kz Ss Por

3.67383e+01 3.67383e+01 3.67383e+00 1.00000e-09 7.00000e-02 $1.46795 \mathrm{e}+001.46795 \mathrm{e}+001.46795 \mathrm{e}-01$ 1.00000e-09 2.12000e-01 $1.00000 \mathrm{e}-02$ 1.00000e-02 1.00000e-03 1.00000e-09 1.00000e-01 $1.00000 \mathrm{e}+001.00000 \mathrm{e}+001.00000 \mathrm{e}-01$ 1.00000e-09 1.00000e-01 Element: 7176 \# of layers: 4

$\mathrm{Kx} \mathrm{Ky} \mathrm{Kz}$ Ss Por

3.67383e+01 3.67383e+01 3.67383e+00 1.00000e-09 7.00000e-02

$1.46795 \mathrm{e}+001.46795 \mathrm{e}+001.46795 \mathrm{e}-01$ 1.00000e-09 2.12000e-01

$1.00000 \mathrm{e}-02$ 1.00000e-02 1.00000e-03 1.00000e-09 1.00000e-01

$1.00000 \mathrm{e}+001.00000 \mathrm{e}+001.00000 \mathrm{e}-01$ 1.00000e-09 1.00000e-01

Element: 7177 \# of layers: 3

Kx Ky Kz Ss Por

3.67383e+01 3.67383e+01 3.67383e+00 1.00000e-09 7.00000e-02 $1.00000 \mathrm{e}-02$ 1.00000e-02 1.00000e-03 1.00000e-09 1.00000e-01

$1.00000 \mathrm{e}+001.00000 \mathrm{e}+001.00000 \mathrm{e}-011.00000 \mathrm{e}-091.00000 \mathrm{e}-01$

Element: 7178 \# of layers: 3

$\mathrm{Kx} \mathrm{Ky} \mathrm{Kz}$ Ss Por

3.67383e+01 3.67383e+01 3.67383e+00 1.00000e-09 7.00000e-02 $1.00000 \mathrm{e}-02$ 1.00000e-02 1.00000e-03 1.00000e-09 1.00000e-01

$1.00000 \mathrm{e}+001.00000 \mathrm{e}+001.00000 \mathrm{e}-011.00000 \mathrm{e}-091.00000 \mathrm{e}-01$

Element: 7179 \# of layers: 3

$\mathrm{Kx} \mathrm{Ky} \mathrm{Kz}$ Ss Por

3.67383e+01 3.67383e+01 3.67383e+00 1.00000e-09 7.00000e-02 $1.00000 \mathrm{e}-02$ 1.00000e-02 1.00000e-03 1.00000e-09 1.00000e-01

$1.00000 \mathrm{e}+001.00000 \mathrm{e}+001.00000 \mathrm{e}-011.00000 \mathrm{e}-091.00000 \mathrm{e}-01$

Element: 7180 \# of layers: 3

$\mathrm{Kx} \mathrm{Ky} \mathrm{Kz}$ Ss Por

$3.67383 \mathrm{e}+013.67383 \mathrm{e}+013.67383 \mathrm{e}+001.00000 \mathrm{e}-09$ 7.00000e-02

$1.00000 \mathrm{e}-02$ 1.00000e-02 1.00000e-03 1.00000e-09 1.00000e-01

$1.00000 \mathrm{e}+001.00000 \mathrm{e}+001.00000 \mathrm{e}-011.00000 \mathrm{e}-091.00000 \mathrm{e}-01$

Element: 7181 \# of layers: 3

$\mathrm{Kx} \mathrm{Ky} \mathrm{Kz}$ Ss Por

3.67383e+01 3.67383e+01 3.67383e+00 1.00000e-09 7.00000e-02 $1.00000 \mathrm{e}-02$ 1.00000e-02 1.00000e-03 1.00000e-09 1.00000e-01 $1.00000 \mathrm{e}+001.00000 \mathrm{e}+001.00000 \mathrm{e}-011.00000 \mathrm{e}-091.00000 \mathrm{e}-01$

Element: 7182 \# of layers: 3

$\mathrm{Kx} \mathrm{Ky} \mathrm{Kz}$ Ss Por

3.67383e+01 3.67383e+01 3.67383e+00 1.00000e-09 7.00000e-02 $1.00000 \mathrm{e}-021.00000 \mathrm{e}-021.00000 \mathrm{e}-031.00000 \mathrm{e}-091.00000 \mathrm{e}-01$

$1.00000 \mathrm{e}+001.00000 \mathrm{e}+001.00000 \mathrm{e}-01$ 1.00000e-09 1.00000e-01

Element: 7183 \# of layers: 3

Kx Ky Kz Ss Por 
$3.67383 e+013.67383 e+013.67383 e+001.00000 e-09$ 7.00000e-02 $1.00000 \mathrm{e}-02$ 1.00000e-02 1.00000e-03 1.00000e-09 1.00000e-01

$1.00000 \mathrm{e}+001.00000 \mathrm{e}+001.00000 \mathrm{e}-011.00000 \mathrm{e}-091.00000 \mathrm{e}-01$

Element: 7184 \# of layers: 3

$\mathrm{Kx} \mathrm{Ky} \mathrm{Kz}$ Ss Por

4.13874e+01 4.13874e+01 4.13874e+00 1.00000e-09 7.00000e-02

1.00000e-02 1.00000e-02 1.00000e-03 1.00000e-09 1.00000e-01

$1.00000 \mathrm{e}+001.00000 \mathrm{e}+001.00000 \mathrm{e}-011.00000 \mathrm{e}-091.00000 \mathrm{e}-01$

Element: 7185 \# of layers: 3

$\mathrm{Kx} \mathrm{Ky} \mathrm{Kz}$ Ss Por

4.13874e+01 4.13874e+01 4.13874e+00 1.00000e-09 7.00000e-02

$1.00000 \mathrm{e}-02$ 1.00000e-02 1.00000e-03 1.00000e-09 1.00000e-01

$1.00000 \mathrm{e}+001.00000 \mathrm{e}+001.00000 \mathrm{e}-011.00000 \mathrm{e}-09$ 1.00000e-01

Element: 7186 \# of layers: 3

$\mathrm{Kx} \mathrm{Ky} \mathrm{Kz}$ Ss Por

4.13874e+01 4.13874e+01 4.13874e+00 1.00000e-09 7.00000e-02

$1.00000 \mathrm{e}-02$ 1.00000e-02 1.00000e-03 1.00000e-09 1.00000e-01

$1.00000 \mathrm{e}+001.00000 \mathrm{e}+001.00000 \mathrm{e}-01$ 1.00000e-09 1.00000e-01

Element: 7187 \# of layers: 3

Kx Ky Kz Ss Por

4.13874e+01 4.13874e+01 4.13874e+00 1.00000e-09 7.00000e-02 $1.00000 \mathrm{e}-021.00000 \mathrm{e}-021.00000 \mathrm{e}-031.00000 \mathrm{e}-091.00000 \mathrm{e}-01$

$1.00000 \mathrm{e}+001.00000 \mathrm{e}+001.00000 \mathrm{e}-01$ 1.00000e-09 1.00000e-01

Element: 7188 \# of layers: 3

$\mathrm{Kx} \mathrm{Ky} \mathrm{Kz}$ Ss Por

4.13874e+01 4.13874e+01 4.13874e+00 1.00000e-09 7.00000e-02

$1.00000 \mathrm{e}-02$ 1.00000e-02 1.00000e-03 1.00000e-09 1.00000e-01

$1.00000 \mathrm{e}+001.00000 \mathrm{e}+001.00000 \mathrm{e}-011.00000 \mathrm{e}-09$ 1.00000e-01

Element: 7189 \# of layers: 3

$\mathrm{Kx} \mathrm{Ky} \mathrm{Kz}$ Ss Por

4.13874e+01 4.13874e+01 4.13874e+00 1.00000e-09 7.00000e-02

$1.00000 \mathrm{e}-02$ 1.00000e-02 1.00000e-03 1.00000e-09 1.00000e-01

$1.00000 \mathrm{e}+001.00000 \mathrm{e}+001.00000 \mathrm{e}-011.00000 \mathrm{e}-091.00000 \mathrm{e}-01$

Element: 7190 \# of layers: 3

$\mathrm{Kx} \mathrm{Ky} \mathrm{Kz}$ Ss Por

4.13874e+01 4.13874e+01 4.13874e+00 1.00000e-09 7.00000e-02

$1.00000 \mathrm{e}-02$ 1.00000e-02 1.00000e-03 1.00000e-09 1.00000e-01

$1.00000 \mathrm{e}+001.00000 \mathrm{e}+001.00000 \mathrm{e}-011.00000 \mathrm{e}-09$ 1.00000e-01

Element: 7191 \# of layers: 3

$\mathrm{Kx} \mathrm{Ky} \mathrm{Kz}$ Ss Por

4.13874e+01 4.13874e+01 4.13874e+00 1.00000e-09 7.00000e-02

$1.00000 \mathrm{e}-02$ 1.00000e-02 1.00000e-03 1.00000e-09 1.00000e-01

$1.00000 \mathrm{e}+001.00000 \mathrm{e}+001.00000 \mathrm{e}-01$ 1.00000e-09 1.00000e-01

Element: 7192 \# of layers: 3

Kx Ky Kz Ss Por

4.13874e+01 4.13874e+01 4.13874e+00 1.00000e-09 7.00000e-02 
$1.00000 \mathrm{e}-02$ 1.00000e-02 1.00000e-03 1.00000e-09 1.00000e-01 $1.00000 \mathrm{e}+001.00000 \mathrm{e}+001.00000 \mathrm{e}-01$ 1.00000e-09 1.00000e-01

Element: 7193 \# of layers: 3

Kx Ky Kz Ss Por

4.45211e+01 4.45211e+01 4.45211e+00 1.00000e-09 7.00000e-02 $1.00000 \mathrm{e}-02$ 1.00000e-02 1.00000e-03 1.00000e-09 1.00000e-01

$1.00000 \mathrm{e}+001.00000 \mathrm{e}+001.00000 \mathrm{e}-011.00000 \mathrm{e}-091.00000 \mathrm{e}-01$

Element: 7194 \# of layers: 3

$\mathrm{Kx} \mathrm{Ky} \mathrm{Kz}$ Ss Por

4.45211e+01 4.45211e+01 4.45211e+00 1.00000e-09 7.00000e-02 $1.00000 \mathrm{e}-02$ 1.00000e-02 1.00000e-03 1.00000e-09 1.00000e-01

$1.00000 \mathrm{e}+001.00000 \mathrm{e}+001.00000 \mathrm{e}-011.00000 \mathrm{e}-091.00000 \mathrm{e}-01$

Element: 7195 \# of layers: 3

$\mathrm{Kx} \mathrm{Ky} \mathrm{Kz}$ Ss Por

4.45211e+01 4.45211e+01 4.45211e+00 1.00000e-09 7.00000e-02 $1.00000 \mathrm{e}-02$ 1.00000e-02 1.00000e-03 1.00000e-09 1.00000e-01

$1.00000 \mathrm{e}+001.00000 \mathrm{e}+001.00000 \mathrm{e}-011.00000 \mathrm{e}-091.00000 \mathrm{e}-01$

Element: 7196 \# of layers: 3

$\mathrm{Kx} \mathrm{Ky} \mathrm{Kz}$ Ss Por

4.45211e+01 4.45211e+01 4.45211e+00 1.00000e-09 7.00000e-02 $1.00000 \mathrm{e}-02$ 1.00000e-02 1.00000e-03 1.00000e-09 1.00000e-01

$1.00000 \mathrm{e}+001.00000 \mathrm{e}+001.00000 \mathrm{e}-01$ 1.00000e-09 1.00000e-01

Element: 7197 \# of layers: 3

Kx Ky Kz Ss Por

4.45211e+01 4.45211e+01 4.45211e+00 1.00000e-09 7.00000e-02 $1.00000 \mathrm{e}-02$ 1.00000e-02 1.00000e-03 1.00000e-09 1.00000e-01

$1.00000 \mathrm{e}+001.00000 \mathrm{e}+001.00000 \mathrm{e}-011.00000 \mathrm{e}-091.00000 \mathrm{e}-01$

Element: 7198 \# of layers: 3

Kx Ky Kz Ss Por

4.45211e+01 4.45211e+01 4.45211e+00 1.00000e-09 7.00000e-02 $1.00000 \mathrm{e}-02$ 1.00000e-02 1.00000e-03 1.00000e-09 1.00000e-01 $1.00000 \mathrm{e}+001.00000 \mathrm{e}+001.00000 \mathrm{e}-011.00000 \mathrm{e}-091.00000 \mathrm{e}-01$

Element: 7199 \# of layers: 3

$\mathrm{Kx} \mathrm{Ky} \mathrm{Kz}$ Ss Por

4.45211e+01 4.45211e+01 4.45211e+00 1.00000e-09 7.00000e-02 $1.00000 \mathrm{e}-02$ 1.00000e-02 1.00000e-03 1.00000e-09 1.00000e-01

$1.00000 \mathrm{e}+001.00000 \mathrm{e}+001.00000 \mathrm{e}-011.00000 \mathrm{e}-091.00000 \mathrm{e}-01$

Element: 7200 \# of layers: 3

$\mathrm{Kx} \mathrm{Ky} \mathrm{Kz}$ Ss Por

4.45211e+01 4.45211e+01 4.45211e+00 1.00000e-09 7.00000e-02 $1.00000 \mathrm{e}-02$ 1.00000e-02 1.00000e-03 1.00000e-09 1.00000e-01 $1.00000 \mathrm{e}+001.00000 \mathrm{e}+001.00000 \mathrm{e}-011.00000 \mathrm{e}-091.00000 \mathrm{e}-01$ Element: 7201 \# of layers: 3

$\mathrm{Kx} \mathrm{Ky} \mathrm{Kz}$ Ss Por

4.45211e+01 4.45211e+01 4.45211e+00 1.00000e-09 7.00000e-02 $1.00000 \mathrm{e}-02$ 1.00000e-02 1.00000e-03 1.00000e-09 1.00000e-01 
$1.00000 \mathrm{e}+001.00000 \mathrm{e}+00$ 1.00000e-01 1.00000e-09 1.00000e-01

Element: 7202 \# of layers: 3

Kx Ky Kz Ss Por

4.00287e+01 4.00287e+01 4.00287e+00 1.00000e-09 7.00000e-02

$1.00000 \mathrm{e}-021.00000 \mathrm{e}-021.00000 \mathrm{e}-031.00000 \mathrm{e}-091.00000 \mathrm{e}-01$

$1.00000 \mathrm{e}+001.00000 \mathrm{e}+001.00000 \mathrm{e}-011.00000 \mathrm{e}-091.00000 \mathrm{e}-01$

Element: 7203 \# of layers: 3

$\mathrm{Kx} \mathrm{Ky} \mathrm{Kz}$ Ss Por

4.00287e+01 4.00287e+01 4.00287e+00 1.00000e-09 7.00000e-02

$1.00000 \mathrm{e}-02$ 1.00000e-02 1.00000e-03 1.00000e-09 1.00000e-01

$1.00000 \mathrm{e}+001.00000 \mathrm{e}+001.00000 \mathrm{e}-011.00000 \mathrm{e}-091.00000 \mathrm{e}-01$

Element: 7204 \# of layers: 3

$\mathrm{Kx} \mathrm{Ky} \mathrm{Kz}$ Ss Por

4.00287e+01 4.00287e+01 4.00287e+00 1.00000e-09 7.00000e-02

$1.00000 \mathrm{e}-02$ 1.00000e-02 1.00000e-03 1.00000e-09 1.00000e-01

$1.00000 \mathrm{e}+001.00000 \mathrm{e}+001.00000 \mathrm{e}-011.00000 \mathrm{e}-091.00000 \mathrm{e}-01$

Element: 7205 \# of layers: 3

$\mathrm{Kx} \mathrm{Ky} \mathrm{Kz}$ Ss Por

4.00287e+01 4.00287e+01 4.00287e+00 1.00000e-09 7.00000e-02

$1.00000 \mathrm{e}-02$ 1.00000e-02 1.00000e-03 1.00000e-09 1.00000e-01

$1.00000 \mathrm{e}+001.00000 \mathrm{e}+001.00000 \mathrm{e}-011.00000 \mathrm{e}-091.00000 \mathrm{e}-01$

Element: 7206 \# of layers: 3

$\mathrm{Kx} \mathrm{Ky} \mathrm{Kz}$ Ss Por

4.00287e+01 4.00287e+01 4.00287e+00 1.00000e-09 7.00000e-02

$1.00000 \mathrm{e}-021.00000 \mathrm{e}-02$ 1.00000e-03 1.00000e-09 1.00000e-01

$1.00000 \mathrm{e}+001.00000 \mathrm{e}+001.00000 \mathrm{e}-01$ 1.00000e-09 1.00000e-01

Element: 7207 \# of layers: 3

$\mathrm{Kx} \mathrm{Ky} \mathrm{Kz}$ Ss Por

4.00287e+01 4.00287e+01 4.00287e+00 1.00000e-09 7.00000e-02

$1.00000 \mathrm{e}-02$ 1.00000e-02 1.00000e-03 1.00000e-09 1.00000e-01

$1.00000 \mathrm{e}+001.00000 \mathrm{e}+001.00000 \mathrm{e}-011.00000 \mathrm{e}-091.00000 \mathrm{e}-01$

Element: 7208 \# of layers: 3

$\mathrm{Kx} \mathrm{Ky} \mathrm{Kz}$ Ss Por

4.00287e+01 4.00287e+01 4.00287e+00 1.00000e-09 7.00000e-02

$1.00000 \mathrm{e}-02$ 1.00000e-02 1.00000e-03 1.00000e-09 1.00000e-01

$1.00000 \mathrm{e}+001.00000 \mathrm{e}+001.00000 \mathrm{e}-011.00000 \mathrm{e}-091.00000 \mathrm{e}-01$

Element: 7209 \# of layers: 3

$\mathrm{Kx} \mathrm{Ky} \mathrm{Kz}$ Ss Por

4.00287e+01 4.00287e+01 4.00287e+00 1.00000e-09 7.00000e-02

$1.00000 \mathrm{e}-02$ 1.00000e-02 1.00000e-03 1.00000e-09 1.00000e-01

$1.00000 \mathrm{e}+001.00000 \mathrm{e}+001.00000 \mathrm{e}-011.00000 \mathrm{e}-091.00000 \mathrm{e}-01$

Element: 7210 \# of layers: 3

$\mathrm{Kx} \mathrm{Ky} \mathrm{Kz}$ Ss Por

4.00287e+01 4.00287e+01 4.00287e+00 1.00000e-09 7.00000e-02

$1.00000 \mathrm{e}-02$ 1.00000e-02 1.00000e-03 1.00000e-09 1.00000e-01

$1.00000 \mathrm{e}+001.00000 \mathrm{e}+001.00000 \mathrm{e}-011.00000 \mathrm{e}-091.00000 \mathrm{e}-01$ 
Element: 7211 \# of layers: 3

$\mathrm{Kx} \mathrm{Ky} \mathrm{Kz}$ Ss Por

5.53313e+01 5.53313e+01 5.53313e+00 1.00000e-09 7.00000e-02

$1.00000 \mathrm{e}-02$ 1.00000e-02 1.00000e-03 1.00000e-09 1.00000e-01

$1.00000 \mathrm{e}+001.00000 \mathrm{e}+001.00000 \mathrm{e}-011.00000 \mathrm{e}-091.00000 \mathrm{e}-01$

Element: 7212 \# of layers: 3

$\mathrm{Kx} \mathrm{Ky} \mathrm{Kz}$ Ss Por

$2.42693 \mathrm{e}+02$ 2.42693e+02 2.42693e+01 1.00000e-09 7.00000e-02

$1.00000 \mathrm{e}-02$ 1.00000e-02 1.00000e-03 1.00000e-09 1.00000e-01

$1.00000 \mathrm{e}+001.00000 \mathrm{e}+001.00000 \mathrm{e}-011.00000 \mathrm{e}-091.00000 \mathrm{e}-01$

Element: 7213 \# of layers: 3

$\mathrm{Kx} \mathrm{Ky} \mathrm{Kz}$ Ss Por

2.42693e+02 2.42693e+02 2.42693e+01 1.00000e-09 7.00000e-02

1.00000e-02 1.00000e-02 1.00000e-03 1.00000e-09 1.00000e-01

$1.00000 \mathrm{e}+001.00000 \mathrm{e}+001.00000 \mathrm{e}-01$ 1.00000e-09 1.00000e-01

Element: 7217 \# of layers: 3

$\mathrm{Kx} \mathrm{Ky} \mathrm{Kz}$ Ss Por

5.53313e+01 5.53313e+01 5.53313e+00 1.00000e-09 7.00000e-02 $1.00000 \mathrm{e}-02$ 1.00000e-02 1.00000e-03 1.00000e-09 1.00000e-01

$1.00000 \mathrm{e}+001.00000 \mathrm{e}+001.00000 \mathrm{e}-011.00000 \mathrm{e}-091.00000 \mathrm{e}-01$

Element: 7218 \# of layers: 3

$\mathrm{Kx} \mathrm{Ky} \mathrm{Kz}$ Ss Por

5.53313e+01 5.53313e+01 5.53313e+00 1.00000e-09 7.00000e-02

$1.00000 \mathrm{e}-02$ 1.00000e-02 1.00000e-03 1.00000e-09 1.00000e-01

$1.00000 \mathrm{e}+001.00000 \mathrm{e}+001.00000 \mathrm{e}-011.00000 \mathrm{e}-091.00000 \mathrm{e}-01$

Element: 7220 \# of layers: 3

$\mathrm{Kx} \mathrm{Ky} \mathrm{Kz}$ Ss Por

$1.05066 \mathrm{e}+02$ 1.05066e+02 1.05066e+01 1.00000e-09 7.00000e-02

$1.00000 \mathrm{e}-02$ 1.00000e-02 1.00000e-03 1.00000e-09 1.00000e-01

$1.00000 \mathrm{e}+001.00000 \mathrm{e}+001.00000 \mathrm{e}-011.00000 \mathrm{e}-091.00000 \mathrm{e}-01$

Element: 7221 \# of layers: 3

$\mathrm{Kx} \mathrm{Ky} \mathrm{Kz}$ Ss Por

$2.48189 \mathrm{e}+012.48189 \mathrm{e}+012.48189 \mathrm{e}+00$ 1.00000e-09 7.00000e-02

$1.00000 \mathrm{e}-021.00000 \mathrm{e}-021.00000 \mathrm{e}-031.00000 \mathrm{e}-091.00000 \mathrm{e}-01$

$1.00000 \mathrm{e}+001.00000 \mathrm{e}+001.00000 \mathrm{e}-011.00000 \mathrm{e}-091.00000 \mathrm{e}-01$

Element: 7222 \# of layers: 3

Kx Ky Kz Ss Por

$2.48189 \mathrm{e}+012.48189 \mathrm{e}+01$ 2.48189e+00 1.00000e-09 7.00000e-02

$1.00000 \mathrm{e}-021.00000 \mathrm{e}-02$ 1.00000e-03 1.00000e-09 1.00000e-01

$1.00000 \mathrm{e}+001.00000 \mathrm{e}+001.00000 \mathrm{e}-011.00000 \mathrm{e}-091.00000 \mathrm{e}-01$

Element: 7223 \# of layers: 3

$\mathrm{Kx} \mathrm{Ky} \mathrm{Kz}$ Ss Por

$1.05066 \mathrm{e}+02$ 1.05066e+02 1.05066e+01 1.00000e-09 7.00000e-02

$1.00000 \mathrm{e}-02$ 1.00000e-02 1.00000e-03 1.00000e-09 1.00000e-01

$1.00000 \mathrm{e}+001.00000 \mathrm{e}+001.00000 \mathrm{e}-011.00000 \mathrm{e}-091.00000 \mathrm{e}-01$

Element: 7224 \# of layers: 3 
$\mathrm{Kx} \mathrm{Ky} \mathrm{Kz}$ Ss Por

$1.05066 \mathrm{e}+02$ 1.05066e+02 1.05066e+01 1.00000e-09 7.00000e-02

$1.00000 \mathrm{e}-02$ 1.00000e-02 1.00000e-03 1.00000e-09 1.00000e-01

$1.00000 \mathrm{e}+001.00000 \mathrm{e}+001.00000 \mathrm{e}-011.00000 \mathrm{e}-091.00000 \mathrm{e}-01$

Element: 7225 \# of layers: 3

$\mathrm{Kx} \mathrm{Ky} \mathrm{Kz}$ Ss Por

$1.05066 \mathrm{e}+02$ 1.05066e+02 1.05066e+01 1.00000e-09 7.00000e-02

$1.00000 \mathrm{e}-02$ 1.00000e-02 1.00000e-03 1.00000e-09 1.00000e-01

$1.00000 \mathrm{e}+001.00000 \mathrm{e}+001.00000 \mathrm{e}-011.00000 \mathrm{e}-091.00000 \mathrm{e}-01$

Element: 7226 \# of layers: 9

$\mathrm{Kx} \mathrm{Ky} \mathrm{Kz}$ Ss Por

$2.82860 \mathrm{e}+02$ 2.82860e+02 2.82860e+01 1.00000e-09 7.00000e-02

$2.82860 \mathrm{e}+02$ 2.82860e+02 2.82860e+01 1.00000e-09 7.00000e-02

$1.13020 \mathrm{e}+011.13020 \mathrm{e}+011.13020 \mathrm{e}+001.00000 \mathrm{e}-092.12000 \mathrm{e}-01$

$1.13020 \mathrm{e}+011.13020 \mathrm{e}+011.13020 \mathrm{e}+001.00000 \mathrm{e}-092.12000 \mathrm{e}-01$

$1.13020 \mathrm{e}+011.13020 \mathrm{e}+011.13020 \mathrm{e}+001.00000 \mathrm{e}-092.12000 \mathrm{e}-01$

$1.13020 \mathrm{e}+011.13020 \mathrm{e}+011.13020 \mathrm{e}+001.00000 \mathrm{e}-092.12000 \mathrm{e}-01$

$1.13020 \mathrm{e}+011.13020 \mathrm{e}+011.13020 \mathrm{e}+001.00000 \mathrm{e}-092.12000 \mathrm{e}-01$

$1.00000 \mathrm{e}-02$ 1.00000e-02 1.00000e-03 1.00000e-09 1.00000e-01

$1.00000 \mathrm{e}+001.00000 \mathrm{e}+001.00000 \mathrm{e}-011.00000 \mathrm{e}-091.00000 \mathrm{e}-01$

Element: 7227 \# of layers: 9

$\mathrm{Kx} \mathrm{Ky} \mathrm{Kz}$ Ss Por

$2.82860 \mathrm{e}+02$ 2.82860e+02 2.82860e+01 1.00000e-09 7.00000e-02

$2.82860 \mathrm{e}+022.82860 \mathrm{e}+02$ 2.82860e+01 1.00000e-09 7.00000e-02

$1.13020 \mathrm{e}+011.13020 \mathrm{e}+011.13020 \mathrm{e}+001.00000 \mathrm{e}-092.12000 \mathrm{e}-01$

$1.13020 \mathrm{e}+011.13020 \mathrm{e}+011.13020 \mathrm{e}+001.00000 \mathrm{e}-092.12000 \mathrm{e}-01$

$1.13020 \mathrm{e}+011.13020 \mathrm{e}+011.13020 \mathrm{e}+001.00000 \mathrm{e}-092.12000 \mathrm{e}-01$

$1.13020 \mathrm{e}+011.13020 \mathrm{e}+011.13020 \mathrm{e}+001.00000 \mathrm{e}-092.12000 \mathrm{e}-01$

$1.13020 \mathrm{e}+011.13020 \mathrm{e}+011.13020 \mathrm{e}+001.00000 \mathrm{e}-092.12000 \mathrm{e}-01$

$1.00000 \mathrm{e}-02$ 1.00000e-02 1.00000e-03 1.00000e-09 1.00000e-01

$1.00000 \mathrm{e}+001.00000 \mathrm{e}+001.00000 \mathrm{e}-011.00000 \mathrm{e}-091.00000 \mathrm{e}-01$

Element: 7228 \# of layers: 10

$\mathrm{Kx} \mathrm{Ky} \mathrm{Kz}$ Ss Por

$2.82860 \mathrm{e}+02$ 2.82860e+02 2.82860e+01 1.00000e-09 7.00000e-02

$2.82860 \mathrm{e}+02$ 2.82860e+02 2.82860e+01 1.00000e-09 7.00000e-02

$2.82860 \mathrm{e}+022.82860 \mathrm{e}+022.82860 \mathrm{e}+01$ 1.00000e-09 7.00000e-02

$1.13020 \mathrm{e}+011.13020 \mathrm{e}+011.13020 \mathrm{e}+001.00000 \mathrm{e}-092.12000 \mathrm{e}-01$

$1.13020 \mathrm{e}+011.13020 \mathrm{e}+011.13020 \mathrm{e}+001.00000 \mathrm{e}-092.12000 \mathrm{e}-01$

$1.13020 \mathrm{e}+011.13020 \mathrm{e}+011.13020 \mathrm{e}+001.00000 \mathrm{e}-092.12000 \mathrm{e}-01$

$1.13020 \mathrm{e}+011.13020 \mathrm{e}+011.13020 \mathrm{e}+001.00000 \mathrm{e}-092.12000 \mathrm{e}-01$

$1.13020 \mathrm{e}+011.13020 \mathrm{e}+011.13020 \mathrm{e}+001.00000 \mathrm{e}-092.12000 \mathrm{e}-01$

$1.00000 \mathrm{e}-02$ 1.00000e-02 1.00000e-03 1.00000e-09 1.00000e-01

$1.00000 \mathrm{e}+001.00000 \mathrm{e}+001.00000 \mathrm{e}-011.00000 \mathrm{e}-091.00000 \mathrm{e}-01$

Element: 7229 \# of layers: 8

$\mathrm{Kx} \mathrm{Ky} \mathrm{Kz}$ Ss Por

6.99113e+02 6.99113e+02 6.99113e+01 1.00000e-09 7.00000e-02 
$2.79343 \mathrm{e}+012.79343 \mathrm{e}+012.79343 \mathrm{e}+00$ 1.00000e-09 2.12000e-01 $2.79343 \mathrm{e}+012.79343 \mathrm{e}+012.79343 \mathrm{e}+00$ 1.00000e-09 2.12000e-01 $2.79343 \mathrm{e}+012.79343 \mathrm{e}+012.79343 \mathrm{e}+00$ 1.00000e-09 2.12000e-01 $2.79343 \mathrm{e}+012.79343 \mathrm{e}+012.79343 \mathrm{e}+001.00000 \mathrm{e}-092.12000 \mathrm{e}-01$ $2.79343 \mathrm{e}+012.79343 \mathrm{e}+012.79343 \mathrm{e}+00$ 1.00000e-09 2.12000e-01 $1.00000 \mathrm{e}-021.00000 \mathrm{e}-02$ 1.00000e-03 1.00000e-09 1.00000e-01 $1.00000 \mathrm{e}+001.00000 \mathrm{e}+001.00000 \mathrm{e}-011.00000 \mathrm{e}-091.00000 \mathrm{e}-01$ Element: 7230 \# of layers: 8

Kx Ky Kz Ss Por

$6.99113 \mathrm{e}+02$ 6.99113e+02 6.99113e+01 1.00000e-09 7.00000e-02 $2.79343 \mathrm{e}+012.79343 \mathrm{e}+012.79343 \mathrm{e}+001.00000 \mathrm{e}-092.12000 \mathrm{e}-01$ $2.79343 \mathrm{e}+012.79343 \mathrm{e}+012.79343 \mathrm{e}+00$ 1.00000e-09 2.12000e-01 $2.79343 \mathrm{e}+012.79343 \mathrm{e}+012.79343 \mathrm{e}+00$ 1.00000e-09 2.12000e-01 $2.79343 \mathrm{e}+012.79343 \mathrm{e}+012.79343 \mathrm{e}+00$ 1.00000e-09 2.12000e-01 $2.79343 \mathrm{e}+012.79343 \mathrm{e}+012.79343 \mathrm{e}+00$ 1.00000e-09 2.12000e-01 $1.00000 \mathrm{e}-021.00000 \mathrm{e}-02$ 1.00000e-03 1.00000e-09 1.00000e-01 $1.00000 \mathrm{e}+001.00000 \mathrm{e}+001.00000 \mathrm{e}-011.00000 \mathrm{e}-091.00000 \mathrm{e}-01$ Element: 7231 \# of layers: 8

Kx Ky Kz Ss Por $6.99113 \mathrm{e}+026.99113 \mathrm{e}+026.99113 \mathrm{e}+01$ 1.00000e-09 7.00000e-02 $2.79343 \mathrm{e}+012.79343 \mathrm{e}+012.79343 \mathrm{e}+001.00000 \mathrm{e}-09$ 2.12000e-01 $2.79343 \mathrm{e}+012.79343 \mathrm{e}+012.79343 \mathrm{e}+00$ 1.00000e-09 2.12000e-01 $2.79343 \mathrm{e}+012.79343 \mathrm{e}+012.79343 \mathrm{e}+00$ 1.00000e-09 2.12000e-01 $2.79343 \mathrm{e}+012.79343 \mathrm{e}+012.79343 \mathrm{e}+001.00000 \mathrm{e}-092.12000 \mathrm{e}-01$ $2.79343 \mathrm{e}+012.79343 \mathrm{e}+012.79343 \mathrm{e}+001.00000 \mathrm{e}-092.12000 \mathrm{e}-01$ $1.00000 \mathrm{e}-02$ 1.00000e-02 1.00000e-03 1.00000e-09 1.00000e-01 $1.00000 \mathrm{e}+001.00000 \mathrm{e}+001.00000 \mathrm{e}-011.00000 \mathrm{e}-091.00000 \mathrm{e}-01$ Element: 7232 \# of layers: 7

Kx Ky Kz Ss Por $1.92003 \mathrm{e}+03$ 1.92003e+03 1.92003e+02 1.00000e-09 7.00000e-02 $7.67199 \mathrm{e}+01$ 7.67199e+01 7.67199e+00 1.00000e-09 2.12000e-01 $7.67199 \mathrm{e}+01$ 7.67199e+01 7.67199e+00 1.00000e-09 2.12000e-01 $7.67199 \mathrm{e}+01$ 7.67199e+01 7.67199e+00 1.00000e-09 2.12000e-01 $7.67199 \mathrm{e}+01$ 7.67199e+01 7.67199e+00 1.00000e-09 2.12000e-01 $1.00000 \mathrm{e}-021.00000 \mathrm{e}-02$ 1.00000e-03 1.00000e-09 1.00000e-01 $1.00000 \mathrm{e}+001.00000 \mathrm{e}+001.00000 \mathrm{e}-011.00000 \mathrm{e}-091.00000 \mathrm{e}-01$ Element: 7233 \# of layers: 8

Kx Ky Kz Ss Por $1.92003 \mathrm{e}+03$ 1.92003e+03 1.92003e+02 1.00000e-09 7.00000e-02 $7.67199 \mathrm{e}+01$ 7.67199e+01 7.67199e+00 1.00000e-09 2.12000e-01 $7.67199 \mathrm{e}+01$ 7.67199e+01 7.67199e+00 1.00000e-09 2.12000e-01 $7.67199 \mathrm{e}+01$ 7.67199e+01 7.67199e+00 1.00000e-09 2.12000e-01 $7.67199 \mathrm{e}+01$ 7.67199e+01 7.67199e+00 1.00000e-09 2.12000e-01 $7.67199 \mathrm{e}+01$ 7.67199e+01 7.67199e+00 1.00000e-09 2.12000e-01 $1.00000 \mathrm{e}-021.00000 \mathrm{e}-02$ 1.00000e-03 1.00000e-09 1.00000e-01 $1.00000 \mathrm{e}+001.00000 \mathrm{e}+001.00000 \mathrm{e}-011.00000 \mathrm{e}-091.00000 \mathrm{e}-01$ 
Element: 7234 \# of layers: 9

$\mathrm{Kx} \mathrm{Ky} \mathrm{Kz}$ Ss Por

$1.92003 e+03$ 1.92003e+03 1.92003e+02 1.00000e-09 7.00000e-02

$1.92003 \mathrm{e}+03$ 1.92003e+03 1.92003e+02 1.00000e-09 7.00000e-02

$7.67199 \mathrm{e}+01$ 7.67199e+01 7.67199e+00 1.00000e-09 2.12000e-01

$7.67199 \mathrm{e}+017.67199 \mathrm{e}+01$ 7.67199e+00 1.00000e-09 2.12000e-01

$7.67199 \mathrm{e}+017.67199 \mathrm{e}+01$ 7.67199e+00 1.00000e-09 2.12000e-01

$7.67199 \mathrm{e}+01$ 7.67199e+01 7.67199e+00 1.00000e-09 2.12000e-01

7.67199e+01 7.67199e+01 7.67199e+00 1.00000e-09 2.12000e-01

1.00000e-02 1.00000e-02 1.00000e-03 1.00000e-09 1.00000e-01

$1.00000 \mathrm{e}+001.00000 \mathrm{e}+001.00000 \mathrm{e}-011.00000 \mathrm{e}-091.00000 \mathrm{e}-01$

Element: 7235 \# of layers: 6

$\mathrm{Kx} \mathrm{Ky} \mathrm{Kz}$ Ss Por

$1.07271 \mathrm{e}+02$ 1.07271e+02 1.07271e+01 1.00000e-09 2.12000e-01

$1.07271 \mathrm{e}+021.07271 \mathrm{e}+02$ 1.07271e+01 1.00000e-09 2.12000e-01

$1.07271 \mathrm{e}+021.07271 \mathrm{e}+021.07271 \mathrm{e}+01$ 1.00000e-09 2.12000e-01

$1.07271 \mathrm{e}+02$ 1.07271e+02 1.07271e+01 1.00000e-09 2.12000e-01

$1.00000 \mathrm{e}-02$ 1.00000e-02 1.00000e-03 1.00000e-09 1.00000e-01

$1.00000 \mathrm{e}+001.00000 \mathrm{e}+001.00000 \mathrm{e}-01$ 1.00000e-09 1.00000e-01

Element: 7236 \# of layers: 6

$\mathrm{Kx} \mathrm{Ky} \mathrm{Kz}$ Ss Por

$1.07271 \mathrm{e}+02$ 1.07271e+02 1.07271e+01 1.00000e-09 2.12000e-01

$1.07271 \mathrm{e}+021.07271 \mathrm{e}+02$ 1.07271e+01 1.00000e-09 2.12000e-01

$1.07271 \mathrm{e}+02$ 1.07271e+02 1.07271e+01 1.00000e-09 2.12000e-01

$1.07271 \mathrm{e}+021.07271 \mathrm{e}+021.07271 \mathrm{e}+01$ 1.00000e-09 2.12000e-01

$1.00000 \mathrm{e}-02$ 1.00000e-02 1.00000e-03 1.00000e-09 1.00000e-01

$1.00000 \mathrm{e}+001.00000 \mathrm{e}+001.00000 \mathrm{e}-01$ 1.00000e-09 1.00000e-01

Element: 7237 \# of layers: 7

Kx Ky Kz Ss Por

$1.92003 \mathrm{e}+031.92003 \mathrm{e}+03$ 1.92003e+02 1.00000e-09 7.00000e-02 $1.07271 \mathrm{e}+021.07271 \mathrm{e}+021.07271 \mathrm{e}+01$ 1.00000e-09 2.12000e-01

$1.07271 \mathrm{e}+021.07271 \mathrm{e}+02$ 1.07271e+01 1.00000e-09 2.12000e-01

$1.07271 \mathrm{e}+021.07271 \mathrm{e}+02 \quad 1.07271 \mathrm{e}+01$ 1.00000e-09 2.12000e-01

$1.07271 \mathrm{e}+02$ 1.07271e+02 1.07271e+01 1.00000e-09 2.12000e-01

$1.00000 \mathrm{e}-02$ 1.00000e-02 1.00000e-03 1.00000e-09 1.00000e-01

$1.00000 \mathrm{e}+001.00000 \mathrm{e}+001.00000 \mathrm{e}-01$ 1.00000e-09 1.00000e-01

Element: 7238 \# of layers: 6

$\mathrm{Kx} \mathrm{Ky} \mathrm{Kz}$ Ss Por

8.51103e+01 8.51103e+01 8.51103e+00 1.00000e-09 2.12000e-01

$8.51103 \mathrm{e}+018.51103 \mathrm{e}+018.51103 \mathrm{e}+00$ 1.00000e-09 2.12000e-01

$8.51103 \mathrm{e}+018.51103 \mathrm{e}+018.51103 \mathrm{e}+00$ 1.00000e-09 2.12000e-01

$8.51103 \mathrm{e}+018.51103 \mathrm{e}+018.51103 \mathrm{e}+00$ 1.00000e-09 2.12000e-01

$1.00000 \mathrm{e}-021.00000 \mathrm{e}-021.00000 \mathrm{e}-031.00000 \mathrm{e}-091.00000 \mathrm{e}-01$

$1.00000 \mathrm{e}+001.00000 \mathrm{e}+001.00000 \mathrm{e}-011.00000 \mathrm{e}-091.00000 \mathrm{e}-01$

Element: 7239 \# of layers: 6

Kx Ky Kz Ss Por 
8.51103e+01 8.51103e+01 8.51103e+00 1.00000e-09 2.12000e-01 $8.51103 \mathrm{e}+018.51103 \mathrm{e}+018.51103 \mathrm{e}+00$ 1.00000e-09 2.12000e-01 $8.51103 \mathrm{e}+018.51103 \mathrm{e}+018.51103 \mathrm{e}+00$ 1.00000e-09 2.12000e-01 $8.51103 \mathrm{e}+018.51103 \mathrm{e}+018.51103 \mathrm{e}+001.00000 \mathrm{e}-092.12000 \mathrm{e}-01$ $1.00000 \mathrm{e}-02$ 1.00000e-02 1.00000e-03 1.00000e-09 1.00000e-01 $1.00000 \mathrm{e}+001.00000 \mathrm{e}+001.00000 \mathrm{e}-011.00000 \mathrm{e}-091.00000 \mathrm{e}-01$ Element: 7240 \# of layers: 6

$\mathrm{Kx} \mathrm{Ky} \mathrm{Kz}$ Ss Por

8.51103e+01 8.51103e+01 8.51103e+00 1.00000e-09 2.12000e-01 $8.51103 \mathrm{e}+018.51103 \mathrm{e}+018.51103 \mathrm{e}+00$ 1.00000e-09 2.12000e-01 $8.51103 \mathrm{e}+018.51103 \mathrm{e}+018.51103 \mathrm{e}+00$ 1.00000e-09 2.12000e-01 $8.51103 \mathrm{e}+018.51103 \mathrm{e}+018.51103 \mathrm{e}+001.00000 \mathrm{e}-092.12000 \mathrm{e}-01$ $1.00000 \mathrm{e}-02$ 1.00000e-02 1.00000e-03 1.00000e-09 1.00000e-01 $1.00000 \mathrm{e}+001.00000 \mathrm{e}+001.00000 \mathrm{e}-011.00000 \mathrm{e}-091.00000 \mathrm{e}-01$ Element: 7241 \# of layers: 6

Kx Ky Kz Ss Por

8.84989e+01 8.84989e+01 8.84989e+00 1.00000e-09 2.12000e-01 $8.84989 \mathrm{e}+01$ 8.84989e+01 8.84989e+00 1.00000e-09 2.12000e-01 $8.84989 \mathrm{e}+018.84989 \mathrm{e}+018.84989 \mathrm{e}+00$ 1.00000e-09 2.12000e-01 $8.84989 \mathrm{e}+01$ 8.84989e+01 8.84989e+00 1.00000e-09 2.12000e-01 $1.00000 \mathrm{e}-02$ 1.00000e-02 1.00000e-03 1.00000e-09 1.00000e-01 $1.00000 \mathrm{e}+001.00000 \mathrm{e}+001.00000 \mathrm{e}-01$ 1.00000e-09 1.00000e-01 Element: 7242 \# of layers: 6

$\mathrm{Kx} \mathrm{Ky} \mathrm{Kz}$ Ss Por

8.84989e+01 8.84989e+01 8.84989e+00 1.00000e-09 2.12000e-01 8.84989e+01 8.84989e+01 8.84989e+00 1.00000e-09 2.12000e-01 8.84989e+01 8.84989e+01 8.84989e+00 1.00000e-09 2.12000e-01 8.84989e+01 8.84989e+01 8.84989e+00 1.00000e-09 2.12000e-01 $1.00000 \mathrm{e}-02$ 1.00000e-02 1.00000e-03 1.00000e-09 1.00000e-01 $1.00000 \mathrm{e}+001.00000 \mathrm{e}+001.00000 \mathrm{e}-011.00000 \mathrm{e}-091.00000 \mathrm{e}-01$ Element: 7243 \# of layers: 6

$\mathrm{Kx} \mathrm{Ky} \mathrm{Kz}$ Ss Por

8.84989e+01 8.84989e+01 8.84989e+00 1.00000e-09 2.12000e-01 $8.84989 \mathrm{e}+01$ 8.84989e+01 8.84989e+00 1.00000e-09 2.12000e-01 $8.84989 \mathrm{e}+01$ 8.84989e+01 8.84989e+00 1.00000e-09 2.12000e-01 $8.84989 \mathrm{e}+01$ 8.84989e+01 8.84989e+00 1.00000e-09 2.12000e-01 $1.00000 \mathrm{e}-02$ 1.00000e-02 1.00000e-03 1.00000e-09 1.00000e-01 $1.00000 \mathrm{e}+001.00000 \mathrm{e}+001.00000 \mathrm{e}-011.00000 \mathrm{e}-091.00000 \mathrm{e}-01$ Element: 7244 \# of layers: 6

$\mathrm{Kx} \mathrm{Ky} \mathrm{Kz}$ Ss Por 9.06049e+01 9.06049e+01 9.06049e+00 1.00000e-09 2.12000e-01 $9.06049 \mathrm{e}+019.06049 \mathrm{e}+019.06049 \mathrm{e}+001.00000 \mathrm{e}-092.12000 \mathrm{e}-01$ 9.06049e+01 9.06049e+01 9.06049e+00 1.00000e-09 2.12000e-01 9.06049e+01 9.06049e+01 9.06049e+00 1.00000e-09 2.12000e-01 $1.00000 \mathrm{e}-02$ 1.00000e-02 1.00000e-03 1.00000e-09 1.00000e-01 $1.00000 \mathrm{e}+001.00000 \mathrm{e}+001.00000 \mathrm{e}-011.00000 \mathrm{e}-091.00000 \mathrm{e}-01$ 
Element: 7245 \# of layers: 6

Kx Ky Kz Ss Por

$9.06049 \mathrm{e}+01$ 9.06049e+01 9.06049e+00 1.00000e-09 2.12000e-01

$9.06049 \mathrm{e}+019.06049 \mathrm{e}+019.06049 \mathrm{e}+001.00000 \mathrm{e}-092.12000 \mathrm{e}-01$

$9.06049 \mathrm{e}+019.06049 \mathrm{e}+019.06049 \mathrm{e}+00$ 1.00000e-09 2.12000e-01

$9.06049 \mathrm{e}+019.06049 \mathrm{e}+019.06049 \mathrm{e}+001.00000 \mathrm{e}-092.12000 \mathrm{e}-01$

$1.00000 \mathrm{e}-02$ 1.00000e-02 $1.00000 \mathrm{e}-031.00000 \mathrm{e}-091.00000 \mathrm{e}-01$

$1.00000 \mathrm{e}+001.00000 \mathrm{e}+001.00000 \mathrm{e}-011.00000 \mathrm{e}-091.00000 \mathrm{e}-01$

Element: 7246 \# of layers: 6

Kx Ky Kz Ss Por

$9.06049 \mathrm{e}+01$ 9.06049e+01 9.06049e+00 1.00000e-09 2.12000e-01

$9.06049 \mathrm{e}+019.06049 \mathrm{e}+019.06049 \mathrm{e}+00$ 1.00000e-09 2.12000e-01

$9.06049 \mathrm{e}+019.06049 \mathrm{e}+019.06049 \mathrm{e}+00$ 1.00000e-09 2.12000e-01

$9.06049 \mathrm{e}+01$ 9.06049e+01 9.06049e+00 1.00000e-09 2.12000e-01

$1.00000 \mathrm{e}-02$ 1.00000e-02 1.00000e-03 1.00000e-09 1.00000e-01

$1.00000 \mathrm{e}+001.00000 \mathrm{e}+001.00000 \mathrm{e}-011.00000 \mathrm{e}-091.00000 \mathrm{e}-01$

Element: 7247 \# of layers: 6

Kx Ky Kz Ss Por

$8.32180 \mathrm{e}+018.32180 \mathrm{e}+018.32180 \mathrm{e}+00$ 1.00000e-09 2.12000e-01

$8.32180 \mathrm{e}+018.32180 \mathrm{e}+018.32180 \mathrm{e}+001.00000 \mathrm{e}-092.12000 \mathrm{e}-01$

$8.32180 \mathrm{e}+018.32180 \mathrm{e}+018.32180 \mathrm{e}+001.00000 \mathrm{e}-092.12000 \mathrm{e}-01$

$8.32180 \mathrm{e}+018.32180 \mathrm{e}+018.32180 \mathrm{e}+00$ 1.00000e-09 2.12000e-01

$1.00000 \mathrm{e}-021.00000 \mathrm{e}-02$ 1.00000e-03 1.00000e-09 1.00000e-01

$1.00000 \mathrm{e}+001.00000 \mathrm{e}+001.00000 \mathrm{e}-011.00000 \mathrm{e}-091.00000 \mathrm{e}-01$

Element: 7248 \# of layers: 6

Kx Ky Kz Ss Por

$8.32180 \mathrm{e}+018.32180 \mathrm{e}+018.32180 \mathrm{e}+00$ 1.00000e-09 2.12000e-01

$8.32180 \mathrm{e}+018.32180 \mathrm{e}+018.32180 \mathrm{e}+001.00000 \mathrm{e}-092.12000 \mathrm{e}-01$

$8.32180 \mathrm{e}+018.32180 \mathrm{e}+018.32180 \mathrm{e}+001.00000 \mathrm{e}-092.12000 \mathrm{e}-01$

$8.32180 \mathrm{e}+018.32180 \mathrm{e}+018.32180 \mathrm{e}+00$ 1.00000e-09 2.12000e-01

$1.00000 \mathrm{e}-021.00000 \mathrm{e}-02$ 1.00000e-03 1.00000e-09 1.00000e-01

$1.00000 \mathrm{e}+001.00000 \mathrm{e}+001.00000 \mathrm{e}-011.00000 \mathrm{e}-091.00000 \mathrm{e}-01$

Element: 7249 \# of layers: 6

Kx Ky Kz Ss Por

$8.32180 \mathrm{e}+018.32180 \mathrm{e}+018.32180 \mathrm{e}+00$ 1.00000e-09 2.12000e-01

$8.32180 \mathrm{e}+018.32180 \mathrm{e}+018.32180 \mathrm{e}+001.00000 \mathrm{e}-092.12000 \mathrm{e}-01$

$8.32180 \mathrm{e}+018.32180 \mathrm{e}+018.32180 \mathrm{e}+001.00000 \mathrm{e}-092.12000 \mathrm{e}-01$

$8.32180 \mathrm{e}+018.32180 \mathrm{e}+018.32180 \mathrm{e}+001.00000 \mathrm{e}-092.12000 \mathrm{e}-01$ $1.00000 \mathrm{e}-021.00000 \mathrm{e}-02$ 1.00000e-03 1.00000e-09 1.00000e-01

$1.00000 \mathrm{e}+001.00000 \mathrm{e}+001.00000 \mathrm{e}-011.00000 \mathrm{e}-091.00000 \mathrm{e}-01$

Element: 7250 \# of layers: 6

$\mathrm{Kx} \mathrm{Ky} \mathrm{Kz}$ Ss Por

$8.75944 \mathrm{e}+018.75944 \mathrm{e}+018.75944 \mathrm{e}+00$ 1.00000e-09 2.12000e-01

$8.75944 \mathrm{e}+018.75944 \mathrm{e}+018.75944 \mathrm{e}+001.00000 \mathrm{e}-092.12000 \mathrm{e}-01$

$8.75944 \mathrm{e}+018.75944 \mathrm{e}+018.75944 \mathrm{e}+001.00000 \mathrm{e}-092.12000 \mathrm{e}-01$

$8.75944 \mathrm{e}+018.75944 \mathrm{e}+018.75944 \mathrm{e}+001.00000 \mathrm{e}-092.12000 \mathrm{e}-01$ 
$1.00000 \mathrm{e}-02$ 1.00000e-02 1.00000e-03 1.00000e-09 1.00000e-01 $1.00000 \mathrm{e}+001.00000 \mathrm{e}+001.00000 \mathrm{e}-01$ 1.00000e-09 1.00000e-01

Element: 7251 \# of layers: 6

Kx Ky Kz Ss Por

8.75944e+01 8.75944e+01 8.75944e+00 1.00000e-09 2.12000e-01

$8.75944 \mathrm{e}+018.75944 \mathrm{e}+018.75944 \mathrm{e}+001.00000 \mathrm{e}-092.12000 \mathrm{e}-01$

$8.75944 \mathrm{e}+018.75944 \mathrm{e}+018.75944 \mathrm{e}+001.00000 \mathrm{e}-092.12000 \mathrm{e}-01$

$8.75944 \mathrm{e}+018.75944 \mathrm{e}+018.75944 \mathrm{e}+001.00000 \mathrm{e}-092.12000 \mathrm{e}-01$

$1.00000 \mathrm{e}-02$ 1.00000e-02 1.00000e-03 1.00000e-09 1.00000e-01

$1.00000 \mathrm{e}+001.00000 \mathrm{e}+00$ 1.00000e-01 1.00000e-09 1.00000e-01

Element: 7252 \# of layers: 6

$\mathrm{Kx} \mathrm{Ky} \mathrm{Kz}$ Ss Por

8.75944e+01 8.75944e+01 8.75944e+00 1.00000e-09 2.12000e-01

$8.75944 \mathrm{e}+018.75944 \mathrm{e}+018.75944 \mathrm{e}+00$ 1.00000e-09 2.12000e-01

$8.75944 \mathrm{e}+018.75944 \mathrm{e}+018.75944 \mathrm{e}+001.00000 \mathrm{e}-092.12000 \mathrm{e}-01$

$8.75944 \mathrm{e}+018.75944 \mathrm{e}+018.75944 \mathrm{e}+001.00000 \mathrm{e}-092.12000 \mathrm{e}-01$

$1.00000 \mathrm{e}-021.00000 \mathrm{e}-021.00000 \mathrm{e}-031.00000 \mathrm{e}-091.00000 \mathrm{e}-01$

$1.00000 \mathrm{e}+001.00000 \mathrm{e}+001.00000 \mathrm{e}-011.00000 \mathrm{e}-091.00000 \mathrm{e}-01$

Element: 7253 \# of layers: 6

$\mathrm{Kx} \mathrm{Ky} \mathrm{Kz}$ Ss Por

8.75944e+01 8.75944e+01 8.75944e+00 1.00000e-09 2.12000e-01

$8.75944 \mathrm{e}+018.75944 \mathrm{e}+018.75944 \mathrm{e}+001.00000 \mathrm{e}-092.12000 \mathrm{e}-01$

8.75944e+01 8.75944e+01 8.75944e+00 1.00000e-09 2.12000e-01

$8.75944 \mathrm{e}+018.75944 \mathrm{e}+018.75944 \mathrm{e}+001.00000 \mathrm{e}-092.12000 \mathrm{e}-01$

$1.00000 \mathrm{e}-021.00000 \mathrm{e}-02$ 1.00000e-03 1.00000e-09 1.00000e-01

$1.00000 \mathrm{e}+001.00000 \mathrm{e}+001.00000 \mathrm{e}-011.00000 \mathrm{e}-091.00000 \mathrm{e}-01$

Element: 7254 \# of layers: 6

Kx Ky Kz Ss Por

8.75944e+01 8.75944e+01 8.75944e+00 1.00000e-09 2.12000e-01

$8.75944 \mathrm{e}+018.75944 \mathrm{e}+018.75944 \mathrm{e}+001.00000 \mathrm{e}-092.12000 \mathrm{e}-01$

$8.75944 \mathrm{e}+018.75944 \mathrm{e}+018.75944 \mathrm{e}+001.00000 \mathrm{e}-092.12000 \mathrm{e}-01$

$8.75944 \mathrm{e}+018.75944 \mathrm{e}+018.75944 \mathrm{e}+00$ 1.00000e-09 2.12000e-01

1.00000e-02 1.00000e-02 1.00000e-03 1.00000e-09 1.00000e-01

$1.00000 \mathrm{e}+001.00000 \mathrm{e}+001.00000 \mathrm{e}-01$ 1.00000e-09 1.00000e-01

Element: 7259 \# of layers: 6

Kx Ky Kz Ss Por

7.77482e+01 7.77482e+01 7.77482e+00 1.00000e-09 2.12000e-01

$7.77482 \mathrm{e}+01$ 7.77482e+01 7.77482e+00 1.00000e-09 2.12000e-01

7.77482e+01 7.77482e+01 7.77482e+00 1.00000e-09 2.12000e-01

$7.77482 \mathrm{e}+01$ 7.77482e+01 7.77482e+00 1.00000e-09 2.12000e-01

1.00000e-02 1.00000e-02 1.00000e-03 1.00000e-09 1.00000e-01

$1.00000 \mathrm{e}+001.00000 \mathrm{e}+001.00000 \mathrm{e}-011.00000 \mathrm{e}-091.00000 \mathrm{e}-01$

Element: 7260 \# of layers: 6

$\mathrm{Kx} \mathrm{Ky} \mathrm{Kz}$ Ss Por

7.77482e+01 7.77482e+01 7.77482e+00 1.00000e-09 2.12000e-01

$7.77482 \mathrm{e}+01$ 7.77482e+01 7.77482e+00 1.00000e-09 2.12000e-01 
7.77482e+01 7.77482e+01 7.77482e+00 1.00000e-09 2.12000e-01 $7.77482 \mathrm{e}+01$ 7.77482e+01 7.77482e+00 1.00000e-09 2.12000e-01 $1.00000 \mathrm{e}-021.00000 \mathrm{e}-02$ 1.00000e-03 1.00000e-09 1.00000e-01 $1.00000 \mathrm{e}+001.00000 \mathrm{e}+001.00000 \mathrm{e}-011.00000 \mathrm{e}-091.00000 \mathrm{e}-01$ Element: 7261 \# of layers: 6

Kx Ky Kz Ss Por

7.77482e+01 7.77482e+01 7.77482e+00 1.00000e-09 2.12000e-01

$7.77482 \mathrm{e}+01$ 7.77482e+01 7.77482e+00 1.00000e-09 2.12000e-01

$7.77482 \mathrm{e}+01$ 7.77482e+01 7.77482e+00 1.00000e-09 2.12000e-01

$7.77482 \mathrm{e}+01$ 7.77482e+01 7.77482e+00 1.00000e-09 2.12000e-01 $1.00000 \mathrm{e}-021.00000 \mathrm{e}-02$ 1.00000e-03 1.00000e-09 1.00000e-01 $1.00000 \mathrm{e}+001.00000 \mathrm{e}+00$ 1.00000e-01 1.00000e-09 1.00000e-01 Element: 7262 \# of layers: 6

Kx Ky Kz Ss Por

7.77482e+01 7.77482e+01 7.77482e+00 1.00000e-09 2.12000e-01

$7.77482 \mathrm{e}+01$ 7.77482e+01 7.77482e+00 1.00000e-09 2.12000e-01

$7.77482 \mathrm{e}+017.77482 \mathrm{e}+01$ 7.77482e+00 1.00000e-09 2.12000e-01

$7.77482 \mathrm{e}+01$ 7.77482e+01 7.77482e+00 1.00000e-09 2.12000e-01 $1.00000 \mathrm{e}-021.00000 \mathrm{e}-02$ 1.00000e-03 1.00000e-09 1.00000e-01 $1.00000 \mathrm{e}+001.00000 \mathrm{e}+001.00000 \mathrm{e}-011.00000 \mathrm{e}-091.00000 \mathrm{e}-01$ Element: 7263 \# of layers: 6

Kx Ky Kz Ss Por

7.77482e+01 7.77482e+01 7.77482e+00 1.00000e-09 2.12000e-01 $7.77482 \mathrm{e}+01$ 7.77482e+01 7.77482e+00 1.00000e-09 2.12000e-01 $7.77482 \mathrm{e}+01$ 7.77482e+01 7.77482e+00 1.00000e-09 2.12000e-01 $7.77482 \mathrm{e}+01$ 7.77482e+01 7.77482e+00 1.00000e-09 2.12000e-01 $1.00000 \mathrm{e}-021.00000 \mathrm{e}-02$ 1.00000e-03 1.00000e-09 1.00000e-01 $1.00000 \mathrm{e}+001.00000 \mathrm{e}+001.00000 \mathrm{e}-011.00000 \mathrm{e}-091.00000 \mathrm{e}-01$ Element: 7264 \# of layers: 6

Kx Ky Kz Ss Por

7.77482e+01 7.77482e+01 7.77482e+00 1.00000e-09 2.12000e-01 $7.77482 \mathrm{e}+01$ 7.77482e+01 7.77482e+00 1.00000e-09 2.12000e-01 $7.77482 \mathrm{e}+01$ 7.77482e+01 7.77482e+00 1.00000e-09 2.12000e-01 $7.77482 \mathrm{e}+01$ 7.77482e+01 7.77482e+00 1.00000e-09 2.12000e-01 $1.00000 \mathrm{e}-021.00000 \mathrm{e}-02$ 1.00000e-03 1.00000e-09 1.00000e-01 $1.00000 \mathrm{e}+001.00000 \mathrm{e}+001.00000 \mathrm{e}-011.00000 \mathrm{e}-091.00000 \mathrm{e}-01$ Element: 7265 \# of layers: 6

Kx Ky Kz Ss Por

7.77482e+01 7.77482e+01 7.77482e+00 1.00000e-09 2.12000e-01 $7.77482 \mathrm{e}+01$ 7.77482e+01 7.77482e+00 1.00000e-09 2.12000e-01 $7.77482 \mathrm{e}+01$ 7.77482e+01 7.77482e+00 1.00000e-09 2.12000e-01 $7.77482 \mathrm{e}+01$ 7.77482e+01 7.77482e+00 1.00000e-09 2.12000e-01 $1.00000 \mathrm{e}-021.00000 \mathrm{e}-02$ 1.00000e-03 1.00000e-09 1.00000e-01 $1.00000 \mathrm{e}+001.00000 \mathrm{e}+001.00000 \mathrm{e}-011.00000 \mathrm{e}-091.00000 \mathrm{e}-01$ Element: 7266 \# of layers: 6

Kx Ky Kz Ss Por 
7.77482e+01 7.77482e+01 7.77482e+00 1.00000e-09 2.12000e-01 $7.77482 \mathrm{e}+01$ 7.77482e+01 7.77482e+00 1.00000e-09 2.12000e-01 $7.77482 \mathrm{e}+01$ 7.77482e+01 7.77482e+00 1.00000e-09 2.12000e-01 $7.77482 \mathrm{e}+01$ 7.77482e+01 7.77482e+00 1.00000e-09 2.12000e-01 $1.00000 \mathrm{e}-02$ 1.00000e-02 1.00000e-03 1.00000e-09 1.00000e-01 $1.00000 \mathrm{e}+001.00000 \mathrm{e}+001.00000 \mathrm{e}-011.00000 \mathrm{e}-091.00000 \mathrm{e}-01$ Element: 7267 \# of layers: 6

Kx Ky Kz Ss Por

7.77482e+01 7.77482e+01 7.77482e+00 1.00000e-09 2.12000e-01 $7.77482 \mathrm{e}+01$ 7.77482e+01 7.77482e+00 1.00000e-09 2.12000e-01 $7.77482 \mathrm{e}+01$ 7.77482e+01 7.77482e+00 1.00000e-09 2.12000e-01 $7.77482 \mathrm{e}+01$ 7.77482e+01 7.77482e+00 1.00000e-09 2.12000e-01 $1.00000 \mathrm{e}-021.00000 \mathrm{e}-02$ 1.00000e-03 1.00000e-09 1.00000e-01 $1.00000 \mathrm{e}+001.00000 \mathrm{e}+001.00000 \mathrm{e}-011.00000 \mathrm{e}-091.00000 \mathrm{e}-01$ Element: 7268 \# of layers: 6

Kx Ky Kz Ss Por

$8.27523 \mathrm{e}+018.27523 \mathrm{e}+01$ 8.27523e+00 1.00000e-09 2.12000e-01 $8.27523 \mathrm{e}+018.27523 \mathrm{e}+018.27523 \mathrm{e}+00$ 1.00000e-09 2.12000e-01 $8.27523 \mathrm{e}+018.27523 \mathrm{e}+018.27523 \mathrm{e}+00$ 1.00000e-09 2.12000e-01 $8.27523 \mathrm{e}+018.27523 \mathrm{e}+018.27523 \mathrm{e}+001.00000 \mathrm{e}-092.12000 \mathrm{e}-01$ $1.00000 \mathrm{e}-021.00000 \mathrm{e}-02$ 1.00000e-03 1.00000e-09 1.00000e-01 $1.00000 \mathrm{e}+001.00000 \mathrm{e}+001.00000 \mathrm{e}-011.00000 \mathrm{e}-091.00000 \mathrm{e}-01$ Element: 7269 \# of layers: 6

Kx Ky Kz Ss Por

$8.27523 \mathrm{e}+018.27523 \mathrm{e}+018.27523 \mathrm{e}+00$ 1.00000e-09 2.12000e-01 $8.27523 \mathrm{e}+018.27523 \mathrm{e}+018.27523 \mathrm{e}+00$ 1.00000e-09 2.12000e-01 $8.27523 \mathrm{e}+018.27523 \mathrm{e}+018.27523 \mathrm{e}+001.00000 \mathrm{e}-092.12000 \mathrm{e}-01$ $8.27523 \mathrm{e}+018.27523 \mathrm{e}+018.27523 \mathrm{e}+001.00000 \mathrm{e}-092.12000 \mathrm{e}-01$ $1.00000 \mathrm{e}-021.00000 \mathrm{e}-02$ 1.00000e-03 1.00000e-09 1.00000e-01 $1.00000 \mathrm{e}+001.00000 \mathrm{e}+001.00000 \mathrm{e}-011.00000 \mathrm{e}-091.00000 \mathrm{e}-01$ Element: 7270 \# of layers: 6

Kx Ky Kz Ss Por

$8.27523 \mathrm{e}+018.27523 \mathrm{e}+018.27523 \mathrm{e}+00$ 1.00000e-09 2.12000e-01 $8.27523 \mathrm{e}+018.27523 \mathrm{e}+018.27523 \mathrm{e}+00$ 1.00000e-09 2.12000e-01 $8.27523 \mathrm{e}+018.27523 \mathrm{e}+018.27523 \mathrm{e}+00$ 1.00000e-09 2.12000e-01 $8.27523 \mathrm{e}+018.27523 \mathrm{e}+018.27523 \mathrm{e}+00$ 1.00000e-09 2.12000e-01 $1.00000 \mathrm{e}-021.00000 \mathrm{e}-02$ 1.00000e-03 1.00000e-09 1.00000e-01 $1.00000 \mathrm{e}+001.00000 \mathrm{e}+00$ 1.00000e-01 1.00000e-09 1.00000e-01 Element: 7271 \# of layers: 6

$\mathrm{Kx} \mathrm{Ky} \mathrm{Kz}$ Ss Por

8.27523e+01 8.27523e+01 8.27523e+00 1.00000e-09 2.12000e-01 $8.27523 \mathrm{e}+018.27523 \mathrm{e}+018.27523 \mathrm{e}+00$ 1.00000e-09 2.12000e-01 8.27523e+01 8.27523e+01 8.27523e+00 1.00000e-09 2.12000e-01 8.27523e+01 8.27523e+01 8.27523e+00 1.00000e-09 2.12000e-01 $1.00000 \mathrm{e}-02$ 1.00000e-02 1.00000e-03 1.00000e-09 1.00000e-01 $1.00000 \mathrm{e}+001.00000 \mathrm{e}+001.00000 \mathrm{e}-011.00000 \mathrm{e}-091.00000 \mathrm{e}-01$ 
Element: 7272 \# of layers: 5

Kx Ky Kz Ss Por

$8.27523 \mathrm{e}+018.27523 \mathrm{e}+018.27523 \mathrm{e}+00$ 1.00000e-09 2.12000e-01

$8.27523 \mathrm{e}+018.27523 \mathrm{e}+018.27523 \mathrm{e}+001.00000 \mathrm{e}-092.12000 \mathrm{e}-01$

$8.27523 \mathrm{e}+018.27523 \mathrm{e}+018.27523 \mathrm{e}+00$ 1.00000e-09 2.12000e-01

$1.00000 \mathrm{e}-021.00000 \mathrm{e}-02$ 1.00000e-03 1.00000e-09 1.00000e-01

$1.00000 \mathrm{e}+001.00000 \mathrm{e}+001.00000 \mathrm{e}-011.00000 \mathrm{e}-091.00000 \mathrm{e}-01$

Element: 7273 \# of layers: 6

$\mathrm{Kx} \mathrm{Ky} \mathrm{Kz}$ Ss Por

$8.27523 \mathrm{e}+018.27523 \mathrm{e}+01$ 8.27523e+00 1.00000e-09 2.12000e-01

$8.27523 \mathrm{e}+018.27523 \mathrm{e}+018.27523 \mathrm{e}+001.00000 \mathrm{e}-092.12000 \mathrm{e}-01$

$8.27523 \mathrm{e}+018.27523 \mathrm{e}+018.27523 \mathrm{e}+00$ 1.00000e-09 2.12000e-01

$8.27523 \mathrm{e}+018.27523 \mathrm{e}+018.27523 \mathrm{e}+00$ 1.00000e-09 2.12000e-01

$1.00000 \mathrm{e}-02$ 1.00000e-02 1.00000e-03 1.00000e-09 1.00000e-01

$1.00000 \mathrm{e}+001.00000 \mathrm{e}+001.00000 \mathrm{e}-011.00000 \mathrm{e}-091.00000 \mathrm{e}-01$

Element: 7274 \# of layers: 6

$\mathrm{Kx} \mathrm{Ky} \mathrm{Kz}$ Ss Por

$8.27523 \mathrm{e}+018.27523 \mathrm{e}+01$ 8.27523e+00 1.00000e-09 2.12000e-01

$8.27523 \mathrm{e}+018.27523 \mathrm{e}+018.27523 \mathrm{e}+00$ 1.00000e-09 2.12000e-01

$8.27523 \mathrm{e}+018.27523 \mathrm{e}+018.27523 \mathrm{e}+001.00000 \mathrm{e}-092.12000 \mathrm{e}-01$

$8.27523 \mathrm{e}+018.27523 \mathrm{e}+018.27523 \mathrm{e}+001.00000 \mathrm{e}-092.12000 \mathrm{e}-01$

$1.00000 \mathrm{e}-02$ 1.00000e-02 1.00000e-03 1.00000e-09 1.00000e-01

$1.00000 \mathrm{e}+001.00000 \mathrm{e}+00$ 1.00000e-01 1.00000e-09 1.00000e-01

Element: 7275 \# of layers: 6

Kx Ky Kz Ss Por

8.27523e+01 8.27523e+01 8.27523e+00 1.00000e-09 2.12000e-01

$8.27523 \mathrm{e}+018.27523 \mathrm{e}+018.27523 \mathrm{e}+00$ 1.00000e-09 2.12000e-01

$8.27523 \mathrm{e}+018.27523 \mathrm{e}+018.27523 \mathrm{e}+00$ 1.00000e-09 2.12000e-01

$8.27523 \mathrm{e}+018.27523 \mathrm{e}+018.27523 \mathrm{e}+00$ 1.00000e-09 2.12000e-01

$1.00000 \mathrm{e}-02$ 1.00000e-02 1.00000e-03 1.00000e-09 1.00000e-01

$1.00000 \mathrm{e}+001.00000 \mathrm{e}+001.00000 \mathrm{e}-011.00000 \mathrm{e}-091.00000 \mathrm{e}-01$

Element: 7276 \# of layers: 6

Kx Ky Kz Ss Por

8.27523e+01 8.27523e+01 8.27523e+00 1.00000e-09 2.12000e-01

8.27523e+01 8.27523e+01 8.27523e+00 1.00000e-09 2.12000e-01

$8.27523 \mathrm{e}+018.27523 \mathrm{e}+018.27523 \mathrm{e}+00$ 1.00000e-09 2.12000e-01

$8.27523 \mathrm{e}+018.27523 \mathrm{e}+018.27523 \mathrm{e}+00$ 1.00000e-09 2.12000e-01

$1.00000 \mathrm{e}-021.00000 \mathrm{e}-02$ 1.00000e-03 1.00000e-09 1.00000e-01

$1.00000 \mathrm{e}+001.00000 \mathrm{e}+00$ 1.00000e-01 1.00000e-09 1.00000e-01

Element: 7277 \# of layers: 6

Kx Ky Kz Ss Por

$5.71400 \mathrm{e}+015.71400 \mathrm{e}+015.71400 \mathrm{e}+001.00000 \mathrm{e}-092.12000 \mathrm{e}-01$

$5.71400 \mathrm{e}+015.71400 \mathrm{e}+015.71400 \mathrm{e}+001.00000 \mathrm{e}-092.12000 \mathrm{e}-01$

$5.71400 \mathrm{e}+015.71400 \mathrm{e}+015.71400 \mathrm{e}+001.00000 \mathrm{e}-092.12000 \mathrm{e}-01$

$5.71400 \mathrm{e}+015.71400 \mathrm{e}+015.71400 \mathrm{e}+001.00000 \mathrm{e}-092.12000 \mathrm{e}-01$

$1.00000 \mathrm{e}-021.00000 \mathrm{e}-02$ 1.00000e-03 1.00000e-09 1.00000e-01 
$1.00000 \mathrm{e}+001.00000 \mathrm{e}+00$ 1.00000e-01 1.00000e-09 1.00000e-01

Element: 7278 \# of layers: 5

$\mathrm{Kx} \mathrm{Ky} \mathrm{Kz}$ Ss Por

$5.71400 \mathrm{e}+015.71400 \mathrm{e}+015.71400 \mathrm{e}+001.00000 \mathrm{e}-09$ 2.12000e-01

$5.71400 \mathrm{e}+015.71400 \mathrm{e}+015.71400 \mathrm{e}+001.00000 \mathrm{e}-092.12000 \mathrm{e}-01$

$5.71400 \mathrm{e}+015.71400 \mathrm{e}+015.71400 \mathrm{e}+001.00000 \mathrm{e}-092.12000 \mathrm{e}-01$

$1.00000 \mathrm{e}-02$ 1.00000e-02 1.00000e-03 1.00000e-09 1.00000e-01

$1.00000 \mathrm{e}+001.00000 \mathrm{e}+001.00000 \mathrm{e}-01$ 1.00000e-09 1.00000e-01

Element: 7279 \# of layers: 6

$\mathrm{Kx} \mathrm{Ky} \mathrm{Kz}$ Ss Por

1.43007e+03 1.43007e+03 1.43007e+02 1.00000e-09 7.00000e-02

$5.71400 \mathrm{e}+015.71400 \mathrm{e}+015.71400 \mathrm{e}+001.00000 \mathrm{e}-092.12000 \mathrm{e}-01$

$5.71400 \mathrm{e}+015.71400 \mathrm{e}+015.71400 \mathrm{e}+001.00000 \mathrm{e}-092.12000 \mathrm{e}-01$

$5.71400 \mathrm{e}+015.71400 \mathrm{e}+015.71400 \mathrm{e}+001.00000 \mathrm{e}-092.12000 \mathrm{e}-01$

$1.00000 \mathrm{e}-02$ 1.00000e-02 1.00000e-03 1.00000e-09 1.00000e-01

$1.00000 \mathrm{e}+001.00000 \mathrm{e}+001.00000 \mathrm{e}-011.00000 \mathrm{e}-091.00000 \mathrm{e}-01$

Element: 7280 \# of layers: 5

$\mathrm{Kx} \mathrm{Ky} \mathrm{Kz}$ Ss Por

$5.71400 \mathrm{e}+015.71400 \mathrm{e}+015.71400 \mathrm{e}+001.00000 \mathrm{e}-092.12000 \mathrm{e}-01$

$5.71400 \mathrm{e}+015.71400 \mathrm{e}+015.71400 \mathrm{e}+001.00000 \mathrm{e}-092.12000 \mathrm{e}-01$

$5.71400 \mathrm{e}+015.71400 \mathrm{e}+015.71400 \mathrm{e}+001.00000 \mathrm{e}-092.12000 \mathrm{e}-01$

$1.00000 \mathrm{e}-02$ 1.00000e-02 1.00000e-03 1.00000e-09 1.00000e-01

$1.00000 \mathrm{e}+001.00000 \mathrm{e}+001.00000 \mathrm{e}-01$ 1.00000e-09 1.00000e-01

Element: 7281 \# of layers: 5

Kx Ky Kz Ss Por

$5.71400 \mathrm{e}+015.71400 \mathrm{e}+015.71400 \mathrm{e}+001.00000 \mathrm{e}-092.12000 \mathrm{e}-01$

$5.71400 \mathrm{e}+015.71400 \mathrm{e}+015.71400 \mathrm{e}+001.00000 \mathrm{e}-092.12000 \mathrm{e}-01$

$5.71400 \mathrm{e}+015.71400 \mathrm{e}+015.71400 \mathrm{e}+001.00000 \mathrm{e}-092.12000 \mathrm{e}-01$

$1.00000 \mathrm{e}-02$ 1.00000e-02 1.00000e-03 1.00000e-09 1.00000e-01

$1.00000 \mathrm{e}+001.00000 \mathrm{e}+001.00000 \mathrm{e}-011.00000 \mathrm{e}-091.00000 \mathrm{e}-01$

Element: 7282 \# of layers: 5

$\mathrm{Kx} \mathrm{Ky} \mathrm{Kz}$ Ss Por

5.71400e+01 5.71400e+01 5.71400e+00 1.00000e-09 2.12000e-01

$5.71400 \mathrm{e}+015.71400 \mathrm{e}+015.71400 \mathrm{e}+001.00000 \mathrm{e}-092.12000 \mathrm{e}-01$

$5.71400 \mathrm{e}+015.71400 \mathrm{e}+015.71400 \mathrm{e}+001.00000 \mathrm{e}-092.12000 \mathrm{e}-01$

$1.00000 \mathrm{e}-02$ 1.00000e-02 1.00000e-03 1.00000e-09 1.00000e-01

$1.00000 \mathrm{e}+001.00000 \mathrm{e}+001.00000 \mathrm{e}-011.00000 \mathrm{e}-091.00000 \mathrm{e}-01$

Element: 7283 \# of layers: 5

Kx Ky Kz Ss Por

$5.71400 \mathrm{e}+015.71400 \mathrm{e}+015.71400 \mathrm{e}+001.00000 \mathrm{e}-09$ 2.12000e-01

$5.71400 \mathrm{e}+015.71400 \mathrm{e}+015.71400 \mathrm{e}+001.00000 \mathrm{e}-092.12000 \mathrm{e}-01$

$5.71400 \mathrm{e}+015.71400 \mathrm{e}+015.71400 \mathrm{e}+001.00000 \mathrm{e}-092.12000 \mathrm{e}-01$ $1.00000 \mathrm{e}-02$ 1.00000e-02 1.00000e-03 1.00000e-09 1.00000e-01

$1.00000 \mathrm{e}+001.00000 \mathrm{e}+001.00000 \mathrm{e}-01$ 1.00000e-09 1.00000e-01

Element: 7284 \# of layers: 5

Kx Ky Kz Ss Por 
$5.71400 \mathrm{e}+015.71400 \mathrm{e}+015.71400 \mathrm{e}+001.00000 \mathrm{e}-092.12000 \mathrm{e}-01$ $5.71400 \mathrm{e}+015.71400 \mathrm{e}+015.71400 \mathrm{e}+001.00000 \mathrm{e}-092.12000 \mathrm{e}-01$ $5.71400 \mathrm{e}+015.71400 \mathrm{e}+015.71400 \mathrm{e}+001.00000 \mathrm{e}-092.12000 \mathrm{e}-01$ $1.00000 \mathrm{e}-021.00000 \mathrm{e}-02$ 1.00000e-03 1.00000e-09 1.00000e-01 $1.00000 \mathrm{e}+001.00000 \mathrm{e}+001.00000 \mathrm{e}-011.00000 \mathrm{e}-091.00000 \mathrm{e}-01$ Element: 7285 \# of layers: 5

Kx Ky Kz Ss Por

$5.71400 \mathrm{e}+015.71400 \mathrm{e}+015.71400 \mathrm{e}+00$ 1.00000e-09 2.12000e-01 $5.71400 \mathrm{e}+015.71400 \mathrm{e}+015.71400 \mathrm{e}+001.00000 \mathrm{e}-092.12000 \mathrm{e}-01$ $5.71400 \mathrm{e}+015.71400 \mathrm{e}+015.71400 \mathrm{e}+001.00000 \mathrm{e}-092.12000 \mathrm{e}-01$ $1.00000 \mathrm{e}-021.00000 \mathrm{e}-02$ 1.00000e-03 1.00000e-09 1.00000e-01 $1.00000 \mathrm{e}+001.00000 \mathrm{e}+00$ 1.00000e-01 1.00000e-09 1.00000e-01 Element: 7286 \# of layers: 6

Kx Ky Kz Ss Por

$1.38538 \mathrm{e}+03$ 1.38538e+03 1.38538e+02 1.00000e-09 7.00000e-02 $5.53534 \mathrm{e}+015.53534 \mathrm{e}+015.53534 \mathrm{e}+001.00000 \mathrm{e}-092.12000 \mathrm{e}-01$ $5.53534 \mathrm{e}+015.53534 \mathrm{e}+015.53534 \mathrm{e}+001.00000 \mathrm{e}-092.12000 \mathrm{e}-01$ $5.53534 \mathrm{e}+015.53534 \mathrm{e}+015.53534 \mathrm{e}+00$ 1.00000e-09 2.12000e-01 $1.00000 \mathrm{e}-021.00000 \mathrm{e}-02$ 1.00000e-03 1.00000e-09 1.00000e-01 $1.00000 \mathrm{e}+001.00000 \mathrm{e}+001.00000 \mathrm{e}-011.00000 \mathrm{e}-091.00000 \mathrm{e}-01$ Element: 7287 \# of layers: 6

Kx Ky Kz Ss Por

$1.38538 \mathrm{e}+03$ 1.38538e+03 1.38538e+02 1.00000e-09 7.00000e-02 $5.53534 \mathrm{e}+015.53534 \mathrm{e}+015.53534 \mathrm{e}+001.00000 \mathrm{e}-092.12000 \mathrm{e}-01$ $5.53534 \mathrm{e}+015.53534 \mathrm{e}+015.53534 \mathrm{e}+001.00000 \mathrm{e}-092.12000 \mathrm{e}-01$ $5.53534 \mathrm{e}+015.53534 \mathrm{e}+015.53534 \mathrm{e}+001.00000 \mathrm{e}-092.12000 \mathrm{e}-01$ $1.00000 \mathrm{e}-02$ 1.00000e-02 1.00000e-03 1.00000e-09 1.00000e-01 $1.00000 \mathrm{e}+001.00000 \mathrm{e}+001.00000 \mathrm{e}-011.00000 \mathrm{e}-091.00000 \mathrm{e}-01$ Element: 7288 \# of layers: 5

Kx Ky Kz Ss Por

$1.38538 \mathrm{e}+03$ 1.38538e+03 1.38538e+02 1.00000e-09 7.00000e-02 $5.53534 \mathrm{e}+015.53534 \mathrm{e}+015.53534 \mathrm{e}+001.00000 \mathrm{e}-092.12000 \mathrm{e}-01$ $5.53534 \mathrm{e}+015.53534 \mathrm{e}+015.53534 \mathrm{e}+001.00000 \mathrm{e}-092.12000 \mathrm{e}-01$ $1.00000 \mathrm{e}-02$ 1.00000e-02 1.00000e-03 1.00000e-09 1.00000e-01 $1.00000 \mathrm{e}+001.00000 \mathrm{e}+001.00000 \mathrm{e}-011.00000 \mathrm{e}-091.00000 \mathrm{e}-01$ Element: 7289 \# of layers: 6

Kx Ky Kz Ss Por

$1.38538 \mathrm{e}+03$ 1.38538e+03 1.38538e+02 1.00000e-09 7.00000e-02 $5.53534 \mathrm{e}+015.53534 \mathrm{e}+015.53534 \mathrm{e}+001.00000 \mathrm{e}-092.12000 \mathrm{e}-01$ $5.53534 \mathrm{e}+015.53534 \mathrm{e}+015.53534 \mathrm{e}+001.00000 \mathrm{e}-092.12000 \mathrm{e}-01$ $5.53534 \mathrm{e}+015.53534 \mathrm{e}+015.53534 \mathrm{e}+001.00000 \mathrm{e}-092.12000 \mathrm{e}-01$ $1.00000 \mathrm{e}-021.00000 \mathrm{e}-02$ 1.00000e-03 1.00000e-09 1.00000e-01 $1.00000 \mathrm{e}+001.00000 \mathrm{e}+001.00000 \mathrm{e}-011.00000 \mathrm{e}-091.00000 \mathrm{e}-01$ Element: 7290 \# of layers: 6

Kx Ky Kz Ss Por

$1.38538 \mathrm{e}+03$ 1.38538e+03 1.38538e+02 1.00000e-09 7.00000e-02 
5.53534e+01 5.53534e+01 5.53534e+00 1.00000e-09 2.12000e-01

$5.53534 \mathrm{e}+015.53534 \mathrm{e}+015.53534 \mathrm{e}+001.00000 \mathrm{e}-092.12000 \mathrm{e}-01$

$5.53534 \mathrm{e}+015.53534 \mathrm{e}+015.53534 \mathrm{e}+001.00000 \mathrm{e}-092.12000 \mathrm{e}-01$

$1.00000 \mathrm{e}-02$ 1.00000e-02 1.00000e-03 1.00000e-09 1.00000e-01

$1.00000 \mathrm{e}+001.00000 \mathrm{e}+001.00000 \mathrm{e}-01$ 1.00000e-09 1.00000e-01

Element: 7291 \# of layers: 6

$\mathrm{Kx} \mathrm{Ky} \mathrm{Kz}$ Ss Por

1.38538e+03 1.38538e+03 1.38538e+02 1.00000e-09 7.00000e-02

$5.53534 \mathrm{e}+015.53534 \mathrm{e}+015.53534 \mathrm{e}+001.00000 \mathrm{e}-092.12000 \mathrm{e}-01$

$5.53534 \mathrm{e}+015.53534 \mathrm{e}+015.53534 \mathrm{e}+001.00000 \mathrm{e}-092.12000 \mathrm{e}-01$

$5.53534 \mathrm{e}+015.53534 \mathrm{e}+015.53534 \mathrm{e}+001.00000 \mathrm{e}-092.12000 \mathrm{e}-01$

$1.00000 \mathrm{e}-02$ 1.00000e-02 1.00000e-03 1.00000e-09 1.00000e-01

$1.00000 \mathrm{e}+001.00000 \mathrm{e}+001.00000 \mathrm{e}-011.00000 \mathrm{e}-091.00000 \mathrm{e}-01$

Element: 7292 \# of layers: 5

$\mathrm{Kx} \mathrm{Ky} \mathrm{Kz}$ Ss Por

5.53534e+01 5.53534e+01 5.53534e+00 1.00000e-09 2.12000e-01

$5.53534 \mathrm{e}+015.53534 \mathrm{e}+015.53534 \mathrm{e}+001.00000 \mathrm{e}-092.12000 \mathrm{e}-01$

$5.53534 \mathrm{e}+015.53534 \mathrm{e}+015.53534 \mathrm{e}+001.00000 \mathrm{e}-092.12000 \mathrm{e}-01$

$1.00000 \mathrm{e}-02$ 1.00000e-02 1.00000e-03 1.00000e-09 1.00000e-01

$1.00000 \mathrm{e}+001.00000 \mathrm{e}+001.00000 \mathrm{e}-011.00000 \mathrm{e}-091.00000 \mathrm{e}-01$

Element: 7293 \# of layers: 6

$\mathrm{Kx} \mathrm{Ky} \mathrm{Kz}$ Ss Por

1.38538e+03 1.38538e+03 1.38538e+02 1.00000e-09 7.00000e-02

$5.53534 \mathrm{e}+015.53534 \mathrm{e}+015.53534 \mathrm{e}+001.00000 \mathrm{e}-092.12000 \mathrm{e}-01$

$5.53534 \mathrm{e}+015.53534 \mathrm{e}+015.53534 \mathrm{e}+001.00000 \mathrm{e}-092.12000 \mathrm{e}-01$

$5.53534 \mathrm{e}+015.53534 \mathrm{e}+015.53534 \mathrm{e}+001.00000 \mathrm{e}-092.12000 \mathrm{e}-01$

$1.00000 \mathrm{e}-02$ 1.00000e-02 1.00000e-03 1.00000e-09 1.00000e-01

$1.00000 \mathrm{e}+001.00000 \mathrm{e}+001.00000 \mathrm{e}-011.00000 \mathrm{e}-09$ 1.00000e-01

Element: 7294 \# of layers: 6

$\mathrm{Kx} \mathrm{Ky} \mathrm{Kz}$ Ss Por

1.38538e+03 1.38538e+03 1.38538e+02 1.00000e-09 7.00000e-02

$5.53534 \mathrm{e}+015.53534 \mathrm{e}+015.53534 \mathrm{e}+001.00000 \mathrm{e}-092.12000 \mathrm{e}-01$

$5.53534 \mathrm{e}+015.53534 \mathrm{e}+015.53534 \mathrm{e}+001.00000 \mathrm{e}-092.12000 \mathrm{e}-01$

$5.53534 \mathrm{e}+015.53534 \mathrm{e}+015.53534 \mathrm{e}+001.00000 \mathrm{e}-092.12000 \mathrm{e}-01$

$1.00000 \mathrm{e}-02$ 1.00000e-02 1.00000e-03 1.00000e-09 1.00000e-01

$1.00000 \mathrm{e}+001.00000 \mathrm{e}+001.00000 \mathrm{e}-011.00000 \mathrm{e}-091.00000 \mathrm{e}-01$

Element: 7295 \# of layers: 5

Kx Ky Kz Ss Por

3.27865e+02 3.27865e+02 3.27865e+01 1.00000e-09 7.00000e-02

$1.31004 \mathrm{e}+011.31004 \mathrm{e}+011.31004 \mathrm{e}+001.00000 \mathrm{e}-092.12000 \mathrm{e}-01$

$1.31004 \mathrm{e}+011.31004 \mathrm{e}+011.31004 \mathrm{e}+001.00000 \mathrm{e}-092.12000 \mathrm{e}-01$

$1.00000 \mathrm{e}-02$ 1.00000e-02 1.00000e-03 1.00000e-09 1.00000e-01

$1.00000 \mathrm{e}+001.00000 \mathrm{e}+001.00000 \mathrm{e}-011.00000 \mathrm{e}-091.00000 \mathrm{e}-01$

Element: 7296 \# of layers: 5

$\mathrm{Kx} \mathrm{Ky} \mathrm{Kz}$ Ss Por

3.27865e+02 3.27865e+02 3.27865e+01 1.00000e-09 7.00000e-02 
$1.31004 \mathrm{e}+011.31004 \mathrm{e}+01$ 1.31004e+00 1.00000e-09 2.12000e-01 $1.31004 \mathrm{e}+011.31004 \mathrm{e}+011.31004 \mathrm{e}+001.00000 \mathrm{e}-092.12000 \mathrm{e}-01$ $1.00000 \mathrm{e}-02$ 1.00000e-02 1.00000e-03 1.00000e-09 1.00000e-01 $1.00000 \mathrm{e}+001.00000 \mathrm{e}+001.00000 \mathrm{e}-011.00000 \mathrm{e}-091.00000 \mathrm{e}-01$ Element: 7297 \# of layers: 5

$\mathrm{Kx} \mathrm{Ky} \mathrm{Kz}$ Ss Por

3.27865e+02 3.27865e+02 3.27865e+01 1.00000e-09 7.00000e-02 $1.31004 \mathrm{e}+011.31004 \mathrm{e}+011.31004 \mathrm{e}+001.00000 \mathrm{e}-092.12000 \mathrm{e}-01$ $1.31004 \mathrm{e}+011.31004 \mathrm{e}+01$ 1.31004e+00 1.00000e-09 2.12000e-01 $1.00000 \mathrm{e}-02$ 1.00000e-02 1.00000e-03 1.00000e-09 1.00000e-01 $1.00000 \mathrm{e}+001.00000 \mathrm{e}+001.00000 \mathrm{e}-011.00000 \mathrm{e}-091.00000 \mathrm{e}-01$

Element: 7298 \# of layers: 5

$\mathrm{Kx} \mathrm{Ky} \mathrm{Kz}$ Ss Por

3.27865e+02 3.27865e+02 3.27865e+01 1.00000e-09 7.00000e-02 $1.31004 \mathrm{e}+011.31004 \mathrm{e}+011.31004 \mathrm{e}+001.00000 \mathrm{e}-092.12000 \mathrm{e}-01$ $1.31004 \mathrm{e}+011.31004 \mathrm{e}+011.31004 \mathrm{e}+001.00000 \mathrm{e}-092.12000 \mathrm{e}-01$ $1.00000 \mathrm{e}-02$ 1.00000e-02 1.00000e-03 1.00000e-09 1.00000e-01 $1.00000 \mathrm{e}+001.00000 \mathrm{e}+001.00000 \mathrm{e}-01$ 1.00000e-09 1.00000e-01 Element: 7299 \# of layers: 5

$\mathrm{Kx} \mathrm{Ky} \mathrm{Kz}$ Ss Por

3.27865e+02 3.27865e+02 3.27865e+01 1.00000e-09 7.00000e-02 $1.31004 \mathrm{e}+011.31004 \mathrm{e}+011.31004 \mathrm{e}+001.00000 \mathrm{e}-092.12000 \mathrm{e}-01$ $1.31004 \mathrm{e}+011.31004 \mathrm{e}+01$ 1.31004e+00 1.00000e-09 2.12000e-01 $1.00000 \mathrm{e}-02$ 1.00000e-02 1.00000e-03 1.00000e-09 1.00000e-01 $1.00000 \mathrm{e}+001.00000 \mathrm{e}+001.00000 \mathrm{e}-011.00000 \mathrm{e}-091.00000 \mathrm{e}-01$ Element: 7300 \# of layers: 5

$\mathrm{Kx} \mathrm{Ky} \mathrm{Kz}$ Ss Por

3.27865e+02 3.27865e+02 3.27865e+01 1.00000e-09 7.00000e-02 $1.31004 \mathrm{e}+011.31004 \mathrm{e}+011.31004 \mathrm{e}+001.00000 \mathrm{e}-092.12000 \mathrm{e}-01$ $1.31004 \mathrm{e}+011.31004 \mathrm{e}+011.31004 \mathrm{e}+001.00000 \mathrm{e}-092.12000 \mathrm{e}-01$ $1.00000 \mathrm{e}-02$ 1.00000e-02 1.00000e-03 1.00000e-09 1.00000e-01 $1.00000 \mathrm{e}+001.00000 \mathrm{e}+001.00000 \mathrm{e}-011.00000 \mathrm{e}-091.00000 \mathrm{e}-01$ Element: 7301 \# of layers: 5

$\mathrm{Kx} \mathrm{Ky} \mathrm{Kz}$ Ss Por

3.27865e+02 3.27865e+02 3.27865e+01 1.00000e-09 7.00000e-02 $1.31004 \mathrm{e}+011.31004 \mathrm{e}+011.31004 \mathrm{e}+001.00000 \mathrm{e}-092.12000 \mathrm{e}-01$ $1.31004 \mathrm{e}+011.31004 \mathrm{e}+011.31004 \mathrm{e}+001.00000 \mathrm{e}-092.12000 \mathrm{e}-01$ $1.00000 \mathrm{e}-02$ 1.00000e-02 1.00000e-03 1.00000e-09 1.00000e-01 $1.00000 \mathrm{e}+001.00000 \mathrm{e}+001.00000 \mathrm{e}-011.00000 \mathrm{e}-091.00000 \mathrm{e}-01$ Element: 7302 \# of layers: 5

$\mathrm{Kx} \mathrm{Ky} \mathrm{Kz}$ Ss Por

3.27865e+02 3.27865e+02 3.27865e+01 1.00000e-09 7.00000e-02 $1.31004 \mathrm{e}+011.31004 \mathrm{e}+011.31004 \mathrm{e}+001.00000 \mathrm{e}-092.12000 \mathrm{e}-01$ $1.31004 \mathrm{e}+011.31004 \mathrm{e}+011.31004 \mathrm{e}+001.00000 \mathrm{e}-092.12000 \mathrm{e}-01$ $1.00000 \mathrm{e}-02$ 1.00000e-02 1.00000e-03 1.00000e-09 1.00000e-01 $1.00000 \mathrm{e}+001.00000 \mathrm{e}+001.00000 \mathrm{e}-011.00000 \mathrm{e}-091.00000 \mathrm{e}-01$ 
Element: 7303 \# of layers: 5

$\mathrm{Kx} \mathrm{Ky} \mathrm{Kz}$ Ss Por

3.27865e+02 3.27865e+02 3.27865e+01 1.00000e-09 7.00000e-02

$1.31004 \mathrm{e}+011.31004 \mathrm{e}+011.31004 \mathrm{e}+001.00000 \mathrm{e}-092.12000 \mathrm{e}-01$

$1.31004 \mathrm{e}+011.31004 \mathrm{e}+011.31004 \mathrm{e}+001.00000 \mathrm{e}-092.12000 \mathrm{e}-01$

$1.00000 \mathrm{e}-02$ 1.00000e-02 1.00000e-03 1.00000e-09 1.00000e-01

$1.00000 \mathrm{e}+001.00000 \mathrm{e}+001.00000 \mathrm{e}-011.00000 \mathrm{e}-091.00000 \mathrm{e}-01$

Element: 7304 \# of layers: 5

$\mathrm{Kx} \mathrm{Ky} \mathrm{Kz}$ Ss Por

2.76211e+02 2.76211e+02 2.76211e+01 1.00000e-09 7.00000e-02

$1.10363 \mathrm{e}+01$ 1.10363e+01 1.10363e+00 1.00000e-09 2.12000e-01

$1.10363 \mathrm{e}+01$ 1.10363e+01 1.10363e+00 1.00000e-09 2.12000e-01

1.00000e-02 1.00000e-02 1.00000e-03 1.00000e-09 1.00000e-01

$1.00000 \mathrm{e}+001.00000 \mathrm{e}+001.00000 \mathrm{e}-01$ 1.00000e-09 1.00000e-01

Element: 7305 \# of layers: 5

Kx Ky Kz Ss Por

2.76211e+02 2.76211e+02 2.76211e+01 1.00000e-09 7.00000e-02

$1.10363 \mathrm{e}+01$ 1.10363e+01 1.10363e+00 1.00000e-09 2.12000e-01

$1.10363 \mathrm{e}+01$ 1.10363e+01 1.10363e+00 1.00000e-09 2.12000e-01

$1.00000 \mathrm{e}-02$ 1.00000e-02 1.00000e-03 1.00000e-09 1.00000e-01

$1.00000 \mathrm{e}+001.00000 \mathrm{e}+001.00000 \mathrm{e}-011.00000 \mathrm{e}-091.00000 \mathrm{e}-01$

Element: 7306 \# of layers: 5

$\mathrm{Kx} \mathrm{Ky} \mathrm{Kz}$ Ss Por

2.76211e+02 2.76211e+02 2.76211e+01 1.00000e-09 7.00000e-02

$1.10363 \mathrm{e}+011.10363 \mathrm{e}+01$ 1.10363e+00 1.00000e-09 2.12000e-01

$1.10363 \mathrm{e}+01$ 1.10363e+01 1.10363e+00 1.00000e-09 2.12000e-01

$1.00000 \mathrm{e}-02$ 1.00000e-02 1.00000e-03 1.00000e-09 1.00000e-01

$1.00000 \mathrm{e}+001.00000 \mathrm{e}+001.00000 \mathrm{e}-011.00000 \mathrm{e}-091.00000 \mathrm{e}-01$

Element: 7307 \# of layers: 5

$\mathrm{Kx} \mathrm{Ky} \mathrm{Kz}$ Ss Por

$2.76211 \mathrm{e}+02$ 2.76211e+02 2.76211e+01 1.00000e-09 7.00000e-02

$1.10363 \mathrm{e}+01$ 1.10363e+01 1.10363e+00 1.00000e-09 2.12000e-01

$1.10363 \mathrm{e}+011.10363 \mathrm{e}+01$ 1.10363e+00 1.00000e-09 2.12000e-01

$1.00000 \mathrm{e}-021.00000 \mathrm{e}-021.00000 \mathrm{e}-031.00000 \mathrm{e}-091.00000 \mathrm{e}-01$

$1.00000 \mathrm{e}+001.00000 \mathrm{e}+001.00000 \mathrm{e}-01$ 1.00000e-09 1.00000e-01

Element: 7308 \# of layers: 5

Kx Ky Kz Ss Por

$2.76211 \mathrm{e}+02$ 2.76211e+02 2.76211e+01 1.00000e-09 7.00000e-02

$1.10363 \mathrm{e}+01$ 1.10363e+01 1.10363e+00 1.00000e-09 2.12000e-01

$1.10363 \mathrm{e}+01$ 1.10363e+01 1.10363e+00 1.00000e-09 2.12000e-01

$1.00000 \mathrm{e}-02$ 1.00000e-02 1.00000e-03 1.00000e-09 1.00000e-01

$1.00000 \mathrm{e}+001.00000 \mathrm{e}+001.00000 \mathrm{e}-011.00000 \mathrm{e}-091.00000 \mathrm{e}-01$

Element: 7309 \# of layers: 5

$\mathrm{Kx} \mathrm{Ky} \mathrm{Kz}$ Ss Por

2.76211e+02 2.76211e+02 2.76211e+01 1.00000e-09 7.00000e-02

$1.10363 \mathrm{e}+011.10363 \mathrm{e}+01$ 1.10363e+00 1.00000e-09 2.12000e-01 
$1.10363 \mathrm{e}+011.10363 \mathrm{e}+01$ 1.10363e+00 1.00000e-09 2.12000e-01 $1.00000 \mathrm{e}-021.00000 \mathrm{e}-02$ 1.00000e-03 1.00000e-09 1.00000e-01

$1.00000 \mathrm{e}+001.00000 \mathrm{e}+001.00000 \mathrm{e}-011.00000 \mathrm{e}-091.00000 \mathrm{e}-01$

Element: 7310 \# of layers: 5

Kx Ky Kz Ss Por

$2.76211 \mathrm{e}+022.76211 \mathrm{e}+022.76211 \mathrm{e}+01$ 1.00000e-09 7.00000e-02

$1.10363 \mathrm{e}+011.10363 \mathrm{e}+011.10363 \mathrm{e}+00$ 1.00000e-09 2.12000e-01

$1.10363 \mathrm{e}+011.10363 \mathrm{e}+011.10363 \mathrm{e}+00$ 1.00000e-09 2.12000e-01

$1.00000 \mathrm{e}-02$ 1.00000e-02 1.00000e-03 1.00000e-09 1.00000e-01

$1.00000 \mathrm{e}+001.00000 \mathrm{e}+001.00000 \mathrm{e}-011.00000 \mathrm{e}-091.00000 \mathrm{e}-01$

Element: 7311 \# of layers: 5

Kx Ky Kz Ss Por

$2.76211 \mathrm{e}+022.76211 \mathrm{e}+022.76211 \mathrm{e}+01$ 1.00000e-09 7.00000e-02

$1.10363 \mathrm{e}+011.10363 \mathrm{e}+011.10363 \mathrm{e}+001.00000 \mathrm{e}-092.12000 \mathrm{e}-01$

$1.10363 \mathrm{e}+011.10363 \mathrm{e}+011.10363 \mathrm{e}+00$ 1.00000e-09 2.12000e-01

$1.00000 \mathrm{e}-021.00000 \mathrm{e}-02$ 1.00000e-03 1.00000e-09 1.00000e-01

$1.00000 \mathrm{e}+001.00000 \mathrm{e}+001.00000 \mathrm{e}-011.00000 \mathrm{e}-091.00000 \mathrm{e}-01$

Element: 7312 \# of layers: 5

Kx Ky Kz Ss Por

$2.76211 \mathrm{e}+022.76211 \mathrm{e}+022.76211 \mathrm{e}+01$ 1.00000e-09 7.00000e-02

$1.10363 \mathrm{e}+011.10363 \mathrm{e}+011.10363 \mathrm{e}+00$ 1.00000e-09 2.12000e-01

$1.10363 \mathrm{e}+011.10363 \mathrm{e}+011.10363 \mathrm{e}+00$ 1.00000e-09 2.12000e-01

$1.00000 \mathrm{e}-021.00000 \mathrm{e}-02$ 1.00000e-03 1.00000e-09 1.00000e-01

$1.00000 \mathrm{e}+001.00000 \mathrm{e}+001.00000 \mathrm{e}-011.00000 \mathrm{e}-091.00000 \mathrm{e}-01$

Element: 7313 \# of layers: 5

Kx Ky Kz Ss Por

$6.38818 \mathrm{e}+026.38818 \mathrm{e}+026.38818 \mathrm{e}+01$ 1.00000e-09 7.00000e-02

$2.55245 \mathrm{e}+012.55245 \mathrm{e}+012.55245 \mathrm{e}+001.00000 \mathrm{e}-092.12000 \mathrm{e}-01$

$2.55245 \mathrm{e}+012.55245 \mathrm{e}+012.55245 \mathrm{e}+001.00000 \mathrm{e}-092.12000 \mathrm{e}-01$

$1.00000 \mathrm{e}-021.00000 \mathrm{e}-02$ 1.00000e-03 1.00000e-09 1.00000e-01

$1.00000 \mathrm{e}+001.00000 \mathrm{e}+001.00000 \mathrm{e}-011.00000 \mathrm{e}-091.00000 \mathrm{e}-01$

Element: 7314 \# of layers: 4

Kx Ky Kz Ss Por

$6.38818 \mathrm{e}+026.38818 \mathrm{e}+026.38818 \mathrm{e}+01$ 1.00000e-09 7.00000e-02

$2.55245 \mathrm{e}+012.55245 \mathrm{e}+012.55245 \mathrm{e}+001.00000 \mathrm{e}-092.12000 \mathrm{e}-01$

$1.00000 \mathrm{e}-021.00000 \mathrm{e}-02$ 1.00000e-03 1.00000e-09 1.00000e-01

$1.00000 \mathrm{e}+001.00000 \mathrm{e}+001.00000 \mathrm{e}-011.00000 \mathrm{e}-091.00000 \mathrm{e}-01$

Element: 7315 \# of layers: 4

Kx Ky Kz Ss Por

$6.38818 \mathrm{e}+026.38818 \mathrm{e}+026.38818 \mathrm{e}+01$ 1.00000e-09 7.00000e-02

$2.55245 \mathrm{e}+012.55245 \mathrm{e}+012.55245 \mathrm{e}+001.00000 \mathrm{e}-092.12000 \mathrm{e}-01$

$1.00000 \mathrm{e}-021.00000 \mathrm{e}-02$ 1.00000e-03 1.00000e-09 1.00000e-01

$1.00000 \mathrm{e}+001.00000 \mathrm{e}+001.00000 \mathrm{e}-011.00000 \mathrm{e}-091.00000 \mathrm{e}-01$

Element: 7316 \# of layers: 4

Kx Ky Kz Ss Por

$6.38818 \mathrm{e}+02$ 6.38818e+02 6.38818e+01 1.00000e-09 7.00000e-02 
$2.55245 \mathrm{e}+012.55245 \mathrm{e}+012.55245 \mathrm{e}+00$ 1.00000e-09 2.12000e-01 $1.00000 \mathrm{e}-02$ 1.00000e-02 1.00000e-03 1.00000e-09 1.00000e-01 $1.00000 \mathrm{e}+001.00000 \mathrm{e}+001.00000 \mathrm{e}-011.00000 \mathrm{e}-091.00000 \mathrm{e}-01$

Element: 7317 \# of layers: 4

$\mathrm{Kx} \mathrm{Ky} \mathrm{Kz}$ Ss Por

6.38818e+02 6.38818e+02 6.38818e+01 1.00000e-09 7.00000e-02

$2.55245 \mathrm{e}+012.55245 \mathrm{e}+012.55245 \mathrm{e}+001.00000 \mathrm{e}-092.12000 \mathrm{e}-01$

$1.00000 \mathrm{e}-02$ 1.00000e-02 1.00000e-03 1.00000e-09 1.00000e-01

$1.00000 \mathrm{e}+001.00000 \mathrm{e}+001.00000 \mathrm{e}-011.00000 \mathrm{e}-091.00000 \mathrm{e}-01$

Element: 7318 \# of layers: 4

$\mathrm{Kx} \mathrm{Ky} \mathrm{Kz}$ Ss Por

6.38818e+02 6.38818e+02 6.38818e+01 1.00000e-09 7.00000e-02

$2.55245 \mathrm{e}+012.55245 \mathrm{e}+012.55245 \mathrm{e}+001.00000 \mathrm{e}-092.12000 \mathrm{e}-01$

$1.00000 \mathrm{e}-02$ 1.00000e-02 1.00000e-03 1.00000e-09 1.00000e-01

$1.00000 \mathrm{e}+001.00000 \mathrm{e}+001.00000 \mathrm{e}-01$ 1.00000e-09 1.00000e-01

Element: 7319 \# of layers: 5

$\mathrm{Kx} \mathrm{Ky} \mathrm{Kz}$ Ss Por

6.38818e+02 6.38818e+02 6.38818e+01 1.00000e-09 7.00000e-02

$2.55245 \mathrm{e}+012.55245 \mathrm{e}+012.55245 \mathrm{e}+00$ 1.00000e-09 2.12000e-01

$2.55245 \mathrm{e}+012.55245 \mathrm{e}+012.55245 \mathrm{e}+001.00000 \mathrm{e}-092.12000 \mathrm{e}-01$

$1.00000 \mathrm{e}-02$ 1.00000e-02 1.00000e-03 1.00000e-09 1.00000e-01

$1.00000 \mathrm{e}+001.00000 \mathrm{e}+001.00000 \mathrm{e}-011.00000 \mathrm{e}-091.00000 \mathrm{e}-01$

Element: 7320 \# of layers: 5

Kx Ky Kz Ss Por

6.38818e+02 6.38818e+02 6.38818e+01 1.00000e-09 7.00000e-02

$2.55245 \mathrm{e}+012.55245 \mathrm{e}+012.55245 \mathrm{e}+001.00000 \mathrm{e}-092.12000 \mathrm{e}-01$

$2.55245 \mathrm{e}+012.55245 \mathrm{e}+012.55245 \mathrm{e}+001.00000 \mathrm{e}-092.12000 \mathrm{e}-01$

$1.00000 \mathrm{e}-02$ 1.00000e-02 1.00000e-03 1.00000e-09 1.00000e-01

$1.00000 \mathrm{e}+001.00000 \mathrm{e}+001.00000 \mathrm{e}-011.00000 \mathrm{e}-091.00000 \mathrm{e}-01$

Element: 7321 \# of layers: 4

$\mathrm{Kx} \mathrm{Ky} \mathrm{Kz}$ Ss Por

6.38818e+02 6.38818e+02 6.38818e+01 1.00000e-09 7.00000e-02

$2.55245 \mathrm{e}+012.55245 \mathrm{e}+012.55245 \mathrm{e}+001.00000 \mathrm{e}-092.12000 \mathrm{e}-01$

$1.00000 \mathrm{e}-02$ 1.00000e-02 1.00000e-03 1.00000e-09 1.00000e-01

$1.00000 \mathrm{e}+001.00000 \mathrm{e}+001.00000 \mathrm{e}-011.00000 \mathrm{e}-091.00000 \mathrm{e}-01$

Element: 7322 \# of layers: 4

Kx Ky Kz Ss Por

$1.55098 \mathrm{e}+03$ 1.55098e+03 1.55098e+02 1.00000e-09 7.00000e-02

6.19731e+01 6.19731e+01 6.19731e+00 1.00000e-09 2.12000e-01

$1.00000 \mathrm{e}-02$ 1.00000e-02 1.00000e-03 1.00000e-09 1.00000e-01

$1.00000 \mathrm{e}+001.00000 \mathrm{e}+001.00000 \mathrm{e}-011.00000 \mathrm{e}-091.00000 \mathrm{e}-01$

Element: 7323 \# of layers: 4

$\mathrm{Kx} \mathrm{Ky} \mathrm{Kz}$ Ss Por

1.55098e+03 1.55098e+03 1.55098e+02 1.00000e-09 7.00000e-02

6.19731e+01 6.19731e+01 6.19731e+00 1.00000e-09 2.12000e-01

$1.00000 \mathrm{e}-02$ 1.00000e-02 1.00000e-03 1.00000e-09 1.00000e-01 
$1.00000 \mathrm{e}+001.00000 \mathrm{e}+00$ 1.00000e-01 1.00000e-09 1.00000e-01

Element: 7324 \# of layers: 4

$\mathrm{Kx} \mathrm{Ky} \mathrm{Kz}$ Ss Por

1.55098e+03 1.55098e+03 1.55098e+02 1.00000e-09 7.00000e-02

$6.19731 \mathrm{e}+016.19731 \mathrm{e}+016.19731 \mathrm{e}+00$ 1.00000e-09 2.12000e-01

$1.00000 \mathrm{e}-02$ 1.00000e-02 1.00000e-03 1.00000e-09 1.00000e-01

$1.00000 \mathrm{e}+001.00000 \mathrm{e}+001.00000 \mathrm{e}-01$ 1.00000e-09 1.00000e-01

Element: 7325 \# of layers: 4

$\mathrm{Kx} \mathrm{Ky} \mathrm{Kz}$ Ss Por

1.55098e+03 1.55098e+03 1.55098e+02 1.00000e-09 7.00000e-02

$6.19731 \mathrm{e}+016.19731 \mathrm{e}+016.19731 \mathrm{e}+00$ 1.00000e-09 2.12000e-01

$1.00000 \mathrm{e}-02$ 1.00000e-02 1.00000e-03 1.00000e-09 1.00000e-01

$1.00000 \mathrm{e}+001.00000 \mathrm{e}+001.00000 \mathrm{e}-011.00000 \mathrm{e}-09$ 1.00000e-01

Element: 7326 \# of layers: 4

$\mathrm{Kx} \mathrm{Ky} \mathrm{Kz}$ Ss Por

1.55098e+03 1.55098e+03 1.55098e+02 1.00000e-09 7.00000e-02

6.19731e+01 6.19731e+01 6.19731e+00 1.00000e-09 2.12000e-01

1.00000e-02 1.00000e-02 1.00000e-03 1.00000e-09 1.00000e-01

$1.00000 \mathrm{e}+001.00000 \mathrm{e}+001.00000 \mathrm{e}-01$ 1.00000e-09 1.00000e-01

Element: 7327 \# of layers: 4

$\mathrm{Kx} \mathrm{Ky} \mathrm{Kz}$ Ss Por

$1.55098 \mathrm{e}+03$ 1.55098e+03 1.55098e+02 1.00000e-09 7.00000e-02

6.19731e+01 6.19731e+01 6.19731e+00 1.00000e-09 2.12000e-01

$1.00000 \mathrm{e}-02$ 1.00000e-02 1.00000e-03 1.00000e-09 1.00000e-01

$1.00000 \mathrm{e}+001.00000 \mathrm{e}+001.00000 \mathrm{e}-011.00000 \mathrm{e}-091.00000 \mathrm{e}-01$

Element: 7328 \# of layers: 4

$\mathrm{Kx} \mathrm{Ky} \mathrm{Kz}$ Ss Por

1.55098e+03 1.55098e+03 1.55098e+02 1.00000e-09 7.00000e-02

$6.19731 \mathrm{e}+016.19731 \mathrm{e}+016.19731 \mathrm{e}+001.00000 \mathrm{e}-092.12000 \mathrm{e}-01$

$1.00000 \mathrm{e}-02$ 1.00000e-02 1.00000e-03 1.00000e-09 1.00000e-01

$1.00000 \mathrm{e}+001.00000 \mathrm{e}+001.00000 \mathrm{e}-011.00000 \mathrm{e}-091.00000 \mathrm{e}-01$

Element: 7329 \# of layers: 4

Kx Ky Kz Ss Por

$1.55098 \mathrm{e}+03$ 1.55098e+03 1.55098e+02 1.00000e-09 7.00000e-02

$6.19731 \mathrm{e}+016.19731 \mathrm{e}+016.19731 \mathrm{e}+00$ 1.00000e-09 2.12000e-01

1.00000e-02 1.00000e-02 1.00000e-03 1.00000e-09 1.00000e-01

$1.00000 \mathrm{e}+001.00000 \mathrm{e}+001.00000 \mathrm{e}-011.00000 \mathrm{e}-091.00000 \mathrm{e}-01$

Element: 7330 \# of layers: 4

$\mathrm{Kx} \mathrm{Ky} \mathrm{Kz}$ Ss Por

$1.55098 \mathrm{e}+03$ 1.55098e+03 1.55098e+02 1.00000e-09 7.00000e-02

$6.19731 \mathrm{e}+016.19731 \mathrm{e}+016.19731 \mathrm{e}+00$ 1.00000e-09 2.12000e-01

$1.00000 \mathrm{e}-02$ 1.00000e-02 1.00000e-03 1.00000e-09 1.00000e-01

$1.00000 \mathrm{e}+001.00000 \mathrm{e}+001.00000 \mathrm{e}-01$ 1.00000e-09 1.00000e-01

Element: 7331 \# of layers: 4

$\mathrm{Kx} \mathrm{Ky} \mathrm{Kz}$ Ss Por

$1.03948 \mathrm{e}+02$ 1.03948e+02 1.03948e+01 1.00000e-09 7.00000e-02 
4.15336e+00 4.15336e+00 4.15336e-01 1.00000e-09 2.12000e-01 $1.00000 \mathrm{e}-02$ 1.00000e-02 1.00000e-03 1.00000e-09 1.00000e-01

$1.00000 \mathrm{e}+001.00000 \mathrm{e}+001.00000 \mathrm{e}-011.00000 \mathrm{e}-091.00000 \mathrm{e}-01$

Element: 7332 \# of layers: 4

$\mathrm{Kx} \mathrm{Ky} \mathrm{Kz}$ Ss Por

1.03948e+02 1.03948e+02 1.03948e+01 1.00000e-09 7.00000e-02

$4.15336 \mathrm{e}+004.15336 \mathrm{e}+00$ 4.15336e-01 1.00000e-09 2.12000e-01

$1.00000 \mathrm{e}-02$ 1.00000e-02 1.00000e-03 1.00000e-09 1.00000e-01

$1.00000 \mathrm{e}+001.00000 \mathrm{e}+001.00000 \mathrm{e}-011.00000 \mathrm{e}-091.00000 \mathrm{e}-01$

Element: 7333 \# of layers: 4

$\mathrm{Kx} \mathrm{Ky} \mathrm{Kz}$ Ss Por

$1.03948 \mathrm{e}+02$ 1.03948e+02 1.03948e+01 1.00000e-09 7.00000e-02

$4.15336 \mathrm{e}+004.15336 \mathrm{e}+00$ 4.15336e-01 1.00000e-09 2.12000e-01

1.00000e-02 1.00000e-02 1.00000e-03 1.00000e-09 1.00000e-01

$1.00000 \mathrm{e}+001.00000 \mathrm{e}+001.00000 \mathrm{e}-01$ 1.00000e-09 1.00000e-01

Element: 7334 \# of layers: 5

$\mathrm{Kx} \mathrm{Ky} \mathrm{Kz}$ Ss Por

1.03948e+02 1.03948e+02 1.03948e+01 1.00000e-09 7.00000e-02

$1.03948 \mathrm{e}+02$ 1.03948e+02 1.03948e+01 1.00000e-09 7.00000e-02

4.15336e+00 4.15336e+00 4.15336e-01 1.00000e-09 2.12000e-01

$1.00000 \mathrm{e}-02$ 1.00000e-02 1.00000e-03 1.00000e-09 1.00000e-01

$1.00000 \mathrm{e}+001.00000 \mathrm{e}+001.00000 \mathrm{e}-011.00000 \mathrm{e}-091.00000 \mathrm{e}-01$

Element: 7335 \# of layers: 5

Kx Ky Kz Ss Por

$1.03948 \mathrm{e}+02$ 1.03948e+02 1.03948e+01 1.00000e-09 7.00000e-02

$1.03948 \mathrm{e}+02$ 1.03948e+02 1.03948e+01 1.00000e-09 7.00000e-02

4.15336e+00 4.15336e+00 4.15336e-01 1.00000e-09 2.12000e-01

$1.00000 \mathrm{e}-02$ 1.00000e-02 1.00000e-03 1.00000e-09 1.00000e-01

$1.00000 \mathrm{e}+001.00000 \mathrm{e}+001.00000 \mathrm{e}-011.00000 \mathrm{e}-091.00000 \mathrm{e}-01$

Element: 7336 \# of layers: 5

$\mathrm{Kx} \mathrm{Ky} \mathrm{Kz}$ Ss Por

$1.03948 \mathrm{e}+02$ 1.03948e+02 1.03948e+01 1.00000e-09 7.00000e-02

$1.03948 \mathrm{e}+02$ 1.03948e+02 1.03948e+01 1.00000e-09 7.00000e-02

$4.15336 \mathrm{e}+004.15336 \mathrm{e}+00$ 4.15336e-01 1.00000e-09 2.12000e-01

$1.00000 \mathrm{e}-02$ 1.00000e-02 1.00000e-03 1.00000e-09 1.00000e-01

$1.00000 \mathrm{e}+001.00000 \mathrm{e}+001.00000 \mathrm{e}-011.00000 \mathrm{e}-09$ 1.00000e-01

Element: 7337 \# of layers: 5

Kx Ky Kz Ss Por

$1.03948 \mathrm{e}+02$ 1.03948e+02 1.03948e+01 1.00000e-09 7.00000e-02

$1.03948 \mathrm{e}+02$ 1.03948e+02 1.03948e+01 1.00000e-09 7.00000e-02

4.15336e+00 4.15336e+00 4.15336e-01 1.00000e-09 2.12000e-01

$1.00000 \mathrm{e}-02$ 1.00000e-02 1.00000e-03 1.00000e-09 1.00000e-01

$1.00000 \mathrm{e}+001.00000 \mathrm{e}+001.00000 \mathrm{e}-011.00000 \mathrm{e}-091.00000 \mathrm{e}-01$

Element: 7338 \# of layers: 4

$\mathrm{Kx} \mathrm{Ky} \mathrm{Kz}$ Ss Por

$1.03948 \mathrm{e}+02$ 1.03948e+02 1.03948e+01 1.00000e-09 7.00000e-02 
4.15336e+00 4.15336e+00 4.15336e-01 1.00000e-09 2.12000e-01 $1.00000 \mathrm{e}-02$ 1.00000e-02 1.00000e-03 1.00000e-09 1.00000e-01 $1.00000 \mathrm{e}+001.00000 \mathrm{e}+001.00000 \mathrm{e}-011.00000 \mathrm{e}-091.00000 \mathrm{e}-01$

Element: 7339 \# of layers: 4

$\mathrm{Kx} \mathrm{Ky} \mathrm{Kz}$ Ss Por

1.03948e+02 1.03948e+02 1.03948e+01 1.00000e-09 7.00000e-02

$4.15336 \mathrm{e}+004.15336 \mathrm{e}+00$ 4.15336e-01 1.00000e-09 2.12000e-01

$1.00000 \mathrm{e}-02$ 1.00000e-02 1.00000e-03 1.00000e-09 1.00000e-01

$1.00000 \mathrm{e}+001.00000 \mathrm{e}+001.00000 \mathrm{e}-011.00000 \mathrm{e}-091.00000 \mathrm{e}-01$

Element: 7340 \# of layers: 5

$\mathrm{Kx} \mathrm{Ky} \mathrm{Kz}$ Ss Por

8.37993e+01 8.37993e+01 8.37993e+00 1.00000e-09 7.00000e-02

8.37993e+01 8.37993e+01 8.37993e+00 1.00000e-09 7.00000e-02

$3.34830 \mathrm{e}+003.34830 \mathrm{e}+00$ 3.34830e-01 1.00000e-09 2.12000e-01

$1.00000 \mathrm{e}-02$ 1.00000e-02 1.00000e-03 1.00000e-09 1.00000e-01

$1.00000 \mathrm{e}+001.00000 \mathrm{e}+001.00000 \mathrm{e}-011.00000 \mathrm{e}-091.00000 \mathrm{e}-01$

Element: 7341 \# of layers: 5

$\mathrm{Kx} \mathrm{Ky} \mathrm{Kz}$ Ss Por

8.37993e+01 8.37993e+01 8.37993e+00 1.00000e-09 7.00000e-02

8.37993e+01 8.37993e+01 8.37993e+00 1.00000e-09 7.00000e-02

$3.34830 \mathrm{e}+003.34830 \mathrm{e}+00$ 3.34830e-01 1.00000e-09 2.12000e-01

$1.00000 \mathrm{e}-02$ 1.00000e-02 1.00000e-03 1.00000e-09 1.00000e-01

$1.00000 \mathrm{e}+001.00000 \mathrm{e}+001.00000 \mathrm{e}-01$ 1.00000e-09 1.00000e-01

Element: 7342 \# of layers: 5

Kx Ky Kz Ss Por

8.37993e+01 8.37993e+01 8.37993e+00 1.00000e-09 7.00000e-02

8.37993e+01 8.37993e+01 8.37993e+00 1.00000e-09 7.00000e-02

$3.34830 \mathrm{e}+003.34830 \mathrm{e}+00$ 3.34830e-01 1.00000e-09 2.12000e-01

$1.00000 \mathrm{e}-02$ 1.00000e-02 1.00000e-03 1.00000e-09 1.00000e-01

$1.00000 \mathrm{e}+001.00000 \mathrm{e}+001.00000 \mathrm{e}-011.00000 \mathrm{e}-091.00000 \mathrm{e}-01$

Element: 7343 \# of layers: 4

$\mathrm{Kx} \mathrm{Ky} \mathrm{Kz}$ Ss Por

8.37993e+01 8.37993e+01 8.37993e+00 1.00000e-09 7.00000e-02

8.37993e+01 8.37993e+01 8.37993e+00 1.00000e-09 7.00000e-02

$1.00000 \mathrm{e}-02$ 1.00000e-02 1.00000e-03 1.00000e-09 1.00000e-01

$1.00000 \mathrm{e}+001.00000 \mathrm{e}+001.00000 \mathrm{e}-011.00000 \mathrm{e}-091.00000 \mathrm{e}-01$

Element: 7344 \# of layers: 4

Kx Ky Kz Ss Por

8.37993e+01 8.37993e+01 8.37993e+00 1.00000e-09 7.00000e-02

8.37993e+01 8.37993e+01 8.37993e+00 1.00000e-09 7.00000e-02

$1.00000 \mathrm{e}-02$ 1.00000e-02 1.00000e-03 1.00000e-09 1.00000e-01

$1.00000 \mathrm{e}+001.00000 \mathrm{e}+001.00000 \mathrm{e}-011.00000 \mathrm{e}-091.00000 \mathrm{e}-01$

Element: 7345 \# of layers: 4

$\mathrm{Kx} \mathrm{Ky} \mathrm{Kz}$ Ss Por

8.37993e+01 8.37993e+01 8.37993e+00 1.00000e-09 7.00000e-02

$8.37993 e+018.37993 e+018.37993 e+001.00000 e-09$ 7.00000e-02 
$1.00000 \mathrm{e}-02$ 1.00000e-02 1.00000e-03 1.00000e-09 1.00000e-01 $1.00000 \mathrm{e}+001.00000 \mathrm{e}+001.00000 \mathrm{e}-01$ 1.00000e-09 1.00000e-01 Element: 7346 \# of layers: 5

Kx Ky Kz Ss Por

8.37993e+01 8.37993e+01 8.37993e+00 1.00000e-09 7.00000e-02

8.37993e+01 8.37993e+01 8.37993e+00 1.00000e-09 7.00000e-02

$3.34830 \mathrm{e}+003.34830 \mathrm{e}+00$ 3.34830e-01 1.00000e-09 2.12000e-01

$1.00000 \mathrm{e}-02$ 1.00000e-02 1.00000e-03 1.00000e-09 1.00000e-01

$1.00000 \mathrm{e}+001.00000 \mathrm{e}+001.00000 \mathrm{e}-011.00000 \mathrm{e}-09$ 1.00000e-01

Element: 7347 \# of layers: 5

$\mathrm{Kx} \mathrm{Ky} \mathrm{Kz}$ Ss Por

8.37993e+01 8.37993e+01 8.37993e+00 1.00000e-09 7.00000e-02

8.37993e+01 8.37993e+01 8.37993e+00 1.00000e-09 7.00000e-02

$3.34830 \mathrm{e}+003.34830 \mathrm{e}+00$ 3.34830e-01 1.00000e-09 2.12000e-01

$1.00000 \mathrm{e}-02$ 1.00000e-02 1.00000e-03 1.00000e-09 1.00000e-01

$1.00000 \mathrm{e}+001.00000 \mathrm{e}+001.00000 \mathrm{e}-011.00000 \mathrm{e}-091.00000 \mathrm{e}-01$

Element: 7348 \# of layers: 5

$\mathrm{Kx} \mathrm{Ky} \mathrm{Kz}$ Ss Por

8.37993e+01 8.37993e+01 8.37993e+00 1.00000e-09 7.00000e-02

8.37993e+01 8.37993e+01 8.37993e+00 1.00000e-09 7.00000e-02

$3.34830 \mathrm{e}+003.34830 \mathrm{e}+00$ 3.34830e-01 1.00000e-09 2.12000e-01

$1.00000 \mathrm{e}-021.00000 \mathrm{e}-021.00000 \mathrm{e}-031.00000 \mathrm{e}-091.00000 \mathrm{e}-01$

$1.00000 \mathrm{e}+001.00000 \mathrm{e}+001.00000 \mathrm{e}-01$ 1.00000e-09 1.00000e-01

Element: 7349 \# of layers: 3

Kx Ky Kz Ss Por

$7.52740 \mathrm{e}+017.52740 \mathrm{e}+01$ 7.52740e+00 1.00000e-09 7.00000e-02

$1.00000 \mathrm{e}-021.00000 \mathrm{e}-021.00000 \mathrm{e}-031.00000 \mathrm{e}-091.00000 \mathrm{e}-01$

$1.00000 \mathrm{e}+001.00000 \mathrm{e}+001.00000 \mathrm{e}-011.00000 \mathrm{e}-09$ 1.00000e-01

Element: 7350 \# of layers: 3

$\mathrm{Kx} \mathrm{Ky} \mathrm{Kz}$ Ss Por

7.52740e+01 7.52740e+01 7.52740e+00 1.00000e-09 7.00000e-02

$1.00000 \mathrm{e}-02$ 1.00000e-02 1.00000e-03 1.00000e-09 1.00000e-01

$1.00000 \mathrm{e}+001.00000 \mathrm{e}+001.00000 \mathrm{e}-011.00000 \mathrm{e}-091.00000 \mathrm{e}-01$

Element: 7351 \# of layers: 3

$\mathrm{Kx} \mathrm{Ky} \mathrm{Kz}$ Ss Por

7.52740e+01 7.52740e+01 7.52740e+00 1.00000e-09 7.00000e-02

$1.00000 \mathrm{e}-02$ 1.00000e-02 1.00000e-03 1.00000e-09 1.00000e-01

$1.00000 \mathrm{e}+001.00000 \mathrm{e}+001.00000 \mathrm{e}-011.00000 \mathrm{e}-09$ 1.00000e-01

Element: 7352 \# of layers: 3

$\mathrm{Kx} \mathrm{Ky} \mathrm{Kz}$ Ss Por

7.52740e+01 7.52740e+01 7.52740e+00 1.00000e-09 7.00000e-02

$1.00000 \mathrm{e}-02$ 1.00000e-02 1.00000e-03 1.00000e-09 1.00000e-01

$1.00000 \mathrm{e}+001.00000 \mathrm{e}+001.00000 \mathrm{e}-01$ 1.00000e-09 1.00000e-01

Element: 7353 \# of layers: 3

$\mathrm{Kx} \mathrm{Ky} \mathrm{Kz}$ Ss Por

7.52740e+01 7.52740e+01 7.52740e+00 1.00000e-09 7.00000e-02 
$1.00000 \mathrm{e}-02$ 1.00000e-02 1.00000e-03 1.00000e-09 1.00000e-01

$1.00000 \mathrm{e}+001.00000 \mathrm{e}+001.00000 \mathrm{e}-01$ 1.00000e-09 1.00000e-01

Element: 7354 \# of layers: 3

Kx Ky Kz Ss Por

7.52740e+01 7.52740e+01 7.52740e+00 1.00000e-09 7.00000e-02

$1.00000 \mathrm{e}-02$ 1.00000e-02 1.00000e-03 1.00000e-09 1.00000e-01

$1.00000 \mathrm{e}+001.00000 \mathrm{e}+001.00000 \mathrm{e}-011.00000 \mathrm{e}-091.00000 \mathrm{e}-01$

Element: 7355 \# of layers: 3

$\mathrm{Kx} \mathrm{Ky} \mathrm{Kz}$ Ss Por

7.52740e+01 7.52740e+01 7.52740e+00 1.00000e-09 7.00000e-02

$1.00000 \mathrm{e}-02$ 1.00000e-02 1.00000e-03 1.00000e-09 1.00000e-01

$1.00000 \mathrm{e}+001.00000 \mathrm{e}+001.00000 \mathrm{e}-011.00000 \mathrm{e}-091.00000 \mathrm{e}-01$

Element: 7356 \# of layers: 3

$\mathrm{Kx} \mathrm{Ky} \mathrm{Kz}$ Ss Por

7.52740e+01 7.52740e+01 7.52740e+00 1.00000e-09 7.00000e-02

$1.00000 \mathrm{e}-02$ 1.00000e-02 1.00000e-03 1.00000e-09 1.00000e-01

$1.00000 \mathrm{e}+001.00000 \mathrm{e}+001.00000 \mathrm{e}-011.00000 \mathrm{e}-091.00000 \mathrm{e}-01$

Element: 7357 \# of layers: 3

$\mathrm{Kx} \mathrm{Ky} \mathrm{Kz}$ Ss Por

7.52740e+01 7.52740e+01 7.52740e+00 1.00000e-09 7.00000e-02

$1.00000 \mathrm{e}-02$ 1.00000e-02 1.00000e-03 1.00000e-09 1.00000e-01

$1.00000 \mathrm{e}+001.00000 \mathrm{e}+001.00000 \mathrm{e}-01$ 1.00000e-09 1.00000e-01

Element: 7358 \# of layers: 3

Kx Ky Kz Ss Por

8.01935e+01 8.01935e+01 8.01935e+00 1.00000e-09 7.00000e-02

$1.00000 \mathrm{e}-021.00000 \mathrm{e}-021.00000 \mathrm{e}-031.00000 \mathrm{e}-091.00000 \mathrm{e}-01$

$1.00000 \mathrm{e}+001.00000 \mathrm{e}+001.00000 \mathrm{e}-011.00000 \mathrm{e}-091.00000 \mathrm{e}-01$

Element: 7359 \# of layers: 3

Kx Ky Kz Ss Por

8.01935e+01 8.01935e+01 8.01935e+00 1.00000e-09 7.00000e-02

$1.00000 \mathrm{e}-02$ 1.00000e-02 1.00000e-03 1.00000e-09 1.00000e-01

$1.00000 \mathrm{e}+001.00000 \mathrm{e}+001.00000 \mathrm{e}-01$ 1.00000e-09 1.00000e-01

Element: 7360 \# of layers: 3

$\mathrm{Kx} \mathrm{Ky} \mathrm{Kz}$ Ss Por

8.01935e+01 8.01935e+01 8.01935e+00 1.00000e-09 7.00000e-02

$1.00000 \mathrm{e}-02$ 1.00000e-02 1.00000e-03 1.00000e-09 1.00000e-01

$1.00000 \mathrm{e}+001.00000 \mathrm{e}+001.00000 \mathrm{e}-011.00000 \mathrm{e}-091.00000 \mathrm{e}-01$

Element: 7361 \# of layers: 3

$\mathrm{Kx} \mathrm{Ky} \mathrm{Kz}$ Ss Por

8.01935e+01 8.01935e+01 8.01935e+00 1.00000e-09 7.00000e-02

$1.00000 \mathrm{e}-02$ 1.00000e-02 1.00000e-03 1.00000e-09 1.00000e-01

$1.00000 \mathrm{e}+001.00000 \mathrm{e}+001.00000 \mathrm{e}-011.00000 \mathrm{e}-091.00000 \mathrm{e}-01$

Element: 7362 \# of layers: 3

Kx Ky Kz Ss Por

8.01935e+01 8.01935e+01 8.01935e+00 1.00000e-09 7.00000e-02

$1.00000 \mathrm{e}-02$ 1.00000e-02 1.00000e-03 1.00000e-09 1.00000e-01 
$1.00000 \mathrm{e}+001.00000 \mathrm{e}+00$ 1.00000e-01 1.00000e-09 1.00000e-01

Element: 7363 \# of layers: 3

Kx Ky Kz Ss Por

8.01935e+01 8.01935e+01 8.01935e+00 1.00000e-09 7.00000e-02

$1.00000 \mathrm{e}-02$ 1.00000e-02 1.00000e-03 1.00000e-09 1.00000e-01

$1.00000 \mathrm{e}+001.00000 \mathrm{e}+001.00000 \mathrm{e}-011.00000 \mathrm{e}-09$ 1.00000e-01

Element: 7364 \# of layers: 3

$\mathrm{Kx} \mathrm{Ky} \mathrm{Kz}$ Ss Por

8.01935e+01 8.01935e+01 8.01935e+00 1.00000e-09 7.00000e-02

$1.00000 \mathrm{e}-02$ 1.00000e-02 1.00000e-03 1.00000e-09 1.00000e-01

$1.00000 \mathrm{e}+001.00000 \mathrm{e}+001.00000 \mathrm{e}-011.00000 \mathrm{e}-091.00000 \mathrm{e}-01$

Element: 7365 \# of layers: 3

$\mathrm{Kx} \mathrm{Ky} \mathrm{Kz}$ Ss Por

8.01935e+01 8.01935e+01 8.01935e+00 1.00000e-09 7.00000e-02

$1.00000 \mathrm{e}-02$ 1.00000e-02 1.00000e-03 1.00000e-09 1.00000e-01

$1.00000 \mathrm{e}+001.00000 \mathrm{e}+001.00000 \mathrm{e}-011.00000 \mathrm{e}-091.00000 \mathrm{e}-01$

Element: 7366 \# of layers: 3

$\mathrm{Kx} \mathrm{Ky} \mathrm{Kz}$ Ss Por

8.01935e+01 8.01935e+01 8.01935e+00 1.00000e-09 7.00000e-02

$1.00000 \mathrm{e}-021.00000 \mathrm{e}-021.00000 \mathrm{e}-031.00000 \mathrm{e}-091.00000 \mathrm{e}-01$

$1.00000 \mathrm{e}+001.00000 \mathrm{e}+001.00000 \mathrm{e}-011.00000 \mathrm{e}-091.00000 \mathrm{e}-01$

Element: 7367 \# of layers: 3

$\mathrm{Kx} \mathrm{Ky} \mathrm{Kz}$ Ss Por

7.43406e+01 7.43406e+01 7.43406e+00 1.00000e-09 7.00000e-02

$1.00000 \mathrm{e}-02$ 1.00000e-02 1.00000e-03 1.00000e-09 1.00000e-01

$1.00000 \mathrm{e}+001.00000 \mathrm{e}+001.00000 \mathrm{e}-011.00000 \mathrm{e}-091.00000 \mathrm{e}-01$

Element: 7368 \# of layers: 3

$\mathrm{Kx} \mathrm{Ky} \mathrm{Kz}$ Ss Por

7.43406e+01 7.43406e+01 7.43406e+00 1.00000e-09 7.00000e-02

$1.00000 \mathrm{e}-02$ 1.00000e-02 1.00000e-03 1.00000e-09 1.00000e-01

$1.00000 \mathrm{e}+001.00000 \mathrm{e}+001.00000 \mathrm{e}-01$ 1.00000e-09 1.00000e-01

Element: 7369 \# of layers: 3

Kx Ky Kz Ss Por

7.43406e+01 7.43406e+01 7.43406e+00 1.00000e-09 7.00000e-02

$1.00000 \mathrm{e}-02$ 1.00000e-02 1.00000e-03 1.00000e-09 1.00000e-01

$1.00000 \mathrm{e}+001.00000 \mathrm{e}+001.00000 \mathrm{e}-011.00000 \mathrm{e}-091.00000 \mathrm{e}-01$

Element: 7370 \# of layers: 3

$\mathrm{Kx} \mathrm{Ky} \mathrm{Kz}$ Ss Por

7.43406e+01 7.43406e+01 7.43406e+00 1.00000e-09 7.00000e-02

$1.00000 \mathrm{e}-02$ 1.00000e-02 1.00000e-03 1.00000e-09 1.00000e-01

$1.00000 \mathrm{e}+001.00000 \mathrm{e}+001.00000 \mathrm{e}-011.00000 \mathrm{e}-091.00000 \mathrm{e}-01$

Element: 7371 \# of layers: 3

$\mathrm{Kx} \mathrm{Ky} \mathrm{Kz}$ Ss Por

7.43406e+01 7.43406e+01 7.43406e+00 1.00000e-09 7.00000e-02

$1.00000 \mathrm{e}-02$ 1.00000e-02 1.00000e-03 1.00000e-09 1.00000e-01

$1.00000 \mathrm{e}+001.00000 \mathrm{e}+001.00000 \mathrm{e}-011.00000 \mathrm{e}-091.00000 \mathrm{e}-01$ 
Element: 7372 \# of layers: 3

$\mathrm{Kx} \mathrm{Ky} \mathrm{Kz}$ Ss Por

7.43406e+01 7.43406e+01 7.43406e+00 1.00000e-09 7.00000e-02

$1.00000 \mathrm{e}-02$ 1.00000e-02 1.00000e-03 1.00000e-09 1.00000e-01

$1.00000 \mathrm{e}+001.00000 \mathrm{e}+001.00000 \mathrm{e}-011.00000 \mathrm{e}-091.00000 \mathrm{e}-01$

Element: 7373 \# of layers: 3

$\mathrm{Kx} \mathrm{Ky} \mathrm{Kz}$ Ss Por

7.43406e+01 7.43406e+01 7.43406e+00 1.00000e-09 7.00000e-02

$1.00000 \mathrm{e}-021.00000 \mathrm{e}-021.00000 \mathrm{e}-031.00000 \mathrm{e}-091.00000 \mathrm{e}-01$

$1.00000 \mathrm{e}+001.00000 \mathrm{e}+001.00000 \mathrm{e}-011.00000 \mathrm{e}-091.00000 \mathrm{e}-01$

Element: 7374 \# of layers: 3

Kx Ky Kz Ss Por

7.43406e+01 7.43406e+01 7.43406e+00 1.00000e-09 7.00000e-02

1.00000e-02 1.00000e-02 1.00000e-03 1.00000e-09 1.00000e-01

$1.00000 \mathrm{e}+001.00000 \mathrm{e}+001.00000 \mathrm{e}-01$ 1.00000e-09 1.00000e-01

Element: 7375 \# of layers: 3

$\mathrm{Kx} \mathrm{Ky} \mathrm{Kz}$ Ss Por

7.43406e+01 7.43406e+01 7.43406e+00 1.00000e-09 7.00000e-02

$1.00000 \mathrm{e}-02$ 1.00000e-02 1.00000e-03 1.00000e-09 1.00000e-01

$1.00000 \mathrm{e}+001.00000 \mathrm{e}+001.00000 \mathrm{e}-011.00000 \mathrm{e}-091.00000 \mathrm{e}-01$

Element: 7376 \# of layers: 3

$\mathrm{Kx} \mathrm{Ky} \mathrm{Kz}$ Ss Por

4.62564e+01 4.62564e+01 4.62564e+00 1.00000e-09 7.00000e-02

$1.00000 \mathrm{e}-021.00000 \mathrm{e}-021.00000 \mathrm{e}-031.00000 \mathrm{e}-091.00000 \mathrm{e}-01$

$1.00000 \mathrm{e}+001.00000 \mathrm{e}+001.00000 \mathrm{e}-011.00000 \mathrm{e}-091.00000 \mathrm{e}-01$

Element: 7377 \# of layers: 3

$\mathrm{Kx} \mathrm{Ky} \mathrm{Kz}$ Ss Por

$4.62564 \mathrm{e}+014.62564 \mathrm{e}+014.62564 \mathrm{e}+001.00000 \mathrm{e}-097.00000 \mathrm{e}-02$

$1.00000 \mathrm{e}-02$ 1.00000e-02 1.00000e-03 1.00000e-09 1.00000e-01

$1.00000 \mathrm{e}+001.00000 \mathrm{e}+001.00000 \mathrm{e}-011.00000 \mathrm{e}-091.00000 \mathrm{e}-01$

Element: 7378 \# of layers: 3

$\mathrm{Kx} \mathrm{Ky} \mathrm{Kz}$ Ss Por

4.62564e+01 4.62564e+01 4.62564e+00 1.00000e-09 7.00000e-02

$1.00000 \mathrm{e}-021.00000 \mathrm{e}-021.00000 \mathrm{e}-031.00000 \mathrm{e}-091.00000 \mathrm{e}-01$

$1.00000 \mathrm{e}+001.00000 \mathrm{e}+001.00000 \mathrm{e}-011.00000 \mathrm{e}-091.00000 \mathrm{e}-01$

Element: 7379 \# of layers: 3

Kx Ky Kz Ss Por

4.62564e+01 4.62564e+01 4.62564e+00 1.00000e-09 7.00000e-02 $1.00000 \mathrm{e}-02$ 1.00000e-02 1.00000e-03 1.00000e-09 1.00000e-01

$1.00000 \mathrm{e}+001.00000 \mathrm{e}+001.00000 \mathrm{e}-011.00000 \mathrm{e}-091.00000 \mathrm{e}-01$

Element: 7380 \# of layers: 3

$\mathrm{Kx} \mathrm{Ky} \mathrm{Kz}$ Ss Por

4.62564e+01 4.62564e+01 4.62564e+00 1.00000e-09 7.00000e-02 $1.00000 \mathrm{e}-02$ 1.00000e-02 1.00000e-03 1.00000e-09 1.00000e-01

$1.00000 \mathrm{e}+001.00000 \mathrm{e}+001.00000 \mathrm{e}-011.00000 \mathrm{e}-091.00000 \mathrm{e}-01$

Element: 7381 \# of layers: 3 


\section{Kx Ky Kz Ss Por}

4.62564e+01 4.62564e+01 4.62564e+00 1.00000e-09 7.00000e-02

$1.00000 \mathrm{e}-02$ 1.00000e-02 1.00000e-03 1.00000e-09 1.00000e-01

$1.00000 \mathrm{e}+001.00000 \mathrm{e}+001.00000 \mathrm{e}-011.00000 \mathrm{e}-091.00000 \mathrm{e}-01$

Element: 7382 \# of layers: 3

$\mathrm{Kx} \mathrm{Ky} \mathrm{Kz}$ Ss Por

4.62564e+01 4.62564e+01 4.62564e+00 1.00000e-09 7.00000e-02

$1.00000 \mathrm{e}-02$ 1.00000e-02 1.00000e-03 1.00000e-09 1.00000e-01

$1.00000 \mathrm{e}+001.00000 \mathrm{e}+001.00000 \mathrm{e}-011.00000 \mathrm{e}-09$ 1.00000e-01

Element: 7383 \# of layers: 3

$\mathrm{Kx} \mathrm{Ky} \mathrm{Kz}$ Ss Por

4.62564e+01 4.62564e+01 4.62564e+00 1.00000e-09 7.00000e-02

$1.00000 \mathrm{e}-02$ 1.00000e-02 1.00000e-03 1.00000e-09 1.00000e-01

$1.00000 \mathrm{e}+001.00000 \mathrm{e}+001.00000 \mathrm{e}-01$ 1.00000e-09 1.00000e-01

Element: 7384 \# of layers: 3

Kx Ky Kz Ss Por

4.62564e+01 4.62564e+01 4.62564e+00 1.00000e-09 7.00000e-02 $1.00000 \mathrm{e}-02$ 1.00000e-02 1.00000e-03 1.00000e-09 1.00000e-01

$1.00000 \mathrm{e}+001.00000 \mathrm{e}+001.00000 \mathrm{e}-011.00000 \mathrm{e}-091.00000 \mathrm{e}-01$

Element: 7385 \# of layers: 3

$\mathrm{Kx} \mathrm{Ky} \mathrm{Kz}$ Ss Por

$3.54300 \mathrm{e}+013.54300 \mathrm{e}+013.54300 \mathrm{e}+00$ 1.00000e-09 7.00000e-02 $1.00000 \mathrm{e}-02$ 1.00000e-02 1.00000e-03 1.00000e-09 1.00000e-01

$1.00000 \mathrm{e}+001.00000 \mathrm{e}+001.00000 \mathrm{e}-011.00000 \mathrm{e}-091.00000 \mathrm{e}-01$

Element: 7386 \# of layers: 3

$\mathrm{Kx} \mathrm{Ky} \mathrm{Kz}$ Ss Por

$3.54300 \mathrm{e}+013.54300 \mathrm{e}+013.54300 \mathrm{e}+00$ 1.00000e-09 7.00000e-02

$1.00000 \mathrm{e}-02$ 1.00000e-02 1.00000e-03 1.00000e-09 1.00000e-01

$1.00000 \mathrm{e}+001.00000 \mathrm{e}+001.00000 \mathrm{e}-011.00000 \mathrm{e}-091.00000 \mathrm{e}-01$

Element: 7387 \# of layers: 3

$\mathrm{Kx} \mathrm{Ky} \mathrm{Kz}$ Ss Por

3.54300e+01 3.54300e+01 3.54300e+00 1.00000e-09 7.00000e-02

$1.00000 \mathrm{e}-02$ 1.00000e-02 1.00000e-03 1.00000e-09 1.00000e-01

$1.00000 \mathrm{e}+001.00000 \mathrm{e}+001.00000 \mathrm{e}-01$ 1.00000e-09 1.00000e-01

Element: 7388 \# of layers: 3

Kx Ky Kz Ss Por

3.54300e+01 3.54300e+01 3.54300e+00 1.00000e-09 7.00000e-02

$1.00000 \mathrm{e}-02$ 1.00000e-02 1.00000e-03 1.00000e-09 1.00000e-01

$1.00000 \mathrm{e}+001.00000 \mathrm{e}+001.00000 \mathrm{e}-01$ 1.00000e-09 1.00000e-01

Element: 7389 \# of layers: 3

$\mathrm{Kx} \mathrm{Ky} \mathrm{Kz}$ Ss Por

3.54300e+01 3.54300e+01 3.54300e+00 1.00000e-09 7.00000e-02 $1.00000 \mathrm{e}-02$ 1.00000e-02 1.00000e-03 1.00000e-09 1.00000e-01

$1.00000 \mathrm{e}+001.00000 \mathrm{e}+001.00000 \mathrm{e}-01$ 1.00000e-09 1.00000e-01

Element: 7390 \# of layers: 3

Kx Ky Kz Ss Por 
$3.54300 \mathrm{e}+013.54300 \mathrm{e}+013.54300 \mathrm{e}+001.00000 \mathrm{e}-09$ 7.00000e-02 $1.00000 \mathrm{e}-02$ 1.00000e-02 1.00000e-03 1.00000e-09 1.00000e-01

$1.00000 \mathrm{e}+001.00000 \mathrm{e}+001.00000 \mathrm{e}-011.00000 \mathrm{e}-091.00000 \mathrm{e}-01$

Element: 7391 \# of layers: 3

$\mathrm{Kx} \mathrm{Ky} \mathrm{Kz}$ Ss Por

$3.54300 \mathrm{e}+013.54300 \mathrm{e}+013.54300 \mathrm{e}+001.00000 \mathrm{e}-097.00000 \mathrm{e}-02$

$1.00000 \mathrm{e}-02$ 1.00000e-02 1.00000e-03 1.00000e-09 1.00000e-01

$1.00000 \mathrm{e}+001.00000 \mathrm{e}+001.00000 \mathrm{e}-011.00000 \mathrm{e}-091.00000 \mathrm{e}-01$

Element: 7392 \# of layers: 3

$\mathrm{Kx} \mathrm{Ky} \mathrm{Kz}$ Ss Por

3.54300e+01 3.54300e+01 3.54300e+00 1.00000e-09 7.00000e-02

$1.00000 \mathrm{e}-02$ 1.00000e-02 1.00000e-03 1.00000e-09 1.00000e-01

$1.00000 \mathrm{e}+001.00000 \mathrm{e}+001.00000 \mathrm{e}-01$ 1.00000e-09 1.00000e-01

Element: 7393 \# of layers: 3

$\mathrm{Kx} \mathrm{Ky} \mathrm{Kz}$ Ss Por

3.54300e+01 3.54300e+01 3.54300e+00 1.00000e-09 7.00000e-02

$1.00000 \mathrm{e}-02$ 1.00000e-02 1.00000e-03 1.00000e-09 1.00000e-01

$1.00000 \mathrm{e}+001.00000 \mathrm{e}+001.00000 \mathrm{e}-01$ 1.00000e-09 1.00000e-01

Element: 7394 \# of layers: 3

Kx Ky Kz Ss Por

5.13165e+01 5.13165e+01 5.13165e+00 1.00000e-09 7.00000e-02

$1.00000 \mathrm{e}-02$ 1.00000e-02 1.00000e-03 1.00000e-09 1.00000e-01

$1.00000 \mathrm{e}+001.00000 \mathrm{e}+001.00000 \mathrm{e}-01$ 1.00000e-09 1.00000e-01

Element: 7395 \# of layers: 3

Kx Ky Kz Ss Por

5.13165e+01 5.13165e+01 5.13165e+00 1.00000e-09 7.00000e-02

$1.00000 \mathrm{e}-02$ 1.00000e-02 1.00000e-03 1.00000e-09 1.00000e-01

$1.00000 \mathrm{e}+001.00000 \mathrm{e}+001.00000 \mathrm{e}-011.00000 \mathrm{e}-091.00000 \mathrm{e}-01$

Element: 7396 \# of layers: 3

$\mathrm{Kx} \mathrm{Ky} \mathrm{Kz}$ Ss Por

5.13165e+01 5.13165e+01 5.13165e+00 1.00000e-09 7.00000e-02

$1.00000 \mathrm{e}-02$ 1.00000e-02 1.00000e-03 1.00000e-09 1.00000e-01

$1.00000 \mathrm{e}+001.00000 \mathrm{e}+001.00000 \mathrm{e}-011.00000 \mathrm{e}-091.00000 \mathrm{e}-01$

Element: 7397 \# of layers: 3

$\mathrm{Kx} \mathrm{Ky} \mathrm{Kz}$ Ss Por

$5.13165 \mathrm{e}+015.13165 \mathrm{e}+015.13165 \mathrm{e}+00$ 1.00000e-09 7.00000e-02

$1.00000 \mathrm{e}-02$ 1.00000e-02 1.00000e-03 1.00000e-09 1.00000e-01

$1.00000 \mathrm{e}+001.00000 \mathrm{e}+001.00000 \mathrm{e}-011.00000 \mathrm{e}-09$ 1.00000e-01

Element: 7398 \# of layers: 3

$\mathrm{Kx} \mathrm{Ky} \mathrm{Kz}$ Ss Por

5.13165e+01 5.13165e+01 5.13165e+00 1.00000e-09 7.00000e-02

$1.00000 \mathrm{e}-02$ 1.00000e-02 1.00000e-03 1.00000e-09 1.00000e-01

$1.00000 \mathrm{e}+001.00000 \mathrm{e}+001.00000 \mathrm{e}-01$ 1.00000e-09 1.00000e-01

Element: 7399 \# of layers: 3

Kx Ky Kz Ss Por

5.13165e+01 5.13165e+01 5.13165e+00 1.00000e-09 7.00000e-02 
$1.00000 \mathrm{e}-02$ 1.00000e-02 1.00000e-03 1.00000e-09 1.00000e-01 $1.00000 \mathrm{e}+001.00000 \mathrm{e}+001.00000 \mathrm{e}-01$ 1.00000e-09 1.00000e-01

Element: 7400 \# of layers: 3

Kx Ky Kz Ss Por

5.13165e+01 5.13165e+01 5.13165e+00 1.00000e-09 7.00000e-02 $1.00000 \mathrm{e}-02$ 1.00000e-02 1.00000e-03 1.00000e-09 1.00000e-01

$1.00000 \mathrm{e}+001.00000 \mathrm{e}+001.00000 \mathrm{e}-011.00000 \mathrm{e}-091.00000 \mathrm{e}-01$

Element: 7401 \# of layers: 3

$\mathrm{Kx} \mathrm{Ky} \mathrm{Kz}$ Ss Por

5.13165e+01 5.13165e+01 5.13165e+00 1.00000e-09 7.00000e-02 $1.00000 \mathrm{e}-02$ 1.00000e-02 1.00000e-03 1.00000e-09 1.00000e-01

$1.00000 \mathrm{e}+001.00000 \mathrm{e}+001.00000 \mathrm{e}-011.00000 \mathrm{e}-091.00000 \mathrm{e}-01$

Element: 7402 \# of layers: 3

$\mathrm{Kx} \mathrm{Ky} \mathrm{Kz}$ Ss Por

5.13165e+01 5.13165e+01 5.13165e+00 1.00000e-09 7.00000e-02 $1.00000 \mathrm{e}-02$ 1.00000e-02 1.00000e-03 1.00000e-09 1.00000e-01

$1.00000 \mathrm{e}+001.00000 \mathrm{e}+001.00000 \mathrm{e}-011.00000 \mathrm{e}-091.00000 \mathrm{e}-01$

Element: 7403 \# of layers: 3

$\mathrm{Kx} \mathrm{Ky} \mathrm{Kz}$ Ss Por

6.71777e+01 6.71777e+01 6.71777e+00 1.00000e-09 7.00000e-02

$1.00000 \mathrm{e}-02$ 1.00000e-02 1.00000e-03 1.00000e-09 1.00000e-01

$1.00000 \mathrm{e}+001.00000 \mathrm{e}+001.00000 \mathrm{e}-01$ 1.00000e-09 1.00000e-01

Element: 7404 \# of layers: 3

Kx Ky Kz Ss Por

6.71777e+01 6.71777e+01 6.71777e+00 1.00000e-09 7.00000e-02 $1.00000 \mathrm{e}-02$ 1.00000e-02 1.00000e-03 1.00000e-09 1.00000e-01

$1.00000 \mathrm{e}+001.00000 \mathrm{e}+001.00000 \mathrm{e}-011.00000 \mathrm{e}-091.00000 \mathrm{e}-01$

Element: 7405 \# of layers: 3

Kx Ky Kz Ss Por

6.71777e+01 6.71777e+01 6.71777e+00 1.00000e-09 7.00000e-02 $1.00000 \mathrm{e}-02$ 1.00000e-02 1.00000e-03 1.00000e-09 1.00000e-01 $1.00000 \mathrm{e}+001.00000 \mathrm{e}+001.00000 \mathrm{e}-011.00000 \mathrm{e}-091.00000 \mathrm{e}-01$

Element: 7406 \# of layers: 3

Kx Ky Kz Ss Por

6.71777e+01 6.71777e+01 6.71777e+00 1.00000e-09 7.00000e-02 $1.00000 \mathrm{e}-02$ 1.00000e-02 1.00000e-03 1.00000e-09 1.00000e-01

$1.00000 \mathrm{e}+001.00000 \mathrm{e}+001.00000 \mathrm{e}-011.00000 \mathrm{e}-091.00000 \mathrm{e}-01$

Element: 7407 \# of layers: 3

Kx Ky Kz Ss Por

6.71777e+01 6.71777e+01 6.71777e+00 1.00000e-09 7.00000e-02 $1.00000 \mathrm{e}-02$ 1.00000e-02 1.00000e-03 1.00000e-09 1.00000e-01

$1.00000 \mathrm{e}+001.00000 \mathrm{e}+001.00000 \mathrm{e}-011.00000 \mathrm{e}-091.00000 \mathrm{e}-01$

Element: 7408 \# of layers: 3

$\mathrm{Kx} \mathrm{Ky} \mathrm{Kz}$ Ss Por

6.71777e+01 6.71777e+01 6.71777e+00 1.00000e-09 7.00000e-02

$1.00000 \mathrm{e}-02$ 1.00000e-02 1.00000e-03 1.00000e-09 1.00000e-01 
$1.00000 \mathrm{e}+001.00000 \mathrm{e}+00$ 1.00000e-01 1.00000e-09 1.00000e-01

Element: 7409 \# of layers: 3

Kx Ky Kz Ss Por

6.71777e+01 6.71777e+01 6.71777e+00 1.00000e-09 7.00000e-02

$1.00000 \mathrm{e}-02$ 1.00000e-02 1.00000e-03 1.00000e-09 1.00000e-01

$1.00000 \mathrm{e}+001.00000 \mathrm{e}+001.00000 \mathrm{e}-01$ 1.00000e-09 1.00000e-01

Element: 7410 \# of layers: 3

Kx Ky Kz Ss Por

6.71777e+01 6.71777e+01 6.71777e+00 1.00000e-09 7.00000e-02 1.00000e-02 1.00000e-02 1.00000e-03 1.00000e-09 1.00000e-01

$1.00000 \mathrm{e}+001.00000 \mathrm{e}+001.00000 \mathrm{e}-011.00000 \mathrm{e}-091.00000 \mathrm{e}-01$

Element: 7411 \# of layers: 3

Kx Ky Kz Ss Por

6.71777e+01 6.71777e+01 6.71777e+00 1.00000e-09 7.00000e-02 $1.00000 \mathrm{e}-02$ 1.00000e-02 1.00000e-03 1.00000e-09 1.00000e-01

$1.00000 \mathrm{e}+001.00000 \mathrm{e}+001.00000 \mathrm{e}-011.00000 \mathrm{e}-091.00000 \mathrm{e}-01$

Element: 7412 \# of layers: 3

$\mathrm{Kx} \mathrm{Ky} \mathrm{Kz}$ Ss Por

3.33226e+01 3.33226e+01 3.33226e+00 1.00000e-09 7.00000e-02

$1.00000 \mathrm{e}-021.00000 \mathrm{e}-021.00000 \mathrm{e}-031.00000 \mathrm{e}-091.00000 \mathrm{e}-01$

$1.00000 \mathrm{e}+001.00000 \mathrm{e}+001.00000 \mathrm{e}-011.00000 \mathrm{e}-091.00000 \mathrm{e}-01$

Element: 7413 \# of layers: 3

$\mathrm{Kx} \mathrm{Ky} \mathrm{Kz}$ Ss Por

3.33226e+01 3.33226e+01 3.33226e+00 1.00000e-09 7.00000e-02

$1.00000 \mathrm{e}-021.00000 \mathrm{e}-02$ 1.00000e-03 1.00000e-09 1.00000e-01

$1.00000 \mathrm{e}+001.00000 \mathrm{e}+001.00000 \mathrm{e}-01$ 1.00000e-09 1.00000e-01

Element: 7414 \# of layers: 3

$\mathrm{Kx} \mathrm{Ky} \mathrm{Kz}$ Ss Por

4.00287e+01 4.00287e+01 4.00287e+00 1.00000e-09 7.00000e-02

$1.00000 \mathrm{e}-02$ 1.00000e-02 1.00000e-03 1.00000e-09 1.00000e-01

$1.00000 \mathrm{e}+001.00000 \mathrm{e}+001.00000 \mathrm{e}-011.00000 \mathrm{e}-091.00000 \mathrm{e}-01$

Element: 7415 \# of layers: 3

$\mathrm{Kx} \mathrm{Ky} \mathrm{Kz}$ Ss Por

3.33226e+01 3.33226e+01 3.33226e+00 1.00000e-09 7.00000e-02

$1.00000 \mathrm{e}-02$ 1.00000e-02 1.00000e-03 1.00000e-09 1.00000e-01

$1.00000 \mathrm{e}+001.00000 \mathrm{e}+001.00000 \mathrm{e}-011.00000 \mathrm{e}-091.00000 \mathrm{e}-01$

Element: 7416 \# of layers: 3

Kx Ky Kz Ss Por

3.33226e+01 3.33226e+01 3.33226e+00 1.00000e-09 7.00000e-02

$1.00000 \mathrm{e}-02$ 1.00000e-02 1.00000e-03 1.00000e-09 1.00000e-01

$1.00000 \mathrm{e}+001.00000 \mathrm{e}+001.00000 \mathrm{e}-011.00000 \mathrm{e}-091.00000 \mathrm{e}-01$

Element: 7417 \# of layers: 3

$\mathrm{Kx} \mathrm{Ky} \mathrm{Kz}$ Ss Por

3.33226e+01 3.33226e+01 3.33226e+00 1.00000e-09 7.00000e-02

$1.00000 \mathrm{e}-02$ 1.00000e-02 1.00000e-03 1.00000e-09 1.00000e-01

$1.00000 \mathrm{e}+001.00000 \mathrm{e}+001.00000 \mathrm{e}-011.00000 \mathrm{e}-091.00000 \mathrm{e}-01$ 
Element: 7418 \# of layers: 3

$\mathrm{Kx} \mathrm{Ky} \mathrm{Kz}$ Ss Por

3.33226e+01 3.33226e+01 3.33226e+00 1.00000e-09 7.00000e-02

$1.00000 \mathrm{e}-02$ 1.00000e-02 1.00000e-03 1.00000e-09 1.00000e-01

$1.00000 \mathrm{e}+001.00000 \mathrm{e}+001.00000 \mathrm{e}-011.00000 \mathrm{e}-091.00000 \mathrm{e}-01$

Element: 7419 \# of layers: 3

$\mathrm{Kx} \mathrm{Ky} \mathrm{Kz}$ Ss Por

3.33226e+01 3.33226e+01 3.33226e+00 1.00000e-09 7.00000e-02

$1.00000 \mathrm{e}-021.00000 \mathrm{e}-021.00000 \mathrm{e}-031.00000 \mathrm{e}-091.00000 \mathrm{e}-01$

$1.00000 \mathrm{e}+001.00000 \mathrm{e}+001.00000 \mathrm{e}-011.00000 \mathrm{e}-091.00000 \mathrm{e}-01$

Element: 7420 \# of layers: 3

Kx Ky Kz Ss Por

3.33226e+01 3.33226e+01 3.33226e+00 1.00000e-09 7.00000e-02 $1.00000 \mathrm{e}-02$ 1.00000e-02 1.00000e-03 1.00000e-09 1.00000e-01

$1.00000 \mathrm{e}+001.00000 \mathrm{e}+001.00000 \mathrm{e}-01$ 1.00000e-09 1.00000e-01

Element: 7421 \# of layers: 3

$\mathrm{Kx} \mathrm{Ky} \mathrm{Kz}$ Ss Por

$2.48189 \mathrm{e}+012.48189 \mathrm{e}+012.48189 \mathrm{e}+00$ 1.00000e-09 7.00000e-02 $1.00000 \mathrm{e}-02$ 1.00000e-02 1.00000e-03 1.00000e-09 1.00000e-01

$1.00000 \mathrm{e}+001.00000 \mathrm{e}+001.00000 \mathrm{e}-011.00000 \mathrm{e}-091.00000 \mathrm{e}-01$

Element: 7422 \# of layers: 4

$\mathrm{Kx} \mathrm{Ky} \mathrm{Kz}$ Ss Por

$2.07581 \mathrm{e}+012.07581 \mathrm{e}+012.07581 \mathrm{e}+00$ 1.00000e-09 7.00000e-02

$2.07581 \mathrm{e}+012.07581 \mathrm{e}+012.07581 \mathrm{e}+001.00000 \mathrm{e}-09$ 7.00000e-02

$1.00000 \mathrm{e}-02$ 1.00000e-02 1.00000e-03 1.00000e-09 1.00000e-01

$1.00000 \mathrm{e}+001.00000 \mathrm{e}+001.00000 \mathrm{e}-011.00000 \mathrm{e}-091.00000 \mathrm{e}-01$

Element: 7423 \# of layers: 4

$\mathrm{Kx} \mathrm{Ky} \mathrm{Kz} \mathrm{Ss} \mathrm{Por}$

$2.07581 \mathrm{e}+012.07581 \mathrm{e}+012.07581 \mathrm{e}+001.00000 \mathrm{e}-09$ 7.00000e-02

$2.07581 \mathrm{e}+012.07581 \mathrm{e}+012.07581 \mathrm{e}+001.00000 \mathrm{e}-09$ 7.00000e-02

$1.00000 \mathrm{e}-02$ 1.00000e-02 1.00000e-03 1.00000e-09 1.00000e-01

$1.00000 \mathrm{e}+001.00000 \mathrm{e}+001.00000 \mathrm{e}-011.00000 \mathrm{e}-091.00000 \mathrm{e}-01$

Element: 7424 \# of layers: 6

$\mathrm{Kx} \mathrm{Ky} \mathrm{Kz}$ Ss Por

7.74309e+01 7.74309e+01 7.74309e+00 1.00000e-09 2.12000e-01

7.74309e+01 7.74309e+01 7.74309e+00 1.00000e-09 2.12000e-01

$7.74309 \mathrm{e}+017.74309 \mathrm{e}+01$ 7.74309e+00 1.00000e-09 2.12000e-01

7.74309e+01 7.74309e+01 7.74309e+00 1.00000e-09 2.12000e-01

$1.00000 \mathrm{e}-021.00000 \mathrm{e}-021.00000 \mathrm{e}-031.00000 \mathrm{e}-091.00000 \mathrm{e}-01$

$1.00000 \mathrm{e}+001.00000 \mathrm{e}+001.00000 \mathrm{e}-011.00000 \mathrm{e}-091.00000 \mathrm{e}-01$

Element: 7425 \# of layers: 6

$\mathrm{Kx} \mathrm{Ky} \mathrm{Kz}$ Ss Por

7.74309e+01 7.74309e+01 7.74309e+00 1.00000e-09 2.12000e-01

7.74309e+01 7.74309e+01 7.74309e+00 1.00000e-09 2.12000e-01

$7.74309 \mathrm{e}+01$ 7.74309e+01 7.74309e+00 1.00000e-09 2.12000e-01

$7.74309 \mathrm{e}+017.74309 \mathrm{e}+017.74309 \mathrm{e}+001.00000 \mathrm{e}-092.12000 \mathrm{e}-01$ 
$1.00000 \mathrm{e}-02$ 1.00000e-02 1.00000e-03 1.00000e-09 1.00000e-01 $1.00000 \mathrm{e}+001.00000 \mathrm{e}+001.00000 \mathrm{e}-01$ 1.00000e-09 1.00000e-01 Element: 7426 \# of layers: 6

Kx Ky Kz Ss Por

7.74309e+01 7.74309e+01 7.74309e+00 1.00000e-09 2.12000e-01

$7.74309 \mathrm{e}+01$ 7.74309e+01 7.74309e+00 1.00000e-09 2.12000e-01

$7.74309 \mathrm{e}+01$ 7.74309e+01 7.74309e+00 1.00000e-09 2.12000e-01

$7.74309 \mathrm{e}+01$ 7.74309e+01 7.74309e+00 1.00000e-09 2.12000e-01

$1.00000 \mathrm{e}-02$ 1.00000e-02 1.00000e-03 1.00000e-09 1.00000e-01

$1.00000 \mathrm{e}+001.00000 \mathrm{e}+001.00000 \mathrm{e}-011.00000 \mathrm{e}-091.00000 \mathrm{e}-01$

Element: 7427 \# of layers: 6

Kx Ky Kz Ss Por

7.91364e+01 7.91364e+01 7.91364e+00 1.00000e-09 2.12000e-01

$7.91364 \mathrm{e}+017.91364 \mathrm{e}+01$ 7.91364e+00 1.00000e-09 2.12000e-01

$7.91364 \mathrm{e}+01$ 7.91364e+01 7.91364e+00 1.00000e-09 2.12000e-01

$7.91364 \mathrm{e}+017.91364 \mathrm{e}+017.91364 \mathrm{e}+001.00000 \mathrm{e}-092.12000 \mathrm{e}-01$

$1.00000 \mathrm{e}-02$ 1.00000e-02 1.00000e-03 1.00000e-09 1.00000e-01

$1.00000 \mathrm{e}+001.00000 \mathrm{e}+001.00000 \mathrm{e}-01$ 1.00000e-09 1.00000e-01

Element: 7428 \# of layers: 6

$\mathrm{Kx} \mathrm{Ky} \mathrm{Kz}$ Ss Por

7.91364e+01 7.91364e+01 7.91364e+00 1.00000e-09 2.12000e-01

$7.91364 \mathrm{e}+01$ 7.91364e+01 7.91364e+00 1.00000e-09 2.12000e-01

$7.91364 \mathrm{e}+01$ 7.91364e+01 7.91364e+00 1.00000e-09 2.12000e-01

$7.91364 \mathrm{e}+017.91364 \mathrm{e}+01$ 7.91364e+00 1.00000e-09 2.12000e-01

$1.00000 \mathrm{e}-02$ 1.00000e-02 1.00000e-03 1.00000e-09 1.00000e-01

$1.00000 \mathrm{e}+001.00000 \mathrm{e}+001.00000 \mathrm{e}-01$ 1.00000e-09 1.00000e-01

Element: 7429 \# of layers: 6

$\mathrm{Kx} \mathrm{Ky} \mathrm{Kz}$ Ss Por

7.91364e+01 7.91364e+01 7.91364e+00 1.00000e-09 2.12000e-01

$7.91364 \mathrm{e}+01$ 7.91364e+01 7.91364e+00 1.00000e-09 2.12000e-01

$7.91364 \mathrm{e}+017.91364 \mathrm{e}+017.91364 \mathrm{e}+001.00000 \mathrm{e}-092.12000 \mathrm{e}-01$

$7.91364 \mathrm{e}+017.91364 \mathrm{e}+017.91364 \mathrm{e}+001.00000 \mathrm{e}-092.12000 \mathrm{e}-01$

$1.00000 \mathrm{e}-02$ 1.00000e-02 1.00000e-03 1.00000e-09 1.00000e-01

$1.00000 \mathrm{e}+001.00000 \mathrm{e}+001.00000 \mathrm{e}-011.00000 \mathrm{e}-091.00000 \mathrm{e}-01$

Element: 7430 \# of layers: 6

$\mathrm{Kx} \mathrm{Ky} \mathrm{Kz}$ Ss Por

8.00950e+01 8.00950e+01 8.00950e+00 1.00000e-09 2.12000e-01

$8.00950 \mathrm{e}+018.00950 \mathrm{e}+018.00950 \mathrm{e}+001.00000 \mathrm{e}-092.12000 \mathrm{e}-01$

$8.00950 \mathrm{e}+018.00950 \mathrm{e}+018.00950 \mathrm{e}+001.00000 \mathrm{e}-092.12000 \mathrm{e}-01$

$8.00950 \mathrm{e}+018.00950 \mathrm{e}+018.00950 \mathrm{e}+001.00000 \mathrm{e}-092.12000 \mathrm{e}-01$

$1.00000 \mathrm{e}-021.00000 \mathrm{e}-021.00000 \mathrm{e}-031.00000 \mathrm{e}-091.00000 \mathrm{e}-01$

$1.00000 \mathrm{e}+001.00000 \mathrm{e}+001.00000 \mathrm{e}-011.00000 \mathrm{e}-091.00000 \mathrm{e}-01$

Element: 7431 \# of layers: 6

$\mathrm{Kx} \mathrm{Ky} \mathrm{Kz}$ Ss Por

8.00950e+01 8.00950e+01 8.00950e+00 1.00000e-09 2.12000e-01

$8.00950 \mathrm{e}+018.00950 \mathrm{e}+018.00950 \mathrm{e}+001.00000 \mathrm{e}-092.12000 \mathrm{e}-01$ 
$8.00950 \mathrm{e}+018.00950 \mathrm{e}+018.00950 \mathrm{e}+001.00000 \mathrm{e}-092.12000 \mathrm{e}-01$ $8.00950 \mathrm{e}+018.00950 \mathrm{e}+018.00950 \mathrm{e}+00$ 1.00000e-09 2.12000e-01 $1.00000 \mathrm{e}-02$ 1.00000e-02 1.00000e-03 1.00000e-09 1.00000e-01 $1.00000 \mathrm{e}+001.00000 \mathrm{e}+001.00000 \mathrm{e}-011.00000 \mathrm{e}-091.00000 \mathrm{e}-01$ Element: 7432 \# of layers: 6

$\mathrm{Kx} \mathrm{Ky} \mathrm{Kz}$ Ss Por

8.00950e+01 8.00950e+01 8.00950e+00 1.00000e-09 2.12000e-01 $8.00950 \mathrm{e}+018.00950 \mathrm{e}+018.00950 \mathrm{e}+001.00000 \mathrm{e}-092.12000 \mathrm{e}-01$ $8.00950 \mathrm{e}+018.00950 \mathrm{e}+018.00950 \mathrm{e}+001.00000 \mathrm{e}-092.12000 \mathrm{e}-01$ $8.00950 \mathrm{e}+018.00950 \mathrm{e}+018.00950 \mathrm{e}+00$ 1.00000e-09 2.12000e-01 1.00000e-02 1.00000e-02 1.00000e-03 1.00000e-09 1.00000e-01 $1.00000 \mathrm{e}+001.00000 \mathrm{e}+001.00000 \mathrm{e}-011.00000 \mathrm{e}-091.00000 \mathrm{e}-01$ Element: 7433 \# of layers: 6

$\mathrm{Kx} \mathrm{Ky} \mathrm{Kz}$ Ss Por

8.00950e+01 8.00950e+01 8.00950e+00 1.00000e-09 2.12000e-01 $8.00950 \mathrm{e}+018.00950 \mathrm{e}+018.00950 \mathrm{e}+001.00000 \mathrm{e}-092.12000 \mathrm{e}-01$ $8.00950 \mathrm{e}+018.00950 \mathrm{e}+018.00950 \mathrm{e}+001.00000 \mathrm{e}-092.12000 \mathrm{e}-01$ $8.00950 \mathrm{e}+018.00950 \mathrm{e}+018.00950 \mathrm{e}+001.00000 \mathrm{e}-092.12000 \mathrm{e}-01$ $1.00000 \mathrm{e}-02$ 1.00000e-02 1.00000e-03 1.00000e-09 1.00000e-01 $1.00000 \mathrm{e}+001.00000 \mathrm{e}+001.00000 \mathrm{e}-011.00000 \mathrm{e}-091.00000 \mathrm{e}-01$ Element: 7434 \# of layers: 6

$\mathrm{Kx} \mathrm{Ky} \mathrm{Kz}$ Ss Por 8.00950e+01 8.00950e+01 8.00950e+00 1.00000e-09 2.12000e-01 $8.00950 \mathrm{e}+018.00950 \mathrm{e}+018.00950 \mathrm{e}+001.00000 \mathrm{e}-092.12000 \mathrm{e}-01$ $8.00950 \mathrm{e}+018.00950 \mathrm{e}+018.00950 \mathrm{e}+001.00000 \mathrm{e}-092.12000 \mathrm{e}-01$ $8.00950 \mathrm{e}+018.00950 \mathrm{e}+018.00950 \mathrm{e}+001.00000 \mathrm{e}-092.12000 \mathrm{e}-01$ $1.00000 \mathrm{e}-02$ 1.00000e-02 1.00000e-03 1.00000e-09 1.00000e-01 $1.00000 \mathrm{e}+001.00000 \mathrm{e}+001.00000 \mathrm{e}-011.00000 \mathrm{e}-09$ 1.00000e-01 Element: 7439 \# of layers: 6

$\mathrm{Kx} \mathrm{Ky} \mathrm{Kz}$ Ss Por

8.55356e+01 8.55356e+01 8.55356e+00 1.00000e-09 2.12000e-01 $8.55356 \mathrm{e}+018.55356 \mathrm{e}+018.55356 \mathrm{e}+001.00000 \mathrm{e}-092.12000 \mathrm{e}-01$ $8.55356 \mathrm{e}+018.55356 \mathrm{e}+018.55356 \mathrm{e}+001.00000 \mathrm{e}-092.12000 \mathrm{e}-01$ $8.55356 \mathrm{e}+018.55356 \mathrm{e}+018.55356 \mathrm{e}+001.00000 \mathrm{e}-092.12000 \mathrm{e}-01$ $1.00000 \mathrm{e}-02$ 1.00000e-02 1.00000e-03 1.00000e-09 1.00000e-01 $1.00000 \mathrm{e}+001.00000 \mathrm{e}+001.00000 \mathrm{e}-011.00000 \mathrm{e}-091.00000 \mathrm{e}-01$ Element: 7440 \# of layers: 5

Kx Ky Kz Ss Por

8.55356e+01 8.55356e+01 8.55356e+00 1.00000e-09 2.12000e-01 $8.55356 \mathrm{e}+018.55356 \mathrm{e}+018.55356 \mathrm{e}+001.00000 \mathrm{e}-092.12000 \mathrm{e}-01$ $8.55356 \mathrm{e}+018.55356 \mathrm{e}+018.55356 \mathrm{e}+001.00000 \mathrm{e}-092.12000 \mathrm{e}-01$ $1.00000 \mathrm{e}-021.00000 \mathrm{e}-021.00000 \mathrm{e}-031.00000 \mathrm{e}-091.00000 \mathrm{e}-01$ $1.00000 \mathrm{e}+001.00000 \mathrm{e}+001.00000 \mathrm{e}-011.00000 \mathrm{e}-091.00000 \mathrm{e}-01$ Element: 7441 \# of layers: 5

$\mathrm{Kx} \mathrm{Ky} \mathrm{Kz} \mathrm{Ss} \mathrm{Por}$

8.55356e+01 8.55356e+01 8.55356e+00 1.00000e-09 2.12000e-01 
8.55356e+01 8.55356e+01 8.55356e+00 1.00000e-09 2.12000e-01 $8.55356 \mathrm{e}+018.55356 \mathrm{e}+018.55356 \mathrm{e}+00$ 1.00000e-09 2.12000e-01 $1.00000 \mathrm{e}-02$ 1.00000e-02 1.00000e-03 1.00000e-09 1.00000e-01 $1.00000 \mathrm{e}+001.00000 \mathrm{e}+001.00000 \mathrm{e}-011.00000 \mathrm{e}-091.00000 \mathrm{e}-01$ Element: 7442 \# of layers: 5

$\mathrm{Kx} \mathrm{Ky} \mathrm{Kz}$ Ss Por

8.55356e+01 8.55356e+01 8.55356e+00 1.00000e-09 2.12000e-01 $8.55356 \mathrm{e}+018.55356 \mathrm{e}+018.55356 \mathrm{e}+001.00000 \mathrm{e}-092.12000 \mathrm{e}-01$ $8.55356 \mathrm{e}+018.55356 \mathrm{e}+018.55356 \mathrm{e}+001.00000 \mathrm{e}-092.12000 \mathrm{e}-01$ $1.00000 \mathrm{e}-02$ 1.00000e-02 1.00000e-03 1.00000e-09 1.00000e-01 $1.00000 \mathrm{e}+001.00000 \mathrm{e}+001.00000 \mathrm{e}-011.00000 \mathrm{e}-091.00000 \mathrm{e}-01$ Element: 7443 \# of layers: 5

Kx Ky Kz Ss Por

8.55356e+01 8.55356e+01 8.55356e+00 1.00000e-09 2.12000e-01 $8.55356 \mathrm{e}+018.55356 \mathrm{e}+018.55356 \mathrm{e}+001.00000 \mathrm{e}-092.12000 \mathrm{e}-01$ $8.55356 \mathrm{e}+018.55356 \mathrm{e}+018.55356 \mathrm{e}+001.00000 \mathrm{e}-092.12000 \mathrm{e}-01$ $1.00000 \mathrm{e}-02$ 1.00000e-02 1.00000e-03 1.00000e-09 1.00000e-01 $1.00000 \mathrm{e}+001.00000 \mathrm{e}+001.00000 \mathrm{e}-011.00000 \mathrm{e}-091.00000 \mathrm{e}-01$ Element: 7444 \# of layers: 5

$\mathrm{Kx} \mathrm{Ky} \mathrm{Kz}$ Ss Por

8.55356e+01 8.55356e+01 8.55356e+00 1.00000e-09 2.12000e-01

$8.55356 \mathrm{e}+018.55356 \mathrm{e}+018.55356 \mathrm{e}+001.00000 \mathrm{e}-092.12000 \mathrm{e}-01$

$8.55356 \mathrm{e}+018.55356 \mathrm{e}+018.55356 \mathrm{e}+001.00000 \mathrm{e}-092.12000 \mathrm{e}-01$ $1.00000 \mathrm{e}-02$ 1.00000e-02 1.00000e-03 1.00000e-09 1.00000e-01

$1.00000 \mathrm{e}+001.00000 \mathrm{e}+001.00000 \mathrm{e}-011.00000 \mathrm{e}-091.00000 \mathrm{e}-01$ Element: 7445 \# of layers: 6

$\mathrm{Kx} \mathrm{Ky} \mathrm{Kz}$ Ss Por

8.55356e+01 8.55356e+01 8.55356e+00 1.00000e-09 2.12000e-01

$8.55356 \mathrm{e}+018.55356 \mathrm{e}+018.55356 \mathrm{e}+001.00000 \mathrm{e}-092.12000 \mathrm{e}-01$

$8.55356 \mathrm{e}+018.55356 \mathrm{e}+018.55356 \mathrm{e}+001.00000 \mathrm{e}-092.12000 \mathrm{e}-01$

$8.55356 \mathrm{e}+018.55356 \mathrm{e}+018.55356 \mathrm{e}+001.00000 \mathrm{e}-092.12000 \mathrm{e}-01$ $1.00000 \mathrm{e}-02$ 1.00000e-02 1.00000e-03 1.00000e-09 1.00000e-01 $1.00000 \mathrm{e}+001.00000 \mathrm{e}+001.00000 \mathrm{e}-011.00000 \mathrm{e}-091.00000 \mathrm{e}-01$ Element: 7446 \# of layers: 6

$\mathrm{Kx} \mathrm{Ky} \mathrm{Kz}$ Ss Por

8.55356e+01 8.55356e+01 8.55356e+00 1.00000e-09 2.12000e-01 $8.55356 \mathrm{e}+018.55356 \mathrm{e}+018.55356 \mathrm{e}+001.00000 \mathrm{e}-092.12000 \mathrm{e}-01$ $8.55356 \mathrm{e}+018.55356 \mathrm{e}+018.55356 \mathrm{e}+001.00000 \mathrm{e}-092.12000 \mathrm{e}-01$ $8.55356 \mathrm{e}+018.55356 \mathrm{e}+018.55356 \mathrm{e}+001.00000 \mathrm{e}-092.12000 \mathrm{e}-01$ 1.00000e-02 1.00000e-02 1.00000e-03 1.00000e-09 1.00000e-01 $1.00000 \mathrm{e}+001.00000 \mathrm{e}+001.00000 \mathrm{e}-011.00000 \mathrm{e}-091.00000 \mathrm{e}-01$ Element: 7447 \# of layers: 5

$\mathrm{Kx} \mathrm{Ky} \mathrm{Kz}$ Ss Por

8.55356e+01 8.55356e+01 8.55356e+00 1.00000e-09 2.12000e-01 $8.55356 \mathrm{e}+018.55356 \mathrm{e}+018.55356 \mathrm{e}+001.00000 \mathrm{e}-092.12000 \mathrm{e}-01$ $8.55356 \mathrm{e}+018.55356 \mathrm{e}+018.55356 \mathrm{e}+00$ 1.00000e-09 2.12000e-01 
$1.00000 \mathrm{e}-02$ 1.00000e-02 1.00000e-03 1.00000e-09 1.00000e-01 $1.00000 \mathrm{e}+001.00000 \mathrm{e}+001.00000 \mathrm{e}-01$ 1.00000e-09 1.00000e-01 Element: 7448 \# of layers: 5

Kx Ky Kz Ss Por

$1.45385 \mathrm{e}+02$ 1.45385e+02 1.45385e+01 1.00000e-09 2.12000e-01 $1.45385 \mathrm{e}+02$ 1.45385e+02 1.45385e+01 1.00000e-09 2.12000e-01 $1.45385 \mathrm{e}+021.45385 \mathrm{e}+02$ 1.45385e+01 1.00000e-09 2.12000e-01 $1.00000 \mathrm{e}-021.00000 \mathrm{e}-02$ 1.00000e-03 1.00000e-09 1.00000e-01 $1.00000 \mathrm{e}+001.00000 \mathrm{e}+001.00000 \mathrm{e}-011.00000 \mathrm{e}-091.00000 \mathrm{e}-01$ Element: 7449 \# of layers: 5

$\mathrm{Kx} \mathrm{Ky} \mathrm{Kz}$ Ss Por

$1.45385 \mathrm{e}+02$ 1.45385e+02 1.45385e+01 1.00000e-09 2.12000e-01 $1.45385 \mathrm{e}+02$ 1.45385e+02 1.45385e+01 1.00000e-09 2.12000e-01 $1.45385 \mathrm{e}+02$ 1.45385e+02 1.45385e+01 1.00000e-09 2.12000e-01 $1.00000 \mathrm{e}-02$ 1.00000e-02 1.00000e-03 1.00000e-09 1.00000e-01 $1.00000 \mathrm{e}+001.00000 \mathrm{e}+001.00000 \mathrm{e}-011.00000 \mathrm{e}-091.00000 \mathrm{e}-01$ Element: 7450 \# of layers: 5

$\mathrm{Kx} \mathrm{Ky} \mathrm{Kz}$ Ss Por

$1.45385 \mathrm{e}+02$ 1.45385e+02 1.45385e+01 1.00000e-09 2.12000e-01 $1.45385 \mathrm{e}+02$ 1.45385e+02 1.45385e+01 1.00000e-09 2.12000e-01 $1.45385 \mathrm{e}+02$ 1.45385e+02 $1.45385 \mathrm{e}+01$ 1.00000e-09 2.12000e-01 $1.00000 \mathrm{e}-02$ 1.00000e-02 1.00000e-03 1.00000e-09 1.00000e-01 $1.00000 \mathrm{e}+001.00000 \mathrm{e}+001.00000 \mathrm{e}-01$ 1.00000e-09 1.00000e-01 Element: 7451 \# of layers: 5

Kx Ky Kz Ss Por

$1.45385 \mathrm{e}+02$ 1.45385e+02 1.45385e+01 1.00000e-09 2.12000e-01 $1.45385 \mathrm{e}+021.45385 \mathrm{e}+02$ 1.45385e+01 1.00000e-09 2.12000e-01 $1.45385 \mathrm{e}+021.45385 \mathrm{e}+02 \quad 1.45385 \mathrm{e}+01$ 1.00000e-09 2.12000e-01 $1.00000 \mathrm{e}-02$ 1.00000e-02 1.00000e-03 1.00000e-09 1.00000e-01 $1.00000 \mathrm{e}+001.00000 \mathrm{e}+001.00000 \mathrm{e}-011.00000 \mathrm{e}-091.00000 \mathrm{e}-01$ Element: 7452 \# of layers: 5

$\mathrm{Kx} \mathrm{Ky} \mathrm{Kz}$ Ss Por

$1.45385 \mathrm{e}+02$ 1.45385e+02 1.45385e+01 1.00000e-09 2.12000e-01 $1.45385 \mathrm{e}+02$ 1.45385e+02 1.45385e+01 1.00000e-09 2.12000e-01 $1.45385 \mathrm{e}+02$ 1.45385e+02 1.45385e+01 1.00000e-09 2.12000e-01 1.00000e-02 1.00000e-02 1.00000e-03 1.00000e-09 1.00000e-01 $1.00000 \mathrm{e}+001.00000 \mathrm{e}+001.00000 \mathrm{e}-011.00000 \mathrm{e}-091.00000 \mathrm{e}-01$ Element: 7453 \# of layers: 5

$\mathrm{Kx} \mathrm{Ky} \mathrm{Kz}$ Ss Por

$1.45385 \mathrm{e}+02$ 1.45385e+02 1.45385e+01 1.00000e-09 2.12000e-01 $1.45385 \mathrm{e}+021.45385 \mathrm{e}+02$ 1.45385e+01 1.00000e-09 2.12000e-01 $1.45385 \mathrm{e}+021.45385 \mathrm{e}+02 \quad 1.45385 \mathrm{e}+01$ 1.00000e-09 2.12000e-01 $1.00000 \mathrm{e}-02$ 1.00000e-02 1.00000e-03 1.00000e-09 1.00000e-01 $1.00000 \mathrm{e}+001.00000 \mathrm{e}+001.00000 \mathrm{e}-01$ 1.00000e-09 1.00000e-01 Element: 7454 \# of layers: 5

Kx Ky Kz Ss Por 
$1.45385 \mathrm{e}+02$ 1.45385e+02 1.45385e+01 1.00000e-09 2.12000e-01 $1.45385 \mathrm{e}+02$ 1.45385e+02 1.45385e+01 1.00000e-09 2.12000e-01 $1.45385 \mathrm{e}+02$ 1.45385e+02 1.45385e+01 1.00000e-09 2.12000e-01 $1.00000 \mathrm{e}-02$ 1.00000e-02 1.00000e-03 1.00000e-09 1.00000e-01 $1.00000 \mathrm{e}+001.00000 \mathrm{e}+001.00000 \mathrm{e}-011.00000 \mathrm{e}-091.00000 \mathrm{e}-01$ Element: 7455 \# of layers: 5

$\mathrm{Kx} \mathrm{Ky} \mathrm{Kz}$ Ss Por

$1.45385 \mathrm{e}+02$ 1.45385e+02 1.45385e+01 1.00000e-09 2.12000e-01 $1.45385 \mathrm{e}+02$ 1.45385e+02 1.45385e+01 1.00000e-09 2.12000e-01 $1.45385 \mathrm{e}+021.45385 \mathrm{e}+02$ 1.45385e+01 1.00000e-09 2.12000e-01 $1.00000 \mathrm{e}-02$ 1.00000e-02 1.00000e-03 1.00000e-09 1.00000e-01 $1.00000 \mathrm{e}+001.00000 \mathrm{e}+001.00000 \mathrm{e}-011.00000 \mathrm{e}-091.00000 \mathrm{e}-01$ Element: 7456 \# of layers: 5

$\mathrm{Kx} \mathrm{Ky} \mathrm{Kz}$ Ss Por

$1.45385 \mathrm{e}+02$ 1.45385e+02 1.45385e+01 1.00000e-09 2.12000e-01 $1.45385 \mathrm{e}+021.45385 \mathrm{e}+021.45385 \mathrm{e}+01$ 1.00000e-09 2.12000e-01 $1.45385 \mathrm{e}+02$ 1.45385e+02 1.45385e+01 1.00000e-09 2.12000e-01 $1.00000 \mathrm{e}-02$ 1.00000e-02 1.00000e-03 1.00000e-09 1.00000e-01 $1.00000 \mathrm{e}+001.00000 \mathrm{e}+001.00000 \mathrm{e}-01$ 1.00000e-09 1.00000e-01 Element: 7457 \# of layers: 5

$\mathrm{Kx} \mathrm{Ky} \mathrm{Kz}$ Ss Por

$1.17486 \mathrm{e}+02$ 1.17486e+02 1.17486e+01 1.00000e-09 2.12000e-01 $1.17486 \mathrm{e}+02$ 1.17486e+02 1.17486e+01 1.00000e-09 2.12000e-01 $1.17486 \mathrm{e}+02$ 1.17486e+02 1.17486e+01 1.00000e-09 2.12000e-01 $1.00000 \mathrm{e}-02$ 1.00000e-02 1.00000e-03 1.00000e-09 1.00000e-01 $1.00000 \mathrm{e}+001.00000 \mathrm{e}+001.00000 \mathrm{e}-01$ 1.00000e-09 1.00000e-01 Element: 7458 \# of layers: 5

$\mathrm{Kx} \mathrm{Ky} \mathrm{Kz}$ Ss Por

$1.17486 \mathrm{e}+02$ 1.17486e+02 1.17486e+01 1.00000e-09 2.12000e-01 $1.17486 \mathrm{e}+02$ 1.17486e+02 1.17486e+01 1.00000e-09 2.12000e-01 $1.17486 \mathrm{e}+02 \quad 1.17486 \mathrm{e}+02 \quad 1.17486 \mathrm{e}+01$ 1.00000e-09 2.12000e-01 1.00000e-02 1.00000e-02 1.00000e-03 1.00000e-09 1.00000e-01 $1.00000 \mathrm{e}+001.00000 \mathrm{e}+001.00000 \mathrm{e}-011.00000 \mathrm{e}-091.00000 \mathrm{e}-01$ Element: 7459 \# of layers: 6

$\mathrm{Kx} \mathrm{Ky} \mathrm{Kz}$ Ss Por

$2.94041 \mathrm{e}+032.94041 \mathrm{e}+032.94041 \mathrm{e}+02$ 1.00000e-09 7.00000e-02 $1.17486 \mathrm{e}+021.17486 \mathrm{e}+021.17486 \mathrm{e}+01$ 1.00000e-09 2.12000e-01 $1.17486 \mathrm{e}+021.17486 \mathrm{e}+021.17486 \mathrm{e}+01$ 1.00000e-09 2.12000e-01 $1.17486 \mathrm{e}+021.17486 \mathrm{e}+02$ 1.17486e+01 1.00000e-09 2.12000e-01 $1.00000 \mathrm{e}-02$ 1.00000e-02 1.00000e-03 1.00000e-09 1.00000e-01 $1.00000 \mathrm{e}+001.00000 \mathrm{e}+001.00000 \mathrm{e}-011.00000 \mathrm{e}-091.00000 \mathrm{e}-01$ Element: 7460 \# of layers: 5

$\mathrm{Kx} \mathrm{Ky} \mathrm{Kz}$ Ss Por

1.17486e+02 1.17486e+02 1.17486e+01 1.00000e-09 2.12000e-01 $1.17486 \mathrm{e}+02$ 1.17486e+02 1.17486e+01 1.00000e-09 2.12000e-01 $1.17486 \mathrm{e}+021.17486 \mathrm{e}+021.17486 \mathrm{e}+01$ 1.00000e-09 2.12000e-01 
$1.00000 \mathrm{e}-02$ 1.00000e-02 1.00000e-03 1.00000e-09 1.00000e-01 $1.00000 \mathrm{e}+001.00000 \mathrm{e}+001.00000 \mathrm{e}-01$ 1.00000e-09 1.00000e-01 Element: 7461 \# of layers: 5

Kx Ky Kz Ss Por

1.17486e+02 1.17486e+02 1.17486e+01 1.00000e-09 2.12000e-01 $1.17486 \mathrm{e}+02$ 1.17486e+02 1.17486e+01 1.00000e-09 2.12000e-01 $1.17486 \mathrm{e}+02$ 1.17486e+02 1.17486e+01 1.00000e-09 2.12000e-01 $1.00000 \mathrm{e}-021.00000 \mathrm{e}-021.00000 \mathrm{e}-031.00000 \mathrm{e}-091.00000 \mathrm{e}-01$ $1.00000 \mathrm{e}+001.00000 \mathrm{e}+001.00000 \mathrm{e}-011.00000 \mathrm{e}-091.00000 \mathrm{e}-01$ Element: 7462 \# of layers: 5

$\mathrm{Kx} \mathrm{Ky} \mathrm{Kz}$ Ss Por

$1.17486 \mathrm{e}+02$ 1.17486e+02 1.17486e+01 1.00000e-09 2.12000e-01 $1.17486 \mathrm{e}+02$ 1.17486e+02 1.17486e+01 1.00000e-09 2.12000e-01 $1.17486 \mathrm{e}+02$ 1.17486e+02 1.17486e+01 1.00000e-09 2.12000e-01 1.00000e-02 1.00000e-02 1.00000e-03 1.00000e-09 1.00000e-01 $1.00000 \mathrm{e}+001.00000 \mathrm{e}+001.00000 \mathrm{e}-011.00000 \mathrm{e}-091.00000 \mathrm{e}-01$ Element: 7463 \# of layers: 5

$\mathrm{Kx} \mathrm{Ky} \mathrm{Kz}$ Ss Por

1.17486e+02 1.17486e+02 1.17486e+01 1.00000e-09 2.12000e-01

$1.17486 \mathrm{e}+02$ 1.17486e+02 1.17486e+01 1.00000e-09 2.12000e-01

$1.17486 \mathrm{e}+021.17486 \mathrm{e}+02 \quad 1.17486 \mathrm{e}+01$ 1.00000e-09 2.12000e-01 $1.00000 \mathrm{e}-02$ 1.00000e-02 1.00000e-03 1.00000e-09 1.00000e-01 $1.00000 \mathrm{e}+001.00000 \mathrm{e}+001.00000 \mathrm{e}-01$ 1.00000e-09 1.00000e-01 Element: 7464 \# of layers: 5

Kx Ky Kz Ss Por

$1.17486 \mathrm{e}+02$ 1.17486e+02 1.17486e+01 1.00000e-09 2.12000e-01 $1.17486 \mathrm{e}+02$ 1.17486e+02 1.17486e+01 1.00000e-09 2.12000e-01 $1.17486 \mathrm{e}+02$ 1.17486e+02 1.17486e+01 1.00000e-09 2.12000e-01 $1.00000 \mathrm{e}-02$ 1.00000e-02 1.00000e-03 1.00000e-09 1.00000e-01 $1.00000 \mathrm{e}+001.00000 \mathrm{e}+001.00000 \mathrm{e}-011.00000 \mathrm{e}-091.00000 \mathrm{e}-01$ Element: 7465 \# of layers: 5

$\mathrm{Kx} \mathrm{Ky} \mathrm{Kz}$ Ss Por

$1.17486 \mathrm{e}+02$ 1.17486e+02 1.17486e+01 1.00000e-09 2.12000e-01 $1.17486 \mathrm{e}+02 \quad 1.17486 \mathrm{e}+02 \quad 1.17486 \mathrm{e}+01$ 1.00000e-09 2.12000e-01 $1.17486 \mathrm{e}+02$ 1.17486e+02 1.17486e+01 1.00000e-09 2.12000e-01 1.00000e-02 1.00000e-02 1.00000e-03 1.00000e-09 1.00000e-01 $1.00000 \mathrm{e}+001.00000 \mathrm{e}+001.00000 \mathrm{e}-011.00000 \mathrm{e}-091.00000 \mathrm{e}-01$ Element: 7466 \# of layers: 5

$\mathrm{Kx} \mathrm{Ky} \mathrm{Kz}$ Ss Por

6.65866e+02 6.65866e+02 6.65866e+01 1.00000e-09 7.00000e-02 $2.66068 \mathrm{e}+012.66068 \mathrm{e}+012.66068 \mathrm{e}+001.00000 \mathrm{e}-092.12000 \mathrm{e}-01$ $2.66068 \mathrm{e}+012.66068 \mathrm{e}+012.66068 \mathrm{e}+00$ 1.00000e-09 2.12000e-01 $1.00000 \mathrm{e}-02$ 1.00000e-02 1.00000e-03 1.00000e-09 1.00000e-01 $1.00000 \mathrm{e}+001.00000 \mathrm{e}+001.00000 \mathrm{e}-01$ 1.00000e-09 1.00000e-01 Element: 7467 \# of layers: 5

Kx Ky Kz Ss Por 
6.65866e+02 6.65866e+02 6.65866e+01 1.00000e-09 7.00000e-02 $2.66068 \mathrm{e}+012.66068 \mathrm{e}+012.66068 \mathrm{e}+001.00000 \mathrm{e}-092.12000 \mathrm{e}-01$

$2.66068 \mathrm{e}+012.66068 \mathrm{e}+012.66068 \mathrm{e}+001.00000 \mathrm{e}-092.12000 \mathrm{e}-01$ $1.00000 \mathrm{e}-021.00000 \mathrm{e}-02 \quad 1.00000 \mathrm{e}-031.00000 \mathrm{e}-091.00000 \mathrm{e}-01$ $1.00000 \mathrm{e}+001.00000 \mathrm{e}+001.00000 \mathrm{e}-01$ 1.00000e-09 1.00000e-01 Element: 7468 \# of layers: 5

$\mathrm{Kx} \mathrm{Ky} \mathrm{Kz}$ Ss Por

6.65866e+02 6.65866e+02 6.65866e+01 1.00000e-09 7.00000e-02 $2.66068 \mathrm{e}+012.66068 \mathrm{e}+012.66068 \mathrm{e}+001.00000 \mathrm{e}-092.12000 \mathrm{e}-01$

$2.66068 \mathrm{e}+012.66068 \mathrm{e}+012.66068 \mathrm{e}+001.00000 \mathrm{e}-092.12000 \mathrm{e}-01$ $1.00000 \mathrm{e}-02$ 1.00000e-02 1.00000e-03 1.00000e-09 1.00000e-01

$1.00000 \mathrm{e}+001.00000 \mathrm{e}+001.00000 \mathrm{e}-011.00000 \mathrm{e}-091.00000 \mathrm{e}-01$

Element: 7469 \# of layers: 5

$\mathrm{Kx} \mathrm{Ky} \mathrm{Kz}$ Ss Por

6.65866e+02 6.65866e+02 6.65866e+01 1.00000e-09 7.00000e-02

$2.66068 \mathrm{e}+012.66068 \mathrm{e}+012.66068 \mathrm{e}+001.00000 \mathrm{e}-092.12000 \mathrm{e}-01$

$2.66068 \mathrm{e}+012.66068 \mathrm{e}+012.66068 \mathrm{e}+001.00000 \mathrm{e}-092.12000 \mathrm{e}-01$

$1.00000 \mathrm{e}-02$ 1.00000e-02 1.00000e-03 1.00000e-09 1.00000e-01

$1.00000 \mathrm{e}+001.00000 \mathrm{e}+001.00000 \mathrm{e}-01$ 1.00000e-09 1.00000e-01

Element: 7470 \# of layers: 6

$\mathrm{Kx} \mathrm{Ky} \mathrm{Kz}$ Ss Por

6.65866e+02 6.65866e+02 6.65866e+01 1.00000e-09 7.00000e-02

$6.65866 \mathrm{e}+026.65866 \mathrm{e}+02$ 6.65866e+01 1.00000e-09 7.00000e-02

$2.66068 \mathrm{e}+012.66068 \mathrm{e}+012.66068 \mathrm{e}+001.00000 \mathrm{e}-092.12000 \mathrm{e}-01$

$2.66068 \mathrm{e}+012.66068 \mathrm{e}+012.66068 \mathrm{e}+001.00000 \mathrm{e}-092.12000 \mathrm{e}-01$

$1.00000 \mathrm{e}-02$ 1.00000e-02 1.00000e-03 1.00000e-09 1.00000e-01

$1.00000 \mathrm{e}+001.00000 \mathrm{e}+001.00000 \mathrm{e}-011.00000 \mathrm{e}-091.00000 \mathrm{e}-01$

Element: 7471 \# of layers: 6

$\mathrm{Kx} \mathrm{Ky} \mathrm{Kz}$ Ss Por

6.65866e+02 6.65866e+02 6.65866e+01 1.00000e-09 7.00000e-02

$6.65866 \mathrm{e}+02$ 6.65866e $+026.65866 \mathrm{e}+01$ 1.00000e-09 7.00000e-02

$2.66068 \mathrm{e}+012.66068 \mathrm{e}+012.66068 \mathrm{e}+001.00000 \mathrm{e}-092.12000 \mathrm{e}-01$

$2.66068 \mathrm{e}+012.66068 \mathrm{e}+012.66068 \mathrm{e}+001.00000 \mathrm{e}-092.12000 \mathrm{e}-01$

$1.00000 \mathrm{e}-02$ 1.00000e-02 1.00000e-03 1.00000e-09 1.00000e-01

$1.00000 \mathrm{e}+001.00000 \mathrm{e}+001.00000 \mathrm{e}-011.00000 \mathrm{e}-091.00000 \mathrm{e}-01$

Element: 7472 \# of layers: 4

Kx Ky Kz Ss Por

$2.66068 \mathrm{e}+012.66068 \mathrm{e}+012.66068 \mathrm{e}+00$ 1.00000e-09 2.12000e-01

$2.66068 \mathrm{e}+012.66068 \mathrm{e}+012.66068 \mathrm{e}+001.00000 \mathrm{e}-092.12000 \mathrm{e}-01$

$1.00000 \mathrm{e}-02$ 1.00000e-02 1.00000e-03 1.00000e-09 1.00000e-01

$1.00000 \mathrm{e}+001.00000 \mathrm{e}+001.00000 \mathrm{e}-011.00000 \mathrm{e}-091.00000 \mathrm{e}-01$

Element: 7473 \# of layers: 5

$\mathrm{Kx} \mathrm{Ky} \mathrm{Kz}$ Ss Por

6.65866e+02 6.65866e+02 6.65866e+01 1.00000e-09 7.00000e-02

$2.66068 \mathrm{e}+012.66068 \mathrm{e}+012.66068 \mathrm{e}+001.00000 \mathrm{e}-092.12000 \mathrm{e}-01$

$2.66068 \mathrm{e}+012.66068 \mathrm{e}+012.66068 \mathrm{e}+001.00000 \mathrm{e}-092.12000 \mathrm{e}-01$ 
$1.00000 \mathrm{e}-02$ 1.00000e-02 1.00000e-03 1.00000e-09 1.00000e-01 $1.00000 \mathrm{e}+001.00000 \mathrm{e}+001.00000 \mathrm{e}-01$ 1.00000e-09 1.00000e-01 Element: 7474 \# of layers: 5

Kx Ky Kz Ss Por

6.65866e+02 6.65866e+02 6.65866e+01 1.00000e-09 7.00000e-02

$2.66068 \mathrm{e}+012.66068 \mathrm{e}+012.66068 \mathrm{e}+00$ 1.00000e-09 2.12000e-01

$2.66068 \mathrm{e}+012.66068 \mathrm{e}+012.66068 \mathrm{e}+00$ 1.00000e-09 2.12000e-01

$1.00000 \mathrm{e}-02$ 1.00000e-02 1.00000e-03 1.00000e-09 1.00000e-01

$1.00000 \mathrm{e}+001.00000 \mathrm{e}+001.00000 \mathrm{e}-011.00000 \mathrm{e}-091.00000 \mathrm{e}-01$

Element: 7475 \# of layers: 5

$\mathrm{Kx} \mathrm{Ky} \mathrm{Kz}$ Ss Por

3.11178e+02 3.11178e+02 3.11178e+01 1.00000e-09 7.00000e-02

$1.24338 \mathrm{e}+01$ 1.24338e+01 1.24338e+00 1.00000e-09 2.12000e-01

$1.24338 \mathrm{e}+01$ 1.24338e+01 1.24338e+00 1.00000e-09 2.12000e-01

$1.00000 \mathrm{e}-02$ 1.00000e-02 1.00000e-03 1.00000e-09 1.00000e-01

$1.00000 \mathrm{e}+001.00000 \mathrm{e}+001.00000 \mathrm{e}-011.00000 \mathrm{e}-091.00000 \mathrm{e}-01$

Element: 7476 \# of layers: 5

$\mathrm{Kx} \mathrm{Ky} \mathrm{Kz}$ Ss Por

3.11178e+02 3.11178e+02 3.11178e+01 1.00000e-09 7.00000e-02

$1.24338 \mathrm{e}+01$ 1.24338e+01 1.24338e+00 1.00000e-09 2.12000e-01

$1.24338 \mathrm{e}+01$ 1.24338e+01 1.24338e+00 1.00000e-09 2.12000e-01

$1.00000 \mathrm{e}-02$ 1.00000e-02 1.00000e-03 1.00000e-09 1.00000e-01

$1.00000 \mathrm{e}+001.00000 \mathrm{e}+001.00000 \mathrm{e}-011.00000 \mathrm{e}-091.00000 \mathrm{e}-01$

Element: 7477 \# of layers: 5

Kx Ky Kz Ss Por

3.11178e+02 3.11178e+02 3.11178e+01 1.00000e-09 7.00000e-02 $1.24338 \mathrm{e}+01$ 1.24338e+01 1.24338e+00 1.00000e-09 2.12000e-01

$1.24338 \mathrm{e}+01$ 1.24338e+01 1.24338e+00 1.00000e-09 2.12000e-01

$1.00000 \mathrm{e}-02$ 1.00000e-02 1.00000e-03 1.00000e-09 1.00000e-01

$1.00000 \mathrm{e}+001.00000 \mathrm{e}+001.00000 \mathrm{e}-011.00000 \mathrm{e}-091.00000 \mathrm{e}-01$

Element: 7478 \# of layers: 5

$\mathrm{Kx} \mathrm{Ky} \mathrm{Kz}$ Ss Por

3.11178e+02 3.11178e+02 3.11178e+01 1.00000e-09 7.00000e-02

$1.24338 \mathrm{e}+01$ 1.24338e+01 1.24338e+00 1.00000e-09 2.12000e-01

$1.24338 \mathrm{e}+011.24338 \mathrm{e}+01 \quad 1.24338 \mathrm{e}+001.00000 \mathrm{e}-092.12000 \mathrm{e}-01$

1.00000e-02 1.00000e-02 1.00000e-03 1.00000e-09 1.00000e-01

$1.00000 \mathrm{e}+001.00000 \mathrm{e}+001.00000 \mathrm{e}-011.00000 \mathrm{e}-091.00000 \mathrm{e}-01$

Element: 7479 \# of layers: 5

$\mathrm{Kx} \mathrm{Ky} \mathrm{Kz}$ Ss Por

3.11178e+02 3.11178e+02 3.11178e+01 1.00000e-09 7.00000e-02

$1.24338 \mathrm{e}+01$ 1.24338e+01 1.24338e+00 1.00000e-09 2.12000e-01

$1.24338 \mathrm{e}+01$ 1.24338e+01 1.24338e+00 1.00000e-09 2.12000e-01

$1.00000 \mathrm{e}-02$ 1.00000e-02 1.00000e-03 1.00000e-09 1.00000e-01

$1.00000 \mathrm{e}+001.00000 \mathrm{e}+001.00000 \mathrm{e}-01$ 1.00000e-09 1.00000e-01

Element: 7480 \# of layers: 5

Kx Ky Kz Ss Por 
$3.11178 \mathrm{e}+023.11178 \mathrm{e}+023.11178 \mathrm{e}+01$ 1.00000e-09 7.00000e-02 $1.24338 \mathrm{e}+011.24338 \mathrm{e}+011.24338 \mathrm{e}+001.00000 \mathrm{e}-092.12000 \mathrm{e}-01$ $1.24338 \mathrm{e}+011.24338 \mathrm{e}+011.24338 \mathrm{e}+00$ 1.00000e-09 2.12000e-01 $1.00000 \mathrm{e}-021.00000 \mathrm{e}-02$ 1.00000e-03 1.00000e-09 1.00000e-01 $1.00000 \mathrm{e}+001.00000 \mathrm{e}+001.00000 \mathrm{e}-011.00000 \mathrm{e}-091.00000 \mathrm{e}-01$ Element: 7481 \# of layers: 5

Kx Ky Kz Ss Por

3.11178e+02 3.11178e+02 3.11178e+01 1.00000e-09 7.00000e-02 $1.24338 \mathrm{e}+011.24338 \mathrm{e}+011.24338 \mathrm{e}+00$ 1.00000e-09 2.12000e-01 $1.24338 \mathrm{e}+011.24338 \mathrm{e}+011.24338 \mathrm{e}+001.00000 \mathrm{e}-092.12000 \mathrm{e}-01$ $1.00000 \mathrm{e}-021.00000 \mathrm{e}-02$ 1.00000e-03 1.00000e-09 1.00000e-01 $1.00000 \mathrm{e}+001.00000 \mathrm{e}+00$ 1.00000e-01 1.00000e-09 1.00000e-01 Element: 7482 \# of layers: 5

Kx Ky Kz Ss Por

3.11178e+02 3.11178e+02 3.11178e+01 1.00000e-09 7.00000e-02 $1.24338 \mathrm{e}+011.24338 \mathrm{e}+011.24338 \mathrm{e}+001.00000 \mathrm{e}-092.12000 \mathrm{e}-01$ $1.24338 \mathrm{e}+011.24338 \mathrm{e}+011.24338 \mathrm{e}+00$ 1.00000e-09 2.12000e-01 $1.00000 \mathrm{e}-02$ 1.00000e-02 1.00000e-03 1.00000e-09 1.00000e-01 $1.00000 \mathrm{e}+001.00000 \mathrm{e}+001.00000 \mathrm{e}-011.00000 \mathrm{e}-091.00000 \mathrm{e}-01$ Element: 7483 \# of layers: 5

Kx Ky Kz Ss Por

3.11178e+02 3.11178e+02 3.11178e+01 1.00000e-09 7.00000e-02 $1.24338 \mathrm{e}+011.24338 \mathrm{e}+011.24338 \mathrm{e}+001.00000 \mathrm{e}-092.12000 \mathrm{e}-01$ $1.24338 \mathrm{e}+011.24338 \mathrm{e}+011.24338 \mathrm{e}+00$ 1.00000e-09 2.12000e-01 $1.00000 \mathrm{e}-021.00000 \mathrm{e}-02$ 1.00000e-03 1.00000e-09 1.00000e-01 $1.00000 \mathrm{e}+001.00000 \mathrm{e}+001.00000 \mathrm{e}-011.00000 \mathrm{e}-091.00000 \mathrm{e}-01$ Element: 7484 \# of layers: 5

Kx Ky Kz Ss Por

$1.84507 \mathrm{e}+02$ 1.84507e+02 1.84507e+01 1.00000e-09 7.00000e-02 $7.37228 \mathrm{e}+007.37228 \mathrm{e}+00$ 7.37228e-01 1.00000e-09 2.12000e-01

$7.37228 \mathrm{e}+007.37228 \mathrm{e}+00$ 7.37228e-01 1.00000e-09 2.12000e-01 $1.00000 \mathrm{e}-021.00000 \mathrm{e}-02$ 1.00000e-03 1.00000e-09 1.00000e-01 $1.00000 \mathrm{e}+001.00000 \mathrm{e}+00$ 1.00000e-01 1.00000e-09 1.00000e-01 Element: 7485 \# of layers: 4

Kx Ky Kz Ss Por

$1.84507 \mathrm{e}+02$ 1.84507e+02 1.84507e+01 1.00000e-09 7.00000e-02 $7.37228 \mathrm{e}+00$ 7.37228e+00 7.37228e-01 1.00000e-09 2.12000e-01 $1.00000 \mathrm{e}-021.00000 \mathrm{e}-02$ 1.00000e-03 1.00000e-09 1.00000e-01 $1.00000 \mathrm{e}+001.00000 \mathrm{e}+001.00000 \mathrm{e}-011.00000 \mathrm{e}-091.00000 \mathrm{e}-01$ Element: 7486 \# of layers: 4

Kx Ky Kz Ss Por

$1.84507 \mathrm{e}+02$ 1.84507e+02 1.84507e+01 1.00000e-09 7.00000e-02 $7.37228 \mathrm{e}+00$ 7.37228e+00 7.37228e-01 1.00000e-09 2.12000e-01 $1.00000 \mathrm{e}-02$ 1.00000e-02 1.00000e-03 1.00000e-09 1.00000e-01 $1.00000 \mathrm{e}+001.00000 \mathrm{e}+001.00000 \mathrm{e}-011.00000 \mathrm{e}-091.00000 \mathrm{e}-01$ Element: 7487 \# of layers: 4 
$\mathrm{Kx} \mathrm{Ky} \mathrm{Kz}$ Ss Por

1.84507e+02 1.84507e+02 1.84507e+01 1.00000e-09 7.00000e-02

7.37228e+00 7.37228e+00 7.37228e-01 1.00000e-09 2.12000e-01

$1.00000 \mathrm{e}-02$ 1.00000e-02 1.00000e-03 1.00000e-09 1.00000e-01

$1.00000 \mathrm{e}+001.00000 \mathrm{e}+001.00000 \mathrm{e}-01$ 1.00000e-09 1.00000e-01

Element: 7488 \# of layers: 4

$\mathrm{Kx} \mathrm{Ky} \mathrm{Kz}$ Ss Por

1.84507e+02 1.84507e+02 1.84507e+01 1.00000e-09 7.00000e-02

7.37228e+00 7.37228e+00 7.37228e-01 1.00000e-09 2.12000e-01

$1.00000 \mathrm{e}-02$ 1.00000e-02 1.00000e-03 1.00000e-09 1.00000e-01

$1.00000 \mathrm{e}+001.00000 \mathrm{e}+001.00000 \mathrm{e}-011.00000 \mathrm{e}-091.00000 \mathrm{e}-01$

Element: 7489 \# of layers: 4

$\mathrm{Kx} \mathrm{Ky} \mathrm{Kz}$ Ss Por

1.84507e+02 1.84507e+02 1.84507e+01 1.00000e-09 7.00000e-02

7.37228e+00 7.37228e+00 7.37228e-01 1.00000e-09 2.12000e-01

$1.00000 \mathrm{e}-02$ 1.00000e-02 1.00000e-03 1.00000e-09 1.00000e-01

$1.00000 \mathrm{e}+001.00000 \mathrm{e}+001.00000 \mathrm{e}-011.00000 \mathrm{e}-09$ 1.00000e-01

Element: 7490 \# of layers: 5

$\mathrm{Kx} \mathrm{Ky} \mathrm{Kz}$ Ss Por

1.84507e+02 1.84507e+02 1.84507e+01 1.00000e-09 7.00000e-02

7.37228e+00 7.37228e+00 7.37228e-01 1.00000e-09 2.12000e-01

7.37228e+00 7.37228e+00 7.37228e-01 1.00000e-09 2.12000e-01

$1.00000 \mathrm{e}-02$ 1.00000e-02 1.00000e-03 1.00000e-09 1.00000e-01

$1.00000 \mathrm{e}+001.00000 \mathrm{e}+001.00000 \mathrm{e}-011.00000 \mathrm{e}-091.00000 \mathrm{e}-01$

Element: 7491 \# of layers: 5

$\mathrm{Kx} \mathrm{Ky} \mathrm{Kz}$ Ss Por

1.84507e+02 1.84507e+02 1.84507e+01 1.00000e-09 7.00000e-02

7.37228e+00 7.37228e+00 7.37228e-01 1.00000e-09 2.12000e-01

$7.37228 \mathrm{e}+00$ 7.37228e+00 7.37228e-01 1.00000e-09 2.12000e-01

$1.00000 \mathrm{e}-02$ 1.00000e-02 1.00000e-03 1.00000e-09 1.00000e-01

$1.00000 \mathrm{e}+001.00000 \mathrm{e}+001.00000 \mathrm{e}-011.00000 \mathrm{e}-091.00000 \mathrm{e}-01$

Element: 7492 \# of layers: 4

Kx Ky Kz Ss Por

1.84507e+02 1.84507e+02 1.84507e+01 1.00000e-09 7.00000e-02

$7.37228 \mathrm{e}+00$ 7.37228e+00 7.37228e-01 1.00000e-09 2.12000e-01

$1.00000 \mathrm{e}-02$ 1.00000e-02 1.00000e-03 1.00000e-09 1.00000e-01

$1.00000 \mathrm{e}+001.00000 \mathrm{e}+001.00000 \mathrm{e}-011.00000 \mathrm{e}-091.00000 \mathrm{e}-01$

Element: 7493 \# of layers: 4

$\mathrm{Kx} \mathrm{Ky} \mathrm{Kz}$ Ss Por

$1.19761 \mathrm{e}+02$ 1.19761e+02 1.19761e+01 1.00000e-09 7.00000e-02

4.78518e+00 4.78518e+00 4.78518e-01 1.00000e-09 2.12000e-01

$1.00000 \mathrm{e}-021.00000 \mathrm{e}-021.00000 \mathrm{e}-031.00000 \mathrm{e}-091.00000 \mathrm{e}-01$

$1.00000 \mathrm{e}+001.00000 \mathrm{e}+001.00000 \mathrm{e}-01$ 1.00000e-09 1.00000e-01

Element: 7494 \# of layers: 4

Kx Ky Kz Ss Por

1.19761e+02 1.19761e+02 1.19761e+01 1.00000e-09 7.00000e-02 
4.78518e+00 4.78518e+00 4.78518e-01 1.00000e-09 2.12000e-01 $1.00000 \mathrm{e}-02$ 1.00000e-02 1.00000e-03 1.00000e-09 1.00000e-01 $1.00000 \mathrm{e}+001.00000 \mathrm{e}+001.00000 \mathrm{e}-011.00000 \mathrm{e}-091.00000 \mathrm{e}-01$

Element: 7495 \# of layers: 4

$\mathrm{Kx} \mathrm{Ky} \mathrm{Kz}$ Ss Por

$1.19761 \mathrm{e}+02$ 1.19761e+02 1.19761e+01 1.00000e-09 7.00000e-02

$4.78518 \mathrm{e}+004.78518 \mathrm{e}+00$ 4.78518e-01 1.00000e-09 2.12000e-01

$1.00000 \mathrm{e}-02$ 1.00000e-02 1.00000e-03 1.00000e-09 1.00000e-01

$1.00000 \mathrm{e}+001.00000 \mathrm{e}+001.00000 \mathrm{e}-011.00000 \mathrm{e}-091.00000 \mathrm{e}-01$

Element: 7496 \# of layers: 5

$\mathrm{Kx} \mathrm{Ky} \mathrm{Kz}$ Ss Por

$1.19761 \mathrm{e}+02$ 1.19761e+02 1.19761e+01 1.00000e-09 7.00000e-02

$1.19761 \mathrm{e}+02$ 1.19761e+02 1.19761e+01 1.00000e-09 7.00000e-02

$4.78518 \mathrm{e}+00$ 4.78518e+00 4.78518e-01 1.00000e-09 2.12000e-01

$1.00000 \mathrm{e}-02$ 1.00000e-02 1.00000e-03 1.00000e-09 1.00000e-01

$1.00000 \mathrm{e}+001.00000 \mathrm{e}+001.00000 \mathrm{e}-011.00000 \mathrm{e}-091.00000 \mathrm{e}-01$

Element: 7497 \# of layers: 5

$\mathrm{Kx} \mathrm{Ky} \mathrm{Kz}$ Ss Por

1.19761e+02 1.19761e+02 1.19761e+01 1.00000e-09 7.00000e-02

$1.19761 \mathrm{e}+021.19761 \mathrm{e}+02$ 1.19761e+01 1.00000e-09 7.00000e-02

$4.78518 \mathrm{e}+004.78518 \mathrm{e}+00$ 4.78518e-01 1.00000e-09 2.12000e-01

$1.00000 \mathrm{e}-021.00000 \mathrm{e}-021.00000 \mathrm{e}-031.00000 \mathrm{e}-091.00000 \mathrm{e}-01$

$1.00000 \mathrm{e}+001.00000 \mathrm{e}+001.00000 \mathrm{e}-01$ 1.00000e-09 1.00000e-01

Element: 7498 \# of layers: 5

Kx Ky Kz Ss Por

$1.19761 \mathrm{e}+02$ 1.19761e+02 1.19761e+01 1.00000e-09 7.00000e-02

$1.19761 \mathrm{e}+021.19761 \mathrm{e}+02$ 1.19761e+01 1.00000e-09 7.00000e-02

$4.78518 \mathrm{e}+00$ 4.78518e+00 4.78518e-01 1.00000e-09 2.12000e-01

$1.00000 \mathrm{e}-02$ 1.00000e-02 1.00000e-03 1.00000e-09 1.00000e-01

$1.00000 \mathrm{e}+001.00000 \mathrm{e}+001.00000 \mathrm{e}-011.00000 \mathrm{e}-091.00000 \mathrm{e}-01$

Element: 7499 \# of layers: 4

Kx Ky Kz Ss Por

1.19761e+02 1.19761e+02 1.19761e+01 1.00000e-09 7.00000e-02

4.78518e+00 4.78518e+00 4.78518e-01 1.00000e-09 2.12000e-01

$1.00000 \mathrm{e}-02$ 1.00000e-02 1.00000e-03 1.00000e-09 1.00000e-01

$1.00000 \mathrm{e}+001.00000 \mathrm{e}+001.00000 \mathrm{e}-011.00000 \mathrm{e}-091.00000 \mathrm{e}-01$

Element: 7500 \# of layers: 4

Kx Ky Kz Ss Por

1.19761e+02 1.19761e+02 1.19761e+01 1.00000e-09 7.00000e-02

4.78518e+00 4.78518e+00 4.78518e-01 1.00000e-09 2.12000e-01

$1.00000 \mathrm{e}-02$ 1.00000e-02 1.00000e-03 1.00000e-09 1.00000e-01

$1.00000 \mathrm{e}+001.00000 \mathrm{e}+001.00000 \mathrm{e}-011.00000 \mathrm{e}-091.00000 \mathrm{e}-01$

Element: 7501 \# of layers: 4

$\mathrm{Kx} \mathrm{Ky} \mathrm{Kz}$ Ss Por

1.19761e+02 1.19761e+02 1.19761e+01 1.00000e-09 7.00000e-02

$4.78518 \mathrm{e}+00$ 4.78518e+00 4.78518e-01 1.00000e-09 2.12000e-01 
$1.00000 \mathrm{e}-02$ 1.00000e-02 1.00000e-03 1.00000e-09 1.00000e-01 $1.00000 \mathrm{e}+001.00000 \mathrm{e}+001.00000 \mathrm{e}-01$ 1.00000e-09 1.00000e-01 Element: 7502 \# of layers: 5

$\mathrm{Kx} \mathrm{Ky} \mathrm{Kz}$ Ss Por

7.78275e+01 7.78275e+01 7.78275e+00 1.00000e-09 7.00000e-02

7.78275e+01 7.78275e+01 7.78275e+00 1.00000e-09 7.00000e-02

3.10979e+00 3.10979e+00 3.10979e-01 1.00000e-09 2.12000e-01

1.00000e-02 1.00000e-02 1.00000e-03 1.00000e-09 1.00000e-01

$1.00000 \mathrm{e}+001.00000 \mathrm{e}+001.00000 \mathrm{e}-011.00000 \mathrm{e}-091.00000 \mathrm{e}-01$

Element: 7503 \# of layers: 5

Kx Ky Kz Ss Por

7.78275e+01 7.78275e+01 7.78275e+00 1.00000e-09 7.00000e-02

$7.78275 \mathrm{e}+01$ 7.78275e+01 7.78275e+00 1.00000e-09 7.00000e-02

3.10979e+00 3.10979e+00 3.10979e-01 1.00000e-09 2.12000e-01

$1.00000 \mathrm{e}-02$ 1.00000e-02 1.00000e-03 1.00000e-09 1.00000e-01

$1.00000 \mathrm{e}+001.00000 \mathrm{e}+001.00000 \mathrm{e}-011.00000 \mathrm{e}-091.00000 \mathrm{e}-01$

Element: 7504 \# of layers: 5

$\mathrm{Kx} \mathrm{Ky} \mathrm{Kz}$ Ss Por

7.78275e+01 7.78275e+01 7.78275e+00 1.00000e-09 7.00000e-02

7.78275e+01 7.78275e+01 7.78275e+00 1.00000e-09 7.00000e-02

$3.10979 \mathrm{e}+003.10979 \mathrm{e}+00$ 3.10979e-01 1.00000e-09 2.12000e-01

$1.00000 \mathrm{e}-02$ 1.00000e-02 1.00000e-03 1.00000e-09 1.00000e-01

$1.00000 \mathrm{e}+001.00000 \mathrm{e}+001.00000 \mathrm{e}-01$ 1.00000e-09 1.00000e-01

Element: 7505 \# of layers: 4

Kx Ky Kz Ss Por

7.78275e+01 7.78275e+01 7.78275e+00 1.00000e-09 7.00000e-02

$7.78275 \mathrm{e}+01$ 7.78275e+01 7.78275e+00 1.00000e-09 7.00000e-02

$1.00000 \mathrm{e}-02$ 1.00000e-02 1.00000e-03 1.00000e-09 1.00000e-01

$1.00000 \mathrm{e}+001.00000 \mathrm{e}+001.00000 \mathrm{e}-011.00000 \mathrm{e}-091.00000 \mathrm{e}-01$

Element: 7506 \# of layers: 4

$\mathrm{Kx} \mathrm{Ky} \mathrm{Kz}$ Ss Por

7.78275e+01 7.78275e+01 7.78275e+00 1.00000e-09 7.00000e-02

$7.78275 \mathrm{e}+017.78275 \mathrm{e}+017.78275 \mathrm{e}+001.00000 \mathrm{e}-09$ 7.00000e-02

$1.00000 \mathrm{e}-021.00000 \mathrm{e}-021.00000 \mathrm{e}-031.00000 \mathrm{e}-091.00000 \mathrm{e}-01$

$1.00000 \mathrm{e}+001.00000 \mathrm{e}+001.00000 \mathrm{e}-011.00000 \mathrm{e}-091.00000 \mathrm{e}-01$

Element: 7507 \# of layers: 5

Kx Ky Kz Ss Por

7.78275e+01 7.78275e+01 7.78275e+00 1.00000e-09 7.00000e-02

7.78275e+01 7.78275e+01 7.78275e+00 1.00000e-09 7.00000e-02

3.10979e+00 3.10979e+00 3.10979e-01 1.00000e-09 2.12000e-01

$1.00000 \mathrm{e}-02$ 1.00000e-02 1.00000e-03 1.00000e-09 1.00000e-01

$1.00000 \mathrm{e}+001.00000 \mathrm{e}+001.00000 \mathrm{e}-011.00000 \mathrm{e}-091.00000 \mathrm{e}-01$

Element: 7508 \# of layers: 5

$\mathrm{Kx} \mathrm{Ky} \mathrm{Kz}$ Ss Por

7.78275e+01 7.78275e+01 7.78275e+00 1.00000e-09 7.00000e-02

$7.78275 \mathrm{e}+017.78275 \mathrm{e}+017.78275 \mathrm{e}+001.00000 \mathrm{e}-09$ 7.00000e-02 
$3.10979 \mathrm{e}+003.10979 \mathrm{e}+00$ 3.10979e-01 1.00000e-09 2.12000e-01 $1.00000 \mathrm{e}-02$ 1.00000e-02 1.00000e-03 1.00000e-09 1.00000e-01 $1.00000 \mathrm{e}+001.00000 \mathrm{e}+001.00000 \mathrm{e}-011.00000 \mathrm{e}-091.00000 \mathrm{e}-01$

Element: 7509 \# of layers: 5

Kx Ky Kz Ss Por

$7.78275 \mathrm{e}+01$ 7.78275e+01 7.78275e+00 1.00000e-09 7.00000e-02

$7.78275 \mathrm{e}+017.78275 \mathrm{e}+017.78275 \mathrm{e}+001.00000 \mathrm{e}-097.00000 \mathrm{e}-02$

$3.10979 \mathrm{e}+003.10979 \mathrm{e}+003.10979 \mathrm{e}-01$ 1.00000e-09 2.12000e-01

$1.00000 \mathrm{e}-02$ 1.00000e-02 1.00000e-03 1.00000e-09 1.00000e-01

$1.00000 \mathrm{e}+001.00000 \mathrm{e}+001.00000 \mathrm{e}-011.00000 \mathrm{e}-091.00000 \mathrm{e}-01$

Element: 7510 \# of layers: 5

Kx Ky Kz Ss Por

7.78275e+01 7.78275e+01 7.78275e+00 1.00000e-09 7.00000e-02

$7.78275 \mathrm{e}+017.78275 \mathrm{e}+01$ 7.78275e+00 1.00000e-09 7.00000e-02

$3.10979 \mathrm{e}+003.10979 \mathrm{e}+003.10979 \mathrm{e}-01$ 1.00000e-09 2.12000e-01

$1.00000 \mathrm{e}-02$ 1.00000e-02 1.00000e-03 1.00000e-09 1.00000e-01

$1.00000 \mathrm{e}+001.00000 \mathrm{e}+001.00000 \mathrm{e}-011.00000 \mathrm{e}-091.00000 \mathrm{e}-01$

Element: 7511 \# of layers: 5

Kx Ky Kz Ss Por

$6.11274 \mathrm{e}+016.11274 \mathrm{e}+016.11274 \mathrm{e}+001.00000 \mathrm{e}-09$ 7.00000e-02

$6.11274 \mathrm{e}+016.11274 \mathrm{e}+016.11274 \mathrm{e}+001.00000 \mathrm{e}-09$ 7.00000e-02

$3.10979 \mathrm{e}+003.10979 \mathrm{e}+003.10979 \mathrm{e}-01$ 1.00000e-09 2.12000e-01

$1.00000 \mathrm{e}-02$ 1.00000e-02 1.00000e-03 1.00000e-09 1.00000e-01

$1.00000 \mathrm{e}+001.00000 \mathrm{e}+001.00000 \mathrm{e}-011.00000 \mathrm{e}-091.00000 \mathrm{e}-01$

Element: 7512 \# of layers: 4

Kx Ky Kz Ss Por

$6.11274 \mathrm{e}+016.11274 \mathrm{e}+016.11274 \mathrm{e}+00$ 1.00000e-09 7.00000e-02

$6.11274 \mathrm{e}+016.11274 \mathrm{e}+016.11274 \mathrm{e}+001.00000 \mathrm{e}-09$ 7.00000e-02

$1.00000 \mathrm{e}-02$ 1.00000e-02 $1.00000 \mathrm{e}-031.00000 \mathrm{e}-09$ 1.00000e-01

$1.00000 \mathrm{e}+001.00000 \mathrm{e}+001.00000 \mathrm{e}-011.00000 \mathrm{e}-091.00000 \mathrm{e}-01$

Element: 7513 \# of layers: 4

Kx Ky Kz Ss Por

$6.11274 \mathrm{e}+016.11274 \mathrm{e}+016.11274 \mathrm{e}+001.00000 \mathrm{e}-09$ 7.00000e-02

$6.11274 \mathrm{e}+016.11274 \mathrm{e}+016.11274 \mathrm{e}+001.00000 \mathrm{e}-09$ 7.00000e-02 $1.00000 \mathrm{e}-02$ 1.00000e-02 1.00000e-03 1.00000e-09 1.00000e-01

$1.00000 \mathrm{e}+001.00000 \mathrm{e}+001.00000 \mathrm{e}-011.00000 \mathrm{e}-091.00000 \mathrm{e}-01$

Element: 7514 \# of layers: 4

Kx Ky Kz Ss Por

$6.11274 \mathrm{e}+016.11274 \mathrm{e}+016.11274 \mathrm{e}+00$ 1.00000e-09 7.00000e-02

$6.11274 \mathrm{e}+016.11274 \mathrm{e}+016.11274 \mathrm{e}+001.00000 \mathrm{e}-09$ 7.00000e-02

$1.00000 \mathrm{e}-021.00000 \mathrm{e}-02$ 1.00000e-03 1.00000e-09 1.00000e-01

$1.00000 \mathrm{e}+001.00000 \mathrm{e}+001.00000 \mathrm{e}-011.00000 \mathrm{e}-091.00000 \mathrm{e}-01$

Element: 7515 \# of layers: 4

Kx Ky Kz Ss Por

$6.11274 \mathrm{e}+016.11274 \mathrm{e}+016.11274 \mathrm{e}+001.00000 \mathrm{e}-09$ 7.00000e-02

$6.11274 \mathrm{e}+016.11274 \mathrm{e}+016.11274 \mathrm{e}+001.00000 \mathrm{e}-09$ 7.00000e-02 
$1.00000 \mathrm{e}-02$ 1.00000e-02 1.00000e-03 1.00000e-09 1.00000e-01 $1.00000 \mathrm{e}+001.00000 \mathrm{e}+001.00000 \mathrm{e}-01$ 1.00000e-09 1.00000e-01

Element: 7516 \# of layers: 4

Kx Ky Kz Ss Por

6.11274e+01 6.11274e+01 6.11274e+00 1.00000e-09 7.00000e-02

$6.11274 \mathrm{e}+016.11274 \mathrm{e}+016.11274 \mathrm{e}+001.00000 \mathrm{e}-097.00000 \mathrm{e}-02$

$1.00000 \mathrm{e}-02$ 1.00000e-02 1.00000e-03 1.00000e-09 1.00000e-01

$1.00000 \mathrm{e}+001.00000 \mathrm{e}+001.00000 \mathrm{e}-01$ 1.00000e-09 1.00000e-01

Element: 7517 \# of layers: 4

$\mathrm{Kx} \mathrm{Ky} \mathrm{Kz}$ Ss Por

6.11274e+01 6.11274e+01 6.11274e+00 1.00000e-09 7.00000e-02

$6.11274 \mathrm{e}+016.11274 \mathrm{e}+016.11274 \mathrm{e}+001.00000 \mathrm{e}-09$ 7.00000e-02

$1.00000 \mathrm{e}-02$ 1.00000e-02 1.00000e-03 1.00000e-09 1.00000e-01

$1.00000 \mathrm{e}+001.00000 \mathrm{e}+001.00000 \mathrm{e}-01$ 1.00000e-09 1.00000e-01

Element: 7518 \# of layers: 4

Kx Ky Kz Ss Por

6.11274e+01 6.11274e+01 6.11274e+00 1.00000e-09 7.00000e-02

$6.11274 \mathrm{e}+016.11274 \mathrm{e}+016.11274 \mathrm{e}+001.00000 \mathrm{e}-09$ 7.00000e-02

$1.00000 \mathrm{e}-02$ 1.00000e-02 1.00000e-03 1.00000e-09 1.00000e-01

$1.00000 \mathrm{e}+001.00000 \mathrm{e}+001.00000 \mathrm{e}-011.00000 \mathrm{e}-091.00000 \mathrm{e}-01$

Element: 7519 \# of layers: 4

$\mathrm{Kx} \mathrm{Ky} \mathrm{Kz}$ Ss Por

6.11274e+01 6.11274e+01 6.11274e+00 1.00000e-09 7.00000e-02

$6.11274 \mathrm{e}+016.11274 \mathrm{e}+016.11274 \mathrm{e}+001.00000 \mathrm{e}-09$ 7.00000e-02

$1.00000 \mathrm{e}-021.00000 \mathrm{e}-02$ 1.00000e-03 1.00000e-09 1.00000e-01

$1.00000 \mathrm{e}+001.00000 \mathrm{e}+001.00000 \mathrm{e}-01$ 1.00000e-09 1.00000e-01

Element: 7520 \# of layers: 3

$\mathrm{Kx} \mathrm{Ky} \mathrm{Kz}$ Ss Por

6.86130e+01 6.86130e+01 6.86130e+00 1.00000e-09 7.00000e-02

$1.00000 \mathrm{e}-02$ 1.00000e-02 1.00000e-03 1.00000e-09 1.00000e-01

$1.00000 \mathrm{e}+001.00000 \mathrm{e}+00$ 1.00000e-01 1.00000e-09 1.00000e-01

Element: 7521 \# of layers: 3

Kx Ky Kz Ss Por

$6.86130 \mathrm{e}+016.86130 \mathrm{e}+016.86130 \mathrm{e}+001.00000 \mathrm{e}-09$ 7.00000e-02 $1.00000 \mathrm{e}-02$ 1.00000e-02 1.00000e-03 1.00000e-09 1.00000e-01

$1.00000 \mathrm{e}+001.00000 \mathrm{e}+001.00000 \mathrm{e}-011.00000 \mathrm{e}-091.00000 \mathrm{e}-01$

Element: 7522 \# of layers: 3

Kx Ky Kz Ss Por

6.86130e+01 6.86130e+01 6.86130e+00 1.00000e-09 7.00000e-02 $1.00000 \mathrm{e}-02$ 1.00000e-02 1.00000e-03 1.00000e-09 1.00000e-01

$1.00000 \mathrm{e}+001.00000 \mathrm{e}+001.00000 \mathrm{e}-011.00000 \mathrm{e}-091.00000 \mathrm{e}-01$

Element: 7523 \# of layers: 3

$\mathrm{Kx} \mathrm{Ky} \mathrm{Kz}$ Ss Por

6.86130e+01 6.86130e+01 6.86130e+00 1.00000e-09 7.00000e-02 $1.00000 \mathrm{e}-02$ 1.00000e-02 1.00000e-03 1.00000e-09 1.00000e-01

$1.00000 \mathrm{e}+001.00000 \mathrm{e}+001.00000 \mathrm{e}-011.00000 \mathrm{e}-091.00000 \mathrm{e}-01$ 
Element: 7524 \# of layers: 3

$\mathrm{Kx} \mathrm{Ky} \mathrm{Kz}$ Ss Por

6.86130e+01 6.86130e+01 6.86130e+00 1.00000e-09 7.00000e-02

$1.00000 \mathrm{e}-02$ 1.00000e-02 1.00000e-03 1.00000e-09 1.00000e-01

$1.00000 \mathrm{e}+001.00000 \mathrm{e}+001.00000 \mathrm{e}-01$ 1.00000e-09 1.00000e-01

Element: 7525 \# of layers: 3

$\mathrm{Kx} \mathrm{Ky} \mathrm{Kz}$ Ss Por

6.86130e+01 6.86130e+01 6.86130e+00 1.00000e-09 7.00000e-02

$1.00000 \mathrm{e}-02$ 1.00000e-02 1.00000e-03 1.00000e-09 1.00000e-01

$1.00000 \mathrm{e}+001.00000 \mathrm{e}+001.00000 \mathrm{e}-011.00000 \mathrm{e}-091.00000 \mathrm{e}-01$

Element: 7526 \# of layers: 4

Kx Ky Kz Ss Por

6.86130e+01 6.86130e+01 6.86130e+00 1.00000e-09 7.00000e-02

$6.86130 \mathrm{e}+016.86130 \mathrm{e}+016.86130 \mathrm{e}+001.00000 \mathrm{e}-09$ 7.00000e-02

$1.00000 \mathrm{e}-02$ 1.00000e-02 1.00000e-03 1.00000e-09 1.00000e-01

$1.00000 \mathrm{e}+001.00000 \mathrm{e}+001.00000 \mathrm{e}-011.00000 \mathrm{e}-091.00000 \mathrm{e}-01$

Element: 7527 \# of layers: 3

$\mathrm{Kx} \mathrm{Ky} \mathrm{Kz}$ Ss Por

6.86130e+01 6.86130e+01 6.86130e+00 1.00000e-09 7.00000e-02

$1.00000 \mathrm{e}-02$ 1.00000e-02 1.00000e-03 1.00000e-09 1.00000e-01

$1.00000 \mathrm{e}+001.00000 \mathrm{e}+001.00000 \mathrm{e}-011.00000 \mathrm{e}-091.00000 \mathrm{e}-01$

Element: 7528 \# of layers: 3

$\mathrm{Kx} \mathrm{Ky} \mathrm{Kz}$ Ss Por

6.86130e+01 6.86130e+01 6.86130e+00 1.00000e-09 7.00000e-02

$1.00000 \mathrm{e}-021.00000 \mathrm{e}-02$ 1.00000e-03 1.00000e-09 1.00000e-01

$1.00000 \mathrm{e}+001.00000 \mathrm{e}+001.00000 \mathrm{e}-01$ 1.00000e-09 1.00000e-01

Element: 7529 \# of layers: 3

$\mathrm{Kx} \mathrm{Ky} \mathrm{Kz} \mathrm{Ss} \mathrm{Por}$

3.90331e+01 3.90331e+01 3.90331e+00 1.00000e-09 7.00000e-02

$1.00000 \mathrm{e}-02$ 1.00000e-02 1.00000e-03 1.00000e-09 1.00000e-01

$1.00000 \mathrm{e}+001.00000 \mathrm{e}+001.00000 \mathrm{e}-011.00000 \mathrm{e}-091.00000 \mathrm{e}-01$

Element: 7530 \# of layers: 3

Kx Ky Kz Ss Por

$3.90331 \mathrm{e}+013.90331 \mathrm{e}+013.90331 \mathrm{e}+001.00000 \mathrm{e}-09$ 7.00000e-02

$1.00000 \mathrm{e}-02$ 1.00000e-02 1.00000e-03 1.00000e-09 1.00000e-01

$1.00000 \mathrm{e}+001.00000 \mathrm{e}+001.00000 \mathrm{e}-011.00000 \mathrm{e}-091.00000 \mathrm{e}-01$

Element: 7531 \# of layers: 3

$\mathrm{Kx} \mathrm{Ky} \mathrm{Kz}$ Ss Por

3.90331e+01 3.90331e+01 3.90331e+00 1.00000e-09 7.00000e-02 $1.00000 \mathrm{e}-02$ 1.00000e-02 1.00000e-03 1.00000e-09 1.00000e-01

$1.00000 \mathrm{e}+001.00000 \mathrm{e}+001.00000 \mathrm{e}-011.00000 \mathrm{e}-091.00000 \mathrm{e}-01$

Element: 7532 \# of layers: 3

$\mathrm{Kx} \mathrm{Ky} \mathrm{Kz}$ Ss Por

3.90331e+01 3.90331e+01 3.90331e+00 1.00000e-09 7.00000e-02

$1.00000 \mathrm{e}-021.00000 \mathrm{e}-021.00000 \mathrm{e}-031.00000 \mathrm{e}-091.00000 \mathrm{e}-01$

$1.00000 \mathrm{e}+001.00000 \mathrm{e}+001.00000 \mathrm{e}-011.00000 \mathrm{e}-091.00000 \mathrm{e}-01$ 
Element: 7533 \# of layers: 3

$\mathrm{Kx} \mathrm{Ky} \mathrm{Kz}$ Ss Por

3.90331e+01 3.90331e+01 3.90331e+00 1.00000e-09 7.00000e-02

$1.00000 \mathrm{e}-02$ 1.00000e-02 1.00000e-03 1.00000e-09 1.00000e-01

$1.00000 \mathrm{e}+001.00000 \mathrm{e}+001.00000 \mathrm{e}-011.00000 \mathrm{e}-091.00000 \mathrm{e}-01$

Element: 7534 \# of layers: 3

$\mathrm{Kx} \mathrm{Ky} \mathrm{Kz}$ Ss Por

$3.90331 \mathrm{e}+013.90331 \mathrm{e}+013.90331 \mathrm{e}+001.00000 \mathrm{e}-09$ 7.00000e-02

$1.00000 \mathrm{e}-02$ 1.00000e-02 1.00000e-03 1.00000e-09 1.00000e-01

$1.00000 \mathrm{e}+001.00000 \mathrm{e}+001.00000 \mathrm{e}-01$ 1.00000e-09 1.00000e-01

Element: 7535 \# of layers: 3

Kx Ky Kz Ss Por

3.90331e+01 3.90331e+01 3.90331e+00 1.00000e-09 7.00000e-02

1.00000e-02 1.00000e-02 1.00000e-03 1.00000e-09 1.00000e-01

$1.00000 \mathrm{e}+001.00000 \mathrm{e}+001.00000 \mathrm{e}-011.00000 \mathrm{e}-091.00000 \mathrm{e}-01$

Element: 7536 \# of layers: 3

$\mathrm{Kx} \mathrm{Ky} \mathrm{Kz}$ Ss Por

3.90331e+01 3.90331e+01 3.90331e+00 1.00000e-09 7.00000e-02

$1.00000 \mathrm{e}-02$ 1.00000e-02 1.00000e-03 1.00000e-09 1.00000e-01

$1.00000 \mathrm{e}+001.00000 \mathrm{e}+001.00000 \mathrm{e}-01$ 1.00000e-09 1.00000e-01

Element: 7537 \# of layers: 3

$\mathrm{Kx} \mathrm{Ky} \mathrm{Kz}$ Ss Por

3.90331e+01 3.90331e+01 3.90331e+00 1.00000e-09 7.00000e-02

$1.00000 \mathrm{e}-02$ 1.00000e-02 1.00000e-03 1.00000e-09 1.00000e-01

$1.00000 \mathrm{e}+001.00000 \mathrm{e}+001.00000 \mathrm{e}-011.00000 \mathrm{e}-091.00000 \mathrm{e}-01$

Element: 7538 \# of layers: 3

$\mathrm{Kx} \mathrm{Ky} \mathrm{Kz}$ Ss Por

$2.55434 \mathrm{e}+012.55434 \mathrm{e}+012.55434 \mathrm{e}+001.00000 \mathrm{e}-09$ 7.00000e-02

$1.00000 \mathrm{e}-02$ 1.00000e-02 1.00000e-03 1.00000e-09 1.00000e-01

$1.00000 \mathrm{e}+001.00000 \mathrm{e}+001.00000 \mathrm{e}-011.00000 \mathrm{e}-091.00000 \mathrm{e}-01$

Element: 7539 \# of layers: 3

$\mathrm{Kx} \mathrm{Ky} \mathrm{Kz}$ Ss Por

$2.55434 \mathrm{e}+012.55434 \mathrm{e}+012.55434 \mathrm{e}+00$ 1.00000e-09 7.00000e-02

$1.00000 \mathrm{e}-02$ 1.00000e-02 1.00000e-03 1.00000e-09 1.00000e-01

$1.00000 \mathrm{e}+001.00000 \mathrm{e}+001.00000 \mathrm{e}-011.00000 \mathrm{e}-091.00000 \mathrm{e}-01$

Element: 7540 \# of layers: 3

Kx Ky Kz Ss Por

$2.55434 \mathrm{e}+012.55434 \mathrm{e}+012.55434 \mathrm{e}+001.00000 \mathrm{e}-09$ 7.00000e-02

$1.00000 \mathrm{e}-021.00000 \mathrm{e}-02$ 1.00000e-03 1.00000e-09 1.00000e-01

$1.00000 \mathrm{e}+001.00000 \mathrm{e}+001.00000 \mathrm{e}-01$ 1.00000e-09 1.00000e-01

Element: 7541 \# of layers: 3

$\mathrm{Kx} \mathrm{Ky} \mathrm{Kz}$ Ss Por

$2.55434 \mathrm{e}+012.55434 \mathrm{e}+012.55434 \mathrm{e}+001.00000 \mathrm{e}-09$ 7.00000e-02

$1.00000 \mathrm{e}-021.00000 \mathrm{e}-021.00000 \mathrm{e}-031.00000 \mathrm{e}-091.00000 \mathrm{e}-01$

$1.00000 \mathrm{e}+001.00000 \mathrm{e}+001.00000 \mathrm{e}-011.00000 \mathrm{e}-091.00000 \mathrm{e}-01$

Element: 7542 \# of layers: 3 


\section{Kx Ky Kz Ss Por}

$2.55434 \mathrm{e}+012.55434 \mathrm{e}+012.55434 \mathrm{e}+001.00000 \mathrm{e}-09$ 7.00000e-02 $1.00000 \mathrm{e}-02$ 1.00000e-02 1.00000e-03 1.00000e-09 1.00000e-01

$1.00000 \mathrm{e}+001.00000 \mathrm{e}+001.00000 \mathrm{e}-011.00000 \mathrm{e}-091.00000 \mathrm{e}-01$

Element: 7543 \# of layers: 3

$\mathrm{Kx} \mathrm{Ky} \mathrm{Kz}$ Ss Por

$2.55434 \mathrm{e}+012.55434 \mathrm{e}+012.55434 \mathrm{e}+00$ 1.00000e-09 7.00000e-02

$1.00000 \mathrm{e}-02$ 1.00000e-02 1.00000e-03 1.00000e-09 1.00000e-01

$1.00000 \mathrm{e}+001.00000 \mathrm{e}+001.00000 \mathrm{e}-011.00000 \mathrm{e}-091.00000 \mathrm{e}-01$

Element: 7544 \# of layers: 3

$\mathrm{Kx} \mathrm{Ky} \mathrm{Kz}$ Ss Por

$2.55434 \mathrm{e}+012.55434 \mathrm{e}+012.55434 \mathrm{e}+00$ 1.00000e-09 7.00000e-02 $1.00000 \mathrm{e}-02$ 1.00000e-02 1.00000e-03 1.00000e-09 1.00000e-01

$1.00000 \mathrm{e}+001.00000 \mathrm{e}+001.00000 \mathrm{e}-011.00000 \mathrm{e}-09$ 1.00000e-01

Element: 7545 \# of layers: 3

$\mathrm{Kx} \mathrm{Ky} \mathrm{Kz}$ Ss Por

$2.55434 \mathrm{e}+012.55434 \mathrm{e}+012.55434 \mathrm{e}+00$ 1.00000e-09 7.00000e-02 $1.00000 \mathrm{e}-021.00000 \mathrm{e}-021.00000 \mathrm{e}-031.00000 \mathrm{e}-091.00000 \mathrm{e}-01$

$1.00000 \mathrm{e}+001.00000 \mathrm{e}+001.00000 \mathrm{e}-01$ 1.00000e-09 1.00000e-01

Element: 7546 \# of layers: 3

$\mathrm{Kx} \mathrm{Ky} \mathrm{Kz}$ Ss Por

$2.55434 \mathrm{e}+012.55434 \mathrm{e}+012.55434 \mathrm{e}+00$ 1.00000e-09 7.00000e-02 $1.00000 \mathrm{e}-02$ 1.00000e-02 1.00000e-03 1.00000e-09 1.00000e-01

$1.00000 \mathrm{e}+001.00000 \mathrm{e}+001.00000 \mathrm{e}-011.00000 \mathrm{e}-091.00000 \mathrm{e}-01$

Element: 7547 \# of layers: 3

$\mathrm{Kx} \mathrm{Ky} \mathrm{Kz}$ Ss Por

3.28261e+01 3.28261e+01 3.28261e+00 1.00000e-09 7.00000e-02 $1.00000 \mathrm{e}-02$ 1.00000e-02 1.00000e-03 1.00000e-09 1.00000e-01

$1.00000 \mathrm{e}+001.00000 \mathrm{e}+001.00000 \mathrm{e}-011.00000 \mathrm{e}-091.00000 \mathrm{e}-01$

Element: 7548 \# of layers: 3

$\mathrm{Kx} \mathrm{Ky} \mathrm{Kz}$ Ss Por

3.28261e+01 3.28261e+01 3.28261e+00 1.00000e-09 7.00000e-02

$1.00000 \mathrm{e}-02$ 1.00000e-02 1.00000e-03 1.00000e-09 1.00000e-01

$1.00000 \mathrm{e}+001.00000 \mathrm{e}+001.00000 \mathrm{e}-011.00000 \mathrm{e}-091.00000 \mathrm{e}-01$

Element: 7549 \# of layers: 3

Kx Ky Kz Ss Por

3.28261e+01 3.28261e+01 3.28261e+00 1.00000e-09 7.00000e-02

$1.00000 \mathrm{e}-02$ 1.00000e-02 1.00000e-03 1.00000e-09 1.00000e-01

$1.00000 \mathrm{e}+001.00000 \mathrm{e}+001.00000 \mathrm{e}-011.00000 \mathrm{e}-09$ 1.00000e-01

Element: 7550 \# of layers: 3

$\mathrm{Kx} \mathrm{Ky} \mathrm{Kz}$ Ss Por

3.28261e+01 3.28261e+01 3.28261e+00 1.00000e-09 7.00000e-02 $1.00000 \mathrm{e}-02$ 1.00000e-02 1.00000e-03 1.00000e-09 1.00000e-01

$1.00000 \mathrm{e}+001.00000 \mathrm{e}+001.00000 \mathrm{e}-01$ 1.00000e-09 1.00000e-01

Element: 7551 \# of layers: 3

Kx Ky Kz Ss Por 
3.28261e+01 3.28261e+01 3.28261e+00 1.00000e-09 7.00000e-02 $1.00000 \mathrm{e}-02$ 1.00000e-02 1.00000e-03 1.00000e-09 1.00000e-01

$1.00000 \mathrm{e}+001.00000 \mathrm{e}+001.00000 \mathrm{e}-011.00000 \mathrm{e}-091.00000 \mathrm{e}-01$

Element: 7552 \# of layers: 3

$\mathrm{Kx} \mathrm{Ky} \mathrm{Kz}$ Ss Por

3.28261e+01 3.28261e+01 3.28261e+00 1.00000e-09 7.00000e-02

$1.00000 \mathrm{e}-02$ 1.00000e-02 1.00000e-03 1.00000e-09 1.00000e-01

$1.00000 \mathrm{e}+001.00000 \mathrm{e}+001.00000 \mathrm{e}-011.00000 \mathrm{e}-091.00000 \mathrm{e}-01$

Element: 7553 \# of layers: 3

$\mathrm{Kx} \mathrm{Ky} \mathrm{Kz}$ Ss Por

3.28261e+01 3.28261e+01 3.28261e+00 1.00000e-09 7.00000e-02

$1.00000 \mathrm{e}-02$ 1.00000e-02 1.00000e-03 1.00000e-09 1.00000e-01

$1.00000 \mathrm{e}+001.00000 \mathrm{e}+001.00000 \mathrm{e}-011.00000 \mathrm{e}-091.00000 \mathrm{e}-01$

Element: 7554 \# of layers: 3

$\mathrm{Kx} \mathrm{Ky} \mathrm{Kz}$ Ss Por

3.28261e+01 3.28261e+01 3.28261e+00 1.00000e-09 7.00000e-02

$1.00000 \mathrm{e}-02$ 1.00000e-02 1.00000e-03 1.00000e-09 1.00000e-01

$1.00000 \mathrm{e}+001.00000 \mathrm{e}+001.00000 \mathrm{e}-01$ 1.00000e-09 1.00000e-01

Element: 7555 \# of layers: 3

$\mathrm{Kx} \mathrm{Ky} \mathrm{Kz}$ Ss Por

3.28261e+01 3.28261e+01 3.28261e+00 1.00000e-09 7.00000e-02

$1.00000 \mathrm{e}-021.00000 \mathrm{e}-021.00000 \mathrm{e}-031.00000 \mathrm{e}-091.00000 \mathrm{e}-01$

$1.00000 \mathrm{e}+001.00000 \mathrm{e}+001.00000 \mathrm{e}-01$ 1.00000e-09 1.00000e-01

Element: 7556 \# of layers: 3

$\mathrm{Kx} \mathrm{Ky} \mathrm{Kz}$ Ss Por

4.68862e+01 4.68862e+01 4.68862e+00 1.00000e-09 7.00000e-02

$1.00000 \mathrm{e}-02$ 1.00000e-02 1.00000e-03 1.00000e-09 1.00000e-01

$1.00000 \mathrm{e}+001.00000 \mathrm{e}+001.00000 \mathrm{e}-011.00000 \mathrm{e}-091.00000 \mathrm{e}-01$

Element: 7557 \# of layers: 3

$\mathrm{Kx} \mathrm{Ky} \mathrm{Kz}$ Ss Por

4.68862e+01 4.68862e+01 4.68862e+00 1.00000e-09 7.00000e-02

$1.00000 \mathrm{e}-02$ 1.00000e-02 1.00000e-03 1.00000e-09 1.00000e-01

$1.00000 \mathrm{e}+001.00000 \mathrm{e}+001.00000 \mathrm{e}-011.00000 \mathrm{e}-091.00000 \mathrm{e}-01$

Element: 7558 \# of layers: 3

$\mathrm{Kx} \mathrm{Ky} \mathrm{Kz}$ Ss Por

4.68862e+01 4.68862e+01 4.68862e+00 1.00000e-09 7.00000e-02

$1.00000 \mathrm{e}-02$ 1.00000e-02 1.00000e-03 1.00000e-09 1.00000e-01

$1.00000 \mathrm{e}+001.00000 \mathrm{e}+001.00000 \mathrm{e}-011.00000 \mathrm{e}-09$ 1.00000e-01

Element: 7559 \# of layers: 3

$\mathrm{Kx} \mathrm{Ky} \mathrm{Kz}$ Ss Por

4.68862e+01 4.68862e+01 4.68862e+00 1.00000e-09 7.00000e-02

$1.00000 \mathrm{e}-02$ 1.00000e-02 1.00000e-03 1.00000e-09 1.00000e-01

$1.00000 \mathrm{e}+001.00000 \mathrm{e}+001.00000 \mathrm{e}-01$ 1.00000e-09 1.00000e-01

Element: 7560 \# of layers: 3

$\mathrm{Kx} \mathrm{Ky} \mathrm{Kz}$ Ss Por

4.68862e+01 4.68862e+01 4.68862e+00 1.00000e-09 7.00000e-02 
$1.00000 \mathrm{e}-02$ 1.00000e-02 1.00000e-03 1.00000e-09 1.00000e-01

$1.00000 \mathrm{e}+001.00000 \mathrm{e}+001.00000 \mathrm{e}-01$ 1.00000e-09 1.00000e-01

Element: 7561 \# of layers: 3

Kx Ky Kz Ss Por

4.68862e+01 4.68862e+01 4.68862e+00 1.00000e-09 7.00000e-02

$1.00000 \mathrm{e}-02$ 1.00000e-02 1.00000e-03 1.00000e-09 1.00000e-01

$1.00000 \mathrm{e}+001.00000 \mathrm{e}+001.00000 \mathrm{e}-011.00000 \mathrm{e}-091.00000 \mathrm{e}-01$

Element: 7562 \# of layers: 3

$\mathrm{Kx} \mathrm{Ky} \mathrm{Kz}$ Ss Por

4.68862e+01 4.68862e+01 4.68862e+00 1.00000e-09 7.00000e-02

$1.00000 \mathrm{e}-02$ 1.00000e-02 1.00000e-03 1.00000e-09 1.00000e-01

$1.00000 \mathrm{e}+001.00000 \mathrm{e}+001.00000 \mathrm{e}-011.00000 \mathrm{e}-091.00000 \mathrm{e}-01$

Element: 7563 \# of layers: 3

$\mathrm{Kx} \mathrm{Ky} \mathrm{Kz}$ Ss Por

4.68862e+01 4.68862e+01 4.68862e+00 1.00000e-09 7.00000e-02

$1.00000 \mathrm{e}-02$ 1.00000e-02 1.00000e-03 1.00000e-09 1.00000e-01

$1.00000 \mathrm{e}+001.00000 \mathrm{e}+001.00000 \mathrm{e}-01$ 1.00000e-09 1.00000e-01

Element: 7564 \# of layers: 3

$\mathrm{Kx} \mathrm{Ky} \mathrm{Kz}$ Ss Por

4.68862e+01 4.68862e+01 4.68862e+00 1.00000e-09 7.00000e-02

$1.00000 \mathrm{e}-02$ 1.00000e-02 1.00000e-03 1.00000e-09 1.00000e-01

$1.00000 \mathrm{e}+001.00000 \mathrm{e}+001.00000 \mathrm{e}-01$ 1.00000e-09 1.00000e-01

Element: 7565 \# of layers: 3

Kx Ky Kz Ss Por

7.68003e+01 7.68003e+01 7.68003e+00 1.00000e-09 7.00000e-02

$1.00000 \mathrm{e}-02$ 1.00000e-02 1.00000e-03 1.00000e-09 1.00000e-01

$1.00000 \mathrm{e}+001.00000 \mathrm{e}+001.00000 \mathrm{e}-011.00000 \mathrm{e}-091.00000 \mathrm{e}-01$

Element: 7566 \# of layers: 3

$\mathrm{Kx} \mathrm{Ky} \mathrm{Kz}$ Ss Por

7.68003e+01 7.68003e+01 7.68003e+00 1.00000e-09 7.00000e-02

$1.00000 \mathrm{e}-02$ 1.00000e-02 1.00000e-03 1.00000e-09 1.00000e-01

$1.00000 \mathrm{e}+001.00000 \mathrm{e}+001.00000 \mathrm{e}-01$ 1.00000e-09 1.00000e-01

Element: 7567 \# of layers: 3

$\mathrm{Kx} \mathrm{Ky} \mathrm{Kz}$ Ss Por

7.68003e+01 7.68003e+01 7.68003e+00 1.00000e-09 7.00000e-02

$1.00000 \mathrm{e}-02$ 1.00000e-02 1.00000e-03 1.00000e-09 1.00000e-01

$1.00000 \mathrm{e}+001.00000 \mathrm{e}+001.00000 \mathrm{e}-011.00000 \mathrm{e}-091.00000 \mathrm{e}-01$

Element: 7568 \# of layers: 3

$\mathrm{Kx} \mathrm{Ky} \mathrm{Kz}$ Ss Por

7.68003e+01 7.68003e+01 7.68003e+00 1.00000e-09 7.00000e-02

$1.00000 \mathrm{e}-02$ 1.00000e-02 1.00000e-03 1.00000e-09 1.00000e-01

$1.00000 \mathrm{e}+001.00000 \mathrm{e}+001.00000 \mathrm{e}-011.00000 \mathrm{e}-091.00000 \mathrm{e}-01$

Element: 7569 \# of layers: 3

$\mathrm{Kx} \mathrm{Ky} \mathrm{Kz}$ Ss Por

7.68003e+01 7.68003e+01 7.68003e+00 1.00000e-09 7.00000e-02

$1.00000 \mathrm{e}-02$ 1.00000e-02 1.00000e-03 1.00000e-09 1.00000e-01 
$1.00000 \mathrm{e}+001.00000 \mathrm{e}+00$ 1.00000e-01 1.00000e-09 1.00000e-01

Element: 7570 \# of layers: 3

Kx Ky Kz Ss Por

7.68003e+01 7.68003e+01 7.68003e+00 1.00000e-09 7.00000e-02

$1.00000 \mathrm{e}-021.00000 \mathrm{e}-021.00000 \mathrm{e}-031.00000 \mathrm{e}-091.00000 \mathrm{e}-01$

$1.00000 \mathrm{e}+001.00000 \mathrm{e}+001.00000 \mathrm{e}-011.00000 \mathrm{e}-091.00000 \mathrm{e}-01$

Element: 7571 \# of layers: 3

Kx Ky Kz Ss Por

7.68003e+01 7.68003e+01 7.68003e+00 1.00000e-09 7.00000e-02

$1.00000 \mathrm{e}-02$ 1.00000e-02 1.00000e-03 1.00000e-09 1.00000e-01

$1.00000 \mathrm{e}+001.00000 \mathrm{e}+001.00000 \mathrm{e}-011.00000 \mathrm{e}-091.00000 \mathrm{e}-01$

Element: 7572 \# of layers: 3

$\mathrm{Kx} \mathrm{Ky} \mathrm{Kz}$ Ss Por

7.68003e+01 7.68003e+01 7.68003e+00 1.00000e-09 7.00000e-02

$1.00000 \mathrm{e}-02$ 1.00000e-02 1.00000e-03 1.00000e-09 1.00000e-01

$1.00000 \mathrm{e}+001.00000 \mathrm{e}+001.00000 \mathrm{e}-011.00000 \mathrm{e}-091.00000 \mathrm{e}-01$

Element: 7573 \# of layers: 3

$\mathrm{Kx} \mathrm{Ky} \mathrm{Kz}$ Ss Por

7.68003e+01 7.68003e+01 7.68003e+00 1.00000e-09 7.00000e-02

$1.00000 \mathrm{e}-02$ 1.00000e-02 1.00000e-03 1.00000e-09 1.00000e-01

$1.00000 \mathrm{e}+001.00000 \mathrm{e}+001.00000 \mathrm{e}-011.00000 \mathrm{e}-091.00000 \mathrm{e}-01$

Element: 7574 \# of layers: 3

$\mathrm{Kx} \mathrm{Ky} \mathrm{Kz}$ Ss Por

6.12779e+01 6.12779e+01 6.12779e+00 1.00000e-09 7.00000e-02

$1.00000 \mathrm{e}-02$ 1.00000e-02 1.00000e-03 1.00000e-09 1.00000e-01

$1.00000 \mathrm{e}+001.00000 \mathrm{e}+001.00000 \mathrm{e}-01$ 1.00000e-09 1.00000e-01

Element: 7575 \# of layers: 3

$\mathrm{Kx} \mathrm{Ky} \mathrm{Kz}$ Ss Por

6.12779e+01 6.12779e+01 6.12779e+00 1.00000e-09 7.00000e-02

$1.00000 \mathrm{e}-02$ 1.00000e-02 1.00000e-03 1.00000e-09 1.00000e-01

$1.00000 \mathrm{e}+001.00000 \mathrm{e}+001.00000 \mathrm{e}-011.00000 \mathrm{e}-091.00000 \mathrm{e}-01$

Element: 7576 \# of layers: 3

Kx Ky Kz Ss Por

6.12779e+01 6.12779e+01 6.12779e+00 1.00000e-09 7.00000e-02 $1.00000 \mathrm{e}-02$ 1.00000e-02 1.00000e-03 1.00000e-09 1.00000e-01

$1.00000 \mathrm{e}+001.00000 \mathrm{e}+001.00000 \mathrm{e}-011.00000 \mathrm{e}-091.00000 \mathrm{e}-01$

Element: 7577 \# of layers: 3

Kx Ky Kz Ss Por

6.12779e+01 6.12779e+01 6.12779e+00 1.00000e-09 7.00000e-02 $1.00000 \mathrm{e}-02$ 1.00000e-02 1.00000e-03 1.00000e-09 1.00000e-01

$1.00000 \mathrm{e}+001.00000 \mathrm{e}+001.00000 \mathrm{e}-011.00000 \mathrm{e}-091.00000 \mathrm{e}-01$

Element: 7578 \# of layers: 3

$\mathrm{Kx} \mathrm{Ky} \mathrm{Kz}$ Ss Por

6.12779e+01 6.12779e+01 6.12779e+00 1.00000e-09 7.00000e-02

$1.00000 \mathrm{e}-02$ 1.00000e-02 1.00000e-03 1.00000e-09 1.00000e-01

$1.00000 \mathrm{e}+001.00000 \mathrm{e}+001.00000 \mathrm{e}-011.00000 \mathrm{e}-091.00000 \mathrm{e}-01$ 
Element: 7579 \# of layers: 3

$\mathrm{Kx} \mathrm{Ky} \mathrm{Kz}$ Ss Por

6.12779e+01 6.12779e+01 6.12779e+00 1.00000e-09 7.00000e-02

$1.00000 \mathrm{e}-02$ 1.00000e-02 1.00000e-03 1.00000e-09 1.00000e-01

$1.00000 \mathrm{e}+001.00000 \mathrm{e}+001.00000 \mathrm{e}-011.00000 \mathrm{e}-091.00000 \mathrm{e}-01$

Element: 7580 \# of layers: 3

$\mathrm{Kx} \mathrm{Ky} \mathrm{Kz}$ Ss Por

6.12779e+01 6.12779e+01 6.12779e+00 1.00000e-09 7.00000e-02

$1.00000 \mathrm{e}-02$ 1.00000e-02 1.00000e-03 1.00000e-09 1.00000e-01

$1.00000 \mathrm{e}+001.00000 \mathrm{e}+001.00000 \mathrm{e}-01$ 1.00000e-09 1.00000e-01

Element: 7581 \# of layers: 3

Kx Ky Kz Ss Por

6.12779e+01 6.12779e+01 6.12779e+00 1.00000e-09 7.00000e-02

$1.00000 \mathrm{e}-021.00000 \mathrm{e}-021.00000 \mathrm{e}-031.00000 \mathrm{e}-091.00000 \mathrm{e}-01$

$1.00000 \mathrm{e}+001.00000 \mathrm{e}+001.00000 \mathrm{e}-011.00000 \mathrm{e}-091.00000 \mathrm{e}-01$

Element: 7582 \# of layers: 3

$\mathrm{Kx} \mathrm{Ky} \mathrm{Kz}$ Ss Por

6.12779e+01 6.12779e+01 6.12779e+00 1.00000e-09 7.00000e-02 $1.00000 \mathrm{e}-02$ 1.00000e-02 1.00000e-03 1.00000e-09 1.00000e-01

$1.00000 \mathrm{e}+001.00000 \mathrm{e}+001.00000 \mathrm{e}-011.00000 \mathrm{e}-091.00000 \mathrm{e}-01$

Element: 7583 \# of layers: 3

$\mathrm{Kx} \mathrm{Ky} \mathrm{Kz}$ Ss Por

4.82026e+01 4.82026e+01 4.82026e+00 1.00000e-09 7.00000e-02

$1.00000 \mathrm{e}-021.00000 \mathrm{e}-021.00000 \mathrm{e}-031.00000 \mathrm{e}-091.00000 \mathrm{e}-01$

$1.00000 \mathrm{e}+001.00000 \mathrm{e}+001.00000 \mathrm{e}-011.00000 \mathrm{e}-091.00000 \mathrm{e}-01$

Element: 7584 \# of layers: 3

$\mathrm{Kx} \mathrm{Ky} \mathrm{Kz}$ Ss Por

4.82026e+01 4.82026e+01 4.82026e+00 1.00000e-09 7.00000e-02

$1.00000 \mathrm{e}-02$ 1.00000e-02 1.00000e-03 1.00000e-09 1.00000e-01

$1.00000 \mathrm{e}+001.00000 \mathrm{e}+001.00000 \mathrm{e}-011.00000 \mathrm{e}-091.00000 \mathrm{e}-01$

Element: 7585 \# of layers: 3

Kx Ky Kz Ss Por

2.07581e+01 2.07581e+01 2.07581e+00 1.00000e-09 7.00000e-02

$1.00000 \mathrm{e}-02$ 1.00000e-02 1.00000e-03 1.00000e-09 1.00000e-01

$1.00000 \mathrm{e}+001.00000 \mathrm{e}+001.00000 \mathrm{e}-011.00000 \mathrm{e}-091.00000 \mathrm{e}-01$

Element: 7589 \# of layers: 3

Kx Ky Kz Ss Por

4.82026e+01 4.82026e+01 4.82026e+00 1.00000e-09 7.00000e-02 $1.00000 \mathrm{e}-021.00000 \mathrm{e}-021.00000 \mathrm{e}-031.00000 \mathrm{e}-091.00000 \mathrm{e}-01$

$1.00000 \mathrm{e}+001.00000 \mathrm{e}+001.00000 \mathrm{e}-01$ 1.00000e-09 1.00000e-01

Element: 7590 \# of layers: 3

$\mathrm{Kx} \mathrm{Ky} \mathrm{Kz}$ Ss Por

4.82026e+01 4.82026e+01 4.82026e+00 1.00000e-09 7.00000e-02 $1.00000 \mathrm{e}-021.00000 \mathrm{e}-021.00000 \mathrm{e}-031.00000 \mathrm{e}-091.00000 \mathrm{e}-01$

$1.00000 \mathrm{e}+001.00000 \mathrm{e}+001.00000 \mathrm{e}-01$ 1.00000e-09 1.00000e-01

Element: 7592 \# of layers: 4 
Kx Ky Kz Ss Por

3.96395e+01 3.96395e+01 3.96395e+00 1.00000e-09 7.00000e-02

$3.96395 \mathrm{e}+013.96395 \mathrm{e}+013.96395 \mathrm{e}+001.00000 \mathrm{e}-09$ 7.00000e-02

$1.00000 \mathrm{e}-02$ 1.00000e-02 1.00000e-03 1.00000e-09 1.00000e-01

$1.00000 \mathrm{e}+001.00000 \mathrm{e}+001.00000 \mathrm{e}-01$ 1.00000e-09 1.00000e-01

Element: 7593 \# of layers: 3

$\mathrm{Kx} \mathrm{Ky} \mathrm{Kz}$ Ss Por

3.96395e+01 3.96395e+01 3.96395e+00 1.00000e-09 7.00000e-02

$1.00000 \mathrm{e}-02$ 1.00000e-02 1.00000e-03 1.00000e-09 1.00000e-01

$1.00000 \mathrm{e}+001.00000 \mathrm{e}+001.00000 \mathrm{e}-011.00000 \mathrm{e}-091.00000 \mathrm{e}-01$

Element: 7594 \# of layers: 3

Kx Ky Kz Ss Por

3.96395e+01 3.96395e+01 3.96395e+00 1.00000e-09 7.00000e-02 1.00000e-02 1.00000e-02 1.00000e-03 1.00000e-09 1.00000e-01

$1.00000 \mathrm{e}+001.00000 \mathrm{e}+001.00000 \mathrm{e}-01$ 1.00000e-09 1.00000e-01

Element: 7595 \# of layers: 4

$\mathrm{Kx} \mathrm{Ky} \mathrm{Kz}$ Ss Por

$2.07581 \mathrm{e}+012.07581 \mathrm{e}+012.07581 \mathrm{e}+00$ 1.00000e-09 7.00000e-02

$2.07581 \mathrm{e}+012.07581 \mathrm{e}+012.07581 \mathrm{e}+001.00000 \mathrm{e}-09$ 7.00000e-02

$1.00000 \mathrm{e}-02$ 1.00000e-02 1.00000e-03 1.00000e-09 1.00000e-01

$1.00000 \mathrm{e}+001.00000 \mathrm{e}+001.00000 \mathrm{e}-011.00000 \mathrm{e}-091.00000 \mathrm{e}-01$

Element: 7596 \# of layers: 4

$\mathrm{Kx} \mathrm{Ky} \mathrm{Kz}$ Ss Por

$2.28764 \mathrm{e}+012.28764 \mathrm{e}+012.28764 \mathrm{e}+00$ 1.00000e-09 7.00000e-02

$2.28764 \mathrm{e}+012.28764 \mathrm{e}+012.28764 \mathrm{e}+001.00000 \mathrm{e}-097.00000 \mathrm{e}-02$

$1.00000 \mathrm{e}-02$ 1.00000e-02 1.00000e-03 1.00000e-09 1.00000e-01

$1.00000 \mathrm{e}+001.00000 \mathrm{e}+001.00000 \mathrm{e}-01$ 1.00000e-09 1.00000e-01

Element: 7597 \# of layers: 4

$\mathrm{Kx} \mathrm{Ky} \mathrm{Kz}$ Ss Por

$2.28764 \mathrm{e}+012.28764 \mathrm{e}+012.28764 \mathrm{e}+00$ 1.00000e-09 7.00000e-02

$2.28764 \mathrm{e}+012.28764 \mathrm{e}+012.28764 \mathrm{e}+001.00000 \mathrm{e}-097.00000 \mathrm{e}-02$

$1.00000 \mathrm{e}-02$ 1.00000e-02 1.00000e-03 1.00000e-09 1.00000e-01

$1.00000 \mathrm{e}+001.00000 \mathrm{e}+001.00000 \mathrm{e}-011.00000 \mathrm{e}-091.00000 \mathrm{e}-01$

Element: 7598 \# of layers: 6

$\mathrm{Kx} \mathrm{Ky} \mathrm{Kz}$ Ss Por

8.26173e+01 8.26173e+01 8.26173e+00 1.00000e-09 2.12000e-01

8.26173e+01 8.26173e+01 8.26173e+00 1.00000e-09 2.12000e-01

8.26173e+01 8.26173e+01 8.26173e+00 1.00000e-09 2.12000e-01

8.26173e+01 8.26173e+01 8.26173e+00 1.00000e-09 2.12000e-01

$1.00000 \mathrm{e}-02$ 1.00000e-02 1.00000e-03 1.00000e-09 1.00000e-01

$1.00000 \mathrm{e}+001.00000 \mathrm{e}+001.00000 \mathrm{e}-011.00000 \mathrm{e}-091.00000 \mathrm{e}-01$

Element: 7599 \# of layers: 6

$\mathrm{Kx} \mathrm{Ky} \mathrm{Kz}$ Ss Por

8.26173e+01 8.26173e+01 8.26173e+00 1.00000e-09 2.12000e-01 $8.26173 \mathrm{e}+018.26173 \mathrm{e}+018.26173 \mathrm{e}+00$ 1.00000e-09 2.12000e-01

$8.26173 \mathrm{e}+018.26173 \mathrm{e}+018.26173 \mathrm{e}+001.00000 \mathrm{e}-092.12000 \mathrm{e}-01$ 
8.26173e+01 8.26173e+01 8.26173e+00 1.00000e-09 2.12000e-01 $1.00000 \mathrm{e}-02$ 1.00000e-02 1.00000e-03 1.00000e-09 1.00000e-01 $1.00000 \mathrm{e}+001.00000 \mathrm{e}+001.00000 \mathrm{e}-011.00000 \mathrm{e}-09$ 1.00000e-01

Element: 7600 \# of layers: 6

$\mathrm{Kx} \mathrm{Ky} \mathrm{Kz}$ Ss Por

8.26173e+01 8.26173e+01 8.26173e+00 1.00000e-09 2.12000e-01

8.26173e+01 8.26173e+01 8.26173e+00 1.00000e-09 2.12000e-01

$8.26173 \mathrm{e}+018.26173 \mathrm{e}+018.26173 \mathrm{e}+00$ 1.00000e-09 2.12000e-01

8.26173e+01 8.26173e+01 8.26173e+00 1.00000e-09 2.12000e-01

$1.00000 \mathrm{e}-02$ 1.00000e-02 1.00000e-03 1.00000e-09 1.00000e-01

$1.00000 \mathrm{e}+001.00000 \mathrm{e}+001.00000 \mathrm{e}-011.00000 \mathrm{e}-091.00000 \mathrm{e}-01$

Element: 7601 \# of layers: 5

Kx Ky Kz Ss Por

1.33979e+02 1.33979e+02 1.33979e+01 1.00000e-09 2.12000e-01

$1.33979 \mathrm{e}+02$ 1.33979e+02 1.33979e+01 1.00000e-09 2.12000e-01

$1.33979 \mathrm{e}+02$ 1.33979e+02 1.33979e+01 1.00000e-09 2.12000e-01

$1.00000 \mathrm{e}-02$ 1.00000e-02 1.00000e-03 1.00000e-09 1.00000e-01

$1.00000 \mathrm{e}+001.00000 \mathrm{e}+001.00000 \mathrm{e}-01$ 1.00000e-09 1.00000e-01

Element: 7602 \# of layers: 6

$\mathrm{Kx} \mathrm{Ky} \mathrm{Kz}$ Ss Por

1.33979e+02 1.33979e+02 1.33979e+01 1.00000e-09 2.12000e-01

$1.33979 \mathrm{e}+02$ 1.33979e+02 1.33979e+01 1.00000e-09 2.12000e-01

1.33979e+02 1.33979e+02 1.33979e+01 1.00000e-09 2.12000e-01

$1.33979 \mathrm{e}+02$ 1.33979e+02 1.33979e+01 1.00000e-09 2.12000e-01

$1.00000 \mathrm{e}-02$ 1.00000e-02 1.00000e-03 1.00000e-09 1.00000e-01

$1.00000 \mathrm{e}+001.00000 \mathrm{e}+001.00000 \mathrm{e}-01$ 1.00000e-09 1.00000e-01

Element: 7603 \# of layers: 6

$\mathrm{Kx} \mathrm{Ky} \mathrm{Kz}$ Ss Por

1.33979e+02 1.33979e+02 1.33979e+01 1.00000e-09 2.12000e-01

$1.33979 \mathrm{e}+02$ 1.33979e+02 1.33979e+01 1.00000e-09 2.12000e-01

$1.33979 \mathrm{e}+02$ 1.33979e+02 1.33979e+01 1.00000e-09 2.12000e-01

$1.33979 \mathrm{e}+02$ 1.33979e+02 1.33979e+01 1.00000e-09 2.12000e-01

$1.00000 \mathrm{e}-02$ 1.00000e-02 1.00000e-03 1.00000e-09 1.00000e-01

$1.00000 \mathrm{e}+001.00000 \mathrm{e}+001.00000 \mathrm{e}-011.00000 \mathrm{e}-091.00000 \mathrm{e}-01$

Element: 7604 \# of layers: 6

Kx Ky Kz Ss Por

$1.08423 \mathrm{e}+02$ 1.08423e+02 1.08423e+01 1.00000e-09 2.12000e-01

$1.08423 \mathrm{e}+021.08423 \mathrm{e}+02$ 1.08423e+01 1.00000e-09 2.12000e-01

$1.08423 \mathrm{e}+02$ 1.08423e+02 1.08423e+01 1.00000e-09 2.12000e-01

$1.08423 \mathrm{e}+021.08423 \mathrm{e}+02$ 1.08423e+01 1.00000e-09 2.12000e-01

$1.00000 \mathrm{e}-02$ 1.00000e-02 1.00000e-03 1.00000e-09 1.00000e-01

$1.00000 \mathrm{e}+001.00000 \mathrm{e}+001.00000 \mathrm{e}-011.00000 \mathrm{e}-091.00000 \mathrm{e}-01$

Element: 7605 \# of layers: 5

$\mathrm{Kx} \mathrm{Ky} \mathrm{Kz}$ Ss Por

$1.08423 \mathrm{e}+02$ 1.08423e+02 1.08423e+01 1.00000e-09 2.12000e-01

$1.08423 \mathrm{e}+021.08423 \mathrm{e}+021.08423 \mathrm{e}+01$ 1.00000e-09 2.12000e-01 
$1.08423 \mathrm{e}+02$ 1.08423e+02 1.08423e+01 1.00000e-09 2.12000e-01 $1.00000 \mathrm{e}-02$ 1.00000e-02 1.00000e-03 1.00000e-09 1.00000e-01

$1.00000 \mathrm{e}+001.00000 \mathrm{e}+001.00000 \mathrm{e}-011.00000 \mathrm{e}-09$ 1.00000e-01

Element: 7606 \# of layers: 5

$\mathrm{Kx} \mathrm{Ky} \mathrm{Kz}$ Ss Por

$1.08423 \mathrm{e}+02$ 1.08423e+02 1.08423e+01 1.00000e-09 2.12000e-01

$1.08423 \mathrm{e}+02$ 1.08423e+02 1.08423e+01 1.00000e-09 2.12000e-01

$1.08423 \mathrm{e}+021.08423 \mathrm{e}+02 \quad 1.08423 \mathrm{e}+01$ 1.00000e-09 2.12000e-01

$1.00000 \mathrm{e}-021.00000 \mathrm{e}-02$ 1.00000e-03 1.00000e-09 1.00000e-01

$1.00000 \mathrm{e}+001.00000 \mathrm{e}+00$ 1.00000e-01 1.00000e-09 1.00000e-01

Element: 7607 \# of layers: 5

$\mathrm{Kx} \mathrm{Ky} \mathrm{Kz}$ Ss Por

$1.08423 \mathrm{e}+02$ 1.08423e+02 1.08423e+01 1.00000e-09 2.12000e-01

$1.08423 \mathrm{e}+021.08423 \mathrm{e}+02$ 1.08423e+01 1.00000e-09 2.12000e-01

$1.08423 \mathrm{e}+021.08423 \mathrm{e}+02$ 1.08423e+01 1.00000e-09 2.12000e-01

$1.00000 \mathrm{e}-02$ 1.00000e-02 1.00000e-03 1.00000e-09 1.00000e-01

$1.00000 \mathrm{e}+001.00000 \mathrm{e}+001.00000 \mathrm{e}-011.00000 \mathrm{e}-091.00000 \mathrm{e}-01$

Element: 7608 \# of layers: 5

$\mathrm{Kx} \mathrm{Ky} \mathrm{Kz}$ Ss Por

$1.08423 \mathrm{e}+02$ 1.08423e+02 1.08423e+01 1.00000e-09 2.12000e-01

$1.08423 \mathrm{e}+02$ 1.08423e+02 1.08423e+01 1.00000e-09 2.12000e-01

$1.08423 \mathrm{e}+02$ 1.08423e+02 1.08423e+01 1.00000e-09 2.12000e-01

$1.00000 \mathrm{e}-021.00000 \mathrm{e}-02$ 1.00000e-03 1.00000e-09 1.00000e-01

$1.00000 \mathrm{e}+001.00000 \mathrm{e}+001.00000 \mathrm{e}-011.00000 \mathrm{e}-09$ 1.00000e-01

Element: 7613 \# of layers: 5

$\mathrm{Kx} \mathrm{Ky} \mathrm{Kz}$ Ss Por

$1.88545 \mathrm{e}+02$ 1.88545e+02 1.88545e+01 1.00000e-09 2.12000e-01

$1.88545 \mathrm{e}+02$ 1.88545e+02 1.88545e+01 1.00000e-09 2.12000e-01

$1.88545 \mathrm{e}+021.88545 \mathrm{e}+02 \quad 1.88545 \mathrm{e}+01$ 1.00000e-09 2.12000e-01

$1.00000 \mathrm{e}-02$ 1.00000e-02 1.00000e-03 1.00000e-09 1.00000e-01

$1.00000 \mathrm{e}+001.00000 \mathrm{e}+00$ 1.00000e-01 1.00000e-09 1.00000e-01

Element: 7614 \# of layers: 5

Kx Ky Kz Ss Por

$1.88545 \mathrm{e}+02$ 1.88545e+02 1.88545e+01 1.00000e-09 2.12000e-01

$1.88545 \mathrm{e}+021.88545 \mathrm{e}+02$ 1.88545e+01 1.00000e-09 2.12000e-01

$1.88545 \mathrm{e}+021.88545 \mathrm{e}+02$ 1.88545e+01 1.00000e-09 2.12000e-01

$1.00000 \mathrm{e}-02$ 1.00000e-02 1.00000e-03 1.00000e-09 1.00000e-01

$1.00000 \mathrm{e}+001.00000 \mathrm{e}+001.00000 \mathrm{e}-011.00000 \mathrm{e}-091.00000 \mathrm{e}-01$

Element: 7615 \# of layers: 5

$\mathrm{Kx} \mathrm{Ky} \mathrm{Kz}$ Ss Por

$1.88545 \mathrm{e}+02$ 1.88545e+02 1.88545e+01 1.00000e-09 2.12000e-01

$1.88545 \mathrm{e}+021.88545 \mathrm{e}+02 \quad 1.88545 \mathrm{e}+01$ 1.00000e-09 2.12000e-01

$1.88545 \mathrm{e}+02$ 1.88545e+02 1.88545e+01 1.00000e-09 2.12000e-01

$1.00000 \mathrm{e}-02$ 1.00000e-02 1.00000e-03 1.00000e-09 1.00000e-01

$1.00000 \mathrm{e}+001.00000 \mathrm{e}+001.00000 \mathrm{e}-011.00000 \mathrm{e}-09$ 1.00000e-01

Element: 7616 \# of layers: 5 
$\mathrm{Kx} \mathrm{Ky} \mathrm{Kz}$ Ss Por

$1.88545 \mathrm{e}+02$ 1.88545e+02 1.88545e+01 1.00000e-09 2.12000e-01

$1.88545 \mathrm{e}+02$ 1.88545e+02 1.88545e+01 1.00000e-09 2.12000e-01

$1.88545 \mathrm{e}+02 \quad 1.88545 \mathrm{e}+02 \quad 1.88545 \mathrm{e}+01 \quad 1.00000 \mathrm{e}-092.12000 \mathrm{e}-01$

$1.00000 \mathrm{e}-02$ 1.00000e-02 1.00000e-03 1.00000e-09 1.00000e-01

$1.00000 \mathrm{e}+001.00000 \mathrm{e}+001.00000 \mathrm{e}-011.00000 \mathrm{e}-091.00000 \mathrm{e}-01$

Element: 7617 \# of layers: 5

Kx Ky Kz Ss Por

$1.88545 \mathrm{e}+021.88545 \mathrm{e}+02$ 1.88545e+01 1.00000e-09 2.12000e-01

$1.88545 \mathrm{e}+02$ 1.88545e+02 1.88545e+01 1.00000e-09 2.12000e-01

$1.88545 \mathrm{e}+021.88545 \mathrm{e}+02$ 1.88545e+01 1.00000e-09 2.12000e-01

$1.00000 \mathrm{e}-02$ 1.00000e-02 1.00000e-03 1.00000e-09 1.00000e-01

$1.00000 \mathrm{e}+001.00000 \mathrm{e}+001.00000 \mathrm{e}-01$ 1.00000e-09 1.00000e-01

Element: 7618 \# of layers: 5

$\mathrm{Kx} \mathrm{Ky} \mathrm{Kz}$ Ss Por

$1.88545 \mathrm{e}+02$ 1.88545e+02 1.88545e+01 1.00000e-09 2.12000e-01

$1.88545 \mathrm{e}+02$ 1.88545e+02 1.88545e+01 1.00000e-09 2.12000e-01

$1.88545 \mathrm{e}+021.88545 \mathrm{e}+02$ 1.88545e+01 1.00000e-09 2.12000e-01

$1.00000 \mathrm{e}-02$ 1.00000e-02 1.00000e-03 1.00000e-09 1.00000e-01

$1.00000 \mathrm{e}+001.00000 \mathrm{e}+001.00000 \mathrm{e}-011.00000 \mathrm{e}-091.00000 \mathrm{e}-01$

Element: 7619 \# of layers: 5

$\mathrm{Kx} \mathrm{Ky} \mathrm{Kz}$ Ss Por

$1.88545 \mathrm{e}+02$ 1.88545e+02 1.88545e+01 1.00000e-09 2.12000e-01

$1.88545 \mathrm{e}+02$ 1.88545e+02 1.88545e+01 1.00000e-09 2.12000e-01

$1.88545 \mathrm{e}+021.88545 \mathrm{e}+021.88545 \mathrm{e}+01$ 1.00000e-09 2.12000e-01

$1.00000 \mathrm{e}-02$ 1.00000e-02 1.00000e-03 1.00000e-09 1.00000e-01

$1.00000 \mathrm{e}+001.00000 \mathrm{e}+001.00000 \mathrm{e}-011.00000 \mathrm{e}-091.00000 \mathrm{e}-01$

Element: 7620 \# of layers: 5

Kx Ky Kz Ss Por

$1.88545 \mathrm{e}+02$ 1.88545e+02 1.88545e+01 1.00000e-09 2.12000e-01

$1.88545 \mathrm{e}+02$ 1.88545e+02 1.88545e+01 1.00000e-09 2.12000e-01

$1.88545 \mathrm{e}+021.88545 \mathrm{e}+02$ 1.88545e+01 1.00000e-09 2.12000e-01

$1.00000 \mathrm{e}-02$ 1.00000e-02 1.00000e-03 1.00000e-09 1.00000e-01

$1.00000 \mathrm{e}+001.00000 \mathrm{e}+001.00000 \mathrm{e}-011.00000 \mathrm{e}-091.00000 \mathrm{e}-01$

Element: 7621 \# of layers: 5

$\mathrm{Kx} \mathrm{Ky} \mathrm{Kz}$ Ss Por

$1.88545 \mathrm{e}+02$ 1.88545e+02 1.88545e+01 1.00000e-09 2.12000e-01

$1.88545 \mathrm{e}+021.88545 \mathrm{e}+021.88545 \mathrm{e}+01$ 1.00000e-09 2.12000e-01

$1.88545 \mathrm{e}+021.88545 \mathrm{e}+02$ 1.88545e+01 1.00000e-09 2.12000e-01

$1.00000 \mathrm{e}-02$ 1.00000e-02 1.00000e-03 1.00000e-09 1.00000e-01

$1.00000 \mathrm{e}+001.00000 \mathrm{e}+001.00000 \mathrm{e}-011.00000 \mathrm{e}-091.00000 \mathrm{e}-01$

Element: 7622 \# of layers: 5

$\mathrm{Kx} \mathrm{Ky} \mathrm{Kz}$ Ss Por

$2.28627 \mathrm{e}+02$ 2.28627e+02 2.28627e+01 1.00000e-09 2.12000e-01

$2.28627 \mathrm{e}+02$ 2.28627e+02 2.28627e+01 1.00000e-09 2.12000e-01

$2.28627 \mathrm{e}+02$ 2.28627e+02 2.28627e+01 1.00000e-09 2.12000e-01 
$1.00000 \mathrm{e}-02$ 1.00000e-02 1.00000e-03 1.00000e-09 1.00000e-01 $1.00000 \mathrm{e}+001.00000 \mathrm{e}+001.00000 \mathrm{e}-01$ 1.00000e-09 1.00000e-01 Element: 7623 \# of layers: 5

$\mathrm{Kx} \mathrm{Ky} \mathrm{Kz}$ Ss Por

$2.28627 \mathrm{e}+02$ 2.28627e+02 2.28627e+01 1.00000e-09 2.12000e-01

$2.28627 \mathrm{e}+02$ 2.28627e+02 2.28627e+01 1.00000e-09 2.12000e-01

$2.28627 \mathrm{e}+02$ 2.28627e+02 2.28627e+01 1.00000e-09 2.12000e-01 $1.00000 \mathrm{e}-02$ 1.00000e-02 1.00000e-03 1.00000e-09 1.00000e-01

$1.00000 \mathrm{e}+001.00000 \mathrm{e}+001.00000 \mathrm{e}-011.00000 \mathrm{e}-091.00000 \mathrm{e}-01$

Element: 7624 \# of layers: 4

$\mathrm{Kx} \mathrm{Ky} \mathrm{Kz}$ Ss Por

2.28627e+02 2.28627e+02 2.28627e+01 1.00000e-09 2.12000e-01

$2.28627 \mathrm{e}+02$ 2.28627e+02 2.28627e+01 1.00000e-09 2.12000e-01

$1.00000 \mathrm{e}-02$ 1.00000e-02 1.00000e-03 1.00000e-09 1.00000e-01

$1.00000 \mathrm{e}+001.00000 \mathrm{e}+001.00000 \mathrm{e}-01$ 1.00000e-09 1.00000e-01

Element: 7625 \# of layers: 4

$\mathrm{Kx} \mathrm{Ky} \mathrm{Kz}$ Ss Por

2.28627e+02 2.28627e+02 2.28627e+01 1.00000e-09 2.12000e-01

$2.28627 \mathrm{e}+02$ 2.28627e+02 2.28627e+01 1.00000e-09 2.12000e-01

$1.00000 \mathrm{e}-02$ 1.00000e-02 1.00000e-03 1.00000e-09 1.00000e-01

$1.00000 \mathrm{e}+001.00000 \mathrm{e}+001.00000 \mathrm{e}-011.00000 \mathrm{e}-091.00000 \mathrm{e}-01$

Element: 7626 \# of layers: 4

$\mathrm{Kx} \mathrm{Ky} \mathrm{Kz}$ Ss Por

2.28627e+02 2.28627e+02 2.28627e+01 1.00000e-09 2.12000e-01

$2.28627 \mathrm{e}+02$ 2.28627e+02 2.28627e+01 1.00000e-09 2.12000e-01

$1.00000 \mathrm{e}-02$ 1.00000e-02 1.00000e-03 1.00000e-09 1.00000e-01

$1.00000 \mathrm{e}+001.00000 \mathrm{e}+001.00000 \mathrm{e}-011.00000 \mathrm{e}-091.00000 \mathrm{e}-01$

Element: 7627 \# of layers: 4

$\mathrm{Kx} \mathrm{Ky} \mathrm{Kz}$ Ss Por

2.28627e+02 2.28627e+02 2.28627e+01 1.00000e-09 2.12000e-01

$2.28627 \mathrm{e}+02$ 2.28627e+02 2.28627e+01 1.00000e-09 2.12000e-01

$1.00000 \mathrm{e}-02$ 1.00000e-02 1.00000e-03 1.00000e-09 1.00000e-01

$1.00000 \mathrm{e}+001.00000 \mathrm{e}+001.00000 \mathrm{e}-011.00000 \mathrm{e}-091.00000 \mathrm{e}-01$

Element: 7628 \# of layers: 5

$\mathrm{Kx} \mathrm{Ky} \mathrm{Kz}$ Ss Por

2.28627e+02 2.28627e+02 2.28627e+01 1.00000e-09 2.12000e-01

$2.28627 \mathrm{e}+02$ 2.28627e+02 2.28627e+01 1.00000e-09 2.12000e-01

$2.28627 \mathrm{e}+02$ 2.28627e+02 2.28627e+01 1.00000e-09 2.12000e-01

$1.00000 \mathrm{e}-02$ 1.00000e-02 1.00000e-03 1.00000e-09 1.00000e-01

$1.00000 \mathrm{e}+001.00000 \mathrm{e}+001.00000 \mathrm{e}-011.00000 \mathrm{e}-091.00000 \mathrm{e}-01$

Element: 7629 \# of layers: 5

$\mathrm{Kx} \mathrm{Ky} \mathrm{Kz}$ Ss Por

2.28627e+02 2.28627e+02 2.28627e+01 1.00000e-09 2.12000e-01

2.28627e+02 2.28627e+02 2.28627e+01 1.00000e-09 2.12000e-01

$2.28627 \mathrm{e}+02$ 2.28627e+02 2.28627e+01 1.00000e-09 2.12000e-01

$1.00000 \mathrm{e}-02$ 1.00000e-02 1.00000e-03 1.00000e-09 1.00000e-01 
$1.00000 \mathrm{e}+001.00000 \mathrm{e}+00$ 1.00000e-01 1.00000e-09 1.00000e-01

Element: 7630 \# of layers: 4

$\mathrm{Kx} \mathrm{Ky} \mathrm{Kz}$ Ss Por

2.28627e+02 2.28627e+02 2.28627e+01 1.00000e-09 2.12000e-01

$2.28627 \mathrm{e}+02$ 2.28627e+02 2.28627e+01 1.00000e-09 2.12000e-01

$1.00000 \mathrm{e}-02$ 1.00000e-02 1.00000e-03 1.00000e-09 1.00000e-01

$1.00000 \mathrm{e}+001.00000 \mathrm{e}+001.00000 \mathrm{e}-01$ 1.00000e-09 1.00000e-01

Element: 7631 \# of layers: 4

$\mathrm{Kx} \mathrm{Ky} \mathrm{Kz}$ Ss Por

9.83294e+01 9.83294e+01 9.83294e+00 1.00000e-09 2.12000e-01

$9.83294 \mathrm{e}+019.83294 \mathrm{e}+019.83294 \mathrm{e}+001.00000 \mathrm{e}-092.12000 \mathrm{e}-01$

$1.00000 \mathrm{e}-02$ 1.00000e-02 1.00000e-03 1.00000e-09 1.00000e-01

$1.00000 \mathrm{e}+001.00000 \mathrm{e}+001.00000 \mathrm{e}-011.00000 \mathrm{e}-091.00000 \mathrm{e}-01$

Element: 7632 \# of layers: 5

$\mathrm{Kx} \mathrm{Ky} \mathrm{Kz}$ Ss Por

$2.46090 \mathrm{e}+032.46090 \mathrm{e}+032.46090 \mathrm{e}+02$ 1.00000e-09 7.00000e-02

$9.83294 \mathrm{e}+019.83294 \mathrm{e}+019.83294 \mathrm{e}+00$ 1.00000e-09 2.12000e-01

$9.83294 \mathrm{e}+019.83294 \mathrm{e}+019.83294 \mathrm{e}+001.00000 \mathrm{e}-092.12000 \mathrm{e}-01$

$1.00000 \mathrm{e}-02$ 1.00000e-02 1.00000e-03 1.00000e-09 1.00000e-01

$1.00000 \mathrm{e}+001.00000 \mathrm{e}+001.00000 \mathrm{e}-011.00000 \mathrm{e}-091.00000 \mathrm{e}-01$

Element: 7633 \# of layers: 6

$\mathrm{Kx} \mathrm{Ky} \mathrm{Kz}$ Ss Por

$2.46090 \mathrm{e}+032.46090 \mathrm{e}+03$ 2.46090e+02 1.00000e-09 7.00000e-02

$2.46090 \mathrm{e}+032.46090 \mathrm{e}+032.46090 \mathrm{e}+02$ 1.00000e-09 7.00000e-02

$9.83294 \mathrm{e}+019.83294 \mathrm{e}+019.83294 \mathrm{e}+001.00000 \mathrm{e}-092.12000 \mathrm{e}-01$

$9.83294 \mathrm{e}+019.83294 \mathrm{e}+01$ 9.83294e+00 1.00000e-09 2.12000e-01

$1.00000 \mathrm{e}-02$ 1.00000e-02 1.00000e-03 1.00000e-09 1.00000e-01

$1.00000 \mathrm{e}+001.00000 \mathrm{e}+001.00000 \mathrm{e}-011.00000 \mathrm{e}-09$ 1.00000e-01

Element: 7634 \# of layers: 5

$\mathrm{Kx} \mathrm{Ky} \mathrm{Kz}$ Ss Por

$2.46090 \mathrm{e}+032.46090 \mathrm{e}+032.46090 \mathrm{e}+02$ 1.00000e-09 7.00000e-02

$9.83294 \mathrm{e}+019.83294 \mathrm{e}+019.83294 \mathrm{e}+001.00000 \mathrm{e}-09$ 2.12000e-01

$9.83294 \mathrm{e}+019.83294 \mathrm{e}+019.83294 \mathrm{e}+00$ 1.00000e-09 2.12000e-01

$1.00000 \mathrm{e}-02$ 1.00000e-02 1.00000e-03 1.00000e-09 1.00000e-01

$1.00000 \mathrm{e}+001.00000 \mathrm{e}+001.00000 \mathrm{e}-011.00000 \mathrm{e}-091.00000 \mathrm{e}-01$

Element: 7635 \# of layers: 4

Kx Ky Kz Ss Por

9.83294e+01 9.83294e+01 9.83294e+00 1.00000e-09 2.12000e-01

$9.83294 \mathrm{e}+019.83294 \mathrm{e}+019.83294 \mathrm{e}+001.00000 \mathrm{e}-092.12000 \mathrm{e}-01$

$1.00000 \mathrm{e}-02$ 1.00000e-02 1.00000e-03 1.00000e-09 1.00000e-01

$1.00000 \mathrm{e}+001.00000 \mathrm{e}+001.00000 \mathrm{e}-011.00000 \mathrm{e}-091.00000 \mathrm{e}-01$

Element: 7636 \# of layers: 4

$\mathrm{Kx} \mathrm{Ky} \mathrm{Kz}$ Ss Por

9.83294e+01 9.83294e+01 9.83294e+00 1.00000e-09 2.12000e-01

$9.83294 \mathrm{e}+019.83294 \mathrm{e}+019.83294 \mathrm{e}+001.00000 \mathrm{e}-092.12000 \mathrm{e}-01$

$1.00000 \mathrm{e}-02$ 1.00000e-02 1.00000e-03 1.00000e-09 1.00000e-01 
$1.00000 \mathrm{e}+001.00000 \mathrm{e}+00$ 1.00000e-01 1.00000e-09 1.00000e-01

Element: 7637 \# of layers: 4

Kx Ky Kz Ss Por

9.83294e+01 9.83294e+01 9.83294e+00 1.00000e-09 2.12000e-01

$9.83294 \mathrm{e}+019.83294 \mathrm{e}+01$ 9.83294e+00 1.00000e-09 2.12000e-01

$1.00000 \mathrm{e}-02$ 1.00000e-02 1.00000e-03 1.00000e-09 1.00000e-01

$1.00000 \mathrm{e}+001.00000 \mathrm{e}+001.00000 \mathrm{e}-01$ 1.00000e-09 1.00000e-01

Element: 7638 \# of layers: 4

$\mathrm{Kx} \mathrm{Ky} \mathrm{Kz}$ Ss Por

9.83294e+01 9.83294e+01 9.83294e+00 1.00000e-09 2.12000e-01

$9.83294 \mathrm{e}+019.83294 \mathrm{e}+019.83294 \mathrm{e}+001.00000 \mathrm{e}-092.12000 \mathrm{e}-01$

$1.00000 \mathrm{e}-02$ 1.00000e-02 1.00000e-03 1.00000e-09 1.00000e-01

$1.00000 \mathrm{e}+001.00000 \mathrm{e}+001.00000 \mathrm{e}-011.00000 \mathrm{e}-091.00000 \mathrm{e}-01$

Element: 7639 \# of layers: 4

$\mathrm{Kx} \mathrm{Ky} \mathrm{Kz}$ Ss Por

9.83294e+01 9.83294e+01 9.83294e+00 1.00000e-09 2.12000e-01

$9.83294 \mathrm{e}+01$ 9.83294e+01 9.83294e+00 1.00000e-09 2.12000e-01

$1.00000 \mathrm{e}-02$ 1.00000e-02 1.00000e-03 1.00000e-09 1.00000e-01

$1.00000 \mathrm{e}+001.00000 \mathrm{e}+001.00000 \mathrm{e}-011.00000 \mathrm{e}-091.00000 \mathrm{e}-01$

Element: 7640 \# of layers: 6

$\mathrm{Kx} \mathrm{Ky} \mathrm{Kz}$ Ss Por

4.26651e+02 4.26651e+02 4.26651e+01 1.00000e-09 7.00000e-02

4.26651e+02 4.26651e+02 4.26651e+01 1.00000e-09 7.00000e-02

$1.70473 \mathrm{e}+01$ 1.70473e+01 1.70473e+00 1.00000e-09 2.12000e-01

$1.70473 \mathrm{e}+01$ 1.70473e+01 1.70473e+00 1.00000e-09 2.12000e-01

$1.00000 \mathrm{e}-02$ 1.00000e-02 1.00000e-03 1.00000e-09 1.00000e-01

$1.00000 \mathrm{e}+001.00000 \mathrm{e}+001.00000 \mathrm{e}-011.00000 \mathrm{e}-091.00000 \mathrm{e}-01$

Element: 7641 \# of layers: 5

$\mathrm{Kx} \mathrm{Ky} \mathrm{Kz}$ Ss Por

4.26651e+02 4.26651e+02 4.26651e+01 1.00000e-09 7.00000e-02

$1.70473 \mathrm{e}+01$ 1.70473e+01 1.70473e+00 1.00000e-09 2.12000e-01

$1.70473 \mathrm{e}+01$ 1.70473e+01 1.70473e+00 1.00000e-09 2.12000e-01

$1.00000 \mathrm{e}-02$ 1.00000e-02 1.00000e-03 1.00000e-09 1.00000e-01

$1.00000 \mathrm{e}+001.00000 \mathrm{e}+001.00000 \mathrm{e}-011.00000 \mathrm{e}-091.00000 \mathrm{e}-01$

Element: 7642 \# of layers: 5

$\mathrm{Kx} \mathrm{Ky} \mathrm{Kz}$ Ss Por

4.26651e+02 4.26651e+02 4.26651e+01 1.00000e-09 7.00000e-02

$1.70473 \mathrm{e}+01$ 1.70473e+01 1.70473e+00 1.00000e-09 2.12000e-01

$1.70473 \mathrm{e}+01$ 1.70473e+01 1.70473e+00 1.00000e-09 2.12000e-01

$1.00000 \mathrm{e}-02$ 1.00000e-02 1.00000e-03 1.00000e-09 1.00000e-01

$1.00000 \mathrm{e}+001.00000 \mathrm{e}+001.00000 \mathrm{e}-011.00000 \mathrm{e}-091.00000 \mathrm{e}-01$

Element: 7643 \# of layers: 5

$\mathrm{Kx} \mathrm{Ky} \mathrm{Kz}$ Ss Por

4.26651e+02 4.26651e+02 4.26651e+01 1.00000e-09 7.00000e-02

$1.70473 \mathrm{e}+01$ 1.70473e+01 1.70473e+00 1.00000e-09 2.12000e-01

$1.70473 \mathrm{e}+01$ 1.70473e+01 1.70473e+00 1.00000e-09 2.12000e-01 
$1.00000 \mathrm{e}-02$ 1.00000e-02 1.00000e-03 1.00000e-09 1.00000e-01 $1.00000 \mathrm{e}+001.00000 \mathrm{e}+001.00000 \mathrm{e}-01$ 1.00000e-09 1.00000e-01 Element: 7644 \# of layers: 5

$\mathrm{Kx} \mathrm{Ky} \mathrm{Kz}$ Ss Por

4.26651e+02 4.26651e+02 4.26651e+01 1.00000e-09 7.00000e-02 $1.70473 \mathrm{e}+01$ 1.70473e+01 1.70473e+00 1.00000e-09 2.12000e-01 $1.70473 \mathrm{e}+01$ 1.70473e+01 1.70473e+00 1.00000e-09 2.12000e-01 $1.00000 \mathrm{e}-02$ 1.00000e-02 1.00000e-03 1.00000e-09 1.00000e-01 $1.00000 \mathrm{e}+001.00000 \mathrm{e}+001.00000 \mathrm{e}-011.00000 \mathrm{e}-091.00000 \mathrm{e}-01$ Element: 7645 \# of layers: 6

$\mathrm{Kx} \mathrm{Ky} \mathrm{Kz}$ Ss Por

4.26651e+02 4.26651e+02 4.26651e+01 1.00000e-09 7.00000e-02 4.26651e+02 4.26651e+02 4.26651e+01 1.00000e-09 7.00000e-02 $1.70473 \mathrm{e}+01$ 1.70473e+01 1.70473e+00 1.00000e-09 2.12000e-01 $1.70473 \mathrm{e}+01$ 1.70473e+01 1.70473e+00 1.00000e-09 2.12000e-01 $1.00000 \mathrm{e}-02$ 1.00000e-02 1.00000e-03 1.00000e-09 1.00000e-01 $1.00000 \mathrm{e}+001.00000 \mathrm{e}+001.00000 \mathrm{e}-011.00000 \mathrm{e}-091.00000 \mathrm{e}-01$ Element: 7646 \# of layers: 6

$\mathrm{Kx} \mathrm{Ky} \mathrm{Kz}$ Ss Por

4.26651e+02 4.26651e+02 4.26651e+01 1.00000e-09 7.00000e-02 $4.26651 \mathrm{e}+02$ 4.26651e+02 4.26651e+01 1.00000e-09 7.00000e-02 $1.70473 \mathrm{e}+01$ 1.70473e+01 1.70473e+00 1.00000e-09 2.12000e-01 1.70473e+01 1.70473e+01 1.70473e+00 1.00000e-09 2.12000e-01 $1.00000 \mathrm{e}-02$ 1.00000e-02 1.00000e-03 1.00000e-09 1.00000e-01 $1.00000 \mathrm{e}+001.00000 \mathrm{e}+001.00000 \mathrm{e}-011.00000 \mathrm{e}-091.00000 \mathrm{e}-01$ Element: 7647 \# of layers: 6

$\mathrm{Kx} \mathrm{Ky} \mathrm{Kz}$ Ss Por

4.26651e+02 4.26651e+02 4.26651e+01 1.00000e-09 7.00000e-02 $4.26651 \mathrm{e}+024.26651 \mathrm{e}+024.26651 \mathrm{e}+01$ 1.00000e-09 7.00000e-02 $1.70473 \mathrm{e}+01$ 1.70473e+01 1.70473e+00 1.00000e-09 2.12000e-01 $1.70473 \mathrm{e}+01$ 1.70473e+01 1.70473e+00 1.00000e-09 2.12000e-01 $1.00000 \mathrm{e}-02$ 1.00000e-02 1.00000e-03 1.00000e-09 1.00000e-01 $1.00000 \mathrm{e}+001.00000 \mathrm{e}+001.00000 \mathrm{e}-011.00000 \mathrm{e}-091.00000 \mathrm{e}-01$ Element: 7648 \# of layers: 5

$\mathrm{Kx} \mathrm{Ky} \mathrm{Kz}$ Ss Por

4.26651e+02 4.26651e+02 4.26651e+01 1.00000e-09 7.00000e-02 $1.70473 \mathrm{e}+01$ 1.70473e+01 1.70473e+00 1.00000e-09 2.12000e-01 $1.70473 \mathrm{e}+01$ 1.70473e+01 1.70473e+00 1.00000e-09 2.12000e-01 $1.00000 \mathrm{e}-02$ 1.00000e-02 1.00000e-03 1.00000e-09 1.00000e-01 $1.00000 \mathrm{e}+001.00000 \mathrm{e}+001.00000 \mathrm{e}-01$ 1.00000e-09 1.00000e-01 Element: 7649 \# of layers: 5

$\mathrm{Kx} \mathrm{Ky} \mathrm{Kz}$ Ss Por

1.70163e+02 1.70163e+02 1.70163e+01 1.00000e-09 7.00000e-02 6.79919e+00 6.79919e+00 6.79919e-01 1.00000e-09 2.12000e-01 6.79919e+00 6.79919e+00 6.79919e-01 1.00000e-09 2.12000e-01 $1.00000 \mathrm{e}-02$ 1.00000e-02 1.00000e-03 1.00000e-09 1.00000e-01 
$1.00000 \mathrm{e}+001.00000 \mathrm{e}+00$ 1.00000e-01 1.00000e-09 1.00000e-01

Element: 7650 \# of layers: 4

Kx Ky Kz Ss Por

$1.70163 e+02$ 1.70163e+02 1.70163e+01 1.00000e-09 7.00000e-02

6.79919e+00 6.79919e+00 6.79919e-01 1.00000e-09 2.12000e-01

$1.00000 \mathrm{e}-02$ 1.00000e-02 1.00000e-03 1.00000e-09 1.00000e-01

$1.00000 \mathrm{e}+001.00000 \mathrm{e}+001.00000 \mathrm{e}-01$ 1.00000e-09 1.00000e-01

Element: 7651 \# of layers: 4

$\mathrm{Kx} \mathrm{Ky} \mathrm{Kz}$ Ss Por

1.70163e+02 1.70163e+02 1.70163e+01 1.00000e-09 7.00000e-02

6.79919e+00 6.79919e+00 6.79919e-01 1.00000e-09 2.12000e-01

$1.00000 \mathrm{e}-02$ 1.00000e-02 1.00000e-03 1.00000e-09 1.00000e-01

$1.00000 \mathrm{e}+001.00000 \mathrm{e}+001.00000 \mathrm{e}-011.00000 \mathrm{e}-091.00000 \mathrm{e}-01$

Element: 7652 \# of layers: 4

$\mathrm{Kx} \mathrm{Ky} \mathrm{Kz}$ Ss Por

1.70163e+02 1.70163e+02 1.70163e+01 1.00000e-09 7.00000e-02

6.79919e+00 6.79919e+00 6.79919e-01 1.00000e-09 2.12000e-01

$1.00000 \mathrm{e}-02$ 1.00000e-02 1.00000e-03 1.00000e-09 1.00000e-01

$1.00000 \mathrm{e}+001.00000 \mathrm{e}+001.00000 \mathrm{e}-011.00000 \mathrm{e}-091.00000 \mathrm{e}-01$

Element: 7653 \# of layers: 4

$\mathrm{Kx} \mathrm{Ky} \mathrm{Kz}$ Ss Por

1.70163e+02 1.70163e+02 1.70163e+01 1.00000e-09 7.00000e-02

6.79919e+00 6.79919e+00 6.79919e-01 1.00000e-09 2.12000e-01

$1.00000 \mathrm{e}-02$ 1.00000e-02 1.00000e-03 1.00000e-09 1.00000e-01

$1.00000 \mathrm{e}+001.00000 \mathrm{e}+001.00000 \mathrm{e}-011.00000 \mathrm{e}-091.00000 \mathrm{e}-01$

Element: 7654 \# of layers: 4

$\mathrm{Kx} \mathrm{Ky} \mathrm{Kz}$ Ss Por

1.70163e+02 1.70163e+02 1.70163e+01 1.00000e-09 7.00000e-02

$6.79919 \mathrm{e}+00$ 6.79919e+00 6.79919e-01 1.00000e-09 2.12000e-01

$1.00000 \mathrm{e}-02$ 1.00000e-02 1.00000e-03 1.00000e-09 1.00000e-01

$1.00000 \mathrm{e}+001.00000 \mathrm{e}+001.00000 \mathrm{e}-011.00000 \mathrm{e}-091.00000 \mathrm{e}-01$

Element: 7655 \# of layers: 5

Kx Ky Kz Ss Por

$1.70163 \mathrm{e}+02$ 1.70163e+02 1.70163e+01 1.00000e-09 7.00000e-02

$6.79919 \mathrm{e}+00$ 6.79919e+00 6.79919e-01 1.00000e-09 2.12000e-01

$6.79919 \mathrm{e}+006.79919 \mathrm{e}+00$ 6.79919e-01 1.00000e-09 2.12000e-01

$1.00000 \mathrm{e}-02$ 1.00000e-02 1.00000e-03 1.00000e-09 1.00000e-01

$1.00000 \mathrm{e}+001.00000 \mathrm{e}+001.00000 \mathrm{e}-011.00000 \mathrm{e}-091.00000 \mathrm{e}-01$

Element: 7656 \# of layers: 5

$\mathrm{Kx} \mathrm{Ky} \mathrm{Kz}$ Ss Por

1.70163e+02 1.70163e+02 1.70163e+01 1.00000e-09 7.00000e-02

$6.79919 \mathrm{e}+00$ 6.79919e+00 6.79919e-01 1.00000e-09 2.12000e-01

6.79919e+00 6.79919e+00 6.79919e-01 1.00000e-09 2.12000e-01

$1.00000 \mathrm{e}-02$ 1.00000e-02 1.00000e-03 1.00000e-09 1.00000e-01

$1.00000 \mathrm{e}+001.00000 \mathrm{e}+001.00000 \mathrm{e}-011.00000 \mathrm{e}-091.00000 \mathrm{e}-01$

Element: 7657 \# of layers: 4 
$\mathrm{Kx} \mathrm{Ky} \mathrm{Kz} \mathrm{Ss} \mathrm{Por}$

1.70163e+02 1.70163e+02 1.70163e+01 1.00000e-09 7.00000e-02

6.79919e+00 6.79919e+00 6.79919e-01 1.00000e-09 2.12000e-01

$1.00000 \mathrm{e}-02$ 1.00000e-02 1.00000e-03 1.00000e-09 1.00000e-01

$1.00000 \mathrm{e}+001.00000 \mathrm{e}+001.00000 \mathrm{e}-01$ 1.00000e-09 1.00000e-01

Element: 7658 \# of layers: 4

Kx Ky Kz Ss Por

9.73891e+01 9.73891e+01 9.73891e+00 1.00000e-09 7.00000e-02

$3.89123 \mathrm{e}+003.89123 \mathrm{e}+00$ 3.89123e-01 1.00000e-09 2.12000e-01

$1.00000 \mathrm{e}-02$ 1.00000e-02 1.00000e-03 1.00000e-09 1.00000e-01

$1.00000 \mathrm{e}+001.00000 \mathrm{e}+001.00000 \mathrm{e}-011.00000 \mathrm{e}-091.00000 \mathrm{e}-01$

Element: 7659 \# of layers: 5

Kx Ky Kz Ss Por

9.73891e+01 9.73891e+01 9.73891e+00 1.00000e-09 7.00000e-02

$9.73891 \mathrm{e}+019.73891 \mathrm{e}+019.73891 \mathrm{e}+001.00000 \mathrm{e}-09$ 7.00000e-02

$3.89123 \mathrm{e}+003.89123 \mathrm{e}+00$ 3.89123e-01 1.00000e-09 2.12000e-01

$1.00000 \mathrm{e}-02$ 1.00000e-02 1.00000e-03 1.00000e-09 1.00000e-01

$1.00000 \mathrm{e}+001.00000 \mathrm{e}+001.00000 \mathrm{e}-01$ 1.00000e-09 1.00000e-01

Element: 7660 \# of layers: 5

$\mathrm{Kx} \mathrm{Ky} \mathrm{Kz}$ Ss Por

9.73891e+01 9.73891e+01 9.73891e+00 1.00000e-09 7.00000e-02

$9.73891 \mathrm{e}+01$ 9.73891e+01 9.73891e+00 1.00000e-09 7.00000e-02

3.89123e+00 3.89123e+00 3.89123e-01 1.00000e-09 2.12000e-01

$1.00000 \mathrm{e}-02$ 1.00000e-02 1.00000e-03 1.00000e-09 1.00000e-01

$1.00000 \mathrm{e}+001.00000 \mathrm{e}+001.00000 \mathrm{e}-011.00000 \mathrm{e}-091.00000 \mathrm{e}-01$

Element: 7661 \# of layers: 5

$\mathrm{Kx} \mathrm{Ky} \mathrm{Kz}$ Ss Por

9.73891e+01 9.73891e+01 9.73891e+00 1.00000e-09 7.00000e-02

$9.73891 \mathrm{e}+019.73891 \mathrm{e}+019.73891 \mathrm{e}+001.00000 \mathrm{e}-09$ 7.00000e-02

$3.89123 \mathrm{e}+003.89123 \mathrm{e}+003.89123 \mathrm{e}-01$ 1.00000e-09 2.12000e-01

$1.00000 \mathrm{e}-02$ 1.00000e-02 1.00000e-03 1.00000e-09 1.00000e-01

$1.00000 \mathrm{e}+001.00000 \mathrm{e}+001.00000 \mathrm{e}-011.00000 \mathrm{e}-091.00000 \mathrm{e}-01$

Element: 7662 \# of layers: 5

$\mathrm{Kx} \mathrm{Ky} \mathrm{Kz}$ Ss Por

9.73891e+01 9.73891e+01 9.73891e+00 1.00000e-09 7.00000e-02

9.73891e+01 9.73891e+01 9.73891e+00 1.00000e-09 7.00000e-02

$3.89123 \mathrm{e}+003.89123 \mathrm{e}+00$ 3.89123e-01 1.00000e-09 2.12000e-01

$1.00000 \mathrm{e}-021.00000 \mathrm{e}-02$ 1.00000e-03 1.00000e-09 1.00000e-01

$1.00000 \mathrm{e}+001.00000 \mathrm{e}+001.00000 \mathrm{e}-011.00000 \mathrm{e}-091.00000 \mathrm{e}-01$

Element: 7663 \# of layers: 5

$\mathrm{Kx} \mathrm{Ky} \mathrm{Kz}$ Ss Por

9.73891e+01 9.73891e+01 9.73891e+00 1.00000e-09 7.00000e-02

$9.73891 \mathrm{e}+01$ 9.73891e+01 9.73891e+00 1.00000e-09 7.00000e-02

3.89123e+00 3.89123e+00 3.89123e-01 1.00000e-09 2.12000e-01

$1.00000 \mathrm{e}-02$ 1.00000e-02 1.00000e-03 1.00000e-09 1.00000e-01

$1.00000 \mathrm{e}+001.00000 \mathrm{e}+001.00000 \mathrm{e}-011.00000 \mathrm{e}-091.00000 \mathrm{e}-01$ 
Element: 7664 \# of layers: 5

$\mathrm{Kx} \mathrm{Ky} \mathrm{Kz}$ Ss Por

9.73891e+01 9.73891e+01 9.73891e+00 1.00000e-09 7.00000e-02

$9.73891 \mathrm{e}+019.73891 \mathrm{e}+019.73891 \mathrm{e}+001.00000 \mathrm{e}-09$ 7.00000e-02

$3.89123 \mathrm{e}+003.89123 \mathrm{e}+00$ 3.89123e-01 1.00000e-09 2.12000e-01

$1.00000 \mathrm{e}-02$ 1.00000e-02 1.00000e-03 1.00000e-09 1.00000e-01

$1.00000 \mathrm{e}+001.00000 \mathrm{e}+001.00000 \mathrm{e}-01$ 1.00000e-09 1.00000e-01

Element: 7665 \# of layers: 4

$\mathrm{Kx} \mathrm{Ky} \mathrm{Kz}$ Ss Por

9.73891e+01 9.73891e+01 9.73891e+00 1.00000e-09 7.00000e-02

3.89123e+00 3.89123e+00 3.89123e-01 1.00000e-09 2.12000e-01

$1.00000 \mathrm{e}-02$ 1.00000e-02 1.00000e-03 1.00000e-09 1.00000e-01

$1.00000 \mathrm{e}+001.00000 \mathrm{e}+001.00000 \mathrm{e}-011.00000 \mathrm{e}-091.00000 \mathrm{e}-01$

Element: 7666 \# of layers: 5

$\mathrm{Kx} \mathrm{Ky} \mathrm{Kz}$ Ss Por

9.73891e+01 9.73891e+01 9.73891e+00 1.00000e-09 7.00000e-02

9.73891e+01 9.73891e+01 9.73891e+00 1.00000e-09 7.00000e-02

3.89123e+00 3.89123e+00 3.89123e-01 1.00000e-09 2.12000e-01

$1.00000 \mathrm{e}-02$ 1.00000e-02 1.00000e-03 1.00000e-09 1.00000e-01

$1.00000 \mathrm{e}+001.00000 \mathrm{e}+001.00000 \mathrm{e}-011.00000 \mathrm{e}-091.00000 \mathrm{e}-01$

Element: 7667 \# of layers: 5

$\mathrm{Kx} \mathrm{Ky} \mathrm{Kz}$ Ss Por

7.12168e+01 7.12168e+01 7.12168e+00 1.00000e-09 7.00000e-02

$7.12168 \mathrm{e}+017.12168 \mathrm{e}+01$ 7.12168e+00 1.00000e-09 7.00000e-02

$2.84564 \mathrm{e}+002.84564 \mathrm{e}+002.84564 \mathrm{e}-01$ 1.00000e-09 2.12000e-01

$1.00000 \mathrm{e}-02$ 1.00000e-02 1.00000e-03 1.00000e-09 1.00000e-01

$1.00000 \mathrm{e}+001.00000 \mathrm{e}+001.00000 \mathrm{e}-011.00000 \mathrm{e}-091.00000 \mathrm{e}-01$

Element: 7668 \# of layers: 4

$\mathrm{Kx} \mathrm{Ky} \mathrm{Kz}$ Ss Por

7.12168e+01 7.12168e+01 7.12168e+00 1.00000e-09 7.00000e-02

$7.12168 \mathrm{e}+017.12168 \mathrm{e}+01$ 7.12168e+00 1.00000e-09 7.00000e-02

$1.00000 \mathrm{e}-02$ 1.00000e-02 1.00000e-03 1.00000e-09 1.00000e-01

$1.00000 \mathrm{e}+001.00000 \mathrm{e}+001.00000 \mathrm{e}-011.00000 \mathrm{e}-091.00000 \mathrm{e}-01$

Element: 7669 \# of layers: 4

$\mathrm{Kx} \mathrm{Ky} \mathrm{Kz}$ Ss Por

7.12168e+01 7.12168e+01 7.12168e+00 1.00000e-09 7.00000e-02

$7.12168 \mathrm{e}+017.12168 \mathrm{e}+017.12168 \mathrm{e}+001.00000 \mathrm{e}-09$ 7.00000e-02

$1.00000 \mathrm{e}-02$ 1.00000e-02 1.00000e-03 1.00000e-09 1.00000e-01

$1.00000 \mathrm{e}+001.00000 \mathrm{e}+001.00000 \mathrm{e}-011.00000 \mathrm{e}-09$ 1.00000e-01

Element: 7670 \# of layers: 4

$\mathrm{Kx} \mathrm{Ky} \mathrm{Kz}$ Ss Por

7.12168e+01 7.12168e+01 7.12168e+00 1.00000e-09 7.00000e-02

7.12168e+01 7.12168e+01 7.12168e+00 1.00000e-09 7.00000e-02

$1.00000 \mathrm{e}-021.00000 \mathrm{e}-021.00000 \mathrm{e}-031.00000 \mathrm{e}-091.00000 \mathrm{e}-01$

$1.00000 \mathrm{e}+001.00000 \mathrm{e}+001.00000 \mathrm{e}-01$ 1.00000e-09 1.00000e-01

Element: 7671 \# of layers: 4 
$\mathrm{Kx} \mathrm{Ky} \mathrm{Kz}$ Ss Por

7.12168e+01 7.12168e+01 7.12168e+00 1.00000e-09 7.00000e-02

$7.12168 \mathrm{e}+017.12168 \mathrm{e}+017.12168 \mathrm{e}+001.00000 \mathrm{e}-09$ 7.00000e-02

$1.00000 \mathrm{e}-02$ 1.00000e-02 1.00000e-03 1.00000e-09 1.00000e-01

$1.00000 \mathrm{e}+001.00000 \mathrm{e}+001.00000 \mathrm{e}-01$ 1.00000e-09 1.00000e-01

Element: 7672 \# of layers: 4

Kx Ky Kz Ss Por

7.12168e+01 7.12168e+01 7.12168e+00 1.00000e-09 7.00000e-02

$7.12168 \mathrm{e}+017.12168 \mathrm{e}+017.12168 \mathrm{e}+001.00000 \mathrm{e}-09$ 7.00000e-02

$1.00000 \mathrm{e}-02$ 1.00000e-02 1.00000e-03 1.00000e-09 1.00000e-01

$1.00000 \mathrm{e}+001.00000 \mathrm{e}+001.00000 \mathrm{e}-011.00000 \mathrm{e}-091.00000 \mathrm{e}-01$

Element: 7673 \# of layers: 4

Kx Ky Kz Ss Por

7.12168e+01 7.12168e+01 7.12168e+00 1.00000e-09 7.00000e-02

$7.12168 \mathrm{e}+017.12168 \mathrm{e}+017.12168 \mathrm{e}+001.00000 \mathrm{e}-09$ 7.00000e-02

$1.00000 \mathrm{e}-02$ 1.00000e-02 1.00000e-03 1.00000e-09 1.00000e-01

$1.00000 \mathrm{e}+001.00000 \mathrm{e}+001.00000 \mathrm{e}-01$ 1.00000e-09 1.00000e-01

Element: 7674 \# of layers: 5

$\mathrm{Kx} \mathrm{Ky} \mathrm{Kz}$ Ss Por

7.12168e+01 7.12168e+01 7.12168e+00 1.00000e-09 7.00000e-02

$7.12168 \mathrm{e}+017.12168 \mathrm{e}+01$ 7.12168e+00 1.00000e-09 7.00000e-02

$2.84564 \mathrm{e}+002.84564 \mathrm{e}+00$ 2.84564e-01 1.00000e-09 2.12000e-01

$1.00000 \mathrm{e}-02$ 1.00000e-02 1.00000e-03 1.00000e-09 1.00000e-01

$1.00000 \mathrm{e}+001.00000 \mathrm{e}+001.00000 \mathrm{e}-011.00000 \mathrm{e}-091.00000 \mathrm{e}-01$

Element: 7675 \# of layers: 4

$\mathrm{Kx} \mathrm{Ky} \mathrm{Kz}$ Ss Por

7.12168e+01 7.12168e+01 7.12168e+00 1.00000e-09 7.00000e-02

$7.12168 \mathrm{e}+01$ 7.12168e+01 7.12168e+00 1.00000e-09 7.00000e-02

$1.00000 \mathrm{e}-02$ 1.00000e-02 1.00000e-03 1.00000e-09 1.00000e-01

$1.00000 \mathrm{e}+001.00000 \mathrm{e}+001.00000 \mathrm{e}-011.00000 \mathrm{e}-091.00000 \mathrm{e}-01$

Element: 7676 \# of layers: 4

$\mathrm{Kx} \mathrm{Ky} \mathrm{Kz}$ Ss Por

6.37737e+01 6.37737e+01 6.37737e+00 1.00000e-09 7.00000e-02

6.37737e+01 6.37737e+01 6.37737e+00 1.00000e-09 7.00000e-02

$1.00000 \mathrm{e}-02$ 1.00000e-02 1.00000e-03 1.00000e-09 1.00000e-01

$1.00000 \mathrm{e}+001.00000 \mathrm{e}+001.00000 \mathrm{e}-011.00000 \mathrm{e}-091.00000 \mathrm{e}-01$

Element: 7677 \# of layers: 4

Kx Ky Kz Ss Por

6.37737e+01 6.37737e+01 6.37737e+00 1.00000e-09 7.00000e-02

6.37737e+01 6.37737e+01 6.37737e+00 1.00000e-09 7.00000e-02

$1.00000 \mathrm{e}-02$ 1.00000e-02 1.00000e-03 1.00000e-09 1.00000e-01

$1.00000 \mathrm{e}+001.00000 \mathrm{e}+001.00000 \mathrm{e}-011.00000 \mathrm{e}-091.00000 \mathrm{e}-01$

Element: 7678 \# of layers: 4

$\mathrm{Kx} \mathrm{Ky} \mathrm{Kz}$ Ss Por

6.37737e+01 6.37737e+01 6.37737e+00 1.00000e-09 7.00000e-02

6.37737e+01 6.37737e+01 6.37737e+00 1.00000e-09 7.00000e-02 
$1.00000 \mathrm{e}-02$ 1.00000e-02 1.00000e-03 1.00000e-09 1.00000e-01 $1.00000 \mathrm{e}+001.00000 \mathrm{e}+001.00000 \mathrm{e}-01$ 1.00000e-09 1.00000e-01 Element: 7679 \# of layers: 4

Kx Ky Kz Ss Por

6.37737e+01 6.37737e+01 6.37737e+00 1.00000e-09 7.00000e-02

6.37737e+01 6.37737e+01 6.37737e+00 1.00000e-09 7.00000e-02

$1.00000 \mathrm{e}-02$ 1.00000e-02 1.00000e-03 1.00000e-09 1.00000e-01

$1.00000 \mathrm{e}+001.00000 \mathrm{e}+001.00000 \mathrm{e}-01$ 1.00000e-09 1.00000e-01

Element: 7680 \# of layers: 4

$\mathrm{Kx} \mathrm{Ky} \mathrm{Kz}$ Ss Por

6.37737e+01 6.37737e+01 6.37737e+00 1.00000e-09 7.00000e-02

6.37737e+01 6.37737e+01 6.37737e+00 1.00000e-09 7.00000e-02

$1.00000 \mathrm{e}-02$ 1.00000e-02 1.00000e-03 1.00000e-09 1.00000e-01

$1.00000 \mathrm{e}+001.00000 \mathrm{e}+001.00000 \mathrm{e}-011.00000 \mathrm{e}-091.00000 \mathrm{e}-01$

Element: 7681 \# of layers: 4

Kx Ky Kz Ss Por

6.37737e+01 6.37737e+01 6.37737e+00 1.00000e-09 7.00000e-02

6.37737e+01 6.37737e+01 6.37737e+00 1.00000e-09 7.00000e-02

$1.00000 \mathrm{e}-02$ 1.00000e-02 1.00000e-03 1.00000e-09 1.00000e-01

$1.00000 \mathrm{e}+001.00000 \mathrm{e}+001.00000 \mathrm{e}-011.00000 \mathrm{e}-091.00000 \mathrm{e}-01$

Element: 7682 \# of layers: 4

$\mathrm{Kx} \mathrm{Ky} \mathrm{Kz}$ Ss Por

6.37737e+01 6.37737e+01 6.37737e+00 1.00000e-09 7.00000e-02

6.37737e+01 6.37737e+01 6.37737e+00 1.00000e-09 7.00000e-02

$1.00000 \mathrm{e}-021.00000 \mathrm{e}-02$ 1.00000e-03 1.00000e-09 1.00000e-01

$1.00000 \mathrm{e}+001.00000 \mathrm{e}+001.00000 \mathrm{e}-01$ 1.00000e-09 1.00000e-01

Element: 7683 \# of layers: 4

$\mathrm{Kx} \mathrm{Ky} \mathrm{Kz}$ Ss Por

6.37737e+01 6.37737e+01 6.37737e+00 1.00000e-09 7.00000e-02

6.37737e+01 6.37737e+01 6.37737e+00 1.00000e-09 7.00000e-02

$1.00000 \mathrm{e}-02$ 1.00000e-02 1.00000e-03 1.00000e-09 1.00000e-01

$1.00000 \mathrm{e}+001.00000 \mathrm{e}+001.00000 \mathrm{e}-011.00000 \mathrm{e}-091.00000 \mathrm{e}-01$

Element: 7684 \# of layers: 4

$\mathrm{Kx} \mathrm{Ky} \mathrm{Kz}$ Ss Por

6.37737e+01 6.37737e+01 6.37737e+00 1.00000e-09 7.00000e-02

6.37737e+01 6.37737e+01 6.37737e+00 1.00000e-09 7.00000e-02

1.00000e-02 1.00000e-02 1.00000e-03 1.00000e-09 1.00000e-01

$1.00000 \mathrm{e}+001.00000 \mathrm{e}+001.00000 \mathrm{e}-011.00000 \mathrm{e}-091.00000 \mathrm{e}-01$

Element: 7685 \# of layers: 4

$\mathrm{Kx} \mathrm{Ky} \mathrm{Kz}$ Ss Por

3.10349e+01 3.10349e+01 3.10349e+00 1.00000e-09 7.00000e-02

$3.10349 \mathrm{e}+013.10349 \mathrm{e}+013.10349 \mathrm{e}+00$ 1.00000e-09 7.00000e-02

$1.00000 \mathrm{e}-02$ 1.00000e-02 1.00000e-03 1.00000e-09 1.00000e-01

$1.00000 \mathrm{e}+001.00000 \mathrm{e}+001.00000 \mathrm{e}-01$ 1.00000e-09 1.00000e-01

Element: 7686 \# of layers: 3

Kx Ky Kz Ss Por 
$3.10349 \mathrm{e}+013.10349 \mathrm{e}+013.10349 \mathrm{e}+00$ 1.00000e-09 7.00000e-02 $1.00000 \mathrm{e}-02$ 1.00000e-02 1.00000e-03 1.00000e-09 1.00000e-01

$1.00000 \mathrm{e}+001.00000 \mathrm{e}+001.00000 \mathrm{e}-011.00000 \mathrm{e}-091.00000 \mathrm{e}-01$

Element: 7687 \# of layers: 3

$\mathrm{Kx} \mathrm{Ky} \mathrm{Kz}$ Ss Por

3.10349e+01 3.10349e+01 3.10349e+00 1.00000e-09 7.00000e-02

$1.00000 \mathrm{e}-02$ 1.00000e-02 1.00000e-03 1.00000e-09 1.00000e-01

$1.00000 \mathrm{e}+001.00000 \mathrm{e}+001.00000 \mathrm{e}-01$ 1.00000e-09 1.00000e-01

Element: 7688 \# of layers: 3

$\mathrm{Kx} \mathrm{Ky} \mathrm{Kz}$ Ss Por

3.10349e+01 3.10349e+01 3.10349e+00 1.00000e-09 7.00000e-02

$1.00000 \mathrm{e}-02$ 1.00000e-02 1.00000e-03 1.00000e-09 1.00000e-01

$1.00000 \mathrm{e}+001.00000 \mathrm{e}+001.00000 \mathrm{e}-011.00000 \mathrm{e}-091.00000 \mathrm{e}-01$

Element: 7689 \# of layers: 3

$\mathrm{Kx} \mathrm{Ky} \mathrm{Kz}$ Ss Por

3.10349e+01 3.10349e+01 3.10349e+00 1.00000e-09 7.00000e-02

$1.00000 \mathrm{e}-02$ 1.00000e-02 1.00000e-03 1.00000e-09 1.00000e-01

$1.00000 \mathrm{e}+001.00000 \mathrm{e}+001.00000 \mathrm{e}-01$ 1.00000e-09 1.00000e-01

Element: 7690 \# of layers: 4

$\mathrm{Kx} \mathrm{Ky} \mathrm{Kz}$ Ss Por

3.10349e+01 3.10349e+01 3.10349e+00 1.00000e-09 7.00000e-02

$3.10349 \mathrm{e}+013.10349 \mathrm{e}+01$ 3.10349e+00 1.00000e-09 7.00000e-02

$1.00000 \mathrm{e}-02$ 1.00000e-02 1.00000e-03 1.00000e-09 1.00000e-01

$1.00000 \mathrm{e}+001.00000 \mathrm{e}+001.00000 \mathrm{e}-011.00000 \mathrm{e}-091.00000 \mathrm{e}-01$

Element: 7691 \# of layers: 4

$\mathrm{Kx} \mathrm{Ky} \mathrm{Kz}$ Ss Por

3.10349e+01 3.10349e+01 3.10349e+00 1.00000e-09 7.00000e-02

$3.10349 \mathrm{e}+013.10349 \mathrm{e}+013.10349 \mathrm{e}+00$ 1.00000e-09 7.00000e-02

$1.00000 \mathrm{e}-02$ 1.00000e-02 1.00000e-03 1.00000e-09 1.00000e-01

$1.00000 \mathrm{e}+001.00000 \mathrm{e}+001.00000 \mathrm{e}-011.00000 \mathrm{e}-091.00000 \mathrm{e}-01$

Element: 7692 \# of layers: 4

Kx Ky Kz Ss Por

3.10349e+01 3.10349e+01 3.10349e+00 1.00000e-09 7.00000e-02

$3.10349 \mathrm{e}+013.10349 \mathrm{e}+013.10349 \mathrm{e}+00$ 1.00000e-09 7.00000e-02

$1.00000 \mathrm{e}-02$ 1.00000e-02 1.00000e-03 1.00000e-09 1.00000e-01

$1.00000 \mathrm{e}+001.00000 \mathrm{e}+001.00000 \mathrm{e}-011.00000 \mathrm{e}-091.00000 \mathrm{e}-01$

Element: 7693 \# of layers: 3

Kx Ky Kz Ss Por

3.10349e+01 3.10349e+01 3.10349e+00 1.00000e-09 7.00000e-02 $1.00000 \mathrm{e}-02$ 1.00000e-02 1.00000e-03 1.00000e-09 1.00000e-01

$1.00000 \mathrm{e}+001.00000 \mathrm{e}+001.00000 \mathrm{e}-011.00000 \mathrm{e}-091.00000 \mathrm{e}-01$

Element: 7694 \# of layers: 3

$\mathrm{Kx} \mathrm{Ky} \mathrm{Kz}$ Ss Por

$1.90381 \mathrm{e}+01$ 1.90381e+01 1.90381e+00 1.00000e-09 7.00000e-02 $1.00000 \mathrm{e}-02$ 1.00000e-02 1.00000e-03 1.00000e-09 1.00000e-01

$1.00000 \mathrm{e}+001.00000 \mathrm{e}+001.00000 \mathrm{e}-011.00000 \mathrm{e}-091.00000 \mathrm{e}-01$ 
Element: 7695 \# of layers: 3

$\mathrm{Kx} \mathrm{Ky} \mathrm{Kz}$ Ss Por

$1.90381 \mathrm{e}+01$ 1.90381e+01 1.90381e+00 1.00000e-09 7.00000e-02

$1.00000 \mathrm{e}-02$ 1.00000e-02 1.00000e-03 1.00000e-09 1.00000e-01

$1.00000 \mathrm{e}+001.00000 \mathrm{e}+001.00000 \mathrm{e}-011.00000 \mathrm{e}-091.00000 \mathrm{e}-01$

Element: 7696 \# of layers: 3

$\mathrm{Kx} \mathrm{Ky} \mathrm{Kz}$ Ss Por

$1.90381 \mathrm{e}+011.90381 \mathrm{e}+011.90381 \mathrm{e}+001.00000 \mathrm{e}-09$ 7.00000e-02

$1.00000 \mathrm{e}-02$ 1.00000e-02 1.00000e-03 1.00000e-09 1.00000e-01

$1.00000 \mathrm{e}+001.00000 \mathrm{e}+001.00000 \mathrm{e}-01$ 1.00000e-09 1.00000e-01

Element: 7697 \# of layers: 3

Kx Ky Kz Ss Por

$1.90381 \mathrm{e}+011.90381 \mathrm{e}+01$ 1.90381e+00 1.00000e-09 7.00000e-02

1.00000e-02 1.00000e-02 1.00000e-03 1.00000e-09 1.00000e-01

$1.00000 \mathrm{e}+001.00000 \mathrm{e}+001.00000 \mathrm{e}-011.00000 \mathrm{e}-091.00000 \mathrm{e}-01$

Element: 7698 \# of layers: 3

$\mathrm{Kx} \mathrm{Ky} \mathrm{Kz}$ Ss Por

$1.90381 \mathrm{e}+011.90381 \mathrm{e}+011.90381 \mathrm{e}+00$ 1.00000e-09 7.00000e-02

$1.00000 \mathrm{e}-02$ 1.00000e-02 1.00000e-03 1.00000e-09 1.00000e-01

$1.00000 \mathrm{e}+001.00000 \mathrm{e}+001.00000 \mathrm{e}-011.00000 \mathrm{e}-091.00000 \mathrm{e}-01$

Element: 7699 \# of layers: 3

$\mathrm{Kx} \mathrm{Ky} \mathrm{Kz}$ Ss Por

$1.90381 \mathrm{e}+011.90381 \mathrm{e}+01$ 1.90381e+00 1.00000e-09 7.00000e-02

$1.00000 \mathrm{e}-02$ 1.00000e-02 1.00000e-03 1.00000e-09 1.00000e-01

$1.00000 \mathrm{e}+001.00000 \mathrm{e}+001.00000 \mathrm{e}-011.00000 \mathrm{e}-091.00000 \mathrm{e}-01$

Element: 7700 \# of layers: 3

$\mathrm{Kx} \mathrm{Ky} \mathrm{Kz}$ Ss Por

$1.90381 \mathrm{e}+01$ 1.90381e+01 1.90381e+00 1.00000e-09 7.00000e-02

$1.00000 \mathrm{e}-02$ 1.00000e-02 1.00000e-03 1.00000e-09 1.00000e-01

$1.00000 \mathrm{e}+001.00000 \mathrm{e}+001.00000 \mathrm{e}-011.00000 \mathrm{e}-091.00000 \mathrm{e}-01$

Element: 7701 \# of layers: 3

Kx Ky Kz Ss Por

$1.90381 \mathrm{e}+011.90381 \mathrm{e}+011.90381 \mathrm{e}+00$ 1.00000e-09 7.00000e-02

$1.00000 \mathrm{e}-021.00000 \mathrm{e}-021.00000 \mathrm{e}-031.00000 \mathrm{e}-091.00000 \mathrm{e}-01$

$1.00000 \mathrm{e}+001.00000 \mathrm{e}+001.00000 \mathrm{e}-011.00000 \mathrm{e}-091.00000 \mathrm{e}-01$

Element: 7702 \# of layers: 3

Kx Ky Kz Ss Por

$1.90381 \mathrm{e}+011.90381 \mathrm{e}+011.90381 \mathrm{e}+001.00000 \mathrm{e}-09$ 7.00000e-02

$1.00000 \mathrm{e}-02$ 1.00000e-02 1.00000e-03 1.00000e-09 1.00000e-01

$1.00000 \mathrm{e}+001.00000 \mathrm{e}+001.00000 \mathrm{e}-01$ 1.00000e-09 1.00000e-01

Element: 7703 \# of layers: 3

$\mathrm{Kx} \mathrm{Ky} \mathrm{Kz}$ Ss Por

$2.41441 \mathrm{e}+012.41441 \mathrm{e}+012.41441 \mathrm{e}+00$ 1.00000e-09 7.00000e-02

$1.00000 \mathrm{e}-02$ 1.00000e-02 1.00000e-03 1.00000e-09 1.00000e-01

$1.00000 \mathrm{e}+001.00000 \mathrm{e}+001.00000 \mathrm{e}-01$ 1.00000e-09 1.00000e-01

Element: 7704 \# of layers: 3 


\section{Kx Ky Kz Ss Por}

$2.41441 \mathrm{e}+012.41441 \mathrm{e}+012.41441 \mathrm{e}+00$ 1.00000e-09 7.00000e-02

$1.00000 \mathrm{e}-021.00000 \mathrm{e}-02$ 1.00000e-03 1.00000e-09 1.00000e-01

$1.00000 \mathrm{e}+001.00000 \mathrm{e}+001.00000 \mathrm{e}-011.00000 \mathrm{e}-091.00000 \mathrm{e}-01$

Element: 7705 \# of layers: 3

Kx Ky Kz Ss Por

$2.41441 \mathrm{e}+012.41441 \mathrm{e}+012.41441 \mathrm{e}+00$ 1.00000e-09 7.00000e-02

$1.00000 \mathrm{e}-021.00000 \mathrm{e}-02$ 1.00000e-03 1.00000e-09 1.00000e-01

$1.00000 \mathrm{e}+001.00000 \mathrm{e}+001.00000 \mathrm{e}-011.00000 \mathrm{e}-091.00000 \mathrm{e}-01$

Element: 7706 \# of layers: 3

Kx Ky Kz Ss Por

$2.41441 \mathrm{e}+012.41441 \mathrm{e}+012.41441 \mathrm{e}+00$ 1.00000e-09 7.00000e-02

$1.00000 \mathrm{e}-02$ 1.00000e-02 1.00000e-03 1.00000e-09 1.00000e-01

$1.00000 \mathrm{e}+001.00000 \mathrm{e}+001.00000 \mathrm{e}-011.00000 \mathrm{e}-091.00000 \mathrm{e}-01$

Element: 7707 \# of layers: 3

Kx Ky Kz Ss Por

$2.41441 \mathrm{e}+012.41441 \mathrm{e}+012.41441 \mathrm{e}+00$ 1.00000e-09 7.00000e-02 $1.00000 \mathrm{e}-02$ 1.00000e-02 1.00000e-03 1.00000e-09 1.00000e-01

$1.00000 \mathrm{e}+001.00000 \mathrm{e}+001.00000 \mathrm{e}-011.00000 \mathrm{e}-091.00000 \mathrm{e}-01$

Element: 7708 \# of layers: 3

Kx Ky Kz Ss Por

$2.41441 \mathrm{e}+012.41441 \mathrm{e}+012.41441 \mathrm{e}+00$ 1.00000e-09 7.00000e-02

$1.00000 \mathrm{e}-02$ 1.00000e-02 1.00000e-03 1.00000e-09 1.00000e-01

$1.00000 \mathrm{e}+001.00000 \mathrm{e}+001.00000 \mathrm{e}-011.00000 \mathrm{e}-091.00000 \mathrm{e}-01$

Element: 7709 \# of layers: 3

Kx Ky Kz Ss Por

$2.41441 \mathrm{e}+012.41441 \mathrm{e}+012.41441 \mathrm{e}+00$ 1.00000e-09 7.00000e-02

$1.00000 \mathrm{e}-02$ 1.00000e-02 1.00000e-03 1.00000e-09 1.00000e-01

$1.00000 \mathrm{e}+001.00000 \mathrm{e}+001.00000 \mathrm{e}-011.00000 \mathrm{e}-091.00000 \mathrm{e}-01$

Element: 7710 \# of layers: 3

Kx Ky Kz Ss Por

$2.41441 \mathrm{e}+012.41441 \mathrm{e}+012.41441 \mathrm{e}+00$ 1.00000e-09 7.00000e-02

$1.00000 \mathrm{e}-021.00000 \mathrm{e}-02$ 1.00000e-03 1.00000e-09 1.00000e-01

$1.00000 \mathrm{e}+001.00000 \mathrm{e}+001.00000 \mathrm{e}-011.00000 \mathrm{e}-091.00000 \mathrm{e}-01$

Element: 7711 \# of layers: 3

Kx Ky Kz Ss Por

$2.41441 \mathrm{e}+012.41441 \mathrm{e}+012.41441 \mathrm{e}+00$ 1.00000e-09 7.00000e-02

$1.00000 \mathrm{e}-02$ 1.00000e-02 1.00000e-03 1.00000e-09 1.00000e-01

$1.00000 \mathrm{e}+001.00000 \mathrm{e}+001.00000 \mathrm{e}-011.00000 \mathrm{e}-091.00000 \mathrm{e}-01$

Element: 7712 \# of layers: 3

Kx Ky Kz Ss Por

$3.94530 \mathrm{e}+013.94530 \mathrm{e}+013.94530 \mathrm{e}+00$ 1.00000e-09 7.00000e-02 $1.00000 \mathrm{e}-021.00000 \mathrm{e}-02$ 1.00000e-03 1.00000e-09 1.00000e-01

$1.00000 \mathrm{e}+001.00000 \mathrm{e}+001.00000 \mathrm{e}-011.00000 \mathrm{e}-091.00000 \mathrm{e}-01$

Element: 7713 \# of layers: 3

Kx Ky Kz Ss Por 
$3.94530 \mathrm{e}+013.94530 \mathrm{e}+013.94530 \mathrm{e}+001.00000 \mathrm{e}-09$ 7.00000e-02 $1.00000 \mathrm{e}-02$ 1.00000e-02 1.00000e-03 1.00000e-09 1.00000e-01

$1.00000 \mathrm{e}+001.00000 \mathrm{e}+001.00000 \mathrm{e}-011.00000 \mathrm{e}-091.00000 \mathrm{e}-01$

Element: 7714 \# of layers: 3

$\mathrm{Kx} \mathrm{Ky} \mathrm{Kz}$ Ss Por

3.94530e+01 3.94530e+01 3.94530e+00 1.00000e-09 7.00000e-02 1.00000e-02 1.00000e-02 1.00000e-03 1.00000e-09 1.00000e-01

$1.00000 \mathrm{e}+001.00000 \mathrm{e}+001.00000 \mathrm{e}-011.00000 \mathrm{e}-091.00000 \mathrm{e}-01$

Element: 7715 \# of layers: 3

$\mathrm{Kx} \mathrm{Ky} \mathrm{Kz}$ Ss Por

3.94530e+01 3.94530e+01 3.94530e+00 1.00000e-09 7.00000e-02

$1.00000 \mathrm{e}-02$ 1.00000e-02 1.00000e-03 1.00000e-09 1.00000e-01

$1.00000 \mathrm{e}+001.00000 \mathrm{e}+001.00000 \mathrm{e}-011.00000 \mathrm{e}-09$ 1.00000e-01

Element: 7716 \# of layers: 3

Kx Ky Kz Ss Por

3.94530e+01 3.94530e+01 3.94530e+00 1.00000e-09 7.00000e-02

$1.00000 \mathrm{e}-02$ 1.00000e-02 1.00000e-03 1.00000e-09 1.00000e-01

$1.00000 \mathrm{e}+001.00000 \mathrm{e}+001.00000 \mathrm{e}-01$ 1.00000e-09 1.00000e-01

Element: 7717 \# of layers: 3

$\mathrm{Kx} \mathrm{Ky} \mathrm{Kz}$ Ss Por

3.94530e+01 3.94530e+01 3.94530e+00 1.00000e-09 7.00000e-02 $1.00000 \mathrm{e}-02$ 1.00000e-02 1.00000e-03 1.00000e-09 1.00000e-01

$1.00000 \mathrm{e}+001.00000 \mathrm{e}+001.00000 \mathrm{e}-01$ 1.00000e-09 1.00000e-01

Element: 7718 \# of layers: 3

$\mathrm{Kx} \mathrm{Ky} \mathrm{Kz}$ Ss Por

$3.94530 \mathrm{e}+013.94530 \mathrm{e}+013.94530 \mathrm{e}+001.00000 \mathrm{e}-09$ 7.00000e-02 $1.00000 \mathrm{e}-02$ 1.00000e-02 1.00000e-03 1.00000e-09 1.00000e-01

$1.00000 \mathrm{e}+001.00000 \mathrm{e}+001.00000 \mathrm{e}-011.00000 \mathrm{e}-091.00000 \mathrm{e}-01$

Element: 7719 \# of layers: 3

$\mathrm{Kx} \mathrm{Ky} \mathrm{Kz}$ Ss Por

3.94530e+01 3.94530e+01 3.94530e+00 1.00000e-09 7.00000e-02 $1.00000 \mathrm{e}-02$ 1.00000e-02 1.00000e-03 1.00000e-09 1.00000e-01

$1.00000 \mathrm{e}+001.00000 \mathrm{e}+001.00000 \mathrm{e}-011.00000 \mathrm{e}-091.00000 \mathrm{e}-01$

Element: 7720 \# of layers: 3

$\mathrm{Kx} \mathrm{Ky} \mathrm{Kz}$ Ss Por

3.94530e+01 3.94530e+01 3.94530e+00 1.00000e-09 7.00000e-02 $1.00000 \mathrm{e}-02$ 1.00000e-02 1.00000e-03 1.00000e-09 1.00000e-01

$1.00000 \mathrm{e}+001.00000 \mathrm{e}+001.00000 \mathrm{e}-011.00000 \mathrm{e}-091.00000 \mathrm{e}-01$

Element: 7721 \# of layers: 3

$\mathrm{Kx} \mathrm{Ky} \mathrm{Kz}$ Ss Por

7.01573e+01 7.01573e+01 7.01573e+00 1.00000e-09 7.00000e-02

$1.00000 \mathrm{e}-02$ 1.00000e-02 1.00000e-03 1.00000e-09 1.00000e-01

$1.00000 \mathrm{e}+001.00000 \mathrm{e}+001.00000 \mathrm{e}-01$ 1.00000e-09 1.00000e-01

Element: 7722 \# of layers: 3

Kx Ky Kz Ss Por

7.01573e+01 7.01573e+01 7.01573e+00 1.00000e-09 7.00000e-02 
$1.00000 \mathrm{e}-02$ 1.00000e-02 1.00000e-03 1.00000e-09 1.00000e-01 $1.00000 \mathrm{e}+001.00000 \mathrm{e}+001.00000 \mathrm{e}-01$ 1.00000e-09 1.00000e-01 Element: 7723 \# of layers: 3

Kx Ky Kz Ss Por

7.01573e+01 7.01573e+01 7.01573e+00 1.00000e-09 7.00000e-02 $1.00000 \mathrm{e}-02$ 1.00000e-02 1.00000e-03 1.00000e-09 1.00000e-01 $1.00000 \mathrm{e}+001.00000 \mathrm{e}+001.00000 \mathrm{e}-011.00000 \mathrm{e}-091.00000 \mathrm{e}-01$

Element: 7724 \# of layers: 3

$\mathrm{Kx} \mathrm{Ky} \mathrm{Kz}$ Ss Por

7.01573e+01 7.01573e+01 7.01573e+00 1.00000e-09 7.00000e-02 $1.00000 \mathrm{e}-02$ 1.00000e-02 1.00000e-03 1.00000e-09 1.00000e-01

$1.00000 \mathrm{e}+001.00000 \mathrm{e}+001.00000 \mathrm{e}-011.00000 \mathrm{e}-091.00000 \mathrm{e}-01$

Element: 7725 \# of layers: 3

$\mathrm{Kx} \mathrm{Ky} \mathrm{Kz}$ Ss Por

7.01573e+01 7.01573e+01 7.01573e+00 1.00000e-09 7.00000e-02 $1.00000 \mathrm{e}-02$ 1.00000e-02 1.00000e-03 1.00000e-09 1.00000e-01

$1.00000 \mathrm{e}+001.00000 \mathrm{e}+001.00000 \mathrm{e}-011.00000 \mathrm{e}-091.00000 \mathrm{e}-01$

Element: 7726 \# of layers: 3

$\mathrm{Kx} \mathrm{Ky} \mathrm{Kz}$ Ss Por

7.01573e+01 7.01573e+01 7.01573e+00 1.00000e-09 7.00000e-02

$1.00000 \mathrm{e}-02$ 1.00000e-02 1.00000e-03 1.00000e-09 1.00000e-01

$1.00000 \mathrm{e}+001.00000 \mathrm{e}+001.00000 \mathrm{e}-01$ 1.00000e-09 1.00000e-01

Element: 7727 \# of layers: 3

Kx Ky Kz Ss Por

7.01573e+01 7.01573e+01 7.01573e+00 1.00000e-09 7.00000e-02 $1.00000 \mathrm{e}-02$ 1.00000e-02 1.00000e-03 1.00000e-09 1.00000e-01

$1.00000 \mathrm{e}+001.00000 \mathrm{e}+001.00000 \mathrm{e}-011.00000 \mathrm{e}-091.00000 \mathrm{e}-01$

Element: 7728 \# of layers: 3

Kx Ky Kz Ss Por

7.01573e+01 7.01573e+01 7.01573e+00 1.00000e-09 7.00000e-02 $1.00000 \mathrm{e}-02$ 1.00000e-02 1.00000e-03 1.00000e-09 1.00000e-01 $1.00000 \mathrm{e}+001.00000 \mathrm{e}+001.00000 \mathrm{e}-01$ 1.00000e-09 1.00000e-01

Element: 7729 \# of layers: 3

$\mathrm{Kx} \mathrm{Ky} \mathrm{Kz}$ Ss Por

7.01573e+01 7.01573e+01 7.01573e+00 1.00000e-09 7.00000e-02 $1.00000 \mathrm{e}-02$ 1.00000e-02 1.00000e-03 1.00000e-09 1.00000e-01

$1.00000 \mathrm{e}+001.00000 \mathrm{e}+001.00000 \mathrm{e}-011.00000 \mathrm{e}-091.00000 \mathrm{e}-01$

Element: 7730 \# of layers: 3

$\mathrm{Kx} \mathrm{Ky} \mathrm{Kz}$ Ss Por

6.58811e+01 6.58811e+01 6.58811e+00 1.00000e-09 7.00000e-02 $1.00000 \mathrm{e}-02$ 1.00000e-02 1.00000e-03 1.00000e-09 1.00000e-01

$1.00000 \mathrm{e}+001.00000 \mathrm{e}+001.00000 \mathrm{e}-011.00000 \mathrm{e}-091.00000 \mathrm{e}-01$

Element: 7731 \# of layers: 3

Kx Ky Kz Ss Por

6.58811e+01 6.58811e+01 6.58811e+00 1.00000e-09 7.00000e-02

$1.00000 \mathrm{e}-02$ 1.00000e-02 1.00000e-03 1.00000e-09 1.00000e-01 
$1.00000 \mathrm{e}+001.00000 \mathrm{e}+00$ 1.00000e-01 1.00000e-09 1.00000e-01

Element: 7732 \# of layers: 3

Kx Ky Kz Ss Por

$6.58811 \mathrm{e}+016.58811 \mathrm{e}+016.58811 \mathrm{e}+001.00000 \mathrm{e}-09$ 7.00000e-02

$1.00000 \mathrm{e}-02$ 1.00000e-02 1.00000e-03 1.00000e-09 1.00000e-01

$1.00000 \mathrm{e}+001.00000 \mathrm{e}+001.00000 \mathrm{e}-011.00000 \mathrm{e}-09$ 1.00000e-01

Element: 7733 \# of layers: 3

$\mathrm{Kx} \mathrm{Ky} \mathrm{Kz}$ Ss Por

6.58811e+01 6.58811e+01 6.58811e+00 1.00000e-09 7.00000e-02

$1.00000 \mathrm{e}-02$ 1.00000e-02 1.00000e-03 1.00000e-09 1.00000e-01

$1.00000 \mathrm{e}+001.00000 \mathrm{e}+001.00000 \mathrm{e}-011.00000 \mathrm{e}-091.00000 \mathrm{e}-01$

Element: 7734 \# of layers: 3

$\mathrm{Kx} \mathrm{Ky} \mathrm{Kz}$ Ss Por

6.58811e+01 6.58811e+01 6.58811e+00 1.00000e-09 7.00000e-02

$1.00000 \mathrm{e}-02$ 1.00000e-02 1.00000e-03 1.00000e-09 1.00000e-01

$1.00000 \mathrm{e}+001.00000 \mathrm{e}+001.00000 \mathrm{e}-011.00000 \mathrm{e}-091.00000 \mathrm{e}-01$

Element: 7735 \# of layers: 3

$\mathrm{Kx} \mathrm{Ky} \mathrm{Kz}$ Ss Por

6.58811e+01 6.58811e+01 6.58811e+00 1.00000e-09 7.00000e-02

$1.00000 \mathrm{e}-02$ 1.00000e-02 1.00000e-03 1.00000e-09 1.00000e-01

$1.00000 \mathrm{e}+001.00000 \mathrm{e}+001.00000 \mathrm{e}-011.00000 \mathrm{e}-091.00000 \mathrm{e}-01$

Element: 7736 \# of layers: 3

$\mathrm{Kx} \mathrm{Ky} \mathrm{Kz}$ Ss Por

6.58811e+01 6.58811e+01 6.58811e+00 1.00000e-09 7.00000e-02

$1.00000 \mathrm{e}-021.00000 \mathrm{e}-02$ 1.00000e-03 1.00000e-09 1.00000e-01

$1.00000 \mathrm{e}+001.00000 \mathrm{e}+001.00000 \mathrm{e}-011.00000 \mathrm{e}-091.00000 \mathrm{e}-01$

Element: 7737 \# of layers: 3

$\mathrm{Kx} \mathrm{Ky} \mathrm{Kz} \mathrm{Ss} \mathrm{Por}$

6.58811e+01 6.58811e+01 6.58811e+00 1.00000e-09 7.00000e-02

$1.00000 \mathrm{e}-02$ 1.00000e-02 1.00000e-03 1.00000e-09 1.00000e-01

$1.00000 \mathrm{e}+001.00000 \mathrm{e}+001.00000 \mathrm{e}-011.00000 \mathrm{e}-091.00000 \mathrm{e}-01$

Element: 7738 \# of layers: 3

Kx Ky Kz Ss Por

6.58811e+01 6.58811e+01 6.58811e+00 1.00000e-09 7.00000e-02

$1.00000 \mathrm{e}-02$ 1.00000e-02 1.00000e-03 1.00000e-09 1.00000e-01

$1.00000 \mathrm{e}+001.00000 \mathrm{e}+001.00000 \mathrm{e}-011.00000 \mathrm{e}-091.00000 \mathrm{e}-01$

Element: 7739 \# of layers: 3

$\mathrm{Kx} \mathrm{Ky} \mathrm{Kz}$ Ss Por

5.20030e+01 5.20030e+01 5.20030e+00 1.00000e-09 7.00000e-02

$1.00000 \mathrm{e}-02$ 1.00000e-02 1.00000e-03 1.00000e-09 1.00000e-01

$1.00000 \mathrm{e}+001.00000 \mathrm{e}+001.00000 \mathrm{e}-011.00000 \mathrm{e}-091.00000 \mathrm{e}-01$

Element: 7740 \# of layers: 3

$\mathrm{Kx} \mathrm{Ky} \mathrm{Kz}$ Ss Por

5.20030e+01 5.20030e+01 5.20030e+00 1.00000e-09 7.00000e-02

$1.00000 \mathrm{e}-02$ 1.00000e-02 1.00000e-03 1.00000e-09 1.00000e-01

$1.00000 \mathrm{e}+001.00000 \mathrm{e}+001.00000 \mathrm{e}-011.00000 \mathrm{e}-091.00000 \mathrm{e}-01$ 
Element: 7741 \# of layers: 3

$\mathrm{Kx} \mathrm{Ky} \mathrm{Kz}$ Ss Por

6.12779e+01 6.12779e+01 6.12779e+00 1.00000e-09 7.00000e-02

$1.00000 \mathrm{e}-02$ 1.00000e-02 1.00000e-03 1.00000e-09 1.00000e-01

$1.00000 \mathrm{e}+001.00000 \mathrm{e}+001.00000 \mathrm{e}-01$ 1.00000e-09 1.00000e-01

Element: 7745 \# of layers: 3

$\mathrm{Kx} \mathrm{Ky} \mathrm{Kz}$ Ss Por

5.20030e+01 5.20030e+01 5.20030e+00 1.00000e-09 7.00000e-02

$1.00000 \mathrm{e}-02$ 1.00000e-02 1.00000e-03 1.00000e-09 1.00000e-01

$1.00000 \mathrm{e}+001.00000 \mathrm{e}+001.00000 \mathrm{e}-011.00000 \mathrm{e}-091.00000 \mathrm{e}-01$

Element: 7746 \# of layers: 3

Kx Ky Kz Ss Por

5.20030e+01 5.20030e+01 5.20030e+00 1.00000e-09 7.00000e-02

$1.00000 \mathrm{e}-02$ 1.00000e-02 1.00000e-03 1.00000e-09 1.00000e-01

$1.00000 \mathrm{e}+001.00000 \mathrm{e}+001.00000 \mathrm{e}-011.00000 \mathrm{e}-091.00000 \mathrm{e}-01$

Element: 7748 \# of layers: 3

Kx Ky Kz Ss Por

4.72223e+01 4.72223e+01 4.72223e+00 1.00000e-09 7.00000e-02 $1.00000 \mathrm{e}-02$ 1.00000e-02 1.00000e-03 1.00000e-09 1.00000e-01

$1.00000 \mathrm{e}+001.00000 \mathrm{e}+001.00000 \mathrm{e}-011.00000 \mathrm{e}-091.00000 \mathrm{e}-01$

Element: 7749 \# of layers: 3

$\mathrm{Kx} \mathrm{Ky} \mathrm{Kz}$ Ss Por

4.72223e+01 4.72223e+01 4.72223e+00 1.00000e-09 7.00000e-02

$1.00000 \mathrm{e}-02$ 1.00000e-02 1.00000e-03 1.00000e-09 1.00000e-01

$1.00000 \mathrm{e}+001.00000 \mathrm{e}+001.00000 \mathrm{e}-011.00000 \mathrm{e}-091.00000 \mathrm{e}-01$

Element: 7750 \# of layers: 3

$\mathrm{Kx} \mathrm{Ky} \mathrm{Kz}$ Ss Por

4.72223e+01 4.72223e+01 4.72223e+00 1.00000e-09 7.00000e-02

$1.00000 \mathrm{e}-02$ 1.00000e-02 1.00000e-03 1.00000e-09 1.00000e-01

$1.00000 \mathrm{e}+001.00000 \mathrm{e}+001.00000 \mathrm{e}-011.00000 \mathrm{e}-091.00000 \mathrm{e}-01$

Element: 7751 \# of layers: 3

Kx Ky Kz Ss Por

4.34111e+01 4.34111e+01 4.34111e+00 1.00000e-09 7.00000e-02

$1.00000 \mathrm{e}-021.00000 \mathrm{e}-021.00000 \mathrm{e}-031.00000 \mathrm{e}-091.00000 \mathrm{e}-01$

$1.00000 \mathrm{e}+001.00000 \mathrm{e}+001.00000 \mathrm{e}-011.00000 \mathrm{e}-091.00000 \mathrm{e}-01$

Element: 7752 \# of layers: 3

Kx Ky Kz Ss Por

4.34111e+01 4.34111e+01 4.34111e+00 1.00000e-09 7.00000e-02

$1.00000 \mathrm{e}-02$ 1.00000e-02 1.00000e-03 1.00000e-09 1.00000e-01

$1.00000 \mathrm{e}+001.00000 \mathrm{e}+001.00000 \mathrm{e}-011.00000 \mathrm{e}-091.00000 \mathrm{e}-01$

Element: 7753 \# of layers: 3

$\mathrm{Kx} \mathrm{Ky} \mathrm{Kz}$ Ss Por

4.34111e+01 4.34111e+01 4.34111e+00 1.00000e-09 7.00000e-02 $1.00000 \mathrm{e}-02$ 1.00000e-02 1.00000e-03 1.00000e-09 1.00000e-01

$1.00000 \mathrm{e}+001.00000 \mathrm{e}+001.00000 \mathrm{e}-01$ 1.00000e-09 1.00000e-01

Element: 7754 \# of layers: 5 
$\mathrm{Kx} \mathrm{Ky} \mathrm{Kz}$ Ss Por

$1.83541 \mathrm{e}+02$ 1.83541e+02 1.83541e+01 1.00000e-09 2.12000e-01

$1.83541 \mathrm{e}+021.83541 \mathrm{e}+02$ 1.83541e+01 1.00000e-09 2.12000e-01

$1.83541 \mathrm{e}+02 \quad 1.83541 \mathrm{e}+02 \quad 1.83541 \mathrm{e}+01$ 1.00000e-09 2.12000e-01

$1.00000 \mathrm{e}-02$ 1.00000e-02 1.00000e-03 1.00000e-09 1.00000e-01

$1.00000 \mathrm{e}+001.00000 \mathrm{e}+001.00000 \mathrm{e}-011.00000 \mathrm{e}-091.00000 \mathrm{e}-01$

Element: 7755 \# of layers: 5

Kx Ky Kz Ss Por

$1.83541 \mathrm{e}+02$ 1.83541e+02 1.83541e+01 1.00000e-09 2.12000e-01

$1.83541 \mathrm{e}+02$ 1.83541e+02 1.83541e+01 1.00000e-09 2.12000e-01

$1.83541 \mathrm{e}+02$ 1.83541e+02 1.83541e+01 1.00000e-09 2.12000e-01

$1.00000 \mathrm{e}-02$ 1.00000e-02 1.00000e-03 1.00000e-09 1.00000e-01

$1.00000 \mathrm{e}+001.00000 \mathrm{e}+001.00000 \mathrm{e}-01$ 1.00000e-09 1.00000e-01

Element: 7756 \# of layers: 5

$\mathrm{Kx} \mathrm{Ky} \mathrm{Kz}$ Ss Por

$1.83541 \mathrm{e}+02$ 1.83541e+02 1.83541e+01 1.00000e-09 2.12000e-01

$1.83541 \mathrm{e}+02$ 1.83541e+02 1.83541e+01 1.00000e-09 2.12000e-01

$1.83541 \mathrm{e}+02$ 1.83541e+02 1.83541e+01 1.00000e-09 2.12000e-01

$1.00000 \mathrm{e}-021.00000 \mathrm{e}-021.00000 \mathrm{e}-031.00000 \mathrm{e}-091.00000 \mathrm{e}-01$

$1.00000 \mathrm{e}+001.00000 \mathrm{e}+001.00000 \mathrm{e}-011.00000 \mathrm{e}-091.00000 \mathrm{e}-01$

Element: 7757 \# of layers: 4

$\mathrm{Kx} \mathrm{Ky} \mathrm{Kz}$ Ss Por

2.22923e+02 2.22923e+02 2.22923e+01 1.00000e-09 2.12000e-01

$2.22923 \mathrm{e}+02$ 2.22923e+02 2.22923e+01 1.00000e-09 2.12000e-01

$1.00000 \mathrm{e}-02$ 1.00000e-02 1.00000e-03 1.00000e-09 1.00000e-01

$1.00000 \mathrm{e}+001.00000 \mathrm{e}+001.00000 \mathrm{e}-01$ 1.00000e-09 1.00000e-01

Element: 7758 \# of layers: 5

$\mathrm{Kx} \mathrm{Ky} \mathrm{Kz}$ Ss Por

$2.22923 \mathrm{e}+02$ 2.22923e+02 2.22923e+01 1.00000e-09 2.12000e-01

$2.22923 \mathrm{e}+02$ 2.22923e+02 2.22923e+01 1.00000e-09 2.12000e-01

$2.22923 \mathrm{e}+02$ 2.22923e+02 2.22923e+01 1.00000e-09 2.12000e-01

$1.00000 \mathrm{e}-02$ 1.00000e-02 1.00000e-03 1.00000e-09 1.00000e-01

$1.00000 \mathrm{e}+001.00000 \mathrm{e}+001.00000 \mathrm{e}-011.00000 \mathrm{e}-091.00000 \mathrm{e}-01$

Element: 7759 \# of layers: 5

$\mathrm{Kx} \mathrm{Ky} \mathrm{Kz}$ Ss Por

$2.22923 \mathrm{e}+02$ 2.22923e+02 2.22923e+01 1.00000e-09 2.12000e-01

$2.22923 \mathrm{e}+02$ 2.22923e+02 2.22923e+01 1.00000e-09 2.12000e-01

$2.22923 \mathrm{e}+02$ 2.22923e+02 2.22923e+01 1.00000e-09 2.12000e-01

$1.00000 \mathrm{e}-02$ 1.00000e-02 1.00000e-03 1.00000e-09 1.00000e-01

$1.00000 \mathrm{e}+001.00000 \mathrm{e}+001.00000 \mathrm{e}-011.00000 \mathrm{e}-091.00000 \mathrm{e}-01$

Element: 7760 \# of layers: 5

$\mathrm{Kx} \mathrm{Ky} \mathrm{Kz}$ Ss Por

2.11853e+02 2.11853e+02 2.11853e+01 1.00000e-09 2.12000e-01

$2.11853 \mathrm{e}+02$ 2.11853e+02 2.11853e+01 1.00000e-09 2.12000e-01

$2.11853 \mathrm{e}+02$ 2.11853e+02 2.11853e+01 1.00000e-09 2.12000e-01

$1.00000 \mathrm{e}-02$ 1.00000e-02 1.00000e-03 1.00000e-09 1.00000e-01 
$1.00000 \mathrm{e}+001.00000 \mathrm{e}+00$ 1.00000e-01 1.00000e-09 1.00000e-01

Element: 7761 \# of layers: 5

Kx Ky Kz Ss Por

$2.11853 e+02$ 2.11853e+02 2.11853e+01 1.00000e-09 2.12000e-01

$2.11853 \mathrm{e}+02$ 2.11853e+02 2.11853e+01 1.00000e-09 2.12000e-01

$2.11853 \mathrm{e}+02$ 2.11853e+02 2.11853e+01 1.00000e-09 2.12000e-01

1.00000e-02 1.00000e-02 1.00000e-03 1.00000e-09 1.00000e-01

$1.00000 \mathrm{e}+001.00000 \mathrm{e}+001.00000 \mathrm{e}-011.00000 \mathrm{e}-091.00000 \mathrm{e}-01$

Element: 7762 \# of layers: 5

$\mathrm{Kx} \mathrm{Ky} \mathrm{Kz}$ Ss Por

2.11853e+02 2.11853e+02 2.11853e+01 1.00000e-09 2.12000e-01

$2.11853 \mathrm{e}+02$ 2.11853e+02 2.11853e+01 1.00000e-09 2.12000e-01

$2.11853 \mathrm{e}+02$ 2.11853e+02 2.11853e+01 1.00000e-09 2.12000e-01

$1.00000 \mathrm{e}-02$ 1.00000e-02 1.00000e-03 1.00000e-09 1.00000e-01

$1.00000 \mathrm{e}+001.00000 \mathrm{e}+001.00000 \mathrm{e}-01$ 1.00000e-09 1.00000e-01

Element: 7763 \# of layers: 5

$\mathrm{Kx} \mathrm{Ky} \mathrm{Kz}$ Ss Por

2.11853e+02 2.11853e+02 2.11853e+01 1.00000e-09 2.12000e-01

2.11853e+02 2.11853e+02 2.11853e+01 1.00000e-09 2.12000e-01

2.11853e+02 2.11853e+02 2.11853e+01 1.00000e-09 2.12000e-01

$1.00000 \mathrm{e}-02$ 1.00000e-02 1.00000e-03 1.00000e-09 1.00000e-01

$1.00000 \mathrm{e}+001.00000 \mathrm{e}+001.00000 \mathrm{e}-011.00000 \mathrm{e}-091.00000 \mathrm{e}-01$

Element: 7764 \# of layers: 4

$\mathrm{Kx} \mathrm{Ky} \mathrm{Kz}$ Ss Por

2.11853e+02 2.11853e+02 2.11853e+01 1.00000e-09 2.12000e-01

$2.11853 \mathrm{e}+02$ 2.11853e+02 2.11853e+01 1.00000e-09 2.12000e-01

$1.00000 \mathrm{e}-02$ 1.00000e-02 1.00000e-03 1.00000e-09 1.00000e-01

$1.00000 \mathrm{e}+001.00000 \mathrm{e}+001.00000 \mathrm{e}-011.00000 \mathrm{e}-09$ 1.00000e-01

Element: 7769 \# of layers: 5

$\mathrm{Kx} \mathrm{Ky} \mathrm{Kz}$ Ss Por

$2.62851 \mathrm{e}+02$ 2.62851e+02 2.62851e+01 1.00000e-09 2.12000e-01

$2.62851 \mathrm{e}+022.62851 \mathrm{e}+02$ 2.62851e+01 1.00000e-09 2.12000e-01

$2.62851 \mathrm{e}+022.62851 \mathrm{e}+022.62851 \mathrm{e}+01$ 1.00000e-09 2.12000e-01

$1.00000 \mathrm{e}-02$ 1.00000e-02 1.00000e-03 1.00000e-09 1.00000e-01

$1.00000 \mathrm{e}+001.00000 \mathrm{e}+001.00000 \mathrm{e}-011.00000 \mathrm{e}-091.00000 \mathrm{e}-01$

Element: 7770 \# of layers: 4

Kx Ky Kz Ss Por

$2.62851 \mathrm{e}+02$ 2.62851e+02 2.62851e+01 1.00000e-09 2.12000e-01

$2.62851 \mathrm{e}+02$ 2.62851e+02 2.62851e+01 1.00000e-09 2.12000e-01

$1.00000 \mathrm{e}-02$ 1.00000e-02 1.00000e-03 1.00000e-09 1.00000e-01

$1.00000 \mathrm{e}+001.00000 \mathrm{e}+001.00000 \mathrm{e}-011.00000 \mathrm{e}-091.00000 \mathrm{e}-01$

Element: 7771 \# of layers: 4

$\mathrm{Kx} \mathrm{Ky} \mathrm{Kz}$ Ss Por

2.62851e+02 2.62851e+02 2.62851e+01 1.00000e-09 2.12000e-01

$2.62851 \mathrm{e}+022.62851 \mathrm{e}+022.62851 \mathrm{e}+01$ 1.00000e-09 2.12000e-01

$1.00000 \mathrm{e}-02$ 1.00000e-02 1.00000e-03 1.00000e-09 1.00000e-01 
$1.00000 \mathrm{e}+001.00000 \mathrm{e}+00$ 1.00000e-01 1.00000e-09 1.00000e-01

Element: 7772 \# of layers: 4

$\mathrm{Kx} \mathrm{Ky} \mathrm{Kz}$ Ss Por

$2.62851 \mathrm{e}+02$ 2.62851e+02 2.62851e+01 1.00000e-09 2.12000e-01

$2.62851 \mathrm{e}+022.62851 \mathrm{e}+02$ 2.62851e+01 1.00000e-09 2.12000e-01

$1.00000 \mathrm{e}-02$ 1.00000e-02 1.00000e-03 1.00000e-09 1.00000e-01

$1.00000 \mathrm{e}+001.00000 \mathrm{e}+001.00000 \mathrm{e}-01$ 1.00000e-09 1.00000e-01

Element: 7773 \# of layers: 4

$\mathrm{Kx} \mathrm{Ky} \mathrm{Kz}$ Ss Por

$2.62851 \mathrm{e}+02$ 2.62851e+02 2.62851e+01 1.00000e-09 2.12000e-01

$2.62851 \mathrm{e}+022.62851 \mathrm{e}+022.62851 \mathrm{e}+01$ 1.00000e-09 2.12000e-01

$1.00000 \mathrm{e}-02$ 1.00000e-02 1.00000e-03 1.00000e-09 1.00000e-01

$1.00000 \mathrm{e}+001.00000 \mathrm{e}+001.00000 \mathrm{e}-011.00000 \mathrm{e}-091.00000 \mathrm{e}-01$

Element: 7774 \# of layers: 4

$\mathrm{Kx} \mathrm{Ky} \mathrm{Kz}$ Ss Por

$2.62851 \mathrm{e}+022.62851 \mathrm{e}+022.62851 \mathrm{e}+01$ 1.00000e-09 2.12000e-01

$2.62851 \mathrm{e}+02$ 2.62851e+02 2.62851e+01 1.00000e-09 2.12000e-01

$1.00000 \mathrm{e}-02$ 1.00000e-02 1.00000e-03 1.00000e-09 1.00000e-01

$1.00000 \mathrm{e}+001.00000 \mathrm{e}+001.00000 \mathrm{e}-01$ 1.00000e-09 1.00000e-01

Element: 7775 \# of layers: 4

$\mathrm{Kx} \mathrm{Ky} \mathrm{Kz}$ Ss Por

$2.62851 \mathrm{e}+02$ 2.62851e+02 2.62851e+01 1.00000e-09 2.12000e-01

$2.62851 \mathrm{e}+02$ 2.62851e+02 2.62851e+01 1.00000e-09 2.12000e-01

$1.00000 \mathrm{e}-02$ 1.00000e-02 1.00000e-03 1.00000e-09 1.00000e-01

$1.00000 \mathrm{e}+001.00000 \mathrm{e}+001.00000 \mathrm{e}-011.00000 \mathrm{e}-091.00000 \mathrm{e}-01$

Element: 7776 \# of layers: 4

$\mathrm{Kx} \mathrm{Ky} \mathrm{Kz}$ Ss Por

$2.62851 \mathrm{e}+02$ 2.62851e+02 2.62851e+01 1.00000e-09 2.12000e-01

$2.62851 \mathrm{e}+022.62851 \mathrm{e}+022.62851 \mathrm{e}+01$ 1.00000e-09 2.12000e-01

$1.00000 \mathrm{e}-02$ 1.00000e-02 1.00000e-03 1.00000e-09 1.00000e-01

$1.00000 \mathrm{e}+001.00000 \mathrm{e}+001.00000 \mathrm{e}-011.00000 \mathrm{e}-091.00000 \mathrm{e}-01$

Element: 7777 \# of layers: 4

$\mathrm{Kx} \mathrm{Ky} \mathrm{Kz}$ Ss Por

$2.62851 \mathrm{e}+02$ 2.62851e+02 2.62851e+01 1.00000e-09 2.12000e-01

$2.62851 \mathrm{e}+022.62851 \mathrm{e}+022.62851 \mathrm{e}+01$ 1.00000e-09 2.12000e-01

1.00000e-02 1.00000e-02 1.00000e-03 1.00000e-09 1.00000e-01

$1.00000 \mathrm{e}+001.00000 \mathrm{e}+001.00000 \mathrm{e}-011.00000 \mathrm{e}-091.00000 \mathrm{e}-01$

Element: 7778 \# of layers: 4

$\mathrm{Kx} \mathrm{Ky} \mathrm{Kz}$ Ss Por

$2.98311 \mathrm{e}+02$ 2.98311e+02 2.98311e+01 1.00000e-09 2.12000e-01

$2.98311 \mathrm{e}+02$ 2.98311e+02 2.98311e+01 1.00000e-09 2.12000e-01

$1.00000 \mathrm{e}-02$ 1.00000e-02 1.00000e-03 1.00000e-09 1.00000e-01

$1.00000 \mathrm{e}+001.00000 \mathrm{e}+001.00000 \mathrm{e}-01$ 1.00000e-09 1.00000e-01

Element: 7779 \# of layers: 4

$\mathrm{Kx} \mathrm{Ky} \mathrm{Kz}$ Ss Por

2.98311e+02 2.98311e+02 2.98311e+01 1.00000e-09 2.12000e-01 
$2.98311 \mathrm{e}+02$ 2.98311e+02 2.98311e+01 1.00000e-09 2.12000e-01 $1.00000 \mathrm{e}-02$ 1.00000e-02 1.00000e-03 1.00000e-09 1.00000e-01

$1.00000 \mathrm{e}+001.00000 \mathrm{e}+001.00000 \mathrm{e}-011.00000 \mathrm{e}-091.00000 \mathrm{e}-01$

Element: 7780 \# of layers: 4

$\mathrm{Kx} \mathrm{Ky} \mathrm{Kz}$ Ss Por

$2.98311 \mathrm{e}+02$ 2.98311e+02 2.98311e+01 1.00000e-09 2.12000e-01

$2.98311 \mathrm{e}+022.98311 \mathrm{e}+022.98311 \mathrm{e}+01$ 1.00000e-09 2.12000e-01

$1.00000 \mathrm{e}-02$ 1.00000e-02 1.00000e-03 1.00000e-09 1.00000e-01

$1.00000 \mathrm{e}+001.00000 \mathrm{e}+001.00000 \mathrm{e}-011.00000 \mathrm{e}-09$ 1.00000e-01

Element: 7781 \# of layers: 4

$\mathrm{Kx} \mathrm{Ky} \mathrm{Kz}$ Ss Por

$2.98311 \mathrm{e}+022.98311 \mathrm{e}+022.98311 \mathrm{e}+01$ 1.00000e-09 2.12000e-01

$2.98311 \mathrm{e}+02$ 2.98311e+02 2.98311e+01 1.00000e-09 2.12000e-01

$1.00000 \mathrm{e}-02$ 1.00000e-02 1.00000e-03 1.00000e-09 1.00000e-01

$1.00000 \mathrm{e}+001.00000 \mathrm{e}+001.00000 \mathrm{e}-01$ 1.00000e-09 1.00000e-01

Element: 7782 \# of layers: 4

$\mathrm{Kx} \mathrm{Ky} \mathrm{Kz}$ Ss Por

$2.98311 \mathrm{e}+02$ 2.98311e+02 2.98311e+01 1.00000e-09 2.12000e-01

$2.98311 \mathrm{e}+02$ 2.98311e+02 2.98311e+01 1.00000e-09 2.12000e-01

$1.00000 \mathrm{e}-02$ 1.00000e-02 1.00000e-03 1.00000e-09 1.00000e-01

$1.00000 \mathrm{e}+001.00000 \mathrm{e}+001.00000 \mathrm{e}-011.00000 \mathrm{e}-091.00000 \mathrm{e}-01$

Element: 7783 \# of layers: 4

$\mathrm{Kx} \mathrm{Ky} \mathrm{Kz}$ Ss Por

$2.98311 \mathrm{e}+02$ 2.98311e+02 2.98311e+01 1.00000e-09 2.12000e-01

$2.98311 \mathrm{e}+02$ 2.98311e+02 2.98311e+01 1.00000e-09 2.12000e-01

$1.00000 \mathrm{e}-021.00000 \mathrm{e}-02$ 1.00000e-03 1.00000e-09 1.00000e-01

$1.00000 \mathrm{e}+001.00000 \mathrm{e}+001.00000 \mathrm{e}-011.00000 \mathrm{e}-091.00000 \mathrm{e}-01$

Element: 7784 \# of layers: 4

$\mathrm{Kx} \mathrm{Ky} \mathrm{Kz}$ Ss Por

2.98311e+02 2.98311e+02 2.98311e+01 1.00000e-09 2.12000e-01

$2.98311 \mathrm{e}+022.98311 \mathrm{e}+022.98311 \mathrm{e}+01$ 1.00000e-09 2.12000e-01

$1.00000 \mathrm{e}-02$ 1.00000e-02 1.00000e-03 1.00000e-09 1.00000e-01

$1.00000 \mathrm{e}+001.00000 \mathrm{e}+001.00000 \mathrm{e}-011.00000 \mathrm{e}-091.00000 \mathrm{e}-01$

Element: 7785 \# of layers: 4

$\mathrm{Kx} \mathrm{Ky} \mathrm{Kz}$ Ss Por

$2.98311 \mathrm{e}+02$ 2.98311e+02 2.98311e+01 1.00000e-09 2.12000e-01

$2.98311 \mathrm{e}+022.98311 \mathrm{e}+022.98311 \mathrm{e}+01$ 1.00000e-09 2.12000e-01

$1.00000 \mathrm{e}-02$ 1.00000e-02 1.00000e-03 1.00000e-09 1.00000e-01

$1.00000 \mathrm{e}+001.00000 \mathrm{e}+001.00000 \mathrm{e}-011.00000 \mathrm{e}-091.00000 \mathrm{e}-01$

Element: 7786 \# of layers: 4

$\mathrm{Kx} \mathrm{Ky} \mathrm{Kz}$ Ss Por

$2.98311 \mathrm{e}+02$ 2.98311e+02 2.98311e+01 1.00000e-09 2.12000e-01

$2.98311 \mathrm{e}+02$ 2.98311e+02 2.98311e+01 1.00000e-09 2.12000e-01

$1.00000 \mathrm{e}-02$ 1.00000e-02 1.00000e-03 1.00000e-09 1.00000e-01

$1.00000 \mathrm{e}+001.00000 \mathrm{e}+001.00000 \mathrm{e}-011.00000 \mathrm{e}-09$ 1.00000e-01

Element: 7787 \# of layers: 5 
$\mathrm{Kx} \mathrm{Ky} \mathrm{Kz} \mathrm{Ss} \mathrm{Por}$

$1.59071 \mathrm{e}+031.59071 \mathrm{e}+03$ 1.59071e+02 1.00000e-09 7.00000e-02

$6.35571 \mathrm{e}+016.35571 \mathrm{e}+016.35571 \mathrm{e}+00$ 1.00000e-09 2.12000e-01

$6.35571 \mathrm{e}+016.35571 \mathrm{e}+016.35571 \mathrm{e}+001.00000 \mathrm{e}-092.12000 \mathrm{e}-01$

$1.00000 \mathrm{e}-02$ 1.00000e-02 1.00000e-03 1.00000e-09 1.00000e-01

$1.00000 \mathrm{e}+001.00000 \mathrm{e}+001.00000 \mathrm{e}-011.00000 \mathrm{e}-091.00000 \mathrm{e}-01$

Element: 7788 \# of layers: 6

Kx Ky Kz Ss Por

$1.59071 \mathrm{e}+031.59071 \mathrm{e}+03$ 1.59071e+02 1.00000e-09 7.00000e-02

$1.59071 \mathrm{e}+031.59071 \mathrm{e}+03$ 1.59071e+02 1.00000e-09 7.00000e-02

$6.35571 \mathrm{e}+016.35571 \mathrm{e}+016.35571 \mathrm{e}+00$ 1.00000e-09 2.12000e-01

$6.35571 \mathrm{e}+016.35571 \mathrm{e}+016.35571 \mathrm{e}+001.00000 \mathrm{e}-092.12000 \mathrm{e}-01$

1.00000e-02 1.00000e-02 1.00000e-03 1.00000e-09 1.00000e-01

$1.00000 \mathrm{e}+001.00000 \mathrm{e}+001.00000 \mathrm{e}-01$ 1.00000e-09 1.00000e-01

Element: 7789 \# of layers: 6

Kx Ky Kz Ss Por

$1.59071 \mathrm{e}+031.59071 \mathrm{e}+03$ 1.59071e+02 1.00000e-09 7.00000e-02

$1.59071 \mathrm{e}+031.59071 \mathrm{e}+03$ 1.59071e+02 1.00000e-09 7.00000e-02

$6.35571 \mathrm{e}+016.35571 \mathrm{e}+016.35571 \mathrm{e}+00$ 1.00000e-09 2.12000e-01

$6.35571 \mathrm{e}+016.35571 \mathrm{e}+016.35571 \mathrm{e}+001.00000 \mathrm{e}-092.12000 \mathrm{e}-01$

$1.00000 \mathrm{e}-02$ 1.00000e-02 1.00000e-03 1.00000e-09 1.00000e-01

$1.00000 \mathrm{e}+001.00000 \mathrm{e}+001.00000 \mathrm{e}-01$ 1.00000e-09 1.00000e-01

Element: 7790 \# of layers: 6

Kx Ky Kz Ss Por

$1.59071 \mathrm{e}+03$ 1.59071e+03 1.59071e+02 1.00000e-09 7.00000e-02

$1.59071 \mathrm{e}+031.59071 \mathrm{e}+03$ 1.59071e+02 1.00000e-09 7.00000e-02

$6.35571 \mathrm{e}+016.35571 \mathrm{e}+016.35571 \mathrm{e}+00$ 1.00000e-09 2.12000e-01

$6.35571 \mathrm{e}+016.35571 \mathrm{e}+016.35571 \mathrm{e}+001.00000 \mathrm{e}-092.12000 \mathrm{e}-01$

$1.00000 \mathrm{e}-02$ 1.00000e-02 1.00000e-03 1.00000e-09 1.00000e-01

$1.00000 \mathrm{e}+001.00000 \mathrm{e}+001.00000 \mathrm{e}-011.00000 \mathrm{e}-091.00000 \mathrm{e}-01$

Element: 7791 \# of layers: 5

$\mathrm{Kx} \mathrm{Ky} \mathrm{Kz}$ Ss Por

$1.59071 \mathrm{e}+03$ 1.59071e+03 1.59071e+02 1.00000e-09 7.00000e-02

$6.35571 \mathrm{e}+016.35571 \mathrm{e}+016.35571 \mathrm{e}+00$ 1.00000e-09 2.12000e-01

$6.35571 \mathrm{e}+016.35571 \mathrm{e}+016.35571 \mathrm{e}+00$ 1.00000e-09 2.12000e-01

1.00000e-02 1.00000e-02 1.00000e-03 1.00000e-09 1.00000e-01

$1.00000 \mathrm{e}+001.00000 \mathrm{e}+001.00000 \mathrm{e}-011.00000 \mathrm{e}-091.00000 \mathrm{e}-01$

Element: 7792 \# of layers: 4

$\mathrm{Kx} \mathrm{Ky} \mathrm{Kz}$ Ss Por

6.35571e+01 6.35571e+01 6.35571e+00 1.00000e-09 2.12000e-01

$6.35571 \mathrm{e}+016.35571 \mathrm{e}+016.35571 \mathrm{e}+00$ 1.00000e-09 2.12000e-01

$1.00000 \mathrm{e}-02$ 1.00000e-02 1.00000e-03 1.00000e-09 1.00000e-01

$1.00000 \mathrm{e}+001.00000 \mathrm{e}+001.00000 \mathrm{e}-01$ 1.00000e-09 1.00000e-01

Element: 7793 \# of layers: 4

$\mathrm{Kx} \mathrm{Ky} \mathrm{Kz} \mathrm{Ss} \mathrm{Por}$

6.35571e+01 6.35571e+01 6.35571e+00 1.00000e-09 2.12000e-01 
$6.35571 \mathrm{e}+016.35571 \mathrm{e}+016.35571 \mathrm{e}+00$ 1.00000e-09 2.12000e-01 $1.00000 \mathrm{e}-021.00000 \mathrm{e}-02$ 1.00000e-03 1.00000e-09 1.00000e-01 $1.00000 \mathrm{e}+001.00000 \mathrm{e}+001.00000 \mathrm{e}-011.00000 \mathrm{e}-091.00000 \mathrm{e}-01$

Element: 7794 \# of layers: 4

$\mathrm{Kx} \mathrm{Ky} \mathrm{Kz}$ Ss Por

6.35571e+01 6.35571e+01 6.35571e+00 1.00000e-09 2.12000e-01

$6.35571 \mathrm{e}+016.35571 \mathrm{e}+016.35571 \mathrm{e}+00$ 1.00000e-09 2.12000e-01

$1.00000 \mathrm{e}-02$ 1.00000e-02 1.00000e-03 1.00000e-09 1.00000e-01

$1.00000 \mathrm{e}+001.00000 \mathrm{e}+00$ 1.00000e-01 1.00000e-09 1.00000e-01

Element: 7795 \# of layers: 5

Kx Ky Kz Ss Por

1.59071e+03 1.59071e+03 1.59071e+02 1.00000e-09 7.00000e-02

$6.35571 \mathrm{e}+016.35571 \mathrm{e}+016.35571 \mathrm{e}+00$ 1.00000e-09 2.12000e-01

$6.35571 \mathrm{e}+016.35571 \mathrm{e}+016.35571 \mathrm{e}+001.00000 \mathrm{e}-092.12000 \mathrm{e}-01$

$1.00000 \mathrm{e}-02$ 1.00000e-02 1.00000e-03 1.00000e-09 1.00000e-01

$1.00000 \mathrm{e}+001.00000 \mathrm{e}+001.00000 \mathrm{e}-011.00000 \mathrm{e}-091.00000 \mathrm{e}-01$

Element: 7796 \# of layers: 5

$\mathrm{Kx} \mathrm{Ky} \mathrm{Kz}$ Ss Por

1.92102e+02 1.92102e+02 1.92102e+01 1.00000e-09 7.00000e-02

$7.67581 \mathrm{e}+00$ 7.67581e+00 7.67581e-01 1.00000e-09 2.12000e-01

$7.67581 \mathrm{e}+007.67581 \mathrm{e}+007.67581 \mathrm{e}-01$ 1.00000e-09 2.12000e-01

$1.00000 \mathrm{e}-02$ 1.00000e-02 1.00000e-03 1.00000e-09 1.00000e-01

$1.00000 \mathrm{e}+001.00000 \mathrm{e}+001.00000 \mathrm{e}-01$ 1.00000e-09 1.00000e-01

Element: 7797 \# of layers: 4

$\mathrm{Kx} \mathrm{Ky} \mathrm{Kz}$ Ss Por

$1.92102 \mathrm{e}+021.92102 \mathrm{e}+02$ 1.92102e+01 1.00000e-09 7.00000e-02

$7.67581 \mathrm{e}+00$ 7.67581e+00 7.67581e-01 1.00000e-09 2.12000e-01

$1.00000 \mathrm{e}-02$ 1.00000e-02 1.00000e-03 1.00000e-09 1.00000e-01

$1.00000 \mathrm{e}+001.00000 \mathrm{e}+001.00000 \mathrm{e}-011.00000 \mathrm{e}-091.00000 \mathrm{e}-01$

Element: 7798 \# of layers: 4

$\mathrm{Kx} \mathrm{Ky} \mathrm{Kz}$ Ss Por

1.92102e+02 1.92102e+02 1.92102e+01 1.00000e-09 7.00000e-02

$7.67581 \mathrm{e}+007.67581 \mathrm{e}+007.67581 \mathrm{e}-01$ 1.00000e-09 2.12000e-01

$1.00000 \mathrm{e}-02$ 1.00000e-02 1.00000e-03 1.00000e-09 1.00000e-01

$1.00000 \mathrm{e}+001.00000 \mathrm{e}+001.00000 \mathrm{e}-011.00000 \mathrm{e}-091.00000 \mathrm{e}-01$

Element: 7799 \# of layers: 4

Kx Ky Kz Ss Por

1.92102e+02 1.92102e+02 1.92102e+01 1.00000e-09 7.00000e-02

$7.67581 \mathrm{e}+00$ 7.67581e+00 7.67581e-01 1.00000e-09 2.12000e-01

$1.00000 \mathrm{e}-02$ 1.00000e-02 1.00000e-03 1.00000e-09 1.00000e-01

$1.00000 \mathrm{e}+001.00000 \mathrm{e}+001.00000 \mathrm{e}-011.00000 \mathrm{e}-091.00000 \mathrm{e}-01$

Element: 7800 \# of layers: 4

$\mathrm{Kx} \mathrm{Ky} \mathrm{Kz}$ Ss Por

1.92102e+02 1.92102e+02 1.92102e+01 1.00000e-09 7.00000e-02

7.67581e+00 7.67581e+00 7.67581e-01 1.00000e-09 2.12000e-01

$1.00000 \mathrm{e}-02$ 1.00000e-02 1.00000e-03 1.00000e-09 1.00000e-01 
$1.00000 \mathrm{e}+001.00000 \mathrm{e}+00$ 1.00000e-01 1.00000e-09 1.00000e-01

Element: 7801 \# of layers: 5

$\mathrm{Kx} \mathrm{Ky} \mathrm{Kz}$ Ss Por

1.92102e+02 1.92102e+02 1.92102e+01 1.00000e-09 7.00000e-02

7.67581e+00 7.67581e+00 7.67581e-01 1.00000e-09 2.12000e-01

$7.67581 \mathrm{e}+007.67581 \mathrm{e}+00$ 7.67581e-01 1.00000e-09 2.12000e-01

$1.00000 \mathrm{e}-02$ 1.00000e-02 1.00000e-03 1.00000e-09 1.00000e-01

$1.00000 \mathrm{e}+001.00000 \mathrm{e}+001.00000 \mathrm{e}-011.00000 \mathrm{e}-091.00000 \mathrm{e}-01$

Element: 7802 \# of layers: 6

$\mathrm{Kx} \mathrm{Ky} \mathrm{Kz}$ Ss Por

1.92102e+02 1.92102e+02 1.92102e+01 1.00000e-09 7.00000e-02

$1.92102 \mathrm{e}+021.92102 \mathrm{e}+02$ 1.92102e+01 1.00000e-09 7.00000e-02

7.67581e+00 7.67581e+00 7.67581e-01 1.00000e-09 2.12000e-01

$7.67581 \mathrm{e}+007.67581 \mathrm{e}+00$ 7.67581e-01 1.00000e-09 2.12000e-01

$1.00000 \mathrm{e}-02$ 1.00000e-02 1.00000e-03 1.00000e-09 1.00000e-01

$1.00000 \mathrm{e}+001.00000 \mathrm{e}+001.00000 \mathrm{e}-011.00000 \mathrm{e}-091.00000 \mathrm{e}-01$

Element: 7803 \# of layers: 6

$\mathrm{Kx} \mathrm{Ky} \mathrm{Kz}$ Ss Por

1.92102e+02 1.92102e+02 1.92102e+01 1.00000e-09 7.00000e-02

$1.92102 \mathrm{e}+021.92102 \mathrm{e}+02$ 1.92102e+01 1.00000e-09 7.00000e-02

7.67581e+00 7.67581e+00 7.67581e-01 1.00000e-09 2.12000e-01

7.67581e+00 7.67581e+00 7.67581e-01 1.00000e-09 2.12000e-01

$1.00000 \mathrm{e}-02$ 1.00000e-02 1.00000e-03 1.00000e-09 1.00000e-01

$1.00000 \mathrm{e}+001.00000 \mathrm{e}+001.00000 \mathrm{e}-011.00000 \mathrm{e}-091.00000 \mathrm{e}-01$

Element: 7804 \# of layers: 5

$\mathrm{Kx} \mathrm{Ky} \mathrm{Kz}$ Ss Por

1.92102e+02 1.92102e+02 1.92102e+01 1.00000e-09 7.00000e-02

7.67581e+00 7.67581e+00 7.67581e-01 1.00000e-09 2.12000e-01

$7.67581 \mathrm{e}+007.67581 \mathrm{e}+007.67581 \mathrm{e}-01$ 1.00000e-09 2.12000e-01

$1.00000 \mathrm{e}-02$ 1.00000e-02 1.00000e-03 1.00000e-09 1.00000e-01

$1.00000 \mathrm{e}+001.00000 \mathrm{e}+001.00000 \mathrm{e}-011.00000 \mathrm{e}-091.00000 \mathrm{e}-01$

Element: 7805 \# of layers: 5

$\mathrm{Kx} \mathrm{Ky} \mathrm{Kz}$ Ss Por

8.32551e+01 8.32551e+01 8.32551e+00 1.00000e-09 7.00000e-02

8.32551e+01 8.32551e+01 8.32551e+00 1.00000e-09 7.00000e-02

$3.32670 \mathrm{e}+003.32670 \mathrm{e}+003.32670 \mathrm{e}-01$ 1.00000e-09 2.12000e-01

$1.00000 \mathrm{e}-02$ 1.00000e-02 1.00000e-03 1.00000e-09 1.00000e-01

$1.00000 \mathrm{e}+001.00000 \mathrm{e}+001.00000 \mathrm{e}-011.00000 \mathrm{e}-091.00000 \mathrm{e}-01$

Element: 7806 \# of layers: 5

$\mathrm{Kx} \mathrm{Ky} \mathrm{Kz}$ Ss Por

8.32551e+01 8.32551e+01 8.32551e+00 1.00000e-09 7.00000e-02

$8.32551 \mathrm{e}+018.32551 \mathrm{e}+018.32551 \mathrm{e}+001.00000 \mathrm{e}-09$ 7.00000e-02

$3.32670 \mathrm{e}+00$ 3.32670e+00 3.32670e-01 1.00000e-09 2.12000e-01

$1.00000 \mathrm{e}-02$ 1.00000e-02 1.00000e-03 1.00000e-09 1.00000e-01

$1.00000 \mathrm{e}+001.00000 \mathrm{e}+001.00000 \mathrm{e}-011.00000 \mathrm{e}-09$ 1.00000e-01

Element: 7807 \# of layers: 5 
$\mathrm{Kx} \mathrm{Ky} \mathrm{Kz}$ Ss Por

8.32551e+01 8.32551e+01 8.32551e+00 1.00000e-09 7.00000e-02

8.32551e+01 8.32551e+01 8.32551e+00 1.00000e-09 7.00000e-02

$3.32670 \mathrm{e}+003.32670 \mathrm{e}+00$ 3.32670e-01 1.00000e-09 2.12000e-01

$1.00000 \mathrm{e}-02$ 1.00000e-02 1.00000e-03 1.00000e-09 1.00000e-01

$1.00000 \mathrm{e}+001.00000 \mathrm{e}+001.00000 \mathrm{e}-011.00000 \mathrm{e}-091.00000 \mathrm{e}-01$

Element: 7808 \# of layers: 5

$\mathrm{Kx} \mathrm{Ky} \mathrm{Kz}$ Ss Por

8.32551e+01 8.32551e+01 8.32551e+00 1.00000e-09 7.00000e-02

$8.32551 \mathrm{e}+018.32551 \mathrm{e}+018.32551 \mathrm{e}+00$ 1.00000e-09 7.00000e-02

$3.32670 \mathrm{e}+003.32670 \mathrm{e}+00$ 3.32670e-01 1.00000e-09 2.12000e-01

$1.00000 \mathrm{e}-02$ 1.00000e-02 1.00000e-03 1.00000e-09 1.00000e-01

$1.00000 \mathrm{e}+001.00000 \mathrm{e}+001.00000 \mathrm{e}-011.00000 \mathrm{e}-091.00000 \mathrm{e}-01$

Element: 7809 \# of layers: 4

$\mathrm{Kx} \mathrm{Ky} \mathrm{Kz}$ Ss Por

8.32551e+01 8.32551e+01 8.32551e+00 1.00000e-09 7.00000e-02

$8.32551 \mathrm{e}+018.32551 \mathrm{e}+018.32551 \mathrm{e}+001.00000 \mathrm{e}-09$ 7.00000e-02

1.00000e-02 1.00000e-02 1.00000e-03 1.00000e-09 1.00000e-01

$1.00000 \mathrm{e}+001.00000 \mathrm{e}+001.00000 \mathrm{e}-011.00000 \mathrm{e}-091.00000 \mathrm{e}-01$

Element: 7810 \# of layers: 5

$\mathrm{Kx} \mathrm{Ky} \mathrm{Kz}$ Ss Por

8.32551e+01 8.32551e+01 8.32551e+00 1.00000e-09 7.00000e-02

8.32551e+01 8.32551e+01 8.32551e+00 1.00000e-09 7.00000e-02

$3.32670 \mathrm{e}+003.32670 \mathrm{e}+003.32670 \mathrm{e}-01$ 1.00000e-09 2.12000e-01

$1.00000 \mathrm{e}-021.00000 \mathrm{e}-02$ 1.00000e-03 1.00000e-09 1.00000e-01

$1.00000 \mathrm{e}+001.00000 \mathrm{e}+001.00000 \mathrm{e}-011.00000 \mathrm{e}-091.00000 \mathrm{e}-01$

Element: 7811 \# of layers: 5

$\mathrm{Kx} \mathrm{Ky} \mathrm{Kz}$ Ss Por

8.32551e+01 8.32551e+01 8.32551e+00 1.00000e-09 7.00000e-02

8.32551e+01 8.32551e+01 8.32551e+00 1.00000e-09 7.00000e-02

$3.32670 \mathrm{e}+003.32670 \mathrm{e}+00$ 3.32670e-01 1.00000e-09 2.12000e-01

$1.00000 \mathrm{e}-02$ 1.00000e-02 1.00000e-03 1.00000e-09 1.00000e-01

$1.00000 \mathrm{e}+001.00000 \mathrm{e}+001.00000 \mathrm{e}-011.00000 \mathrm{e}-091.00000 \mathrm{e}-01$

Element: 7812 \# of layers: 5

$\mathrm{Kx} \mathrm{Ky} \mathrm{Kz}$ Ss Por

8.32551e+01 8.32551e+01 8.32551e+00 1.00000e-09 7.00000e-02

$8.32551 \mathrm{e}+018.32551 \mathrm{e}+018.32551 \mathrm{e}+00$ 1.00000e-09 7.00000e-02

$3.32670 \mathrm{e}+003.32670 \mathrm{e}+003.32670 \mathrm{e}-01$ 1.00000e-09 2.12000e-01

$1.00000 \mathrm{e}-02$ 1.00000e-02 1.00000e-03 1.00000e-09 1.00000e-01

$1.00000 \mathrm{e}+001.00000 \mathrm{e}+001.00000 \mathrm{e}-01$ 1.00000e-09 1.00000e-01

Element: 7813 \# of layers: 5

$\mathrm{Kx} \mathrm{Ky} \mathrm{Kz}$ Ss Por

8.32551e+01 8.32551e+01 8.32551e+00 1.00000e-09 7.00000e-02

8.32551e+01 8.32551e+01 8.32551e+00 1.00000e-09 7.00000e-02

$3.32670 \mathrm{e}+00$ 3.32670e+00 3.32670e-01 1.00000e-09 2.12000e-01

$1.00000 \mathrm{e}-02$ 1.00000e-02 1.00000e-03 1.00000e-09 1.00000e-01 
$1.00000 \mathrm{e}+001.00000 \mathrm{e}+00$ 1.00000e-01 1.00000e-09 1.00000e-01

Element: 7814 \# of layers: 4

Kx Ky Kz Ss Por

6.67596e+01 6.67596e+01 6.67596e+00 1.00000e-09 7.00000e-02

$6.67596 \mathrm{e}+016.67596 \mathrm{e}+016.67596 \mathrm{e}+001.00000 \mathrm{e}-09$ 7.00000e-02

$1.00000 \mathrm{e}-02$ 1.00000e-02 1.00000e-03 1.00000e-09 1.00000e-01

$1.00000 \mathrm{e}+001.00000 \mathrm{e}+001.00000 \mathrm{e}-01$ 1.00000e-09 1.00000e-01

Element: 7815 \# of layers: 4

$\mathrm{Kx} \mathrm{Ky} \mathrm{Kz}$ Ss Por

6.67596e+01 6.67596e+01 6.67596e+00 1.00000e-09 7.00000e-02

$6.67596 \mathrm{e}+016.67596 \mathrm{e}+016.67596 \mathrm{e}+001.00000 \mathrm{e}-09$ 7.00000e-02

$1.00000 \mathrm{e}-02$ 1.00000e-02 1.00000e-03 1.00000e-09 1.00000e-01

$1.00000 \mathrm{e}+001.00000 \mathrm{e}+001.00000 \mathrm{e}-01$ 1.00000e-09 1.00000e-01

Element: 7816 \# of layers: 4

$\mathrm{Kx} \mathrm{Ky} \mathrm{Kz}$ Ss Por

6.67596e+01 6.67596e+01 6.67596e+00 1.00000e-09 7.00000e-02

$6.67596 \mathrm{e}+016.67596 \mathrm{e}+016.67596 \mathrm{e}+001.00000 \mathrm{e}-09$ 7.00000e-02

$1.00000 \mathrm{e}-02$ 1.00000e-02 1.00000e-03 1.00000e-09 1.00000e-01

$1.00000 \mathrm{e}+001.00000 \mathrm{e}+001.00000 \mathrm{e}-01$ 1.00000e-09 1.00000e-01

Element: 7817 \# of layers: 4

$\mathrm{Kx} \mathrm{Ky} \mathrm{Kz}$ Ss Por

6.67596e+01 6.67596e+01 6.67596e+00 1.00000e-09 7.00000e-02

6.67596e+01 6.67596e+01 6.67596e+00 1.00000e-09 7.00000e-02

$1.00000 \mathrm{e}-02$ 1.00000e-02 1.00000e-03 1.00000e-09 1.00000e-01

$1.00000 \mathrm{e}+001.00000 \mathrm{e}+001.00000 \mathrm{e}-011.00000 \mathrm{e}-091.00000 \mathrm{e}-01$

Element: 7818 \# of layers: 4

$\mathrm{Kx} \mathrm{Ky} \mathrm{Kz}$ Ss Por

6.67596e+01 6.67596e+01 6.67596e+00 1.00000e-09 7.00000e-02

$6.67596 \mathrm{e}+016.67596 \mathrm{e}+016.67596 \mathrm{e}+001.00000 \mathrm{e}-097.00000 \mathrm{e}-02$

$1.00000 \mathrm{e}-021.00000 \mathrm{e}-021.00000 \mathrm{e}-031.00000 \mathrm{e}-091.00000 \mathrm{e}-01$

$1.00000 \mathrm{e}+001.00000 \mathrm{e}+001.00000 \mathrm{e}-011.00000 \mathrm{e}-091.00000 \mathrm{e}-01$

Element: 7819 \# of layers: 4

Kx Ky Kz Ss Por

6.67596e+01 6.67596e+01 6.67596e+00 1.00000e-09 7.00000e-02

$6.67596 \mathrm{e}+016.67596 \mathrm{e}+016.67596 \mathrm{e}+001.00000 \mathrm{e}-09$ 7.00000e-02

$1.00000 \mathrm{e}-02$ 1.00000e-02 1.00000e-03 1.00000e-09 1.00000e-01

$1.00000 \mathrm{e}+001.00000 \mathrm{e}+001.00000 \mathrm{e}-011.00000 \mathrm{e}-091.00000 \mathrm{e}-01$

Element: 7820 \# of layers: 4

$\mathrm{Kx} \mathrm{Ky} \mathrm{Kz}$ Ss Por

6.67596e+01 6.67596e+01 6.67596e+00 1.00000e-09 7.00000e-02

$6.67596 \mathrm{e}+016.67596 \mathrm{e}+016.67596 \mathrm{e}+001.00000 \mathrm{e}-09$ 7.00000e-02

$1.00000 \mathrm{e}-02$ 1.00000e-02 1.00000e-03 1.00000e-09 1.00000e-01

$1.00000 \mathrm{e}+001.00000 \mathrm{e}+001.00000 \mathrm{e}-01$ 1.00000e-09 1.00000e-01

Element: 7821 \# of layers: 4

Kx Ky Kz Ss Por

6.67596e+01 6.67596e+01 6.67596e+00 1.00000e-09 7.00000e-02 
6.67596e+01 6.67596e+01 6.67596e+00 1.00000e-09 7.00000e-02 $1.00000 \mathrm{e}-02$ 1.00000e-02 1.00000e-03 1.00000e-09 1.00000e-01

$1.00000 \mathrm{e}+001.00000 \mathrm{e}+001.00000 \mathrm{e}-011.00000 \mathrm{e}-091.00000 \mathrm{e}-01$

Element: 7822 \# of layers: 4

$\mathrm{Kx} \mathrm{Ky} \mathrm{Kz}$ Ss Por

6.67596e+01 6.67596e+01 6.67596e+00 1.00000e-09 7.00000e-02

$6.67596 \mathrm{e}+016.67596 \mathrm{e}+016.67596 \mathrm{e}+00$ 1.00000e-09 7.00000e-02

$1.00000 \mathrm{e}-02$ 1.00000e-02 1.00000e-03 1.00000e-09 1.00000e-01

$1.00000 \mathrm{e}+001.00000 \mathrm{e}+001.00000 \mathrm{e}-011.00000 \mathrm{e}-091.00000 \mathrm{e}-01$

Element: 7823 \# of layers: 4

$\mathrm{Kx} \mathrm{Ky} \mathrm{Kz}$ Ss Por

7.18791e+01 7.18791e+01 7.18791e+00 1.00000e-09 7.00000e-02

$7.18791 \mathrm{e}+017.18791 \mathrm{e}+01$ 7.18791e+00 1.00000e-09 7.00000e-02

$1.00000 \mathrm{e}-02$ 1.00000e-02 1.00000e-03 1.00000e-09 1.00000e-01

$1.00000 \mathrm{e}+001.00000 \mathrm{e}+001.00000 \mathrm{e}-011.00000 \mathrm{e}-091.00000 \mathrm{e}-01$

Element: 7824 \# of layers: 4

$\mathrm{Kx} \mathrm{Ky} \mathrm{Kz}$ Ss Por

7.18791e+01 7.18791e+01 7.18791e+00 1.00000e-09 7.00000e-02

7.18791e+01 7.18791e+01 7.18791e+00 1.00000e-09 7.00000e-02

$1.00000 \mathrm{e}-02$ 1.00000e-02 1.00000e-03 1.00000e-09 1.00000e-01

$1.00000 \mathrm{e}+001.00000 \mathrm{e}+001.00000 \mathrm{e}-011.00000 \mathrm{e}-091.00000 \mathrm{e}-01$

Element: 7825 \# of layers: 4

$\mathrm{Kx} \mathrm{Ky} \mathrm{Kz}$ Ss Por

7.18791e+01 7.18791e+01 7.18791e+00 1.00000e-09 7.00000e-02

$7.18791 \mathrm{e}+017.18791 \mathrm{e}+017.18791 \mathrm{e}+001.00000 \mathrm{e}-097.00000 \mathrm{e}-02$

$1.00000 \mathrm{e}-021.00000 \mathrm{e}-021.00000 \mathrm{e}-031.00000 \mathrm{e}-091.00000 \mathrm{e}-01$

$1.00000 \mathrm{e}+001.00000 \mathrm{e}+001.00000 \mathrm{e}-011.00000 \mathrm{e}-09$ 1.00000e-01

Element: 7826 \# of layers: 4

Kx Ky Kz Ss Por

7.18791e+01 7.18791e+01 7.18791e+00 1.00000e-09 7.00000e-02

7.18791e+01 7.18791e+01 7.18791e+00 1.00000e-09 7.00000e-02

$1.00000 \mathrm{e}-02$ 1.00000e-02 1.00000e-03 1.00000e-09 1.00000e-01

$1.00000 \mathrm{e}+001.00000 \mathrm{e}+001.00000 \mathrm{e}-011.00000 \mathrm{e}-091.00000 \mathrm{e}-01$

Element: 7827 \# of layers: 4

$\mathrm{Kx} \mathrm{Ky} \mathrm{Kz}$ Ss Por

7.18791e+01 7.18791e+01 7.18791e+00 1.00000e-09 7.00000e-02

$7.18791 \mathrm{e}+017.18791 \mathrm{e}+017.18791 \mathrm{e}+001.00000 \mathrm{e}-09$ 7.00000e-02

$1.00000 \mathrm{e}-02$ 1.00000e-02 1.00000e-03 1.00000e-09 1.00000e-01

$1.00000 \mathrm{e}+001.00000 \mathrm{e}+001.00000 \mathrm{e}-011.00000 \mathrm{e}-091.00000 \mathrm{e}-01$

Element: 7828 \# of layers: 4

$\mathrm{Kx} \mathrm{Ky} \mathrm{Kz}$ Ss Por

7.18791e+01 7.18791e+01 7.18791e+00 1.00000e-09 7.00000e-02

7.18791e+01 7.18791e+01 7.18791e+00 1.00000e-09 7.00000e-02

$1.00000 \mathrm{e}-02$ 1.00000e-02 1.00000e-03 1.00000e-09 1.00000e-01

$1.00000 \mathrm{e}+001.00000 \mathrm{e}+001.00000 \mathrm{e}-011.00000 \mathrm{e}-091.00000 \mathrm{e}-01$

Element: 7829 \# of layers: 4 
Kx Ky Kz Ss Por

7.18791e+01 7.18791e+01 7.18791e+00 1.00000e-09 7.00000e-02

7.18791e+01 7.18791e+01 7.18791e+00 1.00000e-09 7.00000e-02

$1.00000 \mathrm{e}-02$ 1.00000e-02 1.00000e-03 1.00000e-09 1.00000e-01

$1.00000 \mathrm{e}+001.00000 \mathrm{e}+001.00000 \mathrm{e}-01$ 1.00000e-09 1.00000e-01

Element: 7830 \# of layers: 4

Kx Ky Kz Ss Por

7.18791e+01 7.18791e+01 7.18791e+00 1.00000e-09 7.00000e-02

$7.18791 \mathrm{e}+017.18791 \mathrm{e}+017.18791 \mathrm{e}+001.00000 \mathrm{e}-09$ 7.00000e-02

$1.00000 \mathrm{e}-02$ 1.00000e-02 1.00000e-03 1.00000e-09 1.00000e-01

$1.00000 \mathrm{e}+001.00000 \mathrm{e}+001.00000 \mathrm{e}-011.00000 \mathrm{e}-091.00000 \mathrm{e}-01$

Element: 7831 \# of layers: 4

Kx Ky Kz Ss Por

7.18791e+01 7.18791e+01 7.18791e+00 1.00000e-09 7.00000e-02

$7.18791 \mathrm{e}+017.18791 \mathrm{e}+017.18791 \mathrm{e}+001.00000 \mathrm{e}-09$ 7.00000e-02

$1.00000 \mathrm{e}-02$ 1.00000e-02 1.00000e-03 1.00000e-09 1.00000e-01

$1.00000 \mathrm{e}+001.00000 \mathrm{e}+001.00000 \mathrm{e}-01$ 1.00000e-09 1.00000e-01

Element: 7832 \# of layers: 4

$\mathrm{Kx} \mathrm{Ky} \mathrm{Kz}$ Ss Por

7.71274e+01 7.71274e+01 7.71274e+00 1.00000e-09 7.00000e-02

$7.71274 \mathrm{e}+017.71274 \mathrm{e}+017.71274 \mathrm{e}+001.00000 \mathrm{e}-097.00000 \mathrm{e}-02$

$1.00000 \mathrm{e}-02$ 1.00000e-02 1.00000e-03 1.00000e-09 1.00000e-01

$1.00000 \mathrm{e}+001.00000 \mathrm{e}+001.00000 \mathrm{e}-01$ 1.00000e-09 1.00000e-01

Element: 7833 \# of layers: 4

Kx Ky Kz Ss Por

7.71274e+01 7.71274e+01 7.71274e+00 1.00000e-09 7.00000e-02

$7.71274 \mathrm{e}+017.71274 \mathrm{e}+017.71274 \mathrm{e}+001.00000 \mathrm{e}-09$ 7.00000e-02

$1.00000 \mathrm{e}-02$ 1.00000e-02 1.00000e-03 1.00000e-09 1.00000e-01

$1.00000 \mathrm{e}+001.00000 \mathrm{e}+001.00000 \mathrm{e}-011.00000 \mathrm{e}-091.00000 \mathrm{e}-01$

Element: 7834 \# of layers: 3

$\mathrm{Kx} \mathrm{Ky} \mathrm{Kz}$ Ss Por

7.71274e+01 7.71274e+01 7.71274e+00 1.00000e-09 7.00000e-02

$1.00000 \mathrm{e}-02$ 1.00000e-02 1.00000e-03 1.00000e-09 1.00000e-01

$1.00000 \mathrm{e}+001.00000 \mathrm{e}+001.00000 \mathrm{e}-011.00000 \mathrm{e}-091.00000 \mathrm{e}-01$

Element: 7835 \# of layers: 3

Kx Ky Kz Ss Por

7.71274e+01 7.71274e+01 7.71274e+00 1.00000e-09 7.00000e-02

$1.00000 \mathrm{e}-021.00000 \mathrm{e}-02$ 1.00000e-03 1.00000e-09 1.00000e-01

$1.00000 \mathrm{e}+001.00000 \mathrm{e}+001.00000 \mathrm{e}-011.00000 \mathrm{e}-09$ 1.00000e-01

Element: 7836 \# of layers: 4

$\mathrm{Kx} \mathrm{Ky} \mathrm{Kz}$ Ss Por

7.71274e+01 7.71274e+01 7.71274e+00 1.00000e-09 7.00000e-02

$7.71274 \mathrm{e}+01$ 7.71274e+01 7.71274e+00 1.00000e-09 7.00000e-02

$1.00000 \mathrm{e}-02$ 1.00000e-02 1.00000e-03 1.00000e-09 1.00000e-01

$1.00000 \mathrm{e}+001.00000 \mathrm{e}+001.00000 \mathrm{e}-01$ 1.00000e-09 1.00000e-01

Element: 7837 \# of layers: 4 
Kx Ky Kz Ss Por

7.71274e+01 7.71274e+01 7.71274e+00 1.00000e-09 7.00000e-02

$7.71274 \mathrm{e}+017.71274 \mathrm{e}+017.71274 \mathrm{e}+001.00000 \mathrm{e}-09$ 7.00000e-02

$1.00000 \mathrm{e}-02$ 1.00000e-02 1.00000e-03 1.00000e-09 1.00000e-01

$1.00000 \mathrm{e}+001.00000 \mathrm{e}+001.00000 \mathrm{e}-01$ 1.00000e-09 1.00000e-01

Element: 7838 \# of layers: 4

$\mathrm{Kx} \mathrm{Ky} \mathrm{Kz}$ Ss Por

7.71274e+01 7.71274e+01 7.71274e+00 1.00000e-09 7.00000e-02

$7.71274 \mathrm{e}+017.71274 \mathrm{e}+017.71274 \mathrm{e}+001.00000 \mathrm{e}-09$ 7.00000e-02

$1.00000 \mathrm{e}-02$ 1.00000e-02 1.00000e-03 1.00000e-09 1.00000e-01

$1.00000 \mathrm{e}+001.00000 \mathrm{e}+001.00000 \mathrm{e}-011.00000 \mathrm{e}-091.00000 \mathrm{e}-01$

Element: 7839 \# of layers: 4

$\mathrm{Kx} \mathrm{Ky} \mathrm{Kz}$ Ss Por

7.71274e+01 7.71274e+01 7.71274e+00 1.00000e-09 7.00000e-02

$7.71274 \mathrm{e}+017.71274 \mathrm{e}+017.71274 \mathrm{e}+001.00000 \mathrm{e}-097.00000 \mathrm{e}-02$

$1.00000 \mathrm{e}-02$ 1.00000e-02 1.00000e-03 1.00000e-09 1.00000e-01

$1.00000 \mathrm{e}+001.00000 \mathrm{e}+001.00000 \mathrm{e}-011.00000 \mathrm{e}-09$ 1.00000e-01

Element: 7840 \# of layers: 4

$\mathrm{Kx} \mathrm{Ky} \mathrm{Kz}$ Ss Por

7.71274e+01 7.71274e+01 7.71274e+00 1.00000e-09 7.00000e-02

$7.71274 \mathrm{e}+017.71274 \mathrm{e}+017.71274 \mathrm{e}+001.00000 \mathrm{e}-097.00000 \mathrm{e}-02$

$1.00000 \mathrm{e}-021.00000 \mathrm{e}-021.00000 \mathrm{e}-031.00000 \mathrm{e}-091.00000 \mathrm{e}-01$

$1.00000 \mathrm{e}+001.00000 \mathrm{e}+001.00000 \mathrm{e}-01$ 1.00000e-09 1.00000e-01

Element: 7841 \# of layers: 3

$\mathrm{Kx} \mathrm{Ky} \mathrm{Kz}$ Ss Por

$3.72122 \mathrm{e}+013.72122 \mathrm{e}+013.72122 \mathrm{e}+001.00000 \mathrm{e}-09$ 7.00000e-02

$1.00000 \mathrm{e}-02$ 1.00000e-02 1.00000e-03 1.00000e-09 1.00000e-01

$1.00000 \mathrm{e}+001.00000 \mathrm{e}+001.00000 \mathrm{e}-011.00000 \mathrm{e}-09$ 1.00000e-01

Element: 7842 \# of layers: 3

$\mathrm{Kx} \mathrm{Ky} \mathrm{Kz}$ Ss Por

3.72122e+01 3.72122e+01 3.72122e+00 1.00000e-09 7.00000e-02

$1.00000 \mathrm{e}-02$ 1.00000e-02 1.00000e-03 1.00000e-09 1.00000e-01

$1.00000 \mathrm{e}+001.00000 \mathrm{e}+001.00000 \mathrm{e}-011.00000 \mathrm{e}-091.00000 \mathrm{e}-01$

Element: 7843 \# of layers: 3

$\mathrm{Kx} \mathrm{Ky} \mathrm{Kz}$ Ss Por

3.72122e+01 3.72122e+01 3.72122e+00 1.00000e-09 7.00000e-02

$1.00000 \mathrm{e}-02$ 1.00000e-02 1.00000e-03 1.00000e-09 1.00000e-01

$1.00000 \mathrm{e}+001.00000 \mathrm{e}+001.00000 \mathrm{e}-011.00000 \mathrm{e}-091.00000 \mathrm{e}-01$

Element: 7844 \# of layers: 3

$\mathrm{Kx} \mathrm{Ky} \mathrm{Kz}$ Ss Por

3.72122e+01 3.72122e+01 3.72122e+00 1.00000e-09 7.00000e-02

$1.00000 \mathrm{e}-02$ 1.00000e-02 1.00000e-03 1.00000e-09 1.00000e-01

$1.00000 \mathrm{e}+001.00000 \mathrm{e}+001.00000 \mathrm{e}-01$ 1.00000e-09 1.00000e-01

Element: 7845 \# of layers: 3

Kx Ky Kz Ss Por

3.72122e+01 3.72122e+01 3.72122e+00 1.00000e-09 7.00000e-02 
$1.00000 \mathrm{e}-02$ 1.00000e-02 1.00000e-03 1.00000e-09 1.00000e-01 $1.00000 \mathrm{e}+001.00000 \mathrm{e}+001.00000 \mathrm{e}-01$ 1.00000e-09 1.00000e-01 Element: 7846 \# of layers: 3

Kx Ky Kz Ss Por

3.72122e+01 3.72122e+01 3.72122e+00 1.00000e-09 7.00000e-02 $1.00000 \mathrm{e}-02$ 1.00000e-02 1.00000e-03 1.00000e-09 1.00000e-01 $1.00000 \mathrm{e}+001.00000 \mathrm{e}+001.00000 \mathrm{e}-011.00000 \mathrm{e}-091.00000 \mathrm{e}-01$

Element: 7847 \# of layers: 3

$\mathrm{Kx} \mathrm{Ky} \mathrm{Kz}$ Ss Por

3.72122e+01 3.72122e+01 3.72122e+00 1.00000e-09 7.00000e-02 $1.00000 \mathrm{e}-02$ 1.00000e-02 1.00000e-03 1.00000e-09 1.00000e-01

$1.00000 \mathrm{e}+001.00000 \mathrm{e}+001.00000 \mathrm{e}-011.00000 \mathrm{e}-091.00000 \mathrm{e}-01$

Element: 7848 \# of layers: 3

$\mathrm{Kx} \mathrm{Ky} \mathrm{Kz}$ Ss Por

3.72122e+01 3.72122e+01 3.72122e+00 1.00000e-09 7.00000e-02 $1.00000 \mathrm{e}-02$ 1.00000e-02 1.00000e-03 1.00000e-09 1.00000e-01

$1.00000 \mathrm{e}+001.00000 \mathrm{e}+001.00000 \mathrm{e}-011.00000 \mathrm{e}-091.00000 \mathrm{e}-01$

Element: 7849 \# of layers: 3

$\mathrm{Kx} \mathrm{Ky} \mathrm{Kz}$ Ss Por

3.72122e+01 3.72122e+01 3.72122e+00 1.00000e-09 7.00000e-02

$1.00000 \mathrm{e}-02$ 1.00000e-02 1.00000e-03 1.00000e-09 1.00000e-01

$1.00000 \mathrm{e}+001.00000 \mathrm{e}+001.00000 \mathrm{e}-01$ 1.00000e-09 1.00000e-01

Element: 7850 \# of layers: 3

Kx Ky Kz Ss Por

3.70518e+01 3.70518e+01 3.70518e+00 1.00000e-09 7.00000e-02

$1.00000 \mathrm{e}-02$ 1.00000e-02 1.00000e-03 1.00000e-09 1.00000e-01

$1.00000 \mathrm{e}+001.00000 \mathrm{e}+001.00000 \mathrm{e}-011.00000 \mathrm{e}-091.00000 \mathrm{e}-01$

Element: 7851 \# of layers: 3

Kx Ky Kz Ss Por

$3.70518 \mathrm{e}+013.70518 \mathrm{e}+013.70518 \mathrm{e}+00$ 1.00000e-09 7.00000e-02

$1.00000 \mathrm{e}-02$ 1.00000e-02 1.00000e-03 1.00000e-09 1.00000e-01

$1.00000 \mathrm{e}+001.00000 \mathrm{e}+001.00000 \mathrm{e}-011.00000 \mathrm{e}-091.00000 \mathrm{e}-01$

Element: 7852 \# of layers: 3

$\mathrm{Kx} \mathrm{Ky} \mathrm{Kz}$ Ss Por

3.70518e+01 3.70518e+01 3.70518e+00 1.00000e-09 7.00000e-02

1.00000e-02 1.00000e-02 1.00000e-03 1.00000e-09 1.00000e-01

$1.00000 \mathrm{e}+001.00000 \mathrm{e}+001.00000 \mathrm{e}-011.00000 \mathrm{e}-091.00000 \mathrm{e}-01$

Element: 7853 \# of layers: 3

$\mathrm{Kx} \mathrm{Ky} \mathrm{Kz}$ Ss Por

3.70518e+01 3.70518e+01 3.70518e+00 1.00000e-09 7.00000e-02

$1.00000 \mathrm{e}-02$ 1.00000e-02 1.00000e-03 1.00000e-09 1.00000e-01

$1.00000 \mathrm{e}+001.00000 \mathrm{e}+001.00000 \mathrm{e}-011.00000 \mathrm{e}-091.00000 \mathrm{e}-01$

Element: 7854 \# of layers: 3

$\mathrm{Kx} \mathrm{Ky} \mathrm{Kz}$ Ss Por

3.70518e+01 3.70518e+01 3.70518e+00 1.00000e-09 7.00000e-02

$1.00000 \mathrm{e}-02$ 1.00000e-02 1.00000e-03 1.00000e-09 1.00000e-01 
$1.00000 \mathrm{e}+001.00000 \mathrm{e}+00$ 1.00000e-01 1.00000e-09 1.00000e-01

Element: 7855 \# of layers: 3

Kx Ky Kz Ss Por

3.70518e+01 3.70518e+01 3.70518e+00 1.00000e-09 7.00000e-02

$1.00000 \mathrm{e}-02$ 1.00000e-02 1.00000e-03 1.00000e-09 1.00000e-01

$1.00000 \mathrm{e}+001.00000 \mathrm{e}+001.00000 \mathrm{e}-01$ 1.00000e-09 1.00000e-01

Element: 7856 \# of layers: 3

$\mathrm{Kx} \mathrm{Ky} \mathrm{Kz}$ Ss Por

3.70518e+01 3.70518e+01 3.70518e+00 1.00000e-09 7.00000e-02

$1.00000 \mathrm{e}-02$ 1.00000e-02 1.00000e-03 1.00000e-09 1.00000e-01

$1.00000 \mathrm{e}+001.00000 \mathrm{e}+001.00000 \mathrm{e}-011.00000 \mathrm{e}-091.00000 \mathrm{e}-01$

Element: 7857 \# of layers: 3

$\mathrm{Kx} \mathrm{Ky} \mathrm{Kz}$ Ss Por

3.70518e+01 3.70518e+01 3.70518e+00 1.00000e-09 7.00000e-02

$1.00000 \mathrm{e}-02$ 1.00000e-02 1.00000e-03 1.00000e-09 1.00000e-01

$1.00000 \mathrm{e}+001.00000 \mathrm{e}+001.00000 \mathrm{e}-011.00000 \mathrm{e}-091.00000 \mathrm{e}-01$

Element: 7858 \# of layers: 3

$\mathrm{Kx} \mathrm{Ky} \mathrm{Kz}$ Ss Por

3.70518e+01 3.70518e+01 3.70518e+00 1.00000e-09 7.00000e-02

$1.00000 \mathrm{e}-02$ 1.00000e-02 1.00000e-03 1.00000e-09 1.00000e-01

$1.00000 \mathrm{e}+001.00000 \mathrm{e}+001.00000 \mathrm{e}-011.00000 \mathrm{e}-091.00000 \mathrm{e}-01$

Element: 7859 \# of layers: 3

$\mathrm{Kx} \mathrm{Ky} \mathrm{Kz}$ Ss Por

$5.22886 \mathrm{e}+015.22886 \mathrm{e}+015.22886 \mathrm{e}+001.00000 \mathrm{e}-09$ 7.00000e-02

$1.00000 \mathrm{e}-021.00000 \mathrm{e}-02$ 1.00000e-03 1.00000e-09 1.00000e-01

$1.00000 \mathrm{e}+001.00000 \mathrm{e}+001.00000 \mathrm{e}-01$ 1.00000e-09 1.00000e-01

Element: 7860 \# of layers: 3

$\mathrm{Kx} \mathrm{Ky} \mathrm{Kz}$ Ss Por

5.22886e+01 5.22886e+01 5.22886e+00 1.00000e-09 7.00000e-02

$1.00000 \mathrm{e}-02$ 1.00000e-02 1.00000e-03 1.00000e-09 1.00000e-01

$1.00000 \mathrm{e}+001.00000 \mathrm{e}+001.00000 \mathrm{e}-011.00000 \mathrm{e}-091.00000 \mathrm{e}-01$

Element: 7861 \# of layers: 3

$\mathrm{Kx} \mathrm{Ky} \mathrm{Kz}$ Ss Por

5.22886e+01 5.22886e+01 5.22886e+00 1.00000e-09 7.00000e-02

$1.00000 \mathrm{e}-02$ 1.00000e-02 1.00000e-03 1.00000e-09 1.00000e-01

$1.00000 \mathrm{e}+001.00000 \mathrm{e}+001.00000 \mathrm{e}-011.00000 \mathrm{e}-091.00000 \mathrm{e}-01$

Element: 7862 \# of layers: 3

$\mathrm{Kx} \mathrm{Ky} \mathrm{Kz}$ Ss Por

5.22886e+01 5.22886e+01 5.22886e+00 1.00000e-09 7.00000e-02

$1.00000 \mathrm{e}-02$ 1.00000e-02 1.00000e-03 1.00000e-09 1.00000e-01

$1.00000 \mathrm{e}+001.00000 \mathrm{e}+001.00000 \mathrm{e}-011.00000 \mathrm{e}-091.00000 \mathrm{e}-01$

Element: 7863 \# of layers: 3

$\mathrm{Kx} \mathrm{Ky} \mathrm{Kz}$ Ss Por

5.22886e+01 5.22886e+01 5.22886e+00 1.00000e-09 7.00000e-02

$1.00000 \mathrm{e}-02$ 1.00000e-02 1.00000e-03 1.00000e-09 1.00000e-01

$1.00000 \mathrm{e}+001.00000 \mathrm{e}+001.00000 \mathrm{e}-011.00000 \mathrm{e}-091.00000 \mathrm{e}-01$ 
Element: 7864 \# of layers: 3

$\mathrm{Kx} \mathrm{Ky} \mathrm{Kz}$ Ss Por

5.22886e+01 5.22886e+01 5.22886e+00 1.00000e-09 7.00000e-02

$1.00000 \mathrm{e}-02$ 1.00000e-02 1.00000e-03 1.00000e-09 1.00000e-01

$1.00000 \mathrm{e}+001.00000 \mathrm{e}+001.00000 \mathrm{e}-011.00000 \mathrm{e}-091.00000 \mathrm{e}-01$

Element: 7865 \# of layers: 3

$\mathrm{Kx} \mathrm{Ky} \mathrm{Kz}$ Ss Por

5.22886e+01 5.22886e+01 5.22886e+00 1.00000e-09 7.00000e-02

$1.00000 \mathrm{e}-02$ 1.00000e-02 1.00000e-03 1.00000e-09 1.00000e-01

$1.00000 \mathrm{e}+001.00000 \mathrm{e}+001.00000 \mathrm{e}-011.00000 \mathrm{e}-091.00000 \mathrm{e}-01$

Element: 7866 \# of layers: 3

$\mathrm{Kx} \mathrm{Ky} \mathrm{Kz}$ Ss Por

5.22886e+01 5.22886e+01 5.22886e+00 1.00000e-09 7.00000e-02

1.00000e-02 1.00000e-02 1.00000e-03 1.00000e-09 1.00000e-01

$1.00000 \mathrm{e}+001.00000 \mathrm{e}+001.00000 \mathrm{e}-011.00000 \mathrm{e}-091.00000 \mathrm{e}-01$

Element: 7867 \# of layers: 3

$\mathrm{Kx} \mathrm{Ky} \mathrm{Kz}$ Ss Por

$5.22886 \mathrm{e}+015.22886 \mathrm{e}+015.22886 \mathrm{e}+00$ 1.00000e-09 7.00000e-02

$1.00000 \mathrm{e}-02$ 1.00000e-02 1.00000e-03 1.00000e-09 1.00000e-01

$1.00000 \mathrm{e}+001.00000 \mathrm{e}+001.00000 \mathrm{e}-011.00000 \mathrm{e}-091.00000 \mathrm{e}-01$

Element: 7868 \# of layers: 3

$\mathrm{Kx} \mathrm{Ky} \mathrm{Kz}$ Ss Por

5.60909e+01 5.60909e+01 5.60909e+00 1.00000e-09 7.00000e-02

$1.00000 \mathrm{e}-02$ 1.00000e-02 1.00000e-03 1.00000e-09 1.00000e-01

$1.00000 \mathrm{e}+001.00000 \mathrm{e}+001.00000 \mathrm{e}-011.00000 \mathrm{e}-091.00000 \mathrm{e}-01$

Element: 7869 \# of layers: 3

$\mathrm{Kx} \mathrm{Ky} \mathrm{Kz}$ Ss Por

5.60909e+01 5.60909e+01 5.60909e+00 1.00000e-09 7.00000e-02

$1.00000 \mathrm{e}-011.00000 \mathrm{e}-011.00000 \mathrm{e}-021.00000 \mathrm{e}-091.00000 \mathrm{e}-01$

$1.00000 \mathrm{e}+001.00000 \mathrm{e}+001.00000 \mathrm{e}-011.00000 \mathrm{e}-091.00000 \mathrm{e}-01$

Element: 7870 \# of layers: 3

$\mathrm{Kx} \mathrm{Ky} \mathrm{Kz}$ Ss Por

5.60909e+01 5.60909e+01 5.60909e+00 1.00000e-09 7.00000e-02

$1.00000 \mathrm{e}-011.00000 \mathrm{e}-011.00000 \mathrm{e}-021.00000 \mathrm{e}-091.00000 \mathrm{e}-01$

$1.00000 \mathrm{e}+001.00000 \mathrm{e}+001.00000 \mathrm{e}-011.00000 \mathrm{e}-091.00000 \mathrm{e}-01$

Element: 7871 \# of layers: 3

Kx Ky Kz Ss Por

5.60909e+01 5.60909e+01 5.60909e+00 1.00000e-09 7.00000e-02

$1.00000 \mathrm{e}-01$ 1.00000e-01 1.00000e-02 1.00000e-09 1.00000e-01

$1.00000 \mathrm{e}+001.00000 \mathrm{e}+001.00000 \mathrm{e}-011.00000 \mathrm{e}-091.00000 \mathrm{e}-01$

Element: 7872 \# of layers: 3

$\mathrm{Kx} \mathrm{Ky} \mathrm{Kz}$ Ss Por

5.60909e+01 5.60909e+01 5.60909e+00 1.00000e-09 7.00000e-02

$1.00000 \mathrm{e}-011.00000 \mathrm{e}-011.00000 \mathrm{e}-021.00000 \mathrm{e}-091.00000 \mathrm{e}-01$

$1.00000 \mathrm{e}+001.00000 \mathrm{e}+001.00000 \mathrm{e}-01$ 1.00000e-09 1.00000e-01

Element: 7873 \# of layers: 3 
Kx Ky Kz Ss Por

5.60909e+01 5.60909e+01 5.60909e+00 1.00000e-09 7.00000e-02

$1.00000 \mathrm{e}-01$ 1.00000e-01 1.00000e-02 1.00000e-09 1.00000e-01

$1.00000 \mathrm{e}+001.00000 \mathrm{e}+001.00000 \mathrm{e}-011.00000 \mathrm{e}-091.00000 \mathrm{e}-01$

Element: 7874 \# of layers: 3

$\mathrm{Kx} \mathrm{Ky} \mathrm{Kz}$ Ss Por

5.60909e+01 5.60909e+01 5.60909e+00 1.00000e-09 7.00000e-02

$1.00000 \mathrm{e}-01$ 1.00000e-01 1.00000e-02 1.00000e-09 1.00000e-01

$1.00000 \mathrm{e}+001.00000 \mathrm{e}+001.00000 \mathrm{e}-011.00000 \mathrm{e}-091.00000 \mathrm{e}-01$

Element: 7875 \# of layers: 3

$\mathrm{Kx} \mathrm{Ky} \mathrm{Kz}$ Ss Por

5.60909e+01 5.60909e+01 5.60909e+00 1.00000e-09 7.00000e-02

$1.00000 \mathrm{e}-02$ 1.00000e-02 1.00000e-03 1.00000e-09 1.00000e-01

$1.00000 \mathrm{e}+001.00000 \mathrm{e}+001.00000 \mathrm{e}-011.00000 \mathrm{e}-09$ 1.00000e-01

Element: 7876 \# of layers: 3

Kx Ky Kz Ss Por

5.60909e+01 5.60909e+01 5.60909e+00 1.00000e-09 7.00000e-02

$1.00000 \mathrm{e}-01$ 1.00000e-01 1.00000e-02 1.00000e-09 1.00000e-01

$1.00000 \mathrm{e}+001.00000 \mathrm{e}+001.00000 \mathrm{e}-01$ 1.00000e-09 1.00000e-01

Element: 7877 \# of layers: 3

$\mathrm{Kx} \mathrm{Ky} \mathrm{Kz}$ Ss Por

5.80577e+01 5.80577e+01 5.80577e+00 1.00000e-09 7.00000e-02

$1.00000 \mathrm{e}-011.00000 \mathrm{e}-011.00000 \mathrm{e}-021.00000 \mathrm{e}-091.00000 \mathrm{e}-01$

$1.00000 \mathrm{e}+001.00000 \mathrm{e}+001.00000 \mathrm{e}-011.00000 \mathrm{e}-091.00000 \mathrm{e}-01$

Element: 7878 \# of layers: 3

$\mathrm{Kx} \mathrm{Ky} \mathrm{Kz}$ Ss Por

5.80577e+01 5.80577e+01 5.80577e+00 1.00000e-09 7.00000e-02

$1.00000 \mathrm{e}-01$ 1.00000e-01 1.00000e-02 1.00000e-09 1.00000e-01

$1.00000 \mathrm{e}+001.00000 \mathrm{e}+001.00000 \mathrm{e}-011.00000 \mathrm{e}-091.00000 \mathrm{e}-01$

Element: 7879 \# of layers: 3

$\mathrm{Kx} \mathrm{Ky} \mathrm{Kz} \mathrm{Ss} \mathrm{Por}$

5.80577e+01 5.80577e+01 5.80577e+00 1.00000e-09 7.00000e-02

$1.00000 \mathrm{e}-011.00000 \mathrm{e}-01$ 1.00000e-02 1.00000e-09 1.00000e-01

$1.00000 \mathrm{e}+001.00000 \mathrm{e}+001.00000 \mathrm{e}-011.00000 \mathrm{e}-091.00000 \mathrm{e}-01$

Element: 7883 \# of layers: 3

Kx Ky Kz Ss Por

5.80577e+01 5.80577e+01 5.80577e+00 1.00000e-09 7.00000e-02

1.00000e-01 1.00000e-01 1.00000e-02 1.00000e-09 1.00000e-01

$1.00000 \mathrm{e}+001.00000 \mathrm{e}+001.00000 \mathrm{e}-011.00000 \mathrm{e}-09$ 1.00000e-01

Element: 7884 \# of layers: 3

$\mathrm{Kx} \mathrm{Ky} \mathrm{Kz}$ Ss Por

5.80577e+01 5.80577e+01 5.80577e+00 1.00000e-09 7.00000e-02 $1.00000 \mathrm{e}-011.00000 \mathrm{e}-011.00000 \mathrm{e}-021.00000 \mathrm{e}-091.00000 \mathrm{e}-01$

$1.00000 \mathrm{e}+001.00000 \mathrm{e}+001.00000 \mathrm{e}-01$ 1.00000e-09 1.00000e-01

Element: 7886 \# of layers: 4

Kx Ky Kz Ss Por 
$3.50332 \mathrm{e}+023.50332 \mathrm{e}+023.50332 \mathrm{e}+01$ 1.00000e-09 2.12000e-01 $3.50332 \mathrm{e}+023.50332 \mathrm{e}+023.50332 \mathrm{e}+01$ 1.00000e-09 2.12000e-01 $1.00000 \mathrm{e}-021.00000 \mathrm{e}-02$ 1.00000e-03 1.00000e-09 1.00000e-01 $1.00000 \mathrm{e}+001.00000 \mathrm{e}+001.00000 \mathrm{e}-011.00000 \mathrm{e}-091.00000 \mathrm{e}-01$ Element: 7887 \# of layers: 4

Kx Ky Kz Ss Por

3.50332e+02 3.50332e+02 3.50332e+01 1.00000e-09 2.12000e-01

$3.50332 \mathrm{e}+023.50332 \mathrm{e}+023.50332 \mathrm{e}+01$ 1.00000e-09 2.12000e-01 $1.00000 \mathrm{e}-021.00000 \mathrm{e}-02$ 1.00000e-03 1.00000e-09 1.00000e-01

$1.00000 \mathrm{e}+001.00000 \mathrm{e}+001.00000 \mathrm{e}-011.00000 \mathrm{e}-091.00000 \mathrm{e}-01$ Element: 7888 \# of layers: 4

Kx Ky Kz Ss Por

$3.50332 \mathrm{e}+023.50332 \mathrm{e}+023.50332 \mathrm{e}+01$ 1.00000e-09 2.12000e-01

$3.50332 \mathrm{e}+023.50332 \mathrm{e}+023.50332 \mathrm{e}+01$ 1.00000e-09 2.12000e-01 $1.00000 \mathrm{e}-021.00000 \mathrm{e}-02$ 1.00000e-03 1.00000e-09 1.00000e-01

$1.00000 \mathrm{e}+001.00000 \mathrm{e}+001.00000 \mathrm{e}-011.00000 \mathrm{e}-091.00000 \mathrm{e}-01$

Element: 7889 \# of layers: 4

Kx Ky Kz Ss Por

$3.50332 \mathrm{e}+02$ 3.50332e $+023.50332 \mathrm{e}+01$ 1.00000e-09 2.12000e-01

$3.50332 \mathrm{e}+023.50332 \mathrm{e}+023.50332 \mathrm{e}+01$ 1.00000e-09 2.12000e-01

$1.00000 \mathrm{e}-021.00000 \mathrm{e}-02$ 1.00000e-03 1.00000e-09 1.00000e-01

$1.00000 \mathrm{e}+001.00000 \mathrm{e}+001.00000 \mathrm{e}-011.00000 \mathrm{e}-091.00000 \mathrm{e}-01$

Element: 7890 \# of layers: 4

Kx Ky Kz Ss Por

3.50332e+02 3.50332e+02 3.50332e+01 1.00000e-09 2.12000e-01

$3.50332 \mathrm{e}+023.50332 \mathrm{e}+023.50332 \mathrm{e}+01$ 1.00000e-09 2.12000e-01

$1.00000 \mathrm{e}-021.00000 \mathrm{e}-021.00000 \mathrm{e}-031.00000 \mathrm{e}-091.00000 \mathrm{e}-01$

$1.00000 \mathrm{e}+001.00000 \mathrm{e}+00$ 1.00000e-01 1.00000e-09 1.00000e-01

Element: 7895 \# of layers: 4

Kx Ky Kz Ss Por

$3.46147 \mathrm{e}+02$ 3.46147e+02 3.46147e+01 1.00000e-09 2.12000e-01

$3.46147 \mathrm{e}+023.46147 \mathrm{e}+023.46147 \mathrm{e}+01$ 1.00000e-09 2.12000e-01

$1.00000 \mathrm{e}-021.00000 \mathrm{e}-02$ 1.00000e-03 1.00000e-09 1.00000e-01

$1.00000 \mathrm{e}+001.00000 \mathrm{e}+001.00000 \mathrm{e}-011.00000 \mathrm{e}-091.00000 \mathrm{e}-01$

Element: 7896 \# of layers: 4

Kx Ky Kz Ss Por

$3.46147 \mathrm{e}+02$ 3.46147e+02 3.46147e+01 1.00000e-09 2.12000e-01

$3.46147 \mathrm{e}+023.46147 \mathrm{e}+023.46147 \mathrm{e}+01$ 1.00000e-09 2.12000e-01

$1.00000 \mathrm{e}-02$ 1.00000e-02 1.00000e-03 1.00000e-09 1.00000e-01

$1.00000 \mathrm{e}+001.00000 \mathrm{e}+001.00000 \mathrm{e}-011.00000 \mathrm{e}-091.00000 \mathrm{e}-01$

Element: 7897 \# of layers: 4

Kx Ky Kz Ss Por

$3.46147 \mathrm{e}+023.46147 \mathrm{e}+023.46147 \mathrm{e}+01$ 1.00000e-09 2.12000e-01

$3.46147 \mathrm{e}+023.46147 \mathrm{e}+023.46147 \mathrm{e}+01$ 1.00000e-09 2.12000e-01

$1.00000 \mathrm{e}-02$ 1.00000e-02 1.00000e-03 1.00000e-09 1.00000e-01

$1.00000 \mathrm{e}+001.00000 \mathrm{e}+001.00000 \mathrm{e}-011.00000 \mathrm{e}-091.00000 \mathrm{e}-01$ 
Element: 7898 \# of layers: 4

$\mathrm{Kx} \mathrm{Ky} \mathrm{Kz}$ Ss Por

3.46147e+02 3.46147e+02 3.46147e+01 1.00000e-09 2.12000e-01

3.46147e+02 3.46147e+02 3.46147e+01 1.00000e-09 2.12000e-01

$1.00000 \mathrm{e}-02$ 1.00000e-02 1.00000e-03 1.00000e-09 1.00000e-01

$1.00000 \mathrm{e}+001.00000 \mathrm{e}+001.00000 \mathrm{e}-01$ 1.00000e-09 1.00000e-01

Element: 7899 \# of layers: 4

$\mathrm{Kx} \mathrm{Ky} \mathrm{Kz}$ Ss Por

3.46147e+02 3.46147e+02 3.46147e+01 1.00000e-09 2.12000e-01

$3.46147 \mathrm{e}+02$ 3.46147e+02 3.46147e+01 1.00000e-09 2.12000e-01

$1.00000 \mathrm{e}-02$ 1.00000e-02 1.00000e-03 1.00000e-09 1.00000e-01

$1.00000 \mathrm{e}+001.00000 \mathrm{e}+001.00000 \mathrm{e}-011.00000 \mathrm{e}-091.00000 \mathrm{e}-01$

Element: 7900 \# of layers: 4

$\mathrm{Kx} \mathrm{Ky} \mathrm{Kz}$ Ss Por

3.46147e+02 3.46147e+02 3.46147e+01 1.00000e-09 2.12000e-01

$3.46147 \mathrm{e}+02$ 3.46147e+02 3.46147e+01 1.00000e-09 2.12000e-01

$1.00000 \mathrm{e}-02$ 1.00000e-02 1.00000e-03 1.00000e-09 1.00000e-01

$1.00000 \mathrm{e}+001.00000 \mathrm{e}+001.00000 \mathrm{e}-011.00000 \mathrm{e}-091.00000 \mathrm{e}-01$

Element: 7901 \# of layers: 4

$\mathrm{Kx} \mathrm{Ky} \mathrm{Kz}$ Ss Por

3.46147e+02 3.46147e+02 3.46147e+01 1.00000e-09 2.12000e-01

3.46147e+02 3.46147e+02 3.46147e+01 1.00000e-09 2.12000e-01

$1.00000 \mathrm{e}-02$ 1.00000e-02 1.00000e-03 1.00000e-09 1.00000e-01

$1.00000 \mathrm{e}+001.00000 \mathrm{e}+001.00000 \mathrm{e}-011.00000 \mathrm{e}-091.00000 \mathrm{e}-01$

Element: 7902 \# of layers: 4

$\mathrm{Kx} \mathrm{Ky} \mathrm{Kz}$ Ss Por

3.46147e+02 3.46147e+02 3.46147e+01 1.00000e-09 2.12000e-01

$3.46147 \mathrm{e}+02$ 3.46147e+02 3.46147e+01 1.00000e-09 2.12000e-01

$1.00000 \mathrm{e}-02$ 1.00000e-02 1.00000e-03 1.00000e-09 1.00000e-01

$1.00000 \mathrm{e}+001.00000 \mathrm{e}+001.00000 \mathrm{e}-011.00000 \mathrm{e}-091.00000 \mathrm{e}-01$

Element: 7903 \# of layers: 4

$\mathrm{Kx} \mathrm{Ky} \mathrm{Kz}$ Ss Por

3.46147e+02 3.46147e+02 3.46147e+01 1.00000e-09 2.12000e-01

$3.46147 \mathrm{e}+02$ 3.46147e+02 3.46147e+01 1.00000e-09 2.12000e-01

$1.00000 \mathrm{e}-02$ 1.00000e-02 1.00000e-03 1.00000e-09 1.00000e-01

$1.00000 \mathrm{e}+001.00000 \mathrm{e}+001.00000 \mathrm{e}-011.00000 \mathrm{e}-091.00000 \mathrm{e}-01$

Element: 7904 \# of layers: 4

$\mathrm{Kx} \mathrm{Ky} \mathrm{Kz}$ Ss Por

3.30960e+02 3.30960e+02 3.30960e+01 1.00000e-09 2.12000e-01

$3.30960 \mathrm{e}+02$ 3.30960e+02 3.30960e+01 1.00000e-09 2.12000e-01

$1.00000 \mathrm{e}-02$ 1.00000e-02 1.00000e-03 1.00000e-09 1.00000e-01

$1.00000 \mathrm{e}+001.00000 \mathrm{e}+001.00000 \mathrm{e}-011.00000 \mathrm{e}-091.00000 \mathrm{e}-01$

Element: 7905 \# of layers: 4

$\mathrm{Kx} \mathrm{Ky} \mathrm{Kz}$ Ss Por

3.30960e+02 3.30960e+02 3.30960e+01 1.00000e-09 2.12000e-01

$3.30960 \mathrm{e}+02$ 3.30960e+02 3.30960e+01 1.00000e-09 2.12000e-01 
$1.00000 \mathrm{e}-02$ 1.00000e-02 1.00000e-03 1.00000e-09 1.00000e-01 $1.00000 \mathrm{e}+001.00000 \mathrm{e}+001.00000 \mathrm{e}-01$ 1.00000e-09 1.00000e-01 Element: 7906 \# of layers: 4

Kx Ky Kz Ss Por

$3.30960 \mathrm{e}+02$ 3.30960e+02 3.30960e+01 1.00000e-09 2.12000e-01

$3.30960 \mathrm{e}+02$ 3.30960e+02 3.30960e+01 1.00000e-09 2.12000e-01

$1.00000 \mathrm{e}-02$ 1.00000e-02 1.00000e-03 1.00000e-09 1.00000e-01

$1.00000 \mathrm{e}+001.00000 \mathrm{e}+001.00000 \mathrm{e}-01$ 1.00000e-09 1.00000e-01

Element: 7907 \# of layers: 4

$\mathrm{Kx} \mathrm{Ky} \mathrm{Kz}$ Ss Por

3.30960e+02 3.30960e+02 3.30960e+01 1.00000e-09 2.12000e-01

$3.30960 \mathrm{e}+02$ 3.30960e+02 3.30960e+01 1.00000e-09 2.12000e-01

$1.00000 \mathrm{e}-02$ 1.00000e-02 1.00000e-03 1.00000e-09 1.00000e-01

$1.00000 \mathrm{e}+001.00000 \mathrm{e}+001.00000 \mathrm{e}-011.00000 \mathrm{e}-091.00000 \mathrm{e}-01$

Element: 7908 \# of layers: 4

Kx Ky Kz Ss Por

3.30960e+02 3.30960e+02 3.30960e+01 1.00000e-09 2.12000e-01

$3.30960 \mathrm{e}+02$ 3.30960e+02 3.30960e+01 1.00000e-09 2.12000e-01

$1.00000 \mathrm{e}-02$ 1.00000e-02 1.00000e-03 1.00000e-09 1.00000e-01

$1.00000 \mathrm{e}+001.00000 \mathrm{e}+001.00000 \mathrm{e}-011.00000 \mathrm{e}-091.00000 \mathrm{e}-01$

Element: 7909 \# of layers: 4

$\mathrm{Kx} \mathrm{Ky} \mathrm{Kz}$ Ss Por

3.30960e+02 3.30960e+02 3.30960e+01 1.00000e-09 2.12000e-01

$3.30960 \mathrm{e}+02$ 3.30960e+02 3.30960e+01 1.00000e-09 2.12000e-01

$1.00000 \mathrm{e}-02$ 1.00000e-02 1.00000e-03 1.00000e-09 1.00000e-01

$1.00000 \mathrm{e}+001.00000 \mathrm{e}+001.00000 \mathrm{e}-01$ 1.00000e-09 1.00000e-01

Element: 7910 \# of layers: 4

$\mathrm{Kx} \mathrm{Ky} \mathrm{Kz}$ Ss Por

3.30960e+02 3.30960e+02 3.30960e+01 1.00000e-09 2.12000e-01

$3.30960 \mathrm{e}+023.30960 \mathrm{e}+023.30960 \mathrm{e}+01$ 1.00000e-09 2.12000e-01

$1.00000 \mathrm{e}-02$ 1.00000e-02 1.00000e-03 1.00000e-09 1.00000e-01

$1.00000 \mathrm{e}+001.00000 \mathrm{e}+001.00000 \mathrm{e}-01$ 1.00000e-09 1.00000e-01

Element: 7911 \# of layers: 4

$\mathrm{Kx} \mathrm{Ky} \mathrm{Kz}$ Ss Por

3.30960e+02 3.30960e+02 3.30960e+01 1.00000e-09 2.12000e-01

$3.30960 \mathrm{e}+02$ 3.30960e+02 3.30960e+01 1.00000e-09 2.12000e-01

1.00000e-02 1.00000e-02 1.00000e-03 1.00000e-09 1.00000e-01

$1.00000 \mathrm{e}+001.00000 \mathrm{e}+001.00000 \mathrm{e}-011.00000 \mathrm{e}-091.00000 \mathrm{e}-01$

Element: 7912 \# of layers: 4

$\mathrm{Kx} \mathrm{Ky} \mathrm{Kz}$ Ss Por

3.30960e+02 3.30960e+02 3.30960e+01 1.00000e-09 2.12000e-01

$3.30960 \mathrm{e}+023.30960 \mathrm{e}+023.30960 \mathrm{e}+01$ 1.00000e-09 2.12000e-01

1.00000e-02 1.00000e-02 1.00000e-03 1.00000e-09 1.00000e-01

$1.00000 \mathrm{e}+001.00000 \mathrm{e}+001.00000 \mathrm{e}-01$ 1.00000e-09 1.00000e-01

Element: 7913 \# of layers: 5

Kx Ky Kz Ss Por 
$2.31242 \mathrm{e}+022.31242 \mathrm{e}+022.31242 \mathrm{e}+01$ 1.00000e-09 7.00000e-02 $9.23960 \mathrm{e}+00$ 9.23960e+00 9.23960e-01 1.00000e-09 2.12000e-01 $9.23960 \mathrm{e}+009.23960 \mathrm{e}+00$ 9.23960e-01 1.00000e-09 2.12000e-01 $1.00000 \mathrm{e}-021.00000 \mathrm{e}-02$ 1.00000e-03 1.00000e-09 1.00000e-01 $1.00000 \mathrm{e}+001.00000 \mathrm{e}+001.00000 \mathrm{e}-011.00000 \mathrm{e}-091.00000 \mathrm{e}-01$ Element: 7914 \# of layers: 5

Kx Ky Kz Ss Por

$2.31242 \mathrm{e}+022.31242 \mathrm{e}+022.31242 \mathrm{e}+01$ 1.00000e-09 7.00000e-02

$9.23960 \mathrm{e}+009.23960 \mathrm{e}+00$ 9.23960e-01 1.00000e-09 2.12000e-01

$9.23960 \mathrm{e}+00$ 9.23960e+00 9.23960e-01 1.00000e-09 2.12000e-01

$1.00000 \mathrm{e}-021.00000 \mathrm{e}-02$ 1.00000e-03 1.00000e-09 1.00000e-01

$1.00000 \mathrm{e}+001.00000 \mathrm{e}+001.00000 \mathrm{e}-011.00000 \mathrm{e}-091.00000 \mathrm{e}-01$

Element: 7915 \# of layers: 4

Kx Ky Kz Ss Por

$2.31242 \mathrm{e}+022.31242 \mathrm{e}+022.31242 \mathrm{e}+01$ 1.00000e-09 7.00000e-02

$9.23960 \mathrm{e}+00$ 9.23960e+00 9.23960e-01 1.00000e-09 2.12000e-01

$1.00000 \mathrm{e}-02$ 1.00000e-02 1.00000e-03 1.00000e-09 1.00000e-01

$1.00000 \mathrm{e}+001.00000 \mathrm{e}+00$ 1.00000e-01 1.00000e-09 1.00000e-01

Element: 7916 \# of layers: 4

Kx Ky Kz Ss Por

$2.31242 \mathrm{e}+022.31242 \mathrm{e}+02$ 2.31242e+01 1.00000e-09 7.00000e-02

$9.23960 \mathrm{e}+00$ 9.23960e+00 9.23960e-01 1.00000e-09 2.12000e-01

$1.00000 \mathrm{e}-021.00000 \mathrm{e}-02$ 1.00000e-03 1.00000e-09 1.00000e-01

$1.00000 \mathrm{e}+001.00000 \mathrm{e}+001.00000 \mathrm{e}-011.00000 \mathrm{e}-091.00000 \mathrm{e}-01$

Element: 7917 \# of layers: 5

Kx Ky Kz Ss Por

$2.31242 \mathrm{e}+02$ 2.31242e+02 2.31242e+01 1.00000e-09 7.00000e-02

$2.31242 \mathrm{e}+022.31242 \mathrm{e}+022.31242 \mathrm{e}+01$ 1.00000e-09 7.00000e-02

$9.23960 \mathrm{e}+00$ 9.23960e+00 9.23960e-01 1.00000e-09 2.12000e-01

$1.00000 \mathrm{e}-021.00000 \mathrm{e}-02$ 1.00000e-03 1.00000e-09 1.00000e-01

$1.00000 \mathrm{e}+001.00000 \mathrm{e}+001.00000 \mathrm{e}-011.00000 \mathrm{e}-091.00000 \mathrm{e}-01$

Element: 7918 \# of layers: 5

Kx Ky Kz Ss Por

$2.31242 \mathrm{e}+022.31242 \mathrm{e}+022.31242 \mathrm{e}+01$ 1.00000e-09 7.00000e-02

$9.23960 \mathrm{e}+00$ 9.23960e+00 9.23960e-01 1.00000e-09 2.12000e-01

$9.23960 \mathrm{e}+00$ 9.23960e+00 9.23960e-01 1.00000e-09 2.12000e-01

$1.00000 \mathrm{e}-02$ 1.00000e-02 $1.00000 \mathrm{e}-031.00000 \mathrm{e}-091.00000 \mathrm{e}-01$

$1.00000 \mathrm{e}+001.00000 \mathrm{e}+001.00000 \mathrm{e}-011.00000 \mathrm{e}-091.00000 \mathrm{e}-01$

Element: 7919 \# of layers: 4

Kx Ky Kz Ss Por

$9.23960 \mathrm{e}+00$ 9.23960e+00 9.23960e-01 1.00000e-09 2.12000e-01

$9.23960 \mathrm{e}+00$ 9.23960e+00 9.23960e-01 1.00000e-09 2.12000e-01

$1.00000 \mathrm{e}-02$ 1.00000e-02 1.00000e-03 1.00000e-09 1.00000e-01

$1.00000 \mathrm{e}+001.00000 \mathrm{e}+001.00000 \mathrm{e}-011.00000 \mathrm{e}-091.00000 \mathrm{e}-01$

Element: 7920 \# of layers: 4

Kx Ky Kz Ss Por 
$9.23960 \mathrm{e}+00$ 9.23960e+00 9.23960e-01 1.00000e-09 2.12000e-01 $9.23960 \mathrm{e}+009.23960 \mathrm{e}+00$ 9.23960e-01 1.00000e-09 2.12000e-01 $1.00000 \mathrm{e}-02$ 1.00000e-02 1.00000e-03 1.00000e-09 1.00000e-01 $1.00000 \mathrm{e}+001.00000 \mathrm{e}+001.00000 \mathrm{e}-011.00000 \mathrm{e}-091.00000 \mathrm{e}-01$ Element: 7921 \# of layers: 5

Kx Ky Kz Ss Por

$2.31242 \mathrm{e}+022.31242 \mathrm{e}+022.31242 \mathrm{e}+01$ 1.00000e-09 7.00000e-02 $9.23960 \mathrm{e}+009.23960 \mathrm{e}+00$ 9.23960e-01 1.00000e-09 2.12000e-01 $9.23960 \mathrm{e}+00$ 9.23960e+00 9.23960e-01 1.00000e-09 2.12000e-01 $1.00000 \mathrm{e}-021.00000 \mathrm{e}-02$ 1.00000e-03 1.00000e-09 1.00000e-01 $1.00000 \mathrm{e}+001.00000 \mathrm{e}+001.00000 \mathrm{e}-011.00000 \mathrm{e}-091.00000 \mathrm{e}-01$ Element: 7922 \# of layers: 5

Kx Ky Kz Ss Por

$7.90682 \mathrm{e}+01$ 7.90682e+01 7.90682e+00 1.00000e-09 7.00000e-02 $7.90682 \mathrm{e}+017.90682 \mathrm{e}+01$ 7.90682e+00 1.00000e-09 7.00000e-02 $3.15929 \mathrm{e}+003.15929 \mathrm{e}+003.15929 \mathrm{e}-01$ 1.00000e-09 2.12000e-01 $1.00000 \mathrm{e}-021.00000 \mathrm{e}-02$ 1.00000e-03 1.00000e-09 1.00000e-01 $1.00000 \mathrm{e}+001.00000 \mathrm{e}+001.00000 \mathrm{e}-011.00000 \mathrm{e}-091.00000 \mathrm{e}-01$ Element: 7923 \# of layers: 5

Kx Ky Kz Ss Por $7.90682 \mathrm{e}+01$ 7.90682e+01 7.90682e+00 1.00000e-09 7.00000e-02 $7.90682 \mathrm{e}+01$ 7.90682e+01 7.90682e+00 1.00000e-09 7.00000e-02 $3.15929 \mathrm{e}+003.15929 \mathrm{e}+00$ 3.15929e-01 1.00000e-09 2.12000e-01 $1.00000 \mathrm{e}-02$ 1.00000e-02 1.00000e-03 1.00000e-09 1.00000e-01 $1.00000 \mathrm{e}+001.00000 \mathrm{e}+001.00000 \mathrm{e}-011.00000 \mathrm{e}-091.00000 \mathrm{e}-01$ Element: 7924 \# of layers: 4

Kx Ky Kz Ss Por

7.90682e+01 7.90682e+01 7.90682e+00 1.00000e-09 7.00000e-02 $7.90682 \mathrm{e}+01$ 7.90682e+01 7.90682e+00 1.00000e-09 7.00000e-02 $1.00000 \mathrm{e}-02$ 1.00000e-02 1.00000e-03 1.00000e-09 1.00000e-01 $1.00000 \mathrm{e}+001.00000 \mathrm{e}+001.00000 \mathrm{e}-011.00000 \mathrm{e}-091.00000 \mathrm{e}-01$ Element: 7925 \# of layers: 4

Kx Ky Kz Ss Por

$7.90682 \mathrm{e}+01$ 7.90682e+01 7.90682e+00 1.00000e-09 7.00000e-02 $7.90682 \mathrm{e}+01$ 7.90682e+01 7.90682e+00 1.00000e-09 7.00000e-02 $1.00000 \mathrm{e}-021.00000 \mathrm{e}-02$ 1.00000e-03 1.00000e-09 1.00000e-01 $1.00000 \mathrm{e}+001.00000 \mathrm{e}+001.00000 \mathrm{e}-011.00000 \mathrm{e}-091.00000 \mathrm{e}-01$ Element: 7926 \# of layers: 4

Kx Ky Kz Ss Por

7.90682e+01 7.90682e+01 7.90682e+00 1.00000e-09 7.00000e-02 $7.90682 \mathrm{e}+01$ 7.90682e+01 7.90682e+00 1.00000e-09 7.00000e-02 $1.00000 \mathrm{e}-021.00000 \mathrm{e}-02$ 1.00000e-03 1.00000e-09 1.00000e-01 $1.00000 \mathrm{e}+001.00000 \mathrm{e}+001.00000 \mathrm{e}-011.00000 \mathrm{e}-091.00000 \mathrm{e}-01$ Element: 7927 \# of layers: 4

Kx Ky Kz Ss Por

7.90682e+01 7.90682e+01 7.90682e+00 1.00000e-09 7.00000e-02 
7.90682e+01 7.90682e+01 7.90682e+00 1.00000e-09 7.00000e-02 $1.00000 \mathrm{e}-02$ 1.00000e-02 1.00000e-03 1.00000e-09 1.00000e-01 $1.00000 \mathrm{e}+001.00000 \mathrm{e}+001.00000 \mathrm{e}-011.00000 \mathrm{e}-091.00000 \mathrm{e}-01$

Element: 7928 \# of layers: 5

Kx Ky Kz Ss Por

7.90682e+01 7.90682e+01 7.90682e+00 1.00000e-09 7.00000e-02

$7.90682 \mathrm{e}+017.90682 \mathrm{e}+017.90682 \mathrm{e}+001.00000 \mathrm{e}-09$ 7.00000e-02

$3.15929 \mathrm{e}+003.15929 \mathrm{e}+003.15929 \mathrm{e}-01$ 1.00000e-09 2.12000e-01

$1.00000 \mathrm{e}-02$ 1.00000e-02 1.00000e-03 1.00000e-09 1.00000e-01

$1.00000 \mathrm{e}+001.00000 \mathrm{e}+001.00000 \mathrm{e}-011.00000 \mathrm{e}-091.00000 \mathrm{e}-01$

Element: 7929 \# of layers: 5

Kx Ky Kz Ss Por

7.90682e+01 7.90682e+01 7.90682e+00 1.00000e-09 7.00000e-02

$7.90682 \mathrm{e}+017.90682 \mathrm{e}+01$ 7.90682e+00 1.00000e-09 7.00000e-02

$3.15929 \mathrm{e}+003.15929 \mathrm{e}+003.15929 \mathrm{e}-01$ 1.00000e-09 2.12000e-01

$1.00000 \mathrm{e}-02$ 1.00000e-02 $1.00000 \mathrm{e}-031.00000 \mathrm{e}-091.00000 \mathrm{e}-01$

$1.00000 \mathrm{e}+001.00000 \mathrm{e}+001.00000 \mathrm{e}-011.00000 \mathrm{e}-091.00000 \mathrm{e}-01$

Element: 7930 \# of layers: 4

Kx Ky Kz Ss Por

7.90682e+01 7.90682e+01 7.90682e+00 1.00000e-09 7.00000e-02

$7.90682 \mathrm{e}+01$ 7.90682e+01 7.90682e+00 1.00000e-09 7.00000e-02

$1.00000 \mathrm{e}-02$ 1.00000e-02 1.00000e-03 1.00000e-09 1.00000e-01

$1.00000 \mathrm{e}+001.00000 \mathrm{e}+001.00000 \mathrm{e}-011.00000 \mathrm{e}-091.00000 \mathrm{e}-01$

Element: 7931 \# of layers: 4

Kx Ky Kz Ss Por

7.18358e+01 7.18358e+01 7.18358e+00 1.00000e-09 7.00000e-02

$7.18358 \mathrm{e}+01$ 7.18358e+01 7.18358e+00 1.00000e-09 7.00000e-02

$1.00000 \mathrm{e}-021.00000 \mathrm{e}-02$ 1.00000e-03 1.00000e-09 1.00000e-01

$1.00000 \mathrm{e}+001.00000 \mathrm{e}+001.00000 \mathrm{e}-011.00000 \mathrm{e}-091.00000 \mathrm{e}-01$

Element: 7932 \# of layers: 4

Kx Ky Kz Ss Por

$7.18358 \mathrm{e}+01$ 7.18358e +01 7.18358e+00 1.00000e-09 7.00000e-02

$7.18358 \mathrm{e}+01$ 7.18358e+01 7.18358e+00 1.00000e-09 7.00000e-02

$1.00000 \mathrm{e}-02$ 1.00000e-02 1.00000e-03 1.00000e-09 1.00000e-01

$1.00000 \mathrm{e}+001.00000 \mathrm{e}+001.00000 \mathrm{e}-011.00000 \mathrm{e}-091.00000 \mathrm{e}-01$

Element: 7933 \# of layers: 4

Kx Ky Kz Ss Por

7.18358e+01 7.18358e+01 7.18358e+00 1.00000e-09 7.00000e-02

$7.18358 \mathrm{e}+01$ 7.18358e+01 7.18358e+00 1.00000e-09 7.00000e-02

$1.00000 \mathrm{e}-02$ 1.00000e-02 1.00000e-03 1.00000e-09 1.00000e-01

$1.00000 \mathrm{e}+001.00000 \mathrm{e}+001.00000 \mathrm{e}-011.00000 \mathrm{e}-091.00000 \mathrm{e}-01$

Element: 7934 \# of layers: 4

Kx Ky Kz Ss Por

7.18358e +01 7.18358e+01 7.18358e+00 1.00000e-09 7.00000e-02

$7.18358 \mathrm{e}+01$ 7.18358e+01 7.18358e+00 1.00000e-09 7.00000e-02

$1.00000 \mathrm{e}-021.00000 \mathrm{e}-02$ 1.00000e-03 1.00000e-09 1.00000e-01 
$1.00000 \mathrm{e}+001.00000 \mathrm{e}+00$ 1.00000e-01 1.00000e-09 1.00000e-01

Element: 7935 \# of layers: 4

Kx Ky Kz Ss Por

7.18358e+01 7.18358e+01 7.18358e+00 1.00000e-09 7.00000e-02

$7.18358 \mathrm{e}+017.18358 \mathrm{e}+017.18358 \mathrm{e}+001.00000 \mathrm{e}-09$ 7.00000e-02

$1.00000 \mathrm{e}-021.00000 \mathrm{e}-02$ 1.00000e-03 1.00000e-09 1.00000e-01

$1.00000 \mathrm{e}+001.00000 \mathrm{e}+001.00000 \mathrm{e}-01$ 1.00000e-09 1.00000e-01

Element: 7936 \# of layers: 4

$\mathrm{Kx} \mathrm{Ky} \mathrm{Kz}$ Ss Por

7.18358e+01 7.18358e+01 7.18358e+00 1.00000e-09 7.00000e-02

$7.18358 \mathrm{e}+017.18358 \mathrm{e}+017.18358 \mathrm{e}+00$ 1.00000e-09 7.00000e-02

$1.00000 \mathrm{e}-02$ 1.00000e-02 1.00000e-03 1.00000e-09 1.00000e-01

$1.00000 \mathrm{e}+001.00000 \mathrm{e}+001.00000 \mathrm{e}-011.00000 \mathrm{e}-091.00000 \mathrm{e}-01$

Element: 7937 \# of layers: 4

Kx Ky Kz Ss Por

7.18358e+01 7.18358e+01 7.18358e+00 1.00000e-09 7.00000e-02

7.18358e+01 7.18358e+01 7.18358e+00 1.00000e-09 7.00000e-02

$1.00000 \mathrm{e}-02$ 1.00000e-02 1.00000e-03 1.00000e-09 1.00000e-01

$1.00000 \mathrm{e}+001.00000 \mathrm{e}+001.00000 \mathrm{e}-01$ 1.00000e-09 1.00000e-01

Element: 7938 \# of layers: 4

$\mathrm{Kx} \mathrm{Ky} \mathrm{Kz}$ Ss Por

7.18358e+01 7.18358e+01 7.18358e+00 1.00000e-09 7.00000e-02

$7.18358 \mathrm{e}+01$ 7.18358e+01 7.18358e+00 1.00000e-09 7.00000e-02

$1.00000 \mathrm{e}-02$ 1.00000e-02 1.00000e-03 1.00000e-09 1.00000e-01

$1.00000 \mathrm{e}+001.00000 \mathrm{e}+001.00000 \mathrm{e}-011.00000 \mathrm{e}-091.00000 \mathrm{e}-01$

Element: 7939 \# of layers: 4

Kx Ky Kz Ss Por

7.18358e+01 7.18358e+01 7.18358e+00 1.00000e-09 7.00000e-02

$7.18358 \mathrm{e}+01$ 7.18358e+01 7.18358e+00 1.00000e-09 7.00000e-02

$1.00000 \mathrm{e}-021.00000 \mathrm{e}-021.00000 \mathrm{e}-031.00000 \mathrm{e}-091.00000 \mathrm{e}-01$

$1.00000 \mathrm{e}+001.00000 \mathrm{e}+001.00000 \mathrm{e}-011.00000 \mathrm{e}-091.00000 \mathrm{e}-01$

Element: 7940 \# of layers: 4

Kx Ky Kz Ss Por

7.47325e+01 7.47325e+01 7.47325e+00 1.00000e-09 7.00000e-02

$7.47325 \mathrm{e}+017.47325 \mathrm{e}+017.47325 \mathrm{e}+001.00000 \mathrm{e}-09$ 7.00000e-02

$1.00000 \mathrm{e}-02$ 1.00000e-02 1.00000e-03 1.00000e-09 1.00000e-01

$1.00000 \mathrm{e}+001.00000 \mathrm{e}+001.00000 \mathrm{e}-011.00000 \mathrm{e}-091.00000 \mathrm{e}-01$

Element: 7941 \# of layers: 4

$\mathrm{Kx} \mathrm{Ky} \mathrm{Kz}$ Ss Por

7.47325e+01 7.47325e+01 7.47325e+00 1.00000e-09 7.00000e-02

$7.47325 \mathrm{e}+017.47325 \mathrm{e}+01$ 7.47325e+00 1.00000e-09 7.00000e-02

$1.00000 \mathrm{e}-02$ 1.00000e-02 1.00000e-03 1.00000e-09 1.00000e-01

$1.00000 \mathrm{e}+001.00000 \mathrm{e}+001.00000 \mathrm{e}-01$ 1.00000e-09 1.00000e-01

Element: 7942 \# of layers: 4

$\mathrm{Kx} \mathrm{Ky} \mathrm{Kz}$ Ss Por

7.47325e+01 7.47325e+01 7.47325e+00 1.00000e-09 7.00000e-02 
7.47325e+01 7.47325e+01 7.47325e+00 1.00000e-09 7.00000e-02 $1.00000 \mathrm{e}-02$ 1.00000e-02 1.00000e-03 1.00000e-09 1.00000e-01 $1.00000 \mathrm{e}+001.00000 \mathrm{e}+001.00000 \mathrm{e}-011.00000 \mathrm{e}-09$ 1.00000e-01

Element: 7943 \# of layers: 4

$\mathrm{Kx} \mathrm{Ky} \mathrm{Kz}$ Ss Por

7.47325e+01 7.47325e+01 7.47325e+00 1.00000e-09 7.00000e-02

$7.47325 \mathrm{e}+017.47325 \mathrm{e}+017.47325 \mathrm{e}+001.00000 \mathrm{e}-097.00000 \mathrm{e}-02$

$1.00000 \mathrm{e}-02$ 1.00000e-02 1.00000e-03 1.00000e-09 1.00000e-01

$1.00000 \mathrm{e}+001.00000 \mathrm{e}+001.00000 \mathrm{e}-011.00000 \mathrm{e}-091.00000 \mathrm{e}-01$

Element: 7944 \# of layers: 4

Kx Ky Kz Ss Por

7.47325e+01 7.47325e+01 7.47325e+00 1.00000e-09 7.00000e-02

$7.47325 \mathrm{e}+01$ 7.47325e+01 7.47325e+00 1.00000e-09 7.00000e-02

$1.00000 \mathrm{e}-02$ 1.00000e-02 1.00000e-03 1.00000e-09 1.00000e-01

$1.00000 \mathrm{e}+001.00000 \mathrm{e}+001.00000 \mathrm{e}-01$ 1.00000e-09 1.00000e-01

Element: 7945 \# of layers: 4

$\mathrm{Kx} \mathrm{Ky} \mathrm{Kz}$ Ss Por

7.47325e+01 7.47325e+01 7.47325e+00 1.00000e-09 7.00000e-02

$7.47325 \mathrm{e}+01$ 7.47325e+01 7.47325e+00 1.00000e-09 7.00000e-02

$1.00000 \mathrm{e}-02$ 1.00000e-02 1.00000e-03 1.00000e-09 1.00000e-01

$1.00000 \mathrm{e}+001.00000 \mathrm{e}+001.00000 \mathrm{e}-011.00000 \mathrm{e}-091.00000 \mathrm{e}-01$

Element: 7946 \# of layers: 4

$\mathrm{Kx} \mathrm{Ky} \mathrm{Kz}$ Ss Por

7.47325e+01 7.47325e+01 7.47325e+00 1.00000e-09 7.00000e-02

$7.47325 \mathrm{e}+017.47325 \mathrm{e}+017.47325 \mathrm{e}+001.00000 \mathrm{e}-097.00000 \mathrm{e}-02$

$1.00000 \mathrm{e}-021.00000 \mathrm{e}-021.00000 \mathrm{e}-031.00000 \mathrm{e}-091.00000 \mathrm{e}-01$

$1.00000 \mathrm{e}+001.00000 \mathrm{e}+001.00000 \mathrm{e}-01$ 1.00000e-09 1.00000e-01

Element: 7947 \# of layers: 4

Kx Ky Kz Ss Por

7.47325e+01 7.47325e+01 7.47325e+00 1.00000e-09 7.00000e-02

$7.47325 \mathrm{e}+017.47325 \mathrm{e}+017.47325 \mathrm{e}+001.00000 \mathrm{e}-097.00000 \mathrm{e}-02$

$1.00000 \mathrm{e}-02$ 1.00000e-02 1.00000e-03 1.00000e-09 1.00000e-01

$1.00000 \mathrm{e}+001.00000 \mathrm{e}+001.00000 \mathrm{e}-011.00000 \mathrm{e}-091.00000 \mathrm{e}-01$

Element: 7948 \# of layers: 4

$\mathrm{Kx} \mathrm{Ky} \mathrm{Kz}$ Ss Por

7.47325e+01 7.47325e+01 7.47325e+00 1.00000e-09 7.00000e-02

$7.47325 \mathrm{e}+017.47325 \mathrm{e}+017.47325 \mathrm{e}+001.00000 \mathrm{e}-09$ 7.00000e-02

$1.00000 \mathrm{e}-02$ 1.00000e-02 1.00000e-03 1.00000e-09 1.00000e-01

$1.00000 \mathrm{e}+001.00000 \mathrm{e}+001.00000 \mathrm{e}-011.00000 \mathrm{e}-091.00000 \mathrm{e}-01$

Element: 7949 \# of layers: 4

Kx Ky Kz Ss Por

8.51112e+01 8.51112e+01 8.51112e+00 1.00000e-09 7.00000e-02

8.51112e+01 8.51112e+01 8.51112e+00 1.00000e-09 7.00000e-02

$1.00000 \mathrm{e}-02$ 1.00000e-02 1.00000e-03 1.00000e-09 1.00000e-01

$1.00000 \mathrm{e}+001.00000 \mathrm{e}+001.00000 \mathrm{e}-011.00000 \mathrm{e}-091.00000 \mathrm{e}-01$

Element: 7950 \# of layers: 4 
Kx Ky Kz Ss Por

8.51112e+01 8.51112e+01 8.51112e+00 1.00000e-09 7.00000e-02

8.51112e+01 8.51112e+01 8.51112e+00 1.00000e-09 7.00000e-02

$1.00000 \mathrm{e}-02$ 1.00000e-02 1.00000e-03 1.00000e-09 1.00000e-01

$1.00000 \mathrm{e}+001.00000 \mathrm{e}+001.00000 \mathrm{e}-011.00000 \mathrm{e}-091.00000 \mathrm{e}-01$

Element: 7951 \# of layers: 4

Kx Ky Kz Ss Por

8.51112e+01 8.51112e+01 8.51112e+00 1.00000e-09 7.00000e-02

8.51112e+01 8.51112e+01 8.51112e+00 1.00000e-09 7.00000e-02

$1.00000 \mathrm{e}-02$ 1.00000e-02 1.00000e-03 1.00000e-09 1.00000e-01

$1.00000 \mathrm{e}+001.00000 \mathrm{e}+001.00000 \mathrm{e}-011.00000 \mathrm{e}-091.00000 \mathrm{e}-01$

Element: 7952 \# of layers: 3

Kx Ky Kz Ss Por

8.51112e+01 8.51112e+01 8.51112e+00 1.00000e-09 7.00000e-02

$1.00000 \mathrm{e}-02$ 1.00000e-02 1.00000e-03 1.00000e-09 1.00000e-01

$1.00000 \mathrm{e}+001.00000 \mathrm{e}+001.00000 \mathrm{e}-011.00000 \mathrm{e}-091.00000 \mathrm{e}-01$

Element: 7953 \# of layers: 3

$\mathrm{Kx} \mathrm{Ky} \mathrm{Kz}$ Ss Por

8.51112e+01 8.51112e+01 8.51112e+00 1.00000e-09 7.00000e-02

$1.00000 \mathrm{e}-02$ 1.00000e-02 1.00000e-03 1.00000e-09 1.00000e-01

$1.00000 \mathrm{e}+001.00000 \mathrm{e}+001.00000 \mathrm{e}-011.00000 \mathrm{e}-091.00000 \mathrm{e}-01$

Element: 7954 \# of layers: 4

$\mathrm{Kx} \mathrm{Ky} \mathrm{Kz}$ Ss Por

8.51112e+01 8.51112e+01 8.51112e+00 1.00000e-09 7.00000e-02

8.51112e+01 8.51112e+01 8.51112e+00 1.00000e-09 7.00000e-02

$1.00000 \mathrm{e}-02$ 1.00000e-02 1.00000e-03 1.00000e-09 1.00000e-01

$1.00000 \mathrm{e}+001.00000 \mathrm{e}+001.00000 \mathrm{e}-011.00000 \mathrm{e}-091.00000 \mathrm{e}-01$

Element: 7955 \# of layers: 4

Kx Ky Kz Ss Por

8.51112e+01 8.51112e+01 8.51112e+00 1.00000e-09 7.00000e-02

8.51112e+01 8.51112e+01 8.51112e+00 1.00000e-09 7.00000e-02

$1.00000 \mathrm{e}-02$ 1.00000e-02 1.00000e-03 1.00000e-09 1.00000e-01

$1.00000 \mathrm{e}+001.00000 \mathrm{e}+001.00000 \mathrm{e}-011.00000 \mathrm{e}-091.00000 \mathrm{e}-01$

Element: 7956 \# of layers: 4

$\mathrm{Kx} \mathrm{Ky} \mathrm{Kz}$ Ss Por

8.51112e+01 8.51112e+01 8.51112e+00 1.00000e-09 7.00000e-02

$8.51112 \mathrm{e}+018.51112 \mathrm{e}+018.51112 \mathrm{e}+00$ 1.00000e-09 7.00000e-02

$1.00000 \mathrm{e}-02$ 1.00000e-02 1.00000e-03 1.00000e-09 1.00000e-01

$1.00000 \mathrm{e}+001.00000 \mathrm{e}+001.00000 \mathrm{e}-01$ 1.00000e-09 1.00000e-01

Element: 7957 \# of layers: 4

$\mathrm{Kx} \mathrm{Ky} \mathrm{Kz}$ Ss Por

8.51112e+01 8.51112e+01 8.51112e+00 1.00000e-09 7.00000e-02

8.51112e+01 8.51112e+01 8.51112e+00 1.00000e-09 7.00000e-02

$1.00000 \mathrm{e}-02$ 1.00000e-02 1.00000e-03 1.00000e-09 1.00000e-01

$1.00000 \mathrm{e}+001.00000 \mathrm{e}+001.00000 \mathrm{e}-011.00000 \mathrm{e}-091.00000 \mathrm{e}-01$

Element: 7958 \# of layers: 3 


\section{Kx Ky Kz Ss Por}

5.57178e+01 5.57178e+01 5.57178e+00 1.00000e-09 7.00000e-02 $1.00000 \mathrm{e}-02$ 1.00000e-02 1.00000e-03 1.00000e-09 1.00000e-01

$1.00000 \mathrm{e}+001.00000 \mathrm{e}+001.00000 \mathrm{e}-011.00000 \mathrm{e}-091.00000 \mathrm{e}-01$

Element: 7959 \# of layers: 3

$\mathrm{Kx} \mathrm{Ky} \mathrm{Kz}$ Ss Por

5.57178e+01 5.57178e+01 5.57178e+00 1.00000e-09 7.00000e-02

$1.00000 \mathrm{e}-02$ 1.00000e-02 1.00000e-03 1.00000e-09 1.00000e-01

$1.00000 \mathrm{e}+001.00000 \mathrm{e}+001.00000 \mathrm{e}-011.00000 \mathrm{e}-091.00000 \mathrm{e}-01$

Element: 7960 \# of layers: 3

Kx Ky Kz Ss Por

5.57178e+01 5.57178e+01 5.57178e+00 1.00000e-09 7.00000e-02

$1.00000 \mathrm{e}-02$ 1.00000e-02 1.00000e-03 1.00000e-09 1.00000e-01

$1.00000 \mathrm{e}+001.00000 \mathrm{e}+001.00000 \mathrm{e}-011.00000 \mathrm{e}-09$ 1.00000e-01

Element: 7961 \# of layers: 3

$\mathrm{Kx} \mathrm{Ky} \mathrm{Kz}$ Ss Por

5.57178e+01 5.57178e+01 5.57178e+00 1.00000e-09 7.00000e-02 $1.00000 \mathrm{e}-02$ 1.00000e-02 1.00000e-03 1.00000e-09 1.00000e-01

$1.00000 \mathrm{e}+001.00000 \mathrm{e}+001.00000 \mathrm{e}-01$ 1.00000e-09 1.00000e-01

Element: 7962 \# of layers: 3

Kx Ky Kz Ss Por

5.57178e+01 5.57178e+01 5.57178e+00 1.00000e-09 7.00000e-02 $1.00000 \mathrm{e}-02$ 1.00000e-02 1.00000e-03 1.00000e-09 1.00000e-01

$1.00000 \mathrm{e}+001.00000 \mathrm{e}+001.00000 \mathrm{e}-011.00000 \mathrm{e}-091.00000 \mathrm{e}-01$

Element: 7963 \# of layers: 3

Kx Ky Kz Ss Por

5.57178e+01 5.57178e+01 5.57178e+00 1.00000e-09 7.00000e-02 $1.00000 \mathrm{e}-02$ 1.00000e-02 1.00000e-03 1.00000e-09 1.00000e-01

$1.00000 \mathrm{e}+001.00000 \mathrm{e}+001.00000 \mathrm{e}-011.00000 \mathrm{e}-091.00000 \mathrm{e}-01$

Element: 7964 \# of layers: 3

$\mathrm{Kx} \mathrm{Ky} \mathrm{Kz} \mathrm{Ss} \mathrm{Por}$

5.57178e+01 5.57178e+01 5.57178e+00 1.00000e-09 7.00000e-02

$1.00000 \mathrm{e}-02$ 1.00000e-02 1.00000e-03 1.00000e-09 1.00000e-01

$1.00000 \mathrm{e}+001.00000 \mathrm{e}+001.00000 \mathrm{e}-011.00000 \mathrm{e}-091.00000 \mathrm{e}-01$

Element: 7965 \# of layers: 3

Kx Ky Kz Ss Por

5.57178e+01 5.57178e+01 5.57178e+00 1.00000e-09 7.00000e-02 $1.00000 \mathrm{e}-02$ 1.00000e-02 1.00000e-03 1.00000e-09 1.00000e-01 $1.00000 \mathrm{e}+001.00000 \mathrm{e}+001.00000 \mathrm{e}-01$ 1.00000e-09 1.00000e-01

Element: 7966 \# of layers: 3

Kx Ky Kz Ss Por

5.57178e+01 5.57178e+01 5.57178e+00 1.00000e-09 7.00000e-02 $1.00000 \mathrm{e}-021.00000 \mathrm{e}-021.00000 \mathrm{e}-031.00000 \mathrm{e}-091.00000 \mathrm{e}-01$

$1.00000 \mathrm{e}+001.00000 \mathrm{e}+001.00000 \mathrm{e}-01$ 1.00000e-09 1.00000e-01

Element: 7967 \# of layers: 3

Kx Ky Kz Ss Por 
4.06558e+01 4.06558e+01 4.06558e+00 1.00000e-09 7.00000e-02 $1.00000 \mathrm{e}-02$ 1.00000e-02 1.00000e-03 1.00000e-09 1.00000e-01

$1.00000 \mathrm{e}+001.00000 \mathrm{e}+001.00000 \mathrm{e}-011.00000 \mathrm{e}-09$ 1.00000e-01

Element: 7968 \# of layers: 3

$\mathrm{Kx} \mathrm{Ky} \mathrm{Kz}$ Ss Por

4.06558e+01 4.06558e+01 4.06558e+00 1.00000e-09 7.00000e-02

1.00000e-02 1.00000e-02 1.00000e-03 1.00000e-09 1.00000e-01

$1.00000 \mathrm{e}+001.00000 \mathrm{e}+001.00000 \mathrm{e}-01$ 1.00000e-09 1.00000e-01

Element: 7969 \# of layers: 3

$\mathrm{Kx} \mathrm{Ky} \mathrm{Kz}$ Ss Por

4.06558e+01 4.06558e+01 4.06558e+00 1.00000e-09 7.00000e-02

$1.00000 \mathrm{e}-02$ 1.00000e-02 1.00000e-03 1.00000e-09 1.00000e-01

$1.00000 \mathrm{e}+001.00000 \mathrm{e}+001.00000 \mathrm{e}-011.00000 \mathrm{e}-091.00000 \mathrm{e}-01$

Element: 7970 \# of layers: 3

Kx Ky Kz Ss Por

4.06558e+01 4.06558e+01 4.06558e+00 1.00000e-09 7.00000e-02

$1.00000 \mathrm{e}-021.00000 \mathrm{e}-021.00000 \mathrm{e}-031.00000 \mathrm{e}-091.00000 \mathrm{e}-01$

$1.00000 \mathrm{e}+001.00000 \mathrm{e}+001.00000 \mathrm{e}-01$ 1.00000e-09 1.00000e-01

Element: 7971 \# of layers: 3

$\mathrm{Kx} \mathrm{Ky} \mathrm{Kz}$ Ss Por

4.06558e+01 4.06558e+01 4.06558e+00 1.00000e-09 7.00000e-02 $1.00000 \mathrm{e}-021.00000 \mathrm{e}-021.00000 \mathrm{e}-031.00000 \mathrm{e}-091.00000 \mathrm{e}-01$

$1.00000 \mathrm{e}+001.00000 \mathrm{e}+001.00000 \mathrm{e}-01$ 1.00000e-09 1.00000e-01

Element: 7972 \# of layers: 3

$\mathrm{Kx} \mathrm{Ky} \mathrm{Kz}$ Ss Por

4.06558e+01 4.06558e+01 4.06558e+00 1.00000e-09 7.00000e-02

$1.00000 \mathrm{e}-02$ 1.00000e-02 1.00000e-03 1.00000e-09 1.00000e-01

$1.00000 \mathrm{e}+001.00000 \mathrm{e}+001.00000 \mathrm{e}-01$ 1.00000e-09 1.00000e-01

Element: 7973 \# of layers: 3

$\mathrm{Kx} \mathrm{Ky} \mathrm{Kz}$ Ss Por

4.06558e+01 4.06558e+01 4.06558e+00 1.00000e-09 7.00000e-02

$1.00000 \mathrm{e}-02$ 1.00000e-02 1.00000e-03 1.00000e-09 1.00000e-01

$1.00000 \mathrm{e}+001.00000 \mathrm{e}+001.00000 \mathrm{e}-011.00000 \mathrm{e}-091.00000 \mathrm{e}-01$

Element: 7974 \# of layers: 3

$\mathrm{Kx} \mathrm{Ky} \mathrm{Kz}$ Ss Por

4.06558e+01 4.06558e+01 4.06558e+00 1.00000e-09 7.00000e-02

$1.00000 \mathrm{e}-021.00000 \mathrm{e}-02$ 1.00000e-03 1.00000e-09 1.00000e-01

$1.00000 \mathrm{e}+001.00000 \mathrm{e}+001.00000 \mathrm{e}-011.00000 \mathrm{e}-09$ 1.00000e-01

Element: 7975 \# of layers: 3

$\mathrm{Kx} \mathrm{Ky} \mathrm{Kz}$ Ss Por

4.06558e+01 4.06558e+01 4.06558e+00 1.00000e-09 7.00000e-02

$1.00000 \mathrm{e}-02$ 1.00000e-02 1.00000e-03 1.00000e-09 1.00000e-01

$1.00000 \mathrm{e}+001.00000 \mathrm{e}+001.00000 \mathrm{e}-01$ 1.00000e-09 1.00000e-01

Element: 7976 \# of layers: 3

Kx Ky Kz Ss Por

4.72421e+01 4.72421e+01 4.72421e+00 1.00000e-09 7.00000e-02 
$1.00000 \mathrm{e}-02$ 1.00000e-02 1.00000e-03 1.00000e-09 1.00000e-01

$1.00000 \mathrm{e}+001.00000 \mathrm{e}+001.00000 \mathrm{e}-01$ 1.00000e-09 1.00000e-01

Element: 7977 \# of layers: 3

Kx Ky Kz Ss Por

4.72421e+01 4.72421e+01 4.72421e+00 1.00000e-09 7.00000e-02

$1.00000 \mathrm{e}-02$ 1.00000e-02 1.00000e-03 1.00000e-09 1.00000e-01

$1.00000 \mathrm{e}+001.00000 \mathrm{e}+001.00000 \mathrm{e}-011.00000 \mathrm{e}-091.00000 \mathrm{e}-01$

Element: 7978 \# of layers: 3

$\mathrm{Kx} \mathrm{Ky} \mathrm{Kz}$ Ss Por

4.72421e+01 4.72421e+01 4.72421e+00 1.00000e-09 7.00000e-02

$1.00000 \mathrm{e}-02$ 1.00000e-02 1.00000e-03 1.00000e-09 1.00000e-01

$1.00000 \mathrm{e}+001.00000 \mathrm{e}+001.00000 \mathrm{e}-011.00000 \mathrm{e}-091.00000 \mathrm{e}-01$

Element: 7979 \# of layers: 3

$\mathrm{Kx} \mathrm{Ky} \mathrm{Kz}$ Ss Por

4.72421e+01 4.72421e+01 4.72421e+00 1.00000e-09 7.00000e-02

$1.00000 \mathrm{e}-021.00000 \mathrm{e}-02$ 1.00000e-03 1.00000e-09 1.00000e-01

$1.00000 \mathrm{e}+001.00000 \mathrm{e}+001.00000 \mathrm{e}-011.00000 \mathrm{e}-091.00000 \mathrm{e}-01$

Element: 7980 \# of layers: 3

$\mathrm{Kx} \mathrm{Ky} \mathrm{Kz}$ Ss Por

4.72421e+01 4.72421e+01 4.72421e+00 1.00000e-09 7.00000e-02

$1.00000 \mathrm{e}-02$ 1.00000e-02 1.00000e-03 1.00000e-09 1.00000e-01

$1.00000 \mathrm{e}+001.00000 \mathrm{e}+001.00000 \mathrm{e}-01$ 1.00000e-09 1.00000e-01

Element: 7981 \# of layers: 3

Kx Ky Kz Ss Por

4.72421e+01 4.72421e+01 4.72421e+00 1.00000e-09 7.00000e-02

$1.00000 \mathrm{e}-021.00000 \mathrm{e}-021.00000 \mathrm{e}-031.00000 \mathrm{e}-091.00000 \mathrm{e}-01$

$1.00000 \mathrm{e}+001.00000 \mathrm{e}+001.00000 \mathrm{e}-011.00000 \mathrm{e}-091.00000 \mathrm{e}-01$

Element: 7982 \# of layers: 3

Kx Ky Kz Ss Por

4.72421e+01 4.72421e+01 4.72421e+00 1.00000e-09 7.00000e-02

$1.00000 \mathrm{e}-02$ 1.00000e-02 1.00000e-03 1.00000e-09 1.00000e-01

$1.00000 \mathrm{e}+001.00000 \mathrm{e}+001.00000 \mathrm{e}-01$ 1.00000e-09 1.00000e-01

Element: 7983 \# of layers: 3

$\mathrm{Kx} \mathrm{Ky} \mathrm{Kz}$ Ss Por

4.72421e+01 4.72421e+01 4.72421e+00 1.00000e-09 7.00000e-02

$1.00000 \mathrm{e}-02$ 1.00000e-02 1.00000e-03 1.00000e-09 1.00000e-01

$1.00000 \mathrm{e}+001.00000 \mathrm{e}+001.00000 \mathrm{e}-011.00000 \mathrm{e}-091.00000 \mathrm{e}-01$

Element: 7984 \# of layers: 3

$\mathrm{Kx} \mathrm{Ky} \mathrm{Kz}$ Ss Por

4.72421e+01 4.72421e+01 4.72421e+00 1.00000e-09 7.00000e-02

$1.00000 \mathrm{e}-02$ 1.00000e-02 1.00000e-03 1.00000e-09 1.00000e-01

$1.00000 \mathrm{e}+001.00000 \mathrm{e}+001.00000 \mathrm{e}-011.00000 \mathrm{e}-091.00000 \mathrm{e}-01$

Element: 7985 \# of layers: 3

$\mathrm{Kx} \mathrm{Ky} \mathrm{Kz}$ Ss Por

4.90685e+01 4.90685e+01 4.90685e+00 1.00000e-09 7.00000e-02

$1.00000 \mathrm{e}-02$ 1.00000e-02 1.00000e-03 1.00000e-09 1.00000e-01 
$1.00000 \mathrm{e}+001.00000 \mathrm{e}+00$ 1.00000e-01 1.00000e-09 1.00000e-01

Element: 7986 \# of layers: 3

Kx Ky Kz Ss Por

4.90685e+01 4.90685e+01 4.90685e+00 1.00000e-09 7.00000e-02

$1.00000 \mathrm{e}-011.00000 \mathrm{e}-011.00000 \mathrm{e}-021.00000 \mathrm{e}-091.00000 \mathrm{e}-01$

$1.00000 \mathrm{e}+001.00000 \mathrm{e}+001.00000 \mathrm{e}-011.00000 \mathrm{e}-091.00000 \mathrm{e}-01$

Element: 7987 \# of layers: 3

$\mathrm{Kx} \mathrm{Ky} \mathrm{Kz}$ Ss Por

4.90685e+01 4.90685e+01 4.90685e+00 1.00000e-09 7.00000e-02

$1.00000 \mathrm{e}-01$ 1.00000e-01 1.00000e-02 1.00000e-09 1.00000e-01

$1.00000 \mathrm{e}+001.00000 \mathrm{e}+001.00000 \mathrm{e}-011.00000 \mathrm{e}-091.00000 \mathrm{e}-01$

Element: 7988 \# of layers: 3

$\mathrm{Kx} \mathrm{Ky} \mathrm{Kz}$ Ss Por

4.90685e+01 4.90685e+01 4.90685e+00 1.00000e-09 7.00000e-02

$1.00000 \mathrm{e}-02$ 1.00000e-02 1.00000e-03 1.00000e-09 1.00000e-01

$1.00000 \mathrm{e}+001.00000 \mathrm{e}+001.00000 \mathrm{e}-011.00000 \mathrm{e}-091.00000 \mathrm{e}-01$

Element: 7989 \# of layers: 3

$\mathrm{Kx} \mathrm{Ky} \mathrm{Kz}$ Ss Por

4.90685e+01 4.90685e+01 4.90685e+00 1.00000e-09 7.00000e-02

$1.00000 \mathrm{e}-02$ 1.00000e-02 1.00000e-03 1.00000e-09 1.00000e-01

$1.00000 \mathrm{e}+001.00000 \mathrm{e}+001.00000 \mathrm{e}-011.00000 \mathrm{e}-091.00000 \mathrm{e}-01$

Element: 7990 \# of layers: 3

$\mathrm{Kx} \mathrm{Ky} \mathrm{Kz}$ Ss Por

4.90685e+01 4.90685e+01 4.90685e+00 1.00000e-09 7.00000e-02

$1.00000 \mathrm{e}-02$ 1.00000e-02 1.00000e-03 1.00000e-09 1.00000e-01

$1.00000 \mathrm{e}+001.00000 \mathrm{e}+001.00000 \mathrm{e}-01$ 1.00000e-09 1.00000e-01

Element: 7991 \# of layers: 3

$\mathrm{Kx} \mathrm{Ky} \mathrm{Kz}$ Ss Por

4.90685e+01 4.90685e+01 4.90685e+00 1.00000e-09 7.00000e-02

$1.00000 \mathrm{e}-02$ 1.00000e-02 1.00000e-03 1.00000e-09 1.00000e-01

$1.00000 \mathrm{e}+001.00000 \mathrm{e}+001.00000 \mathrm{e}-011.00000 \mathrm{e}-091.00000 \mathrm{e}-01$

Element: 7992 \# of layers: 3

$\mathrm{Kx} \mathrm{Ky} \mathrm{Kz}$ Ss Por

4.90685e+01 4.90685e+01 4.90685e+00 1.00000e-09 7.00000e-02

$1.00000 \mathrm{e}-02$ 1.00000e-02 1.00000e-03 1.00000e-09 1.00000e-01

$1.00000 \mathrm{e}+001.00000 \mathrm{e}+001.00000 \mathrm{e}-011.00000 \mathrm{e}-091.00000 \mathrm{e}-01$

Element: 7993 \# of layers: 3

$\mathrm{Kx} \mathrm{Ky} \mathrm{Kz}$ Ss Por

4.90685e+01 4.90685e+01 4.90685e+00 1.00000e-09 7.00000e-02

$1.00000 \mathrm{e}-02$ 1.00000e-02 1.00000e-03 1.00000e-09 1.00000e-01

$1.00000 \mathrm{e}+001.00000 \mathrm{e}+001.00000 \mathrm{e}-011.00000 \mathrm{e}-091.00000 \mathrm{e}-01$

Element: 7994 \# of layers: 3

$\mathrm{Kx} \mathrm{Ky} \mathrm{Kz}$ Ss Por

4.98190e+01 4.98190e+01 4.98190e+00 1.00000e-09 7.00000e-02

$1.00000 \mathrm{e}-01$ 1.00000e-01 1.00000e-02 1.00000e-09 1.00000e-01

$1.00000 \mathrm{e}+001.00000 \mathrm{e}+001.00000 \mathrm{e}-011.00000 \mathrm{e}-091.00000 \mathrm{e}-01$ 
Element: 7995 \# of layers: 3

$\mathrm{Kx} \mathrm{Ky} \mathrm{Kz}$ Ss Por

4.98190e+01 4.98190e+01 4.98190e+00 1.00000e-09 7.00000e-02

$1.00000 \mathrm{e}-011.00000 \mathrm{e}-01$ 1.00000e-02 1.00000e-09 1.00000e-01

$1.00000 \mathrm{e}+001.00000 \mathrm{e}+001.00000 \mathrm{e}-01$ 1.00000e-09 1.00000e-01

Element: 7996 \# of layers: 3

$\mathrm{Kx} \mathrm{Ky} \mathrm{Kz}$ Ss Por

6.66947e+01 6.66947e+01 6.66947e+00 1.00000e-09 7.00000e-02

$1.00000 \mathrm{e}-021.00000 \mathrm{e}-02$ 1.00000e-03 1.00000e-09 1.00000e-01

$1.00000 \mathrm{e}+001.00000 \mathrm{e}+001.00000 \mathrm{e}-011.00000 \mathrm{e}-091.00000 \mathrm{e}-01$

Element: 7997 \# of layers: 4

$\mathrm{Kx} \mathrm{Ky} \mathrm{Kz}$ Ss Por

3.12037e+02 3.12037e+02 3.12037e+01 1.00000e-09 2.12000e-01

$3.12037 \mathrm{e}+02$ 3.12037e+02 3.12037e+01 1.00000e-09 2.12000e-01

$1.00000 \mathrm{e}-02$ 1.00000e-02 1.00000e-03 1.00000e-09 1.00000e-01

$1.00000 \mathrm{e}+001.00000 \mathrm{e}+001.00000 \mathrm{e}-011.00000 \mathrm{e}-091.00000 \mathrm{e}-01$

Element: 7998 \# of layers: 4

$\mathrm{Kx} \mathrm{Ky} \mathrm{Kz}$ Ss Por

3.12037e+02 3.12037e+02 3.12037e+01 1.00000e-09 2.12000e-01

3.12037e+02 3.12037e+02 3.12037e+01 1.00000e-09 2.12000e-01

$1.00000 \mathrm{e}-02$ 1.00000e-02 1.00000e-03 1.00000e-09 1.00000e-01

$1.00000 \mathrm{e}+001.00000 \mathrm{e}+001.00000 \mathrm{e}-01$ 1.00000e-09 1.00000e-01

Element: 7999 \# of layers: 4

Kx Ky Kz Ss Por

3.12037e+02 3.12037e+02 3.12037e+01 1.00000e-09 2.12000e-01

3.12037e+02 3.12037e+02 3.12037e+01 1.00000e-09 2.12000e-01

$1.00000 \mathrm{e}-02$ 1.00000e-02 1.00000e-03 1.00000e-09 1.00000e-01

$1.00000 \mathrm{e}+001.00000 \mathrm{e}+001.00000 \mathrm{e}-011.00000 \mathrm{e}-091.00000 \mathrm{e}-01$

Element: 8000 \# of layers: 4

$\mathrm{Kx} \mathrm{Ky} \mathrm{Kz}$ Ss Por

4.13536e+02 4.13536e+02 4.13536e+01 1.00000e-09 2.12000e-01

4.13536e+02 4.13536e+02 4.13536e+01 1.00000e-09 2.12000e-01

$1.00000 \mathrm{e}-02$ 1.00000e-02 1.00000e-03 1.00000e-09 1.00000e-01

$1.00000 \mathrm{e}+001.00000 \mathrm{e}+001.00000 \mathrm{e}-011.00000 \mathrm{e}-091.00000 \mathrm{e}-01$

Element: 8001 \# of layers: 4

Kx Ky Kz Ss Por

4.13536e+02 4.13536e+02 4.13536e+01 1.00000e-09 2.12000e-01

$4.13536 \mathrm{e}+024.13536 \mathrm{e}+024.13536 \mathrm{e}+01$ 1.00000e-09 2.12000e-01

$1.00000 \mathrm{e}-02$ 1.00000e-02 1.00000e-03 1.00000e-09 1.00000e-01

$1.00000 \mathrm{e}+001.00000 \mathrm{e}+001.00000 \mathrm{e}-01$ 1.00000e-09 1.00000e-01

Element: 8002 \# of layers: 4

$\mathrm{Kx} \mathrm{Ky} \mathrm{Kz}$ Ss Por

4.13536e+02 4.13536e+02 4.13536e+01 1.00000e-09 2.12000e-01

4.13536e+02 4.13536e+02 4.13536e+01 1.00000e-09 2.12000e-01

$1.00000 \mathrm{e}-021.00000 \mathrm{e}-021.00000 \mathrm{e}-031.00000 \mathrm{e}-091.00000 \mathrm{e}-01$

$1.00000 \mathrm{e}+001.00000 \mathrm{e}+001.00000 \mathrm{e}-011.00000 \mathrm{e}-091.00000 \mathrm{e}-01$ 
Element: 8003 \# of layers: 4

$\mathrm{Kx} \mathrm{Ky} \mathrm{Kz}$ Ss Por

$4.05684 \mathrm{e}+02$ 4.05684e+02 4.05684e+01 1.00000e-09 2.12000e-01

$4.05684 \mathrm{e}+02$ 4.05684e+02 4.05684e+01 1.00000e-09 2.12000e-01

$1.00000 \mathrm{e}-02$ 1.00000e-02 1.00000e-03 1.00000e-09 1.00000e-01

$1.00000 \mathrm{e}+001.00000 \mathrm{e}+001.00000 \mathrm{e}-011.00000 \mathrm{e}-09$ 1.00000e-01

Element: 8004 \# of layers: 4

$\mathrm{Kx} \mathrm{Ky} \mathrm{Kz}$ Ss Por

$4.05684 \mathrm{e}+02$ 4.05684e+02 4.05684e+01 1.00000e-09 2.12000e-01

$4.05684 \mathrm{e}+02$ 4.05684e+02 4.05684e+01 1.00000e-09 2.12000e-01

$1.00000 \mathrm{e}-021.00000 \mathrm{e}-021.00000 \mathrm{e}-031.00000 \mathrm{e}-091.00000 \mathrm{e}-01$

$1.00000 \mathrm{e}+001.00000 \mathrm{e}+001.00000 \mathrm{e}-011.00000 \mathrm{e}-091.00000 \mathrm{e}-01$

Element: 8005 \# of layers: 4

$\mathrm{Kx} \mathrm{Ky} \mathrm{Kz}$ Ss Por

4.05684e+02 4.05684e+02 4.05684e+01 1.00000e-09 2.12000e-01

$4.05684 \mathrm{e}+024.05684 \mathrm{e}+024.05684 \mathrm{e}+01$ 1.00000e-09 2.12000e-01

$1.00000 \mathrm{e}-02$ 1.00000e-02 1.00000e-03 1.00000e-09 1.00000e-01

$1.00000 \mathrm{e}+001.00000 \mathrm{e}+001.00000 \mathrm{e}-01$ 1.00000e-09 1.00000e-01

Element: 8006 \# of layers: 4

$\mathrm{Kx} \mathrm{Ky} \mathrm{Kz}$ Ss Por

$4.05684 \mathrm{e}+02$ 4.05684e+02 4.05684e+01 1.00000e-09 2.12000e-01

$4.05684 \mathrm{e}+02$ 4.05684e+02 4.05684e+01 1.00000e-09 2.12000e-01

$1.00000 \mathrm{e}-02$ 1.00000e-02 1.00000e-03 1.00000e-09 1.00000e-01

$1.00000 \mathrm{e}+001.00000 \mathrm{e}+001.00000 \mathrm{e}-011.00000 \mathrm{e}-091.00000 \mathrm{e}-01$

Element: 8007 \# of layers: 4

$\mathrm{Kx} \mathrm{Ky} \mathrm{Kz}$ Ss Por

4.05684e+02 4.05684e+02 4.05684e+01 1.00000e-09 2.12000e-01

$4.05684 \mathrm{e}+02$ 4.05684e+02 4.05684e+01 1.00000e-09 2.12000e-01

$1.00000 \mathrm{e}-02$ 1.00000e-02 1.00000e-03 1.00000e-09 1.00000e-01

$1.00000 \mathrm{e}+001.00000 \mathrm{e}+001.00000 \mathrm{e}-011.00000 \mathrm{e}-091.00000 \mathrm{e}-01$

Element: 8008 \# of layers: 4

$\mathrm{Kx} \mathrm{Ky} \mathrm{Kz}$ Ss Por

$4.05684 \mathrm{e}+02$ 4.05684e+02 4.05684e+01 1.00000e-09 2.12000e-01

$4.05684 \mathrm{e}+024.05684 \mathrm{e}+02$ 4.05684e+01 1.00000e-09 2.12000e-01

$1.00000 \mathrm{e}-021.00000 \mathrm{e}-021.00000 \mathrm{e}-031.00000 \mathrm{e}-091.00000 \mathrm{e}-01$

$1.00000 \mathrm{e}+001.00000 \mathrm{e}+001.00000 \mathrm{e}-011.00000 \mathrm{e}-091.00000 \mathrm{e}-01$

Element: 8009 \# of layers: 4

$\mathrm{Kx} \mathrm{Ky} \mathrm{Kz}$ Ss Por

4.05684e+02 4.05684e+02 4.05684e+01 1.00000e-09 2.12000e-01

$4.05684 \mathrm{e}+02$ 4.05684e+02 4.05684e+01 1.00000e-09 2.12000e-01

$1.00000 \mathrm{e}-02$ 1.00000e-02 1.00000e-03 1.00000e-09 1.00000e-01

$1.00000 \mathrm{e}+001.00000 \mathrm{e}+001.00000 \mathrm{e}-011.00000 \mathrm{e}-091.00000 \mathrm{e}-01$

Element: 8010 \# of layers: 4

$\mathrm{Kx} \mathrm{Ky} \mathrm{Kz}$ Ss Por

4.05684e+02 4.05684e+02 4.05684e+01 1.00000e-09 2.12000e-01

$4.05684 \mathrm{e}+02$ 4.05684e+02 4.05684e+01 1.00000e-09 2.12000e-01 
$1.00000 \mathrm{e}-02$ 1.00000e-02 1.00000e-03 1.00000e-09 1.00000e-01 $1.00000 \mathrm{e}+001.00000 \mathrm{e}+001.00000 \mathrm{e}-01$ 1.00000e-09 1.00000e-01

Element: 8011 \# of layers: 4

Kx Ky Kz Ss Por

4.05684e+02 4.05684e+02 4.05684e+01 1.00000e-09 2.12000e-01 $4.05684 \mathrm{e}+024.05684 \mathrm{e}+024.05684 \mathrm{e}+01$ 1.00000e-09 2.12000e-01 $1.00000 \mathrm{e}-02$ 1.00000e-02 1.00000e-03 1.00000e-09 1.00000e-01 $1.00000 \mathrm{e}+001.00000 \mathrm{e}+001.00000 \mathrm{e}-01$ 1.00000e-09 1.00000e-01

Element: 8012 \# of layers: 4

$\mathrm{Kx} \mathrm{Ky} \mathrm{Kz}$ Ss Por

4.30952e+01 4.30952e+01 4.30952e+00 1.00000e-09 2.12000e-01 4.30952e+01 4.30952e+01 4.30952e+00 1.00000e-09 2.12000e-01 $1.00000 \mathrm{e}-02$ 1.00000e-02 1.00000e-03 1.00000e-09 1.00000e-01 $1.00000 \mathrm{e}+001.00000 \mathrm{e}+001.00000 \mathrm{e}-011.00000 \mathrm{e}-091.00000 \mathrm{e}-01$ Element: 8013 \# of layers: 4

Kx Ky Kz Ss Por

4.30952e+01 4.30952e+01 4.30952e+00 1.00000e-09 2.12000e-01

4.30952e+01 4.30952e+01 4.30952e+00 1.00000e-09 2.12000e-01 $1.00000 \mathrm{e}-02$ 1.00000e-02 1.00000e-03 1.00000e-09 1.00000e-01 $1.00000 \mathrm{e}+001.00000 \mathrm{e}+001.00000 \mathrm{e}-011.00000 \mathrm{e}-091.00000 \mathrm{e}-01$ Element: 8014 \# of layers: 4

$\mathrm{Kx} \mathrm{Ky} \mathrm{Kz}$ Ss Por

4.30952e+01 4.30952e+01 4.30952e+00 1.00000e-09 2.12000e-01 4.30952e+01 4.30952e+01 4.30952e+00 1.00000e-09 2.12000e-01 $1.00000 \mathrm{e}-02$ 1.00000e-02 1.00000e-03 1.00000e-09 1.00000e-01 $1.00000 \mathrm{e}+001.00000 \mathrm{e}+001.00000 \mathrm{e}-011.00000 \mathrm{e}-091.00000 \mathrm{e}-01$ Element: 8015 \# of layers: 6

$\mathrm{Kx} \mathrm{Ky} \mathrm{Kz}$ Ss Por

$1.07859 \mathrm{e}+03$ 1.07859e+03 1.07859e+02 1.00000e-09 7.00000e-02 $1.07859 \mathrm{e}+03$ 1.07859e+03 1.07859e+02 1.00000e-09 7.00000e-02 4.30952e+01 4.30952e+01 4.30952e+00 1.00000e-09 2.12000e-01 4.30952e+01 4.30952e+01 4.30952e+00 1.00000e-09 2.12000e-01 1.00000e-02 1.00000e-02 1.00000e-03 1.00000e-09 1.00000e-01 $1.00000 \mathrm{e}+001.00000 \mathrm{e}+001.00000 \mathrm{e}-011.00000 \mathrm{e}-091.00000 \mathrm{e}-01$ Element: 8016 \# of layers: 6

$\mathrm{Kx} \mathrm{Ky} \mathrm{Kz}$ Ss Por

$1.07859 \mathrm{e}+03$ 1.07859e+03 1.07859e+02 1.00000e-09 7.00000e-02 $1.07859 \mathrm{e}+031.07859 \mathrm{e}+03$ 1.07859e+02 1.00000e-09 7.00000e-02 4.30952e+01 4.30952e+01 4.30952e+00 1.00000e-09 2.12000e-01 4.30952e+01 4.30952e+01 4.30952e+00 1.00000e-09 2.12000e-01 1.00000e-02 1.00000e-02 1.00000e-03 1.00000e-09 1.00000e-01 $1.00000 \mathrm{e}+001.00000 \mathrm{e}+001.00000 \mathrm{e}-011.00000 \mathrm{e}-091.00000 \mathrm{e}-01$ Element: 8017 \# of layers: 5

$\mathrm{Kx} \mathrm{Ky} \mathrm{Kz}$ Ss Por

$1.07859 \mathrm{e}+03$ 1.07859e+03 1.07859e+02 1.00000e-09 7.00000e-02 $4.30952 \mathrm{e}+014.30952 \mathrm{e}+014.30952 \mathrm{e}+00$ 1.00000e-09 2.12000e-01 
4.30952e+01 4.30952e+01 4.30952e+00 1.00000e-09 2.12000e-01 $1.00000 \mathrm{e}-02$ 1.00000e-02 1.00000e-03 1.00000e-09 1.00000e-01

$1.00000 \mathrm{e}+001.00000 \mathrm{e}+001.00000 \mathrm{e}-011.00000 \mathrm{e}-091.00000 \mathrm{e}-01$

Element: 8018 \# of layers: 5

$\mathrm{Kx} \mathrm{Ky} \mathrm{Kz}$ Ss Por

1.07859e+03 1.07859e+03 1.07859e+02 1.00000e-09 7.00000e-02

$4.30952 \mathrm{e}+014.30952 \mathrm{e}+014.30952 \mathrm{e}+00$ 1.00000e-09 2.12000e-01

4.30952e+01 4.30952e+01 4.30952e+00 1.00000e-09 2.12000e-01

$1.00000 \mathrm{e}-02$ 1.00000e-02 1.00000e-03 1.00000e-09 1.00000e-01

$1.00000 \mathrm{e}+001.00000 \mathrm{e}+001.00000 \mathrm{e}-011.00000 \mathrm{e}-091.00000 \mathrm{e}-01$

Element: 8019 \# of layers: 4

$\mathrm{Kx} \mathrm{Ky} \mathrm{Kz}$ Ss Por

4.30952e+01 4.30952e+01 4.30952e+00 1.00000e-09 2.12000e-01

4.30952e+01 4.30952e+01 4.30952e+00 1.00000e-09 2.12000e-01

$1.00000 \mathrm{e}-02$ 1.00000e-02 1.00000e-03 1.00000e-09 1.00000e-01

$1.00000 \mathrm{e}+001.00000 \mathrm{e}+001.00000 \mathrm{e}-011.00000 \mathrm{e}-091.00000 \mathrm{e}-01$

Element: 8020 \# of layers: 4

$\mathrm{Kx} \mathrm{Ky} \mathrm{Kz}$ Ss Por

4.30952e+01 4.30952e+01 4.30952e+00 1.00000e-09 2.12000e-01

$4.30952 \mathrm{e}+014.30952 \mathrm{e}+014.30952 \mathrm{e}+00$ 1.00000e-09 2.12000e-01

$1.00000 \mathrm{e}-02$ 1.00000e-02 1.00000e-03 1.00000e-09 1.00000e-01

$1.00000 \mathrm{e}+001.00000 \mathrm{e}+001.00000 \mathrm{e}-01$ 1.00000e-09 1.00000e-01

Element: 8021 \# of layers: 5

Kx Ky Kz Ss Por

$1.38583 e+02$ 1.38583e+02 1.38583e+01 1.00000e-09 7.00000e-02

5.53737e+00 5.53737e+00 5.53737e-01 1.00000e-09 2.12000e-01

5.53737e+00 5.53737e+00 5.53737e-01 1.00000e-09 2.12000e-01

$1.00000 \mathrm{e}-02$ 1.00000e-02 1.00000e-03 1.00000e-09 1.00000e-01

$1.00000 \mathrm{e}+001.00000 \mathrm{e}+001.00000 \mathrm{e}-011.00000 \mathrm{e}-091.00000 \mathrm{e}-01$

Element: 8022 \# of layers: 5

$\mathrm{Kx} \mathrm{Ky} \mathrm{Kz}$ Ss Por

$1.38583 e+02$ 1.38583e+02 1.38583e+01 1.00000e-09 7.00000e-02

$5.53737 \mathrm{e}+00$ 5.53737e+00 5.53737e-01 1.00000e-09 2.12000e-01

5.53737e+00 5.53737e+00 5.53737e-01 1.00000e-09 2.12000e-01

$1.00000 \mathrm{e}-02$ 1.00000e-02 1.00000e-03 1.00000e-09 1.00000e-01

$1.00000 \mathrm{e}+001.00000 \mathrm{e}+001.00000 \mathrm{e}-011.00000 \mathrm{e}-091.00000 \mathrm{e}-01$

Element: 8023 \# of layers: 5

Kx Ky Kz Ss Por

1.38583e+02 1.38583e+02 1.38583e+01 1.00000e-09 7.00000e-02

$1.38583 \mathrm{e}+02$ 1.38583e+02 1.38583e+01 1.00000e-09 7.00000e-02

$5.53737 \mathrm{e}+00$ 5.53737e+00 5.53737e-01 1.00000e-09 2.12000e-01

$1.00000 \mathrm{e}-02$ 1.00000e-02 1.00000e-03 1.00000e-09 1.00000e-01

$1.00000 \mathrm{e}+001.00000 \mathrm{e}+001.00000 \mathrm{e}-011.00000 \mathrm{e}-091.00000 \mathrm{e}-01$

Element: 8024 \# of layers: 3

$\mathrm{Kx} \mathrm{Ky} \mathrm{Kz}$ Ss Por

$1.38583 e+02$ 1.38583e+02 1.38583e+01 1.00000e-09 7.00000e-02 
$1.00000 \mathrm{e}-02$ 1.00000e-02 1.00000e-03 1.00000e-09 1.00000e-01 $1.00000 \mathrm{e}+001.00000 \mathrm{e}+001.00000 \mathrm{e}-01$ 1.00000e-09 1.00000e-01 Element: 8025 \# of layers: 3

Kx Ky Kz Ss Por

$1.38583 \mathrm{e}+02$ 1.38583e+02 1.38583e+01 1.00000e-09 7.00000e-02 $1.00000 \mathrm{e}-02$ 1.00000e-02 1.00000e-03 1.00000e-09 1.00000e-01 $1.00000 \mathrm{e}+001.00000 \mathrm{e}+001.00000 \mathrm{e}-011.00000 \mathrm{e}-091.00000 \mathrm{e}-01$ Element: 8026 \# of layers: 4

$\mathrm{Kx} \mathrm{Ky} \mathrm{Kz}$ Ss Por

1.38583e+02 1.38583e+02 1.38583e+01 1.00000e-09 7.00000e-02 $5.53737 \mathrm{e}+00$ 5.53737e+00 5.53737e-01 1.00000e-09 2.12000e-01 $1.00000 \mathrm{e}-02$ 1.00000e-02 1.00000e-03 1.00000e-09 1.00000e-01 $1.00000 \mathrm{e}+001.00000 \mathrm{e}+001.00000 \mathrm{e}-01$ 1.00000e-09 1.00000e-01 Element: 8027 \# of layers: 5

$\mathrm{Kx} \mathrm{Ky} \mathrm{Kz}$ Ss Por

1.38583e+02 1.38583e+02 1.38583e+01 1.00000e-09 7.00000e-02 $1.38583 \mathrm{e}+02$ 1.38583e+02 1.38583e+01 1.00000e-09 7.00000e-02 5.53737e+00 5.53737e+00 5.53737e-01 1.00000e-09 2.12000e-01 $1.00000 \mathrm{e}-02$ 1.00000e-02 1.00000e-03 1.00000e-09 1.00000e-01 $1.00000 \mathrm{e}+001.00000 \mathrm{e}+001.00000 \mathrm{e}-011.00000 \mathrm{e}-091.00000 \mathrm{e}-01$ Element: 8028 \# of layers: 6

$\mathrm{Kx} \mathrm{Ky} \mathrm{Kz}$ Ss Por

1.38583e+02 1.38583e+02 1.38583e+01 1.00000e-09 7.00000e-02 $1.38583 \mathrm{e}+02$ 1.38583e+02 1.38583e+01 1.00000e-09 7.00000e-02 $5.53737 \mathrm{e}+00$ 5.53737e+00 5.53737e-01 1.00000e-09 2.12000e-01 5.53737e+00 5.53737e+00 5.53737e-01 1.00000e-09 2.12000e-01 $1.00000 \mathrm{e}-02$ 1.00000e-02 1.00000e-03 1.00000e-09 1.00000e-01 $1.00000 \mathrm{e}+001.00000 \mathrm{e}+001.00000 \mathrm{e}-011.00000 \mathrm{e}-091.00000 \mathrm{e}-01$ Element: 8029 \# of layers: 4

$\mathrm{Kx} \mathrm{Ky} \mathrm{Kz}$ Ss Por

1.38583e+02 1.38583e+02 1.38583e+01 1.00000e-09 7.00000e-02 5.53737e+00 5.53737e+00 5.53737e-01 1.00000e-09 2.12000e-01 $1.00000 \mathrm{e}-02$ 1.00000e-02 1.00000e-03 1.00000e-09 1.00000e-01 $1.00000 \mathrm{e}+001.00000 \mathrm{e}+001.00000 \mathrm{e}-011.00000 \mathrm{e}-091.00000 \mathrm{e}-01$ Element: 8030 \# of layers: 4

$\mathrm{Kx} \mathrm{Ky} \mathrm{Kz}$ Ss Por

7.71986e+01 7.71986e+01 7.71986e+00 1.00000e-09 7.00000e-02

$7.71986 \mathrm{e}+017.71986 \mathrm{e}+017.71986 \mathrm{e}+001.00000 \mathrm{e}-09$ 7.00000e-02 $1.00000 \mathrm{e}-02$ 1.00000e-02 1.00000e-03 1.00000e-09 1.00000e-01 $1.00000 \mathrm{e}+001.00000 \mathrm{e}+001.00000 \mathrm{e}-01$ 1.00000e-09 1.00000e-01 Element: 8031 \# of layers: 4

$\mathrm{Kx} \mathrm{Ky} \mathrm{Kz}$ Ss Por

7.71986e+01 7.71986e+01 7.71986e+00 1.00000e-09 7.00000e-02 7.71986e+01 7.71986e+01 7.71986e+00 1.00000e-09 7.00000e-02 $1.00000 \mathrm{e}-02$ 1.00000e-02 1.00000e-03 1.00000e-09 1.00000e-01 $1.00000 \mathrm{e}+001.00000 \mathrm{e}+001.00000 \mathrm{e}-011.00000 \mathrm{e}-091.00000 \mathrm{e}-01$ 
Element: 8032 \# of layers: 4

$\mathrm{Kx} \mathrm{Ky} \mathrm{Kz}$ Ss Por

7.71986e+01 7.71986e+01 7.71986e+00 1.00000e-09 7.00000e-02

7.71986e+01 7.71986e+01 7.71986e+00 1.00000e-09 7.00000e-02

$1.00000 \mathrm{e}-02$ 1.00000e-02 1.00000e-03 1.00000e-09 1.00000e-01

$1.00000 \mathrm{e}+001.00000 \mathrm{e}+00$ 1.00000e-01 1.00000e-09 1.00000e-01

Element: 8033 \# of layers: 3

Kx Ky Kz Ss Por

7.71986e+01 7.71986e+01 7.71986e+00 1.00000e-09 7.00000e-02

$1.00000 \mathrm{e}-02$ 1.00000e-02 1.00000e-03 1.00000e-09 1.00000e-01

$1.00000 \mathrm{e}+001.00000 \mathrm{e}+001.00000 \mathrm{e}-011.00000 \mathrm{e}-091.00000 \mathrm{e}-01$

Element: 8034 \# of layers: 3

$\mathrm{Kx} \mathrm{Ky} \mathrm{Kz}$ Ss Por

7.71986e+01 7.71986e+01 7.71986e+00 1.00000e-09 7.00000e-02

$1.00000 \mathrm{e}-02$ 1.00000e-02 1.00000e-03 1.00000e-09 1.00000e-01

$1.00000 \mathrm{e}+001.00000 \mathrm{e}+001.00000 \mathrm{e}-011.00000 \mathrm{e}-091.00000 \mathrm{e}-01$

Element: 8035 \# of layers: 3

$\mathrm{Kx} \mathrm{Ky} \mathrm{Kz}$ Ss Por

7.71986e+01 7.71986e+01 7.71986e+00 1.00000e-09 7.00000e-02

$1.00000 \mathrm{e}-02$ 1.00000e-02 1.00000e-03 1.00000e-09 1.00000e-01

$1.00000 \mathrm{e}+001.00000 \mathrm{e}+001.00000 \mathrm{e}-011.00000 \mathrm{e}-091.00000 \mathrm{e}-01$

Element: 8036 \# of layers: 3

$\mathrm{Kx} \mathrm{Ky} \mathrm{Kz}$ Ss Por

7.71986e+01 7.71986e+01 7.71986e+00 1.00000e-09 7.00000e-02

$1.00000 \mathrm{e}-02$ 1.00000e-02 1.00000e-03 1.00000e-09 1.00000e-01

$1.00000 \mathrm{e}+001.00000 \mathrm{e}+001.00000 \mathrm{e}-011.00000 \mathrm{e}-091.00000 \mathrm{e}-01$

Element: 8037 \# of layers: 3

$\mathrm{Kx} \mathrm{Ky} \mathrm{Kz}$ Ss Por

7.71986e+01 7.71986e+01 7.71986e+00 1.00000e-09 7.00000e-02

$1.00000 \mathrm{e}-021.00000 \mathrm{e}-021.00000 \mathrm{e}-031.00000 \mathrm{e}-091.00000 \mathrm{e}-01$

$1.00000 \mathrm{e}+001.00000 \mathrm{e}+00$ 1.00000e-01 1.00000e-09 1.00000e-01

Element: 8038 \# of layers: 3

Kx Ky Kz Ss Por

7.71986e+01 7.71986e+01 7.71986e+00 1.00000e-09 7.00000e-02

$1.00000 \mathrm{e}-021.00000 \mathrm{e}-021.00000 \mathrm{e}-031.00000 \mathrm{e}-091.00000 \mathrm{e}-01$

$1.00000 \mathrm{e}+001.00000 \mathrm{e}+001.00000 \mathrm{e}-011.00000 \mathrm{e}-091.00000 \mathrm{e}-01$

Element: 8039 \# of layers: 4

$\mathrm{Kx} \mathrm{Ky} \mathrm{Kz}$ Ss Por

8.58248e+01 8.58248e+01 8.58248e+00 1.00000e-09 7.00000e-02

$8.58248 \mathrm{e}+018.58248 \mathrm{e}+018.58248 \mathrm{e}+00$ 1.00000e-09 7.00000e-02

$1.00000 \mathrm{e}-02$ 1.00000e-02 1.00000e-03 1.00000e-09 1.00000e-01

$1.00000 \mathrm{e}+001.00000 \mathrm{e}+001.00000 \mathrm{e}-011.00000 \mathrm{e}-091.00000 \mathrm{e}-01$

Element: 8040 \# of layers: 4

$\mathrm{Kx} \mathrm{Ky} \mathrm{Kz}$ Ss Por

8.58248e+01 8.58248e+01 8.58248e+00 1.00000e-09 7.00000e-02

8.58248e+01 8.58248e+01 8.58248e+00 1.00000e-09 7.00000e-02 
$1.00000 \mathrm{e}-02$ 1.00000e-02 1.00000e-03 1.00000e-09 1.00000e-01 $1.00000 \mathrm{e}+001.00000 \mathrm{e}+001.00000 \mathrm{e}-01$ 1.00000e-09 1.00000e-01 Element: 8041 \# of layers: 4

Kx Ky Kz Ss Por

8.58248e+01 8.58248e+01 8.58248e+00 1.00000e-09 7.00000e-02

8.58248e+01 8.58248e+01 8.58248e+00 1.00000e-09 7.00000e-02

$1.00000 \mathrm{e}-02$ 1.00000e-02 1.00000e-03 1.00000e-09 1.00000e-01

$1.00000 \mathrm{e}+001.00000 \mathrm{e}+001.00000 \mathrm{e}-011.00000 \mathrm{e}-091.00000 \mathrm{e}-01$

Element: 8042 \# of layers: 3

$\mathrm{Kx} \mathrm{Ky} \mathrm{Kz}$ Ss Por

8.58248e+01 8.58248e+01 8.58248e+00 1.00000e-09 7.00000e-02

$1.00000 \mathrm{e}-02$ 1.00000e-02 1.00000e-03 1.00000e-09 1.00000e-01

$1.00000 \mathrm{e}+001.00000 \mathrm{e}+001.00000 \mathrm{e}-011.00000 \mathrm{e}-091.00000 \mathrm{e}-01$

Element: 8043 \# of layers: 3

$\mathrm{Kx} \mathrm{Ky} \mathrm{Kz}$ Ss Por

8.58248e+01 8.58248e+01 8.58248e+00 1.00000e-09 7.00000e-02

$1.00000 \mathrm{e}-02$ 1.00000e-02 1.00000e-03 1.00000e-09 1.00000e-01

$1.00000 \mathrm{e}+001.00000 \mathrm{e}+001.00000 \mathrm{e}-011.00000 \mathrm{e}-091.00000 \mathrm{e}-01$

Element: 8044 \# of layers: 3

$\mathrm{Kx} \mathrm{Ky} \mathrm{Kz}$ Ss Por

8.58248e+01 8.58248e+01 8.58248e+00 1.00000e-09 7.00000e-02

$1.00000 \mathrm{e}-021.00000 \mathrm{e}-02$ 1.00000e-03 1.00000e-09 1.00000e-01

$1.00000 \mathrm{e}+001.00000 \mathrm{e}+001.00000 \mathrm{e}-011.00000 \mathrm{e}-091.00000 \mathrm{e}-01$

Element: 8045 \# of layers: 3

Kx Ky Kz Ss Por

8.58248e+01 8.58248e+01 8.58248e+00 1.00000e-09 7.00000e-02

$1.00000 \mathrm{e}-02$ 1.00000e-02 1.00000e-03 1.00000e-09 1.00000e-01

$1.00000 \mathrm{e}+001.00000 \mathrm{e}+001.00000 \mathrm{e}-011.00000 \mathrm{e}-091.00000 \mathrm{e}-01$

Element: 8046 \# of layers: 3

$\mathrm{Kx} \mathrm{Ky} \mathrm{Kz}$ Ss Por

8.58248e+01 8.58248e+01 8.58248e+00 1.00000e-09 7.00000e-02

$1.00000 \mathrm{e}-02$ 1.00000e-02 1.00000e-03 1.00000e-09 1.00000e-01

$1.00000 \mathrm{e}+001.00000 \mathrm{e}+001.00000 \mathrm{e}-011.00000 \mathrm{e}-091.00000 \mathrm{e}-01$

Element: 8047 \# of layers: 3

$\mathrm{Kx} \mathrm{Ky} \mathrm{Kz}$ Ss Por

8.58248e+01 8.58248e+01 8.58248e+00 1.00000e-09 7.00000e-02

$1.00000 \mathrm{e}-02$ 1.00000e-02 1.00000e-03 1.00000e-09 1.00000e-01

$1.00000 \mathrm{e}+001.00000 \mathrm{e}+001.00000 \mathrm{e}-011.00000 \mathrm{e}-091.00000 \mathrm{e}-01$

Element: 8048 \# of layers: 4

$\mathrm{Kx} \mathrm{Ky} \mathrm{Kz}$ Ss Por

8.84602e+01 8.84602e+01 8.84602e+00 1.00000e-09 7.00000e-02

8.84602e+01 8.84602e+01 8.84602e+00 1.00000e-09 7.00000e-02

$1.00000 \mathrm{e}-021.00000 \mathrm{e}-021.00000 \mathrm{e}-031.00000 \mathrm{e}-091.00000 \mathrm{e}-01$

$1.00000 \mathrm{e}+001.00000 \mathrm{e}+001.00000 \mathrm{e}-011.00000 \mathrm{e}-091.00000 \mathrm{e}-01$

Element: 8049 \# of layers: 4

Kx Ky Kz Ss Por 
8.84602e+01 8.84602e+01 8.84602e+00 1.00000e-09 7.00000e-02 8.84602e+01 8.84602e+01 8.84602e+00 1.00000e-09 7.00000e-02 $1.00000 \mathrm{e}-02$ 1.00000e-02 1.00000e-03 1.00000e-09 1.00000e-01

$1.00000 \mathrm{e}+001.00000 \mathrm{e}+001.00000 \mathrm{e}-011.00000 \mathrm{e}-091.00000 \mathrm{e}-01$

Element: 8050 \# of layers: 4

$\mathrm{Kx} \mathrm{Ky} \mathrm{Kz}$ Ss Por

8.84602e+01 8.84602e+01 8.84602e+00 1.00000e-09 7.00000e-02

$8.84602 \mathrm{e}+018.84602 \mathrm{e}+018.84602 \mathrm{e}+00$ 1.00000e-09 7.00000e-02

$1.00000 \mathrm{e}-02$ 1.00000e-02 1.00000e-03 1.00000e-09 1.00000e-01

$1.00000 \mathrm{e}+001.00000 \mathrm{e}+001.00000 \mathrm{e}-011.00000 \mathrm{e}-09$ 1.00000e-01

Element: 8051 \# of layers: 3

$\mathrm{Kx} \mathrm{Ky} \mathrm{Kz}$ Ss Por

8.84602e+01 8.84602e+01 8.84602e+00 1.00000e-09 7.00000e-02 $1.00000 \mathrm{e}-02$ 1.00000e-02 1.00000e-03 1.00000e-09 1.00000e-01

$1.00000 \mathrm{e}+001.00000 \mathrm{e}+001.00000 \mathrm{e}-011.00000 \mathrm{e}-091.00000 \mathrm{e}-01$

Element: 8052 \# of layers: 3

$\mathrm{Kx} \mathrm{Ky} \mathrm{Kz}$ Ss Por

8.84602e+01 8.84602e+01 8.84602e+00 1.00000e-09 7.00000e-02 $1.00000 \mathrm{e}-02$ 1.00000e-02 1.00000e-03 1.00000e-09 1.00000e-01

$1.00000 \mathrm{e}+001.00000 \mathrm{e}+001.00000 \mathrm{e}-011.00000 \mathrm{e}-091.00000 \mathrm{e}-01$

Element: 8053 \# of layers: 3

$\mathrm{Kx} \mathrm{Ky} \mathrm{Kz}$ Ss Por

8.84602e+01 8.84602e+01 8.84602e+00 1.00000e-09 7.00000e-02 $1.00000 \mathrm{e}-02$ 1.00000e-02 1.00000e-03 1.00000e-09 1.00000e-01

$1.00000 \mathrm{e}+001.00000 \mathrm{e}+001.00000 \mathrm{e}-011.00000 \mathrm{e}-091.00000 \mathrm{e}-01$

Element: 8054 \# of layers: 3

$\mathrm{Kx} \mathrm{Ky} \mathrm{Kz}$ Ss Por

8.84602e+01 8.84602e+01 8.84602e+00 1.00000e-09 7.00000e-02

$1.00000 \mathrm{e}-02$ 1.00000e-02 1.00000e-03 1.00000e-09 1.00000e-01

$1.00000 \mathrm{e}+001.00000 \mathrm{e}+001.00000 \mathrm{e}-011.00000 \mathrm{e}-091.00000 \mathrm{e}-01$

Element: 8055 \# of layers: 3

$\mathrm{Kx} \mathrm{Ky} \mathrm{Kz}$ Ss Por

8.84602e+01 8.84602e+01 8.84602e+00 1.00000e-09 7.00000e-02

$1.00000 \mathrm{e}-021.00000 \mathrm{e}-021.00000 \mathrm{e}-031.00000 \mathrm{e}-091.00000 \mathrm{e}-01$

$1.00000 \mathrm{e}+001.00000 \mathrm{e}+001.00000 \mathrm{e}-011.00000 \mathrm{e}-091.00000 \mathrm{e}-01$

Element: 8056 \# of layers: 3

$\mathrm{Kx} \mathrm{Ky} \mathrm{Kz}$ Ss Por

8.84602e+01 8.84602e+01 8.84602e+00 1.00000e-09 7.00000e-02 $1.00000 \mathrm{e}-02$ 1.00000e-02 1.00000e-03 1.00000e-09 1.00000e-01

$1.00000 \mathrm{e}+001.00000 \mathrm{e}+001.00000 \mathrm{e}-01$ 1.00000e-09 1.00000e-01

Element: 8057 \# of layers: 4

$\mathrm{Kx} \mathrm{Ky} \mathrm{Kz}$ Ss Por

9.25147e+01 9.25147e+01 9.25147e+00 1.00000e-09 7.00000e-02

9.25147e+01 9.25147e+01 9.25147e+00 1.00000e-09 7.00000e-02

$1.00000 \mathrm{e}-02$ 1.00000e-02 1.00000e-03 1.00000e-09 1.00000e-01

$1.00000 \mathrm{e}+001.00000 \mathrm{e}+001.00000 \mathrm{e}-011.00000 \mathrm{e}-091.00000 \mathrm{e}-01$ 
Element: 8058 \# of layers: 3

$\mathrm{Kx} \mathrm{Ky} \mathrm{Kz}$ Ss Por

9.25147e+01 9.25147e+01 9.25147e+00 1.00000e-09 7.00000e-02

$1.00000 \mathrm{e}-02$ 1.00000e-02 1.00000e-03 1.00000e-09 1.00000e-01

$1.00000 \mathrm{e}+001.00000 \mathrm{e}+001.00000 \mathrm{e}-011.00000 \mathrm{e}-091.00000 \mathrm{e}-01$

Element: 8059 \# of layers: 3

$\mathrm{Kx} \mathrm{Ky} \mathrm{Kz}$ Ss Por

9.25147e+01 9.25147e+01 9.25147e+00 1.00000e-09 7.00000e-02

$1.00000 \mathrm{e}-02$ 1.00000e-02 1.00000e-03 1.00000e-09 1.00000e-01

$1.00000 \mathrm{e}+001.00000 \mathrm{e}+001.00000 \mathrm{e}-011.00000 \mathrm{e}-09$ 1.00000e-01

Element: 8060 \# of layers: 3

$\mathrm{Kx} \mathrm{Ky} \mathrm{Kz}$ Ss Por

9.25147e+01 9.25147e+01 9.25147e+00 1.00000e-09 7.00000e-02

1.00000e-02 1.00000e-02 1.00000e-03 1.00000e-09 1.00000e-01

$1.00000 \mathrm{e}+001.00000 \mathrm{e}+001.00000 \mathrm{e}-011.00000 \mathrm{e}-091.00000 \mathrm{e}-01$

Element: 8061 \# of layers: 3

$\mathrm{Kx} \mathrm{Ky} \mathrm{Kz}$ Ss Por

9.25147e+01 9.25147e+01 9.25147e+00 1.00000e-09 7.00000e-02

$1.00000 \mathrm{e}-02$ 1.00000e-02 1.00000e-03 1.00000e-09 1.00000e-01

$1.00000 \mathrm{e}+001.00000 \mathrm{e}+001.00000 \mathrm{e}-011.00000 \mathrm{e}-091.00000 \mathrm{e}-01$

Element: 8062 \# of layers: 3

$\mathrm{Kx} \mathrm{Ky} \mathrm{Kz}$ Ss Por

9.25147e+01 9.25147e+01 9.25147e+00 1.00000e-09 7.00000e-02

$1.00000 \mathrm{e}-02$ 1.00000e-02 1.00000e-03 1.00000e-09 1.00000e-01

$1.00000 \mathrm{e}+001.00000 \mathrm{e}+001.00000 \mathrm{e}-011.00000 \mathrm{e}-091.00000 \mathrm{e}-01$

Element: 8063 \# of layers: 3

$\mathrm{Kx} \mathrm{Ky} \mathrm{Kz}$ Ss Por

9.25147e+01 9.25147e+01 9.25147e+00 1.00000e-09 7.00000e-02

$1.00000 \mathrm{e}-02$ 1.00000e-02 1.00000e-03 1.00000e-09 1.00000e-01

$1.00000 \mathrm{e}+001.00000 \mathrm{e}+001.00000 \mathrm{e}-011.00000 \mathrm{e}-091.00000 \mathrm{e}-01$

Element: 8064 \# of layers: 3

$\mathrm{Kx} \mathrm{Ky} \mathrm{Kz}$ Ss Por

9.25147e+01 9.25147e+01 9.25147e+00 1.00000e-09 7.00000e-02

$1.00000 \mathrm{e}-02$ 1.00000e-02 1.00000e-03 1.00000e-09 1.00000e-01

$1.00000 \mathrm{e}+001.00000 \mathrm{e}+001.00000 \mathrm{e}-011.00000 \mathrm{e}-091.00000 \mathrm{e}-01$

Element: 8065 \# of layers: 3

Kx Ky Kz Ss Por

9.25147e+01 9.25147e+01 9.25147e+00 1.00000e-09 7.00000e-02

$1.00000 \mathrm{e}-02$ 1.00000e-02 1.00000e-03 1.00000e-09 1.00000e-01

$1.00000 \mathrm{e}+001.00000 \mathrm{e}+001.00000 \mathrm{e}-01$ 1.00000e-09 1.00000e-01

Element: 8066 \# of layers: 3

$\mathrm{Kx} \mathrm{Ky} \mathrm{Kz}$ Ss Por

3.77861e+01 3.77861e+01 3.77861e+00 1.00000e-09 7.00000e-02

$1.00000 \mathrm{e}-021.00000 \mathrm{e}-021.00000 \mathrm{e}-031.00000 \mathrm{e}-091.00000 \mathrm{e}-01$

$1.00000 \mathrm{e}+001.00000 \mathrm{e}+001.00000 \mathrm{e}-01$ 1.00000e-09 1.00000e-01

Element: 8067 \# of layers: 3 
Kx Ky Kz Ss Por

3.77861e+01 3.77861e+01 3.77861e+00 1.00000e-09 7.00000e-02

$1.00000 \mathrm{e}-02$ 1.00000e-02 1.00000e-03 1.00000e-09 1.00000e-01

$1.00000 \mathrm{e}+001.00000 \mathrm{e}+001.00000 \mathrm{e}-011.00000 \mathrm{e}-091.00000 \mathrm{e}-01$

Element: 8068 \# of layers: 3

$\mathrm{Kx} \mathrm{Ky} \mathrm{Kz}$ Ss Por

3.77861e+01 3.77861e+01 3.77861e+00 1.00000e-09 7.00000e-02

$1.00000 \mathrm{e}-02$ 1.00000e-02 1.00000e-03 1.00000e-09 1.00000e-01

$1.00000 \mathrm{e}+001.00000 \mathrm{e}+001.00000 \mathrm{e}-011.00000 \mathrm{e}-09$ 1.00000e-01

Element: 8069 \# of layers: 3

Kx Ky Kz Ss Por

3.77861e+01 3.77861e+01 3.77861e+00 1.00000e-09 7.00000e-02

$1.00000 \mathrm{e}-02$ 1.00000e-02 1.00000e-03 1.00000e-09 1.00000e-01

$1.00000 \mathrm{e}+001.00000 \mathrm{e}+001.00000 \mathrm{e}-011.00000 \mathrm{e}-091.00000 \mathrm{e}-01$

Element: 8070 \# of layers: 3

$\mathrm{Kx} \mathrm{Ky} \mathrm{Kz}$ Ss Por

3.77861e+01 3.77861e+01 3.77861e+00 1.00000e-09 7.00000e-02 $1.00000 \mathrm{e}-02$ 1.00000e-02 1.00000e-03 1.00000e-09 1.00000e-01

$1.00000 \mathrm{e}+001.00000 \mathrm{e}+001.00000 \mathrm{e}-011.00000 \mathrm{e}-091.00000 \mathrm{e}-01$

Element: 8071 \# of layers: 3

Kx Ky Kz Ss Por

3.77861e+01 3.77861e+01 3.77861e+00 1.00000e-09 7.00000e-02

$1.00000 \mathrm{e}-02$ 1.00000e-02 1.00000e-03 1.00000e-09 1.00000e-01

$1.00000 \mathrm{e}+001.00000 \mathrm{e}+001.00000 \mathrm{e}-011.00000 \mathrm{e}-091.00000 \mathrm{e}-01$

Element: 8072 \# of layers: 3

$\mathrm{Kx} \mathrm{Ky} \mathrm{Kz}$ Ss Por

3.77861e+01 3.77861e+01 3.77861e+00 1.00000e-09 7.00000e-02

$1.00000 \mathrm{e}-02$ 1.00000e-02 1.00000e-03 1.00000e-09 1.00000e-01

$1.00000 \mathrm{e}+001.00000 \mathrm{e}+001.00000 \mathrm{e}-011.00000 \mathrm{e}-091.00000 \mathrm{e}-01$

Element: 8073 \# of layers: 3

$\mathrm{Kx} \mathrm{Ky} \mathrm{Kz}$ Ss Por

3.77861e+01 3.77861e+01 3.77861e+00 1.00000e-09 7.00000e-02

$1.00000 \mathrm{e}-02$ 1.00000e-02 1.00000e-03 1.00000e-09 1.00000e-01

$1.00000 \mathrm{e}+001.00000 \mathrm{e}+001.00000 \mathrm{e}-011.00000 \mathrm{e}-091.00000 \mathrm{e}-01$

Element: 8074 \# of layers: 3

Kx Ky Kz Ss Por

3.77861e+01 3.77861e+01 3.77861e+00 1.00000e-09 7.00000e-02

$1.00000 \mathrm{e}-02$ 1.00000e-02 1.00000e-03 1.00000e-09 1.00000e-01

$1.00000 \mathrm{e}+001.00000 \mathrm{e}+001.00000 \mathrm{e}-011.00000 \mathrm{e}-09$ 1.00000e-01

Element: 8075 \# of layers: 3

$\mathrm{Kx} \mathrm{Ky} \mathrm{Kz}$ Ss Por

4.27542e+01 4.27542e+01 4.27543e+00 1.00000e-09 7.00000e-02 $1.00000 \mathrm{e}-02$ 1.00000e-02 1.00000e-03 1.00000e-09 1.00000e-01

$1.00000 \mathrm{e}+001.00000 \mathrm{e}+001.00000 \mathrm{e}-01$ 1.00000e-09 1.00000e-01

Element: 8076 \# of layers: 3

Kx Ky Kz Ss Por 
4.27542e+01 4.27542e+01 4.27543e+00 1.00000e-09 7.00000e-02 $1.00000 \mathrm{e}-02$ 1.00000e-02 1.00000e-03 1.00000e-09 1.00000e-01

$1.00000 \mathrm{e}+001.00000 \mathrm{e}+001.00000 \mathrm{e}-011.00000 \mathrm{e}-091.00000 \mathrm{e}-01$

Element: 8077 \# of layers: 3

$\mathrm{Kx} \mathrm{Ky} \mathrm{Kz}$ Ss Por

4.27542e+01 4.27542e+01 4.27543e+00 1.00000e-09 7.00000e-02 $1.00000 \mathrm{e}-02$ 1.00000e-02 1.00000e-03 1.00000e-09 1.00000e-01

$1.00000 \mathrm{e}+001.00000 \mathrm{e}+001.00000 \mathrm{e}-011.00000 \mathrm{e}-091.00000 \mathrm{e}-01$

Element: 8078 \# of layers: 3

$\mathrm{Kx} \mathrm{Ky} \mathrm{Kz}$ Ss Por

4.27542e+01 4.27542e+01 4.27543e+00 1.00000e-09 7.00000e-02

$1.00000 \mathrm{e}-02$ 1.00000e-02 1.00000e-03 1.00000e-09 1.00000e-01

$1.00000 \mathrm{e}+001.00000 \mathrm{e}+001.00000 \mathrm{e}-011.00000 \mathrm{e}-091.00000 \mathrm{e}-01$

Element: 8079 \# of layers: 3

$\mathrm{Kx} \mathrm{Ky} \mathrm{Kz}$ Ss Por

4.27542e+01 4.27542e+01 4.27543e+00 1.00000e-09 7.00000e-02

$1.00000 \mathrm{e}-02$ 1.00000e-02 1.00000e-03 1.00000e-09 1.00000e-01

$1.00000 \mathrm{e}+001.00000 \mathrm{e}+001.00000 \mathrm{e}-011.00000 \mathrm{e}-091.00000 \mathrm{e}-01$

Element: 8080 \# of layers: 3

$\mathrm{Kx} \mathrm{Ky} \mathrm{Kz}$ Ss Por

4.27542e+01 4.27542e+01 4.27543e+00 1.00000e-09 7.00000e-02 $1.00000 \mathrm{e}-02$ 1.00000e-02 1.00000e-03 1.00000e-09 1.00000e-01

$1.00000 \mathrm{e}+001.00000 \mathrm{e}+001.00000 \mathrm{e}-01$ 1.00000e-09 1.00000e-01

Element: 8081 \# of layers: 3

Kx Ky Kz Ss Por

4.27542e+01 4.27542e+01 4.27543e+00 1.00000e-09 7.00000e-02

$1.00000 \mathrm{e}-021.00000 \mathrm{e}-021.00000 \mathrm{e}-031.00000 \mathrm{e}-091.00000 \mathrm{e}-01$

$1.00000 \mathrm{e}+001.00000 \mathrm{e}+001.00000 \mathrm{e}-011.00000 \mathrm{e}-09$ 1.00000e-01

Element: 8082 \# of layers: 3

$\mathrm{Kx} \mathrm{Ky} \mathrm{Kz}$ Ss Por

4.27542e+01 4.27542e+01 4.27543e+00 1.00000e-09 7.00000e-02

$1.00000 \mathrm{e}-02$ 1.00000e-02 1.00000e-03 1.00000e-09 1.00000e-01

$1.00000 \mathrm{e}+001.00000 \mathrm{e}+001.00000 \mathrm{e}-011.00000 \mathrm{e}-091.00000 \mathrm{e}-01$

Element: 8083 \# of layers: 3

$\mathrm{Kx} \mathrm{Ky} \mathrm{Kz}$ Ss Por

4.27542e+01 4.27542e+01 4.27543e+00 1.00000e-09 7.00000e-02

$1.00000 \mathrm{e}-02$ 1.00000e-02 1.00000e-03 1.00000e-09 1.00000e-01

$1.00000 \mathrm{e}+001.00000 \mathrm{e}+001.00000 \mathrm{e}-011.00000 \mathrm{e}-091.00000 \mathrm{e}-01$

Element: 8084 \# of layers: 3

$\mathrm{Kx} \mathrm{Ky} \mathrm{Kz}$ Ss Por

5.57142e+01 5.57142e+01 5.57142e+00 1.00000e-09 7.00000e-02

$1.00000 \mathrm{e}-02$ 1.00000e-02 1.00000e-03 1.00000e-09 1.00000e-01

$1.00000 \mathrm{e}+001.00000 \mathrm{e}+001.00000 \mathrm{e}-011.00000 \mathrm{e}-091.00000 \mathrm{e}-01$

Element: 8085 \# of layers: 3

Kx Ky Kz Ss Por

5.57142e+01 5.57142e+01 5.57142e+00 1.00000e-09 7.00000e-02 
$1.00000 \mathrm{e}-02$ 1.00000e-02 1.00000e-03 1.00000e-09 1.00000e-01 $1.00000 \mathrm{e}+001.00000 \mathrm{e}+001.00000 \mathrm{e}-011.00000 \mathrm{e}-091.00000 \mathrm{e}-01$

Element: 8086 \# of layers: 3

Kx Ky Kz Ss Por

$5.57142 \mathrm{e}+015.57142 \mathrm{e}+015.57142 \mathrm{e}+001.00000 \mathrm{e}-09$ 7.00000e-02 $1.00000 \mathrm{e}-02$ 1.00000e-02 1.00000e-03 1.00000e-09 1.00000e-01 $1.00000 \mathrm{e}+001.00000 \mathrm{e}+001.00000 \mathrm{e}-01$ 1.00000e-09 1.00000e-01

Element: 8087 \# of layers: 3

$\mathrm{Kx} \mathrm{Ky} \mathrm{Kz}$ Ss Por

5.57142e+01 5.57142e+01 5.57142e+00 1.00000e-09 7.00000e-02 $1.00000 \mathrm{e}-02$ 1.00000e-02 1.00000e-03 1.00000e-09 1.00000e-01

$1.00000 \mathrm{e}+001.00000 \mathrm{e}+001.00000 \mathrm{e}-011.00000 \mathrm{e}-091.00000 \mathrm{e}-01$

Element: 8088 \# of layers: 3

$\mathrm{Kx} \mathrm{Ky} \mathrm{Kz}$ Ss Por

5.57142e+01 5.57142e+01 5.57142e+00 1.00000e-09 7.00000e-02 $1.00000 \mathrm{e}-02$ 1.00000e-02 1.00000e-03 1.00000e-09 1.00000e-01

$1.00000 \mathrm{e}+001.00000 \mathrm{e}+001.00000 \mathrm{e}-011.00000 \mathrm{e}-09$ 1.00000e-01

Element: 8089 \# of layers: 3

$\mathrm{Kx} \mathrm{Ky} \mathrm{Kz}$ Ss Por

5.57142e+01 5.57142e+01 5.57142e+00 1.00000e-09 7.00000e-02 $1.00000 \mathrm{e}-02$ 1.00000e-02 1.00000e-03 1.00000e-09 1.00000e-01 $1.00000 \mathrm{e}+001.00000 \mathrm{e}+001.00000 \mathrm{e}-011.00000 \mathrm{e}-091.00000 \mathrm{e}-01$

Element: 8090 \# of layers: 3

Kx Ky Kz Ss Por

5.57142e+01 5.57142e+01 5.57142e+00 1.00000e-09 7.00000e-02 $1.00000 \mathrm{e}-02$ 1.00000e-02 1.00000e-03 1.00000e-09 1.00000e-01

$1.00000 \mathrm{e}+001.00000 \mathrm{e}+001.00000 \mathrm{e}-011.00000 \mathrm{e}-091.00000 \mathrm{e}-01$

Element: 8091 \# of layers: 3

$\mathrm{Kx} \mathrm{Ky} \mathrm{Kz}$ Ss Por

$5.57142 \mathrm{e}+015.57142 \mathrm{e}+015.57142 \mathrm{e}+001.00000 \mathrm{e}-09$ 7.00000e-02 $1.00000 \mathrm{e}-02$ 1.00000e-02 1.00000e-03 1.00000e-09 1.00000e-01 $1.00000 \mathrm{e}+001.00000 \mathrm{e}+001.00000 \mathrm{e}-011.00000 \mathrm{e}-091.00000 \mathrm{e}-01$

Element: 8092 \# of layers: 3

$\mathrm{Kx} \mathrm{Ky} \mathrm{Kz}$ Ss Por

$5.57142 \mathrm{e}+015.57142 \mathrm{e}+015.57142 \mathrm{e}+001.00000 \mathrm{e}-09$ 7.00000e-02 $1.00000 \mathrm{e}-02$ 1.00000e-02 1.00000e-03 1.00000e-09 1.00000e-01

$1.00000 \mathrm{e}+001.00000 \mathrm{e}+001.00000 \mathrm{e}-011.00000 \mathrm{e}-091.00000 \mathrm{e}-01$

Element: 8093 \# of layers: 3

$\mathrm{Kx} \mathrm{Ky} \mathrm{Kz}$ Ss Por

6.60892e+01 6.60892e+01 6.60892e+00 1.00000e-09 7.00000e-02 $1.00000 \mathrm{e}-02$ 1.00000e-02 1.00000e-03 1.00000e-09 1.00000e-01 $1.00000 \mathrm{e}+001.00000 \mathrm{e}+001.00000 \mathrm{e}-011.00000 \mathrm{e}-091.00000 \mathrm{e}-01$ Element: 8094 \# of layers: 3

$\mathrm{Kx} \mathrm{Ky} \mathrm{Kz}$ Ss Por $6.60892 \mathrm{e}+016.60892 \mathrm{e}+016.60892 \mathrm{e}+00$ 1.00000e-09 7.00000e-02 $1.00000 \mathrm{e}-02$ 1.00000e-02 1.00000e-03 1.00000e-09 1.00000e-01 
$1.00000 \mathrm{e}+001.00000 \mathrm{e}+00$ 1.00000e-01 1.00000e-09 1.00000e-01

Element: 8095 \# of layers: 3

Kx Ky Kz Ss Por

6.60892e+01 6.60892e+01 6.60892e+00 1.00000e-09 7.00000e-02

$1.00000 \mathrm{e}-02$ 1.00000e-02 1.00000e-03 1.00000e-09 1.00000e-01

$1.00000 \mathrm{e}+001.00000 \mathrm{e}+00$ 1.00000e-01 1.00000e-09 1.00000e-01

Element: 8096 \# of layers: 3

$\mathrm{Kx} \mathrm{Ky} \mathrm{Kz}$ Ss Por

6.60892e+01 6.60892e+01 6.60892e+00 1.00000e-09 7.00000e-02

$1.00000 \mathrm{e}-02$ 1.00000e-02 1.00000e-03 1.00000e-09 1.00000e-01

$1.00000 \mathrm{e}+001.00000 \mathrm{e}+001.00000 \mathrm{e}-011.00000 \mathrm{e}-091.00000 \mathrm{e}-01$

Element: 8097 \# of layers: 3

$\mathrm{Kx} \mathrm{Ky} \mathrm{Kz}$ Ss Por

6.60892e+01 6.60892e+01 6.60892e+00 1.00000e-09 7.00000e-02

$1.00000 \mathrm{e}-02$ 1.00000e-02 1.00000e-03 1.00000e-09 1.00000e-01

$1.00000 \mathrm{e}+001.00000 \mathrm{e}+001.00000 \mathrm{e}-011.00000 \mathrm{e}-091.00000 \mathrm{e}-01$

Element: 8098 \# of layers: 3

$\mathrm{Kx} \mathrm{Ky} \mathrm{Kz}$ Ss Por

6.60892e+01 6.60892e+01 6.60892e+00 1.00000e-09 7.00000e-02

$1.00000 \mathrm{e}-02$ 1.00000e-02 1.00000e-03 1.00000e-09 1.00000e-01

$1.00000 \mathrm{e}+001.00000 \mathrm{e}+001.00000 \mathrm{e}-011.00000 \mathrm{e}-091.00000 \mathrm{e}-01$

Element: 8099 \# of layers: 3

$\mathrm{Kx} \mathrm{Ky} \mathrm{Kz}$ Ss Por

6.60892e+01 6.60892e+01 6.60892e+00 1.00000e-09 7.00000e-02

$1.00000 \mathrm{e}-021.00000 \mathrm{e}-02$ 1.00000e-03 1.00000e-09 1.00000e-01

$1.00000 \mathrm{e}+001.00000 \mathrm{e}+001.00000 \mathrm{e}-01$ 1.00000e-09 1.00000e-01

Element: 8100 \# of layers: 3

$\mathrm{Kx} \mathrm{Ky} \mathrm{Kz}$ Ss Por

6.60892e+01 6.60892e+01 6.60892e+00 1.00000e-09 7.00000e-02

$1.00000 \mathrm{e}-02$ 1.00000e-02 1.00000e-03 1.00000e-09 1.00000e-01

$1.00000 \mathrm{e}+001.00000 \mathrm{e}+00$ 1.00000e-01 1.00000e-09 1.00000e-01

Element: 8101 \# of layers: 3

$\mathrm{Kx} \mathrm{Ky} \mathrm{Kz}$ Ss Por

6.60892e+01 6.60892e+01 6.60892e+00 1.00000e-09 7.00000e-02

$1.00000 \mathrm{e}-02$ 1.00000e-02 1.00000e-03 1.00000e-09 1.00000e-01

$1.00000 \mathrm{e}+001.00000 \mathrm{e}+001.00000 \mathrm{e}-011.00000 \mathrm{e}-091.00000 \mathrm{e}-01$

Element: 8102 \# of layers: 3

Kx Ky Kz Ss Por

6.66947e+01 6.66947e+01 6.66947e+00 1.00000e-09 7.00000e-02

$1.00000 \mathrm{e}-02$ 1.00000e-02 1.00000e-03 1.00000e-09 1.00000e-01

$1.00000 \mathrm{e}+001.00000 \mathrm{e}+001.00000 \mathrm{e}-011.00000 \mathrm{e}-091.00000 \mathrm{e}-01$

Element: 8103 \# of layers: 3

$\mathrm{Kx} \mathrm{Ky} \mathrm{Kz}$ Ss Por

6.66947e+01 6.66947e+01 6.66947e+00 1.00000e-09 7.00000e-02

$1.00000 \mathrm{e}-02$ 1.00000e-02 1.00000e-03 1.00000e-09 1.00000e-01

$1.00000 \mathrm{e}+001.00000 \mathrm{e}+001.00000 \mathrm{e}-011.00000 \mathrm{e}-091.00000 \mathrm{e}-01$ 
Element: 8104 \# of layers: 3

$\mathrm{Kx} \mathrm{Ky} \mathrm{Kz}$ Ss Por

6.66947e+01 6.66947e+01 6.66947e+00 1.00000e-09 7.00000e-02

$1.00000 \mathrm{e}-02$ 1.00000e-02 1.00000e-03 1.00000e-09 1.00000e-01

$1.00000 \mathrm{e}+001.00000 \mathrm{e}+001.00000 \mathrm{e}-01$ 1.00000e-09 1.00000e-01

Element: 8105 \# of layers: 4

$\mathrm{Kx} \mathrm{Ky} \mathrm{Kz}$ Ss Por

4.40964e+02 4.40964e+02 4.40964e+01 1.00000e-09 2.12000e-01

$4.40964 \mathrm{e}+02$ 4.40964e+02 4.40964e+01 1.00000e-09 2.12000e-01

$1.00000 \mathrm{e}-02$ 1.00000e-02 1.00000e-03 1.00000e-09 1.00000e-01

$1.00000 \mathrm{e}+001.00000 \mathrm{e}+001.00000 \mathrm{e}-011.00000 \mathrm{e}-091.00000 \mathrm{e}-01$

Element: 8106 \# of layers: 4

$\mathrm{Kx} \mathrm{Ky} \mathrm{Kz}$ Ss Por

4.40964e+02 4.40964e+02 4.40964e+01 1.00000e-09 2.12000e-01

$4.40964 \mathrm{e}+02$ 4.40964e+02 4.40964e+01 1.00000e-09 2.12000e-01

$1.00000 \mathrm{e}-02$ 1.00000e-02 1.00000e-03 1.00000e-09 1.00000e-01

$1.00000 \mathrm{e}+001.00000 \mathrm{e}+001.00000 \mathrm{e}-011.00000 \mathrm{e}-09$ 1.00000e-01

Element: 8107 \# of layers: 4

$\mathrm{Kx} \mathrm{Ky} \mathrm{Kz}$ Ss Por

4.40964e+02 4.40964e+02 4.40964e+01 1.00000e-09 2.12000e-01

$4.40964 \mathrm{e}+02$ 4.40964e+02 4.40964e+01 1.00000e-09 2.12000e-01

$1.00000 \mathrm{e}-02$ 1.00000e-02 1.00000e-03 1.00000e-09 1.00000e-01

$1.00000 \mathrm{e}+001.00000 \mathrm{e}+001.00000 \mathrm{e}-01$ 1.00000e-09 1.00000e-01

Element: 8108 \# of layers: 5

$\mathrm{Kx} \mathrm{Ky} \mathrm{Kz}$ Ss Por

4.60006e+03 4.60006e+03 4.60006e+02 1.00000e-09 7.00000e-02

$4.69855 \mathrm{e}+02$ 4.69855e+02 4.69855e+01 1.00000e-09 2.12000e-01

$4.69855 \mathrm{e}+02$ 4.69855e+02 4.69855e+01 1.00000e-09 2.12000e-01

$1.00000 \mathrm{e}-02$ 1.00000e-02 1.00000e-03 1.00000e-09 1.00000e-01

$1.00000 \mathrm{e}+001.00000 \mathrm{e}+001.00000 \mathrm{e}-011.00000 \mathrm{e}-091.00000 \mathrm{e}-01$

Element: 8109 \# of layers: 5

$\mathrm{Kx} \mathrm{Ky} \mathrm{Kz}$ Ss Por

4.40445e+03 4.40445e+03 4.40445e+02 1.00000e-09 7.00000e-02

$4.69855 \mathrm{e}+02$ 4.69855e+02 4.69855e+01 1.00000e-09 2.12000e-01

$4.69855 \mathrm{e}+02$ 4.69855e+02 4.69855e+01 1.00000e-09 2.12000e-01

$1.00000 \mathrm{e}-02$ 1.00000e-02 1.00000e-03 1.00000e-09 1.00000e-01

$1.00000 \mathrm{e}+001.00000 \mathrm{e}+001.00000 \mathrm{e}-011.00000 \mathrm{e}-091.00000 \mathrm{e}-01$

Element: 8110 \# of layers: 4

$\mathrm{Kx} \mathrm{Ky} \mathrm{Kz}$ Ss Por

4.69855e+02 4.69855e+02 4.69855e+01 1.00000e-09 2.12000e-01

$4.69855 \mathrm{e}+02$ 4.69855e+02 4.69855e+01 1.00000e-09 2.12000e-01

$1.00000 \mathrm{e}-02$ 1.00000e-02 1.00000e-03 1.00000e-09 1.00000e-01

$1.00000 \mathrm{e}+001.00000 \mathrm{e}+001.00000 \mathrm{e}-011.00000 \mathrm{e}-091.00000 \mathrm{e}-01$

Element: 8111 \# of layers: 5

$\mathrm{Kx} \mathrm{Ky} \mathrm{Kz}$ Ss Por

4.60006e+03 4.60006e+03 4.60006e+02 1.00000e-09 7.00000e-02 
4.60006e+03 4.60006e+03 4.60006e+02 1.00000e-09 7.00000e-02 $1.83802 \mathrm{e}+021.83802 \mathrm{e}+02$ 1.83802e+01 1.00000e-09 2.12000e-01 $1.00000 \mathrm{e}-02$ 1.00000e-02 1.00000e-03 1.00000e-09 1.00000e-01

$1.00000 \mathrm{e}+001.00000 \mathrm{e}+001.00000 \mathrm{e}-011.00000 \mathrm{e}-091.00000 \mathrm{e}-01$

Element: 8112 \# of layers: 5

$\mathrm{Kx} \mathrm{Ky} \mathrm{Kz}$ Ss Por

4.60006e+03 4.60006e+03 4.60006e+02 1.00000e-09 7.00000e-02

$4.60006 \mathrm{e}+03$ 4.60006e+03 4.60006e+02 1.00000e-09 7.00000e-02

$1.83802 \mathrm{e}+02$ 1.83802e+02 1.83802e+01 1.00000e-09 2.12000e-01

$1.00000 \mathrm{e}-02$ 1.00000e-02 1.00000e-03 1.00000e-09 1.00000e-01

$1.00000 \mathrm{e}+001.00000 \mathrm{e}+001.00000 \mathrm{e}-011.00000 \mathrm{e}-091.00000 \mathrm{e}-01$

Element: 8113 \# of layers: 4

$\mathrm{Kx} \mathrm{Ky} \mathrm{Kz}$ Ss Por

4.60006e+03 4.60006e+03 4.60006e+02 1.00000e-09 7.00000e-02 $1.83802 \mathrm{e}+021.83802 \mathrm{e}+02$ 1.83802e+01 1.00000e-09 2.12000e-01 $1.00000 \mathrm{e}-02$ 1.00000e-02 1.00000e-03 1.00000e-09 1.00000e-01

$1.00000 \mathrm{e}+001.00000 \mathrm{e}+001.00000 \mathrm{e}-01$ 1.00000e-09 1.00000e-01

Element: 8114 \# of layers: 4

$\mathrm{Kx} \mathrm{Ky} \mathrm{Kz}$ Ss Por

$1.75985 \mathrm{e}+02$ 1.75985e+02 1.75985e+01 1.00000e-09 2.12000e-01

$1.75985 \mathrm{e}+021.75985 \mathrm{e}+02 \quad 1.75985 \mathrm{e}+01$ 1.00000e-09 2.12000e-01

$1.00000 \mathrm{e}-02$ 1.00000e-02 1.00000e-03 1.00000e-09 1.00000e-01

$1.00000 \mathrm{e}+001.00000 \mathrm{e}+001.00000 \mathrm{e}-01$ 1.00000e-09 1.00000e-01

Element: 8115 \# of layers: 5

Kx Ky Kz Ss Por

$1.75985 \mathrm{e}+02$ 1.75985e+02 1.75985e+01 1.00000e-09 2.12000e-01

$1.75985 \mathrm{e}+02$ 1.75985e+02 1.75985e+01 1.00000e-09 2.12000e-01

$1.75985 \mathrm{e}+02$ 1.75985e+02 1.75985e+01 1.00000e-09 2.12000e-01

$1.00000 \mathrm{e}-02$ 1.00000e-02 1.00000e-03 1.00000e-09 1.00000e-01

$1.00000 \mathrm{e}+001.00000 \mathrm{e}+001.00000 \mathrm{e}-011.00000 \mathrm{e}-091.00000 \mathrm{e}-01$

Element: 8116 \# of layers: 6

Kx Ky Kz Ss Por

1.07859e+03 1.07859e+03 1.07859e+02 1.00000e-09 7.00000e-02

$4.30952 \mathrm{e}+01$ 4.30952e+01 4.30952e+00 1.00000e-09 2.12000e-01

4.30952e+01 4.30952e+01 4.30952e+00 1.00000e-09 2.12000e-01

4.30952e+01 4.30952e+01 4.30952e+00 1.00000e-09 2.12000e-01

$1.00000 \mathrm{e}-02$ 1.00000e-02 1.00000e-03 1.00000e-09 1.00000e-01

$1.00000 \mathrm{e}+001.00000 \mathrm{e}+001.00000 \mathrm{e}-011.00000 \mathrm{e}-091.00000 \mathrm{e}-01$

Element: 8117 \# of layers: 5

$\mathrm{Kx} \mathrm{Ky} \mathrm{Kz}$ Ss Por

4.40445e+03 4.40445e+03 4.40445e+02 1.00000e-09 7.00000e-02

$1.75985 \mathrm{e}+02$ 1.75985e+02 1.75985e+01 1.00000e-09 2.12000e-01

$1.75985 \mathrm{e}+02$ 1.75985e+02 1.75985e+01 1.00000e-09 2.12000e-01

$1.00000 \mathrm{e}-02$ 1.00000e-02 1.00000e-03 1.00000e-09 1.00000e-01

$1.00000 \mathrm{e}+001.00000 \mathrm{e}+001.00000 \mathrm{e}-011.00000 \mathrm{e}-091.00000 \mathrm{e}-01$

Element: 8118 \# of layers: 4 
Kx Ky Kz Ss Por

4.40445e+03 4.40445e+03 4.40445e+02 1.00000e-09 7.00000e-02

$1.75985 \mathrm{e}+02$ 1.75985e+02 1.75985e+01 1.00000e-09 2.12000e-01

$1.00000 \mathrm{e}-02$ 1.00000e-02 1.00000e-03 1.00000e-09 1.00000e-01

$1.00000 \mathrm{e}+001.00000 \mathrm{e}+001.00000 \mathrm{e}-01$ 1.00000e-09 1.00000e-01

Element: 8123 \# of layers: 5

$\mathrm{Kx} \mathrm{Ky} \mathrm{Kz}$ Ss Por

4.76178e+02 4.76178e+02 4.76179e+01 1.00000e-09 7.00000e-02

$1.90264 \mathrm{e}+011.90264 \mathrm{e}+011.90264 \mathrm{e}+001.00000 \mathrm{e}-092.12000 \mathrm{e}-01$

$1.90264 \mathrm{e}+011.90264 \mathrm{e}+011.90264 \mathrm{e}+001.00000 \mathrm{e}-092.12000 \mathrm{e}-01$

$1.00000 \mathrm{e}-02$ 1.00000e-02 1.00000e-03 1.00000e-09 1.00000e-01

$1.00000 \mathrm{e}+001.00000 \mathrm{e}+001.00000 \mathrm{e}-011.00000 \mathrm{e}-091.00000 \mathrm{e}-01$

Element: 8124 \# of layers: 4

$\mathrm{Kx} \mathrm{Ky} \mathrm{Kz}$ Ss Por

4.76178e+02 4.76178e+02 4.76179e+01 1.00000e-09 7.00000e-02

$1.90264 \mathrm{e}+011.90264 \mathrm{e}+011.90264 \mathrm{e}+001.00000 \mathrm{e}-092.12000 \mathrm{e}-01$

$1.00000 \mathrm{e}-02$ 1.00000e-02 1.00000e-03 1.00000e-09 1.00000e-01

$1.00000 \mathrm{e}+001.00000 \mathrm{e}+001.00000 \mathrm{e}-01$ 1.00000e-09 1.00000e-01

Element: 8125 \# of layers: 4

$\mathrm{Kx} \mathrm{Ky} \mathrm{Kz}$ Ss Por

4.76178e+02 4.76178e+02 4.76179e+01 1.00000e-09 7.00000e-02

$1.90264 \mathrm{e}+011.90264 \mathrm{e}+011.90264 \mathrm{e}+001.00000 \mathrm{e}-092.12000 \mathrm{e}-01$

$1.00000 \mathrm{e}-02$ 1.00000e-02 1.00000e-03 1.00000e-09 1.00000e-01

$1.00000 \mathrm{e}+001.00000 \mathrm{e}+001.00000 \mathrm{e}-011.00000 \mathrm{e}-091.00000 \mathrm{e}-01$

Element: 8126 \# of layers: 4

$\mathrm{Kx} \mathrm{Ky} \mathrm{Kz}$ Ss Por

4.76178e+02 4.76178e+02 4.76179e+01 1.00000e-09 7.00000e-02

$1.90264 \mathrm{e}+011.90264 \mathrm{e}+011.90264 \mathrm{e}+001.00000 \mathrm{e}-092.12000 \mathrm{e}-01$

$1.00000 \mathrm{e}-02$ 1.00000e-02 1.00000e-03 1.00000e-09 1.00000e-01

$1.00000 \mathrm{e}+001.00000 \mathrm{e}+001.00000 \mathrm{e}-011.00000 \mathrm{e}-091.00000 \mathrm{e}-01$

Element: 8127 \# of layers: 4

$\mathrm{Kx} \mathrm{Ky} \mathrm{Kz}$ Ss Por

4.76178e+02 4.76178e+02 4.76179e+01 1.00000e-09 7.00000e-02

$1.90264 \mathrm{e}+011.90264 \mathrm{e}+011.90264 \mathrm{e}+001.00000 \mathrm{e}-092.12000 \mathrm{e}-01$

$1.00000 \mathrm{e}-02$ 1.00000e-02 1.00000e-03 1.00000e-09 1.00000e-01

$1.00000 \mathrm{e}+001.00000 \mathrm{e}+001.00000 \mathrm{e}-011.00000 \mathrm{e}-091.00000 \mathrm{e}-01$

Element: 8128 \# of layers: 4

$\mathrm{Kx} \mathrm{Ky} \mathrm{Kz}$ Ss Por

4.76178e+02 4.76178e+02 4.76179e+01 1.00000e-09 7.00000e-02

$1.90264 \mathrm{e}+011.90264 \mathrm{e}+011.90264 \mathrm{e}+001.00000 \mathrm{e}-092.12000 \mathrm{e}-01$

$1.00000 \mathrm{e}-02$ 1.00000e-02 1.00000e-03 1.00000e-09 1.00000e-01

$1.00000 \mathrm{e}+001.00000 \mathrm{e}+001.00000 \mathrm{e}-011.00000 \mathrm{e}-091.00000 \mathrm{e}-01$

Element: 8129 \# of layers: 4

$\mathrm{Kx} \mathrm{Ky} \mathrm{Kz}$ Ss Por

4.76178e+02 4.76178e+02 4.76179e+01 1.00000e-09 7.00000e-02

$1.90264 \mathrm{e}+011.90264 \mathrm{e}+011.90264 \mathrm{e}+001.00000 \mathrm{e}-092.12000 \mathrm{e}-01$ 
$1.00000 \mathrm{e}-02$ 1.00000e-02 1.00000e-03 1.00000e-09 1.00000e-01 $1.00000 \mathrm{e}+001.00000 \mathrm{e}+001.00000 \mathrm{e}-01$ 1.00000e-09 1.00000e-01

Element: 8130 \# of layers: 4

Kx Ky Kz Ss Por

4.76178e+02 4.76178e+02 4.76179e+01 1.00000e-09 7.00000e-02 $1.90264 \mathrm{e}+011.90264 \mathrm{e}+011.90264 \mathrm{e}+001.00000 \mathrm{e}-092.12000 \mathrm{e}-01$ 1.00000e-02 1.00000e-02 1.00000e-03 1.00000e-09 1.00000e-01 $1.00000 \mathrm{e}+001.00000 \mathrm{e}+001.00000 \mathrm{e}-01$ 1.00000e-09 1.00000e-01

Element: 8131 \# of layers: 4

$\mathrm{Kx} \mathrm{Ky} \mathrm{Kz}$ Ss Por

4.76178e+02 4.76178e+02 4.76179e+01 1.00000e-09 7.00000e-02

$1.90264 \mathrm{e}+011.90264 \mathrm{e}+011.90264 \mathrm{e}+001.00000 \mathrm{e}-092.12000 \mathrm{e}-01$ $1.00000 \mathrm{e}-02$ 1.00000e-02 1.00000e-03 1.00000e-09 1.00000e-01 $1.00000 \mathrm{e}+001.00000 \mathrm{e}+001.00000 \mathrm{e}-011.00000 \mathrm{e}-091.00000 \mathrm{e}-01$ Element: 8132 \# of layers: 4

Kx Ky Kz Ss Por

1.07733e+02 1.07733e+02 1.07733e+01 1.00000e-09 7.00000e-02 4.30479e+00 4.30479e+00 4.30479e-01 1.00000e-09 2.12000e-01 $1.00000 \mathrm{e}-02$ 1.00000e-02 1.00000e-03 1.00000e-09 1.00000e-01 $1.00000 \mathrm{e}+001.00000 \mathrm{e}+001.00000 \mathrm{e}-011.00000 \mathrm{e}-091.00000 \mathrm{e}-01$ Element: 8133 \# of layers: 3

$\mathrm{Kx} \mathrm{Ky} \mathrm{Kz}$ Ss Por

1.07733e+02 1.07733e+02 1.07733e+01 1.00000e-09 7.00000e-02 $1.00000 \mathrm{e}-02$ 1.00000e-02 1.00000e-03 1.00000e-09 1.00000e-01

$1.00000 \mathrm{e}+001.00000 \mathrm{e}+001.00000 \mathrm{e}-011.00000 \mathrm{e}-091.00000 \mathrm{e}-01$ Element: 8134 \# of layers: 3

Kx Ky Kz Ss Por

1.07733e+02 1.07733e+02 1.07733e+01 1.00000e-09 7.00000e-02 $1.00000 \mathrm{e}-02$ 1.00000e-02 1.00000e-03 1.00000e-09 1.00000e-01 $1.00000 \mathrm{e}+001.00000 \mathrm{e}+001.00000 \mathrm{e}-011.00000 \mathrm{e}-091.00000 \mathrm{e}-01$ Element: 8135 \# of layers: 3

$\mathrm{Kx} \mathrm{Ky} \mathrm{Kz}$ Ss Por

1.07733e+02 1.07733e+02 1.07733e+01 1.00000e-09 7.00000e-02 $1.00000 \mathrm{e}-021.00000 \mathrm{e}-021.00000 \mathrm{e}-031.00000 \mathrm{e}-091.00000 \mathrm{e}-01$ $1.00000 \mathrm{e}+001.00000 \mathrm{e}+001.00000 \mathrm{e}-011.00000 \mathrm{e}-091.00000 \mathrm{e}-01$ Element: 8136 \# of layers: 3

Kx Ky Kz Ss Por

$1.07733 \mathrm{e}+02$ 1.07733e+02 1.07733e+01 1.00000e-09 7.00000e-02 $1.00000 \mathrm{e}-02$ 1.00000e-02 1.00000e-03 1.00000e-09 1.00000e-01 $1.00000 \mathrm{e}+001.00000 \mathrm{e}+001.00000 \mathrm{e}-01$ 1.00000e-09 1.00000e-01 Element: 8137 \# of layers: 3

$\mathrm{Kx} \mathrm{Ky} \mathrm{Kz}$ Ss Por

1.07733e+02 1.07733e+02 1.07733e+01 1.00000e-09 7.00000e-02 $1.00000 \mathrm{e}-02$ 1.00000e-02 1.00000e-03 1.00000e-09 1.00000e-01 $1.00000 \mathrm{e}+001.00000 \mathrm{e}+001.00000 \mathrm{e}-011.00000 \mathrm{e}-091.00000 \mathrm{e}-01$ Element: 8138 \# of layers: 3 
Kx Ky Kz Ss Por

1.07733e+02 1.07733e+02 1.07733e+01 1.00000e-09 7.00000e-02

$1.00000 \mathrm{e}-02$ 1.00000e-02 1.00000e-03 1.00000e-09 1.00000e-01

$1.00000 \mathrm{e}+001.00000 \mathrm{e}+001.00000 \mathrm{e}-011.00000 \mathrm{e}-091.00000 \mathrm{e}-01$

Element: 8139 \# of layers: 3

$\mathrm{Kx} \mathrm{Ky} \mathrm{Kz}$ Ss Por

1.07733e+02 1.07733e+02 1.07733e+01 1.00000e-09 7.00000e-02

$1.00000 \mathrm{e}-02$ 1.00000e-02 1.00000e-03 1.00000e-09 1.00000e-01

$1.00000 \mathrm{e}+001.00000 \mathrm{e}+001.00000 \mathrm{e}-011.00000 \mathrm{e}-091.00000 \mathrm{e}-01$

Element: 8140 \# of layers: 3

Kx Ky Kz Ss Por

1.07733e+02 1.07733e+02 1.07733e+01 1.00000e-09 7.00000e-02

$1.00000 \mathrm{e}-02$ 1.00000e-02 1.00000e-03 1.00000e-09 1.00000e-01

$1.00000 \mathrm{e}+001.00000 \mathrm{e}+001.00000 \mathrm{e}-011.00000 \mathrm{e}-09$ 1.00000e-01

Element: 8141 \# of layers: 3

Kx Ky Kz Ss Por

9.94253e+01 9.94253e+01 9.94253e+00 1.00000e-09 7.00000e-02 $1.00000 \mathrm{e}-021.00000 \mathrm{e}-021.00000 \mathrm{e}-031.00000 \mathrm{e}-091.00000 \mathrm{e}-01$

$1.00000 \mathrm{e}+001.00000 \mathrm{e}+001.00000 \mathrm{e}-01$ 1.00000e-09 1.00000e-01

Element: 8142 \# of layers: 3

$\mathrm{Kx} \mathrm{Ky} \mathrm{Kz}$ Ss Por

9.94253e+01 9.94253e+01 9.94253e+00 1.00000e-09 7.00000e-02 $1.00000 \mathrm{e}-021.00000 \mathrm{e}-021.00000 \mathrm{e}-031.00000 \mathrm{e}-091.00000 \mathrm{e}-01$

$1.00000 \mathrm{e}+001.00000 \mathrm{e}+001.00000 \mathrm{e}-011.00000 \mathrm{e}-091.00000 \mathrm{e}-01$

Element: 8143 \# of layers: 3

Kx Ky Kz Ss Por

9.94253e+01 9.94253e+01 9.94253e+00 1.00000e-09 7.00000e-02

$1.00000 \mathrm{e}-02$ 1.00000e-02 1.00000e-03 1.00000e-09 1.00000e-01

$1.00000 \mathrm{e}+001.00000 \mathrm{e}+001.00000 \mathrm{e}-011.00000 \mathrm{e}-091.00000 \mathrm{e}-01$

Element: 8144 \# of layers: 3

$\mathrm{Kx} \mathrm{Ky} \mathrm{Kz}$ Ss Por

9.94253e+01 9.94253e+01 9.94253e+00 1.00000e-09 7.00000e-02

$1.00000 \mathrm{e}-02$ 1.00000e-02 1.00000e-03 1.00000e-09 1.00000e-01

$1.00000 \mathrm{e}+001.00000 \mathrm{e}+001.00000 \mathrm{e}-011.00000 \mathrm{e}-091.00000 \mathrm{e}-01$

Element: 8145 \# of layers: 3

Kx Ky Kz Ss Por

9.94253e+01 9.94253e+01 9.94253e+00 1.00000e-09 7.00000e-02

$1.00000 \mathrm{e}-02$ 1.00000e-02 1.00000e-03 1.00000e-09 1.00000e-01

$1.00000 \mathrm{e}+001.00000 \mathrm{e}+001.00000 \mathrm{e}-011.00000 \mathrm{e}-09$ 1.00000e-01

Element: 8146 \# of layers: 3

$\mathrm{Kx} \mathrm{Ky} \mathrm{Kz}$ Ss Por

9.94253e+01 9.94253e+01 9.94253e+00 1.00000e-09 7.00000e-02 $1.00000 \mathrm{e}-02$ 1.00000e-02 1.00000e-03 1.00000e-09 1.00000e-01

$1.00000 \mathrm{e}+001.00000 \mathrm{e}+001.00000 \mathrm{e}-01$ 1.00000e-09 1.00000e-01

Element: 8147 \# of layers: 3

Kx Ky Kz Ss Por 
9.94253e+01 9.94253e+01 9.94253e+00 1.00000e-09 7.00000e-02 $1.00000 \mathrm{e}-02$ 1.00000e-02 1.00000e-03 1.00000e-09 1.00000e-01

$1.00000 \mathrm{e}+001.00000 \mathrm{e}+001.00000 \mathrm{e}-011.00000 \mathrm{e}-091.00000 \mathrm{e}-01$

Element: 8148 \# of layers: 3

$\mathrm{Kx} \mathrm{Ky} \mathrm{Kz}$ Ss Por

9.94253e+01 9.94253e+01 9.94253e+00 1.00000e-09 7.00000e-02 1.00000e-02 1.00000e-02 1.00000e-03 1.00000e-09 1.00000e-01

$1.00000 \mathrm{e}+001.00000 \mathrm{e}+001.00000 \mathrm{e}-011.00000 \mathrm{e}-091.00000 \mathrm{e}-01$

Element: 8149 \# of layers: 3

$\mathrm{Kx} \mathrm{Ky} \mathrm{Kz}$ Ss Por

9.94253e+01 9.94253e+01 9.94253e+00 1.00000e-09 7.00000e-02

$1.00000 \mathrm{e}-02$ 1.00000e-02 1.00000e-03 1.00000e-09 1.00000e-01

$1.00000 \mathrm{e}+001.00000 \mathrm{e}+001.00000 \mathrm{e}-011.00000 \mathrm{e}-091.00000 \mathrm{e}-01$

Element: 8150 \# of layers: 3

$\mathrm{Kx} \mathrm{Ky} \mathrm{Kz}$ Ss Por

9.75693e+01 9.75693e+01 9.75693e+00 1.00000e-09 7.00000e-02

$1.00000 \mathrm{e}-02$ 1.00000e-02 1.00000e-03 1.00000e-09 1.00000e-01

$1.00000 \mathrm{e}+001.00000 \mathrm{e}+001.00000 \mathrm{e}-01$ 1.00000e-09 1.00000e-01

Element: 8151 \# of layers: 3

$\mathrm{Kx} \mathrm{Ky} \mathrm{Kz}$ Ss Por

9.75693e+01 9.75693e+01 9.75693e+00 1.00000e-09 7.00000e-02

$1.00000 \mathrm{e}-021.00000 \mathrm{e}-021.00000 \mathrm{e}-031.00000 \mathrm{e}-091.00000 \mathrm{e}-01$

$1.00000 \mathrm{e}+001.00000 \mathrm{e}+001.00000 \mathrm{e}-01$ 1.00000e-09 1.00000e-01

Element: 8152 \# of layers: 3

Kx Ky Kz Ss Por

9.75693e+01 9.75693e+01 9.75693e+00 1.00000e-09 7.00000e-02

$1.00000 \mathrm{e}-02$ 1.00000e-02 1.00000e-03 1.00000e-09 1.00000e-01

$1.00000 \mathrm{e}+001.00000 \mathrm{e}+001.00000 \mathrm{e}-011.00000 \mathrm{e}-091.00000 \mathrm{e}-01$

Element: 8153 \# of layers: 3

$\mathrm{Kx} \mathrm{Ky} \mathrm{Kz}$ Ss Por

9.75693e+01 9.75693e+01 9.75693e+00 1.00000e-09 7.00000e-02

$1.00000 \mathrm{e}-02$ 1.00000e-02 1.00000e-03 1.00000e-09 1.00000e-01

$1.00000 \mathrm{e}+001.00000 \mathrm{e}+001.00000 \mathrm{e}-011.00000 \mathrm{e}-091.00000 \mathrm{e}-01$

Element: 8154 \# of layers: 3

$\mathrm{Kx} \mathrm{Ky} \mathrm{Kz}$ Ss Por

9.75693e+01 9.75693e+01 9.75693e+00 1.00000e-09 7.00000e-02

$1.00000 \mathrm{e}-02$ 1.00000e-02 1.00000e-03 1.00000e-09 1.00000e-01

$1.00000 \mathrm{e}+001.00000 \mathrm{e}+001.00000 \mathrm{e}-011.00000 \mathrm{e}-091.00000 \mathrm{e}-01$

Element: 8155 \# of layers: 3

$\mathrm{Kx} \mathrm{Ky} \mathrm{Kz}$ Ss Por

9.75693e+01 9.75693e+01 9.75693e+00 1.00000e-09 7.00000e-02

$1.00000 \mathrm{e}-02$ 1.00000e-02 1.00000e-03 1.00000e-09 1.00000e-01

$1.00000 \mathrm{e}+001.00000 \mathrm{e}+001.00000 \mathrm{e}-01$ 1.00000e-09 1.00000e-01

Element: 8156 \# of layers: 3

$\mathrm{Kx} \mathrm{Ky} \mathrm{Kz}$ Ss Por

9.75693e+01 9.75693e+01 9.75693e+00 1.00000e-09 7.00000e-02 
$1.00000 \mathrm{e}-02$ 1.00000e-02 1.00000e-03 1.00000e-09 1.00000e-01 $1.00000 \mathrm{e}+001.00000 \mathrm{e}+001.00000 \mathrm{e}-01$ 1.00000e-09 1.00000e-01

Element: 8157 \# of layers: 3

Kx Ky Kz Ss Por

9.75693e+01 9.75693e+01 9.75693e+00 1.00000e-09 7.00000e-02 $1.00000 \mathrm{e}-02$ 1.00000e-02 1.00000e-03 1.00000e-09 1.00000e-01 $1.00000 \mathrm{e}+001.00000 \mathrm{e}+001.00000 \mathrm{e}-011.00000 \mathrm{e}-091.00000 \mathrm{e}-01$

Element: 8158 \# of layers: 3

$\mathrm{Kx} \mathrm{Ky} \mathrm{Kz}$ Ss Por

9.75693e+01 9.75693e+01 9.75693e+00 1.00000e-09 7.00000e-02 1.00000e-02 1.00000e-02 1.00000e-03 1.00000e-09 1.00000e-01

$1.00000 \mathrm{e}+001.00000 \mathrm{e}+001.00000 \mathrm{e}-011.00000 \mathrm{e}-091.00000 \mathrm{e}-01$

Element: 8159 \# of layers: 3

$\mathrm{Kx} \mathrm{Ky} \mathrm{Kz}$ Ss Por

$1.12021 \mathrm{e}+021.12021 \mathrm{e}+02$ 1.12021e+01 1.00000e-09 7.00000e-02 $1.00000 \mathrm{e}-02$ 1.00000e-02 1.00000e-03 1.00000e-09 1.00000e-01 $1.00000 \mathrm{e}+001.00000 \mathrm{e}+001.00000 \mathrm{e}-011.00000 \mathrm{e}-091.00000 \mathrm{e}-01$

Element: 8160 \# of layers: 3

$\mathrm{Kx} \mathrm{Ky} \mathrm{Kz}$ Ss Por

$1.12021 \mathrm{e}+02$ 1.12021e+02 1.12021e+01 1.00000e-09 7.00000e-02 $1.00000 \mathrm{e}-02$ 1.00000e-02 1.00000e-03 1.00000e-09 1.00000e-01 $1.00000 \mathrm{e}+001.00000 \mathrm{e}+001.00000 \mathrm{e}-01$ 1.00000e-09 1.00000e-01

Element: 8161 \# of layers: 3

Kx Ky Kz Ss Por

$1.12021 \mathrm{e}+02$ 1.12021e+02 1.12021e+01 1.00000e-09 7.00000e-02 $1.00000 \mathrm{e}-02$ 1.00000e-02 1.00000e-03 1.00000e-09 1.00000e-01

$1.00000 \mathrm{e}+001.00000 \mathrm{e}+001.00000 \mathrm{e}-011.00000 \mathrm{e}-091.00000 \mathrm{e}-01$

Element: 8162 \# of layers: 3

$\mathrm{Kx} \mathrm{Ky} \mathrm{Kz}$ Ss Por

$1.12021 \mathrm{e}+021.12021 \mathrm{e}+02$ 1.12021e+01 1.00000e-09 7.00000e-02 $1.00000 \mathrm{e}-02$ 1.00000e-02 1.00000e-03 1.00000e-09 1.00000e-01 $1.00000 \mathrm{e}+001.00000 \mathrm{e}+001.00000 \mathrm{e}-01$ 1.00000e-09 1.00000e-01

Element: 8163 \# of layers: 3

$\mathrm{Kx} \mathrm{Ky} \mathrm{Kz}$ Ss Por

1.12021e+02 1.12021e+02 1.12021e+01 1.00000e-09 7.00000e-02 1.00000e-02 1.00000e-02 1.00000e-03 1.00000e-09 1.00000e-01 $1.00000 \mathrm{e}+001.00000 \mathrm{e}+001.00000 \mathrm{e}-011.00000 \mathrm{e}-091.00000 \mathrm{e}-01$

Element: 8164 \# of layers: 3

$\mathrm{Kx} \mathrm{Ky} \mathrm{Kz}$ Ss Por

$1.12021 \mathrm{e}+02$ 1.12021e+02 1.12021e+01 1.00000e-09 7.00000e-02 $1.00000 \mathrm{e}-02$ 1.00000e-02 1.00000e-03 1.00000e-09 1.00000e-01 $1.00000 \mathrm{e}+001.00000 \mathrm{e}+001.00000 \mathrm{e}-011.00000 \mathrm{e}-091.00000 \mathrm{e}-01$ Element: 8165 \# of layers: 3

$\mathrm{Kx} \mathrm{Ky} \mathrm{Kz}$ Ss Por

$1.12021 \mathrm{e}+02$ 1.12021e+02 1.12021e+01 1.00000e-09 7.00000e-02 $1.00000 \mathrm{e}-02$ 1.00000e-02 1.00000e-03 1.00000e-09 1.00000e-01 
$1.00000 \mathrm{e}+001.00000 \mathrm{e}+00$ 1.00000e-01 1.00000e-09 1.00000e-01

Element: 8166 \# of layers: 3

$\mathrm{Kx} \mathrm{Ky} \mathrm{Kz}$ Ss Por

$1.12021 \mathrm{e}+02$ 1.12021e+02 1.12021e+01 1.00000e-09 7.00000e-02

$1.00000 \mathrm{e}-02$ 1.00000e-02 1.00000e-03 1.00000e-09 1.00000e-01

$1.00000 \mathrm{e}+001.00000 \mathrm{e}+001.00000 \mathrm{e}-01$ 1.00000e-09 1.00000e-01

Element: 8167 \# of layers: 3

$\mathrm{Kx} \mathrm{Ky} \mathrm{Kz}$ Ss Por

$1.12021 \mathrm{e}+021.12021 \mathrm{e}+02$ 1.12021e+01 1.00000e-09 7.00000e-02

$1.00000 \mathrm{e}-02$ 1.00000e-02 1.00000e-03 1.00000e-09 1.00000e-01

$1.00000 \mathrm{e}+001.00000 \mathrm{e}+001.00000 \mathrm{e}-011.00000 \mathrm{e}-091.00000 \mathrm{e}-01$

Element: 8168 \# of layers: 3

$\mathrm{Kx} \mathrm{Ky} \mathrm{Kz}$ Ss Por

9.18569e+01 9.18569e+01 9.18570e+00 1.00000e-09 7.00000e-02

$1.00000 \mathrm{e}-02$ 1.00000e-02 1.00000e-03 1.00000e-09 1.00000e-01

$1.00000 \mathrm{e}+001.00000 \mathrm{e}+001.00000 \mathrm{e}-011.00000 \mathrm{e}-091.00000 \mathrm{e}-01$

Element: 8169 \# of layers: 3

$\mathrm{Kx} \mathrm{Ky} \mathrm{Kz}$ Ss Por

9.18569e+01 9.18569e+01 9.18570e+00 1.00000e-09 7.00000e-02

$1.00000 \mathrm{e}-02$ 1.00000e-02 1.00000e-03 1.00000e-09 1.00000e-01

$1.00000 \mathrm{e}+001.00000 \mathrm{e}+001.00000 \mathrm{e}-011.00000 \mathrm{e}-091.00000 \mathrm{e}-01$

Element: 8170 \# of layers: 3

$\mathrm{Kx} \mathrm{Ky} \mathrm{Kz}$ Ss Por

9.18569e+01 9.18569e+01 9.18570e+00 1.00000e-09 7.00000e-02

$1.00000 \mathrm{e}-02$ 1.00000e-02 1.00000e-03 1.00000e-09 1.00000e-01

$1.00000 \mathrm{e}+001.00000 \mathrm{e}+001.00000 \mathrm{e}-01$ 1.00000e-09 1.00000e-01

Element: 8171 \# of layers: 3

$\mathrm{Kx} \mathrm{Ky} \mathrm{Kz} \mathrm{Ss} \mathrm{Por}$

9.18569e+01 9.18569e+01 9.18570e+00 1.00000e-09 7.00000e-02

$1.00000 \mathrm{e}-02$ 1.00000e-02 1.00000e-03 1.00000e-09 1.00000e-01

$1.00000 \mathrm{e}+001.00000 \mathrm{e}+001.00000 \mathrm{e}-011.00000 \mathrm{e}-091.00000 \mathrm{e}-01$

Element: 8172 \# of layers: 3

Kx Ky Kz Ss Por

9.18569e+01 9.18569e+01 9.18570e+00 1.00000e-09 7.00000e-02

$1.00000 \mathrm{e}-02$ 1.00000e-02 1.00000e-03 1.00000e-09 1.00000e-01

$1.00000 \mathrm{e}+001.00000 \mathrm{e}+001.00000 \mathrm{e}-011.00000 \mathrm{e}-091.00000 \mathrm{e}-01$

Element: 8173 \# of layers: 3

Kx Ky Kz Ss Por

9.18569e+01 9.18569e+01 9.18570e+00 1.00000e-09 7.00000e-02

$1.00000 \mathrm{e}-02$ 1.00000e-02 1.00000e-03 1.00000e-09 1.00000e-01

$1.00000 \mathrm{e}+001.00000 \mathrm{e}+001.00000 \mathrm{e}-011.00000 \mathrm{e}-091.00000 \mathrm{e}-01$

Element: 8174 \# of layers: 3

$\mathrm{Kx} \mathrm{Ky} \mathrm{Kz}$ Ss Por

9.18569e+01 9.18569e+01 9.18570e+00 1.00000e-09 7.00000e-02

$1.00000 \mathrm{e}-02$ 1.00000e-02 1.00000e-03 1.00000e-09 1.00000e-01

$1.00000 \mathrm{e}+001.00000 \mathrm{e}+001.00000 \mathrm{e}-011.00000 \mathrm{e}-091.00000 \mathrm{e}-01$ 
Element: 8175 \# of layers: 3

$\mathrm{Kx} \mathrm{Ky} \mathrm{Kz}$ Ss Por

9.18569e+01 9.18569e+01 9.18570e+00 1.00000e-09 7.00000e-02

$1.00000 \mathrm{e}-02$ 1.00000e-02 1.00000e-03 1.00000e-09 1.00000e-01

$1.00000 \mathrm{e}+001.00000 \mathrm{e}+001.00000 \mathrm{e}-011.00000 \mathrm{e}-091.00000 \mathrm{e}-01$

Element: 8176 \# of layers: 3

$\mathrm{Kx} \mathrm{Ky} \mathrm{Kz}$ Ss Por

9.18569e+01 9.18569e+01 9.18570e+00 1.00000e-09 7.00000e-02

$1.00000 \mathrm{e}-02$ 1.00000e-02 1.00000e-03 1.00000e-09 1.00000e-01

$1.00000 \mathrm{e}+001.00000 \mathrm{e}+001.00000 \mathrm{e}-01$ 1.00000e-09 1.00000e-01

Element: 8177 \# of layers: 3

$\mathrm{Kx} \mathrm{Ky} \mathrm{Kz}$ Ss Por

5.23229e+01 5.23229e+01 5.23229e+00 1.00000e-09 7.00000e-02

$1.00000 \mathrm{e}-02$ 1.00000e-02 1.00000e-03 1.00000e-09 1.00000e-01

$1.00000 \mathrm{e}+001.00000 \mathrm{e}+001.00000 \mathrm{e}-01$ 1.00000e-09 1.00000e-01

Element: 8178 \# of layers: 3

$\mathrm{Kx} \mathrm{Ky} \mathrm{Kz}$ Ss Por

5.23229e+01 5.23229e+01 5.23229e+00 1.00000e-09 7.00000e-02 $1.00000 \mathrm{e}-02$ 1.00000e-02 1.00000e-03 1.00000e-09 1.00000e-01

$1.00000 \mathrm{e}+001.00000 \mathrm{e}+001.00000 \mathrm{e}-011.00000 \mathrm{e}-091.00000 \mathrm{e}-01$

Element: 8179 \# of layers: 3

$\mathrm{Kx} \mathrm{Ky} \mathrm{Kz}$ Ss Por

5.23229e+01 5.23229e+01 5.23229e+00 1.00000e-09 7.00000e-02

$1.00000 \mathrm{e}-021.00000 \mathrm{e}-021.00000 \mathrm{e}-031.00000 \mathrm{e}-091.00000 \mathrm{e}-01$

$1.00000 \mathrm{e}+001.00000 \mathrm{e}+001.00000 \mathrm{e}-011.00000 \mathrm{e}-091.00000 \mathrm{e}-01$

Element: 8180 \# of layers: 3

$\mathrm{Kx} \mathrm{Ky} \mathrm{Kz}$ Ss Por

$5.23229 \mathrm{e}+01$ 5.23229e+01 5.23229e+00 1.00000e-09 7.00000e-02

$1.00000 \mathrm{e}-02$ 1.00000e-02 1.00000e-03 1.00000e-09 1.00000e-01

$1.00000 \mathrm{e}+001.00000 \mathrm{e}+001.00000 \mathrm{e}-011.00000 \mathrm{e}-091.00000 \mathrm{e}-01$

Element: 8181 \# of layers: 3

$\mathrm{Kx} \mathrm{Ky} \mathrm{Kz}$ Ss Por

5.23229e+01 5.23229e+01 5.23229e+00 1.00000e-09 7.00000e-02

$1.00000 \mathrm{e}-021.00000 \mathrm{e}-021.00000 \mathrm{e}-031.00000 \mathrm{e}-091.00000 \mathrm{e}-01$

$1.00000 \mathrm{e}+001.00000 \mathrm{e}+001.00000 \mathrm{e}-011.00000 \mathrm{e}-091.00000 \mathrm{e}-01$

Element: 8182 \# of layers: 3

$\mathrm{Kx} \mathrm{Ky} \mathrm{Kz}$ Ss Por

5.23229e+01 5.23229e+01 5.23229e+00 1.00000e-09 7.00000e-02

$1.00000 \mathrm{e}-02$ 1.00000e-02 1.00000e-03 1.00000e-09 1.00000e-01

$1.00000 \mathrm{e}+001.00000 \mathrm{e}+001.00000 \mathrm{e}-011.00000 \mathrm{e}-091.00000 \mathrm{e}-01$

Element: 8183 \# of layers: 3

$\mathrm{Kx} \mathrm{Ky} \mathrm{Kz}$ Ss Por

5.23229e+01 5.23229e+01 5.23229e+00 1.00000e-09 7.00000e-02

$1.00000 \mathrm{e}-02$ 1.00000e-02 1.00000e-03 1.00000e-09 1.00000e-01

$1.00000 \mathrm{e}+001.00000 \mathrm{e}+001.00000 \mathrm{e}-011.00000 \mathrm{e}-091.00000 \mathrm{e}-01$

Element: 8184 \# of layers: 3 


\section{$\mathrm{Kx} \mathrm{Ky} \mathrm{Kz}$ Ss Por}

5.23229e+01 5.23229e+01 5.23229e+00 1.00000e-09 7.00000e-02 $1.00000 \mathrm{e}-02$ 1.00000e-02 1.00000e-03 1.00000e-09 1.00000e-01

$1.00000 \mathrm{e}+001.00000 \mathrm{e}+001.00000 \mathrm{e}-011.00000 \mathrm{e}-091.00000 \mathrm{e}-01$

Element: 8185 \# of layers: 3

$\mathrm{Kx} \mathrm{Ky} \mathrm{Kz}$ Ss Por

5.23229e+01 5.23229e+01 5.23229e+00 1.00000e-09 7.00000e-02

$1.00000 \mathrm{e}-02$ 1.00000e-02 1.00000e-03 1.00000e-09 1.00000e-01

$1.00000 \mathrm{e}+001.00000 \mathrm{e}+001.00000 \mathrm{e}-011.00000 \mathrm{e}-091.00000 \mathrm{e}-01$

Element: 8186 \# of layers: 3

$\mathrm{Kx} \mathrm{Ky} \mathrm{Kz}$ Ss Por

6.84318e+01 6.84318e+01 6.84318e+00 1.00000e-09 7.00000e-02

$1.00000 \mathrm{e}-02$ 1.00000e-02 1.00000e-03 1.00000e-09 1.00000e-01

$1.00000 \mathrm{e}+001.00000 \mathrm{e}+001.00000 \mathrm{e}-011.00000 \mathrm{e}-091.00000 \mathrm{e}-01$

Element: 8187 \# of layers: 3

Kx Ky Kz Ss Por

6.84318e+01 6.84318e+01 6.84318e+00 1.00000e-09 7.00000e-02

$1.00000 \mathrm{e}-02$ 1.00000e-02 1.00000e-03 1.00000e-09 1.00000e-01

$1.00000 \mathrm{e}+001.00000 \mathrm{e}+001.00000 \mathrm{e}-011.00000 \mathrm{e}-091.00000 \mathrm{e}-01$

Element: 8188 \# of layers: 3

$\mathrm{Kx} \mathrm{Ky} \mathrm{Kz}$ Ss Por

6.84318e+01 6.84318e+01 6.84318e+00 1.00000e-09 7.00000e-02

$1.00000 \mathrm{e}-021.00000 \mathrm{e}-021.00000 \mathrm{e}-031.00000 \mathrm{e}-091.00000 \mathrm{e}-01$

$1.00000 \mathrm{e}+001.00000 \mathrm{e}+001.00000 \mathrm{e}-011.00000 \mathrm{e}-091.00000 \mathrm{e}-01$

Element: 8189 \# of layers: 3

$\mathrm{Kx} \mathrm{Ky} \mathrm{Kz}$ Ss Por

6.84318e+01 6.84318e+01 6.84318e+00 1.00000e-09 7.00000e-02

$1.00000 \mathrm{e}-02$ 1.00000e-02 1.00000e-03 1.00000e-09 1.00000e-01

$1.00000 \mathrm{e}+001.00000 \mathrm{e}+001.00000 \mathrm{e}-011.00000 \mathrm{e}-091.00000 \mathrm{e}-01$

Element: 8190 \# of layers: 3

$\mathrm{Kx} \mathrm{Ky} \mathrm{Kz}$ Ss Por

6.84318e+01 6.84318e+01 6.84318e+00 1.00000e-09 7.00000e-02

$1.00000 \mathrm{e}-02$ 1.00000e-02 1.00000e-03 1.00000e-09 1.00000e-01

$1.00000 \mathrm{e}+001.00000 \mathrm{e}+001.00000 \mathrm{e}-011.00000 \mathrm{e}-091.00000 \mathrm{e}-01$

Element: 8191 \# of layers: 3

Kx Ky Kz Ss Por

6.84318e+01 6.84318e+01 6.84318e+00 1.00000e-09 7.00000e-02

$1.00000 \mathrm{e}-021.00000 \mathrm{e}-02$ 1.00000e-03 1.00000e-09 1.00000e-01

$1.00000 \mathrm{e}+001.00000 \mathrm{e}+001.00000 \mathrm{e}-011.00000 \mathrm{e}-09$ 1.00000e-01

Element: 8192 \# of layers: 3

$\mathrm{Kx} \mathrm{Ky} \mathrm{Kz}$ Ss Por

6.84318e+01 6.84318e+01 6.84318e+00 1.00000e-09 7.00000e-02 $1.00000 \mathrm{e}-02$ 1.00000e-02 1.00000e-03 1.00000e-09 1.00000e-01

$1.00000 \mathrm{e}+001.00000 \mathrm{e}+001.00000 \mathrm{e}-01$ 1.00000e-09 1.00000e-01

Element: 8193 \# of layers: 3

Kx Ky Kz Ss Por 
6.84318e+01 6.84318e+01 6.84318e+00 1.00000e-09 7.00000e-02 $1.00000 \mathrm{e}-02$ 1.00000e-02 1.00000e-03 1.00000e-09 1.00000e-01

$1.00000 \mathrm{e}+001.00000 \mathrm{e}+001.00000 \mathrm{e}-011.00000 \mathrm{e}-091.00000 \mathrm{e}-01$

Element: 8194 \# of layers: 3

$\mathrm{Kx} \mathrm{Ky} \mathrm{Kz}$ Ss Por

6.84318e+01 6.84318e+01 6.84318e+00 1.00000e-09 7.00000e-02

1.00000e-02 1.00000e-02 1.00000e-03 1.00000e-09 1.00000e-01

$1.00000 \mathrm{e}+001.00000 \mathrm{e}+001.00000 \mathrm{e}-011.00000 \mathrm{e}-091.00000 \mathrm{e}-01$

Element: 8195 \# of layers: 3

$\mathrm{Kx} \mathrm{Ky} \mathrm{Kz}$ Ss Por

7.08141e+01 7.08141e+01 7.08141e+00 1.00000e-09 7.00000e-02

$1.00000 \mathrm{e}-02$ 1.00000e-02 1.00000e-03 1.00000e-09 1.00000e-01

$1.00000 \mathrm{e}+001.00000 \mathrm{e}+001.00000 \mathrm{e}-011.00000 \mathrm{e}-091.00000 \mathrm{e}-01$

Element: 8196 \# of layers: 3

Kx Ky Kz Ss Por

7.08141e+01 7.08141e+01 7.08141e+00 1.00000e-09 7.00000e-02

$1.00000 \mathrm{e}-02$ 1.00000e-02 1.00000e-03 1.00000e-09 1.00000e-01

$1.00000 \mathrm{e}+001.00000 \mathrm{e}+001.00000 \mathrm{e}-01$ 1.00000e-09 1.00000e-01

Element: 8197 \# of layers: 3

$\mathrm{Kx} \mathrm{Ky} \mathrm{Kz}$ Ss Por

7.08141e+01 7.08141e+01 7.08141e+00 1.00000e-09 7.00000e-02

$1.00000 \mathrm{e}-02$ 1.00000e-02 1.00000e-03 1.00000e-09 1.00000e-01

$1.00000 \mathrm{e}+001.00000 \mathrm{e}+001.00000 \mathrm{e}-01$ 1.00000e-09 1.00000e-01

Element: 8198 \# of layers: 3

$\mathrm{Kx} \mathrm{Ky} \mathrm{Kz}$ Ss Por

7.08141e+01 7.08141e+01 7.08141e+00 1.00000e-09 7.00000e-02

$1.00000 \mathrm{e}-021.00000 \mathrm{e}-021.00000 \mathrm{e}-031.00000 \mathrm{e}-091.00000 \mathrm{e}-01$

$1.00000 \mathrm{e}+001.00000 \mathrm{e}+001.00000 \mathrm{e}-011.00000 \mathrm{e}-09$ 1.00000e-01

Element: 8199 \# of layers: 3

$\mathrm{Kx} \mathrm{Ky} \mathrm{Kz}$ Ss Por

7.08141e+01 7.08141e+01 7.08141e+00 1.00000e-09 7.00000e-02

$1.00000 \mathrm{e}-02$ 1.00000e-02 1.00000e-03 1.00000e-09 1.00000e-01

$1.00000 \mathrm{e}+001.00000 \mathrm{e}+001.00000 \mathrm{e}-011.00000 \mathrm{e}-091.00000 \mathrm{e}-01$

Element: 8200 \# of layers: 3

$\mathrm{Kx} \mathrm{Ky} \mathrm{Kz}$ Ss Por

7.08141e+01 7.08141e+01 7.08141e+00 1.00000e-09 7.00000e-02

$1.00000 \mathrm{e}-02$ 1.00000e-02 1.00000e-03 1.00000e-09 1.00000e-01

$1.00000 \mathrm{e}+001.00000 \mathrm{e}+001.00000 \mathrm{e}-011.00000 \mathrm{e}-091.00000 \mathrm{e}-01$

Element: 8201 \# of layers: 3

$\mathrm{Kx} \mathrm{Ky} \mathrm{Kz}$ Ss Por

7.08141e+01 7.08141e+01 7.08141e+00 1.00000e-09 7.00000e-02

$1.00000 \mathrm{e}-02$ 1.00000e-02 1.00000e-03 1.00000e-09 1.00000e-01

$1.00000 \mathrm{e}+001.00000 \mathrm{e}+001.00000 \mathrm{e}-011.00000 \mathrm{e}-091.00000 \mathrm{e}-01$

Element: 8202 \# of layers: 3

Kx Ky Kz Ss Por

7.08141e+01 7.08141e+01 7.08141e+00 1.00000e-09 7.00000e-02 
$1.00000 \mathrm{e}-02$ 1.00000e-02 1.00000e-03 1.00000e-09 1.00000e-01

$1.00000 \mathrm{e}+001.00000 \mathrm{e}+001.00000 \mathrm{e}-01$ 1.00000e-09 1.00000e-01

Element: 8203 \# of layers: 3

Kx Ky Kz Ss Por

7.08141e+01 7.08141e+01 7.08141e+00 1.00000e-09 7.00000e-02

$1.00000 \mathrm{e}-02$ 1.00000e-02 1.00000e-03 1.00000e-09 1.00000e-01

$1.00000 \mathrm{e}+001.00000 \mathrm{e}+001.00000 \mathrm{e}-011.00000 \mathrm{e}-091.00000 \mathrm{e}-01$

Element: 8204 \# of layers: 3

$\mathrm{Kx} \mathrm{Ky} \mathrm{Kz}$ Ss Por

7.07429e+01 7.07429e+01 7.07429e+00 1.00000e-09 7.00000e-02

$1.00000 \mathrm{e}-02$ 1.00000e-02 1.00000e-03 1.00000e-09 1.00000e-01

$1.00000 \mathrm{e}+001.00000 \mathrm{e}+001.00000 \mathrm{e}-011.00000 \mathrm{e}-091.00000 \mathrm{e}-01$

Element: 8205 \# of layers: 3

$\mathrm{Kx} \mathrm{Ky} \mathrm{Kz}$ Ss Por

7.07429e+01 7.07429e+01 7.07429e+00 1.00000e-09 7.00000e-02

$1.00000 \mathrm{e}-02$ 1.00000e-02 1.00000e-03 1.00000e-09 1.00000e-01

$1.00000 \mathrm{e}+001.00000 \mathrm{e}+001.00000 \mathrm{e}-011.00000 \mathrm{e}-091.00000 \mathrm{e}-01$

Element: 8206 \# of layers: 3

$\mathrm{Kx} \mathrm{Ky} \mathrm{Kz}$ Ss Por

7.07429e+01 7.07429e+01 7.07429e+00 1.00000e-09 7.00000e-02

$1.00000 \mathrm{e}-02$ 1.00000e-02 1.00000e-03 1.00000e-09 1.00000e-01

$1.00000 \mathrm{e}+001.00000 \mathrm{e}+001.00000 \mathrm{e}-01$ 1.00000e-09 1.00000e-01

Element: 8210 \# of layers: 3

Kx Ky Kz Ss Por

7.07429e+01 7.07429e+01 7.07429e+00 1.00000e-09 7.00000e-02

$1.00000 \mathrm{e}-021.00000 \mathrm{e}-021.00000 \mathrm{e}-031.00000 \mathrm{e}-091.00000 \mathrm{e}-01$

$1.00000 \mathrm{e}+001.00000 \mathrm{e}+001.00000 \mathrm{e}-011.00000 \mathrm{e}-091.00000 \mathrm{e}-01$

Element: 8211 \# of layers: 3

Kx Ky Kz Ss Por

7.07429e+01 7.07429e+01 7.07429e+00 1.00000e-09 7.00000e-02

$1.00000 \mathrm{e}-02$ 1.00000e-02 1.00000e-03 1.00000e-09 1.00000e-01

$1.00000 \mathrm{e}+001.00000 \mathrm{e}+001.00000 \mathrm{e}-01$ 1.00000e-09 1.00000e-01

Element: 8213 \# of layers: 3

$\mathrm{Kx} \mathrm{Ky} \mathrm{Kz}$ Ss Por

6.37917e+01 6.37917e+01 6.37917e+00 1.00000e-09 7.00000e-02

1.00000e-02 1.00000e-02 1.00000e-03 1.00000e-09 1.00000e-01

$1.00000 \mathrm{e}+001.00000 \mathrm{e}+001.00000 \mathrm{e}-011.00000 \mathrm{e}-091.00000 \mathrm{e}-01$

Element: 8214 \# of layers: 3

Kx Ky Kz Ss Por

6.37917e+01 6.37917e+01 6.37917e+00 1.00000e-09 7.00000e-02

$1.00000 \mathrm{e}-02$ 1.00000e-02 1.00000e-03 1.00000e-09 1.00000e-01

$1.00000 \mathrm{e}+001.00000 \mathrm{e}+001.00000 \mathrm{e}-011.00000 \mathrm{e}-091.00000 \mathrm{e}-01$

Element: 8215 \# of layers: 3

Kx Ky Kz Ss Por

6.37917e+01 6.37917e+01 6.37917e+00 1.00000e-09 7.00000e-02

$1.00000 \mathrm{e}-02$ 1.00000e-02 1.00000e-03 1.00000e-09 1.00000e-01 
$1.00000 \mathrm{e}+001.00000 \mathrm{e}+00$ 1.00000e-01 1.00000e-09 1.00000e-01

Element: 8216 \# of layers: 3

Kx Ky Kz Ss Por

6.40359e+01 6.40359e+01 6.40359e+00 1.00000e-09 7.00000e-02

$1.00000 \mathrm{e}-02$ 1.00000e-02 1.00000e-03 1.00000e-09 1.00000e-01

$1.00000 \mathrm{e}+001.00000 \mathrm{e}+00$ 1.00000e-01 1.00000e-09 1.00000e-01

Element: 8217 \# of layers: 3

$\mathrm{Kx} \mathrm{Ky} \mathrm{Kz}$ Ss Por

6.40359e+01 6.40359e+01 6.40359e+00 1.00000e-09 7.00000e-02

$1.00000 \mathrm{e}-02$ 1.00000e-02 1.00000e-03 1.00000e-09 1.00000e-01

$1.00000 \mathrm{e}+001.00000 \mathrm{e}+001.00000 \mathrm{e}-011.00000 \mathrm{e}-091.00000 \mathrm{e}-01$

Element: 8218 \# of layers: 3

$\mathrm{Kx} \mathrm{Ky} \mathrm{Kz}$ Ss Por

6.40359e+01 6.40359e+01 6.40359e+00 1.00000e-09 7.00000e-02

$1.00000 \mathrm{e}-02$ 1.00000e-02 1.00000e-03 1.00000e-09 1.00000e-01

$1.00000 \mathrm{e}+001.00000 \mathrm{e}+001.00000 \mathrm{e}-011.00000 \mathrm{e}-091.00000 \mathrm{e}-01$

Element: 8219 \# of layers: 5

$\mathrm{Kx} \mathrm{Ky} \mathrm{Kz}$ Ss Por

4.95820e+03 4.95820e+03 4.95820e+02 1.00000e-09 7.00000e-02

$4.95820 \mathrm{e}+03$ 4.95820e+03 4.95820e+02 1.00000e-09 7.00000e-02

$1.98112 \mathrm{e}+021.98112 \mathrm{e}+02$ 1.98112e+01 1.00000e-09 2.12000e-01

$1.00000 \mathrm{e}-021.00000 \mathrm{e}-021.00000 \mathrm{e}-031.00000 \mathrm{e}-091.00000 \mathrm{e}-01$

$1.00000 \mathrm{e}+001.00000 \mathrm{e}+001.00000 \mathrm{e}-01$ 1.00000e-09 1.00000e-01

Element: 8220 \# of layers: 5

Kx Ky Kz Ss Por

$4.95820 \mathrm{e}+03$ 4.95820e+03 4.95820e+02 1.00000e-09 7.00000e-02

$4.95820 \mathrm{e}+034.95820 \mathrm{e}+034.95820 \mathrm{e}+021.00000 \mathrm{e}-097.00000 \mathrm{e}-02$

$1.98112 \mathrm{e}+02$ 1.98112e+02 1.98112e+01 1.00000e-09 2.12000e-01

$1.00000 \mathrm{e}-02$ 1.00000e-02 1.00000e-03 1.00000e-09 1.00000e-01

$1.00000 \mathrm{e}+001.00000 \mathrm{e}+001.00000 \mathrm{e}-011.00000 \mathrm{e}-091.00000 \mathrm{e}-01$

Element: 8221 \# of layers: 5

$\mathrm{Kx} \mathrm{Ky} \mathrm{Kz}$ Ss Por

4.95820e+03 4.95820e+03 4.95820e+02 1.00000e-09 7.00000e-02

$4.95820 \mathrm{e}+03$ 4.95820e+03 4.95820e+02 1.00000e-09 7.00000e-02

$1.98112 \mathrm{e}+02$ 1.98112e+02 1.98112e+01 1.00000e-09 2.12000e-01

1.00000e-02 1.00000e-02 1.00000e-03 1.00000e-09 1.00000e-01

$1.00000 \mathrm{e}+001.00000 \mathrm{e}+001.00000 \mathrm{e}-011.00000 \mathrm{e}-091.00000 \mathrm{e}-01$

Element: 8222 \# of layers: 3

$\mathrm{Kx} \mathrm{Ky} \mathrm{Kz}$ Ss Por

3.95468e+02 3.95468e+02 3.95468e+01 1.00000e-09 2.12000e-01 1.00000e-02 1.00000e-02 1.00000e-03 1.00000e-09 1.00000e-01

$1.00000 \mathrm{e}+001.00000 \mathrm{e}+001.00000 \mathrm{e}-011.00000 \mathrm{e}-091.00000 \mathrm{e}-01$

Element: 8223 \# of layers: 3

$\mathrm{Kx} \mathrm{Ky} \mathrm{Kz}$ Ss Por

3.95468e+02 3.95468e+02 3.95468e+01 1.00000e-09 2.12000e-01

$1.00000 \mathrm{e}-02$ 1.00000e-02 1.00000e-03 1.00000e-09 1.00000e-01 
$1.00000 \mathrm{e}+001.00000 \mathrm{e}+001.00000 \mathrm{e}-01$ 1.00000e-09 1.00000e-01

Element: 8224 \# of layers: 4

$\mathrm{Kx} \mathrm{Ky} \mathrm{Kz}$ Ss Por

$4.95820 \mathrm{e}+03$ 4.95820e+03 4.95820e+02 1.00000e-09 7.00000e-02

$3.95468 \mathrm{e}+02$ 3.95468e+02 3.95468e+01 1.00000e-09 2.12000e-01

$1.00000 \mathrm{e}-02$ 1.00000e-02 1.00000e-03 1.00000e-09 1.00000e-01

$1.00000 \mathrm{e}+001.00000 \mathrm{e}+001.00000 \mathrm{e}-01$ 1.00000e-09 1.00000e-01

Element: 8225 \# of layers: 4

$\mathrm{Kx} \mathrm{Ky} \mathrm{Kz}$ Ss Por

5.73856e+02 5.73856e+02 5.73856e+01 1.00000e-09 7.00000e-02

$2.29302 \mathrm{e}+012.29302 \mathrm{e}+012.29302 \mathrm{e}+00$ 1.00000e-09 2.12000e-01

$1.00000 \mathrm{e}-02$ 1.00000e-02 1.00000e-03 1.00000e-09 1.00000e-01

$1.00000 \mathrm{e}+001.00000 \mathrm{e}+001.00000 \mathrm{e}-011.00000 \mathrm{e}-091.00000 \mathrm{e}-01$

Element: 8226 \# of layers: 4

$\mathrm{Kx} \mathrm{Ky} \mathrm{Kz}$ Ss Por

5.73856e+02 5.73856e+02 5.73856e+01 1.00000e-09 7.00000e-02

$2.29302 \mathrm{e}+012.29302 \mathrm{e}+012.29302 \mathrm{e}+00$ 1.00000e-09 2.12000e-01

$1.00000 \mathrm{e}-02$ 1.00000e-02 1.00000e-03 1.00000e-09 1.00000e-01

$1.00000 \mathrm{e}+001.00000 \mathrm{e}+001.00000 \mathrm{e}-01$ 1.00000e-09 1.00000e-01

Element: 8227 \# of layers: 4

$\mathrm{Kx} \mathrm{Ky} \mathrm{Kz}$ Ss Por

5.73856e+02 5.73856e+02 5.73856e+01 1.00000e-09 7.00000e-02

$2.29302 \mathrm{e}+012.29302 \mathrm{e}+012.29302 \mathrm{e}+00$ 1.00000e-09 2.12000e-01

$1.00000 \mathrm{e}-02$ 1.00000e-02 1.00000e-03 1.00000e-09 1.00000e-01

$1.00000 \mathrm{e}+001.00000 \mathrm{e}+001.00000 \mathrm{e}-011.00000 \mathrm{e}-091.00000 \mathrm{e}-01$

Element: 8228 \# of layers: 4

$\mathrm{Kx} \mathrm{Ky} \mathrm{Kz}$ Ss Por

5.73856e+02 5.73856e+02 5.73856e+01 1.00000e-09 7.00000e-02

$2.29302 \mathrm{e}+012.29302 \mathrm{e}+012.29302 \mathrm{e}+001.00000 \mathrm{e}-092.12000 \mathrm{e}-01$

$1.00000 \mathrm{e}-02$ 1.00000e-02 1.00000e-03 1.00000e-09 1.00000e-01

$1.00000 \mathrm{e}+001.00000 \mathrm{e}+001.00000 \mathrm{e}-011.00000 \mathrm{e}-091.00000 \mathrm{e}-01$

Element: 8229 \# of layers: 3

$\mathrm{Kx} \mathrm{Ky} \mathrm{Kz}$ Ss Por

$2.29302 \mathrm{e}+012.29302 \mathrm{e}+012.29302 \mathrm{e}+00$ 1.00000e-09 2.12000e-01

$1.00000 \mathrm{e}-02$ 1.00000e-02 1.00000e-03 1.00000e-09 1.00000e-01

$1.00000 \mathrm{e}+001.00000 \mathrm{e}+001.00000 \mathrm{e}-011.00000 \mathrm{e}-091.00000 \mathrm{e}-01$

Element: 8234 \# of layers: 3

Kx Ky Kz Ss Por

1.74911e+02 1.74911e+02 1.74911e+01 1.00000e-09 7.00000e-02

$1.00000 \mathrm{e}-02$ 1.00000e-02 1.00000e-03 1.00000e-09 1.00000e-01

$1.00000 \mathrm{e}+001.00000 \mathrm{e}+001.00000 \mathrm{e}-011.00000 \mathrm{e}-091.00000 \mathrm{e}-01$

Element: 8235 \# of layers: 3

$\mathrm{Kx} \mathrm{Ky} \mathrm{Kz}$ Ss Por

1.74911e+02 1.74911e+02 1.74911e+01 1.00000e-09 7.00000e-02

$1.00000 \mathrm{e}-02$ 1.00000e-02 1.00000e-03 1.00000e-09 1.00000e-01

$1.00000 \mathrm{e}+001.00000 \mathrm{e}+001.00000 \mathrm{e}-011.00000 \mathrm{e}-091.00000 \mathrm{e}-01$ 
Element: 8236 \# of layers: 3

$\mathrm{Kx} \mathrm{Ky} \mathrm{Kz}$ Ss Por

1.74911e+02 1.74911e+02 1.74911e+01 1.00000e-09 7.00000e-02

$1.00000 \mathrm{e}-02$ 1.00000e-02 1.00000e-03 1.00000e-09 1.00000e-01

$1.00000 \mathrm{e}+001.00000 \mathrm{e}+001.00000 \mathrm{e}-01$ 1.00000e-09 1.00000e-01

Element: 8237 \# of layers: 3

$\mathrm{Kx} \mathrm{Ky} \mathrm{Kz}$ Ss Por

$1.74911 \mathrm{e}+02$ 1.74911e+02 1.74911e+01 1.00000e-09 7.00000e-02

$1.00000 \mathrm{e}-021.00000 \mathrm{e}-021.00000 \mathrm{e}-031.00000 \mathrm{e}-091.00000 \mathrm{e}-01$

$1.00000 \mathrm{e}+001.00000 \mathrm{e}+001.00000 \mathrm{e}-011.00000 \mathrm{e}-09$ 1.00000e-01

Element: 8238 \# of layers: 3

Kx Ky Kz Ss Por

1.74911e+02 1.74911e+02 1.74911e+01 1.00000e-09 7.00000e-02

$1.00000 \mathrm{e}-02$ 1.00000e-02 1.00000e-03 1.00000e-09 1.00000e-01

$1.00000 \mathrm{e}+001.00000 \mathrm{e}+001.00000 \mathrm{e}-011.00000 \mathrm{e}-091.00000 \mathrm{e}-01$

Element: 8239 \# of layers: 4

$\mathrm{Kx} \mathrm{Ky} \mathrm{Kz}$ Ss Por

$1.74911 \mathrm{e}+02$ 1.74911e+02 1.74911e+01 1.00000e-09 7.00000e-02

6.98887e+00 6.98887e+00 6.98887e-01 1.00000e-09 2.12000e-01

$1.00000 \mathrm{e}-02$ 1.00000e-02 1.00000e-03 1.00000e-09 1.00000e-01

$1.00000 \mathrm{e}+001.00000 \mathrm{e}+001.00000 \mathrm{e}-011.00000 \mathrm{e}-091.00000 \mathrm{e}-01$

Element: 8240 \# of layers: 3

$\mathrm{Kx} \mathrm{Ky} \mathrm{Kz}$ Ss Por

6.98887e+00 6.98887e+00 6.98887e-01 1.00000e-09 2.12000e-01

$1.00000 \mathrm{e}-021.00000 \mathrm{e}-02$ 1.00000e-03 1.00000e-09 1.00000e-01

$1.00000 \mathrm{e}+001.00000 \mathrm{e}+001.00000 \mathrm{e}-011.00000 \mathrm{e}-091.00000 \mathrm{e}-01$

Element: 8241 \# of layers: 4

$\mathrm{Kx} \mathrm{Ky} \mathrm{Kz}$ Ss Por

$1.74911 \mathrm{e}+02$ 1.74911e+02 1.74911e+01 1.00000e-09 7.00000e-02

6.98887e+00 6.98887e+00 6.98887e-01 1.00000e-09 2.12000e-01

$1.00000 \mathrm{e}-02$ 1.00000e-02 1.00000e-03 1.00000e-09 1.00000e-01

$1.00000 \mathrm{e}+001.00000 \mathrm{e}+001.00000 \mathrm{e}-011.00000 \mathrm{e}-091.00000 \mathrm{e}-01$

Element: 8242 \# of layers: 4

$\mathrm{Kx} \mathrm{Ky} \mathrm{Kz}$ Ss Por

1.74911e+02 1.74911e+02 1.74911e+01 1.00000e-09 7.00000e-02

6.98887e+00 6.98887e+00 6.98887e-01 1.00000e-09 2.12000e-01

$1.00000 \mathrm{e}-02$ 1.00000e-02 1.00000e-03 1.00000e-09 1.00000e-01

$1.00000 \mathrm{e}+001.00000 \mathrm{e}+001.00000 \mathrm{e}-011.00000 \mathrm{e}-091.00000 \mathrm{e}-01$

Element: 8243 \# of layers: 3

$\mathrm{Kx} \mathrm{Ky} \mathrm{Kz}$ Ss Por

1.26095e+02 1.26095e+02 1.26095e+01 1.00000e-09 7.00000e-02

$1.00000 \mathrm{e}-02$ 1.00000e-02 1.00000e-03 1.00000e-09 1.00000e-01

$1.00000 \mathrm{e}+001.00000 \mathrm{e}+001.00000 \mathrm{e}-01$ 1.00000e-09 1.00000e-01

Element: 8244 \# of layers: 3

$\mathrm{Kx} \mathrm{Ky} \mathrm{Kz}$ Ss Por

1.26095e+02 1.26095e+02 1.26095e+01 1.00000e-09 7.00000e-02 
$1.00000 \mathrm{e}-02$ 1.00000e-02 1.00000e-03 1.00000e-09 1.00000e-01 $1.00000 \mathrm{e}+001.00000 \mathrm{e}+001.00000 \mathrm{e}-01$ 1.00000e-09 1.00000e-01

Element: 8245 \# of layers: 3

$\mathrm{Kx} \mathrm{Ky} \mathrm{Kz}$ Ss Por

$1.26095 \mathrm{e}+021.26095 \mathrm{e}+02$ 1.26095e+01 1.00000e-09 7.00000e-02

$1.00000 \mathrm{e}-02$ 1.00000e-02 1.00000e-03 1.00000e-09 1.00000e-01

$1.00000 \mathrm{e}+001.00000 \mathrm{e}+001.00000 \mathrm{e}-01$ 1.00000e-09 1.00000e-01

Element: 8246 \# of layers: 3

$\mathrm{Kx} \mathrm{Ky} \mathrm{Kz}$ Ss Por

$1.26095 \mathrm{e}+02$ 1.26095e+02 1.26095e+01 1.00000e-09 7.00000e-02

$1.00000 \mathrm{e}-02$ 1.00000e-02 1.00000e-03 1.00000e-09 1.00000e-01

$1.00000 \mathrm{e}+001.00000 \mathrm{e}+001.00000 \mathrm{e}-011.00000 \mathrm{e}-091.00000 \mathrm{e}-01$

Element: 8247 \# of layers: 3

$\mathrm{Kx} \mathrm{Ky} \mathrm{Kz}$ Ss Por

$1.26095 \mathrm{e}+02$ 1.26095e+02 1.26095e+01 1.00000e-09 7.00000e-02

$1.00000 \mathrm{e}-02$ 1.00000e-02 1.00000e-03 1.00000e-09 1.00000e-01

$1.00000 \mathrm{e}+001.00000 \mathrm{e}+001.00000 \mathrm{e}-011.00000 \mathrm{e}-09$ 1.00000e-01

Element: 8248 \# of layers: 3

$\mathrm{Kx} \mathrm{Ky} \mathrm{Kz}$ Ss Por

1.26095e+02 1.26095e+02 1.26095e+01 1.00000e-09 7.00000e-02

$1.00000 \mathrm{e}-02$ 1.00000e-02 1.00000e-03 1.00000e-09 1.00000e-01

$1.00000 \mathrm{e}+001.00000 \mathrm{e}+001.00000 \mathrm{e}-01$ 1.00000e-09 1.00000e-01

Element: 8249 \# of layers: 3

$\mathrm{Kx} \mathrm{Ky} \mathrm{Kz}$ Ss Por

1.26095e+02 1.26095e+02 1.26095e+01 1.00000e-09 7.00000e-02

$1.00000 \mathrm{e}-02$ 1.00000e-02 1.00000e-03 1.00000e-09 1.00000e-01

$1.00000 \mathrm{e}+001.00000 \mathrm{e}+001.00000 \mathrm{e}-011.00000 \mathrm{e}-091.00000 \mathrm{e}-01$

Element: 8250 \# of layers: 3

$\mathrm{Kx} \mathrm{Ky} \mathrm{Kz}$ Ss Por

$1.26095 \mathrm{e}+02$ 1.26095e+02 1.26095e+01 1.00000e-09 7.00000e-02

$1.00000 \mathrm{e}-02$ 1.00000e-02 1.00000e-03 1.00000e-09 1.00000e-01

$1.00000 \mathrm{e}+001.00000 \mathrm{e}+001.00000 \mathrm{e}-011.00000 \mathrm{e}-091.00000 \mathrm{e}-01$

Element: 8251 \# of layers: 3

$\mathrm{Kx} \mathrm{Ky} \mathrm{Kz}$ Ss Por

$1.26095 \mathrm{e}+02$ 1.26095e+02 1.26095e+01 1.00000e-09 7.00000e-02

$1.00000 \mathrm{e}-02$ 1.00000e-02 1.00000e-03 1.00000e-09 1.00000e-01

$1.00000 \mathrm{e}+001.00000 \mathrm{e}+001.00000 \mathrm{e}-011.00000 \mathrm{e}-091.00000 \mathrm{e}-01$

Element: 8252 \# of layers: 3

$\mathrm{Kx} \mathrm{Ky} \mathrm{Kz}$ Ss Por

$1.13733 \mathrm{e}+02$ 1.13733e+02 1.13733e+01 1.00000e-09 7.00000e-02

$1.00000 \mathrm{e}-02$ 1.00000e-02 1.00000e-03 1.00000e-09 1.00000e-01

$1.00000 \mathrm{e}+001.00000 \mathrm{e}+001.00000 \mathrm{e}-011.00000 \mathrm{e}-091.00000 \mathrm{e}-01$

Element: 8253 \# of layers: 3

$\mathrm{Kx} \mathrm{Ky} \mathrm{Kz}$ Ss Por

$1.13733 \mathrm{e}+02$ 1.13733e+02 1.13733e+01 1.00000e-09 7.00000e-02

$1.00000 \mathrm{e}-02$ 1.00000e-02 1.00000e-03 1.00000e-09 1.00000e-01 
$1.00000 \mathrm{e}+001.00000 \mathrm{e}+00$ 1.00000e-01 1.00000e-09 1.00000e-01

Element: 8254 \# of layers: 3

Kx Ky Kz Ss Por

$1.13733 \mathrm{e}+02$ 1.13733e+02 1.13733e+01 1.00000e-09 7.00000e-02

$1.00000 \mathrm{e}-02$ 1.00000e-02 1.00000e-03 1.00000e-09 1.00000e-01

$1.00000 \mathrm{e}+001.00000 \mathrm{e}+001.00000 \mathrm{e}-01$ 1.00000e-09 1.00000e-01

Element: 8255 \# of layers: 3

$\mathrm{Kx} \mathrm{Ky} \mathrm{Kz}$ Ss Por

$1.13733 \mathrm{e}+02$ 1.13733e+02 1.13733e+01 1.00000e-09 7.00000e-02

$1.00000 \mathrm{e}-02$ 1.00000e-02 1.00000e-03 1.00000e-09 1.00000e-01

$1.00000 \mathrm{e}+001.00000 \mathrm{e}+001.00000 \mathrm{e}-011.00000 \mathrm{e}-091.00000 \mathrm{e}-01$

Element: 8256 \# of layers: 3

$\mathrm{Kx} \mathrm{Ky} \mathrm{Kz}$ Ss Por

1.13733e+02 1.13733e+02 1.13733e+01 1.00000e-09 7.00000e-02

$1.00000 \mathrm{e}-02$ 1.00000e-02 1.00000e-03 1.00000e-09 1.00000e-01

$1.00000 \mathrm{e}+001.00000 \mathrm{e}+001.00000 \mathrm{e}-011.00000 \mathrm{e}-091.00000 \mathrm{e}-01$

Element: 8257 \# of layers: 3

$\mathrm{Kx} \mathrm{Ky} \mathrm{Kz}$ Ss Por

1.13733e+02 1.13733e+02 1.13733e+01 1.00000e-09 7.00000e-02

$1.00000 \mathrm{e}-02$ 1.00000e-02 1.00000e-03 1.00000e-09 1.00000e-01

$1.00000 \mathrm{e}+001.00000 \mathrm{e}+001.00000 \mathrm{e}-011.00000 \mathrm{e}-091.00000 \mathrm{e}-01$

Element: 8258 \# of layers: 3

$\mathrm{Kx} \mathrm{Ky} \mathrm{Kz}$ Ss Por

$1.13733 \mathrm{e}+02$ 1.13733e+02 1.13733e+01 1.00000e-09 7.00000e-02

$1.00000 \mathrm{e}-02$ 1.00000e-02 1.00000e-03 1.00000e-09 1.00000e-01

$1.00000 \mathrm{e}+001.00000 \mathrm{e}+001.00000 \mathrm{e}-01$ 1.00000e-09 1.00000e-01

Element: 8259 \# of layers: 3

$\mathrm{Kx} \mathrm{Ky} \mathrm{Kz} \mathrm{Ss} \mathrm{Por}$

$1.13733 \mathrm{e}+02$ 1.13733e+02 1.13733e+01 1.00000e-09 7.00000e-02

$1.00000 \mathrm{e}-02$ 1.00000e-02 1.00000e-03 1.00000e-09 1.00000e-01

$1.00000 \mathrm{e}+001.00000 \mathrm{e}+001.00000 \mathrm{e}-011.00000 \mathrm{e}-091.00000 \mathrm{e}-01$

Element: 8260 \# of layers: 3

Kx Ky Kz Ss Por

1.13733e+02 1.13733e+02 1.13733e+01 1.00000e-09 7.00000e-02

$1.00000 \mathrm{e}-02$ 1.00000e-02 1.00000e-03 1.00000e-09 1.00000e-01

$1.00000 \mathrm{e}+001.00000 \mathrm{e}+001.00000 \mathrm{e}-011.00000 \mathrm{e}-091.00000 \mathrm{e}-01$

Element: 8261 \# of layers: 3

$\mathrm{Kx} \mathrm{Ky} \mathrm{Kz}$ Ss Por

$1.08399 \mathrm{e}+02$ 1.08399e+02 1.08399e+01 1.00000e-09 7.00000e-02

$1.00000 \mathrm{e}-02$ 1.00000e-02 1.00000e-03 1.00000e-09 1.00000e-01

$1.00000 \mathrm{e}+001.00000 \mathrm{e}+001.00000 \mathrm{e}-011.00000 \mathrm{e}-091.00000 \mathrm{e}-01$

Element: 8262 \# of layers: 3

$\mathrm{Kx} \mathrm{Ky} \mathrm{Kz}$ Ss Por

1.08399e+02 1.08399e+02 1.08399e+01 1.00000e-09 7.00000e-02

$1.00000 \mathrm{e}-02$ 1.00000e-02 1.00000e-03 1.00000e-09 1.00000e-01

$1.00000 \mathrm{e}+001.00000 \mathrm{e}+001.00000 \mathrm{e}-011.00000 \mathrm{e}-091.00000 \mathrm{e}-01$ 
Element: 8263 \# of layers: 3

$\mathrm{Kx} \mathrm{Ky} \mathrm{Kz}$ Ss Por

$1.08399 \mathrm{e}+02$ 1.08399e+02 1.08399e+01 1.00000e-09 7.00000e-02

$1.00000 \mathrm{e}-02$ 1.00000e-02 1.00000e-03 1.00000e-09 1.00000e-01

$1.00000 \mathrm{e}+001.00000 \mathrm{e}+001.00000 \mathrm{e}-011.00000 \mathrm{e}-091.00000 \mathrm{e}-01$

Element: 8264 \# of layers: 3

$\mathrm{Kx} \mathrm{Ky} \mathrm{Kz}$ Ss Por

$1.08399 \mathrm{e}+02$ 1.08399e+02 1.08399e+01 1.00000e-09 7.00000e-02

$1.00000 \mathrm{e}-02$ 1.00000e-02 1.00000e-03 1.00000e-09 1.00000e-01

$1.00000 \mathrm{e}+001.00000 \mathrm{e}+001.00000 \mathrm{e}-011.00000 \mathrm{e}-091.00000 \mathrm{e}-01$

Element: 8265 \# of layers: 3

$\mathrm{Kx} \mathrm{Ky} \mathrm{Kz}$ Ss Por

$1.08399 \mathrm{e}+02$ 1.08399e+02 1.08399e+01 1.00000e-09 7.00000e-02

$1.00000 \mathrm{e}-02$ 1.00000e-02 1.00000e-03 1.00000e-09 1.00000e-01

$1.00000 \mathrm{e}+001.00000 \mathrm{e}+001.00000 \mathrm{e}-01$ 1.00000e-09 1.00000e-01

Element: 8266 \# of layers: 3

$\mathrm{Kx} \mathrm{Ky} \mathrm{Kz}$ Ss Por

$1.08399 \mathrm{e}+02$ 1.08399e+02 1.08399e+01 1.00000e-09 7.00000e-02

$1.00000 \mathrm{e}-02$ 1.00000e-02 1.00000e-03 1.00000e-09 1.00000e-01

$1.00000 \mathrm{e}+001.00000 \mathrm{e}+001.00000 \mathrm{e}-011.00000 \mathrm{e}-091.00000 \mathrm{e}-01$

Element: 8267 \# of layers: 3

$\mathrm{Kx} \mathrm{Ky} \mathrm{Kz}$ Ss Por

1.08399e+02 1.08399e+02 1.08399e+01 1.00000e-09 7.00000e-02

$1.00000 \mathrm{e}-02$ 1.00000e-02 1.00000e-03 1.00000e-09 1.00000e-01

$1.00000 \mathrm{e}+001.00000 \mathrm{e}+001.00000 \mathrm{e}-011.00000 \mathrm{e}-091.00000 \mathrm{e}-01$

Element: 8268 \# of layers: 3

$\mathrm{Kx} \mathrm{Ky} \mathrm{Kz}$ Ss Por

$1.08399 \mathrm{e}+02$ 1.08399e+02 1.08399e+01 1.00000e-09 7.00000e-02

$1.00000 \mathrm{e}-02$ 1.00000e-02 1.00000e-03 1.00000e-09 1.00000e-01

$1.00000 \mathrm{e}+001.00000 \mathrm{e}+001.00000 \mathrm{e}-011.00000 \mathrm{e}-091.00000 \mathrm{e}-01$

Element: 8269 \# of layers: 3

$\mathrm{Kx} \mathrm{Ky} \mathrm{Kz}$ Ss Por

$1.08399 \mathrm{e}+02$ 1.08399e+02 1.08399e+01 1.00000e-09 7.00000e-02

$1.00000 \mathrm{e}-02$ 1.00000e-02 1.00000e-03 1.00000e-09 1.00000e-01

$1.00000 \mathrm{e}+001.00000 \mathrm{e}+001.00000 \mathrm{e}-011.00000 \mathrm{e}-091.00000 \mathrm{e}-01$

Element: 8270 \# of layers: 3

Kx Ky Kz Ss Por

9.74161e+01 9.74161e+01 9.74161e+00 1.00000e-09 7.00000e-02

$1.00000 \mathrm{e}-02$ 1.00000e-02 1.00000e-03 1.00000e-09 1.00000e-01

$1.00000 \mathrm{e}+001.00000 \mathrm{e}+001.00000 \mathrm{e}-01$ 1.00000e-09 1.00000e-01

Element: 8271 \# of layers: 3

$\mathrm{Kx} \mathrm{Ky} \mathrm{Kz}$ Ss Por

9.74161e+01 9.74161e+01 9.74161e+00 1.00000e-09 7.00000e-02

$1.00000 \mathrm{e}-02$ 1.00000e-02 1.00000e-03 1.00000e-09 1.00000e-01

$1.00000 \mathrm{e}+001.00000 \mathrm{e}+001.00000 \mathrm{e}-011.00000 \mathrm{e}-091.00000 \mathrm{e}-01$

Element: 8272 \# of layers: 3 
Kx Ky Kz Ss Por

9.74161e+01 9.74161e+01 9.74161e+00 1.00000e-09 7.00000e-02

$1.00000 \mathrm{e}-02$ 1.00000e-02 1.00000e-03 1.00000e-09 1.00000e-01

$1.00000 \mathrm{e}+001.00000 \mathrm{e}+001.00000 \mathrm{e}-011.00000 \mathrm{e}-091.00000 \mathrm{e}-01$

Element: 8273 \# of layers: 3

$\mathrm{Kx} \mathrm{Ky} \mathrm{Kz}$ Ss Por

9.74161e+01 9.74161e+01 9.74161e+00 1.00000e-09 7.00000e-02

$1.00000 \mathrm{e}-02$ 1.00000e-02 1.00000e-03 1.00000e-09 1.00000e-01

$1.00000 \mathrm{e}+001.00000 \mathrm{e}+001.00000 \mathrm{e}-011.00000 \mathrm{e}-091.00000 \mathrm{e}-01$

Element: 8274 \# of layers: 3

Kx Ky Kz Ss Por

9.74161e+01 9.74161e+01 9.74161e+00 1.00000e-09 7.00000e-02

$1.00000 \mathrm{e}-02$ 1.00000e-02 1.00000e-03 1.00000e-09 1.00000e-01

$1.00000 \mathrm{e}+001.00000 \mathrm{e}+001.00000 \mathrm{e}-011.00000 \mathrm{e}-091.00000 \mathrm{e}-01$

Element: 8275 \# of layers: 3

Kx Ky Kz Ss Por

9.74161e+01 9.74161e+01 9.74161e+00 1.00000e-09 7.00000e-02 $1.00000 \mathrm{e}-02$ 1.00000e-02 1.00000e-03 1.00000e-09 1.00000e-01

$1.00000 \mathrm{e}+001.00000 \mathrm{e}+001.00000 \mathrm{e}-01$ 1.00000e-09 1.00000e-01

Element: 8276 \# of layers: 3

$\mathrm{Kx} \mathrm{Ky} \mathrm{Kz}$ Ss Por

9.74161e+01 9.74161e+01 9.74161e+00 1.00000e-09 7.00000e-02

$1.00000 \mathrm{e}-02$ 1.00000e-02 1.00000e-03 1.00000e-09 1.00000e-01

$1.00000 \mathrm{e}+001.00000 \mathrm{e}+001.00000 \mathrm{e}-011.00000 \mathrm{e}-091.00000 \mathrm{e}-01$

Element: 8277 \# of layers: 3

Kx Ky Kz Ss Por

9.74161e+01 9.74161e+01 9.74161e+00 1.00000e-09 7.00000e-02

$1.00000 \mathrm{e}-021.00000 \mathrm{e}-021.00000 \mathrm{e}-031.00000 \mathrm{e}-091.00000 \mathrm{e}-01$

$1.00000 \mathrm{e}+001.00000 \mathrm{e}+001.00000 \mathrm{e}-011.00000 \mathrm{e}-091.00000 \mathrm{e}-01$

Element: 8278 \# of layers: 3

$\mathrm{Kx} \mathrm{Ky} \mathrm{Kz}$ Ss Por

9.74161e+01 9.74161e+01 9.74161e+00 1.00000e-09 7.00000e-02

$1.00000 \mathrm{e}-02$ 1.00000e-02 1.00000e-03 1.00000e-09 1.00000e-01

$1.00000 \mathrm{e}+001.00000 \mathrm{e}+001.00000 \mathrm{e}-01$ 1.00000e-09 1.00000e-01

Element: 8279 \# of layers: 3

Kx Ky Kz Ss Por

9.28661e+01 9.28661e+01 9.28661e+00 1.00000e-09 7.00000e-02

$1.00000 \mathrm{e}-02$ 1.00000e-02 1.00000e-03 1.00000e-09 1.00000e-01

$1.00000 \mathrm{e}+001.00000 \mathrm{e}+001.00000 \mathrm{e}-011.00000 \mathrm{e}-09$ 1.00000e-01

Element: 8280 \# of layers: 3

$\mathrm{Kx} \mathrm{Ky} \mathrm{Kz}$ Ss Por

9.28661e+01 9.28661e+01 9.28661e+00 1.00000e-09 7.00000e-02 $1.00000 \mathrm{e}-021.00000 \mathrm{e}-021.00000 \mathrm{e}-031.00000 \mathrm{e}-091.00000 \mathrm{e}-01$

$1.00000 \mathrm{e}+001.00000 \mathrm{e}+001.00000 \mathrm{e}-01$ 1.00000e-09 1.00000e-01

Element: 8281 \# of layers: 3

Kx Ky Kz Ss Por 
9.28661e+01 9.28661e+01 9.28661e+00 1.00000e-09 7.00000e-02 $1.00000 \mathrm{e}-02$ 1.00000e-02 1.00000e-03 1.00000e-09 1.00000e-01

$1.00000 \mathrm{e}+001.00000 \mathrm{e}+001.00000 \mathrm{e}-011.00000 \mathrm{e}-091.00000 \mathrm{e}-01$

Element: 8282 \# of layers: 3

$\mathrm{Kx} \mathrm{Ky} \mathrm{Kz}$ Ss Por

9.28661e+01 9.28661e+01 9.28661e+00 1.00000e-09 7.00000e-02

$1.00000 \mathrm{e}-02$ 1.00000e-02 1.00000e-03 1.00000e-09 1.00000e-01

$1.00000 \mathrm{e}+001.00000 \mathrm{e}+001.00000 \mathrm{e}-01$ 1.00000e-09 1.00000e-01

Element: 8283 \# of layers: 3

$\mathrm{Kx} \mathrm{Ky} \mathrm{Kz}$ Ss Por

9.28661e+01 9.28661e+01 9.28661e+00 1.00000e-09 7.00000e-02

$1.00000 \mathrm{e}-02$ 1.00000e-02 1.00000e-03 1.00000e-09 1.00000e-01

$1.00000 \mathrm{e}+001.00000 \mathrm{e}+001.00000 \mathrm{e}-011.00000 \mathrm{e}-091.00000 \mathrm{e}-01$

Element: 8284 \# of layers: 3

$\mathrm{Kx} \mathrm{Ky} \mathrm{Kz}$ Ss Por

9.28661e+01 9.28661e+01 9.28661e+00 1.00000e-09 7.00000e-02

$1.00000 \mathrm{e}-02$ 1.00000e-02 1.00000e-03 1.00000e-09 1.00000e-01

$1.00000 \mathrm{e}+001.00000 \mathrm{e}+001.00000 \mathrm{e}-01$ 1.00000e-09 1.00000e-01

Element: 8285 \# of layers: 3

$\mathrm{Kx} \mathrm{Ky} \mathrm{Kz}$ Ss Por

9.28661e+01 9.28661e+01 9.28661e+00 1.00000e-09 7.00000e-02

$1.00000 \mathrm{e}-02$ 1.00000e-02 1.00000e-03 1.00000e-09 1.00000e-01

$1.00000 \mathrm{e}+001.00000 \mathrm{e}+001.00000 \mathrm{e}-01$ 1.00000e-09 1.00000e-01

Element: 8286 \# of layers: 3

$\mathrm{Kx} \mathrm{Ky} \mathrm{Kz}$ Ss Por

9.28661e+01 9.28661e+01 9.28661e+00 1.00000e-09 7.00000e-02

$1.00000 \mathrm{e}-021.00000 \mathrm{e}-02$ 1.00000e-03 1.00000e-09 1.00000e-01

$1.00000 \mathrm{e}+001.00000 \mathrm{e}+001.00000 \mathrm{e}-011.00000 \mathrm{e}-09$ 1.00000e-01

Element: 8287 \# of layers: 3

$\mathrm{Kx} \mathrm{Ky} \mathrm{Kz}$ Ss Por

9.28661e+01 9.28661e+01 9.28661e+00 1.00000e-09 7.00000e-02

$1.00000 \mathrm{e}-02$ 1.00000e-02 1.00000e-03 1.00000e-09 1.00000e-01

$1.00000 \mathrm{e}+001.00000 \mathrm{e}+001.00000 \mathrm{e}-011.00000 \mathrm{e}-091.00000 \mathrm{e}-01$

Element: 8288 \# of layers: 3

$\mathrm{Kx} \mathrm{Ky} \mathrm{Kz}$ Ss Por

7.57417e+01 7.57417e+01 7.57417e+00 1.00000e-09 7.00000e-02

$1.00000 \mathrm{e}-02$ 1.00000e-02 1.00000e-03 1.00000e-09 1.00000e-01

$1.00000 \mathrm{e}+001.00000 \mathrm{e}+001.00000 \mathrm{e}-011.00000 \mathrm{e}-091.00000 \mathrm{e}-01$

Element: 8289 \# of layers: 3

$\mathrm{Kx} \mathrm{Ky} \mathrm{Kz}$ Ss Por

7.57417e+01 7.57417e+01 7.57417e+00 1.00000e-09 7.00000e-02

$1.00000 \mathrm{e}-02$ 1.00000e-02 1.00000e-03 1.00000e-09 1.00000e-01

$1.00000 \mathrm{e}+001.00000 \mathrm{e}+001.00000 \mathrm{e}-011.00000 \mathrm{e}-091.00000 \mathrm{e}-01$

Element: 8290 \# of layers: 3

Kx Ky Kz Ss Por

7.57417e+01 7.57417e+01 7.57417e+00 1.00000e-09 7.00000e-02 
$1.00000 \mathrm{e}-02$ 1.00000e-02 1.00000e-03 1.00000e-09 1.00000e-01 $1.00000 \mathrm{e}+001.00000 \mathrm{e}+001.00000 \mathrm{e}-01$ 1.00000e-09 1.00000e-01

Element: 8291 \# of layers: 3

Kx Ky Kz Ss Por

7.57417e+01 7.57417e+01 7.57417e+00 1.00000e-09 7.00000e-02

$1.00000 \mathrm{e}-02$ 1.00000e-02 1.00000e-03 1.00000e-09 1.00000e-01

$1.00000 \mathrm{e}+001.00000 \mathrm{e}+001.00000 \mathrm{e}-011.00000 \mathrm{e}-091.00000 \mathrm{e}-01$

Element: 8292 \# of layers: 3

$\mathrm{Kx} \mathrm{Ky} \mathrm{Kz}$ Ss Por

7.57417e+01 7.57417e+01 7.57417e+00 1.00000e-09 7.00000e-02

$1.00000 \mathrm{e}-02$ 1.00000e-02 1.00000e-03 1.00000e-09 1.00000e-01

$1.00000 \mathrm{e}+001.00000 \mathrm{e}+001.00000 \mathrm{e}-011.00000 \mathrm{e}-091.00000 \mathrm{e}-01$

Element: 8293 \# of layers: 3

$\mathrm{Kx} \mathrm{Ky} \mathrm{Kz}$ Ss Por

7.57417e+01 7.57417e+01 7.57417e+00 1.00000e-09 7.00000e-02

$1.00000 \mathrm{e}-02$ 1.00000e-02 1.00000e-03 1.00000e-09 1.00000e-01

$1.00000 \mathrm{e}+001.00000 \mathrm{e}+001.00000 \mathrm{e}-011.00000 \mathrm{e}-091.00000 \mathrm{e}-01$

Element: 8294 \# of layers: 3

$\mathrm{Kx} \mathrm{Ky} \mathrm{Kz}$ Ss Por

7.57417e+01 7.57417e+01 7.57417e+00 1.00000e-09 7.00000e-02

$1.00000 \mathrm{e}-02$ 1.00000e-02 1.00000e-03 1.00000e-09 1.00000e-01

$1.00000 \mathrm{e}+001.00000 \mathrm{e}+001.00000 \mathrm{e}-01$ 1.00000e-09 1.00000e-01

Element: 8295 \# of layers: 3

Kx Ky Kz Ss Por

7.57417e+01 7.57417e+01 7.57417e+00 1.00000e-09 7.00000e-02

$1.00000 \mathrm{e}-021.00000 \mathrm{e}-021.00000 \mathrm{e}-031.00000 \mathrm{e}-091.00000 \mathrm{e}-01$

$1.00000 \mathrm{e}+001.00000 \mathrm{e}+001.00000 \mathrm{e}-011.00000 \mathrm{e}-091.00000 \mathrm{e}-01$

Element: 8296 \# of layers: 3

Kx Ky Kz Ss Por

7.57417e+01 7.57417e+01 7.57417e+00 1.00000e-09 7.00000e-02

$1.00000 \mathrm{e}-02$ 1.00000e-02 1.00000e-03 1.00000e-09 1.00000e-01

$1.00000 \mathrm{e}+001.00000 \mathrm{e}+001.00000 \mathrm{e}-01$ 1.00000e-09 1.00000e-01

Element: 8297 \# of layers: 3

$\mathrm{Kx} \mathrm{Ky} \mathrm{Kz}$ Ss Por

6.60847e+01 6.60847e+01 6.60847e+00 1.00000e-09 7.00000e-02

$1.00000 \mathrm{e}-02$ 1.00000e-02 1.00000e-03 1.00000e-09 1.00000e-01

$1.00000 \mathrm{e}+001.00000 \mathrm{e}+001.00000 \mathrm{e}-011.00000 \mathrm{e}-091.00000 \mathrm{e}-01$

Element: 8298 \# of layers: 3

$\mathrm{Kx} \mathrm{Ky} \mathrm{Kz}$ Ss Por

6.60847e+01 6.60847e+01 6.60847e+00 1.00000e-09 7.00000e-02

$1.00000 \mathrm{e}-02$ 1.00000e-02 1.00000e-03 1.00000e-09 1.00000e-01

$1.00000 \mathrm{e}+001.00000 \mathrm{e}+001.00000 \mathrm{e}-011.00000 \mathrm{e}-091.00000 \mathrm{e}-01$

Element: 8299 \# of layers: 3

$\mathrm{Kx} \mathrm{Ky} \mathrm{Kz}$ Ss Por

6.60847e+01 6.60847e+01 6.60847e+00 1.00000e-09 7.00000e-02

$1.00000 \mathrm{e}-02$ 1.00000e-02 1.00000e-03 1.00000e-09 1.00000e-01 
$1.00000 \mathrm{e}+001.00000 \mathrm{e}+00$ 1.00000e-01 1.00000e-09 1.00000e-01

Element: 8300 \# of layers: 3

Kx Ky Kz Ss Por

6.60847e+01 6.60847e+01 6.60847e+00 1.00000e-09 7.00000e-02

$1.00000 \mathrm{e}-02$ 1.00000e-02 1.00000e-03 1.00000e-09 1.00000e-01

$1.00000 \mathrm{e}+001.00000 \mathrm{e}+001.00000 \mathrm{e}-01$ 1.00000e-09 1.00000e-01

Element: 8301 \# of layers: 5

$\mathrm{Kx} \mathrm{Ky} \mathrm{Kz}$ Ss Por

6.60847e+01 6.60847e+01 6.60847e+00 1.00000e-09 7.00000e-02

$2.64043 \mathrm{e}+002.64043 \mathrm{e}+00$ 2.64043e-01 1.00000e-09 2.12000e-01

$2.64043 \mathrm{e}+002.64043 \mathrm{e}+00$ 2.64043e-01 1.00000e-09 2.12000e-01

$1.00000 \mathrm{e}-02$ 1.00000e-02 1.00000e-03 1.00000e-09 1.00000e-01

$1.00000 \mathrm{e}+001.00000 \mathrm{e}+001.00000 \mathrm{e}-011.00000 \mathrm{e}-091.00000 \mathrm{e}-01$

Element: 8302 \# of layers: 4

$\mathrm{Kx} \mathrm{Ky} \mathrm{Kz}$ Ss Por

6.60847e+01 6.60847e+01 6.60847e+00 1.00000e-09 7.00000e-02

$2.64043 \mathrm{e}+00$ 2.64043e+00 2.64043e-01 1.00000e-09 2.12000e-01

$1.00000 \mathrm{e}-02$ 1.00000e-02 1.00000e-03 1.00000e-09 1.00000e-01

$1.00000 \mathrm{e}+001.00000 \mathrm{e}+001.00000 \mathrm{e}-011.00000 \mathrm{e}-091.00000 \mathrm{e}-01$

Element: 8303 \# of layers: 3

$\mathrm{Kx} \mathrm{Ky} \mathrm{Kz}$ Ss Por

6.60847e+01 6.60847e+01 6.60847e+00 1.00000e-09 7.00000e-02

$1.00000 \mathrm{e}-02$ 1.00000e-02 1.00000e-03 1.00000e-09 1.00000e-01

$1.00000 \mathrm{e}+001.00000 \mathrm{e}+001.00000 \mathrm{e}-011.00000 \mathrm{e}-091.00000 \mathrm{e}-01$

Element: 8304 \# of layers: 3

$\mathrm{Kx} \mathrm{Ky} \mathrm{Kz}$ Ss Por

6.60847e+01 6.60847e+01 6.60847e+00 1.00000e-09 7.00000e-02

$1.00000 \mathrm{e}-02$ 1.00000e-02 1.00000e-03 1.00000e-09 1.00000e-01

$1.00000 \mathrm{e}+001.00000 \mathrm{e}+001.00000 \mathrm{e}-011.00000 \mathrm{e}-091.00000 \mathrm{e}-01$

Element: 8305 \# of layers: 3

$\mathrm{Kx} \mathrm{Ky} \mathrm{Kz}$ Ss Por

6.60847e+01 6.60847e+01 6.60847e+00 1.00000e-09 7.00000e-02

$1.00000 \mathrm{e}-02$ 1.00000e-02 1.00000e-03 1.00000e-09 1.00000e-01

$1.00000 \mathrm{e}+001.00000 \mathrm{e}+001.00000 \mathrm{e}-011.00000 \mathrm{e}-091.00000 \mathrm{e}-01$

Element: 8306 \# of layers: 3

$\mathrm{Kx} \mathrm{Ky} \mathrm{Kz}$ Ss Por

6.72984e+01 6.72984e+01 6.72984e+00 1.00000e-09 7.00000e-02

$1.00000 \mathrm{e}-021.00000 \mathrm{e}-021.00000 \mathrm{e}-031.00000 \mathrm{e}-091.00000 \mathrm{e}-01$

$1.00000 \mathrm{e}+001.00000 \mathrm{e}+001.00000 \mathrm{e}-011.00000 \mathrm{e}-09$ 1.00000e-01

Element: 8307 \# of layers: 4

$\mathrm{Kx} \mathrm{Ky} \mathrm{Kz}$ Ss Por

6.72984e+01 6.72984e+01 6.72984e+00 1.00000e-09 7.00000e-02

$2.68903 \mathrm{e}+00$ 2.68903e+00 2.68903e-01 1.00000e-09 2.12000e-01

$1.00000 \mathrm{e}-02$ 1.00000e-02 1.00000e-03 1.00000e-09 1.00000e-01

$1.00000 \mathrm{e}+001.00000 \mathrm{e}+001.00000 \mathrm{e}-011.00000 \mathrm{e}-091.00000 \mathrm{e}-01$

Element: 8308 \# of layers: 4 
$\mathrm{Kx} \mathrm{Ky} \mathrm{Kz}$ Ss Por

6.72984e+01 6.72984e+01 6.72984e+00 1.00000e-09 7.00000e-02

$2.68903 \mathrm{e}+002.68903 \mathrm{e}+00$ 2.68903e-01 1.00000e-09 2.12000e-01

$1.00000 \mathrm{e}-02$ 1.00000e-02 1.00000e-03 1.00000e-09 1.00000e-01

$1.00000 \mathrm{e}+001.00000 \mathrm{e}+001.00000 \mathrm{e}-011.00000 \mathrm{e}-091.00000 \mathrm{e}-01$

Element: 8309 \# of layers: 5

$\mathrm{Kx} \mathrm{Ky} \mathrm{Kz}$ Ss Por

$1.07543 \mathrm{e}+031.07543 \mathrm{e}+03$ 1.07543e+02 1.00000e-09 7.00000e-02

$1.07543 \mathrm{e}+03$ 1.07543e+03 1.07543e+02 1.00000e-09 7.00000e-02

$4.29714 \mathrm{e}+014.29714 \mathrm{e}+014.29714 \mathrm{e}+001.00000 \mathrm{e}-092.12000 \mathrm{e}-01$

$1.00000 \mathrm{e}-02$ 1.00000e-02 1.00000e-03 1.00000e-09 1.00000e-01

$1.00000 \mathrm{e}+001.00000 \mathrm{e}+001.00000 \mathrm{e}-011.00000 \mathrm{e}-091.00000 \mathrm{e}-01$

Element: 8310 \# of layers: 3

$\mathrm{Kx} \mathrm{Ky} \mathrm{Kz}$ Ss Por

$4.29714 \mathrm{e}+014.29714 \mathrm{e}+014.29714 \mathrm{e}+001.00000 \mathrm{e}-092.12000 \mathrm{e}-01$

$1.00000 \mathrm{e}-02$ 1.00000e-02 1.00000e-03 1.00000e-09 1.00000e-01

$1.00000 \mathrm{e}+001.00000 \mathrm{e}+001.00000 \mathrm{e}-011.00000 \mathrm{e}-09$ 1.00000e-01

Element: 8311 \# of layers: 3

$\mathrm{Kx} \mathrm{Ky} \mathrm{Kz}$ Ss Por

4.29714e+01 4.29714e+01 4.29714e+00 1.00000e-09 2.12000e-01

$1.00000 \mathrm{e}-02$ 1.00000e-02 1.00000e-03 1.00000e-09 1.00000e-01

$1.00000 \mathrm{e}+001.00000 \mathrm{e}+001.00000 \mathrm{e}-01$ 1.00000e-09 1.00000e-01

Element: 8312 \# of layers: 4

Kx Ky Kz Ss Por

2.70687e+02 2.70687e+02 2.70687e+01 1.00000e-09 7.00000e-02

$1.08160 \mathrm{e}+011.08160 \mathrm{e}+011.08160 \mathrm{e}+001.00000 \mathrm{e}-092.12000 \mathrm{e}-01$

$1.00000 \mathrm{e}-02$ 1.00000e-02 1.00000e-03 1.00000e-09 1.00000e-01

$1.00000 \mathrm{e}+001.00000 \mathrm{e}+001.00000 \mathrm{e}-011.00000 \mathrm{e}-091.00000 \mathrm{e}-01$

Element: 8313 \# of layers: 4

$\mathrm{Kx} \mathrm{Ky} \mathrm{Kz}$ Ss Por

2.70687e+02 2.70687e+02 2.70687e+01 1.00000e-09 7.00000e-02

$1.08160 \mathrm{e}+011.08160 \mathrm{e}+011.08160 \mathrm{e}+001.00000 \mathrm{e}-092.12000 \mathrm{e}-01$

$1.00000 \mathrm{e}-02$ 1.00000e-02 1.00000e-03 1.00000e-09 1.00000e-01

$1.00000 \mathrm{e}+001.00000 \mathrm{e}+001.00000 \mathrm{e}-01$ 1.00000e-09 1.00000e-01

Element: 8314 \# of layers: 5

Kx Ky Kz Ss Por

2.70687e+02 2.70687e+02 2.70687e+01 1.00000e-09 7.00000e-02

$2.70687 \mathrm{e}+02$ 2.70687e+02 2.70687e+01 1.00000e-09 7.00000e-02

$1.08160 \mathrm{e}+011.08160 \mathrm{e}+011.08160 \mathrm{e}+001.00000 \mathrm{e}-092.12000 \mathrm{e}-01$

$1.00000 \mathrm{e}-02$ 1.00000e-02 1.00000e-03 1.00000e-09 1.00000e-01

$1.00000 \mathrm{e}+001.00000 \mathrm{e}+001.00000 \mathrm{e}-011.00000 \mathrm{e}-091.00000 \mathrm{e}-01$

Element: 8315 \# of layers: 3

$\mathrm{Kx} \mathrm{Ky} \mathrm{Kz}$ Ss Por

9.43040e+00 9.43040e+00 9.43040e-01 1.00000e-09 2.12000e-01

$1.00000 \mathrm{e}-021.00000 \mathrm{e}-021.00000 \mathrm{e}-031.00000 \mathrm{e}-091.00000 \mathrm{e}-01$

$1.00000 \mathrm{e}+001.00000 \mathrm{e}+001.00000 \mathrm{e}-011.00000 \mathrm{e}-091.00000 \mathrm{e}-01$ 
Element: 8316 \# of layers: 4

$\mathrm{Kx} \mathrm{Ky} \mathrm{Kz}$ Ss Por

2.36017e+02 2.36017e+02 2.36017e+01 1.00000e-09 7.00000e-02

$9.43040 \mathrm{e}+009.43040 \mathrm{e}+00$ 9.43040e-01 1.00000e-09 2.12000e-01

$1.00000 \mathrm{e}-02$ 1.00000e-02 1.00000e-03 1.00000e-09 1.00000e-01

$1.00000 \mathrm{e}+001.00000 \mathrm{e}+001.00000 \mathrm{e}-011.00000 \mathrm{e}-091.00000 \mathrm{e}-01$

Element: 8317 \# of layers: 3

$\mathrm{Kx} \mathrm{Ky} \mathrm{Kz}$ Ss Por

2.36017e+02 2.36017e+02 2.36017e+01 1.00000e-09 7.00000e-02

$1.00000 \mathrm{e}-02$ 1.00000e-02 1.00000e-03 1.00000e-09 1.00000e-01

$1.00000 \mathrm{e}+001.00000 \mathrm{e}+001.00000 \mathrm{e}-011.00000 \mathrm{e}-091.00000 \mathrm{e}-01$

Element: 8318 \# of layers: 4

$\mathrm{Kx} \mathrm{Ky} \mathrm{Kz}$ Ss Por

$1.20266 \mathrm{e}+021.20266 \mathrm{e}+02$ 1.20266e+01 1.00000e-09 7.00000e-02

$4.80520 \mathrm{e}+004.80520 \mathrm{e}+004.80520 \mathrm{e}-01$ 1.00000e-09 2.12000e-01

$1.00000 \mathrm{e}-02$ 1.00000e-02 1.00000e-03 1.00000e-09 1.00000e-01

$1.00000 \mathrm{e}+001.00000 \mathrm{e}+001.00000 \mathrm{e}-011.00000 \mathrm{e}-091.00000 \mathrm{e}-01$

Element: 8319 \# of layers: 4

$\mathrm{Kx} \mathrm{Ky} \mathrm{Kz}$ Ss Por

2.36017e+02 2.36017e+02 2.36017e+01 1.00000e-09 7.00000e-02

$9.43040 \mathrm{e}+009.43040 \mathrm{e}+00$ 9.43040e-01 1.00000e-09 2.12000e-01

$1.00000 \mathrm{e}-02$ 1.00000e-02 1.00000e-03 1.00000e-09 1.00000e-01

$1.00000 \mathrm{e}+001.00000 \mathrm{e}+001.00000 \mathrm{e}-01$ 1.00000e-09 1.00000e-01

Element: 8324 \# of layers: 3

$\mathrm{Kx} \mathrm{Ky} \mathrm{Kz}$ Ss Por

$1.20266 \mathrm{e}+021.20266 \mathrm{e}+021.20266 \mathrm{e}+01$ 1.00000e-09 7.00000e-02

$1.00000 \mathrm{e}-02$ 1.00000e-02 1.00000e-03 1.00000e-09 1.00000e-01

$1.00000 \mathrm{e}+001.00000 \mathrm{e}+001.00000 \mathrm{e}-011.00000 \mathrm{e}-09$ 1.00000e-01

Element: 8325 \# of layers: 3

$\mathrm{Kx} \mathrm{Ky} \mathrm{Kz}$ Ss Por

1.20266e+02 1.20266e+02 1.20266e+01 1.00000e-09 7.00000e-02

$1.00000 \mathrm{e}-02$ 1.00000e-02 1.00000e-03 1.00000e-09 1.00000e-01

$1.00000 \mathrm{e}+001.00000 \mathrm{e}+001.00000 \mathrm{e}-011.00000 \mathrm{e}-091.00000 \mathrm{e}-01$

Element: 8326 \# of layers: 3

$\mathrm{Kx} \mathrm{Ky} \mathrm{Kz}$ Ss Por

$1.20266 \mathrm{e}+02$ 1.20266e+02 1.20266e+01 1.00000e-09 7.00000e-02

$1.00000 \mathrm{e}-02$ 1.00000e-02 1.00000e-03 1.00000e-09 1.00000e-01

$1.00000 \mathrm{e}+001.00000 \mathrm{e}+001.00000 \mathrm{e}-011.00000 \mathrm{e}-091.00000 \mathrm{e}-01$

Element: 8327 \# of layers: 3

$\mathrm{Kx} \mathrm{Ky} \mathrm{Kz}$ Ss Por

1.20266e+02 1.20266e+02 1.20266e+01 1.00000e-09 7.00000e-02

$1.00000 \mathrm{e}-02$ 1.00000e-02 1.00000e-03 1.00000e-09 1.00000e-01

$1.00000 \mathrm{e}+001.00000 \mathrm{e}+001.00000 \mathrm{e}-01$ 1.00000e-09 1.00000e-01

Element: 8328 \# of layers: 3

$\mathrm{Kx} \mathrm{Ky} \mathrm{Kz}$ Ss Por

1.20266e+02 1.20266e+02 1.20266e+01 1.00000e-09 7.00000e-02 
$1.00000 \mathrm{e}-02$ 1.00000e-02 1.00000e-03 1.00000e-09 1.00000e-01 $1.00000 \mathrm{e}+001.00000 \mathrm{e}+001.00000 \mathrm{e}-01$ 1.00000e-09 1.00000e-01

Element: 8329 \# of layers: 3

$\mathrm{Kx} \mathrm{Ky} \mathrm{Kz}$ Ss Por

$1.20266 \mathrm{e}+021.20266 \mathrm{e}+021.20266 \mathrm{e}+01$ 1.00000e-09 7.00000e-02 $1.00000 \mathrm{e}-02$ 1.00000e-02 1.00000e-03 1.00000e-09 1.00000e-01 $1.00000 \mathrm{e}+001.00000 \mathrm{e}+001.00000 \mathrm{e}-011.00000 \mathrm{e}-091.00000 \mathrm{e}-01$

Element: 8330 \# of layers: 4

$\mathrm{Kx} \mathrm{Ky} \mathrm{Kz}$ Ss Por

1.20266e+02 1.20266e+02 1.20266e+01 1.00000e-09 7.00000e-02 $4.80520 \mathrm{e}+004.80520 \mathrm{e}+004.80520 \mathrm{e}-01$ 1.00000e-09 2.12000e-01 $1.00000 \mathrm{e}-02$ 1.00000e-02 1.00000e-03 1.00000e-09 1.00000e-01 $1.00000 \mathrm{e}+001.00000 \mathrm{e}+001.00000 \mathrm{e}-01$ 1.00000e-09 1.00000e-01 Element: 8331 \# of layers: 3

$\mathrm{Kx} \mathrm{Ky} \mathrm{Kz}$ Ss Por

$1.20266 \mathrm{e}+02$ 1.20266e+02 1.20266e+01 1.00000e-09 7.00000e-02 $1.00000 \mathrm{e}-02$ 1.00000e-02 1.00000e-03 1.00000e-09 1.00000e-01 $1.00000 \mathrm{e}+001.00000 \mathrm{e}+001.00000 \mathrm{e}-01$ 1.00000e-09 1.00000e-01

Element: 8332 \# of layers: 3

$\mathrm{Kx} \mathrm{Ky} \mathrm{Kz}$ Ss Por

$1.20266 \mathrm{e}+02$ 1.20266e+02 1.20266e+01 1.00000e-09 7.00000e-02 $1.00000 \mathrm{e}-02$ 1.00000e-02 1.00000e-03 1.00000e-09 1.00000e-01

$1.00000 \mathrm{e}+001.00000 \mathrm{e}+001.00000 \mathrm{e}-01$ 1.00000e-09 1.00000e-01

Element: 8333 \# of layers: 3

$\mathrm{Kx} \mathrm{Ky} \mathrm{Kz}$ Ss Por

7.76995e+01 7.76995e+01 7.76995e+00 1.00000e-09 7.00000e-02 $1.00000 \mathrm{e}-02$ 1.00000e-02 1.00000e-03 1.00000e-09 1.00000e-01 $1.00000 \mathrm{e}+001.00000 \mathrm{e}+001.00000 \mathrm{e}-011.00000 \mathrm{e}-091.00000 \mathrm{e}-01$

Element: 8334 \# of layers: 3

$\mathrm{Kx} \mathrm{Ky} \mathrm{Kz}$ Ss Por

7.76995e+01 7.76995e+01 7.76995e+00 1.00000e-09 7.00000e-02 $1.00000 \mathrm{e}-02$ 1.00000e-02 1.00000e-03 1.00000e-09 1.00000e-01 $1.00000 \mathrm{e}+001.00000 \mathrm{e}+001.00000 \mathrm{e}-011.00000 \mathrm{e}-091.00000 \mathrm{e}-01$ Element: 8335 \# of layers: 3

$\mathrm{Kx} \mathrm{Ky} \mathrm{Kz}$ Ss Por

7.76995e+01 7.76995e+01 7.76995e+00 1.00000e-09 7.00000e-02 $1.00000 \mathrm{e}-02$ 1.00000e-02 1.00000e-03 1.00000e-09 1.00000e-01 $1.00000 \mathrm{e}+001.00000 \mathrm{e}+001.00000 \mathrm{e}-011.00000 \mathrm{e}-091.00000 \mathrm{e}-01$ Element: 8336 \# of layers: 3

$\mathrm{Kx} \mathrm{Ky} \mathrm{Kz}$ Ss Por 7.76995e+01 7.76995e+01 7.76995e+00 1.00000e-09 7.00000e-02 $1.00000 \mathrm{e}-02$ 1.00000e-02 1.00000e-03 1.00000e-09 1.00000e-01 $1.00000 \mathrm{e}+001.00000 \mathrm{e}+001.00000 \mathrm{e}-01$ 1.00000e-09 1.00000e-01 Element: 8337 \# of layers: 3

$\mathrm{Kx} \mathrm{Ky} \mathrm{Kz}$ Ss Por

7.76995e+01 7.76995e+01 7.76995e+00 1.00000e-09 7.00000e-02 
$1.00000 \mathrm{e}-02$ 1.00000e-02 1.00000e-03 1.00000e-09 1.00000e-01

$1.00000 \mathrm{e}+001.00000 \mathrm{e}+001.00000 \mathrm{e}-01$ 1.00000e-09 1.00000e-01

Element: 8338 \# of layers: 3

Kx Ky Kz Ss Por

7.76995e+01 7.76995e+01 7.76995e+00 1.00000e-09 7.00000e-02

$1.00000 \mathrm{e}-02$ 1.00000e-02 1.00000e-03 1.00000e-09 1.00000e-01

$1.00000 \mathrm{e}+001.00000 \mathrm{e}+001.00000 \mathrm{e}-011.00000 \mathrm{e}-091.00000 \mathrm{e}-01$

Element: 8339 \# of layers: 3

$\mathrm{Kx} \mathrm{Ky} \mathrm{Kz}$ Ss Por

7.76995e+01 7.76995e+01 7.76995e+00 1.00000e-09 7.00000e-02

$1.00000 \mathrm{e}-02$ 1.00000e-02 1.00000e-03 1.00000e-09 1.00000e-01

$1.00000 \mathrm{e}+001.00000 \mathrm{e}+001.00000 \mathrm{e}-011.00000 \mathrm{e}-091.00000 \mathrm{e}-01$

Element: 8340 \# of layers: 3

$\mathrm{Kx} \mathrm{Ky} \mathrm{Kz}$ Ss Por

7.76995e+01 7.76995e+01 7.76995e+00 1.00000e-09 7.00000e-02

$1.00000 \mathrm{e}-02$ 1.00000e-02 1.00000e-03 1.00000e-09 1.00000e-01

$1.00000 \mathrm{e}+001.00000 \mathrm{e}+001.00000 \mathrm{e}-011.00000 \mathrm{e}-091.00000 \mathrm{e}-01$

Element: 8341 \# of layers: 3

$\mathrm{Kx} \mathrm{Ky} \mathrm{Kz}$ Ss Por

7.76995e+01 7.76995e+01 7.76995e+00 1.00000e-09 7.00000e-02

$1.00000 \mathrm{e}-02$ 1.00000e-02 1.00000e-03 1.00000e-09 1.00000e-01

$1.00000 \mathrm{e}+001.00000 \mathrm{e}+001.00000 \mathrm{e}-01$ 1.00000e-09 1.00000e-01

Element: 8342 \# of layers: 3

Kx Ky Kz Ss Por

7.59813e+01 7.59813e+01 7.59813e+00 1.00000e-09 7.00000e-02

$1.00000 \mathrm{e}-02$ 1.00000e-02 1.00000e-03 1.00000e-09 1.00000e-01

$1.00000 \mathrm{e}+001.00000 \mathrm{e}+001.00000 \mathrm{e}-011.00000 \mathrm{e}-091.00000 \mathrm{e}-01$

Element: 8343 \# of layers: 3

Kx Ky Kz Ss Por

7.59813e+01 7.59813e+01 7.59813e+00 1.00000e-09 7.00000e-02

$1.00000 \mathrm{e}-02$ 1.00000e-02 1.00000e-03 1.00000e-09 1.00000e-01

$1.00000 \mathrm{e}+001.00000 \mathrm{e}+001.00000 \mathrm{e}-011.00000 \mathrm{e}-091.00000 \mathrm{e}-01$

Element: 8344 \# of layers: 3

$\mathrm{Kx} \mathrm{Ky} \mathrm{Kz}$ Ss Por

7.59813e+01 7.59813e+01 7.59813e+00 1.00000e-09 7.00000e-02

1.00000e-02 1.00000e-02 1.00000e-03 1.00000e-09 1.00000e-01

$1.00000 \mathrm{e}+001.00000 \mathrm{e}+001.00000 \mathrm{e}-011.00000 \mathrm{e}-091.00000 \mathrm{e}-01$

Element: 8345 \# of layers: 3

Kx Ky Kz Ss Por

7.59813e+01 7.59813e+01 7.59813e+00 1.00000e-09 7.00000e-02

$1.00000 \mathrm{e}-02$ 1.00000e-02 1.00000e-03 1.00000e-09 1.00000e-01

$1.00000 \mathrm{e}+001.00000 \mathrm{e}+001.00000 \mathrm{e}-011.00000 \mathrm{e}-091.00000 \mathrm{e}-01$

Element: 8346 \# of layers: 3

$\mathrm{Kx} \mathrm{Ky} \mathrm{Kz}$ Ss Por

7.59813e+01 7.59813e+01 7.59813e+00 1.00000e-09 7.00000e-02

1.00000e-02 1.00000e-02 1.00000e-03 1.00000e-09 1.00000e-01 
$1.00000 \mathrm{e}+001.00000 \mathrm{e}+00$ 1.00000e-01 1.00000e-09 1.00000e-01

Element: 8347 \# of layers: 3

Kx Ky Kz Ss Por

7.59813e+01 7.59813e+01 7.59813e+00 1.00000e-09 7.00000e-02

$1.00000 \mathrm{e}-021.00000 \mathrm{e}-02$ 1.00000e-03 1.00000e-09 1.00000e-01

$1.00000 \mathrm{e}+001.00000 \mathrm{e}+00$ 1.00000e-01 1.00000e-09 1.00000e-01

Element: 8348 \# of layers: 3

$\mathrm{Kx} \mathrm{Ky} \mathrm{Kz}$ Ss Por

7.59813e+01 7.59813e+01 7.59813e+00 1.00000e-09 7.00000e-02

$1.00000 \mathrm{e}-02$ 1.00000e-02 1.00000e-03 1.00000e-09 1.00000e-01

$1.00000 \mathrm{e}+001.00000 \mathrm{e}+001.00000 \mathrm{e}-011.00000 \mathrm{e}-091.00000 \mathrm{e}-01$

Element: 8349 \# of layers: 3

$\mathrm{Kx} \mathrm{Ky} \mathrm{Kz}$ Ss Por

7.59813e+01 7.59813e+01 7.59813e+00 1.00000e-09 7.00000e-02

$1.00000 \mathrm{e}-02$ 1.00000e-02 1.00000e-03 1.00000e-09 1.00000e-01

$1.00000 \mathrm{e}+001.00000 \mathrm{e}+001.00000 \mathrm{e}-011.00000 \mathrm{e}-091.00000 \mathrm{e}-01$

Element: 8350 \# of layers: 3

$\mathrm{Kx} \mathrm{Ky} \mathrm{Kz}$ Ss Por

7.59813e+01 7.59813e+01 7.59813e+00 1.00000e-09 7.00000e-02

$1.00000 \mathrm{e}-02$ 1.00000e-02 1.00000e-03 1.00000e-09 1.00000e-01

$1.00000 \mathrm{e}+001.00000 \mathrm{e}+001.00000 \mathrm{e}-011.00000 \mathrm{e}-091.00000 \mathrm{e}-01$

Element: 8351 \# of layers: 3

$\mathrm{Kx} \mathrm{Ky} \mathrm{Kz}$ Ss Por

$1.22761 \mathrm{e}+02$ 1.22761e+02 1.22761e+01 1.00000e-09 7.00000e-02

$1.00000 \mathrm{e}-02$ 1.00000e-02 1.00000e-03 1.00000e-09 1.00000e-01

$1.00000 \mathrm{e}+001.00000 \mathrm{e}+001.00000 \mathrm{e}-01$ 1.00000e-09 1.00000e-01

Element: 8352 \# of layers: 3

$\mathrm{Kx} \mathrm{Ky} \mathrm{Kz}$ Ss Por

$1.22761 \mathrm{e}+02$ 1.22761e+02 1.22761e+01 1.00000e-09 7.00000e-02

$1.00000 \mathrm{e}-02$ 1.00000e-02 1.00000e-03 1.00000e-09 1.00000e-01

$1.00000 \mathrm{e}+001.00000 \mathrm{e}+001.00000 \mathrm{e}-011.00000 \mathrm{e}-091.00000 \mathrm{e}-01$

Element: 8353 \# of layers: 3

$\mathrm{Kx} \mathrm{Ky} \mathrm{Kz}$ Ss Por

$1.22761 \mathrm{e}+02$ 1.22761e+02 1.22761e+01 1.00000e-09 7.00000e-02

$1.00000 \mathrm{e}-02$ 1.00000e-02 1.00000e-03 1.00000e-09 1.00000e-01

$1.00000 \mathrm{e}+001.00000 \mathrm{e}+001.00000 \mathrm{e}-011.00000 \mathrm{e}-091.00000 \mathrm{e}-01$

Element: 8354 \# of layers: 3

Kx Ky Kz Ss Por

$1.22761 \mathrm{e}+021.22761 \mathrm{e}+02$ 1.22761e+01 1.00000e-09 7.00000e-02

$1.00000 \mathrm{e}-02$ 1.00000e-02 1.00000e-03 1.00000e-09 1.00000e-01

$1.00000 \mathrm{e}+001.00000 \mathrm{e}+001.00000 \mathrm{e}-011.00000 \mathrm{e}-091.00000 \mathrm{e}-01$

Element: 8355 \# of layers: 3

$\mathrm{Kx} \mathrm{Ky} \mathrm{Kz}$ Ss Por

1.22761e+02 1.22761e+02 1.22761e+01 1.00000e-09 7.00000e-02

$1.00000 \mathrm{e}-02$ 1.00000e-02 1.00000e-03 1.00000e-09 1.00000e-01

$1.00000 \mathrm{e}+001.00000 \mathrm{e}+001.00000 \mathrm{e}-011.00000 \mathrm{e}-091.00000 \mathrm{e}-01$ 
Element: 8356 \# of layers: 3

$\mathrm{Kx} \mathrm{Ky} \mathrm{Kz}$ Ss Por

$1.22761 \mathrm{e}+021.22761 \mathrm{e}+02$ 1.22761e+01 1.00000e-09 7.00000e-02

$1.00000 \mathrm{e}-02$ 1.00000e-02 1.00000e-03 1.00000e-09 1.00000e-01

$1.00000 \mathrm{e}+001.00000 \mathrm{e}+001.00000 \mathrm{e}-011.00000 \mathrm{e}-091.00000 \mathrm{e}-01$

Element: 8357 \# of layers: 3

$\mathrm{Kx} \mathrm{Ky} \mathrm{Kz}$ Ss Por

$1.22761 \mathrm{e}+02$ 1.22761e+02 1.22761e+01 1.00000e-09 7.00000e-02

$1.00000 \mathrm{e}-02$ 1.00000e-02 1.00000e-03 1.00000e-09 1.00000e-01

$1.00000 \mathrm{e}+001.00000 \mathrm{e}+001.00000 \mathrm{e}-011.00000 \mathrm{e}-09$ 1.00000e-01

Element: 8358 \# of layers: 3

$\mathrm{Kx} \mathrm{Ky} \mathrm{Kz}$ Ss Por

$1.22761 \mathrm{e}+02$ 1.22761e+02 1.22761e+01 1.00000e-09 7.00000e-02

$1.00000 \mathrm{e}-02$ 1.00000e-02 1.00000e-03 1.00000e-09 1.00000e-01

$1.00000 \mathrm{e}+001.00000 \mathrm{e}+001.00000 \mathrm{e}-01$ 1.00000e-09 1.00000e-01

Element: 8359 \# of layers: 3

$\mathrm{Kx} \mathrm{Ky} \mathrm{Kz}$ Ss Por

$1.22761 \mathrm{e}+021.22761 \mathrm{e}+02$ 1.22761e+01 1.00000e-09 7.00000e-02

$1.00000 \mathrm{e}-02$ 1.00000e-02 1.00000e-03 1.00000e-09 1.00000e-01

$1.00000 \mathrm{e}+001.00000 \mathrm{e}+001.00000 \mathrm{e}-011.00000 \mathrm{e}-091.00000 \mathrm{e}-01$

Element: 8360 \# of layers: 3

$\mathrm{Kx} \mathrm{Ky} \mathrm{Kz}$ Ss Por

1.66676e+02 1.66676e+02 1.66676e+01 1.00000e-09 7.00000e-02

$1.00000 \mathrm{e}-02$ 1.00000e-02 1.00000e-03 1.00000e-09 1.00000e-01

$1.00000 \mathrm{e}+001.00000 \mathrm{e}+001.00000 \mathrm{e}-011.00000 \mathrm{e}-091.00000 \mathrm{e}-01$

Element: 8361 \# of layers: 3

$\mathrm{Kx} \mathrm{Ky} \mathrm{Kz}$ Ss Por

$1.66676 \mathrm{e}+02$ 1.66676e+02 1.66676e+01 1.00000e-09 7.00000e-02

$1.00000 \mathrm{e}-02$ 1.00000e-02 1.00000e-03 1.00000e-09 1.00000e-01

$1.00000 \mathrm{e}+001.00000 \mathrm{e}+001.00000 \mathrm{e}-011.00000 \mathrm{e}-091.00000 \mathrm{e}-01$

Element: 8362 \# of layers: 3

$\mathrm{Kx} \mathrm{Ky} \mathrm{Kz}$ Ss Por

$1.66676 \mathrm{e}+02$ 1.66676e+02 1.66676e+01 1.00000e-09 7.00000e-02

$1.00000 \mathrm{e}-021.00000 \mathrm{e}-021.00000 \mathrm{e}-031.00000 \mathrm{e}-091.00000 \mathrm{e}-01$

$1.00000 \mathrm{e}+001.00000 \mathrm{e}+001.00000 \mathrm{e}-011.00000 \mathrm{e}-091.00000 \mathrm{e}-01$

Element: 8363 \# of layers: 3

Kx Ky Kz Ss Por

$1.66676 \mathrm{e}+02$ 1.66676e+02 1.66676e+01 1.00000e-09 7.00000e-02

$1.00000 \mathrm{e}-02$ 1.00000e-02 1.00000e-03 1.00000e-09 1.00000e-01

$1.00000 \mathrm{e}+001.00000 \mathrm{e}+001.00000 \mathrm{e}-01$ 1.00000e-09 1.00000e-01

Element: 8364 \# of layers: 3

$\mathrm{Kx} \mathrm{Ky} \mathrm{Kz}$ Ss Por

$1.66676 \mathrm{e}+02$ 1.66676e+02 1.66676e+01 1.00000e-09 7.00000e-02

$1.00000 \mathrm{e}-02$ 1.00000e-02 1.00000e-03 1.00000e-09 1.00000e-01

$1.00000 \mathrm{e}+001.00000 \mathrm{e}+001.00000 \mathrm{e}-011.00000 \mathrm{e}-091.00000 \mathrm{e}-01$

Element: 8365 \# of layers: 3 
$\mathrm{Kx} \mathrm{Ky} \mathrm{Kz} \mathrm{Ss} \mathrm{Por}$

$1.66676 \mathrm{e}+02$ 1.66676e+02 1.66676e+01 1.00000e-09 7.00000e-02

$1.00000 \mathrm{e}-02$ 1.00000e-02 1.00000e-03 1.00000e-09 1.00000e-01

$1.00000 \mathrm{e}+001.00000 \mathrm{e}+001.00000 \mathrm{e}-011.00000 \mathrm{e}-091.00000 \mathrm{e}-01$

Element: 8366 \# of layers: 3

$\mathrm{Kx} \mathrm{Ky} \mathrm{Kz}$ Ss Por

$1.66676 \mathrm{e}+02$ 1.66676e+02 1.66676e+01 1.00000e-09 7.00000e-02

$1.00000 \mathrm{e}-02$ 1.00000e-02 1.00000e-03 1.00000e-09 1.00000e-01

$1.00000 \mathrm{e}+001.00000 \mathrm{e}+001.00000 \mathrm{e}-011.00000 \mathrm{e}-091.00000 \mathrm{e}-01$

Element: 8367 \# of layers: 3

$\mathrm{Kx} \mathrm{Ky} \mathrm{Kz}$ Ss Por

$1.66676 \mathrm{e}+021.66676 \mathrm{e}+02$ 1.66676e+01 1.00000e-09 7.00000e-02

$1.00000 \mathrm{e}-02$ 1.00000e-02 1.00000e-03 1.00000e-09 1.00000e-01

$1.00000 \mathrm{e}+001.00000 \mathrm{e}+001.00000 \mathrm{e}-011.00000 \mathrm{e}-091.00000 \mathrm{e}-01$

Element: 8368 \# of layers: 3

Kx Ky Kz Ss Por

$1.66676 \mathrm{e}+02$ 1.66676e+02 1.66676e+01 1.00000e-09 7.00000e-02 $1.00000 \mathrm{e}-02$ 1.00000e-02 1.00000e-03 1.00000e-09 1.00000e-01

$1.00000 \mathrm{e}+001.00000 \mathrm{e}+001.00000 \mathrm{e}-011.00000 \mathrm{e}-091.00000 \mathrm{e}-01$

Element: 8369 \# of layers: 3

Kx Ky Kz Ss Por

$1.17220 \mathrm{e}+021.17220 \mathrm{e}+02$ 1.17220e+01 1.00000e-09 7.00000e-02

$1.00000 \mathrm{e}-02$ 1.00000e-02 1.00000e-03 1.00000e-09 1.00000e-01

$1.00000 \mathrm{e}+001.00000 \mathrm{e}+001.00000 \mathrm{e}-011.00000 \mathrm{e}-091.00000 \mathrm{e}-01$

Element: 8370 \# of layers: 3

$\mathrm{Kx} \mathrm{Ky} \mathrm{Kz}$ Ss Por

$1.17220 \mathrm{e}+021.17220 \mathrm{e}+021.17220 \mathrm{e}+01$ 1.00000e-09 7.00000e-02

$1.00000 \mathrm{e}-02$ 1.00000e-02 1.00000e-03 1.00000e-09 1.00000e-01

$1.00000 \mathrm{e}+001.00000 \mathrm{e}+001.00000 \mathrm{e}-011.00000 \mathrm{e}-091.00000 \mathrm{e}-01$

Element: 8371 \# of layers: 3

$\mathrm{Kx} \mathrm{Ky} \mathrm{Kz}$ Ss Por

$1.17220 \mathrm{e}+02$ 1.17220e+02 1.17220e+01 1.00000e-09 7.00000e-02

$1.00000 \mathrm{e}-02$ 1.00000e-02 1.00000e-03 1.00000e-09 1.00000e-01

$1.00000 \mathrm{e}+001.00000 \mathrm{e}+001.00000 \mathrm{e}-011.00000 \mathrm{e}-091.00000 \mathrm{e}-01$

Element: 8372 \# of layers: 5

Kx Ky Kz Ss Por

$1.17220 \mathrm{e}+02$ 1.17220e+02 1.17220e+01 1.00000e-09 7.00000e-02

$1.17220 \mathrm{e}+021.17220 \mathrm{e}+021.17220 \mathrm{e}+01$ 1.00000e-09 7.00000e-02

$4.68370 \mathrm{e}+00$ 4.68370e+00 4.68370e-01 1.00000e-09 2.12000e-01

$1.00000 \mathrm{e}-02$ 1.00000e-02 1.00000e-03 1.00000e-09 1.00000e-01

$1.00000 \mathrm{e}+001.00000 \mathrm{e}+001.00000 \mathrm{e}-011.00000 \mathrm{e}-091.00000 \mathrm{e}-01$

Element: 8373 \# of layers: 5

$\mathrm{Kx} \mathrm{Ky} \mathrm{Kz}$ Ss Por

$1.17220 \mathrm{e}+02$ 1.17220e+02 1.17220e+01 1.00000e-09 7.00000e-02

$1.17220 \mathrm{e}+021.17220 \mathrm{e}+021.17220 \mathrm{e}+01$ 1.00000e-09 7.00000e-02

$4.68370 \mathrm{e}+004.68370 \mathrm{e}+00$ 4.68370e-01 1.00000e-09 2.12000e-01 
$1.00000 \mathrm{e}-02$ 1.00000e-02 1.00000e-03 1.00000e-09 1.00000e-01 $1.00000 \mathrm{e}+001.00000 \mathrm{e}+001.00000 \mathrm{e}-01$ 1.00000e-09 1.00000e-01 Element: 8374 \# of layers: 6

Kx Ky Kz Ss Por

$1.17220 \mathrm{e}+021.17220 \mathrm{e}+02$ 1.17220e+01 1.00000e-09 7.00000e-02 $1.17220 \mathrm{e}+021.17220 \mathrm{e}+02$ 1.17220e+01 1.00000e-09 7.00000e-02 $4.68370 \mathrm{e}+004.68370 \mathrm{e}+00$ 4.68370e-01 1.00000e-09 2.12000e-01 $4.68370 \mathrm{e}+004.68370 \mathrm{e}+004.68370 \mathrm{e}-01$ 1.00000e-09 2.12000e-01 $1.00000 \mathrm{e}-02$ 1.00000e-02 1.00000e-03 1.00000e-09 1.00000e-01 $1.00000 \mathrm{e}+001.00000 \mathrm{e}+001.00000 \mathrm{e}-011.00000 \mathrm{e}-091.00000 \mathrm{e}-01$ Element: 8375 \# of layers: 4

Kx Ky Kz Ss Por

1.17220e+02 1.17220e+02 1.17220e+01 1.00000e-09 7.00000e-02 $4.68370 \mathrm{e}+004.68370 \mathrm{e}+00$ 4.68370e-01 1.00000e-09 2.12000e-01 $1.00000 \mathrm{e}-02$ 1.00000e-02 1.00000e-03 1.00000e-09 1.00000e-01 $1.00000 \mathrm{e}+001.00000 \mathrm{e}+001.00000 \mathrm{e}-011.00000 \mathrm{e}-091.00000 \mathrm{e}-01$ Element: 8376 \# of layers: 3

$\mathrm{Kx} \mathrm{Ky} \mathrm{Kz}$ Ss Por

$1.17220 \mathrm{e}+02$ 1.17220e+02 1.17220e+01 1.00000e-09 7.00000e-02 $1.00000 \mathrm{e}-02$ 1.00000e-02 1.00000e-03 1.00000e-09 1.00000e-01 $1.00000 \mathrm{e}+001.00000 \mathrm{e}+001.00000 \mathrm{e}-011.00000 \mathrm{e}-091.00000 \mathrm{e}-01$ Element: 8377 \# of layers: 5

$\mathrm{Kx} \mathrm{Ky} \mathrm{Kz}$ Ss Por

1.17220e+02 1.17220e+02 1.17220e+01 1.00000e-09 7.00000e-02

$1.17220 \mathrm{e}+02$ 1.17220e+02 1.17220e+01 1.00000e-09 7.00000e-02 $4.68370 \mathrm{e}+004.68370 \mathrm{e}+004.68370 \mathrm{e}-01$ 1.00000e-09 2.12000e-01 $1.00000 \mathrm{e}-02$ 1.00000e-02 1.00000e-03 1.00000e-09 1.00000e-01 $1.00000 \mathrm{e}+001.00000 \mathrm{e}+001.00000 \mathrm{e}-011.00000 \mathrm{e}-09$ 1.00000e-01 Element: 8378 \# of layers: 3

$\mathrm{Kx} \mathrm{Ky} \mathrm{Kz}$ Ss Por

8.38372e+01 8.38372e+01 8.38372e+00 1.00000e-09 7.00000e-02 $1.00000 \mathrm{e}-02$ 1.00000e-02 1.00000e-03 1.00000e-09 1.00000e-01 $1.00000 \mathrm{e}+001.00000 \mathrm{e}+001.00000 \mathrm{e}-011.00000 \mathrm{e}-091.00000 \mathrm{e}-01$ Element: 8379 \# of layers: 5

$\mathrm{Kx} \mathrm{Ky} \mathrm{Kz}$ Ss Por

8.38372e+01 8.38372e+01 8.38372e+00 1.00000e-09 7.00000e-02 $3.34987 \mathrm{e}+003.34987 \mathrm{e}+00$ 3.34987e-01 1.00000e-09 2.12000e-01 $3.34987 \mathrm{e}+00$ 3.34987e+00 3.34987e-01 1.00000e-09 2.12000e-01 $1.00000 \mathrm{e}-02$ 1.00000e-02 1.00000e-03 1.00000e-09 1.00000e-01 $1.00000 \mathrm{e}+001.00000 \mathrm{e}+001.00000 \mathrm{e}-01$ 1.00000e-09 1.00000e-01 Element: 8380 \# of layers: 5

$\mathrm{Kx} \mathrm{Ky} \mathrm{Kz}$ Ss Por

8.38372e+01 8.38372e+01 8.38372e+00 1.00000e-09 7.00000e-02 3.34987e+00 3.34987e+00 3.34987e-01 1.00000e-09 2.12000e-01 3.34987e+00 3.34987e+00 3.34987e-01 1.00000e-09 2.12000e-01 $1.00000 \mathrm{e}-02$ 1.00000e-02 1.00000e-03 1.00000e-09 1.00000e-01 
$1.00000 \mathrm{e}+001.00000 \mathrm{e}+001.00000 \mathrm{e}-01$ 1.00000e-09 1.00000e-01

Element: 8384 \# of layers: 4

Kx Ky Kz Ss Por

8.38372e+01 8.38372e+01 8.38372e+00 1.00000e-09 7.00000e-02

$3.34987 \mathrm{e}+00$ 3.34987e+00 3.34987e-01 1.00000e-09 2.12000e-01

$1.00000 \mathrm{e}-02$ 1.00000e-02 1.00000e-03 1.00000e-09 1.00000e-01

$1.00000 \mathrm{e}+001.00000 \mathrm{e}+001.00000 \mathrm{e}-01$ 1.00000e-09 1.00000e-01

Element: 8385 \# of layers: 4

$\mathrm{Kx} \mathrm{Ky} \mathrm{Kz}$ Ss Por

8.38372e+01 8.38372e+01 8.38372e+00 1.00000e-09 7.00000e-02

$3.34987 \mathrm{e}+00$ 3.34987e+00 3.34987e-01 1.00000e-09 2.12000e-01

$1.00000 \mathrm{e}-02$ 1.00000e-02 1.00000e-03 1.00000e-09 1.00000e-01

$1.00000 \mathrm{e}+001.00000 \mathrm{e}+001.00000 \mathrm{e}-011.00000 \mathrm{e}-091.00000 \mathrm{e}-01$

Element: 8387 \# of layers: 4

$\mathrm{Kx} \mathrm{Ky} \mathrm{Kz}$ Ss Por

1.30789e+02 1.30789e+02 1.30789e+01 1.00000e-09 7.00000e-02

$5.22596 \mathrm{e}+00$ 5.22596e+00 5.22596e-01 1.00000e-09 2.12000e-01

$1.00000 \mathrm{e}-02$ 1.00000e-02 1.00000e-03 1.00000e-09 1.00000e-01

$1.00000 \mathrm{e}+001.00000 \mathrm{e}+001.00000 \mathrm{e}-011.00000 \mathrm{e}-091.00000 \mathrm{e}-01$

Element: 8388 \# of layers: 4

Kx Ky Kz Ss Por

$1.30789 \mathrm{e}+02$ 1.30789e+02 1.30789e+01 1.00000e-09 7.00000e-02

5.22596e+00 5.22596e+00 5.22596e-01 1.00000e-09 2.12000e-01

$1.00000 \mathrm{e}-02$ 1.00000e-02 1.00000e-03 1.00000e-09 1.00000e-01

$1.00000 \mathrm{e}+001.00000 \mathrm{e}+001.00000 \mathrm{e}-011.00000 \mathrm{e}-091.00000 \mathrm{e}-01$

Element: 8389 \# of layers: 4

$\mathrm{Kx} \mathrm{Ky} \mathrm{Kz}$ Ss Por

1.30789e+02 1.30789e+02 1.30789e+01 1.00000e-09 7.00000e-02

$5.22596 \mathrm{e}+00$ 5.22596e+00 5.22596e-01 1.00000e-09 2.12000e-01

$1.00000 \mathrm{e}-02$ 1.00000e-02 1.00000e-03 1.00000e-09 1.00000e-01

$1.00000 \mathrm{e}+001.00000 \mathrm{e}+001.00000 \mathrm{e}-011.00000 \mathrm{e}-091.00000 \mathrm{e}-01$

Element: 8390 \# of layers: 4

Kx Ky Kz Ss Por

8.03620e+01 8.03620e+01 8.03620e+00 1.00000e-09 7.00000e-02

$3.21104 \mathrm{e}+003.21104 \mathrm{e}+003.21104 \mathrm{e}-01$ 1.00000e-09 2.12000e-01

1.00000e-02 1.00000e-02 1.00000e-03 1.00000e-09 1.00000e-01

$1.00000 \mathrm{e}+001.00000 \mathrm{e}+001.00000 \mathrm{e}-011.00000 \mathrm{e}-091.00000 \mathrm{e}-01$

Element: 8391 \# of layers: 4

$\mathrm{Kx} \mathrm{Ky} \mathrm{Kz}$ Ss Por

8.03620e+01 8.03620e+01 8.03620e+00 1.00000e-09 7.00000e-02

$3.21104 \mathrm{e}+003.21104 \mathrm{e}+003.21104 \mathrm{e}-01$ 1.00000e-09 2.12000e-01

$1.00000 \mathrm{e}-02$ 1.00000e-02 1.00000e-03 1.00000e-09 1.00000e-01

$1.00000 \mathrm{e}+001.00000 \mathrm{e}+001.00000 \mathrm{e}-01$ 1.00000e-09 1.00000e-01

Element: 8392 \# of layers: 4

$\mathrm{Kx} \mathrm{Ky} \mathrm{Kz} \mathrm{Ss} \mathrm{Por}$

8.03620e+01 8.03620e+01 8.03620e+00 1.00000e-09 7.00000e-02 
$3.21104 \mathrm{e}+003.21104 \mathrm{e}+003.21104 \mathrm{e}-01$ 1.00000e-09 2.12000e-01 $1.00000 \mathrm{e}-02$ 1.00000e-02 1.00000e-03 1.00000e-09 1.00000e-01 $1.00000 \mathrm{e}+001.00000 \mathrm{e}+001.00000 \mathrm{e}-011.00000 \mathrm{e}-091.00000 \mathrm{e}-01$ Element: 8393 \# of layers: 4

Kx Ky Kz Ss Por

$1.38069 \mathrm{e}+02$ 1.38069e $+021.38069 \mathrm{e}+01$ 1.00000e-09 7.00000e-02 $5.51667 \mathrm{e}+00$ 5.51667e+00 5.51667e-01 1.00000e-09 2.12000e-01 $1.00000 \mathrm{e}-021.00000 \mathrm{e}-02$ 1.00000e-03 1.00000e-09 1.00000e-01 $1.00000 \mathrm{e}+001.00000 \mathrm{e}+001.00000 \mathrm{e}-011.00000 \mathrm{e}-091.00000 \mathrm{e}-01$ Element: 8394 \# of layers: 4

Kx Ky Kz Ss Por

$1.38069 \mathrm{e}+02$ 1.38069e+02 1.38069e+01 1.00000e-09 7.00000e-02 $5.51667 \mathrm{e}+00$ 5.51667e+00 5.51667e-01 1.00000e-09 2.12000e-01 $1.00000 \mathrm{e}-021.00000 \mathrm{e}-02$ 1.00000e-03 1.00000e-09 1.00000e-01 $1.00000 \mathrm{e}+001.00000 \mathrm{e}+001.00000 \mathrm{e}-011.00000 \mathrm{e}-091.00000 \mathrm{e}-01$ Element: 8395 \# of layers: 4

Kx Ky Kz Ss Por

$1.38069 \mathrm{e}+021.38069 \mathrm{e}+021.38069 \mathrm{e}+01$ 1.00000e-09 7.00000e-02 $5.51667 \mathrm{e}+00$ 5.51667e+00 5.51667e-01 1.00000e-09 2.12000e-01 $1.00000 \mathrm{e}-021.00000 \mathrm{e}-02$ 1.00000e-03 1.00000e-09 1.00000e-01 $1.00000 \mathrm{e}+001.00000 \mathrm{e}+001.00000 \mathrm{e}-011.00000 \mathrm{e}-091.00000 \mathrm{e}-01$ Element: 8396 \# of layers: 4

Kx Ky Kz Ss Por $6.73101 \mathrm{e}+016.73101 \mathrm{e}+016.73101 \mathrm{e}+001.00000 \mathrm{e}-09$ 7.00000e-02 $2.68948 \mathrm{e}+002.68948 \mathrm{e}+002.68948 \mathrm{e}-011.00000 \mathrm{e}-092.12000 \mathrm{e}-01$ $1.00000 \mathrm{e}-02$ 1.00000e-02 1.00000e-03 1.00000e-09 1.00000e-01 $1.00000 \mathrm{e}+001.00000 \mathrm{e}+001.00000 \mathrm{e}-011.00000 \mathrm{e}-091.00000 \mathrm{e}-01$ Element: 8397 \# of layers: 3

Kx Ky Kz Ss Por

$6.73101 \mathrm{e}+016.73101 \mathrm{e}+016.73101 \mathrm{e}+00$ 1.00000e-09 7.00000e-02 $1.00000 \mathrm{e}-021.00000 \mathrm{e}-02$ 1.00000e-03 1.00000e-09 1.00000e-01 $1.00000 \mathrm{e}+001.00000 \mathrm{e}+001.00000 \mathrm{e}-011.00000 \mathrm{e}-091.00000 \mathrm{e}-01$ Element: 8398 \# of layers: 3

Kx Ky Kz Ss Por

$6.73101 \mathrm{e}+016.73101 \mathrm{e}+016.73101 \mathrm{e}+00$ 1.00000e-09 7.00000e-02 $1.00000 \mathrm{e}-021.00000 \mathrm{e}-02$ 1.00000e-03 1.00000e-09 1.00000e-01 $1.00000 \mathrm{e}+001.00000 \mathrm{e}+001.00000 \mathrm{e}-011.00000 \mathrm{e}-091.00000 \mathrm{e}-01$ Element: 8399 \# of layers: 3

Kx Ky Kz Ss Por $6.73101 \mathrm{e}+016.73101 \mathrm{e}+016.73101 \mathrm{e}+00$ 1.00000e-09 7.00000e-02 $1.00000 \mathrm{e}-02$ 1.00000e-02 $1.00000 \mathrm{e}-031.00000 \mathrm{e}-091.00000 \mathrm{e}-01$ $1.00000 \mathrm{e}+001.00000 \mathrm{e}+001.00000 \mathrm{e}-011.00000 \mathrm{e}-091.00000 \mathrm{e}-01$ Element: 8400 \# of layers: 5

Kx Ky Kz Ss Por $6.73101 \mathrm{e}+016.73101 \mathrm{e}+016.73101 \mathrm{e}+001.00000 \mathrm{e}-09$ 7.00000e-02 $6.73101 \mathrm{e}+016.73101 \mathrm{e}+016.73101 \mathrm{e}+001.00000 \mathrm{e}-09$ 7.00000e-02 
$2.68948 \mathrm{e}+002.68948 \mathrm{e}+002.68948 \mathrm{e}-01$ 1.00000e-09 2.12000e-01 $1.00000 \mathrm{e}-021.00000 \mathrm{e}-02$ 1.00000e-03 1.00000e-09 1.00000e-01 $1.00000 \mathrm{e}+001.00000 \mathrm{e}+001.00000 \mathrm{e}-011.00000 \mathrm{e}-091.00000 \mathrm{e}-01$ Element: 8401 \# of layers: 4

Kx Ky Kz Ss Por

$6.73101 \mathrm{e}+016.73101 \mathrm{e}+016.73101 \mathrm{e}+00$ 1.00000e-09 7.00000e-02

$2.68948 \mathrm{e}+002.68948 \mathrm{e}+002.68948 \mathrm{e}-011.00000 \mathrm{e}-092.12000 \mathrm{e}-01$

$1.00000 \mathrm{e}-021.00000 \mathrm{e}-02$ 1.00000e-03 1.00000e-09 1.00000e-01

$1.00000 \mathrm{e}+001.00000 \mathrm{e}+001.00000 \mathrm{e}-011.00000 \mathrm{e}-091.00000 \mathrm{e}-01$

Element: 8402 \# of layers: 4

Kx Ky Kz Ss Por

$6.73101 \mathrm{e}+016.73101 \mathrm{e}+016.73101 \mathrm{e}+001.00000 \mathrm{e}-09$ 7.00000e-02

$2.68948 \mathrm{e}+002.68948 \mathrm{e}+002.68948 \mathrm{e}-01$ 1.00000e-09 2.12000e-01

$1.00000 \mathrm{e}-021.00000 \mathrm{e}-02$ 1.00000e-03 1.00000e-09 1.00000e-01

$1.00000 \mathrm{e}+001.00000 \mathrm{e}+001.00000 \mathrm{e}-011.00000 \mathrm{e}-091.00000 \mathrm{e}-01$

Element: 8403 \# of layers: 4

Kx Ky Kz Ss Por

$6.73101 \mathrm{e}+016.73101 \mathrm{e}+016.73101 \mathrm{e}+00$ 1.00000e-09 7.00000e-02

$2.68948 \mathrm{e}+002.68948 \mathrm{e}+00$ 2.68948e-01 1.00000e-09 2.12000e-01

$1.00000 \mathrm{e}-02$ 1.00000e-02 1.00000e-03 1.00000e-09 1.00000e-01

$1.00000 \mathrm{e}+001.00000 \mathrm{e}+001.00000 \mathrm{e}-011.00000 \mathrm{e}-091.00000 \mathrm{e}-01$

Element: 8404 \# of layers: 4

Kx Ky Kz Ss Por

$6.73101 \mathrm{e}+016.73101 \mathrm{e}+016.73101 \mathrm{e}+001.00000 \mathrm{e}-09$ 7.00000e-02

$2.68948 \mathrm{e}+002.68948 \mathrm{e}+002.68948 \mathrm{e}-011.00000 \mathrm{e}-092.12000 \mathrm{e}-01$

$1.00000 \mathrm{e}-02$ 1.00000e-02 1.00000e-03 1.00000e-09 1.00000e-01

$1.00000 \mathrm{e}+001.00000 \mathrm{e}+001.00000 \mathrm{e}-011.00000 \mathrm{e}-091.00000 \mathrm{e}-01$

Element: 8405 \# of layers: 3

Kx Ky Kz Ss Por

4.72737e+01 4.72737e+01 4.72737e+00 1.00000e-09 7.00000e-02 $1.00000 \mathrm{e}-02$ 1.00000e-02 1.00000e-03 1.00000e-09 1.00000e-01 $1.00000 \mathrm{e}+001.00000 \mathrm{e}+001.00000 \mathrm{e}-011.00000 \mathrm{e}-091.00000 \mathrm{e}-01$

Element: 8406 \# of layers: 3

Kx Ky Kz Ss Por

4.72737e+01 4.72737e+01 4.72737e+00 1.00000e-09 7.00000e-02 $1.00000 \mathrm{e}-021.00000 \mathrm{e}-02$ 1.00000e-03 1.00000e-09 1.00000e-01

$1.00000 \mathrm{e}+001.00000 \mathrm{e}+001.00000 \mathrm{e}-011.00000 \mathrm{e}-091.00000 \mathrm{e}-01$

Element: 8407 \# of layers: 3

Kx Ky Kz Ss Por

4.72737e+01 4.72737e+01 4.72737e+00 1.00000e-09 7.00000e-02

$1.00000 \mathrm{e}-021.00000 \mathrm{e}-02$ 1.00000e-03 1.00000e-09 1.00000e-01

$1.00000 \mathrm{e}+001.00000 \mathrm{e}+001.00000 \mathrm{e}-011.00000 \mathrm{e}-091.00000 \mathrm{e}-01$

Element: 8408 \# of layers: 4

Kx Ky Kz Ss Por

$4.72737 \mathrm{e}+014.72737 \mathrm{e}+014.72737 \mathrm{e}+00$ 1.00000e-09 7.00000e-02

$4.72737 \mathrm{e}+014.72737 \mathrm{e}+014.72737 \mathrm{e}+001.00000 \mathrm{e}-09$ 7.00000e-02 
$1.00000 \mathrm{e}-02$ 1.00000e-02 1.00000e-03 1.00000e-09 1.00000e-01 $1.00000 \mathrm{e}+001.00000 \mathrm{e}+001.00000 \mathrm{e}-01$ 1.00000e-09 1.00000e-01 Element: 8409 \# of layers: 4

Kx Ky Kz Ss Por

4.72737e+01 4.72737e+01 4.72737e+00 1.00000e-09 7.00000e-02 4.72737e+01 4.72737e+01 4.72737e+00 1.00000e-09 7.00000e-02 $1.00000 \mathrm{e}-02$ 1.00000e-02 1.00000e-03 1.00000e-09 1.00000e-01 $1.00000 \mathrm{e}+001.00000 \mathrm{e}+001.00000 \mathrm{e}-01$ 1.00000e-09 1.00000e-01 Element: 8410 \# of layers: 4

$\mathrm{Kx} \mathrm{Ky} \mathrm{Kz}$ Ss Por

4.72737e+01 4.72737e+01 4.72737e+00 1.00000e-09 7.00000e-02 4.72737e+01 4.72737e+01 4.72737e+00 1.00000e-09 7.00000e-02 $1.00000 \mathrm{e}-02$ 1.00000e-02 1.00000e-03 1.00000e-09 1.00000e-01 $1.00000 \mathrm{e}+001.00000 \mathrm{e}+001.00000 \mathrm{e}-011.00000 \mathrm{e}-091.00000 \mathrm{e}-01$ Element: 8411 \# of layers: 4

Kx Ky Kz Ss Por

4.72737e+01 4.72737e+01 4.72737e+00 1.00000e-09 7.00000e-02 4.72737e+01 4.72737e+01 4.72737e+00 1.00000e-09 7.00000e-02 $1.00000 \mathrm{e}-02$ 1.00000e-02 1.00000e-03 1.00000e-09 1.00000e-01 $1.00000 \mathrm{e}+001.00000 \mathrm{e}+001.00000 \mathrm{e}-011.00000 \mathrm{e}-091.00000 \mathrm{e}-01$ Element: 8412 \# of layers: 3

$\mathrm{Kx} \mathrm{Ky} \mathrm{Kz}$ Ss Por

4.72737e+01 4.72737e+01 4.72737e+00 1.00000e-09 7.00000e-02 $1.00000 \mathrm{e}-02$ 1.00000e-02 1.00000e-03 1.00000e-09 1.00000e-01 $1.00000 \mathrm{e}+001.00000 \mathrm{e}+001.00000 \mathrm{e}-011.00000 \mathrm{e}-091.00000 \mathrm{e}-01$ Element: 8413 \# of layers: 4

$\mathrm{Kx} \mathrm{Ky} \mathrm{Kz}$ Ss Por

4.72737e+01 4.72737e+01 4.72737e+00 1.00000e-09 7.00000e-02 4.72737e+01 4.72737e+01 4.72737e+00 1.00000e-09 7.00000e-02 $1.00000 \mathrm{e}-021.00000 \mathrm{e}-021.00000 \mathrm{e}-031.00000 \mathrm{e}-091.00000 \mathrm{e}-01$ $1.00000 \mathrm{e}+001.00000 \mathrm{e}+001.00000 \mathrm{e}-011.00000 \mathrm{e}-091.00000 \mathrm{e}-01$ Element: 8414 \# of layers: 3

Kx Ky Kz Ss Por 5.55097e+01 5.55097e+01 5.55097e+00 1.00000e-09 7.00000e-02 $1.00000 \mathrm{e}-02$ 1.00000e-02 1.00000e-03 1.00000e-09 1.00000e-01 $1.00000 \mathrm{e}+001.00000 \mathrm{e}+001.00000 \mathrm{e}-011.00000 \mathrm{e}-091.00000 \mathrm{e}-01$ Element: 8415 \# of layers: 3

$\mathrm{Kx} \mathrm{Ky} \mathrm{Kz}$ Ss Por

5.55097e+01 5.55097e+01 5.55097e+00 1.00000e-09 7.00000e-02 $1.00000 \mathrm{e}-02$ 1.00000e-02 1.00000e-03 1.00000e-09 1.00000e-01 $1.00000 \mathrm{e}+001.00000 \mathrm{e}+001.00000 \mathrm{e}-011.00000 \mathrm{e}-091.00000 \mathrm{e}-01$ Element: 8416 \# of layers: 3

$\mathrm{Kx} \mathrm{Ky} \mathrm{Kz}$ Ss Por

5.55097e+01 5.55097e+01 5.55097e+00 1.00000e-09 7.00000e-02 $1.00000 \mathrm{e}-02$ 1.00000e-02 1.00000e-03 1.00000e-09 1.00000e-01 $1.00000 \mathrm{e}+001.00000 \mathrm{e}+001.00000 \mathrm{e}-011.00000 \mathrm{e}-091.00000 \mathrm{e}-01$ 
Element: 8417 \# of layers: 3

$\mathrm{Kx} \mathrm{Ky} \mathrm{Kz}$ Ss Por

5.55097e+01 5.55097e+01 5.55097e+00 1.00000e-09 7.00000e-02

$1.00000 \mathrm{e}-02$ 1.00000e-02 1.00000e-03 1.00000e-09 1.00000e-01

$1.00000 \mathrm{e}+001.00000 \mathrm{e}+001.00000 \mathrm{e}-011.00000 \mathrm{e}-091.00000 \mathrm{e}-01$

Element: 8418 \# of layers: 3

$\mathrm{Kx} \mathrm{Ky} \mathrm{Kz}$ Ss Por

5.55097e+01 5.55097e+01 5.55097e+00 1.00000e-09 7.00000e-02

$1.00000 \mathrm{e}-02$ 1.00000e-02 1.00000e-03 1.00000e-09 1.00000e-01

$1.00000 \mathrm{e}+001.00000 \mathrm{e}+001.00000 \mathrm{e}-011.00000 \mathrm{e}-091.00000 \mathrm{e}-01$

Element: 8419 \# of layers: 4

Kx Ky Kz Ss Por

5.55097e+01 5.55097e+01 5.55097e+00 1.00000e-09 7.00000e-02

$5.55097 \mathrm{e}+015.55097 \mathrm{e}+015.55097 \mathrm{e}+001.00000 \mathrm{e}-09$ 7.00000e-02

$1.00000 \mathrm{e}-02$ 1.00000e-02 1.00000e-03 1.00000e-09 1.00000e-01

$1.00000 \mathrm{e}+001.00000 \mathrm{e}+001.00000 \mathrm{e}-011.00000 \mathrm{e}-091.00000 \mathrm{e}-01$

Element: 8420 \# of layers: 4

$\mathrm{Kx} \mathrm{Ky} \mathrm{Kz}$ Ss Por

5.55097e+01 5.55097e+01 5.55097e+00 1.00000e-09 7.00000e-02

5.55097e+01 5.55097e+01 5.55097e+00 1.00000e-09 7.00000e-02

$1.00000 \mathrm{e}-02$ 1.00000e-02 1.00000e-03 1.00000e-09 1.00000e-01

$1.00000 \mathrm{e}+001.00000 \mathrm{e}+001.00000 \mathrm{e}-01$ 1.00000e-09 1.00000e-01

Element: 8421 \# of layers: 3

Kx Ky Kz Ss Por

5.55097e+01 5.55097e+01 5.55097e+00 1.00000e-09 7.00000e-02

$1.00000 \mathrm{e}-02$ 1.00000e-02 1.00000e-03 1.00000e-09 1.00000e-01

$1.00000 \mathrm{e}+001.00000 \mathrm{e}+001.00000 \mathrm{e}-011.00000 \mathrm{e}-091.00000 \mathrm{e}-01$

Element: 8422 \# of layers: 3

$\mathrm{Kx} \mathrm{Ky} \mathrm{Kz}$ Ss Por

5.55097e+01 5.55097e+01 5.55097e+00 1.00000e-09 7.00000e-02

$1.00000 \mathrm{e}-02$ 1.00000e-02 1.00000e-03 1.00000e-09 1.00000e-01

$1.00000 \mathrm{e}+001.00000 \mathrm{e}+001.00000 \mathrm{e}-011.00000 \mathrm{e}-091.00000 \mathrm{e}-01$

Element: 8423 \# of layers: 3

$\mathrm{Kx} \mathrm{Ky} \mathrm{Kz}$ Ss Por

1.01957e+02 1.01957e+02 1.01957e+01 1.00000e-09 7.00000e-02

1.00000e-02 1.00000e-02 1.00000e-03 1.00000e-09 1.00000e-01

$1.00000 \mathrm{e}+001.00000 \mathrm{e}+001.00000 \mathrm{e}-011.00000 \mathrm{e}-091.00000 \mathrm{e}-01$

Element: 8424 \# of layers: 3

$\mathrm{Kx} \mathrm{Ky} \mathrm{Kz}$ Ss Por

$1.01957 \mathrm{e}+02$ 1.01957e+02 1.01957e+01 1.00000e-09 7.00000e-02

$1.00000 \mathrm{e}-02$ 1.00000e-02 1.00000e-03 1.00000e-09 1.00000e-01

$1.00000 \mathrm{e}+001.00000 \mathrm{e}+001.00000 \mathrm{e}-011.00000 \mathrm{e}-091.00000 \mathrm{e}-01$

Element: 8425 \# of layers: 3

$\mathrm{Kx} \mathrm{Ky} \mathrm{Kz}$ Ss Por

1.01957e+02 1.01957e+02 1.01957e+01 1.00000e-09 7.00000e-02

$1.00000 \mathrm{e}-02$ 1.00000e-02 1.00000e-03 1.00000e-09 1.00000e-01 
$1.00000 \mathrm{e}+001.00000 \mathrm{e}+00$ 1.00000e-01 1.00000e-09 1.00000e-01

Element: 8426 \# of layers: 3

Kx Ky Kz Ss Por

1.01957e+02 1.01957e+02 1.01957e+01 1.00000e-09 7.00000e-02

$1.00000 \mathrm{e}-02$ 1.00000e-02 1.00000e-03 1.00000e-09 1.00000e-01

$1.00000 \mathrm{e}+001.00000 \mathrm{e}+001.00000 \mathrm{e}-011.00000 \mathrm{e}-091.00000 \mathrm{e}-01$

Element: 8427 \# of layers: 3

$\mathrm{Kx} \mathrm{Ky} \mathrm{Kz}$ Ss Por

$1.01957 \mathrm{e}+02$ 1.01957e+02 1.01957e+01 1.00000e-09 7.00000e-02

$1.00000 \mathrm{e}-02$ 1.00000e-02 1.00000e-03 1.00000e-09 1.00000e-01

$1.00000 \mathrm{e}+001.00000 \mathrm{e}+001.00000 \mathrm{e}-011.00000 \mathrm{e}-091.00000 \mathrm{e}-01$

Element: 8428 \# of layers: 3

$\mathrm{Kx} \mathrm{Ky} \mathrm{Kz}$ Ss Por

$1.01957 \mathrm{e}+02$ 1.01957e+02 1.01957e+01 1.00000e-09 7.00000e-02

$1.00000 \mathrm{e}-02$ 1.00000e-02 1.00000e-03 1.00000e-09 1.00000e-01

$1.00000 \mathrm{e}+001.00000 \mathrm{e}+001.00000 \mathrm{e}-011.00000 \mathrm{e}-091.00000 \mathrm{e}-01$

Element: 8429 \# of layers: 3

$\mathrm{Kx} \mathrm{Ky} \mathrm{Kz}$ Ss Por

1.01957e+02 1.01957e+02 1.01957e+01 1.00000e-09 7.00000e-02

$1.00000 \mathrm{e}-02$ 1.00000e-02 1.00000e-03 1.00000e-09 1.00000e-01

$1.00000 \mathrm{e}+001.00000 \mathrm{e}+001.00000 \mathrm{e}-011.00000 \mathrm{e}-091.00000 \mathrm{e}-01$

Element: 8430 \# of layers: 3

$\mathrm{Kx} \mathrm{Ky} \mathrm{Kz}$ Ss Por

$1.01957 \mathrm{e}+02$ 1.01957e+02 1.01957e+01 1.00000e-09 7.00000e-02

$1.00000 \mathrm{e}-02$ 1.00000e-02 1.00000e-03 1.00000e-09 1.00000e-01

$1.00000 \mathrm{e}+001.00000 \mathrm{e}+001.00000 \mathrm{e}-01$ 1.00000e-09 1.00000e-01

Element: 8431 \# of layers: 3

$\mathrm{Kx} \mathrm{Ky} \mathrm{Kz}$ Ss Por

1.01957e+02 1.01957e+02 1.01957e+01 1.00000e-09 7.00000e-02

$1.00000 \mathrm{e}-021.00000 \mathrm{e}-021.00000 \mathrm{e}-031.00000 \mathrm{e}-091.00000 \mathrm{e}-01$

$1.00000 \mathrm{e}+001.00000 \mathrm{e}+001.00000 \mathrm{e}-011.00000 \mathrm{e}-091.00000 \mathrm{e}-01$

Element: 8432 \# of layers: 3

$\mathrm{Kx} \mathrm{Ky} \mathrm{Kz}$ Ss Por

$2.75264 \mathrm{e}+02$ 2.75264e+02 2.75264e+01 1.00000e-09 7.00000e-02

$1.00000 \mathrm{e}-02$ 1.00000e-02 1.00000e-03 1.00000e-09 1.00000e-01

$1.00000 \mathrm{e}+001.00000 \mathrm{e}+001.00000 \mathrm{e}-011.00000 \mathrm{e}-091.00000 \mathrm{e}-01$

Element: 8433 \# of layers: 3

$\mathrm{Kx} \mathrm{Ky} \mathrm{Kz}$ Ss Por

2.75264e+02 2.75264e+02 2.75264e+01 1.00000e-09 7.00000e-02

$1.00000 \mathrm{e}-02$ 1.00000e-02 1.00000e-03 1.00000e-09 1.00000e-01

$1.00000 \mathrm{e}+001.00000 \mathrm{e}+001.00000 \mathrm{e}-011.00000 \mathrm{e}-091.00000 \mathrm{e}-01$

Element: 8434 \# of layers: 3

$\mathrm{Kx} \mathrm{Ky} \mathrm{Kz}$ Ss Por

2.75264e+02 2.75264e+02 2.75264e+01 1.00000e-09 7.00000e-02

$1.00000 \mathrm{e}-02$ 1.00000e-02 1.00000e-03 1.00000e-09 1.00000e-01

$1.00000 \mathrm{e}+001.00000 \mathrm{e}+001.00000 \mathrm{e}-011.00000 \mathrm{e}-091.00000 \mathrm{e}-01$ 
Element: 8435 \# of layers: 4

$\mathrm{Kx} \mathrm{Ky} \mathrm{Kz}$ Ss Por

$2.75264 \mathrm{e}+02$ 2.75264e+02 2.75264e+01 1.00000e-09 7.00000e-02

$1.09987 \mathrm{e}+01$ 1.09987e+01 1.09987e+00 1.00000e-09 2.12000e-01

$1.00000 \mathrm{e}-02$ 1.00000e-02 1.00000e-03 1.00000e-09 1.00000e-01

$1.00000 \mathrm{e}+001.00000 \mathrm{e}+001.00000 \mathrm{e}-01$ 1.00000e-09 1.00000e-01

Element: 8436 \# of layers: 5

$\mathrm{Kx} \mathrm{Ky} \mathrm{Kz}$ Ss Por

2.75264e+02 2.75264e+02 2.75264e+01 1.00000e-09 7.00000e-02

$2.75264 \mathrm{e}+022.75264 \mathrm{e}+02 \quad 2.75264 \mathrm{e}+01$ 1.00000e-09 7.00000e-02

$1.09987 \mathrm{e}+01$ 1.09987e+01 1.09987e+00 1.00000e-09 2.12000e-01

$1.00000 \mathrm{e}-02$ 1.00000e-02 1.00000e-03 1.00000e-09 1.00000e-01

$1.00000 \mathrm{e}+001.00000 \mathrm{e}+001.00000 \mathrm{e}-01$ 1.00000e-09 1.00000e-01

Element: 8437 \# of layers: 4

$\mathrm{Kx} \mathrm{Ky} \mathrm{Kz}$ Ss Por

2.75264e+02 2.75264e+02 2.75264e+01 1.00000e-09 7.00000e-02

$1.09987 \mathrm{e}+01$ 1.09987e+01 1.09987e+00 1.00000e-09 2.12000e-01

$1.00000 \mathrm{e}-02$ 1.00000e-02 1.00000e-03 1.00000e-09 1.00000e-01

$1.00000 \mathrm{e}+001.00000 \mathrm{e}+001.00000 \mathrm{e}-011.00000 \mathrm{e}-091.00000 \mathrm{e}-01$

Element: 8438 \# of layers: 3

$\mathrm{Kx} \mathrm{Ky} \mathrm{Kz}$ Ss Por

2.75264e+02 2.75264e+02 2.75264e+01 1.00000e-09 7.00000e-02

$1.00000 \mathrm{e}-02$ 1.00000e-02 1.00000e-03 1.00000e-09 1.00000e-01

$1.00000 \mathrm{e}+001.00000 \mathrm{e}+001.00000 \mathrm{e}-011.00000 \mathrm{e}-091.00000 \mathrm{e}-01$

Element: 8439 \# of layers: 3

$\mathrm{Kx} \mathrm{Ky} \mathrm{Kz}$ Ss Por

$2.75264 \mathrm{e}+02$ 2.75264e+02 2.75264e+01 1.00000e-09 7.00000e-02

$1.00000 \mathrm{e}-02$ 1.00000e-02 1.00000e-03 1.00000e-09 1.00000e-01

$1.00000 \mathrm{e}+001.00000 \mathrm{e}+001.00000 \mathrm{e}-011.00000 \mathrm{e}-091.00000 \mathrm{e}-01$

Element: 8440 \# of layers: 3

$\mathrm{Kx} \mathrm{Ky} \mathrm{Kz}$ Ss Por

$2.75264 \mathrm{e}+02$ 2.75264e+02 2.75264e+01 1.00000e-09 7.00000e-02

$1.00000 \mathrm{e}-02$ 1.00000e-02 1.00000e-03 1.00000e-09 1.00000e-01

$1.00000 \mathrm{e}+001.00000 \mathrm{e}+001.00000 \mathrm{e}-011.00000 \mathrm{e}-091.00000 \mathrm{e}-01$

Element: 8441 \# of layers: 5

$\mathrm{Kx} \mathrm{Ky} \mathrm{Kz}$ Ss Por

4.35769e+02 4.35769e+02 4.35769e+01 1.00000e-09 7.00000e-02

$1.74120 \mathrm{e}+011.74120 \mathrm{e}+011.74120 \mathrm{e}+001.00000 \mathrm{e}-092.12000 \mathrm{e}-01$

$1.74120 \mathrm{e}+011.74120 \mathrm{e}+011.74120 \mathrm{e}+001.00000 \mathrm{e}-092.12000 \mathrm{e}-01$

$1.00000 \mathrm{e}-02$ 1.00000e-02 1.00000e-03 1.00000e-09 1.00000e-01

$1.00000 \mathrm{e}+001.00000 \mathrm{e}+001.00000 \mathrm{e}-011.00000 \mathrm{e}-091.00000 \mathrm{e}-01$

Element: 8442 \# of layers: 5

$\mathrm{Kx} \mathrm{Ky} \mathrm{Kz}$ Ss Por

4.35769e+02 4.35769e+02 4.35769e+01 1.00000e-09 7.00000e-02

$1.74120 \mathrm{e}+011.74120 \mathrm{e}+011.74120 \mathrm{e}+001.00000 \mathrm{e}-092.12000 \mathrm{e}-01$

$1.74120 \mathrm{e}+011.74120 \mathrm{e}+011.74120 \mathrm{e}+001.00000 \mathrm{e}-092.12000 \mathrm{e}-01$ 
$1.00000 \mathrm{e}-02$ 1.00000e-02 1.00000e-03 1.00000e-09 1.00000e-01 $1.00000 \mathrm{e}+001.00000 \mathrm{e}+001.00000 \mathrm{e}-01$ 1.00000e-09 1.00000e-01

Element: 8443 \# of layers: 4

Kx Ky Kz Ss Por

4.35769e+02 4.35769e+02 4.35769e+01 1.00000e-09 7.00000e-02 $1.74120 \mathrm{e}+011.74120 \mathrm{e}+011.74120 \mathrm{e}+001.00000 \mathrm{e}-092.12000 \mathrm{e}-01$ $1.00000 \mathrm{e}-02$ 1.00000e-02 1.00000e-03 1.00000e-09 1.00000e-01 $1.00000 \mathrm{e}+001.00000 \mathrm{e}+001.00000 \mathrm{e}-01$ 1.00000e-09 1.00000e-01 Element: 8447 \# of layers: 4

$\mathrm{Kx} \mathrm{Ky} \mathrm{Kz}$ Ss Por

4.35769e+02 4.35769e+02 4.35769e+01 1.00000e-09 7.00000e-02 $1.74120 \mathrm{e}+011.74120 \mathrm{e}+01 \quad 1.74120 \mathrm{e}+001.00000 \mathrm{e}-092.12000 \mathrm{e}-01$ $1.00000 \mathrm{e}-02$ 1.00000e-02 1.00000e-03 1.00000e-09 1.00000e-01 $1.00000 \mathrm{e}+001.00000 \mathrm{e}+001.00000 \mathrm{e}-011.00000 \mathrm{e}-091.00000 \mathrm{e}-01$ Element: 8448 \# of layers: 4

Kx Ky Kz Ss Por

4.35769e+02 4.35769e+02 4.35769e+01 1.00000e-09 7.00000e-02 $1.74120 \mathrm{e}+011.74120 \mathrm{e}+011.74120 \mathrm{e}+001.00000 \mathrm{e}-092.12000 \mathrm{e}-01$ $1.00000 \mathrm{e}-02$ 1.00000e-02 1.00000e-03 1.00000e-09 1.00000e-01 $1.00000 \mathrm{e}+001.00000 \mathrm{e}+001.00000 \mathrm{e}-011.00000 \mathrm{e}-091.00000 \mathrm{e}-01$ Element: 8450 \# of layers: 4

$\mathrm{Kx} \mathrm{Ky} \mathrm{Kz}$ Ss Por

4.19280e+02 4.19280e+02 4.19280e+01 1.00000e-09 7.00000e-02 $2.06986 \mathrm{e}+022.06986 \mathrm{e}+02$ 2.06986e+01 1.00000e-09 2.12000e-01 $1.00000 \mathrm{e}-02$ 1.00000e-02 1.00000e-03 1.00000e-09 1.00000e-01 $1.00000 \mathrm{e}+001.00000 \mathrm{e}+001.00000 \mathrm{e}-01$ 1.00000e-09 1.00000e-01

Element: 8451 \# of layers: 4

$\mathrm{Kx} \mathrm{Ky} \mathrm{Kz}$ Ss Por

4.35769e+02 4.35769e+02 4.35769e+01 1.00000e-09 7.00000e-02 $2.06986 \mathrm{e}+02$ 2.06986e+02 2.06986e+01 1.00000e-09 2.12000e-01 $1.00000 \mathrm{e}-02$ 1.00000e-02 1.00000e-03 1.00000e-09 1.00000e-01 $1.00000 \mathrm{e}+001.00000 \mathrm{e}+001.00000 \mathrm{e}-011.00000 \mathrm{e}-091.00000 \mathrm{e}-01$

Element: 8452 \# of layers: 4

$\mathrm{Kx} \mathrm{Ky} \mathrm{Kz}$ Ss Por

4.35769e+02 4.35769e+02 4.35769e+01 1.00000e-09 7.00000e-02 $2.06986 \mathrm{e}+022.06986 \mathrm{e}+022.06986 \mathrm{e}+01$ 1.00000e-09 2.12000e-01 $1.00000 \mathrm{e}-02$ 1.00000e-02 1.00000e-03 1.00000e-09 1.00000e-01 $1.00000 \mathrm{e}+001.00000 \mathrm{e}+001.00000 \mathrm{e}-011.00000 \mathrm{e}-091.00000 \mathrm{e}-01$ Element: 8453 \# of layers: 4

$\mathrm{Kx} \mathrm{Ky} \mathrm{Kz}$ Ss Por 4.19280e+02 4.19280e+02 4.19280e+01 1.00000e-09 7.00000e-02 $1.67527 \mathrm{e}+01$ 1.67527e+01 1.67527e+00 1.00000e-09 2.12000e-01 $1.00000 \mathrm{e}-021.00000 \mathrm{e}-021.00000 \mathrm{e}-031.00000 \mathrm{e}-091.00000 \mathrm{e}-01$ $1.00000 \mathrm{e}+001.00000 \mathrm{e}+001.00000 \mathrm{e}-01$ 1.00000e-09 1.00000e-01 Element: 8454 \# of layers: 5

Kx Ky Kz Ss Por 
4.19280e+02 4.19280e+02 4.19280e+01 1.00000e-09 7.00000e-02 4.19280e+02 4.19280e+02 4.19280e+01 1.00000e-09 7.00000e-02 $1.67527 \mathrm{e}+011.67527 \mathrm{e}+01$ 1.67527e+00 1.00000e-09 2.12000e-01 $1.00000 \mathrm{e}-02$ 1.00000e-02 1.00000e-03 1.00000e-09 1.00000e-01 $1.00000 \mathrm{e}+001.00000 \mathrm{e}+001.00000 \mathrm{e}-011.00000 \mathrm{e}-091.00000 \mathrm{e}-01$ Element: 8455 \# of layers: 4

$\mathrm{Kx} \mathrm{Ky} \mathrm{Kz}$ Ss Por

4.19280e+02 4.19280e+02 4.19280e+01 1.00000e-09 7.00000e-02 $1.67527 \mathrm{e}+01$ 1.67527e+01 1.67527e+00 1.00000e-09 2.12000e-01 $1.00000 \mathrm{e}-02$ 1.00000e-02 1.00000e-03 1.00000e-09 1.00000e-01 $1.00000 \mathrm{e}+001.00000 \mathrm{e}+001.00000 \mathrm{e}-011.00000 \mathrm{e}-091.00000 \mathrm{e}-01$

Element: 8456 \# of layers: 4

$\mathrm{Kx} \mathrm{Ky} \mathrm{Kz}$ Ss Por

8.07611e+01 8.07611e+01 8.07611e+00 1.00000e-09 7.00000e-02 3.22702e+00 3.22702e+00 3.22702e-01 1.00000e-09 2.12000e-01 $1.00000 \mathrm{e}-02$ 1.00000e-02 1.00000e-03 1.00000e-09 1.00000e-01 $1.00000 \mathrm{e}+001.00000 \mathrm{e}+001.00000 \mathrm{e}-01$ 1.00000e-09 1.00000e-01 Element: 8457 \# of layers: 4

$\mathrm{Kx} \mathrm{Ky} \mathrm{Kz}$ Ss Por

8.07611e+01 8.07611e+01 8.07611e+00 1.00000e-09 7.00000e-02 $3.22702 \mathrm{e}+003.22702 \mathrm{e}+00$ 3.22702e-01 1.00000e-09 2.12000e-01 $1.00000 \mathrm{e}-02$ 1.00000e-02 1.00000e-03 1.00000e-09 1.00000e-01 $1.00000 \mathrm{e}+001.00000 \mathrm{e}+001.00000 \mathrm{e}-01$ 1.00000e-09 1.00000e-01 Element: 8458 \# of layers: 4

$\mathrm{Kx} \mathrm{Ky} \mathrm{Kz}$ Ss Por

8.07611e+01 8.07611e+01 8.07611e+00 1.00000e-09 7.00000e-02 $3.22702 \mathrm{e}+003.22702 \mathrm{e}+003.22702 \mathrm{e}-01$ 1.00000e-09 2.12000e-01 $1.00000 \mathrm{e}-02$ 1.00000e-02 1.00000e-03 1.00000e-09 1.00000e-01 $1.00000 \mathrm{e}+001.00000 \mathrm{e}+001.00000 \mathrm{e}-011.00000 \mathrm{e}-091.00000 \mathrm{e}-01$ Element: 8459 \# of layers: 4

$\mathrm{Kx} \mathrm{Ky} \mathrm{Kz}$ Ss Por

7.95943e+01 7.95943e+01 7.95943e+00 1.00000e-09 7.00000e-02 $3.18022 \mathrm{e}+003.18022 \mathrm{e}+00$ 3.18022e-01 1.00000e-09 2.12000e-01 $1.00000 \mathrm{e}-02$ 1.00000e-02 1.00000e-03 1.00000e-09 1.00000e-01 $1.00000 \mathrm{e}+001.00000 \mathrm{e}+001.00000 \mathrm{e}-011.00000 \mathrm{e}-091.00000 \mathrm{e}-01$ Element: 8460 \# of layers: 4

Kx Ky Kz Ss Por

7.95943e+01 7.95943e+01 7.95943e+00 1.00000e-09 7.00000e-02 3.18022e+00 3.18022e+00 3.18022e-01 1.00000e-09 2.12000e-01 $1.00000 \mathrm{e}-02$ 1.00000e-02 1.00000e-03 1.00000e-09 1.00000e-01 $1.00000 \mathrm{e}+001.00000 \mathrm{e}+001.00000 \mathrm{e}-011.00000 \mathrm{e}-091.00000 \mathrm{e}-01$ Element: 8461 \# of layers: 4

$\mathrm{Kx} \mathrm{Ky} \mathrm{Kz}$ Ss Por

7.95943e+01 7.95943e+01 7.95943e+00 1.00000e-09 7.00000e-02 $3.18022 \mathrm{e}+003.18022 \mathrm{e}+003.18022 \mathrm{e}-01$ 1.00000e-09 2.12000e-01 $1.00000 \mathrm{e}-02$ 1.00000e-02 1.00000e-03 1.00000e-09 1.00000e-01 
$1.00000 \mathrm{e}+001.00000 \mathrm{e}+001.00000 \mathrm{e}-01$ 1.00000e-09 1.00000e-01

Element: 8462 \# of layers: 4

Kx Ky Kz Ss Por

5.98147e+01 5.98147e+01 5.98147e+00 1.00000e-09 7.00000e-02

$2.39000 \mathrm{e}+002.39000 \mathrm{e}+002.39000 \mathrm{e}-01$ 1.00000e-09 2.12000e-01

$1.00000 \mathrm{e}-02$ 1.00000e-02 1.00000e-03 1.00000e-09 1.00000e-01

$1.00000 \mathrm{e}+001.00000 \mathrm{e}+001.00000 \mathrm{e}-01$ 1.00000e-09 1.00000e-01

Element: 8463 \# of layers: 4

$\mathrm{Kx} \mathrm{Ky} \mathrm{Kz}$ Ss Por

5.98147e+01 5.98147e+01 5.98147e+00 1.00000e-09 7.00000e-02

$2.39000 \mathrm{e}+002.39000 \mathrm{e}+00$ 2.39000e-01 1.00000e-09 2.12000e-01

$1.00000 \mathrm{e}-02$ 1.00000e-02 1.00000e-03 1.00000e-09 1.00000e-01

$1.00000 \mathrm{e}+001.00000 \mathrm{e}+001.00000 \mathrm{e}-011.00000 \mathrm{e}-091.00000 \mathrm{e}-01$

Element: 8464 \# of layers: 5

$\mathrm{Kx} \mathrm{Ky} \mathrm{Kz}$ Ss Por

4.80927e+01 4.80927e+01 4.80927e+00 1.00000e-09 7.00000e-02

4.80927e+01 4.80927e+01 4.80927e+00 1.00000e-09 7.00000e-02

$1.92161 \mathrm{e}+001.92161 \mathrm{e}+001.92161 \mathrm{e}-011.00000 \mathrm{e}-09$ 2.12000e-01

$1.00000 \mathrm{e}-02$ 1.00000e-02 1.00000e-03 1.00000e-09 1.00000e-01

$1.00000 \mathrm{e}+001.00000 \mathrm{e}+001.00000 \mathrm{e}-011.00000 \mathrm{e}-091.00000 \mathrm{e}-01$

Element: 8465 \# of layers: 5

$\mathrm{Kx} \mathrm{Ky} \mathrm{Kz}$ Ss Por

4.80927e+01 4.80927e+01 4.80927e+00 1.00000e-09 7.00000e-02

4.80927e+01 4.80927e+01 4.80927e+00 1.00000e-09 7.00000e-02

$1.92161 \mathrm{e}+001.92161 \mathrm{e}+001.92161 \mathrm{e}-01$ 1.00000e-09 2.12000e-01

$1.00000 \mathrm{e}-02$ 1.00000e-02 1.00000e-03 1.00000e-09 1.00000e-01

$1.00000 \mathrm{e}+001.00000 \mathrm{e}+001.00000 \mathrm{e}-011.00000 \mathrm{e}-091.00000 \mathrm{e}-01$

Element: 8466 \# of layers: 4

$\mathrm{Kx} \mathrm{Ky} \mathrm{Kz}$ Ss Por

4.80927e+01 4.80927e+01 4.80927e+00 1.00000e-09 7.00000e-02

$1.92161 \mathrm{e}+001.92161 \mathrm{e}+001.92161 \mathrm{e}-01$ 1.00000e-09 2.12000e-01

1.00000e-02 1.00000e-02 1.00000e-03 1.00000e-09 1.00000e-01

$1.00000 \mathrm{e}+001.00000 \mathrm{e}+001.00000 \mathrm{e}-011.00000 \mathrm{e}-091.00000 \mathrm{e}-01$

Element: 8471 \# of layers: 5

$\mathrm{Kx} \mathrm{Ky} \mathrm{Kz}$ Ss Por

4.80927e+01 4.80927e+01 4.80927e+00 1.00000e-09 7.00000e-02

$4.80927 \mathrm{e}+014.80927 \mathrm{e}+014.80927 \mathrm{e}+00$ 1.00000e-09 7.00000e-02

$1.92161 \mathrm{e}+001.92161 \mathrm{e}+001.92161 \mathrm{e}-011.00000 \mathrm{e}-092.12000 \mathrm{e}-01$

$1.00000 \mathrm{e}-02$ 1.00000e-02 1.00000e-03 1.00000e-09 1.00000e-01

$1.00000 \mathrm{e}+001.00000 \mathrm{e}+001.00000 \mathrm{e}-01$ 1.00000e-09 1.00000e-01

Element: 8472 \# of layers: 4

$\mathrm{Kx} \mathrm{Ky} \mathrm{Kz}$ Ss Por

4.80927e+01 4.80927e+01 4.80927e+00 1.00000e-09 7.00000e-02

4.80927e+01 4.80927e+01 4.80927e+00 1.00000e-09 7.00000e-02

$1.00000 \mathrm{e}-02$ 1.00000e-02 1.00000e-03 1.00000e-09 1.00000e-01

$1.00000 \mathrm{e}+001.00000 \mathrm{e}+001.00000 \mathrm{e}-011.00000 \mathrm{e}-091.00000 \mathrm{e}-01$ 
Element: 8473 \# of layers: 4

$\mathrm{Kx} \mathrm{Ky} \mathrm{Kz}$ Ss Por

4.80927e+01 4.80927e+01 4.80927e+00 1.00000e-09 7.00000e-02

4.80927e+01 4.80927e+01 4.80927e+00 1.00000e-09 7.00000e-02

$1.00000 \mathrm{e}-021.00000 \mathrm{e}-021.00000 \mathrm{e}-031.00000 \mathrm{e}-091.00000 \mathrm{e}-01$

$1.00000 \mathrm{e}+001.00000 \mathrm{e}+001.00000 \mathrm{e}-011.00000 \mathrm{e}-091.00000 \mathrm{e}-01$

Element: 8474 \# of layers: 5

$\mathrm{Kx} \mathrm{Ky} \mathrm{Kz}$ Ss Por

4.80927e+01 4.80927e+01 4.80927e+00 1.00000e-09 7.00000e-02

4.80927e+01 4.80927e+01 4.80927e+00 1.00000e-09 7.00000e-02

$1.92161 \mathrm{e}+001.92161 \mathrm{e}+001.92161 \mathrm{e}-01$ 1.00000e-09 2.12000e-01

$1.00000 \mathrm{e}-02$ 1.00000e-02 1.00000e-03 1.00000e-09 1.00000e-01

$1.00000 \mathrm{e}+001.00000 \mathrm{e}+001.00000 \mathrm{e}-01$ 1.00000e-09 1.00000e-01

Element: 8475 \# of layers: 5

$\mathrm{Kx} \mathrm{Ky} \mathrm{Kz}$ Ss Por

4.80927e+01 4.80927e+01 4.80927e+00 1.00000e-09 7.00000e-02

4.80927e+01 4.80927e+01 4.80927e+00 1.00000e-09 7.00000e-02

$1.92161 \mathrm{e}+001.92161 \mathrm{e}+001.92161 \mathrm{e}-01$ 1.00000e-09 2.12000e-01

$1.00000 \mathrm{e}-02$ 1.00000e-02 1.00000e-03 1.00000e-09 1.00000e-01

$1.00000 \mathrm{e}+001.00000 \mathrm{e}+001.00000 \mathrm{e}-011.00000 \mathrm{e}-091.00000 \mathrm{e}-01$

Element: 8476 \# of layers: 5

$\mathrm{Kx} \mathrm{Ky} \mathrm{Kz}$ Ss Por

4.80927e+01 4.80927e+01 4.80927e+00 1.00000e-09 7.00000e-02

4.80927e+01 4.80927e+01 4.80927e+00 1.00000e-09 7.00000e-02

$1.92161 \mathrm{e}+001.92161 \mathrm{e}+001.92161 \mathrm{e}-011.00000 \mathrm{e}-092.12000 \mathrm{e}-01$

$1.00000 \mathrm{e}-02$ 1.00000e-02 1.00000e-03 1.00000e-09 1.00000e-01

$1.00000 \mathrm{e}+001.00000 \mathrm{e}+001.00000 \mathrm{e}-01$ 1.00000e-09 1.00000e-01

Element: 8477 \# of layers: 5

Kx Ky Kz Ss Por

4.80927e+01 4.80927e+01 4.80927e+00 1.00000e-09 7.00000e-02

4.80927e+01 4.80927e+01 4.80927e+00 1.00000e-09 7.00000e-02

$1.92161 \mathrm{e}+001.92161 \mathrm{e}+001.92161 \mathrm{e}-01$ 1.00000e-09 2.12000e-01

$1.00000 \mathrm{e}-02$ 1.00000e-02 1.00000e-03 1.00000e-09 1.00000e-01

$1.00000 \mathrm{e}+001.00000 \mathrm{e}+001.00000 \mathrm{e}-011.00000 \mathrm{e}-091.00000 \mathrm{e}-01$

Element: 8478 \# of layers: 5

$\mathrm{Kx} \mathrm{Ky} \mathrm{Kz}$ Ss Por

4.80927e+01 4.80927e+01 4.80927e+00 1.00000e-09 7.00000e-02

4.80927e+01 4.80927e+01 4.80927e+00 1.00000e-09 7.00000e-02

$1.92161 \mathrm{e}+001.92161 \mathrm{e}+001.92161 \mathrm{e}-01$ 1.00000e-09 2.12000e-01

$1.00000 \mathrm{e}-02$ 1.00000e-02 1.00000e-03 1.00000e-09 1.00000e-01

$1.00000 \mathrm{e}+001.00000 \mathrm{e}+001.00000 \mathrm{e}-011.00000 \mathrm{e}-091.00000 \mathrm{e}-01$

Element: 8479 \# of layers: 5

$\mathrm{Kx} \mathrm{Ky} \mathrm{Kz}$ Ss Por

4.80927e+01 4.80927e+01 4.80927e+00 1.00000e-09 7.00000e-02

4.80927e+01 4.80927e+01 4.80927e+00 1.00000e-09 7.00000e-02

$1.92161 \mathrm{e}+001.92161 \mathrm{e}+001.92161 \mathrm{e}-011.00000 \mathrm{e}-092.12000 \mathrm{e}-01$ 
$1.00000 \mathrm{e}-02$ 1.00000e-02 1.00000e-03 1.00000e-09 1.00000e-01 $1.00000 \mathrm{e}+001.00000 \mathrm{e}+001.00000 \mathrm{e}-01$ 1.00000e-09 1.00000e-01 Element: 8480 \# of layers: 4

Kx Ky Kz Ss Por

5.13912e+01 5.13912e+01 5.13912e+00 1.00000e-09 7.00000e-02

$5.13912 \mathrm{e}+015.13912 \mathrm{e}+015.13912 \mathrm{e}+00$ 1.00000e-09 7.00000e-02

$1.00000 \mathrm{e}-02$ 1.00000e-02 1.00000e-03 1.00000e-09 1.00000e-01

$1.00000 \mathrm{e}+001.00000 \mathrm{e}+001.00000 \mathrm{e}-01$ 1.00000e-09 1.00000e-01

Element: 8481 \# of layers: 4

$\mathrm{Kx} \mathrm{Ky} \mathrm{Kz}$ Ss Por

5.13912e+01 5.13912e+01 5.13912e+00 1.00000e-09 7.00000e-02

$5.13912 \mathrm{e}+015.13912 \mathrm{e}+015.13912 \mathrm{e}+001.00000 \mathrm{e}-09$ 7.00000e-02

$1.00000 \mathrm{e}-02$ 1.00000e-02 1.00000e-03 1.00000e-09 1.00000e-01

$1.00000 \mathrm{e}+001.00000 \mathrm{e}+001.00000 \mathrm{e}-011.00000 \mathrm{e}-091.00000 \mathrm{e}-01$

Element: 8482 \# of layers: 3

Kx Ky Kz Ss Por

5.13912e+01 5.13912e+01 5.13912e+00 1.00000e-09 7.00000e-02 $1.00000 \mathrm{e}-02$ 1.00000e-02 1.00000e-03 1.00000e-09 1.00000e-01

$1.00000 \mathrm{e}+001.00000 \mathrm{e}+001.00000 \mathrm{e}-01$ 1.00000e-09 1.00000e-01

Element: 8483 \# of layers: 4

$\mathrm{Kx} \mathrm{Ky} \mathrm{Kz}$ Ss Por

5.13912e+01 5.13912e+01 5.13912e+00 1.00000e-09 7.00000e-02

$2.05342 \mathrm{e}+002.05342 \mathrm{e}+00$ 2.05342e-01 1.00000e-09 2.12000e-01

$1.00000 \mathrm{e}-02$ 1.00000e-02 1.00000e-03 1.00000e-09 1.00000e-01

$1.00000 \mathrm{e}+001.00000 \mathrm{e}+001.00000 \mathrm{e}-011.00000 \mathrm{e}-091.00000 \mathrm{e}-01$

Element: 8484 \# of layers: 4

$\mathrm{Kx} \mathrm{Ky} \mathrm{Kz}$ Ss Por

5.13912e+01 5.13912e+01 5.13912e+00 1.00000e-09 7.00000e-02

$2.05342 \mathrm{e}+002.05342 \mathrm{e}+002.05342 \mathrm{e}-01$ 1.00000e-09 2.12000e-01

$1.00000 \mathrm{e}-02$ 1.00000e-02 1.00000e-03 1.00000e-09 1.00000e-01

$1.00000 \mathrm{e}+001.00000 \mathrm{e}+001.00000 \mathrm{e}-011.00000 \mathrm{e}-091.00000 \mathrm{e}-01$

Element: 8485 \# of layers: 5

Kx Ky Kz Ss Por

5.13912e+01 5.13912e+01 5.13912e+00 1.00000e-09 7.00000e-02

$5.13912 \mathrm{e}+015.13912 \mathrm{e}+015.13912 \mathrm{e}+00$ 1.00000e-09 7.00000e-02

$2.05342 \mathrm{e}+002.05342 \mathrm{e}+00$ 2.05342e-01 1.00000e-09 2.12000e-01

$1.00000 \mathrm{e}-02$ 1.00000e-02 1.00000e-03 1.00000e-09 1.00000e-01

$1.00000 \mathrm{e}+001.00000 \mathrm{e}+001.00000 \mathrm{e}-011.00000 \mathrm{e}-091.00000 \mathrm{e}-01$

Element: 8486 \# of layers: 5

Kx Ky Kz Ss Por

5.13912e+01 5.13912e+01 5.13912e+00 1.00000e-09 7.00000e-02

$5.13912 \mathrm{e}+015.13912 \mathrm{e}+015.13912 \mathrm{e}+00$ 1.00000e-09 7.00000e-02

2.05342e+00 2.05342e+00 2.05342e-01 1.00000e-09 2.12000e-01

$1.00000 \mathrm{e}-02$ 1.00000e-02 1.00000e-03 1.00000e-09 1.00000e-01

$1.00000 \mathrm{e}+001.00000 \mathrm{e}+001.00000 \mathrm{e}-011.00000 \mathrm{e}-091.00000 \mathrm{e}-01$

Element: 8487 \# of layers: 5 
$\mathrm{Kx} \mathrm{Ky} \mathrm{Kz}$ Ss Por

5.13912e+01 5.13912e+01 5.13912e+00 1.00000e-09 7.00000e-02

5.13912e+01 5.13912e+01 5.13912e+00 1.00000e-09 7.00000e-02

$2.05342 \mathrm{e}+002.05342 \mathrm{e}+00$ 2.05342e-01 1.00000e-09 2.12000e-01

$1.00000 \mathrm{e}-02$ 1.00000e-02 1.00000e-03 1.00000e-09 1.00000e-01

$1.00000 \mathrm{e}+001.00000 \mathrm{e}+001.00000 \mathrm{e}-011.00000 \mathrm{e}-09$ 1.00000e-01

Element: 8488 \# of layers: 5

Kx Ky Kz Ss Por

5.13912e+01 5.13912e+01 5.13912e+00 1.00000e-09 7.00000e-02

$5.13912 \mathrm{e}+015.13912 \mathrm{e}+015.13912 \mathrm{e}+00$ 1.00000e-09 7.00000e-02

$2.05342 \mathrm{e}+002.05342 \mathrm{e}+00$ 2.05342e-01 1.00000e-09 2.12000e-01

$1.00000 \mathrm{e}-02$ 1.00000e-02 1.00000e-03 1.00000e-09 1.00000e-01

$1.00000 \mathrm{e}+001.00000 \mathrm{e}+001.00000 \mathrm{e}-011.00000 \mathrm{e}-091.00000 \mathrm{e}-01$

Element: 8489 \# of layers: 3

$\mathrm{Kx} \mathrm{Ky} \mathrm{Kz}$ Ss Por

8.80763e+01 8.80763e+01 8.80763e+00 1.00000e-09 7.00000e-02

$1.00000 \mathrm{e}-02$ 1.00000e-02 1.00000e-03 1.00000e-09 1.00000e-01

$1.00000 \mathrm{e}+001.00000 \mathrm{e}+001.00000 \mathrm{e}-01$ 1.00000e-09 1.00000e-01

Element: 8490 \# of layers: 3

$\mathrm{Kx} \mathrm{Ky} \mathrm{Kz}$ Ss Por

8.80763e+01 8.80763e+01 8.80763e+00 1.00000e-09 7.00000e-02

$1.00000 \mathrm{e}-02$ 1.00000e-02 1.00000e-03 1.00000e-09 1.00000e-01

$1.00000 \mathrm{e}+001.00000 \mathrm{e}+001.00000 \mathrm{e}-01$ 1.00000e-09 1.00000e-01

Element: 8491 \# of layers: 3

Kx Ky Kz Ss Por

8.80763e+01 8.80763e+01 8.80763e+00 1.00000e-09 7.00000e-02

$1.00000 \mathrm{e}-021.00000 \mathrm{e}-021.00000 \mathrm{e}-031.00000 \mathrm{e}-091.00000 \mathrm{e}-01$

$1.00000 \mathrm{e}+001.00000 \mathrm{e}+001.00000 \mathrm{e}-011.00000 \mathrm{e}-091.00000 \mathrm{e}-01$

Element: 8492 \# of layers: 4

$\mathrm{Kx} \mathrm{Ky} \mathrm{Kz}$ Ss Por

8.80763e+01 8.80763e+01 8.80763e+00 1.00000e-09 7.00000e-02

$3.51930 \mathrm{e}+003.51930 \mathrm{e}+00$ 3.51930e-01 1.00000e-09 2.12000e-01

1.00000e-02 1.00000e-02 1.00000e-03 1.00000e-09 1.00000e-01

$1.00000 \mathrm{e}+001.00000 \mathrm{e}+001.00000 \mathrm{e}-011.00000 \mathrm{e}-091.00000 \mathrm{e}-01$

Element: 8493 \# of layers: 4

Kx Ky Kz Ss Por

8.80763e+01 8.80763e+01 8.80763e+00 1.00000e-09 7.00000e-02

$3.51930 \mathrm{e}+003.51930 \mathrm{e}+003.51930 \mathrm{e}-01$ 1.00000e-09 2.12000e-01

$1.00000 \mathrm{e}-021.00000 \mathrm{e}-021.00000 \mathrm{e}-031.00000 \mathrm{e}-091.00000 \mathrm{e}-01$

$1.00000 \mathrm{e}+001.00000 \mathrm{e}+001.00000 \mathrm{e}-01$ 1.00000e-09 1.00000e-01

Element: 8494 \# of layers: 4

$\mathrm{Kx} \mathrm{Ky} \mathrm{Kz}$ Ss Por

8.80763e+01 8.80763e+01 8.80763e+00 1.00000e-09 7.00000e-02

$3.51930 \mathrm{e}+003.51930 \mathrm{e}+00$ 3.51930e-01 1.00000e-09 2.12000e-01

1.00000e-02 1.00000e-02 1.00000e-03 1.00000e-09 1.00000e-01

$1.00000 \mathrm{e}+001.00000 \mathrm{e}+001.00000 \mathrm{e}-011.00000 \mathrm{e}-091.00000 \mathrm{e}-01$ 
Element: 8495 \# of layers: 4

$\mathrm{Kx} \mathrm{Ky} \mathrm{Kz}$ Ss Por

8.80763e+01 8.80763e+01 8.80763e+00 1.00000e-09 7.00000e-02

$3.51930 \mathrm{e}+003.51930 \mathrm{e}+00$ 3.51930e-01 1.00000e-09 2.12000e-01

$1.00000 \mathrm{e}-02$ 1.00000e-02 1.00000e-03 1.00000e-09 1.00000e-01

$1.00000 \mathrm{e}+001.00000 \mathrm{e}+001.00000 \mathrm{e}-011.00000 \mathrm{e}-091.00000 \mathrm{e}-01$

Element: 8496 \# of layers: 4

$\mathrm{Kx} \mathrm{Ky} \mathrm{Kz}$ Ss Por

8.80763e+01 8.80763e+01 8.80763e+00 1.00000e-09 7.00000e-02

$3.51930 \mathrm{e}+003.51930 \mathrm{e}+003.51930 \mathrm{e}-01$ 1.00000e-09 2.12000e-01

1.00000e-02 1.00000e-02 1.00000e-03 1.00000e-09 1.00000e-01

$1.00000 \mathrm{e}+001.00000 \mathrm{e}+001.00000 \mathrm{e}-011.00000 \mathrm{e}-091.00000 \mathrm{e}-01$

Element: 8497 \# of layers: 4

$\mathrm{Kx} \mathrm{Ky} \mathrm{Kz}$ Ss Por

8.80763e+01 8.80763e+01 8.80763e+00 1.00000e-09 7.00000e-02

$3.51930 \mathrm{e}+003.51930 \mathrm{e}+003.51930 \mathrm{e}-01$ 1.00000e-09 2.12000e-01

1.00000e-02 1.00000e-02 1.00000e-03 1.00000e-09 1.00000e-01

$1.00000 \mathrm{e}+001.00000 \mathrm{e}+001.00000 \mathrm{e}-011.00000 \mathrm{e}-091.00000 \mathrm{e}-01$

Element: 8498 \# of layers: 3

$\mathrm{Kx} \mathrm{Ky} \mathrm{Kz}$ Ss Por

$2.86194 \mathrm{e}+02$ 2.86194e+02 2.86194e+01 1.00000e-09 7.00000e-02

$1.00000 \mathrm{e}-021.00000 \mathrm{e}-02$ 1.00000e-03 1.00000e-09 1.00000e-01

$1.00000 \mathrm{e}+001.00000 \mathrm{e}+001.00000 \mathrm{e}-01$ 1.00000e-09 1.00000e-01

Element: 8499 \# of layers: 4

$\mathrm{Kx} \mathrm{Ky} \mathrm{Kz}$ Ss Por

2.86194e+02 2.86194e+02 2.86194e+01 1.00000e-09 7.00000e-02

$1.14354 \mathrm{e}+011.14354 \mathrm{e}+011.14354 \mathrm{e}+001.00000 \mathrm{e}-092.12000 \mathrm{e}-01$

$1.00000 \mathrm{e}-02$ 1.00000e-02 1.00000e-03 1.00000e-09 1.00000e-01

$1.00000 \mathrm{e}+001.00000 \mathrm{e}+001.00000 \mathrm{e}-011.00000 \mathrm{e}-091.00000 \mathrm{e}-01$

Element: 8500 \# of layers: 5

$\mathrm{Kx} \mathrm{Ky} \mathrm{Kz}$ Ss Por

$2.86194 \mathrm{e}+022.86194 \mathrm{e}+02$ 2.86194e+01 1.00000e-09 7.00000e-02

$2.86194 \mathrm{e}+02$ 2.86194e+02 2.86194e+01 1.00000e-09 7.00000e-02

$1.14354 \mathrm{e}+011.14354 \mathrm{e}+011.14354 \mathrm{e}+001.00000 \mathrm{e}-092.12000 \mathrm{e}-01$

$1.00000 \mathrm{e}-02$ 1.00000e-02 1.00000e-03 1.00000e-09 1.00000e-01

$1.00000 \mathrm{e}+001.00000 \mathrm{e}+001.00000 \mathrm{e}-01$ 1.00000e-09 1.00000e-01

Element: 8504 \# of layers: 5

Kx Ky Kz Ss Por

2.86194e+02 2.86194e+02 2.86194e+01 1.00000e-09 7.00000e-02

$1.14354 \mathrm{e}+011.14354 \mathrm{e}+011.14354 \mathrm{e}+001.00000 \mathrm{e}-092.12000 \mathrm{e}-01$

$1.14354 \mathrm{e}+011.14354 \mathrm{e}+011.14354 \mathrm{e}+001.00000 \mathrm{e}-092.12000 \mathrm{e}-01$

$1.00000 \mathrm{e}-02$ 1.00000e-02 1.00000e-03 1.00000e-09 1.00000e-01

$1.00000 \mathrm{e}+001.00000 \mathrm{e}+001.00000 \mathrm{e}-011.00000 \mathrm{e}-091.00000 \mathrm{e}-01$

Element: 8505 \# of layers: 4

$\mathrm{Kx} \mathrm{Ky} \mathrm{Kz}$ Ss Por

2.86194e+02 2.86194e+02 2.86194e+01 1.00000e-09 7.00000e-02 
$1.14354 \mathrm{e}+011.14354 \mathrm{e}+011.14354 \mathrm{e}+001.00000 \mathrm{e}-092.12000 \mathrm{e}-01$ $1.00000 \mathrm{e}-02$ 1.00000e-02 1.00000e-03 1.00000e-09 1.00000e-01

$1.00000 \mathrm{e}+001.00000 \mathrm{e}+001.00000 \mathrm{e}-011.00000 \mathrm{e}-091.00000 \mathrm{e}-01$

Element: 8507 \# of layers: 5

$\mathrm{Kx} \mathrm{Ky} \mathrm{Kz}$ Ss Por

5.86587e+02 5.86587e+02 5.86587e+01 1.00000e-09 7.00000e-02

5.86587e+02 5.86587e+02 5.86587e+01 1.00000e-09 7.00000e-02

$2.34387 \mathrm{e}+012.34387 \mathrm{e}+012.34387 \mathrm{e}+00$ 1.00000e-09 2.12000e-01

$1.00000 \mathrm{e}-02$ 1.00000e-02 1.00000e-03 1.00000e-09 1.00000e-01

$1.00000 \mathrm{e}+001.00000 \mathrm{e}+001.00000 \mathrm{e}-011.00000 \mathrm{e}-091.00000 \mathrm{e}-01$

Element: 8508 \# of layers: 4

Kx Ky Kz Ss Por

5.86587e+02 5.86587e+02 5.86587e+01 1.00000e-09 7.00000e-02

$2.34387 \mathrm{e}+012.34387 \mathrm{e}+012.34387 \mathrm{e}+00$ 1.00000e-09 2.12000e-01

$1.00000 \mathrm{e}-02$ 1.00000e-02 1.00000e-03 1.00000e-09 1.00000e-01

$1.00000 \mathrm{e}+001.00000 \mathrm{e}+001.00000 \mathrm{e}-011.00000 \mathrm{e}-091.00000 \mathrm{e}-01$

Element: 8509 \# of layers: 4

$\mathrm{Kx} \mathrm{Ky} \mathrm{Kz}$ Ss Por

5.86587e+02 5.86587e+02 5.86587e+01 1.00000e-09 7.00000e-02

$2.34387 \mathrm{e}+012.34387 \mathrm{e}+012.34387 \mathrm{e}+00$ 1.00000e-09 2.12000e-01

$1.00000 \mathrm{e}-02$ 1.00000e-02 1.00000e-03 1.00000e-09 1.00000e-01

$1.00000 \mathrm{e}+001.00000 \mathrm{e}+001.00000 \mathrm{e}-011.00000 \mathrm{e}-091.00000 \mathrm{e}-01$

Element: 8510 \# of layers: 4

Kx Ky Kz Ss Por

$2.86194 \mathrm{e}+02$ 2.86194e+02 2.86194e+01 1.00000e-09 7.00000e-02

$2.44423 \mathrm{e}+02$ 2.44423e+02 2.44423e+01 1.00000e-09 2.12000e-01

$1.00000 \mathrm{e}-02$ 1.00000e-02 1.00000e-03 1.00000e-09 1.00000e-01

$1.00000 \mathrm{e}+001.00000 \mathrm{e}+001.00000 \mathrm{e}-011.00000 \mathrm{e}-09$ 1.00000e-01

Element: 8511 \# of layers: 4

$\mathrm{Kx} \mathrm{Ky} \mathrm{Kz}$ Ss Por

2.86194e+02 2.86194e+02 2.86194e+01 1.00000e-09 7.00000e-02

$2.44423 \mathrm{e}+02$ 2.44423e+02 2.44423e+01 1.00000e-09 2.12000e-01

$1.00000 \mathrm{e}-02$ 1.00000e-02 1.00000e-03 1.00000e-09 1.00000e-01

$1.00000 \mathrm{e}+001.00000 \mathrm{e}+001.00000 \mathrm{e}-011.00000 \mathrm{e}-091.00000 \mathrm{e}-01$

Element: 8512 \# of layers: 4

Kx Ky Kz Ss Por

5.86587e+02 5.86587e+02 5.86587e+01 1.00000e-09 7.00000e-02

$2.44423 \mathrm{e}+02$ 2.44423e+02 2.44423e+01 1.00000e-09 2.12000e-01

$1.00000 \mathrm{e}-02$ 1.00000e-02 1.00000e-03 1.00000e-09 1.00000e-01

$1.00000 \mathrm{e}+001.00000 \mathrm{e}+001.00000 \mathrm{e}-01$ 1.00000e-09 1.00000e-01

Element: 8513 \# of layers: 5

$\mathrm{Kx} \mathrm{Ky} \mathrm{Kz}$ Ss Por

8.82061e+01 8.82061e+01 8.82061e+00 1.00000e-09 7.00000e-02

8.82061e+01 8.82061e+01 8.82061e+00 1.00000e-09 7.00000e-02

$3.52448 \mathrm{e}+003.52448 \mathrm{e}+003.52448 \mathrm{e}-01$ 1.00000e-09 2.12000e-01

$1.00000 \mathrm{e}-02$ 1.00000e-02 1.00000e-03 1.00000e-09 1.00000e-01 
$1.00000 \mathrm{e}+001.00000 \mathrm{e}+001.00000 \mathrm{e}-01$ 1.00000e-09 1.00000e-01

Element: 8514 \# of layers: 4

$\mathrm{Kx} \mathrm{Ky} \mathrm{Kz}$ Ss Por

8.82061e+01 8.82061e+01 8.82061e+00 1.00000e-09 7.00000e-02

$3.52448 \mathrm{e}+003.52448 \mathrm{e}+00$ 3.52448e-01 1.00000e-09 2.12000e-01

$1.00000 \mathrm{e}-02$ 1.00000e-02 1.00000e-03 1.00000e-09 1.00000e-01

$1.00000 \mathrm{e}+001.00000 \mathrm{e}+001.00000 \mathrm{e}-01$ 1.00000e-09 1.00000e-01

Element: 8515 \# of layers: 4

$\mathrm{Kx} \mathrm{Ky} \mathrm{Kz}$ Ss Por

8.82061e+01 8.82061e+01 8.82061e+00 1.00000e-09 7.00000e-02

$3.52448 \mathrm{e}+003.52448 \mathrm{e}+00$ 3.52448e-01 1.00000e-09 2.12000e-01

$1.00000 \mathrm{e}-02$ 1.00000e-02 1.00000e-03 1.00000e-09 1.00000e-01

$1.00000 \mathrm{e}+001.00000 \mathrm{e}+001.00000 \mathrm{e}-011.00000 \mathrm{e}-091.00000 \mathrm{e}-01$

Element: 8516 \# of layers: 5

$\mathrm{Kx} \mathrm{Ky} \mathrm{Kz}$ Ss Por

1.13265e+02 1.13265e+02 1.13265e+01 1.00000e-09 7.00000e-02

$1.13265 \mathrm{e}+02$ 1.13265e+02 1.13265e+01 1.00000e-09 7.00000e-02

4.52575e+00 4.52575e+00 4.52575e-01 1.00000e-09 2.12000e-01

$1.00000 \mathrm{e}-02$ 1.00000e-02 1.00000e-03 1.00000e-09 1.00000e-01

$1.00000 \mathrm{e}+001.00000 \mathrm{e}+001.00000 \mathrm{e}-011.00000 \mathrm{e}-091.00000 \mathrm{e}-01$

Element: 8517 \# of layers: 5

$\mathrm{Kx} \mathrm{Ky} \mathrm{Kz}$ Ss Por

1.13265e+02 1.13265e+02 1.13265e+01 1.00000e-09 7.00000e-02

$1.13265 \mathrm{e}+021.13265 \mathrm{e}+02$ 1.13265e+01 1.00000e-09 7.00000e-02

$4.52575 \mathrm{e}+004.52575 \mathrm{e}+00$ 4.52575e-01 1.00000e-09 2.12000e-01

$1.00000 \mathrm{e}-02$ 1.00000e-02 1.00000e-03 1.00000e-09 1.00000e-01

$1.00000 \mathrm{e}+001.00000 \mathrm{e}+001.00000 \mathrm{e}-011.00000 \mathrm{e}-091.00000 \mathrm{e}-01$

Element: 8518 \# of layers: 5

$\mathrm{Kx} \mathrm{Ky} \mathrm{Kz}$ Ss Por

$1.13265 \mathrm{e}+02$ 1.13265e+02 1.13265e+01 1.00000e-09 7.00000e-02

$1.13265 \mathrm{e}+02$ 1.13265e+02 1.13265e+01 1.00000e-09 7.00000e-02

$4.52575 \mathrm{e}+00$ 4.52575e+00 4.52575e-01 1.00000e-09 2.12000e-01

$1.00000 \mathrm{e}-02$ 1.00000e-02 1.00000e-03 1.00000e-09 1.00000e-01

$1.00000 \mathrm{e}+001.00000 \mathrm{e}+001.00000 \mathrm{e}-01$ 1.00000e-09 1.00000e-01

Element: 8519 \# of layers: 4

Kx Ky Kz Ss Por

1.86876e+02 1.86876e+02 1.86876e+01 1.00000e-09 7.00000e-02

7.46678e+00 7.46678e+00 7.46678e-01 1.00000e-09 2.12000e-01

$1.00000 \mathrm{e}-02$ 1.00000e-02 1.00000e-03 1.00000e-09 1.00000e-01

$1.00000 \mathrm{e}+001.00000 \mathrm{e}+001.00000 \mathrm{e}-01$ 1.00000e-09 1.00000e-01

Element: 8520 \# of layers: 5

$\mathrm{Kx} \mathrm{Ky} \mathrm{Kz}$ Ss Por

$1.86876 \mathrm{e}+02$ 1.86876e+02 1.86876e+01 1.00000e-09 7.00000e-02

$1.86876 \mathrm{e}+02$ 1.86876e+02 1.86876e+01 1.00000e-09 7.00000e-02

7.46678e+00 7.46678e+00 7.46678e-01 1.00000e-09 2.12000e-01

$1.00000 \mathrm{e}-02$ 1.00000e-02 1.00000e-03 1.00000e-09 1.00000e-01 
$1.00000 \mathrm{e}+001.00000 \mathrm{e}+00$ 1.00000e-01 1.00000e-09 1.00000e-01

Element: 8521 \# of layers: 5

Kx Ky Kz Ss Por

$1.86876 \mathrm{e}+02$ 1.86876e+02 1.86876e+01 1.00000e-09 7.00000e-02

$1.86876 \mathrm{e}+021.86876 \mathrm{e}+02$ 1.86876e+01 1.00000e-09 7.00000e-02

7.46678e+00 7.46678e+00 7.46678e-01 1.00000e-09 2.12000e-01

$1.00000 \mathrm{e}-02$ 1.00000e-02 1.00000e-03 1.00000e-09 1.00000e-01

$1.00000 \mathrm{e}+001.00000 \mathrm{e}+001.00000 \mathrm{e}-01$ 1.00000e-09 1.00000e-01

Element: 8522 \# of layers: 3

$\mathrm{Kx} \mathrm{Ky} \mathrm{Kz}$ Ss Por

5.11399e+01 5.11399e+01 5.11399e+00 1.00000e-09 7.00000e-02

1.00000e-01 1.00000e-01 1.00000e-02 1.00000e-09 1.00000e-01

$1.00000 \mathrm{e}+001.00000 \mathrm{e}+001.00000 \mathrm{e}-011.00000 \mathrm{e}-091.00000 \mathrm{e}-01$

Element: 8523 \# of layers: 3

$\mathrm{Kx} \mathrm{Ky} \mathrm{Kz}$ Ss Por

5.11399e+01 5.11399e+01 5.11399e+00 1.00000e-09 7.00000e-02

$1.00000 \mathrm{e}-01$ 1.00000e-01 1.00000e-02 1.00000e-09 1.00000e-01

$1.00000 \mathrm{e}+001.00000 \mathrm{e}+001.00000 \mathrm{e}-011.00000 \mathrm{e}-091.00000 \mathrm{e}-01$

Element: 8524 \# of layers: 3

$\mathrm{Kx} \mathrm{Ky} \mathrm{Kz}$ Ss Por

5.11399e+01 5.11399e+01 5.11399e+00 1.00000e-09 7.00000e-02

1.00000e-01 1.00000e-01 1.00000e-02 1.00000e-09 1.00000e-01

$1.00000 \mathrm{e}+001.00000 \mathrm{e}+001.00000 \mathrm{e}-01$ 1.00000e-09 1.00000e-01

Element: 8525 \# of layers: 3

$\mathrm{Kx} \mathrm{Ky} \mathrm{Kz}$ Ss Por

4.71890e+01 4.71890e+01 4.71890e+00 1.00000e-09 7.00000e-02

$1.00000 \mathrm{e}-011.00000 \mathrm{e}-011.00000 \mathrm{e}-021.00000 \mathrm{e}-091.00000 \mathrm{e}-01$

$1.00000 \mathrm{e}+001.00000 \mathrm{e}+001.00000 \mathrm{e}-011.00000 \mathrm{e}-09$ 1.00000e-01

Element: 8526 \# of layers: 3

$\mathrm{Kx} \mathrm{Ky} \mathrm{Kz}$ Ss Por

4.71890e+01 4.71890e+01 4.71890e+00 1.00000e-09 7.00000e-02

$1.00000 \mathrm{e}-01$ 1.00000e-01 1.00000e-02 1.00000e-09 1.00000e-01

$1.00000 \mathrm{e}+001.00000 \mathrm{e}+001.00000 \mathrm{e}-011.00000 \mathrm{e}-091.00000 \mathrm{e}-01$

Element: 8527 \# of layers: 3

$\mathrm{Kx} \mathrm{Ky} \mathrm{Kz}$ Ss Por

4.71890e+01 4.71890e+01 4.71890e+00 1.00000e-09 7.00000e-02

$1.00000 \mathrm{e}-01$ 1.00000e-01 1.00000e-02 1.00000e-09 1.00000e-01

$1.00000 \mathrm{e}+001.00000 \mathrm{e}+001.00000 \mathrm{e}-011.00000 \mathrm{e}-091.00000 \mathrm{e}-01$

Element: 8528 \# of layers: 8

$\mathrm{Kx} \mathrm{Ky} \mathrm{Kz}$ Ss Por

5.43429e+02 5.43429e+02 5.43429e+01 1.00000e-09 7.00000e-02

$2.17136 \mathrm{e}+012.17136 \mathrm{e}+012.17136 \mathrm{e}+001.00000 \mathrm{e}-092.12000 \mathrm{e}-01$

$2.17136 \mathrm{e}+012.17136 \mathrm{e}+012.17136 \mathrm{e}+00$ 1.00000e-09 2.12000e-01

2.17136e+01 2.17136e+01 2.17136e+00 1.00000e-09 2.12000e-01

$2.17136 \mathrm{e}+012.17136 \mathrm{e}+012.17136 \mathrm{e}+00$ 1.00000e-09 2.12000e-01

$2.17136 \mathrm{e}+012.17136 \mathrm{e}+012.17136 \mathrm{e}+00$ 1.00000e-09 2.12000e-01 
$1.00000 \mathrm{e}-02$ 1.00000e-02 1.00000e-03 1.00000e-09 1.00000e-01 $1.00000 \mathrm{e}+001.00000 \mathrm{e}+001.00000 \mathrm{e}-01$ 1.00000e-09 1.00000e-01 Element: 8529 \# of layers: 8

Kx Ky Kz Ss Por

5.43429e+02 5.43429e+02 5.43429e+01 1.00000e-09 7.00000e-02

$2.17136 \mathrm{e}+012.17136 \mathrm{e}+012.17136 \mathrm{e}+00$ 1.00000e-09 2.12000e-01

$2.17136 \mathrm{e}+012.17136 \mathrm{e}+012.17136 \mathrm{e}+00$ 1.00000e-09 2.12000e-01

$2.17136 \mathrm{e}+012.17136 \mathrm{e}+012.17136 \mathrm{e}+001.00000 \mathrm{e}-092.12000 \mathrm{e}-01$

$2.17136 \mathrm{e}+012.17136 \mathrm{e}+012.17136 \mathrm{e}+00 \quad 1.00000 \mathrm{e}-092.12000 \mathrm{e}-01$

$2.17136 \mathrm{e}+012.17136 \mathrm{e}+012.17136 \mathrm{e}+001.00000 \mathrm{e}-092.12000 \mathrm{e}-01$ $1.00000 \mathrm{e}-02$ 1.00000e-02 1.00000e-03 1.00000e-09 1.00000e-01

$1.00000 \mathrm{e}+001.00000 \mathrm{e}+001.00000 \mathrm{e}-011.00000 \mathrm{e}-091.00000 \mathrm{e}-01$

Element: 8530 \# of layers: 9

$\mathrm{Kx} \mathrm{Ky} \mathrm{Kz}$ Ss Por

5.43429e+02 5.43429e+02 5.43429e+01 1.00000e-09 7.00000e-02

$5.43429 \mathrm{e}+025.43429 \mathrm{e}+025.43429 \mathrm{e}+01$ 1.00000e-09 7.00000e-02

$2.17136 \mathrm{e}+012.17136 \mathrm{e}+012.17136 \mathrm{e}+00$ 1.00000e-09 2.12000e-01

$2.17136 \mathrm{e}+012.17136 \mathrm{e}+012.17136 \mathrm{e}+00$ 1.00000e-09 2.12000e-01

$2.17136 \mathrm{e}+012.17136 \mathrm{e}+012.17136 \mathrm{e}+00$ 1.00000e-09 2.12000e-01

$2.17136 \mathrm{e}+012.17136 \mathrm{e}+012.17136 \mathrm{e}+00$ 1.00000e-09 2.12000e-01

$2.17136 \mathrm{e}+012.17136 \mathrm{e}+012.17136 \mathrm{e}+001.00000 \mathrm{e}-092.12000 \mathrm{e}-01$ 1.00000e-02 1.00000e-02 1.00000e-03 1.00000e-09 1.00000e-01

$1.00000 \mathrm{e}+001.00000 \mathrm{e}+001.00000 \mathrm{e}-01$ 1.00000e-09 1.00000e-01

Element: 8531 \# of layers: 9

$\mathrm{Kx} \mathrm{Ky} \mathrm{Kz}$ Ss Por

$2.03706 \mathrm{e}+012.03706 \mathrm{e}+012.03706 \mathrm{e}+001.00000 \mathrm{e}-092.12000 \mathrm{e}-01$

$2.03706 \mathrm{e}+012.03706 \mathrm{e}+012.03706 \mathrm{e}+001.00000 \mathrm{e}-092.12000 \mathrm{e}-01$

$2.03706 \mathrm{e}+012.03706 \mathrm{e}+012.03706 \mathrm{e}+001.00000 \mathrm{e}-092.12000 \mathrm{e}-01$

$2.03706 \mathrm{e}+012.03706 \mathrm{e}+012.03706 \mathrm{e}+001.00000 \mathrm{e}-092.12000 \mathrm{e}-01$

$2.03706 \mathrm{e}+012.03706 \mathrm{e}+012.03706 \mathrm{e}+001.00000 \mathrm{e}-092.12000 \mathrm{e}-01$

$1.00000 \mathrm{e}-02$ 1.00000e-02 1.00000e-03 1.00000e-09 1.00000e-01

$1.00000 \mathrm{e}+001.00000 \mathrm{e}+001.00000 \mathrm{e}-011.00000 \mathrm{e}-091.00000 \mathrm{e}-01$

1.00000e-05 1.00000e-05 1.00000e-06 1.00000e-09 1.00000e-01

$1.00000 \mathrm{e}+001.00000 \mathrm{e}+001.00000 \mathrm{e}-011.00000 \mathrm{e}-091.00000 \mathrm{e}-01$

Element: 8532 \# of layers: 8

$\mathrm{Kx} \mathrm{Ky} \mathrm{Kz}$ Ss Por

$2.03706 \mathrm{e}+012.03706 \mathrm{e}+012.03706 \mathrm{e}+00$ 1.00000e-09 2.12000e-01

$2.03706 \mathrm{e}+012.03706 \mathrm{e}+012.03706 \mathrm{e}+001.00000 \mathrm{e}-092.12000 \mathrm{e}-01$

$2.03706 \mathrm{e}+012.03706 \mathrm{e}+012.03706 \mathrm{e}+001.00000 \mathrm{e}-092.12000 \mathrm{e}-01$

$2.03706 \mathrm{e}+012.03706 \mathrm{e}+012.03706 \mathrm{e}+001.00000 \mathrm{e}-092.12000 \mathrm{e}-01$

$2.03706 \mathrm{e}+012.03706 \mathrm{e}+012.03706 \mathrm{e}+001.00000 \mathrm{e}-092.12000 \mathrm{e}-01$

$1.00000 \mathrm{e}-02$ 1.00000e-02 1.00000e-03 1.00000e-09 1.00000e-01

$1.00000 \mathrm{e}-05$ 1.00000e-05 1.00000e-06 1.00000e-09 1.00000e-01

$1.00000 \mathrm{e}+001.00000 \mathrm{e}+001.00000 \mathrm{e}-01$ 1.00000e-09 1.00000e-01

Element: 8533 \# of layers: 8

Kx Ky Kz Ss Por 
$2.03706 \mathrm{e}+012.03706 \mathrm{e}+012.03706 \mathrm{e}+00$ 1.00000e-09 2.12000e-01 $2.03706 \mathrm{e}+012.03706 \mathrm{e}+012.03706 \mathrm{e}+001.00000 \mathrm{e}-092.12000 \mathrm{e}-01$ $2.03706 \mathrm{e}+012.03706 \mathrm{e}+012.03706 \mathrm{e}+001.00000 \mathrm{e}-092.12000 \mathrm{e}-01$ $2.03706 \mathrm{e}+012.03706 \mathrm{e}+012.03706 \mathrm{e}+001.00000 \mathrm{e}-092.12000 \mathrm{e}-01$ $2.03706 \mathrm{e}+012.03706 \mathrm{e}+012.03706 \mathrm{e}+001.00000 \mathrm{e}-092.12000 \mathrm{e}-01$ $1.00000 \mathrm{e}-02$ 1.00000e-02 1.00000e-03 1.00000e-09 1.00000e-01 1.00000e-05 1.00000e-05 1.00000e-06 1.00000e-09 1.00000e-01 $1.00000 \mathrm{e}+001.00000 \mathrm{e}+001.00000 \mathrm{e}-01$ 1.00000e-09 1.00000e-01 Element: 8534 \# of layers: 7

$\mathrm{Kx} \mathrm{Ky} \mathrm{Kz}$ Ss Por

$2.03706 \mathrm{e}+012.03706 \mathrm{e}+012.03706 \mathrm{e}+00$ 1.00000e-09 2.12000e-01 $2.03706 \mathrm{e}+012.03706 \mathrm{e}+012.03706 \mathrm{e}+001.00000 \mathrm{e}-092.12000 \mathrm{e}-01$ $2.03706 \mathrm{e}+012.03706 \mathrm{e}+012.03706 \mathrm{e}+001.00000 \mathrm{e}-092.12000 \mathrm{e}-01$ $2.03706 \mathrm{e}+012.03706 \mathrm{e}+012.03706 \mathrm{e}+001.00000 \mathrm{e}-092.12000 \mathrm{e}-01$ $2.03706 \mathrm{e}+012.03706 \mathrm{e}+012.03706 \mathrm{e}+001.00000 \mathrm{e}-092.12000 \mathrm{e}-01$ $1.00000 \mathrm{e}-05$ 1.00000e-05 1.00000e-06 1.00000e-09 1.00000e-01 $1.00000 \mathrm{e}+001.00000 \mathrm{e}+001.00000 \mathrm{e}-011.00000 \mathrm{e}-091.00000 \mathrm{e}-01$ Element: 8535 \# of layers: 9

$\mathrm{Kx} \mathrm{Ky} \mathrm{Kz}$ Ss Por

$2.03706 \mathrm{e}+012.03706 \mathrm{e}+012.03706 \mathrm{e}+00$ 1.00000e-09 2.12000e-01 $2.03706 \mathrm{e}+012.03706 \mathrm{e}+012.03706 \mathrm{e}+00 \quad 1.00000 \mathrm{e}-092.12000 \mathrm{e}-01$ $2.03706 \mathrm{e}+012.03706 \mathrm{e}+012.03706 \mathrm{e}+001.00000 \mathrm{e}-092.12000 \mathrm{e}-01$ $2.03706 \mathrm{e}+012.03706 \mathrm{e}+012.03706 \mathrm{e}+001.00000 \mathrm{e}-092.12000 \mathrm{e}-01$ $2.03706 \mathrm{e}+012.03706 \mathrm{e}+012.03706 \mathrm{e}+001.00000 \mathrm{e}-092.12000 \mathrm{e}-01$ $1.00000 \mathrm{e}-02$ 1.00000e-02 1.00000e-03 1.00000e-09 1.00000e-01 $1.00000 \mathrm{e}+001.00000 \mathrm{e}+001.00000 \mathrm{e}-011.00000 \mathrm{e}-091.00000 \mathrm{e}-01$ $1.00000 \mathrm{e}-05$ 1.00000e-05 1.00000e-06 1.00000e-09 1.00000e-01 $1.00000 \mathrm{e}+001.00000 \mathrm{e}+001.00000 \mathrm{e}-011.00000 \mathrm{e}-091.00000 \mathrm{e}-01$ Element: 8536 \# of layers: 7

$\mathrm{Kx} \mathrm{Ky} \mathrm{Kz}$ Ss Por

$2.03706 \mathrm{e}+012.03706 \mathrm{e}+012.03706 \mathrm{e}+00$ 1.00000e-09 2.12000e-01 $2.03706 \mathrm{e}+012.03706 \mathrm{e}+012.03706 \mathrm{e}+001.00000 \mathrm{e}-092.12000 \mathrm{e}-01$ $2.03706 \mathrm{e}+012.03706 \mathrm{e}+012.03706 \mathrm{e}+001.00000 \mathrm{e}-092.12000 \mathrm{e}-01$ $2.03706 \mathrm{e}+012.03706 \mathrm{e}+012.03706 \mathrm{e}+001.00000 \mathrm{e}-092.12000 \mathrm{e}-01$ $2.03706 \mathrm{e}+012.03706 \mathrm{e}+012.03706 \mathrm{e}+001.00000 \mathrm{e}-092.12000 \mathrm{e}-01$ $1.00000 \mathrm{e}-05$ 1.00000e-05 1.00000e-06 1.00000e-09 1.00000e-01 $1.00000 \mathrm{e}+001.00000 \mathrm{e}+001.00000 \mathrm{e}-011.00000 \mathrm{e}-091.00000 \mathrm{e}-01$ Element: 8537 \# of layers: 7

$\mathrm{Kx} \mathrm{Ky} \mathrm{Kz}$ Ss Por

$2.03706 \mathrm{e}+012.03706 \mathrm{e}+012.03706 \mathrm{e}+00$ 1.00000e-09 2.12000e-01 $2.03706 \mathrm{e}+012.03706 \mathrm{e}+012.03706 \mathrm{e}+001.00000 \mathrm{e}-092.12000 \mathrm{e}-01$ $2.03706 \mathrm{e}+012.03706 \mathrm{e}+012.03706 \mathrm{e}+001.00000 \mathrm{e}-092.12000 \mathrm{e}-01$ $2.03706 \mathrm{e}+012.03706 \mathrm{e}+012.03706 \mathrm{e}+001.00000 \mathrm{e}-092.12000 \mathrm{e}-01$ 2.03706e+01 2.03706e+01 2.03706e+00 1.00000e-09 2.12000e-01 $1.00000 \mathrm{e}-05$ 1.00000e-05 1.00000e-06 1.00000e-09 1.00000e-01 $1.00000 \mathrm{e}+001.00000 \mathrm{e}+001.00000 \mathrm{e}-011.00000 \mathrm{e}-091.00000 \mathrm{e}-01$ 
Element: 8538 \# of layers: 7

$\mathrm{Kx} \mathrm{Ky} \mathrm{Kz}$ Ss Por

$2.03706 \mathrm{e}+012.03706 \mathrm{e}+012.03706 \mathrm{e}+00$ 1.00000e-09 2.12000e-01

$2.03706 \mathrm{e}+012.03706 \mathrm{e}+012.03706 \mathrm{e}+001.00000 \mathrm{e}-092.12000 \mathrm{e}-01$

$2.03706 \mathrm{e}+012.03706 \mathrm{e}+012.03706 \mathrm{e}+001.00000 \mathrm{e}-092.12000 \mathrm{e}-01$

$2.03706 \mathrm{e}+012.03706 \mathrm{e}+012.03706 \mathrm{e}+001.00000 \mathrm{e}-092.12000 \mathrm{e}-01$

$2.03706 \mathrm{e}+012.03706 \mathrm{e}+012.03706 \mathrm{e}+001.00000 \mathrm{e}-092.12000 \mathrm{e}-01$

$1.00000 \mathrm{e}-05$ 1.00000e-05 1.00000e-06 1.00000e-09 1.00000e-01

$1.00000 \mathrm{e}+001.00000 \mathrm{e}+001.00000 \mathrm{e}-011.00000 \mathrm{e}-091.00000 \mathrm{e}-01$

Element: 8539 \# of layers: 7

$\mathrm{Kx} \mathrm{Ky} \mathrm{Kz}$ Ss Por

$2.03706 \mathrm{e}+012.03706 \mathrm{e}+012.03706 \mathrm{e}+00$ 1.00000e-09 2.12000e-01

$2.03706 \mathrm{e}+012.03706 \mathrm{e}+012.03706 \mathrm{e}+001.00000 \mathrm{e}-092.12000 \mathrm{e}-01$

$2.03706 \mathrm{e}+012.03706 \mathrm{e}+012.03706 \mathrm{e}+001.00000 \mathrm{e}-092.12000 \mathrm{e}-01$

$2.03706 \mathrm{e}+012.03706 \mathrm{e}+012.03706 \mathrm{e}+001.00000 \mathrm{e}-092.12000 \mathrm{e}-01$

$2.03706 \mathrm{e}+012.03706 \mathrm{e}+012.03706 \mathrm{e}+001.00000 \mathrm{e}-092.12000 \mathrm{e}-01$

$1.00000 \mathrm{e}-05$ 1.00000e-05 1.00000e-06 1.00000e-09 1.00000e-01

$1.00000 \mathrm{e}+001.00000 \mathrm{e}+001.00000 \mathrm{e}-01$ 1.00000e-09 1.00000e-01

Element: 8540 \# of layers: 7

$\mathrm{Kx} \mathrm{Ky} \mathrm{Kz}$ Ss Por

$2.00263 \mathrm{e}+012.00263 \mathrm{e}+012.00263 \mathrm{e}+001.00000 \mathrm{e}-092.12000 \mathrm{e}-01$

$2.00263 \mathrm{e}+012.00263 \mathrm{e}+012.00263 \mathrm{e}+00$ 1.00000e-09 2.12000e-01

$2.00263 \mathrm{e}+012.00263 \mathrm{e}+012.00263 \mathrm{e}+00$ 1.00000e-09 2.12000e-01

$2.00263 \mathrm{e}+012.00263 \mathrm{e}+012.00263 \mathrm{e}+001.00000 \mathrm{e}-092.12000 \mathrm{e}-01$

$2.00263 \mathrm{e}+012.00263 \mathrm{e}+012.00263 \mathrm{e}+001.00000 \mathrm{e}-092.12000 \mathrm{e}-01$

$1.00000 \mathrm{e}-05$ 1.00000e-05 1.00000e-06 1.00000e-09 1.00000e-01

$1.00000 \mathrm{e}+001.00000 \mathrm{e}+001.00000 \mathrm{e}-011.00000 \mathrm{e}-091.00000 \mathrm{e}-01$

Element: 8541 \# of layers: 7

$\mathrm{Kx} \mathrm{Ky} \mathrm{Kz}$ Ss Por

$2.00263 \mathrm{e}+012.00263 \mathrm{e}+012.00263 \mathrm{e}+001.00000 \mathrm{e}-092.12000 \mathrm{e}-01$

$2.00263 \mathrm{e}+012.00263 \mathrm{e}+012.00263 \mathrm{e}+00$ 1.00000e-09 2.12000e-01

$2.00263 \mathrm{e}+012.00263 \mathrm{e}+012.00263 \mathrm{e}+00$ 1.00000e-09 2.12000e-01

$2.00263 \mathrm{e}+012.00263 \mathrm{e}+012.00263 \mathrm{e}+00$ 1.00000e-09 2.12000e-01

$2.00263 \mathrm{e}+012.00263 \mathrm{e}+012.00263 \mathrm{e}+00$ 1.00000e-09 2.12000e-01

$1.00000 \mathrm{e}-05$ 1.00000e-05 1.00000e-06 1.00000e-09 1.00000e-01

$1.00000 \mathrm{e}+001.00000 \mathrm{e}+001.00000 \mathrm{e}-011.00000 \mathrm{e}-091.00000 \mathrm{e}-01$

Element: 8542 \# of layers: 7

$\mathrm{Kx} \mathrm{Ky} \mathrm{Kz}$ Ss Por

$2.00263 \mathrm{e}+012.00263 \mathrm{e}+012.00263 \mathrm{e}+00$ 1.00000e-09 2.12000e-01

$2.00263 \mathrm{e}+012.00263 \mathrm{e}+012.00263 \mathrm{e}+001.00000 \mathrm{e}-092.12000 \mathrm{e}-01$

$2.00263 \mathrm{e}+012.00263 \mathrm{e}+012.00263 \mathrm{e}+001.00000 \mathrm{e}-092.12000 \mathrm{e}-01$

$2.00263 \mathrm{e}+012.00263 \mathrm{e}+012.00263 \mathrm{e}+00$ 1.00000e-09 2.12000e-01

$2.00263 \mathrm{e}+012.00263 \mathrm{e}+012.00263 \mathrm{e}+00$ 1.00000e-09 2.12000e-01

$1.00000 \mathrm{e}-05$ 1.00000e-05 1.00000e-06 1.00000e-09 1.00000e-01

$1.00000 \mathrm{e}+001.00000 \mathrm{e}+001.00000 \mathrm{e}-011.00000 \mathrm{e}-09$ 1.00000e-01

Element: 8543 \# of layers: 7 
Kx Ky Kz Ss Por

$2.00263 \mathrm{e}+012.00263 \mathrm{e}+012.00263 \mathrm{e}+00$ 1.00000e-09 2.12000e-01

$2.00263 \mathrm{e}+012.00263 \mathrm{e}+012.00263 \mathrm{e}+001.00000 \mathrm{e}-092.12000 \mathrm{e}-01$

$2.00263 \mathrm{e}+012.00263 \mathrm{e}+012.00263 \mathrm{e}+001.00000 \mathrm{e}-092.12000 \mathrm{e}-01$

$2.00263 \mathrm{e}+012.00263 \mathrm{e}+012.00263 \mathrm{e}+001.00000 \mathrm{e}-092.12000 \mathrm{e}-01$

$2.00263 \mathrm{e}+012.00263 \mathrm{e}+012.00263 \mathrm{e}+001.00000 \mathrm{e}-092.12000 \mathrm{e}-01$

$1.00000 \mathrm{e}-05$ 1.00000e-05 1.00000e-06 1.00000e-09 1.00000e-01

$1.00000 \mathrm{e}+001.00000 \mathrm{e}+001.00000 \mathrm{e}-01$ 1.00000e-09 1.00000e-01

Element: 8544 \# of layers: 7

$\mathrm{Kx} \mathrm{Ky} \mathrm{Kz}$ Ss Por

$2.00263 \mathrm{e}+012.00263 \mathrm{e}+012.00263 \mathrm{e}+00$ 1.00000e-09 2.12000e-01 $2.00263 \mathrm{e}+012.00263 \mathrm{e}+012.00263 \mathrm{e}+001.00000 \mathrm{e}-092.12000 \mathrm{e}-01$ $2.00263 \mathrm{e}+012.00263 \mathrm{e}+012.00263 \mathrm{e}+001.00000 \mathrm{e}-092.12000 \mathrm{e}-01$ $2.00263 \mathrm{e}+012.00263 \mathrm{e}+012.00263 \mathrm{e}+001.00000 \mathrm{e}-092.12000 \mathrm{e}-01$ $2.00263 \mathrm{e}+012.00263 \mathrm{e}+012.00263 \mathrm{e}+001.00000 \mathrm{e}-092.12000 \mathrm{e}-01$ $1.00000 \mathrm{e}-05$ 1.00000e-05 1.00000e-06 1.00000e-09 1.00000e-01 $1.00000 \mathrm{e}+001.00000 \mathrm{e}+001.00000 \mathrm{e}-01$ 1.00000e-09 1.00000e-01 Element: 8545 \# of layers: 7

$\mathrm{Kx} \mathrm{Ky} \mathrm{Kz}$ Ss Por

$2.00263 \mathrm{e}+012.00263 \mathrm{e}+012.00263 \mathrm{e}+00$ 1.00000e-09 2.12000e-01 $2.00263 \mathrm{e}+012.00263 \mathrm{e}+012.00263 \mathrm{e}+001.00000 \mathrm{e}-092.12000 \mathrm{e}-01$ $2.00263 \mathrm{e}+012.00263 \mathrm{e}+012.00263 \mathrm{e}+00$ 1.00000e-09 2.12000e-01 $2.00263 \mathrm{e}+012.00263 \mathrm{e}+012.00263 \mathrm{e}+00$ 1.00000e-09 2.12000e-01 $2.00263 \mathrm{e}+012.00263 \mathrm{e}+012.00263 \mathrm{e}+001.00000 \mathrm{e}-092.12000 \mathrm{e}-01$ $1.00000 \mathrm{e}-05$ 1.00000e-05 1.00000e-06 1.00000e-09 1.00000e-01 $1.00000 \mathrm{e}+001.00000 \mathrm{e}+001.00000 \mathrm{e}-011.00000 \mathrm{e}-091.00000 \mathrm{e}-01$ Element: 8546 \# of layers: 9

$\mathrm{Kx} \mathrm{Ky} \mathrm{Kz}$ Ss Por

$1.96332 \mathrm{e}+01$ 1.96332e+01 1.96332e+00 1.00000e-09 2.12000e-01 $1.96332 \mathrm{e}+01$ 1.96332e+01 1.96332e+00 1.00000e-09 2.12000e-01 $1.96332 \mathrm{e}+01$ 1.96332e+01 1.96332e+00 1.00000e-09 2.12000e-01 $1.96332 \mathrm{e}+01$ 1.96332e+01 1.96332e+00 1.00000e-09 2.12000e-01 $1.96332 \mathrm{e}+011.96332 \mathrm{e}+01$ 1.96332e+00 1.00000e-09 2.12000e-01 $1.00000 \mathrm{e}-02$ 1.00000e-02 1.00000e-03 1.00000e-09 1.00000e-01 $1.00000 \mathrm{e}+001.00000 \mathrm{e}+001.00000 \mathrm{e}-011.00000 \mathrm{e}-091.00000 \mathrm{e}-01$ 1.00000e-05 1.00000e-05 1.00000e-06 1.00000e-09 1.00000e-01 $1.00000 \mathrm{e}+001.00000 \mathrm{e}+001.00000 \mathrm{e}-011.00000 \mathrm{e}-091.00000 \mathrm{e}-01$ Element: 8547 \# of layers: 9

$\mathrm{Kx} \mathrm{Ky} \mathrm{Kz}$ Ss Por

$1.96332 \mathrm{e}+01$ 1.96332e+01 1.96332e+00 1.00000e-09 2.12000e-01 $1.96332 \mathrm{e}+01$ 1.96332e+01 1.96332e+00 1.00000e-09 2.12000e-01 $1.96332 \mathrm{e}+01$ 1.96332e+01 1.96332e+00 1.00000e-09 2.12000e-01 $1.96332 \mathrm{e}+01$ 1.96332e+01 1.96332e+00 1.00000e-09 2.12000e-01 $1.96332 \mathrm{e}+01$ 1.96332e+01 1.96332e+00 1.00000e-09 2.12000e-01 $1.00000 \mathrm{e}-02$ 1.00000e-02 1.00000e-03 1.00000e-09 1.00000e-01 $1.00000 \mathrm{e}+001.00000 \mathrm{e}+001.00000 \mathrm{e}-011.00000 \mathrm{e}-091.00000 \mathrm{e}-01$ 
$1.00000 \mathrm{e}-05$ 1.00000e-05 1.00000e-06 1.00000e-09 1.00000e-01 $1.00000 \mathrm{e}+001.00000 \mathrm{e}+001.00000 \mathrm{e}-011.00000 \mathrm{e}-091.00000 \mathrm{e}-01$ Element: 8548 \# of layers: 8

Kx Ky Kz Ss Por

$1.96332 \mathrm{e}+01$ 1.96332e+01 1.96332e+00 1.00000e-09 2.12000e-01 $1.96332 \mathrm{e}+01$ 1.96332e+01 1.96332e+00 1.00000e-09 2.12000e-01 $1.96332 \mathrm{e}+01$ 1.96332e+01 1.96332e+00 1.00000e-09 2.12000e-01 $1.96332 \mathrm{e}+01$ 1.96332e+01 1.96332e+00 1.00000e-09 2.12000e-01 1.96332e+01 1.96332e+01 1.96332e+00 1.00000e-09 2.12000e-01 $1.00000 \mathrm{e}-02$ 1.00000e-02 1.00000e-03 1.00000e-09 1.00000e-01 $1.00000 \mathrm{e}-05$ 1.00000e-05 1.00000e-06 1.00000e-09 1.00000e-01 $1.00000 \mathrm{e}+001.00000 \mathrm{e}+001.00000 \mathrm{e}-011.00000 \mathrm{e}-091.00000 \mathrm{e}-01$ Element: 8549 \# of layers: 9

$\mathrm{Kx} \mathrm{Ky} \mathrm{Kz}$ Ss Por

1.96332e+01 1.96332e+01 1.96332e+00 1.00000e-09 2.12000e-01 $1.96332 \mathrm{e}+01$ 1.96332e+01 1.96332e+00 1.00000e-09 2.12000e-01 $1.96332 \mathrm{e}+011.96332 \mathrm{e}+01$ 1.96332e+00 1.00000e-09 2.12000e-01 $1.96332 \mathrm{e}+01$ 1.96332e+01 1.96332e+00 1.00000e-09 2.12000e-01 $1.96332 \mathrm{e}+01$ 1.96332e+01 1.96332e+00 1.00000e-09 2.12000e-01 $1.00000 \mathrm{e}-02$ 1.00000e-02 1.00000e-03 1.00000e-09 1.00000e-01 $1.00000 \mathrm{e}+001.00000 \mathrm{e}+001.00000 \mathrm{e}-011.00000 \mathrm{e}-091.00000 \mathrm{e}-01$ $1.00000 \mathrm{e}-05$ 1.00000e-05 1.00000e-06 1.00000e-09 1.00000e-01 $1.00000 \mathrm{e}+001.00000 \mathrm{e}+001.00000 \mathrm{e}-01$ 1.00000e-09 1.00000e-01 Element: 8550 \# of layers: 9

$\mathrm{Kx} \mathrm{Ky} \mathrm{Kz}$ Ss Por

$1.96332 \mathrm{e}+01$ 1.96332e+01 1.96332e+00 1.00000e-09 2.12000e-01 $1.96332 \mathrm{e}+01$ 1.96332e+01 1.96332e+00 1.00000e-09 2.12000e-01 $1.96332 \mathrm{e}+01$ 1.96332e+01 1.96332e+00 1.00000e-09 2.12000e-01 $1.96332 \mathrm{e}+01$ 1.96332e+01 1.96332e+00 1.00000e-09 2.12000e-01 $1.96332 \mathrm{e}+01$ 1.96332e+01 1.96332e+00 1.00000e-09 2.12000e-01 $1.00000 \mathrm{e}-02$ 1.00000e-02 1.00000e-03 1.00000e-09 1.00000e-01 $1.00000 \mathrm{e}+001.00000 \mathrm{e}+001.00000 \mathrm{e}-011.00000 \mathrm{e}-091.00000 \mathrm{e}-01$ $1.00000 \mathrm{e}-05$ 1.00000e-05 1.00000e-06 1.00000e-09 1.00000e-01 $1.00000 \mathrm{e}+001.00000 \mathrm{e}+001.00000 \mathrm{e}-011.00000 \mathrm{e}-091.00000 \mathrm{e}-01$ Element: 8551 \# of layers: 9

$\mathrm{Kx} \mathrm{Ky} \mathrm{Kz}$ Ss Por 4.29872e+00 4.29872e+00 4.29872e-01 1.00000e-09 2.12000e-01 $4.29872 \mathrm{e}+004.29872 \mathrm{e}+00$ 4.29872e-01 1.00000e-09 2.12000e-01 $4.29872 \mathrm{e}+00$ 4.29872e+00 4.29872e-01 1.00000e-09 2.12000e-01 4.29872e+00 4.29872e+00 4.29872e-01 1.00000e-09 2.12000e-01 4.29872e+00 4.29872e+00 4.29872e-01 1.00000e-09 2.12000e-01 $1.00000 \mathrm{e}-02$ 1.00000e-02 1.00000e-03 1.00000e-09 1.00000e-01 $1.00000 \mathrm{e}+001.00000 \mathrm{e}+001.00000 \mathrm{e}-011.00000 \mathrm{e}-091.00000 \mathrm{e}-01$ $1.00000 \mathrm{e}-05$ 1.00000e-05 1.00000e-06 1.00000e-09 1.00000e-01 $1.00000 \mathrm{e}+001.00000 \mathrm{e}+001.00000 \mathrm{e}-011.00000 \mathrm{e}-091.00000 \mathrm{e}-01$ Element: 8552 \# of layers: 8 
$\mathrm{Kx} \mathrm{Ky} \mathrm{Kz}$ Ss Por

4.29872e+00 4.29872e+00 4.29872e-01 1.00000e-09 2.12000e-01 4.29872e+00 4.29872e+00 4.29872e-01 1.00000e-09 2.12000e-01 $4.29872 \mathrm{e}+00$ 4.29872e+00 4.29872e-01 1.00000e-09 2.12000e-01 4.29872e+00 4.29872e+00 4.29872e-01 1.00000e-09 2.12000e-01 4.29872e+00 4.29872e+00 4.29872e-01 1.00000e-09 2.12000e-01 $1.00000 \mathrm{e}-02$ 1.00000e-02 1.00000e-03 1.00000e-09 1.00000e-01 $1.00000 \mathrm{e}-05$ 1.00000e-05 1.00000e-06 1.00000e-09 1.00000e-01 $1.00000 \mathrm{e}+001.00000 \mathrm{e}+001.00000 \mathrm{e}-011.00000 \mathrm{e}-091.00000 \mathrm{e}-01$ Element: 8553 \# of layers: 9

$\mathrm{Kx} \mathrm{Ky} \mathrm{Kz}$ Ss Por

$1.96332 \mathrm{e}+01$ 1.96332e+01 1.96332e+00 1.00000e-09 2.12000e-01 $1.96332 \mathrm{e}+01$ 1.96332e+01 1.96332e+00 1.00000e-09 2.12000e-01 $1.96332 \mathrm{e}+01$ 1.96332e+01 1.96332e+00 1.00000e-09 2.12000e-01 $1.96332 \mathrm{e}+01$ 1.96332e+01 1.96332e+00 1.00000e-09 2.12000e-01 $1.96332 \mathrm{e}+01$ 1.96332e+01 1.96332e+00 1.00000e-09 2.12000e-01 $1.00000 \mathrm{e}-02$ 1.00000e-02 1.00000e-03 1.00000e-09 1.00000e-01 $1.00000 \mathrm{e}+001.00000 \mathrm{e}+001.00000 \mathrm{e}-011.00000 \mathrm{e}-091.00000 \mathrm{e}-01$ $1.00000 \mathrm{e}-051.00000 \mathrm{e}-051.00000 \mathrm{e}-061.00000 \mathrm{e}-091.00000 \mathrm{e}-01$ $1.00000 \mathrm{e}+001.00000 \mathrm{e}+001.00000 \mathrm{e}-011.00000 \mathrm{e}-091.00000 \mathrm{e}-01$ Element: 8554 \# of layers: 9

$\mathrm{Kx} \mathrm{Ky} \mathrm{Kz}$ Ss Por

4.29872e+00 4.29872e+00 4.29872e-01 1.00000e-09 2.12000e-01 $4.29872 \mathrm{e}+004.29872 \mathrm{e}+00$ 4.29872e-01 1.00000e-09 2.12000e-01 $4.29872 \mathrm{e}+004.29872 \mathrm{e}+00$ 4.29872e-01 1.00000e-09 2.12000e-01 $4.29872 \mathrm{e}+004.29872 \mathrm{e}+00$ 4.29872e-01 1.00000e-09 2.12000e-01 4.29872e+00 4.29872e+00 4.29872e-01 1.00000e-09 2.12000e-01 $1.00000 \mathrm{e}-02$ 1.00000e-02 1.00000e-03 1.00000e-09 1.00000e-01 $1.00000 \mathrm{e}+001.00000 \mathrm{e}+001.00000 \mathrm{e}-011.00000 \mathrm{e}-091.00000 \mathrm{e}-01$ $1.00000 \mathrm{e}-05$ 1.00000e-05 1.00000e-06 1.00000e-09 1.00000e-01 $1.00000 \mathrm{e}+001.00000 \mathrm{e}+001.00000 \mathrm{e}-011.00000 \mathrm{e}-091.00000 \mathrm{e}-01$ Element: 8555 \# of layers: 9

$\mathrm{Kx} \mathrm{Ky} \mathrm{Kz}$ Ss Por

4.29872e+00 4.29872e+00 4.29872e-01 1.00000e-09 2.12000e-01 4.29872e+00 4.29872e+00 4.29872e-01 1.00000e-09 2.12000e-01 4.29872e+00 4.29872e+00 4.29872e-01 1.00000e-09 2.12000e-01 $4.29872 \mathrm{e}+004.29872 \mathrm{e}+00$ 4.29872e-01 1.00000e-09 2.12000e-01 4.29872e+00 4.29872e+00 4.29872e-01 1.00000e-09 2.12000e-01 $1.00000 \mathrm{e}-02$ 1.00000e-02 1.00000e-03 1.00000e-09 1.00000e-01 $1.00000 \mathrm{e}+001.00000 \mathrm{e}+001.00000 \mathrm{e}-011.00000 \mathrm{e}-091.00000 \mathrm{e}-01$ $1.00000 \mathrm{e}-05$ 1.00000e-05 1.00000e-06 1.00000e-09 1.00000e-01 $1.00000 \mathrm{e}+001.00000 \mathrm{e}+001.00000 \mathrm{e}-011.00000 \mathrm{e}-091.00000 \mathrm{e}-01$ Element: 8556 \# of layers: 9

$\mathrm{Kx} \mathrm{Ky} \mathrm{Kz}$ Ss Por

$4.29872 \mathrm{e}+00$ 4.29872e+00 4.29872e-01 1.00000e-09 2.12000e-01 $4.29872 \mathrm{e}+004.29872 \mathrm{e}+00$ 4.29872e-01 1.00000e-09 2.12000e-01 
4.29872e+00 4.29872e+00 4.29872e-01 1.00000e-09 2.12000e-01 4.29872e+00 4.29872e+00 4.29872e-01 1.00000e-09 2.12000e-01 4.29872e+00 4.29872e+00 4.29872e-01 1.00000e-09 2.12000e-01 $1.00000 \mathrm{e}-02$ 1.00000e-02 1.00000e-03 1.00000e-09 1.00000e-01 $1.00000 \mathrm{e}+001.00000 \mathrm{e}+001.00000 \mathrm{e}-011.00000 \mathrm{e}-091.00000 \mathrm{e}-01$ $1.00000 \mathrm{e}-05$ 1.00000e-05 1.00000e-06 1.00000e-09 1.00000e-01 $1.00000 \mathrm{e}+001.00000 \mathrm{e}+00$ 1.00000e-01 1.00000e-09 1.00000e-01 Element: 8557 \# of layers: 9

$\mathrm{Kx} \mathrm{Ky} \mathrm{Kz}$ Ss Por

4.29872e+00 4.29872e+00 4.29872e-01 1.00000e-09 2.12000e-01 $4.29872 \mathrm{e}+00$ 4.29872e+00 4.29872e-01 1.00000e-09 2.12000e-01 4.29872e+00 4.29872e+00 4.29872e-01 1.00000e-09 2.12000e-01 4.29872e+00 4.29872e+00 4.29872e-01 1.00000e-09 2.12000e-01 4.29872e+00 4.29872e+00 4.29872e-01 1.00000e-09 2.12000e-01 $1.00000 \mathrm{e}-02$ 1.00000e-02 1.00000e-03 1.00000e-09 1.00000e-01 $1.00000 \mathrm{e}+001.00000 \mathrm{e}+001.00000 \mathrm{e}-011.00000 \mathrm{e}-091.00000 \mathrm{e}-01$ $1.00000 \mathrm{e}-05$ 1.00000e-05 1.00000e-06 1.00000e-09 1.00000e-01 $1.00000 \mathrm{e}+001.00000 \mathrm{e}+001.00000 \mathrm{e}-01$ 1.00000e-09 1.00000e-01 Element: 8558 \# of layers: 9

$\mathrm{Kx} \mathrm{Ky} \mathrm{Kz}$ Ss Por

4.29872e+00 4.29872e+00 4.29872e-01 1.00000e-09 2.12000e-01 4.29872e+00 4.29872e+00 4.29872e-01 1.00000e-09 2.12000e-01 4.29872e+00 4.29872e+00 4.29872e-01 1.00000e-09 2.12000e-01 4.29872e+00 4.29872e+00 4.29872e-01 1.00000e-09 2.12000e-01 $4.29872 \mathrm{e}+00$ 4.29872e+00 4.29872e-01 1.00000e-09 2.12000e-01 $1.00000 \mathrm{e}-021.00000 \mathrm{e}-021.00000 \mathrm{e}-031.00000 \mathrm{e}-091.00000 \mathrm{e}-01$ $1.00000 \mathrm{e}+001.00000 \mathrm{e}+001.00000 \mathrm{e}-011.00000 \mathrm{e}-091.00000 \mathrm{e}-01$ $1.00000 \mathrm{e}-05$ 1.00000e-05 1.00000e-06 1.00000e-09 1.00000e-01 $1.00000 \mathrm{e}+001.00000 \mathrm{e}+001.00000 \mathrm{e}-011.00000 \mathrm{e}-091.00000 \mathrm{e}-01$ Element: 8559 \# of layers: 7

$\mathrm{Kx} \mathrm{Ky} \mathrm{Kz}$ Ss Por

4.29872e+00 4.29872e+00 4.29872e-01 1.00000e-09 2.12000e-01 $4.29872 \mathrm{e}+004.29872 \mathrm{e}+00$ 4.29872e-01 1.00000e-09 2.12000e-01 $4.29872 \mathrm{e}+00$ 4.29872e+00 4.29872e-01 1.00000e-09 2.12000e-01 4.29872e+00 4.29872e+00 4.29872e-01 1.00000e-09 2.12000e-01 4.29872e+00 4.29872e+00 4.29872e-01 1.00000e-09 2.12000e-01 $1.00000 \mathrm{e}-05$ 1.00000e-05 1.00000e-06 1.00000e-09 1.00000e-01 $1.00000 \mathrm{e}+001.00000 \mathrm{e}+001.00000 \mathrm{e}-011.00000 \mathrm{e}-091.00000 \mathrm{e}-01$ Element: 8560 \# of layers: 7

$\mathrm{Kx} \mathrm{Ky} \mathrm{Kz}$ Ss Por 4.29872e+00 4.29872e+00 4.29872e-01 1.00000e-09 2.12000e-01 $4.29872 \mathrm{e}+004.29872 \mathrm{e}+00$ 4.29872e-01 1.00000e-09 2.12000e-01 $4.29872 \mathrm{e}+00$ 4.29872e+00 4.29872e-01 1.00000e-09 2.12000e-01 4.29872e+00 4.29872e+00 4.29872e-01 1.00000e-09 2.12000e-01 4.29872e+00 4.29872e+00 4.29872e-01 1.00000e-09 2.12000e-01 $1.00000 \mathrm{e}-05$ 1.00000e-05 1.00000e-06 1.00000e-09 1.00000e-01 
$1.00000 \mathrm{e}+001.00000 \mathrm{e}+001.00000 \mathrm{e}-01$ 1.00000e-09 1.00000e-01 Element: 8561 \# of layers: 7

$\mathrm{Kx} \mathrm{Ky} \mathrm{Kz}$ Ss Por

3.55103e+00 3.55103e+00 3.55103e-01 1.00000e-09 2.12000e-01

3.55103e+00 3.55103e+00 3.55103e-01 1.00000e-09 2.12000e-01

3.55103e+00 3.55103e+00 3.55103e-01 1.00000e-09 2.12000e-01

$3.55103 \mathrm{e}+00$ 3.55103e+00 3.55103e-01 1.00000e-09 2.12000e-01

$3.55103 \mathrm{e}+003.55103 \mathrm{e}+00$ 3.55103e-01 1.00000e-09 2.12000e-01

$1.00000 \mathrm{e}-05$ 1.00000e-05 1.00000e-06 1.00000e-09 1.00000e-01

$1.00000 \mathrm{e}+001.00000 \mathrm{e}+001.00000 \mathrm{e}-01$ 1.00000e-09 1.00000e-01

Element: 8562 \# of layers: 7

$\mathrm{Kx} \mathrm{Ky} \mathrm{Kz}$ Ss Por

3.55103e+00 3.55103e+00 3.55103e-01 1.00000e-09 2.12000e-01

$3.55103 \mathrm{e}+003.55103 \mathrm{e}+00$ 3.55103e-01 1.00000e-09 2.12000e-01

$3.55103 \mathrm{e}+003.55103 \mathrm{e}+00$ 3.55103e-01 1.00000e-09 2.12000e-01

$3.55103 \mathrm{e}+003.55103 \mathrm{e}+003.55103 \mathrm{e}-01$ 1.00000e-09 2.12000e-01

$3.55103 \mathrm{e}+00$ 3.55103e+00 3.55103e-01 1.00000e-09 2.12000e-01

$1.00000 \mathrm{e}-05$ 1.00000e-05 1.00000e-06 1.00000e-09 1.00000e-01

$1.00000 \mathrm{e}+001.00000 \mathrm{e}+001.00000 \mathrm{e}-011.00000 \mathrm{e}-091.00000 \mathrm{e}-01$

Element: 8563 \# of layers: 7

$\mathrm{Kx} \mathrm{Ky} \mathrm{Kz}$ Ss Por

3.55103e+00 3.55103e+00 3.55103e-01 1.00000e-09 2.12000e-01

$3.55103 \mathrm{e}+003.55103 \mathrm{e}+00$ 3.55103e-01 1.00000e-09 2.12000e-01

$3.55103 \mathrm{e}+003.55103 \mathrm{e}+00$ 3.55103e-01 1.00000e-09 2.12000e-01

$3.55103 \mathrm{e}+003.55103 \mathrm{e}+00$ 3.55103e-01 1.00000e-09 2.12000e-01

$3.55103 e+003.55103 e+003.55103 e-01$ 1.00000e-09 2.12000e-01

$1.00000 \mathrm{e}-05$ 1.00000e-05 1.00000e-06 1.00000e-09 1.00000e-01

$1.00000 \mathrm{e}+001.00000 \mathrm{e}+001.00000 \mathrm{e}-011.00000 \mathrm{e}-09$ 1.00000e-01

Element: 8564 \# of layers: 7

$\mathrm{Kx} \mathrm{Ky} \mathrm{Kz}$ Ss Por

4.29872e+00 4.29872e+00 4.29872e-01 1.00000e-09 2.12000e-01

4.29872e+00 4.29872e+00 4.29872e-01 1.00000e-09 2.12000e-01

$4.29872 \mathrm{e}+004.29872 \mathrm{e}+00$ 4.29872e-01 1.00000e-09 2.12000e-01

$4.29872 \mathrm{e}+00$ 4.29872e+00 4.29872e-01 1.00000e-09 2.12000e-01

4.29872e+00 4.29872e+00 4.29872e-01 1.00000e-09 2.12000e-01

$1.00000 \mathrm{e}-05$ 1.00000e-05 1.00000e-06 1.00000e-09 1.00000e-01

$1.00000 \mathrm{e}+001.00000 \mathrm{e}+001.00000 \mathrm{e}-011.00000 \mathrm{e}-091.00000 \mathrm{e}-01$

Element: 8565 \# of layers: 8

$\mathrm{Kx} \mathrm{Ky} \mathrm{Kz}$ Ss Por

4.29872e+00 4.29872e+00 4.29872e-01 1.00000e-09 2.12000e-01 $4.29872 \mathrm{e}+004.29872 \mathrm{e}+00$ 4.29872e-01 1.00000e-09 2.12000e-01 $4.29872 \mathrm{e}+004.29872 \mathrm{e}+00$ 4.29872e-01 1.00000e-09 2.12000e-01 $4.29872 \mathrm{e}+00$ 4.29872e+00 4.29872e-01 1.00000e-09 2.12000e-01 4.29872e+00 4.29872e+00 4.29872e-01 1.00000e-09 2.12000e-01 $1.00000 \mathrm{e}-02$ 1.00000e-02 1.00000e-03 1.00000e-09 1.00000e-01 $1.00000 \mathrm{e}-05$ 1.00000e-05 1.00000e-06 1.00000e-09 1.00000e-01 
$1.00000 \mathrm{e}+001.00000 \mathrm{e}+001.00000 \mathrm{e}-011.00000 \mathrm{e}-091.00000 \mathrm{e}-01$ Element: 8566 \# of layers: 7

$\mathrm{Kx} \mathrm{Ky} \mathrm{Kz}$ Ss Por

4.29872e+00 4.29872e+00 4.29872e-01 1.00000e-09 2.12000e-01 4.29872e+00 4.29872e+00 4.29872e-01 1.00000e-09 2.12000e-01 4.29872e+00 4.29872e+00 4.29872e-01 1.00000e-09 2.12000e-01 $4.29872 \mathrm{e}+00$ 4.29872e+00 4.29872e-01 1.00000e-09 2.12000e-01 $4.29872 \mathrm{e}+00$ 4.29872e+00 4.29872e-01 1.00000e-09 2.12000e-01 $1.00000 \mathrm{e}-05$ 1.00000e-05 1.00000e-06 1.00000e-09 1.00000e-01 $1.00000 \mathrm{e}+001.00000 \mathrm{e}+00$ 1.00000e-01 1.00000e-09 1.00000e-01 Element: 8567 \# of layers: 7

$\mathrm{Kx} \mathrm{Ky} \mathrm{Kz}$ Ss Por

4.29872e+00 4.29872e+00 4.29872e-01 1.00000e-09 2.12000e-01 4.29872e+00 4.29872e+00 4.29872e-01 1.00000e-09 2.12000e-01 4.29872e+00 4.29872e+00 4.29872e-01 1.00000e-09 2.12000e-01 $4.29872 \mathrm{e}+004.29872 \mathrm{e}+00$ 4.29872e-01 1.00000e-09 2.12000e-01 4.29872e+00 4.29872e+00 4.29872e-01 1.00000e-09 2.12000e-01 $1.00000 \mathrm{e}-05$ 1.00000e-05 1.00000e-06 1.00000e-09 1.00000e-01 $1.00000 \mathrm{e}+001.00000 \mathrm{e}+001.00000 \mathrm{e}-011.00000 \mathrm{e}-091.00000 \mathrm{e}-01$ Element: 8568 \# of layers: 7

$\mathrm{Kx} \mathrm{Ky} \mathrm{Kz}$ Ss Por

3.55103e+00 3.55103e+00 3.55103e-01 1.00000e-09 2.12000e-01 $3.55103 \mathrm{e}+003.55103 \mathrm{e}+00$ 3.55103e-01 1.00000e-09 2.12000e-01 $3.55103 \mathrm{e}+003.55103 \mathrm{e}+00$ 3.55103e-01 1.00000e-09 2.12000e-01 $3.55103 \mathrm{e}+003.55103 \mathrm{e}+00$ 3.55103e-01 1.00000e-09 2.12000e-01 $3.55103 \mathrm{e}+003.55103 \mathrm{e}+00$ 3.55103e-01 1.00000e-09 2.12000e-01 $1.00000 \mathrm{e}-05$ 1.00000e-05 1.00000e-06 1.00000e-09 1.00000e-01 $1.00000 \mathrm{e}+001.00000 \mathrm{e}+001.00000 \mathrm{e}-011.00000 \mathrm{e}-09$ 1.00000e-01 Element: 8569 \# of layers: 7

$\mathrm{Kx} \mathrm{Ky} \mathrm{Kz}$ Ss Por

3.55103e+00 3.55103e+00 3.55103e-01 1.00000e-09 2.12000e-01 3.55103e+00 3.55103e+00 3.55103e-01 1.00000e-09 2.12000e-01 $3.55103 e+003.55103 e+003.55103 e-01$ 1.00000e-09 2.12000e-01 $3.55103 \mathrm{e}+00$ 3.55103e+00 3.55103e-01 1.00000e-09 2.12000e-01 $3.55103 \mathrm{e}+003.55103 \mathrm{e}+003.55103 \mathrm{e}-01$ 1.00000e-09 2.12000e-01 1.00000e-05 1.00000e-05 1.00000e-06 1.00000e-09 1.00000e-01 $1.00000 \mathrm{e}+001.00000 \mathrm{e}+001.00000 \mathrm{e}-011.00000 \mathrm{e}-091.00000 \mathrm{e}-01$ Element: 8570 \# of layers: 7

$\mathrm{Kx} \mathrm{Ky} \mathrm{Kz}$ Ss Por

3.55103e+00 3.55103e+00 3.55103e-01 1.00000e-09 2.12000e-01 $3.55103 \mathrm{e}+003.55103 \mathrm{e}+00$ 3.55103e-01 1.00000e-09 2.12000e-01 $3.55103 \mathrm{e}+003.55103 \mathrm{e}+003.55103 \mathrm{e}-01$ 1.00000e-09 2.12000e-01 $3.55103 \mathrm{e}+00$ 3.55103e+00 3.55103e-01 1.00000e-09 2.12000e-01 3.55103e+00 3.55103e+00 3.55103e-01 1.00000e-09 2.12000e-01 $1.00000 \mathrm{e}-05$ 1.00000e-05 1.00000e-06 1.00000e-09 1.00000e-01 $1.00000 \mathrm{e}+001.00000 \mathrm{e}+001.00000 \mathrm{e}-011.00000 \mathrm{e}-091.00000 \mathrm{e}-01$ 
Element: 8571 \# of layers: 7

$\mathrm{Kx} \mathrm{Ky} \mathrm{Kz}$ Ss Por

3.55103e+00 3.55103e+00 3.55103e-01 1.00000e-09 2.12000e-01

$3.55103 e+003.55103 e+003.55103 e-01$ 1.00000e-09 2.12000e-01

3.55103e+00 3.55103e+00 3.55103e-01 1.00000e-09 2.12000e-01

$3.55103 \mathrm{e}+003.55103 \mathrm{e}+00$ 3.55103e-01 1.00000e-09 2.12000e-01

$3.55103 \mathrm{e}+003.55103 \mathrm{e}+00$ 3.55103e-01 1.00000e-09 2.12000e-01

$1.00000 \mathrm{e}-05$ 1.00000e-05 1.00000e-06 1.00000e-09 1.00000e-01

$1.00000 \mathrm{e}+001.00000 \mathrm{e}+001.00000 \mathrm{e}-011.00000 \mathrm{e}-091.00000 \mathrm{e}-01$

Element: 8572 \# of layers: 7

$\mathrm{Kx} \mathrm{Ky} \mathrm{Kz}$ Ss Por

3.55103e+00 3.55103e+00 3.55103e-01 1.00000e-09 2.12000e-01

$3.55103 \mathrm{e}+003.55103 \mathrm{e}+00$ 3.55103e-01 1.00000e-09 2.12000e-01

$3.55103 \mathrm{e}+003.55103 \mathrm{e}+00$ 3.55103e-01 1.00000e-09 2.12000e-01

$3.55103 \mathrm{e}+003.55103 \mathrm{e}+00$ 3.55103e-01 1.00000e-09 2.12000e-01

$3.55103 \mathrm{e}+003.55103 \mathrm{e}+003.55103 \mathrm{e}-01$ 1.00000e-09 2.12000e-01

$1.00000 \mathrm{e}-05$ 1.00000e-05 1.00000e-06 1.00000e-09 1.00000e-01

$1.00000 \mathrm{e}+001.00000 \mathrm{e}+001.00000 \mathrm{e}-011.00000 \mathrm{e}-091.00000 \mathrm{e}-01$

Element: 8573 \# of layers: 7

$\mathrm{Kx} \mathrm{Ky} \mathrm{Kz}$ Ss Por

3.55103e+00 3.55103e+00 3.55103e-01 1.00000e-09 2.12000e-01

3.55103e+00 3.55103e+00 3.55103e-01 1.00000e-09 2.12000e-01

$3.55103 \mathrm{e}+003.55103 \mathrm{e}+00$ 3.55103e-01 1.00000e-09 2.12000e-01

$3.55103 \mathrm{e}+003.55103 \mathrm{e}+00$ 3.55103e-01 1.00000e-09 2.12000e-01

$3.55103 \mathrm{e}+003.55103 \mathrm{e}+003.55103 \mathrm{e}-01$ 1.00000e-09 2.12000e-01

$1.00000 \mathrm{e}-05$ 1.00000e-05 1.00000e-06 1.00000e-09 1.00000e-01

$1.00000 \mathrm{e}+001.00000 \mathrm{e}+001.00000 \mathrm{e}-011.00000 \mathrm{e}-091.00000 \mathrm{e}-01$

Element: 8574 \# of layers: 7

Kx Ky Kz Ss Por

3.55103e+00 3.55103e+00 3.55103e-01 1.00000e-09 2.12000e-01

$3.55103 \mathrm{e}+003.55103 \mathrm{e}+00$ 3.55103e-01 1.00000e-09 2.12000e-01

$3.55103 \mathrm{e}+003.55103 \mathrm{e}+00$ 3.55103e-01 1.00000e-09 2.12000e-01

$3.55103 \mathrm{e}+003.55103 \mathrm{e}+00$ 3.55103e-01 1.00000e-09 2.12000e-01

$3.55103 \mathrm{e}+00$ 3.55103e+00 3.55103e-01 1.00000e-09 2.12000e-01

$1.00000 \mathrm{e}-05$ 1.00000e-05 1.00000e-06 1.00000e-09 1.00000e-01

$1.00000 \mathrm{e}+001.00000 \mathrm{e}+001.00000 \mathrm{e}-011.00000 \mathrm{e}-091.00000 \mathrm{e}-01$

Element: 8575 \# of layers: 7

$\mathrm{Kx} \mathrm{Ky} \mathrm{Kz}$ Ss Por

3.55103e+00 3.55103e+00 3.55103e-01 1.00000e-09 2.12000e-01

$3.55103 \mathrm{e}+003.55103 \mathrm{e}+00$ 3.55103e-01 1.00000e-09 2.12000e-01

$3.55103 \mathrm{e}+003.55103 \mathrm{e}+003.55103 \mathrm{e}-01$ 1.00000e-09 2.12000e-01

$3.55103 \mathrm{e}+003.55103 \mathrm{e}+00$ 3.55103e-01 1.00000e-09 2.12000e-01

$3.55103 \mathrm{e}+00$ 3.55103e+00 3.55103e-01 1.00000e-09 2.12000e-01

$1.00000 \mathrm{e}-05$ 1.00000e-05 1.00000e-06 1.00000e-09 1.00000e-01

$1.00000 \mathrm{e}+001.00000 \mathrm{e}+001.00000 \mathrm{e}-011.00000 \mathrm{e}-09$ 1.00000e-01

Element: 8576 \# of layers: 7 
$\mathrm{Kx} \mathrm{Ky} \mathrm{Kz}$ Ss Por

3.55103e+00 3.55103e+00 3.55103e-01 1.00000e-09 2.12000e-01

$3.55103 \mathrm{e}+003.55103 \mathrm{e}+00$ 3.55103e-01 1.00000e-09 2.12000e-01

$3.55103 \mathrm{e}+003.55103 \mathrm{e}+00$ 3.55103e-01 1.00000e-09 2.12000e-01

$3.55103 \mathrm{e}+003.55103 \mathrm{e}+00$ 3.55103e-01 1.00000e-09 2.12000e-01

$3.55103 \mathrm{e}+003.55103 \mathrm{e}+00$ 3.55103e-01 1.00000e-09 2.12000e-01

$1.00000 \mathrm{e}-05$ 1.00000e-05 1.00000e-06 1.00000e-09 1.00000e-01

$1.00000 \mathrm{e}+001.00000 \mathrm{e}+001.00000 \mathrm{e}-01$ 1.00000e-09 1.00000e-01

Element: 8577 \# of layers: 7

$\mathrm{Kx} \mathrm{Ky} \mathrm{Kz}$ Ss Por

3.55103e+00 3.55103e+00 3.55103e-01 1.00000e-09 2.12000e-01

$3.55103 \mathrm{e}+003.55103 \mathrm{e}+00$ 3.55103e-01 1.00000e-09 2.12000e-01

$3.55103 \mathrm{e}+003.55103 \mathrm{e}+003.55103 \mathrm{e}-01$ 1.00000e-09 2.12000e-01

$3.55103 \mathrm{e}+003.55103 \mathrm{e}+00$ 3.55103e-01 1.00000e-09 2.12000e-01

$3.55103 \mathrm{e}+003.55103 \mathrm{e}+00$ 3.55103e-01 1.00000e-09 2.12000e-01

$1.00000 \mathrm{e}-05$ 1.00000e-05 1.00000e-06 1.00000e-09 1.00000e-01

$1.00000 \mathrm{e}+001.00000 \mathrm{e}+001.00000 \mathrm{e}-011.00000 \mathrm{e}-09$ 1.00000e-01

Element: 8578 \# of layers: 7

$\mathrm{Kx} \mathrm{Ky} \mathrm{Kz}$ Ss Por

3.55103e+00 3.55103e+00 3.55103e-01 1.00000e-09 2.12000e-01

$3.55103 \mathrm{e}+003.55103 \mathrm{e}+00$ 3.55103e-01 1.00000e-09 2.12000e-01

3.55103e+00 3.55103e+00 3.55103e-01 1.00000e-09 2.12000e-01

$3.55103 \mathrm{e}+003.55103 \mathrm{e}+00$ 3.55103e-01 1.00000e-09 2.12000e-01

$3.55103 \mathrm{e}+00$ 3.55103e+00 3.55103e-01 1.00000e-09 2.12000e-01

$1.00000 \mathrm{e}-05$ 1.00000e-05 1.00000e-06 1.00000e-09 1.00000e-01

$1.00000 \mathrm{e}+001.00000 \mathrm{e}+001.00000 \mathrm{e}-01$ 1.00000e-09 1.00000e-01

Element: 8579 \# of layers: 7

$\mathrm{Kx} \mathrm{Ky} \mathrm{Kz}$ Ss Por

9.58700e+00 9.58700e+00 9.58700e-01 1.00000e-09 2.12000e-01

$9.58700 \mathrm{e}+009.58700 \mathrm{e}+00$ 9.58700e-01 1.00000e-09 2.12000e-01

$9.58700 \mathrm{e}+009.58700 \mathrm{e}+00$ 9.58700e-01 1.00000e-09 2.12000e-01

$9.58700 \mathrm{e}+009.58700 \mathrm{e}+009.58700 \mathrm{e}-01$ 1.00000e-09 2.12000e-01

$9.58700 \mathrm{e}+009.58700 \mathrm{e}+009.58700 \mathrm{e}-01$ 1.00000e-09 2.12000e-01

$1.00000 \mathrm{e}-05$ 1.00000e-05 1.00000e-06 1.00000e-09 1.00000e-01

$1.00000 \mathrm{e}+001.00000 \mathrm{e}+001.00000 \mathrm{e}-011.00000 \mathrm{e}-091.00000 \mathrm{e}-01$

Element: 8580 \# of layers: 7

Kx Ky Kz Ss Por

9.58700e+00 9.58700e+00 9.58700e-01 1.00000e-09 2.12000e-01

$9.58700 \mathrm{e}+009.58700 \mathrm{e}+00$ 9.58700e-01 1.00000e-09 2.12000e-01

$9.58700 \mathrm{e}+00$ 9.58700e+00 9.58700e-01 1.00000e-09 2.12000e-01

$9.58700 \mathrm{e}+009.58700 \mathrm{e}+009.58700 \mathrm{e}-011.00000 \mathrm{e}-092.12000 \mathrm{e}-01$

$9.58700 \mathrm{e}+00$ 9.58700e+00 9.58700e-01 1.00000e-09 2.12000e-01

$1.00000 \mathrm{e}-05$ 1.00000e-05 1.00000e-06 1.00000e-09 1.00000e-01

$1.00000 \mathrm{e}+001.00000 \mathrm{e}+001.00000 \mathrm{e}-01$ 1.00000e-09 1.00000e-01

Element: 8581 \# of layers: 7

Kx Ky Kz Ss Por 
9.58700e+00 9.58700e+00 9.58700e-01 1.00000e-09 2.12000e-01

$9.58700 \mathrm{e}+009.58700 \mathrm{e}+00$ 9.58700e-01 1.00000e-09 2.12000e-01

$9.58700 \mathrm{e}+00$ 9.58700e+00 9.58700e-01 1.00000e-09 2.12000e-01

$9.58700 \mathrm{e}+009.58700 \mathrm{e}+00 \quad 9.58700 \mathrm{e}-01$ 1.00000e-09 2.12000e-01

$9.58700 \mathrm{e}+00$ 9.58700e+00 9.58700e-01 1.00000e-09 2.12000e-01

$1.00000 \mathrm{e}-05$ 1.00000e-05 1.00000e-06 1.00000e-09 1.00000e-01

$1.00000 \mathrm{e}+001.00000 \mathrm{e}+00$ 1.00000e-01 1.00000e-09 1.00000e-01

Element: 8582 \# of layers: 7

$\mathrm{Kx} \mathrm{Ky} \mathrm{Kz}$ Ss Por

3.55103e+00 3.55103e+00 3.55103e-01 1.00000e-09 2.12000e-01

$3.55103 \mathrm{e}+003.55103 \mathrm{e}+00$ 3.55103e-01 1.00000e-09 2.12000e-01

$3.55103 \mathrm{e}+003.55103 \mathrm{e}+003.55103 \mathrm{e}-01$ 1.00000e-09 2.12000e-01

$3.55103 \mathrm{e}+003.55103 \mathrm{e}+00$ 3.55103e-01 1.00000e-09 2.12000e-01

$3.55103 \mathrm{e}+003.55103 \mathrm{e}+00$ 3.55103e-01 1.00000e-09 2.12000e-01

$1.00000 \mathrm{e}-05$ 1.00000e-05 1.00000e-06 1.00000e-09 1.00000e-01

$1.00000 \mathrm{e}+001.00000 \mathrm{e}+001.00000 \mathrm{e}-011.00000 \mathrm{e}-091.00000 \mathrm{e}-01$

Element: 8583 \# of layers: 7

$\mathrm{Kx} \mathrm{Ky} \mathrm{Kz}$ Ss Por

3.55103e+00 3.55103e+00 3.55103e-01 1.00000e-09 2.12000e-01

$3.55103 \mathrm{e}+003.55103 \mathrm{e}+00$ 3.55103e-01 1.00000e-09 2.12000e-01

$3.55103 e+003.55103 e+003.55103 e-01$ 1.00000e-09 2.12000e-01

3.55103e+00 3.55103e+00 3.55103e-01 1.00000e-09 2.12000e-01

$3.55103 \mathrm{e}+003.55103 \mathrm{e}+00$ 3.55103e-01 1.00000e-09 2.12000e-01

$1.00000 \mathrm{e}-051.00000 \mathrm{e}-05$ 1.00000e-06 1.00000e-09 1.00000e-01

$1.00000 \mathrm{e}+001.00000 \mathrm{e}+001.00000 \mathrm{e}-011.00000 \mathrm{e}-091.00000 \mathrm{e}-01$

Element: 8584 \# of layers: 7

$\mathrm{Kx} \mathrm{Ky} \mathrm{Kz}$ Ss Por

3.55103e+00 3.55103e+00 3.55103e-01 1.00000e-09 2.12000e-01

$3.55103 \mathrm{e}+003.55103 \mathrm{e}+00$ 3.55103e-01 1.00000e-09 2.12000e-01

$3.55103 \mathrm{e}+00$ 3.55103e+00 3.55103e-01 1.00000e-09 2.12000e-01

$3.55103 \mathrm{e}+003.55103 \mathrm{e}+00$ 3.55103e-01 1.00000e-09 2.12000e-01

$3.55103 \mathrm{e}+003.55103 \mathrm{e}+00$ 3.55103e-01 1.00000e-09 2.12000e-01

$1.00000 \mathrm{e}-05$ 1.00000e-05 1.00000e-06 1.00000e-09 1.00000e-01

$1.00000 \mathrm{e}+001.00000 \mathrm{e}+001.00000 \mathrm{e}-011.00000 \mathrm{e}-091.00000 \mathrm{e}-01$

Element: 8585 \# of layers: 7

$\mathrm{Kx} \mathrm{Ky} \mathrm{Kz}$ Ss Por

3.55103e+00 3.55103e+00 3.55103e-01 1.00000e-09 2.12000e-01

$3.55103 \mathrm{e}+003.55103 \mathrm{e}+00$ 3.55103e-01 1.00000e-09 2.12000e-01

$3.55103 \mathrm{e}+00$ 3.55103e+00 3.55103e-01 1.00000e-09 2.12000e-01

$3.55103 \mathrm{e}+003.55103 \mathrm{e}+00$ 3.55103e-01 1.00000e-09 2.12000e-01

$3.55103 \mathrm{e}+003.55103 \mathrm{e}+003.55103 \mathrm{e}-01$ 1.00000e-09 2.12000e-01

$1.00000 \mathrm{e}-05$ 1.00000e-05 1.00000e-06 1.00000e-09 1.00000e-01

$1.00000 \mathrm{e}+001.00000 \mathrm{e}+001.00000 \mathrm{e}-011.00000 \mathrm{e}-091.00000 \mathrm{e}-01$

Element: 8586 \# of layers: 7

$\mathrm{Kx} \mathrm{Ky} \mathrm{Kz}$ Ss Por

9.58700e+00 9.58700e+00 9.58700e-01 1.00000e-09 2.12000e-01 
$9.58700 \mathrm{e}+009.58700 \mathrm{e}+00$ 9.58700e-01 1.00000e-09 2.12000e-01

$9.58700 \mathrm{e}+009.58700 \mathrm{e}+009.58700 \mathrm{e}-011.00000 \mathrm{e}-092.12000 \mathrm{e}-01$

$9.58700 \mathrm{e}+009.58700 \mathrm{e}+009.58700 \mathrm{e}-011.00000 \mathrm{e}-092.12000 \mathrm{e}-01$

$9.58700 \mathrm{e}+009.58700 \mathrm{e}+00$ 9.58700e-01 1.00000e-09 2.12000e-01

$1.00000 \mathrm{e}-05$ 1.00000e-05 1.00000e-06 1.00000e-09 1.00000e-01

$1.00000 \mathrm{e}+001.00000 \mathrm{e}+001.00000 \mathrm{e}-011.00000 \mathrm{e}-091.00000 \mathrm{e}-01$

Element: 8587 \# of layers: 7

Kx Ky Kz Ss Por

$9.58700 \mathrm{e}+009.58700 \mathrm{e}+00$ 9.58700e-01 1.00000e-09 2.12000e-01

$9.58700 \mathrm{e}+009.58700 \mathrm{e}+009.58700 \mathrm{e}-011.00000 \mathrm{e}-092.12000 \mathrm{e}-01$

$9.58700 \mathrm{e}+009.58700 \mathrm{e}+009.58700 \mathrm{e}-011.00000 \mathrm{e}-092.12000 \mathrm{e}-01$

$9.58700 \mathrm{e}+009.58700 \mathrm{e}+009.58700 \mathrm{e}-011.00000 \mathrm{e}-092.12000 \mathrm{e}-01$

$9.58700 \mathrm{e}+009.58700 \mathrm{e}+00$ 9.58700e-01 1.00000e-09 2.12000e-01

$1.00000 \mathrm{e}-05$ 1.00000e-05 1.00000e-06 1.00000e-09 1.00000e-01

$1.00000 \mathrm{e}+001.00000 \mathrm{e}+001.00000 \mathrm{e}-011.00000 \mathrm{e}-091.00000 \mathrm{e}-01$

Element: 8588 \# of layers: 7

Kx Ky Kz Ss Por

9.58700e+00 9.58700e+00 9.58700e-01 1.00000e-09 2.12000e-01

$9.58700 \mathrm{e}+009.58700 \mathrm{e}+009.58700 \mathrm{e}-011.00000 \mathrm{e}-092.12000 \mathrm{e}-01$

$9.58700 \mathrm{e}+009.58700 \mathrm{e}+009.58700 \mathrm{e}-011.00000 \mathrm{e}-092.12000 \mathrm{e}-01$

$9.58700 \mathrm{e}+009.58700 \mathrm{e}+009.58700 \mathrm{e}-011.00000 \mathrm{e}-092.12000 \mathrm{e}-01$

$9.58700 \mathrm{e}+009.58700 \mathrm{e}+00$ 9.58700e-01 1.00000e-09 2.12000e-01

$1.00000 \mathrm{e}-05$ 1.00000e-05 1.00000e-06 1.00000e-09 1.00000e-01

$1.00000 \mathrm{e}+001.00000 \mathrm{e}+001.00000 \mathrm{e}-011.00000 \mathrm{e}-091.00000 \mathrm{e}-01$

Element: 8589 \# of layers: 7

Kx Ky Kz Ss Por

$9.58700 \mathrm{e}+009.58700 \mathrm{e}+00$ 9.58700e-01 1.00000e-09 2.12000e-01

$9.58700 \mathrm{e}+009.58700 \mathrm{e}+009.58700 \mathrm{e}-011.00000 \mathrm{e}-092.12000 \mathrm{e}-01$

$9.58700 \mathrm{e}+009.58700 \mathrm{e}+00$ 9.58700e-01 1.00000e-09 2.12000e-01

$9.58700 \mathrm{e}+009.58700 \mathrm{e}+009.58700 \mathrm{e}-011.00000 \mathrm{e}-092.12000 \mathrm{e}-01$

$9.58700 \mathrm{e}+009.58700 \mathrm{e}+00$ 9.58700e-01 1.00000e-09 2.12000e-01

$1.00000 \mathrm{e}-05$ 1.00000e-05 1.00000e-06 1.00000e-09 1.00000e-01

$1.00000 \mathrm{e}+001.00000 \mathrm{e}+001.00000 \mathrm{e}-011.00000 \mathrm{e}-091.00000 \mathrm{e}-01$

Element: 8590 \# of layers: 7

Kx Ky Kz Ss Por

$9.58700 \mathrm{e}+009.58700 \mathrm{e}+00$ 9.58700e-01 1.00000e-09 2.12000e-01

$9.58700 \mathrm{e}+009.58700 \mathrm{e}+009.58700 \mathrm{e}-011.00000 \mathrm{e}-092.12000 \mathrm{e}-01$

$9.58700 \mathrm{e}+009.58700 \mathrm{e}+00$ 9.58700e-01 1.00000e-09 2.12000e-01

$9.58700 \mathrm{e}+009.58700 \mathrm{e}+00$ 9.58700e-01 1.00000e-09 2.12000e-01

$9.58700 \mathrm{e}+009.58700 \mathrm{e}+009.58700 \mathrm{e}-011.00000 \mathrm{e}-092.12000 \mathrm{e}-01$

$1.00000 \mathrm{e}-05$ 1.00000e-05 1.00000e-06 1.00000e-09 1.00000e-01

$1.00000 \mathrm{e}+001.00000 \mathrm{e}+001.00000 \mathrm{e}-011.00000 \mathrm{e}-091.00000 \mathrm{e}-01$

Element: 8591 \# of layers: 7

Kx Ky Kz Ss Por

$9.58700 \mathrm{e}+009.58700 \mathrm{e}+00$ 9.58700e-01 1.00000e-09 2.12000e-01

$9.58700 \mathrm{e}+009.58700 \mathrm{e}+00$ 9.58700e-01 1.00000e-09 2.12000e-01 
$9.58700 \mathrm{e}+009.58700 \mathrm{e}+00$ 9.58700e-01 1.00000e-09 2.12000e-01

$9.58700 \mathrm{e}+009.58700 \mathrm{e}+009.58700 \mathrm{e}-011.00000 \mathrm{e}-092.12000 \mathrm{e}-01$

$9.58700 \mathrm{e}+009.58700 \mathrm{e}+00$ 9.58700e-01 1.00000e-09 2.12000e-01

$1.00000 \mathrm{e}-05$ 1.00000e-05 1.00000e-06 1.00000e-09 1.00000e-01

$1.00000 \mathrm{e}+001.00000 \mathrm{e}+001.00000 \mathrm{e}-011.00000 \mathrm{e}-091.00000 \mathrm{e}-01$

Element: 8592 \# of layers: 7

Kx Ky Kz Ss Por

$9.58700 \mathrm{e}+009.58700 \mathrm{e}+00$ 9.58700e-01 1.00000e-09 2.12000e-01

$9.58700 \mathrm{e}+009.58700 \mathrm{e}+00$ 9.58700e-01 1.00000e-09 2.12000e-01

$9.58700 \mathrm{e}+009.58700 \mathrm{e}+009.58700 \mathrm{e}-011.00000 \mathrm{e}-092.12000 \mathrm{e}-01$

$9.58700 \mathrm{e}+009.58700 \mathrm{e}+009.58700 \mathrm{e}-011.00000 \mathrm{e}-092.12000 \mathrm{e}-01$

$9.58700 \mathrm{e}+009.58700 \mathrm{e}+009.58700 \mathrm{e}-011.00000 \mathrm{e}-09$ 2.12000e-01

$1.00000 \mathrm{e}-05$ 1.00000e-05 1.00000e-06 1.00000e-09 1.00000e-01

$1.00000 \mathrm{e}+001.00000 \mathrm{e}+001.00000 \mathrm{e}-011.00000 \mathrm{e}-091.00000 \mathrm{e}-01$

Element: 8593 \# of layers: 7

Kx Ky Kz Ss Por

$9.58700 \mathrm{e}+009.58700 \mathrm{e}+00$ 9.58700e-01 1.00000e-09 2.12000e-01

$9.58700 \mathrm{e}+009.58700 \mathrm{e}+009.58700 \mathrm{e}-011.00000 \mathrm{e}-092.12000 \mathrm{e}-01$

$9.58700 \mathrm{e}+009.58700 \mathrm{e}+00$ 9.58700e-01 1.00000e-09 2.12000e-01

$9.58700 \mathrm{e}+009.58700 \mathrm{e}+00$ 9.58700e-01 1.00000e-09 2.12000e-01

$9.58700 \mathrm{e}+009.58700 \mathrm{e}+009.58700 \mathrm{e}-011.00000 \mathrm{e}-092.12000 \mathrm{e}-01$

$1.00000 \mathrm{e}-05$ 1.00000e-05 1.00000e-06 1.00000e-09 1.00000e-01

$1.00000 \mathrm{e}+001.00000 \mathrm{e}+001.00000 \mathrm{e}-011.00000 \mathrm{e}-091.00000 \mathrm{e}-01$

Element: 8594 \# of layers: 7

Kx Ky Kz Ss Por

$9.58700 \mathrm{e}+009.58700 \mathrm{e}+00$ 9.58700e-01 1.00000e-09 2.12000e-01

$9.58700 \mathrm{e}+009.58700 \mathrm{e}+00$ 9.58700e-01 1.00000e-09 2.12000e-01

$9.58700 \mathrm{e}+009.58700 \mathrm{e}+00$ 9.58700e-01 1.00000e-09 2.12000e-01

$9.58700 \mathrm{e}+009.58700 \mathrm{e}+00$ 9.58700e-01 1.00000e-09 2.12000e-01

$9.58700 \mathrm{e}+009.58700 \mathrm{e}+00$ 9.58700e-01 1.00000e-09 2.12000e-01

$1.00000 \mathrm{e}-05$ 1.00000e-05 1.00000e-06 1.00000e-09 1.00000e-01

$1.00000 \mathrm{e}+001.00000 \mathrm{e}+001.00000 \mathrm{e}-011.00000 \mathrm{e}-091.00000 \mathrm{e}-01$

Element: 8595 \# of layers: 7

Kx Ky Kz Ss Por

$9.58700 \mathrm{e}+009.58700 \mathrm{e}+00$ 9.58700e-01 1.00000e-09 2.12000e-01

$9.58700 \mathrm{e}+009.58700 \mathrm{e}+00$ 9.58700e-01 1.00000e-09 2.12000e-01

$9.58700 \mathrm{e}+009.58700 \mathrm{e}+00$ 9.58700e-01 1.00000e-09 2.12000e-01

$9.58700 \mathrm{e}+009.58700 \mathrm{e}+00$ 9.58700e-01 1.00000e-09 2.12000e-01

$9.58700 \mathrm{e}+009.58700 \mathrm{e}+009.58700 \mathrm{e}-011.00000 \mathrm{e}-092.12000 \mathrm{e}-01$

$1.00000 \mathrm{e}-05$ 1.00000e-05 1.00000e-06 1.00000e-09 1.00000e-01

$1.00000 \mathrm{e}+001.00000 \mathrm{e}+001.00000 \mathrm{e}-011.00000 \mathrm{e}-091.00000 \mathrm{e}-01$

Element: 8596 \# of layers: 7

Kx Ky Kz Ss Por

$1.96332 \mathrm{e}+011.96332 \mathrm{e}+011.96332 \mathrm{e}+00$ 1.00000e-09 2.12000e-01

$1.96332 \mathrm{e}+011.96332 \mathrm{e}+011.96332 \mathrm{e}+00$ 1.00000e-09 2.12000e-01

$1.96332 \mathrm{e}+011.96332 \mathrm{e}+011.96332 \mathrm{e}+001.00000 \mathrm{e}-092.12000 \mathrm{e}-01$ 
$1.96332 \mathrm{e}+01$ 1.96332e+01 1.96332e+00 1.00000e-09 2.12000e-01 $1.96332 \mathrm{e}+01$ 1.96332e+01 1.96332e+00 1.00000e-09 2.12000e-01 $1.00000 \mathrm{e}-051.00000 \mathrm{e}-05$ 1.00000e-06 1.00000e-09 1.00000e-01

$1.00000 \mathrm{e}+001.00000 \mathrm{e}+001.00000 \mathrm{e}-011.00000 \mathrm{e}-091.00000 \mathrm{e}-01$ Element: 8597 \# of layers: 7

$\mathrm{Kx} \mathrm{Ky} \mathrm{Kz}$ Ss Por

$1.96332 \mathrm{e}+01$ 1.96332e+01 1.96332e+00 1.00000e-09 2.12000e-01 $1.96332 \mathrm{e}+01$ 1.96332e+01 1.96332e+00 1.00000e-09 2.12000e-01 $1.96332 \mathrm{e}+01$ 1.96332e+01 1.96332e+00 1.00000e-09 2.12000e-01 $1.96332 \mathrm{e}+01$ 1.96332e+01 1.96332e+00 1.00000e-09 2.12000e-01 $1.96332 \mathrm{e}+01$ 1.96332e+01 1.96332e+00 1.00000e-09 2.12000e-01 $1.00000 \mathrm{e}-05$ 1.00000e-05 1.00000e-06 1.00000e-09 1.00000e-01 $1.00000 \mathrm{e}+001.00000 \mathrm{e}+001.00000 \mathrm{e}-011.00000 \mathrm{e}-091.00000 \mathrm{e}-01$ Element: 8598 \# of layers: 8

$\mathrm{Kx} \mathrm{Ky} \mathrm{Kz}$ Ss Por

1.96332e+01 1.96332e+01 1.96332e+00 1.00000e-09 2.12000e-01 $1.96332 \mathrm{e}+01$ 1.96332e+01 1.96332e+00 1.00000e-09 2.12000e-01 $1.96332 \mathrm{e}+01$ 1.96332e+01 1.96332e+00 1.00000e-09 2.12000e-01 $1.96332 \mathrm{e}+01$ 1.96332e+01 1.96332e+00 1.00000e-09 2.12000e-01 $1.96332 \mathrm{e}+01$ 1.96332e+01 1.96332e+00 1.00000e-09 2.12000e-01 $1.00000 \mathrm{e}-02$ 1.00000e-02 1.00000e-03 1.00000e-09 1.00000e-01 $1.00000 \mathrm{e}-05$ 1.00000e-05 1.00000e-06 1.00000e-09 1.00000e-01 $1.00000 \mathrm{e}+001.00000 \mathrm{e}+001.00000 \mathrm{e}-01$ 1.00000e-09 1.00000e-01 Element: 8599 \# of layers: 8

Kx Ky Kz Ss Por

$1.96332 \mathrm{e}+01$ 1.96332e+01 1.96332e+00 1.00000e-09 2.12000e-01 $1.96332 \mathrm{e}+011.96332 \mathrm{e}+011.96332 \mathrm{e}+001.00000 \mathrm{e}-092.12000 \mathrm{e}-01$ $1.96332 \mathrm{e}+01$ 1.96332e+01 1.96332e+00 1.00000e-09 2.12000e-01 $1.96332 \mathrm{e}+01$ 1.96332e+01 1.96332e+00 1.00000e-09 2.12000e-01 $1.96332 \mathrm{e}+01$ 1.96332e+01 1.96332e+00 1.00000e-09 2.12000e-01 $1.00000 \mathrm{e}-02$ 1.00000e-02 1.00000e-03 1.00000e-09 1.00000e-01 $1.00000 \mathrm{e}-05$ 1.00000e-05 1.00000e-06 1.00000e-09 1.00000e-01 $1.00000 \mathrm{e}+001.00000 \mathrm{e}+001.00000 \mathrm{e}-011.00000 \mathrm{e}-091.00000 \mathrm{e}-01$ Element: 8600 \# of layers: 8

$\mathrm{Kx} \mathrm{Ky} \mathrm{Kz}$ Ss Por

1.96332e+01 1.96332e+01 1.96332e+00 1.00000e-09 2.12000e-01 $1.96332 \mathrm{e}+01$ 1.96332e+01 1.96332e+00 1.00000e-09 2.12000e-01 $1.96332 \mathrm{e}+01$ 1.96332e+01 1.96332e+00 1.00000e-09 2.12000e-01 $1.96332 \mathrm{e}+01$ 1.96332e+01 1.96332e+00 1.00000e-09 2.12000e-01 $1.96332 \mathrm{e}+01$ 1.96332e+01 1.96332e+00 1.00000e-09 2.12000e-01 1.00000e-02 1.00000e-02 1.00000e-03 1.00000e-09 1.00000e-01 $1.00000 \mathrm{e}-05$ 1.00000e-05 1.00000e-06 1.00000e-09 1.00000e-01 $1.00000 \mathrm{e}+001.00000 \mathrm{e}+001.00000 \mathrm{e}-011.00000 \mathrm{e}-091.00000 \mathrm{e}-01$ Element: 8601 \# of layers: 7

$\mathrm{Kx} \mathrm{Ky} \mathrm{Kz}$ Ss Por

9.58700e+00 9.58700e+00 9.58700e-01 1.00000e-09 2.12000e-01 
$9.58700 \mathrm{e}+009.58700 \mathrm{e}+00$ 9.58700e-01 1.00000e-09 2.12000e-01

$9.58700 \mathrm{e}+009.58700 \mathrm{e}+00$ 9.58700e-01 1.00000e-09 2.12000e-01

$9.58700 \mathrm{e}+009.58700 \mathrm{e}+009.58700 \mathrm{e}-011.00000 \mathrm{e}-092.12000 \mathrm{e}-01$

$9.58700 \mathrm{e}+009.58700 \mathrm{e}+00$ 9.58700e-01 1.00000e-09 2.12000e-01

$1.00000 \mathrm{e}-05$ 1.00000e-05 1.00000e-06 1.00000e-09 1.00000e-01

$1.00000 \mathrm{e}+001.00000 \mathrm{e}+001.00000 \mathrm{e}-011.00000 \mathrm{e}-091.00000 \mathrm{e}-01$

Element: 8602 \# of layers: 7

Kx Ky Kz Ss Por

$9.58700 \mathrm{e}+009.58700 \mathrm{e}+00$ 9.58700e-01 1.00000e-09 2.12000e-01

$9.58700 \mathrm{e}+009.58700 \mathrm{e}+009.58700 \mathrm{e}-011.00000 \mathrm{e}-092.12000 \mathrm{e}-01$

$9.58700 \mathrm{e}+009.58700 \mathrm{e}+009.58700 \mathrm{e}-011.00000 \mathrm{e}-092.12000 \mathrm{e}-01$

$9.58700 \mathrm{e}+009.58700 \mathrm{e}+009.58700 \mathrm{e}-011.00000 \mathrm{e}-092.12000 \mathrm{e}-01$

$9.58700 \mathrm{e}+009.58700 \mathrm{e}+00$ 9.58700e-01 1.00000e-09 2.12000e-01

$1.00000 \mathrm{e}-05$ 1.00000e-05 1.00000e-06 1.00000e-09 1.00000e-01

$1.00000 \mathrm{e}+001.00000 \mathrm{e}+001.00000 \mathrm{e}-011.00000 \mathrm{e}-091.00000 \mathrm{e}-01$

Element: 8603 \# of layers: 7

Kx Ky Kz Ss Por

$1.96332 \mathrm{e}+011.96332 \mathrm{e}+011.96332 \mathrm{e}+00$ 1.00000e-09 2.12000e-01

$1.96332 \mathrm{e}+011.96332 \mathrm{e}+011.96332 \mathrm{e}+00$ 1.00000e-09 2.12000e-01

$1.96332 \mathrm{e}+011.96332 \mathrm{e}+011.96332 \mathrm{e}+001.00000 \mathrm{e}-092.12000 \mathrm{e}-01$

$1.96332 \mathrm{e}+011.96332 \mathrm{e}+011.96332 \mathrm{e}+001.00000 \mathrm{e}-092.12000 \mathrm{e}-01$

$1.96332 \mathrm{e}+011.96332 \mathrm{e}+011.96332 \mathrm{e}+00$ 1.00000e-09 2.12000e-01

$1.00000 \mathrm{e}-05$ 1.00000e-05 1.00000e-06 1.00000e-09 1.00000e-01

$1.00000 \mathrm{e}+001.00000 \mathrm{e}+001.00000 \mathrm{e}-011.00000 \mathrm{e}-091.00000 \mathrm{e}-01$

Element: 8604 \# of layers: 8

Kx Ky Kz Ss Por

$1.96332 \mathrm{e}+011.96332 \mathrm{e}+01$ 1.96332e+00 1.00000e-09 2.12000e-01

$1.96332 \mathrm{e}+011.96332 \mathrm{e}+011.96332 \mathrm{e}+00$ 1.00000e-09 2.12000e-01

$1.96332 \mathrm{e}+011.96332 \mathrm{e}+011.96332 \mathrm{e}+001.00000 \mathrm{e}-092.12000 \mathrm{e}-01$

$1.96332 \mathrm{e}+011.96332 \mathrm{e}+011.96332 \mathrm{e}+001.00000 \mathrm{e}-092.12000 \mathrm{e}-01$

$1.96332 \mathrm{e}+011.96332 \mathrm{e}+011.96332 \mathrm{e}+001.00000 \mathrm{e}-092.12000 \mathrm{e}-01$

$1.00000 \mathrm{e}-02$ 1.00000e-02 1.00000e-03 1.00000e-09 1.00000e-01

$1.00000 \mathrm{e}-05$ 1.00000e-05 1.00000e-06 1.00000e-09 1.00000e-01

$1.00000 \mathrm{e}+001.00000 \mathrm{e}+001.00000 \mathrm{e}-011.00000 \mathrm{e}-091.00000 \mathrm{e}-01$

Element: 8605 \# of layers: 8

Kx Ky Kz Ss Por

$4.29872 \mathrm{e}+00$ 4.29872e+00 4.29872e-01 1.00000e-09 2.12000e-01

$4.29872 \mathrm{e}+004.29872 \mathrm{e}+00$ 4.29872e-01 1.00000e-09 2.12000e-01

$4.29872 \mathrm{e}+004.29872 \mathrm{e}+00$ 4.29872e-01 1.00000e-09 2.12000e-01

$4.29872 \mathrm{e}+004.29872 \mathrm{e}+00$ 4.29872e-01 1.00000e-09 2.12000e-01

$4.29872 \mathrm{e}+004.29872 \mathrm{e}+00$ 4.29872e-01 1.00000e-09 2.12000e-01

$1.00000 \mathrm{e}-02$ 1.00000e-02 1.00000e-03 1.00000e-09 1.00000e-01

$1.00000 \mathrm{e}-05$ 1.00000e-05 1.00000e-06 1.00000e-09 1.00000e-01

$1.00000 \mathrm{e}+001.00000 \mathrm{e}+001.00000 \mathrm{e}-011.00000 \mathrm{e}-091.00000 \mathrm{e}-01$

Element: 8606 \# of layers: 8

Kx Ky Kz Ss Por 
4.29872e+00 4.29872e+00 4.29872e-01 1.00000e-09 2.12000e-01 $4.29872 \mathrm{e}+004.29872 \mathrm{e}+00$ 4.29872e-01 1.00000e-09 2.12000e-01 4.29872e+00 4.29872e+00 4.29872e-01 1.00000e-09 2.12000e-01 $4.29872 \mathrm{e}+00$ 4.29872e+00 4.29872e-01 1.00000e-09 2.12000e-01 4.29872e+00 4.29872e+00 4.29872e-01 1.00000e-09 2.12000e-01 $1.00000 \mathrm{e}-02$ 1.00000e-02 1.00000e-03 1.00000e-09 1.00000e-01 $1.00000 \mathrm{e}-05$ 1.00000e-05 1.00000e-06 1.00000e-09 1.00000e-01 $1.00000 \mathrm{e}+001.00000 \mathrm{e}+001.00000 \mathrm{e}-011.00000 \mathrm{e}-091.00000 \mathrm{e}-01$ Element: 8607 \# of layers: 8

$\mathrm{Kx} \mathrm{Ky} \mathrm{Kz}$ Ss Por

4.29872e+00 4.29872e+00 4.29872e-01 1.00000e-09 2.12000e-01 $4.29872 \mathrm{e}+004.29872 \mathrm{e}+00$ 4.29872e-01 1.00000e-09 2.12000e-01 4.29872e+00 4.29872e+00 4.29872e-01 1.00000e-09 2.12000e-01 4.29872e+00 4.29872e+00 4.29872e-01 1.00000e-09 2.12000e-01 4.29872e+00 4.29872e+00 4.29872e-01 1.00000e-09 2.12000e-01 $1.00000 \mathrm{e}-02$ 1.00000e-02 1.00000e-03 1.00000e-09 1.00000e-01 $1.00000 \mathrm{e}-05$ 1.00000e-05 1.00000e-06 1.00000e-09 1.00000e-01 $1.00000 \mathrm{e}+001.00000 \mathrm{e}+001.00000 \mathrm{e}-01$ 1.00000e-09 1.00000e-01 Element: 8608 \# of layers: 7

$\mathrm{Kx} \mathrm{Ky} \mathrm{Kz}$ Ss Por

3.55103e+00 3.55103e+00 3.55103e-01 1.00000e-09 2.12000e-01 3.55103e+00 3.55103e+00 3.55103e-01 1.00000e-09 2.12000e-01 $3.55103 \mathrm{e}+003.55103 \mathrm{e}+00$ 3.55103e-01 1.00000e-09 2.12000e-01 $3.55103 \mathrm{e}+003.55103 \mathrm{e}+00$ 3.55103e-01 1.00000e-09 2.12000e-01 $3.55103 \mathrm{e}+003.55103 \mathrm{e}+003.55103 \mathrm{e}-01$ 1.00000e-09 2.12000e-01 $1.00000 \mathrm{e}-051.00000 \mathrm{e}-05$ 1.00000e-06 1.00000e-09 1.00000e-01 $1.00000 \mathrm{e}+001.00000 \mathrm{e}+001.00000 \mathrm{e}-011.00000 \mathrm{e}-091.00000 \mathrm{e}-01$ Element: 8609 \# of layers: 7

$\mathrm{Kx} \mathrm{Ky} \mathrm{Kz}$ Ss Por

3.55103e+00 3.55103e+00 3.55103e-01 1.00000e-09 2.12000e-01

$3.55103 \mathrm{e}+003.55103 \mathrm{e}+00$ 3.55103e-01 1.00000e-09 2.12000e-01

$3.55103 \mathrm{e}+003.55103 \mathrm{e}+00$ 3.55103e-01 1.00000e-09 2.12000e-01

$3.55103 \mathrm{e}+003.55103 \mathrm{e}+00$ 3.55103e-01 1.00000e-09 2.12000e-01 $3.55103 \mathrm{e}+00$ 3.55103e+00 3.55103e-01 1.00000e-09 2.12000e-01 $1.00000 \mathrm{e}-05$ 1.00000e-05 1.00000e-06 1.00000e-09 1.00000e-01 $1.00000 \mathrm{e}+001.00000 \mathrm{e}+001.00000 \mathrm{e}-01$ 1.00000e-09 1.00000e-01 Element: 8610 \# of layers: 7

$\mathrm{Kx} \mathrm{Ky} \mathrm{Kz}$ Ss Por

$9.58700 \mathrm{e}+009.58700 \mathrm{e}+00$ 9.58700e-01 1.00000e-09 2.12000e-01 $9.58700 \mathrm{e}+009.58700 \mathrm{e}+00$ 9.58700e-01 1.00000e-09 2.12000e-01 $9.58700 \mathrm{e}+009.58700 \mathrm{e}+00$ 9.58700e-01 1.00000e-09 2.12000e-01 $9.58700 \mathrm{e}+00 \quad 9.58700 \mathrm{e}+00$ 9.58700e-01 1.00000e-09 2.12000e-01 $9.58700 \mathrm{e}+00$ 9.58700e+00 9.58700e-01 1.00000e-09 2.12000e-01 $1.00000 \mathrm{e}-05$ 1.00000e-05 1.00000e-06 1.00000e-09 1.00000e-01 $1.00000 \mathrm{e}+001.00000 \mathrm{e}+001.00000 \mathrm{e}-011.00000 \mathrm{e}-091.00000 \mathrm{e}-01$ Element: 8611 \# of layers: 8 
$\mathrm{Kx} \mathrm{Ky} \mathrm{Kz}$ Ss Por

$1.96332 \mathrm{e}+01$ 1.96332e+01 1.96332e+00 1.00000e-09 2.12000e-01

$1.96332 \mathrm{e}+01$ 1.96332e+01 1.96332e+00 1.00000e-09 2.12000e-01

$1.96332 \mathrm{e}+01$ 1.96332e+01 1.96332e+00 1.00000e-09 2.12000e-01

$1.96332 \mathrm{e}+01$ 1.96332e+01 1.96332e+00 1.00000e-09 2.12000e-01

$1.96332 \mathrm{e}+01$ 1.96332e+01 1.96332e+00 1.00000e-09 2.12000e-01

$1.00000 \mathrm{e}-02$ 1.00000e-02 1.00000e-03 1.00000e-09 1.00000e-01

$1.00000 \mathrm{e}-05$ 1.00000e-05 1.00000e-06 1.00000e-09 1.00000e-01

$1.00000 \mathrm{e}+001.00000 \mathrm{e}+001.00000 \mathrm{e}-011.00000 \mathrm{e}-091.00000 \mathrm{e}-01$

Element: 8612 \# of layers: 8

$\mathrm{Kx} \mathrm{Ky} \mathrm{Kz}$ Ss Por

4.29872e+00 4.29872e+00 4.29872e-01 1.00000e-09 2.12000e-01 4.29872e+00 4.29872e+00 4.29872e-01 1.00000e-09 2.12000e-01

4.29872e+00 4.29872e+00 4.29872e-01 1.00000e-09 2.12000e-01

4.29872e+00 4.29872e+00 4.29872e-01 1.00000e-09 2.12000e-01

4.29872e+00 4.29872e+00 4.29872e-01 1.00000e-09 2.12000e-01

$1.00000 \mathrm{e}-02$ 1.00000e-02 1.00000e-03 1.00000e-09 1.00000e-01

$1.00000 \mathrm{e}-05$ 1.00000e-05 1.00000e-06 1.00000e-09 1.00000e-01

$1.00000 \mathrm{e}+001.00000 \mathrm{e}+001.00000 \mathrm{e}-01$ 1.00000e-09 1.00000e-01

Element: 8613 \# of layers: 9

$\mathrm{Kx} \mathrm{Ky} \mathrm{Kz}$ Ss Por

4.30502e+00 4.30502e+00 4.30502e-01 1.00000e-09 2.12000e-01

4.30502e+00 4.30502e+00 4.30502e-01 1.00000e-09 2.12000e-01

4.30502e+00 4.30502e+00 4.30502e-01 1.00000e-09 2.12000e-01

$4.30502 \mathrm{e}+004.30502 \mathrm{e}+00$ 4.30502e-01 1.00000e-09 2.12000e-01

4.30502e+00 4.30502e+00 4.30502e-01 1.00000e-09 2.12000e-01

$1.00000 \mathrm{e}-02$ 1.00000e-02 1.00000e-03 1.00000e-09 1.00000e-01

$1.00000 \mathrm{e}+001.00000 \mathrm{e}+001.00000 \mathrm{e}-01$ 1.00000e-09 1.00000e-01

$1.00000 \mathrm{e}-05$ 1.00000e-05 1.00000e-06 1.00000e-09 1.00000e-01

$1.00000 \mathrm{e}+001.00000 \mathrm{e}+001.00000 \mathrm{e}-011.00000 \mathrm{e}-091.00000 \mathrm{e}-01$

Element: 8614 \# of layers: 9

$\mathrm{Kx} \mathrm{Ky} \mathrm{Kz}$ Ss Por

4.30502e+00 4.30502e+00 4.30502e-01 1.00000e-09 2.12000e-01

4.30502e+00 4.30502e+00 4.30502e-01 1.00000e-09 2.12000e-01

4.30502e+00 4.30502e+00 4.30502e-01 1.00000e-09 2.12000e-01

4.30502e+00 4.30502e+00 4.30502e-01 1.00000e-09 2.12000e-01

$4.30502 \mathrm{e}+004.30502 \mathrm{e}+00$ 4.30502e-01 1.00000e-09 2.12000e-01

$1.00000 \mathrm{e}-021.00000 \mathrm{e}-021.00000 \mathrm{e}-031.00000 \mathrm{e}-091.00000 \mathrm{e}-01$

$1.00000 \mathrm{e}+001.00000 \mathrm{e}+001.00000 \mathrm{e}-011.00000 \mathrm{e}-091.00000 \mathrm{e}-01$

$1.00000 \mathrm{e}-05$ 1.00000e-05 1.00000e-06 1.00000e-09 1.00000e-01

$1.00000 \mathrm{e}+001.00000 \mathrm{e}+001.00000 \mathrm{e}-011.00000 \mathrm{e}-091.00000 \mathrm{e}-01$

Element: 8615 \# of layers: 9

$\mathrm{Kx} \mathrm{Ky} \mathrm{Kz}$ Ss Por

4.30502e+00 4.30502e+00 4.30502e-01 1.00000e-09 2.12000e-01

4.30502e+00 4.30502e+00 4.30502e-01 1.00000e-09 2.12000e-01

$4.30502 \mathrm{e}+004.30502 \mathrm{e}+00$ 4.30502e-01 1.00000e-09 2.12000e-01 
$4.30502 \mathrm{e}+004.30502 \mathrm{e}+00$ 4.30502e-01 1.00000e-09 2.12000e-01 4.30502e+00 4.30502e+00 4.30502e-01 1.00000e-09 2.12000e-01 $1.00000 \mathrm{e}-021.00000 \mathrm{e}-02$ 1.00000e-03 1.00000e-09 1.00000e-01 $1.00000 \mathrm{e}+001.00000 \mathrm{e}+001.00000 \mathrm{e}-011.00000 \mathrm{e}-091.00000 \mathrm{e}-01$ $1.00000 \mathrm{e}-05$ 1.00000e-05 1.00000e-06 1.00000e-09 1.00000e-01 $1.00000 \mathrm{e}+001.00000 \mathrm{e}+001.00000 \mathrm{e}-011.00000 \mathrm{e}-091.00000 \mathrm{e}-01$ Element: 8616 \# of layers: 9

Kx Ky Kz Ss Por

4.30502e+00 4.30502e+00 4.30502e-01 1.00000e-09 2.12000e-01 $4.30502 \mathrm{e}+004.30502 \mathrm{e}+004.30502 \mathrm{e}-01$ 1.00000e-09 2.12000e-01 $4.30502 \mathrm{e}+004.30502 \mathrm{e}+004.30502 \mathrm{e}-01$ 1.00000e-09 2.12000e-01 $4.30502 \mathrm{e}+004.30502 \mathrm{e}+004.30502 \mathrm{e}-01$ 1.00000e-09 2.12000e-01 $4.30502 \mathrm{e}+004.30502 \mathrm{e}+00$ 4.30502e-01 1.00000e-09 2.12000e-01 $1.00000 \mathrm{e}-02$ 1.00000e-02 1.00000e-03 1.00000e-09 1.00000e-01 $1.00000 \mathrm{e}+001.00000 \mathrm{e}+001.00000 \mathrm{e}-011.00000 \mathrm{e}-091.00000 \mathrm{e}-01$ $1.00000 \mathrm{e}-05$ 1.00000e-05 1.00000e-06 1.00000e-09 1.00000e-01 $1.00000 \mathrm{e}+001.00000 \mathrm{e}+001.00000 \mathrm{e}-011.00000 \mathrm{e}-091.00000 \mathrm{e}-01$ Element: 8617 \# of layers: 9

Kx Ky Kz Ss Por

$4.29242 \mathrm{e}+004.29242 \mathrm{e}+00$ 4.29242e-01 1.00000e-09 2.12000e-01 $4.29242 \mathrm{e}+004.29242 \mathrm{e}+004.29242 \mathrm{e}-01$ 1.00000e-09 2.12000e-01 $4.29242 \mathrm{e}+004.29242 \mathrm{e}+00$ 4.29242e-01 1.00000e-09 2.12000e-01 $4.29242 \mathrm{e}+004.29242 \mathrm{e}+00$ 4.29242e-01 1.00000e-09 2.12000e-01 $4.29242 \mathrm{e}+004.29242 \mathrm{e}+004.29242 \mathrm{e}-011.00000 \mathrm{e}-092.12000 \mathrm{e}-01$ $1.00000 \mathrm{e}-021.00000 \mathrm{e}-02$ 1.00000e-03 1.00000e-09 1.00000e-01 $1.00000 \mathrm{e}+001.00000 \mathrm{e}+001.00000 \mathrm{e}-011.00000 \mathrm{e}-091.00000 \mathrm{e}-01$ $1.00000 \mathrm{e}-05$ 1.00000e-05 1.00000e-06 1.00000e-09 1.00000e-01 $1.00000 \mathrm{e}+001.00000 \mathrm{e}+001.00000 \mathrm{e}-011.00000 \mathrm{e}-091.00000 \mathrm{e}-01$ Element: 8618 \# of layers: 9

Kx Ky Kz Ss Por

4.29242e+00 4.29242e+00 4.29242e-01 1.00000e-09 2.12000e-01 $4.29242 \mathrm{e}+004.29242 \mathrm{e}+004.29242 \mathrm{e}-01$ 1.00000e-09 2.12000e-01 $4.29242 \mathrm{e}+004.29242 \mathrm{e}+004.29242 \mathrm{e}-011.00000 \mathrm{e}-09$ 2.12000e-01 $4.29242 \mathrm{e}+004.29242 \mathrm{e}+004.29242 \mathrm{e}-011.00000 \mathrm{e}-09$ 2.12000e-01 $4.29242 \mathrm{e}+004.29242 \mathrm{e}+00$ 4.29242e-01 1.00000e-09 2.12000e-01 $1.00000 \mathrm{e}-02$ 1.00000e-02 1.00000e-03 1.00000e-09 1.00000e-01 $1.00000 \mathrm{e}+001.00000 \mathrm{e}+001.00000 \mathrm{e}-011.00000 \mathrm{e}-091.00000 \mathrm{e}-01$ $1.00000 \mathrm{e}-05$ 1.00000e-05 1.00000e-06 1.00000e-09 1.00000e-01 $1.00000 \mathrm{e}+001.00000 \mathrm{e}+001.00000 \mathrm{e}-011.00000 \mathrm{e}-091.00000 \mathrm{e}-01$ Element: 8619 \# of layers: 9

Kx Ky Kz Ss Por

$4.30502 \mathrm{e}+00$ 4.30502e+00 4.30502e-01 1.00000e-09 2.12000e-01 $4.30502 \mathrm{e}+004.30502 \mathrm{e}+004.30502 \mathrm{e}-011.00000 \mathrm{e}-092.12000 \mathrm{e}-01$ $4.30502 \mathrm{e}+004.30502 \mathrm{e}+004.30502 \mathrm{e}-01$ 1.00000e-09 2.12000e-01 $4.30502 \mathrm{e}+004.30502 \mathrm{e}+004.30502 \mathrm{e}-011.00000 \mathrm{e}-092.12000 \mathrm{e}-01$ $4.30502 \mathrm{e}+00$ 4.30502e+00 4.30502e-01 1.00000e-09 2.12000e-01 
$1.00000 \mathrm{e}-02$ 1.00000e-02 1.00000e-03 1.00000e-09 1.00000e-01 $1.00000 \mathrm{e}+001.00000 \mathrm{e}+001.00000 \mathrm{e}-011.00000 \mathrm{e}-091.00000 \mathrm{e}-01$ $1.00000 \mathrm{e}-051.00000 \mathrm{e}-05$ 1.00000e-06 1.00000e-09 1.00000e-01 $1.00000 \mathrm{e}+001.00000 \mathrm{e}+001.00000 \mathrm{e}-011.00000 \mathrm{e}-091.00000 \mathrm{e}-01$ Element: 8620 \# of layers: 9

Kx Ky Kz Ss Por

$4.29242 \mathrm{e}+00$ 4.29242e+00 4.29242e-01 1.00000e-09 2.12000e-01 $4.29242 \mathrm{e}+004.29242 \mathrm{e}+004.29242 \mathrm{e}-01$ 1.00000e-09 2.12000e-01 $4.29242 \mathrm{e}+004.29242 \mathrm{e}+00$ 4.29242e-01 1.00000e-09 2.12000e-01 $4.29242 \mathrm{e}+004.29242 \mathrm{e}+00$ 4.29242e-01 1.00000e-09 2.12000e-01 $4.29242 \mathrm{e}+004.29242 \mathrm{e}+00$ 4.29242e-01 1.00000e-09 2.12000e-01 $1.00000 \mathrm{e}-021.00000 \mathrm{e}-02$ 1.00000e-03 1.00000e-09 1.00000e-01 $1.00000 \mathrm{e}+001.00000 \mathrm{e}+001.00000 \mathrm{e}-011.00000 \mathrm{e}-091.00000 \mathrm{e}-01$ $1.00000 \mathrm{e}-05$ 1.00000e-05 1.00000e-06 1.00000e-09 1.00000e-01 $1.00000 \mathrm{e}+001.00000 \mathrm{e}+001.00000 \mathrm{e}-011.00000 \mathrm{e}-091.00000 \mathrm{e}-01$ Element: 8621 \# of layers: 9

Kx Ky Kz Ss Por

$4.29242 \mathrm{e}+00$ 4.29242e+00 4.29242e-01 1.00000e-09 2.12000e-01 $4.29242 \mathrm{e}+004.29242 \mathrm{e}+00$ 4.29242e-01 1.00000e-09 2.12000e-01 $4.29242 \mathrm{e}+004.29242 \mathrm{e}+00$ 4.29242e-01 1.00000e-09 2.12000e-01 $4.29242 \mathrm{e}+004.29242 \mathrm{e}+004.29242 \mathrm{e}-011.00000 \mathrm{e}-092.12000 \mathrm{e}-01$ $4.29242 \mathrm{e}+004.29242 \mathrm{e}+00$ 4.29242e-01 1.00000e-09 2.12000e-01 $1.00000 \mathrm{e}-02$ 1.00000e-02 1.00000e-03 1.00000e-09 1.00000e-01 $1.00000 \mathrm{e}+001.00000 \mathrm{e}+001.00000 \mathrm{e}-011.00000 \mathrm{e}-091.00000 \mathrm{e}-01$ $1.00000 \mathrm{e}-05$ 1.00000e-05 1.00000e-06 1.00000e-09 1.00000e-01 $1.00000 \mathrm{e}+001.00000 \mathrm{e}+001.00000 \mathrm{e}-011.00000 \mathrm{e}-091.00000 \mathrm{e}-01$ Element: 8622 \# of layers: 9

Kx Ky Kz Ss Por

$4.29242 \mathrm{e}+00$ 4.29242e+00 4.29242e-01 1.00000e-09 2.12000e-01 $4.29242 \mathrm{e}+004.29242 \mathrm{e}+00$ 4.29242e-01 1.00000e-09 2.12000e-01 $4.29242 \mathrm{e}+004.29242 \mathrm{e}+00$ 4.29242e-01 1.00000e-09 2.12000e-01 $4.29242 \mathrm{e}+004.29242 \mathrm{e}+004.29242 \mathrm{e}-01$ 1.00000e-09 2.12000e-01 $4.29242 \mathrm{e}+004.29242 \mathrm{e}+00$ 4.29242e-01 1.00000e-09 2.12000e-01 $1.00000 \mathrm{e}-021.00000 \mathrm{e}-02$ 1.00000e-03 1.00000e-09 1.00000e-01 $1.00000 \mathrm{e}+001.00000 \mathrm{e}+001.00000 \mathrm{e}-011.00000 \mathrm{e}-091.00000 \mathrm{e}-01$ $1.00000 \mathrm{e}-05$ 1.00000e-05 1.00000e-06 1.00000e-09 1.00000e-01 $1.00000 \mathrm{e}+001.00000 \mathrm{e}+001.00000 \mathrm{e}-011.00000 \mathrm{e}-091.00000 \mathrm{e}-01$ Element: 8623 \# of layers: 9

Kx Ky Kz Ss Por

4.29242e+00 4.29242e+00 4.29242e-01 1.00000e-09 2.12000e-01 $4.29242 \mathrm{e}+004.29242 \mathrm{e}+00$ 4.29242e-01 1.00000e-09 2.12000e-01 $4.29242 \mathrm{e}+004.29242 \mathrm{e}+004.29242 \mathrm{e}-011.00000 \mathrm{e}-092.12000 \mathrm{e}-01$ $4.29242 \mathrm{e}+004.29242 \mathrm{e}+004.29242 \mathrm{e}-01$ 1.00000e-09 2.12000e-01 $4.29242 \mathrm{e}+004.29242 \mathrm{e}+00$ 4.29242e-01 1.00000e-09 2.12000e-01 $1.00000 \mathrm{e}-02$ 1.00000e-02 1.00000e-03 1.00000e-09 1.00000e-01 $1.00000 \mathrm{e}+001.00000 \mathrm{e}+001.00000 \mathrm{e}-011.00000 \mathrm{e}-091.00000 \mathrm{e}-01$ 
$1.00000 \mathrm{e}-05$ 1.00000e-05 1.00000e-06 1.00000e-09 1.00000e-01 $1.00000 \mathrm{e}+001.00000 \mathrm{e}+001.00000 \mathrm{e}-01$ 1.00000e-09 1.00000e-01 Element: 8624 \# of layers: 9

$\mathrm{Kx} \mathrm{Ky} \mathrm{Kz}$ Ss Por

4.29242e+00 4.29242e+00 4.29242e-01 1.00000e-09 2.12000e-01 4.29242e+00 4.29242e+00 4.29242e-01 1.00000e-09 2.12000e-01 4.29242e+00 4.29242e+00 4.29242e-01 1.00000e-09 2.12000e-01 $4.29242 \mathrm{e}+00$ 4.29242e+00 4.29242e-01 1.00000e-09 2.12000e-01 $4.29242 \mathrm{e}+00$ 4.29242e+00 4.29242e-01 1.00000e-09 2.12000e-01 $1.00000 \mathrm{e}-02$ 1.00000e-02 1.00000e-03 1.00000e-09 1.00000e-01 $1.00000 \mathrm{e}+001.00000 \mathrm{e}+001.00000 \mathrm{e}-011.00000 \mathrm{e}-091.00000 \mathrm{e}-01$ $1.00000 \mathrm{e}-05$ 1.00000e-05 1.00000e-06 1.00000e-09 1.00000e-01 $1.00000 \mathrm{e}+001.00000 \mathrm{e}+001.00000 \mathrm{e}-01$ 1.00000e-09 1.00000e-01 Element: 8625 \# of layers: 9

$\mathrm{Kx} \mathrm{Ky} \mathrm{Kz}$ Ss Por

4.29242e+00 4.29242e+00 4.29242e-01 1.00000e-09 2.12000e-01 4.29242e+00 4.29242e+00 4.29242e-01 1.00000e-09 2.12000e-01 4.29242e+00 4.29242e+00 4.29242e-01 1.00000e-09 2.12000e-01 4.29242e+00 4.29242e+00 4.29242e-01 1.00000e-09 2.12000e-01 $4.29242 \mathrm{e}+00$ 4.29242e+00 4.29242e-01 1.00000e-09 2.12000e-01 $1.00000 \mathrm{e}-02$ 1.00000e-02 1.00000e-03 1.00000e-09 1.00000e-01 $1.00000 \mathrm{e}+001.00000 \mathrm{e}+001.00000 \mathrm{e}-011.00000 \mathrm{e}-091.00000 \mathrm{e}-01$ $1.00000 \mathrm{e}-051.00000 \mathrm{e}-05$ 1.00000e-06 1.00000e-09 1.00000e-01 $1.00000 \mathrm{e}+001.00000 \mathrm{e}+001.00000 \mathrm{e}-011.00000 \mathrm{e}-091.00000 \mathrm{e}-01$ Element: 8626 \# of layers: 9

$\mathrm{Kx} \mathrm{Ky} \mathrm{Kz}$ Ss Por

4.29242e+00 4.29242e+00 4.29242e-01 1.00000e-09 2.12000e-01 4.29242e+00 4.29242e+00 4.29242e-01 1.00000e-09 2.12000e-01 $4.29242 \mathrm{e}+00$ 4.29242e+00 4.29242e-01 1.00000e-09 2.12000e-01 4.29242e+00 4.29242e+00 4.29242e-01 1.00000e-09 2.12000e-01 4.29242e+00 4.29242e+00 4.29242e-01 1.00000e-09 2.12000e-01 $1.00000 \mathrm{e}-02$ 1.00000e-02 1.00000e-03 1.00000e-09 1.00000e-01 $1.00000 \mathrm{e}+001.00000 \mathrm{e}+001.00000 \mathrm{e}-011.00000 \mathrm{e}-091.00000 \mathrm{e}-01$ $1.00000 \mathrm{e}-05$ 1.00000e-05 1.00000e-06 1.00000e-09 1.00000e-01 $1.00000 \mathrm{e}+001.00000 \mathrm{e}+001.00000 \mathrm{e}-011.00000 \mathrm{e}-091.00000 \mathrm{e}-01$ Element: 8627 \# of layers: 9

Kx Ky Kz Ss Por

$1.53998 \mathrm{e}+01$ 1.53998e+01 1.53998e+00 1.00000e-09 2.12000e-01 $1.53998 \mathrm{e}+01$ 1.53998e+01 1.53998e+00 1.00000e-09 2.12000e-01 $1.53998 \mathrm{e}+01$ 1.53998e+01 1.53998e+00 1.00000e-09 2.12000e-01 $1.53998 \mathrm{e}+01$ 1.53998e+01 1.53998e+00 1.00000e-09 2.12000e-01 $1.53998 \mathrm{e}+01$ 1.53998e+01 1.53998e+00 1.00000e-09 2.12000e-01 $1.00000 \mathrm{e}-02$ 1.00000e-02 1.00000e-03 1.00000e-09 1.00000e-01 $1.00000 \mathrm{e}+001.00000 \mathrm{e}+001.00000 \mathrm{e}-011.00000 \mathrm{e}-091.00000 \mathrm{e}-01$ $1.00000 \mathrm{e}-05$ 1.00000e-05 1.00000e-06 1.00000e-09 1.00000e-01 $1.00000 \mathrm{e}+001.00000 \mathrm{e}+001.00000 \mathrm{e}-011.00000 \mathrm{e}-091.00000 \mathrm{e}-01$ 
Element: 8628 \# of layers: 9

$\mathrm{Kx} \mathrm{Ky} \mathrm{Kz}$ Ss Por

$1.53998 \mathrm{e}+01$ 1.53998e+01 1.53998e+00 1.00000e-09 2.12000e-01

$1.53998 \mathrm{e}+01$ 1.53998e+01 1.53998e+00 1.00000e-09 2.12000e-01

$1.53998 \mathrm{e}+01$ 1.53998e+01 1.53998e+00 1.00000e-09 2.12000e-01

$1.53998 \mathrm{e}+01$ 1.53998e+01 1.53998e+00 1.00000e-09 2.12000e-01

$1.53998 \mathrm{e}+01$ 1.53998e+01 1.53998e+00 1.00000e-09 2.12000e-01

$1.00000 \mathrm{e}-02$ 1.00000e-02 1.00000e-03 1.00000e-09 1.00000e-01

$1.00000 \mathrm{e}+001.00000 \mathrm{e}+001.00000 \mathrm{e}-011.00000 \mathrm{e}-091.00000 \mathrm{e}-01$

$1.00000 \mathrm{e}-05$ 1.00000e-05 1.00000e-06 1.00000e-09 1.00000e-01

$1.00000 \mathrm{e}+001.00000 \mathrm{e}+001.00000 \mathrm{e}-01$ 1.00000e-09 1.00000e-01

Element: 8629 \# of layers: 9

$\mathrm{Kx} \mathrm{Ky} \mathrm{Kz}$ Ss Por

$1.53998 \mathrm{e}+01$ 1.53998e+01 1.53998e+00 1.00000e-09 2.12000e-01

$1.53998 \mathrm{e}+01$ 1.53998e+01 1.53998e+00 1.00000e-09 2.12000e-01

$1.53998 \mathrm{e}+01$ 1.53998e+01 1.53998e+00 1.00000e-09 2.12000e-01

$1.53998 \mathrm{e}+01$ 1.53998e+01 1.53998e+00 1.00000e-09 2.12000e-01

$1.53998 \mathrm{e}+01$ 1.53998e+01 1.53998e+00 1.00000e-09 2.12000e-01

$1.00000 \mathrm{e}-02$ 1.00000e-02 1.00000e-03 1.00000e-09 1.00000e-01

$1.00000 \mathrm{e}+001.00000 \mathrm{e}+001.00000 \mathrm{e}-011.00000 \mathrm{e}-091.00000 \mathrm{e}-01$

$1.00000 \mathrm{e}-05$ 1.00000e-05 1.00000e-06 1.00000e-09 1.00000e-01

$1.00000 \mathrm{e}+001.00000 \mathrm{e}+001.00000 \mathrm{e}-01$ 1.00000e-09 1.00000e-01

Element: 8630 \# of layers: 9

$\mathrm{Kx} \mathrm{Ky} \mathrm{Kz}$ Ss Por

4.29242e+00 4.29242e+00 4.29242e-01 1.00000e-09 2.12000e-01

4.29242e+00 4.29242e+00 4.29242e-01 1.00000e-09 2.12000e-01

4.29242e+00 4.29242e+00 4.29242e-01 1.00000e-09 2.12000e-01

4.29242e+00 4.29242e+00 4.29242e-01 1.00000e-09 2.12000e-01

$4.29242 \mathrm{e}+00$ 4.29242e+00 4.29242e-01 1.00000e-09 2.12000e-01

$1.00000 \mathrm{e}-02$ 1.00000e-02 1.00000e-03 1.00000e-09 1.00000e-01

$1.00000 \mathrm{e}+001.00000 \mathrm{e}+001.00000 \mathrm{e}-011.00000 \mathrm{e}-091.00000 \mathrm{e}-01$

$1.00000 \mathrm{e}-05$ 1.00000e-05 1.00000e-06 1.00000e-09 1.00000e-01

$1.00000 \mathrm{e}+001.00000 \mathrm{e}+001.00000 \mathrm{e}-011.00000 \mathrm{e}-091.00000 \mathrm{e}-01$

Element: 8631 \# of layers: 9

$\mathrm{Kx} \mathrm{Ky} \mathrm{Kz}$ Ss Por

4.29242e+00 4.29242e+00 4.29242e-01 1.00000e-09 2.12000e-01 $4.29242 \mathrm{e}+004.29242 \mathrm{e}+00$ 4.29242e-01 1.00000e-09 2.12000e-01 4.29242e+00 4.29242e+00 4.29242e-01 1.00000e-09 2.12000e-01 4.29242e+00 4.29242e+00 4.29242e-01 1.00000e-09 2.12000e-01 4.29242e+00 4.29242e+00 4.29242e-01 1.00000e-09 2.12000e-01 $1.00000 \mathrm{e}-02$ 1.00000e-02 1.00000e-03 1.00000e-09 1.00000e-01 $1.00000 \mathrm{e}+001.00000 \mathrm{e}+001.00000 \mathrm{e}-011.00000 \mathrm{e}-091.00000 \mathrm{e}-01$ $1.00000 \mathrm{e}-05$ 1.00000e-05 1.00000e-06 1.00000e-09 1.00000e-01 $1.00000 \mathrm{e}+001.00000 \mathrm{e}+001.00000 \mathrm{e}-01$ 1.00000e-09 1.00000e-01 Element: 8632 \# of layers: 9

Kx Ky Kz Ss Por 
4.29242e+00 4.29242e+00 4.29242e-01 1.00000e-09 2.12000e-01 4.29242e+00 4.29242e+00 4.29242e-01 1.00000e-09 2.12000e-01 4.29242e+00 4.29242e+00 4.29242e-01 1.00000e-09 2.12000e-01 $4.29242 \mathrm{e}+00$ 4.29242e+00 4.29242e-01 1.00000e-09 2.12000e-01 4.29242e+00 4.29242e+00 4.29242e-01 1.00000e-09 2.12000e-01 $1.00000 \mathrm{e}-02$ 1.00000e-02 1.00000e-03 1.00000e-09 1.00000e-01 $1.00000 \mathrm{e}+001.00000 \mathrm{e}+001.00000 \mathrm{e}-011.00000 \mathrm{e}-091.00000 \mathrm{e}-01$ $1.00000 \mathrm{e}-05$ 1.00000e-05 1.00000e-06 1.00000e-09 1.00000e-01 $1.00000 \mathrm{e}+001.00000 \mathrm{e}+001.00000 \mathrm{e}-011.00000 \mathrm{e}-091.00000 \mathrm{e}-01$ Element: 8633 \# of layers: 9

$\mathrm{Kx} \mathrm{Ky} \mathrm{Kz}$ Ss Por

4.29242e+00 4.29242e+00 4.29242e-01 1.00000e-09 2.12000e-01 4.29242e+00 4.29242e+00 4.29242e-01 1.00000e-09 2.12000e-01 4.29242e+00 4.29242e+00 4.29242e-01 1.00000e-09 2.12000e-01 4.29242e+00 4.29242e+00 4.29242e-01 1.00000e-09 2.12000e-01 4.29242e+00 4.29242e+00 4.29242e-01 1.00000e-09 2.12000e-01 $1.00000 \mathrm{e}-02$ 1.00000e-02 1.00000e-03 1.00000e-09 1.00000e-01 $1.00000 \mathrm{e}+001.00000 \mathrm{e}+001.00000 \mathrm{e}-011.00000 \mathrm{e}-091.00000 \mathrm{e}-01$ $1.00000 \mathrm{e}-05$ 1.00000e-05 1.00000e-06 1.00000e-09 1.00000e-01 $1.00000 \mathrm{e}+001.00000 \mathrm{e}+001.00000 \mathrm{e}-011.00000 \mathrm{e}-091.00000 \mathrm{e}-01$ Element: 8634 \# of layers: 7

$\mathrm{Kx} \mathrm{Ky} \mathrm{Kz}$ Ss Por

$1.53998 \mathrm{e}+01$ 1.53998e+01 1.53998e+00 1.00000e-09 2.12000e-01 $1.53998 \mathrm{e}+011.53998 \mathrm{e}+01$ 1.53998e+00 1.00000e-09 2.12000e-01 $1.53998 \mathrm{e}+011.53998 \mathrm{e}+011.53998 \mathrm{e}+001.00000 \mathrm{e}-092.12000 \mathrm{e}-01$ $1.53998 \mathrm{e}+01$ 1.53998e+01 1.53998e+00 1.00000e-09 2.12000e-01 $1.53998 \mathrm{e}+01$ 1.53998e+01 1.53998e+00 1.00000e-09 2.12000e-01 $1.00000 \mathrm{e}-05$ 1.00000e-05 1.00000e-06 1.00000e-09 1.00000e-01 $1.00000 \mathrm{e}+001.00000 \mathrm{e}+001.00000 \mathrm{e}-011.00000 \mathrm{e}-091.00000 \mathrm{e}-01$ Element: 8635 \# of layers: 7

$\mathrm{Kx} \mathrm{Ky} \mathrm{Kz}$ Ss Por

$1.53998 \mathrm{e}+01$ 1.53998e+01 1.53998e+00 1.00000e-09 2.12000e-01 $1.53998 \mathrm{e}+01$ 1.53998e+01 1.53998e+00 1.00000e-09 2.12000e-01 $1.53998 \mathrm{e}+01$ 1.53998e+01 1.53998e+00 1.00000e-09 2.12000e-01 $1.53998 \mathrm{e}+01$ 1.53998e+01 1.53998e+00 1.00000e-09 2.12000e-01 $1.53998 \mathrm{e}+01$ 1.53998e+01 1.53998e+00 1.00000e-09 2.12000e-01 $1.00000 \mathrm{e}-05$ 1.00000e-05 1.00000e-06 1.00000e-09 1.00000e-01 $1.00000 \mathrm{e}+001.00000 \mathrm{e}+001.00000 \mathrm{e}-011.00000 \mathrm{e}-091.00000 \mathrm{e}-01$ Element: 8636 \# of layers: 7

$\mathrm{Kx} \mathrm{Ky} \mathrm{Kz}$ Ss Por

$1.53998 \mathrm{e}+01$ 1.53998e+01 1.53998e+00 1.00000e-09 2.12000e-01 $1.53998 \mathrm{e}+01$ 1.53998e+01 1.53998e+00 1.00000e-09 2.12000e-01 $1.53998 \mathrm{e}+01$ 1.53998e+01 1.53998e+00 1.00000e-09 2.12000e-01 $1.53998 \mathrm{e}+01$ 1.53998e+01 1.53998e+00 1.00000e-09 2.12000e-01 $1.53998 \mathrm{e}+011.53998 \mathrm{e}+01$ 1.53998e+00 1.00000e-09 2.12000e-01 $1.00000 \mathrm{e}-05$ 1.00000e-05 1.00000e-06 1.00000e-09 1.00000e-01 
$1.00000 \mathrm{e}+001.00000 \mathrm{e}+00$ 1.00000e-01 1.00000e-09 1.00000e-01

Element: 8637 \# of layers: 7

$\mathrm{Kx} \mathrm{Ky} \mathrm{Kz}$ Ss Por

$1.53998 \mathrm{e}+01$ 1.53998e+01 1.53998e+00 1.00000e-09 2.12000e-01

$1.53998 \mathrm{e}+01$ 1.53998e+01 1.53998e+00 1.00000e-09 2.12000e-01

$1.53998 \mathrm{e}+01$ 1.53998e+01 1.53998e+00 1.00000e-09 2.12000e-01

$1.53998 \mathrm{e}+01$ 1.53998e+01 1.53998e+00 1.00000e-09 2.12000e-01

$1.53998 \mathrm{e}+01$ 1.53998e+01 1.53998e+00 1.00000e-09 2.12000e-01

$1.00000 \mathrm{e}-05$ 1.00000e-05 1.00000e-06 1.00000e-09 1.00000e-01

$1.00000 \mathrm{e}+001.00000 \mathrm{e}+001.00000 \mathrm{e}-011.00000 \mathrm{e}-091.00000 \mathrm{e}-01$

Element: 8638 \# of layers: 7

$\mathrm{Kx} \mathrm{Ky} \mathrm{Kz}$ Ss Por

1.53998e+01 1.53998e+01 1.53998e+00 1.00000e-09 2.12000e-01

$1.53998 \mathrm{e}+01$ 1.53998e+01 1.53998e+00 1.00000e-09 2.12000e-01

$1.53998 \mathrm{e}+01$ 1.53998e+01 1.53998e+00 1.00000e-09 2.12000e-01

$1.53998 \mathrm{e}+01$ 1.53998e+01 1.53998e+00 1.00000e-09 2.12000e-01

$1.53998 \mathrm{e}+01$ 1.53998e+01 1.53998e+00 1.00000e-09 2.12000e-01

$1.00000 \mathrm{e}-05$ 1.00000e-05 1.00000e-06 1.00000e-09 1.00000e-01

$1.00000 \mathrm{e}+001.00000 \mathrm{e}+001.00000 \mathrm{e}-011.00000 \mathrm{e}-091.00000 \mathrm{e}-01$

Element: 8639 \# of layers: 7

$\mathrm{Kx} \mathrm{Ky} \mathrm{Kz}$ Ss Por

$1.53998 \mathrm{e}+01$ 1.53998e+01 1.53998e+00 1.00000e-09 2.12000e-01

$1.53998 \mathrm{e}+01$ 1.53998e+01 1.53998e+00 1.00000e-09 2.12000e-01

$1.53998 \mathrm{e}+011.53998 \mathrm{e}+01$ 1.53998e+00 1.00000e-09 2.12000e-01

$1.53998 \mathrm{e}+011.53998 \mathrm{e}+011.53998 \mathrm{e}+001.00000 \mathrm{e}-092.12000 \mathrm{e}-01$

$1.53998 \mathrm{e}+01$ 1.53998e+01 1.53998e+00 1.00000e-09 2.12000e-01

$1.00000 \mathrm{e}-05$ 1.00000e-05 1.00000e-06 1.00000e-09 1.00000e-01

$1.00000 \mathrm{e}+001.00000 \mathrm{e}+001.00000 \mathrm{e}-011.00000 \mathrm{e}-091.00000 \mathrm{e}-01$

Element: 8640 \# of layers: 7

$\mathrm{Kx} \mathrm{Ky} \mathrm{Kz}$ Ss Por

$1.53998 \mathrm{e}+01$ 1.53998e+01 1.53998e+00 1.00000e-09 2.12000e-01

$1.53998 \mathrm{e}+01$ 1.53998e+01 1.53998e+00 1.00000e-09 2.12000e-01

$1.53998 \mathrm{e}+01$ 1.53998e+01 1.53998e+00 1.00000e-09 2.12000e-01

$1.53998 \mathrm{e}+01$ 1.53998e+01 1.53998e+00 1.00000e-09 2.12000e-01

$1.53998 \mathrm{e}+01$ 1.53998e+01 1.53998e+00 1.00000e-09 2.12000e-01

$1.00000 \mathrm{e}-05$ 1.00000e-05 1.00000e-06 1.00000e-09 1.00000e-01

$1.00000 \mathrm{e}+001.00000 \mathrm{e}+001.00000 \mathrm{e}-011.00000 \mathrm{e}-091.00000 \mathrm{e}-01$

Element: 8641 \# of layers: 7

$\mathrm{Kx} \mathrm{Ky} \mathrm{Kz}$ Ss Por

$1.53998 \mathrm{e}+01$ 1.53998e+01 1.53998e+00 1.00000e-09 2.12000e-01

$1.53998 \mathrm{e}+01$ 1.53998e+01 1.53998e+00 1.00000e-09 2.12000e-01

$1.53998 \mathrm{e}+01$ 1.53998e+01 1.53998e+00 1.00000e-09 2.12000e-01

$1.53998 \mathrm{e}+01$ 1.53998e+01 1.53998e+00 1.00000e-09 2.12000e-01

$1.53998 \mathrm{e}+01$ 1.53998e+01 1.53998e+00 1.00000e-09 2.12000e-01 $1.00000 \mathrm{e}-05$ 1.00000e-05 1.00000e-06 1.00000e-09 1.00000e-01

$1.00000 \mathrm{e}+001.00000 \mathrm{e}+001.00000 \mathrm{e}-011.00000 \mathrm{e}-091.00000 \mathrm{e}-01$ 
Element: 8642 \# of layers: 7

$\mathrm{Kx} \mathrm{Ky} \mathrm{Kz}$ Ss Por

$1.53998 \mathrm{e}+01$ 1.53998e+01 1.53998e+00 1.00000e-09 2.12000e-01

$1.53998 \mathrm{e}+01$ 1.53998e+01 1.53998e+00 1.00000e-09 2.12000e-01

$1.53998 \mathrm{e}+01$ 1.53998e+01 1.53998e+00 1.00000e-09 2.12000e-01

$1.53998 \mathrm{e}+01$ 1.53998e+01 1.53998e+00 1.00000e-09 2.12000e-01

$1.53998 \mathrm{e}+01$ 1.53998e+01 1.53998e+00 1.00000e-09 2.12000e-01

$1.00000 \mathrm{e}-05$ 1.00000e-05 1.00000e-06 1.00000e-09 1.00000e-01

$1.00000 \mathrm{e}+001.00000 \mathrm{e}+001.00000 \mathrm{e}-011.00000 \mathrm{e}-091.00000 \mathrm{e}-01$

Element: 8643 \# of layers: 7

$\mathrm{Kx} \mathrm{Ky} \mathrm{Kz}$ Ss Por

$1.53998 \mathrm{e}+01$ 1.53998e+01 1.53998e+00 1.00000e-09 2.12000e-01

$1.53998 \mathrm{e}+01$ 1.53998e+01 1.53998e+00 1.00000e-09 2.12000e-01

$1.53998 \mathrm{e}+01$ 1.53998e+01 1.53998e+00 1.00000e-09 2.12000e-01

$1.53998 \mathrm{e}+01$ 1.53998e+01 1.53998e+00 1.00000e-09 2.12000e-01

$1.53998 \mathrm{e}+01$ 1.53998e+01 1.53998e+00 1.00000e-09 2.12000e-01

$1.00000 \mathrm{e}-05$ 1.00000e-05 1.00000e-06 1.00000e-09 1.00000e-01

$1.00000 \mathrm{e}+001.00000 \mathrm{e}+001.00000 \mathrm{e}-01$ 1.00000e-09 1.00000e-01

Element: 8644 \# of layers: 7

$\mathrm{Kx} \mathrm{Ky} \mathrm{Kz}$ Ss Por

$1.53998 \mathrm{e}+01$ 1.53998e+01 1.53998e+00 1.00000e-09 2.12000e-01

$1.53998 \mathrm{e}+01$ 1.53998e+01 1.53998e+00 1.00000e-09 2.12000e-01

$1.53998 \mathrm{e}+01$ 1.53998e+01 1.53998e+00 1.00000e-09 2.12000e-01

$1.53998 \mathrm{e}+01$ 1.53998e+01 1.53998e+00 1.00000e-09 2.12000e-01

$1.53998 \mathrm{e}+01$ 1.53998e+01 1.53998e+00 1.00000e-09 2.12000e-01

$1.00000 \mathrm{e}-05$ 1.00000e-05 1.00000e-06 1.00000e-09 1.00000e-01

$1.00000 \mathrm{e}+001.00000 \mathrm{e}+001.00000 \mathrm{e}-011.00000 \mathrm{e}-091.00000 \mathrm{e}-01$

Element: 8645 \# of layers: 7

$\mathrm{Kx} \mathrm{Ky} \mathrm{Kz}$ Ss Por

5.59249e+00 5.59249e+00 5.59249e-01 1.00000e-09 2.12000e-01

5.59249e+00 5.59249e+00 5.59249e-01 1.00000e-09 2.12000e-01

5.59249e+00 5.59249e+00 5.59249e-01 1.00000e-09 2.12000e-01

$5.59249 \mathrm{e}+005.59249 \mathrm{e}+00$ 5.59249e-01 1.00000e-09 2.12000e-01

$5.59249 \mathrm{e}+00$ 5.59249e+00 5.59249e-01 1.00000e-09 2.12000e-01

$1.00000 \mathrm{e}-05$ 1.00000e-05 1.00000e-06 1.00000e-09 1.00000e-01

$1.00000 \mathrm{e}+001.00000 \mathrm{e}+001.00000 \mathrm{e}-011.00000 \mathrm{e}-091.00000 \mathrm{e}-01$

Element: 8646 \# of layers: 7

$\mathrm{Kx} \mathrm{Ky} \mathrm{Kz}$ Ss Por

5.59249e+00 5.59249e+00 5.59249e-01 1.00000e-09 2.12000e-01

5.59249e+00 5.59249e+00 5.59249e-01 1.00000e-09 2.12000e-01

$5.59249 \mathrm{e}+005.59249 \mathrm{e}+00$ 5.59249e-01 1.00000e-09 2.12000e-01

$5.59249 \mathrm{e}+00$ 5.59249e+00 5.59249e-01 1.00000e-09 2.12000e-01

5.59249e+00 5.59249e+00 5.59249e-01 1.00000e-09 2.12000e-01

$1.00000 \mathrm{e}-05$ 1.00000e-05 1.00000e-06 1.00000e-09 1.00000e-01

$1.00000 \mathrm{e}+001.00000 \mathrm{e}+001.00000 \mathrm{e}-011.00000 \mathrm{e}-091.00000 \mathrm{e}-01$

Element: 8647 \# of layers: 7 
$\mathrm{Kx} \mathrm{Ky} \mathrm{Kz}$ Ss Por

5.59249e+00 5.59249e+00 5.59249e-01 1.00000e-09 2.12000e-01

$5.59249 \mathrm{e}+00$ 5.59249e+00 5.59249e-01 1.00000e-09 2.12000e-01

$5.59249 \mathrm{e}+00$ 5.59249e+00 5.59249e-01 1.00000e-09 2.12000e-01

$5.59249 \mathrm{e}+00$ 5.59249e+00 5.59249e-01 1.00000e-09 2.12000e-01

$5.59249 \mathrm{e}+005.59249 \mathrm{e}+00$ 5.59249e-01 1.00000e-09 2.12000e-01

$1.00000 \mathrm{e}-05$ 1.00000e-05 1.00000e-06 1.00000e-09 1.00000e-01

$1.00000 \mathrm{e}+001.00000 \mathrm{e}+001.00000 \mathrm{e}-011.00000 \mathrm{e}-091.00000 \mathrm{e}-01$

Element: 8648 \# of layers: 7

$\mathrm{Kx} \mathrm{Ky} \mathrm{Kz}$ Ss Por

$1.53998 \mathrm{e}+01$ 1.53998e+01 1.53998e+00 1.00000e-09 2.12000e-01

$1.53998 \mathrm{e}+01$ 1.53998e+01 1.53998e+00 1.00000e-09 2.12000e-01

$1.53998 \mathrm{e}+01$ 1.53998e+01 1.53998e+00 1.00000e-09 2.12000e-01

$1.53998 \mathrm{e}+01$ 1.53998e+01 1.53998e+00 1.00000e-09 2.12000e-01

$1.53998 \mathrm{e}+01$ 1.53998e+01 1.53998e+00 1.00000e-09 2.12000e-01 $1.00000 \mathrm{e}-05$ 1.00000e-05 1.00000e-06 1.00000e-09 1.00000e-01

$1.00000 \mathrm{e}+001.00000 \mathrm{e}+001.00000 \mathrm{e}-011.00000 \mathrm{e}-091.00000 \mathrm{e}-01$

Element: 8649 \# of layers: 7

$\mathrm{Kx} \mathrm{Ky} \mathrm{Kz}$ Ss Por

$1.53998 \mathrm{e}+01$ 1.53998e+01 1.53998e+00 1.00000e-09 2.12000e-01

$1.53998 \mathrm{e}+011.53998 \mathrm{e}+011.53998 \mathrm{e}+001.00000 \mathrm{e}-092.12000 \mathrm{e}-01$

$1.53998 \mathrm{e}+01$ 1.53998e+01 1.53998e+00 1.00000e-09 2.12000e-01

$1.53998 \mathrm{e}+01$ 1.53998e+01 1.53998e+00 1.00000e-09 2.12000e-01

$1.53998 \mathrm{e}+011.53998 \mathrm{e}+01$ 1.53998e+00 1.00000e-09 2.12000e-01

$1.00000 \mathrm{e}-05$ 1.00000e-05 1.00000e-06 1.00000e-09 1.00000e-01

$1.00000 \mathrm{e}+001.00000 \mathrm{e}+001.00000 \mathrm{e}-01$ 1.00000e-09 1.00000e-01

Element: 8650 \# of layers: 7

$\mathrm{Kx} \mathrm{Ky} \mathrm{Kz}$ Ss Por

$1.53998 \mathrm{e}+01$ 1.53998e+01 1.53998e+00 1.00000e-09 2.12000e-01

$1.53998 \mathrm{e}+01$ 1.53998e+01 1.53998e+00 1.00000e-09 2.12000e-01

$1.53998 \mathrm{e}+01$ 1.53998e+01 1.53998e+00 1.00000e-09 2.12000e-01

$1.53998 \mathrm{e}+011.53998 \mathrm{e}+01$ 1.53998e+00 1.00000e-09 2.12000e-01

$1.53998 \mathrm{e}+01$ 1.53998e+01 1.53998e+00 1.00000e-09 2.12000e-01

$1.00000 \mathrm{e}-05$ 1.00000e-05 1.00000e-06 1.00000e-09 1.00000e-01

$1.00000 \mathrm{e}+001.00000 \mathrm{e}+001.00000 \mathrm{e}-011.00000 \mathrm{e}-091.00000 \mathrm{e}-01$

Element: 8651 \# of layers: 7

Kx Ky Kz Ss Por

$1.53998 \mathrm{e}+01$ 1.53998e+01 1.53998e+00 1.00000e-09 2.12000e-01

$1.53998 \mathrm{e}+011.53998 \mathrm{e}+01$ 1.53998e+00 1.00000e-09 2.12000e-01

$1.53998 \mathrm{e}+01$ 1.53998e+01 1.53998e+00 1.00000e-09 2.12000e-01

$1.53998 \mathrm{e}+01$ 1.53998e+01 1.53998e+00 1.00000e-09 2.12000e-01

$1.53998 \mathrm{e}+01$ 1.53998e+01 1.53998e+00 1.00000e-09 2.12000e-01

1.00000e-05 1.00000e-05 1.00000e-06 1.00000e-09 1.00000e-01

$1.00000 \mathrm{e}+001.00000 \mathrm{e}+001.00000 \mathrm{e}-01$ 1.00000e-09 1.00000e-01

Element: 8652 \# of layers: 7

Kx Ky Kz Ss Por 
$5.59249 \mathrm{e}+00$ 5.59249e+00 5.59249e-01 1.00000e-09 2.12000e-01 $5.59249 \mathrm{e}+005.59249 \mathrm{e}+00$ 5.59249e-01 1.00000e-09 2.12000e-01 $5.59249 \mathrm{e}+005.59249 \mathrm{e}+00$ 5.59249e-01 1.00000e-09 2.12000e-01 $5.59249 \mathrm{e}+00$ 5.59249e+00 5.59249e-01 1.00000e-09 2.12000e-01 $5.59249 \mathrm{e}+00$ 5.59249e+00 5.59249e-01 1.00000e-09 2.12000e-01 $1.00000 \mathrm{e}-05$ 1.00000e-05 1.00000e-06 1.00000e-09 1.00000e-01 $1.00000 \mathrm{e}+001.00000 \mathrm{e}+001.00000 \mathrm{e}-011.00000 \mathrm{e}-091.00000 \mathrm{e}-01$ Element: 8653 \# of layers: 7

Kx Ky Kz Ss Por

$5.59249 \mathrm{e}+00$ 5.59249e+00 5.59249e-01 1.00000e-09 2.12000e-01 $5.59249 \mathrm{e}+00$ 5.59249e+00 5.59249e-01 1.00000e-09 2.12000e-01 $5.59249 \mathrm{e}+00$ 5.59249e+00 5.59249e-01 1.00000e-09 2.12000e-01 $5.59249 \mathrm{e}+005.59249 \mathrm{e}+00$ 5.59249e-01 1.00000e-09 2.12000e-01 $5.59249 \mathrm{e}+00$ 5.59249e+00 5.59249e-01 1.00000e-09 2.12000e-01 $1.00000 \mathrm{e}-05$ 1.00000e-05 1.00000e-06 1.00000e-09 1.00000e-01 $1.00000 \mathrm{e}+001.00000 \mathrm{e}+001.00000 \mathrm{e}-011.00000 \mathrm{e}-091.00000 \mathrm{e}-01$ Element: 8654 \# of layers: 7

Kx Ky Kz Ss Por

$5.59249 \mathrm{e}+00$ 5.59249e+00 5.59249e-01 1.00000e-09 2.12000e-01 $5.59249 \mathrm{e}+005.59249 \mathrm{e}+00$ 5.59249e-01 1.00000e-09 2.12000e-01 $5.59249 \mathrm{e}+00$ 5.59249e+00 5.59249e-01 1.00000e-09 2.12000e-01 $5.59249 \mathrm{e}+005.59249 \mathrm{e}+00$ 5.59249e-01 1.00000e-09 2.12000e-01 $5.59249 \mathrm{e}+00$ 5.59249e+00 5.59249e-01 1.00000e-09 2.12000e-01 $1.00000 \mathrm{e}-05$ 1.00000e-05 1.00000e-06 1.00000e-09 1.00000e-01 $1.00000 \mathrm{e}+001.00000 \mathrm{e}+001.00000 \mathrm{e}-011.00000 \mathrm{e}-091.00000 \mathrm{e}-01$ Element: 8655 \# of layers: 7

Kx Ky Kz Ss Por

$5.59249 \mathrm{e}+00$ 5.59249e+00 5.59249e-01 1.00000e-09 2.12000e-01 $5.59249 \mathrm{e}+00$ 5.59249e+00 5.59249e-01 1.00000e-09 2.12000e-01 $5.59249 \mathrm{e}+005.59249 \mathrm{e}+00$ 5.59249e-01 1.00000e-09 2.12000e-01 $5.59249 \mathrm{e}+00$ 5.59249e+00 5.59249e-01 1.00000e-09 2.12000e-01 $5.59249 \mathrm{e}+00$ 5.59249e+00 5.59249e-01 1.00000e-09 2.12000e-01 $1.00000 \mathrm{e}-05$ 1.00000e-05 1.00000e-06 1.00000e-09 1.00000e-01 $1.00000 \mathrm{e}+001.00000 \mathrm{e}+001.00000 \mathrm{e}-011.00000 \mathrm{e}-091.00000 \mathrm{e}-01$ Element: 8656 \# of layers: 7

Kx Ky Kz Ss Por

$5.59249 \mathrm{e}+00$ 5.59249e+00 5.59249e-01 1.00000e-09 2.12000e-01 $5.59249 \mathrm{e}+005.59249 \mathrm{e}+00$ 5.59249e-01 1.00000e-09 2.12000e-01 $5.59249 \mathrm{e}+005.59249 \mathrm{e}+00$ 5.59249e-01 1.00000e-09 2.12000e-01 $5.59249 \mathrm{e}+00$ 5.59249e+00 5.59249e-01 1.00000e-09 2.12000e-01 $5.59249 \mathrm{e}+00$ 5.59249e+00 5.59249e-01 1.00000e-09 2.12000e-01 $1.00000 \mathrm{e}-05$ 1.00000e-05 1.00000e-06 1.00000e-09 1.00000e-01 $1.00000 \mathrm{e}+001.00000 \mathrm{e}+001.00000 \mathrm{e}-011.00000 \mathrm{e}-091.00000 \mathrm{e}-01$ Element: 8657 \# of layers: 7

Kx Ky Kz Ss Por

5.59249e+00 5.59249e+00 5.59249e-01 1.00000e-09 2.12000e-01 
$5.59249 \mathrm{e}+00$ 5.59249e+00 5.59249e-01 1.00000e-09 2.12000e-01 $5.59249 \mathrm{e}+005.59249 \mathrm{e}+00$ 5.59249e-01 1.00000e-09 2.12000e-01 $5.59249 \mathrm{e}+005.59249 \mathrm{e}+00$ 5.59249e-01 1.00000e-09 2.12000e-01 $5.59249 \mathrm{e}+00$ 5.59249e+00 5.59249e-01 1.00000e-09 2.12000e-01 $1.00000 \mathrm{e}-05$ 1.00000e-05 1.00000e-06 1.00000e-09 1.00000e-01 $1.00000 \mathrm{e}+001.00000 \mathrm{e}+001.00000 \mathrm{e}-011.00000 \mathrm{e}-091.00000 \mathrm{e}-01$ Element: 8658 \# of layers: 7

Kx Ky Kz Ss Por

$5.59249 \mathrm{e}+00$ 5.59249e+00 5.59249e-01 1.00000e-09 2.12000e-01

$5.59249 \mathrm{e}+00$ 5.59249e+00 5.59249e-01 1.00000e-09 2.12000e-01 $5.59249 \mathrm{e}+00$ 5.59249e+00 5.59249e-01 1.00000e-09 2.12000e-01 $5.59249 \mathrm{e}+00$ 5.59249e+00 5.59249e-01 1.00000e-09 2.12000e-01 $5.59249 \mathrm{e}+005.59249 \mathrm{e}+00$ 5.59249e-01 1.00000e-09 2.12000e-01 $1.00000 \mathrm{e}-05$ 1.00000e-05 1.00000e-06 1.00000e-09 1.00000e-01 $1.00000 \mathrm{e}+001.00000 \mathrm{e}+001.00000 \mathrm{e}-011.00000 \mathrm{e}-091.00000 \mathrm{e}-01$ Element: 8659 \# of layers: 7

Kx Ky Kz Ss Por

5.59249e+00 5.59249e+00 5.59249e-01 1.00000e-09 2.12000e-01 $5.59249 \mathrm{e}+005.59249 \mathrm{e}+00$ 5.59249e-01 1.00000e-09 2.12000e-01 $5.59249 \mathrm{e}+005.59249 \mathrm{e}+00$ 5.59249e-01 1.00000e-09 2.12000e-01 $5.59249 \mathrm{e}+00$ 5.59249e+00 5.59249e-01 1.00000e-09 2.12000e-01 $5.59249 \mathrm{e}+00$ 5.59249e+00 5.59249e-01 1.00000e-09 2.12000e-01 $1.00000 \mathrm{e}-05$ 1.00000e-05 1.00000e-06 1.00000e-09 1.00000e-01 $1.00000 \mathrm{e}+001.00000 \mathrm{e}+001.00000 \mathrm{e}-011.00000 \mathrm{e}-091.00000 \mathrm{e}-01$ Element: 8660 \# of layers: 7

Kx Ky Kz Ss Por

5.59249e+00 5.59249e+00 5.59249e-01 1.00000e-09 2.12000e-01 $5.59249 \mathrm{e}+00$ 5.59249e+00 5.59249e-01 1.00000e-09 2.12000e-01 $5.59249 \mathrm{e}+00$ 5.59249e+00 5.59249e-01 1.00000e-09 2.12000e-01 $5.59249 \mathrm{e}+005.59249 \mathrm{e}+00$ 5.59249e-01 1.00000e-09 2.12000e-01 $5.59249 \mathrm{e}+00$ 5.59249e+00 5.59249e-01 1.00000e-09 2.12000e-01 $1.00000 \mathrm{e}-05$ 1.00000e-05 1.00000e-06 1.00000e-09 1.00000e-01 $1.00000 \mathrm{e}+001.00000 \mathrm{e}+001.00000 \mathrm{e}-011.00000 \mathrm{e}-091.00000 \mathrm{e}-01$ Element: 8661 \# of layers: 7

Kx Ky Kz Ss Por

$5.59249 \mathrm{e}+00$ 5.59249e+00 5.59249e-01 1.00000e-09 2.12000e-01 $5.59249 \mathrm{e}+005.59249 \mathrm{e}+00$ 5.59249e-01 1.00000e-09 2.12000e-01 $5.59249 \mathrm{e}+005.59249 \mathrm{e}+00$ 5.59249e-01 1.00000e-09 2.12000e-01 $5.59249 \mathrm{e}+005.59249 \mathrm{e}+00$ 5.59249e-01 1.00000e-09 2.12000e-01 $5.59249 \mathrm{e}+00$ 5.59249e+00 5.59249e-01 1.00000e-09 2.12000e-01 $1.00000 \mathrm{e}-05$ 1.00000e-05 1.00000e-06 1.00000e-09 1.00000e-01 $1.00000 \mathrm{e}+001.00000 \mathrm{e}+001.00000 \mathrm{e}-011.00000 \mathrm{e}-091.00000 \mathrm{e}-01$ Element: 8662 \# of layers: 8

Kx Ky Kz Ss Por $4.30502 \mathrm{e}+00$ 4.30502e+00 4.30502e-01 1.00000e-09 2.12000e-01 $4.30502 \mathrm{e}+004.30502 \mathrm{e}+004.30502 \mathrm{e}-01$ 1.00000e-09 2.12000e-01 
$4.30502 \mathrm{e}+004.30502 \mathrm{e}+00$ 4.30502e-01 1.00000e-09 2.12000e-01 $4.30502 \mathrm{e}+004.30502 \mathrm{e}+00$ 4.30502e-01 1.00000e-09 2.12000e-01 $4.30502 \mathrm{e}+004.30502 \mathrm{e}+00$ 4.30502e-01 1.00000e-09 2.12000e-01 $1.00000 \mathrm{e}-021.00000 \mathrm{e}-02$ 1.00000e-03 1.00000e-09 1.00000e-01 $1.00000 \mathrm{e}-05$ 1.00000e-05 1.00000e-06 1.00000e-09 1.00000e-01 $1.00000 \mathrm{e}+001.00000 \mathrm{e}+001.00000 \mathrm{e}-011.00000 \mathrm{e}-091.00000 \mathrm{e}-01$ Element: 8663 \# of layers: 8

Kx Ky Kz Ss Por

4.30502e+00 4.30502e+00 4.30502e-01 1.00000e-09 2.12000e-01 $4.30502 \mathrm{e}+004.30502 \mathrm{e}+004.30502 \mathrm{e}-01$ 1.00000e-09 2.12000e-01 $4.30502 \mathrm{e}+004.30502 \mathrm{e}+004.30502 \mathrm{e}-01$ 1.00000e-09 2.12000e-01 $4.30502 \mathrm{e}+004.30502 \mathrm{e}+004.30502 \mathrm{e}-01$ 1.00000e-09 2.12000e-01 $4.30502 \mathrm{e}+004.30502 \mathrm{e}+00$ 4.30502e-01 1.00000e-09 2.12000e-01 $1.00000 \mathrm{e}-02$ 1.00000e-02 1.00000e-03 1.00000e-09 1.00000e-01 $1.00000 \mathrm{e}-05$ 1.00000e-05 1.00000e-06 1.00000e-09 1.00000e-01 $1.00000 \mathrm{e}+001.00000 \mathrm{e}+001.00000 \mathrm{e}-011.00000 \mathrm{e}-091.00000 \mathrm{e}-01$ Element: 8664 \# of layers: 9

Kx Ky Kz Ss Por

4.30502e+00 4.30502e+00 4.30502e-01 1.00000e-09 2.12000e-01 $4.30502 \mathrm{e}+004.30502 \mathrm{e}+004.30502 \mathrm{e}-01$ 1.00000e-09 2.12000e-01 $4.30502 \mathrm{e}+004.30502 \mathrm{e}+004.30502 \mathrm{e}-01$ 1.00000e-09 2.12000e-01 $4.30502 \mathrm{e}+004.30502 \mathrm{e}+004.30502 \mathrm{e}-011.00000 \mathrm{e}-092.12000 \mathrm{e}-01$ $4.30502 \mathrm{e}+004.30502 \mathrm{e}+004.30502 \mathrm{e}-01$ 1.00000e-09 2.12000e-01 $1.00000 \mathrm{e}-021.00000 \mathrm{e}-02$ 1.00000e-03 $1.00000 \mathrm{e}-091.00000 \mathrm{e}-01$ $1.00000 \mathrm{e}+001.00000 \mathrm{e}+001.00000 \mathrm{e}-011.00000 \mathrm{e}-091.00000 \mathrm{e}-01$ $1.00000 \mathrm{e}-05$ 1.00000e-05 1.00000e-06 1.00000e-09 1.00000e-01 $1.00000 \mathrm{e}+001.00000 \mathrm{e}+001.00000 \mathrm{e}-011.00000 \mathrm{e}-091.00000 \mathrm{e}-01$ Element: 8665 \# of layers: 9

Kx Ky Kz Ss Por

4.30502e+00 4.30502e+00 4.30502e-01 1.00000e-09 2.12000e-01 $4.30502 \mathrm{e}+004.30502 \mathrm{e}+004.30502 \mathrm{e}-01$ 1.00000e-09 2.12000e-01 $4.30502 \mathrm{e}+004.30502 \mathrm{e}+004.30502 \mathrm{e}-01$ 1.00000e-09 2.12000e-01 $4.30502 \mathrm{e}+004.30502 \mathrm{e}+004.30502 \mathrm{e}-01$ 1.00000e-09 2.12000e-01 $4.30502 \mathrm{e}+004.30502 \mathrm{e}+00$ 4.30502e-01 1.00000e-09 2.12000e-01 $1.00000 \mathrm{e}-02$ 1.00000e-02 1.00000e-03 1.00000e-09 1.00000e-01 $1.00000 \mathrm{e}+001.00000 \mathrm{e}+001.00000 \mathrm{e}-011.00000 \mathrm{e}-091.00000 \mathrm{e}-01$ $1.00000 \mathrm{e}-05$ 1.00000e-05 1.00000e-06 1.00000e-09 1.00000e-01 $1.00000 \mathrm{e}+001.00000 \mathrm{e}+001.00000 \mathrm{e}-011.00000 \mathrm{e}-091.00000 \mathrm{e}-01$ Element: 8666 \# of layers: 9

Kx Ky Kz Ss Por $4.30502 \mathrm{e}+00$ 4.30502e+00 4.30502e-01 1.00000e-09 2.12000e-01 $4.30502 \mathrm{e}+004.30502 \mathrm{e}+004.30502 \mathrm{e}-01$ 1.00000e-09 2.12000e-01 $4.30502 \mathrm{e}+004.30502 \mathrm{e}+00$ 4.30502e-01 1.00000e-09 2.12000e-01 $4.30502 \mathrm{e}+004.30502 \mathrm{e}+004.30502 \mathrm{e}-01$ 1.00000e-09 2.12000e-01 $4.30502 \mathrm{e}+004.30502 \mathrm{e}+00$ 4.30502e-01 1.00000e-09 2.12000e-01 $1.00000 \mathrm{e}-021.00000 \mathrm{e}-02$ 1.00000e-03 1.00000e-09 1.00000e-01 
$1.00000 \mathrm{e}+001.00000 \mathrm{e}+001.00000 \mathrm{e}-011.00000 \mathrm{e}-091.00000 \mathrm{e}-01$ $1.00000 \mathrm{e}-05$ 1.00000e-05 1.00000e-06 1.00000e-09 1.00000e-01 $1.00000 \mathrm{e}+001.00000 \mathrm{e}+001.00000 \mathrm{e}-01$ 1.00000e-09 1.00000e-01 Element: 8667 \# of layers: 7

$\mathrm{Kx} \mathrm{Ky} \mathrm{Kz}$ Ss Por

5.59249e+00 5.59249e+00 5.59249e-01 1.00000e-09 2.12000e-01 $5.59249 \mathrm{e}+00$ 5.59249e+00 5.59249e-01 1.00000e-09 2.12000e-01 $5.59249 \mathrm{e}+00$ 5.59249e+00 5.59249e-01 1.00000e-09 2.12000e-01 $5.59249 \mathrm{e}+00$ 5.59249e+00 5.59249e-01 1.00000e-09 2.12000e-01 $5.59249 \mathrm{e}+00$ 5.59249e+00 5.59249e-01 1.00000e-09 2.12000e-01 $1.00000 \mathrm{e}-05$ 1.00000e-05 1.00000e-06 1.00000e-09 1.00000e-01 $1.00000 \mathrm{e}+001.00000 \mathrm{e}+001.00000 \mathrm{e}-011.00000 \mathrm{e}-091.00000 \mathrm{e}-01$ Element: 8668 \# of layers: 7

$\mathrm{Kx} \mathrm{Ky} \mathrm{Kz}$ Ss Por

5.59249e+00 5.59249e+00 5.59249e-01 1.00000e-09 2.12000e-01 $5.59249 \mathrm{e}+00$ 5.59249e+00 5.59249e-01 1.00000e-09 2.12000e-01 5.59249e+00 5.59249e+00 5.59249e-01 1.00000e-09 2.12000e-01 5.59249e+00 5.59249e+00 5.59249e-01 1.00000e-09 2.12000e-01 5.59249e+00 5.59249e+00 5.59249e-01 1.00000e-09 2.12000e-01 $1.00000 \mathrm{e}-05$ 1.00000e-05 1.00000e-06 1.00000e-09 1.00000e-01 $1.00000 \mathrm{e}+001.00000 \mathrm{e}+001.00000 \mathrm{e}-011.00000 \mathrm{e}-091.00000 \mathrm{e}-01$ Element: 8669 \# of layers: 8

$\mathrm{Kx} \mathrm{Ky} \mathrm{Kz}$ Ss Por

4.30502e+00 4.30502e+00 4.30502e-01 1.00000e-09 2.12000e-01 $4.30502 \mathrm{e}+004.30502 \mathrm{e}+00$ 4.30502e-01 1.00000e-09 2.12000e-01 $4.30502 \mathrm{e}+004.30502 \mathrm{e}+00$ 4.30502e-01 1.00000e-09 2.12000e-01 4.30502e+00 4.30502e+00 4.30502e-01 1.00000e-09 2.12000e-01 4.30502e+00 4.30502e+00 4.30502e-01 1.00000e-09 2.12000e-01 $1.00000 \mathrm{e}-02$ 1.00000e-02 1.00000e-03 1.00000e-09 1.00000e-01 $1.00000 \mathrm{e}-05$ 1.00000e-05 1.00000e-06 1.00000e-09 1.00000e-01 $1.00000 \mathrm{e}+001.00000 \mathrm{e}+001.00000 \mathrm{e}-011.00000 \mathrm{e}-091.00000 \mathrm{e}-01$ Element: 8670 \# of layers: 9

$\mathrm{Kx} \mathrm{Ky} \mathrm{Kz}$ Ss Por

4.30502e+00 4.30502e+00 4.30502e-01 1.00000e-09 2.12000e-01 4.30502e+00 4.30502e+00 4.30502e-01 1.00000e-09 2.12000e-01 4.30502e+00 4.30502e+00 4.30502e-01 1.00000e-09 2.12000e-01 $4.30502 \mathrm{e}+004.30502 \mathrm{e}+00$ 4.30502e-01 1.00000e-09 2.12000e-01 4.30502e+00 4.30502e+00 4.30502e-01 1.00000e-09 2.12000e-01 $1.00000 \mathrm{e}-02$ 1.00000e-02 1.00000e-03 1.00000e-09 1.00000e-01 $1.00000 \mathrm{e}+001.00000 \mathrm{e}+001.00000 \mathrm{e}-011.00000 \mathrm{e}-091.00000 \mathrm{e}-01$ $1.00000 \mathrm{e}-05$ 1.00000e-05 1.00000e-06 1.00000e-09 1.00000e-01 $1.00000 \mathrm{e}+001.00000 \mathrm{e}+001.00000 \mathrm{e}-011.00000 \mathrm{e}-091.00000 \mathrm{e}-01$ Element: 8671 \# of layers: 9

$\mathrm{Kx} \mathrm{Ky} \mathrm{Kz}$ Ss Por

4.29242e+00 4.29242e+00 4.29242e-01 1.00000e-09 2.12000e-01 $4.29242 \mathrm{e}+004.29242 \mathrm{e}+00$ 4.29242e-01 1.00000e-09 2.12000e-01 
4.29242e+00 4.29242e+00 4.29242e-01 1.00000e-09 2.12000e-01 $4.29242 \mathrm{e}+004.29242 \mathrm{e}+00$ 4.29242e-01 1.00000e-09 2.12000e-01 4.29242e+00 4.29242e+00 4.29242e-01 1.00000e-09 2.12000e-01 $1.00000 \mathrm{e}-02$ 1.00000e-02 1.00000e-03 1.00000e-09 1.00000e-01 $1.00000 \mathrm{e}+001.00000 \mathrm{e}+001.00000 \mathrm{e}-011.00000 \mathrm{e}-091.00000 \mathrm{e}-01$ $1.00000 \mathrm{e}-05$ 1.00000e-05 1.00000e-06 1.00000e-09 1.00000e-01 $1.00000 \mathrm{e}+001.00000 \mathrm{e}+00$ 1.00000e-01 1.00000e-09 1.00000e-01 Element: 8672 \# of layers: 9

$\mathrm{Kx} \mathrm{Ky} \mathrm{Kz}$ Ss Por

4.29242e+00 4.29242e+00 4.29242e-01 1.00000e-09 2.12000e-01 4.29242e+00 4.29242e+00 4.29242e-01 1.00000e-09 2.12000e-01 4.29242e+00 4.29242e+00 4.29242e-01 1.00000e-09 2.12000e-01 4.29242e+00 4.29242e+00 4.29242e-01 1.00000e-09 2.12000e-01 4.29242e+00 4.29242e+00 4.29242e-01 1.00000e-09 2.12000e-01 $1.00000 \mathrm{e}-02$ 1.00000e-02 1.00000e-03 1.00000e-09 1.00000e-01 $1.00000 \mathrm{e}+001.00000 \mathrm{e}+001.00000 \mathrm{e}-011.00000 \mathrm{e}-091.00000 \mathrm{e}-01$ $1.00000 \mathrm{e}-05$ 1.00000e-05 1.00000e-06 1.00000e-09 1.00000e-01 $1.00000 \mathrm{e}+001.00000 \mathrm{e}+001.00000 \mathrm{e}-011.00000 \mathrm{e}-091.00000 \mathrm{e}-01$ Element: 8673 \# of layers: 9

$\mathrm{Kx} \mathrm{Ky} \mathrm{Kz}$ Ss Por

4.29242e+00 4.29242e+00 4.29242e-01 1.00000e-09 2.12000e-01 4.29242e+00 4.29242e+00 4.29242e-01 1.00000e-09 2.12000e-01 4.29242e+00 4.29242e+00 4.29242e-01 1.00000e-09 2.12000e-01 $4.29242 \mathrm{e}+004.29242 \mathrm{e}+00$ 4.29242e-01 1.00000e-09 2.12000e-01 $4.29242 \mathrm{e}+004.29242 \mathrm{e}+004.29242 \mathrm{e}-01$ 1.00000e-09 2.12000e-01 $1.00000 \mathrm{e}-021.00000 \mathrm{e}-021.00000 \mathrm{e}-031.00000 \mathrm{e}-091.00000 \mathrm{e}-01$ $1.00000 \mathrm{e}+001.00000 \mathrm{e}+001.00000 \mathrm{e}-011.00000 \mathrm{e}-091.00000 \mathrm{e}-01$ $1.00000 \mathrm{e}-05$ 1.00000e-05 1.00000e-06 1.00000e-09 1.00000e-01 $1.00000 \mathrm{e}+001.00000 \mathrm{e}+001.00000 \mathrm{e}-011.00000 \mathrm{e}-091.00000 \mathrm{e}-01$ Element: 8674 \# of layers: 8

$\mathrm{Kx} \mathrm{Ky} \mathrm{Kz}$ Ss Por

$1.53998 \mathrm{e}+01$ 1.53998e+01 1.53998e+00 1.00000e-09 2.12000e-01 $1.53998 \mathrm{e}+01$ 1.53998e+01 1.53998e+00 1.00000e-09 2.12000e-01 $1.53998 \mathrm{e}+01$ 1.53998e+01 1.53998e+00 1.00000e-09 2.12000e-01 $1.53998 \mathrm{e}+01$ 1.53998e+01 1.53998e+00 1.00000e-09 2.12000e-01 $1.53998 \mathrm{e}+01$ 1.53998e+01 1.53998e+00 1.00000e-09 2.12000e-01 $1.00000 \mathrm{e}+001.00000 \mathrm{e}+001.00000 \mathrm{e}-011.00000 \mathrm{e}-091.00000 \mathrm{e}-01$ $1.00000 \mathrm{e}-05$ 1.00000e-05 1.00000e-06 1.00000e-09 1.00000e-01 $1.00000 \mathrm{e}+001.00000 \mathrm{e}+001.00000 \mathrm{e}-011.00000 \mathrm{e}-091.00000 \mathrm{e}-01$ Element: 8675 \# of layers: 7

$\mathrm{Kx} \mathrm{Ky} \mathrm{Kz}$ Ss Por

$1.53998 \mathrm{e}+01$ 1.53998e+01 1.53998e+00 1.00000e-09 2.12000e-01 $1.53998 \mathrm{e}+01$ 1.53998e+01 1.53998e+00 1.00000e-09 2.12000e-01 $1.53998 \mathrm{e}+01$ 1.53998e+01 1.53998e+00 1.00000e-09 2.12000e-01 $1.53998 \mathrm{e}+011.53998 \mathrm{e}+01$ 1.53998e+00 1.00000e-09 2.12000e-01 $1.53998 \mathrm{e}+011.53998 \mathrm{e}+011.53998 \mathrm{e}+001.00000 \mathrm{e}-092.12000 \mathrm{e}-01$ 
$1.00000 \mathrm{e}-05$ 1.00000e-05 1.00000e-06 1.00000e-09 1.00000e-01 $1.00000 \mathrm{e}+001.00000 \mathrm{e}+001.00000 \mathrm{e}-01$ 1.00000e-09 1.00000e-01 Element: 8676 \# of layers: 7

Kx Ky Kz Ss Por

5.59249e+00 5.59249e+00 5.59249e-01 1.00000e-09 2.12000e-01

5.59249e+00 5.59249e+00 5.59249e-01 1.00000e-09 2.12000e-01

5.59249e+00 5.59249e+00 5.59249e-01 1.00000e-09 2.12000e-01

$5.59249 \mathrm{e}+00$ 5.59249e+00 5.59249e-01 1.00000e-09 2.12000e-01

$5.59249 \mathrm{e}+00$ 5.59249e+00 5.59249e-01 1.00000e-09 2.12000e-01

$1.00000 \mathrm{e}-05$ 1.00000e-05 1.00000e-06 1.00000e-09 1.00000e-01

$1.00000 \mathrm{e}+001.00000 \mathrm{e}+001.00000 \mathrm{e}-011.00000 \mathrm{e}-091.00000 \mathrm{e}-01$

Element: 8677 \# of layers: 8

$\mathrm{Kx} \mathrm{Ky} \mathrm{Kz}$ Ss Por

4.30502e+00 4.30502e+00 4.30502e-01 1.00000e-09 2.12000e-01

4.30502e+00 4.30502e+00 4.30502e-01 1.00000e-09 2.12000e-01

$4.30502 \mathrm{e}+004.30502 \mathrm{e}+00$ 4.30502e-01 1.00000e-09 2.12000e-01

4.30502e+00 4.30502e+00 4.30502e-01 1.00000e-09 2.12000e-01

$4.30502 \mathrm{e}+004.30502 \mathrm{e}+004.30502 \mathrm{e}-01$ 1.00000e-09 2.12000e-01

$1.00000 \mathrm{e}+001.00000 \mathrm{e}+001.00000 \mathrm{e}-011.00000 \mathrm{e}-091.00000 \mathrm{e}-01$

1.00000e-05 1.00000e-05 1.00000e-06 1.00000e-09 1.00000e-01

$1.00000 \mathrm{e}+001.00000 \mathrm{e}+001.00000 \mathrm{e}-011.00000 \mathrm{e}-091.00000 \mathrm{e}-01$

Element: 8678 \# of layers: 9

$\mathrm{Kx} \mathrm{Ky} \mathrm{Kz}$ Ss Por

4.29242e+00 4.29242e+00 4.29242e-01 1.00000e-09 2.12000e-01 $4.29242 \mathrm{e}+004.29242 \mathrm{e}+00$ 4.29242e-01 1.00000e-09 2.12000e-01 $4.29242 \mathrm{e}+00$ 4.29242e+00 4.29242e-01 1.00000e-09 2.12000e-01 $4.29242 \mathrm{e}+004.29242 \mathrm{e}+00$ 4.29242e-01 1.00000e-09 2.12000e-01 $4.29242 \mathrm{e}+004.29242 \mathrm{e}+00$ 4.29242e-01 1.00000e-09 2.12000e-01 $1.00000 \mathrm{e}-02$ 1.00000e-02 1.00000e-03 1.00000e-09 1.00000e-01 $1.00000 \mathrm{e}+001.00000 \mathrm{e}+001.00000 \mathrm{e}-011.00000 \mathrm{e}-091.00000 \mathrm{e}-01$ $1.00000 \mathrm{e}-05$ 1.00000e-05 1.00000e-06 1.00000e-09 1.00000e-01 $1.00000 \mathrm{e}+001.00000 \mathrm{e}+001.00000 \mathrm{e}-011.00000 \mathrm{e}-091.00000 \mathrm{e}-01$ Element: 8679 \# of layers: 9

$\mathrm{Kx} \mathrm{Ky} \mathrm{Kz}$ Ss Por

4.31379e+00 4.31379e+00 4.31379e-01 1.00000e-09 2.12000e-01 4.31379e+00 4.31379e+00 4.31379e-01 1.00000e-09 2.12000e-01 4.31379e+00 4.31379e+00 4.31379e-01 1.00000e-09 2.12000e-01 4.31379e+00 4.31379e+00 4.31379e-01 1.00000e-09 2.12000e-01 4.31379e+00 4.31379e+00 4.31379e-01 1.00000e-09 2.12000e-01 1.00000e-02 1.00000e-02 1.00000e-03 1.00000e-09 1.00000e-01 $1.00000 \mathrm{e}+001.00000 \mathrm{e}+001.00000 \mathrm{e}-011.00000 \mathrm{e}-091.00000 \mathrm{e}-01$ $1.00000 \mathrm{e}-05$ 1.00000e-05 1.00000e-06 1.00000e-09 1.00000e-01 $1.00000 \mathrm{e}+001.00000 \mathrm{e}+001.00000 \mathrm{e}-011.00000 \mathrm{e}-091.00000 \mathrm{e}-01$ Element: 8680 \# of layers: 9

$\mathrm{Kx} \mathrm{Ky} \mathrm{Kz}$ Ss Por

4.31379e+00 4.31379e+00 4.31379e-01 1.00000e-09 2.12000e-01 
4.31379e+00 4.31379e+00 4.31379e-01 1.00000e-09 2.12000e-01 $4.31379 \mathrm{e}+004.31379 \mathrm{e}+00$ 4.31379e-01 1.00000e-09 2.12000e-01 $4.31379 \mathrm{e}+004.31379 \mathrm{e}+00$ 4.31379e-01 1.00000e-09 2.12000e-01 $4.31379 \mathrm{e}+00$ 4.31379e+00 4.31379e-01 1.00000e-09 2.12000e-01 $1.00000 \mathrm{e}-02$ 1.00000e-02 1.00000e-03 1.00000e-09 1.00000e-01 $1.00000 \mathrm{e}+001.00000 \mathrm{e}+001.00000 \mathrm{e}-011.00000 \mathrm{e}-091.00000 \mathrm{e}-01$ $1.00000 \mathrm{e}-051.00000 \mathrm{e}-05$ 1.00000e-06 1.00000e-09 1.00000e-01 $1.00000 \mathrm{e}+001.00000 \mathrm{e}+001.00000 \mathrm{e}-011.00000 \mathrm{e}-091.00000 \mathrm{e}-01$ Element: 8681 \# of layers: 9

Kx Ky Kz Ss Por

4.31379e+00 4.31379e+00 4.31379e-01 1.00000e-09 2.12000e-01 $4.31379 \mathrm{e}+004.31379 \mathrm{e}+00$ 4.31379e-01 1.00000e-09 2.12000e-01 $4.31379 \mathrm{e}+004.31379 \mathrm{e}+00$ 4.31379e-01 1.00000e-09 2.12000e-01 $4.31379 \mathrm{e}+004.31379 \mathrm{e}+00$ 4.31379e-01 1.00000e-09 2.12000e-01 $4.31379 \mathrm{e}+00$ 4.31379e+00 4.31379e-01 1.00000e-09 2.12000e-01 $1.00000 \mathrm{e}-02$ 1.00000e-02 1.00000e-03 1.00000e-09 1.00000e-01 $1.00000 \mathrm{e}+001.00000 \mathrm{e}+001.00000 \mathrm{e}-011.00000 \mathrm{e}-091.00000 \mathrm{e}-01$ $1.00000 \mathrm{e}-05$ 1.00000e-05 1.00000e-06 1.00000e-09 1.00000e-01 $1.00000 \mathrm{e}+001.00000 \mathrm{e}+001.00000 \mathrm{e}-011.00000 \mathrm{e}-091.00000 \mathrm{e}-01$ Element: 8682 \# of layers: 9

Kx Ky Kz Ss Por

4.31379e+00 4.31379e+00 4.31379e-01 1.00000e-09 2.12000e-01 $4.31379 \mathrm{e}+004.31379 \mathrm{e}+00$ 4.31379e-01 1.00000e-09 2.12000e-01 $4.31379 \mathrm{e}+004.31379 \mathrm{e}+00$ 4.31379e-01 1.00000e-09 2.12000e-01 $4.31379 \mathrm{e}+004.31379 \mathrm{e}+00$ 4.31379e-01 1.00000e-09 2.12000e-01 $4.31379 \mathrm{e}+00$ 4.31379e+00 4.31379e-01 1.00000e-09 2.12000e-01 $1.00000 \mathrm{e}-02$ 1.00000e-02 1.00000e-03 1.00000e-09 1.00000e-01 $1.00000 \mathrm{e}+001.00000 \mathrm{e}+001.00000 \mathrm{e}-011.00000 \mathrm{e}-091.00000 \mathrm{e}-01$ $1.00000 \mathrm{e}-05$ 1.00000e-05 1.00000e-06 1.00000e-09 1.00000e-01 $1.00000 \mathrm{e}+001.00000 \mathrm{e}+001.00000 \mathrm{e}-011.00000 \mathrm{e}-091.00000 \mathrm{e}-01$ Element: 8683 \# of layers: 9

Kx Ky Kz Ss Por

$1.83559 \mathrm{e}+011.83559 \mathrm{e}+011.83559 \mathrm{e}+00$ 1.00000e-09 2.12000e-01 $1.83559 \mathrm{e}+011.83559 \mathrm{e}+011.83559 \mathrm{e}+001.00000 \mathrm{e}-092.12000 \mathrm{e}-01$ $1.83559 \mathrm{e}+011.83559 \mathrm{e}+011.83559 \mathrm{e}+001.00000 \mathrm{e}-092.12000 \mathrm{e}-01$ $1.83559 \mathrm{e}+011.83559 \mathrm{e}+011.83559 \mathrm{e}+001.00000 \mathrm{e}-092.12000 \mathrm{e}-01$ $1.83559 \mathrm{e}+011.83559 \mathrm{e}+011.83559 \mathrm{e}+001.00000 \mathrm{e}-092.12000 \mathrm{e}-01$ $1.00000 \mathrm{e}-021.00000 \mathrm{e}-02$ 1.00000e-03 1.00000e-09 1.00000e-01 $1.00000 \mathrm{e}+001.00000 \mathrm{e}+001.00000 \mathrm{e}-011.00000 \mathrm{e}-091.00000 \mathrm{e}-01$ $1.00000 \mathrm{e}-05$ 1.00000e-05 1.00000e-06 1.00000e-09 1.00000e-01 $1.00000 \mathrm{e}+001.00000 \mathrm{e}+001.00000 \mathrm{e}-011.00000 \mathrm{e}-091.00000 \mathrm{e}-01$ Element: 8684 \# of layers: 9

Kx Ky Kz Ss Por

$1.83559 \mathrm{e}+011.83559 \mathrm{e}+011.83559 \mathrm{e}+00$ 1.00000e-09 2.12000e-01 $1.83559 \mathrm{e}+011.83559 \mathrm{e}+011.83559 \mathrm{e}+001.00000 \mathrm{e}-092.12000 \mathrm{e}-01$ $1.83559 \mathrm{e}+011.83559 \mathrm{e}+011.83559 \mathrm{e}+001.00000 \mathrm{e}-092.12000 \mathrm{e}-01$ 
$1.83559 \mathrm{e}+01$ 1.83559e+01 1.83559e+00 1.00000e-09 2.12000e-01 $1.83559 \mathrm{e}+01$ 1.83559e+01 1.83559e+00 1.00000e-09 2.12000e-01 $1.00000 \mathrm{e}-02$ 1.00000e-02 1.00000e-03 1.00000e-09 1.00000e-01 $1.00000 \mathrm{e}+001.00000 \mathrm{e}+001.00000 \mathrm{e}-011.00000 \mathrm{e}-091.00000 \mathrm{e}-01$ $1.00000 \mathrm{e}-05$ 1.00000e-05 1.00000e-06 1.00000e-09 1.00000e-01 $1.00000 \mathrm{e}+001.00000 \mathrm{e}+001.00000 \mathrm{e}-011.00000 \mathrm{e}-091.00000 \mathrm{e}-01$ Element: 8685 \# of layers: 9

$\mathrm{Kx} \mathrm{Ky} \mathrm{Kz}$ Ss Por

4.31379e+00 4.31379e+00 4.31379e-01 1.00000e-09 2.12000e-01 4.31379e+00 4.31379e+00 4.31379e-01 1.00000e-09 2.12000e-01 4.31379e+00 4.31379e+00 4.31379e-01 1.00000e-09 2.12000e-01 4.31379e+00 4.31379e+00 4.31379e-01 1.00000e-09 2.12000e-01 4.31379e+00 4.31379e+00 4.31379e-01 1.00000e-09 2.12000e-01 $1.00000 \mathrm{e}-02$ 1.00000e-02 1.00000e-03 1.00000e-09 1.00000e-01 $1.00000 \mathrm{e}+001.00000 \mathrm{e}+001.00000 \mathrm{e}-011.00000 \mathrm{e}-091.00000 \mathrm{e}-01$ $1.00000 \mathrm{e}-051.00000 \mathrm{e}-05$ 1.00000e-06 1.00000e-09 1.00000e-01 $1.00000 \mathrm{e}+001.00000 \mathrm{e}+001.00000 \mathrm{e}-011.00000 \mathrm{e}-091.00000 \mathrm{e}-01$ Element: 8686 \# of layers: 9

$\mathrm{Kx} \mathrm{Ky} \mathrm{Kz}$ Ss Por

$1.83559 \mathrm{e}+01$ 1.83559e+01 1.83559e+00 1.00000e-09 2.12000e-01 $1.83559 \mathrm{e}+011.83559 \mathrm{e}+011.83559 \mathrm{e}+001.00000 \mathrm{e}-092.12000 \mathrm{e}-01$ $1.83559 \mathrm{e}+01$ 1.83559e+01 1.83559e+00 1.00000e-09 2.12000e-01 $1.83559 \mathrm{e}+01$ 1.83559e+01 1.83559e+00 1.00000e-09 2.12000e-01 $1.83559 \mathrm{e}+01$ 1.83559e+01 1.83559e+00 1.00000e-09 2.12000e-01 $1.00000 \mathrm{e}-02$ 1.00000e-02 1.00000e-03 1.00000e-09 1.00000e-01 $1.00000 \mathrm{e}+001.00000 \mathrm{e}+001.00000 \mathrm{e}-011.00000 \mathrm{e}-091.00000 \mathrm{e}-01$ $1.00000 \mathrm{e}-05$ 1.00000e-05 1.00000e-06 1.00000e-09 1.00000e-01 $1.00000 \mathrm{e}+001.00000 \mathrm{e}+001.00000 \mathrm{e}-011.00000 \mathrm{e}-091.00000 \mathrm{e}-01$ Element: 8687 \# of layers: 9

$\mathrm{Kx} \mathrm{Ky} \mathrm{Kz}$ Ss Por

$1.83559 \mathrm{e}+01$ 1.83559e+01 1.83559e+00 1.00000e-09 2.12000e-01 $1.83559 \mathrm{e}+01$ 1.83559e+01 1.83559e+00 1.00000e-09 2.12000e-01 $1.83559 \mathrm{e}+011.83559 \mathrm{e}+011.83559 \mathrm{e}+001.00000 \mathrm{e}-092.12000 \mathrm{e}-01$ $1.83559 \mathrm{e}+01$ 1.83559e+01 1.83559e+00 1.00000e-09 2.12000e-01 $1.83559 \mathrm{e}+01$ 1.83559e+01 1.83559e+00 1.00000e-09 2.12000e-01 1.00000e-02 1.00000e-02 1.00000e-03 1.00000e-09 1.00000e-01 $1.00000 \mathrm{e}+001.00000 \mathrm{e}+001.00000 \mathrm{e}-011.00000 \mathrm{e}-091.00000 \mathrm{e}-01$ $1.00000 \mathrm{e}-05$ 1.00000e-05 1.00000e-06 1.00000e-09 1.00000e-01 $1.00000 \mathrm{e}+001.00000 \mathrm{e}+001.00000 \mathrm{e}-011.00000 \mathrm{e}-091.00000 \mathrm{e}-01$ Element: 8688 \# of layers: 9

$\mathrm{Kx} \mathrm{Ky} \mathrm{Kz}$ Ss Por

$1.83559 \mathrm{e}+01$ 1.83559e+01 1.83559e+00 1.00000e-09 2.12000e-01 $1.83559 \mathrm{e}+01$ 1.83559e+01 1.83559e+00 1.00000e-09 2.12000e-01 $1.83559 \mathrm{e}+01$ 1.83559e+01 1.83559e+00 1.00000e-09 2.12000e-01 $1.83559 \mathrm{e}+01$ 1.83559e+01 1.83559e+00 1.00000e-09 2.12000e-01 $1.83559 \mathrm{e}+011.83559 \mathrm{e}+011.83559 \mathrm{e}+001.00000 \mathrm{e}-092.12000 \mathrm{e}-01$ 
$1.00000 \mathrm{e}-02$ 1.00000e-02 1.00000e-03 1.00000e-09 1.00000e-01 $1.00000 \mathrm{e}+001.00000 \mathrm{e}+001.00000 \mathrm{e}-011.00000 \mathrm{e}-091.00000 \mathrm{e}-01$ $1.00000 \mathrm{e}-05$ 1.00000e-05 1.00000e-06 1.00000e-09 1.00000e-01 $1.00000 \mathrm{e}+001.00000 \mathrm{e}+001.00000 \mathrm{e}-011.00000 \mathrm{e}-091.00000 \mathrm{e}-01$ Element: 8689 \# of layers: 9

$\mathrm{Kx} \mathrm{Ky} \mathrm{Kz}$ Ss Por

$1.83559 \mathrm{e}+01$ 1.83559e+01 1.83559e+00 1.00000e-09 2.12000e-01 $1.83559 \mathrm{e}+01$ 1.83559e+01 1.83559e+00 1.00000e-09 2.12000e-01 $1.83559 \mathrm{e}+01$ 1.83559e+01 1.83559e+00 1.00000e-09 2.12000e-01 $1.83559 \mathrm{e}+01$ 1.83559e+01 1.83559e+00 1.00000e-09 2.12000e-01 $1.83559 \mathrm{e}+01$ 1.83559e+01 1.83559e+00 1.00000e-09 2.12000e-01 $1.00000 \mathrm{e}-02$ 1.00000e-02 1.00000e-03 1.00000e-09 1.00000e-01 $1.00000 \mathrm{e}+001.00000 \mathrm{e}+001.00000 \mathrm{e}-011.00000 \mathrm{e}-091.00000 \mathrm{e}-01$ $1.00000 \mathrm{e}-05$ 1.00000e-05 1.00000e-06 1.00000e-09 1.00000e-01 $1.00000 \mathrm{e}+001.00000 \mathrm{e}+001.00000 \mathrm{e}-01$ 1.00000e-09 1.00000e-01 Element: 8690 \# of layers: 9

$\mathrm{Kx} \mathrm{Ky} \mathrm{Kz}$ Ss Por

$1.83559 \mathrm{e}+01$ 1.83559e+01 1.83559e+00 1.00000e-09 2.12000e-01 $1.83559 \mathrm{e}+01$ 1.83559e+01 1.83559e+00 1.00000e-09 2.12000e-01 $1.83559 \mathrm{e}+01$ 1.83559e+01 1.83559e+00 1.00000e-09 2.12000e-01 $1.83559 \mathrm{e}+011.83559 \mathrm{e}+011.83559 \mathrm{e}+001.00000 \mathrm{e}-092.12000 \mathrm{e}-01$ $1.83559 \mathrm{e}+01$ 1.83559e+01 1.83559e+00 1.00000e-09 2.12000e-01 $1.00000 \mathrm{e}-02$ 1.00000e-02 1.00000e-03 1.00000e-09 1.00000e-01 $1.00000 \mathrm{e}+001.00000 \mathrm{e}+001.00000 \mathrm{e}-011.00000 \mathrm{e}-091.00000 \mathrm{e}-01$ $1.00000 \mathrm{e}-05$ 1.00000e-05 1.00000e-06 1.00000e-09 1.00000e-01 $1.00000 \mathrm{e}+001.00000 \mathrm{e}+001.00000 \mathrm{e}-011.00000 \mathrm{e}-091.00000 \mathrm{e}-01$ Element: 8691 \# of layers: 9

$\mathrm{Kx} \mathrm{Ky} \mathrm{Kz}$ Ss Por

$1.83559 \mathrm{e}+01$ 1.83559e+01 1.83559e+00 1.00000e-09 2.12000e-01 $1.83559 \mathrm{e}+01$ 1.83559e+01 1.83559e+00 1.00000e-09 2.12000e-01 $1.83559 \mathrm{e}+01$ 1.83559e+01 1.83559e+00 1.00000e-09 2.12000e-01 $1.83559 \mathrm{e}+01$ 1.83559e+01 1.83559e+00 1.00000e-09 2.12000e-01 $1.83559 \mathrm{e}+011.83559 \mathrm{e}+011.83559 \mathrm{e}+001.00000 \mathrm{e}-092.12000 \mathrm{e}-01$ $1.00000 \mathrm{e}-02$ 1.00000e-02 1.00000e-03 1.00000e-09 1.00000e-01 $1.00000 \mathrm{e}+001.00000 \mathrm{e}+001.00000 \mathrm{e}-011.00000 \mathrm{e}-091.00000 \mathrm{e}-01$ $1.00000 \mathrm{e}-05$ 1.00000e-05 1.00000e-06 1.00000e-09 1.00000e-01 $1.00000 \mathrm{e}+001.00000 \mathrm{e}+001.00000 \mathrm{e}-011.00000 \mathrm{e}-091.00000 \mathrm{e}-01$ Element: 8692 \# of layers: 9

$\mathrm{Kx} \mathrm{Ky} \mathrm{Kz}$ Ss Por

$1.83559 \mathrm{e}+01$ 1.83559e+01 1.83559e+00 1.00000e-09 2.12000e-01 $1.83559 \mathrm{e}+01$ 1.83559e+01 1.83559e+00 1.00000e-09 2.12000e-01 $1.83559 \mathrm{e}+01$ 1.83559e+01 1.83559e+00 1.00000e-09 2.12000e-01 $1.83559 \mathrm{e}+01$ 1.83559e+01 1.83559e+00 1.00000e-09 2.12000e-01 $1.83559 \mathrm{e}+01$ 1.83559e+01 1.83559e+00 1.00000e-09 2.12000e-01 $1.00000 \mathrm{e}-02$ 1.00000e-02 1.00000e-03 1.00000e-09 1.00000e-01 $1.00000 \mathrm{e}+001.00000 \mathrm{e}+001.00000 \mathrm{e}-011.00000 \mathrm{e}-091.00000 \mathrm{e}-01$ 
$1.00000 \mathrm{e}-05$ 1.00000e-05 1.00000e-06 1.00000e-09 1.00000e-01 $1.00000 \mathrm{e}+001.00000 \mathrm{e}+001.00000 \mathrm{e}-01$ 1.00000e-09 1.00000e-01 Element: 8693 \# of layers: 9

Kx Ky Kz Ss Por

$2.66698 \mathrm{e}+012.66698 \mathrm{e}+012.66698 \mathrm{e}+001.00000 \mathrm{e}-092.12000 \mathrm{e}-01$

$2.66698 \mathrm{e}+012.66698 \mathrm{e}+012.66698 \mathrm{e}+00$ 1.00000e-09 2.12000e-01

$2.66698 \mathrm{e}+012.66698 \mathrm{e}+012.66698 \mathrm{e}+00$ 1.00000e-09 2.12000e-01

$2.66698 \mathrm{e}+012.66698 \mathrm{e}+012.66698 \mathrm{e}+001.00000 \mathrm{e}-092.12000 \mathrm{e}-01$

$2.66698 \mathrm{e}+012.66698 \mathrm{e}+012.66698 \mathrm{e}+001.00000 \mathrm{e}-092.12000 \mathrm{e}-01$

$1.00000 \mathrm{e}-02$ 1.00000e-02 1.00000e-03 1.00000e-09 1.00000e-01

$1.00000 \mathrm{e}+001.00000 \mathrm{e}+001.00000 \mathrm{e}-011.00000 \mathrm{e}-091.00000 \mathrm{e}-01$

$1.00000 \mathrm{e}-05$ 1.00000e-05 1.00000e-06 1.00000e-09 1.00000e-01

$1.00000 \mathrm{e}+001.00000 \mathrm{e}+001.00000 \mathrm{e}-011.00000 \mathrm{e}-091.00000 \mathrm{e}-01$

Element: 8694 \# of layers: 9

$\mathrm{Kx} \mathrm{Ky} \mathrm{Kz}$ Ss Por

$2.66698 \mathrm{e}+012.66698 \mathrm{e}+012.66698 \mathrm{e}+00$ 1.00000e-09 2.12000e-01

$2.66698 \mathrm{e}+012.66698 \mathrm{e}+012.66698 \mathrm{e}+00$ 1.00000e-09 2.12000e-01

$2.66698 \mathrm{e}+012.66698 \mathrm{e}+012.66698 \mathrm{e}+001.00000 \mathrm{e}-092.12000 \mathrm{e}-01$

$2.66698 \mathrm{e}+012.66698 \mathrm{e}+012.66698 \mathrm{e}+00$ 1.00000e-09 2.12000e-01

$2.66698 \mathrm{e}+012.66698 \mathrm{e}+012.66698 \mathrm{e}+001.00000 \mathrm{e}-092.12000 \mathrm{e}-01$

$1.00000 \mathrm{e}-02$ 1.00000e-02 1.00000e-03 1.00000e-09 1.00000e-01

$1.00000 \mathrm{e}+001.00000 \mathrm{e}+001.00000 \mathrm{e}-011.00000 \mathrm{e}-091.00000 \mathrm{e}-01$

$1.00000 \mathrm{e}-05$ 1.00000e-05 1.00000e-06 1.00000e-09 1.00000e-01

$1.00000 \mathrm{e}+001.00000 \mathrm{e}+001.00000 \mathrm{e}-011.00000 \mathrm{e}-091.00000 \mathrm{e}-01$

Element: 8695 \# of layers: 9

$\mathrm{Kx} \mathrm{Ky} \mathrm{Kz}$ Ss Por

$2.66698 \mathrm{e}+012.66698 \mathrm{e}+012.66698 \mathrm{e}+00$ 1.00000e-09 2.12000e-01

$2.66698 \mathrm{e}+012.66698 \mathrm{e}+012.66698 \mathrm{e}+00$ 1.00000e-09 2.12000e-01

$2.66698 \mathrm{e}+012.66698 \mathrm{e}+012.66698 \mathrm{e}+001.00000 \mathrm{e}-092.12000 \mathrm{e}-01$

$2.66698 \mathrm{e}+012.66698 \mathrm{e}+012.66698 \mathrm{e}+001.00000 \mathrm{e}-092.12000 \mathrm{e}-01$

$2.66698 \mathrm{e}+012.66698 \mathrm{e}+012.66698 \mathrm{e}+001.00000 \mathrm{e}-092.12000 \mathrm{e}-01$

$1.00000 \mathrm{e}-02$ 1.00000e-02 1.00000e-03 1.00000e-09 1.00000e-01

$1.00000 \mathrm{e}+001.00000 \mathrm{e}+001.00000 \mathrm{e}-011.00000 \mathrm{e}-091.00000 \mathrm{e}-01$

$1.00000 \mathrm{e}-05$ 1.00000e-05 1.00000e-06 1.00000e-09 1.00000e-01

$1.00000 \mathrm{e}+001.00000 \mathrm{e}+001.00000 \mathrm{e}-011.00000 \mathrm{e}-091.00000 \mathrm{e}-01$

Element: 8696 \# of layers: 9

Kx Ky Kz Ss Por

$1.83559 \mathrm{e}+01$ 1.83559e+01 1.83559e+00 1.00000e-09 2.12000e-01

$1.83559 \mathrm{e}+01$ 1.83559e+01 1.83559e+00 1.00000e-09 2.12000e-01

$1.83559 \mathrm{e}+01$ 1.83559e+01 1.83559e+00 1.00000e-09 2.12000e-01

$1.83559 \mathrm{e}+01$ 1.83559e+01 1.83559e+00 1.00000e-09 2.12000e-01

$1.83559 \mathrm{e}+01$ 1.83559e+01 1.83559e+00 1.00000e-09 2.12000e-01

$1.00000 \mathrm{e}-02$ 1.00000e-02 1.00000e-03 1.00000e-09 1.00000e-01

$1.00000 \mathrm{e}+001.00000 \mathrm{e}+001.00000 \mathrm{e}-011.00000 \mathrm{e}-091.00000 \mathrm{e}-01$

$1.00000 \mathrm{e}-05$ 1.00000e-05 1.00000e-06 1.00000e-09 1.00000e-01

$1.00000 \mathrm{e}+001.00000 \mathrm{e}+001.00000 \mathrm{e}-011.00000 \mathrm{e}-091.00000 \mathrm{e}-01$ 
Element: 8697 \# of layers: 9

$\mathrm{Kx} \mathrm{Ky} \mathrm{Kz}$ Ss Por

$1.83559 \mathrm{e}+01$ 1.83559e+01 1.83559e+00 1.00000e-09 2.12000e-01

$1.83559 \mathrm{e}+011.83559 \mathrm{e}+011.83559 \mathrm{e}+001.00000 \mathrm{e}-092.12000 \mathrm{e}-01$

$1.83559 \mathrm{e}+01$ 1.83559e+01 1.83559e+00 1.00000e-09 2.12000e-01

$1.83559 \mathrm{e}+01$ 1.83559e+01 1.83559e+00 1.00000e-09 2.12000e-01

$1.83559 \mathrm{e}+011.83559 \mathrm{e}+01$ 1.83559e+00 1.00000e-09 2.12000e-01

$1.00000 \mathrm{e}-02$ 1.00000e-02 1.00000e-03 1.00000e-09 1.00000e-01

$1.00000 \mathrm{e}+001.00000 \mathrm{e}+001.00000 \mathrm{e}-011.00000 \mathrm{e}-091.00000 \mathrm{e}-01$

$1.00000 \mathrm{e}-05$ 1.00000e-05 1.00000e-06 1.00000e-09 1.00000e-01

$1.00000 \mathrm{e}+001.00000 \mathrm{e}+001.00000 \mathrm{e}-011.00000 \mathrm{e}-091.00000 \mathrm{e}-01$

Element: 8698 \# of layers: 9

$\mathrm{Kx} \mathrm{Ky} \mathrm{Kz}$ Ss Por

$1.83559 \mathrm{e}+01$ 1.83559e+01 1.83559e+00 1.00000e-09 2.12000e-01

$1.83559 \mathrm{e}+01$ 1.83559e+01 1.83559e+00 1.00000e-09 2.12000e-01

$1.83559 \mathrm{e}+011.83559 \mathrm{e}+011.83559 \mathrm{e}+001.00000 \mathrm{e}-092.12000 \mathrm{e}-01$

$1.83559 \mathrm{e}+011.83559 \mathrm{e}+01$ 1.83559e+00 1.00000e-09 2.12000e-01

$1.83559 \mathrm{e}+01$ 1.83559e+01 1.83559e+00 1.00000e-09 2.12000e-01

$1.00000 \mathrm{e}-02$ 1.00000e-02 1.00000e-03 1.00000e-09 1.00000e-01

$1.00000 \mathrm{e}+001.00000 \mathrm{e}+001.00000 \mathrm{e}-011.00000 \mathrm{e}-091.00000 \mathrm{e}-01$

$1.00000 \mathrm{e}-05$ 1.00000e-05 1.00000e-06 1.00000e-09 1.00000e-01

$1.00000 \mathrm{e}+001.00000 \mathrm{e}+001.00000 \mathrm{e}-01$ 1.00000e-09 1.00000e-01

Element: 8699 \# of layers: 9

Kx Ky Kz Ss Por

$1.83559 \mathrm{e}+01$ 1.83559e+01 1.83559e+00 1.00000e-09 2.12000e-01

$1.83559 \mathrm{e}+011.83559 \mathrm{e}+01$ 1.83559e+00 1.00000e-09 2.12000e-01

$1.83559 \mathrm{e}+01$ 1.83559e+01 1.83559e+00 1.00000e-09 2.12000e-01

$1.83559 \mathrm{e}+011.83559 \mathrm{e}+01$ 1.83559e+00 1.00000e-09 2.12000e-01

$1.83559 \mathrm{e}+01$ 1.83559e+01 1.83559e+00 1.00000e-09 2.12000e-01

$1.00000 \mathrm{e}-02$ 1.00000e-02 1.00000e-03 1.00000e-09 1.00000e-01

$1.00000 \mathrm{e}+001.00000 \mathrm{e}+001.00000 \mathrm{e}-011.00000 \mathrm{e}-091.00000 \mathrm{e}-01$

1.00000e-05 1.00000e-05 1.00000e-06 1.00000e-09 1.00000e-01

$1.00000 \mathrm{e}+001.00000 \mathrm{e}+001.00000 \mathrm{e}-011.00000 \mathrm{e}-091.00000 \mathrm{e}-01$

Element: 8700 \# of layers: 9

$\mathrm{Kx} \mathrm{Ky} \mathrm{Kz}$ Ss Por

$2.66698 \mathrm{e}+012.66698 \mathrm{e}+012.66698 \mathrm{e}+00$ 1.00000e-09 2.12000e-01

$2.66698 \mathrm{e}+012.66698 \mathrm{e}+012.66698 \mathrm{e}+001.00000 \mathrm{e}-092.12000 \mathrm{e}-01$

$2.66698 \mathrm{e}+012.66698 \mathrm{e}+012.66698 \mathrm{e}+001.00000 \mathrm{e}-092.12000 \mathrm{e}-01$

$2.66698 \mathrm{e}+012.66698 \mathrm{e}+012.66698 \mathrm{e}+001.00000 \mathrm{e}-092.12000 \mathrm{e}-01$

$2.66698 \mathrm{e}+012.66698 \mathrm{e}+012.66698 \mathrm{e}+00$ 1.00000e-09 2.12000e-01

$1.00000 \mathrm{e}-02$ 1.00000e-02 1.00000e-03 1.00000e-09 1.00000e-01

$1.00000 \mathrm{e}+001.00000 \mathrm{e}+001.00000 \mathrm{e}-011.00000 \mathrm{e}-091.00000 \mathrm{e}-01$

$1.00000 \mathrm{e}-05$ 1.00000e-05 1.00000e-06 1.00000e-09 1.00000e-01

$1.00000 \mathrm{e}+001.00000 \mathrm{e}+001.00000 \mathrm{e}-01$ 1.00000e-09 1.00000e-01

Element: 8701 \# of layers: 9

Kx Ky Kz Ss Por 
$2.66698 \mathrm{e}+012.66698 \mathrm{e}+012.66698 \mathrm{e}+00$ 1.00000e-09 2.12000e-01

$2.66698 \mathrm{e}+012.66698 \mathrm{e}+012.66698 \mathrm{e}+001.00000 \mathrm{e}-092.12000 \mathrm{e}-01$

$2.66698 \mathrm{e}+012.66698 \mathrm{e}+012.66698 \mathrm{e}+001.00000 \mathrm{e}-092.12000 \mathrm{e}-01$

$2.66698 \mathrm{e}+012.66698 \mathrm{e}+012.66698 \mathrm{e}+001.00000 \mathrm{e}-092.12000 \mathrm{e}-01$

$2.66698 \mathrm{e}+012.66698 \mathrm{e}+012.66698 \mathrm{e}+001.00000 \mathrm{e}-092.12000 \mathrm{e}-01$

$1.00000 \mathrm{e}-02$ 1.00000e-02 1.00000e-03 1.00000e-09 1.00000e-01

$1.00000 \mathrm{e}+001.00000 \mathrm{e}+001.00000 \mathrm{e}-011.00000 \mathrm{e}-091.00000 \mathrm{e}-01$

$1.00000 \mathrm{e}-05$ 1.00000e-05 1.00000e-06 1.00000e-09 1.00000e-01

$1.00000 \mathrm{e}+001.00000 \mathrm{e}+001.00000 \mathrm{e}-011.00000 \mathrm{e}-091.00000 \mathrm{e}-01$

Element: 8702 \# of layers: 9

$\mathrm{Kx} \mathrm{Ky} \mathrm{Kz}$ Ss Por

$2.66698 \mathrm{e}+012.66698 \mathrm{e}+012.66698 \mathrm{e}+00$ 1.00000e-09 2.12000e-01

$2.66698 \mathrm{e}+012.66698 \mathrm{e}+012.66698 \mathrm{e}+001.00000 \mathrm{e}-092.12000 \mathrm{e}-01$

$2.66698 \mathrm{e}+012.66698 \mathrm{e}+012.66698 \mathrm{e}+001.00000 \mathrm{e}-092.12000 \mathrm{e}-01$

$2.66698 \mathrm{e}+012.66698 \mathrm{e}+012.66698 \mathrm{e}+00$ 1.00000e-09 2.12000e-01

$2.66698 \mathrm{e}+012.66698 \mathrm{e}+012.66698 \mathrm{e}+00$ 1.00000e-09 2.12000e-01

$1.00000 \mathrm{e}-02$ 1.00000e-02 1.00000e-03 1.00000e-09 1.00000e-01

$1.00000 \mathrm{e}+001.00000 \mathrm{e}+001.00000 \mathrm{e}-011.00000 \mathrm{e}-091.00000 \mathrm{e}-01$

$1.00000 \mathrm{e}-05$ 1.00000e-05 1.00000e-06 1.00000e-09 1.00000e-01

$1.00000 \mathrm{e}+001.00000 \mathrm{e}+001.00000 \mathrm{e}-011.00000 \mathrm{e}-091.00000 \mathrm{e}-01$

Element: 8703 \# of layers: 9

$\mathrm{Kx} \mathrm{Ky} \mathrm{Kz}$ Ss Por

$2.66698 \mathrm{e}+012.66698 \mathrm{e}+012.66698 \mathrm{e}+00$ 1.00000e-09 2.12000e-01

$2.66698 \mathrm{e}+012.66698 \mathrm{e}+012.66698 \mathrm{e}+001.00000 \mathrm{e}-092.12000 \mathrm{e}-01$

$2.66698 \mathrm{e}+012.66698 \mathrm{e}+012.66698 \mathrm{e}+001.00000 \mathrm{e}-092.12000 \mathrm{e}-01$

$2.66698 \mathrm{e}+012.66698 \mathrm{e}+012.66698 \mathrm{e}+001.00000 \mathrm{e}-092.12000 \mathrm{e}-01$

$2.66698 \mathrm{e}+012.66698 \mathrm{e}+012.66698 \mathrm{e}+001.00000 \mathrm{e}-092.12000 \mathrm{e}-01$

1.00000e-02 1.00000e-02 1.00000e-03 1.00000e-09 1.00000e-01

$1.00000 \mathrm{e}+001.00000 \mathrm{e}+001.00000 \mathrm{e}-011.00000 \mathrm{e}-091.00000 \mathrm{e}-01$

$1.00000 \mathrm{e}-05$ 1.00000e-05 1.00000e-06 1.00000e-09 1.00000e-01

$1.00000 \mathrm{e}+001.00000 \mathrm{e}+001.00000 \mathrm{e}-011.00000 \mathrm{e}-091.00000 \mathrm{e}-01$

Element: 8704 \# of layers: 9

$\mathrm{Kx} \mathrm{Ky} \mathrm{Kz}$ Ss Por

$2.66698 \mathrm{e}+012.66698 \mathrm{e}+012.66698 \mathrm{e}+00$ 1.00000e-09 2.12000e-01

$2.66698 \mathrm{e}+012.66698 \mathrm{e}+012.66698 \mathrm{e}+001.00000 \mathrm{e}-092.12000 \mathrm{e}-01$

$2.66698 \mathrm{e}+012.66698 \mathrm{e}+012.66698 \mathrm{e}+001.00000 \mathrm{e}-092.12000 \mathrm{e}-01$

$2.66698 \mathrm{e}+012.66698 \mathrm{e}+012.66698 \mathrm{e}+001.00000 \mathrm{e}-092.12000 \mathrm{e}-01$

$2.66698 \mathrm{e}+012.66698 \mathrm{e}+012.66698 \mathrm{e}+00$ 1.00000e-09 2.12000e-01

$1.00000 \mathrm{e}-02$ 1.00000e-02 1.00000e-03 1.00000e-09 1.00000e-01

$1.00000 \mathrm{e}+001.00000 \mathrm{e}+001.00000 \mathrm{e}-011.00000 \mathrm{e}-091.00000 \mathrm{e}-01$

$1.00000 \mathrm{e}-05$ 1.00000e-05 1.00000e-06 1.00000e-09 1.00000e-01

$1.00000 \mathrm{e}+001.00000 \mathrm{e}+001.00000 \mathrm{e}-011.00000 \mathrm{e}-091.00000 \mathrm{e}-01$

Element: 8705 \# of layers: 9

$\mathrm{Kx} \mathrm{Ky} \mathrm{Kz}$ Ss Por

$2.66698 \mathrm{e}+012.66698 \mathrm{e}+012.66698 \mathrm{e}+00$ 1.00000e-09 2.12000e-01

$2.66698 \mathrm{e}+012.66698 \mathrm{e}+012.66698 \mathrm{e}+001.00000 \mathrm{e}-092.12000 \mathrm{e}-01$ 
$2.66698 \mathrm{e}+012.66698 \mathrm{e}+012.66698 \mathrm{e}+00$ 1.00000e-09 2.12000e-01

$2.66698 \mathrm{e}+012.66698 \mathrm{e}+012.66698 \mathrm{e}+001.00000 \mathrm{e}-092.12000 \mathrm{e}-01$

$2.66698 \mathrm{e}+012.66698 \mathrm{e}+012.66698 \mathrm{e}+001.00000 \mathrm{e}-092.12000 \mathrm{e}-01$

$1.00000 \mathrm{e}-02$ 1.00000e-02 1.00000e-03 1.00000e-09 1.00000e-01

$1.00000 \mathrm{e}+001.00000 \mathrm{e}+001.00000 \mathrm{e}-011.00000 \mathrm{e}-091.00000 \mathrm{e}-01$

$1.00000 \mathrm{e}-05$ 1.00000e-05 1.00000e-06 1.00000e-09 1.00000e-01

$1.00000 \mathrm{e}+001.00000 \mathrm{e}+001.00000 \mathrm{e}-01$ 1.00000e-09 1.00000e-01

Element: 8706 \# of layers: 9

$\mathrm{Kx} \mathrm{Ky} \mathrm{Kz}$ Ss Por

$2.66698 \mathrm{e}+012.66698 \mathrm{e}+012.66698 \mathrm{e}+00$ 1.00000e-09 2.12000e-01

$2.66698 \mathrm{e}+012.66698 \mathrm{e}+012.66698 \mathrm{e}+00$ 1.00000e-09 2.12000e-01

$2.66698 \mathrm{e}+012.66698 \mathrm{e}+012.66698 \mathrm{e}+001.00000 \mathrm{e}-092.12000 \mathrm{e}-01$

$2.66698 \mathrm{e}+012.66698 \mathrm{e}+012.66698 \mathrm{e}+001.00000 \mathrm{e}-092.12000 \mathrm{e}-01$

$2.66698 \mathrm{e}+012.66698 \mathrm{e}+012.66698 \mathrm{e}+00$ 1.00000e-09 2.12000e-01

$1.00000 \mathrm{e}-02$ 1.00000e-02 1.00000e-03 1.00000e-09 1.00000e-01

$1.00000 \mathrm{e}+001.00000 \mathrm{e}+001.00000 \mathrm{e}-011.00000 \mathrm{e}-091.00000 \mathrm{e}-01$

$1.00000 \mathrm{e}-05$ 1.00000e-05 1.00000e-06 1.00000e-09 1.00000e-01

$1.00000 \mathrm{e}+001.00000 \mathrm{e}+001.00000 \mathrm{e}-01$ 1.00000e-09 1.00000e-01

Element: 8707 \# of layers: 9

$\mathrm{Kx} \mathrm{Ky} \mathrm{Kz}$ Ss Por

$2.66698 \mathrm{e}+012.66698 \mathrm{e}+012.66698 \mathrm{e}+00$ 1.00000e-09 2.12000e-01

$2.66698 \mathrm{e}+012.66698 \mathrm{e}+012.66698 \mathrm{e}+00$ 1.00000e-09 2.12000e-01

$2.66698 \mathrm{e}+012.66698 \mathrm{e}+012.66698 \mathrm{e}+00$ 1.00000e-09 2.12000e-01

$2.66698 \mathrm{e}+012.66698 \mathrm{e}+012.66698 \mathrm{e}+001.00000 \mathrm{e}-092.12000 \mathrm{e}-01$

$2.66698 \mathrm{e}+012.66698 \mathrm{e}+012.66698 \mathrm{e}+001.00000 \mathrm{e}-092.12000 \mathrm{e}-01$

$1.00000 \mathrm{e}-02$ 1.00000e-02 1.00000e-03 1.00000e-09 1.00000e-01

$1.00000 \mathrm{e}+001.00000 \mathrm{e}+001.00000 \mathrm{e}-011.00000 \mathrm{e}-091.00000 \mathrm{e}-01$

$1.00000 \mathrm{e}-05$ 1.00000e-05 1.00000e-06 1.00000e-09 1.00000e-01

$1.00000 \mathrm{e}+001.00000 \mathrm{e}+001.00000 \mathrm{e}-011.00000 \mathrm{e}-091.00000 \mathrm{e}-01$

Element: 8708 \# of layers: 9

$\mathrm{Kx} \mathrm{Ky} \mathrm{Kz}$ Ss Por

$2.66698 \mathrm{e}+012.66698 \mathrm{e}+012.66698 \mathrm{e}+001.00000 \mathrm{e}-092.12000 \mathrm{e}-01$

$2.66698 \mathrm{e}+012.66698 \mathrm{e}+012.66698 \mathrm{e}+001.00000 \mathrm{e}-092.12000 \mathrm{e}-01$

$2.66698 \mathrm{e}+012.66698 \mathrm{e}+012.66698 \mathrm{e}+001.00000 \mathrm{e}-092.12000 \mathrm{e}-01$

$2.66698 \mathrm{e}+012.66698 \mathrm{e}+012.66698 \mathrm{e}+001.00000 \mathrm{e}-092.12000 \mathrm{e}-01$

$2.66698 \mathrm{e}+012.66698 \mathrm{e}+012.66698 \mathrm{e}+00$ 1.00000e-09 2.12000e-01

1.00000e-02 1.00000e-02 1.00000e-03 1.00000e-09 1.00000e-01

$1.00000 \mathrm{e}+001.00000 \mathrm{e}+001.00000 \mathrm{e}-011.00000 \mathrm{e}-091.00000 \mathrm{e}-01$

$1.00000 \mathrm{e}-05$ 1.00000e-05 1.00000e-06 1.00000e-09 1.00000e-01

$1.00000 \mathrm{e}+001.00000 \mathrm{e}+001.00000 \mathrm{e}-01$ 1.00000e-09 1.00000e-01

Element: 8709 \# of layers: 9

$\mathrm{Kx} \mathrm{Ky} \mathrm{Kz}$ Ss Por

$2.66698 \mathrm{e}+012.66698 \mathrm{e}+012.66698 \mathrm{e}+00$ 1.00000e-09 2.12000e-01

$2.66698 \mathrm{e}+012.66698 \mathrm{e}+012.66698 \mathrm{e}+00$ 1.00000e-09 2.12000e-01

$2.66698 \mathrm{e}+012.66698 \mathrm{e}+012.66698 \mathrm{e}+001.00000 \mathrm{e}-092.12000 \mathrm{e}-01$

$2.66698 \mathrm{e}+012.66698 \mathrm{e}+012.66698 \mathrm{e}+001.00000 \mathrm{e}-092.12000 \mathrm{e}-01$ 
$2.66698 \mathrm{e}+012.66698 \mathrm{e}+012.66698 \mathrm{e}+00$ 1.00000e-09 2.12000e-01 $1.00000 \mathrm{e}-02$ 1.00000e-02 1.00000e-03 1.00000e-09 1.00000e-01 $1.00000 \mathrm{e}+001.00000 \mathrm{e}+001.00000 \mathrm{e}-011.00000 \mathrm{e}-091.00000 \mathrm{e}-01$ $1.00000 \mathrm{e}-05$ 1.00000e-05 1.00000e-06 1.00000e-09 1.00000e-01 $1.00000 \mathrm{e}+001.00000 \mathrm{e}+001.00000 \mathrm{e}-01$ 1.00000e-09 1.00000e-01 Element: 8710 \# of layers: 7

$\mathrm{Kx} \mathrm{Ky} \mathrm{Kz}$ Ss Por

$2.66698 \mathrm{e}+012.66698 \mathrm{e}+012.66698 \mathrm{e}+00$ 1.00000e-09 2.12000e-01

$2.66698 \mathrm{e}+012.66698 \mathrm{e}+012.66698 \mathrm{e}+001.00000 \mathrm{e}-092.12000 \mathrm{e}-01$

$2.66698 \mathrm{e}+012.66698 \mathrm{e}+012.66698 \mathrm{e}+001.00000 \mathrm{e}-092.12000 \mathrm{e}-01$

$2.66698 \mathrm{e}+012.66698 \mathrm{e}+012.66698 \mathrm{e}+001.00000 \mathrm{e}-092.12000 \mathrm{e}-01$

$2.66698 \mathrm{e}+012.66698 \mathrm{e}+012.66698 \mathrm{e}+001.00000 \mathrm{e}-092.12000 \mathrm{e}-01$

$1.00000 \mathrm{e}-05$ 1.00000e-05 1.00000e-06 1.00000e-09 1.00000e-01

$1.00000 \mathrm{e}+001.00000 \mathrm{e}+001.00000 \mathrm{e}-011.00000 \mathrm{e}-09$ 1.00000e-01

Element: 8711 \# of layers: 7

Kx Ky Kz Ss Por

$2.34005 \mathrm{e}+012.34005 \mathrm{e}+012.34005 \mathrm{e}+00$ 1.00000e-09 2.12000e-01

$2.34005 \mathrm{e}+012.34005 \mathrm{e}+012.34005 \mathrm{e}+00$ 1.00000e-09 2.12000e-01

$2.34005 \mathrm{e}+012.34005 \mathrm{e}+012.34005 \mathrm{e}+00$ 1.00000e-09 2.12000e-01

$2.34005 \mathrm{e}+012.34005 \mathrm{e}+012.34005 \mathrm{e}+00$ 1.00000e-09 2.12000e-01

$2.34005 \mathrm{e}+012.34005 \mathrm{e}+012.34005 \mathrm{e}+00$ 1.00000e-09 2.12000e-01

$1.00000 \mathrm{e}-05$ 1.00000e-05 1.00000e-06 1.00000e-09 1.00000e-01

$1.00000 \mathrm{e}+001.00000 \mathrm{e}+001.00000 \mathrm{e}-01$ 1.00000e-09 1.00000e-01

Element: 8712 \# of layers: 9

$\mathrm{Kx} \mathrm{Ky} \mathrm{Kz}$ Ss Por

$2.34005 \mathrm{e}+012.34005 \mathrm{e}+012.34005 \mathrm{e}+00$ 1.00000e-09 2.12000e-01

$2.34005 \mathrm{e}+012.34005 \mathrm{e}+012.34005 \mathrm{e}+00$ 1.00000e-09 2.12000e-01

$2.34005 \mathrm{e}+012.34005 \mathrm{e}+012.34005 \mathrm{e}+00$ 1.00000e-09 2.12000e-01

$2.34005 \mathrm{e}+012.34005 \mathrm{e}+012.34005 \mathrm{e}+001.00000 \mathrm{e}-092.12000 \mathrm{e}-01$

$2.34005 \mathrm{e}+012.34005 \mathrm{e}+012.34005 \mathrm{e}+001.00000 \mathrm{e}-092.12000 \mathrm{e}-01$

$1.00000 \mathrm{e}-02$ 1.00000e-02 1.00000e-03 1.00000e-09 1.00000e-01

$1.00000 \mathrm{e}+001.00000 \mathrm{e}+001.00000 \mathrm{e}-011.00000 \mathrm{e}-091.00000 \mathrm{e}-01$

1.00000e-05 1.00000e-05 1.00000e-06 1.00000e-09 1.00000e-01

$1.00000 \mathrm{e}+001.00000 \mathrm{e}+001.00000 \mathrm{e}-011.00000 \mathrm{e}-091.00000 \mathrm{e}-01$

Element: 8713 \# of layers: 9

Kx Ky Kz Ss Por

$2.34005 \mathrm{e}+012.34005 \mathrm{e}+012.34005 \mathrm{e}+00$ 1.00000e-09 2.12000e-01

$2.34005 \mathrm{e}+012.34005 \mathrm{e}+012.34005 \mathrm{e}+001.00000 \mathrm{e}-092.12000 \mathrm{e}-01$

$2.34005 \mathrm{e}+012.34005 \mathrm{e}+012.34005 \mathrm{e}+00$ 1.00000e-09 2.12000e-01

$2.34005 \mathrm{e}+012.34005 \mathrm{e}+012.34005 \mathrm{e}+00$ 1.00000e-09 2.12000e-01

$2.34005 \mathrm{e}+012.34005 \mathrm{e}+012.34005 \mathrm{e}+00$ 1.00000e-09 2.12000e-01

$1.00000 \mathrm{e}-02$ 1.00000e-02 1.00000e-03 1.00000e-09 1.00000e-01

$1.00000 \mathrm{e}+001.00000 \mathrm{e}+001.00000 \mathrm{e}-011.00000 \mathrm{e}-091.00000 \mathrm{e}-01$

$1.00000 \mathrm{e}-05$ 1.00000e-05 1.00000e-06 1.00000e-09 1.00000e-01

$1.00000 \mathrm{e}+001.00000 \mathrm{e}+001.00000 \mathrm{e}-01$ 1.00000e-09 1.00000e-01

Element: 8714 \# of layers: 9 
$\mathrm{Kx} \mathrm{Ky} \mathrm{Kz}$ Ss Por

$2.66698 \mathrm{e}+012.66698 \mathrm{e}+012.66698 \mathrm{e}+00$ 1.00000e-09 2.12000e-01

$2.66698 \mathrm{e}+012.66698 \mathrm{e}+012.66698 \mathrm{e}+001.00000 \mathrm{e}-092.12000 \mathrm{e}-01$

$2.66698 \mathrm{e}+012.66698 \mathrm{e}+012.66698 \mathrm{e}+001.00000 \mathrm{e}-092.12000 \mathrm{e}-01$

$2.66698 \mathrm{e}+012.66698 \mathrm{e}+012.66698 \mathrm{e}+001.00000 \mathrm{e}-092.12000 \mathrm{e}-01$

$2.66698 \mathrm{e}+012.66698 \mathrm{e}+012.66698 \mathrm{e}+001.00000 \mathrm{e}-092.12000 \mathrm{e}-01$

$1.00000 \mathrm{e}-02$ 1.00000e-02 1.00000e-03 1.00000e-09 1.00000e-01

$1.00000 \mathrm{e}+001.00000 \mathrm{e}+001.00000 \mathrm{e}-011.00000 \mathrm{e}-091.00000 \mathrm{e}-01$

$1.00000 \mathrm{e}-05$ 1.00000e-05 1.00000e-06 1.00000e-09 1.00000e-01

$1.00000 \mathrm{e}+001.00000 \mathrm{e}+001.00000 \mathrm{e}-011.00000 \mathrm{e}-09$ 1.00000e-01

Element: 8715 \# of layers: 9

Kx Ky Kz Ss Por

$2.66698 \mathrm{e}+012.66698 \mathrm{e}+012.66698 \mathrm{e}+00$ 1.00000e-09 2.12000e-01

$2.66698 \mathrm{e}+012.66698 \mathrm{e}+012.66698 \mathrm{e}+001.00000 \mathrm{e}-092.12000 \mathrm{e}-01$

$2.66698 \mathrm{e}+012.66698 \mathrm{e}+012.66698 \mathrm{e}+00$ 1.00000e-09 2.12000e-01

$2.66698 \mathrm{e}+012.66698 \mathrm{e}+012.66698 \mathrm{e}+001.00000 \mathrm{e}-092.12000 \mathrm{e}-01$

$2.66698 \mathrm{e}+012.66698 \mathrm{e}+012.66698 \mathrm{e}+00$ 1.00000e-09 2.12000e-01

$1.00000 \mathrm{e}-02$ 1.00000e-02 1.00000e-03 1.00000e-09 1.00000e-01

$1.00000 \mathrm{e}+001.00000 \mathrm{e}+001.00000 \mathrm{e}-011.00000 \mathrm{e}-091.00000 \mathrm{e}-01$

$1.00000 \mathrm{e}-05$ 1.00000e-05 1.00000e-06 1.00000e-09 1.00000e-01

$1.00000 \mathrm{e}+001.00000 \mathrm{e}+001.00000 \mathrm{e}-011.00000 \mathrm{e}-091.00000 \mathrm{e}-01$

Element: 8716 \# of layers: 9

$\mathrm{Kx} \mathrm{Ky} \mathrm{Kz}$ Ss Por

$2.66698 \mathrm{e}+012.66698 \mathrm{e}+012.66698 \mathrm{e}+00$ 1.00000e-09 2.12000e-01

$2.66698 \mathrm{e}+012.66698 \mathrm{e}+012.66698 \mathrm{e}+001.00000 \mathrm{e}-092.12000 \mathrm{e}-01$

$2.66698 \mathrm{e}+012.66698 \mathrm{e}+012.66698 \mathrm{e}+001.00000 \mathrm{e}-092.12000 \mathrm{e}-01$

$2.66698 \mathrm{e}+012.66698 \mathrm{e}+012.66698 \mathrm{e}+001.00000 \mathrm{e}-092.12000 \mathrm{e}-01$

$2.66698 \mathrm{e}+012.66698 \mathrm{e}+012.66698 \mathrm{e}+001.00000 \mathrm{e}-092.12000 \mathrm{e}-01$

$1.00000 \mathrm{e}-02$ 1.00000e-02 1.00000e-03 1.00000e-09 1.00000e-01

$1.00000 \mathrm{e}+001.00000 \mathrm{e}+001.00000 \mathrm{e}-011.00000 \mathrm{e}-091.00000 \mathrm{e}-01$

$1.00000 \mathrm{e}-05$ 1.00000e-05 1.00000e-06 1.00000e-09 1.00000e-01

$1.00000 \mathrm{e}+001.00000 \mathrm{e}+001.00000 \mathrm{e}-011.00000 \mathrm{e}-091.00000 \mathrm{e}-01$

Element: 8717 \# of layers: 9

$\mathrm{Kx} \mathrm{Ky} \mathrm{Kz}$ Ss Por

$2.66698 \mathrm{e}+012.66698 \mathrm{e}+012.66698 \mathrm{e}+00$ 1.00000e-09 2.12000e-01

$2.66698 \mathrm{e}+012.66698 \mathrm{e}+012.66698 \mathrm{e}+001.00000 \mathrm{e}-092.12000 \mathrm{e}-01$

$2.66698 \mathrm{e}+012.66698 \mathrm{e}+012.66698 \mathrm{e}+001.00000 \mathrm{e}-092.12000 \mathrm{e}-01$

$2.66698 \mathrm{e}+012.66698 \mathrm{e}+012.66698 \mathrm{e}+001.00000 \mathrm{e}-092.12000 \mathrm{e}-01$

$2.66698 \mathrm{e}+012.66698 \mathrm{e}+012.66698 \mathrm{e}+00$ 1.00000e-09 2.12000e-01

$1.00000 \mathrm{e}-02$ 1.00000e-02 1.00000e-03 1.00000e-09 1.00000e-01

$1.00000 \mathrm{e}+001.00000 \mathrm{e}+001.00000 \mathrm{e}-011.00000 \mathrm{e}-091.00000 \mathrm{e}-01$

$1.00000 \mathrm{e}-05$ 1.00000e-05 1.00000e-06 1.00000e-09 1.00000e-01

$1.00000 \mathrm{e}+001.00000 \mathrm{e}+001.00000 \mathrm{e}-011.00000 \mathrm{e}-091.00000 \mathrm{e}-01$

Element: 8718 \# of layers: 7

$\mathrm{Kx} \mathrm{Ky} \mathrm{Kz}$ Ss Por

$2.34005 \mathrm{e}+012.34005 \mathrm{e}+012.34005 \mathrm{e}+00$ 1.00000e-09 2.12000e-01 
$2.34005 \mathrm{e}+012.34005 \mathrm{e}+012.34005 \mathrm{e}+00$ 1.00000e-09 2.12000e-01 $2.34005 \mathrm{e}+012.34005 \mathrm{e}+012.34005 \mathrm{e}+001.00000 \mathrm{e}-092.12000 \mathrm{e}-01$ $2.34005 \mathrm{e}+012.34005 \mathrm{e}+012.34005 \mathrm{e}+001.00000 \mathrm{e}-092.12000 \mathrm{e}-01$ $2.34005 \mathrm{e}+012.34005 \mathrm{e}+012.34005 \mathrm{e}+001.00000 \mathrm{e}-092.12000 \mathrm{e}-01$ $1.00000 \mathrm{e}-05$ 1.00000e-05 1.00000e-06 1.00000e-09 1.00000e-01 $1.00000 \mathrm{e}+001.00000 \mathrm{e}+001.00000 \mathrm{e}-011.00000 \mathrm{e}-091.00000 \mathrm{e}-01$ Element: 8719 \# of layers: 7

Kx Ky Kz Ss Por

$2.34005 \mathrm{e}+012.34005 \mathrm{e}+012.34005 \mathrm{e}+00$ 1.00000e-09 2.12000e-01

$2.34005 \mathrm{e}+012.34005 \mathrm{e}+012.34005 \mathrm{e}+001.00000 \mathrm{e}-092.12000 \mathrm{e}-01$ $2.34005 \mathrm{e}+012.34005 \mathrm{e}+012.34005 \mathrm{e}+001.00000 \mathrm{e}-092.12000 \mathrm{e}-01$ $2.34005 \mathrm{e}+012.34005 \mathrm{e}+012.34005 \mathrm{e}+001.00000 \mathrm{e}-092.12000 \mathrm{e}-01$ $2.34005 \mathrm{e}+012.34005 \mathrm{e}+012.34005 \mathrm{e}+001.00000 \mathrm{e}-092.12000 \mathrm{e}-01$ $1.00000 \mathrm{e}-05$ 1.00000e-05 1.00000e-06 1.00000e-09 1.00000e-01 $1.00000 \mathrm{e}+001.00000 \mathrm{e}+001.00000 \mathrm{e}-011.00000 \mathrm{e}-091.00000 \mathrm{e}-01$ Element: 8720 \# of layers: 7

Kx Ky Kz Ss Por

$2.34005 \mathrm{e}+012.34005 \mathrm{e}+012.34005 \mathrm{e}+00$ 1.00000e-09 2.12000e-01 $2.34005 \mathrm{e}+012.34005 \mathrm{e}+012.34005 \mathrm{e}+001.00000 \mathrm{e}-092.12000 \mathrm{e}-01$ $2.34005 \mathrm{e}+012.34005 \mathrm{e}+012.34005 \mathrm{e}+001.00000 \mathrm{e}-092.12000 \mathrm{e}-01$ $2.34005 \mathrm{e}+012.34005 \mathrm{e}+012.34005 \mathrm{e}+001.00000 \mathrm{e}-092.12000 \mathrm{e}-01$ $2.34005 \mathrm{e}+012.34005 \mathrm{e}+012.34005 \mathrm{e}+00$ 1.00000e-09 2.12000e-01 $1.00000 \mathrm{e}-05$ 1.00000e-05 1.00000e-06 1.00000e-09 1.00000e-01 $1.00000 \mathrm{e}+001.00000 \mathrm{e}+001.00000 \mathrm{e}-011.00000 \mathrm{e}-091.00000 \mathrm{e}-01$ Element: 8721 \# of layers: 7

Kx Ky Kz Ss Por

$2.34005 \mathrm{e}+012.34005 \mathrm{e}+012.34005 \mathrm{e}+00$ 1.00000e-09 2.12000e-01 $2.34005 \mathrm{e}+012.34005 \mathrm{e}+012.34005 \mathrm{e}+001.00000 \mathrm{e}-092.12000 \mathrm{e}-01$ $2.34005 \mathrm{e}+012.34005 \mathrm{e}+012.34005 \mathrm{e}+001.00000 \mathrm{e}-092.12000 \mathrm{e}-01$ $2.34005 \mathrm{e}+012.34005 \mathrm{e}+012.34005 \mathrm{e}+001.00000 \mathrm{e}-092.12000 \mathrm{e}-01$ $2.34005 \mathrm{e}+012.34005 \mathrm{e}+012.34005 \mathrm{e}+001.00000 \mathrm{e}-092.12000 \mathrm{e}-01$ $1.00000 \mathrm{e}-05$ 1.00000e-05 1.00000e-06 1.00000e-09 1.00000e-01 $1.00000 \mathrm{e}+001.00000 \mathrm{e}+001.00000 \mathrm{e}-011.00000 \mathrm{e}-091.00000 \mathrm{e}-01$ Element: 8722 \# of layers: 7

Kx Ky Kz Ss Por

$2.34005 \mathrm{e}+012.34005 \mathrm{e}+012.34005 \mathrm{e}+00$ 1.00000e-09 2.12000e-01 $2.34005 \mathrm{e}+012.34005 \mathrm{e}+012.34005 \mathrm{e}+001.00000 \mathrm{e}-092.12000 \mathrm{e}-01$ $2.34005 \mathrm{e}+012.34005 \mathrm{e}+012.34005 \mathrm{e}+001.00000 \mathrm{e}-092.12000 \mathrm{e}-01$ $2.34005 \mathrm{e}+012.34005 \mathrm{e}+012.34005 \mathrm{e}+001.00000 \mathrm{e}-092.12000 \mathrm{e}-01$ $2.34005 \mathrm{e}+012.34005 \mathrm{e}+012.34005 \mathrm{e}+00$ 1.00000e-09 2.12000e-01 $1.00000 \mathrm{e}-05$ 1.00000e-05 1.00000e-06 1.00000e-09 1.00000e-01 $1.00000 \mathrm{e}+001.00000 \mathrm{e}+001.00000 \mathrm{e}-011.00000 \mathrm{e}-091.00000 \mathrm{e}-01$ Element: 8723 \# of layers: 9

Kx Ky Kz Ss Por

$2.34005 \mathrm{e}+012.34005 \mathrm{e}+012.34005 \mathrm{e}+00$ 1.00000e-09 2.12000e-01 $2.34005 \mathrm{e}+012.34005 \mathrm{e}+012.34005 \mathrm{e}+001.00000 \mathrm{e}-092.12000 \mathrm{e}-01$ 
$2.34005 \mathrm{e}+012.34005 \mathrm{e}+012.34005 \mathrm{e}+00$ 1.00000e-09 2.12000e-01 $2.34005 \mathrm{e}+012.34005 \mathrm{e}+012.34005 \mathrm{e}+001.00000 \mathrm{e}-092.12000 \mathrm{e}-01$ $2.34005 \mathrm{e}+012.34005 \mathrm{e}+012.34005 \mathrm{e}+001.00000 \mathrm{e}-092.12000 \mathrm{e}-01$ $1.00000 \mathrm{e}-021.00000 \mathrm{e}-02$ 1.00000e-03 1.00000e-09 1.00000e-01 $1.00000 \mathrm{e}+001.00000 \mathrm{e}+001.00000 \mathrm{e}-011.00000 \mathrm{e}-091.00000 \mathrm{e}-01$ $1.00000 \mathrm{e}-05$ 1.00000e-05 1.00000e-06 1.00000e-09 1.00000e-01 $1.00000 \mathrm{e}+001.00000 \mathrm{e}+001.00000 \mathrm{e}-011.00000 \mathrm{e}-091.00000 \mathrm{e}-01$ Element: 8724 \# of layers: 9

Kx Ky Kz Ss Por

$2.34005 \mathrm{e}+012.34005 \mathrm{e}+012.34005 \mathrm{e}+00$ 1.00000e-09 2.12000e-01 $2.34005 \mathrm{e}+012.34005 \mathrm{e}+012.34005 \mathrm{e}+001.00000 \mathrm{e}-092.12000 \mathrm{e}-01$ $2.34005 \mathrm{e}+012.34005 \mathrm{e}+012.34005 \mathrm{e}+001.00000 \mathrm{e}-092.12000 \mathrm{e}-01$ $2.34005 \mathrm{e}+012.34005 \mathrm{e}+012.34005 \mathrm{e}+001.00000 \mathrm{e}-092.12000 \mathrm{e}-01$ $2.34005 \mathrm{e}+012.34005 \mathrm{e}+012.34005 \mathrm{e}+001.00000 \mathrm{e}-092.12000 \mathrm{e}-01$ $1.00000 \mathrm{e}-021.00000 \mathrm{e}-02$ 1.00000e-03 1.00000e-09 1.00000e-01 $1.00000 \mathrm{e}+001.00000 \mathrm{e}+001.00000 \mathrm{e}-011.00000 \mathrm{e}-091.00000 \mathrm{e}-01$ $1.00000 \mathrm{e}-05$ 1.00000e-05 1.00000e-06 1.00000e-09 1.00000e-01 $1.00000 \mathrm{e}+001.00000 \mathrm{e}+001.00000 \mathrm{e}-011.00000 \mathrm{e}-091.00000 \mathrm{e}-01$ Element: 8725 \# of layers: 9

Kx Ky Kz Ss Por

$2.34005 \mathrm{e}+012.34005 \mathrm{e}+012.34005 \mathrm{e}+00$ 1.00000e-09 2.12000e-01

$2.34005 \mathrm{e}+012.34005 \mathrm{e}+012.34005 \mathrm{e}+001.00000 \mathrm{e}-092.12000 \mathrm{e}-01$

$2.34005 \mathrm{e}+012.34005 \mathrm{e}+012.34005 \mathrm{e}+00$ 1.00000e-09 2.12000e-01 $2.34005 \mathrm{e}+012.34005 \mathrm{e}+012.34005 \mathrm{e}+001.00000 \mathrm{e}-092.12000 \mathrm{e}-01$ $2.34005 \mathrm{e}+012.34005 \mathrm{e}+012.34005 \mathrm{e}+001.00000 \mathrm{e}-092.12000 \mathrm{e}-01$ $1.00000 \mathrm{e}-02$ 1.00000e-02 1.00000e-03 1.00000e-09 1.00000e-01 $1.00000 \mathrm{e}+001.00000 \mathrm{e}+001.00000 \mathrm{e}-011.00000 \mathrm{e}-091.00000 \mathrm{e}-01$ $1.00000 \mathrm{e}-05$ 1.00000e-05 1.00000e-06 1.00000e-09 1.00000e-01 $1.00000 \mathrm{e}+001.00000 \mathrm{e}+001.00000 \mathrm{e}-011.00000 \mathrm{e}-091.00000 \mathrm{e}-01$ Element: 8726 \# of layers: 9

Kx Ky Kz Ss Por

$2.34005 \mathrm{e}+012.34005 \mathrm{e}+012.34005 \mathrm{e}+00$ 1.00000e-09 2.12000e-01 $2.34005 \mathrm{e}+012.34005 \mathrm{e}+012.34005 \mathrm{e}+001.00000 \mathrm{e}-092.12000 \mathrm{e}-01$ $2.34005 \mathrm{e}+012.34005 \mathrm{e}+012.34005 \mathrm{e}+001.00000 \mathrm{e}-092.12000 \mathrm{e}-01$ $2.34005 \mathrm{e}+012.34005 \mathrm{e}+012.34005 \mathrm{e}+001.00000 \mathrm{e}-092.12000 \mathrm{e}-01$ $2.34005 \mathrm{e}+012.34005 \mathrm{e}+012.34005 \mathrm{e}+001.00000 \mathrm{e}-092.12000 \mathrm{e}-01$ $1.00000 \mathrm{e}-02$ 1.00000e-02 1.00000e-03 1.00000e-09 1.00000e-01 $1.00000 \mathrm{e}+001.00000 \mathrm{e}+001.00000 \mathrm{e}-011.00000 \mathrm{e}-091.00000 \mathrm{e}-01$ $1.00000 \mathrm{e}-05$ 1.00000e-05 1.00000e-06 1.00000e-09 1.00000e-01 $1.00000 \mathrm{e}+001.00000 \mathrm{e}+001.00000 \mathrm{e}-011.00000 \mathrm{e}-091.00000 \mathrm{e}-01$ Element: 8727 \# of layers: 9

Kx Ky Kz Ss Por

$2.34005 \mathrm{e}+012.34005 \mathrm{e}+012.34005 \mathrm{e}+00$ 1.00000e-09 2.12000e-01 $2.34005 \mathrm{e}+012.34005 \mathrm{e}+012.34005 \mathrm{e}+001.00000 \mathrm{e}-092.12000 \mathrm{e}-01$ $2.34005 \mathrm{e}+012.34005 \mathrm{e}+012.34005 \mathrm{e}+001.00000 \mathrm{e}-092.12000 \mathrm{e}-01$ $2.34005 \mathrm{e}+012.34005 \mathrm{e}+012.34005 \mathrm{e}+001.00000 \mathrm{e}-092.12000 \mathrm{e}-01$ 
$2.34005 \mathrm{e}+012.34005 \mathrm{e}+012.34005 \mathrm{e}+00$ 1.00000e-09 2.12000e-01 $1.00000 \mathrm{e}-02$ 1.00000e-02 1.00000e-03 1.00000e-09 1.00000e-01 $1.00000 \mathrm{e}+001.00000 \mathrm{e}+001.00000 \mathrm{e}-011.00000 \mathrm{e}-091.00000 \mathrm{e}-01$ $1.00000 \mathrm{e}-05$ 1.00000e-05 1.00000e-06 1.00000e-09 1.00000e-01 $1.00000 \mathrm{e}+001.00000 \mathrm{e}+001.00000 \mathrm{e}-01$ 1.00000e-09 1.00000e-01 Element: 8728 \# of layers: 9

$\mathrm{Kx} \mathrm{Ky} \mathrm{Kz}$ Ss Por

4.31379e+00 4.31379e+00 4.31379e-01 1.00000e-09 2.12000e-01 4.31379e+00 4.31379e+00 4.31379e-01 1.00000e-09 2.12000e-01 4.31379e+00 4.31379e+00 4.31379e-01 1.00000e-09 2.12000e-01 4.31379e+00 4.31379e+00 4.31379e-01 1.00000e-09 2.12000e-01 $4.31379 \mathrm{e}+004.31379 \mathrm{e}+00$ 4.31379e-01 1.00000e-09 2.12000e-01 $1.00000 \mathrm{e}-02$ 1.00000e-02 1.00000e-03 1.00000e-09 1.00000e-01 $1.00000 \mathrm{e}+001.00000 \mathrm{e}+001.00000 \mathrm{e}-011.00000 \mathrm{e}-091.00000 \mathrm{e}-01$ $1.00000 \mathrm{e}-05$ 1.00000e-05 1.00000e-06 1.00000e-09 1.00000e-01 $1.00000 \mathrm{e}+001.00000 \mathrm{e}+001.00000 \mathrm{e}-011.00000 \mathrm{e}-091.00000 \mathrm{e}-01$ Element: 8729 \# of layers: 9

$\mathrm{Kx} \mathrm{Ky} \mathrm{Kz}$ Ss Por

4.31379e+00 4.31379e+00 4.31379e-01 1.00000e-09 2.12000e-01 4.31379e+00 4.31379e+00 4.31379e-01 1.00000e-09 2.12000e-01 4.31379e+00 4.31379e+00 4.31379e-01 1.00000e-09 2.12000e-01 4.31379e+00 4.31379e+00 4.31379e-01 1.00000e-09 2.12000e-01 4.31379e+00 4.31379e+00 4.31379e-01 1.00000e-09 2.12000e-01 $1.00000 \mathrm{e}-02$ 1.00000e-02 1.00000e-03 1.00000e-09 1.00000e-01 $1.00000 \mathrm{e}+001.00000 \mathrm{e}+001.00000 \mathrm{e}-011.00000 \mathrm{e}-091.00000 \mathrm{e}-01$ $1.00000 \mathrm{e}-05$ 1.00000e-05 1.00000e-06 1.00000e-09 1.00000e-01 $1.00000 \mathrm{e}+001.00000 \mathrm{e}+001.00000 \mathrm{e}-011.00000 \mathrm{e}-091.00000 \mathrm{e}-01$ Element: 8730 \# of layers: 9

Kx Ky Kz Ss Por

4.31379e+00 4.31379e+00 4.31379e-01 1.00000e-09 2.12000e-01 4.31379e+00 4.31379e+00 4.31379e-01 1.00000e-09 2.12000e-01 4.31379e+00 4.31379e+00 4.31379e-01 1.00000e-09 2.12000e-01 4.31379e+00 4.31379e+00 4.31379e-01 1.00000e-09 2.12000e-01 $4.31379 \mathrm{e}+00$ 4.31379e+00 4.31379e-01 1.00000e-09 2.12000e-01 $1.00000 \mathrm{e}-02$ 1.00000e-02 1.00000e-03 1.00000e-09 1.00000e-01 $1.00000 \mathrm{e}+001.00000 \mathrm{e}+001.00000 \mathrm{e}-011.00000 \mathrm{e}-091.00000 \mathrm{e}-01$ $1.00000 \mathrm{e}-05$ 1.00000e-05 1.00000e-06 1.00000e-09 1.00000e-01 $1.00000 \mathrm{e}+001.00000 \mathrm{e}+001.00000 \mathrm{e}-011.00000 \mathrm{e}-091.00000 \mathrm{e}-01$ Element: 8731 \# of layers: 9

$\mathrm{Kx} \mathrm{Ky} \mathrm{Kz}$ Ss Por

4.31379e+00 4.31379e+00 4.31379e-01 1.00000e-09 2.12000e-01 4.31379e+00 4.31379e+00 4.31379e-01 1.00000e-09 2.12000e-01 4.31379e+00 4.31379e+00 4.31379e-01 1.00000e-09 2.12000e-01 4.31379e+00 4.31379e+00 4.31379e-01 1.00000e-09 2.12000e-01 $4.31379 \mathrm{e}+00$ 4.31379e+00 4.31379e-01 1.00000e-09 2.12000e-01 $1.00000 \mathrm{e}-02$ 1.00000e-02 1.00000e-03 1.00000e-09 1.00000e-01 
$1.00000 \mathrm{e}+001.00000 \mathrm{e}+001.00000 \mathrm{e}-011.00000 \mathrm{e}-091.00000 \mathrm{e}-01$ $1.00000 \mathrm{e}-05$ 1.00000e-05 1.00000e-06 1.00000e-09 1.00000e-01 $1.00000 \mathrm{e}+001.00000 \mathrm{e}+001.00000 \mathrm{e}-011.00000 \mathrm{e}-091.00000 \mathrm{e}-01$ Element: 8732 \# of layers: 9

$\mathrm{Kx} \mathrm{Ky} \mathrm{Kz}$ Ss Por

4.31379e+00 4.31379e+00 4.31379e-01 1.00000e-09 2.12000e-01 4.31379e+00 4.31379e+00 4.31379e-01 1.00000e-09 2.12000e-01 $4.31379 \mathrm{e}+00$ 4.31379e+00 4.31379e-01 1.00000e-09 2.12000e-01 4.31379e+00 4.31379e+00 4.31379e-01 1.00000e-09 2.12000e-01 4.31379e+00 4.31379e+00 4.31379e-01 1.00000e-09 2.12000e-01 1.00000e-02 1.00000e-02 1.00000e-03 1.00000e-09 1.00000e-01 $1.00000 \mathrm{e}+001.00000 \mathrm{e}+001.00000 \mathrm{e}-011.00000 \mathrm{e}-091.00000 \mathrm{e}-01$ $1.00000 \mathrm{e}-05$ 1.00000e-05 1.00000e-06 1.00000e-09 1.00000e-01 $1.00000 \mathrm{e}+001.00000 \mathrm{e}+001.00000 \mathrm{e}-011.00000 \mathrm{e}-091.00000 \mathrm{e}-01$ Element: 8733 \# of layers: 9

Kx Ky Kz Ss Por

$2.34005 \mathrm{e}+012.34005 \mathrm{e}+012.34005 \mathrm{e}+00$ 1.00000e-09 2.12000e-01

$2.34005 \mathrm{e}+012.34005 \mathrm{e}+012.34005 \mathrm{e}+00$ 1.00000e-09 2.12000e-01 $2.34005 \mathrm{e}+012.34005 \mathrm{e}+012.34005 \mathrm{e}+00$ 1.00000e-09 2.12000e-01 $2.34005 \mathrm{e}+012.34005 \mathrm{e}+012.34005 \mathrm{e}+00$ 1.00000e-09 2.12000e-01 $2.34005 \mathrm{e}+012.34005 \mathrm{e}+012.34005 \mathrm{e}+001.00000 \mathrm{e}-092.12000 \mathrm{e}-01$ $1.00000 \mathrm{e}-02$ 1.00000e-02 1.00000e-03 1.00000e-09 1.00000e-01 $1.00000 \mathrm{e}+001.00000 \mathrm{e}+001.00000 \mathrm{e}-011.00000 \mathrm{e}-091.00000 \mathrm{e}-01$ $1.00000 \mathrm{e}-05$ 1.00000e-05 1.00000e-06 1.00000e-09 1.00000e-01 $1.00000 \mathrm{e}+001.00000 \mathrm{e}+001.00000 \mathrm{e}-011.00000 \mathrm{e}-091.00000 \mathrm{e}-01$ Element: 8734 \# of layers: 9

$\mathrm{Kx} \mathrm{Ky} \mathrm{Kz}$ Ss Por

$2.34005 \mathrm{e}+012.34005 \mathrm{e}+012.34005 \mathrm{e}+00$ 1.00000e-09 2.12000e-01 $2.34005 \mathrm{e}+012.34005 \mathrm{e}+012.34005 \mathrm{e}+001.00000 \mathrm{e}-092.12000 \mathrm{e}-01$ $2.34005 \mathrm{e}+012.34005 \mathrm{e}+012.34005 \mathrm{e}+00$ 1.00000e-09 2.12000e-01 $2.34005 \mathrm{e}+012.34005 \mathrm{e}+012.34005 \mathrm{e}+00$ 1.00000e-09 2.12000e-01 $2.34005 \mathrm{e}+012.34005 \mathrm{e}+012.34005 \mathrm{e}+001.00000 \mathrm{e}-092.12000 \mathrm{e}-01$ 1.00000e-02 1.00000e-02 1.00000e-03 1.00000e-09 1.00000e-01 $1.00000 \mathrm{e}+001.00000 \mathrm{e}+001.00000 \mathrm{e}-011.00000 \mathrm{e}-091.00000 \mathrm{e}-01$ $1.00000 \mathrm{e}-05$ 1.00000e-05 1.00000e-06 1.00000e-09 1.00000e-01 $1.00000 \mathrm{e}+001.00000 \mathrm{e}+001.00000 \mathrm{e}-011.00000 \mathrm{e}-091.00000 \mathrm{e}-01$ Element: 8735 \# of layers: 9

Kx Ky Kz Ss Por

4.31379e+00 4.31379e+00 4.31379e-01 1.00000e-09 2.12000e-01 4.31379e+00 4.31379e+00 4.31379e-01 1.00000e-09 2.12000e-01 4.31379e+00 4.31379e+00 4.31379e-01 1.00000e-09 2.12000e-01 4.31379e+00 4.31379e+00 4.31379e-01 1.00000e-09 2.12000e-01 4.31379e+00 4.31379e+00 4.31379e-01 1.00000e-09 2.12000e-01 $1.00000 \mathrm{e}-02$ 1.00000e-02 1.00000e-03 1.00000e-09 1.00000e-01 $1.00000 \mathrm{e}+001.00000 \mathrm{e}+001.00000 \mathrm{e}-011.00000 \mathrm{e}-091.00000 \mathrm{e}-01$ $1.00000 \mathrm{e}-05$ 1.00000e-05 1.00000e-06 1.00000e-09 1.00000e-01 
$1.00000 \mathrm{e}+001.00000 \mathrm{e}+00$ 1.00000e-01 1.00000e-09 1.00000e-01

Element: 8736 \# of layers: 9

Kx Ky Kz Ss Por

4.31379e+00 4.31379e+00 4.31379e-01 1.00000e-09 2.12000e-01

4.31379e+00 4.31379e+00 4.31379e-01 1.00000e-09 2.12000e-01

4.31379e+00 4.31379e+00 4.31379e-01 1.00000e-09 2.12000e-01

4.31379e+00 4.31379e+00 4.31379e-01 1.00000e-09 2.12000e-01

$4.31379 \mathrm{e}+00$ 4.31379e+00 4.31379e-01 1.00000e-09 2.12000e-01

$1.00000 \mathrm{e}-02$ 1.00000e-02 1.00000e-03 1.00000e-09 1.00000e-01

$1.00000 \mathrm{e}+001.00000 \mathrm{e}+001.00000 \mathrm{e}-011.00000 \mathrm{e}-091.00000 \mathrm{e}-01$

$1.00000 \mathrm{e}-05$ 1.00000e-05 1.00000e-06 1.00000e-09 1.00000e-01

$1.00000 \mathrm{e}+001.00000 \mathrm{e}+001.00000 \mathrm{e}-011.00000 \mathrm{e}-091.00000 \mathrm{e}-01$

Element: 8737 \# of layers: 9

$\mathrm{Kx} \mathrm{Ky} \mathrm{Kz}$ Ss Por

$1.83559 \mathrm{e}+01$ 1.83559e+01 1.83559e+00 1.00000e-09 2.12000e-01

$1.83559 \mathrm{e}+011.83559 \mathrm{e}+011.83559 \mathrm{e}+001.00000 \mathrm{e}-092.12000 \mathrm{e}-01$

$1.83559 \mathrm{e}+011.83559 \mathrm{e}+01$ 1.83559e+00 1.00000e-09 2.12000e-01

$1.83559 \mathrm{e}+01$ 1.83559e+01 1.83559e+00 1.00000e-09 2.12000e-01

$1.83559 \mathrm{e}+01$ 1.83559e+01 1.83559e+00 1.00000e-09 2.12000e-01

$1.00000 \mathrm{e}-02$ 1.00000e-02 1.00000e-03 1.00000e-09 1.00000e-01

$1.00000 \mathrm{e}+001.00000 \mathrm{e}+001.00000 \mathrm{e}-011.00000 \mathrm{e}-091.00000 \mathrm{e}-01$

$1.00000 \mathrm{e}-05$ 1.00000e-05 1.00000e-06 1.00000e-09 1.00000e-01

$1.00000 \mathrm{e}+001.00000 \mathrm{e}+001.00000 \mathrm{e}-01$ 1.00000e-09 1.00000e-01

Element: 8738 \# of layers: 9

Kx Ky Kz Ss Por

$1.83559 \mathrm{e}+01$ 1.83559e+01 1.83559e+00 1.00000e-09 2.12000e-01

$1.83559 \mathrm{e}+01$ 1.83559e+01 1.83559e+00 1.00000e-09 2.12000e-01

$1.83559 \mathrm{e}+011.83559 \mathrm{e}+01$ 1.83559e+00 1.00000e-09 2.12000e-01

$1.83559 \mathrm{e}+01$ 1.83559e+01 1.83559e+00 1.00000e-09 2.12000e-01

$1.83559 \mathrm{e}+01$ 1.83559e+01 1.83559e+00 1.00000e-09 2.12000e-01

$1.00000 \mathrm{e}-02$ 1.00000e-02 1.00000e-03 1.00000e-09 1.00000e-01

$1.00000 \mathrm{e}+001.00000 \mathrm{e}+001.00000 \mathrm{e}-011.00000 \mathrm{e}-091.00000 \mathrm{e}-01$

$1.00000 \mathrm{e}-05$ 1.00000e-05 1.00000e-06 1.00000e-09 1.00000e-01

$1.00000 \mathrm{e}+001.00000 \mathrm{e}+001.00000 \mathrm{e}-011.00000 \mathrm{e}-091.00000 \mathrm{e}-01$

Element: 8739 \# of layers: 9

Kx Ky Kz Ss Por

$1.83559 \mathrm{e}+01$ 1.83559e+01 1.83559e+00 1.00000e-09 2.12000e-01

$1.83559 \mathrm{e}+011.83559 \mathrm{e}+011.83559 \mathrm{e}+001.00000 \mathrm{e}-092.12000 \mathrm{e}-01$

$1.83559 \mathrm{e}+01$ 1.83559e+01 1.83559e+00 1.00000e-09 2.12000e-01

$1.83559 \mathrm{e}+011.83559 \mathrm{e}+011.83559 \mathrm{e}+001.00000 \mathrm{e}-092.12000 \mathrm{e}-01$

$1.83559 \mathrm{e}+01$ 1.83559e+01 1.83559e+00 1.00000e-09 2.12000e-01

$1.00000 \mathrm{e}-02$ 1.00000e-02 1.00000e-03 1.00000e-09 1.00000e-01

$1.00000 \mathrm{e}+001.00000 \mathrm{e}+001.00000 \mathrm{e}-011.00000 \mathrm{e}-091.00000 \mathrm{e}-01$

$1.00000 \mathrm{e}-051.00000 \mathrm{e}-051.00000 \mathrm{e}-061.00000 \mathrm{e}-091.00000 \mathrm{e}-01$

$1.00000 \mathrm{e}+001.00000 \mathrm{e}+001.00000 \mathrm{e}-01$ 1.00000e-09 1.00000e-01

Element: 8740 \# of layers: 9 
$\mathrm{Kx} \mathrm{Ky} \mathrm{Kz}$ Ss Por

$2.66698 \mathrm{e}+012.66698 \mathrm{e}+012.66698 \mathrm{e}+00$ 1.00000e-09 2.12000e-01

$2.66698 \mathrm{e}+012.66698 \mathrm{e}+012.66698 \mathrm{e}+001.00000 \mathrm{e}-092.12000 \mathrm{e}-01$

$2.66698 \mathrm{e}+012.66698 \mathrm{e}+012.66698 \mathrm{e}+001.00000 \mathrm{e}-092.12000 \mathrm{e}-01$

$2.66698 \mathrm{e}+012.66698 \mathrm{e}+012.66698 \mathrm{e}+001.00000 \mathrm{e}-092.12000 \mathrm{e}-01$

$2.66698 \mathrm{e}+012.66698 \mathrm{e}+012.66698 \mathrm{e}+00$ 1.00000e-09 2.12000e-01

$1.00000 \mathrm{e}-021.00000 \mathrm{e}-021.00000 \mathrm{e}-031.00000 \mathrm{e}-091.00000 \mathrm{e}-01$

$1.00000 \mathrm{e}+001.00000 \mathrm{e}+001.00000 \mathrm{e}-011.00000 \mathrm{e}-091.00000 \mathrm{e}-01$

$1.00000 \mathrm{e}-05$ 1.00000e-05 1.00000e-06 1.00000e-09 1.00000e-01

$1.00000 \mathrm{e}+001.00000 \mathrm{e}+001.00000 \mathrm{e}-011.00000 \mathrm{e}-091.00000 \mathrm{e}-01$

Element: 8741 \# of layers: 9

Kx Ky Kz Ss Por

$2.66698 \mathrm{e}+012.66698 \mathrm{e}+012.66698 \mathrm{e}+00$ 1.00000e-09 2.12000e-01

$2.66698 \mathrm{e}+012.66698 \mathrm{e}+012.66698 \mathrm{e}+001.00000 \mathrm{e}-092.12000 \mathrm{e}-01$

$2.66698 \mathrm{e}+012.66698 \mathrm{e}+012.66698 \mathrm{e}+00$ 1.00000e-09 2.12000e-01

$2.66698 \mathrm{e}+012.66698 \mathrm{e}+012.66698 \mathrm{e}+001.00000 \mathrm{e}-092.12000 \mathrm{e}-01$

$2.66698 \mathrm{e}+012.66698 \mathrm{e}+012.66698 \mathrm{e}+00$ 1.00000e-09 2.12000e-01

$1.00000 \mathrm{e}-02$ 1.00000e-02 1.00000e-03 1.00000e-09 1.00000e-01

$1.00000 \mathrm{e}+001.00000 \mathrm{e}+001.00000 \mathrm{e}-011.00000 \mathrm{e}-091.00000 \mathrm{e}-01$

$1.00000 \mathrm{e}-05$ 1.00000e-05 1.00000e-06 1.00000e-09 1.00000e-01

$1.00000 \mathrm{e}+001.00000 \mathrm{e}+001.00000 \mathrm{e}-011.00000 \mathrm{e}-091.00000 \mathrm{e}-01$

Element: 8742 \# of layers: 9

$\mathrm{Kx} \mathrm{Ky} \mathrm{Kz}$ Ss Por

$2.34005 \mathrm{e}+012.34005 \mathrm{e}+012.34005 \mathrm{e}+00$ 1.00000e-09 2.12000e-01

$2.34005 \mathrm{e}+012.34005 \mathrm{e}+012.34005 \mathrm{e}+001.00000 \mathrm{e}-092.12000 \mathrm{e}-01$

$2.34005 \mathrm{e}+012.34005 \mathrm{e}+012.34005 \mathrm{e}+00$ 1.00000e-09 2.12000e-01

$2.34005 \mathrm{e}+012.34005 \mathrm{e}+012.34005 \mathrm{e}+00$ 1.00000e-09 2.12000e-01

$2.34005 \mathrm{e}+012.34005 \mathrm{e}+012.34005 \mathrm{e}+001.00000 \mathrm{e}-092.12000 \mathrm{e}-01$

$1.00000 \mathrm{e}-02$ 1.00000e-02 1.00000e-03 1.00000e-09 1.00000e-01

$1.00000 \mathrm{e}+001.00000 \mathrm{e}+001.00000 \mathrm{e}-011.00000 \mathrm{e}-091.00000 \mathrm{e}-01$

$1.00000 \mathrm{e}-05$ 1.00000e-05 1.00000e-06 1.00000e-09 1.00000e-01

$1.00000 \mathrm{e}+001.00000 \mathrm{e}+001.00000 \mathrm{e}-011.00000 \mathrm{e}-091.00000 \mathrm{e}-01$

Element: 8743 \# of layers: 9

$\mathrm{Kx} \mathrm{Ky} \mathrm{Kz}$ Ss Por

4.31379e+00 4.31379e+00 4.31379e-01 1.00000e-09 2.12000e-01

4.31379e+00 4.31379e+00 4.31379e-01 1.00000e-09 2.12000e-01

4.31379e+00 4.31379e+00 4.31379e-01 1.00000e-09 2.12000e-01

4.31379e+00 4.31379e+00 4.31379e-01 1.00000e-09 2.12000e-01

4.31379e+00 4.31379e+00 4.31379e-01 1.00000e-09 2.12000e-01

$1.00000 \mathrm{e}-02$ 1.00000e-02 1.00000e-03 1.00000e-09 1.00000e-01

$1.00000 \mathrm{e}+001.00000 \mathrm{e}+001.00000 \mathrm{e}-011.00000 \mathrm{e}-091.00000 \mathrm{e}-01$

$1.00000 \mathrm{e}-05$ 1.00000e-05 1.00000e-06 1.00000e-09 1.00000e-01

$1.00000 \mathrm{e}+001.00000 \mathrm{e}+001.00000 \mathrm{e}-011.00000 \mathrm{e}-091.00000 \mathrm{e}-01$

Element: 8744 \# of layers: 9

$\mathrm{Kx} \mathrm{Ky} \mathrm{Kz}$ Ss Por

$1.83559 \mathrm{e}+01$ 1.83559e+01 1.83559e+00 1.00000e-09 2.12000e-01 
$1.83559 \mathrm{e}+01$ 1.83559e+01 1.83559e+00 1.00000e-09 2.12000e-01 $1.83559 \mathrm{e}+01$ 1.83559e+01 1.83559e+00 1.00000e-09 2.12000e-01 $1.83559 \mathrm{e}+01$ 1.83559e+01 1.83559e+00 1.00000e-09 2.12000e-01 $1.83559 \mathrm{e}+011.83559 \mathrm{e}+01 \quad 1.83559 \mathrm{e}+001.00000 \mathrm{e}-092.12000 \mathrm{e}-01$ $1.00000 \mathrm{e}-02$ 1.00000e-02 1.00000e-03 1.00000e-09 1.00000e-01 $1.00000 \mathrm{e}+001.00000 \mathrm{e}+001.00000 \mathrm{e}-011.00000 \mathrm{e}-091.00000 \mathrm{e}-01$ 1.00000e-05 1.00000e-05 1.00000e-06 1.00000e-09 1.00000e-01 $1.00000 \mathrm{e}+001.00000 \mathrm{e}+001.00000 \mathrm{e}-011.00000 \mathrm{e}-091.00000 \mathrm{e}-01$ Element: 8745 \# of layers: 9

$\mathrm{Kx} \mathrm{Ky} \mathrm{Kz}$ Ss Por

$4.60000 \mathrm{e}+014.60000 \mathrm{e}+014.60000 \mathrm{e}+001.00000 \mathrm{e}-09$ 2.12000e-01 $4.60000 \mathrm{e}+014.60000 \mathrm{e}+014.60000 \mathrm{e}+001.00000 \mathrm{e}-092.12000 \mathrm{e}-01$ $4.60000 \mathrm{e}+014.60000 \mathrm{e}+014.60000 \mathrm{e}+001.00000 \mathrm{e}-09$ 2.12000e-01 $4.60000 \mathrm{e}+014.60000 \mathrm{e}+014.60000 \mathrm{e}+001.00000 \mathrm{e}-09$ 2.12000e-01 $4.60000 \mathrm{e}+014.60000 \mathrm{e}+014.60000 \mathrm{e}+001.00000 \mathrm{e}-092.12000 \mathrm{e}-01$ $1.00000 \mathrm{e}-02$ 1.00000e-02 1.00000e-03 1.00000e-09 1.00000e-01 $1.00000 \mathrm{e}+001.00000 \mathrm{e}+001.00000 \mathrm{e}-011.00000 \mathrm{e}-091.00000 \mathrm{e}-01$ $1.00000 \mathrm{e}-05$ 1.00000e-05 1.00000e-06 1.00000e-09 1.00000e-01 $1.00000 \mathrm{e}+001.00000 \mathrm{e}+001.00000 \mathrm{e}-011.00000 \mathrm{e}-091.00000 \mathrm{e}-01$ Element: 8746 \# of layers: 9

$\mathrm{Kx} \mathrm{Ky} \mathrm{Kz}$ Ss Por

$4.60000 \mathrm{e}+014.60000 \mathrm{e}+014.60000 \mathrm{e}+001.00000 \mathrm{e}-09$ 2.12000e-01 $4.60000 \mathrm{e}+014.60000 \mathrm{e}+014.60000 \mathrm{e}+001.00000 \mathrm{e}-092.12000 \mathrm{e}-01$ $4.60000 \mathrm{e}+014.60000 \mathrm{e}+014.60000 \mathrm{e}+001.00000 \mathrm{e}-092.12000 \mathrm{e}-01$ $4.60000 \mathrm{e}+014.60000 \mathrm{e}+014.60000 \mathrm{e}+001.00000 \mathrm{e}-092.12000 \mathrm{e}-01$ $4.60000 \mathrm{e}+014.60000 \mathrm{e}+014.60000 \mathrm{e}+001.00000 \mathrm{e}-092.12000 \mathrm{e}-01$ $1.00000 \mathrm{e}-02$ 1.00000e-02 1.00000e-03 1.00000e-09 1.00000e-01 $1.00000 \mathrm{e}+001.00000 \mathrm{e}+001.00000 \mathrm{e}-011.00000 \mathrm{e}-091.00000 \mathrm{e}-01$ $1.00000 \mathrm{e}-05$ 1.00000e-05 1.00000e-06 1.00000e-09 1.00000e-01 $1.00000 \mathrm{e}+001.00000 \mathrm{e}+001.00000 \mathrm{e}-011.00000 \mathrm{e}-091.00000 \mathrm{e}-01$ Element: 8747 \# of layers: 9

$\mathrm{Kx} \mathrm{Ky} \mathrm{Kz}$ Ss Por

$4.60000 \mathrm{e}+014.60000 \mathrm{e}+014.60000 \mathrm{e}+00$ 1.00000e-09 2.12000e-01 $4.60000 \mathrm{e}+014.60000 \mathrm{e}+014.60000 \mathrm{e}+001.00000 \mathrm{e}-092.12000 \mathrm{e}-01$ $4.60000 \mathrm{e}+014.60000 \mathrm{e}+014.60000 \mathrm{e}+001.00000 \mathrm{e}-09$ 2.12000e-01 $4.60000 \mathrm{e}+014.60000 \mathrm{e}+014.60000 \mathrm{e}+001.00000 \mathrm{e}-09$ 2.12000e-01 $4.60000 \mathrm{e}+014.60000 \mathrm{e}+014.60000 \mathrm{e}+001.00000 \mathrm{e}-092.12000 \mathrm{e}-01$ $1.00000 \mathrm{e}-02$ 1.00000e-02 1.00000e-03 1.00000e-09 1.00000e-01 $1.00000 \mathrm{e}+001.00000 \mathrm{e}+001.00000 \mathrm{e}-011.00000 \mathrm{e}-091.00000 \mathrm{e}-01$ $1.00000 \mathrm{e}-05$ 1.00000e-05 1.00000e-06 1.00000e-09 1.00000e-01 $1.00000 \mathrm{e}+001.00000 \mathrm{e}+001.00000 \mathrm{e}-011.00000 \mathrm{e}-091.00000 \mathrm{e}-01$ Element: 8748 \# of layers: 9

$\mathrm{Kx} \mathrm{Ky} \mathrm{Kz}$ Ss Por 4.60000e+01 4.60000e+01 4.60000e+00 1.00000e-09 2.12000e-01 $4.60000 \mathrm{e}+014.60000 \mathrm{e}+014.60000 \mathrm{e}+001.00000 \mathrm{e}-092.12000 \mathrm{e}-01$ $4.60000 \mathrm{e}+014.60000 \mathrm{e}+014.60000 \mathrm{e}+001.00000 \mathrm{e}-092.12000 \mathrm{e}-01$ 
$4.60000 \mathrm{e}+014.60000 \mathrm{e}+014.60000 \mathrm{e}+00$ 1.00000e-09 2.12000e-01 $4.60000 \mathrm{e}+014.60000 \mathrm{e}+014.60000 \mathrm{e}+00$ 1.00000e-09 2.12000e-01 $1.00000 \mathrm{e}-02$ 1.00000e-02 1.00000e-03 1.00000e-09 1.00000e-01 $1.00000 \mathrm{e}+001.00000 \mathrm{e}+001.00000 \mathrm{e}-011.00000 \mathrm{e}-091.00000 \mathrm{e}-01$ $1.00000 \mathrm{e}-05$ 1.00000e-05 1.00000e-06 1.00000e-09 1.00000e-01 $1.00000 \mathrm{e}+001.00000 \mathrm{e}+001.00000 \mathrm{e}-011.00000 \mathrm{e}-091.00000 \mathrm{e}-01$ Element: 8749 \# of layers: 9

Kx Ky Kz Ss Por $5.42689 \mathrm{e}+015.42689 \mathrm{e}+015.42689 \mathrm{e}+001.00000 \mathrm{e}-092.12000 \mathrm{e}-01$ $5.42689 \mathrm{e}+015.42689 \mathrm{e}+015.42689 \mathrm{e}+00$ 1.00000e-09 2.12000e-01 $5.42689 \mathrm{e}+015.42689 \mathrm{e}+015.42689 \mathrm{e}+00$ 1.00000e-09 2.12000e-01 $5.42689 \mathrm{e}+01$ 5.42689e+01 5.42689e+00 1.00000e-09 2.12000e-01 $5.42689 \mathrm{e}+015.42689 \mathrm{e}+015.42689 \mathrm{e}+001.00000 \mathrm{e}-09$ 2.12000e-01 $1.00000 \mathrm{e}-02$ 1.00000e-02 1.00000e-03 1.00000e-09 1.00000e-01 $1.00000 \mathrm{e}+001.00000 \mathrm{e}+001.00000 \mathrm{e}-011.00000 \mathrm{e}-091.00000 \mathrm{e}-01$ $1.00000 \mathrm{e}-05$ 1.00000e-05 1.00000e-06 1.00000e-09 1.00000e-01 $1.00000 \mathrm{e}+001.00000 \mathrm{e}+001.00000 \mathrm{e}-011.00000 \mathrm{e}-091.00000 \mathrm{e}-01$ Element: 8750 \# of layers: 9

$\mathrm{Kx} \mathrm{Ky} \mathrm{Kz}$ Ss Por

$5.42689 \mathrm{e}+015.42689 \mathrm{e}+015.42689 \mathrm{e}+00$ 1.00000e-09 2.12000e-01 $5.42689 \mathrm{e}+015.42689 \mathrm{e}+015.42689 \mathrm{e}+001.00000 \mathrm{e}-092.12000 \mathrm{e}-01$ $5.42689 \mathrm{e}+01$ 5.42689e+01 5.42689e+00 1.00000e-09 2.12000e-01 $5.42689 \mathrm{e}+015.42689 \mathrm{e}+015.42689 \mathrm{e}+00$ 1.00000e-09 2.12000e-01 $5.42689 \mathrm{e}+015.42689 \mathrm{e}+015.42689 \mathrm{e}+00$ 1.00000e-09 2.12000e-01 $1.00000 \mathrm{e}-021.00000 \mathrm{e}-02$ 1.00000e-03 1.00000e-09 1.00000e-01 $1.00000 \mathrm{e}+001.00000 \mathrm{e}+001.00000 \mathrm{e}-011.00000 \mathrm{e}-091.00000 \mathrm{e}-01$ $1.00000 \mathrm{e}-05$ 1.00000e-05 1.00000e-06 1.00000e-09 1.00000e-01 $1.00000 \mathrm{e}+001.00000 \mathrm{e}+001.00000 \mathrm{e}-011.00000 \mathrm{e}-091.00000 \mathrm{e}-01$ Element: 8751 \# of layers: 9

$\mathrm{Kx} \mathrm{Ky} \mathrm{Kz}$ Ss Por

$4.60000 \mathrm{e}+014.60000 \mathrm{e}+014.60000 \mathrm{e}+001.00000 \mathrm{e}-092.12000 \mathrm{e}-01$ $4.60000 \mathrm{e}+014.60000 \mathrm{e}+014.60000 \mathrm{e}+00$ 1.00000e-09 2.12000e-01 $4.60000 \mathrm{e}+014.60000 \mathrm{e}+014.60000 \mathrm{e}+001.00000 \mathrm{e}-09$ 2.12000e-01 $4.60000 \mathrm{e}+014.60000 \mathrm{e}+014.60000 \mathrm{e}+001.00000 \mathrm{e}-092.12000 \mathrm{e}-01$ $4.60000 \mathrm{e}+014.60000 \mathrm{e}+014.60000 \mathrm{e}+00$ 1.00000e-09 2.12000e-01 1.00000e-02 1.00000e-02 1.00000e-03 1.00000e-09 1.00000e-01 $1.00000 \mathrm{e}+001.00000 \mathrm{e}+001.00000 \mathrm{e}-011.00000 \mathrm{e}-091.00000 \mathrm{e}-01$ $1.00000 \mathrm{e}-05$ 1.00000e-05 1.00000e-06 1.00000e-09 1.00000e-01 $1.00000 \mathrm{e}+001.00000 \mathrm{e}+001.00000 \mathrm{e}-011.00000 \mathrm{e}-091.00000 \mathrm{e}-01$ Element: 8752 \# of layers: 9

$\mathrm{Kx} \mathrm{Ky} \mathrm{Kz}$ Ss Por 5.42689e+01 5.42689e+01 5.42689e+00 1.00000e-09 2.12000e-01 $5.42689 \mathrm{e}+015.42689 \mathrm{e}+015.42689 \mathrm{e}+001.00000 \mathrm{e}-092.12000 \mathrm{e}-01$ 5.42689e+01 5.42689e+01 5.42689e+00 1.00000e-09 2.12000e-01 $5.42689 \mathrm{e}+015.42689 \mathrm{e}+015.42689 \mathrm{e}+001.00000 \mathrm{e}-09$ 2.12000e-01 $5.42689 \mathrm{e}+015.42689 \mathrm{e}+015.42689 \mathrm{e}+001.00000 \mathrm{e}-092.12000 \mathrm{e}-01$ 
$1.00000 \mathrm{e}-02$ 1.00000e-02 1.00000e-03 1.00000e-09 1.00000e-01 $1.00000 \mathrm{e}+001.00000 \mathrm{e}+001.00000 \mathrm{e}-011.00000 \mathrm{e}-091.00000 \mathrm{e}-01$ $1.00000 \mathrm{e}-05$ 1.00000e-05 1.00000e-06 1.00000e-09 1.00000e-01 $1.00000 \mathrm{e}+001.00000 \mathrm{e}+001.00000 \mathrm{e}-011.00000 \mathrm{e}-091.00000 \mathrm{e}-01$ Element: 8753 \# of layers: 9

Kx Ky Kz Ss Por

$5.42689 \mathrm{e}+015.42689 \mathrm{e}+01$ 5.42689e+00 1.00000e-09 2.12000e-01 $5.42689 \mathrm{e}+015.42689 \mathrm{e}+015.42689 \mathrm{e}+001.00000 \mathrm{e}-092.12000 \mathrm{e}-01$ $5.42689 \mathrm{e}+015.42689 \mathrm{e}+015.42689 \mathrm{e}+001.00000 \mathrm{e}-092.12000 \mathrm{e}-01$ $5.42689 \mathrm{e}+015.42689 \mathrm{e}+015.42689 \mathrm{e}+001.00000 \mathrm{e}-092.12000 \mathrm{e}-01$ $5.42689 \mathrm{e}+015.42689 \mathrm{e}+015.42689 \mathrm{e}+001.00000 \mathrm{e}-092.12000 \mathrm{e}-01$ $1.00000 \mathrm{e}-021.00000 \mathrm{e}-02$ 1.00000e-03 1.00000e-09 1.00000e-01 $1.00000 \mathrm{e}+001.00000 \mathrm{e}+001.00000 \mathrm{e}-011.00000 \mathrm{e}-091.00000 \mathrm{e}-01$ $1.00000 \mathrm{e}-05$ 1.00000e-05 1.00000e-06 1.00000e-09 1.00000e-01 $1.00000 \mathrm{e}+001.00000 \mathrm{e}+001.00000 \mathrm{e}-011.00000 \mathrm{e}-091.00000 \mathrm{e}-01$ Element: 8754 \# of layers: 9

Kx Ky Kz Ss Por

$5.42689 \mathrm{e}+015.42689 \mathrm{e}+01$ 5.42689e+00 1.00000e-09 2.12000e-01 $5.42689 \mathrm{e}+015.42689 \mathrm{e}+015.42689 \mathrm{e}+001.00000 \mathrm{e}-092.12000 \mathrm{e}-01$ $5.42689 \mathrm{e}+015.42689 \mathrm{e}+015.42689 \mathrm{e}+001.00000 \mathrm{e}-092.12000 \mathrm{e}-01$ $5.42689 \mathrm{e}+015.42689 \mathrm{e}+015.42689 \mathrm{e}+001.00000 \mathrm{e}-092.12000 \mathrm{e}-01$ $5.42689 \mathrm{e}+015.42689 \mathrm{e}+015.42689 \mathrm{e}+00$ 1.00000e-09 2.12000e-01 $1.00000 \mathrm{e}-02$ 1.00000e-02 1.00000e-03 1.00000e-09 1.00000e-01 $1.00000 \mathrm{e}+001.00000 \mathrm{e}+001.00000 \mathrm{e}-011.00000 \mathrm{e}-091.00000 \mathrm{e}-01$ $1.00000 \mathrm{e}-05$ 1.00000e-05 1.00000e-06 1.00000e-09 1.00000e-01 $1.00000 \mathrm{e}+001.00000 \mathrm{e}+001.00000 \mathrm{e}-011.00000 \mathrm{e}-091.00000 \mathrm{e}-01$ Element: 8755 \# of layers: 9

Kx Ky Kz Ss Por

$5.42689 \mathrm{e}+015.42689 \mathrm{e}+015.42689 \mathrm{e}+00$ 1.00000e-09 2.12000e-01 $5.42689 \mathrm{e}+015.42689 \mathrm{e}+015.42689 \mathrm{e}+001.00000 \mathrm{e}-092.12000 \mathrm{e}-01$ $5.42689 \mathrm{e}+015.42689 \mathrm{e}+015.42689 \mathrm{e}+001.00000 \mathrm{e}-092.12000 \mathrm{e}-01$ $5.42689 \mathrm{e}+015.42689 \mathrm{e}+015.42689 \mathrm{e}+001.00000 \mathrm{e}-092.12000 \mathrm{e}-01$ $5.42689 \mathrm{e}+015.42689 \mathrm{e}+015.42689 \mathrm{e}+00$ 1.00000e-09 2.12000e-01 $1.00000 \mathrm{e}-021.00000 \mathrm{e}-02$ 1.00000e-03 1.00000e-09 1.00000e-01 $1.00000 \mathrm{e}+001.00000 \mathrm{e}+001.00000 \mathrm{e}-011.00000 \mathrm{e}-091.00000 \mathrm{e}-01$ $1.00000 \mathrm{e}-05$ 1.00000e-05 1.00000e-06 1.00000e-09 1.00000e-01 $1.00000 \mathrm{e}+001.00000 \mathrm{e}+001.00000 \mathrm{e}-011.00000 \mathrm{e}-091.00000 \mathrm{e}-01$ Element: 8756 \# of layers: 9

Kx Ky Kz Ss Por

$5.42689 \mathrm{e}+015.42689 \mathrm{e}+015.42689 \mathrm{e}+00$ 1.00000e-09 2.12000e-01 $5.42689 \mathrm{e}+015.42689 \mathrm{e}+015.42689 \mathrm{e}+001.00000 \mathrm{e}-092.12000 \mathrm{e}-01$ $5.42689 \mathrm{e}+015.42689 \mathrm{e}+015.42689 \mathrm{e}+001.00000 \mathrm{e}-092.12000 \mathrm{e}-01$ $5.42689 \mathrm{e}+015.42689 \mathrm{e}+015.42689 \mathrm{e}+001.00000 \mathrm{e}-092.12000 \mathrm{e}-01$ $5.42689 \mathrm{e}+015.42689 \mathrm{e}+015.42689 \mathrm{e}+00$ 1.00000e-09 2.12000e-01 $1.00000 \mathrm{e}-021.00000 \mathrm{e}-02$ 1.00000e-03 1.00000e-09 1.00000e-01 $1.00000 \mathrm{e}+001.00000 \mathrm{e}+001.00000 \mathrm{e}-011.00000 \mathrm{e}-091.00000 \mathrm{e}-01$ 
$1.00000 \mathrm{e}-05$ 1.00000e-05 1.00000e-06 1.00000e-09 1.00000e-01 $1.00000 \mathrm{e}+001.00000 \mathrm{e}+001.00000 \mathrm{e}-01$ 1.00000e-09 1.00000e-01 Element: 8757 \# of layers: 9

Kx Ky Kz Ss Por

$5.42689 \mathrm{e}+015.42689 \mathrm{e}+015.42689 \mathrm{e}+00$ 1.00000e-09 2.12000e-01

$5.42689 \mathrm{e}+015.42689 \mathrm{e}+015.42689 \mathrm{e}+00$ 1.00000e-09 2.12000e-01

$5.42689 \mathrm{e}+015.42689 \mathrm{e}+015.42689 \mathrm{e}+001.00000 \mathrm{e}-09$ 2.12000e-01

$5.42689 \mathrm{e}+015.42689 \mathrm{e}+015.42689 \mathrm{e}+001.00000 \mathrm{e}-092.12000 \mathrm{e}-01$

$5.42689 \mathrm{e}+015.42689 \mathrm{e}+015.42689 \mathrm{e}+001.00000 \mathrm{e}-092.12000 \mathrm{e}-01$

$1.00000 \mathrm{e}-02$ 1.00000e-02 1.00000e-03 1.00000e-09 1.00000e-01

$1.00000 \mathrm{e}+001.00000 \mathrm{e}+001.00000 \mathrm{e}-011.00000 \mathrm{e}-091.00000 \mathrm{e}-01$

$1.00000 \mathrm{e}-05$ 1.00000e-05 1.00000e-06 1.00000e-09 1.00000e-01

$1.00000 \mathrm{e}+001.00000 \mathrm{e}+001.00000 \mathrm{e}-011.00000 \mathrm{e}-091.00000 \mathrm{e}-01$

Element: 8758 \# of layers: 9

$\mathrm{Kx} \mathrm{Ky} \mathrm{Kz}$ Ss Por

$5.42689 \mathrm{e}+015.42689 \mathrm{e}+015.42689 \mathrm{e}+00$ 1.00000e-09 2.12000e-01

$5.42689 \mathrm{e}+015.42689 \mathrm{e}+015.42689 \mathrm{e}+001.00000 \mathrm{e}-092.12000 \mathrm{e}-01$

$5.42689 \mathrm{e}+015.42689 \mathrm{e}+015.42689 \mathrm{e}+001.00000 \mathrm{e}-092.12000 \mathrm{e}-01$

$5.42689 \mathrm{e}+015.42689 \mathrm{e}+015.42689 \mathrm{e}+001.00000 \mathrm{e}-092.12000 \mathrm{e}-01$

$5.42689 \mathrm{e}+015.42689 \mathrm{e}+015.42689 \mathrm{e}+001.00000 \mathrm{e}-092.12000 \mathrm{e}-01$

$1.00000 \mathrm{e}-021.00000 \mathrm{e}-02$ 1.00000e-03 1.00000e-09 1.00000e-01

$1.00000 \mathrm{e}+001.00000 \mathrm{e}+001.00000 \mathrm{e}-011.00000 \mathrm{e}-091.00000 \mathrm{e}-01$

$1.00000 \mathrm{e}-05$ 1.00000e-05 1.00000e-06 1.00000e-09 1.00000e-01

$1.00000 \mathrm{e}+001.00000 \mathrm{e}+001.00000 \mathrm{e}-011.00000 \mathrm{e}-091.00000 \mathrm{e}-01$

Element: 8759 \# of layers: 8

$\mathrm{Kx} \mathrm{Ky} \mathrm{Kz}$ Ss Por

$5.91740 \mathrm{e}+015.91740 \mathrm{e}+015.91740 \mathrm{e}+001.00000 \mathrm{e}-092.12000 \mathrm{e}-01$

$5.91740 \mathrm{e}+015.91740 \mathrm{e}+015.91740 \mathrm{e}+001.00000 \mathrm{e}-092.12000 \mathrm{e}-01$

$5.91740 \mathrm{e}+015.91740 \mathrm{e}+015.91740 \mathrm{e}+001.00000 \mathrm{e}-092.12000 \mathrm{e}-01$

$5.91740 \mathrm{e}+015.91740 \mathrm{e}+015.91740 \mathrm{e}+001.00000 \mathrm{e}-092.12000 \mathrm{e}-01$

$1.00000 \mathrm{e}-02$ 1.00000e-02 1.00000e-03 1.00000e-09 1.00000e-01

$1.00000 \mathrm{e}+001.00000 \mathrm{e}+001.00000 \mathrm{e}-011.00000 \mathrm{e}-091.00000 \mathrm{e}-01$

1.00000e-05 1.00000e-05 1.00000e-06 1.00000e-09 1.00000e-01

$1.00000 \mathrm{e}+001.00000 \mathrm{e}+001.00000 \mathrm{e}-011.00000 \mathrm{e}-091.00000 \mathrm{e}-01$

Element: 8760 \# of layers: 8

Kx Ky Kz Ss Por

5.91740e+01 5.91740e+01 5.91740e+00 1.00000e-09 2.12000e-01

$5.91740 \mathrm{e}+015.91740 \mathrm{e}+015.91740 \mathrm{e}+001.00000 \mathrm{e}-092.12000 \mathrm{e}-01$

$5.91740 \mathrm{e}+015.91740 \mathrm{e}+015.91740 \mathrm{e}+001.00000 \mathrm{e}-092.12000 \mathrm{e}-01$

$5.91740 \mathrm{e}+015.91740 \mathrm{e}+015.91740 \mathrm{e}+001.00000 \mathrm{e}-092.12000 \mathrm{e}-01$ 1.00000e-02 1.00000e-02 1.00000e-03 1.00000e-09 1.00000e-01

$1.00000 \mathrm{e}+001.00000 \mathrm{e}+001.00000 \mathrm{e}-011.00000 \mathrm{e}-091.00000 \mathrm{e}-01$ $1.00000 \mathrm{e}-05$ 1.00000e-05 1.00000e-06 1.00000e-09 1.00000e-01

$1.00000 \mathrm{e}+001.00000 \mathrm{e}+001.00000 \mathrm{e}-01$ 1.00000e-09 1.00000e-01

Element: 8761 \# of layers: 8

Kx Ky Kz Ss Por 
5.91740e+01 5.91740e+01 5.91740e+00 1.00000e-09 2.12000e-01 $5.91740 \mathrm{e}+015.91740 \mathrm{e}+015.91740 \mathrm{e}+001.00000 \mathrm{e}-092.12000 \mathrm{e}-01$ $5.91740 \mathrm{e}+015.91740 \mathrm{e}+015.91740 \mathrm{e}+001.00000 \mathrm{e}-092.12000 \mathrm{e}-01$ $5.91740 \mathrm{e}+015.91740 \mathrm{e}+015.91740 \mathrm{e}+001.00000 \mathrm{e}-092.12000 \mathrm{e}-01$ $1.00000 \mathrm{e}-02$ 1.00000e-02 1.00000e-03 1.00000e-09 1.00000e-01 $1.00000 \mathrm{e}+001.00000 \mathrm{e}+001.00000 \mathrm{e}-011.00000 \mathrm{e}-091.00000 \mathrm{e}-01$ $1.00000 \mathrm{e}-05$ 1.00000e-05 1.00000e-06 1.00000e-09 1.00000e-01 $1.00000 \mathrm{e}+001.00000 \mathrm{e}+001.00000 \mathrm{e}-01$ 1.00000e-09 1.00000e-01 Element: 8762 \# of layers: 8

$\mathrm{Kx} \mathrm{Ky} \mathrm{Kz}$ Ss Por

5.42689e+01 5.42689e+01 5.42689e+00 1.00000e-09 2.12000e-01 $5.42689 \mathrm{e}+015.42689 \mathrm{e}+015.42689 \mathrm{e}+001.00000 \mathrm{e}-092.12000 \mathrm{e}-01$ $5.42689 \mathrm{e}+015.42689 \mathrm{e}+015.42689 \mathrm{e}+001.00000 \mathrm{e}-09$ 2.12000e-01 $5.42689 \mathrm{e}+015.42689 \mathrm{e}+015.42689 \mathrm{e}+001.00000 \mathrm{e}-09$ 2.12000e-01 $1.00000 \mathrm{e}-02$ 1.00000e-02 1.00000e-03 1.00000e-09 1.00000e-01 $1.00000 \mathrm{e}+001.00000 \mathrm{e}+001.00000 \mathrm{e}-011.00000 \mathrm{e}-091.00000 \mathrm{e}-01$ $1.00000 \mathrm{e}-05$ 1.00000e-05 1.00000e-06 1.00000e-09 1.00000e-01 $1.00000 \mathrm{e}+001.00000 \mathrm{e}+001.00000 \mathrm{e}-01$ 1.00000e-09 1.00000e-01 Element: 8763 \# of layers: 9

$\mathrm{Kx} \mathrm{Ky} \mathrm{Kz}$ Ss Por

5.42689e+01 5.42689e+01 5.42689e+00 1.00000e-09 2.12000e-01

$5.42689 \mathrm{e}+01$ 5.42689e+01 5.42689e+00 1.00000e-09 2.12000e-01

$5.42689 \mathrm{e}+015.42689 \mathrm{e}+015.42689 \mathrm{e}+001.00000 \mathrm{e}-092.12000 \mathrm{e}-01$ $5.42689 \mathrm{e}+015.42689 \mathrm{e}+015.42689 \mathrm{e}+001.00000 \mathrm{e}-09$ 2.12000e-01 $5.42689 \mathrm{e}+015.42689 \mathrm{e}+015.42689 \mathrm{e}+001.00000 \mathrm{e}-092.12000 \mathrm{e}-01$ $1.00000 \mathrm{e}-02$ 1.00000e-02 1.00000e-03 1.00000e-09 1.00000e-01 $1.00000 \mathrm{e}+001.00000 \mathrm{e}+001.00000 \mathrm{e}-011.00000 \mathrm{e}-091.00000 \mathrm{e}-01$ $1.00000 \mathrm{e}-05$ 1.00000e-05 1.00000e-06 1.00000e-09 1.00000e-01 $1.00000 \mathrm{e}+001.00000 \mathrm{e}+001.00000 \mathrm{e}-011.00000 \mathrm{e}-091.00000 \mathrm{e}-01$ Element: 8764 \# of layers: 9

$\mathrm{Kx} \mathrm{Ky} \mathrm{Kz}$ Ss Por

5.42689e+01 5.42689e+01 5.42689e+00 1.00000e-09 2.12000e-01 $5.42689 \mathrm{e}+015.42689 \mathrm{e}+015.42689 \mathrm{e}+001.00000 \mathrm{e}-092.12000 \mathrm{e}-01$ $5.42689 \mathrm{e}+015.42689 \mathrm{e}+015.42689 \mathrm{e}+001.00000 \mathrm{e}-092.12000 \mathrm{e}-01$ $5.42689 \mathrm{e}+015.42689 \mathrm{e}+015.42689 \mathrm{e}+001.00000 \mathrm{e}-09$ 2.12000e-01 $5.42689 \mathrm{e}+015.42689 \mathrm{e}+015.42689 \mathrm{e}+001.00000 \mathrm{e}-092.12000 \mathrm{e}-01$ 1.00000e-02 1.00000e-02 1.00000e-03 1.00000e-09 1.00000e-01 $1.00000 \mathrm{e}+001.00000 \mathrm{e}+001.00000 \mathrm{e}-011.00000 \mathrm{e}-091.00000 \mathrm{e}-01$ $1.00000 \mathrm{e}-05$ 1.00000e-05 1.00000e-06 1.00000e-09 1.00000e-01 $1.00000 \mathrm{e}+001.00000 \mathrm{e}+001.00000 \mathrm{e}-01$ 1.00000e-09 1.00000e-01 Element: 8765 \# of layers: 9

$\mathrm{Kx} \mathrm{Ky} \mathrm{Kz}$ Ss Por 5.42689e+01 5.42689e+01 5.42689e+00 1.00000e-09 2.12000e-01 5.42689e+01 5.42689e+01 5.42689e+00 1.00000e-09 2.12000e-01 $5.42689 \mathrm{e}+015.42689 \mathrm{e}+015.42689 \mathrm{e}+001.00000 \mathrm{e}-09$ 2.12000e-01 $5.42689 \mathrm{e}+015.42689 \mathrm{e}+015.42689 \mathrm{e}+001.00000 \mathrm{e}-092.12000 \mathrm{e}-01$ 
$5.42689 \mathrm{e}+01$ 5.42689e+01 5.42689e+00 1.00000e-09 2.12000e-01 $1.00000 \mathrm{e}-02$ 1.00000e-02 1.00000e-03 1.00000e-09 1.00000e-01 $1.00000 \mathrm{e}+001.00000 \mathrm{e}+001.00000 \mathrm{e}-011.00000 \mathrm{e}-091.00000 \mathrm{e}-01$ $1.00000 \mathrm{e}-05$ 1.00000e-05 1.00000e-06 1.00000e-09 1.00000e-01 $1.00000 \mathrm{e}+001.00000 \mathrm{e}+001.00000 \mathrm{e}-011.00000 \mathrm{e}-091.00000 \mathrm{e}-01$ Element: 8766 \# of layers: 8

$\mathrm{Kx} \mathrm{Ky} \mathrm{Kz}$ Ss Por

5.91740e+01 5.91740e+01 5.91740e+00 1.00000e-09 2.12000e-01 $5.91740 \mathrm{e}+015.91740 \mathrm{e}+015.91740 \mathrm{e}+001.00000 \mathrm{e}-092.12000 \mathrm{e}-01$ $5.91740 \mathrm{e}+015.91740 \mathrm{e}+015.91740 \mathrm{e}+001.00000 \mathrm{e}-092.12000 \mathrm{e}-01$ $5.91740 \mathrm{e}+015.91740 \mathrm{e}+015.91740 \mathrm{e}+001.00000 \mathrm{e}-092.12000 \mathrm{e}-01$ 1.00000e-02 1.00000e-02 1.00000e-03 1.00000e-09 1.00000e-01 $1.00000 \mathrm{e}+001.00000 \mathrm{e}+001.00000 \mathrm{e}-011.00000 \mathrm{e}-091.00000 \mathrm{e}-01$ $1.00000 \mathrm{e}-05$ 1.00000e-05 1.00000e-06 1.00000e-09 1.00000e-01 $1.00000 \mathrm{e}+001.00000 \mathrm{e}+001.00000 \mathrm{e}-01$ 1.00000e-09 1.00000e-01 Element: 8767 \# of layers: 8

$\mathrm{Kx} \mathrm{Ky} \mathrm{Kz}$ Ss Por

$5.91740 \mathrm{e}+015.91740 \mathrm{e}+015.91740 \mathrm{e}+001.00000 \mathrm{e}-092.12000 \mathrm{e}-01$ $5.91740 \mathrm{e}+015.91740 \mathrm{e}+015.91740 \mathrm{e}+001.00000 \mathrm{e}-092.12000 \mathrm{e}-01$ $5.91740 \mathrm{e}+015.91740 \mathrm{e}+015.91740 \mathrm{e}+001.00000 \mathrm{e}-092.12000 \mathrm{e}-01$ $5.91740 \mathrm{e}+015.91740 \mathrm{e}+015.91740 \mathrm{e}+001.00000 \mathrm{e}-092.12000 \mathrm{e}-01$ $1.00000 \mathrm{e}-02$ 1.00000e-02 1.00000e-03 1.00000e-09 1.00000e-01 $1.00000 \mathrm{e}+001.00000 \mathrm{e}+001.00000 \mathrm{e}-011.00000 \mathrm{e}-091.00000 \mathrm{e}-01$ $1.00000 \mathrm{e}-05$ 1.00000e-05 1.00000e-06 1.00000e-09 1.00000e-01 $1.00000 \mathrm{e}+001.00000 \mathrm{e}+001.00000 \mathrm{e}-011.00000 \mathrm{e}-091.00000 \mathrm{e}-01$ Element: 8768 \# of layers: 8

$\mathrm{Kx} \mathrm{Ky} \mathrm{Kz}$ Ss Por

$5.91740 \mathrm{e}+01$ 5.91740e+01 5.91740e+00 1.00000e-09 2.12000e-01 $5.91740 \mathrm{e}+015.91740 \mathrm{e}+015.91740 \mathrm{e}+001.00000 \mathrm{e}-092.12000 \mathrm{e}-01$ $5.91740 \mathrm{e}+015.91740 \mathrm{e}+015.91740 \mathrm{e}+001.00000 \mathrm{e}-092.12000 \mathrm{e}-01$ $5.91740 \mathrm{e}+015.91740 \mathrm{e}+015.91740 \mathrm{e}+001.00000 \mathrm{e}-092.12000 \mathrm{e}-01$ $1.00000 \mathrm{e}-02$ 1.00000e-02 1.00000e-03 1.00000e-09 1.00000e-01 $1.00000 \mathrm{e}+001.00000 \mathrm{e}+001.00000 \mathrm{e}-011.00000 \mathrm{e}-091.00000 \mathrm{e}-01$ $1.00000 \mathrm{e}-05$ 1.00000e-05 1.00000e-06 1.00000e-09 1.00000e-01 $1.00000 \mathrm{e}+001.00000 \mathrm{e}+001.00000 \mathrm{e}-011.00000 \mathrm{e}-091.00000 \mathrm{e}-01$ Element: 8769 \# of layers: 8

Kx Ky Kz Ss Por

5.91740e+01 5.91740e+01 5.91740e+00 1.00000e-09 2.12000e-01 $5.91740 \mathrm{e}+015.91740 \mathrm{e}+015.91740 \mathrm{e}+001.00000 \mathrm{e}-092.12000 \mathrm{e}-01$ $5.91740 \mathrm{e}+015.91740 \mathrm{e}+015.91740 \mathrm{e}+001.00000 \mathrm{e}-092.12000 \mathrm{e}-01$ $5.91740 \mathrm{e}+015.91740 \mathrm{e}+015.91740 \mathrm{e}+001.00000 \mathrm{e}-092.12000 \mathrm{e}-01$ $1.00000 \mathrm{e}-02$ 1.00000e-02 1.00000e-03 1.00000e-09 1.00000e-01 $1.00000 \mathrm{e}+001.00000 \mathrm{e}+001.00000 \mathrm{e}-011.00000 \mathrm{e}-091.00000 \mathrm{e}-01$ $1.00000 \mathrm{e}-05$ 1.00000e-05 1.00000e-06 1.00000e-09 1.00000e-01 $1.00000 \mathrm{e}+001.00000 \mathrm{e}+001.00000 \mathrm{e}-011.00000 \mathrm{e}-091.00000 \mathrm{e}-01$ Element: 8770 \# of layers: 8 
Kx Ky Kz Ss Por

5.91740e+01 5.91740e+01 5.91740e+00 1.00000e-09 2.12000e-01

$5.91740 \mathrm{e}+015.91740 \mathrm{e}+015.91740 \mathrm{e}+001.00000 \mathrm{e}-092.12000 \mathrm{e}-01$

$5.91740 \mathrm{e}+015.91740 \mathrm{e}+015.91740 \mathrm{e}+001.00000 \mathrm{e}-092.12000 \mathrm{e}-01$

$5.91740 \mathrm{e}+015.91740 \mathrm{e}+015.91740 \mathrm{e}+001.00000 \mathrm{e}-092.12000 \mathrm{e}-01$

$1.00000 \mathrm{e}-02$ 1.00000e-02 1.00000e-03 1.00000e-09 1.00000e-01

$1.00000 \mathrm{e}+001.00000 \mathrm{e}+001.00000 \mathrm{e}-011.00000 \mathrm{e}-091.00000 \mathrm{e}-01$

$1.00000 \mathrm{e}-05$ 1.00000e-05 1.00000e-06 1.00000e-09 1.00000e-01

$1.00000 \mathrm{e}+001.00000 \mathrm{e}+001.00000 \mathrm{e}-011.00000 \mathrm{e}-09$ 1.00000e-01

Element: 8771 \# of layers: 8

Kx Ky Kz Ss Por

5.91740e+01 5.91740e+01 5.91740e+00 1.00000e-09 2.12000e-01

$5.91740 \mathrm{e}+015.91740 \mathrm{e}+015.91740 \mathrm{e}+001.00000 \mathrm{e}-092.12000 \mathrm{e}-01$

$5.91740 \mathrm{e}+015.91740 \mathrm{e}+015.91740 \mathrm{e}+001.00000 \mathrm{e}-092.12000 \mathrm{e}-01$

$5.91740 \mathrm{e}+015.91740 \mathrm{e}+015.91740 \mathrm{e}+001.00000 \mathrm{e}-092.12000 \mathrm{e}-01$

1.00000e-02 1.00000e-02 1.00000e-03 1.00000e-09 1.00000e-01

$1.00000 \mathrm{e}+001.00000 \mathrm{e}+001.00000 \mathrm{e}-011.00000 \mathrm{e}-091.00000 \mathrm{e}-01$

$1.00000 \mathrm{e}-05$ 1.00000e-05 1.00000e-06 1.00000e-09 1.00000e-01

$1.00000 \mathrm{e}+001.00000 \mathrm{e}+001.00000 \mathrm{e}-011.00000 \mathrm{e}-091.00000 \mathrm{e}-01$

Element: 8772 \# of layers: 8

$\mathrm{Kx} \mathrm{Ky} \mathrm{Kz}$ Ss Por

5.91740e+01 5.91740e+01 5.91740e+00 1.00000e-09 2.12000e-01

$5.91740 \mathrm{e}+015.91740 \mathrm{e}+015.91740 \mathrm{e}+001.00000 \mathrm{e}-092.12000 \mathrm{e}-01$

$5.91740 \mathrm{e}+015.91740 \mathrm{e}+015.91740 \mathrm{e}+001.00000 \mathrm{e}-092.12000 \mathrm{e}-01$

$5.91740 \mathrm{e}+015.91740 \mathrm{e}+015.91740 \mathrm{e}+001.00000 \mathrm{e}-092.12000 \mathrm{e}-01$

$1.00000 \mathrm{e}-02$ 1.00000e-02 1.00000e-03 1.00000e-09 1.00000e-01

$1.00000 \mathrm{e}+001.00000 \mathrm{e}+001.00000 \mathrm{e}-011.00000 \mathrm{e}-091.00000 \mathrm{e}-01$

$1.00000 \mathrm{e}-05$ 1.00000e-05 1.00000e-06 1.00000e-09 1.00000e-01

$1.00000 \mathrm{e}+001.00000 \mathrm{e}+001.00000 \mathrm{e}-011.00000 \mathrm{e}-091.00000 \mathrm{e}-01$

Element: 8773 \# of layers: 8

$\mathrm{Kx} \mathrm{Ky} \mathrm{Kz}$ Ss Por

5.91740e+01 5.91740e+01 5.91740e+00 1.00000e-09 2.12000e-01

$5.91740 \mathrm{e}+015.91740 \mathrm{e}+015.91740 \mathrm{e}+001.00000 \mathrm{e}-092.12000 \mathrm{e}-01$

$5.91740 \mathrm{e}+015.91740 \mathrm{e}+015.91740 \mathrm{e}+001.00000 \mathrm{e}-092.12000 \mathrm{e}-01$

$5.91740 \mathrm{e}+015.91740 \mathrm{e}+015.91740 \mathrm{e}+001.00000 \mathrm{e}-092.12000 \mathrm{e}-01$

$1.00000 \mathrm{e}-02$ 1.00000e-02 1.00000e-03 1.00000e-09 1.00000e-01

$1.00000 \mathrm{e}+001.00000 \mathrm{e}+001.00000 \mathrm{e}-011.00000 \mathrm{e}-091.00000 \mathrm{e}-01$

$1.00000 \mathrm{e}-05$ 1.00000e-05 1.00000e-06 1.00000e-09 1.00000e-01

$1.00000 \mathrm{e}+001.00000 \mathrm{e}+001.00000 \mathrm{e}-011.00000 \mathrm{e}-09$ 1.00000e-01

Element: 8774 \# of layers: 8

Kx Ky Kz Ss Por

5.91740e+01 5.91740e+01 5.91740e+00 1.00000e-09 2.12000e-01

$5.91740 \mathrm{e}+015.91740 \mathrm{e}+015.91740 \mathrm{e}+001.00000 \mathrm{e}-092.12000 \mathrm{e}-01$

$5.91740 \mathrm{e}+015.91740 \mathrm{e}+015.91740 \mathrm{e}+001.00000 \mathrm{e}-092.12000 \mathrm{e}-01$

$5.91740 \mathrm{e}+015.91740 \mathrm{e}+015.91740 \mathrm{e}+001.00000 \mathrm{e}-092.12000 \mathrm{e}-01$

$1.00000 \mathrm{e}-02$ 1.00000e-02 1.00000e-03 1.00000e-09 1.00000e-01 
$1.00000 \mathrm{e}+001.00000 \mathrm{e}+001.00000 \mathrm{e}-011.00000 \mathrm{e}-091.00000 \mathrm{e}-01$ $1.00000 \mathrm{e}-05$ 1.00000e-05 1.00000e-06 1.00000e-09 1.00000e-01 $1.00000 \mathrm{e}+001.00000 \mathrm{e}+001.00000 \mathrm{e}-011.00000 \mathrm{e}-091.00000 \mathrm{e}-01$ Element: 8775 \# of layers: 8

$\mathrm{Kx} \mathrm{Ky} \mathrm{Kz}$ Ss Por

$5.91740 \mathrm{e}+015.91740 \mathrm{e}+015.91740 \mathrm{e}+001.00000 \mathrm{e}-092.12000 \mathrm{e}-01$ $5.91740 \mathrm{e}+015.91740 \mathrm{e}+015.91740 \mathrm{e}+001.00000 \mathrm{e}-092.12000 \mathrm{e}-01$ $5.91740 \mathrm{e}+015.91740 \mathrm{e}+015.91740 \mathrm{e}+001.00000 \mathrm{e}-092.12000 \mathrm{e}-01$ $5.91740 \mathrm{e}+015.91740 \mathrm{e}+015.91740 \mathrm{e}+001.00000 \mathrm{e}-092.12000 \mathrm{e}-01$ $1.00000 \mathrm{e}-02$ 1.00000e-02 1.00000e-03 1.00000e-09 1.00000e-01 $1.00000 \mathrm{e}+001.00000 \mathrm{e}+001.00000 \mathrm{e}-011.00000 \mathrm{e}-091.00000 \mathrm{e}-01$ $1.00000 \mathrm{e}-05$ 1.00000e-05 1.00000e-06 1.00000e-09 1.00000e-01 $1.00000 \mathrm{e}+001.00000 \mathrm{e}+001.00000 \mathrm{e}-011.00000 \mathrm{e}-091.00000 \mathrm{e}-01$ Element: 8776 \# of layers: 9

$\mathrm{Kx} \mathrm{Ky} \mathrm{Kz}$ Ss Por

$5.91740 \mathrm{e}+015.91740 \mathrm{e}+015.91740 \mathrm{e}+00$ 1.00000e-09 2.12000e-01 $5.91740 \mathrm{e}+015.91740 \mathrm{e}+015.91740 \mathrm{e}+001.00000 \mathrm{e}-092.12000 \mathrm{e}-01$ $5.91740 \mathrm{e}+015.91740 \mathrm{e}+015.91740 \mathrm{e}+001.00000 \mathrm{e}-092.12000 \mathrm{e}-01$ $5.91740 \mathrm{e}+015.91740 \mathrm{e}+015.91740 \mathrm{e}+001.00000 \mathrm{e}-092.12000 \mathrm{e}-01$ $5.91740 \mathrm{e}+015.91740 \mathrm{e}+015.91740 \mathrm{e}+001.00000 \mathrm{e}-092.12000 \mathrm{e}-01$ $1.00000 \mathrm{e}-02$ 1.00000e-02 1.00000e-03 1.00000e-09 1.00000e-01 $1.00000 \mathrm{e}+001.00000 \mathrm{e}+001.00000 \mathrm{e}-011.00000 \mathrm{e}-091.00000 \mathrm{e}-01$ $1.00000 \mathrm{e}-05$ 1.00000e-05 1.00000e-06 1.00000e-09 1.00000e-01 $1.00000 \mathrm{e}+001.00000 \mathrm{e}+001.00000 \mathrm{e}-011.00000 \mathrm{e}-091.00000 \mathrm{e}-01$ Element: 8777 \# of layers: 9

$\mathrm{Kx} \mathrm{Ky} \mathrm{Kz}$ Ss Por

$3.69278 \mathrm{e}+013.69278 \mathrm{e}+01$ 3.69278e+00 1.00000e-09 2.12000e-01 $3.69278 \mathrm{e}+013.69278 \mathrm{e}+013.69278 \mathrm{e}+00$ 1.00000e-09 2.12000e-01 $3.69278 \mathrm{e}+013.69278 \mathrm{e}+013.69278 \mathrm{e}+001.00000 \mathrm{e}-092.12000 \mathrm{e}-01$ $3.69278 \mathrm{e}+013.69278 \mathrm{e}+013.69278 \mathrm{e}+001.00000 \mathrm{e}-092.12000 \mathrm{e}-01$ $3.69278 \mathrm{e}+013.69278 \mathrm{e}+013.69278 \mathrm{e}+00$ 1.00000e-09 2.12000e-01 $1.00000 \mathrm{e}-02$ 1.00000e-02 1.00000e-03 1.00000e-09 1.00000e-01 $1.00000 \mathrm{e}+001.00000 \mathrm{e}+001.00000 \mathrm{e}-011.00000 \mathrm{e}-091.00000 \mathrm{e}-01$ $1.00000 \mathrm{e}-05$ 1.00000e-05 1.00000e-06 1.00000e-09 1.00000e-01 $1.00000 \mathrm{e}+001.00000 \mathrm{e}+001.00000 \mathrm{e}-011.00000 \mathrm{e}-091.00000 \mathrm{e}-01$ Element: 8778 \# of layers: 9

Kx Ky Kz Ss Por

3.69278e+01 3.69278e+01 3.69278e+00 1.00000e-09 2.12000e-01 $3.69278 \mathrm{e}+013.69278 \mathrm{e}+013.69278 \mathrm{e}+001.00000 \mathrm{e}-092.12000 \mathrm{e}-01$ $3.69278 \mathrm{e}+013.69278 \mathrm{e}+013.69278 \mathrm{e}+001.00000 \mathrm{e}-092.12000 \mathrm{e}-01$ $3.69278 \mathrm{e}+013.69278 \mathrm{e}+013.69278 \mathrm{e}+00$ 1.00000e-09 2.12000e-01 $3.69278 \mathrm{e}+013.69278 \mathrm{e}+013.69278 \mathrm{e}+00$ 1.00000e-09 2.12000e-01 $1.00000 \mathrm{e}-02$ 1.00000e-02 1.00000e-03 1.00000e-09 1.00000e-01 $1.00000 \mathrm{e}+001.00000 \mathrm{e}+001.00000 \mathrm{e}-011.00000 \mathrm{e}-091.00000 \mathrm{e}-01$ $1.00000 \mathrm{e}-05$ 1.00000e-05 1.00000e-06 1.00000e-09 1.00000e-01 $1.00000 \mathrm{e}+001.00000 \mathrm{e}+001.00000 \mathrm{e}-011.00000 \mathrm{e}-091.00000 \mathrm{e}-01$ 
Element: 8779 \# of layers: 9

$\mathrm{Kx} \mathrm{Ky} \mathrm{Kz}$ Ss Por

3.69278e+01 3.69278e+01 3.69278e+00 1.00000e-09 2.12000e-01

$3.69278 \mathrm{e}+013.69278 \mathrm{e}+013.69278 \mathrm{e}+00$ 1.00000e-09 2.12000e-01

$3.69278 \mathrm{e}+013.69278 \mathrm{e}+013.69278 \mathrm{e}+00$ 1.00000e-09 2.12000e-01

$3.69278 \mathrm{e}+013.69278 \mathrm{e}+013.69278 \mathrm{e}+001.00000 \mathrm{e}-09$ 2.12000e-01

$3.69278 \mathrm{e}+013.69278 \mathrm{e}+013.69278 \mathrm{e}+00$ 1.00000e-09 2.12000e-01

$1.00000 \mathrm{e}-02$ 1.00000e-02 1.00000e-03 1.00000e-09 1.00000e-01

$1.00000 \mathrm{e}+001.00000 \mathrm{e}+001.00000 \mathrm{e}-011.00000 \mathrm{e}-091.00000 \mathrm{e}-01$

$1.00000 \mathrm{e}-05$ 1.00000e-05 1.00000e-06 1.00000e-09 1.00000e-01

$1.00000 \mathrm{e}+001.00000 \mathrm{e}+001.00000 \mathrm{e}-011.00000 \mathrm{e}-091.00000 \mathrm{e}-01$

Element: 8780 \# of layers: 9

$\mathrm{Kx} \mathrm{Ky} \mathrm{Kz}$ Ss Por

$5.91740 \mathrm{e}+015.91740 \mathrm{e}+015.91740 \mathrm{e}+001.00000 \mathrm{e}-092.12000 \mathrm{e}-01$

$5.91740 \mathrm{e}+015.91740 \mathrm{e}+015.91740 \mathrm{e}+001.00000 \mathrm{e}-092.12000 \mathrm{e}-01$

$5.91740 \mathrm{e}+015.91740 \mathrm{e}+015.91740 \mathrm{e}+001.00000 \mathrm{e}-092.12000 \mathrm{e}-01$

$5.91740 \mathrm{e}+015.91740 \mathrm{e}+015.91740 \mathrm{e}+001.00000 \mathrm{e}-092.12000 \mathrm{e}-01$

$5.91740 \mathrm{e}+015.91740 \mathrm{e}+015.91740 \mathrm{e}+001.00000 \mathrm{e}-092.12000 \mathrm{e}-01$

$1.00000 \mathrm{e}-02$ 1.00000e-02 1.00000e-03 1.00000e-09 1.00000e-01

$1.00000 \mathrm{e}+001.00000 \mathrm{e}+001.00000 \mathrm{e}-011.00000 \mathrm{e}-091.00000 \mathrm{e}-01$

$1.00000 \mathrm{e}-05$ 1.00000e-05 1.00000e-06 1.00000e-09 1.00000e-01

$1.00000 \mathrm{e}+001.00000 \mathrm{e}+001.00000 \mathrm{e}-01$ 1.00000e-09 1.00000e-01

Element: 8781 \# of layers: 8

Kx Ky Kz Ss Por

5.91740e+01 5.91740e+01 5.91740e+00 1.00000e-09 2.12000e-01

$5.91740 \mathrm{e}+015.91740 \mathrm{e}+015.91740 \mathrm{e}+001.00000 \mathrm{e}-092.12000 \mathrm{e}-01$

$5.91740 \mathrm{e}+015.91740 \mathrm{e}+015.91740 \mathrm{e}+001.00000 \mathrm{e}-092.12000 \mathrm{e}-01$

$5.91740 \mathrm{e}+015.91740 \mathrm{e}+015.91740 \mathrm{e}+001.00000 \mathrm{e}-092.12000 \mathrm{e}-01$

$1.00000 \mathrm{e}-02$ 1.00000e-02 1.00000e-03 1.00000e-09 1.00000e-01

$1.00000 \mathrm{e}+001.00000 \mathrm{e}+001.00000 \mathrm{e}-011.00000 \mathrm{e}-091.00000 \mathrm{e}-01$

$1.00000 \mathrm{e}-051.00000 \mathrm{e}-051.00000 \mathrm{e}-061.00000 \mathrm{e}-091.00000 \mathrm{e}-01$

$1.00000 \mathrm{e}+001.00000 \mathrm{e}+001.00000 \mathrm{e}-011.00000 \mathrm{e}-091.00000 \mathrm{e}-01$

Element: 8782 \# of layers: 8

$\mathrm{Kx} \mathrm{Ky} \mathrm{Kz}$ Ss Por

5.91740e+01 5.91740e+01 5.91740e+00 1.00000e-09 2.12000e-01

$5.91740 \mathrm{e}+015.91740 \mathrm{e}+015.91740 \mathrm{e}+001.00000 \mathrm{e}-092.12000 \mathrm{e}-01$

$5.91740 \mathrm{e}+015.91740 \mathrm{e}+015.91740 \mathrm{e}+001.00000 \mathrm{e}-092.12000 \mathrm{e}-01$

$5.91740 \mathrm{e}+015.91740 \mathrm{e}+015.91740 \mathrm{e}+001.00000 \mathrm{e}-092.12000 \mathrm{e}-01$

$1.00000 \mathrm{e}-02$ 1.00000e-02 1.00000e-03 1.00000e-09 1.00000e-01

$1.00000 \mathrm{e}+001.00000 \mathrm{e}+001.00000 \mathrm{e}-011.00000 \mathrm{e}-091.00000 \mathrm{e}-01$

$1.00000 \mathrm{e}-05$ 1.00000e-05 1.00000e-06 1.00000e-09 1.00000e-01

$1.00000 \mathrm{e}+001.00000 \mathrm{e}+001.00000 \mathrm{e}-011.00000 \mathrm{e}-091.00000 \mathrm{e}-01$

Element: 8783 \# of layers: 9

$\mathrm{Kx} \mathrm{Ky} \mathrm{Kz}$ Ss Por

5.91740e+01 5.91740e+01 5.91740e+00 1.00000e-09 2.12000e-01

$5.91740 \mathrm{e}+015.91740 \mathrm{e}+015.91740 \mathrm{e}+001.00000 \mathrm{e}-09$ 2.12000e-01 
5.91740e+01 5.91740e+01 5.91740e+00 1.00000e-09 2.12000e-01 $5.91740 \mathrm{e}+015.91740 \mathrm{e}+015.91740 \mathrm{e}+001.00000 \mathrm{e}-092.12000 \mathrm{e}-01$ $5.91740 \mathrm{e}+015.91740 \mathrm{e}+015.91740 \mathrm{e}+001.00000 \mathrm{e}-09$ 2.12000e-01 $1.00000 \mathrm{e}-02$ 1.00000e-02 1.00000e-03 1.00000e-09 1.00000e-01 $1.00000 \mathrm{e}+001.00000 \mathrm{e}+001.00000 \mathrm{e}-011.00000 \mathrm{e}-091.00000 \mathrm{e}-01$ $1.00000 \mathrm{e}-05$ 1.00000e-05 1.00000e-06 1.00000e-09 1.00000e-01 $1.00000 \mathrm{e}+001.00000 \mathrm{e}+001.00000 \mathrm{e}-01$ 1.00000e-09 1.00000e-01 Element: 8784 \# of layers: 9

$\mathrm{Kx} \mathrm{Ky} \mathrm{Kz}$ Ss Por

$3.69278 \mathrm{e}+013.69278 \mathrm{e}+01$ 3.69278e+00 1.00000e-09 2.12000e-01 $3.69278 \mathrm{e}+013.69278 \mathrm{e}+013.69278 \mathrm{e}+001.00000 \mathrm{e}-09$ 2.12000e-01 $3.69278 \mathrm{e}+013.69278 \mathrm{e}+013.69278 \mathrm{e}+00$ 1.00000e-09 2.12000e-01 $3.69278 \mathrm{e}+013.69278 \mathrm{e}+013.69278 \mathrm{e}+001.00000 \mathrm{e}-092.12000 \mathrm{e}-01$ $3.69278 \mathrm{e}+013.69278 \mathrm{e}+013.69278 \mathrm{e}+00$ 1.00000e-09 2.12000e-01 $1.00000 \mathrm{e}-021.00000 \mathrm{e}-02$ 1.00000e-03 1.00000e-09 1.00000e-01 $1.00000 \mathrm{e}+001.00000 \mathrm{e}+001.00000 \mathrm{e}-011.00000 \mathrm{e}-091.00000 \mathrm{e}-01$ $1.00000 \mathrm{e}-05$ 1.00000e-05 1.00000e-06 1.00000e-09 1.00000e-01 $1.00000 \mathrm{e}+001.00000 \mathrm{e}+001.00000 \mathrm{e}-01$ 1.00000e-09 1.00000e-01 Element: 8785 \# of layers: 9

$\mathrm{Kx} \mathrm{Ky} \mathrm{Kz}$ Ss Por

3.69278e+01 3.69278e+01 3.69278e+00 1.00000e-09 2.12000e-01 $3.69278 \mathrm{e}+013.69278 \mathrm{e}+013.69278 \mathrm{e}+00$ 1.00000e-09 2.12000e-01 $3.69278 \mathrm{e}+013.69278 \mathrm{e}+013.69278 \mathrm{e}+00$ 1.00000e-09 2.12000e-01 $3.69278 \mathrm{e}+013.69278 \mathrm{e}+013.69278 \mathrm{e}+001.00000 \mathrm{e}-092.12000 \mathrm{e}-01$ $3.69278 \mathrm{e}+013.69278 \mathrm{e}+013.69278 \mathrm{e}+00$ 1.00000e-09 2.12000e-01 $1.00000 \mathrm{e}-021.00000 \mathrm{e}-021.00000 \mathrm{e}-031.00000 \mathrm{e}-091.00000 \mathrm{e}-01$ $1.00000 \mathrm{e}+001.00000 \mathrm{e}+001.00000 \mathrm{e}-011.00000 \mathrm{e}-091.00000 \mathrm{e}-01$ $1.00000 \mathrm{e}-051.00000 \mathrm{e}-051.00000 \mathrm{e}-061.00000 \mathrm{e}-091.00000 \mathrm{e}-01$ $1.00000 \mathrm{e}+001.00000 \mathrm{e}+001.00000 \mathrm{e}-011.00000 \mathrm{e}-091.00000 \mathrm{e}-01$ Element: 8786 \# of layers: 9

$\mathrm{Kx} \mathrm{Ky} \mathrm{Kz}$ Ss Por

3.69278e+01 3.69278e+01 3.69278e+00 1.00000e-09 2.12000e-01 $3.69278 \mathrm{e}+013.69278 \mathrm{e}+013.69278 \mathrm{e}+00$ 1.00000e-09 2.12000e-01 $3.69278 \mathrm{e}+013.69278 \mathrm{e}+013.69278 \mathrm{e}+001.00000 \mathrm{e}-092.12000 \mathrm{e}-01$ $3.69278 \mathrm{e}+013.69278 \mathrm{e}+013.69278 \mathrm{e}+00$ 1.00000e-09 2.12000e-01 $3.69278 \mathrm{e}+013.69278 \mathrm{e}+013.69278 \mathrm{e}+00$ 1.00000e-09 2.12000e-01 $1.00000 \mathrm{e}-02$ 1.00000e-02 1.00000e-03 1.00000e-09 1.00000e-01 $1.00000 \mathrm{e}+001.00000 \mathrm{e}+001.00000 \mathrm{e}-011.00000 \mathrm{e}-091.00000 \mathrm{e}-01$ $1.00000 \mathrm{e}-05$ 1.00000e-05 1.00000e-06 1.00000e-09 1.00000e-01 $1.00000 \mathrm{e}+001.00000 \mathrm{e}+001.00000 \mathrm{e}-011.00000 \mathrm{e}-091.00000 \mathrm{e}-01$ Element: 8787 \# of layers: 9

$\mathrm{Kx} \mathrm{Ky} \mathrm{Kz}$ Ss Por

$3.69278 \mathrm{e}+013.69278 \mathrm{e}+013.69278 \mathrm{e}+00$ 1.00000e-09 2.12000e-01 $3.69278 \mathrm{e}+013.69278 \mathrm{e}+01$ 3.69278e+00 1.00000e-09 2.12000e-01 $3.69278 \mathrm{e}+013.69278 \mathrm{e}+013.69278 \mathrm{e}+00$ 1.00000e-09 2.12000e-01 $3.69278 \mathrm{e}+013.69278 \mathrm{e}+013.69278 \mathrm{e}+00$ 1.00000e-09 2.12000e-01 
$3.69278 \mathrm{e}+013.69278 \mathrm{e}+013.69278 \mathrm{e}+00$ 1.00000e-09 2.12000e-01 $1.00000 \mathrm{e}-02$ 1.00000e-02 1.00000e-03 1.00000e-09 1.00000e-01 $1.00000 \mathrm{e}+001.00000 \mathrm{e}+001.00000 \mathrm{e}-011.00000 \mathrm{e}-091.00000 \mathrm{e}-01$ $1.00000 \mathrm{e}-05$ 1.00000e-05 1.00000e-06 1.00000e-09 1.00000e-01 $1.00000 \mathrm{e}+001.00000 \mathrm{e}+001.00000 \mathrm{e}-011.00000 \mathrm{e}-091.00000 \mathrm{e}-01$ Element: 8788 \# of layers: 9

$\mathrm{Kx} \mathrm{Ky} \mathrm{Kz}$ Ss Por

$3.69278 \mathrm{e}+013.69278 \mathrm{e}+01$ 3.69278e+00 1.00000e-09 2.12000e-01 $3.69278 \mathrm{e}+013.69278 \mathrm{e}+013.69278 \mathrm{e}+001.00000 \mathrm{e}-092.12000 \mathrm{e}-01$ $3.69278 \mathrm{e}+013.69278 \mathrm{e}+013.69278 \mathrm{e}+00$ 1.00000e-09 2.12000e-01 $3.69278 \mathrm{e}+013.69278 \mathrm{e}+013.69278 \mathrm{e}+00$ 1.00000e-09 2.12000e-01 $3.69278 \mathrm{e}+013.69278 \mathrm{e}+013.69278 \mathrm{e}+001.00000 \mathrm{e}-092.12000 \mathrm{e}-01$ $1.00000 \mathrm{e}-02$ 1.00000e-02 1.00000e-03 1.00000e-09 1.00000e-01 $1.00000 \mathrm{e}+001.00000 \mathrm{e}+001.00000 \mathrm{e}-011.00000 \mathrm{e}-091.00000 \mathrm{e}-01$ $1.00000 \mathrm{e}-05$ 1.00000e-05 1.00000e-06 1.00000e-09 1.00000e-01 $1.00000 \mathrm{e}+001.00000 \mathrm{e}+001.00000 \mathrm{e}-011.00000 \mathrm{e}-091.00000 \mathrm{e}-01$ Element: 8789 \# of layers: 9

$\mathrm{Kx} \mathrm{Ky} \mathrm{Kz}$ Ss Por

$3.69278 \mathrm{e}+013.69278 \mathrm{e}+013.69278 \mathrm{e}+00$ 1.00000e-09 2.12000e-01 $3.69278 \mathrm{e}+013.69278 \mathrm{e}+013.69278 \mathrm{e}+001.00000 \mathrm{e}-092.12000 \mathrm{e}-01$ $3.69278 \mathrm{e}+013.69278 \mathrm{e}+013.69278 \mathrm{e}+001.00000 \mathrm{e}-092.12000 \mathrm{e}-01$ $3.69278 \mathrm{e}+013.69278 \mathrm{e}+013.69278 \mathrm{e}+001.00000 \mathrm{e}-092.12000 \mathrm{e}-01$ $3.69278 \mathrm{e}+013.69278 \mathrm{e}+013.69278 \mathrm{e}+00$ 1.00000e-09 2.12000e-01 $1.00000 \mathrm{e}-02$ 1.00000e-02 1.00000e-03 1.00000e-09 1.00000e-01 $1.00000 \mathrm{e}+001.00000 \mathrm{e}+001.00000 \mathrm{e}-011.00000 \mathrm{e}-091.00000 \mathrm{e}-01$ $1.00000 \mathrm{e}-05$ 1.00000e-05 1.00000e-06 1.00000e-09 1.00000e-01 $1.00000 \mathrm{e}+001.00000 \mathrm{e}+001.00000 \mathrm{e}-011.00000 \mathrm{e}-091.00000 \mathrm{e}-01$ Element: 8790 \# of layers: 9

Kx Ky Kz Ss Por

$3.69278 \mathrm{e}+013.69278 \mathrm{e}+01$ 3.69278e+00 1.00000e-09 2.12000e-01 $3.69278 \mathrm{e}+013.69278 \mathrm{e}+013.69278 \mathrm{e}+00$ 1.00000e-09 2.12000e-01 $3.69278 \mathrm{e}+013.69278 \mathrm{e}+013.69278 \mathrm{e}+00$ 1.00000e-09 2.12000e-01 $3.69278 \mathrm{e}+013.69278 \mathrm{e}+013.69278 \mathrm{e}+00$ 1.00000e-09 2.12000e-01 $3.69278 \mathrm{e}+013.69278 \mathrm{e}+013.69278 \mathrm{e}+00$ 1.00000e-09 2.12000e-01 $1.00000 \mathrm{e}-02$ 1.00000e-02 1.00000e-03 1.00000e-09 1.00000e-01 $1.00000 \mathrm{e}+001.00000 \mathrm{e}+001.00000 \mathrm{e}-011.00000 \mathrm{e}-091.00000 \mathrm{e}-01$ $1.00000 \mathrm{e}-05$ 1.00000e-05 1.00000e-06 1.00000e-09 1.00000e-01 $1.00000 \mathrm{e}+001.00000 \mathrm{e}+001.00000 \mathrm{e}-011.00000 \mathrm{e}-091.00000 \mathrm{e}-01$ Element: 8791 \# of layers: 9

$\mathrm{Kx} \mathrm{Ky} \mathrm{Kz}$ Ss Por

$3.69278 \mathrm{e}+013.69278 \mathrm{e}+01$ 3.69278e+00 1.00000e-09 2.12000e-01 $3.69278 \mathrm{e}+013.69278 \mathrm{e}+013.69278 \mathrm{e}+001.00000 \mathrm{e}-092.12000 \mathrm{e}-01$ $3.69278 \mathrm{e}+013.69278 \mathrm{e}+013.69278 \mathrm{e}+001.00000 \mathrm{e}-092.12000 \mathrm{e}-01$ $3.69278 \mathrm{e}+013.69278 \mathrm{e}+01$ 3.69278e+00 1.00000e-09 2.12000e-01 $3.69278 \mathrm{e}+013.69278 \mathrm{e}+013.69278 \mathrm{e}+001.00000 \mathrm{e}-092.12000 \mathrm{e}-01$ $1.00000 \mathrm{e}-02$ 1.00000e-02 1.00000e-03 1.00000e-09 1.00000e-01 
$1.00000 \mathrm{e}+001.00000 \mathrm{e}+001.00000 \mathrm{e}-011.00000 \mathrm{e}-091.00000 \mathrm{e}-01$ $1.00000 \mathrm{e}-05$ 1.00000e-05 1.00000e-06 1.00000e-09 1.00000e-01 $1.00000 \mathrm{e}+001.00000 \mathrm{e}+001.00000 \mathrm{e}-01$ 1.00000e-09 1.00000e-01 Element: 8792 \# of layers: 9

$\mathrm{Kx} \mathrm{Ky} \mathrm{Kz}$ Ss Por

$3.69278 \mathrm{e}+013.69278 \mathrm{e}+01$ 3.69278e+00 1.00000e-09 2.12000e-01 $3.69278 \mathrm{e}+013.69278 \mathrm{e}+013.69278 \mathrm{e}+00$ 1.00000e-09 2.12000e-01 $3.69278 \mathrm{e}+013.69278 \mathrm{e}+013.69278 \mathrm{e}+001.00000 \mathrm{e}-092.12000 \mathrm{e}-01$ $3.69278 \mathrm{e}+013.69278 \mathrm{e}+013.69278 \mathrm{e}+001.00000 \mathrm{e}-092.12000 \mathrm{e}-01$ $3.69278 \mathrm{e}+013.69278 \mathrm{e}+013.69278 \mathrm{e}+00$ 1.00000e-09 2.12000e-01 $1.00000 \mathrm{e}-02$ 1.00000e-02 1.00000e-03 1.00000e-09 1.00000e-01 $1.00000 \mathrm{e}+001.00000 \mathrm{e}+001.00000 \mathrm{e}-011.00000 \mathrm{e}-091.00000 \mathrm{e}-01$ $1.00000 \mathrm{e}-05$ 1.00000e-05 1.00000e-06 1.00000e-09 1.00000e-01 $1.00000 \mathrm{e}+001.00000 \mathrm{e}+001.00000 \mathrm{e}-011.00000 \mathrm{e}-091.00000 \mathrm{e}-01$ Element: 8793 \# of layers: 9

Kx Ky Kz Ss Por

$3.69278 \mathrm{e}+013.69278 \mathrm{e}+013.69278 \mathrm{e}+00$ 1.00000e-09 2.12000e-01 $3.69278 \mathrm{e}+013.69278 \mathrm{e}+013.69278 \mathrm{e}+001.00000 \mathrm{e}-092.12000 \mathrm{e}-01$ $3.69278 \mathrm{e}+013.69278 \mathrm{e}+013.69278 \mathrm{e}+001.00000 \mathrm{e}-092.12000 \mathrm{e}-01$ $3.69278 \mathrm{e}+013.69278 \mathrm{e}+013.69278 \mathrm{e}+001.00000 \mathrm{e}-092.12000 \mathrm{e}-01$ $3.69278 \mathrm{e}+013.69278 \mathrm{e}+013.69278 \mathrm{e}+001.00000 \mathrm{e}-092.12000 \mathrm{e}-01$ $1.00000 \mathrm{e}-02$ 1.00000e-02 1.00000e-03 1.00000e-09 1.00000e-01 $1.00000 \mathrm{e}+001.00000 \mathrm{e}+001.00000 \mathrm{e}-011.00000 \mathrm{e}-091.00000 \mathrm{e}-01$ $1.00000 \mathrm{e}-05$ 1.00000e-05 1.00000e-06 1.00000e-09 1.00000e-01 $1.00000 \mathrm{e}+001.00000 \mathrm{e}+001.00000 \mathrm{e}-011.00000 \mathrm{e}-091.00000 \mathrm{e}-01$ Element: 8794 \# of layers: 9

$\mathrm{Kx} \mathrm{Ky} \mathrm{Kz}$ Ss Por

$4.60000 \mathrm{e}+014.60000 \mathrm{e}+014.60000 \mathrm{e}+001.00000 \mathrm{e}-09$ 2.12000e-01 $4.60000 \mathrm{e}+014.60000 \mathrm{e}+014.60000 \mathrm{e}+001.00000 \mathrm{e}-092.12000 \mathrm{e}-01$ $4.60000 \mathrm{e}+014.60000 \mathrm{e}+014.60000 \mathrm{e}+00$ 1.00000e-09 2.12000e-01 $4.60000 \mathrm{e}+014.60000 \mathrm{e}+014.60000 \mathrm{e}+001.00000 \mathrm{e}-092.12000 \mathrm{e}-01$ $4.60000 \mathrm{e}+014.60000 \mathrm{e}+014.60000 \mathrm{e}+00$ 1.00000e-09 2.12000e-01 $1.00000 \mathrm{e}-02$ 1.00000e-02 1.00000e-03 1.00000e-09 1.00000e-01 $1.00000 \mathrm{e}+001.00000 \mathrm{e}+001.00000 \mathrm{e}-011.00000 \mathrm{e}-091.00000 \mathrm{e}-01$ $1.00000 \mathrm{e}-05$ 1.00000e-05 1.00000e-06 1.00000e-09 1.00000e-01 $1.00000 \mathrm{e}+001.00000 \mathrm{e}+001.00000 \mathrm{e}-011.00000 \mathrm{e}-091.00000 \mathrm{e}-01$ Element: 8795 \# of layers: 9

$\mathrm{Kx} \mathrm{Ky} \mathrm{Kz}$ Ss Por $4.60000 \mathrm{e}+014.60000 \mathrm{e}+014.60000 \mathrm{e}+001.00000 \mathrm{e}-092.12000 \mathrm{e}-01$ $4.60000 \mathrm{e}+014.60000 \mathrm{e}+014.60000 \mathrm{e}+001.00000 \mathrm{e}-092.12000 \mathrm{e}-01$ $4.60000 \mathrm{e}+014.60000 \mathrm{e}+014.60000 \mathrm{e}+001.00000 \mathrm{e}-092.12000 \mathrm{e}-01$ $4.60000 \mathrm{e}+014.60000 \mathrm{e}+014.60000 \mathrm{e}+001.00000 \mathrm{e}-092.12000 \mathrm{e}-01$ $4.60000 \mathrm{e}+014.60000 \mathrm{e}+014.60000 \mathrm{e}+001.00000 \mathrm{e}-092.12000 \mathrm{e}-01$ $1.00000 \mathrm{e}-02$ 1.00000e-02 1.00000e-03 1.00000e-09 1.00000e-01 $1.00000 \mathrm{e}+001.00000 \mathrm{e}+001.00000 \mathrm{e}-011.00000 \mathrm{e}-091.00000 \mathrm{e}-01$ $1.00000 \mathrm{e}-05$ 1.00000e-05 1.00000e-06 1.00000e-09 1.00000e-01 
$1.00000 \mathrm{e}+001.00000 \mathrm{e}+00$ 1.00000e-01 1.00000e-09 1.00000e-01

Element: 8796 \# of layers: 9

$\mathrm{Kx} \mathrm{Ky} \mathrm{Kz}$ Ss Por

4.60000e+01 4.60000e+01 4.60000e+00 1.00000e-09 2.12000e-01

$4.60000 \mathrm{e}+014.60000 \mathrm{e}+014.60000 \mathrm{e}+001.00000 \mathrm{e}-092.12000 \mathrm{e}-01$

$4.60000 \mathrm{e}+014.60000 \mathrm{e}+014.60000 \mathrm{e}+001.00000 \mathrm{e}-092.12000 \mathrm{e}-01$

$4.60000 \mathrm{e}+014.60000 \mathrm{e}+014.60000 \mathrm{e}+00$ 1.00000e-09 2.12000e-01

$4.60000 \mathrm{e}+014.60000 \mathrm{e}+014.60000 \mathrm{e}+00$ 1.00000e-09 2.12000e-01

$1.00000 \mathrm{e}-021.00000 \mathrm{e}-021.00000 \mathrm{e}-031.00000 \mathrm{e}-091.00000 \mathrm{e}-01$

$1.00000 \mathrm{e}+001.00000 \mathrm{e}+001.00000 \mathrm{e}-011.00000 \mathrm{e}-091.00000 \mathrm{e}-01$

$1.00000 \mathrm{e}-05$ 1.00000e-05 1.00000e-06 1.00000e-09 1.00000e-01

$1.00000 \mathrm{e}+001.00000 \mathrm{e}+001.00000 \mathrm{e}-01$ 1.00000e-09 1.00000e-01

Element: 8797 \# of layers: 9

$\mathrm{Kx} \mathrm{Ky} \mathrm{Kz}$ Ss Por

$4.60000 \mathrm{e}+014.60000 \mathrm{e}+014.60000 \mathrm{e}+001.00000 \mathrm{e}-092.12000 \mathrm{e}-01$

$4.60000 \mathrm{e}+014.60000 \mathrm{e}+014.60000 \mathrm{e}+001.00000 \mathrm{e}-092.12000 \mathrm{e}-01$

$4.60000 \mathrm{e}+014.60000 \mathrm{e}+014.60000 \mathrm{e}+001.00000 \mathrm{e}-09$ 2.12000e-01

$4.60000 \mathrm{e}+014.60000 \mathrm{e}+014.60000 \mathrm{e}+001.00000 \mathrm{e}-092.12000 \mathrm{e}-01$

$4.60000 \mathrm{e}+014.60000 \mathrm{e}+014.60000 \mathrm{e}+001.00000 \mathrm{e}-092.12000 \mathrm{e}-01$

$1.00000 \mathrm{e}-02$ 1.00000e-02 1.00000e-03 1.00000e-09 1.00000e-01

$1.00000 \mathrm{e}+001.00000 \mathrm{e}+001.00000 \mathrm{e}-011.00000 \mathrm{e}-091.00000 \mathrm{e}-01$

$1.00000 \mathrm{e}-05$ 1.00000e-05 1.00000e-06 1.00000e-09 1.00000e-01

$1.00000 \mathrm{e}+001.00000 \mathrm{e}+001.00000 \mathrm{e}-011.00000 \mathrm{e}-091.00000 \mathrm{e}-01$

Element: 8798 \# of layers: 9

Kx Ky Kz Ss Por

$4.60000 \mathrm{e}+014.60000 \mathrm{e}+014.60000 \mathrm{e}+001.00000 \mathrm{e}-092.12000 \mathrm{e}-01$

$4.60000 \mathrm{e}+014.60000 \mathrm{e}+014.60000 \mathrm{e}+001.00000 \mathrm{e}-092.12000 \mathrm{e}-01$

$4.60000 \mathrm{e}+014.60000 \mathrm{e}+014.60000 \mathrm{e}+001.00000 \mathrm{e}-09$ 2.12000e-01

$4.60000 \mathrm{e}+014.60000 \mathrm{e}+014.60000 \mathrm{e}+001.00000 \mathrm{e}-092.12000 \mathrm{e}-01$

$4.60000 \mathrm{e}+014.60000 \mathrm{e}+014.60000 \mathrm{e}+001.00000 \mathrm{e}-09$ 2.12000e-01

$1.00000 \mathrm{e}-02$ 1.00000e-02 1.00000e-03 1.00000e-09 1.00000e-01

$1.00000 \mathrm{e}+001.00000 \mathrm{e}+001.00000 \mathrm{e}-011.00000 \mathrm{e}-091.00000 \mathrm{e}-01$

$1.00000 \mathrm{e}-05$ 1.00000e-05 1.00000e-06 1.00000e-09 1.00000e-01

$1.00000 \mathrm{e}+001.00000 \mathrm{e}+001.00000 \mathrm{e}-011.00000 \mathrm{e}-091.00000 \mathrm{e}-01$

Element: 8799 \# of layers: 9

Kx Ky Kz Ss Por

3.69278e+01 3.69278e+01 3.69278e+00 1.00000e-09 2.12000e-01

$3.69278 \mathrm{e}+013.69278 \mathrm{e}+013.69278 \mathrm{e}+00$ 1.00000e-09 2.12000e-01

$3.69278 \mathrm{e}+013.69278 \mathrm{e}+013.69278 \mathrm{e}+001.00000 \mathrm{e}-09$ 2.12000e-01

$3.69278 \mathrm{e}+013.69278 \mathrm{e}+013.69278 \mathrm{e}+001.00000 \mathrm{e}-092.12000 \mathrm{e}-01$

$3.69278 \mathrm{e}+013.69278 \mathrm{e}+013.69278 \mathrm{e}+00$ 1.00000e-09 2.12000e-01

$1.00000 \mathrm{e}-02$ 1.00000e-02 1.00000e-03 1.00000e-09 1.00000e-01

$1.00000 \mathrm{e}+001.00000 \mathrm{e}+001.00000 \mathrm{e}-011.00000 \mathrm{e}-091.00000 \mathrm{e}-01$

$1.00000 \mathrm{e}-05$ 1.00000e-05 1.00000e-06 1.00000e-09 1.00000e-01

$1.00000 \mathrm{e}+001.00000 \mathrm{e}+001.00000 \mathrm{e}-011.00000 \mathrm{e}-091.00000 \mathrm{e}-01$

Element: 8800 \# of layers: 9 
$\mathrm{Kx} \mathrm{Ky} \mathrm{Kz}$ Ss Por

$3.69278 \mathrm{e}+013.69278 \mathrm{e}+013.69278 \mathrm{e}+00$ 1.00000e-09 2.12000e-01

$3.69278 \mathrm{e}+013.69278 \mathrm{e}+013.69278 \mathrm{e}+00$ 1.00000e-09 2.12000e-01

$3.69278 \mathrm{e}+013.69278 \mathrm{e}+013.69278 \mathrm{e}+001.00000 \mathrm{e}-092.12000 \mathrm{e}-01$

$3.69278 \mathrm{e}+013.69278 \mathrm{e}+013.69278 \mathrm{e}+001.00000 \mathrm{e}-092.12000 \mathrm{e}-01$

$3.69278 \mathrm{e}+013.69278 \mathrm{e}+013.69278 \mathrm{e}+00$ 1.00000e-09 2.12000e-01

$1.00000 \mathrm{e}-02$ 1.00000e-02 1.00000e-03 1.00000e-09 1.00000e-01

$1.00000 \mathrm{e}+001.00000 \mathrm{e}+001.00000 \mathrm{e}-011.00000 \mathrm{e}-091.00000 \mathrm{e}-01$

$1.00000 \mathrm{e}-051.00000 \mathrm{e}-051.00000 \mathrm{e}-061.00000 \mathrm{e}-091.00000 \mathrm{e}-01$

$1.00000 \mathrm{e}+001.00000 \mathrm{e}+001.00000 \mathrm{e}-011.00000 \mathrm{e}-091.00000 \mathrm{e}-01$

Element: 8801 \# of layers: 9

$\mathrm{Kx} \mathrm{Ky} \mathrm{Kz}$ Ss Por

4.60000e+01 4.60000e+01 4.60000e+00 1.00000e-09 2.12000e-01

$4.60000 \mathrm{e}+014.60000 \mathrm{e}+014.60000 \mathrm{e}+001.00000 \mathrm{e}-092.12000 \mathrm{e}-01$

$4.60000 \mathrm{e}+014.60000 \mathrm{e}+014.60000 \mathrm{e}+001.00000 \mathrm{e}-092.12000 \mathrm{e}-01$

$4.60000 \mathrm{e}+014.60000 \mathrm{e}+014.60000 \mathrm{e}+001.00000 \mathrm{e}-092.12000 \mathrm{e}-01$

$4.60000 \mathrm{e}+014.60000 \mathrm{e}+014.60000 \mathrm{e}+001.00000 \mathrm{e}-092.12000 \mathrm{e}-01$

$1.00000 \mathrm{e}-02$ 1.00000e-02 1.00000e-03 1.00000e-09 1.00000e-01

$1.00000 \mathrm{e}+001.00000 \mathrm{e}+001.00000 \mathrm{e}-011.00000 \mathrm{e}-091.00000 \mathrm{e}-01$

$1.00000 \mathrm{e}-05$ 1.00000e-05 1.00000e-06 1.00000e-09 1.00000e-01

$1.00000 \mathrm{e}+001.00000 \mathrm{e}+001.00000 \mathrm{e}-011.00000 \mathrm{e}-091.00000 \mathrm{e}-01$

Element: 8802 \# of layers: 9

$\mathrm{Kx} \mathrm{Ky} \mathrm{Kz}$ Ss Por

4.60000e+01 4.60000e+01 4.60000e+00 1.00000e-09 2.12000e-01

$4.60000 \mathrm{e}+014.60000 \mathrm{e}+014.60000 \mathrm{e}+001.00000 \mathrm{e}-09$ 2.12000e-01

$4.60000 \mathrm{e}+014.60000 \mathrm{e}+014.60000 \mathrm{e}+001.00000 \mathrm{e}-092.12000 \mathrm{e}-01$

$4.60000 \mathrm{e}+014.60000 \mathrm{e}+014.60000 \mathrm{e}+001.00000 \mathrm{e}-092.12000 \mathrm{e}-01$

$4.60000 \mathrm{e}+014.60000 \mathrm{e}+014.60000 \mathrm{e}+001.00000 \mathrm{e}-092.12000 \mathrm{e}-01$

$1.00000 \mathrm{e}-02$ 1.00000e-02 1.00000e-03 1.00000e-09 1.00000e-01

$1.00000 \mathrm{e}+001.00000 \mathrm{e}+001.00000 \mathrm{e}-011.00000 \mathrm{e}-091.00000 \mathrm{e}-01$

$1.00000 \mathrm{e}-05$ 1.00000e-05 1.00000e-06 1.00000e-09 1.00000e-01

$1.00000 \mathrm{e}+001.00000 \mathrm{e}+001.00000 \mathrm{e}-01$ 1.00000e-09 1.00000e-01

Element: 8803 \# of layers: 9

$\mathrm{Kx} \mathrm{Ky} \mathrm{Kz}$ Ss Por

$5.42689 \mathrm{e}+015.42689 \mathrm{e}+015.42689 \mathrm{e}+00$ 1.00000e-09 2.12000e-01

$5.42689 \mathrm{e}+015.42689 \mathrm{e}+015.42689 \mathrm{e}+001.00000 \mathrm{e}-092.12000 \mathrm{e}-01$

$5.42689 \mathrm{e}+015.42689 \mathrm{e}+015.42689 \mathrm{e}+001.00000 \mathrm{e}-092.12000 \mathrm{e}-01$

$5.42689 \mathrm{e}+015.42689 \mathrm{e}+015.42689 \mathrm{e}+001.00000 \mathrm{e}-092.12000 \mathrm{e}-01$

$5.42689 \mathrm{e}+015.42689 \mathrm{e}+015.42689 \mathrm{e}+001.00000 \mathrm{e}-09$ 2.12000e-01

$1.00000 \mathrm{e}-02$ 1.00000e-02 1.00000e-03 1.00000e-09 1.00000e-01

$1.00000 \mathrm{e}+001.00000 \mathrm{e}+001.00000 \mathrm{e}-011.00000 \mathrm{e}-091.00000 \mathrm{e}-01$

$1.00000 \mathrm{e}-05$ 1.00000e-05 1.00000e-06 1.00000e-09 1.00000e-01

$1.00000 \mathrm{e}+001.00000 \mathrm{e}+001.00000 \mathrm{e}-011.00000 \mathrm{e}-091.00000 \mathrm{e}-01$

Element: 8804 \# of layers: 9

$\mathrm{Kx} \mathrm{Ky} \mathrm{Kz}$ Ss Por

5.42689e+01 5.42689e+01 5.42689e+00 1.00000e-09 2.12000e-01 
$5.42689 \mathrm{e}+01$ 5.42689e+01 5.42689e+00 1.00000e-09 2.12000e-01 $5.42689 \mathrm{e}+015.42689 \mathrm{e}+015.42689 \mathrm{e}+001.00000 \mathrm{e}-092.12000 \mathrm{e}-01$ $5.42689 \mathrm{e}+015.42689 \mathrm{e}+015.42689 \mathrm{e}+001.00000 \mathrm{e}-09$ 2.12000e-01 $5.42689 \mathrm{e}+01$ 5.42689e+01 5.42689e+00 1.00000e-09 2.12000e-01 $1.00000 \mathrm{e}-02$ 1.00000e-02 1.00000e-03 1.00000e-09 1.00000e-01 $1.00000 \mathrm{e}+001.00000 \mathrm{e}+001.00000 \mathrm{e}-011.00000 \mathrm{e}-091.00000 \mathrm{e}-01$ $1.00000 \mathrm{e}-05$ 1.00000e-05 1.00000e-06 1.00000e-09 1.00000e-01 $1.00000 \mathrm{e}+001.00000 \mathrm{e}+001.00000 \mathrm{e}-011.00000 \mathrm{e}-091.00000 \mathrm{e}-01$ Element: 8805 \# of layers: 9

$\mathrm{Kx} \mathrm{Ky} \mathrm{Kz}$ Ss Por

5.42689e+01 5.42689e+01 5.42689e+00 1.00000e-09 2.12000e-01 $5.42689 \mathrm{e}+015.42689 \mathrm{e}+015.42689 \mathrm{e}+001.00000 \mathrm{e}-092.12000 \mathrm{e}-01$ $5.42689 \mathrm{e}+015.42689 \mathrm{e}+015.42689 \mathrm{e}+001.00000 \mathrm{e}-09$ 2.12000e-01 $5.42689 \mathrm{e}+015.42689 \mathrm{e}+015.42689 \mathrm{e}+001.00000 \mathrm{e}-09$ 2.12000e-01 $5.42689 \mathrm{e}+015.42689 \mathrm{e}+015.42689 \mathrm{e}+001.00000 \mathrm{e}-092.12000 \mathrm{e}-01$ $1.00000 \mathrm{e}-02$ 1.00000e-02 1.00000e-03 1.00000e-09 1.00000e-01 $1.00000 \mathrm{e}+001.00000 \mathrm{e}+001.00000 \mathrm{e}-011.00000 \mathrm{e}-091.00000 \mathrm{e}-01$ $1.00000 \mathrm{e}-05$ 1.00000e-05 1.00000e-06 1.00000e-09 1.00000e-01 $1.00000 \mathrm{e}+001.00000 \mathrm{e}+001.00000 \mathrm{e}-011.00000 \mathrm{e}-091.00000 \mathrm{e}-01$ Element: 8806 \# of layers: 8

$\mathrm{Kx} \mathrm{Ky} \mathrm{Kz}$ Ss Por

$5.91740 \mathrm{e}+015.91740 \mathrm{e}+015.91740 \mathrm{e}+001.00000 \mathrm{e}-092.12000 \mathrm{e}-01$ $5.91740 \mathrm{e}+015.91740 \mathrm{e}+015.91740 \mathrm{e}+001.00000 \mathrm{e}-092.12000 \mathrm{e}-01$ $5.91740 \mathrm{e}+015.91740 \mathrm{e}+015.91740 \mathrm{e}+001.00000 \mathrm{e}-092.12000 \mathrm{e}-01$ $5.91740 \mathrm{e}+015.91740 \mathrm{e}+015.91740 \mathrm{e}+001.00000 \mathrm{e}-092.12000 \mathrm{e}-01$ $1.00000 \mathrm{e}-021.00000 \mathrm{e}-02$ 1.00000e-03 1.00000e-09 1.00000e-01 $1.00000 \mathrm{e}+001.00000 \mathrm{e}+001.00000 \mathrm{e}-011.00000 \mathrm{e}-091.00000 \mathrm{e}-01$ $1.00000 \mathrm{e}-05$ 1.00000e-05 1.00000e-06 1.00000e-09 1.00000e-01 $1.00000 \mathrm{e}+001.00000 \mathrm{e}+001.00000 \mathrm{e}-011.00000 \mathrm{e}-091.00000 \mathrm{e}-01$ Element: 8807 \# of layers: 9

$\mathrm{Kx} \mathrm{Ky} \mathrm{Kz}$ Ss Por

5.91740e+01 5.91740e+01 5.91740e+00 1.00000e-09 2.12000e-01 $5.91740 \mathrm{e}+015.91740 \mathrm{e}+015.91740 \mathrm{e}+001.00000 \mathrm{e}-092.12000 \mathrm{e}-01$ $5.91740 \mathrm{e}+015.91740 \mathrm{e}+015.91740 \mathrm{e}+001.00000 \mathrm{e}-092.12000 \mathrm{e}-01$ $5.91740 \mathrm{e}+015.91740 \mathrm{e}+015.91740 \mathrm{e}+001.00000 \mathrm{e}-092.12000 \mathrm{e}-01$ $5.91740 \mathrm{e}+015.91740 \mathrm{e}+015.91740 \mathrm{e}+001.00000 \mathrm{e}-092.12000 \mathrm{e}-01$ 1.00000e-02 1.00000e-02 1.00000e-03 1.00000e-09 1.00000e-01 $1.00000 \mathrm{e}+001.00000 \mathrm{e}+001.00000 \mathrm{e}-011.00000 \mathrm{e}-091.00000 \mathrm{e}-01$ $1.00000 \mathrm{e}-051.00000 \mathrm{e}-05$ 1.00000e-06 1.00000e-09 1.00000e-01 $1.00000 \mathrm{e}+001.00000 \mathrm{e}+001.00000 \mathrm{e}-01$ 1.00000e-09 1.00000e-01 Element: 8808 \# of layers: 9

$\mathrm{Kx} \mathrm{Ky} \mathrm{Kz}$ Ss Por

$3.69278 \mathrm{e}+013.69278 \mathrm{e}+013.69278 \mathrm{e}+00$ 1.00000e-09 2.12000e-01 $3.69278 \mathrm{e}+013.69278 \mathrm{e}+01$ 3.69278e+00 1.00000e-09 2.12000e-01 $3.69278 \mathrm{e}+013.69278 \mathrm{e}+013.69278 \mathrm{e}+001.00000 \mathrm{e}-092.12000 \mathrm{e}-01$ $3.69278 \mathrm{e}+013.69278 \mathrm{e}+013.69278 \mathrm{e}+001.00000 \mathrm{e}-092.12000 \mathrm{e}-01$ 
$3.69278 \mathrm{e}+013.69278 \mathrm{e}+013.69278 \mathrm{e}+00$ 1.00000e-09 2.12000e-01 $1.00000 \mathrm{e}-02$ 1.00000e-02 1.00000e-03 1.00000e-09 1.00000e-01 $1.00000 \mathrm{e}+001.00000 \mathrm{e}+001.00000 \mathrm{e}-011.00000 \mathrm{e}-091.00000 \mathrm{e}-01$ $1.00000 \mathrm{e}-05$ 1.00000e-05 1.00000e-06 1.00000e-09 1.00000e-01 $1.00000 \mathrm{e}+001.00000 \mathrm{e}+001.00000 \mathrm{e}-011.00000 \mathrm{e}-091.00000 \mathrm{e}-01$ Element: 8809 \# of layers: 9

$\mathrm{Kx} \mathrm{Ky} \mathrm{Kz}$ Ss Por

4.60000e+01 4.60000e+01 4.60000e+00 1.00000e-09 2.12000e-01 $4.60000 \mathrm{e}+014.60000 \mathrm{e}+014.60000 \mathrm{e}+001.00000 \mathrm{e}-092.12000 \mathrm{e}-01$ $4.60000 \mathrm{e}+014.60000 \mathrm{e}+014.60000 \mathrm{e}+001.00000 \mathrm{e}-092.12000 \mathrm{e}-01$ $4.60000 \mathrm{e}+014.60000 \mathrm{e}+014.60000 \mathrm{e}+00$ 1.00000e-09 2.12000e-01 $4.60000 \mathrm{e}+014.60000 \mathrm{e}+014.60000 \mathrm{e}+001.00000 \mathrm{e}-092.12000 \mathrm{e}-01$ $1.00000 \mathrm{e}-02$ 1.00000e-02 1.00000e-03 1.00000e-09 1.00000e-01 $1.00000 \mathrm{e}+001.00000 \mathrm{e}+001.00000 \mathrm{e}-011.00000 \mathrm{e}-091.00000 \mathrm{e}-01$ $1.00000 \mathrm{e}-05$ 1.00000e-05 1.00000e-06 1.00000e-09 1.00000e-01 $1.00000 \mathrm{e}+001.00000 \mathrm{e}+001.00000 \mathrm{e}-011.00000 \mathrm{e}-091.00000 \mathrm{e}-01$ Element: 8810 \# of layers: 9

$\mathrm{Kx} \mathrm{Ky} \mathrm{Kz}$ Ss Por

$5.42689 \mathrm{e}+015.42689 \mathrm{e}+015.42689 \mathrm{e}+00$ 1.00000e-09 2.12000e-01 $5.42689 \mathrm{e}+015.42689 \mathrm{e}+01$ 5.42689e+00 1.00000e-09 2.12000e-01 $5.42689 \mathrm{e}+015.42689 \mathrm{e}+015.42689 \mathrm{e}+001.00000 \mathrm{e}-092.12000 \mathrm{e}-01$ $5.42689 \mathrm{e}+015.42689 \mathrm{e}+015.42689 \mathrm{e}+001.00000 \mathrm{e}-092.12000 \mathrm{e}-01$ $5.42689 \mathrm{e}+015.42689 \mathrm{e}+015.42689 \mathrm{e}+001.00000 \mathrm{e}-092.12000 \mathrm{e}-01$ $1.00000 \mathrm{e}-02$ 1.00000e-02 1.00000e-03 1.00000e-09 1.00000e-01 $1.00000 \mathrm{e}+001.00000 \mathrm{e}+001.00000 \mathrm{e}-011.00000 \mathrm{e}-091.00000 \mathrm{e}-01$ $1.00000 \mathrm{e}-05$ 1.00000e-05 1.00000e-06 1.00000e-09 1.00000e-01 $1.00000 \mathrm{e}+001.00000 \mathrm{e}+001.00000 \mathrm{e}-011.00000 \mathrm{e}-091.00000 \mathrm{e}-01$ Element: 8811 \# of layers: 9

$\mathrm{Kx} \mathrm{Ky} \mathrm{Kz}$ Ss Por $5.43364 \mathrm{e}+015.43364 \mathrm{e}+015.43364 \mathrm{e}+001.00000 \mathrm{e}-092.12000 \mathrm{e}-01$ $5.43364 \mathrm{e}+015.43364 \mathrm{e}+015.43364 \mathrm{e}+001.00000 \mathrm{e}-092.12000 \mathrm{e}-01$ $5.43364 \mathrm{e}+015.43364 \mathrm{e}+015.43364 \mathrm{e}+001.00000 \mathrm{e}-092.12000 \mathrm{e}-01$ $5.43364 \mathrm{e}+015.43364 \mathrm{e}+015.43364 \mathrm{e}+001.00000 \mathrm{e}-092.12000 \mathrm{e}-01$ $5.43364 \mathrm{e}+015.43364 \mathrm{e}+015.43364 \mathrm{e}+001.00000 \mathrm{e}-092.12000 \mathrm{e}-01$ $1.00000 \mathrm{e}-02$ 1.00000e-02 1.00000e-03 1.00000e-09 1.00000e-01 $1.00000 \mathrm{e}+001.00000 \mathrm{e}+001.00000 \mathrm{e}-011.00000 \mathrm{e}-091.00000 \mathrm{e}-01$ $1.00000 \mathrm{e}-05$ 1.00000e-05 1.00000e-06 1.00000e-09 1.00000e-01 $1.00000 \mathrm{e}+001.00000 \mathrm{e}+001.00000 \mathrm{e}-011.00000 \mathrm{e}-091.00000 \mathrm{e}-01$ Element: 8812 \# of layers: 9

$\mathrm{Kx} \mathrm{Ky} \mathrm{Kz}$ Ss Por $5.43364 \mathrm{e}+01$ 5.43364e+01 5.43364e+00 1.00000e-09 2.12000e-01 $5.43364 \mathrm{e}+015.43364 \mathrm{e}+015.43364 \mathrm{e}+001.00000 \mathrm{e}-092.12000 \mathrm{e}-01$ $5.43364 \mathrm{e}+015.43364 \mathrm{e}+015.43364 \mathrm{e}+001.00000 \mathrm{e}-092.12000 \mathrm{e}-01$ $5.43364 \mathrm{e}+015.43364 \mathrm{e}+015.43364 \mathrm{e}+001.00000 \mathrm{e}-092.12000 \mathrm{e}-01$ $5.43364 \mathrm{e}+015.43364 \mathrm{e}+015.43364 \mathrm{e}+001.00000 \mathrm{e}-092.12000 \mathrm{e}-01$ $1.00000 \mathrm{e}-02$ 1.00000e-02 1.00000e-03 1.00000e-09 1.00000e-01 
$1.00000 \mathrm{e}+001.00000 \mathrm{e}+001.00000 \mathrm{e}-011.00000 \mathrm{e}-091.00000 \mathrm{e}-01$ $1.00000 \mathrm{e}-05$ 1.00000e-05 1.00000e-06 1.00000e-09 1.00000e-01 $1.00000 \mathrm{e}+001.00000 \mathrm{e}+001.00000 \mathrm{e}-011.00000 \mathrm{e}-091.00000 \mathrm{e}-01$ Element: 8813 \# of layers: 9

$\mathrm{Kx} \mathrm{Ky} \mathrm{Kz}$ Ss Por

$5.43364 \mathrm{e}+015.43364 \mathrm{e}+015.43364 \mathrm{e}+001.00000 \mathrm{e}-092.12000 \mathrm{e}-01$ $5.43364 \mathrm{e}+015.43364 \mathrm{e}+015.43364 \mathrm{e}+001.00000 \mathrm{e}-092.12000 \mathrm{e}-01$ $5.43364 \mathrm{e}+015.43364 \mathrm{e}+015.43364 \mathrm{e}+001.00000 \mathrm{e}-092.12000 \mathrm{e}-01$ $5.43364 \mathrm{e}+015.43364 \mathrm{e}+015.43364 \mathrm{e}+001.00000 \mathrm{e}-092.12000 \mathrm{e}-01$ $5.43364 \mathrm{e}+015.43364 \mathrm{e}+015.43364 \mathrm{e}+001.00000 \mathrm{e}-092.12000 \mathrm{e}-01$ $1.00000 \mathrm{e}-02$ 1.00000e-02 1.00000e-03 1.00000e-09 1.00000e-01 $1.00000 \mathrm{e}+001.00000 \mathrm{e}+001.00000 \mathrm{e}-011.00000 \mathrm{e}-091.00000 \mathrm{e}-01$ $1.00000 \mathrm{e}-05$ 1.00000e-05 1.00000e-06 1.00000e-09 1.00000e-01 $1.00000 \mathrm{e}+001.00000 \mathrm{e}+001.00000 \mathrm{e}-011.00000 \mathrm{e}-091.00000 \mathrm{e}-01$ Element: 8814 \# of layers: 9

Kx Ky Kz Ss Por

$5.43364 \mathrm{e}+015.43364 \mathrm{e}+015.43364 \mathrm{e}+00$ 1.00000e-09 2.12000e-01

$5.43364 \mathrm{e}+015.43364 \mathrm{e}+015.43364 \mathrm{e}+001.00000 \mathrm{e}-092.12000 \mathrm{e}-01$ $5.43364 \mathrm{e}+015.43364 \mathrm{e}+015.43364 \mathrm{e}+001.00000 \mathrm{e}-092.12000 \mathrm{e}-01$ $5.43364 \mathrm{e}+015.43364 \mathrm{e}+015.43364 \mathrm{e}+001.00000 \mathrm{e}-092.12000 \mathrm{e}-01$ $5.43364 \mathrm{e}+015.43364 \mathrm{e}+015.43364 \mathrm{e}+001.00000 \mathrm{e}-092.12000 \mathrm{e}-01$ $1.00000 \mathrm{e}-02$ 1.00000e-02 1.00000e-03 1.00000e-09 1.00000e-01 $1.00000 \mathrm{e}+001.00000 \mathrm{e}+001.00000 \mathrm{e}-011.00000 \mathrm{e}-091.00000 \mathrm{e}-01$ $1.00000 \mathrm{e}-05$ 1.00000e-05 1.00000e-06 1.00000e-09 1.00000e-01 $1.00000 \mathrm{e}+001.00000 \mathrm{e}+001.00000 \mathrm{e}-011.00000 \mathrm{e}-091.00000 \mathrm{e}-01$ Element: 8815 \# of layers: 9

$\mathrm{Kx} \mathrm{Ky} \mathrm{Kz}$ Ss Por

5.38977e+02 5.38977e+02 5.38977e+01 1.00000e-09 2.12000e-01 $5.38977 \mathrm{e}+02$ 5.38977e+02 5.38977e+01 1.00000e-09 2.12000e-01 5.38977e+02 5.38977e+02 5.38977e+01 1.00000e-09 2.12000e-01 $5.38977 \mathrm{e}+02$ 5.38977e+02 5.38977e+01 1.00000e-09 2.12000e-01 $5.38977 \mathrm{e}+02$ 5.38977e+02 5.38977e+01 1.00000e-09 2.12000e-01 1.00000e-02 1.00000e-02 1.00000e-03 1.00000e-09 1.00000e-01 $1.00000 \mathrm{e}+001.00000 \mathrm{e}+001.00000 \mathrm{e}-011.00000 \mathrm{e}-091.00000 \mathrm{e}-01$ $1.00000 \mathrm{e}-05$ 1.00000e-05 1.00000e-06 1.00000e-09 1.00000e-01 $1.00000 \mathrm{e}+001.00000 \mathrm{e}+001.00000 \mathrm{e}-011.00000 \mathrm{e}-091.00000 \mathrm{e}-01$ Element: 8816 \# of layers: 9

Kx Ky Kz Ss Por

5.38977e+02 5.38977e+02 5.38977e+01 1.00000e-09 2.12000e-01 5.38977e+02 5.38977e+02 5.38977e+01 1.00000e-09 2.12000e-01 5.38977e+02 5.38977e+02 5.38977e+01 1.00000e-09 2.12000e-01 $5.38977 \mathrm{e}+02$ 5.38977e+02 5.38977e+01 1.00000e-09 2.12000e-01 5.38977e+02 5.38977e+02 5.38977e+01 1.00000e-09 2.12000e-01 $1.00000 \mathrm{e}-021.00000 \mathrm{e}-021.00000 \mathrm{e}-031.00000 \mathrm{e}-091.00000 \mathrm{e}-01$ $1.00000 \mathrm{e}+001.00000 \mathrm{e}+001.00000 \mathrm{e}-011.00000 \mathrm{e}-091.00000 \mathrm{e}-01$ $1.00000 \mathrm{e}-05$ 1.00000e-05 1.00000e-06 1.00000e-09 1.00000e-01 
$1.00000 \mathrm{e}+001.00000 \mathrm{e}+00$ 1.00000e-01 1.00000e-09 1.00000e-01

Element: 8817 \# of layers: 9

$\mathrm{Kx} \mathrm{Ky} \mathrm{Kz}$ Ss Por

$5.43364 \mathrm{e}+015.43364 \mathrm{e}+015.43364 \mathrm{e}+001.00000 \mathrm{e}-09$ 2.12000e-01

$5.43364 \mathrm{e}+015.43364 \mathrm{e}+015.43364 \mathrm{e}+001.00000 \mathrm{e}-092.12000 \mathrm{e}-01$

$5.43364 \mathrm{e}+015.43364 \mathrm{e}+015.43364 \mathrm{e}+001.00000 \mathrm{e}-092.12000 \mathrm{e}-01$

$5.43364 \mathrm{e}+015.43364 \mathrm{e}+015.43364 \mathrm{e}+001.00000 \mathrm{e}-092.12000 \mathrm{e}-01$

$5.43364 \mathrm{e}+015.43364 \mathrm{e}+015.43364 \mathrm{e}+001.00000 \mathrm{e}-092.12000 \mathrm{e}-01$

$1.00000 \mathrm{e}-02$ 1.00000e-02 1.00000e-03 1.00000e-09 1.00000e-01

$1.00000 \mathrm{e}+001.00000 \mathrm{e}+001.00000 \mathrm{e}-01$ 1.00000e-09 1.00000e-01

$1.00000 \mathrm{e}-05$ 1.00000e-05 1.00000e-06 1.00000e-09 1.00000e-01

$1.00000 \mathrm{e}+001.00000 \mathrm{e}+001.00000 \mathrm{e}-011.00000 \mathrm{e}-091.00000 \mathrm{e}-01$

Element: 8818 \# of layers: 9

$\mathrm{Kx} \mathrm{Ky} \mathrm{Kz}$ Ss Por

5.38977e+02 5.38977e+02 5.38977e+01 1.00000e-09 2.12000e-01

$5.38977 \mathrm{e}+025.38977 \mathrm{e}+02$ 5.38977e+01 1.00000e-09 2.12000e-01

5.38977e+02 5.38977e+02 5.38977e+01 1.00000e-09 2.12000e-01

5.38977e+02 5.38977e+02 5.38977e+01 1.00000e-09 2.12000e-01

5.38977e+02 5.38977e+02 5.38977e+01 1.00000e-09 2.12000e-01

$1.00000 \mathrm{e}-02$ 1.00000e-02 1.00000e-03 1.00000e-09 1.00000e-01

$1.00000 \mathrm{e}+001.00000 \mathrm{e}+001.00000 \mathrm{e}-011.00000 \mathrm{e}-091.00000 \mathrm{e}-01$

$1.00000 \mathrm{e}-05$ 1.00000e-05 1.00000e-06 1.00000e-09 1.00000e-01

$1.00000 \mathrm{e}+001.00000 \mathrm{e}+001.00000 \mathrm{e}-01$ 1.00000e-09 1.00000e-01

Element: 8819 \# of layers: 9

Kx Ky Kz Ss Por

5.38977e+02 5.38977e+02 5.38977e+01 1.00000e-09 2.12000e-01

5.38977e+02 5.38977e+02 5.38977e+01 1.00000e-09 2.12000e-01

5.38977e+02 5.38977e+02 5.38977e+01 1.00000e-09 2.12000e-01

$5.38977 \mathrm{e}+02$ 5.38977e+02 5.38977e+01 1.00000e-09 2.12000e-01

5.38977e+02 5.38977e+02 5.38977e+01 1.00000e-09 2.12000e-01

$1.00000 \mathrm{e}-02$ 1.00000e-02 1.00000e-03 1.00000e-09 1.00000e-01

$1.00000 \mathrm{e}+001.00000 \mathrm{e}+001.00000 \mathrm{e}-011.00000 \mathrm{e}-091.00000 \mathrm{e}-01$

1.00000e-05 1.00000e-05 1.00000e-06 1.00000e-09 1.00000e-01

$1.00000 \mathrm{e}+001.00000 \mathrm{e}+001.00000 \mathrm{e}-011.00000 \mathrm{e}-091.00000 \mathrm{e}-01$

Element: 8820 \# of layers: 9

$\mathrm{Kx} \mathrm{Ky} \mathrm{Kz}$ Ss Por

5.38977e+02 5.38977e+02 5.38977e+01 1.00000e-09 2.12000e-01

$5.38977 \mathrm{e}+02$ 5.38977e+02 5.38977e+01 1.00000e-09 2.12000e-01

5.38977e+02 5.38977e+02 5.38977e+01 1.00000e-09 2.12000e-01

5.38977e+02 5.38977e+02 5.38977e+01 1.00000e-09 2.12000e-01

5.38977e+02 5.38977e+02 5.38977e+01 1.00000e-09 2.12000e-01

$1.00000 \mathrm{e}-02$ 1.00000e-02 1.00000e-03 1.00000e-09 1.00000e-01

$1.00000 \mathrm{e}+001.00000 \mathrm{e}+001.00000 \mathrm{e}-011.00000 \mathrm{e}-091.00000 \mathrm{e}-01$

$1.00000 \mathrm{e}-05$ 1.00000e-05 1.00000e-06 1.00000e-09 1.00000e-01

$1.00000 \mathrm{e}+001.00000 \mathrm{e}+001.00000 \mathrm{e}-011.00000 \mathrm{e}-091.00000 \mathrm{e}-01$

Element: 8821 \# of layers: 9 
$\mathrm{Kx} \mathrm{Ky} \mathrm{Kz}$ Ss Por

5.38977e+02 5.38977e+02 5.38977e+01 1.00000e-09 2.12000e-01

5.38977e+02 5.38977e+02 5.38977e+01 1.00000e-09 2.12000e-01

5.38977e+02 5.38977e+02 5.38977e+01 1.00000e-09 2.12000e-01

5.38977e+02 5.38977e+02 5.38977e+01 1.00000e-09 2.12000e-01

5.38977e+02 5.38977e+02 5.38977e+01 1.00000e-09 2.12000e-01

$1.00000 \mathrm{e}-02$ 1.00000e-02 1.00000e-03 1.00000e-09 1.00000e-01

$1.00000 \mathrm{e}+001.00000 \mathrm{e}+001.00000 \mathrm{e}-011.00000 \mathrm{e}-091.00000 \mathrm{e}-01$

$1.00000 \mathrm{e}-05$ 1.00000e-05 1.00000e-06 1.00000e-09 1.00000e-01

$1.00000 \mathrm{e}+001.00000 \mathrm{e}+001.00000 \mathrm{e}-011.00000 \mathrm{e}-091.00000 \mathrm{e}-01$

Element: 8822 \# of layers: 9

$\mathrm{Kx} \mathrm{Ky} \mathrm{Kz}$ Ss Por

5.38977e+02 5.38977e+02 5.38977e+01 1.00000e-09 2.12000e-01

$5.38977 \mathrm{e}+02$ 5.38977e+02 5.38977e+01 1.00000e-09 2.12000e-01

5.38977e+02 5.38977e+02 5.38977e+01 1.00000e-09 2.12000e-01

$5.38977 \mathrm{e}+02$ 5.38977e+02 5.38977e+01 1.00000e-09 2.12000e-01

$5.38977 \mathrm{e}+02$ 5.38977e+02 5.38977e+01 1.00000e-09 2.12000e-01

$1.00000 \mathrm{e}-02$ 1.00000e-02 1.00000e-03 1.00000e-09 1.00000e-01

$1.00000 \mathrm{e}+001.00000 \mathrm{e}+001.00000 \mathrm{e}-011.00000 \mathrm{e}-091.00000 \mathrm{e}-01$

$1.00000 \mathrm{e}-05$ 1.00000e-05 1.00000e-06 1.00000e-09 1.00000e-01

$1.00000 \mathrm{e}+001.00000 \mathrm{e}+001.00000 \mathrm{e}-011.00000 \mathrm{e}-091.00000 \mathrm{e}-01$

Element: 8823 \# of layers: 9

$\mathrm{Kx} \mathrm{Ky} \mathrm{Kz}$ Ss Por

5.70500e+01 5.70500e+01 5.70500e+00 1.00000e-09 2.12000e-01

$5.70500 \mathrm{e}+015.70500 \mathrm{e}+015.70500 \mathrm{e}+001.00000 \mathrm{e}-092.12000 \mathrm{e}-01$

$5.70500 \mathrm{e}+015.70500 \mathrm{e}+015.70500 \mathrm{e}+001.00000 \mathrm{e}-092.12000 \mathrm{e}-01$

$5.70500 \mathrm{e}+015.70500 \mathrm{e}+015.70500 \mathrm{e}+001.00000 \mathrm{e}-092.12000 \mathrm{e}-01$

$5.70500 \mathrm{e}+015.70500 \mathrm{e}+015.70500 \mathrm{e}+001.00000 \mathrm{e}-092.12000 \mathrm{e}-01$

$1.00000 \mathrm{e}-02$ 1.00000e-02 1.00000e-03 1.00000e-09 1.00000e-01

$1.00000 \mathrm{e}+001.00000 \mathrm{e}+001.00000 \mathrm{e}-011.00000 \mathrm{e}-091.00000 \mathrm{e}-01$

$1.00000 \mathrm{e}-05$ 1.00000e-05 1.00000e-06 1.00000e-09 1.00000e-01

$1.00000 \mathrm{e}+001.00000 \mathrm{e}+001.00000 \mathrm{e}-01$ 1.00000e-09 1.00000e-01

Element: 8824 \# of layers: 9

$\mathrm{Kx} \mathrm{Ky} \mathrm{Kz}$ Ss Por

5.38977e+02 5.38977e+02 5.38977e+01 1.00000e-09 2.12000e-01

5.38977e+02 5.38977e+02 5.38977e+01 1.00000e-09 2.12000e-01

$5.38977 \mathrm{e}+025.38977 \mathrm{e}+02$ 5.38977e+01 1.00000e-09 2.12000e-01

5.38977e+02 5.38977e+02 5.38977e+01 1.00000e-09 2.12000e-01

5.38977e+02 5.38977e+02 5.38977e+01 1.00000e-09 2.12000e-01

$1.00000 \mathrm{e}-02$ 1.00000e-02 1.00000e-03 1.00000e-09 1.00000e-01

$1.00000 \mathrm{e}+001.00000 \mathrm{e}+001.00000 \mathrm{e}-011.00000 \mathrm{e}-091.00000 \mathrm{e}-01$

$1.00000 \mathrm{e}-05$ 1.00000e-05 1.00000e-06 1.00000e-09 1.00000e-01

$1.00000 \mathrm{e}+001.00000 \mathrm{e}+001.00000 \mathrm{e}-01$ 1.00000e-09 1.00000e-01

Element: 8825 \# of layers: 9

$\mathrm{Kx} \mathrm{Ky} \mathrm{Kz} \mathrm{Ss} \mathrm{Por}$

5.38977e+02 5.38977e+02 5.38977e+01 1.00000e-09 2.12000e-01 
5.38977e+02 5.38977e+02 5.38977e+01 1.00000e-09 2.12000e-01 5.38977e+02 5.38977e+02 5.38977e+01 1.00000e-09 2.12000e-01 5.38977e+02 5.38977e+02 5.38977e+01 1.00000e-09 2.12000e-01 5.38977e+02 5.38977e+02 5.38977e+01 1.00000e-09 2.12000e-01 $1.00000 \mathrm{e}-02$ 1.00000e-02 1.00000e-03 1.00000e-09 1.00000e-01 $1.00000 \mathrm{e}+001.00000 \mathrm{e}+001.00000 \mathrm{e}-011.00000 \mathrm{e}-091.00000 \mathrm{e}-01$ $1.00000 \mathrm{e}-05$ 1.00000e-05 1.00000e-06 1.00000e-09 1.00000e-01 $1.00000 \mathrm{e}+001.00000 \mathrm{e}+001.00000 \mathrm{e}-011.00000 \mathrm{e}-091.00000 \mathrm{e}-01$ Element: 8826 \# of layers: 9

$\mathrm{Kx} \mathrm{Ky} \mathrm{Kz}$ Ss Por

5.38977e+02 5.38977e+02 5.38977e+01 1.00000e-09 2.12000e-01 5.38977e+02 5.38977e+02 5.38977e+01 1.00000e-09 2.12000e-01 5.38977e+02 5.38977e+02 5.38977e+01 1.00000e-09 2.12000e-01 $5.38977 \mathrm{e}+02$ 5.38977e+02 5.38977e+01 1.00000e-09 2.12000e-01 $5.38977 \mathrm{e}+02$ 5.38977e+02 5.38977e+01 1.00000e-09 2.12000e-01 $1.00000 \mathrm{e}-02$ 1.00000e-02 1.00000e-03 1.00000e-09 1.00000e-01 $1.00000 \mathrm{e}+001.00000 \mathrm{e}+001.00000 \mathrm{e}-011.00000 \mathrm{e}-091.00000 \mathrm{e}-01$ $1.00000 \mathrm{e}-051.00000 \mathrm{e}-05$ 1.00000e-06 1.00000e-09 1.00000e-01 $1.00000 \mathrm{e}+001.00000 \mathrm{e}+001.00000 \mathrm{e}-011.00000 \mathrm{e}-091.00000 \mathrm{e}-01$ Element: 8827 \# of layers: 9

$\mathrm{Kx} \mathrm{Ky} \mathrm{Kz}$ Ss Por

5.38977e+02 5.38977e+02 5.38977e+01 1.00000e-09 2.12000e-01 5.38977e+02 5.38977e+02 5.38977e+01 1.00000e-09 2.12000e-01 5.38977e+02 5.38977e+02 5.38977e+01 1.00000e-09 2.12000e-01 5.38977e+02 5.38977e+02 5.38977e+01 1.00000e-09 2.12000e-01 5.38977e+02 5.38977e+02 5.38977e+01 1.00000e-09 2.12000e-01 $1.00000 \mathrm{e}-02$ 1.00000e-02 1.00000e-03 1.00000e-09 1.00000e-01 $1.00000 \mathrm{e}+001.00000 \mathrm{e}+001.00000 \mathrm{e}-011.00000 \mathrm{e}-091.00000 \mathrm{e}-01$ $1.00000 \mathrm{e}-05$ 1.00000e-05 1.00000e-06 1.00000e-09 1.00000e-01 $1.00000 \mathrm{e}+001.00000 \mathrm{e}+001.00000 \mathrm{e}-011.00000 \mathrm{e}-091.00000 \mathrm{e}-01$ Element: 8828 \# of layers: 9

$\mathrm{Kx} \mathrm{Ky} \mathrm{Kz}$ Ss Por

5.70500e+01 5.70500e+01 5.70500e+00 1.00000e-09 2.12000e-01 $5.70500 \mathrm{e}+015.70500 \mathrm{e}+015.70500 \mathrm{e}+001.00000 \mathrm{e}-092.12000 \mathrm{e}-01$ $5.70500 \mathrm{e}+015.70500 \mathrm{e}+015.70500 \mathrm{e}+001.00000 \mathrm{e}-092.12000 \mathrm{e}-01$ $5.70500 \mathrm{e}+015.70500 \mathrm{e}+015.70500 \mathrm{e}+001.00000 \mathrm{e}-092.12000 \mathrm{e}-01$ $5.70500 \mathrm{e}+015.70500 \mathrm{e}+015.70500 \mathrm{e}+001.00000 \mathrm{e}-092.12000 \mathrm{e}-01$ $1.00000 \mathrm{e}-02$ 1.00000e-02 1.00000e-03 1.00000e-09 1.00000e-01 $1.00000 \mathrm{e}+001.00000 \mathrm{e}+001.00000 \mathrm{e}-011.00000 \mathrm{e}-091.00000 \mathrm{e}-01$ $1.00000 \mathrm{e}-05$ 1.00000e-05 1.00000e-06 1.00000e-09 1.00000e-01 $1.00000 \mathrm{e}+001.00000 \mathrm{e}+001.00000 \mathrm{e}-011.00000 \mathrm{e}-091.00000 \mathrm{e}-01$ Element: 8829 \# of layers: 9

$\mathrm{Kx} \mathrm{Ky} \mathrm{Kz}$ Ss Por

5.70500e+01 5.70500e+01 5.70500e+00 1.00000e-09 2.12000e-01 $5.70500 \mathrm{e}+015.70500 \mathrm{e}+015.70500 \mathrm{e}+001.00000 \mathrm{e}-092.12000 \mathrm{e}-01$ $5.70500 \mathrm{e}+015.70500 \mathrm{e}+015.70500 \mathrm{e}+001.00000 \mathrm{e}-092.12000 \mathrm{e}-01$ 
$5.70500 \mathrm{e}+015.70500 \mathrm{e}+015.70500 \mathrm{e}+00$ 1.00000e-09 2.12000e-01 $5.70500 \mathrm{e}+015.70500 \mathrm{e}+015.70500 \mathrm{e}+001.00000 \mathrm{e}-092.12000 \mathrm{e}-01$ $1.00000 \mathrm{e}-021.00000 \mathrm{e}-02$ 1.00000e-03 1.00000e-09 1.00000e-01 $1.00000 \mathrm{e}+001.00000 \mathrm{e}+001.00000 \mathrm{e}-011.00000 \mathrm{e}-091.00000 \mathrm{e}-01$ $1.00000 \mathrm{e}-05$ 1.00000e-05 1.00000e-06 1.00000e-09 1.00000e-01 $1.00000 \mathrm{e}+001.00000 \mathrm{e}+001.00000 \mathrm{e}-011.00000 \mathrm{e}-091.00000 \mathrm{e}-01$ Element: 8830 \# of layers: 9

Kx Ky Kz Ss Por

$5.70500 \mathrm{e}+015.70500 \mathrm{e}+015.70500 \mathrm{e}+00$ 1.00000e-09 2.12000e-01 $5.70500 \mathrm{e}+015.70500 \mathrm{e}+015.70500 \mathrm{e}+001.00000 \mathrm{e}-092.12000 \mathrm{e}-01$ $5.70500 \mathrm{e}+015.70500 \mathrm{e}+015.70500 \mathrm{e}+001.00000 \mathrm{e}-092.12000 \mathrm{e}-01$ $5.70500 \mathrm{e}+015.70500 \mathrm{e}+015.70500 \mathrm{e}+001.00000 \mathrm{e}-092.12000 \mathrm{e}-01$ $5.70500 \mathrm{e}+015.70500 \mathrm{e}+015.70500 \mathrm{e}+001.00000 \mathrm{e}-092.12000 \mathrm{e}-01$ $1.00000 \mathrm{e}-021.00000 \mathrm{e}-02$ 1.00000e-03 1.00000e-09 1.00000e-01 $1.00000 \mathrm{e}+001.00000 \mathrm{e}+001.00000 \mathrm{e}-011.00000 \mathrm{e}-091.00000 \mathrm{e}-01$ $1.00000 \mathrm{e}-05$ 1.00000e-05 1.00000e-06 1.00000e-09 1.00000e-01 $1.00000 \mathrm{e}+001.00000 \mathrm{e}+001.00000 \mathrm{e}-011.00000 \mathrm{e}-091.00000 \mathrm{e}-01$ Element: 8831 \# of layers: 9

$\mathrm{Kx} \mathrm{Ky} \mathrm{Kz}$ Ss Por

$5.70500 \mathrm{e}+015.70500 \mathrm{e}+015.70500 \mathrm{e}+001.00000 \mathrm{e}-092.12000 \mathrm{e}-01$ $5.70500 \mathrm{e}+015.70500 \mathrm{e}+015.70500 \mathrm{e}+001.00000 \mathrm{e}-092.12000 \mathrm{e}-01$ $5.70500 \mathrm{e}+015.70500 \mathrm{e}+015.70500 \mathrm{e}+001.00000 \mathrm{e}-092.12000 \mathrm{e}-01$ $5.70500 \mathrm{e}+015.70500 \mathrm{e}+015.70500 \mathrm{e}+001.00000 \mathrm{e}-092.12000 \mathrm{e}-01$ $5.70500 \mathrm{e}+015.70500 \mathrm{e}+015.70500 \mathrm{e}+001.00000 \mathrm{e}-092.12000 \mathrm{e}-01$ $1.00000 \mathrm{e}-021.00000 \mathrm{e}-02$ 1.00000e-03 1.00000e-09 1.00000e-01 $1.00000 \mathrm{e}+001.00000 \mathrm{e}+001.00000 \mathrm{e}-011.00000 \mathrm{e}-091.00000 \mathrm{e}-01$ $1.00000 \mathrm{e}-05$ 1.00000e-05 1.00000e-06 1.00000e-09 1.00000e-01 $1.00000 \mathrm{e}+001.00000 \mathrm{e}+001.00000 \mathrm{e}-011.00000 \mathrm{e}-091.00000 \mathrm{e}-01$ Element: 8832 \# of layers: 9

$\mathrm{Kx} \mathrm{Ky} \mathrm{Kz}$ Ss Por

$5.70500 \mathrm{e}+015.70500 \mathrm{e}+015.70500 \mathrm{e}+001.00000 \mathrm{e}-092.12000 \mathrm{e}-01$ $5.70500 \mathrm{e}+015.70500 \mathrm{e}+015.70500 \mathrm{e}+001.00000 \mathrm{e}-092.12000 \mathrm{e}-01$ $5.70500 \mathrm{e}+015.70500 \mathrm{e}+015.70500 \mathrm{e}+001.00000 \mathrm{e}-092.12000 \mathrm{e}-01$ $5.70500 \mathrm{e}+015.70500 \mathrm{e}+015.70500 \mathrm{e}+001.00000 \mathrm{e}-092.12000 \mathrm{e}-01$ $5.70500 \mathrm{e}+015.70500 \mathrm{e}+015.70500 \mathrm{e}+001.00000 \mathrm{e}-092.12000 \mathrm{e}-01$ 1.00000e-02 1.00000e-02 1.00000e-03 1.00000e-09 1.00000e-01 $1.00000 \mathrm{e}+001.00000 \mathrm{e}+001.00000 \mathrm{e}-011.00000 \mathrm{e}-091.00000 \mathrm{e}-01$ $1.00000 \mathrm{e}-05$ 1.00000e-05 1.00000e-06 1.00000e-09 1.00000e-01 $1.00000 \mathrm{e}+001.00000 \mathrm{e}+001.00000 \mathrm{e}-011.00000 \mathrm{e}-091.00000 \mathrm{e}-01$ Element: 8833 \# of layers: 9

$\mathrm{Kx} \mathrm{Ky} \mathrm{Kz}$ Ss Por

5.70500e+01 5.70500e+01 5.70500e+00 1.00000e-09 2.12000e-01 $5.70500 \mathrm{e}+015.70500 \mathrm{e}+015.70500 \mathrm{e}+001.00000 \mathrm{e}-092.12000 \mathrm{e}-01$ $5.70500 \mathrm{e}+015.70500 \mathrm{e}+015.70500 \mathrm{e}+001.00000 \mathrm{e}-092.12000 \mathrm{e}-01$ $5.70500 \mathrm{e}+015.70500 \mathrm{e}+015.70500 \mathrm{e}+001.00000 \mathrm{e}-092.12000 \mathrm{e}-01$ $5.70500 \mathrm{e}+015.70500 \mathrm{e}+015.70500 \mathrm{e}+001.00000 \mathrm{e}-092.12000 \mathrm{e}-01$ 
$1.00000 \mathrm{e}-02$ 1.00000e-02 1.00000e-03 1.00000e-09 1.00000e-01 $1.00000 \mathrm{e}+001.00000 \mathrm{e}+001.00000 \mathrm{e}-011.00000 \mathrm{e}-091.00000 \mathrm{e}-01$ $1.00000 \mathrm{e}-05$ 1.00000e-05 1.00000e-06 1.00000e-09 1.00000e-01 $1.00000 \mathrm{e}+001.00000 \mathrm{e}+001.00000 \mathrm{e}-011.00000 \mathrm{e}-091.00000 \mathrm{e}-01$ Element: 8834 \# of layers: 9

Kx Ky Kz Ss Por

$5.97163 \mathrm{e}+015.97163 \mathrm{e}+01$ 5.97163e+00 1.00000e-09 2.12000e-01 $5.97163 \mathrm{e}+015.97163 \mathrm{e}+015.97163 \mathrm{e}+001.00000 \mathrm{e}-092.12000 \mathrm{e}-01$ $5.97163 \mathrm{e}+015.97163 \mathrm{e}+015.97163 \mathrm{e}+00$ 1.00000e-09 2.12000e-01 $5.97163 \mathrm{e}+015.97163 \mathrm{e}+015.97163 \mathrm{e}+001.00000 \mathrm{e}-092.12000 \mathrm{e}-01$ $5.97163 \mathrm{e}+015.97163 \mathrm{e}+015.97163 \mathrm{e}+001.00000 \mathrm{e}-092.12000 \mathrm{e}-01$ $1.00000 \mathrm{e}-021.00000 \mathrm{e}-02$ 1.00000e-03 1.00000e-09 1.00000e-01 $1.00000 \mathrm{e}+001.00000 \mathrm{e}+001.00000 \mathrm{e}-011.00000 \mathrm{e}-091.00000 \mathrm{e}-01$ $1.00000 \mathrm{e}-05$ 1.00000e-05 1.00000e-06 1.00000e-09 1.00000e-01 $1.00000 \mathrm{e}+001.00000 \mathrm{e}+001.00000 \mathrm{e}-011.00000 \mathrm{e}-091.00000 \mathrm{e}-01$ Element: 8835 \# of layers: 9

Kx Ky Kz Ss Por

$5.97163 \mathrm{e}+015.97163 \mathrm{e}+01$ 5.97163e+00 1.00000e-09 2.12000e-01 $5.97163 \mathrm{e}+015.97163 \mathrm{e}+015.97163 \mathrm{e}+001.00000 \mathrm{e}-092.12000 \mathrm{e}-01$ $5.97163 \mathrm{e}+015.97163 \mathrm{e}+015.97163 \mathrm{e}+001.00000 \mathrm{e}-092.12000 \mathrm{e}-01$ $5.97163 \mathrm{e}+015.97163 \mathrm{e}+015.97163 \mathrm{e}+001.00000 \mathrm{e}-092.12000 \mathrm{e}-01$ $5.97163 \mathrm{e}+015.97163 \mathrm{e}+01$ 5.97163e+00 1.00000e-09 2.12000e-01 $1.00000 \mathrm{e}-02$ 1.00000e-02 1.00000e-03 1.00000e-09 1.00000e-01 $1.00000 \mathrm{e}+001.00000 \mathrm{e}+001.00000 \mathrm{e}-011.00000 \mathrm{e}-091.00000 \mathrm{e}-01$ $1.00000 \mathrm{e}-05$ 1.00000e-05 1.00000e-06 1.00000e-09 1.00000e-01 $1.00000 \mathrm{e}+001.00000 \mathrm{e}+00$ 1.00000e-01 1.00000e-09 1.00000e-01 Element: 8836 \# of layers: 9

Kx Ky Kz Ss Por

$5.97163 e+015.97163 e+015.97163 e+001.00000 e-092.12000 e-01$ $5.97163 \mathrm{e}+015.97163 \mathrm{e}+015.97163 \mathrm{e}+001.00000 \mathrm{e}-092.12000 \mathrm{e}-01$ $5.97163 \mathrm{e}+015.97163 \mathrm{e}+015.97163 \mathrm{e}+001.00000 \mathrm{e}-092.12000 \mathrm{e}-01$ $5.97163 \mathrm{e}+015.97163 \mathrm{e}+015.97163 \mathrm{e}+001.00000 \mathrm{e}-092.12000 \mathrm{e}-01$ $5.97163 \mathrm{e}+015.97163 \mathrm{e}+015.97163 \mathrm{e}+001.00000 \mathrm{e}-092.12000 \mathrm{e}-01$ $1.00000 \mathrm{e}-021.00000 \mathrm{e}-02$ 1.00000e-03 1.00000e-09 1.00000e-01 $1.00000 \mathrm{e}+001.00000 \mathrm{e}+001.00000 \mathrm{e}-011.00000 \mathrm{e}-091.00000 \mathrm{e}-01$ $1.00000 \mathrm{e}-05$ 1.00000e-05 1.00000e-06 1.00000e-09 1.00000e-01 $1.00000 \mathrm{e}+001.00000 \mathrm{e}+001.00000 \mathrm{e}-011.00000 \mathrm{e}-091.00000 \mathrm{e}-01$ Element: 8837 \# of layers: 9

Kx Ky Kz Ss Por

$5.70500 \mathrm{e}+015.70500 \mathrm{e}+015.70500 \mathrm{e}+00$ 1.00000e-09 2.12000e-01 $5.70500 \mathrm{e}+015.70500 \mathrm{e}+015.70500 \mathrm{e}+001.00000 \mathrm{e}-092.12000 \mathrm{e}-01$ $5.70500 \mathrm{e}+015.70500 \mathrm{e}+015.70500 \mathrm{e}+001.00000 \mathrm{e}-092.12000 \mathrm{e}-01$ $5.70500 \mathrm{e}+015.70500 \mathrm{e}+015.70500 \mathrm{e}+001.00000 \mathrm{e}-092.12000 \mathrm{e}-01$ $5.70500 \mathrm{e}+015.70500 \mathrm{e}+015.70500 \mathrm{e}+001.00000 \mathrm{e}-092.12000 \mathrm{e}-01$ $1.00000 \mathrm{e}-02$ 1.00000e-02 1.00000e-03 1.00000e-09 1.00000e-01 $1.00000 \mathrm{e}+001.00000 \mathrm{e}+001.00000 \mathrm{e}-011.00000 \mathrm{e}-091.00000 \mathrm{e}-01$ 
$1.00000 \mathrm{e}-05$ 1.00000e-05 1.00000e-06 1.00000e-09 1.00000e-01 $1.00000 \mathrm{e}+001.00000 \mathrm{e}+001.00000 \mathrm{e}-01$ 1.00000e-09 1.00000e-01 Element: 8838 \# of layers: 9

Kx Ky Kz Ss Por

$5.70500 \mathrm{e}+015.70500 \mathrm{e}+015.70500 \mathrm{e}+001.00000 \mathrm{e}-092.12000 \mathrm{e}-01$

$5.70500 \mathrm{e}+015.70500 \mathrm{e}+015.70500 \mathrm{e}+001.00000 \mathrm{e}-092.12000 \mathrm{e}-01$

$5.70500 \mathrm{e}+015.70500 \mathrm{e}+015.70500 \mathrm{e}+001.00000 \mathrm{e}-092.12000 \mathrm{e}-01$

$5.70500 \mathrm{e}+015.70500 \mathrm{e}+015.70500 \mathrm{e}+001.00000 \mathrm{e}-092.12000 \mathrm{e}-01$

$5.70500 \mathrm{e}+015.70500 \mathrm{e}+015.70500 \mathrm{e}+001.00000 \mathrm{e}-092.12000 \mathrm{e}-01$

1.00000e-02 1.00000e-02 1.00000e-03 1.00000e-09 1.00000e-01

$1.00000 \mathrm{e}+001.00000 \mathrm{e}+001.00000 \mathrm{e}-011.00000 \mathrm{e}-091.00000 \mathrm{e}-01$

$1.00000 \mathrm{e}-05$ 1.00000e-05 1.00000e-06 1.00000e-09 1.00000e-01

$1.00000 \mathrm{e}+001.00000 \mathrm{e}+001.00000 \mathrm{e}-01$ 1.00000e-09 1.00000e-01

Element: 8839 \# of layers: 9

$\mathrm{Kx} \mathrm{Ky} \mathrm{Kz}$ Ss Por

5.70500e+01 5.70500e+01 5.70500e+00 1.00000e-09 2.12000e-01

$5.70500 \mathrm{e}+015.70500 \mathrm{e}+015.70500 \mathrm{e}+001.00000 \mathrm{e}-092.12000 \mathrm{e}-01$

$5.70500 \mathrm{e}+015.70500 \mathrm{e}+015.70500 \mathrm{e}+001.00000 \mathrm{e}-092.12000 \mathrm{e}-01$

$5.70500 \mathrm{e}+015.70500 \mathrm{e}+015.70500 \mathrm{e}+001.00000 \mathrm{e}-092.12000 \mathrm{e}-01$

$5.70500 \mathrm{e}+015.70500 \mathrm{e}+015.70500 \mathrm{e}+001.00000 \mathrm{e}-092.12000 \mathrm{e}-01$

$1.00000 \mathrm{e}-02$ 1.00000e-02 1.00000e-03 1.00000e-09 1.00000e-01

$1.00000 \mathrm{e}+001.00000 \mathrm{e}+001.00000 \mathrm{e}-011.00000 \mathrm{e}-091.00000 \mathrm{e}-01$

$1.00000 \mathrm{e}-05$ 1.00000e-05 1.00000e-06 1.00000e-09 1.00000e-01

$1.00000 \mathrm{e}+001.00000 \mathrm{e}+001.00000 \mathrm{e}-011.00000 \mathrm{e}-091.00000 \mathrm{e}-01$

Element: 8840 \# of layers: 9

$\mathrm{Kx} \mathrm{Ky} \mathrm{Kz}$ Ss Por

$5.70500 \mathrm{e}+015.70500 \mathrm{e}+015.70500 \mathrm{e}+00$ 1.00000e-09 2.12000e-01

$5.70500 \mathrm{e}+015.70500 \mathrm{e}+015.70500 \mathrm{e}+001.00000 \mathrm{e}-092.12000 \mathrm{e}-01$

$5.70500 \mathrm{e}+015.70500 \mathrm{e}+015.70500 \mathrm{e}+001.00000 \mathrm{e}-092.12000 \mathrm{e}-01$

$5.70500 \mathrm{e}+015.70500 \mathrm{e}+015.70500 \mathrm{e}+001.00000 \mathrm{e}-092.12000 \mathrm{e}-01$

$5.70500 \mathrm{e}+015.70500 \mathrm{e}+015.70500 \mathrm{e}+001.00000 \mathrm{e}-092.12000 \mathrm{e}-01$

$1.00000 \mathrm{e}-02$ 1.00000e-02 1.00000e-03 1.00000e-09 1.00000e-01

$1.00000 \mathrm{e}+001.00000 \mathrm{e}+001.00000 \mathrm{e}-011.00000 \mathrm{e}-091.00000 \mathrm{e}-01$

$1.00000 \mathrm{e}-05$ 1.00000e-05 1.00000e-06 1.00000e-09 1.00000e-01

$1.00000 \mathrm{e}+001.00000 \mathrm{e}+001.00000 \mathrm{e}-011.00000 \mathrm{e}-091.00000 \mathrm{e}-01$

Element: 8841 \# of layers: 8

Kx Ky Kz Ss Por

5.97163e+01 5.97163e+01 5.97163e+00 1.00000e-09 2.12000e-01

$5.97163 \mathrm{e}+015.97163 \mathrm{e}+01$ 5.97163e+00 1.00000e-09 2.12000e-01

$5.97163 \mathrm{e}+015.97163 \mathrm{e}+015.97163 \mathrm{e}+001.00000 \mathrm{e}-092.12000 \mathrm{e}-01$

$5.97163 \mathrm{e}+015.97163 \mathrm{e}+015.97163 \mathrm{e}+001.00000 \mathrm{e}-092.12000 \mathrm{e}-01$

$1.00000 \mathrm{e}-02$ 1.00000e-02 1.00000e-03 1.00000e-09 1.00000e-01

$1.00000 \mathrm{e}+001.00000 \mathrm{e}+001.00000 \mathrm{e}-011.00000 \mathrm{e}-091.00000 \mathrm{e}-01$

$1.00000 \mathrm{e}-05$ 1.00000e-05 1.00000e-06 1.00000e-09 1.00000e-01

$1.00000 \mathrm{e}+001.00000 \mathrm{e}+001.00000 \mathrm{e}-011.00000 \mathrm{e}-091.00000 \mathrm{e}-01$

Element: 8842 \# of layers: 8 
$\mathrm{Kx} \mathrm{Ky} \mathrm{Kz}$ Ss Por

5.97163e+01 5.97163e+01 5.97163e+00 1.00000e-09 2.12000e-01

$5.97163 \mathrm{e}+015.97163 \mathrm{e}+015.97163 \mathrm{e}+001.00000 \mathrm{e}-09$ 2.12000e-01

$5.97163 e+015.97163 e+015.97163 e+001.00000 e-092.12000 e-01$

$5.97163 \mathrm{e}+015.97163 \mathrm{e}+015.97163 \mathrm{e}+001.00000 \mathrm{e}-092.12000 \mathrm{e}-01$

$1.00000 \mathrm{e}-02$ 1.00000e-02 1.00000e-03 1.00000e-09 1.00000e-01

$1.00000 \mathrm{e}+001.00000 \mathrm{e}+001.00000 \mathrm{e}-011.00000 \mathrm{e}-091.00000 \mathrm{e}-01$

$1.00000 \mathrm{e}-05$ 1.00000e-05 1.00000e-06 1.00000e-09 1.00000e-01

$1.00000 \mathrm{e}+001.00000 \mathrm{e}+001.00000 \mathrm{e}-011.00000 \mathrm{e}-091.00000 \mathrm{e}-01$

Element: 8843 \# of layers: 8

Kx Ky Kz Ss Por

5.97163e+01 5.97163e+01 5.97163e+00 1.00000e-09 2.12000e-01

$5.97163 \mathrm{e}+01$ 5.97163e+01 5.97163e+00 1.00000e-09 2.12000e-01

5.97163e+01 5.97163e+01 5.97163e+00 1.00000e-09 2.12000e-01

$5.97163 \mathrm{e}+015.97163 \mathrm{e}+015.97163 \mathrm{e}+001.00000 \mathrm{e}-092.12000 \mathrm{e}-01$

$1.00000 \mathrm{e}-02$ 1.00000e-02 1.00000e-03 1.00000e-09 1.00000e-01

$1.00000 \mathrm{e}+001.00000 \mathrm{e}+001.00000 \mathrm{e}-011.00000 \mathrm{e}-091.00000 \mathrm{e}-01$

$1.00000 \mathrm{e}-05$ 1.00000e-05 1.00000e-06 1.00000e-09 1.00000e-01

$1.00000 \mathrm{e}+001.00000 \mathrm{e}+001.00000 \mathrm{e}-011.00000 \mathrm{e}-091.00000 \mathrm{e}-01$

Element: 8844 \# of layers: 8

$\mathrm{Kx} \mathrm{Ky} \mathrm{Kz}$ Ss Por

5.97163e+01 5.97163e+01 5.97163e+00 1.00000e-09 2.12000e-01

5.97163e+01 5.97163e+01 5.97163e+00 1.00000e-09 2.12000e-01

$5.97163 \mathrm{e}+015.97163 \mathrm{e}+015.97163 \mathrm{e}+001.00000 \mathrm{e}-092.12000 \mathrm{e}-01$

$5.97163 \mathrm{e}+015.97163 \mathrm{e}+015.97163 \mathrm{e}+00$ 1.00000e-09 2.12000e-01

$1.00000 \mathrm{e}-02$ 1.00000e-02 1.00000e-03 1.00000e-09 1.00000e-01

$1.00000 \mathrm{e}+001.00000 \mathrm{e}+001.00000 \mathrm{e}-011.00000 \mathrm{e}-091.00000 \mathrm{e}-01$

$1.00000 \mathrm{e}-05$ 1.00000e-05 1.00000e-06 1.00000e-09 1.00000e-01

$1.00000 \mathrm{e}+001.00000 \mathrm{e}+001.00000 \mathrm{e}-011.00000 \mathrm{e}-091.00000 \mathrm{e}-01$

Element: 8845 \# of layers: 8

$\mathrm{Kx} \mathrm{Ky} \mathrm{Kz}$ Ss Por

5.97163e+01 5.97163e+01 5.97163e+00 1.00000e-09 2.12000e-01

$5.97163 \mathrm{e}+015.97163 \mathrm{e}+015.97163 \mathrm{e}+001.00000 \mathrm{e}-092.12000 \mathrm{e}-01$

5.97163e+01 5.97163e+01 5.97163e+00 1.00000e-09 2.12000e-01

$5.97163 \mathrm{e}+015.97163 \mathrm{e}+015.97163 \mathrm{e}+00$ 1.00000e-09 2.12000e-01

1.00000e-02 1.00000e-02 1.00000e-03 1.00000e-09 1.00000e-01

$1.00000 \mathrm{e}+001.00000 \mathrm{e}+001.00000 \mathrm{e}-011.00000 \mathrm{e}-091.00000 \mathrm{e}-01$

$1.00000 \mathrm{e}-05$ 1.00000e-05 1.00000e-06 1.00000e-09 1.00000e-01

$1.00000 \mathrm{e}+001.00000 \mathrm{e}+001.00000 \mathrm{e}-011.00000 \mathrm{e}-091.00000 \mathrm{e}-01$

Element: 8846 \# of layers: 8

$\mathrm{Kx} \mathrm{Ky} \mathrm{Kz}$ Ss Por

5.97163e+01 5.97163e+01 5.97163e+00 1.00000e-09 2.12000e-01

5.97163e+01 5.97163e+01 5.97163e+00 1.00000e-09 2.12000e-01

5.97163e+01 5.97163e+01 5.97163e+00 1.00000e-09 2.12000e-01

$5.97163 \mathrm{e}+015.97163 \mathrm{e}+015.97163 \mathrm{e}+001.00000 \mathrm{e}-092.12000 \mathrm{e}-01$

$1.00000 \mathrm{e}-02$ 1.00000e-02 1.00000e-03 1.00000e-09 1.00000e-01 
$1.00000 \mathrm{e}+001.00000 \mathrm{e}+001.00000 \mathrm{e}-011.00000 \mathrm{e}-091.00000 \mathrm{e}-01$ $1.00000 \mathrm{e}-05$ 1.00000e-05 1.00000e-06 1.00000e-09 1.00000e-01 $1.00000 \mathrm{e}+001.00000 \mathrm{e}+001.00000 \mathrm{e}-011.00000 \mathrm{e}-091.00000 \mathrm{e}-01$ Element: 8847 \# of layers: 9

$\mathrm{Kx} \mathrm{Ky} \mathrm{Kz}$ Ss Por

5.97163e+01 5.97163e+01 5.97163e+00 1.00000e-09 2.12000e-01 $5.97163 \mathrm{e}+015.97163 \mathrm{e}+01$ 5.97163e+00 1.00000e-09 2.12000e-01 $5.97163 \mathrm{e}+015.97163 \mathrm{e}+015.97163 \mathrm{e}+001.00000 \mathrm{e}-092.12000 \mathrm{e}-01$ $5.97163 \mathrm{e}+015.97163 \mathrm{e}+015.97163 \mathrm{e}+001.00000 \mathrm{e}-092.12000 \mathrm{e}-01$ $5.97163 \mathrm{e}+015.97163 \mathrm{e}+015.97163 \mathrm{e}+001.00000 \mathrm{e}-092.12000 \mathrm{e}-01$ $1.00000 \mathrm{e}-02$ 1.00000e-02 1.00000e-03 1.00000e-09 1.00000e-01 $1.00000 \mathrm{e}+001.00000 \mathrm{e}+001.00000 \mathrm{e}-011.00000 \mathrm{e}-091.00000 \mathrm{e}-01$ $1.00000 \mathrm{e}-05$ 1.00000e-05 1.00000e-06 1.00000e-09 1.00000e-01 $1.00000 \mathrm{e}+001.00000 \mathrm{e}+001.00000 \mathrm{e}-011.00000 \mathrm{e}-091.00000 \mathrm{e}-01$ Element: 8848 \# of layers: 8

Kx Ky Kz Ss Por

5.97163e+01 5.97163e+01 5.97163e+00 1.00000e-09 2.12000e-01 $5.97163 \mathrm{e}+015.97163 \mathrm{e}+015.97163 \mathrm{e}+001.00000 \mathrm{e}-09$ 2.12000e-01 $5.97163 \mathrm{e}+015.97163 \mathrm{e}+015.97163 \mathrm{e}+001.00000 \mathrm{e}-092.12000 \mathrm{e}-01$ $5.97163 \mathrm{e}+015.97163 \mathrm{e}+015.97163 \mathrm{e}+001.00000 \mathrm{e}-092.12000 \mathrm{e}-01$ $1.00000 \mathrm{e}-02$ 1.00000e-02 1.00000e-03 1.00000e-09 1.00000e-01 $1.00000 \mathrm{e}+001.00000 \mathrm{e}+001.00000 \mathrm{e}-011.00000 \mathrm{e}-091.00000 \mathrm{e}-01$ $1.00000 \mathrm{e}-05$ 1.00000e-05 1.00000e-06 1.00000e-09 1.00000e-01 $1.00000 \mathrm{e}+001.00000 \mathrm{e}+001.00000 \mathrm{e}-011.00000 \mathrm{e}-091.00000 \mathrm{e}-01$ Element: 8849 \# of layers: 8

$\mathrm{Kx} \mathrm{Ky} \mathrm{Kz}$ Ss Por

5.97163e+01 5.97163e+01 5.97163e+00 1.00000e-09 2.12000e-01 $5.97163 \mathrm{e}+015.97163 \mathrm{e}+01$ 5.97163e+00 1.00000e-09 2.12000e-01 $5.97163 \mathrm{e}+015.97163 \mathrm{e}+015.97163 \mathrm{e}+001.00000 \mathrm{e}-092.12000 \mathrm{e}-01$ $5.97163 \mathrm{e}+015.97163 \mathrm{e}+015.97163 \mathrm{e}+001.00000 \mathrm{e}-092.12000 \mathrm{e}-01$ $1.00000 \mathrm{e}-02$ 1.00000e-02 1.00000e-03 1.00000e-09 1.00000e-01 $1.00000 \mathrm{e}+001.00000 \mathrm{e}+001.00000 \mathrm{e}-011.00000 \mathrm{e}-091.00000 \mathrm{e}-01$ 1.00000e-05 1.00000e-05 1.00000e-06 1.00000e-09 1.00000e-01 $1.00000 \mathrm{e}+001.00000 \mathrm{e}+001.00000 \mathrm{e}-011.00000 \mathrm{e}-091.00000 \mathrm{e}-01$ Element: 8850 \# of layers: 9

Kx Ky Kz Ss Por

5.97163e+01 5.97163e+01 5.97163e+00 1.00000e-09 2.12000e-01 $5.97163 \mathrm{e}+015.97163 \mathrm{e}+015.97163 \mathrm{e}+00$ 1.00000e-09 2.12000e-01 $5.97163 \mathrm{e}+015.97163 \mathrm{e}+01$ 5.97163e+00 1.00000e-09 2.12000e-01 $5.97163 \mathrm{e}+015.97163 \mathrm{e}+01$ 5.97163e+00 1.00000e-09 2.12000e-01 $5.97163 \mathrm{e}+015.97163 \mathrm{e}+015.97163 \mathrm{e}+001.00000 \mathrm{e}-092.12000 \mathrm{e}-01$ $1.00000 \mathrm{e}-02$ 1.00000e-02 1.00000e-03 1.00000e-09 1.00000e-01 $1.00000 \mathrm{e}+001.00000 \mathrm{e}+001.00000 \mathrm{e}-011.00000 \mathrm{e}-091.00000 \mathrm{e}-01$ $1.00000 \mathrm{e}-05$ 1.00000e-05 1.00000e-06 1.00000e-09 1.00000e-01 $1.00000 \mathrm{e}+001.00000 \mathrm{e}+001.00000 \mathrm{e}-01$ 1.00000e-09 1.00000e-01 Element: 8851 \# of layers: 9 
$\mathrm{Kx} \mathrm{Ky} \mathrm{Kz} \mathrm{Ss} \mathrm{Por}$

$5.43364 \mathrm{e}+015.43364 \mathrm{e}+015.43364 \mathrm{e}+00$ 1.00000e-09 2.12000e-01

$5.43364 \mathrm{e}+015.43364 \mathrm{e}+015.43364 \mathrm{e}+001.00000 \mathrm{e}-092.12000 \mathrm{e}-01$

$5.43364 \mathrm{e}+015.43364 \mathrm{e}+015.43364 \mathrm{e}+001.00000 \mathrm{e}-092.12000 \mathrm{e}-01$

$5.43364 \mathrm{e}+015.43364 \mathrm{e}+015.43364 \mathrm{e}+001.00000 \mathrm{e}-092.12000 \mathrm{e}-01$

$5.43364 \mathrm{e}+015.43364 \mathrm{e}+015.43364 \mathrm{e}+001.00000 \mathrm{e}-092.12000 \mathrm{e}-01$

$1.00000 \mathrm{e}-02$ 1.00000e-02 1.00000e-03 1.00000e-09 1.00000e-01

$1.00000 \mathrm{e}+001.00000 \mathrm{e}+001.00000 \mathrm{e}-011.00000 \mathrm{e}-091.00000 \mathrm{e}-01$

$1.00000 \mathrm{e}-05$ 1.00000e-05 1.00000e-06 1.00000e-09 1.00000e-01

$1.00000 \mathrm{e}+001.00000 \mathrm{e}+001.00000 \mathrm{e}-011.00000 \mathrm{e}-09$ 1.00000e-01

Element: 8852 \# of layers: 9

Kx Ky Kz Ss Por

5.43364e+01 5.43364e+01 5.43364e+00 1.00000e-09 2.12000e-01

$5.43364 \mathrm{e}+015.43364 \mathrm{e}+015.43364 \mathrm{e}+001.00000 \mathrm{e}-092.12000 \mathrm{e}-01$

$5.43364 \mathrm{e}+015.43364 \mathrm{e}+015.43364 \mathrm{e}+001.00000 \mathrm{e}-092.12000 \mathrm{e}-01$

$5.43364 \mathrm{e}+015.43364 \mathrm{e}+015.43364 \mathrm{e}+001.00000 \mathrm{e}-092.12000 \mathrm{e}-01$

$5.43364 \mathrm{e}+015.43364 \mathrm{e}+015.43364 \mathrm{e}+001.00000 \mathrm{e}-092.12000 \mathrm{e}-01$

$1.00000 \mathrm{e}-02$ 1.00000e-02 1.00000e-03 1.00000e-09 1.00000e-01

$1.00000 \mathrm{e}+001.00000 \mathrm{e}+001.00000 \mathrm{e}-011.00000 \mathrm{e}-091.00000 \mathrm{e}-01$

$1.00000 \mathrm{e}-05$ 1.00000e-05 1.00000e-06 1.00000e-09 1.00000e-01

$1.00000 \mathrm{e}+001.00000 \mathrm{e}+001.00000 \mathrm{e}-011.00000 \mathrm{e}-091.00000 \mathrm{e}-01$

Element: 8853 \# of layers: 9

$\mathrm{Kx} \mathrm{Ky} \mathrm{Kz}$ Ss Por

$5.43364 \mathrm{e}+015.43364 \mathrm{e}+015.43364 \mathrm{e}+00$ 1.00000e-09 2.12000e-01

$5.43364 \mathrm{e}+015.43364 \mathrm{e}+015.43364 \mathrm{e}+001.00000 \mathrm{e}-092.12000 \mathrm{e}-01$

$5.43364 \mathrm{e}+015.43364 \mathrm{e}+015.43364 \mathrm{e}+001.00000 \mathrm{e}-092.12000 \mathrm{e}-01$

$5.43364 \mathrm{e}+015.43364 \mathrm{e}+015.43364 \mathrm{e}+001.00000 \mathrm{e}-092.12000 \mathrm{e}-01$

$5.43364 \mathrm{e}+015.43364 \mathrm{e}+015.43364 \mathrm{e}+001.00000 \mathrm{e}-092.12000 \mathrm{e}-01$

$1.00000 \mathrm{e}-02$ 1.00000e-02 1.00000e-03 1.00000e-09 1.00000e-01

$1.00000 \mathrm{e}+001.00000 \mathrm{e}+001.00000 \mathrm{e}-011.00000 \mathrm{e}-091.00000 \mathrm{e}-01$

$1.00000 \mathrm{e}-05$ 1.00000e-05 1.00000e-06 1.00000e-09 1.00000e-01

$1.00000 \mathrm{e}+001.00000 \mathrm{e}+001.00000 \mathrm{e}-011.00000 \mathrm{e}-091.00000 \mathrm{e}-01$

Element: 8854 \# of layers: 9

$\mathrm{Kx} \mathrm{Ky} \mathrm{Kz}$ Ss Por

$5.43364 \mathrm{e}+015.43364 \mathrm{e}+015.43364 \mathrm{e}+00$ 1.00000e-09 2.12000e-01

$5.43364 \mathrm{e}+015.43364 \mathrm{e}+015.43364 \mathrm{e}+001.00000 \mathrm{e}-092.12000 \mathrm{e}-01$

$5.43364 \mathrm{e}+015.43364 \mathrm{e}+015.43364 \mathrm{e}+001.00000 \mathrm{e}-092.12000 \mathrm{e}-01$

$5.43364 \mathrm{e}+015.43364 \mathrm{e}+015.43364 \mathrm{e}+001.00000 \mathrm{e}-092.12000 \mathrm{e}-01$

$5.43364 \mathrm{e}+015.43364 \mathrm{e}+015.43364 \mathrm{e}+001.00000 \mathrm{e}-092.12000 \mathrm{e}-01$

$1.00000 \mathrm{e}-02$ 1.00000e-02 1.00000e-03 1.00000e-09 1.00000e-01

$1.00000 \mathrm{e}+001.00000 \mathrm{e}+001.00000 \mathrm{e}-011.00000 \mathrm{e}-091.00000 \mathrm{e}-01$

$1.00000 \mathrm{e}-05$ 1.00000e-05 1.00000e-06 1.00000e-09 1.00000e-01

$1.00000 \mathrm{e}+001.00000 \mathrm{e}+001.00000 \mathrm{e}-011.00000 \mathrm{e}-091.00000 \mathrm{e}-01$

Element: 8855 \# of layers: 9

$\mathrm{Kx} \mathrm{Ky} \mathrm{Kz}$ Ss Por

5.43364e+01 5.43364e+01 5.43364e+00 1.00000e-09 2.12000e-01 
$5.43364 \mathrm{e}+015.43364 \mathrm{e}+015.43364 \mathrm{e}+001.00000 \mathrm{e}-092.12000 \mathrm{e}-01$ $5.43364 \mathrm{e}+015.43364 \mathrm{e}+015.43364 \mathrm{e}+001.00000 \mathrm{e}-092.12000 \mathrm{e}-01$ $5.43364 \mathrm{e}+015.43364 \mathrm{e}+015.43364 \mathrm{e}+001.00000 \mathrm{e}-092.12000 \mathrm{e}-01$ $5.43364 \mathrm{e}+015.43364 \mathrm{e}+015.43364 \mathrm{e}+001.00000 \mathrm{e}-092.12000 \mathrm{e}-01$ $1.00000 \mathrm{e}-021.00000 \mathrm{e}-021.00000 \mathrm{e}-031.00000 \mathrm{e}-091.00000 \mathrm{e}-01$ $1.00000 \mathrm{e}+001.00000 \mathrm{e}+001.00000 \mathrm{e}-011.00000 \mathrm{e}-091.00000 \mathrm{e}-01$ $1.00000 \mathrm{e}-05$ 1.00000e-05 1.00000e-06 1.00000e-09 1.00000e-01 $1.00000 \mathrm{e}+001.00000 \mathrm{e}+001.00000 \mathrm{e}-011.00000 \mathrm{e}-091.00000 \mathrm{e}-01$ Element: 8856 \# of layers: 9

$\mathrm{Kx} \mathrm{Ky} \mathrm{Kz}$ Ss Por

5.97163e+01 5.97163e+01 5.97163e+00 1.00000e-09 2.12000e-01 $5.97163 \mathrm{e}+015.97163 \mathrm{e}+015.97163 \mathrm{e}+001.00000 \mathrm{e}-092.12000 \mathrm{e}-01$ $5.97163 \mathrm{e}+01$ 5.97163e+01 5.97163e+00 1.00000e-09 2.12000e-01 $5.97163 \mathrm{e}+015.97163 \mathrm{e}+015.97163 \mathrm{e}+001.00000 \mathrm{e}-092.12000 \mathrm{e}-01$ $5.97163 \mathrm{e}+015.97163 \mathrm{e}+015.97163 \mathrm{e}+001.00000 \mathrm{e}-092.12000 \mathrm{e}-01$ $1.00000 \mathrm{e}-02$ 1.00000e-02 1.00000e-03 1.00000e-09 1.00000e-01 $1.00000 \mathrm{e}+001.00000 \mathrm{e}+001.00000 \mathrm{e}-011.00000 \mathrm{e}-091.00000 \mathrm{e}-01$ $1.00000 \mathrm{e}-051.00000 \mathrm{e}-05$ 1.00000e-06 1.00000e-09 1.00000e-01 $1.00000 \mathrm{e}+001.00000 \mathrm{e}+001.00000 \mathrm{e}-01$ 1.00000e-09 1.00000e-01 Element: 8857 \# of layers: 9

$\mathrm{Kx} \mathrm{Ky} \mathrm{Kz}$ Ss Por

5.97163e+01 5.97163e+01 5.97163e+00 1.00000e-09 2.12000e-01 5.97163e+01 5.97163e+01 5.97163e+00 1.00000e-09 2.12000e-01 $5.97163 \mathrm{e}+015.97163 \mathrm{e}+015.97163 \mathrm{e}+001.00000 \mathrm{e}-092.12000 \mathrm{e}-01$ $5.97163 e+015.97163 e+015.97163 e+001.00000 e-092.12000 e-01$ $5.97163 \mathrm{e}+015.97163 \mathrm{e}+015.97163 \mathrm{e}+001.00000 \mathrm{e}-092.12000 \mathrm{e}-01$ $1.00000 \mathrm{e}-02$ 1.00000e-02 1.00000e-03 1.00000e-09 1.00000e-01 $1.00000 \mathrm{e}+001.00000 \mathrm{e}+001.00000 \mathrm{e}-011.00000 \mathrm{e}-091.00000 \mathrm{e}-01$ $1.00000 \mathrm{e}-05$ 1.00000e-05 1.00000e-06 1.00000e-09 1.00000e-01 $1.00000 \mathrm{e}+001.00000 \mathrm{e}+001.00000 \mathrm{e}-011.00000 \mathrm{e}-091.00000 \mathrm{e}-01$ Element: 8858 \# of layers: 9

$\mathrm{Kx} \mathrm{Ky} \mathrm{Kz}$ Ss Por

$5.43364 \mathrm{e}+01$ 5.43364e+01 5.43364e+00 1.00000e-09 2.12000e-01 $5.43364 \mathrm{e}+015.43364 \mathrm{e}+015.43364 \mathrm{e}+001.00000 \mathrm{e}-092.12000 \mathrm{e}-01$ $5.43364 \mathrm{e}+015.43364 \mathrm{e}+015.43364 \mathrm{e}+001.00000 \mathrm{e}-092.12000 \mathrm{e}-01$ $5.43364 \mathrm{e}+015.43364 \mathrm{e}+015.43364 \mathrm{e}+001.00000 \mathrm{e}-092.12000 \mathrm{e}-01$ $5.43364 \mathrm{e}+015.43364 \mathrm{e}+015.43364 \mathrm{e}+001.00000 \mathrm{e}-092.12000 \mathrm{e}-01$ $1.00000 \mathrm{e}-02$ 1.00000e-02 1.00000e-03 1.00000e-09 1.00000e-01 $1.00000 \mathrm{e}+001.00000 \mathrm{e}+001.00000 \mathrm{e}-011.00000 \mathrm{e}-091.00000 \mathrm{e}-01$ $1.00000 \mathrm{e}-05$ 1.00000e-05 1.00000e-06 1.00000e-09 1.00000e-01 $1.00000 \mathrm{e}+001.00000 \mathrm{e}+001.00000 \mathrm{e}-011.00000 \mathrm{e}-091.00000 \mathrm{e}-01$ Element: 8859 \# of layers: 9

$\mathrm{Kx} \mathrm{Ky} \mathrm{Kz}$ Ss Por

5.43364e+01 5.43364e+01 5.43364e+00 1.00000e-09 2.12000e-01 $5.43364 \mathrm{e}+015.43364 \mathrm{e}+015.43364 \mathrm{e}+001.00000 \mathrm{e}-092.12000 \mathrm{e}-01$ $5.43364 \mathrm{e}+015.43364 \mathrm{e}+015.43364 \mathrm{e}+001.00000 \mathrm{e}-092.12000 \mathrm{e}-01$ 
$5.43364 \mathrm{e}+015.43364 \mathrm{e}+015.43364 \mathrm{e}+001.00000 \mathrm{e}-092.12000 \mathrm{e}-01$ $5.43364 \mathrm{e}+015.43364 \mathrm{e}+015.43364 \mathrm{e}+001.00000 \mathrm{e}-092.12000 \mathrm{e}-01$ $1.00000 \mathrm{e}-02$ 1.00000e-02 1.00000e-03 1.00000e-09 1.00000e-01 $1.00000 \mathrm{e}+001.00000 \mathrm{e}+001.00000 \mathrm{e}-011.00000 \mathrm{e}-091.00000 \mathrm{e}-01$ $1.00000 \mathrm{e}-05$ 1.00000e-05 1.00000e-06 1.00000e-09 1.00000e-01 $1.00000 \mathrm{e}+001.00000 \mathrm{e}+001.00000 \mathrm{e}-011.00000 \mathrm{e}-091.00000 \mathrm{e}-01$ Element: 8860 \# of layers: 9

$\mathrm{Kx} \mathrm{Ky} \mathrm{Kz}$ Ss Por

5.38977e+02 5.38977e+02 5.38977e+01 1.00000e-09 2.12000e-01

$5.38977 \mathrm{e}+02$ 5.38977e+02 5.38977e+01 1.00000e-09 2.12000e-01

5.38977e+02 5.38977e+02 5.38977e+01 1.00000e-09 2.12000e-01

5.38977e+02 5.38977e+02 5.38977e+01 1.00000e-09 2.12000e-01

5.38977e+02 5.38977e+02 5.38977e+01 1.00000e-09 2.12000e-01

$1.00000 \mathrm{e}-02$ 1.00000e-02 1.00000e-03 1.00000e-09 1.00000e-01

$1.00000 \mathrm{e}+001.00000 \mathrm{e}+001.00000 \mathrm{e}-011.00000 \mathrm{e}-091.00000 \mathrm{e}-01$ $1.00000 \mathrm{e}-05$ 1.00000e-05 1.00000e-06 1.00000e-09 1.00000e-01

$1.00000 \mathrm{e}+001.00000 \mathrm{e}+001.00000 \mathrm{e}-011.00000 \mathrm{e}-091.00000 \mathrm{e}-01$

Element: 8861 \# of layers: 9

$\mathrm{Kx} \mathrm{Ky} \mathrm{Kz}$ Ss Por

5.38977e+02 5.38977e+02 5.38977e+01 1.00000e-09 2.12000e-01

5.38977e+02 5.38977e+02 5.38977e+01 1.00000e-09 2.12000e-01

5.38977e+02 5.38977e+02 5.38977e+01 1.00000e-09 2.12000e-01

5.38977e+02 5.38977e+02 5.38977e+01 1.00000e-09 2.12000e-01

5.38977e+02 5.38977e+02 5.38977e+01 1.00000e-09 2.12000e-01

$1.00000 \mathrm{e}-02$ 1.00000e-02 1.00000e-03 1.00000e-09 1.00000e-01

$1.00000 \mathrm{e}+001.00000 \mathrm{e}+001.00000 \mathrm{e}-011.00000 \mathrm{e}-091.00000 \mathrm{e}-01$

$1.00000 \mathrm{e}-05$ 1.00000e-05 1.00000e-06 1.00000e-09 1.00000e-01

$1.00000 \mathrm{e}+001.00000 \mathrm{e}+001.00000 \mathrm{e}-011.00000 \mathrm{e}-091.00000 \mathrm{e}-01$

Element: 8862 \# of layers: 9

$\mathrm{Kx} \mathrm{Ky} \mathrm{Kz}$ Ss Por

5.38977e+02 5.38977e+02 5.38977e+01 1.00000e-09 2.12000e-01

5.38977e+02 5.38977e+02 5.38977e+01 1.00000e-09 2.12000e-01

$5.38977 \mathrm{e}+02$ 5.38977e+02 5.38977e+01 1.00000e-09 2.12000e-01

5.38977e+02 5.38977e+02 5.38977e+01 1.00000e-09 2.12000e-01

$5.38977 \mathrm{e}+02$ 5.38977e+02 5.38977e+01 1.00000e-09 2.12000e-01

1.00000e-02 1.00000e-02 1.00000e-03 1.00000e-09 1.00000e-01

$1.00000 \mathrm{e}+001.00000 \mathrm{e}+001.00000 \mathrm{e}-011.00000 \mathrm{e}-091.00000 \mathrm{e}-01$

$1.00000 \mathrm{e}-05$ 1.00000e-05 1.00000e-06 1.00000e-09 1.00000e-01

$1.00000 \mathrm{e}+001.00000 \mathrm{e}+001.00000 \mathrm{e}-011.00000 \mathrm{e}-091.00000 \mathrm{e}-01$

Element: 8863 \# of layers: 9

$\mathrm{Kx} \mathrm{Ky} \mathrm{Kz}$ Ss Por

5.70500e+01 5.70500e+01 5.70500e+00 1.00000e-09 2.12000e-01

$5.70500 \mathrm{e}+015.70500 \mathrm{e}+015.70500 \mathrm{e}+001.00000 \mathrm{e}-092.12000 \mathrm{e}-01$

$5.70500 \mathrm{e}+015.70500 \mathrm{e}+015.70500 \mathrm{e}+001.00000 \mathrm{e}-092.12000 \mathrm{e}-01$

$5.70500 \mathrm{e}+015.70500 \mathrm{e}+015.70500 \mathrm{e}+001.00000 \mathrm{e}-092.12000 \mathrm{e}-01$

$5.70500 \mathrm{e}+015.70500 \mathrm{e}+015.70500 \mathrm{e}+00$ 1.00000e-09 2.12000e-01 
$1.00000 \mathrm{e}-02$ 1.00000e-02 1.00000e-03 1.00000e-09 1.00000e-01 $1.00000 \mathrm{e}+001.00000 \mathrm{e}+001.00000 \mathrm{e}-011.00000 \mathrm{e}-091.00000 \mathrm{e}-01$ $1.00000 \mathrm{e}-05$ 1.00000e-05 1.00000e-06 1.00000e-09 1.00000e-01 $1.00000 \mathrm{e}+001.00000 \mathrm{e}+001.00000 \mathrm{e}-011.00000 \mathrm{e}-091.00000 \mathrm{e}-01$ Element: 8864 \# of layers: 9

Kx Ky Kz Ss Por

$5.70500 \mathrm{e}+015.70500 \mathrm{e}+015.70500 \mathrm{e}+00$ 1.00000e-09 2.12000e-01 $5.70500 \mathrm{e}+015.70500 \mathrm{e}+015.70500 \mathrm{e}+001.00000 \mathrm{e}-092.12000 \mathrm{e}-01$ $5.70500 \mathrm{e}+015.70500 \mathrm{e}+015.70500 \mathrm{e}+001.00000 \mathrm{e}-092.12000 \mathrm{e}-01$ $5.70500 \mathrm{e}+015.70500 \mathrm{e}+015.70500 \mathrm{e}+001.00000 \mathrm{e}-092.12000 \mathrm{e}-01$ $5.70500 \mathrm{e}+015.70500 \mathrm{e}+015.70500 \mathrm{e}+001.00000 \mathrm{e}-092.12000 \mathrm{e}-01$ $1.00000 \mathrm{e}-021.00000 \mathrm{e}-02$ 1.00000e-03 1.00000e-09 1.00000e-01 $1.00000 \mathrm{e}+001.00000 \mathrm{e}+001.00000 \mathrm{e}-011.00000 \mathrm{e}-091.00000 \mathrm{e}-01$ $1.00000 \mathrm{e}-05$ 1.00000e-05 1.00000e-06 1.00000e-09 1.00000e-01 $1.00000 \mathrm{e}+001.00000 \mathrm{e}+001.00000 \mathrm{e}-011.00000 \mathrm{e}-091.00000 \mathrm{e}-01$ Element: 8865 \# of layers: 9

Kx Ky Kz Ss Por

$5.97163 \mathrm{e}+015.97163 \mathrm{e}+01$ 5.97163e+00 1.00000e-09 2.12000e-01 $5.97163 \mathrm{e}+015.97163 \mathrm{e}+015.97163 \mathrm{e}+001.00000 \mathrm{e}-092.12000 \mathrm{e}-01$ $5.97163 \mathrm{e}+015.97163 \mathrm{e}+015.97163 \mathrm{e}+001.00000 \mathrm{e}-092.12000 \mathrm{e}-01$ $5.97163 \mathrm{e}+015.97163 \mathrm{e}+015.97163 \mathrm{e}+001.00000 \mathrm{e}-092.12000 \mathrm{e}-01$ $5.97163 \mathrm{e}+015.97163 \mathrm{e}+01$ 5.97163e+00 1.00000e-09 2.12000e-01 $1.00000 \mathrm{e}-02$ 1.00000e-02 1.00000e-03 1.00000e-09 1.00000e-01 $1.00000 \mathrm{e}+001.00000 \mathrm{e}+001.00000 \mathrm{e}-011.00000 \mathrm{e}-091.00000 \mathrm{e}-01$ $1.00000 \mathrm{e}-05$ 1.00000e-05 1.00000e-06 1.00000e-09 1.00000e-01 $1.00000 \mathrm{e}+001.00000 \mathrm{e}+00$ 1.00000e-01 1.00000e-09 1.00000e-01 Element: 8866 \# of layers: 9

Kx Ky Kz Ss Por

$5.43364 \mathrm{e}+015.43364 \mathrm{e}+015.43364 \mathrm{e}+001.00000 \mathrm{e}-092.12000 \mathrm{e}-01$ $5.43364 \mathrm{e}+015.43364 \mathrm{e}+015.43364 \mathrm{e}+001.00000 \mathrm{e}-092.12000 \mathrm{e}-01$ $5.43364 \mathrm{e}+015.43364 \mathrm{e}+015.43364 \mathrm{e}+001.00000 \mathrm{e}-092.12000 \mathrm{e}-01$ $5.43364 \mathrm{e}+015.43364 \mathrm{e}+015.43364 \mathrm{e}+001.00000 \mathrm{e}-092.12000 \mathrm{e}-01$ $5.43364 \mathrm{e}+015.43364 \mathrm{e}+015.43364 \mathrm{e}+001.00000 \mathrm{e}-092.12000 \mathrm{e}-01$ $1.00000 \mathrm{e}-021.00000 \mathrm{e}-02$ 1.00000e-03 1.00000e-09 1.00000e-01 $1.00000 \mathrm{e}+001.00000 \mathrm{e}+001.00000 \mathrm{e}-011.00000 \mathrm{e}-091.00000 \mathrm{e}-01$ $1.00000 \mathrm{e}-05$ 1.00000e-05 1.00000e-06 1.00000e-09 1.00000e-01 $1.00000 \mathrm{e}+001.00000 \mathrm{e}+001.00000 \mathrm{e}-011.00000 \mathrm{e}-091.00000 \mathrm{e}-01$ Element: 8867 \# of layers: 9

Kx Ky Kz Ss Por

$5.38977 \mathrm{e}+02$ 5.38977e+02 5.38977e+01 1.00000e-09 2.12000e-01 $5.38977 \mathrm{e}+025.38977 \mathrm{e}+025.38977 \mathrm{e}+01$ 1.00000e-09 2.12000e-01 $5.38977 \mathrm{e}+025.38977 \mathrm{e}+025.38977 \mathrm{e}+01$ 1.00000e-09 2.12000e-01 $5.38977 \mathrm{e}+025.38977 \mathrm{e}+025.38977 \mathrm{e}+01$ 1.00000e-09 2.12000e-01 $5.38977 \mathrm{e}+02$ 5.38977e+02 5.38977e+01 1.00000e-09 2.12000e-01 $1.00000 \mathrm{e}-02$ 1.00000e-02 1.00000e-03 1.00000e-09 1.00000e-01 $1.00000 \mathrm{e}+001.00000 \mathrm{e}+001.00000 \mathrm{e}-011.00000 \mathrm{e}-091.00000 \mathrm{e}-01$ 
$1.00000 \mathrm{e}-05$ 1.00000e-05 1.00000e-06 1.00000e-09 1.00000e-01 $1.00000 \mathrm{e}+001.00000 \mathrm{e}+001.00000 \mathrm{e}-01$ 1.00000e-09 1.00000e-01 Element: 8868 \# of layers: 7

Kx Ky Kz Ss Por

$2.02756 \mathrm{e}+012.02756 \mathrm{e}+012.02756 \mathrm{e}+001.00000 \mathrm{e}-092.12000 \mathrm{e}-01$ $2.02756 \mathrm{e}+012.02756 \mathrm{e}+012.02756 \mathrm{e}+001.00000 \mathrm{e}-092.12000 \mathrm{e}-01$ $2.02756 \mathrm{e}+012.02756 \mathrm{e}+012.02756 \mathrm{e}+001.00000 \mathrm{e}-092.12000 \mathrm{e}-01$ $2.02756 \mathrm{e}+012.02756 \mathrm{e}+012.02756 \mathrm{e}+001.00000 \mathrm{e}-092.12000 \mathrm{e}-01$ $2.02756 \mathrm{e}+012.02756 \mathrm{e}+012.02756 \mathrm{e}+001.00000 \mathrm{e}-092.12000 \mathrm{e}-01$ $1.00000 \mathrm{e}-051.00000 \mathrm{e}-05$ 1.00000e-06 1.00000e-09 1.00000e-01 $1.00000 \mathrm{e}+001.00000 \mathrm{e}+001.00000 \mathrm{e}-01$ 1.00000e-09 1.00000e-01 Element: 8869 \# of layers: 7

$\mathrm{Kx} \mathrm{Ky} \mathrm{Kz}$ Ss Por

$2.02756 \mathrm{e}+012.02756 \mathrm{e}+012.02756 \mathrm{e}+00$ 1.00000e-09 2.12000e-01 $2.02756 \mathrm{e}+012.02756 \mathrm{e}+012.02756 \mathrm{e}+001.00000 \mathrm{e}-092.12000 \mathrm{e}-01$ $2.02756 \mathrm{e}+012.02756 \mathrm{e}+012.02756 \mathrm{e}+001.00000 \mathrm{e}-092.12000 \mathrm{e}-01$ $2.02756 \mathrm{e}+012.02756 \mathrm{e}+012.02756 \mathrm{e}+001.00000 \mathrm{e}-092.12000 \mathrm{e}-01$ $2.02756 \mathrm{e}+012.02756 \mathrm{e}+012.02756 \mathrm{e}+001.00000 \mathrm{e}-092.12000 \mathrm{e}-01$ $1.00000 \mathrm{e}-05$ 1.00000e-05 1.00000e-06 1.00000e-09 1.00000e-01 $1.00000 \mathrm{e}+001.00000 \mathrm{e}+001.00000 \mathrm{e}-011.00000 \mathrm{e}-091.00000 \mathrm{e}-01$ Element: 8870 \# of layers: 7

$\mathrm{Kx} \mathrm{Ky} \mathrm{Kz}$ Ss Por

$2.05999 \mathrm{e}+012.05999 \mathrm{e}+012.05999 \mathrm{e}+00$ 1.00000e-09 2.12000e-01 $2.05999 \mathrm{e}+012.05999 \mathrm{e}+012.05999 \mathrm{e}+001.00000 \mathrm{e}-092.12000 \mathrm{e}-01$ $2.05999 \mathrm{e}+012.05999 \mathrm{e}+012.05999 \mathrm{e}+001.00000 \mathrm{e}-092.12000 \mathrm{e}-01$ $2.05999 \mathrm{e}+012.05999 \mathrm{e}+012.05999 \mathrm{e}+001.00000 \mathrm{e}-092.12000 \mathrm{e}-01$ $2.05999 \mathrm{e}+012.05999 \mathrm{e}+012.05999 \mathrm{e}+001.00000 \mathrm{e}-092.12000 \mathrm{e}-01$ $1.00000 \mathrm{e}-05$ 1.00000e-05 1.00000e-06 1.00000e-09 1.00000e-01 $1.00000 \mathrm{e}+001.00000 \mathrm{e}+001.00000 \mathrm{e}-011.00000 \mathrm{e}-091.00000 \mathrm{e}-01$ Element: 8871 \# of layers: 7

$\mathrm{Kx} \mathrm{Ky} \mathrm{Kz}$ Ss Por

$2.05999 \mathrm{e}+012.05999 \mathrm{e}+012.05999 \mathrm{e}+001.00000 \mathrm{e}-092.12000 \mathrm{e}-01$ $2.05999 \mathrm{e}+012.05999 \mathrm{e}+012.05999 \mathrm{e}+001.00000 \mathrm{e}-092.12000 \mathrm{e}-01$ $2.05999 \mathrm{e}+012.05999 \mathrm{e}+012.05999 \mathrm{e}+001.00000 \mathrm{e}-092.12000 \mathrm{e}-01$ $2.05999 \mathrm{e}+012.05999 \mathrm{e}+012.05999 \mathrm{e}+00 \quad 1.00000 \mathrm{e}-092.12000 \mathrm{e}-01$ $2.05999 \mathrm{e}+012.05999 \mathrm{e}+012.05999 \mathrm{e}+00$ 1.00000e-09 2.12000e-01 1.00000e-05 1.00000e-05 1.00000e-06 1.00000e-09 1.00000e-01 $1.00000 \mathrm{e}+001.00000 \mathrm{e}+001.00000 \mathrm{e}-011.00000 \mathrm{e}-091.00000 \mathrm{e}-01$ Element: 8872 \# of layers: 7

$\mathrm{Kx} \mathrm{Ky} \mathrm{Kz}$ Ss Por $2.02756 \mathrm{e}+012.02756 \mathrm{e}+012.02756 \mathrm{e}+00$ 1.00000e-09 2.12000e-01 $2.02756 \mathrm{e}+012.02756 \mathrm{e}+012.02756 \mathrm{e}+001.00000 \mathrm{e}-092.12000 \mathrm{e}-01$ $2.02756 \mathrm{e}+012.02756 \mathrm{e}+012.02756 \mathrm{e}+001.00000 \mathrm{e}-092.12000 \mathrm{e}-01$ $2.02756 \mathrm{e}+012.02756 \mathrm{e}+012.02756 \mathrm{e}+001.00000 \mathrm{e}-092.12000 \mathrm{e}-01$ $2.02756 \mathrm{e}+012.02756 \mathrm{e}+012.02756 \mathrm{e}+001.00000 \mathrm{e}-092.12000 \mathrm{e}-01$ 1.00000e-05 1.00000e-05 1.00000e-06 1.00000e-09 1.00000e-01 
$1.00000 \mathrm{e}+001.00000 \mathrm{e}+00$ 1.00000e-01 1.00000e-09 1.00000e-01

Element: 8873 \# of layers: 7

$\mathrm{Kx} \mathrm{Ky} \mathrm{Kz}$ Ss Por

$2.05999 \mathrm{e}+012.05999 \mathrm{e}+012.05999 \mathrm{e}+00$ 1.00000e-09 2.12000e-01

$2.05999 \mathrm{e}+012.05999 \mathrm{e}+012.05999 \mathrm{e}+001.00000 \mathrm{e}-092.12000 \mathrm{e}-01$

$2.05999 \mathrm{e}+012.05999 \mathrm{e}+012.05999 \mathrm{e}+001.00000 \mathrm{e}-092.12000 \mathrm{e}-01$

$2.05999 \mathrm{e}+012.05999 \mathrm{e}+012.05999 \mathrm{e}+001.00000 \mathrm{e}-092.12000 \mathrm{e}-01$

$2.05999 \mathrm{e}+012.05999 \mathrm{e}+012.05999 \mathrm{e}+001.00000 \mathrm{e}-092.12000 \mathrm{e}-01$

$1.00000 \mathrm{e}-05$ 1.00000e-05 1.00000e-06 1.00000e-09 1.00000e-01

$1.00000 \mathrm{e}+001.00000 \mathrm{e}+001.00000 \mathrm{e}-011.00000 \mathrm{e}-09$ 1.00000e-01

Element: 8874 \# of layers: 7

$\mathrm{Kx} \mathrm{Ky} \mathrm{Kz}$ Ss Por

$2.05999 \mathrm{e}+01$ 2.05999e+01 2.05999e+00 1.00000e-09 2.12000e-01

$2.05999 \mathrm{e}+012.05999 \mathrm{e}+012.05999 \mathrm{e}+00$ 1.00000e-09 2.12000e-01

$2.05999 \mathrm{e}+012.05999 \mathrm{e}+012.05999 \mathrm{e}+001.00000 \mathrm{e}-092.12000 \mathrm{e}-01$

$2.05999 \mathrm{e}+012.05999 \mathrm{e}+012.05999 \mathrm{e}+001.00000 \mathrm{e}-092.12000 \mathrm{e}-01$

$2.05999 \mathrm{e}+012.05999 \mathrm{e}+012.05999 \mathrm{e}+00$ 1.00000e-09 2.12000e-01

$1.00000 \mathrm{e}-05$ 1.00000e-05 1.00000e-06 1.00000e-09 1.00000e-01

$1.00000 \mathrm{e}+001.00000 \mathrm{e}+001.00000 \mathrm{e}-011.00000 \mathrm{e}-091.00000 \mathrm{e}-01$

Element: 8875 \# of layers: 7

$\mathrm{Kx} \mathrm{Ky} \mathrm{Kz}$ Ss Por

$2.05999 \mathrm{e}+012.05999 \mathrm{e}+012.05999 \mathrm{e}+00$ 1.00000e-09 2.12000e-01

$2.05999 \mathrm{e}+012.05999 \mathrm{e}+012.05999 \mathrm{e}+00$ 1.00000e-09 2.12000e-01

$2.05999 \mathrm{e}+012.05999 \mathrm{e}+012.05999 \mathrm{e}+001.00000 \mathrm{e}-092.12000 \mathrm{e}-01$

$2.05999 \mathrm{e}+012.05999 \mathrm{e}+012.05999 \mathrm{e}+001.00000 \mathrm{e}-092.12000 \mathrm{e}-01$

$2.05999 \mathrm{e}+012.05999 \mathrm{e}+012.05999 \mathrm{e}+001.00000 \mathrm{e}-092.12000 \mathrm{e}-01$

$1.00000 \mathrm{e}-05$ 1.00000e-05 1.00000e-06 1.00000e-09 1.00000e-01

$1.00000 \mathrm{e}+001.00000 \mathrm{e}+001.00000 \mathrm{e}-011.00000 \mathrm{e}-091.00000 \mathrm{e}-01$

Element: 8876 \# of layers: 7

$\mathrm{Kx} \mathrm{Ky} \mathrm{Kz}$ Ss Por

$2.05999 \mathrm{e}+012.05999 \mathrm{e}+012.05999 \mathrm{e}+00$ 1.00000e-09 2.12000e-01

$2.05999 \mathrm{e}+012.05999 \mathrm{e}+012.05999 \mathrm{e}+00$ 1.00000e-09 2.12000e-01

$2.05999 \mathrm{e}+012.05999 \mathrm{e}+012.05999 \mathrm{e}+00$ 1.00000e-09 2.12000e-01

$2.05999 \mathrm{e}+012.05999 \mathrm{e}+012.05999 \mathrm{e}+001.00000 \mathrm{e}-092.12000 \mathrm{e}-01$

$2.05999 \mathrm{e}+012.05999 \mathrm{e}+012.05999 \mathrm{e}+00$ 1.00000e-09 2.12000e-01

1.00000e-05 1.00000e-05 1.00000e-06 1.00000e-09 1.00000e-01

$1.00000 \mathrm{e}+001.00000 \mathrm{e}+001.00000 \mathrm{e}-011.00000 \mathrm{e}-091.00000 \mathrm{e}-01$

Element: 8877 \# of layers: 7

$\mathrm{Kx} \mathrm{Ky} \mathrm{Kz}$ Ss Por

$2.05999 \mathrm{e}+012.05999 \mathrm{e}+012.05999 \mathrm{e}+00$ 1.00000e-09 2.12000e-01

$2.05999 \mathrm{e}+012.05999 \mathrm{e}+012.05999 \mathrm{e}+001.00000 \mathrm{e}-092.12000 \mathrm{e}-01$

$2.05999 \mathrm{e}+012.05999 \mathrm{e}+012.05999 \mathrm{e}+00$ 1.00000e-09 2.12000e-01

$2.05999 \mathrm{e}+012.05999 \mathrm{e}+012.05999 \mathrm{e}+001.00000 \mathrm{e}-092.12000 \mathrm{e}-01$

2.05999e+01 2.05999e+01 2.05999e+00 1.00000e-09 2.12000e-01

$1.00000 \mathrm{e}-05$ 1.00000e-05 1.00000e-06 1.00000e-09 1.00000e-01

$1.00000 \mathrm{e}+001.00000 \mathrm{e}+001.00000 \mathrm{e}-011.00000 \mathrm{e}-091.00000 \mathrm{e}-01$ 
Element: 8878 \# of layers: 7

$\mathrm{Kx} \mathrm{Ky} \mathrm{Kz}$ Ss Por

$2.05999 \mathrm{e}+012.05999 \mathrm{e}+012.05999 \mathrm{e}+00$ 1.00000e-09 2.12000e-01

$2.05999 \mathrm{e}+012.05999 \mathrm{e}+012.05999 \mathrm{e}+001.00000 \mathrm{e}-092.12000 \mathrm{e}-01$

$2.05999 \mathrm{e}+012.05999 \mathrm{e}+012.05999 \mathrm{e}+001.00000 \mathrm{e}-092.12000 \mathrm{e}-01$

$2.05999 \mathrm{e}+012.05999 \mathrm{e}+012.05999 \mathrm{e}+00$ 1.00000e-09 2.12000e-01

$2.05999 \mathrm{e}+012.05999 \mathrm{e}+012.05999 \mathrm{e}+00$ 1.00000e-09 2.12000e-01

$1.00000 \mathrm{e}-05$ 1.00000e-05 1.00000e-06 1.00000e-09 1.00000e-01

$1.00000 \mathrm{e}+001.00000 \mathrm{e}+001.00000 \mathrm{e}-011.00000 \mathrm{e}-091.00000 \mathrm{e}-01$

Element: 8879 \# of layers: 7

$\mathrm{Kx} \mathrm{Ky} \mathrm{Kz}$ Ss Por

$2.05999 \mathrm{e}+012.05999 \mathrm{e}+012.05999 \mathrm{e}+00$ 1.00000e-09 2.12000e-01

$2.05999 \mathrm{e}+012.05999 \mathrm{e}+012.05999 \mathrm{e}+001.00000 \mathrm{e}-092.12000 \mathrm{e}-01$

$2.05999 \mathrm{e}+012.05999 \mathrm{e}+012.05999 \mathrm{e}+00$ 1.00000e-09 2.12000e-01

$2.05999 \mathrm{e}+012.05999 \mathrm{e}+012.05999 \mathrm{e}+001.00000 \mathrm{e}-092.12000 \mathrm{e}-01$

$2.05999 \mathrm{e}+012.05999 \mathrm{e}+012.05999 \mathrm{e}+001.00000 \mathrm{e}-092.12000 \mathrm{e}-01$

$1.00000 \mathrm{e}-05$ 1.00000e-05 1.00000e-06 1.00000e-09 1.00000e-01

$1.00000 \mathrm{e}+001.00000 \mathrm{e}+001.00000 \mathrm{e}-01$ 1.00000e-09 1.00000e-01

Element: 8880 \# of layers: 7

$\mathrm{Kx} \mathrm{Ky} \mathrm{Kz}$ Ss Por

$2.05999 \mathrm{e}+012.05999 \mathrm{e}+012.05999 \mathrm{e}+00$ 1.00000e-09 2.12000e-01

$2.05999 \mathrm{e}+012.05999 \mathrm{e}+012.05999 \mathrm{e}+00$ 1.00000e-09 2.12000e-01

$2.05999 \mathrm{e}+012.05999 \mathrm{e}+012.05999 \mathrm{e}+00$ 1.00000e-09 2.12000e-01

$2.05999 \mathrm{e}+012.05999 \mathrm{e}+012.05999 \mathrm{e}+001.00000 \mathrm{e}-092.12000 \mathrm{e}-01$

$2.05999 \mathrm{e}+012.05999 \mathrm{e}+012.05999 \mathrm{e}+001.00000 \mathrm{e}-092.12000 \mathrm{e}-01$

$1.00000 \mathrm{e}-051.00000 \mathrm{e}-05$ 1.00000e-06 1.00000e-09 1.00000e-01

$1.00000 \mathrm{e}+001.00000 \mathrm{e}+001.00000 \mathrm{e}-011.00000 \mathrm{e}-091.00000 \mathrm{e}-01$

Element: 8881 \# of layers: 7

$\mathrm{Kx} \mathrm{Ky} \mathrm{Kz}$ Ss Por

$2.05999 \mathrm{e}+012.05999 \mathrm{e}+012.05999 \mathrm{e}+00$ 1.00000e-09 2.12000e-01

$2.05999 \mathrm{e}+012.05999 \mathrm{e}+012.05999 \mathrm{e}+00$ 1.00000e-09 2.12000e-01

$2.05999 \mathrm{e}+012.05999 \mathrm{e}+012.05999 \mathrm{e}+001.00000 \mathrm{e}-092.12000 \mathrm{e}-01$

$2.05999 \mathrm{e}+012.05999 \mathrm{e}+012.05999 \mathrm{e}+00$ 1.00000e-09 2.12000e-01

$2.05999 \mathrm{e}+012.05999 \mathrm{e}+012.05999 \mathrm{e}+00$ 1.00000e-09 2.12000e-01

$1.00000 \mathrm{e}-05$ 1.00000e-05 1.00000e-06 1.00000e-09 1.00000e-01

$1.00000 \mathrm{e}+001.00000 \mathrm{e}+001.00000 \mathrm{e}-011.00000 \mathrm{e}-091.00000 \mathrm{e}-01$

Element: 8882 \# of layers: 7

$\mathrm{Kx} \mathrm{Ky} \mathrm{Kz}$ Ss Por

$2.05999 \mathrm{e}+012.05999 \mathrm{e}+012.05999 \mathrm{e}+00$ 1.00000e-09 2.12000e-01

$2.05999 \mathrm{e}+012.05999 \mathrm{e}+012.05999 \mathrm{e}+001.00000 \mathrm{e}-092.12000 \mathrm{e}-01$

$2.05999 \mathrm{e}+012.05999 \mathrm{e}+012.05999 \mathrm{e}+00$ 1.00000e-09 2.12000e-01

$2.05999 \mathrm{e}+012.05999 \mathrm{e}+012.05999 \mathrm{e}+00$ 1.00000e-09 2.12000e-01

$2.05999 \mathrm{e}+012.05999 \mathrm{e}+012.05999 \mathrm{e}+00$ 1.00000e-09 2.12000e-01

$1.00000 \mathrm{e}-051.00000 \mathrm{e}-051.00000 \mathrm{e}-061.00000 \mathrm{e}-091.00000 \mathrm{e}-01$

$1.00000 \mathrm{e}+001.00000 \mathrm{e}+001.00000 \mathrm{e}-011.00000 \mathrm{e}-09$ 1.00000e-01

Element: 8883 \# of layers: 7 
$\mathrm{Kx} \mathrm{Ky} \mathrm{Kz}$ Ss Por

$2.05999 \mathrm{e}+012.05999 \mathrm{e}+012.05999 \mathrm{e}+00$ 1.00000e-09 2.12000e-01

$2.05999 \mathrm{e}+012.05999 \mathrm{e}+012.05999 \mathrm{e}+00$ 1.00000e-09 2.12000e-01

$2.05999 \mathrm{e}+012.05999 \mathrm{e}+012.05999 \mathrm{e}+001.00000 \mathrm{e}-092.12000 \mathrm{e}-01$

$2.05999 \mathrm{e}+012.05999 \mathrm{e}+012.05999 \mathrm{e}+001.00000 \mathrm{e}-092.12000 \mathrm{e}-01$

$2.05999 \mathrm{e}+012.05999 \mathrm{e}+012.05999 \mathrm{e}+001.00000 \mathrm{e}-092.12000 \mathrm{e}-01$

$1.00000 \mathrm{e}-05$ 1.00000e-05 1.00000e-06 1.00000e-09 1.00000e-01

$1.00000 \mathrm{e}+001.00000 \mathrm{e}+001.00000 \mathrm{e}-01$ 1.00000e-09 1.00000e-01

Element: 8884 \# of layers: 7

$\mathrm{Kx} \mathrm{Ky} \mathrm{Kz}$ Ss Por

$2.05999 \mathrm{e}+012.05999 \mathrm{e}+012.05999 \mathrm{e}+00$ 1.00000e-09 2.12000e-01

$2.05999 \mathrm{e}+012.05999 \mathrm{e}+012.05999 \mathrm{e}+001.00000 \mathrm{e}-092.12000 \mathrm{e}-01$

$2.05999 \mathrm{e}+012.05999 \mathrm{e}+012.05999 \mathrm{e}+00$ 1.00000e-09 2.12000e-01

$2.05999 \mathrm{e}+012.05999 \mathrm{e}+012.05999 \mathrm{e}+001.00000 \mathrm{e}-092.12000 \mathrm{e}-01$

$2.05999 \mathrm{e}+012.05999 \mathrm{e}+012.05999 \mathrm{e}+001.00000 \mathrm{e}-092.12000 \mathrm{e}-01$

$1.00000 \mathrm{e}-05$ 1.00000e-05 1.00000e-06 1.00000e-09 1.00000e-01

$1.00000 \mathrm{e}+001.00000 \mathrm{e}+001.00000 \mathrm{e}-01$ 1.00000e-09 1.00000e-01

Element: 8885 \# of layers: 7

$\mathrm{Kx} \mathrm{Ky} \mathrm{Kz}$ Ss Por

$2.05999 \mathrm{e}+012.05999 \mathrm{e}+012.05999 \mathrm{e}+00$ 1.00000e-09 2.12000e-01

$2.05999 \mathrm{e}+012.05999 \mathrm{e}+012.05999 \mathrm{e}+00$ 1.00000e-09 2.12000e-01

$2.05999 \mathrm{e}+012.05999 \mathrm{e}+012.05999 \mathrm{e}+00$ 1.00000e-09 2.12000e-01

$2.05999 \mathrm{e}+012.05999 \mathrm{e}+012.05999 \mathrm{e}+00$ 1.00000e-09 2.12000e-01

$2.05999 \mathrm{e}+012.05999 \mathrm{e}+012.05999 \mathrm{e}+001.00000 \mathrm{e}-092.12000 \mathrm{e}-01$

$1.00000 \mathrm{e}-05$ 1.00000e-05 1.00000e-06 1.00000e-09 1.00000e-01

$1.00000 \mathrm{e}+001.00000 \mathrm{e}+001.00000 \mathrm{e}-011.00000 \mathrm{e}-091.00000 \mathrm{e}-01$

Element: 8886 \# of layers: 7

$\mathrm{Kx} \mathrm{Ky} \mathrm{Kz} \mathrm{Ss} \mathrm{Por}$

$2.03233 \mathrm{e}+012.03233 \mathrm{e}+012.03233 \mathrm{e}+00$ 1.00000e-09 2.12000e-01

$2.03233 \mathrm{e}+012.03233 \mathrm{e}+012.03233 \mathrm{e}+001.00000 \mathrm{e}-092.12000 \mathrm{e}-01$

$2.03233 \mathrm{e}+012.03233 \mathrm{e}+012.03233 \mathrm{e}+00$ 1.00000e-09 2.12000e-01

$2.03233 \mathrm{e}+012.03233 \mathrm{e}+012.03233 \mathrm{e}+00$ 1.00000e-09 2.12000e-01

$2.03233 \mathrm{e}+012.03233 \mathrm{e}+012.03233 \mathrm{e}+00$ 1.00000e-09 2.12000e-01

$1.00000 \mathrm{e}-05$ 1.00000e-05 1.00000e-06 1.00000e-09 1.00000e-01

$1.00000 \mathrm{e}+001.00000 \mathrm{e}+001.00000 \mathrm{e}-011.00000 \mathrm{e}-091.00000 \mathrm{e}-01$

Element: 8887 \# of layers: 7

Kx Ky Kz Ss Por

$2.63368 \mathrm{e}+012.63368 \mathrm{e}+012.63368 \mathrm{e}+00$ 1.00000e-09 2.12000e-01

$2.63368 \mathrm{e}+012.63368 \mathrm{e}+012.63368 \mathrm{e}+001.00000 \mathrm{e}-092.12000 \mathrm{e}-01$

$2.63368 \mathrm{e}+012.63368 \mathrm{e}+012.63368 \mathrm{e}+00$ 1.00000e-09 2.12000e-01

$2.63368 \mathrm{e}+012.63368 \mathrm{e}+012.63368 \mathrm{e}+001.00000 \mathrm{e}-092.12000 \mathrm{e}-01$

$2.63368 \mathrm{e}+012.63368 \mathrm{e}+012.63368 \mathrm{e}+00$ 1.00000e-09 2.12000e-01

$1.00000 \mathrm{e}-05$ 1.00000e-05 1.00000e-06 1.00000e-09 1.00000e-01

$1.00000 \mathrm{e}+001.00000 \mathrm{e}+001.00000 \mathrm{e}-011.00000 \mathrm{e}-091.00000 \mathrm{e}-01$

Element: 8888 \# of layers: 7

Kx Ky Kz Ss Por 
$2.63368 \mathrm{e}+012.63368 \mathrm{e}+012.63368 \mathrm{e}+00$ 1.00000e-09 2.12000e-01

$2.63368 \mathrm{e}+012.63368 \mathrm{e}+012.63368 \mathrm{e}+001.00000 \mathrm{e}-092.12000 \mathrm{e}-01$

$2.63368 \mathrm{e}+012.63368 \mathrm{e}+012.63368 \mathrm{e}+001.00000 \mathrm{e}-092.12000 \mathrm{e}-01$

$2.63368 \mathrm{e}+012.63368 \mathrm{e}+012.63368 \mathrm{e}+001.00000 \mathrm{e}-092.12000 \mathrm{e}-01$

$2.63368 \mathrm{e}+012.63368 \mathrm{e}+012.63368 \mathrm{e}+001.00000 \mathrm{e}-092.12000 \mathrm{e}-01$

$1.00000 \mathrm{e}-05$ 1.00000e-05 1.00000e-06 1.00000e-09 1.00000e-01

$1.00000 \mathrm{e}+001.00000 \mathrm{e}+001.00000 \mathrm{e}-01$ 1.00000e-09 1.00000e-01

Element: 8889 \# of layers: 7

$\mathrm{Kx} \mathrm{Ky} \mathrm{Kz}$ Ss Por

$2.63368 \mathrm{e}+012.63368 \mathrm{e}+012.63368 \mathrm{e}+00$ 1.00000e-09 2.12000e-01

$2.63368 \mathrm{e}+012.63368 \mathrm{e}+012.63368 \mathrm{e}+00$ 1.00000e-09 2.12000e-01

$2.63368 \mathrm{e}+012.63368 \mathrm{e}+012.63368 \mathrm{e}+001.00000 \mathrm{e}-092.12000 \mathrm{e}-01$

$2.63368 \mathrm{e}+012.63368 \mathrm{e}+012.63368 \mathrm{e}+001.00000 \mathrm{e}-092.12000 \mathrm{e}-01$

$2.63368 \mathrm{e}+012.63368 \mathrm{e}+012.63368 \mathrm{e}+001.00000 \mathrm{e}-092.12000 \mathrm{e}-01$

$1.00000 \mathrm{e}-05$ 1.00000e-05 1.00000e-06 1.00000e-09 1.00000e-01

$1.00000 \mathrm{e}+001.00000 \mathrm{e}+001.00000 \mathrm{e}-011.00000 \mathrm{e}-091.00000 \mathrm{e}-01$

Element: 8890 \# of layers: 7

$\mathrm{Kx} \mathrm{Ky} \mathrm{Kz}$ Ss Por

$2.63368 \mathrm{e}+012.63368 \mathrm{e}+012.63368 \mathrm{e}+00$ 1.00000e-09 2.12000e-01

$2.63368 \mathrm{e}+012.63368 \mathrm{e}+012.63368 \mathrm{e}+001.00000 \mathrm{e}-092.12000 \mathrm{e}-01$

$2.63368 \mathrm{e}+012.63368 \mathrm{e}+012.63368 \mathrm{e}+001.00000 \mathrm{e}-092.12000 \mathrm{e}-01$

$2.63368 \mathrm{e}+012.63368 \mathrm{e}+012.63368 \mathrm{e}+00$ 1.00000e-09 2.12000e-01

$2.63368 \mathrm{e}+012.63368 \mathrm{e}+012.63368 \mathrm{e}+00$ 1.00000e-09 2.12000e-01 $1.00000 \mathrm{e}-05$ 1.00000e-05 1.00000e-06 1.00000e-09 1.00000e-01

$1.00000 \mathrm{e}+001.00000 \mathrm{e}+001.00000 \mathrm{e}-011.00000 \mathrm{e}-091.00000 \mathrm{e}-01$

Element: 8891 \# of layers: 7

$\mathrm{Kx} \mathrm{Ky} \mathrm{Kz}$ Ss Por

$2.63368 \mathrm{e}+012.63368 \mathrm{e}+012.63368 \mathrm{e}+00$ 1.00000e-09 2.12000e-01

$2.63368 \mathrm{e}+012.63368 \mathrm{e}+012.63368 \mathrm{e}+001.00000 \mathrm{e}-092.12000 \mathrm{e}-01$

$2.63368 \mathrm{e}+012.63368 \mathrm{e}+012.63368 \mathrm{e}+001.00000 \mathrm{e}-092.12000 \mathrm{e}-01$

$2.63368 \mathrm{e}+012.63368 \mathrm{e}+012.63368 \mathrm{e}+00$ 1.00000e-09 2.12000e-01

$2.63368 \mathrm{e}+012.63368 \mathrm{e}+012.63368 \mathrm{e}+00$ 1.00000e-09 2.12000e-01

1.00000e-05 1.00000e-05 1.00000e-06 1.00000e-09 1.00000e-01

$1.00000 \mathrm{e}+001.00000 \mathrm{e}+001.00000 \mathrm{e}-011.00000 \mathrm{e}-091.00000 \mathrm{e}-01$

Element: 8892 \# of layers: 7

Kx Ky Kz Ss Por

$2.80581 \mathrm{e}+012.80581 \mathrm{e}+012.80581 \mathrm{e}+00$ 1.00000e-09 2.12000e-01

$2.80581 \mathrm{e}+012.80581 \mathrm{e}+012.80581 \mathrm{e}+001.00000 \mathrm{e}-092.12000 \mathrm{e}-01$

$2.80581 \mathrm{e}+012.80581 \mathrm{e}+012.80581 \mathrm{e}+001.00000 \mathrm{e}-092.12000 \mathrm{e}-01$

$2.80581 \mathrm{e}+012.80581 \mathrm{e}+012.80581 \mathrm{e}+001.00000 \mathrm{e}-092.12000 \mathrm{e}-01$

$2.80581 \mathrm{e}+012.80581 \mathrm{e}+012.80581 \mathrm{e}+001.00000 \mathrm{e}-092.12000 \mathrm{e}-01$

$1.00000 \mathrm{e}-05$ 1.00000e-05 1.00000e-06 1.00000e-09 1.00000e-01

$1.00000 \mathrm{e}+001.00000 \mathrm{e}+001.00000 \mathrm{e}-011.00000 \mathrm{e}-091.00000 \mathrm{e}-01$

Element: 8893 \# of layers: 7

$\mathrm{Kx} \mathrm{Ky} \mathrm{Kz}$ Ss Por

$2.80581 \mathrm{e}+012.80581 \mathrm{e}+012.80581 \mathrm{e}+00$ 1.00000e-09 2.12000e-01 
$2.80581 \mathrm{e}+012.80581 \mathrm{e}+012.80581 \mathrm{e}+00$ 1.00000e-09 2.12000e-01 $2.80581 \mathrm{e}+012.80581 \mathrm{e}+012.80581 \mathrm{e}+001.00000 \mathrm{e}-092.12000 \mathrm{e}-01$ $2.80581 \mathrm{e}+012.80581 \mathrm{e}+012.80581 \mathrm{e}+001.00000 \mathrm{e}-092.12000 \mathrm{e}-01$ $2.80581 \mathrm{e}+012.80581 \mathrm{e}+012.80581 \mathrm{e}+001.00000 \mathrm{e}-092.12000 \mathrm{e}-01$ $1.00000 \mathrm{e}-05$ 1.00000e-05 1.00000e-06 1.00000e-09 1.00000e-01 $1.00000 \mathrm{e}+001.00000 \mathrm{e}+001.00000 \mathrm{e}-011.00000 \mathrm{e}-091.00000 \mathrm{e}-01$ Element: 8894 \# of layers: 7

Kx Ky Kz Ss Por

$2.63368 \mathrm{e}+012.63368 \mathrm{e}+012.63368 \mathrm{e}+00$ 1.00000e-09 2.12000e-01

$2.63368 \mathrm{e}+012.63368 \mathrm{e}+012.63368 \mathrm{e}+001.00000 \mathrm{e}-092.12000 \mathrm{e}-01$

$2.63368 \mathrm{e}+012.63368 \mathrm{e}+012.63368 \mathrm{e}+001.00000 \mathrm{e}-092.12000 \mathrm{e}-01$

$2.63368 \mathrm{e}+012.63368 \mathrm{e}+012.63368 \mathrm{e}+001.00000 \mathrm{e}-092.12000 \mathrm{e}-01$

$2.63368 \mathrm{e}+012.63368 \mathrm{e}+012.63368 \mathrm{e}+001.00000 \mathrm{e}-092.12000 \mathrm{e}-01$ $1.00000 \mathrm{e}-05$ 1.00000e-05 1.00000e-06 1.00000e-09 1.00000e-01 $1.00000 \mathrm{e}+001.00000 \mathrm{e}+001.00000 \mathrm{e}-011.00000 \mathrm{e}-091.00000 \mathrm{e}-01$ Element: 8895 \# of layers: 7

Kx Ky Kz Ss Por

$2.63368 \mathrm{e}+012.63368 \mathrm{e}+012.63368 \mathrm{e}+00$ 1.00000e-09 2.12000e-01 $2.63368 \mathrm{e}+012.63368 \mathrm{e}+012.63368 \mathrm{e}+001.00000 \mathrm{e}-092.12000 \mathrm{e}-01$ $2.63368 \mathrm{e}+012.63368 \mathrm{e}+012.63368 \mathrm{e}+001.00000 \mathrm{e}-092.12000 \mathrm{e}-01$ $2.63368 \mathrm{e}+012.63368 \mathrm{e}+012.63368 \mathrm{e}+001.00000 \mathrm{e}-092.12000 \mathrm{e}-01$ $2.63368 \mathrm{e}+012.63368 \mathrm{e}+012.63368 \mathrm{e}+001.00000 \mathrm{e}-092.12000 \mathrm{e}-01$ $1.00000 \mathrm{e}-05$ 1.00000e-05 1.00000e-06 1.00000e-09 1.00000e-01 $1.00000 \mathrm{e}+001.00000 \mathrm{e}+001.00000 \mathrm{e}-011.00000 \mathrm{e}-091.00000 \mathrm{e}-01$ Element: 8896 \# of layers: 7

Kx Ky Kz Ss Por

$2.80581 \mathrm{e}+012.80581 \mathrm{e}+012.80581 \mathrm{e}+00$ 1.00000e-09 2.12000e-01 $2.80581 \mathrm{e}+012.80581 \mathrm{e}+012.80581 \mathrm{e}+001.00000 \mathrm{e}-092.12000 \mathrm{e}-01$ $2.80581 \mathrm{e}+012.80581 \mathrm{e}+012.80581 \mathrm{e}+001.00000 \mathrm{e}-092.12000 \mathrm{e}-01$ $2.80581 \mathrm{e}+012.80581 \mathrm{e}+012.80581 \mathrm{e}+001.00000 \mathrm{e}-092.12000 \mathrm{e}-01$ $2.80581 \mathrm{e}+012.80581 \mathrm{e}+012.80581 \mathrm{e}+001.00000 \mathrm{e}-092.12000 \mathrm{e}-01$ $1.00000 \mathrm{e}-05$ 1.00000e-05 1.00000e-06 1.00000e-09 1.00000e-01 $1.00000 \mathrm{e}+001.00000 \mathrm{e}+001.00000 \mathrm{e}-011.00000 \mathrm{e}-091.00000 \mathrm{e}-01$ Element: 8897 \# of layers: 7

Kx Ky Kz Ss Por

$2.80581 \mathrm{e}+012.80581 \mathrm{e}+012.80581 \mathrm{e}+00$ 1.00000e-09 2.12000e-01 $2.80581 \mathrm{e}+012.80581 \mathrm{e}+012.80581 \mathrm{e}+001.00000 \mathrm{e}-092.12000 \mathrm{e}-01$ $2.80581 \mathrm{e}+012.80581 \mathrm{e}+012.80581 \mathrm{e}+001.00000 \mathrm{e}-092.12000 \mathrm{e}-01$ $2.80581 \mathrm{e}+012.80581 \mathrm{e}+012.80581 \mathrm{e}+001.00000 \mathrm{e}-092.12000 \mathrm{e}-01$ $2.80581 \mathrm{e}+012.80581 \mathrm{e}+012.80581 \mathrm{e}+001.00000 \mathrm{e}-092.12000 \mathrm{e}-01$ $1.00000 \mathrm{e}-05$ 1.00000e-05 1.00000e-06 1.00000e-09 1.00000e-01 $1.00000 \mathrm{e}+001.00000 \mathrm{e}+001.00000 \mathrm{e}-011.00000 \mathrm{e}-091.00000 \mathrm{e}-01$ Element: 8898 \# of layers: 7

Kx Ky Kz Ss Por

$2.80581 \mathrm{e}+012.80581 \mathrm{e}+012.80581 \mathrm{e}+00$ 1.00000e-09 2.12000e-01 $2.80581 \mathrm{e}+012.80581 \mathrm{e}+012.80581 \mathrm{e}+001.00000 \mathrm{e}-092.12000 \mathrm{e}-01$ 
$2.80581 \mathrm{e}+012.80581 \mathrm{e}+012.80581 \mathrm{e}+00$ 1.00000e-09 2.12000e-01 $2.80581 \mathrm{e}+012.80581 \mathrm{e}+012.80581 \mathrm{e}+001.00000 \mathrm{e}-092.12000 \mathrm{e}-01$ $2.80581 \mathrm{e}+012.80581 \mathrm{e}+012.80581 \mathrm{e}+001.00000 \mathrm{e}-092.12000 \mathrm{e}-01$ $1.00000 \mathrm{e}-05$ 1.00000e-05 1.00000e-06 1.00000e-09 1.00000e-01 $1.00000 \mathrm{e}+001.00000 \mathrm{e}+001.00000 \mathrm{e}-011.00000 \mathrm{e}-091.00000 \mathrm{e}-01$ Element: 8899 \# of layers: 7

Kx Ky Kz Ss Por

$2.80581 \mathrm{e}+012.80581 \mathrm{e}+012.80581 \mathrm{e}+00$ 1.00000e-09 2.12000e-01 $2.80581 \mathrm{e}+012.80581 \mathrm{e}+012.80581 \mathrm{e}+001.00000 \mathrm{e}-092.12000 \mathrm{e}-01$ $2.80581 \mathrm{e}+012.80581 \mathrm{e}+012.80581 \mathrm{e}+001.00000 \mathrm{e}-092.12000 \mathrm{e}-01$ $2.80581 \mathrm{e}+012.80581 \mathrm{e}+012.80581 \mathrm{e}+001.00000 \mathrm{e}-092.12000 \mathrm{e}-01$ $2.80581 \mathrm{e}+012.80581 \mathrm{e}+012.80581 \mathrm{e}+001.00000 \mathrm{e}-092.12000 \mathrm{e}-01$ $1.00000 \mathrm{e}-05$ 1.00000e-05 1.00000e-06 1.00000e-09 1.00000e-01 $1.00000 \mathrm{e}+001.00000 \mathrm{e}+001.00000 \mathrm{e}-011.00000 \mathrm{e}-091.00000 \mathrm{e}-01$ Element: 8900 \# of layers: 7

Kx Ky Kz Ss Por

$2.80581 \mathrm{e}+012.80581 \mathrm{e}+012.80581 \mathrm{e}+00$ 1.00000e-09 2.12000e-01

$2.80581 \mathrm{e}+012.80581 \mathrm{e}+012.80581 \mathrm{e}+001.00000 \mathrm{e}-092.12000 \mathrm{e}-01$

$2.80581 \mathrm{e}+012.80581 \mathrm{e}+012.80581 \mathrm{e}+001.00000 \mathrm{e}-092.12000 \mathrm{e}-01$ $2.80581 \mathrm{e}+012.80581 \mathrm{e}+012.80581 \mathrm{e}+001.00000 \mathrm{e}-092.12000 \mathrm{e}-01$ $2.80581 \mathrm{e}+012.80581 \mathrm{e}+012.80581 \mathrm{e}+001.00000 \mathrm{e}-092.12000 \mathrm{e}-01$ $1.00000 \mathrm{e}-05$ 1.00000e-05 1.00000e-06 1.00000e-09 1.00000e-01 $1.00000 \mathrm{e}+001.00000 \mathrm{e}+001.00000 \mathrm{e}-011.00000 \mathrm{e}-091.00000 \mathrm{e}-01$ Element: 8901 \# of layers: 7

Kx Ky Kz Ss Por

$2.80581 \mathrm{e}+012.80581 \mathrm{e}+012.80581 \mathrm{e}+00$ 1.00000e-09 2.12000e-01 $2.80581 \mathrm{e}+012.80581 \mathrm{e}+012.80581 \mathrm{e}+001.00000 \mathrm{e}-092.12000 \mathrm{e}-01$ $2.80581 \mathrm{e}+012.80581 \mathrm{e}+012.80581 \mathrm{e}+001.00000 \mathrm{e}-092.12000 \mathrm{e}-01$ $2.80581 \mathrm{e}+012.80581 \mathrm{e}+012.80581 \mathrm{e}+001.00000 \mathrm{e}-092.12000 \mathrm{e}-01$ $2.80581 \mathrm{e}+012.80581 \mathrm{e}+012.80581 \mathrm{e}+001.00000 \mathrm{e}-092.12000 \mathrm{e}-01$ $1.00000 \mathrm{e}-05$ 1.00000e-05 1.00000e-06 1.00000e-09 1.00000e-01 $1.00000 \mathrm{e}+001.00000 \mathrm{e}+001.00000 \mathrm{e}-011.00000 \mathrm{e}-091.00000 \mathrm{e}-01$ Element: 8902 \# of layers: 7

Kx Ky Kz Ss Por

$2.80581 \mathrm{e}+012.80581 \mathrm{e}+012.80581 \mathrm{e}+00$ 1.00000e-09 2.12000e-01 $2.80581 \mathrm{e}+012.80581 \mathrm{e}+012.80581 \mathrm{e}+001.00000 \mathrm{e}-092.12000 \mathrm{e}-01$ $2.80581 \mathrm{e}+012.80581 \mathrm{e}+012.80581 \mathrm{e}+001.00000 \mathrm{e}-092.12000 \mathrm{e}-01$ $2.80581 \mathrm{e}+012.80581 \mathrm{e}+012.80581 \mathrm{e}+001.00000 \mathrm{e}-092.12000 \mathrm{e}-01$ $2.80581 \mathrm{e}+012.80581 \mathrm{e}+012.80581 \mathrm{e}+001.00000 \mathrm{e}-092.12000 \mathrm{e}-01$ $1.00000 \mathrm{e}-05$ 1.00000e-05 1.00000e-06 1.00000e-09 1.00000e-01 $1.00000 \mathrm{e}+001.00000 \mathrm{e}+001.00000 \mathrm{e}-011.00000 \mathrm{e}-091.00000 \mathrm{e}-01$ Element: 8903 \# of layers: 7

Kx Ky Kz Ss Por

$2.89469 \mathrm{e}+012.89469 \mathrm{e}+012.89469 \mathrm{e}+00$ 1.00000e-09 2.12000e-01 $2.89469 \mathrm{e}+012.89469 \mathrm{e}+012.89469 \mathrm{e}+001.00000 \mathrm{e}-092.12000 \mathrm{e}-01$ $2.89469 \mathrm{e}+012.89469 \mathrm{e}+012.89469 \mathrm{e}+001.00000 \mathrm{e}-092.12000 \mathrm{e}-01$ 
$2.89469 \mathrm{e}+012.89469 \mathrm{e}+012.89469 \mathrm{e}+00$ 1.00000e-09 2.12000e-01 $2.89469 \mathrm{e}+012.89469 \mathrm{e}+012.89469 \mathrm{e}+00$ 1.00000e-09 2.12000e-01 $1.00000 \mathrm{e}-05$ 1.00000e-05 1.00000e-06 1.00000e-09 1.00000e-01 $1.00000 \mathrm{e}+001.00000 \mathrm{e}+001.00000 \mathrm{e}-011.00000 \mathrm{e}-091.00000 \mathrm{e}-01$ Element: 8904 \# of layers: 7

Kx Ky Kz Ss Por

$2.89469 \mathrm{e}+012.89469 \mathrm{e}+012.89469 \mathrm{e}+00$ 1.00000e-09 2.12000e-01 $2.89469 \mathrm{e}+012.89469 \mathrm{e}+012.89469 \mathrm{e}+001.00000 \mathrm{e}-092.12000 \mathrm{e}-01$ $2.89469 \mathrm{e}+012.89469 \mathrm{e}+012.89469 \mathrm{e}+001.00000 \mathrm{e}-092.12000 \mathrm{e}-01$ $2.89469 \mathrm{e}+012.89469 \mathrm{e}+012.89469 \mathrm{e}+001.00000 \mathrm{e}-092.12000 \mathrm{e}-01$ $2.89469 \mathrm{e}+012.89469 \mathrm{e}+012.89469 \mathrm{e}+001.00000 \mathrm{e}-092.12000 \mathrm{e}-01$ $1.00000 \mathrm{e}-05$ 1.00000e-05 1.00000e-06 1.00000e-09 1.00000e-01 $1.00000 \mathrm{e}+001.00000 \mathrm{e}+001.00000 \mathrm{e}-011.00000 \mathrm{e}-091.00000 \mathrm{e}-01$ Element: 8905 \# of layers: 7

Kx Ky Kz Ss Por

$2.89469 \mathrm{e}+012.89469 \mathrm{e}+012.89469 \mathrm{e}+00$ 1.00000e-09 2.12000e-01 $2.89469 \mathrm{e}+012.89469 \mathrm{e}+012.89469 \mathrm{e}+001.00000 \mathrm{e}-092.12000 \mathrm{e}-01$ $2.89469 \mathrm{e}+012.89469 \mathrm{e}+012.89469 \mathrm{e}+001.00000 \mathrm{e}-092.12000 \mathrm{e}-01$ $2.89469 \mathrm{e}+012.89469 \mathrm{e}+012.89469 \mathrm{e}+001.00000 \mathrm{e}-092.12000 \mathrm{e}-01$ $2.89469 \mathrm{e}+012.89469 \mathrm{e}+012.89469 \mathrm{e}+00$ 1.00000e-09 2.12000e-01 $1.00000 \mathrm{e}-05$ 1.00000e-05 1.00000e-06 1.00000e-09 1.00000e-01 $1.00000 \mathrm{e}+001.00000 \mathrm{e}+001.00000 \mathrm{e}-011.00000 \mathrm{e}-091.00000 \mathrm{e}-01$ Element: 8906 \# of layers: 7

$\mathrm{Kx} \mathrm{Ky} \mathrm{Kz}$ Ss Por

$2.80581 \mathrm{e}+012.80581 \mathrm{e}+012.80581 \mathrm{e}+001.00000 \mathrm{e}-092.12000 \mathrm{e}-01$

$2.80581 \mathrm{e}+012.80581 \mathrm{e}+012.80581 \mathrm{e}+001.00000 \mathrm{e}-092.12000 \mathrm{e}-01$

$2.80581 \mathrm{e}+012.80581 \mathrm{e}+012.80581 \mathrm{e}+001.00000 \mathrm{e}-092.12000 \mathrm{e}-01$ $2.80581 \mathrm{e}+012.80581 \mathrm{e}+012.80581 \mathrm{e}+001.00000 \mathrm{e}-092.12000 \mathrm{e}-01$ $2.80581 \mathrm{e}+012.80581 \mathrm{e}+012.80581 \mathrm{e}+001.00000 \mathrm{e}-092.12000 \mathrm{e}-01$ $1.00000 \mathrm{e}-05$ 1.00000e-05 1.00000e-06 1.00000e-09 1.00000e-01 $1.00000 \mathrm{e}+001.00000 \mathrm{e}+001.00000 \mathrm{e}-011.00000 \mathrm{e}-091.00000 \mathrm{e}-01$ Element: 8907 \# of layers: 7

Kx Ky Kz Ss Por

$2.80581 \mathrm{e}+012.80581 \mathrm{e}+012.80581 \mathrm{e}+00$ 1.00000e-09 2.12000e-01 $2.80581 \mathrm{e}+012.80581 \mathrm{e}+012.80581 \mathrm{e}+001.00000 \mathrm{e}-092.12000 \mathrm{e}-01$ $2.80581 \mathrm{e}+012.80581 \mathrm{e}+012.80581 \mathrm{e}+001.00000 \mathrm{e}-092.12000 \mathrm{e}-01$ $2.80581 \mathrm{e}+012.80581 \mathrm{e}+012.80581 \mathrm{e}+001.00000 \mathrm{e}-092.12000 \mathrm{e}-01$ $2.80581 \mathrm{e}+012.80581 \mathrm{e}+012.80581 \mathrm{e}+001.00000 \mathrm{e}-092.12000 \mathrm{e}-01$ $1.00000 \mathrm{e}-05$ 1.00000e-05 1.00000e-06 1.00000e-09 1.00000e-01 $1.00000 \mathrm{e}+001.00000 \mathrm{e}+001.00000 \mathrm{e}-011.00000 \mathrm{e}-091.00000 \mathrm{e}-01$ Element: 8908 \# of layers: 7

Kx Ky Kz Ss Por

$2.80581 \mathrm{e}+012.80581 \mathrm{e}+012.80581 \mathrm{e}+00$ 1.00000e-09 2.12000e-01 $2.80581 \mathrm{e}+012.80581 \mathrm{e}+012.80581 \mathrm{e}+001.00000 \mathrm{e}-092.12000 \mathrm{e}-01$ $2.80581 \mathrm{e}+012.80581 \mathrm{e}+012.80581 \mathrm{e}+001.00000 \mathrm{e}-092.12000 \mathrm{e}-01$ $2.80581 \mathrm{e}+012.80581 \mathrm{e}+012.80581 \mathrm{e}+001.00000 \mathrm{e}-092.12000 \mathrm{e}-01$ 
$2.80581 \mathrm{e}+012.80581 \mathrm{e}+012.80581 \mathrm{e}+00$ 1.00000e-09 2.12000e-01 $1.00000 \mathrm{e}-05$ 1.00000e-05 1.00000e-06 1.00000e-09 1.00000e-01 $1.00000 \mathrm{e}+001.00000 \mathrm{e}+001.00000 \mathrm{e}-011.00000 \mathrm{e}-09$ 1.00000e-01

Element: 8909 \# of layers: 7

$\mathrm{Kx} \mathrm{Ky} \mathrm{Kz}$ Ss Por

$2.80581 \mathrm{e}+012.80581 \mathrm{e}+012.80581 \mathrm{e}+00$ 1.00000e-09 2.12000e-01

$2.80581 \mathrm{e}+012.80581 \mathrm{e}+012.80581 \mathrm{e}+001.00000 \mathrm{e}-092.12000 \mathrm{e}-01$

$2.80581 \mathrm{e}+012.80581 \mathrm{e}+012.80581 \mathrm{e}+001.00000 \mathrm{e}-092.12000 \mathrm{e}-01$

$2.80581 \mathrm{e}+012.80581 \mathrm{e}+012.80581 \mathrm{e}+001.00000 \mathrm{e}-092.12000 \mathrm{e}-01$

$2.80581 \mathrm{e}+012.80581 \mathrm{e}+012.80581 \mathrm{e}+001.00000 \mathrm{e}-092.12000 \mathrm{e}-01$

$1.00000 \mathrm{e}-05$ 1.00000e-05 1.00000e-06 1.00000e-09 1.00000e-01

$1.00000 \mathrm{e}+001.00000 \mathrm{e}+001.00000 \mathrm{e}-011.00000 \mathrm{e}-091.00000 \mathrm{e}-01$

Element: 8910 \# of layers: 7

$\mathrm{Kx} \mathrm{Ky} \mathrm{Kz}$ Ss Por

$2.89469 \mathrm{e}+012.89469 \mathrm{e}+012.89469 \mathrm{e}+00$ 1.00000e-09 2.12000e-01

$2.89469 \mathrm{e}+012.89469 \mathrm{e}+012.89469 \mathrm{e}+001.00000 \mathrm{e}-092.12000 \mathrm{e}-01$

$2.89469 \mathrm{e}+012.89469 \mathrm{e}+012.89469 \mathrm{e}+00$ 1.00000e-09 2.12000e-01

$2.89469 \mathrm{e}+012.89469 \mathrm{e}+012.89469 \mathrm{e}+00$ 1.00000e-09 2.12000e-01

$2.89469 \mathrm{e}+012.89469 \mathrm{e}+012.89469 \mathrm{e}+00$ 1.00000e-09 2.12000e-01

$1.00000 \mathrm{e}-05$ 1.00000e-05 1.00000e-06 1.00000e-09 1.00000e-01

$1.00000 \mathrm{e}+001.00000 \mathrm{e}+001.00000 \mathrm{e}-011.00000 \mathrm{e}-091.00000 \mathrm{e}-01$

Element: 8911 \# of layers: 7

$\mathrm{Kx} \mathrm{Ky} \mathrm{Kz}$ Ss Por

$2.89469 \mathrm{e}+012.89469 \mathrm{e}+012.89469 \mathrm{e}+00$ 1.00000e-09 2.12000e-01

$2.89469 \mathrm{e}+012.89469 \mathrm{e}+012.89469 \mathrm{e}+001.00000 \mathrm{e}-092.12000 \mathrm{e}-01$

$2.89469 \mathrm{e}+012.89469 \mathrm{e}+012.89469 \mathrm{e}+001.00000 \mathrm{e}-092.12000 \mathrm{e}-01$

$2.89469 \mathrm{e}+012.89469 \mathrm{e}+012.89469 \mathrm{e}+001.00000 \mathrm{e}-092.12000 \mathrm{e}-01$

$2.89469 \mathrm{e}+012.89469 \mathrm{e}+012.89469 \mathrm{e}+00$ 1.00000e-09 2.12000e-01

$1.00000 \mathrm{e}-05$ 1.00000e-05 1.00000e-06 1.00000e-09 1.00000e-01

$1.00000 \mathrm{e}+001.00000 \mathrm{e}+001.00000 \mathrm{e}-011.00000 \mathrm{e}-091.00000 \mathrm{e}-01$

Element: 8912 \# of layers: 7

$\mathrm{Kx} \mathrm{Ky} \mathrm{Kz}$ Ss Por

$2.89469 \mathrm{e}+012.89469 \mathrm{e}+012.89469 \mathrm{e}+00$ 1.00000e-09 2.12000e-01

$2.89469 \mathrm{e}+012.89469 \mathrm{e}+012.89469 \mathrm{e}+001.00000 \mathrm{e}-092.12000 \mathrm{e}-01$

$2.89469 \mathrm{e}+012.89469 \mathrm{e}+012.89469 \mathrm{e}+001.00000 \mathrm{e}-092.12000 \mathrm{e}-01$

$2.89469 \mathrm{e}+012.89469 \mathrm{e}+012.89469 \mathrm{e}+00$ 1.00000e-09 2.12000e-01

$2.89469 \mathrm{e}+012.89469 \mathrm{e}+012.89469 \mathrm{e}+001.00000 \mathrm{e}-092.12000 \mathrm{e}-01$

$1.00000 \mathrm{e}-05$ 1.00000e-05 1.00000e-06 1.00000e-09 1.00000e-01

$1.00000 \mathrm{e}+001.00000 \mathrm{e}+001.00000 \mathrm{e}-011.00000 \mathrm{e}-091.00000 \mathrm{e}-01$

Element: 8913 \# of layers: 7

$\mathrm{Kx} \mathrm{Ky} \mathrm{Kz}$ Ss Por

$2.89469 \mathrm{e}+012.89469 \mathrm{e}+012.89469 \mathrm{e}+00$ 1.00000e-09 2.12000e-01

$2.89469 \mathrm{e}+012.89469 \mathrm{e}+012.89469 \mathrm{e}+00$ 1.00000e-09 2.12000e-01

$2.89469 \mathrm{e}+012.89469 \mathrm{e}+01$ 2.89469e+00 1.00000e-09 2.12000e-01

$2.89469 \mathrm{e}+012.89469 \mathrm{e}+012.89469 \mathrm{e}+001.00000 \mathrm{e}-092.12000 \mathrm{e}-01$

$2.89469 \mathrm{e}+012.89469 \mathrm{e}+012.89469 \mathrm{e}+001.00000 \mathrm{e}-092.12000 \mathrm{e}-01$ 
$1.00000 \mathrm{e}-05$ 1.00000e-05 1.00000e-06 1.00000e-09 1.00000e-01 $1.00000 \mathrm{e}+001.00000 \mathrm{e}+001.00000 \mathrm{e}-01$ 1.00000e-09 1.00000e-01 Element: 8914 \# of layers: 7

Kx Ky Kz Ss Por

$2.89469 \mathrm{e}+012.89469 \mathrm{e}+012.89469 \mathrm{e}+00$ 1.00000e-09 2.12000e-01

$2.89469 \mathrm{e}+012.89469 \mathrm{e}+012.89469 \mathrm{e}+00$ 1.00000e-09 2.12000e-01

$2.89469 \mathrm{e}+012.89469 \mathrm{e}+012.89469 \mathrm{e}+00$ 1.00000e-09 2.12000e-01

$2.89469 \mathrm{e}+012.89469 \mathrm{e}+012.89469 \mathrm{e}+001.00000 \mathrm{e}-092.12000 \mathrm{e}-01$

$2.89469 \mathrm{e}+012.89469 \mathrm{e}+012.89469 \mathrm{e}+00$ 1.00000e-09 2.12000e-01

$1.00000 \mathrm{e}-05$ 1.00000e-05 1.00000e-06 1.00000e-09 1.00000e-01

$1.00000 \mathrm{e}+001.00000 \mathrm{e}+001.00000 \mathrm{e}-01$ 1.00000e-09 1.00000e-01

Element: 8915 \# of layers: 7

$\mathrm{Kx} \mathrm{Ky} \mathrm{Kz}$ Ss Por

$2.89469 \mathrm{e}+012.89469 \mathrm{e}+012.89469 \mathrm{e}+00$ 1.00000e-09 2.12000e-01

$2.89469 \mathrm{e}+012.89469 \mathrm{e}+012.89469 \mathrm{e}+00$ 1.00000e-09 2.12000e-01

$2.89469 \mathrm{e}+012.89469 \mathrm{e}+012.89469 \mathrm{e}+001.00000 \mathrm{e}-092.12000 \mathrm{e}-01$

$2.89469 \mathrm{e}+012.89469 \mathrm{e}+012.89469 \mathrm{e}+00$ 1.00000e-09 2.12000e-01

$2.89469 \mathrm{e}+012.89469 \mathrm{e}+012.89469 \mathrm{e}+00$ 1.00000e-09 2.12000e-01

$1.00000 \mathrm{e}-05$ 1.00000e-05 1.00000e-06 1.00000e-09 1.00000e-01

$1.00000 \mathrm{e}+001.00000 \mathrm{e}+001.00000 \mathrm{e}-011.00000 \mathrm{e}-091.00000 \mathrm{e}-01$

Element: 8916 \# of layers: 7

$\mathrm{Kx} \mathrm{Ky} \mathrm{Kz}$ Ss Por

$2.89469 \mathrm{e}+012.89469 \mathrm{e}+012.89469 \mathrm{e}+00$ 1.00000e-09 2.12000e-01

$2.89469 \mathrm{e}+012.89469 \mathrm{e}+012.89469 \mathrm{e}+001.00000 \mathrm{e}-092.12000 \mathrm{e}-01$

$2.89469 \mathrm{e}+012.89469 \mathrm{e}+012.89469 \mathrm{e}+001.00000 \mathrm{e}-092.12000 \mathrm{e}-01$

$2.89469 \mathrm{e}+012.89469 \mathrm{e}+012.89469 \mathrm{e}+001.00000 \mathrm{e}-092.12000 \mathrm{e}-01$

$2.89469 \mathrm{e}+012.89469 \mathrm{e}+012.89469 \mathrm{e}+00$ 1.00000e-09 2.12000e-01

$1.00000 \mathrm{e}-05$ 1.00000e-05 1.00000e-06 1.00000e-09 1.00000e-01

$1.00000 \mathrm{e}+001.00000 \mathrm{e}+001.00000 \mathrm{e}-011.00000 \mathrm{e}-091.00000 \mathrm{e}-01$

Element: 8917 \# of layers: 7

$\mathrm{Kx} \mathrm{Ky} \mathrm{Kz}$ Ss Por

$2.89469 \mathrm{e}+012.89469 \mathrm{e}+012.89469 \mathrm{e}+00$ 1.00000e-09 2.12000e-01

$2.89469 \mathrm{e}+012.89469 \mathrm{e}+012.89469 \mathrm{e}+001.00000 \mathrm{e}-092.12000 \mathrm{e}-01$

$2.89469 \mathrm{e}+012.89469 \mathrm{e}+012.89469 \mathrm{e}+001.00000 \mathrm{e}-092.12000 \mathrm{e}-01$

$2.89469 \mathrm{e}+012.89469 \mathrm{e}+012.89469 \mathrm{e}+00$ 1.00000e-09 2.12000e-01

$2.89469 \mathrm{e}+012.89469 \mathrm{e}+012.89469 \mathrm{e}+00$ 1.00000e-09 2.12000e-01 1.00000e-05 1.00000e-05 1.00000e-06 1.00000e-09 1.00000e-01

$1.00000 \mathrm{e}+001.00000 \mathrm{e}+001.00000 \mathrm{e}-011.00000 \mathrm{e}-091.00000 \mathrm{e}-01$

Element: 8918 \# of layers: 7

$\mathrm{Kx} \mathrm{Ky} \mathrm{Kz}$ Ss Por

$2.89469 \mathrm{e}+012.89469 \mathrm{e}+012.89469 \mathrm{e}+00$ 1.00000e-09 2.12000e-01

$2.89469 \mathrm{e}+012.89469 \mathrm{e}+012.89469 \mathrm{e}+001.00000 \mathrm{e}-092.12000 \mathrm{e}-01$

$2.89469 \mathrm{e}+012.89469 \mathrm{e}+012.89469 \mathrm{e}+00$ 1.00000e-09 2.12000e-01

$2.89469 \mathrm{e}+012.89469 \mathrm{e}+01$ 2.89469e+00 1.00000e-09 2.12000e-01

$2.89469 \mathrm{e}+012.89469 \mathrm{e}+012.89469 \mathrm{e}+001.00000 \mathrm{e}-092.12000 \mathrm{e}-01$

$1.00000 \mathrm{e}-05$ 1.00000e-05 1.00000e-06 1.00000e-09 1.00000e-01 
$1.00000 \mathrm{e}+001.00000 \mathrm{e}+001.00000 \mathrm{e}-011.00000 \mathrm{e}-091.00000 \mathrm{e}-01$

Element: 8919 \# of layers: 7

$\mathrm{Kx} \mathrm{Ky} \mathrm{Kz}$ Ss Por

$2.89469 \mathrm{e}+012.89469 \mathrm{e}+012.89469 \mathrm{e}+00$ 1.00000e-09 2.12000e-01

$2.89469 \mathrm{e}+012.89469 \mathrm{e}+012.89469 \mathrm{e}+001.00000 \mathrm{e}-092.12000 \mathrm{e}-01$

$2.89469 \mathrm{e}+012.89469 \mathrm{e}+012.89469 \mathrm{e}+00$ 1.00000e-09 2.12000e-01

$2.89469 \mathrm{e}+012.89469 \mathrm{e}+012.89469 \mathrm{e}+00$ 1.00000e-09 2.12000e-01

$2.89469 \mathrm{e}+012.89469 \mathrm{e}+012.89469 \mathrm{e}+00$ 1.00000e-09 2.12000e-01

$1.00000 \mathrm{e}-05$ 1.00000e-05 1.00000e-06 1.00000e-09 1.00000e-01

$1.00000 \mathrm{e}+001.00000 \mathrm{e}+001.00000 \mathrm{e}-011.00000 \mathrm{e}-091.00000 \mathrm{e}-01$

Element: 8920 \# of layers: 7

$\mathrm{Kx} \mathrm{Ky} \mathrm{Kz}$ Ss Por

$2.89469 \mathrm{e}+012.89469 \mathrm{e}+01$ 2.89469e+00 1.00000e-09 2.12000e-01

$2.89469 \mathrm{e}+012.89469 \mathrm{e}+012.89469 \mathrm{e}+00$ 1.00000e-09 2.12000e-01

$2.89469 \mathrm{e}+012.89469 \mathrm{e}+012.89469 \mathrm{e}+00$ 1.00000e-09 2.12000e-01

$2.89469 \mathrm{e}+012.89469 \mathrm{e}+012.89469 \mathrm{e}+001.00000 \mathrm{e}-092.12000 \mathrm{e}-01$

$2.89469 \mathrm{e}+012.89469 \mathrm{e}+012.89469 \mathrm{e}+00$ 1.00000e-09 2.12000e-01

$1.00000 \mathrm{e}-05$ 1.00000e-05 1.00000e-06 1.00000e-09 1.00000e-01

$1.00000 \mathrm{e}+001.00000 \mathrm{e}+001.00000 \mathrm{e}-011.00000 \mathrm{e}-091.00000 \mathrm{e}-01$

Element: 8921 \# of layers: 7

Kx Ky Kz Ss Por

$2.58778 \mathrm{e}+012.58778 \mathrm{e}+012.58778 \mathrm{e}+00$ 1.00000e-09 2.12000e-01

$2.58778 \mathrm{e}+012.58778 \mathrm{e}+012.58778 \mathrm{e}+00$ 1.00000e-09 2.12000e-01

$2.58778 \mathrm{e}+012.58778 \mathrm{e}+012.58778 \mathrm{e}+001.00000 \mathrm{e}-092.12000 \mathrm{e}-01$

$2.58778 \mathrm{e}+012.58778 \mathrm{e}+012.58778 \mathrm{e}+001.00000 \mathrm{e}-092.12000 \mathrm{e}-01$

$2.58778 \mathrm{e}+012.58778 \mathrm{e}+012.58778 \mathrm{e}+00$ 1.00000e-09 2.12000e-01

$1.00000 \mathrm{e}-05$ 1.00000e-05 1.00000e-06 1.00000e-09 1.00000e-01

$1.00000 \mathrm{e}+001.00000 \mathrm{e}+001.00000 \mathrm{e}-011.00000 \mathrm{e}-09$ 1.00000e-01

Element: 8922 \# of layers: 7

$\mathrm{Kx} \mathrm{Ky} \mathrm{Kz}$ Ss Por

$2.58778 \mathrm{e}+012.58778 \mathrm{e}+012.58778 \mathrm{e}+00$ 1.00000e-09 2.12000e-01

$2.58778 \mathrm{e}+012.58778 \mathrm{e}+012.58778 \mathrm{e}+00$ 1.00000e-09 2.12000e-01

$2.58778 \mathrm{e}+012.58778 \mathrm{e}+012.58778 \mathrm{e}+00$ 1.00000e-09 2.12000e-01

$2.58778 \mathrm{e}+012.58778 \mathrm{e}+012.58778 \mathrm{e}+001.00000 \mathrm{e}-092.12000 \mathrm{e}-01$

$2.58778 \mathrm{e}+012.58778 \mathrm{e}+012.58778 \mathrm{e}+00$ 1.00000e-09 2.12000e-01

1.00000e-05 1.00000e-05 1.00000e-06 1.00000e-09 1.00000e-01

$1.00000 \mathrm{e}+001.00000 \mathrm{e}+001.00000 \mathrm{e}-011.00000 \mathrm{e}-091.00000 \mathrm{e}-01$

Element: 8923 \# of layers: 7

$\mathrm{Kx} \mathrm{Ky} \mathrm{Kz}$ Ss Por

$2.58778 \mathrm{e}+012.58778 \mathrm{e}+012.58778 \mathrm{e}+00$ 1.00000e-09 2.12000e-01

$2.58778 \mathrm{e}+012.58778 \mathrm{e}+012.58778 \mathrm{e}+001.00000 \mathrm{e}-092.12000 \mathrm{e}-01$

$2.58778 \mathrm{e}+012.58778 \mathrm{e}+012.58778 \mathrm{e}+001.00000 \mathrm{e}-092.12000 \mathrm{e}-01$

$2.58778 \mathrm{e}+012.58778 \mathrm{e}+012.58778 \mathrm{e}+00$ 1.00000e-09 2.12000e-01

$2.58778 \mathrm{e}+012.58778 \mathrm{e}+012.58778 \mathrm{e}+00$ 1.00000e-09 2.12000e-01 $1.00000 \mathrm{e}-05$ 1.00000e-05 1.00000e-06 1.00000e-09 1.00000e-01

$1.00000 \mathrm{e}+001.00000 \mathrm{e}+001.00000 \mathrm{e}-011.00000 \mathrm{e}-091.00000 \mathrm{e}-01$ 
Element: 8924 \# of layers: 7

$\mathrm{Kx} \mathrm{Ky} \mathrm{Kz}$ Ss Por

$2.89469 \mathrm{e}+012.89469 \mathrm{e}+012.89469 \mathrm{e}+00$ 1.00000e-09 2.12000e-01

$2.89469 \mathrm{e}+012.89469 \mathrm{e}+012.89469 \mathrm{e}+001.00000 \mathrm{e}-092.12000 \mathrm{e}-01$

$2.89469 \mathrm{e}+012.89469 \mathrm{e}+012.89469 \mathrm{e}+001.00000 \mathrm{e}-092.12000 \mathrm{e}-01$

$2.89469 \mathrm{e}+012.89469 \mathrm{e}+012.89469 \mathrm{e}+00$ 1.00000e-09 2.12000e-01

$2.89469 \mathrm{e}+012.89469 \mathrm{e}+012.89469 \mathrm{e}+00$ 1.00000e-09 2.12000e-01

$1.00000 \mathrm{e}-05$ 1.00000e-05 1.00000e-06 1.00000e-09 1.00000e-01

$1.00000 \mathrm{e}+001.00000 \mathrm{e}+001.00000 \mathrm{e}-011.00000 \mathrm{e}-091.00000 \mathrm{e}-01$

Element: 8925 \# of layers: 7

$\mathrm{Kx} \mathrm{Ky} \mathrm{Kz}$ Ss Por

$2.89469 \mathrm{e}+012.89469 \mathrm{e}+012.89469 \mathrm{e}+00$ 1.00000e-09 2.12000e-01

$2.89469 \mathrm{e}+012.89469 \mathrm{e}+012.89469 \mathrm{e}+001.00000 \mathrm{e}-092.12000 \mathrm{e}-01$

$2.89469 \mathrm{e}+012.89469 \mathrm{e}+012.89469 \mathrm{e}+00$ 1.00000e-09 2.12000e-01

$2.89469 \mathrm{e}+012.89469 \mathrm{e}+012.89469 \mathrm{e}+00$ 1.00000e-09 2.12000e-01

$2.89469 \mathrm{e}+012.89469 \mathrm{e}+012.89469 \mathrm{e}+001.00000 \mathrm{e}-092.12000 \mathrm{e}-01$

$1.00000 \mathrm{e}-05$ 1.00000e-05 1.00000e-06 1.00000e-09 1.00000e-01

$1.00000 \mathrm{e}+001.00000 \mathrm{e}+001.00000 \mathrm{e}-011.00000 \mathrm{e}-091.00000 \mathrm{e}-01$

Element: 8926 \# of layers: 7

$\mathrm{Kx} \mathrm{Ky} \mathrm{Kz}$ Ss Por

$2.89469 \mathrm{e}+012.89469 \mathrm{e}+012.89469 \mathrm{e}+00$ 1.00000e-09 2.12000e-01

$2.89469 \mathrm{e}+012.89469 \mathrm{e}+012.89469 \mathrm{e}+00$ 1.00000e-09 2.12000e-01

$2.89469 \mathrm{e}+012.89469 \mathrm{e}+012.89469 \mathrm{e}+00$ 1.00000e-09 2.12000e-01

$2.89469 \mathrm{e}+012.89469 \mathrm{e}+012.89469 \mathrm{e}+001.00000 \mathrm{e}-092.12000 \mathrm{e}-01$

$2.89469 \mathrm{e}+012.89469 \mathrm{e}+012.89469 \mathrm{e}+001.00000 \mathrm{e}-092.12000 \mathrm{e}-01$

$1.00000 \mathrm{e}-05$ 1.00000e-05 1.00000e-06 1.00000e-09 1.00000e-01

$1.00000 \mathrm{e}+001.00000 \mathrm{e}+001.00000 \mathrm{e}-011.00000 \mathrm{e}-091.00000 \mathrm{e}-01$

Element: 8927 \# of layers: 7

$\mathrm{Kx} \mathrm{Ky} \mathrm{Kz}$ Ss Por

$2.89469 \mathrm{e}+012.89469 \mathrm{e}+012.89469 \mathrm{e}+00$ 1.00000e-09 2.12000e-01

$2.89469 \mathrm{e}+012.89469 \mathrm{e}+012.89469 \mathrm{e}+00$ 1.00000e-09 2.12000e-01

$2.89469 \mathrm{e}+012.89469 \mathrm{e}+012.89469 \mathrm{e}+00$ 1.00000e-09 2.12000e-01

$2.89469 \mathrm{e}+012.89469 \mathrm{e}+012.89469 \mathrm{e}+00$ 1.00000e-09 2.12000e-01

$2.89469 \mathrm{e}+012.89469 \mathrm{e}+012.89469 \mathrm{e}+00$ 1.00000e-09 2.12000e-01

$1.00000 \mathrm{e}-05$ 1.00000e-05 1.00000e-06 1.00000e-09 1.00000e-01

$1.00000 \mathrm{e}+001.00000 \mathrm{e}+001.00000 \mathrm{e}-011.00000 \mathrm{e}-091.00000 \mathrm{e}-01$

Element: 8928 \# of layers: 7

$\mathrm{Kx} \mathrm{Ky} \mathrm{Kz}$ Ss Por

$2.58778 \mathrm{e}+012.58778 \mathrm{e}+012.58778 \mathrm{e}+00$ 1.00000e-09 2.12000e-01

$2.58778 \mathrm{e}+012.58778 \mathrm{e}+012.58778 \mathrm{e}+00$ 1.00000e-09 2.12000e-01

$2.58778 \mathrm{e}+012.58778 \mathrm{e}+012.58778 \mathrm{e}+00$ 1.00000e-09 2.12000e-01

$2.58778 \mathrm{e}+012.58778 \mathrm{e}+012.58778 \mathrm{e}+001.00000 \mathrm{e}-092.12000 \mathrm{e}-01$

$2.58778 \mathrm{e}+012.58778 \mathrm{e}+012.58778 \mathrm{e}+00$ 1.00000e-09 2.12000e-01

$1.00000 \mathrm{e}-051.00000 \mathrm{e}-051.00000 \mathrm{e}-061.00000 \mathrm{e}-091.00000 \mathrm{e}-01$

$1.00000 \mathrm{e}+001.00000 \mathrm{e}+001.00000 \mathrm{e}-011.00000 \mathrm{e}-09$ 1.00000e-01

Element: 8929 \# of layers: 7 
Kx Ky Kz Ss Por

$2.58778 \mathrm{e}+012.58778 \mathrm{e}+012.58778 \mathrm{e}+00$ 1.00000e-09 2.12000e-01

$2.58778 \mathrm{e}+012.58778 \mathrm{e}+012.58778 \mathrm{e}+00$ 1.00000e-09 2.12000e-01

$2.58778 \mathrm{e}+012.58778 \mathrm{e}+012.58778 \mathrm{e}+001.00000 \mathrm{e}-092.12000 \mathrm{e}-01$

$2.58778 \mathrm{e}+012.58778 \mathrm{e}+012.58778 \mathrm{e}+001.00000 \mathrm{e}-092.12000 \mathrm{e}-01$

$2.58778 \mathrm{e}+012.58778 \mathrm{e}+012.58778 \mathrm{e}+00$ 1.00000e-09 2.12000e-01 $1.00000 \mathrm{e}-05$ 1.00000e-05 1.00000e-06 1.00000e-09 1.00000e-01

$1.00000 \mathrm{e}+001.00000 \mathrm{e}+001.00000 \mathrm{e}-01$ 1.00000e-09 1.00000e-01

Element: 8930 \# of layers: 7

$\mathrm{Kx} \mathrm{Ky} \mathrm{Kz}$ Ss Por

$2.58778 \mathrm{e}+012.58778 \mathrm{e}+012.58778 \mathrm{e}+00$ 1.00000e-09 2.12000e-01

$2.58778 \mathrm{e}+012.58778 \mathrm{e}+012.58778 \mathrm{e}+001.00000 \mathrm{e}-092.12000 \mathrm{e}-01$

$2.58778 \mathrm{e}+012.58778 \mathrm{e}+012.58778 \mathrm{e}+001.00000 \mathrm{e}-092.12000 \mathrm{e}-01$

$2.58778 \mathrm{e}+012.58778 \mathrm{e}+012.58778 \mathrm{e}+00$ 1.00000e-09 2.12000e-01

$2.58778 \mathrm{e}+012.58778 \mathrm{e}+012.58778 \mathrm{e}+001.00000 \mathrm{e}-092.12000 \mathrm{e}-01$ $1.00000 \mathrm{e}-05$ 1.00000e-05 1.00000e-06 1.00000e-09 1.00000e-01

$1.00000 \mathrm{e}+001.00000 \mathrm{e}+001.00000 \mathrm{e}-011.00000 \mathrm{e}-091.00000 \mathrm{e}-01$

Element: 8931 \# of layers: 7

$\mathrm{Kx} \mathrm{Ky} \mathrm{Kz}$ Ss Por

$2.58778 \mathrm{e}+012.58778 \mathrm{e}+012.58778 \mathrm{e}+00$ 1.00000e-09 2.12000e-01

$2.58778 \mathrm{e}+012.58778 \mathrm{e}+012.58778 \mathrm{e}+001.00000 \mathrm{e}-092.12000 \mathrm{e}-01$

$2.58778 \mathrm{e}+012.58778 \mathrm{e}+012.58778 \mathrm{e}+00$ 1.00000e-09 2.12000e-01

$2.58778 \mathrm{e}+012.58778 \mathrm{e}+012.58778 \mathrm{e}+00$ 1.00000e-09 2.12000e-01

$2.58778 \mathrm{e}+012.58778 \mathrm{e}+012.58778 \mathrm{e}+00$ 1.00000e-09 2.12000e-01

$1.00000 \mathrm{e}-05$ 1.00000e-05 1.00000e-06 1.00000e-09 1.00000e-01

$1.00000 \mathrm{e}+001.00000 \mathrm{e}+001.00000 \mathrm{e}-01$ 1.00000e-09 1.00000e-01

Element: 8932 \# of layers: 7

$\mathrm{Kx} \mathrm{Ky} \mathrm{Kz}$ Ss Por

$2.58778 \mathrm{e}+012.58778 \mathrm{e}+012.58778 \mathrm{e}+00$ 1.00000e-09 2.12000e-01

$2.58778 \mathrm{e}+012.58778 \mathrm{e}+012.58778 \mathrm{e}+001.00000 \mathrm{e}-092.12000 \mathrm{e}-01$

$2.58778 \mathrm{e}+012.58778 \mathrm{e}+012.58778 \mathrm{e}+001.00000 \mathrm{e}-092.12000 \mathrm{e}-01$

$2.58778 \mathrm{e}+012.58778 \mathrm{e}+012.58778 \mathrm{e}+001.00000 \mathrm{e}-092.12000 \mathrm{e}-01$

$2.58778 \mathrm{e}+012.58778 \mathrm{e}+012.58778 \mathrm{e}+001.00000 \mathrm{e}-092.12000 \mathrm{e}-01$

$1.00000 \mathrm{e}-05$ 1.00000e-05 1.00000e-06 1.00000e-09 1.00000e-01

$1.00000 \mathrm{e}+001.00000 \mathrm{e}+001.00000 \mathrm{e}-01$ 1.00000e-09 1.00000e-01

Element: 8933 \# of layers: 7

Kx Ky Kz Ss Por

$2.58778 \mathrm{e}+012.58778 \mathrm{e}+012.58778 \mathrm{e}+00$ 1.00000e-09 2.12000e-01

$2.58778 \mathrm{e}+012.58778 \mathrm{e}+012.58778 \mathrm{e}+00$ 1.00000e-09 2.12000e-01

$2.58778 \mathrm{e}+012.58778 \mathrm{e}+012.58778 \mathrm{e}+001.00000 \mathrm{e}-092.12000 \mathrm{e}-01$

$2.58778 \mathrm{e}+012.58778 \mathrm{e}+012.58778 \mathrm{e}+00$ 1.00000e-09 2.12000e-01

$2.58778 \mathrm{e}+012.58778 \mathrm{e}+012.58778 \mathrm{e}+00$ 1.00000e-09 2.12000e-01

$1.00000 \mathrm{e}-051.00000 \mathrm{e}-051.00000 \mathrm{e}-061.00000 \mathrm{e}-091.00000 \mathrm{e}-01$

$1.00000 \mathrm{e}+001.00000 \mathrm{e}+001.00000 \mathrm{e}-01$ 1.00000e-09 1.00000e-01

Element: 8934 \# of layers: 7

Kx Ky Kz Ss Por 
$2.58778 \mathrm{e}+012.58778 \mathrm{e}+012.58778 \mathrm{e}+00$ 1.00000e-09 2.12000e-01 $2.58778 \mathrm{e}+012.58778 \mathrm{e}+012.58778 \mathrm{e}+00$ 1.00000e-09 2.12000e-01 $2.58778 \mathrm{e}+012.58778 \mathrm{e}+012.58778 \mathrm{e}+00$ 1.00000e-09 2.12000e-01 $2.58778 \mathrm{e}+012.58778 \mathrm{e}+012.58778 \mathrm{e}+001.00000 \mathrm{e}-092.12000 \mathrm{e}-01$ $2.58778 \mathrm{e}+012.58778 \mathrm{e}+012.58778 \mathrm{e}+001.00000 \mathrm{e}-092.12000 \mathrm{e}-01$ $1.00000 \mathrm{e}-05$ 1.00000e-05 1.00000e-06 1.00000e-09 1.00000e-01 $1.00000 \mathrm{e}+001.00000 \mathrm{e}+001.00000 \mathrm{e}-011.00000 \mathrm{e}-091.00000 \mathrm{e}-01$ Element: 8935 \# of layers: 7

$\mathrm{Kx} \mathrm{Ky} \mathrm{Kz}$ Ss Por

$2.58778 \mathrm{e}+012.58778 \mathrm{e}+012.58778 \mathrm{e}+00$ 1.00000e-09 2.12000e-01 $2.58778 \mathrm{e}+012.58778 \mathrm{e}+012.58778 \mathrm{e}+00$ 1.00000e-09 2.12000e-01 $2.58778 \mathrm{e}+012.58778 \mathrm{e}+012.58778 \mathrm{e}+001.00000 \mathrm{e}-092.12000 \mathrm{e}-01$ $2.58778 \mathrm{e}+012.58778 \mathrm{e}+012.58778 \mathrm{e}+00$ 1.00000e-09 2.12000e-01 $2.58778 \mathrm{e}+012.58778 \mathrm{e}+012.58778 \mathrm{e}+00$ 1.00000e-09 2.12000e-01 $1.00000 \mathrm{e}-05$ 1.00000e-05 1.00000e-06 1.00000e-09 1.00000e-01 $1.00000 \mathrm{e}+001.00000 \mathrm{e}+001.00000 \mathrm{e}-011.00000 \mathrm{e}-091.00000 \mathrm{e}-01$ Element: 8936 \# of layers: 7

$\mathrm{Kx} \mathrm{Ky} \mathrm{Kz}$ Ss Por

$2.58778 \mathrm{e}+012.58778 \mathrm{e}+012.58778 \mathrm{e}+00$ 1.00000e-09 2.12000e-01 $2.58778 \mathrm{e}+012.58778 \mathrm{e}+012.58778 \mathrm{e}+001.00000 \mathrm{e}-092.12000 \mathrm{e}-01$ $2.58778 \mathrm{e}+012.58778 \mathrm{e}+012.58778 \mathrm{e}+001.00000 \mathrm{e}-092.12000 \mathrm{e}-01$ $2.58778 \mathrm{e}+012.58778 \mathrm{e}+012.58778 \mathrm{e}+001.00000 \mathrm{e}-092.12000 \mathrm{e}-01$ $2.58778 \mathrm{e}+012.58778 \mathrm{e}+012.58778 \mathrm{e}+00$ 1.00000e-09 2.12000e-01 $1.00000 \mathrm{e}-05$ 1.00000e-05 1.00000e-06 1.00000e-09 1.00000e-01 $1.00000 \mathrm{e}+001.00000 \mathrm{e}+001.00000 \mathrm{e}-011.00000 \mathrm{e}-091.00000 \mathrm{e}-01$ Element: 8937 \# of layers: 7

Kx Ky Kz Ss Por

$2.58778 \mathrm{e}+012.58778 \mathrm{e}+012.58778 \mathrm{e}+00$ 1.00000e-09 2.12000e-01 $2.58778 \mathrm{e}+012.58778 \mathrm{e}+012.58778 \mathrm{e}+001.00000 \mathrm{e}-092.12000 \mathrm{e}-01$ $2.58778 \mathrm{e}+012.58778 \mathrm{e}+012.58778 \mathrm{e}+001.00000 \mathrm{e}-092.12000 \mathrm{e}-01$ $2.58778 \mathrm{e}+012.58778 \mathrm{e}+012.58778 \mathrm{e}+001.00000 \mathrm{e}-092.12000 \mathrm{e}-01$ $2.58778 \mathrm{e}+012.58778 \mathrm{e}+012.58778 \mathrm{e}+001.00000 \mathrm{e}-092.12000 \mathrm{e}-01$ $1.00000 \mathrm{e}-05$ 1.00000e-05 1.00000e-06 1.00000e-09 1.00000e-01 $1.00000 \mathrm{e}+001.00000 \mathrm{e}+001.00000 \mathrm{e}-011.00000 \mathrm{e}-091.00000 \mathrm{e}-01$ Element: 8938 \# of layers: 7

$\mathrm{Kx} \mathrm{Ky} \mathrm{Kz}$ Ss Por

$2.63368 \mathrm{e}+012.63368 \mathrm{e}+012.63368 \mathrm{e}+00$ 1.00000e-09 2.12000e-01 $2.63368 \mathrm{e}+012.63368 \mathrm{e}+012.63368 \mathrm{e}+001.00000 \mathrm{e}-092.12000 \mathrm{e}-01$ $2.63368 \mathrm{e}+012.63368 \mathrm{e}+012.63368 \mathrm{e}+001.00000 \mathrm{e}-092.12000 \mathrm{e}-01$ $2.63368 \mathrm{e}+012.63368 \mathrm{e}+012.63368 \mathrm{e}+00$ 1.00000e-09 2.12000e-01 $2.63368 \mathrm{e}+012.63368 \mathrm{e}+012.63368 \mathrm{e}+001.00000 \mathrm{e}-092.12000 \mathrm{e}-01$ $1.00000 \mathrm{e}-05$ 1.00000e-05 1.00000e-06 1.00000e-09 1.00000e-01 $1.00000 \mathrm{e}+001.00000 \mathrm{e}+001.00000 \mathrm{e}-011.00000 \mathrm{e}-091.00000 \mathrm{e}-01$ Element: 8939 \# of layers: 7

$\mathrm{Kx} \mathrm{Ky} \mathrm{Kz}$ Ss Por $2.63368 \mathrm{e}+012.63368 \mathrm{e}+012.63368 \mathrm{e}+00$ 1.00000e-09 2.12000e-01 
$2.63368 \mathrm{e}+012.63368 \mathrm{e}+012.63368 \mathrm{e}+00$ 1.00000e-09 2.12000e-01

$2.63368 \mathrm{e}+012.63368 \mathrm{e}+012.63368 \mathrm{e}+001.00000 \mathrm{e}-092.12000 \mathrm{e}-01$

$2.63368 \mathrm{e}+012.63368 \mathrm{e}+012.63368 \mathrm{e}+001.00000 \mathrm{e}-092.12000 \mathrm{e}-01$

$2.63368 \mathrm{e}+012.63368 \mathrm{e}+012.63368 \mathrm{e}+001.00000 \mathrm{e}-092.12000 \mathrm{e}-01$

$1.00000 \mathrm{e}-05$ 1.00000e-05 1.00000e-06 1.00000e-09 1.00000e-01

$1.00000 \mathrm{e}+001.00000 \mathrm{e}+001.00000 \mathrm{e}-011.00000 \mathrm{e}-091.00000 \mathrm{e}-01$

Element: 8940 \# of layers: 7

$\mathrm{Kx} \mathrm{Ky} \mathrm{Kz}$ Ss Por

$2.63368 \mathrm{e}+012.63368 \mathrm{e}+012.63368 \mathrm{e}+001.00000 \mathrm{e}-092.12000 \mathrm{e}-01$

$2.63368 \mathrm{e}+012.63368 \mathrm{e}+012.63368 \mathrm{e}+00$ 1.00000e-09 2.12000e-01

$2.63368 \mathrm{e}+012.63368 \mathrm{e}+012.63368 \mathrm{e}+00$ 1.00000e-09 2.12000e-01

$2.63368 \mathrm{e}+012.63368 \mathrm{e}+012.63368 \mathrm{e}+001.00000 \mathrm{e}-092.12000 \mathrm{e}-01$

$2.63368 \mathrm{e}+012.63368 \mathrm{e}+012.63368 \mathrm{e}+001.00000 \mathrm{e}-092.12000 \mathrm{e}-01$

$1.00000 \mathrm{e}-05$ 1.00000e-05 1.00000e-06 1.00000e-09 1.00000e-01

$1.00000 \mathrm{e}+001.00000 \mathrm{e}+001.00000 \mathrm{e}-01$ 1.00000e-09 1.00000e-01

Element: 8941 \# of layers: 7

$\mathrm{Kx} \mathrm{Ky} \mathrm{Kz}$ Ss Por

$2.63368 \mathrm{e}+012.63368 \mathrm{e}+012.63368 \mathrm{e}+00$ 1.00000e-09 2.12000e-01

$2.63368 \mathrm{e}+012.63368 \mathrm{e}+012.63368 \mathrm{e}+00$ 1.00000e-09 2.12000e-01

$2.63368 \mathrm{e}+012.63368 \mathrm{e}+012.63368 \mathrm{e}+001.00000 \mathrm{e}-092.12000 \mathrm{e}-01$

$2.63368 \mathrm{e}+012.63368 \mathrm{e}+012.63368 \mathrm{e}+001.00000 \mathrm{e}-092.12000 \mathrm{e}-01$

$2.63368 \mathrm{e}+012.63368 \mathrm{e}+012.63368 \mathrm{e}+00$ 1.00000e-09 2.12000e-01

$1.00000 \mathrm{e}-051.00000 \mathrm{e}-051.00000 \mathrm{e}-061.00000 \mathrm{e}-091.00000 \mathrm{e}-01$

$1.00000 \mathrm{e}+001.00000 \mathrm{e}+00$ 1.00000e-01 1.00000e-09 1.00000e-01

Element: 8942 \# of layers: 7

$\mathrm{Kx} \mathrm{Ky} \mathrm{Kz}$ Ss Por

$2.63368 \mathrm{e}+012.63368 \mathrm{e}+012.63368 \mathrm{e}+00$ 1.00000e-09 2.12000e-01

$2.63368 \mathrm{e}+012.63368 \mathrm{e}+012.63368 \mathrm{e}+001.00000 \mathrm{e}-092.12000 \mathrm{e}-01$

$2.63368 \mathrm{e}+012.63368 \mathrm{e}+012.63368 \mathrm{e}+001.00000 \mathrm{e}-092.12000 \mathrm{e}-01$

$2.63368 \mathrm{e}+012.63368 \mathrm{e}+012.63368 \mathrm{e}+001.00000 \mathrm{e}-092.12000 \mathrm{e}-01$

$2.63368 \mathrm{e}+012.63368 \mathrm{e}+012.63368 \mathrm{e}+00$ 1.00000e-09 2.12000e-01

$1.00000 \mathrm{e}-05$ 1.00000e-05 1.00000e-06 1.00000e-09 1.00000e-01

$1.00000 \mathrm{e}+001.00000 \mathrm{e}+001.00000 \mathrm{e}-011.00000 \mathrm{e}-091.00000 \mathrm{e}-01$

Element: 8943 \# of layers: 7

$\mathrm{Kx} \mathrm{Ky} \mathrm{Kz}$ Ss Por

$2.58778 \mathrm{e}+012.58778 \mathrm{e}+012.58778 \mathrm{e}+00$ 1.00000e-09 2.12000e-01

$2.58778 \mathrm{e}+012.58778 \mathrm{e}+012.58778 \mathrm{e}+001.00000 \mathrm{e}-092.12000 \mathrm{e}-01$

$2.58778 \mathrm{e}+012.58778 \mathrm{e}+012.58778 \mathrm{e}+001.00000 \mathrm{e}-092.12000 \mathrm{e}-01$

$2.58778 \mathrm{e}+012.58778 \mathrm{e}+012.58778 \mathrm{e}+00$ 1.00000e-09 2.12000e-01

$2.58778 \mathrm{e}+012.58778 \mathrm{e}+012.58778 \mathrm{e}+00$ 1.00000e-09 2.12000e-01 1.00000e-05 1.00000e-05 1.00000e-06 1.00000e-09 1.00000e-01

$1.00000 \mathrm{e}+001.00000 \mathrm{e}+001.00000 \mathrm{e}-011.00000 \mathrm{e}-091.00000 \mathrm{e}-01$

Element: 8944 \# of layers: 7

$\mathrm{Kx} \mathrm{Ky} \mathrm{Kz}$ Ss Por

$2.58778 \mathrm{e}+012.58778 \mathrm{e}+012.58778 \mathrm{e}+00$ 1.00000e-09 2.12000e-01

$2.58778 \mathrm{e}+012.58778 \mathrm{e}+012.58778 \mathrm{e}+001.00000 \mathrm{e}-092.12000 \mathrm{e}-01$ 
$2.58778 \mathrm{e}+012.58778 \mathrm{e}+012.58778 \mathrm{e}+00$ 1.00000e-09 2.12000e-01 $2.58778 \mathrm{e}+012.58778 \mathrm{e}+012.58778 \mathrm{e}+00$ 1.00000e-09 2.12000e-01 $2.58778 \mathrm{e}+012.58778 \mathrm{e}+012.58778 \mathrm{e}+00$ 1.00000e-09 2.12000e-01 $1.00000 \mathrm{e}-05$ 1.00000e-05 1.00000e-06 1.00000e-09 1.00000e-01 $1.00000 \mathrm{e}+001.00000 \mathrm{e}+001.00000 \mathrm{e}-01$ 1.00000e-09 1.00000e-01 Element: 8945 \# of layers: 7

$\mathrm{Kx} \mathrm{Ky} \mathrm{Kz}$ Ss Por

$2.63368 \mathrm{e}+012.63368 \mathrm{e}+012.63368 \mathrm{e}+00$ 1.00000e-09 2.12000e-01 $2.63368 \mathrm{e}+012.63368 \mathrm{e}+012.63368 \mathrm{e}+001.00000 \mathrm{e}-092.12000 \mathrm{e}-01$

$2.63368 \mathrm{e}+012.63368 \mathrm{e}+012.63368 \mathrm{e}+001.00000 \mathrm{e}-092.12000 \mathrm{e}-01$ $2.63368 \mathrm{e}+012.63368 \mathrm{e}+012.63368 \mathrm{e}+001.00000 \mathrm{e}-092.12000 \mathrm{e}-01$ $2.63368 \mathrm{e}+012.63368 \mathrm{e}+012.63368 \mathrm{e}+001.00000 \mathrm{e}-092.12000 \mathrm{e}-01$ $1.00000 \mathrm{e}-05$ 1.00000e-05 1.00000e-06 1.00000e-09 1.00000e-01 $1.00000 \mathrm{e}+001.00000 \mathrm{e}+001.00000 \mathrm{e}-011.00000 \mathrm{e}-09$ 1.00000e-01 Element: 8946 \# of layers: 7

Kx Ky Kz Ss Por

$2.63368 \mathrm{e}+012.63368 \mathrm{e}+012.63368 \mathrm{e}+00$ 1.00000e-09 2.12000e-01 $2.63368 \mathrm{e}+012.63368 \mathrm{e}+012.63368 \mathrm{e}+001.00000 \mathrm{e}-092.12000 \mathrm{e}-01$ $2.63368 \mathrm{e}+012.63368 \mathrm{e}+012.63368 \mathrm{e}+00$ 1.00000e-09 2.12000e-01 $2.63368 \mathrm{e}+012.63368 \mathrm{e}+012.63368 \mathrm{e}+001.00000 \mathrm{e}-092.12000 \mathrm{e}-01$ $2.63368 \mathrm{e}+012.63368 \mathrm{e}+012.63368 \mathrm{e}+001.00000 \mathrm{e}-092.12000 \mathrm{e}-01$ $1.00000 \mathrm{e}-05$ 1.00000e-05 1.00000e-06 1.00000e-09 1.00000e-01 $1.00000 \mathrm{e}+001.00000 \mathrm{e}+001.00000 \mathrm{e}-01$ 1.00000e-09 1.00000e-01 Element: 8947 \# of layers: 7

$\mathrm{Kx} \mathrm{Ky} \mathrm{Kz}$ Ss Por

$2.80581 \mathrm{e}+012.80581 \mathrm{e}+012.80581 \mathrm{e}+001.00000 \mathrm{e}-092.12000 \mathrm{e}-01$ $2.80581 \mathrm{e}+012.80581 \mathrm{e}+012.80581 \mathrm{e}+001.00000 \mathrm{e}-092.12000 \mathrm{e}-01$ $2.80581 \mathrm{e}+012.80581 \mathrm{e}+012.80581 \mathrm{e}+001.00000 \mathrm{e}-092.12000 \mathrm{e}-01$ $2.80581 \mathrm{e}+012.80581 \mathrm{e}+012.80581 \mathrm{e}+001.00000 \mathrm{e}-092.12000 \mathrm{e}-01$ $2.80581 \mathrm{e}+012.80581 \mathrm{e}+012.80581 \mathrm{e}+001.00000 \mathrm{e}-092.12000 \mathrm{e}-01$ $1.00000 \mathrm{e}-05$ 1.00000e-05 1.00000e-06 1.00000e-09 1.00000e-01 $1.00000 \mathrm{e}+001.00000 \mathrm{e}+001.00000 \mathrm{e}-011.00000 \mathrm{e}-091.00000 \mathrm{e}-01$ Element: 8948 \# of layers: 7

$\mathrm{Kx} \mathrm{Ky} \mathrm{Kz}$ Ss Por

$2.80581 \mathrm{e}+012.80581 \mathrm{e}+012.80581 \mathrm{e}+00$ 1.00000e-09 2.12000e-01 $2.80581 \mathrm{e}+012.80581 \mathrm{e}+012.80581 \mathrm{e}+001.00000 \mathrm{e}-092.12000 \mathrm{e}-01$ $2.80581 \mathrm{e}+012.80581 \mathrm{e}+012.80581 \mathrm{e}+001.00000 \mathrm{e}-092.12000 \mathrm{e}-01$ $2.80581 \mathrm{e}+012.80581 \mathrm{e}+012.80581 \mathrm{e}+001.00000 \mathrm{e}-092.12000 \mathrm{e}-01$ $2.80581 \mathrm{e}+012.80581 \mathrm{e}+012.80581 \mathrm{e}+001.00000 \mathrm{e}-092.12000 \mathrm{e}-01$ $1.00000 \mathrm{e}-05$ 1.00000e-05 1.00000e-06 1.00000e-09 1.00000e-01 $1.00000 \mathrm{e}+001.00000 \mathrm{e}+001.00000 \mathrm{e}-011.00000 \mathrm{e}-091.00000 \mathrm{e}-01$ Element: 8949 \# of layers: 7

$\mathrm{Kx} \mathrm{Ky} \mathrm{Kz}$ Ss Por

$2.80581 \mathrm{e}+012.80581 \mathrm{e}+012.80581 \mathrm{e}+00$ 1.00000e-09 2.12000e-01 $2.80581 \mathrm{e}+012.80581 \mathrm{e}+012.80581 \mathrm{e}+00$ 1.00000e-09 2.12000e-01 $2.80581 \mathrm{e}+012.80581 \mathrm{e}+012.80581 \mathrm{e}+00$ 1.00000e-09 2.12000e-01 
$2.80581 \mathrm{e}+012.80581 \mathrm{e}+012.80581 \mathrm{e}+00$ 1.00000e-09 2.12000e-01 $2.80581 \mathrm{e}+012.80581 \mathrm{e}+012.80581 \mathrm{e}+001.00000 \mathrm{e}-092.12000 \mathrm{e}-01$ $1.00000 \mathrm{e}-05$ 1.00000e-05 1.00000e-06 1.00000e-09 1.00000e-01 $1.00000 \mathrm{e}+001.00000 \mathrm{e}+001.00000 \mathrm{e}-011.00000 \mathrm{e}-091.00000 \mathrm{e}-01$ Element: 8950 \# of layers: 7

Kx Ky Kz Ss Por

$2.89469 \mathrm{e}+012.89469 \mathrm{e}+012.89469 \mathrm{e}+00$ 1.00000e-09 2.12000e-01 $2.89469 \mathrm{e}+012.89469 \mathrm{e}+012.89469 \mathrm{e}+001.00000 \mathrm{e}-092.12000 \mathrm{e}-01$ $2.89469 \mathrm{e}+012.89469 \mathrm{e}+012.89469 \mathrm{e}+001.00000 \mathrm{e}-092.12000 \mathrm{e}-01$ $2.89469 \mathrm{e}+012.89469 \mathrm{e}+012.89469 \mathrm{e}+001.00000 \mathrm{e}-092.12000 \mathrm{e}-01$ $2.89469 \mathrm{e}+012.89469 \mathrm{e}+012.89469 \mathrm{e}+001.00000 \mathrm{e}-092.12000 \mathrm{e}-01$ $1.00000 \mathrm{e}-05$ 1.00000e-05 1.00000e-06 1.00000e-09 1.00000e-01 $1.00000 \mathrm{e}+001.00000 \mathrm{e}+001.00000 \mathrm{e}-011.00000 \mathrm{e}-091.00000 \mathrm{e}-01$ Element: 8951 \# of layers: 7

Kx Ky Kz Ss Por

$2.89469 \mathrm{e}+012.89469 \mathrm{e}+012.89469 \mathrm{e}+00$ 1.00000e-09 2.12000e-01 $2.89469 \mathrm{e}+012.89469 \mathrm{e}+012.89469 \mathrm{e}+001.00000 \mathrm{e}-092.12000 \mathrm{e}-01$ $2.89469 \mathrm{e}+012.89469 \mathrm{e}+012.89469 \mathrm{e}+001.00000 \mathrm{e}-092.12000 \mathrm{e}-01$ $2.89469 \mathrm{e}+012.89469 \mathrm{e}+012.89469 \mathrm{e}+001.00000 \mathrm{e}-092.12000 \mathrm{e}-01$ $2.89469 \mathrm{e}+012.89469 \mathrm{e}+012.89469 \mathrm{e}+00$ 1.00000e-09 2.12000e-01 $1.00000 \mathrm{e}-05$ 1.00000e-05 1.00000e-06 1.00000e-09 1.00000e-01 $1.00000 \mathrm{e}+001.00000 \mathrm{e}+001.00000 \mathrm{e}-011.00000 \mathrm{e}-091.00000 \mathrm{e}-01$ Element: 8952 \# of layers: 7

Kx Ky Kz Ss Por

$2.58778 \mathrm{e}+012.58778 \mathrm{e}+012.58778 \mathrm{e}+00$ 1.00000e-09 2.12000e-01

$2.58778 \mathrm{e}+012.58778 \mathrm{e}+012.58778 \mathrm{e}+001.00000 \mathrm{e}-092.12000 \mathrm{e}-01$

$2.58778 \mathrm{e}+012.58778 \mathrm{e}+012.58778 \mathrm{e}+001.00000 \mathrm{e}-092.12000 \mathrm{e}-01$

$2.58778 \mathrm{e}+012.58778 \mathrm{e}+012.58778 \mathrm{e}+001.00000 \mathrm{e}-092.12000 \mathrm{e}-01$

$2.58778 \mathrm{e}+012.58778 \mathrm{e}+012.58778 \mathrm{e}+001.00000 \mathrm{e}-092.12000 \mathrm{e}-01$ $1.00000 \mathrm{e}-05$ 1.00000e-05 1.00000e-06 1.00000e-09 1.00000e-01

$1.00000 \mathrm{e}+001.00000 \mathrm{e}+001.00000 \mathrm{e}-011.00000 \mathrm{e}-091.00000 \mathrm{e}-01$ Element: 8953 \# of layers: 7

Kx Ky Kz Ss Por

$2.63368 \mathrm{e}+012.63368 \mathrm{e}+012.63368 \mathrm{e}+00$ 1.00000e-09 2.12000e-01 $2.63368 \mathrm{e}+012.63368 \mathrm{e}+012.63368 \mathrm{e}+001.00000 \mathrm{e}-092.12000 \mathrm{e}-01$ $2.63368 \mathrm{e}+012.63368 \mathrm{e}+012.63368 \mathrm{e}+001.00000 \mathrm{e}-092.12000 \mathrm{e}-01$ $2.63368 \mathrm{e}+012.63368 \mathrm{e}+012.63368 \mathrm{e}+001.00000 \mathrm{e}-092.12000 \mathrm{e}-01$ $2.63368 \mathrm{e}+012.63368 \mathrm{e}+012.63368 \mathrm{e}+001.00000 \mathrm{e}-092.12000 \mathrm{e}-01$ $1.00000 \mathrm{e}-05$ 1.00000e-05 1.00000e-06 1.00000e-09 1.00000e-01 $1.00000 \mathrm{e}+001.00000 \mathrm{e}+001.00000 \mathrm{e}-011.00000 \mathrm{e}-091.00000 \mathrm{e}-01$ Element: 8954 \# of layers: 7

Kx Ky Kz Ss Por

$2.80581 \mathrm{e}+012.80581 \mathrm{e}+012.80581 \mathrm{e}+00$ 1.00000e-09 2.12000e-01 $2.80581 \mathrm{e}+012.80581 \mathrm{e}+012.80581 \mathrm{e}+001.00000 \mathrm{e}-092.12000 \mathrm{e}-01$ $2.80581 \mathrm{e}+012.80581 \mathrm{e}+012.80581 \mathrm{e}+001.00000 \mathrm{e}-092.12000 \mathrm{e}-01$ $2.80581 \mathrm{e}+012.80581 \mathrm{e}+012.80581 \mathrm{e}+001.00000 \mathrm{e}-092.12000 \mathrm{e}-01$ 
$2.80581 \mathrm{e}+012.80581 \mathrm{e}+012.80581 \mathrm{e}+00$ 1.00000e-09 2.12000e-01 $1.00000 \mathrm{e}-05$ 1.00000e-05 1.00000e-06 1.00000e-09 1.00000e-01 $1.00000 \mathrm{e}+001.00000 \mathrm{e}+001.00000 \mathrm{e}-011.00000 \mathrm{e}-091.00000 \mathrm{e}-01$ Element: 8955 \# of layers: 7

Kx Ky Kz Ss Por

$2.84249 \mathrm{e}+012.84249 \mathrm{e}+012.84249 \mathrm{e}+00$ 1.00000e-09 2.12000e-01 $2.84249 \mathrm{e}+012.84249 \mathrm{e}+012.84249 \mathrm{e}+001.00000 \mathrm{e}-092.12000 \mathrm{e}-01$ $2.84249 \mathrm{e}+012.84249 \mathrm{e}+012.84249 \mathrm{e}+001.00000 \mathrm{e}-092.12000 \mathrm{e}-01$ $2.84249 \mathrm{e}+012.84249 \mathrm{e}+012.84249 \mathrm{e}+001.00000 \mathrm{e}-092.12000 \mathrm{e}-01$ $2.84249 \mathrm{e}+012.84249 \mathrm{e}+012.84249 \mathrm{e}+001.00000 \mathrm{e}-092.12000 \mathrm{e}-01$ $1.00000 \mathrm{e}-05$ 1.00000e-05 1.00000e-06 1.00000e-09 1.00000e-01 $1.00000 \mathrm{e}+001.00000 \mathrm{e}+001.00000 \mathrm{e}-011.00000 \mathrm{e}-091.00000 \mathrm{e}-01$ Element: 8956 \# of layers: 7

Kx Ky Kz Ss Por

$2.84249 \mathrm{e}+012.84249 \mathrm{e}+012.84249 \mathrm{e}+00$ 1.00000e-09 2.12000e-01 $2.84249 \mathrm{e}+012.84249 \mathrm{e}+012.84249 \mathrm{e}+001.00000 \mathrm{e}-092.12000 \mathrm{e}-01$ $2.84249 \mathrm{e}+012.84249 \mathrm{e}+012.84249 \mathrm{e}+001.00000 \mathrm{e}-092.12000 \mathrm{e}-01$ $2.84249 \mathrm{e}+012.84249 \mathrm{e}+012.84249 \mathrm{e}+001.00000 \mathrm{e}-092.12000 \mathrm{e}-01$ $2.84249 \mathrm{e}+012.84249 \mathrm{e}+012.84249 \mathrm{e}+00$ 1.00000e-09 2.12000e-01 $1.00000 \mathrm{e}-05$ 1.00000e-05 1.00000e-06 1.00000e-09 1.00000e-01 $1.00000 \mathrm{e}+001.00000 \mathrm{e}+001.00000 \mathrm{e}-011.00000 \mathrm{e}-091.00000 \mathrm{e}-01$ Element: 8957 \# of layers: 7

Kx Ky Kz Ss Por

$2.84249 \mathrm{e}+012.84249 \mathrm{e}+012.84249 \mathrm{e}+00$ 1.00000e-09 2.12000e-01 $2.84249 \mathrm{e}+012.84249 \mathrm{e}+012.84249 \mathrm{e}+001.00000 \mathrm{e}-092.12000 \mathrm{e}-01$ $2.84249 \mathrm{e}+012.84249 \mathrm{e}+012.84249 \mathrm{e}+001.00000 \mathrm{e}-092.12000 \mathrm{e}-01$ $2.84249 \mathrm{e}+012.84249 \mathrm{e}+012.84249 \mathrm{e}+001.00000 \mathrm{e}-092.12000 \mathrm{e}-01$ $2.84249 \mathrm{e}+012.84249 \mathrm{e}+012.84249 \mathrm{e}+001.00000 \mathrm{e}-092.12000 \mathrm{e}-01$ $1.00000 \mathrm{e}-05$ 1.00000e-05 1.00000e-06 1.00000e-09 1.00000e-01 $1.00000 \mathrm{e}+001.00000 \mathrm{e}+001.00000 \mathrm{e}-011.00000 \mathrm{e}-091.00000 \mathrm{e}-01$ Element: 8958 \# of layers: 7

Kx Ky Kz Ss Por

$2.84249 \mathrm{e}+012.84249 \mathrm{e}+012.84249 \mathrm{e}+00$ 1.00000e-09 2.12000e-01 $2.84249 \mathrm{e}+012.84249 \mathrm{e}+012.84249 \mathrm{e}+001.00000 \mathrm{e}-092.12000 \mathrm{e}-01$ $2.84249 \mathrm{e}+012.84249 \mathrm{e}+012.84249 \mathrm{e}+001.00000 \mathrm{e}-092.12000 \mathrm{e}-01$ $2.84249 \mathrm{e}+012.84249 \mathrm{e}+012.84249 \mathrm{e}+001.00000 \mathrm{e}-092.12000 \mathrm{e}-01$ $2.84249 \mathrm{e}+012.84249 \mathrm{e}+012.84249 \mathrm{e}+001.00000 \mathrm{e}-092.12000 \mathrm{e}-01$ $1.00000 \mathrm{e}-05$ 1.00000e-05 1.00000e-06 1.00000e-09 1.00000e-01 $1.00000 \mathrm{e}+001.00000 \mathrm{e}+001.00000 \mathrm{e}-011.00000 \mathrm{e}-091.00000 \mathrm{e}-01$ Element: 8959 \# of layers: 7

Kx Ky Kz Ss Por

$1.95651 \mathrm{e}+011.95651 \mathrm{e}+011.95651 \mathrm{e}+00$ 1.00000e-09 2.12000e-01 $1.95651 \mathrm{e}+011.95651 \mathrm{e}+011.95651 \mathrm{e}+001.00000 \mathrm{e}-092.12000 \mathrm{e}-01$ $1.95651 \mathrm{e}+011.95651 \mathrm{e}+011.95651 \mathrm{e}+001.00000 \mathrm{e}-092.12000 \mathrm{e}-01$ $1.95651 \mathrm{e}+011.95651 \mathrm{e}+011.95651 \mathrm{e}+001.00000 \mathrm{e}-092.12000 \mathrm{e}-01$ $1.95651 \mathrm{e}+011.95651 \mathrm{e}+011.95651 \mathrm{e}+001.00000 \mathrm{e}-092.12000 \mathrm{e}-01$ 
$1.00000 \mathrm{e}-05$ 1.00000e-05 1.00000e-06 1.00000e-09 1.00000e-01 $1.00000 \mathrm{e}+001.00000 \mathrm{e}+001.00000 \mathrm{e}-011.00000 \mathrm{e}-091.00000 \mathrm{e}-01$ Element: 8960 \# of layers: 7

Kx Ky Kz Ss Por

$1.95651 \mathrm{e}+01$ 1.95651e+01 1.95651e+00 1.00000e-09 2.12000e-01 $1.95651 \mathrm{e}+011.95651 \mathrm{e}+011.95651 \mathrm{e}+001.00000 \mathrm{e}-092.12000 \mathrm{e}-01$ $1.95651 \mathrm{e}+011.95651 \mathrm{e}+011.95651 \mathrm{e}+001.00000 \mathrm{e}-092.12000 \mathrm{e}-01$ $1.95651 \mathrm{e}+011.95651 \mathrm{e}+011.95651 \mathrm{e}+001.00000 \mathrm{e}-092.12000 \mathrm{e}-01$ $1.95651 \mathrm{e}+011.95651 \mathrm{e}+01$ 1.95651e+00 1.00000e-09 2.12000e-01 $1.00000 \mathrm{e}-05$ 1.00000e-05 1.00000e-06 1.00000e-09 1.00000e-01 $1.00000 \mathrm{e}+001.00000 \mathrm{e}+001.00000 \mathrm{e}-011.00000 \mathrm{e}-091.00000 \mathrm{e}-01$ Element: 8961 \# of layers: 7

$\mathrm{Kx} \mathrm{Ky} \mathrm{Kz}$ Ss Por

$2.84249 \mathrm{e}+012.84249 \mathrm{e}+012.84249 \mathrm{e}+00$ 1.00000e-09 2.12000e-01 $2.84249 \mathrm{e}+012.84249 \mathrm{e}+012.84249 \mathrm{e}+00$ 1.00000e-09 2.12000e-01 $2.84249 \mathrm{e}+012.84249 \mathrm{e}+012.84249 \mathrm{e}+001.00000 \mathrm{e}-092.12000 \mathrm{e}-01$ $2.84249 \mathrm{e}+012.84249 \mathrm{e}+012.84249 \mathrm{e}+00$ 1.00000e-09 2.12000e-01 $2.84249 \mathrm{e}+012.84249 \mathrm{e}+012.84249 \mathrm{e}+00$ 1.00000e-09 2.12000e-01 $1.00000 \mathrm{e}-05$ 1.00000e-05 1.00000e-06 1.00000e-09 1.00000e-01 $1.00000 \mathrm{e}+001.00000 \mathrm{e}+001.00000 \mathrm{e}-011.00000 \mathrm{e}-091.00000 \mathrm{e}-01$ Element: 8962 \# of layers: 7

$\mathrm{Kx} \mathrm{Ky} \mathrm{Kz}$ Ss Por

$1.95651 \mathrm{e}+01$ 1.95651e+01 1.95651e+00 1.00000e-09 2.12000e-01 $1.95651 \mathrm{e}+011.95651 \mathrm{e}+011.95651 \mathrm{e}+001.00000 \mathrm{e}-092.12000 \mathrm{e}-01$ $1.95651 \mathrm{e}+011.95651 \mathrm{e}+011.95651 \mathrm{e}+001.00000 \mathrm{e}-092.12000 \mathrm{e}-01$ $1.95651 \mathrm{e}+011.95651 \mathrm{e}+011.95651 \mathrm{e}+001.00000 \mathrm{e}-092.12000 \mathrm{e}-01$ $1.95651 \mathrm{e}+011.95651 \mathrm{e}+011.95651 \mathrm{e}+001.00000 \mathrm{e}-092.12000 \mathrm{e}-01$ $1.00000 \mathrm{e}-05$ 1.00000e-05 1.00000e-06 1.00000e-09 1.00000e-01 $1.00000 \mathrm{e}+001.00000 \mathrm{e}+001.00000 \mathrm{e}-011.00000 \mathrm{e}-091.00000 \mathrm{e}-01$ Element: 8963 \# of layers: 7

$\mathrm{Kx} \mathrm{Ky} \mathrm{Kz}$ Ss Por

$1.95651 \mathrm{e}+011.95651 \mathrm{e}+011.95651 \mathrm{e}+001.00000 \mathrm{e}-092.12000 \mathrm{e}-01$ $1.95651 \mathrm{e}+011.95651 \mathrm{e}+011.95651 \mathrm{e}+001.00000 \mathrm{e}-092.12000 \mathrm{e}-01$ $1.95651 \mathrm{e}+011.95651 \mathrm{e}+011.95651 \mathrm{e}+001.00000 \mathrm{e}-092.12000 \mathrm{e}-01$ $1.95651 \mathrm{e}+011.95651 \mathrm{e}+011.95651 \mathrm{e}+001.00000 \mathrm{e}-092.12000 \mathrm{e}-01$ $1.95651 \mathrm{e}+011.95651 \mathrm{e}+011.95651 \mathrm{e}+001.00000 \mathrm{e}-092.12000 \mathrm{e}-01$ $1.00000 \mathrm{e}-05$ 1.00000e-05 1.00000e-06 1.00000e-09 1.00000e-01 $1.00000 \mathrm{e}+001.00000 \mathrm{e}+001.00000 \mathrm{e}-011.00000 \mathrm{e}-091.00000 \mathrm{e}-01$ Element: 8964 \# of layers: 7

$\mathrm{Kx} \mathrm{Ky} \mathrm{Kz}$ Ss Por $1.95651 \mathrm{e}+011.95651 \mathrm{e}+01$ 1.95651e+00 1.00000e-09 2.12000e-01 $1.95651 \mathrm{e}+011.95651 \mathrm{e}+011.95651 \mathrm{e}+001.00000 \mathrm{e}-092.12000 \mathrm{e}-01$ $1.95651 \mathrm{e}+011.95651 \mathrm{e}+011.95651 \mathrm{e}+001.00000 \mathrm{e}-092.12000 \mathrm{e}-01$ $1.95651 \mathrm{e}+011.95651 \mathrm{e}+011.95651 \mathrm{e}+001.00000 \mathrm{e}-092.12000 \mathrm{e}-01$ $1.95651 \mathrm{e}+011.95651 \mathrm{e}+011.95651 \mathrm{e}+001.00000 \mathrm{e}-092.12000 \mathrm{e}-01$ $1.00000 \mathrm{e}-05$ 1.00000e-05 1.00000e-06 1.00000e-09 1.00000e-01 
$1.00000 \mathrm{e}+001.00000 \mathrm{e}+00$ 1.00000e-01 1.00000e-09 1.00000e-01

Element: 8965 \# of layers: 7

Kx Ky Kz Ss Por

$1.95651 \mathrm{e}+01$ 1.95651e+01 1.95651e+00 1.00000e-09 2.12000e-01

$1.95651 \mathrm{e}+011.95651 \mathrm{e}+011.95651 \mathrm{e}+001.00000 \mathrm{e}-092.12000 \mathrm{e}-01$

$1.95651 \mathrm{e}+011.95651 \mathrm{e}+011.95651 \mathrm{e}+001.00000 \mathrm{e}-092.12000 \mathrm{e}-01$

$1.95651 \mathrm{e}+011.95651 \mathrm{e}+011.95651 \mathrm{e}+001.00000 \mathrm{e}-092.12000 \mathrm{e}-01$

$1.95651 \mathrm{e}+011.95651 \mathrm{e}+011.95651 \mathrm{e}+001.00000 \mathrm{e}-092.12000 \mathrm{e}-01$

$1.00000 \mathrm{e}-051.00000 \mathrm{e}-051.00000 \mathrm{e}-061.00000 \mathrm{e}-091.00000 \mathrm{e}-01$

$1.00000 \mathrm{e}+001.00000 \mathrm{e}+001.00000 \mathrm{e}-01$ 1.00000e-09 1.00000e-01

Element: 8966 \# of layers: 7

$\mathrm{Kx} \mathrm{Ky} \mathrm{Kz}$ Ss Por

$1.95651 \mathrm{e}+011.95651 \mathrm{e}+01$ 1.95651e+00 1.00000e-09 2.12000e-01

$1.95651 \mathrm{e}+011.95651 \mathrm{e}+011.95651 \mathrm{e}+001.00000 \mathrm{e}-092.12000 \mathrm{e}-01$

$1.95651 \mathrm{e}+011.95651 \mathrm{e}+011.95651 \mathrm{e}+001.00000 \mathrm{e}-092.12000 \mathrm{e}-01$

$1.95651 \mathrm{e}+011.95651 \mathrm{e}+011.95651 \mathrm{e}+001.00000 \mathrm{e}-092.12000 \mathrm{e}-01$

$1.95651 \mathrm{e}+011.95651 \mathrm{e}+011.95651 \mathrm{e}+001.00000 \mathrm{e}-092.12000 \mathrm{e}-01$

$1.00000 \mathrm{e}-05$ 1.00000e-05 1.00000e-06 1.00000e-09 1.00000e-01

$1.00000 \mathrm{e}+001.00000 \mathrm{e}+001.00000 \mathrm{e}-011.00000 \mathrm{e}-091.00000 \mathrm{e}-01$

Element: 8967 \# of layers: 7

$\mathrm{Kx} \mathrm{Ky} \mathrm{Kz}$ Ss Por

$1.95651 \mathrm{e}+01$ 1.95651e+01 1.95651e+00 1.00000e-09 2.12000e-01

$1.95651 \mathrm{e}+011.95651 \mathrm{e}+011.95651 \mathrm{e}+001.00000 \mathrm{e}-092.12000 \mathrm{e}-01$

$1.95651 \mathrm{e}+011.95651 \mathrm{e}+011.95651 \mathrm{e}+001.00000 \mathrm{e}-092.12000 \mathrm{e}-01$

$1.95651 \mathrm{e}+011.95651 \mathrm{e}+011.95651 \mathrm{e}+001.00000 \mathrm{e}-092.12000 \mathrm{e}-01$

$1.95651 \mathrm{e}+011.95651 \mathrm{e}+011.95651 \mathrm{e}+001.00000 \mathrm{e}-092.12000 \mathrm{e}-01$

$1.00000 \mathrm{e}-05$ 1.00000e-05 1.00000e-06 1.00000e-09 1.00000e-01

$1.00000 \mathrm{e}+001.00000 \mathrm{e}+001.00000 \mathrm{e}-01$ 1.00000e-09 1.00000e-01

Element: 8968 \# of layers: 7

$\mathrm{Kx} \mathrm{Ky} \mathrm{Kz}$ Ss Por

$1.95651 \mathrm{e}+011.95651 \mathrm{e}+011.95651 \mathrm{e}+00$ 1.00000e-09 2.12000e-01

$1.95651 \mathrm{e}+011.95651 \mathrm{e}+011.95651 \mathrm{e}+001.00000 \mathrm{e}-092.12000 \mathrm{e}-01$

$1.95651 \mathrm{e}+011.95651 \mathrm{e}+011.95651 \mathrm{e}+001.00000 \mathrm{e}-092.12000 \mathrm{e}-01$

$1.95651 \mathrm{e}+011.95651 \mathrm{e}+01$ 1.95651e+00 1.00000e-09 2.12000e-01

$1.95651 \mathrm{e}+011.95651 \mathrm{e}+011.95651 \mathrm{e}+001.00000 \mathrm{e}-092.12000 \mathrm{e}-01$

1.00000e-05 1.00000e-05 1.00000e-06 1.00000e-09 1.00000e-01

$1.00000 \mathrm{e}+001.00000 \mathrm{e}+001.00000 \mathrm{e}-011.00000 \mathrm{e}-091.00000 \mathrm{e}-01$

Element: 8969 \# of layers: 7

$\mathrm{Kx} \mathrm{Ky} \mathrm{Kz}$ Ss Por

$2.36367 \mathrm{e}+012.36367 \mathrm{e}+012.36367 \mathrm{e}+00$ 1.00000e-09 2.12000e-01

$2.36367 \mathrm{e}+012.36367 \mathrm{e}+012.36367 \mathrm{e}+00$ 1.00000e-09 2.12000e-01

$2.36367 \mathrm{e}+012.36367 \mathrm{e}+012.36367 \mathrm{e}+00$ 1.00000e-09 2.12000e-01

$2.36367 \mathrm{e}+012.36367 \mathrm{e}+01$ 2.36367e+00 1.00000e-09 2.12000e-01

2.36367e+01 2.36367e+01 2.36367e+00 1.00000e-09 2.12000e-01

$1.00000 \mathrm{e}-05$ 1.00000e-05 1.00000e-06 1.00000e-09 1.00000e-01

$1.00000 \mathrm{e}+001.00000 \mathrm{e}+001.00000 \mathrm{e}-011.00000 \mathrm{e}-091.00000 \mathrm{e}-01$ 
Element: 8970 \# of layers: 7

$\mathrm{Kx} \mathrm{Ky} \mathrm{Kz}$ Ss Por

$2.36367 \mathrm{e}+012.36367 \mathrm{e}+012.36367 \mathrm{e}+00$ 1.00000e-09 2.12000e-01

$2.36367 e+012.36367 e+012.36367 e+001.00000 e-09$ 2.12000e-01

$2.36367 \mathrm{e}+012.36367 \mathrm{e}+012.36367 \mathrm{e}+00$ 1.00000e-09 2.12000e-01

$2.36367 \mathrm{e}+012.36367 \mathrm{e}+012.36367 \mathrm{e}+00$ 1.00000e-09 2.12000e-01

$2.36367 \mathrm{e}+012.36367 \mathrm{e}+012.36367 \mathrm{e}+00$ 1.00000e-09 2.12000e-01

$1.00000 \mathrm{e}-05$ 1.00000e-05 1.00000e-06 1.00000e-09 1.00000e-01

$1.00000 \mathrm{e}+001.00000 \mathrm{e}+001.00000 \mathrm{e}-011.00000 \mathrm{e}-091.00000 \mathrm{e}-01$

Element: 8971 \# of layers: 7

$\mathrm{Kx} \mathrm{Ky} \mathrm{Kz}$ Ss Por

$2.36367 e+012.36367 e+012.36367 e+00$ 1.00000e-09 2.12000e-01

$2.36367 \mathrm{e}+012.36367 \mathrm{e}+012.36367 \mathrm{e}+00$ 1.00000e-09 2.12000e-01

$2.36367 \mathrm{e}+012.36367 \mathrm{e}+012.36367 \mathrm{e}+00$ 1.00000e-09 2.12000e-01

$2.36367 \mathrm{e}+012.36367 \mathrm{e}+012.36367 \mathrm{e}+00$ 1.00000e-09 2.12000e-01

$2.36367 \mathrm{e}+012.36367 \mathrm{e}+012.36367 \mathrm{e}+00$ 1.00000e-09 2.12000e-01

$1.00000 \mathrm{e}-05$ 1.00000e-05 1.00000e-06 1.00000e-09 1.00000e-01

$1.00000 \mathrm{e}+001.00000 \mathrm{e}+001.00000 \mathrm{e}-011.00000 \mathrm{e}-091.00000 \mathrm{e}-01$

Element: 8972 \# of layers: 7

$\mathrm{Kx} \mathrm{Ky} \mathrm{Kz}$ Ss Por

$1.95651 \mathrm{e}+011.95651 \mathrm{e}+011.95651 \mathrm{e}+001.00000 \mathrm{e}-092.12000 \mathrm{e}-01$

$1.95651 \mathrm{e}+01$ 1.95651e+01 1.95651e+00 1.00000e-09 2.12000e-01

$1.95651 \mathrm{e}+011.95651 \mathrm{e}+011.95651 \mathrm{e}+001.00000 \mathrm{e}-092.12000 \mathrm{e}-01$

$1.95651 \mathrm{e}+011.95651 \mathrm{e}+011.95651 \mathrm{e}+001.00000 \mathrm{e}-092.12000 \mathrm{e}-01$

$1.95651 \mathrm{e}+011.95651 \mathrm{e}+011.95651 \mathrm{e}+001.00000 \mathrm{e}-092.12000 \mathrm{e}-01$

$1.00000 \mathrm{e}-05$ 1.00000e-05 1.00000e-06 1.00000e-09 1.00000e-01

$1.00000 \mathrm{e}+001.00000 \mathrm{e}+001.00000 \mathrm{e}-011.00000 \mathrm{e}-091.00000 \mathrm{e}-01$

Element: 8973 \# of layers: 7

Kx Ky Kz Ss Por

$1.95651 \mathrm{e}+011.95651 \mathrm{e}+011.95651 \mathrm{e}+001.00000 \mathrm{e}-092.12000 \mathrm{e}-01$

$1.95651 \mathrm{e}+011.95651 \mathrm{e}+011.95651 \mathrm{e}+001.00000 \mathrm{e}-092.12000 \mathrm{e}-01$

$1.95651 \mathrm{e}+011.95651 \mathrm{e}+011.95651 \mathrm{e}+001.00000 \mathrm{e}-092.12000 \mathrm{e}-01$

$1.95651 \mathrm{e}+011.95651 \mathrm{e}+011.95651 \mathrm{e}+001.00000 \mathrm{e}-092.12000 \mathrm{e}-01$

$1.95651 \mathrm{e}+011.95651 \mathrm{e}+01$ 1.95651e+00 1.00000e-09 2.12000e-01

$1.00000 \mathrm{e}-05$ 1.00000e-05 1.00000e-06 1.00000e-09 1.00000e-01

$1.00000 \mathrm{e}+001.00000 \mathrm{e}+001.00000 \mathrm{e}-011.00000 \mathrm{e}-091.00000 \mathrm{e}-01$

Element: 8974 \# of layers: 7

Kx Ky Kz Ss Por

$1.95651 \mathrm{e}+01$ 1.95651e+01 1.95651e+00 1.00000e-09 2.12000e-01

$1.95651 \mathrm{e}+011.95651 \mathrm{e}+011.95651 \mathrm{e}+001.00000 \mathrm{e}-092.12000 \mathrm{e}-01$

$1.95651 \mathrm{e}+011.95651 \mathrm{e}+011.95651 \mathrm{e}+001.00000 \mathrm{e}-092.12000 \mathrm{e}-01$

$1.95651 \mathrm{e}+011.95651 \mathrm{e}+011.95651 \mathrm{e}+001.00000 \mathrm{e}-092.12000 \mathrm{e}-01$

$1.95651 \mathrm{e}+011.95651 \mathrm{e}+01$ 1.95651e+00 1.00000e-09 2.12000e-01

$1.00000 \mathrm{e}-05$ 1.00000e-05 1.00000e-06 1.00000e-09 1.00000e-01

$1.00000 \mathrm{e}+001.00000 \mathrm{e}+001.00000 \mathrm{e}-011.00000 \mathrm{e}-09$ 1.00000e-01

Element: 8975 \# of layers: 7 
$\mathrm{Kx} \mathrm{Ky} \mathrm{Kz}$ Ss Por

$1.95651 \mathrm{e}+011.95651 \mathrm{e}+011.95651 \mathrm{e}+001.00000 \mathrm{e}-092.12000 \mathrm{e}-01$

$1.95651 \mathrm{e}+011.95651 \mathrm{e}+011.95651 \mathrm{e}+001.00000 \mathrm{e}-092.12000 \mathrm{e}-01$

$1.95651 \mathrm{e}+011.95651 \mathrm{e}+011.95651 \mathrm{e}+001.00000 \mathrm{e}-092.12000 \mathrm{e}-01$

$1.95651 \mathrm{e}+011.95651 \mathrm{e}+011.95651 \mathrm{e}+001.00000 \mathrm{e}-092.12000 \mathrm{e}-01$

$1.95651 \mathrm{e}+011.95651 \mathrm{e}+011.95651 \mathrm{e}+001.00000 \mathrm{e}-092.12000 \mathrm{e}-01$

$1.00000 \mathrm{e}-05$ 1.00000e-05 1.00000e-06 1.00000e-09 1.00000e-01

$1.00000 \mathrm{e}+001.00000 \mathrm{e}+001.00000 \mathrm{e}-01$ 1.00000e-09 1.00000e-01

Element: 8976 \# of layers: 7

$\mathrm{Kx} \mathrm{Ky} \mathrm{Kz}$ Ss Por

$2.36367 \mathrm{e}+012.36367 \mathrm{e}+012.36367 \mathrm{e}+00$ 1.00000e-09 2.12000e-01

$2.36367 \mathrm{e}+012.36367 \mathrm{e}+012.36367 \mathrm{e}+00$ 1.00000e-09 2.12000e-01

$2.36367 \mathrm{e}+012.36367 \mathrm{e}+012.36367 \mathrm{e}+00$ 1.00000e-09 2.12000e-01

$2.36367 \mathrm{e}+012.36367 \mathrm{e}+012.36367 \mathrm{e}+00$ 1.00000e-09 2.12000e-01

$2.36367 \mathrm{e}+012.36367 \mathrm{e}+012.36367 \mathrm{e}+00$ 1.00000e-09 2.12000e-01

$1.00000 \mathrm{e}-05$ 1.00000e-05 1.00000e-06 1.00000e-09 1.00000e-01

$1.00000 \mathrm{e}+001.00000 \mathrm{e}+001.00000 \mathrm{e}-011.00000 \mathrm{e}-091.00000 \mathrm{e}-01$

Element: 8977 \# of layers: 7

$\mathrm{Kx} \mathrm{Ky} \mathrm{Kz}$ Ss Por

2.36367e+01 2.36367e+01 2.36367e+00 1.00000e-09 2.12000e-01

$2.36367 \mathrm{e}+012.36367 \mathrm{e}+012.36367 \mathrm{e}+00$ 1.00000e-09 2.12000e-01

$2.36367 \mathrm{e}+012.36367 \mathrm{e}+01$ 2.36367e+00 1.00000e-09 2.12000e-01

$2.36367 \mathrm{e}+012.36367 \mathrm{e}+01$ 2.36367e+00 1.00000e-09 2.12000e-01

$2.36367 \mathrm{e}+012.36367 \mathrm{e}+012.36367 \mathrm{e}+00$ 1.00000e-09 2.12000e-01

$1.00000 \mathrm{e}-05$ 1.00000e-05 1.00000e-06 1.00000e-09 1.00000e-01

$1.00000 \mathrm{e}+001.00000 \mathrm{e}+001.00000 \mathrm{e}-01$ 1.00000e-09 1.00000e-01

Element: 8978 \# of layers: 7

$\mathrm{Kx} \mathrm{Ky} \mathrm{Kz}$ Ss Por

$2.36367 e+012.36367 e+012.36367 e+001.00000 e-09$ 2.12000e-01

$2.36367 \mathrm{e}+012.36367 \mathrm{e}+01$ 2.36367e+00 1.00000e-09 2.12000e-01

$2.36367 \mathrm{e}+012.36367 \mathrm{e}+012.36367 \mathrm{e}+00$ 1.00000e-09 2.12000e-01

$2.36367 \mathrm{e}+012.36367 \mathrm{e}+012.36367 \mathrm{e}+00$ 1.00000e-09 2.12000e-01

$2.36367 \mathrm{e}+012.36367 \mathrm{e}+012.36367 \mathrm{e}+00$ 1.00000e-09 2.12000e-01

$1.00000 \mathrm{e}-05$ 1.00000e-05 1.00000e-06 1.00000e-09 1.00000e-01

$1.00000 \mathrm{e}+001.00000 \mathrm{e}+001.00000 \mathrm{e}-011.00000 \mathrm{e}-091.00000 \mathrm{e}-01$

Element: 8979 \# of layers: 7

Kx Ky Kz Ss Por

$2.36367 \mathrm{e}+012.36367 \mathrm{e}+012.36367 \mathrm{e}+00$ 1.00000e-09 2.12000e-01

$2.36367 \mathrm{e}+012.36367 \mathrm{e}+01$ 2.36367e+00 1.00000e-09 2.12000e-01

$2.36367 \mathrm{e}+012.36367 \mathrm{e}+012.36367 \mathrm{e}+00$ 1.00000e-09 2.12000e-01

$2.36367 \mathrm{e}+012.36367 \mathrm{e}+012.36367 \mathrm{e}+00$ 1.00000e-09 2.12000e-01

$2.36367 \mathrm{e}+012.36367 \mathrm{e}+012.36367 \mathrm{e}+00$ 1.00000e-09 2.12000e-01

$1.00000 \mathrm{e}-05$ 1.00000e-05 1.00000e-06 1.00000e-09 1.00000e-01

$1.00000 \mathrm{e}+001.00000 \mathrm{e}+001.00000 \mathrm{e}-01$ 1.00000e-09 1.00000e-01

Element: 8980 \# of layers: 7

Kx Ky Kz Ss Por 
$2.36367 \mathrm{e}+012.36367 \mathrm{e}+012.36367 \mathrm{e}+00$ 1.00000e-09 2.12000e-01 $2.36367 \mathrm{e}+012.36367 \mathrm{e}+012.36367 \mathrm{e}+001.00000 \mathrm{e}-092.12000 \mathrm{e}-01$ $2.36367 \mathrm{e}+012.36367 \mathrm{e}+012.36367 \mathrm{e}+001.00000 \mathrm{e}-092.12000 \mathrm{e}-01$ $2.36367 \mathrm{e}+012.36367 \mathrm{e}+012.36367 \mathrm{e}+001.00000 \mathrm{e}-092.12000 \mathrm{e}-01$ $2.36367 \mathrm{e}+012.36367 \mathrm{e}+012.36367 \mathrm{e}+00$ 1.00000e-09 2.12000e-01 $1.00000 \mathrm{e}-05$ 1.00000e-05 1.00000e-06 1.00000e-09 1.00000e-01 $1.00000 \mathrm{e}+001.00000 \mathrm{e}+001.00000 \mathrm{e}-011.00000 \mathrm{e}-091.00000 \mathrm{e}-01$ Element: 8981 \# of layers: 7

Kx Ky Kz Ss Por

$2.36367 \mathrm{e}+012.36367 \mathrm{e}+012.36367 \mathrm{e}+00$ 1.00000e-09 2.12000e-01 $2.36367 \mathrm{e}+012.36367 \mathrm{e}+012.36367 \mathrm{e}+001.00000 \mathrm{e}-092.12000 \mathrm{e}-01$ $2.36367 \mathrm{e}+012.36367 \mathrm{e}+012.36367 \mathrm{e}+001.00000 \mathrm{e}-092.12000 \mathrm{e}-01$ $2.36367 \mathrm{e}+012.36367 \mathrm{e}+012.36367 \mathrm{e}+001.00000 \mathrm{e}-092.12000 \mathrm{e}-01$

$2.36367 \mathrm{e}+012.36367 \mathrm{e}+012.36367 \mathrm{e}+001.00000 \mathrm{e}-092.12000 \mathrm{e}-01$ $1.00000 \mathrm{e}-05$ 1.00000e-05 1.00000e-06 1.00000e-09 1.00000e-01 $1.00000 \mathrm{e}+001.00000 \mathrm{e}+001.00000 \mathrm{e}-011.00000 \mathrm{e}-091.00000 \mathrm{e}-01$ Element: 8982 \# of layers: 7

Kx Ky Kz Ss Por

$2.36367 \mathrm{e}+012.36367 \mathrm{e}+012.36367 \mathrm{e}+00$ 1.00000e-09 2.12000e-01 $2.36367 \mathrm{e}+012.36367 \mathrm{e}+012.36367 \mathrm{e}+001.00000 \mathrm{e}-092.12000 \mathrm{e}-01$ $2.36367 \mathrm{e}+012.36367 \mathrm{e}+012.36367 \mathrm{e}+001.00000 \mathrm{e}-092.12000 \mathrm{e}-01$ $2.36367 \mathrm{e}+012.36367 \mathrm{e}+012.36367 \mathrm{e}+001.00000 \mathrm{e}-092.12000 \mathrm{e}-01$ $2.36367 \mathrm{e}+012.36367 \mathrm{e}+012.36367 \mathrm{e}+00$ 1.00000e-09 2.12000e-01 $1.00000 \mathrm{e}-05$ 1.00000e-05 1.00000e-06 1.00000e-09 1.00000e-01 $1.00000 \mathrm{e}+001.00000 \mathrm{e}+001.00000 \mathrm{e}-011.00000 \mathrm{e}-091.00000 \mathrm{e}-01$ Element: 8983 \# of layers: 7

Kx Ky Kz Ss Por

$2.36367 \mathrm{e}+012.36367 \mathrm{e}+012.36367 \mathrm{e}+00$ 1.00000e-09 2.12000e-01 $2.36367 \mathrm{e}+012.36367 \mathrm{e}+012.36367 \mathrm{e}+001.00000 \mathrm{e}-092.12000 \mathrm{e}-01$ $2.36367 \mathrm{e}+012.36367 \mathrm{e}+012.36367 \mathrm{e}+001.00000 \mathrm{e}-092.12000 \mathrm{e}-01$ $2.36367 \mathrm{e}+012.36367 \mathrm{e}+012.36367 \mathrm{e}+001.00000 \mathrm{e}-092.12000 \mathrm{e}-01$ $2.36367 \mathrm{e}+012.36367 \mathrm{e}+012.36367 \mathrm{e}+001.00000 \mathrm{e}-092.12000 \mathrm{e}-01$ $1.00000 \mathrm{e}-05$ 1.00000e-05 1.00000e-06 1.00000e-09 1.00000e-01 $1.00000 \mathrm{e}+001.00000 \mathrm{e}+001.00000 \mathrm{e}-011.00000 \mathrm{e}-091.00000 \mathrm{e}-01$ Element: 8984 \# of layers: 7

Kx Ky Kz Ss Por

$2.36367 \mathrm{e}+012.36367 \mathrm{e}+012.36367 \mathrm{e}+00$ 1.00000e-09 2.12000e-01 $2.36367 \mathrm{e}+012.36367 \mathrm{e}+012.36367 \mathrm{e}+00$ 1.00000e-09 2.12000e-01

$2.36367 \mathrm{e}+012.36367 \mathrm{e}+012.36367 \mathrm{e}+001.00000 \mathrm{e}-092.12000 \mathrm{e}-01$ $2.36367 \mathrm{e}+012.36367 \mathrm{e}+012.36367 \mathrm{e}+001.00000 \mathrm{e}-092.12000 \mathrm{e}-01$ $2.36367 \mathrm{e}+012.36367 \mathrm{e}+012.36367 \mathrm{e}+001.00000 \mathrm{e}-092.12000 \mathrm{e}-01$ $1.00000 \mathrm{e}-05$ 1.00000e-05 1.00000e-06 1.00000e-09 1.00000e-01 $1.00000 \mathrm{e}+001.00000 \mathrm{e}+001.00000 \mathrm{e}-011.00000 \mathrm{e}-091.00000 \mathrm{e}-01$ Element: 8985 \# of layers: 7

Kx Ky Kz Ss Por

$2.36367 \mathrm{e}+012.36367 \mathrm{e}+012.36367 \mathrm{e}+00$ 1.00000e-09 2.12000e-01 
$2.36367 \mathrm{e}+012.36367 \mathrm{e}+012.36367 \mathrm{e}+00$ 1.00000e-09 2.12000e-01 $2.36367 \mathrm{e}+012.36367 \mathrm{e}+012.36367 \mathrm{e}+001.00000 \mathrm{e}-092.12000 \mathrm{e}-01$ $2.36367 \mathrm{e}+012.36367 \mathrm{e}+012.36367 \mathrm{e}+001.00000 \mathrm{e}-092.12000 \mathrm{e}-01$ $2.36367 \mathrm{e}+012.36367 \mathrm{e}+012.36367 \mathrm{e}+001.00000 \mathrm{e}-092.12000 \mathrm{e}-01$ $1.00000 \mathrm{e}-05$ 1.00000e-05 1.00000e-06 1.00000e-09 1.00000e-01 $1.00000 \mathrm{e}+001.00000 \mathrm{e}+001.00000 \mathrm{e}-011.00000 \mathrm{e}-091.00000 \mathrm{e}-01$ Element: 8986 \# of layers: 7

Kx Ky Kz Ss Por

$2.36367 \mathrm{e}+012.36367 \mathrm{e}+012.36367 \mathrm{e}+00$ 1.00000e-09 2.12000e-01

$2.36367 \mathrm{e}+012.36367 \mathrm{e}+012.36367 \mathrm{e}+001.00000 \mathrm{e}-092.12000 \mathrm{e}-01$ $2.36367 \mathrm{e}+012.36367 \mathrm{e}+012.36367 \mathrm{e}+001.00000 \mathrm{e}-092.12000 \mathrm{e}-01$ $2.36367 \mathrm{e}+012.36367 \mathrm{e}+012.36367 \mathrm{e}+001.00000 \mathrm{e}-092.12000 \mathrm{e}-01$ $2.36367 \mathrm{e}+012.36367 \mathrm{e}+012.36367 \mathrm{e}+00$ 1.00000e-09 2.12000e-01 $1.00000 \mathrm{e}-05$ 1.00000e-05 1.00000e-06 1.00000e-09 1.00000e-01 $1.00000 \mathrm{e}+001.00000 \mathrm{e}+001.00000 \mathrm{e}-011.00000 \mathrm{e}-091.00000 \mathrm{e}-01$ Element: 8987 \# of layers: 7

Kx Ky Kz Ss Por

$2.92304 \mathrm{e}+012.92304 \mathrm{e}+012.92304 \mathrm{e}+00$ 1.00000e-09 2.12000e-01 $2.92304 \mathrm{e}+012.92304 \mathrm{e}+012.92304 \mathrm{e}+001.00000 \mathrm{e}-092.12000 \mathrm{e}-01$ $2.92304 \mathrm{e}+012.92304 \mathrm{e}+012.92304 \mathrm{e}+001.00000 \mathrm{e}-092.12000 \mathrm{e}-01$ $2.92304 \mathrm{e}+012.92304 \mathrm{e}+012.92304 \mathrm{e}+001.00000 \mathrm{e}-092.12000 \mathrm{e}-01$ $2.92304 \mathrm{e}+012.92304 \mathrm{e}+012.92304 \mathrm{e}+001.00000 \mathrm{e}-092.12000 \mathrm{e}-01$ $1.00000 \mathrm{e}-05$ 1.00000e-05 1.00000e-06 1.00000e-09 1.00000e-01 $1.00000 \mathrm{e}+001.00000 \mathrm{e}+001.00000 \mathrm{e}-011.00000 \mathrm{e}-091.00000 \mathrm{e}-01$ Element: 8988 \# of layers: 7

Kx Ky Kz Ss Por

$2.92304 \mathrm{e}+012.92304 \mathrm{e}+012.92304 \mathrm{e}+00$ 1.00000e-09 2.12000e-01 $2.92304 \mathrm{e}+012.92304 \mathrm{e}+012.92304 \mathrm{e}+001.00000 \mathrm{e}-092.12000 \mathrm{e}-01$ $2.92304 \mathrm{e}+012.92304 \mathrm{e}+012.92304 \mathrm{e}+001.00000 \mathrm{e}-092.12000 \mathrm{e}-01$ $2.92304 \mathrm{e}+012.92304 \mathrm{e}+012.92304 \mathrm{e}+001.00000 \mathrm{e}-092.12000 \mathrm{e}-01$ $2.92304 \mathrm{e}+012.92304 \mathrm{e}+012.92304 \mathrm{e}+001.00000 \mathrm{e}-092.12000 \mathrm{e}-01$ $1.00000 \mathrm{e}-05$ 1.00000e-05 1.00000e-06 1.00000e-09 1.00000e-01 $1.00000 \mathrm{e}+001.00000 \mathrm{e}+001.00000 \mathrm{e}-011.00000 \mathrm{e}-091.00000 \mathrm{e}-01$ Element: 8989 \# of layers: 7

Kx Ky Kz Ss Por

$2.92304 \mathrm{e}+012.92304 \mathrm{e}+012.92304 \mathrm{e}+00$ 1.00000e-09 2.12000e-01 $2.92304 \mathrm{e}+012.92304 \mathrm{e}+012.92304 \mathrm{e}+001.00000 \mathrm{e}-092.12000 \mathrm{e}-01$ $2.92304 \mathrm{e}+012.92304 \mathrm{e}+012.92304 \mathrm{e}+001.00000 \mathrm{e}-092.12000 \mathrm{e}-01$ $2.92304 \mathrm{e}+012.92304 \mathrm{e}+012.92304 \mathrm{e}+001.00000 \mathrm{e}-092.12000 \mathrm{e}-01$ $2.92304 \mathrm{e}+012.92304 \mathrm{e}+012.92304 \mathrm{e}+001.00000 \mathrm{e}-092.12000 \mathrm{e}-01$ $1.00000 \mathrm{e}-05$ 1.00000e-05 1.00000e-06 1.00000e-09 1.00000e-01 $1.00000 \mathrm{e}+001.00000 \mathrm{e}+001.00000 \mathrm{e}-011.00000 \mathrm{e}-091.00000 \mathrm{e}-01$ Element: 8990 \# of layers: 7

Kx Ky Kz Ss Por

$2.36367 \mathrm{e}+012.36367 \mathrm{e}+012.36367 \mathrm{e}+00$ 1.00000e-09 2.12000e-01 $2.36367 \mathrm{e}+012.36367 \mathrm{e}+012.36367 \mathrm{e}+001.00000 \mathrm{e}-092.12000 \mathrm{e}-01$ 
$2.36367 \mathrm{e}+012.36367 \mathrm{e}+012.36367 \mathrm{e}+00$ 1.00000e-09 2.12000e-01 $2.36367 \mathrm{e}+012.36367 \mathrm{e}+012.36367 \mathrm{e}+001.00000 \mathrm{e}-092.12000 \mathrm{e}-01$ $2.36367 \mathrm{e}+012.36367 \mathrm{e}+012.36367 \mathrm{e}+001.00000 \mathrm{e}-092.12000 \mathrm{e}-01$ $1.00000 \mathrm{e}-05$ 1.00000e-05 1.00000e-06 1.00000e-09 1.00000e-01 $1.00000 \mathrm{e}+001.00000 \mathrm{e}+001.00000 \mathrm{e}-011.00000 \mathrm{e}-091.00000 \mathrm{e}-01$ Element: 8991 \# of layers: 7

Kx Ky Kz Ss Por

$2.36367 \mathrm{e}+012.36367 \mathrm{e}+012.36367 \mathrm{e}+00$ 1.00000e-09 2.12000e-01 $2.36367 \mathrm{e}+012.36367 \mathrm{e}+012.36367 \mathrm{e}+001.00000 \mathrm{e}-092.12000 \mathrm{e}-01$

$2.36367 \mathrm{e}+012.36367 \mathrm{e}+012.36367 \mathrm{e}+001.00000 \mathrm{e}-092.12000 \mathrm{e}-01$ $2.36367 \mathrm{e}+012.36367 \mathrm{e}+012.36367 \mathrm{e}+001.00000 \mathrm{e}-092.12000 \mathrm{e}-01$ $2.36367 \mathrm{e}+012.36367 \mathrm{e}+012.36367 \mathrm{e}+001.00000 \mathrm{e}-092.12000 \mathrm{e}-01$ $1.00000 \mathrm{e}-05$ 1.00000e-05 1.00000e-06 1.00000e-09 1.00000e-01 $1.00000 \mathrm{e}+001.00000 \mathrm{e}+001.00000 \mathrm{e}-011.00000 \mathrm{e}-091.00000 \mathrm{e}-01$ Element: 8992 \# of layers: 7

Kx Ky Kz Ss Por

$2.36367 \mathrm{e}+012.36367 \mathrm{e}+012.36367 \mathrm{e}+00$ 1.00000e-09 2.12000e-01

$2.36367 \mathrm{e}+012.36367 \mathrm{e}+012.36367 \mathrm{e}+001.00000 \mathrm{e}-092.12000 \mathrm{e}-01$ $2.36367 \mathrm{e}+012.36367 \mathrm{e}+012.36367 \mathrm{e}+001.00000 \mathrm{e}-092.12000 \mathrm{e}-01$ $2.36367 \mathrm{e}+012.36367 \mathrm{e}+012.36367 \mathrm{e}+001.00000 \mathrm{e}-092.12000 \mathrm{e}-01$ $2.36367 \mathrm{e}+012.36367 \mathrm{e}+012.36367 \mathrm{e}+001.00000 \mathrm{e}-092.12000 \mathrm{e}-01$ $1.00000 \mathrm{e}-05$ 1.00000e-05 1.00000e-06 1.00000e-09 1.00000e-01 $1.00000 \mathrm{e}+001.00000 \mathrm{e}+001.00000 \mathrm{e}-011.00000 \mathrm{e}-091.00000 \mathrm{e}-01$ Element: 8993 \# of layers: 7

Kx Ky Kz Ss Por

$2.36367 \mathrm{e}+012.36367 \mathrm{e}+012.36367 \mathrm{e}+00$ 1.00000e-09 2.12000e-01 $2.36367 \mathrm{e}+012.36367 \mathrm{e}+012.36367 \mathrm{e}+001.00000 \mathrm{e}-092.12000 \mathrm{e}-01$ $2.36367 \mathrm{e}+012.36367 \mathrm{e}+012.36367 \mathrm{e}+001.00000 \mathrm{e}-092.12000 \mathrm{e}-01$ $2.36367 \mathrm{e}+012.36367 \mathrm{e}+012.36367 \mathrm{e}+001.00000 \mathrm{e}-092.12000 \mathrm{e}-01$ $2.36367 \mathrm{e}+012.36367 \mathrm{e}+012.36367 \mathrm{e}+001.00000 \mathrm{e}-092.12000 \mathrm{e}-01$ $1.00000 \mathrm{e}-05$ 1.00000e-05 1.00000e-06 1.00000e-09 1.00000e-01 $1.00000 \mathrm{e}+001.00000 \mathrm{e}+001.00000 \mathrm{e}-011.00000 \mathrm{e}-091.00000 \mathrm{e}-01$ Element: 8994 \# of layers: 7

Kx Ky Kz Ss Por

$2.92304 \mathrm{e}+012.92304 \mathrm{e}+012.92304 \mathrm{e}+00$ 1.00000e-09 2.12000e-01 $2.92304 \mathrm{e}+012.92304 \mathrm{e}+012.92304 \mathrm{e}+001.00000 \mathrm{e}-092.12000 \mathrm{e}-01$ $2.92304 \mathrm{e}+012.92304 \mathrm{e}+012.92304 \mathrm{e}+001.00000 \mathrm{e}-092.12000 \mathrm{e}-01$ $2.92304 \mathrm{e}+012.92304 \mathrm{e}+012.92304 \mathrm{e}+001.00000 \mathrm{e}-092.12000 \mathrm{e}-01$ $2.92304 \mathrm{e}+012.92304 \mathrm{e}+012.92304 \mathrm{e}+001.00000 \mathrm{e}-092.12000 \mathrm{e}-01$ $1.00000 \mathrm{e}-05$ 1.00000e-05 1.00000e-06 1.00000e-09 1.00000e-01 $1.00000 \mathrm{e}+001.00000 \mathrm{e}+001.00000 \mathrm{e}-011.00000 \mathrm{e}-091.00000 \mathrm{e}-01$ Element: 8995 \# of layers: 7

Kx Ky Kz Ss Por

$2.92304 \mathrm{e}+012.92304 \mathrm{e}+012.92304 \mathrm{e}+00$ 1.00000e-09 2.12000e-01 $2.92304 \mathrm{e}+012.92304 \mathrm{e}+012.92304 \mathrm{e}+001.00000 \mathrm{e}-092.12000 \mathrm{e}-01$ $2.92304 \mathrm{e}+012.92304 \mathrm{e}+012.92304 \mathrm{e}+001.00000 \mathrm{e}-092.12000 \mathrm{e}-01$ 
$2.92304 \mathrm{e}+012.92304 \mathrm{e}+012.92304 \mathrm{e}+001.00000 \mathrm{e}-092.12000 \mathrm{e}-01$ $2.92304 \mathrm{e}+012.92304 \mathrm{e}+012.92304 \mathrm{e}+001.00000 \mathrm{e}-092.12000 \mathrm{e}-01$ $1.00000 \mathrm{e}-05$ 1.00000e-05 1.00000e-06 1.00000e-09 1.00000e-01 $1.00000 \mathrm{e}+001.00000 \mathrm{e}+001.00000 \mathrm{e}-011.00000 \mathrm{e}-091.00000 \mathrm{e}-01$ Element: 8996 \# of layers: 7

Kx Ky Kz Ss Por

$2.92304 \mathrm{e}+012.92304 \mathrm{e}+012.92304 \mathrm{e}+00$ 1.00000e-09 2.12000e-01 $2.92304 \mathrm{e}+012.92304 \mathrm{e}+012.92304 \mathrm{e}+001.00000 \mathrm{e}-092.12000 \mathrm{e}-01$ $2.92304 \mathrm{e}+012.92304 \mathrm{e}+012.92304 \mathrm{e}+001.00000 \mathrm{e}-092.12000 \mathrm{e}-01$ $2.92304 \mathrm{e}+012.92304 \mathrm{e}+012.92304 \mathrm{e}+001.00000 \mathrm{e}-092.12000 \mathrm{e}-01$ $2.92304 \mathrm{e}+012.92304 \mathrm{e}+012.92304 \mathrm{e}+001.00000 \mathrm{e}-092.12000 \mathrm{e}-01$ $1.00000 \mathrm{e}-05$ 1.00000e-05 1.00000e-06 1.00000e-09 1.00000e-01 $1.00000 \mathrm{e}+001.00000 \mathrm{e}+001.00000 \mathrm{e}-011.00000 \mathrm{e}-091.00000 \mathrm{e}-01$ Element: 8997 \# of layers: 7

Kx Ky Kz Ss Por

$2.92304 \mathrm{e}+012.92304 \mathrm{e}+012.92304 \mathrm{e}+00$ 1.00000e-09 2.12000e-01 $2.92304 \mathrm{e}+012.92304 \mathrm{e}+012.92304 \mathrm{e}+001.00000 \mathrm{e}-092.12000 \mathrm{e}-01$ $2.92304 \mathrm{e}+012.92304 \mathrm{e}+012.92304 \mathrm{e}+001.00000 \mathrm{e}-092.12000 \mathrm{e}-01$ $2.92304 \mathrm{e}+012.92304 \mathrm{e}+012.92304 \mathrm{e}+001.00000 \mathrm{e}-092.12000 \mathrm{e}-01$ $2.92304 \mathrm{e}+012.92304 \mathrm{e}+012.92304 \mathrm{e}+001.00000 \mathrm{e}-092.12000 \mathrm{e}-01$ $1.00000 \mathrm{e}-05$ 1.00000e-05 1.00000e-06 1.00000e-09 1.00000e-01 $1.00000 \mathrm{e}+001.00000 \mathrm{e}+001.00000 \mathrm{e}-011.00000 \mathrm{e}-091.00000 \mathrm{e}-01$ Element: 8998 \# of layers: 7

Kx Ky Kz Ss Por

$2.92304 \mathrm{e}+012.92304 \mathrm{e}+012.92304 \mathrm{e}+001.00000 \mathrm{e}-092.12000 \mathrm{e}-01$ $2.92304 \mathrm{e}+012.92304 \mathrm{e}+012.92304 \mathrm{e}+001.00000 \mathrm{e}-092.12000 \mathrm{e}-01$ $2.92304 \mathrm{e}+012.92304 \mathrm{e}+012.92304 \mathrm{e}+001.00000 \mathrm{e}-092.12000 \mathrm{e}-01$ $2.92304 \mathrm{e}+012.92304 \mathrm{e}+012.92304 \mathrm{e}+001.00000 \mathrm{e}-092.12000 \mathrm{e}-01$ $2.92304 \mathrm{e}+012.92304 \mathrm{e}+012.92304 \mathrm{e}+001.00000 \mathrm{e}-092.12000 \mathrm{e}-01$ $1.00000 \mathrm{e}-05$ 1.00000e-05 1.00000e-06 1.00000e-09 1.00000e-01 $1.00000 \mathrm{e}+001.00000 \mathrm{e}+001.00000 \mathrm{e}-011.00000 \mathrm{e}-091.00000 \mathrm{e}-01$ Element: 8999 \# of layers: 7

Kx Ky Kz Ss Por

$2.92304 \mathrm{e}+012.92304 \mathrm{e}+012.92304 \mathrm{e}+001.00000 \mathrm{e}-092.12000 \mathrm{e}-01$ $2.92304 \mathrm{e}+012.92304 \mathrm{e}+012.92304 \mathrm{e}+001.00000 \mathrm{e}-092.12000 \mathrm{e}-01$ $2.92304 \mathrm{e}+012.92304 \mathrm{e}+012.92304 \mathrm{e}+001.00000 \mathrm{e}-092.12000 \mathrm{e}-01$ $2.92304 \mathrm{e}+012.92304 \mathrm{e}+012.92304 \mathrm{e}+001.00000 \mathrm{e}-092.12000 \mathrm{e}-01$ $2.92304 \mathrm{e}+012.92304 \mathrm{e}+012.92304 \mathrm{e}+00$ 1.00000e-09 2.12000e-01 $1.00000 \mathrm{e}-05$ 1.00000e-05 1.00000e-06 1.00000e-09 1.00000e-01 $1.00000 \mathrm{e}+001.00000 \mathrm{e}+001.00000 \mathrm{e}-011.00000 \mathrm{e}-091.00000 \mathrm{e}-01$ Element: 9000 \# of layers: 7

Kx Ky Kz Ss Por

$2.92304 \mathrm{e}+012.92304 \mathrm{e}+012.92304 \mathrm{e}+00$ 1.00000e-09 2.12000e-01 $2.92304 \mathrm{e}+012.92304 \mathrm{e}+012.92304 \mathrm{e}+001.00000 \mathrm{e}-092.12000 \mathrm{e}-01$ $2.92304 \mathrm{e}+012.92304 \mathrm{e}+012.92304 \mathrm{e}+001.00000 \mathrm{e}-092.12000 \mathrm{e}-01$ $2.92304 \mathrm{e}+012.92304 \mathrm{e}+012.92304 \mathrm{e}+001.00000 \mathrm{e}-092.12000 \mathrm{e}-01$ 
$2.92304 \mathrm{e}+012.92304 \mathrm{e}+012.92304 \mathrm{e}+001.00000 \mathrm{e}-092.12000 \mathrm{e}-01$ $1.00000 \mathrm{e}-05$ 1.00000e-05 1.00000e-06 1.00000e-09 1.00000e-01 $1.00000 \mathrm{e}+001.00000 \mathrm{e}+001.00000 \mathrm{e}-011.00000 \mathrm{e}-09$ 1.00000e-01

Element: 9001 \# of layers: 7

$\mathrm{Kx} \mathrm{Ky} \mathrm{Kz}$ Ss Por

$2.92304 \mathrm{e}+012.92304 \mathrm{e}+012.92304 \mathrm{e}+00$ 1.00000e-09 2.12000e-01

$2.92304 \mathrm{e}+012.92304 \mathrm{e}+012.92304 \mathrm{e}+001.00000 \mathrm{e}-092.12000 \mathrm{e}-01$

$2.92304 \mathrm{e}+012.92304 \mathrm{e}+012.92304 \mathrm{e}+001.00000 \mathrm{e}-092.12000 \mathrm{e}-01$

$2.92304 \mathrm{e}+012.92304 \mathrm{e}+012.92304 \mathrm{e}+00 \quad 1.00000 \mathrm{e}-092.12000 \mathrm{e}-01$

$2.92304 \mathrm{e}+012.92304 \mathrm{e}+012.92304 \mathrm{e}+00 \quad 1.00000 \mathrm{e}-092.12000 \mathrm{e}-01$

$1.00000 \mathrm{e}-05$ 1.00000e-05 1.00000e-06 1.00000e-09 1.00000e-01

$1.00000 \mathrm{e}+001.00000 \mathrm{e}+001.00000 \mathrm{e}-011.00000 \mathrm{e}-091.00000 \mathrm{e}-01$

Element: 9002 \# of layers: 7

$\mathrm{Kx} \mathrm{Ky} \mathrm{Kz}$ Ss Por

$2.92304 \mathrm{e}+012.92304 \mathrm{e}+012.92304 \mathrm{e}+00$ 1.00000e-09 2.12000e-01

$2.92304 \mathrm{e}+012.92304 \mathrm{e}+012.92304 \mathrm{e}+001.00000 \mathrm{e}-092.12000 \mathrm{e}-01$

$2.92304 \mathrm{e}+012.92304 \mathrm{e}+012.92304 \mathrm{e}+001.00000 \mathrm{e}-092.12000 \mathrm{e}-01$

$2.92304 \mathrm{e}+012.92304 \mathrm{e}+012.92304 \mathrm{e}+001.00000 \mathrm{e}-092.12000 \mathrm{e}-01$

$2.92304 \mathrm{e}+012.92304 \mathrm{e}+012.92304 \mathrm{e}+001.00000 \mathrm{e}-092.12000 \mathrm{e}-01$

$1.00000 \mathrm{e}-05$ 1.00000e-05 1.00000e-06 1.00000e-09 1.00000e-01

$1.00000 \mathrm{e}+001.00000 \mathrm{e}+001.00000 \mathrm{e}-011.00000 \mathrm{e}-091.00000 \mathrm{e}-01$

Element: 9003 \# of layers: 7

$\mathrm{Kx} \mathrm{Ky} \mathrm{Kz}$ Ss Por

$2.92304 \mathrm{e}+012.92304 \mathrm{e}+012.92304 \mathrm{e}+00$ 1.00000e-09 2.12000e-01

$2.92304 \mathrm{e}+012.92304 \mathrm{e}+012.92304 \mathrm{e}+001.00000 \mathrm{e}-092.12000 \mathrm{e}-01$

$2.92304 \mathrm{e}+012.92304 \mathrm{e}+012.92304 \mathrm{e}+001.00000 \mathrm{e}-092.12000 \mathrm{e}-01$

$2.92304 \mathrm{e}+012.92304 \mathrm{e}+012.92304 \mathrm{e}+001.00000 \mathrm{e}-092.12000 \mathrm{e}-01$

$2.92304 \mathrm{e}+012.92304 \mathrm{e}+012.92304 \mathrm{e}+001.00000 \mathrm{e}-092.12000 \mathrm{e}-01$

$1.00000 \mathrm{e}-05$ 1.00000e-05 1.00000e-06 1.00000e-09 1.00000e-01

$1.00000 \mathrm{e}+001.00000 \mathrm{e}+001.00000 \mathrm{e}-011.00000 \mathrm{e}-091.00000 \mathrm{e}-01$

Element: 9004 \# of layers: 7

$\mathrm{Kx} \mathrm{Ky} \mathrm{Kz}$ Ss Por

$2.84249 \mathrm{e}+012.84249 \mathrm{e}+012.84249 \mathrm{e}+00$ 1.00000e-09 2.12000e-01

$2.84249 \mathrm{e}+012.84249 \mathrm{e}+012.84249 \mathrm{e}+00$ 1.00000e-09 2.12000e-01

$2.84249 \mathrm{e}+012.84249 \mathrm{e}+012.84249 \mathrm{e}+00$ 1.00000e-09 2.12000e-01

$2.84249 \mathrm{e}+012.84249 \mathrm{e}+012.84249 \mathrm{e}+00$ 1.00000e-09 2.12000e-01

$2.84249 \mathrm{e}+012.84249 \mathrm{e}+012.84249 \mathrm{e}+001.00000 \mathrm{e}-092.12000 \mathrm{e}-01$

$1.00000 \mathrm{e}-05$ 1.00000e-05 1.00000e-06 1.00000e-09 1.00000e-01

$1.00000 \mathrm{e}+001.00000 \mathrm{e}+001.00000 \mathrm{e}-011.00000 \mathrm{e}-091.00000 \mathrm{e}-01$

Element: 9005 \# of layers: 7

$\mathrm{Kx} \mathrm{Ky} \mathrm{Kz}$ Ss Por

$2.84249 \mathrm{e}+012.84249 \mathrm{e}+012.84249 \mathrm{e}+00$ 1.00000e-09 2.12000e-01

$2.84249 \mathrm{e}+012.84249 \mathrm{e}+012.84249 \mathrm{e}+00$ 1.00000e-09 2.12000e-01

$2.84249 \mathrm{e}+012.84249 \mathrm{e}+01$ 2.84249e+00 1.00000e-09 2.12000e-01

$2.84249 \mathrm{e}+012.84249 \mathrm{e}+012.84249 \mathrm{e}+00$ 1.00000e-09 2.12000e-01

$2.84249 \mathrm{e}+012.84249 \mathrm{e}+012.84249 \mathrm{e}+00$ 1.00000e-09 2.12000e-01 
$1.00000 \mathrm{e}-05$ 1.00000e-05 1.00000e-06 1.00000e-09 1.00000e-01 $1.00000 \mathrm{e}+001.00000 \mathrm{e}+001.00000 \mathrm{e}-011.00000 \mathrm{e}-091.00000 \mathrm{e}-01$ Element: 9006 \# of layers: 7

$\mathrm{Kx} \mathrm{Ky} \mathrm{Kz}$ Ss Por

$2.84249 \mathrm{e}+012.84249 \mathrm{e}+012.84249 \mathrm{e}+00$ 1.00000e-09 2.12000e-01 $2.84249 \mathrm{e}+012.84249 \mathrm{e}+012.84249 \mathrm{e}+00$ 1.00000e-09 2.12000e-01 $2.84249 \mathrm{e}+012.84249 \mathrm{e}+012.84249 \mathrm{e}+00$ 1.00000e-09 2.12000e-01 $2.84249 \mathrm{e}+012.84249 \mathrm{e}+012.84249 \mathrm{e}+00$ 1.00000e-09 2.12000e-01 $2.84249 \mathrm{e}+012.84249 \mathrm{e}+012.84249 \mathrm{e}+00$ 1.00000e-09 2.12000e-01 $1.00000 \mathrm{e}-05$ 1.00000e-05 1.00000e-06 1.00000e-09 1.00000e-01 $1.00000 \mathrm{e}+001.00000 \mathrm{e}+001.00000 \mathrm{e}-011.00000 \mathrm{e}-091.00000 \mathrm{e}-01$ Element: 9007 \# of layers: 7

$\mathrm{Kx} \mathrm{Ky} \mathrm{Kz}$ Ss Por

$2.84249 \mathrm{e}+012.84249 \mathrm{e}+012.84249 \mathrm{e}+00$ 1.00000e-09 2.12000e-01 $2.84249 \mathrm{e}+012.84249 \mathrm{e}+012.84249 \mathrm{e}+00$ 1.00000e-09 2.12000e-01 $2.84249 \mathrm{e}+012.84249 \mathrm{e}+012.84249 \mathrm{e}+001.00000 \mathrm{e}-092.12000 \mathrm{e}-01$ $2.84249 \mathrm{e}+012.84249 \mathrm{e}+012.84249 \mathrm{e}+00$ 1.00000e-09 2.12000e-01 $2.84249 \mathrm{e}+012.84249 \mathrm{e}+012.84249 \mathrm{e}+00$ 1.00000e-09 2.12000e-01 $1.00000 \mathrm{e}-051.00000 \mathrm{e}-051.00000 \mathrm{e}-061.00000 \mathrm{e}-091.00000 \mathrm{e}-01$ $1.00000 \mathrm{e}+001.00000 \mathrm{e}+001.00000 \mathrm{e}-011.00000 \mathrm{e}-091.00000 \mathrm{e}-01$ Element: 9008 \# of layers: 7

$\mathrm{Kx} \mathrm{Ky} \mathrm{Kz}$ Ss Por

$2.84249 \mathrm{e}+012.84249 \mathrm{e}+012.84249 \mathrm{e}+00$ 1.00000e-09 2.12000e-01 $2.84249 \mathrm{e}+012.84249 \mathrm{e}+012.84249 \mathrm{e}+00$ 1.00000e-09 2.12000e-01 $2.84249 \mathrm{e}+012.84249 \mathrm{e}+012.84249 \mathrm{e}+001.00000 \mathrm{e}-092.12000 \mathrm{e}-01$ $2.84249 \mathrm{e}+012.84249 \mathrm{e}+012.84249 \mathrm{e}+001.00000 \mathrm{e}-092.12000 \mathrm{e}-01$ $2.84249 \mathrm{e}+012.84249 \mathrm{e}+012.84249 \mathrm{e}+00$ 1.00000e-09 2.12000e-01 $1.00000 \mathrm{e}-05$ 1.00000e-05 1.00000e-06 1.00000e-09 1.00000e-01 $1.00000 \mathrm{e}+001.00000 \mathrm{e}+001.00000 \mathrm{e}-011.00000 \mathrm{e}-091.00000 \mathrm{e}-01$ Element: 9009 \# of layers: 7

$\mathrm{Kx} \mathrm{Ky} \mathrm{Kz}$ Ss Por

$2.92304 \mathrm{e}+012.92304 \mathrm{e}+012.92304 \mathrm{e}+00$ 1.00000e-09 2.12000e-01 $2.92304 \mathrm{e}+012.92304 \mathrm{e}+012.92304 \mathrm{e}+001.00000 \mathrm{e}-092.12000 \mathrm{e}-01$ $2.92304 \mathrm{e}+012.92304 \mathrm{e}+012.92304 \mathrm{e}+001.00000 \mathrm{e}-092.12000 \mathrm{e}-01$ $2.92304 \mathrm{e}+012.92304 \mathrm{e}+012.92304 \mathrm{e}+00$ 1.00000e-09 2.12000e-01 $2.92304 \mathrm{e}+012.92304 \mathrm{e}+012.92304 \mathrm{e}+001.00000 \mathrm{e}-092.12000 \mathrm{e}-01$ $1.00000 \mathrm{e}-05$ 1.00000e-05 1.00000e-06 1.00000e-09 1.00000e-01 $1.00000 \mathrm{e}+001.00000 \mathrm{e}+001.00000 \mathrm{e}-011.00000 \mathrm{e}-091.00000 \mathrm{e}-01$ Element: 9010 \# of layers: 7

$\mathrm{Kx} \mathrm{Ky} \mathrm{Kz}$ Ss Por

$2.92304 \mathrm{e}+012.92304 \mathrm{e}+012.92304 \mathrm{e}+00$ 1.00000e-09 2.12000e-01 $2.92304 \mathrm{e}+012.92304 \mathrm{e}+012.92304 \mathrm{e}+001.00000 \mathrm{e}-092.12000 \mathrm{e}-01$ $2.92304 \mathrm{e}+012.92304 \mathrm{e}+012.92304 \mathrm{e}+001.00000 \mathrm{e}-092.12000 \mathrm{e}-01$ $2.92304 \mathrm{e}+012.92304 \mathrm{e}+012.92304 \mathrm{e}+001.00000 \mathrm{e}-092.12000 \mathrm{e}-01$ $2.92304 \mathrm{e}+012.92304 \mathrm{e}+012.92304 \mathrm{e}+001.00000 \mathrm{e}-092.12000 \mathrm{e}-01$ $1.00000 \mathrm{e}-05$ 1.00000e-05 1.00000e-06 1.00000e-09 1.00000e-01 
$1.00000 \mathrm{e}+001.00000 \mathrm{e}+00$ 1.00000e-01 1.00000e-09 1.00000e-01

Element: 9011 \# of layers: 7

$\mathrm{Kx} \mathrm{Ky} \mathrm{Kz}$ Ss Por

$2.84249 \mathrm{e}+01$ 2.84249e+01 2.84249e+00 1.00000e-09 2.12000e-01

$2.84249 \mathrm{e}+012.84249 \mathrm{e}+012.84249 \mathrm{e}+001.00000 \mathrm{e}-092.12000 \mathrm{e}-01$

$2.84249 \mathrm{e}+012.84249 \mathrm{e}+012.84249 \mathrm{e}+00$ 1.00000e-09 2.12000e-01

$2.84249 \mathrm{e}+012.84249 \mathrm{e}+012.84249 \mathrm{e}+00$ 1.00000e-09 2.12000e-01

$2.84249 \mathrm{e}+012.84249 \mathrm{e}+012.84249 \mathrm{e}+00$ 1.00000e-09 2.12000e-01

$1.00000 \mathrm{e}-05$ 1.00000e-05 1.00000e-06 1.00000e-09 1.00000e-01

$1.00000 \mathrm{e}+001.00000 \mathrm{e}+001.00000 \mathrm{e}-011.00000 \mathrm{e}-091.00000 \mathrm{e}-01$

Element: 9012 \# of layers: 7

$\mathrm{Kx} \mathrm{Ky} \mathrm{Kz}$ Ss Por

2.84249e+01 2.84249e+01 2.84249e+00 1.00000e-09 2.12000e-01

$2.84249 \mathrm{e}+012.84249 \mathrm{e}+012.84249 \mathrm{e}+00$ 1.00000e-09 2.12000e-01

$2.84249 \mathrm{e}+012.84249 \mathrm{e}+012.84249 \mathrm{e}+001.00000 \mathrm{e}-092.12000 \mathrm{e}-01$

$2.84249 \mathrm{e}+012.84249 \mathrm{e}+012.84249 \mathrm{e}+001.00000 \mathrm{e}-092.12000 \mathrm{e}-01$

$2.84249 \mathrm{e}+012.84249 \mathrm{e}+012.84249 \mathrm{e}+00$ 1.00000e-09 2.12000e-01

$1.00000 \mathrm{e}-05$ 1.00000e-05 1.00000e-06 1.00000e-09 1.00000e-01

$1.00000 \mathrm{e}+001.00000 \mathrm{e}+001.00000 \mathrm{e}-011.00000 \mathrm{e}-091.00000 \mathrm{e}-01$

Element: 9013 \# of layers: 7

$\mathrm{Kx} \mathrm{Ky} \mathrm{Kz}$ Ss Por

$1.95651 \mathrm{e}+01$ 1.95651e+01 1.95651e+00 1.00000e-09 2.12000e-01

$1.95651 \mathrm{e}+011.95651 \mathrm{e}+011.95651 \mathrm{e}+001.00000 \mathrm{e}-092.12000 \mathrm{e}-01$

$1.95651 \mathrm{e}+011.95651 \mathrm{e}+011.95651 \mathrm{e}+001.00000 \mathrm{e}-092.12000 \mathrm{e}-01$

$1.95651 \mathrm{e}+011.95651 \mathrm{e}+011.95651 \mathrm{e}+001.00000 \mathrm{e}-092.12000 \mathrm{e}-01$

$1.95651 \mathrm{e}+01$ 1.95651e+01 1.95651e+00 1.00000e-09 2.12000e-01

$1.00000 \mathrm{e}-05$ 1.00000e-05 1.00000e-06 1.00000e-09 1.00000e-01

$1.00000 \mathrm{e}+001.00000 \mathrm{e}+001.00000 \mathrm{e}-011.00000 \mathrm{e}-09$ 1.00000e-01

Element: 9014 \# of layers: 7

$\mathrm{Kx} \mathrm{Ky} \mathrm{Kz}$ Ss Por

$1.95651 \mathrm{e}+011.95651 \mathrm{e}+011.95651 \mathrm{e}+00$ 1.00000e-09 2.12000e-01 $1.95651 \mathrm{e}+011.95651 \mathrm{e}+011.95651 \mathrm{e}+001.00000 \mathrm{e}-092.12000 \mathrm{e}-01$ $1.95651 \mathrm{e}+011.95651 \mathrm{e}+011.95651 \mathrm{e}+001.00000 \mathrm{e}-092.12000 \mathrm{e}-01$ $1.95651 \mathrm{e}+011.95651 \mathrm{e}+01$ 1.95651e+00 1.00000e-09 2.12000e-01 $1.95651 \mathrm{e}+011.95651 \mathrm{e}+011.95651 \mathrm{e}+001.00000 \mathrm{e}-092.12000 \mathrm{e}-01$ 1.00000e-05 1.00000e-05 1.00000e-06 1.00000e-09 1.00000e-01

$1.00000 \mathrm{e}+001.00000 \mathrm{e}+001.00000 \mathrm{e}-011.00000 \mathrm{e}-091.00000 \mathrm{e}-01$

Element: 9015 \# of layers: 7

$\mathrm{Kx} \mathrm{Ky} \mathrm{Kz}$ Ss Por

$1.95651 \mathrm{e}+011.95651 \mathrm{e}+01$ 1.95651e+00 1.00000e-09 2.12000e-01 $1.95651 \mathrm{e}+011.95651 \mathrm{e}+011.95651 \mathrm{e}+001.00000 \mathrm{e}-092.12000 \mathrm{e}-01$ $1.95651 \mathrm{e}+011.95651 \mathrm{e}+011.95651 \mathrm{e}+001.00000 \mathrm{e}-092.12000 \mathrm{e}-01$ $1.95651 \mathrm{e}+011.95651 \mathrm{e}+01$ 1.95651e+00 1.00000e-09 2.12000e-01 $1.95651 \mathrm{e}+01$ 1.95651e+01 1.95651e+00 1.00000e-09 2.12000e-01 $1.00000 \mathrm{e}-05$ 1.00000e-05 1.00000e-06 1.00000e-09 1.00000e-01

$1.00000 \mathrm{e}+001.00000 \mathrm{e}+001.00000 \mathrm{e}-011.00000 \mathrm{e}-091.00000 \mathrm{e}-01$ 
Element: 9016 \# of layers: 7

$\mathrm{Kx} \mathrm{Ky} \mathrm{Kz}$ Ss Por

$2.36367 \mathrm{e}+012.36367 \mathrm{e}+012.36367 \mathrm{e}+00$ 1.00000e-09 2.12000e-01

$2.36367 e+012.36367 e+012.36367 e+001.00000 e-09$ 2.12000e-01

$2.36367 \mathrm{e}+012.36367 \mathrm{e}+012.36367 \mathrm{e}+00$ 1.00000e-09 2.12000e-01

$2.36367 \mathrm{e}+012.36367 \mathrm{e}+012.36367 \mathrm{e}+00$ 1.00000e-09 2.12000e-01

$2.36367 \mathrm{e}+012.36367 \mathrm{e}+012.36367 \mathrm{e}+00$ 1.00000e-09 2.12000e-01

$1.00000 \mathrm{e}-05$ 1.00000e-05 1.00000e-06 1.00000e-09 1.00000e-01

$1.00000 \mathrm{e}+001.00000 \mathrm{e}+001.00000 \mathrm{e}-011.00000 \mathrm{e}-091.00000 \mathrm{e}-01$

Element: 9017 \# of layers: 7

$\mathrm{Kx} \mathrm{Ky} \mathrm{Kz}$ Ss Por

$2.36367 \mathrm{e}+012.36367 \mathrm{e}+012.36367 \mathrm{e}+00$ 1.00000e-09 2.12000e-01

$2.36367 \mathrm{e}+012.36367 \mathrm{e}+012.36367 \mathrm{e}+00$ 1.00000e-09 2.12000e-01

$2.36367 \mathrm{e}+012.36367 \mathrm{e}+012.36367 \mathrm{e}+00$ 1.00000e-09 2.12000e-01

$2.36367 \mathrm{e}+012.36367 \mathrm{e}+012.36367 \mathrm{e}+00$ 1.00000e-09 2.12000e-01

$2.36367 \mathrm{e}+012.36367 \mathrm{e}+012.36367 \mathrm{e}+00$ 1.00000e-09 2.12000e-01

$1.00000 \mathrm{e}-05$ 1.00000e-05 1.00000e-06 1.00000e-09 1.00000e-01

$1.00000 \mathrm{e}+001.00000 \mathrm{e}+001.00000 \mathrm{e}-01$ 1.00000e-09 1.00000e-01

Element: 9018 \# of layers: 7

$\mathrm{Kx} \mathrm{Ky} \mathrm{Kz}$ Ss Por

$2.92304 \mathrm{e}+012.92304 \mathrm{e}+012.92304 \mathrm{e}+00$ 1.00000e-09 2.12000e-01

$2.92304 \mathrm{e}+012.92304 \mathrm{e}+012.92304 \mathrm{e}+001.00000 \mathrm{e}-092.12000 \mathrm{e}-01$

$2.92304 \mathrm{e}+012.92304 \mathrm{e}+012.92304 \mathrm{e}+001.00000 \mathrm{e}-092.12000 \mathrm{e}-01$

$2.92304 \mathrm{e}+012.92304 \mathrm{e}+012.92304 \mathrm{e}+001.00000 \mathrm{e}-092.12000 \mathrm{e}-01$

$2.92304 \mathrm{e}+012.92304 \mathrm{e}+012.92304 \mathrm{e}+001.00000 \mathrm{e}-092.12000 \mathrm{e}-01$

$1.00000 \mathrm{e}-05$ 1.00000e-05 1.00000e-06 1.00000e-09 1.00000e-01

$1.00000 \mathrm{e}+001.00000 \mathrm{e}+001.00000 \mathrm{e}-011.00000 \mathrm{e}-091.00000 \mathrm{e}-01$

Element: 9019 \# of layers: 7

$\mathrm{Kx} \mathrm{Ky} \mathrm{Kz}$ Ss Por

$2.84249 \mathrm{e}+012.84249 \mathrm{e}+01$ 2.84249e+00 1.00000e-09 2.12000e-01

$2.84249 \mathrm{e}+012.84249 \mathrm{e}+012.84249 \mathrm{e}+00$ 1.00000e-09 2.12000e-01

$2.84249 \mathrm{e}+012.84249 \mathrm{e}+012.84249 \mathrm{e}+00$ 1.00000e-09 2.12000e-01

$2.84249 \mathrm{e}+012.84249 \mathrm{e}+012.84249 \mathrm{e}+00$ 1.00000e-09 2.12000e-01

$2.84249 \mathrm{e}+012.84249 \mathrm{e}+012.84249 \mathrm{e}+00$ 1.00000e-09 2.12000e-01

$1.00000 \mathrm{e}-05$ 1.00000e-05 1.00000e-06 1.00000e-09 1.00000e-01

$1.00000 \mathrm{e}+001.00000 \mathrm{e}+001.00000 \mathrm{e}-011.00000 \mathrm{e}-091.00000 \mathrm{e}-01$

Element: 9020 \# of layers: 7

Kx Ky Kz Ss Por

$1.95651 \mathrm{e}+01$ 1.95651e+01 1.95651e+00 1.00000e-09 2.12000e-01

$1.95651 \mathrm{e}+011.95651 \mathrm{e}+011.95651 \mathrm{e}+001.00000 \mathrm{e}-092.12000 \mathrm{e}-01$

$1.95651 \mathrm{e}+011.95651 \mathrm{e}+011.95651 \mathrm{e}+001.00000 \mathrm{e}-092.12000 \mathrm{e}-01$

$1.95651 \mathrm{e}+011.95651 \mathrm{e}+011.95651 \mathrm{e}+001.00000 \mathrm{e}-092.12000 \mathrm{e}-01$

$1.95651 \mathrm{e}+011.95651 \mathrm{e}+01$ 1.95651e+00 1.00000e-09 2.12000e-01

$1.00000 \mathrm{e}-05$ 1.00000e-05 1.00000e-06 1.00000e-09 1.00000e-01

$1.00000 \mathrm{e}+001.00000 \mathrm{e}+001.00000 \mathrm{e}-011.00000 \mathrm{e}-091.00000 \mathrm{e}-01$

Element: 9021 \# of layers: 7 
$\mathrm{Kx} \mathrm{Ky} \mathrm{Kz}$ Ss Por

$1.34501 \mathrm{e}+011.34501 \mathrm{e}+01$ 1.34501e+00 1.00000e-09 2.12000e-01

$1.34501 \mathrm{e}+011.34501 \mathrm{e}+011.34501 \mathrm{e}+001.00000 \mathrm{e}-092.12000 \mathrm{e}-01$

$1.34501 \mathrm{e}+011.34501 \mathrm{e}+011.34501 \mathrm{e}+001.00000 \mathrm{e}-092.12000 \mathrm{e}-01$

$1.34501 \mathrm{e}+011.34501 \mathrm{e}+011.34501 \mathrm{e}+001.00000 \mathrm{e}-092.12000 \mathrm{e}-01$

$1.34501 \mathrm{e}+011.34501 \mathrm{e}+011.34501 \mathrm{e}+001.00000 \mathrm{e}-092.12000 \mathrm{e}-01$

$1.00000 \mathrm{e}-05$ 1.00000e-05 1.00000e-06 1.00000e-09 1.00000e-01

$1.00000 \mathrm{e}+001.00000 \mathrm{e}+001.00000 \mathrm{e}-01$ 1.00000e-09 1.00000e-01

Element: 9022 \# of layers: 7

$\mathrm{Kx} \mathrm{Ky} \mathrm{Kz}$ Ss Por

$1.34501 \mathrm{e}+01$ 1.34501e+01 1.34501e+00 1.00000e-09 2.12000e-01

$1.34501 \mathrm{e}+011.34501 \mathrm{e}+011.34501 \mathrm{e}+001.00000 \mathrm{e}-092.12000 \mathrm{e}-01$

$1.34501 \mathrm{e}+011.34501 \mathrm{e}+011.34501 \mathrm{e}+001.00000 \mathrm{e}-092.12000 \mathrm{e}-01$

$1.34501 \mathrm{e}+011.34501 \mathrm{e}+011.34501 \mathrm{e}+001.00000 \mathrm{e}-092.12000 \mathrm{e}-01$

$1.34501 \mathrm{e}+011.34501 \mathrm{e}+011.34501 \mathrm{e}+001.00000 \mathrm{e}-092.12000 \mathrm{e}-01$

$1.00000 \mathrm{e}-05$ 1.00000e-05 1.00000e-06 1.00000e-09 1.00000e-01

$1.00000 \mathrm{e}+001.00000 \mathrm{e}+001.00000 \mathrm{e}-011.00000 \mathrm{e}-091.00000 \mathrm{e}-01$

Element: 9023 \# of layers: 7

$\mathrm{Kx} \mathrm{Ky} \mathrm{Kz}$ Ss Por

$1.34501 \mathrm{e}+01$ 1.34501e+01 1.34501e+00 1.00000e-09 2.12000e-01

$1.34501 \mathrm{e}+011.34501 \mathrm{e}+011.34501 \mathrm{e}+001.00000 \mathrm{e}-092.12000 \mathrm{e}-01$

$1.34501 \mathrm{e}+011.34501 \mathrm{e}+01$ 1.34501e+00 1.00000e-09 2.12000e-01

$1.34501 \mathrm{e}+011.34501 \mathrm{e}+01$ 1.34501e+00 1.00000e-09 2.12000e-01

$1.34501 \mathrm{e}+011.34501 \mathrm{e}+011.34501 \mathrm{e}+001.00000 \mathrm{e}-092.12000 \mathrm{e}-01$

$1.00000 \mathrm{e}-05$ 1.00000e-05 1.00000e-06 1.00000e-09 1.00000e-01

$1.00000 \mathrm{e}+001.00000 \mathrm{e}+001.00000 \mathrm{e}-01$ 1.00000e-09 1.00000e-01

Element: 9024 \# of layers: 7

$\mathrm{Kx} \mathrm{Ky} \mathrm{Kz}$ Ss Por

$1.34501 \mathrm{e}+01$ 1.34501e+01 1.34501e+00 1.00000e-09 2.12000e-01

$1.34501 \mathrm{e}+011.34501 \mathrm{e}+01$ 1.34501e+00 1.00000e-09 2.12000e-01

$1.34501 \mathrm{e}+011.34501 \mathrm{e}+011.34501 \mathrm{e}+001.00000 \mathrm{e}-092.12000 \mathrm{e}-01$

$1.34501 \mathrm{e}+011.34501 \mathrm{e}+011.34501 \mathrm{e}+001.00000 \mathrm{e}-092.12000 \mathrm{e}-01$

$1.34501 \mathrm{e}+011.34501 \mathrm{e}+011.34501 \mathrm{e}+001.00000 \mathrm{e}-092.12000 \mathrm{e}-01$

$1.00000 \mathrm{e}-05$ 1.00000e-05 1.00000e-06 1.00000e-09 1.00000e-01

$1.00000 \mathrm{e}+001.00000 \mathrm{e}+001.00000 \mathrm{e}-011.00000 \mathrm{e}-091.00000 \mathrm{e}-01$

Element: 9025 \# of layers: 7

Kx Ky Kz Ss Por

$1.46008 \mathrm{e}+01$ 1.46008e+01 1.46008e+00 1.00000e-09 2.12000e-01

$1.46008 \mathrm{e}+011.46008 \mathrm{e}+011.46008 \mathrm{e}+001.00000 \mathrm{e}-092.12000 \mathrm{e}-01$

$1.46008 \mathrm{e}+01$ 1.46008e+01 1.46008e+00 1.00000e-09 2.12000e-01

$1.46008 \mathrm{e}+011.46008 \mathrm{e}+011.46008 \mathrm{e}+001.00000 \mathrm{e}-092.12000 \mathrm{e}-01$

$1.46008 \mathrm{e}+011.46008 \mathrm{e}+011.46008 \mathrm{e}+001.00000 \mathrm{e}-092.12000 \mathrm{e}-01$

$1.00000 \mathrm{e}-05$ 1.00000e-05 1.00000e-06 1.00000e-09 1.00000e-01

$1.00000 \mathrm{e}+001.00000 \mathrm{e}+001.00000 \mathrm{e}-011.00000 \mathrm{e}-091.00000 \mathrm{e}-01$

Element: 9026 \# of layers: 7

Kx Ky Kz Ss Por 
$1.46008 \mathrm{e}+01$ 1.46008e+01 1.46008e+00 1.00000e-09 2.12000e-01 $1.46008 \mathrm{e}+01$ 1.46008e+01 1.46008e+00 1.00000e-09 2.12000e-01 $1.46008 \mathrm{e}+011.46008 \mathrm{e}+011.46008 \mathrm{e}+001.00000 \mathrm{e}-092.12000 \mathrm{e}-01$ $1.46008 \mathrm{e}+011.46008 \mathrm{e}+011.46008 \mathrm{e}+001.00000 \mathrm{e}-092.12000 \mathrm{e}-01$ $1.46008 \mathrm{e}+011.46008 \mathrm{e}+01$ 1.46008e+00 1.00000e-09 2.12000e-01 $1.00000 \mathrm{e}-051.00000 \mathrm{e}-051.00000 \mathrm{e}-061.00000 \mathrm{e}-091.00000 \mathrm{e}-01$ $1.00000 \mathrm{e}+001.00000 \mathrm{e}+001.00000 \mathrm{e}-01$ 1.00000e-09 1.00000e-01 Element: 9027 \# of layers: 7

$\mathrm{Kx} \mathrm{Ky} \mathrm{Kz}$ Ss Por

$1.34501 \mathrm{e}+011.34501 \mathrm{e}+011.34501 \mathrm{e}+001.00000 \mathrm{e}-092.12000 \mathrm{e}-01$ $1.34501 \mathrm{e}+011.34501 \mathrm{e}+01$ 1.34501e+00 1.00000e-09 2.12000e-01 $1.34501 \mathrm{e}+011.34501 \mathrm{e}+011.34501 \mathrm{e}+001.00000 \mathrm{e}-092.12000 \mathrm{e}-01$ $1.34501 \mathrm{e}+011.34501 \mathrm{e}+011.34501 \mathrm{e}+001.00000 \mathrm{e}-092.12000 \mathrm{e}-01$ $1.34501 \mathrm{e}+011.34501 \mathrm{e}+011.34501 \mathrm{e}+001.00000 \mathrm{e}-092.12000 \mathrm{e}-01$ $1.00000 \mathrm{e}-051.00000 \mathrm{e}-051.00000 \mathrm{e}-061.00000 \mathrm{e}-091.00000 \mathrm{e}-01$ $1.00000 \mathrm{e}+001.00000 \mathrm{e}+001.00000 \mathrm{e}-011.00000 \mathrm{e}-091.00000 \mathrm{e}-01$ Element: 9028 \# of layers: 7

$\mathrm{Kx} \mathrm{Ky} \mathrm{Kz}$ Ss Por

$1.46008 \mathrm{e}+01$ 1.46008e+01 1.46008e+00 1.00000e-09 2.12000e-01 $1.46008 \mathrm{e}+01$ 1.46008e+01 1.46008e+00 1.00000e-09 2.12000e-01 $1.46008 \mathrm{e}+011.46008 \mathrm{e}+01$ 1.46008e+00 1.00000e-09 2.12000e-01 $1.46008 \mathrm{e}+011.46008 \mathrm{e}+01$ 1.46008e+00 1.00000e-09 2.12000e-01 $1.46008 \mathrm{e}+01$ 1.46008e+01 1.46008e+00 1.00000e-09 2.12000e-01 $1.00000 \mathrm{e}-05$ 1.00000e-05 1.00000e-06 1.00000e-09 1.00000e-01 $1.00000 \mathrm{e}+001.00000 \mathrm{e}+001.00000 \mathrm{e}-011.00000 \mathrm{e}-091.00000 \mathrm{e}-01$ Element: 9029 \# of layers: 7

$\mathrm{Kx} \mathrm{Ky} \mathrm{Kz}$ Ss Por

$1.46008 \mathrm{e}+01$ 1.46008e+01 1.46008e+00 1.00000e-09 2.12000e-01 $1.46008 \mathrm{e}+011.46008 \mathrm{e}+011.46008 \mathrm{e}+001.00000 \mathrm{e}-092.12000 \mathrm{e}-01$ $1.46008 \mathrm{e}+011.46008 \mathrm{e}+011.46008 \mathrm{e}+001.00000 \mathrm{e}-092.12000 \mathrm{e}-01$ $1.46008 \mathrm{e}+011.46008 \mathrm{e}+01$ 1.46008e+00 1.00000e-09 2.12000e-01 $1.46008 \mathrm{e}+01$ 1.46008e+01 1.46008e+00 1.00000e-09 2.12000e-01 $1.00000 \mathrm{e}-05$ 1.00000e-05 1.00000e-06 1.00000e-09 1.00000e-01 $1.00000 \mathrm{e}+001.00000 \mathrm{e}+001.00000 \mathrm{e}-011.00000 \mathrm{e}-091.00000 \mathrm{e}-01$ Element: 9030 \# of layers: 7

$\mathrm{Kx} \mathrm{Ky} \mathrm{Kz}$ Ss Por

$1.46008 \mathrm{e}+01$ 1.46008e+01 1.46008e+00 1.00000e-09 2.12000e-01 $1.46008 \mathrm{e}+011.46008 \mathrm{e}+011.46008 \mathrm{e}+001.00000 \mathrm{e}-092.12000 \mathrm{e}-01$ $1.46008 \mathrm{e}+011.46008 \mathrm{e}+011.46008 \mathrm{e}+001.00000 \mathrm{e}-092.12000 \mathrm{e}-01$ $1.46008 \mathrm{e}+011.46008 \mathrm{e}+01$ 1.46008e+00 1.00000e-09 2.12000e-01 $1.46008 \mathrm{e}+01$ 1.46008e+01 1.46008e+00 1.00000e-09 2.12000e-01 $1.00000 \mathrm{e}-05$ 1.00000e-05 1.00000e-06 1.00000e-09 1.00000e-01 $1.00000 \mathrm{e}+001.00000 \mathrm{e}+001.00000 \mathrm{e}-011.00000 \mathrm{e}-091.00000 \mathrm{e}-01$ Element: 9031 \# of layers: 7

$\mathrm{Kx} \mathrm{Ky} \mathrm{Kz}$ Ss Por

$1.46008 \mathrm{e}+011.46008 \mathrm{e}+011.46008 \mathrm{e}+001.00000 \mathrm{e}-092.12000 \mathrm{e}-01$ 
$1.46008 \mathrm{e}+01$ 1.46008e+01 1.46008e+00 1.00000e-09 2.12000e-01 $1.46008 \mathrm{e}+01$ 1.46008e+01 1.46008e+00 1.00000e-09 2.12000e-01 $1.46008 \mathrm{e}+011.46008 \mathrm{e}+011.46008 \mathrm{e}+001.00000 \mathrm{e}-092.12000 \mathrm{e}-01$ $1.46008 \mathrm{e}+011.46008 \mathrm{e}+011.46008 \mathrm{e}+001.00000 \mathrm{e}-092.12000 \mathrm{e}-01$ $1.00000 \mathrm{e}-05$ 1.00000e-05 1.00000e-06 1.00000e-09 1.00000e-01 $1.00000 \mathrm{e}+001.00000 \mathrm{e}+001.00000 \mathrm{e}-011.00000 \mathrm{e}-091.00000 \mathrm{e}-01$ Element: 9032 \# of layers: 7

$\mathrm{Kx} \mathrm{Ky} \mathrm{Kz}$ Ss Por

$1.46008 \mathrm{e}+01$ 1.46008e+01 1.46008e+00 1.00000e-09 2.12000e-01 $1.46008 \mathrm{e}+01$ 1.46008e+01 1.46008e+00 1.00000e-09 2.12000e-01 $1.46008 \mathrm{e}+01$ 1.46008e+01 1.46008e+00 1.00000e-09 2.12000e-01 $1.46008 \mathrm{e}+011.46008 \mathrm{e}+011.46008 \mathrm{e}+001.00000 \mathrm{e}-092.12000 \mathrm{e}-01$ $1.46008 \mathrm{e}+011.46008 \mathrm{e}+01$ 1.46008e+00 1.00000e-09 2.12000e-01 $1.00000 \mathrm{e}-05$ 1.00000e-05 1.00000e-06 1.00000e-09 1.00000e-01 $1.00000 \mathrm{e}+001.00000 \mathrm{e}+001.00000 \mathrm{e}-01$ 1.00000e-09 1.00000e-01 Element: 9033 \# of layers: 7

$\mathrm{Kx} \mathrm{Ky} \mathrm{Kz}$ Ss Por

$1.46008 \mathrm{e}+01$ 1.46008e+01 1.46008e+00 1.00000e-09 2.12000e-01 $1.46008 \mathrm{e}+01$ 1.46008e+01 1.46008e+00 1.00000e-09 2.12000e-01 $1.46008 \mathrm{e}+011.46008 \mathrm{e}+011.46008 \mathrm{e}+001.00000 \mathrm{e}-092.12000 \mathrm{e}-01$ $1.46008 \mathrm{e}+011.46008 \mathrm{e}+011.46008 \mathrm{e}+001.00000 \mathrm{e}-092.12000 \mathrm{e}-01$ $1.46008 \mathrm{e}+01$ 1.46008e+01 1.46008e+00 1.00000e-09 2.12000e-01 $1.00000 \mathrm{e}-05$ 1.00000e-05 1.00000e-06 1.00000e-09 1.00000e-01 $1.00000 \mathrm{e}+001.00000 \mathrm{e}+001.00000 \mathrm{e}-011.00000 \mathrm{e}-091.00000 \mathrm{e}-01$ Element: 9034 \# of layers: 7

$\mathrm{Kx} \mathrm{Ky} \mathrm{Kz}$ Ss Por

$1.46008 \mathrm{e}+01$ 1.46008e+01 1.46008e+00 1.00000e-09 2.12000e-01 $1.46008 \mathrm{e}+011.46008 \mathrm{e}+011.46008 \mathrm{e}+001.00000 \mathrm{e}-092.12000 \mathrm{e}-01$ $1.46008 \mathrm{e}+011.46008 \mathrm{e}+011.46008 \mathrm{e}+001.00000 \mathrm{e}-092.12000 \mathrm{e}-01$ $1.46008 \mathrm{e}+011.46008 \mathrm{e}+01$ 1.46008e+00 1.00000e-09 2.12000e-01 $1.46008 \mathrm{e}+01$ 1.46008e+01 1.46008e+00 1.00000e-09 2.12000e-01 $1.00000 \mathrm{e}-05$ 1.00000e-05 1.00000e-06 1.00000e-09 1.00000e-01 $1.00000 \mathrm{e}+001.00000 \mathrm{e}+001.00000 \mathrm{e}-011.00000 \mathrm{e}-091.00000 \mathrm{e}-01$ Element: 9035 \# of layers: 7

$\mathrm{Kx} \mathrm{Ky} \mathrm{Kz}$ Ss Por

$1.33201 \mathrm{e}+011.33201 \mathrm{e}+01$ 1.33201e+00 1.00000e-09 2.12000e-01 $1.33201 \mathrm{e}+011.33201 \mathrm{e}+011.33201 \mathrm{e}+001.00000 \mathrm{e}-092.12000 \mathrm{e}-01$ $1.33201 \mathrm{e}+011.33201 \mathrm{e}+011.33201 \mathrm{e}+001.00000 \mathrm{e}-092.12000 \mathrm{e}-01$ $1.33201 \mathrm{e}+01$ 1.33201e+01 1.33201e+00 1.00000e-09 2.12000e-01 $1.33201 \mathrm{e}+011.33201 \mathrm{e}+011.33201 \mathrm{e}+001.00000 \mathrm{e}-092.12000 \mathrm{e}-01$ $1.00000 \mathrm{e}-05$ 1.00000e-05 1.00000e-06 1.00000e-09 1.00000e-01 $1.00000 \mathrm{e}+001.00000 \mathrm{e}+001.00000 \mathrm{e}-011.00000 \mathrm{e}-091.00000 \mathrm{e}-01$ Element: 9036 \# of layers: 7

$\mathrm{Kx} \mathrm{Ky} \mathrm{Kz}$ Ss Por

$1.33201 \mathrm{e}+011.33201 \mathrm{e}+01$ 1.33201e+00 1.00000e-09 2.12000e-01 $1.33201 \mathrm{e}+011.33201 \mathrm{e}+011.33201 \mathrm{e}+001.00000 \mathrm{e}-092.12000 \mathrm{e}-01$ 
$1.33201 \mathrm{e}+011.33201 \mathrm{e}+01$ 1.33201e+00 1.00000e-09 2.12000e-01 $1.33201 \mathrm{e}+011.33201 \mathrm{e}+011.33201 \mathrm{e}+001.00000 \mathrm{e}-092.12000 \mathrm{e}-01$ $1.33201 \mathrm{e}+011.33201 \mathrm{e}+011.33201 \mathrm{e}+001.00000 \mathrm{e}-092.12000 \mathrm{e}-01$ $1.00000 \mathrm{e}-05$ 1.00000e-05 1.00000e-06 1.00000e-09 1.00000e-01 $1.00000 \mathrm{e}+001.00000 \mathrm{e}+001.00000 \mathrm{e}-01$ 1.00000e-09 1.00000e-01 Element: 9037 \# of layers: 7

$\mathrm{Kx} \mathrm{Ky} \mathrm{Kz}$ Ss Por

$1.33201 \mathrm{e}+011.33201 \mathrm{e}+011.33201 \mathrm{e}+001.00000 \mathrm{e}-092.12000 \mathrm{e}-01$ $1.33201 \mathrm{e}+011.33201 \mathrm{e}+01$ 1.33201e+00 1.00000e-09 2.12000e-01 $1.33201 \mathrm{e}+011.33201 \mathrm{e}+011.33201 \mathrm{e}+001.00000 \mathrm{e}-092.12000 \mathrm{e}-01$ $1.33201 \mathrm{e}+011.33201 \mathrm{e}+011.33201 \mathrm{e}+001.00000 \mathrm{e}-092.12000 \mathrm{e}-01$ $1.33201 \mathrm{e}+011.33201 \mathrm{e}+011.33201 \mathrm{e}+001.00000 \mathrm{e}-092.12000 \mathrm{e}-01$ $1.00000 \mathrm{e}-05$ 1.00000e-05 1.00000e-06 1.00000e-09 1.00000e-01 $1.00000 \mathrm{e}+001.00000 \mathrm{e}+001.00000 \mathrm{e}-011.00000 \mathrm{e}-09$ 1.00000e-01 Element: 9038 \# of layers: 7

Kx Ky Kz Ss Por

$1.46008 \mathrm{e}+01$ 1.46008e+01 1.46008e+00 1.00000e-09 2.12000e-01 $1.46008 \mathrm{e}+011.46008 \mathrm{e}+011.46008 \mathrm{e}+001.00000 \mathrm{e}-092.12000 \mathrm{e}-01$ $1.46008 \mathrm{e}+01$ 1.46008e+01 1.46008e+00 1.00000e-09 2.12000e-01 $1.46008 \mathrm{e}+01$ 1.46008e+01 1.46008e+00 1.00000e-09 2.12000e-01 $1.46008 \mathrm{e}+011.46008 \mathrm{e}+011.46008 \mathrm{e}+001.00000 \mathrm{e}-092.12000 \mathrm{e}-01$ $1.00000 \mathrm{e}-05$ 1.00000e-05 1.00000e-06 1.00000e-09 1.00000e-01 $1.00000 \mathrm{e}+001.00000 \mathrm{e}+001.00000 \mathrm{e}-01$ 1.00000e-09 1.00000e-01 Element: 9039 \# of layers: 7

Kx Ky Kz Ss Por $1.46008 \mathrm{e}+011.46008 \mathrm{e}+01$ 1.46008e+00 1.00000e-09 2.12000e-01 $1.46008 \mathrm{e}+011.46008 \mathrm{e}+01$ 1.46008e+00 1.00000e-09 2.12000e-01 $1.46008 \mathrm{e}+011.46008 \mathrm{e}+011.46008 \mathrm{e}+001.00000 \mathrm{e}-092.12000 \mathrm{e}-01$ $1.46008 \mathrm{e}+011.46008 \mathrm{e}+011.46008 \mathrm{e}+001.00000 \mathrm{e}-092.12000 \mathrm{e}-01$ $1.46008 \mathrm{e}+011.46008 \mathrm{e}+011.46008 \mathrm{e}+001.00000 \mathrm{e}-092.12000 \mathrm{e}-01$ $1.00000 \mathrm{e}-05$ 1.00000e-05 1.00000e-06 1.00000e-09 1.00000e-01 $1.00000 \mathrm{e}+001.00000 \mathrm{e}+001.00000 \mathrm{e}-011.00000 \mathrm{e}-091.00000 \mathrm{e}-01$ Element: 9040 \# of layers: 7

$\mathrm{Kx} \mathrm{Ky} \mathrm{Kz}$ Ss Por

$1.46008 \mathrm{e}+01$ 1.46008e+01 1.46008e+00 1.00000e-09 2.12000e-01 $1.46008 \mathrm{e}+01$ 1.46008e+01 1.46008e+00 1.00000e-09 2.12000e-01 $1.46008 \mathrm{e}+011.46008 \mathrm{e}+011.46008 \mathrm{e}+001.00000 \mathrm{e}-092.12000 \mathrm{e}-01$ $1.46008 \mathrm{e}+011.46008 \mathrm{e}+011.46008 \mathrm{e}+001.00000 \mathrm{e}-092.12000 \mathrm{e}-01$ $1.46008 \mathrm{e}+011.46008 \mathrm{e}+011.46008 \mathrm{e}+001.00000 \mathrm{e}-092.12000 \mathrm{e}-01$ $1.00000 \mathrm{e}-05$ 1.00000e-05 1.00000e-06 1.00000e-09 1.00000e-01 $1.00000 \mathrm{e}+001.00000 \mathrm{e}+001.00000 \mathrm{e}-011.00000 \mathrm{e}-091.00000 \mathrm{e}-01$ Element: 9041 \# of layers: 7

$\mathrm{Kx} \mathrm{Ky} \mathrm{Kz}$ Ss Por

$1.46008 \mathrm{e}+01$ 1.46008e+01 1.46008e+00 1.00000e-09 2.12000e-01 $1.46008 \mathrm{e}+011.46008 \mathrm{e}+011.46008 \mathrm{e}+001.00000 \mathrm{e}-092.12000 \mathrm{e}-01$ $1.46008 \mathrm{e}+011.46008 \mathrm{e}+011.46008 \mathrm{e}+001.00000 \mathrm{e}-092.12000 \mathrm{e}-01$ 
$1.46008 \mathrm{e}+01$ 1.46008e+01 1.46008e+00 1.00000e-09 2.12000e-01 $1.46008 \mathrm{e}+01$ 1.46008e+01 1.46008e+00 1.00000e-09 2.12000e-01 $1.00000 \mathrm{e}-05$ 1.00000e-05 1.00000e-06 1.00000e-09 1.00000e-01 $1.00000 \mathrm{e}+001.00000 \mathrm{e}+001.00000 \mathrm{e}-011.00000 \mathrm{e}-091.00000 \mathrm{e}-01$ Element: 9042 \# of layers: 7

$\mathrm{Kx} \mathrm{Ky} \mathrm{Kz}$ Ss Por

$1.33201 \mathrm{e}+011.33201 \mathrm{e}+01$ 1.33201e+00 1.00000e-09 2.12000e-01 $1.33201 \mathrm{e}+011.33201 \mathrm{e}+011.33201 \mathrm{e}+001.00000 \mathrm{e}-092.12000 \mathrm{e}-01$ $1.33201 \mathrm{e}+011.33201 \mathrm{e}+011.33201 \mathrm{e}+001.00000 \mathrm{e}-092.12000 \mathrm{e}-01$ $1.33201 \mathrm{e}+011.33201 \mathrm{e}+011.33201 \mathrm{e}+001.00000 \mathrm{e}-092.12000 \mathrm{e}-01$ $1.33201 \mathrm{e}+011.33201 \mathrm{e}+011.33201 \mathrm{e}+001.00000 \mathrm{e}-092.12000 \mathrm{e}-01$ $1.00000 \mathrm{e}-05$ 1.00000e-05 1.00000e-06 1.00000e-09 1.00000e-01 $1.00000 \mathrm{e}+001.00000 \mathrm{e}+001.00000 \mathrm{e}-011.00000 \mathrm{e}-091.00000 \mathrm{e}-01$ Element: 9043 \# of layers: 8

$\mathrm{Kx} \mathrm{Ky} \mathrm{Kz}$ Ss Por

3.50000e+02 3.50000e+02 3.50000e+01 1.00000e-09 1.00000e-01 $1.33201 \mathrm{e}+011.33201 \mathrm{e}+011.33201 \mathrm{e}+001.00000 \mathrm{e}-092.12000 \mathrm{e}-01$ $1.33201 \mathrm{e}+011.33201 \mathrm{e}+011.33201 \mathrm{e}+001.00000 \mathrm{e}-092.12000 \mathrm{e}-01$ $1.33201 \mathrm{e}+01$ 1.33201e+01 1.33201e+00 1.00000e-09 2.12000e-01 $1.33201 \mathrm{e}+011.33201 \mathrm{e}+011.33201 \mathrm{e}+001.00000 \mathrm{e}-092.12000 \mathrm{e}-01$ $1.33201 \mathrm{e}+011.33201 \mathrm{e}+011.33201 \mathrm{e}+001.00000 \mathrm{e}-092.12000 \mathrm{e}-01$ $1.00000 \mathrm{e}-05$ 1.00000e-05 1.00000e-06 1.00000e-09 1.00000e-01 $1.00000 \mathrm{e}+001.00000 \mathrm{e}+001.00000 \mathrm{e}-011.00000 \mathrm{e}-091.00000 \mathrm{e}-01$ Element: 9044 \# of layers: 8

$\mathrm{Kx} \mathrm{Ky} \mathrm{Kz}$ Ss Por

3.50000e+02 3.50000e+02 3.50000e+01 1.00000e-09 1.00000e-01 $1.33201 \mathrm{e}+011.33201 \mathrm{e}+01$ 1.33201e+00 1.00000e-09 2.12000e-01 $1.33201 \mathrm{e}+011.33201 \mathrm{e}+01$ 1.33201e+00 1.00000e-09 2.12000e-01 $1.33201 \mathrm{e}+011.33201 \mathrm{e}+011.33201 \mathrm{e}+001.00000 \mathrm{e}-092.12000 \mathrm{e}-01$ $1.33201 \mathrm{e}+011.33201 \mathrm{e}+011.33201 \mathrm{e}+001.00000 \mathrm{e}-092.12000 \mathrm{e}-01$ $1.33201 \mathrm{e}+011.33201 \mathrm{e}+011.33201 \mathrm{e}+001.00000 \mathrm{e}-092.12000 \mathrm{e}-01$ 1.00000e-05 1.00000e-05 1.00000e-06 1.00000e-09 1.00000e-01 $1.00000 \mathrm{e}+001.00000 \mathrm{e}+001.00000 \mathrm{e}-011.00000 \mathrm{e}-091.00000 \mathrm{e}-01$ Element: 9045 \# of layers: 8

$\mathrm{Kx} \mathrm{Ky} \mathrm{Kz}$ Ss Por

3.50000e+02 3.50000e+02 3.50000e+01 1.00000e-09 1.00000e-01 $1.33201 \mathrm{e}+011.33201 \mathrm{e}+011.33201 \mathrm{e}+001.00000 \mathrm{e}-092.12000 \mathrm{e}-01$ $1.33201 \mathrm{e}+011.33201 \mathrm{e}+011.33201 \mathrm{e}+001.00000 \mathrm{e}-092.12000 \mathrm{e}-01$ $1.33201 \mathrm{e}+011.33201 \mathrm{e}+011.33201 \mathrm{e}+001.00000 \mathrm{e}-092.12000 \mathrm{e}-01$ $1.33201 \mathrm{e}+011.33201 \mathrm{e}+01$ 1.33201e+00 1.00000e-09 2.12000e-01 $1.33201 \mathrm{e}+011.33201 \mathrm{e}+011.33201 \mathrm{e}+001.00000 \mathrm{e}-092.12000 \mathrm{e}-01$ $1.00000 \mathrm{e}-05$ 1.00000e-05 1.00000e-06 1.00000e-09 1.00000e-01 $1.00000 \mathrm{e}+001.00000 \mathrm{e}+001.00000 \mathrm{e}-011.00000 \mathrm{e}-091.00000 \mathrm{e}-01$ Element: 9046 \# of layers: 8

$\mathrm{Kx} \mathrm{Ky} \mathrm{Kz} \mathrm{Ss} \mathrm{Por}$

3.50000e+02 3.50000e+02 3.50000e+01 1.00000e-09 1.00000e-01 
$1.33201 \mathrm{e}+011.33201 \mathrm{e}+01$ 1.33201e+00 1.00000e-09 2.12000e-01 $1.33201 \mathrm{e}+011.33201 \mathrm{e}+011.33201 \mathrm{e}+001.00000 \mathrm{e}-092.12000 \mathrm{e}-01$ $1.33201 \mathrm{e}+011.33201 \mathrm{e}+011.33201 \mathrm{e}+001.00000 \mathrm{e}-092.12000 \mathrm{e}-01$ $1.33201 \mathrm{e}+011.33201 \mathrm{e}+011.33201 \mathrm{e}+001.00000 \mathrm{e}-092.12000 \mathrm{e}-01$ $1.33201 \mathrm{e}+011.33201 \mathrm{e}+01$ 1.33201e+00 1.00000e-09 2.12000e-01 $1.00000 \mathrm{e}-05$ 1.00000e-05 1.00000e-06 1.00000e-09 1.00000e-01 $1.00000 \mathrm{e}+001.00000 \mathrm{e}+001.00000 \mathrm{e}-01$ 1.00000e-09 1.00000e-01 Element: 9047 \# of layers: 7

$\mathrm{Kx} \mathrm{Ky} \mathrm{Kz}$ Ss Por

$1.33201 \mathrm{e}+01$ 1.33201e+01 1.33201e+00 1.00000e-09 2.12000e-01 $1.33201 \mathrm{e}+011.33201 \mathrm{e}+011.33201 \mathrm{e}+001.00000 \mathrm{e}-092.12000 \mathrm{e}-01$ $1.33201 \mathrm{e}+011.33201 \mathrm{e}+011.33201 \mathrm{e}+001.00000 \mathrm{e}-092.12000 \mathrm{e}-01$ $1.33201 \mathrm{e}+011.33201 \mathrm{e}+011.33201 \mathrm{e}+001.00000 \mathrm{e}-092.12000 \mathrm{e}-01$ $1.33201 \mathrm{e}+011.33201 \mathrm{e}+011.33201 \mathrm{e}+001.00000 \mathrm{e}-092.12000 \mathrm{e}-01$ $1.00000 \mathrm{e}-05$ 1.00000e-05 1.00000e-06 1.00000e-09 1.00000e-01 $1.00000 \mathrm{e}+001.00000 \mathrm{e}+001.00000 \mathrm{e}-011.00000 \mathrm{e}-091.00000 \mathrm{e}-01$ Element: 9048 \# of layers: 7

$\mathrm{Kx} \mathrm{Ky} \mathrm{Kz}$ Ss Por

$1.33201 \mathrm{e}+01$ 1.33201e+01 1.33201e+00 1.00000e-09 2.12000e-01 $1.33201 \mathrm{e}+011.33201 \mathrm{e}+011.33201 \mathrm{e}+001.00000 \mathrm{e}-092.12000 \mathrm{e}-01$ $1.33201 \mathrm{e}+011.33201 \mathrm{e}+011.33201 \mathrm{e}+001.00000 \mathrm{e}-092.12000 \mathrm{e}-01$ $1.33201 \mathrm{e}+011.33201 \mathrm{e}+011.33201 \mathrm{e}+001.00000 \mathrm{e}-092.12000 \mathrm{e}-01$ $1.33201 \mathrm{e}+01$ 1.33201e+01 1.33201e+00 1.00000e-09 2.12000e-01 $1.00000 \mathrm{e}-05$ 1.00000e-05 1.00000e-06 1.00000e-09 1.00000e-01 $1.00000 \mathrm{e}+001.00000 \mathrm{e}+001.00000 \mathrm{e}-011.00000 \mathrm{e}-091.00000 \mathrm{e}-01$ Element: 9049 \# of layers: 7

$\mathrm{Kx} \mathrm{Ky} \mathrm{Kz}$ Ss Por

$1.33201 \mathrm{e}+01$ 1.33201e+01 1.33201e+00 1.00000e-09 2.12000e-01 $1.33201 \mathrm{e}+011.33201 \mathrm{e}+011.33201 \mathrm{e}+001.00000 \mathrm{e}-092.12000 \mathrm{e}-01$ $1.33201 \mathrm{e}+011.33201 \mathrm{e}+01$ 1.33201e+00 1.00000e-09 2.12000e-01 $1.33201 \mathrm{e}+011.33201 \mathrm{e}+011.33201 \mathrm{e}+001.00000 \mathrm{e}-092.12000 \mathrm{e}-01$ $1.33201 \mathrm{e}+011.33201 \mathrm{e}+011.33201 \mathrm{e}+001.00000 \mathrm{e}-092.12000 \mathrm{e}-01$ $1.00000 \mathrm{e}-05$ 1.00000e-05 1.00000e-06 1.00000e-09 1.00000e-01 $1.00000 \mathrm{e}+001.00000 \mathrm{e}+001.00000 \mathrm{e}-011.00000 \mathrm{e}-091.00000 \mathrm{e}-01$ Element: 9050 \# of layers: 7

$\mathrm{Kx} \mathrm{Ky} \mathrm{Kz}$ Ss Por

$1.33201 \mathrm{e}+01$ 1.33201e+01 1.33201e+00 1.00000e-09 2.12000e-01 $1.33201 \mathrm{e}+011.33201 \mathrm{e}+011.33201 \mathrm{e}+001.00000 \mathrm{e}-092.12000 \mathrm{e}-01$ $1.33201 \mathrm{e}+011.33201 \mathrm{e}+01$ 1.33201e+00 1.00000e-09 2.12000e-01 $1.33201 \mathrm{e}+011.33201 \mathrm{e}+011.33201 \mathrm{e}+001.00000 \mathrm{e}-092.12000 \mathrm{e}-01$ $1.33201 \mathrm{e}+011.33201 \mathrm{e}+011.33201 \mathrm{e}+001.00000 \mathrm{e}-092.12000 \mathrm{e}-01$ $1.00000 \mathrm{e}-05$ 1.00000e-05 1.00000e-06 1.00000e-09 1.00000e-01 $1.00000 \mathrm{e}+001.00000 \mathrm{e}+001.00000 \mathrm{e}-011.00000 \mathrm{e}-091.00000 \mathrm{e}-01$ Element: 9051 \# of layers: 7

$\mathrm{Kx} \mathrm{Ky} \mathrm{Kz}$ Ss Por

$1.33201 \mathrm{e}+011.33201 \mathrm{e}+011.33201 \mathrm{e}+001.00000 \mathrm{e}-092.12000 \mathrm{e}-01$ 
$1.33201 \mathrm{e}+011.33201 \mathrm{e}+01$ 1.33201e+00 1.00000e-09 2.12000e-01 $1.33201 \mathrm{e}+011.33201 \mathrm{e}+011.33201 \mathrm{e}+001.00000 \mathrm{e}-092.12000 \mathrm{e}-01$ $1.33201 \mathrm{e}+011.33201 \mathrm{e}+011.33201 \mathrm{e}+001.00000 \mathrm{e}-092.12000 \mathrm{e}-01$ $1.33201 \mathrm{e}+011.33201 \mathrm{e}+011.33201 \mathrm{e}+001.00000 \mathrm{e}-092.12000 \mathrm{e}-01$ $1.00000 \mathrm{e}-051.00000 \mathrm{e}-05$ 1.00000e-06 1.00000e-09 1.00000e-01 $1.00000 \mathrm{e}+001.00000 \mathrm{e}+001.00000 \mathrm{e}-011.00000 \mathrm{e}-091.00000 \mathrm{e}-01$ Element: 9052 \# of layers: 7

$\mathrm{Kx} \mathrm{Ky} \mathrm{Kz}$ Ss Por

$1.33201 \mathrm{e}+01$ 1.33201e+01 1.33201e+00 1.00000e-09 2.12000e-01 $1.33201 \mathrm{e}+011.33201 \mathrm{e}+011.33201 \mathrm{e}+001.00000 \mathrm{e}-092.12000 \mathrm{e}-01$ $1.33201 \mathrm{e}+011.33201 \mathrm{e}+011.33201 \mathrm{e}+001.00000 \mathrm{e}-092.12000 \mathrm{e}-01$ $1.33201 \mathrm{e}+011.33201 \mathrm{e}+011.33201 \mathrm{e}+001.00000 \mathrm{e}-092.12000 \mathrm{e}-01$ $1.33201 \mathrm{e}+011.33201 \mathrm{e}+011.33201 \mathrm{e}+001.00000 \mathrm{e}-092.12000 \mathrm{e}-01$ $1.00000 \mathrm{e}-05$ 1.00000e-05 1.00000e-06 1.00000e-09 1.00000e-01 $1.00000 \mathrm{e}+001.00000 \mathrm{e}+001.00000 \mathrm{e}-01$ 1.00000e-09 1.00000e-01 Element: 9053 \# of layers: 7

$\mathrm{Kx} \mathrm{Ky} \mathrm{Kz}$ Ss Por

$1.46222 \mathrm{e}+01$ 1.46222e+01 1.46222e+00 1.00000e-09 2.12000e-01 $1.46222 \mathrm{e}+01$ 1.46222e+01 1.46222e+00 1.00000e-09 2.12000e-01 $1.46222 \mathrm{e}+011.46222 \mathrm{e}+011.46222 \mathrm{e}+001.00000 \mathrm{e}-092.12000 \mathrm{e}-01$ $1.46222 \mathrm{e}+011.46222 \mathrm{e}+011.46222 \mathrm{e}+001.00000 \mathrm{e}-092.12000 \mathrm{e}-01$ $1.46222 \mathrm{e}+01$ 1.46222e+01 1.46222e+00 1.00000e-09 2.12000e-01 $1.00000 \mathrm{e}-05$ 1.00000e-05 1.00000e-06 1.00000e-09 1.00000e-01 $1.00000 \mathrm{e}+001.00000 \mathrm{e}+001.00000 \mathrm{e}-011.00000 \mathrm{e}-091.00000 \mathrm{e}-01$ Element: 9054 \# of layers: 7

$\mathrm{Kx} \mathrm{Ky} \mathrm{Kz}$ Ss Por

$1.46222 \mathrm{e}+011.46222 \mathrm{e}+011.46222 \mathrm{e}+001.00000 \mathrm{e}-092.12000 \mathrm{e}-01$ $1.46222 \mathrm{e}+011.46222 \mathrm{e}+01$ 1.46222e+00 1.00000e-09 2.12000e-01 $1.46222 \mathrm{e}+011.46222 \mathrm{e}+011.46222 \mathrm{e}+001.00000 \mathrm{e}-092.12000 \mathrm{e}-01$ $1.46222 \mathrm{e}+01$ 1.46222e+01 1.46222e+00 1.00000e-09 2.12000e-01 $1.46222 \mathrm{e}+01$ 1.46222e+01 1.46222e+00 1.00000e-09 2.12000e-01 $1.00000 \mathrm{e}-05$ 1.00000e-05 1.00000e-06 1.00000e-09 1.00000e-01 $1.00000 \mathrm{e}+001.00000 \mathrm{e}+001.00000 \mathrm{e}-011.00000 \mathrm{e}-091.00000 \mathrm{e}-01$ Element: 9055 \# of layers: 7

$\mathrm{Kx} \mathrm{Ky} \mathrm{Kz}$ Ss Por

$1.46222 \mathrm{e}+01$ 1.46222e+01 1.46222e+00 1.00000e-09 2.12000e-01 $1.46222 \mathrm{e}+011.46222 \mathrm{e}+011.46222 \mathrm{e}+001.00000 \mathrm{e}-092.12000 \mathrm{e}-01$ $1.46222 \mathrm{e}+011.46222 \mathrm{e}+011.46222 \mathrm{e}+001.00000 \mathrm{e}-092.12000 \mathrm{e}-01$ $1.46222 \mathrm{e}+011.46222 \mathrm{e}+01$ 1.46222e+00 1.00000e-09 2.12000e-01 $1.46222 \mathrm{e}+01$ 1.46222e+01 1.46222e+00 1.00000e-09 2.12000e-01 $1.00000 \mathrm{e}-05$ 1.00000e-05 1.00000e-06 1.00000e-09 1.00000e-01 $1.00000 \mathrm{e}+001.00000 \mathrm{e}+001.00000 \mathrm{e}-011.00000 \mathrm{e}-091.00000 \mathrm{e}-01$ Element: 9056 \# of layers: 7

$\mathrm{Kx} \mathrm{Ky} \mathrm{Kz}$ Ss Por

$1.33201 \mathrm{e}+01$ 1.33201e+01 1.33201e+00 1.00000e-09 2.12000e-01 $1.33201 \mathrm{e}+011.33201 \mathrm{e}+011.33201 \mathrm{e}+001.00000 \mathrm{e}-092.12000 \mathrm{e}-01$ 
$1.33201 \mathrm{e}+011.33201 \mathrm{e}+01$ 1.33201e+00 1.00000e-09 2.12000e-01 $1.33201 \mathrm{e}+011.33201 \mathrm{e}+011.33201 \mathrm{e}+001.00000 \mathrm{e}-092.12000 \mathrm{e}-01$ $1.33201 \mathrm{e}+011.33201 \mathrm{e}+011.33201 \mathrm{e}+001.00000 \mathrm{e}-092.12000 \mathrm{e}-01$ $1.00000 \mathrm{e}-05$ 1.00000e-05 1.00000e-06 1.00000e-09 1.00000e-01 $1.00000 \mathrm{e}+001.00000 \mathrm{e}+001.00000 \mathrm{e}-01$ 1.00000e-09 1.00000e-01 Element: 9057 \# of layers: 7

$\mathrm{Kx} \mathrm{Ky} \mathrm{Kz}$ Ss Por

$1.33201 \mathrm{e}+011.33201 \mathrm{e}+011.33201 \mathrm{e}+001.00000 \mathrm{e}-092.12000 \mathrm{e}-01$ $1.33201 \mathrm{e}+011.33201 \mathrm{e}+01$ 1.33201e+00 1.00000e-09 2.12000e-01 $1.33201 \mathrm{e}+011.33201 \mathrm{e}+011.33201 \mathrm{e}+001.00000 \mathrm{e}-092.12000 \mathrm{e}-01$ $1.33201 \mathrm{e}+011.33201 \mathrm{e}+011.33201 \mathrm{e}+001.00000 \mathrm{e}-092.12000 \mathrm{e}-01$ $1.33201 \mathrm{e}+011.33201 \mathrm{e}+011.33201 \mathrm{e}+001.00000 \mathrm{e}-092.12000 \mathrm{e}-01$ $1.00000 \mathrm{e}-05$ 1.00000e-05 1.00000e-06 1.00000e-09 1.00000e-01 $1.00000 \mathrm{e}+001.00000 \mathrm{e}+001.00000 \mathrm{e}-011.00000 \mathrm{e}-09$ 1.00000e-01 Element: 9058 \# of layers: 7

Kx Ky Kz Ss Por

$1.33201 \mathrm{e}+01$ 1.33201e+01 1.33201e+00 1.00000e-09 2.12000e-01 $1.33201 \mathrm{e}+011.33201 \mathrm{e}+01$ 1.33201e+00 1.00000e-09 2.12000e-01 $1.33201 \mathrm{e}+01$ 1.33201e+01 1.33201e+00 1.00000e-09 2.12000e-01 $1.33201 \mathrm{e}+011.33201 \mathrm{e}+011.33201 \mathrm{e}+001.00000 \mathrm{e}-092.12000 \mathrm{e}-01$ $1.33201 \mathrm{e}+011.33201 \mathrm{e}+011.33201 \mathrm{e}+001.00000 \mathrm{e}-092.12000 \mathrm{e}-01$ $1.00000 \mathrm{e}-051.00000 \mathrm{e}-051.00000 \mathrm{e}-061.00000 \mathrm{e}-091.00000 \mathrm{e}-01$ $1.00000 \mathrm{e}+001.00000 \mathrm{e}+001.00000 \mathrm{e}-011.00000 \mathrm{e}-091.00000 \mathrm{e}-01$ Element: 9059 \# of layers: 7

$\mathrm{Kx} \mathrm{Ky} \mathrm{Kz}$ Ss Por

$1.33201 \mathrm{e}+011.33201 \mathrm{e}+011.33201 \mathrm{e}+001.00000 \mathrm{e}-092.12000 \mathrm{e}-01$ $1.33201 \mathrm{e}+011.33201 \mathrm{e}+011.33201 \mathrm{e}+001.00000 \mathrm{e}-092.12000 \mathrm{e}-01$ $1.33201 \mathrm{e}+011.33201 \mathrm{e}+01$ 1.33201e+00 1.00000e-09 2.12000e-01 $1.33201 \mathrm{e}+011.33201 \mathrm{e}+011.33201 \mathrm{e}+001.00000 \mathrm{e}-092.12000 \mathrm{e}-01$ $1.33201 \mathrm{e}+011.33201 \mathrm{e}+011.33201 \mathrm{e}+001.00000 \mathrm{e}-092.12000 \mathrm{e}-01$ $1.00000 \mathrm{e}-05$ 1.00000e-05 1.00000e-06 1.00000e-09 1.00000e-01 $1.00000 \mathrm{e}+001.00000 \mathrm{e}+001.00000 \mathrm{e}-011.00000 \mathrm{e}-091.00000 \mathrm{e}-01$ Element: 9060 \# of layers: 7

$\mathrm{Kx} \mathrm{Ky} \mathrm{Kz}$ Ss Por

$1.46222 \mathrm{e}+01$ 1.46222e+01 1.46222e+00 1.00000e-09 2.12000e-01 $1.46222 \mathrm{e}+01$ 1.46222e+01 1.46222e+00 1.00000e-09 2.12000e-01 $1.46222 \mathrm{e}+011.46222 \mathrm{e}+011.46222 \mathrm{e}+001.00000 \mathrm{e}-092.12000 \mathrm{e}-01$ $1.46222 \mathrm{e}+011.46222 \mathrm{e}+011.46222 \mathrm{e}+001.00000 \mathrm{e}-092.12000 \mathrm{e}-01$ $1.46222 \mathrm{e}+011.46222 \mathrm{e}+01$ 1.46222e+00 1.00000e-09 2.12000e-01 $1.00000 \mathrm{e}-05$ 1.00000e-05 1.00000e-06 1.00000e-09 1.00000e-01 $1.00000 \mathrm{e}+001.00000 \mathrm{e}+001.00000 \mathrm{e}-011.00000 \mathrm{e}-091.00000 \mathrm{e}-01$ Element: 9061 \# of layers: 7

$\mathrm{Kx} \mathrm{Ky} \mathrm{Kz}$ Ss Por

1.46222e+01 1.46222e+01 1.46222e+00 1.00000e-09 2.12000e-01 $1.46222 \mathrm{e}+01$ 1.46222e+01 1.46222e+00 1.00000e-09 2.12000e-01 $1.46222 \mathrm{e}+011.46222 \mathrm{e}+011.46222 \mathrm{e}+001.00000 \mathrm{e}-092.12000 \mathrm{e}-01$ 
$1.46222 \mathrm{e}+01$ 1.46222e+01 1.46222e+00 1.00000e-09 2.12000e-01 $1.46222 \mathrm{e}+011.46222 \mathrm{e}+01$ 1.46222e+00 1.00000e-09 2.12000e-01 $1.00000 \mathrm{e}-05$ 1.00000e-05 1.00000e-06 1.00000e-09 1.00000e-01 $1.00000 \mathrm{e}+001.00000 \mathrm{e}+001.00000 \mathrm{e}-011.00000 \mathrm{e}-091.00000 \mathrm{e}-01$ Element: 9062 \# of layers: 7

$\mathrm{Kx} \mathrm{Ky} \mathrm{Kz}$ Ss Por

$1.46222 \mathrm{e}+01$ 1.46222e+01 1.46222e+00 1.00000e-09 2.12000e-01 $1.46222 \mathrm{e}+01$ 1.46222e+01 1.46222e+00 1.00000e-09 2.12000e-01 $1.46222 \mathrm{e}+01$ 1.46222e+01 1.46222e+00 1.00000e-09 2.12000e-01 $1.46222 \mathrm{e}+011.46222 \mathrm{e}+01$ 1.46222e+00 1.00000e-09 2.12000e-01 $1.46222 \mathrm{e}+01$ 1.46222e+01 1.46222e+00 1.00000e-09 2.12000e-01 $1.00000 \mathrm{e}-05$ 1.00000e-05 1.00000e-06 1.00000e-09 1.00000e-01 $1.00000 \mathrm{e}+001.00000 \mathrm{e}+001.00000 \mathrm{e}-011.00000 \mathrm{e}-091.00000 \mathrm{e}-01$ Element: 9063 \# of layers: 7

$\mathrm{Kx} \mathrm{Ky} \mathrm{Kz}$ Ss Por

$1.46222 \mathrm{e}+01$ 1.46222e+01 1.46222e+00 1.00000e-09 2.12000e-01 $1.46222 \mathrm{e}+01$ 1.46222e+01 1.46222e+00 1.00000e-09 2.12000e-01 $1.46222 \mathrm{e}+011.46222 \mathrm{e}+01$ 1.46222e+00 1.00000e-09 2.12000e-01 $1.46222 \mathrm{e}+01$ 1.46222e+01 1.46222e+00 1.00000e-09 2.12000e-01 $1.46222 \mathrm{e}+01$ 1.46222e+01 1.46222e+00 1.00000e-09 2.12000e-01 $1.00000 \mathrm{e}-05$ 1.00000e-05 1.00000e-06 1.00000e-09 1.00000e-01 $1.00000 \mathrm{e}+001.00000 \mathrm{e}+001.00000 \mathrm{e}-011.00000 \mathrm{e}-091.00000 \mathrm{e}-01$ Element: 9064 \# of layers: 7

$\mathrm{Kx} \mathrm{Ky} \mathrm{Kz}$ Ss Por

$1.46222 \mathrm{e}+01$ 1.46222e+01 1.46222e+00 1.00000e-09 2.12000e-01 $1.46222 \mathrm{e}+011.46222 \mathrm{e}+011.46222 \mathrm{e}+001.00000 \mathrm{e}-092.12000 \mathrm{e}-01$ $1.46222 \mathrm{e}+011.46222 \mathrm{e}+011.46222 \mathrm{e}+001.00000 \mathrm{e}-092.12000 \mathrm{e}-01$ $1.46222 \mathrm{e}+01$ 1.46222e+01 1.46222e+00 1.00000e-09 2.12000e-01 $1.46222 \mathrm{e}+01$ 1.46222e+01 1.46222e+00 1.00000e-09 2.12000e-01 $1.00000 \mathrm{e}-05$ 1.00000e-05 1.00000e-06 1.00000e-09 1.00000e-01 $1.00000 \mathrm{e}+001.00000 \mathrm{e}+001.00000 \mathrm{e}-01$ 1.00000e-09 1.00000e-01 Element: 9065 \# of layers: 7

$\mathrm{Kx} \mathrm{Ky} \mathrm{Kz}$ Ss Por

$1.46222 \mathrm{e}+01$ 1.46222e+01 1.46222e+00 1.00000e-09 2.12000e-01 $1.46222 \mathrm{e}+01$ 1.46222e+01 1.46222e+00 1.00000e-09 2.12000e-01 $1.46222 \mathrm{e}+011.46222 \mathrm{e}+011.46222 \mathrm{e}+001.00000 \mathrm{e}-092.12000 \mathrm{e}-01$ $1.46222 \mathrm{e}+011.46222 \mathrm{e}+011.46222 \mathrm{e}+001.00000 \mathrm{e}-092.12000 \mathrm{e}-01$ $1.46222 \mathrm{e}+01$ 1.46222e+01 1.46222e+00 1.00000e-09 2.12000e-01 $1.00000 \mathrm{e}-05$ 1.00000e-05 1.00000e-06 1.00000e-09 1.00000e-01 $1.00000 \mathrm{e}+001.00000 \mathrm{e}+001.00000 \mathrm{e}-01$ 1.00000e-09 1.00000e-01 Element: 9066 \# of layers: 7

$\mathrm{Kx} \mathrm{Ky} \mathrm{Kz}$ Ss Por

$1.46222 \mathrm{e}+01$ 1.46222e+01 1.46222e+00 1.00000e-09 2.12000e-01 $1.46222 \mathrm{e}+01$ 1.46222e+01 1.46222e+00 1.00000e-09 2.12000e-01 $1.46222 \mathrm{e}+01$ 1.46222e+01 1.46222e+00 1.00000e-09 2.12000e-01 $1.46222 \mathrm{e}+01$ 1.46222e+01 1.46222e+00 1.00000e-09 2.12000e-01 
$1.46222 \mathrm{e}+011.46222 \mathrm{e}+011.46222 \mathrm{e}+00$ 1.00000e-09 2.12000e-01 $1.00000 \mathrm{e}-05$ 1.00000e-05 1.00000e-06 1.00000e-09 1.00000e-01 $1.00000 \mathrm{e}+001.00000 \mathrm{e}+001.00000 \mathrm{e}-011.00000 \mathrm{e}-091.00000 \mathrm{e}-01$ Element: 9067 \# of layers: 7

Kx Ky Kz Ss Por

$1.46222 \mathrm{e}+011.46222 \mathrm{e}+011.46222 \mathrm{e}+00$ 1.00000e-09 2.12000e-01 $1.46222 \mathrm{e}+011.46222 \mathrm{e}+011.46222 \mathrm{e}+001.00000 \mathrm{e}-092.12000 \mathrm{e}-01$ $1.46222 \mathrm{e}+011.46222 \mathrm{e}+011.46222 \mathrm{e}+001.00000 \mathrm{e}-092.12000 \mathrm{e}-01$ $1.46222 \mathrm{e}+011.46222 \mathrm{e}+011.46222 \mathrm{e}+001.00000 \mathrm{e}-092.12000 \mathrm{e}-01$ $1.46222 \mathrm{e}+011.46222 \mathrm{e}+011.46222 \mathrm{e}+001.00000 \mathrm{e}-092.12000 \mathrm{e}-01$ $1.00000 \mathrm{e}-05$ 1.00000e-05 1.00000e-06 1.00000e-09 1.00000e-01 $1.00000 \mathrm{e}+001.00000 \mathrm{e}+001.00000 \mathrm{e}-011.00000 \mathrm{e}-091.00000 \mathrm{e}-01$ Element: 9068 \# of layers: 7

Kx Ky Kz Ss Por

$1.46222 \mathrm{e}+011.46222 \mathrm{e}+011.46222 \mathrm{e}+00$ 1.00000e-09 2.12000e-01 $1.46222 \mathrm{e}+011.46222 \mathrm{e}+011.46222 \mathrm{e}+001.00000 \mathrm{e}-092.12000 \mathrm{e}-01$ $1.46222 \mathrm{e}+011.46222 \mathrm{e}+011.46222 \mathrm{e}+001.00000 \mathrm{e}-092.12000 \mathrm{e}-01$ $1.46222 \mathrm{e}+011.46222 \mathrm{e}+011.46222 \mathrm{e}+001.00000 \mathrm{e}-092.12000 \mathrm{e}-01$ $1.46222 \mathrm{e}+011.46222 \mathrm{e}+011.46222 \mathrm{e}+001.00000 \mathrm{e}-092.12000 \mathrm{e}-01$ $1.00000 \mathrm{e}-05$ 1.00000e-05 1.00000e-06 1.00000e-09 1.00000e-01 $1.00000 \mathrm{e}+001.00000 \mathrm{e}+001.00000 \mathrm{e}-011.00000 \mathrm{e}-091.00000 \mathrm{e}-01$ Element: 9069 \# of layers: 7

Kx Ky Kz Ss Por

$1.46222 \mathrm{e}+011.46222 \mathrm{e}+011.46222 \mathrm{e}+00$ 1.00000e-09 2.12000e-01 $1.46222 \mathrm{e}+011.46222 \mathrm{e}+011.46222 \mathrm{e}+001.00000 \mathrm{e}-092.12000 \mathrm{e}-01$ $1.46222 \mathrm{e}+011.46222 \mathrm{e}+011.46222 \mathrm{e}+001.00000 \mathrm{e}-092.12000 \mathrm{e}-01$ $1.46222 \mathrm{e}+011.46222 \mathrm{e}+011.46222 \mathrm{e}+001.00000 \mathrm{e}-092.12000 \mathrm{e}-01$ $1.46222 \mathrm{e}+011.46222 \mathrm{e}+011.46222 \mathrm{e}+001.00000 \mathrm{e}-092.12000 \mathrm{e}-01$ $1.00000 \mathrm{e}-05$ 1.00000e-05 1.00000e-06 1.00000e-09 1.00000e-01 $1.00000 \mathrm{e}+001.00000 \mathrm{e}+001.00000 \mathrm{e}-011.00000 \mathrm{e}-091.00000 \mathrm{e}-01$ Element: 9070 \# of layers: 7

Kx Ky Kz Ss Por

$1.34501 \mathrm{e}+011.34501 \mathrm{e}+011.34501 \mathrm{e}+001.00000 \mathrm{e}-092.12000 \mathrm{e}-01$ $1.34501 \mathrm{e}+011.34501 \mathrm{e}+011.34501 \mathrm{e}+001.00000 \mathrm{e}-092.12000 \mathrm{e}-01$ $1.34501 \mathrm{e}+011.34501 \mathrm{e}+011.34501 \mathrm{e}+001.00000 \mathrm{e}-092.12000 \mathrm{e}-01$ $1.34501 \mathrm{e}+011.34501 \mathrm{e}+011.34501 \mathrm{e}+001.00000 \mathrm{e}-092.12000 \mathrm{e}-01$ $1.34501 \mathrm{e}+011.34501 \mathrm{e}+011.34501 \mathrm{e}+001.00000 \mathrm{e}-092.12000 \mathrm{e}-01$ $1.00000 \mathrm{e}-05$ 1.00000e-05 1.00000e-06 1.00000e-09 1.00000e-01 $1.00000 \mathrm{e}+001.00000 \mathrm{e}+001.00000 \mathrm{e}-011.00000 \mathrm{e}-091.00000 \mathrm{e}-01$ Element: 9071 \# of layers: 7

Kx Ky Kz Ss Por

$1.34501 \mathrm{e}+011.34501 \mathrm{e}+011.34501 \mathrm{e}+00$ 1.00000e-09 2.12000e-01 $1.34501 \mathrm{e}+011.34501 \mathrm{e}+011.34501 \mathrm{e}+001.00000 \mathrm{e}-092.12000 \mathrm{e}-01$ $1.34501 \mathrm{e}+011.34501 \mathrm{e}+011.34501 \mathrm{e}+001.00000 \mathrm{e}-092.12000 \mathrm{e}-01$ $1.34501 \mathrm{e}+011.34501 \mathrm{e}+011.34501 \mathrm{e}+001.00000 \mathrm{e}-092.12000 \mathrm{e}-01$ $1.34501 \mathrm{e}+011.34501 \mathrm{e}+011.34501 \mathrm{e}+001.00000 \mathrm{e}-092.12000 \mathrm{e}-01$ 
$1.00000 \mathrm{e}-05$ 1.00000e-05 1.00000e-06 1.00000e-09 1.00000e-01 $1.00000 \mathrm{e}+001.00000 \mathrm{e}+001.00000 \mathrm{e}-011.00000 \mathrm{e}-091.00000 \mathrm{e}-01$ Element: 9072 \# of layers: 7

Kx Ky Kz Ss Por

$1.34501 \mathrm{e}+011.34501 \mathrm{e}+011.34501 \mathrm{e}+001.00000 \mathrm{e}-092.12000 \mathrm{e}-01$ $1.34501 \mathrm{e}+011.34501 \mathrm{e}+011.34501 \mathrm{e}+001.00000 \mathrm{e}-092.12000 \mathrm{e}-01$ $1.34501 \mathrm{e}+011.34501 \mathrm{e}+011.34501 \mathrm{e}+001.00000 \mathrm{e}-092.12000 \mathrm{e}-01$ $1.34501 \mathrm{e}+011.34501 \mathrm{e}+011.34501 \mathrm{e}+001.00000 \mathrm{e}-092.12000 \mathrm{e}-01$ $1.34501 \mathrm{e}+011.34501 \mathrm{e}+01$ 1.34501e+00 1.00000e-09 2.12000e-01 $1.00000 \mathrm{e}-05$ 1.00000e-05 1.00000e-06 1.00000e-09 1.00000e-01 $1.00000 \mathrm{e}+001.00000 \mathrm{e}+001.00000 \mathrm{e}-011.00000 \mathrm{e}-091.00000 \mathrm{e}-01$ Element: 9073 \# of layers: 7

$\mathrm{Kx} \mathrm{Ky} \mathrm{Kz}$ Ss Por

$1.34501 \mathrm{e}+011.34501 \mathrm{e}+01$ 1.34501e+00 1.00000e-09 2.12000e-01 $1.34501 \mathrm{e}+011.34501 \mathrm{e}+011.34501 \mathrm{e}+001.00000 \mathrm{e}-092.12000 \mathrm{e}-01$ $1.34501 \mathrm{e}+011.34501 \mathrm{e}+011.34501 \mathrm{e}+001.00000 \mathrm{e}-092.12000 \mathrm{e}-01$ $1.34501 \mathrm{e}+011.34501 \mathrm{e}+011.34501 \mathrm{e}+001.00000 \mathrm{e}-092.12000 \mathrm{e}-01$ $1.34501 \mathrm{e}+011.34501 \mathrm{e}+011.34501 \mathrm{e}+001.00000 \mathrm{e}-092.12000 \mathrm{e}-01$ $1.00000 \mathrm{e}-05$ 1.00000e-05 1.00000e-06 1.00000e-09 1.00000e-01 $1.00000 \mathrm{e}+001.00000 \mathrm{e}+001.00000 \mathrm{e}-011.00000 \mathrm{e}-091.00000 \mathrm{e}-01$ Element: 9074 \# of layers: 7

$\mathrm{Kx} \mathrm{Ky} \mathrm{Kz}$ Ss Por

$1.34501 \mathrm{e}+01$ 1.34501e+01 1.34501e+00 1.00000e-09 2.12000e-01 $1.34501 \mathrm{e}+011.34501 \mathrm{e}+011.34501 \mathrm{e}+001.00000 \mathrm{e}-092.12000 \mathrm{e}-01$ $1.34501 \mathrm{e}+011.34501 \mathrm{e}+011.34501 \mathrm{e}+001.00000 \mathrm{e}-092.12000 \mathrm{e}-01$ $1.34501 \mathrm{e}+011.34501 \mathrm{e}+01$ 1.34501e+00 1.00000e-09 2.12000e-01 $1.34501 \mathrm{e}+011.34501 \mathrm{e}+011.34501 \mathrm{e}+001.00000 \mathrm{e}-092.12000 \mathrm{e}-01$ $1.00000 \mathrm{e}-05$ 1.00000e-05 1.00000e-06 1.00000e-09 1.00000e-01 $1.00000 \mathrm{e}+001.00000 \mathrm{e}+001.00000 \mathrm{e}-011.00000 \mathrm{e}-091.00000 \mathrm{e}-01$ Element: 9075 \# of layers: 7

$\mathrm{Kx} \mathrm{Ky} \mathrm{Kz}$ Ss Por

$1.46222 \mathrm{e}+01$ 1.46222e+01 1.46222e+00 1.00000e-09 2.12000e-01 $1.46222 \mathrm{e}+011.46222 \mathrm{e}+011.46222 \mathrm{e}+001.00000 \mathrm{e}-092.12000 \mathrm{e}-01$ $1.46222 \mathrm{e}+011.46222 \mathrm{e}+011.46222 \mathrm{e}+001.00000 \mathrm{e}-092.12000 \mathrm{e}-01$ $1.46222 \mathrm{e}+011.46222 \mathrm{e}+011.46222 \mathrm{e}+001.00000 \mathrm{e}-092.12000 \mathrm{e}-01$ $1.46222 \mathrm{e}+01$ 1.46222e+01 1.46222e+00 1.00000e-09 2.12000e-01 $1.00000 \mathrm{e}-05$ 1.00000e-05 1.00000e-06 1.00000e-09 1.00000e-01 $1.00000 \mathrm{e}+001.00000 \mathrm{e}+001.00000 \mathrm{e}-011.00000 \mathrm{e}-091.00000 \mathrm{e}-01$ Element: 9076 \# of layers: 7

$\mathrm{Kx} \mathrm{Ky} \mathrm{Kz}$ Ss Por

$1.46222 \mathrm{e}+01$ 1.46222e+01 1.46222e+00 1.00000e-09 2.12000e-01 $1.46222 \mathrm{e}+01$ 1.46222e+01 1.46222e+00 1.00000e-09 2.12000e-01 $1.46222 \mathrm{e}+01$ 1.46222e+01 1.46222e+00 1.00000e-09 2.12000e-01 $1.46222 \mathrm{e}+01$ 1.46222e+01 1.46222e+00 1.00000e-09 2.12000e-01 $1.46222 \mathrm{e}+011.46222 \mathrm{e}+011.46222 \mathrm{e}+001.00000 \mathrm{e}-092.12000 \mathrm{e}-01$ $1.00000 \mathrm{e}-05$ 1.00000e-05 1.00000e-06 1.00000e-09 1.00000e-01 
$1.00000 \mathrm{e}+001.00000 \mathrm{e}+00$ 1.00000e-01 1.00000e-09 1.00000e-01

Element: 9077 \# of layers: 7

Kx Ky Kz Ss Por

$1.34501 \mathrm{e}+01$ 1.34501e+01 1.34501e+00 1.00000e-09 2.12000e-01

$1.34501 \mathrm{e}+011.34501 \mathrm{e}+011.34501 \mathrm{e}+001.00000 \mathrm{e}-092.12000 \mathrm{e}-01$

$1.34501 \mathrm{e}+011.34501 \mathrm{e}+011.34501 \mathrm{e}+001.00000 \mathrm{e}-092.12000 \mathrm{e}-01$

$1.34501 \mathrm{e}+011.34501 \mathrm{e}+011.34501 \mathrm{e}+001.00000 \mathrm{e}-092.12000 \mathrm{e}-01$

$1.34501 \mathrm{e}+011.34501 \mathrm{e}+011.34501 \mathrm{e}+001.00000 \mathrm{e}-092.12000 \mathrm{e}-01$

$1.00000 \mathrm{e}-05$ 1.00000e-05 1.00000e-06 1.00000e-09 1.00000e-01

$1.00000 \mathrm{e}+001.00000 \mathrm{e}+001.00000 \mathrm{e}-011.00000 \mathrm{e}-091.00000 \mathrm{e}-01$

Element: 9078 \# of layers: 7

$\mathrm{Kx} \mathrm{Ky} \mathrm{Kz}$ Ss Por

1.34501e+01 1.34501e+01 1.34501e+00 1.00000e-09 2.12000e-01

$1.34501 \mathrm{e}+011.34501 \mathrm{e}+011.34501 \mathrm{e}+001.00000 \mathrm{e}-092.12000 \mathrm{e}-01$

$1.34501 \mathrm{e}+011.34501 \mathrm{e}+011.34501 \mathrm{e}+001.00000 \mathrm{e}-092.12000 \mathrm{e}-01$

$1.34501 \mathrm{e}+011.34501 \mathrm{e}+011.34501 \mathrm{e}+001.00000 \mathrm{e}-092.12000 \mathrm{e}-01$

$1.34501 \mathrm{e}+011.34501 \mathrm{e}+011.34501 \mathrm{e}+001.00000 \mathrm{e}-092.12000 \mathrm{e}-01$

$1.00000 \mathrm{e}-05$ 1.00000e-05 1.00000e-06 1.00000e-09 1.00000e-01

$1.00000 \mathrm{e}+001.00000 \mathrm{e}+001.00000 \mathrm{e}-011.00000 \mathrm{e}-091.00000 \mathrm{e}-01$

Element: 9079 \# of layers: 7

$\mathrm{Kx} \mathrm{Ky} \mathrm{Kz}$ Ss Por

$1.46008 \mathrm{e}+01$ 1.46008e+01 1.46008e+00 1.00000e-09 2.12000e-01

$1.46008 \mathrm{e}+01$ 1.46008e+01 1.46008e+00 1.00000e-09 2.12000e-01

$1.46008 \mathrm{e}+011.46008 \mathrm{e}+011.46008 \mathrm{e}+001.00000 \mathrm{e}-092.12000 \mathrm{e}-01$

$1.46008 \mathrm{e}+011.46008 \mathrm{e}+011.46008 \mathrm{e}+001.00000 \mathrm{e}-092.12000 \mathrm{e}-01$

$1.46008 \mathrm{e}+011.46008 \mathrm{e}+01$ 1.46008e+00 1.00000e-09 2.12000e-01

$1.00000 \mathrm{e}-05$ 1.00000e-05 1.00000e-06 1.00000e-09 1.00000e-01

$1.00000 \mathrm{e}+001.00000 \mathrm{e}+001.00000 \mathrm{e}-011.00000 \mathrm{e}-091.00000 \mathrm{e}-01$

Element: 9080 \# of layers: 7

$\mathrm{Kx} \mathrm{Ky} \mathrm{Kz}$ Ss Por

$1.46008 \mathrm{e}+01$ 1.46008e+01 1.46008e+00 1.00000e-09 2.12000e-01

$1.46008 \mathrm{e}+01$ 1.46008e+01 1.46008e+00 1.00000e-09 2.12000e-01

$1.46008 \mathrm{e}+011.46008 \mathrm{e}+011.46008 \mathrm{e}+001.00000 \mathrm{e}-092.12000 \mathrm{e}-01$

$1.46008 \mathrm{e}+011.46008 \mathrm{e}+01$ 1.46008e+00 1.00000e-09 2.12000e-01

$1.46008 \mathrm{e}+01$ 1.46008e+01 1.46008e+00 1.00000e-09 2.12000e-01

$1.00000 \mathrm{e}-05$ 1.00000e-05 1.00000e-06 1.00000e-09 1.00000e-01

$1.00000 \mathrm{e}+001.00000 \mathrm{e}+001.00000 \mathrm{e}-011.00000 \mathrm{e}-091.00000 \mathrm{e}-01$

Element: 9081 \# of layers: 7

$\mathrm{Kx} \mathrm{Ky} \mathrm{Kz}$ Ss Por

$1.46008 \mathrm{e}+01$ 1.46008e+01 1.46008e+00 1.00000e-09 2.12000e-01

$1.46008 \mathrm{e}+011.46008 \mathrm{e}+01$ 1.46008e+00 1.00000e-09 2.12000e-01

$1.46008 \mathrm{e}+01$ 1.46008e+01 1.46008e+00 1.00000e-09 2.12000e-01

$1.46008 \mathrm{e}+01$ 1.46008e+01 1.46008e+00 1.00000e-09 2.12000e-01

$1.46008 \mathrm{e}+01$ 1.46008e+01 1.46008e+00 1.00000e-09 2.12000e-01

$1.00000 \mathrm{e}-05$ 1.00000e-05 1.00000e-06 1.00000e-09 1.00000e-01

$1.00000 \mathrm{e}+001.00000 \mathrm{e}+001.00000 \mathrm{e}-011.00000 \mathrm{e}-091.00000 \mathrm{e}-01$ 
Element: 9082 \# of layers: 7

Kx Ky Kz Ss Por

$1.33201 \mathrm{e}+011.33201 \mathrm{e}+011.33201 \mathrm{e}+00$ 1.00000e-09 2.12000e-01

$1.33201 \mathrm{e}+011.33201 \mathrm{e}+011.33201 \mathrm{e}+001.00000 \mathrm{e}-092.12000 \mathrm{e}-01$

$1.33201 \mathrm{e}+011.33201 \mathrm{e}+011.33201 \mathrm{e}+001.00000 \mathrm{e}-092.12000 \mathrm{e}-01$

$1.33201 \mathrm{e}+011.33201 \mathrm{e}+011.33201 \mathrm{e}+001.00000 \mathrm{e}-092.12000 \mathrm{e}-01$

$1.33201 \mathrm{e}+011.33201 \mathrm{e}+011.33201 \mathrm{e}+001.00000 \mathrm{e}-092.12000 \mathrm{e}-01$

$1.00000 \mathrm{e}-05$ 1.00000e-05 1.00000e-06 1.00000e-09 1.00000e-01

$1.00000 \mathrm{e}+001.00000 \mathrm{e}+001.00000 \mathrm{e}-011.00000 \mathrm{e}-091.00000 \mathrm{e}-01$

Element: 9083 \# of layers: 7

Kx Ky Kz Ss Por

$1.33201 \mathrm{e}+011.33201 \mathrm{e}+011.33201 \mathrm{e}+00$ 1.00000e-09 2.12000e-01

$1.33201 \mathrm{e}+011.33201 \mathrm{e}+011.33201 \mathrm{e}+001.00000 \mathrm{e}-092.12000 \mathrm{e}-01$

$1.33201 \mathrm{e}+011.33201 \mathrm{e}+011.33201 \mathrm{e}+001.00000 \mathrm{e}-092.12000 \mathrm{e}-01$

$1.33201 \mathrm{e}+011.33201 \mathrm{e}+011.33201 \mathrm{e}+001.00000 \mathrm{e}-092.12000 \mathrm{e}-01$

$1.33201 \mathrm{e}+011.33201 \mathrm{e}+011.33201 \mathrm{e}+001.00000 \mathrm{e}-092.12000 \mathrm{e}-01$

$1.00000 \mathrm{e}-05$ 1.00000e-05 1.00000e-06 1.00000e-09 1.00000e-01

$1.00000 \mathrm{e}+001.00000 \mathrm{e}+001.00000 \mathrm{e}-011.00000 \mathrm{e}-091.00000 \mathrm{e}-01$

Element: 9084 \# of layers: 7

Kx Ky Kz Ss Por

$1.46222 \mathrm{e}+011.46222 \mathrm{e}+011.46222 \mathrm{e}+00$ 1.00000e-09 2.12000e-01

$1.46222 \mathrm{e}+011.46222 \mathrm{e}+011.46222 \mathrm{e}+001.00000 \mathrm{e}-092.12000 \mathrm{e}-01$

$1.46222 \mathrm{e}+011.46222 \mathrm{e}+011.46222 \mathrm{e}+001.00000 \mathrm{e}-092.12000 \mathrm{e}-01$

$1.46222 \mathrm{e}+011.46222 \mathrm{e}+011.46222 \mathrm{e}+001.00000 \mathrm{e}-092.12000 \mathrm{e}-01$

$1.46222 \mathrm{e}+011.46222 \mathrm{e}+011.46222 \mathrm{e}+001.00000 \mathrm{e}-092.12000 \mathrm{e}-01$

$1.00000 \mathrm{e}-05$ 1.00000e-05 1.00000e-06 1.00000e-09 1.00000e-01

$1.00000 \mathrm{e}+001.00000 \mathrm{e}+001.00000 \mathrm{e}-011.00000 \mathrm{e}-091.00000 \mathrm{e}-01$

Element: 9085 \# of layers: 7

$\mathrm{Kx} \mathrm{Ky} \mathrm{Kz}$ Ss Por

$1.34501 \mathrm{e}+011.34501 \mathrm{e}+011.34501 \mathrm{e}+00$ 1.00000e-09 2.12000e-01

$1.34501 \mathrm{e}+011.34501 \mathrm{e}+011.34501 \mathrm{e}+001.00000 \mathrm{e}-092.12000 \mathrm{e}-01$

$1.34501 \mathrm{e}+011.34501 \mathrm{e}+011.34501 \mathrm{e}+001.00000 \mathrm{e}-092.12000 \mathrm{e}-01$

$1.34501 \mathrm{e}+011.34501 \mathrm{e}+011.34501 \mathrm{e}+001.00000 \mathrm{e}-092.12000 \mathrm{e}-01$

$1.34501 \mathrm{e}+011.34501 \mathrm{e}+011.34501 \mathrm{e}+001.00000 \mathrm{e}-092.12000 \mathrm{e}-01$

$1.00000 \mathrm{e}-05$ 1.00000e-05 1.00000e-06 1.00000e-09 1.00000e-01

$1.00000 \mathrm{e}+001.00000 \mathrm{e}+001.00000 \mathrm{e}-011.00000 \mathrm{e}-091.00000 \mathrm{e}-01$

Element: 9086 \# of layers: 7

Kx Ky Kz Ss Por

$1.46008 \mathrm{e}+011.46008 \mathrm{e}+011.46008 \mathrm{e}+00$ 1.00000e-09 2.12000e-01

$1.46008 \mathrm{e}+011.46008 \mathrm{e}+011.46008 \mathrm{e}+001.00000 \mathrm{e}-092.12000 \mathrm{e}-01$

$1.46008 \mathrm{e}+011.46008 \mathrm{e}+011.46008 \mathrm{e}+001.00000 \mathrm{e}-092.12000 \mathrm{e}-01$

$1.46008 \mathrm{e}+011.46008 \mathrm{e}+011.46008 \mathrm{e}+001.00000 \mathrm{e}-092.12000 \mathrm{e}-01$

$1.46008 \mathrm{e}+011.46008 \mathrm{e}+011.46008 \mathrm{e}+001.00000 \mathrm{e}-092.12000 \mathrm{e}-01$

$1.00000 \mathrm{e}-05$ 1.00000e-05 1.00000e-06 1.00000e-09 1.00000e-01

$1.00000 \mathrm{e}+001.00000 \mathrm{e}+001.00000 \mathrm{e}-011.00000 \mathrm{e}-091.00000 \mathrm{e}-01$

Element: 9087 \# of layers: 7 
$\mathrm{Kx} \mathrm{Ky} \mathrm{Kz}$ Ss Por

$1.52090 \mathrm{e}+01$ 1.52090e+01 1.52090e+00 1.00000e-09 2.12000e-01

$1.52090 \mathrm{e}+011.52090 \mathrm{e}+01$ 1.52090e+00 1.00000e-09 2.12000e-01

$1.52090 \mathrm{e}+011.52090 \mathrm{e}+011.52090 \mathrm{e}+001.00000 \mathrm{e}-092.12000 \mathrm{e}-01$

$1.52090 \mathrm{e}+011.52090 \mathrm{e}+01$ 1.52090e+00 1.00000e-09 2.12000e-01

$1.52090 \mathrm{e}+011.52090 \mathrm{e}+011.52090 \mathrm{e}+001.00000 \mathrm{e}-092.12000 \mathrm{e}-01$

$1.00000 \mathrm{e}-05$ 1.00000e-05 1.00000e-06 1.00000e-09 1.00000e-01

$1.00000 \mathrm{e}+001.00000 \mathrm{e}+001.00000 \mathrm{e}-011.00000 \mathrm{e}-091.00000 \mathrm{e}-01$

Element: 9088 \# of layers: 7

$\mathrm{Kx} \mathrm{Ky} \mathrm{Kz}$ Ss Por

$1.52090 \mathrm{e}+01$ 1.52090e+01 1.52090e+00 1.00000e-09 2.12000e-01

$1.52090 \mathrm{e}+011.52090 \mathrm{e}+011.52090 \mathrm{e}+001.00000 \mathrm{e}-092.12000 \mathrm{e}-01$

$1.52090 \mathrm{e}+011.52090 \mathrm{e}+011.52090 \mathrm{e}+001.00000 \mathrm{e}-092.12000 \mathrm{e}-01$

$1.52090 \mathrm{e}+011.52090 \mathrm{e}+011.52090 \mathrm{e}+001.00000 \mathrm{e}-092.12000 \mathrm{e}-01$

$1.52090 \mathrm{e}+011.52090 \mathrm{e}+011.52090 \mathrm{e}+001.00000 \mathrm{e}-092.12000 \mathrm{e}-01$

$1.00000 \mathrm{e}-05$ 1.00000e-05 1.00000e-06 1.00000e-09 1.00000e-01

$1.00000 \mathrm{e}+001.00000 \mathrm{e}+001.00000 \mathrm{e}-01$ 1.00000e-09 1.00000e-01

Element: 9089 \# of layers: 7

$\mathrm{Kx} \mathrm{Ky} \mathrm{Kz}$ Ss Por

$1.52090 \mathrm{e}+01$ 1.52090e+01 1.52090e+00 1.00000e-09 2.12000e-01

$1.52090 \mathrm{e}+011.52090 \mathrm{e}+011.52090 \mathrm{e}+001.00000 \mathrm{e}-092.12000 \mathrm{e}-01$

$1.52090 \mathrm{e}+011.52090 \mathrm{e}+01$ 1.52090e+00 1.00000e-09 2.12000e-01

$1.52090 \mathrm{e}+011.52090 \mathrm{e}+011.52090 \mathrm{e}+001.00000 \mathrm{e}-092.12000 \mathrm{e}-01$

$1.52090 \mathrm{e}+011.52090 \mathrm{e}+011.52090 \mathrm{e}+001.00000 \mathrm{e}-092.12000 \mathrm{e}-01$

$1.00000 \mathrm{e}-05$ 1.00000e-05 1.00000e-06 1.00000e-09 1.00000e-01

$1.00000 \mathrm{e}+001.00000 \mathrm{e}+001.00000 \mathrm{e}-01$ 1.00000e-09 1.00000e-01

Element: 9090 \# of layers: 7

$\mathrm{Kx} \mathrm{Ky} \mathrm{Kz}$ Ss Por

$1.52090 \mathrm{e}+01$ 1.52090e+01 1.52090e+00 1.00000e-09 2.12000e-01

$1.52090 \mathrm{e}+011.52090 \mathrm{e}+01$ 1.52090e+00 1.00000e-09 2.12000e-01

$1.52090 \mathrm{e}+011.52090 \mathrm{e}+011.52090 \mathrm{e}+001.00000 \mathrm{e}-092.12000 \mathrm{e}-01$

$1.52090 \mathrm{e}+011.52090 \mathrm{e}+011.52090 \mathrm{e}+001.00000 \mathrm{e}-092.12000 \mathrm{e}-01$

$1.52090 \mathrm{e}+011.52090 \mathrm{e}+011.52090 \mathrm{e}+001.00000 \mathrm{e}-092.12000 \mathrm{e}-01$

$1.00000 \mathrm{e}-05$ 1.00000e-05 1.00000e-06 1.00000e-09 1.00000e-01

$1.00000 \mathrm{e}+001.00000 \mathrm{e}+001.00000 \mathrm{e}-011.00000 \mathrm{e}-091.00000 \mathrm{e}-01$

Element: 9091 \# of layers: 7

$\mathrm{Kx} \mathrm{Ky} \mathrm{Kz}$ Ss Por

$1.22862 \mathrm{e}+01$ 1.22862e+01 1.22862e+00 1.00000e-09 2.12000e-01

$1.22862 \mathrm{e}+011.22862 \mathrm{e}+011.22862 \mathrm{e}+001.00000 \mathrm{e}-092.12000 \mathrm{e}-01$

$1.22862 \mathrm{e}+011.22862 \mathrm{e}+011.22862 \mathrm{e}+001.00000 \mathrm{e}-092.12000 \mathrm{e}-01$

$1.22862 \mathrm{e}+011.22862 \mathrm{e}+01$ 1.22862e+00 1.00000e-09 2.12000e-01

$1.22862 \mathrm{e}+01$ 1.22862e+01 1.22862e+00 1.00000e-09 2.12000e-01

$1.00000 \mathrm{e}-05$ 1.00000e-05 1.00000e-06 1.00000e-09 1.00000e-01

$1.00000 \mathrm{e}+001.00000 \mathrm{e}+001.00000 \mathrm{e}-01$ 1.00000e-09 1.00000e-01

Element: 9092 \# of layers: 7

Kx Ky Kz Ss Por 
$1.22862 \mathrm{e}+011.22862 \mathrm{e}+01$ 1.22862e+00 1.00000e-09 2.12000e-01 $1.22862 \mathrm{e}+01$ 1.22862e+01 1.22862e+00 1.00000e-09 2.12000e-01 $1.22862 \mathrm{e}+011.22862 \mathrm{e}+011.22862 \mathrm{e}+001.00000 \mathrm{e}-092.12000 \mathrm{e}-01$ $1.22862 \mathrm{e}+011.22862 \mathrm{e}+011.22862 \mathrm{e}+001.00000 \mathrm{e}-092.12000 \mathrm{e}-01$ $1.22862 \mathrm{e}+011.22862 \mathrm{e}+011.22862 \mathrm{e}+001.00000 \mathrm{e}-092.12000 \mathrm{e}-01$ $1.00000 \mathrm{e}-05$ 1.00000e-05 1.00000e-06 1.00000e-09 1.00000e-01 $1.00000 \mathrm{e}+001.00000 \mathrm{e}+001.00000 \mathrm{e}-01$ 1.00000e-09 1.00000e-01 Element: 9093 \# of layers: 7

$\mathrm{Kx} \mathrm{Ky} \mathrm{Kz}$ Ss Por

$1.52090 \mathrm{e}+011.52090 \mathrm{e}+011.52090 \mathrm{e}+001.00000 \mathrm{e}-092.12000 \mathrm{e}-01$ $1.52090 \mathrm{e}+011.52090 \mathrm{e}+01$ 1.52090e+00 1.00000e-09 2.12000e-01 $1.52090 \mathrm{e}+011.52090 \mathrm{e}+011.52090 \mathrm{e}+001.00000 \mathrm{e}-092.12000 \mathrm{e}-01$ $1.52090 \mathrm{e}+011.52090 \mathrm{e}+011.52090 \mathrm{e}+001.00000 \mathrm{e}-092.12000 \mathrm{e}-01$ $1.52090 \mathrm{e}+01$ 1.52090e+01 1.52090e+00 1.00000e-09 2.12000e-01 $1.00000 \mathrm{e}-05$ 1.00000e-05 1.00000e-06 1.00000e-09 1.00000e-01 $1.00000 \mathrm{e}+001.00000 \mathrm{e}+001.00000 \mathrm{e}-011.00000 \mathrm{e}-091.00000 \mathrm{e}-01$ Element: 9094 \# of layers: 7

$\mathrm{Kx} \mathrm{Ky} \mathrm{Kz}$ Ss Por

$1.22862 \mathrm{e}+01$ 1.22862e+01 1.22862e+00 1.00000e-09 2.12000e-01 $1.22862 \mathrm{e}+011.22862 \mathrm{e}+01$ 1.22862e+00 1.00000e-09 2.12000e-01 $1.22862 \mathrm{e}+011.22862 \mathrm{e}+011.22862 \mathrm{e}+001.00000 \mathrm{e}-092.12000 \mathrm{e}-01$ $1.22862 \mathrm{e}+011.22862 \mathrm{e}+01$ 1.22862e+00 1.00000e-09 2.12000e-01 $1.22862 \mathrm{e}+01$ 1.22862e+01 1.22862e+00 1.00000e-09 2.12000e-01 $1.00000 \mathrm{e}-05$ 1.00000e-05 1.00000e-06 1.00000e-09 1.00000e-01 $1.00000 \mathrm{e}+001.00000 \mathrm{e}+001.00000 \mathrm{e}-011.00000 \mathrm{e}-091.00000 \mathrm{e}-01$ Element: 9095 \# of layers: 7

$\mathrm{Kx} \mathrm{Ky} \mathrm{Kz}$ Ss Por

$1.22862 \mathrm{e}+01$ 1.22862e+01 1.22862e+00 1.00000e-09 2.12000e-01 $1.22862 \mathrm{e}+011.22862 \mathrm{e}+011.22862 \mathrm{e}+001.00000 \mathrm{e}-092.12000 \mathrm{e}-01$ $1.22862 \mathrm{e}+011.22862 \mathrm{e}+011.22862 \mathrm{e}+001.00000 \mathrm{e}-092.12000 \mathrm{e}-01$ $1.22862 \mathrm{e}+011.22862 \mathrm{e}+01$ 1.22862e+00 1.00000e-09 2.12000e-01 $1.22862 \mathrm{e}+01$ 1.22862e+01 1.22862e+00 1.00000e-09 2.12000e-01 $1.00000 \mathrm{e}-05$ 1.00000e-05 1.00000e-06 1.00000e-09 1.00000e-01 $1.00000 \mathrm{e}+001.00000 \mathrm{e}+001.00000 \mathrm{e}-011.00000 \mathrm{e}-091.00000 \mathrm{e}-01$ Element: 9096 \# of layers: 7

$\mathrm{Kx} \mathrm{Ky} \mathrm{Kz}$ Ss Por

$1.22862 \mathrm{e}+01$ 1.22862e+01 1.22862e+00 1.00000e-09 2.12000e-01 $1.22862 \mathrm{e}+011.22862 \mathrm{e}+011.22862 \mathrm{e}+001.00000 \mathrm{e}-092.12000 \mathrm{e}-01$ $1.22862 \mathrm{e}+011.22862 \mathrm{e}+011.22862 \mathrm{e}+001.00000 \mathrm{e}-092.12000 \mathrm{e}-01$ $1.22862 \mathrm{e}+011.22862 \mathrm{e}+011.22862 \mathrm{e}+001.00000 \mathrm{e}-092.12000 \mathrm{e}-01$ $1.22862 \mathrm{e}+011.22862 \mathrm{e}+01$ 1.22862e+00 1.00000e-09 2.12000e-01 $1.00000 \mathrm{e}-05$ 1.00000e-05 1.00000e-06 1.00000e-09 1.00000e-01 $1.00000 \mathrm{e}+001.00000 \mathrm{e}+001.00000 \mathrm{e}-011.00000 \mathrm{e}-091.00000 \mathrm{e}-01$ Element: 9097 \# of layers: 7

$\mathrm{Kx} \mathrm{Ky} \mathrm{Kz}$ Ss Por

$1.22862 \mathrm{e}+01$ 1.22862e+01 1.22862e+00 1.00000e-09 2.12000e-01 
$1.22862 \mathrm{e}+01$ 1.22862e+01 1.22862e+00 1.00000e-09 2.12000e-01 $1.22862 \mathrm{e}+01$ 1.22862e+01 1.22862e+00 1.00000e-09 2.12000e-01 $1.22862 \mathrm{e}+011.22862 \mathrm{e}+011.22862 \mathrm{e}+001.00000 \mathrm{e}-092.12000 \mathrm{e}-01$ $1.22862 \mathrm{e}+01$ 1.22862e+01 1.22862e+00 1.00000e-09 2.12000e-01 $1.00000 \mathrm{e}-05$ 1.00000e-05 1.00000e-06 1.00000e-09 1.00000e-01 $1.00000 \mathrm{e}+001.00000 \mathrm{e}+001.00000 \mathrm{e}-011.00000 \mathrm{e}-091.00000 \mathrm{e}-01$ Element: 9098 \# of layers: 7

$\mathrm{Kx} \mathrm{Ky} \mathrm{Kz} \mathrm{Ss} \mathrm{Por}$

$1.22862 \mathrm{e}+01$ 1.22862e+01 1.22862e+00 1.00000e-09 2.12000e-01 $1.22862 \mathrm{e}+01$ 1.22862e+01 1.22862e+00 1.00000e-09 2.12000e-01 $1.22862 \mathrm{e}+01$ 1.22862e+01 1.22862e+00 1.00000e-09 2.12000e-01 $1.22862 \mathrm{e}+011.22862 \mathrm{e}+011.22862 \mathrm{e}+001.00000 \mathrm{e}-092.12000 \mathrm{e}-01$ $1.22862 \mathrm{e}+01$ 1.22862e+01 1.22862e+00 1.00000e-09 2.12000e-01 $1.00000 \mathrm{e}-05$ 1.00000e-05 1.00000e-06 1.00000e-09 1.00000e-01 $1.00000 \mathrm{e}+001.00000 \mathrm{e}+001.00000 \mathrm{e}-01$ 1.00000e-09 1.00000e-01 Element: 9099 \# of layers: 7

$\mathrm{Kx} \mathrm{Ky} \mathrm{Kz}$ Ss Por

$1.22862 \mathrm{e}+01$ 1.22862e+01 1.22862e+00 1.00000e-09 2.12000e-01 $1.22862 \mathrm{e}+01$ 1.22862e+01 1.22862e+00 1.00000e-09 2.12000e-01 $1.22862 \mathrm{e}+011.22862 \mathrm{e}+01 \quad 1.22862 \mathrm{e}+001.00000 \mathrm{e}-092.12000 \mathrm{e}-01$ $1.22862 \mathrm{e}+011.22862 \mathrm{e}+011.22862 \mathrm{e}+001.00000 \mathrm{e}-092.12000 \mathrm{e}-01$ $1.22862 \mathrm{e}+01$ 1.22862e+01 1.22862e+00 1.00000e-09 2.12000e-01 $1.00000 \mathrm{e}-05$ 1.00000e-05 1.00000e-06 1.00000e-09 1.00000e-01 $1.00000 \mathrm{e}+001.00000 \mathrm{e}+001.00000 \mathrm{e}-011.00000 \mathrm{e}-091.00000 \mathrm{e}-01$ Element: 9100 \# of layers: 7

$\mathrm{Kx} \mathrm{Ky} \mathrm{Kz}$ Ss Por

$1.22862 \mathrm{e}+01$ 1.22862e+01 1.22862e+00 1.00000e-09 2.12000e-01 $1.22862 \mathrm{e}+011.22862 \mathrm{e}+011.22862 \mathrm{e}+001.00000 \mathrm{e}-092.12000 \mathrm{e}-01$ $1.22862 \mathrm{e}+011.22862 \mathrm{e}+011.22862 \mathrm{e}+001.00000 \mathrm{e}-092.12000 \mathrm{e}-01$ $1.22862 \mathrm{e}+011.22862 \mathrm{e}+01$ 1.22862e+00 1.00000e-09 2.12000e-01 $1.22862 \mathrm{e}+01$ 1.22862e+01 1.22862e+00 1.00000e-09 2.12000e-01 $1.00000 \mathrm{e}-051.00000 \mathrm{e}-05$ 1.00000e-06 1.00000e-09 1.00000e-01 $1.00000 \mathrm{e}+001.00000 \mathrm{e}+001.00000 \mathrm{e}-011.00000 \mathrm{e}-091.00000 \mathrm{e}-01$ Element: 9101 \# of layers: 7

$\mathrm{Kx} \mathrm{Ky} \mathrm{Kz}$ Ss Por

$1.29695 \mathrm{e}+01$ 1.29695e+01 1.29695e+00 1.00000e-09 2.12000e-01 $1.29695 \mathrm{e}+011.29695 \mathrm{e}+011.29695 \mathrm{e}+001.00000 \mathrm{e}-092.12000 \mathrm{e}-01$ $1.29695 \mathrm{e}+011.29695 \mathrm{e}+011.29695 \mathrm{e}+001.00000 \mathrm{e}-092.12000 \mathrm{e}-01$ $1.29695 \mathrm{e}+011.29695 \mathrm{e}+011.29695 \mathrm{e}+001.00000 \mathrm{e}-092.12000 \mathrm{e}-01$ $1.29695 \mathrm{e}+011.29695 \mathrm{e}+01$ 1.29695e+00 1.00000e-09 2.12000e-01 $1.00000 \mathrm{e}-05$ 1.00000e-05 1.00000e-06 1.00000e-09 1.00000e-01 $1.00000 \mathrm{e}+001.00000 \mathrm{e}+001.00000 \mathrm{e}-011.00000 \mathrm{e}-091.00000 \mathrm{e}-01$ Element: 9102 \# of layers: 7

$\mathrm{Kx} \mathrm{Ky} \mathrm{Kz}$ Ss Por

$1.29695 \mathrm{e}+01$ 1.29695e+01 1.29695e+00 1.00000e-09 2.12000e-01 $1.29695 \mathrm{e}+011.29695 \mathrm{e}+011.29695 \mathrm{e}+001.00000 \mathrm{e}-092.12000 \mathrm{e}-01$ 
$1.29695 \mathrm{e}+01$ 1.29695e+01 1.29695e+00 1.00000e-09 2.12000e-01 $1.29695 \mathrm{e}+01$ 1.29695e+01 1.29695e+00 1.00000e-09 2.12000e-01 $1.29695 \mathrm{e}+011.29695 \mathrm{e}+01$ 1.29695e+00 1.00000e-09 2.12000e-01 $1.00000 \mathrm{e}-05$ 1.00000e-05 1.00000e-06 1.00000e-09 1.00000e-01 $1.00000 \mathrm{e}+001.00000 \mathrm{e}+001.00000 \mathrm{e}-01$ 1.00000e-09 1.00000e-01 Element: 9103 \# of layers: 7

$\mathrm{Kx} \mathrm{Ky} \mathrm{Kz}$ Ss Por

$1.29695 \mathrm{e}+01$ 1.29695e+01 1.29695e+00 1.00000e-09 2.12000e-01 $1.29695 \mathrm{e}+011.29695 \mathrm{e}+01$ 1.29695e+00 1.00000e-09 2.12000e-01 $1.29695 \mathrm{e}+011.29695 \mathrm{e}+01 \quad 1.29695 \mathrm{e}+001.00000 \mathrm{e}-092.12000 \mathrm{e}-01$ $1.29695 \mathrm{e}+01$ 1.29695e+01 1.29695e+00 1.00000e-09 2.12000e-01 $1.29695 \mathrm{e}+011.29695 \mathrm{e}+011.29695 \mathrm{e}+001.00000 \mathrm{e}-092.12000 \mathrm{e}-01$ $1.00000 \mathrm{e}-05$ 1.00000e-05 1.00000e-06 1.00000e-09 1.00000e-01 $1.00000 \mathrm{e}+001.00000 \mathrm{e}+001.00000 \mathrm{e}-011.00000 \mathrm{e}-09$ 1.00000e-01 Element: 9104 \# of layers: 7

Kx Ky Kz Ss Por

$1.22862 \mathrm{e}+01$ 1.22862e+01 1.22862e+00 1.00000e-09 2.12000e-01 $1.22862 \mathrm{e}+011.22862 \mathrm{e}+011.22862 \mathrm{e}+001.00000 \mathrm{e}-092.12000 \mathrm{e}-01$ $1.22862 \mathrm{e}+01$ 1.22862e+01 1.22862e+00 1.00000e-09 2.12000e-01 $1.22862 \mathrm{e}+011.22862 \mathrm{e}+01$ 1.22862e+00 1.00000e-09 2.12000e-01 $1.22862 \mathrm{e}+011.22862 \mathrm{e}+011.22862 \mathrm{e}+001.00000 \mathrm{e}-092.12000 \mathrm{e}-01$ $1.00000 \mathrm{e}-05$ 1.00000e-05 1.00000e-06 1.00000e-09 1.00000e-01 $1.00000 \mathrm{e}+001.00000 \mathrm{e}+001.00000 \mathrm{e}-01$ 1.00000e-09 1.00000e-01 Element: 9105 \# of layers: 7

$\mathrm{Kx} \mathrm{Ky} \mathrm{Kz}$ Ss Por

$1.22862 \mathrm{e}+011.22862 \mathrm{e}+011.22862 \mathrm{e}+001.00000 \mathrm{e}-092.12000 \mathrm{e}-01$ $1.22862 \mathrm{e}+011.22862 \mathrm{e}+011.22862 \mathrm{e}+001.00000 \mathrm{e}-092.12000 \mathrm{e}-01$ $1.22862 \mathrm{e}+011.22862 \mathrm{e}+011.22862 \mathrm{e}+001.00000 \mathrm{e}-092.12000 \mathrm{e}-01$ $1.22862 \mathrm{e}+011.22862 \mathrm{e}+011.22862 \mathrm{e}+001.00000 \mathrm{e}-092.12000 \mathrm{e}-01$ $1.22862 \mathrm{e}+01$ 1.22862e+01 1.22862e+00 1.00000e-09 2.12000e-01 $1.00000 \mathrm{e}-05$ 1.00000e-05 1.00000e-06 1.00000e-09 1.00000e-01 $1.00000 \mathrm{e}+001.00000 \mathrm{e}+001.00000 \mathrm{e}-011.00000 \mathrm{e}-091.00000 \mathrm{e}-01$ Element: 9106 \# of layers: 7

$\mathrm{Kx} \mathrm{Ky} \mathrm{Kz}$ Ss Por

$1.22862 \mathrm{e}+01$ 1.22862e+01 1.22862e+00 1.00000e-09 2.12000e-01 $1.22862 \mathrm{e}+011.22862 \mathrm{e}+011.22862 \mathrm{e}+001.00000 \mathrm{e}-092.12000 \mathrm{e}-01$ $1.22862 \mathrm{e}+011.22862 \mathrm{e}+011.22862 \mathrm{e}+001.00000 \mathrm{e}-092.12000 \mathrm{e}-01$ $1.22862 \mathrm{e}+011.22862 \mathrm{e}+011.22862 \mathrm{e}+001.00000 \mathrm{e}-092.12000 \mathrm{e}-01$ $1.22862 \mathrm{e}+011.22862 \mathrm{e}+011.22862 \mathrm{e}+001.00000 \mathrm{e}-092.12000 \mathrm{e}-01$ $1.00000 \mathrm{e}-05$ 1.00000e-05 1.00000e-06 1.00000e-09 1.00000e-01 $1.00000 \mathrm{e}+001.00000 \mathrm{e}+001.00000 \mathrm{e}-011.00000 \mathrm{e}-091.00000 \mathrm{e}-01$ Element: 9107 \# of layers: 7

$\mathrm{Kx} \mathrm{Ky} \mathrm{Kz}$ Ss Por

1.22862e+01 1.22862e+01 1.22862e+00 1.00000e-09 2.12000e-01 $1.22862 \mathrm{e}+011.22862 \mathrm{e}+011.22862 \mathrm{e}+001.00000 \mathrm{e}-092.12000 \mathrm{e}-01$ $1.22862 \mathrm{e}+011.22862 \mathrm{e}+011.22862 \mathrm{e}+001.00000 \mathrm{e}-092.12000 \mathrm{e}-01$ 
$1.22862 \mathrm{e}+011.22862 \mathrm{e}+01$ 1.22862e+00 1.00000e-09 2.12000e-01 $1.22862 \mathrm{e}+01$ 1.22862e+01 1.22862e+00 1.00000e-09 2.12000e-01 $1.00000 \mathrm{e}-05$ 1.00000e-05 1.00000e-06 1.00000e-09 1.00000e-01 $1.00000 \mathrm{e}+001.00000 \mathrm{e}+001.00000 \mathrm{e}-011.00000 \mathrm{e}-091.00000 \mathrm{e}-01$ Element: 9108 \# of layers: 7

$\mathrm{Kx} \mathrm{Ky} \mathrm{Kz}$ Ss Por

$1.29695 \mathrm{e}+011.29695 \mathrm{e}+01$ 1.29695e+00 1.00000e-09 2.12000e-01 $1.29695 \mathrm{e}+011.29695 \mathrm{e}+011.29695 \mathrm{e}+001.00000 \mathrm{e}-092.12000 \mathrm{e}-01$ $1.29695 \mathrm{e}+011.29695 \mathrm{e}+011.29695 \mathrm{e}+001.00000 \mathrm{e}-092.12000 \mathrm{e}-01$ $1.29695 \mathrm{e}+011.29695 \mathrm{e}+01 \quad 1.29695 \mathrm{e}+001.00000 \mathrm{e}-092.12000 \mathrm{e}-01$ $1.29695 \mathrm{e}+01$ 1.29695e+01 1.29695e+00 1.00000e-09 2.12000e-01 $1.00000 \mathrm{e}-05$ 1.00000e-05 1.00000e-06 1.00000e-09 1.00000e-01 $1.00000 \mathrm{e}+001.00000 \mathrm{e}+001.00000 \mathrm{e}-011.00000 \mathrm{e}-091.00000 \mathrm{e}-01$ Element: 9109 \# of layers: 7

$\mathrm{Kx} \mathrm{Ky} \mathrm{Kz}$ Ss Por

$1.29695 \mathrm{e}+01$ 1.29695e+01 1.29695e+00 1.00000e-09 2.12000e-01 $1.29695 \mathrm{e}+011.29695 \mathrm{e}+011.29695 \mathrm{e}+001.00000 \mathrm{e}-092.12000 \mathrm{e}-01$ $1.29695 \mathrm{e}+011.29695 \mathrm{e}+011.29695 \mathrm{e}+001.00000 \mathrm{e}-092.12000 \mathrm{e}-01$ $1.29695 \mathrm{e}+01$ 1.29695e+01 1.29695e+00 1.00000e-09 2.12000e-01 $1.29695 \mathrm{e}+01$ 1.29695e+01 1.29695e+00 1.00000e-09 2.12000e-01 $1.00000 \mathrm{e}-05$ 1.00000e-05 1.00000e-06 1.00000e-09 1.00000e-01 $1.00000 \mathrm{e}+001.00000 \mathrm{e}+001.00000 \mathrm{e}-011.00000 \mathrm{e}-091.00000 \mathrm{e}-01$ Element: 9110 \# of layers: 7

Kx Ky Kz Ss Por

$1.29695 \mathrm{e}+01$ 1.29695e+01 1.29695e+00 1.00000e-09 2.12000e-01 $1.29695 \mathrm{e}+011.29695 \mathrm{e}+01$ 1.29695e+00 1.00000e-09 2.12000e-01 $1.29695 \mathrm{e}+011.29695 \mathrm{e}+01$ 1.29695e+00 1.00000e-09 2.12000e-01 $1.29695 \mathrm{e}+011.29695 \mathrm{e}+011.29695 \mathrm{e}+001.00000 \mathrm{e}-092.12000 \mathrm{e}-01$ $1.29695 \mathrm{e}+011.29695 \mathrm{e}+011.29695 \mathrm{e}+001.00000 \mathrm{e}-092.12000 \mathrm{e}-01$ $1.00000 \mathrm{e}-05$ 1.00000e-05 1.00000e-06 1.00000e-09 1.00000e-01 $1.00000 \mathrm{e}+001.00000 \mathrm{e}+001.00000 \mathrm{e}-01$ 1.00000e-09 1.00000e-01 Element: 9111 \# of layers: 7

Kx Ky Kz Ss Por

$1.29695 \mathrm{e}+01$ 1.29695e+01 1.29695e+00 1.00000e-09 2.12000e-01 $1.29695 \mathrm{e}+011.29695 \mathrm{e}+011.29695 \mathrm{e}+001.00000 \mathrm{e}-092.12000 \mathrm{e}-01$ $1.29695 \mathrm{e}+011.29695 \mathrm{e}+01$ 1.29695e+00 1.00000e-09 2.12000e-01 $1.29695 \mathrm{e}+011.29695 \mathrm{e}+011.29695 \mathrm{e}+001.00000 \mathrm{e}-092.12000 \mathrm{e}-01$ $1.29695 \mathrm{e}+011.29695 \mathrm{e}+011.29695 \mathrm{e}+001.00000 \mathrm{e}-092.12000 \mathrm{e}-01$ $1.00000 \mathrm{e}-05$ 1.00000e-05 1.00000e-06 1.00000e-09 1.00000e-01 $1.00000 \mathrm{e}+001.00000 \mathrm{e}+001.00000 \mathrm{e}-01$ 1.00000e-09 1.00000e-01 Element: 9112 \# of layers: 7

$\mathrm{Kx} \mathrm{Ky} \mathrm{Kz}$ Ss Por

$1.29695 \mathrm{e}+01$ 1.29695e+01 1.29695e+00 1.00000e-09 2.12000e-01 $1.29695 \mathrm{e}+01$ 1.29695e+01 1.29695e+00 1.00000e-09 2.12000e-01 $1.29695 \mathrm{e}+01$ 1.29695e+01 1.29695e+00 1.00000e-09 2.12000e-01 $1.29695 \mathrm{e}+011.29695 \mathrm{e}+011.29695 \mathrm{e}+00$ 1.00000e-09 2.12000e-01 
$1.29695 \mathrm{e}+011.29695 \mathrm{e}+011.29695 \mathrm{e}+00$ 1.00000e-09 2.12000e-01 $1.00000 \mathrm{e}-05$ 1.00000e-05 1.00000e-06 1.00000e-09 1.00000e-01 $1.00000 \mathrm{e}+001.00000 \mathrm{e}+001.00000 \mathrm{e}-011.00000 \mathrm{e}-091.00000 \mathrm{e}-01$ Element: 9113 \# of layers: 7

Kx Ky Kz Ss Por

$1.29695 \mathrm{e}+011.29695 \mathrm{e}+011.29695 \mathrm{e}+00$ 1.00000e-09 2.12000e-01 $1.29695 \mathrm{e}+011.29695 \mathrm{e}+011.29695 \mathrm{e}+001.00000 \mathrm{e}-092.12000 \mathrm{e}-01$ $1.29695 \mathrm{e}+011.29695 \mathrm{e}+011.29695 \mathrm{e}+001.00000 \mathrm{e}-092.12000 \mathrm{e}-01$ $1.29695 \mathrm{e}+011.29695 \mathrm{e}+011.29695 \mathrm{e}+001.00000 \mathrm{e}-092.12000 \mathrm{e}-01$ $1.29695 \mathrm{e}+011.29695 \mathrm{e}+011.29695 \mathrm{e}+001.00000 \mathrm{e}-092.12000 \mathrm{e}-01$ $1.00000 \mathrm{e}-05$ 1.00000e-05 1.00000e-06 1.00000e-09 1.00000e-01 $1.00000 \mathrm{e}+001.00000 \mathrm{e}+001.00000 \mathrm{e}-011.00000 \mathrm{e}-091.00000 \mathrm{e}-01$ Element: 9114 \# of layers: 7

Kx Ky Kz Ss Por

$1.29695 \mathrm{e}+011.29695 \mathrm{e}+011.29695 \mathrm{e}+00$ 1.00000e-09 2.12000e-01 $1.29695 \mathrm{e}+011.29695 \mathrm{e}+011.29695 \mathrm{e}+001.00000 \mathrm{e}-092.12000 \mathrm{e}-01$ $1.29695 \mathrm{e}+011.29695 \mathrm{e}+011.29695 \mathrm{e}+001.00000 \mathrm{e}-092.12000 \mathrm{e}-01$ $1.29695 \mathrm{e}+011.29695 \mathrm{e}+011.29695 \mathrm{e}+001.00000 \mathrm{e}-092.12000 \mathrm{e}-01$ $1.29695 \mathrm{e}+011.29695 \mathrm{e}+011.29695 \mathrm{e}+001.00000 \mathrm{e}-092.12000 \mathrm{e}-01$ $1.00000 \mathrm{e}-05$ 1.00000e-05 1.00000e-06 1.00000e-09 1.00000e-01 $1.00000 \mathrm{e}+001.00000 \mathrm{e}+001.00000 \mathrm{e}-011.00000 \mathrm{e}-091.00000 \mathrm{e}-01$ Element: 9115 \# of layers: 7

Kx Ky Kz Ss Por

$1.29695 \mathrm{e}+011.29695 \mathrm{e}+011.29695 \mathrm{e}+001.00000 \mathrm{e}-092.12000 \mathrm{e}-01$ $1.29695 \mathrm{e}+011.29695 \mathrm{e}+011.29695 \mathrm{e}+001.00000 \mathrm{e}-092.12000 \mathrm{e}-01$ $1.29695 \mathrm{e}+011.29695 \mathrm{e}+011.29695 \mathrm{e}+001.00000 \mathrm{e}-092.12000 \mathrm{e}-01$ $1.29695 \mathrm{e}+011.29695 \mathrm{e}+011.29695 \mathrm{e}+001.00000 \mathrm{e}-092.12000 \mathrm{e}-01$ $1.29695 \mathrm{e}+011.29695 \mathrm{e}+011.29695 \mathrm{e}+001.00000 \mathrm{e}-092.12000 \mathrm{e}-01$ $1.00000 \mathrm{e}-051.00000 \mathrm{e}-05$ 1.00000e-06 1.00000e-09 1.00000e-01 $1.00000 \mathrm{e}+001.00000 \mathrm{e}+001.00000 \mathrm{e}-011.00000 \mathrm{e}-091.00000 \mathrm{e}-01$ Element: 9116 \# of layers: 7

Kx Ky Kz Ss Por

$1.29695 \mathrm{e}+011.29695 \mathrm{e}+011.29695 \mathrm{e}+00$ 1.00000e-09 2.12000e-01 $1.29695 \mathrm{e}+011.29695 \mathrm{e}+011.29695 \mathrm{e}+001.00000 \mathrm{e}-092.12000 \mathrm{e}-01$ $1.29695 \mathrm{e}+011.29695 \mathrm{e}+011.29695 \mathrm{e}+001.00000 \mathrm{e}-092.12000 \mathrm{e}-01$ $1.29695 \mathrm{e}+011.29695 \mathrm{e}+011.29695 \mathrm{e}+001.00000 \mathrm{e}-092.12000 \mathrm{e}-01$ $1.29695 \mathrm{e}+011.29695 \mathrm{e}+011.29695 \mathrm{e}+001.00000 \mathrm{e}-092.12000 \mathrm{e}-01$ $1.00000 \mathrm{e}-05$ 1.00000e-05 1.00000e-06 1.00000e-09 1.00000e-01 $1.00000 \mathrm{e}+001.00000 \mathrm{e}+001.00000 \mathrm{e}-011.00000 \mathrm{e}-091.00000 \mathrm{e}-01$ Element: 9117 \# of layers: 7

Kx Ky Kz Ss Por

$1.29695 \mathrm{e}+011.29695 \mathrm{e}+011.29695 \mathrm{e}+00$ 1.00000e-09 2.12000e-01 $1.29695 \mathrm{e}+011.29695 \mathrm{e}+011.29695 \mathrm{e}+001.00000 \mathrm{e}-092.12000 \mathrm{e}-01$ $1.29695 \mathrm{e}+011.29695 \mathrm{e}+011.29695 \mathrm{e}+001.00000 \mathrm{e}-092.12000 \mathrm{e}-01$ $1.29695 \mathrm{e}+011.29695 \mathrm{e}+011.29695 \mathrm{e}+001.00000 \mathrm{e}-092.12000 \mathrm{e}-01$ $1.29695 \mathrm{e}+011.29695 \mathrm{e}+011.29695 \mathrm{e}+001.00000 \mathrm{e}-092.12000 \mathrm{e}-01$ 
$1.00000 \mathrm{e}-05$ 1.00000e-05 1.00000e-06 1.00000e-09 1.00000e-01 $1.00000 \mathrm{e}+001.00000 \mathrm{e}+001.00000 \mathrm{e}-01$ 1.00000e-09 1.00000e-01 Element: 9118 \# of layers: 7

Kx Ky Kz Ss Por

$1.29695 \mathrm{e}+011.29695 \mathrm{e}+011.29695 \mathrm{e}+001.00000 \mathrm{e}-092.12000 \mathrm{e}-01$

$1.29695 \mathrm{e}+011.29695 \mathrm{e}+011.29695 \mathrm{e}+001.00000 \mathrm{e}-092.12000 \mathrm{e}-01$

$1.29695 \mathrm{e}+011.29695 \mathrm{e}+01 \quad 1.29695 \mathrm{e}+001.00000 \mathrm{e}-092.12000 \mathrm{e}-01$

$1.29695 \mathrm{e}+011.29695 \mathrm{e}+011.29695 \mathrm{e}+001.00000 \mathrm{e}-092.12000 \mathrm{e}-01$

$1.29695 \mathrm{e}+011.29695 \mathrm{e}+01$ 1.29695e+00 1.00000e-09 2.12000e-01

$1.00000 \mathrm{e}-05$ 1.00000e-05 1.00000e-06 1.00000e-09 1.00000e-01

$1.00000 \mathrm{e}+001.00000 \mathrm{e}+001.00000 \mathrm{e}-011.00000 \mathrm{e}-091.00000 \mathrm{e}-01$

Element: 9119 \# of layers: 7

$\mathrm{Kx} \mathrm{Ky} \mathrm{Kz}$ Ss Por

$1.36004 \mathrm{e}+011.36004 \mathrm{e}+011.36004 \mathrm{e}+001.00000 \mathrm{e}-092.12000 \mathrm{e}-01$

$1.36004 \mathrm{e}+011.36004 \mathrm{e}+011.36004 \mathrm{e}+001.00000 \mathrm{e}-092.12000 \mathrm{e}-01$

$1.36004 \mathrm{e}+011.36004 \mathrm{e}+011.36004 \mathrm{e}+001.00000 \mathrm{e}-092.12000 \mathrm{e}-01$

$1.36004 \mathrm{e}+011.36004 \mathrm{e}+011.36004 \mathrm{e}+001.00000 \mathrm{e}-092.12000 \mathrm{e}-01$

$1.36004 \mathrm{e}+011.36004 \mathrm{e}+011.36004 \mathrm{e}+001.00000 \mathrm{e}-092.12000 \mathrm{e}-01$

$1.00000 \mathrm{e}-051.00000 \mathrm{e}-051.00000 \mathrm{e}-061.00000 \mathrm{e}-091.00000 \mathrm{e}-01$

$1.00000 \mathrm{e}+001.00000 \mathrm{e}+001.00000 \mathrm{e}-011.00000 \mathrm{e}-091.00000 \mathrm{e}-01$

Element: 9120 \# of layers: 7

$\mathrm{Kx} \mathrm{Ky} \mathrm{Kz}$ Ss Por

$1.36004 \mathrm{e}+01$ 1.36004e+01 1.36004e+00 1.00000e-09 2.12000e-01

$1.36004 \mathrm{e}+011.36004 \mathrm{e}+011.36004 \mathrm{e}+001.00000 \mathrm{e}-092.12000 \mathrm{e}-01$

$1.36004 \mathrm{e}+011.36004 \mathrm{e}+011.36004 \mathrm{e}+001.00000 \mathrm{e}-092.12000 \mathrm{e}-01$

$1.36004 \mathrm{e}+011.36004 \mathrm{e}+011.36004 \mathrm{e}+001.00000 \mathrm{e}-092.12000 \mathrm{e}-01$

$1.36004 \mathrm{e}+011.36004 \mathrm{e}+011.36004 \mathrm{e}+001.00000 \mathrm{e}-092.12000 \mathrm{e}-01$

$1.00000 \mathrm{e}-05$ 1.00000e-05 1.00000e-06 1.00000e-09 1.00000e-01

$1.00000 \mathrm{e}+001.00000 \mathrm{e}+001.00000 \mathrm{e}-011.00000 \mathrm{e}-091.00000 \mathrm{e}-01$

Element: 9121 \# of layers: 7

$\mathrm{Kx} \mathrm{Ky} \mathrm{Kz}$ Ss Por

$1.36004 \mathrm{e}+011.36004 \mathrm{e}+011.36004 \mathrm{e}+001.00000 \mathrm{e}-092.12000 \mathrm{e}-01$

$1.36004 \mathrm{e}+011.36004 \mathrm{e}+011.36004 \mathrm{e}+001.00000 \mathrm{e}-092.12000 \mathrm{e}-01$

$1.36004 \mathrm{e}+011.36004 \mathrm{e}+011.36004 \mathrm{e}+001.00000 \mathrm{e}-092.12000 \mathrm{e}-01$

$1.36004 \mathrm{e}+011.36004 \mathrm{e}+011.36004 \mathrm{e}+001.00000 \mathrm{e}-092.12000 \mathrm{e}-01$

$1.36004 \mathrm{e}+011.36004 \mathrm{e}+011.36004 \mathrm{e}+001.00000 \mathrm{e}-092.12000 \mathrm{e}-01$

$1.00000 \mathrm{e}-05$ 1.00000e-05 1.00000e-06 1.00000e-09 1.00000e-01

$1.00000 \mathrm{e}+001.00000 \mathrm{e}+001.00000 \mathrm{e}-011.00000 \mathrm{e}-091.00000 \mathrm{e}-01$

Element: 9122 \# of layers: 7

$\mathrm{Kx} \mathrm{Ky} \mathrm{Kz}$ Ss Por

$1.29695 \mathrm{e}+01$ 1.29695e+01 1.29695e+00 1.00000e-09 2.12000e-01

$1.29695 \mathrm{e}+011.29695 \mathrm{e}+011.29695 \mathrm{e}+001.00000 \mathrm{e}-092.12000 \mathrm{e}-01$

$1.29695 \mathrm{e}+011.29695 \mathrm{e}+01$ 1.29695e+00 1.00000e-09 2.12000e-01

$1.29695 \mathrm{e}+01$ 1.29695e+01 1.29695e+00 1.00000e-09 2.12000e-01

$1.29695 \mathrm{e}+011.29695 \mathrm{e}+011.29695 \mathrm{e}+001.00000 \mathrm{e}-092.12000 \mathrm{e}-01$

$1.00000 \mathrm{e}-05$ 1.00000e-05 1.00000e-06 1.00000e-09 1.00000e-01 
$1.00000 \mathrm{e}+001.00000 \mathrm{e}+00$ 1.00000e-01 1.00000e-09 1.00000e-01

Element: 9123 \# of layers: 7

$\mathrm{Kx} \mathrm{Ky} \mathrm{Kz}$ Ss Por

$1.29695 \mathrm{e}+01$ 1.29695e+01 1.29695e+00 1.00000e-09 2.12000e-01

$1.29695 \mathrm{e}+011.29695 \mathrm{e}+011.29695 \mathrm{e}+001.00000 \mathrm{e}-092.12000 \mathrm{e}-01$

$1.29695 \mathrm{e}+011.29695 \mathrm{e}+011.29695 \mathrm{e}+001.00000 \mathrm{e}-092.12000 \mathrm{e}-01$

$1.29695 \mathrm{e}+01$ 1.29695e+01 1.29695e+00 1.00000e-09 2.12000e-01

$1.29695 \mathrm{e}+011.29695 \mathrm{e}+011.29695 \mathrm{e}+001.00000 \mathrm{e}-092.12000 \mathrm{e}-01$

$1.00000 \mathrm{e}-051.00000 \mathrm{e}-051.00000 \mathrm{e}-061.00000 \mathrm{e}-091.00000 \mathrm{e}-01$

$1.00000 \mathrm{e}+001.00000 \mathrm{e}+001.00000 \mathrm{e}-011.00000 \mathrm{e}-091.00000 \mathrm{e}-01$

Element: 9124 \# of layers: 7

Kx Ky Kz Ss Por

$1.29695 \mathrm{e}+01$ 1.29695e+01 1.29695e+00 1.00000e-09 2.12000e-01

$1.29695 \mathrm{e}+01$ 1.29695e+01 1.29695e+00 1.00000e-09 2.12000e-01

$1.29695 \mathrm{e}+01$ 1.29695e+01 1.29695e+00 1.00000e-09 2.12000e-01

$1.29695 \mathrm{e}+011.29695 \mathrm{e}+011.29695 \mathrm{e}+001.00000 \mathrm{e}-092.12000 \mathrm{e}-01$

$1.29695 \mathrm{e}+011.29695 \mathrm{e}+011.29695 \mathrm{e}+001.00000 \mathrm{e}-092.12000 \mathrm{e}-01$

$1.00000 \mathrm{e}-05$ 1.00000e-05 1.00000e-06 1.00000e-09 1.00000e-01

$1.00000 \mathrm{e}+001.00000 \mathrm{e}+001.00000 \mathrm{e}-01$ 1.00000e-09 1.00000e-01

Element: 9125 \# of layers: 7

$\mathrm{Kx} \mathrm{Ky} \mathrm{Kz}$ Ss Por

$1.29695 \mathrm{e}+01$ 1.29695e+01 1.29695e+00 1.00000e-09 2.12000e-01

$1.29695 \mathrm{e}+01$ 1.29695e+01 1.29695e+00 1.00000e-09 2.12000e-01

$1.29695 \mathrm{e}+011.29695 \mathrm{e}+011.29695 \mathrm{e}+001.00000 \mathrm{e}-092.12000 \mathrm{e}-01$

$1.29695 \mathrm{e}+011.29695 \mathrm{e}+011.29695 \mathrm{e}+001.00000 \mathrm{e}-092.12000 \mathrm{e}-01$

$1.29695 \mathrm{e}+011.29695 \mathrm{e}+011.29695 \mathrm{e}+001.00000 \mathrm{e}-092.12000 \mathrm{e}-01$

$1.00000 \mathrm{e}-05$ 1.00000e-05 1.00000e-06 1.00000e-09 1.00000e-01

$1.00000 \mathrm{e}+001.00000 \mathrm{e}+001.00000 \mathrm{e}-011.00000 \mathrm{e}-09$ 1.00000e-01

Element: 9126 \# of layers: 7

$\mathrm{Kx} \mathrm{Ky} \mathrm{Kz}$ Ss Por

$1.36004 \mathrm{e}+01$ 1.36004e+01 1.36004e+00 1.00000e-09 2.12000e-01

$1.36004 \mathrm{e}+011.36004 \mathrm{e}+011.36004 \mathrm{e}+001.00000 \mathrm{e}-092.12000 \mathrm{e}-01$

$1.36004 \mathrm{e}+011.36004 \mathrm{e}+011.36004 \mathrm{e}+001.00000 \mathrm{e}-092.12000 \mathrm{e}-01$

$1.36004 \mathrm{e}+011.36004 \mathrm{e}+011.36004 \mathrm{e}+001.00000 \mathrm{e}-092.12000 \mathrm{e}-01$

$1.36004 \mathrm{e}+011.36004 \mathrm{e}+011.36004 \mathrm{e}+001.00000 \mathrm{e}-092.12000 \mathrm{e}-01$

$1.00000 \mathrm{e}-05$ 1.00000e-05 1.00000e-06 1.00000e-09 1.00000e-01

$1.00000 \mathrm{e}+001.00000 \mathrm{e}+001.00000 \mathrm{e}-011.00000 \mathrm{e}-091.00000 \mathrm{e}-01$

Element: 9127 \# of layers: 8

$\mathrm{Kx} \mathrm{Ky} \mathrm{Kz}$ Ss Por

$3.50000 \mathrm{e}+02$ 3.50000e+02 3.50000e+01 1.00000e-09 1.00000e-01

$1.36004 \mathrm{e}+011.36004 \mathrm{e}+011.36004 \mathrm{e}+001.00000 \mathrm{e}-092.12000 \mathrm{e}-01$

$1.36004 \mathrm{e}+011.36004 \mathrm{e}+011.36004 \mathrm{e}+001.00000 \mathrm{e}-092.12000 \mathrm{e}-01$

$1.36004 \mathrm{e}+011.36004 \mathrm{e}+011.36004 \mathrm{e}+001.00000 \mathrm{e}-092.12000 \mathrm{e}-01$

$1.36004 \mathrm{e}+011.36004 \mathrm{e}+01$ 1.36004e+00 1.00000e-09 2.12000e-01

$1.36004 \mathrm{e}+011.36004 \mathrm{e}+011.36004 \mathrm{e}+001.00000 \mathrm{e}-092.12000 \mathrm{e}-01$

$1.00000 \mathrm{e}-05$ 1.00000e-05 1.00000e-06 1.00000e-09 1.00000e-01 
$1.00000 \mathrm{e}+001.00000 \mathrm{e}+00$ 1.00000e-01 1.00000e-09 1.00000e-01

Element: 9128 \# of layers: 8

$\mathrm{Kx} \mathrm{Ky} \mathrm{Kz}$ Ss Por

$3.50000 \mathrm{e}+02$ 3.50000e+02 3.50000e+01 1.00000e-09 1.00000e-01

$1.36004 \mathrm{e}+011.36004 \mathrm{e}+011.36004 \mathrm{e}+001.00000 \mathrm{e}-092.12000 \mathrm{e}-01$

$1.36004 \mathrm{e}+011.36004 \mathrm{e}+011.36004 \mathrm{e}+001.00000 \mathrm{e}-092.12000 \mathrm{e}-01$

$1.36004 \mathrm{e}+011.36004 \mathrm{e}+011.36004 \mathrm{e}+001.00000 \mathrm{e}-092.12000 \mathrm{e}-01$

$1.36004 \mathrm{e}+011.36004 \mathrm{e}+011.36004 \mathrm{e}+001.00000 \mathrm{e}-092.12000 \mathrm{e}-01$

$1.36004 \mathrm{e}+011.36004 \mathrm{e}+011.36004 \mathrm{e}+001.00000 \mathrm{e}-092.12000 \mathrm{e}-01$

$1.00000 \mathrm{e}-05$ 1.00000e-05 1.00000e-06 1.00000e-09 1.00000e-01

$1.00000 \mathrm{e}+001.00000 \mathrm{e}+001.00000 \mathrm{e}-011.00000 \mathrm{e}-091.00000 \mathrm{e}-01$

Element: 9129 \# of layers: 8

$\mathrm{Kx} \mathrm{Ky} \mathrm{Kz}$ Ss Por

$3.50000 \mathrm{e}+023.50000 \mathrm{e}+023.50000 \mathrm{e}+01$ 1.00000e-09 1.00000e-01

$1.36004 \mathrm{e}+011.36004 \mathrm{e}+011.36004 \mathrm{e}+001.00000 \mathrm{e}-092.12000 \mathrm{e}-01$

$1.36004 \mathrm{e}+011.36004 \mathrm{e}+011.36004 \mathrm{e}+001.00000 \mathrm{e}-092.12000 \mathrm{e}-01$

$1.36004 \mathrm{e}+011.36004 \mathrm{e}+011.36004 \mathrm{e}+001.00000 \mathrm{e}-092.12000 \mathrm{e}-01$

$1.36004 \mathrm{e}+011.36004 \mathrm{e}+011.36004 \mathrm{e}+001.00000 \mathrm{e}-092.12000 \mathrm{e}-01$

$1.36004 \mathrm{e}+011.36004 \mathrm{e}+011.36004 \mathrm{e}+001.00000 \mathrm{e}-092.12000 \mathrm{e}-01$

$1.00000 \mathrm{e}-05$ 1.00000e-05 1.00000e-06 1.00000e-09 1.00000e-01

$1.00000 \mathrm{e}+001.00000 \mathrm{e}+001.00000 \mathrm{e}-011.00000 \mathrm{e}-091.00000 \mathrm{e}-01$

Element: 9130 \# of layers: 7

$\mathrm{Kx} \mathrm{Ky} \mathrm{Kz}$ Ss Por

$1.36004 \mathrm{e}+011.36004 \mathrm{e}+011.36004 \mathrm{e}+001.00000 \mathrm{e}-092.12000 \mathrm{e}-01$

$1.36004 \mathrm{e}+011.36004 \mathrm{e}+011.36004 \mathrm{e}+001.00000 \mathrm{e}-092.12000 \mathrm{e}-01$

$1.36004 \mathrm{e}+011.36004 \mathrm{e}+011.36004 \mathrm{e}+001.00000 \mathrm{e}-092.12000 \mathrm{e}-01$

$1.36004 \mathrm{e}+011.36004 \mathrm{e}+011.36004 \mathrm{e}+001.00000 \mathrm{e}-092.12000 \mathrm{e}-01$

$1.36004 \mathrm{e}+011.36004 \mathrm{e}+011.36004 \mathrm{e}+001.00000 \mathrm{e}-092.12000 \mathrm{e}-01$

$1.00000 \mathrm{e}-05$ 1.00000e-05 1.00000e-06 1.00000e-09 1.00000e-01

$1.00000 \mathrm{e}+001.00000 \mathrm{e}+001.00000 \mathrm{e}-011.00000 \mathrm{e}-091.00000 \mathrm{e}-01$

Element: 9131 \# of layers: 7

$\mathrm{Kx} \mathrm{Ky} \mathrm{Kz}$ Ss Por

$1.36004 \mathrm{e}+011.36004 \mathrm{e}+011.36004 \mathrm{e}+001.00000 \mathrm{e}-092.12000 \mathrm{e}-01$

$1.36004 \mathrm{e}+011.36004 \mathrm{e}+011.36004 \mathrm{e}+001.00000 \mathrm{e}-092.12000 \mathrm{e}-01$

$1.36004 \mathrm{e}+011.36004 \mathrm{e}+011.36004 \mathrm{e}+001.00000 \mathrm{e}-092.12000 \mathrm{e}-01$

$1.36004 \mathrm{e}+011.36004 \mathrm{e}+011.36004 \mathrm{e}+001.00000 \mathrm{e}-092.12000 \mathrm{e}-01$

$1.36004 \mathrm{e}+011.36004 \mathrm{e}+011.36004 \mathrm{e}+001.00000 \mathrm{e}-092.12000 \mathrm{e}-01$

$1.00000 \mathrm{e}-05$ 1.00000e-05 1.00000e-06 1.00000e-09 1.00000e-01

$1.00000 \mathrm{e}+001.00000 \mathrm{e}+001.00000 \mathrm{e}-01$ 1.00000e-09 1.00000e-01

Element: 9132 \# of layers: 7

$\mathrm{Kx} \mathrm{Ky} \mathrm{Kz}$ Ss Por

$1.36004 \mathrm{e}+01$ 1.36004e+01 1.36004e+00 1.00000e-09 2.12000e-01

$1.36004 \mathrm{e}+011.36004 \mathrm{e}+01$ 1.36004e+00 1.00000e-09 2.12000e-01

$1.36004 \mathrm{e}+011.36004 \mathrm{e}+01$ 1.36004e+00 1.00000e-09 2.12000e-01

$1.36004 \mathrm{e}+011.36004 \mathrm{e}+011.36004 \mathrm{e}+001.00000 \mathrm{e}-092.12000 \mathrm{e}-01$

$1.36004 \mathrm{e}+011.36004 \mathrm{e}+011.36004 \mathrm{e}+001.00000 \mathrm{e}-092.12000 \mathrm{e}-01$ 
$1.00000 \mathrm{e}-05$ 1.00000e-05 1.00000e-06 1.00000e-09 1.00000e-01 $1.00000 \mathrm{e}+001.00000 \mathrm{e}+001.00000 \mathrm{e}-01$ 1.00000e-09 1.00000e-01 Element: 9133 \# of layers: 7

Kx Ky Kz Ss Por

$1.36004 \mathrm{e}+011.36004 \mathrm{e}+011.36004 \mathrm{e}+001.00000 \mathrm{e}-092.12000 \mathrm{e}-01$

$1.36004 \mathrm{e}+011.36004 \mathrm{e}+011.36004 \mathrm{e}+001.00000 \mathrm{e}-092.12000 \mathrm{e}-01$

$1.36004 \mathrm{e}+011.36004 \mathrm{e}+011.36004 \mathrm{e}+001.00000 \mathrm{e}-092.12000 \mathrm{e}-01$

$1.36004 \mathrm{e}+011.36004 \mathrm{e}+011.36004 \mathrm{e}+001.00000 \mathrm{e}-092.12000 \mathrm{e}-01$

$1.36004 \mathrm{e}+011.36004 \mathrm{e}+011.36004 \mathrm{e}+001.00000 \mathrm{e}-092.12000 \mathrm{e}-01$

$1.00000 \mathrm{e}-05$ 1.00000e-05 1.00000e-06 1.00000e-09 1.00000e-01

$1.00000 \mathrm{e}+001.00000 \mathrm{e}+001.00000 \mathrm{e}-011.00000 \mathrm{e}-091.00000 \mathrm{e}-01$

Element: 9134 \# of layers: 7

$\mathrm{Kx} \mathrm{Ky} \mathrm{Kz}$ Ss Por

$1.36004 \mathrm{e}+011.36004 \mathrm{e}+011.36004 \mathrm{e}+001.00000 \mathrm{e}-092.12000 \mathrm{e}-01$

$1.36004 \mathrm{e}+011.36004 \mathrm{e}+011.36004 \mathrm{e}+001.00000 \mathrm{e}-092.12000 \mathrm{e}-01$

$1.36004 \mathrm{e}+011.36004 \mathrm{e}+011.36004 \mathrm{e}+001.00000 \mathrm{e}-092.12000 \mathrm{e}-01$

$1.36004 \mathrm{e}+011.36004 \mathrm{e}+011.36004 \mathrm{e}+001.00000 \mathrm{e}-092.12000 \mathrm{e}-01$

$1.36004 \mathrm{e}+011.36004 \mathrm{e}+011.36004 \mathrm{e}+001.00000 \mathrm{e}-092.12000 \mathrm{e}-01$

$1.00000 \mathrm{e}-05$ 1.00000e-05 1.00000e-06 1.00000e-09 1.00000e-01

$1.00000 \mathrm{e}+001.00000 \mathrm{e}+001.00000 \mathrm{e}-011.00000 \mathrm{e}-091.00000 \mathrm{e}-01$

Element: 9135 \# of layers: 7

$\mathrm{Kx} \mathrm{Ky} \mathrm{Kz}$ Ss Por

$1.36004 \mathrm{e}+01$ 1.36004e+01 1.36004e+00 1.00000e-09 2.12000e-01

$1.36004 \mathrm{e}+011.36004 \mathrm{e}+011.36004 \mathrm{e}+001.00000 \mathrm{e}-092.12000 \mathrm{e}-01$

$1.36004 \mathrm{e}+011.36004 \mathrm{e}+011.36004 \mathrm{e}+001.00000 \mathrm{e}-092.12000 \mathrm{e}-01$

$1.36004 \mathrm{e}+011.36004 \mathrm{e}+011.36004 \mathrm{e}+001.00000 \mathrm{e}-092.12000 \mathrm{e}-01$

$1.36004 \mathrm{e}+011.36004 \mathrm{e}+011.36004 \mathrm{e}+001.00000 \mathrm{e}-092.12000 \mathrm{e}-01$

$1.00000 \mathrm{e}-05$ 1.00000e-05 1.00000e-06 1.00000e-09 1.00000e-01

$1.00000 \mathrm{e}+001.00000 \mathrm{e}+001.00000 \mathrm{e}-011.00000 \mathrm{e}-091.00000 \mathrm{e}-01$

Element: 9136 \# of layers: 7

$\mathrm{Kx} \mathrm{Ky} \mathrm{Kz}$ Ss Por

$1.52090 \mathrm{e}+011.52090 \mathrm{e}+01$ 1.52090e+00 1.00000e-09 2.12000e-01

$1.52090 \mathrm{e}+011.52090 \mathrm{e}+011.52090 \mathrm{e}+001.00000 \mathrm{e}-092.12000 \mathrm{e}-01$

$1.52090 \mathrm{e}+011.52090 \mathrm{e}+011.52090 \mathrm{e}+001.00000 \mathrm{e}-092.12000 \mathrm{e}-01$

$1.52090 \mathrm{e}+011.52090 \mathrm{e}+011.52090 \mathrm{e}+001.00000 \mathrm{e}-092.12000 \mathrm{e}-01$

$1.52090 \mathrm{e}+01$ 1.52090e+01 1.52090e+00 1.00000e-09 2.12000e-01

$1.00000 \mathrm{e}-05$ 1.00000e-05 1.00000e-06 1.00000e-09 1.00000e-01

$1.00000 \mathrm{e}+001.00000 \mathrm{e}+001.00000 \mathrm{e}-011.00000 \mathrm{e}-091.00000 \mathrm{e}-01$

Element: 9137 \# of layers: 7

$\mathrm{Kx} \mathrm{Ky} \mathrm{Kz}$ Ss Por

$1.52090 \mathrm{e}+01$ 1.52090e+01 1.52090e+00 1.00000e-09 2.12000e-01

$1.52090 \mathrm{e}+011.52090 \mathrm{e}+011.52090 \mathrm{e}+001.00000 \mathrm{e}-092.12000 \mathrm{e}-01$

$1.52090 \mathrm{e}+011.52090 \mathrm{e}+01$ 1.52090e+00 1.00000e-09 2.12000e-01

$1.52090 \mathrm{e}+01$ 1.52090e+01 1.52090e+00 1.00000e-09 2.12000e-01

$1.52090 \mathrm{e}+011.52090 \mathrm{e}+011.52090 \mathrm{e}+001.00000 \mathrm{e}-092.12000 \mathrm{e}-01$

$1.00000 \mathrm{e}-05$ 1.00000e-05 1.00000e-06 1.00000e-09 1.00000e-01 
$1.00000 \mathrm{e}+001.00000 \mathrm{e}+00$ 1.00000e-01 1.00000e-09 1.00000e-01

Element: 9138 \# of layers: 7

Kx Ky Kz Ss Por

$1.52090 \mathrm{e}+011.52090 \mathrm{e}+01$ 1.52090e+00 1.00000e-09 2.12000e-01

$1.52090 \mathrm{e}+011.52090 \mathrm{e}+011.52090 \mathrm{e}+001.00000 \mathrm{e}-092.12000 \mathrm{e}-01$

$1.52090 \mathrm{e}+011.52090 \mathrm{e}+011.52090 \mathrm{e}+001.00000 \mathrm{e}-092.12000 \mathrm{e}-01$

$1.52090 \mathrm{e}+011.52090 \mathrm{e}+011.52090 \mathrm{e}+001.00000 \mathrm{e}-092.12000 \mathrm{e}-01$

$1.52090 \mathrm{e}+011.52090 \mathrm{e}+01 \quad 1.52090 \mathrm{e}+001.00000 \mathrm{e}-092.12000 \mathrm{e}-01$

$1.00000 \mathrm{e}-05$ 1.00000e-05 1.00000e-06 1.00000e-09 1.00000e-01

$1.00000 \mathrm{e}+001.00000 \mathrm{e}+001.00000 \mathrm{e}-011.00000 \mathrm{e}-091.00000 \mathrm{e}-01$

Element: 9139 \# of layers: 7

Kx Ky Kz Ss Por

$1.52090 \mathrm{e}+01$ 1.52090e+01 1.52090e+00 1.00000e-09 2.12000e-01

$1.52090 \mathrm{e}+01$ 1.52090e+01 1.52090e+00 1.00000e-09 2.12000e-01

$1.52090 \mathrm{e}+01$ 1.52090e+01 1.52090e+00 1.00000e-09 2.12000e-01

$1.52090 \mathrm{e}+011.52090 \mathrm{e}+011.52090 \mathrm{e}+001.00000 \mathrm{e}-092.12000 \mathrm{e}-01$

$1.52090 \mathrm{e}+011.52090 \mathrm{e}+011.52090 \mathrm{e}+001.00000 \mathrm{e}-092.12000 \mathrm{e}-01$

$1.00000 \mathrm{e}-05$ 1.00000e-05 1.00000e-06 1.00000e-09 1.00000e-01

$1.00000 \mathrm{e}+001.00000 \mathrm{e}+001.00000 \mathrm{e}-011.00000 \mathrm{e}-091.00000 \mathrm{e}-01$

Element: 9140 \# of layers: 7

$\mathrm{Kx} \mathrm{Ky} \mathrm{Kz}$ Ss Por

$1.52090 \mathrm{e}+01$ 1.52090e+01 1.52090e+00 1.00000e-09 2.12000e-01

$1.52090 \mathrm{e}+01$ 1.52090e+01 1.52090e+00 1.00000e-09 2.12000e-01

$1.52090 \mathrm{e}+011.52090 \mathrm{e}+011.52090 \mathrm{e}+001.00000 \mathrm{e}-092.12000 \mathrm{e}-01$

$1.52090 \mathrm{e}+011.52090 \mathrm{e}+011.52090 \mathrm{e}+001.00000 \mathrm{e}-092.12000 \mathrm{e}-01$

$1.52090 \mathrm{e}+011.52090 \mathrm{e}+01$ 1.52090e+00 1.00000e-09 2.12000e-01

$1.00000 \mathrm{e}-05$ 1.00000e-05 1.00000e-06 1.00000e-09 1.00000e-01

$1.00000 \mathrm{e}+001.00000 \mathrm{e}+001.00000 \mathrm{e}-011.00000 \mathrm{e}-09$ 1.00000e-01

Element: 9141 \# of layers: 7

$\mathrm{Kx} \mathrm{Ky} \mathrm{Kz}$ Ss Por

$1.36004 \mathrm{e}+011.36004 \mathrm{e}+011.36004 \mathrm{e}+001.00000 \mathrm{e}-092.12000 \mathrm{e}-01$

$1.36004 \mathrm{e}+011.36004 \mathrm{e}+011.36004 \mathrm{e}+001.00000 \mathrm{e}-092.12000 \mathrm{e}-01$

$1.36004 \mathrm{e}+011.36004 \mathrm{e}+011.36004 \mathrm{e}+001.00000 \mathrm{e}-092.12000 \mathrm{e}-01$

$1.36004 \mathrm{e}+011.36004 \mathrm{e}+011.36004 \mathrm{e}+001.00000 \mathrm{e}-092.12000 \mathrm{e}-01$

$1.36004 \mathrm{e}+011.36004 \mathrm{e}+011.36004 \mathrm{e}+001.00000 \mathrm{e}-092.12000 \mathrm{e}-01$

$1.00000 \mathrm{e}-05$ 1.00000e-05 1.00000e-06 1.00000e-09 1.00000e-01

$1.00000 \mathrm{e}+001.00000 \mathrm{e}+001.00000 \mathrm{e}-011.00000 \mathrm{e}-091.00000 \mathrm{e}-01$

Element: 9142 \# of layers: 7

$\mathrm{Kx} \mathrm{Ky} \mathrm{Kz}$ Ss Por

$1.36004 \mathrm{e}+011.36004 \mathrm{e}+011.36004 \mathrm{e}+001.00000 \mathrm{e}-092.12000 \mathrm{e}-01$

$1.36004 \mathrm{e}+011.36004 \mathrm{e}+011.36004 \mathrm{e}+001.00000 \mathrm{e}-092.12000 \mathrm{e}-01$

$1.36004 \mathrm{e}+011.36004 \mathrm{e}+011.36004 \mathrm{e}+001.00000 \mathrm{e}-092.12000 \mathrm{e}-01$

$1.36004 \mathrm{e}+011.36004 \mathrm{e}+011.36004 \mathrm{e}+001.00000 \mathrm{e}-092.12000 \mathrm{e}-01$

$1.36004 \mathrm{e}+01$ 1.36004e+01 1.36004e+00 1.00000e-09 2.12000e-01 $1.00000 \mathrm{e}-05$ 1.00000e-05 1.00000e-06 1.00000e-09 1.00000e-01

$1.00000 \mathrm{e}+001.00000 \mathrm{e}+001.00000 \mathrm{e}-011.00000 \mathrm{e}-091.00000 \mathrm{e}-01$ 
Element: 9143 \# of layers: 7

$\mathrm{Kx} \mathrm{Ky} \mathrm{Kz}$ Ss Por

$1.52090 \mathrm{e}+01$ 1.52090e+01 1.52090e+00 1.00000e-09 2.12000e-01

$1.52090 \mathrm{e}+011.52090 \mathrm{e}+011.52090 \mathrm{e}+001.00000 \mathrm{e}-092.12000 \mathrm{e}-01$

$1.52090 \mathrm{e}+011.52090 \mathrm{e}+011.52090 \mathrm{e}+001.00000 \mathrm{e}-092.12000 \mathrm{e}-01$

$1.52090 \mathrm{e}+011.52090 \mathrm{e}+011.52090 \mathrm{e}+001.00000 \mathrm{e}-092.12000 \mathrm{e}-01$

$1.52090 \mathrm{e}+011.52090 \mathrm{e}+011.52090 \mathrm{e}+001.00000 \mathrm{e}-092.12000 \mathrm{e}-01$

$1.00000 \mathrm{e}-05$ 1.00000e-05 1.00000e-06 1.00000e-09 1.00000e-01

$1.00000 \mathrm{e}+001.00000 \mathrm{e}+001.00000 \mathrm{e}-011.00000 \mathrm{e}-091.00000 \mathrm{e}-01$

Element: 9144 \# of layers: 7

$\mathrm{Kx} \mathrm{Ky} \mathrm{Kz}$ Ss Por

$1.52090 \mathrm{e}+01$ 1.52090e+01 1.52090e+00 1.00000e-09 2.12000e-01

$1.52090 \mathrm{e}+011.52090 \mathrm{e}+01$ 1.52090e+00 1.00000e-09 2.12000e-01

$1.52090 \mathrm{e}+01$ 1.52090e+01 1.52090e+00 1.00000e-09 2.12000e-01

$1.52090 \mathrm{e}+011.52090 \mathrm{e}+01$ 1.52090e+00 1.00000e-09 2.12000e-01

$1.52090 \mathrm{e}+011.52090 \mathrm{e}+011.52090 \mathrm{e}+001.00000 \mathrm{e}-092.12000 \mathrm{e}-01$

$1.00000 \mathrm{e}-05$ 1.00000e-05 1.00000e-06 1.00000e-09 1.00000e-01

$1.00000 \mathrm{e}+001.00000 \mathrm{e}+001.00000 \mathrm{e}-01$ 1.00000e-09 1.00000e-01

Element: 9145 \# of layers: 7

$\mathrm{Kx} \mathrm{Ky} \mathrm{Kz}$ Ss Por

$1.22862 \mathrm{e}+01$ 1.22862e+01 1.22862e+00 1.00000e-09 2.12000e-01

$1.22862 \mathrm{e}+011.22862 \mathrm{e}+01$ 1.22862e+00 1.00000e-09 2.12000e-01

$1.22862 \mathrm{e}+01$ 1.22862e+01 1.22862e+00 1.00000e-09 2.12000e-01

$1.22862 \mathrm{e}+011.22862 \mathrm{e}+011.22862 \mathrm{e}+001.00000 \mathrm{e}-092.12000 \mathrm{e}-01$

$1.22862 \mathrm{e}+011.22862 \mathrm{e}+011.22862 \mathrm{e}+001.00000 \mathrm{e}-092.12000 \mathrm{e}-01$

$1.00000 \mathrm{e}-05$ 1.00000e-05 1.00000e-06 1.00000e-09 1.00000e-01

$1.00000 \mathrm{e}+001.00000 \mathrm{e}+001.00000 \mathrm{e}-011.00000 \mathrm{e}-091.00000 \mathrm{e}-01$

Element: 9146 \# of layers: 7

$\mathrm{Kx} \mathrm{Ky} \mathrm{Kz}$ Ss Por

$1.22862 \mathrm{e}+01$ 1.22862e+01 1.22862e+00 1.00000e-09 2.12000e-01

$1.22862 \mathrm{e}+011.22862 \mathrm{e}+01$ 1.22862e+00 1.00000e-09 2.12000e-01

$1.22862 \mathrm{e}+011.22862 \mathrm{e}+01$ 1.22862e+00 1.00000e-09 2.12000e-01

$1.22862 \mathrm{e}+011.22862 \mathrm{e}+011.22862 \mathrm{e}+001.00000 \mathrm{e}-092.12000 \mathrm{e}-01$

$1.22862 \mathrm{e}+01$ 1.22862e+01 1.22862e+00 1.00000e-09 2.12000e-01

$1.00000 \mathrm{e}-05$ 1.00000e-05 1.00000e-06 1.00000e-09 1.00000e-01

$1.00000 \mathrm{e}+001.00000 \mathrm{e}+001.00000 \mathrm{e}-011.00000 \mathrm{e}-091.00000 \mathrm{e}-01$

Element: 9147 \# of layers: 7

$\mathrm{Kx} \mathrm{Ky} \mathrm{Kz}$ Ss Por

$1.22862 \mathrm{e}+01$ 1.22862e+01 1.22862e+00 1.00000e-09 2.12000e-01

$1.22862 \mathrm{e}+01$ 1.22862e+01 1.22862e+00 1.00000e-09 2.12000e-01

$1.22862 \mathrm{e}+011.22862 \mathrm{e}+01$ 1.22862e+00 1.00000e-09 2.12000e-01

$1.22862 \mathrm{e}+011.22862 \mathrm{e}+01$ 1.22862e+00 1.00000e-09 2.12000e-01

$1.22862 \mathrm{e}+01$ 1.22862e+01 1.22862e+00 1.00000e-09 2.12000e-01

$1.00000 \mathrm{e}-05$ 1.00000e-05 1.00000e-06 1.00000e-09 1.00000e-01

$1.00000 \mathrm{e}+001.00000 \mathrm{e}+001.00000 \mathrm{e}-01$ 1.00000e-09 1.00000e-01

Element: 9148 \# of layers: 7 
$\mathrm{Kx} \mathrm{Ky} \mathrm{Kz}$ Ss Por

$1.29695 \mathrm{e}+01$ 1.29695e+01 1.29695e+00 1.00000e-09 2.12000e-01

$1.29695 \mathrm{e}+011.29695 \mathrm{e}+01$ 1.29695e+00 1.00000e-09 2.12000e-01

$1.29695 \mathrm{e}+011.29695 \mathrm{e}+011.29695 \mathrm{e}+001.00000 \mathrm{e}-092.12000 \mathrm{e}-01$

$1.29695 \mathrm{e}+011.29695 \mathrm{e}+01$ 1.29695e+00 1.00000e-09 2.12000e-01

$1.29695 \mathrm{e}+011.29695 \mathrm{e}+01 \quad 1.29695 \mathrm{e}+001.00000 \mathrm{e}-092.12000 \mathrm{e}-01$

$1.00000 \mathrm{e}-05$ 1.00000e-05 1.00000e-06 1.00000e-09 1.00000e-01

$1.00000 \mathrm{e}+001.00000 \mathrm{e}+001.00000 \mathrm{e}-01$ 1.00000e-09 1.00000e-01

Element: 9149 \# of layers: 7

$\mathrm{Kx} \mathrm{Ky} \mathrm{Kz}$ Ss Por

$1.29695 \mathrm{e}+01$ 1.29695e+01 1.29695e+00 1.00000e-09 2.12000e-01

$1.29695 \mathrm{e}+011.29695 \mathrm{e}+011.29695 \mathrm{e}+001.00000 \mathrm{e}-092.12000 \mathrm{e}-01$

$1.29695 \mathrm{e}+011.29695 \mathrm{e}+01$ 1.29695e+00 1.00000e-09 2.12000e-01

$1.29695 \mathrm{e}+011.29695 \mathrm{e}+011.29695 \mathrm{e}+001.00000 \mathrm{e}-092.12000 \mathrm{e}-01$

$1.29695 \mathrm{e}+011.29695 \mathrm{e}+011.29695 \mathrm{e}+001.00000 \mathrm{e}-092.12000 \mathrm{e}-01$

$1.00000 \mathrm{e}-05$ 1.00000e-05 1.00000e-06 1.00000e-09 1.00000e-01

$1.00000 \mathrm{e}+001.00000 \mathrm{e}+001.00000 \mathrm{e}-011.00000 \mathrm{e}-091.00000 \mathrm{e}-01$

Element: 9150 \# of layers: 7

$\mathrm{Kx} \mathrm{Ky} \mathrm{Kz}$ Ss Por

$1.36004 \mathrm{e}+01$ 1.36004e+01 1.36004e+00 1.00000e-09 2.12000e-01

$1.36004 \mathrm{e}+011.36004 \mathrm{e}+011.36004 \mathrm{e}+001.00000 \mathrm{e}-092.12000 \mathrm{e}-01$

$1.36004 \mathrm{e}+011.36004 \mathrm{e}+011.36004 \mathrm{e}+001.00000 \mathrm{e}-092.12000 \mathrm{e}-01$

$1.36004 \mathrm{e}+011.36004 \mathrm{e}+011.36004 \mathrm{e}+001.00000 \mathrm{e}-092.12000 \mathrm{e}-01$

$1.36004 \mathrm{e}+011.36004 \mathrm{e}+011.36004 \mathrm{e}+001.00000 \mathrm{e}-092.12000 \mathrm{e}-01$

$1.00000 \mathrm{e}-05$ 1.00000e-05 1.00000e-06 1.00000e-09 1.00000e-01

$1.00000 \mathrm{e}+001.00000 \mathrm{e}+001.00000 \mathrm{e}-01$ 1.00000e-09 1.00000e-01

Element: 9151 \# of layers: 7

$\mathrm{Kx} \mathrm{Ky} \mathrm{Kz}$ Ss Por

$1.52090 \mathrm{e}+01$ 1.52090e+01 1.52090e+00 1.00000e-09 2.12000e-01

$1.52090 \mathrm{e}+011.52090 \mathrm{e}+011.52090 \mathrm{e}+001.00000 \mathrm{e}-092.12000 \mathrm{e}-01$

$1.52090 \mathrm{e}+011.52090 \mathrm{e}+011.52090 \mathrm{e}+001.00000 \mathrm{e}-092.12000 \mathrm{e}-01$

$1.52090 \mathrm{e}+011.52090 \mathrm{e}+011.52090 \mathrm{e}+001.00000 \mathrm{e}-092.12000 \mathrm{e}-01$

$1.52090 \mathrm{e}+011.52090 \mathrm{e}+011.52090 \mathrm{e}+001.00000 \mathrm{e}-092.12000 \mathrm{e}-01$

$1.00000 \mathrm{e}-05$ 1.00000e-05 1.00000e-06 1.00000e-09 1.00000e-01

$1.00000 \mathrm{e}+001.00000 \mathrm{e}+001.00000 \mathrm{e}-011.00000 \mathrm{e}-091.00000 \mathrm{e}-01$

Element: 9152 \# of layers: 7

$\mathrm{Kx} \mathrm{Ky} \mathrm{Kz}$ Ss Por

$1.22862 \mathrm{e}+011.22862 \mathrm{e}+011.22862 \mathrm{e}+001.00000 \mathrm{e}-092.12000 \mathrm{e}-01$

$1.22862 \mathrm{e}+011.22862 \mathrm{e}+011.22862 \mathrm{e}+001.00000 \mathrm{e}-092.12000 \mathrm{e}-01$

$1.22862 \mathrm{e}+01$ 1.22862e+01 1.22862e+00 1.00000e-09 2.12000e-01

$1.22862 \mathrm{e}+011.22862 \mathrm{e}+01$ 1.22862e+00 1.00000e-09 2.12000e-01

$1.22862 \mathrm{e}+01$ 1.22862e+01 1.22862e+00 1.00000e-09 2.12000e-01

$1.00000 \mathrm{e}-05$ 1.00000e-05 1.00000e-06 1.00000e-09 1.00000e-01

$1.00000 \mathrm{e}+001.00000 \mathrm{e}+001.00000 \mathrm{e}-01$ 1.00000e-09 1.00000e-01

Element: 9153 \# of layers: 7

Kx Ky Kz Ss Por 
$1.39525 \mathrm{e}+01$ 1.39525e+01 1.39526e+00 1.00000e-09 2.12000e-01 $1.39525 \mathrm{e}+01$ 1.39525e+01 1.39526e+00 1.00000e-09 2.12000e-01 $1.39525 \mathrm{e}+011.39525 \mathrm{e}+011.39526 \mathrm{e}+001.00000 \mathrm{e}-092.12000 \mathrm{e}-01$ $1.39525 \mathrm{e}+011.39525 \mathrm{e}+011.39526 \mathrm{e}+001.00000 \mathrm{e}-092.12000 \mathrm{e}-01$ $1.39525 \mathrm{e}+011.39525 \mathrm{e}+011.39526 \mathrm{e}+001.00000 \mathrm{e}-092.12000 \mathrm{e}-01$ $1.00000 \mathrm{e}-051.00000 \mathrm{e}-05$ 1.00000e-06 1.00000e-09 1.00000e-01 $1.00000 \mathrm{e}+001.00000 \mathrm{e}+001.00000 \mathrm{e}-01$ 1.00000e-09 1.00000e-01 Element: 9154 \# of layers: 7

$\mathrm{Kx} \mathrm{Ky} \mathrm{Kz}$ Ss Por

$1.39525 \mathrm{e}+01$ 1.39525e+01 1.39526e+00 1.00000e-09 2.12000e-01 $1.39525 \mathrm{e}+01$ 1.39525e+01 1.39526e+00 1.00000e-09 2.12000e-01 $1.39525 \mathrm{e}+011.39525 \mathrm{e}+011.39526 \mathrm{e}+001.00000 \mathrm{e}-092.12000 \mathrm{e}-01$ $1.39525 \mathrm{e}+011.39525 \mathrm{e}+011.39526 \mathrm{e}+001.00000 \mathrm{e}-092.12000 \mathrm{e}-01$ $1.39525 \mathrm{e}+011.39525 \mathrm{e}+011.39526 \mathrm{e}+001.00000 \mathrm{e}-092.12000 \mathrm{e}-01$ $1.00000 \mathrm{e}-051.00000 \mathrm{e}-051.00000 \mathrm{e}-061.00000 \mathrm{e}-091.00000 \mathrm{e}-01$ $1.00000 \mathrm{e}+001.00000 \mathrm{e}+001.00000 \mathrm{e}-011.00000 \mathrm{e}-091.00000 \mathrm{e}-01$ Element: 9155 \# of layers: 7

$\mathrm{Kx} \mathrm{Ky} \mathrm{Kz}$ Ss Por

$1.39525 \mathrm{e}+01$ 1.39525e+01 1.39526e+00 1.00000e-09 2.12000e-01 $1.39525 \mathrm{e}+011.39525 \mathrm{e}+01$ 1.39526e+00 1.00000e-09 2.12000e-01 $1.39525 \mathrm{e}+011.39525 \mathrm{e}+011.39526 \mathrm{e}+001.00000 \mathrm{e}-092.12000 \mathrm{e}-01$ $1.39525 \mathrm{e}+01$ 1.39525e+01 1.39526e+00 1.00000e-09 2.12000e-01 $1.39525 \mathrm{e}+01$ 1.39525e+01 1.39526e+00 1.00000e-09 2.12000e-01 $1.00000 \mathrm{e}-05$ 1.00000e-05 1.00000e-06 1.00000e-09 1.00000e-01 $1.00000 \mathrm{e}+001.00000 \mathrm{e}+001.00000 \mathrm{e}-011.00000 \mathrm{e}-091.00000 \mathrm{e}-01$ Element: 9156 \# of layers: 7

$\mathrm{Kx} \mathrm{Ky} \mathrm{Kz}$ Ss Por

$1.39525 \mathrm{e}+01$ 1.39525e+01 1.39526e+00 1.00000e-09 2.12000e-01 $1.39525 \mathrm{e}+011.39525 \mathrm{e}+011.39526 \mathrm{e}+001.00000 \mathrm{e}-092.12000 \mathrm{e}-01$ $1.39525 \mathrm{e}+01$ 1.39525e+01 1.39526e+00 1.00000e-09 2.12000e-01 $1.39525 \mathrm{e}+011.39525 \mathrm{e}+01$ 1.39526e+00 1.00000e-09 2.12000e-01 $1.39525 \mathrm{e}+011.39525 \mathrm{e}+011.39526 \mathrm{e}+001.00000 \mathrm{e}-092.12000 \mathrm{e}-01$ $1.00000 \mathrm{e}-05$ 1.00000e-05 1.00000e-06 1.00000e-09 1.00000e-01 $1.00000 \mathrm{e}+001.00000 \mathrm{e}+001.00000 \mathrm{e}-011.00000 \mathrm{e}-091.00000 \mathrm{e}-01$ Element: 9157 \# of layers: 7

Kx Ky Kz Ss Por

$1.52153 \mathrm{e}+01$ 1.52153e+01 1.52153e+00 1.00000e-09 2.12000e-01 $1.52153 \mathrm{e}+011.52153 \mathrm{e}+011.52153 \mathrm{e}+001.00000 \mathrm{e}-092.12000 \mathrm{e}-01$ $1.52153 \mathrm{e}+011.52153 \mathrm{e}+01$ 1.52153e+00 1.00000e-09 2.12000e-01 $1.52153 \mathrm{e}+011.52153 \mathrm{e}+01$ 1.52153e+00 1.00000e-09 2.12000e-01 $1.52153 \mathrm{e}+01$ 1.52153e+01 1.52153e+00 1.00000e-09 2.12000e-01 $1.00000 \mathrm{e}-05$ 1.00000e-05 1.00000e-06 1.00000e-09 1.00000e-01 $1.00000 \mathrm{e}+001.00000 \mathrm{e}+001.00000 \mathrm{e}-011.00000 \mathrm{e}-091.00000 \mathrm{e}-01$ Element: 9158 \# of layers: 7

$\mathrm{Kx} \mathrm{Ky} \mathrm{Kz}$ Ss Por

$1.52153 e+011.52153 e+011.52153 e+001.00000 e-092.12000 e-01$ 
1.52153e+01 1.52153e+01 1.52153e+00 1.00000e-09 2.12000e-01 $1.52153 \mathrm{e}+01$ 1.52153e+01 1.52153e+00 1.00000e-09 2.12000e-01 $1.52153 \mathrm{e}+011.52153 \mathrm{e}+01$ 1.52153e+00 1.00000e-09 2.12000e-01 $1.52153 \mathrm{e}+011.52153 \mathrm{e}+011.52153 \mathrm{e}+001.00000 \mathrm{e}-092.12000 \mathrm{e}-01$ $1.00000 \mathrm{e}-05$ 1.00000e-05 1.00000e-06 1.00000e-09 1.00000e-01 $1.00000 \mathrm{e}+001.00000 \mathrm{e}+001.00000 \mathrm{e}-011.00000 \mathrm{e}-091.00000 \mathrm{e}-01$ Element: 9159 \# of layers: 7

$\mathrm{Kx} \mathrm{Ky} \mathrm{Kz}$ Ss Por

$1.39525 \mathrm{e}+011.39525 \mathrm{e}+01$ 1.39526e+00 1.00000e-09 2.12000e-01 $1.39525 \mathrm{e}+01$ 1.39525e+01 1.39526e+00 1.00000e-09 2.12000e-01 $1.39525 \mathrm{e}+01$ 1.39525e+01 1.39526e+00 1.00000e-09 2.12000e-01 $1.39525 \mathrm{e}+011.39525 \mathrm{e}+011.39526 \mathrm{e}+001.00000 \mathrm{e}-092.12000 \mathrm{e}-01$ $1.39525 \mathrm{e}+01$ 1.39525e+01 1.39526e+00 1.00000e-09 2.12000e-01 $1.00000 \mathrm{e}-05$ 1.00000e-05 1.00000e-06 1.00000e-09 1.00000e-01 $1.00000 \mathrm{e}+001.00000 \mathrm{e}+001.00000 \mathrm{e}-011.00000 \mathrm{e}-091.00000 \mathrm{e}-01$ Element: 9160 \# of layers: 7

$\mathrm{Kx} \mathrm{Ky} \mathrm{Kz}$ Ss Por

$1.52153 \mathrm{e}+01$ 1.52153e+01 1.52153e+00 1.00000e-09 2.12000e-01 $1.52153 \mathrm{e}+01$ 1.52153e+01 1.52153e+00 1.00000e-09 2.12000e-01 $1.52153 \mathrm{e}+011.52153 \mathrm{e}+011.52153 \mathrm{e}+001.00000 \mathrm{e}-092.12000 \mathrm{e}-01$ $1.52153 \mathrm{e}+011.52153 \mathrm{e}+011.52153 \mathrm{e}+001.00000 \mathrm{e}-092.12000 \mathrm{e}-01$ $1.52153 \mathrm{e}+01$ 1.52153e+01 1.52153e+00 1.00000e-09 2.12000e-01 $1.00000 \mathrm{e}-05$ 1.00000e-05 1.00000e-06 1.00000e-09 1.00000e-01 $1.00000 \mathrm{e}+001.00000 \mathrm{e}+001.00000 \mathrm{e}-011.00000 \mathrm{e}-091.00000 \mathrm{e}-01$ Element: 9161 \# of layers: 7

$\mathrm{Kx} \mathrm{Ky} \mathrm{Kz}$ Ss Por

$1.52153 \mathrm{e}+01$ 1.52153e+01 1.52153e+00 1.00000e-09 2.12000e-01 $1.52153 \mathrm{e}+011.52153 \mathrm{e}+01$ 1.52153e+00 1.00000e-09 2.12000e-01 $1.52153 \mathrm{e}+011.52153 \mathrm{e}+011.52153 \mathrm{e}+001.00000 \mathrm{e}-092.12000 \mathrm{e}-01$ $1.52153 \mathrm{e}+01$ 1.52153e+01 1.52153e+00 1.00000e-09 2.12000e-01 $1.52153 \mathrm{e}+011.52153 \mathrm{e}+011.52153 \mathrm{e}+001.00000 \mathrm{e}-092.12000 \mathrm{e}-01$ $1.00000 \mathrm{e}-05$ 1.00000e-05 1.00000e-06 1.00000e-09 1.00000e-01 $1.00000 \mathrm{e}+001.00000 \mathrm{e}+001.00000 \mathrm{e}-011.00000 \mathrm{e}-091.00000 \mathrm{e}-01$ Element: 9162 \# of layers: 7

$\mathrm{Kx} \mathrm{Ky} \mathrm{Kz}$ Ss Por

$1.52153 \mathrm{e}+011.52153 \mathrm{e}+01$ 1.52153e+00 1.00000e-09 2.12000e-01 $1.52153 \mathrm{e}+011.52153 \mathrm{e}+011.52153 \mathrm{e}+001.00000 \mathrm{e}-092.12000 \mathrm{e}-01$ $1.52153 \mathrm{e}+011.52153 \mathrm{e}+01$ 1.52153e+00 1.00000e-09 2.12000e-01 $1.52153 \mathrm{e}+01$ 1.52153e+01 1.52153e+00 1.00000e-09 2.12000e-01 $1.52153 \mathrm{e}+01$ 1.52153e+01 1.52153e+00 1.00000e-09 2.12000e-01 $1.00000 \mathrm{e}-05$ 1.00000e-05 1.00000e-06 1.00000e-09 1.00000e-01 $1.00000 \mathrm{e}+001.00000 \mathrm{e}+001.00000 \mathrm{e}-011.00000 \mathrm{e}-091.00000 \mathrm{e}-01$ Element: 9163 \# of layers: 7

$\mathrm{Kx} \mathrm{Ky} \mathrm{Kz}$ Ss Por

$1.52153 \mathrm{e}+01$ 1.52153e+01 1.52153e+00 1.00000e-09 2.12000e-01 $1.52153 \mathrm{e}+011.52153 \mathrm{e}+011.52153 \mathrm{e}+001.00000 \mathrm{e}-092.12000 \mathrm{e}-01$ 
1.52153e+01 1.52153e+01 1.52153e+00 1.00000e-09 2.12000e-01 $1.52153 \mathrm{e}+01$ 1.52153e+01 1.52153e+00 1.00000e-09 2.12000e-01 $1.52153 \mathrm{e}+011.52153 \mathrm{e}+01$ 1.52153e+00 1.00000e-09 2.12000e-01 $1.00000 \mathrm{e}-05$ 1.00000e-05 1.00000e-06 1.00000e-09 1.00000e-01 $1.00000 \mathrm{e}+001.00000 \mathrm{e}+001.00000 \mathrm{e}-01$ 1.00000e-09 1.00000e-01 Element: 9164 \# of layers: 7

$\mathrm{Kx} \mathrm{Ky} \mathrm{Kz}$ Ss Por

$1.52153 \mathrm{e}+01$ 1.52153e+01 1.52153e+00 1.00000e-09 2.12000e-01 $1.52153 \mathrm{e}+011.52153 \mathrm{e}+01$ 1.52153e+00 1.00000e-09 2.12000e-01 $1.52153 \mathrm{e}+011.52153 \mathrm{e}+01$ 1.52153e+00 1.00000e-09 2.12000e-01 $1.52153 \mathrm{e}+011.52153 \mathrm{e}+011.52153 \mathrm{e}+001.00000 \mathrm{e}-092.12000 \mathrm{e}-01$ $1.52153 \mathrm{e}+011.52153 \mathrm{e}+011.52153 \mathrm{e}+001.00000 \mathrm{e}-092.12000 \mathrm{e}-01$ $1.00000 \mathrm{e}-05$ 1.00000e-05 1.00000e-06 1.00000e-09 1.00000e-01 $1.00000 \mathrm{e}+001.00000 \mathrm{e}+001.00000 \mathrm{e}-011.00000 \mathrm{e}-09$ 1.00000e-01 Element: 9165 \# of layers: 7

Kx Ky Kz Ss Por

$1.52153 \mathrm{e}+01$ 1.52153e+01 1.52153e+00 1.00000e-09 2.12000e-01 $1.52153 \mathrm{e}+011.52153 \mathrm{e}+01$ 1.52153e+00 1.00000e-09 2.12000e-01 $1.52153 \mathrm{e}+01$ 1.52153e+01 1.52153e+00 1.00000e-09 2.12000e-01 $1.52153 \mathrm{e}+01$ 1.52153e+01 1.52153e+00 1.00000e-09 2.12000e-01 $1.52153 \mathrm{e}+01$ 1.52153e+01 1.52153e+00 1.00000e-09 2.12000e-01 $1.00000 \mathrm{e}-05$ 1.00000e-05 1.00000e-06 1.00000e-09 1.00000e-01 $1.00000 \mathrm{e}+001.00000 \mathrm{e}+001.00000 \mathrm{e}-01$ 1.00000e-09 1.00000e-01 Element: 9166 \# of layers: 7

Kx Ky Kz Ss Por

$1.52153 \mathrm{e}+01$ 1.52153e+01 1.52153e+00 1.00000e-09 2.12000e-01 $1.52153 \mathrm{e}+01$ 1.52153e+01 1.52153e+00 1.00000e-09 2.12000e-01 $1.52153 \mathrm{e}+011.52153 \mathrm{e}+01$ 1.52153e+00 1.00000e-09 2.12000e-01 $1.52153 \mathrm{e}+011.52153 \mathrm{e}+011.52153 \mathrm{e}+001.00000 \mathrm{e}-092.12000 \mathrm{e}-01$ $1.52153 \mathrm{e}+011.52153 \mathrm{e}+011.52153 \mathrm{e}+001.00000 \mathrm{e}-092.12000 \mathrm{e}-01$ $1.00000 \mathrm{e}-05$ 1.00000e-05 1.00000e-06 1.00000e-09 1.00000e-01 $1.00000 \mathrm{e}+001.00000 \mathrm{e}+001.00000 \mathrm{e}-011.00000 \mathrm{e}-091.00000 \mathrm{e}-01$ Element: 9167 \# of layers: 7

$\mathrm{Kx} \mathrm{Ky} \mathrm{Kz}$ Ss Por

$1.17347 \mathrm{e}+01$ 1.17347e+01 1.17347e+00 1.00000e-09 2.12000e-01

$1.17347 \mathrm{e}+011.17347 \mathrm{e}+01$ 1.17347e+00 1.00000e-09 2.12000e-01 $1.17347 \mathrm{e}+01$ 1.17347e+01 1.17347e+00 1.00000e-09 2.12000e-01 $1.17347 \mathrm{e}+01$ 1.17347e+01 1.17347e+00 1.00000e-09 2.12000e-01 $1.17347 \mathrm{e}+011.17347 \mathrm{e}+01$ 1.17347e+00 1.00000e-09 2.12000e-01 $1.00000 \mathrm{e}-05$ 1.00000e-05 1.00000e-06 1.00000e-09 1.00000e-01 $1.00000 \mathrm{e}+001.00000 \mathrm{e}+001.00000 \mathrm{e}-011.00000 \mathrm{e}-091.00000 \mathrm{e}-01$ Element: 9168 \# of layers: 7

$\mathrm{Kx} \mathrm{Ky} \mathrm{Kz}$ Ss Por

1.17347e+01 1.17347e+01 1.17347e+00 1.00000e-09 2.12000e-01 $1.17347 \mathrm{e}+01$ 1.17347e+01 1.17347e+00 1.00000e-09 2.12000e-01 $1.17347 \mathrm{e}+01$ 1.17347e+01 1.17347e+00 1.00000e-09 2.12000e-01 
$1.17347 \mathrm{e}+01$ 1.17347e+01 1.17347e+00 1.00000e-09 2.12000e-01 $1.17347 \mathrm{e}+01$ 1.17347e+01 1.17347e+00 1.00000e-09 2.12000e-01 $1.00000 \mathrm{e}-05$ 1.00000e-05 1.00000e-06 1.00000e-09 1.00000e-01 $1.00000 \mathrm{e}+001.00000 \mathrm{e}+001.00000 \mathrm{e}-011.00000 \mathrm{e}-091.00000 \mathrm{e}-01$ Element: 9169 \# of layers: 7

Kx Ky Kz Ss Por

$1.17347 \mathrm{e}+01$ 1.17347e+01 1.17347e+00 1.00000e-09 2.12000e-01 $1.17347 \mathrm{e}+01$ 1.17347e+01 1.17347e+00 1.00000e-09 2.12000e-01 $1.17347 \mathrm{e}+01$ 1.17347e+01 1.17347e+00 1.00000e-09 2.12000e-01 $1.17347 \mathrm{e}+011.17347 \mathrm{e}+01$ 1.17347e+00 1.00000e-09 2.12000e-01 $1.17347 \mathrm{e}+01$ 1.17347e+01 1.17347e+00 1.00000e-09 2.12000e-01 $1.00000 \mathrm{e}-05$ 1.00000e-05 1.00000e-06 1.00000e-09 1.00000e-01 $1.00000 \mathrm{e}+001.00000 \mathrm{e}+001.00000 \mathrm{e}-011.00000 \mathrm{e}-09$ 1.00000e-01 Element: 9170 \# of layers: 7

$\mathrm{Kx} \mathrm{Ky} \mathrm{Kz}$ Ss Por

$1.52153 \mathrm{e}+01$ 1.52153e+01 1.52153e+00 1.00000e-09 2.12000e-01 $1.52153 \mathrm{e}+011.52153 \mathrm{e}+011.52153 \mathrm{e}+00$ 1.00000e-09 2.12000e-01 $1.52153 \mathrm{e}+011.52153 \mathrm{e}+01$ 1.52153e+00 1.00000e-09 2.12000e-01 $1.52153 \mathrm{e}+01$ 1.52153e+01 1.52153e+00 1.00000e-09 2.12000e-01 $1.52153 \mathrm{e}+01$ 1.52153e+01 1.52153e+00 1.00000e-09 2.12000e-01 $1.00000 \mathrm{e}-05$ 1.00000e-05 1.00000e-06 1.00000e-09 1.00000e-01 $1.00000 \mathrm{e}+001.00000 \mathrm{e}+001.00000 \mathrm{e}-01$ 1.00000e-09 1.00000e-01 Element: 9171 \# of layers: 7

Kx Ky Kz Ss Por

$1.52153 \mathrm{e}+011.52153 \mathrm{e}+01$ 1.52153e+00 1.00000e-09 2.12000e-01 $1.52153 \mathrm{e}+01$ 1.52153e+01 1.52153e+00 1.00000e-09 2.12000e-01 $1.52153 \mathrm{e}+011.52153 \mathrm{e}+01$ 1.52153e+00 1.00000e-09 2.12000e-01 $1.52153 \mathrm{e}+01$ 1.52153e+01 1.52153e+00 1.00000e-09 2.12000e-01 $1.52153 \mathrm{e}+011.52153 \mathrm{e}+011.52153 \mathrm{e}+001.00000 \mathrm{e}-092.12000 \mathrm{e}-01$ $1.00000 \mathrm{e}-05$ 1.00000e-05 1.00000e-06 1.00000e-09 1.00000e-01 $1.00000 \mathrm{e}+001.00000 \mathrm{e}+001.00000 \mathrm{e}-01$ 1.00000e-09 1.00000e-01 Element: 9172 \# of layers: 7

Kx Ky Kz Ss Por

$1.52153 \mathrm{e}+01$ 1.52153e+01 1.52153e+00 1.00000e-09 2.12000e-01 $1.52153 \mathrm{e}+011.52153 \mathrm{e}+011.52153 \mathrm{e}+001.00000 \mathrm{e}-092.12000 \mathrm{e}-01$ $1.52153 \mathrm{e}+011.52153 \mathrm{e}+011.52153 \mathrm{e}+001.00000 \mathrm{e}-092.12000 \mathrm{e}-01$ $1.52153 \mathrm{e}+011.52153 \mathrm{e}+011.52153 \mathrm{e}+001.00000 \mathrm{e}-092.12000 \mathrm{e}-01$ $1.52153 \mathrm{e}+011.52153 \mathrm{e}+01$ 1.52153e+00 1.00000e-09 2.12000e-01 $1.00000 \mathrm{e}-05$ 1.00000e-05 1.00000e-06 1.00000e-09 1.00000e-01 $1.00000 \mathrm{e}+001.00000 \mathrm{e}+001.00000 \mathrm{e}-01$ 1.00000e-09 1.00000e-01 Element: 9173 \# of layers: 7

Kx Ky Kz Ss Por

$1.52153 \mathrm{e}+01$ 1.52153e+01 1.52153e+00 1.00000e-09 2.12000e-01 $1.52153 \mathrm{e}+01$ 1.52153e+01 1.52153e+00 1.00000e-09 2.12000e-01 $1.52153 \mathrm{e}+01$ 1.52153e+01 1.52153e+00 1.00000e-09 2.12000e-01 $1.52153 \mathrm{e}+01$ 1.52153e+01 1.52153e+00 1.00000e-09 2.12000e-01 
$1.52153 \mathrm{e}+01$ 1.52153e+01 1.52153e+00 1.00000e-09 2.12000e-01 $1.00000 \mathrm{e}-05$ 1.00000e-05 1.00000e-06 1.00000e-09 1.00000e-01 $1.00000 \mathrm{e}+001.00000 \mathrm{e}+001.00000 \mathrm{e}-011.00000 \mathrm{e}-091.00000 \mathrm{e}-01$

Element: 9174 \# of layers: 7

Kx Ky Kz Ss Por

1.17347e+01 1.17347e+01 1.17347e+00 1.00000e-09 2.12000e-01

$1.17347 \mathrm{e}+011.17347 \mathrm{e}+01$ 1.17347e+00 1.00000e-09 2.12000e-01

$1.17347 \mathrm{e}+011.17347 \mathrm{e}+01$ 1.17347e+00 1.00000e-09 2.12000e-01

$1.17347 \mathrm{e}+01$ 1.17347e+01 1.17347e+00 1.00000e-09 2.12000e-01

$1.17347 \mathrm{e}+01$ 1.17347e+01 1.17347e+00 1.00000e-09 2.12000e-01 $1.00000 \mathrm{e}-05$ 1.00000e-05 1.00000e-06 1.00000e-09 1.00000e-01

$1.00000 \mathrm{e}+001.00000 \mathrm{e}+001.00000 \mathrm{e}-011.00000 \mathrm{e}-091.00000 \mathrm{e}-01$

Element: 9175 \# of layers: 7

$\mathrm{Kx} \mathrm{Ky} \mathrm{Kz}$ Ss Por

1.17347e+01 1.17347e+01 1.17347e+00 1.00000e-09 2.12000e-01

$1.17347 \mathrm{e}+01$ 1.17347e+01 1.17347e+00 1.00000e-09 2.12000e-01

$1.17347 \mathrm{e}+01$ 1.17347e+01 1.17347e+00 1.00000e-09 2.12000e-01

$1.17347 \mathrm{e}+011.17347 \mathrm{e}+01$ 1.17347e+00 1.00000e-09 2.12000e-01

$1.17347 \mathrm{e}+01$ 1.17347e+01 1.17347e+00 1.00000e-09 2.12000e-01 $1.00000 \mathrm{e}-05$ 1.00000e-05 1.00000e-06 1.00000e-09 1.00000e-01

$1.00000 \mathrm{e}+001.00000 \mathrm{e}+001.00000 \mathrm{e}-011.00000 \mathrm{e}-091.00000 \mathrm{e}-01$

Element: 9176 \# of layers: 7

$\mathrm{Kx} \mathrm{Ky} \mathrm{Kz}$ Ss Por

1.17347e+01 1.17347e+01 1.17347e+00 1.00000e-09 2.12000e-01

$1.17347 \mathrm{e}+01$ 1.17347e+01 1.17347e+00 1.00000e-09 2.12000e-01

$1.17347 \mathrm{e}+01$ 1.17347e+01 1.17347e+00 1.00000e-09 2.12000e-01

$1.17347 \mathrm{e}+01$ 1.17347e+01 1.17347e+00 1.00000e-09 2.12000e-01

$1.17347 \mathrm{e}+01$ 1.17347e+01 1.17347e+00 1.00000e-09 2.12000e-01

$1.00000 \mathrm{e}-05$ 1.00000e-05 1.00000e-06 1.00000e-09 1.00000e-01

$1.00000 \mathrm{e}+001.00000 \mathrm{e}+001.00000 \mathrm{e}-011.00000 \mathrm{e}-091.00000 \mathrm{e}-01$

Element: 9177 \# of layers: 7

Kx Ky Kz Ss Por

$1.17347 \mathrm{e}+01$ 1.17347e+01 1.17347e+00 1.00000e-09 2.12000e-01

$1.17347 \mathrm{e}+01$ 1.17347e+01 1.17347e+00 1.00000e-09 2.12000e-01

$1.17347 \mathrm{e}+011.17347 \mathrm{e}+01$ 1.17347e+00 1.00000e-09 2.12000e-01

$1.17347 \mathrm{e}+011.17347 \mathrm{e}+01$ 1.17347e+00 1.00000e-09 2.12000e-01

$1.17347 \mathrm{e}+01$ 1.17347e+01 1.17347e+00 1.00000e-09 2.12000e-01

$1.00000 \mathrm{e}-05$ 1.00000e-05 1.00000e-06 1.00000e-09 1.00000e-01

$1.00000 \mathrm{e}+001.00000 \mathrm{e}+001.00000 \mathrm{e}-011.00000 \mathrm{e}-091.00000 \mathrm{e}-01$

Element: 9178 \# of layers: 7

Kx Ky Kz Ss Por

1.17347e+01 1.17347e+01 1.17347e+00 1.00000e-09 2.12000e-01

$1.17347 \mathrm{e}+01$ 1.17347e+01 1.17347e+00 1.00000e-09 2.12000e-01

1.17347e+01 1.17347e+01 1.17347e+00 1.00000e-09 2.12000e-01

$1.17347 \mathrm{e}+01$ 1.17347e+01 1.17347e+00 1.00000e-09 2.12000e-01

$1.17347 \mathrm{e}+01$ 1.17347e+01 1.17347e+00 1.00000e-09 2.12000e-01 
$1.00000 \mathrm{e}-05$ 1.00000e-05 1.00000e-06 1.00000e-09 1.00000e-01 $1.00000 \mathrm{e}+001.00000 \mathrm{e}+001.00000 \mathrm{e}-01$ 1.00000e-09 1.00000e-01 Element: 9179 \# of layers: 7

Kx Ky Kz Ss Por

$1.17347 \mathrm{e}+01$ 1.17347e+01 1.17347e+00 1.00000e-09 2.12000e-01 $1.17347 \mathrm{e}+01$ 1.17347e+01 1.17347e+00 1.00000e-09 2.12000e-01 $1.17347 \mathrm{e}+01$ 1.17347e+01 1.17347e+00 1.00000e-09 2.12000e-01 $1.17347 \mathrm{e}+01$ 1.17347e+01 1.17347e+00 1.00000e-09 2.12000e-01 $1.17347 \mathrm{e}+01$ 1.17347e+01 1.17347e+00 1.00000e-09 2.12000e-01 $1.00000 \mathrm{e}-05$ 1.00000e-05 1.00000e-06 1.00000e-09 1.00000e-01 $1.00000 \mathrm{e}+001.00000 \mathrm{e}+001.00000 \mathrm{e}-01$ 1.00000e-09 1.00000e-01 Element: 9180 \# of layers: 7

Kx Ky Kz Ss Por

1.17347e+01 1.17347e+01 1.17347e+00 1.00000e-09 2.12000e-01 $1.17347 \mathrm{e}+01$ 1.17347e+01 1.17347e+00 1.00000e-09 2.12000e-01 $1.17347 \mathrm{e}+01$ 1.17347e+01 1.17347e+00 1.00000e-09 2.12000e-01 $1.17347 \mathrm{e}+01$ 1.17347e+01 1.17347e+00 1.00000e-09 2.12000e-01 $1.17347 \mathrm{e}+01$ 1.17347e+01 1.17347e+00 1.00000e-09 2.12000e-01 $1.00000 \mathrm{e}-05$ 1.00000e-05 1.00000e-06 1.00000e-09 1.00000e-01 $1.00000 \mathrm{e}+001.00000 \mathrm{e}+001.00000 \mathrm{e}-011.00000 \mathrm{e}-091.00000 \mathrm{e}-01$ Element: 9181 \# of layers: 7

$\mathrm{Kx} \mathrm{Ky} \mathrm{Kz}$ Ss Por

1.17347e+01 1.17347e+01 1.17347e+00 1.00000e-09 2.12000e-01 $1.17347 \mathrm{e}+011.17347 \mathrm{e}+01$ 1.17347e+00 1.00000e-09 2.12000e-01 $1.17347 \mathrm{e}+01$ 1.17347e+01 1.17347e+00 1.00000e-09 2.12000e-01 $1.17347 \mathrm{e}+01$ 1.17347e+01 1.17347e+00 1.00000e-09 2.12000e-01 $1.17347 \mathrm{e}+01$ 1.17347e+01 1.17347e+00 1.00000e-09 2.12000e-01 $1.00000 \mathrm{e}-05$ 1.00000e-05 1.00000e-06 1.00000e-09 1.00000e-01 $1.00000 \mathrm{e}+001.00000 \mathrm{e}+001.00000 \mathrm{e}-011.00000 \mathrm{e}-091.00000 \mathrm{e}-01$ Element: 9182 \# of layers: 7

$\mathrm{Kx} \mathrm{Ky} \mathrm{Kz}$ Ss Por

$1.17347 \mathrm{e}+01$ 1.17347e+01 1.17347e+00 1.00000e-09 2.12000e-01 $1.17347 \mathrm{e}+01$ 1.17347e+01 1.17347e+00 1.00000e-09 2.12000e-01 $1.17347 \mathrm{e}+01$ 1.17347e+01 1.17347e+00 1.00000e-09 2.12000e-01 $1.17347 \mathrm{e}+01$ 1.17347e+01 1.17347e+00 1.00000e-09 2.12000e-01 $1.17347 \mathrm{e}+01$ 1.17347e+01 1.17347e+00 1.00000e-09 2.12000e-01 $1.00000 \mathrm{e}-05$ 1.00000e-05 1.00000e-06 1.00000e-09 1.00000e-01 $1.00000 \mathrm{e}+001.00000 \mathrm{e}+001.00000 \mathrm{e}-011.00000 \mathrm{e}-091.00000 \mathrm{e}-01$ Element: 9183 \# of layers: 7

$\mathrm{Kx} \mathrm{Ky} \mathrm{Kz}$ Ss Por

1.17347e+01 1.17347e+01 1.17347e+00 1.00000e-09 2.12000e-01 $1.17347 \mathrm{e}+01$ 1.17347e+01 1.17347e+00 1.00000e-09 2.12000e-01 $1.17347 \mathrm{e}+01$ 1.17347e+01 1.17347e+00 1.00000e-09 2.12000e-01 $1.17347 \mathrm{e}+01$ 1.17347e+01 1.17347e+00 1.00000e-09 2.12000e-01 $1.17347 \mathrm{e}+011.17347 \mathrm{e}+01$ 1.17347e+00 1.00000e-09 2.12000e-01 1.00000e-05 1.00000e-05 1.00000e-06 1.00000e-09 1.00000e-01 
$1.00000 \mathrm{e}+001.00000 \mathrm{e}+00$ 1.00000e-01 1.00000e-09 1.00000e-01

Element: 9184 \# of layers: 7

Kx Ky Kz Ss Por

1.17347e+01 1.17347e+01 1.17347e+00 1.00000e-09 2.12000e-01

$1.17347 \mathrm{e}+01$ 1.17347e+01 1.17347e+00 1.00000e-09 2.12000e-01

$1.17347 \mathrm{e}+01$ 1.17347e+01 1.17347e+00 1.00000e-09 2.12000e-01

$1.17347 \mathrm{e}+011.17347 \mathrm{e}+01$ 1.17347e+00 1.00000e-09 2.12000e-01

$1.17347 \mathrm{e}+011.17347 \mathrm{e}+01$ 1.17347e+00 1.00000e-09 2.12000e-01

$1.00000 \mathrm{e}-05$ 1.00000e-05 1.00000e-06 1.00000e-09 1.00000e-01

$1.00000 \mathrm{e}+001.00000 \mathrm{e}+001.00000 \mathrm{e}-011.00000 \mathrm{e}-091.00000 \mathrm{e}-01$

Element: 9185 \# of layers: 7

Kx Ky Kz Ss Por

$1.43519 \mathrm{e}+01$ 1.43519e+01 1.43519e+00 1.00000e-09 2.12000e-01

$1.43519 \mathrm{e}+01$ 1.43519e+01 1.43519e+00 1.00000e-09 2.12000e-01

$1.43519 \mathrm{e}+01$ 1.43519e+01 1.43519e+00 1.00000e-09 2.12000e-01

$1.43519 \mathrm{e}+011.43519 \mathrm{e}+011.43519 \mathrm{e}+001.00000 \mathrm{e}-092.12000 \mathrm{e}-01$

$1.43519 \mathrm{e}+011.43519 \mathrm{e}+01$ 1.43519e+00 1.00000e-09 2.12000e-01

$1.00000 \mathrm{e}-05$ 1.00000e-05 1.00000e-06 1.00000e-09 1.00000e-01

$1.00000 \mathrm{e}+001.00000 \mathrm{e}+001.00000 \mathrm{e}-011.00000 \mathrm{e}-091.00000 \mathrm{e}-01$

Element: 9186 \# of layers: 7

Kx Ky Kz Ss Por

$1.43519 \mathrm{e}+01$ 1.43519e+01 1.43519e+00 1.00000e-09 2.12000e-01

$1.43519 \mathrm{e}+01$ 1.43519e+01 1.43519e+00 1.00000e-09 2.12000e-01

$1.43519 \mathrm{e}+011.43519 \mathrm{e}+01$ 1.43519e+00 1.00000e-09 2.12000e-01

$1.43519 \mathrm{e}+011.43519 \mathrm{e}+011.43519 \mathrm{e}+001.00000 \mathrm{e}-092.12000 \mathrm{e}-01$

$1.43519 \mathrm{e}+01$ 1.43519e+01 1.43519e+00 1.00000e-09 2.12000e-01

$1.00000 \mathrm{e}-05$ 1.00000e-05 1.00000e-06 1.00000e-09 1.00000e-01

$1.00000 \mathrm{e}+001.00000 \mathrm{e}+001.00000 \mathrm{e}-011.00000 \mathrm{e}-09$ 1.00000e-01

Element: 9187 \# of layers: 7

$\mathrm{Kx} \mathrm{Ky} \mathrm{Kz}$ Ss Por

$1.43519 \mathrm{e}+01$ 1.43519e+01 1.43519e+00 1.00000e-09 2.12000e-01

$1.43519 \mathrm{e}+01$ 1.43519e+01 1.43519e+00 1.00000e-09 2.12000e-01

$1.43519 \mathrm{e}+011.43519 \mathrm{e}+011.43519 \mathrm{e}+001.00000 \mathrm{e}-092.12000 \mathrm{e}-01$

$1.43519 \mathrm{e}+01$ 1.43519e+01 1.43519e+00 1.00000e-09 2.12000e-01

$1.43519 \mathrm{e}+01$ 1.43519e+01 1.43519e+00 1.00000e-09 2.12000e-01

1.00000e-05 1.00000e-05 1.00000e-06 1.00000e-09 1.00000e-01

$1.00000 \mathrm{e}+001.00000 \mathrm{e}+001.00000 \mathrm{e}-011.00000 \mathrm{e}-091.00000 \mathrm{e}-01$

Element: 9188 \# of layers: 7

$\mathrm{Kx} \mathrm{Ky} \mathrm{Kz}$ Ss Por

$1.17347 \mathrm{e}+01$ 1.17347e+01 1.17347e+00 1.00000e-09 2.12000e-01

$1.17347 \mathrm{e}+01$ 1.17347e+01 1.17347e+00 1.00000e-09 2.12000e-01

$1.17347 \mathrm{e}+01$ 1.17347e+01 1.17347e+00 1.00000e-09 2.12000e-01

$1.17347 \mathrm{e}+01$ 1.17347e+01 1.17347e+00 1.00000e-09 2.12000e-01

1.17347e+01 1.17347e+01 1.17347e+00 1.00000e-09 2.12000e-01

$1.00000 \mathrm{e}-051.00000 \mathrm{e}-05$ 1.00000e-06 1.00000e-09 1.00000e-01

$1.00000 \mathrm{e}+001.00000 \mathrm{e}+001.00000 \mathrm{e}-011.00000 \mathrm{e}-091.00000 \mathrm{e}-01$ 
Element: 9189 \# of layers: 7

$\mathrm{Kx} \mathrm{Ky} \mathrm{Kz}$ Ss Por

$1.17347 \mathrm{e}+01$ 1.17347e+01 1.17347e+00 1.00000e-09 2.12000e-01

$1.17347 \mathrm{e}+01$ 1.17347e+01 1.17347e+00 1.00000e-09 2.12000e-01

$1.17347 \mathrm{e}+01$ 1.17347e+01 1.17347e+00 1.00000e-09 2.12000e-01

$1.17347 \mathrm{e}+01$ 1.17347e+01 1.17347e+00 1.00000e-09 2.12000e-01

$1.17347 \mathrm{e}+011.17347 \mathrm{e}+01$ 1.17347e+00 1.00000e-09 2.12000e-01

$1.00000 \mathrm{e}-05$ 1.00000e-05 1.00000e-06 1.00000e-09 1.00000e-01

$1.00000 \mathrm{e}+001.00000 \mathrm{e}+001.00000 \mathrm{e}-011.00000 \mathrm{e}-091.00000 \mathrm{e}-01$

Element: 9190 \# of layers: 7

$\mathrm{Kx} \mathrm{Ky} \mathrm{Kz}$ Ss Por

1.17347e+01 1.17347e+01 1.17347e+00 1.00000e-09 2.12000e-01

$1.17347 \mathrm{e}+01$ 1.17347e+01 1.17347e+00 1.00000e-09 2.12000e-01

$1.17347 \mathrm{e}+01$ 1.17347e+01 1.17347e+00 1.00000e-09 2.12000e-01

$1.17347 \mathrm{e}+01$ 1.17347e+01 1.17347e+00 1.00000e-09 2.12000e-01

$1.17347 \mathrm{e}+01$ 1.17347e+01 1.17347e+00 1.00000e-09 2.12000e-01

$1.00000 \mathrm{e}-05$ 1.00000e-05 1.00000e-06 1.00000e-09 1.00000e-01

$1.00000 \mathrm{e}+001.00000 \mathrm{e}+001.00000 \mathrm{e}-01$ 1.00000e-09 1.00000e-01

Element: 9191 \# of layers: 7

Kx Ky Kz Ss Por

1.17347e+01 1.17347e+01 1.17347e+00 1.00000e-09 2.12000e-01

$1.17347 \mathrm{e}+01$ 1.17347e+01 1.17347e+00 1.00000e-09 2.12000e-01

1.17347e+01 1.17347e+01 1.17347e+00 1.00000e-09 2.12000e-01

$1.17347 \mathrm{e}+01$ 1.17347e+01 1.17347e+00 1.00000e-09 2.12000e-01

$1.17347 \mathrm{e}+011.17347 \mathrm{e}+01$ 1.17347e+00 1.00000e-09 2.12000e-01

$1.00000 \mathrm{e}-05$ 1.00000e-05 1.00000e-06 1.00000e-09 1.00000e-01

$1.00000 \mathrm{e}+001.00000 \mathrm{e}+001.00000 \mathrm{e}-011.00000 \mathrm{e}-091.00000 \mathrm{e}-01$

Element: 9192 \# of layers: 7

Kx Ky Kz Ss Por

$1.43519 \mathrm{e}+01$ 1.43519e+01 1.43519e+00 1.00000e-09 2.12000e-01

$1.43519 \mathrm{e}+01$ 1.43519e+01 1.43519e+00 1.00000e-09 2.12000e-01

$1.43519 \mathrm{e}+01$ 1.43519e+01 1.43519e+00 1.00000e-09 2.12000e-01

$1.43519 \mathrm{e}+011.43519 \mathrm{e}+011.43519 \mathrm{e}+001.00000 \mathrm{e}-092.12000 \mathrm{e}-01$

$1.43519 \mathrm{e}+01$ 1.43519e+01 1.43519e+00 1.00000e-09 2.12000e-01

$1.00000 \mathrm{e}-05$ 1.00000e-05 1.00000e-06 1.00000e-09 1.00000e-01

$1.00000 \mathrm{e}+001.00000 \mathrm{e}+001.00000 \mathrm{e}-011.00000 \mathrm{e}-09$ 1.00000e-01

Element: 9193 \# of layers: 7

Kx Ky Kz Ss Por

$1.43519 \mathrm{e}+01$ 1.43519e+01 1.43519e+00 1.00000e-09 2.12000e-01

$1.43519 \mathrm{e}+01$ 1.43519e+01 1.43519e+00 1.00000e-09 2.12000e-01

$1.43519 \mathrm{e}+01$ 1.43519e+01 1.43519e+00 1.00000e-09 2.12000e-01

$1.43519 \mathrm{e}+01$ 1.43519e+01 1.43519e+00 1.00000e-09 2.12000e-01

$1.43519 \mathrm{e}+01$ 1.43519e+01 1.43519e+00 1.00000e-09 2.12000e-01

$1.00000 \mathrm{e}-05$ 1.00000e-05 1.00000e-06 1.00000e-09 1.00000e-01

$1.00000 \mathrm{e}+001.00000 \mathrm{e}+001.00000 \mathrm{e}-011.00000 \mathrm{e}-09$ 1.00000e-01

Element: 9194 \# of layers: 7 
Kx Ky Kz Ss Por

$1.43519 \mathrm{e}+01$ 1.43519e+01 1.43519e+00 1.00000e-09 2.12000e-01

$1.43519 \mathrm{e}+011.43519 \mathrm{e}+01$ 1.43519e+00 1.00000e-09 2.12000e-01

$1.43519 \mathrm{e}+01$ 1.43519e+01 1.43519e+00 1.00000e-09 2.12000e-01

$1.43519 \mathrm{e}+011.43519 \mathrm{e}+01$ 1.43519e+00 1.00000e-09 2.12000e-01

$1.43519 \mathrm{e}+01$ 1.43519e+01 1.43519e+00 1.00000e-09 2.12000e-01

$1.00000 \mathrm{e}-05$ 1.00000e-05 1.00000e-06 1.00000e-09 1.00000e-01

$1.00000 \mathrm{e}+001.00000 \mathrm{e}+001.00000 \mathrm{e}-01$ 1.00000e-09 1.00000e-01

Element: 9195 \# of layers: 7

$\mathrm{Kx} \mathrm{Ky} \mathrm{Kz}$ Ss Por

$1.43519 \mathrm{e}+01$ 1.43519e+01 1.43519e+00 1.00000e-09 2.12000e-01

$1.43519 \mathrm{e}+01$ 1.43519e+01 1.43519e+00 1.00000e-09 2.12000e-01

$1.43519 \mathrm{e}+01$ 1.43519e+01 1.43519e+00 1.00000e-09 2.12000e-01

$1.43519 \mathrm{e}+01$ 1.43519e+01 1.43519e+00 1.00000e-09 2.12000e-01

$1.43519 \mathrm{e}+01$ 1.43519e+01 1.43519e+00 1.00000e-09 2.12000e-01

$1.00000 \mathrm{e}-05$ 1.00000e-05 1.00000e-06 1.00000e-09 1.00000e-01

$1.00000 \mathrm{e}+001.00000 \mathrm{e}+001.00000 \mathrm{e}-011.00000 \mathrm{e}-091.00000 \mathrm{e}-01$

Element: 9196 \# of layers: 7

$\mathrm{Kx} \mathrm{Ky} \mathrm{Kz}$ Ss Por

$1.43519 \mathrm{e}+01$ 1.43519e+01 1.43519e+00 1.00000e-09 2.12000e-01

$1.43519 \mathrm{e}+01$ 1.43519e+01 1.43519e+00 1.00000e-09 2.12000e-01

$1.43519 \mathrm{e}+01$ 1.43519e+01 1.43519e+00 1.00000e-09 2.12000e-01

$1.43519 \mathrm{e}+01$ 1.43519e+01 1.43519e+00 1.00000e-09 2.12000e-01

$1.43519 \mathrm{e}+011.43519 \mathrm{e}+01 \quad 1.43519 \mathrm{e}+001.00000 \mathrm{e}-092.12000 \mathrm{e}-01$

$1.00000 \mathrm{e}-05$ 1.00000e-05 1.00000e-06 1.00000e-09 1.00000e-01

$1.00000 \mathrm{e}+001.00000 \mathrm{e}+001.00000 \mathrm{e}-01$ 1.00000e-09 1.00000e-01

Element: 9197 \# of layers: 7

$\mathrm{Kx} \mathrm{Ky} \mathrm{Kz}$ Ss Por

$1.43519 \mathrm{e}+01$ 1.43519e+01 1.43519e+00 1.00000e-09 2.12000e-01

$1.43519 \mathrm{e}+01$ 1.43519e+01 1.43519e+00 1.00000e-09 2.12000e-01

$1.43519 \mathrm{e}+01$ 1.43519e+01 1.43519e+00 1.00000e-09 2.12000e-01

$1.43519 \mathrm{e}+01$ 1.43519e+01 1.43519e+00 1.00000e-09 2.12000e-01

$1.43519 \mathrm{e}+011.43519 \mathrm{e}+011.43519 \mathrm{e}+001.00000 \mathrm{e}-092.12000 \mathrm{e}-01$

$1.00000 \mathrm{e}-05$ 1.00000e-05 1.00000e-06 1.00000e-09 1.00000e-01

$1.00000 \mathrm{e}+001.00000 \mathrm{e}+001.00000 \mathrm{e}-011.00000 \mathrm{e}-091.00000 \mathrm{e}-01$

Element: 9198 \# of layers: 7

Kx Ky Kz Ss Por

$1.43519 \mathrm{e}+01$ 1.43519e+01 1.43519e+00 1.00000e-09 2.12000e-01

$1.43519 \mathrm{e}+01$ 1.43519e+01 1.43519e+00 1.00000e-09 2.12000e-01

$1.43519 \mathrm{e}+01$ 1.43519e+01 1.43519e+00 1.00000e-09 2.12000e-01

$1.43519 \mathrm{e}+01$ 1.43519e+01 1.43519e+00 1.00000e-09 2.12000e-01

$1.43519 \mathrm{e}+01$ 1.43519e+01 1.43519e+00 1.00000e-09 2.12000e-01

$1.00000 \mathrm{e}-05$ 1.00000e-05 1.00000e-06 1.00000e-09 1.00000e-01

$1.00000 \mathrm{e}+001.00000 \mathrm{e}+001.00000 \mathrm{e}-011.00000 \mathrm{e}-091.00000 \mathrm{e}-01$

Element: 9199 \# of layers: 7

Kx Ky Kz Ss Por 
$1.43519 \mathrm{e}+01$ 1.43519e+01 1.43519e+00 1.00000e-09 2.12000e-01 $1.43519 \mathrm{e}+01$ 1.43519e+01 1.43519e+00 1.00000e-09 2.12000e-01 $1.43519 \mathrm{e}+011.43519 \mathrm{e}+01$ 1.43519e+00 1.00000e-09 2.12000e-01 $1.43519 \mathrm{e}+01$ 1.43519e+01 1.43519e+00 1.00000e-09 2.12000e-01 $1.43519 \mathrm{e}+011.43519 \mathrm{e}+01$ 1.43519e+00 1.00000e-09 2.12000e-01 $1.00000 \mathrm{e}-05$ 1.00000e-05 1.00000e-06 1.00000e-09 1.00000e-01 $1.00000 \mathrm{e}+001.00000 \mathrm{e}+001.00000 \mathrm{e}-01$ 1.00000e-09 1.00000e-01 Element: 9200 \# of layers: 7

$\mathrm{Kx} \mathrm{Ky} \mathrm{Kz}$ Ss Por

$1.43519 \mathrm{e}+01$ 1.43519e+01 1.43519e+00 1.00000e-09 2.12000e-01 $1.43519 \mathrm{e}+01$ 1.43519e+01 1.43519e+00 1.00000e-09 2.12000e-01 $1.43519 \mathrm{e}+011.43519 \mathrm{e}+011.43519 \mathrm{e}+001.00000 \mathrm{e}-092.12000 \mathrm{e}-01$ $1.43519 \mathrm{e}+01$ 1.43519e+01 1.43519e+00 1.00000e-09 2.12000e-01 $1.43519 \mathrm{e}+01$ 1.43519e+01 1.43519e+00 1.00000e-09 2.12000e-01 $1.00000 \mathrm{e}-051.00000 \mathrm{e}-051.00000 \mathrm{e}-061.00000 \mathrm{e}-091.00000 \mathrm{e}-01$ $1.00000 \mathrm{e}+001.00000 \mathrm{e}+001.00000 \mathrm{e}-011.00000 \mathrm{e}-091.00000 \mathrm{e}-01$ Element: 9201 \# of layers: 7

$\mathrm{Kx} \mathrm{Ky} \mathrm{Kz}$ Ss Por

$1.43519 \mathrm{e}+01$ 1.43519e+01 1.43519e+00 1.00000e-09 2.12000e-01 $1.43519 \mathrm{e}+01$ 1.43519e+01 1.43519e+00 1.00000e-09 2.12000e-01 $1.43519 \mathrm{e}+01$ 1.43519e+01 1.43519e+00 1.00000e-09 2.12000e-01 $1.43519 \mathrm{e}+01$ 1.43519e+01 1.43519e+00 1.00000e-09 2.12000e-01 $1.43519 \mathrm{e}+01$ 1.43519e+01 1.43519e+00 1.00000e-09 2.12000e-01 $1.00000 \mathrm{e}-05$ 1.00000e-05 1.00000e-06 1.00000e-09 1.00000e-01 $1.00000 \mathrm{e}+001.00000 \mathrm{e}+001.00000 \mathrm{e}-011.00000 \mathrm{e}-091.00000 \mathrm{e}-01$ Element: 9202 \# of layers: 7

$\mathrm{Kx} \mathrm{Ky} \mathrm{Kz}$ Ss Por

$1.39525 \mathrm{e}+01$ 1.39525e+01 1.39526e+00 1.00000e-09 2.12000e-01 $1.39525 \mathrm{e}+011.39525 \mathrm{e}+011.39526 \mathrm{e}+001.00000 \mathrm{e}-092.12000 \mathrm{e}-01$ $1.39525 \mathrm{e}+011.39525 \mathrm{e}+011.39526 \mathrm{e}+001.00000 \mathrm{e}-092.12000 \mathrm{e}-01$ $1.39525 \mathrm{e}+011.39525 \mathrm{e}+01$ 1.39526e+00 1.00000e-09 2.12000e-01 $1.39525 \mathrm{e}+011.39525 \mathrm{e}+011.39526 \mathrm{e}+001.00000 \mathrm{e}-092.12000 \mathrm{e}-01$ $1.00000 \mathrm{e}-05$ 1.00000e-05 1.00000e-06 1.00000e-09 1.00000e-01 $1.00000 \mathrm{e}+001.00000 \mathrm{e}+001.00000 \mathrm{e}-011.00000 \mathrm{e}-091.00000 \mathrm{e}-01$ Element: 9203 \# of layers: 7

$\mathrm{Kx} \mathrm{Ky} \mathrm{Kz}$ Ss Por

$1.39525 \mathrm{e}+01$ 1.39525e+01 1.39526e+00 1.00000e-09 2.12000e-01 $1.39525 \mathrm{e}+011.39525 \mathrm{e}+011.39526 \mathrm{e}+001.00000 \mathrm{e}-092.12000 \mathrm{e}-01$ $1.39525 \mathrm{e}+011.39525 \mathrm{e}+011.39526 \mathrm{e}+001.00000 \mathrm{e}-092.12000 \mathrm{e}-01$ $1.39525 \mathrm{e}+011.39525 \mathrm{e}+011.39526 \mathrm{e}+001.00000 \mathrm{e}-092.12000 \mathrm{e}-01$ $1.39525 \mathrm{e}+01$ 1.39525e+01 1.39526e+00 1.00000e-09 2.12000e-01 $1.00000 \mathrm{e}-05$ 1.00000e-05 1.00000e-06 1.00000e-09 1.00000e-01 $1.00000 \mathrm{e}+001.00000 \mathrm{e}+001.00000 \mathrm{e}-011.00000 \mathrm{e}-091.00000 \mathrm{e}-01$ Element: 9204 \# of layers: 7

$\mathrm{Kx} \mathrm{Ky} \mathrm{Kz}$ Ss Por

$1.39525 \mathrm{e}+01$ 1.39525e+01 1.39526e+00 1.00000e-09 2.12000e-01 
$1.39525 \mathrm{e}+01$ 1.39525e+01 1.39526e+00 1.00000e-09 2.12000e-01 $1.39525 \mathrm{e}+01$ 1.39525e+01 1.39526e+00 1.00000e-09 2.12000e-01 $1.39525 \mathrm{e}+011.39525 \mathrm{e}+011.39526 \mathrm{e}+001.00000 \mathrm{e}-092.12000 \mathrm{e}-01$ $1.39525 \mathrm{e}+011.39525 \mathrm{e}+011.39526 \mathrm{e}+001.00000 \mathrm{e}-092.12000 \mathrm{e}-01$ $1.00000 \mathrm{e}-05$ 1.00000e-05 1.00000e-06 1.00000e-09 1.00000e-01 $1.00000 \mathrm{e}+001.00000 \mathrm{e}+001.00000 \mathrm{e}-011.00000 \mathrm{e}-091.00000 \mathrm{e}-01$ Element: 9205 \# of layers: 7

$\mathrm{Kx} \mathrm{Ky} \mathrm{Kz}$ Ss Por

$1.39525 \mathrm{e}+01$ 1.39525e+01 1.39526e+00 1.00000e-09 2.12000e-01 $1.39525 \mathrm{e}+01$ 1.39525e+01 1.39526e+00 1.00000e-09 2.12000e-01 $1.39525 \mathrm{e}+01$ 1.39525e+01 1.39526e+00 1.00000e-09 2.12000e-01 $1.39525 \mathrm{e}+011.39525 \mathrm{e}+011.39526 \mathrm{e}+001.00000 \mathrm{e}-092.12000 \mathrm{e}-01$ $1.39525 \mathrm{e}+011.39525 \mathrm{e}+01$ 1.39526e+00 1.00000e-09 2.12000e-01 $1.00000 \mathrm{e}-05$ 1.00000e-05 1.00000e-06 1.00000e-09 1.00000e-01 $1.00000 \mathrm{e}+001.00000 \mathrm{e}+001.00000 \mathrm{e}-01$ 1.00000e-09 1.00000e-01 Element: 9206 \# of layers: 7

$\mathrm{Kx} \mathrm{Ky} \mathrm{Kz}$ Ss Por

$1.39525 \mathrm{e}+01$ 1.39525e+01 1.39526e+00 1.00000e-09 2.12000e-01 $1.39525 \mathrm{e}+01$ 1.39525e+01 1.39526e+00 1.00000e-09 2.12000e-01 $1.39525 \mathrm{e}+011.39525 \mathrm{e}+011.39526 \mathrm{e}+001.00000 \mathrm{e}-092.12000 \mathrm{e}-01$ $1.39525 \mathrm{e}+011.39525 \mathrm{e}+011.39526 \mathrm{e}+001.00000 \mathrm{e}-092.12000 \mathrm{e}-01$ $1.39525 \mathrm{e}+011.39525 \mathrm{e}+01$ 1.39526e+00 1.00000e-09 2.12000e-01 $1.00000 \mathrm{e}-05$ 1.00000e-05 1.00000e-06 1.00000e-09 1.00000e-01 $1.00000 \mathrm{e}+001.00000 \mathrm{e}+001.00000 \mathrm{e}-011.00000 \mathrm{e}-09$ 1.00000e-01 Element: 9207 \# of layers: 7

$\mathrm{Kx} \mathrm{Ky} \mathrm{Kz}$ Ss Por

$1.43519 \mathrm{e}+01$ 1.43519e+01 1.43519e+00 1.00000e-09 2.12000e-01 $1.43519 \mathrm{e}+011.43519 \mathrm{e}+01$ 1.43519e+00 1.00000e-09 2.12000e-01 $1.43519 \mathrm{e}+01$ 1.43519e+01 1.43519e+00 1.00000e-09 2.12000e-01 $1.43519 \mathrm{e}+01$ 1.43519e+01 1.43519e+00 1.00000e-09 2.12000e-01 $1.43519 \mathrm{e}+01$ 1.43519e+01 1.43519e+00 1.00000e-09 2.12000e-01 $1.00000 \mathrm{e}-05$ 1.00000e-05 1.00000e-06 1.00000e-09 1.00000e-01 $1.00000 \mathrm{e}+001.00000 \mathrm{e}+001.00000 \mathrm{e}-011.00000 \mathrm{e}-091.00000 \mathrm{e}-01$ Element: 9208 \# of layers: 7

$\mathrm{Kx} \mathrm{Ky} \mathrm{Kz}$ Ss Por

$1.43519 \mathrm{e}+01$ 1.43519e+01 1.43519e+00 1.00000e-09 2.12000e-01 $1.43519 \mathrm{e}+011.43519 \mathrm{e}+011.43519 \mathrm{e}+001.00000 \mathrm{e}-092.12000 \mathrm{e}-01$ $1.43519 \mathrm{e}+011.43519 \mathrm{e}+011.43519 \mathrm{e}+001.00000 \mathrm{e}-092.12000 \mathrm{e}-01$ $1.43519 \mathrm{e}+011.43519 \mathrm{e}+01$ 1.43519e+00 1.00000e-09 2.12000e-01 $1.43519 \mathrm{e}+01$ 1.43519e+01 1.43519e+00 1.00000e-09 2.12000e-01 $1.00000 \mathrm{e}-05$ 1.00000e-05 1.00000e-06 1.00000e-09 1.00000e-01 $1.00000 \mathrm{e}+001.00000 \mathrm{e}+001.00000 \mathrm{e}-011.00000 \mathrm{e}-091.00000 \mathrm{e}-01$ Element: 9209 \# of layers: 7

$\mathrm{Kx} \mathrm{Ky} \mathrm{Kz}$ Ss Por

$1.39525 \mathrm{e}+01$ 1.39525e+01 1.39526e+00 1.00000e-09 2.12000e-01 $1.39525 \mathrm{e}+011.39525 \mathrm{e}+011.39526 \mathrm{e}+001.00000 \mathrm{e}-092.12000 \mathrm{e}-01$ 
$1.39525 \mathrm{e}+01$ 1.39525e+01 1.39526e+00 1.00000e-09 2.12000e-01 $1.39525 \mathrm{e}+01$ 1.39525e+01 1.39526e+00 1.00000e-09 2.12000e-01 $1.39525 \mathrm{e}+011.39525 \mathrm{e}+011.39526 \mathrm{e}+001.00000 \mathrm{e}-092.12000 \mathrm{e}-01$ $1.00000 \mathrm{e}-05$ 1.00000e-05 1.00000e-06 1.00000e-09 1.00000e-01 $1.00000 \mathrm{e}+001.00000 \mathrm{e}+001.00000 \mathrm{e}-01$ 1.00000e-09 1.00000e-01 Element: 9210 \# of layers: 7

$\mathrm{Kx} \mathrm{Ky} \mathrm{Kz}$ Ss Por

$1.39525 \mathrm{e}+01$ 1.39525e+01 1.39526e+00 1.00000e-09 2.12000e-01 $1.39525 \mathrm{e}+011.39525 \mathrm{e}+01$ 1.39526e+00 1.00000e-09 2.12000e-01 $1.39525 \mathrm{e}+01$ 1.39525e+01 1.39526e+00 1.00000e-09 2.12000e-01 $1.39525 \mathrm{e}+01$ 1.39525e+01 1.39526e+00 1.00000e-09 2.12000e-01 $1.39525 \mathrm{e}+011.39525 \mathrm{e}+011.39526 \mathrm{e}+001.00000 \mathrm{e}-092.12000 \mathrm{e}-01$ $1.00000 \mathrm{e}-05$ 1.00000e-05 1.00000e-06 1.00000e-09 1.00000e-01 $1.00000 \mathrm{e}+001.00000 \mathrm{e}+001.00000 \mathrm{e}-011.00000 \mathrm{e}-09$ 1.00000e-01 Element: 9211 \# of layers: 7

Kx Ky Kz Ss Por

$1.52153 \mathrm{e}+01$ 1.52153e+01 1.52153e+00 1.00000e-09 2.12000e-01 $1.52153 \mathrm{e}+011.52153 \mathrm{e}+01$ 1.52153e+00 1.00000e-09 2.12000e-01 $1.52153 \mathrm{e}+01$ 1.52153e+01 1.52153e+00 1.00000e-09 2.12000e-01 $1.52153 \mathrm{e}+01$ 1.52153e+01 1.52153e+00 1.00000e-09 2.12000e-01 $1.52153 \mathrm{e}+011.52153 \mathrm{e}+011.52153 \mathrm{e}+001.00000 \mathrm{e}-092.12000 \mathrm{e}-01$ $1.00000 \mathrm{e}-051.00000 \mathrm{e}-051.00000 \mathrm{e}-061.00000 \mathrm{e}-091.00000 \mathrm{e}-01$ $1.00000 \mathrm{e}+001.00000 \mathrm{e}+001.00000 \mathrm{e}-01$ 1.00000e-09 1.00000e-01 Element: 9212 \# of layers: 7

Kx Ky Kz Ss Por

$1.52153 \mathrm{e}+01$ 1.52153e+01 1.52153e+00 1.00000e-09 2.12000e-01 $1.52153 \mathrm{e}+01$ 1.52153e+01 1.52153e+00 1.00000e-09 2.12000e-01 $1.52153 \mathrm{e}+011.52153 \mathrm{e}+01$ 1.52153e+00 1.00000e-09 2.12000e-01 $1.52153 \mathrm{e}+011.52153 \mathrm{e}+011.52153 \mathrm{e}+001.00000 \mathrm{e}-092.12000 \mathrm{e}-01$ $1.52153 \mathrm{e}+011.52153 \mathrm{e}+011.52153 \mathrm{e}+001.00000 \mathrm{e}-092.12000 \mathrm{e}-01$ $1.00000 \mathrm{e}-05$ 1.00000e-05 1.00000e-06 1.00000e-09 1.00000e-01 $1.00000 \mathrm{e}+001.00000 \mathrm{e}+001.00000 \mathrm{e}-011.00000 \mathrm{e}-091.00000 \mathrm{e}-01$ Element: 9213 \# of layers: 7

$\mathrm{Kx} \mathrm{Ky} \mathrm{Kz}$ Ss Por

$1.52153 \mathrm{e}+01$ 1.52153e+01 1.52153e+00 1.00000e-09 2.12000e-01 $1.52153 \mathrm{e}+011.52153 \mathrm{e}+01$ 1.52153e+00 1.00000e-09 2.12000e-01 $1.52153 \mathrm{e}+011.52153 \mathrm{e}+01$ 1.52153e+00 1.00000e-09 2.12000e-01 $1.52153 \mathrm{e}+011.52153 \mathrm{e}+01$ 1.52153e+00 1.00000e-09 2.12000e-01 $1.52153 \mathrm{e}+011.52153 \mathrm{e}+01$ 1.52153e+00 1.00000e-09 2.12000e-01 $1.00000 \mathrm{e}-05$ 1.00000e-05 1.00000e-06 1.00000e-09 1.00000e-01 $1.00000 \mathrm{e}+001.00000 \mathrm{e}+001.00000 \mathrm{e}-011.00000 \mathrm{e}-091.00000 \mathrm{e}-01$ Element: 9214 \# of layers: 7

$\mathrm{Kx} \mathrm{Ky} \mathrm{Kz}$ Ss Por

1.17347e+01 1.17347e+01 1.17347e+00 1.00000e-09 2.12000e-01 $1.17347 \mathrm{e}+01$ 1.17347e+01 1.17347e+00 1.00000e-09 2.12000e-01 $1.17347 \mathrm{e}+01$ 1.17347e+01 1.17347e+00 1.00000e-09 2.12000e-01 
$1.17347 \mathrm{e}+01$ 1.17347e+01 1.17347e+00 1.00000e-09 2.12000e-01 $1.17347 \mathrm{e}+01$ 1.17347e+01 1.17347e+00 1.00000e-09 2.12000e-01 $1.00000 \mathrm{e}-051.00000 \mathrm{e}-05$ 1.00000e-06 1.00000e-09 1.00000e-01 $1.00000 \mathrm{e}+001.00000 \mathrm{e}+001.00000 \mathrm{e}-011.00000 \mathrm{e}-091.00000 \mathrm{e}-01$ Element: 9215 \# of layers: 7

Kx Ky Kz Ss Por

$1.17347 \mathrm{e}+01$ 1.17347e+01 1.17347e+00 1.00000e-09 2.12000e-01 $1.17347 \mathrm{e}+01$ 1.17347e+01 1.17347e+00 1.00000e-09 2.12000e-01 $1.17347 \mathrm{e}+01$ 1.17347e+01 1.17347e+00 1.00000e-09 2.12000e-01 $1.17347 \mathrm{e}+011.17347 \mathrm{e}+01$ 1.17347e+00 1.00000e-09 2.12000e-01 $1.17347 \mathrm{e}+01$ 1.17347e+01 1.17347e+00 1.00000e-09 2.12000e-01 $1.00000 \mathrm{e}-05$ 1.00000e-05 1.00000e-06 1.00000e-09 1.00000e-01 $1.00000 \mathrm{e}+001.00000 \mathrm{e}+001.00000 \mathrm{e}-011.00000 \mathrm{e}-09$ 1.00000e-01 Element: 9216 \# of layers: 7

$\mathrm{Kx} \mathrm{Ky} \mathrm{Kz}$ Ss Por

$1.43519 \mathrm{e}+01$ 1.43519e+01 1.43519e+00 1.00000e-09 2.12000e-01 $1.43519 \mathrm{e}+01$ 1.43519e+01 1.43519e+00 1.00000e-09 2.12000e-01 $1.43519 \mathrm{e}+011.43519 \mathrm{e}+01$ 1.43519e+00 1.00000e-09 2.12000e-01 $1.43519 \mathrm{e}+01$ 1.43519e+01 1.43519e+00 1.00000e-09 2.12000e-01 $1.43519 \mathrm{e}+01$ 1.43519e+01 1.43519e+00 1.00000e-09 2.12000e-01 $1.00000 \mathrm{e}-05$ 1.00000e-05 1.00000e-06 1.00000e-09 1.00000e-01 $1.00000 \mathrm{e}+001.00000 \mathrm{e}+001.00000 \mathrm{e}-011.00000 \mathrm{e}-09$ 1.00000e-01 Element: 9217 \# of layers: 7

Kx Ky Kz Ss Por

$1.39525 \mathrm{e}+01$ 1.39525e+01 1.39526e+00 1.00000e-09 2.12000e-01 $1.39525 \mathrm{e}+011.39525 \mathrm{e}+011.39526 \mathrm{e}+001.00000 \mathrm{e}-092.12000 \mathrm{e}-01$ $1.39525 \mathrm{e}+011.39525 \mathrm{e}+011.39526 \mathrm{e}+001.00000 \mathrm{e}-092.12000 \mathrm{e}-01$ $1.39525 \mathrm{e}+01$ 1.39525e+01 1.39526e+00 1.00000e-09 2.12000e-01 $1.39525 \mathrm{e}+011.39525 \mathrm{e}+01 \quad 1.39526 \mathrm{e}+001.00000 \mathrm{e}-092.12000 \mathrm{e}-01$ $1.00000 \mathrm{e}-05$ 1.00000e-05 1.00000e-06 1.00000e-09 1.00000e-01 $1.00000 \mathrm{e}+001.00000 \mathrm{e}+001.00000 \mathrm{e}-01$ 1.00000e-09 1.00000e-01 Element: 9218 \# of layers: 7

Kx Ky Kz Ss Por

$1.52153 \mathrm{e}+01$ 1.52153e+01 1.52153e+00 1.00000e-09 2.12000e-01 $1.52153 \mathrm{e}+011.52153 \mathrm{e}+011.52153 \mathrm{e}+001.00000 \mathrm{e}-092.12000 \mathrm{e}-01$ $1.52153 \mathrm{e}+011.52153 \mathrm{e}+011.52153 \mathrm{e}+001.00000 \mathrm{e}-092.12000 \mathrm{e}-01$ $1.52153 \mathrm{e}+011.52153 \mathrm{e}+011.52153 \mathrm{e}+001.00000 \mathrm{e}-092.12000 \mathrm{e}-01$ $1.52153 \mathrm{e}+011.52153 \mathrm{e}+01$ 1.52153e+00 1.00000e-09 2.12000e-01 $1.00000 \mathrm{e}-05$ 1.00000e-05 1.00000e-06 1.00000e-09 1.00000e-01 $1.00000 \mathrm{e}+001.00000 \mathrm{e}+001.00000 \mathrm{e}-01$ 1.00000e-09 1.00000e-01 Element: 9219 \# of layers: 7

Kx Ky Kz Ss Por $1.63628 \mathrm{e}+01$ 1.63628e+01 1.63628e+00 1.00000e-09 2.12000e-01 $1.63628 \mathrm{e}+011.63628 \mathrm{e}+01$ 1.63628e+00 1.00000e-09 2.12000e-01 $1.63628 \mathrm{e}+011.63628 \mathrm{e}+011.63628 \mathrm{e}+001.00000 \mathrm{e}-092.12000 \mathrm{e}-01$ $1.63628 \mathrm{e}+011.63628 \mathrm{e}+011.63628 \mathrm{e}+00$ 1.00000e-09 2.12000e-01 
$1.63628 \mathrm{e}+01$ 1.63628e+01 1.63628e+00 1.00000e-09 2.12000e-01 $1.00000 \mathrm{e}-05$ 1.00000e-05 1.00000e-06 1.00000e-09 1.00000e-01 $1.00000 \mathrm{e}+001.00000 \mathrm{e}+001.00000 \mathrm{e}-011.00000 \mathrm{e}-091.00000 \mathrm{e}-01$

Element: 9220 \# of layers: 7

$\mathrm{Kx} \mathrm{Ky} \mathrm{Kz}$ Ss Por

$1.63628 \mathrm{e}+01$ 1.63628e+01 1.63628e+00 1.00000e-09 2.12000e-01

$1.63628 \mathrm{e}+011.63628 \mathrm{e}+011.63628 \mathrm{e}+001.00000 \mathrm{e}-092.12000 \mathrm{e}-01$

$1.63628 \mathrm{e}+011.63628 \mathrm{e}+011.63628 \mathrm{e}+001.00000 \mathrm{e}-092.12000 \mathrm{e}-01$

$1.63628 \mathrm{e}+01$ 1.63628e+01 1.63628e+00 1.00000e-09 2.12000e-01

$1.63628 \mathrm{e}+01$ 1.63628e+01 1.63628e+00 1.00000e-09 2.12000e-01 $1.00000 \mathrm{e}-05$ 1.00000e-05 1.00000e-06 1.00000e-09 1.00000e-01

$1.00000 \mathrm{e}+001.00000 \mathrm{e}+001.00000 \mathrm{e}-011.00000 \mathrm{e}-091.00000 \mathrm{e}-01$

Element: 9221 \# of layers: 7

$\mathrm{Kx} \mathrm{Ky} \mathrm{Kz}$ Ss Por

$1.63628 \mathrm{e}+01$ 1.63628e+01 1.63628e+00 1.00000e-09 2.12000e-01

$1.63628 \mathrm{e}+011.63628 \mathrm{e}+011.63628 \mathrm{e}+001.00000 \mathrm{e}-092.12000 \mathrm{e}-01$

$1.63628 \mathrm{e}+011.63628 \mathrm{e}+011.63628 \mathrm{e}+001.00000 \mathrm{e}-092.12000 \mathrm{e}-01$

$1.63628 \mathrm{e}+011.63628 \mathrm{e}+011.63628 \mathrm{e}+001.00000 \mathrm{e}-092.12000 \mathrm{e}-01$

$1.63628 \mathrm{e}+01$ 1.63628e+01 1.63628e+00 1.00000e-09 2.12000e-01 $1.00000 \mathrm{e}-05$ 1.00000e-05 1.00000e-06 1.00000e-09 1.00000e-01

$1.00000 \mathrm{e}+001.00000 \mathrm{e}+001.00000 \mathrm{e}-011.00000 \mathrm{e}-091.00000 \mathrm{e}-01$

Element: 9222 \# of layers: 7

$\mathrm{Kx} \mathrm{Ky} \mathrm{Kz}$ Ss Por

$1.63628 \mathrm{e}+01$ 1.63628e+01 1.63628e+00 1.00000e-09 2.12000e-01

$1.63628 \mathrm{e}+011.63628 \mathrm{e}+011.63628 \mathrm{e}+001.00000 \mathrm{e}-092.12000 \mathrm{e}-01$

$1.63628 \mathrm{e}+011.63628 \mathrm{e}+01$ 1.63628e+00 1.00000e-09 2.12000e-01

$1.63628 \mathrm{e}+011.63628 \mathrm{e}+011.63628 \mathrm{e}+001.00000 \mathrm{e}-092.12000 \mathrm{e}-01$

$1.63628 \mathrm{e}+011.63628 \mathrm{e}+011.63628 \mathrm{e}+001.00000 \mathrm{e}-092.12000 \mathrm{e}-01$

$1.00000 \mathrm{e}-05$ 1.00000e-05 1.00000e-06 1.00000e-09 1.00000e-01

$1.00000 \mathrm{e}+001.00000 \mathrm{e}+001.00000 \mathrm{e}-011.00000 \mathrm{e}-091.00000 \mathrm{e}-01$

Element: 9223 \# of layers: 7

$\mathrm{Kx} \mathrm{Ky} \mathrm{Kz}$ Ss Por

6.70222e+00 6.70222e+00 6.70222e-01 1.00000e-09 2.12000e-01

6.70222e+00 6.70222e+00 6.70222e-01 1.00000e-09 2.12000e-01

6.70222e+00 6.70222e+00 6.70222e-01 1.00000e-09 2.12000e-01

6.70222e+00 6.70222e+00 6.70222e-01 1.00000e-09 2.12000e-01

$6.70222 \mathrm{e}+006.70222 \mathrm{e}+00$ 6.70222e-01 1.00000e-09 2.12000e-01

$1.00000 \mathrm{e}-05$ 1.00000e-05 1.00000e-06 1.00000e-09 1.00000e-01

$1.00000 \mathrm{e}+001.00000 \mathrm{e}+001.00000 \mathrm{e}-011.00000 \mathrm{e}-091.00000 \mathrm{e}-01$

Element: 9224 \# of layers: 7

$\mathrm{Kx} \mathrm{Ky} \mathrm{Kz}$ Ss Por

6.70222e+00 6.70222e+00 6.70222e-01 1.00000e-09 2.12000e-01

6.70222e+00 6.70222e+00 6.70222e-01 1.00000e-09 2.12000e-01

$6.70222 \mathrm{e}+006.70222 \mathrm{e}+00$ 6.70222e-01 1.00000e-09 2.12000e-01

6.70222e+00 6.70222e+00 6.70222e-01 1.00000e-09 2.12000e-01

$6.70222 \mathrm{e}+00$ 6.70222e+00 6.70222e-01 1.00000e-09 2.12000e-01 
$1.00000 \mathrm{e}-05$ 1.00000e-05 1.00000e-06 1.00000e-09 1.00000e-01 $1.00000 \mathrm{e}+001.00000 \mathrm{e}+001.00000 \mathrm{e}-011.00000 \mathrm{e}-091.00000 \mathrm{e}-01$ Element: 9225 \# of layers: 7

$\mathrm{Kx} \mathrm{Ky} \mathrm{Kz}$ Ss Por

6.70222e+00 6.70222e+00 6.70222e-01 1.00000e-09 2.12000e-01 $6.70222 \mathrm{e}+00$ 6.70222e+00 6.70222e-01 1.00000e-09 2.12000e-01 $6.70222 \mathrm{e}+00$ 6.70222e+00 6.70222e-01 1.00000e-09 2.12000e-01 $6.70222 \mathrm{e}+00$ 6.70222e+00 6.70222e-01 1.00000e-09 2.12000e-01 $6.70222 \mathrm{e}+006.70222 \mathrm{e}+006.70222 \mathrm{e}-01$ 1.00000e-09 2.12000e-01 $1.00000 \mathrm{e}-05$ 1.00000e-05 1.00000e-06 1.00000e-09 1.00000e-01 $1.00000 \mathrm{e}+001.00000 \mathrm{e}+001.00000 \mathrm{e}-011.00000 \mathrm{e}-091.00000 \mathrm{e}-01$ Element: 9226 \# of layers: 7

$\mathrm{Kx} \mathrm{Ky} \mathrm{Kz}$ Ss Por

6.70222e+00 6.70222e+00 6.70222e-01 1.00000e-09 2.12000e-01 6.70222e+00 6.70222e+00 6.70222e-01 1.00000e-09 2.12000e-01 $6.70222 \mathrm{e}+00$ 6.70222e+00 6.70222e-01 1.00000e-09 2.12000e-01 $6.70222 \mathrm{e}+00$ 6.70222e+00 6.70222e-01 1.00000e-09 2.12000e-01 6.70222e+00 6.70222e+00 6.70222e-01 1.00000e-09 2.12000e-01 $1.00000 \mathrm{e}-05$ 1.00000e-05 1.00000e-06 1.00000e-09 1.00000e-01 $1.00000 \mathrm{e}+001.00000 \mathrm{e}+001.00000 \mathrm{e}-011.00000 \mathrm{e}-091.00000 \mathrm{e}-01$ Element: 9227 \# of layers: 7

$\mathrm{Kx} \mathrm{Ky} \mathrm{Kz}$ Ss Por

$1.63628 \mathrm{e}+01$ 1.63628e+01 1.63628e+00 1.00000e-09 2.12000e-01 $1.63628 \mathrm{e}+011.63628 \mathrm{e}+011.63628 \mathrm{e}+001.00000 \mathrm{e}-092.12000 \mathrm{e}-01$ $1.63628 \mathrm{e}+011.63628 \mathrm{e}+011.63628 \mathrm{e}+001.00000 \mathrm{e}-092.12000 \mathrm{e}-01$ $1.63628 \mathrm{e}+011.63628 \mathrm{e}+01$ 1.63628e+00 1.00000e-09 2.12000e-01 $1.63628 \mathrm{e}+011.63628 \mathrm{e}+011.63628 \mathrm{e}+001.00000 \mathrm{e}-092.12000 \mathrm{e}-01$ $1.00000 \mathrm{e}-05$ 1.00000e-05 1.00000e-06 1.00000e-09 1.00000e-01 $1.00000 \mathrm{e}+001.00000 \mathrm{e}+001.00000 \mathrm{e}-011.00000 \mathrm{e}-091.00000 \mathrm{e}-01$ Element: 9228 \# of layers: 7

$\mathrm{Kx} \mathrm{Ky} \mathrm{Kz}$ Ss Por

6.70222e+00 6.70222e+00 6.70222e-01 1.00000e-09 2.12000e-01 $6.70222 \mathrm{e}+00$ 6.70222e+00 6.70222e-01 1.00000e-09 2.12000e-01 6.70222e+00 6.70222e+00 6.70222e-01 1.00000e-09 2.12000e-01 6.70222e+00 6.70222e+00 6.70222e-01 1.00000e-09 2.12000e-01 6.70222e+00 6.70222e+00 6.70222e-01 1.00000e-09 2.12000e-01 $1.00000 \mathrm{e}-05$ 1.00000e-05 1.00000e-06 1.00000e-09 1.00000e-01 $1.00000 \mathrm{e}+001.00000 \mathrm{e}+001.00000 \mathrm{e}-011.00000 \mathrm{e}-091.00000 \mathrm{e}-01$ Element: 9229 \# of layers: 7

$\mathrm{Kx} \mathrm{Ky} \mathrm{Kz}$ Ss Por

6.70222e+00 6.70222e+00 6.70222e-01 1.00000e-09 2.12000e-01 $6.70222 \mathrm{e}+00$ 6.70222e+00 6.70222e-01 1.00000e-09 2.12000e-01 $6.70222 \mathrm{e}+00$ 6.70222e+00 6.70222e-01 1.00000e-09 2.12000e-01 6.70222e+00 6.70222e+00 6.70222e-01 1.00000e-09 2.12000e-01 6.70222e+00 6.70222e+00 6.70222e-01 1.00000e-09 2.12000e-01 $1.00000 \mathrm{e}-05$ 1.00000e-05 1.00000e-06 1.00000e-09 1.00000e-01 
$1.00000 \mathrm{e}+001.00000 \mathrm{e}+001.00000 \mathrm{e}-01$ 1.00000e-09 1.00000e-01

Element: 9230 \# of layers: 7

$\mathrm{Kx} \mathrm{Ky} \mathrm{Kz}$ Ss Por

6.70222e+00 6.70222e+00 6.70222e-01 1.00000e-09 2.12000e-01

6.70222e+00 6.70222e+00 6.70222e-01 1.00000e-09 2.12000e-01

$6.70222 \mathrm{e}+00$ 6.70222e+00 6.70222e-01 1.00000e-09 2.12000e-01

$6.70222 \mathrm{e}+00$ 6.70222e+00 6.70222e-01 1.00000e-09 2.12000e-01

$6.70222 \mathrm{e}+006.70222 \mathrm{e}+006.70222 \mathrm{e}-01$ 1.00000e-09 2.12000e-01

$1.00000 \mathrm{e}-051.00000 \mathrm{e}-051.00000 \mathrm{e}-061.00000 \mathrm{e}-091.00000 \mathrm{e}-01$

$1.00000 \mathrm{e}+001.00000 \mathrm{e}+001.00000 \mathrm{e}-011.00000 \mathrm{e}-091.00000 \mathrm{e}-01$

Element: 9231 \# of layers: 7

$\mathrm{Kx} \mathrm{Ky} \mathrm{Kz}$ Ss Por

6.70222e+00 6.70222e+00 6.70222e-01 1.00000e-09 2.12000e-01

$6.70222 \mathrm{e}+006.70222 \mathrm{e}+00$ 6.70222e-01 1.00000e-09 2.12000e-01

$6.70222 \mathrm{e}+006.70222 \mathrm{e}+00$ 6.70222e-01 1.00000e-09 2.12000e-01

6.70222e+00 6.70222e+00 6.70222e-01 1.00000e-09 2.12000e-01

6.70222e+00 6.70222e+00 6.70222e-01 1.00000e-09 2.12000e-01

$1.00000 \mathrm{e}-05$ 1.00000e-05 1.00000e-06 1.00000e-09 1.00000e-01

$1.00000 \mathrm{e}+001.00000 \mathrm{e}+001.00000 \mathrm{e}-01$ 1.00000e-09 1.00000e-01

Element: 9232 \# of layers: 7

$\mathrm{Kx} \mathrm{Ky} \mathrm{Kz}$ Ss Por

6.70222e+00 6.70222e+00 6.70222e-01 1.00000e-09 2.12000e-01

6.70222e+00 6.70222e+00 6.70222e-01 1.00000e-09 2.12000e-01

6.70222e+00 6.70222e+00 6.70222e-01 1.00000e-09 2.12000e-01

$6.70222 \mathrm{e}+006.70222 \mathrm{e}+00$ 6.70222e-01 1.00000e-09 2.12000e-01

$6.70222 \mathrm{e}+006.70222 \mathrm{e}+00$ 6.70222e-01 1.00000e-09 2.12000e-01

$1.00000 \mathrm{e}-05$ 1.00000e-05 1.00000e-06 1.00000e-09 1.00000e-01

$1.00000 \mathrm{e}+001.00000 \mathrm{e}+001.00000 \mathrm{e}-011.00000 \mathrm{e}-09$ 1.00000e-01

Element: 9233 \# of layers: 7

$\mathrm{Kx} \mathrm{Ky} \mathrm{Kz}$ Ss Por

6.70222e+00 6.70222e+00 6.70222e-01 1.00000e-09 2.12000e-01

$6.70222 \mathrm{e}+006.70222 \mathrm{e}+00$ 6.70222e-01 1.00000e-09 2.12000e-01

$6.70222 \mathrm{e}+00$ 6.70222e+00 6.70222e-01 1.00000e-09 2.12000e-01

6.70222e+00 6.70222e+00 6.70222e-01 1.00000e-09 2.12000e-01

$6.70222 \mathrm{e}+006.70222 \mathrm{e}+00$ 6.70222e-01 1.00000e-09 2.12000e-01

$1.00000 \mathrm{e}-05$ 1.00000e-05 1.00000e-06 1.00000e-09 1.00000e-01

$1.00000 \mathrm{e}+001.00000 \mathrm{e}+001.00000 \mathrm{e}-011.00000 \mathrm{e}-091.00000 \mathrm{e}-01$

Element: 9234 \# of layers: 7

$\mathrm{Kx} \mathrm{Ky} \mathrm{Kz}$ Ss Por

6.70222e+00 6.70222e+00 6.70222e-01 1.00000e-09 2.12000e-01

$6.70222 \mathrm{e}+00$ 6.70222e+00 6.70222e-01 1.00000e-09 2.12000e-01

$6.70222 \mathrm{e}+006.70222 \mathrm{e}+006.70222 \mathrm{e}-01$ 1.00000e-09 2.12000e-01

6.70222e+00 6.70222e+00 6.70222e-01 1.00000e-09 2.12000e-01

$6.70222 \mathrm{e}+00$ 6.70222e+00 6.70222e-01 1.00000e-09 2.12000e-01

$1.00000 \mathrm{e}-05$ 1.00000e-05 1.00000e-06 1.00000e-09 1.00000e-01

$1.00000 \mathrm{e}+001.00000 \mathrm{e}+001.00000 \mathrm{e}-011.00000 \mathrm{e}-091.00000 \mathrm{e}-01$ 
Element: 9235 \# of layers: 7

Kx Ky Kz Ss Por

6.70222e+00 6.70222e+00 6.70222e-01 1.00000e-09 2.12000e-01

$6.70222 \mathrm{e}+006.70222 \mathrm{e}+00$ 6.70222e-01 1.00000e-09 2.12000e-01

$6.70222 \mathrm{e}+006.70222 \mathrm{e}+00$ 6.70222e-01 1.00000e-09 2.12000e-01

$6.70222 \mathrm{e}+006.70222 \mathrm{e}+006.70222 \mathrm{e}-011.00000 \mathrm{e}-092.12000 \mathrm{e}-01$

$6.70222 \mathrm{e}+006.70222 \mathrm{e}+00$ 6.70222e-01 1.00000e-09 2.12000e-01

$1.00000 \mathrm{e}-05$ 1.00000e-05 1.00000e-06 1.00000e-09 1.00000e-01

$1.00000 \mathrm{e}+001.00000 \mathrm{e}+001.00000 \mathrm{e}-011.00000 \mathrm{e}-091.00000 \mathrm{e}-01$

Element: 9236 \# of layers: 7

Kx Ky Kz Ss Por

$6.70222 \mathrm{e}+006.70222 \mathrm{e}+00$ 6.70222e-01 1.00000e-09 2.12000e-01

$6.70222 \mathrm{e}+006.70222 \mathrm{e}+006.70222 \mathrm{e}-011.00000 \mathrm{e}-092.12000 \mathrm{e}-01$

$6.70222 \mathrm{e}+006.70222 \mathrm{e}+006.70222 \mathrm{e}-011.00000 \mathrm{e}-092.12000 \mathrm{e}-01$

$6.70222 \mathrm{e}+006.70222 \mathrm{e}+006.70222 \mathrm{e}-011.00000 \mathrm{e}-092.12000 \mathrm{e}-01$

$6.70222 \mathrm{e}+006.70222 \mathrm{e}+00$ 6.70222e-01 1.00000e-09 2.12000e-01

$1.00000 \mathrm{e}-05$ 1.00000e-05 1.00000e-06 1.00000e-09 1.00000e-01

$1.00000 \mathrm{e}+001.00000 \mathrm{e}+00$ 1.00000e-01 1.00000e-09 1.00000e-01

Element: 9237 \# of layers: 7

Kx Ky Kz Ss Por

$6.70222 \mathrm{e}+006.70222 \mathrm{e}+00$ 6.70222e-01 1.00000e-09 2.12000e-01

$6.70222 \mathrm{e}+006.70222 \mathrm{e}+00$ 6.70222e-01 1.00000e-09 2.12000e-01

$6.70222 \mathrm{e}+006.70222 \mathrm{e}+006.70222 \mathrm{e}-01$ 1.00000e-09 2.12000e-01

$6.70222 \mathrm{e}+006.70222 \mathrm{e}+00$ 6.70222e-01 1.00000e-09 2.12000e-01

$6.70222 \mathrm{e}+006.70222 \mathrm{e}+00$ 6.70222e-01 1.00000e-09 2.12000e-01

$1.00000 \mathrm{e}-05$ 1.00000e-05 1.00000e-06 1.00000e-09 1.00000e-01

$1.00000 \mathrm{e}+001.00000 \mathrm{e}+001.00000 \mathrm{e}-011.00000 \mathrm{e}-091.00000 \mathrm{e}-01$

Element: 9238 \# of layers: 7

Kx Ky Kz Ss Por

$6.70222 \mathrm{e}+006.70222 \mathrm{e}+00$ 6.70222e-01 1.00000e-09 2.12000e-01

$6.70222 \mathrm{e}+006.70222 \mathrm{e}+00$ 6.70222e-01 1.00000e-09 2.12000e-01

$6.70222 \mathrm{e}+006.70222 \mathrm{e}+00$ 6.70222e-01 1.00000e-09 2.12000e-01

$6.70222 \mathrm{e}+006.70222 \mathrm{e}+00$ 6.70222e-01 1.00000e-09 2.12000e-01

$6.70222 \mathrm{e}+006.70222 \mathrm{e}+00$ 6.70222e-01 1.00000e-09 2.12000e-01

$1.00000 \mathrm{e}-05$ 1.00000e-05 1.00000e-06 1.00000e-09 1.00000e-01

$1.00000 \mathrm{e}+001.00000 \mathrm{e}+001.00000 \mathrm{e}-011.00000 \mathrm{e}-091.00000 \mathrm{e}-01$

Element: 9239 \# of layers: 6

Kx Ky Kz Ss Por

$3.56475 \mathrm{e}+003.56475 \mathrm{e}+00$ 3.56475e-01 1.00000e-09 2.12000e-01

$3.56475 \mathrm{e}+003.56475 \mathrm{e}+003.56475 \mathrm{e}-011.00000 \mathrm{e}-092.12000 \mathrm{e}-01$

$3.56475 \mathrm{e}+003.56475 \mathrm{e}+003.56475 \mathrm{e}-011.00000 \mathrm{e}-092.12000 \mathrm{e}-01$

$3.56475 \mathrm{e}+003.56475 \mathrm{e}+003.56475 \mathrm{e}-011.00000 \mathrm{e}-092.12000 \mathrm{e}-01$

$1.00000 \mathrm{e}-05$ 1.00000e-05 1.00000e-06 1.00000e-09 1.00000e-01

$1.00000 \mathrm{e}+001.00000 \mathrm{e}+001.00000 \mathrm{e}-011.00000 \mathrm{e}-091.00000 \mathrm{e}-01$

Element: 9240 \# of layers: 7

Kx Ky Kz Ss Por 
3.56475e+00 3.56475e+00 3.56475e-01 1.00000e-09 2.12000e-01 3.56475e+00 3.56475e+00 3.56475e-01 1.00000e-09 2.12000e-01 $3.56475 \mathrm{e}+003.56475 \mathrm{e}+003.56475 \mathrm{e}-01$ 1.00000e-09 2.12000e-01 $3.56475 \mathrm{e}+003.56475 \mathrm{e}+003.56475 \mathrm{e}-01$ 1.00000e-09 2.12000e-01 $3.56475 \mathrm{e}+003.56475 \mathrm{e}+003.56475 \mathrm{e}-01$ 1.00000e-09 2.12000e-01 $1.00000 \mathrm{e}-05$ 1.00000e-05 1.00000e-06 1.00000e-09 1.00000e-01 $1.00000 \mathrm{e}+001.00000 \mathrm{e}+00$ 1.00000e-01 1.00000e-09 1.00000e-01 Element: 9241 \# of layers: 7

$\mathrm{Kx} \mathrm{Ky} \mathrm{Kz}$ Ss Por

3.56475e+00 3.56475e+00 3.56475e-01 1.00000e-09 2.12000e-01 $3.56475 \mathrm{e}+003.56475 \mathrm{e}+00$ 3.56475e-01 1.00000e-09 2.12000e-01 $3.56475 \mathrm{e}+003.56475 \mathrm{e}+003.56475 \mathrm{e}-01$ 1.00000e-09 2.12000e-01 $3.56475 \mathrm{e}+003.56475 \mathrm{e}+003.56475 \mathrm{e}-01$ 1.00000e-09 2.12000e-01 $3.56475 \mathrm{e}+003.56475 \mathrm{e}+003.56475 \mathrm{e}-01$ 1.00000e-09 2.12000e-01 $1.00000 \mathrm{e}-05$ 1.00000e-05 1.00000e-06 1.00000e-09 1.00000e-01 $1.00000 \mathrm{e}+001.00000 \mathrm{e}+001.00000 \mathrm{e}-011.00000 \mathrm{e}-091.00000 \mathrm{e}-01$ Element: 9242 \# of layers: 7

$\mathrm{Kx} \mathrm{Ky} \mathrm{Kz}$ Ss Por

6.70222e+00 6.70222e+00 6.70222e-01 1.00000e-09 2.12000e-01 $6.70222 \mathrm{e}+00$ 6.70222e+00 6.70222e-01 1.00000e-09 2.12000e-01 $6.70222 \mathrm{e}+00$ 6.70222e+00 6.70222e-01 1.00000e-09 2.12000e-01 6.70222e+00 6.70222e+00 6.70222e-01 1.00000e-09 2.12000e-01 6.70222e+00 6.70222e+00 6.70222e-01 1.00000e-09 2.12000e-01 $1.00000 \mathrm{e}-05$ 1.00000e-05 1.00000e-06 1.00000e-09 1.00000e-01 $1.00000 \mathrm{e}+001.00000 \mathrm{e}+001.00000 \mathrm{e}-011.00000 \mathrm{e}-091.00000 \mathrm{e}-01$ Element: 9243 \# of layers: 7

$\mathrm{Kx} \mathrm{Ky} \mathrm{Kz}$ Ss Por

6.70222e+00 6.70222e+00 6.70222e-01 1.00000e-09 2.12000e-01 $6.70222 \mathrm{e}+00$ 6.70222e+00 6.70222e-01 1.00000e-09 2.12000e-01 6.70222e+00 6.70222e+00 6.70222e-01 1.00000e-09 2.12000e-01 $6.70222 \mathrm{e}+00$ 6.70222e+00 6.70222e-01 1.00000e-09 2.12000e-01 6.70222e+00 6.70222e+00 6.70222e-01 1.00000e-09 2.12000e-01 $1.00000 \mathrm{e}-05$ 1.00000e-05 1.00000e-06 1.00000e-09 1.00000e-01 $1.00000 \mathrm{e}+001.00000 \mathrm{e}+001.00000 \mathrm{e}-011.00000 \mathrm{e}-091.00000 \mathrm{e}-01$ Element: 9244 \# of layers: 7

$\mathrm{Kx} \mathrm{Ky} \mathrm{Kz}$ Ss Por

6.70222e+00 6.70222e+00 6.70222e-01 1.00000e-09 2.12000e-01 6.70222e+00 6.70222e+00 6.70222e-01 1.00000e-09 2.12000e-01 $6.70222 \mathrm{e}+006.70222 \mathrm{e}+00$ 6.70222e-01 1.00000e-09 2.12000e-01 6.70222e+00 6.70222e+00 6.70222e-01 1.00000e-09 2.12000e-01 $6.70222 \mathrm{e}+006.70222 \mathrm{e}+00$ 6.70222e-01 1.00000e-09 2.12000e-01 $1.00000 \mathrm{e}-05$ 1.00000e-05 1.00000e-06 1.00000e-09 1.00000e-01 $1.00000 \mathrm{e}+001.00000 \mathrm{e}+001.00000 \mathrm{e}-011.00000 \mathrm{e}-091.00000 \mathrm{e}-01$ Element: 9245 \# of layers: 7

$\mathrm{Kx} \mathrm{Ky} \mathrm{Kz}$ Ss Por

6.70222e+00 6.70222e+00 6.70222e-01 1.00000e-09 2.12000e-01 
$6.70222 \mathrm{e}+00$ 6.70222e+00 6.70222e-01 1.00000e-09 2.12000e-01 $6.70222 \mathrm{e}+006.70222 \mathrm{e}+00$ 6.70222e-01 1.00000e-09 2.12000e-01 $6.70222 \mathrm{e}+006.70222 \mathrm{e}+00$ 6.70222e-01 1.00000e-09 2.12000e-01 $6.70222 \mathrm{e}+006.70222 \mathrm{e}+00$ 6.70222e-01 1.00000e-09 2.12000e-01 $1.00000 \mathrm{e}-05$ 1.00000e-05 1.00000e-06 1.00000e-09 1.00000e-01 $1.00000 \mathrm{e}+001.00000 \mathrm{e}+001.00000 \mathrm{e}-011.00000 \mathrm{e}-091.00000 \mathrm{e}-01$ Element: 9246 \# of layers: 7

Kx Ky Kz Ss Por

$3.56475 \mathrm{e}+003.56475 \mathrm{e}+00$ 3.56475e-01 1.00000e-09 2.12000e-01

$3.56475 \mathrm{e}+003.56475 \mathrm{e}+003.56475 \mathrm{e}-011.00000 \mathrm{e}-092.12000 \mathrm{e}-01$ $3.56475 \mathrm{e}+003.56475 \mathrm{e}+003.56475 \mathrm{e}-011.00000 \mathrm{e}-092.12000 \mathrm{e}-01$ $3.56475 \mathrm{e}+003.56475 \mathrm{e}+003.56475 \mathrm{e}-011.00000 \mathrm{e}-092.12000 \mathrm{e}-01$ $3.56475 \mathrm{e}+003.56475 \mathrm{e}+003.56475 \mathrm{e}-01$ 1.00000e-09 2.12000e-01 $1.00000 \mathrm{e}-05$ 1.00000e-05 1.00000e-06 1.00000e-09 1.00000e-01 $1.00000 \mathrm{e}+001.00000 \mathrm{e}+001.00000 \mathrm{e}-011.00000 \mathrm{e}-091.00000 \mathrm{e}-01$ Element: 9247 \# of layers: 7

Kx Ky Kz Ss Por

3.56475e+00 3.56475e+00 3.56475e-01 1.00000e-09 2.12000e-01 $3.56475 \mathrm{e}+003.56475 \mathrm{e}+003.56475 \mathrm{e}-011.00000 \mathrm{e}-092.12000 \mathrm{e}-01$ $3.56475 \mathrm{e}+003.56475 \mathrm{e}+003.56475 \mathrm{e}-011.00000 \mathrm{e}-092.12000 \mathrm{e}-01$ $3.56475 \mathrm{e}+003.56475 \mathrm{e}+003.56475 \mathrm{e}-011.00000 \mathrm{e}-092.12000 \mathrm{e}-01$ $3.56475 \mathrm{e}+003.56475 \mathrm{e}+003.56475 \mathrm{e}-011.00000 \mathrm{e}-092.12000 \mathrm{e}-01$ $1.00000 \mathrm{e}-05$ 1.00000e-05 1.00000e-06 1.00000e-09 1.00000e-01 $1.00000 \mathrm{e}+001.00000 \mathrm{e}+001.00000 \mathrm{e}-011.00000 \mathrm{e}-091.00000 \mathrm{e}-01$ Element: 9248 \# of layers: 7

Kx Ky Kz Ss Por

$3.56475 \mathrm{e}+003.56475 \mathrm{e}+00$ 3.56475e-01 1.00000e-09 2.12000e-01 $3.56475 \mathrm{e}+003.56475 \mathrm{e}+003.56475 \mathrm{e}-011.00000 \mathrm{e}-092.12000 \mathrm{e}-01$ $3.56475 \mathrm{e}+003.56475 \mathrm{e}+003.56475 \mathrm{e}-011.00000 \mathrm{e}-092.12000 \mathrm{e}-01$ $3.56475 \mathrm{e}+003.56475 \mathrm{e}+003.56475 \mathrm{e}-011.00000 \mathrm{e}-092.12000 \mathrm{e}-01$ $3.56475 \mathrm{e}+003.56475 \mathrm{e}+003.56475 \mathrm{e}-011.00000 \mathrm{e}-092.12000 \mathrm{e}-01$ $1.00000 \mathrm{e}-05$ 1.00000e-05 1.00000e-06 1.00000e-09 1.00000e-01 $1.00000 \mathrm{e}+001.00000 \mathrm{e}+001.00000 \mathrm{e}-011.00000 \mathrm{e}-091.00000 \mathrm{e}-01$ Element: 9249 \# of layers: 6

Kx Ky Kz Ss Por

$3.56475 \mathrm{e}+003.56475 \mathrm{e}+003.56475 \mathrm{e}-01$ 1.00000e-09 2.12000e-01 $3.56475 \mathrm{e}+003.56475 \mathrm{e}+003.56475 \mathrm{e}-011.00000 \mathrm{e}-092.12000 \mathrm{e}-01$ $3.56475 \mathrm{e}+003.56475 \mathrm{e}+003.56475 \mathrm{e}-011.00000 \mathrm{e}-092.12000 \mathrm{e}-01$ $3.56475 \mathrm{e}+003.56475 \mathrm{e}+003.56475 \mathrm{e}-01$ 1.00000e-09 2.12000e-01 $1.00000 \mathrm{e}-05$ 1.00000e-05 1.00000e-06 1.00000e-09 1.00000e-01 $1.00000 \mathrm{e}+001.00000 \mathrm{e}+001.00000 \mathrm{e}-011.00000 \mathrm{e}-091.00000 \mathrm{e}-01$ Element: 9250 \# of layers: 6

Kx Ky Kz Ss Por

$3.56475 \mathrm{e}+003.56475 \mathrm{e}+003.56475 \mathrm{e}-01$ 1.00000e-09 2.12000e-01 $3.56475 \mathrm{e}+003.56475 \mathrm{e}+003.56475 \mathrm{e}-011.00000 \mathrm{e}-092.12000 \mathrm{e}-01$ $3.56475 \mathrm{e}+003.56475 \mathrm{e}+003.56475 \mathrm{e}-01$ 1.00000e-09 2.12000e-01 
$3.56475 \mathrm{e}+003.56475 \mathrm{e}+003.56475 \mathrm{e}-01$ 1.00000e-09 2.12000e-01 $1.00000 \mathrm{e}-05$ 1.00000e-05 1.00000e-06 1.00000e-09 1.00000e-01 $1.00000 \mathrm{e}+001.00000 \mathrm{e}+001.00000 \mathrm{e}-011.00000 \mathrm{e}-091.00000 \mathrm{e}-01$ Element: 9251 \# of layers: 6

$\mathrm{Kx} \mathrm{Ky} \mathrm{Kz}$ Ss Por

3.56475e+00 3.56475e+00 3.56475e-01 1.00000e-09 2.12000e-01 $3.56475 \mathrm{e}+003.56475 \mathrm{e}+00$ 3.56475e-01 1.00000e-09 2.12000e-01 $3.56475 \mathrm{e}+003.56475 \mathrm{e}+003.56475 \mathrm{e}-01$ 1.00000e-09 2.12000e-01 $3.56475 \mathrm{e}+003.56475 \mathrm{e}+00$ 3.56475e-01 1.00000e-09 2.12000e-01 $1.00000 \mathrm{e}-05$ 1.00000e-05 1.00000e-06 1.00000e-09 1.00000e-01 $1.00000 \mathrm{e}+001.00000 \mathrm{e}+001.00000 \mathrm{e}-011.00000 \mathrm{e}-091.00000 \mathrm{e}-01$ Element: 9252 \# of layers: 6

$\mathrm{Kx} \mathrm{Ky} \mathrm{Kz}$ Ss Por

3.56475e+00 3.56475e+00 3.56475e-01 1.00000e-09 2.12000e-01 $3.56475 \mathrm{e}+003.56475 \mathrm{e}+003.56475 \mathrm{e}-01$ 1.00000e-09 2.12000e-01 $3.56475 \mathrm{e}+003.56475 \mathrm{e}+003.56475 \mathrm{e}-01$ 1.00000e-09 2.12000e-01 $3.56475 \mathrm{e}+003.56475 \mathrm{e}+003.56475 \mathrm{e}-01$ 1.00000e-09 2.12000e-01 $1.00000 \mathrm{e}-05$ 1.00000e-05 1.00000e-06 1.00000e-09 1.00000e-01 $1.00000 \mathrm{e}+001.00000 \mathrm{e}+001.00000 \mathrm{e}-01$ 1.00000e-09 1.00000e-01 Element: 9253 \# of layers: 6

$\mathrm{Kx} \mathrm{Ky} \mathrm{Kz}$ Ss Por

3.56475e+00 3.56475e+00 3.56475e-01 1.00000e-09 2.12000e-01 $3.56475 \mathrm{e}+003.56475 \mathrm{e}+003.56475 \mathrm{e}-01$ 1.00000e-09 2.12000e-01 $3.56475 \mathrm{e}+003.56475 \mathrm{e}+003.56475 \mathrm{e}-01$ 1.00000e-09 2.12000e-01 $3.56475 \mathrm{e}+003.56475 \mathrm{e}+003.56475 \mathrm{e}-01$ 1.00000e-09 2.12000e-01 $1.00000 \mathrm{e}-05$ 1.00000e-05 1.00000e-06 1.00000e-09 1.00000e-01 $1.00000 \mathrm{e}+001.00000 \mathrm{e}+001.00000 \mathrm{e}-011.00000 \mathrm{e}-091.00000 \mathrm{e}-01$ Element: 9254 \# of layers: 6

$\mathrm{Kx} \mathrm{Ky} \mathrm{Kz}$ Ss Por

3.56475e+00 3.56475e+00 3.56475e-01 1.00000e-09 2.12000e-01 $3.56475 \mathrm{e}+003.56475 \mathrm{e}+003.56475 \mathrm{e}-01$ 1.00000e-09 2.12000e-01 $3.56475 \mathrm{e}+003.56475 \mathrm{e}+00$ 3.56475e-01 1.00000e-09 2.12000e-01 $3.56475 \mathrm{e}+003.56475 \mathrm{e}+003.56475 \mathrm{e}-01$ 1.00000e-09 2.12000e-01 $1.00000 \mathrm{e}-05$ 1.00000e-05 1.00000e-06 1.00000e-09 1.00000e-01 $1.00000 \mathrm{e}+001.00000 \mathrm{e}+001.00000 \mathrm{e}-011.00000 \mathrm{e}-091.00000 \mathrm{e}-01$ Element: 9255 \# of layers: 6

Kx Ky Kz Ss Por

3.56475e+00 3.56475e+00 3.56475e-01 1.00000e-09 2.12000e-01 $3.56475 \mathrm{e}+003.56475 \mathrm{e}+003.56475 \mathrm{e}-01$ 1.00000e-09 2.12000e-01 3.56475e+00 3.56475e+00 3.56475e-01 1.00000e-09 2.12000e-01 $3.56475 \mathrm{e}+003.56475 \mathrm{e}+00$ 3.56475e-01 1.00000e-09 2.12000e-01 $1.00000 \mathrm{e}-05$ 1.00000e-05 1.00000e-06 1.00000e-09 1.00000e-01 $1.00000 \mathrm{e}+001.00000 \mathrm{e}+001.00000 \mathrm{e}-011.00000 \mathrm{e}-091.00000 \mathrm{e}-01$ Element: 9256 \# of layers: 7

$\mathrm{Kx} \mathrm{Ky} \mathrm{Kz} \mathrm{Ss} \mathrm{Por}$ 3.56475e+00 3.56475e+00 3.56475e-01 1.00000e-09 2.12000e-01 
$3.56475 \mathrm{e}+003.56475 \mathrm{e}+003.56475 \mathrm{e}-011.00000 \mathrm{e}-092.12000 \mathrm{e}-01$ $3.56475 \mathrm{e}+003.56475 \mathrm{e}+003.56475 \mathrm{e}-011.00000 \mathrm{e}-092.12000 \mathrm{e}-01$ $3.56475 \mathrm{e}+003.56475 \mathrm{e}+003.56475 \mathrm{e}-01$ 1.00000e-09 2.12000e-01 $3.56475 \mathrm{e}+003.56475 \mathrm{e}+003.56475 \mathrm{e}-011.00000 \mathrm{e}-092.12000 \mathrm{e}-01$ $1.00000 \mathrm{e}-05$ 1.00000e-05 1.00000e-06 1.00000e-09 1.00000e-01 $1.00000 \mathrm{e}+001.00000 \mathrm{e}+001.00000 \mathrm{e}-011.00000 \mathrm{e}-091.00000 \mathrm{e}-01$ Element: 9257 \# of layers: 7

Kx Ky Kz Ss Por

4.19027e+00 4.19027e+00 4.19027e-01 1.00000e-09 2.12000e-01 $4.19027 \mathrm{e}+004.19027 \mathrm{e}+004.19027 \mathrm{e}-011.00000 \mathrm{e}-092.12000 \mathrm{e}-01$ $4.19027 \mathrm{e}+004.19027 \mathrm{e}+00$ 4.19027e-01 1.00000e-09 2.12000e-01 $4.19027 \mathrm{e}+004.19027 \mathrm{e}+00$ 4.19027e-01 1.00000e-09 2.12000e-01 $4.19027 \mathrm{e}+004.19027 \mathrm{e}+00$ 4.19027e-01 1.00000e-09 2.12000e-01 $1.00000 \mathrm{e}-05$ 1.00000e-05 1.00000e-06 1.00000e-09 1.00000e-01 $1.00000 \mathrm{e}+001.00000 \mathrm{e}+001.00000 \mathrm{e}-011.00000 \mathrm{e}-091.00000 \mathrm{e}-01$ Element: 9258 \# of layers: 7

Kx Ky Kz Ss Por

4.19027e+00 4.19027e+00 4.19027e-01 1.00000e-09 2.12000e-01 $4.19027 \mathrm{e}+004.19027 \mathrm{e}+004.19027 \mathrm{e}-011.00000 \mathrm{e}-092.12000 \mathrm{e}-01$ $4.19027 \mathrm{e}+004.19027 \mathrm{e}+00$ 4.19027e-01 1.00000e-09 2.12000e-01 $4.19027 \mathrm{e}+004.19027 \mathrm{e}+004.19027 \mathrm{e}-011.00000 \mathrm{e}-092.12000 \mathrm{e}-01$ $4.19027 \mathrm{e}+004.19027 \mathrm{e}+00$ 4.19027e-01 1.00000e-09 2.12000e-01 $1.00000 \mathrm{e}-05$ 1.00000e-05 1.00000e-06 1.00000e-09 1.00000e-01 $1.00000 \mathrm{e}+001.00000 \mathrm{e}+001.00000 \mathrm{e}-011.00000 \mathrm{e}-091.00000 \mathrm{e}-01$ Element: 9259 \# of layers: 7

Kx Ky Kz Ss Por

4.19027e+00 4.19027e+00 4.19027e-01 1.00000e-09 2.12000e-01 $4.19027 \mathrm{e}+004.19027 \mathrm{e}+004.19027 \mathrm{e}-011.00000 \mathrm{e}-092.12000 \mathrm{e}-01$ $4.19027 \mathrm{e}+004.19027 \mathrm{e}+00$ 4.19027e-01 1.00000e-09 2.12000e-01 $4.19027 \mathrm{e}+004.19027 \mathrm{e}+004.19027 \mathrm{e}-011.00000 \mathrm{e}-09$ 2.12000e-01 $4.19027 \mathrm{e}+004.19027 \mathrm{e}+00$ 4.19027e-01 1.00000e-09 2.12000e-01 $1.00000 \mathrm{e}-05$ 1.00000e-05 1.00000e-06 1.00000e-09 1.00000e-01 $1.00000 \mathrm{e}+001.00000 \mathrm{e}+001.00000 \mathrm{e}-011.00000 \mathrm{e}-091.00000 \mathrm{e}-01$ Element: 9260 \# of layers: 7

Kx Ky Kz Ss Por

$3.56475 \mathrm{e}+003.56475 \mathrm{e}+003.56475 \mathrm{e}-01$ 1.00000e-09 2.12000e-01 $3.56475 \mathrm{e}+003.56475 \mathrm{e}+003.56475 \mathrm{e}-011.00000 \mathrm{e}-092.12000 \mathrm{e}-01$ $3.56475 \mathrm{e}+003.56475 \mathrm{e}+003.56475 \mathrm{e}-011.00000 \mathrm{e}-092.12000 \mathrm{e}-01$ $3.56475 \mathrm{e}+003.56475 \mathrm{e}+003.56475 \mathrm{e}-011.00000 \mathrm{e}-092.12000 \mathrm{e}-01$ $3.56475 \mathrm{e}+003.56475 \mathrm{e}+003.56475 \mathrm{e}-011.00000 \mathrm{e}-092.12000 \mathrm{e}-01$ $1.00000 \mathrm{e}-05$ 1.00000e-05 1.00000e-06 1.00000e-09 1.00000e-01 $1.00000 \mathrm{e}+001.00000 \mathrm{e}+001.00000 \mathrm{e}-011.00000 \mathrm{e}-091.00000 \mathrm{e}-01$ Element: 9261 \# of layers: 7

Kx Ky Kz Ss Por

$3.56475 \mathrm{e}+003.56475 \mathrm{e}+003.56475 \mathrm{e}-01$ 1.00000e-09 2.12000e-01 $3.56475 \mathrm{e}+003.56475 \mathrm{e}+003.56475 \mathrm{e}-01$ 1.00000e-09 2.12000e-01 
3.56475e+00 3.56475e+00 3.56475e-01 1.00000e-09 2.12000e-01 $3.56475 \mathrm{e}+003.56475 \mathrm{e}+003.56475 \mathrm{e}-01$ 1.00000e-09 2.12000e-01 $3.56475 \mathrm{e}+003.56475 \mathrm{e}+003.56475 \mathrm{e}-01$ 1.00000e-09 2.12000e-01 $1.00000 \mathrm{e}-05$ 1.00000e-05 1.00000e-06 1.00000e-09 1.00000e-01 $1.00000 \mathrm{e}+001.00000 \mathrm{e}+001.00000 \mathrm{e}-01$ 1.00000e-09 1.00000e-01 Element: 9262 \# of layers: 6

$\mathrm{Kx} \mathrm{Ky} \mathrm{Kz}$ Ss Por

3.56475e+00 3.56475e+00 3.56475e-01 1.00000e-09 2.12000e-01 $3.56475 \mathrm{e}+003.56475 \mathrm{e}+003.56475 \mathrm{e}-01$ 1.00000e-09 2.12000e-01 $3.56475 \mathrm{e}+003.56475 \mathrm{e}+00$ 3.56475e-01 1.00000e-09 2.12000e-01 $3.56475 \mathrm{e}+003.56475 \mathrm{e}+003.56475 \mathrm{e}-01$ 1.00000e-09 2.12000e-01 $1.00000 \mathrm{e}-05$ 1.00000e-05 1.00000e-06 1.00000e-09 1.00000e-01 $1.00000 \mathrm{e}+001.00000 \mathrm{e}+001.00000 \mathrm{e}-011.00000 \mathrm{e}-09$ 1.00000e-01 Element: 9263 \# of layers: 7

$\mathrm{Kx} \mathrm{Ky} \mathrm{Kz}$ Ss Por

3.56475e+00 3.56475e+00 3.56475e-01 1.00000e-09 2.12000e-01 $3.56475 \mathrm{e}+003.56475 \mathrm{e}+003.56475 \mathrm{e}-01$ 1.00000e-09 2.12000e-01

$3.56475 \mathrm{e}+003.56475 \mathrm{e}+003.56475 \mathrm{e}-01$ 1.00000e-09 2.12000e-01 $3.56475 \mathrm{e}+003.56475 \mathrm{e}+003.56475 \mathrm{e}-01$ 1.00000e-09 2.12000e-01 $3.56475 \mathrm{e}+003.56475 \mathrm{e}+003.56475 \mathrm{e}-01$ 1.00000e-09 2.12000e-01 $1.00000 \mathrm{e}-05$ 1.00000e-05 1.00000e-06 1.00000e-09 1.00000e-01 $1.00000 \mathrm{e}+001.00000 \mathrm{e}+001.00000 \mathrm{e}-011.00000 \mathrm{e}-091.00000 \mathrm{e}-01$ Element: 9264 \# of layers: 7

Kx Ky Kz Ss Por

4.19027e+00 4.19027e+00 4.19027e-01 1.00000e-09 2.12000e-01 4.19027e+00 4.19027e+00 4.19027e-01 1.00000e-09 2.12000e-01 4.19027e+00 4.19027e+00 4.19027e-01 1.00000e-09 2.12000e-01 4.19027e+00 4.19027e+00 4.19027e-01 1.00000e-09 2.12000e-01 $4.19027 \mathrm{e}+004.19027 \mathrm{e}+00$ 4.19027e-01 1.00000e-09 2.12000e-01 $1.00000 \mathrm{e}-05$ 1.00000e-05 1.00000e-06 1.00000e-09 1.00000e-01 $1.00000 \mathrm{e}+001.00000 \mathrm{e}+001.00000 \mathrm{e}-011.00000 \mathrm{e}-091.00000 \mathrm{e}-01$ Element: 9265 \# of layers: 7

$\mathrm{Kx} \mathrm{Ky} \mathrm{Kz}$ Ss Por

4.19027e+00 4.19027e+00 4.19027e-01 1.00000e-09 2.12000e-01 4.19027e+00 4.19027e+00 4.19027e-01 1.00000e-09 2.12000e-01 4.19027e+00 4.19027e+00 4.19027e-01 1.00000e-09 2.12000e-01 $4.19027 \mathrm{e}+004.19027 \mathrm{e}+00$ 4.19027e-01 1.00000e-09 2.12000e-01 4.19027e+00 4.19027e+00 4.19027e-01 1.00000e-09 2.12000e-01 $1.00000 \mathrm{e}-05$ 1.00000e-05 1.00000e-06 1.00000e-09 1.00000e-01 $1.00000 \mathrm{e}+001.00000 \mathrm{e}+001.00000 \mathrm{e}-01$ 1.00000e-09 1.00000e-01 Element: 9266 \# of layers: 7

$\mathrm{Kx} \mathrm{Ky} \mathrm{Kz}$ Ss Por

4.19027e+00 4.19027e+00 4.19027e-01 1.00000e-09 2.12000e-01 4.19027e+00 4.19027e+00 4.19027e-01 1.00000e-09 2.12000e-01 4.19027e+00 4.19027e+00 4.19027e-01 1.00000e-09 2.12000e-01 $4.19027 \mathrm{e}+00$ 4.19027e+00 4.19027e-01 1.00000e-09 2.12000e-01 
4.19027e+00 4.19027e+00 4.19027e-01 1.00000e-09 2.12000e-01 $1.00000 \mathrm{e}-05$ 1.00000e-05 1.00000e-06 1.00000e-09 1.00000e-01 $1.00000 \mathrm{e}+001.00000 \mathrm{e}+001.00000 \mathrm{e}-01$ 1.00000e-09 1.00000e-01 Element: 9267 \# of layers: 7

$\mathrm{Kx} \mathrm{Ky} \mathrm{Kz}$ Ss Por

4.19027e+00 4.19027e+00 4.19027e-01 1.00000e-09 2.12000e-01 4.19027e+00 4.19027e+00 4.19027e-01 1.00000e-09 2.12000e-01 4.19027e+00 4.19027e+00 4.19027e-01 1.00000e-09 2.12000e-01 4.19027e+00 4.19027e+00 4.19027e-01 1.00000e-09 2.12000e-01 4.19027e+00 4.19027e+00 4.19027e-01 1.00000e-09 2.12000e-01 $1.00000 \mathrm{e}-05$ 1.00000e-05 1.00000e-06 1.00000e-09 1.00000e-01 $1.00000 \mathrm{e}+001.00000 \mathrm{e}+001.00000 \mathrm{e}-01$ 1.00000e-09 1.00000e-01 Element: 9268 \# of layers: 7

$\mathrm{Kx} \mathrm{Ky} \mathrm{Kz}$ Ss Por

4.19027e+00 4.19027e+00 4.19027e-01 1.00000e-09 2.12000e-01 $4.19027 \mathrm{e}+00$ 4.19027e+00 4.19027e-01 1.00000e-09 2.12000e-01 4.19027e+00 4.19027e+00 4.19027e-01 1.00000e-09 2.12000e-01 4.19027e+00 4.19027e+00 4.19027e-01 1.00000e-09 2.12000e-01 4.19027e+00 4.19027e+00 4.19027e-01 1.00000e-09 2.12000e-01 $1.00000 \mathrm{e}-05$ 1.00000e-05 1.00000e-06 1.00000e-09 1.00000e-01 $1.00000 \mathrm{e}+001.00000 \mathrm{e}+001.00000 \mathrm{e}-011.00000 \mathrm{e}-091.00000 \mathrm{e}-01$ Element: 9269 \# of layers: 7

$\mathrm{Kx} \mathrm{Ky} \mathrm{Kz}$ Ss Por

4.19027e+00 4.19027e+00 4.19027e-01 1.00000e-09 2.12000e-01 $4.19027 \mathrm{e}+00$ 4.19027e+00 4.19027e-01 1.00000e-09 2.12000e-01 4.19027e+00 4.19027e+00 4.19027e-01 1.00000e-09 2.12000e-01 4.19027e+00 4.19027e+00 4.19027e-01 1.00000e-09 2.12000e-01 4.19027e+00 4.19027e+00 4.19027e-01 1.00000e-09 2.12000e-01 $1.00000 \mathrm{e}-05$ 1.00000e-05 1.00000e-06 1.00000e-09 1.00000e-01 $1.00000 \mathrm{e}+001.00000 \mathrm{e}+001.00000 \mathrm{e}-011.00000 \mathrm{e}-091.00000 \mathrm{e}-01$ Element: 9270 \# of layers: 7

$\mathrm{Kx} \mathrm{Ky} \mathrm{Kz}$ Ss Por

4.19027e+00 4.19027e+00 4.19027e-01 1.00000e-09 2.12000e-01 4.19027e+00 4.19027e+00 4.19027e-01 1.00000e-09 2.12000e-01 4.19027e+00 4.19027e+00 4.19027e-01 1.00000e-09 2.12000e-01 4.19027e+00 4.19027e+00 4.19027e-01 1.00000e-09 2.12000e-01 4.19027e+00 4.19027e+00 4.19027e-01 1.00000e-09 2.12000e-01 $1.00000 \mathrm{e}-05$ 1.00000e-05 1.00000e-06 1.00000e-09 1.00000e-01 $1.00000 \mathrm{e}+001.00000 \mathrm{e}+001.00000 \mathrm{e}-01$ 1.00000e-09 1.00000e-01 Element: 9271 \# of layers: 7

$\mathrm{Kx} \mathrm{Ky} \mathrm{Kz}$ Ss Por

4.19027e+00 4.19027e+00 4.19027e-01 1.00000e-09 2.12000e-01 4.19027e+00 4.19027e+00 4.19027e-01 1.00000e-09 2.12000e-01 4.19027e+00 4.19027e+00 4.19027e-01 1.00000e-09 2.12000e-01 4.19027e+00 4.19027e+00 4.19027e-01 1.00000e-09 2.12000e-01 $4.19027 \mathrm{e}+00$ 4.19027e+00 4.19027e-01 1.00000e-09 2.12000e-01 
$1.00000 \mathrm{e}-05$ 1.00000e-05 1.00000e-06 1.00000e-09 1.00000e-01 $1.00000 \mathrm{e}+001.00000 \mathrm{e}+001.00000 \mathrm{e}-01$ 1.00000e-09 1.00000e-01 Element: 9272 \# of layers: 7

$\mathrm{Kx} \mathrm{Ky} \mathrm{Kz}$ Ss Por

4.19027e+00 4.19027e+00 4.19027e-01 1.00000e-09 2.12000e-01 4.19027e+00 4.19027e+00 4.19027e-01 1.00000e-09 2.12000e-01 4.19027e+00 4.19027e+00 4.19027e-01 1.00000e-09 2.12000e-01 4.19027e+00 4.19027e+00 4.19027e-01 1.00000e-09 2.12000e-01 4.19027e+00 4.19027e+00 4.19027e-01 1.00000e-09 2.12000e-01 $1.00000 \mathrm{e}-05$ 1.00000e-05 1.00000e-06 1.00000e-09 1.00000e-01 $1.00000 \mathrm{e}+001.00000 \mathrm{e}+001.00000 \mathrm{e}-011.00000 \mathrm{e}-091.00000 \mathrm{e}-01$ Element: 9273 \# of layers: 7

$\mathrm{Kx} \mathrm{Ky} \mathrm{Kz}$ Ss Por

4.19027e+00 4.19027e+00 4.19027e-01 1.00000e-09 2.12000e-01 4.19027e+00 4.19027e+00 4.19027e-01 1.00000e-09 2.12000e-01 $4.19027 \mathrm{e}+00$ 4.19027e+00 4.19027e-01 1.00000e-09 2.12000e-01 4.19027e+00 4.19027e+00 4.19027e-01 1.00000e-09 2.12000e-01 4.19027e+00 4.19027e+00 4.19027e-01 1.00000e-09 2.12000e-01 $1.00000 \mathrm{e}-05$ 1.00000e-05 1.00000e-06 1.00000e-09 1.00000e-01 $1.00000 \mathrm{e}+001.00000 \mathrm{e}+001.00000 \mathrm{e}-011.00000 \mathrm{e}-091.00000 \mathrm{e}-01$ Element: 9274 \# of layers: 7

$\mathrm{Kx} \mathrm{Ky} \mathrm{Kz}$ Ss Por

$1.63628 \mathrm{e}+01$ 1.63628e+01 1.63628e+00 1.00000e-09 2.12000e-01 $1.63628 \mathrm{e}+011.63628 \mathrm{e}+011.63628 \mathrm{e}+001.00000 \mathrm{e}-092.12000 \mathrm{e}-01$ $1.63628 \mathrm{e}+011.63628 \mathrm{e}+011.63628 \mathrm{e}+001.00000 \mathrm{e}-092.12000 \mathrm{e}-01$ $1.63628 \mathrm{e}+011.63628 \mathrm{e}+01$ 1.63628e+00 1.00000e-09 2.12000e-01 $1.63628 \mathrm{e}+01$ 1.63628e+01 1.63628e+00 1.00000e-09 2.12000e-01 $1.00000 \mathrm{e}-051.00000 \mathrm{e}-05$ 1.00000e-06 1.00000e-09 1.00000e-01 $1.00000 \mathrm{e}+001.00000 \mathrm{e}+001.00000 \mathrm{e}-011.00000 \mathrm{e}-091.00000 \mathrm{e}-01$ Element: 9275 \# of layers: 7

$\mathrm{Kx} \mathrm{Ky} \mathrm{Kz}$ Ss Por

$1.63628 \mathrm{e}+01$ 1.63628e+01 1.63628e+00 1.00000e-09 2.12000e-01 $1.63628 \mathrm{e}+011.63628 \mathrm{e}+011.63628 \mathrm{e}+001.00000 \mathrm{e}-092.12000 \mathrm{e}-01$ $1.63628 \mathrm{e}+011.63628 \mathrm{e}+011.63628 \mathrm{e}+001.00000 \mathrm{e}-092.12000 \mathrm{e}-01$ $1.63628 \mathrm{e}+01$ 1.63628e+01 1.63628e+00 1.00000e-09 2.12000e-01 $1.63628 \mathrm{e}+011.63628 \mathrm{e}+011.63628 \mathrm{e}+001.00000 \mathrm{e}-092.12000 \mathrm{e}-01$ $1.00000 \mathrm{e}-05$ 1.00000e-05 1.00000e-06 1.00000e-09 1.00000e-01 $1.00000 \mathrm{e}+001.00000 \mathrm{e}+001.00000 \mathrm{e}-011.00000 \mathrm{e}-091.00000 \mathrm{e}-01$ Element: 9276 \# of layers: 7

$\mathrm{Kx} \mathrm{Ky} \mathrm{Kz}$ Ss Por

$1.63628 \mathrm{e}+01$ 1.63628e+01 1.63628e+00 1.00000e-09 2.12000e-01 $1.63628 \mathrm{e}+011.63628 \mathrm{e}+011.63628 \mathrm{e}+001.00000 \mathrm{e}-092.12000 \mathrm{e}-01$ $1.63628 \mathrm{e}+011.63628 \mathrm{e}+011.63628 \mathrm{e}+001.00000 \mathrm{e}-092.12000 \mathrm{e}-01$ $1.63628 \mathrm{e}+011.63628 \mathrm{e}+011.63628 \mathrm{e}+001.00000 \mathrm{e}-092.12000 \mathrm{e}-01$ $1.63628 \mathrm{e}+011.63628 \mathrm{e}+011.63628 \mathrm{e}+001.00000 \mathrm{e}-092.12000 \mathrm{e}-01$ $1.00000 \mathrm{e}-05$ 1.00000e-05 1.00000e-06 1.00000e-09 1.00000e-01 
$1.00000 \mathrm{e}+001.00000 \mathrm{e}+00$ 1.00000e-01 1.00000e-09 1.00000e-01

Element: 9277 \# of layers: 7

$\mathrm{Kx} \mathrm{Ky} \mathrm{Kz}$ Ss Por

$1.63628 \mathrm{e}+01$ 1.63628e+01 1.63628e+00 1.00000e-09 2.12000e-01

$1.63628 \mathrm{e}+011.63628 \mathrm{e}+011.63628 \mathrm{e}+001.00000 \mathrm{e}-092.12000 \mathrm{e}-01$

$1.63628 \mathrm{e}+01$ 1.63628e+01 1.63628e+00 1.00000e-09 2.12000e-01

$1.63628 \mathrm{e}+011.63628 \mathrm{e}+011.63628 \mathrm{e}+001.00000 \mathrm{e}-092.12000 \mathrm{e}-01$

$1.63628 \mathrm{e}+011.63628 \mathrm{e}+011.63628 \mathrm{e}+001.00000 \mathrm{e}-092.12000 \mathrm{e}-01$

$1.00000 \mathrm{e}-05$ 1.00000e-05 1.00000e-06 1.00000e-09 1.00000e-01

$1.00000 \mathrm{e}+001.00000 \mathrm{e}+001.00000 \mathrm{e}-011.00000 \mathrm{e}-091.00000 \mathrm{e}-01$

Element: 9278 \# of layers: 7

Kx Ky Kz Ss Por

$1.63628 \mathrm{e}+01$ 1.63628e+01 1.63628e+00 1.00000e-09 2.12000e-01

$1.63628 \mathrm{e}+01$ 1.63628e+01 1.63628e+00 1.00000e-09 2.12000e-01

$1.63628 \mathrm{e}+01$ 1.63628e+01 1.63628e+00 1.00000e-09 2.12000e-01

$1.63628 \mathrm{e}+011.63628 \mathrm{e}+011.63628 \mathrm{e}+001.00000 \mathrm{e}-092.12000 \mathrm{e}-01$

$1.63628 \mathrm{e}+011.63628 \mathrm{e}+011.63628 \mathrm{e}+001.00000 \mathrm{e}-092.12000 \mathrm{e}-01$

$1.00000 \mathrm{e}-05$ 1.00000e-05 1.00000e-06 1.00000e-09 1.00000e-01

$1.00000 \mathrm{e}+001.00000 \mathrm{e}+001.00000 \mathrm{e}-01$ 1.00000e-09 1.00000e-01

Element: 9279 \# of layers: 7

$\mathrm{Kx} \mathrm{Ky} \mathrm{Kz}$ Ss Por

4.19027e+00 4.19027e+00 4.19027e-01 1.00000e-09 2.12000e-01

4.19027e+00 4.19027e+00 4.19027e-01 1.00000e-09 2.12000e-01

4.19027e+00 4.19027e+00 4.19027e-01 1.00000e-09 2.12000e-01

$4.19027 \mathrm{e}+00$ 4.19027e+00 4.19027e-01 1.00000e-09 2.12000e-01

4.19027e+00 4.19027e+00 4.19027e-01 1.00000e-09 2.12000e-01

$1.00000 \mathrm{e}-05$ 1.00000e-05 1.00000e-06 1.00000e-09 1.00000e-01

$1.00000 \mathrm{e}+001.00000 \mathrm{e}+001.00000 \mathrm{e}-011.00000 \mathrm{e}-09$ 1.00000e-01

Element: 9280 \# of layers: 7

$\mathrm{Kx} \mathrm{Ky} \mathrm{Kz}$ Ss Por

4.19027e+00 4.19027e+00 4.19027e-01 1.00000e-09 2.12000e-01

4.19027e+00 4.19027e+00 4.19027e-01 1.00000e-09 2.12000e-01

4.19027e+00 4.19027e+00 4.19027e-01 1.00000e-09 2.12000e-01

4.19027e+00 4.19027e+00 4.19027e-01 1.00000e-09 2.12000e-01

4.19027e+00 4.19027e+00 4.19027e-01 1.00000e-09 2.12000e-01

$1.00000 \mathrm{e}-05$ 1.00000e-05 1.00000e-06 1.00000e-09 1.00000e-01

$1.00000 \mathrm{e}+001.00000 \mathrm{e}+001.00000 \mathrm{e}-011.00000 \mathrm{e}-091.00000 \mathrm{e}-01$

Element: 9281 \# of layers: 7

$\mathrm{Kx} \mathrm{Ky} \mathrm{Kz}$ Ss Por

$1.63628 \mathrm{e}+01$ 1.63628e+01 1.63628e+00 1.00000e-09 2.12000e-01

$1.63628 \mathrm{e}+011.63628 \mathrm{e}+01$ 1.63628e+00 1.00000e-09 2.12000e-01

$1.63628 \mathrm{e}+011.63628 \mathrm{e}+01$ 1.63628e+00 1.00000e-09 2.12000e-01

$1.63628 \mathrm{e}+011.63628 \mathrm{e}+01$ 1.63628e+00 1.00000e-09 2.12000e-01

$1.63628 \mathrm{e}+01$ 1.63628e+01 1.63628e+00 1.00000e-09 2.12000e-01 $1.00000 \mathrm{e}-05$ 1.00000e-05 1.00000e-06 1.00000e-09 1.00000e-01

$1.00000 \mathrm{e}+001.00000 \mathrm{e}+001.00000 \mathrm{e}-011.00000 \mathrm{e}-091.00000 \mathrm{e}-01$ 
Element: 9282 \# of layers: 7

Kx Ky Kz Ss Por

$1.63628 \mathrm{e}+011.63628 \mathrm{e}+011.63628 \mathrm{e}+00$ 1.00000e-09 2.12000e-01

$1.63628 \mathrm{e}+011.63628 \mathrm{e}+011.63628 \mathrm{e}+001.00000 \mathrm{e}-092.12000 \mathrm{e}-01$

$1.63628 \mathrm{e}+011.63628 \mathrm{e}+011.63628 \mathrm{e}+001.00000 \mathrm{e}-092.12000 \mathrm{e}-01$

$1.63628 \mathrm{e}+011.63628 \mathrm{e}+011.63628 \mathrm{e}+001.00000 \mathrm{e}-092.12000 \mathrm{e}-01$

$1.63628 \mathrm{e}+011.63628 \mathrm{e}+011.63628 \mathrm{e}+001.00000 \mathrm{e}-092.12000 \mathrm{e}-01$

$1.00000 \mathrm{e}-05$ 1.00000e-05 1.00000e-06 1.00000e-09 1.00000e-01

$1.00000 \mathrm{e}+001.00000 \mathrm{e}+001.00000 \mathrm{e}-011.00000 \mathrm{e}-091.00000 \mathrm{e}-01$

Element: 9283 \# of layers: 7

Kx Ky Kz Ss Por

$6.70222 \mathrm{e}+006.70222 \mathrm{e}+00$ 6.70222e-01 1.00000e-09 2.12000e-01

$6.70222 \mathrm{e}+006.70222 \mathrm{e}+006.70222 \mathrm{e}-011.00000 \mathrm{e}-092.12000 \mathrm{e}-01$

$6.70222 \mathrm{e}+006.70222 \mathrm{e}+006.70222 \mathrm{e}-011.00000 \mathrm{e}-092.12000 \mathrm{e}-01$

$6.70222 \mathrm{e}+006.70222 \mathrm{e}+006.70222 \mathrm{e}-011.00000 \mathrm{e}-092.12000 \mathrm{e}-01$

$6.70222 \mathrm{e}+006.70222 \mathrm{e}+00$ 6.70222e-01 1.00000e-09 2.12000e-01

$1.00000 \mathrm{e}-05$ 1.00000e-05 1.00000e-06 1.00000e-09 1.00000e-01

$1.00000 \mathrm{e}+001.00000 \mathrm{e}+00$ 1.00000e-01 1.00000e-09 1.00000e-01

Element: 9284 \# of layers: 7

Kx Ky Kz Ss Por

$6.70222 \mathrm{e}+006.70222 \mathrm{e}+00$ 6.70222e-01 1.00000e-09 2.12000e-01

$6.70222 \mathrm{e}+006.70222 \mathrm{e}+00$ 6.70222e-01 1.00000e-09 2.12000e-01

$6.70222 \mathrm{e}+006.70222 \mathrm{e}+00$ 6.70222e-01 1.00000e-09 2.12000e-01

$6.70222 \mathrm{e}+006.70222 \mathrm{e}+00$ 6.70222e-01 1.00000e-09 2.12000e-01

$6.70222 \mathrm{e}+006.70222 \mathrm{e}+00$ 6.70222e-01 1.00000e-09 2.12000e-01

$1.00000 \mathrm{e}-05$ 1.00000e-05 1.00000e-06 1.00000e-09 1.00000e-01

$1.00000 \mathrm{e}+001.00000 \mathrm{e}+001.00000 \mathrm{e}-011.00000 \mathrm{e}-091.00000 \mathrm{e}-01$

Element: 9285 \# of layers: 7

Kx Ky Kz Ss Por

$6.70222 \mathrm{e}+00$ 6.70222e+00 6.70222e-01 1.00000e-09 2.12000e-01

$6.70222 \mathrm{e}+006.70222 \mathrm{e}+00$ 6.70222e-01 1.00000e-09 2.12000e-01

$6.70222 \mathrm{e}+006.70222 \mathrm{e}+00$ 6.70222e-01 1.00000e-09 2.12000e-01

$6.70222 \mathrm{e}+006.70222 \mathrm{e}+00$ 6.70222e-01 1.00000e-09 2.12000e-01

$6.70222 \mathrm{e}+006.70222 \mathrm{e}+00$ 6.70222e-01 1.00000e-09 2.12000e-01

$1.00000 \mathrm{e}-05$ 1.00000e-05 1.00000e-06 1.00000e-09 1.00000e-01

$1.00000 \mathrm{e}+001.00000 \mathrm{e}+001.00000 \mathrm{e}-011.00000 \mathrm{e}-091.00000 \mathrm{e}-01$

Element: 9286 \# of layers: 7

Kx Ky Kz Ss Por

$3.56475 \mathrm{e}+003.56475 \mathrm{e}+00$ 3.56475e-01 1.00000e-09 2.12000e-01

$3.56475 \mathrm{e}+003.56475 \mathrm{e}+003.56475 \mathrm{e}-011.00000 \mathrm{e}-092.12000 \mathrm{e}-01$

$3.56475 \mathrm{e}+003.56475 \mathrm{e}+003.56475 \mathrm{e}-011.00000 \mathrm{e}-092.12000 \mathrm{e}-01$

$3.56475 \mathrm{e}+003.56475 \mathrm{e}+003.56475 \mathrm{e}-011.00000 \mathrm{e}-092.12000 \mathrm{e}-01$

$3.56475 \mathrm{e}+003.56475 \mathrm{e}+003.56475 \mathrm{e}-01$ 1.00000e-09 2.12000e-01

$1.00000 \mathrm{e}-05$ 1.00000e-05 1.00000e-06 1.00000e-09 1.00000e-01

$1.00000 \mathrm{e}+001.00000 \mathrm{e}+001.00000 \mathrm{e}-011.00000 \mathrm{e}-091.00000 \mathrm{e}-01$

Element: 9287 \# of layers: 7 
$\mathrm{Kx} \mathrm{Ky} \mathrm{Kz} \mathrm{Ss} \mathrm{Por}$

3.56475e+00 3.56475e+00 3.56475e-01 1.00000e-09 2.12000e-01

$3.56475 \mathrm{e}+003.56475 \mathrm{e}+003.56475 \mathrm{e}-01$ 1.00000e-09 2.12000e-01

$3.56475 \mathrm{e}+003.56475 \mathrm{e}+003.56475 \mathrm{e}-01$ 1.00000e-09 2.12000e-01

$3.56475 \mathrm{e}+003.56475 \mathrm{e}+003.56475 \mathrm{e}-01$ 1.00000e-09 2.12000e-01

$3.56475 \mathrm{e}+003.56475 \mathrm{e}+003.56475 \mathrm{e}-01$ 1.00000e-09 2.12000e-01

$1.00000 \mathrm{e}-051.00000 \mathrm{e}-051.00000 \mathrm{e}-061.00000 \mathrm{e}-091.00000 \mathrm{e}-01$

$1.00000 \mathrm{e}+001.00000 \mathrm{e}+001.00000 \mathrm{e}-011.00000 \mathrm{e}-091.00000 \mathrm{e}-01$

Element: 9288 \# of layers: 7

$\mathrm{Kx} \mathrm{Ky} \mathrm{Kz}$ Ss Por

4.19027e+00 4.19027e+00 4.19027e-01 1.00000e-09 2.12000e-01

$4.19027 \mathrm{e}+00$ 4.19027e+00 4.19027e-01 1.00000e-09 2.12000e-01

4.19027e+00 4.19027e+00 4.19027e-01 1.00000e-09 2.12000e-01

4.19027e+00 4.19027e+00 4.19027e-01 1.00000e-09 2.12000e-01

4.19027e+00 4.19027e+00 4.19027e-01 1.00000e-09 2.12000e-01

$1.00000 \mathrm{e}-05$ 1.00000e-05 1.00000e-06 1.00000e-09 1.00000e-01

$1.00000 \mathrm{e}+001.00000 \mathrm{e}+001.00000 \mathrm{e}-01$ 1.00000e-09 1.00000e-01

Element: 9289 \# of layers: 7

$\mathrm{Kx} \mathrm{Ky} \mathrm{Kz}$ Ss Por

$1.63628 \mathrm{e}+01$ 1.63628e+01 1.63628e+00 1.00000e-09 2.12000e-01

$1.63628 \mathrm{e}+011.63628 \mathrm{e}+01$ 1.63628e+00 1.00000e-09 2.12000e-01

$1.63628 \mathrm{e}+011.63628 \mathrm{e}+01$ 1.63628e+00 1.00000e-09 2.12000e-01

$1.63628 \mathrm{e}+01$ 1.63628e+01 1.63628e+00 1.00000e-09 2.12000e-01

$1.63628 \mathrm{e}+01$ 1.63628e+01 1.63628e+00 1.00000e-09 2.12000e-01

$1.00000 \mathrm{e}-051.00000 \mathrm{e}-05$ 1.00000e-06 1.00000e-09 1.00000e-01

$1.00000 \mathrm{e}+001.00000 \mathrm{e}+001.00000 \mathrm{e}-01$ 1.00000e-09 1.00000e-01

Element: 9290 \# of layers: 7

$\mathrm{Kx} \mathrm{Ky} \mathrm{Kz} \mathrm{Ss} \mathrm{Por}$

6.70222e+00 6.70222e+00 6.70222e-01 1.00000e-09 2.12000e-01

6.70222e+00 6.70222e+00 6.70222e-01 1.00000e-09 2.12000e-01

6.70222e+00 6.70222e+00 6.70222e-01 1.00000e-09 2.12000e-01

$6.70222 \mathrm{e}+006.70222 \mathrm{e}+00$ 6.70222e-01 1.00000e-09 2.12000e-01

$6.70222 \mathrm{e}+006.70222 \mathrm{e}+00$ 6.70222e-01 1.00000e-09 2.12000e-01

$1.00000 \mathrm{e}-05$ 1.00000e-05 1.00000e-06 1.00000e-09 1.00000e-01

$1.00000 \mathrm{e}+001.00000 \mathrm{e}+001.00000 \mathrm{e}-011.00000 \mathrm{e}-091.00000 \mathrm{e}-01$

Element: 9291 \# of layers: 7

Kx Ky Kz Ss Por

3.41422e+00 3.41422e+00 3.41422e-01 1.00000e-09 2.12000e-01

$3.41422 \mathrm{e}+003.41422 \mathrm{e}+00$ 3.41422e-01 1.00000e-09 2.12000e-01

3.41422e+00 3.41422e+00 3.41422e-01 1.00000e-09 2.12000e-01

$3.41422 \mathrm{e}+003.41422 \mathrm{e}+00$ 3.41422e-01 1.00000e-09 2.12000e-01

$3.41422 \mathrm{e}+003.41422 \mathrm{e}+00$ 3.41422e-01 1.00000e-09 2.12000e-01

$1.00000 \mathrm{e}-05$ 1.00000e-05 1.00000e-06 1.00000e-09 1.00000e-01

$1.00000 \mathrm{e}+001.00000 \mathrm{e}+001.00000 \mathrm{e}-01$ 1.00000e-09 1.00000e-01

Element: 9292 \# of layers: 7

Kx Ky Kz Ss Por 
3.41422e+00 3.41422e+00 3.41422e-01 1.00000e-09 2.12000e-01 $3.41422 \mathrm{e}+003.41422 \mathrm{e}+00$ 3.41422e-01 1.00000e-09 2.12000e-01 $3.41422 \mathrm{e}+003.41422 \mathrm{e}+003.41422 \mathrm{e}-01$ 1.00000e-09 2.12000e-01 $3.41422 \mathrm{e}+003.41422 \mathrm{e}+003.41422 \mathrm{e}-01$ 1.00000e-09 2.12000e-01 3.41422e+00 3.41422e+00 3.41422e-01 1.00000e-09 2.12000e-01 $1.00000 \mathrm{e}-05$ 1.00000e-05 1.00000e-06 1.00000e-09 1.00000e-01 $1.00000 \mathrm{e}+001.00000 \mathrm{e}+00$ 1.00000e-01 1.00000e-09 1.00000e-01 Element: 9293 \# of layers: 7

$\mathrm{Kx} \mathrm{Ky} \mathrm{Kz}$ Ss Por

3.41422e+00 3.41422e+00 3.41422e-01 1.00000e-09 2.12000e-01 $3.41422 \mathrm{e}+003.41422 \mathrm{e}+003.41422 \mathrm{e}-01$ 1.00000e-09 2.12000e-01 $3.41422 \mathrm{e}+003.41422 \mathrm{e}+003.41422 \mathrm{e}-01$ 1.00000e-09 2.12000e-01 3.41422e+00 3.41422e+00 3.41422e-01 1.00000e-09 2.12000e-01 $3.41422 \mathrm{e}+00$ 3.41422e+00 3.41422e-01 1.00000e-09 2.12000e-01 $1.00000 \mathrm{e}-05$ 1.00000e-05 1.00000e-06 1.00000e-09 1.00000e-01 $1.00000 \mathrm{e}+001.00000 \mathrm{e}+001.00000 \mathrm{e}-011.00000 \mathrm{e}-091.00000 \mathrm{e}-01$ Element: 9294 \# of layers: 7

$\mathrm{Kx} \mathrm{Ky} \mathrm{Kz}$ Ss Por

3.41422e+00 3.41422e+00 3.41422e-01 1.00000e-09 2.12000e-01 $3.41422 \mathrm{e}+003.41422 \mathrm{e}+003.41422 \mathrm{e}-01$ 1.00000e-09 2.12000e-01 $3.41422 \mathrm{e}+003.41422 \mathrm{e}+003.41422 \mathrm{e}-01$ 1.00000e-09 2.12000e-01 $3.41422 \mathrm{e}+003.41422 \mathrm{e}+00$ 3.41422e-01 1.00000e-09 2.12000e-01 3.41422e+00 3.41422e+00 3.41422e-01 1.00000e-09 2.12000e-01 $1.00000 \mathrm{e}-05$ 1.00000e-05 1.00000e-06 1.00000e-09 1.00000e-01 $1.00000 \mathrm{e}+001.00000 \mathrm{e}+001.00000 \mathrm{e}-011.00000 \mathrm{e}-091.00000 \mathrm{e}-01$ Element: 9295 \# of layers: 7

$\mathrm{Kx} \mathrm{Ky} \mathrm{Kz}$ Ss Por

3.41422e+00 3.41422e+00 3.41422e-01 1.00000e-09 2.12000e-01 $3.41422 \mathrm{e}+003.41422 \mathrm{e}+003.41422 \mathrm{e}-01$ 1.00000e-09 2.12000e-01 $3.41422 \mathrm{e}+00$ 3.41422e+00 3.41422e-01 1.00000e-09 2.12000e-01 $3.41422 \mathrm{e}+003.41422 \mathrm{e}+003.41422 \mathrm{e}-01$ 1.00000e-09 2.12000e-01 $3.41422 \mathrm{e}+003.41422 \mathrm{e}+00$ 3.41422e-01 1.00000e-09 2.12000e-01 $1.00000 \mathrm{e}-05$ 1.00000e-05 1.00000e-06 1.00000e-09 1.00000e-01 $1.00000 \mathrm{e}+001.00000 \mathrm{e}+001.00000 \mathrm{e}-011.00000 \mathrm{e}-091.00000 \mathrm{e}-01$ Element: 9296 \# of layers: 7

$\mathrm{Kx} \mathrm{Ky} \mathrm{Kz}$ Ss Por

3.41422e+00 3.41422e+00 3.41422e-01 1.00000e-09 2.12000e-01 $3.41422 \mathrm{e}+003.41422 \mathrm{e}+00$ 3.41422e-01 1.00000e-09 2.12000e-01 3.41422e+00 3.41422e+00 3.41422e-01 1.00000e-09 2.12000e-01 3.41422e+00 3.41422e+00 3.41422e-01 1.00000e-09 2.12000e-01 $3.41422 \mathrm{e}+003.41422 \mathrm{e}+003.41422 \mathrm{e}-01$ 1.00000e-09 2.12000e-01 $1.00000 \mathrm{e}-051.00000 \mathrm{e}-051.00000 \mathrm{e}-061.00000 \mathrm{e}-091.00000 \mathrm{e}-01$ $1.00000 \mathrm{e}+001.00000 \mathrm{e}+001.00000 \mathrm{e}-011.00000 \mathrm{e}-091.00000 \mathrm{e}-01$ Element: 9297 \# of layers: 7

$\mathrm{Kx} \mathrm{Ky} \mathrm{Kz}$ Ss Por 3.41422e+00 3.41422e+00 3.41422e-01 1.00000e-09 2.12000e-01 
3.41422e+00 3.41422e+00 3.41422e-01 1.00000e-09 2.12000e-01 $3.41422 \mathrm{e}+003.41422 \mathrm{e}+003.41422 \mathrm{e}-01$ 1.00000e-09 2.12000e-01 $3.41422 \mathrm{e}+003.41422 \mathrm{e}+003.41422 \mathrm{e}-01$ 1.00000e-09 2.12000e-01 $3.41422 \mathrm{e}+003.41422 \mathrm{e}+00$ 3.41422e-01 1.00000e-09 2.12000e-01 $1.00000 \mathrm{e}-05$ 1.00000e-05 1.00000e-06 1.00000e-09 1.00000e-01 $1.00000 \mathrm{e}+001.00000 \mathrm{e}+001.00000 \mathrm{e}-011.00000 \mathrm{e}-091.00000 \mathrm{e}-01$ Element: 9298 \# of layers: 7

$\mathrm{Kx} \mathrm{Ky} \mathrm{Kz}$ Ss Por

3.41422e+00 3.41422e+00 3.41422e-01 1.00000e-09 2.12000e-01 $3.41422 \mathrm{e}+003.41422 \mathrm{e}+003.41422 \mathrm{e}-01$ 1.00000e-09 2.12000e-01 $3.41422 \mathrm{e}+003.41422 \mathrm{e}+003.41422 \mathrm{e}-01$ 1.00000e-09 2.12000e-01 $3.41422 \mathrm{e}+003.41422 \mathrm{e}+003.41422 \mathrm{e}-01$ 1.00000e-09 2.12000e-01 $3.41422 \mathrm{e}+003.41422 \mathrm{e}+00$ 3.41422e-01 1.00000e-09 2.12000e-01 $1.00000 \mathrm{e}-05$ 1.00000e-05 1.00000e-06 1.00000e-09 1.00000e-01 $1.00000 \mathrm{e}+001.00000 \mathrm{e}+00$ 1.00000e-01 1.00000e-09 1.00000e-01 Element: 9299 \# of layers: 7

$\mathrm{Kx} \mathrm{Ky} \mathrm{Kz}$ Ss Por

3.41422e+00 3.41422e+00 3.41422e-01 1.00000e-09 2.12000e-01 3.41422e+00 3.41422e+00 3.41422e-01 1.00000e-09 2.12000e-01 $3.41422 \mathrm{e}+003.41422 \mathrm{e}+003.41422 \mathrm{e}-01$ 1.00000e-09 2.12000e-01 $3.41422 \mathrm{e}+003.41422 \mathrm{e}+003.41422 \mathrm{e}-01$ 1.00000e-09 2.12000e-01 3.41422e+00 3.41422e+00 3.41422e-01 1.00000e-09 2.12000e-01 $1.00000 \mathrm{e}-051.00000 \mathrm{e}-051.00000 \mathrm{e}-061.00000 \mathrm{e}-091.00000 \mathrm{e}-01$ $1.00000 \mathrm{e}+001.00000 \mathrm{e}+001.00000 \mathrm{e}-011.00000 \mathrm{e}-091.00000 \mathrm{e}-01$ Element: 9300 \# of layers: 7

$\mathrm{Kx} \mathrm{Ky} \mathrm{Kz}$ Ss Por

3.41422e+00 3.41422e+00 3.41422e-01 1.00000e-09 2.12000e-01 $3.41422 \mathrm{e}+00$ 3.41422e+00 3.41422e-01 1.00000e-09 2.12000e-01 $3.41422 \mathrm{e}+003.41422 \mathrm{e}+003.41422 \mathrm{e}-01$ 1.00000e-09 2.12000e-01 $3.41422 \mathrm{e}+00$ 3.41422e+00 3.41422e-01 1.00000e-09 2.12000e-01 $3.41422 \mathrm{e}+003.41422 \mathrm{e}+003.41422 \mathrm{e}-01$ 1.00000e-09 2.12000e-01 1.00000e-05 1.00000e-05 1.00000e-06 1.00000e-09 1.00000e-01 $1.00000 \mathrm{e}+001.00000 \mathrm{e}+001.00000 \mathrm{e}-011.00000 \mathrm{e}-091.00000 \mathrm{e}-01$ Element: 9301 \# of layers: 7

$\mathrm{Kx} \mathrm{Ky} \mathrm{Kz}$ Ss Por

3.44842e+00 3.44842e+00 3.44842e-01 1.00000e-09 2.12000e-01 $3.44842 \mathrm{e}+003.44842 \mathrm{e}+00$ 3.44842e-01 1.00000e-09 2.12000e-01 3.44842e+00 3.44842e+00 3.44842e-01 1.00000e-09 2.12000e-01 3.44842e+00 3.44842e+00 3.44842e-01 1.00000e-09 2.12000e-01 3.44842e+00 3.44842e+00 3.44842e-01 1.00000e-09 2.12000e-01 $1.00000 \mathrm{e}-05$ 1.00000e-05 1.00000e-06 1.00000e-09 1.00000e-01 $1.00000 \mathrm{e}+001.00000 \mathrm{e}+001.00000 \mathrm{e}-011.00000 \mathrm{e}-091.00000 \mathrm{e}-01$ Element: 9302 \# of layers: 7

$\mathrm{Kx} \mathrm{Ky} \mathrm{Kz}$ Ss Por

3.44842e+00 3.44842e+00 3.44842e-01 1.00000e-09 2.12000e-01 $3.44842 \mathrm{e}+00$ 3.44842e+00 3.44842e-01 1.00000e-09 2.12000e-01 
$3.44842 \mathrm{e}+003.44842 \mathrm{e}+003.44842 \mathrm{e}-011.00000 \mathrm{e}-092.12000 \mathrm{e}-01$ $3.44842 \mathrm{e}+003.44842 \mathrm{e}+003.44842 \mathrm{e}-01$ 1.00000e-09 2.12000e-01 $3.44842 \mathrm{e}+003.44842 \mathrm{e}+003.44842 \mathrm{e}-01$ 1.00000e-09 2.12000e-01 $1.00000 \mathrm{e}-05$ 1.00000e-05 1.00000e-06 1.00000e-09 1.00000e-01 $1.00000 \mathrm{e}+001.00000 \mathrm{e}+001.00000 \mathrm{e}-011.00000 \mathrm{e}-091.00000 \mathrm{e}-01$ Element: 9303 \# of layers: 7

Kx Ky Kz Ss Por

$3.44842 \mathrm{e}+003.44842 \mathrm{e}+003.44842 \mathrm{e}-01$ 1.00000e-09 2.12000e-01 $3.44842 \mathrm{e}+003.44842 \mathrm{e}+003.44842 \mathrm{e}-01$ 1.00000e-09 2.12000e-01 $3.44842 \mathrm{e}+003.44842 \mathrm{e}+003.44842 \mathrm{e}-011.00000 \mathrm{e}-092.12000 \mathrm{e}-01$ $3.44842 \mathrm{e}+003.44842 \mathrm{e}+003.44842 \mathrm{e}-011.00000 \mathrm{e}-092.12000 \mathrm{e}-01$ $3.44842 \mathrm{e}+003.44842 \mathrm{e}+003.44842 \mathrm{e}-01$ 1.00000e-09 2.12000e-01 $1.00000 \mathrm{e}-051.00000 \mathrm{e}-05$ 1.00000e-06 1.00000e-09 1.00000e-01 $1.00000 \mathrm{e}+001.00000 \mathrm{e}+001.00000 \mathrm{e}-011.00000 \mathrm{e}-091.00000 \mathrm{e}-01$ Element: 9304 \# of layers: 7

Kx Ky Kz Ss Por

$3.44842 \mathrm{e}+003.44842 \mathrm{e}+00$ 3.44842e-01 1.00000e-09 2.12000e-01 $3.44842 \mathrm{e}+003.44842 \mathrm{e}+003.44842 \mathrm{e}-011.00000 \mathrm{e}-092.12000 \mathrm{e}-01$ $3.44842 \mathrm{e}+003.44842 \mathrm{e}+003.44842 \mathrm{e}-011.00000 \mathrm{e}-092.12000 \mathrm{e}-01$ $3.44842 \mathrm{e}+003.44842 \mathrm{e}+003.44842 \mathrm{e}-011.00000 \mathrm{e}-092.12000 \mathrm{e}-01$ $3.44842 \mathrm{e}+003.44842 \mathrm{e}+003.44842 \mathrm{e}-01$ 1.00000e-09 2.12000e-01 $1.00000 \mathrm{e}-05$ 1.00000e-05 1.00000e-06 1.00000e-09 1.00000e-01 $1.00000 \mathrm{e}+001.00000 \mathrm{e}+00$ 1.00000e-01 1.00000e-09 1.00000e-01 Element: 9305 \# of layers: 7

Kx Ky Kz Ss Por $3.44842 \mathrm{e}+003.44842 \mathrm{e}+003.44842 \mathrm{e}-011.00000 \mathrm{e}-092.12000 \mathrm{e}-01$ $3.44842 \mathrm{e}+003.44842 \mathrm{e}+003.44842 \mathrm{e}-01$ 1.00000e-09 2.12000e-01 $3.44842 \mathrm{e}+003.44842 \mathrm{e}+003.44842 \mathrm{e}-01$ 1.00000e-09 2.12000e-01 $3.44842 \mathrm{e}+003.44842 \mathrm{e}+003.44842 \mathrm{e}-011.00000 \mathrm{e}-09$ 2.12000e-01 $3.44842 \mathrm{e}+003.44842 \mathrm{e}+003.44842 \mathrm{e}-01$ 1.00000e-09 2.12000e-01 $1.00000 \mathrm{e}-05$ 1.00000e-05 1.00000e-06 1.00000e-09 1.00000e-01 $1.00000 \mathrm{e}+001.00000 \mathrm{e}+001.00000 \mathrm{e}-011.00000 \mathrm{e}-091.00000 \mathrm{e}-01$ Element: 9306 \# of layers: 7

Kx Ky Kz Ss Por

$3.41422 \mathrm{e}+003.41422 \mathrm{e}+003.41422 \mathrm{e}-01$ 1.00000e-09 2.12000e-01 $3.41422 \mathrm{e}+003.41422 \mathrm{e}+003.41422 \mathrm{e}-011.00000 \mathrm{e}-092.12000 \mathrm{e}-01$ $3.41422 \mathrm{e}+003.41422 \mathrm{e}+003.41422 \mathrm{e}-01$ 1.00000e-09 2.12000e-01 $3.41422 \mathrm{e}+003.41422 \mathrm{e}+003.41422 \mathrm{e}-011.00000 \mathrm{e}-092.12000 \mathrm{e}-01$ $3.41422 \mathrm{e}+003.41422 \mathrm{e}+003.41422 \mathrm{e}-01$ 1.00000e-09 2.12000e-01 $1.00000 \mathrm{e}-05$ 1.00000e-05 1.00000e-06 1.00000e-09 1.00000e-01 $1.00000 \mathrm{e}+001.00000 \mathrm{e}+001.00000 \mathrm{e}-011.00000 \mathrm{e}-091.00000 \mathrm{e}-01$ Element: 9307 \# of layers: 7

Kx Ky Kz Ss Por

$3.41422 \mathrm{e}+003.41422 \mathrm{e}+003.41422 \mathrm{e}-011.00000 \mathrm{e}-092.12000 \mathrm{e}-01$ $3.41422 \mathrm{e}+003.41422 \mathrm{e}+003.41422 \mathrm{e}-011.00000 \mathrm{e}-092.12000 \mathrm{e}-01$ $3.41422 \mathrm{e}+003.41422 \mathrm{e}+003.41422 \mathrm{e}-01$ 1.00000e-09 2.12000e-01 
$3.41422 \mathrm{e}+003.41422 \mathrm{e}+003.41422 \mathrm{e}-011.00000 \mathrm{e}-092.12000 \mathrm{e}-01$ $3.41422 \mathrm{e}+003.41422 \mathrm{e}+003.41422 \mathrm{e}-011.00000 \mathrm{e}-092.12000 \mathrm{e}-01$ $1.00000 \mathrm{e}-051.00000 \mathrm{e}-05$ 1.00000e-06 1.00000e-09 1.00000e-01 $1.00000 \mathrm{e}+001.00000 \mathrm{e}+001.00000 \mathrm{e}-011.00000 \mathrm{e}-091.00000 \mathrm{e}-01$ Element: 9308 \# of layers: 7

Kx Ky Kz Ss Por

3.44842e+00 3.44842e+00 3.44842e-01 1.00000e-09 2.12000e-01 $3.44842 \mathrm{e}+003.44842 \mathrm{e}+003.44842 \mathrm{e}-011.00000 \mathrm{e}-092.12000 \mathrm{e}-01$ $3.44842 \mathrm{e}+003.44842 \mathrm{e}+003.44842 \mathrm{e}-011.00000 \mathrm{e}-092.12000 \mathrm{e}-01$ $3.44842 \mathrm{e}+003.44842 \mathrm{e}+003.44842 \mathrm{e}-01$ 1.00000e-09 2.12000e-01 $3.44842 \mathrm{e}+003.44842 \mathrm{e}+003.44842 \mathrm{e}-01$ 1.00000e-09 2.12000e-01 $1.00000 \mathrm{e}-05$ 1.00000e-05 1.00000e-06 1.00000e-09 1.00000e-01 $1.00000 \mathrm{e}+001.00000 \mathrm{e}+001.00000 \mathrm{e}-011.00000 \mathrm{e}-091.00000 \mathrm{e}-01$ Element: 9309 \# of layers: 7

Kx Ky Kz Ss Por

3.44842e+00 3.44842e+00 3.44842e-01 1.00000e-09 2.12000e-01 $3.44842 \mathrm{e}+003.44842 \mathrm{e}+003.44842 \mathrm{e}-011.00000 \mathrm{e}-092.12000 \mathrm{e}-01$ $3.44842 \mathrm{e}+003.44842 \mathrm{e}+003.44842 \mathrm{e}-01$ 1.00000e-09 2.12000e-01 $3.44842 \mathrm{e}+003.44842 \mathrm{e}+003.44842 \mathrm{e}-011.00000 \mathrm{e}-092.12000 \mathrm{e}-01$ $3.44842 \mathrm{e}+003.44842 \mathrm{e}+003.44842 \mathrm{e}-011.00000 \mathrm{e}-092.12000 \mathrm{e}-01$ $1.00000 \mathrm{e}-05$ 1.00000e-05 1.00000e-06 1.00000e-09 1.00000e-01 $1.00000 \mathrm{e}+001.00000 \mathrm{e}+001.00000 \mathrm{e}-011.00000 \mathrm{e}-091.00000 \mathrm{e}-01$ Element: 9310 \# of layers: 7

Kx Ky Kz Ss Por

$3.44842 \mathrm{e}+003.44842 \mathrm{e}+003.44842 \mathrm{e}-01$ 1.00000e-09 2.12000e-01 $3.44842 \mathrm{e}+003.44842 \mathrm{e}+003.44842 \mathrm{e}-01$ 1.00000e-09 2.12000e-01 $3.44842 \mathrm{e}+003.44842 \mathrm{e}+003.44842 \mathrm{e}-011.00000 \mathrm{e}-092.12000 \mathrm{e}-01$ $3.44842 \mathrm{e}+003.44842 \mathrm{e}+003.44842 \mathrm{e}-011.00000 \mathrm{e}-092.12000 \mathrm{e}-01$ $3.44842 \mathrm{e}+003.44842 \mathrm{e}+003.44842 \mathrm{e}-01$ 1.00000e-09 2.12000e-01 $1.00000 \mathrm{e}-05$ 1.00000e-05 1.00000e-06 1.00000e-09 1.00000e-01 $1.00000 \mathrm{e}+001.00000 \mathrm{e}+001.00000 \mathrm{e}-011.00000 \mathrm{e}-091.00000 \mathrm{e}-01$ Element: 9311 \# of layers: 7

Kx Ky Kz Ss Por $3.44842 \mathrm{e}+003.44842 \mathrm{e}+003.44842 \mathrm{e}-01$ 1.00000e-09 2.12000e-01 $3.44842 \mathrm{e}+003.44842 \mathrm{e}+003.44842 \mathrm{e}-01$ 1.00000e-09 2.12000e-01 $3.44842 \mathrm{e}+003.44842 \mathrm{e}+003.44842 \mathrm{e}-011.00000 \mathrm{e}-092.12000 \mathrm{e}-01$ $3.44842 \mathrm{e}+003.44842 \mathrm{e}+003.44842 \mathrm{e}-011.00000 \mathrm{e}-092.12000 \mathrm{e}-01$ $3.44842 \mathrm{e}+003.44842 \mathrm{e}+003.44842 \mathrm{e}-01$ 1.00000e-09 2.12000e-01 $1.00000 \mathrm{e}-05$ 1.00000e-05 1.00000e-06 1.00000e-09 1.00000e-01 $1.00000 \mathrm{e}+001.00000 \mathrm{e}+001.00000 \mathrm{e}-011.00000 \mathrm{e}-091.00000 \mathrm{e}-01$ Element: 9312 \# of layers: 7

Kx Ky Kz Ss Por

$3.44842 \mathrm{e}+003.44842 \mathrm{e}+003.44842 \mathrm{e}-01$ 1.00000e-09 2.12000e-01 $3.44842 \mathrm{e}+003.44842 \mathrm{e}+003.44842 \mathrm{e}-011.00000 \mathrm{e}-092.12000 \mathrm{e}-01$ $3.44842 \mathrm{e}+003.44842 \mathrm{e}+003.44842 \mathrm{e}-011.00000 \mathrm{e}-092.12000 \mathrm{e}-01$ $3.44842 \mathrm{e}+003.44842 \mathrm{e}+003.44842 \mathrm{e}-01$ 1.00000e-09 2.12000e-01 
3.44842e+00 3.44842e+00 3.44842e-01 1.00000e-09 2.12000e-01 $1.00000 \mathrm{e}-05$ 1.00000e-05 1.00000e-06 1.00000e-09 1.00000e-01 $1.00000 \mathrm{e}+001.00000 \mathrm{e}+001.00000 \mathrm{e}-011.00000 \mathrm{e}-091.00000 \mathrm{e}-01$ Element: 9313 \# of layers: 7

$\mathrm{Kx} \mathrm{Ky} \mathrm{Kz}$ Ss Por

3.44842e+00 3.44842e+00 3.44842e-01 1.00000e-09 2.12000e-01 3.44842e+00 3.44842e+00 3.44842e-01 1.00000e-09 2.12000e-01 $3.44842 \mathrm{e}+003.44842 \mathrm{e}+00$ 3.44842e-01 1.00000e-09 2.12000e-01 $3.44842 \mathrm{e}+003.44842 \mathrm{e}+00$ 3.44842e-01 1.00000e-09 2.12000e-01 $3.44842 \mathrm{e}+003.44842 \mathrm{e}+00$ 3.44842e-01 1.00000e-09 2.12000e-01 $1.00000 \mathrm{e}-05$ 1.00000e-05 1.00000e-06 1.00000e-09 1.00000e-01 $1.00000 \mathrm{e}+001.00000 \mathrm{e}+001.00000 \mathrm{e}-011.00000 \mathrm{e}-091.00000 \mathrm{e}-01$ Element: 9314 \# of layers: 7

$\mathrm{Kx} \mathrm{Ky} \mathrm{Kz}$ Ss Por

3.44842e+00 3.44842e+00 3.44842e-01 1.00000e-09 2.12000e-01 $3.44842 \mathrm{e}+003.44842 \mathrm{e}+00$ 3.44842e-01 1.00000e-09 2.12000e-01 3.44842e+00 3.44842e+00 3.44842e-01 1.00000e-09 2.12000e-01 3.44842e+00 3.44842e+00 3.44842e-01 1.00000e-09 2.12000e-01 3.44842e+00 3.44842e+00 3.44842e-01 1.00000e-09 2.12000e-01 $1.00000 \mathrm{e}-05$ 1.00000e-05 1.00000e-06 1.00000e-09 1.00000e-01 $1.00000 \mathrm{e}+001.00000 \mathrm{e}+001.00000 \mathrm{e}-011.00000 \mathrm{e}-091.00000 \mathrm{e}-01$ Element: 9315 \# of layers: 7

$\mathrm{Kx} \mathrm{Ky} \mathrm{Kz}$ Ss Por

3.44842e+00 3.44842e+00 3.44842e-01 1.00000e-09 2.12000e-01 $3.44842 \mathrm{e}+003.44842 \mathrm{e}+00$ 3.44842e-01 1.00000e-09 2.12000e-01 $3.44842 \mathrm{e}+003.44842 \mathrm{e}+00$ 3.44842e-01 1.00000e-09 2.12000e-01 3.44842e+00 3.44842e+00 3.44842e-01 1.00000e-09 2.12000e-01 3.44842e+00 3.44842e+00 3.44842e-01 1.00000e-09 2.12000e-01 $1.00000 \mathrm{e}-05$ 1.00000e-05 1.00000e-06 1.00000e-09 1.00000e-01 $1.00000 \mathrm{e}+001.00000 \mathrm{e}+001.00000 \mathrm{e}-011.00000 \mathrm{e}-091.00000 \mathrm{e}-01$ Element: 9316 \# of layers: 7

$\mathrm{Kx} \mathrm{Ky} \mathrm{Kz}$ Ss Por

3.44842e+00 3.44842e+00 3.44842e-01 1.00000e-09 2.12000e-01 $3.44842 \mathrm{e}+003.44842 \mathrm{e}+003.44842 \mathrm{e}-01$ 1.00000e-09 2.12000e-01 $3.44842 \mathrm{e}+003.44842 \mathrm{e}+003.44842 \mathrm{e}-01$ 1.00000e-09 2.12000e-01 3.44842e+00 3.44842e+00 3.44842e-01 1.00000e-09 2.12000e-01 3.44842e+00 3.44842e+00 3.44842e-01 1.00000e-09 2.12000e-01 $1.00000 \mathrm{e}-05$ 1.00000e-05 1.00000e-06 1.00000e-09 1.00000e-01 $1.00000 \mathrm{e}+001.00000 \mathrm{e}+001.00000 \mathrm{e}-011.00000 \mathrm{e}-091.00000 \mathrm{e}-01$ Element: 9317 \# of layers: 7

$\mathrm{Kx} \mathrm{Ky} \mathrm{Kz}$ Ss Por 3.44842e+00 3.44842e+00 3.44842e-01 1.00000e-09 2.12000e-01 $3.44842 \mathrm{e}+003.44842 \mathrm{e}+00$ 3.44842e-01 1.00000e-09 2.12000e-01 3.44842e+00 3.44842e+00 3.44842e-01 1.00000e-09 2.12000e-01 $3.44842 \mathrm{e}+003.44842 \mathrm{e}+003.44842 \mathrm{e}-01$ 1.00000e-09 2.12000e-01 $3.44842 \mathrm{e}+003.44842 \mathrm{e}+00$ 3.44842e-01 1.00000e-09 2.12000e-01 
$1.00000 \mathrm{e}-05$ 1.00000e-05 1.00000e-06 1.00000e-09 1.00000e-01 $1.00000 \mathrm{e}+001.00000 \mathrm{e}+001.00000 \mathrm{e}-01$ 1.00000e-09 1.00000e-01 Element: 9318 \# of layers: 6

Kx Ky Kz Ss Por

3.44842e+00 3.44842e+00 3.44842e-01 1.00000e-09 2.12000e-01

$3.44842 \mathrm{e}+003.44842 \mathrm{e}+00$ 3.44842e-01 1.00000e-09 2.12000e-01

$3.44842 \mathrm{e}+003.44842 \mathrm{e}+00$ 3.44842e-01 1.00000e-09 2.12000e-01

$3.44842 \mathrm{e}+003.44842 \mathrm{e}+003.44842 \mathrm{e}-01$ 1.00000e-09 2.12000e-01

$1.00000 \mathrm{e}-051.00000 \mathrm{e}-051.00000 \mathrm{e}-061.00000 \mathrm{e}-091.00000 \mathrm{e}-01$

$1.00000 \mathrm{e}+001.00000 \mathrm{e}+00$ 1.00000e-01 1.00000e-09 1.00000e-01

Element: 9319 \# of layers: 6

Kx Ky Kz Ss Por

3.44842e+00 3.44842e+00 3.44842e-01 1.00000e-09 2.12000e-01

$3.44842 \mathrm{e}+003.44842 \mathrm{e}+003.44842 \mathrm{e}-01$ 1.00000e-09 2.12000e-01

3.44842e+00 3.44842e+00 3.44842e-01 1.00000e-09 2.12000e-01

$3.44842 \mathrm{e}+003.44842 \mathrm{e}+003.44842 \mathrm{e}-01$ 1.00000e-09 2.12000e-01

$1.00000 \mathrm{e}-05$ 1.00000e-05 1.00000e-06 1.00000e-09 1.00000e-01

$1.00000 \mathrm{e}+001.00000 \mathrm{e}+001.00000 \mathrm{e}-01$ 1.00000e-09 1.00000e-01

Element: 9320 \# of layers: 6

$\mathrm{Kx} \mathrm{Ky} \mathrm{Kz}$ Ss Por

3.85096e+00 3.85096e+00 3.85096e-01 1.00000e-09 2.12000e-01

$3.85096 \mathrm{e}+003.85096 \mathrm{e}+00$ 3.85096e-01 1.00000e-09 2.12000e-01

3.85096e+00 3.85096e+00 3.85096e-01 1.00000e-09 2.12000e-01

$3.85096 \mathrm{e}+003.85096 \mathrm{e}+00$ 3.85096e-01 1.00000e-09 2.12000e-01

$1.00000 \mathrm{e}-051.00000 \mathrm{e}-05$ 1.00000e-06 1.00000e-09 1.00000e-01

$1.00000 \mathrm{e}+001.00000 \mathrm{e}+001.00000 \mathrm{e}-01$ 1.00000e-09 1.00000e-01

Element: 9321 \# of layers: 6

$\mathrm{Kx} \mathrm{Ky} \mathrm{Kz}$ Ss Por

3.85096e+00 3.85096e+00 3.85096e-01 1.00000e-09 2.12000e-01

$3.85096 \mathrm{e}+003.85096 \mathrm{e}+003.85096 \mathrm{e}-01$ 1.00000e-09 2.12000e-01

$3.85096 \mathrm{e}+003.85096 \mathrm{e}+003.85096 \mathrm{e}-01$ 1.00000e-09 2.12000e-01

$3.85096 \mathrm{e}+003.85096 \mathrm{e}+003.85096 \mathrm{e}-01$ 1.00000e-09 2.12000e-01

$1.00000 \mathrm{e}-05$ 1.00000e-05 1.00000e-06 1.00000e-09 1.00000e-01

$1.00000 \mathrm{e}+001.00000 \mathrm{e}+001.00000 \mathrm{e}-011.00000 \mathrm{e}-091.00000 \mathrm{e}-01$

Element: 9322 \# of layers: 6

$\mathrm{Kx} \mathrm{Ky} \mathrm{Kz}$ Ss Por

3.85096e+00 3.85096e+00 3.85096e-01 1.00000e-09 2.12000e-01

$3.85096 \mathrm{e}+003.85096 \mathrm{e}+003.85096 \mathrm{e}-01$ 1.00000e-09 2.12000e-01

$3.85096 \mathrm{e}+003.85096 \mathrm{e}+003.85096 \mathrm{e}-01$ 1.00000e-09 2.12000e-01

$3.85096 \mathrm{e}+003.85096 \mathrm{e}+003.85096 \mathrm{e}-01$ 1.00000e-09 2.12000e-01

$1.00000 \mathrm{e}-05$ 1.00000e-05 1.00000e-06 1.00000e-09 1.00000e-01

$1.00000 \mathrm{e}+001.00000 \mathrm{e}+001.00000 \mathrm{e}-011.00000 \mathrm{e}-091.00000 \mathrm{e}-01$

Element: 9323 \# of layers: 6

$\mathrm{Kx} \mathrm{Ky} \mathrm{Kz}$ Ss Por

3.44842e+00 3.44842e+00 3.44842e-01 1.00000e-09 2.12000e-01

$3.44842 \mathrm{e}+003.44842 \mathrm{e}+00$ 3.44842e-01 1.00000e-09 2.12000e-01 
$3.44842 \mathrm{e}+003.44842 \mathrm{e}+003.44842 \mathrm{e}-011.00000 \mathrm{e}-092.12000 \mathrm{e}-01$ $3.44842 \mathrm{e}+003.44842 \mathrm{e}+003.44842 \mathrm{e}-01$ 1.00000e-09 2.12000e-01 $1.00000 \mathrm{e}-051.00000 \mathrm{e}-05$ 1.00000e-06 1.00000e-09 1.00000e-01 $1.00000 \mathrm{e}+001.00000 \mathrm{e}+001.00000 \mathrm{e}-011.00000 \mathrm{e}-091.00000 \mathrm{e}-01$ Element: 9324 \# of layers: 6

Kx Ky Kz Ss Por

3.44842e+00 3.44842e+00 3.44842e-01 1.00000e-09 2.12000e-01 $3.44842 \mathrm{e}+003.44842 \mathrm{e}+003.44842 \mathrm{e}-011.00000 \mathrm{e}-092.12000 \mathrm{e}-01$ $3.44842 \mathrm{e}+003.44842 \mathrm{e}+003.44842 \mathrm{e}-011.00000 \mathrm{e}-092.12000 \mathrm{e}-01$ $3.44842 \mathrm{e}+003.44842 \mathrm{e}+003.44842 \mathrm{e}-01$ 1.00000e-09 2.12000e-01 $1.00000 \mathrm{e}-05$ 1.00000e-05 1.00000e-06 1.00000e-09 1.00000e-01 $1.00000 \mathrm{e}+001.00000 \mathrm{e}+001.00000 \mathrm{e}-011.00000 \mathrm{e}-091.00000 \mathrm{e}-01$ Element: 9325 \# of layers: 6

Kx Ky Kz Ss Por

$3.44842 \mathrm{e}+003.44842 \mathrm{e}+003.44842 \mathrm{e}-01$ 1.00000e-09 2.12000e-01 $3.44842 \mathrm{e}+003.44842 \mathrm{e}+003.44842 \mathrm{e}-01$ 1.00000e-09 2.12000e-01 $3.44842 \mathrm{e}+003.44842 \mathrm{e}+003.44842 \mathrm{e}-011.00000 \mathrm{e}-092.12000 \mathrm{e}-01$ $3.44842 \mathrm{e}+003.44842 \mathrm{e}+003.44842 \mathrm{e}-01$ 1.00000e-09 2.12000e-01 $1.00000 \mathrm{e}-05$ 1.00000e-05 1.00000e-06 1.00000e-09 1.00000e-01 $1.00000 \mathrm{e}+001.00000 \mathrm{e}+001.00000 \mathrm{e}-011.00000 \mathrm{e}-091.00000 \mathrm{e}-01$ Element: 9326 \# of layers: 6

Kx Ky Kz Ss Por

$3.44842 \mathrm{e}+003.44842 \mathrm{e}+00$ 3.44842e-01 1.00000e-09 2.12000e-01 $3.44842 \mathrm{e}+003.44842 \mathrm{e}+003.44842 \mathrm{e}-011.00000 \mathrm{e}-092.12000 \mathrm{e}-01$ $3.44842 \mathrm{e}+003.44842 \mathrm{e}+003.44842 \mathrm{e}-011.00000 \mathrm{e}-092.12000 \mathrm{e}-01$ $3.44842 \mathrm{e}+003.44842 \mathrm{e}+003.44842 \mathrm{e}-01$ 1.00000e-09 2.12000e-01 $1.00000 \mathrm{e}-05$ 1.00000e-05 1.00000e-06 1.00000e-09 1.00000e-01 $1.00000 \mathrm{e}+001.00000 \mathrm{e}+001.00000 \mathrm{e}-011.00000 \mathrm{e}-091.00000 \mathrm{e}-01$ Element: 9327 \# of layers: 7

Kx Ky Kz Ss Por

3.85096e+00 3.85096e+00 3.85096e-01 1.00000e-09 2.12000e-01 $3.85096 \mathrm{e}+003.85096 \mathrm{e}+003.85096 \mathrm{e}-011.00000 \mathrm{e}-092.12000 \mathrm{e}-01$ $3.85096 \mathrm{e}+003.85096 \mathrm{e}+003.85096 \mathrm{e}-011.00000 \mathrm{e}-092.12000 \mathrm{e}-01$ $3.85096 \mathrm{e}+003.85096 \mathrm{e}+003.85096 \mathrm{e}-011.00000 \mathrm{e}-092.12000 \mathrm{e}-01$ $3.85096 \mathrm{e}+003.85096 \mathrm{e}+003.85096 \mathrm{e}-01$ 1.00000e-09 2.12000e-01 $1.00000 \mathrm{e}-05$ 1.00000e-05 1.00000e-06 1.00000e-09 1.00000e-01 $1.00000 \mathrm{e}+001.00000 \mathrm{e}+001.00000 \mathrm{e}-011.00000 \mathrm{e}-091.00000 \mathrm{e}-01$ Element: 9328 \# of layers: 6

Kx Ky Kz Ss Por

$3.85096 \mathrm{e}+003.85096 \mathrm{e}+00$ 3.85096e-01 1.00000e-09 2.12000e-01 $3.85096 \mathrm{e}+003.85096 \mathrm{e}+003.85096 \mathrm{e}-01$ 1.00000e-09 2.12000e-01 $3.85096 \mathrm{e}+003.85096 \mathrm{e}+003.85096 \mathrm{e}-011.00000 \mathrm{e}-092.12000 \mathrm{e}-01$ $3.85096 \mathrm{e}+003.85096 \mathrm{e}+00$ 3.85096e-01 1.00000e-09 2.12000e-01 $1.00000 \mathrm{e}-05$ 1.00000e-05 1.00000e-06 1.00000e-09 1.00000e-01 $1.00000 \mathrm{e}+001.00000 \mathrm{e}+001.00000 \mathrm{e}-011.00000 \mathrm{e}-091.00000 \mathrm{e}-01$ Element: 9329 \# of layers: 6 
$\mathrm{Kx} \mathrm{Ky} \mathrm{Kz}$ Ss Por

$3.85096 \mathrm{e}+00$ 3.85096e+00 3.85096e-01 1.00000e-09 2.12000e-01

$3.85096 \mathrm{e}+003.85096 \mathrm{e}+003.85096 \mathrm{e}-01$ 1.00000e-09 2.12000e-01

$3.85096 \mathrm{e}+003.85096 \mathrm{e}+003.85096 \mathrm{e}-01$ 1.00000e-09 2.12000e-01

$3.85096 \mathrm{e}+003.85096 \mathrm{e}+003.85096 \mathrm{e}-01$ 1.00000e-09 2.12000e-01

$1.00000 \mathrm{e}-05$ 1.00000e-05 1.00000e-06 1.00000e-09 1.00000e-01

$1.00000 \mathrm{e}+001.00000 \mathrm{e}+001.00000 \mathrm{e}-01$ 1.00000e-09 1.00000e-01

Element: 9330 \# of layers: 6

$\mathrm{Kx} \mathrm{Ky} \mathrm{Kz}$ Ss Por

3.85096e+00 3.85096e+00 3.85096e-01 1.00000e-09 2.12000e-01

$3.85096 \mathrm{e}+003.85096 \mathrm{e}+00$ 3.85096e-01 1.00000e-09 2.12000e-01

$3.85096 \mathrm{e}+003.85096 \mathrm{e}+003.85096 \mathrm{e}-01$ 1.00000e-09 2.12000e-01

$3.85096 \mathrm{e}+003.85096 \mathrm{e}+00$ 3.85096e-01 1.00000e-09 2.12000e-01

$1.00000 \mathrm{e}-05$ 1.00000e-05 1.00000e-06 1.00000e-09 1.00000e-01

$1.00000 \mathrm{e}+001.00000 \mathrm{e}+001.00000 \mathrm{e}-01$ 1.00000e-09 1.00000e-01

Element: 9331 \# of layers: 6

$\mathrm{Kx} \mathrm{Ky} \mathrm{Kz}$ Ss Por

3.85096e+00 3.85096e+00 3.85096e-01 1.00000e-09 2.12000e-01

$3.85096 \mathrm{e}+003.85096 \mathrm{e}+003.85096 \mathrm{e}-01$ 1.00000e-09 2.12000e-01

$3.85096 \mathrm{e}+003.85096 \mathrm{e}+003.85096 \mathrm{e}-01$ 1.00000e-09 2.12000e-01

$3.85096 \mathrm{e}+003.85096 \mathrm{e}+003.85096 \mathrm{e}-01$ 1.00000e-09 2.12000e-01

$1.00000 \mathrm{e}-05$ 1.00000e-05 1.00000e-06 1.00000e-09 1.00000e-01

$1.00000 \mathrm{e}+001.00000 \mathrm{e}+001.00000 \mathrm{e}-01$ 1.00000e-09 1.00000e-01

Element: 9332 \# of layers: 6

Kx Ky Kz Ss Por

3.85096e+00 3.85096e+00 3.85096e-01 1.00000e-09 2.12000e-01

$3.85096 \mathrm{e}+003.85096 \mathrm{e}+003.85096 \mathrm{e}-01$ 1.00000e-09 2.12000e-01

$3.85096 \mathrm{e}+003.85096 \mathrm{e}+00$ 3.85096e-01 1.00000e-09 2.12000e-01

$3.85096 \mathrm{e}+003.85096 \mathrm{e}+003.85096 \mathrm{e}-01$ 1.00000e-09 2.12000e-01

$1.00000 \mathrm{e}-05$ 1.00000e-05 1.00000e-06 1.00000e-09 1.00000e-01

$1.00000 \mathrm{e}+001.00000 \mathrm{e}+001.00000 \mathrm{e}-01$ 1.00000e-09 1.00000e-01

Element: 9333 \# of layers: 7

$\mathrm{Kx} \mathrm{Ky} \mathrm{Kz}$ Ss Por

3.85096e+00 3.85096e+00 3.85096e-01 1.00000e-09 2.12000e-01

$3.85096 \mathrm{e}+003.85096 \mathrm{e}+003.85096 \mathrm{e}-01$ 1.00000e-09 2.12000e-01

$3.85096 \mathrm{e}+003.85096 \mathrm{e}+003.85096 \mathrm{e}-01$ 1.00000e-09 2.12000e-01

$3.85096 \mathrm{e}+003.85096 \mathrm{e}+003.85096 \mathrm{e}-01$ 1.00000e-09 2.12000e-01

3.85096e+00 3.85096e+00 3.85096e-01 1.00000e-09 2.12000e-01

$1.00000 \mathrm{e}-05$ 1.00000e-05 1.00000e-06 1.00000e-09 1.00000e-01

$1.00000 \mathrm{e}+001.00000 \mathrm{e}+001.00000 \mathrm{e}-01$ 1.00000e-09 1.00000e-01

Element: 9334 \# of layers: 7

$\mathrm{Kx} \mathrm{Ky} \mathrm{Kz}$ Ss Por

3.85096e+00 3.85096e+00 3.85096e-01 1.00000e-09 2.12000e-01

$3.85096 \mathrm{e}+003.85096 \mathrm{e}+003.85096 \mathrm{e}-01$ 1.00000e-09 2.12000e-01

$3.85096 \mathrm{e}+003.85096 \mathrm{e}+003.85096 \mathrm{e}-01$ 1.00000e-09 2.12000e-01

$3.85096 \mathrm{e}+003.85096 \mathrm{e}+00$ 3.85096e-01 1.00000e-09 2.12000e-01 
$3.85096 \mathrm{e}+003.85096 \mathrm{e}+003.85096 \mathrm{e}-01$ 1.00000e-09 2.12000e-01 $1.00000 \mathrm{e}-05$ 1.00000e-05 1.00000e-06 1.00000e-09 1.00000e-01 $1.00000 \mathrm{e}+001.00000 \mathrm{e}+001.00000 \mathrm{e}-011.00000 \mathrm{e}-091.00000 \mathrm{e}-01$ Element: 9335 \# of layers: 6

Kx Ky Kz Ss Por

$3.85096 \mathrm{e}+003.85096 \mathrm{e}+00$ 3.85096e-01 1.00000e-09 2.12000e-01 $3.85096 \mathrm{e}+003.85096 \mathrm{e}+003.85096 \mathrm{e}-011.00000 \mathrm{e}-092.12000 \mathrm{e}-01$ $3.85096 \mathrm{e}+003.85096 \mathrm{e}+003.85096 \mathrm{e}-011.00000 \mathrm{e}-092.12000 \mathrm{e}-01$ $3.85096 \mathrm{e}+003.85096 \mathrm{e}+003.85096 \mathrm{e}-01$ 1.00000e-09 2.12000e-01 $1.00000 \mathrm{e}-05$ 1.00000e-05 1.00000e-06 1.00000e-09 1.00000e-01 $1.00000 \mathrm{e}+001.00000 \mathrm{e}+001.00000 \mathrm{e}-011.00000 \mathrm{e}-091.00000 \mathrm{e}-01$ Element: 9336 \# of layers: 6

Kx Ky Kz Ss Por

3.85096e+00 3.85096e+00 3.85096e-01 1.00000e-09 2.12000e-01 $3.85096 \mathrm{e}+003.85096 \mathrm{e}+003.85096 \mathrm{e}-011.00000 \mathrm{e}-092.12000 \mathrm{e}-01$ $3.85096 \mathrm{e}+003.85096 \mathrm{e}+003.85096 \mathrm{e}-01$ 1.00000e-09 2.12000e-01 $3.85096 \mathrm{e}+003.85096 \mathrm{e}+003.85096 \mathrm{e}-011.00000 \mathrm{e}-092.12000 \mathrm{e}-01$ $1.00000 \mathrm{e}-05$ 1.00000e-05 1.00000e-06 1.00000e-09 1.00000e-01 $1.00000 \mathrm{e}+001.00000 \mathrm{e}+001.00000 \mathrm{e}-011.00000 \mathrm{e}-091.00000 \mathrm{e}-01$ Element: 9337 \# of layers: 6

Kx Ky Kz Ss Por

3.85096e+00 3.85096e+00 3.85096e-01 1.00000e-09 2.12000e-01 $3.85096 \mathrm{e}+003.85096 \mathrm{e}+003.85096 \mathrm{e}-01$ 1.00000e-09 2.12000e-01 $3.85096 \mathrm{e}+003.85096 \mathrm{e}+003.85096 \mathrm{e}-011.00000 \mathrm{e}-092.12000 \mathrm{e}-01$ $3.85096 \mathrm{e}+003.85096 \mathrm{e}+003.85096 \mathrm{e}-01$ 1.00000e-09 2.12000e-01 $1.00000 \mathrm{e}-05$ 1.00000e-05 1.00000e-06 1.00000e-09 1.00000e-01 $1.00000 \mathrm{e}+001.00000 \mathrm{e}+001.00000 \mathrm{e}-011.00000 \mathrm{e}-091.00000 \mathrm{e}-01$ Element: 9338 \# of layers: 6

Kx Ky Kz Ss Por

$3.74071 \mathrm{e}+003.74071 \mathrm{e}+003.74071 \mathrm{e}-01$ 1.00000e-09 2.12000e-01 $3.74071 \mathrm{e}+003.74071 \mathrm{e}+003.74071 \mathrm{e}-011.00000 \mathrm{e}-092.12000 \mathrm{e}-01$ $3.74071 \mathrm{e}+003.74071 \mathrm{e}+003.74071 \mathrm{e}-011.00000 \mathrm{e}-092.12000 \mathrm{e}-01$ $3.74071 \mathrm{e}+003.74071 \mathrm{e}+003.74071 \mathrm{e}-011.00000 \mathrm{e}-092.12000 \mathrm{e}-01$ $1.00000 \mathrm{e}-05$ 1.00000e-05 1.00000e-06 1.00000e-09 1.00000e-01 $1.00000 \mathrm{e}+001.00000 \mathrm{e}+001.00000 \mathrm{e}-011.00000 \mathrm{e}-091.00000 \mathrm{e}-01$ Element: 9339 \# of layers: 6

Kx Ky Kz Ss Por

3.74071e+00 3.74071e+00 3.74071e-01 1.00000e-09 2.12000e-01 $3.74071 \mathrm{e}+003.74071 \mathrm{e}+003.74071 \mathrm{e}-011.00000 \mathrm{e}-092.12000 \mathrm{e}-01$ $3.74071 \mathrm{e}+003.74071 \mathrm{e}+003.74071 \mathrm{e}-011.00000 \mathrm{e}-092.12000 \mathrm{e}-01$ $3.74071 \mathrm{e}+003.74071 \mathrm{e}+003.74071 \mathrm{e}-011.00000 \mathrm{e}-092.12000 \mathrm{e}-01$ $1.00000 \mathrm{e}-05$ 1.00000e-05 1.00000e-06 1.00000e-09 1.00000e-01 $1.00000 \mathrm{e}+001.00000 \mathrm{e}+001.00000 \mathrm{e}-011.00000 \mathrm{e}-091.00000 \mathrm{e}-01$ Element: 9340 \# of layers: 7

Kx Ky Kz Ss Por 3.74071e+00 3.74071e+00 3.74071e-01 1.00000e-09 2.12000e-01 
$3.74071 \mathrm{e}+003.74071 \mathrm{e}+003.74071 \mathrm{e}-01$ 1.00000e-09 2.12000e-01 $3.74071 \mathrm{e}+003.74071 \mathrm{e}+003.74071 \mathrm{e}-011.00000 \mathrm{e}-09$ 2.12000e-01 $3.74071 \mathrm{e}+003.74071 \mathrm{e}+003.74071 \mathrm{e}-01$ 1.00000e-09 2.12000e-01 $3.74071 \mathrm{e}+003.74071 \mathrm{e}+003.74071 \mathrm{e}-011.00000 \mathrm{e}-092.12000 \mathrm{e}-01$ $1.00000 \mathrm{e}-05$ 1.00000e-05 1.00000e-06 1.00000e-09 1.00000e-01 $1.00000 \mathrm{e}+001.00000 \mathrm{e}+001.00000 \mathrm{e}-011.00000 \mathrm{e}-091.00000 \mathrm{e}-01$ Element: 9341 \# of layers: 7

Kx Ky Kz Ss Por

$3.85096 \mathrm{e}+003.85096 \mathrm{e}+00$ 3.85096e-01 1.00000e-09 2.12000e-01 $3.85096 \mathrm{e}+003.85096 \mathrm{e}+003.85096 \mathrm{e}-011.00000 \mathrm{e}-092.12000 \mathrm{e}-01$ $3.85096 \mathrm{e}+003.85096 \mathrm{e}+003.85096 \mathrm{e}-011.00000 \mathrm{e}-092.12000 \mathrm{e}-01$ $3.85096 \mathrm{e}+003.85096 \mathrm{e}+003.85096 \mathrm{e}-011.00000 \mathrm{e}-092.12000 \mathrm{e}-01$ $3.85096 \mathrm{e}+003.85096 \mathrm{e}+003.85096 \mathrm{e}-01$ 1.00000e-09 2.12000e-01 $1.00000 \mathrm{e}-05$ 1.00000e-05 1.00000e-06 1.00000e-09 1.00000e-01 $1.00000 \mathrm{e}+001.00000 \mathrm{e}+001.00000 \mathrm{e}-011.00000 \mathrm{e}-091.00000 \mathrm{e}-01$ Element: 9342 \# of layers: 7

Kx Ky Kz Ss Por

$3.85096 \mathrm{e}+003.85096 \mathrm{e}+00$ 3.85096e-01 1.00000e-09 2.12000e-01 $3.85096 \mathrm{e}+003.85096 \mathrm{e}+003.85096 \mathrm{e}-011.00000 \mathrm{e}-092.12000 \mathrm{e}-01$ $3.85096 \mathrm{e}+003.85096 \mathrm{e}+003.85096 \mathrm{e}-01$ 1.00000e-09 2.12000e-01 $3.85096 \mathrm{e}+003.85096 \mathrm{e}+003.85096 \mathrm{e}-011.00000 \mathrm{e}-092.12000 \mathrm{e}-01$ $3.85096 \mathrm{e}+003.85096 \mathrm{e}+00$ 3.85096e-01 1.00000e-09 2.12000e-01 $1.00000 \mathrm{e}-05$ 1.00000e-05 1.00000e-06 1.00000e-09 1.00000e-01 $1.00000 \mathrm{e}+001.00000 \mathrm{e}+001.00000 \mathrm{e}-011.00000 \mathrm{e}-091.00000 \mathrm{e}-01$ Element: 9343 \# of layers: 6

Kx Ky Kz Ss Por

$3.85096 \mathrm{e}+003.85096 \mathrm{e}+00$ 3.85096e-01 1.00000e-09 2.12000e-01 $3.85096 \mathrm{e}+003.85096 \mathrm{e}+003.85096 \mathrm{e}-011.00000 \mathrm{e}-092.12000 \mathrm{e}-01$ $3.85096 \mathrm{e}+003.85096 \mathrm{e}+003.85096 \mathrm{e}-011.00000 \mathrm{e}-092.12000 \mathrm{e}-01$ $3.85096 \mathrm{e}+003.85096 \mathrm{e}+00$ 3.85096e-01 1.00000e-09 2.12000e-01 $1.00000 \mathrm{e}-05$ 1.00000e-05 1.00000e-06 1.00000e-09 1.00000e-01 $1.00000 \mathrm{e}+001.00000 \mathrm{e}+001.00000 \mathrm{e}-011.00000 \mathrm{e}-091.00000 \mathrm{e}-01$ Element: 9344 \# of layers: 6

Kx Ky Kz Ss Por

$3.85096 \mathrm{e}+003.85096 \mathrm{e}+00$ 3.85096e-01 1.00000e-09 2.12000e-01 $3.85096 \mathrm{e}+003.85096 \mathrm{e}+003.85096 \mathrm{e}-011.00000 \mathrm{e}-092.12000 \mathrm{e}-01$ $3.85096 \mathrm{e}+003.85096 \mathrm{e}+003.85096 \mathrm{e}-011.00000 \mathrm{e}-092.12000 \mathrm{e}-01$ $3.85096 \mathrm{e}+003.85096 \mathrm{e}+003.85096 \mathrm{e}-01$ 1.00000e-09 2.12000e-01 $1.00000 \mathrm{e}-05$ 1.00000e-05 1.00000e-06 1.00000e-09 1.00000e-01 $1.00000 \mathrm{e}+001.00000 \mathrm{e}+001.00000 \mathrm{e}-011.00000 \mathrm{e}-091.00000 \mathrm{e}-01$ Element: 9345 \# of layers: 6

Kx Ky Kz Ss Por

$3.74071 \mathrm{e}+003.74071 \mathrm{e}+003.74071 \mathrm{e}-01$ 1.00000e-09 2.12000e-01 $3.74071 \mathrm{e}+003.74071 \mathrm{e}+003.74071 \mathrm{e}-011.00000 \mathrm{e}-092.12000 \mathrm{e}-01$ $3.74071 \mathrm{e}+003.74071 \mathrm{e}+003.74071 \mathrm{e}-011.00000 \mathrm{e}-092.12000 \mathrm{e}-01$ $3.74071 \mathrm{e}+003.74071 \mathrm{e}+003.74071 \mathrm{e}-01$ 1.00000e-09 2.12000e-01 
$1.00000 \mathrm{e}-05$ 1.00000e-05 1.00000e-06 1.00000e-09 1.00000e-01 $1.00000 \mathrm{e}+001.00000 \mathrm{e}+001.00000 \mathrm{e}-01$ 1.00000e-09 1.00000e-01 Element: 9346 \# of layers: 6

Kx Ky Kz Ss Por

3.74071e+00 3.74071e+00 3.74071e-01 1.00000e-09 2.12000e-01 $3.74071 \mathrm{e}+003.74071 \mathrm{e}+003.74071 \mathrm{e}-01$ 1.00000e-09 2.12000e-01 $3.74071 \mathrm{e}+003.74071 \mathrm{e}+003.74071 \mathrm{e}-01$ 1.00000e-09 2.12000e-01 $3.74071 \mathrm{e}+003.74071 \mathrm{e}+003.74071 \mathrm{e}-01$ 1.00000e-09 2.12000e-01 $1.00000 \mathrm{e}-05$ 1.00000e-05 1.00000e-06 1.00000e-09 1.00000e-01 $1.00000 \mathrm{e}+001.00000 \mathrm{e}+001.00000 \mathrm{e}-011.00000 \mathrm{e}-091.00000 \mathrm{e}-01$ Element: 9347 \# of layers: 6

Kx Ky Kz Ss Por

3.74071e+00 3.74071e+00 3.74071e-01 1.00000e-09 2.12000e-01 $3.74071 \mathrm{e}+003.74071 \mathrm{e}+003.74071 \mathrm{e}-01$ 1.00000e-09 2.12000e-01 $3.74071 \mathrm{e}+003.74071 \mathrm{e}+003.74071 \mathrm{e}-01$ 1.00000e-09 2.12000e-01 $3.74071 \mathrm{e}+003.74071 \mathrm{e}+003.74071 \mathrm{e}-01$ 1.00000e-09 2.12000e-01 $1.00000 \mathrm{e}-05$ 1.00000e-05 1.00000e-06 1.00000e-09 1.00000e-01 $1.00000 \mathrm{e}+001.00000 \mathrm{e}+001.00000 \mathrm{e}-01$ 1.00000e-09 1.00000e-01 Element: 9348 \# of layers: 6

$\mathrm{Kx} \mathrm{Ky} \mathrm{Kz}$ Ss Por

3.74071e+00 3.74071e+00 3.74071e-01 1.00000e-09 2.12000e-01

3.74071e+00 3.74071e+00 3.74071e-01 1.00000e-09 2.12000e-01

$3.74071 \mathrm{e}+003.74071 \mathrm{e}+003.74071 \mathrm{e}-01$ 1.00000e-09 2.12000e-01

$3.74071 \mathrm{e}+003.74071 \mathrm{e}+003.74071 \mathrm{e}-01$ 1.00000e-09 2.12000e-01

$1.00000 \mathrm{e}-051.00000 \mathrm{e}-05$ 1.00000e-06 1.00000e-09 1.00000e-01

$1.00000 \mathrm{e}+001.00000 \mathrm{e}+001.00000 \mathrm{e}-01$ 1.00000e-09 1.00000e-01

Element: 9349 \# of layers: 7

$\mathrm{Kx} \mathrm{Ky} \mathrm{Kz}$ Ss Por

3.74071e+00 3.74071e+00 3.74071e-01 1.00000e-09 2.12000e-01

3.74071e+00 3.74071e+00 3.74071e-01 1.00000e-09 2.12000e-01

$3.74071 \mathrm{e}+003.74071 \mathrm{e}+003.74071 \mathrm{e}-01$ 1.00000e-09 2.12000e-01

$3.74071 \mathrm{e}+003.74071 \mathrm{e}+003.74071 \mathrm{e}-01$ 1.00000e-09 2.12000e-01

$3.74071 \mathrm{e}+003.74071 \mathrm{e}+003.74071 \mathrm{e}-01$ 1.00000e-09 2.12000e-01

$1.00000 \mathrm{e}-051.00000 \mathrm{e}-051.00000 \mathrm{e}-061.00000 \mathrm{e}-091.00000 \mathrm{e}-01$

$1.00000 \mathrm{e}+001.00000 \mathrm{e}+001.00000 \mathrm{e}-011.00000 \mathrm{e}-091.00000 \mathrm{e}-01$

Element: 9350 \# of layers: 7

Kx Ky Kz Ss Por

3.74071e+00 3.74071e+00 3.74071e-01 1.00000e-09 2.12000e-01

$3.74071 \mathrm{e}+003.74071 \mathrm{e}+00$ 3.74071e-01 1.00000e-09 2.12000e-01

$3.74071 \mathrm{e}+003.74071 \mathrm{e}+003.74071 \mathrm{e}-01$ 1.00000e-09 2.12000e-01

$3.74071 \mathrm{e}+003.74071 \mathrm{e}+003.74071 \mathrm{e}-01$ 1.00000e-09 2.12000e-01

$3.74071 \mathrm{e}+003.74071 \mathrm{e}+003.74071 \mathrm{e}-01$ 1.00000e-09 2.12000e-01 $1.00000 \mathrm{e}-051.00000 \mathrm{e}-051.00000 \mathrm{e}-061.00000 \mathrm{e}-091.00000 \mathrm{e}-01$

$1.00000 \mathrm{e}+001.00000 \mathrm{e}+001.00000 \mathrm{e}-01$ 1.00000e-09 1.00000e-01

Element: 9351 \# of layers: 7

Kx Ky Kz Ss Por 
$3.74071 \mathrm{e}+003.74071 \mathrm{e}+003.74071 \mathrm{e}-011.00000 \mathrm{e}-092.12000 \mathrm{e}-01$ $3.74071 \mathrm{e}+003.74071 \mathrm{e}+003.74071 \mathrm{e}-011.00000 \mathrm{e}-092.12000 \mathrm{e}-01$ $3.74071 \mathrm{e}+003.74071 \mathrm{e}+003.74071 \mathrm{e}-01$ 1.00000e-09 2.12000e-01 $3.74071 \mathrm{e}+003.74071 \mathrm{e}+003.74071 \mathrm{e}-011.00000 \mathrm{e}-092.12000 \mathrm{e}-01$ $3.74071 \mathrm{e}+003.74071 \mathrm{e}+003.74071 \mathrm{e}-011.00000 \mathrm{e}-092.12000 \mathrm{e}-01$ $1.00000 \mathrm{e}-05$ 1.00000e-05 1.00000e-06 1.00000e-09 1.00000e-01 $1.00000 \mathrm{e}+001.00000 \mathrm{e}+001.00000 \mathrm{e}-011.00000 \mathrm{e}-091.00000 \mathrm{e}-01$ Element: 9352 \# of layers: 6

$\mathrm{Kx} \mathrm{Ky} \mathrm{Kz}$ Ss Por

3.74071e+00 3.74071e+00 3.74071e-01 1.00000e-09 2.12000e-01 $3.74071 \mathrm{e}+003.74071 \mathrm{e}+003.74071 \mathrm{e}-011.00000 \mathrm{e}-092.12000 \mathrm{e}-01$ $3.74071 \mathrm{e}+003.74071 \mathrm{e}+003.74071 \mathrm{e}-011.00000 \mathrm{e}-092.12000 \mathrm{e}-01$ $3.74071 \mathrm{e}+003.74071 \mathrm{e}+003.74071 \mathrm{e}-01$ 1.00000e-09 2.12000e-01 $1.00000 \mathrm{e}-05$ 1.00000e-05 1.00000e-06 1.00000e-09 1.00000e-01 $1.00000 \mathrm{e}+001.00000 \mathrm{e}+001.00000 \mathrm{e}-011.00000 \mathrm{e}-091.00000 \mathrm{e}-01$ Element: 9353 \# of layers: 6

Kx Ky Kz Ss Por

$3.74071 \mathrm{e}+003.74071 \mathrm{e}+00$ 3.74071e-01 1.00000e-09 2.12000e-01 $3.74071 \mathrm{e}+003.74071 \mathrm{e}+003.74071 \mathrm{e}-011.00000 \mathrm{e}-092.12000 \mathrm{e}-01$ $3.74071 \mathrm{e}+003.74071 \mathrm{e}+003.74071 \mathrm{e}-011.00000 \mathrm{e}-092.12000 \mathrm{e}-01$ $3.74071 \mathrm{e}+003.74071 \mathrm{e}+003.74071 \mathrm{e}-011.00000 \mathrm{e}-092.12000 \mathrm{e}-01$ $1.00000 \mathrm{e}-05$ 1.00000e-05 1.00000e-06 1.00000e-09 1.00000e-01 $1.00000 \mathrm{e}+001.00000 \mathrm{e}+00$ 1.00000e-01 1.00000e-09 1.00000e-01 Element: 9354 \# of layers: 6

Kx Ky Kz Ss Por

$3.74071 \mathrm{e}+003.74071 \mathrm{e}+003.74071 \mathrm{e}-011.00000 \mathrm{e}-092.12000 \mathrm{e}-01$ $3.74071 \mathrm{e}+003.74071 \mathrm{e}+003.74071 \mathrm{e}-011.00000 \mathrm{e}-092.12000 \mathrm{e}-01$ $3.74071 \mathrm{e}+003.74071 \mathrm{e}+003.74071 \mathrm{e}-011.00000 \mathrm{e}-092.12000 \mathrm{e}-01$ $3.74071 \mathrm{e}+003.74071 \mathrm{e}+003.74071 \mathrm{e}-011.00000 \mathrm{e}-092.12000 \mathrm{e}-01$ $1.00000 \mathrm{e}-05$ 1.00000e-05 1.00000e-06 1.00000e-09 1.00000e-01 $1.00000 \mathrm{e}+001.00000 \mathrm{e}+001.00000 \mathrm{e}-011.00000 \mathrm{e}-091.00000 \mathrm{e}-01$ Element: 9355 \# of layers: 7

Kx Ky Kz Ss Por

$3.41422 \mathrm{e}+003.41422 \mathrm{e}+003.41422 \mathrm{e}-01$ 1.00000e-09 2.12000e-01 $3.41422 \mathrm{e}+003.41422 \mathrm{e}+003.41422 \mathrm{e}-011.00000 \mathrm{e}-092.12000 \mathrm{e}-01$ $3.41422 \mathrm{e}+003.41422 \mathrm{e}+003.41422 \mathrm{e}-011.00000 \mathrm{e}-092.12000 \mathrm{e}-01$ $3.41422 \mathrm{e}+003.41422 \mathrm{e}+003.41422 \mathrm{e}-011.00000 \mathrm{e}-092.12000 \mathrm{e}-01$ $3.41422 \mathrm{e}+003.41422 \mathrm{e}+003.41422 \mathrm{e}-011.00000 \mathrm{e}-092.12000 \mathrm{e}-01$ $1.00000 \mathrm{e}-05$ 1.00000e-05 1.00000e-06 1.00000e-09 1.00000e-01 $1.00000 \mathrm{e}+001.00000 \mathrm{e}+001.00000 \mathrm{e}-011.00000 \mathrm{e}-091.00000 \mathrm{e}-01$ Element: 9356 \# of layers: 7

Kx Ky Kz Ss Por

$3.41422 \mathrm{e}+003.41422 \mathrm{e}+003.41422 \mathrm{e}-011.00000 \mathrm{e}-092.12000 \mathrm{e}-01$ $3.41422 \mathrm{e}+003.41422 \mathrm{e}+003.41422 \mathrm{e}-011.00000 \mathrm{e}-092.12000 \mathrm{e}-01$ $3.41422 \mathrm{e}+003.41422 \mathrm{e}+003.41422 \mathrm{e}-011.00000 \mathrm{e}-092.12000 \mathrm{e}-01$ $3.41422 \mathrm{e}+003.41422 \mathrm{e}+003.41422 \mathrm{e}-01$ 1.00000e-09 2.12000e-01 
3.41422e+00 3.41422e+00 3.41422e-01 1.00000e-09 2.12000e-01 $1.00000 \mathrm{e}-05$ 1.00000e-05 1.00000e-06 1.00000e-09 1.00000e-01 $1.00000 \mathrm{e}+001.00000 \mathrm{e}+001.00000 \mathrm{e}-011.00000 \mathrm{e}-091.00000 \mathrm{e}-01$ Element: 9357 \# of layers: 7

$\mathrm{Kx} \mathrm{Ky} \mathrm{Kz}$ Ss Por

3.41422e+00 3.41422e+00 3.41422e-01 1.00000e-09 2.12000e-01 3.41422e+00 3.41422e+00 3.41422e-01 1.00000e-09 2.12000e-01 $3.41422 \mathrm{e}+003.41422 \mathrm{e}+003.41422 \mathrm{e}-01$ 1.00000e-09 2.12000e-01 3.41422e+00 3.41422e+00 3.41422e-01 1.00000e-09 2.12000e-01 $3.41422 \mathrm{e}+003.41422 \mathrm{e}+003.41422 \mathrm{e}-01$ 1.00000e-09 2.12000e-01 $1.00000 \mathrm{e}-05$ 1.00000e-05 1.00000e-06 1.00000e-09 1.00000e-01 $1.00000 \mathrm{e}+001.00000 \mathrm{e}+001.00000 \mathrm{e}-011.00000 \mathrm{e}-091.00000 \mathrm{e}-01$ Element: 9358 \# of layers: 7

$\mathrm{Kx} \mathrm{Ky} \mathrm{Kz}$ Ss Por

3.41422e+00 3.41422e+00 3.41422e-01 1.00000e-09 2.12000e-01

$3.41422 \mathrm{e}+003.41422 \mathrm{e}+003.41422 \mathrm{e}-01$ 1.00000e-09 2.12000e-01 3.41422e+00 3.41422e+00 3.41422e-01 1.00000e-09 2.12000e-01 $3.41422 \mathrm{e}+00$ 3.41422e+00 3.41422e-01 1.00000e-09 2.12000e-01 3.41422e+00 3.41422e+00 3.41422e-01 1.00000e-09 2.12000e-01 $1.00000 \mathrm{e}-05$ 1.00000e-05 1.00000e-06 1.00000e-09 1.00000e-01 $1.00000 \mathrm{e}+001.00000 \mathrm{e}+001.00000 \mathrm{e}-011.00000 \mathrm{e}-091.00000 \mathrm{e}-01$ Element: 9359 \# of layers: 6

$\mathrm{Kx} \mathrm{Ky} \mathrm{Kz}$ Ss Por

3.41422e+00 3.41422e+00 3.41422e-01 1.00000e-09 2.12000e-01 $3.41422 \mathrm{e}+003.41422 \mathrm{e}+003.41422 \mathrm{e}-01$ 1.00000e-09 2.12000e-01 $3.41422 \mathrm{e}+003.41422 \mathrm{e}+00$ 3.41422e-01 1.00000e-09 2.12000e-01 $3.41422 \mathrm{e}+00$ 3.41422e+00 3.41422e-01 1.00000e-09 2.12000e-01 $1.00000 \mathrm{e}-05$ 1.00000e-05 1.00000e-06 1.00000e-09 1.00000e-01 $1.00000 \mathrm{e}+001.00000 \mathrm{e}+001.00000 \mathrm{e}-011.00000 \mathrm{e}-091.00000 \mathrm{e}-01$ Element: 9360 \# of layers: 6

$\mathrm{Kx} \mathrm{Ky} \mathrm{Kz}$ Ss Por

3.74071e+00 3.74071e+00 3.74071e-01 1.00000e-09 2.12000e-01 $3.74071 \mathrm{e}+003.74071 \mathrm{e}+003.74071 \mathrm{e}-01$ 1.00000e-09 2.12000e-01 $3.74071 \mathrm{e}+003.74071 \mathrm{e}+003.74071 \mathrm{e}-01$ 1.00000e-09 2.12000e-01 $3.74071 \mathrm{e}+003.74071 \mathrm{e}+003.74071 \mathrm{e}-01$ 1.00000e-09 2.12000e-01 $1.00000 \mathrm{e}-05$ 1.00000e-05 1.00000e-06 1.00000e-09 1.00000e-01 $1.00000 \mathrm{e}+001.00000 \mathrm{e}+001.00000 \mathrm{e}-011.00000 \mathrm{e}-091.00000 \mathrm{e}-01$ Element: 9361 \# of layers: 6

$\mathrm{Kx} \mathrm{Ky} \mathrm{Kz}$ Ss Por

3.74071e+00 3.74071e+00 3.74071e-01 1.00000e-09 2.12000e-01 $3.74071 \mathrm{e}+003.74071 \mathrm{e}+003.74071 \mathrm{e}-01$ 1.00000e-09 2.12000e-01 $3.74071 \mathrm{e}+003.74071 \mathrm{e}+003.74071 \mathrm{e}-01$ 1.00000e-09 2.12000e-01 $3.74071 \mathrm{e}+003.74071 \mathrm{e}+003.74071 \mathrm{e}-01$ 1.00000e-09 2.12000e-01 $1.00000 \mathrm{e}-05$ 1.00000e-05 1.00000e-06 1.00000e-09 1.00000e-01 $1.00000 \mathrm{e}+001.00000 \mathrm{e}+001.00000 \mathrm{e}-011.00000 \mathrm{e}-091.00000 \mathrm{e}-01$ Element: 9362 \# of layers: 6 
$\mathrm{Kx} \mathrm{Ky} \mathrm{Kz}$ Ss Por

3.41422e+00 3.41422e+00 3.41422e-01 1.00000e-09 2.12000e-01

$3.41422 \mathrm{e}+003.41422 \mathrm{e}+003.41422 \mathrm{e}-01$ 1.00000e-09 2.12000e-01

$3.41422 \mathrm{e}+003.41422 \mathrm{e}+00$ 3.41422e-01 1.00000e-09 2.12000e-01

3.41422e+00 3.41422e+00 3.41422e-01 1.00000e-09 2.12000e-01

$1.00000 \mathrm{e}-05$ 1.00000e-05 1.00000e-06 1.00000e-09 1.00000e-01

$1.00000 \mathrm{e}+001.00000 \mathrm{e}+001.00000 \mathrm{e}-01$ 1.00000e-09 1.00000e-01

Element: 9363 \# of layers: 7

$\mathrm{Kx} \mathrm{Ky} \mathrm{Kz}$ Ss Por

3.41422e+00 3.41422e+00 3.41422e-01 1.00000e-09 2.12000e-01

$3.41422 \mathrm{e}+00$ 3.41422e+00 3.41422e-01 1.00000e-09 2.12000e-01

$3.41422 \mathrm{e}+003.41422 \mathrm{e}+00$ 3.41422e-01 1.00000e-09 2.12000e-01

$3.41422 \mathrm{e}+003.41422 \mathrm{e}+003.41422 \mathrm{e}-01$ 1.00000e-09 2.12000e-01

$3.41422 \mathrm{e}+00$ 3.41422e+00 3.41422e-01 1.00000e-09 2.12000e-01

$1.00000 \mathrm{e}-051.00000 \mathrm{e}-051.00000 \mathrm{e}-061.00000 \mathrm{e}-091.00000 \mathrm{e}-01$

$1.00000 \mathrm{e}+001.00000 \mathrm{e}+001.00000 \mathrm{e}-011.00000 \mathrm{e}-091.00000 \mathrm{e}-01$

Element: 9364 \# of layers: 6

$\mathrm{Kx} \mathrm{Ky} \mathrm{Kz}$ Ss Por

3.44842e+00 3.44842e+00 3.44842e-01 1.00000e-09 2.12000e-01

$3.44842 \mathrm{e}+003.44842 \mathrm{e}+00$ 3.44842e-01 1.00000e-09 2.12000e-01

$3.44842 \mathrm{e}+003.44842 \mathrm{e}+00$ 3.44842e-01 1.00000e-09 2.12000e-01

$3.44842 \mathrm{e}+003.44842 \mathrm{e}+00$ 3.44842e-01 1.00000e-09 2.12000e-01

$1.00000 \mathrm{e}-05$ 1.00000e-05 1.00000e-06 1.00000e-09 1.00000e-01

$1.00000 \mathrm{e}+001.00000 \mathrm{e}+001.00000 \mathrm{e}-011.00000 \mathrm{e}-091.00000 \mathrm{e}-01$

Element: 9365 \# of layers: 6

$\mathrm{Kx} \mathrm{Ky} \mathrm{Kz}$ Ss Por

3.44842e+00 3.44842e+00 3.44842e-01 1.00000e-09 2.12000e-01

$3.44842 \mathrm{e}+003.44842 \mathrm{e}+003.44842 \mathrm{e}-01$ 1.00000e-09 2.12000e-01

$3.44842 \mathrm{e}+003.44842 \mathrm{e}+00$ 3.44842e-01 1.00000e-09 2.12000e-01

$3.44842 \mathrm{e}+003.44842 \mathrm{e}+003.44842 \mathrm{e}-01$ 1.00000e-09 2.12000e-01

$1.00000 \mathrm{e}-05$ 1.00000e-05 1.00000e-06 1.00000e-09 1.00000e-01

$1.00000 \mathrm{e}+001.00000 \mathrm{e}+001.00000 \mathrm{e}-011.00000 \mathrm{e}-091.00000 \mathrm{e}-01$

Element: 9366 \# of layers: 6

$\mathrm{Kx} \mathrm{Ky} \mathrm{Kz}$ Ss Por

3.44842e+00 3.44842e+00 3.44842e-01 1.00000e-09 2.12000e-01

$3.44842 \mathrm{e}+003.44842 \mathrm{e}+00$ 3.44842e-01 1.00000e-09 2.12000e-01

$3.44842 \mathrm{e}+003.44842 \mathrm{e}+00$ 3.44842e-01 1.00000e-09 2.12000e-01

$3.44842 \mathrm{e}+003.44842 \mathrm{e}+00$ 3.44842e-01 1.00000e-09 2.12000e-01

$1.00000 \mathrm{e}-05$ 1.00000e-05 1.00000e-06 1.00000e-09 1.00000e-01

$1.00000 \mathrm{e}+001.00000 \mathrm{e}+001.00000 \mathrm{e}-01$ 1.00000e-09 1.00000e-01

Element: 9367 \# of layers: 6

$\mathrm{Kx} \mathrm{Ky} \mathrm{Kz}$ Ss Por

3.85096e+00 3.85096e+00 3.85096e-01 1.00000e-09 2.12000e-01

$3.85096 \mathrm{e}+003.85096 \mathrm{e}+003.85096 \mathrm{e}-01$ 1.00000e-09 2.12000e-01

$3.85096 \mathrm{e}+003.85096 \mathrm{e}+003.85096 \mathrm{e}-01$ 1.00000e-09 2.12000e-01

$3.85096 \mathrm{e}+003.85096 \mathrm{e}+00$ 3.85096e-01 1.00000e-09 2.12000e-01 
$1.00000 \mathrm{e}-05$ 1.00000e-05 1.00000e-06 1.00000e-09 1.00000e-01 $1.00000 \mathrm{e}+001.00000 \mathrm{e}+001.00000 \mathrm{e}-01$ 1.00000e-09 1.00000e-01 Element: 9368 \# of layers: 6

$\mathrm{Kx} \mathrm{Ky} \mathrm{Kz}$ Ss Por

3.85096e+00 3.85096e+00 3.85096e-01 1.00000e-09 2.12000e-01

$3.85096 \mathrm{e}+003.85096 \mathrm{e}+00$ 3.85096e-01 1.00000e-09 2.12000e-01

$3.85096 \mathrm{e}+003.85096 \mathrm{e}+00$ 3.85096e-01 1.00000e-09 2.12000e-01

$3.85096 \mathrm{e}+003.85096 \mathrm{e}+003.85096 \mathrm{e}-01$ 1.00000e-09 2.12000e-01

$1.00000 \mathrm{e}-05$ 1.00000e-05 1.00000e-06 1.00000e-09 1.00000e-01

$1.00000 \mathrm{e}+001.00000 \mathrm{e}+001.00000 \mathrm{e}-011.00000 \mathrm{e}-091.00000 \mathrm{e}-01$

Element: 9369 \# of layers: 6

Kx Ky Kz Ss Por

3.74071e+00 3.74071e+00 3.74071e-01 1.00000e-09 2.12000e-01

$3.74071 \mathrm{e}+003.74071 \mathrm{e}+003.74071 \mathrm{e}-01$ 1.00000e-09 2.12000e-01

$3.74071 \mathrm{e}+003.74071 \mathrm{e}+003.74071 \mathrm{e}-01$ 1.00000e-09 2.12000e-01

$3.74071 \mathrm{e}+003.74071 \mathrm{e}+003.74071 \mathrm{e}-01$ 1.00000e-09 2.12000e-01

$1.00000 \mathrm{e}-05$ 1.00000e-05 1.00000e-06 1.00000e-09 1.00000e-01

$1.00000 \mathrm{e}+001.00000 \mathrm{e}+001.00000 \mathrm{e}-01$ 1.00000e-09 1.00000e-01

Element: 9370 \# of layers: 6

$\mathrm{Kx} \mathrm{Ky} \mathrm{Kz}$ Ss Por

3.41422e+00 3.41422e+00 3.41422e-01 1.00000e-09 2.12000e-01

3.41422e+00 3.41422e+00 3.41422e-01 1.00000e-09 2.12000e-01

$3.41422 \mathrm{e}+003.41422 \mathrm{e}+003.41422 \mathrm{e}-01$ 1.00000e-09 2.12000e-01

$3.41422 \mathrm{e}+003.41422 \mathrm{e}+00$ 3.41422e-01 1.00000e-09 2.12000e-01

$1.00000 \mathrm{e}-05$ 1.00000e-05 1.00000e-06 1.00000e-09 1.00000e-01

$1.00000 \mathrm{e}+001.00000 \mathrm{e}+001.00000 \mathrm{e}-01$ 1.00000e-09 1.00000e-01

Element: 9371 \# of layers: 6

$\mathrm{Kx} \mathrm{Ky} \mathrm{Kz}$ Ss Por

3.44842e+00 3.44842e+00 3.44842e-01 1.00000e-09 2.12000e-01

3.44842e+00 3.44842e+00 3.44842e-01 1.00000e-09 2.12000e-01

$3.44842 \mathrm{e}+003.44842 \mathrm{e}+00$ 3.44842e-01 1.00000e-09 2.12000e-01

$3.44842 \mathrm{e}+003.44842 \mathrm{e}+003.44842 \mathrm{e}-01$ 1.00000e-09 2.12000e-01

$1.00000 \mathrm{e}-05$ 1.00000e-05 1.00000e-06 1.00000e-09 1.00000e-01

$1.00000 \mathrm{e}+001.00000 \mathrm{e}+001.00000 \mathrm{e}-011.00000 \mathrm{e}-091.00000 \mathrm{e}-01$

Element: 9372 \# of layers: 7

$\mathrm{Kx} \mathrm{Ky} \mathrm{Kz}$ Ss Por

3.46755e+00 3.46755e+00 3.46755e-01 1.00000e-09 2.12000e-01

$3.46755 \mathrm{e}+003.46755 \mathrm{e}+00$ 3.46755e-01 1.00000e-09 2.12000e-01

$3.46755 \mathrm{e}+003.46755 \mathrm{e}+00$ 3.46755e-01 1.00000e-09 2.12000e-01

$3.46755 \mathrm{e}+003.46755 \mathrm{e}+003.46755 \mathrm{e}-01$ 1.00000e-09 2.12000e-01

$3.46755 \mathrm{e}+003.46755 \mathrm{e}+00 \quad 3.46755 \mathrm{e}-01$ 1.00000e-09 2.12000e-01

$1.00000 \mathrm{e}-05$ 1.00000e-05 1.00000e-06 1.00000e-09 1.00000e-01

$1.00000 \mathrm{e}+001.00000 \mathrm{e}+001.00000 \mathrm{e}-011.00000 \mathrm{e}-091.00000 \mathrm{e}-01$

Element: 9373 \# of layers: 7

$\mathrm{Kx} \mathrm{Ky} \mathrm{Kz}$ Ss Por

3.46755e+00 3.46755e+00 3.46755e-01 1.00000e-09 2.12000e-01 
3.46755e+00 3.46755e+00 3.46755e-01 1.00000e-09 2.12000e-01 $3.46755 \mathrm{e}+003.46755 \mathrm{e}+00$ 3.46755e-01 1.00000e-09 2.12000e-01 $3.46755 \mathrm{e}+003.46755 \mathrm{e}+00$ 3.46755e-01 1.00000e-09 2.12000e-01 $3.46755 \mathrm{e}+003.46755 \mathrm{e}+003.46755 \mathrm{e}-01$ 1.00000e-09 2.12000e-01 $1.00000 \mathrm{e}-05$ 1.00000e-05 1.00000e-06 1.00000e-09 1.00000e-01 $1.00000 \mathrm{e}+001.00000 \mathrm{e}+001.00000 \mathrm{e}-011.00000 \mathrm{e}-091.00000 \mathrm{e}-01$ Element: 9374 \# of layers: 7

Kx Ky Kz Ss Por

3.46755e+00 3.46755e+00 3.46755e-01 1.00000e-09 2.12000e-01

$3.46755 \mathrm{e}+003.46755 \mathrm{e}+00$ 3.46755e-01 1.00000e-09 2.12000e-01 $3.46755 \mathrm{e}+003.46755 \mathrm{e}+00$ 3.46755e-01 1.00000e-09 2.12000e-01 $3.46755 \mathrm{e}+003.46755 \mathrm{e}+003.46755 \mathrm{e}-01$ 1.00000e-09 2.12000e-01 $3.46755 \mathrm{e}+003.46755 \mathrm{e}+00$ 3.46755e-01 1.00000e-09 2.12000e-01 $1.00000 \mathrm{e}-05$ 1.00000e-05 1.00000e-06 1.00000e-09 1.00000e-01 $1.00000 \mathrm{e}+001.00000 \mathrm{e}+00$ 1.00000e-01 1.00000e-09 1.00000e-01 Element: 9375 \# of layers: 7

$\mathrm{Kx} \mathrm{Ky} \mathrm{Kz}$ Ss Por

3.46755e+00 3.46755e+00 3.46755e-01 1.00000e-09 2.12000e-01 $3.46755 \mathrm{e}+003.46755 \mathrm{e}+003.46755 \mathrm{e}-01$ 1.00000e-09 2.12000e-01 $3.46755 \mathrm{e}+003.46755 \mathrm{e}+00 \quad 3.46755 \mathrm{e}-01$ 1.00000e-09 2.12000e-01 $3.46755 \mathrm{e}+003.46755 \mathrm{e}+003.46755 \mathrm{e}-01$ 1.00000e-09 2.12000e-01 3.46755e+00 3.46755e+00 3.46755e-01 1.00000e-09 2.12000e-01 $1.00000 \mathrm{e}-05$ 1.00000e-05 1.00000e-06 1.00000e-09 1.00000e-01 $1.00000 \mathrm{e}+001.00000 \mathrm{e}+001.00000 \mathrm{e}-011.00000 \mathrm{e}-09$ 1.00000e-01 Element: 9376 \# of layers: 7

$\mathrm{Kx} \mathrm{Ky} \mathrm{Kz}$ Ss Por

3.46755e+00 3.46755e+00 3.46755e-01 1.00000e-09 2.12000e-01 $3.46755 \mathrm{e}+003.46755 \mathrm{e}+00$ 3.46755e-01 1.00000e-09 2.12000e-01 $3.46755 \mathrm{e}+003.46755 \mathrm{e}+003.46755 \mathrm{e}-01$ 1.00000e-09 2.12000e-01 $3.46755 \mathrm{e}+003.46755 \mathrm{e}+00$ 3.46755e-01 1.00000e-09 2.12000e-01 $3.46755 \mathrm{e}+003.46755 \mathrm{e}+003.46755 \mathrm{e}-01$ 1.00000e-09 2.12000e-01 $1.00000 \mathrm{e}-05$ 1.00000e-05 1.00000e-06 1.00000e-09 1.00000e-01 $1.00000 \mathrm{e}+001.00000 \mathrm{e}+001.00000 \mathrm{e}-011.00000 \mathrm{e}-091.00000 \mathrm{e}-01$ Element: 9377 \# of layers: 7

$\mathrm{Kx} \mathrm{Ky} \mathrm{Kz}$ Ss Por

3.46755e+00 3.46755e+00 3.46755e-01 1.00000e-09 2.12000e-01 $3.46755 \mathrm{e}+003.46755 \mathrm{e}+003.46755 \mathrm{e}-01$ 1.00000e-09 2.12000e-01 $3.46755 \mathrm{e}+003.46755 \mathrm{e}+00$ 3.46755e-01 1.00000e-09 2.12000e-01 3.46755e+00 3.46755e+00 3.46755e-01 1.00000e-09 2.12000e-01 $3.46755 \mathrm{e}+003.46755 \mathrm{e}+003.46755 \mathrm{e}-01$ 1.00000e-09 2.12000e-01 $1.00000 \mathrm{e}-05$ 1.00000e-05 1.00000e-06 1.00000e-09 1.00000e-01 $1.00000 \mathrm{e}+001.00000 \mathrm{e}+001.00000 \mathrm{e}-011.00000 \mathrm{e}-091.00000 \mathrm{e}-01$ Element: 9378 \# of layers: 7

$\mathrm{Kx} \mathrm{Ky} \mathrm{Kz}$ Ss Por

3.46755e+00 3.46755e+00 3.46755e-01 1.00000e-09 2.12000e-01 $3.46755 \mathrm{e}+003.46755 \mathrm{e}+003.46755 \mathrm{e}-01$ 1.00000e-09 2.12000e-01 
3.46755e+00 3.46755e+00 3.46755e-01 1.00000e-09 2.12000e-01 $3.46755 \mathrm{e}+003.46755 \mathrm{e}+00$ 3.46755e-01 1.00000e-09 2.12000e-01 $3.46755 \mathrm{e}+003.46755 \mathrm{e}+003.46755 \mathrm{e}-01$ 1.00000e-09 2.12000e-01 $1.00000 \mathrm{e}-05$ 1.00000e-05 1.00000e-06 1.00000e-09 1.00000e-01 $1.00000 \mathrm{e}+001.00000 \mathrm{e}+001.00000 \mathrm{e}-01$ 1.00000e-09 1.00000e-01 Element: 9379 \# of layers: 7

$\mathrm{Kx} \mathrm{Ky} \mathrm{Kz}$ Ss Por

3.46755e+00 3.46755e+00 3.46755e-01 1.00000e-09 2.12000e-01 $3.46755 \mathrm{e}+003.46755 \mathrm{e}+00$ 3.46755e-01 1.00000e-09 2.12000e-01 $3.46755 \mathrm{e}+003.46755 \mathrm{e}+00$ 3.46755e-01 1.00000e-09 2.12000e-01 $3.46755 \mathrm{e}+003.46755 \mathrm{e}+00$ 3.46755e-01 1.00000e-09 2.12000e-01 $3.46755 \mathrm{e}+003.46755 \mathrm{e}+003.46755 \mathrm{e}-01$ 1.00000e-09 2.12000e-01 $1.00000 \mathrm{e}-05$ 1.00000e-05 1.00000e-06 1.00000e-09 1.00000e-01 $1.00000 \mathrm{e}+001.00000 \mathrm{e}+001.00000 \mathrm{e}-011.00000 \mathrm{e}-091.00000 \mathrm{e}-01$ Element: 9380 \# of layers: 7

Kx Ky Kz Ss Por

3.46755e+00 3.46755e+00 3.46755e-01 1.00000e-09 2.12000e-01 $3.46755 \mathrm{e}+003.46755 \mathrm{e}+00$ 3.46755e-01 1.00000e-09 2.12000e-01 $3.46755 \mathrm{e}+003.46755 \mathrm{e}+003.46755 \mathrm{e}-01$ 1.00000e-09 2.12000e-01 $3.46755 \mathrm{e}+003.46755 \mathrm{e}+003.46755 \mathrm{e}-01$ 1.00000e-09 2.12000e-01 $3.46755 \mathrm{e}+003.46755 \mathrm{e}+003.46755 \mathrm{e}-01$ 1.00000e-09 2.12000e-01 $1.00000 \mathrm{e}-051.00000 \mathrm{e}-051.00000 \mathrm{e}-061.00000 \mathrm{e}-091.00000 \mathrm{e}-01$ $1.00000 \mathrm{e}+001.00000 \mathrm{e}+001.00000 \mathrm{e}-01$ 1.00000e-09 1.00000e-01 Element: 9381 \# of layers: 7

Kx Ky Kz Ss Por

3.46755e+00 3.46755e+00 3.46755e-01 1.00000e-09 2.12000e-01 $3.46755 \mathrm{e}+003.46755 \mathrm{e}+00$ 3.46755e-01 1.00000e-09 2.12000e-01 $3.46755 \mathrm{e}+003.46755 \mathrm{e}+00$ 3.46755e-01 1.00000e-09 2.12000e-01 $3.46755 \mathrm{e}+003.46755 \mathrm{e}+00$ 3.46755e-01 1.00000e-09 2.12000e-01 $3.46755 \mathrm{e}+003.46755 \mathrm{e}+00$ 3.46755e-01 1.00000e-09 2.12000e-01 $1.00000 \mathrm{e}-05$ 1.00000e-05 1.00000e-06 1.00000e-09 1.00000e-01 $1.00000 \mathrm{e}+001.00000 \mathrm{e}+001.00000 \mathrm{e}-011.00000 \mathrm{e}-091.00000 \mathrm{e}-01$ Element: 9382 \# of layers: 7

$\mathrm{Kx} \mathrm{Ky} \mathrm{Kz}$ Ss Por $1.02852 \mathrm{e}+011.02852 \mathrm{e}+011.02852 \mathrm{e}+001.00000 \mathrm{e}-092.12000 \mathrm{e}-01$ $1.02852 \mathrm{e}+011.02852 \mathrm{e}+01$ 1.02852e+00 1.00000e-09 2.12000e-01 $1.02852 \mathrm{e}+011.02852 \mathrm{e}+011.02852 \mathrm{e}+001.00000 \mathrm{e}-092.12000 \mathrm{e}-01$ $1.02852 \mathrm{e}+011.02852 \mathrm{e}+011.02852 \mathrm{e}+001.00000 \mathrm{e}-092.12000 \mathrm{e}-01$ $1.02852 \mathrm{e}+011.02852 \mathrm{e}+01$ 1.02852e+00 1.00000e-09 2.12000e-01 $1.00000 \mathrm{e}-05$ 1.00000e-05 1.00000e-06 1.00000e-09 1.00000e-01 $1.00000 \mathrm{e}+001.00000 \mathrm{e}+001.00000 \mathrm{e}-011.00000 \mathrm{e}-091.00000 \mathrm{e}-01$ Element: 9383 \# of layers: 7

$\mathrm{Kx} \mathrm{Ky} \mathrm{Kz}$ Ss Por 1.02852e+01 1.02852e+01 1.02852e+00 1.00000e-09 2.12000e-01 $1.02852 \mathrm{e}+01$ 1.02852e+01 1.02852e+00 1.00000e-09 2.12000e-01 $1.02852 \mathrm{e}+01$ 1.02852e+01 1.02852e+00 1.00000e-09 2.12000e-01 
$1.02852 \mathrm{e}+01$ 1.02852e+01 1.02852e+00 1.00000e-09 2.12000e-01 $1.02852 \mathrm{e}+01$ 1.02852e+01 1.02852e+00 1.00000e-09 2.12000e-01 $1.00000 \mathrm{e}-05$ 1.00000e-05 1.00000e-06 1.00000e-09 1.00000e-01 $1.00000 \mathrm{e}+001.00000 \mathrm{e}+001.00000 \mathrm{e}-011.00000 \mathrm{e}-091.00000 \mathrm{e}-01$ Element: 9384 \# of layers: 7

$\mathrm{Kx} \mathrm{Ky} \mathrm{Kz}$ Ss Por

$1.02852 \mathrm{e}+01$ 1.02852e+01 1.02852e+00 1.00000e-09 2.12000e-01 $1.02852 \mathrm{e}+011.02852 \mathrm{e}+011.02852 \mathrm{e}+001.00000 \mathrm{e}-092.12000 \mathrm{e}-01$ $1.02852 \mathrm{e}+011.02852 \mathrm{e}+01$ 1.02852e+00 1.00000e-09 2.12000e-01 $1.02852 \mathrm{e}+011.02852 \mathrm{e}+01$ 1.02852e+00 1.00000e-09 2.12000e-01 $1.02852 \mathrm{e}+01$ 1.02852e+01 1.02852e+00 1.00000e-09 2.12000e-01 $1.00000 \mathrm{e}-05$ 1.00000e-05 1.00000e-06 1.00000e-09 1.00000e-01 $1.00000 \mathrm{e}+001.00000 \mathrm{e}+001.00000 \mathrm{e}-011.00000 \mathrm{e}-09$ 1.00000e-01 Element: 9385 \# of layers: 7

$\mathrm{Kx} \mathrm{Ky} \mathrm{Kz}$ Ss Por $1.02852 \mathrm{e}+01$ 1.02852e+01 1.02852e+00 1.00000e-09 2.12000e-01 $1.02852 \mathrm{e}+01$ 1.02852e+01 1.02852e+00 1.00000e-09 2.12000e-01 $1.02852 \mathrm{e}+011.02852 \mathrm{e}+011.02852 \mathrm{e}+001.00000 \mathrm{e}-092.12000 \mathrm{e}-01$ $1.02852 \mathrm{e}+01$ 1.02852e+01 1.02852e+00 1.00000e-09 2.12000e-01 $1.02852 \mathrm{e}+01$ 1.02852e+01 1.02852e+00 1.00000e-09 2.12000e-01 $1.00000 \mathrm{e}-05$ 1.00000e-05 1.00000e-06 1.00000e-09 1.00000e-01 $1.00000 \mathrm{e}+001.00000 \mathrm{e}+001.00000 \mathrm{e}-011.00000 \mathrm{e}-091.00000 \mathrm{e}-01$ Element: 9386 \# of layers: 7

Kx Ky Kz Ss Por

$1.02852 \mathrm{e}+01$ 1.02852e+01 1.02852e+00 1.00000e-09 2.12000e-01 $1.02852 \mathrm{e}+011.02852 \mathrm{e}+011.02852 \mathrm{e}+001.00000 \mathrm{e}-092.12000 \mathrm{e}-01$ $1.02852 \mathrm{e}+011.02852 \mathrm{e}+011.02852 \mathrm{e}+001.00000 \mathrm{e}-092.12000 \mathrm{e}-01$ $1.02852 \mathrm{e}+011.02852 \mathrm{e}+011.02852 \mathrm{e}+001.00000 \mathrm{e}-092.12000 \mathrm{e}-01$ $1.02852 \mathrm{e}+011.02852 \mathrm{e}+011.02852 \mathrm{e}+001.00000 \mathrm{e}-092.12000 \mathrm{e}-01$ $1.00000 \mathrm{e}-05$ 1.00000e-05 1.00000e-06 1.00000e-09 1.00000e-01 $1.00000 \mathrm{e}+001.00000 \mathrm{e}+001.00000 \mathrm{e}-011.00000 \mathrm{e}-091.00000 \mathrm{e}-01$ Element: 9387 \# of layers: 7

Kx Ky Kz Ss Por

3.46755e+00 3.46755e+00 3.46755e-01 1.00000e-09 2.12000e-01 $3.46755 \mathrm{e}+003.46755 \mathrm{e}+003.46755 \mathrm{e}-01$ 1.00000e-09 2.12000e-01 $3.46755 \mathrm{e}+003.46755 \mathrm{e}+003.46755 \mathrm{e}-01$ 1.00000e-09 2.12000e-01 $3.46755 \mathrm{e}+003.46755 \mathrm{e}+00$ 3.46755e-01 1.00000e-09 2.12000e-01 $3.46755 \mathrm{e}+003.46755 \mathrm{e}+00$ 3.46755e-01 1.00000e-09 2.12000e-01 $1.00000 \mathrm{e}-05$ 1.00000e-05 1.00000e-06 1.00000e-09 1.00000e-01 $1.00000 \mathrm{e}+001.00000 \mathrm{e}+001.00000 \mathrm{e}-01$ 1.00000e-09 1.00000e-01 Element: 9388 \# of layers: 7

Kx Ky Kz Ss Por

3.46755e+00 3.46755e+00 3.46755e-01 1.00000e-09 2.12000e-01 $3.46755 \mathrm{e}+003.46755 \mathrm{e}+00$ 3.46755e-01 1.00000e-09 2.12000e-01 $3.46755 \mathrm{e}+003.46755 \mathrm{e}+003.46755 \mathrm{e}-01$ 1.00000e-09 2.12000e-01 $3.46755 \mathrm{e}+003.46755 \mathrm{e}+003.46755 \mathrm{e}-01$ 1.00000e-09 2.12000e-01 
$3.46755 \mathrm{e}+00$ 3.46755e+00 3.46755e-01 1.00000e-09 2.12000e-01 $1.00000 \mathrm{e}-05$ 1.00000e-05 1.00000e-06 1.00000e-09 1.00000e-01 $1.00000 \mathrm{e}+001.00000 \mathrm{e}+001.00000 \mathrm{e}-011.00000 \mathrm{e}-09$ 1.00000e-01 Element: 9389 \# of layers: 7

$\mathrm{Kx} \mathrm{Ky} \mathrm{Kz}$ Ss Por

$1.02852 \mathrm{e}+01$ 1.02852e+01 1.02852e+00 1.00000e-09 2.12000e-01 $1.02852 \mathrm{e}+011.02852 \mathrm{e}+011.02852 \mathrm{e}+001.00000 \mathrm{e}-092.12000 \mathrm{e}-01$ $1.02852 \mathrm{e}+011.02852 \mathrm{e}+011.02852 \mathrm{e}+001.00000 \mathrm{e}-092.12000 \mathrm{e}-01$ $1.02852 \mathrm{e}+011.02852 \mathrm{e}+011.02852 \mathrm{e}+001.00000 \mathrm{e}-092.12000 \mathrm{e}-01$ $1.02852 \mathrm{e}+01$ 1.02852e+01 1.02852e+00 1.00000e-09 2.12000e-01 $1.00000 \mathrm{e}-05$ 1.00000e-05 1.00000e-06 1.00000e-09 1.00000e-01 $1.00000 \mathrm{e}+001.00000 \mathrm{e}+001.00000 \mathrm{e}-011.00000 \mathrm{e}-091.00000 \mathrm{e}-01$ Element: 9390 \# of layers: 7

$\mathrm{Kx} \mathrm{Ky} \mathrm{Kz}$ Ss Por $1.02852 \mathrm{e}+01$ 1.02852e+01 1.02852e+00 1.00000e-09 2.12000e-01 $1.02852 \mathrm{e}+011.02852 \mathrm{e}+01 \quad 1.02852 \mathrm{e}+001.00000 \mathrm{e}-092.12000 \mathrm{e}-01$ $1.02852 \mathrm{e}+01$ 1.02852e+01 1.02852e+00 1.00000e-09 2.12000e-01 $1.02852 \mathrm{e}+01$ 1.02852e+01 1.02852e+00 1.00000e-09 2.12000e-01 $1.02852 \mathrm{e}+01$ 1.02852e+01 1.02852e+00 1.00000e-09 2.12000e-01 $1.00000 \mathrm{e}-05$ 1.00000e-05 1.00000e-06 1.00000e-09 1.00000e-01 $1.00000 \mathrm{e}+001.00000 \mathrm{e}+001.00000 \mathrm{e}-011.00000 \mathrm{e}-091.00000 \mathrm{e}-01$ Element: 9391 \# of layers: 7

$\mathrm{Kx} \mathrm{Ky} \mathrm{Kz}$ Ss Por $1.02852 \mathrm{e}+01$ 1.02852e+01 1.02852e+00 1.00000e-09 2.12000e-01 $1.02852 \mathrm{e}+011.02852 \mathrm{e}+01 \quad 1.02852 \mathrm{e}+001.00000 \mathrm{e}-092.12000 \mathrm{e}-01$ $1.02852 \mathrm{e}+011.02852 \mathrm{e}+011.02852 \mathrm{e}+001.00000 \mathrm{e}-092.12000 \mathrm{e}-01$ $1.02852 \mathrm{e}+011.02852 \mathrm{e}+011.02852 \mathrm{e}+001.00000 \mathrm{e}-092.12000 \mathrm{e}-01$ $1.02852 \mathrm{e}+01$ 1.02852e+01 1.02852e+00 1.00000e-09 2.12000e-01 $1.00000 \mathrm{e}-05$ 1.00000e-05 1.00000e-06 1.00000e-09 1.00000e-01 $1.00000 \mathrm{e}+001.00000 \mathrm{e}+001.00000 \mathrm{e}-011.00000 \mathrm{e}-091.00000 \mathrm{e}-01$ Element: 9392 \# of layers: 7

$\mathrm{Kx} \mathrm{Ky} \mathrm{Kz}$ Ss Por $1.02852 \mathrm{e}+01$ 1.02852e+01 1.02852e+00 1.00000e-09 2.12000e-01 $1.02852 \mathrm{e}+011.02852 \mathrm{e}+011.02852 \mathrm{e}+001.00000 \mathrm{e}-092.12000 \mathrm{e}-01$ $1.02852 \mathrm{e}+01$ 1.02852e+01 1.02852e+00 1.00000e-09 2.12000e-01 $1.02852 \mathrm{e}+011.02852 \mathrm{e}+011.02852 \mathrm{e}+001.00000 \mathrm{e}-092.12000 \mathrm{e}-01$ $1.02852 \mathrm{e}+01 \quad 1.02852 \mathrm{e}+01 \quad 1.02852 \mathrm{e}+001.00000 \mathrm{e}-092.12000 \mathrm{e}-01$ $1.00000 \mathrm{e}-05$ 1.00000e-05 1.00000e-06 1.00000e-09 1.00000e-01 $1.00000 \mathrm{e}+001.00000 \mathrm{e}+001.00000 \mathrm{e}-011.00000 \mathrm{e}-091.00000 \mathrm{e}-01$ Element: 9393 \# of layers: 7

$\mathrm{Kx} \mathrm{Ky} \mathrm{Kz}$ Ss Por $1.02852 \mathrm{e}+01$ 1.02852e+01 1.02852e+00 1.00000e-09 2.12000e-01 $1.02852 \mathrm{e}+01$ 1.02852e+01 1.02852e+00 1.00000e-09 2.12000e-01 $1.02852 \mathrm{e}+01$ 1.02852e+01 1.02852e+00 1.00000e-09 2.12000e-01 $1.02852 \mathrm{e}+011.02852 \mathrm{e}+011.02852 \mathrm{e}+001.00000 \mathrm{e}-092.12000 \mathrm{e}-01$ $1.02852 \mathrm{e}+011.02852 \mathrm{e}+01 \quad 1.02852 \mathrm{e}+00$ 1.00000e-09 2.12000e-01 
$1.00000 \mathrm{e}-05$ 1.00000e-05 1.00000e-06 1.00000e-09 1.00000e-01 $1.00000 \mathrm{e}+001.00000 \mathrm{e}+001.00000 \mathrm{e}-01$ 1.00000e-09 1.00000e-01 Element: 9394 \# of layers: 7

Kx Ky Kz Ss Por

$1.02852 \mathrm{e}+011.02852 \mathrm{e}+011.02852 \mathrm{e}+001.00000 \mathrm{e}-092.12000 \mathrm{e}-01$ $1.02852 \mathrm{e}+011.02852 \mathrm{e}+011.02852 \mathrm{e}+001.00000 \mathrm{e}-092.12000 \mathrm{e}-01$ $1.02852 \mathrm{e}+011.02852 \mathrm{e}+011.02852 \mathrm{e}+001.00000 \mathrm{e}-092.12000 \mathrm{e}-01$ $1.02852 \mathrm{e}+011.02852 \mathrm{e}+011.02852 \mathrm{e}+001.00000 \mathrm{e}-092.12000 \mathrm{e}-01$ $1.02852 \mathrm{e}+01$ 1.02852e+01 1.02852e+00 1.00000e-09 2.12000e-01 $1.00000 \mathrm{e}-05$ 1.00000e-05 1.00000e-06 1.00000e-09 1.00000e-01 $1.00000 \mathrm{e}+001.00000 \mathrm{e}+001.00000 \mathrm{e}-011.00000 \mathrm{e}-091.00000 \mathrm{e}-01$ Element: 9395 \# of layers: 7

$\mathrm{Kx} \mathrm{Ky} \mathrm{Kz}$ Ss Por $1.02852 \mathrm{e}+01$ 1.02852e+01 1.02852e+00 1.00000e-09 2.12000e-01 $1.02852 \mathrm{e}+01$ 1.02852e+01 1.02852e+00 1.00000e-09 2.12000e-01 $1.02852 \mathrm{e}+011.02852 \mathrm{e}+01 \quad 1.02852 \mathrm{e}+001.00000 \mathrm{e}-092.12000 \mathrm{e}-01$ $1.02852 \mathrm{e}+011.02852 \mathrm{e}+01 \quad 1.02852 \mathrm{e}+001.00000 \mathrm{e}-092.12000 \mathrm{e}-01$ $1.02852 \mathrm{e}+01$ 1.02852e+01 1.02852e+00 1.00000e-09 2.12000e-01 $1.00000 \mathrm{e}-05$ 1.00000e-05 1.00000e-06 1.00000e-09 1.00000e-01 $1.00000 \mathrm{e}+001.00000 \mathrm{e}+001.00000 \mathrm{e}-011.00000 \mathrm{e}-091.00000 \mathrm{e}-01$ Element: 9396 \# of layers: 7

$\mathrm{Kx} \mathrm{Ky} \mathrm{Kz}$ Ss Por

$1.02852 \mathrm{e}+01$ 1.02852e+01 1.02852e+00 1.00000e-09 2.12000e-01 $1.02852 \mathrm{e}+011.02852 \mathrm{e}+011.02852 \mathrm{e}+001.00000 \mathrm{e}-092.12000 \mathrm{e}-01$ $1.02852 \mathrm{e}+011.02852 \mathrm{e}+01 \quad 1.02852 \mathrm{e}+001.00000 \mathrm{e}-092.12000 \mathrm{e}-01$ $1.02852 \mathrm{e}+011.02852 \mathrm{e}+011.02852 \mathrm{e}+001.00000 \mathrm{e}-092.12000 \mathrm{e}-01$ $1.02852 \mathrm{e}+01$ 1.02852e+01 1.02852e+00 1.00000e-09 2.12000e-01 $1.00000 \mathrm{e}-05$ 1.00000e-05 1.00000e-06 1.00000e-09 1.00000e-01 $1.00000 \mathrm{e}+001.00000 \mathrm{e}+001.00000 \mathrm{e}-011.00000 \mathrm{e}-091.00000 \mathrm{e}-01$ Element: 9397 \# of layers: 7

$\mathrm{Kx} \mathrm{Ky} \mathrm{Kz}$ Ss Por

$1.02852 \mathrm{e}+01$ 1.02852e+01 1.02852e+00 1.00000e-09 2.12000e-01 $1.02852 \mathrm{e}+011.02852 \mathrm{e}+011.02852 \mathrm{e}+001.00000 \mathrm{e}-092.12000 \mathrm{e}-01$ $1.02852 \mathrm{e}+011.02852 \mathrm{e}+01$ 1.02852e+00 1.00000e-09 2.12000e-01 $1.02852 \mathrm{e}+011.02852 \mathrm{e}+01 \quad 1.02852 \mathrm{e}+001.00000 \mathrm{e}-092.12000 \mathrm{e}-01$ $1.02852 \mathrm{e}+01$ 1.02852e+01 1.02852e+00 1.00000e-09 2.12000e-01 $1.00000 \mathrm{e}-05$ 1.00000e-05 1.00000e-06 1.00000e-09 1.00000e-01 $1.00000 \mathrm{e}+001.00000 \mathrm{e}+001.00000 \mathrm{e}-011.00000 \mathrm{e}-091.00000 \mathrm{e}-01$ Element: 9398 \# of layers: 7

$\mathrm{Kx} \mathrm{Ky} \mathrm{Kz}$ Ss Por $1.02852 \mathrm{e}+01$ 1.02852e+01 1.02852e+00 1.00000e-09 2.12000e-01 $1.02852 \mathrm{e}+011.02852 \mathrm{e}+01 \quad 1.02852 \mathrm{e}+001.00000 \mathrm{e}-092.12000 \mathrm{e}-01$ $1.02852 \mathrm{e}+011.02852 \mathrm{e}+011.02852 \mathrm{e}+001.00000 \mathrm{e}-092.12000 \mathrm{e}-01$ $1.02852 \mathrm{e}+01$ 1.02852e+01 1.02852e+00 1.00000e-09 2.12000e-01 $1.02852 \mathrm{e}+011.02852 \mathrm{e}+01 \quad 1.02852 \mathrm{e}+001.00000 \mathrm{e}-092.12000 \mathrm{e}-01$ $1.00000 \mathrm{e}-05$ 1.00000e-05 1.00000e-06 1.00000e-09 1.00000e-01 
$1.00000 \mathrm{e}+001.00000 \mathrm{e}+00$ 1.00000e-01 1.00000e-09 1.00000e-01

Element: 9399 \# of layers: 7

Kx Ky Kz Ss Por

$1.02852 \mathrm{e}+01$ 1.02852e+01 1.02852e+00 1.00000e-09 2.12000e-01

$1.02852 \mathrm{e}+011.02852 \mathrm{e}+011.02852 \mathrm{e}+001.00000 \mathrm{e}-092.12000 \mathrm{e}-01$

$1.02852 \mathrm{e}+01$ 1.02852e+01 1.02852e+00 1.00000e-09 2.12000e-01

$1.02852 \mathrm{e}+011.02852 \mathrm{e}+011.02852 \mathrm{e}+001.00000 \mathrm{e}-092.12000 \mathrm{e}-01$

$1.02852 \mathrm{e}+011.02852 \mathrm{e}+011.02852 \mathrm{e}+001.00000 \mathrm{e}-092.12000 \mathrm{e}-01$

$1.00000 \mathrm{e}-05$ 1.00000e-05 1.00000e-06 1.00000e-09 1.00000e-01

$1.00000 \mathrm{e}+001.00000 \mathrm{e}+001.00000 \mathrm{e}-01$ 1.00000e-09 1.00000e-01

Element: 9400 \# of layers: 7

Kx Ky Kz Ss Por

$1.02852 \mathrm{e}+01$ 1.02852e+01 1.02852e+00 1.00000e-09 2.12000e-01 $1.02852 \mathrm{e}+01$ 1.02852e+01 1.02852e+00 1.00000e-09 2.12000e-01 $1.02852 \mathrm{e}+01$ 1.02852e+01 1.02852e+00 1.00000e-09 2.12000e-01 $1.02852 \mathrm{e}+011.02852 \mathrm{e}+011.02852 \mathrm{e}+001.00000 \mathrm{e}-092.12000 \mathrm{e}-01$ $1.02852 \mathrm{e}+011.02852 \mathrm{e}+01$ 1.02852e+00 1.00000e-09 2.12000e-01 $1.00000 \mathrm{e}-05$ 1.00000e-05 1.00000e-06 1.00000e-09 1.00000e-01

$1.00000 \mathrm{e}+001.00000 \mathrm{e}+001.00000 \mathrm{e}-011.00000 \mathrm{e}-091.00000 \mathrm{e}-01$ Element: 9401 \# of layers: 7

$\mathrm{Kx} \mathrm{Ky} \mathrm{Kz}$ Ss Por

6.30081e+00 6.30081e+00 6.30081e-01 1.00000e-09 2.12000e-01

$6.30081 \mathrm{e}+006.30081 \mathrm{e}+00$ 6.30081e-01 1.00000e-09 2.12000e-01

$6.30081 \mathrm{e}+006.30081 \mathrm{e}+00$ 6.30081e-01 1.00000e-09 2.12000e-01

$6.30081 \mathrm{e}+006.30081 \mathrm{e}+00$ 6.30081e-01 1.00000e-09 2.12000e-01

$6.30081 \mathrm{e}+006.30081 \mathrm{e}+00$ 6.30081e-01 1.00000e-09 2.12000e-01

$1.00000 \mathrm{e}-05$ 1.00000e-05 1.00000e-06 1.00000e-09 1.00000e-01

$1.00000 \mathrm{e}+001.00000 \mathrm{e}+001.00000 \mathrm{e}-011.00000 \mathrm{e}-09$ 1.00000e-01

Element: 9402 \# of layers: 6

$\mathrm{Kx} \mathrm{Ky} \mathrm{Kz}$ Ss Por

$6.30081 \mathrm{e}+006.30081 \mathrm{e}+00$ 6.30081e-01 1.00000e-09 2.12000e-01

$6.30081 \mathrm{e}+006.30081 \mathrm{e}+00$ 6.30081e-01 1.00000e-09 2.12000e-01

$6.30081 \mathrm{e}+006.30081 \mathrm{e}+00$ 6.30081e-01 1.00000e-09 2.12000e-01

6.30081e+00 6.30081e+00 6.30081e-01 1.00000e-09 2.12000e-01

$1.00000 \mathrm{e}-05$ 1.00000e-05 1.00000e-06 1.00000e-09 1.00000e-01

$1.00000 \mathrm{e}+001.00000 \mathrm{e}+001.00000 \mathrm{e}-011.00000 \mathrm{e}-091.00000 \mathrm{e}-01$

Element: 9403 \# of layers: 6

$\mathrm{Kx} \mathrm{Ky} \mathrm{Kz}$ Ss Por

$6.30081 \mathrm{e}+006.30081 \mathrm{e}+00$ 6.30081e-01 1.00000e-09 2.12000e-01

$6.30081 \mathrm{e}+006.30081 \mathrm{e}+00$ 6.30081e-01 1.00000e-09 2.12000e-01

$6.30081 \mathrm{e}+006.30081 \mathrm{e}+00$ 6.30081e-01 1.00000e-09 2.12000e-01

$6.30081 \mathrm{e}+006.30081 \mathrm{e}+006.30081 \mathrm{e}-01$ 1.00000e-09 2.12000e-01

$1.00000 \mathrm{e}-05$ 1.00000e-05 1.00000e-06 1.00000e-09 1.00000e-01

$1.00000 \mathrm{e}+001.00000 \mathrm{e}+001.00000 \mathrm{e}-01$ 1.00000e-09 1.00000e-01

Element: 9404 \# of layers: 7

Kx Ky Kz Ss Por 
$1.02852 \mathrm{e}+011.02852 \mathrm{e}+01$ 1.02852e+00 1.00000e-09 2.12000e-01 $1.02852 \mathrm{e}+01$ 1.02852e+01 1.02852e+00 1.00000e-09 2.12000e-01 $1.02852 \mathrm{e}+011.02852 \mathrm{e}+011.02852 \mathrm{e}+001.00000 \mathrm{e}-092.12000 \mathrm{e}-01$ $1.02852 \mathrm{e}+011.02852 \mathrm{e}+011.02852 \mathrm{e}+001.00000 \mathrm{e}-092.12000 \mathrm{e}-01$ $1.02852 \mathrm{e}+011.02852 \mathrm{e}+01$ 1.02852e+00 1.00000e-09 2.12000e-01 $1.00000 \mathrm{e}-05$ 1.00000e-05 1.00000e-06 1.00000e-09 1.00000e-01 $1.00000 \mathrm{e}+001.00000 \mathrm{e}+001.00000 \mathrm{e}-01$ 1.00000e-09 1.00000e-01

Element: 9405 \# of layers: 7

$\mathrm{Kx} \mathrm{Ky} \mathrm{Kz}$ Ss Por

$1.02852 \mathrm{e}+01$ 1.02852e+01 1.02852e+00 1.00000e-09 2.12000e-01 $1.02852 \mathrm{e}+011.02852 \mathrm{e}+01$ 1.02852e+00 1.00000e-09 2.12000e-01 $1.02852 \mathrm{e}+011.02852 \mathrm{e}+011.02852 \mathrm{e}+001.00000 \mathrm{e}-092.12000 \mathrm{e}-01$ $1.02852 \mathrm{e}+011.02852 \mathrm{e}+011.02852 \mathrm{e}+001.00000 \mathrm{e}-092.12000 \mathrm{e}-01$ $1.02852 \mathrm{e}+01$ 1.02852e+01 1.02852e+00 1.00000e-09 2.12000e-01 $1.00000 \mathrm{e}-051.00000 \mathrm{e}-051.00000 \mathrm{e}-061.00000 \mathrm{e}-091.00000 \mathrm{e}-01$ $1.00000 \mathrm{e}+001.00000 \mathrm{e}+001.00000 \mathrm{e}-011.00000 \mathrm{e}-091.00000 \mathrm{e}-01$ Element: 9406 \# of layers: 7

$\mathrm{Kx} \mathrm{Ky} \mathrm{Kz}$ Ss Por

$1.02852 \mathrm{e}+01$ 1.02852e+01 1.02852e+00 1.00000e-09 2.12000e-01 $1.02852 \mathrm{e}+011.02852 \mathrm{e}+011.02852 \mathrm{e}+001.00000 \mathrm{e}-092.12000 \mathrm{e}-01$ $1.02852 \mathrm{e}+011.02852 \mathrm{e}+011.02852 \mathrm{e}+001.00000 \mathrm{e}-092.12000 \mathrm{e}-01$ $1.02852 \mathrm{e}+01$ 1.02852e+01 1.02852e+00 1.00000e-09 2.12000e-01 $1.02852 \mathrm{e}+01$ 1.02852e+01 1.02852e+00 1.00000e-09 2.12000e-01 $1.00000 \mathrm{e}-05$ 1.00000e-05 1.00000e-06 1.00000e-09 1.00000e-01 $1.00000 \mathrm{e}+001.00000 \mathrm{e}+001.00000 \mathrm{e}-011.00000 \mathrm{e}-091.00000 \mathrm{e}-01$ Element: 9407 \# of layers: 7

$\mathrm{Kx} \mathrm{Ky} \mathrm{Kz}$ Ss Por

$1.02852 \mathrm{e}+01$ 1.02852e+01 1.02852e+00 1.00000e-09 2.12000e-01 $1.02852 \mathrm{e}+011.02852 \mathrm{e}+011.02852 \mathrm{e}+001.00000 \mathrm{e}-092.12000 \mathrm{e}-01$ $1.02852 \mathrm{e}+011.02852 \mathrm{e}+01$ 1.02852e+00 1.00000e-09 2.12000e-01 $1.02852 \mathrm{e}+011.02852 \mathrm{e}+01$ 1.02852e+00 1.00000e-09 2.12000e-01 $1.02852 \mathrm{e}+01$ 1.02852e+01 1.02852e+00 1.00000e-09 2.12000e-01 $1.00000 \mathrm{e}-05$ 1.00000e-05 1.00000e-06 1.00000e-09 1.00000e-01 $1.00000 \mathrm{e}+001.00000 \mathrm{e}+001.00000 \mathrm{e}-011.00000 \mathrm{e}-091.00000 \mathrm{e}-01$ Element: 9408 \# of layers: 7

$\mathrm{Kx} \mathrm{Ky} \mathrm{Kz}$ Ss Por

6.30081e+00 6.30081e+00 6.30081e-01 1.00000e-09 2.12000e-01 $6.30081 \mathrm{e}+006.30081 \mathrm{e}+006.30081 \mathrm{e}-01$ 1.00000e-09 2.12000e-01 $6.30081 \mathrm{e}+006.30081 \mathrm{e}+00$ 6.30081e-01 1.00000e-09 2.12000e-01 $6.30081 \mathrm{e}+006.30081 \mathrm{e}+00$ 6.30081e-01 1.00000e-09 2.12000e-01 $6.30081 \mathrm{e}+006.30081 \mathrm{e}+00$ 6.30081e-01 1.00000e-09 2.12000e-01 $1.00000 \mathrm{e}-05$ 1.00000e-05 1.00000e-06 1.00000e-09 1.00000e-01 $1.00000 \mathrm{e}+001.00000 \mathrm{e}+001.00000 \mathrm{e}-011.00000 \mathrm{e}-091.00000 \mathrm{e}-01$ Element: 9409 \# of layers: 6

$\mathrm{Kx} \mathrm{Ky} \mathrm{Kz}$ Ss Por

6.30081e+00 6.30081e+00 6.30081e-01 1.00000e-09 2.12000e-01 
$6.30081 \mathrm{e}+006.30081 \mathrm{e}+00$ 6.30081e-01 1.00000e-09 2.12000e-01 $6.30081 \mathrm{e}+006.30081 \mathrm{e}+00$ 6.30081e-01 1.00000e-09 2.12000e-01 $6.30081 \mathrm{e}+006.30081 \mathrm{e}+00$ 6.30081e-01 1.00000e-09 2.12000e-01 $1.00000 \mathrm{e}-05$ 1.00000e-05 1.00000e-06 1.00000e-09 1.00000e-01 $1.00000 \mathrm{e}+001.00000 \mathrm{e}+001.00000 \mathrm{e}-011.00000 \mathrm{e}-091.00000 \mathrm{e}-01$ Element: 9410 \# of layers: 6

Kx Ky Kz Ss Por

$6.30081 \mathrm{e}+006.30081 \mathrm{e}+00$ 6.30081e-01 1.00000e-09 2.12000e-01 $6.30081 \mathrm{e}+006.30081 \mathrm{e}+006.30081 \mathrm{e}-011.00000 \mathrm{e}-092.12000 \mathrm{e}-01$ $6.30081 \mathrm{e}+006.30081 \mathrm{e}+006.30081 \mathrm{e}-011.00000 \mathrm{e}-092.12000 \mathrm{e}-01$ $6.30081 \mathrm{e}+006.30081 \mathrm{e}+006.30081 \mathrm{e}-011.00000 \mathrm{e}-092.12000 \mathrm{e}-01$ $1.00000 \mathrm{e}-05$ 1.00000e-05 1.00000e-06 1.00000e-09 1.00000e-01 $1.00000 \mathrm{e}+001.00000 \mathrm{e}+001.00000 \mathrm{e}-011.00000 \mathrm{e}-091.00000 \mathrm{e}-01$ Element: 9411 \# of layers: 6

Kx Ky Kz Ss Por

$6.30081 \mathrm{e}+006.30081 \mathrm{e}+00$ 6.30081e-01 1.00000e-09 2.12000e-01 $6.30081 \mathrm{e}+006.30081 \mathrm{e}+006.30081 \mathrm{e}-011.00000 \mathrm{e}-092.12000 \mathrm{e}-01$ $6.30081 \mathrm{e}+006.30081 \mathrm{e}+006.30081 \mathrm{e}-011.00000 \mathrm{e}-092.12000 \mathrm{e}-01$ $6.30081 \mathrm{e}+006.30081 \mathrm{e}+006.30081 \mathrm{e}-011.00000 \mathrm{e}-092.12000 \mathrm{e}-01$ $1.00000 \mathrm{e}-05$ 1.00000e-05 1.00000e-06 1.00000e-09 1.00000e-01 $1.00000 \mathrm{e}+001.00000 \mathrm{e}+001.00000 \mathrm{e}-011.00000 \mathrm{e}-091.00000 \mathrm{e}-01$ Element: 9412 \# of layers: 6

Kx Ky Kz Ss Por

$6.30081 \mathrm{e}+006.30081 \mathrm{e}+00$ 6.30081e-01 1.00000e-09 2.12000e-01 $6.30081 \mathrm{e}+006.30081 \mathrm{e}+006.30081 \mathrm{e}-011.00000 \mathrm{e}-092.12000 \mathrm{e}-01$ $6.30081 \mathrm{e}+006.30081 \mathrm{e}+006.30081 \mathrm{e}-011.00000 \mathrm{e}-092.12000 \mathrm{e}-01$ $6.30081 \mathrm{e}+006.30081 \mathrm{e}+006.30081 \mathrm{e}-011.00000 \mathrm{e}-092.12000 \mathrm{e}-01$ $1.00000 \mathrm{e}-05$ 1.00000e-05 1.00000e-06 1.00000e-09 1.00000e-01 $1.00000 \mathrm{e}+001.00000 \mathrm{e}+001.00000 \mathrm{e}-011.00000 \mathrm{e}-091.00000 \mathrm{e}-01$ Element: 9413 \# of layers: 6

Kx Ky Kz Ss Por

$6.30081 \mathrm{e}+006.30081 \mathrm{e}+00$ 6.30081e-01 1.00000e-09 2.12000e-01 $6.30081 \mathrm{e}+006.30081 \mathrm{e}+006.30081 \mathrm{e}-011.00000 \mathrm{e}-092.12000 \mathrm{e}-01$ $6.30081 \mathrm{e}+006.30081 \mathrm{e}+006.30081 \mathrm{e}-011.00000 \mathrm{e}-092.12000 \mathrm{e}-01$ $6.30081 \mathrm{e}+006.30081 \mathrm{e}+006.30081 \mathrm{e}-011.00000 \mathrm{e}-092.12000 \mathrm{e}-01$ $1.00000 \mathrm{e}-05$ 1.00000e-05 1.00000e-06 1.00000e-09 1.00000e-01 $1.00000 \mathrm{e}+001.00000 \mathrm{e}+001.00000 \mathrm{e}-011.00000 \mathrm{e}-091.00000 \mathrm{e}-01$ Element: 9414 \# of layers: 7

Kx Ky Kz Ss Por

$6.30081 \mathrm{e}+006.30081 \mathrm{e}+00$ 6.30081e-01 1.00000e-09 2.12000e-01 $6.30081 \mathrm{e}+006.30081 \mathrm{e}+006.30081 \mathrm{e}-011.00000 \mathrm{e}-092.12000 \mathrm{e}-01$ $6.30081 \mathrm{e}+006.30081 \mathrm{e}+006.30081 \mathrm{e}-011.00000 \mathrm{e}-092.12000 \mathrm{e}-01$ $6.30081 \mathrm{e}+006.30081 \mathrm{e}+006.30081 \mathrm{e}-011.00000 \mathrm{e}-092.12000 \mathrm{e}-01$ $6.30081 \mathrm{e}+006.30081 \mathrm{e}+006.30081 \mathrm{e}-011.00000 \mathrm{e}-092.12000 \mathrm{e}-01$ $1.00000 \mathrm{e}-05$ 1.00000e-05 1.00000e-06 1.00000e-09 1.00000e-01 $1.00000 \mathrm{e}+001.00000 \mathrm{e}+001.00000 \mathrm{e}-011.00000 \mathrm{e}-091.00000 \mathrm{e}-01$ 
Element: 9415 \# of layers: 7

$\mathrm{Kx} \mathrm{Ky} \mathrm{Kz}$ Ss Por

6.30081e+00 6.30081e+00 6.30081e-01 1.00000e-09 2.12000e-01

$6.30081 \mathrm{e}+006.30081 \mathrm{e}+006.30081 \mathrm{e}-01$ 1.00000e-09 2.12000e-01

$6.30081 \mathrm{e}+006.30081 \mathrm{e}+00$ 6.30081e-01 1.00000e-09 2.12000e-01

$6.30081 \mathrm{e}+006.30081 \mathrm{e}+00$ 6.30081e-01 1.00000e-09 2.12000e-01

$6.30081 \mathrm{e}+006.30081 \mathrm{e}+00$ 6.30081e-01 1.00000e-09 2.12000e-01

$1.00000 \mathrm{e}-05$ 1.00000e-05 1.00000e-06 1.00000e-09 1.00000e-01

$1.00000 \mathrm{e}+001.00000 \mathrm{e}+001.00000 \mathrm{e}-01$ 1.00000e-09 1.00000e-01

Element: 9416 \# of layers: 6

$\mathrm{Kx} \mathrm{Ky} \mathrm{Kz}$ Ss Por

6.30081e+00 6.30081e+00 6.30081e-01 1.00000e-09 2.12000e-01

$6.30081 \mathrm{e}+006.30081 \mathrm{e}+00$ 6.30081e-01 1.00000e-09 2.12000e-01

$6.30081 \mathrm{e}+006.30081 \mathrm{e}+00$ 6.30081e-01 1.00000e-09 2.12000e-01

$6.30081 \mathrm{e}+006.30081 \mathrm{e}+006.30081 \mathrm{e}-01$ 1.00000e-09 2.12000e-01

$1.00000 \mathrm{e}-051.00000 \mathrm{e}-05$ 1.00000e-06 1.00000e-09 1.00000e-01

$1.00000 \mathrm{e}+001.00000 \mathrm{e}+001.00000 \mathrm{e}-011.00000 \mathrm{e}-091.00000 \mathrm{e}-01$

Element: 9417 \# of layers: 6

$\mathrm{Kx} \mathrm{Ky} \mathrm{Kz}$ Ss Por

6.30081e+00 6.30081e+00 6.30081e-01 1.00000e-09 2.12000e-01

$6.30081 \mathrm{e}+006.30081 \mathrm{e}+006.30081 \mathrm{e}-01$ 1.00000e-09 2.12000e-01

6.30081e+00 6.30081e+00 6.30081e-01 1.00000e-09 2.12000e-01

6.30081e+00 6.30081e+00 6.30081e-01 1.00000e-09 2.12000e-01

$1.00000 \mathrm{e}-05$ 1.00000e-05 1.00000e-06 1.00000e-09 1.00000e-01

$1.00000 \mathrm{e}+001.00000 \mathrm{e}+001.00000 \mathrm{e}-011.00000 \mathrm{e}-091.00000 \mathrm{e}-01$

Element: 9418 \# of layers: 6

$\mathrm{Kx} \mathrm{Ky} \mathrm{Kz}$ Ss Por

$6.30081 \mathrm{e}+00$ 6.30081e+00 6.30081e-01 1.00000e-09 2.12000e-01

$6.30081 \mathrm{e}+006.30081 \mathrm{e}+006.30081 \mathrm{e}-01$ 1.00000e-09 2.12000e-01

6.30081e+00 6.30081e+00 6.30081e-01 1.00000e-09 2.12000e-01

$6.30081 \mathrm{e}+006.30081 \mathrm{e}+006.30081 \mathrm{e}-01$ 1.00000e-09 2.12000e-01

$1.00000 \mathrm{e}-05$ 1.00000e-05 1.00000e-06 1.00000e-09 1.00000e-01

$1.00000 \mathrm{e}+001.00000 \mathrm{e}+001.00000 \mathrm{e}-011.00000 \mathrm{e}-091.00000 \mathrm{e}-01$

Element: 9419 \# of layers: 6

$\mathrm{Kx} \mathrm{Ky} \mathrm{Kz}$ Ss Por

$3.86918 \mathrm{e}+003.86918 \mathrm{e}+00$ 3.86918e-01 1.00000e-09 2.12000e-01

$3.86918 \mathrm{e}+003.86918 \mathrm{e}+00$ 3.86918e-01 1.00000e-09 2.12000e-01

$3.86918 \mathrm{e}+003.86918 \mathrm{e}+00$ 3.86918e-01 1.00000e-09 2.12000e-01

$3.86918 \mathrm{e}+00$ 3.86918e+00 3.86918e-01 1.00000e-09 2.12000e-01

$1.00000 \mathrm{e}-05$ 1.00000e-05 1.00000e-06 1.00000e-09 1.00000e-01

$1.00000 \mathrm{e}+001.00000 \mathrm{e}+001.00000 \mathrm{e}-011.00000 \mathrm{e}-091.00000 \mathrm{e}-01$

Element: 9420 \# of layers: 6

$\mathrm{Kx} \mathrm{Ky} \mathrm{Kz}$ Ss Por

$3.86918 \mathrm{e}+003.86918 \mathrm{e}+003.86918 \mathrm{e}-01$ 1.00000e-09 2.12000e-01

$3.86918 \mathrm{e}+003.86918 \mathrm{e}+00$ 3.86918e-01 1.00000e-09 2.12000e-01

$3.86918 \mathrm{e}+003.86918 \mathrm{e}+003.86918 \mathrm{e}-01$ 1.00000e-09 2.12000e-01 
$3.86918 \mathrm{e}+003.86918 \mathrm{e}+00$ 3.86918e-01 1.00000e-09 2.12000e-01 $1.00000 \mathrm{e}-05$ 1.00000e-05 1.00000e-06 1.00000e-09 1.00000e-01 $1.00000 \mathrm{e}+001.00000 \mathrm{e}+001.00000 \mathrm{e}-011.00000 \mathrm{e}-091.00000 \mathrm{e}-01$ Element: 9421 \# of layers: 7

Kx Ky Kz Ss Por

$3.86918 \mathrm{e}+003.86918 \mathrm{e}+003.86918 \mathrm{e}-01$ 1.00000e-09 2.12000e-01 $3.86918 \mathrm{e}+003.86918 \mathrm{e}+003.86918 \mathrm{e}-011.00000 \mathrm{e}-092.12000 \mathrm{e}-01$ $3.86918 \mathrm{e}+003.86918 \mathrm{e}+003.86918 \mathrm{e}-011.00000 \mathrm{e}-092.12000 \mathrm{e}-01$ $3.86918 \mathrm{e}+003.86918 \mathrm{e}+003.86918 \mathrm{e}-011.00000 \mathrm{e}-092.12000 \mathrm{e}-01$ $3.86918 \mathrm{e}+003.86918 \mathrm{e}+003.86918 \mathrm{e}-01$ 1.00000e-09 2.12000e-01 $1.00000 \mathrm{e}-05$ 1.00000e-05 1.00000e-06 1.00000e-09 1.00000e-01 $1.00000 \mathrm{e}+001.00000 \mathrm{e}+001.00000 \mathrm{e}-011.00000 \mathrm{e}-091.00000 \mathrm{e}-01$ Element: 9422 \# of layers: 7

Kx Ky Kz Ss Por

$6.30081 \mathrm{e}+006.30081 \mathrm{e}+00$ 6.30081e-01 1.00000e-09 2.12000e-01 $6.30081 \mathrm{e}+006.30081 \mathrm{e}+006.30081 \mathrm{e}-011.00000 \mathrm{e}-092.12000 \mathrm{e}-01$ $6.30081 \mathrm{e}+006.30081 \mathrm{e}+006.30081 \mathrm{e}-011.00000 \mathrm{e}-092.12000 \mathrm{e}-01$ $6.30081 \mathrm{e}+006.30081 \mathrm{e}+006.30081 \mathrm{e}-011.00000 \mathrm{e}-092.12000 \mathrm{e}-01$ $6.30081 \mathrm{e}+006.30081 \mathrm{e}+006.30081 \mathrm{e}-011.00000 \mathrm{e}-092.12000 \mathrm{e}-01$ $1.00000 \mathrm{e}-05$ 1.00000e-05 1.00000e-06 1.00000e-09 1.00000e-01 $1.00000 \mathrm{e}+001.00000 \mathrm{e}+001.00000 \mathrm{e}-011.00000 \mathrm{e}-091.00000 \mathrm{e}-01$ Element: 9423 \# of layers: 7

Kx Ky Kz Ss Por

$6.30081 \mathrm{e}+006.30081 \mathrm{e}+00$ 6.30081e-01 1.00000e-09 2.12000e-01 $6.30081 \mathrm{e}+006.30081 \mathrm{e}+006.30081 \mathrm{e}-011.00000 \mathrm{e}-092.12000 \mathrm{e}-01$ $6.30081 \mathrm{e}+006.30081 \mathrm{e}+006.30081 \mathrm{e}-011.00000 \mathrm{e}-092.12000 \mathrm{e}-01$ $6.30081 \mathrm{e}+006.30081 \mathrm{e}+00$ 6.30081e-01 1.00000e-09 2.12000e-01 $6.30081 \mathrm{e}+006.30081 \mathrm{e}+006.30081 \mathrm{e}-011.00000 \mathrm{e}-092.12000 \mathrm{e}-01$ $1.00000 \mathrm{e}-05$ 1.00000e-05 1.00000e-06 1.00000e-09 1.00000e-01 $1.00000 \mathrm{e}+001.00000 \mathrm{e}+001.00000 \mathrm{e}-011.00000 \mathrm{e}-091.00000 \mathrm{e}-01$ Element: 9424 \# of layers: 6

Kx Ky Kz Ss Por

$6.30081 \mathrm{e}+006.30081 \mathrm{e}+00$ 6.30081e-01 1.00000e-09 2.12000e-01 $6.30081 \mathrm{e}+006.30081 \mathrm{e}+006.30081 \mathrm{e}-011.00000 \mathrm{e}-092.12000 \mathrm{e}-01$ $6.30081 \mathrm{e}+006.30081 \mathrm{e}+00$ 6.30081e-01 1.00000e-09 2.12000e-01 $6.30081 \mathrm{e}+006.30081 \mathrm{e}+006.30081 \mathrm{e}-01$ 1.00000e-09 2.12000e-01 $1.00000 \mathrm{e}-05$ 1.00000e-05 1.00000e-06 1.00000e-09 1.00000e-01 $1.00000 \mathrm{e}+001.00000 \mathrm{e}+001.00000 \mathrm{e}-011.00000 \mathrm{e}-091.00000 \mathrm{e}-01$ Element: 9425 \# of layers: 6

Kx Ky Kz Ss Por

$6.30081 \mathrm{e}+006.30081 \mathrm{e}+00$ 6.30081e-01 1.00000e-09 2.12000e-01 $6.30081 \mathrm{e}+006.30081 \mathrm{e}+006.30081 \mathrm{e}-011.00000 \mathrm{e}-092.12000 \mathrm{e}-01$ $6.30081 \mathrm{e}+006.30081 \mathrm{e}+00$ 6.30081e-01 1.00000e-09 2.12000e-01 $6.30081 \mathrm{e}+006.30081 \mathrm{e}+006.30081 \mathrm{e}-01$ 1.00000e-09 2.12000e-01 $1.00000 \mathrm{e}-05$ 1.00000e-05 1.00000e-06 1.00000e-09 1.00000e-01 $1.00000 \mathrm{e}+001.00000 \mathrm{e}+001.00000 \mathrm{e}-011.00000 \mathrm{e}-091.00000 \mathrm{e}-01$ 
Element: 9426 \# of layers: 6

$\mathrm{Kx} \mathrm{Ky} \mathrm{Kz}$ Ss Por

3.86918e+00 3.86918e+00 3.86918e-01 1.00000e-09 2.12000e-01

$3.86918 \mathrm{e}+003.86918 \mathrm{e}+003.86918 \mathrm{e}-01$ 1.00000e-09 2.12000e-01

$3.86918 \mathrm{e}+003.86918 \mathrm{e}+00$ 3.86918e-01 1.00000e-09 2.12000e-01

$3.86918 \mathrm{e}+003.86918 \mathrm{e}+00$ 3.86918e-01 1.00000e-09 2.12000e-01

$1.00000 \mathrm{e}-05$ 1.00000e-05 1.00000e-06 1.00000e-09 1.00000e-01

$1.00000 \mathrm{e}+001.00000 \mathrm{e}+001.00000 \mathrm{e}-011.00000 \mathrm{e}-091.00000 \mathrm{e}-01$

Element: 9427 \# of layers: 6

$\mathrm{Kx} \mathrm{Ky} \mathrm{Kz}$ Ss Por

$3.86918 \mathrm{e}+003.86918 \mathrm{e}+00$ 3.86918e-01 1.00000e-09 2.12000e-01

$3.86918 \mathrm{e}+003.86918 \mathrm{e}+003.86918 \mathrm{e}-01$ 1.00000e-09 2.12000e-01

$3.86918 \mathrm{e}+003.86918 \mathrm{e}+003.86918 \mathrm{e}-01$ 1.00000e-09 2.12000e-01

$3.86918 \mathrm{e}+003.86918 \mathrm{e}+003.86918 \mathrm{e}-01$ 1.00000e-09 2.12000e-01

$1.00000 \mathrm{e}-05$ 1.00000e-05 1.00000e-06 1.00000e-09 1.00000e-01

$1.00000 \mathrm{e}+001.00000 \mathrm{e}+001.00000 \mathrm{e}-011.00000 \mathrm{e}-091.00000 \mathrm{e}-01$

Element: 9428 \# of layers: 6

$\mathrm{Kx} \mathrm{Ky} \mathrm{Kz}$ Ss Por

3.86918e+00 3.86918e+00 3.86918e-01 1.00000e-09 2.12000e-01

$3.86918 \mathrm{e}+003.86918 \mathrm{e}+003.86918 \mathrm{e}-01$ 1.00000e-09 2.12000e-01

$3.86918 \mathrm{e}+003.86918 \mathrm{e}+003.86918 \mathrm{e}-01$ 1.00000e-09 2.12000e-01

$3.86918 \mathrm{e}+00$ 3.86918e+00 3.86918e-01 1.00000e-09 2.12000e-01

$1.00000 \mathrm{e}-05$ 1.00000e-05 1.00000e-06 1.00000e-09 1.00000e-01

$1.00000 \mathrm{e}+001.00000 \mathrm{e}+001.00000 \mathrm{e}-01$ 1.00000e-09 1.00000e-01

Element: 9429 \# of layers: 6

$\mathrm{Kx} \mathrm{Ky} \mathrm{Kz}$ Ss Por

3.86918e+00 3.86918e+00 3.86918e-01 1.00000e-09 2.12000e-01

$3.86918 \mathrm{e}+003.86918 \mathrm{e}+00$ 3.86918e-01 1.00000e-09 2.12000e-01

$3.86918 \mathrm{e}+003.86918 \mathrm{e}+003.86918 \mathrm{e}-01$ 1.00000e-09 2.12000e-01

$3.86918 \mathrm{e}+00$ 3.86918e+00 3.86918e-01 1.00000e-09 2.12000e-01

$1.00000 \mathrm{e}-05$ 1.00000e-05 1.00000e-06 1.00000e-09 1.00000e-01

$1.00000 \mathrm{e}+001.00000 \mathrm{e}+001.00000 \mathrm{e}-01$ 1.00000e-09 1.00000e-01

Element: 9430 \# of layers: 7

$\mathrm{Kx} \mathrm{Ky} \mathrm{Kz}$ Ss Por

$3.86918 \mathrm{e}+003.86918 \mathrm{e}+00$ 3.86918e-01 1.00000e-09 2.12000e-01

$3.86918 \mathrm{e}+003.86918 \mathrm{e}+003.86918 \mathrm{e}-01$ 1.00000e-09 2.12000e-01

$3.86918 \mathrm{e}+003.86918 \mathrm{e}+003.86918 \mathrm{e}-01$ 1.00000e-09 2.12000e-01

$3.86918 \mathrm{e}+003.86918 \mathrm{e}+00$ 3.86918e-01 1.00000e-09 2.12000e-01

$3.86918 \mathrm{e}+00$ 3.86918e+00 3.86918e-01 1.00000e-09 2.12000e-01

$1.00000 \mathrm{e}-05$ 1.00000e-05 1.00000e-06 1.00000e-09 1.00000e-01

$1.00000 \mathrm{e}+001.00000 \mathrm{e}+001.00000 \mathrm{e}-011.00000 \mathrm{e}-091.00000 \mathrm{e}-01$

Element: 9431 \# of layers: 7

$\mathrm{Kx} \mathrm{Ky} \mathrm{Kz}$ Ss Por

3.86918e+00 3.86918e+00 3.86918e-01 1.00000e-09 2.12000e-01

$3.86918 \mathrm{e}+003.86918 \mathrm{e}+00$ 3.86918e-01 1.00000e-09 2.12000e-01

$3.86918 \mathrm{e}+003.86918 \mathrm{e}+003.86918 \mathrm{e}-01$ 1.00000e-09 2.12000e-01 
$3.86918 \mathrm{e}+003.86918 \mathrm{e}+00$ 3.86918e-01 1.00000e-09 2.12000e-01 $3.86918 \mathrm{e}+003.86918 \mathrm{e}+003.86918 \mathrm{e}-01$ 1.00000e-09 2.12000e-01 $1.00000 \mathrm{e}-05$ 1.00000e-05 1.00000e-06 1.00000e-09 1.00000e-01 $1.00000 \mathrm{e}+001.00000 \mathrm{e}+001.00000 \mathrm{e}-011.00000 \mathrm{e}-091.00000 \mathrm{e}-01$ Element: 9432 \# of layers: 7

Kx Ky Kz Ss Por

$3.86918 \mathrm{e}+003.86918 \mathrm{e}+00$ 3.86918e-01 1.00000e-09 2.12000e-01 $3.86918 \mathrm{e}+003.86918 \mathrm{e}+003.86918 \mathrm{e}-011.00000 \mathrm{e}-092.12000 \mathrm{e}-01$ $3.86918 \mathrm{e}+003.86918 \mathrm{e}+003.86918 \mathrm{e}-011.00000 \mathrm{e}-092.12000 \mathrm{e}-01$ $3.86918 \mathrm{e}+003.86918 \mathrm{e}+003.86918 \mathrm{e}-011.00000 \mathrm{e}-092.12000 \mathrm{e}-01$ $3.86918 \mathrm{e}+003.86918 \mathrm{e}+003.86918 \mathrm{e}-01$ 1.00000e-09 2.12000e-01 $1.00000 \mathrm{e}-05$ 1.00000e-05 1.00000e-06 1.00000e-09 1.00000e-01 $1.00000 \mathrm{e}+001.00000 \mathrm{e}+00$ 1.00000e-01 1.00000e-09 1.00000e-01 Element: 9433 \# of layers: 6

Kx Ky Kz Ss Por

3.86918e+00 3.86918e+00 3.86918e-01 1.00000e-09 2.12000e-01 $3.86918 \mathrm{e}+003.86918 \mathrm{e}+003.86918 \mathrm{e}-011.00000 \mathrm{e}-092.12000 \mathrm{e}-01$ $3.86918 \mathrm{e}+003.86918 \mathrm{e}+003.86918 \mathrm{e}-011.00000 \mathrm{e}-092.12000 \mathrm{e}-01$ $3.86918 \mathrm{e}+003.86918 \mathrm{e}+003.86918 \mathrm{e}-011.00000 \mathrm{e}-092.12000 \mathrm{e}-01$ $1.00000 \mathrm{e}-05$ 1.00000e-05 1.00000e-06 1.00000e-09 1.00000e-01 $1.00000 \mathrm{e}+001.00000 \mathrm{e}+001.00000 \mathrm{e}-011.00000 \mathrm{e}-091.00000 \mathrm{e}-01$ Element: 9434 \# of layers: 6

$\mathrm{Kx} \mathrm{Ky} \mathrm{Kz}$ Ss Por

$3.86918 \mathrm{e}+003.86918 \mathrm{e}+00$ 3.86918e-01 1.00000e-09 2.12000e-01 $3.86918 \mathrm{e}+003.86918 \mathrm{e}+003.86918 \mathrm{e}-011.00000 \mathrm{e}-092.12000 \mathrm{e}-01$ $3.86918 \mathrm{e}+003.86918 \mathrm{e}+003.86918 \mathrm{e}-011.00000 \mathrm{e}-092.12000 \mathrm{e}-01$ $3.86918 \mathrm{e}+003.86918 \mathrm{e}+003.86918 \mathrm{e}-011.00000 \mathrm{e}-092.12000 \mathrm{e}-01$ $1.00000 \mathrm{e}-05$ 1.00000e-05 1.00000e-06 1.00000e-09 1.00000e-01 $1.00000 \mathrm{e}+001.00000 \mathrm{e}+001.00000 \mathrm{e}-011.00000 \mathrm{e}-091.00000 \mathrm{e}-01$ Element: 9435 \# of layers: 6

Kx Ky Kz Ss Por

$3.86918 \mathrm{e}+003.86918 \mathrm{e}+003.86918 \mathrm{e}-01$ 1.00000e-09 2.12000e-01 $3.86918 \mathrm{e}+003.86918 \mathrm{e}+003.86918 \mathrm{e}-01$ 1.00000e-09 2.12000e-01 $3.86918 \mathrm{e}+003.86918 \mathrm{e}+003.86918 \mathrm{e}-011.00000 \mathrm{e}-092.12000 \mathrm{e}-01$ $3.86918 \mathrm{e}+003.86918 \mathrm{e}+003.86918 \mathrm{e}-01$ 1.00000e-09 2.12000e-01 $1.00000 \mathrm{e}-05$ 1.00000e-05 1.00000e-06 1.00000e-09 1.00000e-01 $1.00000 \mathrm{e}+001.00000 \mathrm{e}+001.00000 \mathrm{e}-011.00000 \mathrm{e}-091.00000 \mathrm{e}-01$ Element: 9436 \# of layers: 6

Kx Ky Kz Ss Por

$3.46755 \mathrm{e}+003.46755 \mathrm{e}+003.46755 \mathrm{e}-011.00000 \mathrm{e}-092.12000 \mathrm{e}-01$ $3.46755 \mathrm{e}+003.46755 \mathrm{e}+003.46755 \mathrm{e}-011.00000 \mathrm{e}-092.12000 \mathrm{e}-01$ $3.46755 \mathrm{e}+003.46755 \mathrm{e}+003.46755 \mathrm{e}-011.00000 \mathrm{e}-092.12000 \mathrm{e}-01$ $3.46755 \mathrm{e}+003.46755 \mathrm{e}+003.46755 \mathrm{e}-011.00000 \mathrm{e}-092.12000 \mathrm{e}-01$ $1.00000 \mathrm{e}-05$ 1.00000e-05 1.00000e-06 1.00000e-09 1.00000e-01 $1.00000 \mathrm{e}+001.00000 \mathrm{e}+001.00000 \mathrm{e}-011.00000 \mathrm{e}-091.00000 \mathrm{e}-01$ Element: 9437 \# of layers: 6 
$\mathrm{Kx} \mathrm{Ky} \mathrm{Kz} \mathrm{Ss} \mathrm{Por}$

3.46755e+00 3.46755e+00 3.46755e-01 1.00000e-09 2.12000e-01

$3.46755 \mathrm{e}+003.46755 \mathrm{e}+003.46755 \mathrm{e}-01$ 1.00000e-09 2.12000e-01

$3.46755 \mathrm{e}+003.46755 \mathrm{e}+00$ 3.46755e-01 1.00000e-09 2.12000e-01

$3.46755 \mathrm{e}+003.46755 \mathrm{e}+00$ 3.46755e-01 1.00000e-09 2.12000e-01

$1.00000 \mathrm{e}-05$ 1.00000e-05 1.00000e-06 1.00000e-09 1.00000e-01

$1.00000 \mathrm{e}+001.00000 \mathrm{e}+001.00000 \mathrm{e}-01$ 1.00000e-09 1.00000e-01

Element: 9438 \# of layers: 7

$\mathrm{Kx} \mathrm{Ky} \mathrm{Kz}$ Ss Por

3.46755e+00 3.46755e+00 3.46755e-01 1.00000e-09 2.12000e-01

3.46755e+00 3.46755e+00 3.46755e-01 1.00000e-09 2.12000e-01

$3.46755 \mathrm{e}+003.46755 \mathrm{e}+003.46755 \mathrm{e}-01$ 1.00000e-09 2.12000e-01

$3.46755 \mathrm{e}+003.46755 \mathrm{e}+00$ 3.46755e-01 1.00000e-09 2.12000e-01

$3.46755 \mathrm{e}+003.46755 \mathrm{e}+00$ 3.46755e-01 1.00000e-09 2.12000e-01

$1.00000 \mathrm{e}-05$ 1.00000e-05 1.00000e-06 1.00000e-09 1.00000e-01

$1.00000 \mathrm{e}+001.00000 \mathrm{e}+001.00000 \mathrm{e}-011.00000 \mathrm{e}-091.00000 \mathrm{e}-01$

Element: 9439 \# of layers: 7

$\mathrm{Kx} \mathrm{Ky} \mathrm{Kz}$ Ss Por

3.46755e+00 3.46755e+00 3.46755e-01 1.00000e-09 2.12000e-01

$3.46755 \mathrm{e}+003.46755 \mathrm{e}+003.46755 \mathrm{e}-01$ 1.00000e-09 2.12000e-01

$3.46755 \mathrm{e}+003.46755 \mathrm{e}+003.46755 \mathrm{e}-01$ 1.00000e-09 2.12000e-01

$3.46755 \mathrm{e}+003.46755 \mathrm{e}+00$ 3.46755e-01 1.00000e-09 2.12000e-01

$3.46755 \mathrm{e}+003.46755 \mathrm{e}+003.46755 \mathrm{e}-01$ 1.00000e-09 2.12000e-01

$1.00000 \mathrm{e}-051.00000 \mathrm{e}-051.00000 \mathrm{e}-061.00000 \mathrm{e}-091.00000 \mathrm{e}-01$

$1.00000 \mathrm{e}+001.00000 \mathrm{e}+001.00000 \mathrm{e}-011.00000 \mathrm{e}-091.00000 \mathrm{e}-01$

Element: 9440 \# of layers: 6

$\mathrm{Kx} \mathrm{Ky} \mathrm{Kz}$ Ss Por

3.46755e+00 3.46755e+00 3.46755e-01 1.00000e-09 2.12000e-01

$3.46755 \mathrm{e}+003.46755 \mathrm{e}+003.46755 \mathrm{e}-01$ 1.00000e-09 2.12000e-01

$3.46755 \mathrm{e}+003.46755 \mathrm{e}+003.46755 \mathrm{e}-01$ 1.00000e-09 2.12000e-01

$3.46755 \mathrm{e}+003.46755 \mathrm{e}+003.46755 \mathrm{e}-01$ 1.00000e-09 2.12000e-01

$1.00000 \mathrm{e}-05$ 1.00000e-05 1.00000e-06 1.00000e-09 1.00000e-01

$1.00000 \mathrm{e}+001.00000 \mathrm{e}+001.00000 \mathrm{e}-011.00000 \mathrm{e}-091.00000 \mathrm{e}-01$

Element: 9441 \# of layers: 6

$\mathrm{Kx} \mathrm{Ky} \mathrm{Kz}$ Ss Por

3.86918e+00 3.86918e+00 3.86918e-01 1.00000e-09 2.12000e-01

$3.86918 \mathrm{e}+003.86918 \mathrm{e}+003.86918 \mathrm{e}-01$ 1.00000e-09 2.12000e-01

$3.86918 \mathrm{e}+003.86918 \mathrm{e}+00$ 3.86918e-01 1.00000e-09 2.12000e-01

$3.86918 \mathrm{e}+00$ 3.86918e+00 3.86918e-01 1.00000e-09 2.12000e-01

$1.00000 \mathrm{e}-05$ 1.00000e-05 1.00000e-06 1.00000e-09 1.00000e-01

$1.00000 \mathrm{e}+001.00000 \mathrm{e}+001.00000 \mathrm{e}-011.00000 \mathrm{e}-091.00000 \mathrm{e}-01$

Element: 9442 \# of layers: 6

$\mathrm{Kx} \mathrm{Ky} \mathrm{Kz}$ Ss Por

3.86918e+00 3.86918e+00 3.86918e-01 1.00000e-09 2.12000e-01

$3.86918 \mathrm{e}+003.86918 \mathrm{e}+003.86918 \mathrm{e}-01$ 1.00000e-09 2.12000e-01

$3.86918 \mathrm{e}+003.86918 \mathrm{e}+00$ 3.86918e-01 1.00000e-09 2.12000e-01 
$3.86918 \mathrm{e}+003.86918 \mathrm{e}+00$ 3.86918e-01 1.00000e-09 2.12000e-01 $1.00000 \mathrm{e}-05$ 1.00000e-05 1.00000e-06 1.00000e-09 1.00000e-01 $1.00000 \mathrm{e}+001.00000 \mathrm{e}+001.00000 \mathrm{e}-011.00000 \mathrm{e}-091.00000 \mathrm{e}-01$ Element: 9443 \# of layers: 6

$\mathrm{Kx} \mathrm{Ky} \mathrm{Kz}$ Ss Por

3.46755e+00 3.46755e+00 3.46755e-01 1.00000e-09 2.12000e-01 $3.46755 \mathrm{e}+003.46755 \mathrm{e}+003.46755 \mathrm{e}-011.00000 \mathrm{e}-092.12000 \mathrm{e}-01$ $3.46755 \mathrm{e}+003.46755 \mathrm{e}+003.46755 \mathrm{e}-011.00000 \mathrm{e}-092.12000 \mathrm{e}-01$ $3.46755 \mathrm{e}+003.46755 \mathrm{e}+003.46755 \mathrm{e}-01$ 1.00000e-09 2.12000e-01 $1.00000 \mathrm{e}-05$ 1.00000e-05 1.00000e-06 1.00000e-09 1.00000e-01 $1.00000 \mathrm{e}+001.00000 \mathrm{e}+001.00000 \mathrm{e}-011.00000 \mathrm{e}-091.00000 \mathrm{e}-01$ Element: 9444 \# of layers: 7

Kx Ky Kz Ss Por

$3.46755 \mathrm{e}+003.46755 \mathrm{e}+00$ 3.46755e-01 1.00000e-09 2.12000e-01 $3.46755 \mathrm{e}+003.46755 \mathrm{e}+003.46755 \mathrm{e}-011.00000 \mathrm{e}-092.12000 \mathrm{e}-01$ $3.46755 \mathrm{e}+003.46755 \mathrm{e}+003.46755 \mathrm{e}-011.00000 \mathrm{e}-092.12000 \mathrm{e}-01$ $3.46755 \mathrm{e}+003.46755 \mathrm{e}+003.46755 \mathrm{e}-011.00000 \mathrm{e}-092.12000 \mathrm{e}-01$ $3.46755 \mathrm{e}+003.46755 \mathrm{e}+003.46755 \mathrm{e}-01$ 1.00000e-09 2.12000e-01 $1.00000 \mathrm{e}-05$ 1.00000e-05 1.00000e-06 1.00000e-09 1.00000e-01 $1.00000 \mathrm{e}+001.00000 \mathrm{e}+001.00000 \mathrm{e}-011.00000 \mathrm{e}-091.00000 \mathrm{e}-01$ Element: 9445 \# of layers: 7

Kx Ky Kz Ss Por

$1.02852 \mathrm{e}+011.02852 \mathrm{e}+011.02852 \mathrm{e}+00$ 1.00000e-09 2.12000e-01 $1.02852 \mathrm{e}+011.02852 \mathrm{e}+011.02852 \mathrm{e}+001.00000 \mathrm{e}-092.12000 \mathrm{e}-01$ $1.02852 \mathrm{e}+011.02852 \mathrm{e}+011.02852 \mathrm{e}+001.00000 \mathrm{e}-092.12000 \mathrm{e}-01$ $1.02852 \mathrm{e}+011.02852 \mathrm{e}+011.02852 \mathrm{e}+001.00000 \mathrm{e}-092.12000 \mathrm{e}-01$ $1.02852 \mathrm{e}+011.02852 \mathrm{e}+011.02852 \mathrm{e}+001.00000 \mathrm{e}-092.12000 \mathrm{e}-01$ $1.00000 \mathrm{e}-05$ 1.00000e-05 1.00000e-06 1.00000e-09 1.00000e-01 $1.00000 \mathrm{e}+001.00000 \mathrm{e}+001.00000 \mathrm{e}-011.00000 \mathrm{e}-091.00000 \mathrm{e}-01$ Element: 9446 \# of layers: 7

Kx Ky Kz Ss Por

$1.02852 \mathrm{e}+011.02852 \mathrm{e}+011.02852 \mathrm{e}+00$ 1.00000e-09 2.12000e-01 $1.02852 \mathrm{e}+011.02852 \mathrm{e}+011.02852 \mathrm{e}+001.00000 \mathrm{e}-092.12000 \mathrm{e}-01$ $1.02852 \mathrm{e}+011.02852 \mathrm{e}+011.02852 \mathrm{e}+001.00000 \mathrm{e}-092.12000 \mathrm{e}-01$ $1.02852 \mathrm{e}+011.02852 \mathrm{e}+011.02852 \mathrm{e}+001.00000 \mathrm{e}-092.12000 \mathrm{e}-01$ $1.02852 \mathrm{e}+011.02852 \mathrm{e}+011.02852 \mathrm{e}+001.00000 \mathrm{e}-092.12000 \mathrm{e}-01$ $1.00000 \mathrm{e}-05$ 1.00000e-05 1.00000e-06 1.00000e-09 1.00000e-01 $1.00000 \mathrm{e}+001.00000 \mathrm{e}+00$ 1.00000e-01 1.00000e-09 1.00000e-01 Element: 9447 \# of layers: 6

Kx Ky Kz Ss Por $1.02852 \mathrm{e}+011.02852 \mathrm{e}+011.02852 \mathrm{e}+001.00000 \mathrm{e}-092.12000 \mathrm{e}-01$ $1.02852 \mathrm{e}+011.02852 \mathrm{e}+011.02852 \mathrm{e}+001.00000 \mathrm{e}-092.12000 \mathrm{e}-01$ $1.02852 \mathrm{e}+011.02852 \mathrm{e}+011.02852 \mathrm{e}+001.00000 \mathrm{e}-092.12000 \mathrm{e}-01$ $1.02852 \mathrm{e}+011.02852 \mathrm{e}+011.02852 \mathrm{e}+001.00000 \mathrm{e}-092.12000 \mathrm{e}-01$ $1.00000 \mathrm{e}-05$ 1.00000e-05 1.00000e-06 1.00000e-09 1.00000e-01 $1.00000 \mathrm{e}+001.00000 \mathrm{e}+001.00000 \mathrm{e}-011.00000 \mathrm{e}-091.00000 \mathrm{e}-01$ 
Element: 9448 \# of layers: 6

$\mathrm{Kx} \mathrm{Ky} \mathrm{Kz}$ Ss Por

6.30081e+00 6.30081e+00 6.30081e-01 1.00000e-09 2.12000e-01

$6.30081 \mathrm{e}+006.30081 \mathrm{e}+006.30081 \mathrm{e}-01$ 1.00000e-09 2.12000e-01

$6.30081 \mathrm{e}+006.30081 \mathrm{e}+00$ 6.30081e-01 1.00000e-09 2.12000e-01

$6.30081 \mathrm{e}+006.30081 \mathrm{e}+006.30081 \mathrm{e}-01$ 1.00000e-09 2.12000e-01

$1.00000 \mathrm{e}-05$ 1.00000e-05 1.00000e-06 1.00000e-09 1.00000e-01

$1.00000 \mathrm{e}+001.00000 \mathrm{e}+001.00000 \mathrm{e}-011.00000 \mathrm{e}-091.00000 \mathrm{e}-01$

Element: 9449 \# of layers: 6

$\mathrm{Kx} \mathrm{Ky} \mathrm{Kz}$ Ss Por

6.30081e+00 6.30081e+00 6.30081e-01 1.00000e-09 2.12000e-01

$6.30081 \mathrm{e}+006.30081 \mathrm{e}+006.30081 \mathrm{e}-01$ 1.00000e-09 2.12000e-01

$6.30081 \mathrm{e}+006.30081 \mathrm{e}+00$ 6.30081e-01 1.00000e-09 2.12000e-01

$6.30081 \mathrm{e}+006.30081 \mathrm{e}+006.30081 \mathrm{e}-01$ 1.00000e-09 2.12000e-01

$1.00000 \mathrm{e}-05$ 1.00000e-05 1.00000e-06 1.00000e-09 1.00000e-01

$1.00000 \mathrm{e}+001.00000 \mathrm{e}+001.00000 \mathrm{e}-011.00000 \mathrm{e}-091.00000 \mathrm{e}-01$

Element: 9450 \# of layers: 6

$\mathrm{Kx} \mathrm{Ky} \mathrm{Kz}$ Ss Por

3.86918e+00 3.86918e+00 3.86918e-01 1.00000e-09 2.12000e-01

$3.86918 \mathrm{e}+003.86918 \mathrm{e}+003.86918 \mathrm{e}-01$ 1.00000e-09 2.12000e-01

$3.86918 \mathrm{e}+003.86918 \mathrm{e}+003.86918 \mathrm{e}-01$ 1.00000e-09 2.12000e-01

$3.86918 \mathrm{e}+003.86918 \mathrm{e}+00$ 3.86918e-01 1.00000e-09 2.12000e-01

$1.00000 \mathrm{e}-05$ 1.00000e-05 1.00000e-06 1.00000e-09 1.00000e-01

$1.00000 \mathrm{e}+001.00000 \mathrm{e}+001.00000 \mathrm{e}-011.00000 \mathrm{e}-091.00000 \mathrm{e}-01$

Element: 9451 \# of layers: 6

$\mathrm{Kx} \mathrm{Ky} \mathrm{Kz}$ Ss Por

3.46755e+00 3.46755e+00 3.46755e-01 1.00000e-09 2.12000e-01

$3.46755 \mathrm{e}+003.46755 \mathrm{e}+00$ 3.46755e-01 1.00000e-09 2.12000e-01

$3.46755 \mathrm{e}+003.46755 \mathrm{e}+003.46755 \mathrm{e}-01$ 1.00000e-09 2.12000e-01

$3.46755 \mathrm{e}+003.46755 \mathrm{e}+003.46755 \mathrm{e}-01$ 1.00000e-09 2.12000e-01

$1.00000 \mathrm{e}-05$ 1.00000e-05 1.00000e-06 1.00000e-09 1.00000e-01

$1.00000 \mathrm{e}+001.00000 \mathrm{e}+001.00000 \mathrm{e}-011.00000 \mathrm{e}-091.00000 \mathrm{e}-01$

Element: 9452 \# of layers: 6

$\mathrm{Kx} \mathrm{Ky} \mathrm{Kz}$ Ss Por

$1.02852 \mathrm{e}+01$ 1.02852e+01 1.02852e+00 1.00000e-09 2.12000e-01

$1.02852 \mathrm{e}+011.02852 \mathrm{e}+011.02852 \mathrm{e}+001.00000 \mathrm{e}-092.12000 \mathrm{e}-01$

$1.02852 \mathrm{e}+011.02852 \mathrm{e}+011.02852 \mathrm{e}+001.00000 \mathrm{e}-092.12000 \mathrm{e}-01$

$1.02852 \mathrm{e}+01$ 1.02852e+01 1.02852e+00 1.00000e-09 2.12000e-01

$1.00000 \mathrm{e}-05$ 1.00000e-05 1.00000e-06 1.00000e-09 1.00000e-01

$1.00000 \mathrm{e}+001.00000 \mathrm{e}+001.00000 \mathrm{e}-01$ 1.00000e-09 1.00000e-01

Element: 9453 \# of layers: 7

$\mathrm{Kx} \mathrm{Ky} \mathrm{Kz}$ Ss Por

$2.52253 \mathrm{e}+012.52253 \mathrm{e}+012.52253 \mathrm{e}+00$ 1.00000e-09 2.12000e-01

$2.52253 \mathrm{e}+012.52253 \mathrm{e}+012.52253 \mathrm{e}+00$ 1.00000e-09 2.12000e-01

$2.52253 \mathrm{e}+012.52253 \mathrm{e}+012.52253 \mathrm{e}+00$ 1.00000e-09 2.12000e-01

$2.52253 \mathrm{e}+012.52253 \mathrm{e}+012.52253 \mathrm{e}+001.00000 \mathrm{e}-092.12000 \mathrm{e}-01$ 
$2.52253 \mathrm{e}+012.52253 \mathrm{e}+012.52253 \mathrm{e}+00$ 1.00000e-09 2.12000e-01 $1.00000 \mathrm{e}-05$ 1.00000e-05 1.00000e-06 1.00000e-09 1.00000e-01 $1.00000 \mathrm{e}+001.00000 \mathrm{e}+001.00000 \mathrm{e}-011.00000 \mathrm{e}-091.00000 \mathrm{e}-01$

Element: 9454 \# of layers: 7

$\mathrm{Kx} \mathrm{Ky} \mathrm{Kz}$ Ss Por

$2.52253 \mathrm{e}+012.52253 \mathrm{e}+012.52253 \mathrm{e}+00$ 1.00000e-09 2.12000e-01

$2.52253 \mathrm{e}+012.52253 \mathrm{e}+012.52253 \mathrm{e}+00$ 1.00000e-09 2.12000e-01

$2.52253 \mathrm{e}+012.52253 \mathrm{e}+012.52253 \mathrm{e}+00$ 1.00000e-09 2.12000e-01

$2.52253 \mathrm{e}+012.52253 \mathrm{e}+012.52253 \mathrm{e}+001.00000 \mathrm{e}-092.12000 \mathrm{e}-01$

$2.52253 \mathrm{e}+012.52253 \mathrm{e}+012.52253 \mathrm{e}+001.00000 \mathrm{e}-092.12000 \mathrm{e}-01$ $1.00000 \mathrm{e}-05$ 1.00000e-05 1.00000e-06 1.00000e-09 1.00000e-01

$1.00000 \mathrm{e}+001.00000 \mathrm{e}+001.00000 \mathrm{e}-011.00000 \mathrm{e}-091.00000 \mathrm{e}-01$

Element: 9455 \# of layers: 7

$\mathrm{Kx} \mathrm{Ky} \mathrm{Kz}$ Ss Por

$2.52253 \mathrm{e}+012.52253 \mathrm{e}+012.52253 \mathrm{e}+00$ 1.00000e-09 2.12000e-01

$2.52253 \mathrm{e}+012.52253 \mathrm{e}+012.52253 \mathrm{e}+00$ 1.00000e-09 2.12000e-01

$2.52253 \mathrm{e}+012.52253 \mathrm{e}+012.52253 \mathrm{e}+00$ 1.00000e-09 2.12000e-01

$2.52253 \mathrm{e}+012.52253 \mathrm{e}+012.52253 \mathrm{e}+00$ 1.00000e-09 2.12000e-01

$2.52253 \mathrm{e}+012.52253 \mathrm{e}+012.52253 \mathrm{e}+00$ 1.00000e-09 2.12000e-01 $1.00000 \mathrm{e}-05$ 1.00000e-05 1.00000e-06 1.00000e-09 1.00000e-01

$1.00000 \mathrm{e}+001.00000 \mathrm{e}+001.00000 \mathrm{e}-011.00000 \mathrm{e}-091.00000 \mathrm{e}-01$

Element: 9456 \# of layers: 7

$\mathrm{Kx} \mathrm{Ky} \mathrm{Kz}$ Ss Por

$2.52253 \mathrm{e}+012.52253 \mathrm{e}+012.52253 \mathrm{e}+00$ 1.00000e-09 2.12000e-01

$2.52253 \mathrm{e}+012.52253 \mathrm{e}+012.52253 \mathrm{e}+001.00000 \mathrm{e}-092.12000 \mathrm{e}-01$

$2.52253 \mathrm{e}+012.52253 \mathrm{e}+012.52253 \mathrm{e}+001.00000 \mathrm{e}-092.12000 \mathrm{e}-01$

$2.52253 \mathrm{e}+012.52253 \mathrm{e}+012.52253 \mathrm{e}+00$ 1.00000e-09 2.12000e-01

$2.52253 \mathrm{e}+012.52253 \mathrm{e}+012.52253 \mathrm{e}+001.00000 \mathrm{e}-092.12000 \mathrm{e}-01$

$1.00000 \mathrm{e}-05$ 1.00000e-05 1.00000e-06 1.00000e-09 1.00000e-01

$1.00000 \mathrm{e}+001.00000 \mathrm{e}+001.00000 \mathrm{e}-011.00000 \mathrm{e}-091.00000 \mathrm{e}-01$

Element: 9457 \# of layers: 7

$\mathrm{Kx} \mathrm{Ky} \mathrm{Kz}$ Ss Por

$2.52253 \mathrm{e}+012.52253 \mathrm{e}+012.52253 \mathrm{e}+00$ 1.00000e-09 2.12000e-01

$2.52253 \mathrm{e}+012.52253 \mathrm{e}+012.52253 \mathrm{e}+001.00000 \mathrm{e}-092.12000 \mathrm{e}-01$

$2.52253 \mathrm{e}+012.52253 \mathrm{e}+012.52253 \mathrm{e}+00$ 1.00000e-09 2.12000e-01

$2.52253 \mathrm{e}+012.52253 \mathrm{e}+012.52253 \mathrm{e}+00$ 1.00000e-09 2.12000e-01

$2.52253 \mathrm{e}+012.52253 \mathrm{e}+012.52253 \mathrm{e}+001.00000 \mathrm{e}-092.12000 \mathrm{e}-01$

$1.00000 \mathrm{e}-05$ 1.00000e-05 1.00000e-06 1.00000e-09 1.00000e-01

$1.00000 \mathrm{e}+001.00000 \mathrm{e}+001.00000 \mathrm{e}-011.00000 \mathrm{e}-091.00000 \mathrm{e}-01$

Element: 9458 \# of layers: 7

$\mathrm{Kx} \mathrm{Ky} \mathrm{Kz}$ Ss Por

$2.52253 \mathrm{e}+012.52253 \mathrm{e}+012.52253 \mathrm{e}+00$ 1.00000e-09 2.12000e-01

$2.52253 \mathrm{e}+012.52253 \mathrm{e}+012.52253 \mathrm{e}+00$ 1.00000e-09 2.12000e-01

$2.52253 \mathrm{e}+012.52253 \mathrm{e}+01$ 2.52253e+00 1.00000e-09 2.12000e-01

$2.52253 \mathrm{e}+012.52253 \mathrm{e}+012.52253 \mathrm{e}+00$ 1.00000e-09 2.12000e-01

$2.52253 \mathrm{e}+012.52253 \mathrm{e}+012.52253 \mathrm{e}+001.00000 \mathrm{e}-092.12000 \mathrm{e}-01$ 
$1.00000 \mathrm{e}-05$ 1.00000e-05 1.00000e-06 1.00000e-09 1.00000e-01 $1.00000 \mathrm{e}+001.00000 \mathrm{e}+001.00000 \mathrm{e}-01$ 1.00000e-09 1.00000e-01 Element: 9459 \# of layers: 7

$\mathrm{Kx} \mathrm{Ky} \mathrm{Kz}$ Ss Por

$2.52253 \mathrm{e}+012.52253 \mathrm{e}+012.52253 \mathrm{e}+001.00000 \mathrm{e}-092.12000 \mathrm{e}-01$

$2.52253 \mathrm{e}+012.52253 \mathrm{e}+012.52253 \mathrm{e}+00$ 1.00000e-09 2.12000e-01

$2.52253 \mathrm{e}+012.52253 \mathrm{e}+012.52253 \mathrm{e}+00$ 1.00000e-09 2.12000e-01

$2.52253 \mathrm{e}+012.52253 \mathrm{e}+012.52253 \mathrm{e}+001.00000 \mathrm{e}-092.12000 \mathrm{e}-01$

$2.52253 \mathrm{e}+012.52253 \mathrm{e}+012.52253 \mathrm{e}+001.00000 \mathrm{e}-092.12000 \mathrm{e}-01$

$1.00000 \mathrm{e}-05$ 1.00000e-05 1.00000e-06 1.00000e-09 1.00000e-01

$1.00000 \mathrm{e}+001.00000 \mathrm{e}+001.00000 \mathrm{e}-01$ 1.00000e-09 1.00000e-01

Element: 9460 \# of layers: 7

$\mathrm{Kx} \mathrm{Ky} \mathrm{Kz}$ Ss Por

$2.52253 \mathrm{e}+012.52253 \mathrm{e}+012.52253 \mathrm{e}+00$ 1.00000e-09 2.12000e-01

$2.52253 \mathrm{e}+012.52253 \mathrm{e}+012.52253 \mathrm{e}+00$ 1.00000e-09 2.12000e-01

$2.52253 \mathrm{e}+012.52253 \mathrm{e}+012.52253 \mathrm{e}+00$ 1.00000e-09 2.12000e-01

$2.52253 \mathrm{e}+012.52253 \mathrm{e}+012.52253 \mathrm{e}+001.00000 \mathrm{e}-092.12000 \mathrm{e}-01$

$2.52253 \mathrm{e}+012.52253 \mathrm{e}+012.52253 \mathrm{e}+00$ 1.00000e-09 2.12000e-01

$1.00000 \mathrm{e}-05$ 1.00000e-05 1.00000e-06 1.00000e-09 1.00000e-01

$1.00000 \mathrm{e}+001.00000 \mathrm{e}+001.00000 \mathrm{e}-011.00000 \mathrm{e}-091.00000 \mathrm{e}-01$

Element: 9461 \# of layers: 7

$\mathrm{Kx} \mathrm{Ky} \mathrm{Kz}$ Ss Por

$2.52253 \mathrm{e}+012.52253 \mathrm{e}+012.52253 \mathrm{e}+00$ 1.00000e-09 2.12000e-01

$2.52253 \mathrm{e}+012.52253 \mathrm{e}+012.52253 \mathrm{e}+00$ 1.00000e-09 2.12000e-01

$2.52253 \mathrm{e}+012.52253 \mathrm{e}+012.52253 \mathrm{e}+001.00000 \mathrm{e}-092.12000 \mathrm{e}-01$

$2.52253 \mathrm{e}+012.52253 \mathrm{e}+012.52253 \mathrm{e}+001.00000 \mathrm{e}-092.12000 \mathrm{e}-01$

$2.52253 \mathrm{e}+012.52253 \mathrm{e}+012.52253 \mathrm{e}+001.00000 \mathrm{e}-092.12000 \mathrm{e}-01$

$1.00000 \mathrm{e}-05$ 1.00000e-05 1.00000e-06 1.00000e-09 1.00000e-01

$1.00000 \mathrm{e}+001.00000 \mathrm{e}+001.00000 \mathrm{e}-011.00000 \mathrm{e}-091.00000 \mathrm{e}-01$

Element: 9462 \# of layers: 7

$\mathrm{Kx} \mathrm{Ky} \mathrm{Kz}$ Ss Por

$2.52253 \mathrm{e}+012.52253 \mathrm{e}+012.52253 \mathrm{e}+00$ 1.00000e-09 2.12000e-01

$2.52253 \mathrm{e}+012.52253 \mathrm{e}+012.52253 \mathrm{e}+00$ 1.00000e-09 2.12000e-01

$2.52253 \mathrm{e}+012.52253 \mathrm{e}+012.52253 \mathrm{e}+001.00000 \mathrm{e}-092.12000 \mathrm{e}-01$

$2.52253 \mathrm{e}+012.52253 \mathrm{e}+012.52253 \mathrm{e}+00$ 1.00000e-09 2.12000e-01

$2.52253 \mathrm{e}+012.52253 \mathrm{e}+012.52253 \mathrm{e}+00$ 1.00000e-09 2.12000e-01 1.00000e-05 1.00000e-05 1.00000e-06 1.00000e-09 1.00000e-01

$1.00000 \mathrm{e}+001.00000 \mathrm{e}+001.00000 \mathrm{e}-011.00000 \mathrm{e}-091.00000 \mathrm{e}-01$

Element: 9463 \# of layers: 7

$\mathrm{Kx} \mathrm{Ky} \mathrm{Kz}$ Ss Por

$2.63976 \mathrm{e}+012.63976 \mathrm{e}+012.63976 \mathrm{e}+00$ 1.00000e-09 2.12000e-01

$2.63976 \mathrm{e}+012.63976 \mathrm{e}+012.63976 \mathrm{e}+001.00000 \mathrm{e}-092.12000 \mathrm{e}-01$

$2.63976 \mathrm{e}+012.63976 \mathrm{e}+012.63976 \mathrm{e}+001.00000 \mathrm{e}-092.12000 \mathrm{e}-01$

$2.63976 \mathrm{e}+012.63976 \mathrm{e}+012.63976 \mathrm{e}+001.00000 \mathrm{e}-092.12000 \mathrm{e}-01$

$2.63976 \mathrm{e}+012.63976 \mathrm{e}+012.63976 \mathrm{e}+001.00000 \mathrm{e}-092.12000 \mathrm{e}-01$

$1.00000 \mathrm{e}-05$ 1.00000e-05 1.00000e-06 1.00000e-09 1.00000e-01 
$1.00000 \mathrm{e}+001.00000 \mathrm{e}+001.00000 \mathrm{e}-01$ 1.00000e-09 1.00000e-01

Element: 9464 \# of layers: 9

Kx Ky Kz Ss Por

$2.63976 \mathrm{e}+012.63976 \mathrm{e}+012.63976 \mathrm{e}+00$ 1.00000e-09 2.12000e-01

$2.63976 \mathrm{e}+012.63976 \mathrm{e}+012.63976 \mathrm{e}+001.00000 \mathrm{e}-092.12000 \mathrm{e}-01$

$2.63976 \mathrm{e}+012.63976 \mathrm{e}+012.63976 \mathrm{e}+001.00000 \mathrm{e}-092.12000 \mathrm{e}-01$

$2.63976 \mathrm{e}+012.63976 \mathrm{e}+012.63976 \mathrm{e}+001.00000 \mathrm{e}-092.12000 \mathrm{e}-01$

$2.63976 \mathrm{e}+012.63976 \mathrm{e}+012.63976 \mathrm{e}+00$ 1.00000e-09 2.12000e-01

$1.00000 \mathrm{e}-02$ 1.00000e-02 1.00000e-03 1.00000e-09 1.00000e-01

$1.00000 \mathrm{e}+001.00000 \mathrm{e}+001.00000 \mathrm{e}-011.00000 \mathrm{e}-091.00000 \mathrm{e}-01$

$1.00000 \mathrm{e}-05$ 1.00000e-05 1.00000e-06 1.00000e-09 1.00000e-01

$1.00000 \mathrm{e}+001.00000 \mathrm{e}+001.00000 \mathrm{e}-011.00000 \mathrm{e}-091.00000 \mathrm{e}-01$

Element: 9465 \# of layers: 7

$\mathrm{Kx} \mathrm{Ky} \mathrm{Kz}$ Ss Por

$2.63976 \mathrm{e}+012.63976 \mathrm{e}+012.63976 \mathrm{e}+00$ 1.00000e-09 2.12000e-01

$2.63976 \mathrm{e}+012.63976 \mathrm{e}+012.63976 \mathrm{e}+001.00000 \mathrm{e}-092.12000 \mathrm{e}-01$

$2.63976 \mathrm{e}+012.63976 \mathrm{e}+012.63976 \mathrm{e}+00$ 1.00000e-09 2.12000e-01

$2.63976 \mathrm{e}+012.63976 \mathrm{e}+012.63976 \mathrm{e}+00$ 1.00000e-09 2.12000e-01

$2.63976 \mathrm{e}+012.63976 \mathrm{e}+012.63976 \mathrm{e}+00$ 1.00000e-09 2.12000e-01

$1.00000 \mathrm{e}-05$ 1.00000e-05 1.00000e-06 1.00000e-09 1.00000e-01

$1.00000 \mathrm{e}+001.00000 \mathrm{e}+001.00000 \mathrm{e}-011.00000 \mathrm{e}-091.00000 \mathrm{e}-01$

Element: 9466 \# of layers: 7

$\mathrm{Kx} \mathrm{Ky} \mathrm{Kz}$ Ss Por

$2.63976 \mathrm{e}+012.63976 \mathrm{e}+012.63976 \mathrm{e}+00$ 1.00000e-09 2.12000e-01

$2.63976 \mathrm{e}+012.63976 \mathrm{e}+012.63976 \mathrm{e}+001.00000 \mathrm{e}-092.12000 \mathrm{e}-01$

$2.63976 \mathrm{e}+012.63976 \mathrm{e}+012.63976 \mathrm{e}+001.00000 \mathrm{e}-092.12000 \mathrm{e}-01$

$2.63976 \mathrm{e}+012.63976 \mathrm{e}+012.63976 \mathrm{e}+001.00000 \mathrm{e}-092.12000 \mathrm{e}-01$

$2.63976 \mathrm{e}+012.63976 \mathrm{e}+012.63976 \mathrm{e}+001.00000 \mathrm{e}-092.12000 \mathrm{e}-01$

$1.00000 \mathrm{e}-05$ 1.00000e-05 1.00000e-06 1.00000e-09 1.00000e-01

$1.00000 \mathrm{e}+001.00000 \mathrm{e}+001.00000 \mathrm{e}-011.00000 \mathrm{e}-091.00000 \mathrm{e}-01$

Element: 9467 \# of layers: 7

Kx Ky Kz Ss Por

$2.63976 \mathrm{e}+012.63976 \mathrm{e}+012.63976 \mathrm{e}+00$ 1.00000e-09 2.12000e-01

$2.63976 \mathrm{e}+012.63976 \mathrm{e}+012.63976 \mathrm{e}+00$ 1.00000e-09 2.12000e-01

$2.63976 \mathrm{e}+012.63976 \mathrm{e}+012.63976 \mathrm{e}+001.00000 \mathrm{e}-092.12000 \mathrm{e}-01$

$2.63976 \mathrm{e}+012.63976 \mathrm{e}+012.63976 \mathrm{e}+00$ 1.00000e-09 2.12000e-01

$2.63976 \mathrm{e}+012.63976 \mathrm{e}+012.63976 \mathrm{e}+001.00000 \mathrm{e}-092.12000 \mathrm{e}-01$

$1.00000 \mathrm{e}-05$ 1.00000e-05 1.00000e-06 1.00000e-09 1.00000e-01

$1.00000 \mathrm{e}+001.00000 \mathrm{e}+001.00000 \mathrm{e}-011.00000 \mathrm{e}-091.00000 \mathrm{e}-01$

Element: 9468 \# of layers: 7

$\mathrm{Kx} \mathrm{Ky} \mathrm{Kz}$ Ss Por

$2.52253 \mathrm{e}+012.52253 \mathrm{e}+012.52253 \mathrm{e}+00$ 1.00000e-09 2.12000e-01

$2.52253 \mathrm{e}+012.52253 \mathrm{e}+012.52253 \mathrm{e}+00$ 1.00000e-09 2.12000e-01

$2.52253 \mathrm{e}+012.52253 \mathrm{e}+012.52253 \mathrm{e}+00$ 1.00000e-09 2.12000e-01

$2.52253 \mathrm{e}+012.52253 \mathrm{e}+012.52253 \mathrm{e}+00$ 1.00000e-09 2.12000e-01

$2.52253 \mathrm{e}+012.52253 \mathrm{e}+012.52253 \mathrm{e}+001.00000 \mathrm{e}-092.12000 \mathrm{e}-01$ 
$1.00000 \mathrm{e}-05$ 1.00000e-05 1.00000e-06 1.00000e-09 1.00000e-01 $1.00000 \mathrm{e}+001.00000 \mathrm{e}+001.00000 \mathrm{e}-01$ 1.00000e-09 1.00000e-01 Element: 9469 \# of layers: 7

$\mathrm{Kx} \mathrm{Ky} \mathrm{Kz}$ Ss Por

$2.52253 \mathrm{e}+012.52253 \mathrm{e}+012.52253 \mathrm{e}+001.00000 \mathrm{e}-092.12000 \mathrm{e}-01$

$2.52253 \mathrm{e}+012.52253 \mathrm{e}+012.52253 \mathrm{e}+00$ 1.00000e-09 2.12000e-01

$2.52253 \mathrm{e}+012.52253 \mathrm{e}+012.52253 \mathrm{e}+00$ 1.00000e-09 2.12000e-01

$2.52253 \mathrm{e}+012.52253 \mathrm{e}+012.52253 \mathrm{e}+001.00000 \mathrm{e}-092.12000 \mathrm{e}-01$

$2.52253 \mathrm{e}+012.52253 \mathrm{e}+012.52253 \mathrm{e}+001.00000 \mathrm{e}-092.12000 \mathrm{e}-01$

$1.00000 \mathrm{e}-05$ 1.00000e-05 1.00000e-06 1.00000e-09 1.00000e-01

$1.00000 \mathrm{e}+001.00000 \mathrm{e}+001.00000 \mathrm{e}-01$ 1.00000e-09 1.00000e-01

Element: 9470 \# of layers: 7

$\mathrm{Kx} \mathrm{Ky} \mathrm{Kz}$ Ss Por

$2.63976 \mathrm{e}+012.63976 \mathrm{e}+012.63976 \mathrm{e}+00$ 1.00000e-09 2.12000e-01

$2.63976 \mathrm{e}+012.63976 \mathrm{e}+012.63976 \mathrm{e}+001.00000 \mathrm{e}-092.12000 \mathrm{e}-01$

$2.63976 \mathrm{e}+012.63976 \mathrm{e}+012.63976 \mathrm{e}+001.00000 \mathrm{e}-092.12000 \mathrm{e}-01$

$2.63976 \mathrm{e}+012.63976 \mathrm{e}+012.63976 \mathrm{e}+001.00000 \mathrm{e}-092.12000 \mathrm{e}-01$

$2.63976 \mathrm{e}+012.63976 \mathrm{e}+012.63976 \mathrm{e}+001.00000 \mathrm{e}-092.12000 \mathrm{e}-01$

$1.00000 \mathrm{e}-051.00000 \mathrm{e}-051.00000 \mathrm{e}-061.00000 \mathrm{e}-091.00000 \mathrm{e}-01$

$1.00000 \mathrm{e}+001.00000 \mathrm{e}+001.00000 \mathrm{e}-011.00000 \mathrm{e}-091.00000 \mathrm{e}-01$

Element: 9471 \# of layers: 9

$\mathrm{Kx} \mathrm{Ky} \mathrm{Kz}$ Ss Por

$2.63976 \mathrm{e}+012.63976 \mathrm{e}+012.63976 \mathrm{e}+00$ 1.00000e-09 2.12000e-01

$2.63976 \mathrm{e}+012.63976 \mathrm{e}+012.63976 \mathrm{e}+001.00000 \mathrm{e}-092.12000 \mathrm{e}-01$

$2.63976 \mathrm{e}+012.63976 \mathrm{e}+012.63976 \mathrm{e}+001.00000 \mathrm{e}-092.12000 \mathrm{e}-01$

$2.63976 \mathrm{e}+012.63976 \mathrm{e}+012.63976 \mathrm{e}+001.00000 \mathrm{e}-092.12000 \mathrm{e}-01$

$2.63976 \mathrm{e}+012.63976 \mathrm{e}+012.63976 \mathrm{e}+001.00000 \mathrm{e}-092.12000 \mathrm{e}-01$

1.00000e-02 1.00000e-02 1.00000e-03 1.00000e-09 1.00000e-01

$1.00000 \mathrm{e}+001.00000 \mathrm{e}+001.00000 \mathrm{e}-011.00000 \mathrm{e}-091.00000 \mathrm{e}-01$

$1.00000 \mathrm{e}-05$ 1.00000e-05 1.00000e-06 1.00000e-09 1.00000e-01

$1.00000 \mathrm{e}+001.00000 \mathrm{e}+001.00000 \mathrm{e}-011.00000 \mathrm{e}-091.00000 \mathrm{e}-01$

Element: 9472 \# of layers: 9

Kx Ky Kz Ss Por

$2.63976 \mathrm{e}+012.63976 \mathrm{e}+012.63976 \mathrm{e}+00$ 1.00000e-09 2.12000e-01

$2.63976 \mathrm{e}+012.63976 \mathrm{e}+012.63976 \mathrm{e}+00$ 1.00000e-09 2.12000e-01

$2.63976 \mathrm{e}+012.63976 \mathrm{e}+012.63976 \mathrm{e}+00$ 1.00000e-09 2.12000e-01

$2.63976 \mathrm{e}+012.63976 \mathrm{e}+012.63976 \mathrm{e}+001.00000 \mathrm{e}-092.12000 \mathrm{e}-01$

$2.63976 \mathrm{e}+012.63976 \mathrm{e}+012.63976 \mathrm{e}+001.00000 \mathrm{e}-092.12000 \mathrm{e}-01$

1.00000e-02 1.00000e-02 1.00000e-03 1.00000e-09 1.00000e-01

$1.00000 \mathrm{e}+001.00000 \mathrm{e}+001.00000 \mathrm{e}-011.00000 \mathrm{e}-091.00000 \mathrm{e}-01$

$1.00000 \mathrm{e}-05$ 1.00000e-05 1.00000e-06 1.00000e-09 1.00000e-01

$1.00000 \mathrm{e}+001.00000 \mathrm{e}+001.00000 \mathrm{e}-011.00000 \mathrm{e}-091.00000 \mathrm{e}-01$

Element: 9473 \# of layers: 9

$\mathrm{Kx} \mathrm{Ky} \mathrm{Kz}$ Ss Por

$2.63976 \mathrm{e}+012.63976 \mathrm{e}+012.63976 \mathrm{e}+00$ 1.00000e-09 2.12000e-01

$2.63976 \mathrm{e}+012.63976 \mathrm{e}+012.63976 \mathrm{e}+001.00000 \mathrm{e}-092.12000 \mathrm{e}-01$ 
$2.63976 \mathrm{e}+012.63976 \mathrm{e}+012.63976 \mathrm{e}+00$ 1.00000e-09 2.12000e-01 $2.63976 \mathrm{e}+012.63976 \mathrm{e}+012.63976 \mathrm{e}+00$ 1.00000e-09 2.12000e-01 $2.63976 \mathrm{e}+012.63976 \mathrm{e}+012.63976 \mathrm{e}+00$ 1.00000e-09 2.12000e-01 $1.00000 \mathrm{e}-02$ 1.00000e-02 1.00000e-03 1.00000e-09 1.00000e-01 $1.00000 \mathrm{e}+001.00000 \mathrm{e}+001.00000 \mathrm{e}-011.00000 \mathrm{e}-091.00000 \mathrm{e}-01$ $1.00000 \mathrm{e}-05$ 1.00000e-05 1.00000e-06 1.00000e-09 1.00000e-01 $1.00000 \mathrm{e}+001.00000 \mathrm{e}+001.00000 \mathrm{e}-01$ 1.00000e-09 1.00000e-01 Element: 9474 \# of layers: 9

$\mathrm{Kx} \mathrm{Ky} \mathrm{Kz}$ Ss Por

$2.63976 \mathrm{e}+012.63976 \mathrm{e}+012.63976 \mathrm{e}+00$ 1.00000e-09 2.12000e-01 $2.63976 \mathrm{e}+012.63976 \mathrm{e}+012.63976 \mathrm{e}+00$ 1.00000e-09 2.12000e-01 $2.63976 \mathrm{e}+012.63976 \mathrm{e}+012.63976 \mathrm{e}+001.00000 \mathrm{e}-092.12000 \mathrm{e}-01$ $2.63976 \mathrm{e}+012.63976 \mathrm{e}+012.63976 \mathrm{e}+00$ 1.00000e-09 2.12000e-01 $2.63976 \mathrm{e}+012.63976 \mathrm{e}+012.63976 \mathrm{e}+001.00000 \mathrm{e}-092.12000 \mathrm{e}-01$ $1.00000 \mathrm{e}-02$ 1.00000e-02 1.00000e-03 1.00000e-09 1.00000e-01 $1.00000 \mathrm{e}+001.00000 \mathrm{e}+001.00000 \mathrm{e}-011.00000 \mathrm{e}-091.00000 \mathrm{e}-01$ $1.00000 \mathrm{e}-05$ 1.00000e-05 1.00000e-06 1.00000e-09 1.00000e-01 $1.00000 \mathrm{e}+001.00000 \mathrm{e}+001.00000 \mathrm{e}-01$ 1.00000e-09 1.00000e-01 Element: 9475 \# of layers: 8

$\mathrm{Kx} \mathrm{Ky} \mathrm{Kz}$ Ss Por

$2.63976 \mathrm{e}+012.63976 \mathrm{e}+012.63976 \mathrm{e}+00$ 1.00000e-09 2.12000e-01 $2.63976 \mathrm{e}+012.63976 \mathrm{e}+012.63976 \mathrm{e}+00$ 1.00000e-09 2.12000e-01 $2.63976 \mathrm{e}+012.63976 \mathrm{e}+012.63976 \mathrm{e}+00$ 1.00000e-09 2.12000e-01 $2.63976 \mathrm{e}+012.63976 \mathrm{e}+012.63976 \mathrm{e}+001.00000 \mathrm{e}-092.12000 \mathrm{e}-01$ $2.63976 \mathrm{e}+012.63976 \mathrm{e}+012.63976 \mathrm{e}+001.00000 \mathrm{e}-092.12000 \mathrm{e}-01$ $1.00000 \mathrm{e}-02$ 1.00000e-02 1.00000e-03 1.00000e-09 1.00000e-01 $1.00000 \mathrm{e}-05$ 1.00000e-05 1.00000e-06 1.00000e-09 1.00000e-01 $1.00000 \mathrm{e}+001.00000 \mathrm{e}+001.00000 \mathrm{e}-011.00000 \mathrm{e}-09$ 1.00000e-01 Element: 9476 \# of layers: 7

$\mathrm{Kx} \mathrm{Ky} \mathrm{Kz}$ Ss Por

$2.63976 \mathrm{e}+012.63976 \mathrm{e}+012.63976 \mathrm{e}+00$ 1.00000e-09 2.12000e-01 $2.63976 \mathrm{e}+012.63976 \mathrm{e}+012.63976 \mathrm{e}+00$ 1.00000e-09 2.12000e-01 $2.63976 \mathrm{e}+012.63976 \mathrm{e}+012.63976 \mathrm{e}+001.00000 \mathrm{e}-092.12000 \mathrm{e}-01$ $2.63976 \mathrm{e}+012.63976 \mathrm{e}+012.63976 \mathrm{e}+001.00000 \mathrm{e}-092.12000 \mathrm{e}-01$ $2.63976 \mathrm{e}+012.63976 \mathrm{e}+012.63976 \mathrm{e}+001.00000 \mathrm{e}-092.12000 \mathrm{e}-01$ $1.00000 \mathrm{e}-05$ 1.00000e-05 1.00000e-06 1.00000e-09 1.00000e-01 $1.00000 \mathrm{e}+001.00000 \mathrm{e}+001.00000 \mathrm{e}-011.00000 \mathrm{e}-091.00000 \mathrm{e}-01$ Element: 9477 \# of layers: 7

$\mathrm{Kx} \mathrm{Ky} \mathrm{Kz}$ Ss Por

$2.63976 \mathrm{e}+012.63976 \mathrm{e}+012.63976 \mathrm{e}+00$ 1.00000e-09 2.12000e-01 $2.63976 \mathrm{e}+012.63976 \mathrm{e}+012.63976 \mathrm{e}+001.00000 \mathrm{e}-092.12000 \mathrm{e}-01$ $2.63976 \mathrm{e}+012.63976 \mathrm{e}+012.63976 \mathrm{e}+001.00000 \mathrm{e}-092.12000 \mathrm{e}-01$ $2.63976 \mathrm{e}+012.63976 \mathrm{e}+012.63976 \mathrm{e}+00$ 1.00000e-09 2.12000e-01 2.63976e+01 2.63976e+01 2.63976e+00 1.00000e-09 2.12000e-01 $1.00000 \mathrm{e}-051.00000 \mathrm{e}-051.00000 \mathrm{e}-061.00000 \mathrm{e}-091.00000 \mathrm{e}-01$ $1.00000 \mathrm{e}+001.00000 \mathrm{e}+001.00000 \mathrm{e}-011.00000 \mathrm{e}-091.00000 \mathrm{e}-01$ 
Element: 9478 \# of layers: 7

$\mathrm{Kx} \mathrm{Ky} \mathrm{Kz}$ Ss Por

$2.63976 \mathrm{e}+012.63976 \mathrm{e}+012.63976 \mathrm{e}+00$ 1.00000e-09 2.12000e-01

$2.63976 \mathrm{e}+012.63976 \mathrm{e}+012.63976 \mathrm{e}+001.00000 \mathrm{e}-092.12000 \mathrm{e}-01$

$2.63976 \mathrm{e}+012.63976 \mathrm{e}+012.63976 \mathrm{e}+001.00000 \mathrm{e}-092.12000 \mathrm{e}-01$

$2.63976 \mathrm{e}+012.63976 \mathrm{e}+012.63976 \mathrm{e}+00$ 1.00000e-09 2.12000e-01

$2.63976 \mathrm{e}+012.63976 \mathrm{e}+012.63976 \mathrm{e}+00$ 1.00000e-09 2.12000e-01

$1.00000 \mathrm{e}-05$ 1.00000e-05 1.00000e-06 1.00000e-09 1.00000e-01

$1.00000 \mathrm{e}+001.00000 \mathrm{e}+001.00000 \mathrm{e}-011.00000 \mathrm{e}-091.00000 \mathrm{e}-01$

Element: 9479 \# of layers: 7

$\mathrm{Kx} \mathrm{Ky} \mathrm{Kz}$ Ss Por

$2.63976 \mathrm{e}+012.63976 \mathrm{e}+012.63976 \mathrm{e}+00$ 1.00000e-09 2.12000e-01

$2.63976 \mathrm{e}+012.63976 \mathrm{e}+012.63976 \mathrm{e}+001.00000 \mathrm{e}-092.12000 \mathrm{e}-01$

$2.63976 \mathrm{e}+012.63976 \mathrm{e}+012.63976 \mathrm{e}+00$ 1.00000e-09 2.12000e-01

$2.63976 \mathrm{e}+012.63976 \mathrm{e}+012.63976 \mathrm{e}+001.00000 \mathrm{e}-092.12000 \mathrm{e}-01$

$2.63976 \mathrm{e}+012.63976 \mathrm{e}+012.63976 \mathrm{e}+001.00000 \mathrm{e}-092.12000 \mathrm{e}-01$

$1.00000 \mathrm{e}-05$ 1.00000e-05 1.00000e-06 1.00000e-09 1.00000e-01

$1.00000 \mathrm{e}+001.00000 \mathrm{e}+001.00000 \mathrm{e}-01$ 1.00000e-09 1.00000e-01

Element: 9480 \# of layers: 7

$\mathrm{Kx} \mathrm{Ky} \mathrm{Kz}$ Ss Por

$2.63976 \mathrm{e}+012.63976 \mathrm{e}+012.63976 \mathrm{e}+001.00000 \mathrm{e}-092.12000 \mathrm{e}-01$

$2.63976 \mathrm{e}+012.63976 \mathrm{e}+012.63976 \mathrm{e}+00$ 1.00000e-09 2.12000e-01

$2.63976 \mathrm{e}+012.63976 \mathrm{e}+012.63976 \mathrm{e}+00$ 1.00000e-09 2.12000e-01

$2.63976 \mathrm{e}+012.63976 \mathrm{e}+012.63976 \mathrm{e}+00$ 1.00000e-09 2.12000e-01

$2.63976 \mathrm{e}+012.63976 \mathrm{e}+012.63976 \mathrm{e}+001.00000 \mathrm{e}-092.12000 \mathrm{e}-01$

$1.00000 \mathrm{e}-05$ 1.00000e-05 1.00000e-06 1.00000e-09 1.00000e-01

$1.00000 \mathrm{e}+001.00000 \mathrm{e}+001.00000 \mathrm{e}-011.00000 \mathrm{e}-091.00000 \mathrm{e}-01$

Element: 9481 \# of layers: 7

Kx Ky Kz Ss Por

$2.63976 \mathrm{e}+012.63976 \mathrm{e}+012.63976 \mathrm{e}+00$ 1.00000e-09 2.12000e-01

$2.63976 \mathrm{e}+012.63976 \mathrm{e}+012.63976 \mathrm{e}+001.00000 \mathrm{e}-092.12000 \mathrm{e}-01$

$2.63976 \mathrm{e}+012.63976 \mathrm{e}+012.63976 \mathrm{e}+00$ 1.00000e-09 2.12000e-01

$2.63976 \mathrm{e}+012.63976 \mathrm{e}+012.63976 \mathrm{e}+00$ 1.00000e-09 2.12000e-01

$2.63976 \mathrm{e}+012.63976 \mathrm{e}+012.63976 \mathrm{e}+001.00000 \mathrm{e}-092.12000 \mathrm{e}-01$

$1.00000 \mathrm{e}-05$ 1.00000e-05 1.00000e-06 1.00000e-09 1.00000e-01

$1.00000 \mathrm{e}+001.00000 \mathrm{e}+001.00000 \mathrm{e}-011.00000 \mathrm{e}-091.00000 \mathrm{e}-01$

Element: 9482 \# of layers: 7

$\mathrm{Kx} \mathrm{Ky} \mathrm{Kz}$ Ss Por

$2.86499 \mathrm{e}+012.86499 \mathrm{e}+012.86499 \mathrm{e}+00$ 1.00000e-09 2.12000e-01

$2.86499 \mathrm{e}+012.86499 \mathrm{e}+012.86499 \mathrm{e}+00$ 1.00000e-09 2.12000e-01

$2.86499 \mathrm{e}+012.86499 \mathrm{e}+012.86499 \mathrm{e}+00$ 1.00000e-09 2.12000e-01

$2.86499 \mathrm{e}+012.86499 \mathrm{e}+012.86499 \mathrm{e}+001.00000 \mathrm{e}-092.12000 \mathrm{e}-01$

$2.86499 \mathrm{e}+012.86499 \mathrm{e}+012.86499 \mathrm{e}+00$ 1.00000e-09 2.12000e-01

$1.00000 \mathrm{e}-05$ 1.00000e-05 1.00000e-06 1.00000e-09 1.00000e-01

$1.00000 \mathrm{e}+001.00000 \mathrm{e}+001.00000 \mathrm{e}-011.00000 \mathrm{e}-09$ 1.00000e-01

Element: 9483 \# of layers: 7 
$\mathrm{Kx} \mathrm{Ky} \mathrm{Kz}$ Ss Por

$2.86499 \mathrm{e}+012.86499 \mathrm{e}+012.86499 \mathrm{e}+00$ 1.00000e-09 2.12000e-01

$2.86499 \mathrm{e}+012.86499 \mathrm{e}+012.86499 \mathrm{e}+00$ 1.00000e-09 2.12000e-01

$2.86499 \mathrm{e}+012.86499 \mathrm{e}+012.86499 \mathrm{e}+001.00000 \mathrm{e}-092.12000 \mathrm{e}-01$

$2.86499 \mathrm{e}+012.86499 \mathrm{e}+012.86499 \mathrm{e}+001.00000 \mathrm{e}-092.12000 \mathrm{e}-01$

$2.86499 \mathrm{e}+012.86499 \mathrm{e}+012.86499 \mathrm{e}+001.00000 \mathrm{e}-092.12000 \mathrm{e}-01$

$1.00000 \mathrm{e}-05$ 1.00000e-05 1.00000e-06 1.00000e-09 1.00000e-01

$1.00000 \mathrm{e}+001.00000 \mathrm{e}+001.00000 \mathrm{e}-01$ 1.00000e-09 1.00000e-01

Element: 9484 \# of layers: 7

$\mathrm{Kx} \mathrm{Ky} \mathrm{Kz}$ Ss Por

$2.86499 \mathrm{e}+012.86499 \mathrm{e}+012.86499 \mathrm{e}+00$ 1.00000e-09 2.12000e-01

$2.86499 \mathrm{e}+012.86499 \mathrm{e}+012.86499 \mathrm{e}+001.00000 \mathrm{e}-092.12000 \mathrm{e}-01$

$2.86499 \mathrm{e}+012.86499 \mathrm{e}+012.86499 \mathrm{e}+00$ 1.00000e-09 2.12000e-01

$2.86499 \mathrm{e}+012.86499 \mathrm{e}+012.86499 \mathrm{e}+00$ 1.00000e-09 2.12000e-01

$2.86499 \mathrm{e}+012.86499 \mathrm{e}+012.86499 \mathrm{e}+001.00000 \mathrm{e}-092.12000 \mathrm{e}-01$

$1.00000 \mathrm{e}-05$ 1.00000e-05 1.00000e-06 1.00000e-09 1.00000e-01

$1.00000 \mathrm{e}+001.00000 \mathrm{e}+001.00000 \mathrm{e}-01$ 1.00000e-09 1.00000e-01

Element: 9485 \# of layers: 7

$\mathrm{Kx} \mathrm{Ky} \mathrm{Kz}$ Ss Por

$2.63976 \mathrm{e}+012.63976 \mathrm{e}+012.63976 \mathrm{e}+00$ 1.00000e-09 2.12000e-01

$2.63976 \mathrm{e}+012.63976 \mathrm{e}+012.63976 \mathrm{e}+00$ 1.00000e-09 2.12000e-01

$2.63976 \mathrm{e}+012.63976 \mathrm{e}+012.63976 \mathrm{e}+00$ 1.00000e-09 2.12000e-01

$2.63976 \mathrm{e}+012.63976 \mathrm{e}+012.63976 \mathrm{e}+00$ 1.00000e-09 2.12000e-01

$2.63976 \mathrm{e}+012.63976 \mathrm{e}+012.63976 \mathrm{e}+00$ 1.00000e-09 2.12000e-01

$1.00000 \mathrm{e}-05$ 1.00000e-05 1.00000e-06 1.00000e-09 1.00000e-01

$1.00000 \mathrm{e}+001.00000 \mathrm{e}+001.00000 \mathrm{e}-01$ 1.00000e-09 1.00000e-01

Element: 9486 \# of layers: 7

$\mathrm{Kx} \mathrm{Ky} \mathrm{Kz} \mathrm{Ss} \mathrm{Por}$

$2.63976 \mathrm{e}+012.63976 \mathrm{e}+012.63976 \mathrm{e}+001.00000 \mathrm{e}-092.12000 \mathrm{e}-01$

$2.63976 \mathrm{e}+012.63976 \mathrm{e}+012.63976 \mathrm{e}+001.00000 \mathrm{e}-092.12000 \mathrm{e}-01$

$2.63976 \mathrm{e}+012.63976 \mathrm{e}+012.63976 \mathrm{e}+001.00000 \mathrm{e}-092.12000 \mathrm{e}-01$

$2.63976 \mathrm{e}+012.63976 \mathrm{e}+012.63976 \mathrm{e}+001.00000 \mathrm{e}-092.12000 \mathrm{e}-01$

$2.63976 \mathrm{e}+012.63976 \mathrm{e}+012.63976 \mathrm{e}+00$ 1.00000e-09 2.12000e-01

$1.00000 \mathrm{e}-05$ 1.00000e-05 1.00000e-06 1.00000e-09 1.00000e-01

$1.00000 \mathrm{e}+001.00000 \mathrm{e}+001.00000 \mathrm{e}-011.00000 \mathrm{e}-091.00000 \mathrm{e}-01$

Element: 9487 \# of layers: 7

Kx Ky Kz Ss Por

$2.63976 \mathrm{e}+012.63976 \mathrm{e}+012.63976 \mathrm{e}+00$ 1.00000e-09 2.12000e-01

$2.63976 \mathrm{e}+012.63976 \mathrm{e}+012.63976 \mathrm{e}+001.00000 \mathrm{e}-092.12000 \mathrm{e}-01$

$2.63976 \mathrm{e}+012.63976 \mathrm{e}+012.63976 \mathrm{e}+001.00000 \mathrm{e}-092.12000 \mathrm{e}-01$

$2.63976 \mathrm{e}+012.63976 \mathrm{e}+012.63976 \mathrm{e}+001.00000 \mathrm{e}-092.12000 \mathrm{e}-01$

$2.63976 \mathrm{e}+012.63976 \mathrm{e}+012.63976 \mathrm{e}+00$ 1.00000e-09 2.12000e-01

$1.00000 \mathrm{e}-05$ 1.00000e-05 1.00000e-06 1.00000e-09 1.00000e-01

$1.00000 \mathrm{e}+001.00000 \mathrm{e}+001.00000 \mathrm{e}-01$ 1.00000e-09 1.00000e-01

Element: 9488 \# of layers: 7

Kx Ky Kz Ss Por 
$2.63976 \mathrm{e}+012.63976 \mathrm{e}+012.63976 \mathrm{e}+00$ 1.00000e-09 2.12000e-01 $2.63976 \mathrm{e}+012.63976 \mathrm{e}+012.63976 \mathrm{e}+00$ 1.00000e-09 2.12000e-01 $2.63976 \mathrm{e}+012.63976 \mathrm{e}+012.63976 \mathrm{e}+00$ 1.00000e-09 2.12000e-01 $2.63976 \mathrm{e}+012.63976 \mathrm{e}+012.63976 \mathrm{e}+001.00000 \mathrm{e}-092.12000 \mathrm{e}-01$ $2.63976 \mathrm{e}+012.63976 \mathrm{e}+012.63976 \mathrm{e}+001.00000 \mathrm{e}-092.12000 \mathrm{e}-01$ $1.00000 \mathrm{e}-05$ 1.00000e-05 1.00000e-06 1.00000e-09 1.00000e-01 $1.00000 \mathrm{e}+001.00000 \mathrm{e}+001.00000 \mathrm{e}-011.00000 \mathrm{e}-091.00000 \mathrm{e}-01$ Element: 9489 \# of layers: 7

$\mathrm{Kx} \mathrm{Ky} \mathrm{Kz}$ Ss Por

$2.86499 \mathrm{e}+012.86499 \mathrm{e}+012.86499 \mathrm{e}+00$ 1.00000e-09 2.12000e-01 $2.86499 \mathrm{e}+012.86499 \mathrm{e}+012.86499 \mathrm{e}+00$ 1.00000e-09 2.12000e-01 $2.86499 \mathrm{e}+012.86499 \mathrm{e}+012.86499 \mathrm{e}+001.00000 \mathrm{e}-092.12000 \mathrm{e}-01$ $2.86499 \mathrm{e}+012.86499 \mathrm{e}+012.86499 \mathrm{e}+00$ 1.00000e-09 2.12000e-01 $2.86499 \mathrm{e}+012.86499 \mathrm{e}+012.86499 \mathrm{e}+00$ 1.00000e-09 2.12000e-01 $1.00000 \mathrm{e}-05$ 1.00000e-05 1.00000e-06 1.00000e-09 1.00000e-01 $1.00000 \mathrm{e}+001.00000 \mathrm{e}+001.00000 \mathrm{e}-011.00000 \mathrm{e}-091.00000 \mathrm{e}-01$ Element: 9490 \# of layers: 7

$\mathrm{Kx} \mathrm{Ky} \mathrm{Kz}$ Ss Por

$2.86499 \mathrm{e}+012.86499 \mathrm{e}+01$ 2.86499e+00 1.00000e-09 2.12000e-01 $2.86499 \mathrm{e}+012.86499 \mathrm{e}+012.86499 \mathrm{e}+00$ 1.00000e-09 2.12000e-01 $2.86499 \mathrm{e}+012.86499 \mathrm{e}+012.86499 \mathrm{e}+001.00000 \mathrm{e}-092.12000 \mathrm{e}-01$ $2.86499 \mathrm{e}+012.86499 \mathrm{e}+012.86499 \mathrm{e}+00$ 1.00000e-09 2.12000e-01 $2.86499 \mathrm{e}+012.86499 \mathrm{e}+012.86499 \mathrm{e}+00$ 1.00000e-09 2.12000e-01 $1.00000 \mathrm{e}-05$ 1.00000e-05 1.00000e-06 1.00000e-09 1.00000e-01 $1.00000 \mathrm{e}+001.00000 \mathrm{e}+001.00000 \mathrm{e}-011.00000 \mathrm{e}-091.00000 \mathrm{e}-01$ Element: 9491 \# of layers: 7

$\mathrm{Kx} \mathrm{Ky} \mathrm{Kz}$ Ss Por

$2.86499 \mathrm{e}+012.86499 \mathrm{e}+012.86499 \mathrm{e}+00$ 1.00000e-09 2.12000e-01 $2.86499 \mathrm{e}+012.86499 \mathrm{e}+012.86499 \mathrm{e}+001.00000 \mathrm{e}-092.12000 \mathrm{e}-01$ $2.86499 \mathrm{e}+012.86499 \mathrm{e}+012.86499 \mathrm{e}+001.00000 \mathrm{e}-092.12000 \mathrm{e}-01$ $2.86499 \mathrm{e}+012.86499 \mathrm{e}+012.86499 \mathrm{e}+00$ 1.00000e-09 2.12000e-01 $2.86499 \mathrm{e}+012.86499 \mathrm{e}+012.86499 \mathrm{e}+001.00000 \mathrm{e}-092.12000 \mathrm{e}-01$ $1.00000 \mathrm{e}-05$ 1.00000e-05 1.00000e-06 1.00000e-09 1.00000e-01 $1.00000 \mathrm{e}+001.00000 \mathrm{e}+001.00000 \mathrm{e}-011.00000 \mathrm{e}-091.00000 \mathrm{e}-01$ Element: 9492 \# of layers: 7

$\mathrm{Kx} \mathrm{Ky} \mathrm{Kz}$ Ss Por

$2.86499 \mathrm{e}+012.86499 \mathrm{e}+012.86499 \mathrm{e}+00$ 1.00000e-09 2.12000e-01 $2.86499 \mathrm{e}+012.86499 \mathrm{e}+012.86499 \mathrm{e}+001.00000 \mathrm{e}-092.12000 \mathrm{e}-01$ $2.86499 \mathrm{e}+012.86499 \mathrm{e}+012.86499 \mathrm{e}+001.00000 \mathrm{e}-092.12000 \mathrm{e}-01$ $2.86499 \mathrm{e}+012.86499 \mathrm{e}+012.86499 \mathrm{e}+00$ 1.00000e-09 2.12000e-01 $2.86499 \mathrm{e}+012.86499 \mathrm{e}+012.86499 \mathrm{e}+001.00000 \mathrm{e}-092.12000 \mathrm{e}-01$ $1.00000 \mathrm{e}-05$ 1.00000e-05 1.00000e-06 1.00000e-09 1.00000e-01 $1.00000 \mathrm{e}+001.00000 \mathrm{e}+001.00000 \mathrm{e}-011.00000 \mathrm{e}-091.00000 \mathrm{e}-01$ Element: 9493 \# of layers: 7

$\mathrm{Kx} \mathrm{Ky} \mathrm{Kz}$ Ss Por

$2.86499 e+012.86499 e+012.86499 e+001.00000 e-09$ 2.12000e-01 
$2.86499 \mathrm{e}+012.86499 \mathrm{e}+012.86499 \mathrm{e}+00$ 1.00000e-09 2.12000e-01 $2.86499 \mathrm{e}+012.86499 \mathrm{e}+012.86499 \mathrm{e}+00$ 1.00000e-09 2.12000e-01 $2.86499 \mathrm{e}+012.86499 \mathrm{e}+012.86499 \mathrm{e}+00$ 1.00000e-09 2.12000e-01 $2.86499 \mathrm{e}+012.86499 \mathrm{e}+012.86499 \mathrm{e}+001.00000 \mathrm{e}-092.12000 \mathrm{e}-01$ $1.00000 \mathrm{e}-05$ 1.00000e-05 1.00000e-06 1.00000e-09 1.00000e-01 $1.00000 \mathrm{e}+001.00000 \mathrm{e}+001.00000 \mathrm{e}-011.00000 \mathrm{e}-091.00000 \mathrm{e}-01$ Element: 9494 \# of layers: 7

$\mathrm{Kx} \mathrm{Ky} \mathrm{Kz}$ Ss Por

$2.86499 \mathrm{e}+012.86499 \mathrm{e}+012.86499 \mathrm{e}+001.00000 \mathrm{e}-092.12000 \mathrm{e}-01$

$2.86499 \mathrm{e}+012.86499 \mathrm{e}+012.86499 \mathrm{e}+00$ 1.00000e-09 2.12000e-01

$2.86499 \mathrm{e}+012.86499 \mathrm{e}+012.86499 \mathrm{e}+00$ 1.00000e-09 2.12000e-01

$2.86499 \mathrm{e}+012.86499 \mathrm{e}+012.86499 \mathrm{e}+001.00000 \mathrm{e}-092.12000 \mathrm{e}-01$

$2.86499 \mathrm{e}+012.86499 \mathrm{e}+012.86499 \mathrm{e}+00$ 1.00000e-09 2.12000e-01

$1.00000 \mathrm{e}-05$ 1.00000e-05 1.00000e-06 1.00000e-09 1.00000e-01

$1.00000 \mathrm{e}+001.00000 \mathrm{e}+001.00000 \mathrm{e}-01$ 1.00000e-09 1.00000e-01

Element: 9495 \# of layers: 7

$\mathrm{Kx} \mathrm{Ky} \mathrm{Kz}$ Ss Por

$2.86499 \mathrm{e}+012.86499 \mathrm{e}+012.86499 \mathrm{e}+00$ 1.00000e-09 2.12000e-01 $2.86499 \mathrm{e}+012.86499 \mathrm{e}+012.86499 \mathrm{e}+00$ 1.00000e-09 2.12000e-01

$2.86499 \mathrm{e}+012.86499 \mathrm{e}+012.86499 \mathrm{e}+00$ 1.00000e-09 2.12000e-01

$2.86499 \mathrm{e}+012.86499 \mathrm{e}+012.86499 \mathrm{e}+001.00000 \mathrm{e}-092.12000 \mathrm{e}-01$

$2.86499 \mathrm{e}+012.86499 \mathrm{e}+012.86499 \mathrm{e}+00$ 1.00000e-09 2.12000e-01

$1.00000 \mathrm{e}-05$ 1.00000e-05 1.00000e-06 1.00000e-09 1.00000e-01

$1.00000 \mathrm{e}+001.00000 \mathrm{e}+001.00000 \mathrm{e}-011.00000 \mathrm{e}-09$ 1.00000e-01

Element: 9496 \# of layers: 7

$\mathrm{Kx} \mathrm{Ky} \mathrm{Kz}$ Ss Por

$2.86499 \mathrm{e}+012.86499 \mathrm{e}+012.86499 \mathrm{e}+00$ 1.00000e-09 2.12000e-01

$2.86499 \mathrm{e}+012.86499 \mathrm{e}+012.86499 \mathrm{e}+001.00000 \mathrm{e}-092.12000 \mathrm{e}-01$

$2.86499 \mathrm{e}+012.86499 \mathrm{e}+012.86499 \mathrm{e}+001.00000 \mathrm{e}-092.12000 \mathrm{e}-01$

$2.86499 \mathrm{e}+012.86499 \mathrm{e}+012.86499 \mathrm{e}+001.00000 \mathrm{e}-092.12000 \mathrm{e}-01$

$2.86499 \mathrm{e}+012.86499 \mathrm{e}+012.86499 \mathrm{e}+00$ 1.00000e-09 2.12000e-01

$1.00000 \mathrm{e}-051.00000 \mathrm{e}-05$ 1.00000e-06 1.00000e-09 1.00000e-01

$1.00000 \mathrm{e}+001.00000 \mathrm{e}+001.00000 \mathrm{e}-011.00000 \mathrm{e}-091.00000 \mathrm{e}-01$

Element: 9497 \# of layers: 7

$\mathrm{Kx} \mathrm{Ky} \mathrm{Kz}$ Ss Por

$2.86499 \mathrm{e}+012.86499 \mathrm{e}+012.86499 \mathrm{e}+00$ 1.00000e-09 2.12000e-01

$2.86499 \mathrm{e}+012.86499 \mathrm{e}+012.86499 \mathrm{e}+001.00000 \mathrm{e}-092.12000 \mathrm{e}-01$

$2.86499 \mathrm{e}+012.86499 \mathrm{e}+012.86499 \mathrm{e}+001.00000 \mathrm{e}-092.12000 \mathrm{e}-01$

$2.86499 \mathrm{e}+012.86499 \mathrm{e}+012.86499 \mathrm{e}+001.00000 \mathrm{e}-092.12000 \mathrm{e}-01$

$2.86499 \mathrm{e}+012.86499 \mathrm{e}+012.86499 \mathrm{e}+00$ 1.00000e-09 2.12000e-01

1.00000e-05 1.00000e-05 1.00000e-06 1.00000e-09 1.00000e-01

$1.00000 \mathrm{e}+001.00000 \mathrm{e}+001.00000 \mathrm{e}-011.00000 \mathrm{e}-091.00000 \mathrm{e}-01$

Element: 9498 \# of layers: 6

$\mathrm{Kx} \mathrm{Ky} \mathrm{Kz}$ Ss Por

$2.86499 \mathrm{e}+012.86499 \mathrm{e}+012.86499 \mathrm{e}+00$ 1.00000e-09 2.12000e-01

$2.86499 \mathrm{e}+012.86499 \mathrm{e}+012.86499 \mathrm{e}+001.00000 \mathrm{e}-092.12000 \mathrm{e}-01$ 
$2.86499 \mathrm{e}+012.86499 \mathrm{e}+012.86499 \mathrm{e}+00$ 1.00000e-09 2.12000e-01 $2.86499 \mathrm{e}+012.86499 \mathrm{e}+012.86499 \mathrm{e}+00$ 1.00000e-09 2.12000e-01 $1.00000 \mathrm{e}-05$ 1.00000e-05 1.00000e-06 1.00000e-09 1.00000e-01 $1.00000 \mathrm{e}+001.00000 \mathrm{e}+001.00000 \mathrm{e}-011.00000 \mathrm{e}-091.00000 \mathrm{e}-01$ Element: 9499 \# of layers: 6

Kx Ky Kz Ss Por

$2.86499 \mathrm{e}+012.86499 \mathrm{e}+012.86499 \mathrm{e}+00$ 1.00000e-09 2.12000e-01 $2.86499 \mathrm{e}+012.86499 \mathrm{e}+012.86499 \mathrm{e}+001.00000 \mathrm{e}-092.12000 \mathrm{e}-01$ $2.86499 \mathrm{e}+012.86499 \mathrm{e}+012.86499 \mathrm{e}+001.00000 \mathrm{e}-092.12000 \mathrm{e}-01$ $2.86499 \mathrm{e}+012.86499 \mathrm{e}+012.86499 \mathrm{e}+001.00000 \mathrm{e}-092.12000 \mathrm{e}-01$ $1.00000 \mathrm{e}-05$ 1.00000e-05 1.00000e-06 1.00000e-09 1.00000e-01 $1.00000 \mathrm{e}+001.00000 \mathrm{e}+001.00000 \mathrm{e}-011.00000 \mathrm{e}-091.00000 \mathrm{e}-01$ Element: 9500 \# of layers: 6

Kx Ky Kz Ss Por

$3.00584 \mathrm{e}+013.00584 \mathrm{e}+013.00584 \mathrm{e}+00$ 1.00000e-09 2.12000e-01 $3.00584 \mathrm{e}+013.00584 \mathrm{e}+013.00584 \mathrm{e}+001.00000 \mathrm{e}-092.12000 \mathrm{e}-01$ $3.00584 \mathrm{e}+013.00584 \mathrm{e}+013.00584 \mathrm{e}+001.00000 \mathrm{e}-092.12000 \mathrm{e}-01$ $3.00584 \mathrm{e}+013.00584 \mathrm{e}+013.00584 \mathrm{e}+00$ 1.00000e-09 2.12000e-01 $1.00000 \mathrm{e}-05$ 1.00000e-05 1.00000e-06 1.00000e-09 1.00000e-01 $1.00000 \mathrm{e}+001.00000 \mathrm{e}+001.00000 \mathrm{e}-011.00000 \mathrm{e}-091.00000 \mathrm{e}-01$ Element: 9501 \# of layers: 6

Kx Ky Kz Ss Por

$3.00584 \mathrm{e}+013.00584 \mathrm{e}+013.00584 \mathrm{e}+00$ 1.00000e-09 2.12000e-01 $3.00584 \mathrm{e}+013.00584 \mathrm{e}+013.00584 \mathrm{e}+001.00000 \mathrm{e}-092.12000 \mathrm{e}-01$ $3.00584 \mathrm{e}+013.00584 \mathrm{e}+013.00584 \mathrm{e}+001.00000 \mathrm{e}-092.12000 \mathrm{e}-01$ $3.00584 \mathrm{e}+013.00584 \mathrm{e}+013.00584 \mathrm{e}+00$ 1.00000e-09 2.12000e-01 $1.00000 \mathrm{e}-05$ 1.00000e-05 1.00000e-06 1.00000e-09 1.00000e-01 $1.00000 \mathrm{e}+001.00000 \mathrm{e}+001.00000 \mathrm{e}-011.00000 \mathrm{e}-091.00000 \mathrm{e}-01$ Element: 9502 \# of layers: 7

Kx Ky Kz Ss Por $3.00584 \mathrm{e}+013.00584 \mathrm{e}+013.00584 \mathrm{e}+00$ 1.00000e-09 2.12000e-01 $3.00584 \mathrm{e}+013.00584 \mathrm{e}+013.00584 \mathrm{e}+001.00000 \mathrm{e}-092.12000 \mathrm{e}-01$ $3.00584 \mathrm{e}+013.00584 \mathrm{e}+013.00584 \mathrm{e}+001.00000 \mathrm{e}-092.12000 \mathrm{e}-01$ $3.00584 \mathrm{e}+013.00584 \mathrm{e}+013.00584 \mathrm{e}+001.00000 \mathrm{e}-092.12000 \mathrm{e}-01$ $3.00584 \mathrm{e}+013.00584 \mathrm{e}+013.00584 \mathrm{e}+001.00000 \mathrm{e}-092.12000 \mathrm{e}-01$ $1.00000 \mathrm{e}-05$ 1.00000e-05 1.00000e-06 1.00000e-09 1.00000e-01 $1.00000 \mathrm{e}+001.00000 \mathrm{e}+001.00000 \mathrm{e}-011.00000 \mathrm{e}-091.00000 \mathrm{e}-01$ Element: 9503 \# of layers: 7

Kx Ky Kz Ss Por

$2.86499 \mathrm{e}+012.86499 \mathrm{e}+012.86499 \mathrm{e}+00$ 1.00000e-09 2.12000e-01 $2.86499 \mathrm{e}+012.86499 \mathrm{e}+012.86499 \mathrm{e}+001.00000 \mathrm{e}-092.12000 \mathrm{e}-01$ $2.86499 \mathrm{e}+012.86499 \mathrm{e}+012.86499 \mathrm{e}+001.00000 \mathrm{e}-092.12000 \mathrm{e}-01$ $2.86499 \mathrm{e}+012.86499 \mathrm{e}+012.86499 \mathrm{e}+001.00000 \mathrm{e}-092.12000 \mathrm{e}-01$ $2.86499 \mathrm{e}+012.86499 \mathrm{e}+012.86499 \mathrm{e}+00$ 1.00000e-09 2.12000e-01 $1.00000 \mathrm{e}-05$ 1.00000e-05 1.00000e-06 1.00000e-09 1.00000e-01 $1.00000 \mathrm{e}+001.00000 \mathrm{e}+001.00000 \mathrm{e}-011.00000 \mathrm{e}-091.00000 \mathrm{e}-01$ 
Element: 9504 \# of layers: 7

$\mathrm{Kx} \mathrm{Ky} \mathrm{Kz}$ Ss Por

$2.86499 \mathrm{e}+012.86499 \mathrm{e}+012.86499 \mathrm{e}+00$ 1.00000e-09 2.12000e-01

$2.86499 \mathrm{e}+012.86499 \mathrm{e}+012.86499 \mathrm{e}+001.00000 \mathrm{e}-092.12000 \mathrm{e}-01$

$2.86499 \mathrm{e}+012.86499 \mathrm{e}+012.86499 \mathrm{e}+001.00000 \mathrm{e}-092.12000 \mathrm{e}-01$

$2.86499 \mathrm{e}+012.86499 \mathrm{e}+012.86499 \mathrm{e}+00$ 1.00000e-09 2.12000e-01

$2.86499 \mathrm{e}+012.86499 \mathrm{e}+012.86499 \mathrm{e}+00$ 1.00000e-09 2.12000e-01

$1.00000 \mathrm{e}-05$ 1.00000e-05 1.00000e-06 1.00000e-09 1.00000e-01

$1.00000 \mathrm{e}+001.00000 \mathrm{e}+001.00000 \mathrm{e}-011.00000 \mathrm{e}-091.00000 \mathrm{e}-01$

Element: 9505 \# of layers: 6

$\mathrm{Kx} \mathrm{Ky} \mathrm{Kz}$ Ss Por

$2.86499 \mathrm{e}+012.86499 \mathrm{e}+012.86499 \mathrm{e}+00$ 1.00000e-09 2.12000e-01

$2.86499 \mathrm{e}+012.86499 \mathrm{e}+012.86499 \mathrm{e}+00$ 1.00000e-09 2.12000e-01

$2.86499 \mathrm{e}+012.86499 \mathrm{e}+012.86499 \mathrm{e}+00$ 1.00000e-09 2.12000e-01

$2.86499 \mathrm{e}+012.86499 \mathrm{e}+012.86499 \mathrm{e}+00$ 1.00000e-09 2.12000e-01

$1.00000 \mathrm{e}-05$ 1.00000e-05 1.00000e-06 1.00000e-09 1.00000e-01

$1.00000 \mathrm{e}+001.00000 \mathrm{e}+001.00000 \mathrm{e}-011.00000 \mathrm{e}-091.00000 \mathrm{e}-01$

Element: 9506 \# of layers: 6

$\mathrm{Kx} \mathrm{Ky} \mathrm{Kz}$ Ss Por

$2.86499 \mathrm{e}+012.86499 \mathrm{e}+012.86499 \mathrm{e}+00$ 1.00000e-09 2.12000e-01

$2.86499 \mathrm{e}+012.86499 \mathrm{e}+012.86499 \mathrm{e}+001.00000 \mathrm{e}-092.12000 \mathrm{e}-01$

$2.86499 \mathrm{e}+012.86499 \mathrm{e}+012.86499 \mathrm{e}+00$ 1.00000e-09 2.12000e-01

$2.86499 \mathrm{e}+012.86499 \mathrm{e}+012.86499 \mathrm{e}+00$ 1.00000e-09 2.12000e-01

$1.00000 \mathrm{e}-05$ 1.00000e-05 1.00000e-06 1.00000e-09 1.00000e-01

$1.00000 \mathrm{e}+001.00000 \mathrm{e}+001.00000 \mathrm{e}-011.00000 \mathrm{e}-091.00000 \mathrm{e}-01$

Element: 9507 \# of layers: 6

$\mathrm{Kx} \mathrm{Ky} \mathrm{Kz}$ Ss Por

$3.00584 \mathrm{e}+013.00584 \mathrm{e}+013.00584 \mathrm{e}+001.00000 \mathrm{e}-092.12000 \mathrm{e}-01$

$3.00584 \mathrm{e}+013.00584 \mathrm{e}+013.00584 \mathrm{e}+001.00000 \mathrm{e}-092.12000 \mathrm{e}-01$

$3.00584 \mathrm{e}+013.00584 \mathrm{e}+013.00584 \mathrm{e}+001.00000 \mathrm{e}-092.12000 \mathrm{e}-01$

$3.00584 \mathrm{e}+013.00584 \mathrm{e}+013.00584 \mathrm{e}+001.00000 \mathrm{e}-092.12000 \mathrm{e}-01$

$1.00000 \mathrm{e}-05$ 1.00000e-05 1.00000e-06 1.00000e-09 1.00000e-01

$1.00000 \mathrm{e}+001.00000 \mathrm{e}+001.00000 \mathrm{e}-011.00000 \mathrm{e}-091.00000 \mathrm{e}-01$

Element: 9508 \# of layers: 6

$\mathrm{Kx} \mathrm{Ky} \mathrm{Kz}$ Ss Por

$3.00584 \mathrm{e}+013.00584 \mathrm{e}+013.00584 \mathrm{e}+00$ 1.00000e-09 2.12000e-01

$3.00584 \mathrm{e}+013.00584 \mathrm{e}+013.00584 \mathrm{e}+001.00000 \mathrm{e}-092.12000 \mathrm{e}-01$

$3.00584 \mathrm{e}+013.00584 \mathrm{e}+013.00584 \mathrm{e}+001.00000 \mathrm{e}-092.12000 \mathrm{e}-01$

$3.00584 \mathrm{e}+013.00584 \mathrm{e}+013.00584 \mathrm{e}+001.00000 \mathrm{e}-092.12000 \mathrm{e}-01$

$1.00000 \mathrm{e}-05$ 1.00000e-05 1.00000e-06 1.00000e-09 1.00000e-01

$1.00000 \mathrm{e}+001.00000 \mathrm{e}+001.00000 \mathrm{e}-011.00000 \mathrm{e}-091.00000 \mathrm{e}-01$

Element: 9509 \# of layers: 6

$\mathrm{Kx} \mathrm{Ky} \mathrm{Kz}$ Ss Por

3.00584e+01 3.00584e+01 3.00584e+00 1.00000e-09 2.12000e-01 $3.00584 \mathrm{e}+013.00584 \mathrm{e}+013.00584 \mathrm{e}+001.00000 \mathrm{e}-092.12000 \mathrm{e}-01$ $3.00584 \mathrm{e}+013.00584 \mathrm{e}+013.00584 \mathrm{e}+001.00000 \mathrm{e}-092.12000 \mathrm{e}-01$ 
$3.00584 \mathrm{e}+013.00584 \mathrm{e}+013.00584 \mathrm{e}+001.00000 \mathrm{e}-092.12000 \mathrm{e}-01$ $1.00000 \mathrm{e}-05$ 1.00000e-05 1.00000e-06 1.00000e-09 1.00000e-01

$1.00000 \mathrm{e}+001.00000 \mathrm{e}+001.00000 \mathrm{e}-011.00000 \mathrm{e}-091.00000 \mathrm{e}-01$

Element: 9510 \# of layers: 6

$\mathrm{Kx} \mathrm{Ky} \mathrm{Kz}$ Ss Por

$3.00584 \mathrm{e}+013.00584 \mathrm{e}+013.00584 \mathrm{e}+001.00000 \mathrm{e}-092.12000 \mathrm{e}-01$

$3.00584 \mathrm{e}+013.00584 \mathrm{e}+013.00584 \mathrm{e}+001.00000 \mathrm{e}-092.12000 \mathrm{e}-01$

$3.00584 \mathrm{e}+013.00584 \mathrm{e}+013.00584 \mathrm{e}+001.00000 \mathrm{e}-092.12000 \mathrm{e}-01$

$3.00584 \mathrm{e}+013.00584 \mathrm{e}+013.00584 \mathrm{e}+001.00000 \mathrm{e}-092.12000 \mathrm{e}-01$

$1.00000 \mathrm{e}-05$ 1.00000e-05 1.00000e-06 1.00000e-09 1.00000e-01

$1.00000 \mathrm{e}+001.00000 \mathrm{e}+001.00000 \mathrm{e}-011.00000 \mathrm{e}-091.00000 \mathrm{e}-01$

Element: 9511 \# of layers: 7

$\mathrm{Kx} \mathrm{Ky} \mathrm{Kz}$ Ss Por

$3.00584 \mathrm{e}+013.00584 \mathrm{e}+013.00584 \mathrm{e}+001.00000 \mathrm{e}-092.12000 \mathrm{e}-01$

$3.00584 \mathrm{e}+013.00584 \mathrm{e}+013.00584 \mathrm{e}+001.00000 \mathrm{e}-092.12000 \mathrm{e}-01$

$3.00584 \mathrm{e}+013.00584 \mathrm{e}+013.00584 \mathrm{e}+001.00000 \mathrm{e}-092.12000 \mathrm{e}-01$

$3.00584 \mathrm{e}+013.00584 \mathrm{e}+013.00584 \mathrm{e}+001.00000 \mathrm{e}-092.12000 \mathrm{e}-01$

$3.00584 \mathrm{e}+013.00584 \mathrm{e}+013.00584 \mathrm{e}+001.00000 \mathrm{e}-092.12000 \mathrm{e}-01$

$1.00000 \mathrm{e}-05$ 1.00000e-05 1.00000e-06 1.00000e-09 1.00000e-01

$1.00000 \mathrm{e}+001.00000 \mathrm{e}+001.00000 \mathrm{e}-011.00000 \mathrm{e}-091.00000 \mathrm{e}-01$

Element: 9512 \# of layers: 7

$\mathrm{Kx} \mathrm{Ky} \mathrm{Kz}$ Ss Por

$3.00584 \mathrm{e}+013.00584 \mathrm{e}+013.00584 \mathrm{e}+001.00000 \mathrm{e}-092.12000 \mathrm{e}-01$ $3.00584 \mathrm{e}+013.00584 \mathrm{e}+013.00584 \mathrm{e}+001.00000 \mathrm{e}-092.12000 \mathrm{e}-01$

$3.00584 \mathrm{e}+013.00584 \mathrm{e}+013.00584 \mathrm{e}+001.00000 \mathrm{e}-092.12000 \mathrm{e}-01$

$3.00584 \mathrm{e}+013.00584 \mathrm{e}+013.00584 \mathrm{e}+001.00000 \mathrm{e}-092.12000 \mathrm{e}-01$

$3.00584 \mathrm{e}+013.00584 \mathrm{e}+013.00584 \mathrm{e}+001.00000 \mathrm{e}-092.12000 \mathrm{e}-01$

$1.00000 \mathrm{e}-05$ 1.00000e-05 1.00000e-06 1.00000e-09 1.00000e-01

$1.00000 \mathrm{e}+001.00000 \mathrm{e}+001.00000 \mathrm{e}-011.00000 \mathrm{e}-091.00000 \mathrm{e}-01$

Element: 9513 \# of layers: 7

$\mathrm{Kx} \mathrm{Ky} \mathrm{Kz}$ Ss Por

$3.00584 \mathrm{e}+013.00584 \mathrm{e}+013.00584 \mathrm{e}+001.00000 \mathrm{e}-092.12000 \mathrm{e}-01$

$3.00584 \mathrm{e}+013.00584 \mathrm{e}+013.00584 \mathrm{e}+001.00000 \mathrm{e}-092.12000 \mathrm{e}-01$

$3.00584 \mathrm{e}+013.00584 \mathrm{e}+013.00584 \mathrm{e}+001.00000 \mathrm{e}-092.12000 \mathrm{e}-01$

$3.00584 \mathrm{e}+013.00584 \mathrm{e}+013.00584 \mathrm{e}+001.00000 \mathrm{e}-092.12000 \mathrm{e}-01$

$3.00584 \mathrm{e}+013.00584 \mathrm{e}+013.00584 \mathrm{e}+001.00000 \mathrm{e}-092.12000 \mathrm{e}-01$

$1.00000 \mathrm{e}-05$ 1.00000e-05 1.00000e-06 1.00000e-09 1.00000e-01

$1.00000 \mathrm{e}+001.00000 \mathrm{e}+001.00000 \mathrm{e}-011.00000 \mathrm{e}-091.00000 \mathrm{e}-01$

Element: 9514 \# of layers: 6

$\mathrm{Kx} \mathrm{Ky} \mathrm{Kz}$ Ss Por

$3.00584 \mathrm{e}+013.00584 \mathrm{e}+013.00584 \mathrm{e}+00$ 1.00000e-09 2.12000e-01

$3.00584 \mathrm{e}+013.00584 \mathrm{e}+013.00584 \mathrm{e}+001.00000 \mathrm{e}-092.12000 \mathrm{e}-01$

$3.00584 \mathrm{e}+013.00584 \mathrm{e}+013.00584 \mathrm{e}+001.00000 \mathrm{e}-092.12000 \mathrm{e}-01$

$3.00584 \mathrm{e}+013.00584 \mathrm{e}+013.00584 \mathrm{e}+00$ 1.00000e-09 2.12000e-01

$1.00000 \mathrm{e}-05$ 1.00000e-05 1.00000e-06 1.00000e-09 1.00000e-01

$1.00000 \mathrm{e}+001.00000 \mathrm{e}+001.00000 \mathrm{e}-011.00000 \mathrm{e}-091.00000 \mathrm{e}-01$ 
Element: 9515 \# of layers: 6

Kx Ky Kz Ss Por

$3.00584 \mathrm{e}+013.00584 \mathrm{e}+013.00584 \mathrm{e}+00$ 1.00000e-09 2.12000e-01

$3.00584 \mathrm{e}+013.00584 \mathrm{e}+013.00584 \mathrm{e}+001.00000 \mathrm{e}-092.12000 \mathrm{e}-01$

$3.00584 \mathrm{e}+013.00584 \mathrm{e}+013.00584 \mathrm{e}+001.00000 \mathrm{e}-092.12000 \mathrm{e}-01$

$3.00584 \mathrm{e}+013.00584 \mathrm{e}+013.00584 \mathrm{e}+001.00000 \mathrm{e}-092.12000 \mathrm{e}-01$

$1.00000 \mathrm{e}-05$ 1.00000e-05 1.00000e-06 1.00000e-09 1.00000e-01

$1.00000 \mathrm{e}+001.00000 \mathrm{e}+001.00000 \mathrm{e}-011.00000 \mathrm{e}-091.00000 \mathrm{e}-01$

Element: 9516 \# of layers: 7

Kx Ky Kz Ss Por

$3.00584 \mathrm{e}+013.00584 \mathrm{e}+013.00584 \mathrm{e}+00$ 1.00000e-09 2.12000e-01

$3.00584 \mathrm{e}+013.00584 \mathrm{e}+013.00584 \mathrm{e}+001.00000 \mathrm{e}-092.12000 \mathrm{e}-01$

$3.00584 \mathrm{e}+013.00584 \mathrm{e}+013.00584 \mathrm{e}+001.00000 \mathrm{e}-092.12000 \mathrm{e}-01$

$3.00584 \mathrm{e}+013.00584 \mathrm{e}+013.00584 \mathrm{e}+001.00000 \mathrm{e}-092.12000 \mathrm{e}-01$

$3.00584 \mathrm{e}+013.00584 \mathrm{e}+013.00584 \mathrm{e}+001.00000 \mathrm{e}-092.12000 \mathrm{e}-01$

$1.00000 \mathrm{e}-05$ 1.00000e-05 1.00000e-06 1.00000e-09 1.00000e-01

$1.00000 \mathrm{e}+001.00000 \mathrm{e}+001.00000 \mathrm{e}-011.00000 \mathrm{e}-091.00000 \mathrm{e}-01$

Element: 9517 \# of layers: 7

Kx Ky Kz Ss Por

$2.52253 \mathrm{e}+012.52253 \mathrm{e}+012.52253 \mathrm{e}+00$ 1.00000e-09 2.12000e-01

$2.52253 \mathrm{e}+012.52253 \mathrm{e}+012.52253 \mathrm{e}+001.00000 \mathrm{e}-092.12000 \mathrm{e}-01$

$2.52253 \mathrm{e}+012.52253 \mathrm{e}+012.52253 \mathrm{e}+00$ 1.00000e-09 2.12000e-01

$2.52253 \mathrm{e}+012.52253 \mathrm{e}+012.52253 \mathrm{e}+00$ 1.00000e-09 2.12000e-01

$2.52253 \mathrm{e}+012.52253 \mathrm{e}+012.52253 \mathrm{e}+00$ 1.00000e-09 2.12000e-01

$1.00000 \mathrm{e}-05$ 1.00000e-05 1.00000e-06 1.00000e-09 1.00000e-01

$1.00000 \mathrm{e}+001.00000 \mathrm{e}+001.00000 \mathrm{e}-011.00000 \mathrm{e}-091.00000 \mathrm{e}-01$

Element: 9518 \# of layers: 7

Kx Ky Kz Ss Por

$2.52253 \mathrm{e}+012.52253 \mathrm{e}+012.52253 \mathrm{e}+00$ 1.00000e-09 2.12000e-01

$2.52253 \mathrm{e}+012.52253 \mathrm{e}+012.52253 \mathrm{e}+001.00000 \mathrm{e}-092.12000 \mathrm{e}-01$

$2.52253 \mathrm{e}+012.52253 \mathrm{e}+012.52253 \mathrm{e}+001.00000 \mathrm{e}-092.12000 \mathrm{e}-01$

$2.52253 \mathrm{e}+012.52253 \mathrm{e}+012.52253 \mathrm{e}+00$ 1.00000e-09 2.12000e-01

$2.52253 \mathrm{e}+012.52253 \mathrm{e}+012.52253 \mathrm{e}+00$ 1.00000e-09 2.12000e-01

$1.00000 \mathrm{e}-05$ 1.00000e-05 1.00000e-06 1.00000e-09 1.00000e-01

$1.00000 \mathrm{e}+001.00000 \mathrm{e}+001.00000 \mathrm{e}-011.00000 \mathrm{e}-091.00000 \mathrm{e}-01$

Element: 9519 \# of layers: 7

Kx Ky Kz Ss Por

$2.52253 \mathrm{e}+012.52253 \mathrm{e}+012.52253 \mathrm{e}+00$ 1.00000e-09 2.12000e-01

$2.52253 \mathrm{e}+012.52253 \mathrm{e}+012.52253 \mathrm{e}+00$ 1.00000e-09 2.12000e-01

$2.52253 \mathrm{e}+012.52253 \mathrm{e}+012.52253 \mathrm{e}+001.00000 \mathrm{e}-092.12000 \mathrm{e}-01$

$2.52253 \mathrm{e}+012.52253 \mathrm{e}+012.52253 \mathrm{e}+001.00000 \mathrm{e}-092.12000 \mathrm{e}-01$

$2.52253 \mathrm{e}+012.52253 \mathrm{e}+012.52253 \mathrm{e}+001.00000 \mathrm{e}-092.12000 \mathrm{e}-01$

$1.00000 \mathrm{e}-05$ 1.00000e-05 1.00000e-06 1.00000e-09 1.00000e-01

$1.00000 \mathrm{e}+001.00000 \mathrm{e}+001.00000 \mathrm{e}-011.00000 \mathrm{e}-091.00000 \mathrm{e}-01$

Element: 9520 \# of layers: 7

Kx Ky Kz Ss Por 
$2.52253 \mathrm{e}+012.52253 \mathrm{e}+012.52253 \mathrm{e}+00$ 1.00000e-09 2.12000e-01 $2.52253 \mathrm{e}+012.52253 \mathrm{e}+012.52253 \mathrm{e}+00$ 1.00000e-09 2.12000e-01 $2.52253 \mathrm{e}+012.52253 \mathrm{e}+012.52253 \mathrm{e}+00$ 1.00000e-09 2.12000e-01 $2.52253 \mathrm{e}+012.52253 \mathrm{e}+012.52253 \mathrm{e}+001.00000 \mathrm{e}-092.12000 \mathrm{e}-01$ $2.52253 \mathrm{e}+012.52253 \mathrm{e}+012.52253 \mathrm{e}+001.00000 \mathrm{e}-092.12000 \mathrm{e}-01$ $1.00000 \mathrm{e}-05$ 1.00000e-05 1.00000e-06 1.00000e-09 1.00000e-01 $1.00000 \mathrm{e}+001.00000 \mathrm{e}+001.00000 \mathrm{e}-01$ 1.00000e-09 1.00000e-01 Element: 9521 \# of layers: 7

$\mathrm{Kx} \mathrm{Ky} \mathrm{Kz}$ Ss Por

$2.52253 \mathrm{e}+012.52253 \mathrm{e}+012.52253 \mathrm{e}+00$ 1.00000e-09 2.12000e-01 $2.52253 \mathrm{e}+012.52253 \mathrm{e}+012.52253 \mathrm{e}+00$ 1.00000e-09 2.12000e-01 $2.52253 \mathrm{e}+012.52253 \mathrm{e}+012.52253 \mathrm{e}+001.00000 \mathrm{e}-092.12000 \mathrm{e}-01$ $2.52253 \mathrm{e}+012.52253 \mathrm{e}+012.52253 \mathrm{e}+00$ 1.00000e-09 2.12000e-01 $2.52253 \mathrm{e}+012.52253 \mathrm{e}+012.52253 \mathrm{e}+00$ 1.00000e-09 2.12000e-01 $1.00000 \mathrm{e}-05$ 1.00000e-05 1.00000e-06 1.00000e-09 1.00000e-01 $1.00000 \mathrm{e}+001.00000 \mathrm{e}+001.00000 \mathrm{e}-011.00000 \mathrm{e}-091.00000 \mathrm{e}-01$ Element: 9522 \# of layers: 7

$\mathrm{Kx} \mathrm{Ky} \mathrm{Kz}$ Ss Por

$3.00584 \mathrm{e}+013.00584 \mathrm{e}+013.00584 \mathrm{e}+001.00000 \mathrm{e}-092.12000 \mathrm{e}-01$ $3.00584 \mathrm{e}+013.00584 \mathrm{e}+013.00584 \mathrm{e}+001.00000 \mathrm{e}-092.12000 \mathrm{e}-01$ $3.00584 \mathrm{e}+013.00584 \mathrm{e}+013.00584 \mathrm{e}+001.00000 \mathrm{e}-092.12000 \mathrm{e}-01$ $3.00584 \mathrm{e}+013.00584 \mathrm{e}+013.00584 \mathrm{e}+001.00000 \mathrm{e}-092.12000 \mathrm{e}-01$ $3.00584 \mathrm{e}+013.00584 \mathrm{e}+013.00584 \mathrm{e}+001.00000 \mathrm{e}-092.12000 \mathrm{e}-01$ $1.00000 \mathrm{e}-05$ 1.00000e-05 1.00000e-06 1.00000e-09 1.00000e-01 $1.00000 \mathrm{e}+001.00000 \mathrm{e}+001.00000 \mathrm{e}-011.00000 \mathrm{e}-091.00000 \mathrm{e}-01$ Element: 9523 \# of layers: 7

$\mathrm{Kx} \mathrm{Ky} \mathrm{Kz}$ Ss Por $3.00584 \mathrm{e}+013.00584 \mathrm{e}+013.00584 \mathrm{e}+001.00000 \mathrm{e}-092.12000 \mathrm{e}-01$ $3.00584 \mathrm{e}+013.00584 \mathrm{e}+013.00584 \mathrm{e}+001.00000 \mathrm{e}-092.12000 \mathrm{e}-01$ $3.00584 \mathrm{e}+013.00584 \mathrm{e}+013.00584 \mathrm{e}+001.00000 \mathrm{e}-092.12000 \mathrm{e}-01$ $3.00584 \mathrm{e}+013.00584 \mathrm{e}+013.00584 \mathrm{e}+001.00000 \mathrm{e}-092.12000 \mathrm{e}-01$ $3.00584 \mathrm{e}+013.00584 \mathrm{e}+013.00584 \mathrm{e}+001.00000 \mathrm{e}-092.12000 \mathrm{e}-01$ $1.00000 \mathrm{e}-05$ 1.00000e-05 1.00000e-06 1.00000e-09 1.00000e-01 $1.00000 \mathrm{e}+001.00000 \mathrm{e}+001.00000 \mathrm{e}-011.00000 \mathrm{e}-091.00000 \mathrm{e}-01$ Element: 9524 \# of layers: 7

$\mathrm{Kx} \mathrm{Ky} \mathrm{Kz}$ Ss Por

$2.52253 \mathrm{e}+012.52253 \mathrm{e}+012.52253 \mathrm{e}+00$ 1.00000e-09 2.12000e-01 $2.52253 \mathrm{e}+012.52253 \mathrm{e}+012.52253 \mathrm{e}+00$ 1.00000e-09 2.12000e-01 $2.52253 \mathrm{e}+012.52253 \mathrm{e}+012.52253 \mathrm{e}+00$ 1.00000e-09 2.12000e-01 $2.52253 \mathrm{e}+012.52253 \mathrm{e}+012.52253 \mathrm{e}+00$ 1.00000e-09 2.12000e-01 $2.52253 \mathrm{e}+012.52253 \mathrm{e}+012.52253 \mathrm{e}+00$ 1.00000e-09 2.12000e-01 $1.00000 \mathrm{e}-05$ 1.00000e-05 1.00000e-06 1.00000e-09 1.00000e-01 $1.00000 \mathrm{e}+001.00000 \mathrm{e}+001.00000 \mathrm{e}-011.00000 \mathrm{e}-091.00000 \mathrm{e}-01$ Element: 9525 \# of layers: 7

$\mathrm{Kx} \mathrm{Ky} \mathrm{Kz}$ Ss Por

$2.52253 e+012.52253 e+012.52253 e+00$ 1.00000e-09 2.12000e-01 
$2.52253 \mathrm{e}+012.52253 \mathrm{e}+012.52253 \mathrm{e}+00$ 1.00000e-09 2.12000e-01 $2.52253 \mathrm{e}+012.52253 \mathrm{e}+012.52253 \mathrm{e}+00$ 1.00000e-09 2.12000e-01 $2.52253 \mathrm{e}+012.52253 \mathrm{e}+012.52253 \mathrm{e}+00$ 1.00000e-09 2.12000e-01 $2.52253 \mathrm{e}+012.52253 \mathrm{e}+012.52253 \mathrm{e}+001.00000 \mathrm{e}-092.12000 \mathrm{e}-01$ $1.00000 \mathrm{e}-051.00000 \mathrm{e}-05$ 1.00000e-06 1.00000e-09 1.00000e-01 $1.00000 \mathrm{e}+001.00000 \mathrm{e}+001.00000 \mathrm{e}-011.00000 \mathrm{e}-091.00000 \mathrm{e}-01$ Element: 9526 \# of layers: 7

$\mathrm{Kx} \mathrm{Ky} \mathrm{Kz}$ Ss Por

$2.63976 \mathrm{e}+012.63976 \mathrm{e}+012.63976 \mathrm{e}+001.00000 \mathrm{e}-092.12000 \mathrm{e}-01$ $2.63976 \mathrm{e}+012.63976 \mathrm{e}+012.63976 \mathrm{e}+00$ 1.00000e-09 2.12000e-01 $2.63976 \mathrm{e}+012.63976 \mathrm{e}+012.63976 \mathrm{e}+00$ 1.00000e-09 2.12000e-01 $2.63976 \mathrm{e}+012.63976 \mathrm{e}+012.63976 \mathrm{e}+001.00000 \mathrm{e}-092.12000 \mathrm{e}-01$ $2.63976 \mathrm{e}+012.63976 \mathrm{e}+012.63976 \mathrm{e}+001.00000 \mathrm{e}-092.12000 \mathrm{e}-01$ $1.00000 \mathrm{e}-05$ 1.00000e-05 1.00000e-06 1.00000e-09 1.00000e-01 $1.00000 \mathrm{e}+001.00000 \mathrm{e}+001.00000 \mathrm{e}-01$ 1.00000e-09 1.00000e-01 Element: 9527 \# of layers: 7

$\mathrm{Kx} \mathrm{Ky} \mathrm{Kz}$ Ss Por

$2.63976 \mathrm{e}+012.63976 \mathrm{e}+012.63976 \mathrm{e}+00$ 1.00000e-09 2.12000e-01 $2.63976 \mathrm{e}+012.63976 \mathrm{e}+012.63976 \mathrm{e}+00$ 1.00000e-09 2.12000e-01 $2.63976 \mathrm{e}+012.63976 \mathrm{e}+012.63976 \mathrm{e}+001.00000 \mathrm{e}-092.12000 \mathrm{e}-01$ $2.63976 \mathrm{e}+012.63976 \mathrm{e}+012.63976 \mathrm{e}+001.00000 \mathrm{e}-092.12000 \mathrm{e}-01$ $2.63976 \mathrm{e}+012.63976 \mathrm{e}+012.63976 \mathrm{e}+001.00000 \mathrm{e}-092.12000 \mathrm{e}-01$ $1.00000 \mathrm{e}-05$ 1.00000e-05 1.00000e-06 1.00000e-09 1.00000e-01 $1.00000 \mathrm{e}+001.00000 \mathrm{e}+001.00000 \mathrm{e}-011.00000 \mathrm{e}-091.00000 \mathrm{e}-01$ Element: 9528 \# of layers: 7

$\mathrm{Kx} \mathrm{Ky} \mathrm{Kz}$ Ss Por

$2.63976 \mathrm{e}+012.63976 \mathrm{e}+012.63976 \mathrm{e}+00$ 1.00000e-09 2.12000e-01 $2.63976 \mathrm{e}+012.63976 \mathrm{e}+012.63976 \mathrm{e}+001.00000 \mathrm{e}-092.12000 \mathrm{e}-01$ $2.63976 \mathrm{e}+012.63976 \mathrm{e}+012.63976 \mathrm{e}+001.00000 \mathrm{e}-092.12000 \mathrm{e}-01$ $2.63976 \mathrm{e}+012.63976 \mathrm{e}+012.63976 \mathrm{e}+001.00000 \mathrm{e}-092.12000 \mathrm{e}-01$ $2.63976 \mathrm{e}+012.63976 \mathrm{e}+012.63976 \mathrm{e}+001.00000 \mathrm{e}-092.12000 \mathrm{e}-01$ $1.00000 \mathrm{e}-05$ 1.00000e-05 1.00000e-06 1.00000e-09 1.00000e-01 $1.00000 \mathrm{e}+001.00000 \mathrm{e}+001.00000 \mathrm{e}-011.00000 \mathrm{e}-091.00000 \mathrm{e}-01$ Element: 9529 \# of layers: 7

$\mathrm{Kx} \mathrm{Ky} \mathrm{Kz}$ Ss Por

$2.86499 \mathrm{e}+012.86499 \mathrm{e}+012.86499 \mathrm{e}+00$ 1.00000e-09 2.12000e-01 $2.86499 \mathrm{e}+012.86499 \mathrm{e}+012.86499 \mathrm{e}+001.00000 \mathrm{e}-092.12000 \mathrm{e}-01$ $2.86499 \mathrm{e}+012.86499 \mathrm{e}+012.86499 \mathrm{e}+001.00000 \mathrm{e}-092.12000 \mathrm{e}-01$ $2.86499 \mathrm{e}+012.86499 \mathrm{e}+012.86499 \mathrm{e}+001.00000 \mathrm{e}-092.12000 \mathrm{e}-01$ $2.86499 \mathrm{e}+012.86499 \mathrm{e}+012.86499 \mathrm{e}+00$ 1.00000e-09 2.12000e-01 1.00000e-05 1.00000e-05 1.00000e-06 1.00000e-09 1.00000e-01 $1.00000 \mathrm{e}+001.00000 \mathrm{e}+001.00000 \mathrm{e}-011.00000 \mathrm{e}-091.00000 \mathrm{e}-01$ Element: 9530 \# of layers: 7

$\mathrm{Kx} \mathrm{Ky} \mathrm{Kz}$ Ss Por

$2.86499 \mathrm{e}+012.86499 \mathrm{e}+012.86499 \mathrm{e}+00$ 1.00000e-09 2.12000e-01 $2.86499 \mathrm{e}+012.86499 \mathrm{e}+012.86499 \mathrm{e}+001.00000 \mathrm{e}-092.12000 \mathrm{e}-01$ 
$2.86499 \mathrm{e}+012.86499 \mathrm{e}+012.86499 \mathrm{e}+00$ 1.00000e-09 2.12000e-01 $2.86499 \mathrm{e}+012.86499 \mathrm{e}+012.86499 \mathrm{e}+001.00000 \mathrm{e}-092.12000 \mathrm{e}-01$ $2.86499 \mathrm{e}+012.86499 \mathrm{e}+012.86499 \mathrm{e}+001.00000 \mathrm{e}-092.12000 \mathrm{e}-01$ $1.00000 \mathrm{e}-05$ 1.00000e-05 1.00000e-06 1.00000e-09 1.00000e-01 $1.00000 \mathrm{e}+001.00000 \mathrm{e}+001.00000 \mathrm{e}-011.00000 \mathrm{e}-091.00000 \mathrm{e}-01$ Element: 9531 \# of layers: 7

Kx Ky Kz Ss Por

$3.00584 \mathrm{e}+013.00584 \mathrm{e}+013.00584 \mathrm{e}+00$ 1.00000e-09 2.12000e-01 $3.00584 \mathrm{e}+013.00584 \mathrm{e}+013.00584 \mathrm{e}+001.00000 \mathrm{e}-092.12000 \mathrm{e}-01$ $3.00584 \mathrm{e}+013.00584 \mathrm{e}+013.00584 \mathrm{e}+001.00000 \mathrm{e}-092.12000 \mathrm{e}-01$ $3.00584 \mathrm{e}+013.00584 \mathrm{e}+013.00584 \mathrm{e}+001.00000 \mathrm{e}-092.12000 \mathrm{e}-01$ $3.00584 \mathrm{e}+013.00584 \mathrm{e}+013.00584 \mathrm{e}+001.00000 \mathrm{e}-092.12000 \mathrm{e}-01$ $1.00000 \mathrm{e}-05$ 1.00000e-05 1.00000e-06 1.00000e-09 1.00000e-01 $1.00000 \mathrm{e}+001.00000 \mathrm{e}+001.00000 \mathrm{e}-011.00000 \mathrm{e}-091.00000 \mathrm{e}-01$ Element: 9532 \# of layers: 7

Kx Ky Kz Ss Por

$2.52253 \mathrm{e}+012.52253 \mathrm{e}+012.52253 \mathrm{e}+00$ 1.00000e-09 2.12000e-01

$2.52253 \mathrm{e}+012.52253 \mathrm{e}+012.52253 \mathrm{e}+00$ 1.00000e-09 2.12000e-01

$2.52253 \mathrm{e}+012.52253 \mathrm{e}+012.52253 \mathrm{e}+00$ 1.00000e-09 2.12000e-01

$2.52253 \mathrm{e}+012.52253 \mathrm{e}+012.52253 \mathrm{e}+00$ 1.00000e-09 2.12000e-01

$2.52253 \mathrm{e}+012.52253 \mathrm{e}+012.52253 \mathrm{e}+001.00000 \mathrm{e}-092.12000 \mathrm{e}-01$ $1.00000 \mathrm{e}-05$ 1.00000e-05 1.00000e-06 1.00000e-09 1.00000e-01

$1.00000 \mathrm{e}+001.00000 \mathrm{e}+00$ 1.00000e-01 1.00000e-09 1.00000e-01 Element: 9533 \# of layers: 7

Kx Ky Kz Ss Por

$2.63976 \mathrm{e}+012.63976 \mathrm{e}+012.63976 \mathrm{e}+00$ 1.00000e-09 2.12000e-01

$2.63976 \mathrm{e}+012.63976 \mathrm{e}+012.63976 \mathrm{e}+001.00000 \mathrm{e}-092.12000 \mathrm{e}-01$

$2.63976 \mathrm{e}+012.63976 \mathrm{e}+012.63976 \mathrm{e}+001.00000 \mathrm{e}-092.12000 \mathrm{e}-01$

$2.63976 \mathrm{e}+012.63976 \mathrm{e}+012.63976 \mathrm{e}+001.00000 \mathrm{e}-092.12000 \mathrm{e}-01$

$2.63976 \mathrm{e}+012.63976 \mathrm{e}+012.63976 \mathrm{e}+001.00000 \mathrm{e}-092.12000 \mathrm{e}-01$

$1.00000 \mathrm{e}-05$ 1.00000e-05 1.00000e-06 1.00000e-09 1.00000e-01

$1.00000 \mathrm{e}+001.00000 \mathrm{e}+001.00000 \mathrm{e}-011.00000 \mathrm{e}-091.00000 \mathrm{e}-01$

Element: 9534 \# of layers: 9

Kx Ky Kz Ss Por

$2.79906 \mathrm{e}+012.79906 \mathrm{e}+012.79906 \mathrm{e}+00$ 1.00000e-09 2.12000e-01

$2.79906 \mathrm{e}+012.79906 \mathrm{e}+012.79906 \mathrm{e}+001.00000 \mathrm{e}-092.12000 \mathrm{e}-01$

$2.79906 \mathrm{e}+012.79906 \mathrm{e}+012.79906 \mathrm{e}+001.00000 \mathrm{e}-092.12000 \mathrm{e}-01$

$2.79906 \mathrm{e}+012.79906 \mathrm{e}+012.79906 \mathrm{e}+001.00000 \mathrm{e}-092.12000 \mathrm{e}-01$

$2.79906 \mathrm{e}+012.79906 \mathrm{e}+012.79906 \mathrm{e}+001.00000 \mathrm{e}-092.12000 \mathrm{e}-01$ $1.00000 \mathrm{e}-02$ 1.00000e-02 1.00000e-03 1.00000e-09 1.00000e-01

$1.00000 \mathrm{e}+001.00000 \mathrm{e}+001.00000 \mathrm{e}-011.00000 \mathrm{e}-091.00000 \mathrm{e}-01$ $1.00000 \mathrm{e}-05$ 1.00000e-05 1.00000e-06 1.00000e-09 1.00000e-01 $1.00000 \mathrm{e}+001.00000 \mathrm{e}+001.00000 \mathrm{e}-011.00000 \mathrm{e}-091.00000 \mathrm{e}-01$ Element: 9535 \# of layers: 9

Kx Ky Kz Ss Por

$2.79906 \mathrm{e}+012.79906 \mathrm{e}+012.79906 \mathrm{e}+00$ 1.00000e-09 2.12000e-01 
$2.79906 \mathrm{e}+012.79906 \mathrm{e}+012.79906 \mathrm{e}+00$ 1.00000e-09 2.12000e-01 $2.79906 \mathrm{e}+012.79906 \mathrm{e}+012.79906 \mathrm{e}+001.00000 \mathrm{e}-092.12000 \mathrm{e}-01$ $2.79906 \mathrm{e}+012.79906 \mathrm{e}+012.79906 \mathrm{e}+001.00000 \mathrm{e}-092.12000 \mathrm{e}-01$ $2.79906 \mathrm{e}+012.79906 \mathrm{e}+012.79906 \mathrm{e}+001.00000 \mathrm{e}-092.12000 \mathrm{e}-01$ $1.00000 \mathrm{e}-02$ 1.00000e-02 1.00000e-03 1.00000e-09 1.00000e-01 $1.00000 \mathrm{e}+001.00000 \mathrm{e}+001.00000 \mathrm{e}-011.00000 \mathrm{e}-091.00000 \mathrm{e}-01$ $1.00000 \mathrm{e}-051.00000 \mathrm{e}-05$ 1.00000e-06 1.00000e-09 1.00000e-01 $1.00000 \mathrm{e}+001.00000 \mathrm{e}+00$ 1.00000e-01 1.00000e-09 1.00000e-01 Element: 9536 \# of layers: 9

Kx Ky Kz Ss Por

$2.79906 \mathrm{e}+012.79906 \mathrm{e}+012.79906 \mathrm{e}+00$ 1.00000e-09 2.12000e-01 $2.79906 \mathrm{e}+012.79906 \mathrm{e}+012.79906 \mathrm{e}+001.00000 \mathrm{e}-092.12000 \mathrm{e}-01$ $2.79906 \mathrm{e}+012.79906 \mathrm{e}+012.79906 \mathrm{e}+001.00000 \mathrm{e}-092.12000 \mathrm{e}-01$ $2.79906 \mathrm{e}+012.79906 \mathrm{e}+012.79906 \mathrm{e}+001.00000 \mathrm{e}-092.12000 \mathrm{e}-01$ $2.79906 \mathrm{e}+012.79906 \mathrm{e}+012.79906 \mathrm{e}+001.00000 \mathrm{e}-092.12000 \mathrm{e}-01$ $1.00000 \mathrm{e}-02$ 1.00000e-02 1.00000e-03 1.00000e-09 1.00000e-01 $1.00000 \mathrm{e}+001.00000 \mathrm{e}+001.00000 \mathrm{e}-011.00000 \mathrm{e}-091.00000 \mathrm{e}-01$ $1.00000 \mathrm{e}-05$ 1.00000e-05 1.00000e-06 1.00000e-09 1.00000e-01 $1.00000 \mathrm{e}+001.00000 \mathrm{e}+001.00000 \mathrm{e}-011.00000 \mathrm{e}-091.00000 \mathrm{e}-01$ Element: 9537 \# of layers: 9

Kx Ky Kz Ss Por

$2.79906 \mathrm{e}+012.79906 \mathrm{e}+012.79906 \mathrm{e}+00$ 1.00000e-09 2.12000e-01 $2.79906 \mathrm{e}+012.79906 \mathrm{e}+012.79906 \mathrm{e}+001.00000 \mathrm{e}-092.12000 \mathrm{e}-01$ $2.79906 \mathrm{e}+012.79906 \mathrm{e}+012.79906 \mathrm{e}+001.00000 \mathrm{e}-092.12000 \mathrm{e}-01$ $2.79906 \mathrm{e}+012.79906 \mathrm{e}+012.79906 \mathrm{e}+001.00000 \mathrm{e}-092.12000 \mathrm{e}-01$ $2.79906 \mathrm{e}+012.79906 \mathrm{e}+012.79906 \mathrm{e}+001.00000 \mathrm{e}-092.12000 \mathrm{e}-01$ $1.00000 \mathrm{e}-02$ 1.00000e-02 1.00000e-03 1.00000e-09 1.00000e-01 $1.00000 \mathrm{e}+001.00000 \mathrm{e}+001.00000 \mathrm{e}-011.00000 \mathrm{e}-091.00000 \mathrm{e}-01$ $1.00000 \mathrm{e}-05$ 1.00000e-05 1.00000e-06 1.00000e-09 1.00000e-01 $1.00000 \mathrm{e}+001.00000 \mathrm{e}+001.00000 \mathrm{e}-011.00000 \mathrm{e}-091.00000 \mathrm{e}-01$ Element: 9538 \# of layers: 9

Kx Ky Kz Ss Por

$2.79906 \mathrm{e}+012.79906 \mathrm{e}+012.79906 \mathrm{e}+00$ 1.00000e-09 2.12000e-01 $2.79906 \mathrm{e}+012.79906 \mathrm{e}+012.79906 \mathrm{e}+001.00000 \mathrm{e}-092.12000 \mathrm{e}-01$

$2.79906 \mathrm{e}+012.79906 \mathrm{e}+012.79906 \mathrm{e}+001.00000 \mathrm{e}-092.12000 \mathrm{e}-01$

$2.79906 \mathrm{e}+012.79906 \mathrm{e}+012.79906 \mathrm{e}+001.00000 \mathrm{e}-092.12000 \mathrm{e}-01$

$2.79906 \mathrm{e}+012.79906 \mathrm{e}+012.79906 \mathrm{e}+001.00000 \mathrm{e}-092.12000 \mathrm{e}-01$ $1.00000 \mathrm{e}-021.00000 \mathrm{e}-02$ 1.00000e-03 1.00000e-09 1.00000e-01 $1.00000 \mathrm{e}+001.00000 \mathrm{e}+001.00000 \mathrm{e}-011.00000 \mathrm{e}-091.00000 \mathrm{e}-01$ $1.00000 \mathrm{e}-05$ 1.00000e-05 1.00000e-06 1.00000e-09 1.00000e-01 $1.00000 \mathrm{e}+001.00000 \mathrm{e}+001.00000 \mathrm{e}-011.00000 \mathrm{e}-091.00000 \mathrm{e}-01$ Element: 9539 \# of layers: 9

Kx Ky Kz Ss Por

$2.79906 \mathrm{e}+012.79906 \mathrm{e}+012.79906 \mathrm{e}+00$ 1.00000e-09 2.12000e-01 $2.79906 \mathrm{e}+012.79906 \mathrm{e}+012.79906 \mathrm{e}+001.00000 \mathrm{e}-092.12000 \mathrm{e}-01$ $2.79906 \mathrm{e}+012.79906 \mathrm{e}+012.79906 \mathrm{e}+001.00000 \mathrm{e}-092.12000 \mathrm{e}-01$ 
$2.79906 \mathrm{e}+012.79906 \mathrm{e}+012.79906 \mathrm{e}+00$ 1.00000e-09 2.12000e-01 $2.79906 \mathrm{e}+012.79906 \mathrm{e}+012.79906 \mathrm{e}+00$ 1.00000e-09 2.12000e-01 $1.00000 \mathrm{e}-021.00000 \mathrm{e}-02$ 1.00000e-03 1.00000e-09 1.00000e-01 $1.00000 \mathrm{e}+001.00000 \mathrm{e}+001.00000 \mathrm{e}-011.00000 \mathrm{e}-091.00000 \mathrm{e}-01$ $1.00000 \mathrm{e}-05$ 1.00000e-05 1.00000e-06 1.00000e-09 1.00000e-01 $1.00000 \mathrm{e}+001.00000 \mathrm{e}+001.00000 \mathrm{e}-011.00000 \mathrm{e}-091.00000 \mathrm{e}-01$ Element: 9540 \# of layers: 9

Kx Ky Kz Ss Por

$2.79906 \mathrm{e}+012.79906 \mathrm{e}+012.79906 \mathrm{e}+00$ 1.00000e-09 2.12000e-01

$2.79906 \mathrm{e}+012.79906 \mathrm{e}+012.79906 \mathrm{e}+001.00000 \mathrm{e}-092.12000 \mathrm{e}-01$

$2.79906 \mathrm{e}+012.79906 \mathrm{e}+012.79906 \mathrm{e}+001.00000 \mathrm{e}-092.12000 \mathrm{e}-01$

$2.79906 \mathrm{e}+012.79906 \mathrm{e}+012.79906 \mathrm{e}+001.00000 \mathrm{e}-092.12000 \mathrm{e}-01$

$2.79906 \mathrm{e}+012.79906 \mathrm{e}+012.79906 \mathrm{e}+001.00000 \mathrm{e}-092.12000 \mathrm{e}-01$

$1.00000 \mathrm{e}-021.00000 \mathrm{e}-02$ 1.00000e-03 1.00000e-09 1.00000e-01

$1.00000 \mathrm{e}+001.00000 \mathrm{e}+001.00000 \mathrm{e}-011.00000 \mathrm{e}-091.00000 \mathrm{e}-01$ $1.00000 \mathrm{e}-05$ 1.00000e-05 1.00000e-06 1.00000e-09 1.00000e-01

$1.00000 \mathrm{e}+001.00000 \mathrm{e}+001.00000 \mathrm{e}-011.00000 \mathrm{e}-091.00000 \mathrm{e}-01$

Element: 9541 \# of layers: 9

Kx Ky Kz Ss Por

$2.79906 \mathrm{e}+012.79906 \mathrm{e}+012.79906 \mathrm{e}+00$ 1.00000e-09 2.12000e-01

$2.79906 \mathrm{e}+012.79906 \mathrm{e}+012.79906 \mathrm{e}+001.00000 \mathrm{e}-092.12000 \mathrm{e}-01$

$2.79906 \mathrm{e}+012.79906 \mathrm{e}+012.79906 \mathrm{e}+001.00000 \mathrm{e}-092.12000 \mathrm{e}-01$

$2.79906 \mathrm{e}+012.79906 \mathrm{e}+012.79906 \mathrm{e}+001.00000 \mathrm{e}-092.12000 \mathrm{e}-01$

$2.79906 \mathrm{e}+012.79906 \mathrm{e}+012.79906 \mathrm{e}+001.00000 \mathrm{e}-092.12000 \mathrm{e}-01$

$1.00000 \mathrm{e}-021.00000 \mathrm{e}-02$ 1.00000e-03 1.00000e-09 1.00000e-01

$1.00000 \mathrm{e}+001.00000 \mathrm{e}+001.00000 \mathrm{e}-011.00000 \mathrm{e}-091.00000 \mathrm{e}-01$

$1.00000 \mathrm{e}-05$ 1.00000e-05 1.00000e-06 1.00000e-09 1.00000e-01

$1.00000 \mathrm{e}+001.00000 \mathrm{e}+001.00000 \mathrm{e}-011.00000 \mathrm{e}-091.00000 \mathrm{e}-01$

Element: 9542 \# of layers: 9

Kx Ky Kz Ss Por

$2.79906 \mathrm{e}+012.79906 \mathrm{e}+012.79906 \mathrm{e}+00$ 1.00000e-09 2.12000e-01

$2.79906 \mathrm{e}+012.79906 \mathrm{e}+012.79906 \mathrm{e}+001.00000 \mathrm{e}-092.12000 \mathrm{e}-01$

$2.79906 \mathrm{e}+012.79906 \mathrm{e}+012.79906 \mathrm{e}+001.00000 \mathrm{e}-092.12000 \mathrm{e}-01$

$2.79906 \mathrm{e}+012.79906 \mathrm{e}+012.79906 \mathrm{e}+001.00000 \mathrm{e}-092.12000 \mathrm{e}-01$

$2.79906 \mathrm{e}+012.79906 \mathrm{e}+012.79906 \mathrm{e}+001.00000 \mathrm{e}-092.12000 \mathrm{e}-01$

$1.00000 \mathrm{e}-021.00000 \mathrm{e}-02$ 1.00000e-03 1.00000e-09 1.00000e-01

$1.00000 \mathrm{e}+001.00000 \mathrm{e}+001.00000 \mathrm{e}-011.00000 \mathrm{e}-091.00000 \mathrm{e}-01$

$1.00000 \mathrm{e}-05$ 1.00000e-05 1.00000e-06 1.00000e-09 1.00000e-01

$1.00000 \mathrm{e}+001.00000 \mathrm{e}+001.00000 \mathrm{e}-011.00000 \mathrm{e}-091.00000 \mathrm{e}-01$

Element: 9543 \# of layers: 9

Kx Ky Kz Ss Por

$2.79906 \mathrm{e}+012.79906 \mathrm{e}+012.79906 \mathrm{e}+00$ 1.00000e-09 2.12000e-01

$2.79906 \mathrm{e}+012.79906 \mathrm{e}+012.79906 \mathrm{e}+001.00000 \mathrm{e}-092.12000 \mathrm{e}-01$

$2.79906 \mathrm{e}+012.79906 \mathrm{e}+012.79906 \mathrm{e}+001.00000 \mathrm{e}-092.12000 \mathrm{e}-01$

$2.79906 \mathrm{e}+012.79906 \mathrm{e}+012.79906 \mathrm{e}+001.00000 \mathrm{e}-092.12000 \mathrm{e}-01$

$2.79906 \mathrm{e}+012.79906 \mathrm{e}+012.79906 \mathrm{e}+001.00000 \mathrm{e}-092.12000 \mathrm{e}-01$ 
$1.00000 \mathrm{e}-02$ 1.00000e-02 1.00000e-03 1.00000e-09 1.00000e-01 $1.00000 \mathrm{e}+001.00000 \mathrm{e}+001.00000 \mathrm{e}-011.00000 \mathrm{e}-091.00000 \mathrm{e}-01$ $1.00000 \mathrm{e}-05$ 1.00000e-05 1.00000e-06 1.00000e-09 1.00000e-01 $1.00000 \mathrm{e}+001.00000 \mathrm{e}+001.00000 \mathrm{e}-011.00000 \mathrm{e}-091.00000 \mathrm{e}-01$ Element: 9544 \# of layers: 9

$\mathrm{Kx} \mathrm{Ky} \mathrm{Kz}$ Ss Por

5.30899e+01 5.30899e+01 5.30899e+00 1.00000e-09 2.12000e-01 $5.30899 \mathrm{e}+01$ 5.30899e+01 5.30899e+00 1.00000e-09 2.12000e-01 $5.30899 \mathrm{e}+015.30899 \mathrm{e}+01$ 5.30899e+00 1.00000e-09 2.12000e-01 $5.30899 \mathrm{e}+015.30899 \mathrm{e}+015.30899 \mathrm{e}+00$ 1.00000e-09 2.12000e-01 $5.30899 \mathrm{e}+015.30899 \mathrm{e}+015.30899 \mathrm{e}+00$ 1.00000e-09 2.12000e-01 $1.00000 \mathrm{e}-02$ 1.00000e-02 1.00000e-03 1.00000e-09 1.00000e-01 $1.00000 \mathrm{e}+001.00000 \mathrm{e}+001.00000 \mathrm{e}-011.00000 \mathrm{e}-091.00000 \mathrm{e}-01$ $1.00000 \mathrm{e}-05$ 1.00000e-05 1.00000e-06 1.00000e-09 1.00000e-01 $1.00000 \mathrm{e}+001.00000 \mathrm{e}+001.00000 \mathrm{e}-01$ 1.00000e-09 1.00000e-01 Element: 9545 \# of layers: 8

$\mathrm{Kx} \mathrm{Ky} \mathrm{Kz}$ Ss Por

5.30899e+01 5.30899e+01 5.30899e+00 1.00000e-09 2.12000e-01 $5.30899 \mathrm{e}+015.30899 \mathrm{e}+015.30899 \mathrm{e}+00$ 1.00000e-09 2.12000e-01 $5.30899 \mathrm{e}+015.30899 \mathrm{e}+01$ 5.30899e+00 1.00000e-09 2.12000e-01 $5.30899 \mathrm{e}+015.30899 \mathrm{e}+015.30899 \mathrm{e}+001.00000 \mathrm{e}-092.12000 \mathrm{e}-01$ $1.00000 \mathrm{e}-02$ 1.00000e-02 1.00000e-03 1.00000e-09 1.00000e-01 $1.00000 \mathrm{e}+001.00000 \mathrm{e}+001.00000 \mathrm{e}-011.00000 \mathrm{e}-091.00000 \mathrm{e}-01$ $1.00000 \mathrm{e}-05$ 1.00000e-05 1.00000e-06 1.00000e-09 1.00000e-01 $1.00000 \mathrm{e}+001.00000 \mathrm{e}+001.00000 \mathrm{e}-011.00000 \mathrm{e}-09$ 1.00000e-01 Element: 9546 \# of layers: 8

$\mathrm{Kx} \mathrm{Ky} \mathrm{Kz}$ Ss Por

5.30899e+01 5.30899e+01 5.30899e+00 1.00000e-09 2.12000e-01 $5.30899 \mathrm{e}+015.30899 \mathrm{e}+015.30899 \mathrm{e}+001.00000 \mathrm{e}-09$ 2.12000e-01 $5.30899 \mathrm{e}+01$ 5.30899e+01 5.30899e+00 1.00000e-09 2.12000e-01 $5.30899 \mathrm{e}+015.30899 \mathrm{e}+015.30899 \mathrm{e}+00$ 1.00000e-09 2.12000e-01 1.00000e-02 1.00000e-02 1.00000e-03 1.00000e-09 1.00000e-01 $1.00000 \mathrm{e}+001.00000 \mathrm{e}+001.00000 \mathrm{e}-011.00000 \mathrm{e}-091.00000 \mathrm{e}-01$ $1.00000 \mathrm{e}-051.00000 \mathrm{e}-051.00000 \mathrm{e}-061.00000 \mathrm{e}-091.00000 \mathrm{e}-01$ $1.00000 \mathrm{e}+001.00000 \mathrm{e}+001.00000 \mathrm{e}-01$ 1.00000e-09 1.00000e-01 Element: 9547 \# of layers: 8

Kx Ky Kz Ss Por

5.30899e+01 5.30899e+01 5.30899e+00 1.00000e-09 2.12000e-01 $5.30899 \mathrm{e}+015.30899 \mathrm{e}+015.30899 \mathrm{e}+00$ 1.00000e-09 2.12000e-01 $5.30899 \mathrm{e}+015.30899 \mathrm{e}+015.30899 \mathrm{e}+00$ 1.00000e-09 2.12000e-01 $5.30899 \mathrm{e}+015.30899 \mathrm{e}+015.30899 \mathrm{e}+00$ 1.00000e-09 2.12000e-01 $1.00000 \mathrm{e}-02$ 1.00000e-02 1.00000e-03 1.00000e-09 1.00000e-01 $1.00000 \mathrm{e}+001.00000 \mathrm{e}+001.00000 \mathrm{e}-011.00000 \mathrm{e}-091.00000 \mathrm{e}-01$ $1.00000 \mathrm{e}-05$ 1.00000e-05 1.00000e-06 1.00000e-09 1.00000e-01 $1.00000 \mathrm{e}+001.00000 \mathrm{e}+001.00000 \mathrm{e}-011.00000 \mathrm{e}-091.00000 \mathrm{e}-01$ Element: 9548 \# of layers: 9 
$\mathrm{Kx} \mathrm{Ky} \mathrm{Kz}$ Ss Por

5.30899e+01 5.30899e+01 5.30899e+00 1.00000e-09 2.12000e-01

$5.30899 \mathrm{e}+01$ 5.30899e+01 5.30899e+00 1.00000e-09 2.12000e-01

$5.30899 e+015.30899 e+015.30899 e+001.00000 e-092.12000 e-01$

$5.30899 \mathrm{e}+015.30899 \mathrm{e}+01$ 5.30899e+00 1.00000e-09 2.12000e-01

$5.30899 \mathrm{e}+015.30899 \mathrm{e}+015.30899 \mathrm{e}+00$ 1.00000e-09 2.12000e-01

$1.00000 \mathrm{e}-02$ 1.00000e-02 1.00000e-03 1.00000e-09 1.00000e-01

$1.00000 \mathrm{e}+001.00000 \mathrm{e}+001.00000 \mathrm{e}-011.00000 \mathrm{e}-091.00000 \mathrm{e}-01$

$1.00000 \mathrm{e}-051.00000 \mathrm{e}-051.00000 \mathrm{e}-061.00000 \mathrm{e}-091.00000 \mathrm{e}-01$

$1.00000 \mathrm{e}+001.00000 \mathrm{e}+001.00000 \mathrm{e}-011.00000 \mathrm{e}-091.00000 \mathrm{e}-01$

Element: 9549 \# of layers: 9

$\mathrm{Kx} \mathrm{Ky} \mathrm{Kz}$ Ss Por

$2.79906 \mathrm{e}+012.79906 \mathrm{e}+01$ 2.79906e+00 1.00000e-09 2.12000e-01

$2.79906 \mathrm{e}+012.79906 \mathrm{e}+012.79906 \mathrm{e}+00$ 1.00000e-09 2.12000e-01

$2.79906 \mathrm{e}+012.79906 \mathrm{e}+012.79906 \mathrm{e}+001.00000 \mathrm{e}-092.12000 \mathrm{e}-01$

$2.79906 \mathrm{e}+012.79906 \mathrm{e}+012.79906 \mathrm{e}+001.00000 \mathrm{e}-092.12000 \mathrm{e}-01$

$2.79906 \mathrm{e}+012.79906 \mathrm{e}+012.79906 \mathrm{e}+001.00000 \mathrm{e}-092.12000 \mathrm{e}-01$

$1.00000 \mathrm{e}-021.00000 \mathrm{e}-021.00000 \mathrm{e}-031.00000 \mathrm{e}-091.00000 \mathrm{e}-01$

$1.00000 \mathrm{e}+001.00000 \mathrm{e}+001.00000 \mathrm{e}-011.00000 \mathrm{e}-091.00000 \mathrm{e}-01$

$1.00000 \mathrm{e}-05$ 1.00000e-05 1.00000e-06 1.00000e-09 1.00000e-01

$1.00000 \mathrm{e}+001.00000 \mathrm{e}+001.00000 \mathrm{e}-011.00000 \mathrm{e}-091.00000 \mathrm{e}-01$

Element: 9550 \# of layers: 9

$\mathrm{Kx} \mathrm{Ky} \mathrm{Kz}$ Ss Por

$2.79906 \mathrm{e}+012.79906 \mathrm{e}+012.79906 \mathrm{e}+00$ 1.00000e-09 2.12000e-01

$2.79906 \mathrm{e}+012.79906 \mathrm{e}+012.79906 \mathrm{e}+001.00000 \mathrm{e}-092.12000 \mathrm{e}-01$

$2.79906 \mathrm{e}+012.79906 \mathrm{e}+012.79906 \mathrm{e}+00$ 1.00000e-09 2.12000e-01

$2.79906 \mathrm{e}+012.79906 \mathrm{e}+012.79906 \mathrm{e}+001.00000 \mathrm{e}-092.12000 \mathrm{e}-01$

$2.79906 \mathrm{e}+012.79906 \mathrm{e}+012.79906 \mathrm{e}+001.00000 \mathrm{e}-092.12000 \mathrm{e}-01$

$1.00000 \mathrm{e}-02$ 1.00000e-02 1.00000e-03 1.00000e-09 1.00000e-01

$1.00000 \mathrm{e}+001.00000 \mathrm{e}+001.00000 \mathrm{e}-011.00000 \mathrm{e}-091.00000 \mathrm{e}-01$

$1.00000 \mathrm{e}-05$ 1.00000e-05 1.00000e-06 1.00000e-09 1.00000e-01

$1.00000 \mathrm{e}+001.00000 \mathrm{e}+001.00000 \mathrm{e}-01$ 1.00000e-09 1.00000e-01

Element: 9551 \# of layers: 9

$\mathrm{Kx} \mathrm{Ky} \mathrm{Kz}$ Ss Por

5.30899e+01 5.30899e+01 5.30899e+00 1.00000e-09 2.12000e-01

$5.30899 \mathrm{e}+015.30899 \mathrm{e}+01$ 5.30899e+00 1.00000e-09 2.12000e-01

$5.30899 \mathrm{e}+015.30899 \mathrm{e}+015.30899 \mathrm{e}+001.00000 \mathrm{e}-092.12000 \mathrm{e}-01$

$5.30899 \mathrm{e}+015.30899 \mathrm{e}+015.30899 \mathrm{e}+00$ 1.00000e-09 2.12000e-01

$5.30899 \mathrm{e}+015.30899 \mathrm{e}+01$ 5.30899e+00 1.00000e-09 2.12000e-01

$1.00000 \mathrm{e}-02$ 1.00000e-02 1.00000e-03 1.00000e-09 1.00000e-01

$1.00000 \mathrm{e}+001.00000 \mathrm{e}+001.00000 \mathrm{e}-011.00000 \mathrm{e}-091.00000 \mathrm{e}-01$

$1.00000 \mathrm{e}-05$ 1.00000e-05 1.00000e-06 1.00000e-09 1.00000e-01

$1.00000 \mathrm{e}+001.00000 \mathrm{e}+001.00000 \mathrm{e}-011.00000 \mathrm{e}-091.00000 \mathrm{e}-01$

Element: 9552 \# of layers: 8

$\mathrm{Kx} \mathrm{Ky} \mathrm{Kz}$ Ss Por

5.30899e+01 5.30899e+01 5.30899e+00 1.00000e-09 2.12000e-01 
5.30899e+01 5.30899e+01 5.30899e+00 1.00000e-09 2.12000e-01 $5.30899 \mathrm{e}+015.30899 \mathrm{e}+01$ 5.30899e+00 1.00000e-09 2.12000e-01 $5.30899 \mathrm{e}+015.30899 \mathrm{e}+01$ 5.30899e+00 1.00000e-09 2.12000e-01 $1.00000 \mathrm{e}-02$ 1.00000e-02 1.00000e-03 1.00000e-09 1.00000e-01 $1.00000 \mathrm{e}+001.00000 \mathrm{e}+001.00000 \mathrm{e}-011.00000 \mathrm{e}-091.00000 \mathrm{e}-01$ $1.00000 \mathrm{e}-05$ 1.00000e-05 1.00000e-06 1.00000e-09 1.00000e-01 $1.00000 \mathrm{e}+001.00000 \mathrm{e}+001.00000 \mathrm{e}-01$ 1.00000e-09 1.00000e-01 Element: 9553 \# of layers: 8

$\mathrm{Kx} \mathrm{Ky} \mathrm{Kz}$ Ss Por

5.30899e+01 5.30899e+01 5.30899e+00 1.00000e-09 2.12000e-01 $5.30899 \mathrm{e}+015.30899 \mathrm{e}+01$ 5.30899e+00 1.00000e-09 2.12000e-01 $5.30899 \mathrm{e}+01$ 5.30899e+01 5.30899e+00 1.00000e-09 2.12000e-01 5.30899e+01 5.30899e+01 5.30899e+00 1.00000e-09 2.12000e-01 $1.00000 \mathrm{e}-02$ 1.00000e-02 1.00000e-03 1.00000e-09 1.00000e-01 $1.00000 \mathrm{e}+001.00000 \mathrm{e}+001.00000 \mathrm{e}-011.00000 \mathrm{e}-091.00000 \mathrm{e}-01$ $1.00000 \mathrm{e}-05$ 1.00000e-05 1.00000e-06 1.00000e-09 1.00000e-01 $1.00000 \mathrm{e}+001.00000 \mathrm{e}+001.00000 \mathrm{e}-011.00000 \mathrm{e}-091.00000 \mathrm{e}-01$ Element: 9554 \# of layers: 8

$\mathrm{Kx} \mathrm{Ky} \mathrm{Kz}$ Ss Por

5.30899e+01 5.30899e+01 5.30899e+00 1.00000e-09 2.12000e-01 $5.30899 e+015.30899 e+015.30899 e+001.00000 e-092.12000 e-01$ $5.30899 \mathrm{e}+015.30899 \mathrm{e}+01$ 5.30899e+00 1.00000e-09 2.12000e-01 $5.30899 \mathrm{e}+015.30899 \mathrm{e}+01$ 5.30899e+00 1.00000e-09 2.12000e-01 $1.00000 \mathrm{e}-02$ 1.00000e-02 1.00000e-03 1.00000e-09 1.00000e-01

$1.00000 \mathrm{e}+001.00000 \mathrm{e}+001.00000 \mathrm{e}-011.00000 \mathrm{e}-091.00000 \mathrm{e}-01$ $1.00000 \mathrm{e}-05$ 1.00000e-05 1.00000e-06 1.00000e-09 1.00000e-01

$1.00000 \mathrm{e}+001.00000 \mathrm{e}+001.00000 \mathrm{e}-011.00000 \mathrm{e}-091.00000 \mathrm{e}-01$ Element: 9555 \# of layers: 8

$\mathrm{Kx} \mathrm{Ky} \mathrm{Kz}$ Ss Por

$5.30899 \mathrm{e}+01$ 5.30899e+01 5.30899e+00 1.00000e-09 2.12000e-01

$5.30899 \mathrm{e}+015.30899 \mathrm{e}+015.30899 \mathrm{e}+00$ 1.00000e-09 2.12000e-01 $5.30899 \mathrm{e}+015.30899 \mathrm{e}+01$ 5.30899e+00 1.00000e-09 2.12000e-01 $5.30899 \mathrm{e}+015.30899 \mathrm{e}+015.30899 \mathrm{e}+00$ 1.00000e-09 2.12000e-01 $1.00000 \mathrm{e}-02$ 1.00000e-02 1.00000e-03 1.00000e-09 1.00000e-01 $1.00000 \mathrm{e}+001.00000 \mathrm{e}+001.00000 \mathrm{e}-011.00000 \mathrm{e}-091.00000 \mathrm{e}-01$ $1.00000 \mathrm{e}-05$ 1.00000e-05 1.00000e-06 1.00000e-09 1.00000e-01 $1.00000 \mathrm{e}+001.00000 \mathrm{e}+001.00000 \mathrm{e}-011.00000 \mathrm{e}-091.00000 \mathrm{e}-01$ Element: 9556 \# of layers: 8

$\mathrm{Kx} \mathrm{Ky} \mathrm{Kz}$ Ss Por

5.30899e+01 5.30899e+01 5.30899e+00 1.00000e-09 2.12000e-01 $5.30899 \mathrm{e}+015.30899 \mathrm{e}+01$ 5.30899e+00 1.00000e-09 2.12000e-01 $5.30899 \mathrm{e}+01$ 5.30899e+01 5.30899e+00 1.00000e-09 2.12000e-01 $5.30899 \mathrm{e}+015.30899 \mathrm{e}+015.30899 \mathrm{e}+001.00000 \mathrm{e}-092.12000 \mathrm{e}-01$ $1.00000 \mathrm{e}-02$ 1.00000e-02 1.00000e-03 1.00000e-09 1.00000e-01 $1.00000 \mathrm{e}+001.00000 \mathrm{e}+001.00000 \mathrm{e}-011.00000 \mathrm{e}-091.00000 \mathrm{e}-01$ $1.00000 \mathrm{e}-05$ 1.00000e-05 1.00000e-06 1.00000e-09 1.00000e-01 
$1.00000 \mathrm{e}+001.00000 \mathrm{e}+00$ 1.00000e-01 1.00000e-09 1.00000e-01

Element: 9557 \# of layers: 8

$\mathrm{Kx} \mathrm{Ky} \mathrm{Kz}$ Ss Por

5.30899e+01 5.30899e+01 5.30899e+00 1.00000e-09 2.12000e-01

$5.30899 \mathrm{e}+015.30899 \mathrm{e}+015.30899 \mathrm{e}+001.00000 \mathrm{e}-092.12000 \mathrm{e}-01$

$5.30899 \mathrm{e}+015.30899 \mathrm{e}+015.30899 \mathrm{e}+00$ 1.00000e-09 2.12000e-01

$5.30899 \mathrm{e}+015.30899 \mathrm{e}+015.30899 \mathrm{e}+00$ 1.00000e-09 2.12000e-01

$1.00000 \mathrm{e}-02$ 1.00000e-02 1.00000e-03 1.00000e-09 1.00000e-01

$1.00000 \mathrm{e}+001.00000 \mathrm{e}+001.00000 \mathrm{e}-011.00000 \mathrm{e}-091.00000 \mathrm{e}-01$

$1.00000 \mathrm{e}-05$ 1.00000e-05 1.00000e-06 1.00000e-09 1.00000e-01

$1.00000 \mathrm{e}+001.00000 \mathrm{e}+001.00000 \mathrm{e}-011.00000 \mathrm{e}-091.00000 \mathrm{e}-01$

Element: 9558 \# of layers: 8

$\mathrm{Kx} \mathrm{Ky} \mathrm{Kz}$ Ss Por

5.30899e+01 5.30899e+01 5.30899e+00 1.00000e-09 2.12000e-01

$5.30899 \mathrm{e}+015.30899 \mathrm{e}+015.30899 \mathrm{e}+001.00000 \mathrm{e}-092.12000 \mathrm{e}-01$

$5.30899 \mathrm{e}+015.30899 \mathrm{e}+015.30899 \mathrm{e}+00$ 1.00000e-09 2.12000e-01

$5.30899 \mathrm{e}+015.30899 \mathrm{e}+01$ 5.30899e+00 1.00000e-09 2.12000e-01

$1.00000 \mathrm{e}-02$ 1.00000e-02 1.00000e-03 1.00000e-09 1.00000e-01

$1.00000 \mathrm{e}+001.00000 \mathrm{e}+001.00000 \mathrm{e}-011.00000 \mathrm{e}-091.00000 \mathrm{e}-01$

1.00000e-05 1.00000e-05 1.00000e-06 1.00000e-09 1.00000e-01

$1.00000 \mathrm{e}+001.00000 \mathrm{e}+001.00000 \mathrm{e}-011.00000 \mathrm{e}-091.00000 \mathrm{e}-01$

Element: 9559 \# of layers: 8

$\mathrm{Kx} \mathrm{Ky} \mathrm{Kz}$ Ss Por

5.30899e+01 5.30899e+01 5.30899e+00 1.00000e-09 2.12000e-01

$5.30899 \mathrm{e}+015.30899 \mathrm{e}+015.30899 \mathrm{e}+001.00000 \mathrm{e}-092.12000 \mathrm{e}-01$

$5.30899 \mathrm{e}+015.30899 \mathrm{e}+01$ 5.30899e+00 1.00000e-09 2.12000e-01

$5.30899 \mathrm{e}+015.30899 \mathrm{e}+015.30899 \mathrm{e}+001.00000 \mathrm{e}-092.12000 \mathrm{e}-01$

$1.00000 \mathrm{e}-02$ 1.00000e-02 1.00000e-03 1.00000e-09 1.00000e-01

$1.00000 \mathrm{e}+001.00000 \mathrm{e}+001.00000 \mathrm{e}-011.00000 \mathrm{e}-091.00000 \mathrm{e}-01$

$1.00000 \mathrm{e}-05$ 1.00000e-05 1.00000e-06 1.00000e-09 1.00000e-01

$1.00000 \mathrm{e}+001.00000 \mathrm{e}+001.00000 \mathrm{e}-011.00000 \mathrm{e}-091.00000 \mathrm{e}-01$

Element: 9560 \# of layers: 8

$\mathrm{Kx} \mathrm{Ky} \mathrm{Kz}$ Ss Por

5.30899e+01 5.30899e+01 5.30899e+00 1.00000e-09 2.12000e-01

$5.30899 \mathrm{e}+015.30899 \mathrm{e}+01$ 5.30899e+00 1.00000e-09 2.12000e-01

$5.30899 \mathrm{e}+015.30899 \mathrm{e}+015.30899 \mathrm{e}+00$ 1.00000e-09 2.12000e-01

$5.30899 \mathrm{e}+015.30899 \mathrm{e}+015.30899 \mathrm{e}+001.00000 \mathrm{e}-092.12000 \mathrm{e}-01$

$1.00000 \mathrm{e}-02$ 1.00000e-02 1.00000e-03 1.00000e-09 1.00000e-01

$1.00000 \mathrm{e}+001.00000 \mathrm{e}+001.00000 \mathrm{e}-011.00000 \mathrm{e}-091.00000 \mathrm{e}-01$

$1.00000 \mathrm{e}-05$ 1.00000e-05 1.00000e-06 1.00000e-09 1.00000e-01

$1.00000 \mathrm{e}+001.00000 \mathrm{e}+001.00000 \mathrm{e}-011.00000 \mathrm{e}-091.00000 \mathrm{e}-01$

Element: 9561 \# of layers: 8

$\mathrm{Kx} \mathrm{Ky} \mathrm{Kz}$ Ss Por

5.30899e+01 5.30899e+01 5.30899e+00 1.00000e-09 2.12000e-01

$5.30899 \mathrm{e}+01$ 5.30899e+01 5.30899e+00 1.00000e-09 2.12000e-01

$5.30899 e+015.30899 e+015.30899 e+001.00000 e-092.12000 e-01$ 
5.30899e+01 5.30899e+01 5.30899e+00 1.00000e-09 2.12000e-01 $1.00000 \mathrm{e}-02$ 1.00000e-02 1.00000e-03 1.00000e-09 1.00000e-01 $1.00000 \mathrm{e}+001.00000 \mathrm{e}+001.00000 \mathrm{e}-011.00000 \mathrm{e}-091.00000 \mathrm{e}-01$ $1.00000 \mathrm{e}-05$ 1.00000e-05 1.00000e-06 1.00000e-09 1.00000e-01 $1.00000 \mathrm{e}+001.00000 \mathrm{e}+001.00000 \mathrm{e}-01$ 1.00000e-09 1.00000e-01 Element: 9562 \# of layers: 8

$\mathrm{Kx} \mathrm{Ky} \mathrm{Kz}$ Ss Por

5.30899e+01 5.30899e+01 5.30899e+00 1.00000e-09 2.12000e-01 $5.30899 \mathrm{e}+015.30899 \mathrm{e}+01$ 5.30899e+00 1.00000e-09 2.12000e-01

$5.30899 \mathrm{e}+015.30899 \mathrm{e}+015.30899 \mathrm{e}+00$ 1.00000e-09 2.12000e-01 $5.30899 \mathrm{e}+015.30899 \mathrm{e}+015.30899 \mathrm{e}+00$ 1.00000e-09 2.12000e-01 $1.00000 \mathrm{e}-02$ 1.00000e-02 1.00000e-03 1.00000e-09 1.00000e-01 $1.00000 \mathrm{e}+001.00000 \mathrm{e}+001.00000 \mathrm{e}-011.00000 \mathrm{e}-091.00000 \mathrm{e}-01$ $1.00000 \mathrm{e}-05$ 1.00000e-05 1.00000e-06 1.00000e-09 1.00000e-01 $1.00000 \mathrm{e}+001.00000 \mathrm{e}+001.00000 \mathrm{e}-01$ 1.00000e-09 1.00000e-01 Element: 9563 \# of layers: 8

$\mathrm{Kx} \mathrm{Ky} \mathrm{Kz}$ Ss Por

5.55582e+01 5.55582e+01 5.55582e+00 1.00000e-09 2.12000e-01 $5.55582 \mathrm{e}+015.55582 \mathrm{e}+015.55582 \mathrm{e}+001.00000 \mathrm{e}-092.12000 \mathrm{e}-01$ $5.55582 \mathrm{e}+015.55582 \mathrm{e}+015.55582 \mathrm{e}+001.00000 \mathrm{e}-092.12000 \mathrm{e}-01$ $5.55582 \mathrm{e}+015.55582 \mathrm{e}+015.55582 \mathrm{e}+001.00000 \mathrm{e}-092.12000 \mathrm{e}-01$ $1.00000 \mathrm{e}-02$ 1.00000e-02 1.00000e-03 1.00000e-09 1.00000e-01 $1.00000 \mathrm{e}+001.00000 \mathrm{e}+001.00000 \mathrm{e}-011.00000 \mathrm{e}-091.00000 \mathrm{e}-01$ $1.00000 \mathrm{e}-051.00000 \mathrm{e}-05$ 1.00000e-06 1.00000e-09 1.00000e-01 $1.00000 \mathrm{e}+001.00000 \mathrm{e}+001.00000 \mathrm{e}-011.00000 \mathrm{e}-091.00000 \mathrm{e}-01$ Element: 9564 \# of layers: 8

$\mathrm{Kx} \mathrm{Ky} \mathrm{Kz}$ Ss Por

5.55582e+01 5.55582e+01 5.55582e+00 1.00000e-09 2.12000e-01 $5.55582 \mathrm{e}+015.55582 \mathrm{e}+015.55582 \mathrm{e}+001.00000 \mathrm{e}-092.12000 \mathrm{e}-01$ $5.55582 \mathrm{e}+015.55582 \mathrm{e}+015.55582 \mathrm{e}+001.00000 \mathrm{e}-092.12000 \mathrm{e}-01$ $5.55582 \mathrm{e}+015.55582 \mathrm{e}+015.55582 \mathrm{e}+001.00000 \mathrm{e}-092.12000 \mathrm{e}-01$ $1.00000 \mathrm{e}-02$ 1.00000e-02 1.00000e-03 1.00000e-09 1.00000e-01 $1.00000 \mathrm{e}+001.00000 \mathrm{e}+001.00000 \mathrm{e}-011.00000 \mathrm{e}-091.00000 \mathrm{e}-01$ $1.00000 \mathrm{e}-05$ 1.00000e-05 1.00000e-06 1.00000e-09 1.00000e-01 $1.00000 \mathrm{e}+001.00000 \mathrm{e}+001.00000 \mathrm{e}-011.00000 \mathrm{e}-091.00000 \mathrm{e}-01$ Element: 9565 \# of layers: 9

Kx Ky Kz Ss Por

5.55582e+01 5.55582e+01 5.55582e+00 1.00000e-09 2.12000e-01 $5.55582 \mathrm{e}+015.55582 \mathrm{e}+015.55582 \mathrm{e}+001.00000 \mathrm{e}-092.12000 \mathrm{e}-01$ $5.55582 \mathrm{e}+015.55582 \mathrm{e}+015.55582 \mathrm{e}+001.00000 \mathrm{e}-092.12000 \mathrm{e}-01$ $5.55582 \mathrm{e}+015.55582 \mathrm{e}+015.55582 \mathrm{e}+001.00000 \mathrm{e}-092.12000 \mathrm{e}-01$ $5.55582 \mathrm{e}+015.55582 \mathrm{e}+015.55582 \mathrm{e}+001.00000 \mathrm{e}-092.12000 \mathrm{e}-01$ $1.00000 \mathrm{e}-02$ 1.00000e-02 1.00000e-03 1.00000e-09 1.00000e-01 $1.00000 \mathrm{e}+001.00000 \mathrm{e}+001.00000 \mathrm{e}-011.00000 \mathrm{e}-091.00000 \mathrm{e}-01$ $1.00000 \mathrm{e}-05$ 1.00000e-05 1.00000e-06 1.00000e-09 1.00000e-01 $1.00000 \mathrm{e}+001.00000 \mathrm{e}+001.00000 \mathrm{e}-011.00000 \mathrm{e}-091.00000 \mathrm{e}-01$ 
Element: 9566 \# of layers: 8

$\mathrm{Kx} \mathrm{Ky} \mathrm{Kz}$ Ss Por

5.30899e+01 5.30899e+01 5.30899e+00 1.00000e-09 2.12000e-01

$5.30899 e+015.30899 e+015.30899 e+001.00000 e-092.12000 e-01$

$5.30899 \mathrm{e}+015.30899 \mathrm{e}+015.30899 \mathrm{e}+001.00000 \mathrm{e}-092.12000 \mathrm{e}-01$

$5.30899 \mathrm{e}+015.30899 \mathrm{e}+015.30899 \mathrm{e}+00$ 1.00000e-09 2.12000e-01

$1.00000 \mathrm{e}-02$ 1.00000e-02 1.00000e-03 1.00000e-09 1.00000e-01

$1.00000 \mathrm{e}+001.00000 \mathrm{e}+001.00000 \mathrm{e}-011.00000 \mathrm{e}-091.00000 \mathrm{e}-01$

$1.00000 \mathrm{e}-051.00000 \mathrm{e}-051.00000 \mathrm{e}-061.00000 \mathrm{e}-091.00000 \mathrm{e}-01$

$1.00000 \mathrm{e}+001.00000 \mathrm{e}+001.00000 \mathrm{e}-011.00000 \mathrm{e}-091.00000 \mathrm{e}-01$

Element: 9567 \# of layers: 8

$\mathrm{Kx} \mathrm{Ky} \mathrm{Kz}$ Ss Por

5.30899e+01 5.30899e+01 5.30899e+00 1.00000e-09 2.12000e-01

$5.30899 \mathrm{e}+015.30899 \mathrm{e}+015.30899 \mathrm{e}+00$ 1.00000e-09 2.12000e-01

$5.30899 \mathrm{e}+015.30899 \mathrm{e}+015.30899 \mathrm{e}+001.00000 \mathrm{e}-092.12000 \mathrm{e}-01$

$5.30899 \mathrm{e}+015.30899 \mathrm{e}+015.30899 \mathrm{e}+00$ 1.00000e-09 2.12000e-01

$1.00000 \mathrm{e}-02$ 1.00000e-02 1.00000e-03 1.00000e-09 1.00000e-01

$1.00000 \mathrm{e}+001.00000 \mathrm{e}+001.00000 \mathrm{e}-011.00000 \mathrm{e}-091.00000 \mathrm{e}-01$

$1.00000 \mathrm{e}-05$ 1.00000e-05 1.00000e-06 1.00000e-09 1.00000e-01

$1.00000 \mathrm{e}+001.00000 \mathrm{e}+001.00000 \mathrm{e}-011.00000 \mathrm{e}-091.00000 \mathrm{e}-01$

Element: 9568 \# of layers: 8

$\mathrm{Kx} \mathrm{Ky} \mathrm{Kz}$ Ss Por

5.30899e+01 5.30899e+01 5.30899e+00 1.00000e-09 2.12000e-01

$5.30899 \mathrm{e}+015.30899 \mathrm{e}+01$ 5.30899e+00 1.00000e-09 2.12000e-01

$5.30899 \mathrm{e}+015.30899 \mathrm{e}+015.30899 \mathrm{e}+001.00000 \mathrm{e}-092.12000 \mathrm{e}-01$

$5.30899 \mathrm{e}+015.30899 \mathrm{e}+015.30899 \mathrm{e}+001.00000 \mathrm{e}-092.12000 \mathrm{e}-01$

$1.00000 \mathrm{e}-02$ 1.00000e-02 1.00000e-03 1.00000e-09 1.00000e-01

$1.00000 \mathrm{e}+001.00000 \mathrm{e}+001.00000 \mathrm{e}-011.00000 \mathrm{e}-091.00000 \mathrm{e}-01$

$1.00000 \mathrm{e}-05$ 1.00000e-05 1.00000e-06 1.00000e-09 1.00000e-01

$1.00000 \mathrm{e}+001.00000 \mathrm{e}+001.00000 \mathrm{e}-011.00000 \mathrm{e}-091.00000 \mathrm{e}-01$

Element: 9569 \# of layers: 8

$\mathrm{Kx} \mathrm{Ky} \mathrm{Kz}$ Ss Por

5.30899e+01 5.30899e+01 5.30899e+00 1.00000e-09 2.12000e-01

$5.30899 \mathrm{e}+01$ 5.30899e+01 5.30899e+00 1.00000e-09 2.12000e-01

$5.30899 \mathrm{e}+015.30899 \mathrm{e}+01$ 5.30899e+00 1.00000e-09 2.12000e-01

$5.30899 \mathrm{e}+015.30899 \mathrm{e}+015.30899 \mathrm{e}+00$ 1.00000e-09 2.12000e-01

$1.00000 \mathrm{e}-02$ 1.00000e-02 1.00000e-03 1.00000e-09 1.00000e-01

$1.00000 \mathrm{e}+001.00000 \mathrm{e}+001.00000 \mathrm{e}-011.00000 \mathrm{e}-091.00000 \mathrm{e}-01$

$1.00000 \mathrm{e}-05$ 1.00000e-05 1.00000e-06 1.00000e-09 1.00000e-01

$1.00000 \mathrm{e}+001.00000 \mathrm{e}+001.00000 \mathrm{e}-01$ 1.00000e-09 1.00000e-01

Element: 9570 \# of layers: 8

$\mathrm{Kx} \mathrm{Ky} \mathrm{Kz}$ Ss Por

5.55582e+01 5.55582e+01 5.55582e+00 1.00000e-09 2.12000e-01

5.55582e+01 5.55582e+01 5.55582e+00 1.00000e-09 2.12000e-01

$5.55582 \mathrm{e}+015.55582 \mathrm{e}+015.55582 \mathrm{e}+001.00000 \mathrm{e}-092.12000 \mathrm{e}-01$

$5.55582 \mathrm{e}+015.55582 \mathrm{e}+015.55582 \mathrm{e}+001.00000 \mathrm{e}-092.12000 \mathrm{e}-01$ 
$1.00000 \mathrm{e}-02$ 1.00000e-02 1.00000e-03 1.00000e-09 1.00000e-01 $1.00000 \mathrm{e}+001.00000 \mathrm{e}+001.00000 \mathrm{e}-011.00000 \mathrm{e}-091.00000 \mathrm{e}-01$ $1.00000 \mathrm{e}-05$ 1.00000e-05 1.00000e-06 1.00000e-09 1.00000e-01 $1.00000 \mathrm{e}+001.00000 \mathrm{e}+001.00000 \mathrm{e}-011.00000 \mathrm{e}-091.00000 \mathrm{e}-01$ Element: 9571 \# of layers: 9

Kx Ky Kz Ss Por

$5.55582 \mathrm{e}+015.55582 \mathrm{e}+01$ 5.55582e+00 1.00000e-09 2.12000e-01 $5.55582 \mathrm{e}+015.55582 \mathrm{e}+015.55582 \mathrm{e}+001.00000 \mathrm{e}-092.12000 \mathrm{e}-01$ $5.55582 \mathrm{e}+015.55582 \mathrm{e}+015.55582 \mathrm{e}+001.00000 \mathrm{e}-092.12000 \mathrm{e}-01$ $5.55582 \mathrm{e}+015.55582 \mathrm{e}+015.55582 \mathrm{e}+001.00000 \mathrm{e}-092.12000 \mathrm{e}-01$ $5.55582 \mathrm{e}+015.55582 \mathrm{e}+015.55582 \mathrm{e}+001.00000 \mathrm{e}-092.12000 \mathrm{e}-01$ $1.00000 \mathrm{e}-021.00000 \mathrm{e}-02$ 1.00000e-03 1.00000e-09 1.00000e-01 $1.00000 \mathrm{e}+001.00000 \mathrm{e}+001.00000 \mathrm{e}-011.00000 \mathrm{e}-091.00000 \mathrm{e}-01$ $1.00000 \mathrm{e}-05$ 1.00000e-05 1.00000e-06 1.00000e-09 1.00000e-01 $1.00000 \mathrm{e}+001.00000 \mathrm{e}+001.00000 \mathrm{e}-011.00000 \mathrm{e}-091.00000 \mathrm{e}-01$ Element: 9572 \# of layers: 9

Kx Ky Kz Ss Por

$5.55582 \mathrm{e}+01$ 5.55582e+01 5.55582e+00 1.00000e-09 2.12000e-01 $5.55582 \mathrm{e}+015.55582 \mathrm{e}+015.55582 \mathrm{e}+001.00000 \mathrm{e}-092.12000 \mathrm{e}-01$ $5.55582 \mathrm{e}+015.55582 \mathrm{e}+015.55582 \mathrm{e}+001.00000 \mathrm{e}-092.12000 \mathrm{e}-01$ $5.55582 \mathrm{e}+015.55582 \mathrm{e}+015.55582 \mathrm{e}+001.00000 \mathrm{e}-092.12000 \mathrm{e}-01$ $5.55582 \mathrm{e}+015.55582 \mathrm{e}+015.55582 \mathrm{e}+00$ 1.00000e-09 2.12000e-01 $1.00000 \mathrm{e}-021.00000 \mathrm{e}-02$ 1.00000e-03 1.00000e-09 1.00000e-01 $1.00000 \mathrm{e}+001.00000 \mathrm{e}+001.00000 \mathrm{e}-011.00000 \mathrm{e}-091.00000 \mathrm{e}-01$ $1.00000 \mathrm{e}-05$ 1.00000e-05 1.00000e-06 1.00000e-09 1.00000e-01 $1.00000 \mathrm{e}+001.00000 \mathrm{e}+00$ 1.00000e-01 1.00000e-09 1.00000e-01 Element: 9573 \# of layers: 8

Kx Ky Kz Ss Por

$5.55582 \mathrm{e}+015.55582 \mathrm{e}+015.55582 \mathrm{e}+00$ 1.00000e-09 2.12000e-01 $5.55582 \mathrm{e}+015.55582 \mathrm{e}+015.55582 \mathrm{e}+001.00000 \mathrm{e}-092.12000 \mathrm{e}-01$ $5.55582 \mathrm{e}+015.55582 \mathrm{e}+015.55582 \mathrm{e}+001.00000 \mathrm{e}-092.12000 \mathrm{e}-01$ $5.55582 \mathrm{e}+015.55582 \mathrm{e}+015.55582 \mathrm{e}+001.00000 \mathrm{e}-092.12000 \mathrm{e}-01$ $5.55582 \mathrm{e}+015.55582 \mathrm{e}+015.55582 \mathrm{e}+001.00000 \mathrm{e}-092.12000 \mathrm{e}-01$ $1.00000 \mathrm{e}-021.00000 \mathrm{e}-02$ 1.00000e-03 1.00000e-09 1.00000e-01 $1.00000 \mathrm{e}-05$ 1.00000e-05 1.00000e-06 1.00000e-09 1.00000e-01 $1.00000 \mathrm{e}+001.00000 \mathrm{e}+001.00000 \mathrm{e}-011.00000 \mathrm{e}-091.00000 \mathrm{e}-01$ Element: 9574 \# of layers: 8

Kx Ky Kz Ss Por

$5.55582 \mathrm{e}+015.55582 \mathrm{e}+01$ 5.55582e+00 1.00000e-09 2.12000e-01 $5.55582 \mathrm{e}+015.55582 \mathrm{e}+015.55582 \mathrm{e}+001.00000 \mathrm{e}-092.12000 \mathrm{e}-01$ $5.55582 \mathrm{e}+015.55582 \mathrm{e}+015.55582 \mathrm{e}+001.00000 \mathrm{e}-092.12000 \mathrm{e}-01$ $5.55582 \mathrm{e}+015.55582 \mathrm{e}+015.55582 \mathrm{e}+001.00000 \mathrm{e}-092.12000 \mathrm{e}-01$ $5.55582 \mathrm{e}+015.55582 \mathrm{e}+015.55582 \mathrm{e}+00$ 1.00000e-09 2.12000e-01 $1.00000 \mathrm{e}-02$ 1.00000e-02 1.00000e-03 1.00000e-09 1.00000e-01 $1.00000 \mathrm{e}-05$ 1.00000e-05 1.00000e-06 1.00000e-09 1.00000e-01 $1.00000 \mathrm{e}+001.00000 \mathrm{e}+001.00000 \mathrm{e}-011.00000 \mathrm{e}-091.00000 \mathrm{e}-01$ 
Element: 9575 \# of layers: 9

$\mathrm{Kx} \mathrm{Ky} \mathrm{Kz}$ Ss Por

5.55582e+01 5.55582e+01 5.55582e+00 1.00000e-09 2.12000e-01

$5.55582 \mathrm{e}+015.55582 \mathrm{e}+015.55582 \mathrm{e}+001.00000 \mathrm{e}-092.12000 \mathrm{e}-01$

$5.55582 \mathrm{e}+015.55582 \mathrm{e}+015.55582 \mathrm{e}+001.00000 \mathrm{e}-092.12000 \mathrm{e}-01$

$5.55582 \mathrm{e}+015.55582 \mathrm{e}+015.55582 \mathrm{e}+001.00000 \mathrm{e}-092.12000 \mathrm{e}-01$

5.55582e+01 5.55582e+01 5.55582e+00 1.00000e-09 2.12000e-01

$1.00000 \mathrm{e}-02$ 1.00000e-02 1.00000e-03 1.00000e-09 1.00000e-01

$1.00000 \mathrm{e}+001.00000 \mathrm{e}+001.00000 \mathrm{e}-011.00000 \mathrm{e}-091.00000 \mathrm{e}-01$

$1.00000 \mathrm{e}-05$ 1.00000e-05 1.00000e-06 1.00000e-09 1.00000e-01

$1.00000 \mathrm{e}+001.00000 \mathrm{e}+001.00000 \mathrm{e}-011.00000 \mathrm{e}-091.00000 \mathrm{e}-01$

Element: 9576 \# of layers: 9

$\mathrm{Kx} \mathrm{Ky} \mathrm{Kz}$ Ss Por

5.55582e+01 5.55582e+01 5.55582e+00 1.00000e-09 2.12000e-01

$5.55582 \mathrm{e}+015.55582 \mathrm{e}+015.55582 \mathrm{e}+001.00000 \mathrm{e}-092.12000 \mathrm{e}-01$

$5.55582 \mathrm{e}+015.55582 \mathrm{e}+015.55582 \mathrm{e}+001.00000 \mathrm{e}-092.12000 \mathrm{e}-01$

$5.55582 \mathrm{e}+015.55582 \mathrm{e}+015.55582 \mathrm{e}+001.00000 \mathrm{e}-092.12000 \mathrm{e}-01$

$5.55582 \mathrm{e}+015.55582 \mathrm{e}+015.55582 \mathrm{e}+001.00000 \mathrm{e}-092.12000 \mathrm{e}-01$

$1.00000 \mathrm{e}-02$ 1.00000e-02 1.00000e-03 1.00000e-09 1.00000e-01

$1.00000 \mathrm{e}+001.00000 \mathrm{e}+001.00000 \mathrm{e}-011.00000 \mathrm{e}-091.00000 \mathrm{e}-01$

$1.00000 \mathrm{e}-05$ 1.00000e-05 1.00000e-06 1.00000e-09 1.00000e-01

$1.00000 \mathrm{e}+001.00000 \mathrm{e}+001.00000 \mathrm{e}-01$ 1.00000e-09 1.00000e-01

Element: 9577 \# of layers: 8

Kx Ky Kz Ss Por

5.55582e+01 5.55582e+01 5.55582e+00 1.00000e-09 2.12000e-01

$5.55582 \mathrm{e}+015.55582 \mathrm{e}+015.55582 \mathrm{e}+001.00000 \mathrm{e}-092.12000 \mathrm{e}-01$

$5.55582 \mathrm{e}+015.55582 \mathrm{e}+015.55582 \mathrm{e}+001.00000 \mathrm{e}-092.12000 \mathrm{e}-01$

$5.55582 \mathrm{e}+015.55582 \mathrm{e}+015.55582 \mathrm{e}+001.00000 \mathrm{e}-092.12000 \mathrm{e}-01$

$1.00000 \mathrm{e}-02$ 1.00000e-02 1.00000e-03 1.00000e-09 1.00000e-01

$1.00000 \mathrm{e}+001.00000 \mathrm{e}+001.00000 \mathrm{e}-011.00000 \mathrm{e}-091.00000 \mathrm{e}-01$

$1.00000 \mathrm{e}-05$ 1.00000e-05 1.00000e-06 1.00000e-09 1.00000e-01

$1.00000 \mathrm{e}+001.00000 \mathrm{e}+001.00000 \mathrm{e}-011.00000 \mathrm{e}-091.00000 \mathrm{e}-01$

Element: 9578 \# of layers: 9

$\mathrm{Kx} \mathrm{Ky} \mathrm{Kz}$ Ss Por

$5.55582 \mathrm{e}+015.55582 \mathrm{e}+01$ 5.55582e+00 1.00000e-09 2.12000e-01

5.55582e+01 5.55582e+01 5.55582e+00 1.00000e-09 2.12000e-01

$5.55582 \mathrm{e}+015.55582 \mathrm{e}+015.55582 \mathrm{e}+001.00000 \mathrm{e}-092.12000 \mathrm{e}-01$

$5.55582 \mathrm{e}+015.55582 \mathrm{e}+015.55582 \mathrm{e}+001.00000 \mathrm{e}-092.12000 \mathrm{e}-01$

$5.55582 \mathrm{e}+015.55582 \mathrm{e}+015.55582 \mathrm{e}+001.00000 \mathrm{e}-092.12000 \mathrm{e}-01$

$1.00000 \mathrm{e}-02$ 1.00000e-02 1.00000e-03 1.00000e-09 1.00000e-01

$1.00000 \mathrm{e}+001.00000 \mathrm{e}+001.00000 \mathrm{e}-011.00000 \mathrm{e}-091.00000 \mathrm{e}-01$

$1.00000 \mathrm{e}-05$ 1.00000e-05 1.00000e-06 1.00000e-09 1.00000e-01

$1.00000 \mathrm{e}+001.00000 \mathrm{e}+001.00000 \mathrm{e}-011.00000 \mathrm{e}-091.00000 \mathrm{e}-01$

Element: 9579 \# of layers: 8

$\mathrm{Kx} \mathrm{Ky} \mathrm{Kz} \mathrm{Ss} \mathrm{Por}$

5.55582e+01 5.55582e+01 5.55582e+00 1.00000e-09 2.12000e-01 
5.55582e+01 5.55582e+01 5.55582e+00 1.00000e-09 2.12000e-01

$5.55582 \mathrm{e}+015.55582 \mathrm{e}+015.55582 \mathrm{e}+001.00000 \mathrm{e}-092.12000 \mathrm{e}-01$

$5.55582 \mathrm{e}+015.55582 \mathrm{e}+015.55582 \mathrm{e}+001.00000 \mathrm{e}-092.12000 \mathrm{e}-01$

$5.55582 \mathrm{e}+015.55582 \mathrm{e}+015.55582 \mathrm{e}+001.00000 \mathrm{e}-092.12000 \mathrm{e}-01$

$1.00000 \mathrm{e}-02$ 1.00000e-02 1.00000e-03 1.00000e-09 1.00000e-01

$1.00000 \mathrm{e}-05$ 1.00000e-05 1.00000e-06 1.00000e-09 1.00000e-01

$1.00000 \mathrm{e}+001.00000 \mathrm{e}+001.00000 \mathrm{e}-011.00000 \mathrm{e}-091.00000 \mathrm{e}-01$

Element: 9580 \# of layers: 7

$\mathrm{Kx} \mathrm{Ky} \mathrm{Kz}$ Ss Por

$5.55582 \mathrm{e}+015.55582 \mathrm{e}+015.55582 \mathrm{e}+00$ 1.00000e-09 2.12000e-01

$5.55582 \mathrm{e}+015.55582 \mathrm{e}+015.55582 \mathrm{e}+001.00000 \mathrm{e}-092.12000 \mathrm{e}-01$

$5.55582 \mathrm{e}+015.55582 \mathrm{e}+015.55582 \mathrm{e}+001.00000 \mathrm{e}-092.12000 \mathrm{e}-01$

$5.55582 \mathrm{e}+015.55582 \mathrm{e}+015.55582 \mathrm{e}+001.00000 \mathrm{e}-092.12000 \mathrm{e}-01$

$5.55582 \mathrm{e}+015.55582 \mathrm{e}+015.55582 \mathrm{e}+001.00000 \mathrm{e}-092.12000 \mathrm{e}-01$

$1.00000 \mathrm{e}-05$ 1.00000e-05 1.00000e-06 1.00000e-09 1.00000e-01

$1.00000 \mathrm{e}+001.00000 \mathrm{e}+001.00000 \mathrm{e}-011.00000 \mathrm{e}-091.00000 \mathrm{e}-01$

Element: 9581 \# of layers: 7

$\mathrm{Kx} \mathrm{Ky} \mathrm{Kz}$ Ss Por

$2.84136 \mathrm{e}+012.84136 \mathrm{e}+012.84136 \mathrm{e}+00$ 1.00000e-09 2.12000e-01

$2.84136 \mathrm{e}+012.84136 \mathrm{e}+012.84136 \mathrm{e}+001.00000 \mathrm{e}-092.12000 \mathrm{e}-01$

$2.84136 \mathrm{e}+012.84136 \mathrm{e}+012.84136 \mathrm{e}+001.00000 \mathrm{e}-092.12000 \mathrm{e}-01$

$2.84136 \mathrm{e}+012.84136 \mathrm{e}+012.84136 \mathrm{e}+00$ 1.00000e-09 2.12000e-01

$2.84136 \mathrm{e}+012.84136 \mathrm{e}+012.84136 \mathrm{e}+001.00000 \mathrm{e}-092.12000 \mathrm{e}-01$

$1.00000 \mathrm{e}-05$ 1.00000e-05 1.00000e-06 1.00000e-09 1.00000e-01

$1.00000 \mathrm{e}+001.00000 \mathrm{e}+001.00000 \mathrm{e}-011.00000 \mathrm{e}-091.00000 \mathrm{e}-01$

Element: 9582 \# of layers: 8

$\mathrm{Kx} \mathrm{Ky} \mathrm{Kz}$ Ss Por

$2.84136 \mathrm{e}+012.84136 \mathrm{e}+012.84136 \mathrm{e}+001.00000 \mathrm{e}-092.12000 \mathrm{e}-01$

$2.84136 \mathrm{e}+012.84136 \mathrm{e}+012.84136 \mathrm{e}+001.00000 \mathrm{e}-092.12000 \mathrm{e}-01$

$2.84136 \mathrm{e}+012.84136 \mathrm{e}+012.84136 \mathrm{e}+001.00000 \mathrm{e}-092.12000 \mathrm{e}-01$

$2.84136 \mathrm{e}+012.84136 \mathrm{e}+012.84136 \mathrm{e}+001.00000 \mathrm{e}-092.12000 \mathrm{e}-01$

$2.84136 \mathrm{e}+012.84136 \mathrm{e}+012.84136 \mathrm{e}+00$ 1.00000e-09 2.12000e-01

$1.00000 \mathrm{e}-02$ 1.00000e-02 1.00000e-03 1.00000e-09 1.00000e-01

$1.00000 \mathrm{e}-05$ 1.00000e-05 1.00000e-06 1.00000e-09 1.00000e-01

$1.00000 \mathrm{e}+001.00000 \mathrm{e}+001.00000 \mathrm{e}-011.00000 \mathrm{e}-091.00000 \mathrm{e}-01$

Element: 9583 \# of layers: 8

Kx Ky Kz Ss Por

$2.84136 \mathrm{e}+012.84136 \mathrm{e}+012.84136 \mathrm{e}+00$ 1.00000e-09 2.12000e-01

$2.84136 \mathrm{e}+012.84136 \mathrm{e}+012.84136 \mathrm{e}+00$ 1.00000e-09 2.12000e-01

$2.84136 \mathrm{e}+012.84136 \mathrm{e}+012.84136 \mathrm{e}+001.00000 \mathrm{e}-092.12000 \mathrm{e}-01$

$2.84136 \mathrm{e}+012.84136 \mathrm{e}+012.84136 \mathrm{e}+00$ 1.00000e-09 2.12000e-01

$2.84136 \mathrm{e}+012.84136 \mathrm{e}+012.84136 \mathrm{e}+00$ 1.00000e-09 2.12000e-01

$1.00000 \mathrm{e}-02$ 1.00000e-02 1.00000e-03 1.00000e-09 1.00000e-01

$1.00000 \mathrm{e}-05$ 1.00000e-05 1.00000e-06 1.00000e-09 1.00000e-01

$1.00000 \mathrm{e}+001.00000 \mathrm{e}+001.00000 \mathrm{e}-011.00000 \mathrm{e}-091.00000 \mathrm{e}-01$

Element: 9584 \# of layers: 8 
$\mathrm{Kx} \mathrm{Ky} \mathrm{Kz} \mathrm{Ss} \mathrm{Por}$

5.55582e+01 5.55582e+01 5.55582e+00 1.00000e-09 2.12000e-01

$5.55582 \mathrm{e}+015.55582 \mathrm{e}+015.55582 \mathrm{e}+001.00000 \mathrm{e}-092.12000 \mathrm{e}-01$

$5.55582 \mathrm{e}+015.55582 \mathrm{e}+015.55582 \mathrm{e}+001.00000 \mathrm{e}-092.12000 \mathrm{e}-01$

$5.55582 \mathrm{e}+015.55582 \mathrm{e}+015.55582 \mathrm{e}+001.00000 \mathrm{e}-092.12000 \mathrm{e}-01$

5.55582e+01 5.55582e+01 5.55582e+00 1.00000e-09 2.12000e-01

$1.00000 \mathrm{e}-02$ 1.00000e-02 1.00000e-03 1.00000e-09 1.00000e-01

$1.00000 \mathrm{e}-05$ 1.00000e-05 1.00000e-06 1.00000e-09 1.00000e-01

$1.00000 \mathrm{e}+001.00000 \mathrm{e}+001.00000 \mathrm{e}-011.00000 \mathrm{e}-091.00000 \mathrm{e}-01$

Element: 9585 \# of layers: 8

$\mathrm{Kx} \mathrm{Ky} \mathrm{Kz}$ Ss Por

5.55582e+01 5.55582e+01 5.55582e+00 1.00000e-09 2.12000e-01

$5.55582 \mathrm{e}+01$ 5.55582e+01 5.55582e+00 1.00000e-09 2.12000e-01

5.55582e+01 5.55582e+01 5.55582e+00 1.00000e-09 2.12000e-01

$5.55582 \mathrm{e}+015.55582 \mathrm{e}+015.55582 \mathrm{e}+001.00000 \mathrm{e}-092.12000 \mathrm{e}-01$

$5.55582 \mathrm{e}+015.55582 \mathrm{e}+015.55582 \mathrm{e}+001.00000 \mathrm{e}-092.12000 \mathrm{e}-01$

$1.00000 \mathrm{e}-02$ 1.00000e-02 1.00000e-03 1.00000e-09 1.00000e-01

$1.00000 \mathrm{e}-05$ 1.00000e-05 1.00000e-06 1.00000e-09 1.00000e-01

$1.00000 \mathrm{e}+001.00000 \mathrm{e}+001.00000 \mathrm{e}-011.00000 \mathrm{e}-091.00000 \mathrm{e}-01$

Element: 9586 \# of layers: 8

Kx Ky Kz Ss Por

$5.55582 \mathrm{e}+01$ 5.55582e+01 5.55582e+00 1.00000e-09 2.12000e-01

$5.55582 \mathrm{e}+015.55582 \mathrm{e}+01$ 5.55582e+00 1.00000e-09 2.12000e-01

$5.55582 \mathrm{e}+015.55582 \mathrm{e}+015.55582 \mathrm{e}+001.00000 \mathrm{e}-092.12000 \mathrm{e}-01$

$5.55582 \mathrm{e}+015.55582 \mathrm{e}+015.55582 \mathrm{e}+001.00000 \mathrm{e}-092.12000 \mathrm{e}-01$

$5.55582 \mathrm{e}+015.55582 \mathrm{e}+015.55582 \mathrm{e}+001.00000 \mathrm{e}-092.12000 \mathrm{e}-01$

$1.00000 \mathrm{e}-02$ 1.00000e-02 1.00000e-03 1.00000e-09 1.00000e-01

$1.00000 \mathrm{e}-05$ 1.00000e-05 1.00000e-06 1.00000e-09 1.00000e-01

$1.00000 \mathrm{e}+001.00000 \mathrm{e}+001.00000 \mathrm{e}-011.00000 \mathrm{e}-091.00000 \mathrm{e}-01$

Element: 9587 \# of layers: 8

$\mathrm{Kx} \mathrm{Ky} \mathrm{Kz}$ Ss Por

5.55582e+01 5.55582e+01 5.55582e+00 1.00000e-09 2.12000e-01

$5.55582 \mathrm{e}+015.55582 \mathrm{e}+015.55582 \mathrm{e}+001.00000 \mathrm{e}-092.12000 \mathrm{e}-01$

$5.55582 \mathrm{e}+015.55582 \mathrm{e}+015.55582 \mathrm{e}+001.00000 \mathrm{e}-092.12000 \mathrm{e}-01$

$5.55582 \mathrm{e}+015.55582 \mathrm{e}+015.55582 \mathrm{e}+001.00000 \mathrm{e}-092.12000 \mathrm{e}-01$

$5.55582 \mathrm{e}+015.55582 \mathrm{e}+015.55582 \mathrm{e}+001.00000 \mathrm{e}-092.12000 \mathrm{e}-01$ $1.00000 \mathrm{e}-02$ 1.00000e-02 1.00000e-03 1.00000e-09 1.00000e-01 $1.00000 \mathrm{e}-05$ 1.00000e-05 1.00000e-06 1.00000e-09 1.00000e-01 $1.00000 \mathrm{e}+001.00000 \mathrm{e}+001.00000 \mathrm{e}-011.00000 \mathrm{e}-09$ 1.00000e-01 Element: 9588 \# of layers: 7

$\mathrm{Kx} \mathrm{Ky} \mathrm{Kz}$ Ss Por

$2.84136 \mathrm{e}+012.84136 \mathrm{e}+012.84136 \mathrm{e}+00$ 1.00000e-09 2.12000e-01

$2.84136 \mathrm{e}+012.84136 \mathrm{e}+012.84136 \mathrm{e}+001.00000 \mathrm{e}-092.12000 \mathrm{e}-01$

$2.84136 \mathrm{e}+012.84136 \mathrm{e}+012.84136 \mathrm{e}+00$ 1.00000e-09 2.12000e-01

$2.84136 \mathrm{e}+012.84136 \mathrm{e}+012.84136 \mathrm{e}+001.00000 \mathrm{e}-092.12000 \mathrm{e}-01$

$2.84136 \mathrm{e}+012.84136 \mathrm{e}+012.84136 \mathrm{e}+001.00000 \mathrm{e}-092.12000 \mathrm{e}-01$ 
$1.00000 \mathrm{e}-05$ 1.00000e-05 1.00000e-06 1.00000e-09 1.00000e-01 $1.00000 \mathrm{e}+001.00000 \mathrm{e}+001.00000 \mathrm{e}-01$ 1.00000e-09 1.00000e-01 Element: 9589 \# of layers: 7

Kx Ky Kz Ss Por

$2.84136 \mathrm{e}+012.84136 \mathrm{e}+012.84136 \mathrm{e}+001.00000 \mathrm{e}-092.12000 \mathrm{e}-01$ $2.84136 \mathrm{e}+012.84136 \mathrm{e}+012.84136 \mathrm{e}+00$ 1.00000e-09 2.12000e-01 $2.84136 \mathrm{e}+012.84136 \mathrm{e}+012.84136 \mathrm{e}+00$ 1.00000e-09 2.12000e-01 $2.84136 \mathrm{e}+012.84136 \mathrm{e}+012.84136 \mathrm{e}+001.00000 \mathrm{e}-092.12000 \mathrm{e}-01$ $2.84136 \mathrm{e}+012.84136 \mathrm{e}+012.84136 \mathrm{e}+001.00000 \mathrm{e}-092.12000 \mathrm{e}-01$ $1.00000 \mathrm{e}-05$ 1.00000e-05 1.00000e-06 1.00000e-09 1.00000e-01 $1.00000 \mathrm{e}+001.00000 \mathrm{e}+001.00000 \mathrm{e}-011.00000 \mathrm{e}-091.00000 \mathrm{e}-01$ Element: 9590 \# of layers: 7

$\mathrm{Kx} \mathrm{Ky} \mathrm{Kz}$ Ss Por

$2.84136 \mathrm{e}+012.84136 \mathrm{e}+012.84136 \mathrm{e}+00$ 1.00000e-09 2.12000e-01 $2.84136 \mathrm{e}+012.84136 \mathrm{e}+012.84136 \mathrm{e}+001.00000 \mathrm{e}-092.12000 \mathrm{e}-01$ $2.84136 \mathrm{e}+012.84136 \mathrm{e}+012.84136 \mathrm{e}+001.00000 \mathrm{e}-092.12000 \mathrm{e}-01$ $2.84136 \mathrm{e}+012.84136 \mathrm{e}+012.84136 \mathrm{e}+001.00000 \mathrm{e}-092.12000 \mathrm{e}-01$ $2.84136 \mathrm{e}+012.84136 \mathrm{e}+012.84136 \mathrm{e}+001.00000 \mathrm{e}-092.12000 \mathrm{e}-01$ $1.00000 \mathrm{e}-051.00000 \mathrm{e}-051.00000 \mathrm{e}-061.00000 \mathrm{e}-091.00000 \mathrm{e}-01$ $1.00000 \mathrm{e}+001.00000 \mathrm{e}+001.00000 \mathrm{e}-011.00000 \mathrm{e}-091.00000 \mathrm{e}-01$ Element: 9591 \# of layers: 7

$\mathrm{Kx} \mathrm{Ky} \mathrm{Kz}$ Ss Por

$2.84136 \mathrm{e}+012.84136 \mathrm{e}+012.84136 \mathrm{e}+00$ 1.00000e-09 2.12000e-01 $2.84136 \mathrm{e}+012.84136 \mathrm{e}+012.84136 \mathrm{e}+001.00000 \mathrm{e}-092.12000 \mathrm{e}-01$ $2.84136 \mathrm{e}+012.84136 \mathrm{e}+012.84136 \mathrm{e}+001.00000 \mathrm{e}-092.12000 \mathrm{e}-01$ $2.84136 \mathrm{e}+012.84136 \mathrm{e}+012.84136 \mathrm{e}+001.00000 \mathrm{e}-092.12000 \mathrm{e}-01$ $2.84136 \mathrm{e}+012.84136 \mathrm{e}+012.84136 \mathrm{e}+001.00000 \mathrm{e}-092.12000 \mathrm{e}-01$ $1.00000 \mathrm{e}-05$ 1.00000e-05 1.00000e-06 1.00000e-09 1.00000e-01 $1.00000 \mathrm{e}+001.00000 \mathrm{e}+001.00000 \mathrm{e}-011.00000 \mathrm{e}-091.00000 \mathrm{e}-01$ Element: 9592 \# of layers: 7

$\mathrm{Kx} \mathrm{Ky} \mathrm{Kz}$ Ss Por

$2.84136 \mathrm{e}+012.84136 \mathrm{e}+012.84136 \mathrm{e}+00$ 1.00000e-09 2.12000e-01 $2.84136 \mathrm{e}+012.84136 \mathrm{e}+012.84136 \mathrm{e}+001.00000 \mathrm{e}-092.12000 \mathrm{e}-01$ $2.84136 \mathrm{e}+012.84136 \mathrm{e}+012.84136 \mathrm{e}+001.00000 \mathrm{e}-092.12000 \mathrm{e}-01$ $2.84136 \mathrm{e}+012.84136 \mathrm{e}+012.84136 \mathrm{e}+00$ 1.00000e-09 2.12000e-01 $2.84136 \mathrm{e}+012.84136 \mathrm{e}+012.84136 \mathrm{e}+00$ 1.00000e-09 2.12000e-01 $1.00000 \mathrm{e}-05$ 1.00000e-05 1.00000e-06 1.00000e-09 1.00000e-01 $1.00000 \mathrm{e}+001.00000 \mathrm{e}+001.00000 \mathrm{e}-011.00000 \mathrm{e}-091.00000 \mathrm{e}-01$ Element: 9593 \# of layers: 7

$\mathrm{Kx} \mathrm{Ky} \mathrm{Kz}$ Ss Por

$2.84136 \mathrm{e}+012.84136 \mathrm{e}+012.84136 \mathrm{e}+00$ 1.00000e-09 2.12000e-01 $2.84136 \mathrm{e}+012.84136 \mathrm{e}+012.84136 \mathrm{e}+001.00000 \mathrm{e}-092.12000 \mathrm{e}-01$ $2.84136 \mathrm{e}+012.84136 \mathrm{e}+012.84136 \mathrm{e}+001.00000 \mathrm{e}-092.12000 \mathrm{e}-01$ $2.84136 \mathrm{e}+012.84136 \mathrm{e}+012.84136 \mathrm{e}+001.00000 \mathrm{e}-092.12000 \mathrm{e}-01$ $2.84136 \mathrm{e}+012.84136 \mathrm{e}+012.84136 \mathrm{e}+001.00000 \mathrm{e}-092.12000 \mathrm{e}-01$ $1.00000 \mathrm{e}-05$ 1.00000e-05 1.00000e-06 1.00000e-09 1.00000e-01 
$1.00000 \mathrm{e}+001.00000 \mathrm{e}+00$ 1.00000e-01 1.00000e-09 1.00000e-01

Element: 9594 \# of layers: 7

Kx Ky Kz Ss Por

$2.84136 \mathrm{e}+012.84136 \mathrm{e}+012.84136 \mathrm{e}+00$ 1.00000e-09 2.12000e-01

$2.84136 \mathrm{e}+012.84136 \mathrm{e}+012.84136 \mathrm{e}+001.00000 \mathrm{e}-092.12000 \mathrm{e}-01$

$2.84136 \mathrm{e}+012.84136 \mathrm{e}+012.84136 \mathrm{e}+00$ 1.00000e-09 2.12000e-01

$2.84136 \mathrm{e}+012.84136 \mathrm{e}+012.84136 \mathrm{e}+001.00000 \mathrm{e}-092.12000 \mathrm{e}-01$

$2.84136 \mathrm{e}+012.84136 \mathrm{e}+012.84136 \mathrm{e}+00$ 1.00000e-09 2.12000e-01

$1.00000 \mathrm{e}-05$ 1.00000e-05 1.00000e-06 1.00000e-09 1.00000e-01

$1.00000 \mathrm{e}+001.00000 \mathrm{e}+001.00000 \mathrm{e}-011.00000 \mathrm{e}-091.00000 \mathrm{e}-01$

Element: 9595 \# of layers: 7

$\mathrm{Kx} \mathrm{Ky} \mathrm{Kz}$ Ss Por

$2.84136 \mathrm{e}+012.84136 \mathrm{e}+012.84136 \mathrm{e}+00$ 1.00000e-09 2.12000e-01

$2.84136 \mathrm{e}+012.84136 \mathrm{e}+012.84136 \mathrm{e}+00$ 1.00000e-09 2.12000e-01

$2.84136 \mathrm{e}+012.84136 \mathrm{e}+012.84136 \mathrm{e}+001.00000 \mathrm{e}-092.12000 \mathrm{e}-01$

$2.84136 \mathrm{e}+012.84136 \mathrm{e}+012.84136 \mathrm{e}+001.00000 \mathrm{e}-092.12000 \mathrm{e}-01$

$2.84136 \mathrm{e}+012.84136 \mathrm{e}+012.84136 \mathrm{e}+001.00000 \mathrm{e}-092.12000 \mathrm{e}-01$

$1.00000 \mathrm{e}-05$ 1.00000e-05 1.00000e-06 1.00000e-09 1.00000e-01

$1.00000 \mathrm{e}+001.00000 \mathrm{e}+001.00000 \mathrm{e}-011.00000 \mathrm{e}-091.00000 \mathrm{e}-01$

Element: 9596 \# of layers: 7

$\mathrm{Kx} \mathrm{Ky} \mathrm{Kz}$ Ss Por

$2.84136 \mathrm{e}+012.84136 \mathrm{e}+012.84136 \mathrm{e}+00$ 1.00000e-09 2.12000e-01

$2.84136 \mathrm{e}+012.84136 \mathrm{e}+012.84136 \mathrm{e}+00$ 1.00000e-09 2.12000e-01

$2.84136 \mathrm{e}+012.84136 \mathrm{e}+012.84136 \mathrm{e}+001.00000 \mathrm{e}-092.12000 \mathrm{e}-01$

$2.84136 \mathrm{e}+012.84136 \mathrm{e}+012.84136 \mathrm{e}+001.00000 \mathrm{e}-092.12000 \mathrm{e}-01$

$2.84136 \mathrm{e}+012.84136 \mathrm{e}+012.84136 \mathrm{e}+001.00000 \mathrm{e}-092.12000 \mathrm{e}-01$

$1.00000 \mathrm{e}-05$ 1.00000e-05 1.00000e-06 1.00000e-09 1.00000e-01

$1.00000 \mathrm{e}+001.00000 \mathrm{e}+001.00000 \mathrm{e}-011.00000 \mathrm{e}-09$ 1.00000e-01

Element: 9597 \# of layers: 7

$\mathrm{Kx} \mathrm{Ky} \mathrm{Kz}$ Ss Por

$2.84136 \mathrm{e}+012.84136 \mathrm{e}+012.84136 \mathrm{e}+00$ 1.00000e-09 2.12000e-01

$2.84136 \mathrm{e}+012.84136 \mathrm{e}+012.84136 \mathrm{e}+001.00000 \mathrm{e}-092.12000 \mathrm{e}-01$

$2.84136 \mathrm{e}+012.84136 \mathrm{e}+012.84136 \mathrm{e}+001.00000 \mathrm{e}-092.12000 \mathrm{e}-01$

$2.84136 \mathrm{e}+012.84136 \mathrm{e}+012.84136 \mathrm{e}+001.00000 \mathrm{e}-092.12000 \mathrm{e}-01$

$2.84136 \mathrm{e}+012.84136 \mathrm{e}+012.84136 \mathrm{e}+00$ 1.00000e-09 2.12000e-01

$1.00000 \mathrm{e}-05$ 1.00000e-05 1.00000e-06 1.00000e-09 1.00000e-01

$1.00000 \mathrm{e}+001.00000 \mathrm{e}+001.00000 \mathrm{e}-011.00000 \mathrm{e}-091.00000 \mathrm{e}-01$

Element: 9598 \# of layers: 7

$\mathrm{Kx} \mathrm{Ky} \mathrm{Kz}$ Ss Por

$2.79906 \mathrm{e}+012.79906 \mathrm{e}+012.79906 \mathrm{e}+00$ 1.00000e-09 2.12000e-01

$2.79906 \mathrm{e}+012.79906 \mathrm{e}+012.79906 \mathrm{e}+001.00000 \mathrm{e}-092.12000 \mathrm{e}-01$

$2.79906 \mathrm{e}+012.79906 \mathrm{e}+012.79906 \mathrm{e}+001.00000 \mathrm{e}-092.12000 \mathrm{e}-01$

$2.79906 \mathrm{e}+012.79906 \mathrm{e}+012.79906 \mathrm{e}+00$ 1.00000e-09 2.12000e-01

$2.79906 \mathrm{e}+012.79906 \mathrm{e}+012.79906 \mathrm{e}+00$ 1.00000e-09 2.12000e-01

$1.00000 \mathrm{e}-05$ 1.00000e-05 1.00000e-06 1.00000e-09 1.00000e-01

$1.00000 \mathrm{e}+001.00000 \mathrm{e}+001.00000 \mathrm{e}-011.00000 \mathrm{e}-091.00000 \mathrm{e}-01$ 
Element: 9599 \# of layers: 7

$\mathrm{Kx} \mathrm{Ky} \mathrm{Kz}$ Ss Por

$2.79906 \mathrm{e}+012.79906 \mathrm{e}+012.79906 \mathrm{e}+00$ 1.00000e-09 2.12000e-01

$2.79906 \mathrm{e}+012.79906 \mathrm{e}+012.79906 \mathrm{e}+001.00000 \mathrm{e}-092.12000 \mathrm{e}-01$

$2.79906 \mathrm{e}+012.79906 \mathrm{e}+012.79906 \mathrm{e}+001.00000 \mathrm{e}-092.12000 \mathrm{e}-01$

$2.79906 \mathrm{e}+012.79906 \mathrm{e}+012.79906 \mathrm{e}+001.00000 \mathrm{e}-092.12000 \mathrm{e}-01$

$2.79906 \mathrm{e}+012.79906 \mathrm{e}+012.79906 \mathrm{e}+001.00000 \mathrm{e}-092.12000 \mathrm{e}-01$

$1.00000 \mathrm{e}-05$ 1.00000e-05 1.00000e-06 1.00000e-09 1.00000e-01

$1.00000 \mathrm{e}+001.00000 \mathrm{e}+001.00000 \mathrm{e}-011.00000 \mathrm{e}-091.00000 \mathrm{e}-01$

Element: 9600 \# of layers: 8

$\mathrm{Kx} \mathrm{Ky} \mathrm{Kz}$ Ss Por

$2.79906 \mathrm{e}+012.79906 \mathrm{e}+012.79906 \mathrm{e}+00$ 1.00000e-09 2.12000e-01

$2.79906 \mathrm{e}+012.79906 \mathrm{e}+012.79906 \mathrm{e}+001.00000 \mathrm{e}-092.12000 \mathrm{e}-01$

$2.79906 \mathrm{e}+012.79906 \mathrm{e}+012.79906 \mathrm{e}+00$ 1.00000e-09 2.12000e-01

$2.79906 \mathrm{e}+012.79906 \mathrm{e}+012.79906 \mathrm{e}+001.00000 \mathrm{e}-092.12000 \mathrm{e}-01$

$2.79906 \mathrm{e}+012.79906 \mathrm{e}+012.79906 \mathrm{e}+00$ 1.00000e-09 2.12000e-01

$1.00000 \mathrm{e}-02$ 1.00000e-02 1.00000e-03 1.00000e-09 1.00000e-01

$1.00000 \mathrm{e}-05$ 1.00000e-05 1.00000e-06 1.00000e-09 1.00000e-01

$1.00000 \mathrm{e}+001.00000 \mathrm{e}+001.00000 \mathrm{e}-011.00000 \mathrm{e}-091.00000 \mathrm{e}-01$

Element: 9601 \# of layers: 8

$\mathrm{Kx} \mathrm{Ky} \mathrm{Kz}$ Ss Por

$2.79906 \mathrm{e}+012.79906 \mathrm{e}+012.79906 \mathrm{e}+00$ 1.00000e-09 2.12000e-01

$2.79906 \mathrm{e}+012.79906 \mathrm{e}+012.79906 \mathrm{e}+00$ 1.00000e-09 2.12000e-01

$2.79906 \mathrm{e}+012.79906 \mathrm{e}+012.79906 \mathrm{e}+001.00000 \mathrm{e}-092.12000 \mathrm{e}-01$

$2.79906 \mathrm{e}+012.79906 \mathrm{e}+012.79906 \mathrm{e}+001.00000 \mathrm{e}-092.12000 \mathrm{e}-01$

$2.79906 \mathrm{e}+012.79906 \mathrm{e}+012.79906 \mathrm{e}+001.00000 \mathrm{e}-092.12000 \mathrm{e}-01$

$1.00000 \mathrm{e}-02$ 1.00000e-02 1.00000e-03 1.00000e-09 1.00000e-01

1.00000e-05 1.00000e-05 1.00000e-06 1.00000e-09 1.00000e-01

$1.00000 \mathrm{e}+001.00000 \mathrm{e}+001.00000 \mathrm{e}-011.00000 \mathrm{e}-091.00000 \mathrm{e}-01$

Element: 9602 \# of layers: 8

$\mathrm{Kx} \mathrm{Ky} \mathrm{Kz}$ Ss Por

$2.79906 \mathrm{e}+012.79906 \mathrm{e}+012.79906 \mathrm{e}+00$ 1.00000e-09 2.12000e-01

$2.79906 \mathrm{e}+012.79906 \mathrm{e}+012.79906 \mathrm{e}+001.00000 \mathrm{e}-092.12000 \mathrm{e}-01$

$2.79906 \mathrm{e}+012.79906 \mathrm{e}+012.79906 \mathrm{e}+001.00000 \mathrm{e}-092.12000 \mathrm{e}-01$

$2.79906 \mathrm{e}+012.79906 \mathrm{e}+012.79906 \mathrm{e}+001.00000 \mathrm{e}-092.12000 \mathrm{e}-01$

$2.79906 \mathrm{e}+012.79906 \mathrm{e}+012.79906 \mathrm{e}+001.00000 \mathrm{e}-092.12000 \mathrm{e}-01$

$1.00000 \mathrm{e}-02$ 1.00000e-02 1.00000e-03 1.00000e-09 1.00000e-01

$1.00000 \mathrm{e}-05$ 1.00000e-05 1.00000e-06 1.00000e-09 1.00000e-01

$1.00000 \mathrm{e}+001.00000 \mathrm{e}+001.00000 \mathrm{e}-011.00000 \mathrm{e}-091.00000 \mathrm{e}-01$

Element: 9603 \# of layers: 7

$\mathrm{Kx} \mathrm{Ky} \mathrm{Kz}$ Ss Por

$2.84136 \mathrm{e}+012.84136 \mathrm{e}+012.84136 \mathrm{e}+00$ 1.00000e-09 2.12000e-01

$2.84136 \mathrm{e}+012.84136 \mathrm{e}+012.84136 \mathrm{e}+001.00000 \mathrm{e}-092.12000 \mathrm{e}-01$

$2.84136 \mathrm{e}+012.84136 \mathrm{e}+012.84136 \mathrm{e}+00$ 1.00000e-09 2.12000e-01

$2.84136 \mathrm{e}+012.84136 \mathrm{e}+012.84136 \mathrm{e}+001.00000 \mathrm{e}-092.12000 \mathrm{e}-01$

$2.84136 \mathrm{e}+012.84136 \mathrm{e}+012.84136 \mathrm{e}+001.00000 \mathrm{e}-092.12000 \mathrm{e}-01$ 
$1.00000 \mathrm{e}-05$ 1.00000e-05 1.00000e-06 1.00000e-09 1.00000e-01 $1.00000 \mathrm{e}+001.00000 \mathrm{e}+001.00000 \mathrm{e}-01$ 1.00000e-09 1.00000e-01 Element: 9604 \# of layers: 7

Kx Ky Kz Ss Por

$2.84136 \mathrm{e}+012.84136 \mathrm{e}+012.84136 \mathrm{e}+001.00000 \mathrm{e}-092.12000 \mathrm{e}-01$ $2.84136 \mathrm{e}+012.84136 \mathrm{e}+012.84136 \mathrm{e}+00$ 1.00000e-09 2.12000e-01 $2.84136 \mathrm{e}+012.84136 \mathrm{e}+012.84136 \mathrm{e}+00$ 1.00000e-09 2.12000e-01 $2.84136 \mathrm{e}+012.84136 \mathrm{e}+012.84136 \mathrm{e}+001.00000 \mathrm{e}-092.12000 \mathrm{e}-01$ $2.84136 \mathrm{e}+012.84136 \mathrm{e}+012.84136 \mathrm{e}+001.00000 \mathrm{e}-092.12000 \mathrm{e}-01$ $1.00000 \mathrm{e}-05$ 1.00000e-05 1.00000e-06 1.00000e-09 1.00000e-01 $1.00000 \mathrm{e}+001.00000 \mathrm{e}+001.00000 \mathrm{e}-011.00000 \mathrm{e}-091.00000 \mathrm{e}-01$ Element: 9605 \# of layers: 8

$\mathrm{Kx} \mathrm{Ky} \mathrm{Kz}$ Ss Por

$2.79906 \mathrm{e}+012.79906 \mathrm{e}+012.79906 \mathrm{e}+00$ 1.00000e-09 2.12000e-01 $2.79906 \mathrm{e}+012.79906 \mathrm{e}+012.79906 \mathrm{e}+001.00000 \mathrm{e}-092.12000 \mathrm{e}-01$ $2.79906 \mathrm{e}+012.79906 \mathrm{e}+012.79906 \mathrm{e}+001.00000 \mathrm{e}-092.12000 \mathrm{e}-01$ $2.79906 \mathrm{e}+012.79906 \mathrm{e}+012.79906 \mathrm{e}+00$ 1.00000e-09 2.12000e-01

$2.79906 \mathrm{e}+012.79906 \mathrm{e}+012.79906 \mathrm{e}+00$ 1.00000e-09 2.12000e-01 $1.00000 \mathrm{e}-02$ 1.00000e-02 1.00000e-03 1.00000e-09 1.00000e-01 $1.00000 \mathrm{e}-05$ 1.00000e-05 1.00000e-06 1.00000e-09 1.00000e-01 $1.00000 \mathrm{e}+001.00000 \mathrm{e}+001.00000 \mathrm{e}-011.00000 \mathrm{e}-091.00000 \mathrm{e}-01$ Element: 9606 \# of layers: 9

$\mathrm{Kx} \mathrm{Ky} \mathrm{Kz}$ Ss Por

$2.79906 \mathrm{e}+012.79906 \mathrm{e}+012.79906 \mathrm{e}+00$ 1.00000e-09 2.12000e-01 $2.79906 \mathrm{e}+012.79906 \mathrm{e}+012.79906 \mathrm{e}+001.00000 \mathrm{e}-092.12000 \mathrm{e}-01$ $2.79906 \mathrm{e}+012.79906 \mathrm{e}+012.79906 \mathrm{e}+001.00000 \mathrm{e}-092.12000 \mathrm{e}-01$ $2.79906 \mathrm{e}+012.79906 \mathrm{e}+012.79906 \mathrm{e}+001.00000 \mathrm{e}-092.12000 \mathrm{e}-01$ $2.79906 \mathrm{e}+012.79906 \mathrm{e}+012.79906 \mathrm{e}+001.00000 \mathrm{e}-092.12000 \mathrm{e}-01$ $1.00000 \mathrm{e}-02$ 1.00000e-02 1.00000e-03 1.00000e-09 1.00000e-01 $1.00000 \mathrm{e}+001.00000 \mathrm{e}+001.00000 \mathrm{e}-011.00000 \mathrm{e}-091.00000 \mathrm{e}-01$ $1.00000 \mathrm{e}-05$ 1.00000e-05 1.00000e-06 1.00000e-09 1.00000e-01 $1.00000 \mathrm{e}+001.00000 \mathrm{e}+001.00000 \mathrm{e}-01$ 1.00000e-09 1.00000e-01 Element: 9607 \# of layers: 9

$\mathrm{Kx} \mathrm{Ky} \mathrm{Kz}$ Ss Por

5.30899e+01 5.30899e+01 5.30899e+00 1.00000e-09 2.12000e-01 $5.30899 \mathrm{e}+015.30899 \mathrm{e}+015.30899 \mathrm{e}+00$ 1.00000e-09 2.12000e-01 $5.30899 \mathrm{e}+015.30899 \mathrm{e}+015.30899 \mathrm{e}+001.00000 \mathrm{e}-09$ 2.12000e-01 $5.30899 \mathrm{e}+01$ 5.30899e+01 5.30899e+00 1.00000e-09 2.12000e-01 $5.30899 \mathrm{e}+015.30899 \mathrm{e}+015.30899 \mathrm{e}+00$ 1.00000e-09 2.12000e-01 $1.00000 \mathrm{e}-02$ 1.00000e-02 1.00000e-03 1.00000e-09 1.00000e-01 $1.00000 \mathrm{e}+001.00000 \mathrm{e}+001.00000 \mathrm{e}-011.00000 \mathrm{e}-091.00000 \mathrm{e}-01$ $1.00000 \mathrm{e}-05$ 1.00000e-05 1.00000e-06 1.00000e-09 1.00000e-01 $1.00000 \mathrm{e}+001.00000 \mathrm{e}+001.00000 \mathrm{e}-011.00000 \mathrm{e}-091.00000 \mathrm{e}-01$ Element: 9608 \# of layers: 8

$\mathrm{Kx} \mathrm{Ky} \mathrm{Kz}$ Ss Por

5.30899e+01 5.30899e+01 5.30899e+00 1.00000e-09 2.12000e-01 
$5.30899 \mathrm{e}+015.30899 \mathrm{e}+01$ 5.30899e+00 1.00000e-09 2.12000e-01 $5.30899 \mathrm{e}+015.30899 \mathrm{e}+015.30899 \mathrm{e}+00$ 1.00000e-09 2.12000e-01 $5.30899 \mathrm{e}+015.30899 \mathrm{e}+015.30899 \mathrm{e}+00$ 1.00000e-09 2.12000e-01 $1.00000 \mathrm{e}-021.00000 \mathrm{e}-02$ 1.00000e-03 1.00000e-09 1.00000e-01 $1.00000 \mathrm{e}+001.00000 \mathrm{e}+001.00000 \mathrm{e}-011.00000 \mathrm{e}-091.00000 \mathrm{e}-01$ $1.00000 \mathrm{e}-05$ 1.00000e-05 1.00000e-06 1.00000e-09 1.00000e-01 $1.00000 \mathrm{e}+001.00000 \mathrm{e}+001.00000 \mathrm{e}-011.00000 \mathrm{e}-091.00000 \mathrm{e}-01$ Element: 9609 \# of layers: 9

Kx Ky Kz Ss Por

$5.30899 \mathrm{e}+015.30899 \mathrm{e}+01$ 5.30899e+00 1.00000e-09 2.12000e-01 $5.30899 \mathrm{e}+015.30899 \mathrm{e}+015.30899 \mathrm{e}+001.00000 \mathrm{e}-092.12000 \mathrm{e}-01$ $5.30899 \mathrm{e}+015.30899 \mathrm{e}+015.30899 \mathrm{e}+001.00000 \mathrm{e}-092.12000 \mathrm{e}-01$ $5.30899 \mathrm{e}+015.30899 \mathrm{e}+015.30899 \mathrm{e}+001.00000 \mathrm{e}-092.12000 \mathrm{e}-01$ $5.30899 \mathrm{e}+015.30899 \mathrm{e}+015.30899 \mathrm{e}+001.00000 \mathrm{e}-092.12000 \mathrm{e}-01$ $1.00000 \mathrm{e}-02$ 1.00000e-02 1.00000e-03 1.00000e-09 1.00000e-01 $1.00000 \mathrm{e}+001.00000 \mathrm{e}+001.00000 \mathrm{e}-011.00000 \mathrm{e}-091.00000 \mathrm{e}-01$ $1.00000 \mathrm{e}-05$ 1.00000e-05 1.00000e-06 1.00000e-09 1.00000e-01 $1.00000 \mathrm{e}+001.00000 \mathrm{e}+001.00000 \mathrm{e}-011.00000 \mathrm{e}-091.00000 \mathrm{e}-01$ Element: 9610 \# of layers: 9

Kx Ky Kz Ss Por

$5.55582 \mathrm{e}+015.55582 \mathrm{e}+015.55582 \mathrm{e}+001.00000 \mathrm{e}-092.12000 \mathrm{e}-01$

$5.55582 \mathrm{e}+015.55582 \mathrm{e}+015.55582 \mathrm{e}+001.00000 \mathrm{e}-092.12000 \mathrm{e}-01$

$5.55582 \mathrm{e}+015.55582 \mathrm{e}+015.55582 \mathrm{e}+001.00000 \mathrm{e}-092.12000 \mathrm{e}-01$

$5.55582 \mathrm{e}+015.55582 \mathrm{e}+015.55582 \mathrm{e}+001.00000 \mathrm{e}-092.12000 \mathrm{e}-01$

$5.55582 \mathrm{e}+015.55582 \mathrm{e}+015.55582 \mathrm{e}+001.00000 \mathrm{e}-092.12000 \mathrm{e}-01$ $1.00000 \mathrm{e}-021.00000 \mathrm{e}-02$ 1.00000e-03 1.00000e-09 1.00000e-01

$1.00000 \mathrm{e}+001.00000 \mathrm{e}+001.00000 \mathrm{e}-011.00000 \mathrm{e}-091.00000 \mathrm{e}-01$ $1.00000 \mathrm{e}-051.00000 \mathrm{e}-05$ 1.00000e-06 1.00000e-09 1.00000e-01 $1.00000 \mathrm{e}+001.00000 \mathrm{e}+001.00000 \mathrm{e}-011.00000 \mathrm{e}-091.00000 \mathrm{e}-01$ Element: 9611 \# of layers: 8

Kx Ky Kz Ss Por

$5.55582 \mathrm{e}+015.55582 \mathrm{e}+015.55582 \mathrm{e}+00$ 1.00000e-09 2.12000e-01 $5.55582 \mathrm{e}+015.55582 \mathrm{e}+015.55582 \mathrm{e}+001.00000 \mathrm{e}-092.12000 \mathrm{e}-01$ $5.55582 \mathrm{e}+015.55582 \mathrm{e}+015.55582 \mathrm{e}+001.00000 \mathrm{e}-092.12000 \mathrm{e}-01$ $5.55582 \mathrm{e}+015.55582 \mathrm{e}+015.55582 \mathrm{e}+001.00000 \mathrm{e}-092.12000 \mathrm{e}-01$ $5.55582 \mathrm{e}+015.55582 \mathrm{e}+015.55582 \mathrm{e}+001.00000 \mathrm{e}-092.12000 \mathrm{e}-01$ $1.00000 \mathrm{e}-02$ 1.00000e-02 1.00000e-03 1.00000e-09 1.00000e-01 $1.00000 \mathrm{e}-05$ 1.00000e-05 1.00000e-06 1.00000e-09 1.00000e-01 $1.00000 \mathrm{e}+001.00000 \mathrm{e}+001.00000 \mathrm{e}-011.00000 \mathrm{e}-091.00000 \mathrm{e}-01$ Element: 9612 \# of layers: 8

Kx Ky Kz Ss Por

$2.84136 \mathrm{e}+012.84136 \mathrm{e}+012.84136 \mathrm{e}+001.00000 \mathrm{e}-092.12000 \mathrm{e}-01$ $2.84136 \mathrm{e}+012.84136 \mathrm{e}+012.84136 \mathrm{e}+001.00000 \mathrm{e}-092.12000 \mathrm{e}-01$ $2.84136 \mathrm{e}+012.84136 \mathrm{e}+012.84136 \mathrm{e}+001.00000 \mathrm{e}-092.12000 \mathrm{e}-01$ $2.84136 \mathrm{e}+012.84136 \mathrm{e}+012.84136 \mathrm{e}+001.00000 \mathrm{e}-092.12000 \mathrm{e}-01$ $2.84136 \mathrm{e}+012.84136 \mathrm{e}+012.84136 \mathrm{e}+001.00000 \mathrm{e}-092.12000 \mathrm{e}-01$ 
1.00000e-02 1.00000e-02 1.00000e-03 1.00000e-09 1.00000e-01 $1.00000 \mathrm{e}-05$ 1.00000e-05 1.00000e-06 1.00000e-09 1.00000e-01 $1.00000 \mathrm{e}+001.00000 \mathrm{e}+001.00000 \mathrm{e}-011.00000 \mathrm{e}-09$ 1.00000e-01 Element: 9613 \# of layers: 9

$\mathrm{Kx} \mathrm{Ky} \mathrm{Kz}$ Ss Por

$2.79906 \mathrm{e}+012.79906 \mathrm{e}+012.79906 \mathrm{e}+00$ 1.00000e-09 2.12000e-01

$2.79906 \mathrm{e}+012.79906 \mathrm{e}+012.79906 \mathrm{e}+001.00000 \mathrm{e}-092.12000 \mathrm{e}-01$

$2.79906 \mathrm{e}+012.79906 \mathrm{e}+012.79906 \mathrm{e}+001.00000 \mathrm{e}-092.12000 \mathrm{e}-01$

$2.79906 \mathrm{e}+012.79906 \mathrm{e}+012.79906 \mathrm{e}+001.00000 \mathrm{e}-092.12000 \mathrm{e}-01$

$2.79906 \mathrm{e}+012.79906 \mathrm{e}+012.79906 \mathrm{e}+001.00000 \mathrm{e}-092.12000 \mathrm{e}-01$ $1.00000 \mathrm{e}-02$ 1.00000e-02 1.00000e-03 1.00000e-09 1.00000e-01

$1.00000 \mathrm{e}+001.00000 \mathrm{e}+001.00000 \mathrm{e}-011.00000 \mathrm{e}-091.00000 \mathrm{e}-01$ $1.00000 \mathrm{e}-05$ 1.00000e-05 1.00000e-06 1.00000e-09 1.00000e-01 $1.00000 \mathrm{e}+001.00000 \mathrm{e}+001.00000 \mathrm{e}-011.00000 \mathrm{e}-091.00000 \mathrm{e}-01$ Element: 9614 \# of layers: 9

Kx Ky Kz Ss Por

5.30899e+01 5.30899e+01 5.30899e+00 1.00000e-09 2.12000e-01

$5.30899 \mathrm{e}+01$ 5.30899e+01 5.30899e+00 1.00000e-09 2.12000e-01

$5.30899 \mathrm{e}+015.30899 \mathrm{e}+015.30899 \mathrm{e}+00$ 1.00000e-09 2.12000e-01

$5.30899 \mathrm{e}+015.30899 \mathrm{e}+01$ 5.30899e+00 1.00000e-09 2.12000e-01

$5.30899 \mathrm{e}+015.30899 \mathrm{e}+015.30899 \mathrm{e}+00$ 1.00000e-09 2.12000e-01

$1.00000 \mathrm{e}-02$ 1.00000e-02 1.00000e-03 1.00000e-09 1.00000e-01

$1.00000 \mathrm{e}+001.00000 \mathrm{e}+001.00000 \mathrm{e}-011.00000 \mathrm{e}-091.00000 \mathrm{e}-01$ $1.00000 \mathrm{e}-05$ 1.00000e-05 1.00000e-06 1.00000e-09 1.00000e-01

$1.00000 \mathrm{e}+001.00000 \mathrm{e}+001.00000 \mathrm{e}-011.00000 \mathrm{e}-091.00000 \mathrm{e}-01$ Element: 9615 \# of layers: 8

$\mathrm{Kx} \mathrm{Ky} \mathrm{Kz}$ Ss Por

6.87480e+01 6.87480e+01 6.87480e+00 1.00000e-09 2.12000e-01

$6.87480 \mathrm{e}+016.87480 \mathrm{e}+016.87480 \mathrm{e}+001.00000 \mathrm{e}-092.12000 \mathrm{e}-01$

$6.87480 \mathrm{e}+016.87480 \mathrm{e}+016.87480 \mathrm{e}+001.00000 \mathrm{e}-092.12000 \mathrm{e}-01$

$6.87480 \mathrm{e}+016.87480 \mathrm{e}+016.87480 \mathrm{e}+00$ 1.00000e-09 2.12000e-01 $1.00000 \mathrm{e}-02$ 1.00000e-02 1.00000e-03 1.00000e-09 1.00000e-01

$1.00000 \mathrm{e}+001.00000 \mathrm{e}+001.00000 \mathrm{e}-011.00000 \mathrm{e}-091.00000 \mathrm{e}-01$ $1.00000 \mathrm{e}-05$ 1.00000e-05 1.00000e-06 1.00000e-09 1.00000e-01

$1.00000 \mathrm{e}+001.00000 \mathrm{e}+001.00000 \mathrm{e}-011.00000 \mathrm{e}-091.00000 \mathrm{e}-01$

Element: 9616 \# of layers: 8

Kx Ky Kz Ss Por

6.87480e+01 6.87480e+01 6.87480e+00 1.00000e-09 2.12000e-01 $6.87480 \mathrm{e}+016.87480 \mathrm{e}+016.87480 \mathrm{e}+001.00000 \mathrm{e}-092.12000 \mathrm{e}-01$ $6.87480 \mathrm{e}+016.87480 \mathrm{e}+016.87480 \mathrm{e}+001.00000 \mathrm{e}-092.12000 \mathrm{e}-01$ $6.87480 \mathrm{e}+016.87480 \mathrm{e}+016.87480 \mathrm{e}+00$ 1.00000e-09 2.12000e-01 $1.00000 \mathrm{e}-021.00000 \mathrm{e}-02$ 1.00000e-03 1.00000e-09 1.00000e-01 $1.00000 \mathrm{e}+001.00000 \mathrm{e}+001.00000 \mathrm{e}-011.00000 \mathrm{e}-091.00000 \mathrm{e}-01$ $1.00000 \mathrm{e}-05$ 1.00000e-05 1.00000e-06 1.00000e-09 1.00000e-01 $1.00000 \mathrm{e}+001.00000 \mathrm{e}+001.00000 \mathrm{e}-011.00000 \mathrm{e}-091.00000 \mathrm{e}-01$ Element: 9617 \# of layers: 8 
$\mathrm{Kx} \mathrm{Ky} \mathrm{Kz}$ Ss Por

6.87480e+01 6.87480e+01 6.87480e+00 1.00000e-09 2.12000e-01

$6.87480 \mathrm{e}+016.87480 \mathrm{e}+016.87480 \mathrm{e}+00$ 1.00000e-09 2.12000e-01

$6.87480 \mathrm{e}+016.87480 \mathrm{e}+016.87480 \mathrm{e}+001.00000 \mathrm{e}-092.12000 \mathrm{e}-01$

$6.87480 \mathrm{e}+016.87480 \mathrm{e}+016.87480 \mathrm{e}+001.00000 \mathrm{e}-092.12000 \mathrm{e}-01$

$1.00000 \mathrm{e}-02$ 1.00000e-02 1.00000e-03 1.00000e-09 1.00000e-01

$1.00000 \mathrm{e}+001.00000 \mathrm{e}+001.00000 \mathrm{e}-011.00000 \mathrm{e}-091.00000 \mathrm{e}-01$

$1.00000 \mathrm{e}-05$ 1.00000e-05 1.00000e-06 1.00000e-09 1.00000e-01

$1.00000 \mathrm{e}+001.00000 \mathrm{e}+001.00000 \mathrm{e}-011.00000 \mathrm{e}-091.00000 \mathrm{e}-01$

Element: 9618 \# of layers: 9

Kx Ky Kz Ss Por

6.87480e+01 6.87480e+01 6.87480e+00 1.00000e-09 2.12000e-01

$6.87480 \mathrm{e}+016.87480 \mathrm{e}+016.87480 \mathrm{e}+001.00000 \mathrm{e}-092.12000 \mathrm{e}-01$

$6.87480 \mathrm{e}+016.87480 \mathrm{e}+016.87480 \mathrm{e}+00$ 1.00000e-09 2.12000e-01

$6.87480 \mathrm{e}+016.87480 \mathrm{e}+016.87480 \mathrm{e}+001.00000 \mathrm{e}-092.12000 \mathrm{e}-01$

$6.87480 \mathrm{e}+016.87480 \mathrm{e}+016.87480 \mathrm{e}+001.00000 \mathrm{e}-092.12000 \mathrm{e}-01$

$1.00000 \mathrm{e}-02$ 1.00000e-02 1.00000e-03 1.00000e-09 1.00000e-01

$1.00000 \mathrm{e}+001.00000 \mathrm{e}+001.00000 \mathrm{e}-011.00000 \mathrm{e}-091.00000 \mathrm{e}-01$

$1.00000 \mathrm{e}-05$ 1.00000e-05 1.00000e-06 1.00000e-09 1.00000e-01

$1.00000 \mathrm{e}+001.00000 \mathrm{e}+001.00000 \mathrm{e}-011.00000 \mathrm{e}-091.00000 \mathrm{e}-01$

Element: 9619 \# of layers: 8

$\mathrm{Kx} \mathrm{Ky} \mathrm{Kz}$ Ss Por

6.87480e+01 6.87480e+01 6.87480e+00 1.00000e-09 2.12000e-01

$6.87480 \mathrm{e}+016.87480 \mathrm{e}+016.87480 \mathrm{e}+001.00000 \mathrm{e}-092.12000 \mathrm{e}-01$

$6.87480 \mathrm{e}+016.87480 \mathrm{e}+016.87480 \mathrm{e}+001.00000 \mathrm{e}-092.12000 \mathrm{e}-01$

$6.87480 \mathrm{e}+016.87480 \mathrm{e}+016.87480 \mathrm{e}+001.00000 \mathrm{e}-092.12000 \mathrm{e}-01$

$1.00000 \mathrm{e}-021.00000 \mathrm{e}-021.00000 \mathrm{e}-031.00000 \mathrm{e}-091.00000 \mathrm{e}-01$

$1.00000 \mathrm{e}+001.00000 \mathrm{e}+001.00000 \mathrm{e}-011.00000 \mathrm{e}-091.00000 \mathrm{e}-01$

$1.00000 \mathrm{e}-05$ 1.00000e-05 1.00000e-06 1.00000e-09 1.00000e-01

$1.00000 \mathrm{e}+001.00000 \mathrm{e}+001.00000 \mathrm{e}-011.00000 \mathrm{e}-091.00000 \mathrm{e}-01$

Element: 9620 \# of layers: 9

Kx Ky Kz Ss Por

6.87480e+01 6.87480e+01 6.87480e+00 1.00000e-09 2.12000e-01

$6.87480 \mathrm{e}+016.87480 \mathrm{e}+016.87480 \mathrm{e}+001.00000 \mathrm{e}-092.12000 \mathrm{e}-01$

$6.87480 \mathrm{e}+016.87480 \mathrm{e}+016.87480 \mathrm{e}+001.00000 \mathrm{e}-092.12000 \mathrm{e}-01$

$6.87480 \mathrm{e}+016.87480 \mathrm{e}+016.87480 \mathrm{e}+001.00000 \mathrm{e}-092.12000 \mathrm{e}-01$

$6.87480 \mathrm{e}+016.87480 \mathrm{e}+016.87480 \mathrm{e}+001.00000 \mathrm{e}-092.12000 \mathrm{e}-01$

$1.00000 \mathrm{e}-02$ 1.00000e-02 1.00000e-03 1.00000e-09 1.00000e-01

$1.00000 \mathrm{e}+001.00000 \mathrm{e}+001.00000 \mathrm{e}-011.00000 \mathrm{e}-091.00000 \mathrm{e}-01$

$1.00000 \mathrm{e}-05$ 1.00000e-05 1.00000e-06 1.00000e-09 1.00000e-01

$1.00000 \mathrm{e}+001.00000 \mathrm{e}+001.00000 \mathrm{e}-011.00000 \mathrm{e}-091.00000 \mathrm{e}-01$

Element: 9621 \# of layers: 8

$\mathrm{Kx} \mathrm{Ky} \mathrm{Kz}$ Ss Por

6.87480e+01 6.87480e+01 6.87480e+00 1.00000e-09 2.12000e-01

$6.87480 \mathrm{e}+016.87480 \mathrm{e}+016.87480 \mathrm{e}+001.00000 \mathrm{e}-092.12000 \mathrm{e}-01$

$6.87480 \mathrm{e}+016.87480 \mathrm{e}+016.87480 \mathrm{e}+00$ 1.00000e-09 2.12000e-01 
6.87480e+01 6.87480e+01 6.87480e+00 1.00000e-09 2.12000e-01 $1.00000 \mathrm{e}-02$ 1.00000e-02 1.00000e-03 1.00000e-09 1.00000e-01 $1.00000 \mathrm{e}+001.00000 \mathrm{e}+001.00000 \mathrm{e}-011.00000 \mathrm{e}-091.00000 \mathrm{e}-01$ $1.00000 \mathrm{e}-05$ 1.00000e-05 1.00000e-06 1.00000e-09 1.00000e-01 $1.00000 \mathrm{e}+001.00000 \mathrm{e}+001.00000 \mathrm{e}-011.00000 \mathrm{e}-091.00000 \mathrm{e}-01$ Element: 9622 \# of layers: 8

$\mathrm{Kx} \mathrm{Ky} \mathrm{Kz}$ Ss Por

6.87480e+01 6.87480e+01 6.87480e+00 1.00000e-09 2.12000e-01 $6.87480 \mathrm{e}+016.87480 \mathrm{e}+016.87480 \mathrm{e}+00$ 1.00000e-09 2.12000e-01 $6.87480 \mathrm{e}+016.87480 \mathrm{e}+016.87480 \mathrm{e}+00$ 1.00000e-09 2.12000e-01 $6.87480 \mathrm{e}+016.87480 \mathrm{e}+016.87480 \mathrm{e}+00$ 1.00000e-09 2.12000e-01 $1.00000 \mathrm{e}-02$ 1.00000e-02 1.00000e-03 1.00000e-09 1.00000e-01 $1.00000 \mathrm{e}+001.00000 \mathrm{e}+001.00000 \mathrm{e}-011.00000 \mathrm{e}-091.00000 \mathrm{e}-01$ $1.00000 \mathrm{e}-05$ 1.00000e-05 1.00000e-06 1.00000e-09 1.00000e-01 $1.00000 \mathrm{e}+001.00000 \mathrm{e}+001.00000 \mathrm{e}-01$ 1.00000e-09 1.00000e-01 Element: 9623 \# of layers: 9

$\mathrm{Kx} \mathrm{Ky} \mathrm{Kz}$ Ss Por

6.87480e+01 6.87480e+01 6.87480e+00 1.00000e-09 2.12000e-01 $6.87480 \mathrm{e}+016.87480 \mathrm{e}+016.87480 \mathrm{e}+001.00000 \mathrm{e}-092.12000 \mathrm{e}-01$ $6.87480 \mathrm{e}+016.87480 \mathrm{e}+016.87480 \mathrm{e}+00$ 1.00000e-09 2.12000e-01 $6.87480 \mathrm{e}+016.87480 \mathrm{e}+016.87480 \mathrm{e}+001.00000 \mathrm{e}-092.12000 \mathrm{e}-01$ $6.87480 \mathrm{e}+016.87480 \mathrm{e}+016.87480 \mathrm{e}+001.00000 \mathrm{e}-092.12000 \mathrm{e}-01$ $1.00000 \mathrm{e}-02$ 1.00000e-02 1.00000e-03 1.00000e-09 1.00000e-01 $1.00000 \mathrm{e}+001.00000 \mathrm{e}+001.00000 \mathrm{e}-011.00000 \mathrm{e}-091.00000 \mathrm{e}-01$ $1.00000 \mathrm{e}-05$ 1.00000e-05 1.00000e-06 1.00000e-09 1.00000e-01 $1.00000 \mathrm{e}+001.00000 \mathrm{e}+001.00000 \mathrm{e}-01$ 1.00000e-09 1.00000e-01 Element: 9624 \# of layers: 9

$\mathrm{Kx} \mathrm{Ky} \mathrm{Kz}$ Ss Por

6.87480e+01 6.87480e+01 6.87480e+00 1.00000e-09 2.12000e-01 $6.87480 \mathrm{e}+016.87480 \mathrm{e}+016.87480 \mathrm{e}+001.00000 \mathrm{e}-092.12000 \mathrm{e}-01$ $6.87480 \mathrm{e}+016.87480 \mathrm{e}+016.87480 \mathrm{e}+00$ 1.00000e-09 2.12000e-01 $6.87480 \mathrm{e}+016.87480 \mathrm{e}+016.87480 \mathrm{e}+001.00000 \mathrm{e}-092.12000 \mathrm{e}-01$ $6.87480 \mathrm{e}+016.87480 \mathrm{e}+016.87480 \mathrm{e}+00$ 1.00000e-09 2.12000e-01 $1.00000 \mathrm{e}-02$ 1.00000e-02 1.00000e-03 1.00000e-09 1.00000e-01 $1.00000 \mathrm{e}+001.00000 \mathrm{e}+001.00000 \mathrm{e}-011.00000 \mathrm{e}-091.00000 \mathrm{e}-01$ $1.00000 \mathrm{e}-05$ 1.00000e-05 1.00000e-06 1.00000e-09 1.00000e-01 $1.00000 \mathrm{e}+001.00000 \mathrm{e}+001.00000 \mathrm{e}-011.00000 \mathrm{e}-091.00000 \mathrm{e}-01$ Element: 9625 \# of layers: 9

$\mathrm{Kx} \mathrm{Ky} \mathrm{Kz}$ Ss Por 6.74924e+01 6.74924e+01 6.74924e+00 1.00000e-09 2.12000e-01 $6.74924 \mathrm{e}+016.74924 \mathrm{e}+016.74924 \mathrm{e}+00$ 1.00000e-09 2.12000e-01 $6.74924 \mathrm{e}+016.74924 \mathrm{e}+016.74924 \mathrm{e}+00$ 1.00000e-09 2.12000e-01 6.74924e+01 6.74924e+01 6.74924e+00 1.00000e-09 2.12000e-01 $6.74924 \mathrm{e}+016.74924 \mathrm{e}+016.74924 \mathrm{e}+001.00000 \mathrm{e}-092.12000 \mathrm{e}-01$ $1.00000 \mathrm{e}-02$ 1.00000e-02 1.00000e-03 1.00000e-09 1.00000e-01 $1.00000 \mathrm{e}+001.00000 \mathrm{e}+001.00000 \mathrm{e}-011.00000 \mathrm{e}-091.00000 \mathrm{e}-01$ 
$1.00000 \mathrm{e}-05$ 1.00000e-05 1.00000e-06 1.00000e-09 1.00000e-01 $1.00000 \mathrm{e}+001.00000 \mathrm{e}+001.00000 \mathrm{e}-01$ 1.00000e-09 1.00000e-01 Element: 9626 \# of layers: 9

Kx Ky Kz Ss Por

6.74924e+01 6.74924e+01 6.74924e+00 1.00000e-09 2.12000e-01 $6.74924 \mathrm{e}+016.74924 \mathrm{e}+016.74924 \mathrm{e}+001.00000 \mathrm{e}-092.12000 \mathrm{e}-01$ $6.74924 \mathrm{e}+016.74924 \mathrm{e}+016.74924 \mathrm{e}+001.00000 \mathrm{e}-092.12000 \mathrm{e}-01$ $6.74924 \mathrm{e}+016.74924 \mathrm{e}+016.74924 \mathrm{e}+001.00000 \mathrm{e}-092.12000 \mathrm{e}-01$ $6.74924 \mathrm{e}+016.74924 \mathrm{e}+016.74924 \mathrm{e}+00$ 1.00000e-09 2.12000e-01 $1.00000 \mathrm{e}-02$ 1.00000e-02 1.00000e-03 1.00000e-09 1.00000e-01 $1.00000 \mathrm{e}+001.00000 \mathrm{e}+001.00000 \mathrm{e}-011.00000 \mathrm{e}-091.00000 \mathrm{e}-01$ $1.00000 \mathrm{e}-05$ 1.00000e-05 1.00000e-06 1.00000e-09 1.00000e-01 $1.00000 \mathrm{e}+001.00000 \mathrm{e}+001.00000 \mathrm{e}-011.00000 \mathrm{e}-091.00000 \mathrm{e}-01$ Element: 9627 \# of layers: 9

$\mathrm{Kx} \mathrm{Ky} \mathrm{Kz}$ Ss Por

6.74924e+01 6.74924e+01 6.74924e+00 1.00000e-09 2.12000e-01 $6.74924 \mathrm{e}+016.74924 \mathrm{e}+016.74924 \mathrm{e}+00$ 1.00000e-09 2.12000e-01 $6.74924 \mathrm{e}+016.74924 \mathrm{e}+016.74924 \mathrm{e}+00$ 1.00000e-09 2.12000e-01 $6.74924 \mathrm{e}+016.74924 \mathrm{e}+016.74924 \mathrm{e}+00$ 1.00000e-09 2.12000e-01 $6.74924 \mathrm{e}+016.74924 \mathrm{e}+016.74924 \mathrm{e}+001.00000 \mathrm{e}-092.12000 \mathrm{e}-01$ $1.00000 \mathrm{e}-02$ 1.00000e-02 1.00000e-03 1.00000e-09 1.00000e-01 $1.00000 \mathrm{e}+001.00000 \mathrm{e}+001.00000 \mathrm{e}-011.00000 \mathrm{e}-091.00000 \mathrm{e}-01$ $1.00000 \mathrm{e}-05$ 1.00000e-05 1.00000e-06 1.00000e-09 1.00000e-01 $1.00000 \mathrm{e}+001.00000 \mathrm{e}+001.00000 \mathrm{e}-011.00000 \mathrm{e}-091.00000 \mathrm{e}-01$ Element: 9628 \# of layers: 8

$\mathrm{Kx} \mathrm{Ky} \mathrm{Kz}$ Ss Por 6.74924e+01 6.74924e+01 6.74924e+00 1.00000e-09 2.12000e-01 $6.74924 \mathrm{e}+016.74924 \mathrm{e}+016.74924 \mathrm{e}+00$ 1.00000e-09 2.12000e-01 $6.74924 \mathrm{e}+016.74924 \mathrm{e}+016.74924 \mathrm{e}+001.00000 \mathrm{e}-092.12000 \mathrm{e}-01$ $6.74924 \mathrm{e}+016.74924 \mathrm{e}+016.74924 \mathrm{e}+001.00000 \mathrm{e}-092.12000 \mathrm{e}-01$ $1.00000 \mathrm{e}-02$ 1.00000e-02 1.00000e-03 1.00000e-09 1.00000e-01 $1.00000 \mathrm{e}+001.00000 \mathrm{e}+001.00000 \mathrm{e}-011.00000 \mathrm{e}-091.00000 \mathrm{e}-01$ $1.00000 \mathrm{e}-05$ 1.00000e-05 1.00000e-06 1.00000e-09 1.00000e-01 $1.00000 \mathrm{e}+001.00000 \mathrm{e}+001.00000 \mathrm{e}-011.00000 \mathrm{e}-091.00000 \mathrm{e}-01$ Element: 9629 \# of layers: 8

$\mathrm{Kx} \mathrm{Ky} \mathrm{Kz}$ Ss Por

6.74924e+01 6.74924e+01 6.74924e+00 1.00000e-09 2.12000e-01 $6.74924 \mathrm{e}+016.74924 \mathrm{e}+016.74924 \mathrm{e}+001.00000 \mathrm{e}-092.12000 \mathrm{e}-01$ $6.74924 \mathrm{e}+016.74924 \mathrm{e}+016.74924 \mathrm{e}+001.00000 \mathrm{e}-092.12000 \mathrm{e}-01$ $6.74924 \mathrm{e}+016.74924 \mathrm{e}+016.74924 \mathrm{e}+001.00000 \mathrm{e}-092.12000 \mathrm{e}-01$ 1.00000e-02 1.00000e-02 1.00000e-03 1.00000e-09 1.00000e-01 $1.00000 \mathrm{e}+001.00000 \mathrm{e}+001.00000 \mathrm{e}-011.00000 \mathrm{e}-091.00000 \mathrm{e}-01$ $1.00000 \mathrm{e}-05$ 1.00000e-05 1.00000e-06 1.00000e-09 1.00000e-01 $1.00000 \mathrm{e}+001.00000 \mathrm{e}+001.00000 \mathrm{e}-01$ 1.00000e-09 1.00000e-01 Element: 9630 \# of layers: 8

Kx Ky Kz Ss Por 
6.87480e+01 6.87480e+01 6.87480e+00 1.00000e-09 2.12000e-01 $6.87480 \mathrm{e}+016.87480 \mathrm{e}+016.87480 \mathrm{e}+001.00000 \mathrm{e}-092.12000 \mathrm{e}-01$ $6.87480 \mathrm{e}+016.87480 \mathrm{e}+016.87480 \mathrm{e}+00$ 1.00000e-09 2.12000e-01 $6.87480 \mathrm{e}+016.87480 \mathrm{e}+016.87480 \mathrm{e}+001.00000 \mathrm{e}-092.12000 \mathrm{e}-01$ $1.00000 \mathrm{e}-021.00000 \mathrm{e}-021.00000 \mathrm{e}-031.00000 \mathrm{e}-091.00000 \mathrm{e}-01$ $1.00000 \mathrm{e}+001.00000 \mathrm{e}+001.00000 \mathrm{e}-011.00000 \mathrm{e}-091.00000 \mathrm{e}-01$ $1.00000 \mathrm{e}-05$ 1.00000e-05 1.00000e-06 1.00000e-09 1.00000e-01 $1.00000 \mathrm{e}+001.00000 \mathrm{e}+001.00000 \mathrm{e}-011.00000 \mathrm{e}-091.00000 \mathrm{e}-01$ Element: 9631 \# of layers: 9

$\mathrm{Kx} \mathrm{Ky} \mathrm{Kz}$ Ss Por

6.87480e+01 6.87480e+01 6.87480e+00 1.00000e-09 2.12000e-01 $6.87480 \mathrm{e}+016.87480 \mathrm{e}+016.87480 \mathrm{e}+001.00000 \mathrm{e}-092.12000 \mathrm{e}-01$ $6.87480 \mathrm{e}+016.87480 \mathrm{e}+016.87480 \mathrm{e}+001.00000 \mathrm{e}-09$ 2.12000e-01 $6.87480 \mathrm{e}+016.87480 \mathrm{e}+016.87480 \mathrm{e}+00$ 1.00000e-09 2.12000e-01 $6.87480 \mathrm{e}+016.87480 \mathrm{e}+016.87480 \mathrm{e}+001.00000 \mathrm{e}-092.12000 \mathrm{e}-01$ $1.00000 \mathrm{e}-02$ 1.00000e-02 1.00000e-03 1.00000e-09 1.00000e-01 $1.00000 \mathrm{e}+001.00000 \mathrm{e}+001.00000 \mathrm{e}-011.00000 \mathrm{e}-091.00000 \mathrm{e}-01$ $1.00000 \mathrm{e}-051.00000 \mathrm{e}-051.00000 \mathrm{e}-061.00000 \mathrm{e}-091.00000 \mathrm{e}-01$ $1.00000 \mathrm{e}+001.00000 \mathrm{e}+001.00000 \mathrm{e}-01$ 1.00000e-09 1.00000e-01 Element: 9632 \# of layers: 9

$\mathrm{Kx} \mathrm{Ky} \mathrm{Kz}$ Ss Por

6.74924e+01 6.74924e+01 6.74924e+00 1.00000e-09 2.12000e-01 6.74924e+01 6.74924e+01 6.74924e+00 1.00000e-09 2.12000e-01 $6.74924 \mathrm{e}+016.74924 \mathrm{e}+016.74924 \mathrm{e}+00$ 1.00000e-09 2.12000e-01 $6.74924 \mathrm{e}+016.74924 \mathrm{e}+016.74924 \mathrm{e}+001.00000 \mathrm{e}-092.12000 \mathrm{e}-01$ $6.74924 \mathrm{e}+016.74924 \mathrm{e}+016.74924 \mathrm{e}+001.00000 \mathrm{e}-092.12000 \mathrm{e}-01$ $1.00000 \mathrm{e}-02$ 1.00000e-02 1.00000e-03 1.00000e-09 1.00000e-01 $1.00000 \mathrm{e}+001.00000 \mathrm{e}+001.00000 \mathrm{e}-011.00000 \mathrm{e}-091.00000 \mathrm{e}-01$ $1.00000 \mathrm{e}-05$ 1.00000e-05 1.00000e-06 1.00000e-09 1.00000e-01 $1.00000 \mathrm{e}+001.00000 \mathrm{e}+001.00000 \mathrm{e}-011.00000 \mathrm{e}-091.00000 \mathrm{e}-01$ Element: 9633 \# of layers: 8

$\mathrm{Kx} \mathrm{Ky} \mathrm{Kz}$ Ss Por

6.74924e+01 6.74924e+01 6.74924e+00 1.00000e-09 2.12000e-01 $6.74924 \mathrm{e}+016.74924 \mathrm{e}+016.74924 \mathrm{e}+001.00000 \mathrm{e}-092.12000 \mathrm{e}-01$ $6.74924 \mathrm{e}+016.74924 \mathrm{e}+016.74924 \mathrm{e}+001.00000 \mathrm{e}-092.12000 \mathrm{e}-01$ $6.74924 \mathrm{e}+016.74924 \mathrm{e}+016.74924 \mathrm{e}+00$ 1.00000e-09 2.12000e-01 1.00000e-02 1.00000e-02 1.00000e-03 1.00000e-09 1.00000e-01 $1.00000 \mathrm{e}+001.00000 \mathrm{e}+001.00000 \mathrm{e}-011.00000 \mathrm{e}-091.00000 \mathrm{e}-01$ $1.00000 \mathrm{e}-05$ 1.00000e-05 1.00000e-06 1.00000e-09 1.00000e-01 $1.00000 \mathrm{e}+001.00000 \mathrm{e}+001.00000 \mathrm{e}-01$ 1.00000e-09 1.00000e-01 Element: 9634 \# of layers: 9

$\mathrm{Kx} \mathrm{Ky} \mathrm{Kz}$ Ss Por

6.74924e+01 6.74924e+01 6.74924e+00 1.00000e-09 2.12000e-01 6.74924e+01 6.74924e+01 6.74924e+00 1.00000e-09 2.12000e-01 $6.74924 \mathrm{e}+016.74924 \mathrm{e}+016.74924 \mathrm{e}+00$ 1.00000e-09 2.12000e-01 $6.74924 \mathrm{e}+016.74924 \mathrm{e}+016.74924 \mathrm{e}+001.00000 \mathrm{e}-092.12000 \mathrm{e}-01$ 
$6.74924 \mathrm{e}+016.74924 \mathrm{e}+016.74924 \mathrm{e}+001.00000 \mathrm{e}-092.12000 \mathrm{e}-01$ $1.00000 \mathrm{e}-02$ 1.00000e-02 1.00000e-03 1.00000e-09 1.00000e-01 $1.00000 \mathrm{e}+001.00000 \mathrm{e}+001.00000 \mathrm{e}-011.00000 \mathrm{e}-091.00000 \mathrm{e}-01$ $1.00000 \mathrm{e}-05$ 1.00000e-05 1.00000e-06 1.00000e-09 1.00000e-01 $1.00000 \mathrm{e}+001.00000 \mathrm{e}+001.00000 \mathrm{e}-01$ 1.00000e-09 1.00000e-01 Element: 9635 \# of layers: 9

$\mathrm{Kx} \mathrm{Ky} \mathrm{Kz}$ Ss Por

6.74924e+01 6.74924e+01 6.74924e+00 1.00000e-09 2.12000e-01 $6.74924 \mathrm{e}+016.74924 \mathrm{e}+016.74924 \mathrm{e}+001.00000 \mathrm{e}-092.12000 \mathrm{e}-01$ $6.74924 \mathrm{e}+016.74924 \mathrm{e}+016.74924 \mathrm{e}+00$ 1.00000e-09 2.12000e-01 $6.74924 \mathrm{e}+016.74924 \mathrm{e}+016.74924 \mathrm{e}+00$ 1.00000e-09 2.12000e-01 $6.74924 \mathrm{e}+016.74924 \mathrm{e}+016.74924 \mathrm{e}+001.00000 \mathrm{e}-092.12000 \mathrm{e}-01$ $1.00000 \mathrm{e}-02$ 1.00000e-02 1.00000e-03 1.00000e-09 1.00000e-01 $1.00000 \mathrm{e}+001.00000 \mathrm{e}+001.00000 \mathrm{e}-011.00000 \mathrm{e}-091.00000 \mathrm{e}-01$ $1.00000 \mathrm{e}-05$ 1.00000e-05 1.00000e-06 1.00000e-09 1.00000e-01 $1.00000 \mathrm{e}+001.00000 \mathrm{e}+001.00000 \mathrm{e}-011.00000 \mathrm{e}-091.00000 \mathrm{e}-01$ Element: 9636 \# of layers: 9

$\mathrm{Kx} \mathrm{Ky} \mathrm{Kz}$ Ss Por

6.74924e+01 6.74924e+01 6.74924e+00 1.00000e-09 2.12000e-01 $6.74924 \mathrm{e}+016.74924 \mathrm{e}+016.74924 \mathrm{e}+001.00000 \mathrm{e}-092.12000 \mathrm{e}-01$ $6.74924 \mathrm{e}+016.74924 \mathrm{e}+016.74924 \mathrm{e}+001.00000 \mathrm{e}-092.12000 \mathrm{e}-01$ $6.74924 \mathrm{e}+016.74924 \mathrm{e}+016.74924 \mathrm{e}+001.00000 \mathrm{e}-092.12000 \mathrm{e}-01$ 6.74924e+01 6.74924e+01 6.74924e+00 1.00000e-09 2.12000e-01 $1.00000 \mathrm{e}-02$ 1.00000e-02 1.00000e-03 1.00000e-09 1.00000e-01 $1.00000 \mathrm{e}+001.00000 \mathrm{e}+001.00000 \mathrm{e}-011.00000 \mathrm{e}-091.00000 \mathrm{e}-01$ $1.00000 \mathrm{e}-05$ 1.00000e-05 1.00000e-06 1.00000e-09 1.00000e-01 $1.00000 \mathrm{e}+001.00000 \mathrm{e}+001.00000 \mathrm{e}-01$ 1.00000e-09 1.00000e-01 Element: 9637 \# of layers: 8

$\mathrm{Kx} \mathrm{Ky} \mathrm{Kz}$ Ss Por

8.02772e+01 8.02772e+01 8.02772e+00 1.00000e-09 2.12000e-01 8.02772e+01 8.02772e+01 8.02772e+00 1.00000e-09 2.12000e-01 $8.02772 \mathrm{e}+018.02772 \mathrm{e}+018.02772 \mathrm{e}+00$ 1.00000e-09 2.12000e-01 $8.02772 \mathrm{e}+018.02772 \mathrm{e}+018.02772 \mathrm{e}+00$ 1.00000e-09 2.12000e-01 $1.00000 \mathrm{e}-02$ 1.00000e-02 1.00000e-03 1.00000e-09 1.00000e-01 $1.00000 \mathrm{e}+001.00000 \mathrm{e}+001.00000 \mathrm{e}-011.00000 \mathrm{e}-091.00000 \mathrm{e}-01$ $1.00000 \mathrm{e}-05$ 1.00000e-05 1.00000e-06 1.00000e-09 1.00000e-01 $1.00000 \mathrm{e}+001.00000 \mathrm{e}+001.00000 \mathrm{e}-011.00000 \mathrm{e}-091.00000 \mathrm{e}-01$ Element: 9638 \# of layers: 8

$\mathrm{Kx} \mathrm{Ky} \mathrm{Kz}$ Ss Por

6.74924e+01 6.74924e+01 6.74924e+00 1.00000e-09 2.12000e-01 $6.74924 \mathrm{e}+016.74924 \mathrm{e}+016.74924 \mathrm{e}+001.00000 \mathrm{e}-092.12000 \mathrm{e}-01$ $6.74924 \mathrm{e}+016.74924 \mathrm{e}+016.74924 \mathrm{e}+001.00000 \mathrm{e}-092.12000 \mathrm{e}-01$ $6.74924 \mathrm{e}+016.74924 \mathrm{e}+016.74924 \mathrm{e}+001.00000 \mathrm{e}-092.12000 \mathrm{e}-01$ $1.00000 \mathrm{e}-021.00000 \mathrm{e}-021.00000 \mathrm{e}-031.00000 \mathrm{e}-091.00000 \mathrm{e}-01$ $1.00000 \mathrm{e}+001.00000 \mathrm{e}+001.00000 \mathrm{e}-011.00000 \mathrm{e}-091.00000 \mathrm{e}-01$ $1.00000 \mathrm{e}-05$ 1.00000e-05 1.00000e-06 1.00000e-09 1.00000e-01 
$1.00000 \mathrm{e}+001.00000 \mathrm{e}+001.00000 \mathrm{e}-011.00000 \mathrm{e}-091.00000 \mathrm{e}-01$

Element: 9639 \# of layers: 8

$\mathrm{Kx} \mathrm{Ky} \mathrm{Kz}$ Ss Por

6.74924e+01 6.74924e+01 6.74924e+00 1.00000e-09 2.12000e-01

$6.74924 \mathrm{e}+016.74924 \mathrm{e}+016.74924 \mathrm{e}+001.00000 \mathrm{e}-092.12000 \mathrm{e}-01$

$6.74924 \mathrm{e}+016.74924 \mathrm{e}+016.74924 \mathrm{e}+00$ 1.00000e-09 2.12000e-01

$6.74924 \mathrm{e}+016.74924 \mathrm{e}+016.74924 \mathrm{e}+00$ 1.00000e-09 2.12000e-01

$1.00000 \mathrm{e}-02$ 1.00000e-02 1.00000e-03 1.00000e-09 1.00000e-01

$1.00000 \mathrm{e}+001.00000 \mathrm{e}+001.00000 \mathrm{e}-011.00000 \mathrm{e}-091.00000 \mathrm{e}-01$

$1.00000 \mathrm{e}-05$ 1.00000e-05 1.00000e-06 1.00000e-09 1.00000e-01

$1.00000 \mathrm{e}+001.00000 \mathrm{e}+001.00000 \mathrm{e}-011.00000 \mathrm{e}-091.00000 \mathrm{e}-01$

Element: 9640 \# of layers: 8

$\mathrm{Kx} \mathrm{Ky} \mathrm{Kz}$ Ss Por

6.74924e+01 6.74924e+01 6.74924e+00 1.00000e-09 2.12000e-01

$6.74924 \mathrm{e}+016.74924 \mathrm{e}+016.74924 \mathrm{e}+001.00000 \mathrm{e}-092.12000 \mathrm{e}-01$

$6.74924 \mathrm{e}+016.74924 \mathrm{e}+016.74924 \mathrm{e}+001.00000 \mathrm{e}-092.12000 \mathrm{e}-01$

$6.74924 \mathrm{e}+016.74924 \mathrm{e}+016.74924 \mathrm{e}+00$ 1.00000e-09 2.12000e-01

$1.00000 \mathrm{e}-02$ 1.00000e-02 1.00000e-03 1.00000e-09 1.00000e-01

$1.00000 \mathrm{e}+001.00000 \mathrm{e}+001.00000 \mathrm{e}-011.00000 \mathrm{e}-091.00000 \mathrm{e}-01$

1.00000e-05 1.00000e-05 1.00000e-06 1.00000e-09 1.00000e-01

$1.00000 \mathrm{e}+001.00000 \mathrm{e}+001.00000 \mathrm{e}-011.00000 \mathrm{e}-091.00000 \mathrm{e}-01$

Element: 9641 \# of layers: 7

$\mathrm{Kx} \mathrm{Ky} \mathrm{Kz}$ Ss Por

8.02772e+01 8.02772e+01 8.02772e+00 1.00000e-09 2.12000e-01

8.02772e+01 8.02772e+01 8.02772e+00 1.00000e-09 2.12000e-01

8.02772e+01 8.02772e+01 8.02772e+00 1.00000e-09 2.12000e-01

$1.00000 \mathrm{e}-02$ 1.00000e-02 1.00000e-03 1.00000e-09 1.00000e-01

$1.00000 \mathrm{e}+001.00000 \mathrm{e}+001.00000 \mathrm{e}-011.00000 \mathrm{e}-091.00000 \mathrm{e}-01$

$1.00000 \mathrm{e}-05$ 1.00000e-05 1.00000e-06 1.00000e-09 1.00000e-01

$1.00000 \mathrm{e}+001.00000 \mathrm{e}+001.00000 \mathrm{e}-011.00000 \mathrm{e}-091.00000 \mathrm{e}-01$

Element: 9642 \# of layers: 7

$\mathrm{Kx} \mathrm{Ky} \mathrm{Kz}$ Ss Por

8.02772e+01 8.02772e+01 8.02772e+00 1.00000e-09 2.12000e-01

8.02772e+01 8.02772e+01 8.02772e+00 1.00000e-09 2.12000e-01

8.02772e+01 8.02772e+01 8.02772e+00 1.00000e-09 2.12000e-01

$1.00000 \mathrm{e}-02$ 1.00000e-02 1.00000e-03 1.00000e-09 1.00000e-01

$1.00000 \mathrm{e}+001.00000 \mathrm{e}+001.00000 \mathrm{e}-011.00000 \mathrm{e}-091.00000 \mathrm{e}-01$

$1.00000 \mathrm{e}-05$ 1.00000e-05 1.00000e-06 1.00000e-09 1.00000e-01

$1.00000 \mathrm{e}+001.00000 \mathrm{e}+001.00000 \mathrm{e}-011.00000 \mathrm{e}-091.00000 \mathrm{e}-01$

Element: 9643 \# of layers: 7

$\mathrm{Kx} \mathrm{Ky} \mathrm{Kz}$ Ss Por

8.02772e+01 8.02772e+01 8.02772e+00 1.00000e-09 2.12000e-01

$8.02772 \mathrm{e}+018.02772 \mathrm{e}+018.02772 \mathrm{e}+001.00000 \mathrm{e}-092.12000 \mathrm{e}-01$

8.02772e+01 8.02772e+01 8.02772e+00 1.00000e-09 2.12000e-01

$1.00000 \mathrm{e}-02$ 1.00000e-02 1.00000e-03 1.00000e-09 1.00000e-01

$1.00000 \mathrm{e}+001.00000 \mathrm{e}+001.00000 \mathrm{e}-011.00000 \mathrm{e}-091.00000 \mathrm{e}-01$ 
$1.00000 \mathrm{e}-05$ 1.00000e-05 1.00000e-06 1.00000e-09 1.00000e-01 $1.00000 \mathrm{e}+001.00000 \mathrm{e}+001.00000 \mathrm{e}-01$ 1.00000e-09 1.00000e-01 Element: 9644 \# of layers: 7

Kx Ky Kz Ss Por

8.02772e+01 8.02772e+01 8.02772e+00 1.00000e-09 2.12000e-01 8.02772e+01 8.02772e+01 8.02772e+00 1.00000e-09 2.12000e-01 8.02772e+01 8.02772e+01 8.02772e+00 1.00000e-09 2.12000e-01 $1.00000 \mathrm{e}-02$ 1.00000e-02 1.00000e-03 1.00000e-09 1.00000e-01 $1.00000 \mathrm{e}+001.00000 \mathrm{e}+001.00000 \mathrm{e}-011.00000 \mathrm{e}-091.00000 \mathrm{e}-01$ $1.00000 \mathrm{e}-05$ 1.00000e-05 1.00000e-06 1.00000e-09 1.00000e-01 $1.00000 \mathrm{e}+001.00000 \mathrm{e}+001.00000 \mathrm{e}-011.00000 \mathrm{e}-091.00000 \mathrm{e}-01$ Element: 9645 \# of layers: 7

Kx Ky Kz Ss Por

8.02772e+01 8.02772e+01 8.02772e+00 1.00000e-09 2.12000e-01 8.02772e+01 8.02772e+01 8.02772e+00 1.00000e-09 2.12000e-01 8.02772e+01 8.02772e+01 8.02772e+00 1.00000e-09 2.12000e-01 $1.00000 \mathrm{e}-02$ 1.00000e-02 1.00000e-03 1.00000e-09 1.00000e-01 $1.00000 \mathrm{e}+001.00000 \mathrm{e}+001.00000 \mathrm{e}-011.00000 \mathrm{e}-091.00000 \mathrm{e}-01$ $1.00000 \mathrm{e}-05$ 1.00000e-05 1.00000e-06 1.00000e-09 1.00000e-01 $1.00000 \mathrm{e}+001.00000 \mathrm{e}+001.00000 \mathrm{e}-011.00000 \mathrm{e}-091.00000 \mathrm{e}-01$ Element: 9646 \# of layers: 7

$\mathrm{Kx} \mathrm{Ky} \mathrm{Kz}$ Ss Por

8.02772e+01 8.02772e+01 8.02772e+00 1.00000e-09 2.12000e-01 8.02772e+01 8.02772e+01 8.02772e+00 1.00000e-09 2.12000e-01 8.02772e+01 8.02772e+01 8.02772e+00 1.00000e-09 2.12000e-01 $1.00000 \mathrm{e}-02$ 1.00000e-02 1.00000e-03 1.00000e-09 1.00000e-01 $1.00000 \mathrm{e}+001.00000 \mathrm{e}+001.00000 \mathrm{e}-011.00000 \mathrm{e}-091.00000 \mathrm{e}-01$ $1.00000 \mathrm{e}-05$ 1.00000e-05 1.00000e-06 1.00000e-09 1.00000e-01 $1.00000 \mathrm{e}+001.00000 \mathrm{e}+001.00000 \mathrm{e}-011.00000 \mathrm{e}-091.00000 \mathrm{e}-01$ Element: 9647 \# of layers: 8

$\mathrm{Kx} \mathrm{Ky} \mathrm{Kz}$ Ss Por

7.52911e+01 7.52911e+01 7.52911e+00 1.00000e-09 2.12000e-01 $7.52911 \mathrm{e}+017.52911 \mathrm{e}+017.52911 \mathrm{e}+001.00000 \mathrm{e}-092.12000 \mathrm{e}-01$ $7.52911 \mathrm{e}+017.52911 \mathrm{e}+017.52911 \mathrm{e}+001.00000 \mathrm{e}-092.12000 \mathrm{e}-01$ $7.52911 \mathrm{e}+017.52911 \mathrm{e}+01$ 7.52911e+00 1.00000e-09 2.12000e-01 $1.00000 \mathrm{e}-02$ 1.00000e-02 1.00000e-03 1.00000e-09 1.00000e-01 $1.00000 \mathrm{e}+001.00000 \mathrm{e}+001.00000 \mathrm{e}-011.00000 \mathrm{e}-091.00000 \mathrm{e}-01$ $1.00000 \mathrm{e}-05$ 1.00000e-05 1.00000e-06 1.00000e-09 1.00000e-01 $1.00000 \mathrm{e}+001.00000 \mathrm{e}+001.00000 \mathrm{e}-011.00000 \mathrm{e}-091.00000 \mathrm{e}-01$ Element: 9648 \# of layers: 8

$\mathrm{Kx} \mathrm{Ky} \mathrm{Kz}$ Ss Por

7.52911e+01 7.52911e+01 7.52911e+00 1.00000e-09 2.12000e-01 $7.52911 \mathrm{e}+017.52911 \mathrm{e}+017.52911 \mathrm{e}+001.00000 \mathrm{e}-092.12000 \mathrm{e}-01$ $7.52911 \mathrm{e}+017.52911 \mathrm{e}+01$ 7.52911e+00 1.00000e-09 2.12000e-01 $7.52911 \mathrm{e}+017.52911 \mathrm{e}+01$ 7.52911e+00 1.00000e-09 2.12000e-01 $1.00000 \mathrm{e}-02$ 1.00000e-02 1.00000e-03 1.00000e-09 1.00000e-01 
$1.00000 \mathrm{e}+001.00000 \mathrm{e}+001.00000 \mathrm{e}-011.00000 \mathrm{e}-091.00000 \mathrm{e}-01$ $1.00000 \mathrm{e}-05$ 1.00000e-05 1.00000e-06 1.00000e-09 1.00000e-01

$1.00000 \mathrm{e}+001.00000 \mathrm{e}+001.00000 \mathrm{e}-011.00000 \mathrm{e}-091.00000 \mathrm{e}-01$

Element: 9649 \# of layers: 8

$\mathrm{Kx} \mathrm{Ky} \mathrm{Kz}$ Ss Por

7.52911e+01 7.52911e+01 7.52911e+00 1.00000e-09 2.12000e-01

7.52911e+01 7.52911e+01 7.52911e+00 1.00000e-09 2.12000e-01

$7.52911 \mathrm{e}+017.52911 \mathrm{e}+017.52911 \mathrm{e}+001.00000 \mathrm{e}-092.12000 \mathrm{e}-01$

7.52911e+01 7.52911e+01 7.52911e+00 1.00000e-09 2.12000e-01

$1.00000 \mathrm{e}-02$ 1.00000e-02 1.00000e-03 1.00000e-09 1.00000e-01

$1.00000 \mathrm{e}+001.00000 \mathrm{e}+001.00000 \mathrm{e}-011.00000 \mathrm{e}-091.00000 \mathrm{e}-01$

$1.00000 \mathrm{e}-05$ 1.00000e-05 1.00000e-06 1.00000e-09 1.00000e-01

$1.00000 \mathrm{e}+001.00000 \mathrm{e}+001.00000 \mathrm{e}-011.00000 \mathrm{e}-09$ 1.00000e-01

Element: 9650 \# of layers: 7

$\mathrm{Kx} \mathrm{Ky} \mathrm{Kz}$ Ss Por

8.02772e+01 8.02772e+01 8.02772e+00 1.00000e-09 2.12000e-01

8.02772e+01 8.02772e+01 8.02772e+00 1.00000e-09 2.12000e-01

8.02772e+01 8.02772e+01 8.02772e+00 1.00000e-09 2.12000e-01

$1.00000 \mathrm{e}-02$ 1.00000e-02 1.00000e-03 1.00000e-09 1.00000e-01

$1.00000 \mathrm{e}+001.00000 \mathrm{e}+001.00000 \mathrm{e}-011.00000 \mathrm{e}-091.00000 \mathrm{e}-01$

$1.00000 \mathrm{e}-05$ 1.00000e-05 1.00000e-06 1.00000e-09 1.00000e-01

$1.00000 \mathrm{e}+001.00000 \mathrm{e}+001.00000 \mathrm{e}-01$ 1.00000e-09 1.00000e-01

Element: 9651 \# of layers: 7

Kx Ky Kz Ss Por

8.02772e+01 8.02772e+01 8.02772e+00 1.00000e-09 2.12000e-01

8.02772e+01 8.02772e+01 8.02772e+00 1.00000e-09 2.12000e-01

8.02772e+01 8.02772e+01 8.02772e+00 1.00000e-09 2.12000e-01

$1.00000 \mathrm{e}-02$ 1.00000e-02 1.00000e-03 1.00000e-09 1.00000e-01

$1.00000 \mathrm{e}+001.00000 \mathrm{e}+001.00000 \mathrm{e}-011.00000 \mathrm{e}-091.00000 \mathrm{e}-01$

$1.00000 \mathrm{e}-05$ 1.00000e-05 1.00000e-06 1.00000e-09 1.00000e-01

$1.00000 \mathrm{e}+001.00000 \mathrm{e}+001.00000 \mathrm{e}-011.00000 \mathrm{e}-091.00000 \mathrm{e}-01$

Element: 9652 \# of layers: 7

$\mathrm{Kx} \mathrm{Ky} \mathrm{Kz}$ Ss Por

8.02772e+01 8.02772e+01 8.02772e+00 1.00000e-09 2.12000e-01

8.02772e+01 8.02772e+01 8.02772e+00 1.00000e-09 2.12000e-01

8.02772e+01 8.02772e+01 8.02772e+00 1.00000e-09 2.12000e-01

$1.00000 \mathrm{e}-02$ 1.00000e-02 1.00000e-03 1.00000e-09 1.00000e-01

$1.00000 \mathrm{e}+001.00000 \mathrm{e}+001.00000 \mathrm{e}-011.00000 \mathrm{e}-091.00000 \mathrm{e}-01$

$1.00000 \mathrm{e}-05$ 1.00000e-05 1.00000e-06 1.00000e-09 1.00000e-01

$1.00000 \mathrm{e}+001.00000 \mathrm{e}+001.00000 \mathrm{e}-01$ 1.00000e-09 1.00000e-01

Element: 9653 \# of layers: 7

$\mathrm{Kx} \mathrm{Ky} \mathrm{Kz}$ Ss Por

8.02772e+01 8.02772e+01 8.02772e+00 1.00000e-09 2.12000e-01

8.02772e+01 8.02772e+01 8.02772e+00 1.00000e-09 2.12000e-01

8.02772e+01 8.02772e+01 8.02772e+00 1.00000e-09 2.12000e-01

$1.00000 \mathrm{e}-02$ 1.00000e-02 1.00000e-03 1.00000e-09 1.00000e-01 
$1.00000 \mathrm{e}+001.00000 \mathrm{e}+001.00000 \mathrm{e}-011.00000 \mathrm{e}-091.00000 \mathrm{e}-01$ $1.00000 \mathrm{e}-05$ 1.00000e-05 1.00000e-06 1.00000e-09 1.00000e-01

$1.00000 \mathrm{e}+001.00000 \mathrm{e}+001.00000 \mathrm{e}-011.00000 \mathrm{e}-091.00000 \mathrm{e}-01$

Element: 9654 \# of layers: 8

$\mathrm{Kx} \mathrm{Ky} \mathrm{Kz}$ Ss Por

7.52911e+01 7.52911e+01 7.52911e+00 1.00000e-09 2.12000e-01

7.52911e+01 7.52911e+01 7.52911e+00 1.00000e-09 2.12000e-01

$7.52911 \mathrm{e}+017.52911 \mathrm{e}+017.52911 \mathrm{e}+001.00000 \mathrm{e}-092.12000 \mathrm{e}-01$

7.52911e+01 7.52911e+01 7.52911e+00 1.00000e-09 2.12000e-01

$1.00000 \mathrm{e}-02$ 1.00000e-02 1.00000e-03 1.00000e-09 1.00000e-01

$1.00000 \mathrm{e}+001.00000 \mathrm{e}+001.00000 \mathrm{e}-011.00000 \mathrm{e}-091.00000 \mathrm{e}-01$

$1.00000 \mathrm{e}-05$ 1.00000e-05 1.00000e-06 1.00000e-09 1.00000e-01

$1.00000 \mathrm{e}+001.00000 \mathrm{e}+001.00000 \mathrm{e}-011.00000 \mathrm{e}-091.00000 \mathrm{e}-01$

Element: 9655 \# of layers: 9

$\mathrm{Kx} \mathrm{Ky} \mathrm{Kz}$ Ss Por

7.52911e+01 7.52911e+01 7.52911e+00 1.00000e-09 2.12000e-01

$7.52911 \mathrm{e}+017.52911 \mathrm{e}+01$ 7.52911e+00 1.00000e-09 2.12000e-01

7.52911e+01 7.52911e+01 7.52911e+00 1.00000e-09 2.12000e-01

$7.52911 \mathrm{e}+01$ 7.52911e+01 7.52911e+00 1.00000e-09 2.12000e-01

$7.52911 \mathrm{e}+01$ 7.52911e+01 7.52911e+00 1.00000e-09 2.12000e-01

$1.00000 \mathrm{e}-02$ 1.00000e-02 1.00000e-03 1.00000e-09 1.00000e-01

$1.00000 \mathrm{e}+001.00000 \mathrm{e}+001.00000 \mathrm{e}-011.00000 \mathrm{e}-091.00000 \mathrm{e}-01$

$1.00000 \mathrm{e}-05$ 1.00000e-05 1.00000e-06 1.00000e-09 1.00000e-01

$1.00000 \mathrm{e}+001.00000 \mathrm{e}+001.00000 \mathrm{e}-011.00000 \mathrm{e}-091.00000 \mathrm{e}-01$

Element: 9656 \# of layers: 9

$\mathrm{Kx} \mathrm{Ky} \mathrm{Kz}$ Ss Por

7.52911e+01 7.52911e+01 7.52911e+00 1.00000e-09 2.12000e-01

7.52911e+01 7.52911e+01 7.52911e+00 1.00000e-09 2.12000e-01

$7.52911 \mathrm{e}+017.52911 \mathrm{e}+017.52911 \mathrm{e}+001.00000 \mathrm{e}-092.12000 \mathrm{e}-01$

$7.52911 \mathrm{e}+017.52911 \mathrm{e}+017.52911 \mathrm{e}+001.00000 \mathrm{e}-092.12000 \mathrm{e}-01$

$7.52911 \mathrm{e}+017.52911 \mathrm{e}+017.52911 \mathrm{e}+001.00000 \mathrm{e}-092.12000 \mathrm{e}-01$

$1.00000 \mathrm{e}-02$ 1.00000e-02 1.00000e-03 1.00000e-09 1.00000e-01

$1.00000 \mathrm{e}+001.00000 \mathrm{e}+001.00000 \mathrm{e}-011.00000 \mathrm{e}-091.00000 \mathrm{e}-01$

1.00000e-05 1.00000e-05 1.00000e-06 1.00000e-09 1.00000e-01

$1.00000 \mathrm{e}+001.00000 \mathrm{e}+001.00000 \mathrm{e}-011.00000 \mathrm{e}-091.00000 \mathrm{e}-01$

Element: 9657 \# of layers: 9

Kx Ky Kz Ss Por

7.52911e+01 7.52911e+01 7.52911e+00 1.00000e-09 2.12000e-01

$7.52911 \mathrm{e}+017.52911 \mathrm{e}+01$ 7.52911e+00 1.00000e-09 2.12000e-01

$7.52911 \mathrm{e}+017.52911 \mathrm{e}+017.52911 \mathrm{e}+001.00000 \mathrm{e}-092.12000 \mathrm{e}-01$

$7.52911 \mathrm{e}+017.52911 \mathrm{e}+01$ 7.52911e+00 1.00000e-09 2.12000e-01

$7.52911 \mathrm{e}+017.52911 \mathrm{e}+017.52911 \mathrm{e}+00$ 1.00000e-09 2.12000e-01

$1.00000 \mathrm{e}-02$ 1.00000e-02 1.00000e-03 1.00000e-09 1.00000e-01

$1.00000 \mathrm{e}+001.00000 \mathrm{e}+001.00000 \mathrm{e}-011.00000 \mathrm{e}-091.00000 \mathrm{e}-01$

$1.00000 \mathrm{e}-05$ 1.00000e-05 1.00000e-06 1.00000e-09 1.00000e-01

$1.00000 \mathrm{e}+001.00000 \mathrm{e}+001.00000 \mathrm{e}-011.00000 \mathrm{e}-091.00000 \mathrm{e}-01$ 
Element: 9658 \# of layers: 8

$\mathrm{Kx} \mathrm{Ky} \mathrm{Kz}$ Ss Por

7.52911e+01 7.52911e+01 7.52911e+00 1.00000e-09 2.12000e-01

7.52911e+01 7.52911e+01 7.52911e+00 1.00000e-09 2.12000e-01

$7.52911 \mathrm{e}+01$ 7.52911e+01 7.52911e+00 1.00000e-09 2.12000e-01

$7.52911 \mathrm{e}+017.52911 \mathrm{e}+017.52911 \mathrm{e}+001.00000 \mathrm{e}-092.12000 \mathrm{e}-01$

$1.00000 \mathrm{e}-02$ 1.00000e-02 1.00000e-03 1.00000e-09 1.00000e-01

$1.00000 \mathrm{e}+001.00000 \mathrm{e}+001.00000 \mathrm{e}-011.00000 \mathrm{e}-091.00000 \mathrm{e}-01$

$1.00000 \mathrm{e}-05$ 1.00000e-05 1.00000e-06 1.00000e-09 1.00000e-01

$1.00000 \mathrm{e}+001.00000 \mathrm{e}+001.00000 \mathrm{e}-011.00000 \mathrm{e}-091.00000 \mathrm{e}-01$

Element: 9659 \# of layers: 9

$\mathrm{Kx} \mathrm{Ky} \mathrm{Kz}$ Ss Por

7.52911e+01 7.52911e+01 7.52911e+00 1.00000e-09 2.12000e-01

$7.52911 \mathrm{e}+017.52911 \mathrm{e}+017.52911 \mathrm{e}+001.00000 \mathrm{e}-092.12000 \mathrm{e}-01$

$7.52911 \mathrm{e}+017.52911 \mathrm{e}+017.52911 \mathrm{e}+001.00000 \mathrm{e}-092.12000 \mathrm{e}-01$

$7.52911 \mathrm{e}+017.52911 \mathrm{e}+017.52911 \mathrm{e}+001.00000 \mathrm{e}-092.12000 \mathrm{e}-01$

7.52911e+01 7.52911e+01 7.52911e+00 1.00000e-09 2.12000e-01

$1.00000 \mathrm{e}-02$ 1.00000e-02 1.00000e-03 1.00000e-09 1.00000e-01

$1.00000 \mathrm{e}+001.00000 \mathrm{e}+001.00000 \mathrm{e}-011.00000 \mathrm{e}-091.00000 \mathrm{e}-01$

$1.00000 \mathrm{e}-051.00000 \mathrm{e}-051.00000 \mathrm{e}-061.00000 \mathrm{e}-091.00000 \mathrm{e}-01$

$1.00000 \mathrm{e}+001.00000 \mathrm{e}+001.00000 \mathrm{e}-011.00000 \mathrm{e}-091.00000 \mathrm{e}-01$

Element: 9660 \# of layers: 8

$\mathrm{Kx} \mathrm{Ky} \mathrm{Kz}$ Ss Por

7.52911e+01 7.52911e+01 7.52911e+00 1.00000e-09 2.12000e-01

$7.52911 \mathrm{e}+017.52911 \mathrm{e}+017.52911 \mathrm{e}+001.00000 \mathrm{e}-092.12000 \mathrm{e}-01$

$7.52911 \mathrm{e}+01$ 7.52911e+01 7.52911e+00 1.00000e-09 2.12000e-01

$7.52911 \mathrm{e}+01$ 7.52911e+01 7.52911e+00 1.00000e-09 2.12000e-01

$1.00000 \mathrm{e}-02$ 1.00000e-02 1.00000e-03 1.00000e-09 1.00000e-01

$1.00000 \mathrm{e}+001.00000 \mathrm{e}+001.00000 \mathrm{e}-011.00000 \mathrm{e}-091.00000 \mathrm{e}-01$

$1.00000 \mathrm{e}-05$ 1.00000e-05 1.00000e-06 1.00000e-09 1.00000e-01

$1.00000 \mathrm{e}+001.00000 \mathrm{e}+001.00000 \mathrm{e}-011.00000 \mathrm{e}-091.00000 \mathrm{e}-01$

Element: 9661 \# of layers: 8

$\mathrm{Kx} \mathrm{Ky} \mathrm{Kz}$ Ss Por

7.52911e+01 7.52911e+01 7.52911e+00 1.00000e-09 2.12000e-01

$7.52911 \mathrm{e}+017.52911 \mathrm{e}+017.52911 \mathrm{e}+00$ 1.00000e-09 2.12000e-01

$7.52911 \mathrm{e}+017.52911 \mathrm{e}+017.52911 \mathrm{e}+001.00000 \mathrm{e}-092.12000 \mathrm{e}-01$

$7.52911 \mathrm{e}+017.52911 \mathrm{e}+017.52911 \mathrm{e}+001.00000 \mathrm{e}-092.12000 \mathrm{e}-01$

$1.00000 \mathrm{e}-02$ 1.00000e-02 1.00000e-03 1.00000e-09 1.00000e-01

$1.00000 \mathrm{e}+001.00000 \mathrm{e}+001.00000 \mathrm{e}-011.00000 \mathrm{e}-091.00000 \mathrm{e}-01$

$1.00000 \mathrm{e}-05$ 1.00000e-05 1.00000e-06 1.00000e-09 1.00000e-01

$1.00000 \mathrm{e}+001.00000 \mathrm{e}+001.00000 \mathrm{e}-011.00000 \mathrm{e}-091.00000 \mathrm{e}-01$

Element: 9662 \# of layers: 9

$\mathrm{Kx} \mathrm{Ky} \mathrm{Kz}$ Ss Por

7.52911e+01 7.52911e+01 7.52911e+00 1.00000e-09 2.12000e-01

$7.52911 \mathrm{e}+01$ 7.52911e+01 7.52911e+00 1.00000e-09 2.12000e-01

$7.52911 \mathrm{e}+017.52911 \mathrm{e}+017.52911 \mathrm{e}+001.00000 \mathrm{e}-092.12000 \mathrm{e}-01$ 
7.52911e+01 7.52911e+01 7.52911e+00 1.00000e-09 2.12000e-01 $7.52911 \mathrm{e}+017.52911 \mathrm{e}+017.52911 \mathrm{e}+00$ 1.00000e-09 2.12000e-01 $1.00000 \mathrm{e}-02$ 1.00000e-02 1.00000e-03 1.00000e-09 1.00000e-01

$1.00000 \mathrm{e}+001.00000 \mathrm{e}+001.00000 \mathrm{e}-011.00000 \mathrm{e}-091.00000 \mathrm{e}-01$ $1.00000 \mathrm{e}-05$ 1.00000e-05 1.00000e-06 1.00000e-09 1.00000e-01

$1.00000 \mathrm{e}+001.00000 \mathrm{e}+001.00000 \mathrm{e}-011.00000 \mathrm{e}-091.00000 \mathrm{e}-01$ Element: 9663 \# of layers: 8

$\mathrm{Kx} \mathrm{Ky} \mathrm{Kz}$ Ss Por

7.52911e+01 7.52911e+01 7.52911e+00 1.00000e-09 2.12000e-01 $7.52911 \mathrm{e}+017.52911 \mathrm{e}+017.52911 \mathrm{e}+001.00000 \mathrm{e}-092.12000 \mathrm{e}-01$ $7.52911 \mathrm{e}+017.52911 \mathrm{e}+017.52911 \mathrm{e}+00$ 1.00000e-09 2.12000e-01 $7.52911 \mathrm{e}+017.52911 \mathrm{e}+017.52911 \mathrm{e}+001.00000 \mathrm{e}-092.12000 \mathrm{e}-01$ $1.00000 \mathrm{e}-02$ 1.00000e-02 1.00000e-03 1.00000e-09 1.00000e-01 $1.00000 \mathrm{e}+001.00000 \mathrm{e}+001.00000 \mathrm{e}-011.00000 \mathrm{e}-091.00000 \mathrm{e}-01$ $1.00000 \mathrm{e}-05$ 1.00000e-05 1.00000e-06 1.00000e-09 1.00000e-01 $1.00000 \mathrm{e}+001.00000 \mathrm{e}+001.00000 \mathrm{e}-011.00000 \mathrm{e}-091.00000 \mathrm{e}-01$ Element: 9664 \# of layers: 8

$\mathrm{Kx} \mathrm{Ky} \mathrm{Kz}$ Ss Por

6.87480e+01 6.87480e+01 6.87480e+00 1.00000e-09 2.12000e-01 $6.87480 \mathrm{e}+016.87480 \mathrm{e}+016.87480 \mathrm{e}+001.00000 \mathrm{e}-092.12000 \mathrm{e}-01$ $6.87480 \mathrm{e}+016.87480 \mathrm{e}+016.87480 \mathrm{e}+001.00000 \mathrm{e}-092.12000 \mathrm{e}-01$ $6.87480 \mathrm{e}+016.87480 \mathrm{e}+016.87480 \mathrm{e}+00$ 1.00000e-09 2.12000e-01 $1.00000 \mathrm{e}-02$ 1.00000e-02 1.00000e-03 1.00000e-09 1.00000e-01 $1.00000 \mathrm{e}+001.00000 \mathrm{e}+001.00000 \mathrm{e}-011.00000 \mathrm{e}-091.00000 \mathrm{e}-01$ $1.00000 \mathrm{e}-05$ 1.00000e-05 1.00000e-06 1.00000e-09 1.00000e-01 $1.00000 \mathrm{e}+001.00000 \mathrm{e}+001.00000 \mathrm{e}-01$ 1.00000e-09 1.00000e-01 Element: 9665 \# of layers: 8

$\mathrm{Kx} \mathrm{Ky} \mathrm{Kz}$ Ss Por

6.87480e+01 6.87480e+01 6.87480e+00 1.00000e-09 2.12000e-01 $6.87480 \mathrm{e}+016.87480 \mathrm{e}+016.87480 \mathrm{e}+001.00000 \mathrm{e}-092.12000 \mathrm{e}-01$ $6.87480 \mathrm{e}+016.87480 \mathrm{e}+016.87480 \mathrm{e}+001.00000 \mathrm{e}-092.12000 \mathrm{e}-01$ $6.87480 \mathrm{e}+016.87480 \mathrm{e}+016.87480 \mathrm{e}+00$ 1.00000e-09 2.12000e-01 $1.00000 \mathrm{e}-02$ 1.00000e-02 1.00000e-03 1.00000e-09 1.00000e-01 $1.00000 \mathrm{e}+001.00000 \mathrm{e}+001.00000 \mathrm{e}-011.00000 \mathrm{e}-091.00000 \mathrm{e}-01$ $1.00000 \mathrm{e}-05$ 1.00000e-05 1.00000e-06 1.00000e-09 1.00000e-01 $1.00000 \mathrm{e}+001.00000 \mathrm{e}+001.00000 \mathrm{e}-011.00000 \mathrm{e}-091.00000 \mathrm{e}-01$ Element: 9666 \# of layers: 9

Kx Ky Kz Ss Por

6.87480e+01 6.87480e+01 6.87480e+00 1.00000e-09 2.12000e-01 $6.87480 \mathrm{e}+016.87480 \mathrm{e}+016.87480 \mathrm{e}+001.00000 \mathrm{e}-092.12000 \mathrm{e}-01$ $6.87480 \mathrm{e}+016.87480 \mathrm{e}+016.87480 \mathrm{e}+001.00000 \mathrm{e}-092.12000 \mathrm{e}-01$ $6.87480 \mathrm{e}+016.87480 \mathrm{e}+016.87480 \mathrm{e}+001.00000 \mathrm{e}-092.12000 \mathrm{e}-01$ $6.87480 \mathrm{e}+016.87480 \mathrm{e}+016.87480 \mathrm{e}+00$ 1.00000e-09 2.12000e-01 $1.00000 \mathrm{e}-02$ 1.00000e-02 1.00000e-03 1.00000e-09 1.00000e-01 $1.00000 \mathrm{e}+001.00000 \mathrm{e}+001.00000 \mathrm{e}-011.00000 \mathrm{e}-091.00000 \mathrm{e}-01$ $1.00000 \mathrm{e}-05$ 1.00000e-05 1.00000e-06 1.00000e-09 1.00000e-01 
$1.00000 \mathrm{e}+001.00000 \mathrm{e}+00$ 1.00000e-01 1.00000e-09 1.00000e-01

Element: 9667 \# of layers: 8

$\mathrm{Kx} \mathrm{Ky} \mathrm{Kz}$ Ss Por

6.87480e+01 6.87480e+01 6.87480e+00 1.00000e-09 2.12000e-01

$6.87480 \mathrm{e}+016.87480 \mathrm{e}+016.87480 \mathrm{e}+001.00000 \mathrm{e}-092.12000 \mathrm{e}-01$

$6.87480 \mathrm{e}+016.87480 \mathrm{e}+016.87480 \mathrm{e}+001.00000 \mathrm{e}-092.12000 \mathrm{e}-01$

$6.87480 \mathrm{e}+016.87480 \mathrm{e}+016.87480 \mathrm{e}+00$ 1.00000e-09 2.12000e-01

$1.00000 \mathrm{e}-02$ 1.00000e-02 1.00000e-03 1.00000e-09 1.00000e-01

$1.00000 \mathrm{e}+001.00000 \mathrm{e}+001.00000 \mathrm{e}-011.00000 \mathrm{e}-091.00000 \mathrm{e}-01$

$1.00000 \mathrm{e}-05$ 1.00000e-05 1.00000e-06 1.00000e-09 1.00000e-01

$1.00000 \mathrm{e}+001.00000 \mathrm{e}+001.00000 \mathrm{e}-011.00000 \mathrm{e}-091.00000 \mathrm{e}-01$

Element: 9668 \# of layers: 8

$\mathrm{Kx} \mathrm{Ky} \mathrm{Kz}$ Ss Por

6.87480e+01 6.87480e+01 6.87480e+00 1.00000e-09 2.12000e-01

$6.87480 \mathrm{e}+016.87480 \mathrm{e}+016.87480 \mathrm{e}+001.00000 \mathrm{e}-092.12000 \mathrm{e}-01$

$6.87480 \mathrm{e}+016.87480 \mathrm{e}+016.87480 \mathrm{e}+001.00000 \mathrm{e}-092.12000 \mathrm{e}-01$

$6.87480 \mathrm{e}+016.87480 \mathrm{e}+016.87480 \mathrm{e}+001.00000 \mathrm{e}-092.12000 \mathrm{e}-01$

$1.00000 \mathrm{e}-02$ 1.00000e-02 1.00000e-03 1.00000e-09 1.00000e-01

$1.00000 \mathrm{e}+001.00000 \mathrm{e}+001.00000 \mathrm{e}-011.00000 \mathrm{e}-091.00000 \mathrm{e}-01$

1.00000e-05 1.00000e-05 1.00000e-06 1.00000e-09 1.00000e-01

$1.00000 \mathrm{e}+001.00000 \mathrm{e}+001.00000 \mathrm{e}-011.00000 \mathrm{e}-091.00000 \mathrm{e}-01$

Element: 9669 \# of layers: 8

$\mathrm{Kx} \mathrm{Ky} \mathrm{Kz}$ Ss Por

7.52911e+01 7.52911e+01 7.52911e+00 1.00000e-09 2.12000e-01

$7.52911 \mathrm{e}+017.52911 \mathrm{e}+017.52911 \mathrm{e}+001.00000 \mathrm{e}-092.12000 \mathrm{e}-01$

$7.52911 \mathrm{e}+01$ 7.52911e+01 7.52911e+00 1.00000e-09 2.12000e-01

$7.52911 \mathrm{e}+017.52911 \mathrm{e}+01$ 7.52911e+00 1.00000e-09 2.12000e-01

$1.00000 \mathrm{e}-02$ 1.00000e-02 1.00000e-03 1.00000e-09 1.00000e-01

$1.00000 \mathrm{e}+001.00000 \mathrm{e}+001.00000 \mathrm{e}-011.00000 \mathrm{e}-091.00000 \mathrm{e}-01$

$1.00000 \mathrm{e}-05$ 1.00000e-05 1.00000e-06 1.00000e-09 1.00000e-01

$1.00000 \mathrm{e}+001.00000 \mathrm{e}+001.00000 \mathrm{e}-011.00000 \mathrm{e}-091.00000 \mathrm{e}-01$

Element: 9670 \# of layers: 9

Kx Ky Kz Ss Por

7.52911e+01 7.52911e+01 7.52911e+00 1.00000e-09 2.12000e-01

$7.52911 \mathrm{e}+017.52911 \mathrm{e}+017.52911 \mathrm{e}+00$ 1.00000e-09 2.12000e-01

$7.52911 \mathrm{e}+017.52911 \mathrm{e}+017.52911 \mathrm{e}+001.00000 \mathrm{e}-092.12000 \mathrm{e}-01$

$7.52911 \mathrm{e}+017.52911 \mathrm{e}+017.52911 \mathrm{e}+00$ 1.00000e-09 2.12000e-01

$7.52911 \mathrm{e}+017.52911 \mathrm{e}+017.52911 \mathrm{e}+00$ 1.00000e-09 2.12000e-01

$1.00000 \mathrm{e}-02$ 1.00000e-02 1.00000e-03 1.00000e-09 1.00000e-01

$1.00000 \mathrm{e}+001.00000 \mathrm{e}+001.00000 \mathrm{e}-011.00000 \mathrm{e}-091.00000 \mathrm{e}-01$

$1.00000 \mathrm{e}-05$ 1.00000e-05 1.00000e-06 1.00000e-09 1.00000e-01

$1.00000 \mathrm{e}+001.00000 \mathrm{e}+001.00000 \mathrm{e}-011.00000 \mathrm{e}-091.00000 \mathrm{e}-01$

Element: 9671 \# of layers: 9

$\mathrm{Kx} \mathrm{Ky} \mathrm{Kz}$ Ss Por

6.87480e+01 6.87480e+01 6.87480e+00 1.00000e-09 2.12000e-01

$6.87480 \mathrm{e}+016.87480 \mathrm{e}+016.87480 \mathrm{e}+001.00000 \mathrm{e}-092.12000 \mathrm{e}-01$ 
6.87480e+01 6.87480e+01 6.87480e+00 1.00000e-09 2.12000e-01 $6.87480 \mathrm{e}+016.87480 \mathrm{e}+016.87480 \mathrm{e}+001.00000 \mathrm{e}-092.12000 \mathrm{e}-01$ $6.87480 \mathrm{e}+016.87480 \mathrm{e}+016.87480 \mathrm{e}+00$ 1.00000e-09 2.12000e-01 $1.00000 \mathrm{e}-02$ 1.00000e-02 1.00000e-03 1.00000e-09 1.00000e-01 $1.00000 \mathrm{e}+001.00000 \mathrm{e}+001.00000 \mathrm{e}-011.00000 \mathrm{e}-091.00000 \mathrm{e}-01$ $1.00000 \mathrm{e}-05$ 1.00000e-05 1.00000e-06 1.00000e-09 1.00000e-01 $1.00000 \mathrm{e}+001.00000 \mathrm{e}+001.00000 \mathrm{e}-01$ 1.00000e-09 1.00000e-01 Element: 9672 \# of layers: 8

$\mathrm{Kx} \mathrm{Ky} \mathrm{Kz}$ Ss Por

6.87480e+01 6.87480e+01 6.87480e+00 1.00000e-09 2.12000e-01 $6.87480 \mathrm{e}+016.87480 \mathrm{e}+016.87480 \mathrm{e}+001.00000 \mathrm{e}-092.12000 \mathrm{e}-01$ $6.87480 \mathrm{e}+016.87480 \mathrm{e}+016.87480 \mathrm{e}+001.00000 \mathrm{e}-092.12000 \mathrm{e}-01$ $6.87480 \mathrm{e}+016.87480 \mathrm{e}+016.87480 \mathrm{e}+001.00000 \mathrm{e}-092.12000 \mathrm{e}-01$ $1.00000 \mathrm{e}-02$ 1.00000e-02 1.00000e-03 1.00000e-09 1.00000e-01 $1.00000 \mathrm{e}+001.00000 \mathrm{e}+001.00000 \mathrm{e}-011.00000 \mathrm{e}-091.00000 \mathrm{e}-01$ $1.00000 \mathrm{e}-05$ 1.00000e-05 1.00000e-06 1.00000e-09 1.00000e-01 $1.00000 \mathrm{e}+001.00000 \mathrm{e}+001.00000 \mathrm{e}-011.00000 \mathrm{e}-09$ 1.00000e-01 Element: 9673 \# of layers: 8

$\mathrm{Kx} \mathrm{Ky} \mathrm{Kz}$ Ss Por

6.74924e+01 6.74924e+01 6.74924e+00 1.00000e-09 2.12000e-01 $6.74924 \mathrm{e}+016.74924 \mathrm{e}+016.74924 \mathrm{e}+001.00000 \mathrm{e}-092.12000 \mathrm{e}-01$ $6.74924 \mathrm{e}+016.74924 \mathrm{e}+016.74924 \mathrm{e}+00$ 1.00000e-09 2.12000e-01 6.74924e+01 6.74924e+01 6.74924e+00 1.00000e-09 2.12000e-01 $1.00000 \mathrm{e}-02$ 1.00000e-02 1.00000e-03 1.00000e-09 1.00000e-01 $1.00000 \mathrm{e}+001.00000 \mathrm{e}+001.00000 \mathrm{e}-011.00000 \mathrm{e}-091.00000 \mathrm{e}-01$ $1.00000 \mathrm{e}-05$ 1.00000e-05 1.00000e-06 1.00000e-09 1.00000e-01 $1.00000 \mathrm{e}+001.00000 \mathrm{e}+001.00000 \mathrm{e}-011.00000 \mathrm{e}-091.00000 \mathrm{e}-01$ Element: 9674 \# of layers: 8

Kx Ky Kz Ss Por

6.74924e+01 6.74924e+01 6.74924e+00 1.00000e-09 2.12000e-01 $6.74924 \mathrm{e}+016.74924 \mathrm{e}+016.74924 \mathrm{e}+001.00000 \mathrm{e}-092.12000 \mathrm{e}-01$ $6.74924 \mathrm{e}+016.74924 \mathrm{e}+016.74924 \mathrm{e}+001.00000 \mathrm{e}-092.12000 \mathrm{e}-01$ $6.74924 \mathrm{e}+016.74924 \mathrm{e}+016.74924 \mathrm{e}+001.00000 \mathrm{e}-092.12000 \mathrm{e}-01$ $1.00000 \mathrm{e}-02$ 1.00000e-02 1.00000e-03 1.00000e-09 1.00000e-01 $1.00000 \mathrm{e}+001.00000 \mathrm{e}+001.00000 \mathrm{e}-011.00000 \mathrm{e}-091.00000 \mathrm{e}-01$ 1.00000e-05 1.00000e-05 1.00000e-06 1.00000e-09 1.00000e-01 $1.00000 \mathrm{e}+001.00000 \mathrm{e}+001.00000 \mathrm{e}-011.00000 \mathrm{e}-091.00000 \mathrm{e}-01$ Element: 9675 \# of layers: 8

$\mathrm{Kx} \mathrm{Ky} \mathrm{Kz}$ Ss Por

6.74924e+01 6.74924e+01 6.74924e+00 1.00000e-09 2.12000e-01 $6.74924 \mathrm{e}+016.74924 \mathrm{e}+016.74924 \mathrm{e}+001.00000 \mathrm{e}-092.12000 \mathrm{e}-01$ $6.74924 \mathrm{e}+016.74924 \mathrm{e}+016.74924 \mathrm{e}+001.00000 \mathrm{e}-092.12000 \mathrm{e}-01$ $6.74924 \mathrm{e}+016.74924 \mathrm{e}+016.74924 \mathrm{e}+001.00000 \mathrm{e}-092.12000 \mathrm{e}-01$ $1.00000 \mathrm{e}-02$ 1.00000e-02 1.00000e-03 1.00000e-09 1.00000e-01 $1.00000 \mathrm{e}+001.00000 \mathrm{e}+001.00000 \mathrm{e}-011.00000 \mathrm{e}-091.00000 \mathrm{e}-01$ $1.00000 \mathrm{e}-05$ 1.00000e-05 1.00000e-06 1.00000e-09 1.00000e-01 
$1.00000 \mathrm{e}+001.00000 \mathrm{e}+00$ 1.00000e-01 1.00000e-09 1.00000e-01

Element: 9676 \# of layers: 8

Kx Ky Kz Ss Por

8.02772e+01 8.02772e+01 8.02772e+00 1.00000e-09 2.12000e-01

8.02772e+01 8.02772e+01 8.02772e+00 1.00000e-09 2.12000e-01

$8.02772 \mathrm{e}+018.02772 \mathrm{e}+018.02772 \mathrm{e}+001.00000 \mathrm{e}-092.12000 \mathrm{e}-01$

8.02772e+01 8.02772e+01 8.02772e+00 1.00000e-09 2.12000e-01

$1.00000 \mathrm{e}-02$ 1.00000e-02 1.00000e-03 1.00000e-09 1.00000e-01

$1.00000 \mathrm{e}+001.00000 \mathrm{e}+001.00000 \mathrm{e}-011.00000 \mathrm{e}-091.00000 \mathrm{e}-01$

$1.00000 \mathrm{e}-05$ 1.00000e-05 1.00000e-06 1.00000e-09 1.00000e-01

$1.00000 \mathrm{e}+001.00000 \mathrm{e}+001.00000 \mathrm{e}-011.00000 \mathrm{e}-091.00000 \mathrm{e}-01$

Element: 9677 \# of layers: 8

$\mathrm{Kx} \mathrm{Ky} \mathrm{Kz}$ Ss Por

8.02772e+01 8.02772e+01 8.02772e+00 1.00000e-09 2.12000e-01

8.02772e+01 8.02772e+01 8.02772e+00 1.00000e-09 2.12000e-01

8.02772e+01 8.02772e+01 8.02772e+00 1.00000e-09 2.12000e-01

8.02772e+01 8.02772e+01 8.02772e+00 1.00000e-09 2.12000e-01

$1.00000 \mathrm{e}-02$ 1.00000e-02 1.00000e-03 1.00000e-09 1.00000e-01

$1.00000 \mathrm{e}+001.00000 \mathrm{e}+001.00000 \mathrm{e}-011.00000 \mathrm{e}-091.00000 \mathrm{e}-01$

1.00000e-05 1.00000e-05 1.00000e-06 1.00000e-09 1.00000e-01

$1.00000 \mathrm{e}+001.00000 \mathrm{e}+001.00000 \mathrm{e}-011.00000 \mathrm{e}-091.00000 \mathrm{e}-01$

Element: 9678 \# of layers: 8

$\mathrm{Kx} \mathrm{Ky} \mathrm{Kz}$ Ss Por

7.52911e+01 7.52911e+01 7.52911e+00 1.00000e-09 2.12000e-01

$7.52911 \mathrm{e}+017.52911 \mathrm{e}+017.52911 \mathrm{e}+001.00000 \mathrm{e}-092.12000 \mathrm{e}-01$

$7.52911 \mathrm{e}+01$ 7.52911e+01 7.52911e+00 1.00000e-09 2.12000e-01

$7.52911 \mathrm{e}+017.52911 \mathrm{e}+01$ 7.52911e+00 1.00000e-09 2.12000e-01

$1.00000 \mathrm{e}-02$ 1.00000e-02 1.00000e-03 1.00000e-09 1.00000e-01

$1.00000 \mathrm{e}+001.00000 \mathrm{e}+001.00000 \mathrm{e}-011.00000 \mathrm{e}-091.00000 \mathrm{e}-01$

$1.00000 \mathrm{e}-05$ 1.00000e-05 1.00000e-06 1.00000e-09 1.00000e-01

$1.00000 \mathrm{e}+001.00000 \mathrm{e}+001.00000 \mathrm{e}-011.00000 \mathrm{e}-091.00000 \mathrm{e}-01$

Element: 9679 \# of layers: 8

Kx Ky Kz Ss Por

6.87480e+01 6.87480e+01 6.87480e+00 1.00000e-09 2.12000e-01

$6.87480 \mathrm{e}+016.87480 \mathrm{e}+016.87480 \mathrm{e}+00$ 1.00000e-09 2.12000e-01

$6.87480 \mathrm{e}+016.87480 \mathrm{e}+016.87480 \mathrm{e}+001.00000 \mathrm{e}-09$ 2.12000e-01

$6.87480 \mathrm{e}+016.87480 \mathrm{e}+016.87480 \mathrm{e}+001.00000 \mathrm{e}-092.12000 \mathrm{e}-01$

$1.00000 \mathrm{e}-02$ 1.00000e-02 1.00000e-03 1.00000e-09 1.00000e-01

$1.00000 \mathrm{e}+001.00000 \mathrm{e}+001.00000 \mathrm{e}-011.00000 \mathrm{e}-091.00000 \mathrm{e}-01$

$1.00000 \mathrm{e}-05$ 1.00000e-05 1.00000e-06 1.00000e-09 1.00000e-01

$1.00000 \mathrm{e}+001.00000 \mathrm{e}+001.00000 \mathrm{e}-011.00000 \mathrm{e}-091.00000 \mathrm{e}-01$

Element: 9680 \# of layers: 8

$\mathrm{Kx} \mathrm{Ky} \mathrm{Kz}$ Ss Por

6.74924e+01 6.74924e+01 6.74924e+00 1.00000e-09 2.12000e-01

$6.74924 \mathrm{e}+016.74924 \mathrm{e}+016.74924 \mathrm{e}+00$ 1.00000e-09 2.12000e-01

$6.74924 \mathrm{e}+016.74924 \mathrm{e}+016.74924 \mathrm{e}+001.00000 \mathrm{e}-092.12000 \mathrm{e}-01$ 
$6.74924 \mathrm{e}+016.74924 \mathrm{e}+016.74924 \mathrm{e}+001.00000 \mathrm{e}-092.12000 \mathrm{e}-01$ $1.00000 \mathrm{e}-02$ 1.00000e-02 1.00000e-03 1.00000e-09 1.00000e-01 $1.00000 \mathrm{e}+001.00000 \mathrm{e}+001.00000 \mathrm{e}-011.00000 \mathrm{e}-091.00000 \mathrm{e}-01$ $1.00000 \mathrm{e}-05$ 1.00000e-05 1.00000e-06 1.00000e-09 1.00000e-01 $1.00000 \mathrm{e}+001.00000 \mathrm{e}+001.00000 \mathrm{e}-01$ 1.00000e-09 1.00000e-01 Element: 9681 \# of layers: 7

$\mathrm{Kx} \mathrm{Ky} \mathrm{Kz}$ Ss Por

$1.91587 \mathrm{e}+01$ 1.91587e+01 1.91587e+00 1.00000e-09 2.12000e-01 $1.91587 \mathrm{e}+01$ 1.91587e+01 1.91587e+00 1.00000e-09 2.12000e-01 $1.91587 \mathrm{e}+01$ 1.91587e+01 1.91587e+00 1.00000e-09 2.12000e-01 $1.91587 \mathrm{e}+01$ 1.91587e+01 1.91587e+00 1.00000e-09 2.12000e-01 $1.91587 \mathrm{e}+01$ 1.91587e+01 1.91587e+00 1.00000e-09 2.12000e-01 $1.00000 \mathrm{e}-051.00000 \mathrm{e}-05$ 1.00000e-06 1.00000e-09 1.00000e-01 $1.00000 \mathrm{e}+001.00000 \mathrm{e}+001.00000 \mathrm{e}-011.00000 \mathrm{e}-09$ 1.00000e-01 Element: 9682 \# of layers: 7

Kx Ky Kz Ss Por

1.91587e+01 1.91587e+01 1.91587e+00 1.00000e-09 2.12000e-01 $1.91587 \mathrm{e}+01$ 1.91587e+01 1.91587e+00 1.00000e-09 2.12000e-01 $1.91587 \mathrm{e}+01$ 1.91587e+01 1.91587e+00 1.00000e-09 2.12000e-01 $1.91587 \mathrm{e}+01$ 1.91587e+01 1.91587e+00 1.00000e-09 2.12000e-01 $1.91587 \mathrm{e}+01$ 1.91587e+01 1.91587e+00 1.00000e-09 2.12000e-01 $1.00000 \mathrm{e}-05$ 1.00000e-05 1.00000e-06 1.00000e-09 1.00000e-01 $1.00000 \mathrm{e}+001.00000 \mathrm{e}+001.00000 \mathrm{e}-01$ 1.00000e-09 1.00000e-01 Element: 9683 \# of layers: 7

Kx Ky Kz Ss Por

$1.61706 \mathrm{e}+011.61706 \mathrm{e}+011.61706 \mathrm{e}+001.00000 \mathrm{e}-092.12000 \mathrm{e}-01$ $1.61706 \mathrm{e}+011.61706 \mathrm{e}+011.61706 \mathrm{e}+001.00000 \mathrm{e}-092.12000 \mathrm{e}-01$ $1.61706 \mathrm{e}+011.61706 \mathrm{e}+011.61706 \mathrm{e}+001.00000 \mathrm{e}-092.12000 \mathrm{e}-01$ $1.61706 \mathrm{e}+011.61706 \mathrm{e}+011.61706 \mathrm{e}+001.00000 \mathrm{e}-092.12000 \mathrm{e}-01$ $1.61706 \mathrm{e}+011.61706 \mathrm{e}+011.61706 \mathrm{e}+001.00000 \mathrm{e}-092.12000 \mathrm{e}-01$ $1.00000 \mathrm{e}-05$ 1.00000e-05 1.00000e-06 1.00000e-09 1.00000e-01 $1.00000 \mathrm{e}+001.00000 \mathrm{e}+001.00000 \mathrm{e}-011.00000 \mathrm{e}-091.00000 \mathrm{e}-01$ Element: 9684 \# of layers: 7

$\mathrm{Kx} \mathrm{Ky} \mathrm{Kz}$ Ss Por

$1.61706 \mathrm{e}+011.61706 \mathrm{e}+011.61706 \mathrm{e}+001.00000 \mathrm{e}-092.12000 \mathrm{e}-01$ $1.61706 \mathrm{e}+011.61706 \mathrm{e}+01$ 1.61706e+00 1.00000e-09 2.12000e-01 $1.61706 \mathrm{e}+011.61706 \mathrm{e}+011.61706 \mathrm{e}+001.00000 \mathrm{e}-092.12000 \mathrm{e}-01$ $1.61706 \mathrm{e}+011.61706 \mathrm{e}+011.61706 \mathrm{e}+001.00000 \mathrm{e}-092.12000 \mathrm{e}-01$ $1.61706 \mathrm{e}+011.61706 \mathrm{e}+011.61706 \mathrm{e}+001.00000 \mathrm{e}-092.12000 \mathrm{e}-01$ $1.00000 \mathrm{e}-05$ 1.00000e-05 1.00000e-06 1.00000e-09 1.00000e-01 $1.00000 \mathrm{e}+001.00000 \mathrm{e}+001.00000 \mathrm{e}-011.00000 \mathrm{e}-091.00000 \mathrm{e}-01$ Element: 9685 \# of layers: 7

$\mathrm{Kx} \mathrm{Ky} \mathrm{Kz}$ Ss Por

$1.91587 \mathrm{e}+01$ 1.91587e+01 1.91587e+00 1.00000e-09 2.12000e-01 $1.91587 \mathrm{e}+01$ 1.91587e+01 1.91587e+00 1.00000e-09 2.12000e-01 $1.91587 \mathrm{e}+01$ 1.91587e+01 1.91587e+00 1.00000e-09 2.12000e-01 
$1.91587 \mathrm{e}+011.91587 \mathrm{e}+01$ 1.91587e+00 1.00000e-09 2.12000e-01 $1.91587 \mathrm{e}+011.91587 \mathrm{e}+011.91587 \mathrm{e}+001.00000 \mathrm{e}-092.12000 \mathrm{e}-01$ $1.00000 \mathrm{e}-05$ 1.00000e-05 1.00000e-06 1.00000e-09 1.00000e-01 $1.00000 \mathrm{e}+001.00000 \mathrm{e}+001.00000 \mathrm{e}-011.00000 \mathrm{e}-091.00000 \mathrm{e}-01$ Element: 9686 \# of layers: 7

Kx Ky Kz Ss Por

$1.61706 \mathrm{e}+011.61706 \mathrm{e}+011.61706 \mathrm{e}+00$ 1.00000e-09 2.12000e-01 $1.61706 \mathrm{e}+011.61706 \mathrm{e}+011.61706 \mathrm{e}+001.00000 \mathrm{e}-092.12000 \mathrm{e}-01$ $1.61706 \mathrm{e}+011.61706 \mathrm{e}+011.61706 \mathrm{e}+001.00000 \mathrm{e}-092.12000 \mathrm{e}-01$ $1.61706 \mathrm{e}+011.61706 \mathrm{e}+011.61706 \mathrm{e}+001.00000 \mathrm{e}-092.12000 \mathrm{e}-01$ $1.61706 \mathrm{e}+011.61706 \mathrm{e}+011.61706 \mathrm{e}+001.00000 \mathrm{e}-092.12000 \mathrm{e}-01$ $1.00000 \mathrm{e}-05$ 1.00000e-05 1.00000e-06 1.00000e-09 1.00000e-01 $1.00000 \mathrm{e}+001.00000 \mathrm{e}+001.00000 \mathrm{e}-011.00000 \mathrm{e}-091.00000 \mathrm{e}-01$ Element: 9687 \# of layers: 7

Kx Ky Kz Ss Por

$1.61706 \mathrm{e}+011.61706 \mathrm{e}+011.61706 \mathrm{e}+00$ 1.00000e-09 2.12000e-01 $1.61706 \mathrm{e}+011.61706 \mathrm{e}+011.61706 \mathrm{e}+001.00000 \mathrm{e}-092.12000 \mathrm{e}-01$ $1.61706 \mathrm{e}+011.61706 \mathrm{e}+011.61706 \mathrm{e}+001.00000 \mathrm{e}-092.12000 \mathrm{e}-01$ $1.61706 \mathrm{e}+011.61706 \mathrm{e}+011.61706 \mathrm{e}+001.00000 \mathrm{e}-092.12000 \mathrm{e}-01$ $1.61706 \mathrm{e}+011.61706 \mathrm{e}+011.61706 \mathrm{e}+001.00000 \mathrm{e}-092.12000 \mathrm{e}-01$ $1.00000 \mathrm{e}-05$ 1.00000e-05 1.00000e-06 1.00000e-09 1.00000e-01 $1.00000 \mathrm{e}+001.00000 \mathrm{e}+001.00000 \mathrm{e}-011.00000 \mathrm{e}-091.00000 \mathrm{e}-01$ Element: 9688 \# of layers: 7

Kx Ky Kz Ss Por

$1.61706 \mathrm{e}+011.61706 \mathrm{e}+011.61706 \mathrm{e}+001.00000 \mathrm{e}-092.12000 \mathrm{e}-01$ $1.61706 \mathrm{e}+011.61706 \mathrm{e}+011.61706 \mathrm{e}+001.00000 \mathrm{e}-092.12000 \mathrm{e}-01$ $1.61706 \mathrm{e}+011.61706 \mathrm{e}+011.61706 \mathrm{e}+001.00000 \mathrm{e}-092.12000 \mathrm{e}-01$ $1.61706 \mathrm{e}+011.61706 \mathrm{e}+011.61706 \mathrm{e}+001.00000 \mathrm{e}-092.12000 \mathrm{e}-01$ $1.61706 \mathrm{e}+011.61706 \mathrm{e}+011.61706 \mathrm{e}+001.00000 \mathrm{e}-092.12000 \mathrm{e}-01$ $1.00000 \mathrm{e}-05$ 1.00000e-05 1.00000e-06 1.00000e-09 1.00000e-01 $1.00000 \mathrm{e}+001.00000 \mathrm{e}+001.00000 \mathrm{e}-011.00000 \mathrm{e}-091.00000 \mathrm{e}-01$ Element: 9689 \# of layers: 7

Kx Ky Kz Ss Por

$1.61706 \mathrm{e}+011.61706 \mathrm{e}+011.61706 \mathrm{e}+001.00000 \mathrm{e}-092.12000 \mathrm{e}-01$ $1.61706 \mathrm{e}+011.61706 \mathrm{e}+011.61706 \mathrm{e}+001.00000 \mathrm{e}-092.12000 \mathrm{e}-01$ $1.61706 \mathrm{e}+011.61706 \mathrm{e}+011.61706 \mathrm{e}+001.00000 \mathrm{e}-092.12000 \mathrm{e}-01$ $1.61706 \mathrm{e}+011.61706 \mathrm{e}+011.61706 \mathrm{e}+001.00000 \mathrm{e}-092.12000 \mathrm{e}-01$ $1.61706 \mathrm{e}+011.61706 \mathrm{e}+011.61706 \mathrm{e}+001.00000 \mathrm{e}-092.12000 \mathrm{e}-01$ $1.00000 \mathrm{e}-05$ 1.00000e-05 1.00000e-06 1.00000e-09 1.00000e-01 $1.00000 \mathrm{e}+001.00000 \mathrm{e}+001.00000 \mathrm{e}-011.00000 \mathrm{e}-091.00000 \mathrm{e}-01$ Element: 9690 \# of layers: 7

Kx Ky Kz Ss Por

$1.61706 \mathrm{e}+011.61706 \mathrm{e}+011.61706 \mathrm{e}+00$ 1.00000e-09 2.12000e-01 $1.61706 \mathrm{e}+011.61706 \mathrm{e}+011.61706 \mathrm{e}+001.00000 \mathrm{e}-092.12000 \mathrm{e}-01$ $1.61706 \mathrm{e}+011.61706 \mathrm{e}+011.61706 \mathrm{e}+001.00000 \mathrm{e}-092.12000 \mathrm{e}-01$ $1.61706 \mathrm{e}+011.61706 \mathrm{e}+011.61706 \mathrm{e}+001.00000 \mathrm{e}-092.12000 \mathrm{e}-01$ 
$1.61706 \mathrm{e}+011.61706 \mathrm{e}+011.61706 \mathrm{e}+001.00000 \mathrm{e}-092.12000 \mathrm{e}-01$ $1.00000 \mathrm{e}-05$ 1.00000e-05 1.00000e-06 1.00000e-09 1.00000e-01

$1.00000 \mathrm{e}+001.00000 \mathrm{e}+001.00000 \mathrm{e}-011.00000 \mathrm{e}-09$ 1.00000e-01

Element: 9691 \# of layers: 7

$\mathrm{Kx} \mathrm{Ky} \mathrm{Kz}$ Ss Por

$1.61706 \mathrm{e}+011.61706 \mathrm{e}+011.61706 \mathrm{e}+001.00000 \mathrm{e}-092.12000 \mathrm{e}-01$

$1.61706 \mathrm{e}+011.61706 \mathrm{e}+011.61706 \mathrm{e}+001.00000 \mathrm{e}-092.12000 \mathrm{e}-01$

$1.61706 \mathrm{e}+011.61706 \mathrm{e}+011.61706 \mathrm{e}+001.00000 \mathrm{e}-092.12000 \mathrm{e}-01$

$1.61706 \mathrm{e}+011.61706 \mathrm{e}+011.61706 \mathrm{e}+001.00000 \mathrm{e}-092.12000 \mathrm{e}-01$

$1.61706 \mathrm{e}+011.61706 \mathrm{e}+011.61706 \mathrm{e}+001.00000 \mathrm{e}-092.12000 \mathrm{e}-01$

$1.00000 \mathrm{e}-05$ 1.00000e-05 1.00000e-06 1.00000e-09 1.00000e-01

$1.00000 \mathrm{e}+001.00000 \mathrm{e}+001.00000 \mathrm{e}-01$ 1.00000e-09 1.00000e-01

Element: 9692 \# of layers: 7

$\mathrm{Kx} \mathrm{Ky} \mathrm{Kz}$ Ss Por

$1.61706 \mathrm{e}+011.61706 \mathrm{e}+011.61706 \mathrm{e}+001.00000 \mathrm{e}-092.12000 \mathrm{e}-01$

$1.61706 \mathrm{e}+011.61706 \mathrm{e}+011.61706 \mathrm{e}+001.00000 \mathrm{e}-092.12000 \mathrm{e}-01$

$1.61706 \mathrm{e}+011.61706 \mathrm{e}+011.61706 \mathrm{e}+001.00000 \mathrm{e}-092.12000 \mathrm{e}-01$

$1.61706 \mathrm{e}+011.61706 \mathrm{e}+011.61706 \mathrm{e}+001.00000 \mathrm{e}-092.12000 \mathrm{e}-01$

$1.61706 \mathrm{e}+011.61706 \mathrm{e}+011.61706 \mathrm{e}+001.00000 \mathrm{e}-092.12000 \mathrm{e}-01$ $1.00000 \mathrm{e}-05$ 1.00000e-05 1.00000e-06 1.00000e-09 1.00000e-01

$1.00000 \mathrm{e}+001.00000 \mathrm{e}+001.00000 \mathrm{e}-011.00000 \mathrm{e}-091.00000 \mathrm{e}-01$

Element: 9693 \# of layers: 7

$\mathrm{Kx} \mathrm{Ky} \mathrm{Kz}$ Ss Por

$1.61706 \mathrm{e}+01$ 1.61706e+01 1.61706e+00 1.00000e-09 2.12000e-01

$1.61706 \mathrm{e}+011.61706 \mathrm{e}+011.61706 \mathrm{e}+001.00000 \mathrm{e}-092.12000 \mathrm{e}-01$

$1.61706 \mathrm{e}+011.61706 \mathrm{e}+011.61706 \mathrm{e}+001.00000 \mathrm{e}-092.12000 \mathrm{e}-01$

$1.61706 \mathrm{e}+011.61706 \mathrm{e}+011.61706 \mathrm{e}+001.00000 \mathrm{e}-092.12000 \mathrm{e}-01$

$1.61706 \mathrm{e}+011.61706 \mathrm{e}+011.61706 \mathrm{e}+001.00000 \mathrm{e}-092.12000 \mathrm{e}-01$

$1.00000 \mathrm{e}-05$ 1.00000e-05 1.00000e-06 1.00000e-09 1.00000e-01

$1.00000 \mathrm{e}+001.00000 \mathrm{e}+001.00000 \mathrm{e}-011.00000 \mathrm{e}-091.00000 \mathrm{e}-01$

Element: 9694 \# of layers: 7

Kx Ky Kz Ss Por

$1.61706 \mathrm{e}+011.61706 \mathrm{e}+011.61706 \mathrm{e}+001.00000 \mathrm{e}-092.12000 \mathrm{e}-01$

$1.61706 \mathrm{e}+011.61706 \mathrm{e}+011.61706 \mathrm{e}+001.00000 \mathrm{e}-092.12000 \mathrm{e}-01$

$1.61706 \mathrm{e}+011.61706 \mathrm{e}+011.61706 \mathrm{e}+001.00000 \mathrm{e}-092.12000 \mathrm{e}-01$

$1.61706 \mathrm{e}+011.61706 \mathrm{e}+011.61706 \mathrm{e}+001.00000 \mathrm{e}-092.12000 \mathrm{e}-01$

$1.61706 \mathrm{e}+011.61706 \mathrm{e}+011.61706 \mathrm{e}+001.00000 \mathrm{e}-092.12000 \mathrm{e}-01$

$1.00000 \mathrm{e}-05$ 1.00000e-05 1.00000e-06 1.00000e-09 1.00000e-01

$1.00000 \mathrm{e}+001.00000 \mathrm{e}+001.00000 \mathrm{e}-011.00000 \mathrm{e}-091.00000 \mathrm{e}-01$

Element: 9695 \# of layers: 7

$\mathrm{Kx} \mathrm{Ky} \mathrm{Kz}$ Ss Por

$1.61706 \mathrm{e}+011.61706 \mathrm{e}+011.61706 \mathrm{e}+001.00000 \mathrm{e}-092.12000 \mathrm{e}-01$

$1.61706 \mathrm{e}+011.61706 \mathrm{e}+011.61706 \mathrm{e}+001.00000 \mathrm{e}-092.12000 \mathrm{e}-01$

$1.61706 \mathrm{e}+01$ 1.61706e+01 1.61706e+00 1.00000e-09 2.12000e-01

$1.61706 \mathrm{e}+011.61706 \mathrm{e}+011.61706 \mathrm{e}+001.00000 \mathrm{e}-092.12000 \mathrm{e}-01$

$1.61706 \mathrm{e}+011.61706 \mathrm{e}+011.61706 \mathrm{e}+001.00000 \mathrm{e}-092.12000 \mathrm{e}-01$ 
$1.00000 \mathrm{e}-05$ 1.00000e-05 1.00000e-06 1.00000e-09 1.00000e-01 $1.00000 \mathrm{e}+001.00000 \mathrm{e}+001.00000 \mathrm{e}-01$ 1.00000e-09 1.00000e-01 Element: 9696 \# of layers: 7

Kx Ky Kz Ss Por

$1.61706 \mathrm{e}+011.61706 \mathrm{e}+011.61706 \mathrm{e}+001.00000 \mathrm{e}-092.12000 \mathrm{e}-01$ $1.61706 \mathrm{e}+011.61706 \mathrm{e}+011.61706 \mathrm{e}+001.00000 \mathrm{e}-092.12000 \mathrm{e}-01$ $1.61706 \mathrm{e}+011.61706 \mathrm{e}+011.61706 \mathrm{e}+001.00000 \mathrm{e}-092.12000 \mathrm{e}-01$ $1.61706 \mathrm{e}+011.61706 \mathrm{e}+011.61706 \mathrm{e}+001.00000 \mathrm{e}-092.12000 \mathrm{e}-01$ $1.61706 \mathrm{e}+011.61706 \mathrm{e}+011.61706 \mathrm{e}+001.00000 \mathrm{e}-092.12000 \mathrm{e}-01$ 1.00000e-05 1.00000e-05 1.00000e-06 1.00000e-09 1.00000e-01 $1.00000 \mathrm{e}+001.00000 \mathrm{e}+001.00000 \mathrm{e}-011.00000 \mathrm{e}-091.00000 \mathrm{e}-01$ Element: 9697 \# of layers: 7

Kx Ky Kz Ss Por

$1.61706 \mathrm{e}+011.61706 \mathrm{e}+011.61706 \mathrm{e}+001.00000 \mathrm{e}-092.12000 \mathrm{e}-01$ $1.61706 \mathrm{e}+011.61706 \mathrm{e}+011.61706 \mathrm{e}+001.00000 \mathrm{e}-092.12000 \mathrm{e}-01$ $1.61706 \mathrm{e}+011.61706 \mathrm{e}+011.61706 \mathrm{e}+001.00000 \mathrm{e}-092.12000 \mathrm{e}-01$ $1.61706 \mathrm{e}+011.61706 \mathrm{e}+011.61706 \mathrm{e}+001.00000 \mathrm{e}-092.12000 \mathrm{e}-01$ $1.61706 \mathrm{e}+011.61706 \mathrm{e}+011.61706 \mathrm{e}+001.00000 \mathrm{e}-092.12000 \mathrm{e}-01$ $1.00000 \mathrm{e}-05$ 1.00000e-05 1.00000e-06 1.00000e-09 1.00000e-01 $1.00000 \mathrm{e}+001.00000 \mathrm{e}+001.00000 \mathrm{e}-011.00000 \mathrm{e}-091.00000 \mathrm{e}-01$ Element: 9698 \# of layers: 7

$\mathrm{Kx} \mathrm{Ky} \mathrm{Kz}$ Ss Por

$1.61706 \mathrm{e}+01$ 1.61706e+01 1.61706e+00 1.00000e-09 2.12000e-01 $1.61706 \mathrm{e}+011.61706 \mathrm{e}+011.61706 \mathrm{e}+001.00000 \mathrm{e}-092.12000 \mathrm{e}-01$ $1.61706 \mathrm{e}+011.61706 \mathrm{e}+011.61706 \mathrm{e}+001.00000 \mathrm{e}-092.12000 \mathrm{e}-01$ $1.61706 \mathrm{e}+011.61706 \mathrm{e}+011.61706 \mathrm{e}+001.00000 \mathrm{e}-092.12000 \mathrm{e}-01$ $1.61706 \mathrm{e}+011.61706 \mathrm{e}+011.61706 \mathrm{e}+001.00000 \mathrm{e}-092.12000 \mathrm{e}-01$ $1.00000 \mathrm{e}-05$ 1.00000e-05 1.00000e-06 1.00000e-09 1.00000e-01 $1.00000 \mathrm{e}+001.00000 \mathrm{e}+001.00000 \mathrm{e}-011.00000 \mathrm{e}-091.00000 \mathrm{e}-01$ Element: 9699 \# of layers: 7

$\mathrm{Kx} \mathrm{Ky} \mathrm{Kz}$ Ss Por

$1.56644 \mathrm{e}+011.56644 \mathrm{e}+011.56644 \mathrm{e}+001.00000 \mathrm{e}-092.12000 \mathrm{e}-01$ $1.56644 \mathrm{e}+011.56644 \mathrm{e}+011.56644 \mathrm{e}+001.00000 \mathrm{e}-092.12000 \mathrm{e}-01$ $1.56644 \mathrm{e}+011.56644 \mathrm{e}+011.56644 \mathrm{e}+001.00000 \mathrm{e}-092.12000 \mathrm{e}-01$ $1.56644 \mathrm{e}+011.56644 \mathrm{e}+011.56644 \mathrm{e}+001.00000 \mathrm{e}-092.12000 \mathrm{e}-01$ $1.56644 \mathrm{e}+011.56644 \mathrm{e}+011.56644 \mathrm{e}+001.00000 \mathrm{e}-092.12000 \mathrm{e}-01$ 1.00000e-05 1.00000e-05 1.00000e-06 1.00000e-09 1.00000e-01 $1.00000 \mathrm{e}+001.00000 \mathrm{e}+001.00000 \mathrm{e}-011.00000 \mathrm{e}-091.00000 \mathrm{e}-01$ Element: 9700 \# of layers: 7

$\mathrm{Kx} \mathrm{Ky} \mathrm{Kz}$ Ss Por

$2.05126 \mathrm{e}+012.05126 \mathrm{e}+012.05126 \mathrm{e}+00$ 1.00000e-09 2.12000e-01 $2.05126 \mathrm{e}+012.05126 \mathrm{e}+012.05126 \mathrm{e}+001.00000 \mathrm{e}-092.12000 \mathrm{e}-01$ $2.05126 \mathrm{e}+012.05126 \mathrm{e}+012.05126 \mathrm{e}+001.00000 \mathrm{e}-092.12000 \mathrm{e}-01$ $2.05126 \mathrm{e}+012.05126 \mathrm{e}+012.05126 \mathrm{e}+001.00000 \mathrm{e}-092.12000 \mathrm{e}-01$ $2.05126 \mathrm{e}+012.05126 \mathrm{e}+012.05126 \mathrm{e}+001.00000 \mathrm{e}-092.12000 \mathrm{e}-01$ 1.00000e-05 1.00000e-05 1.00000e-06 1.00000e-09 1.00000e-01 
$1.00000 \mathrm{e}+001.00000 \mathrm{e}+00$ 1.00000e-01 1.00000e-09 1.00000e-01

Element: 9701 \# of layers: 7

Kx Ky Kz Ss Por

$2.05126 \mathrm{e}+012.05126 \mathrm{e}+012.05126 \mathrm{e}+001.00000 \mathrm{e}-092.12000 \mathrm{e}-01$

$2.05126 \mathrm{e}+012.05126 \mathrm{e}+012.05126 \mathrm{e}+001.00000 \mathrm{e}-092.12000 \mathrm{e}-01$

$2.05126 \mathrm{e}+012.05126 \mathrm{e}+012.05126 \mathrm{e}+001.00000 \mathrm{e}-092.12000 \mathrm{e}-01$

$2.05126 \mathrm{e}+012.05126 \mathrm{e}+012.05126 \mathrm{e}+001.00000 \mathrm{e}-092.12000 \mathrm{e}-01$

$2.05126 \mathrm{e}+012.05126 \mathrm{e}+012.05126 \mathrm{e}+001.00000 \mathrm{e}-092.12000 \mathrm{e}-01$

$1.00000 \mathrm{e}-05$ 1.00000e-05 1.00000e-06 1.00000e-09 1.00000e-01

$1.00000 \mathrm{e}+001.00000 \mathrm{e}+001.00000 \mathrm{e}-01$ 1.00000e-09 1.00000e-01

Element: 9702 \# of layers: 7

$\mathrm{Kx} \mathrm{Ky} \mathrm{Kz}$ Ss Por

$2.05126 \mathrm{e}+012.05126 \mathrm{e}+012.05126 \mathrm{e}+00$ 1.00000e-09 2.12000e-01

$2.05126 \mathrm{e}+012.05126 \mathrm{e}+012.05126 \mathrm{e}+001.00000 \mathrm{e}-092.12000 \mathrm{e}-01$

$2.05126 \mathrm{e}+012.05126 \mathrm{e}+012.05126 \mathrm{e}+001.00000 \mathrm{e}-092.12000 \mathrm{e}-01$

$2.05126 \mathrm{e}+012.05126 \mathrm{e}+012.05126 \mathrm{e}+001.00000 \mathrm{e}-092.12000 \mathrm{e}-01$

$2.05126 \mathrm{e}+012.05126 \mathrm{e}+012.05126 \mathrm{e}+001.00000 \mathrm{e}-092.12000 \mathrm{e}-01$

$1.00000 \mathrm{e}-05$ 1.00000e-05 1.00000e-06 1.00000e-09 1.00000e-01

$1.00000 \mathrm{e}+001.00000 \mathrm{e}+001.00000 \mathrm{e}-011.00000 \mathrm{e}-091.00000 \mathrm{e}-01$

Element: 9703 \# of layers: 7

$\mathrm{Kx} \mathrm{Ky} \mathrm{Kz}$ Ss Por

$2.05126 \mathrm{e}+012.05126 \mathrm{e}+012.05126 \mathrm{e}+001.00000 \mathrm{e}-092.12000 \mathrm{e}-01$

$2.05126 \mathrm{e}+012.05126 \mathrm{e}+012.05126 \mathrm{e}+001.00000 \mathrm{e}-092.12000 \mathrm{e}-01$

$2.05126 \mathrm{e}+012.05126 \mathrm{e}+012.05126 \mathrm{e}+001.00000 \mathrm{e}-092.12000 \mathrm{e}-01$

$2.05126 \mathrm{e}+012.05126 \mathrm{e}+012.05126 \mathrm{e}+001.00000 \mathrm{e}-092.12000 \mathrm{e}-01$

$2.05126 \mathrm{e}+012.05126 \mathrm{e}+012.05126 \mathrm{e}+001.00000 \mathrm{e}-092.12000 \mathrm{e}-01$

$1.00000 \mathrm{e}-05$ 1.00000e-05 1.00000e-06 1.00000e-09 1.00000e-01

$1.00000 \mathrm{e}+001.00000 \mathrm{e}+001.00000 \mathrm{e}-011.00000 \mathrm{e}-091.00000 \mathrm{e}-01$

Element: 9704 \# of layers: 7

$\mathrm{Kx} \mathrm{Ky} \mathrm{Kz}$ Ss Por

$2.05126 \mathrm{e}+012.05126 \mathrm{e}+012.05126 \mathrm{e}+00$ 1.00000e-09 2.12000e-01

$2.05126 \mathrm{e}+012.05126 \mathrm{e}+012.05126 \mathrm{e}+001.00000 \mathrm{e}-092.12000 \mathrm{e}-01$

$2.05126 \mathrm{e}+012.05126 \mathrm{e}+012.05126 \mathrm{e}+001.00000 \mathrm{e}-092.12000 \mathrm{e}-01$

$2.05126 \mathrm{e}+012.05126 \mathrm{e}+012.05126 \mathrm{e}+001.00000 \mathrm{e}-092.12000 \mathrm{e}-01$

$2.05126 \mathrm{e}+012.05126 \mathrm{e}+012.05126 \mathrm{e}+001.00000 \mathrm{e}-092.12000 \mathrm{e}-01$

1.00000e-05 1.00000e-05 1.00000e-06 1.00000e-09 1.00000e-01

$1.00000 \mathrm{e}+001.00000 \mathrm{e}+001.00000 \mathrm{e}-011.00000 \mathrm{e}-091.00000 \mathrm{e}-01$

Element: 9705 \# of layers: 7

$\mathrm{Kx} \mathrm{Ky} \mathrm{Kz}$ Ss Por

$2.05126 \mathrm{e}+012.05126 \mathrm{e}+012.05126 \mathrm{e}+001.00000 \mathrm{e}-092.12000 \mathrm{e}-01$

$2.05126 \mathrm{e}+012.05126 \mathrm{e}+012.05126 \mathrm{e}+001.00000 \mathrm{e}-092.12000 \mathrm{e}-01$

$2.05126 \mathrm{e}+012.05126 \mathrm{e}+012.05126 \mathrm{e}+001.00000 \mathrm{e}-092.12000 \mathrm{e}-01$

$2.05126 \mathrm{e}+012.05126 \mathrm{e}+012.05126 \mathrm{e}+001.00000 \mathrm{e}-092.12000 \mathrm{e}-01$

$2.05126 \mathrm{e}+012.05126 \mathrm{e}+012.05126 \mathrm{e}+001.00000 \mathrm{e}-092.12000 \mathrm{e}-01$ $1.00000 \mathrm{e}-05$ 1.00000e-05 1.00000e-06 1.00000e-09 1.00000e-01

$1.00000 \mathrm{e}+001.00000 \mathrm{e}+001.00000 \mathrm{e}-011.00000 \mathrm{e}-091.00000 \mathrm{e}-01$ 
Element: 9706 \# of layers: 7

Kx Ky Kz Ss Por

$2.08035 \mathrm{e}+012.08035 \mathrm{e}+012.08035 \mathrm{e}+00$ 1.00000e-09 2.12000e-01

$2.08035 \mathrm{e}+012.08035 \mathrm{e}+012.08035 \mathrm{e}+001.00000 \mathrm{e}-092.12000 \mathrm{e}-01$

$2.08035 \mathrm{e}+012.08035 \mathrm{e}+012.08035 \mathrm{e}+001.00000 \mathrm{e}-092.12000 \mathrm{e}-01$

$2.08035 \mathrm{e}+012.08035 \mathrm{e}+012.08035 \mathrm{e}+001.00000 \mathrm{e}-092.12000 \mathrm{e}-01$

$2.08035 \mathrm{e}+012.08035 \mathrm{e}+012.08035 \mathrm{e}+001.00000 \mathrm{e}-092.12000 \mathrm{e}-01$

$1.00000 \mathrm{e}-05$ 1.00000e-05 1.00000e-06 1.00000e-09 1.00000e-01

$1.00000 \mathrm{e}+001.00000 \mathrm{e}+001.00000 \mathrm{e}-011.00000 \mathrm{e}-091.00000 \mathrm{e}-01$

Element: 9707 \# of layers: 7

Kx Ky Kz Ss Por

$2.08035 \mathrm{e}+012.08035 \mathrm{e}+012.08035 \mathrm{e}+00$ 1.00000e-09 2.12000e-01

$2.08035 \mathrm{e}+012.08035 \mathrm{e}+012.08035 \mathrm{e}+001.00000 \mathrm{e}-092.12000 \mathrm{e}-01$

$2.08035 \mathrm{e}+012.08035 \mathrm{e}+012.08035 \mathrm{e}+001.00000 \mathrm{e}-092.12000 \mathrm{e}-01$

$2.08035 \mathrm{e}+012.08035 \mathrm{e}+012.08035 \mathrm{e}+001.00000 \mathrm{e}-092.12000 \mathrm{e}-01$

$2.08035 \mathrm{e}+012.08035 \mathrm{e}+012.08035 \mathrm{e}+001.00000 \mathrm{e}-092.12000 \mathrm{e}-01$

$1.00000 \mathrm{e}-05$ 1.00000e-05 1.00000e-06 1.00000e-09 1.00000e-01

$1.00000 \mathrm{e}+001.00000 \mathrm{e}+001.00000 \mathrm{e}-011.00000 \mathrm{e}-091.00000 \mathrm{e}-01$

Element: 9708 \# of layers: 7

Kx Ky Kz Ss Por

$2.08035 \mathrm{e}+012.08035 \mathrm{e}+012.08035 \mathrm{e}+00$ 1.00000e-09 2.12000e-01

$2.08035 \mathrm{e}+012.08035 \mathrm{e}+012.08035 \mathrm{e}+001.00000 \mathrm{e}-092.12000 \mathrm{e}-01$

$2.08035 \mathrm{e}+012.08035 \mathrm{e}+012.08035 \mathrm{e}+001.00000 \mathrm{e}-092.12000 \mathrm{e}-01$

$2.08035 \mathrm{e}+012.08035 \mathrm{e}+012.08035 \mathrm{e}+001.00000 \mathrm{e}-092.12000 \mathrm{e}-01$

$2.08035 \mathrm{e}+012.08035 \mathrm{e}+012.08035 \mathrm{e}+001.00000 \mathrm{e}-092.12000 \mathrm{e}-01$

$1.00000 \mathrm{e}-05$ 1.00000e-05 1.00000e-06 1.00000e-09 1.00000e-01

$1.00000 \mathrm{e}+001.00000 \mathrm{e}+001.00000 \mathrm{e}-011.00000 \mathrm{e}-091.00000 \mathrm{e}-01$

Element: 9709 \# of layers: 7

Kx Ky Kz Ss Por

$2.08035 \mathrm{e}+012.08035 \mathrm{e}+012.08035 \mathrm{e}+00$ 1.00000e-09 2.12000e-01

$2.08035 \mathrm{e}+012.08035 \mathrm{e}+012.08035 \mathrm{e}+001.00000 \mathrm{e}-092.12000 \mathrm{e}-01$

$2.08035 \mathrm{e}+012.08035 \mathrm{e}+012.08035 \mathrm{e}+001.00000 \mathrm{e}-092.12000 \mathrm{e}-01$

$2.08035 \mathrm{e}+012.08035 \mathrm{e}+012.08035 \mathrm{e}+001.00000 \mathrm{e}-092.12000 \mathrm{e}-01$

$2.08035 \mathrm{e}+012.08035 \mathrm{e}+012.08035 \mathrm{e}+001.00000 \mathrm{e}-092.12000 \mathrm{e}-01$

$1.00000 \mathrm{e}-05$ 1.00000e-05 1.00000e-06 1.00000e-09 1.00000e-01

$1.00000 \mathrm{e}+001.00000 \mathrm{e}+001.00000 \mathrm{e}-011.00000 \mathrm{e}-091.00000 \mathrm{e}-01$

Element: 9710 \# of layers: 7

Kx Ky Kz Ss Por

$2.08035 \mathrm{e}+012.08035 \mathrm{e}+012.08035 \mathrm{e}+00$ 1.00000e-09 2.12000e-01

$2.08035 \mathrm{e}+012.08035 \mathrm{e}+012.08035 \mathrm{e}+001.00000 \mathrm{e}-092.12000 \mathrm{e}-01$

$2.08035 \mathrm{e}+012.08035 \mathrm{e}+012.08035 \mathrm{e}+001.00000 \mathrm{e}-092.12000 \mathrm{e}-01$

$2.08035 \mathrm{e}+012.08035 \mathrm{e}+012.08035 \mathrm{e}+001.00000 \mathrm{e}-092.12000 \mathrm{e}-01$

$2.08035 \mathrm{e}+012.08035 \mathrm{e}+012.08035 \mathrm{e}+001.00000 \mathrm{e}-092.12000 \mathrm{e}-01$

$1.00000 \mathrm{e}-05$ 1.00000e-05 1.00000e-06 1.00000e-09 1.00000e-01

$1.00000 \mathrm{e}+001.00000 \mathrm{e}+001.00000 \mathrm{e}-011.00000 \mathrm{e}-091.00000 \mathrm{e}-01$

Element: 9711 \# of layers: 7 
$\mathrm{Kx} \mathrm{Ky} \mathrm{Kz}$ Ss Por

$2.05126 \mathrm{e}+012.05126 \mathrm{e}+012.05126 \mathrm{e}+00$ 1.00000e-09 2.12000e-01

$2.05126 \mathrm{e}+012.05126 \mathrm{e}+012.05126 \mathrm{e}+001.00000 \mathrm{e}-092.12000 \mathrm{e}-01$

$2.05126 \mathrm{e}+012.05126 \mathrm{e}+012.05126 \mathrm{e}+001.00000 \mathrm{e}-092.12000 \mathrm{e}-01$

$2.05126 \mathrm{e}+012.05126 \mathrm{e}+012.05126 \mathrm{e}+001.00000 \mathrm{e}-092.12000 \mathrm{e}-01$

$2.05126 \mathrm{e}+012.05126 \mathrm{e}+012.05126 \mathrm{e}+001.00000 \mathrm{e}-092.12000 \mathrm{e}-01$

$1.00000 \mathrm{e}-05$ 1.00000e-05 1.00000e-06 1.00000e-09 1.00000e-01

$1.00000 \mathrm{e}+001.00000 \mathrm{e}+001.00000 \mathrm{e}-01$ 1.00000e-09 1.00000e-01

Element: 9712 \# of layers: 7

$\mathrm{Kx} \mathrm{Ky} \mathrm{Kz}$ Ss Por

$2.05126 \mathrm{e}+012.05126 \mathrm{e}+012.05126 \mathrm{e}+001.00000 \mathrm{e}-092.12000 \mathrm{e}-01$ $2.05126 \mathrm{e}+012.05126 \mathrm{e}+012.05126 \mathrm{e}+001.00000 \mathrm{e}-092.12000 \mathrm{e}-01$ $2.05126 \mathrm{e}+012.05126 \mathrm{e}+012.05126 \mathrm{e}+001.00000 \mathrm{e}-092.12000 \mathrm{e}-01$ $2.05126 \mathrm{e}+012.05126 \mathrm{e}+012.05126 \mathrm{e}+001.00000 \mathrm{e}-092.12000 \mathrm{e}-01$ $2.05126 \mathrm{e}+012.05126 \mathrm{e}+012.05126 \mathrm{e}+001.00000 \mathrm{e}-092.12000 \mathrm{e}-01$ $1.00000 \mathrm{e}-05$ 1.00000e-05 1.00000e-06 1.00000e-09 1.00000e-01 $1.00000 \mathrm{e}+001.00000 \mathrm{e}+001.00000 \mathrm{e}-011.00000 \mathrm{e}-091.00000 \mathrm{e}-01$ Element: 9713 \# of layers: 7

$\mathrm{Kx} \mathrm{Ky} \mathrm{Kz}$ Ss Por

$2.08035 \mathrm{e}+012.08035 \mathrm{e}+012.08035 \mathrm{e}+00$ 1.00000e-09 2.12000e-01 $2.08035 \mathrm{e}+012.08035 \mathrm{e}+012.08035 \mathrm{e}+00 \quad 1.00000 \mathrm{e}-092.12000 \mathrm{e}-01$ $2.08035 \mathrm{e}+012.08035 \mathrm{e}+012.08035 \mathrm{e}+00$ 1.00000e-09 2.12000e-01 $2.08035 \mathrm{e}+012.08035 \mathrm{e}+012.08035 \mathrm{e}+001.00000 \mathrm{e}-092.12000 \mathrm{e}-01$ $2.08035 \mathrm{e}+012.08035 \mathrm{e}+012.08035 \mathrm{e}+001.00000 \mathrm{e}-092.12000 \mathrm{e}-01$ $1.00000 \mathrm{e}-05$ 1.00000e-05 1.00000e-06 1.00000e-09 1.00000e-01 $1.00000 \mathrm{e}+001.00000 \mathrm{e}+001.00000 \mathrm{e}-01$ 1.00000e-09 1.00000e-01 Element: 9714 \# of layers: 7

$\mathrm{Kx} \mathrm{Ky} \mathrm{Kz}$ Ss Por

$2.08035 \mathrm{e}+012.08035 \mathrm{e}+012.08035 \mathrm{e}+001.00000 \mathrm{e}-092.12000 \mathrm{e}-01$ $2.08035 \mathrm{e}+012.08035 \mathrm{e}+012.08035 \mathrm{e}+001.00000 \mathrm{e}-092.12000 \mathrm{e}-01$ $2.08035 \mathrm{e}+012.08035 \mathrm{e}+012.08035 \mathrm{e}+001.00000 \mathrm{e}-092.12000 \mathrm{e}-01$ $2.08035 \mathrm{e}+012.08035 \mathrm{e}+012.08035 \mathrm{e}+00$ 1.00000e-09 2.12000e-01 $2.08035 \mathrm{e}+012.08035 \mathrm{e}+012.08035 \mathrm{e}+001.00000 \mathrm{e}-092.12000 \mathrm{e}-01$ $1.00000 \mathrm{e}-05$ 1.00000e-05 1.00000e-06 1.00000e-09 1.00000e-01 $1.00000 \mathrm{e}+001.00000 \mathrm{e}+001.00000 \mathrm{e}-011.00000 \mathrm{e}-091.00000 \mathrm{e}-01$ Element: 9715 \# of layers: 7

Kx Ky Kz Ss Por

$2.08035 \mathrm{e}+012.08035 \mathrm{e}+012.08035 \mathrm{e}+00$ 1.00000e-09 2.12000e-01 $2.08035 \mathrm{e}+012.08035 \mathrm{e}+012.08035 \mathrm{e}+001.00000 \mathrm{e}-092.12000 \mathrm{e}-01$ $2.08035 \mathrm{e}+012.08035 \mathrm{e}+012.08035 \mathrm{e}+001.00000 \mathrm{e}-092.12000 \mathrm{e}-01$ $2.08035 \mathrm{e}+012.08035 \mathrm{e}+012.08035 \mathrm{e}+001.00000 \mathrm{e}-092.12000 \mathrm{e}-01$ $2.08035 \mathrm{e}+012.08035 \mathrm{e}+012.08035 \mathrm{e}+001.00000 \mathrm{e}-092.12000 \mathrm{e}-01$ $1.00000 \mathrm{e}-05$ 1.00000e-05 1.00000e-06 1.00000e-09 1.00000e-01 $1.00000 \mathrm{e}+001.00000 \mathrm{e}+001.00000 \mathrm{e}-01$ 1.00000e-09 1.00000e-01 Element: 9716 \# of layers: 7

Kx Ky Kz Ss Por 
$2.08035 \mathrm{e}+012.08035 \mathrm{e}+012.08035 \mathrm{e}+00$ 1.00000e-09 2.12000e-01 $2.08035 \mathrm{e}+012.08035 \mathrm{e}+012.08035 \mathrm{e}+001.00000 \mathrm{e}-092.12000 \mathrm{e}-01$ $2.08035 \mathrm{e}+012.08035 \mathrm{e}+012.08035 \mathrm{e}+001.00000 \mathrm{e}-092.12000 \mathrm{e}-01$ $2.08035 \mathrm{e}+012.08035 \mathrm{e}+012.08035 \mathrm{e}+001.00000 \mathrm{e}-092.12000 \mathrm{e}-01$ $2.08035 \mathrm{e}+012.08035 \mathrm{e}+012.08035 \mathrm{e}+001.00000 \mathrm{e}-092.12000 \mathrm{e}-01$ $1.00000 \mathrm{e}-05$ 1.00000e-05 1.00000e-06 1.00000e-09 1.00000e-01 $1.00000 \mathrm{e}+001.00000 \mathrm{e}+001.00000 \mathrm{e}-01$ 1.00000e-09 1.00000e-01 Element: 9717 \# of layers: 7

$\mathrm{Kx} \mathrm{Ky} \mathrm{Kz}$ Ss Por

$2.08035 \mathrm{e}+012.08035 \mathrm{e}+012.08035 \mathrm{e}+00$ 1.00000e-09 2.12000e-01 $2.08035 \mathrm{e}+012.08035 \mathrm{e}+012.08035 \mathrm{e}+001.00000 \mathrm{e}-092.12000 \mathrm{e}-01$ $2.08035 \mathrm{e}+012.08035 \mathrm{e}+012.08035 \mathrm{e}+001.00000 \mathrm{e}-092.12000 \mathrm{e}-01$ $2.08035 \mathrm{e}+012.08035 \mathrm{e}+012.08035 \mathrm{e}+00$ 1.00000e-09 2.12000e-01 $2.08035 \mathrm{e}+012.08035 \mathrm{e}+012.08035 \mathrm{e}+001.00000 \mathrm{e}-092.12000 \mathrm{e}-01$ $1.00000 \mathrm{e}-05$ 1.00000e-05 1.00000e-06 1.00000e-09 1.00000e-01 $1.00000 \mathrm{e}+001.00000 \mathrm{e}+001.00000 \mathrm{e}-011.00000 \mathrm{e}-091.00000 \mathrm{e}-01$ Element: 9718 \# of layers: 7

$\mathrm{Kx} \mathrm{Ky} \mathrm{Kz}$ Ss Por

$2.08035 \mathrm{e}+012.08035 \mathrm{e}+012.08035 \mathrm{e}+00$ 1.00000e-09 2.12000e-01 $2.08035 \mathrm{e}+012.08035 \mathrm{e}+012.08035 \mathrm{e}+001.00000 \mathrm{e}-092.12000 \mathrm{e}-01$ $2.08035 \mathrm{e}+012.08035 \mathrm{e}+012.08035 \mathrm{e}+001.00000 \mathrm{e}-092.12000 \mathrm{e}-01$ $2.08035 \mathrm{e}+012.08035 \mathrm{e}+012.08035 \mathrm{e}+00$ 1.00000e-09 2.12000e-01 $2.08035 \mathrm{e}+012.08035 \mathrm{e}+012.08035 \mathrm{e}+00$ 1.00000e-09 2.12000e-01 $1.00000 \mathrm{e}-05$ 1.00000e-05 1.00000e-06 1.00000e-09 1.00000e-01 $1.00000 \mathrm{e}+001.00000 \mathrm{e}+001.00000 \mathrm{e}-011.00000 \mathrm{e}-091.00000 \mathrm{e}-01$ Element: 9719 \# of layers: 7

$\mathrm{Kx} \mathrm{Ky} \mathrm{Kz}$ Ss Por

$2.08035 \mathrm{e}+012.08035 \mathrm{e}+012.08035 \mathrm{e}+00$ 1.00000e-09 2.12000e-01 $2.08035 \mathrm{e}+012.08035 \mathrm{e}+012.08035 \mathrm{e}+001.00000 \mathrm{e}-092.12000 \mathrm{e}-01$ $2.08035 \mathrm{e}+012.08035 \mathrm{e}+012.08035 \mathrm{e}+001.00000 \mathrm{e}-092.12000 \mathrm{e}-01$ $2.08035 \mathrm{e}+012.08035 \mathrm{e}+012.08035 \mathrm{e}+001.00000 \mathrm{e}-092.12000 \mathrm{e}-01$ $2.08035 \mathrm{e}+012.08035 \mathrm{e}+012.08035 \mathrm{e}+00$ 1.00000e-09 2.12000e-01 $1.00000 \mathrm{e}-05$ 1.00000e-05 1.00000e-06 1.00000e-09 1.00000e-01 $1.00000 \mathrm{e}+001.00000 \mathrm{e}+001.00000 \mathrm{e}-011.00000 \mathrm{e}-091.00000 \mathrm{e}-01$ Element: 9720 \# of layers: 7

$\mathrm{Kx} \mathrm{Ky} \mathrm{Kz}$ Ss Por $2.08035 \mathrm{e}+012.08035 \mathrm{e}+012.08035 \mathrm{e}+00$ 1.00000e-09 2.12000e-01 $2.08035 \mathrm{e}+012.08035 \mathrm{e}+012.08035 \mathrm{e}+001.00000 \mathrm{e}-092.12000 \mathrm{e}-01$ $2.08035 \mathrm{e}+012.08035 \mathrm{e}+012.08035 \mathrm{e}+001.00000 \mathrm{e}-092.12000 \mathrm{e}-01$ $2.08035 \mathrm{e}+012.08035 \mathrm{e}+012.08035 \mathrm{e}+001.00000 \mathrm{e}-092.12000 \mathrm{e}-01$ $2.08035 \mathrm{e}+012.08035 \mathrm{e}+012.08035 \mathrm{e}+001.00000 \mathrm{e}-092.12000 \mathrm{e}-01$ $1.00000 \mathrm{e}-05$ 1.00000e-05 1.00000e-06 1.00000e-09 1.00000e-01 $1.00000 \mathrm{e}+001.00000 \mathrm{e}+001.00000 \mathrm{e}-011.00000 \mathrm{e}-091.00000 \mathrm{e}-01$ Element: 9721 \# of layers: 7

$\mathrm{Kx} \mathrm{Ky} \mathrm{Kz}$ Ss Por $2.08035 \mathrm{e}+012.08035 \mathrm{e}+012.08035 \mathrm{e}+00$ 1.00000e-09 2.12000e-01 
$2.08035 \mathrm{e}+012.08035 \mathrm{e}+012.08035 \mathrm{e}+00$ 1.00000e-09 2.12000e-01 $2.08035 \mathrm{e}+012.08035 \mathrm{e}+012.08035 \mathrm{e}+001.00000 \mathrm{e}-092.12000 \mathrm{e}-01$ $2.08035 \mathrm{e}+012.08035 \mathrm{e}+012.08035 \mathrm{e}+001.00000 \mathrm{e}-092.12000 \mathrm{e}-01$ $2.08035 \mathrm{e}+012.08035 \mathrm{e}+012.08035 \mathrm{e}+001.00000 \mathrm{e}-092.12000 \mathrm{e}-01$ $1.00000 \mathrm{e}-05$ 1.00000e-05 1.00000e-06 1.00000e-09 1.00000e-01 $1.00000 \mathrm{e}+001.00000 \mathrm{e}+001.00000 \mathrm{e}-011.00000 \mathrm{e}-091.00000 \mathrm{e}-01$ Element: 9722 \# of layers: 7

$\mathrm{Kx} \mathrm{Ky} \mathrm{Kz}$ Ss Por

$2.08035 \mathrm{e}+012.08035 \mathrm{e}+012.08035 \mathrm{e}+001.00000 \mathrm{e}-092.12000 \mathrm{e}-01$ $2.08035 \mathrm{e}+012.08035 \mathrm{e}+012.08035 \mathrm{e}+001.00000 \mathrm{e}-092.12000 \mathrm{e}-01$ $2.08035 \mathrm{e}+012.08035 \mathrm{e}+012.08035 \mathrm{e}+00$ 1.00000e-09 2.12000e-01 $2.08035 \mathrm{e}+012.08035 \mathrm{e}+012.08035 \mathrm{e}+001.00000 \mathrm{e}-092.12000 \mathrm{e}-01$ $2.08035 \mathrm{e}+012.08035 \mathrm{e}+012.08035 \mathrm{e}+001.00000 \mathrm{e}-092.12000 \mathrm{e}-01$ $1.00000 \mathrm{e}-05$ 1.00000e-05 1.00000e-06 1.00000e-09 1.00000e-01 $1.00000 \mathrm{e}+001.00000 \mathrm{e}+001.00000 \mathrm{e}-01$ 1.00000e-09 1.00000e-01 Element: 9723 \# of layers: 7

$\mathrm{Kx} \mathrm{Ky} \mathrm{Kz}$ Ss Por

$2.08035 \mathrm{e}+012.08035 \mathrm{e}+012.08035 \mathrm{e}+00$ 1.00000e-09 2.12000e-01 $2.08035 \mathrm{e}+012.08035 \mathrm{e}+012.08035 \mathrm{e}+001.00000 \mathrm{e}-092.12000 \mathrm{e}-01$ $2.08035 \mathrm{e}+012.08035 \mathrm{e}+012.08035 \mathrm{e}+001.00000 \mathrm{e}-092.12000 \mathrm{e}-01$ $2.08035 \mathrm{e}+012.08035 \mathrm{e}+012.08035 \mathrm{e}+00 \quad 1.00000 \mathrm{e}-092.12000 \mathrm{e}-01$ $2.08035 \mathrm{e}+012.08035 \mathrm{e}+012.08035 \mathrm{e}+00$ 1.00000e-09 2.12000e-01 $1.00000 \mathrm{e}-05$ 1.00000e-05 1.00000e-06 1.00000e-09 1.00000e-01 $1.00000 \mathrm{e}+001.00000 \mathrm{e}+001.00000 \mathrm{e}-011.00000 \mathrm{e}-091.00000 \mathrm{e}-01$ Element: 9724 \# of layers: 7

$\mathrm{Kx} \mathrm{Ky} \mathrm{Kz}$ Ss Por

$2.08035 \mathrm{e}+012.08035 \mathrm{e}+012.08035 \mathrm{e}+00$ 1.00000e-09 2.12000e-01 $2.08035 \mathrm{e}+012.08035 \mathrm{e}+012.08035 \mathrm{e}+001.00000 \mathrm{e}-092.12000 \mathrm{e}-01$ $2.08035 \mathrm{e}+012.08035 \mathrm{e}+012.08035 \mathrm{e}+001.00000 \mathrm{e}-092.12000 \mathrm{e}-01$ $2.08035 \mathrm{e}+012.08035 \mathrm{e}+012.08035 \mathrm{e}+001.00000 \mathrm{e}-092.12000 \mathrm{e}-01$ $2.08035 \mathrm{e}+012.08035 \mathrm{e}+012.08035 \mathrm{e}+001.00000 \mathrm{e}-092.12000 \mathrm{e}-01$ $1.00000 \mathrm{e}-05$ 1.00000e-05 1.00000e-06 1.00000e-09 1.00000e-01 $1.00000 \mathrm{e}+001.00000 \mathrm{e}+001.00000 \mathrm{e}-011.00000 \mathrm{e}-091.00000 \mathrm{e}-01$ Element: 9725 \# of layers: 7

$\mathrm{Kx} \mathrm{Ky} \mathrm{Kz}$ Ss Por

$2.10267 \mathrm{e}+012.10267 \mathrm{e}+012.10267 \mathrm{e}+00$ 1.00000e-09 2.12000e-01 $2.10267 \mathrm{e}+012.10267 \mathrm{e}+012.10267 \mathrm{e}+00$ 1.00000e-09 2.12000e-01 $2.10267 \mathrm{e}+012.10267 \mathrm{e}+012.10267 \mathrm{e}+00$ 1.00000e-09 2.12000e-01 $2.10267 \mathrm{e}+012.10267 \mathrm{e}+01$ 2.10267e+00 1.00000e-09 2.12000e-01 $2.10267 \mathrm{e}+012.10267 \mathrm{e}+012.10267 \mathrm{e}+00$ 1.00000e-09 2.12000e-01 $1.00000 \mathrm{e}-05$ 1.00000e-05 1.00000e-06 1.00000e-09 1.00000e-01 $1.00000 \mathrm{e}+001.00000 \mathrm{e}+001.00000 \mathrm{e}-011.00000 \mathrm{e}-091.00000 \mathrm{e}-01$ Element: 9726 \# of layers: 7

$\mathrm{Kx} \mathrm{Ky} \mathrm{Kz}$ Ss Por

2.10267e+01 2.10267e+01 2.10267e+00 1.00000e-09 2.12000e-01 $2.10267 \mathrm{e}+012.10267 \mathrm{e}+012.10267 \mathrm{e}+00$ 1.00000e-09 2.12000e-01 
$2.10267 \mathrm{e}+012.10267 \mathrm{e}+012.10267 \mathrm{e}+00$ 1.00000e-09 2.12000e-01 $2.10267 \mathrm{e}+012.10267 \mathrm{e}+012.10267 \mathrm{e}+00$ 1.00000e-09 2.12000e-01 $2.10267 \mathrm{e}+012.10267 \mathrm{e}+012.10267 \mathrm{e}+00$ 1.00000e-09 2.12000e-01 $1.00000 \mathrm{e}-05$ 1.00000e-05 1.00000e-06 1.00000e-09 1.00000e-01 $1.00000 \mathrm{e}+001.00000 \mathrm{e}+001.00000 \mathrm{e}-011.00000 \mathrm{e}-091.00000 \mathrm{e}-01$ Element: 9727 \# of layers: 7

Kx Ky Kz Ss Por

$2.10267 \mathrm{e}+012.10267 \mathrm{e}+012.10267 \mathrm{e}+00$ 1.00000e-09 2.12000e-01 $2.10267 \mathrm{e}+012.10267 \mathrm{e}+012.10267 \mathrm{e}+00$ 1.00000e-09 2.12000e-01 $2.10267 \mathrm{e}+012.10267 \mathrm{e}+012.10267 \mathrm{e}+001.00000 \mathrm{e}-092.12000 \mathrm{e}-01$ $2.10267 \mathrm{e}+012.10267 \mathrm{e}+012.10267 \mathrm{e}+001.00000 \mathrm{e}-092.12000 \mathrm{e}-01$ $2.10267 \mathrm{e}+012.10267 \mathrm{e}+012.10267 \mathrm{e}+001.00000 \mathrm{e}-092.12000 \mathrm{e}-01$ $1.00000 \mathrm{e}-05$ 1.00000e-05 1.00000e-06 1.00000e-09 1.00000e-01 $1.00000 \mathrm{e}+001.00000 \mathrm{e}+001.00000 \mathrm{e}-011.00000 \mathrm{e}-091.00000 \mathrm{e}-01$ Element: 9728 \# of layers: 7

Kx Ky Kz Ss Por $2.08035 \mathrm{e}+012.08035 \mathrm{e}+012.08035 \mathrm{e}+00$ 1.00000e-09 2.12000e-01 $2.08035 \mathrm{e}+012.08035 \mathrm{e}+012.08035 \mathrm{e}+001.00000 \mathrm{e}-092.12000 \mathrm{e}-01$ $2.08035 \mathrm{e}+012.08035 \mathrm{e}+012.08035 \mathrm{e}+001.00000 \mathrm{e}-092.12000 \mathrm{e}-01$ $2.08035 \mathrm{e}+012.08035 \mathrm{e}+012.08035 \mathrm{e}+001.00000 \mathrm{e}-092.12000 \mathrm{e}-01$ $2.08035 \mathrm{e}+012.08035 \mathrm{e}+012.08035 \mathrm{e}+001.00000 \mathrm{e}-092.12000 \mathrm{e}-01$ $1.00000 \mathrm{e}-05$ 1.00000e-05 1.00000e-06 1.00000e-09 1.00000e-01 $1.00000 \mathrm{e}+001.00000 \mathrm{e}+001.00000 \mathrm{e}-011.00000 \mathrm{e}-091.00000 \mathrm{e}-01$ Element: 9729 \# of layers: 7

Kx Ky Kz Ss Por $2.08035 \mathrm{e}+012.08035 \mathrm{e}+012.08035 \mathrm{e}+00$ 1.00000e-09 2.12000e-01 $2.08035 \mathrm{e}+012.08035 \mathrm{e}+012.08035 \mathrm{e}+001.00000 \mathrm{e}-092.12000 \mathrm{e}-01$ $2.08035 \mathrm{e}+012.08035 \mathrm{e}+012.08035 \mathrm{e}+001.00000 \mathrm{e}-092.12000 \mathrm{e}-01$ $2.08035 \mathrm{e}+012.08035 \mathrm{e}+012.08035 \mathrm{e}+001.00000 \mathrm{e}-092.12000 \mathrm{e}-01$ $2.08035 \mathrm{e}+012.08035 \mathrm{e}+012.08035 \mathrm{e}+001.00000 \mathrm{e}-092.12000 \mathrm{e}-01$ $1.00000 \mathrm{e}-05$ 1.00000e-05 1.00000e-06 1.00000e-09 1.00000e-01 $1.00000 \mathrm{e}+001.00000 \mathrm{e}+001.00000 \mathrm{e}-011.00000 \mathrm{e}-091.00000 \mathrm{e}-01$ Element: 9730 \# of layers: 7

Kx Ky Kz Ss Por

$2.08035 \mathrm{e}+012.08035 \mathrm{e}+012.08035 \mathrm{e}+00$ 1.00000e-09 2.12000e-01 $2.08035 \mathrm{e}+012.08035 \mathrm{e}+012.08035 \mathrm{e}+001.00000 \mathrm{e}-092.12000 \mathrm{e}-01$ $2.08035 \mathrm{e}+012.08035 \mathrm{e}+012.08035 \mathrm{e}+001.00000 \mathrm{e}-092.12000 \mathrm{e}-01$ $2.08035 \mathrm{e}+012.08035 \mathrm{e}+012.08035 \mathrm{e}+001.00000 \mathrm{e}-092.12000 \mathrm{e}-01$ $2.08035 \mathrm{e}+012.08035 \mathrm{e}+012.08035 \mathrm{e}+00$ 1.00000e-09 2.12000e-01 $1.00000 \mathrm{e}-05$ 1.00000e-05 1.00000e-06 1.00000e-09 1.00000e-01 $1.00000 \mathrm{e}+001.00000 \mathrm{e}+001.00000 \mathrm{e}-011.00000 \mathrm{e}-091.00000 \mathrm{e}-01$ Element: 9731 \# of layers: 7

Kx Ky Kz Ss Por

$2.08035 \mathrm{e}+012.08035 \mathrm{e}+012.08035 \mathrm{e}+00$ 1.00000e-09 2.12000e-01 $2.08035 \mathrm{e}+012.08035 \mathrm{e}+012.08035 \mathrm{e}+001.00000 \mathrm{e}-092.12000 \mathrm{e}-01$ $2.08035 \mathrm{e}+012.08035 \mathrm{e}+012.08035 \mathrm{e}+001.00000 \mathrm{e}-092.12000 \mathrm{e}-01$ 
$2.08035 \mathrm{e}+012.08035 \mathrm{e}+012.08035 \mathrm{e}+00$ 1.00000e-09 2.12000e-01 $2.08035 \mathrm{e}+012.08035 \mathrm{e}+012.08035 \mathrm{e}+00$ 1.00000e-09 2.12000e-01 $1.00000 \mathrm{e}-05$ 1.00000e-05 1.00000e-06 1.00000e-09 1.00000e-01 $1.00000 \mathrm{e}+001.00000 \mathrm{e}+001.00000 \mathrm{e}-011.00000 \mathrm{e}-091.00000 \mathrm{e}-01$ Element: 9732 \# of layers: 7

Kx Ky Kz Ss Por

$2.10267 \mathrm{e}+012.10267 \mathrm{e}+012.10267 \mathrm{e}+00$ 1.00000e-09 2.12000e-01 $2.10267 \mathrm{e}+012.10267 \mathrm{e}+012.10267 \mathrm{e}+00$ 1.00000e-09 2.12000e-01 $2.10267 \mathrm{e}+012.10267 \mathrm{e}+012.10267 \mathrm{e}+001.00000 \mathrm{e}-092.12000 \mathrm{e}-01$ $2.10267 \mathrm{e}+012.10267 \mathrm{e}+012.10267 \mathrm{e}+001.00000 \mathrm{e}-092.12000 \mathrm{e}-01$ $2.10267 \mathrm{e}+012.10267 \mathrm{e}+012.10267 \mathrm{e}+001.00000 \mathrm{e}-092.12000 \mathrm{e}-01$ $1.00000 \mathrm{e}-05$ 1.00000e-05 1.00000e-06 1.00000e-09 1.00000e-01 $1.00000 \mathrm{e}+001.00000 \mathrm{e}+001.00000 \mathrm{e}-011.00000 \mathrm{e}-091.00000 \mathrm{e}-01$ Element: 9733 \# of layers: 7

Kx Ky Kz Ss Por

$2.10267 \mathrm{e}+012.10267 \mathrm{e}+012.10267 \mathrm{e}+00$ 1.00000e-09 2.12000e-01 $2.10267 \mathrm{e}+012.10267 \mathrm{e}+012.10267 \mathrm{e}+00$ 1.00000e-09 2.12000e-01 $2.10267 \mathrm{e}+012.10267 \mathrm{e}+012.10267 \mathrm{e}+00$ 1.00000e-09 2.12000e-01 $2.10267 \mathrm{e}+012.10267 \mathrm{e}+012.10267 \mathrm{e}+00$ 1.00000e-09 2.12000e-01 $2.10267 \mathrm{e}+012.10267 \mathrm{e}+012.10267 \mathrm{e}+00$ 1.00000e-09 2.12000e-01 $1.00000 \mathrm{e}-05$ 1.00000e-05 1.00000e-06 1.00000e-09 1.00000e-01 $1.00000 \mathrm{e}+001.00000 \mathrm{e}+00$ 1.00000e-01 1.00000e-09 1.00000e-01 Element: 9734 \# of layers: 7

Kx Ky Kz Ss Por

$2.10267 \mathrm{e}+012.10267 \mathrm{e}+012.10267 \mathrm{e}+00$ 1.00000e-09 2.12000e-01 $2.10267 \mathrm{e}+012.10267 \mathrm{e}+012.10267 \mathrm{e}+00$ 1.00000e-09 2.12000e-01 $2.10267 \mathrm{e}+012.10267 \mathrm{e}+012.10267 \mathrm{e}+001.00000 \mathrm{e}-092.12000 \mathrm{e}-01$ $2.10267 \mathrm{e}+012.10267 \mathrm{e}+012.10267 \mathrm{e}+00$ 1.00000e-09 2.12000e-01 $2.10267 \mathrm{e}+012.10267 \mathrm{e}+012.10267 \mathrm{e}+001.00000 \mathrm{e}-092.12000 \mathrm{e}-01$ $1.00000 \mathrm{e}-05$ 1.00000e-05 1.00000e-06 1.00000e-09 1.00000e-01 $1.00000 \mathrm{e}+001.00000 \mathrm{e}+001.00000 \mathrm{e}-011.00000 \mathrm{e}-091.00000 \mathrm{e}-01$ Element: 9735 \# of layers: 7

Kx Ky Kz Ss Por

$2.10267 \mathrm{e}+012.10267 \mathrm{e}+012.10267 \mathrm{e}+00$ 1.00000e-09 2.12000e-01 $2.10267 \mathrm{e}+012.10267 \mathrm{e}+012.10267 \mathrm{e}+00$ 1.00000e-09 2.12000e-01 $2.10267 \mathrm{e}+012.10267 \mathrm{e}+012.10267 \mathrm{e}+001.00000 \mathrm{e}-092.12000 \mathrm{e}-01$ $2.10267 \mathrm{e}+012.10267 \mathrm{e}+012.10267 \mathrm{e}+00$ 1.00000e-09 2.12000e-01 $2.10267 \mathrm{e}+012.10267 \mathrm{e}+012.10267 \mathrm{e}+00$ 1.00000e-09 2.12000e-01 $1.00000 \mathrm{e}-05$ 1.00000e-05 1.00000e-06 1.00000e-09 1.00000e-01 $1.00000 \mathrm{e}+001.00000 \mathrm{e}+001.00000 \mathrm{e}-011.00000 \mathrm{e}-091.00000 \mathrm{e}-01$ Element: 9736 \# of layers: 7

Kx Ky Kz Ss Por

$2.10267 \mathrm{e}+012.10267 \mathrm{e}+012.10267 \mathrm{e}+00$ 1.00000e-09 2.12000e-01 $2.10267 \mathrm{e}+012.10267 \mathrm{e}+012.10267 \mathrm{e}+00$ 1.00000e-09 2.12000e-01 $2.10267 \mathrm{e}+012.10267 \mathrm{e}+012.10267 \mathrm{e}+00$ 1.00000e-09 2.12000e-01 $2.10267 \mathrm{e}+012.10267 \mathrm{e}+012.10267 \mathrm{e}+001.00000 \mathrm{e}-092.12000 \mathrm{e}-01$ 
$2.10267 \mathrm{e}+012.10267 \mathrm{e}+012.10267 \mathrm{e}+00$ 1.00000e-09 2.12000e-01 $1.00000 \mathrm{e}-05$ 1.00000e-05 1.00000e-06 1.00000e-09 1.00000e-01 $1.00000 \mathrm{e}+001.00000 \mathrm{e}+001.00000 \mathrm{e}-011.00000 \mathrm{e}-091.00000 \mathrm{e}-01$ Element: 9737 \# of layers: 7

Kx Ky Kz Ss Por

$2.10267 \mathrm{e}+012.10267 \mathrm{e}+012.10267 \mathrm{e}+00$ 1.00000e-09 2.12000e-01

$2.10267 \mathrm{e}+012.10267 \mathrm{e}+012.10267 \mathrm{e}+00$ 1.00000e-09 2.12000e-01 $2.10267 \mathrm{e}+012.10267 \mathrm{e}+012.10267 \mathrm{e}+00$ 1.00000e-09 2.12000e-01 $2.10267 \mathrm{e}+012.10267 \mathrm{e}+012.10267 \mathrm{e}+001.00000 \mathrm{e}-092.12000 \mathrm{e}-01$ $2.10267 \mathrm{e}+012.10267 \mathrm{e}+012.10267 \mathrm{e}+001.00000 \mathrm{e}-092.12000 \mathrm{e}-01$ $1.00000 \mathrm{e}-05$ 1.00000e-05 1.00000e-06 1.00000e-09 1.00000e-01 $1.00000 \mathrm{e}+001.00000 \mathrm{e}+001.00000 \mathrm{e}-011.00000 \mathrm{e}-091.00000 \mathrm{e}-01$ Element: 9738 \# of layers: 7

Kx Ky Kz Ss Por

$2.10267 \mathrm{e}+012.10267 \mathrm{e}+012.10267 \mathrm{e}+00$ 1.00000e-09 2.12000e-01 $2.10267 \mathrm{e}+012.10267 \mathrm{e}+012.10267 \mathrm{e}+00$ 1.00000e-09 2.12000e-01 $2.10267 \mathrm{e}+012.10267 \mathrm{e}+012.10267 \mathrm{e}+00$ 1.00000e-09 2.12000e-01 $2.10267 \mathrm{e}+012.10267 \mathrm{e}+012.10267 \mathrm{e}+00$ 1.00000e-09 2.12000e-01 $2.10267 \mathrm{e}+012.10267 \mathrm{e}+012.10267 \mathrm{e}+00$ 1.00000e-09 2.12000e-01 $1.00000 \mathrm{e}-05$ 1.00000e-05 1.00000e-06 1.00000e-09 1.00000e-01 $1.00000 \mathrm{e}+001.00000 \mathrm{e}+001.00000 \mathrm{e}-011.00000 \mathrm{e}-091.00000 \mathrm{e}-01$ Element: 9739 \# of layers: 7

Kx Ky Kz Ss Por

$2.10267 \mathrm{e}+012.10267 \mathrm{e}+012.10267 \mathrm{e}+00$ 1.00000e-09 2.12000e-01 $2.10267 \mathrm{e}+012.10267 \mathrm{e}+012.10267 \mathrm{e}+001.00000 \mathrm{e}-092.12000 \mathrm{e}-01$ $2.10267 \mathrm{e}+012.10267 \mathrm{e}+012.10267 \mathrm{e}+00$ 1.00000e-09 2.12000e-01 $2.10267 \mathrm{e}+012.10267 \mathrm{e}+012.10267 \mathrm{e}+001.00000 \mathrm{e}-092.12000 \mathrm{e}-01$ $2.10267 \mathrm{e}+012.10267 \mathrm{e}+012.10267 \mathrm{e}+001.00000 \mathrm{e}-092.12000 \mathrm{e}-01$ $1.00000 \mathrm{e}-05$ 1.00000e-05 1.00000e-06 1.00000e-09 1.00000e-01 $1.00000 \mathrm{e}+001.00000 \mathrm{e}+001.00000 \mathrm{e}-011.00000 \mathrm{e}-091.00000 \mathrm{e}-01$ Element: 9740 \# of layers: 7

$\mathrm{Kx} \mathrm{Ky} \mathrm{Kz}$ Ss Por

$2.10267 \mathrm{e}+012.10267 \mathrm{e}+012.10267 \mathrm{e}+00$ 1.00000e-09 2.12000e-01 $2.10267 \mathrm{e}+012.10267 \mathrm{e}+012.10267 \mathrm{e}+001.00000 \mathrm{e}-092.12000 \mathrm{e}-01$ $2.10267 \mathrm{e}+012.10267 \mathrm{e}+012.10267 \mathrm{e}+00$ 1.00000e-09 2.12000e-01 $2.10267 \mathrm{e}+012.10267 \mathrm{e}+012.10267 \mathrm{e}+001.00000 \mathrm{e}-092.12000 \mathrm{e}-01$ $2.10267 \mathrm{e}+012.10267 \mathrm{e}+012.10267 \mathrm{e}+00$ 1.00000e-09 2.12000e-01 $1.00000 \mathrm{e}-05$ 1.00000e-05 1.00000e-06 1.00000e-09 1.00000e-01 $1.00000 \mathrm{e}+001.00000 \mathrm{e}+001.00000 \mathrm{e}-011.00000 \mathrm{e}-091.00000 \mathrm{e}-01$ Element: 9741 \# of layers: 7

Kx Ky Kz Ss Por

$2.10267 \mathrm{e}+012.10267 \mathrm{e}+012.10267 \mathrm{e}+00$ 1.00000e-09 2.12000e-01 $2.10267 \mathrm{e}+012.10267 \mathrm{e}+012.10267 \mathrm{e}+00$ 1.00000e-09 2.12000e-01 $2.10267 \mathrm{e}+012.10267 \mathrm{e}+012.10267 \mathrm{e}+00$ 1.00000e-09 2.12000e-01 $2.10267 \mathrm{e}+012.10267 \mathrm{e}+012.10267 \mathrm{e}+00$ 1.00000e-09 2.12000e-01 $2.10267 \mathrm{e}+012.10267 \mathrm{e}+012.10267 \mathrm{e}+001.00000 \mathrm{e}-092.12000 \mathrm{e}-01$ 
$1.00000 \mathrm{e}-05$ 1.00000e-05 1.00000e-06 1.00000e-09 1.00000e-01 $1.00000 \mathrm{e}+001.00000 \mathrm{e}+001.00000 \mathrm{e}-01$ 1.00000e-09 1.00000e-01 Element: 9742 \# of layers: 7

$\mathrm{Kx} \mathrm{Ky} \mathrm{Kz}$ Ss Por

$2.10267 \mathrm{e}+012.10267 \mathrm{e}+01$ 2.10267e+00 1.00000e-09 2.12000e-01 $2.10267 \mathrm{e}+012.10267 \mathrm{e}+012.10267 \mathrm{e}+00$ 1.00000e-09 2.12000e-01 $2.10267 \mathrm{e}+012.10267 \mathrm{e}+012.10267 \mathrm{e}+00$ 1.00000e-09 2.12000e-01 $2.10267 \mathrm{e}+012.10267 \mathrm{e}+012.10267 \mathrm{e}+00$ 1.00000e-09 2.12000e-01 2.10267e+01 2.10267e+01 2.10267e+00 1.00000e-09 2.12000e-01 $1.00000 \mathrm{e}-05$ 1.00000e-05 1.00000e-06 1.00000e-09 1.00000e-01 $1.00000 \mathrm{e}+001.00000 \mathrm{e}+001.00000 \mathrm{e}-011.00000 \mathrm{e}-091.00000 \mathrm{e}-01$ Element: 9743 \# of layers: 7

$\mathrm{Kx} \mathrm{Ky} \mathrm{Kz}$ Ss Por

$2.01224 \mathrm{e}+012.01224 \mathrm{e}+012.01224 \mathrm{e}+001.00000 \mathrm{e}-092.12000 \mathrm{e}-01$ $2.01224 \mathrm{e}+012.01224 \mathrm{e}+012.01224 \mathrm{e}+001.00000 \mathrm{e}-092.12000 \mathrm{e}-01$ $2.01224 \mathrm{e}+012.01224 \mathrm{e}+012.01224 \mathrm{e}+001.00000 \mathrm{e}-092.12000 \mathrm{e}-01$ $2.01224 \mathrm{e}+012.01224 \mathrm{e}+012.01224 \mathrm{e}+001.00000 \mathrm{e}-092.12000 \mathrm{e}-01$ $2.01224 \mathrm{e}+012.01224 \mathrm{e}+012.01224 \mathrm{e}+001.00000 \mathrm{e}-092.12000 \mathrm{e}-01$ $1.00000 \mathrm{e}-05$ 1.00000e-05 1.00000e-06 1.00000e-09 1.00000e-01 $1.00000 \mathrm{e}+001.00000 \mathrm{e}+001.00000 \mathrm{e}-011.00000 \mathrm{e}-091.00000 \mathrm{e}-01$ Element: 9744 \# of layers: 7

$\mathrm{Kx} \mathrm{Ky} \mathrm{Kz}$ Ss Por

$2.01224 \mathrm{e}+012.01224 \mathrm{e}+012.01224 \mathrm{e}+001.00000 \mathrm{e}-092.12000 \mathrm{e}-01$ $2.01224 \mathrm{e}+012.01224 \mathrm{e}+012.01224 \mathrm{e}+001.00000 \mathrm{e}-092.12000 \mathrm{e}-01$ $2.01224 \mathrm{e}+012.01224 \mathrm{e}+012.01224 \mathrm{e}+001.00000 \mathrm{e}-092.12000 \mathrm{e}-01$ $2.01224 \mathrm{e}+012.01224 \mathrm{e}+012.01224 \mathrm{e}+001.00000 \mathrm{e}-092.12000 \mathrm{e}-01$ $2.01224 \mathrm{e}+012.01224 \mathrm{e}+012.01224 \mathrm{e}+001.00000 \mathrm{e}-092.12000 \mathrm{e}-01$ $1.00000 \mathrm{e}-05$ 1.00000e-05 1.00000e-06 1.00000e-09 1.00000e-01 $1.00000 \mathrm{e}+001.00000 \mathrm{e}+001.00000 \mathrm{e}-011.00000 \mathrm{e}-091.00000 \mathrm{e}-01$ Element: 9745 \# of layers: 7

$\mathrm{Kx} \mathrm{Ky} \mathrm{Kz}$ Ss Por

$2.01224 \mathrm{e}+012.01224 \mathrm{e}+012.01224 \mathrm{e}+001.00000 \mathrm{e}-092.12000 \mathrm{e}-01$ $2.01224 \mathrm{e}+012.01224 \mathrm{e}+012.01224 \mathrm{e}+001.00000 \mathrm{e}-092.12000 \mathrm{e}-01$ $2.01224 \mathrm{e}+012.01224 \mathrm{e}+012.01224 \mathrm{e}+001.00000 \mathrm{e}-092.12000 \mathrm{e}-01$ $2.01224 \mathrm{e}+012.01224 \mathrm{e}+012.01224 \mathrm{e}+001.00000 \mathrm{e}-092.12000 \mathrm{e}-01$ $2.01224 \mathrm{e}+012.01224 \mathrm{e}+012.01224 \mathrm{e}+001.00000 \mathrm{e}-092.12000 \mathrm{e}-01$ 1.00000e-05 1.00000e-05 1.00000e-06 1.00000e-09 1.00000e-01 $1.00000 \mathrm{e}+001.00000 \mathrm{e}+001.00000 \mathrm{e}-011.00000 \mathrm{e}-091.00000 \mathrm{e}-01$ Element: 9746 \# of layers: 7

$\mathrm{Kx} \mathrm{Ky} \mathrm{Kz}$ Ss Por

2.10267e+01 2.10267e+01 2.10267e+00 1.00000e-09 2.12000e-01 $2.10267 \mathrm{e}+012.10267 \mathrm{e}+012.10267 \mathrm{e}+00$ 1.00000e-09 2.12000e-01 $2.10267 \mathrm{e}+012.10267 \mathrm{e}+012.10267 \mathrm{e}+001.00000 \mathrm{e}-092.12000 \mathrm{e}-01$ $2.10267 \mathrm{e}+012.10267 \mathrm{e}+012.10267 \mathrm{e}+00$ 1.00000e-09 2.12000e-01 $2.10267 \mathrm{e}+012.10267 \mathrm{e}+012.10267 \mathrm{e}+00$ 1.00000e-09 2.12000e-01 $1.00000 \mathrm{e}-05$ 1.00000e-05 1.00000e-06 1.00000e-09 1.00000e-01 
$1.00000 \mathrm{e}+001.00000 \mathrm{e}+001.00000 \mathrm{e}-011.00000 \mathrm{e}-091.00000 \mathrm{e}-01$

Element: 9747 \# of layers: 7

Kx Ky Kz Ss Por

2.10267e+01 2.10267e+01 2.10267e+00 1.00000e-09 2.12000e-01

$2.10267 \mathrm{e}+012.10267 \mathrm{e}+012.10267 \mathrm{e}+00$ 1.00000e-09 2.12000e-01

$2.10267 \mathrm{e}+012.10267 \mathrm{e}+012.10267 \mathrm{e}+00$ 1.00000e-09 2.12000e-01

$2.10267 \mathrm{e}+012.10267 \mathrm{e}+012.10267 \mathrm{e}+00$ 1.00000e-09 2.12000e-01

$2.10267 \mathrm{e}+012.10267 \mathrm{e}+012.10267 \mathrm{e}+00$ 1.00000e-09 2.12000e-01

$1.00000 \mathrm{e}-05$ 1.00000e-05 1.00000e-06 1.00000e-09 1.00000e-01

$1.00000 \mathrm{e}+001.00000 \mathrm{e}+001.00000 \mathrm{e}-011.00000 \mathrm{e}-091.00000 \mathrm{e}-01$

Element: 9748 \# of layers: 7

$\mathrm{Kx} \mathrm{Ky} \mathrm{Kz}$ Ss Por

2.10267e+01 2.10267e+01 2.10267e+00 1.00000e-09 2.12000e-01

$2.10267 \mathrm{e}+012.10267 \mathrm{e}+012.10267 \mathrm{e}+00$ 1.00000e-09 2.12000e-01

$2.10267 \mathrm{e}+012.10267 \mathrm{e}+012.10267 \mathrm{e}+00$ 1.00000e-09 2.12000e-01

$2.10267 \mathrm{e}+012.10267 \mathrm{e}+012.10267 \mathrm{e}+00$ 1.00000e-09 2.12000e-01

$2.10267 \mathrm{e}+012.10267 \mathrm{e}+012.10267 \mathrm{e}+00$ 1.00000e-09 2.12000e-01

$1.00000 \mathrm{e}-05$ 1.00000e-05 1.00000e-06 1.00000e-09 1.00000e-01

$1.00000 \mathrm{e}+001.00000 \mathrm{e}+001.00000 \mathrm{e}-011.00000 \mathrm{e}-091.00000 \mathrm{e}-01$

Element: 9749 \# of layers: 7

$\mathrm{Kx} \mathrm{Ky} \mathrm{Kz}$ Ss Por

2.10267e+01 2.10267e+01 2.10267e+00 1.00000e-09 2.12000e-01

$2.10267 \mathrm{e}+012.10267 \mathrm{e}+01$ 2.10267e+00 1.00000e-09 2.12000e-01

$2.10267 \mathrm{e}+012.10267 \mathrm{e}+012.10267 \mathrm{e}+00$ 1.00000e-09 2.12000e-01

$2.10267 \mathrm{e}+012.10267 \mathrm{e}+012.10267 \mathrm{e}+00$ 1.00000e-09 2.12000e-01

$2.10267 \mathrm{e}+012.10267 \mathrm{e}+012.10267 \mathrm{e}+00$ 1.00000e-09 2.12000e-01

$1.00000 \mathrm{e}-05$ 1.00000e-05 1.00000e-06 1.00000e-09 1.00000e-01

$1.00000 \mathrm{e}+001.00000 \mathrm{e}+001.00000 \mathrm{e}-011.00000 \mathrm{e}-09$ 1.00000e-01

Element: 9750 \# of layers: 7

$\mathrm{Kx} \mathrm{Ky} \mathrm{Kz}$ Ss Por

$2.01224 \mathrm{e}+012.01224 \mathrm{e}+012.01224 \mathrm{e}+001.00000 \mathrm{e}-092.12000 \mathrm{e}-01$

$2.01224 \mathrm{e}+012.01224 \mathrm{e}+012.01224 \mathrm{e}+001.00000 \mathrm{e}-092.12000 \mathrm{e}-01$

$2.01224 \mathrm{e}+012.01224 \mathrm{e}+012.01224 \mathrm{e}+001.00000 \mathrm{e}-092.12000 \mathrm{e}-01$

$2.01224 \mathrm{e}+012.01224 \mathrm{e}+012.01224 \mathrm{e}+001.00000 \mathrm{e}-092.12000 \mathrm{e}-01$

$2.01224 \mathrm{e}+012.01224 \mathrm{e}+012.01224 \mathrm{e}+001.00000 \mathrm{e}-092.12000 \mathrm{e}-01$

1.00000e-05 1.00000e-05 1.00000e-06 1.00000e-09 1.00000e-01

$1.00000 \mathrm{e}+001.00000 \mathrm{e}+001.00000 \mathrm{e}-011.00000 \mathrm{e}-091.00000 \mathrm{e}-01$

Element: 9751 \# of layers: 7

$\mathrm{Kx} \mathrm{Ky} \mathrm{Kz}$ Ss Por

$2.01224 \mathrm{e}+012.01224 \mathrm{e}+012.01224 \mathrm{e}+001.00000 \mathrm{e}-092.12000 \mathrm{e}-01$ $2.01224 \mathrm{e}+012.01224 \mathrm{e}+012.01224 \mathrm{e}+001.00000 \mathrm{e}-092.12000 \mathrm{e}-01$ $2.01224 \mathrm{e}+012.01224 \mathrm{e}+012.01224 \mathrm{e}+001.00000 \mathrm{e}-092.12000 \mathrm{e}-01$ $2.01224 \mathrm{e}+012.01224 \mathrm{e}+012.01224 \mathrm{e}+001.00000 \mathrm{e}-092.12000 \mathrm{e}-01$ $2.01224 \mathrm{e}+012.01224 \mathrm{e}+012.01224 \mathrm{e}+00$ 1.00000e-09 2.12000e-01 $1.00000 \mathrm{e}-05$ 1.00000e-05 1.00000e-06 1.00000e-09 1.00000e-01 $1.00000 \mathrm{e}+001.00000 \mathrm{e}+001.00000 \mathrm{e}-011.00000 \mathrm{e}-091.00000 \mathrm{e}-01$ 
Element: 9752 \# of layers: 7

Kx Ky Kz Ss Por

$2.01224 \mathrm{e}+012.01224 \mathrm{e}+012.01224 \mathrm{e}+00$ 1.00000e-09 2.12000e-01

$2.01224 \mathrm{e}+012.01224 \mathrm{e}+012.01224 \mathrm{e}+001.00000 \mathrm{e}-092.12000 \mathrm{e}-01$

$2.01224 \mathrm{e}+012.01224 \mathrm{e}+012.01224 \mathrm{e}+001.00000 \mathrm{e}-092.12000 \mathrm{e}-01$

$2.01224 \mathrm{e}+012.01224 \mathrm{e}+012.01224 \mathrm{e}+001.00000 \mathrm{e}-092.12000 \mathrm{e}-01$

$2.01224 \mathrm{e}+012.01224 \mathrm{e}+012.01224 \mathrm{e}+001.00000 \mathrm{e}-092.12000 \mathrm{e}-01$

$1.00000 \mathrm{e}-05$ 1.00000e-05 1.00000e-06 1.00000e-09 1.00000e-01

$1.00000 \mathrm{e}+001.00000 \mathrm{e}+001.00000 \mathrm{e}-011.00000 \mathrm{e}-091.00000 \mathrm{e}-01$

Element: 9753 \# of layers: 7

Kx Ky Kz Ss Por

$2.01224 \mathrm{e}+012.01224 \mathrm{e}+012.01224 \mathrm{e}+001.00000 \mathrm{e}-092.12000 \mathrm{e}-01$

$2.01224 \mathrm{e}+012.01224 \mathrm{e}+012.01224 \mathrm{e}+001.00000 \mathrm{e}-092.12000 \mathrm{e}-01$

$2.01224 \mathrm{e}+012.01224 \mathrm{e}+012.01224 \mathrm{e}+001.00000 \mathrm{e}-092.12000 \mathrm{e}-01$

$2.01224 \mathrm{e}+012.01224 \mathrm{e}+012.01224 \mathrm{e}+001.00000 \mathrm{e}-092.12000 \mathrm{e}-01$

$2.01224 \mathrm{e}+012.01224 \mathrm{e}+012.01224 \mathrm{e}+001.00000 \mathrm{e}-092.12000 \mathrm{e}-01$

$1.00000 \mathrm{e}-05$ 1.00000e-05 1.00000e-06 1.00000e-09 1.00000e-01

$1.00000 \mathrm{e}+001.00000 \mathrm{e}+00$ 1.00000e-01 1.00000e-09 1.00000e-01

Element: 9754 \# of layers: 7

Kx Ky Kz Ss Por

$2.01224 \mathrm{e}+012.01224 \mathrm{e}+012.01224 \mathrm{e}+001.00000 \mathrm{e}-092.12000 \mathrm{e}-01$

$2.01224 \mathrm{e}+012.01224 \mathrm{e}+012.01224 \mathrm{e}+001.00000 \mathrm{e}-092.12000 \mathrm{e}-01$

$2.01224 \mathrm{e}+012.01224 \mathrm{e}+012.01224 \mathrm{e}+001.00000 \mathrm{e}-092.12000 \mathrm{e}-01$

$2.01224 \mathrm{e}+012.01224 \mathrm{e}+012.01224 \mathrm{e}+001.00000 \mathrm{e}-092.12000 \mathrm{e}-01$

$2.01224 \mathrm{e}+012.01224 \mathrm{e}+012.01224 \mathrm{e}+001.00000 \mathrm{e}-092.12000 \mathrm{e}-01$

$1.00000 \mathrm{e}-05$ 1.00000e-05 1.00000e-06 1.00000e-09 1.00000e-01

$1.00000 \mathrm{e}+001.00000 \mathrm{e}+001.00000 \mathrm{e}-011.00000 \mathrm{e}-091.00000 \mathrm{e}-01$

Element: 9755 \# of layers: 7

Kx Ky Kz Ss Por

$2.01224 \mathrm{e}+012.01224 \mathrm{e}+012.01224 \mathrm{e}+001.00000 \mathrm{e}-092.12000 \mathrm{e}-01$

$2.01224 \mathrm{e}+012.01224 \mathrm{e}+012.01224 \mathrm{e}+001.00000 \mathrm{e}-092.12000 \mathrm{e}-01$

$2.01224 \mathrm{e}+012.01224 \mathrm{e}+012.01224 \mathrm{e}+001.00000 \mathrm{e}-092.12000 \mathrm{e}-01$

$2.01224 \mathrm{e}+012.01224 \mathrm{e}+012.01224 \mathrm{e}+001.00000 \mathrm{e}-092.12000 \mathrm{e}-01$

$2.01224 \mathrm{e}+012.01224 \mathrm{e}+012.01224 \mathrm{e}+001.00000 \mathrm{e}-092.12000 \mathrm{e}-01$

$1.00000 \mathrm{e}-05$ 1.00000e-05 1.00000e-06 1.00000e-09 1.00000e-01

$1.00000 \mathrm{e}+001.00000 \mathrm{e}+001.00000 \mathrm{e}-011.00000 \mathrm{e}-091.00000 \mathrm{e}-01$

Element: 9756 \# of layers: 7

Kx Ky Kz Ss Por

$2.01224 \mathrm{e}+012.01224 \mathrm{e}+012.01224 \mathrm{e}+00$ 1.00000e-09 2.12000e-01

$2.01224 \mathrm{e}+012.01224 \mathrm{e}+012.01224 \mathrm{e}+001.00000 \mathrm{e}-092.12000 \mathrm{e}-01$

$2.01224 \mathrm{e}+012.01224 \mathrm{e}+012.01224 \mathrm{e}+001.00000 \mathrm{e}-092.12000 \mathrm{e}-01$

$2.01224 \mathrm{e}+012.01224 \mathrm{e}+012.01224 \mathrm{e}+001.00000 \mathrm{e}-092.12000 \mathrm{e}-01$

$2.01224 \mathrm{e}+012.01224 \mathrm{e}+012.01224 \mathrm{e}+001.00000 \mathrm{e}-092.12000 \mathrm{e}-01$

$1.00000 \mathrm{e}-05$ 1.00000e-05 1.00000e-06 1.00000e-09 1.00000e-01

$1.00000 \mathrm{e}+001.00000 \mathrm{e}+001.00000 \mathrm{e}-011.00000 \mathrm{e}-091.00000 \mathrm{e}-01$

Element: 9757 \# of layers: 7 
$\mathrm{Kx} \mathrm{Ky} \mathrm{Kz}$ Ss Por

$2.01224 \mathrm{e}+012.01224 \mathrm{e}+012.01224 \mathrm{e}+00$ 1.00000e-09 2.12000e-01

$2.01224 \mathrm{e}+012.01224 \mathrm{e}+012.01224 \mathrm{e}+001.00000 \mathrm{e}-092.12000 \mathrm{e}-01$

$2.01224 \mathrm{e}+012.01224 \mathrm{e}+012.01224 \mathrm{e}+001.00000 \mathrm{e}-092.12000 \mathrm{e}-01$

$2.01224 \mathrm{e}+012.01224 \mathrm{e}+012.01224 \mathrm{e}+001.00000 \mathrm{e}-092.12000 \mathrm{e}-01$

$2.01224 \mathrm{e}+012.01224 \mathrm{e}+012.01224 \mathrm{e}+001.00000 \mathrm{e}-092.12000 \mathrm{e}-01$

$1.00000 \mathrm{e}-05$ 1.00000e-05 1.00000e-06 1.00000e-09 1.00000e-01

$1.00000 \mathrm{e}+001.00000 \mathrm{e}+001.00000 \mathrm{e}-011.00000 \mathrm{e}-091.00000 \mathrm{e}-01$

Element: 9758 \# of layers: 7

$\mathrm{Kx} \mathrm{Ky} \mathrm{Kz}$ Ss Por

$2.01224 \mathrm{e}+012.01224 \mathrm{e}+012.01224 \mathrm{e}+00$ 1.00000e-09 2.12000e-01 $2.01224 \mathrm{e}+012.01224 \mathrm{e}+012.01224 \mathrm{e}+001.00000 \mathrm{e}-092.12000 \mathrm{e}-01$ $2.01224 \mathrm{e}+012.01224 \mathrm{e}+012.01224 \mathrm{e}+001.00000 \mathrm{e}-092.12000 \mathrm{e}-01$ $2.01224 \mathrm{e}+012.01224 \mathrm{e}+012.01224 \mathrm{e}+001.00000 \mathrm{e}-092.12000 \mathrm{e}-01$ $2.01224 \mathrm{e}+012.01224 \mathrm{e}+012.01224 \mathrm{e}+001.00000 \mathrm{e}-092.12000 \mathrm{e}-01$ $1.00000 \mathrm{e}-05$ 1.00000e-05 1.00000e-06 1.00000e-09 1.00000e-01 $1.00000 \mathrm{e}+001.00000 \mathrm{e}+001.00000 \mathrm{e}-01$ 1.00000e-09 1.00000e-01 Element: 9759 \# of layers: 7

$\mathrm{Kx} \mathrm{Ky} \mathrm{Kz}$ Ss Por

$2.01224 \mathrm{e}+012.01224 \mathrm{e}+012.01224 \mathrm{e}+001.00000 \mathrm{e}-092.12000 \mathrm{e}-01$ $2.01224 \mathrm{e}+012.01224 \mathrm{e}+012.01224 \mathrm{e}+001.00000 \mathrm{e}-092.12000 \mathrm{e}-01$ $2.01224 \mathrm{e}+012.01224 \mathrm{e}+012.01224 \mathrm{e}+001.00000 \mathrm{e}-092.12000 \mathrm{e}-01$ $2.01224 \mathrm{e}+012.01224 \mathrm{e}+012.01224 \mathrm{e}+001.00000 \mathrm{e}-092.12000 \mathrm{e}-01$ $2.01224 \mathrm{e}+012.01224 \mathrm{e}+012.01224 \mathrm{e}+001.00000 \mathrm{e}-092.12000 \mathrm{e}-01$ $1.00000 \mathrm{e}-05$ 1.00000e-05 1.00000e-06 1.00000e-09 1.00000e-01 $1.00000 \mathrm{e}+001.00000 \mathrm{e}+001.00000 \mathrm{e}-01$ 1.00000e-09 1.00000e-01 Element: 9760 \# of layers: 7

$\mathrm{Kx} \mathrm{Ky} \mathrm{Kz} \mathrm{Ss} \mathrm{Por}$

$2.05126 \mathrm{e}+012.05126 \mathrm{e}+012.05126 \mathrm{e}+001.00000 \mathrm{e}-092.12000 \mathrm{e}-01$ $2.05126 \mathrm{e}+012.05126 \mathrm{e}+012.05126 \mathrm{e}+001.00000 \mathrm{e}-092.12000 \mathrm{e}-01$ $2.05126 \mathrm{e}+012.05126 \mathrm{e}+012.05126 \mathrm{e}+001.00000 \mathrm{e}-092.12000 \mathrm{e}-01$ $2.05126 \mathrm{e}+012.05126 \mathrm{e}+012.05126 \mathrm{e}+001.00000 \mathrm{e}-092.12000 \mathrm{e}-01$ $2.05126 \mathrm{e}+012.05126 \mathrm{e}+012.05126 \mathrm{e}+001.00000 \mathrm{e}-092.12000 \mathrm{e}-01$ $1.00000 \mathrm{e}-05$ 1.00000e-05 1.00000e-06 1.00000e-09 1.00000e-01 $1.00000 \mathrm{e}+001.00000 \mathrm{e}+001.00000 \mathrm{e}-011.00000 \mathrm{e}-091.00000 \mathrm{e}-01$ Element: 9761 \# of layers: 7

$\mathrm{Kx} \mathrm{Ky} \mathrm{Kz}$ Ss Por

$2.05126 \mathrm{e}+012.05126 \mathrm{e}+012.05126 \mathrm{e}+001.00000 \mathrm{e}-092.12000 \mathrm{e}-01$ $2.05126 \mathrm{e}+012.05126 \mathrm{e}+012.05126 \mathrm{e}+001.00000 \mathrm{e}-092.12000 \mathrm{e}-01$ $2.05126 \mathrm{e}+012.05126 \mathrm{e}+012.05126 \mathrm{e}+001.00000 \mathrm{e}-092.12000 \mathrm{e}-01$ $2.05126 \mathrm{e}+012.05126 \mathrm{e}+012.05126 \mathrm{e}+001.00000 \mathrm{e}-092.12000 \mathrm{e}-01$ $2.05126 \mathrm{e}+012.05126 \mathrm{e}+012.05126 \mathrm{e}+001.00000 \mathrm{e}-092.12000 \mathrm{e}-01$ $1.00000 \mathrm{e}-05$ 1.00000e-05 1.00000e-06 1.00000e-09 1.00000e-01 $1.00000 \mathrm{e}+001.00000 \mathrm{e}+001.00000 \mathrm{e}-01$ 1.00000e-09 1.00000e-01 Element: 9762 \# of layers: 7

Kx Ky Kz Ss Por 
$2.05126 \mathrm{e}+012.05126 \mathrm{e}+012.05126 \mathrm{e}+00$ 1.00000e-09 2.12000e-01 $2.05126 \mathrm{e}+012.05126 \mathrm{e}+012.05126 \mathrm{e}+001.00000 \mathrm{e}-092.12000 \mathrm{e}-01$ $2.05126 \mathrm{e}+012.05126 \mathrm{e}+012.05126 \mathrm{e}+001.00000 \mathrm{e}-092.12000 \mathrm{e}-01$ $2.05126 \mathrm{e}+012.05126 \mathrm{e}+012.05126 \mathrm{e}+001.00000 \mathrm{e}-092.12000 \mathrm{e}-01$ $2.05126 \mathrm{e}+012.05126 \mathrm{e}+012.05126 \mathrm{e}+001.00000 \mathrm{e}-092.12000 \mathrm{e}-01$ $1.00000 \mathrm{e}-05$ 1.00000e-05 1.00000e-06 1.00000e-09 1.00000e-01 $1.00000 \mathrm{e}+001.00000 \mathrm{e}+001.00000 \mathrm{e}-01$ 1.00000e-09 1.00000e-01 Element: 9763 \# of layers: 7

$\mathrm{Kx} \mathrm{Ky} \mathrm{Kz}$ Ss Por

$2.05126 \mathrm{e}+012.05126 \mathrm{e}+012.05126 \mathrm{e}+001.00000 \mathrm{e}-092.12000 \mathrm{e}-01$ $2.05126 \mathrm{e}+012.05126 \mathrm{e}+012.05126 \mathrm{e}+001.00000 \mathrm{e}-092.12000 \mathrm{e}-01$ $2.05126 \mathrm{e}+012.05126 \mathrm{e}+012.05126 \mathrm{e}+001.00000 \mathrm{e}-092.12000 \mathrm{e}-01$ $2.05126 \mathrm{e}+012.05126 \mathrm{e}+012.05126 \mathrm{e}+001.00000 \mathrm{e}-092.12000 \mathrm{e}-01$ $2.05126 \mathrm{e}+012.05126 \mathrm{e}+012.05126 \mathrm{e}+001.00000 \mathrm{e}-092.12000 \mathrm{e}-01$ $1.00000 \mathrm{e}-05$ 1.00000e-05 1.00000e-06 1.00000e-09 1.00000e-01 $1.00000 \mathrm{e}+001.00000 \mathrm{e}+001.00000 \mathrm{e}-011.00000 \mathrm{e}-091.00000 \mathrm{e}-01$ Element: 9764 \# of layers: 7

$\mathrm{Kx} \mathrm{Ky} \mathrm{Kz}$ Ss Por

$2.05126 \mathrm{e}+012.05126 \mathrm{e}+012.05126 \mathrm{e}+00$ 1.00000e-09 2.12000e-01 $2.05126 \mathrm{e}+012.05126 \mathrm{e}+012.05126 \mathrm{e}+001.00000 \mathrm{e}-092.12000 \mathrm{e}-01$ $2.05126 \mathrm{e}+012.05126 \mathrm{e}+012.05126 \mathrm{e}+001.00000 \mathrm{e}-092.12000 \mathrm{e}-01$ $2.05126 \mathrm{e}+012.05126 \mathrm{e}+012.05126 \mathrm{e}+001.00000 \mathrm{e}-092.12000 \mathrm{e}-01$ $2.05126 \mathrm{e}+012.05126 \mathrm{e}+012.05126 \mathrm{e}+001.00000 \mathrm{e}-092.12000 \mathrm{e}-01$ $1.00000 \mathrm{e}-05$ 1.00000e-05 1.00000e-06 1.00000e-09 1.00000e-01 $1.00000 \mathrm{e}+001.00000 \mathrm{e}+001.00000 \mathrm{e}-011.00000 \mathrm{e}-091.00000 \mathrm{e}-01$ Element: 9765 \# of layers: 7

$\mathrm{Kx} \mathrm{Ky} \mathrm{Kz}$ Ss Por

$2.01224 \mathrm{e}+012.01224 \mathrm{e}+012.01224 \mathrm{e}+001.00000 \mathrm{e}-092.12000 \mathrm{e}-01$ $2.01224 \mathrm{e}+012.01224 \mathrm{e}+012.01224 \mathrm{e}+001.00000 \mathrm{e}-092.12000 \mathrm{e}-01$ $2.01224 \mathrm{e}+012.01224 \mathrm{e}+012.01224 \mathrm{e}+001.00000 \mathrm{e}-092.12000 \mathrm{e}-01$ $2.01224 \mathrm{e}+012.01224 \mathrm{e}+012.01224 \mathrm{e}+001.00000 \mathrm{e}-092.12000 \mathrm{e}-01$ $2.01224 \mathrm{e}+012.01224 \mathrm{e}+012.01224 \mathrm{e}+001.00000 \mathrm{e}-092.12000 \mathrm{e}-01$ $1.00000 \mathrm{e}-05$ 1.00000e-05 1.00000e-06 1.00000e-09 1.00000e-01 $1.00000 \mathrm{e}+001.00000 \mathrm{e}+001.00000 \mathrm{e}-011.00000 \mathrm{e}-091.00000 \mathrm{e}-01$ Element: 9766 \# of layers: 7

$\mathrm{Kx} \mathrm{Ky} \mathrm{Kz}$ Ss Por

$2.01224 \mathrm{e}+012.01224 \mathrm{e}+012.01224 \mathrm{e}+001.00000 \mathrm{e}-092.12000 \mathrm{e}-01$ $2.01224 \mathrm{e}+012.01224 \mathrm{e}+012.01224 \mathrm{e}+001.00000 \mathrm{e}-092.12000 \mathrm{e}-01$ $2.01224 \mathrm{e}+012.01224 \mathrm{e}+012.01224 \mathrm{e}+001.00000 \mathrm{e}-092.12000 \mathrm{e}-01$ $2.01224 \mathrm{e}+012.01224 \mathrm{e}+012.01224 \mathrm{e}+001.00000 \mathrm{e}-092.12000 \mathrm{e}-01$ $2.01224 \mathrm{e}+012.01224 \mathrm{e}+012.01224 \mathrm{e}+001.00000 \mathrm{e}-092.12000 \mathrm{e}-01$ $1.00000 \mathrm{e}-05$ 1.00000e-05 1.00000e-06 1.00000e-09 1.00000e-01 $1.00000 \mathrm{e}+001.00000 \mathrm{e}+001.00000 \mathrm{e}-011.00000 \mathrm{e}-091.00000 \mathrm{e}-01$ Element: 9767 \# of layers: 7

$\mathrm{Kx} \mathrm{Ky} \mathrm{Kz}$ Ss Por

2.05126e+01 2.05126e+01 2.05126e+00 1.00000e-09 2.12000e-01 
$2.05126 \mathrm{e}+012.05126 \mathrm{e}+012.05126 \mathrm{e}+00$ 1.00000e-09 2.12000e-01 $2.05126 \mathrm{e}+012.05126 \mathrm{e}+012.05126 \mathrm{e}+001.00000 \mathrm{e}-092.12000 \mathrm{e}-01$ $2.05126 \mathrm{e}+012.05126 \mathrm{e}+012.05126 \mathrm{e}+001.00000 \mathrm{e}-092.12000 \mathrm{e}-01$ $2.05126 \mathrm{e}+012.05126 \mathrm{e}+012.05126 \mathrm{e}+001.00000 \mathrm{e}-092.12000 \mathrm{e}-01$ $1.00000 \mathrm{e}-05$ 1.00000e-05 1.00000e-06 1.00000e-09 1.00000e-01 $1.00000 \mathrm{e}+001.00000 \mathrm{e}+001.00000 \mathrm{e}-011.00000 \mathrm{e}-091.00000 \mathrm{e}-01$ Element: 9768 \# of layers: 7

$\mathrm{Kx} \mathrm{Ky} \mathrm{Kz}$ Ss Por

$2.05126 \mathrm{e}+012.05126 \mathrm{e}+012.05126 \mathrm{e}+001.00000 \mathrm{e}-092.12000 \mathrm{e}-01$ $2.05126 \mathrm{e}+012.05126 \mathrm{e}+012.05126 \mathrm{e}+001.00000 \mathrm{e}-092.12000 \mathrm{e}-01$ $2.05126 \mathrm{e}+012.05126 \mathrm{e}+012.05126 \mathrm{e}+001.00000 \mathrm{e}-092.12000 \mathrm{e}-01$ $2.05126 \mathrm{e}+012.05126 \mathrm{e}+012.05126 \mathrm{e}+001.00000 \mathrm{e}-092.12000 \mathrm{e}-01$ $2.05126 \mathrm{e}+012.05126 \mathrm{e}+012.05126 \mathrm{e}+001.00000 \mathrm{e}-092.12000 \mathrm{e}-01$ $1.00000 \mathrm{e}-05$ 1.00000e-05 1.00000e-06 1.00000e-09 1.00000e-01 $1.00000 \mathrm{e}+001.00000 \mathrm{e}+001.00000 \mathrm{e}-01$ 1.00000e-09 1.00000e-01 Element: 9769 \# of layers: 7

$\mathrm{Kx} \mathrm{Ky} \mathrm{Kz}$ Ss Por

$2.08035 \mathrm{e}+012.08035 \mathrm{e}+012.08035 \mathrm{e}+00$ 1.00000e-09 2.12000e-01 $2.08035 \mathrm{e}+012.08035 \mathrm{e}+012.08035 \mathrm{e}+001.00000 \mathrm{e}-092.12000 \mathrm{e}-01$ $2.08035 \mathrm{e}+012.08035 \mathrm{e}+012.08035 \mathrm{e}+001.00000 \mathrm{e}-092.12000 \mathrm{e}-01$ $2.08035 \mathrm{e}+012.08035 \mathrm{e}+012.08035 \mathrm{e}+00 \quad 1.00000 \mathrm{e}-092.12000 \mathrm{e}-01$ $2.08035 \mathrm{e}+012.08035 \mathrm{e}+012.08035 \mathrm{e}+00$ 1.00000e-09 2.12000e-01 $1.00000 \mathrm{e}-051.00000 \mathrm{e}-05$ 1.00000e-06 1.00000e-09 1.00000e-01 $1.00000 \mathrm{e}+001.00000 \mathrm{e}+001.00000 \mathrm{e}-011.00000 \mathrm{e}-091.00000 \mathrm{e}-01$ Element: 9770 \# of layers: 7

$\mathrm{Kx} \mathrm{Ky} \mathrm{Kz}$ Ss Por

$2.08035 \mathrm{e}+012.08035 \mathrm{e}+012.08035 \mathrm{e}+00$ 1.00000e-09 2.12000e-01 $2.08035 \mathrm{e}+012.08035 \mathrm{e}+012.08035 \mathrm{e}+001.00000 \mathrm{e}-092.12000 \mathrm{e}-01$ $2.08035 \mathrm{e}+012.08035 \mathrm{e}+012.08035 \mathrm{e}+001.00000 \mathrm{e}-092.12000 \mathrm{e}-01$ $2.08035 \mathrm{e}+012.08035 \mathrm{e}+012.08035 \mathrm{e}+001.00000 \mathrm{e}-092.12000 \mathrm{e}-01$ $2.08035 \mathrm{e}+012.08035 \mathrm{e}+012.08035 \mathrm{e}+001.00000 \mathrm{e}-092.12000 \mathrm{e}-01$ $1.00000 \mathrm{e}-05$ 1.00000e-05 1.00000e-06 1.00000e-09 1.00000e-01 $1.00000 \mathrm{e}+001.00000 \mathrm{e}+001.00000 \mathrm{e}-011.00000 \mathrm{e}-091.00000 \mathrm{e}-01$ Element: 9771 \# of layers: 7

$\mathrm{Kx} \mathrm{Ky} \mathrm{Kz}$ Ss Por

$2.08035 \mathrm{e}+012.08035 \mathrm{e}+012.08035 \mathrm{e}+00$ 1.00000e-09 2.12000e-01 $2.08035 \mathrm{e}+012.08035 \mathrm{e}+012.08035 \mathrm{e}+001.00000 \mathrm{e}-092.12000 \mathrm{e}-01$ $2.08035 \mathrm{e}+012.08035 \mathrm{e}+012.08035 \mathrm{e}+001.00000 \mathrm{e}-092.12000 \mathrm{e}-01$ $2.08035 \mathrm{e}+012.08035 \mathrm{e}+012.08035 \mathrm{e}+001.00000 \mathrm{e}-092.12000 \mathrm{e}-01$ $2.08035 \mathrm{e}+012.08035 \mathrm{e}+012.08035 \mathrm{e}+001.00000 \mathrm{e}-092.12000 \mathrm{e}-01$ $1.00000 \mathrm{e}-05$ 1.00000e-05 1.00000e-06 1.00000e-09 1.00000e-01 $1.00000 \mathrm{e}+001.00000 \mathrm{e}+001.00000 \mathrm{e}-011.00000 \mathrm{e}-091.00000 \mathrm{e}-01$ Element: 9772 \# of layers: 7

$\mathrm{Kx} \mathrm{Ky} \mathrm{Kz}$ Ss Por

2.10267e+01 2.10267e+01 2.10267e+00 1.00000e-09 2.12000e-01 $2.10267 \mathrm{e}+012.10267 \mathrm{e}+012.10267 \mathrm{e}+00$ 1.00000e-09 2.12000e-01 
$2.10267 \mathrm{e}+012.10267 \mathrm{e}+012.10267 \mathrm{e}+00$ 1.00000e-09 2.12000e-01 $2.10267 \mathrm{e}+012.10267 \mathrm{e}+012.10267 \mathrm{e}+00$ 1.00000e-09 2.12000e-01 $2.10267 \mathrm{e}+012.10267 \mathrm{e}+012.10267 \mathrm{e}+00$ 1.00000e-09 2.12000e-01 $1.00000 \mathrm{e}-05$ 1.00000e-05 1.00000e-06 1.00000e-09 1.00000e-01 $1.00000 \mathrm{e}+001.00000 \mathrm{e}+001.00000 \mathrm{e}-011.00000 \mathrm{e}-091.00000 \mathrm{e}-01$ Element: 9773 \# of layers: 7

Kx Ky Kz Ss Por

$2.10267 \mathrm{e}+012.10267 \mathrm{e}+012.10267 \mathrm{e}+00$ 1.00000e-09 2.12000e-01 $2.10267 \mathrm{e}+012.10267 \mathrm{e}+012.10267 \mathrm{e}+00$ 1.00000e-09 2.12000e-01 $2.10267 \mathrm{e}+012.10267 \mathrm{e}+012.10267 \mathrm{e}+001.00000 \mathrm{e}-092.12000 \mathrm{e}-01$ $2.10267 \mathrm{e}+012.10267 \mathrm{e}+012.10267 \mathrm{e}+001.00000 \mathrm{e}-092.12000 \mathrm{e}-01$ $2.10267 \mathrm{e}+012.10267 \mathrm{e}+012.10267 \mathrm{e}+001.00000 \mathrm{e}-092.12000 \mathrm{e}-01$ $1.00000 \mathrm{e}-05$ 1.00000e-05 1.00000e-06 1.00000e-09 1.00000e-01 $1.00000 \mathrm{e}+001.00000 \mathrm{e}+001.00000 \mathrm{e}-011.00000 \mathrm{e}-091.00000 \mathrm{e}-01$ Element: 9774 \# of layers: 7

Kx Ky Kz Ss Por

$2.01224 \mathrm{e}+012.01224 \mathrm{e}+012.01224 \mathrm{e}+00$ 1.00000e-09 2.12000e-01 $2.01224 \mathrm{e}+012.01224 \mathrm{e}+012.01224 \mathrm{e}+001.00000 \mathrm{e}-092.12000 \mathrm{e}-01$ $2.01224 \mathrm{e}+012.01224 \mathrm{e}+012.01224 \mathrm{e}+001.00000 \mathrm{e}-092.12000 \mathrm{e}-01$ $2.01224 \mathrm{e}+012.01224 \mathrm{e}+012.01224 \mathrm{e}+001.00000 \mathrm{e}-092.12000 \mathrm{e}-01$ $2.01224 \mathrm{e}+012.01224 \mathrm{e}+012.01224 \mathrm{e}+001.00000 \mathrm{e}-092.12000 \mathrm{e}-01$ $1.00000 \mathrm{e}-05$ 1.00000e-05 1.00000e-06 1.00000e-09 1.00000e-01 $1.00000 \mathrm{e}+001.00000 \mathrm{e}+00$ 1.00000e-01 1.00000e-09 1.00000e-01 Element: 9775 \# of layers: 7

Kx Ky Kz Ss Por

$2.05126 \mathrm{e}+012.05126 \mathrm{e}+012.05126 \mathrm{e}+00$ 1.00000e-09 2.12000e-01 $2.05126 \mathrm{e}+012.05126 \mathrm{e}+012.05126 \mathrm{e}+001.00000 \mathrm{e}-092.12000 \mathrm{e}-01$ $2.05126 \mathrm{e}+012.05126 \mathrm{e}+012.05126 \mathrm{e}+001.00000 \mathrm{e}-092.12000 \mathrm{e}-01$ $2.05126 \mathrm{e}+012.05126 \mathrm{e}+012.05126 \mathrm{e}+001.00000 \mathrm{e}-092.12000 \mathrm{e}-01$ $2.05126 \mathrm{e}+012.05126 \mathrm{e}+012.05126 \mathrm{e}+001.00000 \mathrm{e}-092.12000 \mathrm{e}-01$ $1.00000 \mathrm{e}-05$ 1.00000e-05 1.00000e-06 1.00000e-09 1.00000e-01 $1.00000 \mathrm{e}+001.00000 \mathrm{e}+001.00000 \mathrm{e}-011.00000 \mathrm{e}-091.00000 \mathrm{e}-01$ Element: 9776 \# of layers: 7

Kx Ky Kz Ss Por $2.08035 \mathrm{e}+012.08035 \mathrm{e}+012.08035 \mathrm{e}+00$ 1.00000e-09 2.12000e-01 $2.08035 \mathrm{e}+012.08035 \mathrm{e}+012.08035 \mathrm{e}+001.00000 \mathrm{e}-092.12000 \mathrm{e}-01$ $2.08035 \mathrm{e}+012.08035 \mathrm{e}+012.08035 \mathrm{e}+001.00000 \mathrm{e}-092.12000 \mathrm{e}-01$ $2.08035 \mathrm{e}+012.08035 \mathrm{e}+012.08035 \mathrm{e}+001.00000 \mathrm{e}-092.12000 \mathrm{e}-01$ $2.08035 \mathrm{e}+012.08035 \mathrm{e}+012.08035 \mathrm{e}+00$ 1.00000e-09 2.12000e-01 $1.00000 \mathrm{e}-05$ 1.00000e-05 1.00000e-06 1.00000e-09 1.00000e-01 $1.00000 \mathrm{e}+001.00000 \mathrm{e}+001.00000 \mathrm{e}-011.00000 \mathrm{e}-091.00000 \mathrm{e}-01$ Element: 9777 \# of layers: 7

Kx Ky Kz Ss Por

$2.57181 \mathrm{e}+012.57181 \mathrm{e}+012.57181 \mathrm{e}+001.00000 \mathrm{e}-092.12000 \mathrm{e}-01$ $2.57181 \mathrm{e}+012.57181 \mathrm{e}+012.57181 \mathrm{e}+001.00000 \mathrm{e}-092.12000 \mathrm{e}-01$ $2.57181 \mathrm{e}+012.57181 \mathrm{e}+012.57181 \mathrm{e}+001.00000 \mathrm{e}-092.12000 \mathrm{e}-01$ 
$2.57181 \mathrm{e}+012.57181 \mathrm{e}+012.57181 \mathrm{e}+001.00000 \mathrm{e}-092.12000 \mathrm{e}-01$ $2.57181 \mathrm{e}+012.57181 \mathrm{e}+012.57181 \mathrm{e}+001.00000 \mathrm{e}-092.12000 \mathrm{e}-01$ $1.00000 \mathrm{e}-05$ 1.00000e-05 1.00000e-06 1.00000e-09 1.00000e-01 $1.00000 \mathrm{e}+001.00000 \mathrm{e}+001.00000 \mathrm{e}-011.00000 \mathrm{e}-091.00000 \mathrm{e}-01$ Element: 9778 \# of layers: 7

Kx Ky Kz Ss Por

$2.57181 \mathrm{e}+012.57181 \mathrm{e}+012.57181 \mathrm{e}+00$ 1.00000e-09 2.12000e-01 $2.57181 \mathrm{e}+012.57181 \mathrm{e}+012.57181 \mathrm{e}+001.00000 \mathrm{e}-092.12000 \mathrm{e}-01$ $2.57181 \mathrm{e}+012.57181 \mathrm{e}+012.57181 \mathrm{e}+001.00000 \mathrm{e}-092.12000 \mathrm{e}-01$ $2.57181 \mathrm{e}+012.57181 \mathrm{e}+012.57181 \mathrm{e}+001.00000 \mathrm{e}-092.12000 \mathrm{e}-01$ $2.57181 \mathrm{e}+012.57181 \mathrm{e}+012.57181 \mathrm{e}+001.00000 \mathrm{e}-092.12000 \mathrm{e}-01$ $1.00000 \mathrm{e}-05$ 1.00000e-05 1.00000e-06 1.00000e-09 1.00000e-01 $1.00000 \mathrm{e}+001.00000 \mathrm{e}+001.00000 \mathrm{e}-011.00000 \mathrm{e}-091.00000 \mathrm{e}-01$ Element: 9779 \# of layers: 7

Kx Ky Kz Ss Por

$2.57181 \mathrm{e}+012.57181 \mathrm{e}+012.57181 \mathrm{e}+00$ 1.00000e-09 2.12000e-01 $2.57181 \mathrm{e}+012.57181 \mathrm{e}+012.57181 \mathrm{e}+001.00000 \mathrm{e}-092.12000 \mathrm{e}-01$

$2.57181 \mathrm{e}+012.57181 \mathrm{e}+012.57181 \mathrm{e}+001.00000 \mathrm{e}-092.12000 \mathrm{e}-01$

$2.57181 \mathrm{e}+012.57181 \mathrm{e}+012.57181 \mathrm{e}+001.00000 \mathrm{e}-092.12000 \mathrm{e}-01$

$2.57181 \mathrm{e}+012.57181 \mathrm{e}+012.57181 \mathrm{e}+001.00000 \mathrm{e}-092.12000 \mathrm{e}-01$ $1.00000 \mathrm{e}-05$ 1.00000e-05 1.00000e-06 1.00000e-09 1.00000e-01 $1.00000 \mathrm{e}+001.00000 \mathrm{e}+001.00000 \mathrm{e}-011.00000 \mathrm{e}-091.00000 \mathrm{e}-01$ Element: 9780 \# of layers: 7

Kx Ky Kz Ss Por

$2.57181 \mathrm{e}+012.57181 \mathrm{e}+012.57181 \mathrm{e}+00$ 1.00000e-09 2.12000e-01

$2.57181 \mathrm{e}+012.57181 \mathrm{e}+012.57181 \mathrm{e}+001.00000 \mathrm{e}-092.12000 \mathrm{e}-01$

$2.57181 \mathrm{e}+012.57181 \mathrm{e}+012.57181 \mathrm{e}+001.00000 \mathrm{e}-092.12000 \mathrm{e}-01$

$2.57181 \mathrm{e}+012.57181 \mathrm{e}+012.57181 \mathrm{e}+001.00000 \mathrm{e}-092.12000 \mathrm{e}-01$

$2.57181 \mathrm{e}+012.57181 \mathrm{e}+012.57181 \mathrm{e}+001.00000 \mathrm{e}-092.12000 \mathrm{e}-01$ $1.00000 \mathrm{e}-05$ 1.00000e-05 1.00000e-06 1.00000e-09 1.00000e-01 $1.00000 \mathrm{e}+001.00000 \mathrm{e}+001.00000 \mathrm{e}-011.00000 \mathrm{e}-091.00000 \mathrm{e}-01$ Element: 9781 \# of layers: 7

Kx Ky Kz Ss Por

$2.57181 \mathrm{e}+012.57181 \mathrm{e}+012.57181 \mathrm{e}+00$ 1.00000e-09 2.12000e-01

$2.57181 \mathrm{e}+012.57181 \mathrm{e}+012.57181 \mathrm{e}+001.00000 \mathrm{e}-092.12000 \mathrm{e}-01$

$2.57181 \mathrm{e}+012.57181 \mathrm{e}+012.57181 \mathrm{e}+001.00000 \mathrm{e}-092.12000 \mathrm{e}-01$

$2.57181 \mathrm{e}+012.57181 \mathrm{e}+012.57181 \mathrm{e}+001.00000 \mathrm{e}-092.12000 \mathrm{e}-01$

$2.57181 \mathrm{e}+012.57181 \mathrm{e}+012.57181 \mathrm{e}+001.00000 \mathrm{e}-092.12000 \mathrm{e}-01$ $1.00000 \mathrm{e}-05$ 1.00000e-05 1.00000e-06 1.00000e-09 1.00000e-01 $1.00000 \mathrm{e}+001.00000 \mathrm{e}+001.00000 \mathrm{e}-011.00000 \mathrm{e}-091.00000 \mathrm{e}-01$ Element: 9782 \# of layers: 7

Kx Ky Kz Ss Por

$2.57181 \mathrm{e}+012.57181 \mathrm{e}+012.57181 \mathrm{e}+00$ 1.00000e-09 2.12000e-01 $2.57181 \mathrm{e}+012.57181 \mathrm{e}+012.57181 \mathrm{e}+001.00000 \mathrm{e}-092.12000 \mathrm{e}-01$ $2.57181 \mathrm{e}+012.57181 \mathrm{e}+012.57181 \mathrm{e}+001.00000 \mathrm{e}-092.12000 \mathrm{e}-01$ $2.57181 \mathrm{e}+012.57181 \mathrm{e}+012.57181 \mathrm{e}+001.00000 \mathrm{e}-092.12000 \mathrm{e}-01$ 
$2.57181 \mathrm{e}+012.57181 \mathrm{e}+012.57181 \mathrm{e}+001.00000 \mathrm{e}-092.12000 \mathrm{e}-01$ $1.00000 \mathrm{e}-05$ 1.00000e-05 1.00000e-06 1.00000e-09 1.00000e-01 $1.00000 \mathrm{e}+001.00000 \mathrm{e}+001.00000 \mathrm{e}-011.00000 \mathrm{e}-091.00000 \mathrm{e}-01$ Element: 9783 \# of layers: 7

Kx Ky Kz Ss Por

$2.57181 \mathrm{e}+012.57181 \mathrm{e}+012.57181 \mathrm{e}+00$ 1.00000e-09 2.12000e-01

$2.57181 \mathrm{e}+012.57181 \mathrm{e}+012.57181 \mathrm{e}+001.00000 \mathrm{e}-092.12000 \mathrm{e}-01$

$2.57181 \mathrm{e}+012.57181 \mathrm{e}+012.57181 \mathrm{e}+001.00000 \mathrm{e}-092.12000 \mathrm{e}-01$

$2.57181 \mathrm{e}+012.57181 \mathrm{e}+012.57181 \mathrm{e}+001.00000 \mathrm{e}-092.12000 \mathrm{e}-01$

$2.57181 \mathrm{e}+012.57181 \mathrm{e}+012.57181 \mathrm{e}+001.00000 \mathrm{e}-092.12000 \mathrm{e}-01$ $1.00000 \mathrm{e}-05$ 1.00000e-05 1.00000e-06 1.00000e-09 1.00000e-01

$1.00000 \mathrm{e}+001.00000 \mathrm{e}+001.00000 \mathrm{e}-011.00000 \mathrm{e}-091.00000 \mathrm{e}-01$

Element: 9784 \# of layers: 7

Kx Ky Kz Ss Por

$2.57181 \mathrm{e}+012.57181 \mathrm{e}+012.57181 \mathrm{e}+00$ 1.00000e-09 2.12000e-01

$2.57181 \mathrm{e}+012.57181 \mathrm{e}+012.57181 \mathrm{e}+001.00000 \mathrm{e}-092.12000 \mathrm{e}-01$

$2.57181 \mathrm{e}+012.57181 \mathrm{e}+012.57181 \mathrm{e}+001.00000 \mathrm{e}-092.12000 \mathrm{e}-01$

$2.57181 \mathrm{e}+012.57181 \mathrm{e}+012.57181 \mathrm{e}+001.00000 \mathrm{e}-092.12000 \mathrm{e}-01$

$2.57181 \mathrm{e}+012.57181 \mathrm{e}+012.57181 \mathrm{e}+001.00000 \mathrm{e}-092.12000 \mathrm{e}-01$ $1.00000 \mathrm{e}-05$ 1.00000e-05 1.00000e-06 1.00000e-09 1.00000e-01 $1.00000 \mathrm{e}+001.00000 \mathrm{e}+001.00000 \mathrm{e}-011.00000 \mathrm{e}-091.00000 \mathrm{e}-01$ Element: 9785 \# of layers: 7

Kx Ky Kz Ss Por

$2.57181 \mathrm{e}+012.57181 \mathrm{e}+012.57181 \mathrm{e}+00$ 1.00000e-09 2.12000e-01

$2.57181 \mathrm{e}+012.57181 \mathrm{e}+012.57181 \mathrm{e}+001.00000 \mathrm{e}-092.12000 \mathrm{e}-01$

$2.57181 \mathrm{e}+012.57181 \mathrm{e}+012.57181 \mathrm{e}+001.00000 \mathrm{e}-092.12000 \mathrm{e}-01$

$2.57181 \mathrm{e}+012.57181 \mathrm{e}+012.57181 \mathrm{e}+001.00000 \mathrm{e}-092.12000 \mathrm{e}-01$

$2.57181 \mathrm{e}+012.57181 \mathrm{e}+012.57181 \mathrm{e}+001.00000 \mathrm{e}-092.12000 \mathrm{e}-01$

$1.00000 \mathrm{e}-05$ 1.00000e-05 1.00000e-06 1.00000e-09 1.00000e-01

$1.00000 \mathrm{e}+001.00000 \mathrm{e}+001.00000 \mathrm{e}-011.00000 \mathrm{e}-091.00000 \mathrm{e}-01$

Element: 9786 \# of layers: 7

Kx Ky Kz Ss Por

$2.57181 \mathrm{e}+012.57181 \mathrm{e}+012.57181 \mathrm{e}+00$ 1.00000e-09 2.12000e-01

$2.57181 \mathrm{e}+012.57181 \mathrm{e}+012.57181 \mathrm{e}+001.00000 \mathrm{e}-092.12000 \mathrm{e}-01$

$2.57181 \mathrm{e}+012.57181 \mathrm{e}+012.57181 \mathrm{e}+001.00000 \mathrm{e}-092.12000 \mathrm{e}-01$

$2.57181 \mathrm{e}+012.57181 \mathrm{e}+012.57181 \mathrm{e}+001.00000 \mathrm{e}-092.12000 \mathrm{e}-01$

$2.57181 \mathrm{e}+012.57181 \mathrm{e}+012.57181 \mathrm{e}+001.00000 \mathrm{e}-092.12000 \mathrm{e}-01$ $1.00000 \mathrm{e}-05$ 1.00000e-05 1.00000e-06 1.00000e-09 1.00000e-01 $1.00000 \mathrm{e}+001.00000 \mathrm{e}+001.00000 \mathrm{e}-011.00000 \mathrm{e}-091.00000 \mathrm{e}-01$ Element: 9787 \# of layers: 7

Kx Ky Kz Ss Por

$2.93901 \mathrm{e}+012.93901 \mathrm{e}+012.93901 \mathrm{e}+00$ 1.00000e-09 2.12000e-01 $2.93901 \mathrm{e}+012.93901 \mathrm{e}+012.93901 \mathrm{e}+001.00000 \mathrm{e}-092.12000 \mathrm{e}-01$ $2.93901 \mathrm{e}+012.93901 \mathrm{e}+012.93901 \mathrm{e}+001.00000 \mathrm{e}-092.12000 \mathrm{e}-01$ $2.93901 \mathrm{e}+012.93901 \mathrm{e}+012.93901 \mathrm{e}+001.00000 \mathrm{e}-092.12000 \mathrm{e}-01$ $2.93901 \mathrm{e}+012.93901 \mathrm{e}+012.93901 \mathrm{e}+001.00000 \mathrm{e}-092.12000 \mathrm{e}-01$ 
$1.00000 \mathrm{e}-05$ 1.00000e-05 1.00000e-06 1.00000e-09 1.00000e-01 $1.00000 \mathrm{e}+001.00000 \mathrm{e}+001.00000 \mathrm{e}-01$ 1.00000e-09 1.00000e-01 Element: 9788 \# of layers: 7

Kx Ky Kz Ss Por

$2.93901 \mathrm{e}+012.93901 \mathrm{e}+012.93901 \mathrm{e}+001.00000 \mathrm{e}-092.12000 \mathrm{e}-01$ $2.93901 \mathrm{e}+012.93901 \mathrm{e}+012.93901 \mathrm{e}+001.00000 \mathrm{e}-092.12000 \mathrm{e}-01$ $2.93901 \mathrm{e}+012.93901 \mathrm{e}+012.93901 \mathrm{e}+001.00000 \mathrm{e}-092.12000 \mathrm{e}-01$ $2.93901 \mathrm{e}+012.93901 \mathrm{e}+012.93901 \mathrm{e}+001.00000 \mathrm{e}-092.12000 \mathrm{e}-01$ $2.93901 \mathrm{e}+012.93901 \mathrm{e}+012.93901 \mathrm{e}+001.00000 \mathrm{e}-092.12000 \mathrm{e}-01$ $1.00000 \mathrm{e}-05$ 1.00000e-05 1.00000e-06 1.00000e-09 1.00000e-01 $1.00000 \mathrm{e}+001.00000 \mathrm{e}+001.00000 \mathrm{e}-011.00000 \mathrm{e}-091.00000 \mathrm{e}-01$ Element: 9789 \# of layers: 7

$\mathrm{Kx} \mathrm{Ky} \mathrm{Kz}$ Ss Por

$2.93901 \mathrm{e}+012.93901 \mathrm{e}+012.93901 \mathrm{e}+00$ 1.00000e-09 2.12000e-01 $2.93901 \mathrm{e}+012.93901 \mathrm{e}+012.93901 \mathrm{e}+001.00000 \mathrm{e}-092.12000 \mathrm{e}-01$ $2.93901 \mathrm{e}+012.93901 \mathrm{e}+012.93901 \mathrm{e}+001.00000 \mathrm{e}-092.12000 \mathrm{e}-01$ $2.93901 \mathrm{e}+012.93901 \mathrm{e}+012.93901 \mathrm{e}+001.00000 \mathrm{e}-092.12000 \mathrm{e}-01$ $2.93901 \mathrm{e}+012.93901 \mathrm{e}+012.93901 \mathrm{e}+001.00000 \mathrm{e}-092.12000 \mathrm{e}-01$ $1.00000 \mathrm{e}-05$ 1.00000e-05 1.00000e-06 1.00000e-09 1.00000e-01 $1.00000 \mathrm{e}+001.00000 \mathrm{e}+001.00000 \mathrm{e}-011.00000 \mathrm{e}-091.00000 \mathrm{e}-01$ Element: 9790 \# of layers: 7

$\mathrm{Kx} \mathrm{Ky} \mathrm{Kz}$ Ss Por

$2.93901 \mathrm{e}+012.93901 \mathrm{e}+012.93901 \mathrm{e}+00$ 1.00000e-09 2.12000e-01 $2.93901 \mathrm{e}+012.93901 \mathrm{e}+012.93901 \mathrm{e}+001.00000 \mathrm{e}-092.12000 \mathrm{e}-01$ $2.93901 \mathrm{e}+012.93901 \mathrm{e}+012.93901 \mathrm{e}+001.00000 \mathrm{e}-092.12000 \mathrm{e}-01$ $2.93901 \mathrm{e}+012.93901 \mathrm{e}+012.93901 \mathrm{e}+001.00000 \mathrm{e}-092.12000 \mathrm{e}-01$ $2.93901 \mathrm{e}+012.93901 \mathrm{e}+012.93901 \mathrm{e}+001.00000 \mathrm{e}-092.12000 \mathrm{e}-01$ 1.00000e-05 1.00000e-05 1.00000e-06 1.00000e-09 1.00000e-01 $1.00000 \mathrm{e}+001.00000 \mathrm{e}+001.00000 \mathrm{e}-011.00000 \mathrm{e}-091.00000 \mathrm{e}-01$ Element: 9791 \# of layers: 7

$\mathrm{Kx} \mathrm{Ky} \mathrm{Kz}$ Ss Por

$2.93901 \mathrm{e}+012.93901 \mathrm{e}+012.93901 \mathrm{e}+00$ 1.00000e-09 2.12000e-01 $2.93901 \mathrm{e}+012.93901 \mathrm{e}+012.93901 \mathrm{e}+001.00000 \mathrm{e}-092.12000 \mathrm{e}-01$ $2.93901 \mathrm{e}+012.93901 \mathrm{e}+012.93901 \mathrm{e}+001.00000 \mathrm{e}-092.12000 \mathrm{e}-01$ $2.93901 \mathrm{e}+012.93901 \mathrm{e}+012.93901 \mathrm{e}+001.00000 \mathrm{e}-092.12000 \mathrm{e}-01$ $2.93901 \mathrm{e}+012.93901 \mathrm{e}+012.93901 \mathrm{e}+001.00000 \mathrm{e}-092.12000 \mathrm{e}-01$ $1.00000 \mathrm{e}-05$ 1.00000e-05 1.00000e-06 1.00000e-09 1.00000e-01 $1.00000 \mathrm{e}+001.00000 \mathrm{e}+001.00000 \mathrm{e}-011.00000 \mathrm{e}-091.00000 \mathrm{e}-01$ Element: 9792 \# of layers: 7

$\mathrm{Kx} \mathrm{Ky} \mathrm{Kz}$ Ss Por

$2.57181 \mathrm{e}+012.57181 \mathrm{e}+012.57181 \mathrm{e}+00$ 1.00000e-09 2.12000e-01 $2.57181 \mathrm{e}+012.57181 \mathrm{e}+012.57181 \mathrm{e}+001.00000 \mathrm{e}-092.12000 \mathrm{e}-01$ $2.57181 \mathrm{e}+012.57181 \mathrm{e}+012.57181 \mathrm{e}+001.00000 \mathrm{e}-092.12000 \mathrm{e}-01$ $2.57181 \mathrm{e}+012.57181 \mathrm{e}+012.57181 \mathrm{e}+001.00000 \mathrm{e}-092.12000 \mathrm{e}-01$ $2.57181 \mathrm{e}+012.57181 \mathrm{e}+012.57181 \mathrm{e}+001.00000 \mathrm{e}-092.12000 \mathrm{e}-01$ $1.00000 \mathrm{e}-05$ 1.00000e-05 1.00000e-06 1.00000e-09 1.00000e-01 
$1.00000 \mathrm{e}+001.00000 \mathrm{e}+001.00000 \mathrm{e}-011.00000 \mathrm{e}-091.00000 \mathrm{e}-01$

Element: 9793 \# of layers: 7

Kx Ky Kz Ss Por

$2.57181 \mathrm{e}+012.57181 \mathrm{e}+012.57181 \mathrm{e}+001.00000 \mathrm{e}-092.12000 \mathrm{e}-01$

$2.57181 \mathrm{e}+012.57181 \mathrm{e}+012.57181 \mathrm{e}+001.00000 \mathrm{e}-092.12000 \mathrm{e}-01$

$2.57181 \mathrm{e}+012.57181 \mathrm{e}+012.57181 \mathrm{e}+001.00000 \mathrm{e}-092.12000 \mathrm{e}-01$

$2.57181 \mathrm{e}+012.57181 \mathrm{e}+012.57181 \mathrm{e}+001.00000 \mathrm{e}-092.12000 \mathrm{e}-01$

$2.57181 \mathrm{e}+012.57181 \mathrm{e}+012.57181 \mathrm{e}+001.00000 \mathrm{e}-092.12000 \mathrm{e}-01$

$1.00000 \mathrm{e}-05$ 1.00000e-05 1.00000e-06 1.00000e-09 1.00000e-01

$1.00000 \mathrm{e}+001.00000 \mathrm{e}+001.00000 \mathrm{e}-011.00000 \mathrm{e}-091.00000 \mathrm{e}-01$

Element: 9794 \# of layers: 7

$\mathrm{Kx} \mathrm{Ky} \mathrm{Kz}$ Ss Por

$2.93901 \mathrm{e}+012.93901 \mathrm{e}+012.93901 \mathrm{e}+00$ 1.00000e-09 2.12000e-01

$2.93901 \mathrm{e}+012.93901 \mathrm{e}+012.93901 \mathrm{e}+001.00000 \mathrm{e}-092.12000 \mathrm{e}-01$

$2.93901 \mathrm{e}+012.93901 \mathrm{e}+012.93901 \mathrm{e}+001.00000 \mathrm{e}-092.12000 \mathrm{e}-01$

$2.93901 \mathrm{e}+012.93901 \mathrm{e}+012.93901 \mathrm{e}+001.00000 \mathrm{e}-092.12000 \mathrm{e}-01$

$2.93901 \mathrm{e}+012.93901 \mathrm{e}+012.93901 \mathrm{e}+001.00000 \mathrm{e}-092.12000 \mathrm{e}-01$

$1.00000 \mathrm{e}-05$ 1.00000e-05 1.00000e-06 1.00000e-09 1.00000e-01

$1.00000 \mathrm{e}+001.00000 \mathrm{e}+001.00000 \mathrm{e}-011.00000 \mathrm{e}-091.00000 \mathrm{e}-01$

Element: 9795 \# of layers: 7

$\mathrm{Kx} \mathrm{Ky} \mathrm{Kz}$ Ss Por

$2.93901 \mathrm{e}+012.93901 \mathrm{e}+012.93901 \mathrm{e}+00$ 1.00000e-09 2.12000e-01

$2.93901 \mathrm{e}+012.93901 \mathrm{e}+012.93901 \mathrm{e}+001.00000 \mathrm{e}-092.12000 \mathrm{e}-01$

$2.93901 \mathrm{e}+012.93901 \mathrm{e}+012.93901 \mathrm{e}+001.00000 \mathrm{e}-092.12000 \mathrm{e}-01$

$2.93901 \mathrm{e}+012.93901 \mathrm{e}+012.93901 \mathrm{e}+001.00000 \mathrm{e}-092.12000 \mathrm{e}-01$

$2.93901 \mathrm{e}+012.93901 \mathrm{e}+012.93901 \mathrm{e}+001.00000 \mathrm{e}-092.12000 \mathrm{e}-01$

$1.00000 \mathrm{e}-05$ 1.00000e-05 1.00000e-06 1.00000e-09 1.00000e-01

$1.00000 \mathrm{e}+001.00000 \mathrm{e}+001.00000 \mathrm{e}-011.00000 \mathrm{e}-09$ 1.00000e-01

Element: 9796 \# of layers: 7

$\mathrm{Kx} \mathrm{Ky} \mathrm{Kz}$ Ss Por

$2.93901 \mathrm{e}+012.93901 \mathrm{e}+012.93901 \mathrm{e}+00$ 1.00000e-09 2.12000e-01 $2.93901 \mathrm{e}+012.93901 \mathrm{e}+012.93901 \mathrm{e}+001.00000 \mathrm{e}-092.12000 \mathrm{e}-01$ $2.93901 \mathrm{e}+012.93901 \mathrm{e}+012.93901 \mathrm{e}+001.00000 \mathrm{e}-092.12000 \mathrm{e}-01$ $2.93901 \mathrm{e}+012.93901 \mathrm{e}+012.93901 \mathrm{e}+001.00000 \mathrm{e}-092.12000 \mathrm{e}-01$ $2.93901 \mathrm{e}+012.93901 \mathrm{e}+012.93901 \mathrm{e}+001.00000 \mathrm{e}-092.12000 \mathrm{e}-01$ $1.00000 \mathrm{e}-05$ 1.00000e-05 1.00000e-06 1.00000e-09 1.00000e-01

$1.00000 \mathrm{e}+001.00000 \mathrm{e}+001.00000 \mathrm{e}-011.00000 \mathrm{e}-091.00000 \mathrm{e}-01$

Element: 9797 \# of layers: 7

$\mathrm{Kx} \mathrm{Ky} \mathrm{Kz}$ Ss Por

$2.93901 \mathrm{e}+012.93901 \mathrm{e}+012.93901 \mathrm{e}+00$ 1.00000e-09 2.12000e-01 $2.93901 \mathrm{e}+012.93901 \mathrm{e}+012.93901 \mathrm{e}+001.00000 \mathrm{e}-092.12000 \mathrm{e}-01$ $2.93901 \mathrm{e}+012.93901 \mathrm{e}+012.93901 \mathrm{e}+001.00000 \mathrm{e}-092.12000 \mathrm{e}-01$ $2.93901 \mathrm{e}+012.93901 \mathrm{e}+012.93901 \mathrm{e}+001.00000 \mathrm{e}-092.12000 \mathrm{e}-01$ $2.93901 \mathrm{e}+012.93901 \mathrm{e}+012.93901 \mathrm{e}+001.00000 \mathrm{e}-092.12000 \mathrm{e}-01$ $1.00000 \mathrm{e}-05$ 1.00000e-05 1.00000e-06 1.00000e-09 1.00000e-01 $1.00000 \mathrm{e}+001.00000 \mathrm{e}+001.00000 \mathrm{e}-011.00000 \mathrm{e}-091.00000 \mathrm{e}-01$ 
Element: 9798 \# of layers: 7

Kx Ky Kz Ss Por

$2.93901 \mathrm{e}+012.93901 \mathrm{e}+012.93901 \mathrm{e}+00$ 1.00000e-09 2.12000e-01

$2.93901 \mathrm{e}+012.93901 \mathrm{e}+012.93901 \mathrm{e}+001.00000 \mathrm{e}-092.12000 \mathrm{e}-01$

$2.93901 \mathrm{e}+012.93901 \mathrm{e}+012.93901 \mathrm{e}+001.00000 \mathrm{e}-092.12000 \mathrm{e}-01$

$2.93901 \mathrm{e}+012.93901 \mathrm{e}+012.93901 \mathrm{e}+001.00000 \mathrm{e}-092.12000 \mathrm{e}-01$

$2.93901 \mathrm{e}+012.93901 \mathrm{e}+012.93901 \mathrm{e}+001.00000 \mathrm{e}-092.12000 \mathrm{e}-01$

$1.00000 \mathrm{e}-05$ 1.00000e-05 1.00000e-06 1.00000e-09 1.00000e-01

$1.00000 \mathrm{e}+001.00000 \mathrm{e}+001.00000 \mathrm{e}-011.00000 \mathrm{e}-091.00000 \mathrm{e}-01$

Element: 9799 \# of layers: 7

Kx Ky Kz Ss Por

$2.93901 \mathrm{e}+012.93901 \mathrm{e}+012.93901 \mathrm{e}+00$ 1.00000e-09 2.12000e-01

$2.93901 \mathrm{e}+012.93901 \mathrm{e}+012.93901 \mathrm{e}+001.00000 \mathrm{e}-092.12000 \mathrm{e}-01$

$2.93901 \mathrm{e}+012.93901 \mathrm{e}+012.93901 \mathrm{e}+001.00000 \mathrm{e}-092.12000 \mathrm{e}-01$

$2.93901 \mathrm{e}+012.93901 \mathrm{e}+012.93901 \mathrm{e}+001.00000 \mathrm{e}-092.12000 \mathrm{e}-01$

$2.93901 \mathrm{e}+012.93901 \mathrm{e}+012.93901 \mathrm{e}+001.00000 \mathrm{e}-092.12000 \mathrm{e}-01$

$1.00000 \mathrm{e}-05$ 1.00000e-05 1.00000e-06 1.00000e-09 1.00000e-01

$1.00000 \mathrm{e}+001.00000 \mathrm{e}+001.00000 \mathrm{e}-011.00000 \mathrm{e}-091.00000 \mathrm{e}-01$

Element: 9800 \# of layers: 7

Kx Ky Kz Ss Por

$2.93901 \mathrm{e}+012.93901 \mathrm{e}+012.93901 \mathrm{e}+001.00000 \mathrm{e}-092.12000 \mathrm{e}-01$

$2.93901 \mathrm{e}+012.93901 \mathrm{e}+012.93901 \mathrm{e}+001.00000 \mathrm{e}-092.12000 \mathrm{e}-01$

$2.93901 \mathrm{e}+012.93901 \mathrm{e}+012.93901 \mathrm{e}+001.00000 \mathrm{e}-092.12000 \mathrm{e}-01$

$2.93901 \mathrm{e}+012.93901 \mathrm{e}+012.93901 \mathrm{e}+001.00000 \mathrm{e}-092.12000 \mathrm{e}-01$

$2.93901 \mathrm{e}+012.93901 \mathrm{e}+012.93901 \mathrm{e}+001.00000 \mathrm{e}-092.12000 \mathrm{e}-01$

$1.00000 \mathrm{e}-05$ 1.00000e-05 1.00000e-06 1.00000e-09 1.00000e-01

$1.00000 \mathrm{e}+001.00000 \mathrm{e}+001.00000 \mathrm{e}-011.00000 \mathrm{e}-091.00000 \mathrm{e}-01$

Element: 9801 \# of layers: 7

Kx Ky Kz Ss Por

$2.93901 \mathrm{e}+012.93901 \mathrm{e}+012.93901 \mathrm{e}+00$ 1.00000e-09 2.12000e-01

$2.93901 \mathrm{e}+012.93901 \mathrm{e}+012.93901 \mathrm{e}+001.00000 \mathrm{e}-092.12000 \mathrm{e}-01$

$2.93901 \mathrm{e}+012.93901 \mathrm{e}+012.93901 \mathrm{e}+001.00000 \mathrm{e}-092.12000 \mathrm{e}-01$

$2.93901 \mathrm{e}+012.93901 \mathrm{e}+012.93901 \mathrm{e}+001.00000 \mathrm{e}-092.12000 \mathrm{e}-01$

$2.93901 \mathrm{e}+012.93901 \mathrm{e}+012.93901 \mathrm{e}+001.00000 \mathrm{e}-092.12000 \mathrm{e}-01$

$1.00000 \mathrm{e}-05$ 1.00000e-05 1.00000e-06 1.00000e-09 1.00000e-01

$1.00000 \mathrm{e}+001.00000 \mathrm{e}+001.00000 \mathrm{e}-011.00000 \mathrm{e}-091.00000 \mathrm{e}-01$

Element: 9802 \# of layers: 7

Kx Ky Kz Ss Por

$2.93901 \mathrm{e}+012.93901 \mathrm{e}+012.93901 \mathrm{e}+00$ 1.00000e-09 2.12000e-01

$2.93901 \mathrm{e}+012.93901 \mathrm{e}+012.93901 \mathrm{e}+001.00000 \mathrm{e}-092.12000 \mathrm{e}-01$

$2.93901 \mathrm{e}+012.93901 \mathrm{e}+012.93901 \mathrm{e}+001.00000 \mathrm{e}-092.12000 \mathrm{e}-01$

$2.93901 \mathrm{e}+012.93901 \mathrm{e}+012.93901 \mathrm{e}+001.00000 \mathrm{e}-092.12000 \mathrm{e}-01$

$2.93901 \mathrm{e}+012.93901 \mathrm{e}+012.93901 \mathrm{e}+001.00000 \mathrm{e}-092.12000 \mathrm{e}-01$

$1.00000 \mathrm{e}-05$ 1.00000e-05 1.00000e-06 1.00000e-09 1.00000e-01

$1.00000 \mathrm{e}+001.00000 \mathrm{e}+001.00000 \mathrm{e}-011.00000 \mathrm{e}-091.00000 \mathrm{e}-01$

Element: 9803 \# of layers: 7 
$\mathrm{Kx} \mathrm{Ky} \mathrm{Kz}$ Ss Por

$2.93901 \mathrm{e}+012.93901 \mathrm{e}+012.93901 \mathrm{e}+00$ 1.00000e-09 2.12000e-01

$2.93901 \mathrm{e}+012.93901 \mathrm{e}+012.93901 \mathrm{e}+001.00000 \mathrm{e}-092.12000 \mathrm{e}-01$

$2.93901 \mathrm{e}+012.93901 \mathrm{e}+012.93901 \mathrm{e}+001.00000 \mathrm{e}-092.12000 \mathrm{e}-01$

$2.93901 \mathrm{e}+012.93901 \mathrm{e}+012.93901 \mathrm{e}+001.00000 \mathrm{e}-092.12000 \mathrm{e}-01$

$2.93901 \mathrm{e}+012.93901 \mathrm{e}+012.93901 \mathrm{e}+001.00000 \mathrm{e}-092.12000 \mathrm{e}-01$

$1.00000 \mathrm{e}-05$ 1.00000e-05 1.00000e-06 1.00000e-09 1.00000e-01

$1.00000 \mathrm{e}+001.00000 \mathrm{e}+001.00000 \mathrm{e}-011.00000 \mathrm{e}-091.00000 \mathrm{e}-01$

Element: 9804 \# of layers: 7

$\mathrm{Kx} \mathrm{Ky} \mathrm{Kz}$ Ss Por

$2.93901 \mathrm{e}+012.93901 \mathrm{e}+012.93901 \mathrm{e}+00$ 1.00000e-09 2.12000e-01 $2.93901 \mathrm{e}+012.93901 \mathrm{e}+012.93901 \mathrm{e}+001.00000 \mathrm{e}-092.12000 \mathrm{e}-01$ $2.93901 \mathrm{e}+012.93901 \mathrm{e}+012.93901 \mathrm{e}+001.00000 \mathrm{e}-092.12000 \mathrm{e}-01$ $2.93901 \mathrm{e}+012.93901 \mathrm{e}+012.93901 \mathrm{e}+001.00000 \mathrm{e}-092.12000 \mathrm{e}-01$ $2.93901 \mathrm{e}+012.93901 \mathrm{e}+012.93901 \mathrm{e}+001.00000 \mathrm{e}-092.12000 \mathrm{e}-01$ $1.00000 \mathrm{e}-05$ 1.00000e-05 1.00000e-06 1.00000e-09 1.00000e-01 $1.00000 \mathrm{e}+001.00000 \mathrm{e}+001.00000 \mathrm{e}-01$ 1.00000e-09 1.00000e-01 Element: 9805 \# of layers: 7

$\mathrm{Kx} \mathrm{Ky} \mathrm{Kz}$ Ss Por

$2.93901 \mathrm{e}+012.93901 \mathrm{e}+012.93901 \mathrm{e}+00$ 1.00000e-09 2.12000e-01 $2.93901 \mathrm{e}+012.93901 \mathrm{e}+012.93901 \mathrm{e}+001.00000 \mathrm{e}-092.12000 \mathrm{e}-01$ $2.93901 \mathrm{e}+012.93901 \mathrm{e}+012.93901 \mathrm{e}+001.00000 \mathrm{e}-092.12000 \mathrm{e}-01$ $2.93901 \mathrm{e}+012.93901 \mathrm{e}+012.93901 \mathrm{e}+001.00000 \mathrm{e}-092.12000 \mathrm{e}-01$ $2.93901 \mathrm{e}+012.93901 \mathrm{e}+012.93901 \mathrm{e}+001.00000 \mathrm{e}-092.12000 \mathrm{e}-01$ $1.00000 \mathrm{e}-05$ 1.00000e-05 1.00000e-06 1.00000e-09 1.00000e-01 $1.00000 \mathrm{e}+001.00000 \mathrm{e}+001.00000 \mathrm{e}-011.00000 \mathrm{e}-091.00000 \mathrm{e}-01$ Element: 9806 \# of layers: 7

$\mathrm{Kx} \mathrm{Ky} \mathrm{Kz}$ Ss Por

$2.87534 \mathrm{e}+012.87534 \mathrm{e}+012.87534 \mathrm{e}+001.00000 \mathrm{e}-092.12000 \mathrm{e}-01$ $2.87534 \mathrm{e}+012.87534 \mathrm{e}+012.87534 \mathrm{e}+001.00000 \mathrm{e}-092.12000 \mathrm{e}-01$ $2.87534 \mathrm{e}+012.87534 \mathrm{e}+012.87534 \mathrm{e}+00 \quad 1.00000 \mathrm{e}-092.12000 \mathrm{e}-01$ $2.87534 \mathrm{e}+012.87534 \mathrm{e}+012.87534 \mathrm{e}+001.00000 \mathrm{e}-092.12000 \mathrm{e}-01$ $2.87534 \mathrm{e}+012.87534 \mathrm{e}+012.87534 \mathrm{e}+001.00000 \mathrm{e}-092.12000 \mathrm{e}-01$ 1.00000e-05 1.00000e-05 1.00000e-06 1.00000e-09 1.00000e-01 $1.00000 \mathrm{e}+001.00000 \mathrm{e}+001.00000 \mathrm{e}-011.00000 \mathrm{e}-091.00000 \mathrm{e}-01$ Element: 9807 \# of layers: 7

$\mathrm{Kx} \mathrm{Ky} \mathrm{Kz}$ Ss Por

$2.87534 \mathrm{e}+012.87534 \mathrm{e}+012.87534 \mathrm{e}+00$ 1.00000e-09 2.12000e-01 $2.87534 \mathrm{e}+012.87534 \mathrm{e}+012.87534 \mathrm{e}+001.00000 \mathrm{e}-092.12000 \mathrm{e}-01$ $2.87534 \mathrm{e}+012.87534 \mathrm{e}+012.87534 \mathrm{e}+001.00000 \mathrm{e}-092.12000 \mathrm{e}-01$ $2.87534 \mathrm{e}+012.87534 \mathrm{e}+012.87534 \mathrm{e}+001.00000 \mathrm{e}-092.12000 \mathrm{e}-01$ $2.87534 \mathrm{e}+012.87534 \mathrm{e}+012.87534 \mathrm{e}+001.00000 \mathrm{e}-092.12000 \mathrm{e}-01$ $1.00000 \mathrm{e}-05$ 1.00000e-05 1.00000e-06 1.00000e-09 1.00000e-01 $1.00000 \mathrm{e}+001.00000 \mathrm{e}+001.00000 \mathrm{e}-01$ 1.00000e-09 1.00000e-01 Element: 9808 \# of layers: 7

Kx Ky Kz Ss Por 
$2.87534 \mathrm{e}+012.87534 \mathrm{e}+012.87534 \mathrm{e}+001.00000 \mathrm{e}-092.12000 \mathrm{e}-01$ $2.87534 \mathrm{e}+012.87534 \mathrm{e}+012.87534 \mathrm{e}+001.00000 \mathrm{e}-092.12000 \mathrm{e}-01$ $2.87534 \mathrm{e}+012.87534 \mathrm{e}+012.87534 \mathrm{e}+001.00000 \mathrm{e}-092.12000 \mathrm{e}-01$ $2.87534 \mathrm{e}+012.87534 \mathrm{e}+012.87534 \mathrm{e}+001.00000 \mathrm{e}-092.12000 \mathrm{e}-01$ $2.87534 \mathrm{e}+012.87534 \mathrm{e}+012.87534 \mathrm{e}+001.00000 \mathrm{e}-092.12000 \mathrm{e}-01$ $1.00000 \mathrm{e}-05$ 1.00000e-05 1.00000e-06 1.00000e-09 1.00000e-01 $1.00000 \mathrm{e}+001.00000 \mathrm{e}+001.00000 \mathrm{e}-01$ 1.00000e-09 1.00000e-01 Element: 9809 \# of layers: 7

$\mathrm{Kx} \mathrm{Ky} \mathrm{Kz}$ Ss Por

$2.93901 \mathrm{e}+012.93901 \mathrm{e}+012.93901 \mathrm{e}+00$ 1.00000e-09 2.12000e-01 $2.93901 \mathrm{e}+012.93901 \mathrm{e}+012.93901 \mathrm{e}+001.00000 \mathrm{e}-09$ 2.12000e-01 $2.93901 \mathrm{e}+012.93901 \mathrm{e}+012.93901 \mathrm{e}+001.00000 \mathrm{e}-092.12000 \mathrm{e}-01$ $2.93901 \mathrm{e}+012.93901 \mathrm{e}+012.93901 \mathrm{e}+001.00000 \mathrm{e}-092.12000 \mathrm{e}-01$ $2.93901 \mathrm{e}+012.93901 \mathrm{e}+012.93901 \mathrm{e}+001.00000 \mathrm{e}-092.12000 \mathrm{e}-01$ $1.00000 \mathrm{e}-05$ 1.00000e-05 1.00000e-06 1.00000e-09 1.00000e-01 $1.00000 \mathrm{e}+001.00000 \mathrm{e}+001.00000 \mathrm{e}-011.00000 \mathrm{e}-091.00000 \mathrm{e}-01$ Element: 9810 \# of layers: 7

$\mathrm{Kx} \mathrm{Ky} \mathrm{Kz}$ Ss Por

$2.93901 \mathrm{e}+012.93901 \mathrm{e}+012.93901 \mathrm{e}+00$ 1.00000e-09 2.12000e-01 $2.93901 \mathrm{e}+012.93901 \mathrm{e}+012.93901 \mathrm{e}+001.00000 \mathrm{e}-092.12000 \mathrm{e}-01$ $2.93901 \mathrm{e}+012.93901 \mathrm{e}+012.93901 \mathrm{e}+001.00000 \mathrm{e}-092.12000 \mathrm{e}-01$ $2.93901 \mathrm{e}+012.93901 \mathrm{e}+012.93901 \mathrm{e}+001.00000 \mathrm{e}-092.12000 \mathrm{e}-01$ $2.93901 \mathrm{e}+012.93901 \mathrm{e}+012.93901 \mathrm{e}+00$ 1.00000e-09 2.12000e-01 $1.00000 \mathrm{e}-05$ 1.00000e-05 1.00000e-06 1.00000e-09 1.00000e-01 $1.00000 \mathrm{e}+001.00000 \mathrm{e}+001.00000 \mathrm{e}-011.00000 \mathrm{e}-091.00000 \mathrm{e}-01$ Element: 9811 \# of layers: 7

$\mathrm{Kx} \mathrm{Ky} \mathrm{Kz}$ Ss Por

$2.93901 \mathrm{e}+012.93901 \mathrm{e}+012.93901 \mathrm{e}+001.00000 \mathrm{e}-09$ 2.12000e-01 $2.93901 \mathrm{e}+012.93901 \mathrm{e}+012.93901 \mathrm{e}+001.00000 \mathrm{e}-092.12000 \mathrm{e}-01$ $2.93901 \mathrm{e}+012.93901 \mathrm{e}+012.93901 \mathrm{e}+001.00000 \mathrm{e}-092.12000 \mathrm{e}-01$ $2.93901 \mathrm{e}+012.93901 \mathrm{e}+012.93901 \mathrm{e}+001.00000 \mathrm{e}-092.12000 \mathrm{e}-01$ $2.93901 \mathrm{e}+012.93901 \mathrm{e}+012.93901 \mathrm{e}+001.00000 \mathrm{e}-092.12000 \mathrm{e}-01$ $1.00000 \mathrm{e}-05$ 1.00000e-05 1.00000e-06 1.00000e-09 1.00000e-01 $1.00000 \mathrm{e}+001.00000 \mathrm{e}+001.00000 \mathrm{e}-011.00000 \mathrm{e}-091.00000 \mathrm{e}-01$ Element: 9812 \# of layers: 7

$\mathrm{Kx} \mathrm{Ky} \mathrm{Kz}$ Ss Por

$2.93901 \mathrm{e}+012.93901 \mathrm{e}+012.93901 \mathrm{e}+00$ 1.00000e-09 2.12000e-01 $2.93901 \mathrm{e}+012.93901 \mathrm{e}+012.93901 \mathrm{e}+001.00000 \mathrm{e}-092.12000 \mathrm{e}-01$ $2.93901 \mathrm{e}+012.93901 \mathrm{e}+012.93901 \mathrm{e}+001.00000 \mathrm{e}-092.12000 \mathrm{e}-01$ $2.93901 \mathrm{e}+012.93901 \mathrm{e}+012.93901 \mathrm{e}+001.00000 \mathrm{e}-092.12000 \mathrm{e}-01$ $2.93901 \mathrm{e}+012.93901 \mathrm{e}+012.93901 \mathrm{e}+001.00000 \mathrm{e}-092.12000 \mathrm{e}-01$ $1.00000 \mathrm{e}-05$ 1.00000e-05 1.00000e-06 1.00000e-09 1.00000e-01 $1.00000 \mathrm{e}+001.00000 \mathrm{e}+001.00000 \mathrm{e}-011.00000 \mathrm{e}-091.00000 \mathrm{e}-01$ Element: 9813 \# of layers: 7

$\mathrm{Kx} \mathrm{Ky} \mathrm{Kz}$ Ss Por

$2.87534 \mathrm{e}+012.87534 \mathrm{e}+012.87534 \mathrm{e}+00$ 1.00000e-09 2.12000e-01 
$2.87534 \mathrm{e}+012.87534 \mathrm{e}+012.87534 \mathrm{e}+001.00000 \mathrm{e}-092.12000 \mathrm{e}-01$ $2.87534 \mathrm{e}+012.87534 \mathrm{e}+012.87534 \mathrm{e}+001.00000 \mathrm{e}-092.12000 \mathrm{e}-01$ $2.87534 \mathrm{e}+012.87534 \mathrm{e}+012.87534 \mathrm{e}+001.00000 \mathrm{e}-092.12000 \mathrm{e}-01$ $2.87534 \mathrm{e}+012.87534 \mathrm{e}+012.87534 \mathrm{e}+001.00000 \mathrm{e}-092.12000 \mathrm{e}-01$ $1.00000 \mathrm{e}-05$ 1.00000e-05 1.00000e-06 1.00000e-09 1.00000e-01 $1.00000 \mathrm{e}+001.00000 \mathrm{e}+001.00000 \mathrm{e}-011.00000 \mathrm{e}-091.00000 \mathrm{e}-01$ Element: 9814 \# of layers: 7

$\mathrm{Kx} \mathrm{Ky} \mathrm{Kz}$ Ss Por

$2.87534 \mathrm{e}+012.87534 \mathrm{e}+012.87534 \mathrm{e}+001.00000 \mathrm{e}-092.12000 \mathrm{e}-01$ $2.87534 \mathrm{e}+012.87534 \mathrm{e}+012.87534 \mathrm{e}+001.00000 \mathrm{e}-092.12000 \mathrm{e}-01$ $2.87534 \mathrm{e}+012.87534 \mathrm{e}+012.87534 \mathrm{e}+001.00000 \mathrm{e}-092.12000 \mathrm{e}-01$ $2.87534 \mathrm{e}+012.87534 \mathrm{e}+012.87534 \mathrm{e}+001.00000 \mathrm{e}-092.12000 \mathrm{e}-01$ $2.87534 \mathrm{e}+012.87534 \mathrm{e}+012.87534 \mathrm{e}+001.00000 \mathrm{e}-092.12000 \mathrm{e}-01$ $1.00000 \mathrm{e}-05$ 1.00000e-05 1.00000e-06 1.00000e-09 1.00000e-01 $1.00000 \mathrm{e}+001.00000 \mathrm{e}+001.00000 \mathrm{e}-01$ 1.00000e-09 1.00000e-01 Element: 9815 \# of layers: 7

$\mathrm{Kx} \mathrm{Ky} \mathrm{Kz}$ Ss Por

$2.87534 \mathrm{e}+012.87534 \mathrm{e}+012.87534 \mathrm{e}+00$ 1.00000e-09 2.12000e-01 $2.87534 \mathrm{e}+012.87534 \mathrm{e}+012.87534 \mathrm{e}+001.00000 \mathrm{e}-092.12000 \mathrm{e}-01$ $2.87534 \mathrm{e}+012.87534 \mathrm{e}+012.87534 \mathrm{e}+00 \quad 1.00000 \mathrm{e}-092.12000 \mathrm{e}-01$ $2.87534 \mathrm{e}+012.87534 \mathrm{e}+012.87534 \mathrm{e}+001.00000 \mathrm{e}-092.12000 \mathrm{e}-01$ $2.87534 \mathrm{e}+012.87534 \mathrm{e}+012.87534 \mathrm{e}+001.00000 \mathrm{e}-092.12000 \mathrm{e}-01$ $1.00000 \mathrm{e}-051.00000 \mathrm{e}-051.00000 \mathrm{e}-061.00000 \mathrm{e}-091.00000 \mathrm{e}-01$ $1.00000 \mathrm{e}+001.00000 \mathrm{e}+001.00000 \mathrm{e}-011.00000 \mathrm{e}-091.00000 \mathrm{e}-01$ Element: 9816 \# of layers: 7

$\mathrm{Kx} \mathrm{Ky} \mathrm{Kz}$ Ss Por

$2.87534 \mathrm{e}+012.87534 \mathrm{e}+012.87534 \mathrm{e}+00$ 1.00000e-09 2.12000e-01 $2.87534 \mathrm{e}+012.87534 \mathrm{e}+012.87534 \mathrm{e}+001.00000 \mathrm{e}-092.12000 \mathrm{e}-01$ $2.87534 \mathrm{e}+012.87534 \mathrm{e}+012.87534 \mathrm{e}+001.00000 \mathrm{e}-092.12000 \mathrm{e}-01$ $2.87534 \mathrm{e}+012.87534 \mathrm{e}+012.87534 \mathrm{e}+00 \quad 1.00000 \mathrm{e}-092.12000 \mathrm{e}-01$ $2.87534 \mathrm{e}+012.87534 \mathrm{e}+012.87534 \mathrm{e}+00 \quad 1.00000 \mathrm{e}-092.12000 \mathrm{e}-01$ $1.00000 \mathrm{e}-05$ 1.00000e-05 1.00000e-06 1.00000e-09 1.00000e-01 $1.00000 \mathrm{e}+001.00000 \mathrm{e}+001.00000 \mathrm{e}-011.00000 \mathrm{e}-091.00000 \mathrm{e}-01$ Element: 9817 \# of layers: 7

$\mathrm{Kx} \mathrm{Ky} \mathrm{Kz}$ Ss Por

$2.87534 \mathrm{e}+012.87534 \mathrm{e}+012.87534 \mathrm{e}+00$ 1.00000e-09 2.12000e-01 $2.87534 \mathrm{e}+012.87534 \mathrm{e}+012.87534 \mathrm{e}+001.00000 \mathrm{e}-092.12000 \mathrm{e}-01$ $2.87534 \mathrm{e}+012.87534 \mathrm{e}+012.87534 \mathrm{e}+001.00000 \mathrm{e}-092.12000 \mathrm{e}-01$ $2.87534 \mathrm{e}+012.87534 \mathrm{e}+012.87534 \mathrm{e}+001.00000 \mathrm{e}-092.12000 \mathrm{e}-01$ $2.87534 \mathrm{e}+012.87534 \mathrm{e}+012.87534 \mathrm{e}+001.00000 \mathrm{e}-092.12000 \mathrm{e}-01$ $1.00000 \mathrm{e}-05$ 1.00000e-05 1.00000e-06 1.00000e-09 1.00000e-01 $1.00000 \mathrm{e}+001.00000 \mathrm{e}+001.00000 \mathrm{e}-011.00000 \mathrm{e}-091.00000 \mathrm{e}-01$ Element: 9818 \# of layers: 7

$\mathrm{Kx} \mathrm{Ky} \mathrm{Kz}$ Ss Por

$2.87534 \mathrm{e}+012.87534 \mathrm{e}+012.87534 \mathrm{e}+00$ 1.00000e-09 2.12000e-01 $2.87534 \mathrm{e}+012.87534 \mathrm{e}+012.87534 \mathrm{e}+001.00000 \mathrm{e}-092.12000 \mathrm{e}-01$ 
$2.87534 \mathrm{e}+012.87534 \mathrm{e}+012.87534 \mathrm{e}+001.00000 \mathrm{e}-092.12000 \mathrm{e}-01$ $2.87534 \mathrm{e}+012.87534 \mathrm{e}+012.87534 \mathrm{e}+001.00000 \mathrm{e}-092.12000 \mathrm{e}-01$ $2.87534 \mathrm{e}+012.87534 \mathrm{e}+012.87534 \mathrm{e}+001.00000 \mathrm{e}-092.12000 \mathrm{e}-01$ $1.00000 \mathrm{e}-05$ 1.00000e-05 1.00000e-06 1.00000e-09 1.00000e-01 $1.00000 \mathrm{e}+001.00000 \mathrm{e}+001.00000 \mathrm{e}-01$ 1.00000e-09 1.00000e-01 Element: 9819 \# of layers: 7

$\mathrm{Kx} \mathrm{Ky} \mathrm{Kz}$ Ss Por

$2.87534 \mathrm{e}+012.87534 \mathrm{e}+012.87534 \mathrm{e}+00$ 1.00000e-09 2.12000e-01 $2.87534 \mathrm{e}+012.87534 \mathrm{e}+012.87534 \mathrm{e}+001.00000 \mathrm{e}-092.12000 \mathrm{e}-01$ $2.87534 \mathrm{e}+012.87534 \mathrm{e}+012.87534 \mathrm{e}+001.00000 \mathrm{e}-092.12000 \mathrm{e}-01$ $2.87534 \mathrm{e}+012.87534 \mathrm{e}+012.87534 \mathrm{e}+001.00000 \mathrm{e}-092.12000 \mathrm{e}-01$ $2.87534 \mathrm{e}+012.87534 \mathrm{e}+012.87534 \mathrm{e}+001.00000 \mathrm{e}-092.12000 \mathrm{e}-01$ $1.00000 \mathrm{e}-05$ 1.00000e-05 1.00000e-06 1.00000e-09 1.00000e-01 $1.00000 \mathrm{e}+001.00000 \mathrm{e}+001.00000 \mathrm{e}-011.00000 \mathrm{e}-091.00000 \mathrm{e}-01$ Element: 9820 \# of layers: 7

$\mathrm{Kx} \mathrm{Ky} \mathrm{Kz}$ Ss Por

$2.87534 \mathrm{e}+012.87534 \mathrm{e}+012.87534 \mathrm{e}+00$ 1.00000e-09 2.12000e-01 $2.87534 \mathrm{e}+012.87534 \mathrm{e}+012.87534 \mathrm{e}+001.00000 \mathrm{e}-092.12000 \mathrm{e}-01$ $2.87534 \mathrm{e}+012.87534 \mathrm{e}+012.87534 \mathrm{e}+001.00000 \mathrm{e}-092.12000 \mathrm{e}-01$ $2.87534 \mathrm{e}+012.87534 \mathrm{e}+012.87534 \mathrm{e}+001.00000 \mathrm{e}-092.12000 \mathrm{e}-01$ $2.87534 \mathrm{e}+012.87534 \mathrm{e}+012.87534 \mathrm{e}+001.00000 \mathrm{e}-092.12000 \mathrm{e}-01$ $1.00000 \mathrm{e}-05$ 1.00000e-05 1.00000e-06 1.00000e-09 1.00000e-01 $1.00000 \mathrm{e}+001.00000 \mathrm{e}+001.00000 \mathrm{e}-01$ 1.00000e-09 1.00000e-01 Element: 9821 \# of layers: 7

Kx Ky Kz Ss Por

$2.87534 \mathrm{e}+012.87534 \mathrm{e}+012.87534 \mathrm{e}+001.00000 \mathrm{e}-092.12000 \mathrm{e}-01$ $2.87534 \mathrm{e}+012.87534 \mathrm{e}+012.87534 \mathrm{e}+001.00000 \mathrm{e}-092.12000 \mathrm{e}-01$ $2.87534 \mathrm{e}+012.87534 \mathrm{e}+012.87534 \mathrm{e}+001.00000 \mathrm{e}-092.12000 \mathrm{e}-01$ $2.87534 \mathrm{e}+012.87534 \mathrm{e}+012.87534 \mathrm{e}+001.00000 \mathrm{e}-092.12000 \mathrm{e}-01$ $2.87534 \mathrm{e}+012.87534 \mathrm{e}+012.87534 \mathrm{e}+001.00000 \mathrm{e}-092.12000 \mathrm{e}-01$ $1.00000 \mathrm{e}-05$ 1.00000e-05 1.00000e-06 1.00000e-09 1.00000e-01 $1.00000 \mathrm{e}+001.00000 \mathrm{e}+001.00000 \mathrm{e}-011.00000 \mathrm{e}-091.00000 \mathrm{e}-01$ Element: 9822 \# of layers: 7

$\mathrm{Kx} \mathrm{Ky} \mathrm{Kz}$ Ss Por

$2.87534 \mathrm{e}+012.87534 \mathrm{e}+012.87534 \mathrm{e}+00$ 1.00000e-09 2.12000e-01

$2.87534 \mathrm{e}+012.87534 \mathrm{e}+012.87534 \mathrm{e}+001.00000 \mathrm{e}-092.12000 \mathrm{e}-01$ $2.87534 \mathrm{e}+012.87534 \mathrm{e}+012.87534 \mathrm{e}+001.00000 \mathrm{e}-092.12000 \mathrm{e}-01$ $2.87534 \mathrm{e}+012.87534 \mathrm{e}+012.87534 \mathrm{e}+001.00000 \mathrm{e}-092.12000 \mathrm{e}-01$ $2.87534 \mathrm{e}+012.87534 \mathrm{e}+012.87534 \mathrm{e}+001.00000 \mathrm{e}-092.12000 \mathrm{e}-01$ $1.00000 \mathrm{e}-05$ 1.00000e-05 1.00000e-06 1.00000e-09 1.00000e-01 $1.00000 \mathrm{e}+001.00000 \mathrm{e}+001.00000 \mathrm{e}-011.00000 \mathrm{e}-091.00000 \mathrm{e}-01$ Element: 9823 \# of layers: 7

$\mathrm{Kx} \mathrm{Ky} \mathrm{Kz}$ Ss Por

2.87534e+01 2.87534e+01 2.87534e+00 1.00000e-09 2.12000e-01 $2.87534 \mathrm{e}+012.87534 \mathrm{e}+012.87534 \mathrm{e}+001.00000 \mathrm{e}-092.12000 \mathrm{e}-01$ $2.87534 \mathrm{e}+012.87534 \mathrm{e}+012.87534 \mathrm{e}+00$ 1.00000e-09 2.12000e-01 
$2.87534 \mathrm{e}+012.87534 \mathrm{e}+012.87534 \mathrm{e}+00$ 1.00000e-09 2.12000e-01 $2.87534 \mathrm{e}+012.87534 \mathrm{e}+012.87534 \mathrm{e}+001.00000 \mathrm{e}-092.12000 \mathrm{e}-01$ $1.00000 \mathrm{e}-05$ 1.00000e-05 1.00000e-06 1.00000e-09 1.00000e-01 $1.00000 \mathrm{e}+001.00000 \mathrm{e}+001.00000 \mathrm{e}-011.00000 \mathrm{e}-091.00000 \mathrm{e}-01$ Element: 9824 \# of layers: 7

Kx Ky Kz Ss Por

$2.50903 \mathrm{e}+012.50903 \mathrm{e}+012.50903 \mathrm{e}+00$ 1.00000e-09 2.12000e-01 $2.50903 \mathrm{e}+012.50903 \mathrm{e}+012.50903 \mathrm{e}+00$ 1.00000e-09 2.12000e-01 $2.50903 \mathrm{e}+012.50903 \mathrm{e}+012.50903 \mathrm{e}+00$ 1.00000e-09 2.12000e-01 $2.50903 \mathrm{e}+012.50903 \mathrm{e}+012.50903 \mathrm{e}+001.00000 \mathrm{e}-092.12000 \mathrm{e}-01$ $2.50903 \mathrm{e}+012.50903 \mathrm{e}+012.50903 \mathrm{e}+001.00000 \mathrm{e}-092.12000 \mathrm{e}-01$ $1.00000 \mathrm{e}-05$ 1.00000e-05 1.00000e-06 1.00000e-09 1.00000e-01 $1.00000 \mathrm{e}+001.00000 \mathrm{e}+001.00000 \mathrm{e}-011.00000 \mathrm{e}-091.00000 \mathrm{e}-01$ Element: 9825 \# of layers: 7

Kx Ky Kz Ss Por

$2.50903 \mathrm{e}+012.50903 \mathrm{e}+012.50903 \mathrm{e}+00$ 1.00000e-09 2.12000e-01 $2.50903 \mathrm{e}+012.50903 \mathrm{e}+012.50903 \mathrm{e}+001.00000 \mathrm{e}-092.12000 \mathrm{e}-01$ $2.50903 \mathrm{e}+012.50903 \mathrm{e}+012.50903 \mathrm{e}+00$ 1.00000e-09 2.12000e-01 $2.50903 \mathrm{e}+012.50903 \mathrm{e}+012.50903 \mathrm{e}+001.00000 \mathrm{e}-092.12000 \mathrm{e}-01$ $2.50903 \mathrm{e}+012.50903 \mathrm{e}+012.50903 \mathrm{e}+00$ 1.00000e-09 2.12000e-01 $1.00000 \mathrm{e}-05$ 1.00000e-05 1.00000e-06 1.00000e-09 1.00000e-01 $1.00000 \mathrm{e}+001.00000 \mathrm{e}+001.00000 \mathrm{e}-011.00000 \mathrm{e}-091.00000 \mathrm{e}-01$ Element: 9826 \# of layers: 7

Kx Ky Kz Ss Por

$2.50903 \mathrm{e}+012.50903 \mathrm{e}+012.50903 \mathrm{e}+001.00000 \mathrm{e}-092.12000 \mathrm{e}-01$

$2.50903 \mathrm{e}+012.50903 \mathrm{e}+012.50903 \mathrm{e}+001.00000 \mathrm{e}-092.12000 \mathrm{e}-01$

$2.50903 \mathrm{e}+012.50903 \mathrm{e}+012.50903 \mathrm{e}+001.00000 \mathrm{e}-092.12000 \mathrm{e}-01$ $2.50903 \mathrm{e}+012.50903 \mathrm{e}+012.50903 \mathrm{e}+001.00000 \mathrm{e}-092.12000 \mathrm{e}-01$ $2.50903 \mathrm{e}+012.50903 \mathrm{e}+012.50903 \mathrm{e}+001.00000 \mathrm{e}-092.12000 \mathrm{e}-01$ $1.00000 \mathrm{e}-05$ 1.00000e-05 1.00000e-06 1.00000e-09 1.00000e-01 $1.00000 \mathrm{e}+001.00000 \mathrm{e}+00$ 1.00000e-01 1.00000e-09 1.00000e-01 Element: 9827 \# of layers: 7

Kx Ky Kz Ss Por

$2.87534 \mathrm{e}+012.87534 \mathrm{e}+012.87534 \mathrm{e}+00$ 1.00000e-09 2.12000e-01 $2.87534 \mathrm{e}+012.87534 \mathrm{e}+012.87534 \mathrm{e}+001.00000 \mathrm{e}-092.12000 \mathrm{e}-01$ $2.87534 \mathrm{e}+012.87534 \mathrm{e}+012.87534 \mathrm{e}+001.00000 \mathrm{e}-092.12000 \mathrm{e}-01$ $2.87534 \mathrm{e}+012.87534 \mathrm{e}+012.87534 \mathrm{e}+001.00000 \mathrm{e}-092.12000 \mathrm{e}-01$ $2.87534 \mathrm{e}+012.87534 \mathrm{e}+012.87534 \mathrm{e}+001.00000 \mathrm{e}-092.12000 \mathrm{e}-01$ $1.00000 \mathrm{e}-05$ 1.00000e-05 1.00000e-06 1.00000e-09 1.00000e-01 $1.00000 \mathrm{e}+001.00000 \mathrm{e}+001.00000 \mathrm{e}-011.00000 \mathrm{e}-091.00000 \mathrm{e}-01$ Element: 9828 \# of layers: 7

Kx Ky Kz Ss Por

$2.87534 \mathrm{e}+012.87534 \mathrm{e}+012.87534 \mathrm{e}+00$ 1.00000e-09 2.12000e-01 $2.87534 \mathrm{e}+012.87534 \mathrm{e}+012.87534 \mathrm{e}+001.00000 \mathrm{e}-092.12000 \mathrm{e}-01$ $2.87534 \mathrm{e}+012.87534 \mathrm{e}+012.87534 \mathrm{e}+001.00000 \mathrm{e}-092.12000 \mathrm{e}-01$ $2.87534 \mathrm{e}+012.87534 \mathrm{e}+012.87534 \mathrm{e}+001.00000 \mathrm{e}-092.12000 \mathrm{e}-01$ 
$2.87534 \mathrm{e}+012.87534 \mathrm{e}+012.87534 \mathrm{e}+001.00000 \mathrm{e}-092.12000 \mathrm{e}-01$ $1.00000 \mathrm{e}-05$ 1.00000e-05 1.00000e-06 1.00000e-09 1.00000e-01 $1.00000 \mathrm{e}+001.00000 \mathrm{e}+001.00000 \mathrm{e}-011.00000 \mathrm{e}-09$ 1.00000e-01 Element: 9829 \# of layers: 7

$\mathrm{Kx} \mathrm{Ky} \mathrm{Kz}$ Ss Por

$2.87534 \mathrm{e}+012.87534 \mathrm{e}+012.87534 \mathrm{e}+00$ 1.00000e-09 2.12000e-01

$2.87534 \mathrm{e}+012.87534 \mathrm{e}+012.87534 \mathrm{e}+001.00000 \mathrm{e}-092.12000 \mathrm{e}-01$

$2.87534 \mathrm{e}+012.87534 \mathrm{e}+012.87534 \mathrm{e}+001.00000 \mathrm{e}-092.12000 \mathrm{e}-01$

$2.87534 \mathrm{e}+012.87534 \mathrm{e}+012.87534 \mathrm{e}+00 \quad 1.00000 \mathrm{e}-092.12000 \mathrm{e}-01$

$2.87534 \mathrm{e}+012.87534 \mathrm{e}+012.87534 \mathrm{e}+001.00000 \mathrm{e}-092.12000 \mathrm{e}-01$

$1.00000 \mathrm{e}-05$ 1.00000e-05 1.00000e-06 1.00000e-09 1.00000e-01

$1.00000 \mathrm{e}+001.00000 \mathrm{e}+001.00000 \mathrm{e}-011.00000 \mathrm{e}-091.00000 \mathrm{e}-01$

Element: 9830 \# of layers: 7

$\mathrm{Kx} \mathrm{Ky} \mathrm{Kz}$ Ss Por

$2.87534 \mathrm{e}+012.87534 \mathrm{e}+012.87534 \mathrm{e}+001.00000 \mathrm{e}-092.12000 \mathrm{e}-01$

$2.87534 \mathrm{e}+012.87534 \mathrm{e}+012.87534 \mathrm{e}+001.00000 \mathrm{e}-092.12000 \mathrm{e}-01$

$2.87534 \mathrm{e}+012.87534 \mathrm{e}+012.87534 \mathrm{e}+00$ 1.00000e-09 2.12000e-01

$2.87534 \mathrm{e}+012.87534 \mathrm{e}+012.87534 \mathrm{e}+001.00000 \mathrm{e}-092.12000 \mathrm{e}-01$

$2.87534 \mathrm{e}+012.87534 \mathrm{e}+012.87534 \mathrm{e}+001.00000 \mathrm{e}-092.12000 \mathrm{e}-01$

$1.00000 \mathrm{e}-05$ 1.00000e-05 1.00000e-06 1.00000e-09 1.00000e-01

$1.00000 \mathrm{e}+001.00000 \mathrm{e}+001.00000 \mathrm{e}-011.00000 \mathrm{e}-091.00000 \mathrm{e}-01$

Element: 9831 \# of layers: 7

$\mathrm{Kx} \mathrm{Ky} \mathrm{Kz}$ Ss Por

$2.50903 \mathrm{e}+012.50903 \mathrm{e}+012.50903 \mathrm{e}+00$ 1.00000e-09 2.12000e-01

$2.50903 \mathrm{e}+012.50903 \mathrm{e}+012.50903 \mathrm{e}+001.00000 \mathrm{e}-092.12000 \mathrm{e}-01$

$2.50903 \mathrm{e}+012.50903 \mathrm{e}+012.50903 \mathrm{e}+001.00000 \mathrm{e}-092.12000 \mathrm{e}-01$

$2.50903 \mathrm{e}+012.50903 \mathrm{e}+012.50903 \mathrm{e}+00$ 1.00000e-09 2.12000e-01

$2.50903 \mathrm{e}+012.50903 \mathrm{e}+012.50903 \mathrm{e}+001.00000 \mathrm{e}-092.12000 \mathrm{e}-01$

$1.00000 \mathrm{e}-05$ 1.00000e-05 1.00000e-06 1.00000e-09 1.00000e-01

$1.00000 \mathrm{e}+001.00000 \mathrm{e}+001.00000 \mathrm{e}-011.00000 \mathrm{e}-091.00000 \mathrm{e}-01$

Element: 9832 \# of layers: 7

$\mathrm{Kx} \mathrm{Ky} \mathrm{Kz}$ Ss Por

$2.50903 \mathrm{e}+012.50903 \mathrm{e}+012.50903 \mathrm{e}+00$ 1.00000e-09 2.12000e-01

$2.50903 \mathrm{e}+012.50903 \mathrm{e}+012.50903 \mathrm{e}+001.00000 \mathrm{e}-092.12000 \mathrm{e}-01$

$2.50903 \mathrm{e}+012.50903 \mathrm{e}+012.50903 \mathrm{e}+00$ 1.00000e-09 2.12000e-01

$2.50903 \mathrm{e}+012.50903 \mathrm{e}+012.50903 \mathrm{e}+00$ 1.00000e-09 2.12000e-01

$2.50903 \mathrm{e}+012.50903 \mathrm{e}+012.50903 \mathrm{e}+00$ 1.00000e-09 2.12000e-01

$1.00000 \mathrm{e}-05$ 1.00000e-05 1.00000e-06 1.00000e-09 1.00000e-01

$1.00000 \mathrm{e}+001.00000 \mathrm{e}+001.00000 \mathrm{e}-011.00000 \mathrm{e}-091.00000 \mathrm{e}-01$

Element: 9833 \# of layers: 7

$\mathrm{Kx} \mathrm{Ky} \mathrm{Kz}$ Ss Por

$2.50903 \mathrm{e}+012.50903 \mathrm{e}+012.50903 \mathrm{e}+00$ 1.00000e-09 2.12000e-01

$2.50903 \mathrm{e}+012.50903 \mathrm{e}+012.50903 \mathrm{e}+00$ 1.00000e-09 2.12000e-01

$2.50903 \mathrm{e}+012.50903 \mathrm{e}+01$ 2.50903e+00 1.00000e-09 2.12000e-01

$2.50903 \mathrm{e}+012.50903 \mathrm{e}+012.50903 \mathrm{e}+00$ 1.00000e-09 2.12000e-01

$2.50903 \mathrm{e}+012.50903 \mathrm{e}+012.50903 \mathrm{e}+001.00000 \mathrm{e}-092.12000 \mathrm{e}-01$ 
$1.00000 \mathrm{e}-05$ 1.00000e-05 1.00000e-06 1.00000e-09 1.00000e-01 $1.00000 \mathrm{e}+001.00000 \mathrm{e}+001.00000 \mathrm{e}-01$ 1.00000e-09 1.00000e-01 Element: 9834 \# of layers: 7

$\mathrm{Kx} \mathrm{Ky} \mathrm{Kz}$ Ss Por

$2.50903 \mathrm{e}+012.50903 \mathrm{e}+012.50903 \mathrm{e}+00$ 1.00000e-09 2.12000e-01

$2.50903 \mathrm{e}+012.50903 \mathrm{e}+012.50903 \mathrm{e}+00$ 1.00000e-09 2.12000e-01

$2.50903 \mathrm{e}+012.50903 \mathrm{e}+012.50903 \mathrm{e}+00$ 1.00000e-09 2.12000e-01

$2.50903 \mathrm{e}+012.50903 \mathrm{e}+012.50903 \mathrm{e}+001.00000 \mathrm{e}-092.12000 \mathrm{e}-01$

$2.50903 \mathrm{e}+012.50903 \mathrm{e}+012.50903 \mathrm{e}+001.00000 \mathrm{e}-092.12000 \mathrm{e}-01$

$1.00000 \mathrm{e}-05$ 1.00000e-05 1.00000e-06 1.00000e-09 1.00000e-01

$1.00000 \mathrm{e}+001.00000 \mathrm{e}+001.00000 \mathrm{e}-01$ 1.00000e-09 1.00000e-01

Element: 9835 \# of layers: 7

$\mathrm{Kx} \mathrm{Ky} \mathrm{Kz}$ Ss Por

$2.50903 \mathrm{e}+012.50903 \mathrm{e}+012.50903 \mathrm{e}+00$ 1.00000e-09 2.12000e-01

$2.50903 \mathrm{e}+012.50903 \mathrm{e}+012.50903 \mathrm{e}+00$ 1.00000e-09 2.12000e-01

$2.50903 \mathrm{e}+012.50903 \mathrm{e}+012.50903 \mathrm{e}+00$ 1.00000e-09 2.12000e-01

$2.50903 \mathrm{e}+012.50903 \mathrm{e}+012.50903 \mathrm{e}+001.00000 \mathrm{e}-092.12000 \mathrm{e}-01$

$2.50903 \mathrm{e}+012.50903 \mathrm{e}+012.50903 \mathrm{e}+00$ 1.00000e-09 2.12000e-01

$1.00000 \mathrm{e}-05$ 1.00000e-05 1.00000e-06 1.00000e-09 1.00000e-01

$1.00000 \mathrm{e}+001.00000 \mathrm{e}+001.00000 \mathrm{e}-011.00000 \mathrm{e}-091.00000 \mathrm{e}-01$

Element: 9836 \# of layers: 7

$\mathrm{Kx} \mathrm{Ky} \mathrm{Kz}$ Ss Por

$2.50903 \mathrm{e}+012.50903 \mathrm{e}+012.50903 \mathrm{e}+00$ 1.00000e-09 2.12000e-01

$2.50903 \mathrm{e}+012.50903 \mathrm{e}+012.50903 \mathrm{e}+00$ 1.00000e-09 2.12000e-01

$2.50903 \mathrm{e}+012.50903 \mathrm{e}+012.50903 \mathrm{e}+001.00000 \mathrm{e}-092.12000 \mathrm{e}-01$

$2.50903 \mathrm{e}+012.50903 \mathrm{e}+012.50903 \mathrm{e}+001.00000 \mathrm{e}-092.12000 \mathrm{e}-01$

$2.50903 \mathrm{e}+012.50903 \mathrm{e}+012.50903 \mathrm{e}+001.00000 \mathrm{e}-092.12000 \mathrm{e}-01$

$1.00000 \mathrm{e}-05$ 1.00000e-05 1.00000e-06 1.00000e-09 1.00000e-01

$1.00000 \mathrm{e}+001.00000 \mathrm{e}+001.00000 \mathrm{e}-011.00000 \mathrm{e}-091.00000 \mathrm{e}-01$

Element: 9837 \# of layers: 7

$\mathrm{Kx} \mathrm{Ky} \mathrm{Kz}$ Ss Por

$2.50903 \mathrm{e}+012.50903 \mathrm{e}+012.50903 \mathrm{e}+00$ 1.00000e-09 2.12000e-01

$2.50903 \mathrm{e}+012.50903 \mathrm{e}+012.50903 \mathrm{e}+00$ 1.00000e-09 2.12000e-01

$2.50903 \mathrm{e}+012.50903 \mathrm{e}+012.50903 \mathrm{e}+001.00000 \mathrm{e}-092.12000 \mathrm{e}-01$

$2.50903 \mathrm{e}+012.50903 \mathrm{e}+012.50903 \mathrm{e}+00$ 1.00000e-09 2.12000e-01

$2.50903 \mathrm{e}+012.50903 \mathrm{e}+012.50903 \mathrm{e}+00$ 1.00000e-09 2.12000e-01 1.00000e-05 1.00000e-05 1.00000e-06 1.00000e-09 1.00000e-01

$1.00000 \mathrm{e}+001.00000 \mathrm{e}+001.00000 \mathrm{e}-011.00000 \mathrm{e}-091.00000 \mathrm{e}-01$

Element: 9838 \# of layers: 7

$\mathrm{Kx} \mathrm{Ky} \mathrm{Kz}$ Ss Por

$2.50903 e+012.50903 e+012.50903 e+001.00000 e-09$ 2.12000e-01

$2.50903 \mathrm{e}+012.50903 \mathrm{e}+012.50903 \mathrm{e}+001.00000 \mathrm{e}-092.12000 \mathrm{e}-01$

$2.50903 \mathrm{e}+012.50903 \mathrm{e}+012.50903 \mathrm{e}+001.00000 \mathrm{e}-092.12000 \mathrm{e}-01$

$2.50903 \mathrm{e}+012.50903 \mathrm{e}+012.50903 \mathrm{e}+00$ 1.00000e-09 2.12000e-01

$2.50903 \mathrm{e}+012.50903 \mathrm{e}+012.50903 \mathrm{e}+001.00000 \mathrm{e}-092.12000 \mathrm{e}-01$

$1.00000 \mathrm{e}-05$ 1.00000e-05 1.00000e-06 1.00000e-09 1.00000e-01 
$1.00000 \mathrm{e}+001.00000 \mathrm{e}+001.00000 \mathrm{e}-011.00000 \mathrm{e}-091.00000 \mathrm{e}-01$

Element: 9839 \# of layers: 7

$\mathrm{Kx} \mathrm{Ky} \mathrm{Kz}$ Ss Por

$2.50903 e+012.50903 e+012.50903 e+001.00000 e-092.12000 e-01$

$2.50903 \mathrm{e}+012.50903 \mathrm{e}+012.50903 \mathrm{e}+001.00000 \mathrm{e}-092.12000 \mathrm{e}-01$

$2.50903 \mathrm{e}+012.50903 \mathrm{e}+012.50903 \mathrm{e}+00$ 1.00000e-09 2.12000e-01

$2.50903 \mathrm{e}+012.50903 \mathrm{e}+012.50903 \mathrm{e}+00$ 1.00000e-09 2.12000e-01

$2.50903 \mathrm{e}+012.50903 \mathrm{e}+012.50903 \mathrm{e}+001.00000 \mathrm{e}-092.12000 \mathrm{e}-01$

$1.00000 \mathrm{e}-05$ 1.00000e-05 1.00000e-06 1.00000e-09 1.00000e-01

$1.00000 \mathrm{e}+001.00000 \mathrm{e}+001.00000 \mathrm{e}-011.00000 \mathrm{e}-09$ 1.00000e-01

Element: 9840 \# of layers: 7

$\mathrm{Kx} \mathrm{Ky} \mathrm{Kz}$ Ss Por

$2.50903 \mathrm{e}+012.50903 \mathrm{e}+012.50903 \mathrm{e}+00$ 1.00000e-09 2.12000e-01

$2.50903 \mathrm{e}+012.50903 \mathrm{e}+012.50903 \mathrm{e}+00$ 1.00000e-09 2.12000e-01

$2.50903 \mathrm{e}+012.50903 \mathrm{e}+012.50903 \mathrm{e}+00$ 1.00000e-09 2.12000e-01

$2.50903 \mathrm{e}+012.50903 \mathrm{e}+012.50903 \mathrm{e}+00$ 1.00000e-09 2.12000e-01

$2.50903 \mathrm{e}+012.50903 \mathrm{e}+012.50903 \mathrm{e}+00$ 1.00000e-09 2.12000e-01

$1.00000 \mathrm{e}-05$ 1.00000e-05 1.00000e-06 1.00000e-09 1.00000e-01

$1.00000 \mathrm{e}+001.00000 \mathrm{e}+001.00000 \mathrm{e}-011.00000 \mathrm{e}-091.00000 \mathrm{e}-01$

Element: 9841 \# of layers: 7

$\mathrm{Kx} \mathrm{Ky} \mathrm{Kz}$ Ss Por

$2.57181 \mathrm{e}+012.57181 \mathrm{e}+012.57181 \mathrm{e}+00$ 1.00000e-09 2.12000e-01

$2.57181 \mathrm{e}+012.57181 \mathrm{e}+012.57181 \mathrm{e}+001.00000 \mathrm{e}-092.12000 \mathrm{e}-01$

$2.57181 \mathrm{e}+012.57181 \mathrm{e}+012.57181 \mathrm{e}+001.00000 \mathrm{e}-092.12000 \mathrm{e}-01$

$2.57181 \mathrm{e}+012.57181 \mathrm{e}+012.57181 \mathrm{e}+001.00000 \mathrm{e}-092.12000 \mathrm{e}-01$

$2.57181 \mathrm{e}+012.57181 \mathrm{e}+012.57181 \mathrm{e}+001.00000 \mathrm{e}-092.12000 \mathrm{e}-01$

$1.00000 \mathrm{e}-05$ 1.00000e-05 1.00000e-06 1.00000e-09 1.00000e-01

$1.00000 \mathrm{e}+001.00000 \mathrm{e}+001.00000 \mathrm{e}-011.00000 \mathrm{e}-09$ 1.00000e-01

Element: 9842 \# of layers: 7

$\mathrm{Kx} \mathrm{Ky} \mathrm{Kz}$ Ss Por

$2.57181 \mathrm{e}+012.57181 \mathrm{e}+012.57181 \mathrm{e}+00$ 1.00000e-09 2.12000e-01

$2.57181 \mathrm{e}+012.57181 \mathrm{e}+012.57181 \mathrm{e}+001.00000 \mathrm{e}-092.12000 \mathrm{e}-01$

$2.57181 \mathrm{e}+012.57181 \mathrm{e}+012.57181 \mathrm{e}+001.00000 \mathrm{e}-092.12000 \mathrm{e}-01$

$2.57181 \mathrm{e}+012.57181 \mathrm{e}+012.57181 \mathrm{e}+001.00000 \mathrm{e}-092.12000 \mathrm{e}-01$

$2.57181 \mathrm{e}+012.57181 \mathrm{e}+012.57181 \mathrm{e}+001.00000 \mathrm{e}-092.12000 \mathrm{e}-01$

1.00000e-05 1.00000e-05 1.00000e-06 1.00000e-09 1.00000e-01

$1.00000 \mathrm{e}+001.00000 \mathrm{e}+001.00000 \mathrm{e}-011.00000 \mathrm{e}-091.00000 \mathrm{e}-01$

Element: 9843 \# of layers: 7

$\mathrm{Kx} \mathrm{Ky} \mathrm{Kz}$ Ss Por

$2.57181 \mathrm{e}+012.57181 \mathrm{e}+012.57181 \mathrm{e}+00$ 1.00000e-09 2.12000e-01

$2.57181 \mathrm{e}+012.57181 \mathrm{e}+012.57181 \mathrm{e}+001.00000 \mathrm{e}-092.12000 \mathrm{e}-01$

$2.57181 \mathrm{e}+012.57181 \mathrm{e}+012.57181 \mathrm{e}+001.00000 \mathrm{e}-092.12000 \mathrm{e}-01$

$2.57181 \mathrm{e}+012.57181 \mathrm{e}+012.57181 \mathrm{e}+001.00000 \mathrm{e}-092.12000 \mathrm{e}-01$

$2.57181 \mathrm{e}+012.57181 \mathrm{e}+012.57181 \mathrm{e}+00$ 1.00000e-09 2.12000e-01 $1.00000 \mathrm{e}-05$ 1.00000e-05 1.00000e-06 1.00000e-09 1.00000e-01

$1.00000 \mathrm{e}+001.00000 \mathrm{e}+001.00000 \mathrm{e}-011.00000 \mathrm{e}-091.00000 \mathrm{e}-01$ 
Element: 9844 \# of layers: 7

$\mathrm{Kx} \mathrm{Ky} \mathrm{Kz}$ Ss Por

$2.57181 \mathrm{e}+012.57181 \mathrm{e}+012.57181 \mathrm{e}+00$ 1.00000e-09 2.12000e-01

$2.57181 \mathrm{e}+012.57181 \mathrm{e}+012.57181 \mathrm{e}+001.00000 \mathrm{e}-092.12000 \mathrm{e}-01$

$2.57181 \mathrm{e}+012.57181 \mathrm{e}+012.57181 \mathrm{e}+001.00000 \mathrm{e}-092.12000 \mathrm{e}-01$

$2.57181 \mathrm{e}+012.57181 \mathrm{e}+012.57181 \mathrm{e}+001.00000 \mathrm{e}-092.12000 \mathrm{e}-01$

$2.57181 \mathrm{e}+012.57181 \mathrm{e}+012.57181 \mathrm{e}+001.00000 \mathrm{e}-092.12000 \mathrm{e}-01$

$1.00000 \mathrm{e}-05$ 1.00000e-05 1.00000e-06 1.00000e-09 1.00000e-01

$1.00000 \mathrm{e}+001.00000 \mathrm{e}+001.00000 \mathrm{e}-011.00000 \mathrm{e}-091.00000 \mathrm{e}-01$

Element: 9845 \# of layers: 7

$\mathrm{Kx} \mathrm{Ky} \mathrm{Kz}$ Ss Por

$2.57181 \mathrm{e}+012.57181 \mathrm{e}+012.57181 \mathrm{e}+00$ 1.00000e-09 2.12000e-01

$2.57181 \mathrm{e}+012.57181 \mathrm{e}+012.57181 \mathrm{e}+001.00000 \mathrm{e}-092.12000 \mathrm{e}-01$

$2.57181 \mathrm{e}+012.57181 \mathrm{e}+012.57181 \mathrm{e}+001.00000 \mathrm{e}-092.12000 \mathrm{e}-01$

$2.57181 \mathrm{e}+012.57181 \mathrm{e}+012.57181 \mathrm{e}+001.00000 \mathrm{e}-092.12000 \mathrm{e}-01$

$2.57181 \mathrm{e}+012.57181 \mathrm{e}+012.57181 \mathrm{e}+001.00000 \mathrm{e}-092.12000 \mathrm{e}-01$

$1.00000 \mathrm{e}-05$ 1.00000e-05 1.00000e-06 1.00000e-09 1.00000e-01

$1.00000 \mathrm{e}+001.00000 \mathrm{e}+001.00000 \mathrm{e}-011.00000 \mathrm{e}-09$ 1.00000e-01

Element: 9846 \# of layers: 7

$\mathrm{Kx} \mathrm{Ky} \mathrm{Kz}$ Ss Por

$2.50903 \mathrm{e}+012.50903 \mathrm{e}+012.50903 \mathrm{e}+00$ 1.00000e-09 2.12000e-01

$2.50903 \mathrm{e}+012.50903 \mathrm{e}+012.50903 \mathrm{e}+00$ 1.00000e-09 2.12000e-01

$2.50903 \mathrm{e}+012.50903 \mathrm{e}+012.50903 \mathrm{e}+00$ 1.00000e-09 2.12000e-01

$2.50903 \mathrm{e}+012.50903 \mathrm{e}+012.50903 \mathrm{e}+00$ 1.00000e-09 2.12000e-01

$2.50903 \mathrm{e}+012.50903 \mathrm{e}+012.50903 \mathrm{e}+00$ 1.00000e-09 2.12000e-01

$1.00000 \mathrm{e}-05$ 1.00000e-05 1.00000e-06 1.00000e-09 1.00000e-01

$1.00000 \mathrm{e}+001.00000 \mathrm{e}+001.00000 \mathrm{e}-011.00000 \mathrm{e}-091.00000 \mathrm{e}-01$

Element: 9847 \# of layers: 7

$\mathrm{Kx} \mathrm{Ky} \mathrm{Kz}$ Ss Por

$2.50903 \mathrm{e}+012.50903 \mathrm{e}+012.50903 \mathrm{e}+00$ 1.00000e-09 2.12000e-01

$2.50903 \mathrm{e}+012.50903 \mathrm{e}+012.50903 \mathrm{e}+001.00000 \mathrm{e}-092.12000 \mathrm{e}-01$

$2.50903 \mathrm{e}+012.50903 \mathrm{e}+012.50903 \mathrm{e}+00$ 1.00000e-09 2.12000e-01

$2.50903 \mathrm{e}+012.50903 \mathrm{e}+012.50903 \mathrm{e}+00$ 1.00000e-09 2.12000e-01

$2.50903 \mathrm{e}+012.50903 \mathrm{e}+012.50903 \mathrm{e}+00$ 1.00000e-09 2.12000e-01

$1.00000 \mathrm{e}-05$ 1.00000e-05 1.00000e-06 1.00000e-09 1.00000e-01

$1.00000 \mathrm{e}+001.00000 \mathrm{e}+001.00000 \mathrm{e}-011.00000 \mathrm{e}-091.00000 \mathrm{e}-01$

Element: 9848 \# of layers: 7

Kx Ky Kz Ss Por

$2.57181 \mathrm{e}+012.57181 \mathrm{e}+012.57181 \mathrm{e}+00$ 1.00000e-09 2.12000e-01

$2.57181 \mathrm{e}+012.57181 \mathrm{e}+012.57181 \mathrm{e}+001.00000 \mathrm{e}-092.12000 \mathrm{e}-01$

$2.57181 \mathrm{e}+012.57181 \mathrm{e}+012.57181 \mathrm{e}+001.00000 \mathrm{e}-092.12000 \mathrm{e}-01$

$2.57181 \mathrm{e}+012.57181 \mathrm{e}+012.57181 \mathrm{e}+001.00000 \mathrm{e}-092.12000 \mathrm{e}-01$

$2.57181 \mathrm{e}+012.57181 \mathrm{e}+012.57181 \mathrm{e}+001.00000 \mathrm{e}-092.12000 \mathrm{e}-01$

$1.00000 \mathrm{e}-051.00000 \mathrm{e}-051.00000 \mathrm{e}-061.00000 \mathrm{e}-091.00000 \mathrm{e}-01$

$1.00000 \mathrm{e}+001.00000 \mathrm{e}+001.00000 \mathrm{e}-011.00000 \mathrm{e}-09$ 1.00000e-01

Element: 9849 \# of layers: 7 
$\mathrm{Kx} \mathrm{Ky} \mathrm{Kz}$ Ss Por

$2.57181 \mathrm{e}+012.57181 \mathrm{e}+012.57181 \mathrm{e}+00$ 1.00000e-09 2.12000e-01

$2.57181 \mathrm{e}+012.57181 \mathrm{e}+012.57181 \mathrm{e}+001.00000 \mathrm{e}-092.12000 \mathrm{e}-01$

$2.57181 \mathrm{e}+012.57181 \mathrm{e}+012.57181 \mathrm{e}+001.00000 \mathrm{e}-092.12000 \mathrm{e}-01$

$2.57181 \mathrm{e}+012.57181 \mathrm{e}+012.57181 \mathrm{e}+001.00000 \mathrm{e}-092.12000 \mathrm{e}-01$

$2.57181 \mathrm{e}+012.57181 \mathrm{e}+012.57181 \mathrm{e}+001.00000 \mathrm{e}-092.12000 \mathrm{e}-01$

$1.00000 \mathrm{e}-051.00000 \mathrm{e}-051.00000 \mathrm{e}-061.00000 \mathrm{e}-091.00000 \mathrm{e}-01$

$1.00000 \mathrm{e}+001.00000 \mathrm{e}+001.00000 \mathrm{e}-01$ 1.00000e-09 1.00000e-01

Element: 9850 \# of layers: 7

$\mathrm{Kx} \mathrm{Ky} \mathrm{Kz}$ Ss Por

$2.93901 \mathrm{e}+012.93901 \mathrm{e}+012.93901 \mathrm{e}+00$ 1.00000e-09 2.12000e-01 $2.93901 \mathrm{e}+012.93901 \mathrm{e}+012.93901 \mathrm{e}+001.00000 \mathrm{e}-092.12000 \mathrm{e}-01$ $2.93901 \mathrm{e}+012.93901 \mathrm{e}+012.93901 \mathrm{e}+001.00000 \mathrm{e}-092.12000 \mathrm{e}-01$ $2.93901 \mathrm{e}+012.93901 \mathrm{e}+012.93901 \mathrm{e}+001.00000 \mathrm{e}-092.12000 \mathrm{e}-01$ $2.93901 \mathrm{e}+012.93901 \mathrm{e}+012.93901 \mathrm{e}+001.00000 \mathrm{e}-092.12000 \mathrm{e}-01$ $1.00000 \mathrm{e}-05$ 1.00000e-05 1.00000e-06 1.00000e-09 1.00000e-01 $1.00000 \mathrm{e}+001.00000 \mathrm{e}+001.00000 \mathrm{e}-01$ 1.00000e-09 1.00000e-01 Element: 9851 \# of layers: 7

$\mathrm{Kx} \mathrm{Ky} \mathrm{Kz}$ Ss Por

$2.93901 \mathrm{e}+012.93901 \mathrm{e}+012.93901 \mathrm{e}+00$ 1.00000e-09 2.12000e-01 $2.93901 \mathrm{e}+012.93901 \mathrm{e}+012.93901 \mathrm{e}+001.00000 \mathrm{e}-092.12000 \mathrm{e}-01$ $2.93901 \mathrm{e}+012.93901 \mathrm{e}+012.93901 \mathrm{e}+001.00000 \mathrm{e}-092.12000 \mathrm{e}-01$ $2.93901 \mathrm{e}+012.93901 \mathrm{e}+012.93901 \mathrm{e}+001.00000 \mathrm{e}-092.12000 \mathrm{e}-01$ $2.93901 \mathrm{e}+012.93901 \mathrm{e}+012.93901 \mathrm{e}+001.00000 \mathrm{e}-092.12000 \mathrm{e}-01$ $1.00000 \mathrm{e}-05$ 1.00000e-05 1.00000e-06 1.00000e-09 1.00000e-01 $1.00000 \mathrm{e}+001.00000 \mathrm{e}+001.00000 \mathrm{e}-011.00000 \mathrm{e}-091.00000 \mathrm{e}-01$ Element: 9852 \# of layers: 7

$\mathrm{Kx} \mathrm{Ky} \mathrm{Kz}$ Ss Por

$2.93901 \mathrm{e}+012.93901 \mathrm{e}+012.93901 \mathrm{e}+001.00000 \mathrm{e}-092.12000 \mathrm{e}-01$ $2.93901 \mathrm{e}+012.93901 \mathrm{e}+012.93901 \mathrm{e}+001.00000 \mathrm{e}-092.12000 \mathrm{e}-01$ $2.93901 \mathrm{e}+012.93901 \mathrm{e}+012.93901 \mathrm{e}+001.00000 \mathrm{e}-092.12000 \mathrm{e}-01$ $2.93901 \mathrm{e}+012.93901 \mathrm{e}+012.93901 \mathrm{e}+001.00000 \mathrm{e}-09$ 2.12000e-01 $2.93901 \mathrm{e}+012.93901 \mathrm{e}+012.93901 \mathrm{e}+001.00000 \mathrm{e}-092.12000 \mathrm{e}-01$ $1.00000 \mathrm{e}-05$ 1.00000e-05 1.00000e-06 1.00000e-09 1.00000e-01 $1.00000 \mathrm{e}+001.00000 \mathrm{e}+001.00000 \mathrm{e}-011.00000 \mathrm{e}-091.00000 \mathrm{e}-01$ Element: 9853 \# of layers: 7

Kx Ky Kz Ss Por

$2.87534 \mathrm{e}+012.87534 \mathrm{e}+012.87534 \mathrm{e}+00$ 1.00000e-09 2.12000e-01 $2.87534 \mathrm{e}+012.87534 \mathrm{e}+012.87534 \mathrm{e}+001.00000 \mathrm{e}-092.12000 \mathrm{e}-01$ $2.87534 \mathrm{e}+012.87534 \mathrm{e}+012.87534 \mathrm{e}+001.00000 \mathrm{e}-092.12000 \mathrm{e}-01$ $2.87534 \mathrm{e}+012.87534 \mathrm{e}+012.87534 \mathrm{e}+001.00000 \mathrm{e}-092.12000 \mathrm{e}-01$ $2.87534 \mathrm{e}+012.87534 \mathrm{e}+012.87534 \mathrm{e}+001.00000 \mathrm{e}-092.12000 \mathrm{e}-01$ $1.00000 \mathrm{e}-05$ 1.00000e-05 1.00000e-06 1.00000e-09 1.00000e-01 $1.00000 \mathrm{e}+001.00000 \mathrm{e}+001.00000 \mathrm{e}-01$ 1.00000e-09 1.00000e-01 Element: 9854 \# of layers: 7

Kx Ky Kz Ss Por 
$2.87534 \mathrm{e}+012.87534 \mathrm{e}+012.87534 \mathrm{e}+001.00000 \mathrm{e}-092.12000 \mathrm{e}-01$ $2.87534 \mathrm{e}+012.87534 \mathrm{e}+012.87534 \mathrm{e}+001.00000 \mathrm{e}-092.12000 \mathrm{e}-01$ $2.87534 \mathrm{e}+012.87534 \mathrm{e}+012.87534 \mathrm{e}+001.00000 \mathrm{e}-092.12000 \mathrm{e}-01$ $2.87534 \mathrm{e}+012.87534 \mathrm{e}+012.87534 \mathrm{e}+001.00000 \mathrm{e}-092.12000 \mathrm{e}-01$ $2.87534 \mathrm{e}+012.87534 \mathrm{e}+012.87534 \mathrm{e}+001.00000 \mathrm{e}-092.12000 \mathrm{e}-01$ $1.00000 \mathrm{e}-05$ 1.00000e-05 1.00000e-06 1.00000e-09 1.00000e-01 $1.00000 \mathrm{e}+001.00000 \mathrm{e}+001.00000 \mathrm{e}-01$ 1.00000e-09 1.00000e-01 Element: 9855 \# of layers: 7

$\mathrm{Kx} \mathrm{Ky} \mathrm{Kz}$ Ss Por

$2.50903 \mathrm{e}+012.50903 \mathrm{e}+012.50903 \mathrm{e}+00$ 1.00000e-09 2.12000e-01 $2.50903 \mathrm{e}+012.50903 \mathrm{e}+012.50903 \mathrm{e}+00$ 1.00000e-09 2.12000e-01 $2.50903 \mathrm{e}+012.50903 \mathrm{e}+012.50903 \mathrm{e}+001.00000 \mathrm{e}-092.12000 \mathrm{e}-01$ $2.50903 \mathrm{e}+012.50903 \mathrm{e}+012.50903 \mathrm{e}+00$ 1.00000e-09 2.12000e-01 $2.50903 \mathrm{e}+012.50903 \mathrm{e}+012.50903 \mathrm{e}+00$ 1.00000e-09 2.12000e-01 $1.00000 \mathrm{e}-05$ 1.00000e-05 1.00000e-06 1.00000e-09 1.00000e-01 $1.00000 \mathrm{e}+001.00000 \mathrm{e}+001.00000 \mathrm{e}-011.00000 \mathrm{e}-091.00000 \mathrm{e}-01$ Element: 9856 \# of layers: 7

$\mathrm{Kx} \mathrm{Ky} \mathrm{Kz}$ Ss Por

$2.57181 \mathrm{e}+012.57181 \mathrm{e}+012.57181 \mathrm{e}+00$ 1.00000e-09 2.12000e-01 $2.57181 \mathrm{e}+012.57181 \mathrm{e}+012.57181 \mathrm{e}+001.00000 \mathrm{e}-092.12000 \mathrm{e}-01$ $2.57181 \mathrm{e}+012.57181 \mathrm{e}+012.57181 \mathrm{e}+001.00000 \mathrm{e}-092.12000 \mathrm{e}-01$ $2.57181 \mathrm{e}+012.57181 \mathrm{e}+012.57181 \mathrm{e}+001.00000 \mathrm{e}-092.12000 \mathrm{e}-01$ $2.57181 \mathrm{e}+012.57181 \mathrm{e}+012.57181 \mathrm{e}+001.00000 \mathrm{e}-092.12000 \mathrm{e}-01$ $1.00000 \mathrm{e}-05$ 1.00000e-05 1.00000e-06 1.00000e-09 1.00000e-01 $1.00000 \mathrm{e}+001.00000 \mathrm{e}+001.00000 \mathrm{e}-011.00000 \mathrm{e}-091.00000 \mathrm{e}-01$ Element: 9857 \# of layers: 7

$\mathrm{Kx} \mathrm{Ky} \mathrm{Kz}$ Ss Por

$2.93901 \mathrm{e}+012.93901 \mathrm{e}+012.93901 \mathrm{e}+001.00000 \mathrm{e}-09$ 2.12000e-01 $2.93901 \mathrm{e}+012.93901 \mathrm{e}+012.93901 \mathrm{e}+001.00000 \mathrm{e}-092.12000 \mathrm{e}-01$ $2.93901 \mathrm{e}+012.93901 \mathrm{e}+012.93901 \mathrm{e}+001.00000 \mathrm{e}-092.12000 \mathrm{e}-01$ $2.93901 \mathrm{e}+012.93901 \mathrm{e}+012.93901 \mathrm{e}+001.00000 \mathrm{e}-092.12000 \mathrm{e}-01$ $2.93901 \mathrm{e}+012.93901 \mathrm{e}+012.93901 \mathrm{e}+001.00000 \mathrm{e}-092.12000 \mathrm{e}-01$ $1.00000 \mathrm{e}-05$ 1.00000e-05 1.00000e-06 1.00000e-09 1.00000e-01 $1.00000 \mathrm{e}+001.00000 \mathrm{e}+001.00000 \mathrm{e}-011.00000 \mathrm{e}-091.00000 \mathrm{e}-01$ Element: 9858 \# of layers: 7

$\mathrm{Kx} \mathrm{Ky} \mathrm{Kz}$ Ss Por

$2.90751 \mathrm{e}+012.90751 \mathrm{e}+012.90751 \mathrm{e}+00$ 1.00000e-09 2.12000e-01 $2.90751 \mathrm{e}+012.90751 \mathrm{e}+012.90751 \mathrm{e}+001.00000 \mathrm{e}-092.12000 \mathrm{e}-01$ $2.90751 \mathrm{e}+012.90751 \mathrm{e}+012.90751 \mathrm{e}+001.00000 \mathrm{e}-092.12000 \mathrm{e}-01$ $2.90751 \mathrm{e}+012.90751 \mathrm{e}+012.90751 \mathrm{e}+001.00000 \mathrm{e}-092.12000 \mathrm{e}-01$ $2.90751 \mathrm{e}+012.90751 \mathrm{e}+012.90751 \mathrm{e}+001.00000 \mathrm{e}-092.12000 \mathrm{e}-01$ $1.00000 \mathrm{e}-05$ 1.00000e-05 1.00000e-06 1.00000e-09 1.00000e-01 $1.00000 \mathrm{e}+001.00000 \mathrm{e}+001.00000 \mathrm{e}-011.00000 \mathrm{e}-091.00000 \mathrm{e}-01$ Element: 9859 \# of layers: 7

$\mathrm{Kx} \mathrm{Ky} \mathrm{Kz}$ Ss Por 2.90751e+01 2.90751e+01 2.90751e+00 1.00000e-09 2.12000e-01 
$2.90751 \mathrm{e}+012.90751 \mathrm{e}+012.90751 \mathrm{e}+00$ 1.00000e-09 2.12000e-01 $2.90751 \mathrm{e}+012.90751 \mathrm{e}+012.90751 \mathrm{e}+00$ 1.00000e-09 2.12000e-01 $2.90751 \mathrm{e}+012.90751 \mathrm{e}+012.90751 \mathrm{e}+001.00000 \mathrm{e}-092.12000 \mathrm{e}-01$ $2.90751 \mathrm{e}+012.90751 \mathrm{e}+012.90751 \mathrm{e}+001.00000 \mathrm{e}-092.12000 \mathrm{e}-01$ $1.00000 \mathrm{e}-05$ 1.00000e-05 1.00000e-06 1.00000e-09 1.00000e-01 $1.00000 \mathrm{e}+001.00000 \mathrm{e}+001.00000 \mathrm{e}-011.00000 \mathrm{e}-091.00000 \mathrm{e}-01$ Element: 9860 \# of layers: 7

$\mathrm{Kx} \mathrm{Ky} \mathrm{Kz}$ Ss Por

$2.90751 \mathrm{e}+012.90751 \mathrm{e}+012.90751 \mathrm{e}+00$ 1.00000e-09 2.12000e-01 $2.90751 \mathrm{e}+012.90751 \mathrm{e}+012.90751 \mathrm{e}+001.00000 \mathrm{e}-092.12000 \mathrm{e}-01$ $2.90751 \mathrm{e}+012.90751 \mathrm{e}+012.90751 \mathrm{e}+00$ 1.00000e-09 2.12000e-01 $2.90751 \mathrm{e}+012.90751 \mathrm{e}+012.90751 \mathrm{e}+001.00000 \mathrm{e}-092.12000 \mathrm{e}-01$ $2.90751 \mathrm{e}+012.90751 \mathrm{e}+012.90751 \mathrm{e}+001.00000 \mathrm{e}-092.12000 \mathrm{e}-01$ $1.00000 \mathrm{e}-05$ 1.00000e-05 1.00000e-06 1.00000e-09 1.00000e-01 $1.00000 \mathrm{e}+001.00000 \mathrm{e}+001.00000 \mathrm{e}-01$ 1.00000e-09 1.00000e-01 Element: 9861 \# of layers: 7

$\mathrm{Kx} \mathrm{Ky} \mathrm{Kz}$ Ss Por

$2.90751 \mathrm{e}+012.90751 \mathrm{e}+012.90751 \mathrm{e}+00$ 1.00000e-09 2.12000e-01 $2.90751 \mathrm{e}+012.90751 \mathrm{e}+012.90751 \mathrm{e}+00$ 1.00000e-09 2.12000e-01 $2.90751 \mathrm{e}+012.90751 \mathrm{e}+012.90751 \mathrm{e}+001.00000 \mathrm{e}-092.12000 \mathrm{e}-01$ $2.90751 \mathrm{e}+012.90751 \mathrm{e}+012.90751 \mathrm{e}+001.00000 \mathrm{e}-092.12000 \mathrm{e}-01$ $2.90751 \mathrm{e}+012.90751 \mathrm{e}+012.90751 \mathrm{e}+00$ 1.00000e-09 2.12000e-01 $1.00000 \mathrm{e}-051.00000 \mathrm{e}-05$ 1.00000e-06 1.00000e-09 1.00000e-01 $1.00000 \mathrm{e}+001.00000 \mathrm{e}+001.00000 \mathrm{e}-011.00000 \mathrm{e}-091.00000 \mathrm{e}-01$ Element: 9862 \# of layers: 7

$\mathrm{Kx} \mathrm{Ky} \mathrm{Kz}$ Ss Por

$2.90751 \mathrm{e}+012.90751 \mathrm{e}+012.90751 \mathrm{e}+00$ 1.00000e-09 2.12000e-01 $2.90751 \mathrm{e}+012.90751 \mathrm{e}+012.90751 \mathrm{e}+001.00000 \mathrm{e}-092.12000 \mathrm{e}-01$ $2.90751 \mathrm{e}+012.90751 \mathrm{e}+012.90751 \mathrm{e}+001.00000 \mathrm{e}-092.12000 \mathrm{e}-01$ $2.90751 \mathrm{e}+012.90751 \mathrm{e}+012.90751 \mathrm{e}+001.00000 \mathrm{e}-092.12000 \mathrm{e}-01$ $2.90751 \mathrm{e}+012.90751 \mathrm{e}+012.90751 \mathrm{e}+001.00000 \mathrm{e}-092.12000 \mathrm{e}-01$ $1.00000 \mathrm{e}-05$ 1.00000e-05 1.00000e-06 1.00000e-09 1.00000e-01 $1.00000 \mathrm{e}+001.00000 \mathrm{e}+001.00000 \mathrm{e}-011.00000 \mathrm{e}-091.00000 \mathrm{e}-01$ Element: 9863 \# of layers: 7

$\mathrm{Kx} \mathrm{Ky} \mathrm{Kz}$ Ss Por

$2.90751 \mathrm{e}+012.90751 \mathrm{e}+012.90751 \mathrm{e}+00$ 1.00000e-09 2.12000e-01 $2.90751 \mathrm{e}+012.90751 \mathrm{e}+012.90751 \mathrm{e}+001.00000 \mathrm{e}-092.12000 \mathrm{e}-01$ $2.90751 \mathrm{e}+012.90751 \mathrm{e}+012.90751 \mathrm{e}+00$ 1.00000e-09 2.12000e-01 $2.90751 \mathrm{e}+012.90751 \mathrm{e}+012.90751 \mathrm{e}+00$ 1.00000e-09 2.12000e-01 $2.90751 \mathrm{e}+012.90751 \mathrm{e}+012.90751 \mathrm{e}+001.00000 \mathrm{e}-092.12000 \mathrm{e}-01$ $1.00000 \mathrm{e}-05$ 1.00000e-05 1.00000e-06 1.00000e-09 1.00000e-01 $1.00000 \mathrm{e}+001.00000 \mathrm{e}+001.00000 \mathrm{e}-011.00000 \mathrm{e}-091.00000 \mathrm{e}-01$ Element: 9864 \# of layers: 7

$\mathrm{Kx} \mathrm{Ky} \mathrm{Kz}$ Ss Por $2.90751 \mathrm{e}+012.90751 \mathrm{e}+012.90751 \mathrm{e}+00$ 1.00000e-09 2.12000e-01 $2.90751 \mathrm{e}+012.90751 \mathrm{e}+012.90751 \mathrm{e}+001.00000 \mathrm{e}-092.12000 \mathrm{e}-01$ 
$2.90751 \mathrm{e}+012.90751 \mathrm{e}+012.90751 \mathrm{e}+00$ 1.00000e-09 2.12000e-01 $2.90751 \mathrm{e}+012.90751 \mathrm{e}+012.90751 \mathrm{e}+001.00000 \mathrm{e}-092.12000 \mathrm{e}-01$ $2.90751 \mathrm{e}+012.90751 \mathrm{e}+012.90751 \mathrm{e}+001.00000 \mathrm{e}-092.12000 \mathrm{e}-01$ $1.00000 \mathrm{e}-05$ 1.00000e-05 1.00000e-06 1.00000e-09 1.00000e-01 $1.00000 \mathrm{e}+001.00000 \mathrm{e}+001.00000 \mathrm{e}-01$ 1.00000e-09 1.00000e-01 Element: 9865 \# of layers: 7

$\mathrm{Kx} \mathrm{Ky} \mathrm{Kz}$ Ss Por

$2.90751 \mathrm{e}+012.90751 \mathrm{e}+012.90751 \mathrm{e}+00$ 1.00000e-09 2.12000e-01 $2.90751 \mathrm{e}+012.90751 \mathrm{e}+012.90751 \mathrm{e}+001.00000 \mathrm{e}-092.12000 \mathrm{e}-01$ $2.90751 \mathrm{e}+012.90751 \mathrm{e}+012.90751 \mathrm{e}+001.00000 \mathrm{e}-092.12000 \mathrm{e}-01$ $2.90751 \mathrm{e}+012.90751 \mathrm{e}+012.90751 \mathrm{e}+00$ 1.00000e-09 2.12000e-01 $2.90751 \mathrm{e}+012.90751 \mathrm{e}+012.90751 \mathrm{e}+001.00000 \mathrm{e}-092.12000 \mathrm{e}-01$ $1.00000 \mathrm{e}-05$ 1.00000e-05 1.00000e-06 1.00000e-09 1.00000e-01 $1.00000 \mathrm{e}+001.00000 \mathrm{e}+001.00000 \mathrm{e}-011.00000 \mathrm{e}-09$ 1.00000e-01 Element: 9866 \# of layers: 7

Kx Ky Kz Ss Por

$2.90751 \mathrm{e}+012.90751 \mathrm{e}+012.90751 \mathrm{e}+00$ 1.00000e-09 2.12000e-01 $2.90751 \mathrm{e}+012.90751 \mathrm{e}+012.90751 \mathrm{e}+001.00000 \mathrm{e}-092.12000 \mathrm{e}-01$ $2.90751 \mathrm{e}+012.90751 \mathrm{e}+012.90751 \mathrm{e}+00$ 1.00000e-09 2.12000e-01 $2.90751 \mathrm{e}+012.90751 \mathrm{e}+012.90751 \mathrm{e}+001.00000 \mathrm{e}-092.12000 \mathrm{e}-01$ $2.90751 \mathrm{e}+012.90751 \mathrm{e}+012.90751 \mathrm{e}+001.00000 \mathrm{e}-092.12000 \mathrm{e}-01$ $1.00000 \mathrm{e}-05$ 1.00000e-05 1.00000e-06 1.00000e-09 1.00000e-01 $1.00000 \mathrm{e}+001.00000 \mathrm{e}+001.00000 \mathrm{e}-01$ 1.00000e-09 1.00000e-01 Element: 9867 \# of layers: 7

$\mathrm{Kx} \mathrm{Ky} \mathrm{Kz}$ Ss Por

$2.90751 \mathrm{e}+012.90751 \mathrm{e}+012.90751 \mathrm{e}+001.00000 \mathrm{e}-092.12000 \mathrm{e}-01$ $2.90751 \mathrm{e}+012.90751 \mathrm{e}+012.90751 \mathrm{e}+001.00000 \mathrm{e}-092.12000 \mathrm{e}-01$ $2.90751 \mathrm{e}+012.90751 \mathrm{e}+012.90751 \mathrm{e}+001.00000 \mathrm{e}-092.12000 \mathrm{e}-01$ $2.90751 \mathrm{e}+012.90751 \mathrm{e}+012.90751 \mathrm{e}+001.00000 \mathrm{e}-092.12000 \mathrm{e}-01$ $2.90751 \mathrm{e}+012.90751 \mathrm{e}+012.90751 \mathrm{e}+001.00000 \mathrm{e}-092.12000 \mathrm{e}-01$ $1.00000 \mathrm{e}-05$ 1.00000e-05 1.00000e-06 1.00000e-09 1.00000e-01 $1.00000 \mathrm{e}+001.00000 \mathrm{e}+001.00000 \mathrm{e}-011.00000 \mathrm{e}-091.00000 \mathrm{e}-01$ Element: 9868 \# of layers: 7

$\mathrm{Kx} \mathrm{Ky} \mathrm{Kz}$ Ss Por

$2.66608 \mathrm{e}+012.66608 \mathrm{e}+012.66608 \mathrm{e}+00$ 1.00000e-09 2.12000e-01

$2.66608 \mathrm{e}+012.66608 \mathrm{e}+012.66608 \mathrm{e}+001.00000 \mathrm{e}-092.12000 \mathrm{e}-01$

$2.66608 \mathrm{e}+012.66608 \mathrm{e}+012.66608 \mathrm{e}+001.00000 \mathrm{e}-092.12000 \mathrm{e}-01$

$2.66608 \mathrm{e}+012.66608 \mathrm{e}+012.66608 \mathrm{e}+001.00000 \mathrm{e}-092.12000 \mathrm{e}-01$

$2.66608 \mathrm{e}+012.66608 \mathrm{e}+012.66608 \mathrm{e}+001.00000 \mathrm{e}-092.12000 \mathrm{e}-01$ $1.00000 \mathrm{e}-05$ 1.00000e-05 1.00000e-06 1.00000e-09 1.00000e-01 $1.00000 \mathrm{e}+001.00000 \mathrm{e}+001.00000 \mathrm{e}-011.00000 \mathrm{e}-091.00000 \mathrm{e}-01$ Element: 9869 \# of layers: 7

$\mathrm{Kx} \mathrm{Ky} \mathrm{Kz}$ Ss Por

$2.66608 \mathrm{e}+012.66608 \mathrm{e}+01$ 2.66608e+00 1.00000e-09 2.12000e-01 $2.66608 \mathrm{e}+012.66608 \mathrm{e}+012.66608 \mathrm{e}+001.00000 \mathrm{e}-092.12000 \mathrm{e}-01$ $2.66608 \mathrm{e}+012.66608 \mathrm{e}+012.66608 \mathrm{e}+001.00000 \mathrm{e}-092.12000 \mathrm{e}-01$ 
$2.66608 \mathrm{e}+012.66608 \mathrm{e}+012.66608 \mathrm{e}+00$ 1.00000e-09 2.12000e-01

$2.66608 \mathrm{e}+012.66608 \mathrm{e}+012.66608 \mathrm{e}+001.00000 \mathrm{e}-092.12000 \mathrm{e}-01$

$1.00000 \mathrm{e}-05$ 1.00000e-05 1.00000e-06 1.00000e-09 1.00000e-01

$1.00000 \mathrm{e}+001.00000 \mathrm{e}+001.00000 \mathrm{e}-011.00000 \mathrm{e}-091.00000 \mathrm{e}-01$

Element: 9870 \# of layers: 7

$\mathrm{Kx} \mathrm{Ky} \mathrm{Kz}$ Ss Por

$2.66608 \mathrm{e}+012.66608 \mathrm{e}+012.66608 \mathrm{e}+00$ 1.00000e-09 2.12000e-01

$2.66608 \mathrm{e}+012.66608 \mathrm{e}+012.66608 \mathrm{e}+001.00000 \mathrm{e}-092.12000 \mathrm{e}-01$

$2.66608 \mathrm{e}+012.66608 \mathrm{e}+012.66608 \mathrm{e}+001.00000 \mathrm{e}-092.12000 \mathrm{e}-01$

$2.66608 \mathrm{e}+012.66608 \mathrm{e}+012.66608 \mathrm{e}+001.00000 \mathrm{e}-092.12000 \mathrm{e}-01$

$2.66608 \mathrm{e}+012.66608 \mathrm{e}+012.66608 \mathrm{e}+00$ 1.00000e-09 2.12000e-01

$1.00000 \mathrm{e}-05$ 1.00000e-05 1.00000e-06 1.00000e-09 1.00000e-01

$1.00000 \mathrm{e}+001.00000 \mathrm{e}+001.00000 \mathrm{e}-011.00000 \mathrm{e}-091.00000 \mathrm{e}-01$

Element: 9871 \# of layers: 7

$\mathrm{Kx} \mathrm{Ky} \mathrm{Kz}$ Ss Por

$2.66608 \mathrm{e}+012.66608 \mathrm{e}+012.66608 \mathrm{e}+00$ 1.00000e-09 2.12000e-01

$2.66608 \mathrm{e}+012.66608 \mathrm{e}+012.66608 \mathrm{e}+00$ 1.00000e-09 2.12000e-01

$2.66608 \mathrm{e}+012.66608 \mathrm{e}+012.66608 \mathrm{e}+00$ 1.00000e-09 2.12000e-01

$2.66608 \mathrm{e}+012.66608 \mathrm{e}+012.66608 \mathrm{e}+001.00000 \mathrm{e}-092.12000 \mathrm{e}-01$

$2.66608 \mathrm{e}+012.66608 \mathrm{e}+012.66608 \mathrm{e}+001.00000 \mathrm{e}-092.12000 \mathrm{e}-01$

$1.00000 \mathrm{e}-05$ 1.00000e-05 1.00000e-06 1.00000e-09 1.00000e-01

$1.00000 \mathrm{e}+001.00000 \mathrm{e}+001.00000 \mathrm{e}-011.00000 \mathrm{e}-091.00000 \mathrm{e}-01$

Element: 9872 \# of layers: 7

Kx Ky Kz Ss Por

$2.66608 \mathrm{e}+012.66608 \mathrm{e}+012.66608 \mathrm{e}+001.00000 \mathrm{e}-092.12000 \mathrm{e}-01$

$2.66608 \mathrm{e}+012.66608 \mathrm{e}+012.66608 \mathrm{e}+001.00000 \mathrm{e}-092.12000 \mathrm{e}-01$

$2.66608 \mathrm{e}+012.66608 \mathrm{e}+012.66608 \mathrm{e}+001.00000 \mathrm{e}-092.12000 \mathrm{e}-01$

$2.66608 \mathrm{e}+012.66608 \mathrm{e}+012.66608 \mathrm{e}+001.00000 \mathrm{e}-092.12000 \mathrm{e}-01$

$2.66608 \mathrm{e}+012.66608 \mathrm{e}+012.66608 \mathrm{e}+001.00000 \mathrm{e}-092.12000 \mathrm{e}-01$

$1.00000 \mathrm{e}-05$ 1.00000e-05 1.00000e-06 1.00000e-09 1.00000e-01

$1.00000 \mathrm{e}+001.00000 \mathrm{e}+001.00000 \mathrm{e}-011.00000 \mathrm{e}-091.00000 \mathrm{e}-01$

Element: 9873 \# of layers: 7

$\mathrm{Kx} \mathrm{Ky} \mathrm{Kz}$ Ss Por

$2.90751 \mathrm{e}+012.90751 \mathrm{e}+012.90751 \mathrm{e}+00$ 1.00000e-09 2.12000e-01

$2.90751 \mathrm{e}+012.90751 \mathrm{e}+012.90751 \mathrm{e}+001.00000 \mathrm{e}-092.12000 \mathrm{e}-01$

$2.90751 \mathrm{e}+012.90751 \mathrm{e}+012.90751 \mathrm{e}+001.00000 \mathrm{e}-092.12000 \mathrm{e}-01$

$2.90751 \mathrm{e}+012.90751 \mathrm{e}+012.90751 \mathrm{e}+001.00000 \mathrm{e}-092.12000 \mathrm{e}-01$

$2.90751 \mathrm{e}+012.90751 \mathrm{e}+012.90751 \mathrm{e}+001.00000 \mathrm{e}-092.12000 \mathrm{e}-01$

$1.00000 \mathrm{e}-05$ 1.00000e-05 1.00000e-06 1.00000e-09 1.00000e-01

$1.00000 \mathrm{e}+001.00000 \mathrm{e}+001.00000 \mathrm{e}-01$ 1.00000e-09 1.00000e-01

Element: 9874 \# of layers: 7

$\mathrm{Kx} \mathrm{Ky} \mathrm{Kz}$ Ss Por

$2.90751 \mathrm{e}+012.90751 \mathrm{e}+012.90751 \mathrm{e}+00$ 1.00000e-09 2.12000e-01

$2.90751 \mathrm{e}+012.90751 \mathrm{e}+012.90751 \mathrm{e}+00$ 1.00000e-09 2.12000e-01

$2.90751 \mathrm{e}+012.90751 \mathrm{e}+012.90751 \mathrm{e}+00$ 1.00000e-09 2.12000e-01

$2.90751 \mathrm{e}+012.90751 \mathrm{e}+012.90751 \mathrm{e}+001.00000 \mathrm{e}-092.12000 \mathrm{e}-01$ 
$2.90751 \mathrm{e}+012.90751 \mathrm{e}+012.90751 \mathrm{e}+00$ 1.00000e-09 2.12000e-01 $1.00000 \mathrm{e}-05$ 1.00000e-05 1.00000e-06 1.00000e-09 1.00000e-01 $1.00000 \mathrm{e}+001.00000 \mathrm{e}+001.00000 \mathrm{e}-011.00000 \mathrm{e}-091.00000 \mathrm{e}-01$ Element: 9875 \# of layers: 7

$\mathrm{Kx} \mathrm{Ky} \mathrm{Kz}$ Ss Por

$2.66608 \mathrm{e}+012.66608 \mathrm{e}+012.66608 \mathrm{e}+00$ 1.00000e-09 2.12000e-01

$2.66608 \mathrm{e}+012.66608 \mathrm{e}+012.66608 \mathrm{e}+001.00000 \mathrm{e}-092.12000 \mathrm{e}-01$

$2.66608 \mathrm{e}+012.66608 \mathrm{e}+012.66608 \mathrm{e}+001.00000 \mathrm{e}-092.12000 \mathrm{e}-01$

$2.66608 \mathrm{e}+012.66608 \mathrm{e}+012.66608 \mathrm{e}+001.00000 \mathrm{e}-092.12000 \mathrm{e}-01$

$2.66608 \mathrm{e}+012.66608 \mathrm{e}+012.66608 \mathrm{e}+00$ 1.00000e-09 2.12000e-01 $1.00000 \mathrm{e}-05$ 1.00000e-05 1.00000e-06 1.00000e-09 1.00000e-01

$1.00000 \mathrm{e}+001.00000 \mathrm{e}+001.00000 \mathrm{e}-011.00000 \mathrm{e}-091.00000 \mathrm{e}-01$

Element: 9876 \# of layers: 7

$\mathrm{Kx} \mathrm{Ky} \mathrm{Kz}$ Ss Por

$2.66608 \mathrm{e}+012.66608 \mathrm{e}+012.66608 \mathrm{e}+001.00000 \mathrm{e}-092.12000 \mathrm{e}-01$

$2.66608 \mathrm{e}+012.66608 \mathrm{e}+012.66608 \mathrm{e}+001.00000 \mathrm{e}-092.12000 \mathrm{e}-01$

$2.66608 \mathrm{e}+012.66608 \mathrm{e}+012.66608 \mathrm{e}+00$ 1.00000e-09 2.12000e-01

$2.66608 \mathrm{e}+012.66608 \mathrm{e}+012.66608 \mathrm{e}+001.00000 \mathrm{e}-092.12000 \mathrm{e}-01$

$2.66608 \mathrm{e}+012.66608 \mathrm{e}+012.66608 \mathrm{e}+00$ 1.00000e-09 2.12000e-01

$1.00000 \mathrm{e}-05$ 1.00000e-05 1.00000e-06 1.00000e-09 1.00000e-01

$1.00000 \mathrm{e}+001.00000 \mathrm{e}+001.00000 \mathrm{e}-011.00000 \mathrm{e}-091.00000 \mathrm{e}-01$

Element: 9877 \# of layers: 7

$\mathrm{Kx} \mathrm{Ky} \mathrm{Kz}$ Ss Por

$2.66608 \mathrm{e}+012.66608 \mathrm{e}+012.66608 \mathrm{e}+00$ 1.00000e-09 2.12000e-01

$2.66608 \mathrm{e}+012.66608 \mathrm{e}+012.66608 \mathrm{e}+001.00000 \mathrm{e}-092.12000 \mathrm{e}-01$

$2.66608 \mathrm{e}+012.66608 \mathrm{e}+012.66608 \mathrm{e}+001.00000 \mathrm{e}-092.12000 \mathrm{e}-01$

$2.66608 \mathrm{e}+012.66608 \mathrm{e}+012.66608 \mathrm{e}+001.00000 \mathrm{e}-092.12000 \mathrm{e}-01$

$2.66608 \mathrm{e}+012.66608 \mathrm{e}+012.66608 \mathrm{e}+001.00000 \mathrm{e}-092.12000 \mathrm{e}-01$

1.00000e-05 1.00000e-05 1.00000e-06 1.00000e-09 1.00000e-01

$1.00000 \mathrm{e}+001.00000 \mathrm{e}+001.00000 \mathrm{e}-011.00000 \mathrm{e}-091.00000 \mathrm{e}-01$

Element: 9878 \# of layers: 7

$\mathrm{Kx} \mathrm{Ky} \mathrm{Kz}$ Ss Por

$2.66608 \mathrm{e}+012.66608 \mathrm{e}+012.66608 \mathrm{e}+00$ 1.00000e-09 2.12000e-01

$2.66608 \mathrm{e}+012.66608 \mathrm{e}+012.66608 \mathrm{e}+001.00000 \mathrm{e}-092.12000 \mathrm{e}-01$

$2.66608 \mathrm{e}+012.66608 \mathrm{e}+012.66608 \mathrm{e}+001.00000 \mathrm{e}-092.12000 \mathrm{e}-01$

$2.66608 \mathrm{e}+012.66608 \mathrm{e}+012.66608 \mathrm{e}+001.00000 \mathrm{e}-092.12000 \mathrm{e}-01$

$2.66608 \mathrm{e}+012.66608 \mathrm{e}+012.66608 \mathrm{e}+001.00000 \mathrm{e}-092.12000 \mathrm{e}-01$

$1.00000 \mathrm{e}-05$ 1.00000e-05 1.00000e-06 1.00000e-09 1.00000e-01

$1.00000 \mathrm{e}+001.00000 \mathrm{e}+001.00000 \mathrm{e}-011.00000 \mathrm{e}-091.00000 \mathrm{e}-01$

Element: 9879 \# of layers: 7

$\mathrm{Kx} \mathrm{Ky} \mathrm{Kz}$ Ss Por

$2.66608 \mathrm{e}+012.66608 \mathrm{e}+012.66608 \mathrm{e}+00$ 1.00000e-09 2.12000e-01

$2.66608 \mathrm{e}+012.66608 \mathrm{e}+012.66608 \mathrm{e}+001.00000 \mathrm{e}-092.12000 \mathrm{e}-01$

$2.66608 \mathrm{e}+012.66608 \mathrm{e}+012.66608 \mathrm{e}+00$ 1.00000e-09 2.12000e-01

$2.66608 \mathrm{e}+012.66608 \mathrm{e}+012.66608 \mathrm{e}+001.00000 \mathrm{e}-092.12000 \mathrm{e}-01$

$2.66608 \mathrm{e}+012.66608 \mathrm{e}+012.66608 \mathrm{e}+001.00000 \mathrm{e}-092.12000 \mathrm{e}-01$ 
$1.00000 \mathrm{e}-05$ 1.00000e-05 1.00000e-06 1.00000e-09 1.00000e-01 $1.00000 \mathrm{e}+001.00000 \mathrm{e}+001.00000 \mathrm{e}-01$ 1.00000e-09 1.00000e-01 Element: 9880 \# of layers: 7

Kx Ky Kz Ss Por

$2.66608 \mathrm{e}+012.66608 \mathrm{e}+012.66608 \mathrm{e}+001.00000 \mathrm{e}-092.12000 \mathrm{e}-01$

$2.66608 \mathrm{e}+012.66608 \mathrm{e}+012.66608 \mathrm{e}+001.00000 \mathrm{e}-092.12000 \mathrm{e}-01$

$2.66608 \mathrm{e}+012.66608 \mathrm{e}+012.66608 \mathrm{e}+00$ 1.00000e-09 2.12000e-01

$2.66608 \mathrm{e}+012.66608 \mathrm{e}+012.66608 \mathrm{e}+001.00000 \mathrm{e}-092.12000 \mathrm{e}-01$

$2.66608 \mathrm{e}+012.66608 \mathrm{e}+012.66608 \mathrm{e}+001.00000 \mathrm{e}-092.12000 \mathrm{e}-01$

$1.00000 \mathrm{e}-05$ 1.00000e-05 1.00000e-06 1.00000e-09 1.00000e-01

$1.00000 \mathrm{e}+001.00000 \mathrm{e}+001.00000 \mathrm{e}-01$ 1.00000e-09 1.00000e-01

Element: 9881 \# of layers: 7

$\mathrm{Kx} \mathrm{Ky} \mathrm{Kz}$ Ss Por

$2.66608 \mathrm{e}+012.66608 \mathrm{e}+012.66608 \mathrm{e}+00$ 1.00000e-09 2.12000e-01

$2.66608 \mathrm{e}+012.66608 \mathrm{e}+012.66608 \mathrm{e}+001.00000 \mathrm{e}-092.12000 \mathrm{e}-01$

$2.66608 \mathrm{e}+012.66608 \mathrm{e}+012.66608 \mathrm{e}+001.00000 \mathrm{e}-092.12000 \mathrm{e}-01$

$2.66608 \mathrm{e}+012.66608 \mathrm{e}+012.66608 \mathrm{e}+001.00000 \mathrm{e}-092.12000 \mathrm{e}-01$

$2.66608 \mathrm{e}+012.66608 \mathrm{e}+012.66608 \mathrm{e}+001.00000 \mathrm{e}-092.12000 \mathrm{e}-01$

$1.00000 \mathrm{e}-05$ 1.00000e-05 1.00000e-06 1.00000e-09 1.00000e-01

$1.00000 \mathrm{e}+001.00000 \mathrm{e}+001.00000 \mathrm{e}-011.00000 \mathrm{e}-091.00000 \mathrm{e}-01$

Element: 9882 \# of layers: 7

$\mathrm{Kx} \mathrm{Ky} \mathrm{Kz}$ Ss Por

$2.66608 \mathrm{e}+012.66608 \mathrm{e}+012.66608 \mathrm{e}+00$ 1.00000e-09 2.12000e-01

$2.66608 \mathrm{e}+012.66608 \mathrm{e}+012.66608 \mathrm{e}+001.00000 \mathrm{e}-092.12000 \mathrm{e}-01$

$2.66608 \mathrm{e}+012.66608 \mathrm{e}+012.66608 \mathrm{e}+001.00000 \mathrm{e}-092.12000 \mathrm{e}-01$

$2.66608 \mathrm{e}+012.66608 \mathrm{e}+012.66608 \mathrm{e}+001.00000 \mathrm{e}-092.12000 \mathrm{e}-01$

$2.66608 \mathrm{e}+012.66608 \mathrm{e}+012.66608 \mathrm{e}+001.00000 \mathrm{e}-092.12000 \mathrm{e}-01$

$1.00000 \mathrm{e}-05$ 1.00000e-05 1.00000e-06 1.00000e-09 1.00000e-01

$1.00000 \mathrm{e}+001.00000 \mathrm{e}+001.00000 \mathrm{e}-011.00000 \mathrm{e}-091.00000 \mathrm{e}-01$

Element: 9883 \# of layers: 7

$\mathrm{Kx} \mathrm{Ky} \mathrm{Kz}$ Ss Por

$2.66608 \mathrm{e}+012.66608 \mathrm{e}+012.66608 \mathrm{e}+001.00000 \mathrm{e}-092.12000 \mathrm{e}-01$

$2.66608 \mathrm{e}+012.66608 \mathrm{e}+012.66608 \mathrm{e}+001.00000 \mathrm{e}-092.12000 \mathrm{e}-01$

$2.66608 \mathrm{e}+012.66608 \mathrm{e}+012.66608 \mathrm{e}+001.00000 \mathrm{e}-092.12000 \mathrm{e}-01$

$2.66608 \mathrm{e}+012.66608 \mathrm{e}+012.66608 \mathrm{e}+00$ 1.00000e-09 2.12000e-01

$2.66608 \mathrm{e}+012.66608 \mathrm{e}+012.66608 \mathrm{e}+00$ 1.00000e-09 2.12000e-01

1.00000e-05 1.00000e-05 1.00000e-06 1.00000e-09 1.00000e-01

$1.00000 \mathrm{e}+001.00000 \mathrm{e}+001.00000 \mathrm{e}-011.00000 \mathrm{e}-091.00000 \mathrm{e}-01$

Element: 9884 \# of layers: 7

$\mathrm{Kx} \mathrm{Ky} \mathrm{Kz}$ Ss Por

$2.66608 \mathrm{e}+012.66608 \mathrm{e}+012.66608 \mathrm{e}+00$ 1.00000e-09 2.12000e-01

$2.66608 \mathrm{e}+012.66608 \mathrm{e}+012.66608 \mathrm{e}+001.00000 \mathrm{e}-092.12000 \mathrm{e}-01$

$2.66608 \mathrm{e}+012.66608 \mathrm{e}+012.66608 \mathrm{e}+001.00000 \mathrm{e}-092.12000 \mathrm{e}-01$

$2.66608 \mathrm{e}+012.66608 \mathrm{e}+012.66608 \mathrm{e}+00$ 1.00000e-09 2.12000e-01

$2.66608 \mathrm{e}+012.66608 \mathrm{e}+012.66608 \mathrm{e}+001.00000 \mathrm{e}-092.12000 \mathrm{e}-01$

$1.00000 \mathrm{e}-05$ 1.00000e-05 1.00000e-06 1.00000e-09 1.00000e-01 
$1.00000 \mathrm{e}+001.00000 \mathrm{e}+00$ 1.00000e-01 1.00000e-09 1.00000e-01

Element: 9885 \# of layers: 7

$\mathrm{Kx} \mathrm{Ky} \mathrm{Kz}$ Ss Por

$2.66608 \mathrm{e}+012.66608 \mathrm{e}+012.66608 \mathrm{e}+00$ 1.00000e-09 2.12000e-01

$2.66608 \mathrm{e}+012.66608 \mathrm{e}+012.66608 \mathrm{e}+001.00000 \mathrm{e}-092.12000 \mathrm{e}-01$

$2.66608 \mathrm{e}+012.66608 \mathrm{e}+012.66608 \mathrm{e}+001.00000 \mathrm{e}-092.12000 \mathrm{e}-01$

$2.66608 \mathrm{e}+012.66608 \mathrm{e}+012.66608 \mathrm{e}+001.00000 \mathrm{e}-092.12000 \mathrm{e}-01$

$2.66608 \mathrm{e}+012.66608 \mathrm{e}+012.66608 \mathrm{e}+001.00000 \mathrm{e}-092.12000 \mathrm{e}-01$

$1.00000 \mathrm{e}-051.00000 \mathrm{e}-051.00000 \mathrm{e}-061.00000 \mathrm{e}-091.00000 \mathrm{e}-01$

$1.00000 \mathrm{e}+001.00000 \mathrm{e}+001.00000 \mathrm{e}-011.00000 \mathrm{e}-091.00000 \mathrm{e}-01$

Element: 9886 \# of layers: 7

$\mathrm{Kx} \mathrm{Ky} \mathrm{Kz}$ Ss Por

$2.66608 \mathrm{e}+012.66608 \mathrm{e}+012.66608 \mathrm{e}+00$ 1.00000e-09 2.12000e-01

$2.66608 \mathrm{e}+012.66608 \mathrm{e}+012.66608 \mathrm{e}+001.00000 \mathrm{e}-092.12000 \mathrm{e}-01$

$2.66608 \mathrm{e}+012.66608 \mathrm{e}+012.66608 \mathrm{e}+001.00000 \mathrm{e}-092.12000 \mathrm{e}-01$

$2.66608 \mathrm{e}+012.66608 \mathrm{e}+012.66608 \mathrm{e}+001.00000 \mathrm{e}-092.12000 \mathrm{e}-01$

$2.66608 \mathrm{e}+012.66608 \mathrm{e}+012.66608 \mathrm{e}+001.00000 \mathrm{e}-092.12000 \mathrm{e}-01$

$1.00000 \mathrm{e}-05$ 1.00000e-05 1.00000e-06 1.00000e-09 1.00000e-01

$1.00000 \mathrm{e}+001.00000 \mathrm{e}+001.00000 \mathrm{e}-011.00000 \mathrm{e}-091.00000 \mathrm{e}-01$

Element: 9887 \# of layers: 7

$\mathrm{Kx} \mathrm{Ky} \mathrm{Kz}$ Ss Por

$2.38528 \mathrm{e}+012.38528 \mathrm{e}+012.38528 \mathrm{e}+00$ 1.00000e-09 2.12000e-01

$2.38528 \mathrm{e}+012.38528 \mathrm{e}+012.38528 \mathrm{e}+00$ 1.00000e-09 2.12000e-01

$2.38528 \mathrm{e}+012.38528 \mathrm{e}+012.38528 \mathrm{e}+00$ 1.00000e-09 2.12000e-01

$2.38528 \mathrm{e}+012.38528 \mathrm{e}+012.38528 \mathrm{e}+001.00000 \mathrm{e}-092.12000 \mathrm{e}-01$

$2.38528 \mathrm{e}+012.38528 \mathrm{e}+012.38528 \mathrm{e}+00$ 1.00000e-09 2.12000e-01

$1.00000 \mathrm{e}-05$ 1.00000e-05 1.00000e-06 1.00000e-09 1.00000e-01

$1.00000 \mathrm{e}+001.00000 \mathrm{e}+001.00000 \mathrm{e}-011.00000 \mathrm{e}-09$ 1.00000e-01

Element: 9888 \# of layers: 7

$\mathrm{Kx} \mathrm{Ky} \mathrm{Kz}$ Ss Por

$2.38528 \mathrm{e}+012.38528 \mathrm{e}+012.38528 \mathrm{e}+00$ 1.00000e-09 2.12000e-01

$2.38528 \mathrm{e}+012.38528 \mathrm{e}+012.38528 \mathrm{e}+00$ 1.00000e-09 2.12000e-01

$2.38528 \mathrm{e}+012.38528 \mathrm{e}+012.38528 \mathrm{e}+00$ 1.00000e-09 2.12000e-01

$2.38528 \mathrm{e}+012.38528 \mathrm{e}+012.38528 \mathrm{e}+00$ 1.00000e-09 2.12000e-01

$2.38528 \mathrm{e}+012.38528 \mathrm{e}+012.38528 \mathrm{e}+00$ 1.00000e-09 2.12000e-01

$1.00000 \mathrm{e}-05$ 1.00000e-05 1.00000e-06 1.00000e-09 1.00000e-01

$1.00000 \mathrm{e}+001.00000 \mathrm{e}+001.00000 \mathrm{e}-011.00000 \mathrm{e}-091.00000 \mathrm{e}-01$

Element: 9889 \# of layers: 7

$\mathrm{Kx} \mathrm{Ky} \mathrm{Kz}$ Ss Por

$2.38528 \mathrm{e}+012.38528 \mathrm{e}+012.38528 \mathrm{e}+00$ 1.00000e-09 2.12000e-01

$2.38528 \mathrm{e}+012.38528 \mathrm{e}+012.38528 \mathrm{e}+001.00000 \mathrm{e}-092.12000 \mathrm{e}-01$

$2.38528 \mathrm{e}+012.38528 \mathrm{e}+012.38528 \mathrm{e}+00$ 1.00000e-09 2.12000e-01

$2.38528 \mathrm{e}+012.38528 \mathrm{e}+012.38528 \mathrm{e}+00$ 1.00000e-09 2.12000e-01

$2.38528 \mathrm{e}+012.38528 \mathrm{e}+012.38528 \mathrm{e}+00$ 1.00000e-09 2.12000e-01 $1.00000 \mathrm{e}-05$ 1.00000e-05 1.00000e-06 1.00000e-09 1.00000e-01

$1.00000 \mathrm{e}+001.00000 \mathrm{e}+001.00000 \mathrm{e}-011.00000 \mathrm{e}-091.00000 \mathrm{e}-01$ 
Element: 9890 \# of layers: 7

Kx Ky Kz Ss Por

$2.66608 \mathrm{e}+012.66608 \mathrm{e}+012.66608 \mathrm{e}+00$ 1.00000e-09 2.12000e-01

$2.66608 \mathrm{e}+012.66608 \mathrm{e}+012.66608 \mathrm{e}+001.00000 \mathrm{e}-092.12000 \mathrm{e}-01$

$2.66608 \mathrm{e}+012.66608 \mathrm{e}+012.66608 \mathrm{e}+001.00000 \mathrm{e}-092.12000 \mathrm{e}-01$

$2.66608 \mathrm{e}+012.66608 \mathrm{e}+012.66608 \mathrm{e}+001.00000 \mathrm{e}-092.12000 \mathrm{e}-01$

$2.66608 \mathrm{e}+012.66608 \mathrm{e}+012.66608 \mathrm{e}+001.00000 \mathrm{e}-092.12000 \mathrm{e}-01$

$1.00000 \mathrm{e}-05$ 1.00000e-05 1.00000e-06 1.00000e-09 1.00000e-01

$1.00000 \mathrm{e}+001.00000 \mathrm{e}+001.00000 \mathrm{e}-011.00000 \mathrm{e}-091.00000 \mathrm{e}-01$

Element: 9891 \# of layers: 7

Kx Ky Kz Ss Por

$2.66608 \mathrm{e}+012.66608 \mathrm{e}+012.66608 \mathrm{e}+00$ 1.00000e-09 2.12000e-01

$2.66608 \mathrm{e}+012.66608 \mathrm{e}+012.66608 \mathrm{e}+001.00000 \mathrm{e}-092.12000 \mathrm{e}-01$

$2.66608 \mathrm{e}+012.66608 \mathrm{e}+012.66608 \mathrm{e}+001.00000 \mathrm{e}-092.12000 \mathrm{e}-01$

$2.66608 \mathrm{e}+012.66608 \mathrm{e}+012.66608 \mathrm{e}+001.00000 \mathrm{e}-092.12000 \mathrm{e}-01$

$2.66608 \mathrm{e}+012.66608 \mathrm{e}+012.66608 \mathrm{e}+001.00000 \mathrm{e}-092.12000 \mathrm{e}-01$

$1.00000 \mathrm{e}-05$ 1.00000e-05 1.00000e-06 1.00000e-09 1.00000e-01

$1.00000 \mathrm{e}+001.00000 \mathrm{e}+00$ 1.00000e-01 1.00000e-09 1.00000e-01

Element: 9892 \# of layers: 7

Kx Ky Kz Ss Por

$2.66608 \mathrm{e}+012.66608 \mathrm{e}+012.66608 \mathrm{e}+001.00000 \mathrm{e}-092.12000 \mathrm{e}-01$

$2.66608 \mathrm{e}+012.66608 \mathrm{e}+012.66608 \mathrm{e}+001.00000 \mathrm{e}-092.12000 \mathrm{e}-01$

$2.66608 \mathrm{e}+012.66608 \mathrm{e}+012.66608 \mathrm{e}+001.00000 \mathrm{e}-092.12000 \mathrm{e}-01$

$2.66608 \mathrm{e}+012.66608 \mathrm{e}+012.66608 \mathrm{e}+001.00000 \mathrm{e}-092.12000 \mathrm{e}-01$

$2.66608 \mathrm{e}+012.66608 \mathrm{e}+012.66608 \mathrm{e}+001.00000 \mathrm{e}-092.12000 \mathrm{e}-01$

$1.00000 \mathrm{e}-051.00000 \mathrm{e}-05$ 1.00000e-06 1.00000e-09 1.00000e-01

$1.00000 \mathrm{e}+001.00000 \mathrm{e}+001.00000 \mathrm{e}-011.00000 \mathrm{e}-091.00000 \mathrm{e}-01$

Element: 9893 \# of layers: 7

Kx Ky Kz Ss Por

$2.66608 \mathrm{e}+012.66608 \mathrm{e}+012.66608 \mathrm{e}+00$ 1.00000e-09 2.12000e-01

$2.66608 \mathrm{e}+012.66608 \mathrm{e}+012.66608 \mathrm{e}+001.00000 \mathrm{e}-092.12000 \mathrm{e}-01$

$2.66608 \mathrm{e}+012.66608 \mathrm{e}+012.66608 \mathrm{e}+001.00000 \mathrm{e}-092.12000 \mathrm{e}-01$

$2.66608 \mathrm{e}+012.66608 \mathrm{e}+012.66608 \mathrm{e}+001.00000 \mathrm{e}-092.12000 \mathrm{e}-01$

$2.66608 \mathrm{e}+012.66608 \mathrm{e}+012.66608 \mathrm{e}+001.00000 \mathrm{e}-092.12000 \mathrm{e}-01$

$1.00000 \mathrm{e}-05$ 1.00000e-05 1.00000e-06 1.00000e-09 1.00000e-01

$1.00000 \mathrm{e}+001.00000 \mathrm{e}+001.00000 \mathrm{e}-011.00000 \mathrm{e}-091.00000 \mathrm{e}-01$

Element: 9894 \# of layers: 7

Kx Ky Kz Ss Por

$2.38528 \mathrm{e}+012.38528 \mathrm{e}+012.38528 \mathrm{e}+00$ 1.00000e-09 2.12000e-01

$2.38528 \mathrm{e}+012.38528 \mathrm{e}+012.38528 \mathrm{e}+001.00000 \mathrm{e}-092.12000 \mathrm{e}-01$

$2.38528 \mathrm{e}+012.38528 \mathrm{e}+012.38528 \mathrm{e}+001.00000 \mathrm{e}-092.12000 \mathrm{e}-01$

$2.38528 \mathrm{e}+012.38528 \mathrm{e}+012.38528 \mathrm{e}+001.00000 \mathrm{e}-092.12000 \mathrm{e}-01$

$2.38528 \mathrm{e}+012.38528 \mathrm{e}+012.38528 \mathrm{e}+00$ 1.00000e-09 2.12000e-01

$1.00000 \mathrm{e}-05$ 1.00000e-05 1.00000e-06 1.00000e-09 1.00000e-01

$1.00000 \mathrm{e}+001.00000 \mathrm{e}+001.00000 \mathrm{e}-011.00000 \mathrm{e}-091.00000 \mathrm{e}-01$

Element: 9895 \# of layers: 7 
$\mathrm{Kx} \mathrm{Ky} \mathrm{Kz}$ Ss Por

$2.38528 \mathrm{e}+012.38528 \mathrm{e}+012.38528 \mathrm{e}+00$ 1.00000e-09 2.12000e-01

$2.38528 \mathrm{e}+012.38528 \mathrm{e}+012.38528 \mathrm{e}+00$ 1.00000e-09 2.12000e-01

$2.38528 \mathrm{e}+012.38528 \mathrm{e}+012.38528 \mathrm{e}+001.00000 \mathrm{e}-092.12000 \mathrm{e}-01$

$2.38528 \mathrm{e}+012.38528 \mathrm{e}+012.38528 \mathrm{e}+00$ 1.00000e-09 2.12000e-01

$2.38528 \mathrm{e}+012.38528 \mathrm{e}+012.38528 \mathrm{e}+00$ 1.00000e-09 2.12000e-01

$1.00000 \mathrm{e}-05$ 1.00000e-05 1.00000e-06 1.00000e-09 1.00000e-01

$1.00000 \mathrm{e}+001.00000 \mathrm{e}+001.00000 \mathrm{e}-011.00000 \mathrm{e}-091.00000 \mathrm{e}-01$

Element: 9896 \# of layers: 7

$\mathrm{Kx} \mathrm{Ky} \mathrm{Kz}$ Ss Por

$2.38528 \mathrm{e}+012.38528 \mathrm{e}+012.38528 \mathrm{e}+00$ 1.00000e-09 2.12000e-01

$2.38528 \mathrm{e}+012.38528 \mathrm{e}+012.38528 \mathrm{e}+00$ 1.00000e-09 2.12000e-01

$2.38528 \mathrm{e}+012.38528 \mathrm{e}+012.38528 \mathrm{e}+00$ 1.00000e-09 2.12000e-01

$2.38528 \mathrm{e}+012.38528 \mathrm{e}+012.38528 \mathrm{e}+00$ 1.00000e-09 2.12000e-01

$2.38528 \mathrm{e}+012.38528 \mathrm{e}+012.38528 \mathrm{e}+00$ 1.00000e-09 2.12000e-01

$1.00000 \mathrm{e}-05$ 1.00000e-05 1.00000e-06 1.00000e-09 1.00000e-01

$1.00000 \mathrm{e}+001.00000 \mathrm{e}+001.00000 \mathrm{e}-011.00000 \mathrm{e}-091.00000 \mathrm{e}-01$

Element: 9897 \# of layers: 7

$\mathrm{Kx} \mathrm{Ky} \mathrm{Kz}$ Ss Por

$2.38528 \mathrm{e}+012.38528 \mathrm{e}+012.38528 \mathrm{e}+00$ 1.00000e-09 2.12000e-01

$2.38528 \mathrm{e}+012.38528 \mathrm{e}+012.38528 \mathrm{e}+00$ 1.00000e-09 2.12000e-01

$2.38528 \mathrm{e}+012.38528 \mathrm{e}+012.38528 \mathrm{e}+00$ 1.00000e-09 2.12000e-01

$2.38528 \mathrm{e}+012.38528 \mathrm{e}+012.38528 \mathrm{e}+00$ 1.00000e-09 2.12000e-01

$2.38528 \mathrm{e}+012.38528 \mathrm{e}+012.38528 \mathrm{e}+001.00000 \mathrm{e}-092.12000 \mathrm{e}-01$

$1.00000 \mathrm{e}-05$ 1.00000e-05 1.00000e-06 1.00000e-09 1.00000e-01

$1.00000 \mathrm{e}+001.00000 \mathrm{e}+001.00000 \mathrm{e}-01$ 1.00000e-09 1.00000e-01

Element: 9898 \# of layers: 7

$\mathrm{Kx} \mathrm{Ky} \mathrm{Kz}$ Ss Por

$2.38528 \mathrm{e}+012.38528 \mathrm{e}+012.38528 \mathrm{e}+00$ 1.00000e-09 2.12000e-01

$2.38528 \mathrm{e}+012.38528 \mathrm{e}+012.38528 \mathrm{e}+00$ 1.00000e-09 2.12000e-01

$2.38528 \mathrm{e}+012.38528 \mathrm{e}+012.38528 \mathrm{e}+00$ 1.00000e-09 2.12000e-01

$2.38528 \mathrm{e}+012.38528 \mathrm{e}+012.38528 \mathrm{e}+00$ 1.00000e-09 2.12000e-01

$2.38528 \mathrm{e}+012.38528 \mathrm{e}+012.38528 \mathrm{e}+00$ 1.00000e-09 2.12000e-01

$1.00000 \mathrm{e}-05$ 1.00000e-05 1.00000e-06 1.00000e-09 1.00000e-01

$1.00000 \mathrm{e}+001.00000 \mathrm{e}+001.00000 \mathrm{e}-01$ 1.00000e-09 1.00000e-01

Element: 9899 \# of layers: 7

$\mathrm{Kx} \mathrm{Ky} \mathrm{Kz}$ Ss Por

$2.38528 \mathrm{e}+012.38528 \mathrm{e}+012.38528 \mathrm{e}+00$ 1.00000e-09 2.12000e-01

$2.38528 \mathrm{e}+012.38528 \mathrm{e}+012.38528 \mathrm{e}+00$ 1.00000e-09 2.12000e-01

$2.38528 \mathrm{e}+012.38528 \mathrm{e}+012.38528 \mathrm{e}+00$ 1.00000e-09 2.12000e-01

$2.38528 \mathrm{e}+012.38528 \mathrm{e}+012.38528 \mathrm{e}+00$ 1.00000e-09 2.12000e-01

$2.38528 \mathrm{e}+012.38528 \mathrm{e}+012.38528 \mathrm{e}+00$ 1.00000e-09 2.12000e-01

$1.00000 \mathrm{e}-051.00000 \mathrm{e}-051.00000 \mathrm{e}-061.00000 \mathrm{e}-091.00000 \mathrm{e}-01$

$1.00000 \mathrm{e}+001.00000 \mathrm{e}+001.00000 \mathrm{e}-01$ 1.00000e-09 1.00000e-01

Element: 9900 \# of layers: 7

Kx Ky Kz Ss Por 
$2.38528 \mathrm{e}+012.38528 \mathrm{e}+012.38528 \mathrm{e}+00$ 1.00000e-09 2.12000e-01 $2.38528 \mathrm{e}+012.38528 \mathrm{e}+012.38528 \mathrm{e}+00$ 1.00000e-09 2.12000e-01 $2.38528 \mathrm{e}+012.38528 \mathrm{e}+012.38528 \mathrm{e}+00$ 1.00000e-09 2.12000e-01 $2.38528 \mathrm{e}+012.38528 \mathrm{e}+012.38528 \mathrm{e}+001.00000 \mathrm{e}-092.12000 \mathrm{e}-01$ $2.38528 \mathrm{e}+012.38528 \mathrm{e}+012.38528 \mathrm{e}+001.00000 \mathrm{e}-092.12000 \mathrm{e}-01$ $1.00000 \mathrm{e}-05$ 1.00000e-05 1.00000e-06 1.00000e-09 1.00000e-01 $1.00000 \mathrm{e}+001.00000 \mathrm{e}+001.00000 \mathrm{e}-01$ 1.00000e-09 1.00000e-01 Element: 9901 \# of layers: 7

$\mathrm{Kx} \mathrm{Ky} \mathrm{Kz}$ Ss Por

$2.38528 \mathrm{e}+012.38528 \mathrm{e}+012.38528 \mathrm{e}+00$ 1.00000e-09 2.12000e-01 $2.38528 \mathrm{e}+012.38528 \mathrm{e}+012.38528 \mathrm{e}+00$ 1.00000e-09 2.12000e-01 $2.38528 \mathrm{e}+012.38528 \mathrm{e}+012.38528 \mathrm{e}+00$ 1.00000e-09 2.12000e-01 $2.38528 \mathrm{e}+012.38528 \mathrm{e}+012.38528 \mathrm{e}+00$ 1.00000e-09 2.12000e-01

$2.38528 \mathrm{e}+012.38528 \mathrm{e}+012.38528 \mathrm{e}+00$ 1.00000e-09 2.12000e-01 $1.00000 \mathrm{e}-05$ 1.00000e-05 1.00000e-06 1.00000e-09 1.00000e-01 $1.00000 \mathrm{e}+001.00000 \mathrm{e}+001.00000 \mathrm{e}-011.00000 \mathrm{e}-091.00000 \mathrm{e}-01$ Element: 9902 \# of layers: 7

$\mathrm{Kx} \mathrm{Ky} \mathrm{Kz}$ Ss Por

$2.38528 \mathrm{e}+012.38528 \mathrm{e}+012.38528 \mathrm{e}+00$ 1.00000e-09 2.12000e-01 $2.38528 \mathrm{e}+012.38528 \mathrm{e}+012.38528 \mathrm{e}+00$ 1.00000e-09 2.12000e-01 $2.38528 \mathrm{e}+012.38528 \mathrm{e}+012.38528 \mathrm{e}+00$ 1.00000e-09 2.12000e-01

$2.38528 \mathrm{e}+012.38528 \mathrm{e}+012.38528 \mathrm{e}+00$ 1.00000e-09 2.12000e-01 $2.38528 \mathrm{e}+012.38528 \mathrm{e}+012.38528 \mathrm{e}+00$ 1.00000e-09 2.12000e-01 $1.00000 \mathrm{e}-05$ 1.00000e-05 1.00000e-06 1.00000e-09 1.00000e-01 $1.00000 \mathrm{e}+001.00000 \mathrm{e}+001.00000 \mathrm{e}-011.00000 \mathrm{e}-091.00000 \mathrm{e}-01$ Element: 9903 \# of layers: 7

$\mathrm{Kx} \mathrm{Ky} \mathrm{Kz}$ Ss Por

$2.38528 \mathrm{e}+012.38528 \mathrm{e}+012.38528 \mathrm{e}+00$ 1.00000e-09 2.12000e-01 $2.38528 \mathrm{e}+012.38528 \mathrm{e}+012.38528 \mathrm{e}+001.00000 \mathrm{e}-092.12000 \mathrm{e}-01$ $2.38528 \mathrm{e}+012.38528 \mathrm{e}+012.38528 \mathrm{e}+00$ 1.00000e-09 2.12000e-01 $2.38528 \mathrm{e}+012.38528 \mathrm{e}+012.38528 \mathrm{e}+001.00000 \mathrm{e}-092.12000 \mathrm{e}-01$ $2.38528 \mathrm{e}+012.38528 \mathrm{e}+012.38528 \mathrm{e}+00$ 1.00000e-09 2.12000e-01 $1.00000 \mathrm{e}-05$ 1.00000e-05 1.00000e-06 1.00000e-09 1.00000e-01 $1.00000 \mathrm{e}+001.00000 \mathrm{e}+001.00000 \mathrm{e}-011.00000 \mathrm{e}-091.00000 \mathrm{e}-01$ Element: 9904 \# of layers: 7

$\mathrm{Kx} \mathrm{Ky} \mathrm{Kz}$ Ss Por

$2.38528 \mathrm{e}+012.38528 \mathrm{e}+012.38528 \mathrm{e}+00$ 1.00000e-09 2.12000e-01 $2.38528 \mathrm{e}+012.38528 \mathrm{e}+012.38528 \mathrm{e}+00$ 1.00000e-09 2.12000e-01

$2.38528 \mathrm{e}+012.38528 \mathrm{e}+012.38528 \mathrm{e}+00$ 1.00000e-09 2.12000e-01 $2.38528 \mathrm{e}+012.38528 \mathrm{e}+012.38528 \mathrm{e}+00$ 1.00000e-09 2.12000e-01 $2.38528 \mathrm{e}+012.38528 \mathrm{e}+012.38528 \mathrm{e}+001.00000 \mathrm{e}-092.12000 \mathrm{e}-01$ $1.00000 \mathrm{e}-05$ 1.00000e-05 1.00000e-06 1.00000e-09 1.00000e-01 $1.00000 \mathrm{e}+001.00000 \mathrm{e}+001.00000 \mathrm{e}-011.00000 \mathrm{e}-091.00000 \mathrm{e}-01$ Element: 9905 \# of layers: 7

$\mathrm{Kx} \mathrm{Ky} \mathrm{Kz}$ Ss Por 2.82291e+01 2.82291e+01 2.82291e+00 1.00000e-09 2.12000e-01 
$2.82291 \mathrm{e}+012.82291 \mathrm{e}+012.82291 \mathrm{e}+00$ 1.00000e-09 2.12000e-01 $2.82291 \mathrm{e}+012.82291 \mathrm{e}+012.82291 \mathrm{e}+00$ 1.00000e-09 2.12000e-01 $2.82291 \mathrm{e}+012.82291 \mathrm{e}+012.82291 \mathrm{e}+001.00000 \mathrm{e}-092.12000 \mathrm{e}-01$ $2.82291 \mathrm{e}+012.82291 \mathrm{e}+012.82291 \mathrm{e}+001.00000 \mathrm{e}-092.12000 \mathrm{e}-01$ $1.00000 \mathrm{e}-05$ 1.00000e-05 1.00000e-06 1.00000e-09 1.00000e-01 $1.00000 \mathrm{e}+001.00000 \mathrm{e}+001.00000 \mathrm{e}-011.00000 \mathrm{e}-091.00000 \mathrm{e}-01$ Element: 9906 \# of layers: 7

$\mathrm{Kx} \mathrm{Ky} \mathrm{Kz}$ Ss Por

$2.82291 \mathrm{e}+012.82291 \mathrm{e}+012.82291 \mathrm{e}+001.00000 \mathrm{e}-092.12000 \mathrm{e}-01$ $2.82291 \mathrm{e}+012.82291 \mathrm{e}+012.82291 \mathrm{e}+00$ 1.00000e-09 2.12000e-01 $2.82291 \mathrm{e}+012.82291 \mathrm{e}+012.82291 \mathrm{e}+00$ 1.00000e-09 2.12000e-01 $2.82291 \mathrm{e}+012.82291 \mathrm{e}+012.82291 \mathrm{e}+001.00000 \mathrm{e}-092.12000 \mathrm{e}-01$ $2.82291 \mathrm{e}+012.82291 \mathrm{e}+012.82291 \mathrm{e}+001.00000 \mathrm{e}-092.12000 \mathrm{e}-01$ $1.00000 \mathrm{e}-05$ 1.00000e-05 1.00000e-06 1.00000e-09 1.00000e-01 $1.00000 \mathrm{e}+001.00000 \mathrm{e}+001.00000 \mathrm{e}-01$ 1.00000e-09 1.00000e-01 Element: 9907 \# of layers: 7

$\mathrm{Kx} \mathrm{Ky} \mathrm{Kz}$ Ss Por

$2.82291 \mathrm{e}+012.82291 \mathrm{e}+012.82291 \mathrm{e}+00$ 1.00000e-09 2.12000e-01 $2.82291 \mathrm{e}+012.82291 \mathrm{e}+012.82291 \mathrm{e}+00$ 1.00000e-09 2.12000e-01 $2.82291 \mathrm{e}+012.82291 \mathrm{e}+012.82291 \mathrm{e}+001.00000 \mathrm{e}-092.12000 \mathrm{e}-01$ $2.82291 \mathrm{e}+012.82291 \mathrm{e}+012.82291 \mathrm{e}+001.00000 \mathrm{e}-092.12000 \mathrm{e}-01$ $2.82291 \mathrm{e}+012.82291 \mathrm{e}+012.82291 \mathrm{e}+001.00000 \mathrm{e}-092.12000 \mathrm{e}-01$ $1.00000 \mathrm{e}-05$ 1.00000e-05 1.00000e-06 1.00000e-09 1.00000e-01 $1.00000 \mathrm{e}+001.00000 \mathrm{e}+001.00000 \mathrm{e}-011.00000 \mathrm{e}-091.00000 \mathrm{e}-01$ Element: 9908 \# of layers: 7

$\mathrm{Kx} \mathrm{Ky} \mathrm{Kz}$ Ss Por

$2.38528 \mathrm{e}+012.38528 \mathrm{e}+012.38528 \mathrm{e}+00$ 1.00000e-09 2.12000e-01 $2.38528 \mathrm{e}+012.38528 \mathrm{e}+012.38528 \mathrm{e}+00$ 1.00000e-09 2.12000e-01 $2.38528 \mathrm{e}+012.38528 \mathrm{e}+012.38528 \mathrm{e}+001.00000 \mathrm{e}-092.12000 \mathrm{e}-01$ $2.38528 \mathrm{e}+012.38528 \mathrm{e}+012.38528 \mathrm{e}+00$ 1.00000e-09 2.12000e-01

$2.38528 \mathrm{e}+012.38528 \mathrm{e}+012.38528 \mathrm{e}+00$ 1.00000e-09 2.12000e-01 $1.00000 \mathrm{e}-05$ 1.00000e-05 1.00000e-06 1.00000e-09 1.00000e-01 $1.00000 \mathrm{e}+001.00000 \mathrm{e}+001.00000 \mathrm{e}-011.00000 \mathrm{e}-091.00000 \mathrm{e}-01$ Element: 9909 \# of layers: 7

$\mathrm{Kx} \mathrm{Ky} \mathrm{Kz}$ Ss Por

$2.38528 \mathrm{e}+012.38528 \mathrm{e}+012.38528 \mathrm{e}+00$ 1.00000e-09 2.12000e-01 $2.38528 \mathrm{e}+012.38528 \mathrm{e}+012.38528 \mathrm{e}+001.00000 \mathrm{e}-092.12000 \mathrm{e}-01$ $2.38528 \mathrm{e}+012.38528 \mathrm{e}+012.38528 \mathrm{e}+00$ 1.00000e-09 2.12000e-01

$2.38528 \mathrm{e}+012.38528 \mathrm{e}+012.38528 \mathrm{e}+00$ 1.00000e-09 2.12000e-01 $2.38528 \mathrm{e}+012.38528 \mathrm{e}+012.38528 \mathrm{e}+00$ 1.00000e-09 2.12000e-01 1.00000e-05 1.00000e-05 1.00000e-06 1.00000e-09 1.00000e-01 $1.00000 \mathrm{e}+001.00000 \mathrm{e}+001.00000 \mathrm{e}-011.00000 \mathrm{e}-091.00000 \mathrm{e}-01$ Element: 9910 \# of layers: 7

$\mathrm{Kx} \mathrm{Ky} \mathrm{Kz}$ Ss Por

$2.38528 \mathrm{e}+012.38528 \mathrm{e}+012.38528 \mathrm{e}+00$ 1.00000e-09 2.12000e-01 $2.38528 \mathrm{e}+012.38528 \mathrm{e}+012.38528 \mathrm{e}+001.00000 \mathrm{e}-092.12000 \mathrm{e}-01$ 
$2.38528 \mathrm{e}+012.38528 \mathrm{e}+012.38528 \mathrm{e}+00$ 1.00000e-09 2.12000e-01

$2.38528 \mathrm{e}+012.38528 \mathrm{e}+012.38528 \mathrm{e}+00$ 1.00000e-09 2.12000e-01

$2.38528 \mathrm{e}+012.38528 \mathrm{e}+012.38528 \mathrm{e}+00$ 1.00000e-09 2.12000e-01

$1.00000 \mathrm{e}-05$ 1.00000e-05 1.00000e-06 1.00000e-09 1.00000e-01

$1.00000 \mathrm{e}+001.00000 \mathrm{e}+001.00000 \mathrm{e}-01$ 1.00000e-09 1.00000e-01

Element: 9911 \# of layers: 7

$\mathrm{Kx} \mathrm{Ky} \mathrm{Kz}$ Ss Por

$2.38528 \mathrm{e}+012.38528 \mathrm{e}+012.38528 \mathrm{e}+00$ 1.00000e-09 2.12000e-01

$2.38528 \mathrm{e}+012.38528 \mathrm{e}+012.38528 \mathrm{e}+00$ 1.00000e-09 2.12000e-01

$2.38528 \mathrm{e}+012.38528 \mathrm{e}+012.38528 \mathrm{e}+00$ 1.00000e-09 2.12000e-01

$2.38528 \mathrm{e}+012.38528 \mathrm{e}+012.38528 \mathrm{e}+00$ 1.00000e-09 2.12000e-01

$2.38528 \mathrm{e}+012.38528 \mathrm{e}+012.38528 \mathrm{e}+001.00000 \mathrm{e}-092.12000 \mathrm{e}-01$

$1.00000 \mathrm{e}-05$ 1.00000e-05 1.00000e-06 1.00000e-09 1.00000e-01

$1.00000 \mathrm{e}+001.00000 \mathrm{e}+001.00000 \mathrm{e}-011.00000 \mathrm{e}-09$ 1.00000e-01

Element: 9912 \# of layers: 7

Kx Ky Kz Ss Por

$2.82291 \mathrm{e}+012.82291 \mathrm{e}+012.82291 \mathrm{e}+00$ 1.00000e-09 2.12000e-01

$2.82291 \mathrm{e}+012.82291 \mathrm{e}+012.82291 \mathrm{e}+001.00000 \mathrm{e}-092.12000 \mathrm{e}-01$

$2.82291 \mathrm{e}+012.82291 \mathrm{e}+012.82291 \mathrm{e}+00$ 1.00000e-09 2.12000e-01

$2.82291 \mathrm{e}+012.82291 \mathrm{e}+012.82291 \mathrm{e}+001.00000 \mathrm{e}-092.12000 \mathrm{e}-01$

$2.82291 \mathrm{e}+012.82291 \mathrm{e}+012.82291 \mathrm{e}+00$ 1.00000e-09 2.12000e-01

$1.00000 \mathrm{e}-05$ 1.00000e-05 1.00000e-06 1.00000e-09 1.00000e-01

$1.00000 \mathrm{e}+001.00000 \mathrm{e}+001.00000 \mathrm{e}-01$ 1.00000e-09 1.00000e-01

Element: 9913 \# of layers: 7

$\mathrm{Kx} \mathrm{Ky} \mathrm{Kz}$ Ss Por

$2.82291 \mathrm{e}+012.82291 \mathrm{e}+012.82291 \mathrm{e}+001.00000 \mathrm{e}-092.12000 \mathrm{e}-01$

$2.82291 \mathrm{e}+012.82291 \mathrm{e}+012.82291 \mathrm{e}+001.00000 \mathrm{e}-092.12000 \mathrm{e}-01$

$2.82291 \mathrm{e}+012.82291 \mathrm{e}+012.82291 \mathrm{e}+00$ 1.00000e-09 2.12000e-01

$2.82291 \mathrm{e}+012.82291 \mathrm{e}+012.82291 \mathrm{e}+001.00000 \mathrm{e}-092.12000 \mathrm{e}-01$

$2.82291 \mathrm{e}+012.82291 \mathrm{e}+012.82291 \mathrm{e}+001.00000 \mathrm{e}-092.12000 \mathrm{e}-01$

$1.00000 \mathrm{e}-05$ 1.00000e-05 1.00000e-06 1.00000e-09 1.00000e-01

$1.00000 \mathrm{e}+001.00000 \mathrm{e}+001.00000 \mathrm{e}-011.00000 \mathrm{e}-091.00000 \mathrm{e}-01$

Element: 9914 \# of layers: 7

$\mathrm{Kx} \mathrm{Ky} \mathrm{Kz}$ Ss Por

$2.82291 \mathrm{e}+012.82291 \mathrm{e}+012.82291 \mathrm{e}+00$ 1.00000e-09 2.12000e-01

$2.82291 \mathrm{e}+012.82291 \mathrm{e}+012.82291 \mathrm{e}+001.00000 \mathrm{e}-092.12000 \mathrm{e}-01$

$2.82291 \mathrm{e}+012.82291 \mathrm{e}+012.82291 \mathrm{e}+001.00000 \mathrm{e}-092.12000 \mathrm{e}-01$

$2.82291 \mathrm{e}+012.82291 \mathrm{e}+012.82291 \mathrm{e}+001.00000 \mathrm{e}-092.12000 \mathrm{e}-01$

$2.82291 \mathrm{e}+012.82291 \mathrm{e}+012.82291 \mathrm{e}+001.00000 \mathrm{e}-092.12000 \mathrm{e}-01$

$1.00000 \mathrm{e}-05$ 1.00000e-05 1.00000e-06 1.00000e-09 1.00000e-01

$1.00000 \mathrm{e}+001.00000 \mathrm{e}+001.00000 \mathrm{e}-011.00000 \mathrm{e}-091.00000 \mathrm{e}-01$

Element: 9915 \# of layers: 7

$\mathrm{Kx} \mathrm{Ky} \mathrm{Kz}$ Ss Por

2.82291e+01 2.82291e+01 2.82291e+00 1.00000e-09 2.12000e-01

$2.82291 \mathrm{e}+012.82291 \mathrm{e}+012.82291 \mathrm{e}+00$ 1.00000e-09 2.12000e-01

$2.82291 \mathrm{e}+012.82291 \mathrm{e}+012.82291 \mathrm{e}+001.00000 \mathrm{e}-092.12000 \mathrm{e}-01$ 
$2.82291 \mathrm{e}+012.82291 \mathrm{e}+012.82291 \mathrm{e}+00$ 1.00000e-09 2.12000e-01 $2.82291 \mathrm{e}+012.82291 \mathrm{e}+012.82291 \mathrm{e}+001.00000 \mathrm{e}-092.12000 \mathrm{e}-01$ $1.00000 \mathrm{e}-05$ 1.00000e-05 1.00000e-06 1.00000e-09 1.00000e-01 $1.00000 \mathrm{e}+001.00000 \mathrm{e}+001.00000 \mathrm{e}-011.00000 \mathrm{e}-091.00000 \mathrm{e}-01$ Element: 9916 \# of layers: 7

Kx Ky Kz Ss Por

$2.82291 \mathrm{e}+012.82291 \mathrm{e}+012.82291 \mathrm{e}+00$ 1.00000e-09 2.12000e-01 $2.82291 \mathrm{e}+012.82291 \mathrm{e}+012.82291 \mathrm{e}+001.00000 \mathrm{e}-092.12000 \mathrm{e}-01$ $2.82291 \mathrm{e}+012.82291 \mathrm{e}+012.82291 \mathrm{e}+001.00000 \mathrm{e}-092.12000 \mathrm{e}-01$ $2.82291 \mathrm{e}+012.82291 \mathrm{e}+012.82291 \mathrm{e}+001.00000 \mathrm{e}-092.12000 \mathrm{e}-01$ $2.82291 \mathrm{e}+012.82291 \mathrm{e}+012.82291 \mathrm{e}+001.00000 \mathrm{e}-092.12000 \mathrm{e}-01$ $1.00000 \mathrm{e}-05$ 1.00000e-05 1.00000e-06 1.00000e-09 1.00000e-01 $1.00000 \mathrm{e}+001.00000 \mathrm{e}+001.00000 \mathrm{e}-011.00000 \mathrm{e}-091.00000 \mathrm{e}-01$ Element: 9917 \# of layers: 7

Kx Ky Kz Ss Por

$2.82291 \mathrm{e}+012.82291 \mathrm{e}+012.82291 \mathrm{e}+00$ 1.00000e-09 2.12000e-01 $2.82291 \mathrm{e}+012.82291 \mathrm{e}+012.82291 \mathrm{e}+001.00000 \mathrm{e}-092.12000 \mathrm{e}-01$ $2.82291 \mathrm{e}+012.82291 \mathrm{e}+012.82291 \mathrm{e}+001.00000 \mathrm{e}-092.12000 \mathrm{e}-01$ $2.82291 \mathrm{e}+012.82291 \mathrm{e}+012.82291 \mathrm{e}+001.00000 \mathrm{e}-092.12000 \mathrm{e}-01$ $2.82291 \mathrm{e}+012.82291 \mathrm{e}+012.82291 \mathrm{e}+001.00000 \mathrm{e}-092.12000 \mathrm{e}-01$ $1.00000 \mathrm{e}-05$ 1.00000e-05 1.00000e-06 1.00000e-09 1.00000e-01 $1.00000 \mathrm{e}+001.00000 \mathrm{e}+001.00000 \mathrm{e}-011.00000 \mathrm{e}-091.00000 \mathrm{e}-01$ Element: 9918 \# of layers: 7

Kx Ky Kz Ss Por

$2.82291 \mathrm{e}+012.82291 \mathrm{e}+012.82291 \mathrm{e}+001.00000 \mathrm{e}-092.12000 \mathrm{e}-01$ $2.82291 \mathrm{e}+012.82291 \mathrm{e}+012.82291 \mathrm{e}+001.00000 \mathrm{e}-092.12000 \mathrm{e}-01$ $2.82291 \mathrm{e}+012.82291 \mathrm{e}+012.82291 \mathrm{e}+001.00000 \mathrm{e}-092.12000 \mathrm{e}-01$ $2.82291 \mathrm{e}+012.82291 \mathrm{e}+012.82291 \mathrm{e}+001.00000 \mathrm{e}-092.12000 \mathrm{e}-01$ $2.82291 \mathrm{e}+012.82291 \mathrm{e}+012.82291 \mathrm{e}+001.00000 \mathrm{e}-092.12000 \mathrm{e}-01$ $1.00000 \mathrm{e}-05$ 1.00000e-05 1.00000e-06 1.00000e-09 1.00000e-01 $1.00000 \mathrm{e}+001.00000 \mathrm{e}+001.00000 \mathrm{e}-011.00000 \mathrm{e}-091.00000 \mathrm{e}-01$ Element: 9919 \# of layers: 7

Kx Ky Kz Ss Por

$2.82291 \mathrm{e}+012.82291 \mathrm{e}+012.82291 \mathrm{e}+00$ 1.00000e-09 2.12000e-01 $2.82291 \mathrm{e}+012.82291 \mathrm{e}+012.82291 \mathrm{e}+001.00000 \mathrm{e}-092.12000 \mathrm{e}-01$ $2.82291 \mathrm{e}+012.82291 \mathrm{e}+012.82291 \mathrm{e}+001.00000 \mathrm{e}-092.12000 \mathrm{e}-01$ $2.82291 \mathrm{e}+012.82291 \mathrm{e}+012.82291 \mathrm{e}+001.00000 \mathrm{e}-092.12000 \mathrm{e}-01$ $2.82291 \mathrm{e}+012.82291 \mathrm{e}+012.82291 \mathrm{e}+00$ 1.00000e-09 2.12000e-01 $1.00000 \mathrm{e}-05$ 1.00000e-05 1.00000e-06 1.00000e-09 1.00000e-01 $1.00000 \mathrm{e}+001.00000 \mathrm{e}+001.00000 \mathrm{e}-011.00000 \mathrm{e}-091.00000 \mathrm{e}-01$ Element: 9920 \# of layers: 7

Kx Ky Kz Ss Por

$2.82291 \mathrm{e}+012.82291 \mathrm{e}+012.82291 \mathrm{e}+00$ 1.00000e-09 2.12000e-01 $2.82291 \mathrm{e}+012.82291 \mathrm{e}+012.82291 \mathrm{e}+001.00000 \mathrm{e}-092.12000 \mathrm{e}-01$ $2.82291 \mathrm{e}+012.82291 \mathrm{e}+012.82291 \mathrm{e}+001.00000 \mathrm{e}-092.12000 \mathrm{e}-01$ $2.82291 \mathrm{e}+012.82291 \mathrm{e}+012.82291 \mathrm{e}+001.00000 \mathrm{e}-092.12000 \mathrm{e}-01$ 
$2.82291 \mathrm{e}+012.82291 \mathrm{e}+012.82291 \mathrm{e}+00$ 1.00000e-09 2.12000e-01 $1.00000 \mathrm{e}-05$ 1.00000e-05 1.00000e-06 1.00000e-09 1.00000e-01 $1.00000 \mathrm{e}+001.00000 \mathrm{e}+001.00000 \mathrm{e}-011.00000 \mathrm{e}-09$ 1.00000e-01

Element: 9921 \# of layers: 7

$\mathrm{Kx} \mathrm{Ky} \mathrm{Kz}$ Ss Por

$2.82291 \mathrm{e}+012.82291 \mathrm{e}+012.82291 \mathrm{e}+00$ 1.00000e-09 2.12000e-01

$2.82291 \mathrm{e}+012.82291 \mathrm{e}+012.82291 \mathrm{e}+001.00000 \mathrm{e}-092.12000 \mathrm{e}-01$

$2.82291 \mathrm{e}+012.82291 \mathrm{e}+012.82291 \mathrm{e}+00$ 1.00000e-09 2.12000e-01

$2.82291 \mathrm{e}+012.82291 \mathrm{e}+012.82291 \mathrm{e}+001.00000 \mathrm{e}-092.12000 \mathrm{e}-01$

$2.82291 \mathrm{e}+012.82291 \mathrm{e}+012.82291 \mathrm{e}+001.00000 \mathrm{e}-092.12000 \mathrm{e}-01$

$1.00000 \mathrm{e}-05$ 1.00000e-05 1.00000e-06 1.00000e-09 1.00000e-01

$1.00000 \mathrm{e}+001.00000 \mathrm{e}+001.00000 \mathrm{e}-011.00000 \mathrm{e}-091.00000 \mathrm{e}-01$

Element: 9922 \# of layers: 7

$\mathrm{Kx} \mathrm{Ky} \mathrm{Kz}$ Ss Por

$2.90751 \mathrm{e}+012.90751 \mathrm{e}+012.90751 \mathrm{e}+00$ 1.00000e-09 2.12000e-01 $2.90751 \mathrm{e}+012.90751 \mathrm{e}+012.90751 \mathrm{e}+001.00000 \mathrm{e}-092.12000 \mathrm{e}-01$ $2.90751 \mathrm{e}+012.90751 \mathrm{e}+012.90751 \mathrm{e}+001.00000 \mathrm{e}-092.12000 \mathrm{e}-01$ $2.90751 \mathrm{e}+012.90751 \mathrm{e}+012.90751 \mathrm{e}+001.00000 \mathrm{e}-092.12000 \mathrm{e}-01$ $2.90751 \mathrm{e}+012.90751 \mathrm{e}+012.90751 \mathrm{e}+00$ 1.00000e-09 2.12000e-01 $1.00000 \mathrm{e}-051.00000 \mathrm{e}-05$ 1.00000e-06 1.00000e-09 1.00000e-01 $1.00000 \mathrm{e}+001.00000 \mathrm{e}+001.00000 \mathrm{e}-011.00000 \mathrm{e}-091.00000 \mathrm{e}-01$ Element: 9923 \# of layers: 7

$\mathrm{Kx} \mathrm{Ky} \mathrm{Kz}$ Ss Por

$2.90751 \mathrm{e}+012.90751 \mathrm{e}+012.90751 \mathrm{e}+00$ 1.00000e-09 2.12000e-01 $2.90751 \mathrm{e}+012.90751 \mathrm{e}+012.90751 \mathrm{e}+001.00000 \mathrm{e}-092.12000 \mathrm{e}-01$ $2.90751 \mathrm{e}+012.90751 \mathrm{e}+012.90751 \mathrm{e}+001.00000 \mathrm{e}-092.12000 \mathrm{e}-01$ $2.90751 \mathrm{e}+012.90751 \mathrm{e}+012.90751 \mathrm{e}+001.00000 \mathrm{e}-092.12000 \mathrm{e}-01$ $2.90751 \mathrm{e}+012.90751 \mathrm{e}+012.90751 \mathrm{e}+001.00000 \mathrm{e}-092.12000 \mathrm{e}-01$ 1.00000e-05 1.00000e-05 1.00000e-06 1.00000e-09 1.00000e-01 $1.00000 \mathrm{e}+001.00000 \mathrm{e}+001.00000 \mathrm{e}-011.00000 \mathrm{e}-091.00000 \mathrm{e}-01$ Element: 9924 \# of layers: 7

$\mathrm{Kx} \mathrm{Ky} \mathrm{Kz}$ Ss Por

$2.90751 \mathrm{e}+012.90751 \mathrm{e}+012.90751 \mathrm{e}+00$ 1.00000e-09 2.12000e-01 $2.90751 \mathrm{e}+012.90751 \mathrm{e}+012.90751 \mathrm{e}+001.00000 \mathrm{e}-092.12000 \mathrm{e}-01$ $2.90751 \mathrm{e}+012.90751 \mathrm{e}+012.90751 \mathrm{e}+001.00000 \mathrm{e}-092.12000 \mathrm{e}-01$ $2.90751 \mathrm{e}+012.90751 \mathrm{e}+012.90751 \mathrm{e}+001.00000 \mathrm{e}-092.12000 \mathrm{e}-01$ $2.90751 \mathrm{e}+012.90751 \mathrm{e}+012.90751 \mathrm{e}+001.00000 \mathrm{e}-092.12000 \mathrm{e}-01$ $1.00000 \mathrm{e}-05$ 1.00000e-05 1.00000e-06 1.00000e-09 1.00000e-01 $1.00000 \mathrm{e}+001.00000 \mathrm{e}+001.00000 \mathrm{e}-011.00000 \mathrm{e}-091.00000 \mathrm{e}-01$ Element: 9925 \# of layers: 7

$\mathrm{Kx} \mathrm{Ky} \mathrm{Kz}$ Ss Por

$2.90751 \mathrm{e}+012.90751 \mathrm{e}+012.90751 \mathrm{e}+00$ 1.00000e-09 2.12000e-01 $2.90751 \mathrm{e}+012.90751 \mathrm{e}+012.90751 \mathrm{e}+001.00000 \mathrm{e}-092.12000 \mathrm{e}-01$ $2.90751 \mathrm{e}+012.90751 \mathrm{e}+012.90751 \mathrm{e}+001.00000 \mathrm{e}-092.12000 \mathrm{e}-01$ $2.90751 \mathrm{e}+012.90751 \mathrm{e}+012.90751 \mathrm{e}+00$ 1.00000e-09 2.12000e-01 $2.90751 \mathrm{e}+012.90751 \mathrm{e}+012.90751 \mathrm{e}+001.00000 \mathrm{e}-092.12000 \mathrm{e}-01$ 
$1.00000 \mathrm{e}-05$ 1.00000e-05 1.00000e-06 1.00000e-09 1.00000e-01 $1.00000 \mathrm{e}+001.00000 \mathrm{e}+001.00000 \mathrm{e}-01$ 1.00000e-09 1.00000e-01 Element: 9926 \# of layers: 7

Kx Ky Kz Ss Por

$2.90751 \mathrm{e}+012.90751 \mathrm{e}+012.90751 \mathrm{e}+001.00000 \mathrm{e}-092.12000 \mathrm{e}-01$ $2.90751 \mathrm{e}+012.90751 \mathrm{e}+012.90751 \mathrm{e}+001.00000 \mathrm{e}-092.12000 \mathrm{e}-01$ $2.90751 \mathrm{e}+012.90751 \mathrm{e}+012.90751 \mathrm{e}+001.00000 \mathrm{e}-092.12000 \mathrm{e}-01$ $2.90751 \mathrm{e}+012.90751 \mathrm{e}+012.90751 \mathrm{e}+001.00000 \mathrm{e}-092.12000 \mathrm{e}-01$ $2.90751 \mathrm{e}+012.90751 \mathrm{e}+012.90751 \mathrm{e}+001.00000 \mathrm{e}-092.12000 \mathrm{e}-01$ $1.00000 \mathrm{e}-05$ 1.00000e-05 1.00000e-06 1.00000e-09 1.00000e-01 $1.00000 \mathrm{e}+001.00000 \mathrm{e}+001.00000 \mathrm{e}-011.00000 \mathrm{e}-091.00000 \mathrm{e}-01$ Element: 9927 \# of layers: 7

$\mathrm{Kx} \mathrm{Ky} \mathrm{Kz}$ Ss Por

$2.82291 \mathrm{e}+012.82291 \mathrm{e}+012.82291 \mathrm{e}+00$ 1.00000e-09 2.12000e-01 $2.82291 \mathrm{e}+012.82291 \mathrm{e}+012.82291 \mathrm{e}+00$ 1.00000e-09 2.12000e-01 $2.82291 \mathrm{e}+012.82291 \mathrm{e}+012.82291 \mathrm{e}+001.00000 \mathrm{e}-092.12000 \mathrm{e}-01$ $2.82291 \mathrm{e}+012.82291 \mathrm{e}+012.82291 \mathrm{e}+001.00000 \mathrm{e}-092.12000 \mathrm{e}-01$ $2.82291 \mathrm{e}+012.82291 \mathrm{e}+012.82291 \mathrm{e}+00$ 1.00000e-09 2.12000e-01 $1.00000 \mathrm{e}-05$ 1.00000e-05 1.00000e-06 1.00000e-09 1.00000e-01 $1.00000 \mathrm{e}+001.00000 \mathrm{e}+001.00000 \mathrm{e}-011.00000 \mathrm{e}-091.00000 \mathrm{e}-01$ Element: 9928 \# of layers: 7

$\mathrm{Kx} \mathrm{Ky} \mathrm{Kz}$ Ss Por

$2.82291 \mathrm{e}+012.82291 \mathrm{e}+012.82291 \mathrm{e}+00$ 1.00000e-09 2.12000e-01 $2.82291 \mathrm{e}+012.82291 \mathrm{e}+012.82291 \mathrm{e}+001.00000 \mathrm{e}-092.12000 \mathrm{e}-01$ $2.82291 \mathrm{e}+012.82291 \mathrm{e}+012.82291 \mathrm{e}+001.00000 \mathrm{e}-092.12000 \mathrm{e}-01$ $2.82291 \mathrm{e}+012.82291 \mathrm{e}+012.82291 \mathrm{e}+001.00000 \mathrm{e}-092.12000 \mathrm{e}-01$ $2.82291 \mathrm{e}+012.82291 \mathrm{e}+012.82291 \mathrm{e}+001.00000 \mathrm{e}-092.12000 \mathrm{e}-01$ $1.00000 \mathrm{e}-05$ 1.00000e-05 1.00000e-06 1.00000e-09 1.00000e-01 $1.00000 \mathrm{e}+001.00000 \mathrm{e}+001.00000 \mathrm{e}-011.00000 \mathrm{e}-091.00000 \mathrm{e}-01$ Element: 9929 \# of layers: 7

$\mathrm{Kx} \mathrm{Ky} \mathrm{Kz}$ Ss Por

$2.90751 \mathrm{e}+012.90751 \mathrm{e}+012.90751 \mathrm{e}+001.00000 \mathrm{e}-092.12000 \mathrm{e}-01$ $2.90751 \mathrm{e}+012.90751 \mathrm{e}+012.90751 \mathrm{e}+001.00000 \mathrm{e}-092.12000 \mathrm{e}-01$ $2.90751 \mathrm{e}+012.90751 \mathrm{e}+012.90751 \mathrm{e}+001.00000 \mathrm{e}-092.12000 \mathrm{e}-01$ $2.90751 \mathrm{e}+012.90751 \mathrm{e}+012.90751 \mathrm{e}+001.00000 \mathrm{e}-092.12000 \mathrm{e}-01$ $2.90751 \mathrm{e}+012.90751 \mathrm{e}+012.90751 \mathrm{e}+00$ 1.00000e-09 2.12000e-01 1.00000e-05 1.00000e-05 1.00000e-06 1.00000e-09 1.00000e-01 $1.00000 \mathrm{e}+001.00000 \mathrm{e}+001.00000 \mathrm{e}-011.00000 \mathrm{e}-091.00000 \mathrm{e}-01$ Element: 9930 \# of layers: 7

$\mathrm{Kx} \mathrm{Ky} \mathrm{Kz}$ Ss Por $2.90751 \mathrm{e}+012.90751 \mathrm{e}+012.90751 \mathrm{e}+00$ 1.00000e-09 2.12000e-01 $2.90751 \mathrm{e}+012.90751 \mathrm{e}+012.90751 \mathrm{e}+001.00000 \mathrm{e}-092.12000 \mathrm{e}-01$ $2.90751 \mathrm{e}+012.90751 \mathrm{e}+012.90751 \mathrm{e}+001.00000 \mathrm{e}-092.12000 \mathrm{e}-01$ $2.90751 \mathrm{e}+012.90751 \mathrm{e}+012.90751 \mathrm{e}+001.00000 \mathrm{e}-092.12000 \mathrm{e}-01$ $2.90751 \mathrm{e}+012.90751 \mathrm{e}+012.90751 \mathrm{e}+001.00000 \mathrm{e}-092.12000 \mathrm{e}-01$ $1.00000 \mathrm{e}-05$ 1.00000e-05 1.00000e-06 1.00000e-09 1.00000e-01 
$1.00000 \mathrm{e}+001.00000 \mathrm{e}+001.00000 \mathrm{e}-011.00000 \mathrm{e}-091.00000 \mathrm{e}-01$

Element: 9931 \# of layers: 7

$\mathrm{Kx} \mathrm{Ky} \mathrm{Kz}$ Ss Por

$2.66608 \mathrm{e}+012.66608 \mathrm{e}+012.66608 \mathrm{e}+00$ 1.00000e-09 2.12000e-01

$2.66608 \mathrm{e}+012.66608 \mathrm{e}+012.66608 \mathrm{e}+001.00000 \mathrm{e}-092.12000 \mathrm{e}-01$

$2.66608 \mathrm{e}+012.66608 \mathrm{e}+012.66608 \mathrm{e}+001.00000 \mathrm{e}-092.12000 \mathrm{e}-01$

$2.66608 \mathrm{e}+012.66608 \mathrm{e}+012.66608 \mathrm{e}+001.00000 \mathrm{e}-092.12000 \mathrm{e}-01$

$2.66608 \mathrm{e}+012.66608 \mathrm{e}+012.66608 \mathrm{e}+001.00000 \mathrm{e}-092.12000 \mathrm{e}-01$

$1.00000 \mathrm{e}-05$ 1.00000e-05 1.00000e-06 1.00000e-09 1.00000e-01

$1.00000 \mathrm{e}+001.00000 \mathrm{e}+001.00000 \mathrm{e}-011.00000 \mathrm{e}-091.00000 \mathrm{e}-01$

Element: 9932 \# of layers: 7

$\mathrm{Kx} \mathrm{Ky} \mathrm{Kz}$ Ss Por

$2.66608 \mathrm{e}+012.66608 \mathrm{e}+012.66608 \mathrm{e}+00$ 1.00000e-09 2.12000e-01

$2.66608 \mathrm{e}+012.66608 \mathrm{e}+012.66608 \mathrm{e}+001.00000 \mathrm{e}-092.12000 \mathrm{e}-01$

$2.66608 \mathrm{e}+012.66608 \mathrm{e}+012.66608 \mathrm{e}+001.00000 \mathrm{e}-092.12000 \mathrm{e}-01$

$2.66608 \mathrm{e}+012.66608 \mathrm{e}+012.66608 \mathrm{e}+001.00000 \mathrm{e}-092.12000 \mathrm{e}-01$

$2.66608 \mathrm{e}+012.66608 \mathrm{e}+012.66608 \mathrm{e}+00$ 1.00000e-09 2.12000e-01

$1.00000 \mathrm{e}-05$ 1.00000e-05 1.00000e-06 1.00000e-09 1.00000e-01

$1.00000 \mathrm{e}+001.00000 \mathrm{e}+001.00000 \mathrm{e}-011.00000 \mathrm{e}-091.00000 \mathrm{e}-01$

Element: 9933 \# of layers: 7

$\mathrm{Kx} \mathrm{Ky} \mathrm{Kz}$ Ss Por

$2.66608 \mathrm{e}+012.66608 \mathrm{e}+012.66608 \mathrm{e}+00$ 1.00000e-09 2.12000e-01

$2.66608 \mathrm{e}+012.66608 \mathrm{e}+012.66608 \mathrm{e}+001.00000 \mathrm{e}-092.12000 \mathrm{e}-01$

$2.66608 \mathrm{e}+012.66608 \mathrm{e}+012.66608 \mathrm{e}+001.00000 \mathrm{e}-092.12000 \mathrm{e}-01$

$2.66608 \mathrm{e}+012.66608 \mathrm{e}+012.66608 \mathrm{e}+001.00000 \mathrm{e}-092.12000 \mathrm{e}-01$

$2.66608 \mathrm{e}+012.66608 \mathrm{e}+012.66608 \mathrm{e}+001.00000 \mathrm{e}-092.12000 \mathrm{e}-01$

$1.00000 \mathrm{e}-05$ 1.00000e-05 1.00000e-06 1.00000e-09 1.00000e-01

$1.00000 \mathrm{e}+001.00000 \mathrm{e}+001.00000 \mathrm{e}-011.00000 \mathrm{e}-091.00000 \mathrm{e}-01$

Element: 9934 \# of layers: 7

$\mathrm{Kx} \mathrm{Ky} \mathrm{Kz}$ Ss Por

$2.38528 \mathrm{e}+012.38528 \mathrm{e}+012.38528 \mathrm{e}+00$ 1.00000e-09 2.12000e-01

$2.38528 \mathrm{e}+012.38528 \mathrm{e}+012.38528 \mathrm{e}+00$ 1.00000e-09 2.12000e-01

$2.38528 \mathrm{e}+012.38528 \mathrm{e}+012.38528 \mathrm{e}+00$ 1.00000e-09 2.12000e-01

$2.38528 \mathrm{e}+012.38528 \mathrm{e}+012.38528 \mathrm{e}+00$ 1.00000e-09 2.12000e-01

$2.38528 \mathrm{e}+012.38528 \mathrm{e}+012.38528 \mathrm{e}+001.00000 \mathrm{e}-092.12000 \mathrm{e}-01$

$1.00000 \mathrm{e}-05$ 1.00000e-05 1.00000e-06 1.00000e-09 1.00000e-01

$1.00000 \mathrm{e}+001.00000 \mathrm{e}+001.00000 \mathrm{e}-011.00000 \mathrm{e}-091.00000 \mathrm{e}-01$

Element: 9935 \# of layers: 7

$\mathrm{Kx} \mathrm{Ky} \mathrm{Kz}$ Ss Por

$2.38528 \mathrm{e}+012.38528 \mathrm{e}+012.38528 \mathrm{e}+00$ 1.00000e-09 2.12000e-01

$2.38528 \mathrm{e}+012.38528 \mathrm{e}+012.38528 \mathrm{e}+00$ 1.00000e-09 2.12000e-01

$2.38528 \mathrm{e}+012.38528 \mathrm{e}+012.38528 \mathrm{e}+00$ 1.00000e-09 2.12000e-01

$2.38528 \mathrm{e}+012.38528 \mathrm{e}+012.38528 \mathrm{e}+00$ 1.00000e-09 2.12000e-01

$2.38528 \mathrm{e}+012.38528 \mathrm{e}+012.38528 \mathrm{e}+00$ 1.00000e-09 2.12000e-01 $1.00000 \mathrm{e}-05$ 1.00000e-05 1.00000e-06 1.00000e-09 1.00000e-01

$1.00000 \mathrm{e}+001.00000 \mathrm{e}+001.00000 \mathrm{e}-011.00000 \mathrm{e}-091.00000 \mathrm{e}-01$ 
Element: 9936 \# of layers: 7

$\mathrm{Kx} \mathrm{Ky} \mathrm{Kz}$ Ss Por

$2.82291 \mathrm{e}+012.82291 \mathrm{e}+012.82291 \mathrm{e}+00$ 1.00000e-09 2.12000e-01

$2.82291 \mathrm{e}+012.82291 \mathrm{e}+012.82291 \mathrm{e}+001.00000 \mathrm{e}-092.12000 \mathrm{e}-01$

$2.82291 \mathrm{e}+012.82291 \mathrm{e}+012.82291 \mathrm{e}+001.00000 \mathrm{e}-092.12000 \mathrm{e}-01$

$2.82291 \mathrm{e}+012.82291 \mathrm{e}+012.82291 \mathrm{e}+00$ 1.00000e-09 2.12000e-01

$2.82291 \mathrm{e}+012.82291 \mathrm{e}+012.82291 \mathrm{e}+001.00000 \mathrm{e}-092.12000 \mathrm{e}-01$

$1.00000 \mathrm{e}-05$ 1.00000e-05 1.00000e-06 1.00000e-09 1.00000e-01

$1.00000 \mathrm{e}+001.00000 \mathrm{e}+001.00000 \mathrm{e}-011.00000 \mathrm{e}-091.00000 \mathrm{e}-01$

Element: 9937 \# of layers: 7

$\mathrm{Kx} \mathrm{Ky} \mathrm{Kz}$ Ss Por

$2.90751 \mathrm{e}+012.90751 \mathrm{e}+012.90751 \mathrm{e}+001.00000 \mathrm{e}-092.12000 \mathrm{e}-01$

$2.90751 \mathrm{e}+012.90751 \mathrm{e}+012.90751 \mathrm{e}+00$ 1.00000e-09 2.12000e-01

$2.90751 \mathrm{e}+012.90751 \mathrm{e}+012.90751 \mathrm{e}+001.00000 \mathrm{e}-092.12000 \mathrm{e}-01$

$2.90751 \mathrm{e}+012.90751 \mathrm{e}+012.90751 \mathrm{e}+001.00000 \mathrm{e}-092.12000 \mathrm{e}-01$

$2.90751 \mathrm{e}+012.90751 \mathrm{e}+012.90751 \mathrm{e}+001.00000 \mathrm{e}-092.12000 \mathrm{e}-01$

$1.00000 \mathrm{e}-05$ 1.00000e-05 1.00000e-06 1.00000e-09 1.00000e-01

$1.00000 \mathrm{e}+001.00000 \mathrm{e}+001.00000 \mathrm{e}-011.00000 \mathrm{e}-09$ 1.00000e-01

Element: 9938 \# of layers: 7

$\mathrm{Kx} \mathrm{Ky} \mathrm{Kz}$ Ss Por

$2.66608 \mathrm{e}+012.66608 \mathrm{e}+012.66608 \mathrm{e}+00$ 1.00000e-09 2.12000e-01

$2.66608 \mathrm{e}+012.66608 \mathrm{e}+012.66608 \mathrm{e}+001.00000 \mathrm{e}-092.12000 \mathrm{e}-01$

$2.66608 \mathrm{e}+012.66608 \mathrm{e}+012.66608 \mathrm{e}+001.00000 \mathrm{e}-092.12000 \mathrm{e}-01$

$2.66608 \mathrm{e}+012.66608 \mathrm{e}+012.66608 \mathrm{e}+001.00000 \mathrm{e}-092.12000 \mathrm{e}-01$

$2.66608 \mathrm{e}+012.66608 \mathrm{e}+012.66608 \mathrm{e}+001.00000 \mathrm{e}-092.12000 \mathrm{e}-01$

$1.00000 \mathrm{e}-05$ 1.00000e-05 1.00000e-06 1.00000e-09 1.00000e-01

$1.00000 \mathrm{e}+001.00000 \mathrm{e}+001.00000 \mathrm{e}-011.00000 \mathrm{e}-091.00000 \mathrm{e}-01$

Element: 9939 \# of layers: 7

Kx Ky Kz Ss Por

$1.46712 \mathrm{e}+01$ 1.46712e+01 1.46712e+00 1.00000e-09 2.12000e-01

$1.46712 \mathrm{e}+011.46712 \mathrm{e}+01$ 1.46712e+00 1.00000e-09 2.12000e-01

$1.46712 \mathrm{e}+01$ 1.46712e+01 1.46712e+00 1.00000e-09 2.12000e-01

$1.46712 \mathrm{e}+011.46712 \mathrm{e}+011.46712 \mathrm{e}+001.00000 \mathrm{e}-092.12000 \mathrm{e}-01$

$1.46712 \mathrm{e}+01$ 1.46712e+01 1.46712e+00 1.00000e-09 2.12000e-01

$1.00000 \mathrm{e}-05$ 1.00000e-05 1.00000e-06 1.00000e-09 1.00000e-01

$1.00000 \mathrm{e}+001.00000 \mathrm{e}+001.00000 \mathrm{e}-011.00000 \mathrm{e}-091.00000 \mathrm{e}-01$

Element: 9940 \# of layers: 7

$\mathrm{Kx} \mathrm{Ky} \mathrm{Kz}$ Ss Por

$1.46712 \mathrm{e}+01$ 1.46712e+01 1.46712e+00 1.00000e-09 2.12000e-01

$1.46712 \mathrm{e}+01$ 1.46712e+01 1.46712e+00 1.00000e-09 2.12000e-01

$1.46712 \mathrm{e}+011.46712 \mathrm{e}+011.46712 \mathrm{e}+001.00000 \mathrm{e}-092.12000 \mathrm{e}-01$

$1.46712 \mathrm{e}+011.46712 \mathrm{e}+01$ 1.46712e+00 1.00000e-09 2.12000e-01

$1.46712 \mathrm{e}+01$ 1.46712e+01 1.46712e+00 1.00000e-09 2.12000e-01

$1.00000 \mathrm{e}-05$ 1.00000e-05 1.00000e-06 1.00000e-09 1.00000e-01

$1.00000 \mathrm{e}+001.00000 \mathrm{e}+001.00000 \mathrm{e}-01$ 1.00000e-09 1.00000e-01

Element: 9941 \# of layers: 7 
Kx Ky Kz Ss Por

$1.46712 \mathrm{e}+01$ 1.46712e+01 1.46712e+00 1.00000e-09 2.12000e-01

$1.46712 \mathrm{e}+011.46712 \mathrm{e}+011.46712 \mathrm{e}+001.00000 \mathrm{e}-092.12000 \mathrm{e}-01$

$1.46712 \mathrm{e}+01$ 1.46712e+01 1.46712e+00 1.00000e-09 2.12000e-01

$1.46712 \mathrm{e}+011.46712 \mathrm{e}+01$ 1.46712e+00 1.00000e-09 2.12000e-01

$1.46712 \mathrm{e}+01$ 1.46712e+01 1.46712e+00 1.00000e-09 2.12000e-01

$1.00000 \mathrm{e}-05$ 1.00000e-05 1.00000e-06 1.00000e-09 1.00000e-01

$1.00000 \mathrm{e}+001.00000 \mathrm{e}+001.00000 \mathrm{e}-011.00000 \mathrm{e}-091.00000 \mathrm{e}-01$

Element: 9942 \# of layers: 7

$\mathrm{Kx} \mathrm{Ky} \mathrm{Kz}$ Ss Por

$1.46712 \mathrm{e}+01$ 1.46712e+01 1.46712e+00 1.00000e-09 2.12000e-01

$1.46712 \mathrm{e}+011.46712 \mathrm{e}+011.46712 \mathrm{e}+001.00000 \mathrm{e}-092.12000 \mathrm{e}-01$

$1.46712 \mathrm{e}+011.46712 \mathrm{e}+011.46712 \mathrm{e}+001.00000 \mathrm{e}-092.12000 \mathrm{e}-01$

$1.46712 \mathrm{e}+01$ 1.46712e+01 1.46712e+00 1.00000e-09 2.12000e-01

$1.46712 \mathrm{e}+011.46712 \mathrm{e}+011.46712 \mathrm{e}+001.00000 \mathrm{e}-092.12000 \mathrm{e}-01$ $1.00000 \mathrm{e}-05$ 1.00000e-05 1.00000e-06 1.00000e-09 1.00000e-01

$1.00000 \mathrm{e}+001.00000 \mathrm{e}+001.00000 \mathrm{e}-011.00000 \mathrm{e}-091.00000 \mathrm{e}-01$

Element: 9943 \# of layers: 7

$\mathrm{Kx} \mathrm{Ky} \mathrm{Kz}$ Ss Por

1.46712e+01 1.46712e+01 1.46712e+00 1.00000e-09 2.12000e-01 $1.46712 \mathrm{e}+011.46712 \mathrm{e}+011.46712 \mathrm{e}+001.00000 \mathrm{e}-092.12000 \mathrm{e}-01$ $1.46712 \mathrm{e}+011.46712 \mathrm{e}+011.46712 \mathrm{e}+001.00000 \mathrm{e}-092.12000 \mathrm{e}-01$ $1.46712 \mathrm{e}+01$ 1.46712e+01 1.46712e+00 1.00000e-09 2.12000e-01 $1.46712 \mathrm{e}+011.46712 \mathrm{e}+011.46712 \mathrm{e}+001.00000 \mathrm{e}-092.12000 \mathrm{e}-01$ $1.00000 \mathrm{e}-05$ 1.00000e-05 1.00000e-06 1.00000e-09 1.00000e-01 $1.00000 \mathrm{e}+001.00000 \mathrm{e}+001.00000 \mathrm{e}-011.00000 \mathrm{e}-091.00000 \mathrm{e}-01$

Element: 9944 \# of layers: 7

$\mathrm{Kx} \mathrm{Ky} \mathrm{Kz}$ Ss Por

$1.46712 \mathrm{e}+01$ 1.46712e+01 1.46712e+00 1.00000e-09 2.12000e-01 $1.46712 \mathrm{e}+01$ 1.46712e+01 1.46712e+00 1.00000e-09 2.12000e-01 $1.46712 \mathrm{e}+01$ 1.46712e+01 1.46712e+00 1.00000e-09 2.12000e-01 $1.46712 \mathrm{e}+011.46712 \mathrm{e}+011.46712 \mathrm{e}+001.00000 \mathrm{e}-092.12000 \mathrm{e}-01$ $1.46712 \mathrm{e}+011.46712 \mathrm{e}+011.46712 \mathrm{e}+001.00000 \mathrm{e}-092.12000 \mathrm{e}-01$ $1.00000 \mathrm{e}-05$ 1.00000e-05 1.00000e-06 1.00000e-09 1.00000e-01 $1.00000 \mathrm{e}+001.00000 \mathrm{e}+001.00000 \mathrm{e}-011.00000 \mathrm{e}-091.00000 \mathrm{e}-01$ Element: 9945 \# of layers: 7

Kx Ky Kz Ss Por

$1.46712 \mathrm{e}+011.46712 \mathrm{e}+011.46712 \mathrm{e}+001.00000 \mathrm{e}-092.12000 \mathrm{e}-01$ $1.46712 \mathrm{e}+011.46712 \mathrm{e}+011.46712 \mathrm{e}+001.00000 \mathrm{e}-092.12000 \mathrm{e}-01$ $1.46712 \mathrm{e}+01$ 1.46712e+01 1.46712e+00 1.00000e-09 2.12000e-01 $1.46712 \mathrm{e}+011.46712 \mathrm{e}+011.46712 \mathrm{e}+001.00000 \mathrm{e}-092.12000 \mathrm{e}-01$ $1.46712 \mathrm{e}+011.46712 \mathrm{e}+01$ 1.46712e+00 1.00000e-09 2.12000e-01 $1.00000 \mathrm{e}-05$ 1.00000e-05 1.00000e-06 1.00000e-09 1.00000e-01 $1.00000 \mathrm{e}+001.00000 \mathrm{e}+001.00000 \mathrm{e}-01$ 1.00000e-09 1.00000e-01 Element: 9946 \# of layers: 7

Kx Ky Kz Ss Por 
1.46712e+01 1.46712e+01 1.46712e+00 1.00000e-09 2.12000e-01 $1.46712 \mathrm{e}+01$ 1.46712e+01 1.46712e+00 1.00000e-09 2.12000e-01 $1.46712 \mathrm{e}+011.46712 \mathrm{e}+011.46712 \mathrm{e}+001.00000 \mathrm{e}-092.12000 \mathrm{e}-01$ $1.46712 \mathrm{e}+011.46712 \mathrm{e}+011.46712 \mathrm{e}+001.00000 \mathrm{e}-092.12000 \mathrm{e}-01$ $1.46712 \mathrm{e}+011.46712 \mathrm{e}+011.46712 \mathrm{e}+001.00000 \mathrm{e}-092.12000 \mathrm{e}-01$ $1.00000 \mathrm{e}-05$ 1.00000e-05 1.00000e-06 1.00000e-09 1.00000e-01 $1.00000 \mathrm{e}+001.00000 \mathrm{e}+001.00000 \mathrm{e}-01$ 1.00000e-09 1.00000e-01 Element: 9947 \# of layers: 7

$\mathrm{Kx} \mathrm{Ky} \mathrm{Kz}$ Ss Por

$1.46712 \mathrm{e}+01$ 1.46712e+01 1.46712e+00 1.00000e-09 2.12000e-01 $1.46712 \mathrm{e}+01$ 1.46712e+01 1.46712e+00 1.00000e-09 2.12000e-01 $1.46712 \mathrm{e}+011.46712 \mathrm{e}+011.46712 \mathrm{e}+001.00000 \mathrm{e}-092.12000 \mathrm{e}-01$ $1.46712 \mathrm{e}+011.46712 \mathrm{e}+011.46712 \mathrm{e}+001.00000 \mathrm{e}-092.12000 \mathrm{e}-01$ $1.46712 \mathrm{e}+011.46712 \mathrm{e}+011.46712 \mathrm{e}+001.00000 \mathrm{e}-092.12000 \mathrm{e}-01$ $1.00000 \mathrm{e}-05$ 1.00000e-05 1.00000e-06 1.00000e-09 1.00000e-01 $1.00000 \mathrm{e}+001.00000 \mathrm{e}+001.00000 \mathrm{e}-011.00000 \mathrm{e}-091.00000 \mathrm{e}-01$ Element: 9948 \# of layers: 7

$\mathrm{Kx} \mathrm{Ky} \mathrm{Kz}$ Ss Por

$1.46712 \mathrm{e}+01$ 1.46712e+01 1.46712e+00 1.00000e-09 2.12000e-01 $1.46712 \mathrm{e}+011.46712 \mathrm{e}+011.46712 \mathrm{e}+001.00000 \mathrm{e}-092.12000 \mathrm{e}-01$ $1.46712 \mathrm{e}+011.46712 \mathrm{e}+011.46712 \mathrm{e}+001.00000 \mathrm{e}-092.12000 \mathrm{e}-01$ $1.46712 \mathrm{e}+01$ 1.46712e+01 1.46712e+00 1.00000e-09 2.12000e-01 $1.46712 \mathrm{e}+01$ 1.46712e+01 1.46712e+00 1.00000e-09 2.12000e-01 $1.00000 \mathrm{e}-05$ 1.00000e-05 1.00000e-06 1.00000e-09 1.00000e-01 $1.00000 \mathrm{e}+001.00000 \mathrm{e}+001.00000 \mathrm{e}-011.00000 \mathrm{e}-091.00000 \mathrm{e}-01$ Element: 9949 \# of layers: 7

$\mathrm{Kx} \mathrm{Ky} \mathrm{Kz}$ Ss Por

$1.37989 e+01$ 1.37989e+01 1.37989e+00 1.00000e-09 2.12000e-01 $1.37989 \mathrm{e}+01$ 1.37989e+01 1.37989e+00 1.00000e-09 2.12000e-01 $1.37989 \mathrm{e}+01$ 1.37989e+01 1.37989e+00 1.00000e-09 2.12000e-01 $1.37989 \mathrm{e}+01$ 1.37989e+01 1.37989e+00 1.00000e-09 2.12000e-01 $1.37989 \mathrm{e}+01$ 1.37989e+01 1.37989e+00 1.00000e-09 2.12000e-01 $1.00000 \mathrm{e}-05$ 1.00000e-05 1.00000e-06 1.00000e-09 1.00000e-01 $1.00000 \mathrm{e}+001.00000 \mathrm{e}+001.00000 \mathrm{e}-011.00000 \mathrm{e}-091.00000 \mathrm{e}-01$ Element: 9950 \# of layers: 7

$\mathrm{Kx} \mathrm{Ky} \mathrm{Kz}$ Ss Por

$1.37989 \mathrm{e}+01$ 1.37989e+01 1.37989e+00 1.00000e-09 2.12000e-01 $1.37989 \mathrm{e}+01$ 1.37989e+01 1.37989e+00 1.00000e-09 2.12000e-01 $1.37989 \mathrm{e}+01$ 1.37989e+01 1.37989e+00 1.00000e-09 2.12000e-01 $1.37989 \mathrm{e}+01$ 1.37989e+01 1.37989e+00 1.00000e-09 2.12000e-01 $1.37989 \mathrm{e}+01$ 1.37989e+01 1.37989e+00 1.00000e-09 2.12000e-01 $1.00000 \mathrm{e}-05$ 1.00000e-05 1.00000e-06 1.00000e-09 1.00000e-01 $1.00000 \mathrm{e}+001.00000 \mathrm{e}+001.00000 \mathrm{e}-011.00000 \mathrm{e}-091.00000 \mathrm{e}-01$ Element: 9951 \# of layers: 7

$\mathrm{Kx} \mathrm{Ky} \mathrm{Kz}$ Ss Por

$1.37989 e+01$ 1.37989e+01 1.37989e+00 1.00000e-09 2.12000e-01 
1.37989e+01 1.37989e+01 1.37989e+00 1.00000e-09 2.12000e-01 $1.37989 \mathrm{e}+01$ 1.37989e+01 1.37989e+00 1.00000e-09 2.12000e-01 $1.37989 \mathrm{e}+01$ 1.37989e+01 1.37989e+00 1.00000e-09 2.12000e-01 $1.37989 \mathrm{e}+01$ 1.37989e+01 1.37989e+00 1.00000e-09 2.12000e-01 $1.00000 \mathrm{e}-05$ 1.00000e-05 1.00000e-06 1.00000e-09 1.00000e-01 $1.00000 \mathrm{e}+001.00000 \mathrm{e}+001.00000 \mathrm{e}-011.00000 \mathrm{e}-091.00000 \mathrm{e}-01$ Element: 9952 \# of layers: 7

$\mathrm{Kx} \mathrm{Ky} \mathrm{Kz}$ Ss Por

$1.37989 \mathrm{e}+01$ 1.37989e+01 1.37989e+00 1.00000e-09 2.12000e-01 $1.37989 \mathrm{e}+01$ 1.37989e+01 1.37989e+00 1.00000e-09 2.12000e-01 $1.37989 \mathrm{e}+01$ 1.37989e+01 1.37989e+00 1.00000e-09 2.12000e-01 $1.37989 \mathrm{e}+01$ 1.37989e+01 1.37989e+00 1.00000e-09 2.12000e-01 $1.37989 \mathrm{e}+01$ 1.37989e+01 1.37989e+00 1.00000e-09 2.12000e-01 $1.00000 \mathrm{e}-05$ 1.00000e-05 1.00000e-06 1.00000e-09 1.00000e-01 $1.00000 \mathrm{e}+001.00000 \mathrm{e}+001.00000 \mathrm{e}-01$ 1.00000e-09 1.00000e-01 Element: 9953 \# of layers: 7

$\mathrm{Kx} \mathrm{Ky} \mathrm{Kz}$ Ss Por

$1.37989 \mathrm{e}+01$ 1.37989e+01 1.37989e+00 1.00000e-09 2.12000e-01 $1.37989 \mathrm{e}+01$ 1.37989e+01 1.37989e+00 1.00000e-09 2.12000e-01 $1.37989 \mathrm{e}+01$ 1.37989e+01 1.37989e+00 1.00000e-09 2.12000e-01 $1.37989 \mathrm{e}+01$ 1.37989e+01 1.37989e+00 1.00000e-09 2.12000e-01 $1.37989 \mathrm{e}+01$ 1.37989e+01 1.37989e+00 1.00000e-09 2.12000e-01 $1.00000 \mathrm{e}-05$ 1.00000e-05 1.00000e-06 1.00000e-09 1.00000e-01 $1.00000 \mathrm{e}+001.00000 \mathrm{e}+001.00000 \mathrm{e}-011.00000 \mathrm{e}-091.00000 \mathrm{e}-01$ Element: 9954 \# of layers: 7

$\mathrm{Kx} \mathrm{Ky} \mathrm{Kz}$ Ss Por

$1.46712 \mathrm{e}+011.46712 \mathrm{e}+011.46712 \mathrm{e}+001.00000 \mathrm{e}-092.12000 \mathrm{e}-01$ $1.46712 \mathrm{e}+011.46712 \mathrm{e}+011.46712 \mathrm{e}+001.00000 \mathrm{e}-092.12000 \mathrm{e}-01$ $1.46712 \mathrm{e}+011.46712 \mathrm{e}+011.46712 \mathrm{e}+001.00000 \mathrm{e}-092.12000 \mathrm{e}-01$ $1.46712 \mathrm{e}+01$ 1.46712e+01 1.46712e+00 1.00000e-09 2.12000e-01 $1.46712 \mathrm{e}+011.46712 \mathrm{e}+011.46712 \mathrm{e}+001.00000 \mathrm{e}-092.12000 \mathrm{e}-01$ $1.00000 \mathrm{e}-05$ 1.00000e-05 1.00000e-06 1.00000e-09 1.00000e-01 $1.00000 \mathrm{e}+001.00000 \mathrm{e}+001.00000 \mathrm{e}-011.00000 \mathrm{e}-091.00000 \mathrm{e}-01$ Element: 9955 \# of layers: 7

$\mathrm{Kx} \mathrm{Ky} \mathrm{Kz}$ Ss Por

$1.46712 \mathrm{e}+011.46712 \mathrm{e}+011.46712 \mathrm{e}+001.00000 \mathrm{e}-092.12000 \mathrm{e}-01$ $1.46712 \mathrm{e}+011.46712 \mathrm{e}+011.46712 \mathrm{e}+001.00000 \mathrm{e}-092.12000 \mathrm{e}-01$ $1.46712 \mathrm{e}+011.46712 \mathrm{e}+011.46712 \mathrm{e}+001.00000 \mathrm{e}-092.12000 \mathrm{e}-01$ $1.46712 \mathrm{e}+011.46712 \mathrm{e}+011.46712 \mathrm{e}+001.00000 \mathrm{e}-092.12000 \mathrm{e}-01$ $1.46712 \mathrm{e}+01$ 1.46712e+01 1.46712e+00 1.00000e-09 2.12000e-01 $1.00000 \mathrm{e}-05$ 1.00000e-05 1.00000e-06 1.00000e-09 1.00000e-01 $1.00000 \mathrm{e}+001.00000 \mathrm{e}+001.00000 \mathrm{e}-011.00000 \mathrm{e}-091.00000 \mathrm{e}-01$ Element: 9956 \# of layers: 7

$\mathrm{Kx} \mathrm{Ky} \mathrm{Kz}$ Ss Por

1.37989e+01 1.37989e+01 1.37989e+00 1.00000e-09 2.12000e-01 $1.37989 e+011.37989 e+011.37989 e+001.00000 e-092.12000 e-01$ 
1.37989e+01 1.37989e+01 1.37989e+00 1.00000e-09 2.12000e-01 $1.37989 \mathrm{e}+01$ 1.37989e+01 1.37989e+00 1.00000e-09 2.12000e-01 $1.37989 \mathrm{e}+01$ 1.37989e+01 1.37989e+00 1.00000e-09 2.12000e-01 $1.00000 \mathrm{e}-05$ 1.00000e-05 1.00000e-06 1.00000e-09 1.00000e-01 $1.00000 \mathrm{e}+001.00000 \mathrm{e}+001.00000 \mathrm{e}-011.00000 \mathrm{e}-091.00000 \mathrm{e}-01$ Element: 9957 \# of layers: 8

Kx Ky Kz Ss Por

3.50000e+02 3.50000e+02 3.50000e+01 1.00000e-09 1.00000e-01 $1.37989 \mathrm{e}+01$ 1.37989e+01 1.37989e+00 1.00000e-09 2.12000e-01 $1.37989 \mathrm{e}+01$ 1.37989e+01 1.37989e+00 1.00000e-09 2.12000e-01 $1.37989 \mathrm{e}+01$ 1.37989e+01 1.37989e+00 1.00000e-09 2.12000e-01 $1.37989 \mathrm{e}+01$ 1.37989e+01 1.37989e+00 1.00000e-09 2.12000e-01 $1.37989 \mathrm{e}+01$ 1.37989e+01 1.37989e+00 1.00000e-09 2.12000e-01 $1.00000 \mathrm{e}-05$ 1.00000e-05 1.00000e-06 1.00000e-09 1.00000e-01 $1.00000 \mathrm{e}+001.00000 \mathrm{e}+001.00000 \mathrm{e}-01$ 1.00000e-09 1.00000e-01 Element: 9958 \# of layers: 8

$\mathrm{Kx} \mathrm{Ky} \mathrm{Kz}$ Ss Por

3.50000e+02 3.50000e+02 3.50000e+01 1.00000e-09 1.00000e-01 $1.37989 \mathrm{e}+01$ 1.37989e+01 1.37989e+00 1.00000e-09 2.12000e-01 $1.37989 \mathrm{e}+01$ 1.37989e+01 1.37989e+00 1.00000e-09 2.12000e-01 $1.37989 \mathrm{e}+01$ 1.37989e+01 1.37989e+00 1.00000e-09 2.12000e-01 $1.37989 \mathrm{e}+01$ 1.37989e+01 1.37989e+00 1.00000e-09 2.12000e-01 $1.37989 \mathrm{e}+01$ 1.37989e+01 1.37989e+00 1.00000e-09 2.12000e-01 $1.00000 \mathrm{e}-05$ 1.00000e-05 1.00000e-06 1.00000e-09 1.00000e-01 $1.00000 \mathrm{e}+001.00000 \mathrm{e}+001.00000 \mathrm{e}-011.00000 \mathrm{e}-091.00000 \mathrm{e}-01$ Element: 9959 \# of layers: 8

$\mathrm{Kx} \mathrm{Ky} \mathrm{Kz}$ Ss Por

3.50000e+02 3.50000e+02 3.50000e+01 1.00000e-09 1.00000e-01 $1.37989 \mathrm{e}+01$ 1.37989e+01 1.37989e+00 1.00000e-09 2.12000e-01 $1.37989 \mathrm{e}+01$ 1.37989e+01 1.37989e+00 1.00000e-09 2.12000e-01 $1.37989 \mathrm{e}+01$ 1.37989e+01 1.37989e+00 1.00000e-09 2.12000e-01 $1.37989 \mathrm{e}+01$ 1.37989e+01 1.37989e+00 1.00000e-09 2.12000e-01 $1.37989 \mathrm{e}+01$ 1.37989e+01 1.37989e+00 1.00000e-09 2.12000e-01 $1.00000 \mathrm{e}-05$ 1.00000e-05 1.00000e-06 1.00000e-09 1.00000e-01 $1.00000 \mathrm{e}+001.00000 \mathrm{e}+001.00000 \mathrm{e}-011.00000 \mathrm{e}-091.00000 \mathrm{e}-01$ Element: 9960 \# of layers: 8

Kx Ky Kz Ss Por

3.50000e+02 3.50000e+02 3.50000e+01 1.00000e-09 1.00000e-01 $1.37989 \mathrm{e}+01$ 1.37989e+01 1.37989e+00 1.00000e-09 2.12000e-01 $1.37989 \mathrm{e}+01$ 1.37989e+01 1.37989e+00 1.00000e-09 2.12000e-01 $1.37989 \mathrm{e}+01$ 1.37989e+01 1.37989e+00 1.00000e-09 2.12000e-01 $1.37989 \mathrm{e}+01$ 1.37989e+01 1.37989e+00 1.00000e-09 2.12000e-01 $1.37989 \mathrm{e}+01$ 1.37989e+01 1.37989e+00 1.00000e-09 2.12000e-01 $1.00000 \mathrm{e}-05$ 1.00000e-05 1.00000e-06 1.00000e-09 1.00000e-01 $1.00000 \mathrm{e}+001.00000 \mathrm{e}+001.00000 \mathrm{e}-011.00000 \mathrm{e}-091.00000 \mathrm{e}-01$ Element: 9961 \# of layers: 9 
$\mathrm{Kx} \mathrm{Ky} \mathrm{Kz} \mathrm{Ss} \mathrm{Por}$

$3.50000 \mathrm{e}+02$ 3.50000e+02 3.50000e+01 1.00000e-09 1.00000e-01 5.00000e-04 5.00000e-04 5.00000e-05 1.00000e-09 1.00000e-01

$1.37989 \mathrm{e}+01$ 1.37989e+01 1.37989e+00 1.00000e-09 2.12000e-01

$1.37989 \mathrm{e}+01$ 1.37989e+01 1.37989e+00 1.00000e-09 2.12000e-01

$1.37989 \mathrm{e}+01$ 1.37989e+01 1.37989e+00 1.00000e-09 2.12000e-01

$1.37989 \mathrm{e}+01$ 1.37989e+01 1.37989e+00 1.00000e-09 2.12000e-01

$1.37989 \mathrm{e}+01$ 1.37989e+01 1.37989e+00 1.00000e-09 2.12000e-01

$1.00000 \mathrm{e}-05$ 1.00000e-05 1.00000e-06 1.00000e-09 1.00000e-01

$1.00000 \mathrm{e}+001.00000 \mathrm{e}+001.00000 \mathrm{e}-011.00000 \mathrm{e}-091.00000 \mathrm{e}-01$

Element: 9962 \# of layers: 8

$\mathrm{Kx} \mathrm{Ky} \mathrm{Kz}$ Ss Por

5.00000e-04 5.00000e-04 5.00000e-05 1.00000e-09 1.00000e-01

$1.37989 \mathrm{e}+01$ 1.37989e+01 1.37989e+00 1.00000e-09 2.12000e-01

$1.37989 \mathrm{e}+01$ 1.37989e+01 1.37989e+00 1.00000e-09 2.12000e-01

$1.37989 \mathrm{e}+01$ 1.37989e+01 1.37989e+00 1.00000e-09 2.12000e-01

$1.37989 \mathrm{e}+01$ 1.37989e+01 1.37989e+00 1.00000e-09 2.12000e-01

$1.37989 \mathrm{e}+01$ 1.37989e+01 1.37989e+00 1.00000e-09 2.12000e-01

$1.00000 \mathrm{e}-05$ 1.00000e-05 1.00000e-06 1.00000e-09 1.00000e-01

$1.00000 \mathrm{e}+001.00000 \mathrm{e}+001.00000 \mathrm{e}-011.00000 \mathrm{e}-091.00000 \mathrm{e}-01$

Element: 9963 \# of layers: 8

$\mathrm{Kx} \mathrm{Ky} \mathrm{Kz}$ Ss Por

5.00000e-04 5.00000e-04 5.00000e-05 1.00000e-09 1.00000e-01

$1.37989 \mathrm{e}+01$ 1.37989e+01 1.37989e+00 1.00000e-09 2.12000e-01

$1.37989 \mathrm{e}+01$ 1.37989e+01 1.37989e+00 1.00000e-09 2.12000e-01

$1.37989 \mathrm{e}+01$ 1.37989e+01 1.37989e+00 1.00000e-09 2.12000e-01

$1.37989 \mathrm{e}+01$ 1.37989e+01 1.37989e+00 1.00000e-09 2.12000e-01

$1.37989 \mathrm{e}+01$ 1.37989e+01 1.37989e+00 1.00000e-09 2.12000e-01

$1.00000 \mathrm{e}-05$ 1.00000e-05 1.00000e-06 1.00000e-09 1.00000e-01

$1.00000 \mathrm{e}+001.00000 \mathrm{e}+001.00000 \mathrm{e}-011.00000 \mathrm{e}-091.00000 \mathrm{e}-01$

Element: 9964 \# of layers: 7

Kx Ky Kz Ss Por

$1.37989 e+01$ 1.37989e+01 1.37989e+00 1.00000e-09 2.12000e-01

$1.37989 \mathrm{e}+01$ 1.37989e+01 1.37989e+00 1.00000e-09 2.12000e-01

$1.37989 \mathrm{e}+01$ 1.37989e+01 1.37989e+00 1.00000e-09 2.12000e-01

$1.37989 \mathrm{e}+01$ 1.37989e+01 1.37989e+00 1.00000e-09 2.12000e-01

$1.37989 \mathrm{e}+01$ 1.37989e+01 1.37989e+00 1.00000e-09 2.12000e-01

$1.00000 \mathrm{e}-05$ 1.00000e-05 1.00000e-06 1.00000e-09 1.00000e-01

$1.00000 \mathrm{e}+001.00000 \mathrm{e}+001.00000 \mathrm{e}-011.00000 \mathrm{e}-091.00000 \mathrm{e}-01$

Element: 9965 \# of layers: 8

$\mathrm{Kx} \mathrm{Ky} \mathrm{Kz}$ Ss Por

$3.50000 \mathrm{e}+023.50000 \mathrm{e}+023.50000 \mathrm{e}+01$ 1.00000e-09 1.00000e-01

$1.37989 \mathrm{e}+01$ 1.37989e+01 1.37989e+00 1.00000e-09 2.12000e-01

1.37989e+01 1.37989e+01 1.37989e+00 1.00000e-09 2.12000e-01

$1.37989 \mathrm{e}+01$ 1.37989e+01 1.37989e+00 1.00000e-09 2.12000e-01

$1.37989 e+011.37989 e+011.37989 e+001.00000 e-092.12000 e-01$ 
$1.37989 \mathrm{e}+011.37989 \mathrm{e}+01$ 1.37989e+00 1.00000e-09 2.12000e-01 $1.00000 \mathrm{e}-05$ 1.00000e-05 1.00000e-06 1.00000e-09 1.00000e-01 $1.00000 \mathrm{e}+001.00000 \mathrm{e}+001.00000 \mathrm{e}-011.00000 \mathrm{e}-091.00000 \mathrm{e}-01$ Element: 9966 \# of layers: 8

Kx Ky Kz Ss Por

5.00000e-04 5.00000e-04 5.00000e-05 1.00000e-09 1.00000e-01

$1.37989 \mathrm{e}+011.37989 \mathrm{e}+011.37989 \mathrm{e}+00$ 1.00000e-09 2.12000e-01

$1.37989 \mathrm{e}+011.37989 \mathrm{e}+011.37989 \mathrm{e}+001.00000 \mathrm{e}-092.12000 \mathrm{e}-01$

$1.37989 \mathrm{e}+011.37989 \mathrm{e}+011.37989 \mathrm{e}+00$ 1.00000e-09 2.12000e-01

$1.37989 \mathrm{e}+011.37989 \mathrm{e}+011.37989 \mathrm{e}+001.00000 \mathrm{e}-092.12000 \mathrm{e}-01$

$1.37989 \mathrm{e}+011.37989 \mathrm{e}+011.37989 \mathrm{e}+001.00000 \mathrm{e}-092.12000 \mathrm{e}-01$

$1.00000 \mathrm{e}-05$ 1.00000e-05 1.00000e-06 1.00000e-09 1.00000e-01

$1.00000 \mathrm{e}+001.00000 \mathrm{e}+001.00000 \mathrm{e}-011.00000 \mathrm{e}-091.00000 \mathrm{e}-01$

Element: 9967 \# of layers: 8

Kx Ky Kz Ss Por

5.00000e-04 5.00000e-04 5.00000e-05 1.00000e-09 1.00000e-01

$1.37989 \mathrm{e}+011.37989 \mathrm{e}+011.37989 \mathrm{e}+001.00000 \mathrm{e}-092.12000 \mathrm{e}-01$

$1.37989 \mathrm{e}+011.37989 \mathrm{e}+011.37989 \mathrm{e}+00$ 1.00000e-09 2.12000e-01

$1.37989 \mathrm{e}+011.37989 \mathrm{e}+011.37989 \mathrm{e}+001.00000 \mathrm{e}-092.12000 \mathrm{e}-01$

$1.37989 \mathrm{e}+011.37989 \mathrm{e}+011.37989 \mathrm{e}+001.00000 \mathrm{e}-092.12000 \mathrm{e}-01$

$1.37989 \mathrm{e}+011.37989 \mathrm{e}+011.37989 \mathrm{e}+001.00000 \mathrm{e}-092.12000 \mathrm{e}-01$

$1.00000 \mathrm{e}-05$ 1.00000e-05 1.00000e-06 1.00000e-09 1.00000e-01

$1.00000 \mathrm{e}+001.00000 \mathrm{e}+001.00000 \mathrm{e}-011.00000 \mathrm{e}-091.00000 \mathrm{e}-01$

Element: 9968 \# of layers: 7

Kx Ky Kz Ss Por

$1.44741 \mathrm{e}+011.44741 \mathrm{e}+011.44741 \mathrm{e}+00$ 1.00000e-09 2.12000e-01

$1.44741 \mathrm{e}+011.44741 \mathrm{e}+011.44741 \mathrm{e}+001.00000 \mathrm{e}-092.12000 \mathrm{e}-01$

$1.44741 \mathrm{e}+011.44741 \mathrm{e}+011.44741 \mathrm{e}+001.00000 \mathrm{e}-092.12000 \mathrm{e}-01$

$1.44741 \mathrm{e}+011.44741 \mathrm{e}+011.44741 \mathrm{e}+001.00000 \mathrm{e}-092.12000 \mathrm{e}-01$

$1.44741 \mathrm{e}+011.44741 \mathrm{e}+011.44741 \mathrm{e}+001.00000 \mathrm{e}-092.12000 \mathrm{e}-01$

$1.00000 \mathrm{e}-05$ 1.00000e-05 1.00000e-06 1.00000e-09 1.00000e-01

$1.00000 \mathrm{e}+001.00000 \mathrm{e}+001.00000 \mathrm{e}-011.00000 \mathrm{e}-091.00000 \mathrm{e}-01$

Element: 9969 \# of layers: 7

Kx Ky Kz Ss Por

$1.44741 \mathrm{e}+011.44741 \mathrm{e}+011.44741 \mathrm{e}+00$ 1.00000e-09 2.12000e-01

$1.44741 \mathrm{e}+011.44741 \mathrm{e}+011.44741 \mathrm{e}+001.00000 \mathrm{e}-092.12000 \mathrm{e}-01$

$1.44741 \mathrm{e}+011.44741 \mathrm{e}+011.44741 \mathrm{e}+001.00000 \mathrm{e}-092.12000 \mathrm{e}-01$

$1.44741 \mathrm{e}+011.44741 \mathrm{e}+011.44741 \mathrm{e}+001.00000 \mathrm{e}-092.12000 \mathrm{e}-01$

$1.44741 \mathrm{e}+011.44741 \mathrm{e}+011.44741 \mathrm{e}+001.00000 \mathrm{e}-092.12000 \mathrm{e}-01$

$1.00000 \mathrm{e}-05$ 1.00000e-05 1.00000e-06 1.00000e-09 1.00000e-01

$1.00000 \mathrm{e}+001.00000 \mathrm{e}+001.00000 \mathrm{e}-011.00000 \mathrm{e}-091.00000 \mathrm{e}-01$

Element: 9970 \# of layers: 7

Kx Ky Kz Ss Por

$1.44741 \mathrm{e}+011.44741 \mathrm{e}+011.44741 \mathrm{e}+001.00000 \mathrm{e}-092.12000 \mathrm{e}-01$ $1.44741 \mathrm{e}+011.44741 \mathrm{e}+011.44741 \mathrm{e}+001.00000 \mathrm{e}-092.12000 \mathrm{e}-01$ $1.44741 \mathrm{e}+011.44741 \mathrm{e}+011.44741 \mathrm{e}+001.00000 \mathrm{e}-092.12000 \mathrm{e}-01$ 
$1.44741 \mathrm{e}+011.44741 \mathrm{e}+011.44741 \mathrm{e}+001.00000 \mathrm{e}-092.12000 \mathrm{e}-01$ $1.44741 \mathrm{e}+011.44741 \mathrm{e}+011.44741 \mathrm{e}+001.00000 \mathrm{e}-092.12000 \mathrm{e}-01$ $1.00000 \mathrm{e}-05$ 1.00000e-05 1.00000e-06 1.00000e-09 1.00000e-01

$1.00000 \mathrm{e}+001.00000 \mathrm{e}+001.00000 \mathrm{e}-011.00000 \mathrm{e}-091.00000 \mathrm{e}-01$ Element: 9971 \# of layers: 8

$\mathrm{Kx} \mathrm{Ky} \mathrm{Kz}$ Ss Por

5.00000e-04 5.00000e-04 5.00000e-05 1.00000e-09 1.00000e-01

$1.37989 \mathrm{e}+01$ 1.37989e+01 1.37989e+00 1.00000e-09 2.12000e-01

$1.37989 \mathrm{e}+01$ 1.37989e+01 1.37989e+00 1.00000e-09 2.12000e-01

$1.37989 \mathrm{e}+01$ 1.37989e+01 1.37989e+00 1.00000e-09 2.12000e-01

$1.37989 \mathrm{e}+01$ 1.37989e+01 1.37989e+00 1.00000e-09 2.12000e-01

$1.37989 \mathrm{e}+01$ 1.37989e+01 1.37989e+00 1.00000e-09 2.12000e-01

$1.00000 \mathrm{e}-05$ 1.00000e-05 1.00000e-06 1.00000e-09 1.00000e-01

$1.00000 \mathrm{e}+001.00000 \mathrm{e}+001.00000 \mathrm{e}-011.00000 \mathrm{e}-091.00000 \mathrm{e}-01$

Element: 9972 \# of layers: 8

Kx Ky Kz Ss Por

5.00000e-04 5.00000e-04 5.00000e-05 1.00000e-09 1.00000e-01

$1.37989 \mathrm{e}+01$ 1.37989e+01 1.37989e+00 1.00000e-09 2.12000e-01

$1.37989 \mathrm{e}+01$ 1.37989e+01 1.37989e+00 1.00000e-09 2.12000e-01

$1.37989 \mathrm{e}+01$ 1.37989e+01 1.37989e+00 1.00000e-09 2.12000e-01

$1.37989 \mathrm{e}+01$ 1.37989e+01 1.37989e+00 1.00000e-09 2.12000e-01

$1.37989 \mathrm{e}+01$ 1.37989e+01 1.37989e+00 1.00000e-09 2.12000e-01

$1.00000 \mathrm{e}-05$ 1.00000e-05 1.00000e-06 1.00000e-09 1.00000e-01

$1.00000 \mathrm{e}+001.00000 \mathrm{e}+001.00000 \mathrm{e}-011.00000 \mathrm{e}-091.00000 \mathrm{e}-01$

Element: 9973 \# of layers: 8

$\mathrm{Kx} \mathrm{Ky} \mathrm{Kz}$ Ss Por

5.00000e-04 5.00000e-04 5.00000e-05 1.00000e-09 1.00000e-01

$1.37989 \mathrm{e}+01$ 1.37989e+01 1.37989e+00 1.00000e-09 2.12000e-01

$1.37989 \mathrm{e}+01$ 1.37989e+01 1.37989e+00 1.00000e-09 2.12000e-01

$1.37989 \mathrm{e}+01$ 1.37989e+01 1.37989e+00 1.00000e-09 2.12000e-01

$1.37989 \mathrm{e}+01$ 1.37989e+01 1.37989e+00 1.00000e-09 2.12000e-01

$1.37989 \mathrm{e}+01$ 1.37989e+01 1.37989e+00 1.00000e-09 2.12000e-01

$1.00000 \mathrm{e}-05$ 1.00000e-05 1.00000e-06 1.00000e-09 1.00000e-01

$1.00000 \mathrm{e}+001.00000 \mathrm{e}+001.00000 \mathrm{e}-011.00000 \mathrm{e}-091.00000 \mathrm{e}-01$

Element: 9974 \# of layers: 8

$\mathrm{Kx} \mathrm{Ky} \mathrm{Kz}$ Ss Por

5.00000e-04 5.00000e-04 5.00000e-05 1.00000e-09 1.00000e-01

$1.37989 \mathrm{e}+01$ 1.37989e+01 1.37989e+00 1.00000e-09 2.12000e-01

$1.37989 \mathrm{e}+01$ 1.37989e+01 1.37989e+00 1.00000e-09 2.12000e-01

$1.37989 \mathrm{e}+01$ 1.37989e+01 1.37989e+00 1.00000e-09 2.12000e-01

$1.37989 \mathrm{e}+01$ 1.37989e+01 1.37989e+00 1.00000e-09 2.12000e-01

$1.37989 \mathrm{e}+01$ 1.37989e+01 1.37989e+00 1.00000e-09 2.12000e-01

$1.00000 \mathrm{e}-05$ 1.00000e-05 1.00000e-06 1.00000e-09 1.00000e-01

$1.00000 \mathrm{e}+001.00000 \mathrm{e}+001.00000 \mathrm{e}-01$ 1.00000e-09 1.00000e-01

Element: 9975 \# of layers: 7

Kx Ky Kz Ss Por 
$1.44741 \mathrm{e}+011.44741 \mathrm{e}+01$ 1.44741e+00 1.00000e-09 2.12000e-01 $1.44741 \mathrm{e}+011.44741 \mathrm{e}+011.44741 \mathrm{e}+001.00000 \mathrm{e}-092.12000 \mathrm{e}-01$ $1.44741 \mathrm{e}+011.44741 \mathrm{e}+011.44741 \mathrm{e}+001.00000 \mathrm{e}-092.12000 \mathrm{e}-01$ $1.44741 \mathrm{e}+011.44741 \mathrm{e}+011.44741 \mathrm{e}+001.00000 \mathrm{e}-092.12000 \mathrm{e}-01$ $1.44741 \mathrm{e}+011.44741 \mathrm{e}+01$ 1.44741e+00 1.00000e-09 2.12000e-01 $1.00000 \mathrm{e}-05$ 1.00000e-05 1.00000e-06 1.00000e-09 1.00000e-01 $1.00000 \mathrm{e}+001.00000 \mathrm{e}+001.00000 \mathrm{e}-01$ 1.00000e-09 1.00000e-01 Element: 9976 \# of layers: 7

$\mathrm{Kx} \mathrm{Ky} \mathrm{Kz}$ Ss Por

$1.44741 \mathrm{e}+011.44741 \mathrm{e}+01$ 1.44741e+00 1.00000e-09 2.12000e-01 $1.44741 \mathrm{e}+011.44741 \mathrm{e}+01$ 1.44741e+00 1.00000e-09 2.12000e-01 $1.44741 \mathrm{e}+011.44741 \mathrm{e}+011.44741 \mathrm{e}+001.00000 \mathrm{e}-092.12000 \mathrm{e}-01$ $1.44741 \mathrm{e}+011.44741 \mathrm{e}+011.44741 \mathrm{e}+001.00000 \mathrm{e}-092.12000 \mathrm{e}-01$ $1.44741 \mathrm{e}+011.44741 \mathrm{e}+011.44741 \mathrm{e}+001.00000 \mathrm{e}-092.12000 \mathrm{e}-01$ $1.00000 \mathrm{e}-05$ 1.00000e-05 1.00000e-06 1.00000e-09 1.00000e-01 $1.00000 \mathrm{e}+001.00000 \mathrm{e}+001.00000 \mathrm{e}-011.00000 \mathrm{e}-091.00000 \mathrm{e}-01$ Element: 9977 \# of layers: 7

$\mathrm{Kx} \mathrm{Ky} \mathrm{Kz}$ Ss Por

$1.44741 \mathrm{e}+01$ 1.44741e+01 1.44741e+00 1.00000e-09 2.12000e-01 $1.44741 \mathrm{e}+011.44741 \mathrm{e}+011.44741 \mathrm{e}+001.00000 \mathrm{e}-092.12000 \mathrm{e}-01$ $1.44741 \mathrm{e}+011.44741 \mathrm{e}+011.44741 \mathrm{e}+001.00000 \mathrm{e}-092.12000 \mathrm{e}-01$ $1.44741 \mathrm{e}+011.44741 \mathrm{e}+01$ 1.44741e+00 1.00000e-09 2.12000e-01 $1.44741 \mathrm{e}+011.44741 \mathrm{e}+011.44741 \mathrm{e}+001.00000 \mathrm{e}-092.12000 \mathrm{e}-01$ $1.00000 \mathrm{e}-05$ 1.00000e-05 1.00000e-06 1.00000e-09 1.00000e-01 $1.00000 \mathrm{e}+001.00000 \mathrm{e}+001.00000 \mathrm{e}-011.00000 \mathrm{e}-091.00000 \mathrm{e}-01$ Element: 9978 \# of layers: 7

$\mathrm{Kx} \mathrm{Ky} \mathrm{Kz}$ Ss Por

$1.44741 \mathrm{e}+011.44741 \mathrm{e}+011.44741 \mathrm{e}+001.00000 \mathrm{e}-092.12000 \mathrm{e}-01$ $1.44741 \mathrm{e}+011.44741 \mathrm{e}+011.44741 \mathrm{e}+001.00000 \mathrm{e}-092.12000 \mathrm{e}-01$ $1.44741 \mathrm{e}+011.44741 \mathrm{e}+01$ 1.44741e+00 1.00000e-09 2.12000e-01 $1.44741 \mathrm{e}+011.44741 \mathrm{e}+01$ 1.44741e+00 1.00000e-09 2.12000e-01 $1.44741 \mathrm{e}+011.44741 \mathrm{e}+01$ 1.44741e+00 1.00000e-09 2.12000e-01 $1.00000 \mathrm{e}-05$ 1.00000e-05 1.00000e-06 1.00000e-09 1.00000e-01 $1.00000 \mathrm{e}+001.00000 \mathrm{e}+001.00000 \mathrm{e}-011.00000 \mathrm{e}-091.00000 \mathrm{e}-01$ Element: 9979 \# of layers: 7

Kx Ky Kz Ss Por

$1.44741 \mathrm{e}+011.44741 \mathrm{e}+011.44741 \mathrm{e}+001.00000 \mathrm{e}-092.12000 \mathrm{e}-01$ $1.44741 \mathrm{e}+011.44741 \mathrm{e}+011.44741 \mathrm{e}+001.00000 \mathrm{e}-092.12000 \mathrm{e}-01$ $1.44741 \mathrm{e}+011.44741 \mathrm{e}+011.44741 \mathrm{e}+001.00000 \mathrm{e}-092.12000 \mathrm{e}-01$ $1.44741 \mathrm{e}+011.44741 \mathrm{e}+011.44741 \mathrm{e}+001.00000 \mathrm{e}-092.12000 \mathrm{e}-01$ $1.44741 \mathrm{e}+011.44741 \mathrm{e}+011.44741 \mathrm{e}+001.00000 \mathrm{e}-092.12000 \mathrm{e}-01$ $1.00000 \mathrm{e}-05$ 1.00000e-05 1.00000e-06 1.00000e-09 1.00000e-01 $1.00000 \mathrm{e}+001.00000 \mathrm{e}+001.00000 \mathrm{e}-011.00000 \mathrm{e}-091.00000 \mathrm{e}-01$ Element: 9980 \# of layers: 7

$\mathrm{Kx} \mathrm{Ky} \mathrm{Kz}$ Ss Por

$1.44741 \mathrm{e}+011.44741 \mathrm{e}+011.44741 \mathrm{e}+001.00000 \mathrm{e}-092.12000 \mathrm{e}-01$ 
$1.44741 \mathrm{e}+011.44741 \mathrm{e}+01$ 1.44741e+00 1.00000e-09 2.12000e-01 $1.44741 \mathrm{e}+011.44741 \mathrm{e}+011.44741 \mathrm{e}+001.00000 \mathrm{e}-092.12000 \mathrm{e}-01$ $1.44741 \mathrm{e}+011.44741 \mathrm{e}+011.44741 \mathrm{e}+001.00000 \mathrm{e}-092.12000 \mathrm{e}-01$ $1.44741 \mathrm{e}+011.44741 \mathrm{e}+011.44741 \mathrm{e}+001.00000 \mathrm{e}-092.12000 \mathrm{e}-01$ $1.00000 \mathrm{e}-051.00000 \mathrm{e}-051.00000 \mathrm{e}-061.00000 \mathrm{e}-091.00000 \mathrm{e}-01$ $1.00000 \mathrm{e}+001.00000 \mathrm{e}+001.00000 \mathrm{e}-01$ 1.00000e-09 1.00000e-01 Element: 9981 \# of layers: 7

Kx Ky Kz Ss Por

$1.44741 \mathrm{e}+011.44741 \mathrm{e}+01$ 1.44741e+00 1.00000e-09 2.12000e-01 $1.44741 \mathrm{e}+011.44741 \mathrm{e}+011.44741 \mathrm{e}+001.00000 \mathrm{e}-092.12000 \mathrm{e}-01$ $1.44741 \mathrm{e}+011.44741 \mathrm{e}+011.44741 \mathrm{e}+001.00000 \mathrm{e}-092.12000 \mathrm{e}-01$ $1.44741 \mathrm{e}+011.44741 \mathrm{e}+011.44741 \mathrm{e}+001.00000 \mathrm{e}-092.12000 \mathrm{e}-01$ $1.44741 \mathrm{e}+011.44741 \mathrm{e}+011.44741 \mathrm{e}+001.00000 \mathrm{e}-092.12000 \mathrm{e}-01$ $1.00000 \mathrm{e}-05$ 1.00000e-05 1.00000e-06 1.00000e-09 1.00000e-01 $1.00000 \mathrm{e}+001.00000 \mathrm{e}+001.00000 \mathrm{e}-01$ 1.00000e-09 1.00000e-01 Element: 9982 \# of layers: 7

$\mathrm{Kx} \mathrm{Ky} \mathrm{Kz}$ Ss Por

$1.44741 \mathrm{e}+011.44741 \mathrm{e}+011.44741 \mathrm{e}+001.00000 \mathrm{e}-092.12000 \mathrm{e}-01$ $1.44741 \mathrm{e}+011.44741 \mathrm{e}+011.44741 \mathrm{e}+001.00000 \mathrm{e}-092.12000 \mathrm{e}-01$ $1.44741 \mathrm{e}+011.44741 \mathrm{e}+011.44741 \mathrm{e}+001.00000 \mathrm{e}-092.12000 \mathrm{e}-01$ $1.44741 \mathrm{e}+011.44741 \mathrm{e}+011.44741 \mathrm{e}+001.00000 \mathrm{e}-092.12000 \mathrm{e}-01$ $1.44741 \mathrm{e}+011.44741 \mathrm{e}+01$ 1.44741e+00 1.00000e-09 2.12000e-01 $1.00000 \mathrm{e}-051.00000 \mathrm{e}-051.00000 \mathrm{e}-061.00000 \mathrm{e}-091.00000 \mathrm{e}-01$ $1.00000 \mathrm{e}+001.00000 \mathrm{e}+001.00000 \mathrm{e}-011.00000 \mathrm{e}-091.00000 \mathrm{e}-01$ Element: 9983 \# of layers: 7

$\mathrm{Kx} \mathrm{Ky} \mathrm{Kz}$ Ss Por

$1.44741 \mathrm{e}+011.44741 \mathrm{e}+011.44741 \mathrm{e}+001.00000 \mathrm{e}-092.12000 \mathrm{e}-01$ $1.44741 \mathrm{e}+011.44741 \mathrm{e}+011.44741 \mathrm{e}+001.00000 \mathrm{e}-092.12000 \mathrm{e}-01$ $1.44741 \mathrm{e}+011.44741 \mathrm{e}+011.44741 \mathrm{e}+001.00000 \mathrm{e}-092.12000 \mathrm{e}-01$ $1.44741 \mathrm{e}+011.44741 \mathrm{e}+01$ 1.44741e+00 1.00000e-09 2.12000e-01 $1.44741 \mathrm{e}+011.44741 \mathrm{e}+011.44741 \mathrm{e}+001.00000 \mathrm{e}-092.12000 \mathrm{e}-01$ $1.00000 \mathrm{e}-051.00000 \mathrm{e}-05$ 1.00000e-06 1.00000e-09 1.00000e-01 $1.00000 \mathrm{e}+001.00000 \mathrm{e}+001.00000 \mathrm{e}-011.00000 \mathrm{e}-091.00000 \mathrm{e}-01$ Element: 9984 \# of layers: 7

$\mathrm{Kx} \mathrm{Ky} \mathrm{Kz}$ Ss Por

$1.44741 \mathrm{e}+011.44741 \mathrm{e}+011.44741 \mathrm{e}+00$ 1.00000e-09 2.12000e-01 $1.44741 \mathrm{e}+011.44741 \mathrm{e}+011.44741 \mathrm{e}+001.00000 \mathrm{e}-092.12000 \mathrm{e}-01$ $1.44741 \mathrm{e}+011.44741 \mathrm{e}+011.44741 \mathrm{e}+001.00000 \mathrm{e}-092.12000 \mathrm{e}-01$ $1.44741 \mathrm{e}+011.44741 \mathrm{e}+011.44741 \mathrm{e}+001.00000 \mathrm{e}-092.12000 \mathrm{e}-01$ $1.44741 \mathrm{e}+011.44741 \mathrm{e}+011.44741 \mathrm{e}+001.00000 \mathrm{e}-092.12000 \mathrm{e}-01$ $1.00000 \mathrm{e}-05$ 1.00000e-05 1.00000e-06 1.00000e-09 1.00000e-01 $1.00000 \mathrm{e}+001.00000 \mathrm{e}+001.00000 \mathrm{e}-011.00000 \mathrm{e}-091.00000 \mathrm{e}-01$ Element: 9985 \# of layers: 7

$\mathrm{Kx} \mathrm{Ky} \mathrm{Kz}$ Ss Por

$1.44741 \mathrm{e}+01$ 1.44741e+01 1.44741e+00 1.00000e-09 2.12000e-01 $1.44741 \mathrm{e}+011.44741 \mathrm{e}+011.44741 \mathrm{e}+001.00000 \mathrm{e}-092.12000 \mathrm{e}-01$ 
$1.44741 \mathrm{e}+011.44741 \mathrm{e}+011.44741 \mathrm{e}+001.00000 \mathrm{e}-092.12000 \mathrm{e}-01$ $1.44741 \mathrm{e}+011.44741 \mathrm{e}+011.44741 \mathrm{e}+001.00000 \mathrm{e}-092.12000 \mathrm{e}-01$ $1.44741 \mathrm{e}+011.44741 \mathrm{e}+011.44741 \mathrm{e}+001.00000 \mathrm{e}-092.12000 \mathrm{e}-01$ $1.00000 \mathrm{e}-05$ 1.00000e-05 1.00000e-06 1.00000e-09 1.00000e-01 $1.00000 \mathrm{e}+001.00000 \mathrm{e}+001.00000 \mathrm{e}-01$ 1.00000e-09 1.00000e-01 Element: 9986 \# of layers: 7

$\mathrm{Kx} \mathrm{Ky} \mathrm{Kz}$ Ss Por

$1.30381 \mathrm{e}+011.30381 \mathrm{e}+011.30381 \mathrm{e}+001.00000 \mathrm{e}-092.12000 \mathrm{e}-01$ $1.30381 \mathrm{e}+011.30381 \mathrm{e}+01$ 1.30381e+00 1.00000e-09 2.12000e-01 $1.30381 \mathrm{e}+011.30381 \mathrm{e}+011.30381 \mathrm{e}+001.00000 \mathrm{e}-092.12000 \mathrm{e}-01$ $1.30381 \mathrm{e}+01$ 1.30381e+01 1.30381e+00 1.00000e-09 2.12000e-01 $1.30381 \mathrm{e}+011.30381 \mathrm{e}+011.30381 \mathrm{e}+001.00000 \mathrm{e}-092.12000 \mathrm{e}-01$ $1.00000 \mathrm{e}-05$ 1.00000e-05 1.00000e-06 1.00000e-09 1.00000e-01 $1.00000 \mathrm{e}+001.00000 \mathrm{e}+001.00000 \mathrm{e}-011.00000 \mathrm{e}-09$ 1.00000e-01 Element: 9987 \# of layers: 7

Kx Ky Kz Ss Por

$1.30381 \mathrm{e}+011.30381 \mathrm{e}+01$ 1.30381e+00 1.00000e-09 2.12000e-01 $1.30381 \mathrm{e}+011.30381 \mathrm{e}+011.30381 \mathrm{e}+001.00000 \mathrm{e}-092.12000 \mathrm{e}-01$ $1.30381 \mathrm{e}+01$ 1.30381e+01 1.30381e+00 1.00000e-09 2.12000e-01 $1.30381 \mathrm{e}+011.30381 \mathrm{e}+011.30381 \mathrm{e}+001.00000 \mathrm{e}-092.12000 \mathrm{e}-01$ $1.30381 \mathrm{e}+011.30381 \mathrm{e}+011.30381 \mathrm{e}+001.00000 \mathrm{e}-092.12000 \mathrm{e}-01$ $1.00000 \mathrm{e}-05$ 1.00000e-05 1.00000e-06 1.00000e-09 1.00000e-01 $1.00000 \mathrm{e}+001.00000 \mathrm{e}+001.00000 \mathrm{e}-011.00000 \mathrm{e}-091.00000 \mathrm{e}-01$ Element: 9988 \# of layers: 7

$\mathrm{Kx} \mathrm{Ky} \mathrm{Kz}$ Ss Por

$1.30381 \mathrm{e}+011.30381 \mathrm{e}+01$ 1.30381e+00 1.00000e-09 2.12000e-01 $1.30381 \mathrm{e}+011.30381 \mathrm{e}+011.30381 \mathrm{e}+001.00000 \mathrm{e}-092.12000 \mathrm{e}-01$ $1.30381 \mathrm{e}+011.30381 \mathrm{e}+01$ 1.30381e+00 1.00000e-09 2.12000e-01 $1.30381 \mathrm{e}+011.30381 \mathrm{e}+011.30381 \mathrm{e}+001.00000 \mathrm{e}-092.12000 \mathrm{e}-01$ $1.30381 \mathrm{e}+011.30381 \mathrm{e}+011.30381 \mathrm{e}+001.00000 \mathrm{e}-092.12000 \mathrm{e}-01$ $1.00000 \mathrm{e}-05$ 1.00000e-05 1.00000e-06 1.00000e-09 1.00000e-01 $1.00000 \mathrm{e}+001.00000 \mathrm{e}+001.00000 \mathrm{e}-011.00000 \mathrm{e}-091.00000 \mathrm{e}-01$ Element: 9989 \# of layers: 7

$\mathrm{Kx} \mathrm{Ky} \mathrm{Kz}$ Ss Por

$1.44741 \mathrm{e}+011.44741 \mathrm{e}+011.44741 \mathrm{e}+00$ 1.00000e-09 2.12000e-01 $1.44741 \mathrm{e}+011.44741 \mathrm{e}+01$ 1.44741e+00 1.00000e-09 2.12000e-01 $1.44741 \mathrm{e}+011.44741 \mathrm{e}+011.44741 \mathrm{e}+001.00000 \mathrm{e}-092.12000 \mathrm{e}-01$ $1.44741 \mathrm{e}+011.44741 \mathrm{e}+011.44741 \mathrm{e}+001.00000 \mathrm{e}-092.12000 \mathrm{e}-01$ $1.44741 \mathrm{e}+011.44741 \mathrm{e}+01$ 1.44741e+00 1.00000e-09 2.12000e-01 $1.00000 \mathrm{e}-05$ 1.00000e-05 1.00000e-06 1.00000e-09 1.00000e-01 $1.00000 \mathrm{e}+001.00000 \mathrm{e}+001.00000 \mathrm{e}-011.00000 \mathrm{e}-091.00000 \mathrm{e}-01$ Element: 9990 \# of layers: 7

$\mathrm{Kx} \mathrm{Ky} \mathrm{Kz}$ Ss Por

1.44741e+01 1.44741e+01 1.44741e+00 1.00000e-09 2.12000e-01 $1.44741 \mathrm{e}+011.44741 \mathrm{e}+011.44741 \mathrm{e}+001.00000 \mathrm{e}-092.12000 \mathrm{e}-01$ $1.44741 \mathrm{e}+011.44741 \mathrm{e}+011.44741 \mathrm{e}+001.00000 \mathrm{e}-092.12000 \mathrm{e}-01$ 
$1.44741 \mathrm{e}+011.44741 \mathrm{e}+01$ 1.44741e+00 1.00000e-09 2.12000e-01 $1.44741 \mathrm{e}+011.44741 \mathrm{e}+011.44741 \mathrm{e}+001.00000 \mathrm{e}-092.12000 \mathrm{e}-01$ $1.00000 \mathrm{e}-05$ 1.00000e-05 1.00000e-06 1.00000e-09 1.00000e-01 $1.00000 \mathrm{e}+001.00000 \mathrm{e}+001.00000 \mathrm{e}-011.00000 \mathrm{e}-091.00000 \mathrm{e}-01$ Element: 9991 \# of layers: 7

$\mathrm{Kx} \mathrm{Ky} \mathrm{Kz}$ Ss Por

$1.44741 \mathrm{e}+011.44741 \mathrm{e}+01$ 1.44741e+00 1.00000e-09 2.12000e-01 $1.44741 \mathrm{e}+011.44741 \mathrm{e}+011.44741 \mathrm{e}+001.00000 \mathrm{e}-092.12000 \mathrm{e}-01$ $1.44741 \mathrm{e}+011.44741 \mathrm{e}+011.44741 \mathrm{e}+001.00000 \mathrm{e}-092.12000 \mathrm{e}-01$ $1.44741 \mathrm{e}+011.44741 \mathrm{e}+011.44741 \mathrm{e}+001.00000 \mathrm{e}-092.12000 \mathrm{e}-01$ $1.44741 \mathrm{e}+011.44741 \mathrm{e}+01$ 1.44741e+00 1.00000e-09 2.12000e-01 $1.00000 \mathrm{e}-05$ 1.00000e-05 1.00000e-06 1.00000e-09 1.00000e-01 $1.00000 \mathrm{e}+001.00000 \mathrm{e}+001.00000 \mathrm{e}-011.00000 \mathrm{e}-091.00000 \mathrm{e}-01$ Element: 9992 \# of layers: 7

$\mathrm{Kx} \mathrm{Ky} \mathrm{Kz}$ Ss Por

$1.44741 \mathrm{e}+01$ 1.44741e+01 1.44741e+00 1.00000e-09 2.12000e-01 $1.44741 \mathrm{e}+011.44741 \mathrm{e}+011.44741 \mathrm{e}+001.00000 \mathrm{e}-092.12000 \mathrm{e}-01$ $1.44741 \mathrm{e}+011.44741 \mathrm{e}+011.44741 \mathrm{e}+001.00000 \mathrm{e}-092.12000 \mathrm{e}-01$ $1.44741 \mathrm{e}+011.44741 \mathrm{e}+01$ 1.44741e+00 1.00000e-09 2.12000e-01 $1.44741 \mathrm{e}+011.44741 \mathrm{e}+011.44741 \mathrm{e}+001.00000 \mathrm{e}-092.12000 \mathrm{e}-01$ $1.00000 \mathrm{e}-05$ 1.00000e-05 1.00000e-06 1.00000e-09 1.00000e-01 $1.00000 \mathrm{e}+001.00000 \mathrm{e}+001.00000 \mathrm{e}-011.00000 \mathrm{e}-091.00000 \mathrm{e}-01$ Element: 9993 \# of layers: 7

Kx Ky Kz Ss Por

$1.30381 \mathrm{e}+011.30381 \mathrm{e}+011.30381 \mathrm{e}+00$ 1.00000e-09 2.12000e-01 $1.30381 \mathrm{e}+011.30381 \mathrm{e}+011.30381 \mathrm{e}+001.00000 \mathrm{e}-092.12000 \mathrm{e}-01$ $1.30381 \mathrm{e}+011.30381 \mathrm{e}+011.30381 \mathrm{e}+001.00000 \mathrm{e}-092.12000 \mathrm{e}-01$ $1.30381 \mathrm{e}+011.30381 \mathrm{e}+011.30381 \mathrm{e}+001.00000 \mathrm{e}-092.12000 \mathrm{e}-01$ $1.30381 \mathrm{e}+011.30381 \mathrm{e}+011.30381 \mathrm{e}+001.00000 \mathrm{e}-092.12000 \mathrm{e}-01$ $1.00000 \mathrm{e}-05$ 1.00000e-05 1.00000e-06 1.00000e-09 1.00000e-01 $1.00000 \mathrm{e}+001.00000 \mathrm{e}+001.00000 \mathrm{e}-01$ 1.00000e-09 1.00000e-01 Element: 9994 \# of layers: 7

Kx Ky Kz Ss Por

$1.30381 \mathrm{e}+011.30381 \mathrm{e}+011.30381 \mathrm{e}+001.00000 \mathrm{e}-092.12000 \mathrm{e}-01$ $1.30381 \mathrm{e}+011.30381 \mathrm{e}+011.30381 \mathrm{e}+001.00000 \mathrm{e}-092.12000 \mathrm{e}-01$ $1.30381 \mathrm{e}+011.30381 \mathrm{e}+011.30381 \mathrm{e}+001.00000 \mathrm{e}-092.12000 \mathrm{e}-01$ $1.30381 \mathrm{e}+011.30381 \mathrm{e}+011.30381 \mathrm{e}+001.00000 \mathrm{e}-092.12000 \mathrm{e}-01$ $1.30381 \mathrm{e}+011.30381 \mathrm{e}+011.30381 \mathrm{e}+001.00000 \mathrm{e}-092.12000 \mathrm{e}-01$ $1.00000 \mathrm{e}-05$ 1.00000e-05 1.00000e-06 1.00000e-09 1.00000e-01 $1.00000 \mathrm{e}+001.00000 \mathrm{e}+001.00000 \mathrm{e}-01$ 1.00000e-09 1.00000e-01 Element: 9995 \# of layers: 7

$\mathrm{Kx} \mathrm{Ky} \mathrm{Kz}$ Ss Por

$1.30381 \mathrm{e}+01$ 1.30381e+01 1.30381e+00 1.00000e-09 2.12000e-01 $1.30381 \mathrm{e}+011.30381 \mathrm{e}+01$ 1.30381e+00 1.00000e-09 2.12000e-01 $1.30381 \mathrm{e}+011.30381 \mathrm{e}+011.30381 \mathrm{e}+001.00000 \mathrm{e}-092.12000 \mathrm{e}-01$ $1.30381 \mathrm{e}+011.30381 \mathrm{e}+011.30381 \mathrm{e}+001.00000 \mathrm{e}-092.12000 \mathrm{e}-01$ 
$1.30381 \mathrm{e}+011.30381 \mathrm{e}+01$ 1.30381e+00 1.00000e-09 2.12000e-01 $1.00000 \mathrm{e}-05$ 1.00000e-05 1.00000e-06 1.00000e-09 1.00000e-01 $1.00000 \mathrm{e}+001.00000 \mathrm{e}+001.00000 \mathrm{e}-011.00000 \mathrm{e}-09$ 1.00000e-01 Element: 9996 \# of layers: 7

$\mathrm{Kx} \mathrm{Ky} \mathrm{Kz}$ Ss Por

$1.30381 \mathrm{e}+01$ 1.30381e+01 1.30381e+00 1.00000e-09 2.12000e-01 $1.30381 \mathrm{e}+011.30381 \mathrm{e}+011.30381 \mathrm{e}+001.00000 \mathrm{e}-092.12000 \mathrm{e}-01$ $1.30381 \mathrm{e}+011.30381 \mathrm{e}+011.30381 \mathrm{e}+001.00000 \mathrm{e}-092.12000 \mathrm{e}-01$ $1.30381 \mathrm{e}+011.30381 \mathrm{e}+011.30381 \mathrm{e}+001.00000 \mathrm{e}-092.12000 \mathrm{e}-01$ $1.30381 \mathrm{e}+011.30381 \mathrm{e}+011.30381 \mathrm{e}+001.00000 \mathrm{e}-092.12000 \mathrm{e}-01$ $1.00000 \mathrm{e}-05$ 1.00000e-05 1.00000e-06 1.00000e-09 1.00000e-01 $1.00000 \mathrm{e}+001.00000 \mathrm{e}+001.00000 \mathrm{e}-011.00000 \mathrm{e}-091.00000 \mathrm{e}-01$ Element: 9997 \# of layers: 7

$\mathrm{Kx} \mathrm{Ky} \mathrm{Kz}$ Ss Por

$1.30381 \mathrm{e}+01$ 1.30381e+01 1.30381e+00 1.00000e-09 2.12000e-01 $1.30381 \mathrm{e}+011.30381 \mathrm{e}+011.30381 \mathrm{e}+001.00000 \mathrm{e}-092.12000 \mathrm{e}-01$ $1.30381 \mathrm{e}+011.30381 \mathrm{e}+011.30381 \mathrm{e}+001.00000 \mathrm{e}-092.12000 \mathrm{e}-01$ $1.30381 \mathrm{e}+01$ 1.30381e+01 1.30381e+00 1.00000e-09 2.12000e-01 $1.30381 \mathrm{e}+01$ 1.30381e+01 1.30381e+00 1.00000e-09 2.12000e-01 $1.00000 \mathrm{e}-05$ 1.00000e-05 1.00000e-06 1.00000e-09 1.00000e-01 $1.00000 \mathrm{e}+001.00000 \mathrm{e}+001.00000 \mathrm{e}-011.00000 \mathrm{e}-091.00000 \mathrm{e}-01$ Element: 9998 \# of layers: 7

$\mathrm{Kx} \mathrm{Ky} \mathrm{Kz}$ Ss Por

$1.30381 \mathrm{e}+011.30381 \mathrm{e}+01$ 1.30381e+00 1.00000e-09 2.12000e-01 $1.30381 \mathrm{e}+011.30381 \mathrm{e}+011.30381 \mathrm{e}+001.00000 \mathrm{e}-092.12000 \mathrm{e}-01$ $1.30381 \mathrm{e}+011.30381 \mathrm{e}+01$ 1.30381e+00 1.00000e-09 2.12000e-01 $1.30381 \mathrm{e}+011.30381 \mathrm{e}+011.30381 \mathrm{e}+001.00000 \mathrm{e}-092.12000 \mathrm{e}-01$ $1.30381 \mathrm{e}+011.30381 \mathrm{e}+011.30381 \mathrm{e}+001.00000 \mathrm{e}-092.12000 \mathrm{e}-01$ $1.00000 \mathrm{e}-05$ 1.00000e-05 1.00000e-06 1.00000e-09 1.00000e-01 $1.00000 \mathrm{e}+001.00000 \mathrm{e}+001.00000 \mathrm{e}-011.00000 \mathrm{e}-091.00000 \mathrm{e}-01$ Element: 9999 \# of layers: 7

$\mathrm{Kx} \mathrm{Ky} \mathrm{Kz}$ Ss Por

$1.30381 \mathrm{e}+01$ 1.30381e+01 1.30381e+00 1.00000e-09 2.12000e-01 $1.30381 \mathrm{e}+011.30381 \mathrm{e}+011.30381 \mathrm{e}+001.00000 \mathrm{e}-092.12000 \mathrm{e}-01$ $1.30381 \mathrm{e}+011.30381 \mathrm{e}+011.30381 \mathrm{e}+001.00000 \mathrm{e}-092.12000 \mathrm{e}-01$ $1.30381 \mathrm{e}+011.30381 \mathrm{e}+011.30381 \mathrm{e}+001.00000 \mathrm{e}-092.12000 \mathrm{e}-01$ $1.30381 \mathrm{e}+011.30381 \mathrm{e}+011.30381 \mathrm{e}+001.00000 \mathrm{e}-092.12000 \mathrm{e}-01$ 1.00000e-05 1.00000e-05 1.00000e-06 1.00000e-09 1.00000e-01 $1.00000 \mathrm{e}+001.00000 \mathrm{e}+001.00000 \mathrm{e}-011.00000 \mathrm{e}-091.00000 \mathrm{e}-01$ Element: 10000 \# of layers: 7

$\mathrm{Kx} \mathrm{Ky} \mathrm{Kz}$ Ss Por

$1.30381 \mathrm{e}+011.30381 \mathrm{e}+01$ 1.30381e+00 1.00000e-09 2.12000e-01 $1.30381 \mathrm{e}+011.30381 \mathrm{e}+01$ 1.30381e+00 1.00000e-09 2.12000e-01 $1.30381 \mathrm{e}+01$ 1.30381e+01 1.30381e+00 1.00000e-09 2.12000e-01 $1.30381 \mathrm{e}+011.30381 \mathrm{e}+01$ 1.30381e+00 1.00000e-09 2.12000e-01 $1.30381 \mathrm{e}+011.30381 \mathrm{e}+011.30381 \mathrm{e}+001.00000 \mathrm{e}-092.12000 \mathrm{e}-01$ 
$1.00000 \mathrm{e}-05$ 1.00000e-05 1.00000e-06 1.00000e-09 1.00000e-01 $1.00000 \mathrm{e}+001.00000 \mathrm{e}+001.00000 \mathrm{e}-01$ 1.00000e-09 1.00000e-01 Element: 10001 \# of layers: 7

Kx Ky Kz Ss Por

$1.30381 \mathrm{e}+01$ 1.30381e+01 1.30381e+00 1.00000e-09 2.12000e-01 $1.30381 \mathrm{e}+011.30381 \mathrm{e}+011.30381 \mathrm{e}+001.00000 \mathrm{e}-092.12000 \mathrm{e}-01$ $1.30381 \mathrm{e}+011.30381 \mathrm{e}+011.30381 \mathrm{e}+001.00000 \mathrm{e}-092.12000 \mathrm{e}-01$ $1.30381 \mathrm{e}+011.30381 \mathrm{e}+011.30381 \mathrm{e}+001.00000 \mathrm{e}-092.12000 \mathrm{e}-01$ $1.30381 \mathrm{e}+011.30381 \mathrm{e}+01$ 1.30381e+00 1.00000e-09 2.12000e-01 $1.00000 \mathrm{e}-05$ 1.00000e-05 1.00000e-06 1.00000e-09 1.00000e-01 $1.00000 \mathrm{e}+001.00000 \mathrm{e}+001.00000 \mathrm{e}-01$ 1.00000e-09 1.00000e-01 Element: 10002 \# of layers: 7

$\mathrm{Kx} \mathrm{Ky} \mathrm{Kz}$ Ss Por

$1.30381 \mathrm{e}+01$ 1.30381e+01 1.30381e+00 1.00000e-09 2.12000e-01 $1.30381 \mathrm{e}+011.30381 \mathrm{e}+01$ 1.30381e+00 1.00000e-09 2.12000e-01 $1.30381 \mathrm{e}+011.30381 \mathrm{e}+011.30381 \mathrm{e}+001.00000 \mathrm{e}-092.12000 \mathrm{e}-01$ $1.30381 \mathrm{e}+011.30381 \mathrm{e}+011.30381 \mathrm{e}+001.00000 \mathrm{e}-092.12000 \mathrm{e}-01$ $1.30381 \mathrm{e}+011.30381 \mathrm{e}+011.30381 \mathrm{e}+001.00000 \mathrm{e}-092.12000 \mathrm{e}-01$ $1.00000 \mathrm{e}-05$ 1.00000e-05 1.00000e-06 1.00000e-09 1.00000e-01 $1.00000 \mathrm{e}+001.00000 \mathrm{e}+001.00000 \mathrm{e}-011.00000 \mathrm{e}-091.00000 \mathrm{e}-01$ Element: 10003 \# of layers: 7

$\mathrm{Kx} \mathrm{Ky} \mathrm{Kz}$ Ss Por

1.46712e+01 1.46712e+01 1.46712e+00 1.00000e-09 2.12000e-01 $1.46712 \mathrm{e}+011.46712 \mathrm{e}+011.46712 \mathrm{e}+001.00000 \mathrm{e}-092.12000 \mathrm{e}-01$ $1.46712 \mathrm{e}+011.46712 \mathrm{e}+011.46712 \mathrm{e}+001.00000 \mathrm{e}-092.12000 \mathrm{e}-01$ $1.46712 \mathrm{e}+011.46712 \mathrm{e}+011.46712 \mathrm{e}+001.00000 \mathrm{e}-092.12000 \mathrm{e}-01$ $1.46712 \mathrm{e}+011.46712 \mathrm{e}+011.46712 \mathrm{e}+001.00000 \mathrm{e}-092.12000 \mathrm{e}-01$ $1.00000 \mathrm{e}-05$ 1.00000e-05 1.00000e-06 1.00000e-09 1.00000e-01 $1.00000 \mathrm{e}+001.00000 \mathrm{e}+001.00000 \mathrm{e}-011.00000 \mathrm{e}-091.00000 \mathrm{e}-01$ Element: 10004 \# of layers: 7

$\mathrm{Kx} \mathrm{Ky} \mathrm{Kz}$ Ss Por

$1.46712 \mathrm{e}+01$ 1.46712e+01 1.46712e+00 1.00000e-09 2.12000e-01 $1.46712 \mathrm{e}+011.46712 \mathrm{e}+011.46712 \mathrm{e}+001.00000 \mathrm{e}-092.12000 \mathrm{e}-01$ $1.46712 \mathrm{e}+011.46712 \mathrm{e}+011.46712 \mathrm{e}+001.00000 \mathrm{e}-092.12000 \mathrm{e}-01$ $1.46712 \mathrm{e}+011.46712 \mathrm{e}+011.46712 \mathrm{e}+001.00000 \mathrm{e}-092.12000 \mathrm{e}-01$ $1.46712 \mathrm{e}+011.46712 \mathrm{e}+011.46712 \mathrm{e}+001.00000 \mathrm{e}-092.12000 \mathrm{e}-01$ 1.00000e-05 1.00000e-05 1.00000e-06 1.00000e-09 1.00000e-01 $1.00000 \mathrm{e}+001.00000 \mathrm{e}+001.00000 \mathrm{e}-011.00000 \mathrm{e}-091.00000 \mathrm{e}-01$ Element: 10005 \# of layers: 7

$\mathrm{Kx} \mathrm{Ky} \mathrm{Kz}$ Ss Por

$1.46712 \mathrm{e}+01$ 1.46712e+01 1.46712e+00 1.00000e-09 2.12000e-01 $1.46712 \mathrm{e}+01$ 1.46712e+01 1.46712e+00 1.00000e-09 2.12000e-01 $1.46712 \mathrm{e}+011.46712 \mathrm{e}+011.46712 \mathrm{e}+001.00000 \mathrm{e}-092.12000 \mathrm{e}-01$ $1.46712 \mathrm{e}+011.46712 \mathrm{e}+011.46712 \mathrm{e}+001.00000 \mathrm{e}-092.12000 \mathrm{e}-01$ $1.46712 \mathrm{e}+011.46712 \mathrm{e}+011.46712 \mathrm{e}+001.00000 \mathrm{e}-092.12000 \mathrm{e}-01$ $1.00000 \mathrm{e}-05$ 1.00000e-05 1.00000e-06 1.00000e-09 1.00000e-01 
$1.00000 \mathrm{e}+001.00000 \mathrm{e}+00$ 1.00000e-01 1.00000e-09 1.00000e-01

Element: 10006 \# of layers: 7

Kx Ky Kz Ss Por

$1.46712 \mathrm{e}+01$ 1.46712e+01 1.46712e+00 1.00000e-09 2.12000e-01

$1.46712 \mathrm{e}+011.46712 \mathrm{e}+01$ 1.46712e+00 1.00000e-09 2.12000e-01

$1.46712 \mathrm{e}+01$ 1.46712e+01 1.46712e+00 1.00000e-09 2.12000e-01

$1.46712 \mathrm{e}+011.46712 \mathrm{e}+011.46712 \mathrm{e}+001.00000 \mathrm{e}-092.12000 \mathrm{e}-01$

$1.46712 \mathrm{e}+011.46712 \mathrm{e}+011.46712 \mathrm{e}+001.00000 \mathrm{e}-092.12000 \mathrm{e}-01$

$1.00000 \mathrm{e}-05$ 1.00000e-05 1.00000e-06 1.00000e-09 1.00000e-01

$1.00000 \mathrm{e}+001.00000 \mathrm{e}+001.00000 \mathrm{e}-011.00000 \mathrm{e}-091.00000 \mathrm{e}-01$

Element: 10007 \# of layers: 7

Kx Ky Kz Ss Por

$1.46712 \mathrm{e}+01$ 1.46712e+01 1.46712e+00 1.00000e-09 2.12000e-01

$1.46712 \mathrm{e}+01$ 1.46712e+01 1.46712e+00 1.00000e-09 2.12000e-01

$1.46712 \mathrm{e}+01$ 1.46712e+01 1.46712e+00 1.00000e-09 2.12000e-01

$1.46712 \mathrm{e}+011.46712 \mathrm{e}+011.46712 \mathrm{e}+001.00000 \mathrm{e}-092.12000 \mathrm{e}-01$

$1.46712 \mathrm{e}+011.46712 \mathrm{e}+011.46712 \mathrm{e}+001.00000 \mathrm{e}-092.12000 \mathrm{e}-01$

$1.00000 \mathrm{e}-05$ 1.00000e-05 1.00000e-06 1.00000e-09 1.00000e-01

$1.00000 \mathrm{e}+001.00000 \mathrm{e}+001.00000 \mathrm{e}-01$ 1.00000e-09 1.00000e-01

Element: 10008 \# of layers: 7

$\mathrm{Kx} \mathrm{Ky} \mathrm{Kz}$ Ss Por

$1.30381 \mathrm{e}+01$ 1.30381e+01 1.30381e+00 1.00000e-09 2.12000e-01

$1.30381 \mathrm{e}+01$ 1.30381e+01 1.30381e+00 1.00000e-09 2.12000e-01

$1.30381 \mathrm{e}+011.30381 \mathrm{e}+011.30381 \mathrm{e}+001.00000 \mathrm{e}-092.12000 \mathrm{e}-01$

$1.30381 \mathrm{e}+011.30381 \mathrm{e}+011.30381 \mathrm{e}+001.00000 \mathrm{e}-092.12000 \mathrm{e}-01$

$1.30381 \mathrm{e}+011.30381 \mathrm{e}+011.30381 \mathrm{e}+001.00000 \mathrm{e}-092.12000 \mathrm{e}-01$

$1.00000 \mathrm{e}-05$ 1.00000e-05 1.00000e-06 1.00000e-09 1.00000e-01

$1.00000 \mathrm{e}+001.00000 \mathrm{e}+001.00000 \mathrm{e}-01$ 1.00000e-09 1.00000e-01

Element: 10009 \# of layers: 7

$\mathrm{Kx} \mathrm{Ky} \mathrm{Kz}$ Ss Por

$1.30381 \mathrm{e}+01$ 1.30381e+01 1.30381e+00 1.00000e-09 2.12000e-01

$1.30381 \mathrm{e}+011.30381 \mathrm{e}+01$ 1.30381e+00 1.00000e-09 2.12000e-01

$1.30381 \mathrm{e}+011.30381 \mathrm{e}+011.30381 \mathrm{e}+001.00000 \mathrm{e}-092.12000 \mathrm{e}-01$

$1.30381 \mathrm{e}+011.30381 \mathrm{e}+01$ 1.30381e+00 1.00000e-09 2.12000e-01

$1.30381 \mathrm{e}+011.30381 \mathrm{e}+011.30381 \mathrm{e}+001.00000 \mathrm{e}-092.12000 \mathrm{e}-01$

$1.00000 \mathrm{e}-05$ 1.00000e-05 1.00000e-06 1.00000e-09 1.00000e-01

$1.00000 \mathrm{e}+001.00000 \mathrm{e}+001.00000 \mathrm{e}-011.00000 \mathrm{e}-091.00000 \mathrm{e}-01$

Element: 10010 \# of layers: 7

$\mathrm{Kx} \mathrm{Ky} \mathrm{Kz}$ Ss Por

$1.46712 \mathrm{e}+01$ 1.46712e+01 1.46712e+00 1.00000e-09 2.12000e-01 $1.46712 \mathrm{e}+011.46712 \mathrm{e}+011.46712 \mathrm{e}+001.00000 \mathrm{e}-092.12000 \mathrm{e}-01$ $1.46712 \mathrm{e}+011.46712 \mathrm{e}+01$ 1.46712e+00 1.00000e-09 2.12000e-01 $1.46712 \mathrm{e}+01$ 1.46712e+01 1.46712e+00 1.00000e-09 2.12000e-01 $1.46712 \mathrm{e}+01$ 1.46712e+01 1.46712e+00 1.00000e-09 2.12000e-01 $1.00000 \mathrm{e}-05$ 1.00000e-05 1.00000e-06 1.00000e-09 1.00000e-01

$1.00000 \mathrm{e}+001.00000 \mathrm{e}+001.00000 \mathrm{e}-011.00000 \mathrm{e}-091.00000 \mathrm{e}-01$ 
Element: 10011 \# of layers: 7

Kx Ky Kz Ss Por

$1.46712 \mathrm{e}+011.46712 \mathrm{e}+011.46712 \mathrm{e}+00$ 1.00000e-09 2.12000e-01

$1.46712 \mathrm{e}+011.46712 \mathrm{e}+011.46712 \mathrm{e}+001.00000 \mathrm{e}-092.12000 \mathrm{e}-01$

$1.46712 \mathrm{e}+011.46712 \mathrm{e}+011.46712 \mathrm{e}+001.00000 \mathrm{e}-092.12000 \mathrm{e}-01$

$1.46712 \mathrm{e}+011.46712 \mathrm{e}+011.46712 \mathrm{e}+001.00000 \mathrm{e}-092.12000 \mathrm{e}-01$

$1.46712 \mathrm{e}+011.46712 \mathrm{e}+011.46712 \mathrm{e}+00$ 1.00000e-09 2.12000e-01

$1.00000 \mathrm{e}-05$ 1.00000e-05 1.00000e-06 1.00000e-09 1.00000e-01

$1.00000 \mathrm{e}+001.00000 \mathrm{e}+001.00000 \mathrm{e}-011.00000 \mathrm{e}-091.00000 \mathrm{e}-01$

Element: 10012 \# of layers: 7

Kx Ky Kz Ss Por

$1.37989 \mathrm{e}+011.37989 \mathrm{e}+01$ 1.37989e+00 1.00000e-09 2.12000e-01

$1.37989 \mathrm{e}+011.37989 \mathrm{e}+011.37989 \mathrm{e}+00$ 1.00000e-09 2.12000e-01

$1.37989 \mathrm{e}+011.37989 \mathrm{e}+011.37989 \mathrm{e}+001.00000 \mathrm{e}-092.12000 \mathrm{e}-01$

$1.37989 \mathrm{e}+011.37989 \mathrm{e}+011.37989 \mathrm{e}+001.00000 \mathrm{e}-092.12000 \mathrm{e}-01$

$1.37989 \mathrm{e}+011.37989 \mathrm{e}+011.37989 \mathrm{e}+00$ 1.00000e-09 2.12000e-01

$1.00000 \mathrm{e}-05$ 1.00000e-05 1.00000e-06 1.00000e-09 1.00000e-01

$1.00000 \mathrm{e}+001.00000 \mathrm{e}+001.00000 \mathrm{e}-011.00000 \mathrm{e}-091.00000 \mathrm{e}-01$

Element: 10013 \# of layers: 7

Kx Ky Kz Ss Por

$1.37989 \mathrm{e}+011.37989 \mathrm{e}+011.37989 \mathrm{e}+00$ 1.00000e-09 2.12000e-01

$1.37989 \mathrm{e}+011.37989 \mathrm{e}+011.37989 \mathrm{e}+00$ 1.00000e-09 2.12000e-01

$1.37989 \mathrm{e}+011.37989 \mathrm{e}+011.37989 \mathrm{e}+00$ 1.00000e-09 2.12000e-01

$1.37989 \mathrm{e}+011.37989 \mathrm{e}+011.37989 \mathrm{e}+001.00000 \mathrm{e}-092.12000 \mathrm{e}-01$

$1.37989 \mathrm{e}+011.37989 \mathrm{e}+011.37989 \mathrm{e}+001.00000 \mathrm{e}-092.12000 \mathrm{e}-01$

$1.00000 \mathrm{e}-05$ 1.00000e-05 1.00000e-06 1.00000e-09 1.00000e-01

$1.00000 \mathrm{e}+001.00000 \mathrm{e}+001.00000 \mathrm{e}-011.00000 \mathrm{e}-091.00000 \mathrm{e}-01$

Element: 10014 \# of layers: 7

Kx Ky Kz Ss Por

$1.37989 \mathrm{e}+011.37989 \mathrm{e}+01$ 1.37989e+00 1.00000e-09 2.12000e-01

$1.37989 \mathrm{e}+011.37989 \mathrm{e}+011.37989 \mathrm{e}+00$ 1.00000e-09 2.12000e-01

$1.37989 \mathrm{e}+011.37989 \mathrm{e}+011.37989 \mathrm{e}+00$ 1.00000e-09 2.12000e-01

$1.37989 \mathrm{e}+011.37989 \mathrm{e}+011.37989 \mathrm{e}+00$ 1.00000e-09 2.12000e-01

$1.37989 \mathrm{e}+011.37989 \mathrm{e}+011.37989 \mathrm{e}+00$ 1.00000e-09 2.12000e-01

$1.00000 \mathrm{e}-05$ 1.00000e-05 1.00000e-06 1.00000e-09 1.00000e-01

$1.00000 \mathrm{e}+001.00000 \mathrm{e}+001.00000 \mathrm{e}-011.00000 \mathrm{e}-091.00000 \mathrm{e}-01$

Element: 10015 \# of layers: 7

Kx Ky Kz Ss Por

$1.44741 \mathrm{e}+011.44741 \mathrm{e}+011.44741 \mathrm{e}+00$ 1.00000e-09 2.12000e-01

$1.44741 \mathrm{e}+011.44741 \mathrm{e}+011.44741 \mathrm{e}+001.00000 \mathrm{e}-092.12000 \mathrm{e}-01$

$1.44741 \mathrm{e}+011.44741 \mathrm{e}+011.44741 \mathrm{e}+001.00000 \mathrm{e}-092.12000 \mathrm{e}-01$

$1.44741 \mathrm{e}+011.44741 \mathrm{e}+011.44741 \mathrm{e}+001.00000 \mathrm{e}-092.12000 \mathrm{e}-01$

$1.44741 \mathrm{e}+011.44741 \mathrm{e}+011.44741 \mathrm{e}+001.00000 \mathrm{e}-092.12000 \mathrm{e}-01$

$1.00000 \mathrm{e}-05$ 1.00000e-05 1.00000e-06 1.00000e-09 1.00000e-01

$1.00000 \mathrm{e}+001.00000 \mathrm{e}+001.00000 \mathrm{e}-011.00000 \mathrm{e}-091.00000 \mathrm{e}-01$

Element: 10016 \# of layers: 7 
$\mathrm{Kx} \mathrm{Ky} \mathrm{Kz} \mathrm{Ss} \mathrm{Por}$

$1.44741 \mathrm{e}+011.44741 \mathrm{e}+01$ 1.44741e+00 1.00000e-09 2.12000e-01

$1.44741 \mathrm{e}+011.44741 \mathrm{e}+011.44741 \mathrm{e}+001.00000 \mathrm{e}-092.12000 \mathrm{e}-01$

$1.44741 \mathrm{e}+011.44741 \mathrm{e}+011.44741 \mathrm{e}+001.00000 \mathrm{e}-092.12000 \mathrm{e}-01$

$1.44741 \mathrm{e}+011.44741 \mathrm{e}+011.44741 \mathrm{e}+001.00000 \mathrm{e}-092.12000 \mathrm{e}-01$

$1.44741 \mathrm{e}+011.44741 \mathrm{e}+011.44741 \mathrm{e}+001.00000 \mathrm{e}-092.12000 \mathrm{e}-01$

$1.00000 \mathrm{e}-05$ 1.00000e-05 1.00000e-06 1.00000e-09 1.00000e-01

$1.00000 \mathrm{e}+001.00000 \mathrm{e}+001.00000 \mathrm{e}-01$ 1.00000e-09 1.00000e-01

Element: 10017 \# of layers: 7

$\mathrm{Kx} \mathrm{Ky} \mathrm{Kz}$ Ss Por

$1.30381 \mathrm{e}+01$ 1.30381e+01 1.30381e+00 1.00000e-09 2.12000e-01

$1.30381 \mathrm{e}+011.30381 \mathrm{e}+011.30381 \mathrm{e}+001.00000 \mathrm{e}-092.12000 \mathrm{e}-01$

$1.30381 \mathrm{e}+011.30381 \mathrm{e}+011.30381 \mathrm{e}+001.00000 \mathrm{e}-092.12000 \mathrm{e}-01$

$1.30381 \mathrm{e}+011.30381 \mathrm{e}+011.30381 \mathrm{e}+001.00000 \mathrm{e}-092.12000 \mathrm{e}-01$

$1.30381 \mathrm{e}+011.30381 \mathrm{e}+011.30381 \mathrm{e}+001.00000 \mathrm{e}-092.12000 \mathrm{e}-01$

$1.00000 \mathrm{e}-05$ 1.00000e-05 1.00000e-06 1.00000e-09 1.00000e-01

$1.00000 \mathrm{e}+001.00000 \mathrm{e}+001.00000 \mathrm{e}-011.00000 \mathrm{e}-091.00000 \mathrm{e}-01$

Element: 10018 \# of layers: 7

$\mathrm{Kx} \mathrm{Ky} \mathrm{Kz}$ Ss Por

$1.46712 \mathrm{e}+01$ 1.46712e+01 1.46712e+00 1.00000e-09 2.12000e-01

$1.46712 \mathrm{e}+011.46712 \mathrm{e}+011.46712 \mathrm{e}+001.00000 \mathrm{e}-092.12000 \mathrm{e}-01$

$1.46712 \mathrm{e}+011.46712 \mathrm{e}+011.46712 \mathrm{e}+001.00000 \mathrm{e}-092.12000 \mathrm{e}-01$

$1.46712 \mathrm{e}+01$ 1.46712e+01 1.46712e+00 1.00000e-09 2.12000e-01

$1.46712 \mathrm{e}+011.46712 \mathrm{e}+011.46712 \mathrm{e}+001.00000 \mathrm{e}-092.12000 \mathrm{e}-01$

$1.00000 \mathrm{e}-05$ 1.00000e-05 1.00000e-06 1.00000e-09 1.00000e-01

$1.00000 \mathrm{e}+001.00000 \mathrm{e}+001.00000 \mathrm{e}-01$ 1.00000e-09 1.00000e-01

Element: 10019 \# of layers: 7

$\mathrm{Kx} \mathrm{Ky} \mathrm{Kz}$ Ss Por

1.37989e+01 1.37989e+01 1.37989e+00 1.00000e-09 2.12000e-01

$1.37989 \mathrm{e}+01$ 1.37989e+01 1.37989e+00 1.00000e-09 2.12000e-01

$1.37989 \mathrm{e}+01$ 1.37989e+01 1.37989e+00 1.00000e-09 2.12000e-01

$1.37989 \mathrm{e}+01$ 1.37989e+01 1.37989e+00 1.00000e-09 2.12000e-01

$1.37989 \mathrm{e}+01$ 1.37989e+01 1.37989e+00 1.00000e-09 2.12000e-01

$1.00000 \mathrm{e}-05$ 1.00000e-05 1.00000e-06 1.00000e-09 1.00000e-01

$1.00000 \mathrm{e}+001.00000 \mathrm{e}+001.00000 \mathrm{e}-011.00000 \mathrm{e}-091.00000 \mathrm{e}-01$

Element: 10020 \# of layers: 8

Kx Ky Kz Ss Por

$3.50000 \mathrm{e}+02$ 3.50000e+02 3.50000e+01 1.00000e-09 1.00000e-01

$1.24909 \mathrm{e}+01$ 1.24909e+01 1.24909e+00 1.00000e-09 2.12000e-01

$1.24909 \mathrm{e}+01$ 1.24909e+01 1.24909e+00 1.00000e-09 2.12000e-01

$1.24909 \mathrm{e}+01$ 1.24909e+01 1.24909e+00 1.00000e-09 2.12000e-01

$1.24909 \mathrm{e}+01$ 1.24909e+01 1.24909e+00 1.00000e-09 2.12000e-01

$1.24909 \mathrm{e}+01$ 1.24909e+01 1.24909e+00 1.00000e-09 2.12000e-01

$1.00000 \mathrm{e}-05$ 1.00000e-05 1.00000e-06 1.00000e-09 1.00000e-01

$1.00000 \mathrm{e}+001.00000 \mathrm{e}+001.00000 \mathrm{e}-011.00000 \mathrm{e}-09$ 1.00000e-01

Element: 10021 \# of layers: 8 
Kx Ky Kz Ss Por

3.50000e+02 3.50000e+02 3.50000e+01 1.00000e-09 1.00000e-01

$1.24909 \mathrm{e}+01$ 1.24909e+01 1.24909e+00 1.00000e-09 2.12000e-01

$1.24909 \mathrm{e}+01$ 1.24909e+01 1.24909e+00 1.00000e-09 2.12000e-01

$1.24909 \mathrm{e}+01$ 1.24909e+01 1.24909e+00 1.00000e-09 2.12000e-01

$1.24909 \mathrm{e}+011.24909 \mathrm{e}+01$ 1.24909e+00 1.00000e-09 2.12000e-01

$1.24909 \mathrm{e}+01$ 1.24909e+01 1.24909e+00 1.00000e-09 2.12000e-01

$1.00000 \mathrm{e}-05$ 1.00000e-05 1.00000e-06 1.00000e-09 1.00000e-01

$1.00000 \mathrm{e}+001.00000 \mathrm{e}+001.00000 \mathrm{e}-011.00000 \mathrm{e}-091.00000 \mathrm{e}-01$

Element: 10022 \# of layers: 7

$\mathrm{Kx} \mathrm{Ky} \mathrm{Kz}$ Ss Por

$1.24909 \mathrm{e}+01$ 1.24909e+01 1.24909e+00 1.00000e-09 2.12000e-01

$1.24909 \mathrm{e}+01$ 1.24909e+01 1.24909e+00 1.00000e-09 2.12000e-01

$1.24909 \mathrm{e}+01$ 1.24909e+01 1.24909e+00 1.00000e-09 2.12000e-01

$1.24909 \mathrm{e}+01$ 1.24909e+01 1.24909e+00 1.00000e-09 2.12000e-01

$1.24909 \mathrm{e}+011.24909 \mathrm{e}+011.24909 \mathrm{e}+001.00000 \mathrm{e}-092.12000 \mathrm{e}-01$

$1.00000 \mathrm{e}-05$ 1.00000e-05 1.00000e-06 1.00000e-09 1.00000e-01

$1.00000 \mathrm{e}+001.00000 \mathrm{e}+001.00000 \mathrm{e}-01$ 1.00000e-09 1.00000e-01

Element: 10023 \# of layers: 7

$\mathrm{Kx} \mathrm{Ky} \mathrm{Kz}$ Ss Por

$1.24909 \mathrm{e}+01$ 1.24909e+01 1.24909e+00 1.00000e-09 2.12000e-01

$1.24909 \mathrm{e}+01$ 1.24909e+01 1.24909e+00 1.00000e-09 2.12000e-01

$1.24909 \mathrm{e}+01$ 1.24909e+01 1.24909e+00 1.00000e-09 2.12000e-01

$1.24909 \mathrm{e}+01$ 1.24909e+01 1.24909e+00 1.00000e-09 2.12000e-01

$1.24909 \mathrm{e}+011.24909 \mathrm{e}+011.24909 \mathrm{e}+001.00000 \mathrm{e}-092.12000 \mathrm{e}-01$

$1.00000 \mathrm{e}-05$ 1.00000e-05 1.00000e-06 1.00000e-09 1.00000e-01

$1.00000 \mathrm{e}+001.00000 \mathrm{e}+001.00000 \mathrm{e}-011.00000 \mathrm{e}-09$ 1.00000e-01

Element: 10024 \# of layers: 7

$\mathrm{Kx} \mathrm{Ky} \mathrm{Kz}$ Ss Por

$1.24909 \mathrm{e}+01$ 1.24909e+01 1.24909e+00 1.00000e-09 2.12000e-01

$1.24909 \mathrm{e}+01$ 1.24909e+01 1.24909e+00 1.00000e-09 2.12000e-01

$1.24909 \mathrm{e}+01$ 1.24909e+01 1.24909e+00 1.00000e-09 2.12000e-01

$1.24909 \mathrm{e}+011.24909 \mathrm{e}+01 \quad 1.24909 \mathrm{e}+001.00000 \mathrm{e}-092.12000 \mathrm{e}-01$

$1.24909 \mathrm{e}+01$ 1.24909e+01 1.24909e+00 1.00000e-09 2.12000e-01

$1.00000 \mathrm{e}-05$ 1.00000e-05 1.00000e-06 1.00000e-09 1.00000e-01

$1.00000 \mathrm{e}+001.00000 \mathrm{e}+001.00000 \mathrm{e}-011.00000 \mathrm{e}-091.00000 \mathrm{e}-01$

Element: 10025 \# of layers: 9

$\mathrm{Kx} \mathrm{Ky} \mathrm{Kz}$ Ss Por

$3.50000 \mathrm{e}+023.50000 \mathrm{e}+023.50000 \mathrm{e}+01$ 1.00000e-09 1.00000e-01

5.00000e-04 5.00000e-04 5.00000e-05 1.00000e-09 1.00000e-01

$1.24909 \mathrm{e}+01$ 1.24909e+01 1.24909e+00 1.00000e-09 2.12000e-01

$1.24909 \mathrm{e}+01$ 1.24909e+01 1.24909e+00 1.00000e-09 2.12000e-01

$1.24909 \mathrm{e}+01$ 1.24909e+01 1.24909e+00 1.00000e-09 2.12000e-01

$1.24909 \mathrm{e}+01$ 1.24909e+01 1.24909e+00 1.00000e-09 2.12000e-01

$1.24909 \mathrm{e}+01$ 1.24909e+01 1.24909e+00 1.00000e-09 2.12000e-01

$1.00000 \mathrm{e}-05$ 1.00000e-05 1.00000e-06 1.00000e-09 1.00000e-01 
$1.00000 \mathrm{e}+001.00000 \mathrm{e}+001.00000 \mathrm{e}-011.00000 \mathrm{e}-091.00000 \mathrm{e}-01$

Element: 10026 \# of layers: 9

$\mathrm{Kx} \mathrm{Ky} \mathrm{Kz}$ Ss Por

$3.50000 \mathrm{e}+02$ 3.50000e+02 3.50000e+01 1.00000e-09 1.00000e-01

5.00000e-04 5.00000e-04 5.00000e-05 1.00000e-09 1.00000e-01

$1.24909 \mathrm{e}+01$ 1.24909e+01 1.24909e+00 1.00000e-09 2.12000e-01

$1.24909 \mathrm{e}+01$ 1.24909e+01 1.24909e+00 1.00000e-09 2.12000e-01

$1.24909 \mathrm{e}+01$ 1.24909e+01 1.24909e+00 1.00000e-09 2.12000e-01

$1.24909 \mathrm{e}+01$ 1.24909e+01 1.24909e+00 1.00000e-09 2.12000e-01

$1.24909 \mathrm{e}+01$ 1.24909e+01 1.24909e+00 1.00000e-09 2.12000e-01

$1.00000 \mathrm{e}-05$ 1.00000e-05 1.00000e-06 1.00000e-09 1.00000e-01

$1.00000 \mathrm{e}+001.00000 \mathrm{e}+001.00000 \mathrm{e}-01$ 1.00000e-09 1.00000e-01

Element: 10027 \# of layers: 8

$\mathrm{Kx} \mathrm{Ky} \mathrm{Kz}$ Ss Por

$3.50000 \mathrm{e}+02$ 3.50000e+02 3.50000e+01 1.00000e-09 1.00000e-01

$1.24909 \mathrm{e}+011.24909 \mathrm{e}+011.24909 \mathrm{e}+001.00000 \mathrm{e}-092.12000 \mathrm{e}-01$

$1.24909 \mathrm{e}+01$ 1.24909e+01 1.24909e+00 1.00000e-09 2.12000e-01

$1.24909 \mathrm{e}+01$ 1.24909e+01 1.24909e+00 1.00000e-09 2.12000e-01

$1.24909 \mathrm{e}+01$ 1.24909e+01 1.24909e+00 1.00000e-09 2.12000e-01

$1.24909 \mathrm{e}+01$ 1.24909e+01 1.24909e+00 1.00000e-09 2.12000e-01

$1.00000 \mathrm{e}-05$ 1.00000e-05 1.00000e-06 1.00000e-09 1.00000e-01

$1.00000 \mathrm{e}+001.00000 \mathrm{e}+001.00000 \mathrm{e}-011.00000 \mathrm{e}-091.00000 \mathrm{e}-01$

Element: 10028 \# of layers: 8

$\mathrm{Kx} \mathrm{Ky} \mathrm{Kz}$ Ss Por

3.50000e+02 3.50000e+02 3.50000e+01 1.00000e-09 1.00000e-01

$1.24909 \mathrm{e}+01$ 1.24909e+01 1.24909e+00 1.00000e-09 2.12000e-01

$1.24909 \mathrm{e}+01$ 1.24909e+01 1.24909e+00 1.00000e-09 2.12000e-01

$1.24909 \mathrm{e}+01$ 1.24909e+01 1.24909e+00 1.00000e-09 2.12000e-01

$1.24909 \mathrm{e}+01$ 1.24909e+01 1.24909e+00 1.00000e-09 2.12000e-01

$1.24909 \mathrm{e}+01$ 1.24909e+01 1.24909e+00 1.00000e-09 2.12000e-01

$1.00000 \mathrm{e}-05$ 1.00000e-05 1.00000e-06 1.00000e-09 1.00000e-01

$1.00000 \mathrm{e}+001.00000 \mathrm{e}+001.00000 \mathrm{e}-011.00000 \mathrm{e}-091.00000 \mathrm{e}-01$

Element: 10029 \# of layers: 7

$\mathrm{Kx} \mathrm{Ky} \mathrm{Kz}$ Ss Por

$1.24909 \mathrm{e}+01$ 1.24909e+01 1.24909e+00 1.00000e-09 2.12000e-01

$1.24909 \mathrm{e}+01$ 1.24909e+01 1.24909e+00 1.00000e-09 2.12000e-01

$1.24909 \mathrm{e}+011.24909 \mathrm{e}+011.24909 \mathrm{e}+001.00000 \mathrm{e}-092.12000 \mathrm{e}-01$

$1.24909 \mathrm{e}+011.24909 \mathrm{e}+011.24909 \mathrm{e}+001.00000 \mathrm{e}-092.12000 \mathrm{e}-01$

$1.24909 \mathrm{e}+01$ 1.24909e+01 1.24909e+00 1.00000e-09 2.12000e-01

$1.00000 \mathrm{e}-05$ 1.00000e-05 1.00000e-06 1.00000e-09 1.00000e-01

$1.00000 \mathrm{e}+001.00000 \mathrm{e}+001.00000 \mathrm{e}-011.00000 \mathrm{e}-091.00000 \mathrm{e}-01$

Element: 10030 \# of layers: 7

$\mathrm{Kx} \mathrm{Ky} \mathrm{Kz}$ Ss Por

$1.30021 \mathrm{e}+01$ 1.30021e+01 1.30021e+00 1.00000e-09 2.12000e-01

$1.30021 \mathrm{e}+011.30021 \mathrm{e}+011.30021 \mathrm{e}+001.00000 \mathrm{e}-092.12000 \mathrm{e}-01$

$1.30021 \mathrm{e}+011.30021 \mathrm{e}+011.30021 \mathrm{e}+001.00000 \mathrm{e}-092.12000 \mathrm{e}-01$ 
$1.30021 \mathrm{e}+011.30021 \mathrm{e}+011.30021 \mathrm{e}+001.00000 \mathrm{e}-092.12000 \mathrm{e}-01$ $1.30021 \mathrm{e}+011.30021 \mathrm{e}+011.30021 \mathrm{e}+001.00000 \mathrm{e}-092.12000 \mathrm{e}-01$ $1.00000 \mathrm{e}-05$ 1.00000e-05 1.00000e-06 1.00000e-09 1.00000e-01 $1.00000 \mathrm{e}+001.00000 \mathrm{e}+001.00000 \mathrm{e}-011.00000 \mathrm{e}-091.00000 \mathrm{e}-01$ Element: 10031 \# of layers: 7

$\mathrm{Kx} \mathrm{Ky} \mathrm{Kz}$ Ss Por

$1.30021 \mathrm{e}+011.30021 \mathrm{e}+011.30021 \mathrm{e}+00$ 1.00000e-09 2.12000e-01 $1.30021 \mathrm{e}+011.30021 \mathrm{e}+011.30021 \mathrm{e}+001.00000 \mathrm{e}-092.12000 \mathrm{e}-01$ $1.30021 \mathrm{e}+011.30021 \mathrm{e}+01$ 1.30021e+00 1.00000e-09 2.12000e-01 $1.30021 \mathrm{e}+011.30021 \mathrm{e}+011.30021 \mathrm{e}+001.00000 \mathrm{e}-092.12000 \mathrm{e}-01$ $1.30021 \mathrm{e}+011.30021 \mathrm{e}+011.30021 \mathrm{e}+001.00000 \mathrm{e}-092.12000 \mathrm{e}-01$ $1.00000 \mathrm{e}-05$ 1.00000e-05 1.00000e-06 1.00000e-09 1.00000e-01 $1.00000 \mathrm{e}+001.00000 \mathrm{e}+001.00000 \mathrm{e}-011.00000 \mathrm{e}-09$ 1.00000e-01 Element: 10032 \# of layers: 7

$\mathrm{Kx} \mathrm{Ky} \mathrm{Kz}$ Ss Por

$1.30021 \mathrm{e}+01$ 1.30021e+01 1.30021e+00 1.00000e-09 2.12000e-01 $1.30021 \mathrm{e}+011.30021 \mathrm{e}+011.30021 \mathrm{e}+001.00000 \mathrm{e}-092.12000 \mathrm{e}-01$ $1.30021 \mathrm{e}+011.30021 \mathrm{e}+011.30021 \mathrm{e}+001.00000 \mathrm{e}-092.12000 \mathrm{e}-01$ $1.30021 \mathrm{e}+011.30021 \mathrm{e}+011.30021 \mathrm{e}+001.00000 \mathrm{e}-092.12000 \mathrm{e}-01$ $1.30021 \mathrm{e}+011.30021 \mathrm{e}+011.30021 \mathrm{e}+001.00000 \mathrm{e}-092.12000 \mathrm{e}-01$ $1.00000 \mathrm{e}-05$ 1.00000e-05 1.00000e-06 1.00000e-09 1.00000e-01 $1.00000 \mathrm{e}+001.00000 \mathrm{e}+001.00000 \mathrm{e}-011.00000 \mathrm{e}-091.00000 \mathrm{e}-01$ Element: 10033 \# of layers: 7

Kx Ky Kz Ss Por

$1.30021 \mathrm{e}+011.30021 \mathrm{e}+011.30021 \mathrm{e}+00$ 1.00000e-09 2.12000e-01 $1.30021 \mathrm{e}+011.30021 \mathrm{e}+011.30021 \mathrm{e}+001.00000 \mathrm{e}-092.12000 \mathrm{e}-01$ $1.30021 \mathrm{e}+011.30021 \mathrm{e}+011.30021 \mathrm{e}+001.00000 \mathrm{e}-092.12000 \mathrm{e}-01$ $1.30021 \mathrm{e}+011.30021 \mathrm{e}+011.30021 \mathrm{e}+001.00000 \mathrm{e}-092.12000 \mathrm{e}-01$ $1.30021 \mathrm{e}+011.30021 \mathrm{e}+011.30021 \mathrm{e}+001.00000 \mathrm{e}-092.12000 \mathrm{e}-01$ $1.00000 \mathrm{e}-05$ 1.00000e-05 1.00000e-06 1.00000e-09 1.00000e-01 $1.00000 \mathrm{e}+001.00000 \mathrm{e}+001.00000 \mathrm{e}-01$ 1.00000e-09 1.00000e-01 Element: 10034 \# of layers: 7

Kx Ky Kz Ss Por

$1.30021 \mathrm{e}+011.30021 \mathrm{e}+011.30021 \mathrm{e}+001.00000 \mathrm{e}-092.12000 \mathrm{e}-01$ $1.30021 \mathrm{e}+011.30021 \mathrm{e}+011.30021 \mathrm{e}+001.00000 \mathrm{e}-092.12000 \mathrm{e}-01$ $1.30021 \mathrm{e}+011.30021 \mathrm{e}+011.30021 \mathrm{e}+001.00000 \mathrm{e}-092.12000 \mathrm{e}-01$ $1.30021 \mathrm{e}+011.30021 \mathrm{e}+011.30021 \mathrm{e}+001.00000 \mathrm{e}-092.12000 \mathrm{e}-01$ $1.30021 \mathrm{e}+011.30021 \mathrm{e}+011.30021 \mathrm{e}+001.00000 \mathrm{e}-092.12000 \mathrm{e}-01$ $1.00000 \mathrm{e}-05$ 1.00000e-05 1.00000e-06 1.00000e-09 1.00000e-01 $1.00000 \mathrm{e}+001.00000 \mathrm{e}+001.00000 \mathrm{e}-01$ 1.00000e-09 1.00000e-01 Element: 10035 \# of layers: 7

$\mathrm{Kx} \mathrm{Ky} \mathrm{Kz}$ Ss Por

$1.24909 \mathrm{e}+01$ 1.24909e+01 1.24909e+00 1.00000e-09 2.12000e-01 $1.24909 \mathrm{e}+01$ 1.24909e+01 1.24909e+00 1.00000e-09 2.12000e-01 $1.24909 \mathrm{e}+01$ 1.24909e+01 1.24909e+00 1.00000e-09 2.12000e-01 $1.24909 \mathrm{e}+01$ 1.24909e+01 1.24909e+00 1.00000e-09 2.12000e-01 
$1.24909 \mathrm{e}+01$ 1.24909e+01 1.24909e+00 1.00000e-09 2.12000e-01 $1.00000 \mathrm{e}-05$ 1.00000e-05 1.00000e-06 1.00000e-09 1.00000e-01 $1.00000 \mathrm{e}+001.00000 \mathrm{e}+001.00000 \mathrm{e}-011.00000 \mathrm{e}-09$ 1.00000e-01 Element: 10036 \# of layers: 7

$\mathrm{Kx} \mathrm{Ky} \mathrm{Kz}$ Ss Por

$1.24909 \mathrm{e}+01$ 1.24909e+01 1.24909e+00 1.00000e-09 2.12000e-01 $1.24909 \mathrm{e}+01$ 1.24909e+01 1.24909e+00 1.00000e-09 2.12000e-01 $1.24909 \mathrm{e}+01$ 1.24909e+01 1.24909e+00 1.00000e-09 2.12000e-01 $1.24909 \mathrm{e}+01$ 1.24909e+01 1.24909e+00 1.00000e-09 2.12000e-01 $1.24909 \mathrm{e}+01$ 1.24909e+01 1.24909e+00 1.00000e-09 2.12000e-01 $1.00000 \mathrm{e}-05$ 1.00000e-05 1.00000e-06 1.00000e-09 1.00000e-01 $1.00000 \mathrm{e}+001.00000 \mathrm{e}+001.00000 \mathrm{e}-011.00000 \mathrm{e}-091.00000 \mathrm{e}-01$ Element: 10037 \# of layers: 7

$\mathrm{Kx} \mathrm{Ky} \mathrm{Kz}$ Ss Por

$1.30021 \mathrm{e}+011.30021 \mathrm{e}+011.30021 \mathrm{e}+00$ 1.00000e-09 2.12000e-01 $1.30021 \mathrm{e}+011.30021 \mathrm{e}+011.30021 \mathrm{e}+001.00000 \mathrm{e}-092.12000 \mathrm{e}-01$ $1.30021 \mathrm{e}+011.30021 \mathrm{e}+011.30021 \mathrm{e}+001.00000 \mathrm{e}-092.12000 \mathrm{e}-01$ $1.30021 \mathrm{e}+011.30021 \mathrm{e}+011.30021 \mathrm{e}+001.00000 \mathrm{e}-092.12000 \mathrm{e}-01$ $1.30021 \mathrm{e}+011.30021 \mathrm{e}+011.30021 \mathrm{e}+001.00000 \mathrm{e}-092.12000 \mathrm{e}-01$ $1.00000 \mathrm{e}-05$ 1.00000e-05 1.00000e-06 1.00000e-09 1.00000e-01 $1.00000 \mathrm{e}+001.00000 \mathrm{e}+001.00000 \mathrm{e}-011.00000 \mathrm{e}-091.00000 \mathrm{e}-01$ Element: 10038 \# of layers: 7

$\mathrm{Kx} \mathrm{Ky} \mathrm{Kz}$ Ss Por

$1.30021 \mathrm{e}+011.30021 \mathrm{e}+01$ 1.30021e+00 1.00000e-09 2.12000e-01 $1.30021 \mathrm{e}+011.30021 \mathrm{e}+011.30021 \mathrm{e}+001.00000 \mathrm{e}-092.12000 \mathrm{e}-01$ $1.30021 \mathrm{e}+011.30021 \mathrm{e}+011.30021 \mathrm{e}+001.00000 \mathrm{e}-092.12000 \mathrm{e}-01$ $1.30021 \mathrm{e}+011.30021 \mathrm{e}+011.30021 \mathrm{e}+001.00000 \mathrm{e}-092.12000 \mathrm{e}-01$ $1.30021 \mathrm{e}+011.30021 \mathrm{e}+011.30021 \mathrm{e}+001.00000 \mathrm{e}-092.12000 \mathrm{e}-01$ $1.00000 \mathrm{e}-05$ 1.00000e-05 1.00000e-06 1.00000e-09 1.00000e-01 $1.00000 \mathrm{e}+001.00000 \mathrm{e}+001.00000 \mathrm{e}-011.00000 \mathrm{e}-091.00000 \mathrm{e}-01$ Element: 10039 \# of layers: 7

$\mathrm{Kx} \mathrm{Ky} \mathrm{Kz}$ Ss Por

$1.30021 \mathrm{e}+011.30021 \mathrm{e}+011.30021 \mathrm{e}+00$ 1.00000e-09 2.12000e-01 $1.30021 \mathrm{e}+011.30021 \mathrm{e}+011.30021 \mathrm{e}+001.00000 \mathrm{e}-092.12000 \mathrm{e}-01$ $1.30021 \mathrm{e}+011.30021 \mathrm{e}+011.30021 \mathrm{e}+001.00000 \mathrm{e}-092.12000 \mathrm{e}-01$ $1.30021 \mathrm{e}+011.30021 \mathrm{e}+011.30021 \mathrm{e}+001.00000 \mathrm{e}-092.12000 \mathrm{e}-01$ $1.30021 \mathrm{e}+011.30021 \mathrm{e}+011.30021 \mathrm{e}+001.00000 \mathrm{e}-092.12000 \mathrm{e}-01$ $1.00000 \mathrm{e}-05$ 1.00000e-05 1.00000e-06 1.00000e-09 1.00000e-01 $1.00000 \mathrm{e}+001.00000 \mathrm{e}+001.00000 \mathrm{e}-01$ 1.00000e-09 1.00000e-01 Element: 10040 \# of layers: 7

$\mathrm{Kx} \mathrm{Ky} \mathrm{Kz}$ Ss Por

$1.30021 \mathrm{e}+01$ 1.30021e+01 1.30021e+00 1.00000e-09 2.12000e-01 $1.30021 \mathrm{e}+011.30021 \mathrm{e}+011.30021 \mathrm{e}+001.00000 \mathrm{e}-092.12000 \mathrm{e}-01$ $1.30021 \mathrm{e}+011.30021 \mathrm{e}+01$ 1.30021e+00 1.00000e-09 2.12000e-01 $1.30021 \mathrm{e}+011.30021 \mathrm{e}+011.30021 \mathrm{e}+001.00000 \mathrm{e}-092.12000 \mathrm{e}-01$ $1.30021 \mathrm{e}+011.30021 \mathrm{e}+011.30021 \mathrm{e}+001.00000 \mathrm{e}-092.12000 \mathrm{e}-01$ 
$1.00000 \mathrm{e}-05$ 1.00000e-05 1.00000e-06 1.00000e-09 1.00000e-01 $1.00000 \mathrm{e}+001.00000 \mathrm{e}+001.00000 \mathrm{e}-01$ 1.00000e-09 1.00000e-01 Element: 10041 \# of layers: 7

Kx Ky Kz Ss Por

$1.30021 \mathrm{e}+011.30021 \mathrm{e}+011.30021 \mathrm{e}+001.00000 \mathrm{e}-092.12000 \mathrm{e}-01$ $1.30021 \mathrm{e}+011.30021 \mathrm{e}+011.30021 \mathrm{e}+001.00000 \mathrm{e}-092.12000 \mathrm{e}-01$ $1.30021 \mathrm{e}+011.30021 \mathrm{e}+011.30021 \mathrm{e}+001.00000 \mathrm{e}-092.12000 \mathrm{e}-01$ $1.30021 \mathrm{e}+011.30021 \mathrm{e}+011.30021 \mathrm{e}+001.00000 \mathrm{e}-092.12000 \mathrm{e}-01$ $1.30021 \mathrm{e}+011.30021 \mathrm{e}+01$ 1.30021e+00 1.00000e-09 2.12000e-01 $1.00000 \mathrm{e}-05$ 1.00000e-05 1.00000e-06 1.00000e-09 1.00000e-01 $1.00000 \mathrm{e}+001.00000 \mathrm{e}+001.00000 \mathrm{e}-011.00000 \mathrm{e}-091.00000 \mathrm{e}-01$ Element: 10042 \# of layers: 7

$\mathrm{Kx} \mathrm{Ky} \mathrm{Kz}$ Ss Por

$1.30021 \mathrm{e}+011.30021 \mathrm{e}+01$ 1.30021e+00 1.00000e-09 2.12000e-01 $1.30021 \mathrm{e}+011.30021 \mathrm{e}+011.30021 \mathrm{e}+001.00000 \mathrm{e}-092.12000 \mathrm{e}-01$ $1.30021 \mathrm{e}+011.30021 \mathrm{e}+011.30021 \mathrm{e}+001.00000 \mathrm{e}-092.12000 \mathrm{e}-01$ $1.30021 \mathrm{e}+011.30021 \mathrm{e}+011.30021 \mathrm{e}+001.00000 \mathrm{e}-092.12000 \mathrm{e}-01$ $1.30021 \mathrm{e}+011.30021 \mathrm{e}+011.30021 \mathrm{e}+001.00000 \mathrm{e}-092.12000 \mathrm{e}-01$ $1.00000 \mathrm{e}-051.00000 \mathrm{e}-05$ 1.00000e-06 1.00000e-09 1.00000e-01 $1.00000 \mathrm{e}+001.00000 \mathrm{e}+001.00000 \mathrm{e}-011.00000 \mathrm{e}-09$ 1.00000e-01 Element: 10043 \# of layers: 7

$\mathrm{Kx} \mathrm{Ky} \mathrm{Kz}$ Ss Por

$1.30021 \mathrm{e}+011.30021 \mathrm{e}+011.30021 \mathrm{e}+00$ 1.00000e-09 2.12000e-01 $1.30021 \mathrm{e}+011.30021 \mathrm{e}+011.30021 \mathrm{e}+001.00000 \mathrm{e}-092.12000 \mathrm{e}-01$ $1.30021 \mathrm{e}+011.30021 \mathrm{e}+011.30021 \mathrm{e}+001.00000 \mathrm{e}-092.12000 \mathrm{e}-01$ $1.30021 \mathrm{e}+011.30021 \mathrm{e}+011.30021 \mathrm{e}+001.00000 \mathrm{e}-092.12000 \mathrm{e}-01$ $1.30021 \mathrm{e}+011.30021 \mathrm{e}+011.30021 \mathrm{e}+001.00000 \mathrm{e}-092.12000 \mathrm{e}-01$ $1.00000 \mathrm{e}-05$ 1.00000e-05 1.00000e-06 1.00000e-09 1.00000e-01 $1.00000 \mathrm{e}+001.00000 \mathrm{e}+001.00000 \mathrm{e}-011.00000 \mathrm{e}-091.00000 \mathrm{e}-01$ Element: 10044 \# of layers: 7

$\mathrm{Kx} \mathrm{Ky} \mathrm{Kz}$ Ss Por

$1.30021 \mathrm{e}+011.30021 \mathrm{e}+011.30021 \mathrm{e}+00$ 1.00000e-09 2.12000e-01 $1.30021 \mathrm{e}+011.30021 \mathrm{e}+011.30021 \mathrm{e}+001.00000 \mathrm{e}-092.12000 \mathrm{e}-01$ $1.30021 \mathrm{e}+011.30021 \mathrm{e}+011.30021 \mathrm{e}+001.00000 \mathrm{e}-092.12000 \mathrm{e}-01$ $1.30021 \mathrm{e}+011.30021 \mathrm{e}+011.30021 \mathrm{e}+001.00000 \mathrm{e}-092.12000 \mathrm{e}-01$ $1.30021 \mathrm{e}+011.30021 \mathrm{e}+011.30021 \mathrm{e}+001.00000 \mathrm{e}-092.12000 \mathrm{e}-01$ $1.00000 \mathrm{e}-05$ 1.00000e-05 1.00000e-06 1.00000e-09 1.00000e-01 $1.00000 \mathrm{e}+001.00000 \mathrm{e}+001.00000 \mathrm{e}-011.00000 \mathrm{e}-091.00000 \mathrm{e}-01$ Element: 10045 \# of layers: 7

$\mathrm{Kx} \mathrm{Ky} \mathrm{Kz}$ Ss Por

$1.30021 \mathrm{e}+011.30021 \mathrm{e}+01$ 1.30021e+00 1.00000e-09 2.12000e-01 $1.30021 \mathrm{e}+011.30021 \mathrm{e}+011.30021 \mathrm{e}+001.00000 \mathrm{e}-092.12000 \mathrm{e}-01$ $1.30021 \mathrm{e}+011.30021 \mathrm{e}+011.30021 \mathrm{e}+001.00000 \mathrm{e}-092.12000 \mathrm{e}-01$ $1.30021 \mathrm{e}+011.30021 \mathrm{e}+01$ 1.30021e+00 1.00000e-09 2.12000e-01 $1.30021 \mathrm{e}+011.30021 \mathrm{e}+011.30021 \mathrm{e}+001.00000 \mathrm{e}-092.12000 \mathrm{e}-01$ $1.00000 \mathrm{e}-05$ 1.00000e-05 1.00000e-06 1.00000e-09 1.00000e-01 
$1.00000 \mathrm{e}+001.00000 \mathrm{e}+00$ 1.00000e-01 1.00000e-09 1.00000e-01

Element: 10046 \# of layers: 7

$\mathrm{Kx} \mathrm{Ky} \mathrm{Kz}$ Ss Por

$1.30021 \mathrm{e}+01$ 1.30021e+01 1.30021e+00 1.00000e-09 2.12000e-01

$1.30021 \mathrm{e}+011.30021 \mathrm{e}+011.30021 \mathrm{e}+001.00000 \mathrm{e}-092.12000 \mathrm{e}-01$

$1.30021 \mathrm{e}+011.30021 \mathrm{e}+011.30021 \mathrm{e}+001.00000 \mathrm{e}-092.12000 \mathrm{e}-01$

$1.30021 \mathrm{e}+011.30021 \mathrm{e}+011.30021 \mathrm{e}+00$ 1.00000e-09 2.12000e-01

$1.30021 \mathrm{e}+011.30021 \mathrm{e}+011.30021 \mathrm{e}+001.00000 \mathrm{e}-092.12000 \mathrm{e}-01$

$1.00000 \mathrm{e}-051.00000 \mathrm{e}-051.00000 \mathrm{e}-061.00000 \mathrm{e}-091.00000 \mathrm{e}-01$

$1.00000 \mathrm{e}+001.00000 \mathrm{e}+001.00000 \mathrm{e}-011.00000 \mathrm{e}-091.00000 \mathrm{e}-01$

Element: 10047 \# of layers: 7

Kx Ky Kz Ss Por

$1.30021 \mathrm{e}+01$ 1.30021e+01 1.30021e+00 1.00000e-09 2.12000e-01

$1.30021 \mathrm{e}+011.30021 \mathrm{e}+011.30021 \mathrm{e}+001.00000 \mathrm{e}-092.12000 \mathrm{e}-01$

$1.30021 \mathrm{e}+011.30021 \mathrm{e}+011.30021 \mathrm{e}+001.00000 \mathrm{e}-092.12000 \mathrm{e}-01$

$1.30021 \mathrm{e}+011.30021 \mathrm{e}+011.30021 \mathrm{e}+001.00000 \mathrm{e}-092.12000 \mathrm{e}-01$

$1.30021 \mathrm{e}+011.30021 \mathrm{e}+011.30021 \mathrm{e}+001.00000 \mathrm{e}-092.12000 \mathrm{e}-01$

$1.00000 \mathrm{e}-051.00000 \mathrm{e}-051.00000 \mathrm{e}-061.00000 \mathrm{e}-091.00000 \mathrm{e}-01$

$1.00000 \mathrm{e}+001.00000 \mathrm{e}+001.00000 \mathrm{e}-01$ 1.00000e-09 1.00000e-01

Element: 10048 \# of layers: 7

$\mathrm{Kx} \mathrm{Ky} \mathrm{Kz}$ Ss Por

$1.30021 \mathrm{e}+01$ 1.30021e+01 1.30021e+00 1.00000e-09 2.12000e-01

$1.30021 \mathrm{e}+011.30021 \mathrm{e}+011.30021 \mathrm{e}+001.00000 \mathrm{e}-092.12000 \mathrm{e}-01$

$1.30021 \mathrm{e}+011.30021 \mathrm{e}+011.30021 \mathrm{e}+001.00000 \mathrm{e}-092.12000 \mathrm{e}-01$

$1.30021 \mathrm{e}+011.30021 \mathrm{e}+011.30021 \mathrm{e}+001.00000 \mathrm{e}-092.12000 \mathrm{e}-01$

$1.30021 \mathrm{e}+011.30021 \mathrm{e}+011.30021 \mathrm{e}+001.00000 \mathrm{e}-092.12000 \mathrm{e}-01$

$1.00000 \mathrm{e}-05$ 1.00000e-05 1.00000e-06 1.00000e-09 1.00000e-01

$1.00000 \mathrm{e}+001.00000 \mathrm{e}+001.00000 \mathrm{e}-01$ 1.00000e-09 1.00000e-01

Element: 10049 \# of layers: 7

$\mathrm{Kx} \mathrm{Ky} \mathrm{Kz}$ Ss Por

9.91551e+00 9.91551e+00 9.91551e-01 1.00000e-09 2.12000e-01

9.91551e+00 9.91551e+00 9.91551e-01 1.00000e-09 2.12000e-01

$9.91551 \mathrm{e}+009.91551 \mathrm{e}+00$ 9.91551e-01 1.00000e-09 2.12000e-01

9.91551e+00 9.91551e+00 9.91551e-01 1.00000e-09 2.12000e-01

9.91551e+00 9.91551e+00 9.91551e-01 1.00000e-09 2.12000e-01

1.00000e-05 1.00000e-05 1.00000e-06 1.00000e-09 1.00000e-01

$1.00000 \mathrm{e}+001.00000 \mathrm{e}+001.00000 \mathrm{e}-011.00000 \mathrm{e}-091.00000 \mathrm{e}-01$

Element: 10050 \# of layers: 7

$\mathrm{Kx} \mathrm{Ky} \mathrm{Kz}$ Ss Por

9.91551e+00 9.91551e+00 9.91551e-01 1.00000e-09 2.12000e-01

$9.91551 \mathrm{e}+00$ 9.91551e+00 9.91551e-01 1.00000e-09 2.12000e-01

$9.91551 \mathrm{e}+009.91551 \mathrm{e}+00$ 9.91551e-01 1.00000e-09 2.12000e-01

9.91551e+00 9.91551e+00 9.91551e-01 1.00000e-09 2.12000e-01

9.91551e+00 9.91551e+00 9.91551e-01 1.00000e-09 2.12000e-01

$1.00000 \mathrm{e}-05$ 1.00000e-05 1.00000e-06 1.00000e-09 1.00000e-01

$1.00000 \mathrm{e}+001.00000 \mathrm{e}+001.00000 \mathrm{e}-011.00000 \mathrm{e}-091.00000 \mathrm{e}-01$ 
Element: 10051 \# of layers: 7

Kx Ky Kz Ss Por

9.91551e+00 9.91551e+00 9.91551e-01 1.00000e-09 2.12000e-01

$9.91551 \mathrm{e}+009.91551 \mathrm{e}+00$ 9.91551e-01 1.00000e-09 2.12000e-01

$9.91551 \mathrm{e}+009.91551 \mathrm{e}+009.91551 \mathrm{e}-011.00000 \mathrm{e}-092.12000 \mathrm{e}-01$

$9.91551 \mathrm{e}+009.91551 \mathrm{e}+009.91551 \mathrm{e}-011.00000 \mathrm{e}-092.12000 \mathrm{e}-01$

$9.91551 \mathrm{e}+009.91551 \mathrm{e}+00$ 9.91551e-01 1.00000e-09 2.12000e-01

$1.00000 \mathrm{e}-05$ 1.00000e-05 1.00000e-06 1.00000e-09 1.00000e-01

$1.00000 \mathrm{e}+001.00000 \mathrm{e}+001.00000 \mathrm{e}-011.00000 \mathrm{e}-091.00000 \mathrm{e}-01$

Element: 10052 \# of layers: 7

Kx Ky Kz Ss Por

$1.30021 \mathrm{e}+011.30021 \mathrm{e}+011.30021 \mathrm{e}+00$ 1.00000e-09 2.12000e-01

$1.30021 \mathrm{e}+011.30021 \mathrm{e}+011.30021 \mathrm{e}+001.00000 \mathrm{e}-092.12000 \mathrm{e}-01$

$1.30021 \mathrm{e}+011.30021 \mathrm{e}+011.30021 \mathrm{e}+001.00000 \mathrm{e}-092.12000 \mathrm{e}-01$

$1.30021 \mathrm{e}+011.30021 \mathrm{e}+011.30021 \mathrm{e}+001.00000 \mathrm{e}-092.12000 \mathrm{e}-01$

$1.30021 \mathrm{e}+011.30021 \mathrm{e}+011.30021 \mathrm{e}+001.00000 \mathrm{e}-092.12000 \mathrm{e}-01$

$1.00000 \mathrm{e}-05$ 1.00000e-05 1.00000e-06 1.00000e-09 1.00000e-01

$1.00000 \mathrm{e}+001.00000 \mathrm{e}+001.00000 \mathrm{e}-011.00000 \mathrm{e}-091.00000 \mathrm{e}-01$

Element: 10053 \# of layers: 7

Kx Ky Kz Ss Por

$1.30021 \mathrm{e}+011.30021 \mathrm{e}+011.30021 \mathrm{e}+00$ 1.00000e-09 2.12000e-01

$1.30021 \mathrm{e}+011.30021 \mathrm{e}+011.30021 \mathrm{e}+001.00000 \mathrm{e}-092.12000 \mathrm{e}-01$

$1.30021 \mathrm{e}+011.30021 \mathrm{e}+011.30021 \mathrm{e}+001.00000 \mathrm{e}-092.12000 \mathrm{e}-01$

$1.30021 \mathrm{e}+011.30021 \mathrm{e}+011.30021 \mathrm{e}+001.00000 \mathrm{e}-092.12000 \mathrm{e}-01$

$1.30021 \mathrm{e}+011.30021 \mathrm{e}+011.30021 \mathrm{e}+001.00000 \mathrm{e}-092.12000 \mathrm{e}-01$

$1.00000 \mathrm{e}-05$ 1.00000e-05 1.00000e-06 1.00000e-09 1.00000e-01

$1.00000 \mathrm{e}+001.00000 \mathrm{e}+001.00000 \mathrm{e}-011.00000 \mathrm{e}-091.00000 \mathrm{e}-01$

Element: 10054 \# of layers: 7

Kx Ky Kz Ss Por

$1.30021 \mathrm{e}+011.30021 \mathrm{e}+011.30021 \mathrm{e}+00$ 1.00000e-09 2.12000e-01

$1.30021 \mathrm{e}+011.30021 \mathrm{e}+011.30021 \mathrm{e}+001.00000 \mathrm{e}-092.12000 \mathrm{e}-01$

$1.30021 \mathrm{e}+011.30021 \mathrm{e}+011.30021 \mathrm{e}+001.00000 \mathrm{e}-092.12000 \mathrm{e}-01$

$1.30021 \mathrm{e}+011.30021 \mathrm{e}+011.30021 \mathrm{e}+001.00000 \mathrm{e}-092.12000 \mathrm{e}-01$

$1.30021 \mathrm{e}+011.30021 \mathrm{e}+011.30021 \mathrm{e}+001.00000 \mathrm{e}-092.12000 \mathrm{e}-01$

$1.00000 \mathrm{e}-05$ 1.00000e-05 1.00000e-06 1.00000e-09 1.00000e-01

$1.00000 \mathrm{e}+001.00000 \mathrm{e}+001.00000 \mathrm{e}-011.00000 \mathrm{e}-091.00000 \mathrm{e}-01$

Element: 10055 \# of layers: 7

Kx Ky Kz Ss Por

$1.30021 \mathrm{e}+011.30021 \mathrm{e}+011.30021 \mathrm{e}+00$ 1.00000e-09 2.12000e-01

$1.30021 \mathrm{e}+011.30021 \mathrm{e}+011.30021 \mathrm{e}+001.00000 \mathrm{e}-092.12000 \mathrm{e}-01$

$1.30021 \mathrm{e}+011.30021 \mathrm{e}+011.30021 \mathrm{e}+001.00000 \mathrm{e}-092.12000 \mathrm{e}-01$

$1.30021 \mathrm{e}+011.30021 \mathrm{e}+011.30021 \mathrm{e}+001.00000 \mathrm{e}-092.12000 \mathrm{e}-01$

$1.30021 \mathrm{e}+011.30021 \mathrm{e}+011.30021 \mathrm{e}+001.00000 \mathrm{e}-092.12000 \mathrm{e}-01$

$1.00000 \mathrm{e}-05$ 1.00000e-05 1.00000e-06 1.00000e-09 1.00000e-01

$1.00000 \mathrm{e}+001.00000 \mathrm{e}+001.00000 \mathrm{e}-011.00000 \mathrm{e}-091.00000 \mathrm{e}-01$

Element: 10056 \# of layers: 7 
Kx Ky Kz Ss Por

9.91551e+00 9.91551e+00 9.91551e-01 1.00000e-09 2.12000e-01

9.91551e+00 9.91551e+00 9.91551e-01 1.00000e-09 2.12000e-01

$9.91551 \mathrm{e}+009.91551 \mathrm{e}+009.91551 \mathrm{e}-01$ 1.00000e-09 2.12000e-01

9.91551e+00 9.91551e+00 9.91551e-01 1.00000e-09 2.12000e-01

9.91551e+00 9.91551e+00 9.91551e-01 1.00000e-09 2.12000e-01

$1.00000 \mathrm{e}-05$ 1.00000e-05 1.00000e-06 1.00000e-09 1.00000e-01

$1.00000 \mathrm{e}+001.00000 \mathrm{e}+001.00000 \mathrm{e}-011.00000 \mathrm{e}-091.00000 \mathrm{e}-01$

Element: 10057 \# of layers: 7

$\mathrm{Kx} \mathrm{Ky} \mathrm{Kz}$ Ss Por

9.91551e+00 9.91551e+00 9.91551e-01 1.00000e-09 2.12000e-01

$9.91551 \mathrm{e}+009.91551 \mathrm{e}+00$ 9.91551e-01 1.00000e-09 2.12000e-01

$9.91551 \mathrm{e}+009.91551 \mathrm{e}+00$ 9.91551e-01 1.00000e-09 2.12000e-01

9.91551e+00 9.91551e+00 9.91551e-01 1.00000e-09 2.12000e-01

9.91551e+00 9.91551e+00 9.91551e-01 1.00000e-09 2.12000e-01

$1.00000 \mathrm{e}-05$ 1.00000e-05 1.00000e-06 1.00000e-09 1.00000e-01

$1.00000 \mathrm{e}+001.00000 \mathrm{e}+001.00000 \mathrm{e}-011.00000 \mathrm{e}-091.00000 \mathrm{e}-01$

Element: 10058 \# of layers: 7

$\mathrm{Kx} \mathrm{Ky} \mathrm{Kz}$ Ss Por

9.91551e+00 9.91551e+00 9.91551e-01 1.00000e-09 2.12000e-01

$9.91551 \mathrm{e}+009.91551 \mathrm{e}+009.91551 \mathrm{e}-01$ 1.00000e-09 2.12000e-01

9.91551e+00 9.91551e+00 9.91551e-01 1.00000e-09 2.12000e-01

9.91551e+00 9.91551e+00 9.91551e-01 1.00000e-09 2.12000e-01

9.91551e+00 9.91551e+00 9.91551e-01 1.00000e-09 2.12000e-01

$1.00000 \mathrm{e}-05$ 1.00000e-05 1.00000e-06 1.00000e-09 1.00000e-01

$1.00000 \mathrm{e}+001.00000 \mathrm{e}+001.00000 \mathrm{e}-011.00000 \mathrm{e}-091.00000 \mathrm{e}-01$

Element: 10059 \# of layers: 7

$\mathrm{Kx} \mathrm{Ky} \mathrm{Kz}$ Ss Por

9.91551e+00 9.91551e+00 9.91551e-01 1.00000e-09 2.12000e-01

9.91551e+00 9.91551e+00 9.91551e-01 1.00000e-09 2.12000e-01

9.91551e+00 9.91551e+00 9.91551e-01 1.00000e-09 2.12000e-01

9.91551e+00 9.91551e+00 9.91551e-01 1.00000e-09 2.12000e-01

$9.91551 \mathrm{e}+009.91551 \mathrm{e}+00$ 9.91551e-01 1.00000e-09 2.12000e-01

$1.00000 \mathrm{e}-05$ 1.00000e-05 1.00000e-06 1.00000e-09 1.00000e-01

$1.00000 \mathrm{e}+001.00000 \mathrm{e}+001.00000 \mathrm{e}-011.00000 \mathrm{e}-091.00000 \mathrm{e}-01$

Element: 10060 \# of layers: 7

Kx Ky Kz Ss Por

9.91551e+00 9.91551e+00 9.91551e-01 1.00000e-09 2.12000e-01

9.91551e+00 9.91551e+00 9.91551e-01 1.00000e-09 2.12000e-01

9.91551e+00 9.91551e+00 9.91551e-01 1.00000e-09 2.12000e-01

9.91551e+00 9.91551e+00 9.91551e-01 1.00000e-09 2.12000e-01

$9.91551 \mathrm{e}+00$ 9.91551e+00 9.91551e-01 1.00000e-09 2.12000e-01

$1.00000 \mathrm{e}-05$ 1.00000e-05 1.00000e-06 1.00000e-09 1.00000e-01

$1.00000 \mathrm{e}+001.00000 \mathrm{e}+001.00000 \mathrm{e}-01$ 1.00000e-09 1.00000e-01

Element: 10061 \# of layers: 7

Kx Ky Kz Ss Por 
9.91551e+00 9.91551e+00 9.91551e-01 1.00000e-09 2.12000e-01 9.91551e+00 9.91551e+00 9.91551e-01 1.00000e-09 2.12000e-01 9.91551e+00 9.91551e+00 9.91551e-01 1.00000e-09 2.12000e-01 $9.91551 \mathrm{e}+009.91551 \mathrm{e}+009.91551 \mathrm{e}-01$ 1.00000e-09 2.12000e-01 9.91551e+00 9.91551e+00 9.91551e-01 1.00000e-09 2.12000e-01 $1.00000 \mathrm{e}-05$ 1.00000e-05 1.00000e-06 1.00000e-09 1.00000e-01 $1.00000 \mathrm{e}+001.00000 \mathrm{e}+00$ 1.00000e-01 1.00000e-09 1.00000e-01 Element: 10062 \# of layers: 7

$\mathrm{Kx} \mathrm{Ky} \mathrm{Kz}$ Ss Por

9.91551e+00 9.91551e+00 9.91551e-01 1.00000e-09 2.12000e-01 9.91551e+00 9.91551e+00 9.91551e-01 1.00000e-09 2.12000e-01 $9.91551 \mathrm{e}+00$ 9.91551e+00 9.91551e-01 1.00000e-09 2.12000e-01 9.91551e+00 9.91551e+00 9.91551e-01 1.00000e-09 2.12000e-01 9.91551e+00 9.91551e+00 9.91551e-01 1.00000e-09 2.12000e-01 $1.00000 \mathrm{e}-05$ 1.00000e-05 1.00000e-06 1.00000e-09 1.00000e-01 $1.00000 \mathrm{e}+001.00000 \mathrm{e}+001.00000 \mathrm{e}-011.00000 \mathrm{e}-091.00000 \mathrm{e}-01$ Element: 10063 \# of layers: 7

$\mathrm{Kx} \mathrm{Ky} \mathrm{Kz}$ Ss Por

9.91551e+00 9.91551e+00 9.91551e-01 1.00000e-09 2.12000e-01 $9.91551 \mathrm{e}+00$ 9.91551e+00 9.91551e-01 1.00000e-09 2.12000e-01 $9.91551 \mathrm{e}+00$ 9.91551e+00 9.91551e-01 1.00000e-09 2.12000e-01 9.91551e+00 9.91551e+00 9.91551e-01 1.00000e-09 2.12000e-01 9.91551e+00 9.91551e+00 9.91551e-01 1.00000e-09 2.12000e-01 $1.00000 \mathrm{e}-05$ 1.00000e-05 1.00000e-06 1.00000e-09 1.00000e-01 $1.00000 \mathrm{e}+001.00000 \mathrm{e}+001.00000 \mathrm{e}-011.00000 \mathrm{e}-091.00000 \mathrm{e}-01$ Element: 10064 \# of layers: 7

$\mathrm{Kx} \mathrm{Ky} \mathrm{Kz}$ Ss Por

9.91551e+00 9.91551e+00 9.91551e-01 1.00000e-09 2.12000e-01 $9.91551 \mathrm{e}+009.91551 \mathrm{e}+00$ 9.91551e-01 1.00000e-09 2.12000e-01 9.91551e+00 9.91551e+00 9.91551e-01 1.00000e-09 2.12000e-01 9.91551e+00 9.91551e+00 9.91551e-01 1.00000e-09 2.12000e-01 9.91551e+00 9.91551e+00 9.91551e-01 1.00000e-09 2.12000e-01 $1.00000 \mathrm{e}-05$ 1.00000e-05 1.00000e-06 1.00000e-09 1.00000e-01 $1.00000 \mathrm{e}+001.00000 \mathrm{e}+00$ 1.00000e-01 1.00000e-09 1.00000e-01 Element: 10065 \# of layers: 7

$\mathrm{Kx} \mathrm{Ky} \mathrm{Kz}$ Ss Por

9.91551e+00 9.91551e+00 9.91551e-01 1.00000e-09 2.12000e-01 $9.91551 \mathrm{e}+009.91551 \mathrm{e}+00$ 9.91551e-01 1.00000e-09 2.12000e-01 9.91551e+00 9.91551e+00 9.91551e-01 1.00000e-09 2.12000e-01 9.91551e+00 9.91551e+00 9.91551e-01 1.00000e-09 2.12000e-01 $9.91551 \mathrm{e}+00$ 9.91551e+00 9.91551e-01 1.00000e-09 2.12000e-01 $1.00000 \mathrm{e}-05$ 1.00000e-05 1.00000e-06 1.00000e-09 1.00000e-01 $1.00000 \mathrm{e}+001.00000 \mathrm{e}+001.00000 \mathrm{e}-01$ 1.00000e-09 1.00000e-01 Element: 10066 \# of layers: 7

$\mathrm{Kx} \mathrm{Ky} \mathrm{Kz}$ Ss Por 9.91551e+00 9.91551e+00 9.91551e-01 1.00000e-09 2.12000e-01 
9.91551e+00 9.91551e+00 9.91551e-01 1.00000e-09 2.12000e-01 9.91551e+00 9.91551e+00 9.91551e-01 1.00000e-09 2.12000e-01 9.91551e+00 9.91551e+00 9.91551e-01 1.00000e-09 2.12000e-01 $9.91551 \mathrm{e}+009.91551 \mathrm{e}+00$ 9.91551e-01 1.00000e-09 2.12000e-01 1.00000e-05 1.00000e-05 1.00000e-06 1.00000e-09 1.00000e-01 $1.00000 \mathrm{e}+001.00000 \mathrm{e}+001.00000 \mathrm{e}-011.00000 \mathrm{e}-091.00000 \mathrm{e}-01$ Element: 10067 \# of layers: 7

Kx Ky Kz Ss Por

$1.18730 \mathrm{e}+011.18730 \mathrm{e}+011.18730 \mathrm{e}+001.00000 \mathrm{e}-092.12000 \mathrm{e}-01$ $1.18730 \mathrm{e}+01$ 1.18730e+01 1.18730e+00 1.00000e-09 2.12000e-01 $1.18730 \mathrm{e}+01$ 1.18730e+01 1.18730e+00 1.00000e-09 2.12000e-01 $1.18730 \mathrm{e}+011.18730 \mathrm{e}+011.18730 \mathrm{e}+001.00000 \mathrm{e}-092.12000 \mathrm{e}-01$ $1.18730 \mathrm{e}+011.18730 \mathrm{e}+011.18730 \mathrm{e}+001.00000 \mathrm{e}-092.12000 \mathrm{e}-01$ $1.00000 \mathrm{e}-05$ 1.00000e-05 1.00000e-06 1.00000e-09 1.00000e-01 $1.00000 \mathrm{e}+001.00000 \mathrm{e}+001.00000 \mathrm{e}-01$ 1.00000e-09 1.00000e-01 Element: 10068 \# of layers: 7

$\mathrm{Kx} \mathrm{Ky} \mathrm{Kz}$ Ss Por

$1.18730 \mathrm{e}+01$ 1.18730e+01 1.18730e+00 1.00000e-09 2.12000e-01 $1.18730 \mathrm{e}+01$ 1.18730e+01 1.18730e+00 1.00000e-09 2.12000e-01 $1.18730 \mathrm{e}+011.18730 \mathrm{e}+01$ 1.18730e+00 1.00000e-09 2.12000e-01 $1.18730 \mathrm{e}+011.18730 \mathrm{e}+011.18730 \mathrm{e}+001.00000 \mathrm{e}-092.12000 \mathrm{e}-01$ $1.18730 \mathrm{e}+011.18730 \mathrm{e}+011.18730 \mathrm{e}+001.00000 \mathrm{e}-092.12000 \mathrm{e}-01$ $1.00000 \mathrm{e}-051.00000 \mathrm{e}-051.00000 \mathrm{e}-061.00000 \mathrm{e}-091.00000 \mathrm{e}-01$ $1.00000 \mathrm{e}+001.00000 \mathrm{e}+001.00000 \mathrm{e}-011.00000 \mathrm{e}-09$ 1.00000e-01 Element: 10069 \# of layers: 7

$\mathrm{Kx} \mathrm{Ky} \mathrm{Kz}$ Ss Por

$1.18730 \mathrm{e}+01$ 1.18730e+01 1.18730e+00 1.00000e-09 2.12000e-01 $1.18730 \mathrm{e}+011.18730 \mathrm{e}+011.18730 \mathrm{e}+001.00000 \mathrm{e}-092.12000 \mathrm{e}-01$ $1.18730 \mathrm{e}+011.18730 \mathrm{e}+011.18730 \mathrm{e}+001.00000 \mathrm{e}-092.12000 \mathrm{e}-01$ $1.18730 \mathrm{e}+011.18730 \mathrm{e}+011.18730 \mathrm{e}+001.00000 \mathrm{e}-092.12000 \mathrm{e}-01$ $1.18730 \mathrm{e}+011.18730 \mathrm{e}+011.18730 \mathrm{e}+001.00000 \mathrm{e}-092.12000 \mathrm{e}-01$ $1.00000 \mathrm{e}-05$ 1.00000e-05 1.00000e-06 1.00000e-09 1.00000e-01 $1.00000 \mathrm{e}+001.00000 \mathrm{e}+001.00000 \mathrm{e}-011.00000 \mathrm{e}-091.00000 \mathrm{e}-01$ Element: 10070 \# of layers: 7

$\mathrm{Kx} \mathrm{Ky} \mathrm{Kz}$ Ss Por

9.91551e+00 9.91551e+00 9.91551e-01 1.00000e-09 2.12000e-01 $9.91551 \mathrm{e}+009.91551 \mathrm{e}+00$ 9.91551e-01 1.00000e-09 2.12000e-01 $9.91551 \mathrm{e}+009.91551 \mathrm{e}+00$ 9.91551e-01 1.00000e-09 2.12000e-01 9.91551e+00 9.91551e+00 9.91551e-01 1.00000e-09 2.12000e-01 9.91551e+00 9.91551e+00 9.91551e-01 1.00000e-09 2.12000e-01 1.00000e-05 1.00000e-05 1.00000e-06 1.00000e-09 1.00000e-01 $1.00000 \mathrm{e}+001.00000 \mathrm{e}+001.00000 \mathrm{e}-011.00000 \mathrm{e}-091.00000 \mathrm{e}-01$ Element: 10071 \# of layers: 7

$\mathrm{Kx} \mathrm{Ky} \mathrm{Kz}$ Ss Por

9.91551e+00 9.91551e+00 9.91551e-01 1.00000e-09 2.12000e-01 $9.91551 \mathrm{e}+00$ 9.91551e+00 9.91551e-01 1.00000e-09 2.12000e-01 
9.91551e+00 9.91551e+00 9.91551e-01 1.00000e-09 2.12000e-01 9.91551e+00 9.91551e+00 9.91551e-01 1.00000e-09 2.12000e-01 9.91551e+00 9.91551e+00 9.91551e-01 1.00000e-09 2.12000e-01 $1.00000 \mathrm{e}-05$ 1.00000e-05 1.00000e-06 1.00000e-09 1.00000e-01 $1.00000 \mathrm{e}+001.00000 \mathrm{e}+001.00000 \mathrm{e}-01$ 1.00000e-09 1.00000e-01 Element: 10072 \# of layers: 7

$\mathrm{Kx} \mathrm{Ky} \mathrm{Kz}$ Ss Por

9.91551e+00 9.91551e+00 9.91551e-01 1.00000e-09 2.12000e-01 9.91551e+00 9.91551e+00 9.91551e-01 1.00000e-09 2.12000e-01 9.91551e+00 9.91551e+00 9.91551e-01 1.00000e-09 2.12000e-01 9.91551e+00 9.91551e+00 9.91551e-01 1.00000e-09 2.12000e-01 $9.91551 \mathrm{e}+009.91551 \mathrm{e}+00$ 9.91551e-01 1.00000e-09 2.12000e-01 $1.00000 \mathrm{e}-05$ 1.00000e-05 1.00000e-06 1.00000e-09 1.00000e-01 $1.00000 \mathrm{e}+001.00000 \mathrm{e}+00$ 1.00000e-01 1.00000e-09 1.00000e-01 Element: 10073 \# of layers: 7

Kx Ky Kz Ss Por

9.91551e+00 9.91551e+00 9.91551e-01 1.00000e-09 2.12000e-01 9.91551e+00 9.91551e+00 9.91551e-01 1.00000e-09 2.12000e-01 9.91551e+00 9.91551e+00 9.91551e-01 1.00000e-09 2.12000e-01 $9.91551 \mathrm{e}+00$ 9.91551e+00 9.91551e-01 1.00000e-09 2.12000e-01 $9.91551 \mathrm{e}+009.91551 \mathrm{e}+00$ 9.91551e-01 1.00000e-09 2.12000e-01 $1.00000 \mathrm{e}-05$ 1.00000e-05 1.00000e-06 1.00000e-09 1.00000e-01 $1.00000 \mathrm{e}+001.00000 \mathrm{e}+001.00000 \mathrm{e}-01$ 1.00000e-09 1.00000e-01 Element: 10074 \# of layers: 7

Kx Ky Kz Ss Por

$1.18730 \mathrm{e}+011.18730 \mathrm{e}+011.18730 \mathrm{e}+001.00000 \mathrm{e}-092.12000 \mathrm{e}-01$ $1.18730 \mathrm{e}+011.18730 \mathrm{e}+011.18730 \mathrm{e}+001.00000 \mathrm{e}-092.12000 \mathrm{e}-01$ $1.18730 \mathrm{e}+011.18730 \mathrm{e}+011.18730 \mathrm{e}+001.00000 \mathrm{e}-092.12000 \mathrm{e}-01$ $1.18730 \mathrm{e}+011.18730 \mathrm{e}+011.18730 \mathrm{e}+001.00000 \mathrm{e}-092.12000 \mathrm{e}-01$ $1.18730 \mathrm{e}+011.18730 \mathrm{e}+01$ 1.18730e+00 1.00000e-09 2.12000e-01 $1.00000 \mathrm{e}-05$ 1.00000e-05 1.00000e-06 1.00000e-09 1.00000e-01 $1.00000 \mathrm{e}+001.00000 \mathrm{e}+001.00000 \mathrm{e}-01$ 1.00000e-09 1.00000e-01 Element: 10075 \# of layers: 7

$\mathrm{Kx} \mathrm{Ky} \mathrm{Kz}$ Ss Por

$1.18730 \mathrm{e}+01$ 1.18730e+01 1.18730e+00 1.00000e-09 2.12000e-01 $1.18730 \mathrm{e}+011.18730 \mathrm{e}+01$ 1.18730e+00 1.00000e-09 2.12000e-01 $1.18730 \mathrm{e}+011.18730 \mathrm{e}+011.18730 \mathrm{e}+001.00000 \mathrm{e}-092.12000 \mathrm{e}-01$ $1.18730 \mathrm{e}+011.18730 \mathrm{e}+011.18730 \mathrm{e}+001.00000 \mathrm{e}-092.12000 \mathrm{e}-01$ $1.18730 \mathrm{e}+011.18730 \mathrm{e}+011.18730 \mathrm{e}+001.00000 \mathrm{e}-092.12000 \mathrm{e}-01$ $1.00000 \mathrm{e}-051.00000 \mathrm{e}-05$ 1.00000e-06 1.00000e-09 1.00000e-01 $1.00000 \mathrm{e}+001.00000 \mathrm{e}+001.00000 \mathrm{e}-011.00000 \mathrm{e}-091.00000 \mathrm{e}-01$ Element: 10076 \# of layers: 7

$\mathrm{Kx} \mathrm{Ky} \mathrm{Kz}$ Ss Por

1.18730e+01 1.18730e+01 1.18730e+00 1.00000e-09 2.12000e-01 $1.18730 \mathrm{e}+01$ 1.18730e+01 1.18730e+00 1.00000e-09 2.12000e-01 $1.18730 \mathrm{e}+011.18730 \mathrm{e}+01$ 1.18730e+00 1.00000e-09 2.12000e-01 
$1.18730 \mathrm{e}+011.18730 \mathrm{e}+01$ 1.18730e+00 1.00000e-09 2.12000e-01 $1.18730 \mathrm{e}+01$ 1.18730e+01 1.18730e+00 1.00000e-09 2.12000e-01 $1.00000 \mathrm{e}-05$ 1.00000e-05 1.00000e-06 1.00000e-09 1.00000e-01 $1.00000 \mathrm{e}+001.00000 \mathrm{e}+001.00000 \mathrm{e}-011.00000 \mathrm{e}-091.00000 \mathrm{e}-01$ Element: 10077 \# of layers: 7

$\mathrm{Kx} \mathrm{Ky} \mathrm{Kz}$ Ss Por

$1.18730 \mathrm{e}+011.18730 \mathrm{e}+01$ 1.18730e+00 1.00000e-09 2.12000e-01 $1.18730 \mathrm{e}+011.18730 \mathrm{e}+011.18730 \mathrm{e}+001.00000 \mathrm{e}-092.12000 \mathrm{e}-01$ $1.18730 \mathrm{e}+011.18730 \mathrm{e}+011.18730 \mathrm{e}+001.00000 \mathrm{e}-092.12000 \mathrm{e}-01$ $1.18730 \mathrm{e}+011.18730 \mathrm{e}+011.18730 \mathrm{e}+001.00000 \mathrm{e}-092.12000 \mathrm{e}-01$ $1.18730 \mathrm{e}+011.18730 \mathrm{e}+011.18730 \mathrm{e}+001.00000 \mathrm{e}-092.12000 \mathrm{e}-01$ $1.00000 \mathrm{e}-05$ 1.00000e-05 1.00000e-06 1.00000e-09 1.00000e-01 $1.00000 \mathrm{e}+001.00000 \mathrm{e}+001.00000 \mathrm{e}-011.00000 \mathrm{e}-09$ 1.00000e-01 Element: 10078 \# of layers: 7

$\mathrm{Kx} \mathrm{Ky} \mathrm{Kz}$ Ss Por

$1.18730 \mathrm{e}+01$ 1.18730e+01 1.18730e+00 1.00000e-09 2.12000e-01 $1.18730 \mathrm{e}+011.18730 \mathrm{e}+011.18730 \mathrm{e}+001.00000 \mathrm{e}-092.12000 \mathrm{e}-01$ $1.18730 \mathrm{e}+011.18730 \mathrm{e}+011.18730 \mathrm{e}+001.00000 \mathrm{e}-092.12000 \mathrm{e}-01$ $1.18730 \mathrm{e}+011.18730 \mathrm{e}+011.18730 \mathrm{e}+001.00000 \mathrm{e}-092.12000 \mathrm{e}-01$ $1.18730 \mathrm{e}+011.18730 \mathrm{e}+011.18730 \mathrm{e}+001.00000 \mathrm{e}-092.12000 \mathrm{e}-01$ $1.00000 \mathrm{e}-05$ 1.00000e-05 1.00000e-06 1.00000e-09 1.00000e-01 $1.00000 \mathrm{e}+001.00000 \mathrm{e}+001.00000 \mathrm{e}-011.00000 \mathrm{e}-09$ 1.00000e-01 Element: 10079 \# of layers: 7

Kx Ky Kz Ss Por

$1.18730 \mathrm{e}+01$ 1.18730e+01 1.18730e+00 1.00000e-09 2.12000e-01 $1.18730 \mathrm{e}+011.18730 \mathrm{e}+011.18730 \mathrm{e}+001.00000 \mathrm{e}-092.12000 \mathrm{e}-01$ $1.18730 \mathrm{e}+011.18730 \mathrm{e}+01$ 1.18730e+00 1.00000e-09 2.12000e-01 $1.18730 \mathrm{e}+01$ 1.18730e+01 1.18730e+00 1.00000e-09 2.12000e-01 $1.18730 \mathrm{e}+011.18730 \mathrm{e}+011.18730 \mathrm{e}+001.00000 \mathrm{e}-092.12000 \mathrm{e}-01$ $1.00000 \mathrm{e}-05$ 1.00000e-05 1.00000e-06 1.00000e-09 1.00000e-01 $1.00000 \mathrm{e}+001.00000 \mathrm{e}+001.00000 \mathrm{e}-01$ 1.00000e-09 1.00000e-01 Element: 10080 \# of layers: 7

Kx Ky Kz Ss Por

$1.18730 \mathrm{e}+01$ 1.18730e+01 1.18730e+00 1.00000e-09 2.12000e-01 $1.18730 \mathrm{e}+011.18730 \mathrm{e}+01$ 1.18730e+00 1.00000e-09 2.12000e-01 $1.18730 \mathrm{e}+011.18730 \mathrm{e}+011.18730 \mathrm{e}+001.00000 \mathrm{e}-092.12000 \mathrm{e}-01$ $1.18730 \mathrm{e}+011.18730 \mathrm{e}+011.18730 \mathrm{e}+001.00000 \mathrm{e}-092.12000 \mathrm{e}-01$ $1.18730 \mathrm{e}+011.18730 \mathrm{e}+011.18730 \mathrm{e}+001.00000 \mathrm{e}-092.12000 \mathrm{e}-01$ $1.00000 \mathrm{e}-05$ 1.00000e-05 1.00000e-06 1.00000e-09 1.00000e-01 $1.00000 \mathrm{e}+001.00000 \mathrm{e}+001.00000 \mathrm{e}-01$ 1.00000e-09 1.00000e-01 Element: 10081 \# of layers: 7

Kx Ky Kz Ss Por

$1.18730 \mathrm{e}+01$ 1.18730e+01 1.18730e+00 1.00000e-09 2.12000e-01 $1.18730 \mathrm{e}+01$ 1.18730e+01 1.18730e+00 1.00000e-09 2.12000e-01 $1.18730 \mathrm{e}+01$ 1.18730e+01 1.18730e+00 1.00000e-09 2.12000e-01 $1.18730 \mathrm{e}+01$ 1.18730e+01 1.18730e+00 1.00000e-09 2.12000e-01 
$1.18730 \mathrm{e}+011.18730 \mathrm{e}+01$ 1.18730e+00 1.00000e-09 2.12000e-01 $1.00000 \mathrm{e}-05$ 1.00000e-05 1.00000e-06 1.00000e-09 1.00000e-01

$1.00000 \mathrm{e}+001.00000 \mathrm{e}+001.00000 \mathrm{e}-011.00000 \mathrm{e}-09$ 1.00000e-01

Element: 10082 \# of layers: 7

$\mathrm{Kx} \mathrm{Ky} \mathrm{Kz}$ Ss Por

$1.18730 \mathrm{e}+01$ 1.18730e+01 1.18730e+00 1.00000e-09 2.12000e-01

$1.18730 \mathrm{e}+01$ 1.18730e+01 1.18730e+00 1.00000e-09 2.12000e-01

$1.18730 \mathrm{e}+011.18730 \mathrm{e}+011.18730 \mathrm{e}+001.00000 \mathrm{e}-092.12000 \mathrm{e}-01$

$1.18730 \mathrm{e}+011.18730 \mathrm{e}+011.18730 \mathrm{e}+001.00000 \mathrm{e}-092.12000 \mathrm{e}-01$

$1.18730 \mathrm{e}+011.18730 \mathrm{e}+011.18730 \mathrm{e}+001.00000 \mathrm{e}-092.12000 \mathrm{e}-01$

$1.00000 \mathrm{e}-05$ 1.00000e-05 1.00000e-06 1.00000e-09 1.00000e-01

$1.00000 \mathrm{e}+001.00000 \mathrm{e}+001.00000 \mathrm{e}-01$ 1.00000e-09 1.00000e-01

Element: 10083 \# of layers: 7

$\mathrm{Kx} \mathrm{Ky} \mathrm{Kz}$ Ss Por

$1.18730 \mathrm{e}+01$ 1.18730e+01 1.18730e+00 1.00000e-09 2.12000e-01

$1.18730 \mathrm{e}+011.18730 \mathrm{e}+011.18730 \mathrm{e}+001.00000 \mathrm{e}-092.12000 \mathrm{e}-01$

$1.18730 \mathrm{e}+011.18730 \mathrm{e}+011.18730 \mathrm{e}+001.00000 \mathrm{e}-092.12000 \mathrm{e}-01$

$1.18730 \mathrm{e}+011.18730 \mathrm{e}+011.18730 \mathrm{e}+001.00000 \mathrm{e}-092.12000 \mathrm{e}-01$

$1.18730 \mathrm{e}+01$ 1.18730e+01 1.18730e+00 1.00000e-09 2.12000e-01

$1.00000 \mathrm{e}-05$ 1.00000e-05 1.00000e-06 1.00000e-09 1.00000e-01

$1.00000 \mathrm{e}+001.00000 \mathrm{e}+001.00000 \mathrm{e}-011.00000 \mathrm{e}-091.00000 \mathrm{e}-01$

Element: 10084 \# of layers: 8

$\mathrm{Kx} \mathrm{Ky} \mathrm{Kz}$ Ss Por

5.00000e-04 5.00000e-04 5.00000e-05 1.00000e-09 1.00000e-01

$1.24909 \mathrm{e}+011.24909 \mathrm{e}+01$ 1.24909e+00 1.00000e-09 2.12000e-01

$1.24909 \mathrm{e}+01$ 1.24909e+01 1.24909e+00 1.00000e-09 2.12000e-01

$1.24909 \mathrm{e}+01$ 1.24909e+01 1.24909e+00 1.00000e-09 2.12000e-01

$1.24909 \mathrm{e}+01$ 1.24909e+01 1.24909e+00 1.00000e-09 2.12000e-01

$1.24909 \mathrm{e}+01$ 1.24909e+01 1.24909e+00 1.00000e-09 2.12000e-01

$1.00000 \mathrm{e}-051.00000 \mathrm{e}-051.00000 \mathrm{e}-061.00000 \mathrm{e}-091.00000 \mathrm{e}-01$

$1.00000 \mathrm{e}+001.00000 \mathrm{e}+00$ 1.00000e-01 1.00000e-09 1.00000e-01

Element: 10085 \# of layers: 8

$\mathrm{Kx} \mathrm{Ky} \mathrm{Kz}$ Ss Por

5.00000e-04 5.00000e-04 5.00000e-05 1.00000e-09 1.00000e-01

$1.24909 \mathrm{e}+01$ 1.24909e+01 1.24909e+00 1.00000e-09 2.12000e-01

$1.24909 \mathrm{e}+01$ 1.24909e+01 1.24909e+00 1.00000e-09 2.12000e-01

$1.24909 \mathrm{e}+011.24909 \mathrm{e}+011.24909 \mathrm{e}+001.00000 \mathrm{e}-092.12000 \mathrm{e}-01$

$1.24909 \mathrm{e}+011.24909 \mathrm{e}+011.24909 \mathrm{e}+001.00000 \mathrm{e}-092.12000 \mathrm{e}-01$

$1.24909 \mathrm{e}+01$ 1.24909e+01 1.24909e+00 1.00000e-09 2.12000e-01

$1.00000 \mathrm{e}-05$ 1.00000e-05 1.00000e-06 1.00000e-09 1.00000e-01

$1.00000 \mathrm{e}+001.00000 \mathrm{e}+001.00000 \mathrm{e}-011.00000 \mathrm{e}-091.00000 \mathrm{e}-01$

Element: 10086 \# of layers: 8

$\mathrm{Kx} \mathrm{Ky} \mathrm{Kz}$ Ss Por

5.00000e-04 5.00000e-04 5.00000e-05 1.00000e-09 1.00000e-01

$1.24909 \mathrm{e}+01$ 1.24909e+01 1.24909e+00 1.00000e-09 2.12000e-01

$1.24909 \mathrm{e}+011.24909 \mathrm{e}+01$ 1.24909e+00 1.00000e-09 2.12000e-01 
$1.24909 \mathrm{e}+01$ 1.24909e+01 1.24909e+00 1.00000e-09 2.12000e-01 $1.24909 \mathrm{e}+01$ 1.24909e+01 1.24909e+00 1.00000e-09 2.12000e-01 $1.24909 \mathrm{e}+01$ 1.24909e+01 1.24909e+00 1.00000e-09 2.12000e-01 $1.00000 \mathrm{e}-05$ 1.00000e-05 1.00000e-06 1.00000e-09 1.00000e-01 $1.00000 \mathrm{e}+001.00000 \mathrm{e}+001.00000 \mathrm{e}-01$ 1.00000e-09 1.00000e-01 Element: 10087 \# of layers: 7

$\mathrm{Kx} \mathrm{Ky} \mathrm{Kz}$ Ss Por

$1.24909 \mathrm{e}+01$ 1.24909e+01 1.24909e+00 1.00000e-09 2.12000e-01 $1.24909 \mathrm{e}+01$ 1.24909e+01 1.24909e+00 1.00000e-09 2.12000e-01 $1.24909 \mathrm{e}+01$ 1.24909e+01 1.24909e+00 1.00000e-09 2.12000e-01 $1.24909 \mathrm{e}+01$ 1.24909e+01 1.24909e+00 1.00000e-09 2.12000e-01 $1.24909 \mathrm{e}+011.24909 \mathrm{e}+011.24909 \mathrm{e}+001.00000 \mathrm{e}-092.12000 \mathrm{e}-01$ $1.00000 \mathrm{e}-05$ 1.00000e-05 1.00000e-06 1.00000e-09 1.00000e-01 $1.00000 \mathrm{e}+001.00000 \mathrm{e}+001.00000 \mathrm{e}-011.00000 \mathrm{e}-09$ 1.00000e-01 Element: 10088 \# of layers: 7

Kx Ky Kz Ss Por

$1.24909 \mathrm{e}+01$ 1.24909e+01 1.24909e+00 1.00000e-09 2.12000e-01 $1.24909 \mathrm{e}+01$ 1.24909e+01 1.24909e+00 1.00000e-09 2.12000e-01 $1.24909 \mathrm{e}+01$ 1.24909e+01 1.24909e+00 1.00000e-09 2.12000e-01 $1.24909 \mathrm{e}+01$ 1.24909e+01 1.24909e+00 1.00000e-09 2.12000e-01 $1.24909 \mathrm{e}+011.24909 \mathrm{e}+01 \quad 1.24909 \mathrm{e}+001.00000 \mathrm{e}-092.12000 \mathrm{e}-01$ $1.00000 \mathrm{e}-05$ 1.00000e-05 1.00000e-06 1.00000e-09 1.00000e-01 $1.00000 \mathrm{e}+001.00000 \mathrm{e}+001.00000 \mathrm{e}-01$ 1.00000e-09 1.00000e-01 Element: 10089 \# of layers: 7

Kx Ky Kz Ss Por

$1.18730 \mathrm{e}+011.18730 \mathrm{e}+011.18730 \mathrm{e}+001.00000 \mathrm{e}-092.12000 \mathrm{e}-01$ $1.18730 \mathrm{e}+01$ 1.18730e+01 1.18730e+00 1.00000e-09 2.12000e-01 $1.18730 \mathrm{e}+011.18730 \mathrm{e}+011.18730 \mathrm{e}+001.00000 \mathrm{e}-092.12000 \mathrm{e}-01$ $1.18730 \mathrm{e}+011.18730 \mathrm{e}+011.18730 \mathrm{e}+001.00000 \mathrm{e}-092.12000 \mathrm{e}-01$ $1.18730 \mathrm{e}+011.18730 \mathrm{e}+01$ 1.18730e+00 1.00000e-09 2.12000e-01 $1.00000 \mathrm{e}-05$ 1.00000e-05 1.00000e-06 1.00000e-09 1.00000e-01 $1.00000 \mathrm{e}+001.00000 \mathrm{e}+001.00000 \mathrm{e}-011.00000 \mathrm{e}-091.00000 \mathrm{e}-01$ Element: 10090 \# of layers: 7

$\mathrm{Kx} \mathrm{Ky} \mathrm{Kz}$ Ss Por

$1.18730 \mathrm{e}+01$ 1.18730e+01 1.18730e+00 1.00000e-09 2.12000e-01

$1.18730 \mathrm{e}+011.18730 \mathrm{e}+01$ 1.18730e+00 1.00000e-09 2.12000e-01

$1.18730 \mathrm{e}+011.18730 \mathrm{e}+011.18730 \mathrm{e}+001.00000 \mathrm{e}-092.12000 \mathrm{e}-01$

$1.18730 \mathrm{e}+011.18730 \mathrm{e}+011.18730 \mathrm{e}+001.00000 \mathrm{e}-092.12000 \mathrm{e}-01$

$1.18730 \mathrm{e}+011.18730 \mathrm{e}+011.18730 \mathrm{e}+001.00000 \mathrm{e}-092.12000 \mathrm{e}-01$ $1.00000 \mathrm{e}-05$ 1.00000e-05 1.00000e-06 1.00000e-09 1.00000e-01 $1.00000 \mathrm{e}+001.00000 \mathrm{e}+001.00000 \mathrm{e}-011.00000 \mathrm{e}-091.00000 \mathrm{e}-01$ Element: 10091 \# of layers: 7

$\mathrm{Kx} \mathrm{Ky} \mathrm{Kz}$ Ss Por

1.24909e+01 1.24909e+01 1.24909e+00 1.00000e-09 2.12000e-01 $1.24909 \mathrm{e}+01$ 1.24909e+01 1.24909e+00 1.00000e-09 2.12000e-01 $1.24909 \mathrm{e}+011.24909 \mathrm{e}+01$ 1.24909e+00 1.00000e-09 2.12000e-01 
$1.24909 \mathrm{e}+01$ 1.24909e+01 1.24909e+00 1.00000e-09 2.12000e-01 $1.24909 \mathrm{e}+01$ 1.24909e+01 1.24909e+00 1.00000e-09 2.12000e-01 $1.00000 \mathrm{e}-05$ 1.00000e-05 1.00000e-06 1.00000e-09 1.00000e-01 $1.00000 \mathrm{e}+001.00000 \mathrm{e}+001.00000 \mathrm{e}-011.00000 \mathrm{e}-091.00000 \mathrm{e}-01$ Element: 10092 \# of layers: 7

$\mathrm{Kx} \mathrm{Ky} \mathrm{Kz}$ Ss Por

$1.24909 \mathrm{e}+01$ 1.24909e+01 1.24909e+00 1.00000e-09 2.12000e-01 $1.24909 \mathrm{e}+01$ 1.24909e+01 1.24909e+00 1.00000e-09 2.12000e-01 $1.24909 \mathrm{e}+01$ 1.24909e+01 1.24909e+00 1.00000e-09 2.12000e-01 $1.24909 \mathrm{e}+01$ 1.24909e+01 1.24909e+00 1.00000e-09 2.12000e-01 $1.24909 \mathrm{e}+01$ 1.24909e+01 1.24909e+00 1.00000e-09 2.12000e-01 $1.00000 \mathrm{e}-05$ 1.00000e-05 1.00000e-06 1.00000e-09 1.00000e-01 $1.00000 \mathrm{e}+001.00000 \mathrm{e}+001.00000 \mathrm{e}-011.00000 \mathrm{e}-09$ 1.00000e-01 Element: 10093 \# of layers: 7

$\mathrm{Kx} \mathrm{Ky} \mathrm{Kz}$ Ss Por

$1.30021 \mathrm{e}+01$ 1.30021e+01 1.30021e+00 1.00000e-09 2.12000e-01 $1.30021 \mathrm{e}+011.30021 \mathrm{e}+011.30021 \mathrm{e}+001.00000 \mathrm{e}-092.12000 \mathrm{e}-01$ $1.30021 \mathrm{e}+011.30021 \mathrm{e}+011.30021 \mathrm{e}+001.00000 \mathrm{e}-092.12000 \mathrm{e}-01$ $1.30021 \mathrm{e}+011.30021 \mathrm{e}+011.30021 \mathrm{e}+001.00000 \mathrm{e}-092.12000 \mathrm{e}-01$ $1.30021 \mathrm{e}+011.30021 \mathrm{e}+011.30021 \mathrm{e}+001.00000 \mathrm{e}-092.12000 \mathrm{e}-01$ $1.00000 \mathrm{e}-05$ 1.00000e-05 1.00000e-06 1.00000e-09 1.00000e-01 $1.00000 \mathrm{e}+001.00000 \mathrm{e}+001.00000 \mathrm{e}-011.00000 \mathrm{e}-091.00000 \mathrm{e}-01$ Element: 10094 \# of layers: 7

Kx Ky Kz Ss Por

$1.30021 \mathrm{e}+011.30021 \mathrm{e}+011.30021 \mathrm{e}+00$ 1.00000e-09 2.12000e-01 $1.30021 \mathrm{e}+011.30021 \mathrm{e}+011.30021 \mathrm{e}+001.00000 \mathrm{e}-092.12000 \mathrm{e}-01$ $1.30021 \mathrm{e}+011.30021 \mathrm{e}+011.30021 \mathrm{e}+001.00000 \mathrm{e}-092.12000 \mathrm{e}-01$ $1.30021 \mathrm{e}+011.30021 \mathrm{e}+011.30021 \mathrm{e}+001.00000 \mathrm{e}-092.12000 \mathrm{e}-01$ $1.30021 \mathrm{e}+011.30021 \mathrm{e}+011.30021 \mathrm{e}+001.00000 \mathrm{e}-092.12000 \mathrm{e}-01$ $1.00000 \mathrm{e}-05$ 1.00000e-05 1.00000e-06 1.00000e-09 1.00000e-01 $1.00000 \mathrm{e}+001.00000 \mathrm{e}+001.00000 \mathrm{e}-01$ 1.00000e-09 1.00000e-01 Element: 10095 \# of layers: 7

Kx Ky Kz Ss Por

$1.30021 \mathrm{e}+011.30021 \mathrm{e}+011.30021 \mathrm{e}+001.00000 \mathrm{e}-092.12000 \mathrm{e}-01$ $1.30021 \mathrm{e}+011.30021 \mathrm{e}+011.30021 \mathrm{e}+001.00000 \mathrm{e}-092.12000 \mathrm{e}-01$ $1.30021 \mathrm{e}+011.30021 \mathrm{e}+011.30021 \mathrm{e}+001.00000 \mathrm{e}-092.12000 \mathrm{e}-01$ $1.30021 \mathrm{e}+011.30021 \mathrm{e}+011.30021 \mathrm{e}+001.00000 \mathrm{e}-092.12000 \mathrm{e}-01$ $1.30021 \mathrm{e}+011.30021 \mathrm{e}+011.30021 \mathrm{e}+001.00000 \mathrm{e}-092.12000 \mathrm{e}-01$ $1.00000 \mathrm{e}-05$ 1.00000e-05 1.00000e-06 1.00000e-09 1.00000e-01 $1.00000 \mathrm{e}+001.00000 \mathrm{e}+001.00000 \mathrm{e}-01$ 1.00000e-09 1.00000e-01 Element: 10096 \# of layers: 7

$\mathrm{Kx} \mathrm{Ky} \mathrm{Kz}$ Ss Por

9.91551e+00 9.91551e+00 9.91551e-01 1.00000e-09 2.12000e-01 9.91551e+00 9.91551e+00 9.91551e-01 1.00000e-09 2.12000e-01 $9.91551 \mathrm{e}+00$ 9.91551e+00 9.91551e-01 1.00000e-09 2.12000e-01 $9.91551 \mathrm{e}+00$ 9.91551e+00 9.91551e-01 1.00000e-09 2.12000e-01 
9.91551e+00 9.91551e+00 9.91551e-01 1.00000e-09 2.12000e-01 $1.00000 \mathrm{e}-05$ 1.00000e-05 1.00000e-06 1.00000e-09 1.00000e-01

$1.00000 \mathrm{e}+001.00000 \mathrm{e}+001.00000 \mathrm{e}-01$ 1.00000e-09 1.00000e-01

Element: 10097 \# of layers: 7

$\mathrm{Kx} \mathrm{Ky} \mathrm{Kz}$ Ss Por

9.91551e+00 9.91551e+00 9.91551e-01 1.00000e-09 2.12000e-01

9.91551e+00 9.91551e+00 9.91551e-01 1.00000e-09 2.12000e-01

$9.91551 \mathrm{e}+009.91551 \mathrm{e}+009.91551 \mathrm{e}-01$ 1.00000e-09 2.12000e-01

$9.91551 \mathrm{e}+00$ 9.91551e+00 9.91551e-01 1.00000e-09 2.12000e-01

9.91551e+00 9.91551e+00 9.91551e-01 1.00000e-09 2.12000e-01

$1.00000 \mathrm{e}-05$ 1.00000e-05 1.00000e-06 1.00000e-09 1.00000e-01

$1.00000 \mathrm{e}+001.00000 \mathrm{e}+001.00000 \mathrm{e}-01$ 1.00000e-09 1.00000e-01

Element: 10098 \# of layers: 7

$\mathrm{Kx} \mathrm{Ky} \mathrm{Kz}$ Ss Por

$1.18730 \mathrm{e}+01$ 1.18730e+01 1.18730e+00 1.00000e-09 2.12000e-01

$1.18730 \mathrm{e}+011.18730 \mathrm{e}+011.18730 \mathrm{e}+001.00000 \mathrm{e}-092.12000 \mathrm{e}-01$

$1.18730 \mathrm{e}+011.18730 \mathrm{e}+011.18730 \mathrm{e}+001.00000 \mathrm{e}-092.12000 \mathrm{e}-01$

$1.18730 \mathrm{e}+011.18730 \mathrm{e}+011.18730 \mathrm{e}+001.00000 \mathrm{e}-092.12000 \mathrm{e}-01$

$1.18730 \mathrm{e}+01$ 1.18730e+01 1.18730e+00 1.00000e-09 2.12000e-01

$1.00000 \mathrm{e}-05$ 1.00000e-05 1.00000e-06 1.00000e-09 1.00000e-01

$1.00000 \mathrm{e}+001.00000 \mathrm{e}+001.00000 \mathrm{e}-011.00000 \mathrm{e}-091.00000 \mathrm{e}-01$

Element: 10099 \# of layers: 7

$\mathrm{Kx} \mathrm{Ky} \mathrm{Kz}$ Ss Por

$1.24909 \mathrm{e}+01$ 1.24909e+01 1.24909e+00 1.00000e-09 2.12000e-01

$1.24909 \mathrm{e}+011.24909 \mathrm{e}+01$ 1.24909e+00 1.00000e-09 2.12000e-01

$1.24909 \mathrm{e}+01$ 1.24909e+01 1.24909e+00 1.00000e-09 2.12000e-01

$1.24909 \mathrm{e}+01$ 1.24909e+01 1.24909e+00 1.00000e-09 2.12000e-01

$1.24909 \mathrm{e}+01$ 1.24909e+01 1.24909e+00 1.00000e-09 2.12000e-01

$1.00000 \mathrm{e}-05$ 1.00000e-05 1.00000e-06 1.00000e-09 1.00000e-01

$1.00000 \mathrm{e}+001.00000 \mathrm{e}+001.00000 \mathrm{e}-011.00000 \mathrm{e}-091.00000 \mathrm{e}-01$

Element: 10100 \# of layers: 7

$\mathrm{Kx} \mathrm{Ky} \mathrm{Kz}$ Ss Por

$1.30021 \mathrm{e}+01$ 1.30021e+01 1.30021e+00 1.00000e-09 2.12000e-01

$1.30021 \mathrm{e}+011.30021 \mathrm{e}+011.30021 \mathrm{e}+001.00000 \mathrm{e}-092.12000 \mathrm{e}-01$

$1.30021 \mathrm{e}+011.30021 \mathrm{e}+011.30021 \mathrm{e}+001.00000 \mathrm{e}-092.12000 \mathrm{e}-01$

$1.30021 \mathrm{e}+011.30021 \mathrm{e}+011.30021 \mathrm{e}+001.00000 \mathrm{e}-092.12000 \mathrm{e}-01$

$1.30021 \mathrm{e}+011.30021 \mathrm{e}+011.30021 \mathrm{e}+001.00000 \mathrm{e}-092.12000 \mathrm{e}-01$

$1.00000 \mathrm{e}-05$ 1.00000e-05 1.00000e-06 1.00000e-09 1.00000e-01

$1.00000 \mathrm{e}+001.00000 \mathrm{e}+001.00000 \mathrm{e}-011.00000 \mathrm{e}-091.00000 \mathrm{e}-01$

Element: 10101 \# of layers: 7

Kx Ky Kz Ss Por

8.73874e+00 8.73874e+00 8.73874e-01 1.00000e-09 2.12000e-01

8.73874e+00 8.73874e+00 8.73874e-01 1.00000e-09 2.12000e-01

$8.73874 \mathrm{e}+00$ 8.73874e+00 8.73874e-01 1.00000e-09 2.12000e-01

$8.73874 \mathrm{e}+008.73874 \mathrm{e}+008.73874 \mathrm{e}-01$ 1.00000e-09 2.12000e-01

$8.73874 \mathrm{e}+008.73874 \mathrm{e}+008.73874 \mathrm{e}-01$ 1.00000e-09 2.12000e-01 
$1.00000 \mathrm{e}-05$ 1.00000e-05 1.00000e-06 1.00000e-09 1.00000e-01 $1.00000 \mathrm{e}+001.00000 \mathrm{e}+001.00000 \mathrm{e}-01$ 1.00000e-09 1.00000e-01 Element: 10102 \# of layers: 7

Kx Ky Kz Ss Por

8.73874e+00 8.73874e+00 8.73874e-01 1.00000e-09 2.12000e-01 $8.73874 \mathrm{e}+008.73874 \mathrm{e}+00$ 8.73874e-01 1.00000e-09 2.12000e-01 $8.73874 \mathrm{e}+00$ 8.73874e+00 8.73874e-01 1.00000e-09 2.12000e-01 $8.73874 \mathrm{e}+008.73874 \mathrm{e}+00 \quad 8.73874 \mathrm{e}-01$ 1.00000e-09 2.12000e-01 $8.73874 \mathrm{e}+008.73874 \mathrm{e}+008.73874 \mathrm{e}-01$ 1.00000e-09 2.12000e-01 $1.00000 \mathrm{e}-05$ 1.00000e-05 1.00000e-06 1.00000e-09 1.00000e-01 $1.00000 \mathrm{e}+001.00000 \mathrm{e}+001.00000 \mathrm{e}-011.00000 \mathrm{e}-091.00000 \mathrm{e}-01$ Element: 10103 \# of layers: 7

$\mathrm{Kx} \mathrm{Ky} \mathrm{Kz}$ Ss Por

8.73874e+00 8.73874e+00 8.73874e-01 1.00000e-09 2.12000e-01 8.73874e+00 8.73874e+00 8.73874e-01 1.00000e-09 2.12000e-01 $8.73874 \mathrm{e}+008.73874 \mathrm{e}+00 \quad 8.73874 \mathrm{e}-01$ 1.00000e-09 2.12000e-01 $8.73874 \mathrm{e}+00 \quad 8.73874 \mathrm{e}+00 \quad 8.73874 \mathrm{e}-01$ 1.00000e-09 2.12000e-01 $8.73874 \mathrm{e}+008.73874 \mathrm{e}+008.73874 \mathrm{e}-01$ 1.00000e-09 2.12000e-01 $1.00000 \mathrm{e}-051.00000 \mathrm{e}-051.00000 \mathrm{e}-061.00000 \mathrm{e}-091.00000 \mathrm{e}-01$ $1.00000 \mathrm{e}+001.00000 \mathrm{e}+001.00000 \mathrm{e}-011.00000 \mathrm{e}-091.00000 \mathrm{e}-01$ Element: 10104 \# of layers: 7

$\mathrm{Kx} \mathrm{Ky} \mathrm{Kz}$ Ss Por

8.73874e+00 8.73874e+00 8.73874e-01 1.00000e-09 2.12000e-01 $8.73874 \mathrm{e}+008.73874 \mathrm{e}+00$ 8.73874e-01 1.00000e-09 2.12000e-01 $8.73874 \mathrm{e}+008.73874 \mathrm{e}+00 \quad 8.73874 \mathrm{e}-01$ 1.00000e-09 2.12000e-01 $8.73874 \mathrm{e}+00$ 8.73874e+00 8.73874e-01 1.00000e-09 2.12000e-01 $8.73874 \mathrm{e}+008.73874 \mathrm{e}+00$ 8.73874e-01 1.00000e-09 2.12000e-01 $1.00000 \mathrm{e}-05$ 1.00000e-05 1.00000e-06 1.00000e-09 1.00000e-01 $1.00000 \mathrm{e}+001.00000 \mathrm{e}+001.00000 \mathrm{e}-011.00000 \mathrm{e}-091.00000 \mathrm{e}-01$ Element: 10105 \# of layers: 7

$\mathrm{Kx} \mathrm{Ky} \mathrm{Kz}$ Ss Por

8.73874e+00 8.73874e+00 8.73874e-01 1.00000e-09 2.12000e-01 $8.73874 \mathrm{e}+008.73874 \mathrm{e}+008.73874 \mathrm{e}-01$ 1.00000e-09 2.12000e-01 $8.73874 \mathrm{e}+008.73874 \mathrm{e}+008.73874 \mathrm{e}-01$ 1.00000e-09 2.12000e-01 $8.73874 \mathrm{e}+008.73874 \mathrm{e}+00$ 8.73874e-01 1.00000e-09 2.12000e-01 $8.73874 \mathrm{e}+008.73874 \mathrm{e}+008.73874 \mathrm{e}-01$ 1.00000e-09 2.12000e-01 $1.00000 \mathrm{e}-05$ 1.00000e-05 1.00000e-06 1.00000e-09 1.00000e-01 $1.00000 \mathrm{e}+001.00000 \mathrm{e}+001.00000 \mathrm{e}-011.00000 \mathrm{e}-091.00000 \mathrm{e}-01$ Element: 10106 \# of layers: 7

$\mathrm{Kx} \mathrm{Ky} \mathrm{Kz}$ Ss Por

8.73874e+00 8.73874e+00 8.73874e-01 1.00000e-09 2.12000e-01 $8.73874 \mathrm{e}+008.73874 \mathrm{e}+00 \quad 8.73874 \mathrm{e}-01$ 1.00000e-09 2.12000e-01 $8.73874 \mathrm{e}+008.73874 \mathrm{e}+00$ 8.73874e-01 1.00000e-09 2.12000e-01 $8.73874 \mathrm{e}+008.73874 \mathrm{e}+00$ 8.73874e-01 1.00000e-09 2.12000e-01 $8.73874 \mathrm{e}+008.73874 \mathrm{e}+008.73874 \mathrm{e}-01$ 1.00000e-09 2.12000e-01 $1.00000 \mathrm{e}-05$ 1.00000e-05 1.00000e-06 1.00000e-09 1.00000e-01 
$1.00000 \mathrm{e}+001.00000 \mathrm{e}+00$ 1.00000e-01 1.00000e-09 1.00000e-01 Element: 10107 \# of layers: 7

Kx Ky Kz Ss Por

8.73874e+00 8.73874e+00 8.73874e-01 1.00000e-09 2.12000e-01

$8.73874 \mathrm{e}+008.73874 \mathrm{e}+00$ 8.73874e-01 1.00000e-09 2.12000e-01

$8.73874 \mathrm{e}+008.73874 \mathrm{e}+008.73874 \mathrm{e}-01$ 1.00000e-09 2.12000e-01

$8.73874 \mathrm{e}+00$ 8.73874e+00 8.73874e-01 1.00000e-09 2.12000e-01

$8.73874 \mathrm{e}+008.73874 \mathrm{e}+00 \quad 8.73874 \mathrm{e}-01$ 1.00000e-09 2.12000e-01

$1.00000 \mathrm{e}-051.00000 \mathrm{e}-051.00000 \mathrm{e}-061.00000 \mathrm{e}-091.00000 \mathrm{e}-01$

$1.00000 \mathrm{e}+001.00000 \mathrm{e}+001.00000 \mathrm{e}-011.00000 \mathrm{e}-091.00000 \mathrm{e}-01$

Element: 10108 \# of layers: 7

Kx Ky Kz Ss Por

8.73874e+00 8.73874e+00 8.73874e-01 1.00000e-09 2.12000e-01

$8.73874 \mathrm{e}+008.73874 \mathrm{e}+00$ 8.73874e-01 1.00000e-09 2.12000e-01

8.73874e+00 8.73874e+00 8.73874e-01 1.00000e-09 2.12000e-01

$8.73874 \mathrm{e}+008.73874 \mathrm{e}+00 \quad 8.73874 \mathrm{e}-01$ 1.00000e-09 2.12000e-01

$8.73874 \mathrm{e}+008.73874 \mathrm{e}+00$ 8.73874e-01 1.00000e-09 2.12000e-01

$1.00000 \mathrm{e}-05$ 1.00000e-05 1.00000e-06 1.00000e-09 1.00000e-01

$1.00000 \mathrm{e}+001.00000 \mathrm{e}+001.00000 \mathrm{e}-01$ 1.00000e-09 1.00000e-01

Element: 10109 \# of layers: 7

Kx Ky Kz Ss Por

8.73874e+00 8.73874e+00 8.73874e-01 1.00000e-09 2.12000e-01

$8.73874 \mathrm{e}+008.73874 \mathrm{e}+008.73874 \mathrm{e}-01$ 1.00000e-09 2.12000e-01

$8.73874 \mathrm{e}+008.73874 \mathrm{e}+00$ 8.73874e-01 1.00000e-09 2.12000e-01

$8.73874 \mathrm{e}+008.73874 \mathrm{e}+00 \quad 8.73874 \mathrm{e}-01$ 1.00000e-09 2.12000e-01

$8.73874 \mathrm{e}+008.73874 \mathrm{e}+008.73874 \mathrm{e}-01$ 1.00000e-09 2.12000e-01

$1.00000 \mathrm{e}-05$ 1.00000e-05 1.00000e-06 1.00000e-09 1.00000e-01

$1.00000 \mathrm{e}+001.00000 \mathrm{e}+001.00000 \mathrm{e}-011.00000 \mathrm{e}-091.00000 \mathrm{e}-01$

Element: 10110 \# of layers: 7

$\mathrm{Kx} \mathrm{Ky} \mathrm{Kz}$ Ss Por

8.73874e+00 8.73874e+00 8.73874e-01 1.00000e-09 2.12000e-01

$8.73874 \mathrm{e}+00$ 8.73874e+00 8.73874e-01 1.00000e-09 2.12000e-01

$8.73874 \mathrm{e}+008.73874 \mathrm{e}+00 \quad 8.73874 \mathrm{e}-01$ 1.00000e-09 2.12000e-01

$8.73874 \mathrm{e}+00$ 8.73874e+00 8.73874e-01 1.00000e-09 2.12000e-01

$8.73874 \mathrm{e}+008.73874 \mathrm{e}+00$ 8.73874e-01 1.00000e-09 2.12000e-01

$1.00000 \mathrm{e}-05$ 1.00000e-05 1.00000e-06 1.00000e-09 1.00000e-01

$1.00000 \mathrm{e}+001.00000 \mathrm{e}+001.00000 \mathrm{e}-011.00000 \mathrm{e}-091.00000 \mathrm{e}-01$

Element: 10111 \# of layers: 7

$\mathrm{Kx} \mathrm{Ky} \mathrm{Kz}$ Ss Por

3.24794e+00 3.24794e+00 3.24794e-01 1.00000e-09 2.12000e-01

$3.24794 \mathrm{e}+003.24794 \mathrm{e}+003.24794 \mathrm{e}-01$ 1.00000e-09 2.12000e-01

$3.24794 \mathrm{e}+003.24794 \mathrm{e}+003.24794 \mathrm{e}-01$ 1.00000e-09 2.12000e-01

$3.24794 \mathrm{e}+003.24794 \mathrm{e}+00$ 3.24794e-01 1.00000e-09 2.12000e-01

$3.24794 \mathrm{e}+003.24794 \mathrm{e}+003.24794 \mathrm{e}-01$ 1.00000e-09 2.12000e-01

$1.00000 \mathrm{e}-05$ 1.00000e-05 1.00000e-06 1.00000e-09 1.00000e-01

$1.00000 \mathrm{e}+001.00000 \mathrm{e}+001.00000 \mathrm{e}-011.00000 \mathrm{e}-091.00000 \mathrm{e}-01$ 
Element: 10112 \# of layers: 7

Kx Ky Kz Ss Por

$3.24794 \mathrm{e}+003.24794 \mathrm{e}+00$ 3.24794e-01 1.00000e-09 2.12000e-01

$3.24794 \mathrm{e}+003.24794 \mathrm{e}+003.24794 \mathrm{e}-011.00000 \mathrm{e}-092.12000 \mathrm{e}-01$

$3.24794 \mathrm{e}+003.24794 \mathrm{e}+003.24794 \mathrm{e}-01$ 1.00000e-09 2.12000e-01

$3.24794 \mathrm{e}+003.24794 \mathrm{e}+003.24794 \mathrm{e}-011.00000 \mathrm{e}-092.12000 \mathrm{e}-01$

$3.24794 \mathrm{e}+003.24794 \mathrm{e}+003.24794 \mathrm{e}-01$ 1.00000e-09 2.12000e-01

$1.00000 \mathrm{e}-05$ 1.00000e-05 1.00000e-06 1.00000e-09 1.00000e-01

$1.00000 \mathrm{e}+001.00000 \mathrm{e}+001.00000 \mathrm{e}-011.00000 \mathrm{e}-091.00000 \mathrm{e}-01$

Element: 10113 \# of layers: 7

Kx Ky Kz Ss Por

$3.24794 \mathrm{e}+003.24794 \mathrm{e}+00$ 3.24794e-01 1.00000e-09 2.12000e-01

$3.24794 \mathrm{e}+003.24794 \mathrm{e}+003.24794 \mathrm{e}-011.00000 \mathrm{e}-092.12000 \mathrm{e}-01$

$3.24794 \mathrm{e}+003.24794 \mathrm{e}+003.24794 \mathrm{e}-011.00000 \mathrm{e}-092.12000 \mathrm{e}-01$

$3.24794 \mathrm{e}+003.24794 \mathrm{e}+003.24794 \mathrm{e}-011.00000 \mathrm{e}-092.12000 \mathrm{e}-01$

$3.24794 \mathrm{e}+003.24794 \mathrm{e}+003.24794 \mathrm{e}-01$ 1.00000e-09 2.12000e-01

$1.00000 \mathrm{e}-05$ 1.00000e-05 1.00000e-06 1.00000e-09 1.00000e-01

$1.00000 \mathrm{e}+001.00000 \mathrm{e}+001.00000 \mathrm{e}-011.00000 \mathrm{e}-091.00000 \mathrm{e}-01$

Element: 10114 \# of layers: 7

Kx Ky Kz Ss Por

$3.24794 \mathrm{e}+003.24794 \mathrm{e}+003.24794 \mathrm{e}-01$ 1.00000e-09 2.12000e-01

$3.24794 \mathrm{e}+003.24794 \mathrm{e}+003.24794 \mathrm{e}-011.00000 \mathrm{e}-092.12000 \mathrm{e}-01$

$3.24794 \mathrm{e}+003.24794 \mathrm{e}+003.24794 \mathrm{e}-011.00000 \mathrm{e}-092.12000 \mathrm{e}-01$

$3.24794 \mathrm{e}+003.24794 \mathrm{e}+003.24794 \mathrm{e}-01$ 1.00000e-09 2.12000e-01

$3.24794 \mathrm{e}+003.24794 \mathrm{e}+003.24794 \mathrm{e}-011.00000 \mathrm{e}-092.12000 \mathrm{e}-01$

$1.00000 \mathrm{e}-05$ 1.00000e-05 1.00000e-06 1.00000e-09 1.00000e-01

$1.00000 \mathrm{e}+001.00000 \mathrm{e}+001.00000 \mathrm{e}-011.00000 \mathrm{e}-091.00000 \mathrm{e}-01$

Element: 10115 \# of layers: 7

Kx Ky Kz Ss Por

$3.24794 \mathrm{e}+003.24794 \mathrm{e}+003.24794 \mathrm{e}-01$ 1.00000e-09 2.12000e-01

$3.24794 \mathrm{e}+003.24794 \mathrm{e}+003.24794 \mathrm{e}-011.00000 \mathrm{e}-092.12000 \mathrm{e}-01$

$3.24794 \mathrm{e}+003.24794 \mathrm{e}+003.24794 \mathrm{e}-01$ 1.00000e-09 2.12000e-01

$3.24794 \mathrm{e}+003.24794 \mathrm{e}+003.24794 \mathrm{e}-01$ 1.00000e-09 2.12000e-01

$3.24794 \mathrm{e}+003.24794 \mathrm{e}+003.24794 \mathrm{e}-01$ 1.00000e-09 2.12000e-01

$1.00000 \mathrm{e}-05$ 1.00000e-05 1.00000e-06 1.00000e-09 1.00000e-01

$1.00000 \mathrm{e}+001.00000 \mathrm{e}+001.00000 \mathrm{e}-011.00000 \mathrm{e}-091.00000 \mathrm{e}-01$

Element: 10116 \# of layers: 7

Kx Ky Kz Ss Por

$8.73874 \mathrm{e}+008.73874 \mathrm{e}+00$ 8.73874e-01 1.00000e-09 2.12000e-01

$8.73874 \mathrm{e}+008.73874 \mathrm{e}+008.73874 \mathrm{e}-011.00000 \mathrm{e}-092.12000 \mathrm{e}-01$

$8.73874 \mathrm{e}+008.73874 \mathrm{e}+008.73874 \mathrm{e}-011.00000 \mathrm{e}-092.12000 \mathrm{e}-01$

$8.73874 \mathrm{e}+008.73874 \mathrm{e}+008.73874 \mathrm{e}-011.00000 \mathrm{e}-092.12000 \mathrm{e}-01$

$8.73874 \mathrm{e}+008.73874 \mathrm{e}+00$ 8.73874e-01 1.00000e-09 2.12000e-01

$1.00000 \mathrm{e}-05$ 1.00000e-05 1.00000e-06 1.00000e-09 1.00000e-01

$1.00000 \mathrm{e}+001.00000 \mathrm{e}+001.00000 \mathrm{e}-011.00000 \mathrm{e}-091.00000 \mathrm{e}-01$

Element: 10117 \# of layers: 7 
Kx Ky Kz Ss Por

8.73874e+00 8.73874e+00 8.73874e-01 1.00000e-09 2.12000e-01

$8.73874 \mathrm{e}+00$ 8.73874e+00 8.73874e-01 1.00000e-09 2.12000e-01

$8.73874 \mathrm{e}+008.73874 \mathrm{e}+00 \quad 8.73874 \mathrm{e}-01$ 1.00000e-09 2.12000e-01

$8.73874 \mathrm{e}+008.73874 \mathrm{e}+00 \quad 8.73874 \mathrm{e}-01$ 1.00000e-09 2.12000e-01

$8.73874 \mathrm{e}+008.73874 \mathrm{e}+00$ 8.73874e-01 1.00000e-09 2.12000e-01

$1.00000 \mathrm{e}-051.00000 \mathrm{e}-051.00000 \mathrm{e}-061.00000 \mathrm{e}-091.00000 \mathrm{e}-01$

$1.00000 \mathrm{e}+001.00000 \mathrm{e}+001.00000 \mathrm{e}-01$ 1.00000e-09 1.00000e-01

Element: 10118 \# of layers: 7

$\mathrm{Kx} \mathrm{Ky} \mathrm{Kz}$ Ss Por

3.24794e+00 3.24794e+00 3.24794e-01 1.00000e-09 2.12000e-01

$3.24794 \mathrm{e}+003.24794 \mathrm{e}+003.24794 \mathrm{e}-01$ 1.00000e-09 2.12000e-01

$3.24794 \mathrm{e}+003.24794 \mathrm{e}+003.24794 \mathrm{e}-01$ 1.00000e-09 2.12000e-01

$3.24794 \mathrm{e}+003.24794 \mathrm{e}+003.24794 \mathrm{e}-01$ 1.00000e-09 2.12000e-01

$3.24794 \mathrm{e}+003.24794 \mathrm{e}+003.24794 \mathrm{e}-01$ 1.00000e-09 2.12000e-01

$1.00000 \mathrm{e}-05$ 1.00000e-05 1.00000e-06 1.00000e-09 1.00000e-01

$1.00000 \mathrm{e}+001.00000 \mathrm{e}+001.00000 \mathrm{e}-01$ 1.00000e-09 1.00000e-01

Element: 10119 \# of layers: 7

$\mathrm{Kx} \mathrm{Ky} \mathrm{Kz}$ Ss Por

3.24794e+00 3.24794e+00 3.24794e-01 1.00000e-09 2.12000e-01

$3.24794 \mathrm{e}+003.24794 \mathrm{e}+003.24794 \mathrm{e}-01$ 1.00000e-09 2.12000e-01

$3.24794 \mathrm{e}+003.24794 \mathrm{e}+00$ 3.24794e-01 1.00000e-09 2.12000e-01

3.24794e+00 3.24794e+00 3.24794e-01 1.00000e-09 2.12000e-01

$3.24794 \mathrm{e}+003.24794 \mathrm{e}+00$ 3.24794e-01 1.00000e-09 2.12000e-01

$1.00000 \mathrm{e}-051.00000 \mathrm{e}-05$ 1.00000e-06 1.00000e-09 1.00000e-01

$1.00000 \mathrm{e}+001.00000 \mathrm{e}+001.00000 \mathrm{e}-01$ 1.00000e-09 1.00000e-01

Element: 10120 \# of layers: 7

$\mathrm{Kx} \mathrm{Ky} \mathrm{Kz}$ Ss Por

3.24794e+00 3.24794e+00 3.24794e-01 1.00000e-09 2.12000e-01

$3.24794 \mathrm{e}+003.24794 \mathrm{e}+00$ 3.24794e-01 1.00000e-09 2.12000e-01

$3.24794 \mathrm{e}+003.24794 \mathrm{e}+003.24794 \mathrm{e}-01$ 1.00000e-09 2.12000e-01

$3.24794 \mathrm{e}+003.24794 \mathrm{e}+003.24794 \mathrm{e}-01$ 1.00000e-09 2.12000e-01

$3.24794 \mathrm{e}+003.24794 \mathrm{e}+003.24794 \mathrm{e}-01$ 1.00000e-09 2.12000e-01

$1.00000 \mathrm{e}-05$ 1.00000e-05 1.00000e-06 1.00000e-09 1.00000e-01

$1.00000 \mathrm{e}+001.00000 \mathrm{e}+001.00000 \mathrm{e}-011.00000 \mathrm{e}-091.00000 \mathrm{e}-01$

Element: 10121 \# of layers: 7

Kx Ky Kz Ss Por

3.24794e+00 3.24794e+00 3.24794e-01 1.00000e-09 2.12000e-01

$3.24794 \mathrm{e}+003.24794 \mathrm{e}+00$ 3.24794e-01 1.00000e-09 2.12000e-01

$3.24794 \mathrm{e}+003.24794 \mathrm{e}+00$ 3.24794e-01 1.00000e-09 2.12000e-01

$3.24794 \mathrm{e}+003.24794 \mathrm{e}+003.24794 \mathrm{e}-01$ 1.00000e-09 2.12000e-01

$3.24794 \mathrm{e}+003.24794 \mathrm{e}+00$ 3.24794e-01 1.00000e-09 2.12000e-01

$1.00000 \mathrm{e}-05$ 1.00000e-05 1.00000e-06 1.00000e-09 1.00000e-01

$1.00000 \mathrm{e}+001.00000 \mathrm{e}+001.00000 \mathrm{e}-01$ 1.00000e-09 1.00000e-01

Element: 10122 \# of layers: 7

Kx Ky Kz Ss Por 
$3.24794 \mathrm{e}+003.24794 \mathrm{e}+003.24794 \mathrm{e}-01$ 1.00000e-09 2.12000e-01 $3.24794 \mathrm{e}+003.24794 \mathrm{e}+003.24794 \mathrm{e}-01$ 1.00000e-09 2.12000e-01 $3.24794 \mathrm{e}+003.24794 \mathrm{e}+003.24794 \mathrm{e}-01$ 1.00000e-09 2.12000e-01 $3.24794 \mathrm{e}+003.24794 \mathrm{e}+003.24794 \mathrm{e}-01$ 1.00000e-09 2.12000e-01 $3.24794 \mathrm{e}+003.24794 \mathrm{e}+003.24794 \mathrm{e}-01$ 1.00000e-09 2.12000e-01 $1.00000 \mathrm{e}-05$ 1.00000e-05 1.00000e-06 1.00000e-09 1.00000e-01 $1.00000 \mathrm{e}+001.00000 \mathrm{e}+00$ 1.00000e-01 1.00000e-09 1.00000e-01 Element: 10123 \# of layers: 7

$\mathrm{Kx} \mathrm{Ky} \mathrm{Kz}$ Ss Por

3.24794e+00 3.24794e+00 3.24794e-01 1.00000e-09 2.12000e-01 $3.24794 \mathrm{e}+003.24794 \mathrm{e}+003.24794 \mathrm{e}-01$ 1.00000e-09 2.12000e-01 $3.24794 \mathrm{e}+003.24794 \mathrm{e}+003.24794 \mathrm{e}-01$ 1.00000e-09 2.12000e-01 $3.24794 \mathrm{e}+003.24794 \mathrm{e}+00 \quad 3.24794 \mathrm{e}-01$ 1.00000e-09 2.12000e-01 $3.24794 \mathrm{e}+003.24794 \mathrm{e}+003.24794 \mathrm{e}-01$ 1.00000e-09 2.12000e-01 $1.00000 \mathrm{e}-05$ 1.00000e-05 1.00000e-06 1.00000e-09 1.00000e-01 $1.00000 \mathrm{e}+001.00000 \mathrm{e}+001.00000 \mathrm{e}-011.00000 \mathrm{e}-091.00000 \mathrm{e}-01$ Element: 10124 \# of layers: 7

$\mathrm{Kx} \mathrm{Ky} \mathrm{Kz}$ Ss Por

3.24794e+00 3.24794e+00 3.24794e-01 1.00000e-09 2.12000e-01 $3.24794 \mathrm{e}+003.24794 \mathrm{e}+00 \quad 3.24794 \mathrm{e}-01$ 1.00000e-09 2.12000e-01 $3.24794 \mathrm{e}+003.24794 \mathrm{e}+00$ 3.24794e-01 1.00000e-09 2.12000e-01 3.24794e+00 3.24794e+00 3.24794e-01 1.00000e-09 2.12000e-01 $3.24794 \mathrm{e}+003.24794 \mathrm{e}+003.24794 \mathrm{e}-01$ 1.00000e-09 2.12000e-01 $1.00000 \mathrm{e}-05$ 1.00000e-05 1.00000e-06 1.00000e-09 1.00000e-01 $1.00000 \mathrm{e}+001.00000 \mathrm{e}+001.00000 \mathrm{e}-011.00000 \mathrm{e}-091.00000 \mathrm{e}-01$ Element: 10125 \# of layers: 7

$\mathrm{Kx} \mathrm{Ky} \mathrm{Kz}$ Ss Por

3.24794e+00 3.24794e+00 3.24794e-01 1.00000e-09 2.12000e-01 $3.24794 \mathrm{e}+003.24794 \mathrm{e}+003.24794 \mathrm{e}-01$ 1.00000e-09 2.12000e-01 $3.24794 \mathrm{e}+003.24794 \mathrm{e}+00$ 3.24794e-01 1.00000e-09 2.12000e-01 $3.24794 \mathrm{e}+003.24794 \mathrm{e}+003.24794 \mathrm{e}-01$ 1.00000e-09 2.12000e-01 $3.24794 \mathrm{e}+003.24794 \mathrm{e}+003.24794 \mathrm{e}-01$ 1.00000e-09 2.12000e-01 $1.00000 \mathrm{e}-051.00000 \mathrm{e}-05$ 1.00000e-06 1.00000e-09 1.00000e-01 $1.00000 \mathrm{e}+001.00000 \mathrm{e}+001.00000 \mathrm{e}-01$ 1.00000e-09 1.00000e-01 Element: 10126 \# of layers: 7

$\mathrm{Kx} \mathrm{Ky} \mathrm{Kz}$ Ss Por

3.24794e+00 3.24794e+00 3.24794e-01 1.00000e-09 2.12000e-01 $3.24794 \mathrm{e}+003.24794 \mathrm{e}+003.24794 \mathrm{e}-01$ 1.00000e-09 2.12000e-01 $3.24794 \mathrm{e}+003.24794 \mathrm{e}+003.24794 \mathrm{e}-01$ 1.00000e-09 2.12000e-01 3.24794e+00 3.24794e+00 3.24794e-01 1.00000e-09 2.12000e-01 $3.24794 \mathrm{e}+003.24794 \mathrm{e}+003.24794 \mathrm{e}-01$ 1.00000e-09 2.12000e-01 $1.00000 \mathrm{e}-05$ 1.00000e-05 1.00000e-06 1.00000e-09 1.00000e-01 $1.00000 \mathrm{e}+001.00000 \mathrm{e}+001.00000 \mathrm{e}-011.00000 \mathrm{e}-091.00000 \mathrm{e}-01$ Element: 10127 \# of layers: 7

$\mathrm{Kx} \mathrm{Ky} \mathrm{Kz}$ Ss Por

3.24794e+00 3.24794e+00 3.24794e-01 1.00000e-09 2.12000e-01 
$3.24794 \mathrm{e}+003.24794 \mathrm{e}+003.24794 \mathrm{e}-01$ 1.00000e-09 2.12000e-01 $3.24794 \mathrm{e}+003.24794 \mathrm{e}+003.24794 \mathrm{e}-01$ 1.00000e-09 2.12000e-01 $3.24794 \mathrm{e}+003.24794 \mathrm{e}+003.24794 \mathrm{e}-01$ 1.00000e-09 2.12000e-01 $3.24794 \mathrm{e}+003.24794 \mathrm{e}+003.24794 \mathrm{e}-01$ 1.00000e-09 2.12000e-01 $1.00000 \mathrm{e}-05$ 1.00000e-05 1.00000e-06 1.00000e-09 1.00000e-01 $1.00000 \mathrm{e}+001.00000 \mathrm{e}+001.00000 \mathrm{e}-011.00000 \mathrm{e}-091.00000 \mathrm{e}-01$ Element: 10128 \# of layers: 7

$\mathrm{Kx} \mathrm{Ky} \mathrm{Kz}$ Ss Por

3.24794e+00 3.24794e+00 3.24794e-01 1.00000e-09 2.12000e-01 $3.24794 \mathrm{e}+003.24794 \mathrm{e}+003.24794 \mathrm{e}-01$ 1.00000e-09 2.12000e-01 $3.24794 \mathrm{e}+003.24794 \mathrm{e}+003.24794 \mathrm{e}-01$ 1.00000e-09 2.12000e-01 $3.24794 \mathrm{e}+003.24794 \mathrm{e}+003.24794 \mathrm{e}-01$ 1.00000e-09 2.12000e-01 $3.24794 \mathrm{e}+003.24794 \mathrm{e}+003.24794 \mathrm{e}-01$ 1.00000e-09 2.12000e-01 $1.00000 \mathrm{e}-05$ 1.00000e-05 1.00000e-06 1.00000e-09 1.00000e-01 $1.00000 \mathrm{e}+001.00000 \mathrm{e}+001.00000 \mathrm{e}-01$ 1.00000e-09 1.00000e-01 Element: 10129 \# of layers: 7

$\mathrm{Kx} \mathrm{Ky} \mathrm{Kz}$ Ss Por

3.24794e+00 3.24794e+00 3.24794e-01 1.00000e-09 2.12000e-01 $3.24794 \mathrm{e}+003.24794 \mathrm{e}+003.24794 \mathrm{e}-01$ 1.00000e-09 2.12000e-01 $3.24794 \mathrm{e}+003.24794 \mathrm{e}+003.24794 \mathrm{e}-01$ 1.00000e-09 2.12000e-01 $3.24794 \mathrm{e}+003.24794 \mathrm{e}+003.24794 \mathrm{e}-01$ 1.00000e-09 2.12000e-01 3.24794e+00 3.24794e+00 3.24794e-01 1.00000e-09 2.12000e-01 $1.00000 \mathrm{e}-05$ 1.00000e-05 1.00000e-06 1.00000e-09 1.00000e-01 $1.00000 \mathrm{e}+001.00000 \mathrm{e}+001.00000 \mathrm{e}-011.00000 \mathrm{e}-09$ 1.00000e-01 Element: 10130 \# of layers: 7

$\mathrm{Kx} \mathrm{Ky} \mathrm{Kz}$ Ss Por

3.89821e+00 3.89821e+00 3.89821e-01 1.00000e-09 2.12000e-01 $3.89821 \mathrm{e}+003.89821 \mathrm{e}+003.89821 \mathrm{e}-01$ 1.00000e-09 2.12000e-01 $3.89821 \mathrm{e}+003.89821 \mathrm{e}+003.89821 \mathrm{e}-01$ 1.00000e-09 2.12000e-01 $3.89821 \mathrm{e}+003.89821 \mathrm{e}+00$ 3.89821e-01 1.00000e-09 2.12000e-01 $3.89821 \mathrm{e}+003.89821 \mathrm{e}+003.89821 \mathrm{e}-01$ 1.00000e-09 2.12000e-01 $1.00000 \mathrm{e}-05$ 1.00000e-05 1.00000e-06 1.00000e-09 1.00000e-01 $1.00000 \mathrm{e}+001.00000 \mathrm{e}+001.00000 \mathrm{e}-011.00000 \mathrm{e}-091.00000 \mathrm{e}-01$ Element: 10131 \# of layers: 7

$\mathrm{Kx} \mathrm{Ky} \mathrm{Kz}$ Ss Por

3.89821e+00 3.89821e+00 3.89821e-01 1.00000e-09 2.12000e-01 $3.89821 \mathrm{e}+003.89821 \mathrm{e}+003.89821 \mathrm{e}-01$ 1.00000e-09 2.12000e-01 $3.89821 \mathrm{e}+003.89821 \mathrm{e}+003.89821 \mathrm{e}-01$ 1.00000e-09 2.12000e-01 $3.89821 \mathrm{e}+003.89821 \mathrm{e}+00$ 3.89821e-01 1.00000e-09 2.12000e-01 $3.89821 \mathrm{e}+003.89821 \mathrm{e}+00$ 3.89821e-01 1.00000e-09 2.12000e-01 $1.00000 \mathrm{e}-05$ 1.00000e-05 1.00000e-06 1.00000e-09 1.00000e-01 $1.00000 \mathrm{e}+001.00000 \mathrm{e}+001.00000 \mathrm{e}-011.00000 \mathrm{e}-091.00000 \mathrm{e}-01$ Element: 10132 \# of layers: 7

$\mathrm{Kx} \mathrm{Ky} \mathrm{Kz}$ Ss Por

3.89821e+00 3.89821e+00 3.89821e-01 1.00000e-09 2.12000e-01 $3.89821 \mathrm{e}+003.89821 \mathrm{e}+003.89821 \mathrm{e}-01$ 1.00000e-09 2.12000e-01 
$3.89821 \mathrm{e}+003.89821 \mathrm{e}+003.89821 \mathrm{e}-011.00000 \mathrm{e}-092.12000 \mathrm{e}-01$ $3.89821 \mathrm{e}+003.89821 \mathrm{e}+003.89821 \mathrm{e}-01$ 1.00000e-09 2.12000e-01 $3.89821 \mathrm{e}+003.89821 \mathrm{e}+003.89821 \mathrm{e}-01$ 1.00000e-09 2.12000e-01 $1.00000 \mathrm{e}-05$ 1.00000e-05 1.00000e-06 1.00000e-09 1.00000e-01 $1.00000 \mathrm{e}+001.00000 \mathrm{e}+001.00000 \mathrm{e}-011.00000 \mathrm{e}-091.00000 \mathrm{e}-01$ Element: 10133 \# of layers: 7

Kx Ky Kz Ss Por

$3.24794 \mathrm{e}+003.24794 \mathrm{e}+00$ 3.24794e-01 1.00000e-09 2.12000e-01 $3.24794 \mathrm{e}+003.24794 \mathrm{e}+003.24794 \mathrm{e}-011.00000 \mathrm{e}-092.12000 \mathrm{e}-01$ $3.24794 \mathrm{e}+003.24794 \mathrm{e}+003.24794 \mathrm{e}-011.00000 \mathrm{e}-092.12000 \mathrm{e}-01$ $3.24794 \mathrm{e}+003.24794 \mathrm{e}+003.24794 \mathrm{e}-01$ 1.00000e-09 2.12000e-01 $3.24794 \mathrm{e}+003.24794 \mathrm{e}+003.24794 \mathrm{e}-01$ 1.00000e-09 2.12000e-01 $1.00000 \mathrm{e}-05$ 1.00000e-05 1.00000e-06 1.00000e-09 1.00000e-01 $1.00000 \mathrm{e}+001.00000 \mathrm{e}+001.00000 \mathrm{e}-011.00000 \mathrm{e}-091.00000 \mathrm{e}-01$ Element: 10134 \# of layers: 7

Kx Ky Kz Ss Por

$3.24794 \mathrm{e}+003.24794 \mathrm{e}+00$ 3.24794e-01 1.00000e-09 2.12000e-01 $3.24794 \mathrm{e}+003.24794 \mathrm{e}+003.24794 \mathrm{e}-011.00000 \mathrm{e}-092.12000 \mathrm{e}-01$ $3.24794 \mathrm{e}+003.24794 \mathrm{e}+003.24794 \mathrm{e}-01$ 1.00000e-09 2.12000e-01 $3.24794 \mathrm{e}+003.24794 \mathrm{e}+003.24794 \mathrm{e}-011.00000 \mathrm{e}-092.12000 \mathrm{e}-01$ $3.24794 \mathrm{e}+003.24794 \mathrm{e}+003.24794 \mathrm{e}-011.00000 \mathrm{e}-092.12000 \mathrm{e}-01$ $1.00000 \mathrm{e}-05$ 1.00000e-05 1.00000e-06 1.00000e-09 1.00000e-01 $1.00000 \mathrm{e}+001.00000 \mathrm{e}+001.00000 \mathrm{e}-011.00000 \mathrm{e}-091.00000 \mathrm{e}-01$ Element: 10135 \# of layers: 7

Kx Ky Kz Ss Por

$3.24794 \mathrm{e}+003.24794 \mathrm{e}+003.24794 \mathrm{e}-01$ 1.00000e-09 2.12000e-01 $3.24794 \mathrm{e}+003.24794 \mathrm{e}+003.24794 \mathrm{e}-01$ 1.00000e-09 2.12000e-01 $3.24794 \mathrm{e}+003.24794 \mathrm{e}+003.24794 \mathrm{e}-01$ 1.00000e-09 2.12000e-01 $3.24794 \mathrm{e}+003.24794 \mathrm{e}+003.24794 \mathrm{e}-01$ 1.00000e-09 2.12000e-01 $3.24794 \mathrm{e}+003.24794 \mathrm{e}+003.24794 \mathrm{e}-011.00000 \mathrm{e}-09$ 2.12000e-01 $1.00000 \mathrm{e}-05$ 1.00000e-05 1.00000e-06 1.00000e-09 1.00000e-01 $1.00000 \mathrm{e}+001.00000 \mathrm{e}+001.00000 \mathrm{e}-011.00000 \mathrm{e}-091.00000 \mathrm{e}-01$ Element: 10136 \# of layers: 7

Kx Ky Kz Ss Por

$3.24794 \mathrm{e}+003.24794 \mathrm{e}+003.24794 \mathrm{e}-01$ 1.00000e-09 2.12000e-01 $3.24794 \mathrm{e}+003.24794 \mathrm{e}+003.24794 \mathrm{e}-011.00000 \mathrm{e}-092.12000 \mathrm{e}-01$ $3.24794 \mathrm{e}+003.24794 \mathrm{e}+003.24794 \mathrm{e}-01$ 1.00000e-09 2.12000e-01 $3.24794 \mathrm{e}+003.24794 \mathrm{e}+003.24794 \mathrm{e}-01$ 1.00000e-09 2.12000e-01 $3.24794 \mathrm{e}+003.24794 \mathrm{e}+003.24794 \mathrm{e}-01$ 1.00000e-09 2.12000e-01 $1.00000 \mathrm{e}-05$ 1.00000e-05 1.00000e-06 1.00000e-09 1.00000e-01 $1.00000 \mathrm{e}+001.00000 \mathrm{e}+001.00000 \mathrm{e}-011.00000 \mathrm{e}-091.00000 \mathrm{e}-01$ Element: 10137 \# of layers: 7

Kx Ky Kz Ss Por

$3.89821 \mathrm{e}+003.89821 \mathrm{e}+003.89821 \mathrm{e}-01$ 1.00000e-09 2.12000e-01 $3.89821 \mathrm{e}+003.89821 \mathrm{e}+003.89821 \mathrm{e}-011.00000 \mathrm{e}-092.12000 \mathrm{e}-01$ $3.89821 \mathrm{e}+003.89821 \mathrm{e}+003.89821 \mathrm{e}-01$ 1.00000e-09 2.12000e-01 
$3.89821 \mathrm{e}+003.89821 \mathrm{e}+003.89821 \mathrm{e}-011.00000 \mathrm{e}-092.12000 \mathrm{e}-01$ $3.89821 \mathrm{e}+003.89821 \mathrm{e}+003.89821 \mathrm{e}-01$ 1.00000e-09 2.12000e-01 $1.00000 \mathrm{e}-05$ 1.00000e-05 1.00000e-06 1.00000e-09 1.00000e-01 $1.00000 \mathrm{e}+001.00000 \mathrm{e}+001.00000 \mathrm{e}-011.00000 \mathrm{e}-091.00000 \mathrm{e}-01$ Element: 10138 \# of layers: 7

Kx Ky Kz Ss Por

$3.89821 \mathrm{e}+003.89821 \mathrm{e}+003.89821 \mathrm{e}-01$ 1.00000e-09 2.12000e-01 $3.89821 \mathrm{e}+003.89821 \mathrm{e}+003.89821 \mathrm{e}-011.00000 \mathrm{e}-092.12000 \mathrm{e}-01$ $3.89821 \mathrm{e}+003.89821 \mathrm{e}+003.89821 \mathrm{e}-011.00000 \mathrm{e}-092.12000 \mathrm{e}-01$ $3.89821 \mathrm{e}+003.89821 \mathrm{e}+003.89821 \mathrm{e}-011.00000 \mathrm{e}-092.12000 \mathrm{e}-01$ $3.89821 \mathrm{e}+003.89821 \mathrm{e}+003.89821 \mathrm{e}-011.00000 \mathrm{e}-092.12000 \mathrm{e}-01$ $1.00000 \mathrm{e}-05$ 1.00000e-05 1.00000e-06 1.00000e-09 1.00000e-01 $1.00000 \mathrm{e}+001.00000 \mathrm{e}+001.00000 \mathrm{e}-011.00000 \mathrm{e}-091.00000 \mathrm{e}-01$ Element: 10139 \# of layers: 7

Kx Ky Kz Ss Por

$3.89821 \mathrm{e}+003.89821 \mathrm{e}+003.89821 \mathrm{e}-01$ 1.00000e-09 2.12000e-01 $3.89821 \mathrm{e}+003.89821 \mathrm{e}+003.89821 \mathrm{e}-01$ 1.00000e-09 2.12000e-01 $3.89821 \mathrm{e}+003.89821 \mathrm{e}+003.89821 \mathrm{e}-011.00000 \mathrm{e}-092.12000 \mathrm{e}-01$ $3.89821 \mathrm{e}+003.89821 \mathrm{e}+003.89821 \mathrm{e}-011.00000 \mathrm{e}-092.12000 \mathrm{e}-01$ $3.89821 \mathrm{e}+003.89821 \mathrm{e}+003.89821 \mathrm{e}-011.00000 \mathrm{e}-092.12000 \mathrm{e}-01$ $1.00000 \mathrm{e}-05$ 1.00000e-05 1.00000e-06 1.00000e-09 1.00000e-01 $1.00000 \mathrm{e}+001.00000 \mathrm{e}+001.00000 \mathrm{e}-011.00000 \mathrm{e}-091.00000 \mathrm{e}-01$ Element: 10140 \# of layers: 7

Kx Ky Kz Ss Por

$3.89821 \mathrm{e}+003.89821 \mathrm{e}+003.89821 \mathrm{e}-011.00000 \mathrm{e}-092.12000 \mathrm{e}-01$ $3.89821 \mathrm{e}+003.89821 \mathrm{e}+003.89821 \mathrm{e}-01$ 1.00000e-09 2.12000e-01 $3.89821 \mathrm{e}+003.89821 \mathrm{e}+003.89821 \mathrm{e}-01$ 1.00000e-09 2.12000e-01 $3.89821 \mathrm{e}+003.89821 \mathrm{e}+003.89821 \mathrm{e}-011.00000 \mathrm{e}-092.12000 \mathrm{e}-01$ $3.89821 \mathrm{e}+003.89821 \mathrm{e}+003.89821 \mathrm{e}-011.00000 \mathrm{e}-092.12000 \mathrm{e}-01$ $1.00000 \mathrm{e}-05$ 1.00000e-05 1.00000e-06 1.00000e-09 1.00000e-01 $1.00000 \mathrm{e}+001.00000 \mathrm{e}+001.00000 \mathrm{e}-011.00000 \mathrm{e}-091.00000 \mathrm{e}-01$ Element: 10141 \# of layers: 7

Kx Ky Kz Ss Por

$3.89821 \mathrm{e}+003.89821 \mathrm{e}+003.89821 \mathrm{e}-01$ 1.00000e-09 2.12000e-01 $3.89821 \mathrm{e}+003.89821 \mathrm{e}+003.89821 \mathrm{e}-011.00000 \mathrm{e}-092.12000 \mathrm{e}-01$ $3.89821 \mathrm{e}+003.89821 \mathrm{e}+003.89821 \mathrm{e}-01$ 1.00000e-09 2.12000e-01 $3.89821 \mathrm{e}+003.89821 \mathrm{e}+003.89821 \mathrm{e}-011.00000 \mathrm{e}-092.12000 \mathrm{e}-01$ $3.89821 \mathrm{e}+003.89821 \mathrm{e}+003.89821 \mathrm{e}-011.00000 \mathrm{e}-092.12000 \mathrm{e}-01$ $1.00000 \mathrm{e}-05$ 1.00000e-05 1.00000e-06 1.00000e-09 1.00000e-01 $1.00000 \mathrm{e}+001.00000 \mathrm{e}+001.00000 \mathrm{e}-011.00000 \mathrm{e}-091.00000 \mathrm{e}-01$ Element: 10142 \# of layers: 7

Kx Ky Kz Ss Por

$3.89821 \mathrm{e}+003.89821 \mathrm{e}+003.89821 \mathrm{e}-011.00000 \mathrm{e}-092.12000 \mathrm{e}-01$ $3.89821 \mathrm{e}+003.89821 \mathrm{e}+003.89821 \mathrm{e}-011.00000 \mathrm{e}-092.12000 \mathrm{e}-01$ $3.89821 \mathrm{e}+003.89821 \mathrm{e}+003.89821 \mathrm{e}-01$ 1.00000e-09 2.12000e-01 $3.89821 \mathrm{e}+003.89821 \mathrm{e}+003.89821 \mathrm{e}-01$ 1.00000e-09 2.12000e-01 
$3.89821 \mathrm{e}+003.89821 \mathrm{e}+00$ 3.89821e-01 1.00000e-09 2.12000e-01 $1.00000 \mathrm{e}-05$ 1.00000e-05 1.00000e-06 1.00000e-09 1.00000e-01 $1.00000 \mathrm{e}+001.00000 \mathrm{e}+001.00000 \mathrm{e}-011.00000 \mathrm{e}-091.00000 \mathrm{e}-01$ Element: 10143 \# of layers: 7

$\mathrm{Kx} \mathrm{Ky} \mathrm{Kz}$ Ss Por

3.89821e+00 3.89821e+00 3.89821e-01 1.00000e-09 2.12000e-01 $3.89821 \mathrm{e}+003.89821 \mathrm{e}+003.89821 \mathrm{e}-01$ 1.00000e-09 2.12000e-01 $3.89821 \mathrm{e}+003.89821 \mathrm{e}+003.89821 \mathrm{e}-01$ 1.00000e-09 2.12000e-01 $3.89821 \mathrm{e}+003.89821 \mathrm{e}+00$ 3.89821e-01 1.00000e-09 2.12000e-01 $3.89821 \mathrm{e}+003.89821 \mathrm{e}+003.89821 \mathrm{e}-01$ 1.00000e-09 2.12000e-01 $1.00000 \mathrm{e}-05$ 1.00000e-05 1.00000e-06 1.00000e-09 1.00000e-01 $1.00000 \mathrm{e}+001.00000 \mathrm{e}+001.00000 \mathrm{e}-011.00000 \mathrm{e}-091.00000 \mathrm{e}-01$ Element: 10144 \# of layers: 7

$\mathrm{Kx} \mathrm{Ky} \mathrm{Kz}$ Ss Por

3.89821e+00 3.89821e+00 3.89821e-01 1.00000e-09 2.12000e-01 $3.89821 \mathrm{e}+003.89821 \mathrm{e}+003.89821 \mathrm{e}-01$ 1.00000e-09 2.12000e-01 $3.89821 \mathrm{e}+003.89821 \mathrm{e}+00$ 3.89821e-01 1.00000e-09 2.12000e-01 $3.89821 \mathrm{e}+003.89821 \mathrm{e}+00$ 3.89821e-01 1.00000e-09 2.12000e-01 $3.89821 \mathrm{e}+003.89821 \mathrm{e}+003.89821 \mathrm{e}-01$ 1.00000e-09 2.12000e-01 $1.00000 \mathrm{e}-05$ 1.00000e-05 1.00000e-06 1.00000e-09 1.00000e-01 $1.00000 \mathrm{e}+001.00000 \mathrm{e}+001.00000 \mathrm{e}-011.00000 \mathrm{e}-091.00000 \mathrm{e}-01$ Element: 10145 \# of layers: 7

$\mathrm{Kx} \mathrm{Ky} \mathrm{Kz}$ Ss Por

3.89821e+00 3.89821e+00 3.89821e-01 1.00000e-09 2.12000e-01 $3.89821 \mathrm{e}+003.89821 \mathrm{e}+003.89821 \mathrm{e}-01$ 1.00000e-09 2.12000e-01 $3.89821 \mathrm{e}+003.89821 \mathrm{e}+003.89821 \mathrm{e}-01$ 1.00000e-09 2.12000e-01 $3.89821 \mathrm{e}+003.89821 \mathrm{e}+003.89821 \mathrm{e}-01$ 1.00000e-09 2.12000e-01 $3.89821 \mathrm{e}+003.89821 \mathrm{e}+00$ 3.89821e-01 1.00000e-09 2.12000e-01 $1.00000 \mathrm{e}-05$ 1.00000e-05 1.00000e-06 1.00000e-09 1.00000e-01 $1.00000 \mathrm{e}+001.00000 \mathrm{e}+001.00000 \mathrm{e}-011.00000 \mathrm{e}-091.00000 \mathrm{e}-01$ Element: 10146 \# of layers: 7

$\mathrm{Kx} \mathrm{Ky} \mathrm{Kz}$ Ss Por

3.89821e+00 3.89821e+00 3.89821e-01 1.00000e-09 2.12000e-01 $3.89821 \mathrm{e}+003.89821 \mathrm{e}+00$ 3.89821e-01 1.00000e-09 2.12000e-01 $3.89821 \mathrm{e}+003.89821 \mathrm{e}+003.89821 \mathrm{e}-01$ 1.00000e-09 2.12000e-01 $3.89821 \mathrm{e}+003.89821 \mathrm{e}+003.89821 \mathrm{e}-01$ 1.00000e-09 2.12000e-01 $3.89821 \mathrm{e}+003.89821 \mathrm{e}+003.89821 \mathrm{e}-01$ 1.00000e-09 2.12000e-01 $1.00000 \mathrm{e}-05$ 1.00000e-05 1.00000e-06 1.00000e-09 1.00000e-01 $1.00000 \mathrm{e}+001.00000 \mathrm{e}+001.00000 \mathrm{e}-01$ 1.00000e-09 1.00000e-01 Element: 10147 \# of layers: 7

$\mathrm{Kx} \mathrm{Ky} \mathrm{Kz}$ Ss Por

3.89821e+00 3.89821e+00 3.89821e-01 1.00000e-09 2.12000e-01 $3.89821 \mathrm{e}+003.89821 \mathrm{e}+003.89821 \mathrm{e}-01$ 1.00000e-09 2.12000e-01 3.89821e+00 3.89821e+00 3.89821e-01 1.00000e-09 2.12000e-01 $3.89821 \mathrm{e}+003.89821 \mathrm{e}+003.89821 \mathrm{e}-01$ 1.00000e-09 2.12000e-01 $3.89821 \mathrm{e}+003.89821 \mathrm{e}+003.89821 \mathrm{e}-01$ 1.00000e-09 2.12000e-01 
$1.00000 \mathrm{e}-05$ 1.00000e-05 1.00000e-06 1.00000e-09 1.00000e-01 $1.00000 \mathrm{e}+001.00000 \mathrm{e}+001.00000 \mathrm{e}-01$ 1.00000e-09 1.00000e-01 Element: 10148 \# of layers: 7

Kx Ky Kz Ss Por

3.57083e+00 3.57083e+00 3.57083e-01 1.00000e-09 2.12000e-01

$3.57083 \mathrm{e}+003.57083 \mathrm{e}+00$ 3.57083e-01 1.00000e-09 2.12000e-01

$3.57083 \mathrm{e}+003.57083 \mathrm{e}+00$ 3.57083e-01 1.00000e-09 2.12000e-01

$3.57083 \mathrm{e}+003.57083 \mathrm{e}+00$ 3.57083e-01 1.00000e-09 2.12000e-01

$3.57083 \mathrm{e}+00$ 3.57083e+00 3.57083e-01 1.00000e-09 2.12000e-01

$1.00000 \mathrm{e}-05$ 1.00000e-05 1.00000e-06 1.00000e-09 1.00000e-01

$1.00000 \mathrm{e}+001.00000 \mathrm{e}+001.00000 \mathrm{e}-011.00000 \mathrm{e}-091.00000 \mathrm{e}-01$

Element: 10149 \# of layers: 7

$\mathrm{Kx} \mathrm{Ky} \mathrm{Kz}$ Ss Por

3.57083e+00 3.57083e+00 3.57083e-01 1.00000e-09 2.12000e-01

3.57083e+00 3.57083e+00 3.57083e-01 1.00000e-09 2.12000e-01

$3.57083 \mathrm{e}+003.57083 \mathrm{e}+00$ 3.57083e-01 1.00000e-09 2.12000e-01

$3.57083 \mathrm{e}+003.57083 \mathrm{e}+00$ 3.57083e-01 1.00000e-09 2.12000e-01

$3.57083 \mathrm{e}+003.57083 \mathrm{e}+00$ 3.57083e-01 1.00000e-09 2.12000e-01

$1.00000 \mathrm{e}-05$ 1.00000e-05 1.00000e-06 1.00000e-09 1.00000e-01

$1.00000 \mathrm{e}+001.00000 \mathrm{e}+001.00000 \mathrm{e}-011.00000 \mathrm{e}-091.00000 \mathrm{e}-01$

Element: 10150 \# of layers: 7

$\mathrm{Kx} \mathrm{Ky} \mathrm{Kz}$ Ss Por

3.57083e+00 3.57083e+00 3.57083e-01 1.00000e-09 2.12000e-01

$3.57083 \mathrm{e}+003.57083 \mathrm{e}+00$ 3.57083e-01 1.00000e-09 2.12000e-01

$3.57083 \mathrm{e}+003.57083 \mathrm{e}+00$ 3.57083e-01 1.00000e-09 2.12000e-01

$3.57083 \mathrm{e}+003.57083 \mathrm{e}+00$ 3.57083e-01 1.00000e-09 2.12000e-01

$3.57083 \mathrm{e}+003.57083 \mathrm{e}+00$ 3.57083e-01 1.00000e-09 2.12000e-01

$1.00000 \mathrm{e}-05$ 1.00000e-05 1.00000e-06 1.00000e-09 1.00000e-01

$1.00000 \mathrm{e}+001.00000 \mathrm{e}+001.00000 \mathrm{e}-011.00000 \mathrm{e}-091.00000 \mathrm{e}-01$

Element: 10151 \# of layers: 7

$\mathrm{Kx} \mathrm{Ky} \mathrm{Kz}$ Ss Por

$3.89821 \mathrm{e}+003.89821 \mathrm{e}+00$ 3.89821e-01 1.00000e-09 2.12000e-01

$3.89821 \mathrm{e}+003.89821 \mathrm{e}+003.89821 \mathrm{e}-01$ 1.00000e-09 2.12000e-01

$3.89821 \mathrm{e}+003.89821 \mathrm{e}+003.89821 \mathrm{e}-011.00000 \mathrm{e}-092.12000 \mathrm{e}-01$

$3.89821 \mathrm{e}+003.89821 \mathrm{e}+003.89821 \mathrm{e}-01$ 1.00000e-09 2.12000e-01

$3.89821 \mathrm{e}+003.89821 \mathrm{e}+003.89821 \mathrm{e}-01$ 1.00000e-09 2.12000e-01

$1.00000 \mathrm{e}-05$ 1.00000e-05 1.00000e-06 1.00000e-09 1.00000e-01

$1.00000 \mathrm{e}+001.00000 \mathrm{e}+001.00000 \mathrm{e}-011.00000 \mathrm{e}-091.00000 \mathrm{e}-01$

Element: 10152 \# of layers: 7

$\mathrm{Kx} \mathrm{Ky} \mathrm{Kz}$ Ss Por

3.89821e+00 3.89821e+00 3.89821e-01 1.00000e-09 2.12000e-01

$3.89821 \mathrm{e}+003.89821 \mathrm{e}+003.89821 \mathrm{e}-01$ 1.00000e-09 2.12000e-01

$3.89821 \mathrm{e}+003.89821 \mathrm{e}+003.89821 \mathrm{e}-01$ 1.00000e-09 2.12000e-01

$3.89821 \mathrm{e}+003.89821 \mathrm{e}+003.89821 \mathrm{e}-01$ 1.00000e-09 2.12000e-01

$3.89821 \mathrm{e}+003.89821 \mathrm{e}+003.89821 \mathrm{e}-01$ 1.00000e-09 2.12000e-01

$1.00000 \mathrm{e}-05$ 1.00000e-05 1.00000e-06 1.00000e-09 1.00000e-01 
$1.00000 \mathrm{e}+001.00000 \mathrm{e}+00$ 1.00000e-01 1.00000e-09 1.00000e-01 Element: 10153 \# of layers: 7

$\mathrm{Kx} \mathrm{Ky} \mathrm{Kz}$ Ss Por

3.89821e+00 3.89821e+00 3.89821e-01 1.00000e-09 2.12000e-01

$3.89821 \mathrm{e}+003.89821 \mathrm{e}+003.89821 \mathrm{e}-01$ 1.00000e-09 2.12000e-01

$3.89821 \mathrm{e}+003.89821 \mathrm{e}+003.89821 \mathrm{e}-01$ 1.00000e-09 2.12000e-01

$3.89821 \mathrm{e}+003.89821 \mathrm{e}+003.89821 \mathrm{e}-01$ 1.00000e-09 2.12000e-01

$3.89821 \mathrm{e}+003.89821 \mathrm{e}+003.89821 \mathrm{e}-01$ 1.00000e-09 2.12000e-01

$1.00000 \mathrm{e}-05$ 1.00000e-05 1.00000e-06 1.00000e-09 1.00000e-01

$1.00000 \mathrm{e}+001.00000 \mathrm{e}+001.00000 \mathrm{e}-011.00000 \mathrm{e}-091.00000 \mathrm{e}-01$

Element: 10154 \# of layers: 7

Kx Ky Kz Ss Por

3.89821e+00 3.89821e+00 3.89821e-01 1.00000e-09 2.12000e-01

$3.89821 \mathrm{e}+003.89821 \mathrm{e}+003.89821 \mathrm{e}-01$ 1.00000e-09 2.12000e-01

$3.89821 \mathrm{e}+003.89821 \mathrm{e}+003.89821 \mathrm{e}-01$ 1.00000e-09 2.12000e-01

$3.89821 \mathrm{e}+003.89821 \mathrm{e}+003.89821 \mathrm{e}-01$ 1.00000e-09 2.12000e-01

$3.89821 \mathrm{e}+003.89821 \mathrm{e}+003.89821 \mathrm{e}-01$ 1.00000e-09 2.12000e-01

$1.00000 \mathrm{e}-05$ 1.00000e-05 1.00000e-06 1.00000e-09 1.00000e-01

$1.00000 \mathrm{e}+001.00000 \mathrm{e}+001.00000 \mathrm{e}-01$ 1.00000e-09 1.00000e-01

Element: 10155 \# of layers: 7

$\mathrm{Kx} \mathrm{Ky} \mathrm{Kz}$ Ss Por

3.57083e+00 3.57083e+00 3.57083e-01 1.00000e-09 2.12000e-01

$3.57083 \mathrm{e}+003.57083 \mathrm{e}+00$ 3.57083e-01 1.00000e-09 2.12000e-01

$3.57083 \mathrm{e}+003.57083 \mathrm{e}+00$ 3.57083e-01 1.00000e-09 2.12000e-01

$3.57083 \mathrm{e}+003.57083 \mathrm{e}+00$ 3.57083e-01 1.00000e-09 2.12000e-01

$3.57083 \mathrm{e}+003.57083 \mathrm{e}+00$ 3.57083e-01 1.00000e-09 2.12000e-01

$1.00000 \mathrm{e}-05$ 1.00000e-05 1.00000e-06 1.00000e-09 1.00000e-01

$1.00000 \mathrm{e}+001.00000 \mathrm{e}+001.00000 \mathrm{e}-011.00000 \mathrm{e}-091.00000 \mathrm{e}-01$

Element: 10156 \# of layers: 7

$\mathrm{Kx} \mathrm{Ky} \mathrm{Kz}$ Ss Por

3.57083e+00 3.57083e+00 3.57083e-01 1.00000e-09 2.12000e-01

$3.57083 \mathrm{e}+003.57083 \mathrm{e}+00$ 3.57083e-01 1.00000e-09 2.12000e-01

$3.57083 \mathrm{e}+003.57083 \mathrm{e}+00$ 3.57083e-01 1.00000e-09 2.12000e-01

$3.57083 \mathrm{e}+00$ 3.57083e+00 3.57083e-01 1.00000e-09 2.12000e-01

$3.57083 \mathrm{e}+003.57083 \mathrm{e}+00$ 3.57083e-01 1.00000e-09 2.12000e-01

$1.00000 \mathrm{e}-05$ 1.00000e-05 1.00000e-06 1.00000e-09 1.00000e-01

$1.00000 \mathrm{e}+001.00000 \mathrm{e}+001.00000 \mathrm{e}-011.00000 \mathrm{e}-091.00000 \mathrm{e}-01$

Element: 10157 \# of layers: 7

$\mathrm{Kx} \mathrm{Ky} \mathrm{Kz}$ Ss Por

3.57083e+00 3.57083e+00 3.57083e-01 1.00000e-09 2.12000e-01

$3.57083 e+003.57083 e+003.57083 e-01$ 1.00000e-09 2.12000e-01

$3.57083 \mathrm{e}+003.57083 \mathrm{e}+00$ 3.57083e-01 1.00000e-09 2.12000e-01

3.57083e+00 3.57083e+00 3.57083e-01 1.00000e-09 2.12000e-01

$3.57083 \mathrm{e}+003.57083 \mathrm{e}+00$ 3.57083e-01 1.00000e-09 2.12000e-01

$1.00000 \mathrm{e}-05$ 1.00000e-05 1.00000e-06 1.00000e-09 1.00000e-01

$1.00000 \mathrm{e}+001.00000 \mathrm{e}+001.00000 \mathrm{e}-011.00000 \mathrm{e}-091.00000 \mathrm{e}-01$ 
Element: 10158 \# of layers: 7

$\mathrm{Kx} \mathrm{Ky} \mathrm{Kz}$ Ss Por

3.57083e+00 3.57083e+00 3.57083e-01 1.00000e-09 2.12000e-01

$3.57083 \mathrm{e}+003.57083 \mathrm{e}+00$ 3.57083e-01 1.00000e-09 2.12000e-01

3.57083e+00 3.57083e+00 3.57083e-01 1.00000e-09 2.12000e-01

$3.57083 \mathrm{e}+003.57083 \mathrm{e}+00$ 3.57083e-01 1.00000e-09 2.12000e-01

$3.57083 \mathrm{e}+00$ 3.57083e+00 3.57083e-01 1.00000e-09 2.12000e-01

$1.00000 \mathrm{e}-05$ 1.00000e-05 1.00000e-06 1.00000e-09 1.00000e-01

$1.00000 \mathrm{e}+001.00000 \mathrm{e}+001.00000 \mathrm{e}-011.00000 \mathrm{e}-091.00000 \mathrm{e}-01$

Element: 10159 \# of layers: 7

$\mathrm{Kx} \mathrm{Ky} \mathrm{Kz}$ Ss Por

3.57083e+00 3.57083e+00 3.57083e-01 1.00000e-09 2.12000e-01

$3.57083 \mathrm{e}+00$ 3.57083e+00 3.57083e-01 1.00000e-09 2.12000e-01

$3.57083 \mathrm{e}+003.57083 \mathrm{e}+00$ 3.57083e-01 1.00000e-09 2.12000e-01

$3.57083 \mathrm{e}+003.57083 \mathrm{e}+00$ 3.57083e-01 1.00000e-09 2.12000e-01

$3.57083 \mathrm{e}+003.57083 \mathrm{e}+00$ 3.57083e-01 1.00000e-09 2.12000e-01

$1.00000 \mathrm{e}-05$ 1.00000e-05 1.00000e-06 1.00000e-09 1.00000e-01

$1.00000 \mathrm{e}+001.00000 \mathrm{e}+001.00000 \mathrm{e}-01$ 1.00000e-09 1.00000e-01

Element: 10160 \# of layers: 7

$\mathrm{Kx} \mathrm{Ky} \mathrm{Kz}$ Ss Por

3.57083e+00 3.57083e+00 3.57083e-01 1.00000e-09 2.12000e-01

3.57083e+00 3.57083e+00 3.57083e-01 1.00000e-09 2.12000e-01

$3.57083 \mathrm{e}+003.57083 \mathrm{e}+00$ 3.57083e-01 1.00000e-09 2.12000e-01

$3.57083 \mathrm{e}+003.57083 \mathrm{e}+00$ 3.57083e-01 1.00000e-09 2.12000e-01

$3.57083 \mathrm{e}+003.57083 \mathrm{e}+00$ 3.57083e-01 1.00000e-09 2.12000e-01

$1.00000 \mathrm{e}-05$ 1.00000e-05 1.00000e-06 1.00000e-09 1.00000e-01

$1.00000 \mathrm{e}+001.00000 \mathrm{e}+001.00000 \mathrm{e}-011.00000 \mathrm{e}-091.00000 \mathrm{e}-01$

Element: 10161 \# of layers: 7

Kx Ky Kz Ss Por

3.57083e+00 3.57083e+00 3.57083e-01 1.00000e-09 2.12000e-01

$3.57083 \mathrm{e}+003.57083 \mathrm{e}+00$ 3.57083e-01 1.00000e-09 2.12000e-01

$3.57083 e+003.57083 e+003.57083 e-01$ 1.00000e-09 2.12000e-01

$3.57083 e+003.57083 e+003.57083 e-01$ 1.00000e-09 2.12000e-01

$3.57083 \mathrm{e}+00$ 3.57083e+00 3.57083e-01 1.00000e-09 2.12000e-01

$1.00000 \mathrm{e}-05$ 1.00000e-05 1.00000e-06 1.00000e-09 1.00000e-01

$1.00000 \mathrm{e}+001.00000 \mathrm{e}+001.00000 \mathrm{e}-011.00000 \mathrm{e}-091.00000 \mathrm{e}-01$

Element: 10162 \# of layers: 7

$\mathrm{Kx} \mathrm{Ky} \mathrm{Kz}$ Ss Por

3.57083e+00 3.57083e+00 3.57083e-01 1.00000e-09 2.12000e-01

$3.57083 \mathrm{e}+00$ 3.57083e+00 3.57083e-01 1.00000e-09 2.12000e-01

$3.57083 \mathrm{e}+003.57083 \mathrm{e}+003.57083 \mathrm{e}-01$ 1.00000e-09 2.12000e-01

$3.57083 \mathrm{e}+003.57083 \mathrm{e}+00$ 3.57083e-01 1.00000e-09 2.12000e-01

$3.57083 \mathrm{e}+00$ 3.57083e+00 3.57083e-01 1.00000e-09 2.12000e-01

$1.00000 \mathrm{e}-05$ 1.00000e-05 1.00000e-06 1.00000e-09 1.00000e-01

$1.00000 \mathrm{e}+001.00000 \mathrm{e}+001.00000 \mathrm{e}-011.00000 \mathrm{e}-091.00000 \mathrm{e}-01$

Element: 10163 \# of layers: 7 
$\mathrm{Kx} \mathrm{Ky} \mathrm{Kz} \mathrm{Ss} \mathrm{Por}$

3.57083e+00 3.57083e+00 3.57083e-01 1.00000e-09 2.12000e-01

$3.57083 \mathrm{e}+003.57083 \mathrm{e}+00$ 3.57083e-01 1.00000e-09 2.12000e-01

$3.57083 \mathrm{e}+003.57083 \mathrm{e}+00$ 3.57083e-01 1.00000e-09 2.12000e-01

$3.57083 \mathrm{e}+003.57083 \mathrm{e}+00$ 3.57083e-01 1.00000e-09 2.12000e-01

$3.57083 \mathrm{e}+003.57083 \mathrm{e}+00$ 3.57083e-01 1.00000e-09 2.12000e-01

$1.00000 \mathrm{e}-05$ 1.00000e-05 1.00000e-06 1.00000e-09 1.00000e-01

$1.00000 \mathrm{e}+001.00000 \mathrm{e}+001.00000 \mathrm{e}-01$ 1.00000e-09 1.00000e-01

Element: 10164 \# of layers: 7

$\mathrm{Kx} \mathrm{Ky} \mathrm{Kz}$ Ss Por

3.57083e+00 3.57083e+00 3.57083e-01 1.00000e-09 2.12000e-01

$3.57083 \mathrm{e}+003.57083 \mathrm{e}+003.57083 \mathrm{e}-01$ 1.00000e-09 2.12000e-01

$3.57083 \mathrm{e}+00$ 3.57083e+00 3.57083e-01 1.00000e-09 2.12000e-01

$3.57083 \mathrm{e}+00$ 3.57083e+00 3.57083e-01 1.00000e-09 2.12000e-01

$3.57083 \mathrm{e}+003.57083 \mathrm{e}+00$ 3.57083e-01 1.00000e-09 2.12000e-01

$1.00000 \mathrm{e}-05$ 1.00000e-05 1.00000e-06 1.00000e-09 1.00000e-01

$1.00000 \mathrm{e}+001.00000 \mathrm{e}+001.00000 \mathrm{e}-01$ 1.00000e-09 1.00000e-01

Element: 10165 \# of layers: 7

$\mathrm{Kx} \mathrm{Ky} \mathrm{Kz}$ Ss Por

8.73874e+00 8.73874e+00 8.73874e-01 1.00000e-09 2.12000e-01

$8.73874 \mathrm{e}+008.73874 \mathrm{e}+00 \quad 8.73874 \mathrm{e}-01$ 1.00000e-09 2.12000e-01

8.73874e+00 8.73874e+00 8.73874e-01 1.00000e-09 2.12000e-01

$8.73874 \mathrm{e}+008.73874 \mathrm{e}+00$ 8.73874e-01 1.00000e-09 2.12000e-01

$8.73874 \mathrm{e}+008.73874 \mathrm{e}+00 \quad 8.73874 \mathrm{e}-01$ 1.00000e-09 2.12000e-01

$1.00000 \mathrm{e}-051.00000 \mathrm{e}-05$ 1.00000e-06 1.00000e-09 1.00000e-01

$1.00000 \mathrm{e}+001.00000 \mathrm{e}+001.00000 \mathrm{e}-01$ 1.00000e-09 1.00000e-01

Element: 10166 \# of layers: 7

$\mathrm{Kx} \mathrm{Ky} \mathrm{Kz}$ Ss Por

8.73874e+00 8.73874e+00 8.73874e-01 1.00000e-09 2.12000e-01

$8.73874 \mathrm{e}+00$ 8.73874e+00 8.73874e-01 1.00000e-09 2.12000e-01

$8.73874 \mathrm{e}+00$ 8.73874e+00 8.73874e-01 1.00000e-09 2.12000e-01

$8.73874 \mathrm{e}+00$ 8.73874e+00 8.73874e-01 1.00000e-09 2.12000e-01

$8.73874 \mathrm{e}+008.73874 \mathrm{e}+008.73874 \mathrm{e}-01$ 1.00000e-09 2.12000e-01

$1.00000 \mathrm{e}-051.00000 \mathrm{e}-051.00000 \mathrm{e}-061.00000 \mathrm{e}-091.00000 \mathrm{e}-01$

$1.00000 \mathrm{e}+001.00000 \mathrm{e}+001.00000 \mathrm{e}-011.00000 \mathrm{e}-091.00000 \mathrm{e}-01$

Element: 10167 \# of layers: 7

Kx Ky Kz Ss Por

8.73874e+00 8.73874e+00 8.73874e-01 1.00000e-09 2.12000e-01

$8.73874 \mathrm{e}+008.73874 \mathrm{e}+00$ 8.73874e-01 1.00000e-09 2.12000e-01

$8.73874 \mathrm{e}+008.73874 \mathrm{e}+00$ 8.73874e-01 1.00000e-09 2.12000e-01

$8.73874 \mathrm{e}+008.73874 \mathrm{e}+00 \quad 8.73874 \mathrm{e}-01$ 1.00000e-09 2.12000e-01

$8.73874 \mathrm{e}+008.73874 \mathrm{e}+00$ 8.73874e-01 1.00000e-09 2.12000e-01

$1.00000 \mathrm{e}-051.00000 \mathrm{e}-051.00000 \mathrm{e}-061.00000 \mathrm{e}-091.00000 \mathrm{e}-01$

$1.00000 \mathrm{e}+001.00000 \mathrm{e}+001.00000 \mathrm{e}-01$ 1.00000e-09 1.00000e-01

Element: 10168 \# of layers: 7

$\mathrm{Kx} \mathrm{Ky} \mathrm{Kz}$ Ss Por 
$8.73874 \mathrm{e}+008.73874 \mathrm{e}+008.73874 \mathrm{e}-01$ 1.00000e-09 2.12000e-01 $8.73874 \mathrm{e}+008.73874 \mathrm{e}+008.73874 \mathrm{e}-011.00000 \mathrm{e}-092.12000 \mathrm{e}-01$ $8.73874 \mathrm{e}+008.73874 \mathrm{e}+008.73874 \mathrm{e}-01$ 1.00000e-09 2.12000e-01 $8.73874 \mathrm{e}+008.73874 \mathrm{e}+008.73874 \mathrm{e}-011.00000 \mathrm{e}-092.12000 \mathrm{e}-01$ $8.73874 \mathrm{e}+008.73874 \mathrm{e}+008.73874 \mathrm{e}-011.00000 \mathrm{e}-092.12000 \mathrm{e}-01$ $1.00000 \mathrm{e}-05$ 1.00000e-05 1.00000e-06 1.00000e-09 1.00000e-01 $1.00000 \mathrm{e}+001.00000 \mathrm{e}+001.00000 \mathrm{e}-011.00000 \mathrm{e}-091.00000 \mathrm{e}-01$ Element: 10169 \# of layers: 7

$\mathrm{Kx} \mathrm{Ky} \mathrm{Kz}$ Ss Por

8.73874e+00 8.73874e+00 8.73874e-01 1.00000e-09 2.12000e-01 $8.73874 \mathrm{e}+008.73874 \mathrm{e}+00$ 8.73874e-01 1.00000e-09 2.12000e-01 $8.73874 \mathrm{e}+008.73874 \mathrm{e}+00 \quad 8.73874 \mathrm{e}-01$ 1.00000e-09 2.12000e-01 $8.73874 \mathrm{e}+008.73874 \mathrm{e}+008.73874 \mathrm{e}-011.00000 \mathrm{e}-092.12000 \mathrm{e}-01$ $8.73874 \mathrm{e}+008.73874 \mathrm{e}+008.73874 \mathrm{e}-011.00000 \mathrm{e}-092.12000 \mathrm{e}-01$ $1.00000 \mathrm{e}-05$ 1.00000e-05 1.00000e-06 1.00000e-09 1.00000e-01 $1.00000 \mathrm{e}+001.00000 \mathrm{e}+001.00000 \mathrm{e}-011.00000 \mathrm{e}-091.00000 \mathrm{e}-01$ Element: 10170 \# of layers: 7

Kx Ky Kz Ss Por

$3.57083 \mathrm{e}+003.57083 \mathrm{e}+00$ 3.57083e-01 1.00000e-09 2.12000e-01

$3.57083 \mathrm{e}+003.57083 \mathrm{e}+003.57083 \mathrm{e}-01$ 1.00000e-09 2.12000e-01 $3.57083 \mathrm{e}+003.57083 \mathrm{e}+003.57083 \mathrm{e}-011.00000 \mathrm{e}-092.12000 \mathrm{e}-01$ $3.57083 \mathrm{e}+003.57083 \mathrm{e}+003.57083 \mathrm{e}-01$ 1.00000e-09 2.12000e-01 $3.57083 \mathrm{e}+003.57083 \mathrm{e}+003.57083 \mathrm{e}-011.00000 \mathrm{e}-092.12000 \mathrm{e}-01$ $1.00000 \mathrm{e}-05$ 1.00000e-05 1.00000e-06 1.00000e-09 1.00000e-01 $1.00000 \mathrm{e}+001.00000 \mathrm{e}+001.00000 \mathrm{e}-011.00000 \mathrm{e}-091.00000 \mathrm{e}-01$ Element: 10171 \# of layers: 7

Kx Ky Kz Ss Por

$3.57083 \mathrm{e}+003.57083 \mathrm{e}+00$ 3.57083e-01 1.00000e-09 2.12000e-01 $3.57083 \mathrm{e}+003.57083 \mathrm{e}+003.57083 \mathrm{e}-01$ 1.00000e-09 2.12000e-01 $3.57083 \mathrm{e}+003.57083 \mathrm{e}+003.57083 \mathrm{e}-01$ 1.00000e-09 2.12000e-01 $3.57083 \mathrm{e}+003.57083 \mathrm{e}+003.57083 \mathrm{e}-01$ 1.00000e-09 2.12000e-01 $3.57083 \mathrm{e}+003.57083 \mathrm{e}+003.57083 \mathrm{e}-01$ 1.00000e-09 2.12000e-01 $1.00000 \mathrm{e}-05$ 1.00000e-05 1.00000e-06 1.00000e-09 1.00000e-01 $1.00000 \mathrm{e}+001.00000 \mathrm{e}+001.00000 \mathrm{e}-011.00000 \mathrm{e}-091.00000 \mathrm{e}-01$ Element: 10172 \# of layers: 7

Kx Ky Kz Ss Por

$8.73874 \mathrm{e}+008.73874 \mathrm{e}+008.73874 \mathrm{e}-01$ 1.00000e-09 2.12000e-01 $8.73874 \mathrm{e}+008.73874 \mathrm{e}+008.73874 \mathrm{e}-011.00000 \mathrm{e}-092.12000 \mathrm{e}-01$ $8.73874 \mathrm{e}+008.73874 \mathrm{e}+008.73874 \mathrm{e}-011.00000 \mathrm{e}-092.12000 \mathrm{e}-01$ $8.73874 \mathrm{e}+008.73874 \mathrm{e}+008.73874 \mathrm{e}-01$ 1.00000e-09 2.12000e-01 $8.73874 \mathrm{e}+008.73874 \mathrm{e}+008.73874 \mathrm{e}-011.00000 \mathrm{e}-092.12000 \mathrm{e}-01$ $1.00000 \mathrm{e}-05$ 1.00000e-05 1.00000e-06 1.00000e-09 1.00000e-01 $1.00000 \mathrm{e}+001.00000 \mathrm{e}+001.00000 \mathrm{e}-011.00000 \mathrm{e}-091.00000 \mathrm{e}-01$ Element: 10173 \# of layers: 7

Kx Ky Kz Ss Por

8.73874e+00 8.73874e+00 8.73874e-01 1.00000e-09 2.12000e-01 
$8.73874 \mathrm{e}+008.73874 \mathrm{e}+00$ 8.73874e-01 1.00000e-09 2.12000e-01 $8.73874 \mathrm{e}+008.73874 \mathrm{e}+008.73874 \mathrm{e}-011.00000 \mathrm{e}-092.12000 \mathrm{e}-01$ $8.73874 \mathrm{e}+008.73874 \mathrm{e}+008.73874 \mathrm{e}-01$ 1.00000e-09 2.12000e-01 $8.73874 \mathrm{e}+008.73874 \mathrm{e}+008.73874 \mathrm{e}-011.00000 \mathrm{e}-092.12000 \mathrm{e}-01$ $1.00000 \mathrm{e}-05$ 1.00000e-05 1.00000e-06 1.00000e-09 1.00000e-01 $1.00000 \mathrm{e}+001.00000 \mathrm{e}+001.00000 \mathrm{e}-011.00000 \mathrm{e}-091.00000 \mathrm{e}-01$ Element: 10174 \# of layers: 7

Kx Ky Kz Ss Por

$3.24794 \mathrm{e}+003.24794 \mathrm{e}+003.24794 \mathrm{e}-01$ 1.00000e-09 2.12000e-01 $3.24794 \mathrm{e}+003.24794 \mathrm{e}+003.24794 \mathrm{e}-011.00000 \mathrm{e}-092.12000 \mathrm{e}-01$ $3.24794 \mathrm{e}+003.24794 \mathrm{e}+003.24794 \mathrm{e}-011.00000 \mathrm{e}-092.12000 \mathrm{e}-01$ $3.24794 \mathrm{e}+003.24794 \mathrm{e}+003.24794 \mathrm{e}-01$ 1.00000e-09 2.12000e-01 $3.24794 \mathrm{e}+003.24794 \mathrm{e}+003.24794 \mathrm{e}-01$ 1.00000e-09 2.12000e-01 $1.00000 \mathrm{e}-05$ 1.00000e-05 1.00000e-06 1.00000e-09 1.00000e-01 $1.00000 \mathrm{e}+001.00000 \mathrm{e}+001.00000 \mathrm{e}-011.00000 \mathrm{e}-091.00000 \mathrm{e}-01$ Element: 10175 \# of layers: 7

Kx Ky Kz Ss Por

$3.24794 \mathrm{e}+003.24794 \mathrm{e}+00$ 3.24794e-01 1.00000e-09 2.12000e-01 $3.24794 \mathrm{e}+003.24794 \mathrm{e}+003.24794 \mathrm{e}-01$ 1.00000e-09 2.12000e-01 $3.24794 \mathrm{e}+003.24794 \mathrm{e}+003.24794 \mathrm{e}-01$ 1.00000e-09 2.12000e-01 $3.24794 \mathrm{e}+003.24794 \mathrm{e}+003.24794 \mathrm{e}-011.00000 \mathrm{e}-092.12000 \mathrm{e}-01$ $3.24794 \mathrm{e}+003.24794 \mathrm{e}+003.24794 \mathrm{e}-011.00000 \mathrm{e}-09$ 2.12000e-01 $1.00000 \mathrm{e}-05$ 1.00000e-05 1.00000e-06 1.00000e-09 1.00000e-01 $1.00000 \mathrm{e}+001.00000 \mathrm{e}+001.00000 \mathrm{e}-011.00000 \mathrm{e}-091.00000 \mathrm{e}-01$ Element: 10176 \# of layers: 7

Kx Ky Kz Ss Por

3.24794e+00 3.24794e+00 3.24794e-01 1.00000e-09 2.12000e-01 $3.24794 \mathrm{e}+003.24794 \mathrm{e}+003.24794 \mathrm{e}-011.00000 \mathrm{e}-092.12000 \mathrm{e}-01$ $3.24794 \mathrm{e}+003.24794 \mathrm{e}+003.24794 \mathrm{e}-01$ 1.00000e-09 2.12000e-01 $3.24794 \mathrm{e}+003.24794 \mathrm{e}+003.24794 \mathrm{e}-01$ 1.00000e-09 2.12000e-01 $3.24794 \mathrm{e}+003.24794 \mathrm{e}+003.24794 \mathrm{e}-01$ 1.00000e-09 2.12000e-01 $1.00000 \mathrm{e}-05$ 1.00000e-05 1.00000e-06 1.00000e-09 1.00000e-01 $1.00000 \mathrm{e}+001.00000 \mathrm{e}+001.00000 \mathrm{e}-011.00000 \mathrm{e}-091.00000 \mathrm{e}-01$ Element: 10177 \# of layers: 7

Kx Ky Kz Ss Por

$3.89821 \mathrm{e}+003.89821 \mathrm{e}+003.89821 \mathrm{e}-01$ 1.00000e-09 2.12000e-01 $3.89821 \mathrm{e}+003.89821 \mathrm{e}+003.89821 \mathrm{e}-011.00000 \mathrm{e}-092.12000 \mathrm{e}-01$ $3.89821 \mathrm{e}+003.89821 \mathrm{e}+003.89821 \mathrm{e}-011.00000 \mathrm{e}-092.12000 \mathrm{e}-01$ $3.89821 \mathrm{e}+003.89821 \mathrm{e}+003.89821 \mathrm{e}-011.00000 \mathrm{e}-092.12000 \mathrm{e}-01$ $3.89821 \mathrm{e}+003.89821 \mathrm{e}+003.89821 \mathrm{e}-011.00000 \mathrm{e}-092.12000 \mathrm{e}-01$ $1.00000 \mathrm{e}-05$ 1.00000e-05 1.00000e-06 1.00000e-09 1.00000e-01 $1.00000 \mathrm{e}+001.00000 \mathrm{e}+001.00000 \mathrm{e}-011.00000 \mathrm{e}-091.00000 \mathrm{e}-01$ Element: 10178 \# of layers: 7

Kx Ky Kz Ss Por

$3.89821 \mathrm{e}+003.89821 \mathrm{e}+003.89821 \mathrm{e}-01$ 1.00000e-09 2.12000e-01 $3.89821 \mathrm{e}+003.89821 \mathrm{e}+003.89821 \mathrm{e}-01$ 1.00000e-09 2.12000e-01 
$3.89821 \mathrm{e}+003.89821 \mathrm{e}+003.89821 \mathrm{e}-011.00000 \mathrm{e}-092.12000 \mathrm{e}-01$ $3.89821 \mathrm{e}+003.89821 \mathrm{e}+003.89821 \mathrm{e}-01$ 1.00000e-09 2.12000e-01 $3.89821 \mathrm{e}+003.89821 \mathrm{e}+003.89821 \mathrm{e}-01$ 1.00000e-09 2.12000e-01 $1.00000 \mathrm{e}-05$ 1.00000e-05 1.00000e-06 1.00000e-09 1.00000e-01 $1.00000 \mathrm{e}+001.00000 \mathrm{e}+001.00000 \mathrm{e}-011.00000 \mathrm{e}-091.00000 \mathrm{e}-01$ Element: 10179 \# of layers: 7

Kx Ky Kz Ss Por

$3.57083 \mathrm{e}+003.57083 \mathrm{e}+00$ 3.57083e-01 1.00000e-09 2.12000e-01 $3.57083 \mathrm{e}+003.57083 \mathrm{e}+003.57083 \mathrm{e}-011.00000 \mathrm{e}-092.12000 \mathrm{e}-01$ $3.57083 \mathrm{e}+003.57083 \mathrm{e}+003.57083 \mathrm{e}-01$ 1.00000e-09 2.12000e-01 $3.57083 \mathrm{e}+003.57083 \mathrm{e}+003.57083 \mathrm{e}-01$ 1.00000e-09 2.12000e-01 $3.57083 \mathrm{e}+003.57083 \mathrm{e}+003.57083 \mathrm{e}-01$ 1.00000e-09 2.12000e-01 $1.00000 \mathrm{e}-05$ 1.00000e-05 1.00000e-06 1.00000e-09 1.00000e-01 $1.00000 \mathrm{e}+001.00000 \mathrm{e}+001.00000 \mathrm{e}-011.00000 \mathrm{e}-091.00000 \mathrm{e}-01$ Element: 10180 \# of layers: 7

Kx Ky Kz Ss Por

$8.73874 \mathrm{e}+008.73874 \mathrm{e}+00$ 8.73874e-01 1.00000e-09 2.12000e-01 $8.73874 \mathrm{e}+008.73874 \mathrm{e}+008.73874 \mathrm{e}-011.00000 \mathrm{e}-092.12000 \mathrm{e}-01$ $8.73874 \mathrm{e}+008.73874 \mathrm{e}+008.73874 \mathrm{e}-011.00000 \mathrm{e}-092.12000 \mathrm{e}-01$ $8.73874 \mathrm{e}+008.73874 \mathrm{e}+008.73874 \mathrm{e}-011.00000 \mathrm{e}-092.12000 \mathrm{e}-01$ $8.73874 \mathrm{e}+008.73874 \mathrm{e}+008.73874 \mathrm{e}-01$ 1.00000e-09 2.12000e-01 $1.00000 \mathrm{e}-05$ 1.00000e-05 1.00000e-06 1.00000e-09 1.00000e-01 $1.00000 \mathrm{e}+001.00000 \mathrm{e}+001.00000 \mathrm{e}-011.00000 \mathrm{e}-091.00000 \mathrm{e}-01$ Element: 10181 \# of layers: 7

Kx Ky Kz Ss Por

$3.24794 \mathrm{e}+003.24794 \mathrm{e}+003.24794 \mathrm{e}-01$ 1.00000e-09 2.12000e-01 $3.24794 \mathrm{e}+003.24794 \mathrm{e}+003.24794 \mathrm{e}-01$ 1.00000e-09 2.12000e-01 $3.24794 \mathrm{e}+003.24794 \mathrm{e}+003.24794 \mathrm{e}-01$ 1.00000e-09 2.12000e-01 $3.24794 \mathrm{e}+003.24794 \mathrm{e}+003.24794 \mathrm{e}-01$ 1.00000e-09 2.12000e-01 $3.24794 \mathrm{e}+003.24794 \mathrm{e}+003.24794 \mathrm{e}-011.00000 \mathrm{e}-09$ 2.12000e-01 $1.00000 \mathrm{e}-05$ 1.00000e-05 1.00000e-06 1.00000e-09 1.00000e-01 $1.00000 \mathrm{e}+001.00000 \mathrm{e}+001.00000 \mathrm{e}-011.00000 \mathrm{e}-091.00000 \mathrm{e}-01$ Element: 10182 \# of layers: 7

Kx Ky Kz Ss Por

3.50962e+00 3.50962e+00 3.50963e-01 1.00000e-09 2.12000e-01 $3.50962 \mathrm{e}+003.50962 \mathrm{e}+003.50963 \mathrm{e}-011.00000 \mathrm{e}-092.12000 \mathrm{e}-01$ $3.50962 \mathrm{e}+003.50962 \mathrm{e}+003.50963 \mathrm{e}-01$ 1.00000e-09 2.12000e-01 $3.50962 \mathrm{e}+003.50962 \mathrm{e}+003.50963 \mathrm{e}-01$ 1.00000e-09 2.12000e-01 $3.50962 \mathrm{e}+003.50962 \mathrm{e}+003.50963 \mathrm{e}-01$ 1.00000e-09 2.12000e-01 $1.00000 \mathrm{e}-05$ 1.00000e-05 1.00000e-06 1.00000e-09 1.00000e-01 $1.00000 \mathrm{e}+001.00000 \mathrm{e}+001.00000 \mathrm{e}-011.00000 \mathrm{e}-091.00000 \mathrm{e}-01$ Element: 10183 \# of layers: 7

Kx Ky Kz Ss Por 3.50962e+00 3.50962e+00 3.50963e-01 1.00000e-09 2.12000e-01 $3.50962 \mathrm{e}+003.50962 \mathrm{e}+003.50963 \mathrm{e}-01$ 1.00000e-09 2.12000e-01 $3.50962 \mathrm{e}+003.50962 \mathrm{e}+003.50963 \mathrm{e}-01$ 1.00000e-09 2.12000e-01 
$3.50962 \mathrm{e}+003.50962 \mathrm{e}+00$ 3.50963e-01 1.00000e-09 2.12000e-01 $3.50962 \mathrm{e}+003.50962 \mathrm{e}+003.50963 \mathrm{e}-011.00000 \mathrm{e}-092.12000 \mathrm{e}-01$ $1.00000 \mathrm{e}-05$ 1.00000e-05 1.00000e-06 1.00000e-09 1.00000e-01 $1.00000 \mathrm{e}+001.00000 \mathrm{e}+001.00000 \mathrm{e}-011.00000 \mathrm{e}-091.00000 \mathrm{e}-01$ Element: 10184 \# of layers: 7

Kx Ky Kz Ss Por

3.50962e+00 3.50962e+00 3.50963e-01 1.00000e-09 2.12000e-01 $3.50962 \mathrm{e}+003.50962 \mathrm{e}+003.50963 \mathrm{e}-01$ 1.00000e-09 2.12000e-01 $3.50962 \mathrm{e}+003.50962 \mathrm{e}+003.50963 \mathrm{e}-011.00000 \mathrm{e}-092.12000 \mathrm{e}-01$ $3.50962 \mathrm{e}+003.50962 \mathrm{e}+003.50963 \mathrm{e}-011.00000 \mathrm{e}-092.12000 \mathrm{e}-01$ $3.50962 \mathrm{e}+003.50962 \mathrm{e}+003.50963 \mathrm{e}-01$ 1.00000e-09 2.12000e-01 $1.00000 \mathrm{e}-05$ 1.00000e-05 1.00000e-06 1.00000e-09 1.00000e-01 $1.00000 \mathrm{e}+001.00000 \mathrm{e}+001.00000 \mathrm{e}-011.00000 \mathrm{e}-091.00000 \mathrm{e}-01$ Element: 10185 \# of layers: 7

Kx Ky Kz Ss Por

3.50962e+00 3.50962e+00 3.50963e-01 1.00000e-09 2.12000e-01 $3.50962 \mathrm{e}+003.50962 \mathrm{e}+003.50963 \mathrm{e}-011.00000 \mathrm{e}-092.12000 \mathrm{e}-01$ $3.50962 \mathrm{e}+003.50962 \mathrm{e}+003.50963 \mathrm{e}-01$ 1.00000e-09 2.12000e-01 $3.50962 \mathrm{e}+003.50962 \mathrm{e}+003.50963 \mathrm{e}-011.00000 \mathrm{e}-092.12000 \mathrm{e}-01$ $3.50962 \mathrm{e}+003.50962 \mathrm{e}+003.50963 \mathrm{e}-01$ 1.00000e-09 2.12000e-01 $1.00000 \mathrm{e}-05$ 1.00000e-05 1.00000e-06 1.00000e-09 1.00000e-01 $1.00000 \mathrm{e}+001.00000 \mathrm{e}+001.00000 \mathrm{e}-011.00000 \mathrm{e}-091.00000 \mathrm{e}-01$ Element: 10186 \# of layers: 7

Kx Ky Kz Ss Por

3.50962e+00 3.50962e+00 3.50963e-01 1.00000e-09 2.12000e-01 $3.50962 \mathrm{e}+003.50962 \mathrm{e}+003.50963 \mathrm{e}-011.00000 \mathrm{e}-092.12000 \mathrm{e}-01$ $3.50962 \mathrm{e}+003.50962 \mathrm{e}+003.50963 \mathrm{e}-011.00000 \mathrm{e}-092.12000 \mathrm{e}-01$ $3.50962 \mathrm{e}+003.50962 \mathrm{e}+003.50963 \mathrm{e}-01$ 1.00000e-09 2.12000e-01 $3.50962 \mathrm{e}+003.50962 \mathrm{e}+003.50963 \mathrm{e}-01$ 1.00000e-09 2.12000e-01 $1.00000 \mathrm{e}-05$ 1.00000e-05 1.00000e-06 1.00000e-09 1.00000e-01 $1.00000 \mathrm{e}+001.00000 \mathrm{e}+001.00000 \mathrm{e}-011.00000 \mathrm{e}-091.00000 \mathrm{e}-01$ Element: 10187 \# of layers: 7

Kx Ky Kz Ss Por

$3.50962 \mathrm{e}+003.50962 \mathrm{e}+00$ 3.50963e-01 1.00000e-09 2.12000e-01 $3.50962 \mathrm{e}+003.50962 \mathrm{e}+003.50963 \mathrm{e}-011.00000 \mathrm{e}-092.12000 \mathrm{e}-01$ $3.50962 \mathrm{e}+003.50962 \mathrm{e}+003.50963 \mathrm{e}-01$ 1.00000e-09 2.12000e-01 $3.50962 \mathrm{e}+003.50962 \mathrm{e}+003.50963 \mathrm{e}-01$ 1.00000e-09 2.12000e-01 $3.50962 \mathrm{e}+003.50962 \mathrm{e}+003.50963 \mathrm{e}-011.00000 \mathrm{e}-092.12000 \mathrm{e}-01$ $1.00000 \mathrm{e}-05$ 1.00000e-05 1.00000e-06 1.00000e-09 1.00000e-01 $1.00000 \mathrm{e}+001.00000 \mathrm{e}+001.00000 \mathrm{e}-011.00000 \mathrm{e}-091.00000 \mathrm{e}-01$ Element: 10188 \# of layers: 7

Kx Ky Kz Ss Por

$3.50962 \mathrm{e}+003.50962 \mathrm{e}+00$ 3.50963e-01 1.00000e-09 2.12000e-01 $3.50962 \mathrm{e}+003.50962 \mathrm{e}+003.50963 \mathrm{e}-011.00000 \mathrm{e}-092.12000 \mathrm{e}-01$ $3.50962 \mathrm{e}+003.50962 \mathrm{e}+003.50963 \mathrm{e}-01$ 1.00000e-09 2.12000e-01 $3.50962 \mathrm{e}+003.50962 \mathrm{e}+003.50963 \mathrm{e}-01$ 1.00000e-09 2.12000e-01 
$3.50962 \mathrm{e}+003.50962 \mathrm{e}+00$ 3.50963e-01 1.00000e-09 2.12000e-01 $1.00000 \mathrm{e}-05$ 1.00000e-05 1.00000e-06 1.00000e-09 1.00000e-01 $1.00000 \mathrm{e}+001.00000 \mathrm{e}+001.00000 \mathrm{e}-011.00000 \mathrm{e}-091.00000 \mathrm{e}-01$ Element: 10189 \# of layers: 7

Kx Ky Kz Ss Por

3.50962e+00 3.50962e+00 3.50963e-01 1.00000e-09 2.12000e-01 $3.50962 \mathrm{e}+003.50962 \mathrm{e}+003.50963 \mathrm{e}-011.00000 \mathrm{e}-092.12000 \mathrm{e}-01$ $3.50962 \mathrm{e}+003.50962 \mathrm{e}+003.50963 \mathrm{e}-011.00000 \mathrm{e}-092.12000 \mathrm{e}-01$ $3.50962 \mathrm{e}+003.50962 \mathrm{e}+003.50963 \mathrm{e}-011.00000 \mathrm{e}-092.12000 \mathrm{e}-01$ $3.50962 \mathrm{e}+003.50962 \mathrm{e}+003.50963 \mathrm{e}-01$ 1.00000e-09 2.12000e-01 $1.00000 \mathrm{e}-05$ 1.00000e-05 1.00000e-06 1.00000e-09 1.00000e-01 $1.00000 \mathrm{e}+001.00000 \mathrm{e}+001.00000 \mathrm{e}-011.00000 \mathrm{e}-091.00000 \mathrm{e}-01$ Element: 10190 \# of layers: 7

Kx Ky Kz Ss Por

3.50962e+00 3.50962e+00 3.50963e-01 1.00000e-09 2.12000e-01 $3.50962 \mathrm{e}+003.50962 \mathrm{e}+003.50963 \mathrm{e}-011.00000 \mathrm{e}-092.12000 \mathrm{e}-01$ $3.50962 \mathrm{e}+003.50962 \mathrm{e}+003.50963 \mathrm{e}-011.00000 \mathrm{e}-092.12000 \mathrm{e}-01$ $3.50962 \mathrm{e}+003.50962 \mathrm{e}+003.50963 \mathrm{e}-01$ 1.00000e-09 2.12000e-01 $3.50962 \mathrm{e}+003.50962 \mathrm{e}+003.50963 \mathrm{e}-01$ 1.00000e-09 2.12000e-01 $1.00000 \mathrm{e}-05$ 1.00000e-05 1.00000e-06 1.00000e-09 1.00000e-01 $1.00000 \mathrm{e}+001.00000 \mathrm{e}+001.00000 \mathrm{e}-011.00000 \mathrm{e}-091.00000 \mathrm{e}-01$ Element: 10191 \# of layers: 7

Kx Ky Kz Ss Por

3.50962e+00 3.50962e+00 3.50963e-01 1.00000e-09 2.12000e-01 $3.50962 \mathrm{e}+003.50962 \mathrm{e}+003.50963 \mathrm{e}-011.00000 \mathrm{e}-092.12000 \mathrm{e}-01$ $3.50962 \mathrm{e}+003.50962 \mathrm{e}+003.50963 \mathrm{e}-011.00000 \mathrm{e}-092.12000 \mathrm{e}-01$ $3.50962 \mathrm{e}+003.50962 \mathrm{e}+003.50963 \mathrm{e}-011.00000 \mathrm{e}-092.12000 \mathrm{e}-01$ $3.50962 \mathrm{e}+003.50962 \mathrm{e}+003.50963 \mathrm{e}-011.00000 \mathrm{e}-092.12000 \mathrm{e}-01$ $1.00000 \mathrm{e}-05$ 1.00000e-05 1.00000e-06 1.00000e-09 1.00000e-01 $1.00000 \mathrm{e}+001.00000 \mathrm{e}+001.00000 \mathrm{e}-011.00000 \mathrm{e}-091.00000 \mathrm{e}-01$ Element: 10192 \# of layers: 6

Kx Ky Kz Ss Por

$3.87616 \mathrm{e}+003.87616 \mathrm{e}+003.87616 \mathrm{e}-01$ 1.00000e-09 2.12000e-01 $3.87616 \mathrm{e}+003.87616 \mathrm{e}+003.87616 \mathrm{e}-011.00000 \mathrm{e}-092.12000 \mathrm{e}-01$ $3.87616 \mathrm{e}+003.87616 \mathrm{e}+003.87616 \mathrm{e}-011.00000 \mathrm{e}-092.12000 \mathrm{e}-01$ $3.87616 \mathrm{e}+003.87616 \mathrm{e}+003.87616 \mathrm{e}-011.00000 \mathrm{e}-092.12000 \mathrm{e}-01$ $1.00000 \mathrm{e}-05$ 1.00000e-05 1.00000e-06 1.00000e-09 1.00000e-01 $1.00000 \mathrm{e}+001.00000 \mathrm{e}+001.00000 \mathrm{e}-011.00000 \mathrm{e}-091.00000 \mathrm{e}-01$ Element: 10193 \# of layers: 6

Kx Ky Kz Ss Por

$3.87616 \mathrm{e}+003.87616 \mathrm{e}+00$ 3.87616e-01 1.00000e-09 2.12000e-01 $3.87616 \mathrm{e}+003.87616 \mathrm{e}+003.87616 \mathrm{e}-011.00000 \mathrm{e}-092.12000 \mathrm{e}-01$ $3.87616 \mathrm{e}+003.87616 \mathrm{e}+003.87616 \mathrm{e}-011.00000 \mathrm{e}-092.12000 \mathrm{e}-01$ $3.87616 \mathrm{e}+003.87616 \mathrm{e}+003.87616 \mathrm{e}-01$ 1.00000e-09 2.12000e-01 $1.00000 \mathrm{e}-05$ 1.00000e-05 1.00000e-06 1.00000e-09 1.00000e-01 $1.00000 \mathrm{e}+001.00000 \mathrm{e}+001.00000 \mathrm{e}-011.00000 \mathrm{e}-091.00000 \mathrm{e}-01$ 
Element: 10194 \# of layers: 6

$\mathrm{Kx} \mathrm{Ky} \mathrm{Kz}$ Ss Por

3.87616e+00 3.87616e+00 3.87616e-01 1.00000e-09 2.12000e-01

$3.87616 \mathrm{e}+003.87616 \mathrm{e}+003.87616 \mathrm{e}-01$ 1.00000e-09 2.12000e-01

$3.87616 \mathrm{e}+003.87616 \mathrm{e}+003.87616 \mathrm{e}-01$ 1.00000e-09 2.12000e-01

$3.87616 \mathrm{e}+003.87616 \mathrm{e}+003.87616 \mathrm{e}-01$ 1.00000e-09 2.12000e-01

$1.00000 \mathrm{e}-05$ 1.00000e-05 1.00000e-06 1.00000e-09 1.00000e-01

$1.00000 \mathrm{e}+001.00000 \mathrm{e}+001.00000 \mathrm{e}-01$ 1.00000e-09 1.00000e-01

Element: 10195 \# of layers: 6

$\mathrm{Kx} \mathrm{Ky} \mathrm{Kz}$ Ss Por

$3.87616 \mathrm{e}+003.87616 \mathrm{e}+00$ 3.87616e-01 1.00000e-09 2.12000e-01

$3.87616 \mathrm{e}+003.87616 \mathrm{e}+003.87616 \mathrm{e}-01$ 1.00000e-09 2.12000e-01

$3.87616 \mathrm{e}+003.87616 \mathrm{e}+00$ 3.87616e-01 1.00000e-09 2.12000e-01

$3.87616 \mathrm{e}+003.87616 \mathrm{e}+003.87616 \mathrm{e}-01$ 1.00000e-09 2.12000e-01

$1.00000 \mathrm{e}-05$ 1.00000e-05 1.00000e-06 1.00000e-09 1.00000e-01

$1.00000 \mathrm{e}+001.00000 \mathrm{e}+001.00000 \mathrm{e}-011.00000 \mathrm{e}-091.00000 \mathrm{e}-01$

Element: 10196 \# of layers: 6

$\mathrm{Kx} \mathrm{Ky} \mathrm{Kz}$ Ss Por

3.87616e+00 3.87616e+00 3.87616e-01 1.00000e-09 2.12000e-01

$3.87616 \mathrm{e}+003.87616 \mathrm{e}+00$ 3.87616e-01 1.00000e-09 2.12000e-01

$3.87616 \mathrm{e}+003.87616 \mathrm{e}+003.87616 \mathrm{e}-01$ 1.00000e-09 2.12000e-01

$3.87616 \mathrm{e}+003.87616 \mathrm{e}+00$ 3.87616e-01 1.00000e-09 2.12000e-01

$1.00000 \mathrm{e}-051.00000 \mathrm{e}-051.00000 \mathrm{e}-061.00000 \mathrm{e}-091.00000 \mathrm{e}-01$

$1.00000 \mathrm{e}+001.00000 \mathrm{e}+001.00000 \mathrm{e}-011.00000 \mathrm{e}-091.00000 \mathrm{e}-01$

Element: 10197 \# of layers: 6

$\mathrm{Kx} \mathrm{Ky} \mathrm{Kz}$ Ss Por

3.50962e+00 3.50962e+00 3.50963e-01 1.00000e-09 2.12000e-01

$3.50962 \mathrm{e}+00$ 3.50962e+00 3.50963e-01 1.00000e-09 2.12000e-01

$3.50962 \mathrm{e}+003.50962 \mathrm{e}+00$ 3.50963e-01 1.00000e-09 2.12000e-01

$3.50962 \mathrm{e}+00$ 3.50962e+00 3.50963e-01 1.00000e-09 2.12000e-01

$1.00000 \mathrm{e}-05$ 1.00000e-05 1.00000e-06 1.00000e-09 1.00000e-01

$1.00000 \mathrm{e}+001.00000 \mathrm{e}+001.00000 \mathrm{e}-01$ 1.00000e-09 1.00000e-01

Element: 10198 \# of layers: 6

$\mathrm{Kx} \mathrm{Ky} \mathrm{Kz}$ Ss Por

3.50962e+00 3.50962e+00 3.50963e-01 1.00000e-09 2.12000e-01

$3.50962 \mathrm{e}+003.50962 \mathrm{e}+00$ 3.50963e-01 1.00000e-09 2.12000e-01

$3.50962 \mathrm{e}+003.50962 \mathrm{e}+00$ 3.50963e-01 1.00000e-09 2.12000e-01

$3.50962 \mathrm{e}+00$ 3.50962e+00 3.50963e-01 1.00000e-09 2.12000e-01

$1.00000 \mathrm{e}-05$ 1.00000e-05 1.00000e-06 1.00000e-09 1.00000e-01

$1.00000 \mathrm{e}+001.00000 \mathrm{e}+001.00000 \mathrm{e}-01$ 1.00000e-09 1.00000e-01

Element: 10199 \# of layers: 6

$\mathrm{Kx} \mathrm{Ky} \mathrm{Kz}$ Ss Por

3.87616e+00 3.87616e+00 3.87616e-01 1.00000e-09 2.12000e-01

$3.87616 \mathrm{e}+003.87616 \mathrm{e}+003.87616 \mathrm{e}-01$ 1.00000e-09 2.12000e-01

$3.87616 \mathrm{e}+003.87616 \mathrm{e}+003.87616 \mathrm{e}-01$ 1.00000e-09 2.12000e-01

$3.87616 \mathrm{e}+003.87616 \mathrm{e}+003.87616 \mathrm{e}-01$ 1.00000e-09 2.12000e-01 
$1.00000 \mathrm{e}-05$ 1.00000e-05 1.00000e-06 1.00000e-09 1.00000e-01 $1.00000 \mathrm{e}+001.00000 \mathrm{e}+001.00000 \mathrm{e}-01$ 1.00000e-09 1.00000e-01 Element: 10200 \# of layers: 6

Kx Ky Kz Ss Por

3.87616e+00 3.87616e+00 3.87616e-01 1.00000e-09 2.12000e-01 $3.87616 \mathrm{e}+003.87616 \mathrm{e}+003.87616 \mathrm{e}-01$ 1.00000e-09 2.12000e-01 $3.87616 \mathrm{e}+003.87616 \mathrm{e}+003.87616 \mathrm{e}-01$ 1.00000e-09 2.12000e-01 $3.87616 \mathrm{e}+003.87616 \mathrm{e}+003.87616 \mathrm{e}-01$ 1.00000e-09 2.12000e-01 $1.00000 \mathrm{e}-051.00000 \mathrm{e}-051.00000 \mathrm{e}-061.00000 \mathrm{e}-091.00000 \mathrm{e}-01$ $1.00000 \mathrm{e}+001.00000 \mathrm{e}+00$ 1.00000e-01 1.00000e-09 1.00000e-01 Element: 10201 \# of layers: 6

Kx Ky Kz Ss Por

3.87616e+00 3.87616e+00 3.87616e-01 1.00000e-09 2.12000e-01 $3.87616 \mathrm{e}+003.87616 \mathrm{e}+003.87616 \mathrm{e}-01$ 1.00000e-09 2.12000e-01 $3.87616 \mathrm{e}+003.87616 \mathrm{e}+003.87616 \mathrm{e}-01$ 1.00000e-09 2.12000e-01 $3.87616 \mathrm{e}+003.87616 \mathrm{e}+003.87616 \mathrm{e}-01$ 1.00000e-09 2.12000e-01 $1.00000 \mathrm{e}-05$ 1.00000e-05 1.00000e-06 1.00000e-09 1.00000e-01 $1.00000 \mathrm{e}+001.00000 \mathrm{e}+001.00000 \mathrm{e}-01$ 1.00000e-09 1.00000e-01 Element: 10202 \# of layers: 7

Kx Ky Kz Ss Por

3.87616e+00 3.87616e+00 3.87616e-01 1.00000e-09 2.12000e-01 3.87616e+00 3.87616e+00 3.87616e-01 1.00000e-09 2.12000e-01 $3.87616 \mathrm{e}+003.87616 \mathrm{e}+003.87616 \mathrm{e}-01$ 1.00000e-09 2.12000e-01 $3.87616 \mathrm{e}+003.87616 \mathrm{e}+003.87616 \mathrm{e}-01$ 1.00000e-09 2.12000e-01 $3.87616 \mathrm{e}+003.87616 \mathrm{e}+003.87616 \mathrm{e}-01$ 1.00000e-09 2.12000e-01 $1.00000 \mathrm{e}-05$ 1.00000e-05 1.00000e-06 1.00000e-09 1.00000e-01 $1.00000 \mathrm{e}+001.00000 \mathrm{e}+001.00000 \mathrm{e}-011.00000 \mathrm{e}-091.00000 \mathrm{e}-01$ Element: 10203 \# of layers: 7

Kx Ky Kz Ss Por

3.87616e+00 3.87616e+00 3.87616e-01 1.00000e-09 2.12000e-01 $3.87616 \mathrm{e}+003.87616 \mathrm{e}+00$ 3.87616e-01 1.00000e-09 2.12000e-01 $3.87616 \mathrm{e}+003.87616 \mathrm{e}+003.87616 \mathrm{e}-01$ 1.00000e-09 2.12000e-01 $3.87616 \mathrm{e}+003.87616 \mathrm{e}+003.87616 \mathrm{e}-01$ 1.00000e-09 2.12000e-01 $3.87616 \mathrm{e}+003.87616 \mathrm{e}+003.87616 \mathrm{e}-01$ 1.00000e-09 2.12000e-01 $1.00000 \mathrm{e}-05$ 1.00000e-05 1.00000e-06 1.00000e-09 1.00000e-01 $1.00000 \mathrm{e}+001.00000 \mathrm{e}+001.00000 \mathrm{e}-011.00000 \mathrm{e}-091.00000 \mathrm{e}-01$ Element: 10204 \# of layers: 7

$\mathrm{Kx} \mathrm{Ky} \mathrm{Kz}$ Ss Por

3.87616e+00 3.87616e+00 3.87616e-01 1.00000e-09 2.12000e-01 $3.87616 \mathrm{e}+003.87616 \mathrm{e}+003.87616 \mathrm{e}-01$ 1.00000e-09 2.12000e-01 $3.87616 \mathrm{e}+003.87616 \mathrm{e}+003.87616 \mathrm{e}-01$ 1.00000e-09 2.12000e-01 $3.87616 \mathrm{e}+003.87616 \mathrm{e}+003.87616 \mathrm{e}-01$ 1.00000e-09 2.12000e-01 $3.87616 \mathrm{e}+00$ 3.87616e+00 3.87616e-01 1.00000e-09 2.12000e-01 $1.00000 \mathrm{e}-051.00000 \mathrm{e}-051.00000 \mathrm{e}-061.00000 \mathrm{e}-091.00000 \mathrm{e}-01$ $1.00000 \mathrm{e}+001.00000 \mathrm{e}+00$ 1.00000e-01 1.00000e-09 1.00000e-01 Element: 10205 \# of layers: 6 
$\mathrm{Kx} \mathrm{Ky} \mathrm{Kz}$ Ss Por

3.87616e+00 3.87616e+00 3.87616e-01 1.00000e-09 2.12000e-01

$3.87616 \mathrm{e}+003.87616 \mathrm{e}+003.87616 \mathrm{e}-01$ 1.00000e-09 2.12000e-01

$3.87616 \mathrm{e}+003.87616 \mathrm{e}+003.87616 \mathrm{e}-01$ 1.00000e-09 2.12000e-01

$3.87616 \mathrm{e}+003.87616 \mathrm{e}+003.87616 \mathrm{e}-01$ 1.00000e-09 2.12000e-01

$1.00000 \mathrm{e}-05$ 1.00000e-05 1.00000e-06 1.00000e-09 1.00000e-01

$1.00000 \mathrm{e}+001.00000 \mathrm{e}+001.00000 \mathrm{e}-01$ 1.00000e-09 1.00000e-01

Element: 10206 \# of layers: 6

$\mathrm{Kx} \mathrm{Ky} \mathrm{Kz}$ Ss Por

3.87616e+00 3.87616e+00 3.87616e-01 1.00000e-09 2.12000e-01

$3.87616 \mathrm{e}+003.87616 \mathrm{e}+003.87616 \mathrm{e}-01$ 1.00000e-09 2.12000e-01

$3.87616 \mathrm{e}+003.87616 \mathrm{e}+003.87616 \mathrm{e}-01$ 1.00000e-09 2.12000e-01

$3.87616 \mathrm{e}+003.87616 \mathrm{e}+003.87616 \mathrm{e}-01$ 1.00000e-09 2.12000e-01

$1.00000 \mathrm{e}-05$ 1.00000e-05 1.00000e-06 1.00000e-09 1.00000e-01

$1.00000 \mathrm{e}+001.00000 \mathrm{e}+001.00000 \mathrm{e}-01$ 1.00000e-09 1.00000e-01

Element: 10207 \# of layers: 6

$\mathrm{Kx} \mathrm{Ky} \mathrm{Kz}$ Ss Por

3.87616e+00 3.87616e+00 3.87616e-01 1.00000e-09 2.12000e-01

$3.87616 \mathrm{e}+003.87616 \mathrm{e}+003.87616 \mathrm{e}-01$ 1.00000e-09 2.12000e-01

$3.87616 \mathrm{e}+003.87616 \mathrm{e}+003.87616 \mathrm{e}-01$ 1.00000e-09 2.12000e-01

$3.87616 \mathrm{e}+003.87616 \mathrm{e}+003.87616 \mathrm{e}-01$ 1.00000e-09 2.12000e-01

$1.00000 \mathrm{e}-051.00000 \mathrm{e}-051.00000 \mathrm{e}-061.00000 \mathrm{e}-091.00000 \mathrm{e}-01$

$1.00000 \mathrm{e}+001.00000 \mathrm{e}+001.00000 \mathrm{e}-01$ 1.00000e-09 1.00000e-01

Element: 10208 \# of layers: 6

Kx Ky Kz Ss Por

3.87616e+00 3.87616e+00 3.87616e-01 1.00000e-09 2.12000e-01

$3.87616 \mathrm{e}+003.87616 \mathrm{e}+003.87616 \mathrm{e}-01$ 1.00000e-09 2.12000e-01

$3.87616 \mathrm{e}+003.87616 \mathrm{e}+003.87616 \mathrm{e}-01$ 1.00000e-09 2.12000e-01

$3.87616 \mathrm{e}+003.87616 \mathrm{e}+003.87616 \mathrm{e}-01$ 1.00000e-09 2.12000e-01

$1.00000 \mathrm{e}-051.00000 \mathrm{e}-051.00000 \mathrm{e}-061.00000 \mathrm{e}-091.00000 \mathrm{e}-01$

$1.00000 \mathrm{e}+001.00000 \mathrm{e}+001.00000 \mathrm{e}-011.00000 \mathrm{e}-091.00000 \mathrm{e}-01$

Element: 10209 \# of layers: 7

Kx Ky Kz Ss Por

$3.87616 \mathrm{e}+003.87616 \mathrm{e}+003.87616 \mathrm{e}-01$ 1.00000e-09 2.12000e-01

$3.87616 \mathrm{e}+003.87616 \mathrm{e}+003.87616 \mathrm{e}-01$ 1.00000e-09 2.12000e-01

$3.87616 \mathrm{e}+003.87616 \mathrm{e}+003.87616 \mathrm{e}-01$ 1.00000e-09 2.12000e-01

$3.87616 \mathrm{e}+003.87616 \mathrm{e}+003.87616 \mathrm{e}-01$ 1.00000e-09 2.12000e-01

$3.87616 \mathrm{e}+003.87616 \mathrm{e}+003.87616 \mathrm{e}-01$ 1.00000e-09 2.12000e-01

$1.00000 \mathrm{e}-05$ 1.00000e-05 1.00000e-06 1.00000e-09 1.00000e-01

$1.00000 \mathrm{e}+001.00000 \mathrm{e}+001.00000 \mathrm{e}-01$ 1.00000e-09 1.00000e-01

Element: 10210 \# of layers: 7

$\mathrm{Kx} \mathrm{Ky} \mathrm{Kz}$ Ss Por

3.87616e+00 3.87616e+00 3.87616e-01 1.00000e-09 2.12000e-01

$3.87616 \mathrm{e}+003.87616 \mathrm{e}+003.87616 \mathrm{e}-01$ 1.00000e-09 2.12000e-01

$3.87616 \mathrm{e}+003.87616 \mathrm{e}+003.87616 \mathrm{e}-01$ 1.00000e-09 2.12000e-01

$3.87616 \mathrm{e}+003.87616 \mathrm{e}+003.87616 \mathrm{e}-01$ 1.00000e-09 2.12000e-01 
3.87616e+00 3.87616e+00 3.87616e-01 1.00000e-09 2.12000e-01 $1.00000 \mathrm{e}-05$ 1.00000e-05 1.00000e-06 1.00000e-09 1.00000e-01

$1.00000 \mathrm{e}+001.00000 \mathrm{e}+001.00000 \mathrm{e}-011.00000 \mathrm{e}-091.00000 \mathrm{e}-01$

Element: 10211 \# of layers: 7

$\mathrm{Kx} \mathrm{Ky} \mathrm{Kz}$ Ss Por

4.55567e+00 4.55567e+00 4.55567e-01 1.00000e-09 2.12000e-01

4.55567e+00 4.55567e+00 4.55567e-01 1.00000e-09 2.12000e-01

$4.55567 \mathrm{e}+00$ 4.55567e+00 4.55567e-01 1.00000e-09 2.12000e-01

$4.55567 \mathrm{e}+004.55567 \mathrm{e}+00$ 4.55567e-01 1.00000e-09 2.12000e-01

$4.55567 \mathrm{e}+004.55567 \mathrm{e}+00$ 4.55567e-01 1.00000e-09 2.12000e-01

$1.00000 \mathrm{e}-05$ 1.00000e-05 1.00000e-06 1.00000e-09 1.00000e-01

$1.00000 \mathrm{e}+001.00000 \mathrm{e}+001.00000 \mathrm{e}-011.00000 \mathrm{e}-091.00000 \mathrm{e}-01$

Element: 10212 \# of layers: 6

$\mathrm{Kx} \mathrm{Ky} \mathrm{Kz}$ Ss Por

4.55567e+00 4.55567e+00 4.55567e-01 1.00000e-09 2.12000e-01

$4.55567 \mathrm{e}+004.55567 \mathrm{e}+00$ 4.55567e-01 1.00000e-09 2.12000e-01

$4.55567 \mathrm{e}+00$ 4.55567e+00 4.55567e-01 1.00000e-09 2.12000e-01

4.55567e+00 4.55567e+00 4.55567e-01 1.00000e-09 2.12000e-01

$1.00000 \mathrm{e}-05$ 1.00000e-05 1.00000e-06 1.00000e-09 1.00000e-01

$1.00000 \mathrm{e}+001.00000 \mathrm{e}+001.00000 \mathrm{e}-011.00000 \mathrm{e}-091.00000 \mathrm{e}-01$

Element: 10213 \# of layers: 6

$\mathrm{Kx} \mathrm{Ky} \mathrm{Kz}$ Ss Por

4.55567e+00 4.55567e+00 4.55567e-01 1.00000e-09 2.12000e-01

4.55567e+00 4.55567e+00 4.55567e-01 1.00000e-09 2.12000e-01

$4.55567 \mathrm{e}+004.55567 \mathrm{e}+00$ 4.55567e-01 1.00000e-09 2.12000e-01

4.55567e+00 4.55567e+00 4.55567e-01 1.00000e-09 2.12000e-01

$1.00000 \mathrm{e}-05$ 1.00000e-05 1.00000e-06 1.00000e-09 1.00000e-01

$1.00000 \mathrm{e}+001.00000 \mathrm{e}+001.00000 \mathrm{e}-011.00000 \mathrm{e}-09$ 1.00000e-01

Element: 10214 \# of layers: 6

$\mathrm{Kx} \mathrm{Ky} \mathrm{Kz}$ Ss Por

3.87616e+00 3.87616e+00 3.87616e-01 1.00000e-09 2.12000e-01

$3.87616 \mathrm{e}+003.87616 \mathrm{e}+003.87616 \mathrm{e}-01$ 1.00000e-09 2.12000e-01

$3.87616 \mathrm{e}+003.87616 \mathrm{e}+003.87616 \mathrm{e}-01$ 1.00000e-09 2.12000e-01

$3.87616 \mathrm{e}+003.87616 \mathrm{e}+003.87616 \mathrm{e}-01$ 1.00000e-09 2.12000e-01

$1.00000 \mathrm{e}-05$ 1.00000e-05 1.00000e-06 1.00000e-09 1.00000e-01

$1.00000 \mathrm{e}+001.00000 \mathrm{e}+001.00000 \mathrm{e}-011.00000 \mathrm{e}-09$ 1.00000e-01

Element: 10215 \# of layers: 6

Kx Ky Kz Ss Por

3.87616e+00 3.87616e+00 3.87616e-01 1.00000e-09 2.12000e-01

$3.87616 \mathrm{e}+003.87616 \mathrm{e}+003.87616 \mathrm{e}-01$ 1.00000e-09 2.12000e-01

$3.87616 \mathrm{e}+003.87616 \mathrm{e}+003.87616 \mathrm{e}-01$ 1.00000e-09 2.12000e-01

$3.87616 \mathrm{e}+003.87616 \mathrm{e}+003.87616 \mathrm{e}-01$ 1.00000e-09 2.12000e-01

$1.00000 \mathrm{e}-05$ 1.00000e-05 1.00000e-06 1.00000e-09 1.00000e-01

$1.00000 \mathrm{e}+001.00000 \mathrm{e}+001.00000 \mathrm{e}-01$ 1.00000e-09 1.00000e-01

Element: 10216 \# of layers: 6

Kx Ky Kz Ss Por 
$3.87616 \mathrm{e}+003.87616 \mathrm{e}+003.87616 \mathrm{e}-011.00000 \mathrm{e}-092.12000 \mathrm{e}-01$ $3.87616 \mathrm{e}+003.87616 \mathrm{e}+003.87616 \mathrm{e}-011.00000 \mathrm{e}-092.12000 \mathrm{e}-01$ $3.87616 \mathrm{e}+003.87616 \mathrm{e}+003.87616 \mathrm{e}-01$ 1.00000e-09 2.12000e-01 $3.87616 \mathrm{e}+003.87616 \mathrm{e}+003.87616 \mathrm{e}-011.00000 \mathrm{e}-092.12000 \mathrm{e}-01$ $1.00000 \mathrm{e}-05$ 1.00000e-05 1.00000e-06 1.00000e-09 1.00000e-01 $1.00000 \mathrm{e}+001.00000 \mathrm{e}+001.00000 \mathrm{e}-011.00000 \mathrm{e}-091.00000 \mathrm{e}-01$ Element: 10217 \# of layers: 6

Kx Ky Kz Ss Por

3.87616e+00 3.87616e+00 3.87616e-01 1.00000e-09 2.12000e-01 $3.87616 \mathrm{e}+003.87616 \mathrm{e}+003.87616 \mathrm{e}-011.00000 \mathrm{e}-092.12000 \mathrm{e}-01$ $3.87616 \mathrm{e}+003.87616 \mathrm{e}+003.87616 \mathrm{e}-011.00000 \mathrm{e}-092.12000 \mathrm{e}-01$ $3.87616 \mathrm{e}+003.87616 \mathrm{e}+003.87616 \mathrm{e}-011.00000 \mathrm{e}-092.12000 \mathrm{e}-01$ $1.00000 \mathrm{e}-05$ 1.00000e-05 1.00000e-06 1.00000e-09 1.00000e-01 $1.00000 \mathrm{e}+001.00000 \mathrm{e}+001.00000 \mathrm{e}-011.00000 \mathrm{e}-091.00000 \mathrm{e}-01$ Element: 10218 \# of layers: 7

Kx Ky Kz Ss Por

$4.55567 \mathrm{e}+004.55567 \mathrm{e}+00$ 4.55567e-01 1.00000e-09 2.12000e-01

$4.55567 \mathrm{e}+004.55567 \mathrm{e}+004.55567 \mathrm{e}-011.00000 \mathrm{e}-092.12000 \mathrm{e}-01$

$4.55567 \mathrm{e}+004.55567 \mathrm{e}+004.55567 \mathrm{e}-011.00000 \mathrm{e}-092.12000 \mathrm{e}-01$

$4.55567 \mathrm{e}+004.55567 \mathrm{e}+004.55567 \mathrm{e}-011.00000 \mathrm{e}-092.12000 \mathrm{e}-01$

$4.55567 \mathrm{e}+004.55567 \mathrm{e}+004.55567 \mathrm{e}-011.00000 \mathrm{e}-092.12000 \mathrm{e}-01$ $1.00000 \mathrm{e}-05$ 1.00000e-05 1.00000e-06 1.00000e-09 1.00000e-01

$1.00000 \mathrm{e}+001.00000 \mathrm{e}+001.00000 \mathrm{e}-011.00000 \mathrm{e}-091.00000 \mathrm{e}-01$ Element: 10219 \# of layers: 6

Kx Ky Kz Ss Por

$4.55567 \mathrm{e}+004.55567 \mathrm{e}+00$ 4.55567e-01 1.00000e-09 2.12000e-01 $4.55567 \mathrm{e}+004.55567 \mathrm{e}+004.55567 \mathrm{e}-011.00000 \mathrm{e}-092.12000 \mathrm{e}-01$ $4.55567 \mathrm{e}+004.55567 \mathrm{e}+004.55567 \mathrm{e}-011.00000 \mathrm{e}-092.12000 \mathrm{e}-01$ $4.55567 \mathrm{e}+004.55567 \mathrm{e}+004.55567 \mathrm{e}-011.00000 \mathrm{e}-092.12000 \mathrm{e}-01$ $1.00000 \mathrm{e}-05$ 1.00000e-05 1.00000e-06 1.00000e-09 1.00000e-01 $1.00000 \mathrm{e}+001.00000 \mathrm{e}+001.00000 \mathrm{e}-011.00000 \mathrm{e}-091.00000 \mathrm{e}-01$ Element: 10220 \# of layers: 5

Kx Ky Kz Ss Por

$4.55567 \mathrm{e}+004.55567 \mathrm{e}+00$ 4.55567e-01 1.00000e-09 2.12000e-01 $4.55567 \mathrm{e}+004.55567 \mathrm{e}+004.55567 \mathrm{e}-011.00000 \mathrm{e}-092.12000 \mathrm{e}-01$ $4.55567 \mathrm{e}+004.55567 \mathrm{e}+00$ 4.55567e-01 1.00000e-09 2.12000e-01 $1.00000 \mathrm{e}-05$ 1.00000e-05 1.00000e-06 1.00000e-09 1.00000e-01 $1.00000 \mathrm{e}+001.00000 \mathrm{e}+001.00000 \mathrm{e}-011.00000 \mathrm{e}-091.00000 \mathrm{e}-01$ Element: 10221 \# of layers: 6

Kx Ky Kz Ss Por

$4.55567 \mathrm{e}+004.55567 \mathrm{e}+00$ 4.55567e-01 1.00000e-09 2.12000e-01 $4.55567 \mathrm{e}+004.55567 \mathrm{e}+004.55567 \mathrm{e}-011.00000 \mathrm{e}-09$ 2.12000e-01 $4.55567 \mathrm{e}+004.55567 \mathrm{e}+004.55567 \mathrm{e}-011.00000 \mathrm{e}-092.12000 \mathrm{e}-01$ $4.55567 \mathrm{e}+004.55567 \mathrm{e}+00$ 4.55567e-01 1.00000e-09 2.12000e-01 $1.00000 \mathrm{e}-05$ 1.00000e-05 1.00000e-06 1.00000e-09 1.00000e-01 $1.00000 \mathrm{e}+001.00000 \mathrm{e}+001.00000 \mathrm{e}-011.00000 \mathrm{e}-091.00000 \mathrm{e}-01$ 
Element: 10222 \# of layers: 7

$\mathrm{Kx} \mathrm{Ky} \mathrm{Kz}$ Ss Por

4.55567e+00 4.55567e+00 4.55567e-01 1.00000e-09 2.12000e-01

$4.55567 \mathrm{e}+00$ 4.55567e+00 4.55567e-01 1.00000e-09 2.12000e-01

4.55567e+00 4.55567e+00 4.55567e-01 1.00000e-09 2.12000e-01

4.55567e+00 4.55567e+00 4.55567e-01 1.00000e-09 2.12000e-01

$4.55567 \mathrm{e}+004.55567 \mathrm{e}+00$ 4.55567e-01 1.00000e-09 2.12000e-01

$1.00000 \mathrm{e}-05$ 1.00000e-05 1.00000e-06 1.00000e-09 1.00000e-01

$1.00000 \mathrm{e}+001.00000 \mathrm{e}+001.00000 \mathrm{e}-011.00000 \mathrm{e}-091.00000 \mathrm{e}-01$

Element: 10223 \# of layers: 6

$\mathrm{Kx} \mathrm{Ky} \mathrm{Kz}$ Ss Por

4.55567e+00 4.55567e+00 4.55567e-01 1.00000e-09 2.12000e-01

$4.55567 \mathrm{e}+00$ 4.55567e+00 4.55567e-01 1.00000e-09 2.12000e-01

4.55567e+00 4.55567e+00 4.55567e-01 1.00000e-09 2.12000e-01

4.55567e+00 4.55567e+00 4.55567e-01 1.00000e-09 2.12000e-01

$1.00000 \mathrm{e}-05$ 1.00000e-05 1.00000e-06 1.00000e-09 1.00000e-01

$1.00000 \mathrm{e}+001.00000 \mathrm{e}+001.00000 \mathrm{e}-01$ 1.00000e-09 1.00000e-01

Element: 10224 \# of layers: 6

$\mathrm{Kx} \mathrm{Ky} \mathrm{Kz}$ Ss Por

4.55567e+00 4.55567e+00 4.55567e-01 1.00000e-09 2.12000e-01

$4.55567 \mathrm{e}+00$ 4.55567e+00 4.55567e-01 1.00000e-09 2.12000e-01

4.55567e+00 4.55567e+00 4.55567e-01 1.00000e-09 2.12000e-01

4.55567e+00 4.55567e+00 4.55567e-01 1.00000e-09 2.12000e-01 $1.00000 \mathrm{e}-051.00000 \mathrm{e}-051.00000 \mathrm{e}-061.00000 \mathrm{e}-091.00000 \mathrm{e}-01$

$1.00000 \mathrm{e}+001.00000 \mathrm{e}+001.00000 \mathrm{e}-011.00000 \mathrm{e}-091.00000 \mathrm{e}-01$ Element: 10225 \# of layers: 7

$\mathrm{Kx} \mathrm{Ky} \mathrm{Kz}$ Ss Por

4.55567e+00 4.55567e+00 4.55567e-01 1.00000e-09 2.12000e-01

$4.55567 \mathrm{e}+004.55567 \mathrm{e}+00$ 4.55567e-01 1.00000e-09 2.12000e-01

4.55567e+00 4.55567e+00 4.55567e-01 1.00000e-09 2.12000e-01

4.55567e+00 4.55567e+00 4.55567e-01 1.00000e-09 2.12000e-01

4.55567e+00 4.55567e+00 4.55567e-01 1.00000e-09 2.12000e-01

$1.00000 \mathrm{e}-05$ 1.00000e-05 1.00000e-06 1.00000e-09 1.00000e-01

$1.00000 \mathrm{e}+001.00000 \mathrm{e}+001.00000 \mathrm{e}-01$ 1.00000e-09 1.00000e-01

Element: 10226 \# of layers: 7

$\mathrm{Kx} \mathrm{Ky} \mathrm{Kz}$ Ss Por

4.55567e+00 4.55567e+00 4.55567e-01 1.00000e-09 2.12000e-01

4.55567e+00 4.55567e+00 4.55567e-01 1.00000e-09 2.12000e-01

4.55567e+00 4.55567e+00 4.55567e-01 1.00000e-09 2.12000e-01

4.55567e+00 4.55567e+00 4.55567e-01 1.00000e-09 2.12000e-01

4.55567e+00 4.55567e+00 4.55567e-01 1.00000e-09 2.12000e-01

$1.00000 \mathrm{e}-05$ 1.00000e-05 1.00000e-06 1.00000e-09 1.00000e-01

$1.00000 \mathrm{e}+001.00000 \mathrm{e}+001.00000 \mathrm{e}-01$ 1.00000e-09 1.00000e-01

Element: 10227 \# of layers: 7

$\mathrm{Kx} \mathrm{Ky} \mathrm{Kz}$ Ss Por

4.55567e+00 4.55567e+00 4.55567e-01 1.00000e-09 2.12000e-01 
4.55567e+00 4.55567e+00 4.55567e-01 1.00000e-09 2.12000e-01 4.55567e+00 4.55567e+00 4.55567e-01 1.00000e-09 2.12000e-01 4.55567e+00 4.55567e+00 4.55567e-01 1.00000e-09 2.12000e-01 $4.55567 \mathrm{e}+00$ 4.55567e+00 4.55567e-01 1.00000e-09 2.12000e-01 $1.00000 \mathrm{e}-05$ 1.00000e-05 1.00000e-06 1.00000e-09 1.00000e-01 $1.00000 \mathrm{e}+001.00000 \mathrm{e}+001.00000 \mathrm{e}-011.00000 \mathrm{e}-091.00000 \mathrm{e}-01$ Element: 10228 \# of layers: 7

$\mathrm{Kx} \mathrm{Ky} \mathrm{Kz}$ Ss Por

4.55567e+00 4.55567e+00 4.55567e-01 1.00000e-09 2.12000e-01 $4.55567 \mathrm{e}+004.55567 \mathrm{e}+00$ 4.55567e-01 1.00000e-09 2.12000e-01 4.55567e+00 4.55567e+00 4.55567e-01 1.00000e-09 2.12000e-01 $4.55567 \mathrm{e}+00$ 4.55567e+00 4.55567e-01 1.00000e-09 2.12000e-01 $4.55567 \mathrm{e}+004.55567 \mathrm{e}+004.55567 \mathrm{e}-01$ 1.00000e-09 2.12000e-01 $1.00000 \mathrm{e}-05$ 1.00000e-05 1.00000e-06 1.00000e-09 1.00000e-01 $1.00000 \mathrm{e}+001.00000 \mathrm{e}+001.00000 \mathrm{e}-01$ 1.00000e-09 1.00000e-01 Element: 10229 \# of layers: 7

$\mathrm{Kx} \mathrm{Ky} \mathrm{Kz}$ Ss Por

4.25259e+00 4.25259e+00 4.25259e-01 1.00000e-09 2.12000e-01 4.25259e+00 4.25259e+00 4.25259e-01 1.00000e-09 2.12000e-01 $4.25259 \mathrm{e}+00$ 4.25259e+00 4.25259e-01 1.00000e-09 2.12000e-01 $4.25259 \mathrm{e}+004.25259 \mathrm{e}+00$ 4.25259e-01 1.00000e-09 2.12000e-01 $4.25259 \mathrm{e}+00$ 4.25259e+00 4.25259e-01 1.00000e-09 2.12000e-01 $1.00000 \mathrm{e}-05$ 1.00000e-05 1.00000e-06 1.00000e-09 1.00000e-01 $1.00000 \mathrm{e}+001.00000 \mathrm{e}+001.00000 \mathrm{e}-011.00000 \mathrm{e}-09$ 1.00000e-01 Element: 10230 \# of layers: 6

$\mathrm{Kx} \mathrm{Ky} \mathrm{Kz}$ Ss Por

4.25259e+00 4.25259e+00 4.25259e-01 1.00000e-09 2.12000e-01 $4.25259 \mathrm{e}+00$ 4.25259e+00 4.25259e-01 1.00000e-09 2.12000e-01 $4.25259 \mathrm{e}+004.25259 \mathrm{e}+00$ 4.25259e-01 1.00000e-09 2.12000e-01 $4.25259 \mathrm{e}+00$ 4.25259e+00 4.25259e-01 1.00000e-09 2.12000e-01 $1.00000 \mathrm{e}-05$ 1.00000e-05 1.00000e-06 1.00000e-09 1.00000e-01 $1.00000 \mathrm{e}+001.00000 \mathrm{e}+001.00000 \mathrm{e}-011.00000 \mathrm{e}-091.00000 \mathrm{e}-01$ Element: 10231 \# of layers: 6

$\mathrm{Kx} \mathrm{Ky} \mathrm{Kz}$ Ss Por

4.25259e+00 4.25259e+00 4.25259e-01 1.00000e-09 2.12000e-01 $4.25259 \mathrm{e}+00$ 4.25259e+00 4.25259e-01 1.00000e-09 2.12000e-01 $4.25259 \mathrm{e}+004.25259 \mathrm{e}+00$ 4.25259e-01 1.00000e-09 2.12000e-01 $4.25259 \mathrm{e}+00$ 4.25259e+00 4.25259e-01 1.00000e-09 2.12000e-01 $1.00000 \mathrm{e}-05$ 1.00000e-05 1.00000e-06 1.00000e-09 1.00000e-01 $1.00000 \mathrm{e}+001.00000 \mathrm{e}+001.00000 \mathrm{e}-01$ 1.00000e-09 1.00000e-01 Element: 10232 \# of layers: 6

$\mathrm{Kx} \mathrm{Ky} \mathrm{Kz}$ Ss Por

4.55567e+00 4.55567e+00 4.55567e-01 1.00000e-09 2.12000e-01 4.55567e+00 4.55567e+00 4.55567e-01 1.00000e-09 2.12000e-01 4.55567e+00 4.55567e+00 4.55567e-01 1.00000e-09 2.12000e-01 $4.55567 \mathrm{e}+004.55567 \mathrm{e}+00$ 4.55567e-01 1.00000e-09 2.12000e-01 
$1.00000 \mathrm{e}-05$ 1.00000e-05 1.00000e-06 1.00000e-09 1.00000e-01 $1.00000 \mathrm{e}+001.00000 \mathrm{e}+001.00000 \mathrm{e}-01$ 1.00000e-09 1.00000e-01 Element: 10233 \# of layers: 6

Kx Ky Kz Ss Por

4.55567e+00 4.55567e+00 4.55567e-01 1.00000e-09 2.12000e-01 $4.55567 \mathrm{e}+004.55567 \mathrm{e}+00$ 4.55567e-01 1.00000e-09 2.12000e-01 4.55567e+00 4.55567e+00 4.55567e-01 1.00000e-09 2.12000e-01 $4.55567 \mathrm{e}+00$ 4.55567e+00 4.55567e-01 1.00000e-09 2.12000e-01 $1.00000 \mathrm{e}-05$ 1.00000e-05 1.00000e-06 1.00000e-09 1.00000e-01 $1.00000 \mathrm{e}+001.00000 \mathrm{e}+00$ 1.00000e-01 1.00000e-09 1.00000e-01 Element: 10234 \# of layers: 6

Kx Ky Kz Ss Por

4.55567e+00 4.55567e+00 4.55567e-01 1.00000e-09 2.12000e-01 4.55567e+00 4.55567e+00 4.55567e-01 1.00000e-09 2.12000e-01 4.55567e+00 4.55567e+00 4.55567e-01 1.00000e-09 2.12000e-01 $4.55567 \mathrm{e}+004.55567 \mathrm{e}+00$ 4.55567e-01 1.00000e-09 2.12000e-01 $1.00000 \mathrm{e}-05$ 1.00000e-05 1.00000e-06 1.00000e-09 1.00000e-01 $1.00000 \mathrm{e}+001.00000 \mathrm{e}+001.00000 \mathrm{e}-01$ 1.00000e-09 1.00000e-01 Element: 10235 \# of layers: 6

$\mathrm{Kx} \mathrm{Ky} \mathrm{Kz}$ Ss Por

4.55567e+00 4.55567e+00 4.55567e-01 1.00000e-09 2.12000e-01 4.55567e+00 4.55567e+00 4.55567e-01 1.00000e-09 2.12000e-01 4.55567e+00 4.55567e+00 4.55567e-01 1.00000e-09 2.12000e-01 4.55567e+00 4.55567e+00 4.55567e-01 1.00000e-09 2.12000e-01 $1.00000 \mathrm{e}-05$ 1.00000e-05 1.00000e-06 1.00000e-09 1.00000e-01 $1.00000 \mathrm{e}+001.00000 \mathrm{e}+001.00000 \mathrm{e}-01$ 1.00000e-09 1.00000e-01 Element: 10236 \# of layers: 7

$\mathrm{Kx} \mathrm{Ky} \mathrm{Kz}$ Ss Por

4.25259e+00 4.25259e+00 4.25259e-01 1.00000e-09 2.12000e-01 $4.25259 \mathrm{e}+00$ 4.25259e+00 4.25259e-01 1.00000e-09 2.12000e-01 $4.25259 \mathrm{e}+00$ 4.25259e+00 4.25259e-01 1.00000e-09 2.12000e-01 $4.25259 \mathrm{e}+00$ 4.25259e+00 4.25259e-01 1.00000e-09 2.12000e-01 $4.25259 \mathrm{e}+004.25259 \mathrm{e}+00$ 4.25259e-01 1.00000e-09 2.12000e-01 $1.00000 \mathrm{e}-05$ 1.00000e-05 1.00000e-06 1.00000e-09 1.00000e-01 $1.00000 \mathrm{e}+001.00000 \mathrm{e}+001.00000 \mathrm{e}-011.00000 \mathrm{e}-091.00000 \mathrm{e}-01$ Element: 10237 \# of layers: 7

Kx Ky Kz Ss Por

4.25259e+00 4.25259e+00 4.25259e-01 1.00000e-09 2.12000e-01 $4.25259 \mathrm{e}+00$ 4.25259e+00 4.25259e-01 1.00000e-09 2.12000e-01 4.25259e+00 4.25259e+00 4.25259e-01 1.00000e-09 2.12000e-01 $4.25259 \mathrm{e}+004.25259 \mathrm{e}+004.25259 \mathrm{e}-01$ 1.00000e-09 2.12000e-01 $4.25259 \mathrm{e}+004.25259 \mathrm{e}+004.25259 \mathrm{e}-01$ 1.00000e-09 2.12000e-01 $1.00000 \mathrm{e}-051.00000 \mathrm{e}-051.00000 \mathrm{e}-061.00000 \mathrm{e}-091.00000 \mathrm{e}-01$ $1.00000 \mathrm{e}+001.00000 \mathrm{e}+001.00000 \mathrm{e}-011.00000 \mathrm{e}-091.00000 \mathrm{e}-01$ Element: 10238 \# of layers: 7

Kx Ky Kz Ss Por 
$4.25259 \mathrm{e}+00$ 4.25259e+00 4.25259e-01 1.00000e-09 2.12000e-01 4.25259e+00 4.25259e+00 4.25259e-01 1.00000e-09 2.12000e-01 $4.25259 \mathrm{e}+00$ 4.25259e+00 4.25259e-01 1.00000e-09 2.12000e-01 $4.25259 \mathrm{e}+00$ 4.25259e+00 4.25259e-01 1.00000e-09 2.12000e-01 $4.25259 \mathrm{e}+00$ 4.25259e+00 4.25259e-01 1.00000e-09 2.12000e-01 $1.00000 \mathrm{e}-05$ 1.00000e-05 1.00000e-06 1.00000e-09 1.00000e-01 $1.00000 \mathrm{e}+001.00000 \mathrm{e}+00$ 1.00000e-01 1.00000e-09 1.00000e-01 Element: 10239 \# of layers: 7

$\mathrm{Kx} \mathrm{Ky} \mathrm{Kz}$ Ss Por

4.25259e+00 4.25259e+00 4.25259e-01 1.00000e-09 2.12000e-01 $4.25259 \mathrm{e}+00$ 4.25259e+00 4.25259e-01 1.00000e-09 2.12000e-01 $4.25259 \mathrm{e}+00$ 4.25259e+00 4.25259e-01 1.00000e-09 2.12000e-01 4.25259e+00 4.25259e+00 4.25259e-01 1.00000e-09 2.12000e-01 $4.25259 \mathrm{e}+004.25259 \mathrm{e}+004.25259 \mathrm{e}-01$ 1.00000e-09 2.12000e-01 $1.00000 \mathrm{e}-05$ 1.00000e-05 1.00000e-06 1.00000e-09 1.00000e-01 $1.00000 \mathrm{e}+001.00000 \mathrm{e}+001.00000 \mathrm{e}-011.00000 \mathrm{e}-091.00000 \mathrm{e}-01$ Element: 10240 \# of layers: 7

$\mathrm{Kx} \mathrm{Ky} \mathrm{Kz}$ Ss Por

4.25259e+00 4.25259e+00 4.25259e-01 1.00000e-09 2.12000e-01 $4.25259 \mathrm{e}+00$ 4.25259e+00 4.25259e-01 1.00000e-09 2.12000e-01 $4.25259 \mathrm{e}+004.25259 \mathrm{e}+00$ 4.25259e-01 1.00000e-09 2.12000e-01 $4.25259 \mathrm{e}+00$ 4.25259e+00 4.25259e-01 1.00000e-09 2.12000e-01 4.25259e+00 4.25259e+00 4.25259e-01 1.00000e-09 2.12000e-01 $1.00000 \mathrm{e}-05$ 1.00000e-05 1.00000e-06 1.00000e-09 1.00000e-01 $1.00000 \mathrm{e}+001.00000 \mathrm{e}+001.00000 \mathrm{e}-011.00000 \mathrm{e}-09$ 1.00000e-01 Element: 10241 \# of layers: 7

$\mathrm{Kx} \mathrm{Ky} \mathrm{Kz}$ Ss Por

4.25259e+00 4.25259e+00 4.25259e-01 1.00000e-09 2.12000e-01 $4.25259 \mathrm{e}+004.25259 \mathrm{e}+00$ 4.25259e-01 1.00000e-09 2.12000e-01 $4.25259 \mathrm{e}+00$ 4.25259e+00 4.25259e-01 1.00000e-09 2.12000e-01 4.25259e+00 4.25259e+00 4.25259e-01 1.00000e-09 2.12000e-01 4.25259e+00 4.25259e+00 4.25259e-01 1.00000e-09 2.12000e-01 $1.00000 \mathrm{e}-05$ 1.00000e-05 1.00000e-06 1.00000e-09 1.00000e-01 $1.00000 \mathrm{e}+001.00000 \mathrm{e}+001.00000 \mathrm{e}-011.00000 \mathrm{e}-091.00000 \mathrm{e}-01$ Element: 10242 \# of layers: 6

$\mathrm{Kx} \mathrm{Ky} \mathrm{Kz}$ Ss Por

4.25259e+00 4.25259e+00 4.25259e-01 1.00000e-09 2.12000e-01 $4.25259 \mathrm{e}+00$ 4.25259e+00 4.25259e-01 1.00000e-09 2.12000e-01 $4.25259 \mathrm{e}+00$ 4.25259e+00 4.25259e-01 1.00000e-09 2.12000e-01 $4.25259 \mathrm{e}+00$ 4.25259e+00 4.25259e-01 1.00000e-09 2.12000e-01 $1.00000 \mathrm{e}-05$ 1.00000e-05 1.00000e-06 1.00000e-09 1.00000e-01 $1.00000 \mathrm{e}+001.00000 \mathrm{e}+001.00000 \mathrm{e}-011.00000 \mathrm{e}-091.00000 \mathrm{e}-01$ Element: 10243 \# of layers: 6

$\mathrm{Kx} \mathrm{Ky} \mathrm{Kz}$ Ss Por

4.25259e+00 4.25259e+00 4.25259e-01 1.00000e-09 2.12000e-01 $4.25259 \mathrm{e}+004.25259 \mathrm{e}+00$ 4.25259e-01 1.00000e-09 2.12000e-01 
$4.25259 \mathrm{e}+004.25259 \mathrm{e}+00$ 4.25259e-01 1.00000e-09 2.12000e-01 $4.25259 \mathrm{e}+004.25259 \mathrm{e}+00$ 4.25259e-01 1.00000e-09 2.12000e-01 $1.00000 \mathrm{e}-05$ 1.00000e-05 1.00000e-06 1.00000e-09 1.00000e-01 $1.00000 \mathrm{e}+001.00000 \mathrm{e}+001.00000 \mathrm{e}-011.00000 \mathrm{e}-091.00000 \mathrm{e}-01$ Element: 10244 \# of layers: 7

Kx Ky Kz Ss Por

4.25259e+00 4.25259e+00 4.25259e-01 1.00000e-09 2.12000e-01 $4.25259 \mathrm{e}+004.25259 \mathrm{e}+00$ 4.25259e-01 1.00000e-09 2.12000e-01 $4.25259 \mathrm{e}+004.25259 \mathrm{e}+00$ 4.25259e-01 1.00000e-09 2.12000e-01 $4.25259 \mathrm{e}+004.25259 \mathrm{e}+004.25259 \mathrm{e}-011.00000 \mathrm{e}-092.12000 \mathrm{e}-01$ $4.25259 \mathrm{e}+004.25259 \mathrm{e}+00$ 4.25259e-01 1.00000e-09 2.12000e-01 $1.00000 \mathrm{e}-05$ 1.00000e-05 1.00000e-06 1.00000e-09 1.00000e-01 $1.00000 \mathrm{e}+001.00000 \mathrm{e}+001.00000 \mathrm{e}-011.00000 \mathrm{e}-091.00000 \mathrm{e}-01$ Element: 10245 \# of layers: 7

Kx Ky Kz Ss Por

$4.25259 \mathrm{e}+004.25259 \mathrm{e}+00$ 4.25259e-01 1.00000e-09 2.12000e-01 $4.25259 \mathrm{e}+004.25259 \mathrm{e}+00$ 4.25259e-01 1.00000e-09 2.12000e-01 $4.25259 \mathrm{e}+004.25259 \mathrm{e}+00$ 4.25259e-01 1.00000e-09 2.12000e-01 $4.25259 \mathrm{e}+004.25259 \mathrm{e}+00$ 4.25259e-01 1.00000e-09 2.12000e-01 $4.25259 \mathrm{e}+004.25259 \mathrm{e}+00$ 4.25259e-01 1.00000e-09 2.12000e-01 $1.00000 \mathrm{e}-05$ 1.00000e-05 1.00000e-06 1.00000e-09 1.00000e-01 $1.00000 \mathrm{e}+001.00000 \mathrm{e}+001.00000 \mathrm{e}-011.00000 \mathrm{e}-091.00000 \mathrm{e}-01$ Element: 10246 \# of layers: 7

Kx Ky Kz Ss Por

3.50962e+00 3.50962e+00 3.50963e-01 1.00000e-09 2.12000e-01 $3.50962 \mathrm{e}+003.50962 \mathrm{e}+003.50963 \mathrm{e}-011.00000 \mathrm{e}-092.12000 \mathrm{e}-01$ $3.50962 \mathrm{e}+003.50962 \mathrm{e}+003.50963 \mathrm{e}-01$ 1.00000e-09 2.12000e-01 $3.50962 \mathrm{e}+003.50962 \mathrm{e}+003.50963 \mathrm{e}-01$ 1.00000e-09 2.12000e-01 $3.50962 \mathrm{e}+003.50962 \mathrm{e}+003.50963 \mathrm{e}-01$ 1.00000e-09 2.12000e-01 $1.00000 \mathrm{e}-05$ 1.00000e-05 1.00000e-06 1.00000e-09 1.00000e-01 $1.00000 \mathrm{e}+001.00000 \mathrm{e}+001.00000 \mathrm{e}-011.00000 \mathrm{e}-091.00000 \mathrm{e}-01$ Element: 10247 \# of layers: 7

Kx Ky Kz Ss Por

$3.50962 \mathrm{e}+003.50962 \mathrm{e}+00$ 3.50963e-01 1.00000e-09 2.12000e-01 $3.50962 \mathrm{e}+003.50962 \mathrm{e}+003.50963 \mathrm{e}-01$ 1.00000e-09 2.12000e-01 $3.50962 \mathrm{e}+003.50962 \mathrm{e}+003.50963 \mathrm{e}-01$ 1.00000e-09 2.12000e-01 $3.50962 \mathrm{e}+003.50962 \mathrm{e}+003.50963 \mathrm{e}-01$ 1.00000e-09 2.12000e-01 $3.50962 \mathrm{e}+003.50962 \mathrm{e}+003.50963 \mathrm{e}-011.00000 \mathrm{e}-092.12000 \mathrm{e}-01$ $1.00000 \mathrm{e}-05$ 1.00000e-05 1.00000e-06 1.00000e-09 1.00000e-01 $1.00000 \mathrm{e}+001.00000 \mathrm{e}+001.00000 \mathrm{e}-011.00000 \mathrm{e}-091.00000 \mathrm{e}-01$ Element: 10248 \# of layers: 7

Kx Ky Kz Ss Por

$3.50962 \mathrm{e}+003.50962 \mathrm{e}+00$ 3.50963e-01 1.00000e-09 2.12000e-01 $3.50962 \mathrm{e}+003.50962 \mathrm{e}+003.50963 \mathrm{e}-011.00000 \mathrm{e}-092.12000 \mathrm{e}-01$ $3.50962 \mathrm{e}+003.50962 \mathrm{e}+003.50963 \mathrm{e}-01$ 1.00000e-09 2.12000e-01 $3.50962 \mathrm{e}+003.50962 \mathrm{e}+003.50963 \mathrm{e}-01$ 1.00000e-09 2.12000e-01 
3.50962e+00 3.50962e+00 3.50963e-01 1.00000e-09 2.12000e-01 $1.00000 \mathrm{e}-05$ 1.00000e-05 1.00000e-06 1.00000e-09 1.00000e-01

$1.00000 \mathrm{e}+001.00000 \mathrm{e}+00$ 1.00000e-01 1.00000e-09 1.00000e-01

Element: 10249 \# of layers: 6

$\mathrm{Kx} \mathrm{Ky} \mathrm{Kz}$ Ss Por

3.50962e+00 3.50962e+00 3.50963e-01 1.00000e-09 2.12000e-01

3.50962e+00 3.50962e+00 3.50963e-01 1.00000e-09 2.12000e-01

$3.50962 \mathrm{e}+003.50962 \mathrm{e}+00$ 3.50963e-01 1.00000e-09 2.12000e-01

3.50962e+00 3.50962e+00 3.50963e-01 1.00000e-09 2.12000e-01

$1.00000 \mathrm{e}-05$ 1.00000e-05 1.00000e-06 1.00000e-09 1.00000e-01

$1.00000 \mathrm{e}+001.00000 \mathrm{e}+001.00000 \mathrm{e}-01$ 1.00000e-09 1.00000e-01

Element: 10250 \# of layers: 6

$\mathrm{Kx} \mathrm{Ky} \mathrm{Kz}$ Ss Por

3.50962e+00 3.50962e+00 3.50963e-01 1.00000e-09 2.12000e-01

$3.50962 \mathrm{e}+003.50962 \mathrm{e}+00$ 3.50963e-01 1.00000e-09 2.12000e-01

$3.50962 \mathrm{e}+003.50962 \mathrm{e}+00$ 3.50963e-01 1.00000e-09 2.12000e-01

3.50962e+00 3.50962e+00 3.50963e-01 1.00000e-09 2.12000e-01

$1.00000 \mathrm{e}-05$ 1.00000e-05 1.00000e-06 1.00000e-09 1.00000e-01

$1.00000 \mathrm{e}+001.00000 \mathrm{e}+001.00000 \mathrm{e}-01$ 1.00000e-09 1.00000e-01

Element: 10251 \# of layers: 6

$\mathrm{Kx} \mathrm{Ky} \mathrm{Kz}$ Ss Por

4.25259e+00 4.25259e+00 4.25259e-01 1.00000e-09 2.12000e-01

4.25259e+00 4.25259e+00 4.25259e-01 1.00000e-09 2.12000e-01

$4.25259 \mathrm{e}+00$ 4.25259e+00 4.25259e-01 1.00000e-09 2.12000e-01

$4.25259 \mathrm{e}+004.25259 \mathrm{e}+00 \quad 4.25259 \mathrm{e}-01$ 1.00000e-09 2.12000e-01

$1.00000 \mathrm{e}-05$ 1.00000e-05 1.00000e-06 1.00000e-09 1.00000e-01

$1.00000 \mathrm{e}+001.00000 \mathrm{e}+001.00000 \mathrm{e}-011.00000 \mathrm{e}-091.00000 \mathrm{e}-01$

Element: 10252 \# of layers: 7

$\mathrm{Kx} \mathrm{Ky} \mathrm{Kz}$ Ss Por

4.25259e+00 4.25259e+00 4.25259e-01 1.00000e-09 2.12000e-01

$4.25259 \mathrm{e}+004.25259 \mathrm{e}+004.25259 \mathrm{e}-01$ 1.00000e-09 2.12000e-01

4.25259e+00 4.25259e+00 4.25259e-01 1.00000e-09 2.12000e-01

$4.25259 \mathrm{e}+004.25259 \mathrm{e}+004.25259 \mathrm{e}-01$ 1.00000e-09 2.12000e-01

$4.25259 \mathrm{e}+004.25259 \mathrm{e}+004.25259 \mathrm{e}-01$ 1.00000e-09 2.12000e-01

$1.00000 \mathrm{e}-05$ 1.00000e-05 1.00000e-06 1.00000e-09 1.00000e-01

$1.00000 \mathrm{e}+001.00000 \mathrm{e}+001.00000 \mathrm{e}-011.00000 \mathrm{e}-091.00000 \mathrm{e}-01$

Element: 10253 \# of layers: 7

$\mathrm{Kx} \mathrm{Ky} \mathrm{Kz}$ Ss Por

3.50962e+00 3.50962e+00 3.50963e-01 1.00000e-09 2.12000e-01

$3.50962 \mathrm{e}+003.50962 \mathrm{e}+003.50963 \mathrm{e}-01$ 1.00000e-09 2.12000e-01

$3.50962 \mathrm{e}+003.50962 \mathrm{e}+00$ 3.50963e-01 1.00000e-09 2.12000e-01

$3.50962 \mathrm{e}+003.50962 \mathrm{e}+00$ 3.50963e-01 1.00000e-09 2.12000e-01

$3.50962 \mathrm{e}+003.50962 \mathrm{e}+00$ 3.50963e-01 1.00000e-09 2.12000e-01

$1.00000 \mathrm{e}-05$ 1.00000e-05 1.00000e-06 1.00000e-09 1.00000e-01

$1.00000 \mathrm{e}+001.00000 \mathrm{e}+001.00000 \mathrm{e}-011.00000 \mathrm{e}-09$ 1.00000e-01

Element: 10254 \# of layers: 6 
$\mathrm{Kx} \mathrm{Ky} \mathrm{Kz}$ Ss Por

3.50962e+00 3.50962e+00 3.50963e-01 1.00000e-09 2.12000e-01

$3.50962 \mathrm{e}+00$ 3.50962e+00 3.50963e-01 1.00000e-09 2.12000e-01

$3.50962 \mathrm{e}+00$ 3.50962e+00 3.50963e-01 1.00000e-09 2.12000e-01

3.50962e+00 3.50962e+00 3.50963e-01 1.00000e-09 2.12000e-01

$1.00000 \mathrm{e}-05$ 1.00000e-05 1.00000e-06 1.00000e-09 1.00000e-01

$1.00000 \mathrm{e}+001.00000 \mathrm{e}+001.00000 \mathrm{e}-01$ 1.00000e-09 1.00000e-01

Element: 10255 \# of layers: 6

$\mathrm{Kx} \mathrm{Ky} \mathrm{Kz}$ Ss Por

3.87616e+00 3.87616e+00 3.87616e-01 1.00000e-09 2.12000e-01

$3.87616 \mathrm{e}+003.87616 \mathrm{e}+003.87616 \mathrm{e}-01$ 1.00000e-09 2.12000e-01

$3.87616 \mathrm{e}+003.87616 \mathrm{e}+003.87616 \mathrm{e}-01$ 1.00000e-09 2.12000e-01

$3.87616 \mathrm{e}+003.87616 \mathrm{e}+003.87616 \mathrm{e}-01$ 1.00000e-09 2.12000e-01

$1.00000 \mathrm{e}-05$ 1.00000e-05 1.00000e-06 1.00000e-09 1.00000e-01

$1.00000 \mathrm{e}+001.00000 \mathrm{e}+001.00000 \mathrm{e}-01$ 1.00000e-09 1.00000e-01

Element: 10256 \# of layers: 6

$\mathrm{Kx} \mathrm{Ky} \mathrm{Kz}$ Ss Por

3.87616e+00 3.87616e+00 3.87616e-01 1.00000e-09 2.12000e-01

$3.87616 \mathrm{e}+003.87616 \mathrm{e}+003.87616 \mathrm{e}-01$ 1.00000e-09 2.12000e-01

$3.87616 \mathrm{e}+003.87616 \mathrm{e}+003.87616 \mathrm{e}-01$ 1.00000e-09 2.12000e-01

$3.87616 \mathrm{e}+003.87616 \mathrm{e}+003.87616 \mathrm{e}-01$ 1.00000e-09 2.12000e-01

$1.00000 \mathrm{e}-051.00000 \mathrm{e}-051.00000 \mathrm{e}-061.00000 \mathrm{e}-091.00000 \mathrm{e}-01$

$1.00000 \mathrm{e}+001.00000 \mathrm{e}+001.00000 \mathrm{e}-01$ 1.00000e-09 1.00000e-01

Element: 10257 \# of layers: 6

Kx Ky Kz Ss Por

3.87616e+00 3.87616e+00 3.87616e-01 1.00000e-09 2.12000e-01

$3.87616 \mathrm{e}+003.87616 \mathrm{e}+003.87616 \mathrm{e}-01$ 1.00000e-09 2.12000e-01

$3.87616 \mathrm{e}+003.87616 \mathrm{e}+003.87616 \mathrm{e}-01$ 1.00000e-09 2.12000e-01

$3.87616 \mathrm{e}+003.87616 \mathrm{e}+003.87616 \mathrm{e}-01$ 1.00000e-09 2.12000e-01

$1.00000 \mathrm{e}-05$ 1.00000e-05 1.00000e-06 1.00000e-09 1.00000e-01

$1.00000 \mathrm{e}+001.00000 \mathrm{e}+001.00000 \mathrm{e}-011.00000 \mathrm{e}-091.00000 \mathrm{e}-01$

Element: 10258 \# of layers: 6

$\mathrm{Kx} \mathrm{Ky} \mathrm{Kz}$ Ss Por

4.55567e+00 4.55567e+00 4.55567e-01 1.00000e-09 2.12000e-01

4.55567e+00 4.55567e+00 4.55567e-01 1.00000e-09 2.12000e-01

4.55567e+00 4.55567e+00 4.55567e-01 1.00000e-09 2.12000e-01

4.55567e+00 4.55567e+00 4.55567e-01 1.00000e-09 2.12000e-01

$1.00000 \mathrm{e}-05$ 1.00000e-05 1.00000e-06 1.00000e-09 1.00000e-01

$1.00000 \mathrm{e}+001.00000 \mathrm{e}+001.00000 \mathrm{e}-01$ 1.00000e-09 1.00000e-01

Element: 10259 \# of layers: 6

$\mathrm{Kx} \mathrm{Ky} \mathrm{Kz}$ Ss Por

4.55567e+00 4.55567e+00 4.55567e-01 1.00000e-09 2.12000e-01

4.55567e+00 4.55567e+00 4.55567e-01 1.00000e-09 2.12000e-01

4.55567e+00 4.55567e+00 4.55567e-01 1.00000e-09 2.12000e-01

4.55567e+00 4.55567e+00 4.55567e-01 1.00000e-09 2.12000e-01

$1.00000 \mathrm{e}-05$ 1.00000e-05 1.00000e-06 1.00000e-09 1.00000e-01 
$1.00000 \mathrm{e}+001.00000 \mathrm{e}+00$ 1.00000e-01 1.00000e-09 1.00000e-01

Element: 10260 \# of layers: 6

$\mathrm{Kx} \mathrm{Ky} \mathrm{Kz}$ Ss Por

4.25259e+00 4.25259e+00 4.25259e-01 1.00000e-09 2.12000e-01

$4.25259 \mathrm{e}+00$ 4.25259e+00 4.25259e-01 1.00000e-09 2.12000e-01

4.25259e+00 4.25259e+00 4.25259e-01 1.00000e-09 2.12000e-01

4.25259e+00 4.25259e+00 4.25259e-01 1.00000e-09 2.12000e-01

$1.00000 \mathrm{e}-05$ 1.00000e-05 1.00000e-06 1.00000e-09 1.00000e-01

$1.00000 \mathrm{e}+001.00000 \mathrm{e}+001.00000 \mathrm{e}-011.00000 \mathrm{e}-091.00000 \mathrm{e}-01$

Element: 10261 \# of layers: 6

$\mathrm{Kx} \mathrm{Ky} \mathrm{Kz}$ Ss Por

3.50962e+00 3.50962e+00 3.50963e-01 1.00000e-09 2.12000e-01

$3.50962 \mathrm{e}+003.50962 \mathrm{e}+00$ 3.50963e-01 1.00000e-09 2.12000e-01

$3.50962 \mathrm{e}+003.50962 \mathrm{e}+00$ 3.50963e-01 1.00000e-09 2.12000e-01

3.50962e+00 3.50962e+00 3.50963e-01 1.00000e-09 2.12000e-01

$1.00000 \mathrm{e}-05$ 1.00000e-05 1.00000e-06 1.00000e-09 1.00000e-01

$1.00000 \mathrm{e}+001.00000 \mathrm{e}+001.00000 \mathrm{e}-011.00000 \mathrm{e}-091.00000 \mathrm{e}-01$

Element: 10262 \# of layers: 6

$\mathrm{Kx} \mathrm{Ky} \mathrm{Kz}$ Ss Por

3.87616e+00 3.87616e+00 3.87616e-01 1.00000e-09 2.12000e-01

$3.87616 \mathrm{e}+003.87616 \mathrm{e}+003.87616 \mathrm{e}-01$ 1.00000e-09 2.12000e-01

$3.87616 \mathrm{e}+00$ 3.87616e+00 3.87616e-01 1.00000e-09 2.12000e-01

$3.87616 \mathrm{e}+003.87616 \mathrm{e}+003.87616 \mathrm{e}-01$ 1.00000e-09 2.12000e-01

$1.00000 \mathrm{e}-05$ 1.00000e-05 1.00000e-06 1.00000e-09 1.00000e-01

$1.00000 \mathrm{e}+001.00000 \mathrm{e}+001.00000 \mathrm{e}-011.00000 \mathrm{e}-091.00000 \mathrm{e}-01$

Element: 10263 \# of layers: 6

$\mathrm{Kx} \mathrm{Ky} \mathrm{Kz}$ Ss Por

4.19431e+00 4.19431e+00 4.19431e-01 1.00000e-09 2.12000e-01

$4.19431 \mathrm{e}+004.19431 \mathrm{e}+004.19431 \mathrm{e}-01$ 1.00000e-09 2.12000e-01

$4.19431 \mathrm{e}+004.19431 \mathrm{e}+004.19431 \mathrm{e}-01$ 1.00000e-09 2.12000e-01

$4.19431 \mathrm{e}+004.19431 \mathrm{e}+00$ 4.19431e-01 1.00000e-09 2.12000e-01

$1.00000 \mathrm{e}-05$ 1.00000e-05 1.00000e-06 1.00000e-09 1.00000e-01

$1.00000 \mathrm{e}+001.00000 \mathrm{e}+001.00000 \mathrm{e}-011.00000 \mathrm{e}-091.00000 \mathrm{e}-01$

Element: 10264 \# of layers: 6

$\mathrm{Kx} \mathrm{Ky} \mathrm{Kz}$ Ss Por

4.19431e+00 4.19431e+00 4.19431e-01 1.00000e-09 2.12000e-01

$4.19431 \mathrm{e}+004.19431 \mathrm{e}+004.19431 \mathrm{e}-01$ 1.00000e-09 2.12000e-01

$4.19431 \mathrm{e}+004.19431 \mathrm{e}+004.19431 \mathrm{e}-01$ 1.00000e-09 2.12000e-01

4.19431e+00 4.19431e+00 4.19431e-01 1.00000e-09 2.12000e-01

$1.00000 \mathrm{e}-05$ 1.00000e-05 1.00000e-06 1.00000e-09 1.00000e-01

$1.00000 \mathrm{e}+001.00000 \mathrm{e}+001.00000 \mathrm{e}-011.00000 \mathrm{e}-091.00000 \mathrm{e}-01$

Element: 10265 \# of layers: 6

$\mathrm{Kx} \mathrm{Ky} \mathrm{Kz}$ Ss Por

4.19431e+00 4.19431e+00 4.19431e-01 1.00000e-09 2.12000e-01

4.19431e+00 4.19431e+00 4.19431e-01 1.00000e-09 2.12000e-01

$4.19431 \mathrm{e}+004.19431 \mathrm{e}+004.19431 \mathrm{e}-01$ 1.00000e-09 2.12000e-01 
4.19431e+00 4.19431e+00 4.19431e-01 1.00000e-09 2.12000e-01 $1.00000 \mathrm{e}-05$ 1.00000e-05 1.00000e-06 1.00000e-09 1.00000e-01

$1.00000 \mathrm{e}+001.00000 \mathrm{e}+001.00000 \mathrm{e}-011.00000 \mathrm{e}-091.00000 \mathrm{e}-01$

Element: 10266 \# of layers: 6

$\mathrm{Kx} \mathrm{Ky} \mathrm{Kz}$ Ss Por

4.19431e+00 4.19431e+00 4.19431e-01 1.00000e-09 2.12000e-01

4.19431e+00 4.19431e+00 4.19431e-01 1.00000e-09 2.12000e-01

$4.19431 \mathrm{e}+00$ 4.19431e+00 4.19431e-01 1.00000e-09 2.12000e-01

$4.19431 \mathrm{e}+004.19431 \mathrm{e}+004.19431 \mathrm{e}-01$ 1.00000e-09 2.12000e-01

$1.00000 \mathrm{e}-05$ 1.00000e-05 1.00000e-06 1.00000e-09 1.00000e-01

$1.00000 \mathrm{e}+001.00000 \mathrm{e}+001.00000 \mathrm{e}-01$ 1.00000e-09 1.00000e-01

Element: 10267 \# of layers: 6

$\mathrm{Kx} \mathrm{Ky} \mathrm{Kz}$ Ss Por

4.19431e+00 4.19431e+00 4.19431e-01 1.00000e-09 2.12000e-01

4.19431e+00 4.19431e+00 4.19431e-01 1.00000e-09 2.12000e-01

$4.19431 \mathrm{e}+004.19431 \mathrm{e}+004.19431 \mathrm{e}-01$ 1.00000e-09 2.12000e-01

$4.19431 \mathrm{e}+004.19431 \mathrm{e}+004.19431 \mathrm{e}-01$ 1.00000e-09 2.12000e-01

$1.00000 \mathrm{e}-05$ 1.00000e-05 1.00000e-06 1.00000e-09 1.00000e-01

$1.00000 \mathrm{e}+001.00000 \mathrm{e}+001.00000 \mathrm{e}-01$ 1.00000e-09 1.00000e-01

Element: 10268 \# of layers: 6

Kx Ky Kz Ss Por

4.19431e+00 4.19431e+00 4.19431e-01 1.00000e-09 2.12000e-01

4.19431e+00 4.19431e+00 4.19431e-01 1.00000e-09 2.12000e-01

4.19431e+00 4.19431e+00 4.19431e-01 1.00000e-09 2.12000e-01

$4.19431 \mathrm{e}+004.19431 \mathrm{e}+004.19431 \mathrm{e}-01$ 1.00000e-09 2.12000e-01

$1.00000 \mathrm{e}-051.00000 \mathrm{e}-05$ 1.00000e-06 1.00000e-09 1.00000e-01

$1.00000 \mathrm{e}+001.00000 \mathrm{e}+001.00000 \mathrm{e}-01$ 1.00000e-09 1.00000e-01

Element: 10269 \# of layers: 6

Kx Ky Kz Ss Por

4.19431e+00 4.19431e+00 4.19431e-01 1.00000e-09 2.12000e-01

4.19431e+00 4.19431e+00 4.19431e-01 1.00000e-09 2.12000e-01

4.19431e+00 4.19431e+00 4.19431e-01 1.00000e-09 2.12000e-01

$4.19431 \mathrm{e}+004.19431 \mathrm{e}+004.19431 \mathrm{e}-01$ 1.00000e-09 2.12000e-01

$1.00000 \mathrm{e}-05$ 1.00000e-05 1.00000e-06 1.00000e-09 1.00000e-01

$1.00000 \mathrm{e}+001.00000 \mathrm{e}+001.00000 \mathrm{e}-011.00000 \mathrm{e}-091.00000 \mathrm{e}-01$

Element: 10270 \# of layers: 6

Kx Ky Kz Ss Por

4.19431e+00 4.19431e+00 4.19431e-01 1.00000e-09 2.12000e-01

4.19431e+00 4.19431e+00 4.19431e-01 1.00000e-09 2.12000e-01

4.19431e+00 4.19431e+00 4.19431e-01 1.00000e-09 2.12000e-01

$4.19431 \mathrm{e}+004.19431 \mathrm{e}+00$ 4.19431e-01 1.00000e-09 2.12000e-01

$1.00000 \mathrm{e}-05$ 1.00000e-05 1.00000e-06 1.00000e-09 1.00000e-01

$1.00000 \mathrm{e}+001.00000 \mathrm{e}+001.00000 \mathrm{e}-01$ 1.00000e-09 1.00000e-01

Element: 10271 \# of layers: 6

$\mathrm{Kx} \mathrm{Ky} \mathrm{Kz}$ Ss Por

4.19431e+00 4.19431e+00 4.19431e-01 1.00000e-09 2.12000e-01 
4.19431e+00 4.19431e+00 4.19431e-01 1.00000e-09 2.12000e-01 4.19431e+00 4.19431e+00 4.19431e-01 1.00000e-09 2.12000e-01 4.19431e+00 4.19431e+00 4.19431e-01 1.00000e-09 2.12000e-01 $1.00000 \mathrm{e}-05$ 1.00000e-05 1.00000e-06 1.00000e-09 1.00000e-01 $1.00000 \mathrm{e}+001.00000 \mathrm{e}+001.00000 \mathrm{e}-01$ 1.00000e-09 1.00000e-01 Element: 10272 \# of layers: 6

$\mathrm{Kx} \mathrm{Ky} \mathrm{Kz}$ Ss Por

4.19431e+00 4.19431e+00 4.19431e-01 1.00000e-09 2.12000e-01 4.19431e+00 4.19431e+00 4.19431e-01 1.00000e-09 2.12000e-01 4.19431e+00 4.19431e+00 4.19431e-01 1.00000e-09 2.12000e-01 $4.19431 \mathrm{e}+004.19431 \mathrm{e}+00$ 4.19431e-01 1.00000e-09 2.12000e-01 $1.00000 \mathrm{e}-05$ 1.00000e-05 1.00000e-06 1.00000e-09 1.00000e-01 $1.00000 \mathrm{e}+001.00000 \mathrm{e}+00$ 1.00000e-01 1.00000e-09 1.00000e-01 Element: 10273 \# of layers: 6

$\mathrm{Kx} \mathrm{Ky} \mathrm{Kz}$ Ss Por

4.43057e+00 4.43057e+00 4.43057e-01 1.00000e-09 2.12000e-01 4.43057e+00 4.43057e+00 4.43057e-01 1.00000e-09 2.12000e-01 4.43057e+00 4.43057e+00 4.43057e-01 1.00000e-09 2.12000e-01 4.43057e+00 4.43057e+00 4.43057e-01 1.00000e-09 2.12000e-01 $1.00000 \mathrm{e}-05$ 1.00000e-05 1.00000e-06 1.00000e-09 1.00000e-01 $1.00000 \mathrm{e}+001.00000 \mathrm{e}+001.00000 \mathrm{e}-011.00000 \mathrm{e}-091.00000 \mathrm{e}-01$ Element: 10274 \# of layers: 6

$\mathrm{Kx} \mathrm{Ky} \mathrm{Kz}$ Ss Por

4.43057e+00 4.43057e+00 4.43057e-01 1.00000e-09 2.12000e-01 4.43057e+00 4.43057e+00 4.43057e-01 1.00000e-09 2.12000e-01 4.43057e+00 4.43057e+00 4.43057e-01 1.00000e-09 2.12000e-01 4.43057e+00 4.43057e+00 4.43057e-01 1.00000e-09 2.12000e-01 $1.00000 \mathrm{e}-05$ 1.00000e-05 1.00000e-06 1.00000e-09 1.00000e-01 $1.00000 \mathrm{e}+001.00000 \mathrm{e}+001.00000 \mathrm{e}-011.00000 \mathrm{e}-091.00000 \mathrm{e}-01$ Element: 10275 \# of layers: 6

$\mathrm{Kx} \mathrm{Ky} \mathrm{Kz}$ Ss Por

4.43057e+00 4.43057e+00 4.43057e-01 1.00000e-09 2.12000e-01 $4.43057 \mathrm{e}+00$ 4.43057e+00 4.43057e-01 1.00000e-09 2.12000e-01 $4.43057 \mathrm{e}+00$ 4.43057e+00 4.43057e-01 1.00000e-09 2.12000e-01 4.43057e+00 4.43057e+00 4.43057e-01 1.00000e-09 2.12000e-01 $1.00000 \mathrm{e}-051.00000 \mathrm{e}-051.00000 \mathrm{e}-061.00000 \mathrm{e}-091.00000 \mathrm{e}-01$ $1.00000 \mathrm{e}+001.00000 \mathrm{e}+001.00000 \mathrm{e}-011.00000 \mathrm{e}-091.00000 \mathrm{e}-01$ Element: 10276 \# of layers: 5

$\mathrm{Kx} \mathrm{Ky} \mathrm{Kz}$ Ss Por

4.43057e+00 4.43057e+00 4.43057e-01 1.00000e-09 2.12000e-01 $4.43057 \mathrm{e}+004.43057 \mathrm{e}+00$ 4.43057e-01 1.00000e-09 2.12000e-01 4.43057e+00 4.43057e+00 4.43057e-01 1.00000e-09 2.12000e-01 $1.00000 \mathrm{e}-05$ 1.00000e-05 1.00000e-06 1.00000e-09 1.00000e-01 $1.00000 \mathrm{e}+001.00000 \mathrm{e}+001.00000 \mathrm{e}-01$ 1.00000e-09 1.00000e-01 Element: 10277 \# of layers: 6

Kx Ky Kz Ss Por 
4.43057e+00 4.43057e+00 4.43057e-01 1.00000e-09 2.12000e-01 4.43057e+00 4.43057e+00 4.43057e-01 1.00000e-09 2.12000e-01 4.43057e+00 4.43057e+00 4.43057e-01 1.00000e-09 2.12000e-01 $4.43057 \mathrm{e}+00$ 4.43057e+00 4.43057e-01 1.00000e-09 2.12000e-01 $1.00000 \mathrm{e}-05$ 1.00000e-05 1.00000e-06 1.00000e-09 1.00000e-01 $1.00000 \mathrm{e}+001.00000 \mathrm{e}+001.00000 \mathrm{e}-011.00000 \mathrm{e}-091.00000 \mathrm{e}-01$ Element: 10278 \# of layers: 6

Kx Ky Kz Ss Por

4.19431e+00 4.19431e+00 4.19431e-01 1.00000e-09 2.12000e-01 4.19431e+00 4.19431e+00 4.19431e-01 1.00000e-09 2.12000e-01 4.19431e+00 4.19431e+00 4.19431e-01 1.00000e-09 2.12000e-01 $4.19431 \mathrm{e}+00$ 4.19431e+00 4.19431e-01 1.00000e-09 2.12000e-01 $1.00000 \mathrm{e}-05$ 1.00000e-05 1.00000e-06 1.00000e-09 1.00000e-01 $1.00000 \mathrm{e}+001.00000 \mathrm{e}+00$ 1.00000e-01 1.00000e-09 1.00000e-01 Element: 10279 \# of layers: 6

Kx Ky Kz Ss Por

4.19431e+00 4.19431e+00 4.19431e-01 1.00000e-09 2.12000e-01 4.19431e+00 4.19431e+00 4.19431e-01 1.00000e-09 2.12000e-01 4.19431e+00 4.19431e+00 4.19431e-01 1.00000e-09 2.12000e-01 $4.19431 \mathrm{e}+004.19431 \mathrm{e}+00$ 4.19431e-01 1.00000e-09 2.12000e-01 $1.00000 \mathrm{e}-05$ 1.00000e-05 1.00000e-06 1.00000e-09 1.00000e-01 $1.00000 \mathrm{e}+001.00000 \mathrm{e}+001.00000 \mathrm{e}-01$ 1.00000e-09 1.00000e-01 Element: 10280 \# of layers: 6

Kx Ky Kz Ss Por

4.43057e+00 4.43057e+00 4.43057e-01 1.00000e-09 2.12000e-01 4.43057e+00 4.43057e+00 4.43057e-01 1.00000e-09 2.12000e-01 4.43057e+00 4.43057e+00 4.43057e-01 1.00000e-09 2.12000e-01 4.43057e+00 4.43057e+00 4.43057e-01 1.00000e-09 2.12000e-01 $1.00000 \mathrm{e}-05$ 1.00000e-05 1.00000e-06 1.00000e-09 1.00000e-01 $1.00000 \mathrm{e}+001.00000 \mathrm{e}+001.00000 \mathrm{e}-011.00000 \mathrm{e}-091.00000 \mathrm{e}-01$ Element: 10281 \# of layers: 6

$\mathrm{Kx} \mathrm{Ky} \mathrm{Kz}$ Ss Por

4.43057e+00 4.43057e+00 4.43057e-01 1.00000e-09 2.12000e-01 4.43057e+00 4.43057e+00 4.43057e-01 1.00000e-09 2.12000e-01 4.43057e+00 4.43057e+00 4.43057e-01 1.00000e-09 2.12000e-01 4.43057e+00 4.43057e+00 4.43057e-01 1.00000e-09 2.12000e-01 $1.00000 \mathrm{e}-05$ 1.00000e-05 1.00000e-06 1.00000e-09 1.00000e-01 $1.00000 \mathrm{e}+001.00000 \mathrm{e}+001.00000 \mathrm{e}-011.00000 \mathrm{e}-09$ 1.00000e-01 Element: 10282 \# of layers: 6

$\mathrm{Kx} \mathrm{Ky} \mathrm{Kz}$ Ss Por 4.43057e+00 4.43057e+00 4.43057e-01 1.00000e-09 2.12000e-01 4.43057e+00 4.43057e+00 4.43057e-01 1.00000e-09 2.12000e-01 4.43057e+00 4.43057e+00 4.43057e-01 1.00000e-09 2.12000e-01 4.43057e+00 4.43057e+00 4.43057e-01 1.00000e-09 2.12000e-01 $1.00000 \mathrm{e}-051.00000 \mathrm{e}-051.00000 \mathrm{e}-061.00000 \mathrm{e}-091.00000 \mathrm{e}-01$ $1.00000 \mathrm{e}+001.00000 \mathrm{e}+001.00000 \mathrm{e}-011.00000 \mathrm{e}-091.00000 \mathrm{e}-01$ 
Element: 10283 \# of layers: 6

Kx Ky Kz Ss Por

$4.43057 \mathrm{e}+00$ 4.43057e+00 4.43057e-01 1.00000e-09 2.12000e-01

$4.43057 \mathrm{e}+004.43057 \mathrm{e}+00$ 4.43057e-01 1.00000e-09 2.12000e-01

$4.43057 \mathrm{e}+004.43057 \mathrm{e}+004.43057 \mathrm{e}-011.00000 \mathrm{e}-092.12000 \mathrm{e}-01$

$4.43057 \mathrm{e}+00 \quad 4.43057 \mathrm{e}+00$ 4.43057e-01 1.00000e-09 2.12000e-01

$1.00000 \mathrm{e}-05$ 1.00000e-05 1.00000e-06 1.00000e-09 1.00000e-01

$1.00000 \mathrm{e}+001.00000 \mathrm{e}+001.00000 \mathrm{e}-011.00000 \mathrm{e}-091.00000 \mathrm{e}-01$

Element: 10284 \# of layers: 5

Kx Ky Kz Ss Por

4.43057e+00 4.43057e+00 4.43057e-01 1.00000e-09 2.12000e-01

$4.43057 \mathrm{e}+004.43057 \mathrm{e}+00$ 4.43057e-01 1.00000e-09 2.12000e-01

$4.43057 \mathrm{e}+004.43057 \mathrm{e}+00$ 4.43057e-01 1.00000e-09 2.12000e-01

$1.00000 \mathrm{e}-05$ 1.00000e-05 1.00000e-06 1.00000e-09 1.00000e-01

$1.00000 \mathrm{e}+001.00000 \mathrm{e}+001.00000 \mathrm{e}-011.00000 \mathrm{e}-091.00000 \mathrm{e}-01$

Element: 10285 \# of layers: 5

Kx Ky Kz Ss Por

$4.43057 \mathrm{e}+00$ 4.43057e+00 4.43057e-01 1.00000e-09 2.12000e-01

$4.43057 \mathrm{e}+004.43057 \mathrm{e}+00$ 4.43057e-01 1.00000e-09 2.12000e-01

$4.43057 \mathrm{e}+00 \quad 4.43057 \mathrm{e}+00$ 4.43057e-01 1.00000e-09 2.12000e-01

$1.00000 \mathrm{e}-05$ 1.00000e-05 1.00000e-06 1.00000e-09 1.00000e-01

$1.00000 \mathrm{e}+001.00000 \mathrm{e}+001.00000 \mathrm{e}-011.00000 \mathrm{e}-091.00000 \mathrm{e}-01$

Element: 10286 \# of layers: 5

Kx Ky Kz Ss Por

$4.43057 \mathrm{e}+00$ 4.43057e+00 4.43057e-01 1.00000e-09 2.12000e-01

$4.43057 \mathrm{e}+004.43057 \mathrm{e}+00$ 4.43057e-01 1.00000e-09 2.12000e-01

$4.43057 \mathrm{e}+00 \quad 4.43057 \mathrm{e}+00$ 4.43057e-01 1.00000e-09 2.12000e-01

$1.00000 \mathrm{e}-05$ 1.00000e-05 1.00000e-06 1.00000e-09 1.00000e-01

$1.00000 \mathrm{e}+001.00000 \mathrm{e}+001.00000 \mathrm{e}-011.00000 \mathrm{e}-091.00000 \mathrm{e}-01$

Element: 10287 \# of layers: 5

Kx Ky Kz Ss Por

4.43057e+00 4.43057e+00 4.43057e-01 1.00000e-09 2.12000e-01

$4.43057 \mathrm{e}+004.43057 \mathrm{e}+00$ 4.43057e-01 1.00000e-09 2.12000e-01

$4.43057 \mathrm{e}+00 \quad 4.43057 \mathrm{e}+00$ 4.43057e-01 1.00000e-09 2.12000e-01

$1.00000 \mathrm{e}-05$ 1.00000e-05 1.00000e-06 1.00000e-09 1.00000e-01

$1.00000 \mathrm{e}+001.00000 \mathrm{e}+001.00000 \mathrm{e}-011.00000 \mathrm{e}-091.00000 \mathrm{e}-01$

Element: 10288 \# of layers: 6

Kx Ky Kz Ss Por

$4.43057 \mathrm{e}+00$ 4.43057e+00 4.43057e-01 1.00000e-09 2.12000e-01

$4.43057 \mathrm{e}+004.43057 \mathrm{e}+00$ 4.43057e-01 1.00000e-09 2.12000e-01

$4.43057 \mathrm{e}+004.43057 \mathrm{e}+00$ 4.43057e-01 1.00000e-09 2.12000e-01

$4.43057 \mathrm{e}+004.43057 \mathrm{e}+004.43057 \mathrm{e}-011.00000 \mathrm{e}-09$ 2.12000e-01

$1.00000 \mathrm{e}-05$ 1.00000e-05 1.00000e-06 1.00000e-09 1.00000e-01

$1.00000 \mathrm{e}+001.00000 \mathrm{e}+001.00000 \mathrm{e}-011.00000 \mathrm{e}-091.00000 \mathrm{e}-01$

Element: 10289 \# of layers: 6

Kx Ky Kz Ss Por 
4.43057e+00 4.43057e+00 4.43057e-01 1.00000e-09 2.12000e-01 4.43057e+00 4.43057e+00 4.43057e-01 1.00000e-09 2.12000e-01 4.43057e+00 4.43057e+00 4.43057e-01 1.00000e-09 2.12000e-01 $4.43057 \mathrm{e}+00$ 4.43057e+00 4.43057e-01 1.00000e-09 2.12000e-01 $1.00000 \mathrm{e}-05$ 1.00000e-05 1.00000e-06 1.00000e-09 1.00000e-01 $1.00000 \mathrm{e}+001.00000 \mathrm{e}+001.00000 \mathrm{e}-011.00000 \mathrm{e}-091.00000 \mathrm{e}-01$ Element: 10290 \# of layers: 5

$\mathrm{Kx} \mathrm{Ky} \mathrm{Kz} \mathrm{Ss} \mathrm{Por}$

4.43057e+00 4.43057e+00 4.43057e-01 1.00000e-09 2.12000e-01 $4.43057 \mathrm{e}+00$ 4.43057e+00 4.43057e-01 1.00000e-09 2.12000e-01 4.43057e+00 4.43057e+00 4.43057e-01 1.00000e-09 2.12000e-01 $1.00000 \mathrm{e}-05$ 1.00000e-05 1.00000e-06 1.00000e-09 1.00000e-01 $1.00000 \mathrm{e}+001.00000 \mathrm{e}+001.00000 \mathrm{e}-011.00000 \mathrm{e}-091.00000 \mathrm{e}-01$ Element: 10291 \# of layers: 5

$\mathrm{Kx} \mathrm{Ky} \mathrm{Kz}$ Ss Por

4.43057e+00 4.43057e+00 4.43057e-01 1.00000e-09 2.12000e-01 4.43057e+00 4.43057e+00 4.43057e-01 1.00000e-09 2.12000e-01 4.43057e+00 4.43057e+00 4.43057e-01 1.00000e-09 2.12000e-01 $1.00000 \mathrm{e}-05$ 1.00000e-05 1.00000e-06 1.00000e-09 1.00000e-01 $1.00000 \mathrm{e}+001.00000 \mathrm{e}+001.00000 \mathrm{e}-011.00000 \mathrm{e}-091.00000 \mathrm{e}-01$ Element: 10292 \# of layers: 5

Kx Ky Kz Ss Por

5.19941e+00 5.19941e+00 5.19941e-01 1.00000e-09 2.12000e-01 5.19941e+00 5.19941e+00 5.19941e-01 1.00000e-09 2.12000e-01 $5.19941 \mathrm{e}+00$ 5.19941e+00 5.19941e-01 1.00000e-09 2.12000e-01 $1.00000 \mathrm{e}-05$ 1.00000e-05 1.00000e-06 1.00000e-09 1.00000e-01 $1.00000 \mathrm{e}+001.00000 \mathrm{e}+001.00000 \mathrm{e}-011.00000 \mathrm{e}-091.00000 \mathrm{e}-01$ Element: 10293 \# of layers: 5

Kx Ky Kz Ss Por

5.19941e+00 5.19941e+00 5.19941e-01 1.00000e-09 2.12000e-01 5.19941e+00 5.19941e+00 5.19941e-01 1.00000e-09 2.12000e-01 $5.19941 \mathrm{e}+00$ 5.19941e+00 5.19941e-01 1.00000e-09 2.12000e-01 $1.00000 \mathrm{e}-05$ 1.00000e-05 1.00000e-06 1.00000e-09 1.00000e-01 $1.00000 \mathrm{e}+001.00000 \mathrm{e}+001.00000 \mathrm{e}-01$ 1.00000e-09 1.00000e-01 Element: 10294 \# of layers: 5

$\mathrm{Kx} \mathrm{Ky} \mathrm{Kz}$ Ss Por

5.19941e+00 5.19941e+00 5.19941e-01 1.00000e-09 2.12000e-01 5.19941e+00 5.19941e+00 5.19941e-01 1.00000e-09 2.12000e-01 5.19941e+00 5.19941e+00 5.19941e-01 1.00000e-09 2.12000e-01 $1.00000 \mathrm{e}-05$ 1.00000e-05 1.00000e-06 1.00000e-09 1.00000e-01 $1.00000 \mathrm{e}+001.00000 \mathrm{e}+001.00000 \mathrm{e}-011.00000 \mathrm{e}-091.00000 \mathrm{e}-01$ Element: 10295 \# of layers: 5

$\mathrm{Kx} \mathrm{Ky} \mathrm{Kz}$ Ss Por

4.43057e+00 4.43057e+00 4.43057e-01 1.00000e-09 2.12000e-01 4.43057e+00 4.43057e+00 4.43057e-01 1.00000e-09 2.12000e-01 $4.43057 \mathrm{e}+00$ 4.43057e+00 4.43057e-01 1.00000e-09 2.12000e-01 
$1.00000 \mathrm{e}-05$ 1.00000e-05 1.00000e-06 1.00000e-09 1.00000e-01 $1.00000 \mathrm{e}+001.00000 \mathrm{e}+001.00000 \mathrm{e}-01$ 1.00000e-09 1.00000e-01 Element: 10296 \# of layers: 5

Kx Ky Kz Ss Por

4.43057e+00 4.43057e+00 4.43057e-01 1.00000e-09 2.12000e-01 4.43057e+00 4.43057e+00 4.43057e-01 1.00000e-09 2.12000e-01 $4.43057 \mathrm{e}+00$ 4.43057e+00 4.43057e-01 1.00000e-09 2.12000e-01 $1.00000 \mathrm{e}-05$ 1.00000e-05 1.00000e-06 1.00000e-09 1.00000e-01 $1.00000 \mathrm{e}+001.00000 \mathrm{e}+001.00000 \mathrm{e}-011.00000 \mathrm{e}-091.00000 \mathrm{e}-01$ Element: 10297 \# of layers: 5

$\mathrm{Kx} \mathrm{Ky} \mathrm{Kz}$ Ss Por

4.43057e+00 4.43057e+00 4.43057e-01 1.00000e-09 2.12000e-01 4.43057e+00 4.43057e+00 4.43057e-01 1.00000e-09 2.12000e-01 4.43057e+00 4.43057e+00 4.43057e-01 1.00000e-09 2.12000e-01 $1.00000 \mathrm{e}-05$ 1.00000e-05 1.00000e-06 1.00000e-09 1.00000e-01 $1.00000 \mathrm{e}+001.00000 \mathrm{e}+001.00000 \mathrm{e}-011.00000 \mathrm{e}-091.00000 \mathrm{e}-01$ Element: 10298 \# of layers: 5

$\mathrm{Kx} \mathrm{Ky} \mathrm{Kz}$ Ss Por

4.43057e+00 4.43057e+00 4.43057e-01 1.00000e-09 2.12000e-01 4.43057e+00 4.43057e+00 4.43057e-01 1.00000e-09 2.12000e-01 $4.43057 \mathrm{e}+00$ 4.43057e+00 4.43057e-01 1.00000e-09 2.12000e-01 $1.00000 \mathrm{e}-051.00000 \mathrm{e}-051.00000 \mathrm{e}-061.00000 \mathrm{e}-091.00000 \mathrm{e}-01$ $1.00000 \mathrm{e}+001.00000 \mathrm{e}+001.00000 \mathrm{e}-01$ 1.00000e-09 1.00000e-01 Element: 10299 \# of layers: 6

Kx Ky Kz Ss Por

5.19941e+00 5.19941e+00 5.19941e-01 1.00000e-09 2.12000e-01 5.19941e+00 5.19941e+00 5.19941e-01 1.00000e-09 2.12000e-01 5.19941e+00 5.19941e+00 5.19941e-01 1.00000e-09 2.12000e-01 $5.19941 \mathrm{e}+00$ 5.19941e+00 5.19941e-01 1.00000e-09 2.12000e-01 $1.00000 \mathrm{e}-05$ 1.00000e-05 1.00000e-06 1.00000e-09 1.00000e-01 $1.00000 \mathrm{e}+001.00000 \mathrm{e}+001.00000 \mathrm{e}-011.00000 \mathrm{e}-091.00000 \mathrm{e}-01$ Element: 10300 \# of layers: 5

Kx Ky Kz Ss Por

5.19941e+00 5.19941e+00 5.19941e-01 1.00000e-09 2.12000e-01 5.19941e+00 5.19941e+00 5.19941e-01 1.00000e-09 2.12000e-01 5.19941e+00 5.19941e+00 5.19941e-01 1.00000e-09 2.12000e-01 $1.00000 \mathrm{e}-05$ 1.00000e-05 1.00000e-06 1.00000e-09 1.00000e-01 $1.00000 \mathrm{e}+001.00000 \mathrm{e}+001.00000 \mathrm{e}-011.00000 \mathrm{e}-09$ 1.00000e-01 Element: 10301 \# of layers: 5

$\mathrm{Kx} \mathrm{Ky} \mathrm{Kz}$ Ss Por

5.19941e+00 5.19941e+00 5.19941e-01 1.00000e-09 2.12000e-01 5.19941e+00 5.19941e+00 5.19941e-01 1.00000e-09 2.12000e-01 5.19941e+00 5.19941e+00 5.19941e-01 1.00000e-09 2.12000e-01 $1.00000 \mathrm{e}-05$ 1.00000e-05 1.00000e-06 1.00000e-09 1.00000e-01 $1.00000 \mathrm{e}+001.00000 \mathrm{e}+001.00000 \mathrm{e}-01$ 1.00000e-09 1.00000e-01 Element: 10302 \# of layers: 5 
Kx Ky Kz Ss Por

5.19941e+00 5.19941e+00 5.19941e-01 1.00000e-09 2.12000e-01

$5.19941 \mathrm{e}+00$ 5.19941e+00 5.19941e-01 1.00000e-09 2.12000e-01

$5.19941 \mathrm{e}+00$ 5.19941e+00 5.19941e-01 1.00000e-09 2.12000e-01

$1.00000 \mathrm{e}-05$ 1.00000e-05 1.00000e-06 1.00000e-09 1.00000e-01

$1.00000 \mathrm{e}+001.00000 \mathrm{e}+001.00000 \mathrm{e}-01$ 1.00000e-09 1.00000e-01

Element: 10303 \# of layers: 6

Kx Ky Kz Ss Por

5.19941e+00 5.19941e+00 5.19941e-01 1.00000e-09 2.12000e-01

5.19941e+00 5.19941e+00 5.19941e-01 1.00000e-09 2.12000e-01

5.19941e+00 5.19941e+00 5.19941e-01 1.00000e-09 2.12000e-01

$5.19941 \mathrm{e}+005.19941 \mathrm{e}+00$ 5.19941e-01 1.00000e-09 2.12000e-01

$1.00000 \mathrm{e}-05$ 1.00000e-05 1.00000e-06 1.00000e-09 1.00000e-01

$1.00000 \mathrm{e}+001.00000 \mathrm{e}+001.00000 \mathrm{e}-01$ 1.00000e-09 1.00000e-01

Element: 10304 \# of layers: 6

$\mathrm{Kx} \mathrm{Ky} \mathrm{Kz}$ Ss Por

5.19941e+00 5.19941e+00 5.19941e-01 1.00000e-09 2.12000e-01

5.19941e+00 5.19941e+00 5.19941e-01 1.00000e-09 2.12000e-01

5.19941e+00 5.19941e+00 5.19941e-01 1.00000e-09 2.12000e-01

$5.19941 \mathrm{e}+00$ 5.19941e+00 5.19941e-01 1.00000e-09 2.12000e-01

$1.00000 \mathrm{e}-05$ 1.00000e-05 1.00000e-06 1.00000e-09 1.00000e-01

$1.00000 \mathrm{e}+001.00000 \mathrm{e}+001.00000 \mathrm{e}-011.00000 \mathrm{e}-091.00000 \mathrm{e}-01$

Element: 10305 \# of layers: 6

Kx Ky Kz Ss Por

5.19941e+00 5.19941e+00 5.19941e-01 1.00000e-09 2.12000e-01

5.19941e+00 5.19941e+00 5.19941e-01 1.00000e-09 2.12000e-01

5.19941e+00 5.19941e+00 5.19941e-01 1.00000e-09 2.12000e-01

5.19941e+00 5.19941e+00 5.19941e-01 1.00000e-09 2.12000e-01

$1.00000 \mathrm{e}-05$ 1.00000e-05 1.00000e-06 1.00000e-09 1.00000e-01

$1.00000 \mathrm{e}+001.00000 \mathrm{e}+001.00000 \mathrm{e}-011.00000 \mathrm{e}-091.00000 \mathrm{e}-01$

Element: 10306 \# of layers: 6

Kx Ky Kz Ss Por

5.19941e+00 5.19941e+00 5.19941e-01 1.00000e-09 2.12000e-01

$5.19941 \mathrm{e}+00$ 5.19941e+00 5.19941e-01 1.00000e-09 2.12000e-01

5.19941e+00 5.19941e+00 5.19941e-01 1.00000e-09 2.12000e-01

5.19941e+00 5.19941e+00 5.19941e-01 1.00000e-09 2.12000e-01

$1.00000 \mathrm{e}-05$ 1.00000e-05 1.00000e-06 1.00000e-09 1.00000e-01

$1.00000 \mathrm{e}+001.00000 \mathrm{e}+001.00000 \mathrm{e}-011.00000 \mathrm{e}-09$ 1.00000e-01

Element: 10307 \# of layers: 5

$\mathrm{Kx} \mathrm{Ky} \mathrm{Kz}$ Ss Por

5.19941e+00 5.19941e+00 5.19941e-01 1.00000e-09 2.12000e-01

5.19941e+00 5.19941e+00 5.19941e-01 1.00000e-09 2.12000e-01

5.19941e+00 5.19941e+00 5.19941e-01 1.00000e-09 2.12000e-01

$1.00000 \mathrm{e}-05$ 1.00000e-05 1.00000e-06 1.00000e-09 1.00000e-01

$1.00000 \mathrm{e}+001.00000 \mathrm{e}+001.00000 \mathrm{e}-01$ 1.00000e-09 1.00000e-01

Element: 10308 \# of layers: 5 


\section{Kx Ky Kz Ss Por}

5.19941e+00 5.19941e+00 5.19941e-01 1.00000e-09 2.12000e-01

$5.19941 \mathrm{e}+005.19941 \mathrm{e}+00$ 5.19941e-01 1.00000e-09 2.12000e-01

$5.19941 \mathrm{e}+005.19941 \mathrm{e}+00$ 5.19941e-01 1.00000e-09 2.12000e-01

$1.00000 \mathrm{e}-05$ 1.00000e-05 1.00000e-06 1.00000e-09 1.00000e-01

$1.00000 \mathrm{e}+001.00000 \mathrm{e}+001.00000 \mathrm{e}-011.00000 \mathrm{e}-091.00000 \mathrm{e}-01$

Element: 10309 \# of layers: 5

Kx Ky Kz Ss Por

$5.19941 \mathrm{e}+00$ 5.19941e+00 5.19941e-01 1.00000e-09 2.12000e-01

$5.19941 \mathrm{e}+00$ 5.19941e+00 5.19941e-01 1.00000e-09 2.12000e-01

$5.19941 \mathrm{e}+005.19941 \mathrm{e}+00$ 5.19941e-01 1.00000e-09 2.12000e-01

$1.00000 \mathrm{e}-05$ 1.00000e-05 1.00000e-06 1.00000e-09 1.00000e-01

$1.00000 \mathrm{e}+001.00000 \mathrm{e}+001.00000 \mathrm{e}-011.00000 \mathrm{e}-091.00000 \mathrm{e}-01$

Element: 10310 \# of layers: 5

Kx Ky Kz Ss Por

$4.85020 \mathrm{e}+004.85020 \mathrm{e}+004.85020 \mathrm{e}-01$ 1.00000e-09 2.12000e-01

$4.85020 \mathrm{e}+004.85020 \mathrm{e}+004.85020 \mathrm{e}-011.00000 \mathrm{e}-092.12000 \mathrm{e}-01$

$4.85020 \mathrm{e}+004.85020 \mathrm{e}+00$ 4.85020e-01 1.00000e-09 2.12000e-01

$1.00000 \mathrm{e}-05$ 1.00000e-05 1.00000e-06 1.00000e-09 1.00000e-01

$1.00000 \mathrm{e}+001.00000 \mathrm{e}+001.00000 \mathrm{e}-011.00000 \mathrm{e}-091.00000 \mathrm{e}-01$

Element: 10311 \# of layers: 5

Kx Ky Kz Ss Por

$4.85020 \mathrm{e}+004.85020 \mathrm{e}+00$ 4.85020e-01 1.00000e-09 2.12000e-01

$4.85020 \mathrm{e}+004.85020 \mathrm{e}+004.85020 \mathrm{e}-011.00000 \mathrm{e}-092.12000 \mathrm{e}-01$

$4.85020 \mathrm{e}+00 \quad 4.85020 \mathrm{e}+00 \quad 4.85020 \mathrm{e}-011.00000 \mathrm{e}-092.12000 \mathrm{e}-01$

$1.00000 \mathrm{e}-05$ 1.00000e-05 1.00000e-06 1.00000e-09 1.00000e-01

$1.00000 \mathrm{e}+001.00000 \mathrm{e}+00$ 1.00000e-01 1.00000e-09 1.00000e-01

Element: 10312 \# of layers: 5

Kx Ky Kz Ss Por

$4.85020 \mathrm{e}+004.85020 \mathrm{e}+004.85020 \mathrm{e}-01$ 1.00000e-09 2.12000e-01

$4.85020 \mathrm{e}+004.85020 \mathrm{e}+004.85020 \mathrm{e}-011.00000 \mathrm{e}-092.12000 \mathrm{e}-01$

$4.85020 \mathrm{e}+004.85020 \mathrm{e}+00 \quad 4.85020 \mathrm{e}-011.00000 \mathrm{e}-092.12000 \mathrm{e}-01$

$1.00000 \mathrm{e}-05$ 1.00000e-05 1.00000e-06 1.00000e-09 1.00000e-01

$1.00000 \mathrm{e}+001.00000 \mathrm{e}+001.00000 \mathrm{e}-011.00000 \mathrm{e}-091.00000 \mathrm{e}-01$

Element: 10313 \# of layers: 5

Kx Ky Kz Ss Por

5.19941e+00 5.19941e+00 5.19941e-01 1.00000e-09 2.12000e-01

$5.19941 \mathrm{e}+005.19941 \mathrm{e}+00$ 5.19941e-01 1.00000e-09 2.12000e-01

$5.19941 \mathrm{e}+00$ 5.19941e+00 5.19941e-01 1.00000e-09 2.12000e-01

$1.00000 \mathrm{e}-05$ 1.00000e-05 1.00000e-06 1.00000e-09 1.00000e-01

$1.00000 \mathrm{e}+001.00000 \mathrm{e}+001.00000 \mathrm{e}-011.00000 \mathrm{e}-091.00000 \mathrm{e}-01$

Element: 10314 \# of layers: 5

Kx Ky Kz Ss Por

$5.19941 \mathrm{e}+00$ 5.19941e+00 5.19941e-01 1.00000e-09 2.12000e-01

$5.19941 \mathrm{e}+005.19941 \mathrm{e}+00$ 5.19941e-01 1.00000e-09 2.12000e-01

$5.19941 \mathrm{e}+00$ 5.19941e+00 5.19941e-01 1.00000e-09 2.12000e-01 
$1.00000 \mathrm{e}-05$ 1.00000e-05 1.00000e-06 1.00000e-09 1.00000e-01 $1.00000 \mathrm{e}+001.00000 \mathrm{e}+001.00000 \mathrm{e}-01$ 1.00000e-09 1.00000e-01 Element: 10315 \# of layers: 5

Kx Ky Kz Ss Por

5.19941e+00 5.19941e+00 5.19941e-01 1.00000e-09 2.12000e-01

5.19941e+00 5.19941e+00 5.19941e-01 1.00000e-09 2.12000e-01

5.19941e+00 5.19941e+00 5.19941e-01 1.00000e-09 2.12000e-01

$1.00000 \mathrm{e}-05$ 1.00000e-05 1.00000e-06 1.00000e-09 1.00000e-01

$1.00000 \mathrm{e}+001.00000 \mathrm{e}+00$ 1.00000e-01 1.00000e-09 1.00000e-01

Element: 10316 \# of layers: 5

$\mathrm{Kx} \mathrm{Ky} \mathrm{Kz}$ Ss Por

5.19941e+00 5.19941e+00 5.19941e-01 1.00000e-09 2.12000e-01

5.19941e+00 5.19941e+00 5.19941e-01 1.00000e-09 2.12000e-01

5.19941e+00 5.19941e+00 5.19941e-01 1.00000e-09 2.12000e-01

$1.00000 \mathrm{e}-05$ 1.00000e-05 1.00000e-06 1.00000e-09 1.00000e-01

$1.00000 \mathrm{e}+001.00000 \mathrm{e}+001.00000 \mathrm{e}-011.00000 \mathrm{e}-091.00000 \mathrm{e}-01$

Element: 10317 \# of layers: 5

$\mathrm{Kx} \mathrm{Ky} \mathrm{Kz}$ Ss Por

$4.85020 \mathrm{e}+004.85020 \mathrm{e}+00$ 4.85020e-01 1.00000e-09 2.12000e-01

$4.85020 \mathrm{e}+004.85020 \mathrm{e}+004.85020 \mathrm{e}-01$ 1.00000e-09 2.12000e-01

$4.85020 \mathrm{e}+004.85020 \mathrm{e}+00 \quad 4.85020 \mathrm{e}-01$ 1.00000e-09 2.12000e-01

$1.00000 \mathrm{e}-051.00000 \mathrm{e}-051.00000 \mathrm{e}-061.00000 \mathrm{e}-091.00000 \mathrm{e}-01$

$1.00000 \mathrm{e}+001.00000 \mathrm{e}+001.00000 \mathrm{e}-01$ 1.00000e-09 1.00000e-01

Element: 10318 \# of layers: 5

Kx Ky Kz Ss Por

4.85020e+00 4.85020e+00 4.85020e-01 1.00000e-09 2.12000e-01

$4.85020 \mathrm{e}+004.85020 \mathrm{e}+004.85020 \mathrm{e}-01$ 1.00000e-09 2.12000e-01

$4.85020 \mathrm{e}+004.85020 \mathrm{e}+004.85020 \mathrm{e}-01$ 1.00000e-09 2.12000e-01

$1.00000 \mathrm{e}-05$ 1.00000e-05 1.00000e-06 1.00000e-09 1.00000e-01

$1.00000 \mathrm{e}+001.00000 \mathrm{e}+001.00000 \mathrm{e}-011.00000 \mathrm{e}-091.00000 \mathrm{e}-01$

Element: 10319 \# of layers: 5

$\mathrm{Kx} \mathrm{Ky} \mathrm{Kz}$ Ss Por

4.85020e+00 4.85020e+00 4.85020e-01 1.00000e-09 2.12000e-01

$4.85020 \mathrm{e}+004.85020 \mathrm{e}+00$ 4.85020e-01 1.00000e-09 2.12000e-01

$4.85020 \mathrm{e}+004.85020 \mathrm{e}+004.85020 \mathrm{e}-01$ 1.00000e-09 2.12000e-01

$1.00000 \mathrm{e}-05$ 1.00000e-05 1.00000e-06 1.00000e-09 1.00000e-01

$1.00000 \mathrm{e}+001.00000 \mathrm{e}+001.00000 \mathrm{e}-011.00000 \mathrm{e}-091.00000 \mathrm{e}-01$

Element: 10320 \# of layers: 5

$\mathrm{Kx} \mathrm{Ky} \mathrm{Kz}$ Ss Por

4.85020e+00 4.85020e+00 4.85020e-01 1.00000e-09 2.12000e-01

$4.85020 \mathrm{e}+004.85020 \mathrm{e}+004.85020 \mathrm{e}-01$ 1.00000e-09 2.12000e-01

$4.85020 \mathrm{e}+004.85020 \mathrm{e}+004.85020 \mathrm{e}-01$ 1.00000e-09 2.12000e-01

$1.00000 \mathrm{e}-05$ 1.00000e-05 1.00000e-06 1.00000e-09 1.00000e-01

$1.00000 \mathrm{e}+001.00000 \mathrm{e}+001.00000 \mathrm{e}-01$ 1.00000e-09 1.00000e-01

Element: 10321 \# of layers: 5

Kx Ky Kz Ss Por 
$4.85020 \mathrm{e}+004.85020 \mathrm{e}+004.85020 \mathrm{e}-011.00000 \mathrm{e}-092.12000 \mathrm{e}-01$ $4.85020 \mathrm{e}+004.85020 \mathrm{e}+004.85020 \mathrm{e}-011.00000 \mathrm{e}-092.12000 \mathrm{e}-01$ $4.85020 \mathrm{e}+004.85020 \mathrm{e}+00 \quad 4.85020 \mathrm{e}-011.00000 \mathrm{e}-092.12000 \mathrm{e}-01$ $1.00000 \mathrm{e}-05$ 1.00000e-05 1.00000e-06 1.00000e-09 1.00000e-01 $1.00000 \mathrm{e}+001.00000 \mathrm{e}+001.00000 \mathrm{e}-011.00000 \mathrm{e}-091.00000 \mathrm{e}-01$ Element: 10322 \# of layers: 5

Kx Ky Kz Ss Por

$4.85020 \mathrm{e}+004.85020 \mathrm{e}+004.85020 \mathrm{e}-01$ 1.00000e-09 2.12000e-01 $4.85020 \mathrm{e}+004.85020 \mathrm{e}+004.85020 \mathrm{e}-011.00000 \mathrm{e}-092.12000 \mathrm{e}-01$ $4.85020 \mathrm{e}+004.85020 \mathrm{e}+00 \quad 4.85020 \mathrm{e}-011.00000 \mathrm{e}-09$ 2.12000e-01 $1.00000 \mathrm{e}-05$ 1.00000e-05 1.00000e-06 1.00000e-09 1.00000e-01 $1.00000 \mathrm{e}+001.00000 \mathrm{e}+001.00000 \mathrm{e}-011.00000 \mathrm{e}-091.00000 \mathrm{e}-01$ Element: 10323 \# of layers: 5

Kx Ky Kz Ss Por

$4.85020 \mathrm{e}+004.85020 \mathrm{e}+00$ 4.85020e-01 1.00000e-09 2.12000e-01 $4.85020 \mathrm{e}+004.85020 \mathrm{e}+004.85020 \mathrm{e}-01$ 1.00000e-09 2.12000e-01 $4.85020 \mathrm{e}+004.85020 \mathrm{e}+00$ 4.85020e-01 1.00000e-09 2.12000e-01 $1.00000 \mathrm{e}-05$ 1.00000e-05 1.00000e-06 1.00000e-09 1.00000e-01 $1.00000 \mathrm{e}+001.00000 \mathrm{e}+001.00000 \mathrm{e}-011.00000 \mathrm{e}-091.00000 \mathrm{e}-01$ Element: 10324 \# of layers: 5

Kx Ky Kz Ss Por

$4.85020 \mathrm{e}+004.85020 \mathrm{e}+004.85020 \mathrm{e}-011.00000 \mathrm{e}-092.12000 \mathrm{e}-01$ $4.85020 \mathrm{e}+004.85020 \mathrm{e}+004.85020 \mathrm{e}-011.00000 \mathrm{e}-092.12000 \mathrm{e}-01$ $4.85020 \mathrm{e}+004.85020 \mathrm{e}+00 \quad 4.85020 \mathrm{e}-011.00000 \mathrm{e}-092.12000 \mathrm{e}-01$ $1.00000 \mathrm{e}-05$ 1.00000e-05 1.00000e-06 1.00000e-09 1.00000e-01 $1.00000 \mathrm{e}+001.00000 \mathrm{e}+001.00000 \mathrm{e}-011.00000 \mathrm{e}-091.00000 \mathrm{e}-01$ Element: 10325 \# of layers: 5

Kx Ky Kz Ss Por

$4.85020 \mathrm{e}+004.85020 \mathrm{e}+004.85020 \mathrm{e}-01$ 1.00000e-09 2.12000e-01 $4.85020 \mathrm{e}+004.85020 \mathrm{e}+004.85020 \mathrm{e}-011.00000 \mathrm{e}-092.12000 \mathrm{e}-01$ $4.85020 \mathrm{e}+004.85020 \mathrm{e}+00 \quad 4.85020 \mathrm{e}-011.00000 \mathrm{e}-09$ 2.12000e-01 $1.00000 \mathrm{e}-05$ 1.00000e-05 1.00000e-06 1.00000e-09 1.00000e-01 $1.00000 \mathrm{e}+001.00000 \mathrm{e}+00$ 1.00000e-01 1.00000e-09 1.00000e-01 Element: 10326 \# of layers: 6

Kx Ky Kz Ss Por

$4.85020 \mathrm{e}+004.85020 \mathrm{e}+00$ 4.85020e-01 1.00000e-09 2.12000e-01 $4.85020 \mathrm{e}+004.85020 \mathrm{e}+004.85020 \mathrm{e}-011.00000 \mathrm{e}-092.12000 \mathrm{e}-01$ $4.85020 \mathrm{e}+004.85020 \mathrm{e}+004.85020 \mathrm{e}-01$ 1.00000e-09 2.12000e-01 $4.85020 \mathrm{e}+004.85020 \mathrm{e}+00$ 4.85020e-01 1.00000e-09 2.12000e-01 $1.00000 \mathrm{e}-05$ 1.00000e-05 1.00000e-06 1.00000e-09 1.00000e-01 $1.00000 \mathrm{e}+001.00000 \mathrm{e}+001.00000 \mathrm{e}-011.00000 \mathrm{e}-091.00000 \mathrm{e}-01$ Element: 10327 \# of layers: 6

Kx Ky Kz Ss Por

$4.19431 \mathrm{e}+004.19431 \mathrm{e}+00$ 4.19431e-01 1.00000e-09 2.12000e-01 $4.19431 \mathrm{e}+004.19431 \mathrm{e}+004.19431 \mathrm{e}-011.00000 \mathrm{e}-092.12000 \mathrm{e}-01$ $4.19431 \mathrm{e}+004.19431 \mathrm{e}+004.19431 \mathrm{e}-01$ 1.00000e-09 2.12000e-01 
4.19431e+00 4.19431e+00 4.19431e-01 1.00000e-09 2.12000e-01 $1.00000 \mathrm{e}-05$ 1.00000e-05 1.00000e-06 1.00000e-09 1.00000e-01 $1.00000 \mathrm{e}+001.00000 \mathrm{e}+001.00000 \mathrm{e}-011.00000 \mathrm{e}-091.00000 \mathrm{e}-01$ Element: 10328 \# of layers: 6

$\mathrm{Kx} \mathrm{Ky} \mathrm{Kz}$ Ss Por

4.19431e+00 4.19431e+00 4.19431e-01 1.00000e-09 2.12000e-01 4.19431e+00 4.19431e+00 4.19431e-01 1.00000e-09 2.12000e-01 $4.19431 \mathrm{e}+00$ 4.19431e+00 4.19431e-01 1.00000e-09 2.12000e-01 4.19431e+00 4.19431e+00 4.19431e-01 1.00000e-09 2.12000e-01 $1.00000 \mathrm{e}-05$ 1.00000e-05 1.00000e-06 1.00000e-09 1.00000e-01 $1.00000 \mathrm{e}+001.00000 \mathrm{e}+001.00000 \mathrm{e}-011.00000 \mathrm{e}-091.00000 \mathrm{e}-01$ Element: 10329 \# of layers: 6

$\mathrm{Kx} \mathrm{Ky} \mathrm{Kz}$ Ss Por

4.19431e+00 4.19431e+00 4.19431e-01 1.00000e-09 2.12000e-01 4.19431e+00 4.19431e+00 4.19431e-01 1.00000e-09 2.12000e-01 $4.19431 \mathrm{e}+004.19431 \mathrm{e}+004.19431 \mathrm{e}-01$ 1.00000e-09 2.12000e-01 $4.19431 \mathrm{e}+004.19431 \mathrm{e}+004.19431 \mathrm{e}-01$ 1.00000e-09 2.12000e-01 $1.00000 \mathrm{e}-05$ 1.00000e-05 1.00000e-06 1.00000e-09 1.00000e-01 $1.00000 \mathrm{e}+001.00000 \mathrm{e}+001.00000 \mathrm{e}-01$ 1.00000e-09 1.00000e-01 Element: 10330 \# of layers: 6

$\mathrm{Kx} \mathrm{Ky} \mathrm{Kz}$ Ss Por

4.19431e+00 4.19431e+00 4.19431e-01 1.00000e-09 2.12000e-01 4.19431e+00 4.19431e+00 4.19431e-01 1.00000e-09 2.12000e-01 4.19431e+00 4.19431e+00 4.19431e-01 1.00000e-09 2.12000e-01 $4.19431 \mathrm{e}+004.19431 \mathrm{e}+004.19431 \mathrm{e}-01$ 1.00000e-09 2.12000e-01 $1.00000 \mathrm{e}-05$ 1.00000e-05 1.00000e-06 1.00000e-09 1.00000e-01 $1.00000 \mathrm{e}+001.00000 \mathrm{e}+001.00000 \mathrm{e}-011.00000 \mathrm{e}-091.00000 \mathrm{e}-01$ Element: 10331 \# of layers: 5

Kx Ky Kz Ss Por

4.19431e+00 4.19431e+00 4.19431e-01 1.00000e-09 2.12000e-01 4.19431e+00 4.19431e+00 4.19431e-01 1.00000e-09 2.12000e-01 4.19431e+00 4.19431e+00 4.19431e-01 1.00000e-09 2.12000e-01 $1.00000 \mathrm{e}-05$ 1.00000e-05 1.00000e-06 1.00000e-09 1.00000e-01 $1.00000 \mathrm{e}+001.00000 \mathrm{e}+001.00000 \mathrm{e}-011.00000 \mathrm{e}-091.00000 \mathrm{e}-01$ Element: 10332 \# of layers: 5

$\mathrm{Kx} \mathrm{Ky} \mathrm{Kz}$ Ss Por 4.85020e+00 4.85020e+00 4.85020e-01 1.00000e-09 2.12000e-01 $4.85020 \mathrm{e}+004.85020 \mathrm{e}+004.85020 \mathrm{e}-01$ 1.00000e-09 2.12000e-01 $4.85020 \mathrm{e}+004.85020 \mathrm{e}+004.85020 \mathrm{e}-01$ 1.00000e-09 2.12000e-01 $1.00000 \mathrm{e}-051.00000 \mathrm{e}-05$ 1.00000e-06 1.00000e-09 1.00000e-01 $1.00000 \mathrm{e}+001.00000 \mathrm{e}+001.00000 \mathrm{e}-011.00000 \mathrm{e}-091.00000 \mathrm{e}-01$ Element: 10333 \# of layers: 5

$\mathrm{Kx} \mathrm{Ky} \mathrm{Kz}$ Ss Por

$4.85020 \mathrm{e}+004.85020 \mathrm{e}+004.85020 \mathrm{e}-01$ 1.00000e-09 2.12000e-01 $4.85020 \mathrm{e}+004.85020 \mathrm{e}+004.85020 \mathrm{e}-01$ 1.00000e-09 2.12000e-01 $4.85020 \mathrm{e}+004.85020 \mathrm{e}+004.85020 \mathrm{e}-01$ 1.00000e-09 2.12000e-01 
$1.00000 \mathrm{e}-05$ 1.00000e-05 1.00000e-06 1.00000e-09 1.00000e-01 $1.00000 \mathrm{e}+001.00000 \mathrm{e}+001.00000 \mathrm{e}-01$ 1.00000e-09 1.00000e-01 Element: 10334 \# of layers: 6

Kx Ky Kz Ss Por

4.19431e+00 4.19431e+00 4.19431e-01 1.00000e-09 2.12000e-01 4.19431e+00 4.19431e+00 4.19431e-01 1.00000e-09 2.12000e-01 4.19431e+00 4.19431e+00 4.19431e-01 1.00000e-09 2.12000e-01 $4.19431 \mathrm{e}+004.19431 \mathrm{e}+00$ 4.19431e-01 1.00000e-09 2.12000e-01 $1.00000 \mathrm{e}-05$ 1.00000e-05 1.00000e-06 1.00000e-09 1.00000e-01 $1.00000 \mathrm{e}+001.00000 \mathrm{e}+00$ 1.00000e-01 1.00000e-09 1.00000e-01 Element: 10335 \# of layers: 6

Kx Ky Kz Ss Por

4.19431e+00 4.19431e+00 4.19431e-01 1.00000e-09 2.12000e-01 4.19431e+00 4.19431e+00 4.19431e-01 1.00000e-09 2.12000e-01 4.19431e+00 4.19431e+00 4.19431e-01 1.00000e-09 2.12000e-01 4.19431e+00 4.19431e+00 4.19431e-01 1.00000e-09 2.12000e-01 $1.00000 \mathrm{e}-05$ 1.00000e-05 1.00000e-06 1.00000e-09 1.00000e-01 $1.00000 \mathrm{e}+001.00000 \mathrm{e}+001.00000 \mathrm{e}-011.00000 \mathrm{e}-091.00000 \mathrm{e}-01$ Element: 10336 \# of layers: 5

$\mathrm{Kx} \mathrm{Ky} \mathrm{Kz}$ Ss Por

4.43057e+00 4.43057e+00 4.43057e-01 1.00000e-09 2.12000e-01 4.43057e+00 4.43057e+00 4.43057e-01 1.00000e-09 2.12000e-01 4.43057e+00 4.43057e+00 4.43057e-01 1.00000e-09 2.12000e-01 $1.00000 \mathrm{e}-05$ 1.00000e-05 1.00000e-06 1.00000e-09 1.00000e-01 $1.00000 \mathrm{e}+001.00000 \mathrm{e}+001.00000 \mathrm{e}-01$ 1.00000e-09 1.00000e-01 Element: 10337 \# of layers: 5

$\mathrm{Kx} \mathrm{Ky} \mathrm{Kz}$ Ss Por

4.43057e+00 4.43057e+00 4.43057e-01 1.00000e-09 2.12000e-01 $4.43057 \mathrm{e}+00$ 4.43057e+00 4.43057e-01 1.00000e-09 2.12000e-01 4.43057e+00 4.43057e+00 4.43057e-01 1.00000e-09 2.12000e-01 $1.00000 \mathrm{e}-05$ 1.00000e-05 1.00000e-06 1.00000e-09 1.00000e-01 $1.00000 \mathrm{e}+001.00000 \mathrm{e}+001.00000 \mathrm{e}-011.00000 \mathrm{e}-091.00000 \mathrm{e}-01$ Element: 10338 \# of layers: 5

$\mathrm{Kx} \mathrm{Ky} \mathrm{Kz}$ Ss Por

4.43057e+00 4.43057e+00 4.43057e-01 1.00000e-09 2.12000e-01 4.43057e+00 4.43057e+00 4.43057e-01 1.00000e-09 2.12000e-01 4.43057e+00 4.43057e+00 4.43057e-01 1.00000e-09 2.12000e-01 $1.00000 \mathrm{e}-05$ 1.00000e-05 1.00000e-06 1.00000e-09 1.00000e-01 $1.00000 \mathrm{e}+001.00000 \mathrm{e}+001.00000 \mathrm{e}-01$ 1.00000e-09 1.00000e-01 Element: 10339 \# of layers: 5

$\mathrm{Kx} \mathrm{Ky} \mathrm{Kz}$ Ss Por

5.19941e+00 5.19941e+00 5.19941e-01 1.00000e-09 2.12000e-01 5.19941e+00 5.19941e+00 5.19941e-01 1.00000e-09 2.12000e-01 5.19941e+00 5.19941e+00 5.19941e-01 1.00000e-09 2.12000e-01 $1.00000 \mathrm{e}-05$ 1.00000e-05 1.00000e-06 1.00000e-09 1.00000e-01 $1.00000 \mathrm{e}+001.00000 \mathrm{e}+001.00000 \mathrm{e}-011.00000 \mathrm{e}-091.00000 \mathrm{e}-01$ 
Element: 10340 \# of layers: 5

Kx Ky Kz Ss Por

5.19941e+00 5.19941e+00 5.19941e-01 1.00000e-09 2.12000e-01

$5.19941 \mathrm{e}+00$ 5.19941e+00 5.19941e-01 1.00000e-09 2.12000e-01

$5.19941 \mathrm{e}+00$ 5.19941e+00 5.19941e-01 1.00000e-09 2.12000e-01

$1.00000 \mathrm{e}-05$ 1.00000e-05 1.00000e-06 1.00000e-09 1.00000e-01

$1.00000 \mathrm{e}+001.00000 \mathrm{e}+001.00000 \mathrm{e}-011.00000 \mathrm{e}-091.00000 \mathrm{e}-01$

Element: 10341 \# of layers: 5

Kx Ky Kz Ss Por

$4.85020 \mathrm{e}+004.85020 \mathrm{e}+004.85020 \mathrm{e}-01$ 1.00000e-09 2.12000e-01

$4.85020 \mathrm{e}+004.85020 \mathrm{e}+004.85020 \mathrm{e}-011.00000 \mathrm{e}-092.12000 \mathrm{e}-01$

$4.85020 \mathrm{e}+00 \quad 4.85020 \mathrm{e}+00 \quad 4.85020 \mathrm{e}-011.00000 \mathrm{e}-092.12000 \mathrm{e}-01$

$1.00000 \mathrm{e}-05$ 1.00000e-05 1.00000e-06 1.00000e-09 1.00000e-01

$1.00000 \mathrm{e}+001.00000 \mathrm{e}+001.00000 \mathrm{e}-011.00000 \mathrm{e}-091.00000 \mathrm{e}-01$

Element: 10342 \# of layers: 5

Kx Ky Kz Ss Por

$4.19431 \mathrm{e}+004.19431 \mathrm{e}+004.19431 \mathrm{e}-01$ 1.00000e-09 2.12000e-01

$4.19431 \mathrm{e}+004.19431 \mathrm{e}+004.19431 \mathrm{e}-011.00000 \mathrm{e}-092.12000 \mathrm{e}-01$

$4.19431 \mathrm{e}+004.19431 \mathrm{e}+004.19431 \mathrm{e}-011.00000 \mathrm{e}-092.12000 \mathrm{e}-01$

$1.00000 \mathrm{e}-05$ 1.00000e-05 1.00000e-06 1.00000e-09 1.00000e-01

$1.00000 \mathrm{e}+001.00000 \mathrm{e}+001.00000 \mathrm{e}-011.00000 \mathrm{e}-091.00000 \mathrm{e}-01$

Element: 10343 \# of layers: 5

Kx Ky Kz Ss Por

$4.43057 \mathrm{e}+00$ 4.43057e+00 4.43057e-01 1.00000e-09 2.12000e-01

$4.43057 \mathrm{e}+004.43057 \mathrm{e}+004.43057 \mathrm{e}-011.00000 \mathrm{e}-09$ 2.12000e-01

$4.43057 \mathrm{e}+00 \quad 4.43057 \mathrm{e}+00$ 4.43057e-01 1.00000e-09 2.12000e-01

$1.00000 \mathrm{e}-05$ 1.00000e-05 1.00000e-06 1.00000e-09 1.00000e-01

$1.00000 \mathrm{e}+001.00000 \mathrm{e}+001.00000 \mathrm{e}-011.00000 \mathrm{e}-091.00000 \mathrm{e}-01$

Element: 10344 \# of layers: 6

Kx Ky Kz Ss Por

$4.58402 \mathrm{e}+004.58402 \mathrm{e}+004.58402 \mathrm{e}-01$ 1.00000e-09 2.12000e-01

$4.58402 \mathrm{e}+004.58402 \mathrm{e}+004.58402 \mathrm{e}-011.00000 \mathrm{e}-09$ 2.12000e-01

$4.58402 \mathrm{e}+004.58402 \mathrm{e}+004.58402 \mathrm{e}-011.00000 \mathrm{e}-092.12000 \mathrm{e}-01$

$4.58402 \mathrm{e}+004.58402 \mathrm{e}+00$ 4.58402e-01 1.00000e-09 2.12000e-01

$1.00000 \mathrm{e}-05$ 1.00000e-05 1.00000e-06 1.00000e-09 1.00000e-01

$1.00000 \mathrm{e}+001.00000 \mathrm{e}+001.00000 \mathrm{e}-011.00000 \mathrm{e}-091.00000 \mathrm{e}-01$

Element: 10345 \# of layers: 6

Kx Ky Kz Ss Por

4.58402e+00 4.58402e+00 4.58402e-01 1.00000e-09 2.12000e-01

$4.58402 \mathrm{e}+004.58402 \mathrm{e}+004.58402 \mathrm{e}-011.00000 \mathrm{e}-092.12000 \mathrm{e}-01$

$4.58402 \mathrm{e}+004.58402 \mathrm{e}+004.58402 \mathrm{e}-011.00000 \mathrm{e}-092.12000 \mathrm{e}-01$

$4.58402 \mathrm{e}+004.58402 \mathrm{e}+004.58402 \mathrm{e}-011.00000 \mathrm{e}-092.12000 \mathrm{e}-01$

$1.00000 \mathrm{e}-05$ 1.00000e-05 1.00000e-06 1.00000e-09 1.00000e-01

$1.00000 \mathrm{e}+001.00000 \mathrm{e}+001.00000 \mathrm{e}-011.00000 \mathrm{e}-091.00000 \mathrm{e}-01$

Element: 10346 \# of layers: 6

Kx Ky Kz Ss Por 
4.58402e+00 4.58402e+00 4.58402e-01 1.00000e-09 2.12000e-01 4.58402e+00 4.58402e+00 4.58402e-01 1.00000e-09 2.12000e-01 4.58402e+00 4.58402e+00 4.58402e-01 1.00000e-09 2.12000e-01 $4.58402 \mathrm{e}+00$ 4.58402e+00 4.58402e-01 1.00000e-09 2.12000e-01 $1.00000 \mathrm{e}-05$ 1.00000e-05 1.00000e-06 1.00000e-09 1.00000e-01 $1.00000 \mathrm{e}+001.00000 \mathrm{e}+001.00000 \mathrm{e}-011.00000 \mathrm{e}-091.00000 \mathrm{e}-01$ Element: 10347 \# of layers: 6

$\mathrm{Kx} \mathrm{Ky} \mathrm{Kz}$ Ss Por

4.58402e+00 4.58402e+00 4.58402e-01 1.00000e-09 2.12000e-01 $4.58402 \mathrm{e}+004.58402 \mathrm{e}+00$ 4.58402e-01 1.00000e-09 2.12000e-01 $4.58402 \mathrm{e}+004.58402 \mathrm{e}+00$ 4.58402e-01 1.00000e-09 2.12000e-01 $4.58402 \mathrm{e}+004.58402 \mathrm{e}+00$ 4.58402e-01 1.00000e-09 2.12000e-01 $1.00000 \mathrm{e}-05$ 1.00000e-05 1.00000e-06 1.00000e-09 1.00000e-01 $1.00000 \mathrm{e}+001.00000 \mathrm{e}+001.00000 \mathrm{e}-011.00000 \mathrm{e}-091.00000 \mathrm{e}-01$ Element: 10348 \# of layers: 5

Kx Ky Kz Ss Por

4.58402e+00 4.58402e+00 4.58402e-01 1.00000e-09 2.12000e-01

4.58402e+00 4.58402e+00 4.58402e-01 1.00000e-09 2.12000e-01

4.58402e+00 4.58402e+00 4.58402e-01 1.00000e-09 2.12000e-01 $1.00000 \mathrm{e}-05$ 1.00000e-05 1.00000e-06 1.00000e-09 1.00000e-01

$1.00000 \mathrm{e}+001.00000 \mathrm{e}+001.00000 \mathrm{e}-011.00000 \mathrm{e}-091.00000 \mathrm{e}-01$ Element: 10349 \# of layers: 5

$\mathrm{Kx} \mathrm{Ky} \mathrm{Kz}$ Ss Por

4.58402e+00 4.58402e+00 4.58402e-01 1.00000e-09 2.12000e-01 4.58402e+00 4.58402e+00 4.58402e-01 1.00000e-09 2.12000e-01 4.58402e+00 4.58402e+00 4.58402e-01 1.00000e-09 2.12000e-01 $1.00000 \mathrm{e}-05$ 1.00000e-05 1.00000e-06 1.00000e-09 1.00000e-01 $1.00000 \mathrm{e}+001.00000 \mathrm{e}+001.00000 \mathrm{e}-01$ 1.00000e-09 1.00000e-01 Element: 10350 \# of layers: 5

$\mathrm{Kx} \mathrm{Ky} \mathrm{Kz}$ Ss Por

4.58402e+00 4.58402e+00 4.58402e-01 1.00000e-09 2.12000e-01 $4.58402 \mathrm{e}+004.58402 \mathrm{e}+00$ 4.58402e-01 1.00000e-09 2.12000e-01 $4.58402 \mathrm{e}+004.58402 \mathrm{e}+00$ 4.58402e-01 1.00000e-09 2.12000e-01 $1.00000 \mathrm{e}-05$ 1.00000e-05 1.00000e-06 1.00000e-09 1.00000e-01 $1.00000 \mathrm{e}+001.00000 \mathrm{e}+001.00000 \mathrm{e}-011.00000 \mathrm{e}-091.00000 \mathrm{e}-01$ Element: 10351 \# of layers: 5

Kx Ky Kz Ss Por

4.58402e+00 4.58402e+00 4.58402e-01 1.00000e-09 2.12000e-01 $4.58402 \mathrm{e}+004.58402 \mathrm{e}+004.58402 \mathrm{e}-01$ 1.00000e-09 2.12000e-01 4.58402e+00 4.58402e+00 4.58402e-01 1.00000e-09 2.12000e-01 $1.00000 \mathrm{e}-05$ 1.00000e-05 1.00000e-06 1.00000e-09 1.00000e-01 $1.00000 \mathrm{e}+001.00000 \mathrm{e}+001.00000 \mathrm{e}-011.00000 \mathrm{e}-091.00000 \mathrm{e}-01$ Element: 10352 \# of layers: 5

$\mathrm{Kx} \mathrm{Ky} \mathrm{Kz}$ Ss Por

4.58402e+00 4.58402e+00 4.58402e-01 1.00000e-09 2.12000e-01 $4.58402 \mathrm{e}+004.58402 \mathrm{e}+00$ 4.58402e-01 1.00000e-09 2.12000e-01 
4.58402e+00 4.58402e+00 4.58402e-01 1.00000e-09 2.12000e-01 $1.00000 \mathrm{e}-05$ 1.00000e-05 1.00000e-06 1.00000e-09 1.00000e-01

$1.00000 \mathrm{e}+001.00000 \mathrm{e}+001.00000 \mathrm{e}-011.00000 \mathrm{e}-09$ 1.00000e-01

Element: 10353 \# of layers: 6

$\mathrm{Kx} \mathrm{Ky} \mathrm{Kz}$ Ss Por

4.58402e+00 4.58402e+00 4.58402e-01 1.00000e-09 2.12000e-01

$4.58402 \mathrm{e}+004.58402 \mathrm{e}+00$ 4.58402e-01 1.00000e-09 2.12000e-01

$4.58402 \mathrm{e}+00$ 4.58402e+00 4.58402e-01 1.00000e-09 2.12000e-01

4.58402e+00 4.58402e+00 4.58402e-01 1.00000e-09 2.12000e-01

$1.00000 \mathrm{e}-05$ 1.00000e-05 1.00000e-06 1.00000e-09 1.00000e-01

$1.00000 \mathrm{e}+001.00000 \mathrm{e}+001.00000 \mathrm{e}-011.00000 \mathrm{e}-091.00000 \mathrm{e}-01$

Element: 10354 \# of layers: 6

$\mathrm{Kx} \mathrm{Ky} \mathrm{Kz}$ Ss Por

$1.95885 \mathrm{e}+01$ 1.95885e+01 1.95885e+00 1.00000e-09 2.12000e-01

$1.95885 \mathrm{e}+011.95885 \mathrm{e}+011.95885 \mathrm{e}+001.00000 \mathrm{e}-092.12000 \mathrm{e}-01$

$1.95885 \mathrm{e}+011.95885 \mathrm{e}+011.95885 \mathrm{e}+001.00000 \mathrm{e}-092.12000 \mathrm{e}-01$

$1.95885 \mathrm{e}+011.95885 \mathrm{e}+011.95885 \mathrm{e}+001.00000 \mathrm{e}-092.12000 \mathrm{e}-01$

$1.00000 \mathrm{e}-05$ 1.00000e-05 1.00000e-06 1.00000e-09 1.00000e-01

$1.00000 \mathrm{e}+001.00000 \mathrm{e}+001.00000 \mathrm{e}-011.00000 \mathrm{e}-091.00000 \mathrm{e}-01$

Element: 10355 \# of layers: 6

Kx Ky Kz Ss Por

$1.95885 \mathrm{e}+01$ 1.95885e+01 1.95885e+00 1.00000e-09 2.12000e-01

$1.95885 \mathrm{e}+01$ 1.95885e+01 1.95885e+00 1.00000e-09 2.12000e-01

$1.95885 \mathrm{e}+011.95885 \mathrm{e}+011.95885 \mathrm{e}+001.00000 \mathrm{e}-092.12000 \mathrm{e}-01$

$1.95885 \mathrm{e}+011.95885 \mathrm{e}+011.95885 \mathrm{e}+001.00000 \mathrm{e}-092.12000 \mathrm{e}-01$

$1.00000 \mathrm{e}-05$ 1.00000e-05 1.00000e-06 1.00000e-09 1.00000e-01

$1.00000 \mathrm{e}+001.00000 \mathrm{e}+001.00000 \mathrm{e}-011.00000 \mathrm{e}-091.00000 \mathrm{e}-01$

Element: 10356 \# of layers: 6

$\mathrm{Kx} \mathrm{Ky} \mathrm{Kz}$ Ss Por

$1.95885 \mathrm{e}+011.95885 \mathrm{e}+011.95885 \mathrm{e}+001.00000 \mathrm{e}-092.12000 \mathrm{e}-01$

$1.95885 \mathrm{e}+01$ 1.95885e+01 1.95885e+00 1.00000e-09 2.12000e-01

$1.95885 \mathrm{e}+01$ 1.95885e+01 1.95885e+00 1.00000e-09 2.12000e-01

$1.95885 \mathrm{e}+011.95885 \mathrm{e}+011.95885 \mathrm{e}+001.00000 \mathrm{e}-092.12000 \mathrm{e}-01$

$1.00000 \mathrm{e}-05$ 1.00000e-05 1.00000e-06 1.00000e-09 1.00000e-01

$1.00000 \mathrm{e}+001.00000 \mathrm{e}+001.00000 \mathrm{e}-011.00000 \mathrm{e}-091.00000 \mathrm{e}-01$

Element: 10357 \# of layers: 5

Kx Ky Kz Ss Por

$1.95885 \mathrm{e}+01$ 1.95885e+01 1.95885e+00 1.00000e-09 2.12000e-01

$1.95885 \mathrm{e}+01$ 1.95885e+01 1.95885e+00 1.00000e-09 2.12000e-01

$1.95885 \mathrm{e}+011.95885 \mathrm{e}+011.95885 \mathrm{e}+001.00000 \mathrm{e}-092.12000 \mathrm{e}-01$

$1.00000 \mathrm{e}-05$ 1.00000e-05 1.00000e-06 1.00000e-09 1.00000e-01

$1.00000 \mathrm{e}+001.00000 \mathrm{e}+001.00000 \mathrm{e}-011.00000 \mathrm{e}-091.00000 \mathrm{e}-01$

Element: 10358 \# of layers: 5

$\mathrm{Kx} \mathrm{Ky} \mathrm{Kz}$ Ss Por

$1.95885 \mathrm{e}+01$ 1.95885e+01 1.95885e+00 1.00000e-09 2.12000e-01

$1.95885 \mathrm{e}+011.95885 \mathrm{e}+011.95885 \mathrm{e}+001.00000 \mathrm{e}-092.12000 \mathrm{e}-01$ 
$1.95885 \mathrm{e}+01$ 1.95885e+01 1.95885e+00 1.00000e-09 2.12000e-01 $1.00000 \mathrm{e}-05$ 1.00000e-05 1.00000e-06 1.00000e-09 1.00000e-01

$1.00000 \mathrm{e}+001.00000 \mathrm{e}+001.00000 \mathrm{e}-011.00000 \mathrm{e}-09$ 1.00000e-01

Element: 10359 \# of layers: 5

$\mathrm{Kx} \mathrm{Ky} \mathrm{Kz}$ Ss Por

4.58402e+00 4.58402e+00 4.58402e-01 1.00000e-09 2.12000e-01

$4.58402 \mathrm{e}+004.58402 \mathrm{e}+00$ 4.58402e-01 1.00000e-09 2.12000e-01

$4.58402 \mathrm{e}+004.58402 \mathrm{e}+004.58402 \mathrm{e}-01$ 1.00000e-09 2.12000e-01

$1.00000 \mathrm{e}-05$ 1.00000e-05 1.00000e-06 1.00000e-09 1.00000e-01

$1.00000 \mathrm{e}+001.00000 \mathrm{e}+001.00000 \mathrm{e}-011.00000 \mathrm{e}-091.00000 \mathrm{e}-01$

Element: 10360 \# of layers: 6

$\mathrm{Kx} \mathrm{Ky} \mathrm{Kz}$ Ss Por

4.58402e+00 4.58402e+00 4.58402e-01 1.00000e-09 2.12000e-01

$4.58402 \mathrm{e}+004.58402 \mathrm{e}+00$ 4.58402e-01 1.00000e-09 2.12000e-01

4.58402e+00 4.58402e+00 4.58402e-01 1.00000e-09 2.12000e-01

$4.58402 \mathrm{e}+004.58402 \mathrm{e}+004.58402 \mathrm{e}-01$ 1.00000e-09 2.12000e-01

$1.00000 \mathrm{e}-051.00000 \mathrm{e}-05$ 1.00000e-06 1.00000e-09 1.00000e-01

$1.00000 \mathrm{e}+001.00000 \mathrm{e}+001.00000 \mathrm{e}-01$ 1.00000e-09 1.00000e-01

Element: 10361 \# of layers: 6

$\mathrm{Kx} \mathrm{Ky} \mathrm{Kz}$ Ss Por

$1.95885 \mathrm{e}+011.95885 \mathrm{e}+011.95885 \mathrm{e}+001.00000 \mathrm{e}-092.12000 \mathrm{e}-01$

$1.95885 \mathrm{e}+01$ 1.95885e+01 1.95885e+00 1.00000e-09 2.12000e-01

$1.95885 \mathrm{e}+01$ 1.95885e+01 1.95885e+00 1.00000e-09 2.12000e-01

$1.95885 \mathrm{e}+011.95885 \mathrm{e}+011.95885 \mathrm{e}+001.00000 \mathrm{e}-092.12000 \mathrm{e}-01$

$1.00000 \mathrm{e}-05$ 1.00000e-05 1.00000e-06 1.00000e-09 1.00000e-01

$1.00000 \mathrm{e}+001.00000 \mathrm{e}+001.00000 \mathrm{e}-01$ 1.00000e-09 1.00000e-01

Element: 10362 \# of layers: 6

$\mathrm{Kx} \mathrm{Ky} \mathrm{Kz}$ Ss Por

$1.95885 \mathrm{e}+011.95885 \mathrm{e}+01$ 1.95885e+00 1.00000e-09 2.12000e-01

$1.95885 \mathrm{e}+01$ 1.95885e+01 1.95885e+00 1.00000e-09 2.12000e-01

$1.95885 \mathrm{e}+01$ 1.95885e+01 1.95885e+00 1.00000e-09 2.12000e-01

$1.95885 \mathrm{e}+011.95885 \mathrm{e}+01$ 1.95885e+00 1.00000e-09 2.12000e-01

$1.00000 \mathrm{e}-05$ 1.00000e-05 1.00000e-06 1.00000e-09 1.00000e-01

$1.00000 \mathrm{e}+001.00000 \mathrm{e}+001.00000 \mathrm{e}-011.00000 \mathrm{e}-091.00000 \mathrm{e}-01$

Element: 10363 \# of layers: 6

$\mathrm{Kx} \mathrm{Ky} \mathrm{Kz}$ Ss Por

$1.95885 \mathrm{e}+01$ 1.95885e+01 1.95885e+00 1.00000e-09 2.12000e-01

$1.95885 \mathrm{e}+011.95885 \mathrm{e}+01$ 1.95885e+00 1.00000e-09 2.12000e-01

$1.95885 \mathrm{e}+011.95885 \mathrm{e}+011.95885 \mathrm{e}+001.00000 \mathrm{e}-092.12000 \mathrm{e}-01$

$1.95885 \mathrm{e}+011.95885 \mathrm{e}+011.95885 \mathrm{e}+001.00000 \mathrm{e}-092.12000 \mathrm{e}-01$

$1.00000 \mathrm{e}-05$ 1.00000e-05 1.00000e-06 1.00000e-09 1.00000e-01

$1.00000 \mathrm{e}+001.00000 \mathrm{e}+001.00000 \mathrm{e}-011.00000 \mathrm{e}-091.00000 \mathrm{e}-01$

Element: 10364 \# of layers: 6

$\mathrm{Kx} \mathrm{Ky} \mathrm{Kz}$ Ss Por

$1.95885 \mathrm{e}+01$ 1.95885e+01 1.95885e+00 1.00000e-09 2.12000e-01

$1.95885 \mathrm{e}+011.95885 \mathrm{e}+011.95885 \mathrm{e}+001.00000 \mathrm{e}-092.12000 \mathrm{e}-01$ 
$1.95885 \mathrm{e}+011.95885 \mathrm{e}+011.95885 \mathrm{e}+001.00000 \mathrm{e}-092.12000 \mathrm{e}-01$ $1.95885 \mathrm{e}+011.95885 \mathrm{e}+011.95885 \mathrm{e}+001.00000 \mathrm{e}-092.12000 \mathrm{e}-01$ $1.00000 \mathrm{e}-05$ 1.00000e-05 1.00000e-06 1.00000e-09 1.00000e-01 $1.00000 \mathrm{e}+001.00000 \mathrm{e}+001.00000 \mathrm{e}-011.00000 \mathrm{e}-091.00000 \mathrm{e}-01$ Element: 10365 \# of layers: 6

Kx Ky Kz Ss Por

$1.95885 \mathrm{e}+011.95885 \mathrm{e}+011.95885 \mathrm{e}+00$ 1.00000e-09 2.12000e-01 $1.95885 \mathrm{e}+011.95885 \mathrm{e}+011.95885 \mathrm{e}+001.00000 \mathrm{e}-092.12000 \mathrm{e}-01$ $1.95885 \mathrm{e}+011.95885 \mathrm{e}+011.95885 \mathrm{e}+001.00000 \mathrm{e}-092.12000 \mathrm{e}-01$ $1.95885 \mathrm{e}+011.95885 \mathrm{e}+011.95885 \mathrm{e}+001.00000 \mathrm{e}-092.12000 \mathrm{e}-01$ $1.00000 \mathrm{e}-05$ 1.00000e-05 1.00000e-06 1.00000e-09 1.00000e-01 $1.00000 \mathrm{e}+001.00000 \mathrm{e}+001.00000 \mathrm{e}-011.00000 \mathrm{e}-091.00000 \mathrm{e}-01$ Element: 10366 \# of layers: 6

Kx Ky Kz Ss Por

$1.95885 \mathrm{e}+011.95885 \mathrm{e}+011.95885 \mathrm{e}+00$ 1.00000e-09 2.12000e-01 $1.95885 \mathrm{e}+011.95885 \mathrm{e}+011.95885 \mathrm{e}+001.00000 \mathrm{e}-092.12000 \mathrm{e}-01$ $1.95885 \mathrm{e}+011.95885 \mathrm{e}+011.95885 \mathrm{e}+001.00000 \mathrm{e}-092.12000 \mathrm{e}-01$ $1.95885 \mathrm{e}+011.95885 \mathrm{e}+011.95885 \mathrm{e}+00$ 1.00000e-09 2.12000e-01 $1.00000 \mathrm{e}-05$ 1.00000e-05 1.00000e-06 1.00000e-09 1.00000e-01 $1.00000 \mathrm{e}+001.00000 \mathrm{e}+001.00000 \mathrm{e}-011.00000 \mathrm{e}-091.00000 \mathrm{e}-01$ Element: 10367 \# of layers: 6

Kx Ky Kz Ss Por

$1.95885 \mathrm{e}+011.95885 \mathrm{e}+011.95885 \mathrm{e}+00$ 1.00000e-09 2.12000e-01 $1.95885 \mathrm{e}+011.95885 \mathrm{e}+011.95885 \mathrm{e}+001.00000 \mathrm{e}-092.12000 \mathrm{e}-01$ $1.95885 \mathrm{e}+011.95885 \mathrm{e}+011.95885 \mathrm{e}+001.00000 \mathrm{e}-092.12000 \mathrm{e}-01$ $1.95885 \mathrm{e}+011.95885 \mathrm{e}+011.95885 \mathrm{e}+001.00000 \mathrm{e}-092.12000 \mathrm{e}-01$ $1.00000 \mathrm{e}-05$ 1.00000e-05 1.00000e-06 1.00000e-09 1.00000e-01 $1.00000 \mathrm{e}+001.00000 \mathrm{e}+001.00000 \mathrm{e}-011.00000 \mathrm{e}-091.00000 \mathrm{e}-01$ Element: 10368 \# of layers: 5

Kx Ky Kz Ss Por

$1.95885 \mathrm{e}+011.95885 \mathrm{e}+011.95885 \mathrm{e}+00$ 1.00000e-09 2.12000e-01 $1.95885 \mathrm{e}+011.95885 \mathrm{e}+011.95885 \mathrm{e}+001.00000 \mathrm{e}-092.12000 \mathrm{e}-01$ $1.95885 \mathrm{e}+011.95885 \mathrm{e}+011.95885 \mathrm{e}+001.00000 \mathrm{e}-092.12000 \mathrm{e}-01$ $1.00000 \mathrm{e}-05$ 1.00000e-05 1.00000e-06 1.00000e-09 1.00000e-01 $1.00000 \mathrm{e}+001.00000 \mathrm{e}+001.00000 \mathrm{e}-011.00000 \mathrm{e}-091.00000 \mathrm{e}-01$ Element: 10369 \# of layers: 6

Kx Ky Kz Ss Por

$1.95885 \mathrm{e}+011.95885 \mathrm{e}+011.95885 \mathrm{e}+00$ 1.00000e-09 2.12000e-01 $1.95885 \mathrm{e}+011.95885 \mathrm{e}+011.95885 \mathrm{e}+001.00000 \mathrm{e}-092.12000 \mathrm{e}-01$ $1.95885 \mathrm{e}+011.95885 \mathrm{e}+011.95885 \mathrm{e}+001.00000 \mathrm{e}-092.12000 \mathrm{e}-01$ $1.95885 \mathrm{e}+011.95885 \mathrm{e}+011.95885 \mathrm{e}+001.00000 \mathrm{e}-092.12000 \mathrm{e}-01$ $1.00000 \mathrm{e}-05$ 1.00000e-05 1.00000e-06 1.00000e-09 1.00000e-01 $1.00000 \mathrm{e}+001.00000 \mathrm{e}+001.00000 \mathrm{e}-011.00000 \mathrm{e}-091.00000 \mathrm{e}-01$ Element: 10370 \# of layers: 6

Kx Ky Kz Ss Por

$1.95885 \mathrm{e}+011.95885 \mathrm{e}+011.95885 \mathrm{e}+00$ 1.00000e-09 2.12000e-01 
$1.95885 \mathrm{e}+01$ 1.95885e+01 1.95885e+00 1.00000e-09 2.12000e-01 $1.95885 \mathrm{e}+01$ 1.95885e+01 1.95885e+00 1.00000e-09 2.12000e-01 $1.95885 \mathrm{e}+011.95885 \mathrm{e}+01$ 1.95885e+00 1.00000e-09 2.12000e-01 $1.00000 \mathrm{e}-05$ 1.00000e-05 1.00000e-06 1.00000e-09 1.00000e-01 $1.00000 \mathrm{e}+001.00000 \mathrm{e}+001.00000 \mathrm{e}-01$ 1.00000e-09 1.00000e-01 Element: 10371 \# of layers: 5

$\mathrm{Kx} \mathrm{Ky} \mathrm{Kz}$ Ss Por

$1.95885 \mathrm{e}+011.95885 \mathrm{e}+011.95885 \mathrm{e}+001.00000 \mathrm{e}-092.12000 \mathrm{e}-01$ $1.95885 \mathrm{e}+011.95885 \mathrm{e}+01$ 1.95885e+00 1.00000e-09 2.12000e-01 $1.95885 \mathrm{e}+011.95885 \mathrm{e}+01 \quad 1.95885 \mathrm{e}+001.00000 \mathrm{e}-092.12000 \mathrm{e}-01$ $1.00000 \mathrm{e}-05$ 1.00000e-05 1.00000e-06 1.00000e-09 1.00000e-01

$1.00000 \mathrm{e}+001.00000 \mathrm{e}+001.00000 \mathrm{e}-011.00000 \mathrm{e}-091.00000 \mathrm{e}-01$ Element: 10372 \# of layers: 5

$\mathrm{Kx} \mathrm{Ky} \mathrm{Kz}$ Ss Por

$1.95885 \mathrm{e}+011.95885 \mathrm{e}+01$ 1.95885e+00 1.00000e-09 2.12000e-01 $1.95885 \mathrm{e}+011.95885 \mathrm{e}+011.95885 \mathrm{e}+001.00000 \mathrm{e}-092.12000 \mathrm{e}-01$ $1.95885 \mathrm{e}+011.95885 \mathrm{e}+011.95885 \mathrm{e}+001.00000 \mathrm{e}-092.12000 \mathrm{e}-01$ $1.00000 \mathrm{e}-05$ 1.00000e-05 1.00000e-06 1.00000e-09 1.00000e-01 $1.00000 \mathrm{e}+001.00000 \mathrm{e}+001.00000 \mathrm{e}-01$ 1.00000e-09 1.00000e-01 Element: 10373 \# of layers: 5

$\mathrm{Kx} \mathrm{Ky} \mathrm{Kz}$ Ss Por

4.11286e+01 4.11286e+01 4.11286e+00 1.00000e-09 2.12000e-01 $4.11286 \mathrm{e}+014.11286 \mathrm{e}+014.11286 \mathrm{e}+00$ 1.00000e-09 2.12000e-01 $4.11286 \mathrm{e}+014.11286 \mathrm{e}+014.11286 \mathrm{e}+001.00000 \mathrm{e}-092.12000 \mathrm{e}-01$ $1.00000 \mathrm{e}-05$ 1.00000e-05 1.00000e-06 1.00000e-09 1.00000e-01 $1.00000 \mathrm{e}+001.00000 \mathrm{e}+001.00000 \mathrm{e}-011.00000 \mathrm{e}-091.00000 \mathrm{e}-01$ Element: 10374 \# of layers: 5

$\mathrm{Kx} \mathrm{Ky} \mathrm{Kz}$ Ss Por

4.11286e+01 4.11286e+01 4.11286e+00 1.00000e-09 2.12000e-01 $4.11286 \mathrm{e}+014.11286 \mathrm{e}+014.11286 \mathrm{e}+001.00000 \mathrm{e}-092.12000 \mathrm{e}-01$ $4.11286 \mathrm{e}+014.11286 \mathrm{e}+014.11286 \mathrm{e}+001.00000 \mathrm{e}-092.12000 \mathrm{e}-01$ $1.00000 \mathrm{e}-051.00000 \mathrm{e}-05$ 1.00000e-06 1.00000e-09 1.00000e-01 $1.00000 \mathrm{e}+001.00000 \mathrm{e}+001.00000 \mathrm{e}-011.00000 \mathrm{e}-091.00000 \mathrm{e}-01$ Element: 10375 \# of layers: 5

$\mathrm{Kx} \mathrm{Ky} \mathrm{Kz}$ Ss Por

4.11286e+01 4.11286e+01 4.11286e+00 1.00000e-09 2.12000e-01 $4.11286 \mathrm{e}+014.11286 \mathrm{e}+014.11286 \mathrm{e}+001.00000 \mathrm{e}-092.12000 \mathrm{e}-01$ $4.11286 \mathrm{e}+014.11286 \mathrm{e}+014.11286 \mathrm{e}+001.00000 \mathrm{e}-092.12000 \mathrm{e}-01$ $1.00000 \mathrm{e}-05$ 1.00000e-05 1.00000e-06 1.00000e-09 1.00000e-01 $1.00000 \mathrm{e}+001.00000 \mathrm{e}+001.00000 \mathrm{e}-01$ 1.00000e-09 1.00000e-01 Element: 10376 \# of layers: 5

$\mathrm{Kx} \mathrm{Ky} \mathrm{Kz}$ Ss Por

$1.95885 \mathrm{e}+01$ 1.95885e+01 1.95885e+00 1.00000e-09 2.12000e-01 $1.95885 \mathrm{e}+01$ 1.95885e+01 1.95885e+00 1.00000e-09 2.12000e-01 $1.95885 \mathrm{e}+011.95885 \mathrm{e}+011.95885 \mathrm{e}+001.00000 \mathrm{e}-092.12000 \mathrm{e}-01$ 1.00000e-05 1.00000e-05 1.00000e-06 1.00000e-09 1.00000e-01 
$1.00000 \mathrm{e}+001.00000 \mathrm{e}+00$ 1.00000e-01 1.00000e-09 1.00000e-01

Element: 10377 \# of layers: 5

$\mathrm{Kx} \mathrm{Ky} \mathrm{Kz}$ Ss Por

$1.95885 e+011.95885 e+011.95885 e+001.00000 e-092.12000 e-01$

$1.95885 \mathrm{e}+011.95885 \mathrm{e}+01$ 1.95885e+00 1.00000e-09 2.12000e-01

$1.95885 \mathrm{e}+011.95885 \mathrm{e}+011.95885 \mathrm{e}+001.00000 \mathrm{e}-092.12000 \mathrm{e}-01$

$1.00000 \mathrm{e}-05$ 1.00000e-05 1.00000e-06 1.00000e-09 1.00000e-01

$1.00000 \mathrm{e}+001.00000 \mathrm{e}+001.00000 \mathrm{e}-01$ 1.00000e-09 1.00000e-01

Element: 10378 \# of layers: 5

$\mathrm{Kx} \mathrm{Ky} \mathrm{Kz}$ Ss Por

$1.95885 \mathrm{e}+01$ 1.95885e+01 1.95885e+00 1.00000e-09 2.12000e-01

$1.95885 \mathrm{e}+011.95885 \mathrm{e}+011.95885 \mathrm{e}+001.00000 \mathrm{e}-092.12000 \mathrm{e}-01$

$1.95885 \mathrm{e}+011.95885 \mathrm{e}+011.95885 \mathrm{e}+001.00000 \mathrm{e}-092.12000 \mathrm{e}-01$

$1.00000 \mathrm{e}-05$ 1.00000e-05 1.00000e-06 1.00000e-09 1.00000e-01

$1.00000 \mathrm{e}+001.00000 \mathrm{e}+001.00000 \mathrm{e}-01$ 1.00000e-09 1.00000e-01

Element: 10379 \# of layers: 5

$\mathrm{Kx} \mathrm{Ky} \mathrm{Kz}$ Ss Por

$1.95885 \mathrm{e}+01$ 1.95885e+01 1.95885e+00 1.00000e-09 2.12000e-01

$1.95885 \mathrm{e}+01$ 1.95885e+01 1.95885e+00 1.00000e-09 2.12000e-01

$1.95885 \mathrm{e}+011.95885 \mathrm{e}+01 \quad 1.95885 \mathrm{e}+001.00000 \mathrm{e}-092.12000 \mathrm{e}-01$

$1.00000 \mathrm{e}-05$ 1.00000e-05 1.00000e-06 1.00000e-09 1.00000e-01

$1.00000 \mathrm{e}+001.00000 \mathrm{e}+001.00000 \mathrm{e}-011.00000 \mathrm{e}-091.00000 \mathrm{e}-01$

Element: 10380 \# of layers: 6

Kx Ky Kz Ss Por

4.11286e+01 4.11286e+01 4.11286e+00 1.00000e-09 2.12000e-01

4.11286e+01 4.11286e+01 4.11286e+00 1.00000e-09 2.12000e-01

$4.11286 \mathrm{e}+014.11286 \mathrm{e}+014.11286 \mathrm{e}+00$ 1.00000e-09 2.12000e-01

$4.11286 \mathrm{e}+014.11286 \mathrm{e}+014.11286 \mathrm{e}+00$ 1.00000e-09 2.12000e-01

$1.00000 \mathrm{e}-05$ 1.00000e-05 1.00000e-06 1.00000e-09 1.00000e-01

$1.00000 \mathrm{e}+001.00000 \mathrm{e}+001.00000 \mathrm{e}-011.00000 \mathrm{e}-091.00000 \mathrm{e}-01$

Element: 10381 \# of layers: 5

$\mathrm{Kx} \mathrm{Ky} \mathrm{Kz}$ Ss Por

4.11286e+01 4.11286e+01 4.11286e+00 1.00000e-09 2.12000e-01

4.11286e+01 4.11286e+01 4.11286e+00 1.00000e-09 2.12000e-01

$4.11286 \mathrm{e}+014.11286 \mathrm{e}+014.11286 \mathrm{e}+00$ 1.00000e-09 2.12000e-01

$1.00000 \mathrm{e}-05$ 1.00000e-05 1.00000e-06 1.00000e-09 1.00000e-01

$1.00000 \mathrm{e}+001.00000 \mathrm{e}+001.00000 \mathrm{e}-011.00000 \mathrm{e}-091.00000 \mathrm{e}-01$

Element: 10382 \# of layers: 5

$\mathrm{Kx} \mathrm{Ky} \mathrm{Kz}$ Ss Por

4.11286e+01 4.11286e+01 4.11286e+00 1.00000e-09 2.12000e-01

$4.11286 \mathrm{e}+014.11286 \mathrm{e}+014.11286 \mathrm{e}+00$ 1.00000e-09 2.12000e-01

$4.11286 \mathrm{e}+014.11286 \mathrm{e}+014.11286 \mathrm{e}+00$ 1.00000e-09 2.12000e-01

$1.00000 \mathrm{e}-05$ 1.00000e-05 1.00000e-06 1.00000e-09 1.00000e-01

$1.00000 \mathrm{e}+001.00000 \mathrm{e}+001.00000 \mathrm{e}-01$ 1.00000e-09 1.00000e-01

Element: 10383 \# of layers: 5

Kx Ky Kz Ss Por 
4.11286e+01 4.11286e+01 4.11286e+00 1.00000e-09 2.12000e-01 $4.11286 \mathrm{e}+014.11286 \mathrm{e}+014.11286 \mathrm{e}+00$ 1.00000e-09 2.12000e-01 $4.11286 \mathrm{e}+014.11286 \mathrm{e}+014.11286 \mathrm{e}+00$ 1.00000e-09 2.12000e-01 $1.00000 \mathrm{e}-05$ 1.00000e-05 1.00000e-06 1.00000e-09 1.00000e-01 $1.00000 \mathrm{e}+001.00000 \mathrm{e}+001.00000 \mathrm{e}-01$ 1.00000e-09 1.00000e-01 Element: 10384 \# of layers: 5

$\mathrm{Kx} \mathrm{Ky} \mathrm{Kz}$ Ss Por

4.11286e+01 4.11286e+01 4.11286e+00 1.00000e-09 2.12000e-01 $4.11286 \mathrm{e}+014.11286 \mathrm{e}+014.11286 \mathrm{e}+001.00000 \mathrm{e}-092.12000 \mathrm{e}-01$ $4.11286 \mathrm{e}+014.11286 \mathrm{e}+014.11286 \mathrm{e}+00$ 1.00000e-09 2.12000e-01 $1.00000 \mathrm{e}-05$ 1.00000e-05 1.00000e-06 1.00000e-09 1.00000e-01 $1.00000 \mathrm{e}+001.00000 \mathrm{e}+001.00000 \mathrm{e}-011.00000 \mathrm{e}-091.00000 \mathrm{e}-01$ Element: 10385 \# of layers: 5

$\mathrm{Kx} \mathrm{Ky} \mathrm{Kz}$ Ss Por

4.11286e+01 4.11286e+01 4.11286e+00 1.00000e-09 2.12000e-01 $4.11286 \mathrm{e}+014.11286 \mathrm{e}+014.11286 \mathrm{e}+001.00000 \mathrm{e}-092.12000 \mathrm{e}-01$ $4.11286 \mathrm{e}+014.11286 \mathrm{e}+014.11286 \mathrm{e}+001.00000 \mathrm{e}-092.12000 \mathrm{e}-01$ $1.00000 \mathrm{e}-05$ 1.00000e-05 1.00000e-06 1.00000e-09 1.00000e-01 $1.00000 \mathrm{e}+001.00000 \mathrm{e}+001.00000 \mathrm{e}-01$ 1.00000e-09 1.00000e-01 Element: 10386 \# of layers: 6

$\mathrm{Kx} \mathrm{Ky} \mathrm{Kz}$ Ss Por

4.11286e+01 4.11286e+01 4.11286e+00 1.00000e-09 2.12000e-01 $4.11286 \mathrm{e}+014.11286 \mathrm{e}+014.11286 \mathrm{e}+00$ 1.00000e-09 2.12000e-01 $4.11286 \mathrm{e}+014.11286 \mathrm{e}+014.11286 \mathrm{e}+001.00000 \mathrm{e}-092.12000 \mathrm{e}-01$ $4.11286 \mathrm{e}+014.11286 \mathrm{e}+014.11286 \mathrm{e}+001.00000 \mathrm{e}-092.12000 \mathrm{e}-01$ $1.00000 \mathrm{e}-05$ 1.00000e-05 1.00000e-06 1.00000e-09 1.00000e-01 $1.00000 \mathrm{e}+001.00000 \mathrm{e}+001.00000 \mathrm{e}-011.00000 \mathrm{e}-09$ 1.00000e-01 Element: 10387 \# of layers: 6

$\mathrm{Kx} \mathrm{Ky} \mathrm{Kz}$ Ss Por

4.11286e+01 4.11286e+01 4.11286e+00 1.00000e-09 2.12000e-01 $4.11286 \mathrm{e}+014.11286 \mathrm{e}+014.11286 \mathrm{e}+001.00000 \mathrm{e}-092.12000 \mathrm{e}-01$ $4.11286 \mathrm{e}+014.11286 \mathrm{e}+014.11286 \mathrm{e}+001.00000 \mathrm{e}-092.12000 \mathrm{e}-01$ $4.11286 \mathrm{e}+014.11286 \mathrm{e}+014.11286 \mathrm{e}+001.00000 \mathrm{e}-092.12000 \mathrm{e}-01$ $1.00000 \mathrm{e}-05$ 1.00000e-05 1.00000e-06 1.00000e-09 1.00000e-01 $1.00000 \mathrm{e}+001.00000 \mathrm{e}+001.00000 \mathrm{e}-01$ 1.00000e-09 1.00000e-01 Element: 10388 \# of layers: 5

$\mathrm{Kx} \mathrm{Ky} \mathrm{Kz}$ Ss Por

$4.11286 \mathrm{e}+014.11286 \mathrm{e}+014.11286 \mathrm{e}+00$ 1.00000e-09 2.12000e-01 $4.11286 \mathrm{e}+014.11286 \mathrm{e}+014.11286 \mathrm{e}+001.00000 \mathrm{e}-09$ 2.12000e-01 $4.11286 \mathrm{e}+014.11286 \mathrm{e}+014.11286 \mathrm{e}+001.00000 \mathrm{e}-092.12000 \mathrm{e}-01$ $1.00000 \mathrm{e}-05$ 1.00000e-05 1.00000e-06 1.00000e-09 1.00000e-01 $1.00000 \mathrm{e}+001.00000 \mathrm{e}+001.00000 \mathrm{e}-011.00000 \mathrm{e}-091.00000 \mathrm{e}-01$ Element: 10389 \# of layers: 5

$\mathrm{Kx} \mathrm{Ky} \mathrm{Kz}$ Ss Por

4.11286e+01 4.11286e+01 4.11286e+00 1.00000e-09 2.12000e-01 4.11286e+01 4.11286e+01 4.11286e+00 1.00000e-09 2.12000e-01 
4.11286e+01 4.11286e+01 4.11286e+00 1.00000e-09 2.12000e-01 $1.00000 \mathrm{e}-05$ 1.00000e-05 1.00000e-06 1.00000e-09 1.00000e-01

$1.00000 \mathrm{e}+001.00000 \mathrm{e}+001.00000 \mathrm{e}-011.00000 \mathrm{e}-09$ 1.00000e-01

Element: 10390 \# of layers: 5

$\mathrm{Kx} \mathrm{Ky} \mathrm{Kz}$ Ss Por

4.11286e+01 4.11286e+01 4.11286e+00 1.00000e-09 2.12000e-01

$4.11286 \mathrm{e}+014.11286 \mathrm{e}+014.11286 \mathrm{e}+001.00000 \mathrm{e}-09$ 2.12000e-01

$4.11286 \mathrm{e}+014.11286 \mathrm{e}+014.11286 \mathrm{e}+001.00000 \mathrm{e}-092.12000 \mathrm{e}-01$

$1.00000 \mathrm{e}-05$ 1.00000e-05 1.00000e-06 1.00000e-09 1.00000e-01

$1.00000 \mathrm{e}+001.00000 \mathrm{e}+001.00000 \mathrm{e}-011.00000 \mathrm{e}-091.00000 \mathrm{e}-01$

Element: 10391 \# of layers: 5

Kx Ky Kz Ss Por

5.62850e+00 5.62850e+00 5.62850e-01 1.00000e-09 2.12000e-01

$5.62850 \mathrm{e}+005.62850 \mathrm{e}+00$ 5.62850e-01 1.00000e-09 2.12000e-01

$5.62850 \mathrm{e}+005.62850 \mathrm{e}+00$ 5.62850e-01 1.00000e-09 2.12000e-01

$1.00000 \mathrm{e}-05$ 1.00000e-05 1.00000e-06 1.00000e-09 1.00000e-01

$1.00000 \mathrm{e}+001.00000 \mathrm{e}+001.00000 \mathrm{e}-011.00000 \mathrm{e}-091.00000 \mathrm{e}-01$

Element: 10392 \# of layers: 5

$\mathrm{Kx} \mathrm{Ky} \mathrm{Kz}$ Ss Por

$5.62850 \mathrm{e}+00$ 5.62850e+00 5.62850e-01 1.00000e-09 2.12000e-01

$5.62850 \mathrm{e}+00$ 5.62850e+00 5.62850e-01 1.00000e-09 2.12000e-01

$5.62850 \mathrm{e}+00$ 5.62850e+00 5.62850e-01 1.00000e-09 2.12000e-01

$1.00000 \mathrm{e}-051.00000 \mathrm{e}-05$ 1.00000e-06 1.00000e-09 1.00000e-01

$1.00000 \mathrm{e}+001.00000 \mathrm{e}+001.00000 \mathrm{e}-011.00000 \mathrm{e}-09$ 1.00000e-01

Element: 10393 \# of layers: 6

$\mathrm{Kx} \mathrm{Ky} \mathrm{Kz}$ Ss Por

$5.62850 \mathrm{e}+005.62850 \mathrm{e}+00$ 5.62850e-01 1.00000e-09 2.12000e-01

$5.62850 \mathrm{e}+005.62850 \mathrm{e}+00$ 5.62850e-01 1.00000e-09 2.12000e-01

$5.62850 \mathrm{e}+005.62850 \mathrm{e}+00$ 5.62850e-01 1.00000e-09 2.12000e-01

$5.62850 \mathrm{e}+00$ 5.62850e+00 5.62850e-01 1.00000e-09 2.12000e-01

$1.00000 \mathrm{e}-05$ 1.00000e-05 1.00000e-06 1.00000e-09 1.00000e-01

$1.00000 \mathrm{e}+001.00000 \mathrm{e}+001.00000 \mathrm{e}-011.00000 \mathrm{e}-091.00000 \mathrm{e}-01$

Element: 10394 \# of layers: 6

$\mathrm{Kx} \mathrm{Ky} \mathrm{Kz}$ Ss Por

4.11286e+01 4.11286e+01 4.11286e+00 1.00000e-09 2.12000e-01

$4.11286 \mathrm{e}+014.11286 \mathrm{e}+014.11286 \mathrm{e}+00$ 1.00000e-09 2.12000e-01

$4.11286 \mathrm{e}+014.11286 \mathrm{e}+014.11286 \mathrm{e}+001.00000 \mathrm{e}-092.12000 \mathrm{e}-01$

$4.11286 \mathrm{e}+014.11286 \mathrm{e}+014.11286 \mathrm{e}+001.00000 \mathrm{e}-092.12000 \mathrm{e}-01$

$1.00000 \mathrm{e}-051.00000 \mathrm{e}-051.00000 \mathrm{e}-061.00000 \mathrm{e}-091.00000 \mathrm{e}-01$

$1.00000 \mathrm{e}+001.00000 \mathrm{e}+001.00000 \mathrm{e}-011.00000 \mathrm{e}-091.00000 \mathrm{e}-01$

Element: 10395 \# of layers: 6

$\mathrm{Kx} \mathrm{Ky} \mathrm{Kz}$ Ss Por

4.11286e+01 4.11286e+01 4.11286e+00 1.00000e-09 2.12000e-01

4.11286e+01 4.11286e+01 4.11286e+00 1.00000e-09 2.12000e-01

$4.11286 \mathrm{e}+014.11286 \mathrm{e}+014.11286 \mathrm{e}+00$ 1.00000e-09 2.12000e-01

$4.11286 \mathrm{e}+014.11286 \mathrm{e}+014.11286 \mathrm{e}+001.00000 \mathrm{e}-092.12000 \mathrm{e}-01$ 
$1.00000 \mathrm{e}-05$ 1.00000e-05 1.00000e-06 1.00000e-09 1.00000e-01 $1.00000 \mathrm{e}+001.00000 \mathrm{e}+001.00000 \mathrm{e}-01$ 1.00000e-09 1.00000e-01 Element: 10396 \# of layers: 5

Kx Ky Kz Ss Por

4.11286e+01 4.11286e+01 4.11286e+00 1.00000e-09 2.12000e-01 $4.11286 \mathrm{e}+014.11286 \mathrm{e}+014.11286 \mathrm{e}+00$ 1.00000e-09 2.12000e-01 $4.11286 \mathrm{e}+014.11286 \mathrm{e}+014.11286 \mathrm{e}+00$ 1.00000e-09 2.12000e-01 $1.00000 \mathrm{e}-05$ 1.00000e-05 1.00000e-06 1.00000e-09 1.00000e-01 $1.00000 \mathrm{e}+001.00000 \mathrm{e}+001.00000 \mathrm{e}-011.00000 \mathrm{e}-09$ 1.00000e-01 Element: 10397 \# of layers: 5

$\mathrm{Kx} \mathrm{Ky} \mathrm{Kz}$ Ss Por

4.11286e+01 4.11286e+01 4.11286e+00 1.00000e-09 2.12000e-01

4.11286e+01 4.11286e+01 4.11286e+00 1.00000e-09 2.12000e-01

$4.11286 \mathrm{e}+014.11286 \mathrm{e}+014.11286 \mathrm{e}+001.00000 \mathrm{e}-09$ 2.12000e-01 $1.00000 \mathrm{e}-05$ 1.00000e-05 1.00000e-06 1.00000e-09 1.00000e-01 $1.00000 \mathrm{e}+001.00000 \mathrm{e}+001.00000 \mathrm{e}-011.00000 \mathrm{e}-091.00000 \mathrm{e}-01$ Element: 10398 \# of layers: 5

$\mathrm{Kx} \mathrm{Ky} \mathrm{Kz}$ Ss Por

$5.62850 \mathrm{e}+00$ 5.62850e+00 5.62850e-01 1.00000e-09 2.12000e-01

$5.62850 \mathrm{e}+005.62850 \mathrm{e}+00$ 5.62850e-01 1.00000e-09 2.12000e-01

$5.62850 \mathrm{e}+005.62850 \mathrm{e}+00$ 5.62850e-01 1.00000e-09 2.12000e-01 $1.00000 \mathrm{e}-05$ 1.00000e-05 1.00000e-06 1.00000e-09 1.00000e-01

$1.00000 \mathrm{e}+001.00000 \mathrm{e}+001.00000 \mathrm{e}-01$ 1.00000e-09 1.00000e-01 Element: 10399 \# of layers: 5

$\mathrm{Kx} \mathrm{Ky} \mathrm{Kz}$ Ss Por

5.62850e+00 5.62850e+00 5.62850e-01 1.00000e-09 2.12000e-01

$5.62850 \mathrm{e}+005.62850 \mathrm{e}+005.62850 \mathrm{e}-011.00000 \mathrm{e}-092.12000 \mathrm{e}-01$

$5.62850 \mathrm{e}+005.62850 \mathrm{e}+005.62850 \mathrm{e}-011.00000 \mathrm{e}-092.12000 \mathrm{e}-01$

$1.00000 \mathrm{e}-05$ 1.00000e-05 1.00000e-06 1.00000e-09 1.00000e-01

$1.00000 \mathrm{e}+001.00000 \mathrm{e}+001.00000 \mathrm{e}-011.00000 \mathrm{e}-091.00000 \mathrm{e}-01$

Element: 10400 \# of layers: 5

$\mathrm{Kx} \mathrm{Ky} \mathrm{Kz}$ Ss Por

5.62850e+00 5.62850e+00 5.62850e-01 1.00000e-09 2.12000e-01

$5.62850 \mathrm{e}+00$ 5.62850e+00 5.62850e-01 1.00000e-09 2.12000e-01

$5.62850 \mathrm{e}+005.62850 \mathrm{e}+005.62850 \mathrm{e}-01$ 1.00000e-09 2.12000e-01

$1.00000 \mathrm{e}-05$ 1.00000e-05 1.00000e-06 1.00000e-09 1.00000e-01

$1.00000 \mathrm{e}+001.00000 \mathrm{e}+001.00000 \mathrm{e}-011.00000 \mathrm{e}-091.00000 \mathrm{e}-01$

Element: 10401 \# of layers: 5

$\mathrm{Kx} \mathrm{Ky} \mathrm{Kz}$ Ss Por

$5.62850 \mathrm{e}+00$ 5.62850e+00 5.62850e-01 1.00000e-09 2.12000e-01

$5.62850 \mathrm{e}+005.62850 \mathrm{e}+00$ 5.62850e-01 1.00000e-09 2.12000e-01

$5.62850 \mathrm{e}+005.62850 \mathrm{e}+00$ 5.62850e-01 1.00000e-09 2.12000e-01 $1.00000 \mathrm{e}-05$ 1.00000e-05 1.00000e-06 1.00000e-09 1.00000e-01

$1.00000 \mathrm{e}+001.00000 \mathrm{e}+001.00000 \mathrm{e}-01$ 1.00000e-09 1.00000e-01

Element: 10402 \# of layers: 6

Kx Ky Kz Ss Por 
$5.62850 \mathrm{e}+005.62850 \mathrm{e}+00$ 5.62850e-01 1.00000e-09 2.12000e-01

$5.62850 \mathrm{e}+005.62850 \mathrm{e}+005.62850 \mathrm{e}-011.00000 \mathrm{e}-092.12000 \mathrm{e}-01$

$5.62850 \mathrm{e}+005.62850 \mathrm{e}+00$ 5.62850e-01 1.00000e-09 2.12000e-01

$5.62850 \mathrm{e}+005.62850 \mathrm{e}+00$ 5.62850e-01 1.00000e-09 2.12000e-01

$1.00000 \mathrm{e}-05$ 1.00000e-05 1.00000e-06 1.00000e-09 1.00000e-01

$1.00000 \mathrm{e}+001.00000 \mathrm{e}+001.00000 \mathrm{e}-011.00000 \mathrm{e}-091.00000 \mathrm{e}-01$

Element: 10403 \# of layers: 6

Kx Ky Kz Ss Por

$5.62850 \mathrm{e}+005.62850 \mathrm{e}+00$ 5.62850e-01 1.00000e-09 2.12000e-01

$5.62850 \mathrm{e}+005.62850 \mathrm{e}+00$ 5.62850e-01 1.00000e-09 2.12000e-01

$5.62850 \mathrm{e}+005.62850 \mathrm{e}+00$ 5.62850e-01 1.00000e-09 2.12000e-01

$5.62850 \mathrm{e}+005.62850 \mathrm{e}+00$ 5.62850e-01 1.00000e-09 2.12000e-01

$1.00000 \mathrm{e}-05$ 1.00000e-05 1.00000e-06 1.00000e-09 1.00000e-01

$1.00000 \mathrm{e}+001.00000 \mathrm{e}+001.00000 \mathrm{e}-011.00000 \mathrm{e}-091.00000 \mathrm{e}-01$

Element: 10404 \# of layers: 6

Kx Ky Kz Ss Por

$5.62850 \mathrm{e}+00$ 5.62850e+00 5.62850e-01 1.00000e-09 2.12000e-01

$5.62850 \mathrm{e}+005.62850 \mathrm{e}+005.62850 \mathrm{e}-011.00000 \mathrm{e}-092.12000 \mathrm{e}-01$

$5.62850 \mathrm{e}+005.62850 \mathrm{e}+005.62850 \mathrm{e}-011.00000 \mathrm{e}-092.12000 \mathrm{e}-01$

$5.62850 \mathrm{e}+005.62850 \mathrm{e}+00$ 5.62850e-01 1.00000e-09 2.12000e-01

$1.00000 \mathrm{e}-05$ 1.00000e-05 1.00000e-06 1.00000e-09 1.00000e-01

$1.00000 \mathrm{e}+001.00000 \mathrm{e}+001.00000 \mathrm{e}-011.00000 \mathrm{e}-091.00000 \mathrm{e}-01$

Element: 10405 \# of layers: 5

Kx Ky Kz Ss Por

$5.62850 \mathrm{e}+005.62850 \mathrm{e}+00$ 5.62850e-01 1.00000e-09 2.12000e-01

$5.62850 \mathrm{e}+005.62850 \mathrm{e}+00$ 5.62850e-01 1.00000e-09 2.12000e-01

$5.62850 \mathrm{e}+005.62850 \mathrm{e}+00$ 5.62850e-01 1.00000e-09 2.12000e-01

$1.00000 \mathrm{e}-051.00000 \mathrm{e}-05$ 1.00000e-06 1.00000e-09 1.00000e-01

$1.00000 \mathrm{e}+001.00000 \mathrm{e}+001.00000 \mathrm{e}-011.00000 \mathrm{e}-091.00000 \mathrm{e}-01$

Element: 10406 \# of layers: 5

Kx Ky Kz Ss Por

$5.62850 \mathrm{e}+005.62850 \mathrm{e}+00$ 5.62850e-01 1.00000e-09 2.12000e-01

$5.62850 \mathrm{e}+005.62850 \mathrm{e}+00$ 5.62850e-01 1.00000e-09 2.12000e-01

$5.62850 \mathrm{e}+005.62850 \mathrm{e}+00$ 5.62850e-01 1.00000e-09 2.12000e-01

$1.00000 \mathrm{e}-05$ 1.00000e-05 1.00000e-06 1.00000e-09 1.00000e-01

$1.00000 \mathrm{e}+001.00000 \mathrm{e}+001.00000 \mathrm{e}-011.00000 \mathrm{e}-091.00000 \mathrm{e}-01$

Element: 10407 \# of layers: 5

Kx Ky Kz Ss Por

$5.62850 \mathrm{e}+00$ 5.62850e+00 5.62850e-01 1.00000e-09 2.12000e-01

$5.62850 \mathrm{e}+005.62850 \mathrm{e}+00$ 5.62850e-01 1.00000e-09 2.12000e-01

$5.62850 \mathrm{e}+005.62850 \mathrm{e}+00$ 5.62850e-01 1.00000e-09 2.12000e-01

$1.00000 \mathrm{e}-05$ 1.00000e-05 1.00000e-06 1.00000e-09 1.00000e-01

$1.00000 \mathrm{e}+001.00000 \mathrm{e}+001.00000 \mathrm{e}-011.00000 \mathrm{e}-091.00000 \mathrm{e}-01$

Element: 10408 \# of layers: 5

Kx Ky Kz Ss Por

4.58402e+00 4.58402e+00 4.58402e-01 1.00000e-09 2.12000e-01 
$4.58402 \mathrm{e}+004.58402 \mathrm{e}+00$ 4.58402e-01 1.00000e-09 2.12000e-01 $4.58402 \mathrm{e}+004.58402 \mathrm{e}+00 \quad 4.58402 \mathrm{e}-011.00000 \mathrm{e}-092.12000 \mathrm{e}-01$ $1.00000 \mathrm{e}-05$ 1.00000e-05 1.00000e-06 1.00000e-09 1.00000e-01 $1.00000 \mathrm{e}+001.00000 \mathrm{e}+001.00000 \mathrm{e}-011.00000 \mathrm{e}-091.00000 \mathrm{e}-01$ Element: 10409 \# of layers: 5

Kx Ky Kz Ss Por

$4.58402 \mathrm{e}+004.58402 \mathrm{e}+004.58402 \mathrm{e}-01$ 1.00000e-09 2.12000e-01 $4.58402 \mathrm{e}+004.58402 \mathrm{e}+004.58402 \mathrm{e}-011.00000 \mathrm{e}-092.12000 \mathrm{e}-01$ $4.58402 \mathrm{e}+004.58402 \mathrm{e}+004.58402 \mathrm{e}-011.00000 \mathrm{e}-092.12000 \mathrm{e}-01$ $1.00000 \mathrm{e}-05$ 1.00000e-05 1.00000e-06 1.00000e-09 1.00000e-01 $1.00000 \mathrm{e}+001.00000 \mathrm{e}+001.00000 \mathrm{e}-011.00000 \mathrm{e}-091.00000 \mathrm{e}-01$ Element: 10410 \# of layers: 5

Kx Ky Kz Ss Por

4.58402e+00 4.58402e+00 4.58402e-01 1.00000e-09 2.12000e-01 $4.58402 \mathrm{e}+004.58402 \mathrm{e}+004.58402 \mathrm{e}-011.00000 \mathrm{e}-092.12000 \mathrm{e}-01$ $4.58402 \mathrm{e}+004.58402 \mathrm{e}+00$ 4.58402e-01 1.00000e-09 2.12000e-01 $1.00000 \mathrm{e}-05$ 1.00000e-05 1.00000e-06 1.00000e-09 1.00000e-01 $1.00000 \mathrm{e}+001.00000 \mathrm{e}+001.00000 \mathrm{e}-011.00000 \mathrm{e}-091.00000 \mathrm{e}-01$ Element: 10411 \# of layers: 5

Kx Ky Kz Ss Por

$4.58402 \mathrm{e}+00$ 4.58402e+00 4.58402e-01 1.00000e-09 2.12000e-01 $4.58402 \mathrm{e}+004.58402 \mathrm{e}+004.58402 \mathrm{e}-011.00000 \mathrm{e}-092.12000 \mathrm{e}-01$ $4.58402 \mathrm{e}+004.58402 \mathrm{e}+00 \quad 4.58402 \mathrm{e}-011.00000 \mathrm{e}-092.12000 \mathrm{e}-01$ $1.00000 \mathrm{e}-05$ 1.00000e-05 1.00000e-06 1.00000e-09 1.00000e-01 $1.00000 \mathrm{e}+001.00000 \mathrm{e}+001.00000 \mathrm{e}-011.00000 \mathrm{e}-091.00000 \mathrm{e}-01$ Element: 10412 \# of layers: 5

Kx Ky Kz Ss Por

$4.58402 \mathrm{e}+004.58402 \mathrm{e}+004.58402 \mathrm{e}-01$ 1.00000e-09 2.12000e-01 $4.58402 \mathrm{e}+004.58402 \mathrm{e}+004.58402 \mathrm{e}-011.00000 \mathrm{e}-092.12000 \mathrm{e}-01$ $4.58402 \mathrm{e}+004.58402 \mathrm{e}+004.58402 \mathrm{e}-011.00000 \mathrm{e}-092.12000 \mathrm{e}-01$ $1.00000 \mathrm{e}-05$ 1.00000e-05 1.00000e-06 1.00000e-09 1.00000e-01 $1.00000 \mathrm{e}+001.00000 \mathrm{e}+001.00000 \mathrm{e}-011.00000 \mathrm{e}-091.00000 \mathrm{e}-01$ Element: 10413 \# of layers: 5

Kx Ky Kz Ss Por

$5.62850 \mathrm{e}+00$ 5.62850e+00 5.62850e-01 1.00000e-09 2.12000e-01 $5.62850 \mathrm{e}+005.62850 \mathrm{e}+00$ 5.62850e-01 1.00000e-09 2.12000e-01 $5.62850 \mathrm{e}+005.62850 \mathrm{e}+00$ 5.62850e-01 1.00000e-09 2.12000e-01 $1.00000 \mathrm{e}-05$ 1.00000e-05 1.00000e-06 1.00000e-09 1.00000e-01 $1.00000 \mathrm{e}+001.00000 \mathrm{e}+001.00000 \mathrm{e}-011.00000 \mathrm{e}-091.00000 \mathrm{e}-01$ Element: 10414 \# of layers: 5

Kx Ky Kz Ss Por

$5.62850 \mathrm{e}+00$ 5.62850e+00 5.62850e-01 1.00000e-09 2.12000e-01 $5.62850 \mathrm{e}+005.62850 \mathrm{e}+005.62850 \mathrm{e}-011.00000 \mathrm{e}-092.12000 \mathrm{e}-01$ $5.62850 \mathrm{e}+005.62850 \mathrm{e}+00$ 5.62850e-01 1.00000e-09 2.12000e-01 $1.00000 \mathrm{e}-05$ 1.00000e-05 1.00000e-06 1.00000e-09 1.00000e-01 $1.00000 \mathrm{e}+001.00000 \mathrm{e}+001.00000 \mathrm{e}-011.00000 \mathrm{e}-091.00000 \mathrm{e}-01$ 
Element: 10415 \# of layers: 5

Kx Ky Kz Ss Por

$4.58402 \mathrm{e}+004.58402 \mathrm{e}+004.58402 \mathrm{e}-01$ 1.00000e-09 2.12000e-01

$4.58402 \mathrm{e}+004.58402 \mathrm{e}+004.58402 \mathrm{e}-011.00000 \mathrm{e}-092.12000 \mathrm{e}-01$

$4.58402 \mathrm{e}+004.58402 \mathrm{e}+00$ 4.58402e-01 1.00000e-09 2.12000e-01

$1.00000 \mathrm{e}-05$ 1.00000e-05 1.00000e-06 1.00000e-09 1.00000e-01

$1.00000 \mathrm{e}+001.00000 \mathrm{e}+001.00000 \mathrm{e}-011.00000 \mathrm{e}-091.00000 \mathrm{e}-01$

Element: 10416 \# of layers: 5

Kx Ky Kz Ss Por

4.58402e+00 4.58402e+00 4.58402e-01 1.00000e-09 2.12000e-01

$4.58402 \mathrm{e}+004.58402 \mathrm{e}+004.58402 \mathrm{e}-011.00000 \mathrm{e}-092.12000 \mathrm{e}-01$

$4.58402 \mathrm{e}+004.58402 \mathrm{e}+004.58402 \mathrm{e}-011.00000 \mathrm{e}-09$ 2.12000e-01

$1.00000 \mathrm{e}-05$ 1.00000e-05 1.00000e-06 1.00000e-09 1.00000e-01

$1.00000 \mathrm{e}+001.00000 \mathrm{e}+001.00000 \mathrm{e}-011.00000 \mathrm{e}-091.00000 \mathrm{e}-01$

Element: 10417 \# of layers: 5

Kx Ky Kz Ss Por

$1.95885 \mathrm{e}+011.95885 \mathrm{e}+011.95885 \mathrm{e}+00$ 1.00000e-09 2.12000e-01

$1.95885 \mathrm{e}+011.95885 \mathrm{e}+011.95885 \mathrm{e}+001.00000 \mathrm{e}-092.12000 \mathrm{e}-01$

$1.95885 \mathrm{e}+011.95885 \mathrm{e}+011.95885 \mathrm{e}+001.00000 \mathrm{e}-092.12000 \mathrm{e}-01$

$1.00000 \mathrm{e}-05$ 1.00000e-05 1.00000e-06 1.00000e-09 1.00000e-01

$1.00000 \mathrm{e}+001.00000 \mathrm{e}+001.00000 \mathrm{e}-011.00000 \mathrm{e}-091.00000 \mathrm{e}-01$

Element: 10418 \# of layers: 5

Kx Ky Kz Ss Por

$1.95885 \mathrm{e}+011.95885 \mathrm{e}+011.95885 \mathrm{e}+00$ 1.00000e-09 2.12000e-01

$1.95885 \mathrm{e}+011.95885 \mathrm{e}+011.95885 \mathrm{e}+001.00000 \mathrm{e}-092.12000 \mathrm{e}-01$

$1.95885 \mathrm{e}+011.95885 \mathrm{e}+011.95885 \mathrm{e}+001.00000 \mathrm{e}-092.12000 \mathrm{e}-01$

$1.00000 \mathrm{e}-05$ 1.00000e-05 1.00000e-06 1.00000e-09 1.00000e-01

$1.00000 \mathrm{e}+001.00000 \mathrm{e}+001.00000 \mathrm{e}-011.00000 \mathrm{e}-091.00000 \mathrm{e}-01$

Element: 10419 \# of layers: 5

Kx Ky Kz Ss Por

$1.95885 \mathrm{e}+011.95885 \mathrm{e}+011.95885 \mathrm{e}+00$ 1.00000e-09 2.12000e-01

$1.95885 \mathrm{e}+011.95885 \mathrm{e}+011.95885 \mathrm{e}+001.00000 \mathrm{e}-092.12000 \mathrm{e}-01$

$1.95885 \mathrm{e}+011.95885 \mathrm{e}+011.95885 \mathrm{e}+001.00000 \mathrm{e}-092.12000 \mathrm{e}-01$

$1.00000 \mathrm{e}-05$ 1.00000e-05 1.00000e-06 1.00000e-09 1.00000e-01

$1.00000 \mathrm{e}+001.00000 \mathrm{e}+001.00000 \mathrm{e}-011.00000 \mathrm{e}-091.00000 \mathrm{e}-01$

Element: 10420 \# of layers: 5

Kx Ky Kz Ss Por

$4.11286 \mathrm{e}+014.11286 \mathrm{e}+014.11286 \mathrm{e}+00$ 1.00000e-09 2.12000e-01

$4.11286 \mathrm{e}+014.11286 \mathrm{e}+014.11286 \mathrm{e}+00$ 1.00000e-09 2.12000e-01

$4.11286 \mathrm{e}+014.11286 \mathrm{e}+014.11286 \mathrm{e}+00$ 1.00000e-09 2.12000e-01

$1.00000 \mathrm{e}-05$ 1.00000e-05 1.00000e-06 1.00000e-09 1.00000e-01

$1.00000 \mathrm{e}+001.00000 \mathrm{e}+001.00000 \mathrm{e}-011.00000 \mathrm{e}-091.00000 \mathrm{e}-01$

Element: 10421 \# of layers: 5

Kx Ky Kz Ss Por

$4.11286 \mathrm{e}+014.11286 \mathrm{e}+014.11286 \mathrm{e}+00$ 1.00000e-09 2.12000e-01

$4.11286 \mathrm{e}+014.11286 \mathrm{e}+014.11286 \mathrm{e}+001.00000 \mathrm{e}-092.12000 \mathrm{e}-01$ 
4.11286e+01 4.11286e+01 4.11286e+00 1.00000e-09 2.12000e-01 $1.00000 \mathrm{e}-05$ 1.00000e-05 1.00000e-06 1.00000e-09 1.00000e-01 $1.00000 \mathrm{e}+001.00000 \mathrm{e}+001.00000 \mathrm{e}-01$ 1.00000e-09 1.00000e-01

Element: 10422 \# of layers: 5

$\mathrm{Kx} \mathrm{Ky} \mathrm{Kz}$ Ss Por

$5.62850 \mathrm{e}+005.62850 \mathrm{e}+005.62850 \mathrm{e}-011.00000 \mathrm{e}-092.12000 \mathrm{e}-01$

$5.62850 \mathrm{e}+005.62850 \mathrm{e}+00$ 5.62850e-01 1.00000e-09 2.12000e-01

$5.62850 \mathrm{e}+005.62850 \mathrm{e}+005.62850 \mathrm{e}-011.00000 \mathrm{e}-092.12000 \mathrm{e}-01$

$1.00000 \mathrm{e}-05$ 1.00000e-05 1.00000e-06 1.00000e-09 1.00000e-01

$1.00000 \mathrm{e}+001.00000 \mathrm{e}+001.00000 \mathrm{e}-01$ 1.00000e-09 1.00000e-01

Element: 10423 \# of layers: 5

Kx Ky Kz Ss Por

4.58402e+00 4.58402e+00 4.58402e-01 1.00000e-09 2.12000e-01

$4.58402 \mathrm{e}+00$ 4.58402e+00 4.58402e-01 1.00000e-09 2.12000e-01

4.58402e+00 4.58402e+00 4.58402e-01 1.00000e-09 2.12000e-01

$1.00000 \mathrm{e}-05$ 1.00000e-05 1.00000e-06 1.00000e-09 1.00000e-01

$1.00000 \mathrm{e}+001.00000 \mathrm{e}+001.00000 \mathrm{e}-011.00000 \mathrm{e}-091.00000 \mathrm{e}-01$

Element: 10424 \# of layers: 5

$\mathrm{Kx} \mathrm{Ky} \mathrm{Kz}$ Ss Por

$1.95885 \mathrm{e}+01$ 1.95885e+01 1.95885e+00 1.00000e-09 2.12000e-01

$1.95885 \mathrm{e}+011.95885 \mathrm{e}+011.95885 \mathrm{e}+001.00000 \mathrm{e}-092.12000 \mathrm{e}-01$

$1.95885 \mathrm{e}+01$ 1.95885e+01 1.95885e+00 1.00000e-09 2.12000e-01

$1.00000 \mathrm{e}-05$ 1.00000e-05 1.00000e-06 1.00000e-09 1.00000e-01

$1.00000 \mathrm{e}+001.00000 \mathrm{e}+001.00000 \mathrm{e}-011.00000 \mathrm{e}-09$ 1.00000e-01

Element: 10425 \# of layers: 6

$\mathrm{Kx} \mathrm{Ky} \mathrm{Kz}$ Ss Por

3.78751e+01 3.78751e+01 3.78751e+00 1.00000e-09 2.12000e-01

$3.78751 \mathrm{e}+013.78751 \mathrm{e}+013.78751 \mathrm{e}+001.00000 \mathrm{e}-092.12000 \mathrm{e}-01$

$3.78751 \mathrm{e}+013.78751 \mathrm{e}+013.78751 \mathrm{e}+001.00000 \mathrm{e}-092.12000 \mathrm{e}-01$

$3.78751 \mathrm{e}+013.78751 \mathrm{e}+013.78751 \mathrm{e}+00$ 1.00000e-09 2.12000e-01

$1.00000 \mathrm{e}-05$ 1.00000e-05 1.00000e-06 1.00000e-09 1.00000e-01

$1.00000 \mathrm{e}+001.00000 \mathrm{e}+001.00000 \mathrm{e}-01$ 1.00000e-09 1.00000e-01

Element: 10426 \# of layers: 6

Kx Ky Kz Ss Por

3.78751e+01 3.78751e+01 3.78751e+00 1.00000e-09 2.12000e-01

$3.78751 \mathrm{e}+013.78751 \mathrm{e}+013.78751 \mathrm{e}+001.00000 \mathrm{e}-092.12000 \mathrm{e}-01$

$3.78751 \mathrm{e}+013.78751 \mathrm{e}+013.78751 \mathrm{e}+001.00000 \mathrm{e}-092.12000 \mathrm{e}-01$

$3.78751 \mathrm{e}+013.78751 \mathrm{e}+013.78751 \mathrm{e}+001.00000 \mathrm{e}-092.12000 \mathrm{e}-01$

$1.00000 \mathrm{e}-051.00000 \mathrm{e}-051.00000 \mathrm{e}-061.00000 \mathrm{e}-091.00000 \mathrm{e}-01$

$1.00000 \mathrm{e}+001.00000 \mathrm{e}+001.00000 \mathrm{e}-01$ 1.00000e-09 1.00000e-01

Element: 10427 \# of layers: 6

$\mathrm{Kx} \mathrm{Ky} \mathrm{Kz}$ Ss Por

3.78751e+01 3.78751e+01 3.78751e+00 1.00000e-09 2.12000e-01

$3.78751 \mathrm{e}+013.78751 \mathrm{e}+013.78751 \mathrm{e}+00$ 1.00000e-09 2.12000e-01

$3.78751 \mathrm{e}+013.78751 \mathrm{e}+013.78751 \mathrm{e}+001.00000 \mathrm{e}-092.12000 \mathrm{e}-01$

$3.78751 \mathrm{e}+013.78751 \mathrm{e}+013.78751 \mathrm{e}+001.00000 \mathrm{e}-092.12000 \mathrm{e}-01$ 
$1.00000 \mathrm{e}-05$ 1.00000e-05 1.00000e-06 1.00000e-09 1.00000e-01 $1.00000 \mathrm{e}+001.00000 \mathrm{e}+001.00000 \mathrm{e}-01$ 1.00000e-09 1.00000e-01 Element: 10428 \# of layers: 6

Kx Ky Kz Ss Por

3.78751e+01 3.78751e+01 3.78751e+00 1.00000e-09 2.12000e-01

$3.78751 \mathrm{e}+013.78751 \mathrm{e}+013.78751 \mathrm{e}+001.00000 \mathrm{e}-092.12000 \mathrm{e}-01$

$3.78751 \mathrm{e}+013.78751 \mathrm{e}+013.78751 \mathrm{e}+001.00000 \mathrm{e}-092.12000 \mathrm{e}-01$

$3.78751 \mathrm{e}+013.78751 \mathrm{e}+013.78751 \mathrm{e}+001.00000 \mathrm{e}-092.12000 \mathrm{e}-01$

$1.00000 \mathrm{e}-05$ 1.00000e-05 1.00000e-06 1.00000e-09 1.00000e-01

$1.00000 \mathrm{e}+001.00000 \mathrm{e}+001.00000 \mathrm{e}-011.00000 \mathrm{e}-091.00000 \mathrm{e}-01$

Element: 10429 \# of layers: 6

Kx Ky Kz Ss Por

3.78751e+01 3.78751e+01 3.78751e+00 1.00000e-09 2.12000e-01

$3.78751 \mathrm{e}+013.78751 \mathrm{e}+013.78751 \mathrm{e}+001.00000 \mathrm{e}-092.12000 \mathrm{e}-01$

$3.78751 \mathrm{e}+013.78751 \mathrm{e}+013.78751 \mathrm{e}+001.00000 \mathrm{e}-092.12000 \mathrm{e}-01$

$3.78751 \mathrm{e}+013.78751 \mathrm{e}+013.78751 \mathrm{e}+001.00000 \mathrm{e}-092.12000 \mathrm{e}-01$

$1.00000 \mathrm{e}-05$ 1.00000e-05 1.00000e-06 1.00000e-09 1.00000e-01

$1.00000 \mathrm{e}+001.00000 \mathrm{e}+001.00000 \mathrm{e}-01$ 1.00000e-09 1.00000e-01

Element: 10430 \# of layers: 6

$\mathrm{Kx} \mathrm{Ky} \mathrm{Kz}$ Ss Por

$3.78751 \mathrm{e}+013.78751 \mathrm{e}+013.78751 \mathrm{e}+001.00000 \mathrm{e}-092.12000 \mathrm{e}-01$

$3.78751 \mathrm{e}+013.78751 \mathrm{e}+013.78751 \mathrm{e}+001.00000 \mathrm{e}-092.12000 \mathrm{e}-01$

$3.78751 \mathrm{e}+013.78751 \mathrm{e}+013.78751 \mathrm{e}+001.00000 \mathrm{e}-092.12000 \mathrm{e}-01$

$3.78751 \mathrm{e}+013.78751 \mathrm{e}+013.78751 \mathrm{e}+001.00000 \mathrm{e}-092.12000 \mathrm{e}-01$

$1.00000 \mathrm{e}-051.00000 \mathrm{e}-05$ 1.00000e-06 1.00000e-09 1.00000e-01

$1.00000 \mathrm{e}+001.00000 \mathrm{e}+001.00000 \mathrm{e}-01$ 1.00000e-09 1.00000e-01

Element: 10431 \# of layers: 6

$\mathrm{Kx} \mathrm{Ky} \mathrm{Kz}$ Ss Por

3.78751e+01 3.78751e+01 3.78751e+00 1.00000e-09 2.12000e-01

$3.78751 \mathrm{e}+013.78751 \mathrm{e}+013.78751 \mathrm{e}+00$ 1.00000e-09 2.12000e-01

$3.78751 \mathrm{e}+013.78751 \mathrm{e}+013.78751 \mathrm{e}+001.00000 \mathrm{e}-092.12000 \mathrm{e}-01$

$3.78751 \mathrm{e}+013.78751 \mathrm{e}+013.78751 \mathrm{e}+00$ 1.00000e-09 2.12000e-01

$1.00000 \mathrm{e}-05$ 1.00000e-05 1.00000e-06 1.00000e-09 1.00000e-01

$1.00000 \mathrm{e}+001.00000 \mathrm{e}+001.00000 \mathrm{e}-011.00000 \mathrm{e}-091.00000 \mathrm{e}-01$

Element: 10432 \# of layers: 6

Kx Ky Kz Ss Por

3.78751e+01 3.78751e+01 3.78751e+00 1.00000e-09 2.12000e-01

$3.78751 \mathrm{e}+013.78751 \mathrm{e}+013.78751 \mathrm{e}+001.00000 \mathrm{e}-092.12000 \mathrm{e}-01$

$3.78751 \mathrm{e}+013.78751 \mathrm{e}+013.78751 \mathrm{e}+001.00000 \mathrm{e}-092.12000 \mathrm{e}-01$

$3.78751 \mathrm{e}+013.78751 \mathrm{e}+013.78751 \mathrm{e}+00$ 1.00000e-09 2.12000e-01

$1.00000 \mathrm{e}-05$ 1.00000e-05 1.00000e-06 1.00000e-09 1.00000e-01

$1.00000 \mathrm{e}+001.00000 \mathrm{e}+001.00000 \mathrm{e}-011.00000 \mathrm{e}-091.00000 \mathrm{e}-01$

Element: 10433 \# of layers: 6

$\mathrm{Kx} \mathrm{Ky} \mathrm{Kz}$ Ss Por

3.78751e+01 3.78751e+01 3.78751e+00 1.00000e-09 2.12000e-01

$3.78751 \mathrm{e}+013.78751 \mathrm{e}+013.78751 \mathrm{e}+001.00000 \mathrm{e}-092.12000 \mathrm{e}-01$ 
$3.78751 \mathrm{e}+013.78751 \mathrm{e}+013.78751 \mathrm{e}+00$ 1.00000e-09 2.12000e-01 $3.78751 \mathrm{e}+013.78751 \mathrm{e}+013.78751 \mathrm{e}+001.00000 \mathrm{e}-092.12000 \mathrm{e}-01$ $1.00000 \mathrm{e}-05$ 1.00000e-05 1.00000e-06 1.00000e-09 1.00000e-01 $1.00000 \mathrm{e}+001.00000 \mathrm{e}+001.00000 \mathrm{e}-011.00000 \mathrm{e}-091.00000 \mathrm{e}-01$ Element: 10434 \# of layers: 6

Kx Ky Kz Ss Por

$3.78751 \mathrm{e}+013.78751 \mathrm{e}+013.78751 \mathrm{e}+00$ 1.00000e-09 2.12000e-01 $3.78751 \mathrm{e}+013.78751 \mathrm{e}+013.78751 \mathrm{e}+001.00000 \mathrm{e}-092.12000 \mathrm{e}-01$ $3.78751 \mathrm{e}+013.78751 \mathrm{e}+013.78751 \mathrm{e}+001.00000 \mathrm{e}-092.12000 \mathrm{e}-01$ $3.78751 \mathrm{e}+013.78751 \mathrm{e}+013.78751 \mathrm{e}+001.00000 \mathrm{e}-092.12000 \mathrm{e}-01$ $1.00000 \mathrm{e}-05$ 1.00000e-05 1.00000e-06 1.00000e-09 1.00000e-01 $1.00000 \mathrm{e}+001.00000 \mathrm{e}+001.00000 \mathrm{e}-011.00000 \mathrm{e}-091.00000 \mathrm{e}-01$ Element: 10435 \# of layers: 6

Kx Ky Kz Ss Por

$3.47767 \mathrm{e}+013.47767 \mathrm{e}+013.47767 \mathrm{e}+00$ 1.00000e-09 2.12000e-01 $3.47767 \mathrm{e}+013.47767 \mathrm{e}+013.47767 \mathrm{e}+001.00000 \mathrm{e}-092.12000 \mathrm{e}-01$ $3.47767 \mathrm{e}+013.47767 \mathrm{e}+013.47767 \mathrm{e}+001.00000 \mathrm{e}-092.12000 \mathrm{e}-01$ $3.47767 \mathrm{e}+013.47767 \mathrm{e}+013.47767 \mathrm{e}+00$ 1.00000e-09 2.12000e-01 $1.00000 \mathrm{e}-05$ 1.00000e-05 1.00000e-06 1.00000e-09 1.00000e-01 $1.00000 \mathrm{e}+001.00000 \mathrm{e}+001.00000 \mathrm{e}-011.00000 \mathrm{e}-091.00000 \mathrm{e}-01$ Element: 10436 \# of layers: 6

Kx Ky Kz Ss Por

$3.47767 \mathrm{e}+013.47767 \mathrm{e}+013.47767 \mathrm{e}+00$ 1.00000e-09 2.12000e-01 $3.47767 \mathrm{e}+013.47767 \mathrm{e}+013.47767 \mathrm{e}+001.00000 \mathrm{e}-092.12000 \mathrm{e}-01$ $3.47767 \mathrm{e}+013.47767 \mathrm{e}+013.47767 \mathrm{e}+001.00000 \mathrm{e}-092.12000 \mathrm{e}-01$ $3.47767 \mathrm{e}+013.47767 \mathrm{e}+013.47767 \mathrm{e}+001.00000 \mathrm{e}-092.12000 \mathrm{e}-01$ $1.00000 \mathrm{e}-05$ 1.00000e-05 1.00000e-06 1.00000e-09 1.00000e-01 $1.00000 \mathrm{e}+001.00000 \mathrm{e}+001.00000 \mathrm{e}-011.00000 \mathrm{e}-091.00000 \mathrm{e}-01$ Element: 10437 \# of layers: 6

Kx Ky Kz Ss Por

$3.47767 \mathrm{e}+013.47767 \mathrm{e}+013.47767 \mathrm{e}+00$ 1.00000e-09 2.12000e-01 $3.47767 \mathrm{e}+013.47767 \mathrm{e}+013.47767 \mathrm{e}+001.00000 \mathrm{e}-092.12000 \mathrm{e}-01$ $3.47767 \mathrm{e}+013.47767 \mathrm{e}+013.47767 \mathrm{e}+001.00000 \mathrm{e}-092.12000 \mathrm{e}-01$ $3.47767 \mathrm{e}+013.47767 \mathrm{e}+013.47767 \mathrm{e}+001.00000 \mathrm{e}-092.12000 \mathrm{e}-01$ $1.00000 \mathrm{e}-05$ 1.00000e-05 1.00000e-06 1.00000e-09 1.00000e-01 $1.00000 \mathrm{e}+001.00000 \mathrm{e}+001.00000 \mathrm{e}-011.00000 \mathrm{e}-091.00000 \mathrm{e}-01$ Element: 10438 \# of layers: 6

Kx Ky Kz Ss Por

$3.47767 \mathrm{e}+013.47767 \mathrm{e}+013.47767 \mathrm{e}+00$ 1.00000e-09 2.12000e-01 $3.47767 \mathrm{e}+013.47767 \mathrm{e}+013.47767 \mathrm{e}+001.00000 \mathrm{e}-092.12000 \mathrm{e}-01$ $3.47767 \mathrm{e}+013.47767 \mathrm{e}+013.47767 \mathrm{e}+001.00000 \mathrm{e}-092.12000 \mathrm{e}-01$ $3.47767 \mathrm{e}+013.47767 \mathrm{e}+013.47767 \mathrm{e}+001.00000 \mathrm{e}-092.12000 \mathrm{e}-01$ $1.00000 \mathrm{e}-05$ 1.00000e-05 1.00000e-06 1.00000e-09 1.00000e-01 $1.00000 \mathrm{e}+001.00000 \mathrm{e}+001.00000 \mathrm{e}-011.00000 \mathrm{e}-091.00000 \mathrm{e}-01$ Element: 10439 \# of layers: 6

Kx Ky Kz Ss Por 
3.47767e+01 3.47767e+01 3.47767e+00 1.00000e-09 2.12000e-01 $3.47767 \mathrm{e}+013.47767 \mathrm{e}+01$ 3.47767e+00 1.00000e-09 2.12000e-01 $3.47767 \mathrm{e}+013.47767 \mathrm{e}+01$ 3.47767e+00 1.00000e-09 2.12000e-01 $3.47767 \mathrm{e}+01$ 3.47767e+01 3.47767e+00 1.00000e-09 2.12000e-01 $1.00000 \mathrm{e}-05$ 1.00000e-05 1.00000e-06 1.00000e-09 1.00000e-01 $1.00000 \mathrm{e}+001.00000 \mathrm{e}+001.00000 \mathrm{e}-011.00000 \mathrm{e}-091.00000 \mathrm{e}-01$ Element: 10440 \# of layers: 6

Kx Ky Kz Ss Por

3.78751e+01 3.78751e+01 3.78751e+00 1.00000e-09 2.12000e-01 $3.78751 \mathrm{e}+013.78751 \mathrm{e}+013.78751 \mathrm{e}+001.00000 \mathrm{e}-092.12000 \mathrm{e}-01$ $3.78751 \mathrm{e}+013.78751 \mathrm{e}+013.78751 \mathrm{e}+001.00000 \mathrm{e}-092.12000 \mathrm{e}-01$ $3.78751 \mathrm{e}+013.78751 \mathrm{e}+013.78751 \mathrm{e}+001.00000 \mathrm{e}-092.12000 \mathrm{e}-01$ $1.00000 \mathrm{e}-05$ 1.00000e-05 1.00000e-06 1.00000e-09 1.00000e-01 $1.00000 \mathrm{e}+001.00000 \mathrm{e}+001.00000 \mathrm{e}-011.00000 \mathrm{e}-09$ 1.00000e-01 Element: 10441 \# of layers: 6

Kx Ky Kz Ss Por

3.78751e+01 3.78751e+01 3.78751e+00 1.00000e-09 2.12000e-01

$3.78751 \mathrm{e}+013.78751 \mathrm{e}+013.78751 \mathrm{e}+001.00000 \mathrm{e}-092.12000 \mathrm{e}-01$

$3.78751 \mathrm{e}+013.78751 \mathrm{e}+013.78751 \mathrm{e}+001.00000 \mathrm{e}-092.12000 \mathrm{e}-01$

$3.78751 \mathrm{e}+013.78751 \mathrm{e}+013.78751 \mathrm{e}+001.00000 \mathrm{e}-092.12000 \mathrm{e}-01$ $1.00000 \mathrm{e}-05$ 1.00000e-05 1.00000e-06 1.00000e-09 1.00000e-01 $1.00000 \mathrm{e}+001.00000 \mathrm{e}+001.00000 \mathrm{e}-01$ 1.00000e-09 1.00000e-01 Element: 10442 \# of layers: 6

Kx Ky Kz Ss Por

3.47767e+01 3.47767e+01 3.47767e+00 1.00000e-09 2.12000e-01 $3.47767 \mathrm{e}+013.47767 \mathrm{e}+01$ 3.47767e+00 1.00000e-09 2.12000e-01 $3.47767 \mathrm{e}+013.47767 \mathrm{e}+01$ 3.47767e+00 1.00000e-09 2.12000e-01 $3.47767 \mathrm{e}+013.47767 \mathrm{e}+013.47767 \mathrm{e}+001.00000 \mathrm{e}-092.12000 \mathrm{e}-01$ $1.00000 \mathrm{e}-051.00000 \mathrm{e}-05$ 1.00000e-06 1.00000e-09 1.00000e-01 $1.00000 \mathrm{e}+001.00000 \mathrm{e}+001.00000 \mathrm{e}-011.00000 \mathrm{e}-091.00000 \mathrm{e}-01$ Element: 10443 \# of layers: 7

$\mathrm{Kx} \mathrm{Ky} \mathrm{Kz}$ Ss Por

3.47767e+01 3.47767e+01 3.47767e+00 1.00000e-09 2.12000e-01 $3.47767 \mathrm{e}+013.47767 \mathrm{e}+013.47767 \mathrm{e}+001.00000 \mathrm{e}-092.12000 \mathrm{e}-01$ $3.47767 \mathrm{e}+013.47767 \mathrm{e}+01$ 3.47767e+00 1.00000e-09 2.12000e-01 $3.47767 \mathrm{e}+013.47767 \mathrm{e}+01$ 3.47767e+00 1.00000e-09 2.12000e-01 $3.47767 \mathrm{e}+013.47767 \mathrm{e}+013.47767 \mathrm{e}+001.00000 \mathrm{e}-092.12000 \mathrm{e}-01$ $1.00000 \mathrm{e}-05$ 1.00000e-05 1.00000e-06 1.00000e-09 1.00000e-01 $1.00000 \mathrm{e}+001.00000 \mathrm{e}+001.00000 \mathrm{e}-01$ 1.00000e-09 1.00000e-01 Element: 10444 \# of layers: 7

Kx Ky Kz Ss Por

3.47767e+01 3.47767e+01 3.47767e+00 1.00000e-09 2.12000e-01 $3.47767 \mathrm{e}+013.47767 \mathrm{e}+013.47767 \mathrm{e}+001.00000 \mathrm{e}-092.12000 \mathrm{e}-01$ 3.47767e+01 3.47767e+01 3.47767e+00 1.00000e-09 2.12000e-01 $3.47767 \mathrm{e}+013.47767 \mathrm{e}+01$ 3.47767e+00 1.00000e-09 2.12000e-01 $3.47767 \mathrm{e}+013.47767 \mathrm{e}+013.47767 \mathrm{e}+001.00000 \mathrm{e}-092.12000 \mathrm{e}-01$ 
$1.00000 \mathrm{e}-05$ 1.00000e-05 1.00000e-06 1.00000e-09 1.00000e-01 $1.00000 \mathrm{e}+001.00000 \mathrm{e}+001.00000 \mathrm{e}-01$ 1.00000e-09 1.00000e-01 Element: 10445 \# of layers: 7

Kx Ky Kz Ss Por

3.47767e+01 3.47767e+01 3.47767e+00 1.00000e-09 2.12000e-01 $3.47767 \mathrm{e}+013.47767 \mathrm{e}+013.47767 \mathrm{e}+00$ 1.00000e-09 2.12000e-01 $3.47767 \mathrm{e}+013.47767 \mathrm{e}+013.47767 \mathrm{e}+00$ 1.00000e-09 2.12000e-01 $3.47767 \mathrm{e}+01$ 3.47767e+01 3.47767e+00 1.00000e-09 2.12000e-01 3.47767e+01 3.47767e+01 3.47767e+00 1.00000e-09 2.12000e-01 $1.00000 \mathrm{e}-05$ 1.00000e-05 1.00000e-06 1.00000e-09 1.00000e-01 $1.00000 \mathrm{e}+001.00000 \mathrm{e}+001.00000 \mathrm{e}-01$ 1.00000e-09 1.00000e-01 Element: 10446 \# of layers: 7

Kx Ky Kz Ss Por

3.47767e+01 3.47767e+01 3.47767e+00 1.00000e-09 2.12000e-01 $3.47767 \mathrm{e}+013.47767 \mathrm{e}+013.47767 \mathrm{e}+001.00000 \mathrm{e}-092.12000 \mathrm{e}-01$ $3.47767 \mathrm{e}+013.47767 \mathrm{e}+013.47767 \mathrm{e}+001.00000 \mathrm{e}-092.12000 \mathrm{e}-01$ $3.47767 \mathrm{e}+013.47767 \mathrm{e}+013.47767 \mathrm{e}+001.00000 \mathrm{e}-092.12000 \mathrm{e}-01$ $3.47767 \mathrm{e}+013.47767 \mathrm{e}+01$ 3.47767e+00 1.00000e-09 2.12000e-01 $1.00000 \mathrm{e}-051.00000 \mathrm{e}-051.00000 \mathrm{e}-061.00000 \mathrm{e}-091.00000 \mathrm{e}-01$ $1.00000 \mathrm{e}+001.00000 \mathrm{e}+001.00000 \mathrm{e}-011.00000 \mathrm{e}-09$ 1.00000e-01 Element: 10447 \# of layers: 7

$\mathrm{Kx} \mathrm{Ky} \mathrm{Kz}$ Ss Por

3.47767e+01 3.47767e+01 3.47767e+00 1.00000e-09 2.12000e-01 $3.47767 \mathrm{e}+013.47767 \mathrm{e}+01$ 3.47767e+00 1.00000e-09 2.12000e-01 $3.47767 \mathrm{e}+013.47767 \mathrm{e}+013.47767 \mathrm{e}+001.00000 \mathrm{e}-092.12000 \mathrm{e}-01$ $3.47767 \mathrm{e}+01$ 3.47767e+01 3.47767e+00 1.00000e-09 2.12000e-01 $3.47767 \mathrm{e}+013.47767 \mathrm{e}+01$ 3.47767e+00 1.00000e-09 2.12000e-01 $1.00000 \mathrm{e}-05$ 1.00000e-05 1.00000e-06 1.00000e-09 1.00000e-01 $1.00000 \mathrm{e}+001.00000 \mathrm{e}+001.00000 \mathrm{e}-011.00000 \mathrm{e}-091.00000 \mathrm{e}-01$ Element: 10448 \# of layers: 7

$\mathrm{Kx} \mathrm{Ky} \mathrm{Kz}$ Ss Por

3.47767e+01 3.47767e+01 3.47767e+00 1.00000e-09 2.12000e-01 $3.47767 \mathrm{e}+013.47767 \mathrm{e}+013.47767 \mathrm{e}+00$ 1.00000e-09 2.12000e-01 $3.47767 \mathrm{e}+013.47767 \mathrm{e}+013.47767 \mathrm{e}+001.00000 \mathrm{e}-09$ 2.12000e-01 $3.47767 \mathrm{e}+013.47767 \mathrm{e}+013.47767 \mathrm{e}+00$ 1.00000e-09 2.12000e-01 $3.47767 \mathrm{e}+013.47767 \mathrm{e}+013.47767 \mathrm{e}+00$ 1.00000e-09 2.12000e-01 $1.00000 \mathrm{e}-05$ 1.00000e-05 1.00000e-06 1.00000e-09 1.00000e-01 $1.00000 \mathrm{e}+001.00000 \mathrm{e}+001.00000 \mathrm{e}-011.00000 \mathrm{e}-091.00000 \mathrm{e}-01$ Element: 10449 \# of layers: 7

$\mathrm{Kx} \mathrm{Ky} \mathrm{Kz}$ Ss Por

3.47767e+01 3.47767e+01 3.47767e+00 1.00000e-09 2.12000e-01 3.47767e+01 3.47767e+01 3.47767e+00 1.00000e-09 2.12000e-01 $3.47767 \mathrm{e}+01$ 3.47767e+01 3.47767e+00 1.00000e-09 2.12000e-01 $3.47767 \mathrm{e}+013.47767 \mathrm{e}+01$ 3.47767e+00 1.00000e-09 2.12000e-01 $3.47767 \mathrm{e}+013.47767 \mathrm{e}+01$ 3.47767e+00 1.00000e-09 2.12000e-01 $1.00000 \mathrm{e}-05$ 1.00000e-05 1.00000e-06 1.00000e-09 1.00000e-01 
$1.00000 \mathrm{e}+001.00000 \mathrm{e}+001.00000 \mathrm{e}-011.00000 \mathrm{e}-091.00000 \mathrm{e}-01$

Element: 10450 \# of layers: 7

Kx Ky Kz Ss Por

3.47767e+01 3.47767e+01 3.47767e+00 1.00000e-09 2.12000e-01

$3.47767 \mathrm{e}+013.47767 \mathrm{e}+013.47767 \mathrm{e}+001.00000 \mathrm{e}-092.12000 \mathrm{e}-01$

$3.47767 \mathrm{e}+013.47767 \mathrm{e}+01$ 3.47767e+00 1.00000e-09 2.12000e-01

$3.47767 \mathrm{e}+013.47767 \mathrm{e}+01$ 3.47767e+00 1.00000e-09 2.12000e-01

$3.47767 \mathrm{e}+013.47767 \mathrm{e}+013.47767 \mathrm{e}+00$ 1.00000e-09 2.12000e-01

$1.00000 \mathrm{e}-05$ 1.00000e-05 1.00000e-06 1.00000e-09 1.00000e-01

$1.00000 \mathrm{e}+001.00000 \mathrm{e}+001.00000 \mathrm{e}-01$ 1.00000e-09 1.00000e-01

Element: 10451 \# of layers: 7

Kx Ky Kz Ss Por

3.47767e+01 3.47767e+01 3.47767e+00 1.00000e-09 2.12000e-01

$3.47767 \mathrm{e}+013.47767 \mathrm{e}+01$ 3.47767e+00 1.00000e-09 2.12000e-01

3.47767e+01 3.47767e+01 3.47767e+00 1.00000e-09 2.12000e-01

$3.47767 \mathrm{e}+013.47767 \mathrm{e}+013.47767 \mathrm{e}+00$ 1.00000e-09 2.12000e-01

3.47767e+01 3.47767e+01 3.47767e+00 1.00000e-09 2.12000e-01

$1.00000 \mathrm{e}-05$ 1.00000e-05 1.00000e-06 1.00000e-09 1.00000e-01

$1.00000 \mathrm{e}+001.00000 \mathrm{e}+001.00000 \mathrm{e}-01$ 1.00000e-09 1.00000e-01

Element: 10452 \# of layers: 6

Kx Ky Kz Ss Por

3.47767e+01 3.47767e+01 3.47767e+00 1.00000e-09 2.12000e-01

3.47767e+01 3.47767e+01 3.47767e+00 1.00000e-09 2.12000e-01

$3.47767 \mathrm{e}+013.47767 \mathrm{e}+01$ 3.47767e+00 1.00000e-09 2.12000e-01

$3.47767 \mathrm{e}+013.47767 \mathrm{e}+013.47767 \mathrm{e}+001.00000 \mathrm{e}-092.12000 \mathrm{e}-01$

$1.00000 \mathrm{e}-05$ 1.00000e-05 1.00000e-06 1.00000e-09 1.00000e-01

$1.00000 \mathrm{e}+001.00000 \mathrm{e}+001.00000 \mathrm{e}-011.00000 \mathrm{e}-09$ 1.00000e-01

Element: 10453 \# of layers: 6

Kx Ky Kz Ss Por

3.47767e+01 3.47767e+01 3.47767e+00 1.00000e-09 2.12000e-01

$3.47767 \mathrm{e}+013.47767 \mathrm{e}+01$ 3.47767e+00 1.00000e-09 2.12000e-01

$3.47767 \mathrm{e}+013.47767 \mathrm{e}+013.47767 \mathrm{e}+001.00000 \mathrm{e}-092.12000 \mathrm{e}-01$

$3.47767 \mathrm{e}+013.47767 \mathrm{e}+013.47767 \mathrm{e}+00$ 1.00000e-09 2.12000e-01

$1.00000 \mathrm{e}-05$ 1.00000e-05 1.00000e-06 1.00000e-09 1.00000e-01

$1.00000 \mathrm{e}+001.00000 \mathrm{e}+001.00000 \mathrm{e}-01$ 1.00000e-09 1.00000e-01

Element: 10454 \# of layers: 6

Kx Ky Kz Ss Por

4.66795e+01 4.66795e+01 4.66795e+00 1.00000e-09 2.12000e-01

$4.66795 \mathrm{e}+01$ 4.66795e+01 4.66795e+00 1.00000e-09 2.12000e-01

$4.66795 \mathrm{e}+014.66795 \mathrm{e}+014.66795 \mathrm{e}+001.00000 \mathrm{e}-092.12000 \mathrm{e}-01$

$4.66795 \mathrm{e}+014.66795 \mathrm{e}+014.66795 \mathrm{e}+001.00000 \mathrm{e}-092.12000 \mathrm{e}-01$

$1.00000 \mathrm{e}-05$ 1.00000e-05 1.00000e-06 1.00000e-09 1.00000e-01

$1.00000 \mathrm{e}+001.00000 \mathrm{e}+001.00000 \mathrm{e}-011.00000 \mathrm{e}-091.00000 \mathrm{e}-01$

Element: 10455 \# of layers: 6

$\mathrm{Kx} \mathrm{Ky} \mathrm{Kz}$ Ss Por

4.66795e+01 4.66795e+01 4.66795e+00 1.00000e-09 2.12000e-01 
4.66795e+01 4.66795e+01 4.66795e+00 1.00000e-09 2.12000e-01 $4.66795 \mathrm{e}+014.66795 \mathrm{e}+01$ 4.66795e+00 1.00000e-09 2.12000e-01 $4.66795 \mathrm{e}+014.66795 \mathrm{e}+014.66795 \mathrm{e}+00$ 1.00000e-09 2.12000e-01 $1.00000 \mathrm{e}-05$ 1.00000e-05 1.00000e-06 1.00000e-09 1.00000e-01 $1.00000 \mathrm{e}+001.00000 \mathrm{e}+001.00000 \mathrm{e}-01$ 1.00000e-09 1.00000e-01 Element: 10456 \# of layers: 6

$\mathrm{Kx} \mathrm{Ky} \mathrm{Kz}$ Ss Por

4.66795e+01 4.66795e+01 4.66795e+00 1.00000e-09 2.12000e-01 4.66795e+01 4.66795e+01 4.66795e+00 1.00000e-09 2.12000e-01 $4.66795 \mathrm{e}+014.66795 \mathrm{e}+014.66795 \mathrm{e}+00$ 1.00000e-09 2.12000e-01 $4.66795 \mathrm{e}+014.66795 \mathrm{e}+014.66795 \mathrm{e}+00$ 1.00000e-09 2.12000e-01 $1.00000 \mathrm{e}-05$ 1.00000e-05 1.00000e-06 1.00000e-09 1.00000e-01 $1.00000 \mathrm{e}+001.00000 \mathrm{e}+001.00000 \mathrm{e}-011.00000 \mathrm{e}-09$ 1.00000e-01 Element: 10457 \# of layers: 6

$\mathrm{Kx} \mathrm{Ky} \mathrm{Kz}$ Ss Por

3.47767e+01 3.47767e+01 3.47767e+00 1.00000e-09 2.12000e-01 3.47767e+01 3.47767e+01 3.47767e+00 1.00000e-09 2.12000e-01 $3.47767 \mathrm{e}+013.47767 \mathrm{e}+01$ 3.47767e+00 1.00000e-09 2.12000e-01 $3.47767 \mathrm{e}+013.47767 \mathrm{e}+01$ 3.47767e+00 1.00000e-09 2.12000e-01 $1.00000 \mathrm{e}-05$ 1.00000e-05 1.00000e-06 1.00000e-09 1.00000e-01 $1.00000 \mathrm{e}+001.00000 \mathrm{e}+001.00000 \mathrm{e}-011.00000 \mathrm{e}-091.00000 \mathrm{e}-01$ Element: 10458 \# of layers: 6

$\mathrm{Kx} \mathrm{Ky} \mathrm{Kz}$ Ss Por

3.47767e+01 3.47767e+01 3.47767e+00 1.00000e-09 2.12000e-01 $3.47767 \mathrm{e}+013.47767 \mathrm{e}+013.47767 \mathrm{e}+001.00000 \mathrm{e}-092.12000 \mathrm{e}-01$ $3.47767 \mathrm{e}+013.47767 \mathrm{e}+013.47767 \mathrm{e}+001.00000 \mathrm{e}-092.12000 \mathrm{e}-01$ $3.47767 \mathrm{e}+013.47767 \mathrm{e}+01$ 3.47767e+00 1.00000e-09 2.12000e-01 $1.00000 \mathrm{e}-05$ 1.00000e-05 1.00000e-06 1.00000e-09 1.00000e-01 $1.00000 \mathrm{e}+001.00000 \mathrm{e}+001.00000 \mathrm{e}-011.00000 \mathrm{e}-091.00000 \mathrm{e}-01$ Element: 10459 \# of layers: 6

$\mathrm{Kx} \mathrm{Ky} \mathrm{Kz}$ Ss Por

3.47767e+01 3.47767e+01 3.47767e+00 1.00000e-09 2.12000e-01 $3.47767 \mathrm{e}+013.47767 \mathrm{e}+013.47767 \mathrm{e}+001.00000 \mathrm{e}-092.12000 \mathrm{e}-01$ $3.47767 \mathrm{e}+013.47767 \mathrm{e}+013.47767 \mathrm{e}+001.00000 \mathrm{e}-092.12000 \mathrm{e}-01$ $3.47767 \mathrm{e}+013.47767 \mathrm{e}+013.47767 \mathrm{e}+00$ 1.00000e-09 2.12000e-01 $1.00000 \mathrm{e}-05$ 1.00000e-05 1.00000e-06 1.00000e-09 1.00000e-01 $1.00000 \mathrm{e}+001.00000 \mathrm{e}+001.00000 \mathrm{e}-011.00000 \mathrm{e}-091.00000 \mathrm{e}-01$ Element: 10460 \# of layers: 6

$\mathrm{Kx} \mathrm{Ky} \mathrm{Kz}$ Ss Por

3.47767e+01 3.47767e+01 3.47767e+00 1.00000e-09 2.12000e-01 $3.47767 \mathrm{e}+013.47767 \mathrm{e}+013.47767 \mathrm{e}+001.00000 \mathrm{e}-092.12000 \mathrm{e}-01$ $3.47767 \mathrm{e}+013.47767 \mathrm{e}+013.47767 \mathrm{e}+001.00000 \mathrm{e}-092.12000 \mathrm{e}-01$ 3.47767e+01 3.47767e+01 3.47767e+00 1.00000e-09 2.12000e-01 $1.00000 \mathrm{e}-051.00000 \mathrm{e}-051.00000 \mathrm{e}-061.00000 \mathrm{e}-091.00000 \mathrm{e}-01$ $1.00000 \mathrm{e}+001.00000 \mathrm{e}+001.00000 \mathrm{e}-01$ 1.00000e-09 1.00000e-01 Element: 10461 \# of layers: 6 
Kx Ky Kz Ss Por

4.66795e+01 4.66795e+01 4.66795e+00 1.00000e-09 2.12000e-01

$4.66795 \mathrm{e}+014.66795 \mathrm{e}+014.66795 \mathrm{e}+00$ 1.00000e-09 2.12000e-01

$4.66795 \mathrm{e}+014.66795 \mathrm{e}+014.66795 \mathrm{e}+001.00000 \mathrm{e}-092.12000 \mathrm{e}-01$

$4.66795 \mathrm{e}+014.66795 \mathrm{e}+014.66795 \mathrm{e}+001.00000 \mathrm{e}-092.12000 \mathrm{e}-01$

$1.00000 \mathrm{e}-05$ 1.00000e-05 1.00000e-06 1.00000e-09 1.00000e-01

$1.00000 \mathrm{e}+001.00000 \mathrm{e}+001.00000 \mathrm{e}-01$ 1.00000e-09 1.00000e-01

Element: 10462 \# of layers: 5

$\mathrm{Kx} \mathrm{Ky} \mathrm{Kz}$ Ss Por

4.66795e+01 4.66795e+01 4.66795e+00 1.00000e-09 2.12000e-01

$4.66795 \mathrm{e}+014.66795 \mathrm{e}+014.66795 \mathrm{e}+00$ 1.00000e-09 2.12000e-01

$4.66795 \mathrm{e}+014.66795 \mathrm{e}+014.66795 \mathrm{e}+001.00000 \mathrm{e}-092.12000 \mathrm{e}-01$

$1.00000 \mathrm{e}-05$ 1.00000e-05 1.00000e-06 1.00000e-09 1.00000e-01

$1.00000 \mathrm{e}+001.00000 \mathrm{e}+001.00000 \mathrm{e}-011.00000 \mathrm{e}-09$ 1.00000e-01

Element: 10463 \# of layers: 5

Kx Ky Kz Ss Por

4.66795e+01 4.66795e+01 4.66795e+00 1.00000e-09 2.12000e-01

$4.66795 \mathrm{e}+014.66795 \mathrm{e}+014.66795 \mathrm{e}+001.00000 \mathrm{e}-09$ 2.12000e-01

$4.66795 \mathrm{e}+014.66795 \mathrm{e}+01$ 4.66795e+00 1.00000e-09 2.12000e-01

$1.00000 \mathrm{e}-051.00000 \mathrm{e}-051.00000 \mathrm{e}-061.00000 \mathrm{e}-091.00000 \mathrm{e}-01$

$1.00000 \mathrm{e}+001.00000 \mathrm{e}+001.00000 \mathrm{e}-011.00000 \mathrm{e}-091.00000 \mathrm{e}-01$

Element: 10464 \# of layers: 5

$\mathrm{Kx} \mathrm{Ky} \mathrm{Kz}$ Ss Por

4.66795e+01 4.66795e+01 4.66795e+00 1.00000e-09 2.12000e-01

$4.66795 \mathrm{e}+014.66795 \mathrm{e}+014.66795 \mathrm{e}+001.00000 \mathrm{e}-092.12000 \mathrm{e}-01$

4.66795e+01 4.66795e+01 4.66795e+00 1.00000e-09 2.12000e-01

$1.00000 \mathrm{e}-05$ 1.00000e-05 1.00000e-06 1.00000e-09 1.00000e-01

$1.00000 \mathrm{e}+001.00000 \mathrm{e}+001.00000 \mathrm{e}-01$ 1.00000e-09 1.00000e-01

Element: 10465 \# of layers: 5

$\mathrm{Kx} \mathrm{Ky} \mathrm{Kz}$ Ss Por

4.66795e+01 4.66795e+01 4.66795e+00 1.00000e-09 2.12000e-01

$4.66795 \mathrm{e}+01$ 4.66795e+01 4.66795e+00 1.00000e-09 2.12000e-01

$4.66795 \mathrm{e}+014.66795 \mathrm{e}+014.66795 \mathrm{e}+00$ 1.00000e-09 2.12000e-01

$1.00000 \mathrm{e}-05$ 1.00000e-05 1.00000e-06 1.00000e-09 1.00000e-01

$1.00000 \mathrm{e}+001.00000 \mathrm{e}+001.00000 \mathrm{e}-011.00000 \mathrm{e}-091.00000 \mathrm{e}-01$

Element: 10466 \# of layers: 5

Kx Ky Kz Ss Por

4.66795e+01 4.66795e+01 4.66795e+00 1.00000e-09 2.12000e-01

$4.66795 \mathrm{e}+01$ 4.66795e+01 4.66795e+00 1.00000e-09 2.12000e-01

$4.66795 \mathrm{e}+014.66795 \mathrm{e}+014.66795 \mathrm{e}+00$ 1.00000e-09 2.12000e-01

$1.00000 \mathrm{e}-05$ 1.00000e-05 1.00000e-06 1.00000e-09 1.00000e-01

$1.00000 \mathrm{e}+001.00000 \mathrm{e}+001.00000 \mathrm{e}-011.00000 \mathrm{e}-091.00000 \mathrm{e}-01$

Element: 10467 \# of layers: 6

$\mathrm{Kx} \mathrm{Ky} \mathrm{Kz}$ Ss Por

4.66795e+01 4.66795e+01 4.66795e+00 1.00000e-09 2.12000e-01

$4.66795 \mathrm{e}+014.66795 \mathrm{e}+014.66795 \mathrm{e}+001.00000 \mathrm{e}-092.12000 \mathrm{e}-01$ 
4.66795e+01 4.66795e+01 4.66795e+00 1.00000e-09 2.12000e-01 $4.66795 \mathrm{e}+014.66795 \mathrm{e}+01$ 4.66795e+00 1.00000e-09 2.12000e-01 $1.00000 \mathrm{e}-05$ 1.00000e-05 1.00000e-06 1.00000e-09 1.00000e-01 $1.00000 \mathrm{e}+001.00000 \mathrm{e}+001.00000 \mathrm{e}-011.00000 \mathrm{e}-091.00000 \mathrm{e}-01$ Element: 10468 \# of layers: 6

$\mathrm{Kx} \mathrm{Ky} \mathrm{Kz}$ Ss Por

4.66795e+01 4.66795e+01 4.66795e+00 1.00000e-09 2.12000e-01 $4.66795 \mathrm{e}+014.66795 \mathrm{e}+014.66795 \mathrm{e}+00$ 1.00000e-09 2.12000e-01 $4.66795 \mathrm{e}+014.66795 \mathrm{e}+014.66795 \mathrm{e}+001.00000 \mathrm{e}-092.12000 \mathrm{e}-01$ $4.66795 \mathrm{e}+014.66795 \mathrm{e}+014.66795 \mathrm{e}+001.00000 \mathrm{e}-09$ 2.12000e-01 $1.00000 \mathrm{e}-05$ 1.00000e-05 1.00000e-06 1.00000e-09 1.00000e-01 $1.00000 \mathrm{e}+001.00000 \mathrm{e}+001.00000 \mathrm{e}-011.00000 \mathrm{e}-091.00000 \mathrm{e}-01$ Element: 10469 \# of layers: 5

$\mathrm{Kx} \mathrm{Ky} \mathrm{Kz}$ Ss Por

4.66795e+01 4.66795e+01 4.66795e+00 1.00000e-09 2.12000e-01 $4.66795 \mathrm{e}+014.66795 \mathrm{e}+014.66795 \mathrm{e}+001.00000 \mathrm{e}-092.12000 \mathrm{e}-01$ $4.66795 \mathrm{e}+014.66795 \mathrm{e}+014.66795 \mathrm{e}+00$ 1.00000e-09 2.12000e-01 $1.00000 \mathrm{e}-05$ 1.00000e-05 1.00000e-06 1.00000e-09 1.00000e-01 $1.00000 \mathrm{e}+001.00000 \mathrm{e}+001.00000 \mathrm{e}-011.00000 \mathrm{e}-091.00000 \mathrm{e}-01$ Element: 10470 \# of layers: 5

Kx Ky Kz Ss Por

4.66795e+01 4.66795e+01 4.66795e+00 1.00000e-09 2.12000e-01 $4.66795 \mathrm{e}+014.66795 \mathrm{e}+01$ 4.66795e+00 1.00000e-09 2.12000e-01 $4.66795 \mathrm{e}+014.66795 \mathrm{e}+014.66795 \mathrm{e}+001.00000 \mathrm{e}-09$ 2.12000e-01 $1.00000 \mathrm{e}-05$ 1.00000e-05 1.00000e-06 1.00000e-09 1.00000e-01 $1.00000 \mathrm{e}+001.00000 \mathrm{e}+001.00000 \mathrm{e}-011.00000 \mathrm{e}-091.00000 \mathrm{e}-01$ Element: 10471 \# of layers: 5

Kx Ky Kz Ss Por

4.66795e+01 4.66795e+01 4.66795e+00 1.00000e-09 2.12000e-01 $4.66795 \mathrm{e}+014.66795 \mathrm{e}+014.66795 \mathrm{e}+001.00000 \mathrm{e}-092.12000 \mathrm{e}-01$ $4.66795 \mathrm{e}+014.66795 \mathrm{e}+014.66795 \mathrm{e}+001.00000 \mathrm{e}-09$ 2.12000e-01 $1.00000 \mathrm{e}-051.00000 \mathrm{e}-05$ 1.00000e-06 1.00000e-09 1.00000e-01 $1.00000 \mathrm{e}+001.00000 \mathrm{e}+001.00000 \mathrm{e}-011.00000 \mathrm{e}-091.00000 \mathrm{e}-01$ Element: 10472 \# of layers: 5

$\mathrm{Kx} \mathrm{Ky} \mathrm{Kz}$ Ss Por

4.98341e+01 4.98341e+01 4.98341e+00 1.00000e-09 2.12000e-01 $4.98341 \mathrm{e}+014.98341 \mathrm{e}+014.98341 \mathrm{e}+001.00000 \mathrm{e}-092.12000 \mathrm{e}-01$ $4.98341 \mathrm{e}+014.98341 \mathrm{e}+014.98341 \mathrm{e}+00$ 1.00000e-09 2.12000e-01 $1.00000 \mathrm{e}-051.00000 \mathrm{e}-051.00000 \mathrm{e}-061.00000 \mathrm{e}-091.00000 \mathrm{e}-01$ $1.00000 \mathrm{e}+001.00000 \mathrm{e}+001.00000 \mathrm{e}-01$ 1.00000e-09 1.00000e-01 Element: 10473 \# of layers: 5

$\mathrm{Kx} \mathrm{Ky} \mathrm{Kz}$ Ss Por 4.98341e+01 4.98341e+01 4.98341e+00 1.00000e-09 2.12000e-01 4.98341e+01 4.98341e+01 4.98341e+00 1.00000e-09 2.12000e-01 $4.98341 \mathrm{e}+014.98341 \mathrm{e}+014.98341 \mathrm{e}+001.00000 \mathrm{e}-092.12000 \mathrm{e}-01$ 1.00000e-05 1.00000e-05 1.00000e-06 1.00000e-09 1.00000e-01 
$1.00000 \mathrm{e}+001.00000 \mathrm{e}+00$ 1.00000e-01 1.00000e-09 1.00000e-01

Element: 10474 \# of layers: 6

Kx Ky Kz Ss Por

$4.98341 \mathrm{e}+014.98341 \mathrm{e}+014.98341 \mathrm{e}+001.00000 \mathrm{e}-092.12000 \mathrm{e}-01$

$4.98341 \mathrm{e}+014.98341 \mathrm{e}+014.98341 \mathrm{e}+001.00000 \mathrm{e}-092.12000 \mathrm{e}-01$

$4.98341 \mathrm{e}+014.98341 \mathrm{e}+014.98341 \mathrm{e}+001.00000 \mathrm{e}-09$ 2.12000e-01

$4.98341 \mathrm{e}+014.98341 \mathrm{e}+014.98341 \mathrm{e}+001.00000 \mathrm{e}-09$ 2.12000e-01

$1.00000 \mathrm{e}-05$ 1.00000e-05 1.00000e-06 1.00000e-09 1.00000e-01

$1.00000 \mathrm{e}+001.00000 \mathrm{e}+001.00000 \mathrm{e}-011.00000 \mathrm{e}-091.00000 \mathrm{e}-01$

Element: 10475 \# of layers: 6

Kx Ky Kz Ss Por

4.66795e+01 4.66795e+01 4.66795e+00 1.00000e-09 2.12000e-01

$4.66795 \mathrm{e}+014.66795 \mathrm{e}+014.66795 \mathrm{e}+00$ 1.00000e-09 2.12000e-01

$4.66795 \mathrm{e}+014.66795 \mathrm{e}+014.66795 \mathrm{e}+00$ 1.00000e-09 2.12000e-01

$4.66795 \mathrm{e}+014.66795 \mathrm{e}+014.66795 \mathrm{e}+001.00000 \mathrm{e}-092.12000 \mathrm{e}-01$

$1.00000 \mathrm{e}-05$ 1.00000e-05 1.00000e-06 1.00000e-09 1.00000e-01

$1.00000 \mathrm{e}+001.00000 \mathrm{e}+001.00000 \mathrm{e}-01$ 1.00000e-09 1.00000e-01

Element: 10476 \# of layers: 6

$\mathrm{Kx} \mathrm{Ky} \mathrm{Kz}$ Ss Por

4.66795e+01 4.66795e+01 4.66795e+00 1.00000e-09 2.12000e-01

$4.66795 \mathrm{e}+014.66795 \mathrm{e}+014.66795 \mathrm{e}+001.00000 \mathrm{e}-092.12000 \mathrm{e}-01$

4.66795e+01 4.66795e+01 4.66795e+00 1.00000e-09 2.12000e-01

4.66795e+01 4.66795e+01 4.66795e+00 1.00000e-09 2.12000e-01

$1.00000 \mathrm{e}-051.00000 \mathrm{e}-051.00000 \mathrm{e}-061.00000 \mathrm{e}-091.00000 \mathrm{e}-01$

$1.00000 \mathrm{e}+001.00000 \mathrm{e}+001.00000 \mathrm{e}-011.00000 \mathrm{e}-091.00000 \mathrm{e}-01$

Element: 10477 \# of layers: 5

$\mathrm{Kx} \mathrm{Ky} \mathrm{Kz}$ Ss Por

4.66795e+01 4.66795e+01 4.66795e+00 1.00000e-09 2.12000e-01

$4.66795 \mathrm{e}+014.66795 \mathrm{e}+014.66795 \mathrm{e}+001.00000 \mathrm{e}-092.12000 \mathrm{e}-01$

$4.66795 \mathrm{e}+014.66795 \mathrm{e}+014.66795 \mathrm{e}+001.00000 \mathrm{e}-092.12000 \mathrm{e}-01$

$1.00000 \mathrm{e}-05$ 1.00000e-05 1.00000e-06 1.00000e-09 1.00000e-01

$1.00000 \mathrm{e}+001.00000 \mathrm{e}+001.00000 \mathrm{e}-01$ 1.00000e-09 1.00000e-01

Element: 10478 \# of layers: 5

$\mathrm{Kx} \mathrm{Ky} \mathrm{Kz}$ Ss Por

4.66795e+01 4.66795e+01 4.66795e+00 1.00000e-09 2.12000e-01

$4.66795 \mathrm{e}+014.66795 \mathrm{e}+014.66795 \mathrm{e}+001.00000 \mathrm{e}-092.12000 \mathrm{e}-01$

$4.66795 \mathrm{e}+014.66795 \mathrm{e}+014.66795 \mathrm{e}+001.00000 \mathrm{e}-092.12000 \mathrm{e}-01$

$1.00000 \mathrm{e}-05$ 1.00000e-05 1.00000e-06 1.00000e-09 1.00000e-01

$1.00000 \mathrm{e}+001.00000 \mathrm{e}+001.00000 \mathrm{e}-01$ 1.00000e-09 1.00000e-01

Element: 10479 \# of layers: 5

$\mathrm{Kx} \mathrm{Ky} \mathrm{Kz}$ Ss Por

4.98341e+01 4.98341e+01 4.98341e+00 1.00000e-09 2.12000e-01

$4.98341 \mathrm{e}+014.98341 \mathrm{e}+014.98341 \mathrm{e}+001.00000 \mathrm{e}-09$ 2.12000e-01

4.98341e+01 4.98341e+01 4.98341e+00 1.00000e-09 2.12000e-01

$1.00000 \mathrm{e}-05$ 1.00000e-05 1.00000e-06 1.00000e-09 1.00000e-01

$1.00000 \mathrm{e}+001.00000 \mathrm{e}+001.00000 \mathrm{e}-011.00000 \mathrm{e}-091.00000 \mathrm{e}-01$ 
Element: 10480 \# of layers: 5

Kx Ky Kz Ss Por

$4.98341 \mathrm{e}+014.98341 \mathrm{e}+014.98341 \mathrm{e}+00$ 1.00000e-09 2.12000e-01

$4.98341 \mathrm{e}+014.98341 \mathrm{e}+014.98341 \mathrm{e}+001.00000 \mathrm{e}-092.12000 \mathrm{e}-01$

$4.98341 \mathrm{e}+014.98341 \mathrm{e}+014.98341 \mathrm{e}+001.00000 \mathrm{e}-092.12000 \mathrm{e}-01$

$1.00000 \mathrm{e}-05$ 1.00000e-05 1.00000e-06 1.00000e-09 1.00000e-01

$1.00000 \mathrm{e}+001.00000 \mathrm{e}+001.00000 \mathrm{e}-011.00000 \mathrm{e}-091.00000 \mathrm{e}-01$

Element: 10481 \# of layers: 5

$\mathrm{Kx} \mathrm{Ky} \mathrm{Kz}$ Ss Por

$4.98341 \mathrm{e}^{+01} 4.98341 \mathrm{e}+014.98341 \mathrm{e}+00$ 1.00000e-09 2.12000e-01

$4.98341 \mathrm{e}+014.98341 \mathrm{e}+014.98341 \mathrm{e}+001.00000 \mathrm{e}-092.12000 \mathrm{e}-01$

$4.98341 \mathrm{e}+014.98341 \mathrm{e}+014.98341 \mathrm{e}+001.00000 \mathrm{e}-092.12000 \mathrm{e}-01$

$1.00000 \mathrm{e}-05$ 1.00000e-05 1.00000e-06 1.00000e-09 1.00000e-01

$1.00000 \mathrm{e}+001.00000 \mathrm{e}+001.00000 \mathrm{e}-011.00000 \mathrm{e}-091.00000 \mathrm{e}-01$

Element: 10482 \# of layers: 5

Kx Ky Kz Ss Por

$4.98341 \mathrm{e}+014.98341 \mathrm{e}+014.98341 \mathrm{e}+00$ 1.00000e-09 2.12000e-01

$4.98341 \mathrm{e}+014.98341 \mathrm{e}+014.98341 \mathrm{e}+001.00000 \mathrm{e}-092.12000 \mathrm{e}-01$

$4.98341 \mathrm{e}+014.98341 \mathrm{e}+014.98341 \mathrm{e}+00$ 1.00000e-09 2.12000e-01

$1.00000 \mathrm{e}-05$ 1.00000e-05 1.00000e-06 1.00000e-09 1.00000e-01

$1.00000 \mathrm{e}+001.00000 \mathrm{e}+001.00000 \mathrm{e}-011.00000 \mathrm{e}-091.00000 \mathrm{e}-01$

Element: 10483 \# of layers: 6

Kx Ky Kz Ss Por

$4.98341 \mathrm{e}+014.98341 \mathrm{e}+014.98341 \mathrm{e}+00$ 1.00000e-09 2.12000e-01

$4.98341 \mathrm{e}+014.98341 \mathrm{e}+014.98341 \mathrm{e}+001.00000 \mathrm{e}-092.12000 \mathrm{e}-01$

$4.98341 \mathrm{e}+014.98341 \mathrm{e}+014.98341 \mathrm{e}+001.00000 \mathrm{e}-092.12000 \mathrm{e}-01$

$4.98341 \mathrm{e}+014.98341 \mathrm{e}+014.98341 \mathrm{e}+001.00000 \mathrm{e}-092.12000 \mathrm{e}-01$

$1.00000 \mathrm{e}-05$ 1.00000e-05 1.00000e-06 1.00000e-09 1.00000e-01

$1.00000 \mathrm{e}+001.00000 \mathrm{e}+001.00000 \mathrm{e}-011.00000 \mathrm{e}-091.00000 \mathrm{e}-01$

Element: 10484 \# of layers: 6

Kx Ky Kz Ss Por

$4.98341 \mathrm{e}+014.98341 \mathrm{e}+014.98341 \mathrm{e}+00$ 1.00000e-09 2.12000e-01

$4.98341 \mathrm{e}+014.98341 \mathrm{e}+014.98341 \mathrm{e}+00$ 1.00000e-09 2.12000e-01

$4.98341 \mathrm{e}+014.98341 \mathrm{e}+014.98341 \mathrm{e}+001.00000 \mathrm{e}-092.12000 \mathrm{e}-01$

$4.98341 \mathrm{e}+014.98341 \mathrm{e}+014.98341 \mathrm{e}+001.00000 \mathrm{e}-092.12000 \mathrm{e}-01$

$1.00000 \mathrm{e}-05$ 1.00000e-05 1.00000e-06 1.00000e-09 1.00000e-01

$1.00000 \mathrm{e}+001.00000 \mathrm{e}+001.00000 \mathrm{e}-011.00000 \mathrm{e}-091.00000 \mathrm{e}-01$

Element: 10485 \# of layers: 6

Kx Ky Kz Ss Por

$4.98341 \mathrm{e}+014.98341 \mathrm{e}+014.98341 \mathrm{e}+00$ 1.00000e-09 2.12000e-01

$4.98341 \mathrm{e}+014.98341 \mathrm{e}+014.98341 \mathrm{e}+001.00000 \mathrm{e}-092.12000 \mathrm{e}-01$

$4.98341 \mathrm{e}+014.98341 \mathrm{e}+014.98341 \mathrm{e}+001.00000 \mathrm{e}-092.12000 \mathrm{e}-01$

$4.98341 \mathrm{e}+014.98341 \mathrm{e}+014.98341 \mathrm{e}+001.00000 \mathrm{e}-092.12000 \mathrm{e}-01$

$1.00000 \mathrm{e}-05$ 1.00000e-05 1.00000e-06 1.00000e-09 1.00000e-01

$1.00000 \mathrm{e}+001.00000 \mathrm{e}+001.00000 \mathrm{e}-011.00000 \mathrm{e}-091.00000 \mathrm{e}-01$

Element: 10486 \# of layers: 5 


\section{Kx Ky Kz Ss Por}

4.98341e+01 4.98341e+01 4.98341e+00 1.00000e-09 2.12000e-01 $4.98341 \mathrm{e}+014.98341 \mathrm{e}+014.98341 \mathrm{e}+001.00000 \mathrm{e}-09$ 2.12000e-01 $4.98341 \mathrm{e}+014.98341 \mathrm{e}+014.98341 \mathrm{e}+001.00000 \mathrm{e}-092.12000 \mathrm{e}-01$ $1.00000 \mathrm{e}-051.00000 \mathrm{e}-051.00000 \mathrm{e}-061.00000 \mathrm{e}-091.00000 \mathrm{e}-01$ $1.00000 \mathrm{e}+001.00000 \mathrm{e}+001.00000 \mathrm{e}-011.00000 \mathrm{e}-091.00000 \mathrm{e}-01$ Element: 10487 \# of layers: 5

Kx Ky Kz Ss Por

$4.98341 \mathrm{e}+014.98341 \mathrm{e}+014.98341 \mathrm{e}+00$ 1.00000e-09 2.12000e-01 $4.98341 \mathrm{e}+014.98341 \mathrm{e}+014.98341 \mathrm{e}+00$ 1.00000e-09 2.12000e-01 $4.98341 \mathrm{e}+014.98341 \mathrm{e}+014.98341 \mathrm{e}+00$ 1.00000e-09 2.12000e-01 $1.00000 \mathrm{e}-05$ 1.00000e-05 1.00000e-06 1.00000e-09 1.00000e-01 $1.00000 \mathrm{e}+001.00000 \mathrm{e}+001.00000 \mathrm{e}-01$ 1.00000e-09 1.00000e-01 Element: 10488 \# of layers: 5

$\mathrm{Kx} \mathrm{Ky} \mathrm{Kz}$ Ss Por 4.98341e+01 4.98341e+01 4.98341e+00 1.00000e-09 2.12000e-01 $4.98341 \mathrm{e}+014.98341 \mathrm{e}+014.98341 \mathrm{e}+001.00000 \mathrm{e}-092.12000 \mathrm{e}-01$ $4.98341 \mathrm{e}+014.98341 \mathrm{e}+014.98341 \mathrm{e}+001.00000 \mathrm{e}-092.12000 \mathrm{e}-01$ $1.00000 \mathrm{e}-05$ 1.00000e-05 1.00000e-06 1.00000e-09 1.00000e-01 $1.00000 \mathrm{e}+001.00000 \mathrm{e}+001.00000 \mathrm{e}-011.00000 \mathrm{e}-091.00000 \mathrm{e}-01$ Element: 10489 \# of layers: 5

$\mathrm{Kx} \mathrm{Ky} \mathrm{Kz}$ Ss Por

3.78751e+01 3.78751e+01 3.78751e+00 1.00000e-09 2.12000e-01 $3.78751 \mathrm{e}+013.78751 \mathrm{e}+013.78751 \mathrm{e}+001.00000 \mathrm{e}-092.12000 \mathrm{e}-01$ $3.78751 \mathrm{e}+013.78751 \mathrm{e}+013.78751 \mathrm{e}+001.00000 \mathrm{e}-092.12000 \mathrm{e}-01$ $1.00000 \mathrm{e}-05$ 1.00000e-05 1.00000e-06 1.00000e-09 1.00000e-01 $1.00000 \mathrm{e}+001.00000 \mathrm{e}+001.00000 \mathrm{e}-011.00000 \mathrm{e}-091.00000 \mathrm{e}-01$ Element: 10490 \# of layers: 6

Kx Ky Kz Ss Por

3.78751e+01 3.78751e+01 3.78751e+00 1.00000e-09 2.12000e-01 $3.78751 \mathrm{e}+013.78751 \mathrm{e}+013.78751 \mathrm{e}+001.00000 \mathrm{e}-092.12000 \mathrm{e}-01$ $3.78751 \mathrm{e}+013.78751 \mathrm{e}+013.78751 \mathrm{e}+001.00000 \mathrm{e}-092.12000 \mathrm{e}-01$ $3.78751 \mathrm{e}+013.78751 \mathrm{e}+013.78751 \mathrm{e}+001.00000 \mathrm{e}-092.12000 \mathrm{e}-01$ $1.00000 \mathrm{e}-05$ 1.00000e-05 1.00000e-06 1.00000e-09 1.00000e-01 $1.00000 \mathrm{e}+001.00000 \mathrm{e}+001.00000 \mathrm{e}-01$ 1.00000e-09 1.00000e-01 Element: 10491 \# of layers: 6

Kx Ky Kz Ss Por

$3.78751 \mathrm{e}+013.78751 \mathrm{e}+013.78751 \mathrm{e}+00$ 1.00000e-09 2.12000e-01 $3.78751 \mathrm{e}+013.78751 \mathrm{e}+013.78751 \mathrm{e}+001.00000 \mathrm{e}-092.12000 \mathrm{e}-01$ $3.78751 \mathrm{e}+013.78751 \mathrm{e}+013.78751 \mathrm{e}+001.00000 \mathrm{e}-092.12000 \mathrm{e}-01$ $3.78751 \mathrm{e}+013.78751 \mathrm{e}+013.78751 \mathrm{e}+001.00000 \mathrm{e}-092.12000 \mathrm{e}-01$ $1.00000 \mathrm{e}-05$ 1.00000e-05 1.00000e-06 1.00000e-09 1.00000e-01 $1.00000 \mathrm{e}+001.00000 \mathrm{e}+001.00000 \mathrm{e}-01$ 1.00000e-09 1.00000e-01 Element: 10492 \# of layers: 6

$\mathrm{Kx} \mathrm{Ky} \mathrm{Kz} \mathrm{Ss} \mathrm{Por}$

3.78751e+01 3.78751e+01 3.78751e+00 1.00000e-09 2.12000e-01 
$3.78751 \mathrm{e}+013.78751 \mathrm{e}+013.78751 \mathrm{e}+00$ 1.00000e-09 2.12000e-01 $3.78751 \mathrm{e}+013.78751 \mathrm{e}+013.78751 \mathrm{e}+001.00000 \mathrm{e}-092.12000 \mathrm{e}-01$ $3.78751 \mathrm{e}+013.78751 \mathrm{e}+013.78751 \mathrm{e}+001.00000 \mathrm{e}-092.12000 \mathrm{e}-01$ $1.00000 \mathrm{e}-05$ 1.00000e-05 1.00000e-06 1.00000e-09 1.00000e-01 $1.00000 \mathrm{e}+001.00000 \mathrm{e}+001.00000 \mathrm{e}-011.00000 \mathrm{e}-091.00000 \mathrm{e}-01$ Element: 10493 \# of layers: 5

Kx Ky Kz Ss Por

$3.78751 \mathrm{e}+013.78751 \mathrm{e}+013.78751 \mathrm{e}+00$ 1.00000e-09 2.12000e-01

$3.78751 \mathrm{e}+013.78751 \mathrm{e}+013.78751 \mathrm{e}+001.00000 \mathrm{e}-092.12000 \mathrm{e}-01$

$3.78751 \mathrm{e}+013.78751 \mathrm{e}+013.78751 \mathrm{e}+001.00000 \mathrm{e}-092.12000 \mathrm{e}-01$ $1.00000 \mathrm{e}-05$ 1.00000e-05 1.00000e-06 1.00000e-09 1.00000e-01

$1.00000 \mathrm{e}+001.00000 \mathrm{e}+001.00000 \mathrm{e}-011.00000 \mathrm{e}-091.00000 \mathrm{e}-01$ Element: 10494 \# of layers: 5

Kx Ky Kz Ss Por

$4.98341 \mathrm{e}+014.98341 \mathrm{e}+014.98341 \mathrm{e}+00$ 1.00000e-09 2.12000e-01 $4.98341 \mathrm{e}+014.98341 \mathrm{e}+014.98341 \mathrm{e}+001.00000 \mathrm{e}-092.12000 \mathrm{e}-01$ $4.98341 \mathrm{e}+014.98341 \mathrm{e}+014.98341 \mathrm{e}+00$ 1.00000e-09 2.12000e-01 $1.00000 \mathrm{e}-05$ 1.00000e-05 1.00000e-06 1.00000e-09 1.00000e-01 $1.00000 \mathrm{e}+001.00000 \mathrm{e}+001.00000 \mathrm{e}-011.00000 \mathrm{e}-091.00000 \mathrm{e}-01$ Element: 10495 \# of layers: 5

Kx Ky Kz Ss Por

$4.98341 \mathrm{e}+014.98341 \mathrm{e}+014.98341 \mathrm{e}+00$ 1.00000e-09 2.12000e-01 $4.98341 \mathrm{e}+014.98341 \mathrm{e}+014.98341 \mathrm{e}+001.00000 \mathrm{e}-092.12000 \mathrm{e}-01$ $4.98341 \mathrm{e}+014.98341 \mathrm{e}+014.98341 \mathrm{e}+001.00000 \mathrm{e}-092.12000 \mathrm{e}-01$ $1.00000 \mathrm{e}-051.00000 \mathrm{e}-05$ 1.00000e-06 1.00000e-09 1.00000e-01 $1.00000 \mathrm{e}+001.00000 \mathrm{e}+001.00000 \mathrm{e}-011.00000 \mathrm{e}-091.00000 \mathrm{e}-01$ Element: 10496 \# of layers: 5

Kx Ky Kz Ss Por

$3.78751 \mathrm{e}+013.78751 \mathrm{e}+013.78751 \mathrm{e}+00$ 1.00000e-09 2.12000e-01

$3.78751 \mathrm{e}+013.78751 \mathrm{e}+013.78751 \mathrm{e}+001.00000 \mathrm{e}-092.12000 \mathrm{e}-01$

$3.78751 \mathrm{e}+013.78751 \mathrm{e}+013.78751 \mathrm{e}+001.00000 \mathrm{e}-092.12000 \mathrm{e}-01$ $1.00000 \mathrm{e}-05$ 1.00000e-05 1.00000e-06 1.00000e-09 1.00000e-01

$1.00000 \mathrm{e}+001.00000 \mathrm{e}+001.00000 \mathrm{e}-011.00000 \mathrm{e}-091.00000 \mathrm{e}-01$ Element: 10497 \# of layers: 6

Kx Ky Kz Ss Por

$3.78751 \mathrm{e}+013.78751 \mathrm{e}+013.78751 \mathrm{e}+00$ 1.00000e-09 2.12000e-01 $3.78751 \mathrm{e}+013.78751 \mathrm{e}+013.78751 \mathrm{e}+001.00000 \mathrm{e}-092.12000 \mathrm{e}-01$ $3.78751 \mathrm{e}+013.78751 \mathrm{e}+013.78751 \mathrm{e}+00$ 1.00000e-09 2.12000e-01 $3.78751 \mathrm{e}+013.78751 \mathrm{e}+013.78751 \mathrm{e}+00$ 1.00000e-09 2.12000e-01 $1.00000 \mathrm{e}-05$ 1.00000e-05 1.00000e-06 1.00000e-09 1.00000e-01 $1.00000 \mathrm{e}+001.00000 \mathrm{e}+001.00000 \mathrm{e}-011.00000 \mathrm{e}-091.00000 \mathrm{e}-01$ Element: 10498 \# of layers: 6

Kx Ky Kz Ss Por

$3.47767 \mathrm{e}+013.47767 \mathrm{e}+013.47767 \mathrm{e}+00$ 1.00000e-09 2.12000e-01 $3.47767 \mathrm{e}+013.47767 \mathrm{e}+013.47767 \mathrm{e}+001.00000 \mathrm{e}-092.12000 \mathrm{e}-01$ $3.47767 e+013.47767 e+013.47767 e+001.00000 e-092.12000 e-01$ 
3.47767e+01 3.47767e+01 3.47767e+00 1.00000e-09 2.12000e-01 $1.00000 \mathrm{e}-05$ 1.00000e-05 1.00000e-06 1.00000e-09 1.00000e-01 $1.00000 \mathrm{e}+001.00000 \mathrm{e}+001.00000 \mathrm{e}-011.00000 \mathrm{e}-09$ 1.00000e-01

Element: 10499 \# of layers: 6

$\mathrm{Kx} \mathrm{Ky} \mathrm{Kz}$ Ss Por

3.47767e+01 3.47767e+01 3.47767e+00 1.00000e-09 2.12000e-01

$3.47767 \mathrm{e}+013.47767 \mathrm{e}+01$ 3.47767e+00 1.00000e-09 2.12000e-01

$3.47767 \mathrm{e}+013.47767 \mathrm{e}+013.47767 \mathrm{e}+001.00000 \mathrm{e}-092.12000 \mathrm{e}-01$

3.47767e+01 3.47767e+01 3.47767e+00 1.00000e-09 2.12000e-01

$1.00000 \mathrm{e}-05$ 1.00000e-05 1.00000e-06 1.00000e-09 1.00000e-01

$1.00000 \mathrm{e}+001.00000 \mathrm{e}+001.00000 \mathrm{e}-011.00000 \mathrm{e}-091.00000 \mathrm{e}-01$

Element: 10500 \# of layers: 6

$\mathrm{Kx} \mathrm{Ky} \mathrm{Kz}$ Ss Por

3.47767e+01 3.47767e+01 3.47767e+00 1.00000e-09 2.12000e-01

$3.47767 \mathrm{e}+013.47767 \mathrm{e}+013.47767 \mathrm{e}+001.00000 \mathrm{e}-09$ 2.12000e-01

$3.47767 \mathrm{e}+013.47767 \mathrm{e}+013.47767 \mathrm{e}+001.00000 \mathrm{e}-092.12000 \mathrm{e}-01$

3.47767e+01 3.47767e+01 3.47767e+00 1.00000e-09 2.12000e-01

$1.00000 \mathrm{e}-05$ 1.00000e-05 1.00000e-06 1.00000e-09 1.00000e-01

$1.00000 \mathrm{e}+001.00000 \mathrm{e}+001.00000 \mathrm{e}-011.00000 \mathrm{e}-091.00000 \mathrm{e}-01$

Element: 10501 \# of layers: 6

$\mathrm{Kx} \mathrm{Ky} \mathrm{Kz}$ Ss Por

4.66795e+01 4.66795e+01 4.66795e+00 1.00000e-09 2.12000e-01

$4.66795 \mathrm{e}+014.66795 \mathrm{e}+01$ 4.66795e+00 1.00000e-09 2.12000e-01

$4.66795 \mathrm{e}+014.66795 \mathrm{e}+014.66795 \mathrm{e}+001.00000 \mathrm{e}-09$ 2.12000e-01

$4.66795 \mathrm{e}+014.66795 \mathrm{e}+014.66795 \mathrm{e}+001.00000 \mathrm{e}-092.12000 \mathrm{e}-01$

$1.00000 \mathrm{e}-05$ 1.00000e-05 1.00000e-06 1.00000e-09 1.00000e-01

$1.00000 \mathrm{e}+001.00000 \mathrm{e}+001.00000 \mathrm{e}-011.00000 \mathrm{e}-091.00000 \mathrm{e}-01$

Element: 10502 \# of layers: 6

Kx Ky Kz Ss Por

4.66795e+01 4.66795e+01 4.66795e+00 1.00000e-09 2.12000e-01

$4.66795 \mathrm{e}+014.66795 \mathrm{e}+014.66795 \mathrm{e}+00$ 1.00000e-09 2.12000e-01

$4.66795 \mathrm{e}+014.66795 \mathrm{e}+014.66795 \mathrm{e}+001.00000 \mathrm{e}-092.12000 \mathrm{e}-01$

$4.66795 \mathrm{e}+014.66795 \mathrm{e}+014.66795 \mathrm{e}+001.00000 \mathrm{e}-092.12000 \mathrm{e}-01$

$1.00000 \mathrm{e}-05$ 1.00000e-05 1.00000e-06 1.00000e-09 1.00000e-01

$1.00000 \mathrm{e}+001.00000 \mathrm{e}+001.00000 \mathrm{e}-011.00000 \mathrm{e}-091.00000 \mathrm{e}-01$

Element: 10503 \# of layers: 5

Kx Ky Kz Ss Por

4.98341e+01 4.98341e+01 4.98341e+00 1.00000e-09 2.12000e-01

$4.98341 \mathrm{e}+014.98341 \mathrm{e}+014.98341 \mathrm{e}+001.00000 \mathrm{e}-09$ 2.12000e-01

$4.98341 \mathrm{e}+014.98341 \mathrm{e}+014.98341 \mathrm{e}+00$ 1.00000e-09 2.12000e-01

$1.00000 \mathrm{e}-05$ 1.00000e-05 1.00000e-06 1.00000e-09 1.00000e-01

$1.00000 \mathrm{e}+001.00000 \mathrm{e}+001.00000 \mathrm{e}-011.00000 \mathrm{e}-091.00000 \mathrm{e}-01$

Element: 10504 \# of layers: 5

$\mathrm{Kx} \mathrm{Ky} \mathrm{Kz}$ Ss Por

3.78751e+01 3.78751e+01 3.78751e+00 1.00000e-09 2.12000e-01

$3.78751 \mathrm{e}+013.78751 \mathrm{e}+013.78751 \mathrm{e}+001.00000 \mathrm{e}-092.12000 \mathrm{e}-01$ 
$3.78751 \mathrm{e}+013.78751 \mathrm{e}+013.78751 \mathrm{e}+00$ 1.00000e-09 2.12000e-01 $1.00000 \mathrm{e}-05$ 1.00000e-05 1.00000e-06 1.00000e-09 1.00000e-01 $1.00000 \mathrm{e}+001.00000 \mathrm{e}+001.00000 \mathrm{e}-011.00000 \mathrm{e}-091.00000 \mathrm{e}-01$ Element: 10505 \# of layers: 6

$\mathrm{Kx} \mathrm{Ky} \mathrm{Kz}$ Ss Por

3.47767e+01 3.47767e+01 3.47767e+00 1.00000e-09 2.12000e-01 $3.47767 \mathrm{e}+013.47767 \mathrm{e}+01$ 3.47767e+00 1.00000e-09 2.12000e-01 $3.47767 \mathrm{e}+013.47767 \mathrm{e}+013.47767 \mathrm{e}+001.00000 \mathrm{e}-092.12000 \mathrm{e}-01$ 3.47767e+01 3.47767e+01 3.47767e+00 1.00000e-09 2.12000e-01 $1.00000 \mathrm{e}-05$ 1.00000e-05 1.00000e-06 1.00000e-09 1.00000e-01 $1.00000 \mathrm{e}+001.00000 \mathrm{e}+001.00000 \mathrm{e}-011.00000 \mathrm{e}-091.00000 \mathrm{e}-01$ Element: 10506 \# of layers: 7

$\mathrm{Kx} \mathrm{Ky} \mathrm{Kz}$ Ss Por

3.18202e+01 3.18202e+01 3.18202e+00 1.00000e-09 2.12000e-01 $3.18202 \mathrm{e}+013.18202 \mathrm{e}+013.18202 \mathrm{e}+00$ 1.00000e-09 2.12000e-01 $3.18202 \mathrm{e}+013.18202 \mathrm{e}+013.18202 \mathrm{e}+00$ 1.00000e-09 2.12000e-01 3.18202e+01 3.18202e+01 3.18202e+00 1.00000e-09 2.12000e-01 3.18202e+01 3.18202e+01 3.18202e+00 1.00000e-09 2.12000e-01 $1.00000 \mathrm{e}-05$ 1.00000e-05 1.00000e-06 1.00000e-09 1.00000e-01 $1.00000 \mathrm{e}+001.00000 \mathrm{e}+001.00000 \mathrm{e}-011.00000 \mathrm{e}-091.00000 \mathrm{e}-01$ Element: 10507 \# of layers: 7

$\mathrm{Kx} \mathrm{Ky} \mathrm{Kz}$ Ss Por

3.18202e+01 3.18202e+01 3.18202e+00 1.00000e-09 2.12000e-01 $3.18202 \mathrm{e}+013.18202 \mathrm{e}+013.18202 \mathrm{e}+00$ 1.00000e-09 2.12000e-01 $3.18202 \mathrm{e}+013.18202 \mathrm{e}+013.18202 \mathrm{e}+001.00000 \mathrm{e}-092.12000 \mathrm{e}-01$ $3.18202 \mathrm{e}+013.18202 \mathrm{e}+013.18202 \mathrm{e}+001.00000 \mathrm{e}-092.12000 \mathrm{e}-01$ $3.18202 \mathrm{e}+013.18202 \mathrm{e}+013.18202 \mathrm{e}+00$ 1.00000e-09 2.12000e-01 $1.00000 \mathrm{e}-05$ 1.00000e-05 1.00000e-06 1.00000e-09 1.00000e-01 $1.00000 \mathrm{e}+001.00000 \mathrm{e}+001.00000 \mathrm{e}-011.00000 \mathrm{e}-091.00000 \mathrm{e}-01$ Element: 10508 \# of layers: 7

$\mathrm{Kx} \mathrm{Ky} \mathrm{Kz}$ Ss Por

3.18202e+01 3.18202e+01 3.18202e+00 1.00000e-09 2.12000e-01 $3.18202 \mathrm{e}+013.18202 \mathrm{e}+013.18202 \mathrm{e}+00$ 1.00000e-09 2.12000e-01 $3.18202 \mathrm{e}+013.18202 \mathrm{e}+013.18202 \mathrm{e}+001.00000 \mathrm{e}-092.12000 \mathrm{e}-01$ $3.18202 \mathrm{e}+013.18202 \mathrm{e}+013.18202 \mathrm{e}+00$ 1.00000e-09 2.12000e-01 $3.18202 \mathrm{e}+013.18202 \mathrm{e}+013.18202 \mathrm{e}+00$ 1.00000e-09 2.12000e-01 $1.00000 \mathrm{e}-05$ 1.00000e-05 1.00000e-06 1.00000e-09 1.00000e-01 $1.00000 \mathrm{e}+001.00000 \mathrm{e}+001.00000 \mathrm{e}-011.00000 \mathrm{e}-091.00000 \mathrm{e}-01$ Element: 10509 \# of layers: 7

$\mathrm{Kx} \mathrm{Ky} \mathrm{Kz}$ Ss Por

3.18202e+01 3.18202e+01 3.18202e+00 1.00000e-09 2.12000e-01 $3.18202 \mathrm{e}+013.18202 \mathrm{e}+013.18202 \mathrm{e}+00$ 1.00000e-09 2.12000e-01 $3.18202 \mathrm{e}+013.18202 \mathrm{e}+013.18202 \mathrm{e}+001.00000 \mathrm{e}-092.12000 \mathrm{e}-01$ 3.18202e+01 3.18202e+01 3.18202e+00 1.00000e-09 2.12000e-01 $3.18202 \mathrm{e}+013.18202 \mathrm{e}+013.18202 \mathrm{e}+00$ 1.00000e-09 2.12000e-01 $1.00000 \mathrm{e}-05$ 1.00000e-05 1.00000e-06 1.00000e-09 1.00000e-01 
$1.00000 \mathrm{e}+001.00000 \mathrm{e}+001.00000 \mathrm{e}-011.00000 \mathrm{e}-091.00000 \mathrm{e}-01$

Element: 10510 \# of layers: 7

$\mathrm{Kx} \mathrm{Ky} \mathrm{Kz}$ Ss Por

3.18202e+01 3.18202e+01 3.18202e+00 1.00000e-09 2.12000e-01

$3.18202 \mathrm{e}+013.18202 \mathrm{e}+013.18202 \mathrm{e}+00$ 1.00000e-09 2.12000e-01

$3.18202 \mathrm{e}+013.18202 \mathrm{e}+013.18202 \mathrm{e}+00$ 1.00000e-09 2.12000e-01

$3.18202 \mathrm{e}+013.18202 \mathrm{e}+01$ 3.18202e+00 1.00000e-09 2.12000e-01

$3.18202 \mathrm{e}+013.18202 \mathrm{e}+013.18202 \mathrm{e}+00$ 1.00000e-09 2.12000e-01

$1.00000 \mathrm{e}-05$ 1.00000e-05 1.00000e-06 1.00000e-09 1.00000e-01

$1.00000 \mathrm{e}+001.00000 \mathrm{e}+001.00000 \mathrm{e}-01$ 1.00000e-09 1.00000e-01

Element: 10511 \# of layers: 7

Kx Ky Kz Ss Por

3.18202e+01 3.18202e+01 3.18202e+00 1.00000e-09 2.12000e-01

$3.18202 \mathrm{e}+013.18202 \mathrm{e}+013.18202 \mathrm{e}+00$ 1.00000e-09 2.12000e-01

$3.18202 \mathrm{e}+013.18202 \mathrm{e}+013.18202 \mathrm{e}+00$ 1.00000e-09 2.12000e-01

$3.18202 \mathrm{e}+013.18202 \mathrm{e}+013.18202 \mathrm{e}+00$ 1.00000e-09 2.12000e-01

$3.18202 \mathrm{e}+013.18202 \mathrm{e}+013.18202 \mathrm{e}+00$ 1.00000e-09 2.12000e-01

$1.00000 \mathrm{e}-05$ 1.00000e-05 1.00000e-06 1.00000e-09 1.00000e-01

$1.00000 \mathrm{e}+001.00000 \mathrm{e}+001.00000 \mathrm{e}-01$ 1.00000e-09 1.00000e-01

Element: 10512 \# of layers: 7

$\mathrm{Kx} \mathrm{Ky} \mathrm{Kz}$ Ss Por

3.18202e+01 3.18202e+01 3.18202e+00 1.00000e-09 2.12000e-01

$3.18202 \mathrm{e}+013.18202 \mathrm{e}+01$ 3.18202e+00 1.00000e-09 2.12000e-01

$3.18202 \mathrm{e}+013.18202 \mathrm{e}+01$ 3.18202e+00 1.00000e-09 2.12000e-01

$3.18202 \mathrm{e}+013.18202 \mathrm{e}+013.18202 \mathrm{e}+001.00000 \mathrm{e}-092.12000 \mathrm{e}-01$

$3.18202 \mathrm{e}+013.18202 \mathrm{e}+013.18202 \mathrm{e}+00$ 1.00000e-09 2.12000e-01

$1.00000 \mathrm{e}-05$ 1.00000e-05 1.00000e-06 1.00000e-09 1.00000e-01

$1.00000 \mathrm{e}+001.00000 \mathrm{e}+001.00000 \mathrm{e}-01$ 1.00000e-09 1.00000e-01

Element: 10513 \# of layers: 7

$\mathrm{Kx} \mathrm{Ky} \mathrm{Kz}$ Ss Por

3.18202e+01 3.18202e+01 3.18202e+00 1.00000e-09 2.12000e-01

$3.18202 \mathrm{e}+013.18202 \mathrm{e}+013.18202 \mathrm{e}+00$ 1.00000e-09 2.12000e-01

$3.18202 \mathrm{e}+013.18202 \mathrm{e}+013.18202 \mathrm{e}+00$ 1.00000e-09 2.12000e-01

$3.18202 \mathrm{e}+013.18202 \mathrm{e}+01$ 3.18202e+00 1.00000e-09 2.12000e-01

$3.18202 \mathrm{e}+013.18202 \mathrm{e}+013.18202 \mathrm{e}+00$ 1.00000e-09 2.12000e-01

$1.00000 \mathrm{e}-05$ 1.00000e-05 1.00000e-06 1.00000e-09 1.00000e-01

$1.00000 \mathrm{e}+001.00000 \mathrm{e}+001.00000 \mathrm{e}-011.00000 \mathrm{e}-091.00000 \mathrm{e}-01$

Element: 10514 \# of layers: 7

$\mathrm{Kx} \mathrm{Ky} \mathrm{Kz}$ Ss Por

3.18202e+01 3.18202e+01 3.18202e+00 1.00000e-09 2.12000e-01

$3.18202 \mathrm{e}+013.18202 \mathrm{e}+013.18202 \mathrm{e}+00$ 1.00000e-09 2.12000e-01

$3.18202 \mathrm{e}+013.18202 \mathrm{e}+013.18202 \mathrm{e}+00$ 1.00000e-09 2.12000e-01

$3.18202 \mathrm{e}+013.18202 \mathrm{e}+01$ 3.18202e+00 1.00000e-09 2.12000e-01

$3.18202 \mathrm{e}+013.18202 \mathrm{e}+01$ 3.18202e+00 1.00000e-09 2.12000e-01 $1.00000 \mathrm{e}-05$ 1.00000e-05 1.00000e-06 1.00000e-09 1.00000e-01

$1.00000 \mathrm{e}+001.00000 \mathrm{e}+001.00000 \mathrm{e}-011.00000 \mathrm{e}-091.00000 \mathrm{e}-01$ 
Element: 10515 \# of layers: 7

Kx Ky Kz Ss Por

$3.18202 \mathrm{e}+013.18202 \mathrm{e}+013.18202 \mathrm{e}+00$ 1.00000e-09 2.12000e-01

$3.18202 \mathrm{e}+013.18202 \mathrm{e}+013.18202 \mathrm{e}+00$ 1.00000e-09 2.12000e-01

$3.18202 \mathrm{e}+013.18202 \mathrm{e}+013.18202 \mathrm{e}+00$ 1.00000e-09 2.12000e-01

$3.18202 \mathrm{e}+013.18202 \mathrm{e}+013.18202 \mathrm{e}+001.00000 \mathrm{e}-092.12000 \mathrm{e}-01$

$3.18202 \mathrm{e}+013.18202 \mathrm{e}+013.18202 \mathrm{e}+001.00000 \mathrm{e}-092.12000 \mathrm{e}-01$

$1.00000 \mathrm{e}-05$ 1.00000e-05 1.00000e-06 1.00000e-09 1.00000e-01

$1.00000 \mathrm{e}+001.00000 \mathrm{e}+001.00000 \mathrm{e}-011.00000 \mathrm{e}-091.00000 \mathrm{e}-01$

Element: 10516 \# of layers: 7

Kx Ky Kz Ss Por

$5.86880 \mathrm{e}+015.86880 \mathrm{e}+015.86880 \mathrm{e}+00$ 1.00000e-09 2.12000e-01

$5.86880 \mathrm{e}+015.86880 \mathrm{e}+015.86880 \mathrm{e}+001.00000 \mathrm{e}-092.12000 \mathrm{e}-01$

$5.86880 \mathrm{e}+015.86880 \mathrm{e}+015.86880 \mathrm{e}+001.00000 \mathrm{e}-092.12000 \mathrm{e}-01$

$5.86880 \mathrm{e}+015.86880 \mathrm{e}+015.86880 \mathrm{e}+001.00000 \mathrm{e}-092.12000 \mathrm{e}-01$

$5.86880 \mathrm{e}+015.86880 \mathrm{e}+015.86880 \mathrm{e}+001.00000 \mathrm{e}-092.12000 \mathrm{e}-01$

$1.00000 \mathrm{e}-05$ 1.00000e-05 1.00000e-06 1.00000e-09 1.00000e-01

$1.00000 \mathrm{e}+001.00000 \mathrm{e}+001.00000 \mathrm{e}-011.00000 \mathrm{e}-091.00000 \mathrm{e}-01$

Element: 10517 \# of layers: 8

Kx Ky Kz Ss Por

$5.86880 \mathrm{e}+015.86880 \mathrm{e}+015.86880 \mathrm{e}+001.00000 \mathrm{e}-092.12000 \mathrm{e}-01$

$5.86880 \mathrm{e}+015.86880 \mathrm{e}+015.86880 \mathrm{e}+001.00000 \mathrm{e}-092.12000 \mathrm{e}-01$

$5.86880 \mathrm{e}+015.86880 \mathrm{e}+015.86880 \mathrm{e}+001.00000 \mathrm{e}-092.12000 \mathrm{e}-01$

$5.86880 \mathrm{e}+015.86880 \mathrm{e}+015.86880 \mathrm{e}+001.00000 \mathrm{e}-092.12000 \mathrm{e}-01$

$5.86880 \mathrm{e}+015.86880 \mathrm{e}+015.86880 \mathrm{e}+001.00000 \mathrm{e}-092.12000 \mathrm{e}-01$

$1.00000 \mathrm{e}-02$ 1.00000e-02 1.00000e-03 1.00000e-09 1.00000e-01

$1.00000 \mathrm{e}-05$ 1.00000e-05 1.00000e-06 1.00000e-09 1.00000e-01

$1.00000 \mathrm{e}+001.00000 \mathrm{e}+001.00000 \mathrm{e}-011.00000 \mathrm{e}-091.00000 \mathrm{e}-01$

Element: 10518 \# of layers: 7

Kx Ky Kz Ss Por

$5.86880 \mathrm{e}+015.86880 \mathrm{e}+015.86880 \mathrm{e}+00$ 1.00000e-09 2.12000e-01

$5.86880 \mathrm{e}+015.86880 \mathrm{e}+015.86880 \mathrm{e}+001.00000 \mathrm{e}-092.12000 \mathrm{e}-01$

$5.86880 \mathrm{e}+015.86880 \mathrm{e}+015.86880 \mathrm{e}+001.00000 \mathrm{e}-092.12000 \mathrm{e}-01$

$5.86880 \mathrm{e}+015.86880 \mathrm{e}+015.86880 \mathrm{e}+001.00000 \mathrm{e}-092.12000 \mathrm{e}-01$

$5.86880 \mathrm{e}+015.86880 \mathrm{e}+015.86880 \mathrm{e}+001.00000 \mathrm{e}-092.12000 \mathrm{e}-01$

$1.00000 \mathrm{e}-05$ 1.00000e-05 1.00000e-06 1.00000e-09 1.00000e-01

$1.00000 \mathrm{e}+001.00000 \mathrm{e}+001.00000 \mathrm{e}-011.00000 \mathrm{e}-091.00000 \mathrm{e}-01$

Element: 10519 \# of layers: 7

Kx Ky Kz Ss Por

$5.86880 \mathrm{e}+015.86880 \mathrm{e}+01$ 5.86880e+00 1.00000e-09 2.12000e-01

$5.86880 \mathrm{e}+015.86880 \mathrm{e}+015.86880 \mathrm{e}+001.00000 \mathrm{e}-092.12000 \mathrm{e}-01$

$5.86880 \mathrm{e}+015.86880 \mathrm{e}+015.86880 \mathrm{e}+001.00000 \mathrm{e}-092.12000 \mathrm{e}-01$

$5.86880 \mathrm{e}+015.86880 \mathrm{e}+015.86880 \mathrm{e}+001.00000 \mathrm{e}-092.12000 \mathrm{e}-01$

$5.86880 \mathrm{e}+015.86880 \mathrm{e}+015.86880 \mathrm{e}+001.00000 \mathrm{e}-092.12000 \mathrm{e}-01$

$1.00000 \mathrm{e}-05$ 1.00000e-05 1.00000e-06 1.00000e-09 1.00000e-01

$1.00000 \mathrm{e}+001.00000 \mathrm{e}+001.00000 \mathrm{e}-011.00000 \mathrm{e}-091.00000 \mathrm{e}-01$ 
Element: 10520 \# of layers: 7

$\mathrm{Kx} \mathrm{Ky} \mathrm{Kz}$ Ss Por

$5.86880 \mathrm{e}+015.86880 \mathrm{e}+015.86880 \mathrm{e}+001.00000 \mathrm{e}-092.12000 \mathrm{e}-01$

$5.86880 \mathrm{e}+015.86880 \mathrm{e}+015.86880 \mathrm{e}+001.00000 \mathrm{e}-092.12000 \mathrm{e}-01$

$5.86880 \mathrm{e}+015.86880 \mathrm{e}+015.86880 \mathrm{e}+001.00000 \mathrm{e}-092.12000 \mathrm{e}-01$

$5.86880 \mathrm{e}+015.86880 \mathrm{e}+015.86880 \mathrm{e}+001.00000 \mathrm{e}-092.12000 \mathrm{e}-01$

$5.86880 \mathrm{e}+015.86880 \mathrm{e}+015.86880 \mathrm{e}+001.00000 \mathrm{e}-092.12000 \mathrm{e}-01$

$1.00000 \mathrm{e}-05$ 1.00000e-05 1.00000e-06 1.00000e-09 1.00000e-01

$1.00000 \mathrm{e}+001.00000 \mathrm{e}+001.00000 \mathrm{e}-011.00000 \mathrm{e}-091.00000 \mathrm{e}-01$

Element: 10521 \# of layers: 7

$\mathrm{Kx} \mathrm{Ky} \mathrm{Kz}$ Ss Por

3.18202e+01 3.18202e+01 3.18202e+00 1.00000e-09 2.12000e-01

$3.18202 \mathrm{e}+01$ 3.18202e+01 3.18202e+00 1.00000e-09 2.12000e-01

$3.18202 \mathrm{e}+013.18202 \mathrm{e}+01$ 3.18202e+00 1.00000e-09 2.12000e-01

$3.18202 \mathrm{e}+013.18202 \mathrm{e}+013.18202 \mathrm{e}+00$ 1.00000e-09 2.12000e-01

$3.18202 \mathrm{e}+013.18202 \mathrm{e}+013.18202 \mathrm{e}+00$ 1.00000e-09 2.12000e-01

$1.00000 \mathrm{e}-05$ 1.00000e-05 1.00000e-06 1.00000e-09 1.00000e-01

$1.00000 \mathrm{e}+001.00000 \mathrm{e}+001.00000 \mathrm{e}-01$ 1.00000e-09 1.00000e-01

Element: 10522 \# of layers: 7

$\mathrm{Kx} \mathrm{Ky} \mathrm{Kz}$ Ss Por

3.18202e+01 3.18202e+01 3.18202e+00 1.00000e-09 2.12000e-01

$3.18202 \mathrm{e}+013.18202 \mathrm{e}+01$ 3.18202e+00 1.00000e-09 2.12000e-01

$3.18202 \mathrm{e}+013.18202 \mathrm{e}+01$ 3.18202e+00 1.00000e-09 2.12000e-01

$3.18202 \mathrm{e}+013.18202 \mathrm{e}+01$ 3.18202e+00 1.00000e-09 2.12000e-01

$3.18202 \mathrm{e}+013.18202 \mathrm{e}+013.18202 \mathrm{e}+00$ 1.00000e-09 2.12000e-01

$1.00000 \mathrm{e}-05$ 1.00000e-05 1.00000e-06 1.00000e-09 1.00000e-01

$1.00000 \mathrm{e}+001.00000 \mathrm{e}+001.00000 \mathrm{e}-011.00000 \mathrm{e}-09$ 1.00000e-01

Element: 10523 \# of layers: 7

Kx Ky Kz Ss Por

$5.86880 \mathrm{e}+015.86880 \mathrm{e}+015.86880 \mathrm{e}+001.00000 \mathrm{e}-092.12000 \mathrm{e}-01$

$5.86880 \mathrm{e}+015.86880 \mathrm{e}+015.86880 \mathrm{e}+001.00000 \mathrm{e}-092.12000 \mathrm{e}-01$

$5.86880 \mathrm{e}+015.86880 \mathrm{e}+015.86880 \mathrm{e}+001.00000 \mathrm{e}-092.12000 \mathrm{e}-01$

$5.86880 \mathrm{e}+015.86880 \mathrm{e}+015.86880 \mathrm{e}+001.00000 \mathrm{e}-092.12000 \mathrm{e}-01$

$5.86880 \mathrm{e}+015.86880 \mathrm{e}+015.86880 \mathrm{e}+001.00000 \mathrm{e}-092.12000 \mathrm{e}-01$

$1.00000 \mathrm{e}-05$ 1.00000e-05 1.00000e-06 1.00000e-09 1.00000e-01

$1.00000 \mathrm{e}+001.00000 \mathrm{e}+001.00000 \mathrm{e}-011.00000 \mathrm{e}-091.00000 \mathrm{e}-01$

Element: 10524 \# of layers: 8

Kx Ky Kz Ss Por

$5.86880 \mathrm{e}+015.86880 \mathrm{e}+015.86880 \mathrm{e}+001.00000 \mathrm{e}-092.12000 \mathrm{e}-01$

$5.86880 \mathrm{e}+015.86880 \mathrm{e}+015.86880 \mathrm{e}+001.00000 \mathrm{e}-092.12000 \mathrm{e}-01$

$5.86880 \mathrm{e}+015.86880 \mathrm{e}+015.86880 \mathrm{e}+001.00000 \mathrm{e}-092.12000 \mathrm{e}-01$

$5.86880 \mathrm{e}+015.86880 \mathrm{e}+015.86880 \mathrm{e}+001.00000 \mathrm{e}-092.12000 \mathrm{e}-01$

$5.86880 \mathrm{e}+015.86880 \mathrm{e}+015.86880 \mathrm{e}+001.00000 \mathrm{e}-092.12000 \mathrm{e}-01$

$1.00000 \mathrm{e}-02$ 1.00000e-02 1.00000e-03 1.00000e-09 1.00000e-01

$1.00000 \mathrm{e}-05$ 1.00000e-05 1.00000e-06 1.00000e-09 1.00000e-01

$1.00000 \mathrm{e}+001.00000 \mathrm{e}+001.00000 \mathrm{e}-011.00000 \mathrm{e}-091.00000 \mathrm{e}-01$ 
Element: 10525 \# of layers: 8

$\mathrm{Kx} \mathrm{Ky} \mathrm{Kz}$ Ss Por

$5.86880 \mathrm{e}+015.86880 \mathrm{e}+015.86880 \mathrm{e}+001.00000 \mathrm{e}-092.12000 \mathrm{e}-01$

$5.86880 \mathrm{e}+015.86880 \mathrm{e}+015.86880 \mathrm{e}+001.00000 \mathrm{e}-092.12000 \mathrm{e}-01$

$5.86880 \mathrm{e}+015.86880 \mathrm{e}+015.86880 \mathrm{e}+001.00000 \mathrm{e}-092.12000 \mathrm{e}-01$

$5.86880 \mathrm{e}+015.86880 \mathrm{e}+015.86880 \mathrm{e}+001.00000 \mathrm{e}-092.12000 \mathrm{e}-01$

$5.86880 \mathrm{e}+015.86880 \mathrm{e}+015.86880 \mathrm{e}+001.00000 \mathrm{e}-092.12000 \mathrm{e}-01$

$1.00000 \mathrm{e}-02$ 1.00000e-02 1.00000e-03 1.00000e-09 1.00000e-01

$1.00000 \mathrm{e}-05$ 1.00000e-05 1.00000e-06 1.00000e-09 1.00000e-01

$1.00000 \mathrm{e}+001.00000 \mathrm{e}+001.00000 \mathrm{e}-011.00000 \mathrm{e}-091.00000 \mathrm{e}-01$

Element: 10526 \# of layers: 9

Kx Ky Kz Ss Por

$5.86880 \mathrm{e}+015.86880 \mathrm{e}+015.86880 \mathrm{e}+001.00000 \mathrm{e}-092.12000 \mathrm{e}-01$

$5.86880 \mathrm{e}+015.86880 \mathrm{e}+015.86880 \mathrm{e}+001.00000 \mathrm{e}-092.12000 \mathrm{e}-01$

$5.86880 \mathrm{e}+015.86880 \mathrm{e}+015.86880 \mathrm{e}+001.00000 \mathrm{e}-092.12000 \mathrm{e}-01$

$5.86880 \mathrm{e}+015.86880 \mathrm{e}+015.86880 \mathrm{e}+001.00000 \mathrm{e}-092.12000 \mathrm{e}-01$

$5.86880 \mathrm{e}+015.86880 \mathrm{e}+015.86880 \mathrm{e}+001.00000 \mathrm{e}-092.12000 \mathrm{e}-01$

$1.00000 \mathrm{e}-02$ 1.00000e-02 1.00000e-03 1.00000e-09 1.00000e-01

$1.00000 \mathrm{e}+001.00000 \mathrm{e}+001.00000 \mathrm{e}-011.00000 \mathrm{e}-091.00000 \mathrm{e}-01$

$1.00000 \mathrm{e}-051.00000 \mathrm{e}-051.00000 \mathrm{e}-061.00000 \mathrm{e}-091.00000 \mathrm{e}-01$

$1.00000 \mathrm{e}+001.00000 \mathrm{e}+001.00000 \mathrm{e}-011.00000 \mathrm{e}-091.00000 \mathrm{e}-01$

Element: 10527 \# of layers: 9

$\mathrm{Kx} \mathrm{Ky} \mathrm{Kz}$ Ss Por

$5.86880 \mathrm{e}+015.86880 \mathrm{e}+015.86880 \mathrm{e}+001.00000 \mathrm{e}-092.12000 \mathrm{e}-01$

$5.86880 \mathrm{e}+015.86880 \mathrm{e}+015.86880 \mathrm{e}+001.00000 \mathrm{e}-092.12000 \mathrm{e}-01$

$5.86880 \mathrm{e}+015.86880 \mathrm{e}+015.86880 \mathrm{e}+001.00000 \mathrm{e}-092.12000 \mathrm{e}-01$

$5.86880 \mathrm{e}+015.86880 \mathrm{e}+015.86880 \mathrm{e}+001.00000 \mathrm{e}-092.12000 \mathrm{e}-01$

$5.86880 \mathrm{e}+015.86880 \mathrm{e}+015.86880 \mathrm{e}+001.00000 \mathrm{e}-092.12000 \mathrm{e}-01$

$1.00000 \mathrm{e}-02$ 1.00000e-02 1.00000e-03 1.00000e-09 1.00000e-01

$1.00000 \mathrm{e}+001.00000 \mathrm{e}+001.00000 \mathrm{e}-011.00000 \mathrm{e}-091.00000 \mathrm{e}-01$

$1.00000 \mathrm{e}-05$ 1.00000e-05 1.00000e-06 1.00000e-09 1.00000e-01

$1.00000 \mathrm{e}+001.00000 \mathrm{e}+001.00000 \mathrm{e}-01$ 1.00000e-09 1.00000e-01

Element: 10528 \# of layers: 9

$\mathrm{Kx} \mathrm{Ky} \mathrm{Kz}$ Ss Por

$5.86880 \mathrm{e}+015.86880 \mathrm{e}+015.86880 \mathrm{e}+00$ 1.00000e-09 2.12000e-01

$5.86880 \mathrm{e}+015.86880 \mathrm{e}+015.86880 \mathrm{e}+001.00000 \mathrm{e}-092.12000 \mathrm{e}-01$

$5.86880 \mathrm{e}+015.86880 \mathrm{e}+015.86880 \mathrm{e}+001.00000 \mathrm{e}-092.12000 \mathrm{e}-01$

$5.86880 \mathrm{e}+015.86880 \mathrm{e}+015.86880 \mathrm{e}+001.00000 \mathrm{e}-092.12000 \mathrm{e}-01$

$5.86880 \mathrm{e}+015.86880 \mathrm{e}+015.86880 \mathrm{e}+001.00000 \mathrm{e}-092.12000 \mathrm{e}-01$

$1.00000 \mathrm{e}-02$ 1.00000e-02 1.00000e-03 1.00000e-09 1.00000e-01

$1.00000 \mathrm{e}+001.00000 \mathrm{e}+001.00000 \mathrm{e}-011.00000 \mathrm{e}-091.00000 \mathrm{e}-01$

$1.00000 \mathrm{e}-05$ 1.00000e-05 1.00000e-06 1.00000e-09 1.00000e-01

$1.00000 \mathrm{e}+001.00000 \mathrm{e}+001.00000 \mathrm{e}-01$ 1.00000e-09 1.00000e-01

Element: 10529 \# of layers: 8

$\mathrm{Kx} \mathrm{Ky} \mathrm{Kz} \mathrm{Ss} \mathrm{Por}$

5.86880e+01 5.86880e+01 5.86880e+00 1.00000e-09 2.12000e-01 
$5.86880 \mathrm{e}+015.86880 \mathrm{e}+015.86880 \mathrm{e}+001.00000 \mathrm{e}-092.12000 \mathrm{e}-01$ $5.86880 \mathrm{e}+015.86880 \mathrm{e}+015.86880 \mathrm{e}+001.00000 \mathrm{e}-092.12000 \mathrm{e}-01$ $5.86880 \mathrm{e}+015.86880 \mathrm{e}+015.86880 \mathrm{e}+001.00000 \mathrm{e}-092.12000 \mathrm{e}-01$ $5.86880 \mathrm{e}+015.86880 \mathrm{e}+015.86880 \mathrm{e}+001.00000 \mathrm{e}-092.12000 \mathrm{e}-01$ $1.00000 \mathrm{e}-02$ 1.00000e-02 1.00000e-03 1.00000e-09 1.00000e-01 $1.00000 \mathrm{e}-05$ 1.00000e-05 1.00000e-06 1.00000e-09 1.00000e-01 $1.00000 \mathrm{e}+001.00000 \mathrm{e}+001.00000 \mathrm{e}-011.00000 \mathrm{e}-091.00000 \mathrm{e}-01$ Element: 10530 \# of layers: 8

$\mathrm{Kx} \mathrm{Ky} \mathrm{Kz}$ Ss Por

$5.86880 \mathrm{e}+015.86880 \mathrm{e}+015.86880 \mathrm{e}+001.00000 \mathrm{e}-092.12000 \mathrm{e}-01$ $5.86880 \mathrm{e}+015.86880 \mathrm{e}+015.86880 \mathrm{e}+001.00000 \mathrm{e}-092.12000 \mathrm{e}-01$ $5.86880 \mathrm{e}+015.86880 \mathrm{e}+015.86880 \mathrm{e}+001.00000 \mathrm{e}-092.12000 \mathrm{e}-01$ $5.86880 \mathrm{e}+015.86880 \mathrm{e}+015.86880 \mathrm{e}+00$ 1.00000e-09 2.12000e-01 $5.86880 \mathrm{e}+015.86880 \mathrm{e}+015.86880 \mathrm{e}+001.00000 \mathrm{e}-092.12000 \mathrm{e}-01$ $1.00000 \mathrm{e}-02$ 1.00000e-02 1.00000e-03 1.00000e-09 1.00000e-01 $1.00000 \mathrm{e}-05$ 1.00000e-05 1.00000e-06 1.00000e-09 1.00000e-01 $1.00000 \mathrm{e}+001.00000 \mathrm{e}+001.00000 \mathrm{e}-011.00000 \mathrm{e}-091.00000 \mathrm{e}-01$ Element: 10531 \# of layers: 8

$\mathrm{Kx} \mathrm{Ky} \mathrm{Kz}$ Ss Por

$5.86880 \mathrm{e}+015.86880 \mathrm{e}+015.86880 \mathrm{e}+001.00000 \mathrm{e}-092.12000 \mathrm{e}-01$ $5.86880 \mathrm{e}+015.86880 \mathrm{e}+015.86880 \mathrm{e}+001.00000 \mathrm{e}-092.12000 \mathrm{e}-01$ $5.86880 \mathrm{e}+015.86880 \mathrm{e}+015.86880 \mathrm{e}+001.00000 \mathrm{e}-092.12000 \mathrm{e}-01$ $5.86880 \mathrm{e}+015.86880 \mathrm{e}+015.86880 \mathrm{e}+001.00000 \mathrm{e}-092.12000 \mathrm{e}-01$ $5.86880 \mathrm{e}+015.86880 \mathrm{e}+015.86880 \mathrm{e}+001.00000 \mathrm{e}-092.12000 \mathrm{e}-01$ $1.00000 \mathrm{e}-02$ 1.00000e-02 1.00000e-03 1.00000e-09 1.00000e-01 $1.00000 \mathrm{e}-05$ 1.00000e-05 1.00000e-06 1.00000e-09 1.00000e-01 $1.00000 \mathrm{e}+001.00000 \mathrm{e}+001.00000 \mathrm{e}-01$ 1.00000e-09 1.00000e-01 Element: 10532 \# of layers: 8

Kx Ky Kz Ss Por

$5.86880 \mathrm{e}+015.86880 \mathrm{e}+015.86880 \mathrm{e}+001.00000 \mathrm{e}-092.12000 \mathrm{e}-01$

$5.86880 \mathrm{e}+015.86880 \mathrm{e}+015.86880 \mathrm{e}+001.00000 \mathrm{e}-092.12000 \mathrm{e}-01$

$5.86880 \mathrm{e}+015.86880 \mathrm{e}+015.86880 \mathrm{e}+001.00000 \mathrm{e}-092.12000 \mathrm{e}-01$

$5.86880 \mathrm{e}+015.86880 \mathrm{e}+015.86880 \mathrm{e}+001.00000 \mathrm{e}-092.12000 \mathrm{e}-01$

$5.86880 \mathrm{e}+015.86880 \mathrm{e}+015.86880 \mathrm{e}+001.00000 \mathrm{e}-092.12000 \mathrm{e}-01$ $1.00000 \mathrm{e}-02$ 1.00000e-02 1.00000e-03 1.00000e-09 1.00000e-01 $1.00000 \mathrm{e}-05$ 1.00000e-05 1.00000e-06 1.00000e-09 1.00000e-01 $1.00000 \mathrm{e}+001.00000 \mathrm{e}+001.00000 \mathrm{e}-011.00000 \mathrm{e}-091.00000 \mathrm{e}-01$ Element: 10533 \# of layers: 7

$\mathrm{Kx} \mathrm{Ky} \mathrm{Kz}$ Ss Por

$5.86880 \mathrm{e}+015.86880 \mathrm{e}+015.86880 \mathrm{e}+00$ 1.00000e-09 2.12000e-01 $5.86880 \mathrm{e}+015.86880 \mathrm{e}+015.86880 \mathrm{e}+001.00000 \mathrm{e}-092.12000 \mathrm{e}-01$ $5.86880 \mathrm{e}+015.86880 \mathrm{e}+015.86880 \mathrm{e}+001.00000 \mathrm{e}-092.12000 \mathrm{e}-01$ $5.86880 \mathrm{e}+015.86880 \mathrm{e}+015.86880 \mathrm{e}+001.00000 \mathrm{e}-092.12000 \mathrm{e}-01$ $1.00000 \mathrm{e}-02$ 1.00000e-02 1.00000e-03 1.00000e-09 1.00000e-01 $1.00000 \mathrm{e}-05$ 1.00000e-05 1.00000e-06 1.00000e-09 1.00000e-01 $1.00000 \mathrm{e}+001.00000 \mathrm{e}+001.00000 \mathrm{e}-011.00000 \mathrm{e}-091.00000 \mathrm{e}-01$ 
Element: 10534 \# of layers: 7

$\mathrm{Kx} \mathrm{Ky} \mathrm{Kz}$ Ss Por

5.86880e+01 5.86880e+01 5.86880e+00 1.00000e-09 2.12000e-01

$5.86880 \mathrm{e}+015.86880 \mathrm{e}+015.86880 \mathrm{e}+001.00000 \mathrm{e}-092.12000 \mathrm{e}-01$

$5.86880 \mathrm{e}+015.86880 \mathrm{e}+015.86880 \mathrm{e}+001.00000 \mathrm{e}-092.12000 \mathrm{e}-01$

$5.86880 \mathrm{e}+015.86880 \mathrm{e}+015.86880 \mathrm{e}+001.00000 \mathrm{e}-092.12000 \mathrm{e}-01$

$1.00000 \mathrm{e}-02$ 1.00000e-02 1.00000e-03 1.00000e-09 1.00000e-01

$1.00000 \mathrm{e}-05$ 1.00000e-05 1.00000e-06 1.00000e-09 1.00000e-01

$1.00000 \mathrm{e}+001.00000 \mathrm{e}+001.00000 \mathrm{e}-011.00000 \mathrm{e}-091.00000 \mathrm{e}-01$

Element: 10535 \# of layers: 7

$\mathrm{Kx} \mathrm{Ky} \mathrm{Kz}$ Ss Por

4.94741e+01 4.94741e+01 4.94741e+00 1.00000e-09 2.12000e-01

$4.94741 \mathrm{e}+014.94741 \mathrm{e}+014.94741 \mathrm{e}+00$ 1.00000e-09 2.12000e-01

$4.94741 \mathrm{e}+014.94741 \mathrm{e}+014.94741 \mathrm{e}+00$ 1.00000e-09 2.12000e-01

4.94741e+01 4.94741e+01 4.94741e+00 1.00000e-09 2.12000e-01

$1.00000 \mathrm{e}-02$ 1.00000e-02 1.00000e-03 1.00000e-09 1.00000e-01

$1.00000 \mathrm{e}-05$ 1.00000e-05 1.00000e-06 1.00000e-09 1.00000e-01

$1.00000 \mathrm{e}+001.00000 \mathrm{e}+001.00000 \mathrm{e}-01$ 1.00000e-09 1.00000e-01

Element: 10536 \# of layers: 6

$\mathrm{Kx} \mathrm{Ky} \mathrm{Kz}$ Ss Por

4.94741e+01 4.94741e+01 4.94741e+00 1.00000e-09 2.12000e-01

4.94741e+01 4.94741e+01 4.94741e+00 1.00000e-09 2.12000e-01

$4.94741 \mathrm{e}+014.94741 \mathrm{e}+014.94741 \mathrm{e}+001.00000 \mathrm{e}-092.12000 \mathrm{e}-01$

$4.94741 \mathrm{e}+014.94741 \mathrm{e}+014.94741 \mathrm{e}+00$ 1.00000e-09 2.12000e-01

$1.00000 \mathrm{e}-05$ 1.00000e-05 1.00000e-06 1.00000e-09 1.00000e-01

$1.00000 \mathrm{e}+001.00000 \mathrm{e}+001.00000 \mathrm{e}-01$ 1.00000e-09 1.00000e-01

Element: 10537 \# of layers: 6

$\mathrm{Kx} \mathrm{Ky} \mathrm{Kz}$ Ss Por

4.94741e+01 4.94741e+01 4.94741e+00 1.00000e-09 2.12000e-01

4.94741e+01 4.94741e+01 4.94741e+00 1.00000e-09 2.12000e-01

$4.94741 \mathrm{e}+014.94741 \mathrm{e}+014.94741 \mathrm{e}+001.00000 \mathrm{e}-092.12000 \mathrm{e}-01$

4.94741e+01 4.94741e+01 4.94741e+00 1.00000e-09 2.12000e-01

$1.00000 \mathrm{e}-05$ 1.00000e-05 1.00000e-06 1.00000e-09 1.00000e-01

$1.00000 \mathrm{e}+001.00000 \mathrm{e}+001.00000 \mathrm{e}-01$ 1.00000e-09 1.00000e-01

Element: 10538 \# of layers: 7

Kx Ky Kz Ss Por

$5.86880 \mathrm{e}+015.86880 \mathrm{e}+015.86880 \mathrm{e}+001.00000 \mathrm{e}-092.12000 \mathrm{e}-01$

$5.86880 \mathrm{e}+015.86880 \mathrm{e}+015.86880 \mathrm{e}+001.00000 \mathrm{e}-092.12000 \mathrm{e}-01$

$5.86880 \mathrm{e}+015.86880 \mathrm{e}+015.86880 \mathrm{e}+001.00000 \mathrm{e}-092.12000 \mathrm{e}-01$

$5.86880 \mathrm{e}+015.86880 \mathrm{e}+015.86880 \mathrm{e}+001.00000 \mathrm{e}-092.12000 \mathrm{e}-01$

$1.00000 \mathrm{e}-02$ 1.00000e-02 1.00000e-03 1.00000e-09 1.00000e-01

$1.00000 \mathrm{e}-05$ 1.00000e-05 1.00000e-06 1.00000e-09 1.00000e-01

$1.00000 \mathrm{e}+001.00000 \mathrm{e}+001.00000 \mathrm{e}-01$ 1.00000e-09 1.00000e-01

Element: 10539 \# of layers: 7

$\mathrm{Kx} \mathrm{Ky} \mathrm{Kz} \mathrm{Ss} \mathrm{Por}$

5.86880e+01 5.86880e+01 5.86880e+00 1.00000e-09 2.12000e-01 
$5.86880 \mathrm{e}+015.86880 \mathrm{e}+015.86880 \mathrm{e}+00$ 1.00000e-09 2.12000e-01 $5.86880 \mathrm{e}+015.86880 \mathrm{e}+015.86880 \mathrm{e}+001.00000 \mathrm{e}-092.12000 \mathrm{e}-01$ $5.86880 \mathrm{e}+015.86880 \mathrm{e}+015.86880 \mathrm{e}+001.00000 \mathrm{e}-092.12000 \mathrm{e}-01$ $1.00000 \mathrm{e}-021.00000 \mathrm{e}-02$ 1.00000e-03 1.00000e-09 1.00000e-01 $1.00000 \mathrm{e}-05$ 1.00000e-05 1.00000e-06 1.00000e-09 1.00000e-01 $1.00000 \mathrm{e}+001.00000 \mathrm{e}+001.00000 \mathrm{e}-011.00000 \mathrm{e}-091.00000 \mathrm{e}-01$ Element: 10540 \# of layers: 7

Kx Ky Kz Ss Por

$5.86880 \mathrm{e}+015.86880 \mathrm{e}+015.86880 \mathrm{e}+00$ 1.00000e-09 2.12000e-01

$5.86880 \mathrm{e}+015.86880 \mathrm{e}+015.86880 \mathrm{e}+001.00000 \mathrm{e}-092.12000 \mathrm{e}-01$

$5.86880 \mathrm{e}+015.86880 \mathrm{e}+015.86880 \mathrm{e}+001.00000 \mathrm{e}-092.12000 \mathrm{e}-01$

$5.86880 \mathrm{e}+015.86880 \mathrm{e}+015.86880 \mathrm{e}+001.00000 \mathrm{e}-092.12000 \mathrm{e}-01$

$1.00000 \mathrm{e}-02$ 1.00000e-02 1.00000e-03 1.00000e-09 1.00000e-01

$1.00000 \mathrm{e}-05$ 1.00000e-05 1.00000e-06 1.00000e-09 1.00000e-01

$1.00000 \mathrm{e}+001.00000 \mathrm{e}+001.00000 \mathrm{e}-011.00000 \mathrm{e}-091.00000 \mathrm{e}-01$

Element: 10541 \# of layers: 7

Kx Ky Kz Ss Por

$5.86880 \mathrm{e}+015.86880 \mathrm{e}+015.86880 \mathrm{e}+00$ 1.00000e-09 2.12000e-01

$5.86880 \mathrm{e}+015.86880 \mathrm{e}+015.86880 \mathrm{e}+001.00000 \mathrm{e}-092.12000 \mathrm{e}-01$

$5.86880 \mathrm{e}+015.86880 \mathrm{e}+015.86880 \mathrm{e}+001.00000 \mathrm{e}-092.12000 \mathrm{e}-01$

$5.86880 \mathrm{e}+015.86880 \mathrm{e}+015.86880 \mathrm{e}+001.00000 \mathrm{e}-092.12000 \mathrm{e}-01$

$1.00000 \mathrm{e}-021.00000 \mathrm{e}-02$ 1.00000e-03 1.00000e-09 1.00000e-01

$1.00000 \mathrm{e}-05$ 1.00000e-05 1.00000e-06 1.00000e-09 1.00000e-01

$1.00000 \mathrm{e}+001.00000 \mathrm{e}+001.00000 \mathrm{e}-011.00000 \mathrm{e}-091.00000 \mathrm{e}-01$

Element: 10542 \# of layers: 6

Kx Ky Kz Ss Por

$1.23824 \mathrm{e}+031.23824 \mathrm{e}+031.23824 \mathrm{e}+021.00000 \mathrm{e}-097.00000 \mathrm{e}-02$ $4.94741 \mathrm{e}+014.94741 \mathrm{e}+014.94741 \mathrm{e}+001.00000 \mathrm{e}-092.12000 \mathrm{e}-01$ $4.94741 \mathrm{e}+014.94741 \mathrm{e}+014.94741 \mathrm{e}+001.00000 \mathrm{e}-092.12000 \mathrm{e}-01$ $4.94741 \mathrm{e}+014.94741 \mathrm{e}+014.94741 \mathrm{e}+001.00000 \mathrm{e}-092.12000 \mathrm{e}-01$ $1.00000 \mathrm{e}-05$ 1.00000e-05 1.00000e-06 1.00000e-09 1.00000e-01 $1.00000 \mathrm{e}+001.00000 \mathrm{e}+001.00000 \mathrm{e}-011.00000 \mathrm{e}-091.00000 \mathrm{e}-01$ Element: 10543 \# of layers: 6

Kx Ky Kz Ss Por

$1.23824 \mathrm{e}+031.23824 \mathrm{e}+031.23824 \mathrm{e}+021.00000 \mathrm{e}-097.00000 \mathrm{e}-02$ $4.94741 \mathrm{e}+014.94741 \mathrm{e}+014.94741 \mathrm{e}+001.00000 \mathrm{e}-092.12000 \mathrm{e}-01$ $4.94741 \mathrm{e}+014.94741 \mathrm{e}+014.94741 \mathrm{e}+001.00000 \mathrm{e}-092.12000 \mathrm{e}-01$ $4.94741 \mathrm{e}+014.94741 \mathrm{e}+014.94741 \mathrm{e}+001.00000 \mathrm{e}-092.12000 \mathrm{e}-01$ $1.00000 \mathrm{e}-05$ 1.00000e-05 1.00000e-06 1.00000e-09 1.00000e-01 $1.00000 \mathrm{e}+001.00000 \mathrm{e}+001.00000 \mathrm{e}-011.00000 \mathrm{e}-091.00000 \mathrm{e}-01$ Element: 10544 \# of layers: 6

$\mathrm{Kx} \mathrm{Ky} \mathrm{Kz}$ Ss Por

4.94741e+01 4.94741e+01 4.94741e+00 1.00000e-09 2.12000e-01 4.94741e+01 4.94741e+01 4.94741e+00 1.00000e-09 2.12000e-01 $4.94741 \mathrm{e}+014.94741 \mathrm{e}+014.94741 \mathrm{e}+00$ 1.00000e-09 2.12000e-01 $4.94741 \mathrm{e}+014.94741 \mathrm{e}+014.94741 \mathrm{e}+001.00000 \mathrm{e}-092.12000 \mathrm{e}-01$ 
$1.00000 \mathrm{e}-05$ 1.00000e-05 1.00000e-06 1.00000e-09 1.00000e-01 $1.00000 \mathrm{e}+001.00000 \mathrm{e}+001.00000 \mathrm{e}-01$ 1.00000e-09 1.00000e-01 Element: 10545 \# of layers: 7

Kx Ky Kz Ss Por

$1.23824 \mathrm{e}+031.23824 \mathrm{e}+031.23824 \mathrm{e}+021.00000 \mathrm{e}-097.00000 \mathrm{e}-02$ 4.94741e+01 4.94741e+01 4.94741e+00 1.00000e-09 2.12000e-01 $4.94741 \mathrm{e}+014.94741 \mathrm{e}+014.94741 \mathrm{e}+001.00000 \mathrm{e}-09$ 2.12000e-01 $4.94741 \mathrm{e}+014.94741 \mathrm{e}+014.94741 \mathrm{e}+00$ 1.00000e-09 2.12000e-01 $4.94741 \mathrm{e}+014.94741 \mathrm{e}+014.94741 \mathrm{e}+001.00000 \mathrm{e}-092.12000 \mathrm{e}-01$ $1.00000 \mathrm{e}-05$ 1.00000e-05 1.00000e-06 1.00000e-09 1.00000e-01 $1.00000 \mathrm{e}+001.00000 \mathrm{e}+001.00000 \mathrm{e}-011.00000 \mathrm{e}-091.00000 \mathrm{e}-01$ Element: 10546 \# of layers: 7

$\mathrm{Kx} \mathrm{Ky} \mathrm{Kz}$ Ss Por

$1.23824 \mathrm{e}+031.23824 \mathrm{e}+03$ 1.23824e+02 1.00000e-09 7.00000e-02 $4.94741 \mathrm{e}+014.94741 \mathrm{e}+014.94741 \mathrm{e}+001.00000 \mathrm{e}-092.12000 \mathrm{e}-01$ $4.94741 \mathrm{e}+014.94741 \mathrm{e}+014.94741 \mathrm{e}+001.00000 \mathrm{e}-092.12000 \mathrm{e}-01$ $4.94741 \mathrm{e}+014.94741 \mathrm{e}+014.94741 \mathrm{e}+00$ 1.00000e-09 2.12000e-01 $4.94741 \mathrm{e}+014.94741 \mathrm{e}+014.94741 \mathrm{e}+00$ 1.00000e-09 2.12000e-01 $1.00000 \mathrm{e}-051.00000 \mathrm{e}-051.00000 \mathrm{e}-061.00000 \mathrm{e}-091.00000 \mathrm{e}-01$ $1.00000 \mathrm{e}+001.00000 \mathrm{e}+001.00000 \mathrm{e}-011.00000 \mathrm{e}-091.00000 \mathrm{e}-01$ Element: 10547 \# of layers: 6

$\mathrm{Kx} \mathrm{Ky} \mathrm{Kz}$ Ss Por

$1.23824 \mathrm{e}+031.23824 \mathrm{e}+03$ 1.23824e+02 1.00000e-09 7.00000e-02 4.94741e+01 4.94741e+01 4.94741e+00 1.00000e-09 2.12000e-01 $4.94741 \mathrm{e}+014.94741 \mathrm{e}+014.94741 \mathrm{e}+001.00000 \mathrm{e}-092.12000 \mathrm{e}-01$ 4.94741e+01 4.94741e+01 4.94741e+00 1.00000e-09 2.12000e-01 $1.00000 \mathrm{e}-05$ 1.00000e-05 1.00000e-06 1.00000e-09 1.00000e-01 $1.00000 \mathrm{e}+001.00000 \mathrm{e}+001.00000 \mathrm{e}-011.00000 \mathrm{e}-091.00000 \mathrm{e}-01$

Element: 10548 \# of layers: 6

$\mathrm{Kx} \mathrm{Ky} \mathrm{Kz}$ Ss Por

$1.23824 \mathrm{e}+031.23824 \mathrm{e}+03$ 1.23824e+02 1.00000e-09 7.00000e-02 $4.94741 \mathrm{e}+014.94741 \mathrm{e}+014.94741 \mathrm{e}+001.00000 \mathrm{e}-092.12000 \mathrm{e}-01$ $4.94741 \mathrm{e}+014.94741 \mathrm{e}+014.94741 \mathrm{e}+00$ 1.00000e-09 2.12000e-01 $4.94741 \mathrm{e}+014.94741 \mathrm{e}+014.94741 \mathrm{e}+00$ 1.00000e-09 2.12000e-01 $1.00000 \mathrm{e}-05$ 1.00000e-05 1.00000e-06 1.00000e-09 1.00000e-01 $1.00000 \mathrm{e}+001.00000 \mathrm{e}+001.00000 \mathrm{e}-011.00000 \mathrm{e}-091.00000 \mathrm{e}-01$ Element: 10549 \# of layers: 6

Kx Ky Kz Ss Por

6.10319e+02 6.10319e+02 6.10319e+01 1.00000e-09 7.00000e-02 $2.43860 \mathrm{e}+012.43860 \mathrm{e}+012.43860 \mathrm{e}+001.00000 \mathrm{e}-092.12000 \mathrm{e}-01$ $2.43860 \mathrm{e}+012.43860 \mathrm{e}+012.43860 \mathrm{e}+00$ 1.00000e-09 2.12000e-01 $2.43860 \mathrm{e}+012.43860 \mathrm{e}+012.43860 \mathrm{e}+001.00000 \mathrm{e}-092.12000 \mathrm{e}-01$ $1.00000 \mathrm{e}-05$ 1.00000e-05 1.00000e-06 1.00000e-09 1.00000e-01 $1.00000 \mathrm{e}+001.00000 \mathrm{e}+001.00000 \mathrm{e}-011.00000 \mathrm{e}-091.00000 \mathrm{e}-01$ Element: 10550 \# of layers: 5

Kx Ky Kz Ss Por 
$2.43860 \mathrm{e}+012.43860 \mathrm{e}+012.43860 \mathrm{e}+00$ 1.00000e-09 2.12000e-01

$2.43860 \mathrm{e}+012.43860 \mathrm{e}+012.43860 \mathrm{e}+001.00000 \mathrm{e}-092.12000 \mathrm{e}-01$

$2.43860 \mathrm{e}+012.43860 \mathrm{e}+012.43860 \mathrm{e}+001.00000 \mathrm{e}-092.12000 \mathrm{e}-01$

$1.00000 \mathrm{e}-05$ 1.00000e-05 1.00000e-06 1.00000e-09 1.00000e-01

$1.00000 \mathrm{e}+001.00000 \mathrm{e}+001.00000 \mathrm{e}-01$ 1.00000e-09 1.00000e-01

Element: 10551 \# of layers: 6

$\mathrm{Kx} \mathrm{Ky} \mathrm{Kz}$ Ss Por

$2.43860 \mathrm{e}+012.43860 \mathrm{e}+012.43860 \mathrm{e}+00$ 1.00000e-09 2.12000e-01

$2.43860 \mathrm{e}+012.43860 \mathrm{e}+012.43860 \mathrm{e}+001.00000 \mathrm{e}-092.12000 \mathrm{e}-01$

$2.43860 \mathrm{e}+012.43860 \mathrm{e}+012.43860 \mathrm{e}+001.00000 \mathrm{e}-092.12000 \mathrm{e}-01$

$2.43860 \mathrm{e}+012.43860 \mathrm{e}+012.43860 \mathrm{e}+001.00000 \mathrm{e}-092.12000 \mathrm{e}-01$

$1.00000 \mathrm{e}-05$ 1.00000e-05 1.00000e-06 1.00000e-09 1.00000e-01

$1.00000 \mathrm{e}+001.00000 \mathrm{e}+001.00000 \mathrm{e}-011.00000 \mathrm{e}-091.00000 \mathrm{e}-01$

Element: 10552 \# of layers: 6

$\mathrm{Kx} \mathrm{Ky} \mathrm{Kz}$ Ss Por

4.94741e+01 4.94741e+01 4.94741e+00 1.00000e-09 2.12000e-01

$4.94741 \mathrm{e}+014.94741 \mathrm{e}+014.94741 \mathrm{e}+001.00000 \mathrm{e}-092.12000 \mathrm{e}-01$

$4.94741 \mathrm{e}+014.94741 \mathrm{e}+014.94741 \mathrm{e}+001.00000 \mathrm{e}-09$ 2.12000e-01

4.94741e+01 4.94741e+01 4.94741e+00 1.00000e-09 2.12000e-01

$1.00000 \mathrm{e}-051.00000 \mathrm{e}-051.00000 \mathrm{e}-061.00000 \mathrm{e}-091.00000 \mathrm{e}-01$

$1.00000 \mathrm{e}+001.00000 \mathrm{e}+001.00000 \mathrm{e}-011.00000 \mathrm{e}-091.00000 \mathrm{e}-01$

Element: 10553 \# of layers: 6

$\mathrm{Kx} \mathrm{Ky} \mathrm{Kz}$ Ss Por

4.94741e+01 4.94741e+01 4.94741e+00 1.00000e-09 2.12000e-01

$4.94741 \mathrm{e}+014.94741 \mathrm{e}+014.94741 \mathrm{e}+001.00000 \mathrm{e}-092.12000 \mathrm{e}-01$

$4.94741 \mathrm{e}+014.94741 \mathrm{e}+014.94741 \mathrm{e}+001.00000 \mathrm{e}-092.12000 \mathrm{e}-01$

4.94741e+01 4.94741e+01 4.94741e+00 1.00000e-09 2.12000e-01

$1.00000 \mathrm{e}-05$ 1.00000e-05 1.00000e-06 1.00000e-09 1.00000e-01

$1.00000 \mathrm{e}+001.00000 \mathrm{e}+001.00000 \mathrm{e}-011.00000 \mathrm{e}-091.00000 \mathrm{e}-01$

Element: 10554 \# of layers: 6

$\mathrm{Kx} \mathrm{Ky} \mathrm{Kz}$ Ss Por

$1.23824 \mathrm{e}+031.23824 \mathrm{e}+03$ 1.23824e+02 1.00000e-09 7.00000e-02

$4.94741 \mathrm{e}+014.94741 \mathrm{e}+014.94741 \mathrm{e}+00$ 1.00000e-09 2.12000e-01

4.94741e+01 4.94741e+01 4.94741e+00 1.00000e-09 2.12000e-01

4.94741e+01 4.94741e+01 4.94741e+00 1.00000e-09 2.12000e-01

$1.00000 \mathrm{e}-05$ 1.00000e-05 1.00000e-06 1.00000e-09 1.00000e-01

$1.00000 \mathrm{e}+001.00000 \mathrm{e}+001.00000 \mathrm{e}-011.00000 \mathrm{e}-091.00000 \mathrm{e}-01$

Element: 10555 \# of layers: 5

$\mathrm{Kx} \mathrm{Ky} \mathrm{Kz}$ Ss Por

4.94741e+01 4.94741e+01 4.94741e+00 1.00000e-09 2.12000e-01 $4.94741 \mathrm{e}+014.94741 \mathrm{e}+014.94741 \mathrm{e}+00$ 1.00000e-09 2.12000e-01 $4.94741 \mathrm{e}+014.94741 \mathrm{e}+014.94741 \mathrm{e}+00$ 1.00000e-09 2.12000e-01 $1.00000 \mathrm{e}-05$ 1.00000e-05 1.00000e-06 1.00000e-09 1.00000e-01 $1.00000 \mathrm{e}+001.00000 \mathrm{e}+001.00000 \mathrm{e}-01$ 1.00000e-09 1.00000e-01 Element: 10556 \# of layers: 5

Kx Ky Kz Ss Por 
$2.43860 \mathrm{e}+012.43860 \mathrm{e}+012.43860 \mathrm{e}+00$ 1.00000e-09 2.12000e-01

$2.43860 \mathrm{e}+012.43860 \mathrm{e}+012.43860 \mathrm{e}+001.00000 \mathrm{e}-092.12000 \mathrm{e}-01$

$2.43860 \mathrm{e}+012.43860 \mathrm{e}+012.43860 \mathrm{e}+001.00000 \mathrm{e}-092.12000 \mathrm{e}-01$

$1.00000 \mathrm{e}-051.00000 \mathrm{e}-05$ 1.00000e-06 1.00000e-09 1.00000e-01

$1.00000 \mathrm{e}+001.00000 \mathrm{e}+001.00000 \mathrm{e}-01$ 1.00000e-09 1.00000e-01

Element: 10557 \# of layers: 5

$\mathrm{Kx} \mathrm{Ky} \mathrm{Kz}$ Ss Por

$2.43860 \mathrm{e}+012.43860 \mathrm{e}+012.43860 \mathrm{e}+00$ 1.00000e-09 2.12000e-01

$2.43860 \mathrm{e}+012.43860 \mathrm{e}+012.43860 \mathrm{e}+001.00000 \mathrm{e}-092.12000 \mathrm{e}-01$

$2.43860 \mathrm{e}+012.43860 \mathrm{e}+012.43860 \mathrm{e}+001.00000 \mathrm{e}-092.12000 \mathrm{e}-01$

$1.00000 \mathrm{e}-05$ 1.00000e-05 1.00000e-06 1.00000e-09 1.00000e-01

$1.00000 \mathrm{e}+001.00000 \mathrm{e}+001.00000 \mathrm{e}-011.00000 \mathrm{e}-091.00000 \mathrm{e}-01$

Element: 10558 \# of layers: 5

$\mathrm{Kx} \mathrm{Ky} \mathrm{Kz}$ Ss Por

$2.43860 \mathrm{e}+012.43860 \mathrm{e}+012.43860 \mathrm{e}+00$ 1.00000e-09 2.12000e-01

$2.43860 \mathrm{e}+012.43860 \mathrm{e}+012.43860 \mathrm{e}+001.00000 \mathrm{e}-092.12000 \mathrm{e}-01$

$2.43860 \mathrm{e}+012.43860 \mathrm{e}+012.43860 \mathrm{e}+001.00000 \mathrm{e}-092.12000 \mathrm{e}-01$

$1.00000 \mathrm{e}-05$ 1.00000e-05 1.00000e-06 1.00000e-09 1.00000e-01

$1.00000 \mathrm{e}+001.00000 \mathrm{e}+001.00000 \mathrm{e}-01$ 1.00000e-09 1.00000e-01

Element: 10559 \# of layers: 5

$\mathrm{Kx} \mathrm{Ky} \mathrm{Kz}$ Ss Por

$2.43860 \mathrm{e}+012.43860 \mathrm{e}+012.43860 \mathrm{e}+00$ 1.00000e-09 2.12000e-01

$2.43860 \mathrm{e}+012.43860 \mathrm{e}+012.43860 \mathrm{e}+001.00000 \mathrm{e}-092.12000 \mathrm{e}-01$

$2.43860 \mathrm{e}+012.43860 \mathrm{e}+012.43860 \mathrm{e}+001.00000 \mathrm{e}-092.12000 \mathrm{e}-01$

$1.00000 \mathrm{e}-05$ 1.00000e-05 1.00000e-06 1.00000e-09 1.00000e-01

$1.00000 \mathrm{e}+001.00000 \mathrm{e}+001.00000 \mathrm{e}-01$ 1.00000e-09 1.00000e-01

Element: 10560 \# of layers: 6

$\mathrm{Kx} \mathrm{Ky} \mathrm{Kz}$ Ss Por

$2.43860 \mathrm{e}+012.43860 \mathrm{e}+012.43860 \mathrm{e}+001.00000 \mathrm{e}-092.12000 \mathrm{e}-01$

$2.43860 \mathrm{e}+012.43860 \mathrm{e}+012.43860 \mathrm{e}+001.00000 \mathrm{e}-092.12000 \mathrm{e}-01$

$2.43860 \mathrm{e}+012.43860 \mathrm{e}+012.43860 \mathrm{e}+001.00000 \mathrm{e}-092.12000 \mathrm{e}-01$

$2.43860 \mathrm{e}+012.43860 \mathrm{e}+012.43860 \mathrm{e}+001.00000 \mathrm{e}-092.12000 \mathrm{e}-01$

1.00000e-05 1.00000e-05 1.00000e-06 1.00000e-09 1.00000e-01

$1.00000 \mathrm{e}+001.00000 \mathrm{e}+001.00000 \mathrm{e}-011.00000 \mathrm{e}-091.00000 \mathrm{e}-01$

Element: 10561 \# of layers: 6

Kx Ky Kz Ss Por

$2.43860 \mathrm{e}+012.43860 \mathrm{e}+012.43860 \mathrm{e}+00$ 1.00000e-09 2.12000e-01

$2.43860 \mathrm{e}+012.43860 \mathrm{e}+012.43860 \mathrm{e}+001.00000 \mathrm{e}-092.12000 \mathrm{e}-01$

$2.43860 \mathrm{e}+012.43860 \mathrm{e}+012.43860 \mathrm{e}+001.00000 \mathrm{e}-092.12000 \mathrm{e}-01$

$2.43860 \mathrm{e}+012.43860 \mathrm{e}+012.43860 \mathrm{e}+001.00000 \mathrm{e}-092.12000 \mathrm{e}-01$

$1.00000 \mathrm{e}-05$ 1.00000e-05 1.00000e-06 1.00000e-09 1.00000e-01

$1.00000 \mathrm{e}+001.00000 \mathrm{e}+001.00000 \mathrm{e}-011.00000 \mathrm{e}-091.00000 \mathrm{e}-01$

Element: 10562 \# of layers: 6

$\mathrm{Kx} \mathrm{Ky} \mathrm{Kz}$ Ss Por

$2.43860 \mathrm{e}+012.43860 \mathrm{e}+012.43860 \mathrm{e}+00$ 1.00000e-09 2.12000e-01

$2.43860 \mathrm{e}+012.43860 \mathrm{e}+012.43860 \mathrm{e}+001.00000 \mathrm{e}-092.12000 \mathrm{e}-01$ 
$2.43860 \mathrm{e}+012.43860 \mathrm{e}+012.43860 \mathrm{e}+00$ 1.00000e-09 2.12000e-01 $2.43860 \mathrm{e}+012.43860 \mathrm{e}+012.43860 \mathrm{e}+001.00000 \mathrm{e}-092.12000 \mathrm{e}-01$ $1.00000 \mathrm{e}-05$ 1.00000e-05 1.00000e-06 1.00000e-09 1.00000e-01 $1.00000 \mathrm{e}+001.00000 \mathrm{e}+001.00000 \mathrm{e}-011.00000 \mathrm{e}-091.00000 \mathrm{e}-01$ Element: 10563 \# of layers: 5

Kx Ky Kz Ss Por

$2.43860 \mathrm{e}+012.43860 \mathrm{e}+012.43860 \mathrm{e}+00$ 1.00000e-09 2.12000e-01 $2.43860 \mathrm{e}+012.43860 \mathrm{e}+012.43860 \mathrm{e}+001.00000 \mathrm{e}-092.12000 \mathrm{e}-01$ $2.43860 \mathrm{e}+012.43860 \mathrm{e}+012.43860 \mathrm{e}+001.00000 \mathrm{e}-092.12000 \mathrm{e}-01$ $1.00000 \mathrm{e}-05$ 1.00000e-05 1.00000e-06 1.00000e-09 1.00000e-01 $1.00000 \mathrm{e}+001.00000 \mathrm{e}+001.00000 \mathrm{e}-011.00000 \mathrm{e}-091.00000 \mathrm{e}-01$ Element: 10564 \# of layers: 5

Kx Ky Kz Ss Por

$2.43860 \mathrm{e}+012.43860 \mathrm{e}+012.43860 \mathrm{e}+00$ 1.00000e-09 2.12000e-01 $2.43860 \mathrm{e}+012.43860 \mathrm{e}+012.43860 \mathrm{e}+001.00000 \mathrm{e}-092.12000 \mathrm{e}-01$ $2.43860 \mathrm{e}+012.43860 \mathrm{e}+012.43860 \mathrm{e}+001.00000 \mathrm{e}-092.12000 \mathrm{e}-01$ $1.00000 \mathrm{e}-05$ 1.00000e-05 1.00000e-06 1.00000e-09 1.00000e-01 $1.00000 \mathrm{e}+001.00000 \mathrm{e}+001.00000 \mathrm{e}-011.00000 \mathrm{e}-091.00000 \mathrm{e}-01$ Element: 10565 \# of layers: 6

Kx Ky Kz Ss Por

$2.43860 \mathrm{e}+012.43860 \mathrm{e}+012.43860 \mathrm{e}+001.00000 \mathrm{e}-092.12000 \mathrm{e}-01$

$2.43860 \mathrm{e}+012.43860 \mathrm{e}+012.43860 \mathrm{e}+001.00000 \mathrm{e}-092.12000 \mathrm{e}-01$

$2.43860 \mathrm{e}+012.43860 \mathrm{e}+012.43860 \mathrm{e}+001.00000 \mathrm{e}-092.12000 \mathrm{e}-01$

$2.43860 \mathrm{e}+012.43860 \mathrm{e}+012.43860 \mathrm{e}+001.00000 \mathrm{e}-092.12000 \mathrm{e}-01$ $1.00000 \mathrm{e}-05$ 1.00000e-05 1.00000e-06 1.00000e-09 1.00000e-01 $1.00000 \mathrm{e}+001.00000 \mathrm{e}+00$ 1.00000e-01 1.00000e-09 1.00000e-01 Element: 10566 \# of layers: 6

Kx Ky Kz Ss Por

$3.18202 \mathrm{e}+013.18202 \mathrm{e}+013.18202 \mathrm{e}+00$ 1.00000e-09 2.12000e-01

$3.18202 \mathrm{e}+013.18202 \mathrm{e}+013.18202 \mathrm{e}+00$ 1.00000e-09 2.12000e-01

$3.18202 \mathrm{e}+013.18202 \mathrm{e}+013.18202 \mathrm{e}+00$ 1.00000e-09 2.12000e-01

$3.18202 \mathrm{e}+013.18202 \mathrm{e}+013.18202 \mathrm{e}+00$ 1.00000e-09 2.12000e-01 $1.00000 \mathrm{e}-05$ 1.00000e-05 1.00000e-06 1.00000e-09 1.00000e-01 $1.00000 \mathrm{e}+001.00000 \mathrm{e}+001.00000 \mathrm{e}-011.00000 \mathrm{e}-091.00000 \mathrm{e}-01$ Element: 10567 \# of layers: 6

Kx Ky Kz Ss Por

$3.18202 \mathrm{e}+013.18202 \mathrm{e}+013.18202 \mathrm{e}+00$ 1.00000e-09 2.12000e-01 $3.18202 \mathrm{e}+013.18202 \mathrm{e}+013.18202 \mathrm{e}+00$ 1.00000e-09 2.12000e-01 $3.18202 \mathrm{e}+013.18202 \mathrm{e}+013.18202 \mathrm{e}+00$ 1.00000e-09 2.12000e-01 $3.18202 \mathrm{e}+013.18202 \mathrm{e}+013.18202 \mathrm{e}+00$ 1.00000e-09 2.12000e-01 $1.00000 \mathrm{e}-051.00000 \mathrm{e}-05$ 1.00000e-06 1.00000e-09 1.00000e-01 $1.00000 \mathrm{e}+001.00000 \mathrm{e}+001.00000 \mathrm{e}-011.00000 \mathrm{e}-091.00000 \mathrm{e}-01$ Element: 10568 \# of layers: 6

Kx Ky Kz Ss Por

$3.18202 \mathrm{e}+013.18202 \mathrm{e}+013.18202 \mathrm{e}+00$ 1.00000e-09 2.12000e-01 $3.18202 \mathrm{e}+013.18202 \mathrm{e}+013.18202 \mathrm{e}+00$ 1.00000e-09 2.12000e-01 
$3.18202 \mathrm{e}+013.18202 \mathrm{e}+013.18202 \mathrm{e}+00$ 1.00000e-09 2.12000e-01 $3.18202 \mathrm{e}+013.18202 \mathrm{e}+013.18202 \mathrm{e}+00$ 1.00000e-09 2.12000e-01 $1.00000 \mathrm{e}-05$ 1.00000e-05 1.00000e-06 1.00000e-09 1.00000e-01 $1.00000 \mathrm{e}+001.00000 \mathrm{e}+001.00000 \mathrm{e}-011.00000 \mathrm{e}-091.00000 \mathrm{e}-01$ Element: 10569 \# of layers: 6

Kx Ky Kz Ss Por

$3.18202 \mathrm{e}+013.18202 \mathrm{e}+013.18202 \mathrm{e}+00$ 1.00000e-09 2.12000e-01 $3.18202 \mathrm{e}+013.18202 \mathrm{e}+013.18202 \mathrm{e}+00$ 1.00000e-09 2.12000e-01 $3.18202 \mathrm{e}+013.18202 \mathrm{e}+013.18202 \mathrm{e}+00$ 1.00000e-09 2.12000e-01 $3.18202 \mathrm{e}+013.18202 \mathrm{e}+013.18202 \mathrm{e}+001.00000 \mathrm{e}-092.12000 \mathrm{e}-01$ $1.00000 \mathrm{e}-05$ 1.00000e-05 1.00000e-06 1.00000e-09 1.00000e-01 $1.00000 \mathrm{e}+001.00000 \mathrm{e}+001.00000 \mathrm{e}-011.00000 \mathrm{e}-091.00000 \mathrm{e}-01$ Element: 10570 \# of layers: 6

Kx Ky Kz Ss Por

$3.18202 \mathrm{e}+013.18202 \mathrm{e}+013.18202 \mathrm{e}+00$ 1.00000e-09 2.12000e-01 $3.18202 \mathrm{e}+013.18202 \mathrm{e}+013.18202 \mathrm{e}+00$ 1.00000e-09 2.12000e-01 $3.18202 \mathrm{e}+013.18202 \mathrm{e}+013.18202 \mathrm{e}+00$ 1.00000e-09 2.12000e-01 $3.18202 \mathrm{e}+013.18202 \mathrm{e}+013.18202 \mathrm{e}+00$ 1.00000e-09 2.12000e-01 $1.00000 \mathrm{e}-05$ 1.00000e-05 1.00000e-06 1.00000e-09 1.00000e-01 $1.00000 \mathrm{e}+001.00000 \mathrm{e}+001.00000 \mathrm{e}-011.00000 \mathrm{e}-091.00000 \mathrm{e}-01$ Element: 10571 \# of layers: 6

Kx Ky Kz Ss Por

$2.43860 \mathrm{e}+012.43860 \mathrm{e}+012.43860 \mathrm{e}+00$ 1.00000e-09 2.12000e-01 $2.43860 \mathrm{e}+012.43860 \mathrm{e}+012.43860 \mathrm{e}+001.00000 \mathrm{e}-092.12000 \mathrm{e}-01$ $2.43860 \mathrm{e}+012.43860 \mathrm{e}+012.43860 \mathrm{e}+001.00000 \mathrm{e}-092.12000 \mathrm{e}-01$ $2.43860 \mathrm{e}+012.43860 \mathrm{e}+012.43860 \mathrm{e}+001.00000 \mathrm{e}-092.12000 \mathrm{e}-01$ $1.00000 \mathrm{e}-05$ 1.00000e-05 1.00000e-06 1.00000e-09 1.00000e-01 $1.00000 \mathrm{e}+001.00000 \mathrm{e}+001.00000 \mathrm{e}-011.00000 \mathrm{e}-091.00000 \mathrm{e}-01$ Element: 10572 \# of layers: 6

Kx Ky Kz Ss Por

$2.43860 \mathrm{e}+012.43860 \mathrm{e}+012.43860 \mathrm{e}+00$ 1.00000e-09 2.12000e-01 $2.43860 \mathrm{e}+012.43860 \mathrm{e}+012.43860 \mathrm{e}+001.00000 \mathrm{e}-092.12000 \mathrm{e}-01$ $2.43860 \mathrm{e}+012.43860 \mathrm{e}+012.43860 \mathrm{e}+001.00000 \mathrm{e}-092.12000 \mathrm{e}-01$ $2.43860 \mathrm{e}+012.43860 \mathrm{e}+012.43860 \mathrm{e}+001.00000 \mathrm{e}-092.12000 \mathrm{e}-01$ $1.00000 \mathrm{e}-05$ 1.00000e-05 1.00000e-06 1.00000e-09 1.00000e-01 $1.00000 \mathrm{e}+001.00000 \mathrm{e}+001.00000 \mathrm{e}-011.00000 \mathrm{e}-091.00000 \mathrm{e}-01$ Element: 10573 \# of layers: 6

Kx Ky Kz Ss Por

$3.18202 \mathrm{e}+013.18202 \mathrm{e}+013.18202 \mathrm{e}+00$ 1.00000e-09 2.12000e-01 $3.18202 \mathrm{e}+013.18202 \mathrm{e}+013.18202 \mathrm{e}+00$ 1.00000e-09 2.12000e-01 $3.18202 \mathrm{e}+013.18202 \mathrm{e}+013.18202 \mathrm{e}+00$ 1.00000e-09 2.12000e-01 $3.18202 \mathrm{e}+013.18202 \mathrm{e}+013.18202 \mathrm{e}+001.00000 \mathrm{e}-092.12000 \mathrm{e}-01$ $1.00000 \mathrm{e}-05$ 1.00000e-05 1.00000e-06 1.00000e-09 1.00000e-01 $1.00000 \mathrm{e}+001.00000 \mathrm{e}+001.00000 \mathrm{e}-011.00000 \mathrm{e}-091.00000 \mathrm{e}-01$ Element: 10574 \# of layers: 6

Kx Ky Kz Ss Por 
$3.18202 \mathrm{e}+013.18202 \mathrm{e}+013.18202 \mathrm{e}+00$ 1.00000e-09 2.12000e-01 $3.18202 \mathrm{e}+013.18202 \mathrm{e}+013.18202 \mathrm{e}+00$ 1.00000e-09 2.12000e-01 $3.18202 \mathrm{e}+013.18202 \mathrm{e}+013.18202 \mathrm{e}+00$ 1.00000e-09 2.12000e-01 $3.18202 \mathrm{e}+013.18202 \mathrm{e}+013.18202 \mathrm{e}+001.00000 \mathrm{e}-092.12000 \mathrm{e}-01$ $1.00000 \mathrm{e}-05$ 1.00000e-05 1.00000e-06 1.00000e-09 1.00000e-01 $1.00000 \mathrm{e}+001.00000 \mathrm{e}+001.00000 \mathrm{e}-011.00000 \mathrm{e}-091.00000 \mathrm{e}-01$ Element: 10575 \# of layers: 6

Kx Ky Kz Ss Por

$5.86880 \mathrm{e}+015.86880 \mathrm{e}+015.86880 \mathrm{e}+00$ 1.00000e-09 2.12000e-01

$5.86880 \mathrm{e}+015.86880 \mathrm{e}+015.86880 \mathrm{e}+001.00000 \mathrm{e}-092.12000 \mathrm{e}-01$

$5.86880 \mathrm{e}+015.86880 \mathrm{e}+015.86880 \mathrm{e}+001.00000 \mathrm{e}-092.12000 \mathrm{e}-01$

$5.86880 \mathrm{e}+015.86880 \mathrm{e}+015.86880 \mathrm{e}+001.00000 \mathrm{e}-092.12000 \mathrm{e}-01$

$1.00000 \mathrm{e}-05$ 1.00000e-05 1.00000e-06 1.00000e-09 1.00000e-01

$1.00000 \mathrm{e}+001.00000 \mathrm{e}+001.00000 \mathrm{e}-011.00000 \mathrm{e}-091.00000 \mathrm{e}-01$

Element: 10576 \# of layers: 6

Kx Ky Kz Ss Por

$5.86880 \mathrm{e}+015.86880 \mathrm{e}+015.86880 \mathrm{e}+00$ 1.00000e-09 2.12000e-01

$5.86880 \mathrm{e}+015.86880 \mathrm{e}+015.86880 \mathrm{e}+001.00000 \mathrm{e}-092.12000 \mathrm{e}-01$

$5.86880 \mathrm{e}+015.86880 \mathrm{e}+015.86880 \mathrm{e}+001.00000 \mathrm{e}-092.12000 \mathrm{e}-01$

$5.86880 \mathrm{e}+015.86880 \mathrm{e}+015.86880 \mathrm{e}+001.00000 \mathrm{e}-092.12000 \mathrm{e}-01$

$1.00000 \mathrm{e}-05$ 1.00000e-05 1.00000e-06 1.00000e-09 1.00000e-01

$1.00000 \mathrm{e}+001.00000 \mathrm{e}+001.00000 \mathrm{e}-011.00000 \mathrm{e}-091.00000 \mathrm{e}-01$

Element: 10577 \# of layers: 6

Kx Ky Kz Ss Por

$5.86880 \mathrm{e}+015.86880 \mathrm{e}+015.86880 \mathrm{e}+001.00000 \mathrm{e}-092.12000 \mathrm{e}-01$

$5.86880 \mathrm{e}+015.86880 \mathrm{e}+015.86880 \mathrm{e}+001.00000 \mathrm{e}-092.12000 \mathrm{e}-01$

$5.86880 \mathrm{e}+015.86880 \mathrm{e}+015.86880 \mathrm{e}+001.00000 \mathrm{e}-092.12000 \mathrm{e}-01$

$5.86880 \mathrm{e}+015.86880 \mathrm{e}+015.86880 \mathrm{e}+001.00000 \mathrm{e}-092.12000 \mathrm{e}-01$

$1.00000 \mathrm{e}-05$ 1.00000e-05 1.00000e-06 1.00000e-09 1.00000e-01

$1.00000 \mathrm{e}+001.00000 \mathrm{e}+001.00000 \mathrm{e}-011.00000 \mathrm{e}-091.00000 \mathrm{e}-01$

Element: 10578 \# of layers: 6

Kx Ky Kz Ss Por

$4.94741 \mathrm{e}+014.94741 \mathrm{e}+014.94741 \mathrm{e}+00$ 1.00000e-09 2.12000e-01

$4.94741 \mathrm{e}+014.94741 \mathrm{e}+014.94741 \mathrm{e}+001.00000 \mathrm{e}-092.12000 \mathrm{e}-01$

$4.94741 \mathrm{e}+014.94741 \mathrm{e}+014.94741 \mathrm{e}+001.00000 \mathrm{e}-092.12000 \mathrm{e}-01$

$4.94741 \mathrm{e}+014.94741 \mathrm{e}+014.94741 \mathrm{e}+001.00000 \mathrm{e}-092.12000 \mathrm{e}-01$ $1.00000 \mathrm{e}-05$ 1.00000e-05 1.00000e-06 1.00000e-09 1.00000e-01

$1.00000 \mathrm{e}+001.00000 \mathrm{e}+001.00000 \mathrm{e}-011.00000 \mathrm{e}-091.00000 \mathrm{e}-01$

Element: 10579 \# of layers: 6

Kx Ky Kz Ss Por

$4.94741 \mathrm{e}+014.94741 \mathrm{e}+014.94741 \mathrm{e}+00$ 1.00000e-09 2.12000e-01

$4.94741 \mathrm{e}+014.94741 \mathrm{e}+014.94741 \mathrm{e}+001.00000 \mathrm{e}-092.12000 \mathrm{e}-01$

$4.94741 \mathrm{e}+014.94741 \mathrm{e}+014.94741 \mathrm{e}+001.00000 \mathrm{e}-092.12000 \mathrm{e}-01$

$4.94741 \mathrm{e}+014.94741 \mathrm{e}+014.94741 \mathrm{e}+001.00000 \mathrm{e}-092.12000 \mathrm{e}-01$

$1.00000 \mathrm{e}-05$ 1.00000e-05 1.00000e-06 1.00000e-09 1.00000e-01

$1.00000 \mathrm{e}+001.00000 \mathrm{e}+001.00000 \mathrm{e}-011.00000 \mathrm{e}-091.00000 \mathrm{e}-01$ 
Element: 10580 \# of layers: 6

Kx Ky Kz Ss Por

$2.43860 \mathrm{e}+012.43860 \mathrm{e}+012.43860 \mathrm{e}+00$ 1.00000e-09 2.12000e-01

$2.43860 \mathrm{e}+012.43860 \mathrm{e}+012.43860 \mathrm{e}+001.00000 \mathrm{e}-092.12000 \mathrm{e}-01$

$2.43860 \mathrm{e}+012.43860 \mathrm{e}+012.43860 \mathrm{e}+001.00000 \mathrm{e}-092.12000 \mathrm{e}-01$

$2.43860 \mathrm{e}+012.43860 \mathrm{e}+012.43860 \mathrm{e}+001.00000 \mathrm{e}-092.12000 \mathrm{e}-01$

$1.00000 \mathrm{e}-05$ 1.00000e-05 1.00000e-06 1.00000e-09 1.00000e-01

$1.00000 \mathrm{e}+001.00000 \mathrm{e}+001.00000 \mathrm{e}-011.00000 \mathrm{e}-091.00000 \mathrm{e}-01$

Element: 10581 \# of layers: 6

Kx Ky Kz Ss Por

$3.18202 \mathrm{e}+013.18202 \mathrm{e}+013.18202 \mathrm{e}+00$ 1.00000e-09 2.12000e-01

$3.18202 \mathrm{e}+013.18202 \mathrm{e}+013.18202 \mathrm{e}+00$ 1.00000e-09 2.12000e-01

$3.18202 \mathrm{e}+013.18202 \mathrm{e}+013.18202 \mathrm{e}+00$ 1.00000e-09 2.12000e-01

$3.18202 \mathrm{e}+013.18202 \mathrm{e}+013.18202 \mathrm{e}+00$ 1.00000e-09 2.12000e-01

$1.00000 \mathrm{e}-05$ 1.00000e-05 1.00000e-06 1.00000e-09 1.00000e-01

$1.00000 \mathrm{e}+001.00000 \mathrm{e}+001.00000 \mathrm{e}-011.00000 \mathrm{e}-091.00000 \mathrm{e}-01$

Element: 10582 \# of layers: 6

$\mathrm{Kx} \mathrm{Ky} \mathrm{Kz}$ Ss Por

$5.86880 \mathrm{e}+015.86880 \mathrm{e}+01$ 5.86880e+00 1.00000e-09 2.12000e-01

$5.86880 \mathrm{e}+015.86880 \mathrm{e}+015.86880 \mathrm{e}+001.00000 \mathrm{e}-092.12000 \mathrm{e}-01$

$5.86880 \mathrm{e}+015.86880 \mathrm{e}+015.86880 \mathrm{e}+001.00000 \mathrm{e}-092.12000 \mathrm{e}-01$

$5.86880 \mathrm{e}+015.86880 \mathrm{e}+015.86880 \mathrm{e}+00$ 1.00000e-09 2.12000e-01

$1.00000 \mathrm{e}-05$ 1.00000e-05 1.00000e-06 1.00000e-09 1.00000e-01

$1.00000 \mathrm{e}+001.00000 \mathrm{e}+001.00000 \mathrm{e}-011.00000 \mathrm{e}-091.00000 \mathrm{e}-01$

Element: 10583 \# of layers: 9

Kx Ky Kz Ss Por

7.30343e+01 7.30343e+01 7.30343e+00 1.00000e-09 2.12000e-01

$7.30343 \mathrm{e}+01$ 7.30343e+01 7.30343e+00 1.00000e-09 2.12000e-01

$7.30343 \mathrm{e}+01$ 7.30343e+01 7.30343e+00 1.00000e-09 2.12000e-01

$7.30343 \mathrm{e}+01$ 7.30343e+01 7.30343e+00 1.00000e-09 2.12000e-01

7.30343e+01 7.30343e+01 7.30343e+00 1.00000e-09 2.12000e-01

$1.00000 \mathrm{e}-021.00000 \mathrm{e}-02$ 1.00000e-03 1.00000e-09 1.00000e-01

$1.00000 \mathrm{e}+001.00000 \mathrm{e}+001.00000 \mathrm{e}-011.00000 \mathrm{e}-091.00000 \mathrm{e}-01$

$1.00000 \mathrm{e}-05$ 1.00000e-05 1.00000e-06 1.00000e-09 1.00000e-01

$1.00000 \mathrm{e}+001.00000 \mathrm{e}+001.00000 \mathrm{e}-011.00000 \mathrm{e}-091.00000 \mathrm{e}-01$

Element: 10584 \# of layers: 9

Kx Ky Kz Ss Por

7.30343e+01 7.30343e+01 7.30343e+00 1.00000e-09 2.12000e-01

$7.30343 \mathrm{e}+01$ 7.30343e+01 7.30343e+00 1.00000e-09 2.12000e-01

$7.30343 \mathrm{e}+01$ 7.30343e+01 7.30343e+00 1.00000e-09 2.12000e-01

$7.30343 \mathrm{e}+01$ 7.30343e+01 7.30343e+00 1.00000e-09 2.12000e-01

$7.30343 \mathrm{e}+01$ 7.30343e+01 7.30343e+00 1.00000e-09 2.12000e-01

$1.00000 \mathrm{e}-02$ 1.00000e-02 1.00000e-03 1.00000e-09 1.00000e-01

$1.00000 \mathrm{e}+001.00000 \mathrm{e}+001.00000 \mathrm{e}-011.00000 \mathrm{e}-091.00000 \mathrm{e}-01$

$1.00000 \mathrm{e}-05$ 1.00000e-05 1.00000e-06 1.00000e-09 1.00000e-01

$1.00000 \mathrm{e}+001.00000 \mathrm{e}+001.00000 \mathrm{e}-011.00000 \mathrm{e}-091.00000 \mathrm{e}-01$ 
Element: 10585 \# of layers: 8

$\mathrm{Kx} \mathrm{Ky} \mathrm{Kz}$ Ss Por

7.30343e+01 7.30343e+01 7.30343e+00 1.00000e-09 2.12000e-01

$7.30343 \mathrm{e}+01$ 7.30343e+01 7.30343e+00 1.00000e-09 2.12000e-01

7.30343e+01 7.30343e+01 7.30343e+00 1.00000e-09 2.12000e-01

7.30343e+01 7.30343e+01 7.30343e+00 1.00000e-09 2.12000e-01

$1.00000 \mathrm{e}-02$ 1.00000e-02 1.00000e-03 1.00000e-09 1.00000e-01

$1.00000 \mathrm{e}+001.00000 \mathrm{e}+001.00000 \mathrm{e}-011.00000 \mathrm{e}-091.00000 \mathrm{e}-01$

$1.00000 \mathrm{e}-05$ 1.00000e-05 1.00000e-06 1.00000e-09 1.00000e-01

$1.00000 \mathrm{e}+001.00000 \mathrm{e}+001.00000 \mathrm{e}-011.00000 \mathrm{e}-091.00000 \mathrm{e}-01$

Element: 10586 \# of layers: 8

$\mathrm{Kx} \mathrm{Ky} \mathrm{Kz}$ Ss Por

7.30343e+01 7.30343e+01 7.30343e+00 1.00000e-09 2.12000e-01

7.30343e+01 7.30343e+01 7.30343e+00 1.00000e-09 2.12000e-01

7.30343e+01 7.30343e+01 7.30343e+00 1.00000e-09 2.12000e-01

7.30343e+01 7.30343e+01 7.30343e+00 1.00000e-09 2.12000e-01

$1.00000 \mathrm{e}-02$ 1.00000e-02 1.00000e-03 1.00000e-09 1.00000e-01

$1.00000 \mathrm{e}+001.00000 \mathrm{e}+001.00000 \mathrm{e}-011.00000 \mathrm{e}-091.00000 \mathrm{e}-01$

$1.00000 \mathrm{e}-05$ 1.00000e-05 1.00000e-06 1.00000e-09 1.00000e-01

$1.00000 \mathrm{e}+001.00000 \mathrm{e}+001.00000 \mathrm{e}-011.00000 \mathrm{e}-091.00000 \mathrm{e}-01$

Element: 10587 \# of layers: 8

$\mathrm{Kx} \mathrm{Ky} \mathrm{Kz}$ Ss Por

7.30343e+01 7.30343e+01 7.30343e+00 1.00000e-09 2.12000e-01

7.30343e+01 7.30343e+01 7.30343e+00 1.00000e-09 2.12000e-01

$7.30343 e+017.30343 e+017.30343 e+001.00000 e-092.12000 e-01$

7.30343e+01 7.30343e+01 7.30343e+00 1.00000e-09 2.12000e-01

$1.00000 \mathrm{e}-02$ 1.00000e-02 1.00000e-03 1.00000e-09 1.00000e-01

$1.00000 \mathrm{e}+001.00000 \mathrm{e}+001.00000 \mathrm{e}-011.00000 \mathrm{e}-091.00000 \mathrm{e}-01$

$1.00000 \mathrm{e}-05$ 1.00000e-05 1.00000e-06 1.00000e-09 1.00000e-01

$1.00000 \mathrm{e}+001.00000 \mathrm{e}+001.00000 \mathrm{e}-011.00000 \mathrm{e}-091.00000 \mathrm{e}-01$

Element: 10588 \# of layers: 9

$\mathrm{Kx} \mathrm{Ky} \mathrm{Kz}$ Ss Por

7.30343e+01 7.30343e+01 7.30343e+00 1.00000e-09 2.12000e-01

7.30343e+01 7.30343e+01 7.30343e+00 1.00000e-09 2.12000e-01

7.30343e+01 7.30343e+01 7.30343e+00 1.00000e-09 2.12000e-01

7.30343e+01 7.30343e+01 7.30343e+00 1.00000e-09 2.12000e-01

$7.30343 \mathrm{e}+01$ 7.30343e+01 7.30343e+00 1.00000e-09 2.12000e-01

$1.00000 \mathrm{e}-02$ 1.00000e-02 1.00000e-03 1.00000e-09 1.00000e-01

$1.00000 \mathrm{e}+001.00000 \mathrm{e}+001.00000 \mathrm{e}-011.00000 \mathrm{e}-091.00000 \mathrm{e}-01$

$1.00000 \mathrm{e}-05$ 1.00000e-05 1.00000e-06 1.00000e-09 1.00000e-01

$1.00000 \mathrm{e}+001.00000 \mathrm{e}+001.00000 \mathrm{e}-011.00000 \mathrm{e}-091.00000 \mathrm{e}-01$

Element: 10589 \# of layers: 9

$\mathrm{Kx} \mathrm{Ky} \mathrm{Kz}$ Ss Por

7.30343e+01 7.30343e+01 7.30343e+00 1.00000e-09 2.12000e-01

7.30343e+01 7.30343e+01 7.30343e+00 1.00000e-09 2.12000e-01

$7.30343 e+017.30343 e+017.30343 e+001.00000 e-092.12000 e-01$ 
7.30343e+01 7.30343e+01 7.30343e+00 1.00000e-09 2.12000e-01 7.30343e+01 7.30343e+01 7.30343e+00 1.00000e-09 2.12000e-01 $1.00000 \mathrm{e}-02$ 1.00000e-02 1.00000e-03 1.00000e-09 1.00000e-01 $1.00000 \mathrm{e}+001.00000 \mathrm{e}+001.00000 \mathrm{e}-011.00000 \mathrm{e}-091.00000 \mathrm{e}-01$ $1.00000 \mathrm{e}-05$ 1.00000e-05 1.00000e-06 1.00000e-09 1.00000e-01 $1.00000 \mathrm{e}+001.00000 \mathrm{e}+001.00000 \mathrm{e}-011.00000 \mathrm{e}-091.00000 \mathrm{e}-01$ Element: 10590 \# of layers: 9

$\mathrm{Kx} \mathrm{Ky} \mathrm{Kz}$ Ss Por

7.30343e+01 7.30343e+01 7.30343e+00 1.00000e-09 2.12000e-01

7.30343e+01 7.30343e+01 7.30343e+00 1.00000e-09 2.12000e-01

7.30343e+01 7.30343e+01 7.30343e+00 1.00000e-09 2.12000e-01

$7.30343 \mathrm{e}+01$ 7.30343e+01 7.30343e+00 1.00000e-09 2.12000e-01

7.30343e+01 7.30343e+01 7.30343e+00 1.00000e-09 2.12000e-01

$1.00000 \mathrm{e}-02$ 1.00000e-02 1.00000e-03 1.00000e-09 1.00000e-01

$1.00000 \mathrm{e}+001.00000 \mathrm{e}+001.00000 \mathrm{e}-011.00000 \mathrm{e}-091.00000 \mathrm{e}-01$ $1.00000 \mathrm{e}-05$ 1.00000e-05 1.00000e-06 1.00000e-09 1.00000e-01

$1.00000 \mathrm{e}+001.00000 \mathrm{e}+001.00000 \mathrm{e}-011.00000 \mathrm{e}-091.00000 \mathrm{e}-01$

Element: 10591 \# of layers: 9

$\mathrm{Kx} \mathrm{Ky} \mathrm{Kz}$ Ss Por

7.30343e+01 7.30343e+01 7.30343e+00 1.00000e-09 2.12000e-01

$7.30343 e+017.30343 e+017.30343 e+001.00000 e-092.12000 e-01$

7.30343e+01 7.30343e+01 7.30343e+00 1.00000e-09 2.12000e-01

7.30343e+01 7.30343e+01 7.30343e+00 1.00000e-09 2.12000e-01

7.30343e+01 7.30343e+01 7.30343e+00 1.00000e-09 2.12000e-01

$1.00000 \mathrm{e}-021.00000 \mathrm{e}-02$ 1.00000e-03 1.00000e-09 1.00000e-01

$1.00000 \mathrm{e}+001.00000 \mathrm{e}+001.00000 \mathrm{e}-011.00000 \mathrm{e}-091.00000 \mathrm{e}-01$

$1.00000 \mathrm{e}-05$ 1.00000e-05 1.00000e-06 1.00000e-09 1.00000e-01

$1.00000 \mathrm{e}+001.00000 \mathrm{e}+001.00000 \mathrm{e}-011.00000 \mathrm{e}-091.00000 \mathrm{e}-01$

Element: 10592 \# of layers: 8

$\mathrm{Kx} \mathrm{Ky} \mathrm{Kz}$ Ss Por

8.47143e+01 8.47143e+01 8.47143e+00 1.00000e-09 2.12000e-01

8.47143e+01 8.47143e+01 8.47143e+00 1.00000e-09 2.12000e-01

$8.47143 \mathrm{e}+018.47143 \mathrm{e}+018.47143 \mathrm{e}+00$ 1.00000e-09 2.12000e-01

8.47143e+01 8.47143e+01 8.47143e+00 1.00000e-09 2.12000e-01

$1.00000 \mathrm{e}-02$ 1.00000e-02 1.00000e-03 1.00000e-09 1.00000e-01

$1.00000 \mathrm{e}+001.00000 \mathrm{e}+001.00000 \mathrm{e}-011.00000 \mathrm{e}-091.00000 \mathrm{e}-01$

$1.00000 \mathrm{e}-05$ 1.00000e-05 1.00000e-06 1.00000e-09 1.00000e-01

$1.00000 \mathrm{e}+001.00000 \mathrm{e}+001.00000 \mathrm{e}-011.00000 \mathrm{e}-091.00000 \mathrm{e}-01$

Element: 10593 \# of layers: 8

$\mathrm{Kx} \mathrm{Ky} \mathrm{Kz}$ Ss Por

7.30343e+01 7.30343e+01 7.30343e+00 1.00000e-09 2.12000e-01

7.30343e+01 7.30343e+01 7.30343e+00 1.00000e-09 2.12000e-01

7.30343e+01 7.30343e+01 7.30343e+00 1.00000e-09 2.12000e-01

7.30343e+01 7.30343e+01 7.30343e+00 1.00000e-09 2.12000e-01

$1.00000 \mathrm{e}-02$ 1.00000e-02 1.00000e-03 1.00000e-09 1.00000e-01

$1.00000 \mathrm{e}+001.00000 \mathrm{e}+001.00000 \mathrm{e}-011.00000 \mathrm{e}-091.00000 \mathrm{e}-01$ 
$1.00000 \mathrm{e}-05$ 1.00000e-05 1.00000e-06 1.00000e-09 1.00000e-01 $1.00000 \mathrm{e}+001.00000 \mathrm{e}+001.00000 \mathrm{e}-01$ 1.00000e-09 1.00000e-01 Element: 10594 \# of layers: 8

Kx Ky Kz Ss Por

7.30343e+01 7.30343e+01 7.30343e+00 1.00000e-09 2.12000e-01

$7.30343 \mathrm{e}+01$ 7.30343e+01 7.30343e+00 1.00000e-09 2.12000e-01

$7.30343 \mathrm{e}+01$ 7.30343e+01 7.30343e+00 1.00000e-09 2.12000e-01

$7.30343 \mathrm{e}+01$ 7.30343e+01 7.30343e+00 1.00000e-09 2.12000e-01

$1.00000 \mathrm{e}-02$ 1.00000e-02 1.00000e-03 1.00000e-09 1.00000e-01

$1.00000 \mathrm{e}+001.00000 \mathrm{e}+001.00000 \mathrm{e}-011.00000 \mathrm{e}-091.00000 \mathrm{e}-01$

$1.00000 \mathrm{e}-05$ 1.00000e-05 1.00000e-06 1.00000e-09 1.00000e-01

$1.00000 \mathrm{e}+001.00000 \mathrm{e}+001.00000 \mathrm{e}-01$ 1.00000e-09 1.00000e-01

Element: 10595 \# of layers: 7

$\mathrm{Kx} \mathrm{Ky} \mathrm{Kz}$ Ss Por

8.47143e+01 8.47143e+01 8.47143e+00 1.00000e-09 2.12000e-01

$8.47143 \mathrm{e}+018.47143 \mathrm{e}+018.47143 \mathrm{e}+001.00000 \mathrm{e}-092.12000 \mathrm{e}-01$

8.47143e+01 8.47143e+01 8.47143e+00 1.00000e-09 2.12000e-01

$1.00000 \mathrm{e}-02$ 1.00000e-02 1.00000e-03 1.00000e-09 1.00000e-01

$1.00000 \mathrm{e}+001.00000 \mathrm{e}+001.00000 \mathrm{e}-011.00000 \mathrm{e}-091.00000 \mathrm{e}-01$

1.00000e-05 1.00000e-05 1.00000e-06 1.00000e-09 1.00000e-01

$1.00000 \mathrm{e}+001.00000 \mathrm{e}+001.00000 \mathrm{e}-011.00000 \mathrm{e}-091.00000 \mathrm{e}-01$

Element: 10596 \# of layers: 7

$\mathrm{Kx} \mathrm{Ky} \mathrm{Kz}$ Ss Por

8.47143e+01 8.47143e+01 8.47143e+00 1.00000e-09 2.12000e-01

$8.47143 \mathrm{e}+018.47143 \mathrm{e}+018.47143 \mathrm{e}+001.00000 \mathrm{e}-092.12000 \mathrm{e}-01$

$8.47143 \mathrm{e}+018.47143 \mathrm{e}+018.47143 \mathrm{e}+001.00000 \mathrm{e}-092.12000 \mathrm{e}-01$

$1.00000 \mathrm{e}-02$ 1.00000e-02 1.00000e-03 1.00000e-09 1.00000e-01

$1.00000 \mathrm{e}+001.00000 \mathrm{e}+001.00000 \mathrm{e}-011.00000 \mathrm{e}-091.00000 \mathrm{e}-01$

$1.00000 \mathrm{e}-05$ 1.00000e-05 1.00000e-06 1.00000e-09 1.00000e-01

$1.00000 \mathrm{e}+001.00000 \mathrm{e}+001.00000 \mathrm{e}-011.00000 \mathrm{e}-091.00000 \mathrm{e}-01$

Element: 10597 \# of layers: 7

Kx Ky Kz Ss Por

$1.08587 \mathrm{e}+02$ 1.08587e+02 1.08587e+01 1.00000e-09 2.12000e-01

$1.08587 \mathrm{e}+02$ 1.08587e+02 1.08587e+01 1.00000e-09 2.12000e-01

$1.08587 \mathrm{e}+02$ 1.08587e+02 1.08587e+01 1.00000e-09 2.12000e-01

$1.08587 \mathrm{e}+02$ 1.08587e+02 1.08587e+01 1.00000e-09 2.12000e-01

$1.00000 \mathrm{e}-02$ 1.00000e-02 1.00000e-03 1.00000e-09 1.00000e-01

$1.00000 \mathrm{e}-05$ 1.00000e-05 1.00000e-06 1.00000e-09 1.00000e-01

$1.00000 \mathrm{e}+001.00000 \mathrm{e}+001.00000 \mathrm{e}-01$ 1.00000e-09 1.00000e-01

Element: 10598 \# of layers: 7

$\mathrm{Kx} \mathrm{Ky} \mathrm{Kz}$ Ss Por

7.30343e+01 7.30343e+01 7.30343e+00 1.00000e-09 2.12000e-01

7.30343e+01 7.30343e+01 7.30343e+00 1.00000e-09 2.12000e-01

7.30343e+01 7.30343e+01 7.30343e+00 1.00000e-09 2.12000e-01

7.30343e+01 7.30343e+01 7.30343e+00 1.00000e-09 2.12000e-01

$1.00000 \mathrm{e}-02$ 1.00000e-02 1.00000e-03 1.00000e-09 1.00000e-01 
$1.00000 \mathrm{e}-05$ 1.00000e-05 1.00000e-06 1.00000e-09 1.00000e-01 $1.00000 \mathrm{e}+001.00000 \mathrm{e}+001.00000 \mathrm{e}-01$ 1.00000e-09 1.00000e-01 Element: 10599 \# of layers: 7

Kx Ky Kz Ss Por

7.30343e+01 7.30343e+01 7.30343e+00 1.00000e-09 2.12000e-01

7.30343e+01 7.30343e+01 7.30343e+00 1.00000e-09 2.12000e-01

7.30343e+01 7.30343e+01 7.30343e+00 1.00000e-09 2.12000e-01

$7.30343 \mathrm{e}+01$ 7.30343e+01 7.30343e+00 1.00000e-09 2.12000e-01

$1.00000 \mathrm{e}-021.00000 \mathrm{e}-02$ 1.00000e-03 1.00000e-09 1.00000e-01

$1.00000 \mathrm{e}-05$ 1.00000e-05 1.00000e-06 1.00000e-09 1.00000e-01

$1.00000 \mathrm{e}+001.00000 \mathrm{e}+001.00000 \mathrm{e}-01$ 1.00000e-09 1.00000e-01

Element: 10600 \# of layers: 8

$\mathrm{Kx} \mathrm{Ky} \mathrm{Kz}$ Ss Por

7.30343e+01 7.30343e+01 7.30343e+00 1.00000e-09 2.12000e-01

7.30343e+01 7.30343e+01 7.30343e+00 1.00000e-09 2.12000e-01

7.30343e+01 7.30343e+01 7.30343e+00 1.00000e-09 2.12000e-01

7.30343e+01 7.30343e+01 7.30343e+00 1.00000e-09 2.12000e-01

$1.00000 \mathrm{e}-02$ 1.00000e-02 1.00000e-03 1.00000e-09 1.00000e-01

$1.00000 \mathrm{e}+001.00000 \mathrm{e}+001.00000 \mathrm{e}-011.00000 \mathrm{e}-091.00000 \mathrm{e}-01$

1.00000e-05 1.00000e-05 1.00000e-06 1.00000e-09 1.00000e-01

$1.00000 \mathrm{e}+001.00000 \mathrm{e}+001.00000 \mathrm{e}-011.00000 \mathrm{e}-091.00000 \mathrm{e}-01$

Element: 10601 \# of layers: 8

$\mathrm{Kx} \mathrm{Ky} \mathrm{Kz}$ Ss Por

7.30343e+01 7.30343e+01 7.30343e+00 1.00000e-09 2.12000e-01

$7.30343 e+017.30343 e+017.30343 e+001.00000 e-092.12000 e-01$

7.30343e+01 7.30343e+01 7.30343e+00 1.00000e-09 2.12000e-01

7.30343e+01 7.30343e+01 7.30343e+00 1.00000e-09 2.12000e-01

$1.00000 \mathrm{e}-02$ 1.00000e-02 1.00000e-03 1.00000e-09 1.00000e-01

$1.00000 \mathrm{e}+001.00000 \mathrm{e}+001.00000 \mathrm{e}-011.00000 \mathrm{e}-091.00000 \mathrm{e}-01$

$1.00000 \mathrm{e}-05$ 1.00000e-05 1.00000e-06 1.00000e-09 1.00000e-01

$1.00000 \mathrm{e}+001.00000 \mathrm{e}+001.00000 \mathrm{e}-011.00000 \mathrm{e}-091.00000 \mathrm{e}-01$

Element: 10602 \# of layers: 7

Kx Ky Kz Ss Por

$1.59704 \mathrm{e}+011.59704 \mathrm{e}+011.59704 \mathrm{e}+001.00000 \mathrm{e}-092.12000 \mathrm{e}-01$

$1.59704 \mathrm{e}+011.59704 \mathrm{e}+011.59704 \mathrm{e}+001.00000 \mathrm{e}-092.12000 \mathrm{e}-01$

$1.59704 \mathrm{e}+011.59704 \mathrm{e}+011.59704 \mathrm{e}+001.00000 \mathrm{e}-092.12000 \mathrm{e}-01$

$1.59704 \mathrm{e}+011.59704 \mathrm{e}+011.59704 \mathrm{e}+001.00000 \mathrm{e}-092.12000 \mathrm{e}-01$

$1.59704 \mathrm{e}+011.59704 \mathrm{e}+011.59704 \mathrm{e}+001.00000 \mathrm{e}-092.12000 \mathrm{e}-01$

$1.00000 \mathrm{e}-05$ 1.00000e-05 1.00000e-06 1.00000e-09 1.00000e-01

$1.00000 \mathrm{e}+001.00000 \mathrm{e}+001.00000 \mathrm{e}-01$ 1.00000e-09 1.00000e-01

Element: 10603 \# of layers: 7

$\mathrm{Kx} \mathrm{Ky} \mathrm{Kz}$ Ss Por

$1.59704 \mathrm{e}+011.59704 \mathrm{e}+01$ 1.59704e+00 1.00000e-09 2.12000e-01

$1.59704 \mathrm{e}+01$ 1.59704e+01 1.59704e+00 1.00000e-09 2.12000e-01

$1.59704 \mathrm{e}+011.59704 \mathrm{e}+011.59704 \mathrm{e}+001.00000 \mathrm{e}-092.12000 \mathrm{e}-01$

$1.59704 \mathrm{e}+011.59704 \mathrm{e}+011.59704 \mathrm{e}+001.00000 \mathrm{e}-092.12000 \mathrm{e}-01$ 
$1.59704 \mathrm{e}+011.59704 \mathrm{e}+01$ 1.59704e+00 1.00000e-09 2.12000e-01 $1.00000 \mathrm{e}-05$ 1.00000e-05 1.00000e-06 1.00000e-09 1.00000e-01 $1.00000 \mathrm{e}+001.00000 \mathrm{e}+001.00000 \mathrm{e}-011.00000 \mathrm{e}-09$ 1.00000e-01 Element: 10604 \# of layers: 7

$\mathrm{Kx} \mathrm{Ky} \mathrm{Kz}$ Ss Por

$1.59704 \mathrm{e}+011.59704 \mathrm{e}+01$ 1.59704e+00 1.00000e-09 2.12000e-01 $1.59704 \mathrm{e}+011.59704 \mathrm{e}+011.59704 \mathrm{e}+001.00000 \mathrm{e}-092.12000 \mathrm{e}-01$ $1.59704 \mathrm{e}+011.59704 \mathrm{e}+011.59704 \mathrm{e}+001.00000 \mathrm{e}-092.12000 \mathrm{e}-01$ $1.59704 \mathrm{e}+011.59704 \mathrm{e}+01$ 1.59704e+00 1.00000e-09 2.12000e-01 $1.59704 \mathrm{e}+011.59704 \mathrm{e}+011.59704 \mathrm{e}+001.00000 \mathrm{e}-092.12000 \mathrm{e}-01$ $1.00000 \mathrm{e}-05$ 1.00000e-05 1.00000e-06 1.00000e-09 1.00000e-01 $1.00000 \mathrm{e}+001.00000 \mathrm{e}+001.00000 \mathrm{e}-011.00000 \mathrm{e}-091.00000 \mathrm{e}-01$ Element: 10605 \# of layers: 7

$\mathrm{Kx} \mathrm{Ky} \mathrm{Kz}$ Ss Por

$1.59704 \mathrm{e}+011.59704 \mathrm{e}+01$ 1.59704e+00 1.00000e-09 2.12000e-01 $1.59704 \mathrm{e}+011.59704 \mathrm{e}+011.59704 \mathrm{e}+001.00000 \mathrm{e}-092.12000 \mathrm{e}-01$ $1.59704 \mathrm{e}+011.59704 \mathrm{e}+011.59704 \mathrm{e}+001.00000 \mathrm{e}-092.12000 \mathrm{e}-01$ $1.59704 \mathrm{e}+011.59704 \mathrm{e}+011.59704 \mathrm{e}+001.00000 \mathrm{e}-092.12000 \mathrm{e}-01$ $1.59704 \mathrm{e}+011.59704 \mathrm{e}+01$ 1.59704e+00 1.00000e-09 2.12000e-01 $1.00000 \mathrm{e}-05$ 1.00000e-05 1.00000e-06 1.00000e-09 1.00000e-01 $1.00000 \mathrm{e}+001.00000 \mathrm{e}+001.00000 \mathrm{e}-011.00000 \mathrm{e}-091.00000 \mathrm{e}-01$ Element: 10606 \# of layers: 7

$\mathrm{Kx} \mathrm{Ky} \mathrm{Kz}$ Ss Por

$1.59704 \mathrm{e}+01$ 1.59704e+01 1.59704e+00 1.00000e-09 2.12000e-01 $1.59704 \mathrm{e}+011.59704 \mathrm{e}+011.59704 \mathrm{e}+001.00000 \mathrm{e}-092.12000 \mathrm{e}-01$ $1.59704 \mathrm{e}+011.59704 \mathrm{e}+011.59704 \mathrm{e}+001.00000 \mathrm{e}-092.12000 \mathrm{e}-01$ $1.59704 \mathrm{e}+011.59704 \mathrm{e}+011.59704 \mathrm{e}+001.00000 \mathrm{e}-092.12000 \mathrm{e}-01$ $1.59704 \mathrm{e}+011.59704 \mathrm{e}+011.59704 \mathrm{e}+001.00000 \mathrm{e}-092.12000 \mathrm{e}-01$ $1.00000 \mathrm{e}-05$ 1.00000e-05 1.00000e-06 1.00000e-09 1.00000e-01 $1.00000 \mathrm{e}+001.00000 \mathrm{e}+001.00000 \mathrm{e}-011.00000 \mathrm{e}-091.00000 \mathrm{e}-01$ Element: 10607 \# of layers: 7

$\mathrm{Kx} \mathrm{Ky} \mathrm{Kz}$ Ss Por

$1.59704 \mathrm{e}+011.59704 \mathrm{e}+011.59704 \mathrm{e}+001.00000 \mathrm{e}-092.12000 \mathrm{e}-01$ $1.59704 \mathrm{e}+011.59704 \mathrm{e}+011.59704 \mathrm{e}+001.00000 \mathrm{e}-092.12000 \mathrm{e}-01$ $1.59704 \mathrm{e}+011.59704 \mathrm{e}+011.59704 \mathrm{e}+001.00000 \mathrm{e}-092.12000 \mathrm{e}-01$ $1.59704 \mathrm{e}+011.59704 \mathrm{e}+011.59704 \mathrm{e}+001.00000 \mathrm{e}-092.12000 \mathrm{e}-01$ $1.59704 \mathrm{e}+011.59704 \mathrm{e}+011.59704 \mathrm{e}+001.00000 \mathrm{e}-092.12000 \mathrm{e}-01$ $1.00000 \mathrm{e}-05$ 1.00000e-05 1.00000e-06 1.00000e-09 1.00000e-01 $1.00000 \mathrm{e}+001.00000 \mathrm{e}+001.00000 \mathrm{e}-011.00000 \mathrm{e}-091.00000 \mathrm{e}-01$ Element: 10608 \# of layers: 7

$\mathrm{Kx} \mathrm{Ky} \mathrm{Kz}$ Ss Por

$1.63320 \mathrm{e}+01$ 1.63320e+01 1.63320e+00 1.00000e-09 2.12000e-01 $1.63320 \mathrm{e}+011.63320 \mathrm{e}+011.63320 \mathrm{e}+001.00000 \mathrm{e}-092.12000 \mathrm{e}-01$ $1.63320 \mathrm{e}+01$ 1.63320e+01 1.63320e+00 1.00000e-09 2.12000e-01 $1.63320 \mathrm{e}+011.63320 \mathrm{e}+011.63320 \mathrm{e}+001.00000 \mathrm{e}-092.12000 \mathrm{e}-01$ $1.63320 \mathrm{e}+011.63320 \mathrm{e}+011.63320 \mathrm{e}+001.00000 \mathrm{e}-092.12000 \mathrm{e}-01$ 
$1.00000 \mathrm{e}-05$ 1.00000e-05 1.00000e-06 1.00000e-09 1.00000e-01 $1.00000 \mathrm{e}+001.00000 \mathrm{e}+001.00000 \mathrm{e}-01$ 1.00000e-09 1.00000e-01 Element: 10609 \# of layers: 7

Kx Ky Kz Ss Por

$1.63320 \mathrm{e}+011.63320 \mathrm{e}+011.63320 \mathrm{e}+001.00000 \mathrm{e}-092.12000 \mathrm{e}-01$ $1.63320 \mathrm{e}+011.63320 \mathrm{e}+011.63320 \mathrm{e}+001.00000 \mathrm{e}-092.12000 \mathrm{e}-01$ $1.63320 \mathrm{e}+011.63320 \mathrm{e}+011.63320 \mathrm{e}+001.00000 \mathrm{e}-092.12000 \mathrm{e}-01$ $1.63320 \mathrm{e}+011.63320 \mathrm{e}+011.63320 \mathrm{e}+001.00000 \mathrm{e}-092.12000 \mathrm{e}-01$ $1.63320 \mathrm{e}+011.63320 \mathrm{e}+011.63320 \mathrm{e}+001.00000 \mathrm{e}-092.12000 \mathrm{e}-01$ $1.00000 \mathrm{e}-05$ 1.00000e-05 1.00000e-06 1.00000e-09 1.00000e-01 $1.00000 \mathrm{e}+001.00000 \mathrm{e}+001.00000 \mathrm{e}-01$ 1.00000e-09 1.00000e-01 Element: 10610 \# of layers: 7

Kx Ky Kz Ss Por

$1.63320 \mathrm{e}+01$ 1.63320e+01 1.63320e+00 1.00000e-09 2.12000e-01 $1.63320 \mathrm{e}+011.63320 \mathrm{e}+011.63320 \mathrm{e}+001.00000 \mathrm{e}-092.12000 \mathrm{e}-01$ $1.63320 \mathrm{e}+011.63320 \mathrm{e}+011.63320 \mathrm{e}+001.00000 \mathrm{e}-092.12000 \mathrm{e}-01$ $1.63320 \mathrm{e}+011.63320 \mathrm{e}+011.63320 \mathrm{e}+001.00000 \mathrm{e}-092.12000 \mathrm{e}-01$ $1.63320 \mathrm{e}+011.63320 \mathrm{e}+011.63320 \mathrm{e}+001.00000 \mathrm{e}-092.12000 \mathrm{e}-01$ $1.00000 \mathrm{e}-05$ 1.00000e-05 1.00000e-06 1.00000e-09 1.00000e-01 $1.00000 \mathrm{e}+001.00000 \mathrm{e}+001.00000 \mathrm{e}-011.00000 \mathrm{e}-091.00000 \mathrm{e}-01$ Element: 10611 \# of layers: 7

$\mathrm{Kx} \mathrm{Ky} \mathrm{Kz}$ Ss Por

$1.63320 \mathrm{e}+01$ 1.63320e+01 1.63320e+00 1.00000e-09 2.12000e-01 $1.63320 \mathrm{e}+011.63320 \mathrm{e}+011.63320 \mathrm{e}+001.00000 \mathrm{e}-092.12000 \mathrm{e}-01$ $1.63320 \mathrm{e}+011.63320 \mathrm{e}+011.63320 \mathrm{e}+001.00000 \mathrm{e}-092.12000 \mathrm{e}-01$ $1.63320 \mathrm{e}+011.63320 \mathrm{e}+011.63320 \mathrm{e}+001.00000 \mathrm{e}-092.12000 \mathrm{e}-01$ $1.63320 \mathrm{e}+011.63320 \mathrm{e}+011.63320 \mathrm{e}+001.00000 \mathrm{e}-092.12000 \mathrm{e}-01$ $1.00000 \mathrm{e}-05$ 1.00000e-05 1.00000e-06 1.00000e-09 1.00000e-01 $1.00000 \mathrm{e}+001.00000 \mathrm{e}+001.00000 \mathrm{e}-011.00000 \mathrm{e}-091.00000 \mathrm{e}-01$ Element: 10612 \# of layers: 7

$\mathrm{Kx} \mathrm{Ky} \mathrm{Kz}$ Ss Por

$1.63320 \mathrm{e}+011.63320 \mathrm{e}+01$ 1.63320e+00 1.00000e-09 2.12000e-01 $1.63320 \mathrm{e}+011.63320 \mathrm{e}+011.63320 \mathrm{e}+001.00000 \mathrm{e}-092.12000 \mathrm{e}-01$ $1.63320 \mathrm{e}+011.63320 \mathrm{e}+011.63320 \mathrm{e}+001.00000 \mathrm{e}-092.12000 \mathrm{e}-01$ $1.63320 \mathrm{e}+011.63320 \mathrm{e}+011.63320 \mathrm{e}+001.00000 \mathrm{e}-092.12000 \mathrm{e}-01$ $1.63320 \mathrm{e}+011.63320 \mathrm{e}+011.63320 \mathrm{e}+001.00000 \mathrm{e}-092.12000 \mathrm{e}-01$ 1.00000e-05 1.00000e-05 1.00000e-06 1.00000e-09 1.00000e-01 $1.00000 \mathrm{e}+001.00000 \mathrm{e}+001.00000 \mathrm{e}-011.00000 \mathrm{e}-091.00000 \mathrm{e}-01$ Element: 10613 \# of layers: 7

$\mathrm{Kx} \mathrm{Ky} \mathrm{Kz}$ Ss Por

$1.59704 \mathrm{e}+01$ 1.59704e+01 1.59704e+00 1.00000e-09 2.12000e-01 $1.59704 \mathrm{e}+011.59704 \mathrm{e}+011.59704 \mathrm{e}+001.00000 \mathrm{e}-092.12000 \mathrm{e}-01$ $1.59704 \mathrm{e}+011.59704 \mathrm{e}+011.59704 \mathrm{e}+001.00000 \mathrm{e}-092.12000 \mathrm{e}-01$ $1.59704 \mathrm{e}+011.59704 \mathrm{e}+011.59704 \mathrm{e}+001.00000 \mathrm{e}-092.12000 \mathrm{e}-01$ $1.59704 \mathrm{e}+011.59704 \mathrm{e}+011.59704 \mathrm{e}+001.00000 \mathrm{e}-092.12000 \mathrm{e}-01$ $1.00000 \mathrm{e}-05$ 1.00000e-05 1.00000e-06 1.00000e-09 1.00000e-01 
$1.00000 \mathrm{e}+001.00000 \mathrm{e}+001.00000 \mathrm{e}-011.00000 \mathrm{e}-091.00000 \mathrm{e}-01$

Element: 10614 \# of layers: 7

Kx Ky Kz Ss Por

$1.59704 \mathrm{e}+011.59704 \mathrm{e}+011.59704 \mathrm{e}+001.00000 \mathrm{e}-092.12000 \mathrm{e}-01$

$1.59704 \mathrm{e}+011.59704 \mathrm{e}+01$ 1.59704e+00 1.00000e-09 2.12000e-01

$1.59704 \mathrm{e}+011.59704 \mathrm{e}+01$ 1.59704e+00 1.00000e-09 2.12000e-01

$1.59704 \mathrm{e}+011.59704 \mathrm{e}+011.59704 \mathrm{e}+001.00000 \mathrm{e}-092.12000 \mathrm{e}-01$

$1.59704 \mathrm{e}+011.59704 \mathrm{e}+011.59704 \mathrm{e}+001.00000 \mathrm{e}-092.12000 \mathrm{e}-01$

$1.00000 \mathrm{e}-051.00000 \mathrm{e}-051.00000 \mathrm{e}-061.00000 \mathrm{e}-091.00000 \mathrm{e}-01$

$1.00000 \mathrm{e}+001.00000 \mathrm{e}+001.00000 \mathrm{e}-011.00000 \mathrm{e}-091.00000 \mathrm{e}-01$

Element: 10615 \# of layers: 7

Kx Ky Kz Ss Por

$1.63320 \mathrm{e}+011.63320 \mathrm{e}+01$ 1.63320e+00 1.00000e-09 2.12000e-01

$1.63320 \mathrm{e}+011.63320 \mathrm{e}+011.63320 \mathrm{e}+001.00000 \mathrm{e}-092.12000 \mathrm{e}-01$

$1.63320 \mathrm{e}+011.63320 \mathrm{e}+011.63320 \mathrm{e}+001.00000 \mathrm{e}-092.12000 \mathrm{e}-01$

$1.63320 \mathrm{e}+011.63320 \mathrm{e}+011.63320 \mathrm{e}+001.00000 \mathrm{e}-092.12000 \mathrm{e}-01$

$1.63320 \mathrm{e}+011.63320 \mathrm{e}+011.63320 \mathrm{e}+001.00000 \mathrm{e}-092.12000 \mathrm{e}-01$

$1.00000 \mathrm{e}-05$ 1.00000e-05 1.00000e-06 1.00000e-09 1.00000e-01

$1.00000 \mathrm{e}+001.00000 \mathrm{e}+001.00000 \mathrm{e}-01$ 1.00000e-09 1.00000e-01

Element: 10616 \# of layers: 7

$\mathrm{Kx} \mathrm{Ky} \mathrm{Kz}$ Ss Por

$1.63320 \mathrm{e}+01$ 1.63320e+01 1.63320e+00 1.00000e-09 2.12000e-01

$1.63320 \mathrm{e}+011.63320 \mathrm{e}+011.63320 \mathrm{e}+001.00000 \mathrm{e}-092.12000 \mathrm{e}-01$

$1.63320 \mathrm{e}+011.63320 \mathrm{e}+011.63320 \mathrm{e}+001.00000 \mathrm{e}-092.12000 \mathrm{e}-01$

$1.63320 \mathrm{e}+011.63320 \mathrm{e}+011.63320 \mathrm{e}+001.00000 \mathrm{e}-092.12000 \mathrm{e}-01$

$1.63320 \mathrm{e}+011.63320 \mathrm{e}+011.63320 \mathrm{e}+001.00000 \mathrm{e}-092.12000 \mathrm{e}-01$

$1.00000 \mathrm{e}-05$ 1.00000e-05 1.00000e-06 1.00000e-09 1.00000e-01

$1.00000 \mathrm{e}+001.00000 \mathrm{e}+001.00000 \mathrm{e}-01$ 1.00000e-09 1.00000e-01

Element: 10617 \# of layers: 7

$\mathrm{Kx} \mathrm{Ky} \mathrm{Kz}$ Ss Por

$1.63320 \mathrm{e}+01$ 1.63320e+01 1.63320e+00 1.00000e-09 2.12000e-01

$1.63320 \mathrm{e}+011.63320 \mathrm{e}+011.63320 \mathrm{e}+00$ 1.00000e-09 2.12000e-01

$1.63320 \mathrm{e}+011.63320 \mathrm{e}+011.63320 \mathrm{e}+001.00000 \mathrm{e}-092.12000 \mathrm{e}-01$

$1.63320 \mathrm{e}+011.63320 \mathrm{e}+011.63320 \mathrm{e}+001.00000 \mathrm{e}-092.12000 \mathrm{e}-01$

$1.63320 \mathrm{e}+011.63320 \mathrm{e}+011.63320 \mathrm{e}+001.00000 \mathrm{e}-092.12000 \mathrm{e}-01$

$1.00000 \mathrm{e}-05$ 1.00000e-05 1.00000e-06 1.00000e-09 1.00000e-01

$1.00000 \mathrm{e}+001.00000 \mathrm{e}+001.00000 \mathrm{e}-011.00000 \mathrm{e}-091.00000 \mathrm{e}-01$

Element: 10618 \# of layers: 7

$\mathrm{Kx} \mathrm{Ky} \mathrm{Kz}$ Ss Por

$1.63320 \mathrm{e}+011.63320 \mathrm{e}+011.63320 \mathrm{e}+001.00000 \mathrm{e}-092.12000 \mathrm{e}-01$

$1.63320 \mathrm{e}+011.63320 \mathrm{e}+011.63320 \mathrm{e}+001.00000 \mathrm{e}-092.12000 \mathrm{e}-01$

$1.63320 \mathrm{e}+011.63320 \mathrm{e}+011.63320 \mathrm{e}+001.00000 \mathrm{e}-092.12000 \mathrm{e}-01$

$1.63320 \mathrm{e}+011.63320 \mathrm{e}+011.63320 \mathrm{e}+001.00000 \mathrm{e}-092.12000 \mathrm{e}-01$

$1.63320 \mathrm{e}+01$ 1.63320e+01 1.63320e+00 1.00000e-09 2.12000e-01

$1.00000 \mathrm{e}-05$ 1.00000e-05 1.00000e-06 1.00000e-09 1.00000e-01

$1.00000 \mathrm{e}+001.00000 \mathrm{e}+001.00000 \mathrm{e}-011.00000 \mathrm{e}-091.00000 \mathrm{e}-01$ 
Element: 10619 \# of layers: 7

Kx Ky Kz Ss Por

$1.63320 \mathrm{e}+011.63320 \mathrm{e}+011.63320 \mathrm{e}+00$ 1.00000e-09 2.12000e-01

$1.63320 \mathrm{e}+011.63320 \mathrm{e}+011.63320 \mathrm{e}+001.00000 \mathrm{e}-092.12000 \mathrm{e}-01$

$1.63320 \mathrm{e}+011.63320 \mathrm{e}+011.63320 \mathrm{e}+001.00000 \mathrm{e}-092.12000 \mathrm{e}-01$

$1.63320 \mathrm{e}+011.63320 \mathrm{e}+011.63320 \mathrm{e}+001.00000 \mathrm{e}-092.12000 \mathrm{e}-01$

$1.63320 \mathrm{e}+011.63320 \mathrm{e}+011.63320 \mathrm{e}+001.00000 \mathrm{e}-092.12000 \mathrm{e}-01$

$1.00000 \mathrm{e}-05$ 1.00000e-05 1.00000e-06 1.00000e-09 1.00000e-01

$1.00000 \mathrm{e}+001.00000 \mathrm{e}+001.00000 \mathrm{e}-011.00000 \mathrm{e}-091.00000 \mathrm{e}-01$

Element: 10620 \# of layers: 7

Kx Ky Kz Ss Por

$1.63320 \mathrm{e}+011.63320 \mathrm{e}+011.63320 \mathrm{e}+001.00000 \mathrm{e}-092.12000 \mathrm{e}-01$

$1.63320 \mathrm{e}+011.63320 \mathrm{e}+011.63320 \mathrm{e}+001.00000 \mathrm{e}-092.12000 \mathrm{e}-01$

$1.63320 \mathrm{e}+011.63320 \mathrm{e}+011.63320 \mathrm{e}+001.00000 \mathrm{e}-092.12000 \mathrm{e}-01$

$1.63320 \mathrm{e}+011.63320 \mathrm{e}+011.63320 \mathrm{e}+001.00000 \mathrm{e}-092.12000 \mathrm{e}-01$

$1.63320 \mathrm{e}+011.63320 \mathrm{e}+011.63320 \mathrm{e}+001.00000 \mathrm{e}-092.12000 \mathrm{e}-01$

$1.00000 \mathrm{e}-05$ 1.00000e-05 1.00000e-06 1.00000e-09 1.00000e-01

$1.00000 \mathrm{e}+001.00000 \mathrm{e}+001.00000 \mathrm{e}-011.00000 \mathrm{e}-091.00000 \mathrm{e}-01$

Element: 10621 \# of layers: 7

Kx Ky Kz Ss Por

$1.63320 \mathrm{e}+011.63320 \mathrm{e}+011.63320 \mathrm{e}+00$ 1.00000e-09 2.12000e-01

$1.63320 \mathrm{e}+011.63320 \mathrm{e}+011.63320 \mathrm{e}+001.00000 \mathrm{e}-092.12000 \mathrm{e}-01$

$1.63320 \mathrm{e}+011.63320 \mathrm{e}+011.63320 \mathrm{e}+001.00000 \mathrm{e}-092.12000 \mathrm{e}-01$

$1.63320 \mathrm{e}+011.63320 \mathrm{e}+011.63320 \mathrm{e}+001.00000 \mathrm{e}-092.12000 \mathrm{e}-01$

$1.63320 \mathrm{e}+011.63320 \mathrm{e}+011.63320 \mathrm{e}+001.00000 \mathrm{e}-092.12000 \mathrm{e}-01$

$1.00000 \mathrm{e}-05$ 1.00000e-05 1.00000e-06 1.00000e-09 1.00000e-01

$1.00000 \mathrm{e}+001.00000 \mathrm{e}+001.00000 \mathrm{e}-011.00000 \mathrm{e}-091.00000 \mathrm{e}-01$

Element: 10622 \# of layers: 7

Kx Ky Kz Ss Por

$1.63320 \mathrm{e}+011.63320 \mathrm{e}+011.63320 \mathrm{e}+00$ 1.00000e-09 2.12000e-01

$1.63320 \mathrm{e}+011.63320 \mathrm{e}+011.63320 \mathrm{e}+001.00000 \mathrm{e}-092.12000 \mathrm{e}-01$

$1.63320 \mathrm{e}+011.63320 \mathrm{e}+011.63320 \mathrm{e}+001.00000 \mathrm{e}-092.12000 \mathrm{e}-01$

$1.63320 \mathrm{e}+011.63320 \mathrm{e}+011.63320 \mathrm{e}+001.00000 \mathrm{e}-092.12000 \mathrm{e}-01$

$1.63320 \mathrm{e}+011.63320 \mathrm{e}+011.63320 \mathrm{e}+001.00000 \mathrm{e}-092.12000 \mathrm{e}-01$

$1.00000 \mathrm{e}-05$ 1.00000e-05 1.00000e-06 1.00000e-09 1.00000e-01

$1.00000 \mathrm{e}+001.00000 \mathrm{e}+001.00000 \mathrm{e}-011.00000 \mathrm{e}-091.00000 \mathrm{e}-01$

Element: 10623 \# of layers: 7

Kx Ky Kz Ss Por

$1.63320 \mathrm{e}+011.63320 \mathrm{e}+011.63320 \mathrm{e}+00$ 1.00000e-09 2.12000e-01

$1.63320 \mathrm{e}+011.63320 \mathrm{e}+011.63320 \mathrm{e}+001.00000 \mathrm{e}-092.12000 \mathrm{e}-01$

$1.63320 \mathrm{e}+011.63320 \mathrm{e}+011.63320 \mathrm{e}+001.00000 \mathrm{e}-092.12000 \mathrm{e}-01$

$1.63320 \mathrm{e}+011.63320 \mathrm{e}+011.63320 \mathrm{e}+001.00000 \mathrm{e}-092.12000 \mathrm{e}-01$

$1.63320 \mathrm{e}+011.63320 \mathrm{e}+011.63320 \mathrm{e}+001.00000 \mathrm{e}-092.12000 \mathrm{e}-01$

$1.00000 \mathrm{e}-05$ 1.00000e-05 1.00000e-06 1.00000e-09 1.00000e-01

$1.00000 \mathrm{e}+001.00000 \mathrm{e}+001.00000 \mathrm{e}-011.00000 \mathrm{e}-091.00000 \mathrm{e}-01$

Element: 10624 \# of layers: 7 
$\mathrm{Kx} \mathrm{Ky} \mathrm{Kz}$ Ss Por

$1.63320 \mathrm{e}+01$ 1.63320e+01 1.63320e+00 1.00000e-09 2.12000e-01

$1.63320 \mathrm{e}+011.63320 \mathrm{e}+011.63320 \mathrm{e}+001.00000 \mathrm{e}-092.12000 \mathrm{e}-01$

$1.63320 \mathrm{e}+011.63320 \mathrm{e}+011.63320 \mathrm{e}+001.00000 \mathrm{e}-092.12000 \mathrm{e}-01$

$1.63320 \mathrm{e}+011.63320 \mathrm{e}+011.63320 \mathrm{e}+001.00000 \mathrm{e}-092.12000 \mathrm{e}-01$

$1.63320 \mathrm{e}+011.63320 \mathrm{e}+011.63320 \mathrm{e}+001.00000 \mathrm{e}-092.12000 \mathrm{e}-01$

$1.00000 \mathrm{e}-05$ 1.00000e-05 1.00000e-06 1.00000e-09 1.00000e-01

$1.00000 \mathrm{e}+001.00000 \mathrm{e}+001.00000 \mathrm{e}-01$ 1.00000e-09 1.00000e-01

Element: 10625 \# of layers: 7

$\mathrm{Kx} \mathrm{Ky} \mathrm{Kz}$ Ss Por

$1.63320 \mathrm{e}+01$ 1.63320e+01 1.63320e+00 1.00000e-09 2.12000e-01

$1.63320 \mathrm{e}+011.63320 \mathrm{e}+011.63320 \mathrm{e}+001.00000 \mathrm{e}-092.12000 \mathrm{e}-01$

$1.63320 \mathrm{e}+011.63320 \mathrm{e}+011.63320 \mathrm{e}+001.00000 \mathrm{e}-092.12000 \mathrm{e}-01$

$1.63320 \mathrm{e}+011.63320 \mathrm{e}+011.63320 \mathrm{e}+001.00000 \mathrm{e}-092.12000 \mathrm{e}-01$

$1.63320 \mathrm{e}+011.63320 \mathrm{e}+011.63320 \mathrm{e}+001.00000 \mathrm{e}-092.12000 \mathrm{e}-01$ $1.00000 \mathrm{e}-05$ 1.00000e-05 1.00000e-06 1.00000e-09 1.00000e-01

$1.00000 \mathrm{e}+001.00000 \mathrm{e}+001.00000 \mathrm{e}-011.00000 \mathrm{e}-091.00000 \mathrm{e}-01$

Element: 10626 \# of layers: 7

$\mathrm{Kx} \mathrm{Ky} \mathrm{Kz}$ Ss Por

$1.63320 \mathrm{e}+01$ 1.63320e+01 1.63320e+00 1.00000e-09 2.12000e-01

$1.63320 \mathrm{e}+011.63320 \mathrm{e}+011.63320 \mathrm{e}+001.00000 \mathrm{e}-092.12000 \mathrm{e}-01$

$1.63320 \mathrm{e}+011.63320 \mathrm{e}+011.63320 \mathrm{e}+001.00000 \mathrm{e}-092.12000 \mathrm{e}-01$

$1.63320 \mathrm{e}+011.63320 \mathrm{e}+011.63320 \mathrm{e}+001.00000 \mathrm{e}-092.12000 \mathrm{e}-01$

$1.63320 \mathrm{e}+011.63320 \mathrm{e}+01 \quad 1.63320 \mathrm{e}+001.00000 \mathrm{e}-092.12000 \mathrm{e}-01$

$1.00000 \mathrm{e}-05$ 1.00000e-05 1.00000e-06 1.00000e-09 1.00000e-01

$1.00000 \mathrm{e}+001.00000 \mathrm{e}+001.00000 \mathrm{e}-01$ 1.00000e-09 1.00000e-01

Element: 10627 \# of layers: 7

$\mathrm{Kx} \mathrm{Ky} \mathrm{Kz}$ Ss Por

$1.66204 \mathrm{e}+011.66204 \mathrm{e}+011.66204 \mathrm{e}+001.00000 \mathrm{e}-092.12000 \mathrm{e}-01$

$1.66204 \mathrm{e}+011.66204 \mathrm{e}+011.66204 \mathrm{e}+001.00000 \mathrm{e}-092.12000 \mathrm{e}-01$

$1.66204 \mathrm{e}+011.66204 \mathrm{e}+011.66204 \mathrm{e}+001.00000 \mathrm{e}-092.12000 \mathrm{e}-01$

$1.66204 \mathrm{e}+011.66204 \mathrm{e}+011.66204 \mathrm{e}+001.00000 \mathrm{e}-092.12000 \mathrm{e}-01$

$1.66204 \mathrm{e}+011.66204 \mathrm{e}+011.66204 \mathrm{e}+001.00000 \mathrm{e}-092.12000 \mathrm{e}-01$

$1.00000 \mathrm{e}-05$ 1.00000e-05 1.00000e-06 1.00000e-09 1.00000e-01

$1.00000 \mathrm{e}+001.00000 \mathrm{e}+001.00000 \mathrm{e}-011.00000 \mathrm{e}-091.00000 \mathrm{e}-01$

Element: 10628 \# of layers: 7

Kx Ky Kz Ss Por

$1.66204 \mathrm{e}+011.66204 \mathrm{e}+011.66204 \mathrm{e}+001.00000 \mathrm{e}-092.12000 \mathrm{e}-01$

$1.66204 \mathrm{e}+011.66204 \mathrm{e}+011.66204 \mathrm{e}+001.00000 \mathrm{e}-092.12000 \mathrm{e}-01$

$1.66204 \mathrm{e}+011.66204 \mathrm{e}+011.66204 \mathrm{e}+001.00000 \mathrm{e}-092.12000 \mathrm{e}-01$

$1.66204 \mathrm{e}+011.66204 \mathrm{e}+011.66204 \mathrm{e}+001.00000 \mathrm{e}-092.12000 \mathrm{e}-01$

$1.66204 \mathrm{e}+011.66204 \mathrm{e}+011.66204 \mathrm{e}+001.00000 \mathrm{e}-092.12000 \mathrm{e}-01$

1.00000e-05 1.00000e-05 1.00000e-06 1.00000e-09 1.00000e-01

$1.00000 \mathrm{e}+001.00000 \mathrm{e}+001.00000 \mathrm{e}-01$ 1.00000e-09 1.00000e-01

Element: 10629 \# of layers: 7

Kx Ky Kz Ss Por 
$1.66204 \mathrm{e}+011.66204 \mathrm{e}+011.66204 \mathrm{e}+001.00000 \mathrm{e}-092.12000 \mathrm{e}-01$ $1.66204 \mathrm{e}+011.66204 \mathrm{e}+011.66204 \mathrm{e}+001.00000 \mathrm{e}-092.12000 \mathrm{e}-01$ $1.66204 \mathrm{e}+011.66204 \mathrm{e}+011.66204 \mathrm{e}+001.00000 \mathrm{e}-092.12000 \mathrm{e}-01$ $1.66204 \mathrm{e}+011.66204 \mathrm{e}+011.66204 \mathrm{e}+001.00000 \mathrm{e}-092.12000 \mathrm{e}-01$ $1.66204 \mathrm{e}+011.66204 \mathrm{e}+011.66204 \mathrm{e}+001.00000 \mathrm{e}-092.12000 \mathrm{e}-01$ $1.00000 \mathrm{e}-05$ 1.00000e-05 1.00000e-06 1.00000e-09 1.00000e-01 $1.00000 \mathrm{e}+001.00000 \mathrm{e}+001.00000 \mathrm{e}-01$ 1.00000e-09 1.00000e-01 Element: 10630 \# of layers: 7

$\mathrm{Kx} \mathrm{Ky} \mathrm{Kz}$ Ss Por

$1.63320 \mathrm{e}+01$ 1.63320e+01 1.63320e+00 1.00000e-09 2.12000e-01 $1.63320 \mathrm{e}+011.63320 \mathrm{e}+011.63320 \mathrm{e}+001.00000 \mathrm{e}-092.12000 \mathrm{e}-01$ $1.63320 \mathrm{e}+011.63320 \mathrm{e}+011.63320 \mathrm{e}+001.00000 \mathrm{e}-092.12000 \mathrm{e}-01$ $1.63320 \mathrm{e}+011.63320 \mathrm{e}+011.63320 \mathrm{e}+001.00000 \mathrm{e}-092.12000 \mathrm{e}-01$ $1.63320 \mathrm{e}+011.63320 \mathrm{e}+011.63320 \mathrm{e}+001.00000 \mathrm{e}-092.12000 \mathrm{e}-01$ $1.00000 \mathrm{e}-051.00000 \mathrm{e}-051.00000 \mathrm{e}-061.00000 \mathrm{e}-091.00000 \mathrm{e}-01$ $1.00000 \mathrm{e}+001.00000 \mathrm{e}+001.00000 \mathrm{e}-011.00000 \mathrm{e}-091.00000 \mathrm{e}-01$ Element: 10631 \# of layers: 7

$\mathrm{Kx} \mathrm{Ky} \mathrm{Kz}$ Ss Por

$1.63320 \mathrm{e}+011.63320 \mathrm{e}+011.63320 \mathrm{e}+001.00000 \mathrm{e}-092.12000 \mathrm{e}-01$ $1.63320 \mathrm{e}+011.63320 \mathrm{e}+011.63320 \mathrm{e}+001.00000 \mathrm{e}-092.12000 \mathrm{e}-01$ $1.63320 \mathrm{e}+011.63320 \mathrm{e}+011.63320 \mathrm{e}+001.00000 \mathrm{e}-092.12000 \mathrm{e}-01$ $1.63320 \mathrm{e}+011.63320 \mathrm{e}+011.63320 \mathrm{e}+001.00000 \mathrm{e}-092.12000 \mathrm{e}-01$ $1.63320 \mathrm{e}+011.63320 \mathrm{e}+011.63320 \mathrm{e}+001.00000 \mathrm{e}-092.12000 \mathrm{e}-01$ $1.00000 \mathrm{e}-05$ 1.00000e-05 1.00000e-06 1.00000e-09 1.00000e-01 $1.00000 \mathrm{e}+001.00000 \mathrm{e}+001.00000 \mathrm{e}-011.00000 \mathrm{e}-091.00000 \mathrm{e}-01$ Element: 10632 \# of layers: 7

$\mathrm{Kx} \mathrm{Ky} \mathrm{Kz}$ Ss Por

$1.63320 \mathrm{e}+01$ 1.63320e+01 1.63320e+00 1.00000e-09 2.12000e-01 $1.63320 \mathrm{e}+011.63320 \mathrm{e}+011.63320 \mathrm{e}+001.00000 \mathrm{e}-092.12000 \mathrm{e}-01$ $1.63320 \mathrm{e}+011.63320 \mathrm{e}+011.63320 \mathrm{e}+001.00000 \mathrm{e}-092.12000 \mathrm{e}-01$ $1.63320 \mathrm{e}+011.63320 \mathrm{e}+011.63320 \mathrm{e}+001.00000 \mathrm{e}-092.12000 \mathrm{e}-01$ $1.63320 \mathrm{e}+011.63320 \mathrm{e}+011.63320 \mathrm{e}+001.00000 \mathrm{e}-092.12000 \mathrm{e}-01$ $1.00000 \mathrm{e}-05$ 1.00000e-05 1.00000e-06 1.00000e-09 1.00000e-01 $1.00000 \mathrm{e}+001.00000 \mathrm{e}+001.00000 \mathrm{e}-011.00000 \mathrm{e}-09$ 1.00000e-01 Element: 10633 \# of layers: 7

$\mathrm{Kx} \mathrm{Ky} \mathrm{Kz}$ Ss Por

$1.63320 \mathrm{e}+011.63320 \mathrm{e}+011.63320 \mathrm{e}+001.00000 \mathrm{e}-092.12000 \mathrm{e}-01$ $1.63320 \mathrm{e}+011.63320 \mathrm{e}+011.63320 \mathrm{e}+001.00000 \mathrm{e}-092.12000 \mathrm{e}-01$ $1.63320 \mathrm{e}+011.63320 \mathrm{e}+011.63320 \mathrm{e}+001.00000 \mathrm{e}-092.12000 \mathrm{e}-01$ $1.63320 \mathrm{e}+011.63320 \mathrm{e}+011.63320 \mathrm{e}+001.00000 \mathrm{e}-092.12000 \mathrm{e}-01$ $1.63320 \mathrm{e}+011.63320 \mathrm{e}+011.63320 \mathrm{e}+001.00000 \mathrm{e}-092.12000 \mathrm{e}-01$ $1.00000 \mathrm{e}-05$ 1.00000e-05 1.00000e-06 1.00000e-09 1.00000e-01 $1.00000 \mathrm{e}+001.00000 \mathrm{e}+001.00000 \mathrm{e}-011.00000 \mathrm{e}-091.00000 \mathrm{e}-01$ Element: 10634 \# of layers: 7

$\mathrm{Kx} \mathrm{Ky} \mathrm{Kz}$ Ss Por

$1.66204 \mathrm{e}+011.66204 \mathrm{e}+011.66204 \mathrm{e}+001.00000 \mathrm{e}-092.12000 \mathrm{e}-01$ 
$1.66204 \mathrm{e}+011.66204 \mathrm{e}+011.66204 \mathrm{e}+001.00000 \mathrm{e}-092.12000 \mathrm{e}-01$ $1.66204 \mathrm{e}+011.66204 \mathrm{e}+011.66204 \mathrm{e}+001.00000 \mathrm{e}-092.12000 \mathrm{e}-01$ $1.66204 \mathrm{e}+011.66204 \mathrm{e}+011.66204 \mathrm{e}+001.00000 \mathrm{e}-092.12000 \mathrm{e}-01$ $1.66204 \mathrm{e}+011.66204 \mathrm{e}+011.66204 \mathrm{e}+001.00000 \mathrm{e}-092.12000 \mathrm{e}-01$ $1.00000 \mathrm{e}-05$ 1.00000e-05 1.00000e-06 1.00000e-09 1.00000e-01 $1.00000 \mathrm{e}+001.00000 \mathrm{e}+001.00000 \mathrm{e}-011.00000 \mathrm{e}-091.00000 \mathrm{e}-01$ Element: 10635 \# of layers: 7

$\mathrm{Kx} \mathrm{Ky} \mathrm{Kz}$ Ss Por

$1.66204 \mathrm{e}+011.66204 \mathrm{e}+011.66204 \mathrm{e}+001.00000 \mathrm{e}-092.12000 \mathrm{e}-01$ $1.66204 \mathrm{e}+011.66204 \mathrm{e}+011.66204 \mathrm{e}+001.00000 \mathrm{e}-092.12000 \mathrm{e}-01$ $1.66204 \mathrm{e}+011.66204 \mathrm{e}+011.66204 \mathrm{e}+001.00000 \mathrm{e}-092.12000 \mathrm{e}-01$ $1.66204 \mathrm{e}+011.66204 \mathrm{e}+011.66204 \mathrm{e}+001.00000 \mathrm{e}-092.12000 \mathrm{e}-01$ $1.66204 \mathrm{e}+011.66204 \mathrm{e}+011.66204 \mathrm{e}+001.00000 \mathrm{e}-092.12000 \mathrm{e}-01$ $1.00000 \mathrm{e}-05$ 1.00000e-05 1.00000e-06 1.00000e-09 1.00000e-01 $1.00000 \mathrm{e}+001.00000 \mathrm{e}+001.00000 \mathrm{e}-01$ 1.00000e-09 1.00000e-01 Element: 10636 \# of layers: 7

$\mathrm{Kx} \mathrm{Ky} \mathrm{Kz}$ Ss Por

$1.66204 \mathrm{e}+011.66204 \mathrm{e}+011.66204 \mathrm{e}+001.00000 \mathrm{e}-092.12000 \mathrm{e}-01$ $1.66204 \mathrm{e}+011.66204 \mathrm{e}+011.66204 \mathrm{e}+001.00000 \mathrm{e}-092.12000 \mathrm{e}-01$ $1.66204 \mathrm{e}+011.66204 \mathrm{e}+011.66204 \mathrm{e}+001.00000 \mathrm{e}-092.12000 \mathrm{e}-01$ $1.66204 \mathrm{e}+011.66204 \mathrm{e}+011.66204 \mathrm{e}+001.00000 \mathrm{e}-092.12000 \mathrm{e}-01$ $1.66204 \mathrm{e}+011.66204 \mathrm{e}+011.66204 \mathrm{e}+001.00000 \mathrm{e}-092.12000 \mathrm{e}-01$ $1.00000 \mathrm{e}-05$ 1.00000e-05 1.00000e-06 1.00000e-09 1.00000e-01 $1.00000 \mathrm{e}+001.00000 \mathrm{e}+001.00000 \mathrm{e}-011.00000 \mathrm{e}-09$ 1.00000e-01 Element: 10637 \# of layers: 7

$\mathrm{Kx} \mathrm{Ky} \mathrm{Kz}$ Ss Por

$1.66204 \mathrm{e}+011.66204 \mathrm{e}+011.66204 \mathrm{e}+001.00000 \mathrm{e}-092.12000 \mathrm{e}-01$ $1.66204 \mathrm{e}+011.66204 \mathrm{e}+011.66204 \mathrm{e}+001.00000 \mathrm{e}-092.12000 \mathrm{e}-01$ $1.66204 \mathrm{e}+011.66204 \mathrm{e}+011.66204 \mathrm{e}+001.00000 \mathrm{e}-092.12000 \mathrm{e}-01$ $1.66204 \mathrm{e}+011.66204 \mathrm{e}+011.66204 \mathrm{e}+001.00000 \mathrm{e}-092.12000 \mathrm{e}-01$ $1.66204 \mathrm{e}+011.66204 \mathrm{e}+011.66204 \mathrm{e}+001.00000 \mathrm{e}-092.12000 \mathrm{e}-01$ $1.00000 \mathrm{e}-05$ 1.00000e-05 1.00000e-06 1.00000e-09 1.00000e-01 $1.00000 \mathrm{e}+001.00000 \mathrm{e}+001.00000 \mathrm{e}-011.00000 \mathrm{e}-091.00000 \mathrm{e}-01$ Element: 10638 \# of layers: 7

$\mathrm{Kx} \mathrm{Ky} \mathrm{Kz}$ Ss Por

$1.66204 \mathrm{e}+011.66204 \mathrm{e}+011.66204 \mathrm{e}+001.00000 \mathrm{e}-092.12000 \mathrm{e}-01$ $1.66204 \mathrm{e}+011.66204 \mathrm{e}+011.66204 \mathrm{e}+001.00000 \mathrm{e}-092.12000 \mathrm{e}-01$ $1.66204 \mathrm{e}+011.66204 \mathrm{e}+011.66204 \mathrm{e}+001.00000 \mathrm{e}-092.12000 \mathrm{e}-01$ $1.66204 \mathrm{e}+011.66204 \mathrm{e}+011.66204 \mathrm{e}+001.00000 \mathrm{e}-092.12000 \mathrm{e}-01$ $1.66204 \mathrm{e}+011.66204 \mathrm{e}+011.66204 \mathrm{e}+001.00000 \mathrm{e}-092.12000 \mathrm{e}-01$ $1.00000 \mathrm{e}-05$ 1.00000e-05 1.00000e-06 1.00000e-09 1.00000e-01 $1.00000 \mathrm{e}+001.00000 \mathrm{e}+001.00000 \mathrm{e}-011.00000 \mathrm{e}-091.00000 \mathrm{e}-01$ Element: 10639 \# of layers: 7

$\mathrm{Kx} \mathrm{Ky} \mathrm{Kz}$ Ss Por

$1.66204 \mathrm{e}+011.66204 \mathrm{e}+011.66204 \mathrm{e}+001.00000 \mathrm{e}-092.12000 \mathrm{e}-01$ $1.66204 \mathrm{e}+011.66204 \mathrm{e}+011.66204 \mathrm{e}+001.00000 \mathrm{e}-092.12000 \mathrm{e}-01$ 
$1.66204 \mathrm{e}+011.66204 \mathrm{e}+011.66204 \mathrm{e}+001.00000 \mathrm{e}-092.12000 \mathrm{e}-01$ $1.66204 \mathrm{e}+011.66204 \mathrm{e}+011.66204 \mathrm{e}+001.00000 \mathrm{e}-092.12000 \mathrm{e}-01$ $1.66204 \mathrm{e}+011.66204 \mathrm{e}+011.66204 \mathrm{e}+001.00000 \mathrm{e}-092.12000 \mathrm{e}-01$ $1.00000 \mathrm{e}-05$ 1.00000e-05 1.00000e-06 1.00000e-09 1.00000e-01 $1.00000 \mathrm{e}+001.00000 \mathrm{e}+001.00000 \mathrm{e}-01$ 1.00000e-09 1.00000e-01 Element: 10640 \# of layers: 7

$\mathrm{Kx} \mathrm{Ky} \mathrm{Kz}$ Ss Por

$1.66204 \mathrm{e}+011.66204 \mathrm{e}+011.66204 \mathrm{e}+001.00000 \mathrm{e}-092.12000 \mathrm{e}-01$ $1.66204 \mathrm{e}+011.66204 \mathrm{e}+011.66204 \mathrm{e}+001.00000 \mathrm{e}-092.12000 \mathrm{e}-01$ $1.66204 \mathrm{e}+011.66204 \mathrm{e}+011.66204 \mathrm{e}+001.00000 \mathrm{e}-092.12000 \mathrm{e}-01$ $1.66204 \mathrm{e}+011.66204 \mathrm{e}+011.66204 \mathrm{e}+001.00000 \mathrm{e}-092.12000 \mathrm{e}-01$ $1.66204 \mathrm{e}+011.66204 \mathrm{e}+011.66204 \mathrm{e}+001.00000 \mathrm{e}-092.12000 \mathrm{e}-01$ $1.00000 \mathrm{e}-051.00000 \mathrm{e}-05$ 1.00000e-06 1.00000e-09 1.00000e-01 $1.00000 \mathrm{e}+001.00000 \mathrm{e}+001.00000 \mathrm{e}-011.00000 \mathrm{e}-09$ 1.00000e-01 Element: 10641 \# of layers: 7

Kx Ky Kz Ss Por

$1.66204 \mathrm{e}+011.66204 \mathrm{e}+011.66204 \mathrm{e}+001.00000 \mathrm{e}-092.12000 \mathrm{e}-01$ $1.66204 \mathrm{e}+011.66204 \mathrm{e}+011.66204 \mathrm{e}+001.00000 \mathrm{e}-092.12000 \mathrm{e}-01$ $1.66204 \mathrm{e}+011.66204 \mathrm{e}+011.66204 \mathrm{e}+001.00000 \mathrm{e}-092.12000 \mathrm{e}-01$ $1.66204 \mathrm{e}+011.66204 \mathrm{e}+011.66204 \mathrm{e}+001.00000 \mathrm{e}-092.12000 \mathrm{e}-01$ $1.66204 \mathrm{e}+011.66204 \mathrm{e}+011.66204 \mathrm{e}+001.00000 \mathrm{e}-092.12000 \mathrm{e}-01$ $1.00000 \mathrm{e}-05$ 1.00000e-05 1.00000e-06 1.00000e-09 1.00000e-01 $1.00000 \mathrm{e}+001.00000 \mathrm{e}+001.00000 \mathrm{e}-01$ 1.00000e-09 1.00000e-01 Element: 10642 \# of layers: 7

$\mathrm{Kx} \mathrm{Ky} \mathrm{Kz}$ Ss Por

$1.66204 \mathrm{e}+011.66204 \mathrm{e}+011.66204 \mathrm{e}+001.00000 \mathrm{e}-092.12000 \mathrm{e}-01$ $1.66204 \mathrm{e}+011.66204 \mathrm{e}+011.66204 \mathrm{e}+001.00000 \mathrm{e}-092.12000 \mathrm{e}-01$ $1.66204 \mathrm{e}+011.66204 \mathrm{e}+011.66204 \mathrm{e}+001.00000 \mathrm{e}-092.12000 \mathrm{e}-01$ $1.66204 \mathrm{e}+011.66204 \mathrm{e}+011.66204 \mathrm{e}+001.00000 \mathrm{e}-092.12000 \mathrm{e}-01$ $1.66204 \mathrm{e}+011.66204 \mathrm{e}+011.66204 \mathrm{e}+001.00000 \mathrm{e}-092.12000 \mathrm{e}-01$ $1.00000 \mathrm{e}-05$ 1.00000e-05 1.00000e-06 1.00000e-09 1.00000e-01 $1.00000 \mathrm{e}+001.00000 \mathrm{e}+001.00000 \mathrm{e}-01$ 1.00000e-09 1.00000e-01 Element: 10643 \# of layers: 7

$\mathrm{Kx} \mathrm{Ky} \mathrm{Kz}$ Ss Por

$1.66204 \mathrm{e}+011.66204 \mathrm{e}+011.66204 \mathrm{e}+001.00000 \mathrm{e}-092.12000 \mathrm{e}-01$ $1.66204 \mathrm{e}+011.66204 \mathrm{e}+01$ 1.66204e+00 1.00000e-09 2.12000e-01 $1.66204 \mathrm{e}+011.66204 \mathrm{e}+011.66204 \mathrm{e}+001.00000 \mathrm{e}-092.12000 \mathrm{e}-01$ $1.66204 \mathrm{e}+011.66204 \mathrm{e}+011.66204 \mathrm{e}+001.00000 \mathrm{e}-092.12000 \mathrm{e}-01$ $1.66204 \mathrm{e}+011.66204 \mathrm{e}+011.66204 \mathrm{e}+001.00000 \mathrm{e}-092.12000 \mathrm{e}-01$ $1.00000 \mathrm{e}-05$ 1.00000e-05 1.00000e-06 1.00000e-09 1.00000e-01 $1.00000 \mathrm{e}+001.00000 \mathrm{e}+001.00000 \mathrm{e}-011.00000 \mathrm{e}-091.00000 \mathrm{e}-01$ Element: 10644 \# of layers: 7

$\mathrm{Kx} \mathrm{Ky} \mathrm{Kz}$ Ss Por

$1.66204 \mathrm{e}+011.66204 \mathrm{e}+011.66204 \mathrm{e}+001.00000 \mathrm{e}-092.12000 \mathrm{e}-01$ $1.66204 \mathrm{e}+011.66204 \mathrm{e}+011.66204 \mathrm{e}+001.00000 \mathrm{e}-092.12000 \mathrm{e}-01$ $1.66204 \mathrm{e}+011.66204 \mathrm{e}+01$ 1.66204e+00 1.00000e-09 2.12000e-01 
$1.66204 \mathrm{e}+011.66204 \mathrm{e}+011.66204 \mathrm{e}+001.00000 \mathrm{e}-092.12000 \mathrm{e}-01$ $1.66204 \mathrm{e}+011.66204 \mathrm{e}+011.66204 \mathrm{e}+001.00000 \mathrm{e}-092.12000 \mathrm{e}-01$ $1.00000 \mathrm{e}-05$ 1.00000e-05 1.00000e-06 1.00000e-09 1.00000e-01 $1.00000 \mathrm{e}+001.00000 \mathrm{e}+001.00000 \mathrm{e}-011.00000 \mathrm{e}-091.00000 \mathrm{e}-01$ Element: 10645 \# of layers: 7

$\mathrm{Kx} \mathrm{Ky} \mathrm{Kz}$ Ss Por

$1.65012 \mathrm{e}+011.65012 \mathrm{e}+011.65012 \mathrm{e}+001.00000 \mathrm{e}-09$ 2.12000e-01 $1.65012 \mathrm{e}+011.65012 \mathrm{e}+011.65012 \mathrm{e}+001.00000 \mathrm{e}-092.12000 \mathrm{e}-01$ $1.65012 \mathrm{e}+011.65012 \mathrm{e}+011.65012 \mathrm{e}+001.00000 \mathrm{e}-092.12000 \mathrm{e}-01$ $1.65012 \mathrm{e}+011.65012 \mathrm{e}+011.65012 \mathrm{e}+001.00000 \mathrm{e}-092.12000 \mathrm{e}-01$ $1.65012 \mathrm{e}+01$ 1.65012e+01 1.65012e+00 1.00000e-09 2.12000e-01 $1.00000 \mathrm{e}-05$ 1.00000e-05 1.00000e-06 1.00000e-09 1.00000e-01 $1.00000 \mathrm{e}+001.00000 \mathrm{e}+001.00000 \mathrm{e}-01$ 1.00000e-09 1.00000e-01 Element: 10646 \# of layers: 7

$\mathrm{Kx} \mathrm{Ky} \mathrm{Kz}$ Ss Por

$1.65012 \mathrm{e}+01$ 1.65012e+01 1.65012e+00 1.00000e-09 2.12000e-01 $1.65012 \mathrm{e}+011.65012 \mathrm{e}+011.65012 \mathrm{e}+001.00000 \mathrm{e}-092.12000 \mathrm{e}-01$ $1.65012 \mathrm{e}+011.65012 \mathrm{e}+011.65012 \mathrm{e}+001.00000 \mathrm{e}-092.12000 \mathrm{e}-01$ $1.65012 \mathrm{e}+011.65012 \mathrm{e}+011.65012 \mathrm{e}+001.00000 \mathrm{e}-09$ 2.12000e-01 $1.65012 \mathrm{e}+011.65012 \mathrm{e}+011.65012 \mathrm{e}+001.00000 \mathrm{e}-092.12000 \mathrm{e}-01$ $1.00000 \mathrm{e}-05$ 1.00000e-05 1.00000e-06 1.00000e-09 1.00000e-01 $1.00000 \mathrm{e}+001.00000 \mathrm{e}+001.00000 \mathrm{e}-01$ 1.00000e-09 1.00000e-01 Element: 10647 \# of layers: 7

Kx Ky Kz Ss Por

$1.65012 \mathrm{e}+011.65012 \mathrm{e}+011.65012 \mathrm{e}+001.00000 \mathrm{e}-092.12000 \mathrm{e}-01$ $1.65012 \mathrm{e}+011.65012 \mathrm{e}+011.65012 \mathrm{e}+001.00000 \mathrm{e}-092.12000 \mathrm{e}-01$ $1.65012 \mathrm{e}+011.65012 \mathrm{e}+011.65012 \mathrm{e}+001.00000 \mathrm{e}-092.12000 \mathrm{e}-01$ $1.65012 \mathrm{e}+011.65012 \mathrm{e}+011.65012 \mathrm{e}+001.00000 \mathrm{e}-092.12000 \mathrm{e}-01$ $1.65012 \mathrm{e}+011.65012 \mathrm{e}+011.65012 \mathrm{e}+001.00000 \mathrm{e}-092.12000 \mathrm{e}-01$ $1.00000 \mathrm{e}-05$ 1.00000e-05 1.00000e-06 1.00000e-09 1.00000e-01 $1.00000 \mathrm{e}+001.00000 \mathrm{e}+001.00000 \mathrm{e}-011.00000 \mathrm{e}-091.00000 \mathrm{e}-01$ Element: 10648 \# of layers: 7

Kx Ky Kz Ss Por

$1.66204 \mathrm{e}+011.66204 \mathrm{e}+011.66204 \mathrm{e}+001.00000 \mathrm{e}-092.12000 \mathrm{e}-01$ $1.66204 \mathrm{e}+011.66204 \mathrm{e}+011.66204 \mathrm{e}+001.00000 \mathrm{e}-092.12000 \mathrm{e}-01$ $1.66204 \mathrm{e}+011.66204 \mathrm{e}+011.66204 \mathrm{e}+001.00000 \mathrm{e}-092.12000 \mathrm{e}-01$ $1.66204 \mathrm{e}+011.66204 \mathrm{e}+011.66204 \mathrm{e}+001.00000 \mathrm{e}-092.12000 \mathrm{e}-01$ $1.66204 \mathrm{e}+011.66204 \mathrm{e}+011.66204 \mathrm{e}+001.00000 \mathrm{e}-092.12000 \mathrm{e}-01$ $1.00000 \mathrm{e}-051.00000 \mathrm{e}-051.00000 \mathrm{e}-061.00000 \mathrm{e}-091.00000 \mathrm{e}-01$ $1.00000 \mathrm{e}+001.00000 \mathrm{e}+00$ 1.00000e-01 1.00000e-09 1.00000e-01 Element: 10649 \# of layers: 7

$\mathrm{Kx} \mathrm{Ky} \mathrm{Kz}$ Ss Por

$1.66204 \mathrm{e}+011.66204 \mathrm{e}+011.66204 \mathrm{e}+001.00000 \mathrm{e}-092.12000 \mathrm{e}-01$ $1.66204 \mathrm{e}+011.66204 \mathrm{e}+011.66204 \mathrm{e}+001.00000 \mathrm{e}-092.12000 \mathrm{e}-01$ $1.66204 \mathrm{e}+011.66204 \mathrm{e}+011.66204 \mathrm{e}+001.00000 \mathrm{e}-092.12000 \mathrm{e}-01$ $1.66204 \mathrm{e}+011.66204 \mathrm{e}+01$ 1.66204e+00 1.00000e-09 2.12000e-01 
$1.66204 \mathrm{e}+011.66204 \mathrm{e}+011.66204 \mathrm{e}+001.00000 \mathrm{e}-092.12000 \mathrm{e}-01$ $1.00000 \mathrm{e}-05$ 1.00000e-05 1.00000e-06 1.00000e-09 1.00000e-01

$1.00000 \mathrm{e}+001.00000 \mathrm{e}+001.00000 \mathrm{e}-011.00000 \mathrm{e}-09$ 1.00000e-01

Element: 10650 \# of layers: 7

$\mathrm{Kx} \mathrm{Ky} \mathrm{Kz}$ Ss Por

$1.66204 \mathrm{e}+011.66204 \mathrm{e}+011.66204 \mathrm{e}+001.00000 \mathrm{e}-092.12000 \mathrm{e}-01$

$1.66204 \mathrm{e}+011.66204 \mathrm{e}+011.66204 \mathrm{e}+001.00000 \mathrm{e}-092.12000 \mathrm{e}-01$

$1.66204 \mathrm{e}+011.66204 \mathrm{e}+011.66204 \mathrm{e}+001.00000 \mathrm{e}-092.12000 \mathrm{e}-01$

$1.66204 \mathrm{e}+011.66204 \mathrm{e}+011.66204 \mathrm{e}+001.00000 \mathrm{e}-092.12000 \mathrm{e}-01$

$1.66204 \mathrm{e}+011.66204 \mathrm{e}+011.66204 \mathrm{e}+001.00000 \mathrm{e}-092.12000 \mathrm{e}-01$

$1.00000 \mathrm{e}-05$ 1.00000e-05 1.00000e-06 1.00000e-09 1.00000e-01

$1.00000 \mathrm{e}+001.00000 \mathrm{e}+001.00000 \mathrm{e}-011.00000 \mathrm{e}-091.00000 \mathrm{e}-01$

Element: 10651 \# of layers: 7

$\mathrm{Kx} \mathrm{Ky} \mathrm{Kz}$ Ss Por

$1.66204 \mathrm{e}+011.66204 \mathrm{e}+01$ 1.66204e+00 1.00000e-09 2.12000e-01

$1.66204 \mathrm{e}+011.66204 \mathrm{e}+011.66204 \mathrm{e}+001.00000 \mathrm{e}-092.12000 \mathrm{e}-01$

$1.66204 \mathrm{e}+011.66204 \mathrm{e}+011.66204 \mathrm{e}+001.00000 \mathrm{e}-092.12000 \mathrm{e}-01$

$1.66204 \mathrm{e}+011.66204 \mathrm{e}+011.66204 \mathrm{e}+001.00000 \mathrm{e}-092.12000 \mathrm{e}-01$

$1.66204 \mathrm{e}+011.66204 \mathrm{e}+011.66204 \mathrm{e}+001.00000 \mathrm{e}-092.12000 \mathrm{e}-01$

$1.00000 \mathrm{e}-051.00000 \mathrm{e}-051.00000 \mathrm{e}-061.00000 \mathrm{e}-091.00000 \mathrm{e}-01$

$1.00000 \mathrm{e}+001.00000 \mathrm{e}+001.00000 \mathrm{e}-011.00000 \mathrm{e}-091.00000 \mathrm{e}-01$

Element: 10652 \# of layers: 7

$\mathrm{Kx} \mathrm{Ky} \mathrm{Kz}$ Ss Por

$1.65012 \mathrm{e}+01$ 1.65012e+01 1.65012e+00 1.00000e-09 2.12000e-01

$1.65012 \mathrm{e}+011.65012 \mathrm{e}+011.65012 \mathrm{e}+001.00000 \mathrm{e}-092.12000 \mathrm{e}-01$

$1.65012 \mathrm{e}+011.65012 \mathrm{e}+011.65012 \mathrm{e}+001.00000 \mathrm{e}-092.12000 \mathrm{e}-01$

$1.65012 \mathrm{e}+011.65012 \mathrm{e}+011.65012 \mathrm{e}+001.00000 \mathrm{e}-092.12000 \mathrm{e}-01$

$1.65012 \mathrm{e}+011.65012 \mathrm{e}+011.65012 \mathrm{e}+001.00000 \mathrm{e}-092.12000 \mathrm{e}-01$

$1.00000 \mathrm{e}-05$ 1.00000e-05 1.00000e-06 1.00000e-09 1.00000e-01

$1.00000 \mathrm{e}+001.00000 \mathrm{e}+001.00000 \mathrm{e}-011.00000 \mathrm{e}-091.00000 \mathrm{e}-01$

Element: 10653 \# of layers: 7

$\mathrm{Kx} \mathrm{Ky} \mathrm{Kz}$ Ss Por

$1.65012 \mathrm{e}+011.65012 \mathrm{e}+011.65012 \mathrm{e}+00$ 1.00000e-09 2.12000e-01

$1.65012 \mathrm{e}+011.65012 \mathrm{e}+011.65012 \mathrm{e}+001.00000 \mathrm{e}-092.12000 \mathrm{e}-01$

$1.65012 \mathrm{e}+011.65012 \mathrm{e}+011.65012 \mathrm{e}+001.00000 \mathrm{e}-092.12000 \mathrm{e}-01$

$1.65012 \mathrm{e}+011.65012 \mathrm{e}+011.65012 \mathrm{e}+001.00000 \mathrm{e}-092.12000 \mathrm{e}-01$

$1.65012 \mathrm{e}+011.65012 \mathrm{e}+011.65012 \mathrm{e}+001.00000 \mathrm{e}-092.12000 \mathrm{e}-01$

$1.00000 \mathrm{e}-051.00000 \mathrm{e}-05$ 1.00000e-06 1.00000e-09 1.00000e-01

$1.00000 \mathrm{e}+001.00000 \mathrm{e}+001.00000 \mathrm{e}-01$ 1.00000e-09 1.00000e-01

Element: 10654 \# of layers: 7

$\mathrm{Kx} \mathrm{Ky} \mathrm{Kz}$ Ss Por

$1.65012 \mathrm{e}+01$ 1.65012e+01 1.65012e+00 1.00000e-09 2.12000e-01

$1.65012 \mathrm{e}+011.65012 \mathrm{e}+01$ 1.65012e+00 1.00000e-09 2.12000e-01

$1.65012 \mathrm{e}+01$ 1.65012e+01 1.65012e+00 1.00000e-09 2.12000e-01

$1.65012 \mathrm{e}+011.65012 \mathrm{e}+011.65012 \mathrm{e}+001.00000 \mathrm{e}-092.12000 \mathrm{e}-01$

$1.65012 \mathrm{e}+011.65012 \mathrm{e}+011.65012 \mathrm{e}+001.00000 \mathrm{e}-092.12000 \mathrm{e}-01$ 
$1.00000 \mathrm{e}-05$ 1.00000e-05 1.00000e-06 1.00000e-09 1.00000e-01 $1.00000 \mathrm{e}+001.00000 \mathrm{e}+001.00000 \mathrm{e}-01$ 1.00000e-09 1.00000e-01 Element: 10655 \# of layers: 7

Kx Ky Kz Ss Por

$1.65012 \mathrm{e}+011.65012 \mathrm{e}+011.65012 \mathrm{e}+001.00000 \mathrm{e}-092.12000 \mathrm{e}-01$ $1.65012 \mathrm{e}+011.65012 \mathrm{e}+011.65012 \mathrm{e}+001.00000 \mathrm{e}-092.12000 \mathrm{e}-01$ $1.65012 \mathrm{e}+011.65012 \mathrm{e}+011.65012 \mathrm{e}+001.00000 \mathrm{e}-092.12000 \mathrm{e}-01$ $1.65012 \mathrm{e}+011.65012 \mathrm{e}+011.65012 \mathrm{e}+001.00000 \mathrm{e}-092.12000 \mathrm{e}-01$ $1.65012 \mathrm{e}+011.65012 \mathrm{e}+01$ 1.65012e+00 1.00000e-09 2.12000e-01 $1.00000 \mathrm{e}-05$ 1.00000e-05 1.00000e-06 1.00000e-09 1.00000e-01 $1.00000 \mathrm{e}+001.00000 \mathrm{e}+001.00000 \mathrm{e}-011.00000 \mathrm{e}-091.00000 \mathrm{e}-01$ Element: 10656 \# of layers: 7

$\mathrm{Kx} \mathrm{Ky} \mathrm{Kz}$ Ss Por

$1.59704 \mathrm{e}+011.59704 \mathrm{e}+01$ 1.59704e+00 1.00000e-09 2.12000e-01 $1.59704 \mathrm{e}+011.59704 \mathrm{e}+011.59704 \mathrm{e}+001.00000 \mathrm{e}-092.12000 \mathrm{e}-01$ $1.59704 \mathrm{e}+011.59704 \mathrm{e}+011.59704 \mathrm{e}+001.00000 \mathrm{e}-092.12000 \mathrm{e}-01$ $1.59704 \mathrm{e}+011.59704 \mathrm{e}+011.59704 \mathrm{e}+001.00000 \mathrm{e}-092.12000 \mathrm{e}-01$ $1.59704 \mathrm{e}+011.59704 \mathrm{e}+011.59704 \mathrm{e}+001.00000 \mathrm{e}-092.12000 \mathrm{e}-01$ $1.00000 \mathrm{e}-051.00000 \mathrm{e}-05$ 1.00000e-06 1.00000e-09 1.00000e-01 $1.00000 \mathrm{e}+001.00000 \mathrm{e}+001.00000 \mathrm{e}-011.00000 \mathrm{e}-09$ 1.00000e-01 Element: 10657 \# of layers: 7

$\mathrm{Kx} \mathrm{Ky} \mathrm{Kz}$ Ss Por

$1.59704 \mathrm{e}+01$ 1.59704e+01 1.59704e+00 1.00000e-09 2.12000e-01 $1.59704 \mathrm{e}+011.59704 \mathrm{e}+011.59704 \mathrm{e}+001.00000 \mathrm{e}-092.12000 \mathrm{e}-01$ $1.59704 \mathrm{e}+011.59704 \mathrm{e}+011.59704 \mathrm{e}+001.00000 \mathrm{e}-092.12000 \mathrm{e}-01$ $1.59704 \mathrm{e}+011.59704 \mathrm{e}+011.59704 \mathrm{e}+001.00000 \mathrm{e}-092.12000 \mathrm{e}-01$ $1.59704 \mathrm{e}+011.59704 \mathrm{e}+011.59704 \mathrm{e}+001.00000 \mathrm{e}-092.12000 \mathrm{e}-01$ $1.00000 \mathrm{e}-05$ 1.00000e-05 1.00000e-06 1.00000e-09 1.00000e-01 $1.00000 \mathrm{e}+001.00000 \mathrm{e}+001.00000 \mathrm{e}-011.00000 \mathrm{e}-091.00000 \mathrm{e}-01$ Element: 10658 \# of layers: 7

$\mathrm{Kx} \mathrm{Ky} \mathrm{Kz}$ Ss Por

$1.59704 \mathrm{e}+011.59704 \mathrm{e}+011.59704 \mathrm{e}+001.00000 \mathrm{e}-092.12000 \mathrm{e}-01$ $1.59704 \mathrm{e}+011.59704 \mathrm{e}+011.59704 \mathrm{e}+001.00000 \mathrm{e}-092.12000 \mathrm{e}-01$ $1.59704 \mathrm{e}+011.59704 \mathrm{e}+011.59704 \mathrm{e}+001.00000 \mathrm{e}-092.12000 \mathrm{e}-01$ $1.59704 \mathrm{e}+011.59704 \mathrm{e}+011.59704 \mathrm{e}+001.00000 \mathrm{e}-092.12000 \mathrm{e}-01$ $1.59704 \mathrm{e}+011.59704 \mathrm{e}+011.59704 \mathrm{e}+001.00000 \mathrm{e}-092.12000 \mathrm{e}-01$ $1.00000 \mathrm{e}-05$ 1.00000e-05 1.00000e-06 1.00000e-09 1.00000e-01 $1.00000 \mathrm{e}+001.00000 \mathrm{e}+001.00000 \mathrm{e}-011.00000 \mathrm{e}-091.00000 \mathrm{e}-01$ Element: 10659 \# of layers: 7

$\mathrm{Kx} \mathrm{Ky} \mathrm{Kz}$ Ss Por

$1.59704 \mathrm{e}+01$ 1.59704e+01 1.59704e+00 1.00000e-09 2.12000e-01 $1.59704 \mathrm{e}+011.59704 \mathrm{e}+011.59704 \mathrm{e}+001.00000 \mathrm{e}-092.12000 \mathrm{e}-01$ $1.59704 \mathrm{e}+011.59704 \mathrm{e}+011.59704 \mathrm{e}+001.00000 \mathrm{e}-092.12000 \mathrm{e}-01$ $1.59704 \mathrm{e}+01$ 1.59704e+01 1.59704e+00 1.00000e-09 2.12000e-01 $1.59704 \mathrm{e}+011.59704 \mathrm{e}+011.59704 \mathrm{e}+001.00000 \mathrm{e}-092.12000 \mathrm{e}-01$ $1.00000 \mathrm{e}-05$ 1.00000e-05 1.00000e-06 1.00000e-09 1.00000e-01 
$1.00000 \mathrm{e}+001.00000 \mathrm{e}+001.00000 \mathrm{e}-011.00000 \mathrm{e}-091.00000 \mathrm{e}-01$

Element: 10660 \# of layers: 7

Kx Ky Kz Ss Por

$1.65012 \mathrm{e}+01$ 1.65012e+01 1.65012e+00 1.00000e-09 2.12000e-01

$1.65012 \mathrm{e}+011.65012 \mathrm{e}+011.65012 \mathrm{e}+001.00000 \mathrm{e}-092.12000 \mathrm{e}-01$

$1.65012 \mathrm{e}+011.65012 \mathrm{e}+011.65012 \mathrm{e}+001.00000 \mathrm{e}-092.12000 \mathrm{e}-01$

$1.65012 \mathrm{e}+011.65012 \mathrm{e}+011.65012 \mathrm{e}+001.00000 \mathrm{e}-092.12000 \mathrm{e}-01$

$1.65012 \mathrm{e}+011.65012 \mathrm{e}+011.65012 \mathrm{e}+001.00000 \mathrm{e}-092.12000 \mathrm{e}-01$

$1.00000 \mathrm{e}-05$ 1.00000e-05 1.00000e-06 1.00000e-09 1.00000e-01

$1.00000 \mathrm{e}+001.00000 \mathrm{e}+001.00000 \mathrm{e}-011.00000 \mathrm{e}-091.00000 \mathrm{e}-01$

Element: 10661 \# of layers: 7

Kx Ky Kz Ss Por

$1.59704 \mathrm{e}+011.59704 \mathrm{e}+011.59704 \mathrm{e}+001.00000 \mathrm{e}-092.12000 \mathrm{e}-01$

$1.59704 \mathrm{e}+011.59704 \mathrm{e}+011.59704 \mathrm{e}+001.00000 \mathrm{e}-092.12000 \mathrm{e}-01$

$1.59704 \mathrm{e}+011.59704 \mathrm{e}+011.59704 \mathrm{e}+001.00000 \mathrm{e}-092.12000 \mathrm{e}-01$

$1.59704 \mathrm{e}+011.59704 \mathrm{e}+011.59704 \mathrm{e}+001.00000 \mathrm{e}-092.12000 \mathrm{e}-01$

$1.59704 \mathrm{e}+011.59704 \mathrm{e}+011.59704 \mathrm{e}+001.00000 \mathrm{e}-092.12000 \mathrm{e}-01$

$1.00000 \mathrm{e}-05$ 1.00000e-05 1.00000e-06 1.00000e-09 1.00000e-01

$1.00000 \mathrm{e}+001.00000 \mathrm{e}+001.00000 \mathrm{e}-01$ 1.00000e-09 1.00000e-01

Element: 10662 \# of layers: 7

$\mathrm{Kx} \mathrm{Ky} \mathrm{Kz}$ Ss Por

$1.63320 \mathrm{e}+011.63320 \mathrm{e}+011.63320 \mathrm{e}+001.00000 \mathrm{e}-092.12000 \mathrm{e}-01$

$1.63320 \mathrm{e}+011.63320 \mathrm{e}+011.63320 \mathrm{e}+001.00000 \mathrm{e}-092.12000 \mathrm{e}-01$

$1.63320 \mathrm{e}+011.63320 \mathrm{e}+011.63320 \mathrm{e}+001.00000 \mathrm{e}-092.12000 \mathrm{e}-01$

$1.63320 \mathrm{e}+011.63320 \mathrm{e}+011.63320 \mathrm{e}+001.00000 \mathrm{e}-092.12000 \mathrm{e}-01$

$1.63320 \mathrm{e}+011.63320 \mathrm{e}+011.63320 \mathrm{e}+001.00000 \mathrm{e}-092.12000 \mathrm{e}-01$

$1.00000 \mathrm{e}-05$ 1.00000e-05 1.00000e-06 1.00000e-09 1.00000e-01

$1.00000 \mathrm{e}+001.00000 \mathrm{e}+001.00000 \mathrm{e}-01$ 1.00000e-09 1.00000e-01

Element: 10663 \# of layers: 7

$\mathrm{Kx} \mathrm{Ky} \mathrm{Kz}$ Ss Por

$1.63320 \mathrm{e}+01$ 1.63320e+01 1.63320e+00 1.00000e-09 2.12000e-01

$1.63320 \mathrm{e}+011.63320 \mathrm{e}+011.63320 \mathrm{e}+00$ 1.00000e-09 2.12000e-01

$1.63320 \mathrm{e}+011.63320 \mathrm{e}+011.63320 \mathrm{e}+001.00000 \mathrm{e}-092.12000 \mathrm{e}-01$

$1.63320 \mathrm{e}+011.63320 \mathrm{e}+011.63320 \mathrm{e}+001.00000 \mathrm{e}-092.12000 \mathrm{e}-01$

$1.63320 \mathrm{e}+011.63320 \mathrm{e}+011.63320 \mathrm{e}+001.00000 \mathrm{e}-092.12000 \mathrm{e}-01$

$1.00000 \mathrm{e}-05$ 1.00000e-05 1.00000e-06 1.00000e-09 1.00000e-01

$1.00000 \mathrm{e}+001.00000 \mathrm{e}+001.00000 \mathrm{e}-011.00000 \mathrm{e}-091.00000 \mathrm{e}-01$

Element: 10664 \# of layers: 7

$\mathrm{Kx} \mathrm{Ky} \mathrm{Kz}$ Ss Por

$1.63320 \mathrm{e}+011.63320 \mathrm{e}+011.63320 \mathrm{e}+001.00000 \mathrm{e}-092.12000 \mathrm{e}-01$

$1.63320 \mathrm{e}+011.63320 \mathrm{e}+011.63320 \mathrm{e}+001.00000 \mathrm{e}-092.12000 \mathrm{e}-01$

$1.63320 \mathrm{e}+011.63320 \mathrm{e}+011.63320 \mathrm{e}+001.00000 \mathrm{e}-092.12000 \mathrm{e}-01$

$1.63320 \mathrm{e}+011.63320 \mathrm{e}+011.63320 \mathrm{e}+001.00000 \mathrm{e}-092.12000 \mathrm{e}-01$

$1.63320 \mathrm{e}+01$ 1.63320e+01 1.63320e+00 1.00000e-09 2.12000e-01 $1.00000 \mathrm{e}-05$ 1.00000e-05 1.00000e-06 1.00000e-09 1.00000e-01

$1.00000 \mathrm{e}+001.00000 \mathrm{e}+001.00000 \mathrm{e}-011.00000 \mathrm{e}-091.00000 \mathrm{e}-01$ 
Element: 10665 \# of layers: 7

$\mathrm{Kx} \mathrm{Ky} \mathrm{Kz}$ Ss Por

$1.66204 \mathrm{e}+01$ 1.66204e+01 1.66204e+00 1.00000e-09 2.12000e-01

$1.66204 \mathrm{e}+011.66204 \mathrm{e}+011.66204 \mathrm{e}+001.00000 \mathrm{e}-092.12000 \mathrm{e}-01$

$1.66204 \mathrm{e}+011.66204 \mathrm{e}+011.66204 \mathrm{e}+001.00000 \mathrm{e}-092.12000 \mathrm{e}-01$

$1.66204 \mathrm{e}+011.66204 \mathrm{e}+011.66204 \mathrm{e}+001.00000 \mathrm{e}-092.12000 \mathrm{e}-01$

$1.66204 \mathrm{e}+011.66204 \mathrm{e}+011.66204 \mathrm{e}+001.00000 \mathrm{e}-092.12000 \mathrm{e}-01$

$1.00000 \mathrm{e}-05$ 1.00000e-05 1.00000e-06 1.00000e-09 1.00000e-01

$1.00000 \mathrm{e}+001.00000 \mathrm{e}+001.00000 \mathrm{e}-011.00000 \mathrm{e}-091.00000 \mathrm{e}-01$

Element: 10666 \# of layers: 7

Kx Ky Kz Ss Por

$1.66204 \mathrm{e}+011.66204 \mathrm{e}+011.66204 \mathrm{e}+001.00000 \mathrm{e}-092.12000 \mathrm{e}-01$

$1.66204 \mathrm{e}+011.66204 \mathrm{e}+011.66204 \mathrm{e}+001.00000 \mathrm{e}-092.12000 \mathrm{e}-01$

$1.66204 \mathrm{e}+011.66204 \mathrm{e}+01$ 1.66204e+00 1.00000e-09 2.12000e-01

$1.66204 \mathrm{e}+011.66204 \mathrm{e}+011.66204 \mathrm{e}+001.00000 \mathrm{e}-092.12000 \mathrm{e}-01$

$1.66204 \mathrm{e}+011.66204 \mathrm{e}+011.66204 \mathrm{e}+001.00000 \mathrm{e}-092.12000 \mathrm{e}-01$

$1.00000 \mathrm{e}-05$ 1.00000e-05 1.00000e-06 1.00000e-09 1.00000e-01

$1.00000 \mathrm{e}+001.00000 \mathrm{e}+001.00000 \mathrm{e}-01$ 1.00000e-09 1.00000e-01

Element: 10667 \# of layers: 7

$\mathrm{Kx} \mathrm{Ky} \mathrm{Kz}$ Ss Por

$1.65012 \mathrm{e}+01$ 1.65012e+01 1.65012e+00 1.00000e-09 2.12000e-01

$1.65012 \mathrm{e}+011.65012 \mathrm{e}+011.65012 \mathrm{e}+001.00000 \mathrm{e}-09$ 2.12000e-01

$1.65012 \mathrm{e}+011.65012 \mathrm{e}+011.65012 \mathrm{e}+001.00000 \mathrm{e}-092.12000 \mathrm{e}-01$

$1.65012 \mathrm{e}+011.65012 \mathrm{e}+011.65012 \mathrm{e}+001.00000 \mathrm{e}-092.12000 \mathrm{e}-01$

$1.65012 \mathrm{e}+011.65012 \mathrm{e}+011.65012 \mathrm{e}+001.00000 \mathrm{e}-092.12000 \mathrm{e}-01$

$1.00000 \mathrm{e}-05$ 1.00000e-05 1.00000e-06 1.00000e-09 1.00000e-01

$1.00000 \mathrm{e}+001.00000 \mathrm{e}+001.00000 \mathrm{e}-011.00000 \mathrm{e}-091.00000 \mathrm{e}-01$

Element: 10668 \# of layers: 7

$\mathrm{Kx} \mathrm{Ky} \mathrm{Kz}$ Ss Por

$1.59704 \mathrm{e}+01$ 1.59704e+01 1.59704e+00 1.00000e-09 2.12000e-01

$1.59704 \mathrm{e}+011.59704 \mathrm{e}+011.59704 \mathrm{e}+001.00000 \mathrm{e}-092.12000 \mathrm{e}-01$

$1.59704 \mathrm{e}+011.59704 \mathrm{e}+011.59704 \mathrm{e}+001.00000 \mathrm{e}-092.12000 \mathrm{e}-01$

$1.59704 \mathrm{e}+011.59704 \mathrm{e}+011.59704 \mathrm{e}+001.00000 \mathrm{e}-092.12000 \mathrm{e}-01$

$1.59704 \mathrm{e}+011.59704 \mathrm{e}+011.59704 \mathrm{e}+001.00000 \mathrm{e}-092.12000 \mathrm{e}-01$

$1.00000 \mathrm{e}-051.00000 \mathrm{e}-051.00000 \mathrm{e}-061.00000 \mathrm{e}-091.00000 \mathrm{e}-01$

$1.00000 \mathrm{e}+001.00000 \mathrm{e}+001.00000 \mathrm{e}-011.00000 \mathrm{e}-091.00000 \mathrm{e}-01$

Element: 10669 \# of layers: 7

$\mathrm{Kx} \mathrm{Ky} \mathrm{Kz}$ Ss Por

$1.63320 \mathrm{e}+01$ 1.63320e+01 1.63320e+00 1.00000e-09 2.12000e-01

$1.63320 \mathrm{e}+011.63320 \mathrm{e}+011.63320 \mathrm{e}+001.00000 \mathrm{e}-092.12000 \mathrm{e}-01$

$1.63320 \mathrm{e}+011.63320 \mathrm{e}+011.63320 \mathrm{e}+001.00000 \mathrm{e}-092.12000 \mathrm{e}-01$

$1.63320 \mathrm{e}+011.63320 \mathrm{e}+011.63320 \mathrm{e}+001.00000 \mathrm{e}-092.12000 \mathrm{e}-01$

$1.63320 \mathrm{e}+011.63320 \mathrm{e}+011.63320 \mathrm{e}+001.00000 \mathrm{e}-092.12000 \mathrm{e}-01$

$1.00000 \mathrm{e}-05$ 1.00000e-05 1.00000e-06 1.00000e-09 1.00000e-01

$1.00000 \mathrm{e}+001.00000 \mathrm{e}+001.00000 \mathrm{e}-01$ 1.00000e-09 1.00000e-01

Element: 10670 \# of layers: 7 
$\mathrm{Kx} \mathrm{Ky} \mathrm{Kz}$ Ss Por

$2.03852 \mathrm{e}+012.03852 \mathrm{e}+012.03852 \mathrm{e}+00$ 1.00000e-09 2.12000e-01

$2.03852 \mathrm{e}+012.03852 \mathrm{e}+012.03852 \mathrm{e}+001.00000 \mathrm{e}-092.12000 \mathrm{e}-01$

$2.03852 \mathrm{e}+012.03852 \mathrm{e}+012.03852 \mathrm{e}+00$ 1.00000e-09 2.12000e-01

$2.03852 \mathrm{e}+012.03852 \mathrm{e}+012.03852 \mathrm{e}+001.00000 \mathrm{e}-092.12000 \mathrm{e}-01$

$2.03852 \mathrm{e}+012.03852 \mathrm{e}+012.03852 \mathrm{e}+001.00000 \mathrm{e}-092.12000 \mathrm{e}-01$

$1.00000 \mathrm{e}-05$ 1.00000e-05 1.00000e-06 1.00000e-09 1.00000e-01

$1.00000 \mathrm{e}+001.00000 \mathrm{e}+001.00000 \mathrm{e}-01$ 1.00000e-09 1.00000e-01

Element: 10671 \# of layers: 7

$\mathrm{Kx} \mathrm{Ky} \mathrm{Kz}$ Ss Por

$2.03852 \mathrm{e}+012.03852 \mathrm{e}+012.03852 \mathrm{e}+00$ 1.00000e-09 2.12000e-01 $2.03852 \mathrm{e}+012.03852 \mathrm{e}+012.03852 \mathrm{e}+001.00000 \mathrm{e}-092.12000 \mathrm{e}-01$ $2.03852 \mathrm{e}+012.03852 \mathrm{e}+012.03852 \mathrm{e}+00$ 1.00000e-09 2.12000e-01 $2.03852 \mathrm{e}+012.03852 \mathrm{e}+012.03852 \mathrm{e}+001.00000 \mathrm{e}-092.12000 \mathrm{e}-01$ $2.03852 \mathrm{e}+012.03852 \mathrm{e}+012.03852 \mathrm{e}+001.00000 \mathrm{e}-092.12000 \mathrm{e}-01$ $1.00000 \mathrm{e}-05$ 1.00000e-05 1.00000e-06 1.00000e-09 1.00000e-01 $1.00000 \mathrm{e}+001.00000 \mathrm{e}+001.00000 \mathrm{e}-01$ 1.00000e-09 1.00000e-01 Element: 10672 \# of layers: 7

$\mathrm{Kx} \mathrm{Ky} \mathrm{Kz}$ Ss Por

$2.03852 \mathrm{e}+012.03852 \mathrm{e}+012.03852 \mathrm{e}+00$ 1.00000e-09 2.12000e-01 $2.03852 \mathrm{e}+012.03852 \mathrm{e}+012.03852 \mathrm{e}+00$ 1.00000e-09 2.12000e-01 $2.03852 \mathrm{e}+012.03852 \mathrm{e}+012.03852 \mathrm{e}+00$ 1.00000e-09 2.12000e-01 $2.03852 \mathrm{e}+012.03852 \mathrm{e}+012.03852 \mathrm{e}+00$ 1.00000e-09 2.12000e-01 $2.03852 \mathrm{e}+012.03852 \mathrm{e}+012.03852 \mathrm{e}+001.00000 \mathrm{e}-092.12000 \mathrm{e}-01$ $1.00000 \mathrm{e}-05$ 1.00000e-05 1.00000e-06 1.00000e-09 1.00000e-01 $1.00000 \mathrm{e}+001.00000 \mathrm{e}+001.00000 \mathrm{e}-01$ 1.00000e-09 1.00000e-01 Element: 10673 \# of layers: 7

$\mathrm{Kx} \mathrm{Ky} \mathrm{Kz} \mathrm{Ss} \mathrm{Por}$

$2.03852 \mathrm{e}+012.03852 \mathrm{e}+012.03852 \mathrm{e}+001.00000 \mathrm{e}-092.12000 \mathrm{e}-01$ $2.03852 \mathrm{e}+012.03852 \mathrm{e}+012.03852 \mathrm{e}+001.00000 \mathrm{e}-092.12000 \mathrm{e}-01$ $2.03852 \mathrm{e}+012.03852 \mathrm{e}+012.03852 \mathrm{e}+001.00000 \mathrm{e}-092.12000 \mathrm{e}-01$ $2.03852 \mathrm{e}+012.03852 \mathrm{e}+012.03852 \mathrm{e}+001.00000 \mathrm{e}-092.12000 \mathrm{e}-01$ $2.03852 \mathrm{e}+012.03852 \mathrm{e}+012.03852 \mathrm{e}+00$ 1.00000e-09 2.12000e-01 $1.00000 \mathrm{e}-05$ 1.00000e-05 1.00000e-06 1.00000e-09 1.00000e-01 $1.00000 \mathrm{e}+001.00000 \mathrm{e}+001.00000 \mathrm{e}-01$ 1.00000e-09 1.00000e-01 Element: 10674 \# of layers: 7

$\mathrm{Kx} \mathrm{Ky} \mathrm{Kz}$ Ss Por $2.03852 \mathrm{e}+012.03852 \mathrm{e}+012.03852 \mathrm{e}+00$ 1.00000e-09 2.12000e-01 $2.03852 \mathrm{e}+012.03852 \mathrm{e}+012.03852 \mathrm{e}+001.00000 \mathrm{e}-092.12000 \mathrm{e}-01$ $2.03852 \mathrm{e}+012.03852 \mathrm{e}+012.03852 \mathrm{e}+001.00000 \mathrm{e}-092.12000 \mathrm{e}-01$ $2.03852 \mathrm{e}+012.03852 \mathrm{e}+012.03852 \mathrm{e}+001.00000 \mathrm{e}-092.12000 \mathrm{e}-01$ $2.03852 \mathrm{e}+012.03852 \mathrm{e}+012.03852 \mathrm{e}+00$ 1.00000e-09 2.12000e-01 $1.00000 \mathrm{e}-051.00000 \mathrm{e}-051.00000 \mathrm{e}-061.00000 \mathrm{e}-091.00000 \mathrm{e}-01$ $1.00000 \mathrm{e}+001.00000 \mathrm{e}+001.00000 \mathrm{e}-01$ 1.00000e-09 1.00000e-01 Element: 10675 \# of layers: 7

Kx Ky Kz Ss Por 
$2.03852 \mathrm{e}+012.03852 \mathrm{e}+012.03852 \mathrm{e}+00$ 1.00000e-09 2.12000e-01 $2.03852 \mathrm{e}+012.03852 \mathrm{e}+012.03852 \mathrm{e}+00$ 1.00000e-09 2.12000e-01 $2.03852 \mathrm{e}+012.03852 \mathrm{e}+012.03852 \mathrm{e}+001.00000 \mathrm{e}-092.12000 \mathrm{e}-01$ $2.03852 \mathrm{e}+012.03852 \mathrm{e}+012.03852 \mathrm{e}+001.00000 \mathrm{e}-092.12000 \mathrm{e}-01$ $2.03852 \mathrm{e}+012.03852 \mathrm{e}+012.03852 \mathrm{e}+001.00000 \mathrm{e}-092.12000 \mathrm{e}-01$ $1.00000 \mathrm{e}-05$ 1.00000e-05 1.00000e-06 1.00000e-09 1.00000e-01 $1.00000 \mathrm{e}+001.00000 \mathrm{e}+001.00000 \mathrm{e}-01$ 1.00000e-09 1.00000e-01 Element: 10676 \# of layers: 7

$\mathrm{Kx} \mathrm{Ky} \mathrm{Kz}$ Ss Por

$2.03852 \mathrm{e}+012.03852 \mathrm{e}+012.03852 \mathrm{e}+00$ 1.00000e-09 2.12000e-01 $2.03852 \mathrm{e}+012.03852 \mathrm{e}+012.03852 \mathrm{e}+00$ 1.00000e-09 2.12000e-01 $2.03852 \mathrm{e}+012.03852 \mathrm{e}+012.03852 \mathrm{e}+001.00000 \mathrm{e}-092.12000 \mathrm{e}-01$ $2.03852 \mathrm{e}+012.03852 \mathrm{e}+012.03852 \mathrm{e}+001.00000 \mathrm{e}-092.12000 \mathrm{e}-01$ $2.03852 \mathrm{e}+012.03852 \mathrm{e}+012.03852 \mathrm{e}+001.00000 \mathrm{e}-092.12000 \mathrm{e}-01$ $1.00000 \mathrm{e}-05$ 1.00000e-05 1.00000e-06 1.00000e-09 1.00000e-01 $1.00000 \mathrm{e}+001.00000 \mathrm{e}+001.00000 \mathrm{e}-011.00000 \mathrm{e}-091.00000 \mathrm{e}-01$ Element: 10677 \# of layers: 7

$\mathrm{Kx} \mathrm{Ky} \mathrm{Kz}$ Ss Por

$2.03852 \mathrm{e}+012.03852 \mathrm{e}+012.03852 \mathrm{e}+00$ 1.00000e-09 2.12000e-01 $2.03852 \mathrm{e}+012.03852 \mathrm{e}+012.03852 \mathrm{e}+001.00000 \mathrm{e}-092.12000 \mathrm{e}-01$ $2.03852 \mathrm{e}+012.03852 \mathrm{e}+012.03852 \mathrm{e}+001.00000 \mathrm{e}-092.12000 \mathrm{e}-01$ $2.03852 \mathrm{e}+012.03852 \mathrm{e}+012.03852 \mathrm{e}+00$ 1.00000e-09 2.12000e-01 $2.03852 \mathrm{e}+012.03852 \mathrm{e}+012.03852 \mathrm{e}+00$ 1.00000e-09 2.12000e-01 $1.00000 \mathrm{e}-05$ 1.00000e-05 1.00000e-06 1.00000e-09 1.00000e-01 $1.00000 \mathrm{e}+001.00000 \mathrm{e}+001.00000 \mathrm{e}-011.00000 \mathrm{e}-091.00000 \mathrm{e}-01$ Element: 10678 \# of layers: 7

$\mathrm{Kx} \mathrm{Ky} \mathrm{Kz}$ Ss Por

$2.03852 \mathrm{e}+012.03852 \mathrm{e}+012.03852 \mathrm{e}+00$ 1.00000e-09 2.12000e-01 $2.03852 \mathrm{e}+012.03852 \mathrm{e}+012.03852 \mathrm{e}+001.00000 \mathrm{e}-092.12000 \mathrm{e}-01$ $2.03852 \mathrm{e}+012.03852 \mathrm{e}+012.03852 \mathrm{e}+001.00000 \mathrm{e}-092.12000 \mathrm{e}-01$ $2.03852 \mathrm{e}+012.03852 \mathrm{e}+012.03852 \mathrm{e}+001.00000 \mathrm{e}-092.12000 \mathrm{e}-01$ $2.03852 \mathrm{e}+012.03852 \mathrm{e}+012.03852 \mathrm{e}+00$ 1.00000e-09 2.12000e-01 $1.00000 \mathrm{e}-05$ 1.00000e-05 1.00000e-06 1.00000e-09 1.00000e-01 $1.00000 \mathrm{e}+001.00000 \mathrm{e}+001.00000 \mathrm{e}-011.00000 \mathrm{e}-09$ 1.00000e-01 Element: 10679 \# of layers: 7

$\mathrm{Kx} \mathrm{Ky} \mathrm{Kz}$ Ss Por $2.03852 \mathrm{e}+012.03852 \mathrm{e}+012.03852 \mathrm{e}+00$ 1.00000e-09 2.12000e-01 $2.03852 \mathrm{e}+012.03852 \mathrm{e}+012.03852 \mathrm{e}+001.00000 \mathrm{e}-092.12000 \mathrm{e}-01$ $2.03852 \mathrm{e}+012.03852 \mathrm{e}+012.03852 \mathrm{e}+001.00000 \mathrm{e}-092.12000 \mathrm{e}-01$ $2.03852 \mathrm{e}+012.03852 \mathrm{e}+012.03852 \mathrm{e}+001.00000 \mathrm{e}-092.12000 \mathrm{e}-01$ $2.03852 \mathrm{e}+012.03852 \mathrm{e}+012.03852 \mathrm{e}+001.00000 \mathrm{e}-092.12000 \mathrm{e}-01$ $1.00000 \mathrm{e}-05$ 1.00000e-05 1.00000e-06 1.00000e-09 1.00000e-01 $1.00000 \mathrm{e}+001.00000 \mathrm{e}+001.00000 \mathrm{e}-01$ 1.00000e-09 1.00000e-01 Element: 10680 \# of layers: 7

$\mathrm{Kx} \mathrm{Ky} \mathrm{Kz}$ Ss Por

$2.10548 \mathrm{e}+012.10548 \mathrm{e}+012.10548 \mathrm{e}+00$ 1.00000e-09 2.12000e-01 
$2.10548 \mathrm{e}+012.10548 \mathrm{e}+012.10548 \mathrm{e}+00$ 1.00000e-09 2.12000e-01 $2.10548 \mathrm{e}+012.10548 \mathrm{e}+012.10548 \mathrm{e}+00$ 1.00000e-09 2.12000e-01 $2.10548 \mathrm{e}+012.10548 \mathrm{e}+012.10548 \mathrm{e}+00$ 1.00000e-09 2.12000e-01 $2.10548 \mathrm{e}+012.10548 \mathrm{e}+012.10548 \mathrm{e}+001.00000 \mathrm{e}-092.12000 \mathrm{e}-01$ $1.00000 \mathrm{e}-05$ 1.00000e-05 1.00000e-06 1.00000e-09 1.00000e-01 $1.00000 \mathrm{e}+001.00000 \mathrm{e}+001.00000 \mathrm{e}-011.00000 \mathrm{e}-091.00000 \mathrm{e}-01$ Element: 10681 \# of layers: 7

Kx Ky Kz Ss Por

$2.10548 \mathrm{e}+012.10548 \mathrm{e}+012.10548 \mathrm{e}+00$ 1.00000e-09 2.12000e-01 $2.10548 \mathrm{e}+012.10548 \mathrm{e}+012.10548 \mathrm{e}+001.00000 \mathrm{e}-092.12000 \mathrm{e}-01$ $2.10548 \mathrm{e}+012.10548 \mathrm{e}+012.10548 \mathrm{e}+001.00000 \mathrm{e}-092.12000 \mathrm{e}-01$ $2.10548 \mathrm{e}+012.10548 \mathrm{e}+012.10548 \mathrm{e}+00$ 1.00000e-09 2.12000e-01 $2.10548 \mathrm{e}+012.10548 \mathrm{e}+012.10548 \mathrm{e}+00$ 1.00000e-09 2.12000e-01 $1.00000 \mathrm{e}-05$ 1.00000e-05 1.00000e-06 1.00000e-09 1.00000e-01 $1.00000 \mathrm{e}+001.00000 \mathrm{e}+001.00000 \mathrm{e}-011.00000 \mathrm{e}-091.00000 \mathrm{e}-01$ Element: 10682 \# of layers: 7

Kx Ky Kz Ss Por

$2.10548 \mathrm{e}+012.10548 \mathrm{e}+012.10548 \mathrm{e}+00$ 1.00000e-09 2.12000e-01 $2.10548 \mathrm{e}+012.10548 \mathrm{e}+012.10548 \mathrm{e}+00$ 1.00000e-09 2.12000e-01 $2.10548 \mathrm{e}+012.10548 \mathrm{e}+012.10548 \mathrm{e}+001.00000 \mathrm{e}-092.12000 \mathrm{e}-01$ $2.10548 \mathrm{e}+012.10548 \mathrm{e}+012.10548 \mathrm{e}+001.00000 \mathrm{e}-092.12000 \mathrm{e}-01$ $2.10548 \mathrm{e}+012.10548 \mathrm{e}+012.10548 \mathrm{e}+00$ 1.00000e-09 2.12000e-01 $1.00000 \mathrm{e}-05$ 1.00000e-05 1.00000e-06 1.00000e-09 1.00000e-01 $1.00000 \mathrm{e}+001.00000 \mathrm{e}+001.00000 \mathrm{e}-011.00000 \mathrm{e}-091.00000 \mathrm{e}-01$ Element: 10683 \# of layers: 7

Kx Ky Kz Ss Por

$2.10548 \mathrm{e}+012.10548 \mathrm{e}+012.10548 \mathrm{e}+00$ 1.00000e-09 2.12000e-01 $2.10548 \mathrm{e}+012.10548 \mathrm{e}+012.10548 \mathrm{e}+00$ 1.00000e-09 2.12000e-01 $2.10548 \mathrm{e}+012.10548 \mathrm{e}+012.10548 \mathrm{e}+001.00000 \mathrm{e}-092.12000 \mathrm{e}-01$ $2.10548 \mathrm{e}+012.10548 \mathrm{e}+012.10548 \mathrm{e}+001.00000 \mathrm{e}-092.12000 \mathrm{e}-01$ $2.10548 \mathrm{e}+012.10548 \mathrm{e}+012.10548 \mathrm{e}+001.00000 \mathrm{e}-092.12000 \mathrm{e}-01$ $1.00000 \mathrm{e}-05$ 1.00000e-05 1.00000e-06 1.00000e-09 1.00000e-01 $1.00000 \mathrm{e}+001.00000 \mathrm{e}+001.00000 \mathrm{e}-011.00000 \mathrm{e}-091.00000 \mathrm{e}-01$ Element: 10684 \# of layers: 7

Kx Ky Kz Ss Por

$2.10548 \mathrm{e}+012.10548 \mathrm{e}+012.10548 \mathrm{e}+00$ 1.00000e-09 2.12000e-01 $2.10548 \mathrm{e}+012.10548 \mathrm{e}+012.10548 \mathrm{e}+00$ 1.00000e-09 2.12000e-01 $2.10548 \mathrm{e}+012.10548 \mathrm{e}+012.10548 \mathrm{e}+00$ 1.00000e-09 2.12000e-01 $2.10548 \mathrm{e}+012.10548 \mathrm{e}+012.10548 \mathrm{e}+00$ 1.00000e-09 2.12000e-01 $2.10548 \mathrm{e}+012.10548 \mathrm{e}+012.10548 \mathrm{e}+00$ 1.00000e-09 2.12000e-01 $1.00000 \mathrm{e}-05$ 1.00000e-05 1.00000e-06 1.00000e-09 1.00000e-01 $1.00000 \mathrm{e}+001.00000 \mathrm{e}+001.00000 \mathrm{e}-011.00000 \mathrm{e}-091.00000 \mathrm{e}-01$ Element: 10685 \# of layers: 7

Kx Ky Kz Ss Por $2.03852 \mathrm{e}+012.03852 \mathrm{e}+012.03852 \mathrm{e}+00$ 1.00000e-09 2.12000e-01 $2.03852 \mathrm{e}+012.03852 \mathrm{e}+012.03852 \mathrm{e}+001.00000 \mathrm{e}-092.12000 \mathrm{e}-01$ 
$2.03852 \mathrm{e}+012.03852 \mathrm{e}+012.03852 \mathrm{e}+00$ 1.00000e-09 2.12000e-01 $2.03852 \mathrm{e}+012.03852 \mathrm{e}+012.03852 \mathrm{e}+001.00000 \mathrm{e}-092.12000 \mathrm{e}-01$ $2.03852 \mathrm{e}+012.03852 \mathrm{e}+012.03852 \mathrm{e}+001.00000 \mathrm{e}-092.12000 \mathrm{e}-01$ $1.00000 \mathrm{e}-05$ 1.00000e-05 1.00000e-06 1.00000e-09 1.00000e-01 $1.00000 \mathrm{e}+001.00000 \mathrm{e}+001.00000 \mathrm{e}-01$ 1.00000e-09 1.00000e-01 Element: 10686 \# of layers: 7

$\mathrm{Kx} \mathrm{Ky} \mathrm{Kz}$ Ss Por

$2.03852 \mathrm{e}+012.03852 \mathrm{e}+012.03852 \mathrm{e}+00$ 1.00000e-09 2.12000e-01 $2.03852 \mathrm{e}+012.03852 \mathrm{e}+012.03852 \mathrm{e}+001.00000 \mathrm{e}-092.12000 \mathrm{e}-01$ $2.03852 \mathrm{e}+012.03852 \mathrm{e}+012.03852 \mathrm{e}+001.00000 \mathrm{e}-092.12000 \mathrm{e}-01$ $2.03852 \mathrm{e}+012.03852 \mathrm{e}+012.03852 \mathrm{e}+001.00000 \mathrm{e}-092.12000 \mathrm{e}-01$ $2.03852 \mathrm{e}+012.03852 \mathrm{e}+012.03852 \mathrm{e}+001.00000 \mathrm{e}-092.12000 \mathrm{e}-01$ $1.00000 \mathrm{e}-05$ 1.00000e-05 1.00000e-06 1.00000e-09 1.00000e-01 $1.00000 \mathrm{e}+001.00000 \mathrm{e}+001.00000 \mathrm{e}-011.00000 \mathrm{e}-09$ 1.00000e-01 Element: 10687 \# of layers: 7

Kx Ky Kz Ss Por

$2.10548 \mathrm{e}+012.10548 \mathrm{e}+012.10548 \mathrm{e}+00$ 1.00000e-09 2.12000e-01 $2.10548 \mathrm{e}+012.10548 \mathrm{e}+012.10548 \mathrm{e}+00$ 1.00000e-09 2.12000e-01 $2.10548 \mathrm{e}+012.10548 \mathrm{e}+012.10548 \mathrm{e}+00$ 1.00000e-09 2.12000e-01 $2.10548 \mathrm{e}+012.10548 \mathrm{e}+012.10548 \mathrm{e}+00$ 1.00000e-09 2.12000e-01 $2.10548 \mathrm{e}+012.10548 \mathrm{e}+012.10548 \mathrm{e}+00$ 1.00000e-09 2.12000e-01 $1.00000 \mathrm{e}-05$ 1.00000e-05 1.00000e-06 1.00000e-09 1.00000e-01 $1.00000 \mathrm{e}+001.00000 \mathrm{e}+001.00000 \mathrm{e}-01$ 1.00000e-09 1.00000e-01 Element: 10688 \# of layers: 7

$\mathrm{Kx} \mathrm{Ky} \mathrm{Kz}$ Ss Por

$2.10548 \mathrm{e}+012.10548 \mathrm{e}+012.10548 \mathrm{e}+00$ 1.00000e-09 2.12000e-01 $2.10548 \mathrm{e}+012.10548 \mathrm{e}+012.10548 \mathrm{e}+00$ 1.00000e-09 2.12000e-01 $2.10548 \mathrm{e}+012.10548 \mathrm{e}+012.10548 \mathrm{e}+00$ 1.00000e-09 2.12000e-01 $2.10548 \mathrm{e}+012.10548 \mathrm{e}+012.10548 \mathrm{e}+00$ 1.00000e-09 2.12000e-01 $2.10548 \mathrm{e}+012.10548 \mathrm{e}+012.10548 \mathrm{e}+001.00000 \mathrm{e}-092.12000 \mathrm{e}-01$ $1.00000 \mathrm{e}-05$ 1.00000e-05 1.00000e-06 1.00000e-09 1.00000e-01 $1.00000 \mathrm{e}+001.00000 \mathrm{e}+001.00000 \mathrm{e}-01$ 1.00000e-09 1.00000e-01 Element: 10689 \# of layers: 7

$\mathrm{Kx} \mathrm{Ky} \mathrm{Kz}$ Ss Por

$2.10548 \mathrm{e}+012.10548 \mathrm{e}+012.10548 \mathrm{e}+00$ 1.00000e-09 2.12000e-01 $2.10548 \mathrm{e}+012.10548 \mathrm{e}+012.10548 \mathrm{e}+00$ 1.00000e-09 2.12000e-01 $2.10548 \mathrm{e}+012.10548 \mathrm{e}+012.10548 \mathrm{e}+001.00000 \mathrm{e}-092.12000 \mathrm{e}-01$ $2.10548 \mathrm{e}+012.10548 \mathrm{e}+012.10548 \mathrm{e}+00$ 1.00000e-09 2.12000e-01 $2.10548 \mathrm{e}+012.10548 \mathrm{e}+012.10548 \mathrm{e}+00$ 1.00000e-09 2.12000e-01 $1.00000 \mathrm{e}-05$ 1.00000e-05 1.00000e-06 1.00000e-09 1.00000e-01 $1.00000 \mathrm{e}+001.00000 \mathrm{e}+001.00000 \mathrm{e}-011.00000 \mathrm{e}-091.00000 \mathrm{e}-01$ Element: 10690 \# of layers: 7

$\mathrm{Kx} \mathrm{Ky} \mathrm{Kz}$ Ss Por

2.10548e+01 2.10548e+01 2.10548e+00 1.00000e-09 2.12000e-01 $2.10548 \mathrm{e}+012.10548 \mathrm{e}+012.10548 \mathrm{e}+00$ 1.00000e-09 2.12000e-01 $2.10548 \mathrm{e}+012.10548 \mathrm{e}+012.10548 \mathrm{e}+00$ 1.00000e-09 2.12000e-01 
$2.10548 \mathrm{e}+012.10548 \mathrm{e}+012.10548 \mathrm{e}+00$ 1.00000e-09 2.12000e-01 $2.10548 \mathrm{e}+012.10548 \mathrm{e}+012.10548 \mathrm{e}+00$ 1.00000e-09 2.12000e-01 $1.00000 \mathrm{e}-05$ 1.00000e-05 1.00000e-06 1.00000e-09 1.00000e-01 $1.00000 \mathrm{e}+001.00000 \mathrm{e}+001.00000 \mathrm{e}-011.00000 \mathrm{e}-091.00000 \mathrm{e}-01$ Element: 10691 \# of layers: 7

Kx Ky Kz Ss Por

$2.10548 \mathrm{e}+012.10548 \mathrm{e}+012.10548 \mathrm{e}+00$ 1.00000e-09 2.12000e-01 $2.10548 \mathrm{e}+012.10548 \mathrm{e}+012.10548 \mathrm{e}+00$ 1.00000e-09 2.12000e-01 $2.10548 \mathrm{e}+012.10548 \mathrm{e}+012.10548 \mathrm{e}+001.00000 \mathrm{e}-092.12000 \mathrm{e}-01$ $2.10548 \mathrm{e}+012.10548 \mathrm{e}+012.10548 \mathrm{e}+001.00000 \mathrm{e}-092.12000 \mathrm{e}-01$ $2.10548 \mathrm{e}+012.10548 \mathrm{e}+012.10548 \mathrm{e}+001.00000 \mathrm{e}-092.12000 \mathrm{e}-01$ $1.00000 \mathrm{e}-05$ 1.00000e-05 1.00000e-06 1.00000e-09 1.00000e-01 $1.00000 \mathrm{e}+001.00000 \mathrm{e}+001.00000 \mathrm{e}-011.00000 \mathrm{e}-091.00000 \mathrm{e}-01$ Element: 10692 \# of layers: 7

Kx Ky Kz Ss Por

$2.10548 \mathrm{e}+012.10548 \mathrm{e}+012.10548 \mathrm{e}+00$ 1.00000e-09 2.12000e-01 $2.10548 \mathrm{e}+012.10548 \mathrm{e}+012.10548 \mathrm{e}+00$ 1.00000e-09 2.12000e-01 $2.10548 \mathrm{e}+012.10548 \mathrm{e}+012.10548 \mathrm{e}+00$ 1.00000e-09 2.12000e-01 $2.10548 \mathrm{e}+012.10548 \mathrm{e}+012.10548 \mathrm{e}+00$ 1.00000e-09 2.12000e-01 $2.10548 \mathrm{e}+012.10548 \mathrm{e}+012.10548 \mathrm{e}+00$ 1.00000e-09 2.12000e-01 $1.00000 \mathrm{e}-05$ 1.00000e-05 1.00000e-06 1.00000e-09 1.00000e-01 $1.00000 \mathrm{e}+001.00000 \mathrm{e}+001.00000 \mathrm{e}-011.00000 \mathrm{e}-091.00000 \mathrm{e}-01$ Element: 10693 \# of layers: 7

Kx Ky Kz Ss Por

$2.10548 \mathrm{e}+012.10548 \mathrm{e}+012.10548 \mathrm{e}+00$ 1.00000e-09 2.12000e-01 $2.10548 \mathrm{e}+012.10548 \mathrm{e}+012.10548 \mathrm{e}+00$ 1.00000e-09 2.12000e-01 $2.10548 \mathrm{e}+012.10548 \mathrm{e}+012.10548 \mathrm{e}+00$ 1.00000e-09 2.12000e-01 $2.10548 \mathrm{e}+012.10548 \mathrm{e}+012.10548 \mathrm{e}+00$ 1.00000e-09 2.12000e-01 $2.10548 \mathrm{e}+012.10548 \mathrm{e}+012.10548 \mathrm{e}+001.00000 \mathrm{e}-092.12000 \mathrm{e}-01$ $1.00000 \mathrm{e}-05$ 1.00000e-05 1.00000e-06 1.00000e-09 1.00000e-01 $1.00000 \mathrm{e}+001.00000 \mathrm{e}+001.00000 \mathrm{e}-011.00000 \mathrm{e}-091.00000 \mathrm{e}-01$ Element: 10694 \# of layers: 7

Kx Ky Kz Ss Por

$2.10548 \mathrm{e}+012.10548 \mathrm{e}+012.10548 \mathrm{e}+00$ 1.00000e-09 2.12000e-01 $2.10548 \mathrm{e}+012.10548 \mathrm{e}+012.10548 \mathrm{e}+00$ 1.00000e-09 2.12000e-01 $2.10548 \mathrm{e}+012.10548 \mathrm{e}+012.10548 \mathrm{e}+00$ 1.00000e-09 2.12000e-01 $2.10548 \mathrm{e}+012.10548 \mathrm{e}+012.10548 \mathrm{e}+00$ 1.00000e-09 2.12000e-01 $2.10548 \mathrm{e}+012.10548 \mathrm{e}+012.10548 \mathrm{e}+00$ 1.00000e-09 2.12000e-01 $1.00000 \mathrm{e}-05$ 1.00000e-05 1.00000e-06 1.00000e-09 1.00000e-01 $1.00000 \mathrm{e}+001.00000 \mathrm{e}+001.00000 \mathrm{e}-011.00000 \mathrm{e}-091.00000 \mathrm{e}-01$ Element: 10695 \# of layers: 7

Kx Ky Kz Ss Por

$2.10548 \mathrm{e}+012.10548 \mathrm{e}+012.10548 \mathrm{e}+00$ 1.00000e-09 2.12000e-01 $2.10548 \mathrm{e}+012.10548 \mathrm{e}+012.10548 \mathrm{e}+00$ 1.00000e-09 2.12000e-01 $2.10548 \mathrm{e}+012.10548 \mathrm{e}+012.10548 \mathrm{e}+00$ 1.00000e-09 2.12000e-01 $2.10548 \mathrm{e}+012.10548 \mathrm{e}+012.10548 \mathrm{e}+001.00000 \mathrm{e}-092.12000 \mathrm{e}-01$ 
$2.10548 \mathrm{e}+012.10548 \mathrm{e}+012.10548 \mathrm{e}+00$ 1.00000e-09 2.12000e-01 $1.00000 \mathrm{e}-05$ 1.00000e-05 1.00000e-06 1.00000e-09 1.00000e-01 $1.00000 \mathrm{e}+001.00000 \mathrm{e}+001.00000 \mathrm{e}-011.00000 \mathrm{e}-091.00000 \mathrm{e}-01$ Element: 10696 \# of layers: 7

$\mathrm{Kx} \mathrm{Ky} \mathrm{Kz}$ Ss Por

2.10548e+01 2.10548e+01 2.10548e+00 1.00000e-09 2.12000e-01

$2.10548 \mathrm{e}+012.10548 \mathrm{e}+012.10548 \mathrm{e}+00$ 1.00000e-09 2.12000e-01

$2.10548 \mathrm{e}+012.10548 \mathrm{e}+012.10548 \mathrm{e}+00$ 1.00000e-09 2.12000e-01

$2.10548 \mathrm{e}+012.10548 \mathrm{e}+012.10548 \mathrm{e}+00$ 1.00000e-09 2.12000e-01

$2.10548 \mathrm{e}+012.10548 \mathrm{e}+012.10548 \mathrm{e}+00$ 1.00000e-09 2.12000e-01 $1.00000 \mathrm{e}-05$ 1.00000e-05 1.00000e-06 1.00000e-09 1.00000e-01

$1.00000 \mathrm{e}+001.00000 \mathrm{e}+001.00000 \mathrm{e}-011.00000 \mathrm{e}-091.00000 \mathrm{e}-01$

Element: 10697 \# of layers: 7

$\mathrm{Kx} \mathrm{Ky} \mathrm{Kz}$ Ss Por

$2.10548 \mathrm{e}+012.10548 \mathrm{e}+012.10548 \mathrm{e}+00$ 1.00000e-09 2.12000e-01

$2.10548 \mathrm{e}+012.10548 \mathrm{e}+012.10548 \mathrm{e}+00$ 1.00000e-09 2.12000e-01

$2.10548 \mathrm{e}+012.10548 \mathrm{e}+012.10548 \mathrm{e}+00$ 1.00000e-09 2.12000e-01

$2.10548 \mathrm{e}+012.10548 \mathrm{e}+012.10548 \mathrm{e}+00$ 1.00000e-09 2.12000e-01

$2.10548 \mathrm{e}+012.10548 \mathrm{e}+012.10548 \mathrm{e}+00$ 1.00000e-09 2.12000e-01 $1.00000 \mathrm{e}-05$ 1.00000e-05 1.00000e-06 1.00000e-09 1.00000e-01

$1.00000 \mathrm{e}+001.00000 \mathrm{e}+001.00000 \mathrm{e}-011.00000 \mathrm{e}-091.00000 \mathrm{e}-01$

Element: 10698 \# of layers: 7

$\mathrm{Kx} \mathrm{Ky} \mathrm{Kz}$ Ss Por

$2.10548 \mathrm{e}+012.10548 \mathrm{e}+012.10548 \mathrm{e}+00$ 1.00000e-09 2.12000e-01

$2.10548 \mathrm{e}+012.10548 \mathrm{e}+012.10548 \mathrm{e}+001.00000 \mathrm{e}-092.12000 \mathrm{e}-01$

$2.10548 \mathrm{e}+012.10548 \mathrm{e}+012.10548 \mathrm{e}+00$ 1.00000e-09 2.12000e-01

$2.10548 \mathrm{e}+012.10548 \mathrm{e}+012.10548 \mathrm{e}+00$ 1.00000e-09 2.12000e-01

$2.10548 \mathrm{e}+012.10548 \mathrm{e}+012.10548 \mathrm{e}+00$ 1.00000e-09 2.12000e-01 $1.00000 \mathrm{e}-05$ 1.00000e-05 1.00000e-06 1.00000e-09 1.00000e-01

$1.00000 \mathrm{e}+001.00000 \mathrm{e}+001.00000 \mathrm{e}-011.00000 \mathrm{e}-091.00000 \mathrm{e}-01$

Element: 10699 \# of layers: 7

$\mathrm{Kx} \mathrm{Ky} \mathrm{Kz}$ Ss Por

2.07837e+01 2.07837e+01 2.07837e+00 1.00000e-09 2.12000e-01

$2.07837 \mathrm{e}+012.07837 \mathrm{e}+012.07837 \mathrm{e}+00$ 1.00000e-09 2.12000e-01

$2.07837 \mathrm{e}+012.07837 \mathrm{e}+012.07837 \mathrm{e}+00$ 1.00000e-09 2.12000e-01

$2.07837 \mathrm{e}+012.07837 \mathrm{e}+012.07837 \mathrm{e}+00$ 1.00000e-09 2.12000e-01

$2.07837 \mathrm{e}+012.07837 \mathrm{e}+012.07837 \mathrm{e}+00$ 1.00000e-09 2.12000e-01

$1.00000 \mathrm{e}-05$ 1.00000e-05 1.00000e-06 1.00000e-09 1.00000e-01

$1.00000 \mathrm{e}+001.00000 \mathrm{e}+001.00000 \mathrm{e}-01$ 1.00000e-09 1.00000e-01

Element: 10700 \# of layers: 7

$\mathrm{Kx} \mathrm{Ky} \mathrm{Kz}$ Ss Por

2.07837e+01 2.07837e+01 2.07837e+00 1.00000e-09 2.12000e-01

$2.07837 \mathrm{e}+012.07837 \mathrm{e}+012.07837 \mathrm{e}+001.00000 \mathrm{e}-092.12000 \mathrm{e}-01$

$2.07837 \mathrm{e}+012.07837 \mathrm{e}+012.07837 \mathrm{e}+00$ 1.00000e-09 2.12000e-01

$2.07837 \mathrm{e}+012.07837 \mathrm{e}+012.07837 \mathrm{e}+00$ 1.00000e-09 2.12000e-01

$2.07837 \mathrm{e}+012.07837 \mathrm{e}+012.07837 \mathrm{e}+001.00000 \mathrm{e}-092.12000 \mathrm{e}-01$ 
$1.00000 \mathrm{e}-05$ 1.00000e-05 1.00000e-06 1.00000e-09 1.00000e-01 $1.00000 \mathrm{e}+001.00000 \mathrm{e}+001.00000 \mathrm{e}-01$ 1.00000e-09 1.00000e-01 Element: 10701 \# of layers: 7

Kx Ky Kz Ss Por

$2.07837 \mathrm{e}+012.07837 \mathrm{e}+012.07837 \mathrm{e}+00$ 1.00000e-09 2.12000e-01 $2.07837 \mathrm{e}+012.07837 \mathrm{e}+012.07837 \mathrm{e}+00$ 1.00000e-09 2.12000e-01 $2.07837 \mathrm{e}+012.07837 \mathrm{e}+012.07837 \mathrm{e}+00$ 1.00000e-09 2.12000e-01 $2.07837 \mathrm{e}+012.07837 \mathrm{e}+012.07837 \mathrm{e}+00$ 1.00000e-09 2.12000e-01 2.07837e+01 2.07837e+01 2.07837e+00 1.00000e-09 2.12000e-01 $1.00000 \mathrm{e}-05$ 1.00000e-05 1.00000e-06 1.00000e-09 1.00000e-01 $1.00000 \mathrm{e}+001.00000 \mathrm{e}+001.00000 \mathrm{e}-011.00000 \mathrm{e}-091.00000 \mathrm{e}-01$ Element: 10702 \# of layers: 7

$\mathrm{Kx} \mathrm{Ky} \mathrm{Kz}$ Ss Por

$2.10548 \mathrm{e}+012.10548 \mathrm{e}+012.10548 \mathrm{e}+00$ 1.00000e-09 2.12000e-01 $2.10548 \mathrm{e}+012.10548 \mathrm{e}+012.10548 \mathrm{e}+00$ 1.00000e-09 2.12000e-01 $2.10548 \mathrm{e}+012.10548 \mathrm{e}+012.10548 \mathrm{e}+00$ 1.00000e-09 2.12000e-01 $2.10548 \mathrm{e}+012.10548 \mathrm{e}+012.10548 \mathrm{e}+00$ 1.00000e-09 2.12000e-01 $2.10548 \mathrm{e}+012.10548 \mathrm{e}+012.10548 \mathrm{e}+00$ 1.00000e-09 2.12000e-01 $1.00000 \mathrm{e}-05$ 1.00000e-05 1.00000e-06 1.00000e-09 1.00000e-01 $1.00000 \mathrm{e}+001.00000 \mathrm{e}+001.00000 \mathrm{e}-011.00000 \mathrm{e}-09$ 1.00000e-01 Element: 10703 \# of layers: 7

$\mathrm{Kx} \mathrm{Ky} \mathrm{Kz}$ Ss Por

$2.10548 \mathrm{e}+012.10548 \mathrm{e}+01$ 2.10548e+00 1.00000e-09 2.12000e-01 $2.10548 \mathrm{e}+012.10548 \mathrm{e}+012.10548 \mathrm{e}+00$ 1.00000e-09 2.12000e-01 $2.10548 \mathrm{e}+012.10548 \mathrm{e}+012.10548 \mathrm{e}+001.00000 \mathrm{e}-092.12000 \mathrm{e}-01$ $2.10548 \mathrm{e}+012.10548 \mathrm{e}+012.10548 \mathrm{e}+001.00000 \mathrm{e}-092.12000 \mathrm{e}-01$ $2.10548 \mathrm{e}+012.10548 \mathrm{e}+012.10548 \mathrm{e}+00$ 1.00000e-09 2.12000e-01 $1.00000 \mathrm{e}-05$ 1.00000e-05 1.00000e-06 1.00000e-09 1.00000e-01 $1.00000 \mathrm{e}+001.00000 \mathrm{e}+001.00000 \mathrm{e}-011.00000 \mathrm{e}-091.00000 \mathrm{e}-01$ Element: 10704 \# of layers: 7

$\mathrm{Kx} \mathrm{Ky} \mathrm{Kz}$ Ss Por

$2.10548 \mathrm{e}+012.10548 \mathrm{e}+012.10548 \mathrm{e}+00$ 1.00000e-09 2.12000e-01 $2.10548 \mathrm{e}+012.10548 \mathrm{e}+012.10548 \mathrm{e}+00$ 1.00000e-09 2.12000e-01 $2.10548 \mathrm{e}+012.10548 \mathrm{e}+012.10548 \mathrm{e}+00$ 1.00000e-09 2.12000e-01 $2.10548 \mathrm{e}+012.10548 \mathrm{e}+012.10548 \mathrm{e}+00$ 1.00000e-09 2.12000e-01 $2.10548 \mathrm{e}+012.10548 \mathrm{e}+012.10548 \mathrm{e}+00$ 1.00000e-09 2.12000e-01 1.00000e-05 1.00000e-05 1.00000e-06 1.00000e-09 1.00000e-01 $1.00000 \mathrm{e}+001.00000 \mathrm{e}+001.00000 \mathrm{e}-011.00000 \mathrm{e}-091.00000 \mathrm{e}-01$ Element: 10705 \# of layers: 7

$\mathrm{Kx} \mathrm{Ky} \mathrm{Kz}$ Ss Por

$2.10548 \mathrm{e}+012.10548 \mathrm{e}+012.10548 \mathrm{e}+00$ 1.00000e-09 2.12000e-01 $2.10548 \mathrm{e}+012.10548 \mathrm{e}+012.10548 \mathrm{e}+00$ 1.00000e-09 2.12000e-01 $2.10548 \mathrm{e}+012.10548 \mathrm{e}+012.10548 \mathrm{e}+001.00000 \mathrm{e}-092.12000 \mathrm{e}-01$ $2.10548 \mathrm{e}+012.10548 \mathrm{e}+012.10548 \mathrm{e}+00$ 1.00000e-09 2.12000e-01 $2.10548 \mathrm{e}+012.10548 \mathrm{e}+012.10548 \mathrm{e}+00$ 1.00000e-09 2.12000e-01 $1.00000 \mathrm{e}-05$ 1.00000e-05 1.00000e-06 1.00000e-09 1.00000e-01 
$1.00000 \mathrm{e}+001.00000 \mathrm{e}+001.00000 \mathrm{e}-011.00000 \mathrm{e}-091.00000 \mathrm{e}-01$

Element: 10706 \# of layers: 7

Kx Ky Kz Ss Por

2.07837e+01 2.07837e+01 2.07837e+00 1.00000e-09 2.12000e-01

$2.07837 \mathrm{e}+012.07837 \mathrm{e}+012.07837 \mathrm{e}+00$ 1.00000e-09 2.12000e-01

$2.07837 \mathrm{e}+012.07837 \mathrm{e}+012.07837 \mathrm{e}+00$ 1.00000e-09 2.12000e-01

$2.07837 \mathrm{e}+012.07837 \mathrm{e}+012.07837 \mathrm{e}+00$ 1.00000e-09 2.12000e-01

$2.07837 \mathrm{e}+012.07837 \mathrm{e}+012.07837 \mathrm{e}+00$ 1.00000e-09 2.12000e-01

$1.00000 \mathrm{e}-05$ 1.00000e-05 1.00000e-06 1.00000e-09 1.00000e-01

$1.00000 \mathrm{e}+001.00000 \mathrm{e}+001.00000 \mathrm{e}-01$ 1.00000e-09 1.00000e-01

Element: 10707 \# of layers: 7

Kx Ky Kz Ss Por

2.07837e+01 2.07837e+01 2.07837e+00 1.00000e-09 2.12000e-01

$2.07837 \mathrm{e}+012.07837 \mathrm{e}+012.07837 \mathrm{e}+00$ 1.00000e-09 2.12000e-01

$2.07837 \mathrm{e}+012.07837 \mathrm{e}+012.07837 \mathrm{e}+001.00000 \mathrm{e}-092.12000 \mathrm{e}-01$

$2.07837 \mathrm{e}+012.07837 \mathrm{e}+012.07837 \mathrm{e}+00$ 1.00000e-09 2.12000e-01

$2.07837 \mathrm{e}+012.07837 \mathrm{e}+012.07837 \mathrm{e}+00$ 1.00000e-09 2.12000e-01

$1.00000 \mathrm{e}-05$ 1.00000e-05 1.00000e-06 1.00000e-09 1.00000e-01

$1.00000 \mathrm{e}+001.00000 \mathrm{e}+001.00000 \mathrm{e}-01$ 1.00000e-09 1.00000e-01

Element: 10708 \# of layers: 7

Kx Ky Kz Ss Por

2.07837e+01 2.07837e+01 2.07837e+00 1.00000e-09 2.12000e-01

2.07837e+01 2.07837e+01 2.07837e+00 1.00000e-09 2.12000e-01

$2.07837 \mathrm{e}+012.07837 \mathrm{e}+012.07837 \mathrm{e}+00$ 1.00000e-09 2.12000e-01

$2.07837 \mathrm{e}+012.07837 \mathrm{e}+012.07837 \mathrm{e}+00$ 1.00000e-09 2.12000e-01

$2.07837 \mathrm{e}+012.07837 \mathrm{e}+012.07837 \mathrm{e}+00$ 1.00000e-09 2.12000e-01

$1.00000 \mathrm{e}-05$ 1.00000e-05 1.00000e-06 1.00000e-09 1.00000e-01

$1.00000 \mathrm{e}+001.00000 \mathrm{e}+001.00000 \mathrm{e}-01$ 1.00000e-09 1.00000e-01

Element: 10709 \# of layers: 7

$\mathrm{Kx} \mathrm{Ky} \mathrm{Kz}$ Ss Por

$2.07837 \mathrm{e}+012.07837 \mathrm{e}+012.07837 \mathrm{e}+00$ 1.00000e-09 2.12000e-01

$2.07837 \mathrm{e}+012.07837 \mathrm{e}+012.07837 \mathrm{e}+00$ 1.00000e-09 2.12000e-01

$2.07837 \mathrm{e}+012.07837 \mathrm{e}+012.07837 \mathrm{e}+00$ 1.00000e-09 2.12000e-01

$2.07837 \mathrm{e}+012.07837 \mathrm{e}+012.07837 \mathrm{e}+00$ 1.00000e-09 2.12000e-01

$2.07837 \mathrm{e}+012.07837 \mathrm{e}+012.07837 \mathrm{e}+001.00000 \mathrm{e}-092.12000 \mathrm{e}-01$

$1.00000 \mathrm{e}-05$ 1.00000e-05 1.00000e-06 1.00000e-09 1.00000e-01

$1.00000 \mathrm{e}+001.00000 \mathrm{e}+001.00000 \mathrm{e}-011.00000 \mathrm{e}-091.00000 \mathrm{e}-01$

Element: 10710 \# of layers: 7

$\mathrm{Kx} \mathrm{Ky} \mathrm{Kz}$ Ss Por

2.07837e+01 2.07837e+01 2.07837e+00 1.00000e-09 2.12000e-01

$2.07837 \mathrm{e}+012.07837 \mathrm{e}+012.07837 \mathrm{e}+00$ 1.00000e-09 2.12000e-01

$2.07837 \mathrm{e}+012.07837 \mathrm{e}+012.07837 \mathrm{e}+00$ 1.00000e-09 2.12000e-01

$2.07837 \mathrm{e}+012.07837 \mathrm{e}+012.07837 \mathrm{e}+00$ 1.00000e-09 2.12000e-01

2.07837e+01 2.07837e+01 2.07837e+00 1.00000e-09 2.12000e-01

$1.00000 \mathrm{e}-05$ 1.00000e-05 1.00000e-06 1.00000e-09 1.00000e-01

$1.00000 \mathrm{e}+001.00000 \mathrm{e}+001.00000 \mathrm{e}-011.00000 \mathrm{e}-091.00000 \mathrm{e}-01$ 
Element: 10711 \# of layers: 7

$\mathrm{Kx} \mathrm{Ky} \mathrm{Kz}$ Ss Por

$2.07837 \mathrm{e}+012.07837 \mathrm{e}+012.07837 \mathrm{e}+00$ 1.00000e-09 2.12000e-01

$2.07837 \mathrm{e}+012.07837 \mathrm{e}+012.07837 \mathrm{e}+001.00000 \mathrm{e}-092.12000 \mathrm{e}-01$

$2.07837 \mathrm{e}+012.07837 \mathrm{e}+012.07837 \mathrm{e}+00$ 1.00000e-09 2.12000e-01

$2.07837 \mathrm{e}+012.07837 \mathrm{e}+012.07837 \mathrm{e}+00$ 1.00000e-09 2.12000e-01

$2.07837 \mathrm{e}+012.07837 \mathrm{e}+012.07837 \mathrm{e}+00$ 1.00000e-09 2.12000e-01

$1.00000 \mathrm{e}-05$ 1.00000e-05 1.00000e-06 1.00000e-09 1.00000e-01

$1.00000 \mathrm{e}+001.00000 \mathrm{e}+001.00000 \mathrm{e}-011.00000 \mathrm{e}-091.00000 \mathrm{e}-01$

Element: 10712 \# of layers: 7

$\mathrm{Kx} \mathrm{Ky} \mathrm{Kz}$ Ss Por

2.07837e+01 2.07837e+01 2.07837e+00 1.00000e-09 2.12000e-01

$2.07837 \mathrm{e}+012.07837 \mathrm{e}+012.07837 \mathrm{e}+00$ 1.00000e-09 2.12000e-01

$2.07837 \mathrm{e}+012.07837 \mathrm{e}+012.07837 \mathrm{e}+00$ 1.00000e-09 2.12000e-01

$2.07837 \mathrm{e}+012.07837 \mathrm{e}+012.07837 \mathrm{e}+00$ 1.00000e-09 2.12000e-01

$2.07837 \mathrm{e}+012.07837 \mathrm{e}+012.07837 \mathrm{e}+00$ 1.00000e-09 2.12000e-01

$1.00000 \mathrm{e}-05$ 1.00000e-05 1.00000e-06 1.00000e-09 1.00000e-01

$1.00000 \mathrm{e}+001.00000 \mathrm{e}+001.00000 \mathrm{e}-01$ 1.00000e-09 1.00000e-01

Element: 10713 \# of layers: 7

$\mathrm{Kx} \mathrm{Ky} \mathrm{Kz}$ Ss Por

$2.07837 \mathrm{e}+012.07837 \mathrm{e}+012.07837 \mathrm{e}+00$ 1.00000e-09 2.12000e-01

$2.07837 \mathrm{e}+012.07837 \mathrm{e}+012.07837 \mathrm{e}+00$ 1.00000e-09 2.12000e-01

$2.07837 \mathrm{e}+012.07837 \mathrm{e}+012.07837 \mathrm{e}+00$ 1.00000e-09 2.12000e-01

$2.07837 \mathrm{e}+012.07837 \mathrm{e}+012.07837 \mathrm{e}+00$ 1.00000e-09 2.12000e-01

$2.07837 \mathrm{e}+012.07837 \mathrm{e}+012.07837 \mathrm{e}+00$ 1.00000e-09 2.12000e-01

$1.00000 \mathrm{e}-051.00000 \mathrm{e}-05$ 1.00000e-06 1.00000e-09 1.00000e-01

$1.00000 \mathrm{e}+001.00000 \mathrm{e}+001.00000 \mathrm{e}-011.00000 \mathrm{e}-091.00000 \mathrm{e}-01$

Element: 10714 \# of layers: 7

Kx Ky Kz Ss Por

$2.07837 \mathrm{e}+012.07837 \mathrm{e}+012.07837 \mathrm{e}+00$ 1.00000e-09 2.12000e-01

$2.07837 \mathrm{e}+012.07837 \mathrm{e}+012.07837 \mathrm{e}+001.00000 \mathrm{e}-092.12000 \mathrm{e}-01$

$2.07837 \mathrm{e}+012.07837 \mathrm{e}+012.07837 \mathrm{e}+00$ 1.00000e-09 2.12000e-01

$2.07837 \mathrm{e}+012.07837 \mathrm{e}+012.07837 \mathrm{e}+00$ 1.00000e-09 2.12000e-01

$2.07837 \mathrm{e}+012.07837 \mathrm{e}+012.07837 \mathrm{e}+001.00000 \mathrm{e}-092.12000 \mathrm{e}-01$

$1.00000 \mathrm{e}-05$ 1.00000e-05 1.00000e-06 1.00000e-09 1.00000e-01

$1.00000 \mathrm{e}+001.00000 \mathrm{e}+001.00000 \mathrm{e}-011.00000 \mathrm{e}-091.00000 \mathrm{e}-01$

Element: 10715 \# of layers: 7

Kx Ky Kz Ss Por

$2.07837 \mathrm{e}+012.07837 \mathrm{e}+012.07837 \mathrm{e}+00$ 1.00000e-09 2.12000e-01

$2.07837 \mathrm{e}+012.07837 \mathrm{e}+012.07837 \mathrm{e}+00$ 1.00000e-09 2.12000e-01

$2.07837 \mathrm{e}+012.07837 \mathrm{e}+012.07837 \mathrm{e}+00$ 1.00000e-09 2.12000e-01

$2.07837 \mathrm{e}+012.07837 \mathrm{e}+012.07837 \mathrm{e}+00$ 1.00000e-09 2.12000e-01

2.07837e+01 2.07837e+01 2.07837e+00 1.00000e-09 2.12000e-01

$1.00000 \mathrm{e}-05$ 1.00000e-05 1.00000e-06 1.00000e-09 1.00000e-01

$1.00000 \mathrm{e}+001.00000 \mathrm{e}+001.00000 \mathrm{e}-01$ 1.00000e-09 1.00000e-01

Element: 10716 \# of layers: 7 
$\mathrm{Kx} \mathrm{Ky} \mathrm{Kz}$ Ss Por

2.07837e+01 2.07837e+01 2.07837e+00 1.00000e-09 2.12000e-01

$2.07837 \mathrm{e}+012.07837 \mathrm{e}+012.07837 \mathrm{e}+00$ 1.00000e-09 2.12000e-01

$2.07837 \mathrm{e}+012.07837 \mathrm{e}+012.07837 \mathrm{e}+001.00000 \mathrm{e}-092.12000 \mathrm{e}-01$

$2.07837 \mathrm{e}+012.07837 \mathrm{e}+012.07837 \mathrm{e}+00$ 1.00000e-09 2.12000e-01

$2.07837 \mathrm{e}+012.07837 \mathrm{e}+012.07837 \mathrm{e}+00$ 1.00000e-09 2.12000e-01

$1.00000 \mathrm{e}-05$ 1.00000e-05 1.00000e-06 1.00000e-09 1.00000e-01

$1.00000 \mathrm{e}+001.00000 \mathrm{e}+001.00000 \mathrm{e}-01$ 1.00000e-09 1.00000e-01

Element: 10717 \# of layers: 7

$\mathrm{Kx} \mathrm{Ky} \mathrm{Kz}$ Ss Por

2.07070e+01 2.07070e+01 2.07070e+00 1.00000e-09 2.12000e-01

$2.07070 \mathrm{e}+012.07070 \mathrm{e}+012.07070 \mathrm{e}+001.00000 \mathrm{e}-092.12000 \mathrm{e}-01$

$2.07070 \mathrm{e}+012.07070 \mathrm{e}+012.07070 \mathrm{e}+001.00000 \mathrm{e}-092.12000 \mathrm{e}-01$

$2.07070 \mathrm{e}+012.07070 \mathrm{e}+012.07070 \mathrm{e}+001.00000 \mathrm{e}-092.12000 \mathrm{e}-01$

$2.07070 \mathrm{e}+012.07070 \mathrm{e}+012.07070 \mathrm{e}+001.00000 \mathrm{e}-092.12000 \mathrm{e}-01$

$1.00000 \mathrm{e}-05$ 1.00000e-05 1.00000e-06 1.00000e-09 1.00000e-01

$1.00000 \mathrm{e}+001.00000 \mathrm{e}+001.00000 \mathrm{e}-011.00000 \mathrm{e}-091.00000 \mathrm{e}-01$

Element: 10718 \# of layers: 7

$\mathrm{Kx} \mathrm{Ky} \mathrm{Kz}$ Ss Por

$2.07070 \mathrm{e}+012.07070 \mathrm{e}+012.07070 \mathrm{e}+00$ 1.00000e-09 2.12000e-01

$2.07070 \mathrm{e}+012.07070 \mathrm{e}+012.07070 \mathrm{e}+001.00000 \mathrm{e}-092.12000 \mathrm{e}-01$

$2.07070 \mathrm{e}+012.07070 \mathrm{e}+012.07070 \mathrm{e}+001.00000 \mathrm{e}-092.12000 \mathrm{e}-01$

$2.07070 \mathrm{e}+012.07070 \mathrm{e}+012.07070 \mathrm{e}+001.00000 \mathrm{e}-092.12000 \mathrm{e}-01$

$2.07070 \mathrm{e}+012.07070 \mathrm{e}+012.07070 \mathrm{e}+00$ 1.00000e-09 2.12000e-01

$1.00000 \mathrm{e}-05$ 1.00000e-05 1.00000e-06 1.00000e-09 1.00000e-01

$1.00000 \mathrm{e}+001.00000 \mathrm{e}+001.00000 \mathrm{e}-01$ 1.00000e-09 1.00000e-01

Element: 10719 \# of layers: 7

$\mathrm{Kx} \mathrm{Ky} \mathrm{Kz}$ Ss Por

2.07070e+01 2.07070e+01 2.07070e+00 1.00000e-09 2.12000e-01

$2.07070 \mathrm{e}+012.07070 \mathrm{e}+012.07070 \mathrm{e}+001.00000 \mathrm{e}-092.12000 \mathrm{e}-01$

$2.07070 \mathrm{e}+012.07070 \mathrm{e}+012.07070 \mathrm{e}+001.00000 \mathrm{e}-092.12000 \mathrm{e}-01$

$2.07070 \mathrm{e}+012.07070 \mathrm{e}+012.07070 \mathrm{e}+001.00000 \mathrm{e}-092.12000 \mathrm{e}-01$

$2.07070 \mathrm{e}+012.07070 \mathrm{e}+012.07070 \mathrm{e}+00$ 1.00000e-09 2.12000e-01

$1.00000 \mathrm{e}-05$ 1.00000e-05 1.00000e-06 1.00000e-09 1.00000e-01

$1.00000 \mathrm{e}+001.00000 \mathrm{e}+001.00000 \mathrm{e}-011.00000 \mathrm{e}-09$ 1.00000e-01

Element: 10720 \# of layers: 7

Kx Ky Kz Ss Por

$2.07837 \mathrm{e}+012.07837 \mathrm{e}+012.07837 \mathrm{e}+00$ 1.00000e-09 2.12000e-01

$2.07837 \mathrm{e}+012.07837 \mathrm{e}+012.07837 \mathrm{e}+00$ 1.00000e-09 2.12000e-01

$2.07837 \mathrm{e}+012.07837 \mathrm{e}+012.07837 \mathrm{e}+00$ 1.00000e-09 2.12000e-01

$2.07837 \mathrm{e}+012.07837 \mathrm{e}+012.07837 \mathrm{e}+00$ 1.00000e-09 2.12000e-01

2.07837e+01 2.07837e+01 2.07837e+00 1.00000e-09 2.12000e-01

$1.00000 \mathrm{e}-05$ 1.00000e-05 1.00000e-06 1.00000e-09 1.00000e-01

$1.00000 \mathrm{e}+001.00000 \mathrm{e}+001.00000 \mathrm{e}-01$ 1.00000e-09 1.00000e-01

Element: 10721 \# of layers: 7

Kx Ky Kz Ss Por 
$2.07837 \mathrm{e}+012.07837 \mathrm{e}+012.07837 \mathrm{e}+00$ 1.00000e-09 2.12000e-01 $2.07837 \mathrm{e}+012.07837 \mathrm{e}+012.07837 \mathrm{e}+00$ 1.00000e-09 2.12000e-01 $2.07837 \mathrm{e}+012.07837 \mathrm{e}+012.07837 \mathrm{e}+00$ 1.00000e-09 2.12000e-01 $2.07837 \mathrm{e}+012.07837 \mathrm{e}+012.07837 \mathrm{e}+001.00000 \mathrm{e}-092.12000 \mathrm{e}-01$ $2.07837 \mathrm{e}+012.07837 \mathrm{e}+012.07837 \mathrm{e}+00$ 1.00000e-09 2.12000e-01 $1.00000 \mathrm{e}-05$ 1.00000e-05 1.00000e-06 1.00000e-09 1.00000e-01 $1.00000 \mathrm{e}+001.00000 \mathrm{e}+001.00000 \mathrm{e}-011.00000 \mathrm{e}-091.00000 \mathrm{e}-01$ Element: 10722 \# of layers: 7

$\mathrm{Kx} \mathrm{Ky} \mathrm{Kz}$ Ss Por

2.07837e+01 2.07837e+01 2.07837e+00 1.00000e-09 2.12000e-01 $2.07837 \mathrm{e}+012.07837 \mathrm{e}+012.07837 \mathrm{e}+00$ 1.00000e-09 2.12000e-01 $2.07837 \mathrm{e}+012.07837 \mathrm{e}+012.07837 \mathrm{e}+00$ 1.00000e-09 2.12000e-01 $2.07837 \mathrm{e}+012.07837 \mathrm{e}+012.07837 \mathrm{e}+00$ 1.00000e-09 2.12000e-01 $2.07837 \mathrm{e}+012.07837 \mathrm{e}+012.07837 \mathrm{e}+00$ 1.00000e-09 2.12000e-01 $1.00000 \mathrm{e}-05$ 1.00000e-05 1.00000e-06 1.00000e-09 1.00000e-01 $1.00000 \mathrm{e}+001.00000 \mathrm{e}+001.00000 \mathrm{e}-011.00000 \mathrm{e}-091.00000 \mathrm{e}-01$ Element: 10723 \# of layers: 7

$\mathrm{Kx} \mathrm{Ky} \mathrm{Kz}$ Ss Por

2.07837e+01 2.07837e+01 2.07837e+00 1.00000e-09 2.12000e-01 $2.07837 \mathrm{e}+012.07837 \mathrm{e}+012.07837 \mathrm{e}+001.00000 \mathrm{e}-092.12000 \mathrm{e}-01$ $2.07837 \mathrm{e}+012.07837 \mathrm{e}+012.07837 \mathrm{e}+001.00000 \mathrm{e}-092.12000 \mathrm{e}-01$ $2.07837 \mathrm{e}+012.07837 \mathrm{e}+012.07837 \mathrm{e}+00$ 1.00000e-09 2.12000e-01 $2.07837 \mathrm{e}+012.07837 \mathrm{e}+012.07837 \mathrm{e}+00$ 1.00000e-09 2.12000e-01 $1.00000 \mathrm{e}-05$ 1.00000e-05 1.00000e-06 1.00000e-09 1.00000e-01 $1.00000 \mathrm{e}+001.00000 \mathrm{e}+001.00000 \mathrm{e}-011.00000 \mathrm{e}-091.00000 \mathrm{e}-01$ Element: 10724 \# of layers: 7

$\mathrm{Kx} \mathrm{Ky} \mathrm{Kz}$ Ss Por

$2.07070 \mathrm{e}+012.07070 \mathrm{e}+012.07070 \mathrm{e}+00$ 1.00000e-09 2.12000e-01 $2.07070 \mathrm{e}+012.07070 \mathrm{e}+012.07070 \mathrm{e}+001.00000 \mathrm{e}-092.12000 \mathrm{e}-01$ $2.07070 \mathrm{e}+012.07070 \mathrm{e}+012.07070 \mathrm{e}+001.00000 \mathrm{e}-092.12000 \mathrm{e}-01$ $2.07070 \mathrm{e}+012.07070 \mathrm{e}+012.07070 \mathrm{e}+001.00000 \mathrm{e}-092.12000 \mathrm{e}-01$ $2.07070 \mathrm{e}+012.07070 \mathrm{e}+012.07070 \mathrm{e}+001.00000 \mathrm{e}-092.12000 \mathrm{e}-01$ 1.00000e-05 1.00000e-05 1.00000e-06 1.00000e-09 1.00000e-01 $1.00000 \mathrm{e}+001.00000 \mathrm{e}+001.00000 \mathrm{e}-011.00000 \mathrm{e}-09$ 1.00000e-01 Element: 10725 \# of layers: 7

$\mathrm{Kx} \mathrm{Ky} \mathrm{Kz}$ Ss Por

$2.07070 \mathrm{e}+012.07070 \mathrm{e}+012.07070 \mathrm{e}+00$ 1.00000e-09 2.12000e-01 $2.07070 \mathrm{e}+012.07070 \mathrm{e}+012.07070 \mathrm{e}+001.00000 \mathrm{e}-092.12000 \mathrm{e}-01$ $2.07070 \mathrm{e}+012.07070 \mathrm{e}+012.07070 \mathrm{e}+001.00000 \mathrm{e}-092.12000 \mathrm{e}-01$ $2.07070 \mathrm{e}+012.07070 \mathrm{e}+012.07070 \mathrm{e}+001.00000 \mathrm{e}-092.12000 \mathrm{e}-01$ $2.07070 \mathrm{e}+012.07070 \mathrm{e}+012.07070 \mathrm{e}+001.00000 \mathrm{e}-092.12000 \mathrm{e}-01$ $1.00000 \mathrm{e}-05$ 1.00000e-05 1.00000e-06 1.00000e-09 1.00000e-01 $1.00000 \mathrm{e}+001.00000 \mathrm{e}+001.00000 \mathrm{e}-011.00000 \mathrm{e}-091.00000 \mathrm{e}-01$ Element: 10726 \# of layers: 7

$\mathrm{Kx} \mathrm{Ky} \mathrm{Kz} \mathrm{Ss} \mathrm{Por}$

2.07070e+01 2.07070e+01 2.07070e+00 1.00000e-09 2.12000e-01 
$2.07070 \mathrm{e}+012.07070 \mathrm{e}+012.07070 \mathrm{e}+00$ 1.00000e-09 2.12000e-01 $2.07070 \mathrm{e}+012.07070 \mathrm{e}+012.07070 \mathrm{e}+001.00000 \mathrm{e}-092.12000 \mathrm{e}-01$ $2.07070 \mathrm{e}+012.07070 \mathrm{e}+012.07070 \mathrm{e}+001.00000 \mathrm{e}-092.12000 \mathrm{e}-01$ $2.07070 \mathrm{e}+012.07070 \mathrm{e}+012.07070 \mathrm{e}+001.00000 \mathrm{e}-092.12000 \mathrm{e}-01$ $1.00000 \mathrm{e}-05$ 1.00000e-05 1.00000e-06 1.00000e-09 1.00000e-01 $1.00000 \mathrm{e}+001.00000 \mathrm{e}+001.00000 \mathrm{e}-011.00000 \mathrm{e}-091.00000 \mathrm{e}-01$ Element: 10727 \# of layers: 7

Kx Ky Kz Ss Por

$2.07070 \mathrm{e}+012.07070 \mathrm{e}+012.07070 \mathrm{e}+00$ 1.00000e-09 2.12000e-01 $2.07070 \mathrm{e}+012.07070 \mathrm{e}+012.07070 \mathrm{e}+001.00000 \mathrm{e}-092.12000 \mathrm{e}-01$ $2.07070 \mathrm{e}+012.07070 \mathrm{e}+012.07070 \mathrm{e}+001.00000 \mathrm{e}-092.12000 \mathrm{e}-01$ $2.07070 \mathrm{e}+012.07070 \mathrm{e}+012.07070 \mathrm{e}+001.00000 \mathrm{e}-092.12000 \mathrm{e}-01$ $2.07070 \mathrm{e}+012.07070 \mathrm{e}+012.07070 \mathrm{e}+00$ 1.00000e-09 2.12000e-01 $1.00000 \mathrm{e}-05$ 1.00000e-05 1.00000e-06 1.00000e-09 1.00000e-01 $1.00000 \mathrm{e}+001.00000 \mathrm{e}+001.00000 \mathrm{e}-011.00000 \mathrm{e}-091.00000 \mathrm{e}-01$ Element: 10728 \# of layers: 7

Kx Ky Kz Ss Por

$2.07070 \mathrm{e}+012.07070 \mathrm{e}+012.07070 \mathrm{e}+00$ 1.00000e-09 2.12000e-01 $2.07070 \mathrm{e}+012.07070 \mathrm{e}+012.07070 \mathrm{e}+001.00000 \mathrm{e}-092.12000 \mathrm{e}-01$ $2.07070 \mathrm{e}+012.07070 \mathrm{e}+012.07070 \mathrm{e}+001.00000 \mathrm{e}-092.12000 \mathrm{e}-01$ $2.07070 \mathrm{e}+012.07070 \mathrm{e}+012.07070 \mathrm{e}+001.00000 \mathrm{e}-092.12000 \mathrm{e}-01$ $2.07070 \mathrm{e}+012.07070 \mathrm{e}+012.07070 \mathrm{e}+001.00000 \mathrm{e}-092.12000 \mathrm{e}-01$ $1.00000 \mathrm{e}-05$ 1.00000e-05 1.00000e-06 1.00000e-09 1.00000e-01 $1.00000 \mathrm{e}+001.00000 \mathrm{e}+001.00000 \mathrm{e}-011.00000 \mathrm{e}-091.00000 \mathrm{e}-01$ Element: 10729 \# of layers: 7

Kx Ky Kz Ss Por

$2.07070 \mathrm{e}+012.07070 \mathrm{e}+012.07070 \mathrm{e}+00$ 1.00000e-09 2.12000e-01 $2.07070 \mathrm{e}+012.07070 \mathrm{e}+012.07070 \mathrm{e}+001.00000 \mathrm{e}-092.12000 \mathrm{e}-01$ $2.07070 \mathrm{e}+012.07070 \mathrm{e}+012.07070 \mathrm{e}+001.00000 \mathrm{e}-092.12000 \mathrm{e}-01$ $2.07070 \mathrm{e}+012.07070 \mathrm{e}+012.07070 \mathrm{e}+001.00000 \mathrm{e}-092.12000 \mathrm{e}-01$ $2.07070 \mathrm{e}+012.07070 \mathrm{e}+012.07070 \mathrm{e}+001.00000 \mathrm{e}-092.12000 \mathrm{e}-01$ $1.00000 \mathrm{e}-05$ 1.00000e-05 1.00000e-06 1.00000e-09 1.00000e-01 $1.00000 \mathrm{e}+001.00000 \mathrm{e}+001.00000 \mathrm{e}-011.00000 \mathrm{e}-091.00000 \mathrm{e}-01$ Element: 10730 \# of layers: 7

Kx Ky Kz Ss Por

$2.07070 \mathrm{e}+012.07070 \mathrm{e}+012.07070 \mathrm{e}+00$ 1.00000e-09 2.12000e-01 $2.07070 \mathrm{e}+012.07070 \mathrm{e}+012.07070 \mathrm{e}+001.00000 \mathrm{e}-092.12000 \mathrm{e}-01$ $2.07070 \mathrm{e}+012.07070 \mathrm{e}+012.07070 \mathrm{e}+001.00000 \mathrm{e}-092.12000 \mathrm{e}-01$ $2.07070 \mathrm{e}+012.07070 \mathrm{e}+012.07070 \mathrm{e}+001.00000 \mathrm{e}-092.12000 \mathrm{e}-01$ $2.07070 \mathrm{e}+012.07070 \mathrm{e}+012.07070 \mathrm{e}+001.00000 \mathrm{e}-092.12000 \mathrm{e}-01$ $1.00000 \mathrm{e}-05$ 1.00000e-05 1.00000e-06 1.00000e-09 1.00000e-01 $1.00000 \mathrm{e}+001.00000 \mathrm{e}+001.00000 \mathrm{e}-011.00000 \mathrm{e}-091.00000 \mathrm{e}-01$ Element: 10731 \# of layers: 7

Kx Ky Kz Ss Por

$2.07070 \mathrm{e}+012.07070 \mathrm{e}+012.07070 \mathrm{e}+00$ 1.00000e-09 2.12000e-01 $2.07070 \mathrm{e}+012.07070 \mathrm{e}+012.07070 \mathrm{e}+001.00000 \mathrm{e}-092.12000 \mathrm{e}-01$ 
$2.07070 \mathrm{e}+012.07070 \mathrm{e}+012.07070 \mathrm{e}+00$ 1.00000e-09 2.12000e-01 $2.07070 \mathrm{e}+012.07070 \mathrm{e}+012.07070 \mathrm{e}+001.00000 \mathrm{e}-092.12000 \mathrm{e}-01$ $2.07070 \mathrm{e}+012.07070 \mathrm{e}+012.07070 \mathrm{e}+001.00000 \mathrm{e}-092.12000 \mathrm{e}-01$ $1.00000 \mathrm{e}-05$ 1.00000e-05 1.00000e-06 1.00000e-09 1.00000e-01 $1.00000 \mathrm{e}+001.00000 \mathrm{e}+001.00000 \mathrm{e}-011.00000 \mathrm{e}-091.00000 \mathrm{e}-01$ Element: 10732 \# of layers: 7

Kx Ky Kz Ss Por

$2.07070 \mathrm{e}+012.07070 \mathrm{e}+012.07070 \mathrm{e}+00$ 1.00000e-09 2.12000e-01 $2.07070 \mathrm{e}+012.07070 \mathrm{e}+012.07070 \mathrm{e}+001.00000 \mathrm{e}-092.12000 \mathrm{e}-01$ $2.07070 \mathrm{e}+012.07070 \mathrm{e}+012.07070 \mathrm{e}+001.00000 \mathrm{e}-092.12000 \mathrm{e}-01$ $2.07070 \mathrm{e}+012.07070 \mathrm{e}+012.07070 \mathrm{e}+001.00000 \mathrm{e}-092.12000 \mathrm{e}-01$ $2.07070 \mathrm{e}+012.07070 \mathrm{e}+012.07070 \mathrm{e}+001.00000 \mathrm{e}-092.12000 \mathrm{e}-01$ $1.00000 \mathrm{e}-05$ 1.00000e-05 1.00000e-06 1.00000e-09 1.00000e-01 $1.00000 \mathrm{e}+001.00000 \mathrm{e}+001.00000 \mathrm{e}-011.00000 \mathrm{e}-091.00000 \mathrm{e}-01$ Element: 10733 \# of layers: 7

Kx Ky Kz Ss Por

$2.07070 \mathrm{e}+012.07070 \mathrm{e}+012.07070 \mathrm{e}+00$ 1.00000e-09 2.12000e-01 $2.07070 \mathrm{e}+012.07070 \mathrm{e}+012.07070 \mathrm{e}+001.00000 \mathrm{e}-092.12000 \mathrm{e}-01$ $2.07070 \mathrm{e}+012.07070 \mathrm{e}+012.07070 \mathrm{e}+001.00000 \mathrm{e}-092.12000 \mathrm{e}-01$ $2.07070 \mathrm{e}+012.07070 \mathrm{e}+012.07070 \mathrm{e}+001.00000 \mathrm{e}-092.12000 \mathrm{e}-01$ $2.07070 \mathrm{e}+012.07070 \mathrm{e}+012.07070 \mathrm{e}+001.00000 \mathrm{e}-092.12000 \mathrm{e}-01$ $1.00000 \mathrm{e}-05$ 1.00000e-05 1.00000e-06 1.00000e-09 1.00000e-01 $1.00000 \mathrm{e}+001.00000 \mathrm{e}+001.00000 \mathrm{e}-011.00000 \mathrm{e}-091.00000 \mathrm{e}-01$ Element: 10734 \# of layers: 7

Kx Ky Kz Ss Por $2.03852 \mathrm{e}+012.03852 \mathrm{e}+012.03852 \mathrm{e}+00$ 1.00000e-09 2.12000e-01 $2.03852 \mathrm{e}+012.03852 \mathrm{e}+012.03852 \mathrm{e}+001.00000 \mathrm{e}-092.12000 \mathrm{e}-01$ $2.03852 \mathrm{e}+012.03852 \mathrm{e}+012.03852 \mathrm{e}+001.00000 \mathrm{e}-092.12000 \mathrm{e}-01$ $2.03852 \mathrm{e}+012.03852 \mathrm{e}+012.03852 \mathrm{e}+001.00000 \mathrm{e}-092.12000 \mathrm{e}-01$ $2.03852 \mathrm{e}+012.03852 \mathrm{e}+012.03852 \mathrm{e}+001.00000 \mathrm{e}-092.12000 \mathrm{e}-01$ $1.00000 \mathrm{e}-05$ 1.00000e-05 1.00000e-06 1.00000e-09 1.00000e-01 $1.00000 \mathrm{e}+001.00000 \mathrm{e}+001.00000 \mathrm{e}-011.00000 \mathrm{e}-091.00000 \mathrm{e}-01$ Element: 10735 \# of layers: 7

Kx Ky Kz Ss Por $2.03852 \mathrm{e}+012.03852 \mathrm{e}+012.03852 \mathrm{e}+00$ 1.00000e-09 2.12000e-01 $2.03852 \mathrm{e}+012.03852 \mathrm{e}+012.03852 \mathrm{e}+001.00000 \mathrm{e}-092.12000 \mathrm{e}-01$ $2.03852 \mathrm{e}+012.03852 \mathrm{e}+012.03852 \mathrm{e}+001.00000 \mathrm{e}-092.12000 \mathrm{e}-01$ $2.03852 \mathrm{e}+012.03852 \mathrm{e}+012.03852 \mathrm{e}+001.00000 \mathrm{e}-092.12000 \mathrm{e}-01$ $2.03852 \mathrm{e}+012.03852 \mathrm{e}+012.03852 \mathrm{e}+00$ 1.00000e-09 2.12000e-01 $1.00000 \mathrm{e}-05$ 1.00000e-05 1.00000e-06 1.00000e-09 1.00000e-01 $1.00000 \mathrm{e}+001.00000 \mathrm{e}+001.00000 \mathrm{e}-011.00000 \mathrm{e}-091.00000 \mathrm{e}-01$ Element: 10736 \# of layers: 7

Kx Ky Kz Ss Por

$2.03852 \mathrm{e}+012.03852 \mathrm{e}+012.03852 \mathrm{e}+00$ 1.00000e-09 2.12000e-01 $2.03852 \mathrm{e}+012.03852 \mathrm{e}+012.03852 \mathrm{e}+001.00000 \mathrm{e}-092.12000 \mathrm{e}-01$ $2.03852 \mathrm{e}+012.03852 \mathrm{e}+012.03852 \mathrm{e}+00$ 1.00000e-09 2.12000e-01 
$2.03852 \mathrm{e}+012.03852 \mathrm{e}+012.03852 \mathrm{e}+00$ 1.00000e-09 2.12000e-01 $2.03852 \mathrm{e}+012.03852 \mathrm{e}+012.03852 \mathrm{e}+00$ 1.00000e-09 2.12000e-01 $1.00000 \mathrm{e}-05$ 1.00000e-05 1.00000e-06 1.00000e-09 1.00000e-01 $1.00000 \mathrm{e}+001.00000 \mathrm{e}+001.00000 \mathrm{e}-011.00000 \mathrm{e}-091.00000 \mathrm{e}-01$ Element: 10737 \# of layers: 7

Kx Ky Kz Ss Por

$2.03852 \mathrm{e}+012.03852 \mathrm{e}+012.03852 \mathrm{e}+00$ 1.00000e-09 2.12000e-01 $2.03852 \mathrm{e}+012.03852 \mathrm{e}+012.03852 \mathrm{e}+001.00000 \mathrm{e}-092.12000 \mathrm{e}-01$ $2.03852 \mathrm{e}+012.03852 \mathrm{e}+012.03852 \mathrm{e}+001.00000 \mathrm{e}-092.12000 \mathrm{e}-01$ $2.03852 \mathrm{e}+012.03852 \mathrm{e}+012.03852 \mathrm{e}+001.00000 \mathrm{e}-092.12000 \mathrm{e}-01$ $2.03852 \mathrm{e}+012.03852 \mathrm{e}+012.03852 \mathrm{e}+001.00000 \mathrm{e}-092.12000 \mathrm{e}-01$ $1.00000 \mathrm{e}-05$ 1.00000e-05 1.00000e-06 1.00000e-09 1.00000e-01 $1.00000 \mathrm{e}+001.00000 \mathrm{e}+001.00000 \mathrm{e}-011.00000 \mathrm{e}-091.00000 \mathrm{e}-01$ Element: 10738 \# of layers: 7

Kx Ky Kz Ss Por

$2.03852 \mathrm{e}+012.03852 \mathrm{e}+012.03852 \mathrm{e}+00$ 1.00000e-09 2.12000e-01 $2.03852 \mathrm{e}+012.03852 \mathrm{e}+012.03852 \mathrm{e}+001.00000 \mathrm{e}-092.12000 \mathrm{e}-01$ $2.03852 \mathrm{e}+012.03852 \mathrm{e}+012.03852 \mathrm{e}+001.00000 \mathrm{e}-092.12000 \mathrm{e}-01$ $2.03852 \mathrm{e}+012.03852 \mathrm{e}+012.03852 \mathrm{e}+001.00000 \mathrm{e}-092.12000 \mathrm{e}-01$ $2.03852 \mathrm{e}+012.03852 \mathrm{e}+012.03852 \mathrm{e}+00$ 1.00000e-09 2.12000e-01 $1.00000 \mathrm{e}-05$ 1.00000e-05 1.00000e-06 1.00000e-09 1.00000e-01 $1.00000 \mathrm{e}+001.00000 \mathrm{e}+001.00000 \mathrm{e}-011.00000 \mathrm{e}-091.00000 \mathrm{e}-01$ Element: 10739 \# of layers: 7

Kx Ky Kz Ss Por

$2.07070 \mathrm{e}+012.07070 \mathrm{e}+012.07070 \mathrm{e}+00$ 1.00000e-09 2.12000e-01 $2.07070 \mathrm{e}+012.07070 \mathrm{e}+012.07070 \mathrm{e}+001.00000 \mathrm{e}-092.12000 \mathrm{e}-01$ $2.07070 \mathrm{e}+012.07070 \mathrm{e}+012.07070 \mathrm{e}+001.00000 \mathrm{e}-092.12000 \mathrm{e}-01$ $2.07070 \mathrm{e}+012.07070 \mathrm{e}+012.07070 \mathrm{e}+001.00000 \mathrm{e}-092.12000 \mathrm{e}-01$ $2.07070 \mathrm{e}+012.07070 \mathrm{e}+012.07070 \mathrm{e}+001.00000 \mathrm{e}-092.12000 \mathrm{e}-01$ $1.00000 \mathrm{e}-05$ 1.00000e-05 1.00000e-06 1.00000e-09 1.00000e-01 $1.00000 \mathrm{e}+001.00000 \mathrm{e}+001.00000 \mathrm{e}-011.00000 \mathrm{e}-091.00000 \mathrm{e}-01$ Element: 10740 \# of layers: 7

Kx Ky Kz Ss Por

$2.07070 \mathrm{e}+012.07070 \mathrm{e}+012.07070 \mathrm{e}+00$ 1.00000e-09 2.12000e-01 $2.07070 \mathrm{e}+012.07070 \mathrm{e}+012.07070 \mathrm{e}+001.00000 \mathrm{e}-092.12000 \mathrm{e}-01$ $2.07070 \mathrm{e}+012.07070 \mathrm{e}+012.07070 \mathrm{e}+001.00000 \mathrm{e}-092.12000 \mathrm{e}-01$ $2.07070 \mathrm{e}+012.07070 \mathrm{e}+012.07070 \mathrm{e}+001.00000 \mathrm{e}-092.12000 \mathrm{e}-01$ $2.07070 \mathrm{e}+012.07070 \mathrm{e}+012.07070 \mathrm{e}+00$ 1.00000e-09 2.12000e-01 $1.00000 \mathrm{e}-05$ 1.00000e-05 1.00000e-06 1.00000e-09 1.00000e-01 $1.00000 \mathrm{e}+001.00000 \mathrm{e}+001.00000 \mathrm{e}-011.00000 \mathrm{e}-091.00000 \mathrm{e}-01$ Element: 10741 \# of layers: 7

Kx Ky Kz Ss Por $2.03852 \mathrm{e}+012.03852 \mathrm{e}+012.03852 \mathrm{e}+00$ 1.00000e-09 2.12000e-01 $2.03852 \mathrm{e}+012.03852 \mathrm{e}+012.03852 \mathrm{e}+001.00000 \mathrm{e}-092.12000 \mathrm{e}-01$ $2.03852 \mathrm{e}+012.03852 \mathrm{e}+012.03852 \mathrm{e}+001.00000 \mathrm{e}-092.12000 \mathrm{e}-01$ $2.03852 \mathrm{e}+012.03852 \mathrm{e}+012.03852 \mathrm{e}+001.00000 \mathrm{e}-092.12000 \mathrm{e}-01$ 
$2.03852 \mathrm{e}+012.03852 \mathrm{e}+012.03852 \mathrm{e}+00$ 1.00000e-09 2.12000e-01 $1.00000 \mathrm{e}-05$ 1.00000e-05 1.00000e-06 1.00000e-09 1.00000e-01 $1.00000 \mathrm{e}+001.00000 \mathrm{e}+001.00000 \mathrm{e}-011.00000 \mathrm{e}-091.00000 \mathrm{e}-01$

Element: 10742 \# of layers: 7

Kx Ky Kz Ss Por

$2.03852 \mathrm{e}+012.03852 \mathrm{e}+012.03852 \mathrm{e}+00$ 1.00000e-09 2.12000e-01

$2.03852 \mathrm{e}+012.03852 \mathrm{e}+012.03852 \mathrm{e}+001.00000 \mathrm{e}-092.12000 \mathrm{e}-01$ $2.03852 \mathrm{e}+012.03852 \mathrm{e}+012.03852 \mathrm{e}+001.00000 \mathrm{e}-092.12000 \mathrm{e}-01$ $2.03852 \mathrm{e}+012.03852 \mathrm{e}+012.03852 \mathrm{e}+001.00000 \mathrm{e}-092.12000 \mathrm{e}-01$ $2.03852 \mathrm{e}+012.03852 \mathrm{e}+012.03852 \mathrm{e}+001.00000 \mathrm{e}-092.12000 \mathrm{e}-01$ $1.00000 \mathrm{e}-05$ 1.00000e-05 1.00000e-06 1.00000e-09 1.00000e-01 $1.00000 \mathrm{e}+001.00000 \mathrm{e}+001.00000 \mathrm{e}-011.00000 \mathrm{e}-091.00000 \mathrm{e}-01$ Element: 10743 \# of layers: 7

Kx Ky Kz Ss Por

$2.10548 \mathrm{e}+012.10548 \mathrm{e}+012.10548 \mathrm{e}+00$ 1.00000e-09 2.12000e-01 $2.10548 \mathrm{e}+012.10548 \mathrm{e}+012.10548 \mathrm{e}+00$ 1.00000e-09 2.12000e-01 $2.10548 \mathrm{e}+012.10548 \mathrm{e}+012.10548 \mathrm{e}+00$ 1.00000e-09 2.12000e-01 $2.10548 \mathrm{e}+012.10548 \mathrm{e}+012.10548 \mathrm{e}+00$ 1.00000e-09 2.12000e-01 $2.10548 \mathrm{e}+012.10548 \mathrm{e}+012.10548 \mathrm{e}+00$ 1.00000e-09 2.12000e-01 $1.00000 \mathrm{e}-05$ 1.00000e-05 1.00000e-06 1.00000e-09 1.00000e-01 $1.00000 \mathrm{e}+001.00000 \mathrm{e}+001.00000 \mathrm{e}-011.00000 \mathrm{e}-091.00000 \mathrm{e}-01$ Element: 10744 \# of layers: 7

Kx Ky Kz Ss Por

$2.10548 \mathrm{e}+012.10548 \mathrm{e}+012.10548 \mathrm{e}+00$ 1.00000e-09 2.12000e-01 $2.10548 \mathrm{e}+012.10548 \mathrm{e}+012.10548 \mathrm{e}+001.00000 \mathrm{e}-092.12000 \mathrm{e}-01$ $2.10548 \mathrm{e}+012.10548 \mathrm{e}+012.10548 \mathrm{e}+00$ 1.00000e-09 2.12000e-01 $2.10548 \mathrm{e}+012.10548 \mathrm{e}+012.10548 \mathrm{e}+00$ 1.00000e-09 2.12000e-01 $2.10548 \mathrm{e}+012.10548 \mathrm{e}+012.10548 \mathrm{e}+00$ 1.00000e-09 2.12000e-01 $1.00000 \mathrm{e}-05$ 1.00000e-05 1.00000e-06 1.00000e-09 1.00000e-01 $1.00000 \mathrm{e}+001.00000 \mathrm{e}+001.00000 \mathrm{e}-011.00000 \mathrm{e}-091.00000 \mathrm{e}-01$ Element: 10745 \# of layers: 7

Kx Ky Kz Ss Por

$2.10548 \mathrm{e}+012.10548 \mathrm{e}+012.10548 \mathrm{e}+00$ 1.00000e-09 2.12000e-01 $2.10548 \mathrm{e}+012.10548 \mathrm{e}+012.10548 \mathrm{e}+001.00000 \mathrm{e}-092.12000 \mathrm{e}-01$ $2.10548 \mathrm{e}+012.10548 \mathrm{e}+012.10548 \mathrm{e}+00$ 1.00000e-09 2.12000e-01 $2.10548 \mathrm{e}+012.10548 \mathrm{e}+012.10548 \mathrm{e}+00$ 1.00000e-09 2.12000e-01 $2.10548 \mathrm{e}+012.10548 \mathrm{e}+012.10548 \mathrm{e}+00$ 1.00000e-09 2.12000e-01 $1.00000 \mathrm{e}-05$ 1.00000e-05 1.00000e-06 1.00000e-09 1.00000e-01 $1.00000 \mathrm{e}+001.00000 \mathrm{e}+001.00000 \mathrm{e}-011.00000 \mathrm{e}-091.00000 \mathrm{e}-01$ Element: 10746 \# of layers: 7

Kx Ky Kz Ss Por $2.07837 \mathrm{e}+012.07837 \mathrm{e}+012.07837 \mathrm{e}+00$ 1.00000e-09 2.12000e-01 $2.07837 \mathrm{e}+012.07837 \mathrm{e}+012.07837 \mathrm{e}+001.00000 \mathrm{e}-092.12000 \mathrm{e}-01$ $2.07837 \mathrm{e}+012.07837 \mathrm{e}+012.07837 \mathrm{e}+001.00000 \mathrm{e}-092.12000 \mathrm{e}-01$ $2.07837 \mathrm{e}+012.07837 \mathrm{e}+012.07837 \mathrm{e}+001.00000 \mathrm{e}-092.12000 \mathrm{e}-01$ $2.07837 \mathrm{e}+012.07837 \mathrm{e}+012.07837 \mathrm{e}+001.00000 \mathrm{e}-092.12000 \mathrm{e}-01$ 
$1.00000 \mathrm{e}-05$ 1.00000e-05 1.00000e-06 1.00000e-09 1.00000e-01 $1.00000 \mathrm{e}+001.00000 \mathrm{e}+001.00000 \mathrm{e}-01$ 1.00000e-09 1.00000e-01 Element: 10747 \# of layers: 7

Kx Ky Kz Ss Por

$2.07837 \mathrm{e}+012.07837 \mathrm{e}+012.07837 \mathrm{e}+00$ 1.00000e-09 2.12000e-01 $2.07837 \mathrm{e}+012.07837 \mathrm{e}+012.07837 \mathrm{e}+00$ 1.00000e-09 2.12000e-01 $2.07837 \mathrm{e}+012.07837 \mathrm{e}+012.07837 \mathrm{e}+00$ 1.00000e-09 2.12000e-01 $2.07837 \mathrm{e}+012.07837 \mathrm{e}+012.07837 \mathrm{e}+001.00000 \mathrm{e}-092.12000 \mathrm{e}-01$ $2.07837 \mathrm{e}+012.07837 \mathrm{e}+012.07837 \mathrm{e}+00$ 1.00000e-09 2.12000e-01 $1.00000 \mathrm{e}-05$ 1.00000e-05 1.00000e-06 1.00000e-09 1.00000e-01 $1.00000 \mathrm{e}+001.00000 \mathrm{e}+001.00000 \mathrm{e}-011.00000 \mathrm{e}-091.00000 \mathrm{e}-01$ Element: 10748 \# of layers: 7

$\mathrm{Kx} \mathrm{Ky} \mathrm{Kz}$ Ss Por

$2.07070 \mathrm{e}+012.07070 \mathrm{e}+012.07070 \mathrm{e}+00$ 1.00000e-09 2.12000e-01 $2.07070 \mathrm{e}+012.07070 \mathrm{e}+012.07070 \mathrm{e}+001.00000 \mathrm{e}-092.12000 \mathrm{e}-01$ $2.07070 \mathrm{e}+012.07070 \mathrm{e}+012.07070 \mathrm{e}+001.00000 \mathrm{e}-092.12000 \mathrm{e}-01$ $2.07070 \mathrm{e}+012.07070 \mathrm{e}+012.07070 \mathrm{e}+001.00000 \mathrm{e}-092.12000 \mathrm{e}-01$ $2.07070 \mathrm{e}+012.07070 \mathrm{e}+012.07070 \mathrm{e}+001.00000 \mathrm{e}-092.12000 \mathrm{e}-01$ $1.00000 \mathrm{e}-051.00000 \mathrm{e}-05$ 1.00000e-06 1.00000e-09 1.00000e-01 $1.00000 \mathrm{e}+001.00000 \mathrm{e}+001.00000 \mathrm{e}-011.00000 \mathrm{e}-091.00000 \mathrm{e}-01$ Element: 10749 \# of layers: 7

$\mathrm{Kx} \mathrm{Ky} \mathrm{Kz}$ Ss Por

$2.03852 \mathrm{e}+012.03852 \mathrm{e}+012.03852 \mathrm{e}+00$ 1.00000e-09 2.12000e-01 $2.03852 \mathrm{e}+012.03852 \mathrm{e}+012.03852 \mathrm{e}+001.00000 \mathrm{e}-092.12000 \mathrm{e}-01$ $2.03852 \mathrm{e}+012.03852 \mathrm{e}+012.03852 \mathrm{e}+001.00000 \mathrm{e}-092.12000 \mathrm{e}-01$ $2.03852 \mathrm{e}+012.03852 \mathrm{e}+012.03852 \mathrm{e}+001.00000 \mathrm{e}-092.12000 \mathrm{e}-01$ $2.03852 \mathrm{e}+012.03852 \mathrm{e}+012.03852 \mathrm{e}+001.00000 \mathrm{e}-092.12000 \mathrm{e}-01$ $1.00000 \mathrm{e}-05$ 1.00000e-05 1.00000e-06 1.00000e-09 1.00000e-01 $1.00000 \mathrm{e}+001.00000 \mathrm{e}+001.00000 \mathrm{e}-011.00000 \mathrm{e}-091.00000 \mathrm{e}-01$ Element: 10750 \# of layers: 7

$\mathrm{Kx} \mathrm{Ky} \mathrm{Kz}$ Ss Por

$2.10548 \mathrm{e}+012.10548 \mathrm{e}+012.10548 \mathrm{e}+00$ 1.00000e-09 2.12000e-01 $2.10548 \mathrm{e}+012.10548 \mathrm{e}+012.10548 \mathrm{e}+00$ 1.00000e-09 2.12000e-01 $2.10548 \mathrm{e}+012.10548 \mathrm{e}+012.10548 \mathrm{e}+00$ 1.00000e-09 2.12000e-01 $2.10548 \mathrm{e}+012.10548 \mathrm{e}+012.10548 \mathrm{e}+00$ 1.00000e-09 2.12000e-01 $2.10548 \mathrm{e}+012.10548 \mathrm{e}+012.10548 \mathrm{e}+00$ 1.00000e-09 2.12000e-01 1.00000e-05 1.00000e-05 1.00000e-06 1.00000e-09 1.00000e-01 $1.00000 \mathrm{e}+001.00000 \mathrm{e}+001.00000 \mathrm{e}-011.00000 \mathrm{e}-091.00000 \mathrm{e}-01$ Element: 10751 \# of layers: 7

Kx Ky Kz Ss Por

$2.10949 \mathrm{e}+012.10949 \mathrm{e}+01$ 2.10949e+00 1.00000e-09 2.12000e-01 $2.10949 \mathrm{e}+012.10949 \mathrm{e}+012.10949 \mathrm{e}+00$ 1.00000e-09 2.12000e-01 $2.10949 \mathrm{e}+012.10949 \mathrm{e}+012.10949 \mathrm{e}+00$ 1.00000e-09 2.12000e-01 $2.10949 \mathrm{e}+012.10949 \mathrm{e}+012.10949 \mathrm{e}+00$ 1.00000e-09 2.12000e-01 $2.10949 \mathrm{e}+012.10949 \mathrm{e}+012.10949 \mathrm{e}+00$ 1.00000e-09 2.12000e-01 $1.00000 \mathrm{e}-05$ 1.00000e-05 1.00000e-06 1.00000e-09 1.00000e-01 
$1.00000 \mathrm{e}+001.00000 \mathrm{e}+001.00000 \mathrm{e}-011.00000 \mathrm{e}-091.00000 \mathrm{e}-01$

Element: 10752 \# of layers: 7

Kx Ky Kz Ss Por

$2.10949 \mathrm{e}+01$ 2.10949e+01 2.10949e+00 1.00000e-09 2.12000e-01

$2.10949 \mathrm{e}+012.10949 \mathrm{e}+012.10949 \mathrm{e}+00$ 1.00000e-09 2.12000e-01

$2.10949 \mathrm{e}+012.10949 \mathrm{e}+012.10949 \mathrm{e}+00$ 1.00000e-09 2.12000e-01

$2.10949 \mathrm{e}+012.10949 \mathrm{e}+012.10949 \mathrm{e}+00$ 1.00000e-09 2.12000e-01

$2.10949 \mathrm{e}+012.10949 \mathrm{e}+012.10949 \mathrm{e}+00$ 1.00000e-09 2.12000e-01

$1.00000 \mathrm{e}-05$ 1.00000e-05 1.00000e-06 1.00000e-09 1.00000e-01

$1.00000 \mathrm{e}+001.00000 \mathrm{e}+001.00000 \mathrm{e}-011.00000 \mathrm{e}-091.00000 \mathrm{e}-01$

Element: 10753 \# of layers: 7

Kx Ky Kz Ss Por

2.10949e+01 2.10949e+01 2.10949e+00 1.00000e-09 2.12000e-01

$2.10949 \mathrm{e}+012.10949 \mathrm{e}+012.10949 \mathrm{e}+00$ 1.00000e-09 2.12000e-01

$2.10949 \mathrm{e}+012.10949 \mathrm{e}+012.10949 \mathrm{e}+00$ 1.00000e-09 2.12000e-01

$2.10949 \mathrm{e}+012.10949 \mathrm{e}+012.10949 \mathrm{e}+00$ 1.00000e-09 2.12000e-01

$2.10949 \mathrm{e}+012.10949 \mathrm{e}+012.10949 \mathrm{e}+00$ 1.00000e-09 2.12000e-01

$1.00000 \mathrm{e}-05$ 1.00000e-05 1.00000e-06 1.00000e-09 1.00000e-01

$1.00000 \mathrm{e}+001.00000 \mathrm{e}+001.00000 \mathrm{e}-01$ 1.00000e-09 1.00000e-01

Element: 10754 \# of layers: 7

$\mathrm{Kx} \mathrm{Ky} \mathrm{Kz}$ Ss Por

$2.10949 \mathrm{e}+01$ 2.10949e+01 2.10949e+00 1.00000e-09 2.12000e-01

$2.10949 \mathrm{e}+012.10949 \mathrm{e}+01$ 2.10949e+00 1.00000e-09 2.12000e-01

$2.10949 \mathrm{e}+012.10949 \mathrm{e}+012.10949 \mathrm{e}+00$ 1.00000e-09 2.12000e-01

$2.10949 \mathrm{e}+012.10949 \mathrm{e}+012.10949 \mathrm{e}+00$ 1.00000e-09 2.12000e-01

$2.10949 \mathrm{e}+012.10949 \mathrm{e}+012.10949 \mathrm{e}+00$ 1.00000e-09 2.12000e-01

$1.00000 \mathrm{e}-05$ 1.00000e-05 1.00000e-06 1.00000e-09 1.00000e-01

$1.00000 \mathrm{e}+001.00000 \mathrm{e}+001.00000 \mathrm{e}-01$ 1.00000e-09 1.00000e-01

Element: 10755 \# of layers: 7

$\mathrm{Kx} \mathrm{Ky} \mathrm{Kz}$ Ss Por

$2.10949 \mathrm{e}+012.10949 \mathrm{e}+012.10949 \mathrm{e}+00$ 1.00000e-09 2.12000e-01

$2.10949 \mathrm{e}+012.10949 \mathrm{e}+012.10949 \mathrm{e}+00$ 1.00000e-09 2.12000e-01

$2.10949 \mathrm{e}+012.10949 \mathrm{e}+012.10949 \mathrm{e}+00$ 1.00000e-09 2.12000e-01

$2.10949 \mathrm{e}+012.10949 \mathrm{e}+012.10949 \mathrm{e}+00$ 1.00000e-09 2.12000e-01

$2.10949 \mathrm{e}+012.10949 \mathrm{e}+012.10949 \mathrm{e}+00$ 1.00000e-09 2.12000e-01

$1.00000 \mathrm{e}-05$ 1.00000e-05 1.00000e-06 1.00000e-09 1.00000e-01

$1.00000 \mathrm{e}+001.00000 \mathrm{e}+001.00000 \mathrm{e}-011.00000 \mathrm{e}-091.00000 \mathrm{e}-01$

Element: 10756 \# of layers: 7

$\mathrm{Kx} \mathrm{Ky} \mathrm{Kz}$ Ss Por

$2.10949 \mathrm{e}+012.10949 \mathrm{e}+012.10949 \mathrm{e}+00$ 1.00000e-09 2.12000e-01

$2.10949 \mathrm{e}+012.10949 \mathrm{e}+012.10949 \mathrm{e}+00$ 1.00000e-09 2.12000e-01

$2.10949 \mathrm{e}+012.10949 \mathrm{e}+012.10949 \mathrm{e}+00$ 1.00000e-09 2.12000e-01

$2.10949 \mathrm{e}+012.10949 \mathrm{e}+01$ 2.10949e+00 1.00000e-09 2.12000e-01

2.10949e+01 2.10949e+01 2.10949e+00 1.00000e-09 2.12000e-01 $1.00000 \mathrm{e}-05$ 1.00000e-05 1.00000e-06 1.00000e-09 1.00000e-01

$1.00000 \mathrm{e}+001.00000 \mathrm{e}+001.00000 \mathrm{e}-011.00000 \mathrm{e}-091.00000 \mathrm{e}-01$ 
Element: 10757 \# of layers: 7

$\mathrm{Kx} \mathrm{Ky} \mathrm{Kz}$ Ss Por

$2.10949 \mathrm{e}+012.10949 \mathrm{e}+012.10949 \mathrm{e}+00$ 1.00000e-09 2.12000e-01

$2.10949 \mathrm{e}+012.10949 \mathrm{e}+012.10949 \mathrm{e}+00$ 1.00000e-09 2.12000e-01

$2.10949 \mathrm{e}+012.10949 \mathrm{e}+012.10949 \mathrm{e}+00$ 1.00000e-09 2.12000e-01

$2.10949 \mathrm{e}+012.10949 \mathrm{e}+012.10949 \mathrm{e}+00$ 1.00000e-09 2.12000e-01

$2.10949 \mathrm{e}+012.10949 \mathrm{e}+012.10949 \mathrm{e}+00$ 1.00000e-09 2.12000e-01

$1.00000 \mathrm{e}-05$ 1.00000e-05 1.00000e-06 1.00000e-09 1.00000e-01

$1.00000 \mathrm{e}+001.00000 \mathrm{e}+001.00000 \mathrm{e}-011.00000 \mathrm{e}-091.00000 \mathrm{e}-01$

Element: 10758 \# of layers: 7

$\mathrm{Kx} \mathrm{Ky} \mathrm{Kz}$ Ss Por

$2.10949 \mathrm{e}+012.10949 \mathrm{e}+012.10949 \mathrm{e}+00$ 1.00000e-09 2.12000e-01

$2.10949 \mathrm{e}+012.10949 \mathrm{e}+012.10949 \mathrm{e}+00$ 1.00000e-09 2.12000e-01

$2.10949 \mathrm{e}+012.10949 \mathrm{e}+012.10949 \mathrm{e}+00$ 1.00000e-09 2.12000e-01

$2.10949 \mathrm{e}+012.10949 \mathrm{e}+012.10949 \mathrm{e}+00$ 1.00000e-09 2.12000e-01

$2.10949 \mathrm{e}+012.10949 \mathrm{e}+012.10949 \mathrm{e}+00$ 1.00000e-09 2.12000e-01

$1.00000 \mathrm{e}-05$ 1.00000e-05 1.00000e-06 1.00000e-09 1.00000e-01

$1.00000 \mathrm{e}+001.00000 \mathrm{e}+001.00000 \mathrm{e}-01$ 1.00000e-09 1.00000e-01

Element: 10759 \# of layers: 7

$\mathrm{Kx} \mathrm{Ky} \mathrm{Kz}$ Ss Por

$2.10949 \mathrm{e}+012.10949 \mathrm{e}+012.10949 \mathrm{e}+00$ 1.00000e-09 2.12000e-01

$2.10949 \mathrm{e}+012.10949 \mathrm{e}+01$ 2.10949e+00 1.00000e-09 2.12000e-01

$2.10949 \mathrm{e}+012.10949 \mathrm{e}+01$ 2.10949e+00 1.00000e-09 2.12000e-01

$2.10949 \mathrm{e}+012.10949 \mathrm{e}+012.10949 \mathrm{e}+00$ 1.00000e-09 2.12000e-01

$2.10949 \mathrm{e}+012.10949 \mathrm{e}+012.10949 \mathrm{e}+001.00000 \mathrm{e}-092.12000 \mathrm{e}-01$

$1.00000 \mathrm{e}-05$ 1.00000e-05 1.00000e-06 1.00000e-09 1.00000e-01

$1.00000 \mathrm{e}+001.00000 \mathrm{e}+001.00000 \mathrm{e}-011.00000 \mathrm{e}-091.00000 \mathrm{e}-01$

Element: 10760 \# of layers: 7

Kx Ky Kz Ss Por

$2.10949 \mathrm{e}+01$ 2.10949e+01 2.10949e+00 1.00000e-09 2.12000e-01

$2.10949 \mathrm{e}+012.10949 \mathrm{e}+012.10949 \mathrm{e}+00$ 1.00000e-09 2.12000e-01

$2.10949 \mathrm{e}+012.10949 \mathrm{e}+012.10949 \mathrm{e}+00$ 1.00000e-09 2.12000e-01

$2.10949 \mathrm{e}+012.10949 \mathrm{e}+012.10949 \mathrm{e}+00$ 1.00000e-09 2.12000e-01

$2.10949 \mathrm{e}+012.10949 \mathrm{e}+012.10949 \mathrm{e}+00$ 1.00000e-09 2.12000e-01

$1.00000 \mathrm{e}-05$ 1.00000e-05 1.00000e-06 1.00000e-09 1.00000e-01

$1.00000 \mathrm{e}+001.00000 \mathrm{e}+001.00000 \mathrm{e}-011.00000 \mathrm{e}-091.00000 \mathrm{e}-01$

Element: 10761 \# of layers: 7

Kx Ky Kz Ss Por

2.31732e+01 2.31732e+01 2.31732e+00 1.00000e-09 2.12000e-01

$2.31732 \mathrm{e}+012.31732 \mathrm{e}+012.31732 \mathrm{e}+00$ 1.00000e-09 2.12000e-01

$2.31732 \mathrm{e}+012.31732 \mathrm{e}+012.31732 \mathrm{e}+00$ 1.00000e-09 2.12000e-01

$2.31732 \mathrm{e}+012.31732 \mathrm{e}+012.31732 \mathrm{e}+00$ 1.00000e-09 2.12000e-01

2.31732e+01 2.31732e+01 2.31732e+00 1.00000e-09 2.12000e-01

$1.00000 \mathrm{e}-05$ 1.00000e-05 1.00000e-06 1.00000e-09 1.00000e-01

$1.00000 \mathrm{e}+001.00000 \mathrm{e}+001.00000 \mathrm{e}-011.00000 \mathrm{e}-09$ 1.00000e-01

Element: 10762 \# of layers: 7 
Kx Ky Kz Ss Por

2.31732e+01 2.31732e+01 2.31732e+00 1.00000e-09 2.12000e-01

$2.31732 \mathrm{e}+012.31732 \mathrm{e}+012.31732 \mathrm{e}+00$ 1.00000e-09 2.12000e-01

$2.31732 \mathrm{e}+012.31732 \mathrm{e}+012.31732 \mathrm{e}+001.00000 \mathrm{e}-092.12000 \mathrm{e}-01$

$2.31732 \mathrm{e}+012.31732 \mathrm{e}+012.31732 \mathrm{e}+00$ 1.00000e-09 2.12000e-01

$2.31732 \mathrm{e}+012.31732 \mathrm{e}+012.31732 \mathrm{e}+00$ 1.00000e-09 2.12000e-01

$1.00000 \mathrm{e}-05$ 1.00000e-05 1.00000e-06 1.00000e-09 1.00000e-01

$1.00000 \mathrm{e}+001.00000 \mathrm{e}+001.00000 \mathrm{e}-01$ 1.00000e-09 1.00000e-01

Element: 10763 \# of layers: 7

$\mathrm{Kx} \mathrm{Ky} \mathrm{Kz}$ Ss Por

$2.31732 \mathrm{e}+012.31732 \mathrm{e}+01$ 2.31732e+00 1.00000e-09 2.12000e-01

$2.31732 \mathrm{e}+012.31732 \mathrm{e}+012.31732 \mathrm{e}+00$ 1.00000e-09 2.12000e-01

$2.31732 \mathrm{e}+012.31732 \mathrm{e}+012.31732 \mathrm{e}+00$ 1.00000e-09 2.12000e-01

$2.31732 \mathrm{e}+012.31732 \mathrm{e}+012.31732 \mathrm{e}+00$ 1.00000e-09 2.12000e-01

$2.31732 \mathrm{e}+012.31732 \mathrm{e}+012.31732 \mathrm{e}+00$ 1.00000e-09 2.12000e-01

$1.00000 \mathrm{e}-05$ 1.00000e-05 1.00000e-06 1.00000e-09 1.00000e-01

$1.00000 \mathrm{e}+001.00000 \mathrm{e}+001.00000 \mathrm{e}-011.00000 \mathrm{e}-091.00000 \mathrm{e}-01$

Element: 10764 \# of layers: 7

$\mathrm{Kx} \mathrm{Ky} \mathrm{Kz}$ Ss Por

$2.31732 \mathrm{e}+012.31732 \mathrm{e}+012.31732 \mathrm{e}+00$ 1.00000e-09 2.12000e-01

$2.31732 \mathrm{e}+012.31732 \mathrm{e}+012.31732 \mathrm{e}+001.00000 \mathrm{e}-092.12000 \mathrm{e}-01$

$2.31732 \mathrm{e}+012.31732 \mathrm{e}+01$ 2.31732e+00 1.00000e-09 2.12000e-01

$2.31732 \mathrm{e}+012.31732 \mathrm{e}+01$ 2.31732e+00 1.00000e-09 2.12000e-01

$2.31732 \mathrm{e}+012.31732 \mathrm{e}+012.31732 \mathrm{e}+001.00000 \mathrm{e}-092.12000 \mathrm{e}-01$

$1.00000 \mathrm{e}-05$ 1.00000e-05 1.00000e-06 1.00000e-09 1.00000e-01

$1.00000 \mathrm{e}+001.00000 \mathrm{e}+001.00000 \mathrm{e}-01$ 1.00000e-09 1.00000e-01

Element: 10765 \# of layers: 7

$\mathrm{Kx} \mathrm{Ky} \mathrm{Kz}$ Ss Por

$2.31732 \mathrm{e}+012.31732 \mathrm{e}+012.31732 \mathrm{e}+00$ 1.00000e-09 2.12000e-01

$2.31732 \mathrm{e}+012.31732 \mathrm{e}+012.31732 \mathrm{e}+00$ 1.00000e-09 2.12000e-01

$2.31732 \mathrm{e}+012.31732 \mathrm{e}+012.31732 \mathrm{e}+00$ 1.00000e-09 2.12000e-01

$2.31732 \mathrm{e}+012.31732 \mathrm{e}+012.31732 \mathrm{e}+001.00000 \mathrm{e}-092.12000 \mathrm{e}-01$

$2.31732 \mathrm{e}+012.31732 \mathrm{e}+012.31732 \mathrm{e}+00$ 1.00000e-09 2.12000e-01

$1.00000 \mathrm{e}-05$ 1.00000e-05 1.00000e-06 1.00000e-09 1.00000e-01

$1.00000 \mathrm{e}+001.00000 \mathrm{e}+001.00000 \mathrm{e}-011.00000 \mathrm{e}-091.00000 \mathrm{e}-01$

Element: 10766 \# of layers: 7

Kx Ky Kz Ss Por

$2.10949 \mathrm{e}+012.10949 \mathrm{e}+012.10949 \mathrm{e}+00$ 1.00000e-09 2.12000e-01

$2.10949 \mathrm{e}+012.10949 \mathrm{e}+01$ 2.10949e+00 1.00000e-09 2.12000e-01

$2.10949 \mathrm{e}+012.10949 \mathrm{e}+012.10949 \mathrm{e}+00$ 1.00000e-09 2.12000e-01

$2.10949 \mathrm{e}+012.10949 \mathrm{e}+012.10949 \mathrm{e}+00$ 1.00000e-09 2.12000e-01

$2.10949 \mathrm{e}+012.10949 \mathrm{e}+012.10949 \mathrm{e}+00$ 1.00000e-09 2.12000e-01

$1.00000 \mathrm{e}-05$ 1.00000e-05 1.00000e-06 1.00000e-09 1.00000e-01

$1.00000 \mathrm{e}+001.00000 \mathrm{e}+001.00000 \mathrm{e}-01$ 1.00000e-09 1.00000e-01

Element: 10767 \# of layers: 7

Kx Ky Kz Ss Por 
$2.10949 \mathrm{e}+012.10949 \mathrm{e}+012.10949 \mathrm{e}+00$ 1.00000e-09 2.12000e-01 $2.10949 \mathrm{e}+012.10949 \mathrm{e}+012.10949 \mathrm{e}+00$ 1.00000e-09 2.12000e-01 $2.10949 \mathrm{e}+012.10949 \mathrm{e}+012.10949 \mathrm{e}+00$ 1.00000e-09 2.12000e-01 $2.10949 \mathrm{e}+012.10949 \mathrm{e}+012.10949 \mathrm{e}+00$ 1.00000e-09 2.12000e-01 $2.10949 \mathrm{e}+012.10949 \mathrm{e}+012.10949 \mathrm{e}+00$ 1.00000e-09 2.12000e-01 $1.00000 \mathrm{e}-05$ 1.00000e-05 1.00000e-06 1.00000e-09 1.00000e-01 $1.00000 \mathrm{e}+001.00000 \mathrm{e}+001.00000 \mathrm{e}-011.00000 \mathrm{e}-091.00000 \mathrm{e}-01$ Element: 10768 \# of layers: 7

Kx Ky Kz Ss Por

$2.31732 \mathrm{e}+012.31732 \mathrm{e}+012.31732 \mathrm{e}+00$ 1.00000e-09 2.12000e-01 $2.31732 \mathrm{e}+012.31732 \mathrm{e}+012.31732 \mathrm{e}+001.00000 \mathrm{e}-092.12000 \mathrm{e}-01$ $2.31732 \mathrm{e}+012.31732 \mathrm{e}+012.31732 \mathrm{e}+001.00000 \mathrm{e}-092.12000 \mathrm{e}-01$ $2.31732 \mathrm{e}+012.31732 \mathrm{e}+012.31732 \mathrm{e}+00$ 1.00000e-09 2.12000e-01 $2.31732 \mathrm{e}+012.31732 \mathrm{e}+012.31732 \mathrm{e}+001.00000 \mathrm{e}-092.12000 \mathrm{e}-01$ $1.00000 \mathrm{e}-05$ 1.00000e-05 1.00000e-06 1.00000e-09 1.00000e-01 $1.00000 \mathrm{e}+001.00000 \mathrm{e}+001.00000 \mathrm{e}-011.00000 \mathrm{e}-091.00000 \mathrm{e}-01$ Element: 10769 \# of layers: 7

Kx Ky Kz Ss Por

$2.31732 \mathrm{e}+012.31732 \mathrm{e}+012.31732 \mathrm{e}+00$ 1.00000e-09 2.12000e-01 $2.31732 \mathrm{e}+012.31732 \mathrm{e}+012.31732 \mathrm{e}+00$ 1.00000e-09 2.12000e-01 $2.31732 \mathrm{e}+012.31732 \mathrm{e}+012.31732 \mathrm{e}+001.00000 \mathrm{e}-092.12000 \mathrm{e}-01$ $2.31732 \mathrm{e}+012.31732 \mathrm{e}+012.31732 \mathrm{e}+00$ 1.00000e-09 2.12000e-01 $2.31732 \mathrm{e}+012.31732 \mathrm{e}+012.31732 \mathrm{e}+00$ 1.00000e-09 2.12000e-01 $1.00000 \mathrm{e}-05$ 1.00000e-05 1.00000e-06 1.00000e-09 1.00000e-01 $1.00000 \mathrm{e}+001.00000 \mathrm{e}+001.00000 \mathrm{e}-011.00000 \mathrm{e}-091.00000 \mathrm{e}-01$ Element: 10770 \# of layers: 7

Kx Ky Kz Ss Por

$2.31732 \mathrm{e}+012.31732 \mathrm{e}+012.31732 \mathrm{e}+00$ 1.00000e-09 2.12000e-01 $2.31732 \mathrm{e}+012.31732 \mathrm{e}+012.31732 \mathrm{e}+001.00000 \mathrm{e}-092.12000 \mathrm{e}-01$ $2.31732 \mathrm{e}+012.31732 \mathrm{e}+012.31732 \mathrm{e}+001.00000 \mathrm{e}-092.12000 \mathrm{e}-01$ $2.31732 \mathrm{e}+012.31732 \mathrm{e}+012.31732 \mathrm{e}+001.00000 \mathrm{e}-092.12000 \mathrm{e}-01$ $2.31732 \mathrm{e}+012.31732 \mathrm{e}+012.31732 \mathrm{e}+00$ 1.00000e-09 2.12000e-01 $1.00000 \mathrm{e}-05$ 1.00000e-05 1.00000e-06 1.00000e-09 1.00000e-01 $1.00000 \mathrm{e}+001.00000 \mathrm{e}+001.00000 \mathrm{e}-011.00000 \mathrm{e}-091.00000 \mathrm{e}-01$ Element: 10771 \# of layers: 7

Kx Ky Kz Ss Por

$2.31732 \mathrm{e}+012.31732 \mathrm{e}+012.31732 \mathrm{e}+00$ 1.00000e-09 2.12000e-01 $2.31732 \mathrm{e}+012.31732 \mathrm{e}+012.31732 \mathrm{e}+001.00000 \mathrm{e}-092.12000 \mathrm{e}-01$ $2.31732 \mathrm{e}+012.31732 \mathrm{e}+012.31732 \mathrm{e}+00$ 1.00000e-09 2.12000e-01 $2.31732 \mathrm{e}+012.31732 \mathrm{e}+012.31732 \mathrm{e}+001.00000 \mathrm{e}-092.12000 \mathrm{e}-01$ $2.31732 \mathrm{e}+012.31732 \mathrm{e}+012.31732 \mathrm{e}+00$ 1.00000e-09 2.12000e-01 $1.00000 \mathrm{e}-05$ 1.00000e-05 1.00000e-06 1.00000e-09 1.00000e-01 $1.00000 \mathrm{e}+001.00000 \mathrm{e}+001.00000 \mathrm{e}-011.00000 \mathrm{e}-091.00000 \mathrm{e}-01$ Element: 10772 \# of layers: 7

Kx Ky Kz Ss Por

$2.31732 \mathrm{e}+012.31732 \mathrm{e}+012.31732 \mathrm{e}+00$ 1.00000e-09 2.12000e-01 
$2.31732 \mathrm{e}+012.31732 \mathrm{e}+012.31732 \mathrm{e}+00$ 1.00000e-09 2.12000e-01 $2.31732 \mathrm{e}+012.31732 \mathrm{e}+012.31732 \mathrm{e}+001.00000 \mathrm{e}-092.12000 \mathrm{e}-01$ $2.31732 \mathrm{e}+012.31732 \mathrm{e}+012.31732 \mathrm{e}+00$ 1.00000e-09 2.12000e-01 $2.31732 \mathrm{e}+012.31732 \mathrm{e}+012.31732 \mathrm{e}+001.00000 \mathrm{e}-092.12000 \mathrm{e}-01$ $1.00000 \mathrm{e}-05$ 1.00000e-05 1.00000e-06 1.00000e-09 1.00000e-01 $1.00000 \mathrm{e}+001.00000 \mathrm{e}+001.00000 \mathrm{e}-011.00000 \mathrm{e}-091.00000 \mathrm{e}-01$ Element: 10773 \# of layers: 7

Kx Ky Kz Ss Por

$2.31732 \mathrm{e}+012.31732 \mathrm{e}+012.31732 \mathrm{e}+00$ 1.00000e-09 2.12000e-01 $2.31732 \mathrm{e}+012.31732 \mathrm{e}+012.31732 \mathrm{e}+001.00000 \mathrm{e}-092.12000 \mathrm{e}-01$ $2.31732 \mathrm{e}+012.31732 \mathrm{e}+012.31732 \mathrm{e}+001.00000 \mathrm{e}-092.12000 \mathrm{e}-01$ $2.31732 \mathrm{e}+012.31732 \mathrm{e}+012.31732 \mathrm{e}+001.00000 \mathrm{e}-092.12000 \mathrm{e}-01$ $2.31732 \mathrm{e}+012.31732 \mathrm{e}+012.31732 \mathrm{e}+00$ 1.00000e-09 2.12000e-01 $1.00000 \mathrm{e}-05$ 1.00000e-05 1.00000e-06 1.00000e-09 1.00000e-01 $1.00000 \mathrm{e}+001.00000 \mathrm{e}+001.00000 \mathrm{e}-011.00000 \mathrm{e}-091.00000 \mathrm{e}-01$ Element: 10774 \# of layers: 7

Kx Ky Kz Ss Por

$2.31732 \mathrm{e}+012.31732 \mathrm{e}+012.31732 \mathrm{e}+00$ 1.00000e-09 2.12000e-01 $2.31732 \mathrm{e}+012.31732 \mathrm{e}+012.31732 \mathrm{e}+00$ 1.00000e-09 2.12000e-01 $2.31732 \mathrm{e}+012.31732 \mathrm{e}+012.31732 \mathrm{e}+001.00000 \mathrm{e}-092.12000 \mathrm{e}-01$ $2.31732 \mathrm{e}+012.31732 \mathrm{e}+012.31732 \mathrm{e}+001.00000 \mathrm{e}-092.12000 \mathrm{e}-01$ $2.31732 \mathrm{e}+012.31732 \mathrm{e}+012.31732 \mathrm{e}+00$ 1.00000e-09 2.12000e-01 $1.00000 \mathrm{e}-05$ 1.00000e-05 1.00000e-06 1.00000e-09 1.00000e-01 $1.00000 \mathrm{e}+001.00000 \mathrm{e}+001.00000 \mathrm{e}-011.00000 \mathrm{e}-091.00000 \mathrm{e}-01$ Element: 10775 \# of layers: 7

Kx Ky Kz Ss Por

$2.31732 \mathrm{e}+012.31732 \mathrm{e}+012.31732 \mathrm{e}+00$ 1.00000e-09 2.12000e-01 $2.31732 \mathrm{e}+012.31732 \mathrm{e}+012.31732 \mathrm{e}+00$ 1.00000e-09 2.12000e-01 $2.31732 \mathrm{e}+012.31732 \mathrm{e}+012.31732 \mathrm{e}+001.00000 \mathrm{e}-092.12000 \mathrm{e}-01$ $2.31732 \mathrm{e}+012.31732 \mathrm{e}+012.31732 \mathrm{e}+00$ 1.00000e-09 2.12000e-01 $2.31732 \mathrm{e}+012.31732 \mathrm{e}+012.31732 \mathrm{e}+001.00000 \mathrm{e}-092.12000 \mathrm{e}-01$ $1.00000 \mathrm{e}-05$ 1.00000e-05 1.00000e-06 1.00000e-09 1.00000e-01 $1.00000 \mathrm{e}+001.00000 \mathrm{e}+001.00000 \mathrm{e}-011.00000 \mathrm{e}-091.00000 \mathrm{e}-01$ Element: 10776 \# of layers: 7

Kx Ky Kz Ss Por

$2.31732 \mathrm{e}+012.31732 \mathrm{e}+012.31732 \mathrm{e}+00$ 1.00000e-09 2.12000e-01 $2.31732 \mathrm{e}+012.31732 \mathrm{e}+012.31732 \mathrm{e}+00$ 1.00000e-09 2.12000e-01 $2.31732 \mathrm{e}+012.31732 \mathrm{e}+012.31732 \mathrm{e}+001.00000 \mathrm{e}-092.12000 \mathrm{e}-01$ $2.31732 \mathrm{e}+012.31732 \mathrm{e}+012.31732 \mathrm{e}+00$ 1.00000e-09 2.12000e-01 $2.31732 \mathrm{e}+012.31732 \mathrm{e}+012.31732 \mathrm{e}+00$ 1.00000e-09 2.12000e-01 $1.00000 \mathrm{e}-05$ 1.00000e-05 1.00000e-06 1.00000e-09 1.00000e-01 $1.00000 \mathrm{e}+001.00000 \mathrm{e}+001.00000 \mathrm{e}-011.00000 \mathrm{e}-091.00000 \mathrm{e}-01$ Element: 10777 \# of layers: 7

Kx Ky Kz Ss Por

$2.31732 \mathrm{e}+012.31732 \mathrm{e}+012.31732 \mathrm{e}+00$ 1.00000e-09 2.12000e-01 $2.31732 \mathrm{e}+012.31732 \mathrm{e}+012.31732 \mathrm{e}+001.00000 \mathrm{e}-092.12000 \mathrm{e}-01$ 
$2.31732 \mathrm{e}+012.31732 \mathrm{e}+012.31732 \mathrm{e}+00$ 1.00000e-09 2.12000e-01 $2.31732 \mathrm{e}+012.31732 \mathrm{e}+012.31732 \mathrm{e}+00$ 1.00000e-09 2.12000e-01 $2.31732 \mathrm{e}+012.31732 \mathrm{e}+012.31732 \mathrm{e}+00$ 1.00000e-09 2.12000e-01 $1.00000 \mathrm{e}-05$ 1.00000e-05 1.00000e-06 1.00000e-09 1.00000e-01 $1.00000 \mathrm{e}+001.00000 \mathrm{e}+001.00000 \mathrm{e}-011.00000 \mathrm{e}-091.00000 \mathrm{e}-01$ Element: 10778 \# of layers: 7

Kx Ky Kz Ss Por

$2.31732 \mathrm{e}+012.31732 \mathrm{e}+012.31732 \mathrm{e}+00$ 1.00000e-09 2.12000e-01 $2.31732 \mathrm{e}+012.31732 \mathrm{e}+012.31732 \mathrm{e}+00$ 1.00000e-09 2.12000e-01 $2.31732 \mathrm{e}+012.31732 \mathrm{e}+012.31732 \mathrm{e}+00$ 1.00000e-09 2.12000e-01 $2.31732 \mathrm{e}+012.31732 \mathrm{e}+012.31732 \mathrm{e}+001.00000 \mathrm{e}-092.12000 \mathrm{e}-01$ $2.31732 \mathrm{e}+012.31732 \mathrm{e}+012.31732 \mathrm{e}+001.00000 \mathrm{e}-092.12000 \mathrm{e}-01$ $1.00000 \mathrm{e}-05$ 1.00000e-05 1.00000e-06 1.00000e-09 1.00000e-01 $1.00000 \mathrm{e}+001.00000 \mathrm{e}+001.00000 \mathrm{e}-011.00000 \mathrm{e}-091.00000 \mathrm{e}-01$ Element: 10779 \# of layers: 7

Kx Ky Kz Ss Por

$2.31732 \mathrm{e}+012.31732 \mathrm{e}+012.31732 \mathrm{e}+00$ 1.00000e-09 2.12000e-01 $2.31732 \mathrm{e}+012.31732 \mathrm{e}+012.31732 \mathrm{e}+00$ 1.00000e-09 2.12000e-01 $2.31732 \mathrm{e}+012.31732 \mathrm{e}+012.31732 \mathrm{e}+00$ 1.00000e-09 2.12000e-01 $2.31732 \mathrm{e}+012.31732 \mathrm{e}+012.31732 \mathrm{e}+00$ 1.00000e-09 2.12000e-01 $2.31732 \mathrm{e}+012.31732 \mathrm{e}+012.31732 \mathrm{e}+00$ 1.00000e-09 2.12000e-01 $1.00000 \mathrm{e}-05$ 1.00000e-05 1.00000e-06 1.00000e-09 1.00000e-01 $1.00000 \mathrm{e}+001.00000 \mathrm{e}+001.00000 \mathrm{e}-011.00000 \mathrm{e}-091.00000 \mathrm{e}-01$ Element: 10780 \# of layers: 7

Kx Ky Kz Ss Por

$2.15935 \mathrm{e}+012.15935 \mathrm{e}+012.15935 \mathrm{e}+00$ 1.00000e-09 2.12000e-01 $2.15935 \mathrm{e}+012.15935 \mathrm{e}+012.15935 \mathrm{e}+001.00000 \mathrm{e}-092.12000 \mathrm{e}-01$ $2.15935 \mathrm{e}+012.15935 \mathrm{e}+012.15935 \mathrm{e}+00$ 1.00000e-09 2.12000e-01 $2.15935 \mathrm{e}+012.15935 \mathrm{e}+012.15935 \mathrm{e}+001.00000 \mathrm{e}-092.12000 \mathrm{e}-01$ $2.15935 \mathrm{e}+012.15935 \mathrm{e}+012.15935 \mathrm{e}+001.00000 \mathrm{e}-092.12000 \mathrm{e}-01$ $1.00000 \mathrm{e}-05$ 1.00000e-05 1.00000e-06 1.00000e-09 1.00000e-01 $1.00000 \mathrm{e}+001.00000 \mathrm{e}+001.00000 \mathrm{e}-011.00000 \mathrm{e}-091.00000 \mathrm{e}-01$ Element: 10781 \# of layers: 7

Kx Ky Kz Ss Por

$2.15935 \mathrm{e}+012.15935 \mathrm{e}+012.15935 \mathrm{e}+00$ 1.00000e-09 2.12000e-01 $2.15935 \mathrm{e}+012.15935 \mathrm{e}+012.15935 \mathrm{e}+00$ 1.00000e-09 2.12000e-01 $2.15935 \mathrm{e}+012.15935 \mathrm{e}+012.15935 \mathrm{e}+00$ 1.00000e-09 2.12000e-01 $2.15935 \mathrm{e}+012.15935 \mathrm{e}+012.15935 \mathrm{e}+00$ 1.00000e-09 2.12000e-01 $2.15935 \mathrm{e}+012.15935 \mathrm{e}+012.15935 \mathrm{e}+00$ 1.00000e-09 2.12000e-01 $1.00000 \mathrm{e}-05$ 1.00000e-05 1.00000e-06 1.00000e-09 1.00000e-01 $1.00000 \mathrm{e}+001.00000 \mathrm{e}+001.00000 \mathrm{e}-011.00000 \mathrm{e}-091.00000 \mathrm{e}-01$ Element: 10782 \# of layers: 7

Kx Ky Kz Ss Por

$2.15935 \mathrm{e}+012.15935 \mathrm{e}+012.15935 \mathrm{e}+00$ 1.00000e-09 2.12000e-01 $2.15935 \mathrm{e}+012.15935 \mathrm{e}+012.15935 \mathrm{e}+00$ 1.00000e-09 2.12000e-01 $2.15935 \mathrm{e}+012.15935 \mathrm{e}+012.15935 \mathrm{e}+00$ 1.00000e-09 2.12000e-01 
$2.15935 \mathrm{e}+012.15935 \mathrm{e}+012.15935 \mathrm{e}+00$ 1.00000e-09 2.12000e-01 $2.15935 \mathrm{e}+012.15935 \mathrm{e}+012.15935 \mathrm{e}+00$ 1.00000e-09 2.12000e-01 $1.00000 \mathrm{e}-05$ 1.00000e-05 1.00000e-06 1.00000e-09 1.00000e-01 $1.00000 \mathrm{e}+001.00000 \mathrm{e}+001.00000 \mathrm{e}-011.00000 \mathrm{e}-091.00000 \mathrm{e}-01$ Element: 10783 \# of layers: 7

Kx Ky Kz Ss Por

$2.31732 \mathrm{e}+012.31732 \mathrm{e}+012.31732 \mathrm{e}+00$ 1.00000e-09 2.12000e-01 $2.31732 \mathrm{e}+012.31732 \mathrm{e}+012.31732 \mathrm{e}+00$ 1.00000e-09 2.12000e-01 $2.31732 \mathrm{e}+012.31732 \mathrm{e}+012.31732 \mathrm{e}+00$ 1.00000e-09 2.12000e-01 $2.31732 \mathrm{e}+012.31732 \mathrm{e}+012.31732 \mathrm{e}+00$ 1.00000e-09 2.12000e-01 $2.31732 \mathrm{e}+012.31732 \mathrm{e}+012.31732 \mathrm{e}+001.00000 \mathrm{e}-092.12000 \mathrm{e}-01$ $1.00000 \mathrm{e}-05$ 1.00000e-05 1.00000e-06 1.00000e-09 1.00000e-01 $1.00000 \mathrm{e}+001.00000 \mathrm{e}+001.00000 \mathrm{e}-011.00000 \mathrm{e}-091.00000 \mathrm{e}-01$ Element: 10784 \# of layers: 7

Kx Ky Kz Ss Por

$2.31732 \mathrm{e}+012.31732 \mathrm{e}+012.31732 \mathrm{e}+00$ 1.00000e-09 2.12000e-01 $2.31732 \mathrm{e}+012.31732 \mathrm{e}+012.31732 \mathrm{e}+00$ 1.00000e-09 2.12000e-01 $2.31732 \mathrm{e}+012.31732 \mathrm{e}+012.31732 \mathrm{e}+00$ 1.00000e-09 2.12000e-01 $2.31732 \mathrm{e}+012.31732 \mathrm{e}+012.31732 \mathrm{e}+00$ 1.00000e-09 2.12000e-01 $2.31732 \mathrm{e}+012.31732 \mathrm{e}+012.31732 \mathrm{e}+00$ 1.00000e-09 2.12000e-01 $1.00000 \mathrm{e}-05$ 1.00000e-05 1.00000e-06 1.00000e-09 1.00000e-01 $1.00000 \mathrm{e}+001.00000 \mathrm{e}+001.00000 \mathrm{e}-011.00000 \mathrm{e}-091.00000 \mathrm{e}-01$ Element: 10785 \# of layers: 7

Kx Ky Kz Ss Por

$2.31732 \mathrm{e}+012.31732 \mathrm{e}+012.31732 \mathrm{e}+00$ 1.00000e-09 2.12000e-01 $2.31732 \mathrm{e}+012.31732 \mathrm{e}+012.31732 \mathrm{e}+00$ 1.00000e-09 2.12000e-01 $2.31732 \mathrm{e}+012.31732 \mathrm{e}+012.31732 \mathrm{e}+00$ 1.00000e-09 2.12000e-01 $2.31732 \mathrm{e}+012.31732 \mathrm{e}+012.31732 \mathrm{e}+00$ 1.00000e-09 2.12000e-01 $2.31732 \mathrm{e}+012.31732 \mathrm{e}+012.31732 \mathrm{e}+001.00000 \mathrm{e}-092.12000 \mathrm{e}-01$ $1.00000 \mathrm{e}-05$ 1.00000e-05 1.00000e-06 1.00000e-09 1.00000e-01 $1.00000 \mathrm{e}+001.00000 \mathrm{e}+001.00000 \mathrm{e}-011.00000 \mathrm{e}-091.00000 \mathrm{e}-01$ Element: 10786 \# of layers: 7

Kx Ky Kz Ss Por

$2.31732 \mathrm{e}+012.31732 \mathrm{e}+012.31732 \mathrm{e}+00$ 1.00000e-09 2.12000e-01 $2.31732 \mathrm{e}+012.31732 \mathrm{e}+012.31732 \mathrm{e}+00$ 1.00000e-09 2.12000e-01 $2.31732 \mathrm{e}+012.31732 \mathrm{e}+012.31732 \mathrm{e}+00$ 1.00000e-09 2.12000e-01 $2.31732 \mathrm{e}+012.31732 \mathrm{e}+012.31732 \mathrm{e}+00$ 1.00000e-09 2.12000e-01 $2.31732 \mathrm{e}+012.31732 \mathrm{e}+012.31732 \mathrm{e}+00$ 1.00000e-09 2.12000e-01 $1.00000 \mathrm{e}-05$ 1.00000e-05 1.00000e-06 1.00000e-09 1.00000e-01 $1.00000 \mathrm{e}+001.00000 \mathrm{e}+001.00000 \mathrm{e}-011.00000 \mathrm{e}-091.00000 \mathrm{e}-01$ Element: 10787 \# of layers: 7

Kx Ky Kz Ss Por

$2.15935 \mathrm{e}+012.15935 \mathrm{e}+012.15935 \mathrm{e}+00$ 1.00000e-09 2.12000e-01 $2.15935 \mathrm{e}+012.15935 \mathrm{e}+012.15935 \mathrm{e}+00$ 1.00000e-09 2.12000e-01 $2.15935 \mathrm{e}+012.15935 \mathrm{e}+012.15935 \mathrm{e}+001.00000 \mathrm{e}-092.12000 \mathrm{e}-01$ $2.15935 \mathrm{e}+012.15935 \mathrm{e}+012.15935 \mathrm{e}+00$ 1.00000e-09 2.12000e-01 
$2.15935 \mathrm{e}+012.15935 \mathrm{e}+012.15935 \mathrm{e}+00$ 1.00000e-09 2.12000e-01 $1.00000 \mathrm{e}-05$ 1.00000e-05 1.00000e-06 1.00000e-09 1.00000e-01 $1.00000 \mathrm{e}+001.00000 \mathrm{e}+001.00000 \mathrm{e}-011.00000 \mathrm{e}-091.00000 \mathrm{e}-01$

Element: 10788 \# of layers: 7

$\mathrm{Kx} \mathrm{Ky} \mathrm{Kz}$ Ss Por

$2.15935 \mathrm{e}+012.15935 \mathrm{e}+012.15935 \mathrm{e}+00$ 1.00000e-09 2.12000e-01

$2.15935 \mathrm{e}+012.15935 \mathrm{e}+012.15935 \mathrm{e}+00$ 1.00000e-09 2.12000e-01

$2.15935 \mathrm{e}+012.15935 \mathrm{e}+012.15935 \mathrm{e}+00$ 1.00000e-09 2.12000e-01

$2.15935 \mathrm{e}+012.15935 \mathrm{e}+012.15935 \mathrm{e}+00$ 1.00000e-09 2.12000e-01

$2.15935 \mathrm{e}+012.15935 \mathrm{e}+012.15935 \mathrm{e}+00$ 1.00000e-09 2.12000e-01 $1.00000 \mathrm{e}-05$ 1.00000e-05 1.00000e-06 1.00000e-09 1.00000e-01

$1.00000 \mathrm{e}+001.00000 \mathrm{e}+001.00000 \mathrm{e}-011.00000 \mathrm{e}-091.00000 \mathrm{e}-01$

Element: 10789 \# of layers: 7

$\mathrm{Kx} \mathrm{Ky} \mathrm{Kz}$ Ss Por

$2.15935 \mathrm{e}+012.15935 \mathrm{e}+012.15935 \mathrm{e}+00$ 1.00000e-09 2.12000e-01

$2.15935 \mathrm{e}+012.15935 \mathrm{e}+012.15935 \mathrm{e}+00$ 1.00000e-09 2.12000e-01

$2.15935 \mathrm{e}+012.15935 \mathrm{e}+012.15935 \mathrm{e}+00$ 1.00000e-09 2.12000e-01

$2.15935 \mathrm{e}+012.15935 \mathrm{e}+012.15935 \mathrm{e}+00$ 1.00000e-09 2.12000e-01

$2.15935 \mathrm{e}+012.15935 \mathrm{e}+012.15935 \mathrm{e}+00$ 1.00000e-09 2.12000e-01 $1.00000 \mathrm{e}-05$ 1.00000e-05 1.00000e-06 1.00000e-09 1.00000e-01

$1.00000 \mathrm{e}+001.00000 \mathrm{e}+001.00000 \mathrm{e}-011.00000 \mathrm{e}-091.00000 \mathrm{e}-01$

Element: 10790 \# of layers: 7

$\mathrm{Kx} \mathrm{Ky} \mathrm{Kz}$ Ss Por

$2.15935 \mathrm{e}+012.15935 \mathrm{e}+012.15935 \mathrm{e}+00$ 1.00000e-09 2.12000e-01

$2.15935 \mathrm{e}+012.15935 \mathrm{e}+012.15935 \mathrm{e}+001.00000 \mathrm{e}-092.12000 \mathrm{e}-01$

$2.15935 \mathrm{e}+012.15935 \mathrm{e}+012.15935 \mathrm{e}+00$ 1.00000e-09 2.12000e-01

$2.15935 \mathrm{e}+012.15935 \mathrm{e}+012.15935 \mathrm{e}+00$ 1.00000e-09 2.12000e-01

$2.15935 \mathrm{e}+012.15935 \mathrm{e}+012.15935 \mathrm{e}+00$ 1.00000e-09 2.12000e-01

$1.00000 \mathrm{e}-05$ 1.00000e-05 1.00000e-06 1.00000e-09 1.00000e-01

$1.00000 \mathrm{e}+001.00000 \mathrm{e}+001.00000 \mathrm{e}-011.00000 \mathrm{e}-091.00000 \mathrm{e}-01$

Element: 10791 \# of layers: 7

$\mathrm{Kx} \mathrm{Ky} \mathrm{Kz}$ Ss Por

$2.15935 \mathrm{e}+012.15935 \mathrm{e}+012.15935 \mathrm{e}+00$ 1.00000e-09 2.12000e-01

$2.15935 \mathrm{e}+012.15935 \mathrm{e}+012.15935 \mathrm{e}+00$ 1.00000e-09 2.12000e-01

$2.15935 \mathrm{e}+012.15935 \mathrm{e}+012.15935 \mathrm{e}+00$ 1.00000e-09 2.12000e-01

$2.15935 \mathrm{e}+012.15935 \mathrm{e}+012.15935 \mathrm{e}+00$ 1.00000e-09 2.12000e-01

$2.15935 \mathrm{e}+012.15935 \mathrm{e}+012.15935 \mathrm{e}+00$ 1.00000e-09 2.12000e-01

$1.00000 \mathrm{e}-05$ 1.00000e-05 1.00000e-06 1.00000e-09 1.00000e-01

$1.00000 \mathrm{e}+001.00000 \mathrm{e}+001.00000 \mathrm{e}-01$ 1.00000e-09 1.00000e-01

Element: 10792 \# of layers: 7

$\mathrm{Kx} \mathrm{Ky} \mathrm{Kz}$ Ss Por

2.15935e+01 2.15935e+01 2.15935e+00 1.00000e-09 2.12000e-01

$2.15935 \mathrm{e}+012.15935 \mathrm{e}+012.15935 \mathrm{e}+00$ 1.00000e-09 2.12000e-01

$2.15935 \mathrm{e}+012.15935 \mathrm{e}+01$ 2.15935e+00 1.00000e-09 2.12000e-01

$2.15935 \mathrm{e}+012.15935 \mathrm{e}+012.15935 \mathrm{e}+00$ 1.00000e-09 2.12000e-01

$2.15935 \mathrm{e}+012.15935 \mathrm{e}+012.15935 \mathrm{e}+001.00000 \mathrm{e}-092.12000 \mathrm{e}-01$ 
$1.00000 \mathrm{e}-05$ 1.00000e-05 1.00000e-06 1.00000e-09 1.00000e-01 $1.00000 \mathrm{e}+001.00000 \mathrm{e}+001.00000 \mathrm{e}-01$ 1.00000e-09 1.00000e-01 Element: 10793 \# of layers: 7

Kx Ky Kz Ss Por

$2.15935 \mathrm{e}+012.15935 \mathrm{e}+012.15935 \mathrm{e}+00$ 1.00000e-09 2.12000e-01 $2.15935 \mathrm{e}+012.15935 \mathrm{e}+012.15935 \mathrm{e}+00$ 1.00000e-09 2.12000e-01 $2.15935 \mathrm{e}+012.15935 \mathrm{e}+012.15935 \mathrm{e}+00$ 1.00000e-09 2.12000e-01 $2.15935 \mathrm{e}+012.15935 \mathrm{e}+012.15935 \mathrm{e}+00$ 1.00000e-09 2.12000e-01 $2.15935 \mathrm{e}+012.15935 \mathrm{e}+012.15935 \mathrm{e}+001.00000 \mathrm{e}-092.12000 \mathrm{e}-01$ $1.00000 \mathrm{e}-05$ 1.00000e-05 1.00000e-06 1.00000e-09 1.00000e-01 $1.00000 \mathrm{e}+001.00000 \mathrm{e}+001.00000 \mathrm{e}-011.00000 \mathrm{e}-091.00000 \mathrm{e}-01$ Element: 10794 \# of layers: 7

$\mathrm{Kx} \mathrm{Ky} \mathrm{Kz}$ Ss Por

$2.15935 \mathrm{e}+012.15935 \mathrm{e}+012.15935 \mathrm{e}+00$ 1.00000e-09 2.12000e-01 $2.15935 \mathrm{e}+012.15935 \mathrm{e}+012.15935 \mathrm{e}+00$ 1.00000e-09 2.12000e-01 $2.15935 \mathrm{e}+012.15935 \mathrm{e}+012.15935 \mathrm{e}+00$ 1.00000e-09 2.12000e-01 $2.15935 \mathrm{e}+012.15935 \mathrm{e}+012.15935 \mathrm{e}+00$ 1.00000e-09 2.12000e-01 $2.15935 \mathrm{e}+012.15935 \mathrm{e}+012.15935 \mathrm{e}+00$ 1.00000e-09 2.12000e-01 $1.00000 \mathrm{e}-051.00000 \mathrm{e}-05$ 1.00000e-06 1.00000e-09 1.00000e-01 $1.00000 \mathrm{e}+001.00000 \mathrm{e}+001.00000 \mathrm{e}-011.00000 \mathrm{e}-09$ 1.00000e-01 Element: 10795 \# of layers: 7

$\mathrm{Kx} \mathrm{Ky} \mathrm{Kz}$ Ss Por

$2.15935 \mathrm{e}+012.15935 \mathrm{e}+01$ 2.15935e+00 1.00000e-09 2.12000e-01 $2.15935 \mathrm{e}+012.15935 \mathrm{e}+012.15935 \mathrm{e}+00$ 1.00000e-09 2.12000e-01 $2.15935 \mathrm{e}+012.15935 \mathrm{e}+012.15935 \mathrm{e}+001.00000 \mathrm{e}-092.12000 \mathrm{e}-01$ $2.15935 \mathrm{e}+012.15935 \mathrm{e}+012.15935 \mathrm{e}+001.00000 \mathrm{e}-092.12000 \mathrm{e}-01$ $2.15935 \mathrm{e}+012.15935 \mathrm{e}+012.15935 \mathrm{e}+001.00000 \mathrm{e}-092.12000 \mathrm{e}-01$ $1.00000 \mathrm{e}-05$ 1.00000e-05 1.00000e-06 1.00000e-09 1.00000e-01 $1.00000 \mathrm{e}+001.00000 \mathrm{e}+001.00000 \mathrm{e}-011.00000 \mathrm{e}-091.00000 \mathrm{e}-01$ Element: 10796 \# of layers: 7

$\mathrm{Kx} \mathrm{Ky} \mathrm{Kz}$ Ss Por

$2.15935 \mathrm{e}+012.15935 \mathrm{e}+012.15935 \mathrm{e}+00$ 1.00000e-09 2.12000e-01 $2.15935 \mathrm{e}+012.15935 \mathrm{e}+012.15935 \mathrm{e}+00$ 1.00000e-09 2.12000e-01 $2.15935 \mathrm{e}+012.15935 \mathrm{e}+012.15935 \mathrm{e}+00$ 1.00000e-09 2.12000e-01 $2.15935 \mathrm{e}+012.15935 \mathrm{e}+012.15935 \mathrm{e}+00$ 1.00000e-09 2.12000e-01 $2.15935 \mathrm{e}+012.15935 \mathrm{e}+012.15935 \mathrm{e}+00$ 1.00000e-09 2.12000e-01 1.00000e-05 1.00000e-05 1.00000e-06 1.00000e-09 1.00000e-01 $1.00000 \mathrm{e}+001.00000 \mathrm{e}+001.00000 \mathrm{e}-011.00000 \mathrm{e}-091.00000 \mathrm{e}-01$ Element: 10797 \# of layers: 7

$\mathrm{Kx} \mathrm{Ky} \mathrm{Kz}$ Ss Por

$2.15935 \mathrm{e}+012.15935 \mathrm{e}+012.15935 \mathrm{e}+00$ 1.00000e-09 2.12000e-01 $2.15935 \mathrm{e}+012.15935 \mathrm{e}+012.15935 \mathrm{e}+00$ 1.00000e-09 2.12000e-01 $2.15935 \mathrm{e}+012.15935 \mathrm{e}+012.15935 \mathrm{e}+00$ 1.00000e-09 2.12000e-01 $2.15935 \mathrm{e}+012.15935 \mathrm{e}+012.15935 \mathrm{e}+00$ 1.00000e-09 2.12000e-01 $2.15935 \mathrm{e}+012.15935 \mathrm{e}+012.15935 \mathrm{e}+00$ 1.00000e-09 2.12000e-01 $1.00000 \mathrm{e}-05$ 1.00000e-05 1.00000e-06 1.00000e-09 1.00000e-01 
$1.00000 \mathrm{e}+001.00000 \mathrm{e}+001.00000 \mathrm{e}-011.00000 \mathrm{e}-091.00000 \mathrm{e}-01$

Element: 10798 \# of layers: 7

Kx Ky Kz Ss Por

$2.10436 \mathrm{e}+012.10436 \mathrm{e}+012.10436 \mathrm{e}+00$ 1.00000e-09 2.12000e-01

$2.10436 \mathrm{e}+012.10436 \mathrm{e}+012.10436 \mathrm{e}+001.00000 \mathrm{e}-092.12000 \mathrm{e}-01$

$2.10436 \mathrm{e}+012.10436 \mathrm{e}+012.10436 \mathrm{e}+001.00000 \mathrm{e}-092.12000 \mathrm{e}-01$

$2.10436 \mathrm{e}+012.10436 \mathrm{e}+012.10436 \mathrm{e}+001.00000 \mathrm{e}-092.12000 \mathrm{e}-01$

$2.10436 \mathrm{e}+012.10436 \mathrm{e}+012.10436 \mathrm{e}+001.00000 \mathrm{e}-092.12000 \mathrm{e}-01$

$1.00000 \mathrm{e}-05$ 1.00000e-05 1.00000e-06 1.00000e-09 1.00000e-01

$1.00000 \mathrm{e}+001.00000 \mathrm{e}+001.00000 \mathrm{e}-011.00000 \mathrm{e}-091.00000 \mathrm{e}-01$

Element: 10799 \# of layers: 7

Kx Ky Kz Ss Por

2.10436e+01 2.10436e+01 2.10436e+00 1.00000e-09 2.12000e-01

$2.10436 \mathrm{e}+012.10436 \mathrm{e}+012.10436 \mathrm{e}+00$ 1.00000e-09 2.12000e-01

$2.10436 \mathrm{e}+012.10436 \mathrm{e}+012.10436 \mathrm{e}+001.00000 \mathrm{e}-092.12000 \mathrm{e}-01$

$2.10436 \mathrm{e}+012.10436 \mathrm{e}+012.10436 \mathrm{e}+001.00000 \mathrm{e}-092.12000 \mathrm{e}-01$

$2.10436 \mathrm{e}+012.10436 \mathrm{e}+012.10436 \mathrm{e}+001.00000 \mathrm{e}-092.12000 \mathrm{e}-01$

$1.00000 \mathrm{e}-05$ 1.00000e-05 1.00000e-06 1.00000e-09 1.00000e-01

$1.00000 \mathrm{e}+001.00000 \mathrm{e}+001.00000 \mathrm{e}-011.00000 \mathrm{e}-091.00000 \mathrm{e}-01$

Element: 10800 \# of layers: 7

$\mathrm{Kx} \mathrm{Ky} \mathrm{Kz}$ Ss Por

$2.10436 \mathrm{e}+012.10436 \mathrm{e}+012.10436 \mathrm{e}+00$ 1.00000e-09 2.12000e-01

$2.10436 \mathrm{e}+012.10436 \mathrm{e}+012.10436 \mathrm{e}+00$ 1.00000e-09 2.12000e-01

$2.10436 \mathrm{e}+012.10436 \mathrm{e}+012.10436 \mathrm{e}+00$ 1.00000e-09 2.12000e-01

$2.10436 \mathrm{e}+012.10436 \mathrm{e}+012.10436 \mathrm{e}+001.00000 \mathrm{e}-092.12000 \mathrm{e}-01$

$2.10436 \mathrm{e}+012.10436 \mathrm{e}+012.10436 \mathrm{e}+00$ 1.00000e-09 2.12000e-01

$1.00000 \mathrm{e}-05$ 1.00000e-05 1.00000e-06 1.00000e-09 1.00000e-01

$1.00000 \mathrm{e}+001.00000 \mathrm{e}+001.00000 \mathrm{e}-01$ 1.00000e-09 1.00000e-01

Element: 10801 \# of layers: 7

$\mathrm{Kx} \mathrm{Ky} \mathrm{Kz}$ Ss Por

$2.15935 \mathrm{e}+012.15935 \mathrm{e}+012.15935 \mathrm{e}+00$ 1.00000e-09 2.12000e-01

$2.15935 \mathrm{e}+012.15935 \mathrm{e}+012.15935 \mathrm{e}+00$ 1.00000e-09 2.12000e-01

$2.15935 \mathrm{e}+012.15935 \mathrm{e}+012.15935 \mathrm{e}+00$ 1.00000e-09 2.12000e-01

$2.15935 \mathrm{e}+012.15935 \mathrm{e}+012.15935 \mathrm{e}+00$ 1.00000e-09 2.12000e-01

$2.15935 \mathrm{e}+012.15935 \mathrm{e}+012.15935 \mathrm{e}+00$ 1.00000e-09 2.12000e-01

$1.00000 \mathrm{e}-05$ 1.00000e-05 1.00000e-06 1.00000e-09 1.00000e-01

$1.00000 \mathrm{e}+001.00000 \mathrm{e}+001.00000 \mathrm{e}-011.00000 \mathrm{e}-091.00000 \mathrm{e}-01$

Element: 10802 \# of layers: 7

$\mathrm{Kx} \mathrm{Ky} \mathrm{Kz}$ Ss Por

$2.15935 \mathrm{e}+012.15935 \mathrm{e}+012.15935 \mathrm{e}+00$ 1.00000e-09 2.12000e-01

$2.15935 \mathrm{e}+012.15935 \mathrm{e}+012.15935 \mathrm{e}+00$ 1.00000e-09 2.12000e-01

$2.15935 \mathrm{e}+012.15935 \mathrm{e}+012.15935 \mathrm{e}+00$ 1.00000e-09 2.12000e-01

$2.15935 \mathrm{e}+012.15935 \mathrm{e}+012.15935 \mathrm{e}+00$ 1.00000e-09 2.12000e-01

$2.15935 \mathrm{e}+012.15935 \mathrm{e}+012.15935 \mathrm{e}+00$ 1.00000e-09 2.12000e-01 $1.00000 \mathrm{e}-05$ 1.00000e-05 1.00000e-06 1.00000e-09 1.00000e-01

$1.00000 \mathrm{e}+001.00000 \mathrm{e}+001.00000 \mathrm{e}-011.00000 \mathrm{e}-091.00000 \mathrm{e}-01$ 
Element: 10803 \# of layers: 7

$\mathrm{Kx} \mathrm{Ky} \mathrm{Kz}$ Ss Por

$2.15935 \mathrm{e}+012.15935 \mathrm{e}+012.15935 \mathrm{e}+00$ 1.00000e-09 2.12000e-01

$2.15935 \mathrm{e}+012.15935 \mathrm{e}+012.15935 \mathrm{e}+001.00000 \mathrm{e}-092.12000 \mathrm{e}-01$

$2.15935 \mathrm{e}+012.15935 \mathrm{e}+012.15935 \mathrm{e}+00$ 1.00000e-09 2.12000e-01

$2.15935 \mathrm{e}+012.15935 \mathrm{e}+012.15935 \mathrm{e}+00$ 1.00000e-09 2.12000e-01

$2.15935 \mathrm{e}+012.15935 \mathrm{e}+012.15935 \mathrm{e}+00$ 1.00000e-09 2.12000e-01

$1.00000 \mathrm{e}-05$ 1.00000e-05 1.00000e-06 1.00000e-09 1.00000e-01

$1.00000 \mathrm{e}+001.00000 \mathrm{e}+001.00000 \mathrm{e}-011.00000 \mathrm{e}-091.00000 \mathrm{e}-01$

Element: 10804 \# of layers: 7

$\mathrm{Kx} \mathrm{Ky} \mathrm{Kz}$ Ss Por

$2.15935 \mathrm{e}+012.15935 \mathrm{e}+012.15935 \mathrm{e}+00$ 1.00000e-09 2.12000e-01

$2.15935 \mathrm{e}+012.15935 \mathrm{e}+012.15935 \mathrm{e}+00$ 1.00000e-09 2.12000e-01

$2.15935 \mathrm{e}+012.15935 \mathrm{e}+012.15935 \mathrm{e}+00$ 1.00000e-09 2.12000e-01

$2.15935 \mathrm{e}+012.15935 \mathrm{e}+012.15935 \mathrm{e}+00$ 1.00000e-09 2.12000e-01

$2.15935 \mathrm{e}+012.15935 \mathrm{e}+012.15935 \mathrm{e}+00$ 1.00000e-09 2.12000e-01

$1.00000 \mathrm{e}-05$ 1.00000e-05 1.00000e-06 1.00000e-09 1.00000e-01

$1.00000 \mathrm{e}+001.00000 \mathrm{e}+001.00000 \mathrm{e}-01$ 1.00000e-09 1.00000e-01

Element: 10805 \# of layers: 7

$\mathrm{Kx} \mathrm{Ky} \mathrm{Kz}$ Ss Por

$2.10436 \mathrm{e}+012.10436 \mathrm{e}+012.10436 \mathrm{e}+00$ 1.00000e-09 2.12000e-01

$2.10436 \mathrm{e}+012.10436 \mathrm{e}+012.10436 \mathrm{e}+00$ 1.00000e-09 2.12000e-01

$2.10436 \mathrm{e}+012.10436 \mathrm{e}+012.10436 \mathrm{e}+00$ 1.00000e-09 2.12000e-01

$2.10436 \mathrm{e}+012.10436 \mathrm{e}+012.10436 \mathrm{e}+001.00000 \mathrm{e}-092.12000 \mathrm{e}-01$

$2.10436 \mathrm{e}+012.10436 \mathrm{e}+012.10436 \mathrm{e}+00$ 1.00000e-09 2.12000e-01

$1.00000 \mathrm{e}-05$ 1.00000e-05 1.00000e-06 1.00000e-09 1.00000e-01

$1.00000 \mathrm{e}+001.00000 \mathrm{e}+001.00000 \mathrm{e}-01$ 1.00000e-09 1.00000e-01

Element: 10806 \# of layers: 7

$\mathrm{Kx} \mathrm{Ky} \mathrm{Kz}$ Ss Por

$2.10436 \mathrm{e}+012.10436 \mathrm{e}+012.10436 \mathrm{e}+00$ 1.00000e-09 2.12000e-01

$2.10436 \mathrm{e}+012.10436 \mathrm{e}+012.10436 \mathrm{e}+001.00000 \mathrm{e}-092.12000 \mathrm{e}-01$

$2.10436 \mathrm{e}+012.10436 \mathrm{e}+012.10436 \mathrm{e}+00$ 1.00000e-09 2.12000e-01

$2.10436 \mathrm{e}+012.10436 \mathrm{e}+012.10436 \mathrm{e}+00$ 1.00000e-09 2.12000e-01

$2.10436 \mathrm{e}+012.10436 \mathrm{e}+012.10436 \mathrm{e}+00$ 1.00000e-09 2.12000e-01

$1.00000 \mathrm{e}-05$ 1.00000e-05 1.00000e-06 1.00000e-09 1.00000e-01

$1.00000 \mathrm{e}+001.00000 \mathrm{e}+001.00000 \mathrm{e}-011.00000 \mathrm{e}-091.00000 \mathrm{e}-01$

Element: 10807 \# of layers: 7

$\mathrm{Kx} \mathrm{Ky} \mathrm{Kz}$ Ss Por

$2.10436 \mathrm{e}+012.10436 \mathrm{e}+012.10436 \mathrm{e}+00$ 1.00000e-09 2.12000e-01

$2.10436 \mathrm{e}+012.10436 \mathrm{e}+012.10436 \mathrm{e}+00$ 1.00000e-09 2.12000e-01

$2.10436 \mathrm{e}+012.10436 \mathrm{e}+012.10436 \mathrm{e}+00$ 1.00000e-09 2.12000e-01

$2.10436 \mathrm{e}+012.10436 \mathrm{e}+012.10436 \mathrm{e}+00$ 1.00000e-09 2.12000e-01

$2.10436 \mathrm{e}+012.10436 \mathrm{e}+012.10436 \mathrm{e}+00$ 1.00000e-09 2.12000e-01

$1.00000 \mathrm{e}-05$ 1.00000e-05 1.00000e-06 1.00000e-09 1.00000e-01

$1.00000 \mathrm{e}+001.00000 \mathrm{e}+001.00000 \mathrm{e}-011.00000 \mathrm{e}-09$ 1.00000e-01

Element: 10808 \# of layers: 7 
$\mathrm{Kx} \mathrm{Ky} \mathrm{Kz}$ Ss Por

2.10436e+01 2.10436e+01 2.10436e+00 1.00000e-09 2.12000e-01

$2.10436 \mathrm{e}+012.10436 \mathrm{e}+012.10436 \mathrm{e}+00$ 1.00000e-09 2.12000e-01

$2.10436 \mathrm{e}+012.10436 \mathrm{e}+012.10436 \mathrm{e}+001.00000 \mathrm{e}-092.12000 \mathrm{e}-01$

$2.10436 \mathrm{e}+012.10436 \mathrm{e}+012.10436 \mathrm{e}+001.00000 \mathrm{e}-092.12000 \mathrm{e}-01$

$2.10436 \mathrm{e}+012.10436 \mathrm{e}+012.10436 \mathrm{e}+00$ 1.00000e-09 2.12000e-01

$1.00000 \mathrm{e}-05$ 1.00000e-05 1.00000e-06 1.00000e-09 1.00000e-01

$1.00000 \mathrm{e}+001.00000 \mathrm{e}+001.00000 \mathrm{e}-01$ 1.00000e-09 1.00000e-01

Element: 10809 \# of layers: 7

$\mathrm{Kx} \mathrm{Ky} \mathrm{Kz}$ Ss Por

$2.10436 \mathrm{e}+012.10436 \mathrm{e}+012.10436 \mathrm{e}+00$ 1.00000e-09 2.12000e-01

$2.10436 \mathrm{e}+012.10436 \mathrm{e}+012.10436 \mathrm{e}+001.00000 \mathrm{e}-092.12000 \mathrm{e}-01$

$2.10436 \mathrm{e}+012.10436 \mathrm{e}+012.10436 \mathrm{e}+00$ 1.00000e-09 2.12000e-01

$2.10436 \mathrm{e}+012.10436 \mathrm{e}+012.10436 \mathrm{e}+00$ 1.00000e-09 2.12000e-01

$2.10436 \mathrm{e}+012.10436 \mathrm{e}+012.10436 \mathrm{e}+001.00000 \mathrm{e}-092.12000 \mathrm{e}-01$ 1.00000e-05 1.00000e-05 1.00000e-06 1.00000e-09 1.00000e-01

$1.00000 \mathrm{e}+001.00000 \mathrm{e}+001.00000 \mathrm{e}-011.00000 \mathrm{e}-091.00000 \mathrm{e}-01$

Element: 10810 \# of layers: 7

$\mathrm{Kx} \mathrm{Ky} \mathrm{Kz}$ Ss Por

$2.10436 \mathrm{e}+012.10436 \mathrm{e}+012.10436 \mathrm{e}+00$ 1.00000e-09 2.12000e-01

$2.10436 \mathrm{e}+012.10436 \mathrm{e}+012.10436 \mathrm{e}+001.00000 \mathrm{e}-092.12000 \mathrm{e}-01$

$2.10436 \mathrm{e}+012.10436 \mathrm{e}+012.10436 \mathrm{e}+00$ 1.00000e-09 2.12000e-01

$2.10436 \mathrm{e}+012.10436 \mathrm{e}+012.10436 \mathrm{e}+00$ 1.00000e-09 2.12000e-01

$2.10436 \mathrm{e}+012.10436 \mathrm{e}+012.10436 \mathrm{e}+001.00000 \mathrm{e}-092.12000 \mathrm{e}-01$

$1.00000 \mathrm{e}-05$ 1.00000e-05 1.00000e-06 1.00000e-09 1.00000e-01

$1.00000 \mathrm{e}+001.00000 \mathrm{e}+001.00000 \mathrm{e}-01$ 1.00000e-09 1.00000e-01

Element: 10811 \# of layers: 7

$\mathrm{Kx} \mathrm{Ky} \mathrm{Kz}$ Ss Por

$2.10436 \mathrm{e}+012.10436 \mathrm{e}+012.10436 \mathrm{e}+00$ 1.00000e-09 2.12000e-01

$2.10436 \mathrm{e}+012.10436 \mathrm{e}+012.10436 \mathrm{e}+001.00000 \mathrm{e}-092.12000 \mathrm{e}-01$

$2.10436 \mathrm{e}+012.10436 \mathrm{e}+012.10436 \mathrm{e}+00$ 1.00000e-09 2.12000e-01

$2.10436 \mathrm{e}+012.10436 \mathrm{e}+012.10436 \mathrm{e}+00$ 1.00000e-09 2.12000e-01

$2.10436 \mathrm{e}+012.10436 \mathrm{e}+012.10436 \mathrm{e}+00$ 1.00000e-09 2.12000e-01

$1.00000 \mathrm{e}-05$ 1.00000e-05 1.00000e-06 1.00000e-09 1.00000e-01

$1.00000 \mathrm{e}+001.00000 \mathrm{e}+001.00000 \mathrm{e}-011.00000 \mathrm{e}-09$ 1.00000e-01

Element: 10812 \# of layers: 7

Kx Ky Kz Ss Por

$2.10436 \mathrm{e}+012.10436 \mathrm{e}+012.10436 \mathrm{e}+00$ 1.00000e-09 2.12000e-01

$2.10436 \mathrm{e}+012.10436 \mathrm{e}+012.10436 \mathrm{e}+00$ 1.00000e-09 2.12000e-01

$2.10436 \mathrm{e}+012.10436 \mathrm{e}+012.10436 \mathrm{e}+00$ 1.00000e-09 2.12000e-01

$2.10436 \mathrm{e}+012.10436 \mathrm{e}+012.10436 \mathrm{e}+00$ 1.00000e-09 2.12000e-01

$2.10436 \mathrm{e}+012.10436 \mathrm{e}+012.10436 \mathrm{e}+00$ 1.00000e-09 2.12000e-01

$1.00000 \mathrm{e}-05$ 1.00000e-05 1.00000e-06 1.00000e-09 1.00000e-01

$1.00000 \mathrm{e}+001.00000 \mathrm{e}+001.00000 \mathrm{e}-01$ 1.00000e-09 1.00000e-01

Element: 10813 \# of layers: 7

Kx Ky Kz Ss Por 
2.10436e+01 2.10436e+01 2.10436e+00 1.00000e-09 2.12000e-01 $2.10436 \mathrm{e}+012.10436 \mathrm{e}+012.10436 \mathrm{e}+00$ 1.00000e-09 2.12000e-01 $2.10436 \mathrm{e}+012.10436 \mathrm{e}+012.10436 \mathrm{e}+00$ 1.00000e-09 2.12000e-01 $2.10436 \mathrm{e}+012.10436 \mathrm{e}+012.10436 \mathrm{e}+001.00000 \mathrm{e}-092.12000 \mathrm{e}-01$ $2.10436 \mathrm{e}+012.10436 \mathrm{e}+012.10436 \mathrm{e}+001.00000 \mathrm{e}-092.12000 \mathrm{e}-01$ $1.00000 \mathrm{e}-05$ 1.00000e-05 1.00000e-06 1.00000e-09 1.00000e-01 $1.00000 \mathrm{e}+001.00000 \mathrm{e}+001.00000 \mathrm{e}-01$ 1.00000e-09 1.00000e-01 Element: 10814 \# of layers: 7

$\mathrm{Kx} \mathrm{Ky} \mathrm{Kz}$ Ss Por

$2.10436 \mathrm{e}+012.10436 \mathrm{e}+012.10436 \mathrm{e}+00$ 1.00000e-09 2.12000e-01 $2.10436 \mathrm{e}+012.10436 \mathrm{e}+012.10436 \mathrm{e}+00$ 1.00000e-09 2.12000e-01 $2.10436 \mathrm{e}+012.10436 \mathrm{e}+012.10436 \mathrm{e}+001.00000 \mathrm{e}-092.12000 \mathrm{e}-01$ $2.10436 \mathrm{e}+012.10436 \mathrm{e}+012.10436 \mathrm{e}+00$ 1.00000e-09 2.12000e-01 $2.10436 \mathrm{e}+012.10436 \mathrm{e}+012.10436 \mathrm{e}+00$ 1.00000e-09 2.12000e-01 $1.00000 \mathrm{e}-05$ 1.00000e-05 1.00000e-06 1.00000e-09 1.00000e-01 $1.00000 \mathrm{e}+001.00000 \mathrm{e}+001.00000 \mathrm{e}-011.00000 \mathrm{e}-091.00000 \mathrm{e}-01$ Element: 10815 \# of layers: 7

$\mathrm{Kx} \mathrm{Ky} \mathrm{Kz}$ Ss Por

$2.10949 \mathrm{e}+01$ 2.10949e+01 2.10949e+00 1.00000e-09 2.12000e-01 $2.10949 \mathrm{e}+012.10949 \mathrm{e}+012.10949 \mathrm{e}+00$ 1.00000e-09 2.12000e-01 $2.10949 \mathrm{e}+012.10949 \mathrm{e}+012.10949 \mathrm{e}+00$ 1.00000e-09 2.12000e-01 $2.10949 \mathrm{e}+012.10949 \mathrm{e}+01$ 2.10949e+00 1.00000e-09 2.12000e-01 $2.10949 \mathrm{e}+012.10949 \mathrm{e}+012.10949 \mathrm{e}+00$ 1.00000e-09 2.12000e-01 $1.00000 \mathrm{e}-05$ 1.00000e-05 1.00000e-06 1.00000e-09 1.00000e-01 $1.00000 \mathrm{e}+001.00000 \mathrm{e}+001.00000 \mathrm{e}-011.00000 \mathrm{e}-091.00000 \mathrm{e}-01$ Element: 10816 \# of layers: 7

$\mathrm{Kx} \mathrm{Ky} \mathrm{Kz}$ Ss Por

$2.10949 \mathrm{e}+012.10949 \mathrm{e}+01$ 2.10949e+00 1.00000e-09 2.12000e-01 $2.10949 \mathrm{e}+012.10949 \mathrm{e}+012.10949 \mathrm{e}+00$ 1.00000e-09 2.12000e-01 $2.10949 \mathrm{e}+012.10949 \mathrm{e}+01$ 2.10949e+00 1.00000e-09 2.12000e-01 $2.10949 \mathrm{e}+012.10949 \mathrm{e}+012.10949 \mathrm{e}+00$ 1.00000e-09 2.12000e-01 $2.10949 \mathrm{e}+012.10949 \mathrm{e}+012.10949 \mathrm{e}+00$ 1.00000e-09 2.12000e-01 $1.00000 \mathrm{e}-05$ 1.00000e-05 1.00000e-06 1.00000e-09 1.00000e-01 $1.00000 \mathrm{e}+001.00000 \mathrm{e}+001.00000 \mathrm{e}-011.00000 \mathrm{e}-09$ 1.00000e-01 Element: 10817 \# of layers: 7

$\mathrm{Kx} \mathrm{Ky} \mathrm{Kz}$ Ss Por

$2.10949 \mathrm{e}+012.10949 \mathrm{e}+012.10949 \mathrm{e}+00$ 1.00000e-09 2.12000e-01 $2.10949 \mathrm{e}+012.10949 \mathrm{e}+012.10949 \mathrm{e}+00$ 1.00000e-09 2.12000e-01 $2.10949 \mathrm{e}+012.10949 \mathrm{e}+012.10949 \mathrm{e}+00$ 1.00000e-09 2.12000e-01 $2.10949 \mathrm{e}+012.10949 \mathrm{e}+012.10949 \mathrm{e}+00$ 1.00000e-09 2.12000e-01 $2.10949 \mathrm{e}+012.10949 \mathrm{e}+012.10949 \mathrm{e}+00$ 1.00000e-09 2.12000e-01 $1.00000 \mathrm{e}-05$ 1.00000e-05 1.00000e-06 1.00000e-09 1.00000e-01 $1.00000 \mathrm{e}+001.00000 \mathrm{e}+001.00000 \mathrm{e}-01$ 1.00000e-09 1.00000e-01 Element: 10818 \# of layers: 7

$\mathrm{Kx} \mathrm{Ky} \mathrm{Kz}$ Ss Por

2.10949e+01 2.10949e+01 2.10949e+00 1.00000e-09 2.12000e-01 
$2.10949 \mathrm{e}+012.10949 \mathrm{e}+012.10949 \mathrm{e}+00$ 1.00000e-09 2.12000e-01 $2.10949 \mathrm{e}+012.10949 \mathrm{e}+012.10949 \mathrm{e}+00$ 1.00000e-09 2.12000e-01 $2.10949 \mathrm{e}+012.10949 \mathrm{e}+012.10949 \mathrm{e}+00$ 1.00000e-09 2.12000e-01 $2.10949 \mathrm{e}+012.10949 \mathrm{e}+012.10949 \mathrm{e}+00$ 1.00000e-09 2.12000e-01 $1.00000 \mathrm{e}-05$ 1.00000e-05 1.00000e-06 1.00000e-09 1.00000e-01 $1.00000 \mathrm{e}+001.00000 \mathrm{e}+001.00000 \mathrm{e}-011.00000 \mathrm{e}-091.00000 \mathrm{e}-01$ Element: 10819 \# of layers: 7

Kx Ky Kz Ss Por

$2.10949 \mathrm{e}+012.10949 \mathrm{e}+012.10949 \mathrm{e}+00$ 1.00000e-09 2.12000e-01 $2.10949 \mathrm{e}+012.10949 \mathrm{e}+012.10949 \mathrm{e}+00$ 1.00000e-09 2.12000e-01 $2.10949 \mathrm{e}+012.10949 \mathrm{e}+012.10949 \mathrm{e}+00$ 1.00000e-09 2.12000e-01 $2.10949 \mathrm{e}+012.10949 \mathrm{e}+012.10949 \mathrm{e}+00$ 1.00000e-09 2.12000e-01 $2.10949 \mathrm{e}+012.10949 \mathrm{e}+012.10949 \mathrm{e}+00$ 1.00000e-09 2.12000e-01 $1.00000 \mathrm{e}-05$ 1.00000e-05 1.00000e-06 1.00000e-09 1.00000e-01 $1.00000 \mathrm{e}+001.00000 \mathrm{e}+001.00000 \mathrm{e}-011.00000 \mathrm{e}-091.00000 \mathrm{e}-01$ Element: 10820 \# of layers: 7

Kx Ky Kz Ss Por

$2.10436 \mathrm{e}+012.10436 \mathrm{e}+012.10436 \mathrm{e}+00$ 1.00000e-09 2.12000e-01 $2.10436 \mathrm{e}+012.10436 \mathrm{e}+012.10436 \mathrm{e}+00$ 1.00000e-09 2.12000e-01 $2.10436 \mathrm{e}+012.10436 \mathrm{e}+012.10436 \mathrm{e}+001.00000 \mathrm{e}-092.12000 \mathrm{e}-01$ $2.10436 \mathrm{e}+012.10436 \mathrm{e}+012.10436 \mathrm{e}+001.00000 \mathrm{e}-092.12000 \mathrm{e}-01$ $2.10436 \mathrm{e}+012.10436 \mathrm{e}+012.10436 \mathrm{e}+00$ 1.00000e-09 2.12000e-01 $1.00000 \mathrm{e}-05$ 1.00000e-05 1.00000e-06 1.00000e-09 1.00000e-01 $1.00000 \mathrm{e}+001.00000 \mathrm{e}+001.00000 \mathrm{e}-011.00000 \mathrm{e}-091.00000 \mathrm{e}-01$ Element: 10821 \# of layers: 7

Kx Ky Kz Ss Por

$2.10436 \mathrm{e}+012.10436 \mathrm{e}+012.10436 \mathrm{e}+00$ 1.00000e-09 2.12000e-01 $2.10436 \mathrm{e}+012.10436 \mathrm{e}+012.10436 \mathrm{e}+00$ 1.00000e-09 2.12000e-01 $2.10436 \mathrm{e}+012.10436 \mathrm{e}+012.10436 \mathrm{e}+001.00000 \mathrm{e}-092.12000 \mathrm{e}-01$ $2.10436 \mathrm{e}+012.10436 \mathrm{e}+012.10436 \mathrm{e}+00$ 1.00000e-09 2.12000e-01 $2.10436 \mathrm{e}+012.10436 \mathrm{e}+012.10436 \mathrm{e}+001.00000 \mathrm{e}-092.12000 \mathrm{e}-01$ $1.00000 \mathrm{e}-05$ 1.00000e-05 1.00000e-06 1.00000e-09 1.00000e-01 $1.00000 \mathrm{e}+001.00000 \mathrm{e}+001.00000 \mathrm{e}-011.00000 \mathrm{e}-091.00000 \mathrm{e}-01$ Element: 10822 \# of layers: 7

Kx Ky Kz Ss Por

$2.10949 \mathrm{e}+012.10949 \mathrm{e}+012.10949 \mathrm{e}+00$ 1.00000e-09 2.12000e-01 $2.10949 \mathrm{e}+012.10949 \mathrm{e}+012.10949 \mathrm{e}+00$ 1.00000e-09 2.12000e-01 $2.10949 \mathrm{e}+012.10949 \mathrm{e}+012.10949 \mathrm{e}+00$ 1.00000e-09 2.12000e-01 $2.10949 \mathrm{e}+012.10949 \mathrm{e}+012.10949 \mathrm{e}+00$ 1.00000e-09 2.12000e-01 $2.10949 \mathrm{e}+012.10949 \mathrm{e}+012.10949 \mathrm{e}+00$ 1.00000e-09 2.12000e-01 $1.00000 \mathrm{e}-05$ 1.00000e-05 1.00000e-06 1.00000e-09 1.00000e-01 $1.00000 \mathrm{e}+001.00000 \mathrm{e}+001.00000 \mathrm{e}-011.00000 \mathrm{e}-091.00000 \mathrm{e}-01$ Element: 10823 \# of layers: 7

Kx Ky Kz Ss Por

$2.10949 \mathrm{e}+012.10949 \mathrm{e}+012.10949 \mathrm{e}+00$ 1.00000e-09 2.12000e-01 $2.10949 \mathrm{e}+012.10949 \mathrm{e}+012.10949 \mathrm{e}+00$ 1.00000e-09 2.12000e-01 
$2.10949 \mathrm{e}+012.10949 \mathrm{e}+012.10949 \mathrm{e}+00$ 1.00000e-09 2.12000e-01 $2.10949 \mathrm{e}+012.10949 \mathrm{e}+012.10949 \mathrm{e}+00$ 1.00000e-09 2.12000e-01 $2.10949 \mathrm{e}+012.10949 \mathrm{e}+012.10949 \mathrm{e}+00$ 1.00000e-09 2.12000e-01 $1.00000 \mathrm{e}-05$ 1.00000e-05 1.00000e-06 1.00000e-09 1.00000e-01 $1.00000 \mathrm{e}+001.00000 \mathrm{e}+001.00000 \mathrm{e}-011.00000 \mathrm{e}-091.00000 \mathrm{e}-01$ Element: 10824 \# of layers: 7

Kx Ky Kz Ss Por

$2.31732 \mathrm{e}+012.31732 \mathrm{e}+012.31732 \mathrm{e}+00$ 1.00000e-09 2.12000e-01 $2.31732 \mathrm{e}+012.31732 \mathrm{e}+012.31732 \mathrm{e}+00$ 1.00000e-09 2.12000e-01 $2.31732 \mathrm{e}+012.31732 \mathrm{e}+012.31732 \mathrm{e}+00$ 1.00000e-09 2.12000e-01 $2.31732 \mathrm{e}+012.31732 \mathrm{e}+012.31732 \mathrm{e}+001.00000 \mathrm{e}-092.12000 \mathrm{e}-01$ $2.31732 \mathrm{e}+012.31732 \mathrm{e}+012.31732 \mathrm{e}+001.00000 \mathrm{e}-092.12000 \mathrm{e}-01$ $1.00000 \mathrm{e}-05$ 1.00000e-05 1.00000e-06 1.00000e-09 1.00000e-01 $1.00000 \mathrm{e}+001.00000 \mathrm{e}+001.00000 \mathrm{e}-011.00000 \mathrm{e}-091.00000 \mathrm{e}-01$ Element: 10825 \# of layers: 7

Kx Ky Kz Ss Por

$2.31732 \mathrm{e}+012.31732 \mathrm{e}+012.31732 \mathrm{e}+00$ 1.00000e-09 2.12000e-01 $2.31732 \mathrm{e}+012.31732 \mathrm{e}+012.31732 \mathrm{e}+00$ 1.00000e-09 2.12000e-01 $2.31732 \mathrm{e}+012.31732 \mathrm{e}+012.31732 \mathrm{e}+00$ 1.00000e-09 2.12000e-01 $2.31732 \mathrm{e}+012.31732 \mathrm{e}+012.31732 \mathrm{e}+00$ 1.00000e-09 2.12000e-01 $2.31732 \mathrm{e}+012.31732 \mathrm{e}+012.31732 \mathrm{e}+00$ 1.00000e-09 2.12000e-01 $1.00000 \mathrm{e}-05$ 1.00000e-05 1.00000e-06 1.00000e-09 1.00000e-01 $1.00000 \mathrm{e}+001.00000 \mathrm{e}+001.00000 \mathrm{e}-011.00000 \mathrm{e}-091.00000 \mathrm{e}-01$ Element: 10826 \# of layers: 7

Kx Ky Kz Ss Por

$2.31732 \mathrm{e}+012.31732 \mathrm{e}+012.31732 \mathrm{e}+00$ 1.00000e-09 2.12000e-01 $2.31732 \mathrm{e}+012.31732 \mathrm{e}+012.31732 \mathrm{e}+001.00000 \mathrm{e}-092.12000 \mathrm{e}-01$ $2.31732 \mathrm{e}+012.31732 \mathrm{e}+012.31732 \mathrm{e}+00$ 1.00000e-09 2.12000e-01 $2.31732 \mathrm{e}+012.31732 \mathrm{e}+012.31732 \mathrm{e}+001.00000 \mathrm{e}-092.12000 \mathrm{e}-01$ $2.31732 \mathrm{e}+012.31732 \mathrm{e}+012.31732 \mathrm{e}+00$ 1.00000e-09 2.12000e-01 $1.00000 \mathrm{e}-05$ 1.00000e-05 1.00000e-06 1.00000e-09 1.00000e-01 $1.00000 \mathrm{e}+001.00000 \mathrm{e}+001.00000 \mathrm{e}-011.00000 \mathrm{e}-091.00000 \mathrm{e}-01$ Element: 10827 \# of layers: 7

Kx Ky Kz Ss Por

$2.15935 \mathrm{e}+012.15935 \mathrm{e}+012.15935 \mathrm{e}+00$ 1.00000e-09 2.12000e-01

$2.15935 \mathrm{e}+012.15935 \mathrm{e}+012.15935 \mathrm{e}+00$ 1.00000e-09 2.12000e-01 $2.15935 \mathrm{e}+012.15935 \mathrm{e}+012.15935 \mathrm{e}+00$ 1.00000e-09 2.12000e-01 $2.15935 \mathrm{e}+012.15935 \mathrm{e}+012.15935 \mathrm{e}+00$ 1.00000e-09 2.12000e-01 $2.15935 \mathrm{e}+012.15935 \mathrm{e}+012.15935 \mathrm{e}+00$ 1.00000e-09 2.12000e-01 $1.00000 \mathrm{e}-05$ 1.00000e-05 1.00000e-06 1.00000e-09 1.00000e-01 $1.00000 \mathrm{e}+001.00000 \mathrm{e}+001.00000 \mathrm{e}-011.00000 \mathrm{e}-091.00000 \mathrm{e}-01$ Element: 10828 \# of layers: 7

Kx Ky Kz Ss Por

$2.15935 \mathrm{e}+012.15935 \mathrm{e}+012.15935 \mathrm{e}+00$ 1.00000e-09 2.12000e-01 $2.15935 \mathrm{e}+012.15935 \mathrm{e}+012.15935 \mathrm{e}+00$ 1.00000e-09 2.12000e-01 $2.15935 \mathrm{e}+012.15935 \mathrm{e}+012.15935 \mathrm{e}+00$ 1.00000e-09 2.12000e-01 
$2.15935 \mathrm{e}+012.15935 \mathrm{e}+012.15935 \mathrm{e}+00$ 1.00000e-09 2.12000e-01 $2.15935 \mathrm{e}+012.15935 \mathrm{e}+012.15935 \mathrm{e}+00$ 1.00000e-09 2.12000e-01 $1.00000 \mathrm{e}-05$ 1.00000e-05 1.00000e-06 1.00000e-09 1.00000e-01 $1.00000 \mathrm{e}+001.00000 \mathrm{e}+001.00000 \mathrm{e}-011.00000 \mathrm{e}-091.00000 \mathrm{e}-01$ Element: 10829 \# of layers: 7

Kx Ky Kz Ss Por

$2.10436 \mathrm{e}+012.10436 \mathrm{e}+012.10436 \mathrm{e}+00$ 1.00000e-09 2.12000e-01 $2.10436 \mathrm{e}+012.10436 \mathrm{e}+012.10436 \mathrm{e}+00$ 1.00000e-09 2.12000e-01 $2.10436 \mathrm{e}+012.10436 \mathrm{e}+012.10436 \mathrm{e}+00$ 1.00000e-09 2.12000e-01 $2.10436 \mathrm{e}+012.10436 \mathrm{e}+012.10436 \mathrm{e}+001.00000 \mathrm{e}-092.12000 \mathrm{e}-01$ $2.10436 \mathrm{e}+012.10436 \mathrm{e}+012.10436 \mathrm{e}+001.00000 \mathrm{e}-092.12000 \mathrm{e}-01$ $1.00000 \mathrm{e}-05$ 1.00000e-05 1.00000e-06 1.00000e-09 1.00000e-01 $1.00000 \mathrm{e}+001.00000 \mathrm{e}+001.00000 \mathrm{e}-011.00000 \mathrm{e}-091.00000 \mathrm{e}-01$ Element: 10830 \# of layers: 7

Kx Ky Kz Ss Por

$2.10949 \mathrm{e}+012.10949 \mathrm{e}+012.10949 \mathrm{e}+00$ 1.00000e-09 2.12000e-01 $2.10949 \mathrm{e}+012.10949 \mathrm{e}+012.10949 \mathrm{e}+00$ 1.00000e-09 2.12000e-01 $2.10949 \mathrm{e}+012.10949 \mathrm{e}+012.10949 \mathrm{e}+00$ 1.00000e-09 2.12000e-01 $2.10949 \mathrm{e}+012.10949 \mathrm{e}+012.10949 \mathrm{e}+00$ 1.00000e-09 2.12000e-01 $2.10949 \mathrm{e}+012.10949 \mathrm{e}+012.10949 \mathrm{e}+00$ 1.00000e-09 2.12000e-01 $1.00000 \mathrm{e}-05$ 1.00000e-05 1.00000e-06 1.00000e-09 1.00000e-01 $1.00000 \mathrm{e}+001.00000 \mathrm{e}+001.00000 \mathrm{e}-011.00000 \mathrm{e}-091.00000 \mathrm{e}-01$ Element: 10831 \# of layers: 7

Kx Ky Kz Ss Por

$2.31732 \mathrm{e}+012.31732 \mathrm{e}+012.31732 \mathrm{e}+00$ 1.00000e-09 2.12000e-01 $2.31732 \mathrm{e}+012.31732 \mathrm{e}+012.31732 \mathrm{e}+00$ 1.00000e-09 2.12000e-01 $2.31732 \mathrm{e}+012.31732 \mathrm{e}+012.31732 \mathrm{e}+001.00000 \mathrm{e}-092.12000 \mathrm{e}-01$ $2.31732 \mathrm{e}+012.31732 \mathrm{e}+012.31732 \mathrm{e}+00$ 1.00000e-09 2.12000e-01 $2.31732 \mathrm{e}+012.31732 \mathrm{e}+012.31732 \mathrm{e}+001.00000 \mathrm{e}-092.12000 \mathrm{e}-01$ $1.00000 \mathrm{e}-05$ 1.00000e-05 1.00000e-06 1.00000e-09 1.00000e-01 $1.00000 \mathrm{e}+001.00000 \mathrm{e}+001.00000 \mathrm{e}-011.00000 \mathrm{e}-091.00000 \mathrm{e}-01$ Element: 10832 \# of layers: 7

Kx Ky Kz Ss Por

$2.47078 \mathrm{e}+012.47078 \mathrm{e}+012.47078 \mathrm{e}+00$ 1.00000e-09 2.12000e-01 $2.47078 \mathrm{e}+012.47078 \mathrm{e}+012.47078 \mathrm{e}+001.00000 \mathrm{e}-092.12000 \mathrm{e}-01$ $2.47078 \mathrm{e}+012.47078 \mathrm{e}+012.47078 \mathrm{e}+001.00000 \mathrm{e}-092.12000 \mathrm{e}-01$ $2.47078 \mathrm{e}+012.47078 \mathrm{e}+012.47078 \mathrm{e}+001.00000 \mathrm{e}-092.12000 \mathrm{e}-01$ $2.47078 \mathrm{e}+012.47078 \mathrm{e}+012.47078 \mathrm{e}+001.00000 \mathrm{e}-092.12000 \mathrm{e}-01$ $1.00000 \mathrm{e}-05$ 1.00000e-05 1.00000e-06 1.00000e-09 1.00000e-01 $1.00000 \mathrm{e}+001.00000 \mathrm{e}+001.00000 \mathrm{e}-011.00000 \mathrm{e}-091.00000 \mathrm{e}-01$ Element: 10833 \# of layers: 7

Kx Ky Kz Ss Por

$2.47078 \mathrm{e}+012.47078 \mathrm{e}+012.47078 \mathrm{e}+00$ 1.00000e-09 2.12000e-01 $2.47078 \mathrm{e}+012.47078 \mathrm{e}+012.47078 \mathrm{e}+001.00000 \mathrm{e}-092.12000 \mathrm{e}-01$ $2.47078 \mathrm{e}+012.47078 \mathrm{e}+012.47078 \mathrm{e}+001.00000 \mathrm{e}-092.12000 \mathrm{e}-01$ $2.47078 \mathrm{e}+012.47078 \mathrm{e}+012.47078 \mathrm{e}+001.00000 \mathrm{e}-092.12000 \mathrm{e}-01$ 
$2.47078 \mathrm{e}+012.47078 \mathrm{e}+012.47078 \mathrm{e}+00$ 1.00000e-09 2.12000e-01 $1.00000 \mathrm{e}-05$ 1.00000e-05 1.00000e-06 1.00000e-09 1.00000e-01 $1.00000 \mathrm{e}+001.00000 \mathrm{e}+001.00000 \mathrm{e}-011.00000 \mathrm{e}-091.00000 \mathrm{e}-01$ Element: 10834 \# of layers: 7

Kx Ky Kz Ss Por

$2.47078 \mathrm{e}+012.47078 \mathrm{e}+012.47078 \mathrm{e}+00$ 1.00000e-09 2.12000e-01

$2.47078 \mathrm{e}+012.47078 \mathrm{e}+012.47078 \mathrm{e}+001.00000 \mathrm{e}-092.12000 \mathrm{e}-01$

$2.47078 \mathrm{e}+012.47078 \mathrm{e}+012.47078 \mathrm{e}+001.00000 \mathrm{e}-092.12000 \mathrm{e}-01$

$2.47078 \mathrm{e}+012.47078 \mathrm{e}+012.47078 \mathrm{e}+001.00000 \mathrm{e}-092.12000 \mathrm{e}-01$

$2.47078 \mathrm{e}+012.47078 \mathrm{e}+012.47078 \mathrm{e}+001.00000 \mathrm{e}-092.12000 \mathrm{e}-01$ $1.00000 \mathrm{e}-05$ 1.00000e-05 1.00000e-06 1.00000e-09 1.00000e-01

$1.00000 \mathrm{e}+001.00000 \mathrm{e}+001.00000 \mathrm{e}-011.00000 \mathrm{e}-091.00000 \mathrm{e}-01$

Element: 10835 \# of layers: 7

Kx Ky Kz Ss Por

$2.47078 \mathrm{e}+012.47078 \mathrm{e}+012.47078 \mathrm{e}+00$ 1.00000e-09 2.12000e-01

$2.47078 \mathrm{e}+012.47078 \mathrm{e}+012.47078 \mathrm{e}+001.00000 \mathrm{e}-092.12000 \mathrm{e}-01$

$2.47078 \mathrm{e}+012.47078 \mathrm{e}+012.47078 \mathrm{e}+001.00000 \mathrm{e}-092.12000 \mathrm{e}-01$

$2.47078 \mathrm{e}+012.47078 \mathrm{e}+012.47078 \mathrm{e}+001.00000 \mathrm{e}-092.12000 \mathrm{e}-01$

$2.47078 \mathrm{e}+012.47078 \mathrm{e}+012.47078 \mathrm{e}+00$ 1.00000e-09 2.12000e-01 $1.00000 \mathrm{e}-05$ 1.00000e-05 1.00000e-06 1.00000e-09 1.00000e-01 $1.00000 \mathrm{e}+001.00000 \mathrm{e}+001.00000 \mathrm{e}-011.00000 \mathrm{e}-091.00000 \mathrm{e}-01$ Element: 10836 \# of layers: 7

Kx Ky Kz Ss Por

$2.47078 \mathrm{e}+012.47078 \mathrm{e}+012.47078 \mathrm{e}+00$ 1.00000e-09 2.12000e-01 $2.47078 \mathrm{e}+012.47078 \mathrm{e}+012.47078 \mathrm{e}+001.00000 \mathrm{e}-092.12000 \mathrm{e}-01$ $2.47078 \mathrm{e}+012.47078 \mathrm{e}+012.47078 \mathrm{e}+001.00000 \mathrm{e}-092.12000 \mathrm{e}-01$ $2.47078 \mathrm{e}+012.47078 \mathrm{e}+012.47078 \mathrm{e}+001.00000 \mathrm{e}-092.12000 \mathrm{e}-01$ $2.47078 \mathrm{e}+012.47078 \mathrm{e}+012.47078 \mathrm{e}+001.00000 \mathrm{e}-092.12000 \mathrm{e}-01$ $1.00000 \mathrm{e}-05$ 1.00000e-05 1.00000e-06 1.00000e-09 1.00000e-01 $1.00000 \mathrm{e}+001.00000 \mathrm{e}+001.00000 \mathrm{e}-011.00000 \mathrm{e}-091.00000 \mathrm{e}-01$ Element: 10837 \# of layers: 7

Kx Ky Kz Ss Por

$2.47078 \mathrm{e}+012.47078 \mathrm{e}+012.47078 \mathrm{e}+00$ 1.00000e-09 2.12000e-01 $2.47078 \mathrm{e}+012.47078 \mathrm{e}+012.47078 \mathrm{e}+001.00000 \mathrm{e}-092.12000 \mathrm{e}-01$

$2.47078 \mathrm{e}+012.47078 \mathrm{e}+012.47078 \mathrm{e}+001.00000 \mathrm{e}-092.12000 \mathrm{e}-01$

$2.47078 \mathrm{e}+012.47078 \mathrm{e}+012.47078 \mathrm{e}+001.00000 \mathrm{e}-092.12000 \mathrm{e}-01$

$2.47078 \mathrm{e}+012.47078 \mathrm{e}+012.47078 \mathrm{e}+001.00000 \mathrm{e}-092.12000 \mathrm{e}-01$ $1.00000 \mathrm{e}-05$ 1.00000e-05 1.00000e-06 1.00000e-09 1.00000e-01 $1.00000 \mathrm{e}+001.00000 \mathrm{e}+001.00000 \mathrm{e}-011.00000 \mathrm{e}-091.00000 \mathrm{e}-01$ Element: 10838 \# of layers: 7

Kx Ky Kz Ss Por

$2.47078 \mathrm{e}+012.47078 \mathrm{e}+012.47078 \mathrm{e}+00$ 1.00000e-09 2.12000e-01 $2.47078 \mathrm{e}+012.47078 \mathrm{e}+012.47078 \mathrm{e}+001.00000 \mathrm{e}-092.12000 \mathrm{e}-01$ $2.47078 \mathrm{e}+012.47078 \mathrm{e}+012.47078 \mathrm{e}+001.00000 \mathrm{e}-092.12000 \mathrm{e}-01$ $2.47078 \mathrm{e}+012.47078 \mathrm{e}+012.47078 \mathrm{e}+001.00000 \mathrm{e}-092.12000 \mathrm{e}-01$ $2.47078 \mathrm{e}+012.47078 \mathrm{e}+012.47078 \mathrm{e}+001.00000 \mathrm{e}-092.12000 \mathrm{e}-01$ 
$1.00000 \mathrm{e}-05$ 1.00000e-05 1.00000e-06 1.00000e-09 1.00000e-01 $1.00000 \mathrm{e}+001.00000 \mathrm{e}+001.00000 \mathrm{e}-01$ 1.00000e-09 1.00000e-01 Element: 10839 \# of layers: 7

Kx Ky Kz Ss Por

$2.47078 \mathrm{e}+012.47078 \mathrm{e}+012.47078 \mathrm{e}+00$ 1.00000e-09 2.12000e-01

$2.47078 \mathrm{e}+012.47078 \mathrm{e}+012.47078 \mathrm{e}+00$ 1.00000e-09 2.12000e-01

$2.47078 \mathrm{e}+012.47078 \mathrm{e}+012.47078 \mathrm{e}+00$ 1.00000e-09 2.12000e-01

$2.47078 \mathrm{e}+012.47078 \mathrm{e}+012.47078 \mathrm{e}+001.00000 \mathrm{e}-092.12000 \mathrm{e}-01$

$2.47078 \mathrm{e}+012.47078 \mathrm{e}+012.47078 \mathrm{e}+001.00000 \mathrm{e}-092.12000 \mathrm{e}-01$

$1.00000 \mathrm{e}-05$ 1.00000e-05 1.00000e-06 1.00000e-09 1.00000e-01

$1.00000 \mathrm{e}+001.00000 \mathrm{e}+001.00000 \mathrm{e}-01$ 1.00000e-09 1.00000e-01

Element: 10840 \# of layers: 7

$\mathrm{Kx} \mathrm{Ky} \mathrm{Kz}$ Ss Por

$2.47078 \mathrm{e}+012.47078 \mathrm{e}+012.47078 \mathrm{e}+00$ 1.00000e-09 2.12000e-01

$2.47078 \mathrm{e}+012.47078 \mathrm{e}+012.47078 \mathrm{e}+00$ 1.00000e-09 2.12000e-01

$2.47078 \mathrm{e}+012.47078 \mathrm{e}+012.47078 \mathrm{e}+001.00000 \mathrm{e}-092.12000 \mathrm{e}-01$

$2.47078 \mathrm{e}+012.47078 \mathrm{e}+012.47078 \mathrm{e}+001.00000 \mathrm{e}-092.12000 \mathrm{e}-01$

$2.47078 \mathrm{e}+012.47078 \mathrm{e}+012.47078 \mathrm{e}+001.00000 \mathrm{e}-092.12000 \mathrm{e}-01$

$1.00000 \mathrm{e}-05$ 1.00000e-05 1.00000e-06 1.00000e-09 1.00000e-01

$1.00000 \mathrm{e}+001.00000 \mathrm{e}+001.00000 \mathrm{e}-011.00000 \mathrm{e}-091.00000 \mathrm{e}-01$

Element: 10841 \# of layers: 7

$\mathrm{Kx} \mathrm{Ky} \mathrm{Kz}$ Ss Por

$2.47078 \mathrm{e}+012.47078 \mathrm{e}+01$ 2.47078e+00 1.00000e-09 2.12000e-01

$2.47078 \mathrm{e}+012.47078 \mathrm{e}+012.47078 \mathrm{e}+00$ 1.00000e-09 2.12000e-01

$2.47078 \mathrm{e}+012.47078 \mathrm{e}+012.47078 \mathrm{e}+001.00000 \mathrm{e}-092.12000 \mathrm{e}-01$

$2.47078 \mathrm{e}+012.47078 \mathrm{e}+012.47078 \mathrm{e}+001.00000 \mathrm{e}-092.12000 \mathrm{e}-01$

$2.47078 \mathrm{e}+012.47078 \mathrm{e}+012.47078 \mathrm{e}+00$ 1.00000e-09 2.12000e-01

$1.00000 \mathrm{e}-05$ 1.00000e-05 1.00000e-06 1.00000e-09 1.00000e-01

$1.00000 \mathrm{e}+001.00000 \mathrm{e}+001.00000 \mathrm{e}-011.00000 \mathrm{e}-091.00000 \mathrm{e}-01$

Element: 10842 \# of layers: 7

$\mathrm{Kx} \mathrm{Ky} \mathrm{Kz}$ Ss Por

1.30892e+01 1.30892e+01 1.30892e+00 1.00000e-09 2.12000e-01

$1.30892 \mathrm{e}+01$ 1.30892e+01 1.30892e+00 1.00000e-09 2.12000e-01

$1.30892 \mathrm{e}+01$ 1.30892e+01 1.30892e+00 1.00000e-09 2.12000e-01

$1.30892 \mathrm{e}+01$ 1.30892e+01 1.30892e+00 1.00000e-09 2.12000e-01

$1.30892 \mathrm{e}+01$ 1.30892e+01 1.30892e+00 1.00000e-09 2.12000e-01

$1.00000 \mathrm{e}-05$ 1.00000e-05 1.00000e-06 1.00000e-09 1.00000e-01

$1.00000 \mathrm{e}+001.00000 \mathrm{e}+001.00000 \mathrm{e}-011.00000 \mathrm{e}-091.00000 \mathrm{e}-01$

Element: 10843 \# of layers: 7

$\mathrm{Kx} \mathrm{Ky} \mathrm{Kz}$ Ss Por

$1.30892 \mathrm{e}+01$ 1.30892e+01 1.30892e+00 1.00000e-09 2.12000e-01

$1.30892 \mathrm{e}+01$ 1.30892e+01 1.30892e+00 1.00000e-09 2.12000e-01

$1.30892 \mathrm{e}+01$ 1.30892e+01 1.30892e+00 1.00000e-09 2.12000e-01

1.30892e+01 1.30892e+01 1.30892e+00 1.00000e-09 2.12000e-01

$1.30892 \mathrm{e}+01$ 1.30892e+01 1.30892e+00 1.00000e-09 2.12000e-01

$1.00000 \mathrm{e}-05$ 1.00000e-05 1.00000e-06 1.00000e-09 1.00000e-01 
$1.00000 \mathrm{e}+001.00000 \mathrm{e}+001.00000 \mathrm{e}-011.00000 \mathrm{e}-091.00000 \mathrm{e}-01$

Element: 10844 \# of layers: 7

$\mathrm{Kx} \mathrm{Ky} \mathrm{Kz}$ Ss Por

$1.30892 \mathrm{e}+01$ 1.30892e+01 1.30892e+00 1.00000e-09 2.12000e-01

$1.30892 \mathrm{e}+01$ 1.30892e+01 1.30892e+00 1.00000e-09 2.12000e-01

$1.30892 \mathrm{e}+01$ 1.30892e+01 1.30892e+00 1.00000e-09 2.12000e-01

$1.30892 \mathrm{e}+01$ 1.30892e+01 1.30892e+00 1.00000e-09 2.12000e-01

$1.30892 \mathrm{e}+01$ 1.30892e+01 1.30892e+00 1.00000e-09 2.12000e-01

$1.00000 \mathrm{e}-051.00000 \mathrm{e}-051.00000 \mathrm{e}-061.00000 \mathrm{e}-091.00000 \mathrm{e}-01$

$1.00000 \mathrm{e}+001.00000 \mathrm{e}+001.00000 \mathrm{e}-011.00000 \mathrm{e}-091.00000 \mathrm{e}-01$

Element: 10845 \# of layers: 7

$\mathrm{Kx} \mathrm{Ky} \mathrm{Kz}$ Ss Por

1.30892e+01 1.30892e+01 1.30892e+00 1.00000e-09 2.12000e-01

$1.30892 \mathrm{e}+01$ 1.30892e+01 1.30892e+00 1.00000e-09 2.12000e-01

$1.30892 \mathrm{e}+01$ 1.30892e+01 1.30892e+00 1.00000e-09 2.12000e-01

$1.30892 \mathrm{e}+01$ 1.30892e+01 1.30892e+00 1.00000e-09 2.12000e-01

$1.30892 \mathrm{e}+01$ 1.30892e+01 1.30892e+00 1.00000e-09 2.12000e-01

$1.00000 \mathrm{e}-05$ 1.00000e-05 1.00000e-06 1.00000e-09 1.00000e-01

$1.00000 \mathrm{e}+001.00000 \mathrm{e}+001.00000 \mathrm{e}-01$ 1.00000e-09 1.00000e-01

Element: 10846 \# of layers: 7

$\mathrm{Kx} \mathrm{Ky} \mathrm{Kz}$ Ss Por

1.30892e+01 1.30892e+01 1.30892e+00 1.00000e-09 2.12000e-01

$1.30892 \mathrm{e}+01$ 1.30892e+01 1.30892e+00 1.00000e-09 2.12000e-01

$1.30892 \mathrm{e}+01$ 1.30892e+01 1.30892e+00 1.00000e-09 2.12000e-01

$1.30892 \mathrm{e}+01$ 1.30892e+01 1.30892e+00 1.00000e-09 2.12000e-01

$1.30892 \mathrm{e}+01$ 1.30892e+01 1.30892e+00 1.00000e-09 2.12000e-01

$1.00000 \mathrm{e}-05$ 1.00000e-05 1.00000e-06 1.00000e-09 1.00000e-01

$1.00000 \mathrm{e}+001.00000 \mathrm{e}+001.00000 \mathrm{e}-011.00000 \mathrm{e}-091.00000 \mathrm{e}-01$

Element: 10847 \# of layers: 7

$\mathrm{Kx} \mathrm{Ky} \mathrm{Kz}$ Ss Por

$2.47078 \mathrm{e}+012.47078 \mathrm{e}+012.47078 \mathrm{e}+00$ 1.00000e-09 2.12000e-01

$2.47078 \mathrm{e}+012.47078 \mathrm{e}+012.47078 \mathrm{e}+00$ 1.00000e-09 2.12000e-01

$2.47078 \mathrm{e}+012.47078 \mathrm{e}+012.47078 \mathrm{e}+001.00000 \mathrm{e}-092.12000 \mathrm{e}-01$

$2.47078 \mathrm{e}+012.47078 \mathrm{e}+012.47078 \mathrm{e}+00$ 1.00000e-09 2.12000e-01

$2.47078 \mathrm{e}+012.47078 \mathrm{e}+012.47078 \mathrm{e}+00$ 1.00000e-09 2.12000e-01

$1.00000 \mathrm{e}-05$ 1.00000e-05 1.00000e-06 1.00000e-09 1.00000e-01

$1.00000 \mathrm{e}+001.00000 \mathrm{e}+001.00000 \mathrm{e}-011.00000 \mathrm{e}-091.00000 \mathrm{e}-01$

Element: 10848 \# of layers: 7

$\mathrm{Kx} \mathrm{Ky} \mathrm{Kz}$ Ss Por

$2.47078 \mathrm{e}+012.47078 \mathrm{e}+012.47078 \mathrm{e}+00$ 1.00000e-09 2.12000e-01

$2.47078 \mathrm{e}+012.47078 \mathrm{e}+012.47078 \mathrm{e}+001.00000 \mathrm{e}-092.12000 \mathrm{e}-01$

$2.47078 \mathrm{e}+012.47078 \mathrm{e}+012.47078 \mathrm{e}+001.00000 \mathrm{e}-092.12000 \mathrm{e}-01$

$2.47078 \mathrm{e}+012.47078 \mathrm{e}+012.47078 \mathrm{e}+00$ 1.00000e-09 2.12000e-01

2.47078e+01 2.47078e+01 2.47078e+00 1.00000e-09 2.12000e-01

$1.00000 \mathrm{e}-051.00000 \mathrm{e}-051.00000 \mathrm{e}-061.00000 \mathrm{e}-091.00000 \mathrm{e}-01$

$1.00000 \mathrm{e}+001.00000 \mathrm{e}+001.00000 \mathrm{e}-011.00000 \mathrm{e}-091.00000 \mathrm{e}-01$ 
Element: 10849 \# of layers: 7

Kx Ky Kz Ss Por

$1.30892 \mathrm{e}+011.30892 \mathrm{e}+011.30892 \mathrm{e}+00$ 1.00000e-09 2.12000e-01

$1.30892 \mathrm{e}+011.30892 \mathrm{e}+011.30892 \mathrm{e}+001.00000 \mathrm{e}-092.12000 \mathrm{e}-01$

$1.30892 \mathrm{e}+011.30892 \mathrm{e}+011.30892 \mathrm{e}+001.00000 \mathrm{e}-092.12000 \mathrm{e}-01$

$1.30892 \mathrm{e}+011.30892 \mathrm{e}+011.30892 \mathrm{e}+001.00000 \mathrm{e}-092.12000 \mathrm{e}-01$

$1.30892 \mathrm{e}+011.30892 \mathrm{e}+011.30892 \mathrm{e}+001.00000 \mathrm{e}-092.12000 \mathrm{e}-01$

$1.00000 \mathrm{e}-05$ 1.00000e-05 1.00000e-06 1.00000e-09 1.00000e-01

$1.00000 \mathrm{e}+001.00000 \mathrm{e}+001.00000 \mathrm{e}-011.00000 \mathrm{e}-091.00000 \mathrm{e}-01$

Element: 10850 \# of layers: 7

Kx Ky Kz Ss Por

$1.30892 \mathrm{e}+011.30892 \mathrm{e}+011.30892 \mathrm{e}+00$ 1.00000e-09 2.12000e-01

$1.30892 \mathrm{e}+011.30892 \mathrm{e}+011.30892 \mathrm{e}+001.00000 \mathrm{e}-092.12000 \mathrm{e}-01$

$1.30892 \mathrm{e}+011.30892 \mathrm{e}+011.30892 \mathrm{e}+00$ 1.00000e-09 2.12000e-01

$1.30892 \mathrm{e}+011.30892 \mathrm{e}+011.30892 \mathrm{e}+001.00000 \mathrm{e}-092.12000 \mathrm{e}-01$

$1.30892 \mathrm{e}+011.30892 \mathrm{e}+011.30892 \mathrm{e}+001.00000 \mathrm{e}-092.12000 \mathrm{e}-01$

$1.00000 \mathrm{e}-05$ 1.00000e-05 1.00000e-06 1.00000e-09 1.00000e-01

$1.00000 \mathrm{e}+001.00000 \mathrm{e}+001.00000 \mathrm{e}-011.00000 \mathrm{e}-091.00000 \mathrm{e}-01$

Element: 10851 \# of layers: 7

Kx Ky Kz Ss Por

$1.30892 \mathrm{e}+011.30892 \mathrm{e}+011.30892 \mathrm{e}+00$ 1.00000e-09 2.12000e-01

$1.30892 \mathrm{e}+011.30892 \mathrm{e}+011.30892 \mathrm{e}+001.00000 \mathrm{e}-092.12000 \mathrm{e}-01$

$1.30892 \mathrm{e}+011.30892 \mathrm{e}+011.30892 \mathrm{e}+001.00000 \mathrm{e}-092.12000 \mathrm{e}-01$

$1.30892 \mathrm{e}+011.30892 \mathrm{e}+011.30892 \mathrm{e}+001.00000 \mathrm{e}-092.12000 \mathrm{e}-01$

$1.30892 \mathrm{e}+011.30892 \mathrm{e}+011.30892 \mathrm{e}+001.00000 \mathrm{e}-092.12000 \mathrm{e}-01$

$1.00000 \mathrm{e}-05$ 1.00000e-05 1.00000e-06 1.00000e-09 1.00000e-01

$1.00000 \mathrm{e}+001.00000 \mathrm{e}+001.00000 \mathrm{e}-011.00000 \mathrm{e}-091.00000 \mathrm{e}-01$

Element: 10852 \# of layers: 7

Kx Ky Kz Ss Por

$1.30892 \mathrm{e}+011.30892 \mathrm{e}+011.30892 \mathrm{e}+00$ 1.00000e-09 2.12000e-01

$1.30892 \mathrm{e}+011.30892 \mathrm{e}+011.30892 \mathrm{e}+001.00000 \mathrm{e}-092.12000 \mathrm{e}-01$

$1.30892 \mathrm{e}+011.30892 \mathrm{e}+011.30892 \mathrm{e}+001.00000 \mathrm{e}-092.12000 \mathrm{e}-01$

$1.30892 \mathrm{e}+011.30892 \mathrm{e}+011.30892 \mathrm{e}+001.00000 \mathrm{e}-092.12000 \mathrm{e}-01$

$1.30892 \mathrm{e}+011.30892 \mathrm{e}+011.30892 \mathrm{e}+001.00000 \mathrm{e}-092.12000 \mathrm{e}-01$

$1.00000 \mathrm{e}-05$ 1.00000e-05 1.00000e-06 1.00000e-09 1.00000e-01

$1.00000 \mathrm{e}+001.00000 \mathrm{e}+001.00000 \mathrm{e}-011.00000 \mathrm{e}-091.00000 \mathrm{e}-01$

Element: 10853 \# of layers: 7

Kx Ky Kz Ss Por

$1.30892 \mathrm{e}+011.30892 \mathrm{e}+01$ 1.30892e+00 1.00000e-09 2.12000e-01

$1.30892 \mathrm{e}+011.30892 \mathrm{e}+011.30892 \mathrm{e}+001.00000 \mathrm{e}-092.12000 \mathrm{e}-01$

$1.30892 \mathrm{e}+011.30892 \mathrm{e}+011.30892 \mathrm{e}+001.00000 \mathrm{e}-092.12000 \mathrm{e}-01$

$1.30892 \mathrm{e}+011.30892 \mathrm{e}+011.30892 \mathrm{e}+001.00000 \mathrm{e}-092.12000 \mathrm{e}-01$

$1.30892 \mathrm{e}+011.30892 \mathrm{e}+011.30892 \mathrm{e}+00$ 1.00000e-09 2.12000e-01

$1.00000 \mathrm{e}-05$ 1.00000e-05 1.00000e-06 1.00000e-09 1.00000e-01

$1.00000 \mathrm{e}+001.00000 \mathrm{e}+001.00000 \mathrm{e}-011.00000 \mathrm{e}-091.00000 \mathrm{e}-01$

Element: 10854 \# of layers: 7 
$\mathrm{Kx} \mathrm{Ky} \mathrm{Kz}$ Ss Por

$1.30892 \mathrm{e}+01$ 1.30892e+01 1.30892e+00 1.00000e-09 2.12000e-01

$1.30892 \mathrm{e}+01$ 1.30892e+01 1.30892e+00 1.00000e-09 2.12000e-01

$1.30892 \mathrm{e}+01$ 1.30892e+01 1.30892e+00 1.00000e-09 2.12000e-01

$1.30892 \mathrm{e}+01$ 1.30892e+01 1.30892e+00 1.00000e-09 2.12000e-01

$1.30892 \mathrm{e}+01$ 1.30892e+01 1.30892e+00 1.00000e-09 2.12000e-01

$1.00000 \mathrm{e}-05$ 1.00000e-05 1.00000e-06 1.00000e-09 1.00000e-01

$1.00000 \mathrm{e}+001.00000 \mathrm{e}+001.00000 \mathrm{e}-01$ 1.00000e-09 1.00000e-01

Element: 10855 \# of layers: 7

$\mathrm{Kx} \mathrm{Ky} \mathrm{Kz}$ Ss Por

1.30892e+01 1.30892e+01 1.30892e+00 1.00000e-09 2.12000e-01

$1.30892 \mathrm{e}+01$ 1.30892e+01 1.30892e+00 1.00000e-09 2.12000e-01

$1.30892 \mathrm{e}+01$ 1.30892e+01 1.30892e+00 1.00000e-09 2.12000e-01

$1.30892 \mathrm{e}+01$ 1.30892e+01 1.30892e+00 1.00000e-09 2.12000e-01

$1.30892 \mathrm{e}+01$ 1.30892e+01 1.30892e+00 1.00000e-09 2.12000e-01

$1.00000 \mathrm{e}-05$ 1.00000e-05 1.00000e-06 1.00000e-09 1.00000e-01

$1.00000 \mathrm{e}+001.00000 \mathrm{e}+001.00000 \mathrm{e}-011.00000 \mathrm{e}-091.00000 \mathrm{e}-01$

Element: 10856 \# of layers: 7

$\mathrm{Kx} \mathrm{Ky} \mathrm{Kz}$ Ss Por

1.30892e+01 1.30892e+01 1.30892e+00 1.00000e-09 2.12000e-01

$1.30892 \mathrm{e}+01$ 1.30892e+01 1.30892e+00 1.00000e-09 2.12000e-01

$1.30892 \mathrm{e}+01$ 1.30892e+01 1.30892e+00 1.00000e-09 2.12000e-01

$1.30892 \mathrm{e}+01$ 1.30892e+01 1.30892e+00 1.00000e-09 2.12000e-01

$1.30892 \mathrm{e}+01$ 1.30892e+01 1.30892e+00 1.00000e-09 2.12000e-01

$1.00000 \mathrm{e}-05$ 1.00000e-05 1.00000e-06 1.00000e-09 1.00000e-01

$1.00000 \mathrm{e}+001.00000 \mathrm{e}+001.00000 \mathrm{e}-01$ 1.00000e-09 1.00000e-01

Element: 10857 \# of layers: 7

$\mathrm{Kx} \mathrm{Ky} \mathrm{Kz}$ Ss Por

$1.30892 \mathrm{e}+01$ 1.30892e+01 1.30892e+00 1.00000e-09 2.12000e-01

$1.30892 \mathrm{e}+01$ 1.30892e+01 1.30892e+00 1.00000e-09 2.12000e-01

$1.30892 \mathrm{e}+01$ 1.30892e+01 1.30892e+00 1.00000e-09 2.12000e-01

$1.30892 \mathrm{e}+01$ 1.30892e+01 1.30892e+00 1.00000e-09 2.12000e-01

$1.30892 \mathrm{e}+01$ 1.30892e+01 1.30892e+00 1.00000e-09 2.12000e-01

$1.00000 \mathrm{e}-05$ 1.00000e-05 1.00000e-06 1.00000e-09 1.00000e-01

$1.00000 \mathrm{e}+001.00000 \mathrm{e}+001.00000 \mathrm{e}-011.00000 \mathrm{e}-091.00000 \mathrm{e}-01$

Element: 10858 \# of layers: 7

Kx Ky Kz Ss Por

$1.30892 \mathrm{e}+01$ 1.30892e+01 1.30892e+00 1.00000e-09 2.12000e-01

$1.30892 \mathrm{e}+01$ 1.30892e+01 1.30892e+00 1.00000e-09 2.12000e-01

$1.30892 \mathrm{e}+01$ 1.30892e+01 1.30892e+00 1.00000e-09 2.12000e-01

$1.30892 \mathrm{e}+01$ 1.30892e+01 1.30892e+00 1.00000e-09 2.12000e-01

$1.30892 \mathrm{e}+01$ 1.30892e+01 1.30892e+00 1.00000e-09 2.12000e-01

$1.00000 \mathrm{e}-051.00000 \mathrm{e}-05$ 1.00000e-06 1.00000e-09 1.00000e-01

$1.00000 \mathrm{e}+001.00000 \mathrm{e}+001.00000 \mathrm{e}-01$ 1.00000e-09 1.00000e-01

Element: 10859 \# of layers: 7

Kx Ky Kz Ss Por 
$1.30892 \mathrm{e}+01$ 1.30892e+01 1.30892e+00 1.00000e-09 2.12000e-01 $1.30892 \mathrm{e}+01$ 1.30892e+01 1.30892e+00 1.00000e-09 2.12000e-01 $1.30892 \mathrm{e}+01$ 1.30892e+01 1.30892e+00 1.00000e-09 2.12000e-01 $1.30892 \mathrm{e}+01$ 1.30892e+01 1.30892e+00 1.00000e-09 2.12000e-01 $1.30892 \mathrm{e}+01$ 1.30892e+01 1.30892e+00 1.00000e-09 2.12000e-01 $1.00000 \mathrm{e}-05$ 1.00000e-05 1.00000e-06 1.00000e-09 1.00000e-01 $1.00000 \mathrm{e}+001.00000 \mathrm{e}+001.00000 \mathrm{e}-011.00000 \mathrm{e}-091.00000 \mathrm{e}-01$ Element: 10860 \# of layers: 7

$\mathrm{Kx} \mathrm{Ky} \mathrm{Kz}$ Ss Por

1.30892e+01 1.30892e+01 1.30892e+00 1.00000e-09 2.12000e-01 $1.30892 \mathrm{e}+01$ 1.30892e+01 1.30892e+00 1.00000e-09 2.12000e-01 $1.30892 \mathrm{e}+01$ 1.30892e+01 1.30892e+00 1.00000e-09 2.12000e-01 $1.30892 \mathrm{e}+01$ 1.30892e+01 1.30892e+00 1.00000e-09 2.12000e-01 $1.30892 \mathrm{e}+01$ 1.30892e+01 1.30892e+00 1.00000e-09 2.12000e-01 $1.00000 \mathrm{e}-05$ 1.00000e-05 1.00000e-06 1.00000e-09 1.00000e-01 $1.00000 \mathrm{e}+001.00000 \mathrm{e}+001.00000 \mathrm{e}-011.00000 \mathrm{e}-091.00000 \mathrm{e}-01$ Element: 10861 \# of layers: 7

$\mathrm{Kx} \mathrm{Ky} \mathrm{Kz}$ Ss Por

1.19687e+01 1.19687e+01 1.19687e+00 1.00000e-09 2.12000e-01 $1.19687 \mathrm{e}+01$ 1.19687e+01 1.19687e+00 1.00000e-09 2.12000e-01 $1.19687 \mathrm{e}+01$ 1.19687e+01 1.19687e+00 1.00000e-09 2.12000e-01 $1.19687 \mathrm{e}+01$ 1.19687e+01 1.19687e+00 1.00000e-09 2.12000e-01 $1.19687 \mathrm{e}+01$ 1.19687e+01 1.19687e+00 1.00000e-09 2.12000e-01 $1.00000 \mathrm{e}-05$ 1.00000e-05 1.00000e-06 1.00000e-09 1.00000e-01 $1.00000 \mathrm{e}+001.00000 \mathrm{e}+001.00000 \mathrm{e}-011.00000 \mathrm{e}-091.00000 \mathrm{e}-01$ Element: 10862 \# of layers: 7

$\mathrm{Kx} \mathrm{Ky} \mathrm{Kz}$ Ss Por

$1.19687 \mathrm{e}+01$ 1.19687e+01 1.19687e+00 1.00000e-09 2.12000e-01 $1.19687 \mathrm{e}+01$ 1.19687e+01 1.19687e+00 1.00000e-09 2.12000e-01 $1.19687 \mathrm{e}+01$ 1.19687e+01 1.19687e+00 1.00000e-09 2.12000e-01 $1.19687 \mathrm{e}+01$ 1.19687e+01 1.19687e+00 1.00000e-09 2.12000e-01 $1.19687 \mathrm{e}+01$ 1.19687e+01 1.19687e+00 1.00000e-09 2.12000e-01 $1.00000 \mathrm{e}-05$ 1.00000e-05 1.00000e-06 1.00000e-09 1.00000e-01 $1.00000 \mathrm{e}+001.00000 \mathrm{e}+001.00000 \mathrm{e}-011.00000 \mathrm{e}-09$ 1.00000e-01 Element: 10863 \# of layers: 7

$\mathrm{Kx} \mathrm{Ky} \mathrm{Kz}$ Ss Por

$1.19687 \mathrm{e}+01$ 1.19687e+01 1.19687e+00 1.00000e-09 2.12000e-01 $1.19687 \mathrm{e}+01$ 1.19687e+01 1.19687e+00 1.00000e-09 2.12000e-01 $1.19687 \mathrm{e}+01$ 1.19687e+01 1.19687e+00 1.00000e-09 2.12000e-01 $1.19687 \mathrm{e}+01$ 1.19687e+01 1.19687e+00 1.00000e-09 2.12000e-01 $1.19687 \mathrm{e}+01$ 1.19687e+01 1.19687e+00 1.00000e-09 2.12000e-01 $1.00000 \mathrm{e}-05$ 1.00000e-05 1.00000e-06 1.00000e-09 1.00000e-01 $1.00000 \mathrm{e}+001.00000 \mathrm{e}+001.00000 \mathrm{e}-011.00000 \mathrm{e}-091.00000 \mathrm{e}-01$ Element: 10864 \# of layers: 7

$\mathrm{Kx} \mathrm{Ky} \mathrm{Kz}$ Ss Por 1.30892e+01 1.30892e+01 1.30892e+00 1.00000e-09 2.12000e-01 
$1.30892 \mathrm{e}+01$ 1.30892e+01 1.30892e+00 1.00000e-09 2.12000e-01 $1.30892 \mathrm{e}+01$ 1.30892e+01 1.30892e+00 1.00000e-09 2.12000e-01 $1.30892 \mathrm{e}+01$ 1.30892e+01 1.30892e+00 1.00000e-09 2.12000e-01 $1.30892 \mathrm{e}+01$ 1.30892e+01 1.30892e+00 1.00000e-09 2.12000e-01 $1.00000 \mathrm{e}-051.00000 \mathrm{e}-05$ 1.00000e-06 1.00000e-09 1.00000e-01 $1.00000 \mathrm{e}+001.00000 \mathrm{e}+001.00000 \mathrm{e}-011.00000 \mathrm{e}-091.00000 \mathrm{e}-01$ Element: 10865 \# of layers: 7

$\mathrm{Kx} \mathrm{Ky} \mathrm{Kz}$ Ss Por

1.30892e+01 1.30892e+01 1.30892e+00 1.00000e-09 2.12000e-01 $1.30892 \mathrm{e}+01$ 1.30892e+01 1.30892e+00 1.00000e-09 2.12000e-01 $1.30892 \mathrm{e}+01$ 1.30892e+01 1.30892e+00 1.00000e-09 2.12000e-01 $1.30892 \mathrm{e}+01$ 1.30892e+01 1.30892e+00 1.00000e-09 2.12000e-01 $1.30892 \mathrm{e}+01$ 1.30892e+01 1.30892e+00 1.00000e-09 2.12000e-01 $1.00000 \mathrm{e}-05$ 1.00000e-05 1.00000e-06 1.00000e-09 1.00000e-01 $1.00000 \mathrm{e}+001.00000 \mathrm{e}+001.00000 \mathrm{e}-01$ 1.00000e-09 1.00000e-01 Element: 10866 \# of layers: 7

$\mathrm{Kx} \mathrm{Ky} \mathrm{Kz}$ Ss Por

1.30892e+01 1.30892e+01 1.30892e+00 1.00000e-09 2.12000e-01 $1.30892 \mathrm{e}+01$ 1.30892e+01 1.30892e+00 1.00000e-09 2.12000e-01 $1.30892 \mathrm{e}+01$ 1.30892e+01 1.30892e+00 1.00000e-09 2.12000e-01 $1.30892 \mathrm{e}+01$ 1.30892e+01 1.30892e+00 1.00000e-09 2.12000e-01 $1.30892 \mathrm{e}+01$ 1.30892e+01 1.30892e+00 1.00000e-09 2.12000e-01 $1.00000 \mathrm{e}-05$ 1.00000e-05 1.00000e-06 1.00000e-09 1.00000e-01 $1.00000 \mathrm{e}+001.00000 \mathrm{e}+001.00000 \mathrm{e}-011.00000 \mathrm{e}-09$ 1.00000e-01 Element: 10867 \# of layers: 7

$\mathrm{Kx} \mathrm{Ky} \mathrm{Kz}$ Ss Por

$1.30892 \mathrm{e}+01$ 1.30892e+01 1.30892e+00 1.00000e-09 2.12000e-01 $1.30892 \mathrm{e}+01$ 1.30892e+01 1.30892e+00 1.00000e-09 2.12000e-01 $1.30892 \mathrm{e}+01$ 1.30892e+01 1.30892e+00 1.00000e-09 2.12000e-01 $1.30892 \mathrm{e}+01$ 1.30892e+01 1.30892e+00 1.00000e-09 2.12000e-01 $1.30892 \mathrm{e}+01$ 1.30892e+01 1.30892e+00 1.00000e-09 2.12000e-01 $1.00000 \mathrm{e}-05$ 1.00000e-05 1.00000e-06 1.00000e-09 1.00000e-01 $1.00000 \mathrm{e}+001.00000 \mathrm{e}+001.00000 \mathrm{e}-011.00000 \mathrm{e}-091.00000 \mathrm{e}-01$ Element: 10868 \# of layers: 7

$\mathrm{Kx} \mathrm{Ky} \mathrm{Kz}$ Ss Por

1.19687e+01 1.19687e+01 1.19687e+00 1.00000e-09 2.12000e-01 $1.19687 \mathrm{e}+01$ 1.19687e+01 1.19687e+00 1.00000e-09 2.12000e-01 $1.19687 \mathrm{e}+01$ 1.19687e+01 1.19687e+00 1.00000e-09 2.12000e-01 $1.19687 \mathrm{e}+01$ 1.19687e+01 1.19687e+00 1.00000e-09 2.12000e-01 $1.19687 \mathrm{e}+01$ 1.19687e+01 1.19687e+00 1.00000e-09 2.12000e-01 $1.00000 \mathrm{e}-05$ 1.00000e-05 1.00000e-06 1.00000e-09 1.00000e-01 $1.00000 \mathrm{e}+001.00000 \mathrm{e}+001.00000 \mathrm{e}-011.00000 \mathrm{e}-091.00000 \mathrm{e}-01$ Element: 10869 \# of layers: 7

$\mathrm{Kx} \mathrm{Ky} \mathrm{Kz}$ Ss Por

1.19687e+01 1.19687e+01 1.19687e+00 1.00000e-09 2.12000e-01 $1.19687 \mathrm{e}+01$ 1.19687e+01 1.19687e+00 1.00000e-09 2.12000e-01 
1.19687e+01 1.19687e+01 1.19687e+00 1.00000e-09 2.12000e-01 $1.19687 \mathrm{e}+01$ 1.19687e+01 1.19687e+00 1.00000e-09 2.12000e-01 $1.19687 \mathrm{e}+01$ 1.19687e+01 1.19687e+00 1.00000e-09 2.12000e-01 $1.00000 \mathrm{e}-05$ 1.00000e-05 1.00000e-06 1.00000e-09 1.00000e-01 $1.00000 \mathrm{e}+001.00000 \mathrm{e}+001.00000 \mathrm{e}-01$ 1.00000e-09 1.00000e-01 Element: 10870 \# of layers: 7

$\mathrm{Kx} \mathrm{Ky} \mathrm{Kz}$ Ss Por

$1.19687 \mathrm{e}+01$ 1.19687e+01 1.19687e+00 1.00000e-09 2.12000e-01 $1.19687 \mathrm{e}+01$ 1.19687e+01 1.19687e+00 1.00000e-09 2.12000e-01 $1.19687 \mathrm{e}+01$ 1.19687e+01 1.19687e+00 1.00000e-09 2.12000e-01 $1.19687 \mathrm{e}+01$ 1.19687e+01 1.19687e+00 1.00000e-09 2.12000e-01 $1.19687 \mathrm{e}+011.19687 \mathrm{e}+01$ 1.19687e+00 1.00000e-09 2.12000e-01 $1.00000 \mathrm{e}-05$ 1.00000e-05 1.00000e-06 1.00000e-09 1.00000e-01 $1.00000 \mathrm{e}+001.00000 \mathrm{e}+001.00000 \mathrm{e}-011.00000 \mathrm{e}-09$ 1.00000e-01 Element: 10871 \# of layers: 7

Kx Ky Kz Ss Por

1.19687e+01 1.19687e+01 1.19687e+00 1.00000e-09 2.12000e-01 $1.19687 \mathrm{e}+01$ 1.19687e+01 1.19687e+00 1.00000e-09 2.12000e-01 $1.19687 \mathrm{e}+01$ 1.19687e+01 1.19687e+00 1.00000e-09 2.12000e-01 $1.19687 \mathrm{e}+01$ 1.19687e+01 1.19687e+00 1.00000e-09 2.12000e-01 $1.19687 \mathrm{e}+011.19687 \mathrm{e}+01$ 1.19687e+00 1.00000e-09 2.12000e-01 $1.00000 \mathrm{e}-05$ 1.00000e-05 1.00000e-06 1.00000e-09 1.00000e-01 $1.00000 \mathrm{e}+001.00000 \mathrm{e}+001.00000 \mathrm{e}-01$ 1.00000e-09 1.00000e-01 Element: 10872 \# of layers: 7

Kx Ky Kz Ss Por

$1.19687 \mathrm{e}+01$ 1.19687e+01 1.19687e+00 1.00000e-09 2.12000e-01 $1.19687 \mathrm{e}+01$ 1.19687e+01 1.19687e+00 1.00000e-09 2.12000e-01 $1.19687 \mathrm{e}+01$ 1.19687e+01 1.19687e+00 1.00000e-09 2.12000e-01 $1.19687 \mathrm{e}+01$ 1.19687e+01 1.19687e+00 1.00000e-09 2.12000e-01 $1.19687 \mathrm{e}+01$ 1.19687e+01 1.19687e+00 1.00000e-09 2.12000e-01 $1.00000 \mathrm{e}-05$ 1.00000e-05 1.00000e-06 1.00000e-09 1.00000e-01 $1.00000 \mathrm{e}+001.00000 \mathrm{e}+001.00000 \mathrm{e}-01$ 1.00000e-09 1.00000e-01 Element: 10873 \# of layers: 7

$\mathrm{Kx} \mathrm{Ky} \mathrm{Kz}$ Ss Por

1.19687e+01 1.19687e+01 1.19687e+00 1.00000e-09 2.12000e-01 $1.19687 \mathrm{e}+01$ 1.19687e+01 1.19687e+00 1.00000e-09 2.12000e-01 $1.19687 \mathrm{e}+01$ 1.19687e+01 1.19687e+00 1.00000e-09 2.12000e-01 $1.19687 \mathrm{e}+01$ 1.19687e+01 1.19687e+00 1.00000e-09 2.12000e-01 $1.19687 \mathrm{e}+01$ 1.19687e+01 1.19687e+00 1.00000e-09 2.12000e-01 $1.00000 \mathrm{e}-05$ 1.00000e-05 1.00000e-06 1.00000e-09 1.00000e-01 $1.00000 \mathrm{e}+001.00000 \mathrm{e}+001.00000 \mathrm{e}-011.00000 \mathrm{e}-091.00000 \mathrm{e}-01$ Element: 10874 \# of layers: 7

$\mathrm{Kx} \mathrm{Ky} \mathrm{Kz}$ Ss Por

1.19687e+01 1.19687e+01 1.19687e+00 1.00000e-09 2.12000e-01 $1.19687 \mathrm{e}+01$ 1.19687e+01 1.19687e+00 1.00000e-09 2.12000e-01 $1.19687 \mathrm{e}+01$ 1.19687e+01 1.19687e+00 1.00000e-09 2.12000e-01 
$1.19687 \mathrm{e}+01$ 1.19687e+01 1.19687e+00 1.00000e-09 2.12000e-01 $1.19687 \mathrm{e}+01$ 1.19687e+01 1.19687e+00 1.00000e-09 2.12000e-01 $1.00000 \mathrm{e}-05$ 1.00000e-05 1.00000e-06 1.00000e-09 1.00000e-01 $1.00000 \mathrm{e}+001.00000 \mathrm{e}+001.00000 \mathrm{e}-011.00000 \mathrm{e}-091.00000 \mathrm{e}-01$ Element: 10875 \# of layers: 7

$\mathrm{Kx} \mathrm{Ky} \mathrm{Kz}$ Ss Por

$1.19687 \mathrm{e}+01$ 1.19687e+01 1.19687e+00 1.00000e-09 2.12000e-01 $1.19687 \mathrm{e}+01$ 1.19687e+01 1.19687e+00 1.00000e-09 2.12000e-01 $1.19687 \mathrm{e}+01$ 1.19687e+01 1.19687e+00 1.00000e-09 2.12000e-01 $1.19687 \mathrm{e}+01$ 1.19687e+01 1.19687e+00 1.00000e-09 2.12000e-01 $1.19687 \mathrm{e}+01$ 1.19687e+01 1.19687e+00 1.00000e-09 2.12000e-01 $1.00000 \mathrm{e}-05$ 1.00000e-05 1.00000e-06 1.00000e-09 1.00000e-01 $1.00000 \mathrm{e}+001.00000 \mathrm{e}+001.00000 \mathrm{e}-011.00000 \mathrm{e}-09$ 1.00000e-01 Element: 10876 \# of layers: 7

$\mathrm{Kx} \mathrm{Ky} \mathrm{Kz}$ Ss Por

1.19687e+01 1.19687e+01 1.19687e+00 1.00000e-09 2.12000e-01 $1.19687 \mathrm{e}+01$ 1.19687e+01 1.19687e+00 1.00000e-09 2.12000e-01 $1.19687 \mathrm{e}+01$ 1.19687e+01 1.19687e+00 1.00000e-09 2.12000e-01 $1.19687 \mathrm{e}+01$ 1.19687e+01 1.19687e+00 1.00000e-09 2.12000e-01 $1.19687 \mathrm{e}+01$ 1.19687e+01 1.19687e+00 1.00000e-09 2.12000e-01 $1.00000 \mathrm{e}-05$ 1.00000e-05 1.00000e-06 1.00000e-09 1.00000e-01 $1.00000 \mathrm{e}+001.00000 \mathrm{e}+001.00000 \mathrm{e}-01$ 1.00000e-09 1.00000e-01 Element: 10877 \# of layers: 7

Kx Ky Kz Ss Por

$1.19687 \mathrm{e}+01$ 1.19687e+01 1.19687e+00 1.00000e-09 2.12000e-01 $1.19687 \mathrm{e}+01$ 1.19687e+01 1.19687e+00 1.00000e-09 2.12000e-01 $1.19687 \mathrm{e}+01$ 1.19687e+01 1.19687e+00 1.00000e-09 2.12000e-01 $1.19687 \mathrm{e}+01$ 1.19687e+01 1.19687e+00 1.00000e-09 2.12000e-01 $1.19687 \mathrm{e}+011.19687 \mathrm{e}+01$ 1.19687e+00 1.00000e-09 2.12000e-01 $1.00000 \mathrm{e}-05$ 1.00000e-05 1.00000e-06 1.00000e-09 1.00000e-01 $1.00000 \mathrm{e}+001.00000 \mathrm{e}+001.00000 \mathrm{e}-01$ 1.00000e-09 1.00000e-01 Element: 10878 \# of layers: 7

Kx Ky Kz Ss Por

$1.19687 \mathrm{e}+01$ 1.19687e+01 1.19687e+00 1.00000e-09 2.12000e-01 $1.19687 \mathrm{e}+01$ 1.19687e+01 1.19687e+00 1.00000e-09 2.12000e-01 $1.19687 \mathrm{e}+011.19687 \mathrm{e}+01$ 1.19687e+00 1.00000e-09 2.12000e-01 $1.19687 \mathrm{e}+01$ 1.19687e+01 1.19687e+00 1.00000e-09 2.12000e-01 $1.19687 \mathrm{e}+01$ 1.19687e+01 1.19687e+00 1.00000e-09 2.12000e-01 $1.00000 \mathrm{e}-05$ 1.00000e-05 1.00000e-06 1.00000e-09 1.00000e-01 $1.00000 \mathrm{e}+001.00000 \mathrm{e}+001.00000 \mathrm{e}-01$ 1.00000e-09 1.00000e-01 Element: 10879 \# of layers: 7

$\mathrm{Kx} \mathrm{Ky} \mathrm{Kz}$ Ss Por

$1.79853 \mathrm{e}+01$ 1.79853e+01 1.79853e+00 1.00000e-09 2.12000e-01 $1.79853 \mathrm{e}+01$ 1.79853e+01 1.79853e+00 1.00000e-09 2.12000e-01 $1.79853 \mathrm{e}+01$ 1.79853e+01 1.79853e+00 1.00000e-09 2.12000e-01 $1.79853 \mathrm{e}+011.79853 \mathrm{e}+01$ 1.79853e+00 1.00000e-09 2.12000e-01 
$1.79853 \mathrm{e}+011.79853 \mathrm{e}+01$ 1.79853e+00 1.00000e-09 2.12000e-01 $1.00000 \mathrm{e}-05$ 1.00000e-05 1.00000e-06 1.00000e-09 1.00000e-01 $1.00000 \mathrm{e}+001.00000 \mathrm{e}+001.00000 \mathrm{e}-011.00000 \mathrm{e}-091.00000 \mathrm{e}-01$ Element: 10880 \# of layers: 7

Kx Ky Kz Ss Por

$1.79853 \mathrm{e}+011.79853 \mathrm{e}+011.79853 \mathrm{e}+00$ 1.00000e-09 2.12000e-01 $1.79853 \mathrm{e}+011.79853 \mathrm{e}+011.79853 \mathrm{e}+001.00000 \mathrm{e}-092.12000 \mathrm{e}-01$ $1.79853 \mathrm{e}+011.79853 \mathrm{e}+011.79853 \mathrm{e}+00$ 1.00000e-09 2.12000e-01 $1.79853 \mathrm{e}+011.79853 \mathrm{e}+011.79853 \mathrm{e}+00$ 1.00000e-09 2.12000e-01 $1.79853 \mathrm{e}+011.79853 \mathrm{e}+011.79853 \mathrm{e}+001.00000 \mathrm{e}-092.12000 \mathrm{e}-01$ $1.00000 \mathrm{e}-05$ 1.00000e-05 1.00000e-06 1.00000e-09 1.00000e-01 $1.00000 \mathrm{e}+001.00000 \mathrm{e}+001.00000 \mathrm{e}-011.00000 \mathrm{e}-091.00000 \mathrm{e}-01$ Element: 10881 \# of layers: 7

Kx Ky Kz Ss Por

$1.79853 \mathrm{e}+011.79853 \mathrm{e}+01$ 1.79853e+00 1.00000e-09 2.12000e-01 $1.79853 \mathrm{e}+011.79853 \mathrm{e}+011.79853 \mathrm{e}+00$ 1.00000e-09 2.12000e-01 $1.79853 \mathrm{e}+011.79853 \mathrm{e}+011.79853 \mathrm{e}+00$ 1.00000e-09 2.12000e-01 $1.79853 \mathrm{e}+011.79853 \mathrm{e}+011.79853 \mathrm{e}+00$ 1.00000e-09 2.12000e-01 $1.79853 \mathrm{e}+011.79853 \mathrm{e}+011.79853 \mathrm{e}+00$ 1.00000e-09 2.12000e-01 $1.00000 \mathrm{e}-05$ 1.00000e-05 1.00000e-06 1.00000e-09 1.00000e-01 $1.00000 \mathrm{e}+001.00000 \mathrm{e}+001.00000 \mathrm{e}-011.00000 \mathrm{e}-091.00000 \mathrm{e}-01$ Element: 10882 \# of layers: 7

Kx Ky Kz Ss Por

$1.19687 \mathrm{e}+011.19687 \mathrm{e}+01$ 1.19687e+00 1.00000e-09 2.12000e-01 $1.19687 \mathrm{e}+011.19687 \mathrm{e}+011.19687 \mathrm{e}+001.00000 \mathrm{e}-092.12000 \mathrm{e}-01$ $1.19687 \mathrm{e}+011.19687 \mathrm{e}+011.19687 \mathrm{e}+00$ 1.00000e-09 2.12000e-01 $1.19687 \mathrm{e}+011.19687 \mathrm{e}+011.19687 \mathrm{e}+001.00000 \mathrm{e}-092.12000 \mathrm{e}-01$ $1.19687 \mathrm{e}+011.19687 \mathrm{e}+011.19687 \mathrm{e}+001.00000 \mathrm{e}-092.12000 \mathrm{e}-01$ $1.00000 \mathrm{e}-05$ 1.00000e-05 1.00000e-06 1.00000e-09 1.00000e-01 $1.00000 \mathrm{e}+001.00000 \mathrm{e}+001.00000 \mathrm{e}-011.00000 \mathrm{e}-091.00000 \mathrm{e}-01$ Element: 10883 \# of layers: 7

Kx Ky Kz Ss Por

$1.19687 \mathrm{e}+011.19687 \mathrm{e}+01$ 1.19687e+00 1.00000e-09 2.12000e-01 $1.19687 \mathrm{e}+011.19687 \mathrm{e}+011.19687 \mathrm{e}+00$ 1.00000e-09 2.12000e-01 $1.19687 \mathrm{e}+011.19687 \mathrm{e}+011.19687 \mathrm{e}+00$ 1.00000e-09 2.12000e-01 $1.19687 \mathrm{e}+011.19687 \mathrm{e}+011.19687 \mathrm{e}+00$ 1.00000e-09 2.12000e-01 $1.19687 \mathrm{e}+011.19687 \mathrm{e}+011.19687 \mathrm{e}+00$ 1.00000e-09 2.12000e-01 $1.00000 \mathrm{e}-05$ 1.00000e-05 1.00000e-06 1.00000e-09 1.00000e-01 $1.00000 \mathrm{e}+001.00000 \mathrm{e}+001.00000 \mathrm{e}-011.00000 \mathrm{e}-091.00000 \mathrm{e}-01$ Element: 10884 \# of layers: 7

Kx Ky Kz Ss Por

$1.19687 \mathrm{e}+011.19687 \mathrm{e}+01$ 1.19687e+00 1.00000e-09 2.12000e-01 $1.19687 \mathrm{e}+011.19687 \mathrm{e}+011.19687 \mathrm{e}+00$ 1.00000e-09 2.12000e-01 $1.19687 \mathrm{e}+011.19687 \mathrm{e}+011.19687 \mathrm{e}+00$ 1.00000e-09 2.12000e-01 $1.19687 \mathrm{e}+011.19687 \mathrm{e}+011.19687 \mathrm{e}+00$ 1.00000e-09 2.12000e-01 $1.19687 \mathrm{e}+011.19687 \mathrm{e}+011.19687 \mathrm{e}+001.00000 \mathrm{e}-092.12000 \mathrm{e}-01$ 
$1.00000 \mathrm{e}-05$ 1.00000e-05 1.00000e-06 1.00000e-09 1.00000e-01 $1.00000 \mathrm{e}+001.00000 \mathrm{e}+001.00000 \mathrm{e}-01$ 1.00000e-09 1.00000e-01 Element: 10885 \# of layers: 7

Kx Ky Kz Ss Por

$1.19687 \mathrm{e}+01$ 1.19687e+01 1.19687e+00 1.00000e-09 2.12000e-01 $1.19687 \mathrm{e}+01$ 1.19687e+01 1.19687e+00 1.00000e-09 2.12000e-01 $1.19687 \mathrm{e}+01$ 1.19687e+01 1.19687e+00 1.00000e-09 2.12000e-01 $1.19687 \mathrm{e}+01$ 1.19687e+01 1.19687e+00 1.00000e-09 2.12000e-01 $1.19687 \mathrm{e}+01$ 1.19687e+01 1.19687e+00 1.00000e-09 2.12000e-01 $1.00000 \mathrm{e}-05$ 1.00000e-05 1.00000e-06 1.00000e-09 1.00000e-01 $1.00000 \mathrm{e}+001.00000 \mathrm{e}+001.00000 \mathrm{e}-011.00000 \mathrm{e}-091.00000 \mathrm{e}-01$ Element: 10886 \# of layers: 7

Kx Ky Kz Ss Por

1.79853e+01 1.79853e+01 1.79853e+00 1.00000e-09 2.12000e-01 $1.79853 \mathrm{e}+01$ 1.79853e+01 1.79853e+00 1.00000e-09 2.12000e-01 $1.79853 \mathrm{e}+011.79853 \mathrm{e}+011.79853 \mathrm{e}+001.00000 \mathrm{e}-092.12000 \mathrm{e}-01$ $1.79853 \mathrm{e}+01$ 1.79853e+01 1.79853e+00 1.00000e-09 2.12000e-01 $1.79853 \mathrm{e}+011.79853 \mathrm{e}+01$ 1.79853e+00 1.00000e-09 2.12000e-01 $1.00000 \mathrm{e}-05$ 1.00000e-05 1.00000e-06 1.00000e-09 1.00000e-01 $1.00000 \mathrm{e}+001.00000 \mathrm{e}+001.00000 \mathrm{e}-011.00000 \mathrm{e}-09$ 1.00000e-01 Element: 10887 \# of layers: 7

$\mathrm{Kx} \mathrm{Ky} \mathrm{Kz}$ Ss Por

1.79853e+01 1.79853e+01 1.79853e+00 1.00000e-09 2.12000e-01 $1.79853 \mathrm{e}+011.79853 \mathrm{e}+01$ 1.79853e+00 1.00000e-09 2.12000e-01 $1.79853 \mathrm{e}+011.79853 \mathrm{e}+011.79853 \mathrm{e}+001.00000 \mathrm{e}-092.12000 \mathrm{e}-01$ $1.79853 \mathrm{e}+01$ 1.79853e+01 1.79853e+00 1.00000e-09 2.12000e-01 $1.79853 \mathrm{e}+01$ 1.79853e+01 1.79853e+00 1.00000e-09 2.12000e-01 $1.00000 \mathrm{e}-05$ 1.00000e-05 1.00000e-06 1.00000e-09 1.00000e-01 $1.00000 \mathrm{e}+001.00000 \mathrm{e}+001.00000 \mathrm{e}-011.00000 \mathrm{e}-091.00000 \mathrm{e}-01$ Element: 10888 \# of layers: 7

$\mathrm{Kx} \mathrm{Ky} \mathrm{Kz}$ Ss Por

$1.79853 \mathrm{e}+01$ 1.79853e+01 1.79853e+00 1.00000e-09 2.12000e-01 $1.79853 \mathrm{e}+011.79853 \mathrm{e}+01$ 1.79853e+00 1.00000e-09 2.12000e-01 $1.79853 \mathrm{e}+011.79853 \mathrm{e}+011.79853 \mathrm{e}+001.00000 \mathrm{e}-092.12000 \mathrm{e}-01$ $1.79853 \mathrm{e}+011.79853 \mathrm{e}+01$ 1.79853e+00 1.00000e-09 2.12000e-01 $1.79853 \mathrm{e}+01$ 1.79853e+01 1.79853e+00 1.00000e-09 2.12000e-01 1.00000e-05 1.00000e-05 1.00000e-06 1.00000e-09 1.00000e-01 $1.00000 \mathrm{e}+001.00000 \mathrm{e}+001.00000 \mathrm{e}-011.00000 \mathrm{e}-091.00000 \mathrm{e}-01$ Element: 10889 \# of layers: 7

$\mathrm{Kx} \mathrm{Ky} \mathrm{Kz}$ Ss Por

$1.79853 e+01$ 1.79853e+01 1.79853e+00 1.00000e-09 2.12000e-01 $1.79853 \mathrm{e}+01$ 1.79853e+01 1.79853e+00 1.00000e-09 2.12000e-01 $1.79853 \mathrm{e}+011.79853 \mathrm{e}+011.79853 \mathrm{e}+001.00000 \mathrm{e}-092.12000 \mathrm{e}-01$ $1.79853 \mathrm{e}+01$ 1.79853e+01 1.79853e+00 1.00000e-09 2.12000e-01 $1.79853 \mathrm{e}+011.79853 \mathrm{e}+01$ 1.79853e+00 1.00000e-09 2.12000e-01 $1.00000 \mathrm{e}-05$ 1.00000e-05 1.00000e-06 1.00000e-09 1.00000e-01 
$1.00000 \mathrm{e}+001.00000 \mathrm{e}+001.00000 \mathrm{e}-011.00000 \mathrm{e}-091.00000 \mathrm{e}-01$

Element: 10890 \# of layers: 7

Kx Ky Kz Ss Por

$1.79853 e+01$ 1.79853e+01 1.79853e+00 1.00000e-09 2.12000e-01

$1.79853 \mathrm{e}+01$ 1.79853e+01 1.79853e+00 1.00000e-09 2.12000e-01

$1.79853 \mathrm{e}+01$ 1.79853e+01 1.79853e+00 1.00000e-09 2.12000e-01

$1.79853 \mathrm{e}+011.79853 \mathrm{e}+01$ 1.79853e+00 1.00000e-09 2.12000e-01

$1.79853 \mathrm{e}+01$ 1.79853e+01 1.79853e+00 1.00000e-09 2.12000e-01

$1.00000 \mathrm{e}-05$ 1.00000e-05 1.00000e-06 1.00000e-09 1.00000e-01

$1.00000 \mathrm{e}+001.00000 \mathrm{e}+001.00000 \mathrm{e}-011.00000 \mathrm{e}-091.00000 \mathrm{e}-01$

Element: 10891 \# of layers: 7

Kx Ky Kz Ss Por

$1.79853 \mathrm{e}+01$ 1.79853e+01 1.79853e+00 1.00000e-09 2.12000e-01

$1.79853 \mathrm{e}+01$ 1.79853e+01 1.79853e+00 1.00000e-09 2.12000e-01

$1.79853 \mathrm{e}+01$ 1.79853e+01 1.79853e+00 1.00000e-09 2.12000e-01

$1.79853 \mathrm{e}+01$ 1.79853e+01 1.79853e+00 1.00000e-09 2.12000e-01

$1.79853 \mathrm{e}+011.79853 \mathrm{e}+01$ 1.79853e+00 1.00000e-09 2.12000e-01

$1.00000 \mathrm{e}-05$ 1.00000e-05 1.00000e-06 1.00000e-09 1.00000e-01

$1.00000 \mathrm{e}+001.00000 \mathrm{e}+001.00000 \mathrm{e}-01$ 1.00000e-09 1.00000e-01

Element: 10892 \# of layers: 7

$\mathrm{Kx} \mathrm{Ky} \mathrm{Kz}$ Ss Por

$1.79853 \mathrm{e}+01$ 1.79853e+01 1.79853e+00 1.00000e-09 2.12000e-01

$1.79853 \mathrm{e}+01$ 1.79853e+01 1.79853e+00 1.00000e-09 2.12000e-01

$1.79853 \mathrm{e}+011.79853 \mathrm{e}+01$ 1.79853e+00 1.00000e-09 2.12000e-01

$1.79853 \mathrm{e}+011.79853 \mathrm{e}+011.79853 \mathrm{e}+001.00000 \mathrm{e}-092.12000 \mathrm{e}-01$

$1.79853 \mathrm{e}+01$ 1.79853e+01 1.79853e+00 1.00000e-09 2.12000e-01

$1.00000 \mathrm{e}-05$ 1.00000e-05 1.00000e-06 1.00000e-09 1.00000e-01

$1.00000 \mathrm{e}+001.00000 \mathrm{e}+001.00000 \mathrm{e}-01$ 1.00000e-09 1.00000e-01

Element: 10893 \# of layers: 7

$\mathrm{Kx} \mathrm{Ky} \mathrm{Kz}$ Ss Por

$1.79853 \mathrm{e}+01$ 1.79853e+01 1.79853e+00 1.00000e-09 2.12000e-01

$1.79853 \mathrm{e}+01$ 1.79853e+01 1.79853e+00 1.00000e-09 2.12000e-01

$1.79853 \mathrm{e}+011.79853 \mathrm{e}+01$ 1.79853e+00 1.00000e-09 2.12000e-01

$1.79853 \mathrm{e}+01$ 1.79853e+01 1.79853e+00 1.00000e-09 2.12000e-01

$1.79853 \mathrm{e}+01$ 1.79853e+01 1.79853e+00 1.00000e-09 2.12000e-01

$1.00000 \mathrm{e}-05$ 1.00000e-05 1.00000e-06 1.00000e-09 1.00000e-01

$1.00000 \mathrm{e}+001.00000 \mathrm{e}+001.00000 \mathrm{e}-011.00000 \mathrm{e}-091.00000 \mathrm{e}-01$

Element: 10894 \# of layers: 7

$\mathrm{Kx} \mathrm{Ky} \mathrm{Kz}$ Ss Por

$1.79853 \mathrm{e}+01$ 1.79853e+01 1.79853e+00 1.00000e-09 2.12000e-01

$1.79853 \mathrm{e}+01$ 1.79853e+01 1.79853e+00 1.00000e-09 2.12000e-01

$1.79853 \mathrm{e}+01$ 1.79853e+01 1.79853e+00 1.00000e-09 2.12000e-01

$1.79853 \mathrm{e}+01$ 1.79853e+01 1.79853e+00 1.00000e-09 2.12000e-01

1.79853e+01 1.79853e+01 1.79853e+00 1.00000e-09 2.12000e-01

$1.00000 \mathrm{e}-05$ 1.00000e-05 1.00000e-06 1.00000e-09 1.00000e-01

$1.00000 \mathrm{e}+001.00000 \mathrm{e}+001.00000 \mathrm{e}-011.00000 \mathrm{e}-091.00000 \mathrm{e}-01$ 
Element: 10895 \# of layers: 7

Kx Ky Kz Ss Por

$1.79853 \mathrm{e}+01$ 1.79853e+01 1.79853e+00 1.00000e-09 2.12000e-01

$1.79853 \mathrm{e}+011.79853 \mathrm{e}+011.79853 \mathrm{e}+001.00000 \mathrm{e}-092.12000 \mathrm{e}-01$

$1.79853 \mathrm{e}+011.79853 \mathrm{e}+011.79853 \mathrm{e}+001.00000 \mathrm{e}-092.12000 \mathrm{e}-01$

$1.79853 \mathrm{e}+011.79853 \mathrm{e}+011.79853 \mathrm{e}+001.00000 \mathrm{e}-092.12000 \mathrm{e}-01$

$1.79853 \mathrm{e}+011.79853 \mathrm{e}+011.79853 \mathrm{e}+00$ 1.00000e-09 2.12000e-01

$1.00000 \mathrm{e}-05$ 1.00000e-05 1.00000e-06 1.00000e-09 1.00000e-01

$1.00000 \mathrm{e}+001.00000 \mathrm{e}+001.00000 \mathrm{e}-011.00000 \mathrm{e}-091.00000 \mathrm{e}-01$

Element: 10896 \# of layers: 7

Kx Ky Kz Ss Por

$2.47078 \mathrm{e}+012.47078 \mathrm{e}+012.47078 \mathrm{e}+00$ 1.00000e-09 2.12000e-01

$2.47078 \mathrm{e}+012.47078 \mathrm{e}+012.47078 \mathrm{e}+001.00000 \mathrm{e}-092.12000 \mathrm{e}-01$

$2.47078 \mathrm{e}+012.47078 \mathrm{e}+012.47078 \mathrm{e}+001.00000 \mathrm{e}-092.12000 \mathrm{e}-01$

$2.47078 \mathrm{e}+012.47078 \mathrm{e}+012.47078 \mathrm{e}+001.00000 \mathrm{e}-092.12000 \mathrm{e}-01$

$2.47078 \mathrm{e}+012.47078 \mathrm{e}+012.47078 \mathrm{e}+00$ 1.00000e-09 2.12000e-01

$1.00000 \mathrm{e}-05$ 1.00000e-05 1.00000e-06 1.00000e-09 1.00000e-01

$1.00000 \mathrm{e}+001.00000 \mathrm{e}+001.00000 \mathrm{e}-011.00000 \mathrm{e}-091.00000 \mathrm{e}-01$

Element: 10897 \# of layers: 7

Kx Ky Kz Ss Por

$2.47078 \mathrm{e}+012.47078 \mathrm{e}+012.47078 \mathrm{e}+00$ 1.00000e-09 2.12000e-01

$2.47078 \mathrm{e}+012.47078 \mathrm{e}+012.47078 \mathrm{e}+001.00000 \mathrm{e}-092.12000 \mathrm{e}-01$

$2.47078 \mathrm{e}+012.47078 \mathrm{e}+012.47078 \mathrm{e}+001.00000 \mathrm{e}-092.12000 \mathrm{e}-01$

$2.47078 \mathrm{e}+012.47078 \mathrm{e}+012.47078 \mathrm{e}+001.00000 \mathrm{e}-092.12000 \mathrm{e}-01$

$2.47078 \mathrm{e}+012.47078 \mathrm{e}+012.47078 \mathrm{e}+001.00000 \mathrm{e}-092.12000 \mathrm{e}-01$

$1.00000 \mathrm{e}-05$ 1.00000e-05 1.00000e-06 1.00000e-09 1.00000e-01

$1.00000 \mathrm{e}+001.00000 \mathrm{e}+001.00000 \mathrm{e}-011.00000 \mathrm{e}-091.00000 \mathrm{e}-01$

Element: 10898 \# of layers: 7

Kx Ky Kz Ss Por

$2.47078 \mathrm{e}+012.47078 \mathrm{e}+012.47078 \mathrm{e}+00$ 1.00000e-09 2.12000e-01

$2.47078 \mathrm{e}+012.47078 \mathrm{e}+012.47078 \mathrm{e}+001.00000 \mathrm{e}-092.12000 \mathrm{e}-01$

$2.47078 \mathrm{e}+012.47078 \mathrm{e}+012.47078 \mathrm{e}+001.00000 \mathrm{e}-092.12000 \mathrm{e}-01$

$2.47078 \mathrm{e}+012.47078 \mathrm{e}+012.47078 \mathrm{e}+001.00000 \mathrm{e}-092.12000 \mathrm{e}-01$

$2.47078 \mathrm{e}+012.47078 \mathrm{e}+012.47078 \mathrm{e}+001.00000 \mathrm{e}-092.12000 \mathrm{e}-01$

$1.00000 \mathrm{e}-05$ 1.00000e-05 1.00000e-06 1.00000e-09 1.00000e-01

$1.00000 \mathrm{e}+001.00000 \mathrm{e}+001.00000 \mathrm{e}-011.00000 \mathrm{e}-091.00000 \mathrm{e}-01$

Element: 10899 \# of layers: 7

Kx Ky Kz Ss Por

$2.47078 \mathrm{e}+012.47078 \mathrm{e}+012.47078 \mathrm{e}+00$ 1.00000e-09 2.12000e-01

$2.47078 \mathrm{e}+012.47078 \mathrm{e}+012.47078 \mathrm{e}+001.00000 \mathrm{e}-092.12000 \mathrm{e}-01$

$2.47078 \mathrm{e}+012.47078 \mathrm{e}+012.47078 \mathrm{e}+001.00000 \mathrm{e}-092.12000 \mathrm{e}-01$

$2.47078 \mathrm{e}+012.47078 \mathrm{e}+012.47078 \mathrm{e}+001.00000 \mathrm{e}-092.12000 \mathrm{e}-01$

$2.47078 \mathrm{e}+012.47078 \mathrm{e}+012.47078 \mathrm{e}+00$ 1.00000e-09 2.12000e-01

$1.00000 \mathrm{e}-05$ 1.00000e-05 1.00000e-06 1.00000e-09 1.00000e-01

$1.00000 \mathrm{e}+001.00000 \mathrm{e}+001.00000 \mathrm{e}-011.00000 \mathrm{e}-091.00000 \mathrm{e}-01$

Element: 10900 \# of layers: 7 
Kx Ky Kz Ss Por

$2.47078 \mathrm{e}+012.47078 \mathrm{e}+01$ 2.47078e+00 1.00000e-09 2.12000e-01

$2.47078 \mathrm{e}+012.47078 \mathrm{e}+012.47078 \mathrm{e}+00$ 1.00000e-09 2.12000e-01

$2.47078 \mathrm{e}+012.47078 \mathrm{e}+012.47078 \mathrm{e}+001.00000 \mathrm{e}-092.12000 \mathrm{e}-01$

$2.47078 \mathrm{e}+012.47078 \mathrm{e}+012.47078 \mathrm{e}+001.00000 \mathrm{e}-092.12000 \mathrm{e}-01$

$2.47078 \mathrm{e}+012.47078 \mathrm{e}+012.47078 \mathrm{e}+00$ 1.00000e-09 2.12000e-01

$1.00000 \mathrm{e}-05$ 1.00000e-05 1.00000e-06 1.00000e-09 1.00000e-01

$1.00000 \mathrm{e}+001.00000 \mathrm{e}+001.00000 \mathrm{e}-01$ 1.00000e-09 1.00000e-01

Element: 10901 \# of layers: 7

$\mathrm{Kx} \mathrm{Ky} \mathrm{Kz}$ Ss Por

$1.79853 \mathrm{e}+01$ 1.79853e+01 1.79853e+00 1.00000e-09 2.12000e-01

$1.79853 \mathrm{e}+011.79853 \mathrm{e}+01$ 1.79853e+00 1.00000e-09 2.12000e-01

$1.79853 \mathrm{e}+01$ 1.79853e+01 1.79853e+00 1.00000e-09 2.12000e-01

$1.79853 \mathrm{e}+011.79853 \mathrm{e}+01$ 1.79853e+00 1.00000e-09 2.12000e-01

$1.79853 \mathrm{e}+011.79853 \mathrm{e}+01$ 1.79853e+00 1.00000e-09 2.12000e-01

$1.00000 \mathrm{e}-05$ 1.00000e-05 1.00000e-06 1.00000e-09 1.00000e-01

$1.00000 \mathrm{e}+001.00000 \mathrm{e}+001.00000 \mathrm{e}-01$ 1.00000e-09 1.00000e-01

Element: 10902 \# of layers: 7

$\mathrm{Kx} \mathrm{Ky} \mathrm{Kz}$ Ss Por

1.79853e+01 1.79853e+01 1.79853e+00 1.00000e-09 2.12000e-01

$1.79853 \mathrm{e}+01$ 1.79853e+01 1.79853e+00 1.00000e-09 2.12000e-01

$1.79853 \mathrm{e}+01$ 1.79853e+01 1.79853e+00 1.00000e-09 2.12000e-01

$1.79853 \mathrm{e}+01$ 1.79853e+01 1.79853e+00 1.00000e-09 2.12000e-01

$1.79853 \mathrm{e}+01$ 1.79853e+01 1.79853e+00 1.00000e-09 2.12000e-01

$1.00000 \mathrm{e}-05$ 1.00000e-05 1.00000e-06 1.00000e-09 1.00000e-01

$1.00000 \mathrm{e}+001.00000 \mathrm{e}+001.00000 \mathrm{e}-01$ 1.00000e-09 1.00000e-01

Element: 10903 \# of layers: 7

$\mathrm{Kx} \mathrm{Ky} \mathrm{Kz} \mathrm{Ss} \mathrm{Por}$

$2.47078 \mathrm{e}+012.47078 \mathrm{e}+012.47078 \mathrm{e}+00$ 1.00000e-09 2.12000e-01

$2.47078 \mathrm{e}+012.47078 \mathrm{e}+012.47078 \mathrm{e}+001.00000 \mathrm{e}-092.12000 \mathrm{e}-01$

$2.47078 \mathrm{e}+012.47078 \mathrm{e}+012.47078 \mathrm{e}+001.00000 \mathrm{e}-092.12000 \mathrm{e}-01$

$2.47078 \mathrm{e}+012.47078 \mathrm{e}+012.47078 \mathrm{e}+001.00000 \mathrm{e}-092.12000 \mathrm{e}-01$

$2.47078 \mathrm{e}+012.47078 \mathrm{e}+012.47078 \mathrm{e}+00$ 1.00000e-09 2.12000e-01

$1.00000 \mathrm{e}-05$ 1.00000e-05 1.00000e-06 1.00000e-09 1.00000e-01

$1.00000 \mathrm{e}+001.00000 \mathrm{e}+001.00000 \mathrm{e}-01$ 1.00000e-09 1.00000e-01

Element: 10904 \# of layers: 7

Kx Ky Kz Ss Por

$2.47078 \mathrm{e}+012.47078 \mathrm{e}+012.47078 \mathrm{e}+00$ 1.00000e-09 2.12000e-01

$2.47078 \mathrm{e}+012.47078 \mathrm{e}+012.47078 \mathrm{e}+00$ 1.00000e-09 2.12000e-01

$2.47078 \mathrm{e}+012.47078 \mathrm{e}+012.47078 \mathrm{e}+00$ 1.00000e-09 2.12000e-01

$2.47078 \mathrm{e}+012.47078 \mathrm{e}+012.47078 \mathrm{e}+001.00000 \mathrm{e}-092.12000 \mathrm{e}-01$

$2.47078 \mathrm{e}+012.47078 \mathrm{e}+012.47078 \mathrm{e}+00$ 1.00000e-09 2.12000e-01

$1.00000 \mathrm{e}-05$ 1.00000e-05 1.00000e-06 1.00000e-09 1.00000e-01

$1.00000 \mathrm{e}+001.00000 \mathrm{e}+001.00000 \mathrm{e}-01$ 1.00000e-09 1.00000e-01

Element: 10905 \# of layers: 7

Kx Ky Kz Ss Por 
$1.30892 \mathrm{e}+01$ 1.30892e+01 1.30892e+00 1.00000e-09 2.12000e-01 $1.30892 \mathrm{e}+01$ 1.30892e+01 1.30892e+00 1.00000e-09 2.12000e-01 $1.30892 \mathrm{e}+01$ 1.30892e+01 1.30892e+00 1.00000e-09 2.12000e-01 $1.30892 \mathrm{e}+01$ 1.30892e+01 1.30892e+00 1.00000e-09 2.12000e-01 $1.30892 \mathrm{e}+01$ 1.30892e+01 1.30892e+00 1.00000e-09 2.12000e-01 $1.00000 \mathrm{e}-05$ 1.00000e-05 1.00000e-06 1.00000e-09 1.00000e-01 $1.00000 \mathrm{e}+001.00000 \mathrm{e}+001.00000 \mathrm{e}-01$ 1.00000e-09 1.00000e-01 Element: 10906 \# of layers: 7

$\mathrm{Kx} \mathrm{Ky} \mathrm{Kz}$ Ss Por

1.30892e+01 1.30892e+01 1.30892e+00 1.00000e-09 2.12000e-01 $1.30892 \mathrm{e}+01$ 1.30892e+01 1.30892e+00 1.00000e-09 2.12000e-01 $1.30892 \mathrm{e}+01$ 1.30892e+01 1.30892e+00 1.00000e-09 2.12000e-01 $1.30892 \mathrm{e}+01$ 1.30892e+01 1.30892e+00 1.00000e-09 2.12000e-01 $1.30892 \mathrm{e}+01$ 1.30892e+01 1.30892e+00 1.00000e-09 2.12000e-01 $1.00000 \mathrm{e}-051.00000 \mathrm{e}-051.00000 \mathrm{e}-061.00000 \mathrm{e}-091.00000 \mathrm{e}-01$ $1.00000 \mathrm{e}+001.00000 \mathrm{e}+001.00000 \mathrm{e}-011.00000 \mathrm{e}-091.00000 \mathrm{e}-01$ Element: 10907 \# of layers: 7

$\mathrm{Kx} \mathrm{Ky} \mathrm{Kz}$ Ss Por

1.30892e+01 1.30892e+01 1.30892e+00 1.00000e-09 2.12000e-01 $1.30892 \mathrm{e}+01$ 1.30892e+01 1.30892e+00 1.00000e-09 2.12000e-01 $1.30892 \mathrm{e}+01$ 1.30892e+01 1.30892e+00 1.00000e-09 2.12000e-01 $1.30892 \mathrm{e}+01$ 1.30892e+01 1.30892e+00 1.00000e-09 2.12000e-01 $1.30892 \mathrm{e}+01$ 1.30892e+01 1.30892e+00 1.00000e-09 2.12000e-01 $1.00000 \mathrm{e}-05$ 1.00000e-05 1.00000e-06 1.00000e-09 1.00000e-01 $1.00000 \mathrm{e}+001.00000 \mathrm{e}+001.00000 \mathrm{e}-011.00000 \mathrm{e}-091.00000 \mathrm{e}-01$ Element: 10908 \# of layers: 7

$\mathrm{Kx} \mathrm{Ky} \mathrm{Kz}$ Ss Por

$1.19687 \mathrm{e}+01$ 1.19687e+01 1.19687e+00 1.00000e-09 2.12000e-01 $1.19687 \mathrm{e}+01$ 1.19687e+01 1.19687e+00 1.00000e-09 2.12000e-01 $1.19687 \mathrm{e}+01$ 1.19687e+01 1.19687e+00 1.00000e-09 2.12000e-01 $1.19687 \mathrm{e}+01$ 1.19687e+01 1.19687e+00 1.00000e-09 2.12000e-01 $1.19687 \mathrm{e}+01$ 1.19687e+01 1.19687e+00 1.00000e-09 2.12000e-01 $1.00000 \mathrm{e}-05$ 1.00000e-05 1.00000e-06 1.00000e-09 1.00000e-01 $1.00000 \mathrm{e}+001.00000 \mathrm{e}+001.00000 \mathrm{e}-011.00000 \mathrm{e}-091.00000 \mathrm{e}-01$ Element: 10909 \# of layers: 7

$\mathrm{Kx} \mathrm{Ky} \mathrm{Kz}$ Ss Por

$1.19687 \mathrm{e}+01$ 1.19687e+01 1.19687e+00 1.00000e-09 2.12000e-01 $1.19687 \mathrm{e}+01$ 1.19687e+01 1.19687e+00 1.00000e-09 2.12000e-01 $1.19687 \mathrm{e}+01$ 1.19687e+01 1.19687e+00 1.00000e-09 2.12000e-01 $1.19687 \mathrm{e}+01$ 1.19687e+01 1.19687e+00 1.00000e-09 2.12000e-01 $1.19687 \mathrm{e}+01$ 1.19687e+01 1.19687e+00 1.00000e-09 2.12000e-01 $1.00000 \mathrm{e}-05$ 1.00000e-05 1.00000e-06 1.00000e-09 1.00000e-01 $1.00000 \mathrm{e}+001.00000 \mathrm{e}+001.00000 \mathrm{e}-011.00000 \mathrm{e}-091.00000 \mathrm{e}-01$ Element: 10910 \# of layers: 7

$\mathrm{Kx} \mathrm{Ky} \mathrm{Kz}$ Ss Por

$1.79853 e+01$ 1.79853e+01 1.79853e+00 1.00000e-09 2.12000e-01 
$1.79853 \mathrm{e}+01$ 1.79853e+01 1.79853e+00 1.00000e-09 2.12000e-01 $1.79853 \mathrm{e}+01$ 1.79853e+01 1.79853e+00 1.00000e-09 2.12000e-01 $1.79853 \mathrm{e}+011.79853 \mathrm{e}+01$ 1.79853e+00 1.00000e-09 2.12000e-01 $1.79853 \mathrm{e}+01$ 1.79853e+01 1.79853e+00 1.00000e-09 2.12000e-01 $1.00000 \mathrm{e}-05$ 1.00000e-05 1.00000e-06 1.00000e-09 1.00000e-01 $1.00000 \mathrm{e}+001.00000 \mathrm{e}+001.00000 \mathrm{e}-011.00000 \mathrm{e}-091.00000 \mathrm{e}-01$ Element: 10911 \# of layers: 7

$\mathrm{Kx} \mathrm{Ky} \mathrm{Kz}$ Ss Por

$2.47078 \mathrm{e}+012.47078 \mathrm{e}+012.47078 \mathrm{e}+00$ 1.00000e-09 2.12000e-01

$2.47078 \mathrm{e}+012.47078 \mathrm{e}+012.47078 \mathrm{e}+00$ 1.00000e-09 2.12000e-01

$2.47078 \mathrm{e}+012.47078 \mathrm{e}+012.47078 \mathrm{e}+00$ 1.00000e-09 2.12000e-01

$2.47078 \mathrm{e}+012.47078 \mathrm{e}+012.47078 \mathrm{e}+001.00000 \mathrm{e}-092.12000 \mathrm{e}-01$

$2.47078 \mathrm{e}+012.47078 \mathrm{e}+012.47078 \mathrm{e}+001.00000 \mathrm{e}-092.12000 \mathrm{e}-01$ $1.00000 \mathrm{e}-05$ 1.00000e-05 1.00000e-06 1.00000e-09 1.00000e-01

$1.00000 \mathrm{e}+001.00000 \mathrm{e}+001.00000 \mathrm{e}-01$ 1.00000e-09 1.00000e-01

Element: 10912 \# of layers: 7

$\mathrm{Kx} \mathrm{Ky} \mathrm{Kz}$ Ss Por

1.30892e+01 1.30892e+01 1.30892e+00 1.00000e-09 2.12000e-01 $1.30892 \mathrm{e}+01$ 1.30892e+01 1.30892e+00 1.00000e-09 2.12000e-01 $1.30892 \mathrm{e}+01$ 1.30892e+01 1.30892e+00 1.00000e-09 2.12000e-01 $1.30892 \mathrm{e}+01$ 1.30892e+01 1.30892e+00 1.00000e-09 2.12000e-01 $1.30892 \mathrm{e}+01$ 1.30892e+01 1.30892e+00 1.00000e-09 2.12000e-01 $1.00000 \mathrm{e}-051.00000 \mathrm{e}-051.00000 \mathrm{e}-061.00000 \mathrm{e}-091.00000 \mathrm{e}-01$ $1.00000 \mathrm{e}+001.00000 \mathrm{e}+001.00000 \mathrm{e}-011.00000 \mathrm{e}-09$ 1.00000e-01 Element: 10913 \# of layers: 7

$\mathrm{Kx} \mathrm{Ky} \mathrm{Kz}$ Ss Por

$1.20672 \mathrm{e}+011.20672 \mathrm{e}+01$ 1.20672e+00 1.00000e-09 2.12000e-01 $1.20672 \mathrm{e}+011.20672 \mathrm{e}+01$ 1.20672e+00 1.00000e-09 2.12000e-01 $1.20672 \mathrm{e}+011.20672 \mathrm{e}+011.20672 \mathrm{e}+001.00000 \mathrm{e}-092.12000 \mathrm{e}-01$ $1.20672 \mathrm{e}+01$ 1.20672e+01 1.20672e+00 1.00000e-09 2.12000e-01 $1.20672 \mathrm{e}+01$ 1.20672e+01 1.20672e+00 1.00000e-09 2.12000e-01 $1.00000 \mathrm{e}-05$ 1.00000e-05 1.00000e-06 1.00000e-09 1.00000e-01 $1.00000 \mathrm{e}+001.00000 \mathrm{e}+001.00000 \mathrm{e}-011.00000 \mathrm{e}-091.00000 \mathrm{e}-01$ Element: 10914 \# of layers: 7

$\mathrm{Kx} \mathrm{Ky} \mathrm{Kz}$ Ss Por

$1.20672 \mathrm{e}+01$ 1.20672e+01 1.20672e+00 1.00000e-09 2.12000e-01 $1.20672 \mathrm{e}+01$ 1.20672e+01 1.20672e+00 1.00000e-09 2.12000e-01 $1.20672 \mathrm{e}+011.20672 \mathrm{e}+011.20672 \mathrm{e}+001.00000 \mathrm{e}-092.12000 \mathrm{e}-01$ $1.20672 \mathrm{e}+011.20672 \mathrm{e}+01$ 1.20672e+00 1.00000e-09 2.12000e-01 $1.20672 \mathrm{e}+01$ 1.20672e+01 1.20672e+00 1.00000e-09 2.12000e-01 $1.00000 \mathrm{e}-05$ 1.00000e-05 1.00000e-06 1.00000e-09 1.00000e-01 $1.00000 \mathrm{e}+001.00000 \mathrm{e}+001.00000 \mathrm{e}-011.00000 \mathrm{e}-091.00000 \mathrm{e}-01$ Element: 10915 \# of layers: 7

$\mathrm{Kx} \mathrm{Ky} \mathrm{Kz}$ Ss Por

$1.20672 \mathrm{e}+01$ 1.20672e+01 1.20672e+00 1.00000e-09 2.12000e-01 $1.20672 \mathrm{e}+011.20672 \mathrm{e}+011.20672 \mathrm{e}+001.00000 \mathrm{e}-092.12000 \mathrm{e}-01$ 
$1.20672 \mathrm{e}+01$ 1.20672e+01 1.20672e+00 1.00000e-09 2.12000e-01 $1.20672 \mathrm{e}+01$ 1.20672e+01 1.20672e+00 1.00000e-09 2.12000e-01 $1.20672 \mathrm{e}+01$ 1.20672e+01 1.20672e+00 1.00000e-09 2.12000e-01 $1.00000 \mathrm{e}-05$ 1.00000e-05 1.00000e-06 1.00000e-09 1.00000e-01 $1.00000 \mathrm{e}+001.00000 \mathrm{e}+001.00000 \mathrm{e}-01$ 1.00000e-09 1.00000e-01 Element: 10916 \# of layers: 7

$\mathrm{Kx} \mathrm{Ky} \mathrm{Kz}$ Ss Por

$1.20672 \mathrm{e}+01$ 1.20672e+01 1.20672e+00 1.00000e-09 2.12000e-01 $1.20672 \mathrm{e}+01$ 1.20672e+01 1.20672e+00 1.00000e-09 2.12000e-01 $1.20672 \mathrm{e}+01$ 1.20672e+01 1.20672e+00 1.00000e-09 2.12000e-01 $1.20672 \mathrm{e}+01$ 1.20672e+01 1.20672e+00 1.00000e-09 2.12000e-01 $1.20672 \mathrm{e}+011.20672 \mathrm{e}+01$ 1.20672e+00 1.00000e-09 2.12000e-01 $1.00000 \mathrm{e}-05$ 1.00000e-05 1.00000e-06 1.00000e-09 1.00000e-01 $1.00000 \mathrm{e}+001.00000 \mathrm{e}+001.00000 \mathrm{e}-011.00000 \mathrm{e}-09$ 1.00000e-01 Element: 10917 \# of layers: 7

Kx Ky Kz Ss Por

$1.20672 \mathrm{e}+01$ 1.20672e+01 1.20672e+00 1.00000e-09 2.12000e-01 $1.20672 \mathrm{e}+011.20672 \mathrm{e}+01$ 1.20672e+00 1.00000e-09 2.12000e-01 $1.20672 \mathrm{e}+01$ 1.20672e+01 1.20672e+00 1.00000e-09 2.12000e-01 $1.20672 \mathrm{e}+01$ 1.20672e+01 1.20672e+00 1.00000e-09 2.12000e-01 $1.20672 \mathrm{e}+011.20672 \mathrm{e}+01$ 1.20672e+00 1.00000e-09 2.12000e-01 $1.00000 \mathrm{e}-05$ 1.00000e-05 1.00000e-06 1.00000e-09 1.00000e-01 $1.00000 \mathrm{e}+001.00000 \mathrm{e}+001.00000 \mathrm{e}-01$ 1.00000e-09 1.00000e-01 Element: 10918 \# of layers: 7

$\mathrm{Kx} \mathrm{Ky} \mathrm{Kz}$ Ss Por

$1.20672 \mathrm{e}+011.20672 \mathrm{e}+011.20672 \mathrm{e}+001.00000 \mathrm{e}-092.12000 \mathrm{e}-01$ $1.20672 \mathrm{e}+011.20672 \mathrm{e}+011.20672 \mathrm{e}+001.00000 \mathrm{e}-092.12000 \mathrm{e}-01$ $1.20672 \mathrm{e}+011.20672 \mathrm{e}+01$ 1.20672e+00 1.00000e-09 2.12000e-01 $1.20672 \mathrm{e}+011.20672 \mathrm{e}+011.20672 \mathrm{e}+001.00000 \mathrm{e}-092.12000 \mathrm{e}-01$ $1.20672 \mathrm{e}+01$ 1.20672e+01 1.20672e+00 1.00000e-09 2.12000e-01 $1.00000 \mathrm{e}-05$ 1.00000e-05 1.00000e-06 1.00000e-09 1.00000e-01 $1.00000 \mathrm{e}+001.00000 \mathrm{e}+001.00000 \mathrm{e}-011.00000 \mathrm{e}-091.00000 \mathrm{e}-01$ Element: 10919 \# of layers: 7

$\mathrm{Kx} \mathrm{Ky} \mathrm{Kz}$ Ss Por

$1.20672 \mathrm{e}+01$ 1.20672e+01 1.20672e+00 1.00000e-09 2.12000e-01 $1.20672 \mathrm{e}+011.20672 \mathrm{e}+011.20672 \mathrm{e}+001.00000 \mathrm{e}-092.12000 \mathrm{e}-01$ $1.20672 \mathrm{e}+01$ 1.20672e+01 1.20672e+00 1.00000e-09 2.12000e-01 $1.20672 \mathrm{e}+01$ 1.20672e+01 1.20672e+00 1.00000e-09 2.12000e-01 $1.20672 \mathrm{e}+01$ 1.20672e+01 1.20672e+00 1.00000e-09 2.12000e-01 $1.00000 \mathrm{e}-05$ 1.00000e-05 1.00000e-06 1.00000e-09 1.00000e-01 $1.00000 \mathrm{e}+001.00000 \mathrm{e}+001.00000 \mathrm{e}-011.00000 \mathrm{e}-091.00000 \mathrm{e}-01$ Element: 10920 \# of layers: 7

$\mathrm{Kx} \mathrm{Ky} \mathrm{Kz}$ Ss Por

1.20672e+01 1.20672e+01 1.20672e+00 1.00000e-09 2.12000e-01 $1.20672 \mathrm{e}+011.20672 \mathrm{e}+011.20672 \mathrm{e}+001.00000 \mathrm{e}-092.12000 \mathrm{e}-01$ $1.20672 \mathrm{e}+011.20672 \mathrm{e}+011.20672 \mathrm{e}+001.00000 \mathrm{e}-092.12000 \mathrm{e}-01$ 
$1.20672 \mathrm{e}+01$ 1.20672e+01 1.20672e+00 1.00000e-09 2.12000e-01 $1.20672 \mathrm{e}+01$ 1.20672e+01 1.20672e+00 1.00000e-09 2.12000e-01 $1.00000 \mathrm{e}-05$ 1.00000e-05 1.00000e-06 1.00000e-09 1.00000e-01 $1.00000 \mathrm{e}+001.00000 \mathrm{e}+001.00000 \mathrm{e}-011.00000 \mathrm{e}-091.00000 \mathrm{e}-01$ Element: 10921 \# of layers: 7

$\mathrm{Kx} \mathrm{Ky} \mathrm{Kz}$ Ss Por

$1.20672 \mathrm{e}+01$ 1.20672e+01 1.20672e+00 1.00000e-09 2.12000e-01 $1.20672 \mathrm{e}+011.20672 \mathrm{e}+011.20672 \mathrm{e}+001.00000 \mathrm{e}-092.12000 \mathrm{e}-01$ $1.20672 \mathrm{e}+01$ 1.20672e+01 1.20672e+00 1.00000e-09 2.12000e-01 $1.20672 \mathrm{e}+01$ 1.20672e+01 1.20672e+00 1.00000e-09 2.12000e-01 $1.20672 \mathrm{e}+01$ 1.20672e+01 1.20672e+00 1.00000e-09 2.12000e-01 $1.00000 \mathrm{e}-05$ 1.00000e-05 1.00000e-06 1.00000e-09 1.00000e-01 $1.00000 \mathrm{e}+001.00000 \mathrm{e}+001.00000 \mathrm{e}-011.00000 \mathrm{e}-09$ 1.00000e-01 Element: 10922 \# of layers: 7

$\mathrm{Kx} \mathrm{Ky} \mathrm{Kz}$ Ss Por

1.20672e+01 1.20672e+01 1.20672e+00 1.00000e-09 2.12000e-01 $1.20672 \mathrm{e}+01$ 1.20672e+01 1.20672e+00 1.00000e-09 2.12000e-01 $1.20672 \mathrm{e}+011.20672 \mathrm{e}+01$ 1.20672e+00 1.00000e-09 2.12000e-01 $1.20672 \mathrm{e}+01$ 1.20672e+01 1.20672e+00 1.00000e-09 2.12000e-01 $1.20672 \mathrm{e}+01$ 1.20672e+01 1.20672e+00 1.00000e-09 2.12000e-01 $1.00000 \mathrm{e}-05$ 1.00000e-05 1.00000e-06 1.00000e-09 1.00000e-01 $1.00000 \mathrm{e}+001.00000 \mathrm{e}+001.00000 \mathrm{e}-01$ 1.00000e-09 1.00000e-01 Element: 10923 \# of layers: 7

Kx Ky Kz Ss Por

$1.04920 \mathrm{e}+011.04920 \mathrm{e}+011.04920 \mathrm{e}+001.00000 \mathrm{e}-092.12000 \mathrm{e}-01$ $1.04920 \mathrm{e}+011.04920 \mathrm{e}+011.04920 \mathrm{e}+001.00000 \mathrm{e}-092.12000 \mathrm{e}-01$ $1.04920 \mathrm{e}+011.04920 \mathrm{e}+011.04920 \mathrm{e}+001.00000 \mathrm{e}-092.12000 \mathrm{e}-01$ $1.04920 \mathrm{e}+011.04920 \mathrm{e}+011.04920 \mathrm{e}+001.00000 \mathrm{e}-092.12000 \mathrm{e}-01$ $1.04920 \mathrm{e}+011.04920 \mathrm{e}+011.04920 \mathrm{e}+001.00000 \mathrm{e}-092.12000 \mathrm{e}-01$ $1.00000 \mathrm{e}-051.00000 \mathrm{e}-051.00000 \mathrm{e}-061.00000 \mathrm{e}-091.00000 \mathrm{e}-01$ $1.00000 \mathrm{e}+001.00000 \mathrm{e}+001.00000 \mathrm{e}-011.00000 \mathrm{e}-091.00000 \mathrm{e}-01$ Element: 10924 \# of layers: 7

Kx Ky Kz Ss Por $1.04920 \mathrm{e}+011.04920 \mathrm{e}+011.04920 \mathrm{e}+001.00000 \mathrm{e}-092.12000 \mathrm{e}-01$ $1.04920 \mathrm{e}+011.04920 \mathrm{e}+011.04920 \mathrm{e}+001.00000 \mathrm{e}-092.12000 \mathrm{e}-01$ $1.04920 \mathrm{e}+011.04920 \mathrm{e}+011.04920 \mathrm{e}+001.00000 \mathrm{e}-092.12000 \mathrm{e}-01$ $1.04920 \mathrm{e}+011.04920 \mathrm{e}+011.04920 \mathrm{e}+001.00000 \mathrm{e}-092.12000 \mathrm{e}-01$ $1.04920 \mathrm{e}+011.04920 \mathrm{e}+011.04920 \mathrm{e}+001.00000 \mathrm{e}-092.12000 \mathrm{e}-01$ $1.00000 \mathrm{e}-051.00000 \mathrm{e}-051.00000 \mathrm{e}-061.00000 \mathrm{e}-091.00000 \mathrm{e}-01$ $1.00000 \mathrm{e}+001.00000 \mathrm{e}+001.00000 \mathrm{e}-01$ 1.00000e-09 1.00000e-01 Element: 10925 \# of layers: 7

$\mathrm{Kx} \mathrm{Ky} \mathrm{Kz}$ Ss Por $1.04920 \mathrm{e}+011.04920 \mathrm{e}+011.04920 \mathrm{e}+001.00000 \mathrm{e}-092.12000 \mathrm{e}-01$ $1.04920 \mathrm{e}+01$ 1.04920e+01 1.04920e+00 1.00000e-09 2.12000e-01 $1.04920 \mathrm{e}+011.04920 \mathrm{e}+011.04920 \mathrm{e}+001.00000 \mathrm{e}-092.12000 \mathrm{e}-01$ $1.04920 \mathrm{e}+011.04920 \mathrm{e}+011.04920 \mathrm{e}+001.00000 \mathrm{e}-092.12000 \mathrm{e}-01$ 
$1.04920 \mathrm{e}+011.04920 \mathrm{e}+011.04920 \mathrm{e}+001.00000 \mathrm{e}-092.12000 \mathrm{e}-01$ $1.00000 \mathrm{e}-05$ 1.00000e-05 1.00000e-06 1.00000e-09 1.00000e-01

$1.00000 \mathrm{e}+001.00000 \mathrm{e}+001.00000 \mathrm{e}-011.00000 \mathrm{e}-09$ 1.00000e-01

Element: 10926 \# of layers: 7

$\mathrm{Kx} \mathrm{Ky} \mathrm{Kz}$ Ss Por

$1.04920 \mathrm{e}+01$ 1.04920e+01 1.04920e+00 1.00000e-09 2.12000e-01

$1.04920 \mathrm{e}+011.04920 \mathrm{e}+011.04920 \mathrm{e}+001.00000 \mathrm{e}-092.12000 \mathrm{e}-01$

$1.04920 \mathrm{e}+011.04920 \mathrm{e}+011.04920 \mathrm{e}+001.00000 \mathrm{e}-092.12000 \mathrm{e}-01$

$1.04920 \mathrm{e}+011.04920 \mathrm{e}+011.04920 \mathrm{e}+001.00000 \mathrm{e}-092.12000 \mathrm{e}-01$

$1.04920 \mathrm{e}+011.04920 \mathrm{e}+011.04920 \mathrm{e}+001.00000 \mathrm{e}-092.12000 \mathrm{e}-01$

$1.00000 \mathrm{e}-05$ 1.00000e-05 1.00000e-06 1.00000e-09 1.00000e-01

$1.00000 \mathrm{e}+001.00000 \mathrm{e}+001.00000 \mathrm{e}-011.00000 \mathrm{e}-091.00000 \mathrm{e}-01$

Element: 10927 \# of layers: 7

$\mathrm{Kx} \mathrm{Ky} \mathrm{Kz}$ Ss Por

$1.04920 \mathrm{e}+011.04920 \mathrm{e}+01$ 1.04920e+00 1.00000e-09 2.12000e-01

$1.04920 \mathrm{e}+011.04920 \mathrm{e}+011.04920 \mathrm{e}+001.00000 \mathrm{e}-092.12000 \mathrm{e}-01$

$1.04920 \mathrm{e}+011.04920 \mathrm{e}+011.04920 \mathrm{e}+001.00000 \mathrm{e}-092.12000 \mathrm{e}-01$

$1.04920 \mathrm{e}+011.04920 \mathrm{e}+011.04920 \mathrm{e}+001.00000 \mathrm{e}-092.12000 \mathrm{e}-01$

$1.04920 \mathrm{e}+011.04920 \mathrm{e}+011.04920 \mathrm{e}+001.00000 \mathrm{e}-092.12000 \mathrm{e}-01$

$1.00000 \mathrm{e}-05$ 1.00000e-05 1.00000e-06 1.00000e-09 1.00000e-01

$1.00000 \mathrm{e}+001.00000 \mathrm{e}+001.00000 \mathrm{e}-011.00000 \mathrm{e}-091.00000 \mathrm{e}-01$

Element: 10928 \# of layers: 7

$\mathrm{Kx} \mathrm{Ky} \mathrm{Kz}$ Ss Por

1.20672e+01 1.20672e+01 1.20672e+00 1.00000e-09 2.12000e-01

$1.20672 \mathrm{e}+011.20672 \mathrm{e}+011.20672 \mathrm{e}+001.00000 \mathrm{e}-092.12000 \mathrm{e}-01$

$1.20672 \mathrm{e}+011.20672 \mathrm{e}+01$ 1.20672e+00 1.00000e-09 2.12000e-01

$1.20672 \mathrm{e}+011.20672 \mathrm{e}+01$ 1.20672e+00 1.00000e-09 2.12000e-01

$1.20672 \mathrm{e}+01$ 1.20672e+01 1.20672e+00 1.00000e-09 2.12000e-01

$1.00000 \mathrm{e}-05$ 1.00000e-05 1.00000e-06 1.00000e-09 1.00000e-01

$1.00000 \mathrm{e}+001.00000 \mathrm{e}+001.00000 \mathrm{e}-011.00000 \mathrm{e}-091.00000 \mathrm{e}-01$

Element: 10929 \# of layers: 7

$\mathrm{Kx} \mathrm{Ky} \mathrm{Kz}$ Ss Por

$1.20672 \mathrm{e}+01$ 1.20672e+01 1.20672e+00 1.00000e-09 2.12000e-01

$1.20672 \mathrm{e}+011.20672 \mathrm{e}+011.20672 \mathrm{e}+001.00000 \mathrm{e}-092.12000 \mathrm{e}-01$

$1.20672 \mathrm{e}+011.20672 \mathrm{e}+011.20672 \mathrm{e}+001.00000 \mathrm{e}-092.12000 \mathrm{e}-01$

$1.20672 \mathrm{e}+011.20672 \mathrm{e}+01$ 1.20672e+00 1.00000e-09 2.12000e-01

$1.20672 \mathrm{e}+01$ 1.20672e+01 1.20672e+00 1.00000e-09 2.12000e-01

$1.00000 \mathrm{e}-05$ 1.00000e-05 1.00000e-06 1.00000e-09 1.00000e-01

$1.00000 \mathrm{e}+001.00000 \mathrm{e}+001.00000 \mathrm{e}-01$ 1.00000e-09 1.00000e-01

Element: 10930 \# of layers: 7

$\mathrm{Kx} \mathrm{Ky} \mathrm{Kz}$ Ss Por

$1.04920 \mathrm{e}+01$ 1.04920e+01 1.04920e+00 1.00000e-09 2.12000e-01 $1.04920 \mathrm{e}+011.04920 \mathrm{e}+011.04920 \mathrm{e}+001.00000 \mathrm{e}-092.12000 \mathrm{e}-01$ $1.04920 \mathrm{e}+01$ 1.04920e+01 1.04920e+00 1.00000e-09 2.12000e-01 $1.04920 \mathrm{e}+011.04920 \mathrm{e}+011.04920 \mathrm{e}+001.00000 \mathrm{e}-092.12000 \mathrm{e}-01$ $1.04920 \mathrm{e}+011.04920 \mathrm{e}+011.04920 \mathrm{e}+001.00000 \mathrm{e}-092.12000 \mathrm{e}-01$ 
$1.00000 \mathrm{e}-05$ 1.00000e-05 1.00000e-06 1.00000e-09 1.00000e-01 $1.00000 \mathrm{e}+001.00000 \mathrm{e}+001.00000 \mathrm{e}-01$ 1.00000e-09 1.00000e-01 Element: 10931 \# of layers: 7

Kx Ky Kz Ss Por

$1.04920 \mathrm{e}+011.04920 \mathrm{e}+011.04920 \mathrm{e}+001.00000 \mathrm{e}-092.12000 \mathrm{e}-01$ $1.04920 \mathrm{e}+011.04920 \mathrm{e}+011.04920 \mathrm{e}+001.00000 \mathrm{e}-092.12000 \mathrm{e}-01$ $1.04920 \mathrm{e}+011.04920 \mathrm{e}+011.04920 \mathrm{e}+001.00000 \mathrm{e}-092.12000 \mathrm{e}-01$ $1.04920 \mathrm{e}+011.04920 \mathrm{e}+011.04920 \mathrm{e}+001.00000 \mathrm{e}-092.12000 \mathrm{e}-01$ $1.04920 \mathrm{e}+011.04920 \mathrm{e}+011.04920 \mathrm{e}+001.00000 \mathrm{e}-092.12000 \mathrm{e}-01$ $1.00000 \mathrm{e}-05$ 1.00000e-05 1.00000e-06 1.00000e-09 1.00000e-01 $1.00000 \mathrm{e}+001.00000 \mathrm{e}+001.00000 \mathrm{e}-011.00000 \mathrm{e}-091.00000 \mathrm{e}-01$ Element: 10932 \# of layers: 7

$\mathrm{Kx} \mathrm{Ky} \mathrm{Kz}$ Ss Por

$1.04920 \mathrm{e}+01$ 1.04920e+01 1.04920e+00 1.00000e-09 2.12000e-01 $1.04920 \mathrm{e}+011.04920 \mathrm{e}+011.04920 \mathrm{e}+001.00000 \mathrm{e}-092.12000 \mathrm{e}-01$ $1.04920 \mathrm{e}+011.04920 \mathrm{e}+011.04920 \mathrm{e}+001.00000 \mathrm{e}-092.12000 \mathrm{e}-01$ $1.04920 \mathrm{e}+011.04920 \mathrm{e}+01 \quad 1.04920 \mathrm{e}+001.00000 \mathrm{e}-092.12000 \mathrm{e}-01$ $1.04920 \mathrm{e}+011.04920 \mathrm{e}+011.04920 \mathrm{e}+001.00000 \mathrm{e}-092.12000 \mathrm{e}-01$ $1.00000 \mathrm{e}-05$ 1.00000e-05 1.00000e-06 1.00000e-09 1.00000e-01 $1.00000 \mathrm{e}+001.00000 \mathrm{e}+001.00000 \mathrm{e}-011.00000 \mathrm{e}-09$ 1.00000e-01 Element: 10933 \# of layers: 7

$\mathrm{Kx} \mathrm{Ky} \mathrm{Kz}$ Ss Por

$1.04920 \mathrm{e}+01$ 1.04920e+01 1.04920e+00 1.00000e-09 2.12000e-01 $1.04920 \mathrm{e}+011.04920 \mathrm{e}+01 \quad 1.04920 \mathrm{e}+001.00000 \mathrm{e}-092.12000 \mathrm{e}-01$ $1.04920 \mathrm{e}+011.04920 \mathrm{e}+011.04920 \mathrm{e}+001.00000 \mathrm{e}-092.12000 \mathrm{e}-01$ $1.04920 \mathrm{e}+011.04920 \mathrm{e}+011.04920 \mathrm{e}+001.00000 \mathrm{e}-092.12000 \mathrm{e}-01$ $1.04920 \mathrm{e}+011.04920 \mathrm{e}+01 \quad 1.04920 \mathrm{e}+001.00000 \mathrm{e}-092.12000 \mathrm{e}-01$ $1.00000 \mathrm{e}-05$ 1.00000e-05 1.00000e-06 1.00000e-09 1.00000e-01 $1.00000 \mathrm{e}+001.00000 \mathrm{e}+001.00000 \mathrm{e}-011.00000 \mathrm{e}-091.00000 \mathrm{e}-01$ Element: 10934 \# of layers: 7

$\mathrm{Kx} \mathrm{Ky} \mathrm{Kz}$ Ss Por

$1.04920 \mathrm{e}+01$ 1.04920e+01 1.04920e+00 1.00000e-09 2.12000e-01 $1.04920 \mathrm{e}+011.04920 \mathrm{e}+011.04920 \mathrm{e}+001.00000 \mathrm{e}-092.12000 \mathrm{e}-01$ $1.04920 \mathrm{e}+011.04920 \mathrm{e}+011.04920 \mathrm{e}+001.00000 \mathrm{e}-092.12000 \mathrm{e}-01$ $1.04920 \mathrm{e}+011.04920 \mathrm{e}+01 \quad 1.04920 \mathrm{e}+001.00000 \mathrm{e}-092.12000 \mathrm{e}-01$ $1.04920 \mathrm{e}+011.04920 \mathrm{e}+011.04920 \mathrm{e}+001.00000 \mathrm{e}-092.12000 \mathrm{e}-01$ 1.00000e-05 1.00000e-05 1.00000e-06 1.00000e-09 1.00000e-01 $1.00000 \mathrm{e}+001.00000 \mathrm{e}+001.00000 \mathrm{e}-011.00000 \mathrm{e}-091.00000 \mathrm{e}-01$ Element: 10935 \# of layers: 7

$\mathrm{Kx} \mathrm{Ky} \mathrm{Kz}$ Ss Por $1.04920 \mathrm{e}+01$ 1.04920e+01 1.04920e+00 1.00000e-09 2.12000e-01 $1.04920 \mathrm{e}+011.04920 \mathrm{e}+011.04920 \mathrm{e}+001.00000 \mathrm{e}-092.12000 \mathrm{e}-01$ $1.04920 \mathrm{e}+011.04920 \mathrm{e}+011.04920 \mathrm{e}+001.00000 \mathrm{e}-092.12000 \mathrm{e}-01$ $1.04920 \mathrm{e}+011.04920 \mathrm{e}+01 \quad 1.04920 \mathrm{e}+001.00000 \mathrm{e}-092.12000 \mathrm{e}-01$ $1.04920 \mathrm{e}+011.04920 \mathrm{e}+01 \quad 1.04920 \mathrm{e}+001.00000 \mathrm{e}-092.12000 \mathrm{e}-01$ $1.00000 \mathrm{e}-05$ 1.00000e-05 1.00000e-06 1.00000e-09 1.00000e-01 
$1.00000 \mathrm{e}+001.00000 \mathrm{e}+00$ 1.00000e-01 1.00000e-09 1.00000e-01

Element: 10936 \# of layers: 7

Kx Ky Kz Ss Por

$1.04920 \mathrm{e}+01$ 1.04920e+01 1.04920e+00 1.00000e-09 2.12000e-01

$1.04920 \mathrm{e}+011.04920 \mathrm{e}+011.04920 \mathrm{e}+001.00000 \mathrm{e}-092.12000 \mathrm{e}-01$

$1.04920 \mathrm{e}+011.04920 \mathrm{e}+011.04920 \mathrm{e}+001.00000 \mathrm{e}-092.12000 \mathrm{e}-01$

$1.04920 \mathrm{e}+011.04920 \mathrm{e}+011.04920 \mathrm{e}+001.00000 \mathrm{e}-092.12000 \mathrm{e}-01$

$1.04920 \mathrm{e}+011.04920 \mathrm{e}+01 \quad 1.04920 \mathrm{e}+001.00000 \mathrm{e}-092.12000 \mathrm{e}-01$

$1.00000 \mathrm{e}-05$ 1.00000e-05 1.00000e-06 1.00000e-09 1.00000e-01

$1.00000 \mathrm{e}+001.00000 \mathrm{e}+001.00000 \mathrm{e}-01$ 1.00000e-09 1.00000e-01

Element: 10937 \# of layers: 7

Kx Ky Kz Ss Por

$1.04920 \mathrm{e}+011.04920 \mathrm{e}+01$ 1.04920e+00 1.00000e-09 2.12000e-01

$1.04920 \mathrm{e}+011.04920 \mathrm{e}+011.04920 \mathrm{e}+001.00000 \mathrm{e}-092.12000 \mathrm{e}-01$

$1.04920 \mathrm{e}+011.04920 \mathrm{e}+011.04920 \mathrm{e}+001.00000 \mathrm{e}-092.12000 \mathrm{e}-01$

$1.04920 \mathrm{e}+011.04920 \mathrm{e}+011.04920 \mathrm{e}+001.00000 \mathrm{e}-092.12000 \mathrm{e}-01$

$1.04920 \mathrm{e}+011.04920 \mathrm{e}+011.04920 \mathrm{e}+001.00000 \mathrm{e}-092.12000 \mathrm{e}-01$

$1.00000 \mathrm{e}-05$ 1.00000e-05 1.00000e-06 1.00000e-09 1.00000e-01

$1.00000 \mathrm{e}+001.00000 \mathrm{e}+001.00000 \mathrm{e}-01$ 1.00000e-09 1.00000e-01

Element: 10938 \# of layers: 7

$\mathrm{Kx} \mathrm{Ky} \mathrm{Kz}$ Ss Por

$1.04920 \mathrm{e}+011.04920 \mathrm{e}+011.04920 \mathrm{e}+001.00000 \mathrm{e}-092.12000 \mathrm{e}-01$

$1.04920 \mathrm{e}+011.04920 \mathrm{e}+011.04920 \mathrm{e}+001.00000 \mathrm{e}-092.12000 \mathrm{e}-01$

$1.04920 \mathrm{e}+011.04920 \mathrm{e}+01 \quad 1.04920 \mathrm{e}+001.00000 \mathrm{e}-092.12000 \mathrm{e}-01$

$1.04920 \mathrm{e}+011.04920 \mathrm{e}+011.04920 \mathrm{e}+001.00000 \mathrm{e}-092.12000 \mathrm{e}-01$

$1.04920 \mathrm{e}+011.04920 \mathrm{e}+011.04920 \mathrm{e}+001.00000 \mathrm{e}-092.12000 \mathrm{e}-01$

$1.00000 \mathrm{e}-05$ 1.00000e-05 1.00000e-06 1.00000e-09 1.00000e-01

$1.00000 \mathrm{e}+001.00000 \mathrm{e}+001.00000 \mathrm{e}-01$ 1.00000e-09 1.00000e-01

Element: 10939 \# of layers: 7

$\mathrm{Kx} \mathrm{Ky} \mathrm{Kz}$ Ss Por

$1.04920 \mathrm{e}+01$ 1.04920e+01 1.04920e+00 1.00000e-09 2.12000e-01

$1.04920 \mathrm{e}+011.04920 \mathrm{e}+011.04920 \mathrm{e}+00$ 1.00000e-09 2.12000e-01

$1.04920 \mathrm{e}+011.04920 \mathrm{e}+011.04920 \mathrm{e}+001.00000 \mathrm{e}-092.12000 \mathrm{e}-01$

$1.04920 \mathrm{e}+011.04920 \mathrm{e}+011.04920 \mathrm{e}+001.00000 \mathrm{e}-092.12000 \mathrm{e}-01$

$1.04920 \mathrm{e}+011.04920 \mathrm{e}+011.04920 \mathrm{e}+001.00000 \mathrm{e}-092.12000 \mathrm{e}-01$

$1.00000 \mathrm{e}-05$ 1.00000e-05 1.00000e-06 1.00000e-09 1.00000e-01

$1.00000 \mathrm{e}+001.00000 \mathrm{e}+001.00000 \mathrm{e}-011.00000 \mathrm{e}-091.00000 \mathrm{e}-01$

Element: 10940 \# of layers: 7

$\mathrm{Kx} \mathrm{Ky} \mathrm{Kz}$ Ss Por

$1.04920 \mathrm{e}+011.04920 \mathrm{e}+011.04920 \mathrm{e}+001.00000 \mathrm{e}-092.12000 \mathrm{e}-01$

$1.04920 \mathrm{e}+011.04920 \mathrm{e}+011.04920 \mathrm{e}+001.00000 \mathrm{e}-092.12000 \mathrm{e}-01$

$1.04920 \mathrm{e}+011.04920 \mathrm{e}+011.04920 \mathrm{e}+001.00000 \mathrm{e}-092.12000 \mathrm{e}-01$

$1.04920 \mathrm{e}+011.04920 \mathrm{e}+011.04920 \mathrm{e}+001.00000 \mathrm{e}-092.12000 \mathrm{e}-01$

$1.04920 \mathrm{e}+01$ 1.04920e+01 1.04920e+00 1.00000e-09 2.12000e-01

$1.00000 \mathrm{e}-05$ 1.00000e-05 1.00000e-06 1.00000e-09 1.00000e-01

$1.00000 \mathrm{e}+001.00000 \mathrm{e}+001.00000 \mathrm{e}-011.00000 \mathrm{e}-091.00000 \mathrm{e}-01$ 
Element: 10941 \# of layers: 7

Kx Ky Kz Ss Por

$1.04920 \mathrm{e}+011.04920 \mathrm{e}+011.04920 \mathrm{e}+001.00000 \mathrm{e}-092.12000 \mathrm{e}-01$

$1.04920 \mathrm{e}+011.04920 \mathrm{e}+011.04920 \mathrm{e}+001.00000 \mathrm{e}-092.12000 \mathrm{e}-01$

$1.04920 \mathrm{e}+011.04920 \mathrm{e}+011.04920 \mathrm{e}+001.00000 \mathrm{e}-092.12000 \mathrm{e}-01$

$1.04920 \mathrm{e}+011.04920 \mathrm{e}+011.04920 \mathrm{e}+001.00000 \mathrm{e}-092.12000 \mathrm{e}-01$

$1.04920 \mathrm{e}+011.04920 \mathrm{e}+011.04920 \mathrm{e}+001.00000 \mathrm{e}-092.12000 \mathrm{e}-01$

$1.00000 \mathrm{e}-05$ 1.00000e-05 1.00000e-06 1.00000e-09 1.00000e-01

$1.00000 \mathrm{e}+001.00000 \mathrm{e}+001.00000 \mathrm{e}-011.00000 \mathrm{e}-091.00000 \mathrm{e}-01$

Element: 10942 \# of layers: 7

Kx Ky Kz Ss Por

$9.86804 \mathrm{e}+009.86804 \mathrm{e}+00$ 9.86804e-01 1.00000e-09 2.12000e-01

$9.86804 \mathrm{e}+009.86804 \mathrm{e}+009.86804 \mathrm{e}-01$ 1.00000e-09 2.12000e-01

$9.86804 \mathrm{e}+009.86804 \mathrm{e}+00$ 9.86804e-01 1.00000e-09 2.12000e-01

$9.86804 \mathrm{e}+009.86804 \mathrm{e}+00$ 9.86804e-01 1.00000e-09 2.12000e-01

$9.86804 \mathrm{e}+009.86804 \mathrm{e}+00$ 9.86804e-01 1.00000e-09 2.12000e-01

$1.00000 \mathrm{e}-05$ 1.00000e-05 1.00000e-06 1.00000e-09 1.00000e-01

$1.00000 \mathrm{e}+001.00000 \mathrm{e}+001.00000 \mathrm{e}-011.00000 \mathrm{e}-091.00000 \mathrm{e}-01$

Element: 10943 \# of layers: 7

Kx Ky Kz Ss Por

$9.86804 \mathrm{e}+009.86804 \mathrm{e}+00$ 9.86804e-01 1.00000e-09 2.12000e-01

$9.86804 \mathrm{e}+009.86804 \mathrm{e}+00$ 9.86804e-01 1.00000e-09 2.12000e-01

$9.86804 \mathrm{e}+009.86804 \mathrm{e}+00$ 9.86804e-01 1.00000e-09 2.12000e-01

$9.86804 \mathrm{e}+009.86804 \mathrm{e}+009.86804 \mathrm{e}-011.00000 \mathrm{e}-092.12000 \mathrm{e}-01$

$9.86804 \mathrm{e}+009.86804 \mathrm{e}+00$ 9.86804e-01 1.00000e-09 2.12000e-01

$1.00000 \mathrm{e}-05$ 1.00000e-05 1.00000e-06 1.00000e-09 1.00000e-01

$1.00000 \mathrm{e}+001.00000 \mathrm{e}+001.00000 \mathrm{e}-011.00000 \mathrm{e}-091.00000 \mathrm{e}-01$

Element: 10944 \# of layers: 7

Kx Ky Kz Ss Por

$9.86804 \mathrm{e}+009.86804 \mathrm{e}+00$ 9.86804e-01 1.00000e-09 2.12000e-01

$9.86804 \mathrm{e}+009.86804 \mathrm{e}+00$ 9.86804e-01 1.00000e-09 2.12000e-01

$9.86804 \mathrm{e}+009.86804 \mathrm{e}+00$ 9.86804e-01 1.00000e-09 2.12000e-01

$9.86804 \mathrm{e}+009.86804 \mathrm{e}+009.86804 \mathrm{e}-01$ 1.00000e-09 2.12000e-01

$9.86804 \mathrm{e}+009.86804 \mathrm{e}+00$ 9.86804e-01 1.00000e-09 2.12000e-01

$1.00000 \mathrm{e}-05$ 1.00000e-05 1.00000e-06 1.00000e-09 1.00000e-01

$1.00000 \mathrm{e}+001.00000 \mathrm{e}+001.00000 \mathrm{e}-011.00000 \mathrm{e}-091.00000 \mathrm{e}-01$

Element: 10945 \# of layers: 7

Kx Ky Kz Ss Por

$1.04920 \mathrm{e}+011.04920 \mathrm{e}+011.04920 \mathrm{e}+00$ 1.00000e-09 2.12000e-01

$1.04920 \mathrm{e}+011.04920 \mathrm{e}+011.04920 \mathrm{e}+001.00000 \mathrm{e}-092.12000 \mathrm{e}-01$

$1.04920 \mathrm{e}+011.04920 \mathrm{e}+011.04920 \mathrm{e}+001.00000 \mathrm{e}-092.12000 \mathrm{e}-01$

$1.04920 \mathrm{e}+011.04920 \mathrm{e}+011.04920 \mathrm{e}+001.00000 \mathrm{e}-092.12000 \mathrm{e}-01$

$1.04920 \mathrm{e}+011.04920 \mathrm{e}+011.04920 \mathrm{e}+001.00000 \mathrm{e}-092.12000 \mathrm{e}-01$

$1.00000 \mathrm{e}-05$ 1.00000e-05 1.00000e-06 1.00000e-09 1.00000e-01

$1.00000 \mathrm{e}+001.00000 \mathrm{e}+001.00000 \mathrm{e}-011.00000 \mathrm{e}-091.00000 \mathrm{e}-01$

Element: 10946 \# of layers: 7 
$\mathrm{Kx} \mathrm{Ky} \mathrm{Kz}$ Ss Por

$1.04920 \mathrm{e}+01$ 1.04920e+01 1.04920e+00 1.00000e-09 2.12000e-01

$1.04920 \mathrm{e}+011.04920 \mathrm{e}+011.04920 \mathrm{e}+001.00000 \mathrm{e}-092.12000 \mathrm{e}-01$

$1.04920 \mathrm{e}+011.04920 \mathrm{e}+01 \quad 1.04920 \mathrm{e}+001.00000 \mathrm{e}-092.12000 \mathrm{e}-01$

$1.04920 \mathrm{e}+011.04920 \mathrm{e}+011.04920 \mathrm{e}+001.00000 \mathrm{e}-092.12000 \mathrm{e}-01$

$1.04920 \mathrm{e}+011.04920 \mathrm{e}+01 \quad 1.04920 \mathrm{e}+001.00000 \mathrm{e}-092.12000 \mathrm{e}-01$

$1.00000 \mathrm{e}-05$ 1.00000e-05 1.00000e-06 1.00000e-09 1.00000e-01

$1.00000 \mathrm{e}+001.00000 \mathrm{e}+001.00000 \mathrm{e}-01$ 1.00000e-09 1.00000e-01

Element: 10947 \# of layers: 7

$\mathrm{Kx} \mathrm{Ky} \mathrm{Kz}$ Ss Por

$1.04920 \mathrm{e}+011.04920 \mathrm{e}+011.04920 \mathrm{e}+001.00000 \mathrm{e}-092.12000 \mathrm{e}-01$

$1.04920 \mathrm{e}+011.04920 \mathrm{e}+01 \quad 1.04920 \mathrm{e}+001.00000 \mathrm{e}-092.12000 \mathrm{e}-01$

$1.04920 \mathrm{e}+011.04920 \mathrm{e}+011.04920 \mathrm{e}+001.00000 \mathrm{e}-092.12000 \mathrm{e}-01$

$1.04920 \mathrm{e}+011.04920 \mathrm{e}+011.04920 \mathrm{e}+001.00000 \mathrm{e}-092.12000 \mathrm{e}-01$

$1.04920 \mathrm{e}+011.04920 \mathrm{e}+011.04920 \mathrm{e}+001.00000 \mathrm{e}-092.12000 \mathrm{e}-01$

$1.00000 \mathrm{e}-05$ 1.00000e-05 1.00000e-06 1.00000e-09 1.00000e-01

$1.00000 \mathrm{e}+001.00000 \mathrm{e}+001.00000 \mathrm{e}-011.00000 \mathrm{e}-091.00000 \mathrm{e}-01$

Element: 10948 \# of layers: 7

$\mathrm{Kx} \mathrm{Ky} \mathrm{Kz}$ Ss Por

$1.04920 \mathrm{e}+01$ 1.04920e+01 1.04920e+00 1.00000e-09 2.12000e-01

$1.04920 \mathrm{e}+011.04920 \mathrm{e}+011.04920 \mathrm{e}+001.00000 \mathrm{e}-092.12000 \mathrm{e}-01$

$1.04920 \mathrm{e}+011.04920 \mathrm{e}+011.04920 \mathrm{e}+001.00000 \mathrm{e}-092.12000 \mathrm{e}-01$

$1.04920 \mathrm{e}+011.04920 \mathrm{e}+011.04920 \mathrm{e}+001.00000 \mathrm{e}-092.12000 \mathrm{e}-01$

$1.04920 \mathrm{e}+011.04920 \mathrm{e}+01 \quad 1.04920 \mathrm{e}+001.00000 \mathrm{e}-092.12000 \mathrm{e}-01$

$1.00000 \mathrm{e}-05$ 1.00000e-05 1.00000e-06 1.00000e-09 1.00000e-01

$1.00000 \mathrm{e}+001.00000 \mathrm{e}+001.00000 \mathrm{e}-01$ 1.00000e-09 1.00000e-01

Element: 10949 \# of layers: 7

$\mathrm{Kx} \mathrm{Ky} \mathrm{Kz}$ Ss Por

$9.86804 \mathrm{e}+009.86804 \mathrm{e}+00$ 9.86804e-01 1.00000e-09 2.12000e-01

$9.86804 \mathrm{e}+009.86804 \mathrm{e}+009.86804 \mathrm{e}-01$ 1.00000e-09 2.12000e-01

$9.86804 \mathrm{e}+00$ 9.86804e+00 9.86804e-01 1.00000e-09 2.12000e-01

$9.86804 \mathrm{e}+009.86804 \mathrm{e}+00$ 9.86804e-01 1.00000e-09 2.12000e-01

$9.86804 \mathrm{e}+009.86804 \mathrm{e}+009.86804 \mathrm{e}-01$ 1.00000e-09 2.12000e-01

$1.00000 \mathrm{e}-05$ 1.00000e-05 1.00000e-06 1.00000e-09 1.00000e-01

$1.00000 \mathrm{e}+001.00000 \mathrm{e}+001.00000 \mathrm{e}-011.00000 \mathrm{e}-091.00000 \mathrm{e}-01$

Element: 10950 \# of layers: 7

Kx Ky Kz Ss Por

9.86804e+00 9.86804e+00 9.86804e-01 1.00000e-09 2.12000e-01

$9.86804 \mathrm{e}+009.86804 \mathrm{e}+009.86804 \mathrm{e}-01$ 1.00000e-09 2.12000e-01

$9.86804 \mathrm{e}+009.86804 \mathrm{e}+00$ 9.86804e-01 1.00000e-09 2.12000e-01

$9.86804 \mathrm{e}+009.86804 \mathrm{e}+009.86804 \mathrm{e}-01$ 1.00000e-09 2.12000e-01

$9.86804 \mathrm{e}+009.86804 \mathrm{e}+009.86804 \mathrm{e}-01$ 1.00000e-09 2.12000e-01

$1.00000 \mathrm{e}-05$ 1.00000e-05 1.00000e-06 1.00000e-09 1.00000e-01

$1.00000 \mathrm{e}+001.00000 \mathrm{e}+001.00000 \mathrm{e}-01$ 1.00000e-09 1.00000e-01

Element: 10951 \# of layers: 7

Kx Ky Kz Ss Por 
$9.86804 \mathrm{e}+009.86804 \mathrm{e}+00$ 9.86804e-01 1.00000e-09 2.12000e-01 9.86804e+00 9.86804e+00 9.86804e-01 1.00000e-09 2.12000e-01 $9.86804 \mathrm{e}+009.86804 \mathrm{e}+009.86804 \mathrm{e}-01$ 1.00000e-09 2.12000e-01 $9.86804 \mathrm{e}+009.86804 \mathrm{e}+009.86804 \mathrm{e}-01$ 1.00000e-09 2.12000e-01 $9.86804 \mathrm{e}+009.86804 \mathrm{e}+009.86804 \mathrm{e}-01$ 1.00000e-09 2.12000e-01 $1.00000 \mathrm{e}-05$ 1.00000e-05 1.00000e-06 1.00000e-09 1.00000e-01 $1.00000 \mathrm{e}+001.00000 \mathrm{e}+001.00000 \mathrm{e}-011.00000 \mathrm{e}-091.00000 \mathrm{e}-01$ Element: 10952 \# of layers: 7

$\mathrm{Kx} \mathrm{Ky} \mathrm{Kz}$ Ss Por

$9.86804 \mathrm{e}+009.86804 \mathrm{e}+00$ 9.86804e-01 1.00000e-09 2.12000e-01 $9.86804 \mathrm{e}+009.86804 \mathrm{e}+00$ 9.86804e-01 1.00000e-09 2.12000e-01 $9.86804 \mathrm{e}+009.86804 \mathrm{e}+00 \quad 9.86804 \mathrm{e}-01$ 1.00000e-09 2.12000e-01 $9.86804 \mathrm{e}+009.86804 \mathrm{e}+00$ 9.86804e-01 1.00000e-09 2.12000e-01 $9.86804 \mathrm{e}+009.86804 \mathrm{e}+00$ 9.86804e-01 1.00000e-09 2.12000e-01 $1.00000 \mathrm{e}-05$ 1.00000e-05 1.00000e-06 1.00000e-09 1.00000e-01 $1.00000 \mathrm{e}+001.00000 \mathrm{e}+001.00000 \mathrm{e}-011.00000 \mathrm{e}-091.00000 \mathrm{e}-01$ Element: 10953 \# of layers: 7

$\mathrm{Kx} \mathrm{Ky} \mathrm{Kz}$ Ss Por

9.86804e+00 9.86804e+00 9.86804e-01 1.00000e-09 2.12000e-01 $9.86804 \mathrm{e}+009.86804 \mathrm{e}+009.86804 \mathrm{e}-01$ 1.00000e-09 2.12000e-01 $9.86804 \mathrm{e}+009.86804 \mathrm{e}+009.86804 \mathrm{e}-01$ 1.00000e-09 2.12000e-01 $9.86804 \mathrm{e}+00$ 9.86804e+00 9.86804e-01 1.00000e-09 2.12000e-01 $9.86804 \mathrm{e}+00$ 9.86804e+00 9.86804e-01 1.00000e-09 2.12000e-01 $1.00000 \mathrm{e}-05$ 1.00000e-05 1.00000e-06 1.00000e-09 1.00000e-01 $1.00000 \mathrm{e}+001.00000 \mathrm{e}+001.00000 \mathrm{e}-011.00000 \mathrm{e}-091.00000 \mathrm{e}-01$ Element: 10954 \# of layers: 7

$\mathrm{Kx} \mathrm{Ky} \mathrm{Kz}$ Ss Por

9.86804e+00 9.86804e+00 9.86804e-01 1.00000e-09 2.12000e-01 $9.86804 \mathrm{e}+009.86804 \mathrm{e}+009.86804 \mathrm{e}-01$ 1.00000e-09 2.12000e-01 $9.86804 \mathrm{e}+00$ 9.86804e+00 9.86804e-01 1.00000e-09 2.12000e-01 $9.86804 \mathrm{e}+009.86804 \mathrm{e}+009.86804 \mathrm{e}-01$ 1.00000e-09 2.12000e-01 $9.86804 \mathrm{e}+009.86804 \mathrm{e}+00$ 9.86804e-01 1.00000e-09 2.12000e-01 $1.00000 \mathrm{e}-05$ 1.00000e-05 1.00000e-06 1.00000e-09 1.00000e-01 $1.00000 \mathrm{e}+001.00000 \mathrm{e}+001.00000 \mathrm{e}-01$ 1.00000e-09 1.00000e-01 Element: 10955 \# of layers: 7

$\mathrm{Kx} \mathrm{Ky} \mathrm{Kz}$ Ss Por

9.86804e+00 9.86804e+00 9.86804e-01 1.00000e-09 2.12000e-01 $9.86804 \mathrm{e}+009.86804 \mathrm{e}+00$ 9.86804e-01 1.00000e-09 2.12000e-01

$9.86804 \mathrm{e}+009.86804 \mathrm{e}+00$ 9.86804e-01 1.00000e-09 2.12000e-01 $9.86804 \mathrm{e}+009.86804 \mathrm{e}+00$ 9.86804e-01 1.00000e-09 2.12000e-01 $9.86804 \mathrm{e}+009.86804 \mathrm{e}+009.86804 \mathrm{e}-01$ 1.00000e-09 2.12000e-01 $1.00000 \mathrm{e}-05$ 1.00000e-05 1.00000e-06 1.00000e-09 1.00000e-01 $1.00000 \mathrm{e}+001.00000 \mathrm{e}+001.00000 \mathrm{e}-01$ 1.00000e-09 1.00000e-01 Element: 10956 \# of layers: 7

$\mathrm{Kx} \mathrm{Ky} \mathrm{Kz} \mathrm{Ss} \mathrm{Por}$

9.86804e+00 9.86804e+00 9.86804e-01 1.00000e-09 2.12000e-01 
$9.86804 \mathrm{e}+009.86804 \mathrm{e}+00$ 9.86804e-01 1.00000e-09 2.12000e-01 9.86804e+00 9.86804e+00 9.86804e-01 1.00000e-09 2.12000e-01 $9.86804 \mathrm{e}+009.86804 \mathrm{e}+009.86804 \mathrm{e}-01$ 1.00000e-09 2.12000e-01 $9.86804 \mathrm{e}+009.86804 \mathrm{e}+00$ 9.86804e-01 1.00000e-09 2.12000e-01 $1.00000 \mathrm{e}-05$ 1.00000e-05 1.00000e-06 1.00000e-09 1.00000e-01 $1.00000 \mathrm{e}+001.00000 \mathrm{e}+00$ 1.00000e-01 1.00000e-09 1.00000e-01 Element: 10957 \# of layers: 7

Kx Ky Kz Ss Por

9.86804e+00 9.86804e+00 9.86804e-01 1.00000e-09 2.12000e-01

$9.86804 \mathrm{e}+00$ 9.86804e+00 9.86804e-01 1.00000e-09 2.12000e-01

$9.86804 \mathrm{e}+009.86804 \mathrm{e}+00$ 9.86804e-01 1.00000e-09 2.12000e-01

$9.86804 \mathrm{e}+009.86804 \mathrm{e}+00 \quad 9.86804 \mathrm{e}-01$ 1.00000e-09 2.12000e-01

$9.86804 \mathrm{e}+009.86804 \mathrm{e}+009.86804 \mathrm{e}-01$ 1.00000e-09 2.12000e-01

$1.00000 \mathrm{e}-05$ 1.00000e-05 1.00000e-06 1.00000e-09 1.00000e-01

$1.00000 \mathrm{e}+001.00000 \mathrm{e}+001.00000 \mathrm{e}-01$ 1.00000e-09 1.00000e-01

Element: 10958 \# of layers: 7

$\mathrm{Kx} \mathrm{Ky} \mathrm{Kz}$ Ss Por

$9.86804 \mathrm{e}+00$ 9.86804e+00 9.86804e-01 1.00000e-09 2.12000e-01

$9.86804 \mathrm{e}+00$ 9.86804e+00 9.86804e-01 1.00000e-09 2.12000e-01

$9.86804 \mathrm{e}+009.86804 \mathrm{e}+009.86804 \mathrm{e}-01$ 1.00000e-09 2.12000e-01

$9.86804 \mathrm{e}+009.86804 \mathrm{e}+00$ 9.86804e-01 1.00000e-09 2.12000e-01

$9.86804 \mathrm{e}+00$ 9.86804e+00 9.86804e-01 1.00000e-09 2.12000e-01

$1.00000 \mathrm{e}-051.00000 \mathrm{e}-051.00000 \mathrm{e}-061.00000 \mathrm{e}-091.00000 \mathrm{e}-01$

$1.00000 \mathrm{e}+001.00000 \mathrm{e}+001.00000 \mathrm{e}-011.00000 \mathrm{e}-09$ 1.00000e-01

Element: 10959 \# of layers: 7

$\mathrm{Kx} \mathrm{Ky} \mathrm{Kz}$ Ss Por

$9.86804 \mathrm{e}+009.86804 \mathrm{e}+00$ 9.86804e-01 1.00000e-09 2.12000e-01

$9.86804 \mathrm{e}+009.86804 \mathrm{e}+00$ 9.86804e-01 1.00000e-09 2.12000e-01

$9.86804 \mathrm{e}+009.86804 \mathrm{e}+00 \quad 9.86804 \mathrm{e}-01$ 1.00000e-09 2.12000e-01

$9.86804 \mathrm{e}+009.86804 \mathrm{e}+00$ 9.86804e-01 1.00000e-09 2.12000e-01

$9.86804 \mathrm{e}+009.86804 \mathrm{e}+00$ 9.86804e-01 1.00000e-09 2.12000e-01

$1.00000 \mathrm{e}-05$ 1.00000e-05 1.00000e-06 1.00000e-09 1.00000e-01

$1.00000 \mathrm{e}+001.00000 \mathrm{e}+001.00000 \mathrm{e}-011.00000 \mathrm{e}-091.00000 \mathrm{e}-01$

Element: 10960 \# of layers: 7

$\mathrm{Kx} \mathrm{Ky} \mathrm{Kz}$ Ss Por

$1.10745 \mathrm{e}+01$ 1.10745e+01 1.10745e+00 1.00000e-09 2.12000e-01

$1.10745 \mathrm{e}+011.10745 \mathrm{e}+011.10745 \mathrm{e}+001.00000 \mathrm{e}-092.12000 \mathrm{e}-01$

$1.10745 \mathrm{e}+011.10745 \mathrm{e}+011.10745 \mathrm{e}+001.00000 \mathrm{e}-092.12000 \mathrm{e}-01$

$1.10745 \mathrm{e}+011.10745 \mathrm{e}+011.10745 \mathrm{e}+001.00000 \mathrm{e}-092.12000 \mathrm{e}-01$

$1.10745 \mathrm{e}+011.10745 \mathrm{e}+011.10745 \mathrm{e}+001.00000 \mathrm{e}-092.12000 \mathrm{e}-01$

$1.00000 \mathrm{e}-05$ 1.00000e-05 1.00000e-06 1.00000e-09 1.00000e-01

$1.00000 \mathrm{e}+001.00000 \mathrm{e}+001.00000 \mathrm{e}-011.00000 \mathrm{e}-09$ 1.00000e-01

Element: 10961 \# of layers: 7

$\mathrm{Kx} \mathrm{Ky} \mathrm{Kz}$ Ss Por

$1.10745 \mathrm{e}+01$ 1.10745e+01 1.10745e+00 1.00000e-09 2.12000e-01

$1.10745 \mathrm{e}+011.10745 \mathrm{e}+011.10745 \mathrm{e}+001.00000 \mathrm{e}-092.12000 \mathrm{e}-01$ 
$1.10745 \mathrm{e}+01$ 1.10745e+01 1.10745e+00 1.00000e-09 2.12000e-01 $1.10745 \mathrm{e}+01$ 1.10745e+01 1.10745e+00 1.00000e-09 2.12000e-01 $1.10745 \mathrm{e}+011.10745 \mathrm{e}+01$ 1.10745e+00 1.00000e-09 2.12000e-01 $1.00000 \mathrm{e}-05$ 1.00000e-05 1.00000e-06 1.00000e-09 1.00000e-01 $1.00000 \mathrm{e}+001.00000 \mathrm{e}+001.00000 \mathrm{e}-01$ 1.00000e-09 1.00000e-01 Element: 10962 \# of layers: 7

$\mathrm{Kx} \mathrm{Ky} \mathrm{Kz}$ Ss Por

$1.10745 \mathrm{e}+01$ 1.10745e+01 1.10745e+00 1.00000e-09 2.12000e-01 $1.10745 \mathrm{e}+011.10745 \mathrm{e}+01$ 1.10745e+00 1.00000e-09 2.12000e-01 $1.10745 \mathrm{e}+011.10745 \mathrm{e}+011.10745 \mathrm{e}+001.00000 \mathrm{e}-092.12000 \mathrm{e}-01$ $1.10745 \mathrm{e}+011.10745 \mathrm{e}+01$ 1.10745e+00 1.00000e-09 2.12000e-01 $1.10745 \mathrm{e}+011.10745 \mathrm{e}+011.10745 \mathrm{e}+001.00000 \mathrm{e}-092.12000 \mathrm{e}-01$ $1.00000 \mathrm{e}-05$ 1.00000e-05 1.00000e-06 1.00000e-09 1.00000e-01 $1.00000 \mathrm{e}+001.00000 \mathrm{e}+001.00000 \mathrm{e}-011.00000 \mathrm{e}-09$ 1.00000e-01 Element: 10963 \# of layers: 7

Kx Ky Kz Ss Por

$9.86804 \mathrm{e}+009.86804 \mathrm{e}+00$ 9.86804e-01 1.00000e-09 2.12000e-01

$9.86804 \mathrm{e}+00$ 9.86804e+00 9.86804e-01 1.00000e-09 2.12000e-01

$9.86804 \mathrm{e}+00$ 9.86804e+00 9.86804e-01 1.00000e-09 2.12000e-01

$9.86804 \mathrm{e}+009.86804 \mathrm{e}+00$ 9.86804e-01 1.00000e-09 2.12000e-01

$9.86804 \mathrm{e}+009.86804 \mathrm{e}+009.86804 \mathrm{e}-01$ 1.00000e-09 2.12000e-01

$1.00000 \mathrm{e}-05$ 1.00000e-05 1.00000e-06 1.00000e-09 1.00000e-01

$1.00000 \mathrm{e}+001.00000 \mathrm{e}+001.00000 \mathrm{e}-01$ 1.00000e-09 1.00000e-01 Element: 10964 \# of layers: 7

$\mathrm{Kx} \mathrm{Ky} \mathrm{Kz}$ Ss Por

9.86804e+00 9.86804e+00 9.86804e-01 1.00000e-09 2.12000e-01

$9.86804 \mathrm{e}+009.86804 \mathrm{e}+00$ 9.86804e-01 1.00000e-09 2.12000e-01

$9.86804 \mathrm{e}+009.86804 \mathrm{e}+00$ 9.86804e-01 1.00000e-09 2.12000e-01

$9.86804 \mathrm{e}+009.86804 \mathrm{e}+009.86804 \mathrm{e}-01$ 1.00000e-09 2.12000e-01

$9.86804 \mathrm{e}+00$ 9.86804e+00 9.86804e-01 1.00000e-09 2.12000e-01

$1.00000 \mathrm{e}-05$ 1.00000e-05 1.00000e-06 1.00000e-09 1.00000e-01

$1.00000 \mathrm{e}+001.00000 \mathrm{e}+001.00000 \mathrm{e}-01$ 1.00000e-09 1.00000e-01

Element: 10965 \# of layers: 7

$\mathrm{Kx} \mathrm{Ky} \mathrm{Kz}$ Ss Por

$9.86804 \mathrm{e}+009.86804 \mathrm{e}+00$ 9.86804e-01 1.00000e-09 2.12000e-01

$9.86804 \mathrm{e}+009.86804 \mathrm{e}+009.86804 \mathrm{e}-01$ 1.00000e-09 2.12000e-01

$9.86804 \mathrm{e}+009.86804 \mathrm{e}+009.86804 \mathrm{e}-01$ 1.00000e-09 2.12000e-01

$9.86804 \mathrm{e}+009.86804 \mathrm{e}+009.86804 \mathrm{e}-01$ 1.00000e-09 2.12000e-01

$9.86804 \mathrm{e}+009.86804 \mathrm{e}+00$ 9.86804e-01 1.00000e-09 2.12000e-01

$1.00000 \mathrm{e}-05$ 1.00000e-05 1.00000e-06 1.00000e-09 1.00000e-01

$1.00000 \mathrm{e}+001.00000 \mathrm{e}+001.00000 \mathrm{e}-011.00000 \mathrm{e}-091.00000 \mathrm{e}-01$

Element: 10966 \# of layers: 7

$\mathrm{Kx} \mathrm{Ky} \mathrm{Kz}$ Ss Por

$9.86804 \mathrm{e}+00$ 9.86804e+00 9.86804e-01 1.00000e-09 2.12000e-01

$9.86804 \mathrm{e}+009.86804 \mathrm{e}+009.86804 \mathrm{e}-01$ 1.00000e-09 2.12000e-01

$9.86804 \mathrm{e}+009.86804 \mathrm{e}+009.86804 \mathrm{e}-01$ 1.00000e-09 2.12000e-01 
$9.86804 \mathrm{e}+009.86804 \mathrm{e}+00$ 9.86804e-01 1.00000e-09 2.12000e-01 $9.86804 \mathrm{e}+009.86804 \mathrm{e}+00$ 9.86804e-01 1.00000e-09 2.12000e-01 $1.00000 \mathrm{e}-05$ 1.00000e-05 1.00000e-06 1.00000e-09 1.00000e-01 $1.00000 \mathrm{e}+001.00000 \mathrm{e}+001.00000 \mathrm{e}-011.00000 \mathrm{e}-091.00000 \mathrm{e}-01$ Element: 10967 \# of layers: 7

Kx Ky Kz Ss Por

$1.10745 \mathrm{e}+011.10745 \mathrm{e}+011.10745 \mathrm{e}+00$ 1.00000e-09 2.12000e-01 $1.10745 \mathrm{e}+011.10745 \mathrm{e}+011.10745 \mathrm{e}+001.00000 \mathrm{e}-092.12000 \mathrm{e}-01$ $1.10745 \mathrm{e}+011.10745 \mathrm{e}+011.10745 \mathrm{e}+00$ 1.00000e-09 2.12000e-01 $1.10745 \mathrm{e}+011.10745 \mathrm{e}+011.10745 \mathrm{e}+00$ 1.00000e-09 2.12000e-01 $1.10745 \mathrm{e}+011.10745 \mathrm{e}+011.10745 \mathrm{e}+00$ 1.00000e-09 2.12000e-01 $1.00000 \mathrm{e}-05$ 1.00000e-05 1.00000e-06 1.00000e-09 1.00000e-01 $1.00000 \mathrm{e}+001.00000 \mathrm{e}+001.00000 \mathrm{e}-011.00000 \mathrm{e}-091.00000 \mathrm{e}-01$ Element: 10968 \# of layers: 7

Kx Ky Kz Ss Por

$1.10745 \mathrm{e}+011.10745 \mathrm{e}+011.10745 \mathrm{e}+00$ 1.00000e-09 2.12000e-01 $1.10745 \mathrm{e}+011.10745 \mathrm{e}+011.10745 \mathrm{e}+00$ 1.00000e-09 2.12000e-01 $1.10745 \mathrm{e}+011.10745 \mathrm{e}+011.10745 \mathrm{e}+00$ 1.00000e-09 2.12000e-01 $1.10745 \mathrm{e}+011.10745 \mathrm{e}+011.10745 \mathrm{e}+00$ 1.00000e-09 2.12000e-01 $1.10745 \mathrm{e}+011.10745 \mathrm{e}+011.10745 \mathrm{e}+00$ 1.00000e-09 2.12000e-01 $1.00000 \mathrm{e}-05$ 1.00000e-05 1.00000e-06 1.00000e-09 1.00000e-01 $1.00000 \mathrm{e}+001.00000 \mathrm{e}+001.00000 \mathrm{e}-011.00000 \mathrm{e}-091.00000 \mathrm{e}-01$ Element: 10969 \# of layers: 7

Kx Ky Kz Ss Por

$1.10745 \mathrm{e}+011.10745 \mathrm{e}+011.10745 \mathrm{e}+00$ 1.00000e-09 2.12000e-01 $1.10745 \mathrm{e}+011.10745 \mathrm{e}+011.10745 \mathrm{e}+001.00000 \mathrm{e}-092.12000 \mathrm{e}-01$ $1.10745 \mathrm{e}+011.10745 \mathrm{e}+011.10745 \mathrm{e}+001.00000 \mathrm{e}-092.12000 \mathrm{e}-01$ $1.10745 \mathrm{e}+011.10745 \mathrm{e}+011.10745 \mathrm{e}+00$ 1.00000e-09 2.12000e-01 $1.10745 \mathrm{e}+011.10745 \mathrm{e}+011.10745 \mathrm{e}+001.00000 \mathrm{e}-092.12000 \mathrm{e}-01$ $1.00000 \mathrm{e}-05$ 1.00000e-05 1.00000e-06 1.00000e-09 1.00000e-01 $1.00000 \mathrm{e}+001.00000 \mathrm{e}+001.00000 \mathrm{e}-011.00000 \mathrm{e}-091.00000 \mathrm{e}-01$ Element: 10970 \# of layers: 7

Kx Ky Kz Ss Por

$1.10745 \mathrm{e}+011.10745 \mathrm{e}+011.10745 \mathrm{e}+00$ 1.00000e-09 2.12000e-01 $1.10745 \mathrm{e}+011.10745 \mathrm{e}+011.10745 \mathrm{e}+001.00000 \mathrm{e}-092.12000 \mathrm{e}-01$ $1.10745 \mathrm{e}+011.10745 \mathrm{e}+011.10745 \mathrm{e}+001.00000 \mathrm{e}-092.12000 \mathrm{e}-01$ $1.10745 \mathrm{e}+011.10745 \mathrm{e}+011.10745 \mathrm{e}+001.00000 \mathrm{e}-092.12000 \mathrm{e}-01$ $1.10745 \mathrm{e}+011.10745 \mathrm{e}+011.10745 \mathrm{e}+00$ 1.00000e-09 2.12000e-01 $1.00000 \mathrm{e}-05$ 1.00000e-05 1.00000e-06 1.00000e-09 1.00000e-01 $1.00000 \mathrm{e}+001.00000 \mathrm{e}+001.00000 \mathrm{e}-011.00000 \mathrm{e}-091.00000 \mathrm{e}-01$ Element: 10971 \# of layers: 7

Kx Ky Kz Ss Por

$1.10745 \mathrm{e}+011.10745 \mathrm{e}+011.10745 \mathrm{e}+00$ 1.00000e-09 2.12000e-01 $1.10745 \mathrm{e}+011.10745 \mathrm{e}+011.10745 \mathrm{e}+001.00000 \mathrm{e}-092.12000 \mathrm{e}-01$ $1.10745 \mathrm{e}+011.10745 \mathrm{e}+011.10745 \mathrm{e}+001.00000 \mathrm{e}-092.12000 \mathrm{e}-01$ $1.10745 \mathrm{e}+011.10745 \mathrm{e}+011.10745 \mathrm{e}+001.00000 \mathrm{e}-092.12000 \mathrm{e}-01$ 
$1.10745 \mathrm{e}+01$ 1.10745e+01 1.10745e+00 1.00000e-09 2.12000e-01 $1.00000 \mathrm{e}-05$ 1.00000e-05 1.00000e-06 1.00000e-09 1.00000e-01

$1.00000 \mathrm{e}+001.00000 \mathrm{e}+001.00000 \mathrm{e}-011.00000 \mathrm{e}-09$ 1.00000e-01

Element: 10972 \# of layers: 7

$\mathrm{Kx} \mathrm{Ky} \mathrm{Kz}$ Ss Por

$1.10745 \mathrm{e}+01$ 1.10745e+01 1.10745e+00 1.00000e-09 2.12000e-01

$1.10745 \mathrm{e}+011.10745 \mathrm{e}+011.10745 \mathrm{e}+001.00000 \mathrm{e}-092.12000 \mathrm{e}-01$

$1.10745 \mathrm{e}+011.10745 \mathrm{e}+011.10745 \mathrm{e}+001.00000 \mathrm{e}-092.12000 \mathrm{e}-01$

$1.10745 \mathrm{e}+011.10745 \mathrm{e}+01$ 1.10745e+00 1.00000e-09 2.12000e-01

$1.10745 \mathrm{e}+011.10745 \mathrm{e}+01$ 1.10745e+00 1.00000e-09 2.12000e-01

$1.00000 \mathrm{e}-05$ 1.00000e-05 1.00000e-06 1.00000e-09 1.00000e-01

$1.00000 \mathrm{e}+001.00000 \mathrm{e}+001.00000 \mathrm{e}-011.00000 \mathrm{e}-091.00000 \mathrm{e}-01$

Element: 10973 \# of layers: 7

$\mathrm{Kx} \mathrm{Ky} \mathrm{Kz}$ Ss Por

$1.10745 \mathrm{e}+01$ 1.10745e+01 1.10745e+00 1.00000e-09 2.12000e-01

$1.10745 \mathrm{e}+011.10745 \mathrm{e}+011.10745 \mathrm{e}+001.00000 \mathrm{e}-092.12000 \mathrm{e}-01$

$1.10745 \mathrm{e}+011.10745 \mathrm{e}+011.10745 \mathrm{e}+00$ 1.00000e-09 2.12000e-01

$1.10745 \mathrm{e}+011.10745 \mathrm{e}+011.10745 \mathrm{e}+001.00000 \mathrm{e}-092.12000 \mathrm{e}-01$

$1.10745 \mathrm{e}+01$ 1.10745e+01 1.10745e+00 1.00000e-09 2.12000e-01

$1.00000 \mathrm{e}-05$ 1.00000e-05 1.00000e-06 1.00000e-09 1.00000e-01

$1.00000 \mathrm{e}+001.00000 \mathrm{e}+001.00000 \mathrm{e}-011.00000 \mathrm{e}-091.00000 \mathrm{e}-01$

Element: 10974 \# of layers: 7

$\mathrm{Kx} \mathrm{Ky} \mathrm{Kz}$ Ss Por

1.10745e+01 1.10745e+01 1.10745e+00 1.00000e-09 2.12000e-01

$1.10745 \mathrm{e}+011.10745 \mathrm{e}+011.10745 \mathrm{e}+001.00000 \mathrm{e}-092.12000 \mathrm{e}-01$

$1.10745 \mathrm{e}+011.10745 \mathrm{e}+01$ 1.10745e+00 1.00000e-09 2.12000e-01

$1.10745 \mathrm{e}+011.10745 \mathrm{e}+01$ 1.10745e+00 1.00000e-09 2.12000e-01

$1.10745 \mathrm{e}+011.10745 \mathrm{e}+011.10745 \mathrm{e}+001.00000 \mathrm{e}-092.12000 \mathrm{e}-01$

$1.00000 \mathrm{e}-05$ 1.00000e-05 1.00000e-06 1.00000e-09 1.00000e-01

$1.00000 \mathrm{e}+001.00000 \mathrm{e}+001.00000 \mathrm{e}-011.00000 \mathrm{e}-091.00000 \mathrm{e}-01$

Element: 10975 \# of layers: 7

Kx Ky Kz Ss Por

$1.10745 \mathrm{e}+011.10745 \mathrm{e}+01$ 1.10745e+00 1.00000e-09 2.12000e-01

$1.10745 \mathrm{e}+011.10745 \mathrm{e}+011.10745 \mathrm{e}+001.00000 \mathrm{e}-092.12000 \mathrm{e}-01$

$1.10745 \mathrm{e}+011.10745 \mathrm{e}+01$ 1.10745e+00 1.00000e-09 2.12000e-01

$1.10745 \mathrm{e}+011.10745 \mathrm{e}+01$ 1.10745e+00 1.00000e-09 2.12000e-01

$1.10745 \mathrm{e}+011.10745 \mathrm{e}+011.10745 \mathrm{e}+001.00000 \mathrm{e}-092.12000 \mathrm{e}-01$

$1.00000 \mathrm{e}-05$ 1.00000e-05 1.00000e-06 1.00000e-09 1.00000e-01

$1.00000 \mathrm{e}+001.00000 \mathrm{e}+001.00000 \mathrm{e}-01$ 1.00000e-09 1.00000e-01

Element: 10976 \# of layers: 7

Kx Ky Kz Ss Por

$1.10745 \mathrm{e}+01$ 1.10745e+01 1.10745e+00 1.00000e-09 2.12000e-01

$1.10745 \mathrm{e}+01$ 1.10745e+01 1.10745e+00 1.00000e-09 2.12000e-01

$1.10745 \mathrm{e}+01$ 1.10745e+01 1.10745e+00 1.00000e-09 2.12000e-01

$1.10745 \mathrm{e}+011.10745 \mathrm{e}+01$ 1.10745e+00 1.00000e-09 2.12000e-01

$1.10745 \mathrm{e}+011.10745 \mathrm{e}+011.10745 \mathrm{e}+001.00000 \mathrm{e}-092.12000 \mathrm{e}-01$ 
$1.00000 \mathrm{e}-05$ 1.00000e-05 1.00000e-06 1.00000e-09 1.00000e-01 $1.00000 \mathrm{e}+001.00000 \mathrm{e}+001.00000 \mathrm{e}-01$ 1.00000e-09 1.00000e-01 Element: 10977 \# of layers: 7

$\mathrm{Kx} \mathrm{Ky} \mathrm{Kz}$ Ss Por

$1.20672 \mathrm{e}+011.20672 \mathrm{e}+01$ 1.20672e+00 1.00000e-09 2.12000e-01 $1.20672 \mathrm{e}+011.20672 \mathrm{e}+01$ 1.20672e+00 1.00000e-09 2.12000e-01 $1.20672 \mathrm{e}+01$ 1.20672e+01 1.20672e+00 1.00000e-09 2.12000e-01 $1.20672 \mathrm{e}+011.20672 \mathrm{e}+011.20672 \mathrm{e}+001.00000 \mathrm{e}-092.12000 \mathrm{e}-01$ $1.20672 \mathrm{e}+01$ 1.20672e+01 1.20672e+00 1.00000e-09 2.12000e-01 $1.00000 \mathrm{e}-05$ 1.00000e-05 1.00000e-06 1.00000e-09 1.00000e-01 $1.00000 \mathrm{e}+001.00000 \mathrm{e}+001.00000 \mathrm{e}-011.00000 \mathrm{e}-091.00000 \mathrm{e}-01$ Element: 10978 \# of layers: 7

$\mathrm{Kx} \mathrm{Ky} \mathrm{Kz}$ Ss Por

$1.20672 \mathrm{e}+01$ 1.20672e+01 1.20672e+00 1.00000e-09 2.12000e-01 $1.20672 \mathrm{e}+01$ 1.20672e+01 1.20672e+00 1.00000e-09 2.12000e-01 $1.20672 \mathrm{e}+01$ 1.20672e+01 1.20672e+00 1.00000e-09 2.12000e-01 $1.20672 \mathrm{e}+011.20672 \mathrm{e}+01$ 1.20672e+00 1.00000e-09 2.12000e-01 $1.20672 \mathrm{e}+01$ 1.20672e+01 1.20672e+00 1.00000e-09 2.12000e-01 $1.00000 \mathrm{e}-05$ 1.00000e-05 1.00000e-06 1.00000e-09 1.00000e-01 $1.00000 \mathrm{e}+001.00000 \mathrm{e}+001.00000 \mathrm{e}-011.00000 \mathrm{e}-09$ 1.00000e-01 Element: 10979 \# of layers: 7

$\mathrm{Kx} \mathrm{Ky} \mathrm{Kz}$ Ss Por

1.20672e+01 1.20672e+01 1.20672e+00 1.00000e-09 2.12000e-01 $1.20672 \mathrm{e}+011.20672 \mathrm{e}+011.20672 \mathrm{e}+001.00000 \mathrm{e}-092.12000 \mathrm{e}-01$ $1.20672 \mathrm{e}+011.20672 \mathrm{e}+011.20672 \mathrm{e}+001.00000 \mathrm{e}-092.12000 \mathrm{e}-01$ $1.20672 \mathrm{e}+011.20672 \mathrm{e}+01$ 1.20672e+00 1.00000e-09 2.12000e-01 $1.20672 \mathrm{e}+01$ 1.20672e+01 1.20672e+00 1.00000e-09 2.12000e-01 $1.00000 \mathrm{e}-05$ 1.00000e-05 1.00000e-06 1.00000e-09 1.00000e-01 $1.00000 \mathrm{e}+001.00000 \mathrm{e}+001.00000 \mathrm{e}-011.00000 \mathrm{e}-091.00000 \mathrm{e}-01$ Element: 10980 \# of layers: 7

$\mathrm{Kx} \mathrm{Ky} \mathrm{Kz}$ Ss Por

$1.20672 \mathrm{e}+01$ 1.20672e+01 1.20672e+00 1.00000e-09 2.12000e-01 $1.20672 \mathrm{e}+011.20672 \mathrm{e}+011.20672 \mathrm{e}+001.00000 \mathrm{e}-092.12000 \mathrm{e}-01$ $1.20672 \mathrm{e}+011.20672 \mathrm{e}+01$ 1.20672e+00 1.00000e-09 2.12000e-01 $1.20672 \mathrm{e}+01$ 1.20672e+01 1.20672e+00 1.00000e-09 2.12000e-01 $1.20672 \mathrm{e}+01$ 1.20672e+01 1.20672e+00 1.00000e-09 2.12000e-01 $1.00000 \mathrm{e}-05$ 1.00000e-05 1.00000e-06 1.00000e-09 1.00000e-01 $1.00000 \mathrm{e}+001.00000 \mathrm{e}+001.00000 \mathrm{e}-011.00000 \mathrm{e}-091.00000 \mathrm{e}-01$ Element: 10981 \# of layers: 7

$\mathrm{Kx} \mathrm{Ky} \mathrm{Kz}$ Ss Por $1.20672 \mathrm{e}+01$ 1.20672e+01 1.20672e+00 1.00000e-09 2.12000e-01 $1.20672 \mathrm{e}+01$ 1.20672e+01 1.20672e+00 1.00000e-09 2.12000e-01 $1.20672 \mathrm{e}+011.20672 \mathrm{e}+01$ 1.20672e+00 1.00000e-09 2.12000e-01 $1.20672 \mathrm{e}+01$ 1.20672e+01 1.20672e+00 1.00000e-09 2.12000e-01 $1.20672 \mathrm{e}+011.20672 \mathrm{e}+01$ 1.20672e+00 1.00000e-09 2.12000e-01 $1.00000 \mathrm{e}-05$ 1.00000e-05 1.00000e-06 1.00000e-09 1.00000e-01 
$1.00000 \mathrm{e}+001.00000 \mathrm{e}+001.00000 \mathrm{e}-011.00000 \mathrm{e}-091.00000 \mathrm{e}-01$

Element: 10982 \# of layers: 7

Kx Ky Kz Ss Por

$1.10745 \mathrm{e}+01$ 1.10745e+01 1.10745e+00 1.00000e-09 2.12000e-01

$1.10745 \mathrm{e}+011.10745 \mathrm{e}+01$ 1.10745e+00 1.00000e-09 2.12000e-01

$1.10745 \mathrm{e}+011.10745 \mathrm{e}+011.10745 \mathrm{e}+001.00000 \mathrm{e}-092.12000 \mathrm{e}-01$

$1.10745 \mathrm{e}+011.10745 \mathrm{e}+011.10745 \mathrm{e}+001.00000 \mathrm{e}-092.12000 \mathrm{e}-01$

$1.10745 \mathrm{e}+011.10745 \mathrm{e}+011.10745 \mathrm{e}+001.00000 \mathrm{e}-092.12000 \mathrm{e}-01$

$1.00000 \mathrm{e}-05$ 1.00000e-05 1.00000e-06 1.00000e-09 1.00000e-01

$1.00000 \mathrm{e}+001.00000 \mathrm{e}+001.00000 \mathrm{e}-011.00000 \mathrm{e}-091.00000 \mathrm{e}-01$

Element: 10983 \# of layers: 7

Kx Ky Kz Ss Por

$1.10745 \mathrm{e}+01$ 1.10745e+01 1.10745e+00 1.00000e-09 2.12000e-01

$1.10745 \mathrm{e}+011.10745 \mathrm{e}+011.10745 \mathrm{e}+001.00000 \mathrm{e}-092.12000 \mathrm{e}-01$

$1.10745 \mathrm{e}+011.10745 \mathrm{e}+01$ 1.10745e+00 1.00000e-09 2.12000e-01

$1.10745 \mathrm{e}+011.10745 \mathrm{e}+011.10745 \mathrm{e}+001.00000 \mathrm{e}-092.12000 \mathrm{e}-01$

$1.10745 \mathrm{e}+011.10745 \mathrm{e}+01$ 1.10745e+00 1.00000e-09 2.12000e-01

$1.00000 \mathrm{e}-05$ 1.00000e-05 1.00000e-06 1.00000e-09 1.00000e-01

$1.00000 \mathrm{e}+001.00000 \mathrm{e}+001.00000 \mathrm{e}-011.00000 \mathrm{e}-091.00000 \mathrm{e}-01$

Element: 10984 \# of layers: 7

$\mathrm{Kx} \mathrm{Ky} \mathrm{Kz}$ Ss Por

$1.20672 \mathrm{e}+01$ 1.20672e+01 1.20672e+00 1.00000e-09 2.12000e-01

$1.20672 \mathrm{e}+01$ 1.20672e+01 1.20672e+00 1.00000e-09 2.12000e-01

$1.20672 \mathrm{e}+011.20672 \mathrm{e}+011.20672 \mathrm{e}+001.00000 \mathrm{e}-092.12000 \mathrm{e}-01$

$1.20672 \mathrm{e}+011.20672 \mathrm{e}+01$ 1.20672e+00 1.00000e-09 2.12000e-01

$1.20672 \mathrm{e}+011.20672 \mathrm{e}+011.20672 \mathrm{e}+001.00000 \mathrm{e}-092.12000 \mathrm{e}-01$

$1.00000 \mathrm{e}-05$ 1.00000e-05 1.00000e-06 1.00000e-09 1.00000e-01

$1.00000 \mathrm{e}+001.00000 \mathrm{e}+001.00000 \mathrm{e}-01$ 1.00000e-09 1.00000e-01

Element: 10985 \# of layers: 7

$\mathrm{Kx} \mathrm{Ky} \mathrm{Kz}$ Ss Por

$1.20672 \mathrm{e}+01$ 1.20672e+01 1.20672e+00 1.00000e-09 2.12000e-01

$1.20672 \mathrm{e}+01$ 1.20672e+01 1.20672e+00 1.00000e-09 2.12000e-01

$1.20672 \mathrm{e}+011.20672 \mathrm{e}+01$ 1.20672e+00 1.00000e-09 2.12000e-01

$1.20672 \mathrm{e}+01$ 1.20672e+01 1.20672e+00 1.00000e-09 2.12000e-01

$1.20672 \mathrm{e}+01$ 1.20672e+01 1.20672e+00 1.00000e-09 2.12000e-01

$1.00000 \mathrm{e}-05$ 1.00000e-05 1.00000e-06 1.00000e-09 1.00000e-01

$1.00000 \mathrm{e}+001.00000 \mathrm{e}+001.00000 \mathrm{e}-011.00000 \mathrm{e}-091.00000 \mathrm{e}-01$

Element: 10986 \# of layers: 7

$\mathrm{Kx} \mathrm{Ky} \mathrm{Kz}$ Ss Por

$1.04920 \mathrm{e}+011.04920 \mathrm{e}+011.04920 \mathrm{e}+001.00000 \mathrm{e}-092.12000 \mathrm{e}-01$

$1.04920 \mathrm{e}+011.04920 \mathrm{e}+011.04920 \mathrm{e}+001.00000 \mathrm{e}-092.12000 \mathrm{e}-01$

$1.04920 \mathrm{e}+011.04920 \mathrm{e}+011.04920 \mathrm{e}+001.00000 \mathrm{e}-092.12000 \mathrm{e}-01$

$1.04920 \mathrm{e}+011.04920 \mathrm{e}+011.04920 \mathrm{e}+001.00000 \mathrm{e}-092.12000 \mathrm{e}-01$

$1.04920 \mathrm{e}+01$ 1.04920e+01 1.04920e+00 1.00000e-09 2.12000e-01

$1.00000 \mathrm{e}-05$ 1.00000e-05 1.00000e-06 1.00000e-09 1.00000e-01

$1.00000 \mathrm{e}+001.00000 \mathrm{e}+001.00000 \mathrm{e}-011.00000 \mathrm{e}-091.00000 \mathrm{e}-01$ 
Element: 10987 \# of layers: 7

Kx Ky Kz Ss Por

$1.04920 \mathrm{e}+011.04920 \mathrm{e}+011.04920 \mathrm{e}+001.00000 \mathrm{e}-092.12000 \mathrm{e}-01$

$1.04920 \mathrm{e}+011.04920 \mathrm{e}+011.04920 \mathrm{e}+001.00000 \mathrm{e}-092.12000 \mathrm{e}-01$

$1.04920 \mathrm{e}+011.04920 \mathrm{e}+011.04920 \mathrm{e}+001.00000 \mathrm{e}-092.12000 \mathrm{e}-01$

$1.04920 \mathrm{e}+011.04920 \mathrm{e}+011.04920 \mathrm{e}+001.00000 \mathrm{e}-092.12000 \mathrm{e}-01$

$1.04920 \mathrm{e}+011.04920 \mathrm{e}+011.04920 \mathrm{e}+001.00000 \mathrm{e}-092.12000 \mathrm{e}-01$

$1.00000 \mathrm{e}-05$ 1.00000e-05 1.00000e-06 1.00000e-09 1.00000e-01

$1.00000 \mathrm{e}+001.00000 \mathrm{e}+001.00000 \mathrm{e}-011.00000 \mathrm{e}-091.00000 \mathrm{e}-01$

Element: 10988 \# of layers: 7

Kx Ky Kz Ss Por

$1.04920 \mathrm{e}+011.04920 \mathrm{e}+011.04920 \mathrm{e}+001.00000 \mathrm{e}-092.12000 \mathrm{e}-01$

$1.04920 \mathrm{e}+011.04920 \mathrm{e}+011.04920 \mathrm{e}+001.00000 \mathrm{e}-092.12000 \mathrm{e}-01$

$1.04920 \mathrm{e}+011.04920 \mathrm{e}+011.04920 \mathrm{e}+001.00000 \mathrm{e}-092.12000 \mathrm{e}-01$

$1.04920 \mathrm{e}+011.04920 \mathrm{e}+011.04920 \mathrm{e}+001.00000 \mathrm{e}-092.12000 \mathrm{e}-01$

$1.04920 \mathrm{e}+011.04920 \mathrm{e}+011.04920 \mathrm{e}+001.00000 \mathrm{e}-092.12000 \mathrm{e}-01$

$1.00000 \mathrm{e}-05$ 1.00000e-05 1.00000e-06 1.00000e-09 1.00000e-01

$1.00000 \mathrm{e}+001.00000 \mathrm{e}+001.00000 \mathrm{e}-011.00000 \mathrm{e}-091.00000 \mathrm{e}-01$

Element: 10989 \# of layers: 7

Kx Ky Kz Ss Por

$9.86804 \mathrm{e}+009.86804 \mathrm{e}+00$ 9.86804e-01 1.00000e-09 2.12000e-01

$9.86804 \mathrm{e}+009.86804 \mathrm{e}+00$ 9.86804e-01 1.00000e-09 2.12000e-01

$9.86804 \mathrm{e}+009.86804 \mathrm{e}+00$ 9.86804e-01 1.00000e-09 2.12000e-01

$9.86804 \mathrm{e}+009.86804 \mathrm{e}+009.86804 \mathrm{e}-011.00000 \mathrm{e}-092.12000 \mathrm{e}-01$

$9.86804 \mathrm{e}+009.86804 \mathrm{e}+00$ 9.86804e-01 1.00000e-09 2.12000e-01

$1.00000 \mathrm{e}-05$ 1.00000e-05 1.00000e-06 1.00000e-09 1.00000e-01

$1.00000 \mathrm{e}+001.00000 \mathrm{e}+001.00000 \mathrm{e}-011.00000 \mathrm{e}-091.00000 \mathrm{e}-01$

Element: 10990 \# of layers: 7

Kx Ky Kz Ss Por

$9.86804 \mathrm{e}+009.86804 \mathrm{e}+00$ 9.86804e-01 1.00000e-09 2.12000e-01

$9.86804 \mathrm{e}+009.86804 \mathrm{e}+009.86804 \mathrm{e}-011.00000 \mathrm{e}-092.12000 \mathrm{e}-01$

$9.86804 \mathrm{e}+009.86804 \mathrm{e}+00$ 9.86804e-01 1.00000e-09 2.12000e-01

$9.86804 \mathrm{e}+009.86804 \mathrm{e}+009.86804 \mathrm{e}-01$ 1.00000e-09 2.12000e-01

$9.86804 \mathrm{e}+009.86804 \mathrm{e}+00$ 9.86804e-01 1.00000e-09 2.12000e-01

$1.00000 \mathrm{e}-05$ 1.00000e-05 1.00000e-06 1.00000e-09 1.00000e-01

$1.00000 \mathrm{e}+001.00000 \mathrm{e}+001.00000 \mathrm{e}-011.00000 \mathrm{e}-091.00000 \mathrm{e}-01$

Element: 10991 \# of layers: 7

Kx Ky Kz Ss Por

$1.10745 \mathrm{e}+011.10745 \mathrm{e}+011.10745 \mathrm{e}+00$ 1.00000e-09 2.12000e-01

$1.10745 \mathrm{e}+011.10745 \mathrm{e}+011.10745 \mathrm{e}+001.00000 \mathrm{e}-092.12000 \mathrm{e}-01$

$1.10745 \mathrm{e}+011.10745 \mathrm{e}+011.10745 \mathrm{e}+001.00000 \mathrm{e}-092.12000 \mathrm{e}-01$

$1.10745 \mathrm{e}+011.10745 \mathrm{e}+011.10745 \mathrm{e}+001.00000 \mathrm{e}-092.12000 \mathrm{e}-01$

$1.10745 \mathrm{e}+011.10745 \mathrm{e}+011.10745 \mathrm{e}+00$ 1.00000e-09 2.12000e-01

$1.00000 \mathrm{e}-05$ 1.00000e-05 1.00000e-06 1.00000e-09 1.00000e-01

$1.00000 \mathrm{e}+001.00000 \mathrm{e}+001.00000 \mathrm{e}-011.00000 \mathrm{e}-091.00000 \mathrm{e}-01$

Element: 10992 \# of layers: 7 
$\mathrm{Kx} \mathrm{Ky} \mathrm{Kz}$ Ss Por

$1.20672 \mathrm{e}+01$ 1.20672e+01 1.20672e+00 1.00000e-09 2.12000e-01

$1.20672 \mathrm{e}+011.20672 \mathrm{e}+011.20672 \mathrm{e}+001.00000 \mathrm{e}-092.12000 \mathrm{e}-01$

$1.20672 \mathrm{e}+01$ 1.20672e+01 1.20672e+00 1.00000e-09 2.12000e-01

$1.20672 \mathrm{e}+011.20672 \mathrm{e}+011.20672 \mathrm{e}+001.00000 \mathrm{e}-092.12000 \mathrm{e}-01$

$1.20672 \mathrm{e}+011.20672 \mathrm{e}+01$ 1.20672e+00 1.00000e-09 2.12000e-01

$1.00000 \mathrm{e}-05$ 1.00000e-05 1.00000e-06 1.00000e-09 1.00000e-01

$1.00000 \mathrm{e}+001.00000 \mathrm{e}+001.00000 \mathrm{e}-01$ 1.00000e-09 1.00000e-01

Element: 10993 \# of layers: 7

$\mathrm{Kx} \mathrm{Ky} \mathrm{Kz}$ Ss Por

$1.04920 \mathrm{e}+011.04920 \mathrm{e}+011.04920 \mathrm{e}+001.00000 \mathrm{e}-092.12000 \mathrm{e}-01$

$1.04920 \mathrm{e}+011.04920 \mathrm{e}+011.04920 \mathrm{e}+001.00000 \mathrm{e}-092.12000 \mathrm{e}-01$

$1.04920 \mathrm{e}+011.04920 \mathrm{e}+011.04920 \mathrm{e}+001.00000 \mathrm{e}-092.12000 \mathrm{e}-01$

$1.04920 \mathrm{e}+011.04920 \mathrm{e}+011.04920 \mathrm{e}+001.00000 \mathrm{e}-092.12000 \mathrm{e}-01$

$1.04920 \mathrm{e}+011.04920 \mathrm{e}+011.04920 \mathrm{e}+001.00000 \mathrm{e}-092.12000 \mathrm{e}-01$

$1.00000 \mathrm{e}-05$ 1.00000e-05 1.00000e-06 1.00000e-09 1.00000e-01

$1.00000 \mathrm{e}+001.00000 \mathrm{e}+001.00000 \mathrm{e}-011.00000 \mathrm{e}-091.00000 \mathrm{e}-01$

Element: 10994 \# of layers: 7

$\mathrm{Kx} \mathrm{Ky} \mathrm{Kz}$ Ss Por

$1.10579 \mathrm{e}+01$ 1.10579e+01 1.10579e+00 1.00000e-09 2.12000e-01

$1.10579 \mathrm{e}+01$ 1.10579e+01 1.10579e+00 1.00000e-09 2.12000e-01

$1.10579 \mathrm{e}+01$ 1.10579e+01 1.10579e+00 1.00000e-09 2.12000e-01

$1.10579 \mathrm{e}+01$ 1.10579e+01 1.10579e+00 1.00000e-09 2.12000e-01

$1.10579 \mathrm{e}+01$ 1.10579e+01 1.10579e+00 1.00000e-09 2.12000e-01

$1.00000 \mathrm{e}-05$ 1.00000e-05 1.00000e-06 1.00000e-09 1.00000e-01

$1.00000 \mathrm{e}+001.00000 \mathrm{e}+001.00000 \mathrm{e}-01$ 1.00000e-09 1.00000e-01

Element: 10995 \# of layers: 7

$\mathrm{Kx} \mathrm{Ky} \mathrm{Kz}$ Ss Por

$1.10579 \mathrm{e}+01$ 1.10579e+01 1.10579e+00 1.00000e-09 2.12000e-01

$1.10579 \mathrm{e}+01$ 1.10579e+01 1.10579e+00 1.00000e-09 2.12000e-01

$1.10579 \mathrm{e}+01$ 1.10579e+01 1.10579e+00 1.00000e-09 2.12000e-01

$1.10579 \mathrm{e}+01$ 1.10579e+01 1.10579e+00 1.00000e-09 2.12000e-01

$1.10579 \mathrm{e}+011.10579 \mathrm{e}+011.10579 \mathrm{e}+001.00000 \mathrm{e}-092.12000 \mathrm{e}-01$

$1.00000 \mathrm{e}-051.00000 \mathrm{e}-051.00000 \mathrm{e}-061.00000 \mathrm{e}-091.00000 \mathrm{e}-01$

$1.00000 \mathrm{e}+001.00000 \mathrm{e}+001.00000 \mathrm{e}-01$ 1.00000e-09 1.00000e-01

Element: 10996 \# of layers: 7

Kx Ky Kz Ss Por

$1.10579 \mathrm{e}+01$ 1.10579e+01 1.10579e+00 1.00000e-09 2.12000e-01

$1.10579 \mathrm{e}+01$ 1.10579e+01 1.10579e+00 1.00000e-09 2.12000e-01

$1.10579 \mathrm{e}+01$ 1.10579e+01 1.10579e+00 1.00000e-09 2.12000e-01

$1.10579 \mathrm{e}+01$ 1.10579e+01 1.10579e+00 1.00000e-09 2.12000e-01

$1.10579 \mathrm{e}+01$ 1.10579e+01 1.10579e+00 1.00000e-09 2.12000e-01

$1.00000 \mathrm{e}-051.00000 \mathrm{e}-051.00000 \mathrm{e}-061.00000 \mathrm{e}-091.00000 \mathrm{e}-01$

$1.00000 \mathrm{e}+001.00000 \mathrm{e}+001.00000 \mathrm{e}-01$ 1.00000e-09 1.00000e-01

Element: 10997 \# of layers: 7

Kx Ky Kz Ss Por 
1.10579e+01 1.10579e+01 1.10579e+00 1.00000e-09 2.12000e-01 $1.10579 \mathrm{e}+01$ 1.10579e+01 1.10579e+00 1.00000e-09 2.12000e-01 $1.10579 \mathrm{e}+01$ 1.10579e+01 1.10579e+00 1.00000e-09 2.12000e-01 $1.10579 \mathrm{e}+01$ 1.10579e+01 1.10579e+00 1.00000e-09 2.12000e-01 $1.10579 \mathrm{e}+01$ 1.10579e+01 1.10579e+00 1.00000e-09 2.12000e-01 $1.00000 \mathrm{e}-051.00000 \mathrm{e}-05$ 1.00000e-06 1.00000e-09 1.00000e-01 $1.00000 \mathrm{e}+001.00000 \mathrm{e}+001.00000 \mathrm{e}-01$ 1.00000e-09 1.00000e-01 Element: 10998 \# of layers: 7

$\mathrm{Kx} \mathrm{Ky} \mathrm{Kz}$ Ss Por

$1.10579 \mathrm{e}+01$ 1.10579e+01 1.10579e+00 1.00000e-09 2.12000e-01 $1.10579 \mathrm{e}+01$ 1.10579e+01 1.10579e+00 1.00000e-09 2.12000e-01 $1.10579 \mathrm{e}+011.10579 \mathrm{e}+011.10579 \mathrm{e}+001.00000 \mathrm{e}-092.12000 \mathrm{e}-01$ $1.10579 \mathrm{e}+01$ 1.10579e+01 1.10579e+00 1.00000e-09 2.12000e-01 $1.10579 \mathrm{e}+01$ 1.10579e+01 1.10579e+00 1.00000e-09 2.12000e-01 $1.00000 \mathrm{e}-05$ 1.00000e-05 1.00000e-06 1.00000e-09 1.00000e-01 $1.00000 \mathrm{e}+001.00000 \mathrm{e}+001.00000 \mathrm{e}-011.00000 \mathrm{e}-091.00000 \mathrm{e}-01$ Element: 10999 \# of layers: 7

$\mathrm{Kx} \mathrm{Ky} \mathrm{Kz}$ Ss Por

1.10579e+01 1.10579e+01 1.10579e+00 1.00000e-09 2.12000e-01 $1.10579 \mathrm{e}+01$ 1.10579e+01 1.10579e+00 1.00000e-09 2.12000e-01 $1.10579 \mathrm{e}+01$ 1.10579e+01 1.10579e+00 1.00000e-09 2.12000e-01 $1.10579 \mathrm{e}+01$ 1.10579e+01 1.10579e+00 1.00000e-09 2.12000e-01 $1.10579 \mathrm{e}+01$ 1.10579e+01 1.10579e+00 1.00000e-09 2.12000e-01 $1.00000 \mathrm{e}-05$ 1.00000e-05 1.00000e-06 1.00000e-09 1.00000e-01 $1.00000 \mathrm{e}+001.00000 \mathrm{e}+001.00000 \mathrm{e}-011.00000 \mathrm{e}-091.00000 \mathrm{e}-01$ Element: 11000 \# of layers: 7

$\mathrm{Kx} \mathrm{Ky} \mathrm{Kz}$ Ss Por

$1.10579 \mathrm{e}+01$ 1.10579e+01 1.10579e+00 1.00000e-09 2.12000e-01 $1.10579 \mathrm{e}+01$ 1.10579e+01 1.10579e+00 1.00000e-09 2.12000e-01 $1.10579 \mathrm{e}+01$ 1.10579e+01 1.10579e+00 1.00000e-09 2.12000e-01 $1.10579 \mathrm{e}+01$ 1.10579e+01 1.10579e+00 1.00000e-09 2.12000e-01 $1.10579 \mathrm{e}+01$ 1.10579e+01 1.10579e+00 1.00000e-09 2.12000e-01 $1.00000 \mathrm{e}-05$ 1.00000e-05 1.00000e-06 1.00000e-09 1.00000e-01 $1.00000 \mathrm{e}+001.00000 \mathrm{e}+001.00000 \mathrm{e}-011.00000 \mathrm{e}-091.00000 \mathrm{e}-01$ Element: 11001 \# of layers: 7

$\mathrm{Kx} \mathrm{Ky} \mathrm{Kz}$ Ss Por

$1.10579 \mathrm{e}+01$ 1.10579e+01 1.10579e+00 1.00000e-09 2.12000e-01 $1.10579 \mathrm{e}+01$ 1.10579e+01 1.10579e+00 1.00000e-09 2.12000e-01 $1.10579 \mathrm{e}+01$ 1.10579e+01 1.10579e+00 1.00000e-09 2.12000e-01 $1.10579 \mathrm{e}+01$ 1.10579e+01 1.10579e+00 1.00000e-09 2.12000e-01 $1.10579 \mathrm{e}+01$ 1.10579e+01 1.10579e+00 1.00000e-09 2.12000e-01 $1.00000 \mathrm{e}-05$ 1.00000e-05 1.00000e-06 1.00000e-09 1.00000e-01 $1.00000 \mathrm{e}+001.00000 \mathrm{e}+001.00000 \mathrm{e}-011.00000 \mathrm{e}-091.00000 \mathrm{e}-01$ Element: 11002 \# of layers: 7

$\mathrm{Kx} \mathrm{Ky} \mathrm{Kz}$ Ss Por

$1.10579 \mathrm{e}+01$ 1.10579e+01 1.10579e+00 1.00000e-09 2.12000e-01 
1.10579e+01 1.10579e+01 1.10579e+00 1.00000e-09 2.12000e-01 $1.10579 \mathrm{e}+01$ 1.10579e+01 1.10579e+00 1.00000e-09 2.12000e-01 $1.10579 \mathrm{e}+01$ 1.10579e+01 1.10579e+00 1.00000e-09 2.12000e-01 $1.10579 \mathrm{e}+01$ 1.10579e+01 1.10579e+00 1.00000e-09 2.12000e-01 $1.00000 \mathrm{e}-05$ 1.00000e-05 1.00000e-06 1.00000e-09 1.00000e-01 $1.00000 \mathrm{e}+001.00000 \mathrm{e}+001.00000 \mathrm{e}-01$ 1.00000e-09 1.00000e-01 Element: 11003 \# of layers: 7

Kx Ky Kz Ss Por

$1.10579 \mathrm{e}+01$ 1.10579e+01 1.10579e+00 1.00000e-09 2.12000e-01 $1.10579 \mathrm{e}+01$ 1.10579e+01 1.10579e+00 1.00000e-09 2.12000e-01 $1.10579 \mathrm{e}+01$ 1.10579e+01 1.10579e+00 1.00000e-09 2.12000e-01 $1.10579 \mathrm{e}+01$ 1.10579e+01 1.10579e+00 1.00000e-09 2.12000e-01 $1.10579 \mathrm{e}+01$ 1.10579e+01 1.10579e+00 1.00000e-09 2.12000e-01 $1.00000 \mathrm{e}-05$ 1.00000e-05 1.00000e-06 1.00000e-09 1.00000e-01 $1.00000 \mathrm{e}+001.00000 \mathrm{e}+001.00000 \mathrm{e}-01$ 1.00000e-09 1.00000e-01 Element: 11004 \# of layers: 7

$\mathrm{Kx} \mathrm{Ky} \mathrm{Kz}$ Ss Por

5.85035e+00 5.85035e+00 5.85035e-01 1.00000e-09 2.12000e-01 $5.85035 \mathrm{e}+00$ 5.85035e+00 5.85035e-01 1.00000e-09 2.12000e-01 $5.85035 \mathrm{e}+005.85035 \mathrm{e}+00$ 5.85035e-01 1.00000e-09 2.12000e-01 $5.85035 \mathrm{e}+00$ 5.85035e+00 5.85035e-01 1.00000e-09 2.12000e-01 $5.85035 \mathrm{e}+00$ 5.85035e+00 5.85035e-01 1.00000e-09 2.12000e-01 $1.00000 \mathrm{e}-05$ 1.00000e-05 1.00000e-06 1.00000e-09 1.00000e-01 $1.00000 \mathrm{e}+001.00000 \mathrm{e}+001.00000 \mathrm{e}-011.00000 \mathrm{e}-09$ 1.00000e-01 Element: 11005 \# of layers: 7

$\mathrm{Kx} \mathrm{Ky} \mathrm{Kz}$ Ss Por

5.85035e+00 5.85035e+00 5.85035e-01 1.00000e-09 2.12000e-01 $5.85035 \mathrm{e}+00$ 5.85035e+00 5.85035e-01 1.00000e-09 2.12000e-01 $5.85035 \mathrm{e}+00$ 5.85035e+00 5.85035e-01 1.00000e-09 2.12000e-01 $5.85035 \mathrm{e}+00$ 5.85035e+00 5.85035e-01 1.00000e-09 2.12000e-01 $5.85035 \mathrm{e}+00$ 5.85035e+00 5.85035e-01 1.00000e-09 2.12000e-01 1.00000e-05 1.00000e-05 1.00000e-06 1.00000e-09 1.00000e-01 $1.00000 \mathrm{e}+001.00000 \mathrm{e}+001.00000 \mathrm{e}-011.00000 \mathrm{e}-091.00000 \mathrm{e}-01$ Element: 11006 \# of layers: 7

$\mathrm{Kx} \mathrm{Ky} \mathrm{Kz}$ Ss Por

5.85035e+00 5.85035e+00 5.85035e-01 1.00000e-09 2.12000e-01 $5.85035 \mathrm{e}+005.85035 \mathrm{e}+00$ 5.85035e-01 1.00000e-09 2.12000e-01 $5.85035 \mathrm{e}+005.85035 \mathrm{e}+00$ 5.85035e-01 1.00000e-09 2.12000e-01 $5.85035 \mathrm{e}+00$ 5.85035e+00 5.85035e-01 1.00000e-09 2.12000e-01 $5.85035 \mathrm{e}+00$ 5.85035e+00 5.85035e-01 1.00000e-09 2.12000e-01 $1.00000 \mathrm{e}-05$ 1.00000e-05 1.00000e-06 1.00000e-09 1.00000e-01 $1.00000 \mathrm{e}+001.00000 \mathrm{e}+001.00000 \mathrm{e}-011.00000 \mathrm{e}-091.00000 \mathrm{e}-01$ Element: 11007 \# of layers: 7

$\mathrm{Kx} \mathrm{Ky} \mathrm{Kz}$ Ss Por 5.85035e+00 5.85035e+00 5.85035e-01 1.00000e-09 2.12000e-01 $5.85035 \mathrm{e}+00$ 5.85035e+00 5.85035e-01 1.00000e-09 2.12000e-01 
$5.85035 \mathrm{e}+00$ 5.85035e+00 5.85035e-01 1.00000e-09 2.12000e-01 $5.85035 \mathrm{e}+005.85035 \mathrm{e}+00$ 5.85035e-01 1.00000e-09 2.12000e-01 $5.85035 \mathrm{e}+005.85035 \mathrm{e}+00$ 5.85035e-01 1.00000e-09 2.12000e-01 $1.00000 \mathrm{e}-05$ 1.00000e-05 1.00000e-06 1.00000e-09 1.00000e-01 $1.00000 \mathrm{e}+001.00000 \mathrm{e}+001.00000 \mathrm{e}-011.00000 \mathrm{e}-091.00000 \mathrm{e}-01$ Element: 11008 \# of layers: 7

Kx Ky Kz Ss Por

$5.85035 \mathrm{e}+00$ 5.85035e+00 5.85035e-01 1.00000e-09 2.12000e-01 $5.85035 \mathrm{e}+005.85035 \mathrm{e}+005.85035 \mathrm{e}-011.00000 \mathrm{e}-092.12000 \mathrm{e}-01$ $5.85035 \mathrm{e}+005.85035 \mathrm{e}+00$ 5.85035e-01 1.00000e-09 2.12000e-01 $5.85035 \mathrm{e}+005.85035 \mathrm{e}+00$ 5.85035e-01 1.00000e-09 2.12000e-01 $5.85035 \mathrm{e}+00$ 5.85035e+00 5.85035e-01 1.00000e-09 2.12000e-01 $1.00000 \mathrm{e}-05$ 1.00000e-05 1.00000e-06 1.00000e-09 1.00000e-01 $1.00000 \mathrm{e}+001.00000 \mathrm{e}+001.00000 \mathrm{e}-011.00000 \mathrm{e}-091.00000 \mathrm{e}-01$ Element: 11009 \# of layers: 7

Kx Ky Kz Ss Por

$1.10579 \mathrm{e}+011.10579 \mathrm{e}+01$ 1.10579e+00 1.00000e-09 2.12000e-01 $1.10579 \mathrm{e}+011.10579 \mathrm{e}+011.10579 \mathrm{e}+00$ 1.00000e-09 2.12000e-01 $1.10579 \mathrm{e}+011.10579 \mathrm{e}+011.10579 \mathrm{e}+00$ 1.00000e-09 2.12000e-01 $1.10579 \mathrm{e}+011.10579 \mathrm{e}+011.10579 \mathrm{e}+00$ 1.00000e-09 2.12000e-01 $1.10579 \mathrm{e}+011.10579 \mathrm{e}+011.10579 \mathrm{e}+001.00000 \mathrm{e}-092.12000 \mathrm{e}-01$ $1.00000 \mathrm{e}-05$ 1.00000e-05 1.00000e-06 1.00000e-09 1.00000e-01 $1.00000 \mathrm{e}+001.00000 \mathrm{e}+001.00000 \mathrm{e}-011.00000 \mathrm{e}-091.00000 \mathrm{e}-01$ Element: 11010 \# of layers: 7

Kx Ky Kz Ss Por

$1.10579 \mathrm{e}+011.10579 \mathrm{e}+011.10579 \mathrm{e}+00$ 1.00000e-09 2.12000e-01 $1.10579 \mathrm{e}+011.10579 \mathrm{e}+011.10579 \mathrm{e}+00$ 1.00000e-09 2.12000e-01 $1.10579 \mathrm{e}+011.10579 \mathrm{e}+011.10579 \mathrm{e}+00$ 1.00000e-09 2.12000e-01 $1.10579 \mathrm{e}+011.10579 \mathrm{e}+011.10579 \mathrm{e}+001.00000 \mathrm{e}-092.12000 \mathrm{e}-01$ $1.10579 \mathrm{e}+011.10579 \mathrm{e}+011.10579 \mathrm{e}+00$ 1.00000e-09 2.12000e-01 $1.00000 \mathrm{e}-05$ 1.00000e-05 1.00000e-06 1.00000e-09 1.00000e-01 $1.00000 \mathrm{e}+001.00000 \mathrm{e}+001.00000 \mathrm{e}-011.00000 \mathrm{e}-091.00000 \mathrm{e}-01$ Element: 11011 \# of layers: 7

Kx Ky Kz Ss Por

$5.85035 \mathrm{e}+00$ 5.85035e+00 5.85035e-01 1.00000e-09 2.12000e-01 $5.85035 \mathrm{e}+005.85035 \mathrm{e}+00$ 5.85035e-01 1.00000e-09 2.12000e-01 $5.85035 \mathrm{e}+005.85035 \mathrm{e}+00$ 5.85035e-01 1.00000e-09 2.12000e-01 $5.85035 \mathrm{e}+005.85035 \mathrm{e}+00$ 5.85035e-01 1.00000e-09 2.12000e-01 $5.85035 \mathrm{e}+005.85035 \mathrm{e}+00$ 5.85035e-01 1.00000e-09 2.12000e-01 $1.00000 \mathrm{e}-05$ 1.00000e-05 1.00000e-06 1.00000e-09 1.00000e-01 $1.00000 \mathrm{e}+001.00000 \mathrm{e}+001.00000 \mathrm{e}-011.00000 \mathrm{e}-091.00000 \mathrm{e}-01$ Element: 11012 \# of layers: 7

Kx Ky Kz Ss Por

$5.85035 \mathrm{e}+00$ 5.85035e+00 5.85035e-01 1.00000e-09 2.12000e-01 $5.85035 \mathrm{e}+005.85035 \mathrm{e}+00$ 5.85035e-01 1.00000e-09 2.12000e-01 $5.85035 \mathrm{e}+005.85035 \mathrm{e}+00$ 5.85035e-01 1.00000e-09 2.12000e-01 
$5.85035 \mathrm{e}+00$ 5.85035e+00 5.85035e-01 1.00000e-09 2.12000e-01 $5.85035 \mathrm{e}+005.85035 \mathrm{e}+00$ 5.85035e-01 1.00000e-09 2.12000e-01 $1.00000 \mathrm{e}-05$ 1.00000e-05 1.00000e-06 1.00000e-09 1.00000e-01 $1.00000 \mathrm{e}+001.00000 \mathrm{e}+001.00000 \mathrm{e}-011.00000 \mathrm{e}-091.00000 \mathrm{e}-01$ Element: 11013 \# of layers: 7

Kx Ky Kz Ss Por

$5.85035 \mathrm{e}+00$ 5.85035e+00 5.85035e-01 1.00000e-09 2.12000e-01 $5.85035 \mathrm{e}+005.85035 \mathrm{e}+00$ 5.85035e-01 1.00000e-09 2.12000e-01 $5.85035 \mathrm{e}+005.85035 \mathrm{e}+00$ 5.85035e-01 1.00000e-09 2.12000e-01 $5.85035 \mathrm{e}+005.85035 \mathrm{e}+00$ 5.85035e-01 1.00000e-09 2.12000e-01 $5.85035 \mathrm{e}+00$ 5.85035e+00 5.85035e-01 1.00000e-09 2.12000e-01 $1.00000 \mathrm{e}-05$ 1.00000e-05 1.00000e-06 1.00000e-09 1.00000e-01 $1.00000 \mathrm{e}+001.00000 \mathrm{e}+001.00000 \mathrm{e}-011.00000 \mathrm{e}-091.00000 \mathrm{e}-01$ Element: 11014 \# of layers: 7

Kx Ky Kz Ss Por

$5.85035 \mathrm{e}+00$ 5.85035e+00 5.85035e-01 1.00000e-09 2.12000e-01 $5.85035 \mathrm{e}+005.85035 \mathrm{e}+00$ 5.85035e-01 1.00000e-09 2.12000e-01 $5.85035 \mathrm{e}+005.85035 \mathrm{e}+00$ 5.85035e-01 1.00000e-09 2.12000e-01 $5.85035 \mathrm{e}+005.85035 \mathrm{e}+00$ 5.85035e-01 1.00000e-09 2.12000e-01 $5.85035 \mathrm{e}+00$ 5.85035e+00 5.85035e-01 1.00000e-09 2.12000e-01 $1.00000 \mathrm{e}-05$ 1.00000e-05 1.00000e-06 1.00000e-09 1.00000e-01 $1.00000 \mathrm{e}+001.00000 \mathrm{e}+001.00000 \mathrm{e}-011.00000 \mathrm{e}-091.00000 \mathrm{e}-01$ Element: 11015 \# of layers: 7

Kx Ky Kz Ss Por

5.85035e+00 5.85035e+00 5.85035e-01 1.00000e-09 2.12000e-01 $5.85035 \mathrm{e}+005.85035 \mathrm{e}+00$ 5.85035e-01 1.00000e-09 2.12000e-01 $5.85035 \mathrm{e}+005.85035 \mathrm{e}+00$ 5.85035e-01 1.00000e-09 2.12000e-01 $5.85035 \mathrm{e}+005.85035 \mathrm{e}+00$ 5.85035e-01 1.00000e-09 2.12000e-01 $5.85035 \mathrm{e}+005.85035 \mathrm{e}+00$ 5.85035e-01 1.00000e-09 2.12000e-01 $1.00000 \mathrm{e}-05$ 1.00000e-05 1.00000e-06 1.00000e-09 1.00000e-01 $1.00000 \mathrm{e}+001.00000 \mathrm{e}+001.00000 \mathrm{e}-011.00000 \mathrm{e}-091.00000 \mathrm{e}-01$ Element: 11016 \# of layers: 7

Kx Ky Kz Ss Por

$5.85035 \mathrm{e}+00$ 5.85035e+00 5.85035e-01 1.00000e-09 2.12000e-01 $5.85035 \mathrm{e}+005.85035 \mathrm{e}+005.85035 \mathrm{e}-011.00000 \mathrm{e}-092.12000 \mathrm{e}-01$ $5.85035 \mathrm{e}+005.85035 \mathrm{e}+00$ 5.85035e-01 1.00000e-09 2.12000e-01 $5.85035 \mathrm{e}+005.85035 \mathrm{e}+00$ 5.85035e-01 1.00000e-09 2.12000e-01 $5.85035 \mathrm{e}+005.85035 \mathrm{e}+00$ 5.85035e-01 1.00000e-09 2.12000e-01 $1.00000 \mathrm{e}-05$ 1.00000e-05 1.00000e-06 1.00000e-09 1.00000e-01 $1.00000 \mathrm{e}+001.00000 \mathrm{e}+001.00000 \mathrm{e}-011.00000 \mathrm{e}-091.00000 \mathrm{e}-01$ Element: 11017 \# of layers: 7

$\mathrm{Kx} \mathrm{Ky} \mathrm{Kz}$ Ss Por

5.85035e+00 5.85035e+00 5.85035e-01 1.00000e-09 2.12000e-01 5.85035e+00 5.85035e+00 5.85035e-01 1.00000e-09 2.12000e-01 $5.85035 \mathrm{e}+005.85035 \mathrm{e}+00$ 5.85035e-01 1.00000e-09 2.12000e-01 $5.85035 \mathrm{e}+00$ 5.85035e+00 5.85035e-01 1.00000e-09 2.12000e-01 
$5.85035 \mathrm{e}+00$ 5.85035e+00 5.85035e-01 1.00000e-09 2.12000e-01 $1.00000 \mathrm{e}-05$ 1.00000e-05 1.00000e-06 1.00000e-09 1.00000e-01 $1.00000 \mathrm{e}+001.00000 \mathrm{e}+001.00000 \mathrm{e}-011.00000 \mathrm{e}-091.00000 \mathrm{e}-01$ Element: 11018 \# of layers: 7

Kx Ky Kz Ss Por

$5.85035 \mathrm{e}+00$ 5.85035e+00 5.85035e-01 1.00000e-09 2.12000e-01

$5.85035 \mathrm{e}+005.85035 \mathrm{e}+005.85035 \mathrm{e}-011.00000 \mathrm{e}-092.12000 \mathrm{e}-01$

$5.85035 \mathrm{e}+005.85035 \mathrm{e}+00$ 5.85035e-01 1.00000e-09 2.12000e-01

$5.85035 \mathrm{e}+005.85035 \mathrm{e}+005.85035 \mathrm{e}-011.00000 \mathrm{e}-092.12000 \mathrm{e}-01$

$5.85035 \mathrm{e}+00$ 5.85035e+00 5.85035e-01 1.00000e-09 2.12000e-01

$1.00000 \mathrm{e}-05$ 1.00000e-05 1.00000e-06 1.00000e-09 1.00000e-01

$1.00000 \mathrm{e}+001.00000 \mathrm{e}+001.00000 \mathrm{e}-011.00000 \mathrm{e}-091.00000 \mathrm{e}-01$

Element: 11019 \# of layers: 7

Kx Ky Kz Ss Por

$5.85035 \mathrm{e}+005.85035 \mathrm{e}+00$ 5.85035e-01 1.00000e-09 2.12000e-01

$5.85035 \mathrm{e}+005.85035 \mathrm{e}+00$ 5.85035e-01 1.00000e-09 2.12000e-01

$5.85035 \mathrm{e}+005.85035 \mathrm{e}+00$ 5.85035e-01 1.00000e-09 2.12000e-01

$5.85035 \mathrm{e}+005.85035 \mathrm{e}+005.85035 \mathrm{e}-011.00000 \mathrm{e}-092.12000 \mathrm{e}-01$

$5.85035 \mathrm{e}+005.85035 \mathrm{e}+00$ 5.85035e-01 1.00000e-09 2.12000e-01 $1.00000 \mathrm{e}-05$ 1.00000e-05 1.00000e-06 1.00000e-09 1.00000e-01

$1.00000 \mathrm{e}+001.00000 \mathrm{e}+001.00000 \mathrm{e}-011.00000 \mathrm{e}-091.00000 \mathrm{e}-01$ Element: 11020 \# of layers: 7

Kx Ky Kz Ss Por

$5.85035 \mathrm{e}+00$ 5.85035e+00 5.85035e-01 1.00000e-09 2.12000e-01

$5.85035 \mathrm{e}+005.85035 \mathrm{e}+00$ 5.85035e-01 1.00000e-09 2.12000e-01

$5.85035 \mathrm{e}+005.85035 \mathrm{e}+00$ 5.85035e-01 1.00000e-09 2.12000e-01

$5.85035 \mathrm{e}+005.85035 \mathrm{e}+00$ 5.85035e-01 1.00000e-09 2.12000e-01

$5.85035 \mathrm{e}+005.85035 \mathrm{e}+00$ 5.85035e-01 1.00000e-09 2.12000e-01

$1.00000 \mathrm{e}-05$ 1.00000e-05 1.00000e-06 1.00000e-09 1.00000e-01

$1.00000 \mathrm{e}+001.00000 \mathrm{e}+001.00000 \mathrm{e}-011.00000 \mathrm{e}-091.00000 \mathrm{e}-01$

Element: 11021 \# of layers: 7

Kx Ky Kz Ss Por

$5.85035 \mathrm{e}+005.85035 \mathrm{e}+00$ 5.85035e-01 1.00000e-09 2.12000e-01

$5.85035 \mathrm{e}+005.85035 \mathrm{e}+00$ 5.85035e-01 1.00000e-09 2.12000e-01

$5.85035 \mathrm{e}+005.85035 \mathrm{e}+005.85035 \mathrm{e}-011.00000 \mathrm{e}-092.12000 \mathrm{e}-01$

$5.85035 \mathrm{e}+005.85035 \mathrm{e}+00$ 5.85035e-01 1.00000e-09 2.12000e-01

$5.85035 \mathrm{e}+005.85035 \mathrm{e}+00$ 5.85035e-01 1.00000e-09 2.12000e-01

$1.00000 \mathrm{e}-05$ 1.00000e-05 1.00000e-06 1.00000e-09 1.00000e-01

$1.00000 \mathrm{e}+001.00000 \mathrm{e}+001.00000 \mathrm{e}-011.00000 \mathrm{e}-091.00000 \mathrm{e}-01$

Element: 11022 \# of layers: 7

Kx Ky Kz Ss Por

$5.85035 \mathrm{e}+00$ 5.85035e+00 5.85035e-01 1.00000e-09 2.12000e-01

$5.85035 \mathrm{e}+005.85035 \mathrm{e}+005.85035 \mathrm{e}-011.00000 \mathrm{e}-092.12000 \mathrm{e}-01$

$5.85035 \mathrm{e}+005.85035 \mathrm{e}+00$ 5.85035e-01 1.00000e-09 2.12000e-01

$5.85035 \mathrm{e}+005.85035 \mathrm{e}+00$ 5.85035e-01 1.00000e-09 2.12000e-01

$5.85035 \mathrm{e}+005.85035 \mathrm{e}+00$ 5.85035e-01 1.00000e-09 2.12000e-01 
$1.00000 \mathrm{e}-05$ 1.00000e-05 1.00000e-06 1.00000e-09 1.00000e-01 $1.00000 \mathrm{e}+001.00000 \mathrm{e}+001.00000 \mathrm{e}-01$ 1.00000e-09 1.00000e-01 Element: 11023 \# of layers: 7

Kx Ky Kz Ss Por

3.17729e+00 3.17729e+00 3.17729e-01 1.00000e-09 2.12000e-01 3.17729e+00 3.17729e+00 3.17729e-01 1.00000e-09 2.12000e-01 3.17729e+00 3.17729e+00 3.17729e-01 1.00000e-09 2.12000e-01 $3.17729 \mathrm{e}+003.17729 \mathrm{e}+003.17729 \mathrm{e}-01$ 1.00000e-09 2.12000e-01 $3.17729 \mathrm{e}+003.17729 \mathrm{e}+00$ 3.17729e-01 1.00000e-09 2.12000e-01 $1.00000 \mathrm{e}-05$ 1.00000e-05 1.00000e-06 1.00000e-09 1.00000e-01 $1.00000 \mathrm{e}+001.00000 \mathrm{e}+001.00000 \mathrm{e}-011.00000 \mathrm{e}-091.00000 \mathrm{e}-01$ Element: 11024 \# of layers: 7

Kx Ky Kz Ss Por

3.17729e+00 3.17729e+00 3.17729e-01 1.00000e-09 2.12000e-01 3.17729e+00 3.17729e+00 3.17729e-01 1.00000e-09 2.12000e-01 $3.17729 \mathrm{e}+003.17729 \mathrm{e}+00$ 3.17729e-01 1.00000e-09 2.12000e-01 $3.17729 \mathrm{e}+003.17729 \mathrm{e}+003.17729 \mathrm{e}-01$ 1.00000e-09 2.12000e-01 3.17729e+00 3.17729e+00 3.17729e-01 1.00000e-09 2.12000e-01 1.00000e-05 1.00000e-05 1.00000e-06 1.00000e-09 1.00000e-01 $1.00000 \mathrm{e}+001.00000 \mathrm{e}+001.00000 \mathrm{e}-011.00000 \mathrm{e}-09$ 1.00000e-01 Element: 11025 \# of layers: 7

$\mathrm{Kx} \mathrm{Ky} \mathrm{Kz}$ Ss Por

3.17729e+00 3.17729e+00 3.17729e-01 1.00000e-09 2.12000e-01 $3.17729 \mathrm{e}+003.17729 \mathrm{e}+00$ 3.17729e-01 1.00000e-09 2.12000e-01 $3.17729 \mathrm{e}+003.17729 \mathrm{e}+00$ 3.17729e-01 1.00000e-09 2.12000e-01 $3.17729 \mathrm{e}+003.17729 \mathrm{e}+00$ 3.17729e-01 1.00000e-09 2.12000e-01 $3.17729 \mathrm{e}+003.17729 \mathrm{e}+003.17729 \mathrm{e}-01$ 1.00000e-09 2.12000e-01 1.00000e-05 1.00000e-05 1.00000e-06 1.00000e-09 1.00000e-01 $1.00000 \mathrm{e}+001.00000 \mathrm{e}+001.00000 \mathrm{e}-011.00000 \mathrm{e}-091.00000 \mathrm{e}-01$ Element: 11026 \# of layers: 7

$\mathrm{Kx} \mathrm{Ky} \mathrm{Kz}$ Ss Por

5.85035e+00 5.85035e+00 5.85035e-01 1.00000e-09 2.12000e-01 $5.85035 \mathrm{e}+005.85035 \mathrm{e}+00$ 5.85035e-01 1.00000e-09 2.12000e-01 $5.85035 \mathrm{e}+00$ 5.85035e+00 5.85035e-01 1.00000e-09 2.12000e-01 $5.85035 \mathrm{e}+005.85035 \mathrm{e}+00$ 5.85035e-01 1.00000e-09 2.12000e-01 $5.85035 \mathrm{e}+005.85035 \mathrm{e}+00$ 5.85035e-01 1.00000e-09 2.12000e-01 1.00000e-05 1.00000e-05 1.00000e-06 1.00000e-09 1.00000e-01 $1.00000 \mathrm{e}+001.00000 \mathrm{e}+001.00000 \mathrm{e}-011.00000 \mathrm{e}-091.00000 \mathrm{e}-01$ Element: 11027 \# of layers: 7

$\mathrm{Kx} \mathrm{Ky} \mathrm{Kz}$ Ss Por

5.85035e+00 5.85035e+00 5.85035e-01 1.00000e-09 2.12000e-01 $5.85035 \mathrm{e}+005.85035 \mathrm{e}+00$ 5.85035e-01 1.00000e-09 2.12000e-01 $5.85035 \mathrm{e}+005.85035 \mathrm{e}+00$ 5.85035e-01 1.00000e-09 2.12000e-01 5.85035e+00 5.85035e+00 5.85035e-01 1.00000e-09 2.12000e-01 $5.85035 \mathrm{e}+00$ 5.85035e+00 5.85035e-01 1.00000e-09 2.12000e-01 $1.00000 \mathrm{e}-05$ 1.00000e-05 1.00000e-06 1.00000e-09 1.00000e-01 
$1.00000 \mathrm{e}+001.00000 \mathrm{e}+001.00000 \mathrm{e}-01$ 1.00000e-09 1.00000e-01 Element: 11028 \# of layers: 7

Kx Ky Kz Ss Por

5.85035e+00 5.85035e+00 5.85035e-01 1.00000e-09 2.12000e-01

$5.85035 \mathrm{e}+005.85035 \mathrm{e}+00$ 5.85035e-01 1.00000e-09 2.12000e-01

5.85035e+00 5.85035e+00 5.85035e-01 1.00000e-09 2.12000e-01

5.85035e+00 5.85035e+00 5.85035e-01 1.00000e-09 2.12000e-01

$5.85035 \mathrm{e}+005.85035 \mathrm{e}+00$ 5.85035e-01 1.00000e-09 2.12000e-01

$1.00000 \mathrm{e}-05$ 1.00000e-05 1.00000e-06 1.00000e-09 1.00000e-01

$1.00000 \mathrm{e}+001.00000 \mathrm{e}+001.00000 \mathrm{e}-01$ 1.00000e-09 1.00000e-01

Element: 11029 \# of layers: 7

Kx Ky Kz Ss Por

5.85035e+00 5.85035e+00 5.85035e-01 1.00000e-09 2.12000e-01

$5.85035 \mathrm{e}+005.85035 \mathrm{e}+00$ 5.85035e-01 1.00000e-09 2.12000e-01

$5.85035 \mathrm{e}+005.85035 \mathrm{e}+00$ 5.85035e-01 1.00000e-09 2.12000e-01

$5.85035 \mathrm{e}+005.85035 \mathrm{e}+00$ 5.85035e-01 1.00000e-09 2.12000e-01

$5.85035 \mathrm{e}+00$ 5.85035e+00 5.85035e-01 1.00000e-09 2.12000e-01

$1.00000 \mathrm{e}-05$ 1.00000e-05 1.00000e-06 1.00000e-09 1.00000e-01

$1.00000 \mathrm{e}+001.00000 \mathrm{e}+001.00000 \mathrm{e}-011.00000 \mathrm{e}-091.00000 \mathrm{e}-01$

Element: 11030 \# of layers: 7

Kx Ky Kz Ss Por

3.17729e+00 3.17729e+00 3.17729e-01 1.00000e-09 2.12000e-01

3.17729e+00 3.17729e+00 3.17729e-01 1.00000e-09 2.12000e-01

$3.17729 \mathrm{e}+003.17729 \mathrm{e}+00$ 3.17729e-01 1.00000e-09 2.12000e-01

$3.17729 \mathrm{e}+003.17729 \mathrm{e}+00$ 3.17729e-01 1.00000e-09 2.12000e-01

$3.17729 \mathrm{e}+003.17729 \mathrm{e}+00$ 3.17729e-01 1.00000e-09 2.12000e-01

$1.00000 \mathrm{e}-05$ 1.00000e-05 1.00000e-06 1.00000e-09 1.00000e-01

$1.00000 \mathrm{e}+001.00000 \mathrm{e}+001.00000 \mathrm{e}-01$ 1.00000e-09 1.00000e-01

Element: 11031 \# of layers: 7

$\mathrm{Kx} \mathrm{Ky} \mathrm{Kz}$ Ss Por

3.17729e+00 3.17729e+00 3.17729e-01 1.00000e-09 2.12000e-01

$3.17729 \mathrm{e}+003.17729 \mathrm{e}+00$ 3.17729e-01 1.00000e-09 2.12000e-01

$3.17729 \mathrm{e}+003.17729 \mathrm{e}+003.17729 \mathrm{e}-01$ 1.00000e-09 2.12000e-01

$3.17729 \mathrm{e}+003.17729 \mathrm{e}+003.17729 \mathrm{e}-01$ 1.00000e-09 2.12000e-01

$3.17729 \mathrm{e}+003.17729 \mathrm{e}+003.17729 \mathrm{e}-01$ 1.00000e-09 2.12000e-01

1.00000e-05 1.00000e-05 1.00000e-06 1.00000e-09 1.00000e-01

$1.00000 \mathrm{e}+001.00000 \mathrm{e}+001.00000 \mathrm{e}-011.00000 \mathrm{e}-091.00000 \mathrm{e}-01$

Element: 11032 \# of layers: 7

$\mathrm{Kx} \mathrm{Ky} \mathrm{Kz}$ Ss Por

3.17729e+00 3.17729e+00 3.17729e-01 1.00000e-09 2.12000e-01

$3.17729 \mathrm{e}+003.17729 \mathrm{e}+00$ 3.17729e-01 1.00000e-09 2.12000e-01

$3.17729 \mathrm{e}+003.17729 \mathrm{e}+00$ 3.17729e-01 1.00000e-09 2.12000e-01

$3.17729 \mathrm{e}+00$ 3.17729e+00 3.17729e-01 1.00000e-09 2.12000e-01

$3.17729 \mathrm{e}+003.17729 \mathrm{e}+003.17729 \mathrm{e}-01$ 1.00000e-09 2.12000e-01

$1.00000 \mathrm{e}-05$ 1.00000e-05 1.00000e-06 1.00000e-09 1.00000e-01

$1.00000 \mathrm{e}+001.00000 \mathrm{e}+001.00000 \mathrm{e}-011.00000 \mathrm{e}-091.00000 \mathrm{e}-01$ 
Element: 11033 \# of layers: 7

Kx Ky Kz Ss Por

3.17729e+00 3.17729e+00 3.17729e-01 1.00000e-09 2.12000e-01

$3.17729 \mathrm{e}+003.17729 \mathrm{e}+003.17729 \mathrm{e}-01$ 1.00000e-09 2.12000e-01

$3.17729 \mathrm{e}+003.17729 \mathrm{e}+003.17729 \mathrm{e}-011.00000 \mathrm{e}-092.12000 \mathrm{e}-01$

$3.17729 \mathrm{e}+003.17729 \mathrm{e}+003.17729 \mathrm{e}-011.00000 \mathrm{e}-092.12000 \mathrm{e}-01$

$3.17729 \mathrm{e}+003.17729 \mathrm{e}+003.17729 \mathrm{e}-01$ 1.00000e-09 2.12000e-01

$1.00000 \mathrm{e}-05$ 1.00000e-05 1.00000e-06 1.00000e-09 1.00000e-01

$1.00000 \mathrm{e}+001.00000 \mathrm{e}+001.00000 \mathrm{e}-011.00000 \mathrm{e}-091.00000 \mathrm{e}-01$

Element: 11034 \# of layers: 7

Kx Ky Kz Ss Por

3.17729e+00 3.17729e+00 3.17729e-01 1.00000e-09 2.12000e-01

$3.17729 \mathrm{e}+003.17729 \mathrm{e}+00$ 3.17729e-01 1.00000e-09 2.12000e-01

$3.17729 \mathrm{e}+003.17729 \mathrm{e}+003.17729 \mathrm{e}-01$ 1.00000e-09 2.12000e-01

$3.17729 \mathrm{e}+003.17729 \mathrm{e}+003.17729 \mathrm{e}-01$ 1.00000e-09 2.12000e-01

$3.17729 \mathrm{e}+003.17729 \mathrm{e}+003.17729 \mathrm{e}-01$ 1.00000e-09 2.12000e-01

$1.00000 \mathrm{e}-05$ 1.00000e-05 1.00000e-06 1.00000e-09 1.00000e-01

$1.00000 \mathrm{e}+001.00000 \mathrm{e}+001.00000 \mathrm{e}-011.00000 \mathrm{e}-091.00000 \mathrm{e}-01$

Element: 11035 \# of layers: 7

Kx Ky Kz Ss Por

3.17729e+00 3.17729e+00 3.17729e-01 1.00000e-09 2.12000e-01

$3.17729 \mathrm{e}+003.17729 \mathrm{e}+00$ 3.17729e-01 1.00000e-09 2.12000e-01

$3.17729 \mathrm{e}+003.17729 \mathrm{e}+003.17729 \mathrm{e}-01$ 1.00000e-09 2.12000e-01

$3.17729 \mathrm{e}+003.17729 \mathrm{e}+00$ 3.17729e-01 1.00000e-09 2.12000e-01

$3.17729 \mathrm{e}+003.17729 \mathrm{e}+003.17729 \mathrm{e}-01$ 1.00000e-09 2.12000e-01

$1.00000 \mathrm{e}-05$ 1.00000e-05 1.00000e-06 1.00000e-09 1.00000e-01

$1.00000 \mathrm{e}+001.00000 \mathrm{e}+001.00000 \mathrm{e}-011.00000 \mathrm{e}-091.00000 \mathrm{e}-01$

Element: 11036 \# of layers: 7

Kx Ky Kz Ss Por

3.17729e+00 3.17729e+00 3.17729e-01 1.00000e-09 2.12000e-01

$3.17729 \mathrm{e}+003.17729 \mathrm{e}+003.17729 \mathrm{e}-01$ 1.00000e-09 2.12000e-01

$3.17729 \mathrm{e}+003.17729 \mathrm{e}+003.17729 \mathrm{e}-01$ 1.00000e-09 2.12000e-01

$3.17729 \mathrm{e}+003.17729 \mathrm{e}+00$ 3.17729e-01 1.00000e-09 2.12000e-01

$3.17729 \mathrm{e}+003.17729 \mathrm{e}+00$ 3.17729e-01 1.00000e-09 2.12000e-01

$1.00000 \mathrm{e}-05$ 1.00000e-05 1.00000e-06 1.00000e-09 1.00000e-01

$1.00000 \mathrm{e}+001.00000 \mathrm{e}+001.00000 \mathrm{e}-011.00000 \mathrm{e}-091.00000 \mathrm{e}-01$

Element: 11037 \# of layers: 7

Kx Ky Kz Ss Por

3.17729e+00 3.17729e+00 3.17729e-01 1.00000e-09 2.12000e-01

$3.17729 \mathrm{e}+003.17729 \mathrm{e}+00$ 3.17729e-01 1.00000e-09 2.12000e-01

$3.17729 \mathrm{e}+003.17729 \mathrm{e}+003.17729 \mathrm{e}-01$ 1.00000e-09 2.12000e-01

$3.17729 \mathrm{e}+003.17729 \mathrm{e}+003.17729 \mathrm{e}-01$ 1.00000e-09 2.12000e-01

$3.17729 \mathrm{e}+003.17729 \mathrm{e}+00$ 3.17729e-01 1.00000e-09 2.12000e-01

$1.00000 \mathrm{e}-05$ 1.00000e-05 1.00000e-06 1.00000e-09 1.00000e-01

$1.00000 \mathrm{e}+001.00000 \mathrm{e}+001.00000 \mathrm{e}-011.00000 \mathrm{e}-091.00000 \mathrm{e}-01$

Element: 11038 \# of layers: 7 
$\mathrm{Kx} \mathrm{Ky} \mathrm{Kz}$ Ss Por

3.17729e+00 3.17729e+00 3.17729e-01 1.00000e-09 2.12000e-01

$3.17729 \mathrm{e}+003.17729 \mathrm{e}+00$ 3.17729e-01 1.00000e-09 2.12000e-01

$3.17729 \mathrm{e}+003.17729 \mathrm{e}+00$ 3.17729e-01 1.00000e-09 2.12000e-01

$3.17729 \mathrm{e}+003.17729 \mathrm{e}+00$ 3.17729e-01 1.00000e-09 2.12000e-01

$3.17729 \mathrm{e}+003.17729 \mathrm{e}+00$ 3.17729e-01 1.00000e-09 2.12000e-01

$1.00000 \mathrm{e}-05$ 1.00000e-05 1.00000e-06 1.00000e-09 1.00000e-01

$1.00000 \mathrm{e}+001.00000 \mathrm{e}+001.00000 \mathrm{e}-01$ 1.00000e-09 1.00000e-01

Element: 11039 \# of layers: 7

$\mathrm{Kx} \mathrm{Ky} \mathrm{Kz}$ Ss Por

3.17729e+00 3.17729e+00 3.17729e-01 1.00000e-09 2.12000e-01

$3.17729 \mathrm{e}+003.17729 \mathrm{e}+003.17729 \mathrm{e}-01$ 1.00000e-09 2.12000e-01

3.17729e+00 3.17729e+00 3.17729e-01 1.00000e-09 2.12000e-01

$3.17729 \mathrm{e}+003.17729 \mathrm{e}+00$ 3.17729e-01 1.00000e-09 2.12000e-01

$3.17729 \mathrm{e}+003.17729 \mathrm{e}+00$ 3.17729e-01 1.00000e-09 2.12000e-01

$1.00000 \mathrm{e}-05$ 1.00000e-05 1.00000e-06 1.00000e-09 1.00000e-01

$1.00000 \mathrm{e}+001.00000 \mathrm{e}+001.00000 \mathrm{e}-01$ 1.00000e-09 1.00000e-01

Element: 11040 \# of layers: 7

$\mathrm{Kx} \mathrm{Ky} \mathrm{Kz}$ Ss Por

3.17729e+00 3.17729e+00 3.17729e-01 1.00000e-09 2.12000e-01

$3.17729 \mathrm{e}+003.17729 \mathrm{e}+00$ 3.17729e-01 1.00000e-09 2.12000e-01

$3.17729 \mathrm{e}+00$ 3.17729e+00 3.17729e-01 1.00000e-09 2.12000e-01

$3.17729 \mathrm{e}+003.17729 \mathrm{e}+00$ 3.17729e-01 1.00000e-09 2.12000e-01

3.17729e+00 3.17729e+00 3.17729e-01 1.00000e-09 2.12000e-01

$1.00000 \mathrm{e}-05$ 1.00000e-05 1.00000e-06 1.00000e-09 1.00000e-01

$1.00000 \mathrm{e}+001.00000 \mathrm{e}+001.00000 \mathrm{e}-01$ 1.00000e-09 1.00000e-01

Element: 11041 \# of layers: 7

$\mathrm{Kx} \mathrm{Ky} \mathrm{Kz} \mathrm{Ss} \mathrm{Por}$

9.62211e+00 9.62211e+00 9.62211e-01 1.00000e-09 2.12000e-01

$9.62211 \mathrm{e}+00$ 9.62211e+00 9.62211e-01 1.00000e-09 2.12000e-01

$9.62211 \mathrm{e}+00$ 9.62211e+00 9.62211e-01 1.00000e-09 2.12000e-01

$9.62211 \mathrm{e}+00$ 9.62211e+00 9.62211e-01 1.00000e-09 2.12000e-01

$9.62211 \mathrm{e}+009.62211 \mathrm{e}+009.62211 \mathrm{e}-01$ 1.00000e-09 2.12000e-01

$1.00000 \mathrm{e}-05$ 1.00000e-05 1.00000e-06 1.00000e-09 1.00000e-01

$1.00000 \mathrm{e}+001.00000 \mathrm{e}+001.00000 \mathrm{e}-011.00000 \mathrm{e}-091.00000 \mathrm{e}-01$

Element: 11042 \# of layers: 7

Kx Ky Kz Ss Por

9.62211e+00 9.62211e+00 9.62211e-01 1.00000e-09 2.12000e-01

$9.62211 \mathrm{e}+009.62211 \mathrm{e}+009.62211 \mathrm{e}-01$ 1.00000e-09 2.12000e-01

$9.62211 \mathrm{e}+009.62211 \mathrm{e}+009.62211 \mathrm{e}-01$ 1.00000e-09 2.12000e-01

$9.62211 \mathrm{e}+009.62211 \mathrm{e}+009.62211 \mathrm{e}-01$ 1.00000e-09 2.12000e-01

$9.62211 \mathrm{e}+009.62211 \mathrm{e}+00$ 9.62211e-01 1.00000e-09 2.12000e-01 $1.00000 \mathrm{e}-05$ 1.00000e-05 1.00000e-06 1.00000e-09 1.00000e-01

$1.00000 \mathrm{e}+001.00000 \mathrm{e}+001.00000 \mathrm{e}-01$ 1.00000e-09 1.00000e-01

Element: 11043 \# of layers: 7

Kx Ky Kz Ss Por 
9.62211e+00 9.62211e+00 9.62211e-01 1.00000e-09 2.12000e-01 $9.62211 \mathrm{e}+009.62211 \mathrm{e}+009.62211 \mathrm{e}-01$ 1.00000e-09 2.12000e-01 $9.62211 \mathrm{e}+00$ 9.62211e+00 9.62211e-01 1.00000e-09 2.12000e-01 $9.62211 \mathrm{e}+009.62211 \mathrm{e}+009.62211 \mathrm{e}-01$ 1.00000e-09 2.12000e-01 $9.62211 \mathrm{e}+00$ 9.62211e+00 9.62211e-01 1.00000e-09 2.12000e-01 $1.00000 \mathrm{e}-05$ 1.00000e-05 1.00000e-06 1.00000e-09 1.00000e-01 $1.00000 \mathrm{e}+001.00000 \mathrm{e}+001.00000 \mathrm{e}-011.00000 \mathrm{e}-091.00000 \mathrm{e}-01$ Element: 11044 \# of layers: 7

$\mathrm{Kx} \mathrm{Ky} \mathrm{Kz}$ Ss Por

3.17729e+00 3.17729e+00 3.17729e-01 1.00000e-09 2.12000e-01 $3.17729 \mathrm{e}+003.17729 \mathrm{e}+00$ 3.17729e-01 1.00000e-09 2.12000e-01 $3.17729 \mathrm{e}+003.17729 \mathrm{e}+00$ 3.17729e-01 1.00000e-09 2.12000e-01 3.17729e+00 3.17729e+00 3.17729e-01 1.00000e-09 2.12000e-01 3.17729e+00 3.17729e+00 3.17729e-01 1.00000e-09 2.12000e-01 1.00000e-05 1.00000e-05 1.00000e-06 1.00000e-09 1.00000e-01 $1.00000 \mathrm{e}+001.00000 \mathrm{e}+001.00000 \mathrm{e}-011.00000 \mathrm{e}-091.00000 \mathrm{e}-01$ Element: 11045 \# of layers: 7

$\mathrm{Kx} \mathrm{Ky} \mathrm{Kz}$ Ss Por

3.17729e+00 3.17729e+00 3.17729e-01 1.00000e-09 2.12000e-01 $3.17729 \mathrm{e}+003.17729 \mathrm{e}+00$ 3.17729e-01 1.00000e-09 2.12000e-01 $3.17729 \mathrm{e}+003.17729 \mathrm{e}+00$ 3.17729e-01 1.00000e-09 2.12000e-01 3.17729e+00 3.17729e+00 3.17729e-01 1.00000e-09 2.12000e-01 $3.17729 \mathrm{e}+003.17729 \mathrm{e}+003.17729 \mathrm{e}-01$ 1.00000e-09 2.12000e-01 $1.00000 \mathrm{e}-05$ 1.00000e-05 1.00000e-06 1.00000e-09 1.00000e-01 $1.00000 \mathrm{e}+001.00000 \mathrm{e}+001.00000 \mathrm{e}-011.00000 \mathrm{e}-091.00000 \mathrm{e}-01$ Element: 11046 \# of layers: 7

Kx Ky Kz Ss Por

3.17729e+00 3.17729e+00 3.17729e-01 1.00000e-09 2.12000e-01 $3.17729 \mathrm{e}+003.17729 \mathrm{e}+00$ 3.17729e-01 1.00000e-09 2.12000e-01 $3.17729 \mathrm{e}+003.17729 \mathrm{e}+00$ 3.17729e-01 1.00000e-09 2.12000e-01 $3.17729 \mathrm{e}+003.17729 \mathrm{e}+00$ 3.17729e-01 1.00000e-09 2.12000e-01 $3.17729 \mathrm{e}+003.17729 \mathrm{e}+003.17729 \mathrm{e}-01$ 1.00000e-09 2.12000e-01 $1.00000 \mathrm{e}-05$ 1.00000e-05 1.00000e-06 1.00000e-09 1.00000e-01 $1.00000 \mathrm{e}+001.00000 \mathrm{e}+001.00000 \mathrm{e}-01$ 1.00000e-09 1.00000e-01 Element: 11047 \# of layers: 7

$\mathrm{Kx} \mathrm{Ky} \mathrm{Kz}$ Ss Por

3.17729e+00 3.17729e+00 3.17729e-01 1.00000e-09 2.12000e-01 $3.17729 \mathrm{e}+003.17729 \mathrm{e}+00$ 3.17729e-01 1.00000e-09 2.12000e-01 $3.17729 \mathrm{e}+003.17729 \mathrm{e}+00$ 3.17729e-01 1.00000e-09 2.12000e-01 $3.17729 \mathrm{e}+003.17729 \mathrm{e}+00$ 3.17729e-01 1.00000e-09 2.12000e-01 $3.17729 \mathrm{e}+003.17729 \mathrm{e}+003.17729 \mathrm{e}-01$ 1.00000e-09 2.12000e-01 $1.00000 \mathrm{e}-05$ 1.00000e-05 1.00000e-06 1.00000e-09 1.00000e-01 $1.00000 \mathrm{e}+001.00000 \mathrm{e}+001.00000 \mathrm{e}-011.00000 \mathrm{e}-091.00000 \mathrm{e}-01$ Element: 11048 \# of layers: 7

$\mathrm{Kx} \mathrm{Ky} \mathrm{Kz}$ Ss Por

9.62211e+00 9.62211e+00 9.62211e-01 1.00000e-09 2.12000e-01 
9.62211e+00 9.62211e+00 9.62211e-01 1.00000e-09 2.12000e-01 $9.62211 \mathrm{e}+009.62211 \mathrm{e}+009.62211 \mathrm{e}-01$ 1.00000e-09 2.12000e-01 $9.62211 \mathrm{e}+00$ 9.62211e+00 9.62211e-01 1.00000e-09 2.12000e-01 $9.62211 \mathrm{e}+009.62211 \mathrm{e}+009.62211 \mathrm{e}-01$ 1.00000e-09 2.12000e-01 $1.00000 \mathrm{e}-05$ 1.00000e-05 1.00000e-06 1.00000e-09 1.00000e-01 $1.00000 \mathrm{e}+001.00000 \mathrm{e}+001.00000 \mathrm{e}-01$ 1.00000e-09 1.00000e-01 Element: 11049 \# of layers: 7

$\mathrm{Kx} \mathrm{Ky} \mathrm{Kz}$ Ss Por

$9.62211 \mathrm{e}+009.62211 \mathrm{e}+009.62211 \mathrm{e}-01$ 1.00000e-09 2.12000e-01 $9.62211 \mathrm{e}+009.62211 \mathrm{e}+00$ 9.62211e-01 1.00000e-09 2.12000e-01 $9.62211 \mathrm{e}+009.62211 \mathrm{e}+00$ 9.62211e-01 1.00000e-09 2.12000e-01 $9.62211 \mathrm{e}+009.62211 \mathrm{e}+009.62211 \mathrm{e}-01$ 1.00000e-09 2.12000e-01 $9.62211 \mathrm{e}+009.62211 \mathrm{e}+009.62211 \mathrm{e}-01$ 1.00000e-09 2.12000e-01 $1.00000 \mathrm{e}-05$ 1.00000e-05 1.00000e-06 1.00000e-09 1.00000e-01 $1.00000 \mathrm{e}+001.00000 \mathrm{e}+001.00000 \mathrm{e}-011.00000 \mathrm{e}-091.00000 \mathrm{e}-01$ Element: 11050 \# of layers: 7

$\mathrm{Kx} \mathrm{Ky} \mathrm{Kz}$ Ss Por

$9.62211 \mathrm{e}+009.62211 \mathrm{e}+00$ 9.62211e-01 1.00000e-09 2.12000e-01 $9.62211 \mathrm{e}+009.62211 \mathrm{e}+009.62211 \mathrm{e}-01$ 1.00000e-09 2.12000e-01 $9.62211 \mathrm{e}+009.62211 \mathrm{e}+009.62211 \mathrm{e}-01$ 1.00000e-09 2.12000e-01 $9.62211 \mathrm{e}+009.62211 \mathrm{e}+009.62211 \mathrm{e}-011.00000 \mathrm{e}-092.12000 \mathrm{e}-01$ $9.62211 \mathrm{e}+009.62211 \mathrm{e}+00$ 9.62211e-01 1.00000e-09 2.12000e-01 $1.00000 \mathrm{e}-05$ 1.00000e-05 1.00000e-06 1.00000e-09 1.00000e-01 $1.00000 \mathrm{e}+001.00000 \mathrm{e}+001.00000 \mathrm{e}-011.00000 \mathrm{e}-09$ 1.00000e-01 Element: 11051 \# of layers: 7

$\mathrm{Kx} \mathrm{Ky} \mathrm{Kz}$ Ss Por

9.62211e+00 9.62211e+00 9.62211e-01 1.00000e-09 2.12000e-01 $9.62211 \mathrm{e}+00$ 9.62211e+00 9.62211e-01 1.00000e-09 2.12000e-01 $9.62211 \mathrm{e}+009.62211 \mathrm{e}+009.62211 \mathrm{e}-01$ 1.00000e-09 2.12000e-01 $9.62211 \mathrm{e}+009.62211 \mathrm{e}+009.62211 \mathrm{e}-011.00000 \mathrm{e}-092.12000 \mathrm{e}-01$ $9.62211 \mathrm{e}+009.62211 \mathrm{e}+00$ 9.62211e-01 1.00000e-09 2.12000e-01 $1.00000 \mathrm{e}-05$ 1.00000e-05 1.00000e-06 1.00000e-09 1.00000e-01 $1.00000 \mathrm{e}+001.00000 \mathrm{e}+001.00000 \mathrm{e}-011.00000 \mathrm{e}-091.00000 \mathrm{e}-01$ Element: 11052 \# of layers: 7

$\mathrm{Kx} \mathrm{Ky} \mathrm{Kz}$ Ss Por

9.62211e+00 9.62211e+00 9.62211e-01 1.00000e-09 2.12000e-01 $9.62211 \mathrm{e}+009.62211 \mathrm{e}+009.62211 \mathrm{e}-01$ 1.00000e-09 2.12000e-01 $9.62211 \mathrm{e}+009.62211 \mathrm{e}+009.62211 \mathrm{e}-01$ 1.00000e-09 2.12000e-01 $9.62211 \mathrm{e}+00$ 9.62211e+00 9.62211e-01 1.00000e-09 2.12000e-01 $9.62211 \mathrm{e}+009.62211 \mathrm{e}+00$ 9.62211e-01 1.00000e-09 2.12000e-01 1.00000e-05 1.00000e-05 1.00000e-06 1.00000e-09 1.00000e-01 $1.00000 \mathrm{e}+001.00000 \mathrm{e}+001.00000 \mathrm{e}-011.00000 \mathrm{e}-091.00000 \mathrm{e}-01$ Element: 11053 \# of layers: 7

$\mathrm{Kx} \mathrm{Ky} \mathrm{Kz}$ Ss Por 9.62211e+00 9.62211e+00 9.62211e-01 1.00000e-09 2.12000e-01 $9.62211 \mathrm{e}+009.62211 \mathrm{e}+009.62211 \mathrm{e}-01$ 1.00000e-09 2.12000e-01 
9.62211e+00 9.62211e+00 9.62211e-01 1.00000e-09 2.12000e-01 $9.62211 \mathrm{e}+009.62211 \mathrm{e}+009.62211 \mathrm{e}-01$ 1.00000e-09 2.12000e-01 $9.62211 \mathrm{e}+00$ 9.62211e+00 9.62211e-01 1.00000e-09 2.12000e-01 $1.00000 \mathrm{e}-05$ 1.00000e-05 1.00000e-06 1.00000e-09 1.00000e-01 $1.00000 \mathrm{e}+001.00000 \mathrm{e}+001.00000 \mathrm{e}-01$ 1.00000e-09 1.00000e-01 Element: 11054 \# of layers: 7

$\mathrm{Kx} \mathrm{Ky} \mathrm{Kz}$ Ss Por

9.62211e+00 9.62211e+00 9.62211e-01 1.00000e-09 2.12000e-01

$9.62211 \mathrm{e}+009.62211 \mathrm{e}+009.62211 \mathrm{e}-01$ 1.00000e-09 2.12000e-01

$9.62211 \mathrm{e}+00$ 9.62211e+00 9.62211e-01 1.00000e-09 2.12000e-01

$9.62211 \mathrm{e}+009.62211 \mathrm{e}+009.62211 \mathrm{e}-01$ 1.00000e-09 2.12000e-01

$9.62211 \mathrm{e}+009.62211 \mathrm{e}+009.62211 \mathrm{e}-01$ 1.00000e-09 2.12000e-01

$1.00000 \mathrm{e}-05$ 1.00000e-05 1.00000e-06 1.00000e-09 1.00000e-01

$1.00000 \mathrm{e}+001.00000 \mathrm{e}+001.00000 \mathrm{e}-011.00000 \mathrm{e}-09$ 1.00000e-01

Element: 11055 \# of layers: 7

Kx Ky Kz Ss Por

9.62211e+00 9.62211e+00 9.62211e-01 1.00000e-09 2.12000e-01

$9.62211 \mathrm{e}+00$ 9.62211e+00 9.62211e-01 1.00000e-09 2.12000e-01

$9.62211 \mathrm{e}+009.62211 \mathrm{e}+00$ 9.62211e-01 1.00000e-09 2.12000e-01

$9.62211 \mathrm{e}+009.62211 \mathrm{e}+009.62211 \mathrm{e}-01$ 1.00000e-09 2.12000e-01

$9.62211 \mathrm{e}+009.62211 \mathrm{e}+009.62211 \mathrm{e}-01$ 1.00000e-09 2.12000e-01

$1.00000 \mathrm{e}-05$ 1.00000e-05 1.00000e-06 1.00000e-09 1.00000e-01

$1.00000 \mathrm{e}+001.00000 \mathrm{e}+001.00000 \mathrm{e}-01$ 1.00000e-09 1.00000e-01

Element: 11056 \# of layers: 7

$\mathrm{Kx} \mathrm{Ky} \mathrm{Kz}$ Ss Por

9.62211e+00 9.62211e+00 9.62211e-01 1.00000e-09 2.12000e-01

$9.62211 \mathrm{e}+009.62211 \mathrm{e}+009.62211 \mathrm{e}-01$ 1.00000e-09 2.12000e-01

$9.62211 \mathrm{e}+00$ 9.62211e+00 9.62211e-01 1.00000e-09 2.12000e-01

$9.62211 \mathrm{e}+009.62211 \mathrm{e}+009.62211 \mathrm{e}-01$ 1.00000e-09 2.12000e-01

$9.62211 \mathrm{e}+009.62211 \mathrm{e}+009.62211 \mathrm{e}-01$ 1.00000e-09 2.12000e-01

$1.00000 \mathrm{e}-05$ 1.00000e-05 1.00000e-06 1.00000e-09 1.00000e-01

$1.00000 \mathrm{e}+001.00000 \mathrm{e}+001.00000 \mathrm{e}-01$ 1.00000e-09 1.00000e-01

Element: 11057 \# of layers: 7

$\mathrm{Kx} \mathrm{Ky} \mathrm{Kz}$ Ss Por

$9.62211 \mathrm{e}+009.62211 \mathrm{e}+00$ 9.62211e-01 1.00000e-09 2.12000e-01

$9.62211 \mathrm{e}+00$ 9.62211e+00 9.62211e-01 1.00000e-09 2.12000e-01

$9.62211 \mathrm{e}+009.62211 \mathrm{e}+009.62211 \mathrm{e}-01$ 1.00000e-09 2.12000e-01

$9.62211 \mathrm{e}+009.62211 \mathrm{e}+009.62211 \mathrm{e}-01$ 1.00000e-09 2.12000e-01

$9.62211 \mathrm{e}+00$ 9.62211e+00 9.62211e-01 1.00000e-09 2.12000e-01

$1.00000 \mathrm{e}-05$ 1.00000e-05 1.00000e-06 1.00000e-09 1.00000e-01

$1.00000 \mathrm{e}+001.00000 \mathrm{e}+001.00000 \mathrm{e}-011.00000 \mathrm{e}-091.00000 \mathrm{e}-01$

Element: 11058 \# of layers: 7

$\mathrm{Kx} \mathrm{Ky} \mathrm{Kz}$ Ss Por

1.10579e+01 1.10579e+01 1.10579e+00 1.00000e-09 2.12000e-01

$1.10579 \mathrm{e}+01$ 1.10579e+01 1.10579e+00 1.00000e-09 2.12000e-01

$1.10579 \mathrm{e}+01$ 1.10579e+01 1.10579e+00 1.00000e-09 2.12000e-01 
$1.10579 \mathrm{e}+01$ 1.10579e+01 1.10579e+00 1.00000e-09 2.12000e-01 $1.10579 \mathrm{e}+01$ 1.10579e+01 1.10579e+00 1.00000e-09 2.12000e-01 $1.00000 \mathrm{e}-05$ 1.00000e-05 1.00000e-06 1.00000e-09 1.00000e-01 $1.00000 \mathrm{e}+001.00000 \mathrm{e}+001.00000 \mathrm{e}-011.00000 \mathrm{e}-091.00000 \mathrm{e}-01$ Element: 11059 \# of layers: 7

$\mathrm{Kx} \mathrm{Ky} \mathrm{Kz}$ Ss Por

$1.10579 \mathrm{e}+01$ 1.10579e+01 1.10579e+00 1.00000e-09 2.12000e-01 $1.10579 \mathrm{e}+01$ 1.10579e+01 1.10579e+00 1.00000e-09 2.12000e-01 $1.10579 \mathrm{e}+01$ 1.10579e+01 1.10579e+00 1.00000e-09 2.12000e-01 $1.10579 \mathrm{e}+01$ 1.10579e+01 1.10579e+00 1.00000e-09 2.12000e-01 $1.10579 \mathrm{e}+01$ 1.10579e+01 1.10579e+00 1.00000e-09 2.12000e-01 $1.00000 \mathrm{e}-05$ 1.00000e-05 1.00000e-06 1.00000e-09 1.00000e-01 $1.00000 \mathrm{e}+001.00000 \mathrm{e}+001.00000 \mathrm{e}-011.00000 \mathrm{e}-09$ 1.00000e-01 Element: 11060 \# of layers: 7

Kx Ky Kz Ss Por

$1.10579 \mathrm{e}+01$ 1.10579e+01 1.10579e+00 1.00000e-09 2.12000e-01 $1.10579 \mathrm{e}+01$ 1.10579e+01 1.10579e+00 1.00000e-09 2.12000e-01 $1.10579 \mathrm{e}+01$ 1.10579e+01 1.10579e+00 1.00000e-09 2.12000e-01 $1.10579 \mathrm{e}+01$ 1.10579e+01 1.10579e+00 1.00000e-09 2.12000e-01 $1.10579 \mathrm{e}+01$ 1.10579e+01 1.10579e+00 1.00000e-09 2.12000e-01 $1.00000 \mathrm{e}-05$ 1.00000e-05 1.00000e-06 1.00000e-09 1.00000e-01 $1.00000 \mathrm{e}+001.00000 \mathrm{e}+001.00000 \mathrm{e}-01$ 1.00000e-09 1.00000e-01 Element: 11061 \# of layers: 7

$\mathrm{Kx} \mathrm{Ky} \mathrm{Kz}$ Ss Por

$1.10579 \mathrm{e}+01$ 1.10579e+01 1.10579e+00 1.00000e-09 2.12000e-01 $1.10579 \mathrm{e}+01$ 1.10579e+01 1.10579e+00 1.00000e-09 2.12000e-01 $1.10579 \mathrm{e}+01$ 1.10579e+01 1.10579e+00 1.00000e-09 2.12000e-01 $1.10579 \mathrm{e}+01$ 1.10579e+01 1.10579e+00 1.00000e-09 2.12000e-01 $1.10579 \mathrm{e}+01$ 1.10579e+01 1.10579e+00 1.00000e-09 2.12000e-01 $1.00000 \mathrm{e}-05$ 1.00000e-05 1.00000e-06 1.00000e-09 1.00000e-01 $1.00000 \mathrm{e}+001.00000 \mathrm{e}+001.00000 \mathrm{e}-01$ 1.00000e-09 1.00000e-01 Element: 11062 \# of layers: 7

Kx Ky Kz Ss Por

$1.10579 \mathrm{e}+01$ 1.10579e+01 1.10579e+00 1.00000e-09 2.12000e-01 $1.10579 \mathrm{e}+01$ 1.10579e+01 1.10579e+00 1.00000e-09 2.12000e-01 $1.10579 \mathrm{e}+011.10579 \mathrm{e}+011.10579 \mathrm{e}+001.00000 \mathrm{e}-092.12000 \mathrm{e}-01$ $1.10579 \mathrm{e}+01$ 1.10579e+01 1.10579e+00 1.00000e-09 2.12000e-01 $1.10579 \mathrm{e}+01$ 1.10579e+01 1.10579e+00 1.00000e-09 2.12000e-01 $1.00000 \mathrm{e}-05$ 1.00000e-05 1.00000e-06 1.00000e-09 1.00000e-01 $1.00000 \mathrm{e}+001.00000 \mathrm{e}+001.00000 \mathrm{e}-01$ 1.00000e-09 1.00000e-01 Element: 11063 \# of layers: 7

$\mathrm{Kx} \mathrm{Ky} \mathrm{Kz}$ Ss Por

9.62211e+00 9.62211e+00 9.62211e-01 1.00000e-09 2.12000e-01 $9.62211 \mathrm{e}+00$ 9.62211e+00 9.62211e-01 1.00000e-09 2.12000e-01 $9.62211 \mathrm{e}+009.62211 \mathrm{e}+009.62211 \mathrm{e}-01$ 1.00000e-09 2.12000e-01 $9.62211 \mathrm{e}+009.62211 \mathrm{e}+009.62211 \mathrm{e}-01$ 1.00000e-09 2.12000e-01 
9.62211e+00 9.62211e+00 9.62211e-01 1.00000e-09 2.12000e-01 $1.00000 \mathrm{e}-05$ 1.00000e-05 1.00000e-06 1.00000e-09 1.00000e-01 $1.00000 \mathrm{e}+001.00000 \mathrm{e}+001.00000 \mathrm{e}-011.00000 \mathrm{e}-09$ 1.00000e-01 Element: 11064 \# of layers: 7

$\mathrm{Kx} \mathrm{Ky} \mathrm{Kz}$ Ss Por

$9.62211 \mathrm{e}+009.62211 \mathrm{e}+009.62211 \mathrm{e}-01$ 1.00000e-09 2.12000e-01 $9.62211 \mathrm{e}+00$ 9.62211e+00 9.62211e-01 1.00000e-09 2.12000e-01 $9.62211 \mathrm{e}+009.62211 \mathrm{e}+009.62211 \mathrm{e}-01$ 1.00000e-09 2.12000e-01 $9.62211 \mathrm{e}+00$ 9.62211e+00 9.62211e-01 1.00000e-09 2.12000e-01 $9.62211 \mathrm{e}+009.62211 \mathrm{e}+00$ 9.62211e-01 1.00000e-09 2.12000e-01 $1.00000 \mathrm{e}-05$ 1.00000e-05 1.00000e-06 1.00000e-09 1.00000e-01 $1.00000 \mathrm{e}+001.00000 \mathrm{e}+001.00000 \mathrm{e}-011.00000 \mathrm{e}-091.00000 \mathrm{e}-01$ Element: 11065 \# of layers: 7

$\mathrm{Kx} \mathrm{Ky} \mathrm{Kz}$ Ss Por

$1.10579 \mathrm{e}+01$ 1.10579e+01 1.10579e+00 1.00000e-09 2.12000e-01 $1.10579 \mathrm{e}+01$ 1.10579e+01 1.10579e+00 1.00000e-09 2.12000e-01 $1.10579 \mathrm{e}+01$ 1.10579e+01 1.10579e+00 1.00000e-09 2.12000e-01 $1.10579 \mathrm{e}+01$ 1.10579e+01 1.10579e+00 1.00000e-09 2.12000e-01 $1.10579 \mathrm{e}+01$ 1.10579e+01 1.10579e+00 1.00000e-09 2.12000e-01 $1.00000 \mathrm{e}-05$ 1.00000e-05 1.00000e-06 1.00000e-09 1.00000e-01 $1.00000 \mathrm{e}+001.00000 \mathrm{e}+001.00000 \mathrm{e}-011.00000 \mathrm{e}-091.00000 \mathrm{e}-01$ Element: 11066 \# of layers: 7

$\mathrm{Kx} \mathrm{Ky} \mathrm{Kz}$ Ss Por

1.10579e+01 1.10579e+01 1.10579e+00 1.00000e-09 2.12000e-01 $1.10579 \mathrm{e}+011.10579 \mathrm{e}+011.10579 \mathrm{e}+001.00000 \mathrm{e}-092.12000 \mathrm{e}-01$ $1.10579 \mathrm{e}+01$ 1.10579e+01 1.10579e+00 1.00000e-09 2.12000e-01 $1.10579 \mathrm{e}+01$ 1.10579e+01 1.10579e+00 1.00000e-09 2.12000e-01 $1.10579 \mathrm{e}+01$ 1.10579e+01 1.10579e+00 1.00000e-09 2.12000e-01 $1.00000 \mathrm{e}-05$ 1.00000e-05 1.00000e-06 1.00000e-09 1.00000e-01 $1.00000 \mathrm{e}+001.00000 \mathrm{e}+001.00000 \mathrm{e}-011.00000 \mathrm{e}-091.00000 \mathrm{e}-01$ Element: 11067 \# of layers: 7

$\mathrm{Kx} \mathrm{Ky} \mathrm{Kz}$ Ss Por

5.85035e+00 5.85035e+00 5.85035e-01 1.00000e-09 2.12000e-01 $5.85035 \mathrm{e}+00$ 5.85035e+00 5.85035e-01 1.00000e-09 2.12000e-01 $5.85035 \mathrm{e}+005.85035 \mathrm{e}+00$ 5.85035e-01 1.00000e-09 2.12000e-01 $5.85035 \mathrm{e}+005.85035 \mathrm{e}+00$ 5.85035e-01 1.00000e-09 2.12000e-01 $5.85035 \mathrm{e}+005.85035 \mathrm{e}+00$ 5.85035e-01 1.00000e-09 2.12000e-01 $1.00000 \mathrm{e}-05$ 1.00000e-05 1.00000e-06 1.00000e-09 1.00000e-01 $1.00000 \mathrm{e}+001.00000 \mathrm{e}+001.00000 \mathrm{e}-01$ 1.00000e-09 1.00000e-01 Element: 11068 \# of layers: 7

$\mathrm{Kx} \mathrm{Ky} \mathrm{Kz}$ Ss Por

5.85035e+00 5.85035e+00 5.85035e-01 1.00000e-09 2.12000e-01 $5.85035 \mathrm{e}+00$ 5.85035e+00 5.85035e-01 1.00000e-09 2.12000e-01 5.85035e+00 5.85035e+00 5.85035e-01 1.00000e-09 2.12000e-01 $5.85035 \mathrm{e}+005.85035 \mathrm{e}+00$ 5.85035e-01 1.00000e-09 2.12000e-01 $5.85035 \mathrm{e}+00$ 5.85035e+00 5.85035e-01 1.00000e-09 2.12000e-01 
$1.00000 \mathrm{e}-05$ 1.00000e-05 1.00000e-06 1.00000e-09 1.00000e-01 $1.00000 \mathrm{e}+001.00000 \mathrm{e}+001.00000 \mathrm{e}-01$ 1.00000e-09 1.00000e-01 Element: 11069 \# of layers: 7

Kx Ky Kz Ss Por

5.85035e+00 5.85035e+00 5.85035e-01 1.00000e-09 2.12000e-01

$5.85035 \mathrm{e}+00$ 5.85035e+00 5.85035e-01 1.00000e-09 2.12000e-01

$5.85035 \mathrm{e}+00$ 5.85035e+00 5.85035e-01 1.00000e-09 2.12000e-01

$5.85035 \mathrm{e}+00$ 5.85035e+00 5.85035e-01 1.00000e-09 2.12000e-01

5.85035e+00 5.85035e+00 5.85035e-01 1.00000e-09 2.12000e-01

$1.00000 \mathrm{e}-05$ 1.00000e-05 1.00000e-06 1.00000e-09 1.00000e-01

$1.00000 \mathrm{e}+001.00000 \mathrm{e}+001.00000 \mathrm{e}-01$ 1.00000e-09 1.00000e-01

Element: 11070 \# of layers: 7

Kx Ky Kz Ss Por

3.17729e+00 3.17729e+00 3.17729e-01 1.00000e-09 2.12000e-01

3.17729e+00 3.17729e+00 3.17729e-01 1.00000e-09 2.12000e-01

$3.17729 \mathrm{e}+003.17729 \mathrm{e}+00$ 3.17729e-01 1.00000e-09 2.12000e-01

$3.17729 \mathrm{e}+003.17729 \mathrm{e}+00$ 3.17729e-01 1.00000e-09 2.12000e-01

$3.17729 \mathrm{e}+00$ 3.17729e+00 3.17729e-01 1.00000e-09 2.12000e-01

1.00000e-05 1.00000e-05 1.00000e-06 1.00000e-09 1.00000e-01

$1.00000 \mathrm{e}+001.00000 \mathrm{e}+001.00000 \mathrm{e}-011.00000 \mathrm{e}-091.00000 \mathrm{e}-01$

Element: 11071 \# of layers: 7

$\mathrm{Kx} \mathrm{Ky} \mathrm{Kz}$ Ss Por

3.17729e+00 3.17729e+00 3.17729e-01 1.00000e-09 2.12000e-01

$3.17729 \mathrm{e}+003.17729 \mathrm{e}+00$ 3.17729e-01 1.00000e-09 2.12000e-01

$3.17729 \mathrm{e}+003.17729 \mathrm{e}+00$ 3.17729e-01 1.00000e-09 2.12000e-01

$3.17729 \mathrm{e}+003.17729 \mathrm{e}+00$ 3.17729e-01 1.00000e-09 2.12000e-01

$3.17729 \mathrm{e}+003.17729 \mathrm{e}+00$ 3.17729e-01 1.00000e-09 2.12000e-01

1.00000e-05 1.00000e-05 1.00000e-06 1.00000e-09 1.00000e-01

$1.00000 \mathrm{e}+001.00000 \mathrm{e}+001.00000 \mathrm{e}-011.00000 \mathrm{e}-091.00000 \mathrm{e}-01$

Element: 11072 \# of layers: 7

$\mathrm{Kx} \mathrm{Ky} \mathrm{Kz}$ Ss Por

9.62211e+00 9.62211e+00 9.62211e-01 1.00000e-09 2.12000e-01

$9.62211 \mathrm{e}+009.62211 \mathrm{e}+009.62211 \mathrm{e}-01$ 1.00000e-09 2.12000e-01

$9.62211 \mathrm{e}+009.62211 \mathrm{e}+009.62211 \mathrm{e}-011.00000 \mathrm{e}-092.12000 \mathrm{e}-01$

$9.62211 \mathrm{e}+009.62211 \mathrm{e}+009.62211 \mathrm{e}-01$ 1.00000e-09 2.12000e-01

$9.62211 \mathrm{e}+009.62211 \mathrm{e}+00$ 9.62211e-01 1.00000e-09 2.12000e-01

1.00000e-05 1.00000e-05 1.00000e-06 1.00000e-09 1.00000e-01

$1.00000 \mathrm{e}+001.00000 \mathrm{e}+001.00000 \mathrm{e}-011.00000 \mathrm{e}-091.00000 \mathrm{e}-01$

Element: 11073 \# of layers: 7

$\mathrm{Kx} \mathrm{Ky} \mathrm{Kz}$ Ss Por

$1.10579 \mathrm{e}+01$ 1.10579e+01 1.10579e+00 1.00000e-09 2.12000e-01

$1.10579 \mathrm{e}+01$ 1.10579e+01 1.10579e+00 1.00000e-09 2.12000e-01

$1.10579 \mathrm{e}+01$ 1.10579e+01 1.10579e+00 1.00000e-09 2.12000e-01

1.10579e+01 1.10579e+01 1.10579e+00 1.00000e-09 2.12000e-01

$1.10579 \mathrm{e}+01$ 1.10579e+01 1.10579e+00 1.00000e-09 2.12000e-01

$1.00000 \mathrm{e}-05$ 1.00000e-05 1.00000e-06 1.00000e-09 1.00000e-01 
$1.00000 \mathrm{e}+001.00000 \mathrm{e}+001.00000 \mathrm{e}-011.00000 \mathrm{e}-091.00000 \mathrm{e}-01$ Element: 11074 \# of layers: 7

Kx Ky Kz Ss Por

5.85035e+00 5.85035e+00 5.85035e-01 1.00000e-09 2.12000e-01

$5.85035 \mathrm{e}+00$ 5.85035e+00 5.85035e-01 1.00000e-09 2.12000e-01

$5.85035 \mathrm{e}+005.85035 \mathrm{e}+00$ 5.85035e-01 1.00000e-09 2.12000e-01

5.85035e+00 5.85035e+00 5.85035e-01 1.00000e-09 2.12000e-01

$5.85035 \mathrm{e}+005.85035 \mathrm{e}+00$ 5.85035e-01 1.00000e-09 2.12000e-01

$1.00000 \mathrm{e}-05$ 1.00000e-05 1.00000e-06 1.00000e-09 1.00000e-01

$1.00000 \mathrm{e}+001.00000 \mathrm{e}+001.00000 \mathrm{e}-01$ 1.00000e-09 1.00000e-01

Element: 11075 \# of layers: 7

Kx Ky Kz Ss Por

3.57465e+00 3.57465e+00 3.57465e-01 1.00000e-09 2.12000e-01

$3.57465 \mathrm{e}+003.57465 \mathrm{e}+00$ 3.57465e-01 1.00000e-09 2.12000e-01

$3.57465 \mathrm{e}+003.57465 \mathrm{e}+00$ 3.57465e-01 1.00000e-09 2.12000e-01

$3.57465 \mathrm{e}+003.57465 \mathrm{e}+003.57465 \mathrm{e}-01$ 1.00000e-09 2.12000e-01

$3.57465 \mathrm{e}+003.57465 \mathrm{e}+003.57465 \mathrm{e}-01$ 1.00000e-09 2.12000e-01

$1.00000 \mathrm{e}-05$ 1.00000e-05 1.00000e-06 1.00000e-09 1.00000e-01

$1.00000 \mathrm{e}+001.00000 \mathrm{e}+001.00000 \mathrm{e}-01$ 1.00000e-09 1.00000e-01

Element: 11076 \# of layers: 7

Kx Ky Kz Ss Por

3.57465e+00 3.57465e+00 3.57465e-01 1.00000e-09 2.12000e-01

3.57465e+00 3.57465e+00 3.57465e-01 1.00000e-09 2.12000e-01

$3.57465 \mathrm{e}+003.57465 \mathrm{e}+003.57465 \mathrm{e}-01$ 1.00000e-09 2.12000e-01

$3.57465 \mathrm{e}+003.57465 \mathrm{e}+00$ 3.57465e-01 1.00000e-09 2.12000e-01

$3.57465 \mathrm{e}+003.57465 \mathrm{e}+00$ 3.57465e-01 1.00000e-09 2.12000e-01

$1.00000 \mathrm{e}-05$ 1.00000e-05 1.00000e-06 1.00000e-09 1.00000e-01

$1.00000 \mathrm{e}+001.00000 \mathrm{e}+001.00000 \mathrm{e}-01$ 1.00000e-09 1.00000e-01

Element: 11077 \# of layers: 7

$\mathrm{Kx} \mathrm{Ky} \mathrm{Kz}$ Ss Por

3.57465e+00 3.57465e+00 3.57465e-01 1.00000e-09 2.12000e-01

$3.57465 \mathrm{e}+003.57465 \mathrm{e}+00$ 3.57465e-01 1.00000e-09 2.12000e-01

$3.57465 \mathrm{e}+003.57465 \mathrm{e}+003.57465 \mathrm{e}-01$ 1.00000e-09 2.12000e-01

$3.57465 \mathrm{e}+003.57465 \mathrm{e}+00$ 3.57465e-01 1.00000e-09 2.12000e-01

$3.57465 \mathrm{e}+003.57465 \mathrm{e}+003.57465 \mathrm{e}-01$ 1.00000e-09 2.12000e-01

$1.00000 \mathrm{e}-05$ 1.00000e-05 1.00000e-06 1.00000e-09 1.00000e-01

$1.00000 \mathrm{e}+001.00000 \mathrm{e}+001.00000 \mathrm{e}-011.00000 \mathrm{e}-091.00000 \mathrm{e}-01$

Element: 11078 \# of layers: 7

$\mathrm{Kx} \mathrm{Ky} \mathrm{Kz}$ Ss Por

3.57465e+00 3.57465e+00 3.57465e-01 1.00000e-09 2.12000e-01

$3.57465 \mathrm{e}+003.57465 \mathrm{e}+00$ 3.57465e-01 1.00000e-09 2.12000e-01

$3.57465 \mathrm{e}+003.57465 \mathrm{e}+003.57465 \mathrm{e}-01$ 1.00000e-09 2.12000e-01

$3.57465 \mathrm{e}+003.57465 \mathrm{e}+003.57465 \mathrm{e}-01$ 1.00000e-09 2.12000e-01

$3.57465 \mathrm{e}+003.57465 \mathrm{e}+00$ 3.57465e-01 1.00000e-09 2.12000e-01

$1.00000 \mathrm{e}-05$ 1.00000e-05 1.00000e-06 1.00000e-09 1.00000e-01

$1.00000 \mathrm{e}+001.00000 \mathrm{e}+001.00000 \mathrm{e}-011.00000 \mathrm{e}-091.00000 \mathrm{e}-01$ 
Element: 11079 \# of layers: 7

Kx Ky Kz Ss Por

$3.57465 \mathrm{e}+003.57465 \mathrm{e}+003.57465 \mathrm{e}-01$ 1.00000e-09 2.12000e-01

$3.57465 \mathrm{e}+003.57465 \mathrm{e}+003.57465 \mathrm{e}-011.00000 \mathrm{e}-092.12000 \mathrm{e}-01$

$3.57465 \mathrm{e}+003.57465 \mathrm{e}+003.57465 \mathrm{e}-011.00000 \mathrm{e}-092.12000 \mathrm{e}-01$

$3.57465 \mathrm{e}+003.57465 \mathrm{e}+003.57465 \mathrm{e}-011.00000 \mathrm{e}-092.12000 \mathrm{e}-01$

$3.57465 \mathrm{e}+003.57465 \mathrm{e}+003.57465 \mathrm{e}-011.00000 \mathrm{e}-092.12000 \mathrm{e}-01$

$1.00000 \mathrm{e}-05$ 1.00000e-05 1.00000e-06 1.00000e-09 1.00000e-01

$1.00000 \mathrm{e}+001.00000 \mathrm{e}+001.00000 \mathrm{e}-011.00000 \mathrm{e}-091.00000 \mathrm{e}-01$

Element: 11080 \# of layers: 7

Kx Ky Kz Ss Por

$3.57465 \mathrm{e}+003.57465 \mathrm{e}+00$ 3.57465e-01 1.00000e-09 2.12000e-01

$3.57465 \mathrm{e}+003.57465 \mathrm{e}+003.57465 \mathrm{e}-011.00000 \mathrm{e}-092.12000 \mathrm{e}-01$

$3.57465 \mathrm{e}+003.57465 \mathrm{e}+003.57465 \mathrm{e}-011.00000 \mathrm{e}-092.12000 \mathrm{e}-01$

$3.57465 \mathrm{e}+003.57465 \mathrm{e}+003.57465 \mathrm{e}-011.00000 \mathrm{e}-092.12000 \mathrm{e}-01$

$3.57465 \mathrm{e}+003.57465 \mathrm{e}+003.57465 \mathrm{e}-011.00000 \mathrm{e}-092.12000 \mathrm{e}-01$

$1.00000 \mathrm{e}-05$ 1.00000e-05 1.00000e-06 1.00000e-09 1.00000e-01

$1.00000 \mathrm{e}+001.00000 \mathrm{e}+001.00000 \mathrm{e}-011.00000 \mathrm{e}-091.00000 \mathrm{e}-01$

Element: 11081 \# of layers: 7

Kx Ky Kz Ss Por

$3.57465 \mathrm{e}+003.57465 \mathrm{e}+00$ 3.57465e-01 1.00000e-09 2.12000e-01

$3.57465 \mathrm{e}+003.57465 \mathrm{e}+003.57465 \mathrm{e}-011.00000 \mathrm{e}-092.12000 \mathrm{e}-01$

$3.57465 \mathrm{e}+003.57465 \mathrm{e}+003.57465 \mathrm{e}-011.00000 \mathrm{e}-092.12000 \mathrm{e}-01$

$3.57465 \mathrm{e}+003.57465 \mathrm{e}+003.57465 \mathrm{e}-011.00000 \mathrm{e}-092.12000 \mathrm{e}-01$

$3.57465 \mathrm{e}+003.57465 \mathrm{e}+003.57465 \mathrm{e}-011.00000 \mathrm{e}-092.12000 \mathrm{e}-01$

$1.00000 \mathrm{e}-05$ 1.00000e-05 1.00000e-06 1.00000e-09 1.00000e-01

$1.00000 \mathrm{e}+001.00000 \mathrm{e}+001.00000 \mathrm{e}-011.00000 \mathrm{e}-091.00000 \mathrm{e}-01$

Element: 11082 \# of layers: 7

Kx Ky Kz Ss Por

$3.57465 \mathrm{e}+003.57465 \mathrm{e}+003.57465 \mathrm{e}-01$ 1.00000e-09 2.12000e-01

$3.57465 \mathrm{e}+003.57465 \mathrm{e}+003.57465 \mathrm{e}-011.00000 \mathrm{e}-092.12000 \mathrm{e}-01$

$3.57465 \mathrm{e}+003.57465 \mathrm{e}+003.57465 \mathrm{e}-011.00000 \mathrm{e}-092.12000 \mathrm{e}-01$

$3.57465 \mathrm{e}+003.57465 \mathrm{e}+003.57465 \mathrm{e}-011.00000 \mathrm{e}-092.12000 \mathrm{e}-01$

$3.57465 \mathrm{e}+003.57465 \mathrm{e}+003.57465 \mathrm{e}-01$ 1.00000e-09 2.12000e-01

$1.00000 \mathrm{e}-05$ 1.00000e-05 1.00000e-06 1.00000e-09 1.00000e-01

$1.00000 \mathrm{e}+001.00000 \mathrm{e}+001.00000 \mathrm{e}-011.00000 \mathrm{e}-091.00000 \mathrm{e}-01$

Element: 11083 \# of layers: 7

Kx Ky Kz Ss Por

$3.57465 \mathrm{e}+003.57465 \mathrm{e}+00$ 3.57465e-01 1.00000e-09 2.12000e-01

$3.57465 \mathrm{e}+003.57465 \mathrm{e}+003.57465 \mathrm{e}-011.00000 \mathrm{e}-092.12000 \mathrm{e}-01$

$3.57465 \mathrm{e}+003.57465 \mathrm{e}+003.57465 \mathrm{e}-011.00000 \mathrm{e}-092.12000 \mathrm{e}-01$

$3.57465 \mathrm{e}+003.57465 \mathrm{e}+003.57465 \mathrm{e}-011.00000 \mathrm{e}-092.12000 \mathrm{e}-01$

$3.57465 \mathrm{e}+003.57465 \mathrm{e}+003.57465 \mathrm{e}-011.00000 \mathrm{e}-092.12000 \mathrm{e}-01$

$1.00000 \mathrm{e}-05$ 1.00000e-05 1.00000e-06 1.00000e-09 1.00000e-01

$1.00000 \mathrm{e}+001.00000 \mathrm{e}+001.00000 \mathrm{e}-011.00000 \mathrm{e}-091.00000 \mathrm{e}-01$

Element: 11084 \# of layers: 7 
$\mathrm{Kx} \mathrm{Ky} \mathrm{Kz}$ Ss Por

3.57465e+00 3.57465e+00 3.57465e-01 1.00000e-09 2.12000e-01

$3.57465 \mathrm{e}+003.57465 \mathrm{e}+003.57465 \mathrm{e}-01$ 1.00000e-09 2.12000e-01

$3.57465 \mathrm{e}+003.57465 \mathrm{e}+00$ 3.57465e-01 1.00000e-09 2.12000e-01

$3.57465 \mathrm{e}+003.57465 \mathrm{e}+00$ 3.57465e-01 1.00000e-09 2.12000e-01

$3.57465 \mathrm{e}+003.57465 \mathrm{e}+003.57465 \mathrm{e}-01$ 1.00000e-09 2.12000e-01

$1.00000 \mathrm{e}-051.00000 \mathrm{e}-051.00000 \mathrm{e}-061.00000 \mathrm{e}-091.00000 \mathrm{e}-01$

$1.00000 \mathrm{e}+001.00000 \mathrm{e}+001.00000 \mathrm{e}-011.00000 \mathrm{e}-091.00000 \mathrm{e}-01$

Element: 11085 \# of layers: 7

$\mathrm{Kx} \mathrm{Ky} \mathrm{Kz}$ Ss Por

4.19049e+00 4.19049e+00 4.19049e-01 1.00000e-09 2.12000e-01

$4.19049 \mathrm{e}+004.19049 \mathrm{e}+00$ 4.19049e-01 1.00000e-09 2.12000e-01

4.19049e+00 4.19049e+00 4.19049e-01 1.00000e-09 2.12000e-01

4.19049e+00 4.19049e+00 4.19049e-01 1.00000e-09 2.12000e-01

4.19049e+00 4.19049e+00 4.19049e-01 1.00000e-09 2.12000e-01

$1.00000 \mathrm{e}-05$ 1.00000e-05 1.00000e-06 1.00000e-09 1.00000e-01

$1.00000 \mathrm{e}+001.00000 \mathrm{e}+001.00000 \mathrm{e}-01$ 1.00000e-09 1.00000e-01

Element: 11086 \# of layers: 7

$\mathrm{Kx} \mathrm{Ky} \mathrm{Kz}$ Ss Por

4.19049e+00 4.19049e+00 4.19049e-01 1.00000e-09 2.12000e-01

$4.19049 \mathrm{e}+00$ 4.19049e+00 4.19049e-01 1.00000e-09 2.12000e-01

4.19049e+00 4.19049e+00 4.19049e-01 1.00000e-09 2.12000e-01

4.19049e+00 4.19049e+00 4.19049e-01 1.00000e-09 2.12000e-01

4.19049e+00 4.19049e+00 4.19049e-01 1.00000e-09 2.12000e-01

$1.00000 \mathrm{e}-05$ 1.00000e-05 1.00000e-06 1.00000e-09 1.00000e-01

$1.00000 \mathrm{e}+001.00000 \mathrm{e}+001.00000 \mathrm{e}-01$ 1.00000e-09 1.00000e-01

Element: 11087 \# of layers: 7

$\mathrm{Kx} \mathrm{Ky} \mathrm{Kz} \mathrm{Ss} \mathrm{Por}$

4.19049e+00 4.19049e+00 4.19049e-01 1.00000e-09 2.12000e-01

4.19049e+00 4.19049e+00 4.19049e-01 1.00000e-09 2.12000e-01

4.19049e+00 4.19049e+00 4.19049e-01 1.00000e-09 2.12000e-01

4.19049e+00 4.19049e+00 4.19049e-01 1.00000e-09 2.12000e-01

$4.19049 \mathrm{e}+004.19049 \mathrm{e}+00$ 4.19049e-01 1.00000e-09 2.12000e-01

$1.00000 \mathrm{e}-05$ 1.00000e-05 1.00000e-06 1.00000e-09 1.00000e-01

$1.00000 \mathrm{e}+001.00000 \mathrm{e}+001.00000 \mathrm{e}-011.00000 \mathrm{e}-091.00000 \mathrm{e}-01$

Element: 11088 \# of layers: 7

$\mathrm{Kx} \mathrm{Ky} \mathrm{Kz}$ Ss Por

4.19049e+00 4.19049e+00 4.19049e-01 1.00000e-09 2.12000e-01

4.19049e+00 4.19049e+00 4.19049e-01 1.00000e-09 2.12000e-01

4.19049e+00 4.19049e+00 4.19049e-01 1.00000e-09 2.12000e-01

$4.19049 \mathrm{e}+004.19049 \mathrm{e}+00$ 4.19049e-01 1.00000e-09 2.12000e-01

4.19049e+00 4.19049e+00 4.19049e-01 1.00000e-09 2.12000e-01

$1.00000 \mathrm{e}-05$ 1.00000e-05 1.00000e-06 1.00000e-09 1.00000e-01

$1.00000 \mathrm{e}+001.00000 \mathrm{e}+001.00000 \mathrm{e}-01$ 1.00000e-09 1.00000e-01

Element: 11089 \# of layers: 7

Kx Ky Kz Ss Por 
4.19049e+00 4.19049e+00 4.19049e-01 1.00000e-09 2.12000e-01 4.19049e+00 4.19049e+00 4.19049e-01 1.00000e-09 2.12000e-01 4.19049e+00 4.19049e+00 4.19049e-01 1.00000e-09 2.12000e-01 $4.19049 \mathrm{e}+00$ 4.19049e+00 4.19049e-01 1.00000e-09 2.12000e-01 4.19049e+00 4.19049e+00 4.19049e-01 1.00000e-09 2.12000e-01 $1.00000 \mathrm{e}-05$ 1.00000e-05 1.00000e-06 1.00000e-09 1.00000e-01 $1.00000 \mathrm{e}+001.00000 \mathrm{e}+00$ 1.00000e-01 1.00000e-09 1.00000e-01 Element: 11090 \# of layers: 7

$\mathrm{Kx} \mathrm{Ky} \mathrm{Kz}$ Ss Por

3.57465e+00 3.57465e+00 3.57465e-01 1.00000e-09 2.12000e-01 $3.57465 \mathrm{e}+003.57465 \mathrm{e}+00$ 3.57465e-01 1.00000e-09 2.12000e-01 $3.57465 \mathrm{e}+003.57465 \mathrm{e}+003.57465 \mathrm{e}-01$ 1.00000e-09 2.12000e-01 $3.57465 \mathrm{e}+003.57465 \mathrm{e}+00$ 3.57465e-01 1.00000e-09 2.12000e-01 $3.57465 \mathrm{e}+003.57465 \mathrm{e}+003.57465 \mathrm{e}-01$ 1.00000e-09 2.12000e-01 $1.00000 \mathrm{e}-05$ 1.00000e-05 1.00000e-06 1.00000e-09 1.00000e-01 $1.00000 \mathrm{e}+001.00000 \mathrm{e}+001.00000 \mathrm{e}-011.00000 \mathrm{e}-091.00000 \mathrm{e}-01$ Element: 11091 \# of layers: 7

$\mathrm{Kx} \mathrm{Ky} \mathrm{Kz}$ Ss Por

3.57465e+00 3.57465e+00 3.57465e-01 1.00000e-09 2.12000e-01

$3.57465 \mathrm{e}+003.57465 \mathrm{e}+00 \quad 3.57465 \mathrm{e}-01$ 1.00000e-09 2.12000e-01 $3.57465 \mathrm{e}+003.57465 \mathrm{e}+00$ 3.57465e-01 1.00000e-09 2.12000e-01 $3.57465 \mathrm{e}+003.57465 \mathrm{e}+00$ 3.57465e-01 1.00000e-09 2.12000e-01 $3.57465 \mathrm{e}+003.57465 \mathrm{e}+00$ 3.57465e-01 1.00000e-09 2.12000e-01 $1.00000 \mathrm{e}-05$ 1.00000e-05 1.00000e-06 1.00000e-09 1.00000e-01 $1.00000 \mathrm{e}+001.00000 \mathrm{e}+001.00000 \mathrm{e}-011.00000 \mathrm{e}-091.00000 \mathrm{e}-01$ Element: 11092 \# of layers: 7

$\mathrm{Kx} \mathrm{Ky} \mathrm{Kz}$ Ss Por

4.19049e+00 4.19049e+00 4.19049e-01 1.00000e-09 2.12000e-01 $4.19049 \mathrm{e}+00$ 4.19049e+00 4.19049e-01 1.00000e-09 2.12000e-01 4.19049e+00 4.19049e+00 4.19049e-01 1.00000e-09 2.12000e-01 4.19049e+00 4.19049e+00 4.19049e-01 1.00000e-09 2.12000e-01 4.19049e+00 4.19049e+00 4.19049e-01 1.00000e-09 2.12000e-01 $1.00000 \mathrm{e}-05$ 1.00000e-05 1.00000e-06 1.00000e-09 1.00000e-01 $1.00000 \mathrm{e}+001.00000 \mathrm{e}+001.00000 \mathrm{e}-011.00000 \mathrm{e}-091.00000 \mathrm{e}-01$ Element: 11093 \# of layers: 7

$\mathrm{Kx} \mathrm{Ky} \mathrm{Kz}$ Ss Por

4.19049e+00 4.19049e+00 4.19049e-01 1.00000e-09 2.12000e-01 4.19049e+00 4.19049e+00 4.19049e-01 1.00000e-09 2.12000e-01 4.19049e+00 4.19049e+00 4.19049e-01 1.00000e-09 2.12000e-01 4.19049e+00 4.19049e+00 4.19049e-01 1.00000e-09 2.12000e-01 4.19049e+00 4.19049e+00 4.19049e-01 1.00000e-09 2.12000e-01 $1.00000 \mathrm{e}-05$ 1.00000e-05 1.00000e-06 1.00000e-09 1.00000e-01 $1.00000 \mathrm{e}+001.00000 \mathrm{e}+001.00000 \mathrm{e}-01$ 1.00000e-09 1.00000e-01 Element: 11094 \# of layers: 6

$\mathrm{Kx} \mathrm{Ky} \mathrm{Kz}$ Ss Por

4.19049e+00 4.19049e+00 4.19049e-01 1.00000e-09 2.12000e-01 
4.19049e+00 4.19049e+00 4.19049e-01 1.00000e-09 2.12000e-01 4.19049e+00 4.19049e+00 4.19049e-01 1.00000e-09 2.12000e-01 4.19049e+00 4.19049e+00 4.19049e-01 1.00000e-09 2.12000e-01 $1.00000 \mathrm{e}-05$ 1.00000e-05 1.00000e-06 1.00000e-09 1.00000e-01 $1.00000 \mathrm{e}+001.00000 \mathrm{e}+00$ 1.00000e-01 1.00000e-09 1.00000e-01 Element: 11095 \# of layers: 6

$\mathrm{Kx} \mathrm{Ky} \mathrm{Kz}$ Ss Por

4.19049e+00 4.19049e+00 4.19049e-01 1.00000e-09 2.12000e-01 4.19049e+00 4.19049e+00 4.19049e-01 1.00000e-09 2.12000e-01 4.19049e+00 4.19049e+00 4.19049e-01 1.00000e-09 2.12000e-01 4.19049e+00 4.19049e+00 4.19049e-01 1.00000e-09 2.12000e-01 $1.00000 \mathrm{e}-05$ 1.00000e-05 1.00000e-06 1.00000e-09 1.00000e-01 $1.00000 \mathrm{e}+001.00000 \mathrm{e}+001.00000 \mathrm{e}-011.00000 \mathrm{e}-091.00000 \mathrm{e}-01$ Element: 11096 \# of layers: 6

$\mathrm{Kx} \mathrm{Ky} \mathrm{Kz}$ Ss Por

4.19049e+00 4.19049e+00 4.19049e-01 1.00000e-09 2.12000e-01 4.19049e+00 4.19049e+00 4.19049e-01 1.00000e-09 2.12000e-01 4.19049e+00 4.19049e+00 4.19049e-01 1.00000e-09 2.12000e-01 4.19049e+00 4.19049e+00 4.19049e-01 1.00000e-09 2.12000e-01 $1.00000 \mathrm{e}-05$ 1.00000e-05 1.00000e-06 1.00000e-09 1.00000e-01 $1.00000 \mathrm{e}+001.00000 \mathrm{e}+001.00000 \mathrm{e}-011.00000 \mathrm{e}-091.00000 \mathrm{e}-01$ Element: 11097 \# of layers: 6

$\mathrm{Kx} \mathrm{Ky} \mathrm{Kz}$ Ss Por

4.19049e+00 4.19049e+00 4.19049e-01 1.00000e-09 2.12000e-01 4.19049e+00 4.19049e+00 4.19049e-01 1.00000e-09 2.12000e-01 4.19049e+00 4.19049e+00 4.19049e-01 1.00000e-09 2.12000e-01 4.19049e+00 4.19049e+00 4.19049e-01 1.00000e-09 2.12000e-01 $1.00000 \mathrm{e}-05$ 1.00000e-05 1.00000e-06 1.00000e-09 1.00000e-01 $1.00000 \mathrm{e}+001.00000 \mathrm{e}+001.00000 \mathrm{e}-011.00000 \mathrm{e}-091.00000 \mathrm{e}-01$ Element: 11098 \# of layers: 6

$\mathrm{Kx} \mathrm{Ky} \mathrm{Kz}$ Ss Por

4.19049e+00 4.19049e+00 4.19049e-01 1.00000e-09 2.12000e-01 4.19049e+00 4.19049e+00 4.19049e-01 1.00000e-09 2.12000e-01 4.19049e+00 4.19049e+00 4.19049e-01 1.00000e-09 2.12000e-01 4.19049e+00 4.19049e+00 4.19049e-01 1.00000e-09 2.12000e-01 $1.00000 \mathrm{e}-05$ 1.00000e-05 1.00000e-06 1.00000e-09 1.00000e-01 $1.00000 \mathrm{e}+001.00000 \mathrm{e}+001.00000 \mathrm{e}-011.00000 \mathrm{e}-091.00000 \mathrm{e}-01$ Element: 11099 \# of layers: 7

$\mathrm{Kx} \mathrm{Ky} \mathrm{Kz}$ Ss Por

4.19049e+00 4.19049e+00 4.19049e-01 1.00000e-09 2.12000e-01 4.19049e+00 4.19049e+00 4.19049e-01 1.00000e-09 2.12000e-01 4.19049e+00 4.19049e+00 4.19049e-01 1.00000e-09 2.12000e-01 4.19049e+00 4.19049e+00 4.19049e-01 1.00000e-09 2.12000e-01 4.19049e+00 4.19049e+00 4.19049e-01 1.00000e-09 2.12000e-01 $1.00000 \mathrm{e}-05$ 1.00000e-05 1.00000e-06 1.00000e-09 1.00000e-01 $1.00000 \mathrm{e}+001.00000 \mathrm{e}+001.00000 \mathrm{e}-011.00000 \mathrm{e}-091.00000 \mathrm{e}-01$ 
Element: 11100 \# of layers: 7

Kx Ky Kz Ss Por

4.19049e+00 4.19049e+00 4.19049e-01 1.00000e-09 2.12000e-01

$4.19049 \mathrm{e}+004.19049 \mathrm{e}+00$ 4.19049e-01 1.00000e-09 2.12000e-01

$4.19049 \mathrm{e}+00$ 4.19049e+00 4.19049e-01 1.00000e-09 2.12000e-01

$4.19049 \mathrm{e}+004.19049 \mathrm{e}+00$ 4.19049e-01 1.00000e-09 2.12000e-01

$4.19049 \mathrm{e}+00$ 4.19049e+00 4.19049e-01 1.00000e-09 2.12000e-01

$1.00000 \mathrm{e}-05$ 1.00000e-05 1.00000e-06 1.00000e-09 1.00000e-01

$1.00000 \mathrm{e}+001.00000 \mathrm{e}+001.00000 \mathrm{e}-011.00000 \mathrm{e}-091.00000 \mathrm{e}-01$

Element: 11101 \# of layers: 6

Kx Ky Kz Ss Por

4.19049e+00 4.19049e+00 4.19049e-01 1.00000e-09 2.12000e-01

$4.19049 \mathrm{e}+004.19049 \mathrm{e}+00$ 4.19049e-01 1.00000e-09 2.12000e-01

$4.19049 \mathrm{e}+004.19049 \mathrm{e}+00$ 4.19049e-01 1.00000e-09 2.12000e-01

$4.19049 \mathrm{e}+00$ 4.19049e+00 4.19049e-01 1.00000e-09 2.12000e-01

$1.00000 \mathrm{e}-05$ 1.00000e-05 1.00000e-06 1.00000e-09 1.00000e-01

$1.00000 \mathrm{e}+001.00000 \mathrm{e}+001.00000 \mathrm{e}-011.00000 \mathrm{e}-091.00000 \mathrm{e}-01$

Element: 11102 \# of layers: 6

Kx Ky Kz Ss Por

4.19049e+00 4.19049e+00 4.19049e-01 1.00000e-09 2.12000e-01

$4.19049 \mathrm{e}+004.19049 \mathrm{e}+00$ 4.19049e-01 1.00000e-09 2.12000e-01

$4.19049 \mathrm{e}+004.19049 \mathrm{e}+00$ 4.19049e-01 1.00000e-09 2.12000e-01

$4.19049 \mathrm{e}+004.19049 \mathrm{e}+00$ 4.19049e-01 1.00000e-09 2.12000e-01

$1.00000 \mathrm{e}-05$ 1.00000e-05 1.00000e-06 1.00000e-09 1.00000e-01

$1.00000 \mathrm{e}+001.00000 \mathrm{e}+001.00000 \mathrm{e}-011.00000 \mathrm{e}-091.00000 \mathrm{e}-01$

Element: 11103 \# of layers: 6

Kx Ky Kz Ss Por

4.19049e+00 4.19049e+00 4.19049e-01 1.00000e-09 2.12000e-01

$4.19049 \mathrm{e}+00$ 4.19049e+00 4.19049e-01 1.00000e-09 2.12000e-01

$4.19049 \mathrm{e}+004.19049 \mathrm{e}+00$ 4.19049e-01 1.00000e-09 2.12000e-01

$4.19049 \mathrm{e}+00$ 4.19049e+00 4.19049e-01 1.00000e-09 2.12000e-01

$1.00000 \mathrm{e}-05$ 1.00000e-05 1.00000e-06 1.00000e-09 1.00000e-01

$1.00000 \mathrm{e}+001.00000 \mathrm{e}+001.00000 \mathrm{e}-011.00000 \mathrm{e}-091.00000 \mathrm{e}-01$

Element: 11104 \# of layers: 6

Kx Ky Kz Ss Por

$4.28702 \mathrm{e}+004.28702 \mathrm{e}+00$ 4.28702e-01 1.00000e-09 2.12000e-01

$4.28702 \mathrm{e}+004.28702 \mathrm{e}+00$ 4.28702e-01 1.00000e-09 2.12000e-01

$4.28702 \mathrm{e}+004.28702 \mathrm{e}+004.28702 \mathrm{e}-011.00000 \mathrm{e}-092.12000 \mathrm{e}-01$

$4.28702 \mathrm{e}+004.28702 \mathrm{e}+00$ 4.28702e-01 1.00000e-09 2.12000e-01

$1.00000 \mathrm{e}-05$ 1.00000e-05 1.00000e-06 1.00000e-09 1.00000e-01

$1.00000 \mathrm{e}+001.00000 \mathrm{e}+001.00000 \mathrm{e}-011.00000 \mathrm{e}-091.00000 \mathrm{e}-01$

Element: 11105 \# of layers: 6

Kx Ky Kz Ss Por

$4.28702 \mathrm{e}+00$ 4.28702e+00 4.28702e-01 1.00000e-09 2.12000e-01

$4.28702 \mathrm{e}+004.28702 \mathrm{e}+00$ 4.28702e-01 1.00000e-09 2.12000e-01

$4.28702 \mathrm{e}+004.28702 \mathrm{e}+004.28702 \mathrm{e}-01$ 1.00000e-09 2.12000e-01 
4.28702e+00 4.28702e+00 4.28702e-01 1.00000e-09 2.12000e-01 $1.00000 \mathrm{e}-05$ 1.00000e-05 1.00000e-06 1.00000e-09 1.00000e-01 $1.00000 \mathrm{e}+001.00000 \mathrm{e}+00$ 1.00000e-01 1.00000e-09 1.00000e-01 Element: 11106 \# of layers: 7

$\mathrm{Kx} \mathrm{Ky} \mathrm{Kz}$ Ss Por

4.28702e+00 4.28702e+00 4.28702e-01 1.00000e-09 2.12000e-01 4.28702e+00 4.28702e+00 4.28702e-01 1.00000e-09 2.12000e-01 $4.28702 \mathrm{e}+00$ 4.28702e+00 4.28702e-01 1.00000e-09 2.12000e-01 $4.28702 \mathrm{e}+00$ 4.28702e+00 4.28702e-01 1.00000e-09 2.12000e-01 $4.28702 \mathrm{e}+00$ 4.28702e+00 4.28702e-01 1.00000e-09 2.12000e-01 $1.00000 \mathrm{e}-05$ 1.00000e-05 1.00000e-06 1.00000e-09 1.00000e-01 $1.00000 \mathrm{e}+001.00000 \mathrm{e}+001.00000 \mathrm{e}-011.00000 \mathrm{e}-091.00000 \mathrm{e}-01$ Element: 11107 \# of layers: 7

$\mathrm{Kx} \mathrm{Ky} \mathrm{Kz}$ Ss Por

4.19049e+00 4.19049e+00 4.19049e-01 1.00000e-09 2.12000e-01 $4.19049 \mathrm{e}+004.19049 \mathrm{e}+00$ 4.19049e-01 1.00000e-09 2.12000e-01 $4.19049 \mathrm{e}+00$ 4.19049e+00 4.19049e-01 1.00000e-09 2.12000e-01 4.19049e+00 4.19049e+00 4.19049e-01 1.00000e-09 2.12000e-01 4.19049e+00 4.19049e+00 4.19049e-01 1.00000e-09 2.12000e-01 $1.00000 \mathrm{e}-05$ 1.00000e-05 1.00000e-06 1.00000e-09 1.00000e-01 $1.00000 \mathrm{e}+001.00000 \mathrm{e}+001.00000 \mathrm{e}-011.00000 \mathrm{e}-091.00000 \mathrm{e}-01$ Element: 11108 \# of layers: 7

$\mathrm{Kx} \mathrm{Ky} \mathrm{Kz}$ Ss Por

4.19049e+00 4.19049e+00 4.19049e-01 1.00000e-09 2.12000e-01 $4.19049 \mathrm{e}+00$ 4.19049e+00 4.19049e-01 1.00000e-09 2.12000e-01 4.19049e+00 4.19049e+00 4.19049e-01 1.00000e-09 2.12000e-01 4.19049e+00 4.19049e+00 4.19049e-01 1.00000e-09 2.12000e-01 4.19049e+00 4.19049e+00 4.19049e-01 1.00000e-09 2.12000e-01 $1.00000 \mathrm{e}-05$ 1.00000e-05 1.00000e-06 1.00000e-09 1.00000e-01 $1.00000 \mathrm{e}+001.00000 \mathrm{e}+001.00000 \mathrm{e}-011.00000 \mathrm{e}-091.00000 \mathrm{e}-01$ Element: 11109 \# of layers: 6

$\mathrm{Kx} \mathrm{Ky} \mathrm{Kz}$ Ss Por

4.19049e+00 4.19049e+00 4.19049e-01 1.00000e-09 2.12000e-01 4.19049e+00 4.19049e+00 4.19049e-01 1.00000e-09 2.12000e-01 4.19049e+00 4.19049e+00 4.19049e-01 1.00000e-09 2.12000e-01 4.19049e+00 4.19049e+00 4.19049e-01 1.00000e-09 2.12000e-01 $1.00000 \mathrm{e}-05$ 1.00000e-05 1.00000e-06 1.00000e-09 1.00000e-01 $1.00000 \mathrm{e}+001.00000 \mathrm{e}+001.00000 \mathrm{e}-011.00000 \mathrm{e}-09$ 1.00000e-01 Element: 11110 \# of layers: 6

$\mathrm{Kx} \mathrm{Ky} \mathrm{Kz}$ Ss Por

4.19049e+00 4.19049e+00 4.19049e-01 1.00000e-09 2.12000e-01 4.19049e+00 4.19049e+00 4.19049e-01 1.00000e-09 2.12000e-01 4.19049e+00 4.19049e+00 4.19049e-01 1.00000e-09 2.12000e-01 4.19049e+00 4.19049e+00 4.19049e-01 1.00000e-09 2.12000e-01 $1.00000 \mathrm{e}-051.00000 \mathrm{e}-051.00000 \mathrm{e}-061.00000 \mathrm{e}-091.00000 \mathrm{e}-01$ $1.00000 \mathrm{e}+001.00000 \mathrm{e}+001.00000 \mathrm{e}-011.00000 \mathrm{e}-091.00000 \mathrm{e}-01$ 
Element: 11111 \# of layers: 6

$\mathrm{Kx} \mathrm{Ky} \mathrm{Kz}$ Ss Por

4.28702e+00 4.28702e+00 4.28702e-01 1.00000e-09 2.12000e-01

$4.28702 \mathrm{e}+004.28702 \mathrm{e}+00$ 4.28702e-01 1.00000e-09 2.12000e-01

4.28702e+00 4.28702e+00 4.28702e-01 1.00000e-09 2.12000e-01

$4.28702 \mathrm{e}+004.28702 \mathrm{e}+00$ 4.28702e-01 1.00000e-09 2.12000e-01

$1.00000 \mathrm{e}-05$ 1.00000e-05 1.00000e-06 1.00000e-09 1.00000e-01

$1.00000 \mathrm{e}+001.00000 \mathrm{e}+001.00000 \mathrm{e}-01$ 1.00000e-09 1.00000e-01

Element: 11112 \# of layers: 6

$\mathrm{Kx} \mathrm{Ky} \mathrm{Kz}$ Ss Por

4.28702e+00 4.28702e+00 4.28702e-01 1.00000e-09 2.12000e-01

$4.28702 \mathrm{e}+004.28702 \mathrm{e}+00$ 4.28702e-01 1.00000e-09 2.12000e-01

$4.28702 \mathrm{e}+00$ 4.28702e+00 4.28702e-01 1.00000e-09 2.12000e-01

4.28702e+00 4.28702e+00 4.28702e-01 1.00000e-09 2.12000e-01

$1.00000 \mathrm{e}-05$ 1.00000e-05 1.00000e-06 1.00000e-09 1.00000e-01

$1.00000 \mathrm{e}+001.00000 \mathrm{e}+001.00000 \mathrm{e}-011.00000 \mathrm{e}-091.00000 \mathrm{e}-01$

Element: 11113 \# of layers: 6

$\mathrm{Kx} \mathrm{Ky} \mathrm{Kz}$ Ss Por

4.28702e+00 4.28702e+00 4.28702e-01 1.00000e-09 2.12000e-01

$4.28702 \mathrm{e}+004.28702 \mathrm{e}+00$ 4.28702e-01 1.00000e-09 2.12000e-01

$4.28702 \mathrm{e}+004.28702 \mathrm{e}+004.28702 \mathrm{e}-01$ 1.00000e-09 2.12000e-01

$4.28702 \mathrm{e}+004.28702 \mathrm{e}+00$ 4.28702e-01 1.00000e-09 2.12000e-01

$1.00000 \mathrm{e}-051.00000 \mathrm{e}-051.00000 \mathrm{e}-061.00000 \mathrm{e}-091.00000 \mathrm{e}-01$

$1.00000 \mathrm{e}+001.00000 \mathrm{e}+001.00000 \mathrm{e}-011.00000 \mathrm{e}-091.00000 \mathrm{e}-01$

Element: 11114 \# of layers: 6

$\mathrm{Kx} \mathrm{Ky} \mathrm{Kz}$ Ss Por

4.28702e+00 4.28702e+00 4.28702e-01 1.00000e-09 2.12000e-01

4.28702e+00 4.28702e+00 4.28702e-01 1.00000e-09 2.12000e-01

$4.28702 \mathrm{e}+004.28702 \mathrm{e}+00$ 4.28702e-01 1.00000e-09 2.12000e-01

$4.28702 \mathrm{e}+004.28702 \mathrm{e}+00$ 4.28702e-01 1.00000e-09 2.12000e-01

$1.00000 \mathrm{e}-05$ 1.00000e-05 1.00000e-06 1.00000e-09 1.00000e-01

$1.00000 \mathrm{e}+001.00000 \mathrm{e}+001.00000 \mathrm{e}-01$ 1.00000e-09 1.00000e-01

Element: 11115 \# of layers: 7

$\mathrm{Kx} \mathrm{Ky} \mathrm{Kz}$ Ss Por

4.28702e+00 4.28702e+00 4.28702e-01 1.00000e-09 2.12000e-01

4.28702e+00 4.28702e+00 4.28702e-01 1.00000e-09 2.12000e-01

$4.28702 \mathrm{e}+004.28702 \mathrm{e}+00$ 4.28702e-01 1.00000e-09 2.12000e-01

$4.28702 \mathrm{e}+004.28702 \mathrm{e}+00$ 4.28702e-01 1.00000e-09 2.12000e-01

4.28702e+00 4.28702e+00 4.28702e-01 1.00000e-09 2.12000e-01

$1.00000 \mathrm{e}-05$ 1.00000e-05 1.00000e-06 1.00000e-09 1.00000e-01

$1.00000 \mathrm{e}+001.00000 \mathrm{e}+001.00000 \mathrm{e}-011.00000 \mathrm{e}-091.00000 \mathrm{e}-01$

Element: 11116 \# of layers: 7

$\mathrm{Kx} \mathrm{Ky} \mathrm{Kz}$ Ss Por

4.28702e+00 4.28702e+00 4.28702e-01 1.00000e-09 2.12000e-01

$4.28702 \mathrm{e}+004.28702 \mathrm{e}+004.28702 \mathrm{e}-01$ 1.00000e-09 2.12000e-01

$4.28702 \mathrm{e}+004.28702 \mathrm{e}+00$ 4.28702e-01 1.00000e-09 2.12000e-01 
$4.28702 \mathrm{e}+004.28702 \mathrm{e}+00$ 4.28702e-01 1.00000e-09 2.12000e-01 $4.28702 \mathrm{e}+004.28702 \mathrm{e}+004.28702 \mathrm{e}-011.00000 \mathrm{e}-092.12000 \mathrm{e}-01$ $1.00000 \mathrm{e}-05$ 1.00000e-05 1.00000e-06 1.00000e-09 1.00000e-01 $1.00000 \mathrm{e}+001.00000 \mathrm{e}+001.00000 \mathrm{e}-011.00000 \mathrm{e}-091.00000 \mathrm{e}-01$ Element: 11117 \# of layers: 7

Kx Ky Kz Ss Por

$4.28702 \mathrm{e}+00$ 4.28702e+00 4.28702e-01 1.00000e-09 2.12000e-01 $4.28702 \mathrm{e}+004.28702 \mathrm{e}+00$ 4.28702e-01 1.00000e-09 2.12000e-01 $4.28702 \mathrm{e}+004.28702 \mathrm{e}+004.28702 \mathrm{e}-011.00000 \mathrm{e}-092.12000 \mathrm{e}-01$ $4.28702 \mathrm{e}+004.28702 \mathrm{e}+00$ 4.28702e-01 1.00000e-09 2.12000e-01 $4.28702 \mathrm{e}+004.28702 \mathrm{e}+00$ 4.28702e-01 1.00000e-09 2.12000e-01 $1.00000 \mathrm{e}-05$ 1.00000e-05 1.00000e-06 1.00000e-09 1.00000e-01 $1.00000 \mathrm{e}+001.00000 \mathrm{e}+001.00000 \mathrm{e}-011.00000 \mathrm{e}-091.00000 \mathrm{e}-01$ Element: 11118 \# of layers: 6

Kx Ky Kz Ss Por $4.28702 \mathrm{e}+00$ 4.28702e+00 4.28702e-01 1.00000e-09 2.12000e-01 $4.28702 \mathrm{e}+004.28702 \mathrm{e}+004.28702 \mathrm{e}-011.00000 \mathrm{e}-09$ 2.12000e-01 $4.28702 \mathrm{e}+004.28702 \mathrm{e}+00$ 4.28702e-01 1.00000e-09 2.12000e-01 $4.28702 \mathrm{e}+004.28702 \mathrm{e}+00$ 4.28702e-01 1.00000e-09 2.12000e-01 $1.00000 \mathrm{e}-05$ 1.00000e-05 1.00000e-06 1.00000e-09 1.00000e-01 $1.00000 \mathrm{e}+001.00000 \mathrm{e}+001.00000 \mathrm{e}-011.00000 \mathrm{e}-091.00000 \mathrm{e}-01$ Element: 11119 \# of layers: 6

Kx Ky Kz Ss Por

$4.28702 \mathrm{e}+00$ 4.28702e+00 4.28702e-01 1.00000e-09 2.12000e-01 $4.28702 \mathrm{e}+004.28702 \mathrm{e}+004.28702 \mathrm{e}-011.00000 \mathrm{e}-09$ 2.12000e-01 $4.28702 \mathrm{e}+004.28702 \mathrm{e}+00$ 4.28702e-01 1.00000e-09 2.12000e-01 $4.28702 \mathrm{e}+004.28702 \mathrm{e}+004.28702 \mathrm{e}-011.00000 \mathrm{e}-092.12000 \mathrm{e}-01$ $1.00000 \mathrm{e}-05$ 1.00000e-05 1.00000e-06 1.00000e-09 1.00000e-01 $1.00000 \mathrm{e}+001.00000 \mathrm{e}+001.00000 \mathrm{e}-011.00000 \mathrm{e}-091.00000 \mathrm{e}-01$ Element: 11120 \# of layers: 7

Kx Ky Kz Ss Por

$4.28702 \mathrm{e}+00$ 4.28702e+00 4.28702e-01 1.00000e-09 2.12000e-01 $4.28702 \mathrm{e}+004.28702 \mathrm{e}+00$ 4.28702e-01 1.00000e-09 2.12000e-01 $4.28702 \mathrm{e}+004.28702 \mathrm{e}+00$ 4.28702e-01 1.00000e-09 2.12000e-01 $4.28702 \mathrm{e}+004.28702 \mathrm{e}+004.28702 \mathrm{e}-01$ 1.00000e-09 2.12000e-01 $4.28702 \mathrm{e}+004.28702 \mathrm{e}+00$ 4.28702e-01 1.00000e-09 2.12000e-01 $1.00000 \mathrm{e}-05$ 1.00000e-05 1.00000e-06 1.00000e-09 1.00000e-01 $1.00000 \mathrm{e}+001.00000 \mathrm{e}+001.00000 \mathrm{e}-011.00000 \mathrm{e}-091.00000 \mathrm{e}-01$ Element: 11121 \# of layers: 7

Kx Ky Kz Ss Por $4.28702 \mathrm{e}+004.28702 \mathrm{e}+00$ 4.28702e-01 1.00000e-09 2.12000e-01 $4.28702 \mathrm{e}+004.28702 \mathrm{e}+00$ 4.28702e-01 1.00000e-09 2.12000e-01 $4.28702 \mathrm{e}+004.28702 \mathrm{e}+00$ 4.28702e-01 1.00000e-09 2.12000e-01 $4.28702 \mathrm{e}+004.28702 \mathrm{e}+00$ 4.28702e-01 1.00000e-09 2.12000e-01 $4.28702 \mathrm{e}+004.28702 \mathrm{e}+004.28702 \mathrm{e}-011.00000 \mathrm{e}-092.12000 \mathrm{e}-01$ $1.00000 \mathrm{e}-05$ 1.00000e-05 1.00000e-06 1.00000e-09 1.00000e-01 
$1.00000 \mathrm{e}+001.00000 \mathrm{e}+001.00000 \mathrm{e}-01$ 1.00000e-09 1.00000e-01

Element: 11122 \# of layers: 7

Kx Ky Kz Ss Por

3.61830e+00 3.61830e+00 3.61830e-01 1.00000e-09 2.12000e-01

$3.61830 \mathrm{e}+003.61830 \mathrm{e}+00$ 3.61830e-01 1.00000e-09 2.12000e-01

$3.61830 \mathrm{e}+003.61830 \mathrm{e}+003.61830 \mathrm{e}-011.00000 \mathrm{e}-092.12000 \mathrm{e}-01$

$3.61830 \mathrm{e}+003.61830 \mathrm{e}+00$ 3.61830e-01 1.00000e-09 2.12000e-01

$3.61830 \mathrm{e}+003.61830 \mathrm{e}+003.61830 \mathrm{e}-01$ 1.00000e-09 2.12000e-01

$1.00000 \mathrm{e}-05$ 1.00000e-05 1.00000e-06 1.00000e-09 1.00000e-01

$1.00000 \mathrm{e}+001.00000 \mathrm{e}+001.00000 \mathrm{e}-01$ 1.00000e-09 1.00000e-01

Element: 11123 \# of layers: 7

Kx Ky Kz Ss Por

3.61830e+00 3.61830e+00 3.61830e-01 1.00000e-09 2.12000e-01

$3.61830 \mathrm{e}+003.61830 \mathrm{e}+003.61830 \mathrm{e}-01$ 1.00000e-09 2.12000e-01

$3.61830 \mathrm{e}+003.61830 \mathrm{e}+003.61830 \mathrm{e}-01$ 1.00000e-09 2.12000e-01

$3.61830 \mathrm{e}+003.61830 \mathrm{e}+003.61830 \mathrm{e}-01$ 1.00000e-09 2.12000e-01

$3.61830 \mathrm{e}+003.61830 \mathrm{e}+00$ 3.61830e-01 1.00000e-09 2.12000e-01

$1.00000 \mathrm{e}-05$ 1.00000e-05 1.00000e-06 1.00000e-09 1.00000e-01

$1.00000 \mathrm{e}+001.00000 \mathrm{e}+001.00000 \mathrm{e}-01$ 1.00000e-09 1.00000e-01

Element: 11124 \# of layers: 7

$\mathrm{Kx} \mathrm{Ky} \mathrm{Kz}$ Ss Por

3.61830e+00 3.61830e+00 3.61830e-01 1.00000e-09 2.12000e-01

$3.61830 \mathrm{e}+003.61830 \mathrm{e}+003.61830 \mathrm{e}-01$ 1.00000e-09 2.12000e-01

$3.61830 \mathrm{e}+003.61830 \mathrm{e}+003.61830 \mathrm{e}-01$ 1.00000e-09 2.12000e-01

$3.61830 \mathrm{e}+003.61830 \mathrm{e}+00$ 3.61830e-01 1.00000e-09 2.12000e-01

$3.61830 \mathrm{e}+003.61830 \mathrm{e}+003.61830 \mathrm{e}-01$ 1.00000e-09 2.12000e-01

$1.00000 \mathrm{e}-05$ 1.00000e-05 1.00000e-06 1.00000e-09 1.00000e-01

$1.00000 \mathrm{e}+001.00000 \mathrm{e}+001.00000 \mathrm{e}-01$ 1.00000e-09 1.00000e-01

Element: 11125 \# of layers: 7

$\mathrm{Kx} \mathrm{Ky} \mathrm{Kz}$ Ss Por

4.28702e+00 4.28702e+00 4.28702e-01 1.00000e-09 2.12000e-01

4.28702e+00 4.28702e+00 4.28702e-01 1.00000e-09 2.12000e-01

$4.28702 \mathrm{e}+004.28702 \mathrm{e}+00$ 4.28702e-01 1.00000e-09 2.12000e-01

$4.28702 \mathrm{e}+00$ 4.28702e+00 4.28702e-01 1.00000e-09 2.12000e-01

4.28702e+00 4.28702e+00 4.28702e-01 1.00000e-09 2.12000e-01

$1.00000 \mathrm{e}-051.00000 \mathrm{e}-05$ 1.00000e-06 1.00000e-09 1.00000e-01

$1.00000 \mathrm{e}+001.00000 \mathrm{e}+001.00000 \mathrm{e}-011.00000 \mathrm{e}-091.00000 \mathrm{e}-01$

Element: 11126 \# of layers: 7

$\mathrm{Kx} \mathrm{Ky} \mathrm{Kz}$ Ss Por

4.28702e+00 4.28702e+00 4.28702e-01 1.00000e-09 2.12000e-01

$4.28702 \mathrm{e}+004.28702 \mathrm{e}+00$ 4.28702e-01 1.00000e-09 2.12000e-01

$4.28702 \mathrm{e}+004.28702 \mathrm{e}+00$ 4.28702e-01 1.00000e-09 2.12000e-01

$4.28702 \mathrm{e}+00$ 4.28702e+00 4.28702e-01 1.00000e-09 2.12000e-01

4.28702e+00 4.28702e+00 4.28702e-01 1.00000e-09 2.12000e-01

$1.00000 \mathrm{e}-05$ 1.00000e-05 1.00000e-06 1.00000e-09 1.00000e-01

$1.00000 \mathrm{e}+001.00000 \mathrm{e}+001.00000 \mathrm{e}-011.00000 \mathrm{e}-091.00000 \mathrm{e}-01$ 
Element: 11127 \# of layers: 7

$\mathrm{Kx} \mathrm{Ky} \mathrm{Kz}$ Ss Por

4.28702e+00 4.28702e+00 4.28702e-01 1.00000e-09 2.12000e-01

$4.28702 \mathrm{e}+004.28702 \mathrm{e}+00$ 4.28702e-01 1.00000e-09 2.12000e-01

4.28702e+00 4.28702e+00 4.28702e-01 1.00000e-09 2.12000e-01

4.28702e+00 4.28702e+00 4.28702e-01 1.00000e-09 2.12000e-01

4.28702e+00 4.28702e+00 4.28702e-01 1.00000e-09 2.12000e-01

$1.00000 \mathrm{e}-05$ 1.00000e-05 1.00000e-06 1.00000e-09 1.00000e-01

$1.00000 \mathrm{e}+001.00000 \mathrm{e}+001.00000 \mathrm{e}-011.00000 \mathrm{e}-091.00000 \mathrm{e}-01$

Element: 11128 \# of layers: 7

$\mathrm{Kx} \mathrm{Ky} \mathrm{Kz}$ Ss Por

4.28702e+00 4.28702e+00 4.28702e-01 1.00000e-09 2.12000e-01

$4.28702 \mathrm{e}+00$ 4.28702e+00 4.28702e-01 1.00000e-09 2.12000e-01

4.28702e+00 4.28702e+00 4.28702e-01 1.00000e-09 2.12000e-01

4.28702e+00 4.28702e+00 4.28702e-01 1.00000e-09 2.12000e-01

$4.28702 \mathrm{e}+004.28702 \mathrm{e}+004.28702 \mathrm{e}-01$ 1.00000e-09 2.12000e-01

$1.00000 \mathrm{e}-05$ 1.00000e-05 1.00000e-06 1.00000e-09 1.00000e-01

$1.00000 \mathrm{e}+001.00000 \mathrm{e}+001.00000 \mathrm{e}-01$ 1.00000e-09 1.00000e-01

Element: 11129 \# of layers: 7

Kx Ky Kz Ss Por

3.61830e+00 3.61830e+00 3.61830e-01 1.00000e-09 2.12000e-01

$3.61830 \mathrm{e}+003.61830 \mathrm{e}+00$ 3.61830e-01 1.00000e-09 2.12000e-01

$3.61830 \mathrm{e}+003.61830 \mathrm{e}+003.61830 \mathrm{e}-01$ 1.00000e-09 2.12000e-01

$3.61830 \mathrm{e}+003.61830 \mathrm{e}+003.61830 \mathrm{e}-01$ 1.00000e-09 2.12000e-01

$3.61830 \mathrm{e}+003.61830 \mathrm{e}+003.61830 \mathrm{e}-01$ 1.00000e-09 2.12000e-01

$1.00000 \mathrm{e}-05$ 1.00000e-05 1.00000e-06 1.00000e-09 1.00000e-01

$1.00000 \mathrm{e}+001.00000 \mathrm{e}+001.00000 \mathrm{e}-011.00000 \mathrm{e}-091.00000 \mathrm{e}-01$

Element: 11130 \# of layers: 7

Kx Ky Kz Ss Por

3.61830e+00 3.61830e+00 3.61830e-01 1.00000e-09 2.12000e-01

$3.61830 \mathrm{e}+003.61830 \mathrm{e}+003.61830 \mathrm{e}-01$ 1.00000e-09 2.12000e-01

$3.61830 \mathrm{e}+003.61830 \mathrm{e}+00$ 3.61830e-01 1.00000e-09 2.12000e-01

$3.61830 \mathrm{e}+003.61830 \mathrm{e}+003.61830 \mathrm{e}-01$ 1.00000e-09 2.12000e-01

$3.61830 \mathrm{e}+003.61830 \mathrm{e}+00$ 3.61830e-01 1.00000e-09 2.12000e-01

$1.00000 \mathrm{e}-05$ 1.00000e-05 1.00000e-06 1.00000e-09 1.00000e-01

$1.00000 \mathrm{e}+001.00000 \mathrm{e}+001.00000 \mathrm{e}-011.00000 \mathrm{e}-091.00000 \mathrm{e}-01$

Element: 11131 \# of layers: 7

$\mathrm{Kx} \mathrm{Ky} \mathrm{Kz}$ Ss Por

3.61830e+00 3.61830e+00 3.61830e-01 1.00000e-09 2.12000e-01

$3.61830 \mathrm{e}+003.61830 \mathrm{e}+00$ 3.61830e-01 1.00000e-09 2.12000e-01

$3.61830 \mathrm{e}+003.61830 \mathrm{e}+003.61830 \mathrm{e}-01$ 1.00000e-09 2.12000e-01

$3.61830 \mathrm{e}+003.61830 \mathrm{e}+00$ 3.61830e-01 1.00000e-09 2.12000e-01

$3.61830 \mathrm{e}+003.61830 \mathrm{e}+00$ 3.61830e-01 1.00000e-09 2.12000e-01

$1.00000 \mathrm{e}-051.00000 \mathrm{e}-051.00000 \mathrm{e}-061.00000 \mathrm{e}-091.00000 \mathrm{e}-01$

$1.00000 \mathrm{e}+001.00000 \mathrm{e}+001.00000 \mathrm{e}-011.00000 \mathrm{e}-091.00000 \mathrm{e}-01$

Element: 11132 \# of layers: 7 
Kx Ky Kz Ss Por

3.61830e+00 3.61830e+00 3.61830e-01 1.00000e-09 2.12000e-01

$3.61830 \mathrm{e}+003.61830 \mathrm{e}+003.61830 \mathrm{e}-01$ 1.00000e-09 2.12000e-01

$3.61830 \mathrm{e}+003.61830 \mathrm{e}+003.61830 \mathrm{e}-01$ 1.00000e-09 2.12000e-01

$3.61830 \mathrm{e}+003.61830 \mathrm{e}+003.61830 \mathrm{e}-01$ 1.00000e-09 2.12000e-01

$3.61830 \mathrm{e}+003.61830 \mathrm{e}+00$ 3.61830e-01 1.00000e-09 2.12000e-01

$1.00000 \mathrm{e}-05$ 1.00000e-05 1.00000e-06 1.00000e-09 1.00000e-01

$1.00000 \mathrm{e}+001.00000 \mathrm{e}+001.00000 \mathrm{e}-01$ 1.00000e-09 1.00000e-01

Element: 11133 \# of layers: 7

$\mathrm{Kx} \mathrm{Ky} \mathrm{Kz}$ Ss Por

$3.61830 \mathrm{e}+003.61830 \mathrm{e}+00$ 3.61830e-01 1.00000e-09 2.12000e-01

$3.61830 \mathrm{e}+003.61830 \mathrm{e}+003.61830 \mathrm{e}-01$ 1.00000e-09 2.12000e-01

$3.61830 \mathrm{e}+003.61830 \mathrm{e}+003.61830 \mathrm{e}-011.00000 \mathrm{e}-092.12000 \mathrm{e}-01$

$3.61830 \mathrm{e}+003.61830 \mathrm{e}+003.61830 \mathrm{e}-01$ 1.00000e-09 2.12000e-01

$3.61830 \mathrm{e}+003.61830 \mathrm{e}+003.61830 \mathrm{e}-01$ 1.00000e-09 2.12000e-01

$1.00000 \mathrm{e}-05$ 1.00000e-05 1.00000e-06 1.00000e-09 1.00000e-01

$1.00000 \mathrm{e}+001.00000 \mathrm{e}+001.00000 \mathrm{e}-01$ 1.00000e-09 1.00000e-01

Element: 11134 \# of layers: 7

$\mathrm{Kx} \mathrm{Ky} \mathrm{Kz}$ Ss Por

3.61830e+00 3.61830e+00 3.61830e-01 1.00000e-09 2.12000e-01

$3.61830 \mathrm{e}+003.61830 \mathrm{e}+003.61830 \mathrm{e}-01$ 1.00000e-09 2.12000e-01

$3.61830 \mathrm{e}+003.61830 \mathrm{e}+00$ 3.61830e-01 1.00000e-09 2.12000e-01

$3.61830 \mathrm{e}+003.61830 \mathrm{e}+003.61830 \mathrm{e}-01$ 1.00000e-09 2.12000e-01

$3.61830 \mathrm{e}+003.61830 \mathrm{e}+003.61830 \mathrm{e}-01$ 1.00000e-09 2.12000e-01

$1.00000 \mathrm{e}-05$ 1.00000e-05 1.00000e-06 1.00000e-09 1.00000e-01

$1.00000 \mathrm{e}+001.00000 \mathrm{e}+001.00000 \mathrm{e}-01$ 1.00000e-09 1.00000e-01

Element: 11135 \# of layers: 7

$\mathrm{Kx} \mathrm{Ky} \mathrm{Kz}$ Ss Por

$3.61830 \mathrm{e}+00$ 3.61830e+00 3.61830e-01 1.00000e-09 2.12000e-01

$3.61830 \mathrm{e}+003.61830 \mathrm{e}+00$ 3.61830e-01 1.00000e-09 2.12000e-01

$3.61830 \mathrm{e}+003.61830 \mathrm{e}+003.61830 \mathrm{e}-01$ 1.00000e-09 2.12000e-01

$3.61830 \mathrm{e}+003.61830 \mathrm{e}+00$ 3.61830e-01 1.00000e-09 2.12000e-01

$3.61830 \mathrm{e}+003.61830 \mathrm{e}+003.61830 \mathrm{e}-01$ 1.00000e-09 2.12000e-01

$1.00000 \mathrm{e}-051.00000 \mathrm{e}-051.00000 \mathrm{e}-061.00000 \mathrm{e}-091.00000 \mathrm{e}-01$

$1.00000 \mathrm{e}+001.00000 \mathrm{e}+001.00000 \mathrm{e}-011.00000 \mathrm{e}-091.00000 \mathrm{e}-01$

Element: 11136 \# of layers: 7

Kx Ky Kz Ss Por

3.61830e+00 3.61830e+00 3.61830e-01 1.00000e-09 2.12000e-01

$3.61830 \mathrm{e}+003.61830 \mathrm{e}+003.61830 \mathrm{e}-011.00000 \mathrm{e}-092.12000 \mathrm{e}-01$

$3.61830 \mathrm{e}+003.61830 \mathrm{e}+003.61830 \mathrm{e}-01$ 1.00000e-09 2.12000e-01

$3.61830 \mathrm{e}+003.61830 \mathrm{e}+003.61830 \mathrm{e}-011.00000 \mathrm{e}-092.12000 \mathrm{e}-01$

$3.61830 \mathrm{e}+003.61830 \mathrm{e}+00$ 3.61830e-01 1.00000e-09 2.12000e-01

$1.00000 \mathrm{e}-05$ 1.00000e-05 1.00000e-06 1.00000e-09 1.00000e-01

$1.00000 \mathrm{e}+001.00000 \mathrm{e}+001.00000 \mathrm{e}-01$ 1.00000e-09 1.00000e-01

Element: 11137 \# of layers: 7

Kx Ky Kz Ss Por 
$3.61830 \mathrm{e}+003.61830 \mathrm{e}+003.61830 \mathrm{e}-01$ 1.00000e-09 2.12000e-01 $3.61830 \mathrm{e}+003.61830 \mathrm{e}+003.61830 \mathrm{e}-011.00000 \mathrm{e}-092.12000 \mathrm{e}-01$ $3.61830 \mathrm{e}+003.61830 \mathrm{e}+003.61830 \mathrm{e}-01$ 1.00000e-09 2.12000e-01 $3.61830 \mathrm{e}+003.61830 \mathrm{e}+003.61830 \mathrm{e}-011.00000 \mathrm{e}-092.12000 \mathrm{e}-01$ $3.61830 \mathrm{e}+003.61830 \mathrm{e}+003.61830 \mathrm{e}-011.00000 \mathrm{e}-092.12000 \mathrm{e}-01$ $1.00000 \mathrm{e}-05$ 1.00000e-05 1.00000e-06 1.00000e-09 1.00000e-01 $1.00000 \mathrm{e}+001.00000 \mathrm{e}+001.00000 \mathrm{e}-011.00000 \mathrm{e}-091.00000 \mathrm{e}-01$ Element: 11138 \# of layers: 7

Kx Ky Kz Ss Por

$3.61830 \mathrm{e}+003.61830 \mathrm{e}+00$ 3.61830e-01 1.00000e-09 2.12000e-01 $3.61830 \mathrm{e}+003.61830 \mathrm{e}+003.61830 \mathrm{e}-011.00000 \mathrm{e}-092.12000 \mathrm{e}-01$ $3.61830 \mathrm{e}+003.61830 \mathrm{e}+003.61830 \mathrm{e}-011.00000 \mathrm{e}-092.12000 \mathrm{e}-01$ $3.61830 \mathrm{e}+003.61830 \mathrm{e}+003.61830 \mathrm{e}-011.00000 \mathrm{e}-092.12000 \mathrm{e}-01$ $3.61830 \mathrm{e}+003.61830 \mathrm{e}+003.61830 \mathrm{e}-011.00000 \mathrm{e}-092.12000 \mathrm{e}-01$ $1.00000 \mathrm{e}-05$ 1.00000e-05 1.00000e-06 1.00000e-09 1.00000e-01 $1.00000 \mathrm{e}+001.00000 \mathrm{e}+001.00000 \mathrm{e}-011.00000 \mathrm{e}-091.00000 \mathrm{e}-01$ Element: 11139 \# of layers: 7

Kx Ky Kz Ss Por

$3.57465 \mathrm{e}+003.57465 \mathrm{e}+00$ 3.57465e-01 1.00000e-09 2.12000e-01

$3.57465 \mathrm{e}+003.57465 \mathrm{e}+003.57465 \mathrm{e}-011.00000 \mathrm{e}-092.12000 \mathrm{e}-01$

$3.57465 \mathrm{e}+003.57465 \mathrm{e}+003.57465 \mathrm{e}-011.00000 \mathrm{e}-092.12000 \mathrm{e}-01$

$3.57465 \mathrm{e}+003.57465 \mathrm{e}+003.57465 \mathrm{e}-011.00000 \mathrm{e}-092.12000 \mathrm{e}-01$

$3.57465 \mathrm{e}+003.57465 \mathrm{e}+003.57465 \mathrm{e}-011.00000 \mathrm{e}-092.12000 \mathrm{e}-01$ $1.00000 \mathrm{e}-05$ 1.00000e-05 1.00000e-06 1.00000e-09 1.00000e-01 $1.00000 \mathrm{e}+001.00000 \mathrm{e}+001.00000 \mathrm{e}-011.00000 \mathrm{e}-091.00000 \mathrm{e}-01$ Element: 11140 \# of layers: 7

Kx Ky Kz Ss Por

$3.57465 \mathrm{e}+003.57465 \mathrm{e}+003.57465 \mathrm{e}-01$ 1.00000e-09 2.12000e-01 $3.57465 \mathrm{e}+003.57465 \mathrm{e}+003.57465 \mathrm{e}-011.00000 \mathrm{e}-092.12000 \mathrm{e}-01$ $3.57465 \mathrm{e}+003.57465 \mathrm{e}+003.57465 \mathrm{e}-011.00000 \mathrm{e}-092.12000 \mathrm{e}-01$ $3.57465 \mathrm{e}+003.57465 \mathrm{e}+003.57465 \mathrm{e}-011.00000 \mathrm{e}-092.12000 \mathrm{e}-01$ $3.57465 \mathrm{e}+003.57465 \mathrm{e}+003.57465 \mathrm{e}-011.00000 \mathrm{e}-092.12000 \mathrm{e}-01$ $1.00000 \mathrm{e}-05$ 1.00000e-05 1.00000e-06 1.00000e-09 1.00000e-01 $1.00000 \mathrm{e}+001.00000 \mathrm{e}+001.00000 \mathrm{e}-011.00000 \mathrm{e}-091.00000 \mathrm{e}-01$ Element: 11141 \# of layers: 7

Kx Ky Kz Ss Por

$3.57465 \mathrm{e}+003.57465 \mathrm{e}+003.57465 \mathrm{e}-011.00000 \mathrm{e}-092.12000 \mathrm{e}-01$ $3.57465 \mathrm{e}+003.57465 \mathrm{e}+003.57465 \mathrm{e}-011.00000 \mathrm{e}-092.12000 \mathrm{e}-01$ $3.57465 \mathrm{e}+003.57465 \mathrm{e}+003.57465 \mathrm{e}-011.00000 \mathrm{e}-092.12000 \mathrm{e}-01$ $3.57465 \mathrm{e}+003.57465 \mathrm{e}+003.57465 \mathrm{e}-011.00000 \mathrm{e}-092.12000 \mathrm{e}-01$ $3.57465 \mathrm{e}+003.57465 \mathrm{e}+003.57465 \mathrm{e}-01$ 1.00000e-09 2.12000e-01 $1.00000 \mathrm{e}-05$ 1.00000e-05 1.00000e-06 1.00000e-09 1.00000e-01 $1.00000 \mathrm{e}+001.00000 \mathrm{e}+001.00000 \mathrm{e}-011.00000 \mathrm{e}-091.00000 \mathrm{e}-01$ Element: 11142 \# of layers: 7

Kx Ky Kz Ss Por

3.57465e+00 3.57465e+00 3.57465e-01 1.00000e-09 2.12000e-01 
3.57465e+00 3.57465e+00 3.57465e-01 1.00000e-09 2.12000e-01 3.57465e+00 3.57465e+00 3.57465e-01 1.00000e-09 2.12000e-01 $3.57465 \mathrm{e}+003.57465 \mathrm{e}+003.57465 \mathrm{e}-01$ 1.00000e-09 2.12000e-01 $3.57465 \mathrm{e}+003.57465 \mathrm{e}+003.57465 \mathrm{e}-01$ 1.00000e-09 2.12000e-01 $1.00000 \mathrm{e}-05$ 1.00000e-05 1.00000e-06 1.00000e-09 1.00000e-01 $1.00000 \mathrm{e}+001.00000 \mathrm{e}+001.00000 \mathrm{e}-011.00000 \mathrm{e}-091.00000 \mathrm{e}-01$ Element: 11143 \# of layers: 7

$\mathrm{Kx} \mathrm{Ky} \mathrm{Kz} \mathrm{Ss} \mathrm{Por}$

3.57465e+00 3.57465e+00 3.57465e-01 1.00000e-09 2.12000e-01

$3.57465 \mathrm{e}+003.57465 \mathrm{e}+00$ 3.57465e-01 1.00000e-09 2.12000e-01

$3.57465 \mathrm{e}+003.57465 \mathrm{e}+00$ 3.57465e-01 1.00000e-09 2.12000e-01

$3.57465 \mathrm{e}+003.57465 \mathrm{e}+003.57465 \mathrm{e}-01$ 1.00000e-09 2.12000e-01

$3.57465 \mathrm{e}+003.57465 \mathrm{e}+003.57465 \mathrm{e}-01$ 1.00000e-09 2.12000e-01 $1.00000 \mathrm{e}-05$ 1.00000e-05 1.00000e-06 1.00000e-09 1.00000e-01

$1.00000 \mathrm{e}+001.00000 \mathrm{e}+001.00000 \mathrm{e}-01$ 1.00000e-09 1.00000e-01 Element: 11144 \# of layers: 7

$\mathrm{Kx} \mathrm{Ky} \mathrm{Kz}$ Ss Por

3.61830e+00 3.61830e+00 3.61830e-01 1.00000e-09 2.12000e-01 $3.61830 \mathrm{e}+003.61830 \mathrm{e}+003.61830 \mathrm{e}-01$ 1.00000e-09 2.12000e-01 $3.61830 \mathrm{e}+003.61830 \mathrm{e}+00$ 3.61830e-01 1.00000e-09 2.12000e-01 $3.61830 \mathrm{e}+003.61830 \mathrm{e}+003.61830 \mathrm{e}-01$ 1.00000e-09 2.12000e-01 $3.61830 \mathrm{e}+003.61830 \mathrm{e}+00$ 3.61830e-01 1.00000e-09 2.12000e-01 $1.00000 \mathrm{e}-051.00000 \mathrm{e}-05$ 1.00000e-06 1.00000e-09 1.00000e-01 $1.00000 \mathrm{e}+001.00000 \mathrm{e}+001.00000 \mathrm{e}-011.00000 \mathrm{e}-09$ 1.00000e-01 Element: 11145 \# of layers: 7

$\mathrm{Kx} \mathrm{Ky} \mathrm{Kz}$ Ss Por

3.61830e+00 3.61830e+00 3.61830e-01 1.00000e-09 2.12000e-01 $3.61830 \mathrm{e}+003.61830 \mathrm{e}+003.61830 \mathrm{e}-01$ 1.00000e-09 2.12000e-01 $3.61830 \mathrm{e}+003.61830 \mathrm{e}+00$ 3.61830e-01 1.00000e-09 2.12000e-01 $3.61830 \mathrm{e}+003.61830 \mathrm{e}+00$ 3.61830e-01 1.00000e-09 2.12000e-01 $3.61830 \mathrm{e}+003.61830 \mathrm{e}+003.61830 \mathrm{e}-01$ 1.00000e-09 2.12000e-01 1.00000e-05 1.00000e-05 1.00000e-06 1.00000e-09 1.00000e-01 $1.00000 \mathrm{e}+001.00000 \mathrm{e}+001.00000 \mathrm{e}-011.00000 \mathrm{e}-091.00000 \mathrm{e}-01$ Element: 11146 \# of layers: 7

$\mathrm{Kx} \mathrm{Ky} \mathrm{Kz}$ Ss Por

3.57465e+00 3.57465e+00 3.57465e-01 1.00000e-09 2.12000e-01

$3.57465 \mathrm{e}+003.57465 \mathrm{e}+003.57465 \mathrm{e}-01$ 1.00000e-09 2.12000e-01

$3.57465 \mathrm{e}+003.57465 \mathrm{e}+003.57465 \mathrm{e}-01$ 1.00000e-09 2.12000e-01

$3.57465 \mathrm{e}+003.57465 \mathrm{e}+00$ 3.57465e-01 1.00000e-09 2.12000e-01

$3.57465 \mathrm{e}+003.57465 \mathrm{e}+00$ 3.57465e-01 1.00000e-09 2.12000e-01 $1.00000 \mathrm{e}-05$ 1.00000e-05 1.00000e-06 1.00000e-09 1.00000e-01 $1.00000 \mathrm{e}+001.00000 \mathrm{e}+001.00000 \mathrm{e}-011.00000 \mathrm{e}-091.00000 \mathrm{e}-01$ Element: 11147 \# of layers: 7

$\mathrm{Kx} \mathrm{Ky} \mathrm{Kz}$ Ss Por

3.57465e+00 3.57465e+00 3.57465e-01 1.00000e-09 2.12000e-01 $3.57465 \mathrm{e}+003.57465 \mathrm{e}+003.57465 \mathrm{e}-01$ 1.00000e-09 2.12000e-01 
3.57465e+00 3.57465e+00 3.57465e-01 1.00000e-09 2.12000e-01 3.57465e+00 3.57465e+00 3.57465e-01 1.00000e-09 2.12000e-01

$3.57465 \mathrm{e}+003.57465 \mathrm{e}+003.57465 \mathrm{e}-01$ 1.00000e-09 2.12000e-01 $1.00000 \mathrm{e}-05$ 1.00000e-05 1.00000e-06 1.00000e-09 1.00000e-01 $1.00000 \mathrm{e}+001.00000 \mathrm{e}+001.00000 \mathrm{e}-01$ 1.00000e-09 1.00000e-01 Element: 11148 \# of layers: 7

$\mathrm{Kx} \mathrm{Ky} \mathrm{Kz}$ Ss Por

4.19049e+00 4.19049e+00 4.19049e-01 1.00000e-09 2.12000e-01 4.19049e+00 4.19049e+00 4.19049e-01 1.00000e-09 2.12000e-01 4.19049e+00 4.19049e+00 4.19049e-01 1.00000e-09 2.12000e-01 4.19049e+00 4.19049e+00 4.19049e-01 1.00000e-09 2.12000e-01 4.19049e+00 4.19049e+00 4.19049e-01 1.00000e-09 2.12000e-01 $1.00000 \mathrm{e}-05$ 1.00000e-05 1.00000e-06 1.00000e-09 1.00000e-01 $1.00000 \mathrm{e}+001.00000 \mathrm{e}+001.00000 \mathrm{e}-011.00000 \mathrm{e}-091.00000 \mathrm{e}-01$ Element: 11149 \# of layers: 7

Kx Ky Kz Ss Por

4.19049e+00 4.19049e+00 4.19049e-01 1.00000e-09 2.12000e-01 4.19049e+00 4.19049e+00 4.19049e-01 1.00000e-09 2.12000e-01 4.19049e+00 4.19049e+00 4.19049e-01 1.00000e-09 2.12000e-01 $4.19049 \mathrm{e}+004.19049 \mathrm{e}+00$ 4.19049e-01 1.00000e-09 2.12000e-01 4.19049e+00 4.19049e+00 4.19049e-01 1.00000e-09 2.12000e-01 $1.00000 \mathrm{e}-05$ 1.00000e-05 1.00000e-06 1.00000e-09 1.00000e-01 $1.00000 \mathrm{e}+001.00000 \mathrm{e}+001.00000 \mathrm{e}-01$ 1.00000e-09 1.00000e-01 Element: 11150 \# of layers: 7

Kx Ky Kz Ss Por

4.19049e+00 4.19049e+00 4.19049e-01 1.00000e-09 2.12000e-01 4.19049e+00 4.19049e+00 4.19049e-01 1.00000e-09 2.12000e-01 4.19049e+00 4.19049e+00 4.19049e-01 1.00000e-09 2.12000e-01 $4.19049 \mathrm{e}+004.19049 \mathrm{e}+00$ 4.19049e-01 1.00000e-09 2.12000e-01 4.19049e+00 4.19049e+00 4.19049e-01 1.00000e-09 2.12000e-01 $1.00000 \mathrm{e}-05$ 1.00000e-05 1.00000e-06 1.00000e-09 1.00000e-01 $1.00000 \mathrm{e}+001.00000 \mathrm{e}+001.00000 \mathrm{e}-01$ 1.00000e-09 1.00000e-01 Element: 11151 \# of layers: 7

$\mathrm{Kx} \mathrm{Ky} \mathrm{Kz}$ Ss Por

4.28702e+00 4.28702e+00 4.28702e-01 1.00000e-09 2.12000e-01 $4.28702 \mathrm{e}+00$ 4.28702e+00 4.28702e-01 1.00000e-09 2.12000e-01 $4.28702 \mathrm{e}+004.28702 \mathrm{e}+00$ 4.28702e-01 1.00000e-09 2.12000e-01 $4.28702 \mathrm{e}+004.28702 \mathrm{e}+00$ 4.28702e-01 1.00000e-09 2.12000e-01 4.28702e+00 4.28702e+00 4.28702e-01 1.00000e-09 2.12000e-01 $1.00000 \mathrm{e}-05$ 1.00000e-05 1.00000e-06 1.00000e-09 1.00000e-01 $1.00000 \mathrm{e}+001.00000 \mathrm{e}+001.00000 \mathrm{e}-011.00000 \mathrm{e}-091.00000 \mathrm{e}-01$ Element: 11152 \# of layers: 7

$\mathrm{Kx} \mathrm{Ky} \mathrm{Kz}$ Ss Por

4.28702e+00 4.28702e+00 4.28702e-01 1.00000e-09 2.12000e-01 $4.28702 \mathrm{e}+004.28702 \mathrm{e}+004.28702 \mathrm{e}-01$ 1.00000e-09 2.12000e-01 $4.28702 \mathrm{e}+004.28702 \mathrm{e}+00$ 4.28702e-01 1.00000e-09 2.12000e-01 
$4.28702 \mathrm{e}+004.28702 \mathrm{e}+00$ 4.28702e-01 1.00000e-09 2.12000e-01 $4.28702 \mathrm{e}+004.28702 \mathrm{e}+00 \quad 4.28702 \mathrm{e}-011.00000 \mathrm{e}-09$ 2.12000e-01 $1.00000 \mathrm{e}-051.00000 \mathrm{e}-05$ 1.00000e-06 1.00000e-09 1.00000e-01 $1.00000 \mathrm{e}+001.00000 \mathrm{e}+001.00000 \mathrm{e}-011.00000 \mathrm{e}-091.00000 \mathrm{e}-01$ Element: 11153 \# of layers: 7

Kx Ky Kz Ss Por

$3.61830 \mathrm{e}+003.61830 \mathrm{e}+00$ 3.61830e-01 1.00000e-09 2.12000e-01 $3.61830 \mathrm{e}+003.61830 \mathrm{e}+003.61830 \mathrm{e}-011.00000 \mathrm{e}-092.12000 \mathrm{e}-01$ $3.61830 \mathrm{e}+003.61830 \mathrm{e}+003.61830 \mathrm{e}-011.00000 \mathrm{e}-092.12000 \mathrm{e}-01$ $3.61830 \mathrm{e}+003.61830 \mathrm{e}+003.61830 \mathrm{e}-011.00000 \mathrm{e}-092.12000 \mathrm{e}-01$ $3.61830 \mathrm{e}+003.61830 \mathrm{e}+003.61830 \mathrm{e}-011.00000 \mathrm{e}-092.12000 \mathrm{e}-01$ $1.00000 \mathrm{e}-05$ 1.00000e-05 1.00000e-06 1.00000e-09 1.00000e-01 $1.00000 \mathrm{e}+001.00000 \mathrm{e}+001.00000 \mathrm{e}-011.00000 \mathrm{e}-091.00000 \mathrm{e}-01$ Element: 11154 \# of layers: 7

Kx Ky Kz Ss Por

$3.57465 \mathrm{e}+003.57465 \mathrm{e}+00$ 3.57465e-01 1.00000e-09 2.12000e-01 $3.57465 \mathrm{e}+003.57465 \mathrm{e}+003.57465 \mathrm{e}-011.00000 \mathrm{e}-092.12000 \mathrm{e}-01$ $3.57465 \mathrm{e}+003.57465 \mathrm{e}+003.57465 \mathrm{e}-011.00000 \mathrm{e}-092.12000 \mathrm{e}-01$ $3.57465 \mathrm{e}+003.57465 \mathrm{e}+003.57465 \mathrm{e}-011.00000 \mathrm{e}-092.12000 \mathrm{e}-01$ $3.57465 \mathrm{e}+003.57465 \mathrm{e}+003.57465 \mathrm{e}-011.00000 \mathrm{e}-092.12000 \mathrm{e}-01$ $1.00000 \mathrm{e}-05$ 1.00000e-05 1.00000e-06 1.00000e-09 1.00000e-01 $1.00000 \mathrm{e}+001.00000 \mathrm{e}+001.00000 \mathrm{e}-011.00000 \mathrm{e}-091.00000 \mathrm{e}-01$ Element: 11155 \# of layers: 7

Kx Ky Kz Ss Por

$4.19049 \mathrm{e}+00$ 4.19049e+00 4.19049e-01 1.00000e-09 2.12000e-01 $4.19049 \mathrm{e}+004.19049 \mathrm{e}+00$ 4.19049e-01 1.00000e-09 2.12000e-01 $4.19049 \mathrm{e}+004.19049 \mathrm{e}+00$ 4.19049e-01 1.00000e-09 2.12000e-01 $4.19049 \mathrm{e}+004.19049 \mathrm{e}+00$ 4.19049e-01 1.00000e-09 2.12000e-01 $4.19049 \mathrm{e}+00$ 4.19049e+00 4.19049e-01 1.00000e-09 2.12000e-01 $1.00000 \mathrm{e}-05$ 1.00000e-05 1.00000e-06 1.00000e-09 1.00000e-01 $1.00000 \mathrm{e}+001.00000 \mathrm{e}+001.00000 \mathrm{e}-011.00000 \mathrm{e}-091.00000 \mathrm{e}-01$ Element: 11156 \# of layers: 6

Kx Ky Kz Ss Por

4.98183e+00 4.98183e+00 4.98183e-01 1.00000e-09 2.12000e-01 $4.98183 \mathrm{e}+004.98183 \mathrm{e}+00$ 4.98183e-01 1.00000e-09 2.12000e-01 $4.98183 \mathrm{e}+004.98183 \mathrm{e}+004.98183 \mathrm{e}-01$ 1.00000e-09 2.12000e-01 $4.98183 \mathrm{e}+004.98183 \mathrm{e}+004.98183 \mathrm{e}-011.00000 \mathrm{e}-092.12000 \mathrm{e}-01$ $1.00000 \mathrm{e}-05$ 1.00000e-05 1.00000e-06 1.00000e-09 1.00000e-01 $1.00000 \mathrm{e}+001.00000 \mathrm{e}+001.00000 \mathrm{e}-011.00000 \mathrm{e}-091.00000 \mathrm{e}-01$ Element: 11157 \# of layers: 6

Kx Ky Kz Ss Por 4.98183e+00 4.98183e+00 4.98183e-01 1.00000e-09 2.12000e-01 $4.98183 \mathrm{e}+004.98183 \mathrm{e}+00$ 4.98183e-01 1.00000e-09 2.12000e-01 $4.98183 \mathrm{e}+004.98183 \mathrm{e}+00$ 4.98183e-01 1.00000e-09 2.12000e-01 $4.98183 \mathrm{e}+004.98183 \mathrm{e}+00$ 4.98183e-01 1.00000e-09 2.12000e-01 $1.00000 \mathrm{e}-05$ 1.00000e-05 1.00000e-06 1.00000e-09 1.00000e-01 
$1.00000 \mathrm{e}+001.00000 \mathrm{e}+00$ 1.00000e-01 1.00000e-09 1.00000e-01

Element: 11158 \# of layers: 6

$\mathrm{Kx} \mathrm{Ky} \mathrm{Kz}$ Ss Por

4.98183e+00 4.98183e+00 4.98183e-01 1.00000e-09 2.12000e-01

4.98183e+00 4.98183e+00 4.98183e-01 1.00000e-09 2.12000e-01

$4.98183 \mathrm{e}+00$ 4.98183e+00 4.98183e-01 1.00000e-09 2.12000e-01

$4.98183 \mathrm{e}+00$ 4.98183e+00 4.98183e-01 1.00000e-09 2.12000e-01

$1.00000 \mathrm{e}-05$ 1.00000e-05 1.00000e-06 1.00000e-09 1.00000e-01

$1.00000 \mathrm{e}+001.00000 \mathrm{e}+00$ 1.00000e-01 1.00000e-09 1.00000e-01

Element: 11159 \# of layers: 6

$\mathrm{Kx} \mathrm{Ky} \mathrm{Kz}$ Ss Por

4.98183e+00 4.98183e+00 4.98183e-01 1.00000e-09 2.12000e-01

$4.98183 \mathrm{e}+00$ 4.98183e+00 4.98183e-01 1.00000e-09 2.12000e-01

4.98183e+00 4.98183e+00 4.98183e-01 1.00000e-09 2.12000e-01

4.98183e+00 4.98183e+00 4.98183e-01 1.00000e-09 2.12000e-01

$1.00000 \mathrm{e}-051.00000 \mathrm{e}-05$ 1.00000e-06 1.00000e-09 1.00000e-01

$1.00000 \mathrm{e}+001.00000 \mathrm{e}+001.00000 \mathrm{e}-011.00000 \mathrm{e}-091.00000 \mathrm{e}-01$

Element: 11160 \# of layers: 6

$\mathrm{Kx} \mathrm{Ky} \mathrm{Kz}$ Ss Por

4.98183e+00 4.98183e+00 4.98183e-01 1.00000e-09 2.12000e-01

$4.98183 \mathrm{e}+004.98183 \mathrm{e}+00$ 4.98183e-01 1.00000e-09 2.12000e-01

4.98183e+00 4.98183e+00 4.98183e-01 1.00000e-09 2.12000e-01

4.98183e+00 4.98183e+00 4.98183e-01 1.00000e-09 2.12000e-01

$1.00000 \mathrm{e}-05$ 1.00000e-05 1.00000e-06 1.00000e-09 1.00000e-01

$1.00000 \mathrm{e}+001.00000 \mathrm{e}+00$ 1.00000e-01 1.00000e-09 1.00000e-01

Element: 11161 \# of layers: 6

$\mathrm{Kx} \mathrm{Ky} \mathrm{Kz}$ Ss Por

4.98183e+00 4.98183e+00 4.98183e-01 1.00000e-09 2.12000e-01

$4.98183 \mathrm{e}+00$ 4.98183e+00 4.98183e-01 1.00000e-09 2.12000e-01

4.98183e+00 4.98183e+00 4.98183e-01 1.00000e-09 2.12000e-01

$4.98183 \mathrm{e}+00$ 4.98183e+00 4.98183e-01 1.00000e-09 2.12000e-01

$1.00000 \mathrm{e}-05$ 1.00000e-05 1.00000e-06 1.00000e-09 1.00000e-01

$1.00000 \mathrm{e}+001.00000 \mathrm{e}+001.00000 \mathrm{e}-011.00000 \mathrm{e}-091.00000 \mathrm{e}-01$

Element: 11162 \# of layers: 6

$\mathrm{Kx} \mathrm{Ky} \mathrm{Kz}$ Ss Por

4.98183e+00 4.98183e+00 4.98183e-01 1.00000e-09 2.12000e-01

$4.98183 \mathrm{e}+00$ 4.98183e+00 4.98183e-01 1.00000e-09 2.12000e-01

$4.98183 e+00$ 4.98183e+00 4.98183e-01 1.00000e-09 2.12000e-01

4.98183e+00 4.98183e+00 4.98183e-01 1.00000e-09 2.12000e-01

$1.00000 \mathrm{e}-05$ 1.00000e-05 1.00000e-06 1.00000e-09 1.00000e-01

$1.00000 \mathrm{e}+001.00000 \mathrm{e}+001.00000 \mathrm{e}-011.00000 \mathrm{e}-091.00000 \mathrm{e}-01$

Element: 11163 \# of layers: 6

$\mathrm{Kx} \mathrm{Ky} \mathrm{Kz}$ Ss Por

4.98183e+00 4.98183e+00 4.98183e-01 1.00000e-09 2.12000e-01

4.98183e+00 4.98183e+00 4.98183e-01 1.00000e-09 2.12000e-01

$4.98183 e+004.98183 e+00$ 4.98183e-01 1.00000e-09 2.12000e-01 
4.98183e+00 4.98183e+00 4.98183e-01 1.00000e-09 2.12000e-01 $1.00000 \mathrm{e}-05$ 1.00000e-05 1.00000e-06 1.00000e-09 1.00000e-01 $1.00000 \mathrm{e}+001.00000 \mathrm{e}+001.00000 \mathrm{e}-011.00000 \mathrm{e}-091.00000 \mathrm{e}-01$ Element: 11164 \# of layers: 6

$\mathrm{Kx} \mathrm{Ky} \mathrm{Kz}$ Ss Por

4.98183e+00 4.98183e+00 4.98183e-01 1.00000e-09 2.12000e-01 $4.98183 \mathrm{e}+00$ 4.98183e+00 4.98183e-01 1.00000e-09 2.12000e-01 $4.98183 \mathrm{e}+00$ 4.98183e+00 4.98183e-01 1.00000e-09 2.12000e-01 $4.98183 \mathrm{e}+00$ 4.98183e+00 4.98183e-01 1.00000e-09 2.12000e-01 $1.00000 \mathrm{e}-05$ 1.00000e-05 1.00000e-06 1.00000e-09 1.00000e-01 $1.00000 \mathrm{e}+001.00000 \mathrm{e}+001.00000 \mathrm{e}-01$ 1.00000e-09 1.00000e-01 Element: 11165 \# of layers: 6

$\mathrm{Kx} \mathrm{Ky} \mathrm{Kz}$ Ss Por

4.98183e+00 4.98183e+00 4.98183e-01 1.00000e-09 2.12000e-01 4.98183e+00 4.98183e+00 4.98183e-01 1.00000e-09 2.12000e-01 $4.98183 \mathrm{e}+00$ 4.98183e+00 4.98183e-01 1.00000e-09 2.12000e-01 4.98183e+00 4.98183e+00 4.98183e-01 1.00000e-09 2.12000e-01 $1.00000 \mathrm{e}-05$ 1.00000e-05 1.00000e-06 1.00000e-09 1.00000e-01 $1.00000 \mathrm{e}+001.00000 \mathrm{e}+001.00000 \mathrm{e}-01$ 1.00000e-09 1.00000e-01 Element: 11166 \# of layers: 6

$\mathrm{Kx} \mathrm{Ky} \mathrm{Kz}$ Ss Por

5.66517e+00 5.66517e+00 5.66517e-01 1.00000e-09 2.12000e-01 $5.66517 \mathrm{e}+005.66517 \mathrm{e}+00$ 5.66517e-01 1.00000e-09 2.12000e-01 5.66517e+00 5.66517e+00 5.66517e-01 1.00000e-09 2.12000e-01 $5.66517 \mathrm{e}+00$ 5.66517e+00 5.66517e-01 1.00000e-09 2.12000e-01 $1.00000 \mathrm{e}-05$ 1.00000e-05 1.00000e-06 1.00000e-09 1.00000e-01 $1.00000 \mathrm{e}+001.00000 \mathrm{e}+001.00000 \mathrm{e}-011.00000 \mathrm{e}-091.00000 \mathrm{e}-01$ Element: 11167 \# of layers: 6

Kx Ky Kz Ss Por

5.66517e+00 5.66517e+00 5.66517e-01 1.00000e-09 2.12000e-01

$5.66517 \mathrm{e}+00$ 5.66517e+00 5.66517e-01 1.00000e-09 2.12000e-01 $5.66517 \mathrm{e}+005.66517 \mathrm{e}+00$ 5.66517e-01 1.00000e-09 2.12000e-01 $5.66517 \mathrm{e}+00$ 5.66517e+00 5.66517e-01 1.00000e-09 2.12000e-01 $1.00000 \mathrm{e}-05$ 1.00000e-05 1.00000e-06 1.00000e-09 1.00000e-01 $1.00000 \mathrm{e}+001.00000 \mathrm{e}+001.00000 \mathrm{e}-011.00000 \mathrm{e}-091.00000 \mathrm{e}-01$ Element: 11168 \# of layers: 6

Kx Ky Kz Ss Por

5.66517e+00 5.66517e+00 5.66517e-01 1.00000e-09 2.12000e-01

$5.66517 \mathrm{e}+005.66517 \mathrm{e}+00$ 5.66517e-01 1.00000e-09 2.12000e-01

5.66517e+00 5.66517e+00 5.66517e-01 1.00000e-09 2.12000e-01

$5.66517 \mathrm{e}+00$ 5.66517e+00 5.66517e-01 1.00000e-09 2.12000e-01 $1.00000 \mathrm{e}-05$ 1.00000e-05 1.00000e-06 1.00000e-09 1.00000e-01 $1.00000 \mathrm{e}+001.00000 \mathrm{e}+001.00000 \mathrm{e}-01$ 1.00000e-09 1.00000e-01 Element: 11169 \# of layers: 6

$\mathrm{Kx} \mathrm{Ky} \mathrm{Kz} \mathrm{Ss} \mathrm{Por}$

5.66517e+00 5.66517e+00 5.66517e-01 1.00000e-09 2.12000e-01 
$5.66517 \mathrm{e}+00$ 5.66517e+00 5.66517e-01 1.00000e-09 2.12000e-01

$5.66517 \mathrm{e}+005.66517 \mathrm{e}+005.66517 \mathrm{e}-011.00000 \mathrm{e}-092.12000 \mathrm{e}-01$

$5.66517 \mathrm{e}+005.66517 \mathrm{e}+00$ 5.66517e-01 1.00000e-09 2.12000e-01

$1.00000 \mathrm{e}-05$ 1.00000e-05 1.00000e-06 1.00000e-09 1.00000e-01

$1.00000 \mathrm{e}+001.00000 \mathrm{e}+001.00000 \mathrm{e}-011.00000 \mathrm{e}-091.00000 \mathrm{e}-01$

Element: 11170 \# of layers: 6

Kx Ky Kz Ss Por

$5.66517 \mathrm{e}+00$ 5.66517e+00 5.66517e-01 1.00000e-09 2.12000e-01

$5.66517 \mathrm{e}+005.66517 \mathrm{e}+00$ 5.66517e-01 1.00000e-09 2.12000e-01

$5.66517 \mathrm{e}+005.66517 \mathrm{e}+005.66517 \mathrm{e}-011.00000 \mathrm{e}-092.12000 \mathrm{e}-01$

$5.66517 \mathrm{e}+005.66517 \mathrm{e}+00$ 5.66517e-01 1.00000e-09 2.12000e-01

$1.00000 \mathrm{e}-05$ 1.00000e-05 1.00000e-06 1.00000e-09 1.00000e-01

$1.00000 \mathrm{e}+001.00000 \mathrm{e}+001.00000 \mathrm{e}-011.00000 \mathrm{e}-091.00000 \mathrm{e}-01$

Element: 11171 \# of layers: 6

Kx Ky Kz Ss Por

4.98183e+00 4.98183e+00 4.98183e-01 1.00000e-09 2.12000e-01

$4.98183 \mathrm{e}+004.98183 \mathrm{e}+00$ 4.98183e-01 1.00000e-09 2.12000e-01

$4.98183 \mathrm{e}+004.98183 \mathrm{e}+00$ 4.98183e-01 1.00000e-09 2.12000e-01

$4.98183 \mathrm{e}+004.98183 \mathrm{e}+00$ 4.98183e-01 1.00000e-09 2.12000e-01

$1.00000 \mathrm{e}-05$ 1.00000e-05 1.00000e-06 1.00000e-09 1.00000e-01

$1.00000 \mathrm{e}+001.00000 \mathrm{e}+001.00000 \mathrm{e}-011.00000 \mathrm{e}-091.00000 \mathrm{e}-01$

Element: 11172 \# of layers: 6

Kx Ky Kz Ss Por

4.98183e+00 4.98183e+00 4.98183e-01 1.00000e-09 2.12000e-01

$4.98183 \mathrm{e}+004.98183 \mathrm{e}+004.98183 \mathrm{e}-011.00000 \mathrm{e}-09$ 2.12000e-01

$4.98183 \mathrm{e}+004.98183 \mathrm{e}+004.98183 \mathrm{e}-011.00000 \mathrm{e}-092.12000 \mathrm{e}-01$

$4.98183 \mathrm{e}+004.98183 \mathrm{e}+00$ 4.98183e-01 1.00000e-09 2.12000e-01

$1.00000 \mathrm{e}-05$ 1.00000e-05 1.00000e-06 1.00000e-09 1.00000e-01

$1.00000 \mathrm{e}+001.00000 \mathrm{e}+001.00000 \mathrm{e}-011.00000 \mathrm{e}-091.00000 \mathrm{e}-01$

Element: 11173 \# of layers: 6

Kx Ky Kz Ss Por

$5.66517 \mathrm{e}+00$ 5.66517e+00 5.66517e-01 1.00000e-09 2.12000e-01

$5.66517 \mathrm{e}+005.66517 \mathrm{e}+00$ 5.66517e-01 1.00000e-09 2.12000e-01

$5.66517 \mathrm{e}+005.66517 \mathrm{e}+00$ 5.66517e-01 1.00000e-09 2.12000e-01

$5.66517 \mathrm{e}+00$ 5.66517e+00 5.66517e-01 1.00000e-09 2.12000e-01

$1.00000 \mathrm{e}-05$ 1.00000e-05 1.00000e-06 1.00000e-09 1.00000e-01

$1.00000 \mathrm{e}+001.00000 \mathrm{e}+001.00000 \mathrm{e}-011.00000 \mathrm{e}-091.00000 \mathrm{e}-01$

Element: 11174 \# of layers: 6

Kx Ky Kz Ss Por

5.66517e+00 5.66517e+00 5.66517e-01 1.00000e-09 2.12000e-01

$5.66517 \mathrm{e}+005.66517 \mathrm{e}+00$ 5.66517e-01 1.00000e-09 2.12000e-01

$5.66517 \mathrm{e}+005.66517 \mathrm{e}+00$ 5.66517e-01 1.00000e-09 2.12000e-01

$5.66517 \mathrm{e}+00$ 5.66517e+00 5.66517e-01 1.00000e-09 2.12000e-01

$1.00000 \mathrm{e}-05$ 1.00000e-05 1.00000e-06 1.00000e-09 1.00000e-01

$1.00000 \mathrm{e}+001.00000 \mathrm{e}+001.00000 \mathrm{e}-011.00000 \mathrm{e}-091.00000 \mathrm{e}-01$

Element: 11175 \# of layers: 5 
Kx Ky Kz Ss Por

5.66517e+00 5.66517e+00 5.66517e-01 1.00000e-09 2.12000e-01

$5.66517 \mathrm{e}+00$ 5.66517e+00 5.66517e-01 1.00000e-09 2.12000e-01

$5.66517 \mathrm{e}+005.66517 \mathrm{e}+00$ 5.66517e-01 1.00000e-09 2.12000e-01

$1.00000 \mathrm{e}-051.00000 \mathrm{e}-05$ 1.00000e-06 1.00000e-09 1.00000e-01

$1.00000 \mathrm{e}+001.00000 \mathrm{e}+001.00000 \mathrm{e}-01$ 1.00000e-09 1.00000e-01

Element: 11176 \# of layers: 5

$\mathrm{Kx} \mathrm{Ky} \mathrm{Kz}$ Ss Por

5.66517e+00 5.66517e+00 5.66517e-01 1.00000e-09 2.12000e-01

$5.66517 \mathrm{e}+00$ 5.66517e+00 5.66517e-01 1.00000e-09 2.12000e-01

5.66517e+00 5.66517e+00 5.66517e-01 1.00000e-09 2.12000e-01

$1.00000 \mathrm{e}-05$ 1.00000e-05 1.00000e-06 1.00000e-09 1.00000e-01

$1.00000 \mathrm{e}+001.00000 \mathrm{e}+001.00000 \mathrm{e}-01$ 1.00000e-09 1.00000e-01

Element: 11177 \# of layers: 5

Kx Ky Kz Ss Por

5.66517e+00 5.66517e+00 5.66517e-01 1.00000e-09 2.12000e-01

$5.66517 \mathrm{e}+005.66517 \mathrm{e}+00$ 5.66517e-01 1.00000e-09 2.12000e-01

5.66517e+00 5.66517e+00 5.66517e-01 1.00000e-09 2.12000e-01

$1.00000 \mathrm{e}-05$ 1.00000e-05 1.00000e-06 1.00000e-09 1.00000e-01

$1.00000 \mathrm{e}+001.00000 \mathrm{e}+001.00000 \mathrm{e}-011.00000 \mathrm{e}-091.00000 \mathrm{e}-01$

Element: 11178 \# of layers: 5

$\mathrm{Kx} \mathrm{Ky} \mathrm{Kz}$ Ss Por

5.66517e+00 5.66517e+00 5.66517e-01 1.00000e-09 2.12000e-01

$5.66517 \mathrm{e}+00$ 5.66517e+00 5.66517e-01 1.00000e-09 2.12000e-01

$5.66517 \mathrm{e}+00$ 5.66517e+00 5.66517e-01 1.00000e-09 2.12000e-01

$1.00000 \mathrm{e}-05$ 1.00000e-05 1.00000e-06 1.00000e-09 1.00000e-01

$1.00000 \mathrm{e}+001.00000 \mathrm{e}+001.00000 \mathrm{e}-011.00000 \mathrm{e}-09$ 1.00000e-01

Element: 11179 \# of layers: 5

$\mathrm{Kx} \mathrm{Ky} \mathrm{Kz}$ Ss Por

5.66517e+00 5.66517e+00 5.66517e-01 1.00000e-09 2.12000e-01

5.66517e+00 5.66517e+00 5.66517e-01 1.00000e-09 2.12000e-01

5.66517e+00 5.66517e+00 5.66517e-01 1.00000e-09 2.12000e-01

1.00000e-05 1.00000e-05 1.00000e-06 1.00000e-09 1.00000e-01

$1.00000 \mathrm{e}+001.00000 \mathrm{e}+001.00000 \mathrm{e}-01$ 1.00000e-09 1.00000e-01

Element: 11180 \# of layers: 6

Kx Ky Kz Ss Por

5.66517e+00 5.66517e+00 5.66517e-01 1.00000e-09 2.12000e-01

$5.66517 \mathrm{e}+005.66517 \mathrm{e}+00$ 5.66517e-01 1.00000e-09 2.12000e-01

5.66517e+00 5.66517e+00 5.66517e-01 1.00000e-09 2.12000e-01

5.66517e+00 5.66517e+00 5.66517e-01 1.00000e-09 2.12000e-01

$1.00000 \mathrm{e}-05$ 1.00000e-05 1.00000e-06 1.00000e-09 1.00000e-01

$1.00000 \mathrm{e}+001.00000 \mathrm{e}+001.00000 \mathrm{e}-011.00000 \mathrm{e}-091.00000 \mathrm{e}-01$

Element: 11181 \# of layers: 6

$\mathrm{Kx} \mathrm{Ky} \mathrm{Kz}$ Ss Por

5.66517e+00 5.66517e+00 5.66517e-01 1.00000e-09 2.12000e-01

5.66517e+00 5.66517e+00 5.66517e-01 1.00000e-09 2.12000e-01 
$5.66517 \mathrm{e}+00$ 5.66517e+00 5.66517e-01 1.00000e-09 2.12000e-01

$5.66517 \mathrm{e}+005.66517 \mathrm{e}+00$ 5.66517e-01 1.00000e-09 2.12000e-01 $1.00000 \mathrm{e}-05$ 1.00000e-05 1.00000e-06 1.00000e-09 1.00000e-01

$1.00000 \mathrm{e}+001.00000 \mathrm{e}+001.00000 \mathrm{e}-011.00000 \mathrm{e}-091.00000 \mathrm{e}-01$

Element: 11182 \# of layers: 5

$\mathrm{Kx} \mathrm{Ky} \mathrm{Kz} \mathrm{Ss} \mathrm{Por}$

$5.66517 \mathrm{e}+00$ 5.66517e+00 5.66517e-01 1.00000e-09 2.12000e-01

$5.66517 \mathrm{e}+005.66517 \mathrm{e}+00$ 5.66517e-01 1.00000e-09 2.12000e-01

$5.66517 \mathrm{e}+005.66517 \mathrm{e}+00$ 5.66517e-01 1.00000e-09 2.12000e-01

$1.00000 \mathrm{e}-05$ 1.00000e-05 1.00000e-06 1.00000e-09 1.00000e-01

$1.00000 \mathrm{e}+001.00000 \mathrm{e}+001.00000 \mathrm{e}-011.00000 \mathrm{e}-091.00000 \mathrm{e}-01$

Element: 11183 \# of layers: 5

Kx Ky Kz Ss Por

$5.66517 \mathrm{e}+00$ 5.66517e+00 5.66517e-01 1.00000e-09 2.12000e-01

$5.66517 \mathrm{e}+005.66517 \mathrm{e}+00$ 5.66517e-01 1.00000e-09 2.12000e-01

$5.66517 \mathrm{e}+005.66517 \mathrm{e}+00$ 5.66517e-01 1.00000e-09 2.12000e-01

$1.00000 \mathrm{e}-05$ 1.00000e-05 1.00000e-06 1.00000e-09 1.00000e-01

$1.00000 \mathrm{e}+001.00000 \mathrm{e}+001.00000 \mathrm{e}-011.00000 \mathrm{e}-091.00000 \mathrm{e}-01$

Element: 11184 \# of layers: 5

Kx Ky Kz Ss Por

$5.66517 \mathrm{e}+00$ 5.66517e+00 5.66517e-01 1.00000e-09 2.12000e-01

$5.66517 \mathrm{e}+005.66517 \mathrm{e}+00$ 5.66517e-01 1.00000e-09 2.12000e-01

$5.66517 \mathrm{e}+005.66517 \mathrm{e}+00$ 5.66517e-01 1.00000e-09 2.12000e-01

$1.00000 \mathrm{e}-05$ 1.00000e-05 1.00000e-06 1.00000e-09 1.00000e-01

$1.00000 \mathrm{e}+001.00000 \mathrm{e}+001.00000 \mathrm{e}-011.00000 \mathrm{e}-091.00000 \mathrm{e}-01$

Element: 11185 \# of layers: 5

Kx Ky Kz Ss Por

$6.00088 \mathrm{e}+00$ 6.00088e+00 6.00088e-01 1.00000e-09 2.12000e-01

$6.00088 \mathrm{e}+006.00088 \mathrm{e}+00$ 6.00088e-01 1.00000e-09 2.12000e-01

$6.00088 \mathrm{e}+006.00088 \mathrm{e}+00$ 6.00088e-01 1.00000e-09 2.12000e-01

$1.00000 \mathrm{e}-05$ 1.00000e-05 1.00000e-06 1.00000e-09 1.00000e-01

$1.00000 \mathrm{e}+001.00000 \mathrm{e}+001.00000 \mathrm{e}-011.00000 \mathrm{e}-091.00000 \mathrm{e}-01$

Element: 11186 \# of layers: 5

Kx Ky Kz Ss Por

$6.00088 \mathrm{e}+00$ 6.00088e+00 6.00088e-01 1.00000e-09 2.12000e-01

$6.00088 \mathrm{e}+006.00088 \mathrm{e}+00$ 6.00088e-01 1.00000e-09 2.12000e-01

$6.00088 \mathrm{e}+006.00088 \mathrm{e}+00$ 6.00088e-01 1.00000e-09 2.12000e-01

$1.00000 \mathrm{e}-05$ 1.00000e-05 1.00000e-06 1.00000e-09 1.00000e-01

$1.00000 \mathrm{e}+001.00000 \mathrm{e}+001.00000 \mathrm{e}-011.00000 \mathrm{e}-091.00000 \mathrm{e}-01$

Element: 11187 \# of layers: 5

Kx Ky Kz Ss Por

$6.00088 \mathrm{e}+006.00088 \mathrm{e}+00$ 6.00088e-01 1.00000e-09 2.12000e-01

$6.00088 \mathrm{e}+006.00088 \mathrm{e}+006.00088 \mathrm{e}-011.00000 \mathrm{e}-092.12000 \mathrm{e}-01$

$6.00088 \mathrm{e}+006.00088 \mathrm{e}+00$ 6.00088e-01 1.00000e-09 2.12000e-01

$1.00000 \mathrm{e}-05$ 1.00000e-05 1.00000e-06 1.00000e-09 1.00000e-01

$1.00000 \mathrm{e}+001.00000 \mathrm{e}+001.00000 \mathrm{e}-011.00000 \mathrm{e}-091.00000 \mathrm{e}-01$ 
Element: 11188 \# of layers: 5

$\mathrm{Kx} \mathrm{Ky} \mathrm{Kz}$ Ss Por

5.66517e+00 5.66517e+00 5.66517e-01 1.00000e-09 2.12000e-01

$5.66517 \mathrm{e}+00$ 5.66517e+00 5.66517e-01 1.00000e-09 2.12000e-01

5.66517e+00 5.66517e+00 5.66517e-01 1.00000e-09 2.12000e-01

$1.00000 \mathrm{e}-05$ 1.00000e-05 1.00000e-06 1.00000e-09 1.00000e-01

$1.00000 \mathrm{e}+001.00000 \mathrm{e}+00$ 1.00000e-01 1.00000e-09 1.00000e-01

Element: 11189 \# of layers: 5

$\mathrm{Kx} \mathrm{Ky} \mathrm{Kz}$ Ss Por

5.66517e+00 5.66517e+00 5.66517e-01 1.00000e-09 2.12000e-01

$5.66517 \mathrm{e}+005.66517 \mathrm{e}+00$ 5.66517e-01 1.00000e-09 2.12000e-01

$5.66517 \mathrm{e}+00$ 5.66517e+00 5.66517e-01 1.00000e-09 2.12000e-01

$1.00000 \mathrm{e}-05$ 1.00000e-05 1.00000e-06 1.00000e-09 1.00000e-01

$1.00000 \mathrm{e}+001.00000 \mathrm{e}+001.00000 \mathrm{e}-011.00000 \mathrm{e}-091.00000 \mathrm{e}-01$

Element: 11190 \# of layers: 5

Kx Ky Kz Ss Por

5.66517e+00 5.66517e+00 5.66517e-01 1.00000e-09 2.12000e-01

$5.66517 \mathrm{e}+005.66517 \mathrm{e}+00$ 5.66517e-01 1.00000e-09 2.12000e-01

5.66517e+00 5.66517e+00 5.66517e-01 1.00000e-09 2.12000e-01

$1.00000 \mathrm{e}-05$ 1.00000e-05 1.00000e-06 1.00000e-09 1.00000e-01

$1.00000 \mathrm{e}+001.00000 \mathrm{e}+001.00000 \mathrm{e}-011.00000 \mathrm{e}-091.00000 \mathrm{e}-01$

Element: 11191 \# of layers: 5

$\mathrm{Kx} \mathrm{Ky} \mathrm{Kz}$ Ss Por

5.66517e+00 5.66517e+00 5.66517e-01 1.00000e-09 2.12000e-01

$5.66517 \mathrm{e}+00$ 5.66517e+00 5.66517e-01 1.00000e-09 2.12000e-01

$5.66517 \mathrm{e}+00$ 5.66517e+00 5.66517e-01 1.00000e-09 2.12000e-01

$1.00000 \mathrm{e}-05$ 1.00000e-05 1.00000e-06 1.00000e-09 1.00000e-01

$1.00000 \mathrm{e}+001.00000 \mathrm{e}+001.00000 \mathrm{e}-01$ 1.00000e-09 1.00000e-01

Element: 11192 \# of layers: 5

$\mathrm{Kx} \mathrm{Ky} \mathrm{Kz}$ Ss Por

$6.00088 \mathrm{e}+00$ 6.00088e+00 6.00088e-01 1.00000e-09 2.12000e-01

$6.00088 \mathrm{e}+006.00088 \mathrm{e}+00$ 6.00088e-01 1.00000e-09 2.12000e-01

$6.00088 \mathrm{e}+006.00088 \mathrm{e}+00$ 6.00088e-01 1.00000e-09 2.12000e-01

$1.00000 \mathrm{e}-05$ 1.00000e-05 1.00000e-06 1.00000e-09 1.00000e-01

$1.00000 \mathrm{e}+001.00000 \mathrm{e}+001.00000 \mathrm{e}-011.00000 \mathrm{e}-091.00000 \mathrm{e}-01$

Element: 11193 \# of layers: 5

Kx Ky Kz Ss Por

6.00088e+00 6.00088e+00 6.00088e-01 1.00000e-09 2.12000e-01

$6.00088 \mathrm{e}+006.00088 \mathrm{e}+006.00088 \mathrm{e}-01$ 1.00000e-09 2.12000e-01

$6.00088 \mathrm{e}+006.00088 \mathrm{e}+00$ 6.00088e-01 1.00000e-09 2.12000e-01

$1.00000 \mathrm{e}-05$ 1.00000e-05 1.00000e-06 1.00000e-09 1.00000e-01

$1.00000 \mathrm{e}+001.00000 \mathrm{e}+001.00000 \mathrm{e}-011.00000 \mathrm{e}-091.00000 \mathrm{e}-01$

Element: 11194 \# of layers: 5

$\mathrm{Kx} \mathrm{Ky} \mathrm{Kz}$ Ss Por

6.00088e+00 6.00088e+00 6.00088e-01 1.00000e-09 2.12000e-01

$6.00088 \mathrm{e}+00$ 6.00088e+00 6.00088e-01 1.00000e-09 2.12000e-01 
$6.00088 \mathrm{e}+006.00088 \mathrm{e}+00$ 6.00088e-01 1.00000e-09 2.12000e-01 $1.00000 \mathrm{e}-05$ 1.00000e-05 1.00000e-06 1.00000e-09 1.00000e-01 $1.00000 \mathrm{e}+001.00000 \mathrm{e}+001.00000 \mathrm{e}-011.00000 \mathrm{e}-091.00000 \mathrm{e}-01$ Element: 11195 \# of layers: 5

Kx Ky Kz Ss Por

$6.00088 \mathrm{e}+006.00088 \mathrm{e}+00$ 6.00088e-01 1.00000e-09 2.12000e-01

$6.00088 \mathrm{e}+006.00088 \mathrm{e}+00$ 6.00088e-01 1.00000e-09 2.12000e-01

$6.00088 \mathrm{e}+00$ 6.00088e+00 6.00088e-01 1.00000e-09 2.12000e-01

$1.00000 \mathrm{e}-05$ 1.00000e-05 1.00000e-06 1.00000e-09 1.00000e-01

$1.00000 \mathrm{e}+001.00000 \mathrm{e}+001.00000 \mathrm{e}-011.00000 \mathrm{e}-091.00000 \mathrm{e}-01$

Element: 11196 \# of layers: 5

Kx Ky Kz Ss Por

$6.00088 \mathrm{e}+00$ 6.00088e+00 6.00088e-01 1.00000e-09 2.12000e-01

$6.00088 \mathrm{e}+006.00088 \mathrm{e}+00$ 6.00088e-01 1.00000e-09 2.12000e-01

$6.00088 \mathrm{e}+006.00088 \mathrm{e}+00$ 6.00088e-01 1.00000e-09 2.12000e-01

$1.00000 \mathrm{e}-05$ 1.00000e-05 1.00000e-06 1.00000e-09 1.00000e-01

$1.00000 \mathrm{e}+001.00000 \mathrm{e}+001.00000 \mathrm{e}-011.00000 \mathrm{e}-091.00000 \mathrm{e}-01$

Element: 11197 \# of layers: 5

Kx Ky Kz Ss Por

$6.00088 \mathrm{e}+00$ 6.00088e+00 6.00088e-01 1.00000e-09 2.12000e-01

$6.00088 \mathrm{e}+006.00088 \mathrm{e}+00$ 6.00088e-01 1.00000e-09 2.12000e-01

$6.00088 \mathrm{e}+006.00088 \mathrm{e}+00$ 6.00088e-01 1.00000e-09 2.12000e-01

$1.00000 \mathrm{e}-05$ 1.00000e-05 1.00000e-06 1.00000e-09 1.00000e-01

$1.00000 \mathrm{e}+001.00000 \mathrm{e}+001.00000 \mathrm{e}-011.00000 \mathrm{e}-091.00000 \mathrm{e}-01$

Element: 11198 \# of layers: 5

Kx Ky Kz Ss Por

$6.00088 \mathrm{e}+006.00088 \mathrm{e}+00$ 6.00088e-01 1.00000e-09 2.12000e-01

$6.00088 \mathrm{e}+006.00088 \mathrm{e}+00$ 6.00088e-01 1.00000e-09 2.12000e-01

$6.00088 \mathrm{e}+006.00088 \mathrm{e}+00$ 6.00088e-01 1.00000e-09 2.12000e-01

$1.00000 \mathrm{e}-05$ 1.00000e-05 1.00000e-06 1.00000e-09 1.00000e-01

$1.00000 \mathrm{e}+001.00000 \mathrm{e}+001.00000 \mathrm{e}-011.00000 \mathrm{e}-091.00000 \mathrm{e}-01$

Element: 11199 \# of layers: 5

Kx Ky Kz Ss Por

6.00088e+00 6.00088e+00 6.00088e-01 1.00000e-09 2.12000e-01

$6.00088 \mathrm{e}+006.00088 \mathrm{e}+00$ 6.00088e-01 1.00000e-09 2.12000e-01

$6.00088 \mathrm{e}+006.00088 \mathrm{e}+00$ 6.00088e-01 1.00000e-09 2.12000e-01

$1.00000 \mathrm{e}-05$ 1.00000e-05 1.00000e-06 1.00000e-09 1.00000e-01

$1.00000 \mathrm{e}+001.00000 \mathrm{e}+001.00000 \mathrm{e}-011.00000 \mathrm{e}-091.00000 \mathrm{e}-01$

Element: 11200 \# of layers: 5

Kx Ky Kz Ss Por

$6.00088 \mathrm{e}+00$ 6.00088e+00 6.00088e-01 1.00000e-09 2.12000e-01

$6.00088 \mathrm{e}+006.00088 \mathrm{e}+00$ 6.00088e-01 1.00000e-09 2.12000e-01

$6.00088 \mathrm{e}+006.00088 \mathrm{e}+00$ 6.00088e-01 1.00000e-09 2.12000e-01

$1.00000 \mathrm{e}-05$ 1.00000e-05 1.00000e-06 1.00000e-09 1.00000e-01

$1.00000 \mathrm{e}+001.00000 \mathrm{e}+001.00000 \mathrm{e}-011.00000 \mathrm{e}-091.00000 \mathrm{e}-01$

Element: 11201 \# of layers: 5 
$\mathrm{Kx} \mathrm{Ky} \mathrm{Kz}$ Ss Por

6.00088e+00 6.00088e+00 6.00088e-01 1.00000e-09 2.12000e-01

$6.00088 \mathrm{e}+006.00088 \mathrm{e}+00$ 6.00088e-01 1.00000e-09 2.12000e-01

$6.00088 \mathrm{e}+00$ 6.00088e+00 6.00088e-01 1.00000e-09 2.12000e-01

$1.00000 \mathrm{e}-05$ 1.00000e-05 1.00000e-06 1.00000e-09 1.00000e-01

$1.00000 \mathrm{e}+001.00000 \mathrm{e}+001.00000 \mathrm{e}-011.00000 \mathrm{e}-09$ 1.00000e-01

Element: 11202 \# of layers: 6

$\mathrm{Kx} \mathrm{Ky} \mathrm{Kz} \mathrm{Ss} \mathrm{Por}$

$6.00088 \mathrm{e}+00$ 6.00088e+00 6.00088e-01 1.00000e-09 2.12000e-01

$6.00088 \mathrm{e}+00$ 6.00088e+00 6.00088e-01 1.00000e-09 2.12000e-01

$6.00088 \mathrm{e}+006.00088 \mathrm{e}+00$ 6.00088e-01 1.00000e-09 2.12000e-01

$6.00088 \mathrm{e}+006.00088 \mathrm{e}+00$ 6.00088e-01 1.00000e-09 2.12000e-01

$1.00000 \mathrm{e}-05$ 1.00000e-05 1.00000e-06 1.00000e-09 1.00000e-01

$1.00000 \mathrm{e}+001.00000 \mathrm{e}+001.00000 \mathrm{e}-011.00000 \mathrm{e}-091.00000 \mathrm{e}-01$

Element: 11203 \# of layers: 6

Kx Ky Kz Ss Por

5.00276e+00 5.00276e+00 5.00276e-01 1.00000e-09 2.12000e-01

$5.00276 \mathrm{e}+005.00276 \mathrm{e}+00$ 5.00276e-01 1.00000e-09 2.12000e-01

5.00276e+00 5.00276e+00 5.00276e-01 1.00000e-09 2.12000e-01

$5.00276 \mathrm{e}+005.00276 \mathrm{e}+005.00276 \mathrm{e}-01$ 1.00000e-09 2.12000e-01

$1.00000 \mathrm{e}-05$ 1.00000e-05 1.00000e-06 1.00000e-09 1.00000e-01

$1.00000 \mathrm{e}+001.00000 \mathrm{e}+001.00000 \mathrm{e}-011.00000 \mathrm{e}-091.00000 \mathrm{e}-01$

Element: 11204 \# of layers: 6

Kx Ky Kz Ss Por

5.00276e+00 5.00276e+00 5.00276e-01 1.00000e-09 2.12000e-01

5.00276e+00 5.00276e+00 5.00276e-01 1.00000e-09 2.12000e-01

$5.00276 \mathrm{e}+005.00276 \mathrm{e}+00$ 5.00276e-01 1.00000e-09 2.12000e-01

$5.00276 \mathrm{e}+00$ 5.00276e+00 5.00276e-01 1.00000e-09 2.12000e-01

$1.00000 \mathrm{e}-05$ 1.00000e-05 1.00000e-06 1.00000e-09 1.00000e-01

$1.00000 \mathrm{e}+001.00000 \mathrm{e}+001.00000 \mathrm{e}-011.00000 \mathrm{e}-091.00000 \mathrm{e}-01$

Element: 11205 \# of layers: 6

$\mathrm{Kx} \mathrm{Ky} \mathrm{Kz}$ Ss Por

5.00276e+00 5.00276e+00 5.00276e-01 1.00000e-09 2.12000e-01

$5.00276 \mathrm{e}+00$ 5.00276e+00 5.00276e-01 1.00000e-09 2.12000e-01

$5.00276 \mathrm{e}+005.00276 \mathrm{e}+00$ 5.00276e-01 1.00000e-09 2.12000e-01

$5.00276 \mathrm{e}+005.00276 \mathrm{e}+00$ 5.00276e-01 1.00000e-09 2.12000e-01

$1.00000 \mathrm{e}-05$ 1.00000e-05 1.00000e-06 1.00000e-09 1.00000e-01

$1.00000 \mathrm{e}+001.00000 \mathrm{e}+001.00000 \mathrm{e}-011.00000 \mathrm{e}-09$ 1.00000e-01

Element: 11206 \# of layers: 6

$\mathrm{Kx} \mathrm{Ky} \mathrm{Kz}$ Ss Por

$6.00088 \mathrm{e}+00$ 6.00088e+00 6.00088e-01 1.00000e-09 2.12000e-01

$6.00088 \mathrm{e}+006.00088 \mathrm{e}+00$ 6.00088e-01 1.00000e-09 2.12000e-01

$6.00088 \mathrm{e}+006.00088 \mathrm{e}+00$ 6.00088e-01 1.00000e-09 2.12000e-01

$6.00088 \mathrm{e}+006.00088 \mathrm{e}+00$ 6.00088e-01 1.00000e-09 2.12000e-01

$1.00000 \mathrm{e}-051.00000 \mathrm{e}-051.00000 \mathrm{e}-061.00000 \mathrm{e}-091.00000 \mathrm{e}-01$

$1.00000 \mathrm{e}+001.00000 \mathrm{e}+001.00000 \mathrm{e}-011.00000 \mathrm{e}-091.00000 \mathrm{e}-01$ 
Element: 11207 \# of layers: 5

$\mathrm{Kx} \mathrm{Ky} \mathrm{Kz}$ Ss Por

6.00088e+00 6.00088e+00 6.00088e-01 1.00000e-09 2.12000e-01

$6.00088 \mathrm{e}+00$ 6.00088e+00 6.00088e-01 1.00000e-09 2.12000e-01

$6.00088 \mathrm{e}+006.00088 \mathrm{e}+00$ 6.00088e-01 1.00000e-09 2.12000e-01

$1.00000 \mathrm{e}-05$ 1.00000e-05 1.00000e-06 1.00000e-09 1.00000e-01

$1.00000 \mathrm{e}+001.00000 \mathrm{e}+00$ 1.00000e-01 1.00000e-09 1.00000e-01

Element: 11208 \# of layers: 5

$\mathrm{Kx} \mathrm{Ky} \mathrm{Kz}$ Ss Por

$6.00088 \mathrm{e}+00$ 6.00088e+00 6.00088e-01 1.00000e-09 2.12000e-01

$6.00088 \mathrm{e}+006.00088 \mathrm{e}+00$ 6.00088e-01 1.00000e-09 2.12000e-01

$6.00088 \mathrm{e}+006.00088 \mathrm{e}+00$ 6.00088e-01 1.00000e-09 2.12000e-01

$1.00000 \mathrm{e}-05$ 1.00000e-05 1.00000e-06 1.00000e-09 1.00000e-01

$1.00000 \mathrm{e}+001.00000 \mathrm{e}+001.00000 \mathrm{e}-011.00000 \mathrm{e}-091.00000 \mathrm{e}-01$

Element: 11209 \# of layers: 6

Kx Ky Kz Ss Por

6.00088e+00 6.00088e+00 6.00088e-01 1.00000e-09 2.12000e-01

$6.00088 \mathrm{e}+006.00088 \mathrm{e}+00$ 6.00088e-01 1.00000e-09 2.12000e-01

$6.00088 \mathrm{e}+006.00088 \mathrm{e}+00$ 6.00088e-01 1.00000e-09 2.12000e-01

$6.00088 \mathrm{e}+006.00088 \mathrm{e}+006.00088 \mathrm{e}-01$ 1.00000e-09 2.12000e-01

$1.00000 \mathrm{e}-05$ 1.00000e-05 1.00000e-06 1.00000e-09 1.00000e-01

$1.00000 \mathrm{e}+001.00000 \mathrm{e}+001.00000 \mathrm{e}-01$ 1.00000e-09 1.00000e-01

Element: 11210 \# of layers: 6

Kx Ky Kz Ss Por

5.00276e+00 5.00276e+00 5.00276e-01 1.00000e-09 2.12000e-01

5.00276e+00 5.00276e+00 5.00276e-01 1.00000e-09 2.12000e-01

$5.00276 \mathrm{e}+005.00276 \mathrm{e}+00$ 5.00276e-01 1.00000e-09 2.12000e-01

$5.00276 \mathrm{e}+00$ 5.00276e+00 5.00276e-01 1.00000e-09 2.12000e-01

$1.00000 \mathrm{e}-05$ 1.00000e-05 1.00000e-06 1.00000e-09 1.00000e-01

$1.00000 \mathrm{e}+001.00000 \mathrm{e}+001.00000 \mathrm{e}-011.00000 \mathrm{e}-091.00000 \mathrm{e}-01$

Element: 11211 \# of layers: 6

$\mathrm{Kx} \mathrm{Ky} \mathrm{Kz}$ Ss Por

5.00276e+00 5.00276e+00 5.00276e-01 1.00000e-09 2.12000e-01

$5.00276 \mathrm{e}+00$ 5.00276e+00 5.00276e-01 1.00000e-09 2.12000e-01

$5.00276 \mathrm{e}+005.00276 \mathrm{e}+00$ 5.00276e-01 1.00000e-09 2.12000e-01

$5.00276 \mathrm{e}+005.00276 \mathrm{e}+00$ 5.00276e-01 1.00000e-09 2.12000e-01

$1.00000 \mathrm{e}-05$ 1.00000e-05 1.00000e-06 1.00000e-09 1.00000e-01

$1.00000 \mathrm{e}+001.00000 \mathrm{e}+001.00000 \mathrm{e}-011.00000 \mathrm{e}-09$ 1.00000e-01

Element: 11212 \# of layers: 6

$\mathrm{Kx} \mathrm{Ky} \mathrm{Kz}$ Ss Por

5.00276e+00 5.00276e+00 5.00276e-01 1.00000e-09 2.12000e-01

$5.00276 \mathrm{e}+005.00276 \mathrm{e}+00$ 5.00276e-01 1.00000e-09 2.12000e-01

5.00276e+00 5.00276e+00 5.00276e-01 1.00000e-09 2.12000e-01

5.00276e+00 5.00276e+00 5.00276e-01 1.00000e-09 2.12000e-01

$1.00000 \mathrm{e}-051.00000 \mathrm{e}-051.00000 \mathrm{e}-061.00000 \mathrm{e}-091.00000 \mathrm{e}-01$

$1.00000 \mathrm{e}+001.00000 \mathrm{e}+001.00000 \mathrm{e}-011.00000 \mathrm{e}-091.00000 \mathrm{e}-01$ 
Element: 11213 \# of layers: 6

$\mathrm{Kx} \mathrm{Ky} \mathrm{Kz}$ Ss Por

5.00276e+00 5.00276e+00 5.00276e-01 1.00000e-09 2.12000e-01

$5.00276 \mathrm{e}+00$ 5.00276e+00 5.00276e-01 1.00000e-09 2.12000e-01

$5.00276 \mathrm{e}+005.00276 \mathrm{e}+00$ 5.00276e-01 1.00000e-09 2.12000e-01

$5.00276 \mathrm{e}+00$ 5.00276e+00 5.00276e-01 1.00000e-09 2.12000e-01

$1.00000 \mathrm{e}-05$ 1.00000e-05 1.00000e-06 1.00000e-09 1.00000e-01

$1.00000 \mathrm{e}+001.00000 \mathrm{e}+001.00000 \mathrm{e}-011.00000 \mathrm{e}-091.00000 \mathrm{e}-01$

Element: 11214 \# of layers: 6

$\mathrm{Kx} \mathrm{Ky} \mathrm{Kz}$ Ss Por

5.00276e+00 5.00276e+00 5.00276e-01 1.00000e-09 2.12000e-01

$5.00276 \mathrm{e}+005.00276 \mathrm{e}+00$ 5.00276e-01 1.00000e-09 2.12000e-01

$5.00276 \mathrm{e}+00$ 5.00276e+00 5.00276e-01 1.00000e-09 2.12000e-01

$5.00276 \mathrm{e}+005.00276 \mathrm{e}+00$ 5.00276e-01 1.00000e-09 2.12000e-01

$1.00000 \mathrm{e}-05$ 1.00000e-05 1.00000e-06 1.00000e-09 1.00000e-01

$1.00000 \mathrm{e}+001.00000 \mathrm{e}+001.00000 \mathrm{e}-011.00000 \mathrm{e}-091.00000 \mathrm{e}-01$

Element: 11215 \# of layers: 6

$\mathrm{Kx} \mathrm{Ky} \mathrm{Kz}$ Ss Por

5.00276e+00 5.00276e+00 5.00276e-01 1.00000e-09 2.12000e-01

$5.00276 \mathrm{e}+00$ 5.00276e+00 5.00276e-01 1.00000e-09 2.12000e-01

$5.00276 \mathrm{e}+00$ 5.00276e+00 5.00276e-01 1.00000e-09 2.12000e-01

5.00276e+00 5.00276e+00 5.00276e-01 1.00000e-09 2.12000e-01

$1.00000 \mathrm{e}-05$ 1.00000e-05 1.00000e-06 1.00000e-09 1.00000e-01

$1.00000 \mathrm{e}+001.00000 \mathrm{e}+001.00000 \mathrm{e}-011.00000 \mathrm{e}-091.00000 \mathrm{e}-01$

Element: 11216 \# of layers: 6

$\mathrm{Kx} \mathrm{Ky} \mathrm{Kz}$ Ss Por

5.00276e+00 5.00276e+00 5.00276e-01 1.00000e-09 2.12000e-01

$5.00276 \mathrm{e}+00$ 5.00276e+00 5.00276e-01 1.00000e-09 2.12000e-01

$5.00276 \mathrm{e}+00$ 5.00276e+00 5.00276e-01 1.00000e-09 2.12000e-01

5.00276e+00 5.00276e+00 5.00276e-01 1.00000e-09 2.12000e-01

$1.00000 \mathrm{e}-05$ 1.00000e-05 1.00000e-06 1.00000e-09 1.00000e-01

$1.00000 \mathrm{e}+001.00000 \mathrm{e}+001.00000 \mathrm{e}-01$ 1.00000e-09 1.00000e-01

Element: 11217 \# of layers: 6

$\mathrm{Kx} \mathrm{Ky} \mathrm{Kz}$ Ss Por

5.00276e+00 5.00276e+00 5.00276e-01 1.00000e-09 2.12000e-01

5.00276e+00 5.00276e+00 5.00276e-01 1.00000e-09 2.12000e-01

$5.00276 \mathrm{e}+005.00276 \mathrm{e}+00$ 5.00276e-01 1.00000e-09 2.12000e-01

$5.00276 \mathrm{e}+00$ 5.00276e+00 5.00276e-01 1.00000e-09 2.12000e-01

$1.00000 \mathrm{e}-05$ 1.00000e-05 1.00000e-06 1.00000e-09 1.00000e-01

$1.00000 \mathrm{e}+001.00000 \mathrm{e}+001.00000 \mathrm{e}-01$ 1.00000e-09 1.00000e-01

Element: 11218 \# of layers: 6

$\mathrm{Kx} \mathrm{Ky} \mathrm{Kz}$ Ss Por

5.00276e+00 5.00276e+00 5.00276e-01 1.00000e-09 2.12000e-01

5.00276e+00 5.00276e+00 5.00276e-01 1.00000e-09 2.12000e-01

$5.00276 \mathrm{e}+00$ 5.00276e+00 5.00276e-01 1.00000e-09 2.12000e-01

$5.00276 \mathrm{e}+00$ 5.00276e+00 5.00276e-01 1.00000e-09 2.12000e-01 
$1.00000 \mathrm{e}-05$ 1.00000e-05 1.00000e-06 1.00000e-09 1.00000e-01 $1.00000 \mathrm{e}+001.00000 \mathrm{e}+001.00000 \mathrm{e}-01$ 1.00000e-09 1.00000e-01 Element: 11219 \# of layers: 6

Kx Ky Kz Ss Por

5.00276e+00 5.00276e+00 5.00276e-01 1.00000e-09 2.12000e-01 $5.00276 \mathrm{e}+00$ 5.00276e+00 5.00276e-01 1.00000e-09 2.12000e-01 $5.00276 \mathrm{e}+00$ 5.00276e+00 5.00276e-01 1.00000e-09 2.12000e-01 $5.00276 \mathrm{e}+005.00276 \mathrm{e}+00$ 5.00276e-01 1.00000e-09 2.12000e-01 $1.00000 \mathrm{e}-05$ 1.00000e-05 1.00000e-06 1.00000e-09 1.00000e-01 $1.00000 \mathrm{e}+001.00000 \mathrm{e}+00$ 1.00000e-01 1.00000e-09 1.00000e-01 Element: 11220 \# of layers: 6

Kx Ky Kz Ss Por

4.98183e+00 4.98183e+00 4.98183e-01 1.00000e-09 2.12000e-01 4.98183e+00 4.98183e+00 4.98183e-01 1.00000e-09 2.12000e-01 4.98183e+00 4.98183e+00 4.98183e-01 1.00000e-09 2.12000e-01 $4.98183 \mathrm{e}+004.98183 \mathrm{e}+00$ 4.98183e-01 1.00000e-09 2.12000e-01 $1.00000 \mathrm{e}-05$ 1.00000e-05 1.00000e-06 1.00000e-09 1.00000e-01 $1.00000 \mathrm{e}+001.00000 \mathrm{e}+001.00000 \mathrm{e}-01$ 1.00000e-09 1.00000e-01 Element: 11221 \# of layers: 6

$\mathrm{Kx} \mathrm{Ky} \mathrm{Kz}$ Ss Por

$4.98183 e+00$ 4.98183e+00 4.98183e-01 1.00000e-09 2.12000e-01 $4.98183 \mathrm{e}+00$ 4.98183e+00 4.98183e-01 1.00000e-09 2.12000e-01 4.98183e+00 4.98183e+00 4.98183e-01 1.00000e-09 2.12000e-01 $4.98183 \mathrm{e}+00$ 4.98183e+00 4.98183e-01 1.00000e-09 2.12000e-01 $1.00000 \mathrm{e}-05$ 1.00000e-05 1.00000e-06 1.00000e-09 1.00000e-01 $1.00000 \mathrm{e}+001.00000 \mathrm{e}+001.00000 \mathrm{e}-01$ 1.00000e-09 1.00000e-01 Element: 11222 \# of layers: 6

$\mathrm{Kx} \mathrm{Ky} \mathrm{Kz}$ Ss Por

4.98183e+00 4.98183e+00 4.98183e-01 1.00000e-09 2.12000e-01 $4.98183 \mathrm{e}+00$ 4.98183e+00 4.98183e-01 1.00000e-09 2.12000e-01 $4.98183 e+00$ 4.98183e+00 4.98183e-01 1.00000e-09 2.12000e-01 $4.98183 \mathrm{e}+00$ 4.98183e+00 4.98183e-01 1.00000e-09 2.12000e-01 $1.00000 \mathrm{e}-05$ 1.00000e-05 1.00000e-06 1.00000e-09 1.00000e-01 $1.00000 \mathrm{e}+001.00000 \mathrm{e}+001.00000 \mathrm{e}-011.00000 \mathrm{e}-091.00000 \mathrm{e}-01$ Element: 11223 \# of layers: 6

$\mathrm{Kx} \mathrm{Ky} \mathrm{Kz}$ Ss Por 4.98183e+00 4.98183e+00 4.98183e-01 1.00000e-09 2.12000e-01 $4.98183 \mathrm{e}+00$ 4.98183e+00 4.98183e-01 1.00000e-09 2.12000e-01 4.98183e+00 4.98183e+00 4.98183e-01 1.00000e-09 2.12000e-01 4.98183e+00 4.98183e+00 4.98183e-01 1.00000e-09 2.12000e-01 $1.00000 \mathrm{e}-05$ 1.00000e-05 1.00000e-06 1.00000e-09 1.00000e-01 $1.00000 \mathrm{e}+001.00000 \mathrm{e}+001.00000 \mathrm{e}-011.00000 \mathrm{e}-091.00000 \mathrm{e}-01$ Element: 11224 \# of layers: 6

$\mathrm{Kx} \mathrm{Ky} \mathrm{Kz}$ Ss Por 4.98183e+00 4.98183e+00 4.98183e-01 1.00000e-09 2.12000e-01 $4.98183 e+004.98183 e+00$ 4.98183e-01 1.00000e-09 2.12000e-01 
4.98183e+00 4.98183e+00 4.98183e-01 1.00000e-09 2.12000e-01 $4.98183 \mathrm{e}+004.98183 \mathrm{e}+004.98183 \mathrm{e}-01$ 1.00000e-09 2.12000e-01 $1.00000 \mathrm{e}-05$ 1.00000e-05 1.00000e-06 1.00000e-09 1.00000e-01 $1.00000 \mathrm{e}+001.00000 \mathrm{e}+001.00000 \mathrm{e}-011.00000 \mathrm{e}-091.00000 \mathrm{e}-01$ Element: 11225 \# of layers: 6

Kx Ky Kz Ss Por

5.00276e+00 5.00276e+00 5.00276e-01 1.00000e-09 2.12000e-01 $5.00276 \mathrm{e}+005.00276 \mathrm{e}+00$ 5.00276e-01 1.00000e-09 2.12000e-01 $5.00276 \mathrm{e}+005.00276 \mathrm{e}+005.00276 \mathrm{e}-011.00000 \mathrm{e}-092.12000 \mathrm{e}-01$ $5.00276 \mathrm{e}+00$ 5.00276e+00 5.00276e-01 1.00000e-09 2.12000e-01 $1.00000 \mathrm{e}-05$ 1.00000e-05 1.00000e-06 1.00000e-09 1.00000e-01 $1.00000 \mathrm{e}+001.00000 \mathrm{e}+001.00000 \mathrm{e}-011.00000 \mathrm{e}-091.00000 \mathrm{e}-01$ Element: 11226 \# of layers: 6

Kx Ky Kz Ss Por

$5.00276 \mathrm{e}+00$ 5.00276e+00 5.00276e-01 1.00000e-09 2.12000e-01 $5.00276 \mathrm{e}+005.00276 \mathrm{e}+00$ 5.00276e-01 1.00000e-09 2.12000e-01 $5.00276 \mathrm{e}+005.00276 \mathrm{e}+005.00276 \mathrm{e}-011.00000 \mathrm{e}-092.12000 \mathrm{e}-01$ $5.00276 \mathrm{e}+005.00276 \mathrm{e}+00$ 5.00276e-01 1.00000e-09 2.12000e-01 $1.00000 \mathrm{e}-05$ 1.00000e-05 1.00000e-06 1.00000e-09 1.00000e-01 $1.00000 \mathrm{e}+001.00000 \mathrm{e}+001.00000 \mathrm{e}-011.00000 \mathrm{e}-091.00000 \mathrm{e}-01$ Element: 11227 \# of layers: 6

Kx Ky Kz Ss Por

4.98183e+00 4.98183e+00 4.98183e-01 1.00000e-09 2.12000e-01 $4.98183 \mathrm{e}+004.98183 \mathrm{e}+00$ 4.98183e-01 1.00000e-09 2.12000e-01 $4.98183 \mathrm{e}+004.98183 \mathrm{e}+004.98183 \mathrm{e}-011.00000 \mathrm{e}-092.12000 \mathrm{e}-01$ $4.98183 \mathrm{e}+004.98183 \mathrm{e}+00$ 4.98183e-01 1.00000e-09 2.12000e-01 $1.00000 \mathrm{e}-05$ 1.00000e-05 1.00000e-06 1.00000e-09 1.00000e-01 $1.00000 \mathrm{e}+001.00000 \mathrm{e}+001.00000 \mathrm{e}-011.00000 \mathrm{e}-091.00000 \mathrm{e}-01$ Element: 11228 \# of layers: 6

Kx Ky Kz Ss Por

4.98183e+00 4.98183e+00 4.98183e-01 1.00000e-09 2.12000e-01 $4.98183 \mathrm{e}+004.98183 \mathrm{e}+004.98183 \mathrm{e}-01$ 1.00000e-09 2.12000e-01 $4.98183 \mathrm{e}+004.98183 \mathrm{e}+004.98183 \mathrm{e}-011.00000 \mathrm{e}-092.12000 \mathrm{e}-01$ $4.98183 \mathrm{e}+004.98183 \mathrm{e}+00$ 4.98183e-01 1.00000e-09 2.12000e-01 $1.00000 \mathrm{e}-05$ 1.00000e-05 1.00000e-06 1.00000e-09 1.00000e-01 $1.00000 \mathrm{e}+001.00000 \mathrm{e}+001.00000 \mathrm{e}-011.00000 \mathrm{e}-091.00000 \mathrm{e}-01$ Element: 11229 \# of layers: 6

Kx Ky Kz Ss Por

$5.66517 \mathrm{e}+00$ 5.66517e+00 5.66517e-01 1.00000e-09 2.12000e-01 $5.66517 \mathrm{e}+005.66517 \mathrm{e}+00$ 5.66517e-01 1.00000e-09 2.12000e-01 $5.66517 \mathrm{e}+005.66517 \mathrm{e}+00$ 5.66517e-01 1.00000e-09 2.12000e-01 $5.66517 \mathrm{e}+005.66517 \mathrm{e}+00$ 5.66517e-01 1.00000e-09 2.12000e-01 $1.00000 \mathrm{e}-05$ 1.00000e-05 1.00000e-06 1.00000e-09 1.00000e-01 $1.00000 \mathrm{e}+001.00000 \mathrm{e}+001.00000 \mathrm{e}-011.00000 \mathrm{e}-091.00000 \mathrm{e}-01$ Element: 11230 \# of layers: 6

Kx Ky Kz Ss Por 
$5.66517 \mathrm{e}+00$ 5.66517e+00 5.66517e-01 1.00000e-09 2.12000e-01

$5.66517 \mathrm{e}+005.66517 \mathrm{e}+005.66517 \mathrm{e}-011.00000 \mathrm{e}-092.12000 \mathrm{e}-01$

$5.66517 \mathrm{e}+005.66517 \mathrm{e}+00$ 5.66517e-01 1.00000e-09 2.12000e-01

$5.66517 \mathrm{e}+00$ 5.66517e+00 5.66517e-01 1.00000e-09 2.12000e-01

$1.00000 \mathrm{e}-05$ 1.00000e-05 1.00000e-06 1.00000e-09 1.00000e-01

$1.00000 \mathrm{e}+001.00000 \mathrm{e}+001.00000 \mathrm{e}-011.00000 \mathrm{e}-091.00000 \mathrm{e}-01$

Element: 11231 \# of layers: 6

Kx Ky Kz Ss Por

$5.66517 \mathrm{e}+00$ 5.66517e+00 5.66517e-01 1.00000e-09 2.12000e-01

$5.66517 \mathrm{e}+005.66517 \mathrm{e}+00$ 5.66517e-01 1.00000e-09 2.12000e-01

$5.66517 \mathrm{e}+005.66517 \mathrm{e}+00$ 5.66517e-01 1.00000e-09 2.12000e-01

$5.66517 \mathrm{e}+00$ 5.66517e+00 5.66517e-01 1.00000e-09 2.12000e-01

$1.00000 \mathrm{e}-05$ 1.00000e-05 1.00000e-06 1.00000e-09 1.00000e-01

$1.00000 \mathrm{e}+001.00000 \mathrm{e}+001.00000 \mathrm{e}-011.00000 \mathrm{e}-091.00000 \mathrm{e}-01$

Element: 11232 \# of layers: 6

Kx Ky Kz Ss Por

$6.00088 \mathrm{e}+006.00088 \mathrm{e}+00$ 6.00088e-01 1.00000e-09 2.12000e-01

$6.00088 \mathrm{e}+006.00088 \mathrm{e}+006.00088 \mathrm{e}-01$ 1.00000e-09 2.12000e-01

$6.00088 \mathrm{e}+006.00088 \mathrm{e}+00$ 6.00088e-01 1.00000e-09 2.12000e-01

$6.00088 \mathrm{e}+006.00088 \mathrm{e}+00$ 6.00088e-01 1.00000e-09 2.12000e-01

$1.00000 \mathrm{e}-05$ 1.00000e-05 1.00000e-06 1.00000e-09 1.00000e-01

$1.00000 \mathrm{e}+001.00000 \mathrm{e}+001.00000 \mathrm{e}-011.00000 \mathrm{e}-091.00000 \mathrm{e}-01$

Element: 11233 \# of layers: 6

Kx Ky Kz Ss Por

$6.00088 \mathrm{e}+006.00088 \mathrm{e}+00$ 6.00088e-01 1.00000e-09 2.12000e-01

$6.00088 \mathrm{e}+006.00088 \mathrm{e}+00$ 6.00088e-01 1.00000e-09 2.12000e-01

$6.00088 \mathrm{e}+006.00088 \mathrm{e}+00$ 6.00088e-01 1.00000e-09 2.12000e-01

$6.00088 \mathrm{e}+006.00088 \mathrm{e}+00$ 6.00088e-01 1.00000e-09 2.12000e-01

$1.00000 \mathrm{e}-05$ 1.00000e-05 1.00000e-06 1.00000e-09 1.00000e-01

$1.00000 \mathrm{e}+001.00000 \mathrm{e}+001.00000 \mathrm{e}-011.00000 \mathrm{e}-091.00000 \mathrm{e}-01$

Element: 11234 \# of layers: 6

Kx Ky Kz Ss Por

$5.00276 \mathrm{e}+00$ 5.00276e+00 5.00276e-01 1.00000e-09 2.12000e-01

$5.00276 \mathrm{e}+005.00276 \mathrm{e}+00$ 5.00276e-01 1.00000e-09 2.12000e-01

$5.00276 \mathrm{e}+005.00276 \mathrm{e}+005.00276 \mathrm{e}-011.00000 \mathrm{e}-092.12000 \mathrm{e}-01$

$5.00276 \mathrm{e}+005.00276 \mathrm{e}+00$ 5.00276e-01 1.00000e-09 2.12000e-01

$1.00000 \mathrm{e}-05$ 1.00000e-05 1.00000e-06 1.00000e-09 1.00000e-01

$1.00000 \mathrm{e}+001.00000 \mathrm{e}+001.00000 \mathrm{e}-011.00000 \mathrm{e}-091.00000 \mathrm{e}-01$

Element: 11235 \# of layers: 6

Kx Ky Kz Ss Por

4.98183e+00 4.98183e+00 4.98183e-01 1.00000e-09 2.12000e-01

$4.98183 \mathrm{e}+004.98183 \mathrm{e}+004.98183 \mathrm{e}-011.00000 \mathrm{e}-092.12000 \mathrm{e}-01$

$4.98183 \mathrm{e}+004.98183 \mathrm{e}+00$ 4.98183e-01 1.00000e-09 2.12000e-01

$4.98183 \mathrm{e}+004.98183 \mathrm{e}+00$ 4.98183e-01 1.00000e-09 2.12000e-01

$1.00000 \mathrm{e}-05$ 1.00000e-05 1.00000e-06 1.00000e-09 1.00000e-01

$1.00000 \mathrm{e}+001.00000 \mathrm{e}+001.00000 \mathrm{e}-011.00000 \mathrm{e}-091.00000 \mathrm{e}-01$ 
Element: 11236 \# of layers: 6

$\mathrm{Kx} \mathrm{Ky} \mathrm{Kz}$ Ss Por

5.66517e+00 5.66517e+00 5.66517e-01 1.00000e-09 2.12000e-01

$5.66517 \mathrm{e}+00$ 5.66517e+00 5.66517e-01 1.00000e-09 2.12000e-01

$5.66517 \mathrm{e}+00$ 5.66517e+00 5.66517e-01 1.00000e-09 2.12000e-01

5.66517e+00 5.66517e+00 5.66517e-01 1.00000e-09 2.12000e-01

1.00000e-05 1.00000e-05 1.00000e-06 1.00000e-09 1.00000e-01

$1.00000 \mathrm{e}+001.00000 \mathrm{e}+001.00000 \mathrm{e}-01$ 1.00000e-09 1.00000e-01

Element: 11237 \# of layers: 5

$\mathrm{Kx} \mathrm{Ky} \mathrm{Kz}$ Ss Por

6.57486e+00 6.57486e+00 6.57486e-01 1.00000e-09 2.12000e-01

$6.57486 \mathrm{e}+006.57486 \mathrm{e}+00$ 6.57486e-01 1.00000e-09 2.12000e-01

$6.57486 \mathrm{e}+006.57486 \mathrm{e}+00$ 6.57486e-01 1.00000e-09 2.12000e-01

$1.00000 \mathrm{e}-05$ 1.00000e-05 1.00000e-06 1.00000e-09 1.00000e-01

$1.00000 \mathrm{e}+001.00000 \mathrm{e}+001.00000 \mathrm{e}-01$ 1.00000e-09 1.00000e-01

Element: 11238 \# of layers: 5

$\mathrm{Kx} \mathrm{Ky} \mathrm{Kz}$ Ss Por

6.57486e+00 6.57486e+00 6.57486e-01 1.00000e-09 2.12000e-01

$6.57486 \mathrm{e}+006.57486 \mathrm{e}+006.57486 \mathrm{e}-01$ 1.00000e-09 2.12000e-01

6.57486e+00 6.57486e+00 6.57486e-01 1.00000e-09 2.12000e-01

$1.00000 \mathrm{e}-05$ 1.00000e-05 1.00000e-06 1.00000e-09 1.00000e-01

$1.00000 \mathrm{e}+001.00000 \mathrm{e}+001.00000 \mathrm{e}-011.00000 \mathrm{e}-091.00000 \mathrm{e}-01$

Element: 11239 \# of layers: 5

Kx Ky Kz Ss Por

6.57486e+00 6.57486e+00 6.57486e-01 1.00000e-09 2.12000e-01

$6.57486 \mathrm{e}+006.57486 \mathrm{e}+00$ 6.57486e-01 1.00000e-09 2.12000e-01

$6.57486 \mathrm{e}+006.57486 \mathrm{e}+00$ 6.57486e-01 1.00000e-09 2.12000e-01

$1.00000 \mathrm{e}-05$ 1.00000e-05 1.00000e-06 1.00000e-09 1.00000e-01

$1.00000 \mathrm{e}+001.00000 \mathrm{e}+001.00000 \mathrm{e}-011.00000 \mathrm{e}-091.00000 \mathrm{e}-01$

Element: 11240 \# of layers: 5

$\mathrm{Kx} \mathrm{Ky} \mathrm{Kz} \mathrm{Ss} \mathrm{Por}$

6.57486e+00 6.57486e+00 6.57486e-01 1.00000e-09 2.12000e-01

$6.57486 \mathrm{e}+006.57486 \mathrm{e}+006.57486 \mathrm{e}-01$ 1.00000e-09 2.12000e-01

6.57486e+00 6.57486e+00 6.57486e-01 1.00000e-09 2.12000e-01

$1.00000 \mathrm{e}-05$ 1.00000e-05 1.00000e-06 1.00000e-09 1.00000e-01

$1.00000 \mathrm{e}+001.00000 \mathrm{e}+001.00000 \mathrm{e}-011.00000 \mathrm{e}-09$ 1.00000e-01

Element: 11241 \# of layers: 5

$\mathrm{Kx} \mathrm{Ky} \mathrm{Kz}$ Ss Por

6.57486e+00 6.57486e+00 6.57486e-01 1.00000e-09 2.12000e-01

$6.57486 \mathrm{e}+006.57486 \mathrm{e}+00$ 6.57486e-01 1.00000e-09 2.12000e-01

6.57486e+00 6.57486e+00 6.57486e-01 1.00000e-09 2.12000e-01

$1.00000 \mathrm{e}-05$ 1.00000e-05 1.00000e-06 1.00000e-09 1.00000e-01

$1.00000 \mathrm{e}+001.00000 \mathrm{e}+001.00000 \mathrm{e}-011.00000 \mathrm{e}-091.00000 \mathrm{e}-01$

Element: 11242 \# of layers: 5

$\mathrm{Kx} \mathrm{Ky} \mathrm{Kz} \mathrm{Ss} \mathrm{Por}$

6.57486e+00 6.57486e+00 6.57486e-01 1.00000e-09 2.12000e-01 
$6.57486 \mathrm{e}+006.57486 \mathrm{e}+00$ 6.57486e-01 1.00000e-09 2.12000e-01

$6.57486 \mathrm{e}+006.57486 \mathrm{e}+00$ 6.57486e-01 1.00000e-09 2.12000e-01 $1.00000 \mathrm{e}-05$ 1.00000e-05 1.00000e-06 1.00000e-09 1.00000e-01

$1.00000 \mathrm{e}+001.00000 \mathrm{e}+001.00000 \mathrm{e}-011.00000 \mathrm{e}-091.00000 \mathrm{e}-01$ Element: 11243 \# of layers: 5

Kx Ky Kz Ss Por

$6.57486 \mathrm{e}+006.57486 \mathrm{e}+00$ 6.57486e-01 1.00000e-09 2.12000e-01

$6.57486 \mathrm{e}+006.57486 \mathrm{e}+006.57486 \mathrm{e}-011.00000 \mathrm{e}-092.12000 \mathrm{e}-01$

$6.57486 \mathrm{e}+006.57486 \mathrm{e}+006.57486 \mathrm{e}-011.00000 \mathrm{e}-092.12000 \mathrm{e}-01$

$1.00000 \mathrm{e}-05$ 1.00000e-05 1.00000e-06 1.00000e-09 1.00000e-01

$1.00000 \mathrm{e}+001.00000 \mathrm{e}+001.00000 \mathrm{e}-011.00000 \mathrm{e}-091.00000 \mathrm{e}-01$

Element: 11244 \# of layers: 5

Kx Ky Kz Ss Por

$6.57486 \mathrm{e}+006.57486 \mathrm{e}+00$ 6.57486e-01 1.00000e-09 2.12000e-01

$6.57486 \mathrm{e}+006.57486 \mathrm{e}+006.57486 \mathrm{e}-011.00000 \mathrm{e}-092.12000 \mathrm{e}-01$

$6.57486 \mathrm{e}+006.57486 \mathrm{e}+006.57486 \mathrm{e}-011.00000 \mathrm{e}-092.12000 \mathrm{e}-01$

$1.00000 \mathrm{e}-05$ 1.00000e-05 1.00000e-06 1.00000e-09 1.00000e-01

$1.00000 \mathrm{e}+001.00000 \mathrm{e}+001.00000 \mathrm{e}-011.00000 \mathrm{e}-091.00000 \mathrm{e}-01$

Element: 11245 \# of layers: 5

Kx Ky Kz Ss Por

$6.57486 \mathrm{e}+006.57486 \mathrm{e}+00$ 6.57486e-01 1.00000e-09 2.12000e-01

$6.57486 \mathrm{e}+006.57486 \mathrm{e}+006.57486 \mathrm{e}-011.00000 \mathrm{e}-092.12000 \mathrm{e}-01$

$6.57486 \mathrm{e}+006.57486 \mathrm{e}+006.57486 \mathrm{e}-011.00000 \mathrm{e}-092.12000 \mathrm{e}-01$

$1.00000 \mathrm{e}-05$ 1.00000e-05 1.00000e-06 1.00000e-09 1.00000e-01

$1.00000 \mathrm{e}+001.00000 \mathrm{e}+001.00000 \mathrm{e}-011.00000 \mathrm{e}-091.00000 \mathrm{e}-01$

Element: 11246 \# of layers: 5

Kx Ky Kz Ss Por

$6.57486 \mathrm{e}+006.57486 \mathrm{e}+00$ 6.57486e-01 1.00000e-09 2.12000e-01

$6.57486 \mathrm{e}+006.57486 \mathrm{e}+00$ 6.57486e-01 1.00000e-09 2.12000e-01

$6.57486 \mathrm{e}+006.57486 \mathrm{e}+006.57486 \mathrm{e}-011.00000 \mathrm{e}-092.12000 \mathrm{e}-01$

$1.00000 \mathrm{e}-05$ 1.00000e-05 1.00000e-06 1.00000e-09 1.00000e-01

$1.00000 \mathrm{e}+001.00000 \mathrm{e}+001.00000 \mathrm{e}-011.00000 \mathrm{e}-091.00000 \mathrm{e}-01$

Element: 11247 \# of layers: 5

Kx Ky Kz Ss Por

7.16168e+00 7.16168e+00 7.16168e-01 1.00000e-09 2.12000e-01

$7.16168 \mathrm{e}+007.16168 \mathrm{e}+00$ 7.16168e-01 1.00000e-09 2.12000e-01

$7.16168 \mathrm{e}+007.16168 \mathrm{e}+00$ 7.16168e-01 1.00000e-09 2.12000e-01

$1.00000 \mathrm{e}-05$ 1.00000e-05 1.00000e-06 1.00000e-09 1.00000e-01

$1.00000 \mathrm{e}+001.00000 \mathrm{e}+001.00000 \mathrm{e}-011.00000 \mathrm{e}-091.00000 \mathrm{e}-01$

Element: 11248 \# of layers: 6

Kx Ky Kz Ss Por

7.16168e+00 7.16168e+00 7.16168e-01 1.00000e-09 2.12000e-01

$7.16168 \mathrm{e}+007.16168 \mathrm{e}+00$ 7.16168e-01 1.00000e-09 2.12000e-01

$7.16168 \mathrm{e}+007.16168 \mathrm{e}+00$ 7.16168e-01 1.00000e-09 2.12000e-01

$7.16168 \mathrm{e}+00$ 7.16168e+00 7.16168e-01 1.00000e-09 2.12000e-01

$1.00000 \mathrm{e}-05$ 1.00000e-05 1.00000e-06 1.00000e-09 1.00000e-01 
$1.00000 \mathrm{e}+001.00000 \mathrm{e}+001.00000 \mathrm{e}-011.00000 \mathrm{e}-091.00000 \mathrm{e}-01$

Element: 11249 \# of layers: 6

$\mathrm{Kx} \mathrm{Ky} \mathrm{Kz}$ Ss Por

7.16168e+00 7.16168e+00 7.16168e-01 1.00000e-09 2.12000e-01

7.16168e+00 7.16168e+00 7.16168e-01 1.00000e-09 2.12000e-01

7.16168e+00 7.16168e+00 7.16168e-01 1.00000e-09 2.12000e-01

$7.16168 \mathrm{e}+00$ 7.16168e+00 7.16168e-01 1.00000e-09 2.12000e-01

$1.00000 \mathrm{e}-05$ 1.00000e-05 1.00000e-06 1.00000e-09 1.00000e-01

$1.00000 \mathrm{e}+001.00000 \mathrm{e}+001.00000 \mathrm{e}-011.00000 \mathrm{e}-091.00000 \mathrm{e}-01$

Element: 11250 \# of layers: 5

$\mathrm{Kx} \mathrm{Ky} \mathrm{Kz}$ Ss Por

7.16168e+00 7.16168e+00 7.16168e-01 1.00000e-09 2.12000e-01

$7.16168 \mathrm{e}+00$ 7.16168e+00 7.16168e-01 1.00000e-09 2.12000e-01

$7.16168 \mathrm{e}+00$ 7.16168e+00 7.16168e-01 1.00000e-09 2.12000e-01

$1.00000 \mathrm{e}-05$ 1.00000e-05 1.00000e-06 1.00000e-09 1.00000e-01

$1.00000 \mathrm{e}+001.00000 \mathrm{e}+001.00000 \mathrm{e}-011.00000 \mathrm{e}-091.00000 \mathrm{e}-01$

Element: 11251 \# of layers: 5

$\mathrm{Kx} \mathrm{Ky} \mathrm{Kz}$ Ss Por

7.16168e+00 7.16168e+00 7.16168e-01 1.00000e-09 2.12000e-01

$7.16168 \mathrm{e}+00$ 7.16168e+00 7.16168e-01 1.00000e-09 2.12000e-01

$7.16168 \mathrm{e}+007.16168 \mathrm{e}+00$ 7.16168e-01 1.00000e-09 2.12000e-01

$1.00000 \mathrm{e}-051.00000 \mathrm{e}-051.00000 \mathrm{e}-061.00000 \mathrm{e}-091.00000 \mathrm{e}-01$

$1.00000 \mathrm{e}+001.00000 \mathrm{e}+001.00000 \mathrm{e}-01$ 1.00000e-09 1.00000e-01

Element: 11252 \# of layers: 5

Kx Ky Kz Ss Por

6.57486e+00 6.57486e+00 6.57486e-01 1.00000e-09 2.12000e-01

$6.57486 \mathrm{e}+006.57486 \mathrm{e}+00$ 6.57486e-01 1.00000e-09 2.12000e-01

$6.57486 \mathrm{e}+006.57486 \mathrm{e}+00 \quad 6.57486 \mathrm{e}-01$ 1.00000e-09 2.12000e-01

$1.00000 \mathrm{e}-05$ 1.00000e-05 1.00000e-06 1.00000e-09 1.00000e-01

$1.00000 \mathrm{e}+001.00000 \mathrm{e}+001.00000 \mathrm{e}-011.00000 \mathrm{e}-091.00000 \mathrm{e}-01$

Element: 11253 \# of layers: 5

$\mathrm{Kx} \mathrm{Ky} \mathrm{Kz}$ Ss Por

6.57486e+00 6.57486e+00 6.57486e-01 1.00000e-09 2.12000e-01

6.57486e+00 6.57486e+00 6.57486e-01 1.00000e-09 2.12000e-01

$6.57486 \mathrm{e}+006.57486 \mathrm{e}+00$ 6.57486e-01 1.00000e-09 2.12000e-01

$1.00000 \mathrm{e}-05$ 1.00000e-05 1.00000e-06 1.00000e-09 1.00000e-01

$1.00000 \mathrm{e}+001.00000 \mathrm{e}+001.00000 \mathrm{e}-011.00000 \mathrm{e}-091.00000 \mathrm{e}-01$

Element: 11254 \# of layers: 5

$\mathrm{Kx} \mathrm{Ky} \mathrm{Kz}$ Ss Por

7.16168e+00 7.16168e+00 7.16168e-01 1.00000e-09 2.12000e-01

$7.16168 \mathrm{e}+00$ 7.16168e+00 7.16168e-01 1.00000e-09 2.12000e-01

$7.16168 \mathrm{e}+00$ 7.16168e+00 7.16168e-01 1.00000e-09 2.12000e-01

$1.00000 \mathrm{e}-05$ 1.00000e-05 1.00000e-06 1.00000e-09 1.00000e-01

$1.00000 \mathrm{e}+001.00000 \mathrm{e}+001.00000 \mathrm{e}-01$ 1.00000e-09 1.00000e-01

Element: 11255 \# of layers: 6

Kx Ky Kz Ss Por 
$7.16168 \mathrm{e}+00$ 7.16168e+00 7.16168e-01 1.00000e-09 2.12000e-01 $7.16168 \mathrm{e}+007.16168 \mathrm{e}+00$ 7.16168e-01 1.00000e-09 2.12000e-01 $7.16168 \mathrm{e}+007.16168 \mathrm{e}+007.16168 \mathrm{e}-011.00000 \mathrm{e}-092.12000 \mathrm{e}-01$ $7.16168 \mathrm{e}+00$ 7.16168e+00 7.16168e-01 1.00000e-09 2.12000e-01 $1.00000 \mathrm{e}-05$ 1.00000e-05 1.00000e-06 1.00000e-09 1.00000e-01 $1.00000 \mathrm{e}+001.00000 \mathrm{e}+001.00000 \mathrm{e}-011.00000 \mathrm{e}-091.00000 \mathrm{e}-01$ Element: 11256 \# of layers: 5

Kx Ky Kz Ss Por

7.16168e+00 7.16168e+00 7.16168e-01 1.00000e-09 2.12000e-01

$7.16168 \mathrm{e}+007.16168 \mathrm{e}+00$ 7.16168e-01 1.00000e-09 2.12000e-01

$7.16168 \mathrm{e}+00$ 7.16168e+00 7.16168e-01 1.00000e-09 2.12000e-01 $1.00000 \mathrm{e}-05$ 1.00000e-05 1.00000e-06 1.00000e-09 1.00000e-01 $1.00000 \mathrm{e}+001.00000 \mathrm{e}+001.00000 \mathrm{e}-011.00000 \mathrm{e}-091.00000 \mathrm{e}-01$ Element: 11257 \# of layers: 5

Kx Ky Kz Ss Por

7.16168e+00 7.16168e+00 7.16168e-01 1.00000e-09 2.12000e-01

$7.16168 \mathrm{e}+007.16168 \mathrm{e}+00$ 7.16168e-01 1.00000e-09 2.12000e-01

$7.16168 \mathrm{e}+00$ 7.16168e+00 7.16168e-01 1.00000e-09 2.12000e-01 $1.00000 \mathrm{e}-05$ 1.00000e-05 1.00000e-06 1.00000e-09 1.00000e-01 $1.00000 \mathrm{e}+001.00000 \mathrm{e}+001.00000 \mathrm{e}-011.00000 \mathrm{e}-091.00000 \mathrm{e}-01$ Element: 11258 \# of layers: 4

Kx Ky Kz Ss Por

7.16168e+00 7.16168e+00 7.16168e-01 1.00000e-09 2.12000e-01

$7.16168 \mathrm{e}+00$ 7.16168e+00 7.16168e-01 1.00000e-09 2.12000e-01 $1.00000 \mathrm{e}-05$ 1.00000e-05 1.00000e-06 1.00000e-09 1.00000e-01 $1.00000 \mathrm{e}+001.00000 \mathrm{e}+001.00000 \mathrm{e}-011.00000 \mathrm{e}-091.00000 \mathrm{e}-01$ Element: 11259 \# of layers: 4

Kx Ky Kz Ss Por

7.16168e+00 7.16168e+00 7.16168e-01 1.00000e-09 2.12000e-01 $7.16168 \mathrm{e}+007.16168 \mathrm{e}+00$ 7.16168e-01 1.00000e-09 2.12000e-01 $1.00000 \mathrm{e}-05$ 1.00000e-05 1.00000e-06 1.00000e-09 1.00000e-01 $1.00000 \mathrm{e}+001.00000 \mathrm{e}+001.00000 \mathrm{e}-011.00000 \mathrm{e}-091.00000 \mathrm{e}-01$ Element: 11260 \# of layers: 4

Kx Ky Kz Ss Por

7.16168e+00 7.16168e+00 7.16168e-01 1.00000e-09 2.12000e-01 $7.16168 \mathrm{e}+00$ 7.16168e+00 7.16168e-01 1.00000e-09 2.12000e-01 $1.00000 \mathrm{e}-05$ 1.00000e-05 1.00000e-06 1.00000e-09 1.00000e-01 $1.00000 \mathrm{e}+001.00000 \mathrm{e}+001.00000 \mathrm{e}-011.00000 \mathrm{e}-091.00000 \mathrm{e}-01$ Element: 11261 \# of layers: 4

Kx Ky Kz Ss Por

7.16168e+00 7.16168e+00 7.16168e-01 1.00000e-09 2.12000e-01 $7.16168 \mathrm{e}+00$ 7.16168e+00 7.16168e-01 1.00000e-09 2.12000e-01 $1.00000 \mathrm{e}-05$ 1.00000e-05 1.00000e-06 1.00000e-09 1.00000e-01 $1.00000 \mathrm{e}+001.00000 \mathrm{e}+001.00000 \mathrm{e}-011.00000 \mathrm{e}-091.00000 \mathrm{e}-01$ Element: 11262 \# of layers: 5

Kx Ky Kz Ss Por 
$7.16168 \mathrm{e}+00$ 7.16168e+00 7.16168e-01 1.00000e-09 2.12000e-01 $7.16168 \mathrm{e}+007.16168 \mathrm{e}+00$ 7.16168e-01 1.00000e-09 2.12000e-01 $7.16168 \mathrm{e}+00$ 7.16168e+00 7.16168e-01 1.00000e-09 2.12000e-01 $1.00000 \mathrm{e}-05$ 1.00000e-05 1.00000e-06 1.00000e-09 1.00000e-01 $1.00000 \mathrm{e}+001.00000 \mathrm{e}+001.00000 \mathrm{e}-011.00000 \mathrm{e}-091.00000 \mathrm{e}-01$ Element: 11263 \# of layers: 4

Kx Ky Kz Ss Por

7.16168e+00 7.16168e+00 7.16168e-01 1.00000e-09 2.12000e-01 $7.16168 \mathrm{e}+00$ 7.16168e+00 7.16168e-01 1.00000e-09 2.12000e-01 $1.00000 \mathrm{e}-05$ 1.00000e-05 1.00000e-06 1.00000e-09 1.00000e-01 $1.00000 \mathrm{e}+001.00000 \mathrm{e}+001.00000 \mathrm{e}-011.00000 \mathrm{e}-091.00000 \mathrm{e}-01$ Element: 11264 \# of layers: 4

Kx Ky Kz Ss Por

7.16168e+00 7.16168e+00 7.16168e-01 1.00000e-09 2.12000e-01 $7.16168 \mathrm{e}+00$ 7.16168e+00 7.16168e-01 1.00000e-09 2.12000e-01 $1.00000 \mathrm{e}-05$ 1.00000e-05 1.00000e-06 1.00000e-09 1.00000e-01 $1.00000 \mathrm{e}+001.00000 \mathrm{e}+001.00000 \mathrm{e}-011.00000 \mathrm{e}-091.00000 \mathrm{e}-01$ Element: 11265 \# of layers: 4

Kx Ky Kz Ss Por

$7.16168 \mathrm{e}+00$ 7.16168e+00 7.16168e-01 1.00000e-09 2.12000e-01

$7.16168 \mathrm{e}+00$ 7.16168e+00 7.16168e-01 1.00000e-09 2.12000e-01 $1.00000 \mathrm{e}-05$ 1.00000e-05 1.00000e-06 1.00000e-09 1.00000e-01 $1.00000 \mathrm{e}+001.00000 \mathrm{e}+001.00000 \mathrm{e}-011.00000 \mathrm{e}-091.00000 \mathrm{e}-01$ Element: 11266 \# of layers: 4

Kx Ky Kz Ss Por

$8.94192 \mathrm{e}+008.94192 \mathrm{e}+00$ 8.94192e-01 1.00000e-09 2.12000e-01 $8.94192 \mathrm{e}+008.94192 \mathrm{e}+008.94192 \mathrm{e}-011.00000 \mathrm{e}-092.12000 \mathrm{e}-01$ $1.00000 \mathrm{e}-051.00000 \mathrm{e}-05$ 1.00000e-06 1.00000e-09 1.00000e-01 $1.00000 \mathrm{e}+001.00000 \mathrm{e}+001.00000 \mathrm{e}-011.00000 \mathrm{e}-091.00000 \mathrm{e}-01$ Element: 11267 \# of layers: 4

Kx Ky Kz Ss Por

$8.94192 \mathrm{e}+008.94192 \mathrm{e}+00$ 8.94192e-01 1.00000e-09 2.12000e-01 $8.94192 \mathrm{e}+008.94192 \mathrm{e}+00$ 8.94192e-01 1.00000e-09 2.12000e-01 $1.00000 \mathrm{e}-05$ 1.00000e-05 1.00000e-06 1.00000e-09 1.00000e-01 $1.00000 \mathrm{e}+001.00000 \mathrm{e}+001.00000 \mathrm{e}-011.00000 \mathrm{e}-091.00000 \mathrm{e}-01$ Element: 11268 \# of layers: 4

Kx Ky Kz Ss Por

$8.94192 \mathrm{e}+008.94192 \mathrm{e}+00$ 8.94192e-01 1.00000e-09 2.12000e-01 $8.94192 \mathrm{e}+008.94192 \mathrm{e}+00$ 8.94192e-01 1.00000e-09 2.12000e-01 $1.00000 \mathrm{e}-05$ 1.00000e-05 1.00000e-06 1.00000e-09 1.00000e-01 $1.00000 \mathrm{e}+001.00000 \mathrm{e}+001.00000 \mathrm{e}-011.00000 \mathrm{e}-091.00000 \mathrm{e}-01$ Element: 11269 \# of layers: 4

Kx Ky Kz Ss Por

7.16168e+00 7.16168e+00 7.16168e-01 1.00000e-09 2.12000e-01 $7.16168 \mathrm{e}+00$ 7.16168e+00 7.16168e-01 1.00000e-09 2.12000e-01 $1.00000 \mathrm{e}-05$ 1.00000e-05 1.00000e-06 1.00000e-09 1.00000e-01 
$1.00000 \mathrm{e}+001.00000 \mathrm{e}+00$ 1.00000e-01 1.00000e-09 1.00000e-01

Element: 11270 \# of layers: 4

$\mathrm{Kx} \mathrm{Ky} \mathrm{Kz}$ Ss Por

7.16168e+00 7.16168e+00 7.16168e-01 1.00000e-09 2.12000e-01

$7.16168 \mathrm{e}+00$ 7.16168e+00 7.16168e-01 1.00000e-09 2.12000e-01

$1.00000 \mathrm{e}-05$ 1.00000e-05 1.00000e-06 1.00000e-09 1.00000e-01

$1.00000 \mathrm{e}+001.00000 \mathrm{e}+001.00000 \mathrm{e}-01$ 1.00000e-09 1.00000e-01

Element: 11271 \# of layers: 4

$\mathrm{Kx} \mathrm{Ky} \mathrm{Kz}$ Ss Por

7.16168e+00 7.16168e+00 7.16168e-01 1.00000e-09 2.12000e-01

$7.16168 \mathrm{e}+00$ 7.16168e+00 7.16168e-01 1.00000e-09 2.12000e-01

$1.00000 \mathrm{e}-05$ 1.00000e-05 1.00000e-06 1.00000e-09 1.00000e-01

$1.00000 \mathrm{e}+001.00000 \mathrm{e}+00$ 1.00000e-01 1.00000e-09 1.00000e-01

Element: 11272 \# of layers: 4

Kx Ky Kz Ss Por

7.16168e+00 7.16168e+00 7.16168e-01 1.00000e-09 2.12000e-01

$7.16168 \mathrm{e}+00$ 7.16168e+00 7.16168e-01 1.00000e-09 2.12000e-01

$1.00000 \mathrm{e}-05$ 1.00000e-05 1.00000e-06 1.00000e-09 1.00000e-01

$1.00000 \mathrm{e}+001.00000 \mathrm{e}+001.00000 \mathrm{e}-01$ 1.00000e-09 1.00000e-01

Element: 11273 \# of layers: 4

$\mathrm{Kx} \mathrm{Ky} \mathrm{Kz}$ Ss Por

8.94192e+00 8.94192e+00 8.94192e-01 1.00000e-09 2.12000e-01

8.94192e+00 8.94192e+00 8.94192e-01 1.00000e-09 2.12000e-01

$1.00000 \mathrm{e}-05$ 1.00000e-05 1.00000e-06 1.00000e-09 1.00000e-01

$1.00000 \mathrm{e}+001.00000 \mathrm{e}+001.00000 \mathrm{e}-011.00000 \mathrm{e}-09$ 1.00000e-01

Element: 11274 \# of layers: 4

$\mathrm{Kx} \mathrm{Ky} \mathrm{Kz}$ Ss Por

8.94192e+00 8.94192e+00 8.94192e-01 1.00000e-09 2.12000e-01

$8.94192 \mathrm{e}+00$ 8.94192e+00 8.94192e-01 1.00000e-09 2.12000e-01

$1.00000 \mathrm{e}-05$ 1.00000e-05 1.00000e-06 1.00000e-09 1.00000e-01

$1.00000 \mathrm{e}+001.00000 \mathrm{e}+001.00000 \mathrm{e}-01$ 1.00000e-09 1.00000e-01

Element: 11275 \# of layers: 4

$\mathrm{Kx} \mathrm{Ky} \mathrm{Kz}$ Ss Por

8.94192e+00 8.94192e+00 8.94192e-01 1.00000e-09 2.12000e-01

8.94192e+00 8.94192e+00 8.94192e-01 1.00000e-09 2.12000e-01

$1.00000 \mathrm{e}-05$ 1.00000e-05 1.00000e-06 1.00000e-09 1.00000e-01

$1.00000 \mathrm{e}+001.00000 \mathrm{e}+001.00000 \mathrm{e}-011.00000 \mathrm{e}-091.00000 \mathrm{e}-01$

Element: 11276 \# of layers: 4

$\mathrm{Kx} \mathrm{Ky} \mathrm{Kz}$ Ss Por

8.94192e+00 8.94192e+00 8.94192e-01 1.00000e-09 2.12000e-01

8.94192e+00 8.94192e+00 8.94192e-01 1.00000e-09 2.12000e-01

$1.00000 \mathrm{e}-05$ 1.00000e-05 1.00000e-06 1.00000e-09 1.00000e-01

$1.00000 \mathrm{e}+001.00000 \mathrm{e}+001.00000 \mathrm{e}-01$ 1.00000e-09 1.00000e-01

Element: 11277 \# of layers: 4

$\mathrm{Kx} \mathrm{Ky} \mathrm{Kz}$ Ss Por

8.94192e+00 8.94192e+00 8.94192e-01 1.00000e-09 2.12000e-01 
$8.94192 \mathrm{e}+008.94192 \mathrm{e}+00$ 8.94192e-01 1.00000e-09 2.12000e-01 $1.00000 \mathrm{e}-05$ 1.00000e-05 1.00000e-06 1.00000e-09 1.00000e-01 $1.00000 \mathrm{e}+001.00000 \mathrm{e}+001.00000 \mathrm{e}-011.00000 \mathrm{e}-091.00000 \mathrm{e}-01$ Element: 11278 \# of layers: 4

Kx Ky Kz Ss Por

$8.94192 \mathrm{e}+008.94192 \mathrm{e}+00$ 8.94192e-01 1.00000e-09 2.12000e-01 $8.94192 \mathrm{e}+008.94192 \mathrm{e}+008.94192 \mathrm{e}-01$ 1.00000e-09 2.12000e-01 $1.00000 \mathrm{e}-05$ 1.00000e-05 1.00000e-06 1.00000e-09 1.00000e-01 $1.00000 \mathrm{e}+001.00000 \mathrm{e}+001.00000 \mathrm{e}-011.00000 \mathrm{e}-091.00000 \mathrm{e}-01$ Element: 11279 \# of layers: 4

Kx Ky Kz Ss Por $8.94192 \mathrm{e}+008.94192 \mathrm{e}+00$ 8.94192e-01 1.00000e-09 2.12000e-01 $8.94192 \mathrm{e}+008.94192 \mathrm{e}+00$ 8.94192e-01 1.00000e-09 2.12000e-01 $1.00000 \mathrm{e}-05$ 1.00000e-05 1.00000e-06 1.00000e-09 1.00000e-01 $1.00000 \mathrm{e}+001.00000 \mathrm{e}+001.00000 \mathrm{e}-011.00000 \mathrm{e}-091.00000 \mathrm{e}-01$ Element: 11280 \# of layers: 4

Kx Ky Kz Ss Por

$8.94192 \mathrm{e}+008.94192 \mathrm{e}+00$ 8.94192e-01 1.00000e-09 2.12000e-01 $8.94192 \mathrm{e}+008.94192 \mathrm{e}+00$ 8.94192e-01 1.00000e-09 2.12000e-01 $1.00000 \mathrm{e}-05$ 1.00000e-05 1.00000e-06 1.00000e-09 1.00000e-01 $1.00000 \mathrm{e}+001.00000 \mathrm{e}+001.00000 \mathrm{e}-011.00000 \mathrm{e}-091.00000 \mathrm{e}-01$ Element: 11281 \# of layers: 4

Kx Ky Kz Ss Por 8.94192e+00 8.94192e+00 8.94192e-01 1.00000e-09 2.12000e-01 $8.94192 \mathrm{e}+008.94192 \mathrm{e}+008.94192 \mathrm{e}-01$ 1.00000e-09 2.12000e-01 $1.00000 \mathrm{e}-05$ 1.00000e-05 1.00000e-06 1.00000e-09 1.00000e-01 $1.00000 \mathrm{e}+001.00000 \mathrm{e}+001.00000 \mathrm{e}-011.00000 \mathrm{e}-091.00000 \mathrm{e}-01$ Element: 11282 \# of layers: 4

Kx Ky Kz Ss Por

$8.94192 \mathrm{e}+008.94192 \mathrm{e}+00$ 8.94192e-01 1.00000e-09 2.12000e-01 $8.94192 \mathrm{e}+008.94192 \mathrm{e}+008.94192 \mathrm{e}-01$ 1.00000e-09 2.12000e-01 $1.00000 \mathrm{e}-05$ 1.00000e-05 1.00000e-06 1.00000e-09 1.00000e-01 $1.00000 \mathrm{e}+001.00000 \mathrm{e}+001.00000 \mathrm{e}-011.00000 \mathrm{e}-091.00000 \mathrm{e}-01$ Element: 11283 \# of layers: 4

Kx Ky Kz Ss Por

$8.94192 \mathrm{e}+008.94192 \mathrm{e}+00$ 8.94192e-01 1.00000e-09 2.12000e-01 $8.94192 \mathrm{e}+008.94192 \mathrm{e}+008.94192 \mathrm{e}-011.00000 \mathrm{e}-092.12000 \mathrm{e}-01$ $1.00000 \mathrm{e}-05$ 1.00000e-05 1.00000e-06 1.00000e-09 1.00000e-01 $1.00000 \mathrm{e}+001.00000 \mathrm{e}+001.00000 \mathrm{e}-011.00000 \mathrm{e}-091.00000 \mathrm{e}-01$ Element: 11284 \# of layers: 4

Kx Ky Kz Ss Por

$7.26698 \mathrm{e}+00$ 7.26698e+00 7.26698e-01 1.00000e-09 2.12000e-01 $7.26698 \mathrm{e}+00$ 7.26698e+00 7.26698e-01 1.00000e-09 2.12000e-01 $1.00000 \mathrm{e}-05$ 1.00000e-05 1.00000e-06 1.00000e-09 1.00000e-01 $1.00000 \mathrm{e}+001.00000 \mathrm{e}+001.00000 \mathrm{e}-011.00000 \mathrm{e}-091.00000 \mathrm{e}-01$ Element: 11285 \# of layers: 4 
Kx Ky Kz Ss Por

7.26698e+00 7.26698e+00 7.26698e-01 1.00000e-09 2.12000e-01

7.26698e+00 7.26698e+00 7.26698e-01 1.00000e-09 2.12000e-01

$1.00000 \mathrm{e}-05$ 1.00000e-05 1.00000e-06 1.00000e-09 1.00000e-01

$1.00000 \mathrm{e}+001.00000 \mathrm{e}+001.00000 \mathrm{e}-01$ 1.00000e-09 1.00000e-01

Element: 11286 \# of layers: 4

$\mathrm{Kx} \mathrm{Ky} \mathrm{Kz}$ Ss Por

7.26698e+00 7.26698e+00 7.26698e-01 1.00000e-09 2.12000e-01

$7.26698 \mathrm{e}+00$ 7.26698e+00 7.26698e-01 1.00000e-09 2.12000e-01

$1.00000 \mathrm{e}-05$ 1.00000e-05 1.00000e-06 1.00000e-09 1.00000e-01

$1.00000 \mathrm{e}+001.00000 \mathrm{e}+001.00000 \mathrm{e}-011.00000 \mathrm{e}-091.00000 \mathrm{e}-01$

Element: 11287 \# of layers: 4

$\mathrm{Kx} \mathrm{Ky} \mathrm{Kz}$ Ss Por

8.94192e+00 8.94192e+00 8.94192e-01 1.00000e-09 2.12000e-01

8.94192e+00 8.94192e+00 8.94192e-01 1.00000e-09 2.12000e-01

1.00000e-05 1.00000e-05 1.00000e-06 1.00000e-09 1.00000e-01

$1.00000 \mathrm{e}+001.00000 \mathrm{e}+001.00000 \mathrm{e}-01$ 1.00000e-09 1.00000e-01

Element: 11288 \# of layers: 4

$\mathrm{Kx} \mathrm{Ky} \mathrm{Kz}$ Ss Por

8.94192e+00 8.94192e+00 8.94192e-01 1.00000e-09 2.12000e-01

8.94192e+00 8.94192e+00 8.94192e-01 1.00000e-09 2.12000e-01

$1.00000 \mathrm{e}-05$ 1.00000e-05 1.00000e-06 1.00000e-09 1.00000e-01

$1.00000 \mathrm{e}+001.00000 \mathrm{e}+001.00000 \mathrm{e}-011.00000 \mathrm{e}-091.00000 \mathrm{e}-01$

Element: 11289 \# of layers: 4

Kx Ky Kz Ss Por

8.94192e+00 8.94192e+00 8.94192e-01 1.00000e-09 2.12000e-01

8.94192e+00 8.94192e+00 8.94192e-01 1.00000e-09 2.12000e-01

$1.00000 \mathrm{e}-05$ 1.00000e-05 1.00000e-06 1.00000e-09 1.00000e-01

$1.00000 \mathrm{e}+001.00000 \mathrm{e}+001.00000 \mathrm{e}-011.00000 \mathrm{e}-091.00000 \mathrm{e}-01$

Element: 11290 \# of layers: 4

$\mathrm{Kx} \mathrm{Ky} \mathrm{Kz}$ Ss Por

8.94192e+00 8.94192e+00 8.94192e-01 1.00000e-09 2.12000e-01

8.94192e+00 8.94192e+00 8.94192e-01 1.00000e-09 2.12000e-01

$1.00000 \mathrm{e}-05$ 1.00000e-05 1.00000e-06 1.00000e-09 1.00000e-01

$1.00000 \mathrm{e}+001.00000 \mathrm{e}+001.00000 \mathrm{e}-01$ 1.00000e-09 1.00000e-01

Element: 11291 \# of layers: 5

Kx Ky Kz Ss Por

7.26698e+00 7.26698e+00 7.26698e-01 1.00000e-09 2.12000e-01

$7.26698 \mathrm{e}+00$ 7.26698e+00 7.26698e-01 1.00000e-09 2.12000e-01

$7.26698 \mathrm{e}+00$ 7.26698e+00 7.26698e-01 1.00000e-09 2.12000e-01

$1.00000 \mathrm{e}-05$ 1.00000e-05 1.00000e-06 1.00000e-09 1.00000e-01

$1.00000 \mathrm{e}+001.00000 \mathrm{e}+001.00000 \mathrm{e}-011.00000 \mathrm{e}-091.00000 \mathrm{e}-01$

Element: 11292 \# of layers: 6

$\mathrm{Kx} \mathrm{Ky} \mathrm{Kz}$ Ss Por

7.26698e+00 7.26698e+00 7.26698e-01 1.00000e-09 2.12000e-01

$7.26698 \mathrm{e}+00$ 7.26698e+00 7.26698e-01 1.00000e-09 2.12000e-01 
$7.26698 \mathrm{e}+00$ 7.26698e+00 7.26698e-01 1.00000e-09 2.12000e-01 $7.26698 \mathrm{e}+00$ 7.26698e+00 7.26698e-01 1.00000e-09 2.12000e-01 $1.00000 \mathrm{e}-05$ 1.00000e-05 1.00000e-06 1.00000e-09 1.00000e-01 $1.00000 \mathrm{e}+001.00000 \mathrm{e}+001.00000 \mathrm{e}-011.00000 \mathrm{e}-091.00000 \mathrm{e}-01$ Element: 11293 \# of layers: 5

Kx Ky Kz Ss Por

$7.26698 \mathrm{e}+00$ 7.26698e+00 7.26698e-01 1.00000e-09 2.12000e-01

$7.26698 \mathrm{e}+007.26698 \mathrm{e}+007.26698 \mathrm{e}-011.00000 \mathrm{e}-092.12000 \mathrm{e}-01$

$7.26698 \mathrm{e}+00$ 7.26698e+00 7.26698e-01 1.00000e-09 2.12000e-01

$1.00000 \mathrm{e}-05$ 1.00000e-05 1.00000e-06 1.00000e-09 1.00000e-01

$1.00000 \mathrm{e}+001.00000 \mathrm{e}+001.00000 \mathrm{e}-011.00000 \mathrm{e}-091.00000 \mathrm{e}-01$

Element: 11294 \# of layers: 5

Kx Ky Kz Ss Por

7.26698e+00 7.26698e+00 7.26698e-01 1.00000e-09 2.12000e-01

$7.26698 \mathrm{e}+007.26698 \mathrm{e}+00$ 7.26698e-01 1.00000e-09 2.12000e-01

$7.26698 \mathrm{e}+00$ 7.26698e+00 7.26698e-01 1.00000e-09 2.12000e-01

$1.00000 \mathrm{e}-05$ 1.00000e-05 1.00000e-06 1.00000e-09 1.00000e-01

$1.00000 \mathrm{e}+001.00000 \mathrm{e}+001.00000 \mathrm{e}-011.00000 \mathrm{e}-091.00000 \mathrm{e}-01$

Element: 11295 \# of layers: 5

Kx Ky Kz Ss Por

$7.26698 \mathrm{e}+00$ 7.26698e+00 7.26698e-01 1.00000e-09 2.12000e-01

$7.26698 \mathrm{e}+00$ 7.26698e+00 7.26698e-01 1.00000e-09 2.12000e-01

$7.26698 \mathrm{e}+007.26698 \mathrm{e}+00$ 7.26698e-01 1.00000e-09 2.12000e-01

$1.00000 \mathrm{e}-05$ 1.00000e-05 1.00000e-06 1.00000e-09 1.00000e-01

$1.00000 \mathrm{e}+001.00000 \mathrm{e}+001.00000 \mathrm{e}-011.00000 \mathrm{e}-091.00000 \mathrm{e}-01$

Element: 11296 \# of layers: 6

Kx Ky Kz Ss Por

$7.26698 \mathrm{e}+00$ 7.26698e+00 7.26698e-01 1.00000e-09 2.12000e-01

$7.26698 \mathrm{e}+007.26698 \mathrm{e}+007.26698 \mathrm{e}-011.00000 \mathrm{e}-092.12000 \mathrm{e}-01$

$7.26698 \mathrm{e}+007.26698 \mathrm{e}+007.26698 \mathrm{e}-011.00000 \mathrm{e}-092.12000 \mathrm{e}-01$

$7.26698 \mathrm{e}+00$ 7.26698e+00 7.26698e-01 1.00000e-09 2.12000e-01

$1.00000 \mathrm{e}-05$ 1.00000e-05 1.00000e-06 1.00000e-09 1.00000e-01

$1.00000 \mathrm{e}+001.00000 \mathrm{e}+001.00000 \mathrm{e}-011.00000 \mathrm{e}-091.00000 \mathrm{e}-01$

Element: 11297 \# of layers: 6

Kx Ky Kz Ss Por

7.26698e+00 7.26698e+00 7.26698e-01 1.00000e-09 2.12000e-01

$7.26698 \mathrm{e}+007.26698 \mathrm{e}+00$ 7.26698e-01 1.00000e-09 2.12000e-01

$7.26698 \mathrm{e}+007.26698 \mathrm{e}+00$ 7.26698e-01 1.00000e-09 2.12000e-01

$7.26698 \mathrm{e}+00$ 7.26698e+00 7.26698e-01 1.00000e-09 2.12000e-01

$1.00000 \mathrm{e}-05$ 1.00000e-05 1.00000e-06 1.00000e-09 1.00000e-01

$1.00000 \mathrm{e}+001.00000 \mathrm{e}+001.00000 \mathrm{e}-011.00000 \mathrm{e}-091.00000 \mathrm{e}-01$

Element: 11298 \# of layers: 5

Kx Ky Kz Ss Por

$7.26698 \mathrm{e}+007.26698 \mathrm{e}+00$ 7.26698e-01 1.00000e-09 2.12000e-01

$7.26698 \mathrm{e}+007.26698 \mathrm{e}+007.26698 \mathrm{e}-011.00000 \mathrm{e}-092.12000 \mathrm{e}-01$

$7.26698 \mathrm{e}+00$ 7.26698e+00 7.26698e-01 1.00000e-09 2.12000e-01 
$1.00000 \mathrm{e}-05$ 1.00000e-05 1.00000e-06 1.00000e-09 1.00000e-01 $1.00000 \mathrm{e}+001.00000 \mathrm{e}+001.00000 \mathrm{e}-01$ 1.00000e-09 1.00000e-01 Element: 11299 \# of layers: 6

Kx Ky Kz Ss Por

7.26698e+00 7.26698e+00 7.26698e-01 1.00000e-09 2.12000e-01

$7.26698 \mathrm{e}+00$ 7.26698e+00 7.26698e-01 1.00000e-09 2.12000e-01

$7.26698 \mathrm{e}+00$ 7.26698e+00 7.26698e-01 1.00000e-09 2.12000e-01

$7.26698 \mathrm{e}+00$ 7.26698e+00 7.26698e-01 1.00000e-09 2.12000e-01

$1.00000 \mathrm{e}-05$ 1.00000e-05 1.00000e-06 1.00000e-09 1.00000e-01

$1.00000 \mathrm{e}+001.00000 \mathrm{e}+001.00000 \mathrm{e}-011.00000 \mathrm{e}-091.00000 \mathrm{e}-01$

Element: 11300 \# of layers: 5

$\mathrm{Kx} \mathrm{Ky} \mathrm{Kz}$ Ss Por

7.26698e+00 7.26698e+00 7.26698e-01 1.00000e-09 2.12000e-01

$7.26698 \mathrm{e}+00$ 7.26698e+00 7.26698e-01 1.00000e-09 2.12000e-01

7.26698e+00 7.26698e+00 7.26698e-01 1.00000e-09 2.12000e-01 $1.00000 \mathrm{e}-05$ 1.00000e-05 1.00000e-06 1.00000e-09 1.00000e-01

$1.00000 \mathrm{e}+001.00000 \mathrm{e}+001.00000 \mathrm{e}-011.00000 \mathrm{e}-091.00000 \mathrm{e}-01$

Element: 11301 \# of layers: 5

$\mathrm{Kx} \mathrm{Ky} \mathrm{Kz}$ Ss Por

6.57486e+00 6.57486e+00 6.57486e-01 1.00000e-09 2.12000e-01

$6.57486 \mathrm{e}+006.57486 \mathrm{e}+00$ 6.57486e-01 1.00000e-09 2.12000e-01

6.57486e+00 6.57486e+00 6.57486e-01 1.00000e-09 2.12000e-01

$1.00000 \mathrm{e}-051.00000 \mathrm{e}-051.00000 \mathrm{e}-061.00000 \mathrm{e}-091.00000 \mathrm{e}-01$

$1.00000 \mathrm{e}+001.00000 \mathrm{e}+001.00000 \mathrm{e}-011.00000 \mathrm{e}-091.00000 \mathrm{e}-01$

Element: 11302 \# of layers: 5

$\mathrm{Kx} \mathrm{Ky} \mathrm{Kz}$ Ss Por

6.57486e+00 6.57486e+00 6.57486e-01 1.00000e-09 2.12000e-01

$6.57486 \mathrm{e}+006.57486 \mathrm{e}+00$ 6.57486e-01 1.00000e-09 2.12000e-01

$6.57486 \mathrm{e}+006.57486 \mathrm{e}+006.57486 \mathrm{e}-01$ 1.00000e-09 2.12000e-01

$1.00000 \mathrm{e}-051.00000 \mathrm{e}-051.00000 \mathrm{e}-061.00000 \mathrm{e}-091.00000 \mathrm{e}-01$

$1.00000 \mathrm{e}+001.00000 \mathrm{e}+00$ 1.00000e-01 1.00000e-09 1.00000e-01

Element: 11303 \# of layers: 5

Kx Ky Kz Ss Por

$6.57486 \mathrm{e}+006.57486 \mathrm{e}+00$ 6.57486e-01 1.00000e-09 2.12000e-01

$6.57486 \mathrm{e}+006.57486 \mathrm{e}+006.57486 \mathrm{e}-01$ 1.00000e-09 2.12000e-01

$6.57486 \mathrm{e}+006.57486 \mathrm{e}+006.57486 \mathrm{e}-01$ 1.00000e-09 2.12000e-01

$1.00000 \mathrm{e}-05$ 1.00000e-05 1.00000e-06 1.00000e-09 1.00000e-01

$1.00000 \mathrm{e}+001.00000 \mathrm{e}+001.00000 \mathrm{e}-011.00000 \mathrm{e}-091.00000 \mathrm{e}-01$

Element: 11304 \# of layers: 5

$\mathrm{Kx} \mathrm{Ky} \mathrm{Kz}$ Ss Por

6.57486e+00 6.57486e+00 6.57486e-01 1.00000e-09 2.12000e-01

$6.57486 \mathrm{e}+006.57486 \mathrm{e}+00$ 6.57486e-01 1.00000e-09 2.12000e-01

6.57486e+00 6.57486e+00 6.57486e-01 1.00000e-09 2.12000e-01

$1.00000 \mathrm{e}-05$ 1.00000e-05 1.00000e-06 1.00000e-09 1.00000e-01

$1.00000 \mathrm{e}+001.00000 \mathrm{e}+001.00000 \mathrm{e}-011.00000 \mathrm{e}-09$ 1.00000e-01

Element: 11305 \# of layers: 5 
$\mathrm{Kx} \mathrm{Ky} \mathrm{Kz}$ Ss Por

6.57486e+00 6.57486e+00 6.57486e-01 1.00000e-09 2.12000e-01

$6.57486 \mathrm{e}+00$ 6.57486e+00 6.57486e-01 1.00000e-09 2.12000e-01

$6.57486 \mathrm{e}+006.57486 \mathrm{e}+006.57486 \mathrm{e}-01$ 1.00000e-09 2.12000e-01

$1.00000 \mathrm{e}-05$ 1.00000e-05 1.00000e-06 1.00000e-09 1.00000e-01

$1.00000 \mathrm{e}+001.00000 \mathrm{e}+001.00000 \mathrm{e}-011.00000 \mathrm{e}-091.00000 \mathrm{e}-01$

Element: 11306 \# of layers: 5

$\mathrm{Kx} \mathrm{Ky} \mathrm{Kz}$ Ss Por

7.26698e+00 7.26698e+00 7.26698e-01 1.00000e-09 2.12000e-01

$7.26698 \mathrm{e}+00$ 7.26698e+00 7.26698e-01 1.00000e-09 2.12000e-01

$7.26698 \mathrm{e}+00$ 7.26698e+00 7.26698e-01 1.00000e-09 2.12000e-01

$1.00000 \mathrm{e}-05$ 1.00000e-05 1.00000e-06 1.00000e-09 1.00000e-01

$1.00000 \mathrm{e}+001.00000 \mathrm{e}+001.00000 \mathrm{e}-01$ 1.00000e-09 1.00000e-01

Element: 11307 \# of layers: 5

$\mathrm{Kx} \mathrm{Ky} \mathrm{Kz}$ Ss Por

7.26698e+00 7.26698e+00 7.26698e-01 1.00000e-09 2.12000e-01

7.26698e+00 7.26698e+00 7.26698e-01 1.00000e-09 2.12000e-01

$7.26698 \mathrm{e}+00$ 7.26698e+00 7.26698e-01 1.00000e-09 2.12000e-01

$1.00000 \mathrm{e}-05$ 1.00000e-05 1.00000e-06 1.00000e-09 1.00000e-01

$1.00000 \mathrm{e}+001.00000 \mathrm{e}+001.00000 \mathrm{e}-011.00000 \mathrm{e}-091.00000 \mathrm{e}-01$

Element: 11308 \# of layers: 5

$\mathrm{Kx} \mathrm{Ky} \mathrm{Kz}$ Ss Por

6.57486e+00 6.57486e+00 6.57486e-01 1.00000e-09 2.12000e-01

$6.57486 \mathrm{e}+006.57486 \mathrm{e}+00$ 6.57486e-01 1.00000e-09 2.12000e-01

6.57486e+00 6.57486e+00 6.57486e-01 1.00000e-09 2.12000e-01

$1.00000 \mathrm{e}-05$ 1.00000e-05 1.00000e-06 1.00000e-09 1.00000e-01

$1.00000 \mathrm{e}+001.00000 \mathrm{e}+001.00000 \mathrm{e}-011.00000 \mathrm{e}-091.00000 \mathrm{e}-01$

Element: 11309 \# of layers: 5

Kx Ky Kz Ss Por

6.57486e+00 6.57486e+00 6.57486e-01 1.00000e-09 2.12000e-01

$6.57486 \mathrm{e}+006.57486 \mathrm{e}+00$ 6.57486e-01 1.00000e-09 2.12000e-01

$6.57486 \mathrm{e}+006.57486 \mathrm{e}+006.57486 \mathrm{e}-01$ 1.00000e-09 2.12000e-01

$1.00000 \mathrm{e}-05$ 1.00000e-05 1.00000e-06 1.00000e-09 1.00000e-01

$1.00000 \mathrm{e}+001.00000 \mathrm{e}+001.00000 \mathrm{e}-011.00000 \mathrm{e}-091.00000 \mathrm{e}-01$

Element: 11310 \# of layers: 5

Kx Ky Kz Ss Por

7.16168e+00 7.16168e+00 7.16168e-01 1.00000e-09 2.12000e-01

$7.16168 \mathrm{e}+00$ 7.16168e+00 7.16168e-01 1.00000e-09 2.12000e-01

7.16168e+00 7.16168e+00 7.16168e-01 1.00000e-09 2.12000e-01

$1.00000 \mathrm{e}-05$ 1.00000e-05 1.00000e-06 1.00000e-09 1.00000e-01

$1.00000 \mathrm{e}+001.00000 \mathrm{e}+001.00000 \mathrm{e}-011.00000 \mathrm{e}-091.00000 \mathrm{e}-01$

Element: 11311 \# of layers: 4

Kx Ky Kz Ss Por

7.16168e+00 7.16168e+00 7.16168e-01 1.00000e-09 2.12000e-01

$7.16168 \mathrm{e}+00$ 7.16168e+00 7.16168e-01 1.00000e-09 2.12000e-01

$1.00000 \mathrm{e}-05$ 1.00000e-05 1.00000e-06 1.00000e-09 1.00000e-01 
$1.00000 \mathrm{e}+001.00000 \mathrm{e}+00$ 1.00000e-01 1.00000e-09 1.00000e-01

Element: 11312 \# of layers: 4

$\mathrm{Kx} \mathrm{Ky} \mathrm{Kz}$ Ss Por

7.16168e+00 7.16168e+00 7.16168e-01 1.00000e-09 2.12000e-01

$7.16168 \mathrm{e}+00$ 7.16168e+00 7.16168e-01 1.00000e-09 2.12000e-01

$1.00000 \mathrm{e}-05$ 1.00000e-05 1.00000e-06 1.00000e-09 1.00000e-01

$1.00000 \mathrm{e}+001.00000 \mathrm{e}+001.00000 \mathrm{e}-01$ 1.00000e-09 1.00000e-01

Element: 11313 \# of layers: 4

$\mathrm{Kx} \mathrm{Ky} \mathrm{Kz}$ Ss Por

8.94192e+00 8.94192e+00 8.94192e-01 1.00000e-09 2.12000e-01

8.94192e+00 8.94192e+00 8.94192e-01 1.00000e-09 2.12000e-01

$1.00000 \mathrm{e}-05$ 1.00000e-05 1.00000e-06 1.00000e-09 1.00000e-01

$1.00000 \mathrm{e}+001.00000 \mathrm{e}+001.00000 \mathrm{e}-011.00000 \mathrm{e}-09$ 1.00000e-01

Element: 11314 \# of layers: 4

$\mathrm{Kx} \mathrm{Ky} \mathrm{Kz}$ Ss Por

8.94192e+00 8.94192e+00 8.94192e-01 1.00000e-09 2.12000e-01

8.94192e+00 8.94192e+00 8.94192e-01 1.00000e-09 2.12000e-01

$1.00000 \mathrm{e}-05$ 1.00000e-05 1.00000e-06 1.00000e-09 1.00000e-01

$1.00000 \mathrm{e}+001.00000 \mathrm{e}+001.00000 \mathrm{e}-01$ 1.00000e-09 1.00000e-01

Element: 11315 \# of layers: 5

$\mathrm{Kx} \mathrm{Ky} \mathrm{Kz}$ Ss Por

7.26698e+00 7.26698e+00 7.26698e-01 1.00000e-09 2.12000e-01

7.26698e+00 7.26698e+00 7.26698e-01 1.00000e-09 2.12000e-01

7.26698e+00 7.26698e+00 7.26698e-01 1.00000e-09 2.12000e-01

$1.00000 \mathrm{e}-05$ 1.00000e-05 1.00000e-06 1.00000e-09 1.00000e-01

$1.00000 \mathrm{e}+001.00000 \mathrm{e}+001.00000 \mathrm{e}-011.00000 \mathrm{e}-091.00000 \mathrm{e}-01$

Element: 11316 \# of layers: 5

$\mathrm{Kx} \mathrm{Ky} \mathrm{Kz}$ Ss Por

6.57486e+00 6.57486e+00 6.57486e-01 1.00000e-09 2.12000e-01

$6.57486 \mathrm{e}+006.57486 \mathrm{e}+00$ 6.57486e-01 1.00000e-09 2.12000e-01

$6.57486 \mathrm{e}+006.57486 \mathrm{e}+00$ 6.57486e-01 1.00000e-09 2.12000e-01

$1.00000 \mathrm{e}-05$ 1.00000e-05 1.00000e-06 1.00000e-09 1.00000e-01

$1.00000 \mathrm{e}+001.00000 \mathrm{e}+001.00000 \mathrm{e}-01$ 1.00000e-09 1.00000e-01

Element: 11317 \# of layers: 4

$\mathrm{Kx} \mathrm{Ky} \mathrm{Kz}$ Ss Por

7.16168e+00 7.16168e+00 7.16168e-01 1.00000e-09 2.12000e-01

$7.16168 \mathrm{e}+007.16168 \mathrm{e}+00$ 7.16168e-01 1.00000e-09 2.12000e-01

$1.00000 \mathrm{e}-05$ 1.00000e-05 1.00000e-06 1.00000e-09 1.00000e-01

$1.00000 \mathrm{e}+001.00000 \mathrm{e}+001.00000 \mathrm{e}-011.00000 \mathrm{e}-091.00000 \mathrm{e}-01$

Element: 11318 \# of layers: 4

Kx Ky Kz Ss Por

$1.35552 \mathrm{e}+01$ 1.35552e+01 1.35552e+00 1.00000e-09 2.12000e-01

$1.35552 \mathrm{e}+01$ 1.35552e+01 1.35552e+00 1.00000e-09 2.12000e-01

$1.00000 \mathrm{e}-05$ 1.00000e-05 1.00000e-06 1.00000e-09 1.00000e-01

$1.00000 \mathrm{e}+001.00000 \mathrm{e}+001.00000 \mathrm{e}-01$ 1.00000e-09 1.00000e-01

Element: 11319 \# of layers: 4 
$\mathrm{Kx} \mathrm{Ky} \mathrm{Kz}$ Ss Por

$1.35552 \mathrm{e}+01$ 1.35552e+01 1.35552e+00 1.00000e-09 2.12000e-01

$1.35552 \mathrm{e}+011.35552 \mathrm{e}+01$ 1.35552e+00 1.00000e-09 2.12000e-01

$1.00000 \mathrm{e}-05$ 1.00000e-05 1.00000e-06 1.00000e-09 1.00000e-01

$1.00000 \mathrm{e}+001.00000 \mathrm{e}+001.00000 \mathrm{e}-01$ 1.00000e-09 1.00000e-01

Element: 11320 \# of layers: 4

$\mathrm{Kx} \mathrm{Ky} \mathrm{Kz}$ Ss Por

$1.35552 \mathrm{e}+01$ 1.35552e+01 1.35552e+00 1.00000e-09 2.12000e-01

$1.35552 \mathrm{e}+01$ 1.35552e+01 1.35552e+00 1.00000e-09 2.12000e-01

$1.00000 \mathrm{e}-05$ 1.00000e-05 1.00000e-06 1.00000e-09 1.00000e-01

$1.00000 \mathrm{e}+001.00000 \mathrm{e}+001.00000 \mathrm{e}-01$ 1.00000e-09 1.00000e-01

Element: 11321 \# of layers: 4

$\mathrm{Kx} \mathrm{Ky} \mathrm{Kz}$ Ss Por

1.35552e+01 1.35552e+01 1.35552e+00 1.00000e-09 2.12000e-01

$1.35552 \mathrm{e}+01$ 1.35552e+01 1.35552e+00 1.00000e-09 2.12000e-01

$1.00000 \mathrm{e}-05$ 1.00000e-05 1.00000e-06 1.00000e-09 1.00000e-01

$1.00000 \mathrm{e}+001.00000 \mathrm{e}+001.00000 \mathrm{e}-01$ 1.00000e-09 1.00000e-01

Element: 11322 \# of layers: 4

$\mathrm{Kx} \mathrm{Ky} \mathrm{Kz}$ Ss Por

1.35552e+01 1.35552e+01 1.35552e+00 1.00000e-09 2.12000e-01

$1.35552 \mathrm{e}+01$ 1.35552e+01 1.35552e+00 1.00000e-09 2.12000e-01

$1.00000 \mathrm{e}-05$ 1.00000e-05 1.00000e-06 1.00000e-09 1.00000e-01

$1.00000 \mathrm{e}+001.00000 \mathrm{e}+001.00000 \mathrm{e}-01$ 1.00000e-09 1.00000e-01

Element: 11323 \# of layers: 4

Kx Ky Kz Ss Por

$1.35552 \mathrm{e}+01$ 1.35552e+01 1.35552e+00 1.00000e-09 2.12000e-01

$1.35552 \mathrm{e}+011.35552 \mathrm{e}+011.35552 \mathrm{e}+001.00000 \mathrm{e}-092.12000 \mathrm{e}-01$

$1.00000 \mathrm{e}-05$ 1.00000e-05 1.00000e-06 1.00000e-09 1.00000e-01

$1.00000 \mathrm{e}+001.00000 \mathrm{e}+001.00000 \mathrm{e}-011.00000 \mathrm{e}-091.00000 \mathrm{e}-01$

Element: 11324 \# of layers: 4

$\mathrm{Kx} \mathrm{Ky} \mathrm{Kz}$ Ss Por

1.35552e+01 1.35552e+01 1.35552e+00 1.00000e-09 2.12000e-01

$1.35552 \mathrm{e}+011.35552 \mathrm{e}+01$ 1.35552e+00 1.00000e-09 2.12000e-01

$1.00000 \mathrm{e}-05$ 1.00000e-05 1.00000e-06 1.00000e-09 1.00000e-01

$1.00000 \mathrm{e}+001.00000 \mathrm{e}+001.00000 \mathrm{e}-011.00000 \mathrm{e}-091.00000 \mathrm{e}-01$

Element: 11325 \# of layers: 4

Kx Ky Kz Ss Por

1.35552e+01 1.35552e+01 1.35552e+00 1.00000e-09 2.12000e-01

$1.35552 \mathrm{e}+01$ 1.35552e+01 1.35552e+00 1.00000e-09 2.12000e-01

$1.00000 \mathrm{e}-05$ 1.00000e-05 1.00000e-06 1.00000e-09 1.00000e-01

$1.00000 \mathrm{e}+001.00000 \mathrm{e}+001.00000 \mathrm{e}-011.00000 \mathrm{e}-091.00000 \mathrm{e}-01$

Element: 11326 \# of layers: 4

$\mathrm{Kx} \mathrm{Ky} \mathrm{Kz}$ Ss Por

$1.35552 \mathrm{e}+01$ 1.35552e+01 1.35552e+00 1.00000e-09 2.12000e-01

$1.35552 \mathrm{e}+01$ 1.35552e+01 1.35552e+00 1.00000e-09 2.12000e-01

$1.00000 \mathrm{e}-05$ 1.00000e-05 1.00000e-06 1.00000e-09 1.00000e-01 
$1.00000 \mathrm{e}+001.00000 \mathrm{e}+00$ 1.00000e-01 1.00000e-09 1.00000e-01

Element: 11327 \# of layers: 4

Kx Ky Kz Ss Por

$1.35552 \mathrm{e}+01$ 1.35552e+01 1.35552e+00 1.00000e-09 2.12000e-01

$1.35552 \mathrm{e}+01$ 1.35552e+01 1.35552e+00 1.00000e-09 2.12000e-01

$1.00000 \mathrm{e}-05$ 1.00000e-05 1.00000e-06 1.00000e-09 1.00000e-01

$1.00000 \mathrm{e}+001.00000 \mathrm{e}+001.00000 \mathrm{e}-01$ 1.00000e-09 1.00000e-01

Element: 11328 \# of layers: 4

$\mathrm{Kx} \mathrm{Ky} \mathrm{Kz}$ Ss Por

9.06117e+01 9.06117e+01 9.06117e+00 1.00000e-09 2.12000e-01

$9.06117 \mathrm{e}+019.06117 \mathrm{e}+01$ 9.06117e+00 1.00000e-09 2.12000e-01

$1.00000 \mathrm{e}-05$ 1.00000e-05 1.00000e-06 1.00000e-09 1.00000e-01

$1.00000 \mathrm{e}+001.00000 \mathrm{e}+001.00000 \mathrm{e}-011.00000 \mathrm{e}-09$ 1.00000e-01

Element: 11329 \# of layers: 5

Kx Ky Kz Ss Por

9.06117e+01 9.06117e+01 9.06117e+00 1.00000e-09 2.12000e-01

9.06117e+01 9.06117e+01 9.06117e+00 1.00000e-09 2.12000e-01

$9.06117 \mathrm{e}+019.06117 \mathrm{e}+01$ 9.06117e+00 1.00000e-09 2.12000e-01

$1.00000 \mathrm{e}-05$ 1.00000e-05 1.00000e-06 1.00000e-09 1.00000e-01

$1.00000 \mathrm{e}+001.00000 \mathrm{e}+001.00000 \mathrm{e}-011.00000 \mathrm{e}-091.00000 \mathrm{e}-01$

Element: 11330 \# of layers: 5

$\mathrm{Kx} \mathrm{Ky} \mathrm{Kz}$ Ss Por

9.06117e+01 9.06117e+01 9.06117e+00 1.00000e-09 2.12000e-01

$9.06117 \mathrm{e}+019.06117 \mathrm{e}+019.06117 \mathrm{e}+001.00000 \mathrm{e}-092.12000 \mathrm{e}-01$

$9.06117 \mathrm{e}+019.06117 \mathrm{e}+019.06117 \mathrm{e}+001.00000 \mathrm{e}-092.12000 \mathrm{e}-01$

$1.00000 \mathrm{e}-05$ 1.00000e-05 1.00000e-06 1.00000e-09 1.00000e-01

$1.00000 \mathrm{e}+001.00000 \mathrm{e}+001.00000 \mathrm{e}-011.00000 \mathrm{e}-091.00000 \mathrm{e}-01$

Element: 11331 \# of layers: 5

Kx Ky Kz Ss Por

9.06117e+01 9.06117e+01 9.06117e+00 1.00000e-09 2.12000e-01

9.06117e+01 9.06117e+01 9.06117e+00 1.00000e-09 2.12000e-01

9.06117e+01 9.06117e+01 9.06117e+00 1.00000e-09 2.12000e-01

$1.00000 \mathrm{e}-05$ 1.00000e-05 1.00000e-06 1.00000e-09 1.00000e-01

$1.00000 \mathrm{e}+001.00000 \mathrm{e}+001.00000 \mathrm{e}-01$ 1.00000e-09 1.00000e-01

Element: 11332 \# of layers: 4

Kx Ky Kz Ss Por

9.06117e+01 9.06117e+01 9.06117e+00 1.00000e-09 2.12000e-01

$9.06117 \mathrm{e}+019.06117 \mathrm{e}+019.06117 \mathrm{e}+00$ 1.00000e-09 2.12000e-01

$1.00000 \mathrm{e}-05$ 1.00000e-05 1.00000e-06 1.00000e-09 1.00000e-01

$1.00000 \mathrm{e}+001.00000 \mathrm{e}+001.00000 \mathrm{e}-01$ 1.00000e-09 1.00000e-01

Element: 11333 \# of layers: 4

Kx Ky Kz Ss Por

$1.35552 \mathrm{e}+01$ 1.35552e+01 1.35552e+00 1.00000e-09 2.12000e-01

1.35552e+01 1.35552e+01 1.35552e+00 1.00000e-09 2.12000e-01

$1.00000 \mathrm{e}-051.00000 \mathrm{e}-051.00000 \mathrm{e}-061.00000 \mathrm{e}-091.00000 \mathrm{e}-01$

$1.00000 \mathrm{e}+001.00000 \mathrm{e}+001.00000 \mathrm{e}-011.00000 \mathrm{e}-091.00000 \mathrm{e}-01$ 
Element: 11334 \# of layers: 4

$\mathrm{Kx} \mathrm{Ky} \mathrm{Kz}$ Ss Por

$1.35552 \mathrm{e}+01$ 1.35552e+01 1.35552e+00 1.00000e-09 2.12000e-01

$1.35552 \mathrm{e}+01$ 1.35552e+01 1.35552e+00 1.00000e-09 2.12000e-01

$1.00000 \mathrm{e}-051.00000 \mathrm{e}-05$ 1.00000e-06 1.00000e-09 1.00000e-01

$1.00000 \mathrm{e}+001.00000 \mathrm{e}+001.00000 \mathrm{e}-01$ 1.00000e-09 1.00000e-01

Element: 11335 \# of layers: 4

Kx Ky Kz Ss Por

9.06117e+01 9.06117e+01 9.06117e+00 1.00000e-09 2.12000e-01

9.06117e+01 9.06117e+01 9.06117e+00 1.00000e-09 2.12000e-01

$1.00000 \mathrm{e}-05$ 1.00000e-05 1.00000e-06 1.00000e-09 1.00000e-01

$1.00000 \mathrm{e}+001.00000 \mathrm{e}+001.00000 \mathrm{e}-011.00000 \mathrm{e}-091.00000 \mathrm{e}-01$

Element: 11336 \# of layers: 5

$\mathrm{Kx} \mathrm{Ky} \mathrm{Kz}$ Ss Por

9.06117e+01 9.06117e+01 9.06117e+00 1.00000e-09 2.12000e-01

$9.06117 \mathrm{e}+019.06117 \mathrm{e}+019.06117 \mathrm{e}+001.00000 \mathrm{e}-092.12000 \mathrm{e}-01$

9.06117e+01 9.06117e+01 9.06117e+00 1.00000e-09 2.12000e-01

$1.00000 \mathrm{e}-05$ 1.00000e-05 1.00000e-06 1.00000e-09 1.00000e-01

$1.00000 \mathrm{e}+001.00000 \mathrm{e}+001.00000 \mathrm{e}-01$ 1.00000e-09 1.00000e-01

Element: 11337 \# of layers: 5

$\mathrm{Kx} \mathrm{Ky} \mathrm{Kz}$ Ss Por

9.06117e+01 9.06117e+01 9.06117e+00 1.00000e-09 2.12000e-01

9.06117e+01 9.06117e+01 9.06117e+00 1.00000e-09 2.12000e-01

$9.06117 \mathrm{e}+019.06117 \mathrm{e}+01$ 9.06117e+00 1.00000e-09 2.12000e-01

$1.00000 \mathrm{e}-05$ 1.00000e-05 1.00000e-06 1.00000e-09 1.00000e-01

$1.00000 \mathrm{e}+001.00000 \mathrm{e}+001.00000 \mathrm{e}-01$ 1.00000e-09 1.00000e-01

Element: 11338 \# of layers: 5

$\mathrm{Kx} \mathrm{Ky} \mathrm{Kz}$ Ss Por

9.06117e+01 9.06117e+01 9.06117e+00 1.00000e-09 2.12000e-01

9.06117e+01 9.06117e+01 9.06117e+00 1.00000e-09 2.12000e-01

$9.06117 \mathrm{e}+019.06117 \mathrm{e}+01$ 9.06117e+00 1.00000e-09 2.12000e-01

$1.00000 \mathrm{e}-05$ 1.00000e-05 1.00000e-06 1.00000e-09 1.00000e-01

$1.00000 \mathrm{e}+001.00000 \mathrm{e}+001.00000 \mathrm{e}-011.00000 \mathrm{e}-091.00000 \mathrm{e}-01$

Element: 11339 \# of layers: 4

$\mathrm{Kx} \mathrm{Ky} \mathrm{Kz}$ Ss Por

9.06117e+01 9.06117e+01 9.06117e+00 1.00000e-09 2.12000e-01

$9.06117 \mathrm{e}+019.06117 \mathrm{e}+019.06117 \mathrm{e}+001.00000 \mathrm{e}-092.12000 \mathrm{e}-01$

$1.00000 \mathrm{e}-05$ 1.00000e-05 1.00000e-06 1.00000e-09 1.00000e-01

$1.00000 \mathrm{e}+001.00000 \mathrm{e}+001.00000 \mathrm{e}-01$ 1.00000e-09 1.00000e-01

Element: 11340 \# of layers: 4

Kx Ky Kz Ss Por

9.06117e+01 9.06117e+01 9.06117e+00 1.00000e-09 2.12000e-01

9.06117e+01 9.06117e+01 9.06117e+00 1.00000e-09 2.12000e-01

$1.00000 \mathrm{e}-05$ 1.00000e-05 1.00000e-06 1.00000e-09 1.00000e-01

$1.00000 \mathrm{e}+001.00000 \mathrm{e}+001.00000 \mathrm{e}-01$ 1.00000e-09 1.00000e-01

Element: 11341 \# of layers: 4 
Kx Ky Kz Ss Por

9.06117e+01 9.06117e+01 9.06117e+00 1.00000e-09 2.12000e-01

$9.06117 \mathrm{e}+019.06117 \mathrm{e}+01$ 9.06117e+00 1.00000e-09 2.12000e-01

$1.00000 \mathrm{e}-05$ 1.00000e-05 1.00000e-06 1.00000e-09 1.00000e-01

$1.00000 \mathrm{e}+001.00000 \mathrm{e}+001.00000 \mathrm{e}-01$ 1.00000e-09 1.00000e-01

Element: 11342 \# of layers: 4

Kx Ky Kz Ss Por

9.06117e+01 9.06117e+01 9.06117e+00 1.00000e-09 2.12000e-01

9.06117e+01 9.06117e+01 9.06117e+00 1.00000e-09 2.12000e-01

$1.00000 \mathrm{e}-05$ 1.00000e-05 1.00000e-06 1.00000e-09 1.00000e-01

$1.00000 \mathrm{e}+001.00000 \mathrm{e}+001.00000 \mathrm{e}-01$ 1.00000e-09 1.00000e-01

Element: 11343 \# of layers: 4

Kx Ky Kz Ss Por

9.06117e+01 9.06117e+01 9.06117e+00 1.00000e-09 2.12000e-01

$9.06117 \mathrm{e}+019.06117 \mathrm{e}+01$ 9.06117e+00 1.00000e-09 2.12000e-01

$1.00000 \mathrm{e}-05$ 1.00000e-05 1.00000e-06 1.00000e-09 1.00000e-01

$1.00000 \mathrm{e}+001.00000 \mathrm{e}+001.00000 \mathrm{e}-01$ 1.00000e-09 1.00000e-01

Element: 11344 \# of layers: 4

$\mathrm{Kx} \mathrm{Ky} \mathrm{Kz}$ Ss Por

9.06117e+01 9.06117e+01 9.06117e+00 1.00000e-09 2.12000e-01

9.06117e+01 9.06117e+01 9.06117e+00 1.00000e-09 2.12000e-01

$1.00000 \mathrm{e}-05$ 1.00000e-05 1.00000e-06 1.00000e-09 1.00000e-01

$1.00000 \mathrm{e}+001.00000 \mathrm{e}+001.00000 \mathrm{e}-01$ 1.00000e-09 1.00000e-01

Element: 11345 \# of layers: 4

Kx Ky Kz Ss Por

9.06117e+01 9.06117e+01 9.06117e+00 1.00000e-09 2.12000e-01

9.06117e+01 9.06117e+01 9.06117e+00 1.00000e-09 2.12000e-01

$1.00000 \mathrm{e}-05$ 1.00000e-05 1.00000e-06 1.00000e-09 1.00000e-01

$1.00000 \mathrm{e}+001.00000 \mathrm{e}+001.00000 \mathrm{e}-011.00000 \mathrm{e}-091.00000 \mathrm{e}-01$

Element: 11346 \# of layers: 4

$\mathrm{Kx} \mathrm{Ky} \mathrm{Kz}$ Ss Por

9.06117e+01 9.06117e+01 9.06117e+00 1.00000e-09 2.12000e-01

$9.06117 \mathrm{e}+019.06117 \mathrm{e}+019.06117 \mathrm{e}+00$ 1.00000e-09 2.12000e-01

$1.00000 \mathrm{e}-05$ 1.00000e-05 1.00000e-06 1.00000e-09 1.00000e-01

$1.00000 \mathrm{e}+001.00000 \mathrm{e}+001.00000 \mathrm{e}-011.00000 \mathrm{e}-091.00000 \mathrm{e}-01$

Element: 11347 \# of layers: 4

Kx Ky Kz Ss Por

3.34447e+01 3.34447e+01 3.34447e+00 1.00000e-09 2.12000e-01

$3.34447 \mathrm{e}+013.34447 \mathrm{e}+01$ 3.34447e+00 1.00000e-09 2.12000e-01

$1.00000 \mathrm{e}-05$ 1.00000e-05 1.00000e-06 1.00000e-09 1.00000e-01

$1.00000 \mathrm{e}+001.00000 \mathrm{e}+001.00000 \mathrm{e}-011.00000 \mathrm{e}-091.00000 \mathrm{e}-01$

Element: 11348 \# of layers: 4

$\mathrm{Kx} \mathrm{Ky} \mathrm{Kz}$ Ss Por

3.34447e+01 3.34447e+01 3.34447e+00 1.00000e-09 2.12000e-01

3.34447e+01 3.34447e+01 3.34447e+00 1.00000e-09 2.12000e-01

$1.00000 \mathrm{e}-05$ 1.00000e-05 1.00000e-06 1.00000e-09 1.00000e-01 
$1.00000 \mathrm{e}+001.00000 \mathrm{e}+00$ 1.00000e-01 1.00000e-09 1.00000e-01

Element: 11349 \# of layers: 4

Kx Ky Kz Ss Por

3.34447e+01 3.34447e+01 3.34447e+00 1.00000e-09 2.12000e-01

$3.34447 \mathrm{e}+013.34447 \mathrm{e}+01$ 3.34447e+00 1.00000e-09 2.12000e-01

$1.00000 \mathrm{e}-05$ 1.00000e-05 1.00000e-06 1.00000e-09 1.00000e-01

$1.00000 \mathrm{e}+001.00000 \mathrm{e}+001.00000 \mathrm{e}-01$ 1.00000e-09 1.00000e-01

Element: 11350 \# of layers: 4

$\mathrm{Kx} \mathrm{Ky} \mathrm{Kz}$ Ss Por

9.06117e+01 9.06117e+01 9.06117e+00 1.00000e-09 2.12000e-01

$9.06117 \mathrm{e}+019.06117 \mathrm{e}+01$ 9.06117e+00 1.00000e-09 2.12000e-01

$1.00000 \mathrm{e}-05$ 1.00000e-05 1.00000e-06 1.00000e-09 1.00000e-01

$1.00000 \mathrm{e}+001.00000 \mathrm{e}+001.00000 \mathrm{e}-01$ 1.00000e-09 1.00000e-01

Element: 11351 \# of layers: 4

Kx Ky Kz Ss Por

9.06117e+01 9.06117e+01 9.06117e+00 1.00000e-09 2.12000e-01

9.06117e+01 9.06117e+01 9.06117e+00 1.00000e-09 2.12000e-01

$1.00000 \mathrm{e}-05$ 1.00000e-05 1.00000e-06 1.00000e-09 1.00000e-01

$1.00000 \mathrm{e}+001.00000 \mathrm{e}+001.00000 \mathrm{e}-01$ 1.00000e-09 1.00000e-01

Element: 11352 \# of layers: 4

Kx Ky Kz Ss Por

9.06117e+01 9.06117e+01 9.06117e+00 1.00000e-09 2.12000e-01

9.06117e+01 9.06117e+01 9.06117e+00 1.00000e-09 2.12000e-01

$1.00000 \mathrm{e}-05$ 1.00000e-05 1.00000e-06 1.00000e-09 1.00000e-01

$1.00000 \mathrm{e}+001.00000 \mathrm{e}+001.00000 \mathrm{e}-011.00000 \mathrm{e}-091.00000 \mathrm{e}-01$

Element: 11353 \# of layers: 4

$\mathrm{Kx} \mathrm{Ky} \mathrm{Kz}$ Ss Por

9.06117e+01 9.06117e+01 9.06117e+00 1.00000e-09 2.12000e-01

9.06117e+01 9.06117e+01 9.06117e+00 1.00000e-09 2.12000e-01

$1.00000 \mathrm{e}-05$ 1.00000e-05 1.00000e-06 1.00000e-09 1.00000e-01

$1.00000 \mathrm{e}+001.00000 \mathrm{e}+001.00000 \mathrm{e}-011.00000 \mathrm{e}-091.00000 \mathrm{e}-01$

Element: 11354 \# of layers: 4

Kx Ky Kz Ss Por

3.34447e+01 3.34447e+01 3.34447e+00 1.00000e-09 2.12000e-01

$3.34447 \mathrm{e}+013.34447 \mathrm{e}+01$ 3.34447e+00 1.00000e-09 2.12000e-01

$1.00000 \mathrm{e}-05$ 1.00000e-05 1.00000e-06 1.00000e-09 1.00000e-01

$1.00000 \mathrm{e}+001.00000 \mathrm{e}+001.00000 \mathrm{e}-011.00000 \mathrm{e}-091.00000 \mathrm{e}-01$

Element: 11355 \# of layers: 4

$\mathrm{Kx} \mathrm{Ky} \mathrm{Kz}$ Ss Por

3.34447e+01 3.34447e+01 3.34447e+00 1.00000e-09 2.12000e-01

$3.34447 \mathrm{e}+013.34447 \mathrm{e}+013.34447 \mathrm{e}+00$ 1.00000e-09 2.12000e-01

$1.00000 \mathrm{e}-05$ 1.00000e-05 1.00000e-06 1.00000e-09 1.00000e-01

$1.00000 \mathrm{e}+001.00000 \mathrm{e}+001.00000 \mathrm{e}-01$ 1.00000e-09 1.00000e-01

Element: 11356 \# of layers: 4

$\mathrm{Kx} \mathrm{Ky} \mathrm{Kz}$ Ss Por

3.34447e+01 3.34447e+01 3.34447e+00 1.00000e-09 2.12000e-01 
3.34447e+01 3.34447e+01 3.34447e+00 1.00000e-09 2.12000e-01 $1.00000 \mathrm{e}-05$ 1.00000e-05 1.00000e-06 1.00000e-09 1.00000e-01 $1.00000 \mathrm{e}+001.00000 \mathrm{e}+001.00000 \mathrm{e}-011.00000 \mathrm{e}-091.00000 \mathrm{e}-01$ Element: 11357 \# of layers: 4

Kx Ky Kz Ss Por

$3.34447 \mathrm{e}+013.34447 \mathrm{e}+013.34447 \mathrm{e}+00$ 1.00000e-09 2.12000e-01 $3.34447 \mathrm{e}+013.34447 \mathrm{e}+013.34447 \mathrm{e}+001.00000 \mathrm{e}-092.12000 \mathrm{e}-01$ $1.00000 \mathrm{e}-05$ 1.00000e-05 1.00000e-06 1.00000e-09 1.00000e-01 $1.00000 \mathrm{e}+001.00000 \mathrm{e}+001.00000 \mathrm{e}-011.00000 \mathrm{e}-091.00000 \mathrm{e}-01$ Element: 11358 \# of layers: 4

Kx Ky Kz Ss Por

$3.34447 \mathrm{e}+013.34447 \mathrm{e}+013.34447 \mathrm{e}+00$ 1.00000e-09 2.12000e-01 $3.34447 \mathrm{e}+013.34447 \mathrm{e}+013.34447 \mathrm{e}+00$ 1.00000e-09 2.12000e-01 $1.00000 \mathrm{e}-05$ 1.00000e-05 1.00000e-06 1.00000e-09 1.00000e-01 $1.00000 \mathrm{e}+001.00000 \mathrm{e}+001.00000 \mathrm{e}-011.00000 \mathrm{e}-091.00000 \mathrm{e}-01$ Element: 11359 \# of layers: 4

Kx Ky Kz Ss Por

$3.34447 \mathrm{e}+013.34447 \mathrm{e}+013.34447 \mathrm{e}+00$ 1.00000e-09 2.12000e-01 $3.34447 \mathrm{e}+013.34447 \mathrm{e}+013.34447 \mathrm{e}+00$ 1.00000e-09 2.12000e-01 $1.00000 \mathrm{e}-05$ 1.00000e-05 1.00000e-06 1.00000e-09 1.00000e-01 $1.00000 \mathrm{e}+001.00000 \mathrm{e}+001.00000 \mathrm{e}-011.00000 \mathrm{e}-091.00000 \mathrm{e}-01$ Element: 11360 \# of layers: 4

Kx Ky Kz Ss Por

$3.34447 \mathrm{e}+013.34447 \mathrm{e}+013.34447 \mathrm{e}+00$ 1.00000e-09 2.12000e-01

$3.34447 \mathrm{e}+013.34447 \mathrm{e}+013.34447 \mathrm{e}+001.00000 \mathrm{e}-092.12000 \mathrm{e}-01$ $1.00000 \mathrm{e}-05$ 1.00000e-05 1.00000e-06 1.00000e-09 1.00000e-01 $1.00000 \mathrm{e}+001.00000 \mathrm{e}+001.00000 \mathrm{e}-011.00000 \mathrm{e}-091.00000 \mathrm{e}-01$ Element: 11361 \# of layers: 4

Kx Ky Kz Ss Por

$3.34447 \mathrm{e}+013.34447 \mathrm{e}+013.34447 \mathrm{e}+00$ 1.00000e-09 2.12000e-01 $3.34447 \mathrm{e}+013.34447 \mathrm{e}+013.34447 \mathrm{e}+001.00000 \mathrm{e}-092.12000 \mathrm{e}-01$ $1.00000 \mathrm{e}-05$ 1.00000e-05 1.00000e-06 1.00000e-09 1.00000e-01 $1.00000 \mathrm{e}+001.00000 \mathrm{e}+001.00000 \mathrm{e}-011.00000 \mathrm{e}-091.00000 \mathrm{e}-01$ Element: 11362 \# of layers: 4

Kx Ky Kz Ss Por

$3.34447 \mathrm{e}+013.34447 \mathrm{e}+013.34447 \mathrm{e}+00$ 1.00000e-09 2.12000e-01 $3.34447 \mathrm{e}+013.34447 \mathrm{e}+013.34447 \mathrm{e}+00$ 1.00000e-09 2.12000e-01 $1.00000 \mathrm{e}-05$ 1.00000e-05 1.00000e-06 1.00000e-09 1.00000e-01 $1.00000 \mathrm{e}+001.00000 \mathrm{e}+001.00000 \mathrm{e}-011.00000 \mathrm{e}-091.00000 \mathrm{e}-01$ Element: 11363 \# of layers: 5

Kx Ky Kz Ss Por $3.34447 \mathrm{e}+013.34447 \mathrm{e}+013.34447 \mathrm{e}+00$ 1.00000e-09 2.12000e-01 $3.34447 \mathrm{e}+013.34447 \mathrm{e}+013.34447 \mathrm{e}+00$ 1.00000e-09 2.12000e-01 $3.34447 \mathrm{e}+013.34447 \mathrm{e}+013.34447 \mathrm{e}+00$ 1.00000e-09 2.12000e-01 $1.00000 \mathrm{e}-05$ 1.00000e-05 1.00000e-06 1.00000e-09 1.00000e-01 $1.00000 \mathrm{e}+001.00000 \mathrm{e}+001.00000 \mathrm{e}-011.00000 \mathrm{e}-091.00000 \mathrm{e}-01$ 
Element: 11364 \# of layers: 4

$\mathrm{Kx} \mathrm{Ky} \mathrm{Kz}$ Ss Por

3.34447e+01 3.34447e+01 3.34447e+00 1.00000e-09 2.12000e-01

$3.34447 \mathrm{e}+01$ 3.34447e+01 3.34447e+00 1.00000e-09 2.12000e-01

$1.00000 \mathrm{e}-05$ 1.00000e-05 1.00000e-06 1.00000e-09 1.00000e-01

$1.00000 \mathrm{e}+001.00000 \mathrm{e}+001.00000 \mathrm{e}-011.00000 \mathrm{e}-091.00000 \mathrm{e}-01$

Element: 11365 \# of layers: 4

Kx Ky Kz Ss Por

$1.45400 \mathrm{e}+011.45400 \mathrm{e}+011.45400 \mathrm{e}+001.00000 \mathrm{e}-092.12000 \mathrm{e}-01$

$1.45400 \mathrm{e}+011.45400 \mathrm{e}+011.45400 \mathrm{e}+001.00000 \mathrm{e}-092.12000 \mathrm{e}-01$

$1.00000 \mathrm{e}-05$ 1.00000e-05 1.00000e-06 1.00000e-09 1.00000e-01

$1.00000 \mathrm{e}+001.00000 \mathrm{e}+001.00000 \mathrm{e}-011.00000 \mathrm{e}-091.00000 \mathrm{e}-01$

Element: 11366 \# of layers: 4

$\mathrm{Kx} \mathrm{Ky} \mathrm{Kz}$ Ss Por

$1.45400 \mathrm{e}+011.45400 \mathrm{e}+011.45400 \mathrm{e}+001.00000 \mathrm{e}-092.12000 \mathrm{e}-01$

$1.45400 \mathrm{e}+011.45400 \mathrm{e}+011.45400 \mathrm{e}+001.00000 \mathrm{e}-092.12000 \mathrm{e}-01$

$1.00000 \mathrm{e}-05$ 1.00000e-05 1.00000e-06 1.00000e-09 1.00000e-01

$1.00000 \mathrm{e}+001.00000 \mathrm{e}+00$ 1.00000e-01 1.00000e-09 1.00000e-01

Element: 11367 \# of layers: 4

Kx Ky Kz Ss Por

$1.45400 \mathrm{e}+011.45400 \mathrm{e}+011.45400 \mathrm{e}+001.00000 \mathrm{e}-092.12000 \mathrm{e}-01$

$1.45400 \mathrm{e}+011.45400 \mathrm{e}+011.45400 \mathrm{e}+001.00000 \mathrm{e}-092.12000 \mathrm{e}-01$

$1.00000 \mathrm{e}-051.00000 \mathrm{e}-051.00000 \mathrm{e}-061.00000 \mathrm{e}-091.00000 \mathrm{e}-01$

$1.00000 \mathrm{e}+001.00000 \mathrm{e}+001.00000 \mathrm{e}-011.00000 \mathrm{e}-091.00000 \mathrm{e}-01$

Element: 11368 \# of layers: 4

$\mathrm{Kx} \mathrm{Ky} \mathrm{Kz}$ Ss Por

3.34447e+01 3.34447e+01 3.34447e+00 1.00000e-09 2.12000e-01

$3.34447 \mathrm{e}+013.34447 \mathrm{e}+01$ 3.34447e+00 1.00000e-09 2.12000e-01

$1.00000 \mathrm{e}-05$ 1.00000e-05 1.00000e-06 1.00000e-09 1.00000e-01

$1.00000 \mathrm{e}+001.00000 \mathrm{e}+001.00000 \mathrm{e}-011.00000 \mathrm{e}-091.00000 \mathrm{e}-01$

Element: 11369 \# of layers: 5

Kx Ky Kz Ss Por

3.34447e+01 3.34447e+01 3.34447e+00 1.00000e-09 2.12000e-01

$3.34447 \mathrm{e}+01$ 3.34447e+01 3.34447e+00 1.00000e-09 2.12000e-01

$3.34447 \mathrm{e}+013.34447 \mathrm{e}+01$ 3.34447e+00 1.00000e-09 2.12000e-01

$1.00000 \mathrm{e}-05$ 1.00000e-05 1.00000e-06 1.00000e-09 1.00000e-01

$1.00000 \mathrm{e}+001.00000 \mathrm{e}+001.00000 \mathrm{e}-011.00000 \mathrm{e}-091.00000 \mathrm{e}-01$

Element: 11370 \# of layers: 5

$\mathrm{Kx} \mathrm{Ky} \mathrm{Kz}$ Ss Por

3.34447e+01 3.34447e+01 3.34447e+00 1.00000e-09 2.12000e-01

3.34447e+01 3.34447e+01 3.34447e+00 1.00000e-09 2.12000e-01

3.34447e+01 3.34447e+01 3.34447e+00 1.00000e-09 2.12000e-01

$1.00000 \mathrm{e}-05$ 1.00000e-05 1.00000e-06 1.00000e-09 1.00000e-01

$1.00000 \mathrm{e}+001.00000 \mathrm{e}+001.00000 \mathrm{e}-01$ 1.00000e-09 1.00000e-01

Element: 11371 \# of layers: 4

Kx Ky Kz Ss Por 
3.34447e+01 3.34447e+01 3.34447e+00 1.00000e-09 2.12000e-01 $3.34447 \mathrm{e}+013.34447 \mathrm{e}+01$ 3.34447e+00 1.00000e-09 2.12000e-01 $1.00000 \mathrm{e}-05$ 1.00000e-05 1.00000e-06 1.00000e-09 1.00000e-01

$1.00000 \mathrm{e}+001.00000 \mathrm{e}+001.00000 \mathrm{e}-011.00000 \mathrm{e}-091.00000 \mathrm{e}-01$

Element: 11372 \# of layers: 4

$\mathrm{Kx} \mathrm{Ky} \mathrm{Kz}$ Ss Por

$1.45400 \mathrm{e}+01$ 1.45400e+01 1.45400e+00 1.00000e-09 2.12000e-01

$1.45400 \mathrm{e}+011.45400 \mathrm{e}+011.45400 \mathrm{e}+001.00000 \mathrm{e}-092.12000 \mathrm{e}-01$

$1.00000 \mathrm{e}-05$ 1.00000e-05 1.00000e-06 1.00000e-09 1.00000e-01

$1.00000 \mathrm{e}+001.00000 \mathrm{e}+001.00000 \mathrm{e}-011.00000 \mathrm{e}-091.00000 \mathrm{e}-01$

Element: 11373 \# of layers: 4

Kx Ky Kz Ss Por

$1.45400 \mathrm{e}+011.45400 \mathrm{e}+011.45400 \mathrm{e}+001.00000 \mathrm{e}-092.12000 \mathrm{e}-01$

$1.45400 \mathrm{e}+011.45400 \mathrm{e}+011.45400 \mathrm{e}+001.00000 \mathrm{e}-092.12000 \mathrm{e}-01$

$1.00000 \mathrm{e}-05$ 1.00000e-05 1.00000e-06 1.00000e-09 1.00000e-01

$1.00000 \mathrm{e}+001.00000 \mathrm{e}+001.00000 \mathrm{e}-011.00000 \mathrm{e}-091.00000 \mathrm{e}-01$

Element: 11374 \# of layers: 4

$\mathrm{Kx} \mathrm{Ky} \mathrm{Kz}$ Ss Por

$1.45400 \mathrm{e}+011.45400 \mathrm{e}+011.45400 \mathrm{e}+001.00000 \mathrm{e}-092.12000 \mathrm{e}-01$

$1.45400 \mathrm{e}+011.45400 \mathrm{e}+011.45400 \mathrm{e}+001.00000 \mathrm{e}-092.12000 \mathrm{e}-01$

$1.00000 \mathrm{e}-05$ 1.00000e-05 1.00000e-06 1.00000e-09 1.00000e-01

$1.00000 \mathrm{e}+001.00000 \mathrm{e}+001.00000 \mathrm{e}-011.00000 \mathrm{e}-09$ 1.00000e-01

Element: 11375 \# of layers: 4

Kx Ky Kz Ss Por

$1.45400 \mathrm{e}+011.45400 \mathrm{e}+011.45400 \mathrm{e}+001.00000 \mathrm{e}-092.12000 \mathrm{e}-01$

$1.45400 \mathrm{e}+011.45400 \mathrm{e}+011.45400 \mathrm{e}+001.00000 \mathrm{e}-092.12000 \mathrm{e}-01$

$1.00000 \mathrm{e}-05$ 1.00000e-05 1.00000e-06 1.00000e-09 1.00000e-01

$1.00000 \mathrm{e}+001.00000 \mathrm{e}+001.00000 \mathrm{e}-01$ 1.00000e-09 1.00000e-01

Element: 11376 \# of layers: 4

$\mathrm{Kx} \mathrm{Ky} \mathrm{Kz}$ Ss Por

$1.45400 \mathrm{e}+011.45400 \mathrm{e}+011.45400 \mathrm{e}+001.00000 \mathrm{e}-092.12000 \mathrm{e}-01$

$1.45400 \mathrm{e}+011.45400 \mathrm{e}+011.45400 \mathrm{e}+001.00000 \mathrm{e}-092.12000 \mathrm{e}-01$

$1.00000 \mathrm{e}-05$ 1.00000e-05 1.00000e-06 1.00000e-09 1.00000e-01

$1.00000 \mathrm{e}+001.00000 \mathrm{e}+001.00000 \mathrm{e}-011.00000 \mathrm{e}-091.00000 \mathrm{e}-01$

Element: 11377 \# of layers: 4

Kx Ky Kz Ss Por

$1.45400 \mathrm{e}+011.45400 \mathrm{e}+011.45400 \mathrm{e}+001.00000 \mathrm{e}-092.12000 \mathrm{e}-01$

$1.45400 \mathrm{e}+011.45400 \mathrm{e}+011.45400 \mathrm{e}+001.00000 \mathrm{e}-092.12000 \mathrm{e}-01$

$1.00000 \mathrm{e}-05$ 1.00000e-05 1.00000e-06 1.00000e-09 1.00000e-01

$1.00000 \mathrm{e}+001.00000 \mathrm{e}+001.00000 \mathrm{e}-01$ 1.00000e-09 1.00000e-01

Element: 11378 \# of layers: 4

Kx Ky Kz Ss Por

$1.45400 \mathrm{e}+011.45400 \mathrm{e}+011.45400 \mathrm{e}+001.00000 \mathrm{e}-092.12000 \mathrm{e}-01$

$1.45400 \mathrm{e}+011.45400 \mathrm{e}+011.45400 \mathrm{e}+001.00000 \mathrm{e}-092.12000 \mathrm{e}-01$

$1.00000 \mathrm{e}-05$ 1.00000e-05 1.00000e-06 1.00000e-09 1.00000e-01

$1.00000 \mathrm{e}+001.00000 \mathrm{e}+001.00000 \mathrm{e}-011.00000 \mathrm{e}-091.00000 \mathrm{e}-01$ 
Element: 11379 \# of layers: 4

$\mathrm{Kx} \mathrm{Ky} \mathrm{Kz}$ Ss Por

$1.45400 \mathrm{e}+011.45400 \mathrm{e}+011.45400 \mathrm{e}+001.00000 \mathrm{e}-092.12000 \mathrm{e}-01$

$1.45400 \mathrm{e}+011.45400 \mathrm{e}+011.45400 \mathrm{e}+001.00000 \mathrm{e}-092.12000 \mathrm{e}-01$

$1.00000 \mathrm{e}-05$ 1.00000e-05 1.00000e-06 1.00000e-09 1.00000e-01

$1.00000 \mathrm{e}+001.00000 \mathrm{e}+001.00000 \mathrm{e}-01$ 1.00000e-09 1.00000e-01

Element: 11380 \# of layers: 4

Kx Ky Kz Ss Por

$1.45400 \mathrm{e}+011.45400 \mathrm{e}+011.45400 \mathrm{e}+001.00000 \mathrm{e}-092.12000 \mathrm{e}-01$

$1.45400 \mathrm{e}+011.45400 \mathrm{e}+011.45400 \mathrm{e}+001.00000 \mathrm{e}-092.12000 \mathrm{e}-01$

$1.00000 \mathrm{e}-05$ 1.00000e-05 1.00000e-06 1.00000e-09 1.00000e-01

$1.00000 \mathrm{e}+001.00000 \mathrm{e}+001.00000 \mathrm{e}-011.00000 \mathrm{e}-091.00000 \mathrm{e}-01$

Element: 11381 \# of layers: 4

Kx Ky Kz Ss Por

$1.45400 \mathrm{e}+011.45400 \mathrm{e}+011.45400 \mathrm{e}+001.00000 \mathrm{e}-092.12000 \mathrm{e}-01$

$1.45400 \mathrm{e}+011.45400 \mathrm{e}+011.45400 \mathrm{e}+001.00000 \mathrm{e}-092.12000 \mathrm{e}-01$

$1.00000 \mathrm{e}-05$ 1.00000e-05 1.00000e-06 1.00000e-09 1.00000e-01

$1.00000 \mathrm{e}+001.00000 \mathrm{e}+001.00000 \mathrm{e}-011.00000 \mathrm{e}-091.00000 \mathrm{e}-01$

Element: 11382 \# of layers: 4

$\mathrm{Kx} \mathrm{Ky} \mathrm{Kz}$ Ss Por

$1.35552 \mathrm{e}+01$ 1.35552e+01 1.35552e+00 1.00000e-09 2.12000e-01

$1.35552 \mathrm{e}+01$ 1.35552e+01 1.35552e+00 1.00000e-09 2.12000e-01

$1.00000 \mathrm{e}-05$ 1.00000e-05 1.00000e-06 1.00000e-09 1.00000e-01

$1.00000 \mathrm{e}+001.00000 \mathrm{e}+001.00000 \mathrm{e}-011.00000 \mathrm{e}-091.00000 \mathrm{e}-01$

Element: 11383 \# of layers: 4

$\mathrm{Kx} \mathrm{Ky} \mathrm{Kz}$ Ss Por

$1.35552 \mathrm{e}+01$ 1.35552e+01 1.35552e+00 1.00000e-09 2.12000e-01

$1.35552 \mathrm{e}+01$ 1.35552e+01 1.35552e+00 1.00000e-09 2.12000e-01

$1.00000 \mathrm{e}-05$ 1.00000e-05 1.00000e-06 1.00000e-09 1.00000e-01

$1.00000 \mathrm{e}+001.00000 \mathrm{e}+001.00000 \mathrm{e}-01$ 1.00000e-09 1.00000e-01

Element: 11384 \# of layers: 4

Kx Ky Kz Ss Por

$1.35552 \mathrm{e}+01$ 1.35552e+01 1.35552e+00 1.00000e-09 2.12000e-01

$1.35552 \mathrm{e}+01$ 1.35552e+01 1.35552e+00 1.00000e-09 2.12000e-01

$1.00000 \mathrm{e}-05$ 1.00000e-05 1.00000e-06 1.00000e-09 1.00000e-01

$1.00000 \mathrm{e}+001.00000 \mathrm{e}+001.00000 \mathrm{e}-011.00000 \mathrm{e}-091.00000 \mathrm{e}-01$

Element: 11385 \# of layers: 4

$\mathrm{Kx} \mathrm{Ky} \mathrm{Kz}$ Ss Por

$1.35552 \mathrm{e}+01$ 1.35552e+01 1.35552e+00 1.00000e-09 2.12000e-01

$1.35552 \mathrm{e}+011.35552 \mathrm{e}+01$ 1.35552e+00 1.00000e-09 2.12000e-01

$1.00000 \mathrm{e}-05$ 1.00000e-05 1.00000e-06 1.00000e-09 1.00000e-01

$1.00000 \mathrm{e}+001.00000 \mathrm{e}+001.00000 \mathrm{e}-011.00000 \mathrm{e}-091.00000 \mathrm{e}-01$

Element: 11386 \# of layers: 4

$\mathrm{Kx} \mathrm{Ky} \mathrm{Kz}$ Ss Por

$1.35552 \mathrm{e}+01$ 1.35552e+01 1.35552e+00 1.00000e-09 2.12000e-01

$1.35552 \mathrm{e}+01$ 1.35552e+01 1.35552e+00 1.00000e-09 2.12000e-01 
$1.00000 \mathrm{e}-05$ 1.00000e-05 1.00000e-06 1.00000e-09 1.00000e-01 $1.00000 \mathrm{e}+001.00000 \mathrm{e}+001.00000 \mathrm{e}-01$ 1.00000e-09 1.00000e-01 Element: 11387 \# of layers: 4

Kx Ky Kz Ss Por

$1.45400 \mathrm{e}+011.45400 \mathrm{e}+011.45400 \mathrm{e}+001.00000 \mathrm{e}-092.12000 \mathrm{e}-01$ $1.45400 \mathrm{e}+011.45400 \mathrm{e}+011.45400 \mathrm{e}+001.00000 \mathrm{e}-092.12000 \mathrm{e}-01$ $1.00000 \mathrm{e}-05$ 1.00000e-05 1.00000e-06 1.00000e-09 1.00000e-01 $1.00000 \mathrm{e}+001.00000 \mathrm{e}+001.00000 \mathrm{e}-01$ 1.00000e-09 1.00000e-01 Element: 11388 \# of layers: 4

$\mathrm{Kx} \mathrm{Ky} \mathrm{Kz}$ Ss Por

$1.45400 \mathrm{e}+011.45400 \mathrm{e}+011.45400 \mathrm{e}+001.00000 \mathrm{e}-092.12000 \mathrm{e}-01$ $1.45400 \mathrm{e}+011.45400 \mathrm{e}+011.45400 \mathrm{e}+001.00000 \mathrm{e}-092.12000 \mathrm{e}-01$ $1.00000 \mathrm{e}-05$ 1.00000e-05 1.00000e-06 1.00000e-09 1.00000e-01 $1.00000 \mathrm{e}+001.00000 \mathrm{e}+001.00000 \mathrm{e}-011.00000 \mathrm{e}-09$ 1.00000e-01 Element: 11389 \# of layers: 4

Kx Ky Kz Ss Por

$1.35552 \mathrm{e}+01$ 1.35552e+01 1.35552e+00 1.00000e-09 2.12000e-01 $1.35552 \mathrm{e}+011.35552 \mathrm{e}+01$ 1.35552e+00 1.00000e-09 2.12000e-01 $1.00000 \mathrm{e}-05$ 1.00000e-05 1.00000e-06 1.00000e-09 1.00000e-01 $1.00000 \mathrm{e}+001.00000 \mathrm{e}+001.00000 \mathrm{e}-011.00000 \mathrm{e}-091.00000 \mathrm{e}-01$ Element: 11390 \# of layers: 4

$\mathrm{Kx} \mathrm{Ky} \mathrm{Kz}$ Ss Por

1.35552e+01 1.35552e+01 1.35552e+00 1.00000e-09 2.12000e-01 $1.35552 \mathrm{e}+011.35552 \mathrm{e}+01$ 1.35552e+00 1.00000e-09 2.12000e-01 $1.00000 \mathrm{e}-05$ 1.00000e-05 1.00000e-06 1.00000e-09 1.00000e-01 $1.00000 \mathrm{e}+001.00000 \mathrm{e}+001.00000 \mathrm{e}-01$ 1.00000e-09 1.00000e-01 Element: 11391 \# of layers: 4

Kx Ky Kz Ss Por

9.06117e+01 9.06117e+01 9.06117e+00 1.00000e-09 2.12000e-01 9.06117e+01 9.06117e+01 9.06117e+00 1.00000e-09 2.12000e-01 $1.00000 \mathrm{e}-05$ 1.00000e-05 1.00000e-06 1.00000e-09 1.00000e-01 $1.00000 \mathrm{e}+001.00000 \mathrm{e}+001.00000 \mathrm{e}-011.00000 \mathrm{e}-091.00000 \mathrm{e}-01$ Element: 11392 \# of layers: 5

$\mathrm{Kx} \mathrm{Ky} \mathrm{Kz}$ Ss Por

9.06117e+01 9.06117e+01 9.06117e+00 1.00000e-09 2.12000e-01 9.06117e+01 9.06117e+01 9.06117e+00 1.00000e-09 2.12000e-01 $9.06117 \mathrm{e}+019.06117 \mathrm{e}+019.06117 \mathrm{e}+001.00000 \mathrm{e}-092.12000 \mathrm{e}-01$ $1.00000 \mathrm{e}-05$ 1.00000e-05 1.00000e-06 1.00000e-09 1.00000e-01 $1.00000 \mathrm{e}+001.00000 \mathrm{e}+001.00000 \mathrm{e}-011.00000 \mathrm{e}-091.00000 \mathrm{e}-01$ Element: 11393 \# of layers: 5

Kx Ky Kz Ss Por 9.06117e+01 9.06117e+01 9.06117e+00 1.00000e-09 2.12000e-01 $9.06117 \mathrm{e}+019.06117 \mathrm{e}+01$ 9.06117e+00 1.00000e-09 2.12000e-01 9.06117e+01 9.06117e+01 9.06117e+00 1.00000e-09 2.12000e-01 $1.00000 \mathrm{e}-05$ 1.00000e-05 1.00000e-06 1.00000e-09 1.00000e-01 $1.00000 \mathrm{e}+001.00000 \mathrm{e}+001.00000 \mathrm{e}-011.00000 \mathrm{e}-091.00000 \mathrm{e}-01$ 
Element: 11394 \# of layers: 5

$\mathrm{Kx} \mathrm{Ky} \mathrm{Kz}$ Ss Por

3.34447e+01 3.34447e+01 3.34447e+00 1.00000e-09 2.12000e-01

$3.34447 \mathrm{e}+01$ 3.34447e+01 3.34447e+00 1.00000e-09 2.12000e-01

$3.34447 \mathrm{e}+01$ 3.34447e+01 3.34447e+00 1.00000e-09 2.12000e-01

$1.00000 \mathrm{e}-05$ 1.00000e-05 1.00000e-06 1.00000e-09 1.00000e-01

$1.00000 \mathrm{e}+001.00000 \mathrm{e}+001.00000 \mathrm{e}-01$ 1.00000e-09 1.00000e-01

Element: 11395 \# of layers: 4

$\mathrm{Kx} \mathrm{Ky} \mathrm{Kz}$ Ss Por

3.34447e+01 3.34447e+01 3.34447e+00 1.00000e-09 2.12000e-01

$3.34447 \mathrm{e}+013.34447 \mathrm{e}+013.34447 \mathrm{e}+00$ 1.00000e-09 2.12000e-01

$1.00000 \mathrm{e}-05$ 1.00000e-05 1.00000e-06 1.00000e-09 1.00000e-01

$1.00000 \mathrm{e}+001.00000 \mathrm{e}+001.00000 \mathrm{e}-011.00000 \mathrm{e}-09$ 1.00000e-01

Element: 11396 \# of layers: 4

$\mathrm{Kx} \mathrm{Ky} \mathrm{Kz}$ Ss Por

$1.45400 \mathrm{e}+011.45400 \mathrm{e}+011.45400 \mathrm{e}+001.00000 \mathrm{e}-092.12000 \mathrm{e}-01$

$1.45400 \mathrm{e}+011.45400 \mathrm{e}+011.45400 \mathrm{e}+001.00000 \mathrm{e}-092.12000 \mathrm{e}-01$

$1.00000 \mathrm{e}-05$ 1.00000e-05 1.00000e-06 1.00000e-09 1.00000e-01

$1.00000 \mathrm{e}+001.00000 \mathrm{e}+001.00000 \mathrm{e}-01$ 1.00000e-09 1.00000e-01

Element: 11397 \# of layers: 4

$\mathrm{Kx} \mathrm{Ky} \mathrm{Kz}$ Ss Por

$1.35552 \mathrm{e}+01$ 1.35552e+01 1.35552e+00 1.00000e-09 2.12000e-01

$1.35552 \mathrm{e}+01$ 1.35552e+01 1.35552e+00 1.00000e-09 2.12000e-01

$1.00000 \mathrm{e}-051.00000 \mathrm{e}-051.00000 \mathrm{e}-061.00000 \mathrm{e}-091.00000 \mathrm{e}-01$

$1.00000 \mathrm{e}+001.00000 \mathrm{e}+001.00000 \mathrm{e}-011.00000 \mathrm{e}-091.00000 \mathrm{e}-01$

Element: 11398 \# of layers: 4

$\mathrm{Kx} \mathrm{Ky} \mathrm{Kz}$ Ss Por

9.06117e+01 9.06117e+01 9.06117e+00 1.00000e-09 2.12000e-01

9.06117e+01 9.06117e+01 9.06117e+00 1.00000e-09 2.12000e-01

$1.00000 \mathrm{e}-05$ 1.00000e-05 1.00000e-06 1.00000e-09 1.00000e-01

$1.00000 \mathrm{e}+001.00000 \mathrm{e}+001.00000 \mathrm{e}-011.00000 \mathrm{e}-091.00000 \mathrm{e}-01$

Element: 11399 \# of layers: 5

Kx Ky Kz Ss Por

$1.13801 \mathrm{e}+02$ 1.13801e+02 1.13801e+01 1.00000e-09 2.12000e-01

$1.13801 \mathrm{e}+021.13801 \mathrm{e}+02$ 1.13801e+01 1.00000e-09 2.12000e-01

$1.13801 \mathrm{e}+021.13801 \mathrm{e}+02$ 1.13801e+01 1.00000e-09 2.12000e-01

$1.00000 \mathrm{e}-05$ 1.00000e-05 1.00000e-06 1.00000e-09 1.00000e-01

$1.00000 \mathrm{e}+001.00000 \mathrm{e}+001.00000 \mathrm{e}-011.00000 \mathrm{e}-09$ 1.00000e-01

Element: 11400 \# of layers: 5

$\mathrm{Kx} \mathrm{Ky} \mathrm{Kz}$ Ss Por

$1.13801 \mathrm{e}+02$ 1.13801e+02 1.13801e+01 1.00000e-09 2.12000e-01

$1.13801 \mathrm{e}+02$ 1.13801e+02 1.13801e+01 1.00000e-09 2.12000e-01

$1.13801 \mathrm{e}+02$ 1.13801e+02 1.13801e+01 1.00000e-09 2.12000e-01

$1.00000 \mathrm{e}-05$ 1.00000e-05 1.00000e-06 1.00000e-09 1.00000e-01

$1.00000 \mathrm{e}+001.00000 \mathrm{e}+001.00000 \mathrm{e}-01$ 1.00000e-09 1.00000e-01

Element: 11401 \# of layers: 5 
$\mathrm{Kx} \mathrm{Ky} \mathrm{Kz}$ Ss Por

$1.13801 \mathrm{e}+02$ 1.13801e+02 1.13801e+01 1.00000e-09 2.12000e-01

$1.13801 \mathrm{e}+02$ 1.13801e+02 1.13801e+01 1.00000e-09 2.12000e-01

$1.13801 \mathrm{e}+021.13801 \mathrm{e}+021.13801 \mathrm{e}+01$ 1.00000e-09 2.12000e-01

$1.00000 \mathrm{e}-05$ 1.00000e-05 1.00000e-06 1.00000e-09 1.00000e-01

$1.00000 \mathrm{e}+001.00000 \mathrm{e}+001.00000 \mathrm{e}-01$ 1.00000e-09 1.00000e-01

Element: 11402 \# of layers: 4

Kx Ky Kz Ss Por

1.13801e+02 1.13801e+02 1.13801e+01 1.00000e-09 2.12000e-01

$1.13801 \mathrm{e}+021.13801 \mathrm{e}+021.13801 \mathrm{e}+01$ 1.00000e-09 2.12000e-01

$1.00000 \mathrm{e}-05$ 1.00000e-05 1.00000e-06 1.00000e-09 1.00000e-01

$1.00000 \mathrm{e}+001.00000 \mathrm{e}+001.00000 \mathrm{e}-011.00000 \mathrm{e}-091.00000 \mathrm{e}-01$

Element: 11403 \# of layers: 4

$\mathrm{Kx} \mathrm{Ky} \mathrm{Kz}$ Ss Por

$1.13801 \mathrm{e}+02$ 1.13801e+02 1.13801e+01 1.00000e-09 2.12000e-01

$1.13801 \mathrm{e}+021.13801 \mathrm{e}+021.13801 \mathrm{e}+01$ 1.00000e-09 2.12000e-01

$1.00000 \mathrm{e}-05$ 1.00000e-05 1.00000e-06 1.00000e-09 1.00000e-01

$1.00000 \mathrm{e}+001.00000 \mathrm{e}+001.00000 \mathrm{e}-011.00000 \mathrm{e}-091.00000 \mathrm{e}-01$

Element: 11404 \# of layers: 4

$\mathrm{Kx} \mathrm{Ky} \mathrm{Kz}$ Ss Por

$1.13801 \mathrm{e}+021.13801 \mathrm{e}+02$ 1.13801e+01 1.00000e-09 2.12000e-01

$1.13801 \mathrm{e}+02$ 1.13801e+02 1.13801e+01 1.00000e-09 2.12000e-01

$1.00000 \mathrm{e}-05$ 1.00000e-05 1.00000e-06 1.00000e-09 1.00000e-01

$1.00000 \mathrm{e}+001.00000 \mathrm{e}+001.00000 \mathrm{e}-011.00000 \mathrm{e}-091.00000 \mathrm{e}-01$

Element: 11405 \# of layers: 4

$\mathrm{Kx} \mathrm{Ky} \mathrm{Kz}$ Ss Por

$1.13801 \mathrm{e}+02$ 1.13801e+02 1.13801e+01 1.00000e-09 2.12000e-01

$1.13801 \mathrm{e}+02$ 1.13801e+02 1.13801e+01 1.00000e-09 2.12000e-01

$1.00000 \mathrm{e}-05$ 1.00000e-05 1.00000e-06 1.00000e-09 1.00000e-01

$1.00000 \mathrm{e}+001.00000 \mathrm{e}+001.00000 \mathrm{e}-011.00000 \mathrm{e}-091.00000 \mathrm{e}-01$

Element: 11406 \# of layers: 4

$\mathrm{Kx} \mathrm{Ky} \mathrm{Kz}$ Ss Por

$1.13801 \mathrm{e}+021.13801 \mathrm{e}+02$ 1.13801e+01 1.00000e-09 2.12000e-01

$1.13801 \mathrm{e}+021.13801 \mathrm{e}+021.13801 \mathrm{e}+01$ 1.00000e-09 2.12000e-01

$1.00000 \mathrm{e}-05$ 1.00000e-05 1.00000e-06 1.00000e-09 1.00000e-01

$1.00000 \mathrm{e}+001.00000 \mathrm{e}+001.00000 \mathrm{e}-011.00000 \mathrm{e}-09$ 1.00000e-01

Element: 11407 \# of layers: 4

Kx Ky Kz Ss Por

$1.13801 \mathrm{e}+021.13801 \mathrm{e}+02$ 1.13801e+01 1.00000e-09 2.12000e-01

$1.13801 \mathrm{e}+021.13801 \mathrm{e}+02$ 1.13801e+01 1.00000e-09 2.12000e-01

$1.00000 \mathrm{e}-05$ 1.00000e-05 1.00000e-06 1.00000e-09 1.00000e-01

$1.00000 \mathrm{e}+001.00000 \mathrm{e}+001.00000 \mathrm{e}-011.00000 \mathrm{e}-091.00000 \mathrm{e}-01$

Element: 11408 \# of layers: 5

$\mathrm{Kx} \mathrm{Ky} \mathrm{Kz}$ Ss Por

$1.13801 \mathrm{e}+021.13801 \mathrm{e}+02$ 1.13801e+01 1.00000e-09 2.12000e-01

$1.13801 \mathrm{e}+021.13801 \mathrm{e}+021.13801 \mathrm{e}+01$ 1.00000e-09 2.12000e-01 
$1.13801 \mathrm{e}+02$ 1.13801e+02 1.13801e+01 1.00000e-09 2.12000e-01 $1.00000 \mathrm{e}-05$ 1.00000e-05 1.00000e-06 1.00000e-09 1.00000e-01

$1.00000 \mathrm{e}+001.00000 \mathrm{e}+001.00000 \mathrm{e}-011.00000 \mathrm{e}-09$ 1.00000e-01

Element: 11409 \# of layers: 5

$\mathrm{Kx} \mathrm{Ky} \mathrm{Kz}$ Ss Por

4.80565e+01 4.80565e+01 4.80565e+00 1.00000e-09 2.12000e-01

$4.80565 \mathrm{e}+014.80565 \mathrm{e}+014.80565 \mathrm{e}+00$ 1.00000e-09 2.12000e-01

$4.80565 \mathrm{e}+014.80565 \mathrm{e}+014.80565 \mathrm{e}+001.00000 \mathrm{e}-092.12000 \mathrm{e}-01$

$1.00000 \mathrm{e}-051.00000 \mathrm{e}-051.00000 \mathrm{e}-061.00000 \mathrm{e}-091.00000 \mathrm{e}-01$

$1.00000 \mathrm{e}+001.00000 \mathrm{e}+001.00000 \mathrm{e}-011.00000 \mathrm{e}-091.00000 \mathrm{e}-01$

Element: 11410 \# of layers: 5

Kx Ky Kz Ss Por

4.80565e+01 4.80565e+01 4.80565e+00 1.00000e-09 2.12000e-01

$4.80565 \mathrm{e}+014.80565 \mathrm{e}+014.80565 \mathrm{e}+00$ 1.00000e-09 2.12000e-01

$4.80565 \mathrm{e}+014.80565 \mathrm{e}+014.80565 \mathrm{e}+00$ 1.00000e-09 2.12000e-01

$1.00000 \mathrm{e}-051.00000 \mathrm{e}-051.00000 \mathrm{e}-061.00000 \mathrm{e}-091.00000 \mathrm{e}-01$

$1.00000 \mathrm{e}+001.00000 \mathrm{e}+001.00000 \mathrm{e}-011.00000 \mathrm{e}-091.00000 \mathrm{e}-01$

Element: 11411 \# of layers: 4

$\mathrm{Kx} \mathrm{Ky} \mathrm{Kz}$ Ss Por

4.80565e+01 4.80565e+01 4.80565e+00 1.00000e-09 2.12000e-01

$4.80565 \mathrm{e}+014.80565 \mathrm{e}+014.80565 \mathrm{e}+001.00000 \mathrm{e}-092.12000 \mathrm{e}-01$

$1.00000 \mathrm{e}-051.00000 \mathrm{e}-05$ 1.00000e-06 1.00000e-09 1.00000e-01

$1.00000 \mathrm{e}+001.00000 \mathrm{e}+001.00000 \mathrm{e}-01$ 1.00000e-09 1.00000e-01

Element: 11412 \# of layers: 4

Kx Ky Kz Ss Por

4.80565e+01 4.80565e+01 4.80565e+00 1.00000e-09 2.12000e-01

$4.80565 \mathrm{e}+014.80565 \mathrm{e}+014.80565 \mathrm{e}+001.00000 \mathrm{e}-092.12000 \mathrm{e}-01$

$1.00000 \mathrm{e}-05$ 1.00000e-05 1.00000e-06 1.00000e-09 1.00000e-01

$1.00000 \mathrm{e}+001.00000 \mathrm{e}+001.00000 \mathrm{e}-011.00000 \mathrm{e}-091.00000 \mathrm{e}-01$

Element: 11413 \# of layers: 4

$\mathrm{Kx} \mathrm{Ky} \mathrm{Kz}$ Ss Por

4.80565e+01 4.80565e+01 4.80565e+00 1.00000e-09 2.12000e-01

$4.80565 \mathrm{e}+014.80565 \mathrm{e}+014.80565 \mathrm{e}+001.00000 \mathrm{e}-092.12000 \mathrm{e}-01$

$1.00000 \mathrm{e}-05$ 1.00000e-05 1.00000e-06 1.00000e-09 1.00000e-01

$1.00000 \mathrm{e}+001.00000 \mathrm{e}+001.00000 \mathrm{e}-01$ 1.00000e-09 1.00000e-01

Element: 11414 \# of layers: 4

Kx Ky Kz Ss Por

$1.13801 \mathrm{e}+02$ 1.13801e+02 1.13801e+01 1.00000e-09 2.12000e-01

$1.13801 \mathrm{e}+021.13801 \mathrm{e}+02$ 1.13801e+01 1.00000e-09 2.12000e-01

$1.00000 \mathrm{e}-051.00000 \mathrm{e}-05$ 1.00000e-06 1.00000e-09 1.00000e-01

$1.00000 \mathrm{e}+001.00000 \mathrm{e}+001.00000 \mathrm{e}-011.00000 \mathrm{e}-091.00000 \mathrm{e}-01$

Element: 11415 \# of layers: 4

$\mathrm{Kx} \mathrm{Ky} \mathrm{Kz}$ Ss Por

1.13801e+02 1.13801e+02 1.13801e+01 1.00000e-09 2.12000e-01

$1.13801 \mathrm{e}+021.13801 \mathrm{e}+02$ 1.13801e+01 1.00000e-09 2.12000e-01

$1.00000 \mathrm{e}-05$ 1.00000e-05 1.00000e-06 1.00000e-09 1.00000e-01 
$1.00000 \mathrm{e}+001.00000 \mathrm{e}+00$ 1.00000e-01 1.00000e-09 1.00000e-01

Element: 11416 \# of layers: 4

Kx Ky Kz Ss Por

4.80565e+01 4.80565e+01 4.80565e+00 1.00000e-09 2.12000e-01

$4.80565 \mathrm{e}+014.80565 \mathrm{e}+014.80565 \mathrm{e}+001.00000 \mathrm{e}-092.12000 \mathrm{e}-01$

$1.00000 \mathrm{e}-05$ 1.00000e-05 1.00000e-06 1.00000e-09 1.00000e-01

$1.00000 \mathrm{e}+001.00000 \mathrm{e}+001.00000 \mathrm{e}-011.00000 \mathrm{e}-091.00000 \mathrm{e}-01$

Element: 11417 \# of layers: 5

$\mathrm{Kx} \mathrm{Ky} \mathrm{Kz}$ Ss Por

4.80565e+01 4.80565e+01 4.80565e+00 1.00000e-09 2.12000e-01

$4.80565 \mathrm{e}+014.80565 \mathrm{e}+014.80565 \mathrm{e}+00$ 1.00000e-09 2.12000e-01

$4.80565 \mathrm{e}+014.80565 \mathrm{e}+014.80565 \mathrm{e}+00$ 1.00000e-09 2.12000e-01

$1.00000 \mathrm{e}-05$ 1.00000e-05 1.00000e-06 1.00000e-09 1.00000e-01

$1.00000 \mathrm{e}+001.00000 \mathrm{e}+001.00000 \mathrm{e}-011.00000 \mathrm{e}-091.00000 \mathrm{e}-01$

Element: 11418 \# of layers: 5

Kx Ky Kz Ss Por

4.80565e+01 4.80565e+01 4.80565e+00 1.00000e-09 2.12000e-01

$4.80565 \mathrm{e}+014.80565 \mathrm{e}+014.80565 \mathrm{e}+00$ 1.00000e-09 2.12000e-01

$4.80565 \mathrm{e}+014.80565 \mathrm{e}+01$ 4.80565e+00 1.00000e-09 2.12000e-01

$1.00000 \mathrm{e}-05$ 1.00000e-05 1.00000e-06 1.00000e-09 1.00000e-01

$1.00000 \mathrm{e}+001.00000 \mathrm{e}+001.00000 \mathrm{e}-011.00000 \mathrm{e}-091.00000 \mathrm{e}-01$

Element: 11419 \# of layers: 5

$\mathrm{Kx} \mathrm{Ky} \mathrm{Kz}$ Ss Por

4.80565e+01 4.80565e+01 4.80565e+00 1.00000e-09 2.12000e-01

$4.80565 \mathrm{e}+014.80565 \mathrm{e}+014.80565 \mathrm{e}+001.00000 \mathrm{e}-092.12000 \mathrm{e}-01$

$4.80565 \mathrm{e}+014.80565 \mathrm{e}+014.80565 \mathrm{e}+001.00000 \mathrm{e}-092.12000 \mathrm{e}-01$

$1.00000 \mathrm{e}-05$ 1.00000e-05 1.00000e-06 1.00000e-09 1.00000e-01

$1.00000 \mathrm{e}+001.00000 \mathrm{e}+001.00000 \mathrm{e}-011.00000 \mathrm{e}-091.00000 \mathrm{e}-01$

Element: 11420 \# of layers: 4

$\mathrm{Kx} \mathrm{Ky} \mathrm{Kz}$ Ss Por

4.80565e+01 4.80565e+01 4.80565e+00 1.00000e-09 2.12000e-01

$4.80565 \mathrm{e}+014.80565 \mathrm{e}+014.80565 \mathrm{e}+00$ 1.00000e-09 2.12000e-01

$1.00000 \mathrm{e}-05$ 1.00000e-05 1.00000e-06 1.00000e-09 1.00000e-01

$1.00000 \mathrm{e}+001.00000 \mathrm{e}+001.00000 \mathrm{e}-011.00000 \mathrm{e}-091.00000 \mathrm{e}-01$

Element: 11421 \# of layers: 5

$\mathrm{Kx} \mathrm{Ky} \mathrm{Kz}$ Ss Por

$1.20274 \mathrm{e}+03$ 1.20274e+03 1.20275e+02 1.00000e-09 7.00000e-02

$4.80565 \mathrm{e}+014.80565 \mathrm{e}+014.80565 \mathrm{e}+00$ 1.00000e-09 2.12000e-01

$4.80565 \mathrm{e}+014.80565 \mathrm{e}+014.80565 \mathrm{e}+001.00000 \mathrm{e}-09$ 2.12000e-01

$1.00000 \mathrm{e}-05$ 1.00000e-05 1.00000e-06 1.00000e-09 1.00000e-01

$1.00000 \mathrm{e}+001.00000 \mathrm{e}+001.00000 \mathrm{e}-011.00000 \mathrm{e}-091.00000 \mathrm{e}-01$

Element: 11422 \# of layers: 4

$\mathrm{Kx} \mathrm{Ky} \mathrm{Kz}$ Ss Por

4.80565e+01 4.80565e+01 4.80565e+00 1.00000e-09 2.12000e-01

$4.80565 \mathrm{e}+014.80565 \mathrm{e}+014.80565 \mathrm{e}+001.00000 \mathrm{e}-092.12000 \mathrm{e}-01$

$1.00000 \mathrm{e}-05$ 1.00000e-05 1.00000e-06 1.00000e-09 1.00000e-01 
$1.00000 \mathrm{e}+001.00000 \mathrm{e}+00$ 1.00000e-01 1.00000e-09 1.00000e-01

Element: 11423 \# of layers: 4

Kx Ky Kz Ss Por

4.80565e+01 4.80565e+01 4.80565e+00 1.00000e-09 2.12000e-01

$4.80565 \mathrm{e}+014.80565 \mathrm{e}+014.80565 \mathrm{e}+001.00000 \mathrm{e}-092.12000 \mathrm{e}-01$

$1.00000 \mathrm{e}-05$ 1.00000e-05 1.00000e-06 1.00000e-09 1.00000e-01

$1.00000 \mathrm{e}+001.00000 \mathrm{e}+001.00000 \mathrm{e}-011.00000 \mathrm{e}-091.00000 \mathrm{e}-01$

Element: 11424 \# of layers: 4

$\mathrm{Kx} \mathrm{Ky} \mathrm{Kz}$ Ss Por

4.80565e+01 4.80565e+01 4.80565e+00 1.00000e-09 2.12000e-01

$4.80565 \mathrm{e}+014.80565 \mathrm{e}+014.80565 \mathrm{e}+00$ 1.00000e-09 2.12000e-01

$1.00000 \mathrm{e}-05$ 1.00000e-05 1.00000e-06 1.00000e-09 1.00000e-01

$1.00000 \mathrm{e}+001.00000 \mathrm{e}+001.00000 \mathrm{e}-01$ 1.00000e-09 1.00000e-01

Element: 11425 \# of layers: 4

$\mathrm{Kx} \mathrm{Ky} \mathrm{Kz}$ Ss Por

4.80565e+01 4.80565e+01 4.80565e+00 1.00000e-09 2.12000e-01

$4.80565 \mathrm{e}+014.80565 \mathrm{e}+014.80565 \mathrm{e}+00$ 1.00000e-09 2.12000e-01

$1.00000 \mathrm{e}-05$ 1.00000e-05 1.00000e-06 1.00000e-09 1.00000e-01

$1.00000 \mathrm{e}+001.00000 \mathrm{e}+001.00000 \mathrm{e}-01$ 1.00000e-09 1.00000e-01

Element: 11426 \# of layers: 6

$\mathrm{Kx} \mathrm{Ky} \mathrm{Kz}$ Ss Por

$1.20274 \mathrm{e}+031.20274 \mathrm{e}+03$ 1.20275e+02 1.00000e-09 7.00000e-02

$1.20274 \mathrm{e}+031.20274 \mathrm{e}+03$ 1.20275e+02 1.00000e-09 7.00000e-02

$4.80565 \mathrm{e}+014.80565 \mathrm{e}+014.80565 \mathrm{e}+00$ 1.00000e-09 2.12000e-01

$4.80565 \mathrm{e}+014.80565 \mathrm{e}+014.80565 \mathrm{e}+001.00000 \mathrm{e}-092.12000 \mathrm{e}-01$

$1.00000 \mathrm{e}-05$ 1.00000e-05 1.00000e-06 1.00000e-09 1.00000e-01

$1.00000 \mathrm{e}+001.00000 \mathrm{e}+001.00000 \mathrm{e}-011.00000 \mathrm{e}-091.00000 \mathrm{e}-01$

Element: 11427 \# of layers: 5

Kx Ky Kz Ss Por

$1.20274 \mathrm{e}+031.20274 \mathrm{e}+03$ 1.20275e+02 1.00000e-09 7.00000e-02

$4.80565 \mathrm{e}+014.80565 \mathrm{e}+014.80565 \mathrm{e}+00$ 1.00000e-09 2.12000e-01

$4.80565 \mathrm{e}+014.80565 \mathrm{e}+014.80565 \mathrm{e}+00$ 1.00000e-09 2.12000e-01

$1.00000 \mathrm{e}-05$ 1.00000e-05 1.00000e-06 1.00000e-09 1.00000e-01

$1.00000 \mathrm{e}+001.00000 \mathrm{e}+001.00000 \mathrm{e}-011.00000 \mathrm{e}-091.00000 \mathrm{e}-01$

Element: 11428 \# of layers: 5

$\mathrm{Kx} \mathrm{Ky} \mathrm{Kz}$ Ss Por

7.29233e+02 7.29233e+02 7.29233e+01 1.00000e-09 7.00000e-02

$2.91381 \mathrm{e}+012.91381 \mathrm{e}+012.91381 \mathrm{e}+001.00000 \mathrm{e}-092.12000 \mathrm{e}-01$

$2.91381 \mathrm{e}+012.91381 \mathrm{e}+012.91381 \mathrm{e}+001.00000 \mathrm{e}-092.12000 \mathrm{e}-01$

$1.00000 \mathrm{e}-051.00000 \mathrm{e}-05$ 1.00000e-06 1.00000e-09 1.00000e-01

$1.00000 \mathrm{e}+001.00000 \mathrm{e}+001.00000 \mathrm{e}-011.00000 \mathrm{e}-091.00000 \mathrm{e}-01$

Element: 11429 \# of layers: 5

$\mathrm{Kx} \mathrm{Ky} \mathrm{Kz}$ Ss Por

7.29233e+02 7.29233e+02 7.29233e+01 1.00000e-09 7.00000e-02

$2.91381 \mathrm{e}+012.91381 \mathrm{e}+012.91381 \mathrm{e}+001.00000 \mathrm{e}-092.12000 \mathrm{e}-01$

$2.91381 \mathrm{e}+012.91381 \mathrm{e}+012.91381 \mathrm{e}+001.00000 \mathrm{e}-092.12000 \mathrm{e}-01$ 
$1.00000 \mathrm{e}-05$ 1.00000e-05 1.00000e-06 1.00000e-09 1.00000e-01 $1.00000 \mathrm{e}+001.00000 \mathrm{e}+001.00000 \mathrm{e}-01$ 1.00000e-09 1.00000e-01 Element: 11430 \# of layers: 5

Kx Ky Kz Ss Por

7.29233e+02 7.29233e+02 7.29233e+01 1.00000e-09 7.00000e-02 $2.91381 \mathrm{e}+012.91381 \mathrm{e}+012.91381 \mathrm{e}+001.00000 \mathrm{e}-092.12000 \mathrm{e}-01$ $2.91381 \mathrm{e}+012.91381 \mathrm{e}+012.91381 \mathrm{e}+001.00000 \mathrm{e}-092.12000 \mathrm{e}-01$ $1.00000 \mathrm{e}-05$ 1.00000e-05 1.00000e-06 1.00000e-09 1.00000e-01 $1.00000 \mathrm{e}+001.00000 \mathrm{e}+001.00000 \mathrm{e}-011.00000 \mathrm{e}-091.00000 \mathrm{e}-01$ Element: 11431 \# of layers: 5

$\mathrm{Kx} \mathrm{Ky} \mathrm{Kz}$ Ss Por

$1.20274 \mathrm{e}+03$ 1.20274e+03 1.20275e+02 1.00000e-09 7.00000e-02 $4.80565 \mathrm{e}+014.80565 \mathrm{e}+014.80565 \mathrm{e}+00$ 1.00000e-09 2.12000e-01 $4.80565 \mathrm{e}+014.80565 \mathrm{e}+014.80565 \mathrm{e}+00$ 1.00000e-09 2.12000e-01 $1.00000 \mathrm{e}-05$ 1.00000e-05 1.00000e-06 1.00000e-09 1.00000e-01 $1.00000 \mathrm{e}+001.00000 \mathrm{e}+001.00000 \mathrm{e}-011.00000 \mathrm{e}-091.00000 \mathrm{e}-01$ Element: 11432 \# of layers: 4

$\mathrm{Kx} \mathrm{Ky} \mathrm{Kz}$ Ss Por

4.80565e+01 4.80565e+01 4.80565e+00 1.00000e-09 2.12000e-01 $4.80565 \mathrm{e}+014.80565 \mathrm{e}+014.80565 \mathrm{e}+00$ 1.00000e-09 2.12000e-01 $1.00000 \mathrm{e}-05$ 1.00000e-05 1.00000e-06 1.00000e-09 1.00000e-01 $1.00000 \mathrm{e}+001.00000 \mathrm{e}+001.00000 \mathrm{e}-011.00000 \mathrm{e}-091.00000 \mathrm{e}-01$ Element: 11433 \# of layers: 5

Kx Ky Kz Ss Por

$1.20274 \mathrm{e}+03$ 1.20274e+03 1.20275e+02 1.00000e-09 7.00000e-02 $4.80565 \mathrm{e}+014.80565 \mathrm{e}+014.80565 \mathrm{e}+00$ 1.00000e-09 2.12000e-01 $4.80565 \mathrm{e}+014.80565 \mathrm{e}+014.80565 \mathrm{e}+00$ 1.00000e-09 2.12000e-01 $1.00000 \mathrm{e}-05$ 1.00000e-05 1.00000e-06 1.00000e-09 1.00000e-01 $1.00000 \mathrm{e}+001.00000 \mathrm{e}+001.00000 \mathrm{e}-011.00000 \mathrm{e}-091.00000 \mathrm{e}-01$ Element: 11434 \# of layers: 5

$\mathrm{Kx} \mathrm{Ky} \mathrm{Kz}$ Ss Por

1.20274e+03 1.20274e+03 1.20275e+02 1.00000e-09 7.00000e-02 $4.80565 \mathrm{e}+014.80565 \mathrm{e}+014.80565 \mathrm{e}+00$ 1.00000e-09 2.12000e-01 $4.80565 \mathrm{e}+014.80565 \mathrm{e}+014.80565 \mathrm{e}+001.00000 \mathrm{e}-092.12000 \mathrm{e}-01$ $1.00000 \mathrm{e}-05$ 1.00000e-05 1.00000e-06 1.00000e-09 1.00000e-01 $1.00000 \mathrm{e}+001.00000 \mathrm{e}+001.00000 \mathrm{e}-011.00000 \mathrm{e}-09$ 1.00000e-01 Element: 11435 \# of layers: 4

Kx Ky Kz Ss Por

7.29233e+02 7.29233e+02 7.29233e+01 1.00000e-09 7.00000e-02 $2.91381 \mathrm{e}+012.91381 \mathrm{e}+012.91381 \mathrm{e}+001.00000 \mathrm{e}-092.12000 \mathrm{e}-01$ 1.00000e-05 1.00000e-05 1.00000e-06 1.00000e-09 1.00000e-01 $1.00000 \mathrm{e}+001.00000 \mathrm{e}+001.00000 \mathrm{e}-011.00000 \mathrm{e}-091.00000 \mathrm{e}-01$ Element: 11436 \# of layers: 4

$\mathrm{Kx} \mathrm{Ky} \mathrm{Kz}$ Ss Por

7.29233e+02 7.29233e+02 7.29233e+01 1.00000e-09 7.00000e-02 $2.91381 \mathrm{e}+012.91381 \mathrm{e}+012.91381 \mathrm{e}+001.00000 \mathrm{e}-092.12000 \mathrm{e}-01$ 
$1.00000 \mathrm{e}-05$ 1.00000e-05 1.00000e-06 1.00000e-09 1.00000e-01 $1.00000 \mathrm{e}+001.00000 \mathrm{e}+001.00000 \mathrm{e}-01$ 1.00000e-09 1.00000e-01 Element: 11437 \# of layers: 4

$\mathrm{Kx} \mathrm{Ky} \mathrm{Kz}$ Ss Por

7.29233e+02 7.29233e+02 7.29233e+01 1.00000e-09 7.00000e-02 $2.91381 \mathrm{e}+012.91381 \mathrm{e}+012.91381 \mathrm{e}+001.00000 \mathrm{e}-092.12000 \mathrm{e}-01$ $1.00000 \mathrm{e}-05$ 1.00000e-05 1.00000e-06 1.00000e-09 1.00000e-01 $1.00000 \mathrm{e}+001.00000 \mathrm{e}+001.00000 \mathrm{e}-01$ 1.00000e-09 1.00000e-01 Element: 11438 \# of layers: 4

$\mathrm{Kx} \mathrm{Ky} \mathrm{Kz}$ Ss Por

7.29233e+02 7.29233e+02 7.29233e+01 1.00000e-09 7.00000e-02 $2.91381 \mathrm{e}+012.91381 \mathrm{e}+012.91381 \mathrm{e}+001.00000 \mathrm{e}-092.12000 \mathrm{e}-01$ $1.00000 \mathrm{e}-05$ 1.00000e-05 1.00000e-06 1.00000e-09 1.00000e-01 $1.00000 \mathrm{e}+001.00000 \mathrm{e}+001.00000 \mathrm{e}-011.00000 \mathrm{e}-09$ 1.00000e-01 Element: 11439 \# of layers: 4

Kx Ky Kz Ss Por

7.29233e+02 7.29233e+02 7.29233e+01 1.00000e-09 7.00000e-02 $2.91381 \mathrm{e}+012.91381 \mathrm{e}+012.91381 \mathrm{e}+001.00000 \mathrm{e}-092.12000 \mathrm{e}-01$ $1.00000 \mathrm{e}-05$ 1.00000e-05 1.00000e-06 1.00000e-09 1.00000e-01 $1.00000 \mathrm{e}+001.00000 \mathrm{e}+001.00000 \mathrm{e}-011.00000 \mathrm{e}-091.00000 \mathrm{e}-01$

Element: 11440 \# of layers: 4

$\mathrm{Kx} \mathrm{Ky} \mathrm{Kz}$ Ss Por

7.29233e+02 7.29233e+02 7.29233e+01 1.00000e-09 7.00000e-02 $2.91381 \mathrm{e}+012.91381 \mathrm{e}+012.91381 \mathrm{e}+001.00000 \mathrm{e}-092.12000 \mathrm{e}-01$ $1.00000 \mathrm{e}-05$ 1.00000e-05 1.00000e-06 1.00000e-09 1.00000e-01 $1.00000 \mathrm{e}+001.00000 \mathrm{e}+001.00000 \mathrm{e}-01$ 1.00000e-09 1.00000e-01 Element: 11441 \# of layers: 5

$\mathrm{Kx} \mathrm{Ky} \mathrm{Kz}$ Ss Por

7.29233e+02 7.29233e+02 7.29233e+01 1.00000e-09 7.00000e-02 $2.91381 \mathrm{e}+012.91381 \mathrm{e}+012.91381 \mathrm{e}+001.00000 \mathrm{e}-092.12000 \mathrm{e}-01$ $2.91381 \mathrm{e}+012.91381 \mathrm{e}+012.91381 \mathrm{e}+001.00000 \mathrm{e}-092.12000 \mathrm{e}-01$ $1.00000 \mathrm{e}-05$ 1.00000e-05 1.00000e-06 1.00000e-09 1.00000e-01 $1.00000 \mathrm{e}+001.00000 \mathrm{e}+001.00000 \mathrm{e}-011.00000 \mathrm{e}-091.00000 \mathrm{e}-01$ Element: 11442 \# of layers: 4

$\mathrm{Kx} \mathrm{Ky} \mathrm{Kz}$ Ss Por

7.29233e+02 7.29233e+02 7.29233e+01 1.00000e-09 7.00000e-02 $2.91381 \mathrm{e}+012.91381 \mathrm{e}+012.91381 \mathrm{e}+001.00000 \mathrm{e}-092.12000 \mathrm{e}-01$ $1.00000 \mathrm{e}-05$ 1.00000e-05 1.00000e-06 1.00000e-09 1.00000e-01 $1.00000 \mathrm{e}+001.00000 \mathrm{e}+001.00000 \mathrm{e}-011.00000 \mathrm{e}-091.00000 \mathrm{e}-01$ Element: 11443 \# of layers: 4

$\mathrm{Kx} \mathrm{Ky} \mathrm{Kz}$ Ss Por

7.29233e+02 7.29233e+02 7.29233e+01 1.00000e-09 7.00000e-02 $2.91381 \mathrm{e}+012.91381 \mathrm{e}+012.91381 \mathrm{e}+001.00000 \mathrm{e}-092.12000 \mathrm{e}-01$ $1.00000 \mathrm{e}-05$ 1.00000e-05 1.00000e-06 1.00000e-09 1.00000e-01 $1.00000 \mathrm{e}+001.00000 \mathrm{e}+001.00000 \mathrm{e}-011.00000 \mathrm{e}-09$ 1.00000e-01 Element: 11444 \# of layers: 4 
$\mathrm{Kx} \mathrm{Ky} \mathrm{Kz}$ Ss Por

7.29233e+02 7.29233e+02 7.29233e+01 1.00000e-09 7.00000e-02

$2.91381 \mathrm{e}+012.91381 \mathrm{e}+012.91381 \mathrm{e}+001.00000 \mathrm{e}-092.12000 \mathrm{e}-01$

$1.00000 \mathrm{e}-05$ 1.00000e-05 1.00000e-06 1.00000e-09 1.00000e-01

$1.00000 \mathrm{e}+001.00000 \mathrm{e}+001.00000 \mathrm{e}-01$ 1.00000e-09 1.00000e-01

Element: 11445 \# of layers: 3

$\mathrm{Kx} \mathrm{Ky} \mathrm{Kz}$ Ss Por

$2.91381 \mathrm{e}+012.91381 \mathrm{e}+012.91381 \mathrm{e}+001.00000 \mathrm{e}-092.12000 \mathrm{e}-01$

$1.00000 \mathrm{e}-05$ 1.00000e-05 1.00000e-06 1.00000e-09 1.00000e-01

$1.00000 \mathrm{e}+001.00000 \mathrm{e}+001.00000 \mathrm{e}-01$ 1.00000e-09 1.00000e-01

Element: 11446 \# of layers: 4

$\mathrm{Kx} \mathrm{Ky} \mathrm{Kz}$ Ss Por

$1.44026 \mathrm{e}+02$ 1.44026e+02 1.44026e+01 1.00000e-09 2.12000e-01

$1.44026 \mathrm{e}+021.44026 \mathrm{e}+02 \quad 1.44026 \mathrm{e}+01$ 1.00000e-09 2.12000e-01

$1.00000 \mathrm{e}-05$ 1.00000e-05 1.00000e-06 1.00000e-09 1.00000e-01

$1.00000 \mathrm{e}+001.00000 \mathrm{e}+001.00000 \mathrm{e}-011.00000 \mathrm{e}-091.00000 \mathrm{e}-01$

Element: 11447 \# of layers: 4

$\mathrm{Kx} \mathrm{Ky} \mathrm{Kz}$ Ss Por

$1.44026 \mathrm{e}+02$ 1.44026e+02 1.44026e+01 1.00000e-09 2.12000e-01

$1.44026 \mathrm{e}+021.44026 \mathrm{e}+021.44026 \mathrm{e}+01$ 1.00000e-09 2.12000e-01

$1.00000 \mathrm{e}-05$ 1.00000e-05 1.00000e-06 1.00000e-09 1.00000e-01

$1.00000 \mathrm{e}+001.00000 \mathrm{e}+001.00000 \mathrm{e}-01$ 1.00000e-09 1.00000e-01

Element: 11448 \# of layers: 4

$\mathrm{Kx} \mathrm{Ky} \mathrm{Kz}$ Ss Por

$1.44026 \mathrm{e}+021.44026 \mathrm{e}+02 \quad 1.44026 \mathrm{e}+01$ 1.00000e-09 2.12000e-01

$1.44026 \mathrm{e}+02$ 1.44026e+02 1.44026e+01 1.00000e-09 2.12000e-01

$1.00000 \mathrm{e}-05$ 1.00000e-05 1.00000e-06 1.00000e-09 1.00000e-01

$1.00000 \mathrm{e}+001.00000 \mathrm{e}+001.00000 \mathrm{e}-01$ 1.00000e-09 1.00000e-01

Element: 11449 \# of layers: 4

$\mathrm{Kx} \mathrm{Ky} \mathrm{Kz}$ Ss Por

$2.91381 \mathrm{e}+012.91381 \mathrm{e}+012.91381 \mathrm{e}+001.00000 \mathrm{e}-092.12000 \mathrm{e}-01$

$2.91381 \mathrm{e}+012.91381 \mathrm{e}+012.91381 \mathrm{e}+001.00000 \mathrm{e}-09$ 2.12000e-01

$1.00000 \mathrm{e}-05$ 1.00000e-05 1.00000e-06 1.00000e-09 1.00000e-01

$1.00000 \mathrm{e}+001.00000 \mathrm{e}+001.00000 \mathrm{e}-01$ 1.00000e-09 1.00000e-01

Element: 11450 \# of layers: 4

Kx Ky Kz Ss Por

$2.91381 \mathrm{e}+012.91381 \mathrm{e}+012.91381 \mathrm{e}+00$ 1.00000e-09 2.12000e-01

$2.91381 \mathrm{e}+012.91381 \mathrm{e}+012.91381 \mathrm{e}+001.00000 \mathrm{e}-092.12000 \mathrm{e}-01$

$1.00000 \mathrm{e}-05$ 1.00000e-05 1.00000e-06 1.00000e-09 1.00000e-01

$1.00000 \mathrm{e}+001.00000 \mathrm{e}+001.00000 \mathrm{e}-01$ 1.00000e-09 1.00000e-01

Element: 11451 \# of layers: 4

$\mathrm{Kx} \mathrm{Ky} \mathrm{Kz}$ Ss Por

$2.91381 \mathrm{e}+012.91381 \mathrm{e}+012.91381 \mathrm{e}+00$ 1.00000e-09 2.12000e-01

$2.91381 \mathrm{e}+012.91381 \mathrm{e}+012.91381 \mathrm{e}+00$ 1.00000e-09 2.12000e-01

$1.00000 \mathrm{e}-051.00000 \mathrm{e}-051.00000 \mathrm{e}-061.00000 \mathrm{e}-091.00000 \mathrm{e}-01$

$1.00000 \mathrm{e}+001.00000 \mathrm{e}+001.00000 \mathrm{e}-011.00000 \mathrm{e}-091.00000 \mathrm{e}-01$ 
Element: 11452 \# of layers: 4

$\mathrm{Kx} \mathrm{Ky} \mathrm{Kz}$ Ss Por

$2.91381 \mathrm{e}+012.91381 \mathrm{e}+012.91381 \mathrm{e}+00$ 1.00000e-09 2.12000e-01

$2.91381 \mathrm{e}+012.91381 \mathrm{e}+012.91381 \mathrm{e}+001.00000 \mathrm{e}-092.12000 \mathrm{e}-01$

$1.00000 \mathrm{e}-05$ 1.00000e-05 1.00000e-06 1.00000e-09 1.00000e-01

$1.00000 \mathrm{e}+001.00000 \mathrm{e}+001.00000 \mathrm{e}-01$ 1.00000e-09 1.00000e-01

Element: 11453 \# of layers: 4

Kx Ky Kz Ss Por

$1.44026 \mathrm{e}+02$ 1.44026e+02 1.44026e+01 1.00000e-09 2.12000e-01

$1.44026 \mathrm{e}+021.44026 \mathrm{e}+02 \quad 1.44026 \mathrm{e}+01$ 1.00000e-09 2.12000e-01

$1.00000 \mathrm{e}-05$ 1.00000e-05 1.00000e-06 1.00000e-09 1.00000e-01

$1.00000 \mathrm{e}+001.00000 \mathrm{e}+001.00000 \mathrm{e}-011.00000 \mathrm{e}-091.00000 \mathrm{e}-01$

Element: 11454 \# of layers: 4

$\mathrm{Kx} \mathrm{Ky} \mathrm{Kz}$ Ss Por

$1.44026 \mathrm{e}+02$ 1.44026e+02 1.44026e+01 1.00000e-09 2.12000e-01

$1.44026 \mathrm{e}+021.44026 \mathrm{e}+02 \quad 1.44026 \mathrm{e}+01$ 1.00000e-09 2.12000e-01

$1.00000 \mathrm{e}-05$ 1.00000e-05 1.00000e-06 1.00000e-09 1.00000e-01

$1.00000 \mathrm{e}+001.00000 \mathrm{e}+001.00000 \mathrm{e}-01$ 1.00000e-09 1.00000e-01

Element: 11455 \# of layers: 4

$\mathrm{Kx} \mathrm{Ky} \mathrm{Kz}$ Ss Por

$1.44026 \mathrm{e}+02$ 1.44026e+02 1.44026e+01 1.00000e-09 2.12000e-01

$1.44026 \mathrm{e}+02$ 1.44026e+02 1.44026e+01 1.00000e-09 2.12000e-01

$1.00000 \mathrm{e}-05$ 1.00000e-05 1.00000e-06 1.00000e-09 1.00000e-01

$1.00000 \mathrm{e}+001.00000 \mathrm{e}+001.00000 \mathrm{e}-011.00000 \mathrm{e}-091.00000 \mathrm{e}-01$

Element: 11456 \# of layers: 4

$\mathrm{Kx} \mathrm{Ky} \mathrm{Kz}$ Ss Por

$1.44026 \mathrm{e}+02$ 1.44026e+02 1.44026e+01 1.00000e-09 2.12000e-01

$1.44026 \mathrm{e}+021.44026 \mathrm{e}+02$ 1.44026e+01 1.00000e-09 2.12000e-01

$1.00000 \mathrm{e}-05$ 1.00000e-05 1.00000e-06 1.00000e-09 1.00000e-01

$1.00000 \mathrm{e}+001.00000 \mathrm{e}+001.00000 \mathrm{e}-011.00000 \mathrm{e}-091.00000 \mathrm{e}-01$

Element: 11457 \# of layers: 4

$\mathrm{Kx} \mathrm{Ky} \mathrm{Kz}$ Ss Por

$1.44026 \mathrm{e}+02$ 1.44026e+02 1.44026e+01 1.00000e-09 2.12000e-01

$1.44026 \mathrm{e}+021.44026 \mathrm{e}+02$ 1.44026e+01 1.00000e-09 2.12000e-01

$1.00000 \mathrm{e}-05$ 1.00000e-05 1.00000e-06 1.00000e-09 1.00000e-01

$1.00000 \mathrm{e}+001.00000 \mathrm{e}+001.00000 \mathrm{e}-011.00000 \mathrm{e}-09$ 1.00000e-01

Element: 11458 \# of layers: 4

Kx Ky Kz Ss Por

$1.44026 \mathrm{e}+02$ 1.44026e+02 1.44026e+01 1.00000e-09 2.12000e-01

$1.44026 \mathrm{e}+021.44026 \mathrm{e}+021.44026 \mathrm{e}+01$ 1.00000e-09 2.12000e-01

$1.00000 \mathrm{e}-05$ 1.00000e-05 1.00000e-06 1.00000e-09 1.00000e-01

$1.00000 \mathrm{e}+001.00000 \mathrm{e}+001.00000 \mathrm{e}-011.00000 \mathrm{e}-091.00000 \mathrm{e}-01$

Element: 11459 \# of layers: 4

$\mathrm{Kx} \mathrm{Ky} \mathrm{Kz}$ Ss Por

$1.44026 \mathrm{e}+021.44026 \mathrm{e}+02$ 1.44026e+01 1.00000e-09 2.12000e-01

$1.44026 \mathrm{e}+021.44026 \mathrm{e}+021.44026 \mathrm{e}+01$ 1.00000e-09 2.12000e-01 
$1.00000 \mathrm{e}-05$ 1.00000e-05 1.00000e-06 1.00000e-09 1.00000e-01 $1.00000 \mathrm{e}+001.00000 \mathrm{e}+001.00000 \mathrm{e}-01$ 1.00000e-09 1.00000e-01 Element: 11460 \# of layers: 4

Kx Ky Kz Ss Por

$1.44026 \mathrm{e}+02$ 1.44026e+02 1.44026e+01 1.00000e-09 2.12000e-01 $1.44026 \mathrm{e}+021.44026 \mathrm{e}+02 \quad 1.44026 \mathrm{e}+01$ 1.00000e-09 2.12000e-01 1.00000e-05 1.00000e-05 1.00000e-06 1.00000e-09 1.00000e-01 $1.00000 \mathrm{e}+001.00000 \mathrm{e}+001.00000 \mathrm{e}-01$ 1.00000e-09 1.00000e-01 Element: 11461 \# of layers: 4

$\mathrm{Kx} \mathrm{Ky} \mathrm{Kz}$ Ss Por

$1.44026 \mathrm{e}+02$ 1.44026e+02 1.44026e+01 1.00000e-09 2.12000e-01 $1.44026 \mathrm{e}+02 \quad 1.44026 \mathrm{e}+02 \quad 1.44026 \mathrm{e}+01$ 1.00000e-09 2.12000e-01 $1.00000 \mathrm{e}-05$ 1.00000e-05 1.00000e-06 1.00000e-09 1.00000e-01 $1.00000 \mathrm{e}+001.00000 \mathrm{e}+001.00000 \mathrm{e}-011.00000 \mathrm{e}-09$ 1.00000e-01 Element: 11462 \# of layers: 4

Kx Ky Kz Ss Por

$1.44026 \mathrm{e}+02$ 1.44026e+02 1.44026e+01 1.00000e-09 2.12000e-01 $1.44026 \mathrm{e}+021.44026 \mathrm{e}+021.44026 \mathrm{e}+01$ 1.00000e-09 2.12000e-01 $1.00000 \mathrm{e}-051.00000 \mathrm{e}-051.00000 \mathrm{e}-061.00000 \mathrm{e}-091.00000 \mathrm{e}-01$ $1.00000 \mathrm{e}+001.00000 \mathrm{e}+001.00000 \mathrm{e}-011.00000 \mathrm{e}-091.00000 \mathrm{e}-01$ Element: 11463 \# of layers: 4

$\mathrm{Kx} \mathrm{Ky} \mathrm{Kz}$ Ss Por

1.13801e+02 1.13801e+02 1.13801e+01 1.00000e-09 2.12000e-01 $1.13801 \mathrm{e}+021.13801 \mathrm{e}+02$ 1.13801e+01 1.00000e-09 2.12000e-01 $1.00000 \mathrm{e}-05$ 1.00000e-05 1.00000e-06 1.00000e-09 1.00000e-01 $1.00000 \mathrm{e}+001.00000 \mathrm{e}+001.00000 \mathrm{e}-01$ 1.00000e-09 1.00000e-01 Element: 11464 \# of layers: 4

$\mathrm{Kx} \mathrm{Ky} \mathrm{Kz}$ Ss Por

$1.13801 \mathrm{e}+02$ 1.13801e+02 1.13801e+01 1.00000e-09 2.12000e-01 $1.13801 \mathrm{e}+02$ 1.13801e+02 1.13801e+01 1.00000e-09 2.12000e-01 $1.00000 \mathrm{e}-05$ 1.00000e-05 1.00000e-06 1.00000e-09 1.00000e-01 $1.00000 \mathrm{e}+001.00000 \mathrm{e}+001.00000 \mathrm{e}-011.00000 \mathrm{e}-091.00000 \mathrm{e}-01$ Element: 11465 \# of layers: 4

$\mathrm{Kx} \mathrm{Ky} \mathrm{Kz}$ Ss Por

$1.13801 \mathrm{e}+02$ 1.13801e+02 1.13801e+01 1.00000e-09 2.12000e-01

$1.13801 \mathrm{e}+02$ 1.13801e+02 1.13801e+01 1.00000e-09 2.12000e-01 1.00000e-05 1.00000e-05 1.00000e-06 1.00000e-09 1.00000e-01 $1.00000 \mathrm{e}+001.00000 \mathrm{e}+001.00000 \mathrm{e}-011.00000 \mathrm{e}-091.00000 \mathrm{e}-01$ Element: 11466 \# of layers: 4

$\mathrm{Kx} \mathrm{Ky} \mathrm{Kz}$ Ss Por

$1.13801 \mathrm{e}+02$ 1.13801e+02 1.13801e+01 1.00000e-09 2.12000e-01 $1.13801 \mathrm{e}+021.13801 \mathrm{e}+02$ 1.13801e+01 1.00000e-09 2.12000e-01 $1.00000 \mathrm{e}-05$ 1.00000e-05 1.00000e-06 1.00000e-09 1.00000e-01 $1.00000 \mathrm{e}+001.00000 \mathrm{e}+001.00000 \mathrm{e}-011.00000 \mathrm{e}-091.00000 \mathrm{e}-01$ Element: 11467 \# of layers: 4

Kx Ky Kz Ss Por 
1.13801e+02 1.13801e+02 1.13801e+01 1.00000e-09 2.12000e-01 $1.13801 \mathrm{e}+021.13801 \mathrm{e}+02$ 1.13801e+01 1.00000e-09 2.12000e-01 $1.00000 \mathrm{e}-051.00000 \mathrm{e}-05$ 1.00000e-06 1.00000e-09 1.00000e-01

$1.00000 \mathrm{e}+001.00000 \mathrm{e}+001.00000 \mathrm{e}-011.00000 \mathrm{e}-091.00000 \mathrm{e}-01$

Element: 11468 \# of layers: 4

$\mathrm{Kx} \mathrm{Ky} \mathrm{Kz}$ Ss Por

$1.44026 \mathrm{e}+02$ 1.44026e+02 1.44026e+01 1.00000e-09 2.12000e-01

$1.44026 \mathrm{e}+021.44026 \mathrm{e}+02 \quad 1.44026 \mathrm{e}+01 \quad 1.00000 \mathrm{e}-092.12000 \mathrm{e}-01$

$1.00000 \mathrm{e}-05$ 1.00000e-05 1.00000e-06 1.00000e-09 1.00000e-01

$1.00000 \mathrm{e}+001.00000 \mathrm{e}+001.00000 \mathrm{e}-011.00000 \mathrm{e}-091.00000 \mathrm{e}-01$

Element: 11469 \# of layers: 4

Kx Ky Kz Ss Por

$1.44026 \mathrm{e}+02$ 1.44026e+02 1.44026e+01 1.00000e-09 2.12000e-01

$1.44026 \mathrm{e}+021.44026 \mathrm{e}+02 \quad 1.44026 \mathrm{e}+01$ 1.00000e-09 2.12000e-01

$1.00000 \mathrm{e}-05$ 1.00000e-05 1.00000e-06 1.00000e-09 1.00000e-01

$1.00000 \mathrm{e}+001.00000 \mathrm{e}+001.00000 \mathrm{e}-011.00000 \mathrm{e}-091.00000 \mathrm{e}-01$

Element: 11470 \# of layers: 4

$\mathrm{Kx} \mathrm{Ky} \mathrm{Kz}$ Ss Por

$1.13801 \mathrm{e}+02$ 1.13801e+02 1.13801e+01 1.00000e-09 2.12000e-01

$1.13801 \mathrm{e}+021.13801 \mathrm{e}+02$ 1.13801e+01 1.00000e-09 2.12000e-01

$1.00000 \mathrm{e}-05$ 1.00000e-05 1.00000e-06 1.00000e-09 1.00000e-01

$1.00000 \mathrm{e}+001.00000 \mathrm{e}+001.00000 \mathrm{e}-011.00000 \mathrm{e}-091.00000 \mathrm{e}-01$

Element: 11471 \# of layers: 4

Kx Ky Kz Ss Por

$1.13801 \mathrm{e}+02$ 1.13801e+02 1.13801e+01 1.00000e-09 2.12000e-01

$1.13801 \mathrm{e}+021.13801 \mathrm{e}+021.13801 \mathrm{e}+01$ 1.00000e-09 2.12000e-01

$1.00000 \mathrm{e}-05$ 1.00000e-05 1.00000e-06 1.00000e-09 1.00000e-01

$1.00000 \mathrm{e}+001.00000 \mathrm{e}+001.00000 \mathrm{e}-011.00000 \mathrm{e}-091.00000 \mathrm{e}-01$

Element: 11472 \# of layers: 4

$\mathrm{Kx} \mathrm{Ky} \mathrm{Kz}$ Ss Por

4.80565e+01 4.80565e+01 4.80565e+00 1.00000e-09 2.12000e-01

$4.80565 \mathrm{e}+014.80565 \mathrm{e}+014.80565 \mathrm{e}+00$ 1.00000e-09 2.12000e-01

1.00000e-05 1.00000e-05 1.00000e-06 1.00000e-09 1.00000e-01

$1.00000 \mathrm{e}+001.00000 \mathrm{e}+001.00000 \mathrm{e}-011.00000 \mathrm{e}-091.00000 \mathrm{e}-01$

Element: 11473 \# of layers: 4

Kx Ky Kz Ss Por

$4.80565 \mathrm{e}+014.80565 \mathrm{e}+014.80565 \mathrm{e}+00$ 1.00000e-09 2.12000e-01

$4.80565 \mathrm{e}+014.80565 \mathrm{e}+014.80565 \mathrm{e}+001.00000 \mathrm{e}-092.12000 \mathrm{e}-01$

$1.00000 \mathrm{e}-05$ 1.00000e-05 1.00000e-06 1.00000e-09 1.00000e-01

$1.00000 \mathrm{e}+001.00000 \mathrm{e}+001.00000 \mathrm{e}-01$ 1.00000e-09 1.00000e-01

Element: 11474 \# of layers: 4

Kx Ky Kz Ss Por

4.80565e+01 4.80565e+01 4.80565e+00 1.00000e-09 2.12000e-01

4.80565e+01 4.80565e+01 4.80565e+00 1.00000e-09 2.12000e-01

$1.00000 \mathrm{e}-05$ 1.00000e-05 1.00000e-06 1.00000e-09 1.00000e-01

$1.00000 \mathrm{e}+001.00000 \mathrm{e}+001.00000 \mathrm{e}-011.00000 \mathrm{e}-091.00000 \mathrm{e}-01$ 
Element: 11475 \# of layers: 4

$\mathrm{Kx} \mathrm{Ky} \mathrm{Kz}$ Ss Por

$2.91381 \mathrm{e}+012.91381 \mathrm{e}+012.91381 \mathrm{e}+00$ 1.00000e-09 2.12000e-01

$2.91381 \mathrm{e}+012.91381 \mathrm{e}+012.91381 \mathrm{e}+001.00000 \mathrm{e}-092.12000 \mathrm{e}-01$

$1.00000 \mathrm{e}-05$ 1.00000e-05 1.00000e-06 1.00000e-09 1.00000e-01

$1.00000 \mathrm{e}+001.00000 \mathrm{e}+001.00000 \mathrm{e}-011.00000 \mathrm{e}-09$ 1.00000e-01

Element: 11476 \# of layers: 4

$\mathrm{Kx} \mathrm{Ky} \mathrm{Kz}$ Ss Por

$2.91381 \mathrm{e}+012.91381 \mathrm{e}+012.91381 \mathrm{e}+001.00000 \mathrm{e}-092.12000 \mathrm{e}-01$

$2.91381 \mathrm{e}+012.91381 \mathrm{e}+012.91381 \mathrm{e}+001.00000 \mathrm{e}-092.12000 \mathrm{e}-01$

1.00000e-05 1.00000e-05 1.00000e-06 1.00000e-09 1.00000e-01

$1.00000 \mathrm{e}+001.00000 \mathrm{e}+001.00000 \mathrm{e}-011.00000 \mathrm{e}-091.00000 \mathrm{e}-01$

Element: 11477 \# of layers: 4

$\mathrm{Kx} \mathrm{Ky} \mathrm{Kz}$ Ss Por

$1.44026 \mathrm{e}+02$ 1.44026e+02 1.44026e+01 1.00000e-09 2.12000e-01

$1.44026 \mathrm{e}+021.44026 \mathrm{e}+021.44026 \mathrm{e}+01$ 1.00000e-09 2.12000e-01

$1.00000 \mathrm{e}-05$ 1.00000e-05 1.00000e-06 1.00000e-09 1.00000e-01

$1.00000 \mathrm{e}+001.00000 \mathrm{e}+001.00000 \mathrm{e}-011.00000 \mathrm{e}-091.00000 \mathrm{e}-01$

Element: 11478 \# of layers: 4

$\mathrm{Kx} \mathrm{Ky} \mathrm{Kz}$ Ss Por

$1.13801 \mathrm{e}+021.13801 \mathrm{e}+02$ 1.13801e+01 1.00000e-09 2.12000e-01

$1.13801 \mathrm{e}+02$ 1.13801e+02 1.13801e+01 1.00000e-09 2.12000e-01

$1.00000 \mathrm{e}-05$ 1.00000e-05 1.00000e-06 1.00000e-09 1.00000e-01

$1.00000 \mathrm{e}+001.00000 \mathrm{e}+001.00000 \mathrm{e}-011.00000 \mathrm{e}-091.00000 \mathrm{e}-01$

Element: 11479 \# of layers: 4

$\mathrm{Kx} \mathrm{Ky} \mathrm{Kz}$ Ss Por

4.80565e+01 4.80565e+01 4.80565e+00 1.00000e-09 2.12000e-01

$4.80565 \mathrm{e}+014.80565 \mathrm{e}+014.80565 \mathrm{e}+001.00000 \mathrm{e}-09$ 2.12000e-01

$1.00000 \mathrm{e}-05$ 1.00000e-05 1.00000e-06 1.00000e-09 1.00000e-01

$1.00000 \mathrm{e}+001.00000 \mathrm{e}+001.00000 \mathrm{e}-011.00000 \mathrm{e}-091.00000 \mathrm{e}-01$

Element: 11480 \# of layers: 5

Kx Ky Kz Ss Por

$1.51586 \mathrm{e}+011.51586 \mathrm{e}+011.51586 \mathrm{e}+00$ 1.00000e-09 2.12000e-01

$1.51586 \mathrm{e}+011.51586 \mathrm{e}+011.51586 \mathrm{e}+001.00000 \mathrm{e}-092.12000 \mathrm{e}-01$

$1.51586 \mathrm{e}+011.51586 \mathrm{e}+011.51586 \mathrm{e}+001.00000 \mathrm{e}-092.12000 \mathrm{e}-01$

$1.00000 \mathrm{e}-05$ 1.00000e-05 1.00000e-06 1.00000e-09 1.00000e-01

$1.00000 \mathrm{e}+001.00000 \mathrm{e}+001.00000 \mathrm{e}-011.00000 \mathrm{e}-091.00000 \mathrm{e}-01$

Element: 11481 \# of layers: 5

$\mathrm{Kx} \mathrm{Ky} \mathrm{Kz}$ Ss Por

$1.51586 \mathrm{e}+011.51586 \mathrm{e}+011.51586 \mathrm{e}+001.00000 \mathrm{e}-092.12000 \mathrm{e}-01$

$1.51586 \mathrm{e}+011.51586 \mathrm{e}+011.51586 \mathrm{e}+001.00000 \mathrm{e}-092.12000 \mathrm{e}-01$

$1.51586 \mathrm{e}+011.51586 \mathrm{e}+011.51586 \mathrm{e}+001.00000 \mathrm{e}-092.12000 \mathrm{e}-01$

$1.00000 \mathrm{e}-05$ 1.00000e-05 1.00000e-06 1.00000e-09 1.00000e-01

$1.00000 \mathrm{e}+001.00000 \mathrm{e}+001.00000 \mathrm{e}-01$ 1.00000e-09 1.00000e-01

Element: 11482 \# of layers: 6

Kx Ky Kz Ss Por 
3.79375e+02 3.79375e+02 3.79375e+01 1.00000e-09 7.00000e-02 $1.51586 \mathrm{e}+01$ 1.51586e+01 1.51586e+00 1.00000e-09 2.12000e-01 $1.51586 \mathrm{e}+011.51586 \mathrm{e}+011.51586 \mathrm{e}+001.00000 \mathrm{e}-092.12000 \mathrm{e}-01$ $1.51586 \mathrm{e}+011.51586 \mathrm{e}+011.51586 \mathrm{e}+001.00000 \mathrm{e}-092.12000 \mathrm{e}-01$ $1.00000 \mathrm{e}-05$ 1.00000e-05 1.00000e-06 1.00000e-09 1.00000e-01 $1.00000 \mathrm{e}+001.00000 \mathrm{e}+001.00000 \mathrm{e}-011.00000 \mathrm{e}-091.00000 \mathrm{e}-01$ Element: 11483 \# of layers: 5

Kx Ky Kz Ss Por

3.79375e+02 3.79375e+02 3.79375e+01 1.00000e-09 7.00000e-02 $1.51586 \mathrm{e}+011.51586 \mathrm{e}+011.51586 \mathrm{e}+001.00000 \mathrm{e}-092.12000 \mathrm{e}-01$ $1.51586 \mathrm{e}+011.51586 \mathrm{e}+011.51586 \mathrm{e}+001.00000 \mathrm{e}-092.12000 \mathrm{e}-01$ $1.00000 \mathrm{e}-05$ 1.00000e-05 1.00000e-06 1.00000e-09 1.00000e-01 $1.00000 \mathrm{e}+001.00000 \mathrm{e}+001.00000 \mathrm{e}-011.00000 \mathrm{e}-09$ 1.00000e-01 Element: 11484 \# of layers: 5

$\mathrm{Kx} \mathrm{Ky} \mathrm{Kz}$ Ss Por

3.79375e+02 3.79375e+02 3.79375e+01 1.00000e-09 7.00000e-02 $1.51586 \mathrm{e}+011.51586 \mathrm{e}+011.51586 \mathrm{e}+001.00000 \mathrm{e}-092.12000 \mathrm{e}-01$ $1.51586 \mathrm{e}+011.51586 \mathrm{e}+011.51586 \mathrm{e}+001.00000 \mathrm{e}-092.12000 \mathrm{e}-01$ $1.00000 \mathrm{e}-05$ 1.00000e-05 1.00000e-06 1.00000e-09 1.00000e-01 $1.00000 \mathrm{e}+001.00000 \mathrm{e}+001.00000 \mathrm{e}-011.00000 \mathrm{e}-091.00000 \mathrm{e}-01$ Element: 11485 \# of layers: 5

$\mathrm{Kx} \mathrm{Ky} \mathrm{Kz}$ Ss Por

3.79375e+02 3.79375e+02 3.79375e+01 1.00000e-09 7.00000e-02 $1.51586 \mathrm{e}+011.51586 \mathrm{e}+011.51586 \mathrm{e}+001.00000 \mathrm{e}-092.12000 \mathrm{e}-01$ $1.51586 \mathrm{e}+011.51586 \mathrm{e}+011.51586 \mathrm{e}+001.00000 \mathrm{e}-092.12000 \mathrm{e}-01$ $1.00000 \mathrm{e}-05$ 1.00000e-05 1.00000e-06 1.00000e-09 1.00000e-01 $1.00000 \mathrm{e}+001.00000 \mathrm{e}+001.00000 \mathrm{e}-011.00000 \mathrm{e}-09$ 1.00000e-01 Element: 11486 \# of layers: 5

Kx Ky Kz Ss Por

3.79375e+02 3.79375e+02 3.79375e+01 1.00000e-09 7.00000e-02 $1.51586 \mathrm{e}+011.51586 \mathrm{e}+011.51586 \mathrm{e}+001.00000 \mathrm{e}-092.12000 \mathrm{e}-01$ $1.51586 \mathrm{e}+011.51586 \mathrm{e}+011.51586 \mathrm{e}+001.00000 \mathrm{e}-092.12000 \mathrm{e}-01$ $1.00000 \mathrm{e}-05$ 1.00000e-05 1.00000e-06 1.00000e-09 1.00000e-01 $1.00000 \mathrm{e}+001.00000 \mathrm{e}+001.00000 \mathrm{e}-011.00000 \mathrm{e}-091.00000 \mathrm{e}-01$ Element: 11487 \# of layers: 5

$\mathrm{Kx} \mathrm{Ky} \mathrm{Kz}$ Ss Por

3.79375e+02 3.79375e+02 3.79375e+01 1.00000e-09 7.00000e-02 $1.51586 \mathrm{e}+011.51586 \mathrm{e}+011.51586 \mathrm{e}+001.00000 \mathrm{e}-092.12000 \mathrm{e}-01$ $1.51586 \mathrm{e}+011.51586 \mathrm{e}+011.51586 \mathrm{e}+001.00000 \mathrm{e}-092.12000 \mathrm{e}-01$ $1.00000 \mathrm{e}-05$ 1.00000e-05 1.00000e-06 1.00000e-09 1.00000e-01 $1.00000 \mathrm{e}+001.00000 \mathrm{e}+001.00000 \mathrm{e}-011.00000 \mathrm{e}-091.00000 \mathrm{e}-01$ Element: 11488 \# of layers: 5

$\mathrm{Kx} \mathrm{Ky} \mathrm{Kz}$ Ss Por

3.79375e+02 3.79375e+02 3.79375e+01 1.00000e-09 7.00000e-02 $1.51586 \mathrm{e}+011.51586 \mathrm{e}+011.51586 \mathrm{e}+001.00000 \mathrm{e}-092.12000 \mathrm{e}-01$ $1.51586 \mathrm{e}+011.51586 \mathrm{e}+011.51586 \mathrm{e}+001.00000 \mathrm{e}-092.12000 \mathrm{e}-01$ 
$1.00000 \mathrm{e}-05$ 1.00000e-05 1.00000e-06 1.00000e-09 1.00000e-01 $1.00000 \mathrm{e}+001.00000 \mathrm{e}+001.00000 \mathrm{e}-01$ 1.00000e-09 1.00000e-01 Element: 11489 \# of layers: 5

Kx Ky Kz Ss Por

3.79375e+02 3.79375e+02 3.79375e+01 1.00000e-09 7.00000e-02

$1.51586 \mathrm{e}+011.51586 \mathrm{e}+011.51586 \mathrm{e}+001.00000 \mathrm{e}-092.12000 \mathrm{e}-01$

$1.51586 \mathrm{e}+011.51586 \mathrm{e}+011.51586 \mathrm{e}+001.00000 \mathrm{e}-092.12000 \mathrm{e}-01$ $1.00000 \mathrm{e}-05$ 1.00000e-05 1.00000e-06 1.00000e-09 1.00000e-01

$1.00000 \mathrm{e}+001.00000 \mathrm{e}+001.00000 \mathrm{e}-011.00000 \mathrm{e}-091.00000 \mathrm{e}-01$

Element: 11490 \# of layers: 5

$\mathrm{Kx} \mathrm{Ky} \mathrm{Kz}$ Ss Por

3.79375e+02 3.79375e+02 3.79375e+01 1.00000e-09 7.00000e-02

$1.51586 \mathrm{e}+011.51586 \mathrm{e}+011.51586 \mathrm{e}+001.00000 \mathrm{e}-092.12000 \mathrm{e}-01$

$1.51586 \mathrm{e}+011.51586 \mathrm{e}+011.51586 \mathrm{e}+001.00000 \mathrm{e}-092.12000 \mathrm{e}-01$ $1.00000 \mathrm{e}-05$ 1.00000e-05 1.00000e-06 1.00000e-09 1.00000e-01

$1.00000 \mathrm{e}+001.00000 \mathrm{e}+001.00000 \mathrm{e}-011.00000 \mathrm{e}-091.00000 \mathrm{e}-01$

Element: 11491 \# of layers: 6

$\mathrm{Kx} \mathrm{Ky} \mathrm{Kz}$ Ss Por

3.79375e+02 3.79375e+02 3.79375e+01 1.00000e-09 7.00000e-02

$1.51586 \mathrm{e}+011.51586 \mathrm{e}+011.51586 \mathrm{e}+001.00000 \mathrm{e}-092.12000 \mathrm{e}-01$

$1.51586 \mathrm{e}+011.51586 \mathrm{e}+011.51586 \mathrm{e}+001.00000 \mathrm{e}-092.12000 \mathrm{e}-01$

$1.51586 \mathrm{e}+01$ 1.51586e+01 1.51586e+00 1.00000e-09 2.12000e-01 $1.00000 \mathrm{e}-05$ 1.00000e-05 1.00000e-06 1.00000e-09 1.00000e-01

$1.00000 \mathrm{e}+001.00000 \mathrm{e}+001.00000 \mathrm{e}-011.00000 \mathrm{e}-09$ 1.00000e-01

Element: 11492 \# of layers: 6

$\mathrm{Kx} \mathrm{Ky} \mathrm{Kz}$ Ss Por

$1.43403 \mathrm{e}+03$ 1.43403e+03 1.43403e+02 1.00000e-09 7.00000e-02

$5.72975 \mathrm{e}+015.72975 \mathrm{e}+015.72975 \mathrm{e}+001.00000 \mathrm{e}-09$ 2.12000e-01

$5.72975 \mathrm{e}+015.72975 \mathrm{e}+015.72975 \mathrm{e}+001.00000 \mathrm{e}-092.12000 \mathrm{e}-01$

$5.72975 \mathrm{e}+01$ 5.72975e+01 5.72975e+00 1.00000e-09 2.12000e-01

$1.00000 \mathrm{e}-05$ 1.00000e-05 1.00000e-06 1.00000e-09 1.00000e-01

$1.00000 \mathrm{e}+001.00000 \mathrm{e}+001.00000 \mathrm{e}-011.00000 \mathrm{e}-091.00000 \mathrm{e}-01$

Element: 11493 \# of layers: 6

$\mathrm{Kx} \mathrm{Ky} \mathrm{Kz}$ Ss Por

1.43403e+03 1.43403e+03 1.43403e+02 1.00000e-09 7.00000e-02

$5.72975 \mathrm{e}+015.72975 \mathrm{e}+015.72975 \mathrm{e}+00$ 1.00000e-09 2.12000e-01

$5.72975 \mathrm{e}+015.72975 \mathrm{e}+015.72975 \mathrm{e}+001.00000 \mathrm{e}-092.12000 \mathrm{e}-01$

$5.72975 \mathrm{e}+015.72975 \mathrm{e}+015.72975 \mathrm{e}+00$ 1.00000e-09 2.12000e-01

$1.00000 \mathrm{e}-05$ 1.00000e-05 1.00000e-06 1.00000e-09 1.00000e-01

$1.00000 \mathrm{e}+001.00000 \mathrm{e}+001.00000 \mathrm{e}-011.00000 \mathrm{e}-091.00000 \mathrm{e}-01$

Element: 11494 \# of layers: 6

$\mathrm{Kx} \mathrm{Ky} \mathrm{Kz}$ Ss Por

$1.43403 \mathrm{e}+03$ 1.43403e+03 1.43403e+02 1.00000e-09 7.00000e-02

5.72975e+01 5.72975e+01 5.72975e+00 1.00000e-09 2.12000e-01

$5.72975 \mathrm{e}+015.72975 \mathrm{e}+015.72975 \mathrm{e}+00$ 1.00000e-09 2.12000e-01

$5.72975 \mathrm{e}+015.72975 \mathrm{e}+015.72975 \mathrm{e}+001.00000 \mathrm{e}-092.12000 \mathrm{e}-01$ 
$1.00000 \mathrm{e}-05$ 1.00000e-05 1.00000e-06 1.00000e-09 1.00000e-01 $1.00000 \mathrm{e}+001.00000 \mathrm{e}+001.00000 \mathrm{e}-01$ 1.00000e-09 1.00000e-01 Element: 11495 \# of layers: 5

Kx Ky Kz Ss Por

$1.43403 \mathrm{e}+03$ 1.43403e+03 1.43403e+02 1.00000e-09 7.00000e-02

$5.72975 \mathrm{e}+015.72975 \mathrm{e}+015.72975 \mathrm{e}+00$ 1.00000e-09 2.12000e-01

$5.72975 \mathrm{e}+015.72975 \mathrm{e}+015.72975 \mathrm{e}+00$ 1.00000e-09 2.12000e-01

$1.00000 \mathrm{e}-05$ 1.00000e-05 1.00000e-06 1.00000e-09 1.00000e-01

$1.00000 \mathrm{e}+001.00000 \mathrm{e}+001.00000 \mathrm{e}-011.00000 \mathrm{e}-091.00000 \mathrm{e}-01$

Element: 11496 \# of layers: 5

$\mathrm{Kx} \mathrm{Ky} \mathrm{Kz}$ Ss Por

3.79375e+02 3.79375e+02 3.79375e+01 1.00000e-09 7.00000e-02

$1.51586 \mathrm{e}+011.51586 \mathrm{e}+011.51586 \mathrm{e}+001.00000 \mathrm{e}-092.12000 \mathrm{e}-01$

$1.51586 \mathrm{e}+011.51586 \mathrm{e}+011.51586 \mathrm{e}+001.00000 \mathrm{e}-092.12000 \mathrm{e}-01$ $1.00000 \mathrm{e}-05$ 1.00000e-05 1.00000e-06 1.00000e-09 1.00000e-01

$1.00000 \mathrm{e}+001.00000 \mathrm{e}+001.00000 \mathrm{e}-011.00000 \mathrm{e}-091.00000 \mathrm{e}-01$

Element: 11497 \# of layers: 4

$\mathrm{Kx} \mathrm{Ky} \mathrm{Kz}$ Ss Por

5.14075e+02 5.14075e+02 5.14075e+01 1.00000e-09 7.00000e-02

$2.05407 \mathrm{e}+012.05407 \mathrm{e}+012.05407 \mathrm{e}+00$ 1.00000e-09 2.12000e-01

$1.00000 \mathrm{e}-05$ 1.00000e-05 1.00000e-06 1.00000e-09 1.00000e-01

$1.00000 \mathrm{e}+001.00000 \mathrm{e}+001.00000 \mathrm{e}-011.00000 \mathrm{e}-091.00000 \mathrm{e}-01$

Element: 11498 \# of layers: 4

Kx Ky Kz Ss Por

5.14075e+02 5.14075e+02 5.14075e+01 1.00000e-09 7.00000e-02

$2.05407 \mathrm{e}+012.05407 \mathrm{e}+012.05407 \mathrm{e}+00$ 1.00000e-09 2.12000e-01

$1.00000 \mathrm{e}-05$ 1.00000e-05 1.00000e-06 1.00000e-09 1.00000e-01

$1.00000 \mathrm{e}+001.00000 \mathrm{e}+001.00000 \mathrm{e}-011.00000 \mathrm{e}-091.00000 \mathrm{e}-01$

Element: 11499 \# of layers: 4

$\mathrm{Kx} \mathrm{Ky} \mathrm{Kz}$ Ss Por

5.14075e+02 5.14075e+02 5.14075e+01 1.00000e-09 7.00000e-02

$2.05407 \mathrm{e}+012.05407 \mathrm{e}+012.05407 \mathrm{e}+00$ 1.00000e-09 2.12000e-01

$1.00000 \mathrm{e}-05$ 1.00000e-05 1.00000e-06 1.00000e-09 1.00000e-01

$1.00000 \mathrm{e}+001.00000 \mathrm{e}+001.00000 \mathrm{e}-011.00000 \mathrm{e}-091.00000 \mathrm{e}-01$

Element: 11500 \# of layers: 4

$\mathrm{Kx} \mathrm{Ky} \mathrm{Kz}$ Ss Por

5.14075e+02 5.14075e+02 5.14075e+01 1.00000e-09 7.00000e-02

$2.05407 \mathrm{e}+012.05407 \mathrm{e}+012.05407 \mathrm{e}+00$ 1.00000e-09 2.12000e-01

$1.00000 \mathrm{e}-051.00000 \mathrm{e}-051.00000 \mathrm{e}-061.00000 \mathrm{e}-091.00000 \mathrm{e}-01$

$1.00000 \mathrm{e}+001.00000 \mathrm{e}+001.00000 \mathrm{e}-01$ 1.00000e-09 1.00000e-01

Element: 11501 \# of layers: 5

$\mathrm{Kx} \mathrm{Ky} \mathrm{Kz}$ Ss Por

5.14075e+02 5.14075e+02 5.14075e+01 1.00000e-09 7.00000e-02 2.05407e+01 2.05407e+01 2.05407e+00 1.00000e-09 2.12000e-01 $1.00000 \mathrm{e}-05$ 1.00000e-05 1.00000e-06 1.00000e-09 1.00000e-01

$1.00000 \mathrm{e}+001.00000 \mathrm{e}+001.00000 \mathrm{e}-011.00000 \mathrm{e}-091.00000 \mathrm{e}-01$ 
1.00000e-06 1.00000e-06 1.00000e-06 1.00000e-09 5.00000e-02

Element: 11502 \# of layers: 5

Kx Ky Kz Ss Por

5.14075e+02 5.14075e+02 5.14075e+01 1.00000e-09 7.00000e-02

$2.05407 \mathrm{e}+012.05407 \mathrm{e}+012.05407 \mathrm{e}+00$ 1.00000e-09 2.12000e-01

$1.00000 \mathrm{e}-05$ 1.00000e-05 1.00000e-06 1.00000e-09 1.00000e-01

$1.00000 \mathrm{e}+001.00000 \mathrm{e}+001.00000 \mathrm{e}-011.00000 \mathrm{e}-091.00000 \mathrm{e}-01$

1.00000e-06 1.00000e-06 1.00000e-06 1.00000e-09 5.00000e-02

Element: 11503 \# of layers: 5

$\mathrm{Kx} \mathrm{Ky} \mathrm{Kz}$ Ss Por

5.14075e+02 5.14075e+02 5.14075e+01 1.00000e-09 7.00000e-02

$2.05407 \mathrm{e}+012.05407 \mathrm{e}+012.05407 \mathrm{e}+00$ 1.00000e-09 2.12000e-01

$1.00000 \mathrm{e}-05$ 1.00000e-05 1.00000e-06 1.00000e-09 1.00000e-01

$1.00000 \mathrm{e}+001.00000 \mathrm{e}+001.00000 \mathrm{e}-011.00000 \mathrm{e}-091.00000 \mathrm{e}-01$

1.00000e-06 1.00000e-06 1.00000e-06 1.00000e-09 5.00000e-02

Element: 11504 \# of layers: 4

Kx Ky Kz Ss Por

5.14075e+02 5.14075e+02 5.14075e+01 1.00000e-09 7.00000e-02 $2.05407 \mathrm{e}+012.05407 \mathrm{e}+012.05407 \mathrm{e}+00$ 1.00000e-09 2.12000e-01 $1.00000 \mathrm{e}-05$ 1.00000e-05 1.00000e-06 1.00000e-09 1.00000e-01

$1.00000 \mathrm{e}+001.00000 \mathrm{e}+001.00000 \mathrm{e}-011.00000 \mathrm{e}-091.00000 \mathrm{e}-01$

Element: 11505 \# of layers: 5

$\mathrm{Kx} \mathrm{Ky} \mathrm{Kz}$ Ss Por

5.14075e+02 5.14075e+02 5.14075e+01 1.00000e-09 7.00000e-02

$2.05407 \mathrm{e}+012.05407 \mathrm{e}+012.05407 \mathrm{e}+001.00000 \mathrm{e}-092.12000 \mathrm{e}-01$

$2.05407 \mathrm{e}+012.05407 \mathrm{e}+012.05407 \mathrm{e}+00$ 1.00000e-09 2.12000e-01

$1.00000 \mathrm{e}-05$ 1.00000e-05 1.00000e-06 1.00000e-09 1.00000e-01

$1.00000 \mathrm{e}+001.00000 \mathrm{e}+001.00000 \mathrm{e}-011.00000 \mathrm{e}-091.00000 \mathrm{e}-01$

Element: 11506 \# of layers: 5

$\mathrm{Kx} \mathrm{Ky} \mathrm{Kz}$ Ss Por

3.79375e+02 3.79375e+02 3.79375e+01 1.00000e-09 7.00000e-02

$1.51586 \mathrm{e}+011.51586 \mathrm{e}+011.51586 \mathrm{e}+00$ 1.00000e-09 2.12000e-01

$1.51586 \mathrm{e}+011.51586 \mathrm{e}+011.51586 \mathrm{e}+001.00000 \mathrm{e}-092.12000 \mathrm{e}-01$

$1.00000 \mathrm{e}-051.00000 \mathrm{e}-051.00000 \mathrm{e}-061.00000 \mathrm{e}-091.00000 \mathrm{e}-01$

$1.00000 \mathrm{e}+001.00000 \mathrm{e}+001.00000 \mathrm{e}-01$ 1.00000e-09 1.00000e-01

Element: 11507 \# of layers: 6

Kx Ky Kz Ss Por

3.79375e+02 3.79375e+02 3.79375e+01 1.00000e-09 7.00000e-02

3.79375e+02 3.79375e+02 3.79375e+01 1.00000e-09 7.00000e-02

$1.51586 \mathrm{e}+011.51586 \mathrm{e}+011.51586 \mathrm{e}+001.00000 \mathrm{e}-092.12000 \mathrm{e}-01$

$1.51586 \mathrm{e}+011.51586 \mathrm{e}+011.51586 \mathrm{e}+001.00000 \mathrm{e}-092.12000 \mathrm{e}-01$

$1.00000 \mathrm{e}-05$ 1.00000e-05 1.00000e-06 1.00000e-09 1.00000e-01

$1.00000 \mathrm{e}+001.00000 \mathrm{e}+001.00000 \mathrm{e}-01$ 1.00000e-09 1.00000e-01

Element: 11508 \# of layers: 6

$\mathrm{Kx} \mathrm{Ky} \mathrm{Kz}$ Ss Por

3.79375e+02 3.79375e+02 3.79375e+01 1.00000e-09 7.00000e-02 
3.79375e+02 3.79375e+02 3.79375e+01 1.00000e-09 7.00000e-02 $1.51586 \mathrm{e}+01$ 1.51586e+01 1.51586e+00 1.00000e-09 2.12000e-01 $1.51586 \mathrm{e}+011.51586 \mathrm{e}+011.51586 \mathrm{e}+001.00000 \mathrm{e}-092.12000 \mathrm{e}-01$ $1.00000 \mathrm{e}-05$ 1.00000e-05 1.00000e-06 1.00000e-09 1.00000e-01 $1.00000 \mathrm{e}+001.00000 \mathrm{e}+001.00000 \mathrm{e}-01$ 1.00000e-09 1.00000e-01 Element: 11509 \# of layers: 6

$\mathrm{Kx} \mathrm{Ky} \mathrm{Kz}$ Ss Por

3.79375e+02 3.79375e+02 3.79375e+01 1.00000e-09 7.00000e-02

$3.79375 \mathrm{e}+02$ 3.79375e+02 3.79375e+01 1.00000e-09 7.00000e-02

$1.51586 \mathrm{e}+011.51586 \mathrm{e}+011.51586 \mathrm{e}+001.00000 \mathrm{e}-092.12000 \mathrm{e}-01$

$1.51586 \mathrm{e}+011.51586 \mathrm{e}+011.51586 \mathrm{e}+001.00000 \mathrm{e}-092.12000 \mathrm{e}-01$ $1.00000 \mathrm{e}-05$ 1.00000e-05 1.00000e-06 1.00000e-09 1.00000e-01 $1.00000 \mathrm{e}+001.00000 \mathrm{e}+001.00000 \mathrm{e}-011.00000 \mathrm{e}-09$ 1.00000e-01 Element: 11510 \# of layers: 4

$\mathrm{Kx} \mathrm{Ky} \mathrm{Kz}$ Ss Por

3.79375e+02 3.79375e+02 3.79375e+01 1.00000e-09 7.00000e-02 $1.51586 \mathrm{e}+011.51586 \mathrm{e}+01$ 1.51586e+00 1.00000e-09 2.12000e-01 $1.00000 \mathrm{e}-05$ 1.00000e-05 1.00000e-06 1.00000e-09 1.00000e-01 $1.00000 \mathrm{e}+001.00000 \mathrm{e}+001.00000 \mathrm{e}-01$ 1.00000e-09 1.00000e-01 Element: 11511 \# of layers: 4

$\mathrm{Kx} \mathrm{Ky} \mathrm{Kz}$ Ss Por

5.14075e+02 5.14075e+02 5.14075e+01 1.00000e-09 7.00000e-02 $2.05407 \mathrm{e}+012.05407 \mathrm{e}+012.05407 \mathrm{e}+00$ 1.00000e-09 2.12000e-01 $1.00000 \mathrm{e}-051.00000 \mathrm{e}-051.00000 \mathrm{e}-061.00000 \mathrm{e}-091.00000 \mathrm{e}-01$ $1.00000 \mathrm{e}+001.00000 \mathrm{e}+001.00000 \mathrm{e}-011.00000 \mathrm{e}-091.00000 \mathrm{e}-01$ Element: 11512 \# of layers: 4

$\mathrm{Kx} \mathrm{Ky} \mathrm{Kz}$ Ss Por

5.14075e+02 5.14075e+02 5.14075e+01 1.00000e-09 7.00000e-02 $2.05407 \mathrm{e}+012.05407 \mathrm{e}+012.05407 \mathrm{e}+001.00000 \mathrm{e}-092.12000 \mathrm{e}-01$ $1.00000 \mathrm{e}-05$ 1.00000e-05 1.00000e-06 1.00000e-09 1.00000e-01 $1.00000 \mathrm{e}+001.00000 \mathrm{e}+001.00000 \mathrm{e}-011.00000 \mathrm{e}-091.00000 \mathrm{e}-01$ Element: 11513 \# of layers: 4

Kx Ky Kz Ss Por

3.79375e+02 3.79375e+02 3.79375e+01 1.00000e-09 7.00000e-02 $1.51586 \mathrm{e}+011.51586 \mathrm{e}+011.51586 \mathrm{e}+001.00000 \mathrm{e}-092.12000 \mathrm{e}-01$ $1.00000 \mathrm{e}-05$ 1.00000e-05 1.00000e-06 1.00000e-09 1.00000e-01 $1.00000 \mathrm{e}+001.00000 \mathrm{e}+001.00000 \mathrm{e}-011.00000 \mathrm{e}-091.00000 \mathrm{e}-01$ Element: 11514 \# of layers: 5

$\mathrm{Kx} \mathrm{Ky} \mathrm{Kz}$ Ss Por

$2.63344 \mathrm{e}+03$ 2.63344e+03 2.63344e+02 1.00000e-09 7.00000e-02 $1.05221 \mathrm{e}+021.05221 \mathrm{e}+021.05221 \mathrm{e}+01$ 1.00000e-09 2.12000e-01 $1.00000 \mathrm{e}-05$ 1.00000e-05 1.00000e-06 1.00000e-09 1.00000e-01 $1.00000 \mathrm{e}+001.00000 \mathrm{e}+001.00000 \mathrm{e}-011.00000 \mathrm{e}-091.00000 \mathrm{e}-01$ 1.00000e-06 1.00000e-06 1.00000e-06 1.00000e-09 5.00000e-02 Element: 11515 \# of layers: 4

Kx Ky Kz Ss Por 
$3.79375 \mathrm{e}+023.79375 \mathrm{e}+023.79375 \mathrm{e}+01$ 1.00000e-09 7.00000e-02 $1.51586 \mathrm{e}+011.51586 \mathrm{e}+011.51586 \mathrm{e}+001.00000 \mathrm{e}-092.12000 \mathrm{e}-01$ $1.00000 \mathrm{e}-05$ 1.00000e-05 1.00000e-06 1.00000e-09 1.00000e-01 $1.00000 \mathrm{e}+001.00000 \mathrm{e}+001.00000 \mathrm{e}-011.00000 \mathrm{e}-091.00000 \mathrm{e}-01$ Element: 11516 \# of layers: 6

Kx Ky Kz Ss Por

$3.79375 \mathrm{e}+02$ 3.79375e+02 3.79375e+01 1.00000e-09 7.00000e-02 $3.79375 \mathrm{e}+023.79375 \mathrm{e}+023.79375 \mathrm{e}+01$ 1.00000e-09 7.00000e-02 $1.51586 \mathrm{e}+011.51586 \mathrm{e}+011.51586 \mathrm{e}+001.00000 \mathrm{e}-092.12000 \mathrm{e}-01$ $1.51586 \mathrm{e}+011.51586 \mathrm{e}+011.51586 \mathrm{e}+001.00000 \mathrm{e}-092.12000 \mathrm{e}-01$ $1.00000 \mathrm{e}-05$ 1.00000e-05 1.00000e-06 1.00000e-09 1.00000e-01 $1.00000 \mathrm{e}+001.00000 \mathrm{e}+00$ 1.00000e-01 1.00000e-09 1.00000e-01 Element: 11517 \# of layers: 6

Kx Ky Kz Ss Por

$1.43403 \mathrm{e}+03$ 1.43403e+03 1.43403e+02 1.00000e-09 7.00000e-02 $1.43403 \mathrm{e}+031.43403 \mathrm{e}+03$ 1.43403e+02 1.00000e-09 7.00000e-02 $5.72975 \mathrm{e}+015.72975 \mathrm{e}+015.72975 \mathrm{e}+00$ 1.00000e-09 2.12000e-01 $5.72975 \mathrm{e}+015.72975 \mathrm{e}+015.72975 \mathrm{e}+00$ 1.00000e-09 2.12000e-01 $1.00000 \mathrm{e}-05$ 1.00000e-05 1.00000e-06 1.00000e-09 1.00000e-01 $1.00000 \mathrm{e}+001.00000 \mathrm{e}+001.00000 \mathrm{e}-011.00000 \mathrm{e}-091.00000 \mathrm{e}-01$ Element: 11518 \# of layers: 7

Kx Ky Kz Ss Por

$1.43403 \mathrm{e}+03$ 1.43403e+03 1.43403e+02 1.00000e-09 7.00000e-02 $1.43403 \mathrm{e}+031.43403 \mathrm{e}+03$ 1.43403e+02 1.00000e-09 7.00000e-02 $5.72975 \mathrm{e}+015.72975 \mathrm{e}+015.72975 \mathrm{e}+001.00000 \mathrm{e}-092.12000 \mathrm{e}-01$ $5.72975 \mathrm{e}+015.72975 \mathrm{e}+015.72975 \mathrm{e}+00$ 1.00000e-09 2.12000e-01 $1.00000 \mathrm{e}-05$ 1.00000e-05 1.00000e-06 1.00000e-09 1.00000e-01 $1.00000 \mathrm{e}+001.00000 \mathrm{e}+001.00000 \mathrm{e}-011.00000 \mathrm{e}-091.00000 \mathrm{e}-01$ $1.00000 \mathrm{e}-061.00000 \mathrm{e}-06$ 1.00000e-06 1.00000e-09 5.00000e-02 Element: 11519 \# of layers: 7

Kx Ky Kz Ss Por

$1.67183 \mathrm{e}+011.67183 \mathrm{e}+011.67183 \mathrm{e}+00$ 1.00000e-09 2.12000e-01 $1.67183 \mathrm{e}+011.67183 \mathrm{e}+011.67183 \mathrm{e}+001.00000 \mathrm{e}-092.12000 \mathrm{e}-01$ $1.67183 \mathrm{e}+011.67183 \mathrm{e}+011.67183 \mathrm{e}+001.00000 \mathrm{e}-092.12000 \mathrm{e}-01$ $1.67183 \mathrm{e}+011.67183 \mathrm{e}+011.67183 \mathrm{e}+001.00000 \mathrm{e}-092.12000 \mathrm{e}-01$ $1.67183 \mathrm{e}+011.67183 \mathrm{e}+011.67183 \mathrm{e}+001.00000 \mathrm{e}-092.12000 \mathrm{e}-01$ $1.00000 \mathrm{e}-05$ 1.00000e-05 1.00000e-06 1.00000e-09 1.00000e-01 $1.00000 \mathrm{e}+001.00000 \mathrm{e}+001.00000 \mathrm{e}-011.00000 \mathrm{e}-091.00000 \mathrm{e}-01$ Element: 11520 \# of layers: 7

Kx Ky Kz Ss Por

$1.67183 \mathrm{e}+011.67183 \mathrm{e}+011.67183 \mathrm{e}+00$ 1.00000e-09 2.12000e-01 $1.67183 \mathrm{e}+011.67183 \mathrm{e}+011.67183 \mathrm{e}+001.00000 \mathrm{e}-092.12000 \mathrm{e}-01$ $1.67183 \mathrm{e}+011.67183 \mathrm{e}+011.67183 \mathrm{e}+001.00000 \mathrm{e}-092.12000 \mathrm{e}-01$ $1.67183 \mathrm{e}+011.67183 \mathrm{e}+011.67183 \mathrm{e}+001.00000 \mathrm{e}-092.12000 \mathrm{e}-01$ $1.67183 \mathrm{e}+011.67183 \mathrm{e}+011.67183 \mathrm{e}+001.00000 \mathrm{e}-092.12000 \mathrm{e}-01$ $1.00000 \mathrm{e}-05$ 1.00000e-05 1.00000e-06 1.00000e-09 1.00000e-01 
$1.00000 \mathrm{e}+001.00000 \mathrm{e}+00$ 1.00000e-01 1.00000e-09 1.00000e-01

Element: 11521 \# of layers: 7

Kx Ky Kz Ss Por

$1.67183 e+011.67183 e+011.67183 e+001.00000 e-092.12000 e-01$

$1.67183 \mathrm{e}+011.67183 \mathrm{e}+011.67183 \mathrm{e}+001.00000 \mathrm{e}-092.12000 \mathrm{e}-01$

$1.67183 \mathrm{e}+01$ 1.67183e+01 1.67183e+00 1.00000e-09 2.12000e-01

$1.67183 \mathrm{e}+011.67183 \mathrm{e}+01$ 1.67183e+00 1.00000e-09 2.12000e-01

$1.67183 \mathrm{e}+011.67183 \mathrm{e}+011.67183 \mathrm{e}+001.00000 \mathrm{e}-092.12000 \mathrm{e}-01$

$1.00000 \mathrm{e}-05$ 1.00000e-05 1.00000e-06 1.00000e-09 1.00000e-01

$1.00000 \mathrm{e}+001.00000 \mathrm{e}+001.00000 \mathrm{e}-011.00000 \mathrm{e}-091.00000 \mathrm{e}-01$

Element: 11522 \# of layers: 7

Kx Ky Kz Ss Por

$1.67183 \mathrm{e}+01$ 1.67183e+01 1.67183e+00 1.00000e-09 2.12000e-01

$1.67183 \mathrm{e}+01$ 1.67183e+01 1.67183e+00 1.00000e-09 2.12000e-01

$1.67183 \mathrm{e}+01$ 1.67183e+01 1.67183e+00 1.00000e-09 2.12000e-01

$1.67183 \mathrm{e}+011.67183 \mathrm{e}+011.67183 \mathrm{e}+001.00000 \mathrm{e}-092.12000 \mathrm{e}-01$

$1.67183 \mathrm{e}+011.67183 \mathrm{e}+01$ 1.67183e+00 1.00000e-09 2.12000e-01

$1.00000 \mathrm{e}-05$ 1.00000e-05 1.00000e-06 1.00000e-09 1.00000e-01

$1.00000 \mathrm{e}+001.00000 \mathrm{e}+001.00000 \mathrm{e}-01$ 1.00000e-09 1.00000e-01

Element: 11523 \# of layers: 7

$\mathrm{Kx} \mathrm{Ky} \mathrm{Kz}$ Ss Por

$1.67183 \mathrm{e}+01$ 1.67183e+01 1.67183e+00 1.00000e-09 2.12000e-01

$1.67183 \mathrm{e}+01$ 1.67183e+01 1.67183e+00 1.00000e-09 2.12000e-01

$1.67183 \mathrm{e}+01$ 1.67183e+01 1.67183e+00 1.00000e-09 2.12000e-01

$1.67183 \mathrm{e}+011.67183 \mathrm{e}+011.67183 \mathrm{e}+001.00000 \mathrm{e}-092.12000 \mathrm{e}-01$

$1.67183 \mathrm{e}+01$ 1.67183e+01 1.67183e+00 1.00000e-09 2.12000e-01

$1.00000 \mathrm{e}-05$ 1.00000e-05 1.00000e-06 1.00000e-09 1.00000e-01

$1.00000 \mathrm{e}+001.00000 \mathrm{e}+001.00000 \mathrm{e}-01$ 1.00000e-09 1.00000e-01

Element: 11524 \# of layers: 7

$\mathrm{Kx} \mathrm{Ky} \mathrm{Kz}$ Ss Por

$1.66929 \mathrm{e}+01$ 1.66929e+01 1.66929e+00 1.00000e-09 2.12000e-01

$1.66929 \mathrm{e}+01$ 1.66929e+01 1.66929e+00 1.00000e-09 2.12000e-01

$1.66929 \mathrm{e}+011.66929 \mathrm{e}+011.66929 \mathrm{e}+001.00000 \mathrm{e}-092.12000 \mathrm{e}-01$

$1.66929 \mathrm{e}+011.66929 \mathrm{e}+01$ 1.66929e+00 1.00000e-09 2.12000e-01

$1.66929 \mathrm{e}+01$ 1.66929e+01 1.66929e+00 1.00000e-09 2.12000e-01

$1.00000 \mathrm{e}-05$ 1.00000e-05 1.00000e-06 1.00000e-09 1.00000e-01

$1.00000 \mathrm{e}+001.00000 \mathrm{e}+001.00000 \mathrm{e}-011.00000 \mathrm{e}-091.00000 \mathrm{e}-01$

Element: 11525 \# of layers: 7

$\mathrm{Kx} \mathrm{Ky} \mathrm{Kz}$ Ss Por

$1.66929 \mathrm{e}+01$ 1.66929e+01 1.66929e+00 1.00000e-09 2.12000e-01

$1.66929 \mathrm{e}+01$ 1.66929e+01 1.66929e+00 1.00000e-09 2.12000e-01

$1.66929 \mathrm{e}+01$ 1.66929e+01 1.66929e+00 1.00000e-09 2.12000e-01

$1.66929 \mathrm{e}+01$ 1.66929e+01 1.66929e+00 1.00000e-09 2.12000e-01

$1.66929 \mathrm{e}+01$ 1.66929e+01 1.66929e+00 1.00000e-09 2.12000e-01

$1.00000 \mathrm{e}-05$ 1.00000e-05 1.00000e-06 1.00000e-09 1.00000e-01

$1.00000 \mathrm{e}+001.00000 \mathrm{e}+001.00000 \mathrm{e}-011.00000 \mathrm{e}-091.00000 \mathrm{e}-01$ 
Element: 11526 \# of layers: 7

Kx Ky Kz Ss Por

$1.66929 \mathrm{e}+011.66929 \mathrm{e}+011.66929 \mathrm{e}+00$ 1.00000e-09 2.12000e-01

$1.66929 \mathrm{e}+011.66929 \mathrm{e}+011.66929 \mathrm{e}+001.00000 \mathrm{e}-092.12000 \mathrm{e}-01$

$1.66929 \mathrm{e}+011.66929 \mathrm{e}+011.66929 \mathrm{e}+001.00000 \mathrm{e}-092.12000 \mathrm{e}-01$

$1.66929 \mathrm{e}+011.66929 \mathrm{e}+011.66929 \mathrm{e}+001.00000 \mathrm{e}-092.12000 \mathrm{e}-01$

$1.66929 \mathrm{e}+011.66929 \mathrm{e}+011.66929 \mathrm{e}+001.00000 \mathrm{e}-092.12000 \mathrm{e}-01$

$1.00000 \mathrm{e}-05$ 1.00000e-05 1.00000e-06 1.00000e-09 1.00000e-01

$1.00000 \mathrm{e}+001.00000 \mathrm{e}+001.00000 \mathrm{e}-011.00000 \mathrm{e}-091.00000 \mathrm{e}-01$

Element: 11527 \# of layers: 7

Kx Ky Kz Ss Por

$1.66929 \mathrm{e}+011.66929 \mathrm{e}+011.66929 \mathrm{e}+00$ 1.00000e-09 2.12000e-01

$1.66929 \mathrm{e}+011.66929 \mathrm{e}+011.66929 \mathrm{e}+001.00000 \mathrm{e}-092.12000 \mathrm{e}-01$

$1.66929 \mathrm{e}+011.66929 \mathrm{e}+011.66929 \mathrm{e}+001.00000 \mathrm{e}-092.12000 \mathrm{e}-01$

$1.66929 \mathrm{e}+011.66929 \mathrm{e}+011.66929 \mathrm{e}+001.00000 \mathrm{e}-092.12000 \mathrm{e}-01$

$1.66929 \mathrm{e}+011.66929 \mathrm{e}+011.66929 \mathrm{e}+001.00000 \mathrm{e}-092.12000 \mathrm{e}-01$

$1.00000 \mathrm{e}-05$ 1.00000e-05 1.00000e-06 1.00000e-09 1.00000e-01

$1.00000 \mathrm{e}+001.00000 \mathrm{e}+001.00000 \mathrm{e}-011.00000 \mathrm{e}-091.00000 \mathrm{e}-01$

Element: 11528 \# of layers: 7

Kx Ky Kz Ss Por

$1.66929 \mathrm{e}+011.66929 \mathrm{e}+011.66929 \mathrm{e}+00$ 1.00000e-09 2.12000e-01

$1.66929 \mathrm{e}+011.66929 \mathrm{e}+011.66929 \mathrm{e}+001.00000 \mathrm{e}-092.12000 \mathrm{e}-01$

$1.66929 \mathrm{e}+011.66929 \mathrm{e}+011.66929 \mathrm{e}+001.00000 \mathrm{e}-092.12000 \mathrm{e}-01$

$1.66929 \mathrm{e}+011.66929 \mathrm{e}+011.66929 \mathrm{e}+001.00000 \mathrm{e}-092.12000 \mathrm{e}-01$

$1.66929 \mathrm{e}+011.66929 \mathrm{e}+011.66929 \mathrm{e}+001.00000 \mathrm{e}-092.12000 \mathrm{e}-01$

$1.00000 \mathrm{e}-05$ 1.00000e-05 1.00000e-06 1.00000e-09 1.00000e-01

$1.00000 \mathrm{e}+001.00000 \mathrm{e}+001.00000 \mathrm{e}-011.00000 \mathrm{e}-091.00000 \mathrm{e}-01$

Element: 11529 \# of layers: 7

Kx Ky Kz Ss Por

$1.67183 \mathrm{e}+011.67183 \mathrm{e}+011.67183 \mathrm{e}+00$ 1.00000e-09 2.12000e-01

$1.67183 \mathrm{e}+011.67183 \mathrm{e}+011.67183 \mathrm{e}+001.00000 \mathrm{e}-092.12000 \mathrm{e}-01$

$1.67183 \mathrm{e}+011.67183 \mathrm{e}+011.67183 \mathrm{e}+001.00000 \mathrm{e}-092.12000 \mathrm{e}-01$

$1.67183 \mathrm{e}+011.67183 \mathrm{e}+011.67183 \mathrm{e}+001.00000 \mathrm{e}-092.12000 \mathrm{e}-01$

$1.67183 \mathrm{e}+011.67183 \mathrm{e}+011.67183 \mathrm{e}+001.00000 \mathrm{e}-092.12000 \mathrm{e}-01$

$1.00000 \mathrm{e}-05$ 1.00000e-05 1.00000e-06 1.00000e-09 1.00000e-01

$1.00000 \mathrm{e}+001.00000 \mathrm{e}+001.00000 \mathrm{e}-011.00000 \mathrm{e}-091.00000 \mathrm{e}-01$

Element: 11530 \# of layers: 7

Kx Ky Kz Ss Por

$1.67183 \mathrm{e}+011.67183 \mathrm{e}+011.67183 \mathrm{e}+00$ 1.00000e-09 2.12000e-01

$1.67183 \mathrm{e}+011.67183 \mathrm{e}+011.67183 \mathrm{e}+001.00000 \mathrm{e}-092.12000 \mathrm{e}-01$

$1.67183 \mathrm{e}+011.67183 \mathrm{e}+011.67183 \mathrm{e}+001.00000 \mathrm{e}-092.12000 \mathrm{e}-01$

$1.67183 \mathrm{e}+011.67183 \mathrm{e}+011.67183 \mathrm{e}+001.00000 \mathrm{e}-092.12000 \mathrm{e}-01$

$1.67183 \mathrm{e}+011.67183 \mathrm{e}+011.67183 \mathrm{e}+00$ 1.00000e-09 2.12000e-01

$1.00000 \mathrm{e}-05$ 1.00000e-05 1.00000e-06 1.00000e-09 1.00000e-01

$1.00000 \mathrm{e}+001.00000 \mathrm{e}+001.00000 \mathrm{e}-011.00000 \mathrm{e}-091.00000 \mathrm{e}-01$

Element: 11531 \# of layers: 7 
Kx Ky Kz Ss Por

$1.66929 \mathrm{e}+01$ 1.66929e+01 1.66929e+00 1.00000e-09 2.12000e-01

$1.66929 \mathrm{e}+01$ 1.66929e+01 1.66929e+00 1.00000e-09 2.12000e-01

$1.66929 \mathrm{e}+011.66929 \mathrm{e}+011.66929 \mathrm{e}+001.00000 \mathrm{e}-092.12000 \mathrm{e}-01$

$1.66929 \mathrm{e}+011.66929 \mathrm{e}+01$ 1.66929e+00 1.00000e-09 2.12000e-01

$1.66929 \mathrm{e}+01$ 1.66929e+01 1.66929e+00 1.00000e-09 2.12000e-01

$1.00000 \mathrm{e}-05$ 1.00000e-05 1.00000e-06 1.00000e-09 1.00000e-01

$1.00000 \mathrm{e}+001.00000 \mathrm{e}+001.00000 \mathrm{e}-01$ 1.00000e-09 1.00000e-01

Element: 11532 \# of layers: 7

$\mathrm{Kx} \mathrm{Ky} \mathrm{Kz}$ Ss Por

$1.66929 \mathrm{e}+01$ 1.66929e+01 1.66929e+00 1.00000e-09 2.12000e-01

$1.66929 \mathrm{e}+011.66929 \mathrm{e}+011.66929 \mathrm{e}+001.00000 \mathrm{e}-092.12000 \mathrm{e}-01$

$1.66929 \mathrm{e}+01$ 1.66929e+01 1.66929e+00 1.00000e-09 2.12000e-01

$1.66929 \mathrm{e}+01$ 1.66929e+01 1.66929e+00 1.00000e-09 2.12000e-01

$1.66929 \mathrm{e}+01$ 1.66929e+01 1.66929e+00 1.00000e-09 2.12000e-01

$1.00000 \mathrm{e}-05$ 1.00000e-05 1.00000e-06 1.00000e-09 1.00000e-01

$1.00000 \mathrm{e}+001.00000 \mathrm{e}+001.00000 \mathrm{e}-011.00000 \mathrm{e}-091.00000 \mathrm{e}-01$

Element: 11533 \# of layers: 7

$\mathrm{Kx} \mathrm{Ky} \mathrm{Kz}$ Ss Por

$1.66929 \mathrm{e}+01$ 1.66929e+01 1.66929e+00 1.00000e-09 2.12000e-01

$1.66929 \mathrm{e}+011.66929 \mathrm{e}+011.66929 \mathrm{e}+001.00000 \mathrm{e}-092.12000 \mathrm{e}-01$

$1.66929 \mathrm{e}+01$ 1.66929e+01 1.66929e+00 1.00000e-09 2.12000e-01

$1.66929 \mathrm{e}+01$ 1.66929e+01 1.66929e+00 1.00000e-09 2.12000e-01

$1.66929 \mathrm{e}+011.66929 \mathrm{e}+01 \quad 1.66929 \mathrm{e}+001.00000 \mathrm{e}-092.12000 \mathrm{e}-01$

$1.00000 \mathrm{e}-05$ 1.00000e-05 1.00000e-06 1.00000e-09 1.00000e-01

$1.00000 \mathrm{e}+001.00000 \mathrm{e}+001.00000 \mathrm{e}-01$ 1.00000e-09 1.00000e-01

Element: 11534 \# of layers: 7

$\mathrm{Kx} \mathrm{Ky} \mathrm{Kz}$ Ss Por

$1.66929 \mathrm{e}+01$ 1.66929e+01 1.66929e+00 1.00000e-09 2.12000e-01

$1.66929 \mathrm{e}+01$ 1.66929e+01 1.66929e+00 1.00000e-09 2.12000e-01

$1.66929 \mathrm{e}+01$ 1.66929e+01 1.66929e+00 1.00000e-09 2.12000e-01

$1.66929 \mathrm{e}+011.66929 \mathrm{e}+01$ 1.66929e+00 1.00000e-09 2.12000e-01

$1.66929 \mathrm{e}+011.66929 \mathrm{e}+011.66929 \mathrm{e}+001.00000 \mathrm{e}-092.12000 \mathrm{e}-01$

$1.00000 \mathrm{e}-05$ 1.00000e-05 1.00000e-06 1.00000e-09 1.00000e-01

$1.00000 \mathrm{e}+001.00000 \mathrm{e}+001.00000 \mathrm{e}-01$ 1.00000e-09 1.00000e-01

Element: 11535 \# of layers: 7

Kx Ky Kz Ss Por

$1.66929 \mathrm{e}+01$ 1.66929e+01 1.66929e+00 1.00000e-09 2.12000e-01

$1.66929 \mathrm{e}+01$ 1.66929e+01 1.66929e+00 1.00000e-09 2.12000e-01

$1.66929 \mathrm{e}+01$ 1.66929e+01 1.66929e+00 1.00000e-09 2.12000e-01

$1.66929 \mathrm{e}+01$ 1.66929e+01 1.66929e+00 1.00000e-09 2.12000e-01

$1.66929 \mathrm{e}+01$ 1.66929e+01 1.66929e+00 1.00000e-09 2.12000e-01

$1.00000 \mathrm{e}-05$ 1.00000e-05 1.00000e-06 1.00000e-09 1.00000e-01

$1.00000 \mathrm{e}+001.00000 \mathrm{e}+001.00000 \mathrm{e}-01$ 1.00000e-09 1.00000e-01

Element: 11536 \# of layers: 7

Kx Ky Kz Ss Por 
$1.66929 \mathrm{e}+01$ 1.66929e+01 1.66929e+00 1.00000e-09 2.12000e-01 $1.66929 \mathrm{e}+01$ 1.66929e+01 1.66929e+00 1.00000e-09 2.12000e-01 $1.66929 \mathrm{e}+01$ 1.66929e+01 1.66929e+00 1.00000e-09 2.12000e-01 $1.66929 \mathrm{e}+011.66929 \mathrm{e}+011.66929 \mathrm{e}+001.00000 \mathrm{e}-092.12000 \mathrm{e}-01$ $1.66929 \mathrm{e}+011.66929 \mathrm{e}+01$ 1.66929e+00 1.00000e-09 2.12000e-01 $1.00000 \mathrm{e}-05$ 1.00000e-05 1.00000e-06 1.00000e-09 1.00000e-01 $1.00000 \mathrm{e}+001.00000 \mathrm{e}+001.00000 \mathrm{e}-01$ 1.00000e-09 1.00000e-01 Element: 11537 \# of layers: 7

$\mathrm{Kx} \mathrm{Ky} \mathrm{Kz}$ Ss Por

$1.66929 \mathrm{e}+01$ 1.66929e+01 1.66929e+00 1.00000e-09 2.12000e-01 $1.66929 \mathrm{e}+01$ 1.66929e+01 1.66929e+00 1.00000e-09 2.12000e-01 $1.66929 \mathrm{e}+011.66929 \mathrm{e}+011.66929 \mathrm{e}+001.00000 \mathrm{e}-092.12000 \mathrm{e}-01$ $1.66929 \mathrm{e}+011.66929 \mathrm{e}+011.66929 \mathrm{e}+001.00000 \mathrm{e}-092.12000 \mathrm{e}-01$ $1.66929 \mathrm{e}+01$ 1.66929e+01 1.66929e+00 1.00000e-09 2.12000e-01 $1.00000 \mathrm{e}-05$ 1.00000e-05 1.00000e-06 1.00000e-09 1.00000e-01 $1.00000 \mathrm{e}+001.00000 \mathrm{e}+001.00000 \mathrm{e}-011.00000 \mathrm{e}-091.00000 \mathrm{e}-01$ Element: 11538 \# of layers: 7

$\mathrm{Kx} \mathrm{Ky} \mathrm{Kz}$ Ss Por

$1.66929 \mathrm{e}+01$ 1.66929e+01 1.66929e+00 1.00000e-09 2.12000e-01 $1.66929 \mathrm{e}+011.66929 \mathrm{e}+011.66929 \mathrm{e}+001.00000 \mathrm{e}-092.12000 \mathrm{e}-01$ $1.66929 \mathrm{e}+011.66929 \mathrm{e}+011.66929 \mathrm{e}+001.00000 \mathrm{e}-092.12000 \mathrm{e}-01$ $1.66929 \mathrm{e}+01$ 1.66929e+01 1.66929e+00 1.00000e-09 2.12000e-01 $1.66929 \mathrm{e}+01$ 1.66929e+01 1.66929e+00 1.00000e-09 2.12000e-01 $1.00000 \mathrm{e}-05$ 1.00000e-05 1.00000e-06 1.00000e-09 1.00000e-01 $1.00000 \mathrm{e}+001.00000 \mathrm{e}+001.00000 \mathrm{e}-011.00000 \mathrm{e}-091.00000 \mathrm{e}-01$ Element: 11539 \# of layers: 7

$\mathrm{Kx} \mathrm{Ky} \mathrm{Kz}$ Ss Por

$1.66929 \mathrm{e}+01$ 1.66929e+01 1.66929e+00 1.00000e-09 2.12000e-01 $1.66929 \mathrm{e}+011.66929 \mathrm{e}+011.66929 \mathrm{e}+001.00000 \mathrm{e}-092.12000 \mathrm{e}-01$ $1.66929 \mathrm{e}+01$ 1.66929e+01 1.66929e+00 1.00000e-09 2.12000e-01 $1.66929 \mathrm{e}+01$ 1.66929e+01 1.66929e+00 1.00000e-09 2.12000e-01 $1.66929 \mathrm{e}+011.66929 \mathrm{e}+01$ 1.66929e+00 1.00000e-09 2.12000e-01 $1.00000 \mathrm{e}-05$ 1.00000e-05 1.00000e-06 1.00000e-09 1.00000e-01 $1.00000 \mathrm{e}+001.00000 \mathrm{e}+001.00000 \mathrm{e}-011.00000 \mathrm{e}-091.00000 \mathrm{e}-01$ Element: 11540 \# of layers: 7

$\mathrm{Kx} \mathrm{Ky} \mathrm{Kz}$ Ss Por $1.66929 \mathrm{e}+01$ 1.66929e+01 1.66929e+00 1.00000e-09 2.12000e-01 $1.66929 \mathrm{e}+011.66929 \mathrm{e}+011.66929 \mathrm{e}+001.00000 \mathrm{e}-092.12000 \mathrm{e}-01$ $1.66929 \mathrm{e}+011.66929 \mathrm{e}+011.66929 \mathrm{e}+001.00000 \mathrm{e}-092.12000 \mathrm{e}-01$ $1.66929 \mathrm{e}+01$ 1.66929e+01 1.66929e+00 1.00000e-09 2.12000e-01 $1.66929 \mathrm{e}+01$ 1.66929e+01 1.66929e+00 1.00000e-09 2.12000e-01 $1.00000 \mathrm{e}-05$ 1.00000e-05 1.00000e-06 1.00000e-09 1.00000e-01 $1.00000 \mathrm{e}+001.00000 \mathrm{e}+001.00000 \mathrm{e}-011.00000 \mathrm{e}-091.00000 \mathrm{e}-01$ Element: 11541 \# of layers: 7

$\mathrm{Kx} \mathrm{Ky} \mathrm{Kz}$ Ss Por $1.66929 \mathrm{e}+01$ 1.66929e+01 1.66929e+00 1.00000e-09 2.12000e-01 
$1.66929 \mathrm{e}+01$ 1.66929e+01 1.66929e+00 1.00000e-09 2.12000e-01 $1.66929 \mathrm{e}+01$ 1.66929e+01 1.66929e+00 1.00000e-09 2.12000e-01 $1.66929 \mathrm{e}+01$ 1.66929e+01 1.66929e+00 1.00000e-09 2.12000e-01 $1.66929 \mathrm{e}+011.66929 \mathrm{e}+011.66929 \mathrm{e}+001.00000 \mathrm{e}-092.12000 \mathrm{e}-01$ $1.00000 \mathrm{e}-051.00000 \mathrm{e}-05$ 1.00000e-06 1.00000e-09 1.00000e-01 $1.00000 \mathrm{e}+001.00000 \mathrm{e}+001.00000 \mathrm{e}-011.00000 \mathrm{e}-091.00000 \mathrm{e}-01$ Element: 11542 \# of layers: 7

$\mathrm{Kx} \mathrm{Ky} \mathrm{Kz}$ Ss Por

$1.66929 \mathrm{e}+01$ 1.66929e+01 1.66929e+00 1.00000e-09 2.12000e-01 $1.66929 \mathrm{e}+01$ 1.66929e+01 1.66929e+00 1.00000e-09 2.12000e-01 $1.66929 \mathrm{e}+01$ 1.66929e+01 1.66929e+00 1.00000e-09 2.12000e-01 $1.66929 \mathrm{e}+011.66929 \mathrm{e}+011.66929 \mathrm{e}+001.00000 \mathrm{e}-092.12000 \mathrm{e}-01$ $1.66929 \mathrm{e}+01$ 1.66929e+01 1.66929e+00 1.00000e-09 2.12000e-01 $1.00000 \mathrm{e}-05$ 1.00000e-05 1.00000e-06 1.00000e-09 1.00000e-01 $1.00000 \mathrm{e}+001.00000 \mathrm{e}+001.00000 \mathrm{e}-01$ 1.00000e-09 1.00000e-01 Element: 11543 \# of layers: 7

$\mathrm{Kx} \mathrm{Ky} \mathrm{Kz}$ Ss Por

$1.62440 \mathrm{e}+01$ 1.62440e+01 1.62440e+00 1.00000e-09 2.12000e-01 $1.62440 \mathrm{e}+011.62440 \mathrm{e}+011.62440 \mathrm{e}+001.00000 \mathrm{e}-092.12000 \mathrm{e}-01$ $1.62440 \mathrm{e}+011.62440 \mathrm{e}+011.62440 \mathrm{e}+001.00000 \mathrm{e}-092.12000 \mathrm{e}-01$ $1.62440 \mathrm{e}+011.62440 \mathrm{e}+011.62440 \mathrm{e}+001.00000 \mathrm{e}-092.12000 \mathrm{e}-01$ $1.62440 \mathrm{e}+011.62440 \mathrm{e}+01$ 1.62440e+00 1.00000e-09 2.12000e-01 $1.00000 \mathrm{e}-05$ 1.00000e-05 1.00000e-06 1.00000e-09 1.00000e-01 $1.00000 \mathrm{e}+001.00000 \mathrm{e}+001.00000 \mathrm{e}-011.00000 \mathrm{e}-09$ 1.00000e-01

Element: 11544 \# of layers: 7

$\mathrm{Kx} \mathrm{Ky} \mathrm{Kz}$ Ss Por

$1.62440 \mathrm{e}+011.62440 \mathrm{e}+011.62440 \mathrm{e}+001.00000 \mathrm{e}-092.12000 \mathrm{e}-01$ $1.62440 \mathrm{e}+011.62440 \mathrm{e}+011.62440 \mathrm{e}+001.00000 \mathrm{e}-092.12000 \mathrm{e}-01$ $1.62440 \mathrm{e}+011.62440 \mathrm{e}+011.62440 \mathrm{e}+001.00000 \mathrm{e}-092.12000 \mathrm{e}-01$ $1.62440 \mathrm{e}+011.62440 \mathrm{e}+011.62440 \mathrm{e}+001.00000 \mathrm{e}-092.12000 \mathrm{e}-01$ $1.62440 \mathrm{e}+011.62440 \mathrm{e}+01 \quad 1.62440 \mathrm{e}+001.00000 \mathrm{e}-092.12000 \mathrm{e}-01$ $1.00000 \mathrm{e}-05$ 1.00000e-05 1.00000e-06 1.00000e-09 1.00000e-01 $1.00000 \mathrm{e}+001.00000 \mathrm{e}+001.00000 \mathrm{e}-011.00000 \mathrm{e}-091.00000 \mathrm{e}-01$ Element: 11545 \# of layers: 7

$\mathrm{Kx} \mathrm{Ky} \mathrm{Kz}$ Ss Por

$1.62440 \mathrm{e}+011.62440 \mathrm{e}+011.62440 \mathrm{e}+001.00000 \mathrm{e}-092.12000 \mathrm{e}-01$ $1.62440 \mathrm{e}+011.62440 \mathrm{e}+011.62440 \mathrm{e}+001.00000 \mathrm{e}-092.12000 \mathrm{e}-01$ $1.62440 \mathrm{e}+011.62440 \mathrm{e}+011.62440 \mathrm{e}+001.00000 \mathrm{e}-092.12000 \mathrm{e}-01$ $1.62440 \mathrm{e}+011.62440 \mathrm{e}+011.62440 \mathrm{e}+001.00000 \mathrm{e}-092.12000 \mathrm{e}-01$ $1.62440 \mathrm{e}+011.62440 \mathrm{e}+011.62440 \mathrm{e}+001.00000 \mathrm{e}-092.12000 \mathrm{e}-01$ $1.00000 \mathrm{e}-05$ 1.00000e-05 1.00000e-06 1.00000e-09 1.00000e-01 $1.00000 \mathrm{e}+001.00000 \mathrm{e}+001.00000 \mathrm{e}-011.00000 \mathrm{e}-091.00000 \mathrm{e}-01$ Element: 11546 \# of layers: 7

$\mathrm{Kx} \mathrm{Ky} \mathrm{Kz}$ Ss Por $1.66929 \mathrm{e}+01$ 1.66929e+01 1.66929e+00 1.00000e-09 2.12000e-01 $1.66929 \mathrm{e}+011.66929 \mathrm{e}+011.66929 \mathrm{e}+001.00000 \mathrm{e}-092.12000 \mathrm{e}-01$ 
$1.66929 \mathrm{e}+01$ 1.66929e+01 1.66929e+00 1.00000e-09 2.12000e-01 $1.66929 \mathrm{e}+01$ 1.66929e+01 1.66929e+00 1.00000e-09 2.12000e-01 $1.66929 \mathrm{e}+01$ 1.66929e+01 1.66929e+00 1.00000e-09 2.12000e-01 $1.00000 \mathrm{e}-05$ 1.00000e-05 1.00000e-06 1.00000e-09 1.00000e-01 $1.00000 \mathrm{e}+001.00000 \mathrm{e}+001.00000 \mathrm{e}-01$ 1.00000e-09 1.00000e-01 Element: 11547 \# of layers: 7

$\mathrm{Kx} \mathrm{Ky} \mathrm{Kz}$ Ss Por

$1.66929 \mathrm{e}+01$ 1.66929e+01 1.66929e+00 1.00000e-09 2.12000e-01 $1.66929 \mathrm{e}+011.66929 \mathrm{e}+01$ 1.66929e+00 1.00000e-09 2.12000e-01 $1.66929 \mathrm{e}+011.66929 \mathrm{e}+011.66929 \mathrm{e}+001.00000 \mathrm{e}-092.12000 \mathrm{e}-01$ $1.66929 \mathrm{e}+01$ 1.66929e+01 1.66929e+00 1.00000e-09 2.12000e-01 $1.66929 \mathrm{e}+011.66929 \mathrm{e}+011.66929 \mathrm{e}+001.00000 \mathrm{e}-092.12000 \mathrm{e}-01$ $1.00000 \mathrm{e}-051.00000 \mathrm{e}-051.00000 \mathrm{e}-061.00000 \mathrm{e}-091.00000 \mathrm{e}-01$ $1.00000 \mathrm{e}+001.00000 \mathrm{e}+001.00000 \mathrm{e}-011.00000 \mathrm{e}-09$ 1.00000e-01 Element: 11548 \# of layers: 7

Kx Ky Kz Ss Por

$1.66929 \mathrm{e}+01$ 1.66929e+01 1.66929e+00 1.00000e-09 2.12000e-01 $1.66929 \mathrm{e}+011.66929 \mathrm{e}+011.66929 \mathrm{e}+001.00000 \mathrm{e}-092.12000 \mathrm{e}-01$ $1.66929 \mathrm{e}+01$ 1.66929e+01 1.66929e+00 1.00000e-09 2.12000e-01 $1.66929 \mathrm{e}+011.66929 \mathrm{e}+011.66929 \mathrm{e}+001.00000 \mathrm{e}-092.12000 \mathrm{e}-01$ $1.66929 \mathrm{e}+01$ 1.66929e+01 1.66929e+00 1.00000e-09 2.12000e-01 $1.00000 \mathrm{e}-05$ 1.00000e-05 1.00000e-06 1.00000e-09 1.00000e-01 $1.00000 \mathrm{e}+001.00000 \mathrm{e}+001.00000 \mathrm{e}-01$ 1.00000e-09 1.00000e-01 Element: 11549 \# of layers: 7

$\mathrm{Kx} \mathrm{Ky} \mathrm{Kz}$ Ss Por $1.66929 \mathrm{e}+01$ 1.66929e+01 1.66929e+00 1.00000e-09 2.12000e-01 $1.66929 \mathrm{e}+011.66929 \mathrm{e}+011.66929 \mathrm{e}+001.00000 \mathrm{e}-092.12000 \mathrm{e}-01$ $1.66929 \mathrm{e}+011.66929 \mathrm{e}+011.66929 \mathrm{e}+001.00000 \mathrm{e}-092.12000 \mathrm{e}-01$ $1.66929 \mathrm{e}+011.66929 \mathrm{e}+011.66929 \mathrm{e}+001.00000 \mathrm{e}-092.12000 \mathrm{e}-01$ $1.66929 \mathrm{e}+01$ 1.66929e+01 1.66929e+00 1.00000e-09 2.12000e-01 $1.00000 \mathrm{e}-05$ 1.00000e-05 1.00000e-06 1.00000e-09 1.00000e-01 $1.00000 \mathrm{e}+001.00000 \mathrm{e}+001.00000 \mathrm{e}-01$ 1.00000e-09 1.00000e-01 Element: 11550 \# of layers: 7

$\mathrm{Kx} \mathrm{Ky} \mathrm{Kz}$ Ss Por

$1.62440 \mathrm{e}+011.62440 \mathrm{e}+011.62440 \mathrm{e}+001.00000 \mathrm{e}-092.12000 \mathrm{e}-01$ $1.62440 \mathrm{e}+011.62440 \mathrm{e}+011.62440 \mathrm{e}+001.00000 \mathrm{e}-092.12000 \mathrm{e}-01$ $1.62440 \mathrm{e}+011.62440 \mathrm{e}+011.62440 \mathrm{e}+001.00000 \mathrm{e}-092.12000 \mathrm{e}-01$ $1.62440 \mathrm{e}+011.62440 \mathrm{e}+011.62440 \mathrm{e}+001.00000 \mathrm{e}-092.12000 \mathrm{e}-01$ $1.62440 \mathrm{e}+011.62440 \mathrm{e}+011.62440 \mathrm{e}+001.00000 \mathrm{e}-092.12000 \mathrm{e}-01$ $1.00000 \mathrm{e}-05$ 1.00000e-05 1.00000e-06 1.00000e-09 1.00000e-01 $1.00000 \mathrm{e}+001.00000 \mathrm{e}+001.00000 \mathrm{e}-011.00000 \mathrm{e}-091.00000 \mathrm{e}-01$ Element: 11551 \# of layers: 7

$\mathrm{Kx} \mathrm{Ky} \mathrm{Kz}$ Ss Por

$1.62440 \mathrm{e}+011.62440 \mathrm{e}+011.62440 \mathrm{e}+001.00000 \mathrm{e}-092.12000 \mathrm{e}-01$ $1.62440 \mathrm{e}+011.62440 \mathrm{e}+011.62440 \mathrm{e}+001.00000 \mathrm{e}-092.12000 \mathrm{e}-01$ $1.62440 \mathrm{e}+01$ 1.62440e+01 1.62440e+00 1.00000e-09 2.12000e-01 
$1.62440 \mathrm{e}+011.62440 \mathrm{e}+011.62440 \mathrm{e}+001.00000 \mathrm{e}-092.12000 \mathrm{e}-01$ $1.62440 \mathrm{e}+011.62440 \mathrm{e}+011.62440 \mathrm{e}+001.00000 \mathrm{e}-092.12000 \mathrm{e}-01$ $1.00000 \mathrm{e}-05$ 1.00000e-05 1.00000e-06 1.00000e-09 1.00000e-01 $1.00000 \mathrm{e}+001.00000 \mathrm{e}+001.00000 \mathrm{e}-011.00000 \mathrm{e}-091.00000 \mathrm{e}-01$ Element: 11552 \# of layers: 7

$\mathrm{Kx} \mathrm{Ky} \mathrm{Kz}$ Ss Por

$1.62440 \mathrm{e}+011.62440 \mathrm{e}+011.62440 \mathrm{e}+001.00000 \mathrm{e}-092.12000 \mathrm{e}-01$ $1.62440 \mathrm{e}+011.62440 \mathrm{e}+011.62440 \mathrm{e}+001.00000 \mathrm{e}-092.12000 \mathrm{e}-01$ $1.62440 \mathrm{e}+011.62440 \mathrm{e}+011.62440 \mathrm{e}+001.00000 \mathrm{e}-092.12000 \mathrm{e}-01$ $1.62440 \mathrm{e}+011.62440 \mathrm{e}+011.62440 \mathrm{e}+001.00000 \mathrm{e}-092.12000 \mathrm{e}-01$ $1.62440 \mathrm{e}+011.62440 \mathrm{e}+011.62440 \mathrm{e}+001.00000 \mathrm{e}-092.12000 \mathrm{e}-01$ $1.00000 \mathrm{e}-05$ 1.00000e-05 1.00000e-06 1.00000e-09 1.00000e-01 $1.00000 \mathrm{e}+001.00000 \mathrm{e}+001.00000 \mathrm{e}-011.00000 \mathrm{e}-09$ 1.00000e-01 Element: 11553 \# of layers: 7

$\mathrm{Kx} \mathrm{Ky} \mathrm{Kz}$ Ss Por

$1.62440 \mathrm{e}+011.62440 \mathrm{e}+011.62440 \mathrm{e}+001.00000 \mathrm{e}-092.12000 \mathrm{e}-01$ $1.62440 \mathrm{e}+011.62440 \mathrm{e}+011.62440 \mathrm{e}+001.00000 \mathrm{e}-092.12000 \mathrm{e}-01$ $1.62440 \mathrm{e}+011.62440 \mathrm{e}+011.62440 \mathrm{e}+001.00000 \mathrm{e}-092.12000 \mathrm{e}-01$ $1.62440 \mathrm{e}+011.62440 \mathrm{e}+011.62440 \mathrm{e}+001.00000 \mathrm{e}-092.12000 \mathrm{e}-01$ $1.62440 \mathrm{e}+011.62440 \mathrm{e}+011.62440 \mathrm{e}+001.00000 \mathrm{e}-092.12000 \mathrm{e}-01$ $1.00000 \mathrm{e}-05$ 1.00000e-05 1.00000e-06 1.00000e-09 1.00000e-01 $1.00000 \mathrm{e}+001.00000 \mathrm{e}+001.00000 \mathrm{e}-01$ 1.00000e-09 1.00000e-01 Element: 11554 \# of layers: 7

Kx Ky Kz Ss Por

$1.62440 \mathrm{e}+011.62440 \mathrm{e}+011.62440 \mathrm{e}+001.00000 \mathrm{e}-092.12000 \mathrm{e}-01$ $1.62440 \mathrm{e}+011.62440 \mathrm{e}+011.62440 \mathrm{e}+001.00000 \mathrm{e}-092.12000 \mathrm{e}-01$ $1.62440 \mathrm{e}+011.62440 \mathrm{e}+011.62440 \mathrm{e}+001.00000 \mathrm{e}-092.12000 \mathrm{e}-01$ $1.62440 \mathrm{e}+011.62440 \mathrm{e}+011.62440 \mathrm{e}+001.00000 \mathrm{e}-092.12000 \mathrm{e}-01$ $1.62440 \mathrm{e}+011.62440 \mathrm{e}+011.62440 \mathrm{e}+001.00000 \mathrm{e}-092.12000 \mathrm{e}-01$ $1.00000 \mathrm{e}-05$ 1.00000e-05 1.00000e-06 1.00000e-09 1.00000e-01 $1.00000 \mathrm{e}+001.00000 \mathrm{e}+001.00000 \mathrm{e}-011.00000 \mathrm{e}-091.00000 \mathrm{e}-01$ Element: 11555 \# of layers: 7

Kx Ky Kz Ss Por

$1.62440 \mathrm{e}+011.62440 \mathrm{e}+011.62440 \mathrm{e}+001.00000 \mathrm{e}-092.12000 \mathrm{e}-01$ $1.62440 \mathrm{e}+011.62440 \mathrm{e}+011.62440 \mathrm{e}+001.00000 \mathrm{e}-092.12000 \mathrm{e}-01$ $1.62440 \mathrm{e}+011.62440 \mathrm{e}+011.62440 \mathrm{e}+001.00000 \mathrm{e}-092.12000 \mathrm{e}-01$ $1.62440 \mathrm{e}+011.62440 \mathrm{e}+011.62440 \mathrm{e}+001.00000 \mathrm{e}-092.12000 \mathrm{e}-01$ $1.62440 \mathrm{e}+011.62440 \mathrm{e}+011.62440 \mathrm{e}+001.00000 \mathrm{e}-092.12000 \mathrm{e}-01$ $1.00000 \mathrm{e}-05$ 1.00000e-05 1.00000e-06 1.00000e-09 1.00000e-01 $1.00000 \mathrm{e}+001.00000 \mathrm{e}+001.00000 \mathrm{e}-01$ 1.00000e-09 1.00000e-01 Element: 11556 \# of layers: 7

$\mathrm{Kx} \mathrm{Ky} \mathrm{Kz}$ Ss Por

$1.62440 \mathrm{e}+011.62440 \mathrm{e}+01$ 1.62440e+00 1.00000e-09 2.12000e-01 $1.62440 \mathrm{e}+011.62440 \mathrm{e}+011.62440 \mathrm{e}+001.00000 \mathrm{e}-092.12000 \mathrm{e}-01$ $1.62440 \mathrm{e}+011.62440 \mathrm{e}+011.62440 \mathrm{e}+001.00000 \mathrm{e}-092.12000 \mathrm{e}-01$ $1.62440 \mathrm{e}+01$ 1.62440e+01 1.62440e+00 1.00000e-09 2.12000e-01 
$1.62440 \mathrm{e}+011.62440 \mathrm{e}+011.62440 \mathrm{e}+001.00000 \mathrm{e}-092.12000 \mathrm{e}-01$ $1.00000 \mathrm{e}-05$ 1.00000e-05 1.00000e-06 1.00000e-09 1.00000e-01 $1.00000 \mathrm{e}+001.00000 \mathrm{e}+001.00000 \mathrm{e}-011.00000 \mathrm{e}-091.00000 \mathrm{e}-01$

Element: 11557 \# of layers: 7

$\mathrm{Kx} \mathrm{Ky} \mathrm{Kz}$ Ss Por

$1.62440 \mathrm{e}+01$ 1.62440e+01 1.62440e+00 1.00000e-09 2.12000e-01

$1.62440 \mathrm{e}+011.62440 \mathrm{e}+011.62440 \mathrm{e}+001.00000 \mathrm{e}-092.12000 \mathrm{e}-01$

$1.62440 \mathrm{e}+011.62440 \mathrm{e}+011.62440 \mathrm{e}+001.00000 \mathrm{e}-092.12000 \mathrm{e}-01$

$1.62440 \mathrm{e}+011.62440 \mathrm{e}+011.62440 \mathrm{e}+001.00000 \mathrm{e}-092.12000 \mathrm{e}-01$

$1.62440 \mathrm{e}+011.62440 \mathrm{e}+011.62440 \mathrm{e}+001.00000 \mathrm{e}-092.12000 \mathrm{e}-01$

$1.00000 \mathrm{e}-05$ 1.00000e-05 1.00000e-06 1.00000e-09 1.00000e-01

$1.00000 \mathrm{e}+001.00000 \mathrm{e}+001.00000 \mathrm{e}-011.00000 \mathrm{e}-091.00000 \mathrm{e}-01$

Element: 11558 \# of layers: 7

$\mathrm{Kx} \mathrm{Ky} \mathrm{Kz}$ Ss Por

$1.62440 \mathrm{e}+011.62440 \mathrm{e}+01$ 1.62440e+00 1.00000e-09 2.12000e-01

$1.62440 \mathrm{e}+011.62440 \mathrm{e}+011.62440 \mathrm{e}+001.00000 \mathrm{e}-092.12000 \mathrm{e}-01$

$1.62440 \mathrm{e}+011.62440 \mathrm{e}+011.62440 \mathrm{e}+001.00000 \mathrm{e}-092.12000 \mathrm{e}-01$

$1.62440 \mathrm{e}+011.62440 \mathrm{e}+011.62440 \mathrm{e}+001.00000 \mathrm{e}-092.12000 \mathrm{e}-01$

$1.62440 \mathrm{e}+011.62440 \mathrm{e}+011.62440 \mathrm{e}+001.00000 \mathrm{e}-092.12000 \mathrm{e}-01$

$1.00000 \mathrm{e}-05$ 1.00000e-05 1.00000e-06 1.00000e-09 1.00000e-01

$1.00000 \mathrm{e}+001.00000 \mathrm{e}+001.00000 \mathrm{e}-011.00000 \mathrm{e}-091.00000 \mathrm{e}-01$

Element: 11559 \# of layers: 7

$\mathrm{Kx} \mathrm{Ky} \mathrm{Kz}$ Ss Por

$1.62440 \mathrm{e}+011.62440 \mathrm{e}+011.62440 \mathrm{e}+001.00000 \mathrm{e}-092.12000 \mathrm{e}-01$

$1.62440 \mathrm{e}+011.62440 \mathrm{e}+011.62440 \mathrm{e}+001.00000 \mathrm{e}-092.12000 \mathrm{e}-01$

$1.62440 \mathrm{e}+011.62440 \mathrm{e}+011.62440 \mathrm{e}+001.00000 \mathrm{e}-092.12000 \mathrm{e}-01$

$1.62440 \mathrm{e}+011.62440 \mathrm{e}+011.62440 \mathrm{e}+001.00000 \mathrm{e}-092.12000 \mathrm{e}-01$

$1.62440 \mathrm{e}+011.62440 \mathrm{e}+011.62440 \mathrm{e}+001.00000 \mathrm{e}-092.12000 \mathrm{e}-01$

$1.00000 \mathrm{e}-05$ 1.00000e-05 1.00000e-06 1.00000e-09 1.00000e-01

$1.00000 \mathrm{e}+001.00000 \mathrm{e}+001.00000 \mathrm{e}-011.00000 \mathrm{e}-091.00000 \mathrm{e}-01$

Element: 11560 \# of layers: 7

$\mathrm{Kx} \mathrm{Ky} \mathrm{Kz}$ Ss Por

$1.62440 \mathrm{e}+011.62440 \mathrm{e}+011.62440 \mathrm{e}+001.00000 \mathrm{e}-092.12000 \mathrm{e}-01$

$1.62440 \mathrm{e}+011.62440 \mathrm{e}+011.62440 \mathrm{e}+001.00000 \mathrm{e}-092.12000 \mathrm{e}-01$

$1.62440 \mathrm{e}+011.62440 \mathrm{e}+011.62440 \mathrm{e}+001.00000 \mathrm{e}-092.12000 \mathrm{e}-01$

$1.62440 \mathrm{e}+011.62440 \mathrm{e}+011.62440 \mathrm{e}+001.00000 \mathrm{e}-092.12000 \mathrm{e}-01$

$1.62440 \mathrm{e}+011.62440 \mathrm{e}+011.62440 \mathrm{e}+001.00000 \mathrm{e}-092.12000 \mathrm{e}-01$

$1.00000 \mathrm{e}-05$ 1.00000e-05 1.00000e-06 1.00000e-09 1.00000e-01

$1.00000 \mathrm{e}+001.00000 \mathrm{e}+001.00000 \mathrm{e}-01$ 1.00000e-09 1.00000e-01

Element: 11561 \# of layers: 7

$\mathrm{Kx} \mathrm{Ky} \mathrm{Kz}$ Ss Por

$1.62384 \mathrm{e}+01$ 1.62384e+01 1.62384e+00 1.00000e-09 2.12000e-01

$1.62384 \mathrm{e}+011.62384 \mathrm{e}+011.62384 \mathrm{e}+001.00000 \mathrm{e}-092.12000 \mathrm{e}-01$

$1.62384 \mathrm{e}+01$ 1.62384e+01 1.62384e+00 1.00000e-09 2.12000e-01

$1.62384 \mathrm{e}+011.62384 \mathrm{e}+011.62384 \mathrm{e}+001.00000 \mathrm{e}-092.12000 \mathrm{e}-01$

$1.62384 \mathrm{e}+011.62384 \mathrm{e}+011.62384 \mathrm{e}+001.00000 \mathrm{e}-092.12000 \mathrm{e}-01$ 
$1.00000 \mathrm{e}-05$ 1.00000e-05 1.00000e-06 1.00000e-09 1.00000e-01 $1.00000 \mathrm{e}+001.00000 \mathrm{e}+001.00000 \mathrm{e}-01$ 1.00000e-09 1.00000e-01 Element: 11562 \# of layers: 7

Kx Ky Kz Ss Por

$1.62384 \mathrm{e}+011.62384 \mathrm{e}+01$ 1.62384e+00 1.00000e-09 2.12000e-01 $1.62384 \mathrm{e}+011.62384 \mathrm{e}+011.62384 \mathrm{e}+001.00000 \mathrm{e}-092.12000 \mathrm{e}-01$ $1.62384 \mathrm{e}+011.62384 \mathrm{e}+011.62384 \mathrm{e}+001.00000 \mathrm{e}-092.12000 \mathrm{e}-01$ $1.62384 \mathrm{e}+011.62384 \mathrm{e}+011.62384 \mathrm{e}+001.00000 \mathrm{e}-092.12000 \mathrm{e}-01$ $1.62384 \mathrm{e}+011.62384 \mathrm{e}+01$ 1.62384e+00 1.00000e-09 2.12000e-01 $1.00000 \mathrm{e}-05$ 1.00000e-05 1.00000e-06 1.00000e-09 1.00000e-01 $1.00000 \mathrm{e}+001.00000 \mathrm{e}+001.00000 \mathrm{e}-011.00000 \mathrm{e}-091.00000 \mathrm{e}-01$ Element: 11563 \# of layers: 7

$\mathrm{Kx} \mathrm{Ky} \mathrm{Kz}$ Ss Por

$1.62384 \mathrm{e}+011.62384 \mathrm{e}+01$ 1.62384e+00 1.00000e-09 2.12000e-01 $1.62384 \mathrm{e}+011.62384 \mathrm{e}+011.62384 \mathrm{e}+001.00000 \mathrm{e}-092.12000 \mathrm{e}-01$ $1.62384 \mathrm{e}+011.62384 \mathrm{e}+011.62384 \mathrm{e}+001.00000 \mathrm{e}-092.12000 \mathrm{e}-01$ $1.62384 \mathrm{e}+011.62384 \mathrm{e}+011.62384 \mathrm{e}+001.00000 \mathrm{e}-092.12000 \mathrm{e}-01$ $1.62384 \mathrm{e}+011.62384 \mathrm{e}+011.62384 \mathrm{e}+001.00000 \mathrm{e}-092.12000 \mathrm{e}-01$ $1.00000 \mathrm{e}-051.00000 \mathrm{e}-05$ 1.00000e-06 1.00000e-09 1.00000e-01 $1.00000 \mathrm{e}+001.00000 \mathrm{e}+001.00000 \mathrm{e}-011.00000 \mathrm{e}-09$ 1.00000e-01 Element: 11564 \# of layers: 7

$\mathrm{Kx} \mathrm{Ky} \mathrm{Kz}$ Ss Por

$1.62440 \mathrm{e}+011.62440 \mathrm{e}+011.62440 \mathrm{e}+001.00000 \mathrm{e}-092.12000 \mathrm{e}-01$ $1.62440 \mathrm{e}+011.62440 \mathrm{e}+011.62440 \mathrm{e}+001.00000 \mathrm{e}-092.12000 \mathrm{e}-01$ $1.62440 \mathrm{e}+011.62440 \mathrm{e}+011.62440 \mathrm{e}+001.00000 \mathrm{e}-092.12000 \mathrm{e}-01$ $1.62440 \mathrm{e}+011.62440 \mathrm{e}+011.62440 \mathrm{e}+001.00000 \mathrm{e}-092.12000 \mathrm{e}-01$ $1.62440 \mathrm{e}+011.62440 \mathrm{e}+011.62440 \mathrm{e}+001.00000 \mathrm{e}-092.12000 \mathrm{e}-01$ $1.00000 \mathrm{e}-05$ 1.00000e-05 1.00000e-06 1.00000e-09 1.00000e-01 $1.00000 \mathrm{e}+001.00000 \mathrm{e}+001.00000 \mathrm{e}-011.00000 \mathrm{e}-091.00000 \mathrm{e}-01$ Element: 11565 \# of layers: 7

$\mathrm{Kx} \mathrm{Ky} \mathrm{Kz}$ Ss Por

$1.62440 \mathrm{e}+011.62440 \mathrm{e}+011.62440 \mathrm{e}+00$ 1.00000e-09 2.12000e-01 $1.62440 \mathrm{e}+011.62440 \mathrm{e}+011.62440 \mathrm{e}+001.00000 \mathrm{e}-092.12000 \mathrm{e}-01$ $1.62440 \mathrm{e}+011.62440 \mathrm{e}+011.62440 \mathrm{e}+001.00000 \mathrm{e}-092.12000 \mathrm{e}-01$ $1.62440 \mathrm{e}+011.62440 \mathrm{e}+011.62440 \mathrm{e}+001.00000 \mathrm{e}-092.12000 \mathrm{e}-01$ $1.62440 \mathrm{e}+011.62440 \mathrm{e}+011.62440 \mathrm{e}+001.00000 \mathrm{e}-092.12000 \mathrm{e}-01$ $1.00000 \mathrm{e}-05$ 1.00000e-05 1.00000e-06 1.00000e-09 1.00000e-01 $1.00000 \mathrm{e}+001.00000 \mathrm{e}+001.00000 \mathrm{e}-011.00000 \mathrm{e}-091.00000 \mathrm{e}-01$ Element: 11566 \# of layers: 7

$\mathrm{Kx} \mathrm{Ky} \mathrm{Kz}$ Ss Por

$1.62440 \mathrm{e}+01$ 1.62440e+01 1.62440e+00 1.00000e-09 2.12000e-01 $1.62440 \mathrm{e}+011.62440 \mathrm{e}+011.62440 \mathrm{e}+001.00000 \mathrm{e}-092.12000 \mathrm{e}-01$ $1.62440 \mathrm{e}+011.62440 \mathrm{e}+011.62440 \mathrm{e}+001.00000 \mathrm{e}-092.12000 \mathrm{e}-01$ $1.62440 \mathrm{e}+01$ 1.62440e+01 1.62440e+00 1.00000e-09 2.12000e-01 $1.62440 \mathrm{e}+011.62440 \mathrm{e}+011.62440 \mathrm{e}+001.00000 \mathrm{e}-092.12000 \mathrm{e}-01$ $1.00000 \mathrm{e}-05$ 1.00000e-05 1.00000e-06 1.00000e-09 1.00000e-01 
$1.00000 \mathrm{e}+001.00000 \mathrm{e}+001.00000 \mathrm{e}-011.00000 \mathrm{e}-091.00000 \mathrm{e}-01$

Element: 11567 \# of layers: 7

$\mathrm{Kx} \mathrm{Ky} \mathrm{Kz}$ Ss Por

$1.62440 \mathrm{e}+011.62440 \mathrm{e}+011.62440 \mathrm{e}+001.00000 \mathrm{e}-092.12000 \mathrm{e}-01$

$1.62440 \mathrm{e}+011.62440 \mathrm{e}+011.62440 \mathrm{e}+001.00000 \mathrm{e}-092.12000 \mathrm{e}-01$

$1.62440 \mathrm{e}+011.62440 \mathrm{e}+011.62440 \mathrm{e}+001.00000 \mathrm{e}-092.12000 \mathrm{e}-01$

$1.62440 \mathrm{e}+011.62440 \mathrm{e}+011.62440 \mathrm{e}+001.00000 \mathrm{e}-092.12000 \mathrm{e}-01$

$1.62440 \mathrm{e}+011.62440 \mathrm{e}+011.62440 \mathrm{e}+001.00000 \mathrm{e}-092.12000 \mathrm{e}-01$

$1.00000 \mathrm{e}-05$ 1.00000e-05 1.00000e-06 1.00000e-09 1.00000e-01

$1.00000 \mathrm{e}+001.00000 \mathrm{e}+001.00000 \mathrm{e}-011.00000 \mathrm{e}-091.00000 \mathrm{e}-01$

Element: 11568 \# of layers: 7

Kx Ky Kz Ss Por

$1.62384 \mathrm{e}+011.62384 \mathrm{e}+01$ 1.62384e+00 1.00000e-09 2.12000e-01

$1.62384 \mathrm{e}+011.62384 \mathrm{e}+011.62384 \mathrm{e}+001.00000 \mathrm{e}-092.12000 \mathrm{e}-01$

$1.62384 \mathrm{e}+011.62384 \mathrm{e}+011.62384 \mathrm{e}+001.00000 \mathrm{e}-092.12000 \mathrm{e}-01$

$1.62384 \mathrm{e}+011.62384 \mathrm{e}+011.62384 \mathrm{e}+001.00000 \mathrm{e}-092.12000 \mathrm{e}-01$

$1.62384 \mathrm{e}+011.62384 \mathrm{e}+011.62384 \mathrm{e}+001.00000 \mathrm{e}-092.12000 \mathrm{e}-01$

$1.00000 \mathrm{e}-05$ 1.00000e-05 1.00000e-06 1.00000e-09 1.00000e-01

$1.00000 \mathrm{e}+001.00000 \mathrm{e}+001.00000 \mathrm{e}-01$ 1.00000e-09 1.00000e-01

Element: 11569 \# of layers: 7

$\mathrm{Kx} \mathrm{Ky} \mathrm{Kz}$ Ss Por

$1.62384 \mathrm{e}+011.62384 \mathrm{e}+011.62384 \mathrm{e}+001.00000 \mathrm{e}-092.12000 \mathrm{e}-01$

$1.62384 \mathrm{e}+011.62384 \mathrm{e}+011.62384 \mathrm{e}+001.00000 \mathrm{e}-092.12000 \mathrm{e}-01$

$1.62384 \mathrm{e}+011.62384 \mathrm{e}+011.62384 \mathrm{e}+001.00000 \mathrm{e}-092.12000 \mathrm{e}-01$

$1.62384 \mathrm{e}+011.62384 \mathrm{e}+011.62384 \mathrm{e}+001.00000 \mathrm{e}-092.12000 \mathrm{e}-01$

$1.62384 \mathrm{e}+011.62384 \mathrm{e}+011.62384 \mathrm{e}+001.00000 \mathrm{e}-092.12000 \mathrm{e}-01$

$1.00000 \mathrm{e}-05$ 1.00000e-05 1.00000e-06 1.00000e-09 1.00000e-01

$1.00000 \mathrm{e}+001.00000 \mathrm{e}+001.00000 \mathrm{e}-01$ 1.00000e-09 1.00000e-01

Element: 11570 \# of layers: 7

$\mathrm{Kx} \mathrm{Ky} \mathrm{Kz}$ Ss Por

$1.62384 \mathrm{e}+011.62384 \mathrm{e}+01$ 1.62384e+00 1.00000e-09 2.12000e-01

$1.62384 \mathrm{e}+011.62384 \mathrm{e}+011.62384 \mathrm{e}+001.00000 \mathrm{e}-092.12000 \mathrm{e}-01$

$1.62384 \mathrm{e}+011.62384 \mathrm{e}+011.62384 \mathrm{e}+001.00000 \mathrm{e}-092.12000 \mathrm{e}-01$

$1.62384 \mathrm{e}+011.62384 \mathrm{e}+011.62384 \mathrm{e}+001.00000 \mathrm{e}-092.12000 \mathrm{e}-01$

$1.62384 \mathrm{e}+011.62384 \mathrm{e}+011.62384 \mathrm{e}+001.00000 \mathrm{e}-092.12000 \mathrm{e}-01$

$1.00000 \mathrm{e}-05$ 1.00000e-05 1.00000e-06 1.00000e-09 1.00000e-01

$1.00000 \mathrm{e}+001.00000 \mathrm{e}+001.00000 \mathrm{e}-01$ 1.00000e-09 1.00000e-01

Element: 11571 \# of layers: 7

$\mathrm{Kx} \mathrm{Ky} \mathrm{Kz}$ Ss Por

$1.62384 \mathrm{e}+011.62384 \mathrm{e}+011.62384 \mathrm{e}+001.00000 \mathrm{e}-092.12000 \mathrm{e}-01$

$1.62384 \mathrm{e}+011.62384 \mathrm{e}+011.62384 \mathrm{e}+001.00000 \mathrm{e}-092.12000 \mathrm{e}-01$

$1.62384 \mathrm{e}+011.62384 \mathrm{e}+011.62384 \mathrm{e}+001.00000 \mathrm{e}-092.12000 \mathrm{e}-01$

$1.62384 \mathrm{e}+011.62384 \mathrm{e}+011.62384 \mathrm{e}+001.00000 \mathrm{e}-092.12000 \mathrm{e}-01$

$1.62384 \mathrm{e}+01$ 1.62384e+01 1.62384e+00 1.00000e-09 2.12000e-01 $1.00000 \mathrm{e}-05$ 1.00000e-05 1.00000e-06 1.00000e-09 1.00000e-01

$1.00000 \mathrm{e}+001.00000 \mathrm{e}+001.00000 \mathrm{e}-011.00000 \mathrm{e}-091.00000 \mathrm{e}-01$ 
Element: 11572 \# of layers: 7

Kx Ky Kz Ss Por

$1.67183 \mathrm{e}+011.67183 \mathrm{e}+01$ 1.67183e+00 1.00000e-09 2.12000e-01

$1.67183 \mathrm{e}+011.67183 \mathrm{e}+011.67183 \mathrm{e}+001.00000 \mathrm{e}-092.12000 \mathrm{e}-01$

$1.67183 \mathrm{e}+011.67183 \mathrm{e}+011.67183 \mathrm{e}+001.00000 \mathrm{e}-092.12000 \mathrm{e}-01$

$1.67183 \mathrm{e}+011.67183 \mathrm{e}+011.67183 \mathrm{e}+001.00000 \mathrm{e}-092.12000 \mathrm{e}-01$

$1.67183 \mathrm{e}+011.67183 \mathrm{e}+011.67183 \mathrm{e}+001.00000 \mathrm{e}-092.12000 \mathrm{e}-01$

$1.00000 \mathrm{e}-05$ 1.00000e-05 1.00000e-06 1.00000e-09 1.00000e-01

$1.00000 \mathrm{e}+001.00000 \mathrm{e}+001.00000 \mathrm{e}-011.00000 \mathrm{e}-091.00000 \mathrm{e}-01$

Element: 11573 \# of layers: 7

Kx Ky Kz Ss Por

$1.67183 \mathrm{e}+011.67183 \mathrm{e}+011.67183 \mathrm{e}+00$ 1.00000e-09 2.12000e-01

$1.67183 \mathrm{e}+011.67183 \mathrm{e}+011.67183 \mathrm{e}+001.00000 \mathrm{e}-092.12000 \mathrm{e}-01$

$1.67183 \mathrm{e}+011.67183 \mathrm{e}+011.67183 \mathrm{e}+001.00000 \mathrm{e}-092.12000 \mathrm{e}-01$

$1.67183 \mathrm{e}+011.67183 \mathrm{e}+011.67183 \mathrm{e}+001.00000 \mathrm{e}-092.12000 \mathrm{e}-01$

$1.67183 \mathrm{e}+011.67183 \mathrm{e}+011.67183 \mathrm{e}+001.00000 \mathrm{e}-092.12000 \mathrm{e}-01$

$1.00000 \mathrm{e}-05$ 1.00000e-05 1.00000e-06 1.00000e-09 1.00000e-01

$1.00000 \mathrm{e}+001.00000 \mathrm{e}+001.00000 \mathrm{e}-011.00000 \mathrm{e}-091.00000 \mathrm{e}-01$

Element: 11574 \# of layers: 7

Kx Ky Kz Ss Por

$1.62384 \mathrm{e}+011.62384 \mathrm{e}+011.62384 \mathrm{e}+001.00000 \mathrm{e}-092.12000 \mathrm{e}-01$

$1.62384 \mathrm{e}+011.62384 \mathrm{e}+011.62384 \mathrm{e}+001.00000 \mathrm{e}-092.12000 \mathrm{e}-01$

$1.62384 \mathrm{e}+011.62384 \mathrm{e}+011.62384 \mathrm{e}+001.00000 \mathrm{e}-092.12000 \mathrm{e}-01$

$1.62384 \mathrm{e}+011.62384 \mathrm{e}+011.62384 \mathrm{e}+001.00000 \mathrm{e}-092.12000 \mathrm{e}-01$

$1.62384 \mathrm{e}+011.62384 \mathrm{e}+011.62384 \mathrm{e}+001.00000 \mathrm{e}-092.12000 \mathrm{e}-01$

$1.00000 \mathrm{e}-05$ 1.00000e-05 1.00000e-06 1.00000e-09 1.00000e-01

$1.00000 \mathrm{e}+001.00000 \mathrm{e}+001.00000 \mathrm{e}-011.00000 \mathrm{e}-091.00000 \mathrm{e}-01$

Element: 11575 \# of layers: 7

Kx Ky Kz Ss Por

$1.67183 \mathrm{e}+011.67183 \mathrm{e}+011.67183 \mathrm{e}+00$ 1.00000e-09 2.12000e-01

$1.67183 \mathrm{e}+011.67183 \mathrm{e}+011.67183 \mathrm{e}+001.00000 \mathrm{e}-092.12000 \mathrm{e}-01$

$1.67183 \mathrm{e}+011.67183 \mathrm{e}+011.67183 \mathrm{e}+001.00000 \mathrm{e}-092.12000 \mathrm{e}-01$

$1.67183 \mathrm{e}+011.67183 \mathrm{e}+011.67183 \mathrm{e}+001.00000 \mathrm{e}-092.12000 \mathrm{e}-01$

$1.67183 \mathrm{e}+011.67183 \mathrm{e}+011.67183 \mathrm{e}+001.00000 \mathrm{e}-092.12000 \mathrm{e}-01$

$1.00000 \mathrm{e}-05$ 1.00000e-05 1.00000e-06 1.00000e-09 1.00000e-01

$1.00000 \mathrm{e}+001.00000 \mathrm{e}+001.00000 \mathrm{e}-011.00000 \mathrm{e}-091.00000 \mathrm{e}-01$

Element: 11576 \# of layers: 7

Kx Ky Kz Ss Por

$1.67183 \mathrm{e}+011.67183 \mathrm{e}+011.67183 \mathrm{e}+00$ 1.00000e-09 2.12000e-01

$1.67183 \mathrm{e}+011.67183 \mathrm{e}+011.67183 \mathrm{e}+001.00000 \mathrm{e}-092.12000 \mathrm{e}-01$

$1.67183 \mathrm{e}+011.67183 \mathrm{e}+011.67183 \mathrm{e}+001.00000 \mathrm{e}-092.12000 \mathrm{e}-01$

$1.67183 \mathrm{e}+011.67183 \mathrm{e}+011.67183 \mathrm{e}+001.00000 \mathrm{e}-092.12000 \mathrm{e}-01$

$1.67183 \mathrm{e}+011.67183 \mathrm{e}+011.67183 \mathrm{e}+00$ 1.00000e-09 2.12000e-01

$1.00000 \mathrm{e}-05$ 1.00000e-05 1.00000e-06 1.00000e-09 1.00000e-01

$1.00000 \mathrm{e}+001.00000 \mathrm{e}+001.00000 \mathrm{e}-011.00000 \mathrm{e}-091.00000 \mathrm{e}-01$

Element: 11577 \# of layers: 7 
$\mathrm{Kx} \mathrm{Ky} \mathrm{Kz}$ Ss Por

$1.66929 \mathrm{e}+01$ 1.66929e+01 1.66929e+00 1.00000e-09 2.12000e-01

$1.66929 \mathrm{e}+01$ 1.66929e+01 1.66929e+00 1.00000e-09 2.12000e-01

$1.66929 \mathrm{e}+011.66929 \mathrm{e}+011.66929 \mathrm{e}+001.00000 \mathrm{e}-092.12000 \mathrm{e}-01$

$1.66929 \mathrm{e}+011.66929 \mathrm{e}+01$ 1.66929e+00 1.00000e-09 2.12000e-01

$1.66929 \mathrm{e}+01$ 1.66929e+01 1.66929e+00 1.00000e-09 2.12000e-01

$1.00000 \mathrm{e}-05$ 1.00000e-05 1.00000e-06 1.00000e-09 1.00000e-01

$1.00000 \mathrm{e}+001.00000 \mathrm{e}+001.00000 \mathrm{e}-01$ 1.00000e-09 1.00000e-01

Element: 11578 \# of layers: 7

$\mathrm{Kx} \mathrm{Ky} \mathrm{Kz}$ Ss Por

$1.66929 \mathrm{e}+01$ 1.66929e+01 1.66929e+00 1.00000e-09 2.12000e-01

$1.66929 \mathrm{e}+011.66929 \mathrm{e}+011.66929 \mathrm{e}+001.00000 \mathrm{e}-092.12000 \mathrm{e}-01$

$1.66929 \mathrm{e}+01$ 1.66929e+01 1.66929e+00 1.00000e-09 2.12000e-01

$1.66929 \mathrm{e}+01$ 1.66929e+01 1.66929e+00 1.00000e-09 2.12000e-01

$1.66929 \mathrm{e}+01$ 1.66929e+01 1.66929e+00 1.00000e-09 2.12000e-01

$1.00000 \mathrm{e}-05$ 1.00000e-05 1.00000e-06 1.00000e-09 1.00000e-01

$1.00000 \mathrm{e}+001.00000 \mathrm{e}+001.00000 \mathrm{e}-011.00000 \mathrm{e}-091.00000 \mathrm{e}-01$

Element: 11579 \# of layers: 7

$\mathrm{Kx} \mathrm{Ky} \mathrm{Kz}$ Ss Por

$1.66929 \mathrm{e}+01$ 1.66929e+01 1.66929e+00 1.00000e-09 2.12000e-01

$1.66929 \mathrm{e}+011.66929 \mathrm{e}+011.66929 \mathrm{e}+001.00000 \mathrm{e}-092.12000 \mathrm{e}-01$

$1.66929 \mathrm{e}+01$ 1.66929e+01 1.66929e+00 1.00000e-09 2.12000e-01

$1.66929 \mathrm{e}+01$ 1.66929e+01 1.66929e+00 1.00000e-09 2.12000e-01

$1.66929 \mathrm{e}+011.66929 \mathrm{e}+01 \quad 1.66929 \mathrm{e}+001.00000 \mathrm{e}-092.12000 \mathrm{e}-01$

$1.00000 \mathrm{e}-05$ 1.00000e-05 1.00000e-06 1.00000e-09 1.00000e-01

$1.00000 \mathrm{e}+001.00000 \mathrm{e}+001.00000 \mathrm{e}-01$ 1.00000e-09 1.00000e-01

Element: 11580 \# of layers: 7

$\mathrm{Kx} \mathrm{Ky} \mathrm{Kz}$ Ss Por

$1.62440 \mathrm{e}+011.62440 \mathrm{e}+011.62440 \mathrm{e}+001.00000 \mathrm{e}-092.12000 \mathrm{e}-01$

$1.62440 \mathrm{e}+011.62440 \mathrm{e}+011.62440 \mathrm{e}+001.00000 \mathrm{e}-092.12000 \mathrm{e}-01$

$1.62440 \mathrm{e}+011.62440 \mathrm{e}+011.62440 \mathrm{e}+001.00000 \mathrm{e}-092.12000 \mathrm{e}-01$

$1.62440 \mathrm{e}+011.62440 \mathrm{e}+011.62440 \mathrm{e}+001.00000 \mathrm{e}-092.12000 \mathrm{e}-01$

$1.62440 \mathrm{e}+011.62440 \mathrm{e}+011.62440 \mathrm{e}+001.00000 \mathrm{e}-092.12000 \mathrm{e}-01$

$1.00000 \mathrm{e}-05$ 1.00000e-05 1.00000e-06 1.00000e-09 1.00000e-01

$1.00000 \mathrm{e}+001.00000 \mathrm{e}+001.00000 \mathrm{e}-011.00000 \mathrm{e}-09$ 1.00000e-01

Element: 11581 \# of layers: 7

Kx Ky Kz Ss Por

$1.62440 \mathrm{e}+011.62440 \mathrm{e}+011.62440 \mathrm{e}+001.00000 \mathrm{e}-092.12000 \mathrm{e}-01$

$1.62440 \mathrm{e}+011.62440 \mathrm{e}+011.62440 \mathrm{e}+001.00000 \mathrm{e}-092.12000 \mathrm{e}-01$

$1.62440 \mathrm{e}+011.62440 \mathrm{e}+011.62440 \mathrm{e}+001.00000 \mathrm{e}-092.12000 \mathrm{e}-01$

$1.62440 \mathrm{e}+011.62440 \mathrm{e}+011.62440 \mathrm{e}+001.00000 \mathrm{e}-092.12000 \mathrm{e}-01$

$1.62440 \mathrm{e}+011.62440 \mathrm{e}+01 \quad 1.62440 \mathrm{e}+001.00000 \mathrm{e}-092.12000 \mathrm{e}-01$

$1.00000 \mathrm{e}-05$ 1.00000e-05 1.00000e-06 1.00000e-09 1.00000e-01

$1.00000 \mathrm{e}+001.00000 \mathrm{e}+001.00000 \mathrm{e}-01$ 1.00000e-09 1.00000e-01

Element: 11582 \# of layers: 7

Kx Ky Kz Ss Por 
$1.62384 \mathrm{e}+011.62384 \mathrm{e}+011.62384 \mathrm{e}+001.00000 \mathrm{e}-092.12000 \mathrm{e}-01$ $1.62384 \mathrm{e}+011.62384 \mathrm{e}+011.62384 \mathrm{e}+001.00000 \mathrm{e}-092.12000 \mathrm{e}-01$ $1.62384 \mathrm{e}+011.62384 \mathrm{e}+011.62384 \mathrm{e}+001.00000 \mathrm{e}-092.12000 \mathrm{e}-01$ $1.62384 \mathrm{e}+011.62384 \mathrm{e}+011.62384 \mathrm{e}+001.00000 \mathrm{e}-092.12000 \mathrm{e}-01$ $1.62384 \mathrm{e}+011.62384 \mathrm{e}+011.62384 \mathrm{e}+001.00000 \mathrm{e}-092.12000 \mathrm{e}-01$ $1.00000 \mathrm{e}-05$ 1.00000e-05 1.00000e-06 1.00000e-09 1.00000e-01 $1.00000 \mathrm{e}+001.00000 \mathrm{e}+001.00000 \mathrm{e}-01$ 1.00000e-09 1.00000e-01 Element: 11583 \# of layers: 7

$\mathrm{Kx} \mathrm{Ky} \mathrm{Kz}$ Ss Por

$1.67183 \mathrm{e}+01$ 1.67183e+01 1.67183e+00 1.00000e-09 2.12000e-01 $1.67183 \mathrm{e}+01$ 1.67183e+01 1.67183e+00 1.00000e-09 2.12000e-01 $1.67183 \mathrm{e}+011.67183 \mathrm{e}+011.67183 \mathrm{e}+001.00000 \mathrm{e}-092.12000 \mathrm{e}-01$ $1.67183 \mathrm{e}+011.67183 \mathrm{e}+011.67183 \mathrm{e}+001.00000 \mathrm{e}-092.12000 \mathrm{e}-01$ $1.67183 \mathrm{e}+011.67183 \mathrm{e}+011.67183 \mathrm{e}+001.00000 \mathrm{e}-092.12000 \mathrm{e}-01$ $1.00000 \mathrm{e}-05$ 1.00000e-05 1.00000e-06 1.00000e-09 1.00000e-01 $1.00000 \mathrm{e}+001.00000 \mathrm{e}+001.00000 \mathrm{e}-011.00000 \mathrm{e}-091.00000 \mathrm{e}-01$ Element: 11584 \# of layers: 7

$\mathrm{Kx} \mathrm{Ky} \mathrm{Kz}$ Ss Por

$1.66929 \mathrm{e}+01$ 1.66929e+01 1.66929e+00 1.00000e-09 2.12000e-01 $1.66929 \mathrm{e}+011.66929 \mathrm{e}+011.66929 \mathrm{e}+001.00000 \mathrm{e}-092.12000 \mathrm{e}-01$ $1.66929 \mathrm{e}+011.66929 \mathrm{e}+011.66929 \mathrm{e}+001.00000 \mathrm{e}-092.12000 \mathrm{e}-01$ $1.66929 \mathrm{e}+01$ 1.66929e+01 1.66929e+00 1.00000e-09 2.12000e-01 $1.66929 \mathrm{e}+01$ 1.66929e+01 1.66929e+00 1.00000e-09 2.12000e-01 $1.00000 \mathrm{e}-05$ 1.00000e-05 1.00000e-06 1.00000e-09 1.00000e-01 $1.00000 \mathrm{e}+001.00000 \mathrm{e}+001.00000 \mathrm{e}-011.00000 \mathrm{e}-091.00000 \mathrm{e}-01$ Element: 11585 \# of layers: 7

$\mathrm{Kx} \mathrm{Ky} \mathrm{Kz}$ Ss Por

$1.79682 \mathrm{e}+01$ 1.79682e+01 1.79682e+00 1.00000e-09 2.12000e-01 $1.79682 \mathrm{e}+011.79682 \mathrm{e}+011.79682 \mathrm{e}+001.00000 \mathrm{e}-092.12000 \mathrm{e}-01$ $1.79682 \mathrm{e}+01$ 1.79682e+01 1.79682e+00 1.00000e-09 2.12000e-01 $1.79682 \mathrm{e}+01$ 1.79682e+01 1.79682e+00 1.00000e-09 2.12000e-01 $1.79682 \mathrm{e}+01$ 1.79682e+01 1.79682e+00 1.00000e-09 2.12000e-01 $1.00000 \mathrm{e}-05$ 1.00000e-05 1.00000e-06 1.00000e-09 1.00000e-01 $1.00000 \mathrm{e}+001.00000 \mathrm{e}+001.00000 \mathrm{e}-011.00000 \mathrm{e}-091.00000 \mathrm{e}-01$ Element: 11586 \# of layers: 7

$\mathrm{Kx} \mathrm{Ky} \mathrm{Kz}$ Ss Por

1.79682e+01 1.79682e+01 1.79682e+00 1.00000e-09 2.12000e-01 $1.79682 \mathrm{e}+011.79682 \mathrm{e}+011.79682 \mathrm{e}+001.00000 \mathrm{e}-092.12000 \mathrm{e}-01$ $1.79682 \mathrm{e}+011.79682 \mathrm{e}+01$ 1.79682e+00 1.00000e-09 2.12000e-01 $1.79682 \mathrm{e}+011.79682 \mathrm{e}+01$ 1.79682e+00 1.00000e-09 2.12000e-01 $1.79682 \mathrm{e}+01$ 1.79682e+01 1.79682e+00 1.00000e-09 2.12000e-01 $1.00000 \mathrm{e}-05$ 1.00000e-05 1.00000e-06 1.00000e-09 1.00000e-01 $1.00000 \mathrm{e}+001.00000 \mathrm{e}+001.00000 \mathrm{e}-011.00000 \mathrm{e}-091.00000 \mathrm{e}-01$ Element: 11587 \# of layers: 7

$\mathrm{Kx} \mathrm{Ky} \mathrm{Kz}$ Ss Por

$1.79682 \mathrm{e}+01$ 1.79682e+01 1.79682e+00 1.00000e-09 2.12000e-01 
1.79682e+01 1.79682e+01 1.79682e+00 1.00000e-09 2.12000e-01 $1.79682 \mathrm{e}+01$ 1.79682e+01 1.79682e+00 1.00000e-09 2.12000e-01 $1.79682 \mathrm{e}+011.79682 \mathrm{e}+011.79682 \mathrm{e}+001.00000 \mathrm{e}-092.12000 \mathrm{e}-01$ $1.79682 \mathrm{e}+01$ 1.79682e+01 1.79682e+00 1.00000e-09 2.12000e-01 $1.00000 \mathrm{e}-05$ 1.00000e-05 1.00000e-06 1.00000e-09 1.00000e-01 $1.00000 \mathrm{e}+001.00000 \mathrm{e}+001.00000 \mathrm{e}-011.00000 \mathrm{e}-091.00000 \mathrm{e}-01$ Element: 11588 \# of layers: 7

$\mathrm{Kx} \mathrm{Ky} \mathrm{Kz}$ Ss Por

$1.79682 \mathrm{e}+01$ 1.79682e+01 1.79682e+00 1.00000e-09 2.12000e-01 $1.79682 \mathrm{e}+01$ 1.79682e+01 1.79682e+00 1.00000e-09 2.12000e-01 $1.79682 \mathrm{e}+01$ 1.79682e+01 1.79682e+00 1.00000e-09 2.12000e-01 $1.79682 \mathrm{e}+011.79682 \mathrm{e}+011.79682 \mathrm{e}+001.00000 \mathrm{e}-092.12000 \mathrm{e}-01$ $1.79682 \mathrm{e}+01$ 1.79682e+01 1.79682e+00 1.00000e-09 2.12000e-01 $1.00000 \mathrm{e}-05$ 1.00000e-05 1.00000e-06 1.00000e-09 1.00000e-01 $1.00000 \mathrm{e}+001.00000 \mathrm{e}+001.00000 \mathrm{e}-01$ 1.00000e-09 1.00000e-01 Element: 11589 \# of layers: 7

$\mathrm{Kx} \mathrm{Ky} \mathrm{Kz}$ Ss Por

1.79682e+01 1.79682e+01 1.79682e+00 1.00000e-09 2.12000e-01 $1.79682 \mathrm{e}+01$ 1.79682e+01 1.79682e+00 1.00000e-09 2.12000e-01 $1.79682 \mathrm{e}+011.79682 \mathrm{e}+011.79682 \mathrm{e}+001.00000 \mathrm{e}-092.12000 \mathrm{e}-01$ $1.79682 \mathrm{e}+011.79682 \mathrm{e}+01$ 1.79682e+00 1.00000e-09 2.12000e-01 $1.79682 \mathrm{e}+01$ 1.79682e+01 1.79682e+00 1.00000e-09 2.12000e-01 $1.00000 \mathrm{e}-05$ 1.00000e-05 1.00000e-06 1.00000e-09 1.00000e-01 $1.00000 \mathrm{e}+001.00000 \mathrm{e}+001.00000 \mathrm{e}-011.00000 \mathrm{e}-09$ 1.00000e-01 Element: 11590 \# of layers: 7

$\mathrm{Kx} \mathrm{Ky} \mathrm{Kz}$ Ss Por

$1.79682 \mathrm{e}+01$ 1.79682e+01 1.79682e+00 1.00000e-09 2.12000e-01 $1.79682 \mathrm{e}+011.79682 \mathrm{e}+01$ 1.79682e+00 1.00000e-09 2.12000e-01 $1.79682 \mathrm{e}+01$ 1.79682e+01 1.79682e+00 1.00000e-09 2.12000e-01 $1.79682 \mathrm{e}+01$ 1.79682e+01 1.79682e+00 1.00000e-09 2.12000e-01 $1.79682 \mathrm{e}+01$ 1.79682e+01 1.79682e+00 1.00000e-09 2.12000e-01 $1.00000 \mathrm{e}-05$ 1.00000e-05 1.00000e-06 1.00000e-09 1.00000e-01 $1.00000 \mathrm{e}+001.00000 \mathrm{e}+001.00000 \mathrm{e}-011.00000 \mathrm{e}-091.00000 \mathrm{e}-01$ Element: 11591 \# of layers: 7

$\mathrm{Kx} \mathrm{Ky} \mathrm{Kz}$ Ss Por

$1.79682 \mathrm{e}+01$ 1.79682e+01 1.79682e+00 1.00000e-09 2.12000e-01 $1.79682 \mathrm{e}+01$ 1.79682e+01 1.79682e+00 1.00000e-09 2.12000e-01 $1.79682 \mathrm{e}+011.79682 \mathrm{e}+011.79682 \mathrm{e}+001.00000 \mathrm{e}-092.12000 \mathrm{e}-01$ $1.79682 \mathrm{e}+011.79682 \mathrm{e}+01$ 1.79682e+00 1.00000e-09 2.12000e-01 $1.79682 \mathrm{e}+01$ 1.79682e+01 1.79682e+00 1.00000e-09 2.12000e-01 $1.00000 \mathrm{e}-05$ 1.00000e-05 1.00000e-06 1.00000e-09 1.00000e-01 $1.00000 \mathrm{e}+001.00000 \mathrm{e}+001.00000 \mathrm{e}-011.00000 \mathrm{e}-091.00000 \mathrm{e}-01$ Element: 11592 \# of layers: 7

$\mathrm{Kx} \mathrm{Ky} \mathrm{Kz}$ Ss Por $1.79682 \mathrm{e}+01$ 1.79682e+01 1.79682e+00 1.00000e-09 2.12000e-01 $1.79682 \mathrm{e}+011.79682 \mathrm{e}+011.79682 \mathrm{e}+001.00000 \mathrm{e}-092.12000 \mathrm{e}-01$ 
1.79682e+01 1.79682e+01 1.79682e+00 1.00000e-09 2.12000e-01 $1.79682 \mathrm{e}+01$ 1.79682e+01 1.79682e+00 1.00000e-09 2.12000e-01 $1.79682 \mathrm{e}+011.79682 \mathrm{e}+01$ 1.79682e+00 1.00000e-09 2.12000e-01 $1.00000 \mathrm{e}-05$ 1.00000e-05 1.00000e-06 1.00000e-09 1.00000e-01 $1.00000 \mathrm{e}+001.00000 \mathrm{e}+001.00000 \mathrm{e}-01$ 1.00000e-09 1.00000e-01 Element: 11593 \# of layers: 7

$\mathrm{Kx} \mathrm{Ky} \mathrm{Kz}$ Ss Por

$1.79682 \mathrm{e}+01$ 1.79682e+01 1.79682e+00 1.00000e-09 2.12000e-01

$1.79682 \mathrm{e}+01$ 1.79682e+01 1.79682e+00 1.00000e-09 2.12000e-01

$1.79682 \mathrm{e}+011.79682 \mathrm{e}+01$ 1.79682e+00 1.00000e-09 2.12000e-01

$1.79682 \mathrm{e}+01$ 1.79682e+01 1.79682e+00 1.00000e-09 2.12000e-01

$1.79682 \mathrm{e}+011.79682 \mathrm{e}+011.79682 \mathrm{e}+001.00000 \mathrm{e}-092.12000 \mathrm{e}-01$ $1.00000 \mathrm{e}-05$ 1.00000e-05 1.00000e-06 1.00000e-09 1.00000e-01 $1.00000 \mathrm{e}+001.00000 \mathrm{e}+001.00000 \mathrm{e}-011.00000 \mathrm{e}-09$ 1.00000e-01 Element: 11594 \# of layers: 7

Kx Ky Kz Ss Por

$1.79682 \mathrm{e}+01$ 1.79682e+01 1.79682e+00 1.00000e-09 2.12000e-01 $1.79682 \mathrm{e}+011.79682 \mathrm{e}+01$ 1.79682e+00 1.00000e-09 2.12000e-01 $1.79682 \mathrm{e}+01$ 1.79682e+01 1.79682e+00 1.00000e-09 2.12000e-01 $1.79682 \mathrm{e}+01$ 1.79682e+01 1.79682e+00 1.00000e-09 2.12000e-01 $1.79682 \mathrm{e}+011.79682 \mathrm{e}+01$ 1.79682e+00 1.00000e-09 2.12000e-01 $1.00000 \mathrm{e}-05$ 1.00000e-05 1.00000e-06 1.00000e-09 1.00000e-01 $1.00000 \mathrm{e}+001.00000 \mathrm{e}+001.00000 \mathrm{e}-01$ 1.00000e-09 1.00000e-01 Element: 11595 \# of layers: 7

Kx Ky Kz Ss Por

$1.79507 \mathrm{e}+01$ 1.79507e+01 1.79507e+00 1.00000e-09 2.12000e-01 $1.79507 \mathrm{e}+01$ 1.79507e+01 1.79507e+00 1.00000e-09 2.12000e-01 $1.79507 \mathrm{e}+01$ 1.79507e+01 1.79507e+00 1.00000e-09 2.12000e-01 $1.79507 \mathrm{e}+01$ 1.79507e+01 1.79507e+00 1.00000e-09 2.12000e-01 $1.79507 \mathrm{e}+01$ 1.79507e+01 1.79507e+00 1.00000e-09 2.12000e-01 $1.00000 \mathrm{e}-05$ 1.00000e-05 1.00000e-06 1.00000e-09 1.00000e-01 $1.00000 \mathrm{e}+001.00000 \mathrm{e}+001.00000 \mathrm{e}-01$ 1.00000e-09 1.00000e-01 Element: 11596 \# of layers: 7

$\mathrm{Kx} \mathrm{Ky} \mathrm{Kz}$ Ss Por

1.79507e+01 1.79507e+01 1.79507e+00 1.00000e-09 2.12000e-01 $1.79507 \mathrm{e}+01$ 1.79507e+01 1.79507e+00 1.00000e-09 2.12000e-01 $1.79507 \mathrm{e}+01$ 1.79507e+01 1.79507e+00 1.00000e-09 2.12000e-01 $1.79507 \mathrm{e}+01$ 1.79507e+01 1.79507e+00 1.00000e-09 2.12000e-01 $1.79507 \mathrm{e}+01$ 1.79507e+01 1.79507e+00 1.00000e-09 2.12000e-01 $1.00000 \mathrm{e}-05$ 1.00000e-05 1.00000e-06 1.00000e-09 1.00000e-01 $1.00000 \mathrm{e}+001.00000 \mathrm{e}+001.00000 \mathrm{e}-011.00000 \mathrm{e}-091.00000 \mathrm{e}-01$ Element: 11597 \# of layers: 7

$\mathrm{Kx} \mathrm{Ky} \mathrm{Kz}$ Ss Por

1.79507e+01 1.79507e+01 1.79507e+00 1.00000e-09 2.12000e-01 $1.79507 e+01$ 1.79507e+01 1.79507e+00 1.00000e-09 2.12000e-01 $1.79507 \mathrm{e}+01$ 1.79507e+01 1.79507e+00 1.00000e-09 2.12000e-01 
$1.79507 \mathrm{e}+011.79507 \mathrm{e}+01$ 1.79507e+00 1.00000e-09 2.12000e-01 $1.79507 \mathrm{e}+011.79507 \mathrm{e}+011.79507 \mathrm{e}+001.00000 \mathrm{e}-092.12000 \mathrm{e}-01$ $1.00000 \mathrm{e}-05$ 1.00000e-05 1.00000e-06 1.00000e-09 1.00000e-01 $1.00000 \mathrm{e}+001.00000 \mathrm{e}+001.00000 \mathrm{e}-011.00000 \mathrm{e}-091.00000 \mathrm{e}-01$ Element: 11598 \# of layers: 7

Kx Ky Kz Ss Por

$1.79507 \mathrm{e}+011.79507 \mathrm{e}+01$ 1.79507e+00 1.00000e-09 2.12000e-01 $1.79507 \mathrm{e}+011.79507 \mathrm{e}+011.79507 \mathrm{e}+001.00000 \mathrm{e}-092.12000 \mathrm{e}-01$ $1.79507 \mathrm{e}+011.79507 \mathrm{e}+011.79507 \mathrm{e}+001.00000 \mathrm{e}-092.12000 \mathrm{e}-01$ $1.79507 \mathrm{e}+011.79507 \mathrm{e}+011.79507 \mathrm{e}+001.00000 \mathrm{e}-092.12000 \mathrm{e}-01$ $1.79507 \mathrm{e}+011.79507 \mathrm{e}+011.79507 \mathrm{e}+001.00000 \mathrm{e}-092.12000 \mathrm{e}-01$ $1.00000 \mathrm{e}-05$ 1.00000e-05 1.00000e-06 1.00000e-09 1.00000e-01 $1.00000 \mathrm{e}+001.00000 \mathrm{e}+001.00000 \mathrm{e}-011.00000 \mathrm{e}-091.00000 \mathrm{e}-01$ Element: 11599 \# of layers: 7

Kx Ky Kz Ss Por

$1.79507 \mathrm{e}+011.79507 \mathrm{e}+01$ 1.79507e+00 1.00000e-09 2.12000e-01 $1.79507 \mathrm{e}+011.79507 \mathrm{e}+011.79507 \mathrm{e}+001.00000 \mathrm{e}-092.12000 \mathrm{e}-01$ $1.79507 \mathrm{e}+011.79507 \mathrm{e}+011.79507 \mathrm{e}+001.00000 \mathrm{e}-092.12000 \mathrm{e}-01$ $1.79507 \mathrm{e}+011.79507 \mathrm{e}+011.79507 \mathrm{e}+001.00000 \mathrm{e}-092.12000 \mathrm{e}-01$ $1.79507 \mathrm{e}+011.79507 \mathrm{e}+011.79507 \mathrm{e}+001.00000 \mathrm{e}-092.12000 \mathrm{e}-01$ $1.00000 \mathrm{e}-05$ 1.00000e-05 1.00000e-06 1.00000e-09 1.00000e-01 $1.00000 \mathrm{e}+001.00000 \mathrm{e}+001.00000 \mathrm{e}-011.00000 \mathrm{e}-091.00000 \mathrm{e}-01$ Element: 11600 \# of layers: 7

Kx Ky Kz Ss Por

$1.79682 \mathrm{e}+011.79682 \mathrm{e}+01$ 1.79682e+00 1.00000e-09 2.12000e-01 $1.79682 \mathrm{e}+011.79682 \mathrm{e}+011.79682 \mathrm{e}+001.00000 \mathrm{e}-092.12000 \mathrm{e}-01$ $1.79682 \mathrm{e}+011.79682 \mathrm{e}+011.79682 \mathrm{e}+001.00000 \mathrm{e}-092.12000 \mathrm{e}-01$ $1.79682 \mathrm{e}+011.79682 \mathrm{e}+011.79682 \mathrm{e}+001.00000 \mathrm{e}-092.12000 \mathrm{e}-01$ $1.79682 \mathrm{e}+011.79682 \mathrm{e}+011.79682 \mathrm{e}+001.00000 \mathrm{e}-092.12000 \mathrm{e}-01$ $1.00000 \mathrm{e}-05$ 1.00000e-05 1.00000e-06 1.00000e-09 1.00000e-01 $1.00000 \mathrm{e}+001.00000 \mathrm{e}+001.00000 \mathrm{e}-011.00000 \mathrm{e}-091.00000 \mathrm{e}-01$ Element: 11601 \# of layers: 7

Kx Ky Kz Ss Por

$1.79682 \mathrm{e}+011.79682 \mathrm{e}+011.79682 \mathrm{e}+00$ 1.00000e-09 2.12000e-01 $1.79682 \mathrm{e}+011.79682 \mathrm{e}+011.79682 \mathrm{e}+001.00000 \mathrm{e}-092.12000 \mathrm{e}-01$ $1.79682 \mathrm{e}+011.79682 \mathrm{e}+011.79682 \mathrm{e}+001.00000 \mathrm{e}-092.12000 \mathrm{e}-01$ $1.79682 \mathrm{e}+011.79682 \mathrm{e}+011.79682 \mathrm{e}+001.00000 \mathrm{e}-092.12000 \mathrm{e}-01$ $1.79682 \mathrm{e}+011.79682 \mathrm{e}+011.79682 \mathrm{e}+001.00000 \mathrm{e}-092.12000 \mathrm{e}-01$ $1.00000 \mathrm{e}-05$ 1.00000e-05 1.00000e-06 1.00000e-09 1.00000e-01 $1.00000 \mathrm{e}+001.00000 \mathrm{e}+001.00000 \mathrm{e}-011.00000 \mathrm{e}-091.00000 \mathrm{e}-01$ Element: 11602 \# of layers: 7

Kx Ky Kz Ss Por

$1.79507 \mathrm{e}+011.79507 \mathrm{e}+01$ 1.79507e+00 1.00000e-09 2.12000e-01 $1.79507 \mathrm{e}+011.79507 \mathrm{e}+011.79507 \mathrm{e}+001.00000 \mathrm{e}-092.12000 \mathrm{e}-01$ $1.79507 \mathrm{e}+011.79507 \mathrm{e}+011.79507 \mathrm{e}+001.00000 \mathrm{e}-092.12000 \mathrm{e}-01$ $1.79507 \mathrm{e}+011.79507 \mathrm{e}+011.79507 \mathrm{e}+001.00000 \mathrm{e}-092.12000 \mathrm{e}-01$ 
$1.79507 \mathrm{e}+011.79507 \mathrm{e}+01$ 1.79507e+00 1.00000e-09 2.12000e-01 $1.00000 \mathrm{e}-05$ 1.00000e-05 1.00000e-06 1.00000e-09 1.00000e-01 $1.00000 \mathrm{e}+001.00000 \mathrm{e}+001.00000 \mathrm{e}-011.00000 \mathrm{e}-091.00000 \mathrm{e}-01$ Element: 11603 \# of layers: 7

$\mathrm{Kx} \mathrm{Ky} \mathrm{Kz}$ Ss Por

1.79507e+01 1.79507e+01 1.79507e+00 1.00000e-09 2.12000e-01 $1.79507 \mathrm{e}+01$ 1.79507e+01 1.79507e+00 1.00000e-09 2.12000e-01 $1.79507 \mathrm{e}+01$ 1.79507e+01 1.79507e+00 1.00000e-09 2.12000e-01 $1.79507 \mathrm{e}+01$ 1.79507e+01 1.79507e+00 1.00000e-09 2.12000e-01 $1.79507 \mathrm{e}+01$ 1.79507e+01 1.79507e+00 1.00000e-09 2.12000e-01 $1.00000 \mathrm{e}-05$ 1.00000e-05 1.00000e-06 1.00000e-09 1.00000e-01 $1.00000 \mathrm{e}+001.00000 \mathrm{e}+001.00000 \mathrm{e}-01$ 1.00000e-09 1.00000e-01 Element: 11604 \# of layers: 7

$\mathrm{Kx} \mathrm{Ky} \mathrm{Kz}$ Ss Por

1.79507e+01 1.79507e+01 1.79507e+00 1.00000e-09 2.12000e-01 $1.79507 \mathrm{e}+01$ 1.79507e+01 1.79507e+00 1.00000e-09 2.12000e-01 $1.79507 \mathrm{e}+01$ 1.79507e+01 1.79507e+00 1.00000e-09 2.12000e-01 $1.79507 \mathrm{e}+01$ 1.79507e+01 1.79507e+00 1.00000e-09 2.12000e-01 $1.79507 \mathrm{e}+01$ 1.79507e+01 1.79507e+00 1.00000e-09 2.12000e-01 $1.00000 \mathrm{e}-051.00000 \mathrm{e}-05$ 1.00000e-06 1.00000e-09 1.00000e-01 $1.00000 \mathrm{e}+001.00000 \mathrm{e}+001.00000 \mathrm{e}-011.00000 \mathrm{e}-091.00000 \mathrm{e}-01$ Element: 11605 \# of layers: 7

$\mathrm{Kx} \mathrm{Ky} \mathrm{Kz}$ Ss Por

$1.79507 \mathrm{e}+01$ 1.79507e+01 1.79507e+00 1.00000e-09 2.12000e-01 $1.79507 \mathrm{e}+01$ 1.79507e+01 1.79507e+00 1.00000e-09 2.12000e-01 $1.79507 \mathrm{e}+01$ 1.79507e+01 1.79507e+00 1.00000e-09 2.12000e-01 $1.79507 \mathrm{e}+01$ 1.79507e+01 1.79507e+00 1.00000e-09 2.12000e-01 $1.79507 \mathrm{e}+01$ 1.79507e+01 1.79507e+00 1.00000e-09 2.12000e-01 $1.00000 \mathrm{e}-05$ 1.00000e-05 1.00000e-06 1.00000e-09 1.00000e-01 $1.00000 \mathrm{e}+001.00000 \mathrm{e}+001.00000 \mathrm{e}-011.00000 \mathrm{e}-091.00000 \mathrm{e}-01$ Element: 11606 \# of layers: 7

$\mathrm{Kx} \mathrm{Ky} \mathrm{Kz}$ Ss Por

$1.79507 \mathrm{e}+01$ 1.79507e+01 1.79507e+00 1.00000e-09 2.12000e-01 $1.79507 \mathrm{e}+01$ 1.79507e+01 1.79507e+00 1.00000e-09 2.12000e-01 $1.79507 \mathrm{e}+011.79507 \mathrm{e}+01$ 1.79507e+00 1.00000e-09 2.12000e-01 $1.79507 \mathrm{e}+01$ 1.79507e+01 1.79507e+00 1.00000e-09 2.12000e-01 $1.79507 \mathrm{e}+01$ 1.79507e+01 1.79507e+00 1.00000e-09 2.12000e-01 $1.00000 \mathrm{e}-05$ 1.00000e-05 1.00000e-06 1.00000e-09 1.00000e-01 $1.00000 \mathrm{e}+001.00000 \mathrm{e}+001.00000 \mathrm{e}-011.00000 \mathrm{e}-091.00000 \mathrm{e}-01$ Element: 11607 \# of layers: 7

Kx Ky Kz Ss Por

1.79507e+01 1.79507e+01 1.79507e+00 1.00000e-09 2.12000e-01 $1.79507 \mathrm{e}+01$ 1.79507e+01 1.79507e+00 1.00000e-09 2.12000e-01 1.79507e+01 1.79507e+01 1.79507e+00 1.00000e-09 2.12000e-01 $1.79507 \mathrm{e}+01$ 1.79507e+01 1.79507e+00 1.00000e-09 2.12000e-01 $1.79507 \mathrm{e}+01$ 1.79507e+01 1.79507e+00 1.00000e-09 2.12000e-01 
$1.00000 \mathrm{e}-05$ 1.00000e-05 1.00000e-06 1.00000e-09 1.00000e-01 $1.00000 \mathrm{e}+001.00000 \mathrm{e}+001.00000 \mathrm{e}-01$ 1.00000e-09 1.00000e-01 Element: 11608 \# of layers: 7

Kx Ky Kz Ss Por

$1.79507 \mathrm{e}+01$ 1.79507e+01 1.79507e+00 1.00000e-09 2.12000e-01 $1.79507 \mathrm{e}+01$ 1.79507e+01 1.79507e+00 1.00000e-09 2.12000e-01 $1.79507 \mathrm{e}+01$ 1.79507e+01 1.79507e+00 1.00000e-09 2.12000e-01 $1.79507 \mathrm{e}+01$ 1.79507e+01 1.79507e+00 1.00000e-09 2.12000e-01 $1.79507 \mathrm{e}+01$ 1.79507e+01 1.79507e+00 1.00000e-09 2.12000e-01 $1.00000 \mathrm{e}-05$ 1.00000e-05 1.00000e-06 1.00000e-09 1.00000e-01 $1.00000 \mathrm{e}+001.00000 \mathrm{e}+001.00000 \mathrm{e}-011.00000 \mathrm{e}-091.00000 \mathrm{e}-01$ Element: 11609 \# of layers: 7

Kx Ky Kz Ss Por

1.79507e+01 1.79507e+01 1.79507e+00 1.00000e-09 2.12000e-01 $1.79507 \mathrm{e}+01$ 1.79507e+01 1.79507e+00 1.00000e-09 2.12000e-01 $1.79507 \mathrm{e}+01$ 1.79507e+01 1.79507e+00 1.00000e-09 2.12000e-01 $1.79507 \mathrm{e}+01$ 1.79507e+01 1.79507e+00 1.00000e-09 2.12000e-01 $1.79507 \mathrm{e}+01$ 1.79507e+01 1.79507e+00 1.00000e-09 2.12000e-01 $1.00000 \mathrm{e}-05$ 1.00000e-05 1.00000e-06 1.00000e-09 1.00000e-01 $1.00000 \mathrm{e}+001.00000 \mathrm{e}+001.00000 \mathrm{e}-011.00000 \mathrm{e}-091.00000 \mathrm{e}-01$ Element: 11610 \# of layers: 7

$\mathrm{Kx} \mathrm{Ky} \mathrm{Kz}$ Ss Por

1.79507e+01 1.79507e+01 1.79507e+00 1.00000e-09 2.12000e-01 $1.79507 \mathrm{e}+01$ 1.79507e+01 1.79507e+00 1.00000e-09 2.12000e-01 $1.79507 \mathrm{e}+01$ 1.79507e+01 1.79507e+00 1.00000e-09 2.12000e-01 $1.79507 \mathrm{e}+01$ 1.79507e+01 1.79507e+00 1.00000e-09 2.12000e-01 $1.79507 \mathrm{e}+01$ 1.79507e+01 1.79507e+00 1.00000e-09 2.12000e-01 1.00000e-05 1.00000e-05 1.00000e-06 1.00000e-09 1.00000e-01 $1.00000 \mathrm{e}+001.00000 \mathrm{e}+001.00000 \mathrm{e}-011.00000 \mathrm{e}-091.00000 \mathrm{e}-01$ Element: 11611 \# of layers: 7

$\mathrm{Kx} \mathrm{Ky} \mathrm{Kz}$ Ss Por

1.79507e+01 1.79507e+01 1.79507e+00 1.00000e-09 2.12000e-01 $1.79507 \mathrm{e}+01$ 1.79507e+01 1.79507e+00 1.00000e-09 2.12000e-01 $1.79507 \mathrm{e}+01$ 1.79507e+01 1.79507e+00 1.00000e-09 2.12000e-01 $1.79507 \mathrm{e}+011.79507 \mathrm{e}+01$ 1.79507e+00 1.00000e-09 2.12000e-01 $1.79507 \mathrm{e}+01$ 1.79507e+01 1.79507e+00 1.00000e-09 2.12000e-01 $1.00000 \mathrm{e}-05$ 1.00000e-05 1.00000e-06 1.00000e-09 1.00000e-01 $1.00000 \mathrm{e}+001.00000 \mathrm{e}+001.00000 \mathrm{e}-011.00000 \mathrm{e}-091.00000 \mathrm{e}-01$ Element: 11612 \# of layers: 7

$\mathrm{Kx} \mathrm{Ky} \mathrm{Kz}$ Ss Por

$1.79507 e+01$ 1.79507e+01 1.79507e+00 1.00000e-09 2.12000e-01 $1.79507 \mathrm{e}+01$ 1.79507e+01 1.79507e+00 1.00000e-09 2.12000e-01 $1.79507 \mathrm{e}+01$ 1.79507e+01 1.79507e+00 1.00000e-09 2.12000e-01 $1.79507 \mathrm{e}+01$ 1.79507e+01 1.79507e+00 1.00000e-09 2.12000e-01 $1.79507 \mathrm{e}+01$ 1.79507e+01 1.79507e+00 1.00000e-09 2.12000e-01 $1.00000 \mathrm{e}-05$ 1.00000e-05 1.00000e-06 1.00000e-09 1.00000e-01 
$1.00000 \mathrm{e}+001.00000 \mathrm{e}+001.00000 \mathrm{e}-011.00000 \mathrm{e}-091.00000 \mathrm{e}-01$

Element: 11613 \# of layers: 7

$\mathrm{Kx} \mathrm{Ky} \mathrm{Kz}$ Ss Por

1.79507e+01 1.79507e+01 1.79507e+00 1.00000e-09 2.12000e-01

$1.79507 \mathrm{e}+01$ 1.79507e+01 1.79507e+00 1.00000e-09 2.12000e-01

$1.79507 \mathrm{e}+01$ 1.79507e+01 1.79507e+00 1.00000e-09 2.12000e-01

$1.79507 \mathrm{e}+01$ 1.79507e+01 1.79507e+00 1.00000e-09 2.12000e-01

$1.79507 \mathrm{e}+01$ 1.79507e+01 1.79507e+00 1.00000e-09 2.12000e-01

$1.00000 \mathrm{e}-05$ 1.00000e-05 1.00000e-06 1.00000e-09 1.00000e-01

$1.00000 \mathrm{e}+001.00000 \mathrm{e}+001.00000 \mathrm{e}-011.00000 \mathrm{e}-091.00000 \mathrm{e}-01$

Element: 11614 \# of layers: 7

Kx Ky Kz Ss Por

$1.55465 \mathrm{e}+01$ 1.55465e+01 1.55465e+00 1.00000e-09 2.12000e-01

$1.55465 \mathrm{e}+011.55465 \mathrm{e}+011.55465 \mathrm{e}+001.00000 \mathrm{e}-092.12000 \mathrm{e}-01$

$1.55465 \mathrm{e}+011.55465 \mathrm{e}+011.55465 \mathrm{e}+001.00000 \mathrm{e}-092.12000 \mathrm{e}-01$

$1.55465 \mathrm{e}+011.55465 \mathrm{e}+011.55465 \mathrm{e}+001.00000 \mathrm{e}-092.12000 \mathrm{e}-01$

$1.55465 \mathrm{e}+011.55465 \mathrm{e}+011.55465 \mathrm{e}+001.00000 \mathrm{e}-092.12000 \mathrm{e}-01$

$1.00000 \mathrm{e}-05$ 1.00000e-05 1.00000e-06 1.00000e-09 1.00000e-01

$1.00000 \mathrm{e}+001.00000 \mathrm{e}+001.00000 \mathrm{e}-01$ 1.00000e-09 1.00000e-01

Element: 11615 \# of layers: 7

$\mathrm{Kx} \mathrm{Ky} \mathrm{Kz}$ Ss Por

$1.55465 \mathrm{e}+01$ 1.55465e+01 1.55465e+00 1.00000e-09 2.12000e-01

$1.55465 \mathrm{e}+01$ 1.55465e+01 1.55465e+00 1.00000e-09 2.12000e-01

$1.55465 \mathrm{e}+011.55465 \mathrm{e}+011.55465 \mathrm{e}+001.00000 \mathrm{e}-092.12000 \mathrm{e}-01$

$1.55465 \mathrm{e}+011.55465 \mathrm{e}+011.55465 \mathrm{e}+001.00000 \mathrm{e}-092.12000 \mathrm{e}-01$

$1.55465 \mathrm{e}+011.55465 \mathrm{e}+011.55465 \mathrm{e}+001.00000 \mathrm{e}-092.12000 \mathrm{e}-01$

$1.00000 \mathrm{e}-05$ 1.00000e-05 1.00000e-06 1.00000e-09 1.00000e-01

$1.00000 \mathrm{e}+001.00000 \mathrm{e}+001.00000 \mathrm{e}-01$ 1.00000e-09 1.00000e-01

Element: 11616 \# of layers: 7

$\mathrm{Kx} \mathrm{Ky} \mathrm{Kz}$ Ss Por

$1.55465 \mathrm{e}+01$ 1.55465e+01 1.55465e+00 1.00000e-09 2.12000e-01

$1.55465 \mathrm{e}+011.55465 \mathrm{e}+01$ 1.55465e+00 1.00000e-09 2.12000e-01

$1.55465 \mathrm{e}+011.55465 \mathrm{e}+011.55465 \mathrm{e}+001.00000 \mathrm{e}-092.12000 \mathrm{e}-01$

$1.55465 \mathrm{e}+011.55465 \mathrm{e}+01$ 1.55465e+00 1.00000e-09 2.12000e-01

$1.55465 \mathrm{e}+011.55465 \mathrm{e}+011.55465 \mathrm{e}+001.00000 \mathrm{e}-092.12000 \mathrm{e}-01$

$1.00000 \mathrm{e}-05$ 1.00000e-05 1.00000e-06 1.00000e-09 1.00000e-01

$1.00000 \mathrm{e}+001.00000 \mathrm{e}+001.00000 \mathrm{e}-011.00000 \mathrm{e}-091.00000 \mathrm{e}-01$

Element: 11617 \# of layers: 7

$\mathrm{Kx} \mathrm{Ky} \mathrm{Kz}$ Ss Por

$1.79507 \mathrm{e}+01$ 1.79507e+01 1.79507e+00 1.00000e-09 2.12000e-01

$1.79507 \mathrm{e}+01$ 1.79507e+01 1.79507e+00 1.00000e-09 2.12000e-01

$1.79507 \mathrm{e}+01$ 1.79507e+01 1.79507e+00 1.00000e-09 2.12000e-01

$1.79507 \mathrm{e}+01$ 1.79507e+01 1.79507e+00 1.00000e-09 2.12000e-01

1.79507e+01 1.79507e+01 1.79507e+00 1.00000e-09 2.12000e-01

$1.00000 \mathrm{e}-05$ 1.00000e-05 1.00000e-06 1.00000e-09 1.00000e-01

$1.00000 \mathrm{e}+001.00000 \mathrm{e}+001.00000 \mathrm{e}-011.00000 \mathrm{e}-091.00000 \mathrm{e}-01$ 
Element: 11618 \# of layers: 7

$\mathrm{Kx} \mathrm{Ky} \mathrm{Kz}$ Ss Por

1.79507e+01 1.79507e+01 1.79507e+00 1.00000e-09 2.12000e-01

$1.79507 e+011.79507 e+01$ 1.79507e+00 1.00000e-09 2.12000e-01

$1.79507 \mathrm{e}+01$ 1.79507e+01 1.79507e+00 1.00000e-09 2.12000e-01

$1.79507 \mathrm{e}+01$ 1.79507e+01 1.79507e+00 1.00000e-09 2.12000e-01

$1.79507 \mathrm{e}+01$ 1.79507e+01 1.79507e+00 1.00000e-09 2.12000e-01

$1.00000 \mathrm{e}-05$ 1.00000e-05 1.00000e-06 1.00000e-09 1.00000e-01

$1.00000 \mathrm{e}+001.00000 \mathrm{e}+001.00000 \mathrm{e}-011.00000 \mathrm{e}-091.00000 \mathrm{e}-01$

Element: 11619 \# of layers: 7

$\mathrm{Kx} \mathrm{Ky} \mathrm{Kz}$ Ss Por

$1.79507 e+01$ 1.79507e+01 1.79507e+00 1.00000e-09 2.12000e-01

$1.79507 \mathrm{e}+01$ 1.79507e+01 1.79507e+00 1.00000e-09 2.12000e-01

$1.79507 \mathrm{e}+01$ 1.79507e+01 1.79507e+00 1.00000e-09 2.12000e-01

$1.79507 \mathrm{e}+01$ 1.79507e+01 1.79507e+00 1.00000e-09 2.12000e-01

$1.79507 \mathrm{e}+01$ 1.79507e+01 1.79507e+00 1.00000e-09 2.12000e-01

$1.00000 \mathrm{e}-05$ 1.00000e-05 1.00000e-06 1.00000e-09 1.00000e-01

$1.00000 \mathrm{e}+001.00000 \mathrm{e}+001.00000 \mathrm{e}-01$ 1.00000e-09 1.00000e-01

Element: 11620 \# of layers: 7

$\mathrm{Kx} \mathrm{Ky} \mathrm{Kz}$ Ss Por

1.79507e+01 1.79507e+01 1.79507e+00 1.00000e-09 2.12000e-01

$1.79507 \mathrm{e}+01$ 1.79507e+01 1.79507e+00 1.00000e-09 2.12000e-01

$1.79507 \mathrm{e}+01$ 1.79507e+01 1.79507e+00 1.00000e-09 2.12000e-01

$1.79507 \mathrm{e}+01$ 1.79507e+01 1.79507e+00 1.00000e-09 2.12000e-01

$1.79507 \mathrm{e}+01$ 1.79507e+01 1.79507e+00 1.00000e-09 2.12000e-01

$1.00000 \mathrm{e}-05$ 1.00000e-05 1.00000e-06 1.00000e-09 1.00000e-01

$1.00000 \mathrm{e}+001.00000 \mathrm{e}+001.00000 \mathrm{e}-01$ 1.00000e-09 1.00000e-01

Element: 11621 \# of layers: 7

Kx Ky Kz Ss Por

$1.55465 \mathrm{e}+01$ 1.55465e+01 1.55465e+00 1.00000e-09 2.12000e-01

$1.55465 \mathrm{e}+011.55465 \mathrm{e}+01$ 1.55465e+00 1.00000e-09 2.12000e-01

$1.55465 \mathrm{e}+011.55465 \mathrm{e}+011.55465 \mathrm{e}+001.00000 \mathrm{e}-092.12000 \mathrm{e}-01$

$1.55465 \mathrm{e}+011.55465 \mathrm{e}+011.55465 \mathrm{e}+001.00000 \mathrm{e}-092.12000 \mathrm{e}-01$

$1.55465 \mathrm{e}+011.55465 \mathrm{e}+01$ 1.55465e+00 1.00000e-09 2.12000e-01

$1.00000 \mathrm{e}-05$ 1.00000e-05 1.00000e-06 1.00000e-09 1.00000e-01

$1.00000 \mathrm{e}+001.00000 \mathrm{e}+001.00000 \mathrm{e}-011.00000 \mathrm{e}-091.00000 \mathrm{e}-01$

Element: 11622 \# of layers: 7

$\mathrm{Kx} \mathrm{Ky} \mathrm{Kz}$ Ss Por

$1.55465 \mathrm{e}+01$ 1.55465e+01 1.55465e+00 1.00000e-09 2.12000e-01

$1.55465 \mathrm{e}+011.55465 \mathrm{e}+011.55465 \mathrm{e}+001.00000 \mathrm{e}-092.12000 \mathrm{e}-01$

$1.55465 \mathrm{e}+011.55465 \mathrm{e}+011.55465 \mathrm{e}+001.00000 \mathrm{e}-092.12000 \mathrm{e}-01$

$1.55465 \mathrm{e}+011.55465 \mathrm{e}+01$ 1.55465e+00 1.00000e-09 2.12000e-01

$1.55465 \mathrm{e}+011.55465 \mathrm{e}+01$ 1.55465e+00 1.00000e-09 2.12000e-01

$1.00000 \mathrm{e}-05$ 1.00000e-05 1.00000e-06 1.00000e-09 1.00000e-01

$1.00000 \mathrm{e}+001.00000 \mathrm{e}+001.00000 \mathrm{e}-01$ 1.00000e-09 1.00000e-01

Element: 11623 \# of layers: 7 
$\mathrm{Kx} \mathrm{Ky} \mathrm{Kz}$ Ss Por

$1.55465 \mathrm{e}+011.55465 \mathrm{e}+01$ 1.55465e+00 1.00000e-09 2.12000e-01

$1.55465 \mathrm{e}+011.55465 \mathrm{e}+011.55465 \mathrm{e}+001.00000 \mathrm{e}-092.12000 \mathrm{e}-01$

$1.55465 \mathrm{e}+011.55465 \mathrm{e}+011.55465 \mathrm{e}+001.00000 \mathrm{e}-092.12000 \mathrm{e}-01$

$1.55465 \mathrm{e}+011.55465 \mathrm{e}+01$ 1.55465e+00 1.00000e-09 2.12000e-01

$1.55465 \mathrm{e}+011.55465 \mathrm{e}+011.55465 \mathrm{e}+001.00000 \mathrm{e}-092.12000 \mathrm{e}-01$

$1.00000 \mathrm{e}-05$ 1.00000e-05 1.00000e-06 1.00000e-09 1.00000e-01

$1.00000 \mathrm{e}+001.00000 \mathrm{e}+001.00000 \mathrm{e}-01$ 1.00000e-09 1.00000e-01

Element: 11624 \# of layers: 7

$\mathrm{Kx} \mathrm{Ky} \mathrm{Kz}$ Ss Por

$1.55465 \mathrm{e}+011.55465 \mathrm{e}+01$ 1.55465e+00 1.00000e-09 2.12000e-01

$1.55465 \mathrm{e}+011.55465 \mathrm{e}+011.55465 \mathrm{e}+001.00000 \mathrm{e}-092.12000 \mathrm{e}-01$

$1.55465 \mathrm{e}+011.55465 \mathrm{e}+011.55465 \mathrm{e}+001.00000 \mathrm{e}-092.12000 \mathrm{e}-01$

$1.55465 \mathrm{e}+011.55465 \mathrm{e}+011.55465 \mathrm{e}+001.00000 \mathrm{e}-092.12000 \mathrm{e}-01$

$1.55465 \mathrm{e}+011.55465 \mathrm{e}+011.55465 \mathrm{e}+001.00000 \mathrm{e}-092.12000 \mathrm{e}-01$ $1.00000 \mathrm{e}-05$ 1.00000e-05 1.00000e-06 1.00000e-09 1.00000e-01

$1.00000 \mathrm{e}+001.00000 \mathrm{e}+001.00000 \mathrm{e}-01$ 1.00000e-09 1.00000e-01

Element: 11625 \# of layers: 7

$\mathrm{Kx} \mathrm{Ky} \mathrm{Kz}$ Ss Por

$1.55465 \mathrm{e}+01$ 1.55465e+01 1.55465e+00 1.00000e-09 2.12000e-01

$1.55465 \mathrm{e}+011.55465 \mathrm{e}+011.55465 \mathrm{e}+001.00000 \mathrm{e}-092.12000 \mathrm{e}-01$

$1.55465 \mathrm{e}+011.55465 \mathrm{e}+01$ 1.55465e+00 1.00000e-09 2.12000e-01

$1.55465 \mathrm{e}+01$ 1.55465e+01 1.55465e+00 1.00000e-09 2.12000e-01

$1.55465 \mathrm{e}+011.55465 \mathrm{e}+01$ 1.55465e+00 1.00000e-09 2.12000e-01

$1.00000 \mathrm{e}-05$ 1.00000e-05 1.00000e-06 1.00000e-09 1.00000e-01

$1.00000 \mathrm{e}+001.00000 \mathrm{e}+001.00000 \mathrm{e}-01$ 1.00000e-09 1.00000e-01

Element: 11626 \# of layers: 7

$\mathrm{Kx} \mathrm{Ky} \mathrm{Kz}$ Ss Por

$1.55465 \mathrm{e}+011.55465 \mathrm{e}+011.55465 \mathrm{e}+001.00000 \mathrm{e}-092.12000 \mathrm{e}-01$

$1.55465 \mathrm{e}+011.55465 \mathrm{e}+01$ 1.55465e+00 1.00000e-09 2.12000e-01

$1.55465 \mathrm{e}+011.55465 \mathrm{e}+01$ 1.55465e+00 1.00000e-09 2.12000e-01

$1.55465 \mathrm{e}+011.55465 \mathrm{e}+01$ 1.55465e+00 1.00000e-09 2.12000e-01

$1.55465 \mathrm{e}+011.55465 \mathrm{e}+011.55465 \mathrm{e}+001.00000 \mathrm{e}-092.12000 \mathrm{e}-01$

$1.00000 \mathrm{e}-05$ 1.00000e-05 1.00000e-06 1.00000e-09 1.00000e-01

$1.00000 \mathrm{e}+001.00000 \mathrm{e}+001.00000 \mathrm{e}-011.00000 \mathrm{e}-091.00000 \mathrm{e}-01$

Element: 11627 \# of layers: 7

Kx Ky Kz Ss Por

$1.55465 \mathrm{e}+01$ 1.55465e+01 1.55465e+00 1.00000e-09 2.12000e-01

$1.55465 \mathrm{e}+01$ 1.55465e+01 1.55465e+00 1.00000e-09 2.12000e-01

$1.55465 \mathrm{e}+011.55465 \mathrm{e}+01$ 1.55465e+00 1.00000e-09 2.12000e-01

$1.55465 \mathrm{e}+011.55465 \mathrm{e}+011.55465 \mathrm{e}+001.00000 \mathrm{e}-092.12000 \mathrm{e}-01$

$1.55465 \mathrm{e}+011.55465 \mathrm{e}+01$ 1.55465e+00 1.00000e-09 2.12000e-01

$1.00000 \mathrm{e}-05$ 1.00000e-05 1.00000e-06 1.00000e-09 1.00000e-01

$1.00000 \mathrm{e}+001.00000 \mathrm{e}+001.00000 \mathrm{e}-01$ 1.00000e-09 1.00000e-01

Element: 11628 \# of layers: 7

Kx Ky Kz Ss Por 
$1.55465 \mathrm{e}+011.55465 \mathrm{e}+01$ 1.55465e+00 1.00000e-09 2.12000e-01 $1.55465 \mathrm{e}+011.55465 \mathrm{e}+01$ 1.55465e+00 1.00000e-09 2.12000e-01 $1.55465 \mathrm{e}+011.55465 \mathrm{e}+011.55465 \mathrm{e}+001.00000 \mathrm{e}-092.12000 \mathrm{e}-01$ $1.55465 \mathrm{e}+011.55465 \mathrm{e}+011.55465 \mathrm{e}+001.00000 \mathrm{e}-092.12000 \mathrm{e}-01$ $1.55465 \mathrm{e}+01$ 1.55465e+01 1.55465e+00 1.00000e-09 2.12000e-01 $1.00000 \mathrm{e}-05$ 1.00000e-05 1.00000e-06 1.00000e-09 1.00000e-01 $1.00000 \mathrm{e}+001.00000 \mathrm{e}+001.00000 \mathrm{e}-01$ 1.00000e-09 1.00000e-01

Element: 11629 \# of layers: 7

$\mathrm{Kx} \mathrm{Ky} \mathrm{Kz}$ Ss Por

$1.55465 \mathrm{e}+01$ 1.55465e+01 1.55465e+00 1.00000e-09 2.12000e-01 $1.55465 \mathrm{e}+011.55465 \mathrm{e}+011.55465 \mathrm{e}+001.00000 \mathrm{e}-092.12000 \mathrm{e}-01$ $1.55465 \mathrm{e}+011.55465 \mathrm{e}+011.55465 \mathrm{e}+001.00000 \mathrm{e}-092.12000 \mathrm{e}-01$ $1.55465 \mathrm{e}+011.55465 \mathrm{e}+011.55465 \mathrm{e}+001.00000 \mathrm{e}-092.12000 \mathrm{e}-01$ $1.55465 \mathrm{e}+011.55465 \mathrm{e}+011.55465 \mathrm{e}+001.00000 \mathrm{e}-092.12000 \mathrm{e}-01$ $1.00000 \mathrm{e}-05$ 1.00000e-05 1.00000e-06 1.00000e-09 1.00000e-01 $1.00000 \mathrm{e}+001.00000 \mathrm{e}+001.00000 \mathrm{e}-011.00000 \mathrm{e}-091.00000 \mathrm{e}-01$ Element: 11630 \# of layers: 7

$\mathrm{Kx} \mathrm{Ky} \mathrm{Kz}$ Ss Por

$1.55465 \mathrm{e}+01$ 1.55465e+01 1.55465e+00 1.00000e-09 2.12000e-01 $1.55465 \mathrm{e}+011.55465 \mathrm{e}+011.55465 \mathrm{e}+001.00000 \mathrm{e}-092.12000 \mathrm{e}-01$ $1.55465 \mathrm{e}+011.55465 \mathrm{e}+011.55465 \mathrm{e}+001.00000 \mathrm{e}-092.12000 \mathrm{e}-01$ $1.55465 \mathrm{e}+011.55465 \mathrm{e}+01$ 1.55465e+00 1.00000e-09 2.12000e-01 $1.55465 \mathrm{e}+01$ 1.55465e+01 1.55465e+00 1.00000e-09 2.12000e-01 $1.00000 \mathrm{e}-05$ 1.00000e-05 1.00000e-06 1.00000e-09 1.00000e-01 $1.00000 \mathrm{e}+001.00000 \mathrm{e}+001.00000 \mathrm{e}-011.00000 \mathrm{e}-091.00000 \mathrm{e}-01$ Element: 11631 \# of layers: 7

$\mathrm{Kx} \mathrm{Ky} \mathrm{Kz}$ Ss Por

$1.55465 \mathrm{e}+011.55465 \mathrm{e}+01$ 1.55465e+00 1.00000e-09 2.12000e-01 $1.55465 \mathrm{e}+011.55465 \mathrm{e}+011.55465 \mathrm{e}+001.00000 \mathrm{e}-092.12000 \mathrm{e}-01$ $1.55465 \mathrm{e}+011.55465 \mathrm{e}+01$ 1.55465e+00 1.00000e-09 2.12000e-01 $1.55465 \mathrm{e}+011.55465 \mathrm{e}+01$ 1.55465e+00 1.00000e-09 2.12000e-01 $1.55465 \mathrm{e}+011.55465 \mathrm{e}+011.55465 \mathrm{e}+001.00000 \mathrm{e}-092.12000 \mathrm{e}-01$ $1.00000 \mathrm{e}-05$ 1.00000e-05 1.00000e-06 1.00000e-09 1.00000e-01 $1.00000 \mathrm{e}+001.00000 \mathrm{e}+001.00000 \mathrm{e}-011.00000 \mathrm{e}-091.00000 \mathrm{e}-01$ Element: 11632 \# of layers: 7

$\mathrm{Kx} \mathrm{Ky} \mathrm{Kz}$ Ss Por

$1.53075 \mathrm{e}+01$ 1.53075e+01 1.53075e+00 1.00000e-09 2.12000e-01 $1.53075 \mathrm{e}+011.53075 \mathrm{e}+011.53075 \mathrm{e}+001.00000 \mathrm{e}-092.12000 \mathrm{e}-01$ $1.53075 \mathrm{e}+011.53075 \mathrm{e}+011.53075 \mathrm{e}+001.00000 \mathrm{e}-092.12000 \mathrm{e}-01$ $1.53075 \mathrm{e}+011.53075 \mathrm{e}+011.53075 \mathrm{e}+001.00000 \mathrm{e}-092.12000 \mathrm{e}-01$ $1.53075 \mathrm{e}+011.53075 \mathrm{e}+01$ 1.53075e+00 1.00000e-09 2.12000e-01 $1.00000 \mathrm{e}-05$ 1.00000e-05 1.00000e-06 1.00000e-09 1.00000e-01 $1.00000 \mathrm{e}+001.00000 \mathrm{e}+001.00000 \mathrm{e}-011.00000 \mathrm{e}-091.00000 \mathrm{e}-01$ Element: 11633 \# of layers: 7

$\mathrm{Kx} \mathrm{Ky} \mathrm{Kz} \mathrm{Ss} \mathrm{Por}$

$1.53075 \mathrm{e}+01$ 1.53075e+01 1.53075e+00 1.00000e-09 2.12000e-01 
$1.53075 \mathrm{e}+01$ 1.53075e+01 1.53075e+00 1.00000e-09 2.12000e-01 $1.53075 \mathrm{e}+01$ 1.53075e+01 1.53075e+00 1.00000e-09 2.12000e-01 $1.53075 \mathrm{e}+011.53075 \mathrm{e}+011.53075 \mathrm{e}+001.00000 \mathrm{e}-092.12000 \mathrm{e}-01$ $1.53075 \mathrm{e}+011.53075 \mathrm{e}+011.53075 \mathrm{e}+001.00000 \mathrm{e}-092.12000 \mathrm{e}-01$ $1.00000 \mathrm{e}-05$ 1.00000e-05 1.00000e-06 1.00000e-09 1.00000e-01 $1.00000 \mathrm{e}+001.00000 \mathrm{e}+001.00000 \mathrm{e}-011.00000 \mathrm{e}-091.00000 \mathrm{e}-01$ Element: 11634 \# of layers: 7

Kx Ky Kz Ss Por

$1.53075 \mathrm{e}+011.53075 \mathrm{e}+01$ 1.53075e+00 1.00000e-09 2.12000e-01 $1.53075 \mathrm{e}+011.53075 \mathrm{e}+01$ 1.53075e+00 1.00000e-09 2.12000e-01 $1.53075 \mathrm{e}+011.53075 \mathrm{e}+01$ 1.53075e+00 1.00000e-09 2.12000e-01 $1.53075 \mathrm{e}+011.53075 \mathrm{e}+011.53075 \mathrm{e}+001.00000 \mathrm{e}-092.12000 \mathrm{e}-01$ $1.53075 \mathrm{e}+011.53075 \mathrm{e}+011.53075 \mathrm{e}+001.00000 \mathrm{e}-092.12000 \mathrm{e}-01$ $1.00000 \mathrm{e}-05$ 1.00000e-05 1.00000e-06 1.00000e-09 1.00000e-01 $1.00000 \mathrm{e}+001.00000 \mathrm{e}+001.00000 \mathrm{e}-01$ 1.00000e-09 1.00000e-01 Element: 11635 \# of layers: 7

$\mathrm{Kx} \mathrm{Ky} \mathrm{Kz}$ Ss Por

$1.55465 \mathrm{e}+011.55465 \mathrm{e}+011.55465 \mathrm{e}+001.00000 \mathrm{e}-092.12000 \mathrm{e}-01$ $1.55465 \mathrm{e}+01$ 1.55465e+01 1.55465e+00 1.00000e-09 2.12000e-01 $1.55465 \mathrm{e}+011.55465 \mathrm{e}+011.55465 \mathrm{e}+001.00000 \mathrm{e}-092.12000 \mathrm{e}-01$ $1.55465 \mathrm{e}+011.55465 \mathrm{e}+011.55465 \mathrm{e}+001.00000 \mathrm{e}-092.12000 \mathrm{e}-01$ $1.55465 \mathrm{e}+011.55465 \mathrm{e}+01$ 1.55465e+00 1.00000e-09 2.12000e-01 $1.00000 \mathrm{e}-05$ 1.00000e-05 1.00000e-06 1.00000e-09 1.00000e-01 $1.00000 \mathrm{e}+001.00000 \mathrm{e}+001.00000 \mathrm{e}-011.00000 \mathrm{e}-09$ 1.00000e-01

Element: 11636 \# of layers: 7

$\mathrm{Kx} \mathrm{Ky} \mathrm{Kz}$ Ss Por

$1.55465 \mathrm{e}+011.55465 \mathrm{e}+011.55465 \mathrm{e}+001.00000 \mathrm{e}-092.12000 \mathrm{e}-01$ $1.55465 \mathrm{e}+011.55465 \mathrm{e}+011.55465 \mathrm{e}+001.00000 \mathrm{e}-092.12000 \mathrm{e}-01$ $1.55465 \mathrm{e}+011.55465 \mathrm{e}+011.55465 \mathrm{e}+001.00000 \mathrm{e}-092.12000 \mathrm{e}-01$ $1.55465 \mathrm{e}+011.55465 \mathrm{e}+01$ 1.55465e+00 1.00000e-09 2.12000e-01 $1.55465 \mathrm{e}+011.55465 \mathrm{e}+011.55465 \mathrm{e}+001.00000 \mathrm{e}-092.12000 \mathrm{e}-01$ $1.00000 \mathrm{e}-05$ 1.00000e-05 1.00000e-06 1.00000e-09 1.00000e-01 $1.00000 \mathrm{e}+001.00000 \mathrm{e}+001.00000 \mathrm{e}-011.00000 \mathrm{e}-091.00000 \mathrm{e}-01$ Element: 11637 \# of layers: 7

$\mathrm{Kx} \mathrm{Ky} \mathrm{Kz}$ Ss Por

$1.55465 \mathrm{e}+011.55465 \mathrm{e}+011.55465 \mathrm{e}+001.00000 \mathrm{e}-092.12000 \mathrm{e}-01$ $1.55465 \mathrm{e}+011.55465 \mathrm{e}+011.55465 \mathrm{e}+001.00000 \mathrm{e}-092.12000 \mathrm{e}-01$ $1.55465 \mathrm{e}+011.55465 \mathrm{e}+011.55465 \mathrm{e}+001.00000 \mathrm{e}-092.12000 \mathrm{e}-01$ $1.55465 \mathrm{e}+011.55465 \mathrm{e}+011.55465 \mathrm{e}+001.00000 \mathrm{e}-092.12000 \mathrm{e}-01$ $1.55465 \mathrm{e}+011.55465 \mathrm{e}+011.55465 \mathrm{e}+001.00000 \mathrm{e}-092.12000 \mathrm{e}-01$ $1.00000 \mathrm{e}-05$ 1.00000e-05 1.00000e-06 1.00000e-09 1.00000e-01 $1.00000 \mathrm{e}+001.00000 \mathrm{e}+001.00000 \mathrm{e}-011.00000 \mathrm{e}-091.00000 \mathrm{e}-01$ Element: 11638 \# of layers: 7

$\mathrm{Kx} \mathrm{Ky} \mathrm{Kz}$ Ss Por

$1.55465 \mathrm{e}+01$ 1.55465e+01 1.55465e+00 1.00000e-09 2.12000e-01 $1.55465 \mathrm{e}+011.55465 \mathrm{e}+011.55465 \mathrm{e}+001.00000 \mathrm{e}-092.12000 \mathrm{e}-01$ 
$1.55465 \mathrm{e}+011.55465 \mathrm{e}+01$ 1.55465e+00 1.00000e-09 2.12000e-01 $1.55465 \mathrm{e}+011.55465 \mathrm{e}+01$ 1.55465e+00 1.00000e-09 2.12000e-01 $1.55465 \mathrm{e}+011.55465 \mathrm{e}+011.55465 \mathrm{e}+001.00000 \mathrm{e}-092.12000 \mathrm{e}-01$ $1.00000 \mathrm{e}-05$ 1.00000e-05 1.00000e-06 1.00000e-09 1.00000e-01 $1.00000 \mathrm{e}+001.00000 \mathrm{e}+001.00000 \mathrm{e}-01$ 1.00000e-09 1.00000e-01 Element: 11639 \# of layers: 7

$\mathrm{Kx} \mathrm{Ky} \mathrm{Kz}$ Ss Por

$1.53075 \mathrm{e}+01$ 1.53075e+01 1.53075e+00 1.00000e-09 2.12000e-01 $1.53075 \mathrm{e}+011.53075 \mathrm{e}+01$ 1.53075e+00 1.00000e-09 2.12000e-01 $1.53075 \mathrm{e}+011.53075 \mathrm{e}+011.53075 \mathrm{e}+001.00000 \mathrm{e}-092.12000 \mathrm{e}-01$ $1.53075 \mathrm{e}+011.53075 \mathrm{e}+01$ 1.53075e+00 1.00000e-09 2.12000e-01 $1.53075 \mathrm{e}+011.53075 \mathrm{e}+011.53075 \mathrm{e}+001.00000 \mathrm{e}-092.12000 \mathrm{e}-01$ $1.00000 \mathrm{e}-051.00000 \mathrm{e}-051.00000 \mathrm{e}-061.00000 \mathrm{e}-091.00000 \mathrm{e}-01$ $1.00000 \mathrm{e}+001.00000 \mathrm{e}+001.00000 \mathrm{e}-011.00000 \mathrm{e}-091.00000 \mathrm{e}-01$ Element: 11640 \# of layers: 7

Kx Ky Kz Ss Por

$1.53075 \mathrm{e}+01$ 1.53075e+01 1.53075e+00 1.00000e-09 2.12000e-01 $1.53075 \mathrm{e}+011.53075 \mathrm{e}+011.53075 \mathrm{e}+001.00000 \mathrm{e}-092.12000 \mathrm{e}-01$ $1.53075 \mathrm{e}+01$ 1.53075e+01 1.53075e+00 1.00000e-09 2.12000e-01 $1.53075 \mathrm{e}+011.53075 \mathrm{e}+01$ 1.53075e+00 1.00000e-09 2.12000e-01 $1.53075 \mathrm{e}+011.53075 \mathrm{e}+01$ 1.53075e+00 1.00000e-09 2.12000e-01 $1.00000 \mathrm{e}-05$ 1.00000e-05 1.00000e-06 1.00000e-09 1.00000e-01 $1.00000 \mathrm{e}+001.00000 \mathrm{e}+001.00000 \mathrm{e}-01$ 1.00000e-09 1.00000e-01 Element: 11641 \# of layers: 7

Kx Ky Kz Ss Por

$1.53075 \mathrm{e}+011.53075 \mathrm{e}+01$ 1.53075e+00 1.00000e-09 2.12000e-01 $1.53075 \mathrm{e}+011.53075 \mathrm{e}+011.53075 \mathrm{e}+001.00000 \mathrm{e}-092.12000 \mathrm{e}-01$ $1.53075 \mathrm{e}+011.53075 \mathrm{e}+011.53075 \mathrm{e}+001.00000 \mathrm{e}-092.12000 \mathrm{e}-01$ $1.53075 \mathrm{e}+011.53075 \mathrm{e}+011.53075 \mathrm{e}+001.00000 \mathrm{e}-092.12000 \mathrm{e}-01$ $1.53075 \mathrm{e}+01$ 1.53075e+01 1.53075e+00 1.00000e-09 2.12000e-01 $1.00000 \mathrm{e}-051.00000 \mathrm{e}-051.00000 \mathrm{e}-061.00000 \mathrm{e}-091.00000 \mathrm{e}-01$ $1.00000 \mathrm{e}+001.00000 \mathrm{e}+001.00000 \mathrm{e}-01$ 1.00000e-09 1.00000e-01 Element: 11642 \# of layers: 7

$\mathrm{Kx} \mathrm{Ky} \mathrm{Kz}$ Ss Por

$1.53075 \mathrm{e}+01$ 1.53075e+01 1.53075e+00 1.00000e-09 2.12000e-01 $1.53075 \mathrm{e}+011.53075 \mathrm{e}+01$ 1.53075e+00 1.00000e-09 2.12000e-01 $1.53075 \mathrm{e}+011.53075 \mathrm{e}+011.53075 \mathrm{e}+001.00000 \mathrm{e}-092.12000 \mathrm{e}-01$ $1.53075 \mathrm{e}+011.53075 \mathrm{e}+011.53075 \mathrm{e}+001.00000 \mathrm{e}-092.12000 \mathrm{e}-01$ $1.53075 \mathrm{e}+011.53075 \mathrm{e}+011.53075 \mathrm{e}+001.00000 \mathrm{e}-092.12000 \mathrm{e}-01$ $1.00000 \mathrm{e}-05$ 1.00000e-05 1.00000e-06 1.00000e-09 1.00000e-01 $1.00000 \mathrm{e}+001.00000 \mathrm{e}+001.00000 \mathrm{e}-011.00000 \mathrm{e}-091.00000 \mathrm{e}-01$ Element: 11643 \# of layers: 7

$\mathrm{Kx} \mathrm{Ky} \mathrm{Kz}$ Ss Por

$1.53075 \mathrm{e}+01$ 1.53075e+01 1.53075e+00 1.00000e-09 2.12000e-01 $1.53075 \mathrm{e}+01$ 1.53075e+01 1.53075e+00 1.00000e-09 2.12000e-01 $1.53075 \mathrm{e}+01$ 1.53075e+01 1.53075e+00 1.00000e-09 2.12000e-01 
$1.53075 \mathrm{e}+01$ 1.53075e+01 1.53075e+00 1.00000e-09 2.12000e-01 $1.53075 \mathrm{e}+01$ 1.53075e+01 1.53075e+00 1.00000e-09 2.12000e-01 $1.00000 \mathrm{e}-051.00000 \mathrm{e}-05$ 1.00000e-06 1.00000e-09 1.00000e-01 $1.00000 \mathrm{e}+001.00000 \mathrm{e}+001.00000 \mathrm{e}-011.00000 \mathrm{e}-091.00000 \mathrm{e}-01$ Element: 11644 \# of layers: 7

$\mathrm{Kx} \mathrm{Ky} \mathrm{Kz}$ Ss Por

$1.53075 \mathrm{e}+01$ 1.53075e+01 1.53075e+00 1.00000e-09 2.12000e-01 $1.53075 \mathrm{e}+011.53075 \mathrm{e}+011.53075 \mathrm{e}+001.00000 \mathrm{e}-092.12000 \mathrm{e}-01$ $1.53075 \mathrm{e}+011.53075 \mathrm{e}+01$ 1.53075e+00 1.00000e-09 2.12000e-01 $1.53075 \mathrm{e}+011.53075 \mathrm{e}+01$ 1.53075e+00 1.00000e-09 2.12000e-01 $1.53075 \mathrm{e}+011.53075 \mathrm{e}+011.53075 \mathrm{e}+001.00000 \mathrm{e}-092.12000 \mathrm{e}-01$ $1.00000 \mathrm{e}-05$ 1.00000e-05 1.00000e-06 1.00000e-09 1.00000e-01 $1.00000 \mathrm{e}+001.00000 \mathrm{e}+001.00000 \mathrm{e}-011.00000 \mathrm{e}-09$ 1.00000e-01 Element: 11645 \# of layers: 7

$\mathrm{Kx} \mathrm{Ky} \mathrm{Kz}$ Ss Por

$1.53075 \mathrm{e}+01$ 1.53075e+01 1.53075e+00 1.00000e-09 2.12000e-01 $1.53075 \mathrm{e}+011.53075 \mathrm{e}+011.53075 \mathrm{e}+001.00000 \mathrm{e}-092.12000 \mathrm{e}-01$ $1.53075 \mathrm{e}+011.53075 \mathrm{e}+011.53075 \mathrm{e}+001.00000 \mathrm{e}-092.12000 \mathrm{e}-01$ $1.53075 \mathrm{e}+01$ 1.53075e+01 1.53075e+00 1.00000e-09 2.12000e-01 $1.53075 \mathrm{e}+011.53075 \mathrm{e}+01$ 1.53075e+00 1.00000e-09 2.12000e-01 $1.00000 \mathrm{e}-05$ 1.00000e-05 1.00000e-06 1.00000e-09 1.00000e-01 $1.00000 \mathrm{e}+001.00000 \mathrm{e}+001.00000 \mathrm{e}-011.00000 \mathrm{e}-091.00000 \mathrm{e}-01$ Element: 11646 \# of layers: 7

Kx Ky Kz Ss Por

$1.53075 \mathrm{e}+011.53075 \mathrm{e}+011.53075 \mathrm{e}+00$ 1.00000e-09 2.12000e-01 $1.53075 \mathrm{e}+011.53075 \mathrm{e}+011.53075 \mathrm{e}+001.00000 \mathrm{e}-092.12000 \mathrm{e}-01$ $1.53075 \mathrm{e}+011.53075 \mathrm{e}+011.53075 \mathrm{e}+001.00000 \mathrm{e}-092.12000 \mathrm{e}-01$ $1.53075 \mathrm{e}+011.53075 \mathrm{e}+011.53075 \mathrm{e}+001.00000 \mathrm{e}-092.12000 \mathrm{e}-01$ $1.53075 \mathrm{e}+011.53075 \mathrm{e}+011.53075 \mathrm{e}+001.00000 \mathrm{e}-092.12000 \mathrm{e}-01$ 1.00000e-05 1.00000e-05 1.00000e-06 1.00000e-09 1.00000e-01 $1.00000 \mathrm{e}+001.00000 \mathrm{e}+001.00000 \mathrm{e}-011.00000 \mathrm{e}-091.00000 \mathrm{e}-01$ Element: 11647 \# of layers: 7

Kx Ky Kz Ss Por

$1.53075 \mathrm{e}+01$ 1.53075e+01 1.53075e+00 1.00000e-09 2.12000e-01 $1.53075 \mathrm{e}+011.53075 \mathrm{e}+011.53075 \mathrm{e}+001.00000 \mathrm{e}-092.12000 \mathrm{e}-01$ $1.53075 \mathrm{e}+011.53075 \mathrm{e}+011.53075 \mathrm{e}+001.00000 \mathrm{e}-092.12000 \mathrm{e}-01$ $1.53075 \mathrm{e}+011.53075 \mathrm{e}+011.53075 \mathrm{e}+001.00000 \mathrm{e}-092.12000 \mathrm{e}-01$ $1.53075 \mathrm{e}+011.53075 \mathrm{e}+011.53075 \mathrm{e}+001.00000 \mathrm{e}-092.12000 \mathrm{e}-01$ $1.00000 \mathrm{e}-05$ 1.00000e-05 1.00000e-06 1.00000e-09 1.00000e-01 $1.00000 \mathrm{e}+001.00000 \mathrm{e}+001.00000 \mathrm{e}-01$ 1.00000e-09 1.00000e-01 Element: 11648 \# of layers: 7

$\mathrm{Kx} \mathrm{Ky} \mathrm{Kz}$ Ss Por

$1.53075 \mathrm{e}+01$ 1.53075e+01 1.53075e+00 1.00000e-09 2.12000e-01 $1.53075 \mathrm{e}+011.53075 \mathrm{e}+011.53075 \mathrm{e}+001.00000 \mathrm{e}-092.12000 \mathrm{e}-01$ $1.53075 \mathrm{e}+01$ 1.53075e+01 1.53075e+00 1.00000e-09 2.12000e-01 $1.53075 \mathrm{e}+011.53075 \mathrm{e}+011.53075 \mathrm{e}+001.00000 \mathrm{e}-092.12000 \mathrm{e}-01$ 
$1.53075 \mathrm{e}+01$ 1.53075e+01 1.53075e+00 1.00000e-09 2.12000e-01 $1.00000 \mathrm{e}-05$ 1.00000e-05 1.00000e-06 1.00000e-09 1.00000e-01 $1.00000 \mathrm{e}+001.00000 \mathrm{e}+001.00000 \mathrm{e}-011.00000 \mathrm{e}-09$ 1.00000e-01

Element: 11649 \# of layers: 7

$\mathrm{Kx} \mathrm{Ky} \mathrm{Kz}$ Ss Por

$1.79682 \mathrm{e}+01$ 1.79682e+01 1.79682e+00 1.00000e-09 2.12000e-01

$1.79682 \mathrm{e}+01$ 1.79682e+01 1.79682e+00 1.00000e-09 2.12000e-01

$1.79682 \mathrm{e}+011.79682 \mathrm{e}+011.79682 \mathrm{e}+001.00000 \mathrm{e}-092.12000 \mathrm{e}-01$

$1.79682 \mathrm{e}+01$ 1.79682e+01 1.79682e+00 1.00000e-09 2.12000e-01

$1.79682 \mathrm{e}+01$ 1.79682e+01 1.79682e+00 1.00000e-09 2.12000e-01 $1.00000 \mathrm{e}-05$ 1.00000e-05 1.00000e-06 1.00000e-09 1.00000e-01

$1.00000 \mathrm{e}+001.00000 \mathrm{e}+001.00000 \mathrm{e}-011.00000 \mathrm{e}-091.00000 \mathrm{e}-01$

Element: 11650 \# of layers: 7

$\mathrm{Kx} \mathrm{Ky} \mathrm{Kz}$ Ss Por

1.79682e+01 1.79682e+01 1.79682e+00 1.00000e-09 2.12000e-01

$1.79682 \mathrm{e}+01$ 1.79682e+01 1.79682e+00 1.00000e-09 2.12000e-01

$1.79682 \mathrm{e}+01$ 1.79682e+01 1.79682e+00 1.00000e-09 2.12000e-01

$1.79682 \mathrm{e}+011.79682 \mathrm{e}+01$ 1.79682e+00 1.00000e-09 2.12000e-01

$1.79682 \mathrm{e}+01$ 1.79682e+01 1.79682e+00 1.00000e-09 2.12000e-01

$1.00000 \mathrm{e}-05$ 1.00000e-05 1.00000e-06 1.00000e-09 1.00000e-01

$1.00000 \mathrm{e}+001.00000 \mathrm{e}+001.00000 \mathrm{e}-011.00000 \mathrm{e}-091.00000 \mathrm{e}-01$

Element: 11651 \# of layers: 7

$\mathrm{Kx} \mathrm{Ky} \mathrm{Kz}$ Ss Por

$1.79682 \mathrm{e}+01$ 1.79682e+01 1.79682e+00 1.00000e-09 2.12000e-01

$1.79682 \mathrm{e}+011.79682 \mathrm{e}+011.79682 \mathrm{e}+001.00000 \mathrm{e}-092.12000 \mathrm{e}-01$

$1.79682 \mathrm{e}+01$ 1.79682e+01 1.79682e+00 1.00000e-09 2.12000e-01

$1.79682 \mathrm{e}+011.79682 \mathrm{e}+011.79682 \mathrm{e}+001.00000 \mathrm{e}-092.12000 \mathrm{e}-01$

$1.79682 \mathrm{e}+01$ 1.79682e+01 1.79682e+00 1.00000e-09 2.12000e-01

$1.00000 \mathrm{e}-05$ 1.00000e-05 1.00000e-06 1.00000e-09 1.00000e-01

$1.00000 \mathrm{e}+001.00000 \mathrm{e}+001.00000 \mathrm{e}-011.00000 \mathrm{e}-091.00000 \mathrm{e}-01$

Element: 11652 \# of layers: 7

$\mathrm{Kx} \mathrm{Ky} \mathrm{Kz}$ Ss Por

$1.79682 \mathrm{e}+01$ 1.79682e+01 1.79682e+00 1.00000e-09 2.12000e-01

$1.79682 \mathrm{e}+01$ 1.79682e+01 1.79682e+00 1.00000e-09 2.12000e-01

$1.79682 \mathrm{e}+01$ 1.79682e+01 1.79682e+00 1.00000e-09 2.12000e-01

$1.79682 \mathrm{e}+011.79682 \mathrm{e}+011.79682 \mathrm{e}+001.00000 \mathrm{e}-092.12000 \mathrm{e}-01$

$1.79682 \mathrm{e}+01$ 1.79682e+01 1.79682e+00 1.00000e-09 2.12000e-01

$1.00000 \mathrm{e}-05$ 1.00000e-05 1.00000e-06 1.00000e-09 1.00000e-01

$1.00000 \mathrm{e}+001.00000 \mathrm{e}+001.00000 \mathrm{e}-011.00000 \mathrm{e}-091.00000 \mathrm{e}-01$

Element: 11653 \# of layers: 7

$\mathrm{Kx} \mathrm{Ky} \mathrm{Kz}$ Ss Por

1.79682e+01 1.79682e+01 1.79682e+00 1.00000e-09 2.12000e-01

$1.79682 \mathrm{e}+01$ 1.79682e+01 1.79682e+00 1.00000e-09 2.12000e-01

1.79682e+01 1.79682e+01 1.79682e+00 1.00000e-09 2.12000e-01

$1.79682 \mathrm{e}+011.79682 \mathrm{e}+011.79682 \mathrm{e}+001.00000 \mathrm{e}-092.12000 \mathrm{e}-01$

$1.79682 \mathrm{e}+011.79682 \mathrm{e}+011.79682 \mathrm{e}+001.00000 \mathrm{e}-092.12000 \mathrm{e}-01$ 
$1.00000 \mathrm{e}-05$ 1.00000e-05 1.00000e-06 1.00000e-09 1.00000e-01 $1.00000 \mathrm{e}+001.00000 \mathrm{e}+001.00000 \mathrm{e}-011.00000 \mathrm{e}-091.00000 \mathrm{e}-01$ Element: 11654 \# of layers: 7

Kx Ky Kz Ss Por

$1.53075 \mathrm{e}+011.53075 \mathrm{e}+01$ 1.53075e+00 1.00000e-09 2.12000e-01 $1.53075 \mathrm{e}+011.53075 \mathrm{e}+011.53075 \mathrm{e}+001.00000 \mathrm{e}-092.12000 \mathrm{e}-01$ $1.53075 \mathrm{e}+011.53075 \mathrm{e}+01$ 1.53075e+00 1.00000e-09 2.12000e-01 $1.53075 \mathrm{e}+011.53075 \mathrm{e}+011.53075 \mathrm{e}+001.00000 \mathrm{e}-092.12000 \mathrm{e}-01$ $1.53075 \mathrm{e}+011.53075 \mathrm{e}+01$ 1.53075e+00 1.00000e-09 2.12000e-01 $1.00000 \mathrm{e}-05$ 1.00000e-05 1.00000e-06 1.00000e-09 1.00000e-01 $1.00000 \mathrm{e}+001.00000 \mathrm{e}+001.00000 \mathrm{e}-011.00000 \mathrm{e}-091.00000 \mathrm{e}-01$ Element: 11655 \# of layers: 7

$\mathrm{Kx} \mathrm{Ky} \mathrm{Kz}$ Ss Por

$1.53075 \mathrm{e}+01$ 1.53075e+01 1.53075e+00 1.00000e-09 2.12000e-01 $1.53075 \mathrm{e}+011.53075 \mathrm{e}+01$ 1.53075e+00 1.00000e-09 2.12000e-01 $1.53075 \mathrm{e}+011.53075 \mathrm{e}+011.53075 \mathrm{e}+001.00000 \mathrm{e}-092.12000 \mathrm{e}-01$ $1.53075 \mathrm{e}+011.53075 \mathrm{e}+011.53075 \mathrm{e}+001.00000 \mathrm{e}-092.12000 \mathrm{e}-01$ $1.53075 \mathrm{e}+011.53075 \mathrm{e}+011.53075 \mathrm{e}+001.00000 \mathrm{e}-092.12000 \mathrm{e}-01$ $1.00000 \mathrm{e}-05$ 1.00000e-05 1.00000e-06 1.00000e-09 1.00000e-01 $1.00000 \mathrm{e}+001.00000 \mathrm{e}+001.00000 \mathrm{e}-011.00000 \mathrm{e}-091.00000 \mathrm{e}-01$ Element: 11656 \# of layers: 7

$\mathrm{Kx} \mathrm{Ky} \mathrm{Kz}$ Ss Por

1.79682e+01 1.79682e+01 1.79682e+00 1.00000e-09 2.12000e-01 $1.79682 \mathrm{e}+011.79682 \mathrm{e}+011.79682 \mathrm{e}+001.00000 \mathrm{e}-092.12000 \mathrm{e}-01$ $1.79682 \mathrm{e}+011.79682 \mathrm{e}+011.79682 \mathrm{e}+001.00000 \mathrm{e}-092.12000 \mathrm{e}-01$ $1.79682 \mathrm{e}+011.79682 \mathrm{e}+011.79682 \mathrm{e}+001.00000 \mathrm{e}-092.12000 \mathrm{e}-01$ $1.79682 \mathrm{e}+01$ 1.79682e+01 1.79682e+00 1.00000e-09 2.12000e-01 $1.00000 \mathrm{e}-05$ 1.00000e-05 1.00000e-06 1.00000e-09 1.00000e-01 $1.00000 \mathrm{e}+001.00000 \mathrm{e}+001.00000 \mathrm{e}-011.00000 \mathrm{e}-091.00000 \mathrm{e}-01$ Element: 11657 \# of layers: 7

$\mathrm{Kx} \mathrm{Ky} \mathrm{Kz}$ Ss Por

1.79682e+01 1.79682e+01 1.79682e+00 1.00000e-09 2.12000e-01 $1.79682 \mathrm{e}+011.79682 \mathrm{e}+01$ 1.79682e+00 1.00000e-09 2.12000e-01 $1.79682 \mathrm{e}+01$ 1.79682e+01 1.79682e+00 1.00000e-09 2.12000e-01 $1.79682 \mathrm{e}+011.79682 \mathrm{e}+011.79682 \mathrm{e}+001.00000 \mathrm{e}-092.12000 \mathrm{e}-01$ $1.79682 \mathrm{e}+01$ 1.79682e+01 1.79682e+00 1.00000e-09 2.12000e-01 $1.00000 \mathrm{e}-05$ 1.00000e-05 1.00000e-06 1.00000e-09 1.00000e-01 $1.00000 \mathrm{e}+001.00000 \mathrm{e}+001.00000 \mathrm{e}-011.00000 \mathrm{e}-091.00000 \mathrm{e}-01$ Element: 11658 \# of layers: 7

$\mathrm{Kx} \mathrm{Ky} \mathrm{Kz}$ Ss Por

$1.79507 e+01$ 1.79507e+01 1.79507e+00 1.00000e-09 2.12000e-01 $1.79507 \mathrm{e}+01$ 1.79507e+01 1.79507e+00 1.00000e-09 2.12000e-01 $1.79507 \mathrm{e}+01$ 1.79507e+01 1.79507e+00 1.00000e-09 2.12000e-01 1.79507e+01 1.79507e+01 1.79507e+00 1.00000e-09 2.12000e-01 $1.79507 \mathrm{e}+01$ 1.79507e+01 1.79507e+00 1.00000e-09 2.12000e-01 $1.00000 \mathrm{e}-05$ 1.00000e-05 1.00000e-06 1.00000e-09 1.00000e-01 
$1.00000 \mathrm{e}+001.00000 \mathrm{e}+001.00000 \mathrm{e}-011.00000 \mathrm{e}-091.00000 \mathrm{e}-01$

Element: 11659 \# of layers: 7

$\mathrm{Kx} \mathrm{Ky} \mathrm{Kz}$ Ss Por

1.79507e+01 1.79507e+01 1.79507e+00 1.00000e-09 2.12000e-01

$1.79507 \mathrm{e}+01$ 1.79507e+01 1.79507e+00 1.00000e-09 2.12000e-01

$1.79507 \mathrm{e}+01$ 1.79507e+01 1.79507e+00 1.00000e-09 2.12000e-01

$1.79507 \mathrm{e}+01$ 1.79507e+01 1.79507e+00 1.00000e-09 2.12000e-01

$1.79507 \mathrm{e}+01$ 1.79507e+01 1.79507e+00 1.00000e-09 2.12000e-01

$1.00000 \mathrm{e}-05$ 1.00000e-05 1.00000e-06 1.00000e-09 1.00000e-01

$1.00000 \mathrm{e}+001.00000 \mathrm{e}+001.00000 \mathrm{e}-011.00000 \mathrm{e}-091.00000 \mathrm{e}-01$

Element: 11660 \# of layers: 7

Kx Ky Kz Ss Por

$1.79507 \mathrm{e}+01$ 1.79507e+01 1.79507e+00 1.00000e-09 2.12000e-01

$1.79507 \mathrm{e}+01$ 1.79507e+01 1.79507e+00 1.00000e-09 2.12000e-01

$1.79507 \mathrm{e}+01$ 1.79507e+01 1.79507e+00 1.00000e-09 2.12000e-01

$1.79507 \mathrm{e}+01$ 1.79507e+01 1.79507e+00 1.00000e-09 2.12000e-01

$1.79507 \mathrm{e}+01$ 1.79507e+01 1.79507e+00 1.00000e-09 2.12000e-01

$1.00000 \mathrm{e}-05$ 1.00000e-05 1.00000e-06 1.00000e-09 1.00000e-01

$1.00000 \mathrm{e}+001.00000 \mathrm{e}+001.00000 \mathrm{e}-01$ 1.00000e-09 1.00000e-01

Element: 11661 \# of layers: 7

$\mathrm{Kx} \mathrm{Ky} \mathrm{Kz}$ Ss Por

$1.55465 \mathrm{e}+01$ 1.55465e+01 1.55465e+00 1.00000e-09 2.12000e-01

$1.55465 \mathrm{e}+01$ 1.55465e+01 1.55465e+00 1.00000e-09 2.12000e-01

$1.55465 \mathrm{e}+011.55465 \mathrm{e}+011.55465 \mathrm{e}+001.00000 \mathrm{e}-092.12000 \mathrm{e}-01$

$1.55465 \mathrm{e}+011.55465 \mathrm{e}+011.55465 \mathrm{e}+001.00000 \mathrm{e}-092.12000 \mathrm{e}-01$

$1.55465 \mathrm{e}+011.55465 \mathrm{e}+011.55465 \mathrm{e}+001.00000 \mathrm{e}-092.12000 \mathrm{e}-01$

$1.00000 \mathrm{e}-05$ 1.00000e-05 1.00000e-06 1.00000e-09 1.00000e-01

$1.00000 \mathrm{e}+001.00000 \mathrm{e}+001.00000 \mathrm{e}-01$ 1.00000e-09 1.00000e-01

Element: 11662 \# of layers: 7

$\mathrm{Kx} \mathrm{Ky} \mathrm{Kz}$ Ss Por

$1.55465 \mathrm{e}+01$ 1.55465e+01 1.55465e+00 1.00000e-09 2.12000e-01

$1.55465 \mathrm{e}+011.55465 \mathrm{e}+01$ 1.55465e+00 1.00000e-09 2.12000e-01

$1.55465 \mathrm{e}+011.55465 \mathrm{e}+011.55465 \mathrm{e}+001.00000 \mathrm{e}-092.12000 \mathrm{e}-01$

$1.55465 \mathrm{e}+011.55465 \mathrm{e}+01$ 1.55465e+00 1.00000e-09 2.12000e-01

$1.55465 \mathrm{e}+011.55465 \mathrm{e}+011.55465 \mathrm{e}+001.00000 \mathrm{e}-092.12000 \mathrm{e}-01$

$1.00000 \mathrm{e}-05$ 1.00000e-05 1.00000e-06 1.00000e-09 1.00000e-01

$1.00000 \mathrm{e}+001.00000 \mathrm{e}+001.00000 \mathrm{e}-011.00000 \mathrm{e}-091.00000 \mathrm{e}-01$

Element: 11663 \# of layers: 7

$\mathrm{Kx} \mathrm{Ky} \mathrm{Kz}$ Ss Por

$1.53075 \mathrm{e}+01$ 1.53075e+01 1.53075e+00 1.00000e-09 2.12000e-01

$1.53075 \mathrm{e}+011.53075 \mathrm{e}+011.53075 \mathrm{e}+001.00000 \mathrm{e}-092.12000 \mathrm{e}-01$

$1.53075 \mathrm{e}+011.53075 \mathrm{e}+01$ 1.53075e+00 1.00000e-09 2.12000e-01

$1.53075 \mathrm{e}+011.53075 \mathrm{e}+01$ 1.53075e+00 1.00000e-09 2.12000e-01

$1.53075 \mathrm{e}+01$ 1.53075e+01 1.53075e+00 1.00000e-09 2.12000e-01 $1.00000 \mathrm{e}-05$ 1.00000e-05 1.00000e-06 1.00000e-09 1.00000e-01

$1.00000 \mathrm{e}+001.00000 \mathrm{e}+001.00000 \mathrm{e}-011.00000 \mathrm{e}-091.00000 \mathrm{e}-01$ 
Element: 11664 \# of layers: 7

$\mathrm{Kx} \mathrm{Ky} \mathrm{Kz}$ Ss Por

1.79682e+01 1.79682e+01 1.79682e+00 1.00000e-09 2.12000e-01

$1.79682 \mathrm{e}+011.79682 \mathrm{e}+01$ 1.79682e+00 1.00000e-09 2.12000e-01

$1.79682 \mathrm{e}+01$ 1.79682e+01 1.79682e+00 1.00000e-09 2.12000e-01

$1.79682 \mathrm{e}+011.79682 \mathrm{e}+01$ 1.79682e+00 1.00000e-09 2.12000e-01

$1.79682 \mathrm{e}+011.79682 \mathrm{e}+01$ 1.79682e+00 1.00000e-09 2.12000e-01

$1.00000 \mathrm{e}-05$ 1.00000e-05 1.00000e-06 1.00000e-09 1.00000e-01

$1.00000 \mathrm{e}+001.00000 \mathrm{e}+001.00000 \mathrm{e}-011.00000 \mathrm{e}-091.00000 \mathrm{e}-01$

Element: 11665 \# of layers: 7

$\mathrm{Kx} \mathrm{Ky} \mathrm{Kz} \mathrm{Ss} \mathrm{Por}$

1.79507e+01 1.79507e+01 1.79507e+00 1.00000e-09 2.12000e-01

$1.79507 \mathrm{e}+01$ 1.79507e+01 1.79507e+00 1.00000e-09 2.12000e-01

1.79507e+01 1.79507e+01 1.79507e+00 1.00000e-09 2.12000e-01

$1.79507 \mathrm{e}+01$ 1.79507e+01 1.79507e+00 1.00000e-09 2.12000e-01

$1.79507 \mathrm{e}+01$ 1.79507e+01 1.79507e+00 1.00000e-09 2.12000e-01

$1.00000 \mathrm{e}-05$ 1.00000e-05 1.00000e-06 1.00000e-09 1.00000e-01

$1.00000 \mathrm{e}+001.00000 \mathrm{e}+001.00000 \mathrm{e}-01$ 1.00000e-09 1.00000e-01

Element: 11666 \# of layers: 7

$\mathrm{Kx} \mathrm{Ky} \mathrm{Kz}$ Ss Por

$1.80888 \mathrm{e}+01$ 1.80888e+01 1.80888e+00 1.00000e-09 2.12000e-01

$1.80888 \mathrm{e}+01$ 1.80888e+01 1.80888e+00 1.00000e-09 2.12000e-01

$1.80888 \mathrm{e}+011.80888 \mathrm{e}+01$ 1.80888e+00 1.00000e-09 2.12000e-01

$1.80888 \mathrm{e}+01$ 1.80888e+01 1.80888e+00 1.00000e-09 2.12000e-01

$1.80888 \mathrm{e}+01$ 1.80888e+01 1.80888e+00 1.00000e-09 2.12000e-01

$1.00000 \mathrm{e}-05$ 1.00000e-05 1.00000e-06 1.00000e-09 1.00000e-01

$1.00000 \mathrm{e}+001.00000 \mathrm{e}+001.00000 \mathrm{e}-011.00000 \mathrm{e}-091.00000 \mathrm{e}-01$

Element: 11667 \# of layers: 7

$\mathrm{Kx} \mathrm{Ky} \mathrm{Kz}$ Ss Por

$1.80888 \mathrm{e}+01$ 1.80888e+01 1.80888e+00 1.00000e-09 2.12000e-01

$1.80888 \mathrm{e}+011.80888 \mathrm{e}+01$ 1.80888e+00 1.00000e-09 2.12000e-01

$1.80888 \mathrm{e}+01$ 1.80888e+01 1.80888e+00 1.00000e-09 2.12000e-01

$1.80888 \mathrm{e}+011.80888 \mathrm{e}+011.80888 \mathrm{e}+001.00000 \mathrm{e}-092.12000 \mathrm{e}-01$

$1.80888 \mathrm{e}+01$ 1.80888e+01 1.80888e+00 1.00000e-09 2.12000e-01

$1.00000 \mathrm{e}-05$ 1.00000e-05 1.00000e-06 1.00000e-09 1.00000e-01

$1.00000 \mathrm{e}+001.00000 \mathrm{e}+001.00000 \mathrm{e}-011.00000 \mathrm{e}-091.00000 \mathrm{e}-01$

Element: 11668 \# of layers: 7

$\mathrm{Kx} \mathrm{Ky} \mathrm{Kz}$ Ss Por

$1.80888 \mathrm{e}+01$ 1.80888e+01 1.80888e+00 1.00000e-09 2.12000e-01

$1.80888 \mathrm{e}+011.80888 \mathrm{e}+01$ 1.80888e+00 1.00000e-09 2.12000e-01

$1.80888 \mathrm{e}+011.80888 \mathrm{e}+011.80888 \mathrm{e}+001.00000 \mathrm{e}-092.12000 \mathrm{e}-01$

$1.80888 \mathrm{e}+011.80888 \mathrm{e}+01$ 1.80888e+00 1.00000e-09 2.12000e-01

$1.80888 \mathrm{e}+01$ 1.80888e+01 1.80888e+00 1.00000e-09 2.12000e-01

$1.00000 \mathrm{e}-05$ 1.00000e-05 1.00000e-06 1.00000e-09 1.00000e-01

$1.00000 \mathrm{e}+001.00000 \mathrm{e}+001.00000 \mathrm{e}-01$ 1.00000e-09 1.00000e-01

Element: 11669 \# of layers: 7 
$\mathrm{Kx} \mathrm{Ky} \mathrm{Kz}$ Ss Por

$1.80888 \mathrm{e}+01$ 1.80888e+01 1.80888e+00 1.00000e-09 2.12000e-01

$1.80888 \mathrm{e}+011.80888 \mathrm{e}+01$ 1.80888e+00 1.00000e-09 2.12000e-01

$1.80888 \mathrm{e}+01$ 1.80888e+01 1.80888e+00 1.00000e-09 2.12000e-01

$1.80888 \mathrm{e}+01$ 1.80888e+01 1.80888e+00 1.00000e-09 2.12000e-01

$1.80888 \mathrm{e}+01$ 1.80888e+01 1.80888e+00 1.00000e-09 2.12000e-01

$1.00000 \mathrm{e}-05$ 1.00000e-05 1.00000e-06 1.00000e-09 1.00000e-01

$1.00000 \mathrm{e}+001.00000 \mathrm{e}+001.00000 \mathrm{e}-011.00000 \mathrm{e}-091.00000 \mathrm{e}-01$

Element: 11670 \# of layers: 7

$\mathrm{Kx} \mathrm{Ky} \mathrm{Kz}$ Ss Por

$1.80888 \mathrm{e}+01$ 1.80888e+01 1.80888e+00 1.00000e-09 2.12000e-01

$1.80888 \mathrm{e}+011.80888 \mathrm{e}+011.80888 \mathrm{e}+001.00000 \mathrm{e}-092.12000 \mathrm{e}-01$

$1.80888 \mathrm{e}+011.80888 \mathrm{e}+01$ 1.80888e+00 1.00000e-09 2.12000e-01

$1.80888 \mathrm{e}+01$ 1.80888e+01 1.80888e+00 1.00000e-09 2.12000e-01

$1.80888 \mathrm{e}+01$ 1.80888e+01 1.80888e+00 1.00000e-09 2.12000e-01

$1.00000 \mathrm{e}-05$ 1.00000e-05 1.00000e-06 1.00000e-09 1.00000e-01

$1.00000 \mathrm{e}+001.00000 \mathrm{e}+001.00000 \mathrm{e}-011.00000 \mathrm{e}-091.00000 \mathrm{e}-01$

Element: 11671 \# of layers: 7

$\mathrm{Kx} \mathrm{Ky} \mathrm{Kz}$ Ss Por

$1.80888 \mathrm{e}+01$ 1.80888e+01 1.80888e+00 1.00000e-09 2.12000e-01

$1.80888 \mathrm{e}+011.80888 \mathrm{e}+011.80888 \mathrm{e}+001.00000 \mathrm{e}-092.12000 \mathrm{e}-01$

$1.80888 \mathrm{e}+01$ 1.80888e+01 1.80888e+00 1.00000e-09 2.12000e-01

$1.80888 \mathrm{e}+01$ 1.80888e+01 1.80888e+00 1.00000e-09 2.12000e-01

$1.80888 \mathrm{e}+011.80888 \mathrm{e}+01$ 1.80888e+00 1.00000e-09 2.12000e-01

$1.00000 \mathrm{e}-05$ 1.00000e-05 1.00000e-06 1.00000e-09 1.00000e-01

$1.00000 \mathrm{e}+001.00000 \mathrm{e}+001.00000 \mathrm{e}-011.00000 \mathrm{e}-091.00000 \mathrm{e}-01$

Element: 11672 \# of layers: 7

$\mathrm{Kx} \mathrm{Ky} \mathrm{Kz}$ Ss Por

$1.80888 \mathrm{e}+011.80888 \mathrm{e}+01$ 1.80888e+00 1.00000e-09 2.12000e-01

$1.80888 \mathrm{e}+011.80888 \mathrm{e}+01$ 1.80888e+00 1.00000e-09 2.12000e-01

$1.80888 \mathrm{e}+01$ 1.80888e+01 1.80888e+00 1.00000e-09 2.12000e-01

$1.80888 \mathrm{e}+01$ 1.80888e+01 1.80888e+00 1.00000e-09 2.12000e-01

$1.80888 \mathrm{e}+011.80888 \mathrm{e}+01$ 1.80888e+00 1.00000e-09 2.12000e-01

$1.00000 \mathrm{e}-05$ 1.00000e-05 1.00000e-06 1.00000e-09 1.00000e-01

$1.00000 \mathrm{e}+001.00000 \mathrm{e}+001.00000 \mathrm{e}-01$ 1.00000e-09 1.00000e-01

Element: 11673 \# of layers: 7

Kx Ky Kz Ss Por

$1.80888 \mathrm{e}+01$ 1.80888e+01 1.80888e+00 1.00000e-09 2.12000e-01

$1.80888 \mathrm{e}+01$ 1.80888e+01 1.80888e+00 1.00000e-09 2.12000e-01

$1.80888 \mathrm{e}+01$ 1.80888e+01 1.80888e+00 1.00000e-09 2.12000e-01

$1.80888 \mathrm{e}+01$ 1.80888e+01 1.80888e+00 1.00000e-09 2.12000e-01

$1.80888 \mathrm{e}+01$ 1.80888e+01 1.80888e+00 1.00000e-09 2.12000e-01

$1.00000 \mathrm{e}-051.00000 \mathrm{e}-051.00000 \mathrm{e}-061.00000 \mathrm{e}-091.00000 \mathrm{e}-01$

$1.00000 \mathrm{e}+001.00000 \mathrm{e}+001.00000 \mathrm{e}-01$ 1.00000e-09 1.00000e-01

Element: 11674 \# of layers: 7

Kx Ky Kz Ss Por 
$1.80888 \mathrm{e}+01$ 1.80888e+01 1.80888e+00 1.00000e-09 2.12000e-01 $1.80888 \mathrm{e}+01$ 1.80888e+01 1.80888e+00 1.00000e-09 2.12000e-01 $1.80888 \mathrm{e}+011.80888 \mathrm{e}+011.80888 \mathrm{e}+001.00000 \mathrm{e}-092.12000 \mathrm{e}-01$ $1.80888 \mathrm{e}+011.80888 \mathrm{e}+011.80888 \mathrm{e}+001.00000 \mathrm{e}-092.12000 \mathrm{e}-01$ $1.80888 \mathrm{e}+011.80888 \mathrm{e}+01$ 1.80888e+00 1.00000e-09 2.12000e-01 $1.00000 \mathrm{e}-05$ 1.00000e-05 1.00000e-06 1.00000e-09 1.00000e-01 $1.00000 \mathrm{e}+001.00000 \mathrm{e}+001.00000 \mathrm{e}-011.00000 \mathrm{e}-091.00000 \mathrm{e}-01$ Element: 11675 \# of layers: 7

$\mathrm{Kx} \mathrm{Ky} \mathrm{Kz}$ Ss Por

$1.80888 \mathrm{e}+01$ 1.80888e+01 1.80888e+00 1.00000e-09 2.12000e-01 $1.80888 \mathrm{e}+01$ 1.80888e+01 1.80888e+00 1.00000e-09 2.12000e-01 $1.80888 \mathrm{e}+011.80888 \mathrm{e}+011.80888 \mathrm{e}+001.00000 \mathrm{e}-092.12000 \mathrm{e}-01$ $1.80888 \mathrm{e}+011.80888 \mathrm{e}+01$ 1.80888e+00 1.00000e-09 2.12000e-01 $1.80888 \mathrm{e}+01$ 1.80888e+01 1.80888e+00 1.00000e-09 2.12000e-01 $1.00000 \mathrm{e}-051.00000 \mathrm{e}-051.00000 \mathrm{e}-061.00000 \mathrm{e}-091.00000 \mathrm{e}-01$ $1.00000 \mathrm{e}+001.00000 \mathrm{e}+001.00000 \mathrm{e}-011.00000 \mathrm{e}-091.00000 \mathrm{e}-01$ Element: 11676 \# of layers: 7

$\mathrm{Kx} \mathrm{Ky} \mathrm{Kz}$ Ss Por

$1.84340 \mathrm{e}+01$ 1.84340e+01 1.84340e+00 1.00000e-09 2.12000e-01 $1.84340 \mathrm{e}+011.84340 \mathrm{e}+011.84340 \mathrm{e}+001.00000 \mathrm{e}-092.12000 \mathrm{e}-01$ $1.84340 \mathrm{e}+011.84340 \mathrm{e}+011.84340 \mathrm{e}+001.00000 \mathrm{e}-092.12000 \mathrm{e}-01$ $1.84340 \mathrm{e}+011.84340 \mathrm{e}+011.84340 \mathrm{e}+001.00000 \mathrm{e}-092.12000 \mathrm{e}-01$ $1.84340 \mathrm{e}+011.84340 \mathrm{e}+011.84340 \mathrm{e}+001.00000 \mathrm{e}-092.12000 \mathrm{e}-01$ $1.00000 \mathrm{e}-05$ 1.00000e-05 1.00000e-06 1.00000e-09 1.00000e-01 $1.00000 \mathrm{e}+001.00000 \mathrm{e}+001.00000 \mathrm{e}-011.00000 \mathrm{e}-091.00000 \mathrm{e}-01$ Element: 11677 \# of layers: 7

$\mathrm{Kx} \mathrm{Ky} \mathrm{Kz}$ Ss Por

$1.84340 \mathrm{e}+011.84340 \mathrm{e}+011.84340 \mathrm{e}+001.00000 \mathrm{e}-092.12000 \mathrm{e}-01$ $1.84340 \mathrm{e}+011.84340 \mathrm{e}+011.84340 \mathrm{e}+001.00000 \mathrm{e}-092.12000 \mathrm{e}-01$ $1.84340 \mathrm{e}+011.84340 \mathrm{e}+011.84340 \mathrm{e}+001.00000 \mathrm{e}-092.12000 \mathrm{e}-01$ $1.84340 \mathrm{e}+01$ 1.84340e+01 1.84340e+00 1.00000e-09 2.12000e-01 $1.84340 \mathrm{e}+01$ 1.84340e+01 1.84340e+00 1.00000e-09 2.12000e-01 $1.00000 \mathrm{e}-05$ 1.00000e-05 1.00000e-06 1.00000e-09 1.00000e-01 $1.00000 \mathrm{e}+001.00000 \mathrm{e}+001.00000 \mathrm{e}-011.00000 \mathrm{e}-091.00000 \mathrm{e}-01$ Element: 11678 \# of layers: 7

$\mathrm{Kx} \mathrm{Ky} \mathrm{Kz}$ Ss Por

$1.84340 \mathrm{e}+01$ 1.84340e+01 1.84340e+00 1.00000e-09 2.12000e-01 $1.84340 \mathrm{e}+011.84340 \mathrm{e}+011.84340 \mathrm{e}+001.00000 \mathrm{e}-092.12000 \mathrm{e}-01$ $1.84340 \mathrm{e}+011.84340 \mathrm{e}+011.84340 \mathrm{e}+001.00000 \mathrm{e}-092.12000 \mathrm{e}-01$ $1.84340 \mathrm{e}+011.84340 \mathrm{e}+011.84340 \mathrm{e}+001.00000 \mathrm{e}-092.12000 \mathrm{e}-01$ $1.84340 \mathrm{e}+011.84340 \mathrm{e}+011.84340 \mathrm{e}+001.00000 \mathrm{e}-092.12000 \mathrm{e}-01$ $1.00000 \mathrm{e}-051.00000 \mathrm{e}-051.00000 \mathrm{e}-061.00000 \mathrm{e}-091.00000 \mathrm{e}-01$ $1.00000 \mathrm{e}+001.00000 \mathrm{e}+001.00000 \mathrm{e}-011.00000 \mathrm{e}-091.00000 \mathrm{e}-01$ Element: 11679 \# of layers: 7

$\mathrm{Kx} \mathrm{Ky} \mathrm{Kz}$ Ss Por

$1.84340 \mathrm{e}+01$ 1.84340e+01 1.84340e+00 1.00000e-09 2.12000e-01 
$1.84340 \mathrm{e}+011.84340 \mathrm{e}+01$ 1.84340e+00 1.00000e-09 2.12000e-01 $1.84340 \mathrm{e}+011.84340 \mathrm{e}+011.84340 \mathrm{e}+001.00000 \mathrm{e}-092.12000 \mathrm{e}-01$ $1.84340 \mathrm{e}+011.84340 \mathrm{e}+011.84340 \mathrm{e}+001.00000 \mathrm{e}-092.12000 \mathrm{e}-01$ $1.84340 \mathrm{e}+011.84340 \mathrm{e}+011.84340 \mathrm{e}+001.00000 \mathrm{e}-092.12000 \mathrm{e}-01$ $1.00000 \mathrm{e}-05$ 1.00000e-05 1.00000e-06 1.00000e-09 1.00000e-01 $1.00000 \mathrm{e}+001.00000 \mathrm{e}+001.00000 \mathrm{e}-011.00000 \mathrm{e}-091.00000 \mathrm{e}-01$ Element: 11680 \# of layers: 7

Kx Ky Kz Ss Por

$1.84340 \mathrm{e}+011.84340 \mathrm{e}+011.84340 \mathrm{e}+001.00000 \mathrm{e}-092.12000 \mathrm{e}-01$ $1.84340 \mathrm{e}+01$ 1.84340e+01 1.84340e+00 1.00000e-09 2.12000e-01 $1.84340 \mathrm{e}+01$ 1.84340e+01 1.84340e+00 1.00000e-09 2.12000e-01 $1.84340 \mathrm{e}+011.84340 \mathrm{e}+011.84340 \mathrm{e}+001.00000 \mathrm{e}-092.12000 \mathrm{e}-01$ $1.84340 \mathrm{e}+011.84340 \mathrm{e}+011.84340 \mathrm{e}+001.00000 \mathrm{e}-092.12000 \mathrm{e}-01$ $1.00000 \mathrm{e}-05$ 1.00000e-05 1.00000e-06 1.00000e-09 1.00000e-01 $1.00000 \mathrm{e}+001.00000 \mathrm{e}+001.00000 \mathrm{e}-01$ 1.00000e-09 1.00000e-01 Element: 11681 \# of layers: 7

$\mathrm{Kx} \mathrm{Ky} \mathrm{Kz}$ Ss Por

$1.80888 \mathrm{e}+01$ 1.80888e+01 1.80888e+00 1.00000e-09 2.12000e-01 $1.80888 \mathrm{e}+01$ 1.80888e+01 1.80888e+00 1.00000e-09 2.12000e-01 $1.80888 \mathrm{e}+01$ 1.80888e+01 1.80888e+00 1.00000e-09 2.12000e-01 $1.80888 \mathrm{e}+011.80888 \mathrm{e}+011.80888 \mathrm{e}+001.00000 \mathrm{e}-092.12000 \mathrm{e}-01$ $1.80888 \mathrm{e}+01$ 1.80888e+01 1.80888e+00 1.00000e-09 2.12000e-01 $1.00000 \mathrm{e}-05$ 1.00000e-05 1.00000e-06 1.00000e-09 1.00000e-01 $1.00000 \mathrm{e}+001.00000 \mathrm{e}+001.00000 \mathrm{e}-011.00000 \mathrm{e}-09$ 1.00000e-01

Element: 11682 \# of layers: 7

$\mathrm{Kx} \mathrm{Ky} \mathrm{Kz}$ Ss Por

$1.80888 \mathrm{e}+01$ 1.80888e+01 1.80888e+00 1.00000e-09 2.12000e-01 $1.80888 \mathrm{e}+011.80888 \mathrm{e}+01$ 1.80888e+00 1.00000e-09 2.12000e-01 $1.80888 \mathrm{e}+011.80888 \mathrm{e}+011.80888 \mathrm{e}+001.00000 \mathrm{e}-092.12000 \mathrm{e}-01$ $1.80888 \mathrm{e}+011.80888 \mathrm{e}+01$ 1.80888e+00 1.00000e-09 2.12000e-01 $1.80888 \mathrm{e}+01$ 1.80888e+01 1.80888e+00 1.00000e-09 2.12000e-01 $1.00000 \mathrm{e}-05$ 1.00000e-05 1.00000e-06 1.00000e-09 1.00000e-01 $1.00000 \mathrm{e}+001.00000 \mathrm{e}+001.00000 \mathrm{e}-011.00000 \mathrm{e}-091.00000 \mathrm{e}-01$ Element: 11683 \# of layers: 7

$\mathrm{Kx} \mathrm{Ky} \mathrm{Kz}$ Ss Por

$1.84340 \mathrm{e}+011.84340 \mathrm{e}+01$ 1.84340e+00 1.00000e-09 2.12000e-01 $1.84340 \mathrm{e}+011.84340 \mathrm{e}+011.84340 \mathrm{e}+001.00000 \mathrm{e}-092.12000 \mathrm{e}-01$ $1.84340 \mathrm{e}+011.84340 \mathrm{e}+011.84340 \mathrm{e}+001.00000 \mathrm{e}-092.12000 \mathrm{e}-01$ $1.84340 \mathrm{e}+011.84340 \mathrm{e}+011.84340 \mathrm{e}+001.00000 \mathrm{e}-092.12000 \mathrm{e}-01$ $1.84340 \mathrm{e}+011.84340 \mathrm{e}+011.84340 \mathrm{e}+001.00000 \mathrm{e}-092.12000 \mathrm{e}-01$ $1.00000 \mathrm{e}-05$ 1.00000e-05 1.00000e-06 1.00000e-09 1.00000e-01 $1.00000 \mathrm{e}+001.00000 \mathrm{e}+001.00000 \mathrm{e}-011.00000 \mathrm{e}-091.00000 \mathrm{e}-01$ Element: 11684 \# of layers: 7

$\mathrm{Kx} \mathrm{Ky} \mathrm{Kz}$ Ss Por

$1.84340 \mathrm{e}+011.84340 \mathrm{e}+011.84340 \mathrm{e}+001.00000 \mathrm{e}-092.12000 \mathrm{e}-01$ $1.84340 \mathrm{e}+011.84340 \mathrm{e}+011.84340 \mathrm{e}+001.00000 \mathrm{e}-092.12000 \mathrm{e}-01$ 
$1.84340 \mathrm{e}+011.84340 \mathrm{e}+01$ 1.84340e+00 1.00000e-09 2.12000e-01 $1.84340 \mathrm{e}+011.84340 \mathrm{e}+011.84340 \mathrm{e}+001.00000 \mathrm{e}-092.12000 \mathrm{e}-01$ $1.84340 \mathrm{e}+011.84340 \mathrm{e}+01 \quad 1.84340 \mathrm{e}+001.00000 \mathrm{e}-092.12000 \mathrm{e}-01$ $1.00000 \mathrm{e}-05$ 1.00000e-05 1.00000e-06 1.00000e-09 1.00000e-01 $1.00000 \mathrm{e}+001.00000 \mathrm{e}+001.00000 \mathrm{e}-01$ 1.00000e-09 1.00000e-01 Element: 11685 \# of layers: 7

$\mathrm{Kx} \mathrm{Ky} \mathrm{Kz}$ Ss Por

$1.84340 \mathrm{e}+01$ 1.84340e+01 1.84340e+00 1.00000e-09 2.12000e-01 $1.84340 \mathrm{e}+011.84340 \mathrm{e}+011.84340 \mathrm{e}+001.00000 \mathrm{e}-092.12000 \mathrm{e}-01$ $1.84340 \mathrm{e}+01$ 1.84340e+01 1.84340e+00 1.00000e-09 2.12000e-01 $1.84340 \mathrm{e}+01$ 1.84340e+01 1.84340e+00 1.00000e-09 2.12000e-01 $1.84340 \mathrm{e}+011.84340 \mathrm{e}+011.84340 \mathrm{e}+001.00000 \mathrm{e}-092.12000 \mathrm{e}-01$ $1.00000 \mathrm{e}-05$ 1.00000e-05 1.00000e-06 1.00000e-09 1.00000e-01 $1.00000 \mathrm{e}+001.00000 \mathrm{e}+00$ 1.00000e-01 1.00000e-09 1.00000e-01 Element: 11686 \# of layers: 7

Kx Ky Kz Ss Por

$1.84340 \mathrm{e}+01$ 1.84340e+01 1.84340e+00 1.00000e-09 2.12000e-01 $1.84340 \mathrm{e}+011.84340 \mathrm{e}+011.84340 \mathrm{e}+001.00000 \mathrm{e}-092.12000 \mathrm{e}-01$ $1.84340 \mathrm{e}+01$ 1.84340e+01 1.84340e+00 1.00000e-09 2.12000e-01 $1.84340 \mathrm{e}+011.84340 \mathrm{e}+011.84340 \mathrm{e}+001.00000 \mathrm{e}-092.12000 \mathrm{e}-01$ $1.84340 \mathrm{e}+011.84340 \mathrm{e}+011.84340 \mathrm{e}+001.00000 \mathrm{e}-092.12000 \mathrm{e}-01$ $1.00000 \mathrm{e}-05$ 1.00000e-05 1.00000e-06 1.00000e-09 1.00000e-01 $1.00000 \mathrm{e}+001.00000 \mathrm{e}+001.00000 \mathrm{e}-01$ 1.00000e-09 1.00000e-01 Element: 11687 \# of layers: 7

Kx Ky Kz Ss Por

$1.84340 \mathrm{e}+011.84340 \mathrm{e}+011.84340 \mathrm{e}+001.00000 \mathrm{e}-092.12000 \mathrm{e}-01$ $1.84340 \mathrm{e}+011.84340 \mathrm{e}+011.84340 \mathrm{e}+001.00000 \mathrm{e}-092.12000 \mathrm{e}-01$ $1.84340 \mathrm{e}+011.84340 \mathrm{e}+011.84340 \mathrm{e}+001.00000 \mathrm{e}-092.12000 \mathrm{e}-01$ $1.84340 \mathrm{e}+011.84340 \mathrm{e}+011.84340 \mathrm{e}+001.00000 \mathrm{e}-092.12000 \mathrm{e}-01$ $1.84340 \mathrm{e}+011.84340 \mathrm{e}+011.84340 \mathrm{e}+001.00000 \mathrm{e}-092.12000 \mathrm{e}-01$ $1.00000 \mathrm{e}-05$ 1.00000e-05 1.00000e-06 1.00000e-09 1.00000e-01 $1.00000 \mathrm{e}+001.00000 \mathrm{e}+001.00000 \mathrm{e}-011.00000 \mathrm{e}-091.00000 \mathrm{e}-01$ Element: 11688 \# of layers: 7

$\mathrm{Kx} \mathrm{Ky} \mathrm{Kz}$ Ss Por

$1.84340 \mathrm{e}+01$ 1.84340e+01 1.84340e+00 1.00000e-09 2.12000e-01 $1.84340 \mathrm{e}+011.84340 \mathrm{e}+011.84340 \mathrm{e}+001.00000 \mathrm{e}-092.12000 \mathrm{e}-01$ $1.84340 \mathrm{e}+011.84340 \mathrm{e}+011.84340 \mathrm{e}+001.00000 \mathrm{e}-092.12000 \mathrm{e}-01$ $1.84340 \mathrm{e}+011.84340 \mathrm{e}+011.84340 \mathrm{e}+001.00000 \mathrm{e}-092.12000 \mathrm{e}-01$ $1.84340 \mathrm{e}+011.84340 \mathrm{e}+011.84340 \mathrm{e}+001.00000 \mathrm{e}-092.12000 \mathrm{e}-01$ $1.00000 \mathrm{e}-05$ 1.00000e-05 1.00000e-06 1.00000e-09 1.00000e-01 $1.00000 \mathrm{e}+001.00000 \mathrm{e}+001.00000 \mathrm{e}-011.00000 \mathrm{e}-091.00000 \mathrm{e}-01$ Element: 11689 \# of layers: 7

$\mathrm{Kx} \mathrm{Ky} \mathrm{Kz}$ Ss Por

$1.84340 \mathrm{e}+01$ 1.84340e+01 1.84340e+00 1.00000e-09 2.12000e-01 $1.84340 \mathrm{e}+011.84340 \mathrm{e}+011.84340 \mathrm{e}+001.00000 \mathrm{e}-092.12000 \mathrm{e}-01$ $1.84340 \mathrm{e}+011.84340 \mathrm{e}+011.84340 \mathrm{e}+001.00000 \mathrm{e}-092.12000 \mathrm{e}-01$ 
$1.84340 \mathrm{e}+011.84340 \mathrm{e}+011.84340 \mathrm{e}+001.00000 \mathrm{e}-092.12000 \mathrm{e}-01$ $1.84340 \mathrm{e}+01$ 1.84340e+01 1.84340e+00 1.00000e-09 2.12000e-01 $1.00000 \mathrm{e}-05$ 1.00000e-05 1.00000e-06 1.00000e-09 1.00000e-01

$1.00000 \mathrm{e}+001.00000 \mathrm{e}+001.00000 \mathrm{e}-011.00000 \mathrm{e}-091.00000 \mathrm{e}-01$ Element: 11690 \# of layers: 7

$\mathrm{Kx} \mathrm{Ky} \mathrm{Kz}$ Ss Por

$1.84340 \mathrm{e}+011.84340 \mathrm{e}+011.84340 \mathrm{e}+001.00000 \mathrm{e}-09$ 2.12000e-01 $1.84340 \mathrm{e}+011.84340 \mathrm{e}+011.84340 \mathrm{e}+001.00000 \mathrm{e}-092.12000 \mathrm{e}-01$ $1.84340 \mathrm{e}+011.84340 \mathrm{e}+011.84340 \mathrm{e}+001.00000 \mathrm{e}-092.12000 \mathrm{e}-01$ $1.84340 \mathrm{e}+011.84340 \mathrm{e}+01 \quad 1.84340 \mathrm{e}+001.00000 \mathrm{e}-092.12000 \mathrm{e}-01$ $1.84340 \mathrm{e}+01$ 1.84340e+01 1.84340e+00 1.00000e-09 2.12000e-01 $1.00000 \mathrm{e}-05$ 1.00000e-05 1.00000e-06 1.00000e-09 1.00000e-01 $1.00000 \mathrm{e}+001.00000 \mathrm{e}+001.00000 \mathrm{e}-011.00000 \mathrm{e}-09$ 1.00000e-01 Element: 11691 \# of layers: 7

$\mathrm{Kx} \mathrm{Ky} \mathrm{Kz}$ Ss Por

$1.84340 \mathrm{e}+01$ 1.84340e+01 1.84340e+00 1.00000e-09 2.12000e-01 $1.84340 \mathrm{e}+011.84340 \mathrm{e}+011.84340 \mathrm{e}+001.00000 \mathrm{e}-092.12000 \mathrm{e}-01$ $1.84340 \mathrm{e}+011.84340 \mathrm{e}+011.84340 \mathrm{e}+001.00000 \mathrm{e}-092.12000 \mathrm{e}-01$ $1.84340 \mathrm{e}+01$ 1.84340e+01 1.84340e+00 1.00000e-09 2.12000e-01 $1.84340 \mathrm{e}+011.84340 \mathrm{e}+011.84340 \mathrm{e}+001.00000 \mathrm{e}-092.12000 \mathrm{e}-01$ $1.00000 \mathrm{e}-051.00000 \mathrm{e}-051.00000 \mathrm{e}-061.00000 \mathrm{e}-091.00000 \mathrm{e}-01$ $1.00000 \mathrm{e}+001.00000 \mathrm{e}+001.00000 \mathrm{e}-01$ 1.00000e-09 1.00000e-01 Element: 11692 \# of layers: 7

Kx Ky Kz Ss Por

$1.84340 \mathrm{e}+011.84340 \mathrm{e}+011.84340 \mathrm{e}+001.00000 \mathrm{e}-092.12000 \mathrm{e}-01$ $1.84340 \mathrm{e}+011.84340 \mathrm{e}+011.84340 \mathrm{e}+001.00000 \mathrm{e}-092.12000 \mathrm{e}-01$ $1.84340 \mathrm{e}+011.84340 \mathrm{e}+011.84340 \mathrm{e}+001.00000 \mathrm{e}-092.12000 \mathrm{e}-01$ $1.84340 \mathrm{e}+011.84340 \mathrm{e}+011.84340 \mathrm{e}+001.00000 \mathrm{e}-092.12000 \mathrm{e}-01$ $1.84340 \mathrm{e}+011.84340 \mathrm{e}+011.84340 \mathrm{e}+001.00000 \mathrm{e}-092.12000 \mathrm{e}-01$ $1.00000 \mathrm{e}-05$ 1.00000e-05 1.00000e-06 1.00000e-09 1.00000e-01 $1.00000 \mathrm{e}+001.00000 \mathrm{e}+001.00000 \mathrm{e}-01$ 1.00000e-09 1.00000e-01 Element: 11693 \# of layers: 7

Kx Ky Kz Ss Por

$1.84340 \mathrm{e}+01$ 1.84340e+01 1.84340e+00 1.00000e-09 2.12000e-01 $1.84340 \mathrm{e}+011.84340 \mathrm{e}+011.84340 \mathrm{e}+001.00000 \mathrm{e}-092.12000 \mathrm{e}-01$ $1.84340 \mathrm{e}+011.84340 \mathrm{e}+011.84340 \mathrm{e}+001.00000 \mathrm{e}-092.12000 \mathrm{e}-01$ $1.84340 \mathrm{e}+011.84340 \mathrm{e}+011.84340 \mathrm{e}+001.00000 \mathrm{e}-092.12000 \mathrm{e}-01$ $1.84340 \mathrm{e}+011.84340 \mathrm{e}+011.84340 \mathrm{e}+001.00000 \mathrm{e}-092.12000 \mathrm{e}-01$ $1.00000 \mathrm{e}-05$ 1.00000e-05 1.00000e-06 1.00000e-09 1.00000e-01 $1.00000 \mathrm{e}+001.00000 \mathrm{e}+001.00000 \mathrm{e}-01$ 1.00000e-09 1.00000e-01 Element: 11694 \# of layers: 7

Kx Ky Kz Ss Por

$1.84340 \mathrm{e}+011.84340 \mathrm{e}+01$ 1.84340e+00 1.00000e-09 2.12000e-01 $1.84340 \mathrm{e}+01$ 1.84340e+01 1.84340e+00 1.00000e-09 2.12000e-01 $1.84340 \mathrm{e}+011.84340 \mathrm{e}+011.84340 \mathrm{e}+001.00000 \mathrm{e}-092.12000 \mathrm{e}-01$ $1.84340 \mathrm{e}+011.84340 \mathrm{e}+011.84340 \mathrm{e}+001.00000 \mathrm{e}-092.12000 \mathrm{e}-01$ 
$1.84340 \mathrm{e}+011.84340 \mathrm{e}+011.84340 \mathrm{e}+001.00000 \mathrm{e}-092.12000 \mathrm{e}-01$ $1.00000 \mathrm{e}-05$ 1.00000e-05 1.00000e-06 1.00000e-09 1.00000e-01 $1.00000 \mathrm{e}+001.00000 \mathrm{e}+001.00000 \mathrm{e}-01$ 1.00000e-09 1.00000e-01

Element: 11695 \# of layers: 7

$\mathrm{Kx} \mathrm{Ky} \mathrm{Kz}$ Ss Por

$1.68436 \mathrm{e}+011.68436 \mathrm{e}+011.68436 \mathrm{e}+001.00000 \mathrm{e}-092.12000 \mathrm{e}-01$

$1.68436 \mathrm{e}+011.68436 \mathrm{e}+011.68436 \mathrm{e}+001.00000 \mathrm{e}-092.12000 \mathrm{e}-01$

$1.68436 \mathrm{e}+011.68436 \mathrm{e}+011.68436 \mathrm{e}+001.00000 \mathrm{e}-092.12000 \mathrm{e}-01$

$1.68436 \mathrm{e}+011.68436 \mathrm{e}+011.68436 \mathrm{e}+001.00000 \mathrm{e}-092.12000 \mathrm{e}-01$

$1.68436 \mathrm{e}+011.68436 \mathrm{e}+011.68436 \mathrm{e}+001.00000 \mathrm{e}-092.12000 \mathrm{e}-01$ $1.00000 \mathrm{e}-05$ 1.00000e-05 1.00000e-06 1.00000e-09 1.00000e-01

$1.00000 \mathrm{e}+001.00000 \mathrm{e}+001.00000 \mathrm{e}-011.00000 \mathrm{e}-091.00000 \mathrm{e}-01$

Element: 11696 \# of layers: 7

$\mathrm{Kx} \mathrm{Ky} \mathrm{Kz}$ Ss Por

$1.68436 \mathrm{e}+011.68436 \mathrm{e}+011.68436 \mathrm{e}+001.00000 \mathrm{e}-092.12000 \mathrm{e}-01$

$1.68436 \mathrm{e}+011.68436 \mathrm{e}+011.68436 \mathrm{e}+001.00000 \mathrm{e}-092.12000 \mathrm{e}-01$

$1.68436 \mathrm{e}+011.68436 \mathrm{e}+011.68436 \mathrm{e}+001.00000 \mathrm{e}-092.12000 \mathrm{e}-01$

$1.68436 \mathrm{e}+011.68436 \mathrm{e}+011.68436 \mathrm{e}+001.00000 \mathrm{e}-092.12000 \mathrm{e}-01$

$1.68436 \mathrm{e}+011.68436 \mathrm{e}+011.68436 \mathrm{e}+001.00000 \mathrm{e}-092.12000 \mathrm{e}-01$

$1.00000 \mathrm{e}-05$ 1.00000e-05 1.00000e-06 1.00000e-09 1.00000e-01

$1.00000 \mathrm{e}+001.00000 \mathrm{e}+001.00000 \mathrm{e}-011.00000 \mathrm{e}-091.00000 \mathrm{e}-01$

Element: 11697 \# of layers: 7

$\mathrm{Kx} \mathrm{Ky} \mathrm{Kz}$ Ss Por

$1.68436 \mathrm{e}+01$ 1.68436e+01 1.68436e+00 1.00000e-09 2.12000e-01

$1.68436 \mathrm{e}+011.68436 \mathrm{e}+011.68436 \mathrm{e}+001.00000 \mathrm{e}-092.12000 \mathrm{e}-01$

$1.68436 \mathrm{e}+011.68436 \mathrm{e}+011.68436 \mathrm{e}+001.00000 \mathrm{e}-092.12000 \mathrm{e}-01$

$1.68436 \mathrm{e}+011.68436 \mathrm{e}+011.68436 \mathrm{e}+001.00000 \mathrm{e}-092.12000 \mathrm{e}-01$

$1.68436 \mathrm{e}+011.68436 \mathrm{e}+011.68436 \mathrm{e}+001.00000 \mathrm{e}-092.12000 \mathrm{e}-01$

$1.00000 \mathrm{e}-05$ 1.00000e-05 1.00000e-06 1.00000e-09 1.00000e-01

$1.00000 \mathrm{e}+001.00000 \mathrm{e}+001.00000 \mathrm{e}-011.00000 \mathrm{e}-091.00000 \mathrm{e}-01$

Element: 11698 \# of layers: 7

$\mathrm{Kx} \mathrm{Ky} \mathrm{Kz}$ Ss Por

$1.84340 \mathrm{e}+01$ 1.84340e+01 1.84340e+00 1.00000e-09 2.12000e-01

$1.84340 \mathrm{e}+011.84340 \mathrm{e}+011.84340 \mathrm{e}+001.00000 \mathrm{e}-092.12000 \mathrm{e}-01$

$1.84340 \mathrm{e}+011.84340 \mathrm{e}+011.84340 \mathrm{e}+001.00000 \mathrm{e}-092.12000 \mathrm{e}-01$

$1.84340 \mathrm{e}+011.84340 \mathrm{e}+011.84340 \mathrm{e}+001.00000 \mathrm{e}-092.12000 \mathrm{e}-01$

$1.84340 \mathrm{e}+011.84340 \mathrm{e}+011.84340 \mathrm{e}+001.00000 \mathrm{e}-092.12000 \mathrm{e}-01$

$1.00000 \mathrm{e}-05$ 1.00000e-05 1.00000e-06 1.00000e-09 1.00000e-01

$1.00000 \mathrm{e}+001.00000 \mathrm{e}+001.00000 \mathrm{e}-01$ 1.00000e-09 1.00000e-01

Element: 11699 \# of layers: 7

Kx Ky Kz Ss Por

$1.84340 \mathrm{e}+01$ 1.84340e+01 1.84340e+00 1.00000e-09 2.12000e-01

$1.84340 \mathrm{e}+011.84340 \mathrm{e}+011.84340 \mathrm{e}+001.00000 \mathrm{e}-092.12000 \mathrm{e}-01$

$1.84340 \mathrm{e}+01$ 1.84340e+01 1.84340e+00 1.00000e-09 2.12000e-01

$1.84340 \mathrm{e}+011.84340 \mathrm{e}+011.84340 \mathrm{e}+001.00000 \mathrm{e}-092.12000 \mathrm{e}-01$

$1.84340 \mathrm{e}+011.84340 \mathrm{e}+011.84340 \mathrm{e}+001.00000 \mathrm{e}-092.12000 \mathrm{e}-01$ 
$1.00000 \mathrm{e}-05$ 1.00000e-05 1.00000e-06 1.00000e-09 1.00000e-01 $1.00000 \mathrm{e}+001.00000 \mathrm{e}+001.00000 \mathrm{e}-01$ 1.00000e-09 1.00000e-01 Element: 11700 \# of layers: 7

Kx Ky Kz Ss Por

$1.84340 \mathrm{e}+011.84340 \mathrm{e}+011.84340 \mathrm{e}+001.00000 \mathrm{e}-092.12000 \mathrm{e}-01$ $1.84340 \mathrm{e}+01$ 1.84340e+01 1.84340e+00 1.00000e-09 2.12000e-01 $1.84340 \mathrm{e}+01$ 1.84340e+01 1.84340e+00 1.00000e-09 2.12000e-01 $1.84340 \mathrm{e}+011.84340 \mathrm{e}+011.84340 \mathrm{e}+001.00000 \mathrm{e}-092.12000 \mathrm{e}-01$ $1.84340 \mathrm{e}+011.84340 \mathrm{e}+011.84340 \mathrm{e}+001.00000 \mathrm{e}-092.12000 \mathrm{e}-01$ $1.00000 \mathrm{e}-05$ 1.00000e-05 1.00000e-06 1.00000e-09 1.00000e-01 $1.00000 \mathrm{e}+001.00000 \mathrm{e}+001.00000 \mathrm{e}-01$ 1.00000e-09 1.00000e-01 Element: 11701 \# of layers: 7

$\mathrm{Kx} \mathrm{Ky} \mathrm{Kz}$ Ss Por

$1.84340 \mathrm{e}+01$ 1.84340e+01 1.84340e+00 1.00000e-09 2.12000e-01 $1.84340 \mathrm{e}+011.84340 \mathrm{e}+011.84340 \mathrm{e}+001.00000 \mathrm{e}-092.12000 \mathrm{e}-01$ $1.84340 \mathrm{e}+011.84340 \mathrm{e}+011.84340 \mathrm{e}+001.00000 \mathrm{e}-092.12000 \mathrm{e}-01$ $1.84340 \mathrm{e}+011.84340 \mathrm{e}+011.84340 \mathrm{e}+001.00000 \mathrm{e}-092.12000 \mathrm{e}-01$ $1.84340 \mathrm{e}+01$ 1.84340e+01 1.84340e+00 1.00000e-09 2.12000e-01 $1.00000 \mathrm{e}-05$ 1.00000e-05 1.00000e-06 1.00000e-09 1.00000e-01 $1.00000 \mathrm{e}+001.00000 \mathrm{e}+001.00000 \mathrm{e}-011.00000 \mathrm{e}-091.00000 \mathrm{e}-01$ Element: 11702 \# of layers: 7

$\mathrm{Kx} \mathrm{Ky} \mathrm{Kz}$ Ss Por

$1.68436 \mathrm{e}+01$ 1.68436e+01 1.68436e+00 1.00000e-09 2.12000e-01 $1.68436 \mathrm{e}+011.68436 \mathrm{e}+011.68436 \mathrm{e}+001.00000 \mathrm{e}-092.12000 \mathrm{e}-01$ $1.68436 \mathrm{e}+011.68436 \mathrm{e}+011.68436 \mathrm{e}+001.00000 \mathrm{e}-092.12000 \mathrm{e}-01$ $1.68436 \mathrm{e}+011.68436 \mathrm{e}+011.68436 \mathrm{e}+001.00000 \mathrm{e}-092.12000 \mathrm{e}-01$ $1.68436 \mathrm{e}+011.68436 \mathrm{e}+011.68436 \mathrm{e}+001.00000 \mathrm{e}-092.12000 \mathrm{e}-01$ $1.00000 \mathrm{e}-05$ 1.00000e-05 1.00000e-06 1.00000e-09 1.00000e-01 $1.00000 \mathrm{e}+001.00000 \mathrm{e}+001.00000 \mathrm{e}-011.00000 \mathrm{e}-091.00000 \mathrm{e}-01$ Element: 11703 \# of layers: 7

$\mathrm{Kx} \mathrm{Ky} \mathrm{Kz}$ Ss Por

$1.68436 \mathrm{e}+011.68436 \mathrm{e}+011.68436 \mathrm{e}+001.00000 \mathrm{e}-092.12000 \mathrm{e}-01$ $1.68436 \mathrm{e}+011.68436 \mathrm{e}+011.68436 \mathrm{e}+001.00000 \mathrm{e}-092.12000 \mathrm{e}-01$ $1.68436 \mathrm{e}+011.68436 \mathrm{e}+011.68436 \mathrm{e}+001.00000 \mathrm{e}-092.12000 \mathrm{e}-01$ $1.68436 \mathrm{e}+011.68436 \mathrm{e}+011.68436 \mathrm{e}+001.00000 \mathrm{e}-092.12000 \mathrm{e}-01$ $1.68436 \mathrm{e}+011.68436 \mathrm{e}+011.68436 \mathrm{e}+001.00000 \mathrm{e}-092.12000 \mathrm{e}-01$ 1.00000e-05 1.00000e-05 1.00000e-06 1.00000e-09 1.00000e-01 $1.00000 \mathrm{e}+001.00000 \mathrm{e}+001.00000 \mathrm{e}-011.00000 \mathrm{e}-091.00000 \mathrm{e}-01$ Element: 11704 \# of layers: 7

$\mathrm{Kx} \mathrm{Ky} \mathrm{Kz}$ Ss Por

$1.68436 \mathrm{e}+011.68436 \mathrm{e}+011.68436 \mathrm{e}+001.00000 \mathrm{e}-092.12000 \mathrm{e}-01$ $1.68436 \mathrm{e}+011.68436 \mathrm{e}+011.68436 \mathrm{e}+001.00000 \mathrm{e}-092.12000 \mathrm{e}-01$ $1.68436 \mathrm{e}+011.68436 \mathrm{e}+011.68436 \mathrm{e}+001.00000 \mathrm{e}-092.12000 \mathrm{e}-01$ $1.68436 \mathrm{e}+011.68436 \mathrm{e}+011.68436 \mathrm{e}+001.00000 \mathrm{e}-092.12000 \mathrm{e}-01$ $1.68436 \mathrm{e}+011.68436 \mathrm{e}+011.68436 \mathrm{e}+001.00000 \mathrm{e}-092.12000 \mathrm{e}-01$ $1.00000 \mathrm{e}-05$ 1.00000e-05 1.00000e-06 1.00000e-09 1.00000e-01 
$1.00000 \mathrm{e}+001.00000 \mathrm{e}+00$ 1.00000e-01 1.00000e-09 1.00000e-01

Element: 11705 \# of layers: 7

Kx Ky Kz Ss Por

$1.68436 \mathrm{e}+011.68436 \mathrm{e}+011.68436 \mathrm{e}+001.00000 \mathrm{e}-092.12000 \mathrm{e}-01$

$1.68436 \mathrm{e}+011.68436 \mathrm{e}+011.68436 \mathrm{e}+001.00000 \mathrm{e}-092.12000 \mathrm{e}-01$

$1.68436 \mathrm{e}+011.68436 \mathrm{e}+011.68436 \mathrm{e}+001.00000 \mathrm{e}-092.12000 \mathrm{e}-01$

$1.68436 \mathrm{e}+011.68436 \mathrm{e}+011.68436 \mathrm{e}+001.00000 \mathrm{e}-092.12000 \mathrm{e}-01$

$1.68436 \mathrm{e}+011.68436 \mathrm{e}+011.68436 \mathrm{e}+001.00000 \mathrm{e}-092.12000 \mathrm{e}-01$

$1.00000 \mathrm{e}-05$ 1.00000e-05 1.00000e-06 1.00000e-09 1.00000e-01

$1.00000 \mathrm{e}+001.00000 \mathrm{e}+001.00000 \mathrm{e}-011.00000 \mathrm{e}-091.00000 \mathrm{e}-01$

Element: 11706 \# of layers: 7

$\mathrm{Kx} \mathrm{Ky} \mathrm{Kz}$ Ss Por

$1.68436 \mathrm{e}+01$ 1.68436e+01 1.68436e+00 1.00000e-09 2.12000e-01

$1.68436 \mathrm{e}+011.68436 \mathrm{e}+011.68436 \mathrm{e}+001.00000 \mathrm{e}-092.12000 \mathrm{e}-01$

$1.68436 \mathrm{e}+011.68436 \mathrm{e}+011.68436 \mathrm{e}+001.00000 \mathrm{e}-092.12000 \mathrm{e}-01$

$1.68436 \mathrm{e}+011.68436 \mathrm{e}+011.68436 \mathrm{e}+001.00000 \mathrm{e}-092.12000 \mathrm{e}-01$

$1.68436 \mathrm{e}+011.68436 \mathrm{e}+011.68436 \mathrm{e}+001.00000 \mathrm{e}-092.12000 \mathrm{e}-01$

$1.00000 \mathrm{e}-05$ 1.00000e-05 1.00000e-06 1.00000e-09 1.00000e-01

$1.00000 \mathrm{e}+001.00000 \mathrm{e}+001.00000 \mathrm{e}-01$ 1.00000e-09 1.00000e-01

Element: 11707 \# of layers: 7

$\mathrm{Kx} \mathrm{Ky} \mathrm{Kz}$ Ss Por

$1.68436 \mathrm{e}+01$ 1.68436e+01 1.68436e+00 1.00000e-09 2.12000e-01

$1.68436 \mathrm{e}+011.68436 \mathrm{e}+011.68436 \mathrm{e}+001.00000 \mathrm{e}-092.12000 \mathrm{e}-01$

$1.68436 \mathrm{e}+011.68436 \mathrm{e}+011.68436 \mathrm{e}+001.00000 \mathrm{e}-092.12000 \mathrm{e}-01$

$1.68436 \mathrm{e}+011.68436 \mathrm{e}+011.68436 \mathrm{e}+001.00000 \mathrm{e}-092.12000 \mathrm{e}-01$

$1.68436 \mathrm{e}+011.68436 \mathrm{e}+011.68436 \mathrm{e}+001.00000 \mathrm{e}-092.12000 \mathrm{e}-01$

$1.00000 \mathrm{e}-05$ 1.00000e-05 1.00000e-06 1.00000e-09 1.00000e-01

$1.00000 \mathrm{e}+001.00000 \mathrm{e}+001.00000 \mathrm{e}-011.00000 \mathrm{e}-091.00000 \mathrm{e}-01$

Element: 11708 \# of layers: 7

$\mathrm{Kx} \mathrm{Ky} \mathrm{Kz}$ Ss Por

$1.68436 \mathrm{e}+01$ 1.68436e+01 1.68436e+00 1.00000e-09 2.12000e-01

$1.68436 \mathrm{e}+011.68436 \mathrm{e}+011.68436 \mathrm{e}+001.00000 \mathrm{e}-092.12000 \mathrm{e}-01$

$1.68436 \mathrm{e}+011.68436 \mathrm{e}+011.68436 \mathrm{e}+001.00000 \mathrm{e}-092.12000 \mathrm{e}-01$

$1.68436 \mathrm{e}+011.68436 \mathrm{e}+011.68436 \mathrm{e}+001.00000 \mathrm{e}-092.12000 \mathrm{e}-01$

$1.68436 \mathrm{e}+011.68436 \mathrm{e}+011.68436 \mathrm{e}+001.00000 \mathrm{e}-092.12000 \mathrm{e}-01$

$1.00000 \mathrm{e}-05$ 1.00000e-05 1.00000e-06 1.00000e-09 1.00000e-01

$1.00000 \mathrm{e}+001.00000 \mathrm{e}+001.00000 \mathrm{e}-011.00000 \mathrm{e}-091.00000 \mathrm{e}-01$

Element: 11709 \# of layers: 7

$\mathrm{Kx} \mathrm{Ky} \mathrm{Kz}$ Ss Por

$1.68436 \mathrm{e}+011.68436 \mathrm{e}+011.68436 \mathrm{e}+001.00000 \mathrm{e}-092.12000 \mathrm{e}-01$

$1.68436 \mathrm{e}+011.68436 \mathrm{e}+011.68436 \mathrm{e}+001.00000 \mathrm{e}-092.12000 \mathrm{e}-01$

$1.68436 \mathrm{e}+011.68436 \mathrm{e}+011.68436 \mathrm{e}+001.00000 \mathrm{e}-092.12000 \mathrm{e}-01$

$1.68436 \mathrm{e}+011.68436 \mathrm{e}+011.68436 \mathrm{e}+001.00000 \mathrm{e}-092.12000 \mathrm{e}-01$

$1.68436 \mathrm{e}+01$ 1.68436e+01 1.68436e+00 1.00000e-09 2.12000e-01

$1.00000 \mathrm{e}-05$ 1.00000e-05 1.00000e-06 1.00000e-09 1.00000e-01

$1.00000 \mathrm{e}+001.00000 \mathrm{e}+001.00000 \mathrm{e}-011.00000 \mathrm{e}-091.00000 \mathrm{e}-01$ 
Element: 11710 \# of layers: 7

Kx Ky Kz Ss Por

$1.68436 \mathrm{e}+011.68436 \mathrm{e}+011.68436 \mathrm{e}+00$ 1.00000e-09 2.12000e-01

$1.68436 \mathrm{e}+011.68436 \mathrm{e}+011.68436 \mathrm{e}+001.00000 \mathrm{e}-092.12000 \mathrm{e}-01$

$1.68436 \mathrm{e}+011.68436 \mathrm{e}+011.68436 \mathrm{e}+001.00000 \mathrm{e}-092.12000 \mathrm{e}-01$

$1.68436 \mathrm{e}+011.68436 \mathrm{e}+011.68436 \mathrm{e}+001.00000 \mathrm{e}-092.12000 \mathrm{e}-01$

$1.68436 \mathrm{e}+011.68436 \mathrm{e}+011.68436 \mathrm{e}+001.00000 \mathrm{e}-092.12000 \mathrm{e}-01$

$1.00000 \mathrm{e}-05$ 1.00000e-05 1.00000e-06 1.00000e-09 1.00000e-01

$1.00000 \mathrm{e}+001.00000 \mathrm{e}+001.00000 \mathrm{e}-011.00000 \mathrm{e}-091.00000 \mathrm{e}-01$

Element: 11711 \# of layers: 7

Kx Ky Kz Ss Por

$1.68436 \mathrm{e}+011.68436 \mathrm{e}+011.68436 \mathrm{e}+00$ 1.00000e-09 2.12000e-01

$1.68436 \mathrm{e}+011.68436 \mathrm{e}+011.68436 \mathrm{e}+001.00000 \mathrm{e}-092.12000 \mathrm{e}-01$

$1.68436 \mathrm{e}+011.68436 \mathrm{e}+011.68436 \mathrm{e}+001.00000 \mathrm{e}-092.12000 \mathrm{e}-01$

$1.68436 \mathrm{e}+011.68436 \mathrm{e}+011.68436 \mathrm{e}+001.00000 \mathrm{e}-092.12000 \mathrm{e}-01$

$1.68436 \mathrm{e}+011.68436 \mathrm{e}+011.68436 \mathrm{e}+001.00000 \mathrm{e}-092.12000 \mathrm{e}-01$

$1.00000 \mathrm{e}-05$ 1.00000e-05 1.00000e-06 1.00000e-09 1.00000e-01

$1.00000 \mathrm{e}+001.00000 \mathrm{e}+001.00000 \mathrm{e}-011.00000 \mathrm{e}-091.00000 \mathrm{e}-01$

Element: 11712 \# of layers: 7

Kx Ky Kz Ss Por

$1.68436 \mathrm{e}+011.68436 \mathrm{e}+011.68436 \mathrm{e}+001.00000 \mathrm{e}-092.12000 \mathrm{e}-01$

$1.68436 \mathrm{e}+011.68436 \mathrm{e}+011.68436 \mathrm{e}+001.00000 \mathrm{e}-092.12000 \mathrm{e}-01$

$1.68436 \mathrm{e}+011.68436 \mathrm{e}+011.68436 \mathrm{e}+001.00000 \mathrm{e}-092.12000 \mathrm{e}-01$

$1.68436 \mathrm{e}+011.68436 \mathrm{e}+011.68436 \mathrm{e}+001.00000 \mathrm{e}-092.12000 \mathrm{e}-01$

$1.68436 \mathrm{e}+011.68436 \mathrm{e}+011.68436 \mathrm{e}+001.00000 \mathrm{e}-092.12000 \mathrm{e}-01$

$1.00000 \mathrm{e}-05$ 1.00000e-05 1.00000e-06 1.00000e-09 1.00000e-01

$1.00000 \mathrm{e}+001.00000 \mathrm{e}+001.00000 \mathrm{e}-011.00000 \mathrm{e}-091.00000 \mathrm{e}-01$

Element: 11713 \# of layers: 7

Kx Ky Kz Ss Por

$1.60714 \mathrm{e}+011.60714 \mathrm{e}+011.60714 \mathrm{e}+00$ 1.00000e-09 2.12000e-01

$1.60714 \mathrm{e}+011.60714 \mathrm{e}+011.60714 \mathrm{e}+001.00000 \mathrm{e}-092.12000 \mathrm{e}-01$

$1.60714 \mathrm{e}+011.60714 \mathrm{e}+011.60714 \mathrm{e}+001.00000 \mathrm{e}-092.12000 \mathrm{e}-01$

$1.60714 \mathrm{e}+011.60714 \mathrm{e}+011.60714 \mathrm{e}+001.00000 \mathrm{e}-092.12000 \mathrm{e}-01$

$1.60714 \mathrm{e}+011.60714 \mathrm{e}+011.60714 \mathrm{e}+001.00000 \mathrm{e}-092.12000 \mathrm{e}-01$

$1.00000 \mathrm{e}-05$ 1.00000e-05 1.00000e-06 1.00000e-09 1.00000e-01

$1.00000 \mathrm{e}+001.00000 \mathrm{e}+001.00000 \mathrm{e}-011.00000 \mathrm{e}-091.00000 \mathrm{e}-01$

Element: 11714 \# of layers: 7

Kx Ky Kz Ss Por

$1.60714 \mathrm{e}+011.60714 \mathrm{e}+011.60714 \mathrm{e}+00$ 1.00000e-09 2.12000e-01

$1.60714 \mathrm{e}+011.60714 \mathrm{e}+011.60714 \mathrm{e}+001.00000 \mathrm{e}-092.12000 \mathrm{e}-01$

$1.60714 \mathrm{e}+011.60714 \mathrm{e}+011.60714 \mathrm{e}+001.00000 \mathrm{e}-092.12000 \mathrm{e}-01$

$1.60714 \mathrm{e}+011.60714 \mathrm{e}+011.60714 \mathrm{e}+001.00000 \mathrm{e}-092.12000 \mathrm{e}-01$

$1.60714 \mathrm{e}+011.60714 \mathrm{e}+011.60714 \mathrm{e}+001.00000 \mathrm{e}-092.12000 \mathrm{e}-01$

$1.00000 \mathrm{e}-05$ 1.00000e-05 1.00000e-06 1.00000e-09 1.00000e-01

$1.00000 \mathrm{e}+001.00000 \mathrm{e}+001.00000 \mathrm{e}-011.00000 \mathrm{e}-091.00000 \mathrm{e}-01$

Element: 11715 \# of layers: 7 
$\mathrm{Kx} \mathrm{Ky} \mathrm{Kz}$ Ss Por

$1.60714 \mathrm{e}+011.60714 \mathrm{e}+011.60714 \mathrm{e}+001.00000 \mathrm{e}-092.12000 \mathrm{e}-01$

$1.60714 \mathrm{e}+011.60714 \mathrm{e}+011.60714 \mathrm{e}+001.00000 \mathrm{e}-092.12000 \mathrm{e}-01$

$1.60714 \mathrm{e}+011.60714 \mathrm{e}+011.60714 \mathrm{e}+001.00000 \mathrm{e}-092.12000 \mathrm{e}-01$

$1.60714 \mathrm{e}+011.60714 \mathrm{e}+011.60714 \mathrm{e}+001.00000 \mathrm{e}-092.12000 \mathrm{e}-01$

$1.60714 \mathrm{e}+011.60714 \mathrm{e}+011.60714 \mathrm{e}+001.00000 \mathrm{e}-092.12000 \mathrm{e}-01$

$1.00000 \mathrm{e}-05$ 1.00000e-05 1.00000e-06 1.00000e-09 1.00000e-01

$1.00000 \mathrm{e}+001.00000 \mathrm{e}+001.00000 \mathrm{e}-01$ 1.00000e-09 1.00000e-01

Element: 11716 \# of layers: 7

$\mathrm{Kx} \mathrm{Ky} \mathrm{Kz}$ Ss Por

$1.68436 \mathrm{e}+011.68436 \mathrm{e}+011.68436 \mathrm{e}+00$ 1.00000e-09 2.12000e-01

$1.68436 \mathrm{e}+011.68436 \mathrm{e}+011.68436 \mathrm{e}+001.00000 \mathrm{e}-092.12000 \mathrm{e}-01$

$1.68436 \mathrm{e}+011.68436 \mathrm{e}+011.68436 \mathrm{e}+001.00000 \mathrm{e}-092.12000 \mathrm{e}-01$

$1.68436 \mathrm{e}+011.68436 \mathrm{e}+011.68436 \mathrm{e}+001.00000 \mathrm{e}-092.12000 \mathrm{e}-01$

$1.68436 \mathrm{e}+011.68436 \mathrm{e}+011.68436 \mathrm{e}+001.00000 \mathrm{e}-092.12000 \mathrm{e}-01$

$1.00000 \mathrm{e}-05$ 1.00000e-05 1.00000e-06 1.00000e-09 1.00000e-01

$1.00000 \mathrm{e}+001.00000 \mathrm{e}+001.00000 \mathrm{e}-011.00000 \mathrm{e}-091.00000 \mathrm{e}-01$

Element: 11717 \# of layers: 7

$\mathrm{Kx} \mathrm{Ky} \mathrm{Kz}$ Ss Por

$1.68436 \mathrm{e}+01$ 1.68436e+01 1.68436e+00 1.00000e-09 2.12000e-01

$1.68436 \mathrm{e}+011.68436 \mathrm{e}+011.68436 \mathrm{e}+001.00000 \mathrm{e}-092.12000 \mathrm{e}-01$

$1.68436 \mathrm{e}+01$ 1.68436e+01 1.68436e+00 1.00000e-09 2.12000e-01

$1.68436 \mathrm{e}+011.68436 \mathrm{e}+011.68436 \mathrm{e}+001.00000 \mathrm{e}-092.12000 \mathrm{e}-01$

$1.68436 \mathrm{e}+011.68436 \mathrm{e}+011.68436 \mathrm{e}+001.00000 \mathrm{e}-092.12000 \mathrm{e}-01$

$1.00000 \mathrm{e}-05$ 1.00000e-05 1.00000e-06 1.00000e-09 1.00000e-01

$1.00000 \mathrm{e}+001.00000 \mathrm{e}+001.00000 \mathrm{e}-01$ 1.00000e-09 1.00000e-01

Element: 11718 \# of layers: 7

$\mathrm{Kx} \mathrm{Ky} \mathrm{Kz}$ Ss Por

$1.68436 \mathrm{e}+011.68436 \mathrm{e}+011.68436 \mathrm{e}+001.00000 \mathrm{e}-092.12000 \mathrm{e}-01$

$1.68436 \mathrm{e}+011.68436 \mathrm{e}+011.68436 \mathrm{e}+001.00000 \mathrm{e}-092.12000 \mathrm{e}-01$

$1.68436 \mathrm{e}+011.68436 \mathrm{e}+011.68436 \mathrm{e}+001.00000 \mathrm{e}-092.12000 \mathrm{e}-01$

$1.68436 \mathrm{e}+011.68436 \mathrm{e}+011.68436 \mathrm{e}+001.00000 \mathrm{e}-092.12000 \mathrm{e}-01$

$1.68436 \mathrm{e}+011.68436 \mathrm{e}+011.68436 \mathrm{e}+001.00000 \mathrm{e}-092.12000 \mathrm{e}-01$

$1.00000 \mathrm{e}-05$ 1.00000e-05 1.00000e-06 1.00000e-09 1.00000e-01

$1.00000 \mathrm{e}+001.00000 \mathrm{e}+001.00000 \mathrm{e}-011.00000 \mathrm{e}-091.00000 \mathrm{e}-01$

Element: 11719 \# of layers: 7

Kx Ky Kz Ss Por

$1.68436 \mathrm{e}+011.68436 \mathrm{e}+011.68436 \mathrm{e}+001.00000 \mathrm{e}-092.12000 \mathrm{e}-01$

$1.68436 \mathrm{e}+011.68436 \mathrm{e}+011.68436 \mathrm{e}+001.00000 \mathrm{e}-092.12000 \mathrm{e}-01$

$1.68436 \mathrm{e}+011.68436 \mathrm{e}+011.68436 \mathrm{e}+001.00000 \mathrm{e}-092.12000 \mathrm{e}-01$

$1.68436 \mathrm{e}+011.68436 \mathrm{e}+011.68436 \mathrm{e}+001.00000 \mathrm{e}-092.12000 \mathrm{e}-01$

$1.68436 \mathrm{e}+011.68436 \mathrm{e}+011.68436 \mathrm{e}+001.00000 \mathrm{e}-092.12000 \mathrm{e}-01$

$1.00000 \mathrm{e}-051.00000 \mathrm{e}-05$ 1.00000e-06 1.00000e-09 1.00000e-01

$1.00000 \mathrm{e}+001.00000 \mathrm{e}+001.00000 \mathrm{e}-01$ 1.00000e-09 1.00000e-01

Element: 11720 \# of layers: 7

Kx Ky Kz Ss Por 
$1.60714 \mathrm{e}+011.60714 \mathrm{e}+011.60714 \mathrm{e}+001.00000 \mathrm{e}-092.12000 \mathrm{e}-01$ $1.60714 \mathrm{e}+011.60714 \mathrm{e}+011.60714 \mathrm{e}+001.00000 \mathrm{e}-092.12000 \mathrm{e}-01$ $1.60714 \mathrm{e}+011.60714 \mathrm{e}+011.60714 \mathrm{e}+001.00000 \mathrm{e}-092.12000 \mathrm{e}-01$ $1.60714 \mathrm{e}+011.60714 \mathrm{e}+011.60714 \mathrm{e}+001.00000 \mathrm{e}-092.12000 \mathrm{e}-01$ $1.60714 \mathrm{e}+011.60714 \mathrm{e}+011.60714 \mathrm{e}+001.00000 \mathrm{e}-092.12000 \mathrm{e}-01$ 1.00000e-05 1.00000e-05 1.00000e-06 1.00000e-09 1.00000e-01 $1.00000 \mathrm{e}+001.00000 \mathrm{e}+001.00000 \mathrm{e}-01$ 1.00000e-09 1.00000e-01

Element: 11721 \# of layers: 7

$\mathrm{Kx} \mathrm{Ky} \mathrm{Kz}$ Ss Por

$1.60714 \mathrm{e}+011.60714 \mathrm{e}+011.60714 \mathrm{e}+001.00000 \mathrm{e}-092.12000 \mathrm{e}-01$ $1.60714 \mathrm{e}+011.60714 \mathrm{e}+011.60714 \mathrm{e}+001.00000 \mathrm{e}-092.12000 \mathrm{e}-01$ $1.60714 \mathrm{e}+011.60714 \mathrm{e}+011.60714 \mathrm{e}+001.00000 \mathrm{e}-092.12000 \mathrm{e}-01$ $1.60714 \mathrm{e}+011.60714 \mathrm{e}+011.60714 \mathrm{e}+001.00000 \mathrm{e}-092.12000 \mathrm{e}-01$ $1.60714 \mathrm{e}+011.60714 \mathrm{e}+011.60714 \mathrm{e}+001.00000 \mathrm{e}-092.12000 \mathrm{e}-01$ $1.00000 \mathrm{e}-05$ 1.00000e-05 1.00000e-06 1.00000e-09 1.00000e-01 $1.00000 \mathrm{e}+001.00000 \mathrm{e}+001.00000 \mathrm{e}-011.00000 \mathrm{e}-091.00000 \mathrm{e}-01$ Element: 11722 \# of layers: 7

$\mathrm{Kx} \mathrm{Ky} \mathrm{Kz}$ Ss Por

$1.60714 \mathrm{e}+011.60714 \mathrm{e}+011.60714 \mathrm{e}+001.00000 \mathrm{e}-092.12000 \mathrm{e}-01$ $1.60714 \mathrm{e}+011.60714 \mathrm{e}+011.60714 \mathrm{e}+001.00000 \mathrm{e}-092.12000 \mathrm{e}-01$ $1.60714 \mathrm{e}+011.60714 \mathrm{e}+011.60714 \mathrm{e}+001.00000 \mathrm{e}-092.12000 \mathrm{e}-01$ $1.60714 \mathrm{e}+011.60714 \mathrm{e}+011.60714 \mathrm{e}+001.00000 \mathrm{e}-092.12000 \mathrm{e}-01$ $1.60714 \mathrm{e}+011.60714 \mathrm{e}+011.60714 \mathrm{e}+001.00000 \mathrm{e}-092.12000 \mathrm{e}-01$ $1.00000 \mathrm{e}-05$ 1.00000e-05 1.00000e-06 1.00000e-09 1.00000e-01 $1.00000 \mathrm{e}+001.00000 \mathrm{e}+001.00000 \mathrm{e}-011.00000 \mathrm{e}-091.00000 \mathrm{e}-01$ Element: 11723 \# of layers: 7

$\mathrm{Kx} \mathrm{Ky} \mathrm{Kz}$ Ss Por

$1.60714 \mathrm{e}+011.60714 \mathrm{e}+011.60714 \mathrm{e}+001.00000 \mathrm{e}-092.12000 \mathrm{e}-01$ $1.60714 \mathrm{e}+011.60714 \mathrm{e}+011.60714 \mathrm{e}+001.00000 \mathrm{e}-092.12000 \mathrm{e}-01$ $1.60714 \mathrm{e}+011.60714 \mathrm{e}+011.60714 \mathrm{e}+001.00000 \mathrm{e}-092.12000 \mathrm{e}-01$ $1.60714 \mathrm{e}+011.60714 \mathrm{e}+011.60714 \mathrm{e}+001.00000 \mathrm{e}-092.12000 \mathrm{e}-01$ $1.60714 \mathrm{e}+011.60714 \mathrm{e}+011.60714 \mathrm{e}+001.00000 \mathrm{e}-092.12000 \mathrm{e}-01$ $1.00000 \mathrm{e}-05$ 1.00000e-05 1.00000e-06 1.00000e-09 1.00000e-01 $1.00000 \mathrm{e}+001.00000 \mathrm{e}+001.00000 \mathrm{e}-011.00000 \mathrm{e}-091.00000 \mathrm{e}-01$ Element: 11724 \# of layers: 7

Kx Ky Kz Ss Por

$1.60714 \mathrm{e}+011.60714 \mathrm{e}+011.60714 \mathrm{e}+001.00000 \mathrm{e}-092.12000 \mathrm{e}-01$ $1.60714 \mathrm{e}+011.60714 \mathrm{e}+011.60714 \mathrm{e}+001.00000 \mathrm{e}-092.12000 \mathrm{e}-01$ $1.60714 \mathrm{e}+011.60714 \mathrm{e}+011.60714 \mathrm{e}+001.00000 \mathrm{e}-092.12000 \mathrm{e}-01$ $1.60714 \mathrm{e}+011.60714 \mathrm{e}+011.60714 \mathrm{e}+001.00000 \mathrm{e}-092.12000 \mathrm{e}-01$ $1.60714 \mathrm{e}+011.60714 \mathrm{e}+011.60714 \mathrm{e}+001.00000 \mathrm{e}-092.12000 \mathrm{e}-01$ $1.00000 \mathrm{e}-05$ 1.00000e-05 1.00000e-06 1.00000e-09 1.00000e-01 $1.00000 \mathrm{e}+001.00000 \mathrm{e}+001.00000 \mathrm{e}-011.00000 \mathrm{e}-091.00000 \mathrm{e}-01$ Element: 11725 \# of layers: 7

$\mathrm{Kx} \mathrm{Ky} \mathrm{Kz}$ Ss Por

$1.60714 \mathrm{e}+011.60714 \mathrm{e}+011.60714 \mathrm{e}+001.00000 \mathrm{e}-092.12000 \mathrm{e}-01$ 
$1.60714 \mathrm{e}+011.60714 \mathrm{e}+011.60714 \mathrm{e}+001.00000 \mathrm{e}-092.12000 \mathrm{e}-01$ $1.60714 \mathrm{e}+011.60714 \mathrm{e}+011.60714 \mathrm{e}+001.00000 \mathrm{e}-092.12000 \mathrm{e}-01$ $1.60714 \mathrm{e}+011.60714 \mathrm{e}+011.60714 \mathrm{e}+001.00000 \mathrm{e}-092.12000 \mathrm{e}-01$ $1.60714 \mathrm{e}+011.60714 \mathrm{e}+011.60714 \mathrm{e}+001.00000 \mathrm{e}-092.12000 \mathrm{e}-01$ $1.00000 \mathrm{e}-05$ 1.00000e-05 1.00000e-06 1.00000e-09 1.00000e-01 $1.00000 \mathrm{e}+001.00000 \mathrm{e}+001.00000 \mathrm{e}-011.00000 \mathrm{e}-091.00000 \mathrm{e}-01$ Element: 11726 \# of layers: 7

Kx Ky Kz Ss Por

$1.60714 \mathrm{e}+011.60714 \mathrm{e}+011.60714 \mathrm{e}+001.00000 \mathrm{e}-092.12000 \mathrm{e}-01$ $1.60714 \mathrm{e}+011.60714 \mathrm{e}+011.60714 \mathrm{e}+001.00000 \mathrm{e}-092.12000 \mathrm{e}-01$ $1.60714 \mathrm{e}+011.60714 \mathrm{e}+011.60714 \mathrm{e}+001.00000 \mathrm{e}-092.12000 \mathrm{e}-01$ $1.60714 \mathrm{e}+011.60714 \mathrm{e}+011.60714 \mathrm{e}+001.00000 \mathrm{e}-092.12000 \mathrm{e}-01$ $1.60714 \mathrm{e}+011.60714 \mathrm{e}+011.60714 \mathrm{e}+001.00000 \mathrm{e}-092.12000 \mathrm{e}-01$ $1.00000 \mathrm{e}-05$ 1.00000e-05 1.00000e-06 1.00000e-09 1.00000e-01 $1.00000 \mathrm{e}+001.00000 \mathrm{e}+001.00000 \mathrm{e}-01$ 1.00000e-09 1.00000e-01 Element: 11727 \# of layers: 7

$\mathrm{Kx} \mathrm{Ky} \mathrm{Kz}$ Ss Por

$1.60714 \mathrm{e}+011.60714 \mathrm{e}+011.60714 \mathrm{e}+001.00000 \mathrm{e}-092.12000 \mathrm{e}-01$ $1.60714 \mathrm{e}+011.60714 \mathrm{e}+011.60714 \mathrm{e}+001.00000 \mathrm{e}-092.12000 \mathrm{e}-01$ $1.60714 \mathrm{e}+011.60714 \mathrm{e}+011.60714 \mathrm{e}+001.00000 \mathrm{e}-092.12000 \mathrm{e}-01$ $1.60714 \mathrm{e}+011.60714 \mathrm{e}+011.60714 \mathrm{e}+001.00000 \mathrm{e}-092.12000 \mathrm{e}-01$ $1.60714 \mathrm{e}+011.60714 \mathrm{e}+011.60714 \mathrm{e}+001.00000 \mathrm{e}-092.12000 \mathrm{e}-01$ $1.00000 \mathrm{e}-05$ 1.00000e-05 1.00000e-06 1.00000e-09 1.00000e-01 $1.00000 \mathrm{e}+001.00000 \mathrm{e}+001.00000 \mathrm{e}-011.00000 \mathrm{e}-09$ 1.00000e-01

Element: 11728 \# of layers: 7

$\mathrm{Kx} \mathrm{Ky} \mathrm{Kz}$ Ss Por

$1.60714 \mathrm{e}+011.60714 \mathrm{e}+011.60714 \mathrm{e}+001.00000 \mathrm{e}-092.12000 \mathrm{e}-01$ $1.60714 \mathrm{e}+011.60714 \mathrm{e}+011.60714 \mathrm{e}+001.00000 \mathrm{e}-092.12000 \mathrm{e}-01$ $1.60714 \mathrm{e}+011.60714 \mathrm{e}+011.60714 \mathrm{e}+001.00000 \mathrm{e}-092.12000 \mathrm{e}-01$ $1.60714 \mathrm{e}+011.60714 \mathrm{e}+011.60714 \mathrm{e}+001.00000 \mathrm{e}-092.12000 \mathrm{e}-01$ $1.60714 \mathrm{e}+011.60714 \mathrm{e}+01 \quad 1.60714 \mathrm{e}+001.00000 \mathrm{e}-092.12000 \mathrm{e}-01$ $1.00000 \mathrm{e}-05$ 1.00000e-05 1.00000e-06 1.00000e-09 1.00000e-01 $1.00000 \mathrm{e}+001.00000 \mathrm{e}+001.00000 \mathrm{e}-011.00000 \mathrm{e}-091.00000 \mathrm{e}-01$ Element: 11729 \# of layers: 7

$\mathrm{Kx} \mathrm{Ky} \mathrm{Kz}$ Ss Por

$1.60714 \mathrm{e}+011.60714 \mathrm{e}+011.60714 \mathrm{e}+001.00000 \mathrm{e}-092.12000 \mathrm{e}-01$ $1.60714 \mathrm{e}+011.60714 \mathrm{e}+011.60714 \mathrm{e}+001.00000 \mathrm{e}-092.12000 \mathrm{e}-01$ $1.60714 \mathrm{e}+011.60714 \mathrm{e}+011.60714 \mathrm{e}+001.00000 \mathrm{e}-092.12000 \mathrm{e}-01$ $1.60714 \mathrm{e}+011.60714 \mathrm{e}+011.60714 \mathrm{e}+001.00000 \mathrm{e}-092.12000 \mathrm{e}-01$ $1.60714 \mathrm{e}+011.60714 \mathrm{e}+011.60714 \mathrm{e}+001.00000 \mathrm{e}-092.12000 \mathrm{e}-01$ $1.00000 \mathrm{e}-05$ 1.00000e-05 1.00000e-06 1.00000e-09 1.00000e-01 $1.00000 \mathrm{e}+001.00000 \mathrm{e}+001.00000 \mathrm{e}-011.00000 \mathrm{e}-091.00000 \mathrm{e}-01$ Element: 11730 \# of layers: 7

$\mathrm{Kx} \mathrm{Ky} \mathrm{Kz}$ Ss Por $1.80888 \mathrm{e}+01$ 1.80888e+01 1.80888e+00 1.00000e-09 2.12000e-01 $1.80888 \mathrm{e}+011.80888 \mathrm{e}+011.80888 \mathrm{e}+001.00000 \mathrm{e}-092.12000 \mathrm{e}-01$ 
$1.80888 \mathrm{e}+01$ 1.80888e+01 1.80888e+00 1.00000e-09 2.12000e-01 $1.80888 \mathrm{e}+01$ 1.80888e+01 1.80888e+00 1.00000e-09 2.12000e-01 $1.80888 \mathrm{e}+011.80888 \mathrm{e}+01$ 1.80888e+00 1.00000e-09 2.12000e-01 $1.00000 \mathrm{e}-05$ 1.00000e-05 1.00000e-06 1.00000e-09 1.00000e-01 $1.00000 \mathrm{e}+001.00000 \mathrm{e}+001.00000 \mathrm{e}-011.00000 \mathrm{e}-091.00000 \mathrm{e}-01$ Element: 11731 \# of layers: 7

$\mathrm{Kx} \mathrm{Ky} \mathrm{Kz}$ Ss Por

$1.80888 \mathrm{e}+011.80888 \mathrm{e}+01$ 1.80888e+00 1.00000e-09 2.12000e-01 $1.80888 \mathrm{e}+01$ 1.80888e+01 1.80888e+00 1.00000e-09 2.12000e-01 $1.80888 \mathrm{e}+01$ 1.80888e+01 1.80888e+00 1.00000e-09 2.12000e-01 $1.80888 \mathrm{e}+01$ 1.80888e+01 1.80888e+00 1.00000e-09 2.12000e-01 $1.80888 \mathrm{e}+011.80888 \mathrm{e}+01$ 1.80888e+00 1.00000e-09 2.12000e-01 $1.00000 \mathrm{e}-05$ 1.00000e-05 1.00000e-06 1.00000e-09 1.00000e-01 $1.00000 \mathrm{e}+001.00000 \mathrm{e}+001.00000 \mathrm{e}-011.00000 \mathrm{e}-09$ 1.00000e-01 Element: 11732 \# of layers: 7

Kx Ky Kz Ss Por

$1.80888 \mathrm{e}+01$ 1.80888e+01 1.80888e+00 1.00000e-09 2.12000e-01 $1.80888 \mathrm{e}+011.80888 \mathrm{e}+01$ 1.80888e+00 1.00000e-09 2.12000e-01 $1.80888 \mathrm{e}+01$ 1.80888e+01 1.80888e+00 1.00000e-09 2.12000e-01 $1.80888 \mathrm{e}+011.80888 \mathrm{e}+01$ 1.80888e+00 1.00000e-09 2.12000e-01 $1.80888 \mathrm{e}+011.80888 \mathrm{e}+01$ 1.80888e+00 1.00000e-09 2.12000e-01 $1.00000 \mathrm{e}-051.00000 \mathrm{e}-05$ 1.00000e-06 1.00000e-09 1.00000e-01 $1.00000 \mathrm{e}+001.00000 \mathrm{e}+001.00000 \mathrm{e}-01$ 1.00000e-09 1.00000e-01 Element: 11733 \# of layers: 7

Kx Ky Kz Ss Por $1.80888 \mathrm{e}+01$ 1.80888e+01 1.80888e+00 1.00000e-09 2.12000e-01 $1.80888 \mathrm{e}+01$ 1.80888e+01 1.80888e+00 1.00000e-09 2.12000e-01 $1.80888 \mathrm{e}+011.80888 \mathrm{e}+01$ 1.80888e+00 1.00000e-09 2.12000e-01 $1.80888 \mathrm{e}+011.80888 \mathrm{e}+011.80888 \mathrm{e}+001.00000 \mathrm{e}-092.12000 \mathrm{e}-01$ $1.80888 \mathrm{e}+01$ 1.80888e+01 1.80888e+00 1.00000e-09 2.12000e-01 $1.00000 \mathrm{e}-05$ 1.00000e-05 1.00000e-06 1.00000e-09 1.00000e-01 $1.00000 \mathrm{e}+001.00000 \mathrm{e}+001.00000 \mathrm{e}-011.00000 \mathrm{e}-091.00000 \mathrm{e}-01$ Element: 11734 \# of layers: 7

$\mathrm{Kx} \mathrm{Ky} \mathrm{Kz}$ Ss Por $1.80888 \mathrm{e}+01$ 1.80888e+01 1.80888e+00 1.00000e-09 2.12000e-01 $1.80888 \mathrm{e}+011.80888 \mathrm{e}+011.80888 \mathrm{e}+001.00000 \mathrm{e}-092.12000 \mathrm{e}-01$ $1.80888 \mathrm{e}+011.80888 \mathrm{e}+01$ 1.80888e+00 1.00000e-09 2.12000e-01 $1.80888 \mathrm{e}+011.80888 \mathrm{e}+01$ 1.80888e+00 1.00000e-09 2.12000e-01 $1.80888 \mathrm{e}+011.80888 \mathrm{e}+01$ 1.80888e+00 1.00000e-09 2.12000e-01 $1.00000 \mathrm{e}-05$ 1.00000e-05 1.00000e-06 1.00000e-09 1.00000e-01 $1.00000 \mathrm{e}+001.00000 \mathrm{e}+001.00000 \mathrm{e}-011.00000 \mathrm{e}-091.00000 \mathrm{e}-01$ Element: 11735 \# of layers: 7

$\mathrm{Kx} \mathrm{Ky} \mathrm{Kz}$ Ss Por

$1.60714 \mathrm{e}+011.60714 \mathrm{e}+01$ 1.60714e+00 1.00000e-09 2.12000e-01 $1.60714 \mathrm{e}+011.60714 \mathrm{e}+011.60714 \mathrm{e}+001.00000 \mathrm{e}-092.12000 \mathrm{e}-01$ $1.60714 \mathrm{e}+011.60714 \mathrm{e}+011.60714 \mathrm{e}+001.00000 \mathrm{e}-092.12000 \mathrm{e}-01$ 
$1.60714 \mathrm{e}+011.60714 \mathrm{e}+011.60714 \mathrm{e}+001.00000 \mathrm{e}-092.12000 \mathrm{e}-01$ $1.60714 \mathrm{e}+011.60714 \mathrm{e}+011.60714 \mathrm{e}+001.00000 \mathrm{e}-092.12000 \mathrm{e}-01$ $1.00000 \mathrm{e}-05$ 1.00000e-05 1.00000e-06 1.00000e-09 1.00000e-01

$1.00000 \mathrm{e}+001.00000 \mathrm{e}+001.00000 \mathrm{e}-011.00000 \mathrm{e}-091.00000 \mathrm{e}-01$ Element: 11736 \# of layers: 7

$\mathrm{Kx} \mathrm{Ky} \mathrm{Kz}$ Ss Por

$1.60714 \mathrm{e}+011.60714 \mathrm{e}+011.60714 \mathrm{e}+001.00000 \mathrm{e}-092.12000 \mathrm{e}-01$

$1.60714 \mathrm{e}+011.60714 \mathrm{e}+011.60714 \mathrm{e}+001.00000 \mathrm{e}-092.12000 \mathrm{e}-01$

$1.60714 \mathrm{e}+011.60714 \mathrm{e}+011.60714 \mathrm{e}+001.00000 \mathrm{e}-092.12000 \mathrm{e}-01$

$1.60714 \mathrm{e}+011.60714 \mathrm{e}+011.60714 \mathrm{e}+001.00000 \mathrm{e}-092.12000 \mathrm{e}-01$

$1.60714 \mathrm{e}+011.60714 \mathrm{e}+011.60714 \mathrm{e}+001.00000 \mathrm{e}-092.12000 \mathrm{e}-01$

$1.00000 \mathrm{e}-05$ 1.00000e-05 1.00000e-06 1.00000e-09 1.00000e-01

$1.00000 \mathrm{e}+001.00000 \mathrm{e}+001.00000 \mathrm{e}-01$ 1.00000e-09 1.00000e-01

Element: 11737 \# of layers: 7

$\mathrm{Kx} \mathrm{Ky} \mathrm{Kz}$ Ss Por

$1.80888 \mathrm{e}+01$ 1.80888e+01 1.80888e+00 1.00000e-09 2.12000e-01

$1.80888 \mathrm{e}+011.80888 \mathrm{e}+011.80888 \mathrm{e}+00$ 1.00000e-09 2.12000e-01

$1.80888 \mathrm{e}+011.80888 \mathrm{e}+01$ 1.80888e+00 1.00000e-09 2.12000e-01

$1.80888 \mathrm{e}+01$ 1.80888e+01 1.80888e+00 1.00000e-09 2.12000e-01

$1.80888 \mathrm{e}+01$ 1.80888e+01 1.80888e+00 1.00000e-09 2.12000e-01

$1.00000 \mathrm{e}-05$ 1.00000e-05 1.00000e-06 1.00000e-09 1.00000e-01

$1.00000 \mathrm{e}+001.00000 \mathrm{e}+001.00000 \mathrm{e}-01$ 1.00000e-09 1.00000e-01

Element: 11738 \# of layers: 7

Kx Ky Kz Ss Por

$1.80888 \mathrm{e}+01$ 1.80888e+01 1.80888e+00 1.00000e-09 2.12000e-01

$1.80888 \mathrm{e}+011.80888 \mathrm{e}+01$ 1.80888e+00 1.00000e-09 2.12000e-01

$1.80888 \mathrm{e}+011.80888 \mathrm{e}+011.80888 \mathrm{e}+001.00000 \mathrm{e}-092.12000 \mathrm{e}-01$

$1.80888 \mathrm{e}+01$ 1.80888e+01 1.80888e+00 1.00000e-09 2.12000e-01

$1.80888 \mathrm{e}+011.80888 \mathrm{e}+01$ 1.80888e+00 1.00000e-09 2.12000e-01

$1.00000 \mathrm{e}-05$ 1.00000e-05 1.00000e-06 1.00000e-09 1.00000e-01

$1.00000 \mathrm{e}+001.00000 \mathrm{e}+001.00000 \mathrm{e}-01$ 1.00000e-09 1.00000e-01

Element: 11739 \# of layers: 7

Kx Ky Kz Ss Por

$1.84340 \mathrm{e}+01$ 1.84340e+01 1.84340e+00 1.00000e-09 2.12000e-01

$1.84340 \mathrm{e}+011.84340 \mathrm{e}+011.84340 \mathrm{e}+001.00000 \mathrm{e}-092.12000 \mathrm{e}-01$

$1.84340 \mathrm{e}+011.84340 \mathrm{e}+011.84340 \mathrm{e}+001.00000 \mathrm{e}-092.12000 \mathrm{e}-01$

$1.84340 \mathrm{e}+011.84340 \mathrm{e}+011.84340 \mathrm{e}+001.00000 \mathrm{e}-092.12000 \mathrm{e}-01$

$1.84340 \mathrm{e}+011.84340 \mathrm{e}+011.84340 \mathrm{e}+001.00000 \mathrm{e}-092.12000 \mathrm{e}-01$

$1.00000 \mathrm{e}-05$ 1.00000e-05 1.00000e-06 1.00000e-09 1.00000e-01

$1.00000 \mathrm{e}+001.00000 \mathrm{e}+001.00000 \mathrm{e}-01$ 1.00000e-09 1.00000e-01

Element: 11740 \# of layers: 7

Kx Ky Kz Ss Por

$1.84340 \mathrm{e}+011.84340 \mathrm{e}+01$ 1.84340e+00 1.00000e-09 2.12000e-01

$1.84340 \mathrm{e}+01$ 1.84340e+01 1.84340e+00 1.00000e-09 2.12000e-01

$1.84340 \mathrm{e}+011.84340 \mathrm{e}+011.84340 \mathrm{e}+001.00000 \mathrm{e}-092.12000 \mathrm{e}-01$

$1.84340 \mathrm{e}+011.84340 \mathrm{e}+011.84340 \mathrm{e}+001.00000 \mathrm{e}-092.12000 \mathrm{e}-01$ 
$1.84340 \mathrm{e}+011.84340 \mathrm{e}+011.84340 \mathrm{e}+001.00000 \mathrm{e}-092.12000 \mathrm{e}-01$ $1.00000 \mathrm{e}-05$ 1.00000e-05 1.00000e-06 1.00000e-09 1.00000e-01

$1.00000 \mathrm{e}+001.00000 \mathrm{e}+001.00000 \mathrm{e}-01$ 1.00000e-09 1.00000e-01

Element: 11741 \# of layers: 7

$\mathrm{Kx} \mathrm{Ky} \mathrm{Kz}$ Ss Por

$1.84340 \mathrm{e}+01$ 1.84340e+01 1.84340e+00 1.00000e-09 2.12000e-01

$1.84340 \mathrm{e}+01$ 1.84340e+01 1.84340e+00 1.00000e-09 2.12000e-01

$1.84340 \mathrm{e}+011.84340 \mathrm{e}+011.84340 \mathrm{e}+001.00000 \mathrm{e}-092.12000 \mathrm{e}-01$

$1.84340 \mathrm{e}+011.84340 \mathrm{e}+011.84340 \mathrm{e}+001.00000 \mathrm{e}-092.12000 \mathrm{e}-01$

$1.84340 \mathrm{e}+01$ 1.84340e+01 1.84340e+00 1.00000e-09 2.12000e-01

$1.00000 \mathrm{e}-05$ 1.00000e-05 1.00000e-06 1.00000e-09 1.00000e-01

$1.00000 \mathrm{e}+001.00000 \mathrm{e}+001.00000 \mathrm{e}-01$ 1.00000e-09 1.00000e-01

Element: 11742 \# of layers: 7

$\mathrm{Kx} \mathrm{Ky} \mathrm{Kz}$ Ss Por

$1.68436 \mathrm{e}+011.68436 \mathrm{e}+011.68436 \mathrm{e}+001.00000 \mathrm{e}-092.12000 \mathrm{e}-01$

$1.68436 \mathrm{e}+011.68436 \mathrm{e}+011.68436 \mathrm{e}+001.00000 \mathrm{e}-092.12000 \mathrm{e}-01$

$1.68436 \mathrm{e}+011.68436 \mathrm{e}+011.68436 \mathrm{e}+001.00000 \mathrm{e}-092.12000 \mathrm{e}-01$

$1.68436 \mathrm{e}+011.68436 \mathrm{e}+011.68436 \mathrm{e}+001.00000 \mathrm{e}-092.12000 \mathrm{e}-01$

$1.68436 \mathrm{e}+011.68436 \mathrm{e}+011.68436 \mathrm{e}+001.00000 \mathrm{e}-092.12000 \mathrm{e}-01$

$1.00000 \mathrm{e}-05$ 1.00000e-05 1.00000e-06 1.00000e-09 1.00000e-01

$1.00000 \mathrm{e}+001.00000 \mathrm{e}+001.00000 \mathrm{e}-011.00000 \mathrm{e}-091.00000 \mathrm{e}-01$

Element: 11743 \# of layers: 7

$\mathrm{Kx} \mathrm{Ky} \mathrm{Kz}$ Ss Por

$1.68436 \mathrm{e}+01$ 1.68436e+01 1.68436e+00 1.00000e-09 2.12000e-01

$1.68436 \mathrm{e}+011.68436 \mathrm{e}+011.68436 \mathrm{e}+001.00000 \mathrm{e}-092.12000 \mathrm{e}-01$

$1.68436 \mathrm{e}+011.68436 \mathrm{e}+011.68436 \mathrm{e}+001.00000 \mathrm{e}-092.12000 \mathrm{e}-01$

$1.68436 \mathrm{e}+011.68436 \mathrm{e}+011.68436 \mathrm{e}+001.00000 \mathrm{e}-092.12000 \mathrm{e}-01$

$1.68436 \mathrm{e}+011.68436 \mathrm{e}+011.68436 \mathrm{e}+001.00000 \mathrm{e}-092.12000 \mathrm{e}-01$

$1.00000 \mathrm{e}-05$ 1.00000e-05 1.00000e-06 1.00000e-09 1.00000e-01

$1.00000 \mathrm{e}+001.00000 \mathrm{e}+001.00000 \mathrm{e}-011.00000 \mathrm{e}-091.00000 \mathrm{e}-01$

Element: 11744 \# of layers: 7

Kx Ky Kz Ss Por

$1.60714 \mathrm{e}+011.60714 \mathrm{e}+011.60714 \mathrm{e}+001.00000 \mathrm{e}-092.12000 \mathrm{e}-01$

$1.60714 \mathrm{e}+011.60714 \mathrm{e}+011.60714 \mathrm{e}+001.00000 \mathrm{e}-092.12000 \mathrm{e}-01$

$1.60714 \mathrm{e}+011.60714 \mathrm{e}+011.60714 \mathrm{e}+001.00000 \mathrm{e}-092.12000 \mathrm{e}-01$

$1.60714 \mathrm{e}+011.60714 \mathrm{e}+011.60714 \mathrm{e}+001.00000 \mathrm{e}-092.12000 \mathrm{e}-01$

$1.60714 \mathrm{e}+011.60714 \mathrm{e}+011.60714 \mathrm{e}+001.00000 \mathrm{e}-092.12000 \mathrm{e}-01$

$1.00000 \mathrm{e}-05$ 1.00000e-05 1.00000e-06 1.00000e-09 1.00000e-01

$1.00000 \mathrm{e}+001.00000 \mathrm{e}+001.00000 \mathrm{e}-01$ 1.00000e-09 1.00000e-01

Element: 11745 \# of layers: 7

$\mathrm{Kx} \mathrm{Ky} \mathrm{Kz}$ Ss Por

$1.80888 \mathrm{e}+01$ 1.80888e+01 1.80888e+00 1.00000e-09 2.12000e-01

$1.80888 \mathrm{e}+011.80888 \mathrm{e}+01$ 1.80888e+00 1.00000e-09 2.12000e-01

$1.80888 \mathrm{e}+01$ 1.80888e+01 1.80888e+00 1.00000e-09 2.12000e-01

$1.80888 \mathrm{e}+011.80888 \mathrm{e}+01$ 1.80888e+00 1.00000e-09 2.12000e-01

$1.80888 \mathrm{e}+011.80888 \mathrm{e}+011.80888 \mathrm{e}+001.00000 \mathrm{e}-092.12000 \mathrm{e}-01$ 
$1.00000 \mathrm{e}-05$ 1.00000e-05 1.00000e-06 1.00000e-09 1.00000e-01 $1.00000 \mathrm{e}+001.00000 \mathrm{e}+001.00000 \mathrm{e}-01$ 1.00000e-09 1.00000e-01 Element: 11746 \# of layers: 7

Kx Ky Kz Ss Por

$1.84340 \mathrm{e}+011.84340 \mathrm{e}+011.84340 \mathrm{e}+001.00000 \mathrm{e}-092.12000 \mathrm{e}-01$ $1.84340 \mathrm{e}+01$ 1.84340e+01 1.84340e+00 1.00000e-09 2.12000e-01 $1.84340 \mathrm{e}+01$ 1.84340e+01 1.84340e+00 1.00000e-09 2.12000e-01 $1.84340 \mathrm{e}+011.84340 \mathrm{e}+011.84340 \mathrm{e}+001.00000 \mathrm{e}-092.12000 \mathrm{e}-01$ $1.84340 \mathrm{e}+011.84340 \mathrm{e}+011.84340 \mathrm{e}+001.00000 \mathrm{e}-092.12000 \mathrm{e}-01$ $1.00000 \mathrm{e}-05$ 1.00000e-05 1.00000e-06 1.00000e-09 1.00000e-01 $1.00000 \mathrm{e}+001.00000 \mathrm{e}+001.00000 \mathrm{e}-011.00000 \mathrm{e}-091.00000 \mathrm{e}-01$ Element: 11747 \# of layers: 7

$\mathrm{Kx} \mathrm{Ky} \mathrm{Kz}$ Ss Por

$1.50008 \mathrm{e}+01$ 1.50008e+01 1.50008e+00 1.00000e-09 2.12000e-01 $1.50008 \mathrm{e}+01$ 1.50008e+01 1.50008e+00 1.00000e-09 2.12000e-01 $1.50008 \mathrm{e}+011.50008 \mathrm{e}+011.50008 \mathrm{e}+001.00000 \mathrm{e}-092.12000 \mathrm{e}-01$ $1.50008 \mathrm{e}+011.50008 \mathrm{e}+011.50008 \mathrm{e}+001.00000 \mathrm{e}-092.12000 \mathrm{e}-01$ $1.50008 \mathrm{e}+011.50008 \mathrm{e}+01$ 1.50008e+00 1.00000e-09 2.12000e-01 $1.00000 \mathrm{e}-05$ 1.00000e-05 1.00000e-06 1.00000e-09 1.00000e-01 $1.00000 \mathrm{e}+001.00000 \mathrm{e}+001.00000 \mathrm{e}-011.00000 \mathrm{e}-091.00000 \mathrm{e}-01$ Element: 11748 \# of layers: 7

$\mathrm{Kx} \mathrm{Ky} \mathrm{Kz}$ Ss Por

$1.50008 \mathrm{e}+01$ 1.50008e+01 1.50008e+00 1.00000e-09 2.12000e-01 $1.50008 \mathrm{e}+011.50008 \mathrm{e}+011.50008 \mathrm{e}+001.00000 \mathrm{e}-092.12000 \mathrm{e}-01$ $1.50008 \mathrm{e}+011.50008 \mathrm{e}+011.50008 \mathrm{e}+001.00000 \mathrm{e}-092.12000 \mathrm{e}-01$ $1.50008 \mathrm{e}+011.50008 \mathrm{e}+01$ 1.50008e+00 1.00000e-09 2.12000e-01 $1.50008 \mathrm{e}+011.50008 \mathrm{e}+01$ 1.50008e+00 1.00000e-09 2.12000e-01 $1.00000 \mathrm{e}-05$ 1.00000e-05 1.00000e-06 1.00000e-09 1.00000e-01 $1.00000 \mathrm{e}+001.00000 \mathrm{e}+001.00000 \mathrm{e}-011.00000 \mathrm{e}-091.00000 \mathrm{e}-01$ Element: 11749 \# of layers: 7

$\mathrm{Kx} \mathrm{Ky} \mathrm{Kz}$ Ss Por

$1.50008 \mathrm{e}+011.50008 \mathrm{e}+01$ 1.50008e+00 1.00000e-09 2.12000e-01 $1.50008 \mathrm{e}+011.50008 \mathrm{e}+011.50008 \mathrm{e}+001.00000 \mathrm{e}-092.12000 \mathrm{e}-01$ $1.50008 \mathrm{e}+011.50008 \mathrm{e}+01$ 1.50008e+00 1.00000e-09 2.12000e-01 $1.50008 \mathrm{e}+011.50008 \mathrm{e}+011.50008 \mathrm{e}+001.00000 \mathrm{e}-092.12000 \mathrm{e}-01$ $1.50008 \mathrm{e}+011.50008 \mathrm{e}+01$ 1.50008e+00 1.00000e-09 2.12000e-01 $1.00000 \mathrm{e}-051.00000 \mathrm{e}-05$ 1.00000e-06 1.00000e-09 1.00000e-01 $1.00000 \mathrm{e}+001.00000 \mathrm{e}+001.00000 \mathrm{e}-011.00000 \mathrm{e}-091.00000 \mathrm{e}-01$ Element: 11750 \# of layers: 7

$\mathrm{Kx} \mathrm{Ky} \mathrm{Kz}$ Ss Por

$1.50008 \mathrm{e}+01$ 1.50008e+01 1.50008e+00 1.00000e-09 2.12000e-01 $1.50008 \mathrm{e}+011.50008 \mathrm{e}+011.50008 \mathrm{e}+001.00000 \mathrm{e}-092.12000 \mathrm{e}-01$ $1.50008 \mathrm{e}+011.50008 \mathrm{e}+011.50008 \mathrm{e}+001.00000 \mathrm{e}-092.12000 \mathrm{e}-01$ $1.50008 \mathrm{e}+011.50008 \mathrm{e}+011.50008 \mathrm{e}+001.00000 \mathrm{e}-092.12000 \mathrm{e}-01$ $1.50008 \mathrm{e}+011.50008 \mathrm{e}+01$ 1.50008e+00 1.00000e-09 2.12000e-01 $1.00000 \mathrm{e}-05$ 1.00000e-05 1.00000e-06 1.00000e-09 1.00000e-01 
$1.00000 \mathrm{e}+001.00000 \mathrm{e}+00$ 1.00000e-01 1.00000e-09 1.00000e-01

Element: 11751 \# of layers: 7

Kx Ky Kz Ss Por

$1.50008 \mathrm{e}+01$ 1.50008e+01 1.50008e+00 1.00000e-09 2.12000e-01

$1.50008 \mathrm{e}+011.50008 \mathrm{e}+01$ 1.50008e+00 1.00000e-09 2.12000e-01

$1.50008 \mathrm{e}+011.50008 \mathrm{e}+01$ 1.50008e+00 1.00000e-09 2.12000e-01

$1.50008 \mathrm{e}+011.50008 \mathrm{e}+011.50008 \mathrm{e}+001.00000 \mathrm{e}-092.12000 \mathrm{e}-01$

$1.50008 \mathrm{e}+011.50008 \mathrm{e}+011.50008 \mathrm{e}+001.00000 \mathrm{e}-092.12000 \mathrm{e}-01$

$1.00000 \mathrm{e}-05$ 1.00000e-05 1.00000e-06 1.00000e-09 1.00000e-01

$1.00000 \mathrm{e}+001.00000 \mathrm{e}+001.00000 \mathrm{e}-011.00000 \mathrm{e}-091.00000 \mathrm{e}-01$

Element: 11752 \# of layers: 7

Kx Ky Kz Ss Por

$1.50008 \mathrm{e}+01$ 1.50008e+01 1.50008e+00 1.00000e-09 2.12000e-01

$1.50008 \mathrm{e}+011.50008 \mathrm{e}+01$ 1.50008e+00 1.00000e-09 2.12000e-01

$1.50008 \mathrm{e}+01$ 1.50008e+01 1.50008e+00 1.00000e-09 2.12000e-01

$1.50008 \mathrm{e}+011.50008 \mathrm{e}+011.50008 \mathrm{e}+001.00000 \mathrm{e}-092.12000 \mathrm{e}-01$

$1.50008 \mathrm{e}+011.50008 \mathrm{e}+01$ 1.50008e+00 1.00000e-09 2.12000e-01

$1.00000 \mathrm{e}-05$ 1.00000e-05 1.00000e-06 1.00000e-09 1.00000e-01

$1.00000 \mathrm{e}+001.00000 \mathrm{e}+001.00000 \mathrm{e}-01$ 1.00000e-09 1.00000e-01

Element: 11753 \# of layers: 7

$\mathrm{Kx} \mathrm{Ky} \mathrm{Kz}$ Ss Por

$1.50008 \mathrm{e}+01$ 1.50008e+01 1.50008e+00 1.00000e-09 2.12000e-01

$1.50008 \mathrm{e}+01$ 1.50008e+01 1.50008e+00 1.00000e-09 2.12000e-01

$1.50008 \mathrm{e}+011.50008 \mathrm{e}+011.50008 \mathrm{e}+001.00000 \mathrm{e}-092.12000 \mathrm{e}-01$

$1.50008 \mathrm{e}+011.50008 \mathrm{e}+011.50008 \mathrm{e}+001.00000 \mathrm{e}-092.12000 \mathrm{e}-01$

$1.50008 \mathrm{e}+01$ 1.50008e+01 1.50008e+00 1.00000e-09 2.12000e-01

$1.00000 \mathrm{e}-05$ 1.00000e-05 1.00000e-06 1.00000e-09 1.00000e-01

$1.00000 \mathrm{e}+001.00000 \mathrm{e}+001.00000 \mathrm{e}-01$ 1.00000e-09 1.00000e-01

Element: 11754 \# of layers: 7

$\mathrm{Kx} \mathrm{Ky} \mathrm{Kz}$ Ss Por

$1.50008 \mathrm{e}+01$ 1.50008e+01 1.50008e+00 1.00000e-09 2.12000e-01

$1.50008 \mathrm{e}+011.50008 \mathrm{e}+01$ 1.50008e+00 1.00000e-09 2.12000e-01

$1.50008 \mathrm{e}+011.50008 \mathrm{e}+011.50008 \mathrm{e}+001.00000 \mathrm{e}-092.12000 \mathrm{e}-01$

$1.50008 \mathrm{e}+011.50008 \mathrm{e}+01$ 1.50008e+00 1.00000e-09 2.12000e-01

$1.50008 \mathrm{e}+01$ 1.50008e+01 1.50008e+00 1.00000e-09 2.12000e-01

$1.00000 \mathrm{e}-05$ 1.00000e-05 1.00000e-06 1.00000e-09 1.00000e-01

$1.00000 \mathrm{e}+001.00000 \mathrm{e}+001.00000 \mathrm{e}-011.00000 \mathrm{e}-091.00000 \mathrm{e}-01$

Element: 11755 \# of layers: 7

$\mathrm{Kx} \mathrm{Ky} \mathrm{Kz}$ Ss Por

$1.50008 \mathrm{e}+01$ 1.50008e+01 1.50008e+00 1.00000e-09 2.12000e-01

$1.50008 \mathrm{e}+011.50008 \mathrm{e}+01$ 1.50008e+00 1.00000e-09 2.12000e-01

$1.50008 \mathrm{e}+01$ 1.50008e+01 1.50008e+00 1.00000e-09 2.12000e-01

$1.50008 \mathrm{e}+011.50008 \mathrm{e}+01$ 1.50008e+00 1.00000e-09 2.12000e-01

$1.50008 \mathrm{e}+01$ 1.50008e+01 1.50008e+00 1.00000e-09 2.12000e-01

$1.00000 \mathrm{e}-05$ 1.00000e-05 1.00000e-06 1.00000e-09 1.00000e-01

$1.00000 \mathrm{e}+001.00000 \mathrm{e}+001.00000 \mathrm{e}-011.00000 \mathrm{e}-091.00000 \mathrm{e}-01$ 
Element: 11756 \# of layers: 7

Kx Ky Kz Ss Por

$1.50008 \mathrm{e}+011.50008 \mathrm{e}+011.50008 \mathrm{e}+00$ 1.00000e-09 2.12000e-01

$1.50008 \mathrm{e}+011.50008 \mathrm{e}+011.50008 \mathrm{e}+001.00000 \mathrm{e}-092.12000 \mathrm{e}-01$

$1.50008 \mathrm{e}+011.50008 \mathrm{e}+011.50008 \mathrm{e}+001.00000 \mathrm{e}-092.12000 \mathrm{e}-01$

$1.50008 \mathrm{e}+011.50008 \mathrm{e}+011.50008 \mathrm{e}+001.00000 \mathrm{e}-092.12000 \mathrm{e}-01$

$1.50008 \mathrm{e}+011.50008 \mathrm{e}+011.50008 \mathrm{e}+001.00000 \mathrm{e}-092.12000 \mathrm{e}-01$

$1.00000 \mathrm{e}-05$ 1.00000e-05 1.00000e-06 1.00000e-09 1.00000e-01

$1.00000 \mathrm{e}+001.00000 \mathrm{e}+001.00000 \mathrm{e}-011.00000 \mathrm{e}-091.00000 \mathrm{e}-01$

Element: 11757 \# of layers: 7

Kx Ky Kz Ss Por

$1.28010 \mathrm{e}+011.28010 \mathrm{e}+011.28010 \mathrm{e}+00$ 1.00000e-09 2.12000e-01

$1.28010 \mathrm{e}+011.28010 \mathrm{e}+011.28010 \mathrm{e}+001.00000 \mathrm{e}-092.12000 \mathrm{e}-01$

$1.28010 \mathrm{e}+011.28010 \mathrm{e}+011.28010 \mathrm{e}+001.00000 \mathrm{e}-092.12000 \mathrm{e}-01$

$1.28010 \mathrm{e}+011.28010 \mathrm{e}+011.28010 \mathrm{e}+001.00000 \mathrm{e}-092.12000 \mathrm{e}-01$

$1.28010 \mathrm{e}+011.28010 \mathrm{e}+011.28010 \mathrm{e}+001.00000 \mathrm{e}-092.12000 \mathrm{e}-01$

$1.00000 \mathrm{e}-05$ 1.00000e-05 1.00000e-06 1.00000e-09 1.00000e-01

$1.00000 \mathrm{e}+001.00000 \mathrm{e}+001.00000 \mathrm{e}-011.00000 \mathrm{e}-091.00000 \mathrm{e}-01$

Element: 11758 \# of layers: 7

Kx Ky Kz Ss Por

$1.28010 \mathrm{e}+011.28010 \mathrm{e}+011.28010 \mathrm{e}+00$ 1.00000e-09 2.12000e-01

$1.28010 \mathrm{e}+011.28010 \mathrm{e}+011.28010 \mathrm{e}+001.00000 \mathrm{e}-092.12000 \mathrm{e}-01$

$1.28010 \mathrm{e}+011.28010 \mathrm{e}+011.28010 \mathrm{e}+001.00000 \mathrm{e}-092.12000 \mathrm{e}-01$

$1.28010 \mathrm{e}+011.28010 \mathrm{e}+011.28010 \mathrm{e}+001.00000 \mathrm{e}-092.12000 \mathrm{e}-01$

$1.28010 \mathrm{e}+011.28010 \mathrm{e}+011.28010 \mathrm{e}+001.00000 \mathrm{e}-092.12000 \mathrm{e}-01$

$1.00000 \mathrm{e}-05$ 1.00000e-05 1.00000e-06 1.00000e-09 1.00000e-01

$1.00000 \mathrm{e}+001.00000 \mathrm{e}+001.00000 \mathrm{e}-011.00000 \mathrm{e}-091.00000 \mathrm{e}-01$

Element: 11759 \# of layers: 7

Kx Ky Kz Ss Por

$1.28010 \mathrm{e}+011.28010 \mathrm{e}+011.28010 \mathrm{e}+00$ 1.00000e-09 2.12000e-01

$1.28010 \mathrm{e}+011.28010 \mathrm{e}+011.28010 \mathrm{e}+001.00000 \mathrm{e}-092.12000 \mathrm{e}-01$

$1.28010 \mathrm{e}+011.28010 \mathrm{e}+011.28010 \mathrm{e}+001.00000 \mathrm{e}-092.12000 \mathrm{e}-01$

$1.28010 \mathrm{e}+011.28010 \mathrm{e}+011.28010 \mathrm{e}+001.00000 \mathrm{e}-092.12000 \mathrm{e}-01$

$1.28010 \mathrm{e}+011.28010 \mathrm{e}+011.28010 \mathrm{e}+001.00000 \mathrm{e}-092.12000 \mathrm{e}-01$

$1.00000 \mathrm{e}-05$ 1.00000e-05 1.00000e-06 1.00000e-09 1.00000e-01

$1.00000 \mathrm{e}+001.00000 \mathrm{e}+001.00000 \mathrm{e}-011.00000 \mathrm{e}-091.00000 \mathrm{e}-01$

Element: 11760 \# of layers: 7

Kx Ky Kz Ss Por

$1.28010 \mathrm{e}+011.28010 \mathrm{e}+011.28010 \mathrm{e}+00$ 1.00000e-09 2.12000e-01

$1.28010 \mathrm{e}+011.28010 \mathrm{e}+011.28010 \mathrm{e}+001.00000 \mathrm{e}-092.12000 \mathrm{e}-01$

$1.28010 \mathrm{e}+011.28010 \mathrm{e}+011.28010 \mathrm{e}+001.00000 \mathrm{e}-092.12000 \mathrm{e}-01$

$1.28010 \mathrm{e}+011.28010 \mathrm{e}+011.28010 \mathrm{e}+001.00000 \mathrm{e}-092.12000 \mathrm{e}-01$

$1.28010 \mathrm{e}+011.28010 \mathrm{e}+011.28010 \mathrm{e}+001.00000 \mathrm{e}-092.12000 \mathrm{e}-01$

$1.00000 \mathrm{e}-05$ 1.00000e-05 1.00000e-06 1.00000e-09 1.00000e-01

$1.00000 \mathrm{e}+001.00000 \mathrm{e}+001.00000 \mathrm{e}-011.00000 \mathrm{e}-091.00000 \mathrm{e}-01$

Element: 11761 \# of layers: 7 
$\mathrm{Kx} \mathrm{Ky} \mathrm{Kz}$ Ss Por

$1.28010 \mathrm{e}+011.28010 \mathrm{e}+01$ 1.28010e+00 1.00000e-09 2.12000e-01

$1.28010 \mathrm{e}+011.28010 \mathrm{e}+011.28010 \mathrm{e}+001.00000 \mathrm{e}-092.12000 \mathrm{e}-01$

$1.28010 \mathrm{e}+011.28010 \mathrm{e}+011.28010 \mathrm{e}+001.00000 \mathrm{e}-092.12000 \mathrm{e}-01$

$1.28010 \mathrm{e}+011.28010 \mathrm{e}+011.28010 \mathrm{e}+001.00000 \mathrm{e}-092.12000 \mathrm{e}-01$

$1.28010 \mathrm{e}+011.28010 \mathrm{e}+011.28010 \mathrm{e}+001.00000 \mathrm{e}-092.12000 \mathrm{e}-01$

1.00000e-05 1.00000e-05 1.00000e-06 1.00000e-09 1.00000e-01

$1.00000 \mathrm{e}+001.00000 \mathrm{e}+001.00000 \mathrm{e}-01$ 1.00000e-09 1.00000e-01

Element: 11762 \# of layers: 7

$\mathrm{Kx} \mathrm{Ky} \mathrm{Kz}$ Ss Por

$1.50008 \mathrm{e}+011.50008 \mathrm{e}+01$ 1.50008e+00 1.00000e-09 2.12000e-01

$1.50008 \mathrm{e}+011.50008 \mathrm{e}+011.50008 \mathrm{e}+001.00000 \mathrm{e}-092.12000 \mathrm{e}-01$

$1.50008 \mathrm{e}+011.50008 \mathrm{e}+011.50008 \mathrm{e}+001.00000 \mathrm{e}-092.12000 \mathrm{e}-01$

$1.50008 \mathrm{e}+011.50008 \mathrm{e}+011.50008 \mathrm{e}+001.00000 \mathrm{e}-092.12000 \mathrm{e}-01$

$1.50008 \mathrm{e}+011.50008 \mathrm{e}+01$ 1.50008e+00 1.00000e-09 2.12000e-01

$1.00000 \mathrm{e}-05$ 1.00000e-05 1.00000e-06 1.00000e-09 1.00000e-01

$1.00000 \mathrm{e}+001.00000 \mathrm{e}+001.00000 \mathrm{e}-011.00000 \mathrm{e}-091.00000 \mathrm{e}-01$

Element: 11763 \# of layers: 7

$\mathrm{Kx} \mathrm{Ky} \mathrm{Kz}$ Ss Por

$1.50008 \mathrm{e}+01$ 1.50008e+01 1.50008e+00 1.00000e-09 2.12000e-01

$1.50008 \mathrm{e}+011.50008 \mathrm{e}+01$ 1.50008e+00 1.00000e-09 2.12000e-01

$1.50008 \mathrm{e}+01$ 1.50008e+01 1.50008e+00 1.00000e-09 2.12000e-01

$1.50008 \mathrm{e}+01$ 1.50008e+01 1.50008e+00 1.00000e-09 2.12000e-01

$1.50008 \mathrm{e}+011.50008 \mathrm{e}+011.50008 \mathrm{e}+001.00000 \mathrm{e}-092.12000 \mathrm{e}-01$

$1.00000 \mathrm{e}-05$ 1.00000e-05 1.00000e-06 1.00000e-09 1.00000e-01

$1.00000 \mathrm{e}+001.00000 \mathrm{e}+001.00000 \mathrm{e}-01$ 1.00000e-09 1.00000e-01

Element: 11764 \# of layers: 7

$\mathrm{Kx} \mathrm{Ky} \mathrm{Kz}$ Ss Por

$1.28010 \mathrm{e}+01$ 1.28010e+01 1.28010e+00 1.00000e-09 2.12000e-01

$1.28010 \mathrm{e}+011.28010 \mathrm{e}+011.28010 \mathrm{e}+001.00000 \mathrm{e}-092.12000 \mathrm{e}-01$

$1.28010 \mathrm{e}+011.28010 \mathrm{e}+011.28010 \mathrm{e}+001.00000 \mathrm{e}-092.12000 \mathrm{e}-01$

$1.28010 \mathrm{e}+011.28010 \mathrm{e}+011.28010 \mathrm{e}+00$ 1.00000e-09 2.12000e-01

$1.28010 \mathrm{e}+011.28010 \mathrm{e}+011.28010 \mathrm{e}+001.00000 \mathrm{e}-092.12000 \mathrm{e}-01$

$1.00000 \mathrm{e}-05$ 1.00000e-05 1.00000e-06 1.00000e-09 1.00000e-01

$1.00000 \mathrm{e}+001.00000 \mathrm{e}+001.00000 \mathrm{e}-01$ 1.00000e-09 1.00000e-01

Element: 11765 \# of layers: 7

Kx Ky Kz Ss Por

$1.28010 \mathrm{e}+011.28010 \mathrm{e}+011.28010 \mathrm{e}+001.00000 \mathrm{e}-092.12000 \mathrm{e}-01$

$1.28010 \mathrm{e}+011.28010 \mathrm{e}+011.28010 \mathrm{e}+001.00000 \mathrm{e}-092.12000 \mathrm{e}-01$

$1.28010 \mathrm{e}+011.28010 \mathrm{e}+011.28010 \mathrm{e}+001.00000 \mathrm{e}-092.12000 \mathrm{e}-01$

$1.28010 \mathrm{e}+011.28010 \mathrm{e}+011.28010 \mathrm{e}+001.00000 \mathrm{e}-092.12000 \mathrm{e}-01$

$1.28010 \mathrm{e}+011.28010 \mathrm{e}+011.28010 \mathrm{e}+001.00000 \mathrm{e}-092.12000 \mathrm{e}-01$

$1.00000 \mathrm{e}-051.00000 \mathrm{e}-05$ 1.00000e-06 1.00000e-09 1.00000e-01

$1.00000 \mathrm{e}+001.00000 \mathrm{e}+001.00000 \mathrm{e}-01$ 1.00000e-09 1.00000e-01

Element: 11766 \# of layers: 7

Kx Ky Kz Ss Por 
$1.28010 \mathrm{e}+011.28010 \mathrm{e}+011.28010 \mathrm{e}+001.00000 \mathrm{e}-092.12000 \mathrm{e}-01$ $1.28010 \mathrm{e}+011.28010 \mathrm{e}+011.28010 \mathrm{e}+001.00000 \mathrm{e}-092.12000 \mathrm{e}-01$ $1.28010 \mathrm{e}+011.28010 \mathrm{e}+011.28010 \mathrm{e}+001.00000 \mathrm{e}-092.12000 \mathrm{e}-01$ $1.28010 \mathrm{e}+011.28010 \mathrm{e}+011.28010 \mathrm{e}+001.00000 \mathrm{e}-092.12000 \mathrm{e}-01$ $1.28010 \mathrm{e}+011.28010 \mathrm{e}+011.28010 \mathrm{e}+001.00000 \mathrm{e}-092.12000 \mathrm{e}-01$ $1.00000 \mathrm{e}-05$ 1.00000e-05 1.00000e-06 1.00000e-09 1.00000e-01 $1.00000 \mathrm{e}+001.00000 \mathrm{e}+001.00000 \mathrm{e}-011.00000 \mathrm{e}-091.00000 \mathrm{e}-01$ Element: 11767 \# of layers: 7

$\mathrm{Kx} \mathrm{Ky} \mathrm{Kz}$ Ss Por

$1.28010 \mathrm{e}+01$ 1.28010e+01 1.28010e+00 1.00000e-09 2.12000e-01 $1.28010 \mathrm{e}+011.28010 \mathrm{e}+011.28010 \mathrm{e}+00$ 1.00000e-09 2.12000e-01 $1.28010 \mathrm{e}+011.28010 \mathrm{e}+011.28010 \mathrm{e}+001.00000 \mathrm{e}-092.12000 \mathrm{e}-01$ $1.28010 \mathrm{e}+011.28010 \mathrm{e}+011.28010 \mathrm{e}+001.00000 \mathrm{e}-092.12000 \mathrm{e}-01$ $1.28010 \mathrm{e}+011.28010 \mathrm{e}+011.28010 \mathrm{e}+001.00000 \mathrm{e}-092.12000 \mathrm{e}-01$ $1.00000 \mathrm{e}-05$ 1.00000e-05 1.00000e-06 1.00000e-09 1.00000e-01 $1.00000 \mathrm{e}+001.00000 \mathrm{e}+001.00000 \mathrm{e}-011.00000 \mathrm{e}-091.00000 \mathrm{e}-01$ Element: 11768 \# of layers: 7

$\mathrm{Kx} \mathrm{Ky} \mathrm{Kz}$ Ss Por

$1.28010 \mathrm{e}+01$ 1.28010e+01 1.28010e+00 1.00000e-09 2.12000e-01 $1.28010 \mathrm{e}+011.28010 \mathrm{e}+01 \quad 1.28010 \mathrm{e}+001.00000 \mathrm{e}-092.12000 \mathrm{e}-01$ $1.28010 \mathrm{e}+011.28010 \mathrm{e}+011.28010 \mathrm{e}+001.00000 \mathrm{e}-092.12000 \mathrm{e}-01$ $1.28010 \mathrm{e}+011.28010 \mathrm{e}+011.28010 \mathrm{e}+001.00000 \mathrm{e}-092.12000 \mathrm{e}-01$ $1.28010 \mathrm{e}+011.28010 \mathrm{e}+011.28010 \mathrm{e}+001.00000 \mathrm{e}-092.12000 \mathrm{e}-01$ $1.00000 \mathrm{e}-05$ 1.00000e-05 1.00000e-06 1.00000e-09 1.00000e-01 $1.00000 \mathrm{e}+001.00000 \mathrm{e}+001.00000 \mathrm{e}-011.00000 \mathrm{e}-091.00000 \mathrm{e}-01$ Element: 11769 \# of layers: 7

$\mathrm{Kx} \mathrm{Ky} \mathrm{Kz}$ Ss Por

$1.28010 \mathrm{e}+011.28010 \mathrm{e}+011.28010 \mathrm{e}+001.00000 \mathrm{e}-092.12000 \mathrm{e}-01$ $1.28010 \mathrm{e}+011.28010 \mathrm{e}+011.28010 \mathrm{e}+001.00000 \mathrm{e}-092.12000 \mathrm{e}-01$ $1.28010 \mathrm{e}+011.28010 \mathrm{e}+011.28010 \mathrm{e}+001.00000 \mathrm{e}-092.12000 \mathrm{e}-01$ $1.28010 \mathrm{e}+011.28010 \mathrm{e}+01 \quad 1.28010 \mathrm{e}+001.00000 \mathrm{e}-092.12000 \mathrm{e}-01$ $1.28010 \mathrm{e}+011.28010 \mathrm{e}+011.28010 \mathrm{e}+001.00000 \mathrm{e}-092.12000 \mathrm{e}-01$ $1.00000 \mathrm{e}-05$ 1.00000e-05 1.00000e-06 1.00000e-09 1.00000e-01 $1.00000 \mathrm{e}+001.00000 \mathrm{e}+001.00000 \mathrm{e}-011.00000 \mathrm{e}-091.00000 \mathrm{e}-01$ Element: 11770 \# of layers: 7

$\mathrm{Kx} \mathrm{Ky} \mathrm{Kz}$ Ss Por

$1.28010 \mathrm{e}+01$ 1.28010e+01 1.28010e+00 1.00000e-09 2.12000e-01 $1.28010 \mathrm{e}+011.28010 \mathrm{e}+011.28010 \mathrm{e}+001.00000 \mathrm{e}-092.12000 \mathrm{e}-01$ $1.28010 \mathrm{e}+011.28010 \mathrm{e}+011.28010 \mathrm{e}+001.00000 \mathrm{e}-092.12000 \mathrm{e}-01$ $1.28010 \mathrm{e}+011.28010 \mathrm{e}+011.28010 \mathrm{e}+001.00000 \mathrm{e}-092.12000 \mathrm{e}-01$ $1.28010 \mathrm{e}+011.28010 \mathrm{e}+01 \quad 1.28010 \mathrm{e}+001.00000 \mathrm{e}-092.12000 \mathrm{e}-01$ $1.00000 \mathrm{e}-05$ 1.00000e-05 1.00000e-06 1.00000e-09 1.00000e-01 $1.00000 \mathrm{e}+001.00000 \mathrm{e}+001.00000 \mathrm{e}-011.00000 \mathrm{e}-091.00000 \mathrm{e}-01$ Element: 11771 \# of layers: 7

$\mathrm{Kx} \mathrm{Ky} \mathrm{Kz}$ Ss Por

$1.28010 \mathrm{e}+01$ 1.28010e+01 1.28010e+00 1.00000e-09 2.12000e-01 
$1.28010 \mathrm{e}+011.28010 \mathrm{e}+011.28010 \mathrm{e}+001.00000 \mathrm{e}-092.12000 \mathrm{e}-01$ $1.28010 \mathrm{e}+011.28010 \mathrm{e}+011.28010 \mathrm{e}+001.00000 \mathrm{e}-092.12000 \mathrm{e}-01$ $1.28010 \mathrm{e}+011.28010 \mathrm{e}+011.28010 \mathrm{e}+001.00000 \mathrm{e}-092.12000 \mathrm{e}-01$ $1.28010 \mathrm{e}+01$ 1.28010e+01 1.28010e+00 1.00000e-09 2.12000e-01 $1.00000 \mathrm{e}-05$ 1.00000e-05 1.00000e-06 1.00000e-09 1.00000e-01 $1.00000 \mathrm{e}+001.00000 \mathrm{e}+001.00000 \mathrm{e}-011.00000 \mathrm{e}-091.00000 \mathrm{e}-01$ Element: 11772 \# of layers: 7

Kx Ky Kz Ss Por

$1.28010 \mathrm{e}+011.28010 \mathrm{e}+011.28010 \mathrm{e}+001.00000 \mathrm{e}-092.12000 \mathrm{e}-01$ $1.28010 \mathrm{e}+011.28010 \mathrm{e}+011.28010 \mathrm{e}+001.00000 \mathrm{e}-092.12000 \mathrm{e}-01$ $1.28010 \mathrm{e}+011.28010 \mathrm{e}+011.28010 \mathrm{e}+00$ 1.00000e-09 2.12000e-01 $1.28010 \mathrm{e}+011.28010 \mathrm{e}+011.28010 \mathrm{e}+001.00000 \mathrm{e}-092.12000 \mathrm{e}-01$ $1.28010 \mathrm{e}+011.28010 \mathrm{e}+011.28010 \mathrm{e}+001.00000 \mathrm{e}-092.12000 \mathrm{e}-01$ $1.00000 \mathrm{e}-05$ 1.00000e-05 1.00000e-06 1.00000e-09 1.00000e-01 $1.00000 \mathrm{e}+001.00000 \mathrm{e}+001.00000 \mathrm{e}-01$ 1.00000e-09 1.00000e-01 Element: 11773 \# of layers: 7

$\mathrm{Kx} \mathrm{Ky} \mathrm{Kz}$ Ss Por

$1.28010 \mathrm{e}+01$ 1.28010e+01 1.28010e+00 1.00000e-09 2.12000e-01 $1.28010 \mathrm{e}+011.28010 \mathrm{e}+011.28010 \mathrm{e}+001.00000 \mathrm{e}-092.12000 \mathrm{e}-01$ $1.28010 \mathrm{e}+011.28010 \mathrm{e}+01 \quad 1.28010 \mathrm{e}+001.00000 \mathrm{e}-092.12000 \mathrm{e}-01$ $1.28010 \mathrm{e}+011.28010 \mathrm{e}+011.28010 \mathrm{e}+001.00000 \mathrm{e}-092.12000 \mathrm{e}-01$ $1.28010 \mathrm{e}+011.28010 \mathrm{e}+011.28010 \mathrm{e}+001.00000 \mathrm{e}-092.12000 \mathrm{e}-01$ $1.00000 \mathrm{e}-05$ 1.00000e-05 1.00000e-06 1.00000e-09 1.00000e-01 $1.00000 \mathrm{e}+001.00000 \mathrm{e}+001.00000 \mathrm{e}-011.00000 \mathrm{e}-09$ 1.00000e-01 Element: 11774 \# of layers: 7

$\mathrm{Kx} \mathrm{Ky} \mathrm{Kz}$ Ss Por

$1.28010 \mathrm{e}+011.28010 \mathrm{e}+011.28010 \mathrm{e}+001.00000 \mathrm{e}-092.12000 \mathrm{e}-01$ $1.28010 \mathrm{e}+011.28010 \mathrm{e}+011.28010 \mathrm{e}+001.00000 \mathrm{e}-092.12000 \mathrm{e}-01$ $1.28010 \mathrm{e}+011.28010 \mathrm{e}+011.28010 \mathrm{e}+001.00000 \mathrm{e}-092.12000 \mathrm{e}-01$ $1.28010 \mathrm{e}+011.28010 \mathrm{e}+011.28010 \mathrm{e}+001.00000 \mathrm{e}-092.12000 \mathrm{e}-01$ $1.28010 \mathrm{e}+011.28010 \mathrm{e}+01 \quad 1.28010 \mathrm{e}+001.00000 \mathrm{e}-092.12000 \mathrm{e}-01$ $1.00000 \mathrm{e}-051.00000 \mathrm{e}-05$ 1.00000e-06 1.00000e-09 1.00000e-01 $1.00000 \mathrm{e}+001.00000 \mathrm{e}+001.00000 \mathrm{e}-011.00000 \mathrm{e}-091.00000 \mathrm{e}-01$ Element: 11775 \# of layers: 7

$\mathrm{Kx} \mathrm{Ky} \mathrm{Kz}$ Ss Por

$1.28010 \mathrm{e}+011.28010 \mathrm{e}+011.28010 \mathrm{e}+001.00000 \mathrm{e}-092.12000 \mathrm{e}-01$ $1.28010 \mathrm{e}+011.28010 \mathrm{e}+011.28010 \mathrm{e}+001.00000 \mathrm{e}-092.12000 \mathrm{e}-01$ $1.28010 \mathrm{e}+011.28010 \mathrm{e}+011.28010 \mathrm{e}+001.00000 \mathrm{e}-092.12000 \mathrm{e}-01$ $1.28010 \mathrm{e}+011.28010 \mathrm{e}+011.28010 \mathrm{e}+001.00000 \mathrm{e}-092.12000 \mathrm{e}-01$ $1.28010 \mathrm{e}+011.28010 \mathrm{e}+011.28010 \mathrm{e}+001.00000 \mathrm{e}-092.12000 \mathrm{e}-01$ $1.00000 \mathrm{e}-05$ 1.00000e-05 1.00000e-06 1.00000e-09 1.00000e-01 $1.00000 \mathrm{e}+001.00000 \mathrm{e}+001.00000 \mathrm{e}-011.00000 \mathrm{e}-091.00000 \mathrm{e}-01$ Element: 11776 \# of layers: 7

$\mathrm{Kx} \mathrm{Ky} \mathrm{Kz}$ Ss Por

$1.35059 \mathrm{e}+01$ 1.35059e+01 1.35059e+00 1.00000e-09 2.12000e-01 $1.35059 \mathrm{e}+011.35059 \mathrm{e}+011.35059 \mathrm{e}+001.00000 \mathrm{e}-092.12000 \mathrm{e}-01$ 
1.35059e+01 1.35059e+01 1.35059e+00 1.00000e-09 2.12000e-01 $1.35059 \mathrm{e}+01$ 1.35059e+01 1.35059e+00 1.00000e-09 2.12000e-01 $1.35059 \mathrm{e}+01$ 1.35059e+01 1.35059e+00 1.00000e-09 2.12000e-01 $1.00000 \mathrm{e}-05$ 1.00000e-05 1.00000e-06 1.00000e-09 1.00000e-01 $1.00000 \mathrm{e}+001.00000 \mathrm{e}+001.00000 \mathrm{e}-01$ 1.00000e-09 1.00000e-01 Element: 11777 \# of layers: 7

$\mathrm{Kx} \mathrm{Ky} \mathrm{Kz}$ Ss Por

$1.35059 \mathrm{e}+01$ 1.35059e+01 1.35059e+00 1.00000e-09 2.12000e-01 $1.35059 \mathrm{e}+01$ 1.35059e+01 1.35059e+00 1.00000e-09 2.12000e-01 $1.35059 \mathrm{e}+01$ 1.35059e+01 1.35059e+00 1.00000e-09 2.12000e-01 $1.35059 \mathrm{e}+01$ 1.35059e+01 1.35059e+00 1.00000e-09 2.12000e-01 $1.35059 \mathrm{e}+011.35059 \mathrm{e}+011.35059 \mathrm{e}+001.00000 \mathrm{e}-092.12000 \mathrm{e}-01$ $1.00000 \mathrm{e}-051.00000 \mathrm{e}-05$ 1.00000e-06 1.00000e-09 1.00000e-01 $1.00000 \mathrm{e}+001.00000 \mathrm{e}+001.00000 \mathrm{e}-01$ 1.00000e-09 1.00000e-01 Element: 11778 \# of layers: 7

Kx Ky Kz Ss Por

$1.35059 \mathrm{e}+01$ 1.35059e+01 1.35059e+00 1.00000e-09 2.12000e-01 $1.35059 \mathrm{e}+01$ 1.35059e+01 1.35059e+00 1.00000e-09 2.12000e-01 $1.35059 \mathrm{e}+01$ 1.35059e+01 1.35059e+00 1.00000e-09 2.12000e-01 $1.35059 \mathrm{e}+01$ 1.35059e+01 1.35059e+00 1.00000e-09 2.12000e-01 $1.35059 \mathrm{e}+01$ 1.35059e+01 1.35059e+00 1.00000e-09 2.12000e-01 $1.00000 \mathrm{e}-05$ 1.00000e-05 1.00000e-06 1.00000e-09 1.00000e-01 $1.00000 \mathrm{e}+001.00000 \mathrm{e}+001.00000 \mathrm{e}-01$ 1.00000e-09 1.00000e-01 Element: 11779 \# of layers: 7

Kx Ky Kz Ss Por

$1.28010 \mathrm{e}+011.28010 \mathrm{e}+011.28010 \mathrm{e}+001.00000 \mathrm{e}-092.12000 \mathrm{e}-01$ $1.28010 \mathrm{e}+011.28010 \mathrm{e}+011.28010 \mathrm{e}+001.00000 \mathrm{e}-092.12000 \mathrm{e}-01$ $1.28010 \mathrm{e}+011.28010 \mathrm{e}+011.28010 \mathrm{e}+001.00000 \mathrm{e}-092.12000 \mathrm{e}-01$ $1.28010 \mathrm{e}+011.28010 \mathrm{e}+011.28010 \mathrm{e}+001.00000 \mathrm{e}-092.12000 \mathrm{e}-01$ $1.28010 \mathrm{e}+011.28010 \mathrm{e}+011.28010 \mathrm{e}+001.00000 \mathrm{e}-092.12000 \mathrm{e}-01$ $1.00000 \mathrm{e}-05$ 1.00000e-05 1.00000e-06 1.00000e-09 1.00000e-01 $1.00000 \mathrm{e}+001.00000 \mathrm{e}+001.00000 \mathrm{e}-01$ 1.00000e-09 1.00000e-01 Element: 11780 \# of layers: 7

$\mathrm{Kx} \mathrm{Ky} \mathrm{Kz}$ Ss Por

$1.28010 \mathrm{e}+011.28010 \mathrm{e}+011.28010 \mathrm{e}+001.00000 \mathrm{e}-092.12000 \mathrm{e}-01$ $1.28010 \mathrm{e}+011.28010 \mathrm{e}+011.28010 \mathrm{e}+001.00000 \mathrm{e}-092.12000 \mathrm{e}-01$ $1.28010 \mathrm{e}+011.28010 \mathrm{e}+011.28010 \mathrm{e}+001.00000 \mathrm{e}-092.12000 \mathrm{e}-01$ $1.28010 \mathrm{e}+011.28010 \mathrm{e}+011.28010 \mathrm{e}+001.00000 \mathrm{e}-092.12000 \mathrm{e}-01$ $1.28010 \mathrm{e}+011.28010 \mathrm{e}+011.28010 \mathrm{e}+001.00000 \mathrm{e}-092.12000 \mathrm{e}-01$ $1.00000 \mathrm{e}-05$ 1.00000e-05 1.00000e-06 1.00000e-09 1.00000e-01 $1.00000 \mathrm{e}+001.00000 \mathrm{e}+001.00000 \mathrm{e}-011.00000 \mathrm{e}-091.00000 \mathrm{e}-01$ Element: 11781 \# of layers: 7

$\mathrm{Kx} \mathrm{Ky} \mathrm{Kz}$ Ss Por

$1.28010 \mathrm{e}+011.28010 \mathrm{e}+011.28010 \mathrm{e}+001.00000 \mathrm{e}-092.12000 \mathrm{e}-01$ $1.28010 \mathrm{e}+011.28010 \mathrm{e}+011.28010 \mathrm{e}+001.00000 \mathrm{e}-092.12000 \mathrm{e}-01$ $1.28010 \mathrm{e}+01$ 1.28010e+01 1.28010e+00 1.00000e-09 2.12000e-01 
$1.28010 \mathrm{e}+011.28010 \mathrm{e}+011.28010 \mathrm{e}+001.00000 \mathrm{e}-092.12000 \mathrm{e}-01$ $1.28010 \mathrm{e}+011.28010 \mathrm{e}+011.28010 \mathrm{e}+001.00000 \mathrm{e}-092.12000 \mathrm{e}-01$ $1.00000 \mathrm{e}-05$ 1.00000e-05 1.00000e-06 1.00000e-09 1.00000e-01 $1.00000 \mathrm{e}+001.00000 \mathrm{e}+001.00000 \mathrm{e}-011.00000 \mathrm{e}-091.00000 \mathrm{e}-01$ Element: 11782 \# of layers: 7

$\mathrm{Kx} \mathrm{Ky} \mathrm{Kz}$ Ss Por

$1.28010 \mathrm{e}+011.28010 \mathrm{e}+011.28010 \mathrm{e}+001.00000 \mathrm{e}-092.12000 \mathrm{e}-01$ $1.28010 \mathrm{e}+011.28010 \mathrm{e}+011.28010 \mathrm{e}+001.00000 \mathrm{e}-092.12000 \mathrm{e}-01$ $1.28010 \mathrm{e}+011.28010 \mathrm{e}+011.28010 \mathrm{e}+001.00000 \mathrm{e}-092.12000 \mathrm{e}-01$ $1.28010 \mathrm{e}+011.28010 \mathrm{e}+011.28010 \mathrm{e}+001.00000 \mathrm{e}-092.12000 \mathrm{e}-01$ $1.28010 \mathrm{e}+011.28010 \mathrm{e}+011.28010 \mathrm{e}+001.00000 \mathrm{e}-092.12000 \mathrm{e}-01$ $1.00000 \mathrm{e}-05$ 1.00000e-05 1.00000e-06 1.00000e-09 1.00000e-01 $1.00000 \mathrm{e}+001.00000 \mathrm{e}+001.00000 \mathrm{e}-011.00000 \mathrm{e}-09$ 1.00000e-01 Element: 11783 \# of layers: 7

$\mathrm{Kx} \mathrm{Ky} \mathrm{Kz}$ Ss Por

$1.35059 \mathrm{e}+01$ 1.35059e+01 1.35059e+00 1.00000e-09 2.12000e-01 $1.35059 \mathrm{e}+01$ 1.35059e+01 1.35059e+00 1.00000e-09 2.12000e-01 $1.35059 \mathrm{e}+01$ 1.35059e+01 1.35059e+00 1.00000e-09 2.12000e-01 $1.35059 \mathrm{e}+01$ 1.35059e+01 1.35059e+00 1.00000e-09 2.12000e-01 $1.35059 \mathrm{e}+01$ 1.35059e+01 1.35059e+00 1.00000e-09 2.12000e-01 $1.00000 \mathrm{e}-05$ 1.00000e-05 1.00000e-06 1.00000e-09 1.00000e-01 $1.00000 \mathrm{e}+001.00000 \mathrm{e}+001.00000 \mathrm{e}-01$ 1.00000e-09 1.00000e-01 Element: 11784 \# of layers: 7

Kx Ky Kz Ss Por

$1.35059 \mathrm{e}+01$ 1.35059e+01 1.35059e+00 1.00000e-09 2.12000e-01 $1.35059 \mathrm{e}+01$ 1.35059e+01 1.35059e+00 1.00000e-09 2.12000e-01 $1.35059 \mathrm{e}+01$ 1.35059e+01 1.35059e+00 1.00000e-09 2.12000e-01 $1.35059 \mathrm{e}+01$ 1.35059e+01 1.35059e+00 1.00000e-09 2.12000e-01 $1.35059 \mathrm{e}+01$ 1.35059e+01 1.35059e+00 1.00000e-09 2.12000e-01 $1.00000 \mathrm{e}-051.00000 \mathrm{e}-051.00000 \mathrm{e}-061.00000 \mathrm{e}-091.00000 \mathrm{e}-01$ $1.00000 \mathrm{e}+001.00000 \mathrm{e}+001.00000 \mathrm{e}-011.00000 \mathrm{e}-091.00000 \mathrm{e}-01$ Element: 11785 \# of layers: 7

Kx Ky Kz Ss Por

$1.35059 \mathrm{e}+01$ 1.35059e+01 1.35059e+00 1.00000e-09 2.12000e-01 $1.35059 \mathrm{e}+01$ 1.35059e+01 1.35059e+00 1.00000e-09 2.12000e-01 $1.35059 \mathrm{e}+011.35059 \mathrm{e}+011.35059 \mathrm{e}+001.00000 \mathrm{e}-092.12000 \mathrm{e}-01$ $1.35059 \mathrm{e}+011.35059 \mathrm{e}+011.35059 \mathrm{e}+001.00000 \mathrm{e}-092.12000 \mathrm{e}-01$ $1.35059 \mathrm{e}+011.35059 \mathrm{e}+01$ 1.35059e+00 1.00000e-09 2.12000e-01 $1.00000 \mathrm{e}-05$ 1.00000e-05 1.00000e-06 1.00000e-09 1.00000e-01 $1.00000 \mathrm{e}+001.00000 \mathrm{e}+001.00000 \mathrm{e}-01$ 1.00000e-09 1.00000e-01 Element: 11786 \# of layers: 7

$\mathrm{Kx} \mathrm{Ky} \mathrm{Kz}$ Ss Por

$1.35059 \mathrm{e}+01$ 1.35059e+01 1.35059e+00 1.00000e-09 2.12000e-01 $1.35059 \mathrm{e}+01$ 1.35059e+01 1.35059e+00 1.00000e-09 2.12000e-01 $1.35059 \mathrm{e}+01$ 1.35059e+01 1.35059e+00 1.00000e-09 2.12000e-01 $1.35059 \mathrm{e}+011.35059 \mathrm{e}+011.35059 \mathrm{e}+001.00000 \mathrm{e}-092.12000 \mathrm{e}-01$ 
$1.35059 \mathrm{e}+01$ 1.35059e+01 1.35059e+00 1.00000e-09 2.12000e-01 $1.00000 \mathrm{e}-05$ 1.00000e-05 1.00000e-06 1.00000e-09 1.00000e-01 $1.00000 \mathrm{e}+001.00000 \mathrm{e}+001.00000 \mathrm{e}-011.00000 \mathrm{e}-09$ 1.00000e-01 Element: 11787 \# of layers: 7

$\mathrm{Kx} \mathrm{Ky} \mathrm{Kz}$ Ss Por

$1.35059 \mathrm{e}+01$ 1.35059e+01 1.35059e+00 1.00000e-09 2.12000e-01 $1.35059 \mathrm{e}+01$ 1.35059e+01 1.35059e+00 1.00000e-09 2.12000e-01 $1.35059 \mathrm{e}+01$ 1.35059e+01 1.35059e+00 1.00000e-09 2.12000e-01 $1.35059 \mathrm{e}+01$ 1.35059e+01 1.35059e+00 1.00000e-09 2.12000e-01 $1.35059 \mathrm{e}+01$ 1.35059e+01 1.35059e+00 1.00000e-09 2.12000e-01 $1.00000 \mathrm{e}-05$ 1.00000e-05 1.00000e-06 1.00000e-09 1.00000e-01 $1.00000 \mathrm{e}+001.00000 \mathrm{e}+001.00000 \mathrm{e}-011.00000 \mathrm{e}-091.00000 \mathrm{e}-01$ Element: 11788 \# of layers: 7

$\mathrm{Kx} \mathrm{Ky} \mathrm{Kz}$ Ss Por

$1.35059 \mathrm{e}+01$ 1.35059e+01 1.35059e+00 1.00000e-09 2.12000e-01 $1.35059 \mathrm{e}+01$ 1.35059e+01 1.35059e+00 1.00000e-09 2.12000e-01 $1.35059 \mathrm{e}+011.35059 \mathrm{e}+01$ 1.35059e+00 1.00000e-09 2.12000e-01 $1.35059 \mathrm{e}+01$ 1.35059e+01 1.35059e+00 1.00000e-09 2.12000e-01 $1.35059 \mathrm{e}+01$ 1.35059e+01 1.35059e+00 1.00000e-09 2.12000e-01 $1.00000 \mathrm{e}-05$ 1.00000e-05 1.00000e-06 1.00000e-09 1.00000e-01 $1.00000 \mathrm{e}+001.00000 \mathrm{e}+001.00000 \mathrm{e}-011.00000 \mathrm{e}-091.00000 \mathrm{e}-01$ Element: 11789 \# of layers: 7

$\mathrm{Kx} \mathrm{Ky} \mathrm{Kz}$ Ss Por

$1.35059 \mathrm{e}+01$ 1.35059e+01 1.35059e+00 1.00000e-09 2.12000e-01 $1.35059 \mathrm{e}+01$ 1.35059e+01 1.35059e+00 1.00000e-09 2.12000e-01 $1.35059 \mathrm{e}+01$ 1.35059e+01 1.35059e+00 1.00000e-09 2.12000e-01 $1.35059 \mathrm{e}+01$ 1.35059e+01 1.35059e+00 1.00000e-09 2.12000e-01 $1.35059 \mathrm{e}+01$ 1.35059e+01 1.35059e+00 1.00000e-09 2.12000e-01 $1.00000 \mathrm{e}-05$ 1.00000e-05 1.00000e-06 1.00000e-09 1.00000e-01 $1.00000 \mathrm{e}+001.00000 \mathrm{e}+001.00000 \mathrm{e}-011.00000 \mathrm{e}-091.00000 \mathrm{e}-01$ Element: 11790 \# of layers: 7

$\mathrm{Kx} \mathrm{Ky} \mathrm{Kz}$ Ss Por

$1.35059 \mathrm{e}+01$ 1.35059e+01 1.35059e+00 1.00000e-09 2.12000e-01 $1.35059 \mathrm{e}+01$ 1.35059e+01 1.35059e+00 1.00000e-09 2.12000e-01 $1.35059 \mathrm{e}+01$ 1.35059e+01 1.35059e+00 1.00000e-09 2.12000e-01 $1.35059 \mathrm{e}+01$ 1.35059e+01 1.35059e+00 1.00000e-09 2.12000e-01 $1.35059 \mathrm{e}+011.35059 \mathrm{e}+011.35059 \mathrm{e}+001.00000 \mathrm{e}-092.12000 \mathrm{e}-01$ $1.00000 \mathrm{e}-05$ 1.00000e-05 1.00000e-06 1.00000e-09 1.00000e-01 $1.00000 \mathrm{e}+001.00000 \mathrm{e}+001.00000 \mathrm{e}-011.00000 \mathrm{e}-091.00000 \mathrm{e}-01$ Element: 11791 \# of layers: 7

Kx Ky Kz Ss Por

$1.35059 \mathrm{e}+01$ 1.35059e+01 1.35059e+00 1.00000e-09 2.12000e-01 $1.35059 \mathrm{e}+01$ 1.35059e+01 1.35059e+00 1.00000e-09 2.12000e-01 $1.35059 \mathrm{e}+01$ 1.35059e+01 1.35059e+00 1.00000e-09 2.12000e-01 $1.35059 \mathrm{e}+01$ 1.35059e+01 1.35059e+00 1.00000e-09 2.12000e-01 $1.35059 \mathrm{e}+011.35059 \mathrm{e}+011.35059 \mathrm{e}+001.00000 \mathrm{e}-092.12000 \mathrm{e}-01$ 
$1.00000 \mathrm{e}-05$ 1.00000e-05 1.00000e-06 1.00000e-09 1.00000e-01 $1.00000 \mathrm{e}+001.00000 \mathrm{e}+001.00000 \mathrm{e}-01$ 1.00000e-09 1.00000e-01 Element: 11792 \# of layers: 7

Kx Ky Kz Ss Por

$1.35059 \mathrm{e}+01$ 1.35059e+01 1.35059e+00 1.00000e-09 2.12000e-01

$1.35059 \mathrm{e}+01$ 1.35059e+01 1.35059e+00 1.00000e-09 2.12000e-01

$1.35059 \mathrm{e}+01$ 1.35059e+01 1.35059e+00 1.00000e-09 2.12000e-01

$1.35059 \mathrm{e}+01$ 1.35059e+01 1.35059e+00 1.00000e-09 2.12000e-01

$1.35059 \mathrm{e}+01$ 1.35059e+01 1.35059e+00 1.00000e-09 2.12000e-01

$1.00000 \mathrm{e}-05$ 1.00000e-05 1.00000e-06 1.00000e-09 1.00000e-01

$1.00000 \mathrm{e}+001.00000 \mathrm{e}+001.00000 \mathrm{e}-011.00000 \mathrm{e}-091.00000 \mathrm{e}-01$

Element: 11793 \# of layers: 7

Kx Ky Kz Ss Por

$1.35059 \mathrm{e}+01$ 1.35059e+01 1.35059e+00 1.00000e-09 2.12000e-01

$1.35059 \mathrm{e}+01$ 1.35059e+01 1.35059e+00 1.00000e-09 2.12000e-01

$1.35059 \mathrm{e}+01$ 1.35059e+01 1.35059e+00 1.00000e-09 2.12000e-01

$1.35059 \mathrm{e}+01$ 1.35059e+01 1.35059e+00 1.00000e-09 2.12000e-01

$1.35059 \mathrm{e}+01$ 1.35059e+01 1.35059e+00 1.00000e-09 2.12000e-01

$1.00000 \mathrm{e}-05$ 1.00000e-05 1.00000e-06 1.00000e-09 1.00000e-01

$1.00000 \mathrm{e}+001.00000 \mathrm{e}+001.00000 \mathrm{e}-011.00000 \mathrm{e}-09$ 1.00000e-01

Element: 11794 \# of layers: 7

Kx Ky Kz Ss Por

1.41413e+01 1.41413e+01 1.41413e+00 1.00000e-09 2.12000e-01 $1.41413 \mathrm{e}+011.41413 \mathrm{e}+011.41413 \mathrm{e}+001.00000 \mathrm{e}-092.12000 \mathrm{e}-01$ $1.41413 \mathrm{e}+011.41413 \mathrm{e}+011.41413 \mathrm{e}+001.00000 \mathrm{e}-092.12000 \mathrm{e}-01$ $1.41413 \mathrm{e}+011.41413 \mathrm{e}+01$ 1.41413e+00 1.00000e-09 2.12000e-01 $1.41413 \mathrm{e}+01$ 1.41413e+01 1.41413e+00 1.00000e-09 2.12000e-01 $1.00000 \mathrm{e}-05$ 1.00000e-05 1.00000e-06 1.00000e-09 1.00000e-01

$1.00000 \mathrm{e}+001.00000 \mathrm{e}+001.00000 \mathrm{e}-011.00000 \mathrm{e}-091.00000 \mathrm{e}-01$ Element: 11795 \# of layers: 7

$\mathrm{Kx} \mathrm{Ky} \mathrm{Kz}$ Ss Por

$1.41413 \mathrm{e}+011.41413 \mathrm{e}+01$ 1.41413e+00 1.00000e-09 2.12000e-01 $1.41413 \mathrm{e}+011.41413 \mathrm{e}+011.41413 \mathrm{e}+001.00000 \mathrm{e}-092.12000 \mathrm{e}-01$ $1.41413 \mathrm{e}+011.41413 \mathrm{e}+011.41413 \mathrm{e}+001.00000 \mathrm{e}-092.12000 \mathrm{e}-01$ $1.41413 \mathrm{e}+011.41413 \mathrm{e}+011.41413 \mathrm{e}+001.00000 \mathrm{e}-092.12000 \mathrm{e}-01$ $1.41413 \mathrm{e}+01$ 1.41413e+01 1.41413e+00 1.00000e-09 2.12000e-01 1.00000e-05 1.00000e-05 1.00000e-06 1.00000e-09 1.00000e-01 $1.00000 \mathrm{e}+001.00000 \mathrm{e}+001.00000 \mathrm{e}-011.00000 \mathrm{e}-091.00000 \mathrm{e}-01$ Element: 11796 \# of layers: 7

$\mathrm{Kx} \mathrm{Ky} \mathrm{Kz}$ Ss Por

$1.41413 \mathrm{e}+01$ 1.41413e+01 1.41413e+00 1.00000e-09 2.12000e-01 $1.41413 \mathrm{e}+011.41413 \mathrm{e}+011.41413 \mathrm{e}+001.00000 \mathrm{e}-092.12000 \mathrm{e}-01$ $1.41413 \mathrm{e}+011.41413 \mathrm{e}+01$ 1.41413e+00 1.00000e-09 2.12000e-01 1.41413e+01 1.41413e+01 1.41413e+00 1.00000e-09 2.12000e-01 $1.41413 \mathrm{e}+011.41413 \mathrm{e}+011.41413 \mathrm{e}+001.00000 \mathrm{e}-092.12000 \mathrm{e}-01$ $1.00000 \mathrm{e}-05$ 1.00000e-05 1.00000e-06 1.00000e-09 1.00000e-01 
$1.00000 \mathrm{e}+001.00000 \mathrm{e}+00$ 1.00000e-01 1.00000e-09 1.00000e-01

Element: 11797 \# of layers: 7

Kx Ky Kz Ss Por

$1.35059 \mathrm{e}+01$ 1.35059e+01 1.35059e+00 1.00000e-09 2.12000e-01

$1.35059 \mathrm{e}+01$ 1.35059e+01 1.35059e+00 1.00000e-09 2.12000e-01

$1.35059 \mathrm{e}+01$ 1.35059e+01 1.35059e+00 1.00000e-09 2.12000e-01

$1.35059 \mathrm{e}+01$ 1.35059e+01 1.35059e+00 1.00000e-09 2.12000e-01

$1.35059 \mathrm{e}+01$ 1.35059e+01 1.35059e+00 1.00000e-09 2.12000e-01

$1.00000 \mathrm{e}-05$ 1.00000e-05 1.00000e-06 1.00000e-09 1.00000e-01

$1.00000 \mathrm{e}+001.00000 \mathrm{e}+001.00000 \mathrm{e}-011.00000 \mathrm{e}-091.00000 \mathrm{e}-01$

Element: 11798 \# of layers: 7

Kx Ky Kz Ss Por

$1.35059 \mathrm{e}+01$ 1.35059e+01 1.35059e+00 1.00000e-09 2.12000e-01

$1.35059 \mathrm{e}+01$ 1.35059e+01 1.35059e+00 1.00000e-09 2.12000e-01

$1.35059 \mathrm{e}+01$ 1.35059e+01 1.35059e+00 1.00000e-09 2.12000e-01

$1.35059 \mathrm{e}+011.35059 \mathrm{e}+011.35059 \mathrm{e}+001.00000 \mathrm{e}-092.12000 \mathrm{e}-01$

$1.35059 \mathrm{e}+01$ 1.35059e+01 1.35059e+00 1.00000e-09 2.12000e-01

$1.00000 \mathrm{e}-05$ 1.00000e-05 1.00000e-06 1.00000e-09 1.00000e-01

$1.00000 \mathrm{e}+001.00000 \mathrm{e}+001.00000 \mathrm{e}-01$ 1.00000e-09 1.00000e-01

Element: 11799 \# of layers: 7

$\mathrm{Kx} \mathrm{Ky} \mathrm{Kz}$ Ss Por

$1.35059 \mathrm{e}+01$ 1.35059e+01 1.35059e+00 1.00000e-09 2.12000e-01

$1.35059 \mathrm{e}+01$ 1.35059e+01 1.35059e+00 1.00000e-09 2.12000e-01

$1.35059 \mathrm{e}+01$ 1.35059e+01 1.35059e+00 1.00000e-09 2.12000e-01

$1.35059 \mathrm{e}+011.35059 \mathrm{e}+011.35059 \mathrm{e}+001.00000 \mathrm{e}-092.12000 \mathrm{e}-01$

$1.35059 \mathrm{e}+01$ 1.35059e+01 1.35059e+00 1.00000e-09 2.12000e-01

$1.00000 \mathrm{e}-05$ 1.00000e-05 1.00000e-06 1.00000e-09 1.00000e-01

$1.00000 \mathrm{e}+001.00000 \mathrm{e}+001.00000 \mathrm{e}-011.00000 \mathrm{e}-09$ 1.00000e-01

Element: 11800 \# of layers: 7

$\mathrm{Kx} \mathrm{Ky} \mathrm{Kz}$ Ss Por

$1.35059 \mathrm{e}+01$ 1.35059e+01 1.35059e+00 1.00000e-09 2.12000e-01

$1.35059 \mathrm{e}+01$ 1.35059e+01 1.35059e+00 1.00000e-09 2.12000e-01

$1.35059 \mathrm{e}+011.35059 \mathrm{e}+01$ 1.35059e+00 1.00000e-09 2.12000e-01

$1.35059 \mathrm{e}+01$ 1.35059e+01 1.35059e+00 1.00000e-09 2.12000e-01

$1.35059 \mathrm{e}+01$ 1.35059e+01 1.35059e+00 1.00000e-09 2.12000e-01

1.00000e-05 1.00000e-05 1.00000e-06 1.00000e-09 1.00000e-01

$1.00000 \mathrm{e}+001.00000 \mathrm{e}+001.00000 \mathrm{e}-011.00000 \mathrm{e}-091.00000 \mathrm{e}-01$

Element: 11801 \# of layers: 7

$\mathrm{Kx} \mathrm{Ky} \mathrm{Kz}$ Ss Por

$1.41413 \mathrm{e}+01$ 1.41413e+01 1.41413e+00 1.00000e-09 2.12000e-01

$1.41413 \mathrm{e}+01$ 1.41413e+01 1.41413e+00 1.00000e-09 2.12000e-01

$1.41413 \mathrm{e}+01$ 1.41413e+01 1.41413e+00 1.00000e-09 2.12000e-01

$1.41413 \mathrm{e}+01$ 1.41413e+01 1.41413e+00 1.00000e-09 2.12000e-01

$1.41413 \mathrm{e}+01$ 1.41413e+01 1.41413e+00 1.00000e-09 2.12000e-01 $1.00000 \mathrm{e}-05$ 1.00000e-05 1.00000e-06 1.00000e-09 1.00000e-01

$1.00000 \mathrm{e}+001.00000 \mathrm{e}+001.00000 \mathrm{e}-011.00000 \mathrm{e}-091.00000 \mathrm{e}-01$ 
Element: 11802 \# of layers: 7

Kx Ky Kz Ss Por

$1.41413 \mathrm{e}+011.41413 \mathrm{e}+011.41413 \mathrm{e}+00$ 1.00000e-09 2.12000e-01

$1.41413 \mathrm{e}+011.41413 \mathrm{e}+011.41413 \mathrm{e}+001.00000 \mathrm{e}-092.12000 \mathrm{e}-01$

$1.41413 \mathrm{e}+011.41413 \mathrm{e}+011.41413 \mathrm{e}+001.00000 \mathrm{e}-092.12000 \mathrm{e}-01$

$1.41413 \mathrm{e}+011.41413 \mathrm{e}+011.41413 \mathrm{e}+001.00000 \mathrm{e}-092.12000 \mathrm{e}-01$

$1.41413 \mathrm{e}+011.41413 \mathrm{e}+011.41413 \mathrm{e}+00$ 1.00000e-09 2.12000e-01

$1.00000 \mathrm{e}-05$ 1.00000e-05 1.00000e-06 1.00000e-09 1.00000e-01

$1.00000 \mathrm{e}+001.00000 \mathrm{e}+001.00000 \mathrm{e}-011.00000 \mathrm{e}-091.00000 \mathrm{e}-01$

Element: 11803 \# of layers: 7

Kx Ky Kz Ss Por

$1.41413 \mathrm{e}+011.41413 \mathrm{e}+011.41413 \mathrm{e}+00$ 1.00000e-09 2.12000e-01

$1.41413 \mathrm{e}+011.41413 \mathrm{e}+011.41413 \mathrm{e}+001.00000 \mathrm{e}-092.12000 \mathrm{e}-01$

$1.41413 \mathrm{e}+011.41413 \mathrm{e}+011.41413 \mathrm{e}+001.00000 \mathrm{e}-092.12000 \mathrm{e}-01$

$1.41413 \mathrm{e}+011.41413 \mathrm{e}+011.41413 \mathrm{e}+001.00000 \mathrm{e}-092.12000 \mathrm{e}-01$

$1.41413 \mathrm{e}+011.41413 \mathrm{e}+011.41413 \mathrm{e}+00$ 1.00000e-09 2.12000e-01

$1.00000 \mathrm{e}-05$ 1.00000e-05 1.00000e-06 1.00000e-09 1.00000e-01

$1.00000 \mathrm{e}+001.00000 \mathrm{e}+001.00000 \mathrm{e}-011.00000 \mathrm{e}-091.00000 \mathrm{e}-01$

Element: 11804 \# of layers: 7

Kx Ky Kz Ss Por

$1.41413 \mathrm{e}+011.41413 \mathrm{e}+011.41413 \mathrm{e}+00$ 1.00000e-09 2.12000e-01

$1.41413 \mathrm{e}+011.41413 \mathrm{e}+011.41413 \mathrm{e}+00$ 1.00000e-09 2.12000e-01

$1.41413 \mathrm{e}+011.41413 \mathrm{e}+011.41413 \mathrm{e}+001.00000 \mathrm{e}-092.12000 \mathrm{e}-01$

$1.41413 \mathrm{e}+011.41413 \mathrm{e}+011.41413 \mathrm{e}+001.00000 \mathrm{e}-092.12000 \mathrm{e}-01$

$1.41413 \mathrm{e}+011.41413 \mathrm{e}+011.41413 \mathrm{e}+00$ 1.00000e-09 2.12000e-01

$1.00000 \mathrm{e}-05$ 1.00000e-05 1.00000e-06 1.00000e-09 1.00000e-01

$1.00000 \mathrm{e}+001.00000 \mathrm{e}+001.00000 \mathrm{e}-011.00000 \mathrm{e}-091.00000 \mathrm{e}-01$

Element: 11805 \# of layers: 7

Kx Ky Kz Ss Por

$1.41413 \mathrm{e}+011.41413 \mathrm{e}+011.41413 \mathrm{e}+00$ 1.00000e-09 2.12000e-01

$1.41413 \mathrm{e}+011.41413 \mathrm{e}+011.41413 \mathrm{e}+001.00000 \mathrm{e}-092.12000 \mathrm{e}-01$

$1.41413 \mathrm{e}+011.41413 \mathrm{e}+011.41413 \mathrm{e}+001.00000 \mathrm{e}-092.12000 \mathrm{e}-01$

$1.41413 \mathrm{e}+011.41413 \mathrm{e}+011.41413 \mathrm{e}+001.00000 \mathrm{e}-092.12000 \mathrm{e}-01$

$1.41413 \mathrm{e}+011.41413 \mathrm{e}+011.41413 \mathrm{e}+001.00000 \mathrm{e}-092.12000 \mathrm{e}-01$

$1.00000 \mathrm{e}-05$ 1.00000e-05 1.00000e-06 1.00000e-09 1.00000e-01

$1.00000 \mathrm{e}+001.00000 \mathrm{e}+001.00000 \mathrm{e}-011.00000 \mathrm{e}-091.00000 \mathrm{e}-01$

Element: 11806 \# of layers: 7

Kx Ky Kz Ss Por

$1.41413 \mathrm{e}+011.41413 \mathrm{e}+011.41413 \mathrm{e}+00$ 1.00000e-09 2.12000e-01

$1.41413 \mathrm{e}+011.41413 \mathrm{e}+011.41413 \mathrm{e}+001.00000 \mathrm{e}-092.12000 \mathrm{e}-01$

$1.41413 \mathrm{e}+011.41413 \mathrm{e}+011.41413 \mathrm{e}+001.00000 \mathrm{e}-092.12000 \mathrm{e}-01$

$1.41413 \mathrm{e}+011.41413 \mathrm{e}+011.41413 \mathrm{e}+001.00000 \mathrm{e}-092.12000 \mathrm{e}-01$

$1.41413 \mathrm{e}+011.41413 \mathrm{e}+011.41413 \mathrm{e}+00$ 1.00000e-09 2.12000e-01

$1.00000 \mathrm{e}-05$ 1.00000e-05 1.00000e-06 1.00000e-09 1.00000e-01

$1.00000 \mathrm{e}+001.00000 \mathrm{e}+001.00000 \mathrm{e}-011.00000 \mathrm{e}-091.00000 \mathrm{e}-01$

Element: 11807 \# of layers: 7 
Kx Ky Kz Ss Por

1.41413e+01 1.41413e+01 1.41413e+00 1.00000e-09 2.12000e-01

$1.41413 \mathrm{e}+011.41413 \mathrm{e}+011.41413 \mathrm{e}+001.00000 \mathrm{e}-09$ 2.12000e-01

$1.41413 \mathrm{e}+011.41413 \mathrm{e}+011.41413 \mathrm{e}+001.00000 \mathrm{e}-092.12000 \mathrm{e}-01$

$1.41413 \mathrm{e}+011.41413 \mathrm{e}+01$ 1.41413e+00 1.00000e-09 2.12000e-01

$1.41413 \mathrm{e}+01$ 1.41413e+01 1.41413e+00 1.00000e-09 2.12000e-01

$1.00000 \mathrm{e}-05$ 1.00000e-05 1.00000e-06 1.00000e-09 1.00000e-01

$1.00000 \mathrm{e}+001.00000 \mathrm{e}+001.00000 \mathrm{e}-01$ 1.00000e-09 1.00000e-01

Element: 11808 \# of layers: 7

$\mathrm{Kx} \mathrm{Ky} \mathrm{Kz}$ Ss Por

$1.41413 \mathrm{e}+01$ 1.41413e+01 1.41413e+00 1.00000e-09 2.12000e-01

$1.41413 \mathrm{e}+011.41413 \mathrm{e}+011.41413 \mathrm{e}+001.00000 \mathrm{e}-092.12000 \mathrm{e}-01$

$1.41413 \mathrm{e}+011.41413 \mathrm{e}+011.41413 \mathrm{e}+001.00000 \mathrm{e}-092.12000 \mathrm{e}-01$

$1.41413 \mathrm{e}+01$ 1.41413e+01 1.41413e+00 1.00000e-09 2.12000e-01

$1.41413 \mathrm{e}+011.41413 \mathrm{e}+01$ 1.41413e+00 1.00000e-09 2.12000e-01 $1.00000 \mathrm{e}-05$ 1.00000e-05 1.00000e-06 1.00000e-09 1.00000e-01

$1.00000 \mathrm{e}+001.00000 \mathrm{e}+001.00000 \mathrm{e}-011.00000 \mathrm{e}-091.00000 \mathrm{e}-01$

Element: 11809 \# of layers: 7

$\mathrm{Kx} \mathrm{Ky} \mathrm{Kz}$ Ss Por

1.41413e+01 1.41413e+01 1.41413e+00 1.00000e-09 2.12000e-01

$1.41413 \mathrm{e}+011.41413 \mathrm{e}+011.41413 \mathrm{e}+001.00000 \mathrm{e}-092.12000 \mathrm{e}-01$

$1.41413 \mathrm{e}+01$ 1.41413e+01 1.41413e+00 1.00000e-09 2.12000e-01

$1.41413 \mathrm{e}+01$ 1.41413e+01 1.41413e+00 1.00000e-09 2.12000e-01

$1.41413 \mathrm{e}+011.41413 \mathrm{e}+011.41413 \mathrm{e}+001.00000 \mathrm{e}-092.12000 \mathrm{e}-01$

$1.00000 \mathrm{e}-05$ 1.00000e-05 1.00000e-06 1.00000e-09 1.00000e-01

$1.00000 \mathrm{e}+001.00000 \mathrm{e}+001.00000 \mathrm{e}-01$ 1.00000e-09 1.00000e-01

Element: 11810 \# of layers: 7

$\mathrm{Kx} \mathrm{Ky} \mathrm{Kz}$ Ss Por

$1.41413 \mathrm{e}+01$ 1.41413e+01 1.41413e+00 1.00000e-09 2.12000e-01

$1.41413 \mathrm{e}+01$ 1.41413e+01 1.41413e+00 1.00000e-09 2.12000e-01

$1.41413 \mathrm{e}+01$ 1.41413e+01 1.41413e+00 1.00000e-09 2.12000e-01

$1.41413 \mathrm{e}+01$ 1.41413e+01 1.41413e+00 1.00000e-09 2.12000e-01

$1.41413 \mathrm{e}+011.41413 \mathrm{e}+011.41413 \mathrm{e}+001.00000 \mathrm{e}-092.12000 \mathrm{e}-01$

$1.00000 \mathrm{e}-051.00000 \mathrm{e}-051.00000 \mathrm{e}-061.00000 \mathrm{e}-091.00000 \mathrm{e}-01$

$1.00000 \mathrm{e}+001.00000 \mathrm{e}+001.00000 \mathrm{e}-011.00000 \mathrm{e}-091.00000 \mathrm{e}-01$

Element: 11811 \# of layers: 7

Kx Ky Kz Ss Por

$1.50008 \mathrm{e}+011.50008 \mathrm{e}+01$ 1.50008e+00 1.00000e-09 2.12000e-01

$1.50008 \mathrm{e}+011.50008 \mathrm{e}+011.50008 \mathrm{e}+001.00000 \mathrm{e}-092.12000 \mathrm{e}-01$

$1.50008 \mathrm{e}+011.50008 \mathrm{e}+01$ 1.50008e+00 1.00000e-09 2.12000e-01

$1.50008 \mathrm{e}+011.50008 \mathrm{e}+011.50008 \mathrm{e}+001.00000 \mathrm{e}-092.12000 \mathrm{e}-01$

$1.50008 \mathrm{e}+01$ 1.50008e+01 1.50008e+00 1.00000e-09 2.12000e-01

$1.00000 \mathrm{e}-051.00000 \mathrm{e}-051.00000 \mathrm{e}-061.00000 \mathrm{e}-091.00000 \mathrm{e}-01$

$1.00000 \mathrm{e}+001.00000 \mathrm{e}+001.00000 \mathrm{e}-01$ 1.00000e-09 1.00000e-01

Element: 11812 \# of layers: 7

Kx Ky Kz Ss Por 
$1.50008 \mathrm{e}+01$ 1.50008e+01 1.50008e+00 1.00000e-09 2.12000e-01 $1.50008 \mathrm{e}+01$ 1.50008e+01 1.50008e+00 1.00000e-09 2.12000e-01 $1.50008 \mathrm{e}+011.50008 \mathrm{e}+011.50008 \mathrm{e}+001.00000 \mathrm{e}-092.12000 \mathrm{e}-01$ $1.50008 \mathrm{e}+011.50008 \mathrm{e}+011.50008 \mathrm{e}+001.00000 \mathrm{e}-092.12000 \mathrm{e}-01$ $1.50008 \mathrm{e}+011.50008 \mathrm{e}+01$ 1.50008e+00 1.00000e-09 2.12000e-01 $1.00000 \mathrm{e}-051.00000 \mathrm{e}-05$ 1.00000e-06 1.00000e-09 1.00000e-01 $1.00000 \mathrm{e}+001.00000 \mathrm{e}+001.00000 \mathrm{e}-01$ 1.00000e-09 1.00000e-01 Element: 11813 \# of layers: 7

$\mathrm{Kx} \mathrm{Ky} \mathrm{Kz}$ Ss Por

$1.50008 \mathrm{e}+01$ 1.50008e+01 1.50008e+00 1.00000e-09 2.12000e-01 $1.50008 \mathrm{e}+01$ 1.50008e+01 1.50008e+00 1.00000e-09 2.12000e-01 $1.50008 \mathrm{e}+011.50008 \mathrm{e}+011.50008 \mathrm{e}+001.00000 \mathrm{e}-092.12000 \mathrm{e}-01$ $1.50008 \mathrm{e}+011.50008 \mathrm{e}+01$ 1.50008e+00 1.00000e-09 2.12000e-01 $1.50008 \mathrm{e}+011.50008 \mathrm{e}+01$ 1.50008e+00 1.00000e-09 2.12000e-01 $1.00000 \mathrm{e}-05$ 1.00000e-05 1.00000e-06 1.00000e-09 1.00000e-01 $1.00000 \mathrm{e}+001.00000 \mathrm{e}+001.00000 \mathrm{e}-011.00000 \mathrm{e}-091.00000 \mathrm{e}-01$ Element: 11814 \# of layers: 7

$\mathrm{Kx} \mathrm{Ky} \mathrm{Kz}$ Ss Por

$1.50008 \mathrm{e}+01$ 1.50008e+01 1.50008e+00 1.00000e-09 2.12000e-01 $1.50008 \mathrm{e}+011.50008 \mathrm{e}+01$ 1.50008e+00 1.00000e-09 2.12000e-01 $1.50008 \mathrm{e}+011.50008 \mathrm{e}+01$ 1.50008e+00 1.00000e-09 2.12000e-01 $1.50008 \mathrm{e}+01$ 1.50008e+01 1.50008e+00 1.00000e-09 2.12000e-01 $1.50008 \mathrm{e}+01$ 1.50008e+01 1.50008e+00 1.00000e-09 2.12000e-01 $1.00000 \mathrm{e}-05$ 1.00000e-05 1.00000e-06 1.00000e-09 1.00000e-01 $1.00000 \mathrm{e}+001.00000 \mathrm{e}+001.00000 \mathrm{e}-011.00000 \mathrm{e}-091.00000 \mathrm{e}-01$ Element: 11815 \# of layers: 7

$\mathrm{Kx} \mathrm{Ky} \mathrm{Kz}$ Ss Por

$1.50008 \mathrm{e}+01$ 1.50008e+01 1.50008e+00 1.00000e-09 2.12000e-01 $1.50008 \mathrm{e}+011.50008 \mathrm{e}+011.50008 \mathrm{e}+001.00000 \mathrm{e}-092.12000 \mathrm{e}-01$ $1.50008 \mathrm{e}+011.50008 \mathrm{e}+01$ 1.50008e+00 1.00000e-09 2.12000e-01 $1.50008 \mathrm{e}+011.50008 \mathrm{e}+011.50008 \mathrm{e}+001.00000 \mathrm{e}-092.12000 \mathrm{e}-01$ $1.50008 \mathrm{e}+011.50008 \mathrm{e}+011.50008 \mathrm{e}+001.00000 \mathrm{e}-092.12000 \mathrm{e}-01$ $1.00000 \mathrm{e}-05$ 1.00000e-05 1.00000e-06 1.00000e-09 1.00000e-01 $1.00000 \mathrm{e}+001.00000 \mathrm{e}+001.00000 \mathrm{e}-011.00000 \mathrm{e}-091.00000 \mathrm{e}-01$ Element: 11816 \# of layers: 7

Kx Ky Kz Ss Por

$1.41413 \mathrm{e}+01$ 1.41413e+01 1.41413e+00 1.00000e-09 2.12000e-01 $1.41413 \mathrm{e}+011.41413 \mathrm{e}+011.41413 \mathrm{e}+001.00000 \mathrm{e}-09$ 2.12000e-01 $1.41413 \mathrm{e}+011.41413 \mathrm{e}+011.41413 \mathrm{e}+001.00000 \mathrm{e}-09$ 2.12000e-01 $1.41413 \mathrm{e}+011.41413 \mathrm{e}+01$ 1.41413e+00 1.00000e-09 2.12000e-01 $1.41413 \mathrm{e}+01$ 1.41413e+01 1.41413e+00 1.00000e-09 2.12000e-01 $1.00000 \mathrm{e}-051.00000 \mathrm{e}-051.00000 \mathrm{e}-061.00000 \mathrm{e}-091.00000 \mathrm{e}-01$ $1.00000 \mathrm{e}+001.00000 \mathrm{e}+001.00000 \mathrm{e}-011.00000 \mathrm{e}-091.00000 \mathrm{e}-01$ Element: 11817 \# of layers: 7

Kx Ky Kz Ss Por

$1.41413 e+011.41413 e+011.41413 e+001.00000 e-092.12000 e-01$ 
1.41413e+01 1.41413e+01 1.41413e+00 1.00000e-09 2.12000e-01 $1.41413 \mathrm{e}+01$ 1.41413e+01 1.41413e+00 1.00000e-09 2.12000e-01 $1.41413 \mathrm{e}+01$ 1.41413e+01 1.41413e+00 1.00000e-09 2.12000e-01 $1.41413 \mathrm{e}+01$ 1.41413e+01 1.41413e+00 1.00000e-09 2.12000e-01 $1.00000 \mathrm{e}-05$ 1.00000e-05 1.00000e-06 1.00000e-09 1.00000e-01 $1.00000 \mathrm{e}+001.00000 \mathrm{e}+001.00000 \mathrm{e}-011.00000 \mathrm{e}-091.00000 \mathrm{e}-01$ Element: 11818 \# of layers: 7

$\mathrm{Kx} \mathrm{Ky} \mathrm{Kz}$ Ss Por

$1.50008 \mathrm{e}+01$ 1.50008e+01 1.50008e+00 1.00000e-09 2.12000e-01

$1.50008 \mathrm{e}+011.50008 \mathrm{e}+011.50008 \mathrm{e}+001.00000 \mathrm{e}-092.12000 \mathrm{e}-01$

$1.50008 \mathrm{e}+01$ 1.50008e+01 1.50008e+00 1.00000e-09 2.12000e-01

$1.50008 \mathrm{e}+011.50008 \mathrm{e}+011.50008 \mathrm{e}+001.00000 \mathrm{e}-092.12000 \mathrm{e}-01$

$1.50008 \mathrm{e}+011.50008 \mathrm{e}+011.50008 \mathrm{e}+001.00000 \mathrm{e}-092.12000 \mathrm{e}-01$

$1.00000 \mathrm{e}-05$ 1.00000e-05 1.00000e-06 1.00000e-09 1.00000e-01

$1.00000 \mathrm{e}+001.00000 \mathrm{e}+001.00000 \mathrm{e}-01$ 1.00000e-09 1.00000e-01

Element: 11819 \# of layers: 7

$\mathrm{Kx} \mathrm{Ky} \mathrm{Kz}$ Ss Por

$1.50008 \mathrm{e}+01$ 1.50008e+01 1.50008e+00 1.00000e-09 2.12000e-01

$1.50008 \mathrm{e}+01$ 1.50008e+01 1.50008e+00 1.00000e-09 2.12000e-01

$1.50008 \mathrm{e}+011.50008 \mathrm{e}+011.50008 \mathrm{e}+001.00000 \mathrm{e}-092.12000 \mathrm{e}-01$

$1.50008 \mathrm{e}+011.50008 \mathrm{e}+011.50008 \mathrm{e}+001.00000 \mathrm{e}-092.12000 \mathrm{e}-01$

$1.50008 \mathrm{e}+01$ 1.50008e+01 1.50008e+00 1.00000e-09 2.12000e-01

$1.00000 \mathrm{e}-05$ 1.00000e-05 1.00000e-06 1.00000e-09 1.00000e-01

$1.00000 \mathrm{e}+001.00000 \mathrm{e}+001.00000 \mathrm{e}-011.00000 \mathrm{e}-09$ 1.00000e-01

Element: 11820 \# of layers: 7

$\mathrm{Kx} \mathrm{Ky} \mathrm{Kz}$ Ss Por

$1.28010 \mathrm{e}+011.28010 \mathrm{e}+011.28010 \mathrm{e}+001.00000 \mathrm{e}-092.12000 \mathrm{e}-01$

$1.28010 \mathrm{e}+011.28010 \mathrm{e}+011.28010 \mathrm{e}+001.00000 \mathrm{e}-092.12000 \mathrm{e}-01$

$1.28010 \mathrm{e}+011.28010 \mathrm{e}+011.28010 \mathrm{e}+001.00000 \mathrm{e}-092.12000 \mathrm{e}-01$

$1.28010 \mathrm{e}+011.28010 \mathrm{e}+011.28010 \mathrm{e}+001.00000 \mathrm{e}-092.12000 \mathrm{e}-01$

$1.28010 \mathrm{e}+011.28010 \mathrm{e}+01 \quad 1.28010 \mathrm{e}+001.00000 \mathrm{e}-092.12000 \mathrm{e}-01$

$1.00000 \mathrm{e}-05$ 1.00000e-05 1.00000e-06 1.00000e-09 1.00000e-01

$1.00000 \mathrm{e}+001.00000 \mathrm{e}+001.00000 \mathrm{e}-011.00000 \mathrm{e}-091.00000 \mathrm{e}-01$

Element: 11821 \# of layers: 7

$\mathrm{Kx} \mathrm{Ky} \mathrm{Kz}$ Ss Por

$1.28010 \mathrm{e}+011.28010 \mathrm{e}+011.28010 \mathrm{e}+001.00000 \mathrm{e}-092.12000 \mathrm{e}-01$

$1.28010 \mathrm{e}+011.28010 \mathrm{e}+011.28010 \mathrm{e}+001.00000 \mathrm{e}-092.12000 \mathrm{e}-01$

$1.28010 \mathrm{e}+011.28010 \mathrm{e}+011.28010 \mathrm{e}+001.00000 \mathrm{e}-092.12000 \mathrm{e}-01$

$1.28010 \mathrm{e}+011.28010 \mathrm{e}+011.28010 \mathrm{e}+001.00000 \mathrm{e}-092.12000 \mathrm{e}-01$

$1.28010 \mathrm{e}+011.28010 \mathrm{e}+011.28010 \mathrm{e}+001.00000 \mathrm{e}-092.12000 \mathrm{e}-01$

$1.00000 \mathrm{e}-05$ 1.00000e-05 1.00000e-06 1.00000e-09 1.00000e-01

$1.00000 \mathrm{e}+001.00000 \mathrm{e}+001.00000 \mathrm{e}-011.00000 \mathrm{e}-091.00000 \mathrm{e}-01$

Element: 11822 \# of layers: 7

$\mathrm{Kx} \mathrm{Ky} \mathrm{Kz}$ Ss Por

$1.28010 \mathrm{e}+011.28010 \mathrm{e}+01$ 1.28010e+00 1.00000e-09 2.12000e-01

$1.28010 \mathrm{e}+011.28010 \mathrm{e}+011.28010 \mathrm{e}+001.00000 \mathrm{e}-092.12000 \mathrm{e}-01$ 
$1.28010 \mathrm{e}+011.28010 \mathrm{e}+011.28010 \mathrm{e}+001.00000 \mathrm{e}-092.12000 \mathrm{e}-01$ $1.28010 \mathrm{e}+011.28010 \mathrm{e}+011.28010 \mathrm{e}+001.00000 \mathrm{e}-092.12000 \mathrm{e}-01$ $1.28010 \mathrm{e}+011.28010 \mathrm{e}+011.28010 \mathrm{e}+001.00000 \mathrm{e}-092.12000 \mathrm{e}-01$ $1.00000 \mathrm{e}-05$ 1.00000e-05 1.00000e-06 1.00000e-09 1.00000e-01 $1.00000 \mathrm{e}+001.00000 \mathrm{e}+001.00000 \mathrm{e}-01$ 1.00000e-09 1.00000e-01 Element: 11823 \# of layers: 7

$\mathrm{Kx} \mathrm{Ky} \mathrm{Kz}$ Ss Por

$1.35059 \mathrm{e}+01$ 1.35059e+01 1.35059e+00 1.00000e-09 2.12000e-01 $1.35059 \mathrm{e}+01$ 1.35059e+01 1.35059e+00 1.00000e-09 2.12000e-01 $1.35059 \mathrm{e}+01$ 1.35059e+01 1.35059e+00 1.00000e-09 2.12000e-01 $1.35059 \mathrm{e}+01$ 1.35059e+01 1.35059e+00 1.00000e-09 2.12000e-01 $1.35059 \mathrm{e}+011.35059 \mathrm{e}+011.35059 \mathrm{e}+001.00000 \mathrm{e}-092.12000 \mathrm{e}-01$ $1.00000 \mathrm{e}-05$ 1.00000e-05 1.00000e-06 1.00000e-09 1.00000e-01 $1.00000 \mathrm{e}+001.00000 \mathrm{e}+001.00000 \mathrm{e}-011.00000 \mathrm{e}-09$ 1.00000e-01 Element: 11824 \# of layers: 7

Kx Ky Kz Ss Por

$1.35059 \mathrm{e}+01$ 1.35059e+01 1.35059e+00 1.00000e-09 2.12000e-01 $1.35059 \mathrm{e}+01$ 1.35059e+01 1.35059e+00 1.00000e-09 2.12000e-01 $1.35059 \mathrm{e}+01$ 1.35059e+01 1.35059e+00 1.00000e-09 2.12000e-01 $1.35059 \mathrm{e}+01$ 1.35059e+01 1.35059e+00 1.00000e-09 2.12000e-01 $1.35059 \mathrm{e}+01$ 1.35059e+01 1.35059e+00 1.00000e-09 2.12000e-01 $1.00000 \mathrm{e}-05$ 1.00000e-05 1.00000e-06 1.00000e-09 1.00000e-01 $1.00000 \mathrm{e}+001.00000 \mathrm{e}+001.00000 \mathrm{e}-01$ 1.00000e-09 1.00000e-01 Element: 11825 \# of layers: 7

Kx Ky Kz Ss Por

$1.41413 \mathrm{e}+01$ 1.41413e+01 1.41413e+00 1.00000e-09 2.12000e-01 $1.41413 \mathrm{e}+01$ 1.41413e+01 1.41413e+00 1.00000e-09 2.12000e-01 $1.41413 \mathrm{e}+011.41413 \mathrm{e}+01$ 1.41413e+00 1.00000e-09 2.12000e-01 $1.41413 \mathrm{e}+011.41413 \mathrm{e}+011.41413 \mathrm{e}+001.00000 \mathrm{e}-092.12000 \mathrm{e}-01$ $1.41413 \mathrm{e}+011.41413 \mathrm{e}+011.41413 \mathrm{e}+001.00000 \mathrm{e}-092.12000 \mathrm{e}-01$ $1.00000 \mathrm{e}-05$ 1.00000e-05 1.00000e-06 1.00000e-09 1.00000e-01 $1.00000 \mathrm{e}+001.00000 \mathrm{e}+001.00000 \mathrm{e}-011.00000 \mathrm{e}-091.00000 \mathrm{e}-01$ Element: 11826 \# of layers: 7

$\mathrm{Kx} \mathrm{Ky} \mathrm{Kz}$ Ss Por

$1.50008 \mathrm{e}+01$ 1.50008e+01 1.50008e+00 1.00000e-09 2.12000e-01 $1.50008 \mathrm{e}+011.50008 \mathrm{e}+011.50008 \mathrm{e}+001.00000 \mathrm{e}-092.12000 \mathrm{e}-01$ $1.50008 \mathrm{e}+011.50008 \mathrm{e}+01$ 1.50008e+00 1.00000e-09 2.12000e-01 $1.50008 \mathrm{e}+011.50008 \mathrm{e}+011.50008 \mathrm{e}+001.00000 \mathrm{e}-092.12000 \mathrm{e}-01$ $1.50008 \mathrm{e}+011.50008 \mathrm{e}+011.50008 \mathrm{e}+001.00000 \mathrm{e}-092.12000 \mathrm{e}-01$ $1.00000 \mathrm{e}-05$ 1.00000e-05 1.00000e-06 1.00000e-09 1.00000e-01 $1.00000 \mathrm{e}+001.00000 \mathrm{e}+001.00000 \mathrm{e}-011.00000 \mathrm{e}-091.00000 \mathrm{e}-01$ Element: 11827 \# of layers: 7

$\mathrm{Kx} \mathrm{Ky} \mathrm{Kz}$ Ss Por

$1.28010 \mathrm{e}+01$ 1.28010e+01 1.28010e+00 1.00000e-09 2.12000e-01 $1.28010 \mathrm{e}+011.28010 \mathrm{e}+011.28010 \mathrm{e}+001.00000 \mathrm{e}-092.12000 \mathrm{e}-01$ $1.28010 \mathrm{e}+011.28010 \mathrm{e}+011.28010 \mathrm{e}+001.00000 \mathrm{e}-092.12000 \mathrm{e}-01$ 
$1.28010 \mathrm{e}+011.28010 \mathrm{e}+011.28010 \mathrm{e}+001.00000 \mathrm{e}-092.12000 \mathrm{e}-01$ $1.28010 \mathrm{e}+011.28010 \mathrm{e}+011.28010 \mathrm{e}+001.00000 \mathrm{e}-092.12000 \mathrm{e}-01$ $1.00000 \mathrm{e}-05$ 1.00000e-05 1.00000e-06 1.00000e-09 1.00000e-01 $1.00000 \mathrm{e}+001.00000 \mathrm{e}+001.00000 \mathrm{e}-011.00000 \mathrm{e}-091.00000 \mathrm{e}-01$ Element: 11828 \# of layers: 7

$\mathrm{Kx} \mathrm{Ky} \mathrm{Kz}$ Ss Por

$1.08221 \mathrm{e}+011.08221 \mathrm{e}+011.08221 \mathrm{e}+001.00000 \mathrm{e}-092.12000 \mathrm{e}-01$ $1.08221 \mathrm{e}+011.08221 \mathrm{e}+011.08221 \mathrm{e}+001.00000 \mathrm{e}-092.12000 \mathrm{e}-01$ $1.08221 \mathrm{e}+011.08221 \mathrm{e}+011.08221 \mathrm{e}+001.00000 \mathrm{e}-092.12000 \mathrm{e}-01$ $1.08221 \mathrm{e}+011.08221 \mathrm{e}+011.08221 \mathrm{e}+001.00000 \mathrm{e}-092.12000 \mathrm{e}-01$ $1.08221 \mathrm{e}+011.08221 \mathrm{e}+011.08221 \mathrm{e}+001.00000 \mathrm{e}-092.12000 \mathrm{e}-01$ $1.00000 \mathrm{e}-05$ 1.00000e-05 1.00000e-06 1.00000e-09 1.00000e-01 $1.00000 \mathrm{e}+001.00000 \mathrm{e}+001.00000 \mathrm{e}-011.00000 \mathrm{e}-09$ 1.00000e-01 Element: 11829 \# of layers: 7

$\mathrm{Kx} \mathrm{Ky} \mathrm{Kz}$ Ss Por

$1.08221 \mathrm{e}+011.08221 \mathrm{e}+011.08221 \mathrm{e}+001.00000 \mathrm{e}-092.12000 \mathrm{e}-01$ $1.08221 \mathrm{e}+011.08221 \mathrm{e}+011.08221 \mathrm{e}+001.00000 \mathrm{e}-092.12000 \mathrm{e}-01$ $1.08221 \mathrm{e}+011.08221 \mathrm{e}+011.08221 \mathrm{e}+001.00000 \mathrm{e}-092.12000 \mathrm{e}-01$ $1.08221 \mathrm{e}+011.08221 \mathrm{e}+011.08221 \mathrm{e}+001.00000 \mathrm{e}-092.12000 \mathrm{e}-01$ $1.08221 \mathrm{e}+011.08221 \mathrm{e}+011.08221 \mathrm{e}+001.00000 \mathrm{e}-092.12000 \mathrm{e}-01$ $1.00000 \mathrm{e}-05$ 1.00000e-05 1.00000e-06 1.00000e-09 1.00000e-01 $1.00000 \mathrm{e}+001.00000 \mathrm{e}+001.00000 \mathrm{e}-01$ 1.00000e-09 1.00000e-01 Element: 11830 \# of layers: 7

$\mathrm{Kx} \mathrm{Ky} \mathrm{Kz}$ Ss Por

$1.08221 \mathrm{e}+011.08221 \mathrm{e}+011.08221 \mathrm{e}+001.00000 \mathrm{e}-092.12000 \mathrm{e}-01$ $1.08221 \mathrm{e}+011.08221 \mathrm{e}+011.08221 \mathrm{e}+001.00000 \mathrm{e}-092.12000 \mathrm{e}-01$ $1.08221 \mathrm{e}+011.08221 \mathrm{e}+011.08221 \mathrm{e}+001.00000 \mathrm{e}-092.12000 \mathrm{e}-01$ $1.08221 \mathrm{e}+011.08221 \mathrm{e}+011.08221 \mathrm{e}+001.00000 \mathrm{e}-092.12000 \mathrm{e}-01$ $1.08221 \mathrm{e}+011.08221 \mathrm{e}+011.08221 \mathrm{e}+001.00000 \mathrm{e}-092.12000 \mathrm{e}-01$ $1.00000 \mathrm{e}-051.00000 \mathrm{e}-051.00000 \mathrm{e}-061.00000 \mathrm{e}-091.00000 \mathrm{e}-01$ $1.00000 \mathrm{e}+001.00000 \mathrm{e}+001.00000 \mathrm{e}-01$ 1.00000e-09 1.00000e-01 Element: 11831 \# of layers: 7

Kx Ky Kz Ss Por

$1.08221 \mathrm{e}+011.08221 \mathrm{e}+011.08221 \mathrm{e}+001.00000 \mathrm{e}-092.12000 \mathrm{e}-01$ $1.08221 \mathrm{e}+011.08221 \mathrm{e}+011.08221 \mathrm{e}+001.00000 \mathrm{e}-092.12000 \mathrm{e}-01$ $1.08221 \mathrm{e}+011.08221 \mathrm{e}+011.08221 \mathrm{e}+001.00000 \mathrm{e}-092.12000 \mathrm{e}-01$ $1.08221 \mathrm{e}+011.08221 \mathrm{e}+011.08221 \mathrm{e}+001.00000 \mathrm{e}-092.12000 \mathrm{e}-01$ $1.08221 \mathrm{e}+011.08221 \mathrm{e}+011.08221 \mathrm{e}+001.00000 \mathrm{e}-092.12000 \mathrm{e}-01$ $1.00000 \mathrm{e}-05$ 1.00000e-05 1.00000e-06 1.00000e-09 1.00000e-01 $1.00000 \mathrm{e}+001.00000 \mathrm{e}+00$ 1.00000e-01 1.00000e-09 1.00000e-01 Element: 11832 \# of layers: 7

$\mathrm{Kx} \mathrm{Ky} \mathrm{Kz}$ Ss Por $1.08221 \mathrm{e}+011.08221 \mathrm{e}+01$ 1.08221e+00 1.00000e-09 2.12000e-01 $1.08221 \mathrm{e}+011.08221 \mathrm{e}+01$ 1.08221e+00 1.00000e-09 2.12000e-01 $1.08221 \mathrm{e}+011.08221 \mathrm{e}+011.08221 \mathrm{e}+001.00000 \mathrm{e}-092.12000 \mathrm{e}-01$ $1.08221 \mathrm{e}+011.08221 \mathrm{e}+011.08221 \mathrm{e}+001.00000 \mathrm{e}-092.12000 \mathrm{e}-01$ 
$1.08221 \mathrm{e}+011.08221 \mathrm{e}+011.08221 \mathrm{e}+001.00000 \mathrm{e}-092.12000 \mathrm{e}-01$ $1.00000 \mathrm{e}-05$ 1.00000e-05 1.00000e-06 1.00000e-09 1.00000e-01 $1.00000 \mathrm{e}+001.00000 \mathrm{e}+001.00000 \mathrm{e}-011.00000 \mathrm{e}-09$ 1.00000e-01

Element: 11833 \# of layers: 7

$\mathrm{Kx} \mathrm{Ky} \mathrm{Kz}$ Ss Por

$1.08221 \mathrm{e}+011.08221 \mathrm{e}+011.08221 \mathrm{e}+001.00000 \mathrm{e}-092.12000 \mathrm{e}-01$ $1.08221 \mathrm{e}+011.08221 \mathrm{e}+011.08221 \mathrm{e}+001.00000 \mathrm{e}-092.12000 \mathrm{e}-01$ $1.08221 \mathrm{e}+011.08221 \mathrm{e}+011.08221 \mathrm{e}+001.00000 \mathrm{e}-092.12000 \mathrm{e}-01$ $1.08221 \mathrm{e}+011.08221 \mathrm{e}+011.08221 \mathrm{e}+001.00000 \mathrm{e}-092.12000 \mathrm{e}-01$ $1.08221 \mathrm{e}+011.08221 \mathrm{e}+011.08221 \mathrm{e}+001.00000 \mathrm{e}-092.12000 \mathrm{e}-01$ $1.00000 \mathrm{e}-05$ 1.00000e-05 1.00000e-06 1.00000e-09 1.00000e-01 $1.00000 \mathrm{e}+001.00000 \mathrm{e}+001.00000 \mathrm{e}-011.00000 \mathrm{e}-091.00000 \mathrm{e}-01$ Element: 11834 \# of layers: 7

$\mathrm{Kx} \mathrm{Ky} \mathrm{Kz}$ Ss Por

$1.08221 \mathrm{e}+011.08221 \mathrm{e}+011.08221 \mathrm{e}+001.00000 \mathrm{e}-092.12000 \mathrm{e}-01$ $1.08221 \mathrm{e}+011.08221 \mathrm{e}+011.08221 \mathrm{e}+001.00000 \mathrm{e}-092.12000 \mathrm{e}-01$ $1.08221 \mathrm{e}+011.08221 \mathrm{e}+011.08221 \mathrm{e}+001.00000 \mathrm{e}-092.12000 \mathrm{e}-01$ $1.08221 \mathrm{e}+011.08221 \mathrm{e}+011.08221 \mathrm{e}+001.00000 \mathrm{e}-092.12000 \mathrm{e}-01$ $1.08221 \mathrm{e}+011.08221 \mathrm{e}+011.08221 \mathrm{e}+001.00000 \mathrm{e}-092.12000 \mathrm{e}-01$ $1.00000 \mathrm{e}-051.00000 \mathrm{e}-05$ 1.00000e-06 1.00000e-09 1.00000e-01 $1.00000 \mathrm{e}+001.00000 \mathrm{e}+001.00000 \mathrm{e}-011.00000 \mathrm{e}-091.00000 \mathrm{e}-01$ Element: 11835 \# of layers: 7

$\mathrm{Kx} \mathrm{Ky} \mathrm{Kz}$ Ss Por

$1.08221 \mathrm{e}+011.08221 \mathrm{e}+011.08221 \mathrm{e}+001.00000 \mathrm{e}-092.12000 \mathrm{e}-01$ $1.08221 \mathrm{e}+011.08221 \mathrm{e}+011.08221 \mathrm{e}+001.00000 \mathrm{e}-092.12000 \mathrm{e}-01$ $1.08221 \mathrm{e}+011.08221 \mathrm{e}+011.08221 \mathrm{e}+001.00000 \mathrm{e}-092.12000 \mathrm{e}-01$ $1.08221 \mathrm{e}+011.08221 \mathrm{e}+011.08221 \mathrm{e}+001.00000 \mathrm{e}-092.12000 \mathrm{e}-01$ $1.08221 \mathrm{e}+011.08221 \mathrm{e}+011.08221 \mathrm{e}+001.00000 \mathrm{e}-092.12000 \mathrm{e}-01$ $1.00000 \mathrm{e}-05$ 1.00000e-05 1.00000e-06 1.00000e-09 1.00000e-01 $1.00000 \mathrm{e}+001.00000 \mathrm{e}+001.00000 \mathrm{e}-011.00000 \mathrm{e}-091.00000 \mathrm{e}-01$ Element: 11836 \# of layers: 7

$\mathrm{Kx} \mathrm{Ky} \mathrm{Kz}$ Ss Por

$1.08221 \mathrm{e}+011.08221 \mathrm{e}+011.08221 \mathrm{e}+001.00000 \mathrm{e}-092.12000 \mathrm{e}-01$ $1.08221 \mathrm{e}+011.08221 \mathrm{e}+011.08221 \mathrm{e}+001.00000 \mathrm{e}-092.12000 \mathrm{e}-01$ $1.08221 \mathrm{e}+011.08221 \mathrm{e}+011.08221 \mathrm{e}+001.00000 \mathrm{e}-092.12000 \mathrm{e}-01$ $1.08221 \mathrm{e}+011.08221 \mathrm{e}+011.08221 \mathrm{e}+001.00000 \mathrm{e}-092.12000 \mathrm{e}-01$ $1.08221 \mathrm{e}+011.08221 \mathrm{e}+011.08221 \mathrm{e}+001.00000 \mathrm{e}-092.12000 \mathrm{e}-01$ $1.00000 \mathrm{e}-051.00000 \mathrm{e}-05$ 1.00000e-06 1.00000e-09 1.00000e-01 $1.00000 \mathrm{e}+001.00000 \mathrm{e}+001.00000 \mathrm{e}-011.00000 \mathrm{e}-091.00000 \mathrm{e}-01$ Element: 11837 \# of layers: 7

$\mathrm{Kx} \mathrm{Ky} \mathrm{Kz}$ Ss Por $1.08221 \mathrm{e}+011.08221 \mathrm{e}+011.08221 \mathrm{e}+001.00000 \mathrm{e}-092.12000 \mathrm{e}-01$ $1.08221 \mathrm{e}+011.08221 \mathrm{e}+011.08221 \mathrm{e}+001.00000 \mathrm{e}-092.12000 \mathrm{e}-01$ $1.08221 \mathrm{e}+011.08221 \mathrm{e}+01$ 1.08221e+00 1.00000e-09 2.12000e-01 $1.08221 \mathrm{e}+011.08221 \mathrm{e}+011.08221 \mathrm{e}+001.00000 \mathrm{e}-092.12000 \mathrm{e}-01$ $1.08221 \mathrm{e}+011.08221 \mathrm{e}+011.08221 \mathrm{e}+001.00000 \mathrm{e}-092.12000 \mathrm{e}-01$ 
$1.00000 \mathrm{e}-05$ 1.00000e-05 1.00000e-06 1.00000e-09 1.00000e-01 $1.00000 \mathrm{e}+001.00000 \mathrm{e}+001.00000 \mathrm{e}-01$ 1.00000e-09 1.00000e-01 Element: 11838 \# of layers: 7

Kx Ky Kz Ss Por

$1.03214 \mathrm{e}+011.03214 \mathrm{e}+011.03214 \mathrm{e}+001.00000 \mathrm{e}-092.12000 \mathrm{e}-01$ $1.03214 \mathrm{e}+011.03214 \mathrm{e}+011.03214 \mathrm{e}+001.00000 \mathrm{e}-092.12000 \mathrm{e}-01$ $1.03214 \mathrm{e}+011.03214 \mathrm{e}+011.03214 \mathrm{e}+001.00000 \mathrm{e}-092.12000 \mathrm{e}-01$ $1.03214 \mathrm{e}+011.03214 \mathrm{e}+011.03214 \mathrm{e}+001.00000 \mathrm{e}-092.12000 \mathrm{e}-01$ $1.03214 \mathrm{e}+011.03214 \mathrm{e}+011.03214 \mathrm{e}+001.00000 \mathrm{e}-092.12000 \mathrm{e}-01$ $1.00000 \mathrm{e}-05$ 1.00000e-05 1.00000e-06 1.00000e-09 1.00000e-01 $1.00000 \mathrm{e}+001.00000 \mathrm{e}+001.00000 \mathrm{e}-011.00000 \mathrm{e}-091.00000 \mathrm{e}-01$ Element: 11839 \# of layers: 7

$\mathrm{Kx} \mathrm{Ky} \mathrm{Kz}$ Ss Por

$1.03214 \mathrm{e}+011.03214 \mathrm{e}+011.03214 \mathrm{e}+001.00000 \mathrm{e}-092.12000 \mathrm{e}-01$ $1.03214 \mathrm{e}+011.03214 \mathrm{e}+011.03214 \mathrm{e}+001.00000 \mathrm{e}-092.12000 \mathrm{e}-01$ $1.03214 \mathrm{e}+011.03214 \mathrm{e}+01 \quad 1.03214 \mathrm{e}+001.00000 \mathrm{e}-092.12000 \mathrm{e}-01$ $1.03214 \mathrm{e}+011.03214 \mathrm{e}+01 \quad 1.03214 \mathrm{e}+001.00000 \mathrm{e}-092.12000 \mathrm{e}-01$ $1.03214 \mathrm{e}+011.03214 \mathrm{e}+011.03214 \mathrm{e}+001.00000 \mathrm{e}-092.12000 \mathrm{e}-01$ $1.00000 \mathrm{e}-05$ 1.00000e-05 1.00000e-06 1.00000e-09 1.00000e-01 $1.00000 \mathrm{e}+001.00000 \mathrm{e}+001.00000 \mathrm{e}-011.00000 \mathrm{e}-091.00000 \mathrm{e}-01$ Element: 11840 \# of layers: 7

$\mathrm{Kx} \mathrm{Ky} \mathrm{Kz}$ Ss Por

$1.03214 \mathrm{e}+011.03214 \mathrm{e}+011.03214 \mathrm{e}+001.00000 \mathrm{e}-092.12000 \mathrm{e}-01$ $1.03214 \mathrm{e}+011.03214 \mathrm{e}+01 \quad 1.03214 \mathrm{e}+001.00000 \mathrm{e}-092.12000 \mathrm{e}-01$ $1.03214 \mathrm{e}+011.03214 \mathrm{e}+011.03214 \mathrm{e}+001.00000 \mathrm{e}-092.12000 \mathrm{e}-01$ $1.03214 \mathrm{e}+011.03214 \mathrm{e}+011.03214 \mathrm{e}+001.00000 \mathrm{e}-092.12000 \mathrm{e}-01$ $1.03214 \mathrm{e}+011.03214 \mathrm{e}+011.03214 \mathrm{e}+001.00000 \mathrm{e}-092.12000 \mathrm{e}-01$ $1.00000 \mathrm{e}-05$ 1.00000e-05 1.00000e-06 1.00000e-09 1.00000e-01 $1.00000 \mathrm{e}+001.00000 \mathrm{e}+001.00000 \mathrm{e}-011.00000 \mathrm{e}-091.00000 \mathrm{e}-01$ Element: 11841 \# of layers: 7

$\mathrm{Kx} \mathrm{Ky} \mathrm{Kz}$ Ss Por

$1.03214 \mathrm{e}+011.03214 \mathrm{e}+011.03214 \mathrm{e}+001.00000 \mathrm{e}-092.12000 \mathrm{e}-01$ $1.03214 \mathrm{e}+011.03214 \mathrm{e}+011.03214 \mathrm{e}+001.00000 \mathrm{e}-092.12000 \mathrm{e}-01$ $1.03214 \mathrm{e}+011.03214 \mathrm{e}+011.03214 \mathrm{e}+001.00000 \mathrm{e}-092.12000 \mathrm{e}-01$ $1.03214 \mathrm{e}+011.03214 \mathrm{e}+01 \quad 1.03214 \mathrm{e}+001.00000 \mathrm{e}-092.12000 \mathrm{e}-01$ $1.03214 \mathrm{e}+011.03214 \mathrm{e}+011.03214 \mathrm{e}+001.00000 \mathrm{e}-092.12000 \mathrm{e}-01$ $1.00000 \mathrm{e}-05$ 1.00000e-05 1.00000e-06 1.00000e-09 1.00000e-01 $1.00000 \mathrm{e}+001.00000 \mathrm{e}+001.00000 \mathrm{e}-011.00000 \mathrm{e}-091.00000 \mathrm{e}-01$ Element: 11842 \# of layers: 7

$\mathrm{Kx} \mathrm{Ky} \mathrm{Kz}$ Ss Por $1.03214 \mathrm{e}+011.03214 \mathrm{e}+01 \quad 1.03214 \mathrm{e}+001.00000 \mathrm{e}-092.12000 \mathrm{e}-01$ $1.03214 \mathrm{e}+011.03214 \mathrm{e}+01 \quad 1.03214 \mathrm{e}+001.00000 \mathrm{e}-092.12000 \mathrm{e}-01$ $1.03214 \mathrm{e}+011.03214 \mathrm{e}+011.03214 \mathrm{e}+001.00000 \mathrm{e}-092.12000 \mathrm{e}-01$ $1.03214 \mathrm{e}+011.03214 \mathrm{e}+011.03214 \mathrm{e}+001.00000 \mathrm{e}-092.12000 \mathrm{e}-01$ $1.03214 \mathrm{e}+011.03214 \mathrm{e}+01 \quad 1.03214 \mathrm{e}+001.00000 \mathrm{e}-092.12000 \mathrm{e}-01$ $1.00000 \mathrm{e}-05$ 1.00000e-05 1.00000e-06 1.00000e-09 1.00000e-01 
$1.00000 \mathrm{e}+001.00000 \mathrm{e}+00$ 1.00000e-01 1.00000e-09 1.00000e-01

Element: 11843 \# of layers: 7

Kx Ky Kz Ss Por

$1.08221 \mathrm{e}+011.08221 \mathrm{e}+011.08221 \mathrm{e}+001.00000 \mathrm{e}-092.12000 \mathrm{e}-01$

$1.08221 \mathrm{e}+011.08221 \mathrm{e}+011.08221 \mathrm{e}+001.00000 \mathrm{e}-092.12000 \mathrm{e}-01$

$1.08221 \mathrm{e}+011.08221 \mathrm{e}+011.08221 \mathrm{e}+001.00000 \mathrm{e}-092.12000 \mathrm{e}-01$

$1.08221 \mathrm{e}+011.08221 \mathrm{e}+011.08221 \mathrm{e}+001.00000 \mathrm{e}-092.12000 \mathrm{e}-01$

$1.08221 \mathrm{e}+011.08221 \mathrm{e}+011.08221 \mathrm{e}+001.00000 \mathrm{e}-092.12000 \mathrm{e}-01$

$1.00000 \mathrm{e}-05$ 1.00000e-05 1.00000e-06 1.00000e-09 1.00000e-01

$1.00000 \mathrm{e}+001.00000 \mathrm{e}+001.00000 \mathrm{e}-011.00000 \mathrm{e}-091.00000 \mathrm{e}-01$

Element: 11844 \# of layers: 7

Kx Ky Kz Ss Por

$1.08221 \mathrm{e}+011.08221 \mathrm{e}+011.08221 \mathrm{e}+001.00000 \mathrm{e}-092.12000 \mathrm{e}-01$

$1.08221 \mathrm{e}+011.08221 \mathrm{e}+011.08221 \mathrm{e}+001.00000 \mathrm{e}-092.12000 \mathrm{e}-01$

$1.08221 \mathrm{e}+011.08221 \mathrm{e}+011.08221 \mathrm{e}+001.00000 \mathrm{e}-092.12000 \mathrm{e}-01$

$1.08221 \mathrm{e}+011.08221 \mathrm{e}+011.08221 \mathrm{e}+001.00000 \mathrm{e}-092.12000 \mathrm{e}-01$

$1.08221 \mathrm{e}+011.08221 \mathrm{e}+011.08221 \mathrm{e}+001.00000 \mathrm{e}-092.12000 \mathrm{e}-01$

$1.00000 \mathrm{e}-05$ 1.00000e-05 1.00000e-06 1.00000e-09 1.00000e-01

$1.00000 \mathrm{e}+001.00000 \mathrm{e}+001.00000 \mathrm{e}-01$ 1.00000e-09 1.00000e-01

Element: 11845 \# of layers: 7

$\mathrm{Kx} \mathrm{Ky} \mathrm{Kz}$ Ss Por

$1.03214 \mathrm{e}+011.03214 \mathrm{e}+011.03214 \mathrm{e}+001.00000 \mathrm{e}-092.12000 \mathrm{e}-01$

$1.03214 \mathrm{e}+011.03214 \mathrm{e}+011.03214 \mathrm{e}+001.00000 \mathrm{e}-092.12000 \mathrm{e}-01$

$1.03214 \mathrm{e}+011.03214 \mathrm{e}+01 \quad 1.03214 \mathrm{e}+001.00000 \mathrm{e}-092.12000 \mathrm{e}-01$

$1.03214 \mathrm{e}+011.03214 \mathrm{e}+011.03214 \mathrm{e}+001.00000 \mathrm{e}-092.12000 \mathrm{e}-01$

$1.03214 \mathrm{e}+011.03214 \mathrm{e}+011.03214 \mathrm{e}+001.00000 \mathrm{e}-092.12000 \mathrm{e}-01$

$1.00000 \mathrm{e}-05$ 1.00000e-05 1.00000e-06 1.00000e-09 1.00000e-01

$1.00000 \mathrm{e}+001.00000 \mathrm{e}+001.00000 \mathrm{e}-01$ 1.00000e-09 1.00000e-01

Element: 11846 \# of layers: 7

$\mathrm{Kx} \mathrm{Ky} \mathrm{Kz}$ Ss Por

$1.03214 \mathrm{e}+011.03214 \mathrm{e}+011.03214 \mathrm{e}+001.00000 \mathrm{e}-092.12000 \mathrm{e}-01$

$1.03214 \mathrm{e}+011.03214 \mathrm{e}+011.03214 \mathrm{e}+001.00000 \mathrm{e}-092.12000 \mathrm{e}-01$

$1.03214 \mathrm{e}+011.03214 \mathrm{e}+011.03214 \mathrm{e}+001.00000 \mathrm{e}-092.12000 \mathrm{e}-01$

$1.03214 \mathrm{e}+011.03214 \mathrm{e}+011.03214 \mathrm{e}+001.00000 \mathrm{e}-092.12000 \mathrm{e}-01$

$1.03214 \mathrm{e}+011.03214 \mathrm{e}+011.03214 \mathrm{e}+001.00000 \mathrm{e}-092.12000 \mathrm{e}-01$

$1.00000 \mathrm{e}-05$ 1.00000e-05 1.00000e-06 1.00000e-09 1.00000e-01

$1.00000 \mathrm{e}+001.00000 \mathrm{e}+001.00000 \mathrm{e}-011.00000 \mathrm{e}-091.00000 \mathrm{e}-01$

Element: 11847 \# of layers: 7

$\mathrm{Kx} \mathrm{Ky} \mathrm{Kz}$ Ss Por

$1.03214 \mathrm{e}+011.03214 \mathrm{e}+011.03214 \mathrm{e}+001.00000 \mathrm{e}-092.12000 \mathrm{e}-01$

$1.03214 \mathrm{e}+011.03214 \mathrm{e}+011.03214 \mathrm{e}+001.00000 \mathrm{e}-092.12000 \mathrm{e}-01$

$1.03214 \mathrm{e}+011.03214 \mathrm{e}+011.03214 \mathrm{e}+001.00000 \mathrm{e}-092.12000 \mathrm{e}-01$

$1.03214 \mathrm{e}+011.03214 \mathrm{e}+011.03214 \mathrm{e}+001.00000 \mathrm{e}-092.12000 \mathrm{e}-01$

$1.03214 \mathrm{e}+011.03214 \mathrm{e}+011.03214 \mathrm{e}+001.00000 \mathrm{e}-092.12000 \mathrm{e}-01$

$1.00000 \mathrm{e}-05$ 1.00000e-05 1.00000e-06 1.00000e-09 1.00000e-01

$1.00000 \mathrm{e}+001.00000 \mathrm{e}+001.00000 \mathrm{e}-011.00000 \mathrm{e}-091.00000 \mathrm{e}-01$ 
Element: 11848 \# of layers: 7

Kx Ky Kz Ss Por

$1.03214 \mathrm{e}+011.03214 \mathrm{e}+011.03214 \mathrm{e}+001.00000 \mathrm{e}-092.12000 \mathrm{e}-01$

$1.03214 \mathrm{e}+011.03214 \mathrm{e}+011.03214 \mathrm{e}+001.00000 \mathrm{e}-092.12000 \mathrm{e}-01$

$1.03214 \mathrm{e}+011.03214 \mathrm{e}+011.03214 \mathrm{e}+001.00000 \mathrm{e}-092.12000 \mathrm{e}-01$

$1.03214 \mathrm{e}+011.03214 \mathrm{e}+011.03214 \mathrm{e}+001.00000 \mathrm{e}-092.12000 \mathrm{e}-01$

$1.03214 \mathrm{e}+011.03214 \mathrm{e}+011.03214 \mathrm{e}+001.00000 \mathrm{e}-092.12000 \mathrm{e}-01$

$1.00000 \mathrm{e}-05$ 1.00000e-05 1.00000e-06 1.00000e-09 1.00000e-01

$1.00000 \mathrm{e}+001.00000 \mathrm{e}+001.00000 \mathrm{e}-011.00000 \mathrm{e}-091.00000 \mathrm{e}-01$

Element: 11849 \# of layers: 7

Kx Ky Kz Ss Por

$1.03214 \mathrm{e}+011.03214 \mathrm{e}+011.03214 \mathrm{e}+001.00000 \mathrm{e}-092.12000 \mathrm{e}-01$

$1.03214 \mathrm{e}+011.03214 \mathrm{e}+011.03214 \mathrm{e}+001.00000 \mathrm{e}-092.12000 \mathrm{e}-01$

$1.03214 \mathrm{e}+011.03214 \mathrm{e}+011.03214 \mathrm{e}+001.00000 \mathrm{e}-092.12000 \mathrm{e}-01$

$1.03214 \mathrm{e}+011.03214 \mathrm{e}+011.03214 \mathrm{e}+001.00000 \mathrm{e}-092.12000 \mathrm{e}-01$

$1.03214 \mathrm{e}+011.03214 \mathrm{e}+011.03214 \mathrm{e}+001.00000 \mathrm{e}-092.12000 \mathrm{e}-01$

$1.00000 \mathrm{e}-05$ 1.00000e-05 1.00000e-06 1.00000e-09 1.00000e-01

$1.00000 \mathrm{e}+001.00000 \mathrm{e}+001.00000 \mathrm{e}-011.00000 \mathrm{e}-091.00000 \mathrm{e}-01$

Element: 11850 \# of layers: 7

Kx Ky Kz Ss Por

$1.03214 \mathrm{e}+011.03214 \mathrm{e}+011.03214 \mathrm{e}+001.00000 \mathrm{e}-092.12000 \mathrm{e}-01$

$1.03214 \mathrm{e}+011.03214 \mathrm{e}+011.03214 \mathrm{e}+001.00000 \mathrm{e}-092.12000 \mathrm{e}-01$

$1.03214 \mathrm{e}+011.03214 \mathrm{e}+011.03214 \mathrm{e}+001.00000 \mathrm{e}-092.12000 \mathrm{e}-01$

$1.03214 \mathrm{e}+011.03214 \mathrm{e}+011.03214 \mathrm{e}+001.00000 \mathrm{e}-092.12000 \mathrm{e}-01$

$1.03214 \mathrm{e}+011.03214 \mathrm{e}+011.03214 \mathrm{e}+001.00000 \mathrm{e}-092.12000 \mathrm{e}-01$

$1.00000 \mathrm{e}-05$ 1.00000e-05 1.00000e-06 1.00000e-09 1.00000e-01

$1.00000 \mathrm{e}+001.00000 \mathrm{e}+001.00000 \mathrm{e}-011.00000 \mathrm{e}-091.00000 \mathrm{e}-01$

Element: 11851 \# of layers: 7

Kx Ky Kz Ss Por

$1.03214 \mathrm{e}+011.03214 \mathrm{e}+011.03214 \mathrm{e}+001.00000 \mathrm{e}-092.12000 \mathrm{e}-01$

$1.03214 \mathrm{e}+011.03214 \mathrm{e}+011.03214 \mathrm{e}+001.00000 \mathrm{e}-092.12000 \mathrm{e}-01$

$1.03214 \mathrm{e}+011.03214 \mathrm{e}+011.03214 \mathrm{e}+001.00000 \mathrm{e}-092.12000 \mathrm{e}-01$

$1.03214 \mathrm{e}+011.03214 \mathrm{e}+011.03214 \mathrm{e}+001.00000 \mathrm{e}-092.12000 \mathrm{e}-01$

$1.03214 \mathrm{e}+011.03214 \mathrm{e}+011.03214 \mathrm{e}+001.00000 \mathrm{e}-092.12000 \mathrm{e}-01$

$1.00000 \mathrm{e}-05$ 1.00000e-05 1.00000e-06 1.00000e-09 1.00000e-01

$1.00000 \mathrm{e}+001.00000 \mathrm{e}+001.00000 \mathrm{e}-011.00000 \mathrm{e}-091.00000 \mathrm{e}-01$

Element: 11852 \# of layers: 7

Kx Ky Kz Ss Por

$1.03214 \mathrm{e}+011.03214 \mathrm{e}+011.03214 \mathrm{e}+001.00000 \mathrm{e}-092.12000 \mathrm{e}-01$

$1.03214 \mathrm{e}+011.03214 \mathrm{e}+011.03214 \mathrm{e}+001.00000 \mathrm{e}-092.12000 \mathrm{e}-01$

$1.03214 \mathrm{e}+011.03214 \mathrm{e}+011.03214 \mathrm{e}+001.00000 \mathrm{e}-092.12000 \mathrm{e}-01$

$1.03214 \mathrm{e}+011.03214 \mathrm{e}+011.03214 \mathrm{e}+001.00000 \mathrm{e}-092.12000 \mathrm{e}-01$

$1.03214 \mathrm{e}+011.03214 \mathrm{e}+011.03214 \mathrm{e}+001.00000 \mathrm{e}-092.12000 \mathrm{e}-01$

$1.00000 \mathrm{e}-05$ 1.00000e-05 1.00000e-06 1.00000e-09 1.00000e-01

$1.00000 \mathrm{e}+001.00000 \mathrm{e}+001.00000 \mathrm{e}-011.00000 \mathrm{e}-091.00000 \mathrm{e}-01$

Element: 11853 \# of layers: 7 
$\mathrm{Kx} \mathrm{Ky} \mathrm{Kz}$ Ss Por

$1.03214 \mathrm{e}+011.03214 \mathrm{e}+011.03214 \mathrm{e}+001.00000 \mathrm{e}-092.12000 \mathrm{e}-01$

$1.03214 \mathrm{e}+011.03214 \mathrm{e}+011.03214 \mathrm{e}+001.00000 \mathrm{e}-092.12000 \mathrm{e}-01$

$1.03214 \mathrm{e}+011.03214 \mathrm{e}+01 \quad 1.03214 \mathrm{e}+001.00000 \mathrm{e}-092.12000 \mathrm{e}-01$

$1.03214 \mathrm{e}+011.03214 \mathrm{e}+011.03214 \mathrm{e}+001.00000 \mathrm{e}-092.12000 \mathrm{e}-01$

$1.03214 \mathrm{e}+011.03214 \mathrm{e}+011.03214 \mathrm{e}+001.00000 \mathrm{e}-092.12000 \mathrm{e}-01$

$1.00000 \mathrm{e}-05$ 1.00000e-05 1.00000e-06 1.00000e-09 1.00000e-01

$1.00000 \mathrm{e}+001.00000 \mathrm{e}+001.00000 \mathrm{e}-01$ 1.00000e-09 1.00000e-01

Element: 11854 \# of layers: 7

$\mathrm{Kx} \mathrm{Ky} \mathrm{Kz}$ Ss Por

$1.03214 \mathrm{e}+011.03214 \mathrm{e}+011.03214 \mathrm{e}+001.00000 \mathrm{e}-092.12000 \mathrm{e}-01$

$1.03214 \mathrm{e}+011.03214 \mathrm{e}+011.03214 \mathrm{e}+001.00000 \mathrm{e}-092.12000 \mathrm{e}-01$

$1.03214 \mathrm{e}+011.03214 \mathrm{e}+011.03214 \mathrm{e}+001.00000 \mathrm{e}-092.12000 \mathrm{e}-01$

$1.03214 \mathrm{e}+011.03214 \mathrm{e}+011.03214 \mathrm{e}+001.00000 \mathrm{e}-092.12000 \mathrm{e}-01$

$1.03214 \mathrm{e}+011.03214 \mathrm{e}+011.03214 \mathrm{e}+001.00000 \mathrm{e}-092.12000 \mathrm{e}-01$

$1.00000 \mathrm{e}-05$ 1.00000e-05 1.00000e-06 1.00000e-09 1.00000e-01

$1.00000 \mathrm{e}+001.00000 \mathrm{e}+001.00000 \mathrm{e}-011.00000 \mathrm{e}-091.00000 \mathrm{e}-01$

Element: 11855 \# of layers: 7

$\mathrm{Kx} \mathrm{Ky} \mathrm{Kz}$ Ss Por

$1.03214 \mathrm{e}+011.03214 \mathrm{e}+011.03214 \mathrm{e}+001.00000 \mathrm{e}-092.12000 \mathrm{e}-01$

$1.03214 \mathrm{e}+011.03214 \mathrm{e}+01 \quad 1.03214 \mathrm{e}+001.00000 \mathrm{e}-092.12000 \mathrm{e}-01$

$1.03214 \mathrm{e}+011.03214 \mathrm{e}+011.03214 \mathrm{e}+001.00000 \mathrm{e}-092.12000 \mathrm{e}-01$

$1.03214 \mathrm{e}+011.03214 \mathrm{e}+011.03214 \mathrm{e}+001.00000 \mathrm{e}-092.12000 \mathrm{e}-01$

$1.03214 \mathrm{e}+011.03214 \mathrm{e}+01 \quad 1.03214 \mathrm{e}+001.00000 \mathrm{e}-092.12000 \mathrm{e}-01$

$1.00000 \mathrm{e}-05$ 1.00000e-05 1.00000e-06 1.00000e-09 1.00000e-01

$1.00000 \mathrm{e}+001.00000 \mathrm{e}+001.00000 \mathrm{e}-01$ 1.00000e-09 1.00000e-01

Element: 11856 \# of layers: 7

$\mathrm{Kx} \mathrm{Ky} \mathrm{Kz}$ Ss Por

$1.03214 \mathrm{e}+011.03214 \mathrm{e}+011.03214 \mathrm{e}+001.00000 \mathrm{e}-092.12000 \mathrm{e}-01$

$1.03214 \mathrm{e}+011.03214 \mathrm{e}+011.03214 \mathrm{e}+001.00000 \mathrm{e}-092.12000 \mathrm{e}-01$

$1.03214 \mathrm{e}+011.03214 \mathrm{e}+011.03214 \mathrm{e}+001.00000 \mathrm{e}-092.12000 \mathrm{e}-01$

$1.03214 \mathrm{e}+011.03214 \mathrm{e}+011.03214 \mathrm{e}+001.00000 \mathrm{e}-092.12000 \mathrm{e}-01$

$1.03214 \mathrm{e}+011.03214 \mathrm{e}+011.03214 \mathrm{e}+001.00000 \mathrm{e}-092.12000 \mathrm{e}-01$

$1.00000 \mathrm{e}-051.00000 \mathrm{e}-051.00000 \mathrm{e}-061.00000 \mathrm{e}-091.00000 \mathrm{e}-01$

$1.00000 \mathrm{e}+001.00000 \mathrm{e}+001.00000 \mathrm{e}-01$ 1.00000e-09 1.00000e-01

Element: 11857 \# of layers: 7

Kx Ky Kz Ss Por

$1.08862 \mathrm{e}+011.08862 \mathrm{e}+011.08862 \mathrm{e}+001.00000 \mathrm{e}-092.12000 \mathrm{e}-01$

$1.08862 \mathrm{e}+01$ 1.08862e+01 1.08862e+00 1.00000e-09 2.12000e-01

$1.08862 \mathrm{e}+01$ 1.08862e+01 1.08862e+00 1.00000e-09 2.12000e-01

$1.08862 \mathrm{e}+011.08862 \mathrm{e}+01 \quad 1.08862 \mathrm{e}+001.00000 \mathrm{e}-092.12000 \mathrm{e}-01$

$1.08862 \mathrm{e}+01$ 1.08862e+01 1.08862e+00 1.00000e-09 2.12000e-01

$1.00000 \mathrm{e}-051.00000 \mathrm{e}-051.00000 \mathrm{e}-061.00000 \mathrm{e}-091.00000 \mathrm{e}-01$

$1.00000 \mathrm{e}+001.00000 \mathrm{e}+001.00000 \mathrm{e}-01$ 1.00000e-09 1.00000e-01

Element: 11858 \# of layers: 7

Kx Ky Kz Ss Por 
$1.08862 \mathrm{e}+011.08862 \mathrm{e}+01$ 1.08862e+00 1.00000e-09 2.12000e-01 $1.08862 \mathrm{e}+011.08862 \mathrm{e}+011.08862 \mathrm{e}+001.00000 \mathrm{e}-092.12000 \mathrm{e}-01$ $1.08862 \mathrm{e}+011.08862 \mathrm{e}+011.08862 \mathrm{e}+001.00000 \mathrm{e}-092.12000 \mathrm{e}-01$ $1.08862 \mathrm{e}+011.08862 \mathrm{e}+011.08862 \mathrm{e}+001.00000 \mathrm{e}-092.12000 \mathrm{e}-01$ $1.08862 \mathrm{e}+011.08862 \mathrm{e}+011.08862 \mathrm{e}+001.00000 \mathrm{e}-092.12000 \mathrm{e}-01$ $1.00000 \mathrm{e}-05$ 1.00000e-05 1.00000e-06 1.00000e-09 1.00000e-01 $1.00000 \mathrm{e}+001.00000 \mathrm{e}+001.00000 \mathrm{e}-011.00000 \mathrm{e}-091.00000 \mathrm{e}-01$ Element: 11859 \# of layers: 7

$\mathrm{Kx} \mathrm{Ky} \mathrm{Kz}$ Ss Por

$1.08862 \mathrm{e}+01$ 1.08862e+01 1.08862e+00 1.00000e-09 2.12000e-01 $1.08862 \mathrm{e}+011.08862 \mathrm{e}+011.08862 \mathrm{e}+001.00000 \mathrm{e}-092.12000 \mathrm{e}-01$ $1.08862 \mathrm{e}+011.08862 \mathrm{e}+011.08862 \mathrm{e}+001.00000 \mathrm{e}-092.12000 \mathrm{e}-01$ $1.08862 \mathrm{e}+011.08862 \mathrm{e}+011.08862 \mathrm{e}+001.00000 \mathrm{e}-092.12000 \mathrm{e}-01$ $1.08862 \mathrm{e}+01$ 1.08862e+01 1.08862e+00 1.00000e-09 2.12000e-01 $1.00000 \mathrm{e}-05$ 1.00000e-05 1.00000e-06 1.00000e-09 1.00000e-01 $1.00000 \mathrm{e}+001.00000 \mathrm{e}+001.00000 \mathrm{e}-011.00000 \mathrm{e}-091.00000 \mathrm{e}-01$ Element: 11860 \# of layers: 7

$\mathrm{Kx} \mathrm{Ky} \mathrm{Kz}$ Ss Por

$1.03214 \mathrm{e}+011.03214 \mathrm{e}+011.03214 \mathrm{e}+001.00000 \mathrm{e}-092.12000 \mathrm{e}-01$ $1.03214 \mathrm{e}+011.03214 \mathrm{e}+01 \quad 1.03214 \mathrm{e}+001.00000 \mathrm{e}-092.12000 \mathrm{e}-01$ $1.03214 \mathrm{e}+011.03214 \mathrm{e}+011.03214 \mathrm{e}+001.00000 \mathrm{e}-092.12000 \mathrm{e}-01$ $1.03214 \mathrm{e}+011.03214 \mathrm{e}+011.03214 \mathrm{e}+001.00000 \mathrm{e}-092.12000 \mathrm{e}-01$ $1.03214 \mathrm{e}+011.03214 \mathrm{e}+011.03214 \mathrm{e}+001.00000 \mathrm{e}-092.12000 \mathrm{e}-01$ $1.00000 \mathrm{e}-05$ 1.00000e-05 1.00000e-06 1.00000e-09 1.00000e-01 $1.00000 \mathrm{e}+001.00000 \mathrm{e}+001.00000 \mathrm{e}-011.00000 \mathrm{e}-091.00000 \mathrm{e}-01$ Element: 11861 \# of layers: 7

$\mathrm{Kx} \mathrm{Ky} \mathrm{Kz}$ Ss Por

$1.03214 \mathrm{e}+011.03214 \mathrm{e}+011.03214 \mathrm{e}+001.00000 \mathrm{e}-092.12000 \mathrm{e}-01$ $1.03214 \mathrm{e}+011.03214 \mathrm{e}+011.03214 \mathrm{e}+001.00000 \mathrm{e}-092.12000 \mathrm{e}-01$ $1.03214 \mathrm{e}+011.03214 \mathrm{e}+011.03214 \mathrm{e}+001.00000 \mathrm{e}-092.12000 \mathrm{e}-01$ $1.03214 \mathrm{e}+011.03214 \mathrm{e}+011.03214 \mathrm{e}+001.00000 \mathrm{e}-092.12000 \mathrm{e}-01$ $1.03214 \mathrm{e}+011.03214 \mathrm{e}+011.03214 \mathrm{e}+001.00000 \mathrm{e}-092.12000 \mathrm{e}-01$ $1.00000 \mathrm{e}-05$ 1.00000e-05 1.00000e-06 1.00000e-09 1.00000e-01 $1.00000 \mathrm{e}+001.00000 \mathrm{e}+001.00000 \mathrm{e}-011.00000 \mathrm{e}-091.00000 \mathrm{e}-01$ Element: 11862 \# of layers: 7

$\mathrm{Kx} \mathrm{Ky} \mathrm{Kz}$ Ss Por

$1.03214 \mathrm{e}+011.03214 \mathrm{e}+011.03214 \mathrm{e}+001.00000 \mathrm{e}-092.12000 \mathrm{e}-01$ $1.03214 \mathrm{e}+011.03214 \mathrm{e}+011.03214 \mathrm{e}+001.00000 \mathrm{e}-092.12000 \mathrm{e}-01$ $1.03214 \mathrm{e}+011.03214 \mathrm{e}+011.03214 \mathrm{e}+001.00000 \mathrm{e}-092.12000 \mathrm{e}-01$ $1.03214 \mathrm{e}+011.03214 \mathrm{e}+011.03214 \mathrm{e}+001.00000 \mathrm{e}-092.12000 \mathrm{e}-01$ $1.03214 \mathrm{e}+011.03214 \mathrm{e}+011.03214 \mathrm{e}+001.00000 \mathrm{e}-092.12000 \mathrm{e}-01$ $1.00000 \mathrm{e}-05$ 1.00000e-05 1.00000e-06 1.00000e-09 1.00000e-01 $1.00000 \mathrm{e}+001.00000 \mathrm{e}+001.00000 \mathrm{e}-01$ 1.00000e-09 1.00000e-01 Element: 11863 \# of layers: 7

$\mathrm{Kx} \mathrm{Ky} \mathrm{Kz}$ Ss Por $1.03214 \mathrm{e}+011.03214 \mathrm{e}+011.03214 \mathrm{e}+00$ 1.00000e-09 2.12000e-01 
$1.03214 \mathrm{e}+011.03214 \mathrm{e}+011.03214 \mathrm{e}+001.00000 \mathrm{e}-092.12000 \mathrm{e}-01$ $1.03214 \mathrm{e}+011.03214 \mathrm{e}+011.03214 \mathrm{e}+001.00000 \mathrm{e}-092.12000 \mathrm{e}-01$ $1.03214 \mathrm{e}+011.03214 \mathrm{e}+011.03214 \mathrm{e}+001.00000 \mathrm{e}-092.12000 \mathrm{e}-01$ $1.03214 \mathrm{e}+011.03214 \mathrm{e}+011.03214 \mathrm{e}+001.00000 \mathrm{e}-092.12000 \mathrm{e}-01$ $1.00000 \mathrm{e}-05$ 1.00000e-05 1.00000e-06 1.00000e-09 1.00000e-01 $1.00000 \mathrm{e}+001.00000 \mathrm{e}+001.00000 \mathrm{e}-011.00000 \mathrm{e}-091.00000 \mathrm{e}-01$ Element: 11864 \# of layers: 7

$\mathrm{Kx} \mathrm{Ky} \mathrm{Kz}$ Ss Por

$1.08862 \mathrm{e}+011.08862 \mathrm{e}+011.08862 \mathrm{e}+001.00000 \mathrm{e}-092.12000 \mathrm{e}-01$ $1.08862 \mathrm{e}+01$ 1.08862e+01 1.08862e+00 1.00000e-09 2.12000e-01 $1.08862 \mathrm{e}+011.08862 \mathrm{e}+011.08862 \mathrm{e}+001.00000 \mathrm{e}-092.12000 \mathrm{e}-01$ $1.08862 \mathrm{e}+011.08862 \mathrm{e}+011.08862 \mathrm{e}+001.00000 \mathrm{e}-092.12000 \mathrm{e}-01$ $1.08862 \mathrm{e}+01$ 1.08862e+01 1.08862e+00 1.00000e-09 2.12000e-01 $1.00000 \mathrm{e}-05$ 1.00000e-05 1.00000e-06 1.00000e-09 1.00000e-01 $1.00000 \mathrm{e}+001.00000 \mathrm{e}+001.00000 \mathrm{e}-01$ 1.00000e-09 1.00000e-01 Element: 11865 \# of layers: 7

$\mathrm{Kx} \mathrm{Ky} \mathrm{Kz}$ Ss Por $1.08862 \mathrm{e}+01$ 1.08862e+01 1.08862e+00 1.00000e-09 2.12000e-01 $1.08862 \mathrm{e}+01$ 1.08862e+01 1.08862e+00 1.00000e-09 2.12000e-01 $1.08862 \mathrm{e}+011.08862 \mathrm{e}+01 \quad 1.08862 \mathrm{e}+001.00000 \mathrm{e}-092.12000 \mathrm{e}-01$ $1.08862 \mathrm{e}+011.08862 \mathrm{e}+011.08862 \mathrm{e}+001.00000 \mathrm{e}-092.12000 \mathrm{e}-01$ $1.08862 \mathrm{e}+01$ 1.08862e+01 1.08862e+00 1.00000e-09 2.12000e-01 $1.00000 \mathrm{e}-05$ 1.00000e-05 1.00000e-06 1.00000e-09 1.00000e-01 $1.00000 \mathrm{e}+001.00000 \mathrm{e}+001.00000 \mathrm{e}-011.00000 \mathrm{e}-09$ 1.00000e-01 Element: 11866 \# of layers: 7

$\mathrm{Kx} \mathrm{Ky} \mathrm{Kz}$ Ss Por

$1.08862 \mathrm{e}+011.08862 \mathrm{e}+011.08862 \mathrm{e}+001.00000 \mathrm{e}-092.12000 \mathrm{e}-01$ $1.08862 \mathrm{e}+011.08862 \mathrm{e}+011.08862 \mathrm{e}+001.00000 \mathrm{e}-092.12000 \mathrm{e}-01$ $1.08862 \mathrm{e}+011.08862 \mathrm{e}+011.08862 \mathrm{e}+001.00000 \mathrm{e}-092.12000 \mathrm{e}-01$ $1.08862 \mathrm{e}+011.08862 \mathrm{e}+011.08862 \mathrm{e}+001.00000 \mathrm{e}-092.12000 \mathrm{e}-01$ $1.08862 \mathrm{e}+01$ 1.08862e+01 1.08862e+00 1.00000e-09 2.12000e-01 $1.00000 \mathrm{e}-05$ 1.00000e-05 1.00000e-06 1.00000e-09 1.00000e-01 $1.00000 \mathrm{e}+001.00000 \mathrm{e}+001.00000 \mathrm{e}-011.00000 \mathrm{e}-091.00000 \mathrm{e}-01$ Element: 11867 \# of layers: 7

$\mathrm{Kx} \mathrm{Ky} \mathrm{Kz}$ Ss Por

$1.08862 \mathrm{e}+011.08862 \mathrm{e}+011.08862 \mathrm{e}+001.00000 \mathrm{e}-092.12000 \mathrm{e}-01$ $1.08862 \mathrm{e}+011.08862 \mathrm{e}+011.08862 \mathrm{e}+001.00000 \mathrm{e}-092.12000 \mathrm{e}-01$ $1.08862 \mathrm{e}+011.08862 \mathrm{e}+011.08862 \mathrm{e}+001.00000 \mathrm{e}-092.12000 \mathrm{e}-01$ $1.08862 \mathrm{e}+011.08862 \mathrm{e}+011.08862 \mathrm{e}+001.00000 \mathrm{e}-092.12000 \mathrm{e}-01$ $1.08862 \mathrm{e}+01$ 1.08862e+01 1.08862e+00 1.00000e-09 2.12000e-01 $1.00000 \mathrm{e}-05$ 1.00000e-05 1.00000e-06 1.00000e-09 1.00000e-01 $1.00000 \mathrm{e}+001.00000 \mathrm{e}+001.00000 \mathrm{e}-011.00000 \mathrm{e}-091.00000 \mathrm{e}-01$ Element: 11868 \# of layers: 7

$\mathrm{Kx} \mathrm{Ky} \mathrm{Kz}$ Ss Por $1.08862 \mathrm{e}+01$ 1.08862e+01 1.08862e+00 1.00000e-09 2.12000e-01 $1.08862 \mathrm{e}+011.08862 \mathrm{e}+011.08862 \mathrm{e}+001.00000 \mathrm{e}-092.12000 \mathrm{e}-01$ 
$1.08862 \mathrm{e}+011.08862 \mathrm{e}+01$ 1.08862e+00 1.00000e-09 2.12000e-01 $1.08862 \mathrm{e}+011.08862 \mathrm{e}+011.08862 \mathrm{e}+001.00000 \mathrm{e}-092.12000 \mathrm{e}-01$ $1.08862 \mathrm{e}+011.08862 \mathrm{e}+011.08862 \mathrm{e}+001.00000 \mathrm{e}-092.12000 \mathrm{e}-01$ $1.00000 \mathrm{e}-05$ 1.00000e-05 1.00000e-06 1.00000e-09 1.00000e-01 $1.00000 \mathrm{e}+001.00000 \mathrm{e}+001.00000 \mathrm{e}-01$ 1.00000e-09 1.00000e-01 Element: 11869 \# of layers: 7

$\mathrm{Kx} \mathrm{Ky} \mathrm{Kz}$ Ss Por

$1.08862 \mathrm{e}+01$ 1.08862e+01 1.08862e+00 1.00000e-09 2.12000e-01 $1.08862 \mathrm{e}+011.08862 \mathrm{e}+01$ 1.08862e+00 1.00000e-09 2.12000e-01 $1.08862 \mathrm{e}+011.08862 \mathrm{e}+011.08862 \mathrm{e}+001.00000 \mathrm{e}-092.12000 \mathrm{e}-01$ $1.08862 \mathrm{e}+011.08862 \mathrm{e}+011.08862 \mathrm{e}+001.00000 \mathrm{e}-092.12000 \mathrm{e}-01$ $1.08862 \mathrm{e}+011.08862 \mathrm{e}+011.08862 \mathrm{e}+001.00000 \mathrm{e}-092.12000 \mathrm{e}-01$ $1.00000 \mathrm{e}-05$ 1.00000e-05 1.00000e-06 1.00000e-09 1.00000e-01 $1.00000 \mathrm{e}+001.00000 \mathrm{e}+001.00000 \mathrm{e}-011.00000 \mathrm{e}-09$ 1.00000e-01 Element: 11870 \# of layers: 7

Kx Ky Kz Ss Por $1.08862 \mathrm{e}+01$ 1.08862e+01 1.08862e+00 1.00000e-09 2.12000e-01 $1.08862 \mathrm{e}+011.08862 \mathrm{e}+011.08862 \mathrm{e}+001.00000 \mathrm{e}-092.12000 \mathrm{e}-01$ $1.08862 \mathrm{e}+01$ 1.08862e+01 1.08862e+00 1.00000e-09 2.12000e-01 $1.08862 \mathrm{e}+011.08862 \mathrm{e}+011.08862 \mathrm{e}+001.00000 \mathrm{e}-092.12000 \mathrm{e}-01$ $1.08862 \mathrm{e}+011.08862 \mathrm{e}+011.08862 \mathrm{e}+001.00000 \mathrm{e}-092.12000 \mathrm{e}-01$ $1.00000 \mathrm{e}-05$ 1.00000e-05 1.00000e-06 1.00000e-09 1.00000e-01 $1.00000 \mathrm{e}+001.00000 \mathrm{e}+001.00000 \mathrm{e}-011.00000 \mathrm{e}-091.00000 \mathrm{e}-01$ Element: 11871 \# of layers: 7

Kx Ky Kz Ss Por $1.08862 \mathrm{e}+011.08862 \mathrm{e}+011.08862 \mathrm{e}+001.00000 \mathrm{e}-092.12000 \mathrm{e}-01$ $1.08862 \mathrm{e}+011.08862 \mathrm{e}+011.08862 \mathrm{e}+001.00000 \mathrm{e}-092.12000 \mathrm{e}-01$ $1.08862 \mathrm{e}+011.08862 \mathrm{e}+011.08862 \mathrm{e}+001.00000 \mathrm{e}-092.12000 \mathrm{e}-01$ $1.08862 \mathrm{e}+011.08862 \mathrm{e}+011.08862 \mathrm{e}+001.00000 \mathrm{e}-092.12000 \mathrm{e}-01$ $1.08862 \mathrm{e}+011.08862 \mathrm{e}+01$ 1.08862e+00 1.00000e-09 2.12000e-01 $1.00000 \mathrm{e}-05$ 1.00000e-05 1.00000e-06 1.00000e-09 1.00000e-01 $1.00000 \mathrm{e}+001.00000 \mathrm{e}+001.00000 \mathrm{e}-011.00000 \mathrm{e}-091.00000 \mathrm{e}-01$ Element: 11872 \# of layers: 7

$\mathrm{Kx} \mathrm{Ky} \mathrm{Kz}$ Ss Por $1.08862 \mathrm{e}+01$ 1.08862e+01 1.08862e+00 1.00000e-09 2.12000e-01 $1.08862 \mathrm{e}+011.08862 \mathrm{e}+011.08862 \mathrm{e}+001.00000 \mathrm{e}-092.12000 \mathrm{e}-01$ $1.08862 \mathrm{e}+011.08862 \mathrm{e}+011.08862 \mathrm{e}+001.00000 \mathrm{e}-092.12000 \mathrm{e}-01$ $1.08862 \mathrm{e}+011.08862 \mathrm{e}+011.08862 \mathrm{e}+001.00000 \mathrm{e}-092.12000 \mathrm{e}-01$ $1.08862 \mathrm{e}+011.08862 \mathrm{e}+011.08862 \mathrm{e}+001.00000 \mathrm{e}-092.12000 \mathrm{e}-01$ $1.00000 \mathrm{e}-05$ 1.00000e-05 1.00000e-06 1.00000e-09 1.00000e-01 $1.00000 \mathrm{e}+001.00000 \mathrm{e}+001.00000 \mathrm{e}-011.00000 \mathrm{e}-091.00000 \mathrm{e}-01$ Element: 11873 \# of layers: 7

$\mathrm{Kx} \mathrm{Ky} \mathrm{Kz}$ Ss Por 1.08862e+01 1.08862e+01 1.08862e+00 1.00000e-09 2.12000e-01 $1.08862 \mathrm{e}+011.08862 \mathrm{e}+011.08862 \mathrm{e}+001.00000 \mathrm{e}-092.12000 \mathrm{e}-01$ $1.08862 \mathrm{e}+011.08862 \mathrm{e}+011.08862 \mathrm{e}+001.00000 \mathrm{e}-092.12000 \mathrm{e}-01$ 
$1.08862 \mathrm{e}+011.08862 \mathrm{e}+01$ 1.08862e+00 1.00000e-09 2.12000e-01 $1.08862 \mathrm{e}+01$ 1.08862e+01 1.08862e+00 1.00000e-09 2.12000e-01 $1.00000 \mathrm{e}-05$ 1.00000e-05 1.00000e-06 1.00000e-09 1.00000e-01 $1.00000 \mathrm{e}+001.00000 \mathrm{e}+001.00000 \mathrm{e}-011.00000 \mathrm{e}-091.00000 \mathrm{e}-01$ Element: 11874 \# of layers: 7

$\mathrm{Kx} \mathrm{Ky} \mathrm{Kz}$ Ss Por

$1.08862 \mathrm{e}+011.08862 \mathrm{e}+01$ 1.08862e+00 1.00000e-09 2.12000e-01 $1.08862 \mathrm{e}+011.08862 \mathrm{e}+011.08862 \mathrm{e}+001.00000 \mathrm{e}-092.12000 \mathrm{e}-01$ $1.08862 \mathrm{e}+011.08862 \mathrm{e}+01$ 1.08862e+00 1.00000e-09 2.12000e-01 $1.08862 \mathrm{e}+011.08862 \mathrm{e}+01 \quad 1.08862 \mathrm{e}+001.00000 \mathrm{e}-092.12000 \mathrm{e}-01$ $1.08862 \mathrm{e}+01$ 1.08862e+01 1.08862e+00 1.00000e-09 2.12000e-01 $1.00000 \mathrm{e}-05$ 1.00000e-05 1.00000e-06 1.00000e-09 1.00000e-01 $1.00000 \mathrm{e}+001.00000 \mathrm{e}+001.00000 \mathrm{e}-011.00000 \mathrm{e}-09$ 1.00000e-01 Element: 11875 \# of layers: 7

$\mathrm{Kx} \mathrm{Ky} \mathrm{Kz}$ Ss Por

$1.06353 \mathrm{e}+01$ 1.06353e+01 1.06353e+00 1.00000e-09 2.12000e-01 $1.06353 \mathrm{e}+011.06353 \mathrm{e}+011.06353 \mathrm{e}+00$ 1.00000e-09 2.12000e-01 $1.06353 \mathrm{e}+011.06353 \mathrm{e}+011.06353 \mathrm{e}+001.00000 \mathrm{e}-092.12000 \mathrm{e}-01$ $1.06353 \mathrm{e}+01$ 1.06353e+01 1.06353e+00 1.00000e-09 2.12000e-01 $1.06353 \mathrm{e}+01$ 1.06353e+01 1.06353e+00 1.00000e-09 2.12000e-01 $1.00000 \mathrm{e}-05$ 1.00000e-05 1.00000e-06 1.00000e-09 1.00000e-01 $1.00000 \mathrm{e}+001.00000 \mathrm{e}+001.00000 \mathrm{e}-01$ 1.00000e-09 1.00000e-01 Element: 11876 \# of layers: 7

$\mathrm{Kx} \mathrm{Ky} \mathrm{Kz}$ Ss Por

$1.06353 \mathrm{e}+01$ 1.06353e+01 1.06353e+00 1.00000e-09 2.12000e-01 $1.06353 \mathrm{e}+011.06353 \mathrm{e}+011.06353 \mathrm{e}+001.00000 \mathrm{e}-092.12000 \mathrm{e}-01$ $1.06353 \mathrm{e}+011.06353 \mathrm{e}+011.06353 \mathrm{e}+001.00000 \mathrm{e}-092.12000 \mathrm{e}-01$ $1.06353 \mathrm{e}+011.06353 \mathrm{e}+01$ 1.06353e+00 1.00000e-09 2.12000e-01 $1.06353 \mathrm{e}+011.06353 \mathrm{e}+011.06353 \mathrm{e}+001.00000 \mathrm{e}-092.12000 \mathrm{e}-01$ $1.00000 \mathrm{e}-05$ 1.00000e-05 1.00000e-06 1.00000e-09 1.00000e-01 $1.00000 \mathrm{e}+001.00000 \mathrm{e}+001.00000 \mathrm{e}-01$ 1.00000e-09 1.00000e-01 Element: 11877 \# of layers: 7

Kx Ky Kz Ss Por

$1.06353 \mathrm{e}+01$ 1.06353e+01 1.06353e+00 1.00000e-09 2.12000e-01 $1.06353 \mathrm{e}+01$ 1.06353e+01 1.06353e+00 1.00000e-09 2.12000e-01 $1.06353 \mathrm{e}+011.06353 \mathrm{e}+011.06353 \mathrm{e}+001.00000 \mathrm{e}-092.12000 \mathrm{e}-01$ $1.06353 \mathrm{e}+011.06353 \mathrm{e}+011.06353 \mathrm{e}+001.00000 \mathrm{e}-092.12000 \mathrm{e}-01$ $1.06353 \mathrm{e}+011.06353 \mathrm{e}+01$ 1.06353e+00 1.00000e-09 2.12000e-01 $1.00000 \mathrm{e}-05$ 1.00000e-05 1.00000e-06 1.00000e-09 1.00000e-01 $1.00000 \mathrm{e}+001.00000 \mathrm{e}+001.00000 \mathrm{e}-01$ 1.00000e-09 1.00000e-01 Element: 11878 \# of layers: 7

$\mathrm{Kx} \mathrm{Ky} \mathrm{Kz}$ Ss Por $1.08862 \mathrm{e}+01$ 1.08862e+01 1.08862e+00 1.00000e-09 2.12000e-01 $1.08862 \mathrm{e}+01$ 1.08862e+01 1.08862e+00 1.00000e-09 2.12000e-01 $1.08862 \mathrm{e}+011.08862 \mathrm{e}+011.08862 \mathrm{e}+001.00000 \mathrm{e}-092.12000 \mathrm{e}-01$ $1.08862 \mathrm{e}+011.08862 \mathrm{e}+011.08862 \mathrm{e}+001.00000 \mathrm{e}-092.12000 \mathrm{e}-01$ 
$1.08862 \mathrm{e}+01$ 1.08862e+01 1.08862e+00 1.00000e-09 2.12000e-01 $1.00000 \mathrm{e}-05$ 1.00000e-05 1.00000e-06 1.00000e-09 1.00000e-01

$1.00000 \mathrm{e}+001.00000 \mathrm{e}+001.00000 \mathrm{e}-011.00000 \mathrm{e}-09$ 1.00000e-01

Element: 11879 \# of layers: 7

$\mathrm{Kx} \mathrm{Ky} \mathrm{Kz}$ Ss Por

$1.08862 \mathrm{e}+01$ 1.08862e+01 1.08862e+00 1.00000e-09 2.12000e-01

$1.08862 \mathrm{e}+011.08862 \mathrm{e}+011.08862 \mathrm{e}+001.00000 \mathrm{e}-092.12000 \mathrm{e}-01$

$1.08862 \mathrm{e}+011.08862 \mathrm{e}+011.08862 \mathrm{e}+001.00000 \mathrm{e}-092.12000 \mathrm{e}-01$

$1.08862 \mathrm{e}+011.08862 \mathrm{e}+01$ 1.08862e+00 1.00000e-09 2.12000e-01

$1.08862 \mathrm{e}+01$ 1.08862e+01 1.08862e+00 1.00000e-09 2.12000e-01

$1.00000 \mathrm{e}-05$ 1.00000e-05 1.00000e-06 1.00000e-09 1.00000e-01

$1.00000 \mathrm{e}+001.00000 \mathrm{e}+001.00000 \mathrm{e}-01$ 1.00000e-09 1.00000e-01

Element: 11880 \# of layers: 7

$\mathrm{Kx} \mathrm{Ky} \mathrm{Kz}$ Ss Por

$1.08862 \mathrm{e}+01$ 1.08862e+01 1.08862e+00 1.00000e-09 2.12000e-01

$1.08862 \mathrm{e}+011.08862 \mathrm{e}+011.08862 \mathrm{e}+001.00000 \mathrm{e}-092.12000 \mathrm{e}-01$

$1.08862 \mathrm{e}+011.08862 \mathrm{e}+011.08862 \mathrm{e}+00$ 1.00000e-09 2.12000e-01

$1.08862 \mathrm{e}+011.08862 \mathrm{e}+011.08862 \mathrm{e}+001.00000 \mathrm{e}-092.12000 \mathrm{e}-01$

$1.08862 \mathrm{e}+01$ 1.08862e+01 1.08862e+00 1.00000e-09 2.12000e-01

$1.00000 \mathrm{e}-05$ 1.00000e-05 1.00000e-06 1.00000e-09 1.00000e-01

$1.00000 \mathrm{e}+001.00000 \mathrm{e}+001.00000 \mathrm{e}-011.00000 \mathrm{e}-091.00000 \mathrm{e}-01$

Element: 11881 \# of layers: 7

$\mathrm{Kx} \mathrm{Ky} \mathrm{Kz}$ Ss Por

$1.08862 \mathrm{e}+011.08862 \mathrm{e}+011.08862 \mathrm{e}+001.00000 \mathrm{e}-092.12000 \mathrm{e}-01$

$1.08862 \mathrm{e}+011.08862 \mathrm{e}+011.08862 \mathrm{e}+001.00000 \mathrm{e}-092.12000 \mathrm{e}-01$

$1.08862 \mathrm{e}+011.08862 \mathrm{e}+011.08862 \mathrm{e}+001.00000 \mathrm{e}-092.12000 \mathrm{e}-01$

$1.08862 \mathrm{e}+011.08862 \mathrm{e}+011.08862 \mathrm{e}+001.00000 \mathrm{e}-092.12000 \mathrm{e}-01$

$1.08862 \mathrm{e}+01$ 1.08862e+01 1.08862e+00 1.00000e-09 2.12000e-01

$1.00000 \mathrm{e}-051.00000 \mathrm{e}-05$ 1.00000e-06 1.00000e-09 1.00000e-01

$1.00000 \mathrm{e}+001.00000 \mathrm{e}+001.00000 \mathrm{e}-011.00000 \mathrm{e}-091.00000 \mathrm{e}-01$

Element: 11882 \# of layers: 7

$\mathrm{Kx} \mathrm{Ky} \mathrm{Kz}$ Ss Por

$1.06353 \mathrm{e}+01$ 1.06353e+01 1.06353e+00 1.00000e-09 2.12000e-01

$1.06353 \mathrm{e}+011.06353 \mathrm{e}+011.06353 \mathrm{e}+001.00000 \mathrm{e}-092.12000 \mathrm{e}-01$

$1.06353 \mathrm{e}+011.06353 \mathrm{e}+011.06353 \mathrm{e}+001.00000 \mathrm{e}-092.12000 \mathrm{e}-01$

$1.06353 \mathrm{e}+011.06353 \mathrm{e}+011.06353 \mathrm{e}+001.00000 \mathrm{e}-092.12000 \mathrm{e}-01$

$1.06353 \mathrm{e}+011.06353 \mathrm{e}+01$ 1.06353e+00 1.00000e-09 2.12000e-01

$1.00000 \mathrm{e}-05$ 1.00000e-05 1.00000e-06 1.00000e-09 1.00000e-01

$1.00000 \mathrm{e}+001.00000 \mathrm{e}+001.00000 \mathrm{e}-01$ 1.00000e-09 1.00000e-01

Element: 11883 \# of layers: 7

$\mathrm{Kx} \mathrm{Ky} \mathrm{Kz}$ Ss Por

1.06353e+01 1.06353e+01 1.06353e+00 1.00000e-09 2.12000e-01 $1.06353 \mathrm{e}+01$ 1.06353e+01 1.06353e+00 1.00000e-09 2.12000e-01 $1.06353 \mathrm{e}+01$ 1.06353e+01 1.06353e+00 1.00000e-09 2.12000e-01 $1.06353 \mathrm{e}+011.06353 \mathrm{e}+011.06353 \mathrm{e}+001.00000 \mathrm{e}-092.12000 \mathrm{e}-01$ $1.06353 \mathrm{e}+011.06353 \mathrm{e}+011.06353 \mathrm{e}+001.00000 \mathrm{e}-092.12000 \mathrm{e}-01$ 
$1.00000 \mathrm{e}-05$ 1.00000e-05 1.00000e-06 1.00000e-09 1.00000e-01 $1.00000 \mathrm{e}+001.00000 \mathrm{e}+001.00000 \mathrm{e}-01$ 1.00000e-09 1.00000e-01 Element: 11884 \# of layers: 7

Kx Ky Kz Ss Por

$1.06353 \mathrm{e}+01$ 1.06353e+01 1.06353e+00 1.00000e-09 2.12000e-01 $1.06353 \mathrm{e}+011.06353 \mathrm{e}+011.06353 \mathrm{e}+001.00000 \mathrm{e}-092.12000 \mathrm{e}-01$ $1.06353 \mathrm{e}+011.06353 \mathrm{e}+011.06353 \mathrm{e}+001.00000 \mathrm{e}-092.12000 \mathrm{e}-01$ $1.06353 \mathrm{e}+011.06353 \mathrm{e}+011.06353 \mathrm{e}+001.00000 \mathrm{e}-092.12000 \mathrm{e}-01$ $1.06353 \mathrm{e}+011.06353 \mathrm{e}+01$ 1.06353e+00 1.00000e-09 2.12000e-01 $1.00000 \mathrm{e}-05$ 1.00000e-05 1.00000e-06 1.00000e-09 1.00000e-01 $1.00000 \mathrm{e}+001.00000 \mathrm{e}+001.00000 \mathrm{e}-011.00000 \mathrm{e}-091.00000 \mathrm{e}-01$ Element: 11885 \# of layers: 7

$\mathrm{Kx} \mathrm{Ky} \mathrm{Kz}$ Ss Por

$1.06353 \mathrm{e}+01$ 1.06353e+01 1.06353e+00 1.00000e-09 2.12000e-01 $1.06353 \mathrm{e}+01$ 1.06353e+01 1.06353e+00 1.00000e-09 2.12000e-01 $1.06353 \mathrm{e}+011.06353 \mathrm{e}+011.06353 \mathrm{e}+001.00000 \mathrm{e}-092.12000 \mathrm{e}-01$ $1.06353 \mathrm{e}+011.06353 \mathrm{e}+011.06353 \mathrm{e}+001.00000 \mathrm{e}-092.12000 \mathrm{e}-01$ $1.06353 \mathrm{e}+01$ 1.06353e+01 1.06353e+00 1.00000e-09 2.12000e-01 $1.00000 \mathrm{e}-05$ 1.00000e-05 1.00000e-06 1.00000e-09 1.00000e-01 $1.00000 \mathrm{e}+001.00000 \mathrm{e}+001.00000 \mathrm{e}-011.00000 \mathrm{e}-091.00000 \mathrm{e}-01$ Element: 11886 \# of layers: 7

$\mathrm{Kx} \mathrm{Ky} \mathrm{Kz}$ Ss Por

$1.06353 \mathrm{e}+01$ 1.06353e+01 1.06353e+00 1.00000e-09 2.12000e-01 $1.06353 \mathrm{e}+011.06353 \mathrm{e}+011.06353 \mathrm{e}+001.00000 \mathrm{e}-092.12000 \mathrm{e}-01$ $1.06353 \mathrm{e}+011.06353 \mathrm{e}+011.06353 \mathrm{e}+001.00000 \mathrm{e}-092.12000 \mathrm{e}-01$ $1.06353 \mathrm{e}+011.06353 \mathrm{e}+011.06353 \mathrm{e}+001.00000 \mathrm{e}-092.12000 \mathrm{e}-01$ $1.06353 \mathrm{e}+01$ 1.06353e+01 1.06353e+00 1.00000e-09 2.12000e-01 $1.00000 \mathrm{e}-05$ 1.00000e-05 1.00000e-06 1.00000e-09 1.00000e-01 $1.00000 \mathrm{e}+001.00000 \mathrm{e}+001.00000 \mathrm{e}-011.00000 \mathrm{e}-091.00000 \mathrm{e}-01$ Element: 11887 \# of layers: 7

$\mathrm{Kx} \mathrm{Ky} \mathrm{Kz}$ Ss Por

$1.06353 \mathrm{e}+01$ 1.06353e+01 1.06353e+00 1.00000e-09 2.12000e-01 $1.06353 \mathrm{e}+011.06353 \mathrm{e}+011.06353 \mathrm{e}+001.00000 \mathrm{e}-092.12000 \mathrm{e}-01$ $1.06353 \mathrm{e}+011.06353 \mathrm{e}+01$ 1.06353e+00 1.00000e-09 2.12000e-01 $1.06353 \mathrm{e}+01$ 1.06353e+01 1.06353e+00 1.00000e-09 2.12000e-01 $1.06353 \mathrm{e}+01$ 1.06353e+01 1.06353e+00 1.00000e-09 2.12000e-01 $1.00000 \mathrm{e}-05$ 1.00000e-05 1.00000e-06 1.00000e-09 1.00000e-01 $1.00000 \mathrm{e}+001.00000 \mathrm{e}+001.00000 \mathrm{e}-011.00000 \mathrm{e}-091.00000 \mathrm{e}-01$ Element: 11888 \# of layers: 7

$\mathrm{Kx} \mathrm{Ky} \mathrm{Kz}$ Ss Por $1.06353 \mathrm{e}+01$ 1.06353e+01 1.06353e+00 1.00000e-09 2.12000e-01 $1.06353 \mathrm{e}+011.06353 \mathrm{e}+011.06353 \mathrm{e}+001.00000 \mathrm{e}-092.12000 \mathrm{e}-01$ $1.06353 \mathrm{e}+01$ 1.06353e+01 1.06353e+00 1.00000e-09 2.12000e-01 $1.06353 \mathrm{e}+01$ 1.06353e+01 1.06353e+00 1.00000e-09 2.12000e-01 $1.06353 \mathrm{e}+011.06353 \mathrm{e}+011.06353 \mathrm{e}+001.00000 \mathrm{e}-092.12000 \mathrm{e}-01$ $1.00000 \mathrm{e}-05$ 1.00000e-05 1.00000e-06 1.00000e-09 1.00000e-01 
$1.00000 \mathrm{e}+001.00000 \mathrm{e}+00$ 1.00000e-01 1.00000e-09 1.00000e-01

Element: 11889 \# of layers: 7

Kx Ky Kz Ss Por

$1.06353 \mathrm{e}+01$ 1.06353e+01 1.06353e+00 1.00000e-09 2.12000e-01

$1.06353 \mathrm{e}+01$ 1.06353e+01 1.06353e+00 1.00000e-09 2.12000e-01

$1.06353 \mathrm{e}+011.06353 \mathrm{e}+011.06353 \mathrm{e}+001.00000 \mathrm{e}-092.12000 \mathrm{e}-01$

$1.06353 \mathrm{e}+011.06353 \mathrm{e}+01$ 1.06353e+00 1.00000e-09 2.12000e-01

$1.06353 \mathrm{e}+011.06353 \mathrm{e}+011.06353 \mathrm{e}+001.00000 \mathrm{e}-092.12000 \mathrm{e}-01$

$1.00000 \mathrm{e}-05$ 1.00000e-05 1.00000e-06 1.00000e-09 1.00000e-01

$1.00000 \mathrm{e}+001.00000 \mathrm{e}+001.00000 \mathrm{e}-011.00000 \mathrm{e}-091.00000 \mathrm{e}-01$

Element: 11890 \# of layers: 7

Kx Ky Kz Ss Por

$1.06353 \mathrm{e}+01$ 1.06353e+01 1.06353e+00 1.00000e-09 2.12000e-01

$1.06353 \mathrm{e}+01$ 1.06353e+01 1.06353e+00 1.00000e-09 2.12000e-01

$1.06353 \mathrm{e}+01$ 1.06353e+01 1.06353e+00 1.00000e-09 2.12000e-01

$1.06353 \mathrm{e}+011.06353 \mathrm{e}+011.06353 \mathrm{e}+001.00000 \mathrm{e}-092.12000 \mathrm{e}-01$

$1.06353 \mathrm{e}+011.06353 \mathrm{e}+01$ 1.06353e+00 1.00000e-09 2.12000e-01

$1.00000 \mathrm{e}-05$ 1.00000e-05 1.00000e-06 1.00000e-09 1.00000e-01

$1.00000 \mathrm{e}+001.00000 \mathrm{e}+001.00000 \mathrm{e}-01$ 1.00000e-09 1.00000e-01

Element: 11891 \# of layers: 7

$\mathrm{Kx} \mathrm{Ky} \mathrm{Kz}$ Ss Por

$1.06353 \mathrm{e}+01$ 1.06353e+01 1.06353e+00 1.00000e-09 2.12000e-01

$1.06353 \mathrm{e}+01$ 1.06353e+01 1.06353e+00 1.00000e-09 2.12000e-01

$1.06353 \mathrm{e}+011.06353 \mathrm{e}+011.06353 \mathrm{e}+001.00000 \mathrm{e}-092.12000 \mathrm{e}-01$

$1.06353 \mathrm{e}+011.06353 \mathrm{e}+011.06353 \mathrm{e}+001.00000 \mathrm{e}-092.12000 \mathrm{e}-01$

$1.06353 \mathrm{e}+01$ 1.06353e+01 1.06353e+00 1.00000e-09 2.12000e-01

$1.00000 \mathrm{e}-05$ 1.00000e-05 1.00000e-06 1.00000e-09 1.00000e-01

$1.00000 \mathrm{e}+001.00000 \mathrm{e}+001.00000 \mathrm{e}-011.00000 \mathrm{e}-09$ 1.00000e-01

Element: 11892 \# of layers: 7

$\mathrm{Kx} \mathrm{Ky} \mathrm{Kz}$ Ss Por

$1.08221 \mathrm{e}+011.08221 \mathrm{e}+011.08221 \mathrm{e}+00$ 1.00000e-09 2.12000e-01

$1.08221 \mathrm{e}+011.08221 \mathrm{e}+011.08221 \mathrm{e}+001.00000 \mathrm{e}-092.12000 \mathrm{e}-01$

$1.08221 \mathrm{e}+011.08221 \mathrm{e}+011.08221 \mathrm{e}+001.00000 \mathrm{e}-092.12000 \mathrm{e}-01$

$1.08221 \mathrm{e}+011.08221 \mathrm{e}+011.08221 \mathrm{e}+001.00000 \mathrm{e}-092.12000 \mathrm{e}-01$

$1.08221 \mathrm{e}+011.08221 \mathrm{e}+011.08221 \mathrm{e}+001.00000 \mathrm{e}-092.12000 \mathrm{e}-01$

1.00000e-05 1.00000e-05 1.00000e-06 1.00000e-09 1.00000e-01

$1.00000 \mathrm{e}+001.00000 \mathrm{e}+001.00000 \mathrm{e}-011.00000 \mathrm{e}-091.00000 \mathrm{e}-01$

Element: 11893 \# of layers: 7

$\mathrm{Kx} \mathrm{Ky} \mathrm{Kz}$ Ss Por

$1.08221 \mathrm{e}+011.08221 \mathrm{e}+011.08221 \mathrm{e}+001.00000 \mathrm{e}-092.12000 \mathrm{e}-01$

$1.08221 \mathrm{e}+011.08221 \mathrm{e}+011.08221 \mathrm{e}+001.00000 \mathrm{e}-092.12000 \mathrm{e}-01$

$1.08221 \mathrm{e}+011.08221 \mathrm{e}+011.08221 \mathrm{e}+001.00000 \mathrm{e}-092.12000 \mathrm{e}-01$

$1.08221 \mathrm{e}+011.08221 \mathrm{e}+011.08221 \mathrm{e}+001.00000 \mathrm{e}-092.12000 \mathrm{e}-01$

$1.08221 \mathrm{e}+011.08221 \mathrm{e}+01$ 1.08221e+00 1.00000e-09 2.12000e-01

$1.00000 \mathrm{e}-05$ 1.00000e-05 1.00000e-06 1.00000e-09 1.00000e-01

$1.00000 \mathrm{e}+001.00000 \mathrm{e}+001.00000 \mathrm{e}-011.00000 \mathrm{e}-091.00000 \mathrm{e}-01$ 
Element: 11894 \# of layers: 7

Kx Ky Kz Ss Por

$1.08221 \mathrm{e}+011.08221 \mathrm{e}+011.08221 \mathrm{e}+001.00000 \mathrm{e}-092.12000 \mathrm{e}-01$

$1.08221 \mathrm{e}+011.08221 \mathrm{e}+011.08221 \mathrm{e}+001.00000 \mathrm{e}-092.12000 \mathrm{e}-01$

$1.08221 \mathrm{e}+011.08221 \mathrm{e}+011.08221 \mathrm{e}+001.00000 \mathrm{e}-092.12000 \mathrm{e}-01$

$1.08221 \mathrm{e}+011.08221 \mathrm{e}+011.08221 \mathrm{e}+001.00000 \mathrm{e}-092.12000 \mathrm{e}-01$

$1.08221 \mathrm{e}+011.08221 \mathrm{e}+011.08221 \mathrm{e}+001.00000 \mathrm{e}-092.12000 \mathrm{e}-01$

$1.00000 \mathrm{e}-05$ 1.00000e-05 1.00000e-06 1.00000e-09 1.00000e-01

$1.00000 \mathrm{e}+001.00000 \mathrm{e}+001.00000 \mathrm{e}-011.00000 \mathrm{e}-091.00000 \mathrm{e}-01$

Element: 11895 \# of layers: 7

Kx Ky Kz Ss Por

$1.08221 \mathrm{e}+011.08221 \mathrm{e}+011.08221 \mathrm{e}+001.00000 \mathrm{e}-092.12000 \mathrm{e}-01$

$1.08221 \mathrm{e}+011.08221 \mathrm{e}+011.08221 \mathrm{e}+001.00000 \mathrm{e}-092.12000 \mathrm{e}-01$

$1.08221 \mathrm{e}+011.08221 \mathrm{e}+011.08221 \mathrm{e}+001.00000 \mathrm{e}-092.12000 \mathrm{e}-01$

$1.08221 \mathrm{e}+011.08221 \mathrm{e}+011.08221 \mathrm{e}+001.00000 \mathrm{e}-092.12000 \mathrm{e}-01$

$1.08221 \mathrm{e}+011.08221 \mathrm{e}+011.08221 \mathrm{e}+001.00000 \mathrm{e}-092.12000 \mathrm{e}-01$

$1.00000 \mathrm{e}-05$ 1.00000e-05 1.00000e-06 1.00000e-09 1.00000e-01

$1.00000 \mathrm{e}+001.00000 \mathrm{e}+001.00000 \mathrm{e}-011.00000 \mathrm{e}-091.00000 \mathrm{e}-01$

Element: 11896 \# of layers: 7

Kx Ky Kz Ss Por

$1.08221 \mathrm{e}+011.08221 \mathrm{e}+011.08221 \mathrm{e}+001.00000 \mathrm{e}-092.12000 \mathrm{e}-01$

$1.08221 \mathrm{e}+011.08221 \mathrm{e}+011.08221 \mathrm{e}+001.00000 \mathrm{e}-092.12000 \mathrm{e}-01$

$1.08221 \mathrm{e}+011.08221 \mathrm{e}+011.08221 \mathrm{e}+001.00000 \mathrm{e}-092.12000 \mathrm{e}-01$

$1.08221 \mathrm{e}+011.08221 \mathrm{e}+011.08221 \mathrm{e}+001.00000 \mathrm{e}-092.12000 \mathrm{e}-01$

$1.08221 \mathrm{e}+011.08221 \mathrm{e}+011.08221 \mathrm{e}+001.00000 \mathrm{e}-092.12000 \mathrm{e}-01$

$1.00000 \mathrm{e}-051.00000 \mathrm{e}-051.00000 \mathrm{e}-061.00000 \mathrm{e}-091.00000 \mathrm{e}-01$

$1.00000 \mathrm{e}+001.00000 \mathrm{e}+001.00000 \mathrm{e}-011.00000 \mathrm{e}-091.00000 \mathrm{e}-01$

Element: 11897 \# of layers: 7

Kx Ky Kz Ss Por

$1.06353 \mathrm{e}+011.06353 \mathrm{e}+011.06353 \mathrm{e}+00$ 1.00000e-09 2.12000e-01

$1.06353 \mathrm{e}+011.06353 \mathrm{e}+011.06353 \mathrm{e}+001.00000 \mathrm{e}-092.12000 \mathrm{e}-01$

$1.06353 \mathrm{e}+011.06353 \mathrm{e}+011.06353 \mathrm{e}+001.00000 \mathrm{e}-092.12000 \mathrm{e}-01$

$1.06353 \mathrm{e}+011.06353 \mathrm{e}+011.06353 \mathrm{e}+00$ 1.00000e-09 2.12000e-01

$1.06353 \mathrm{e}+011.06353 \mathrm{e}+011.06353 \mathrm{e}+00$ 1.00000e-09 2.12000e-01

$1.00000 \mathrm{e}-05$ 1.00000e-05 1.00000e-06 1.00000e-09 1.00000e-01

$1.00000 \mathrm{e}+001.00000 \mathrm{e}+001.00000 \mathrm{e}-011.00000 \mathrm{e}-091.00000 \mathrm{e}-01$

Element: 11898 \# of layers: 7

Kx Ky Kz Ss Por

$1.06353 \mathrm{e}+011.06353 \mathrm{e}+011.06353 \mathrm{e}+00$ 1.00000e-09 2.12000e-01

$1.06353 \mathrm{e}+011.06353 \mathrm{e}+011.06353 \mathrm{e}+00$ 1.00000e-09 2.12000e-01

$1.06353 \mathrm{e}+011.06353 \mathrm{e}+011.06353 \mathrm{e}+001.00000 \mathrm{e}-092.12000 \mathrm{e}-01$

$1.06353 \mathrm{e}+011.06353 \mathrm{e}+011.06353 \mathrm{e}+001.00000 \mathrm{e}-092.12000 \mathrm{e}-01$

$1.06353 \mathrm{e}+011.06353 \mathrm{e}+011.06353 \mathrm{e}+00$ 1.00000e-09 2.12000e-01

$1.00000 \mathrm{e}-05$ 1.00000e-05 1.00000e-06 1.00000e-09 1.00000e-01

$1.00000 \mathrm{e}+001.00000 \mathrm{e}+001.00000 \mathrm{e}-011.00000 \mathrm{e}-091.00000 \mathrm{e}-01$

Element: 11899 \# of layers: 7 
$\mathrm{Kx} \mathrm{Ky} \mathrm{Kz}$ Ss Por

$1.08221 \mathrm{e}+011.08221 \mathrm{e}+011.08221 \mathrm{e}+001.00000 \mathrm{e}-092.12000 \mathrm{e}-01$

$1.08221 \mathrm{e}+011.08221 \mathrm{e}+011.08221 \mathrm{e}+001.00000 \mathrm{e}-092.12000 \mathrm{e}-01$

$1.08221 \mathrm{e}+011.08221 \mathrm{e}+011.08221 \mathrm{e}+001.00000 \mathrm{e}-092.12000 \mathrm{e}-01$

$1.08221 \mathrm{e}+011.08221 \mathrm{e}+011.08221 \mathrm{e}+001.00000 \mathrm{e}-092.12000 \mathrm{e}-01$

$1.08221 \mathrm{e}+011.08221 \mathrm{e}+011.08221 \mathrm{e}+001.00000 \mathrm{e}-092.12000 \mathrm{e}-01$

1.00000e-05 1.00000e-05 1.00000e-06 1.00000e-09 1.00000e-01

$1.00000 \mathrm{e}+001.00000 \mathrm{e}+001.00000 \mathrm{e}-01$ 1.00000e-09 1.00000e-01

Element: 11900 \# of layers: 7

$\mathrm{Kx} \mathrm{Ky} \mathrm{Kz}$ Ss Por

$1.08221 \mathrm{e}+011.08221 \mathrm{e}+01$ 1.08221e+00 1.00000e-09 2.12000e-01

$1.08221 \mathrm{e}+011.08221 \mathrm{e}+011.08221 \mathrm{e}+001.00000 \mathrm{e}-092.12000 \mathrm{e}-01$

$1.08221 \mathrm{e}+011.08221 \mathrm{e}+011.08221 \mathrm{e}+001.00000 \mathrm{e}-092.12000 \mathrm{e}-01$

$1.08221 \mathrm{e}+011.08221 \mathrm{e}+011.08221 \mathrm{e}+001.00000 \mathrm{e}-092.12000 \mathrm{e}-01$

$1.08221 \mathrm{e}+011.08221 \mathrm{e}+011.08221 \mathrm{e}+001.00000 \mathrm{e}-092.12000 \mathrm{e}-01$

$1.00000 \mathrm{e}-05$ 1.00000e-05 1.00000e-06 1.00000e-09 1.00000e-01

$1.00000 \mathrm{e}+001.00000 \mathrm{e}+001.00000 \mathrm{e}-011.00000 \mathrm{e}-091.00000 \mathrm{e}-01$

Element: 11901 \# of layers: 7

$\mathrm{Kx} \mathrm{Ky} \mathrm{Kz}$ Ss Por

$1.03214 \mathrm{e}+011.03214 \mathrm{e}+011.03214 \mathrm{e}+001.00000 \mathrm{e}-092.12000 \mathrm{e}-01$

$1.03214 \mathrm{e}+011.03214 \mathrm{e}+01 \quad 1.03214 \mathrm{e}+001.00000 \mathrm{e}-092.12000 \mathrm{e}-01$

$1.03214 \mathrm{e}+011.03214 \mathrm{e}+011.03214 \mathrm{e}+001.00000 \mathrm{e}-092.12000 \mathrm{e}-01$

$1.03214 \mathrm{e}+011.03214 \mathrm{e}+011.03214 \mathrm{e}+001.00000 \mathrm{e}-092.12000 \mathrm{e}-01$

$1.03214 \mathrm{e}+011.03214 \mathrm{e}+01 \quad 1.03214 \mathrm{e}+001.00000 \mathrm{e}-092.12000 \mathrm{e}-01$

$1.00000 \mathrm{e}-05$ 1.00000e-05 1.00000e-06 1.00000e-09 1.00000e-01

$1.00000 \mathrm{e}+001.00000 \mathrm{e}+001.00000 \mathrm{e}-01$ 1.00000e-09 1.00000e-01

Element: 11902 \# of layers: 7

$\mathrm{Kx} \mathrm{Ky} \mathrm{Kz}$ Ss Por

$1.03214 \mathrm{e}+011.03214 \mathrm{e}+011.03214 \mathrm{e}+001.00000 \mathrm{e}-092.12000 \mathrm{e}-01$

$1.03214 \mathrm{e}+011.03214 \mathrm{e}+011.03214 \mathrm{e}+001.00000 \mathrm{e}-092.12000 \mathrm{e}-01$

$1.03214 \mathrm{e}+011.03214 \mathrm{e}+011.03214 \mathrm{e}+001.00000 \mathrm{e}-092.12000 \mathrm{e}-01$

$1.03214 \mathrm{e}+011.03214 \mathrm{e}+011.03214 \mathrm{e}+001.00000 \mathrm{e}-092.12000 \mathrm{e}-01$

$1.03214 \mathrm{e}+011.03214 \mathrm{e}+011.03214 \mathrm{e}+001.00000 \mathrm{e}-092.12000 \mathrm{e}-01$

$1.00000 \mathrm{e}-051.00000 \mathrm{e}-051.00000 \mathrm{e}-061.00000 \mathrm{e}-091.00000 \mathrm{e}-01$

$1.00000 \mathrm{e}+001.00000 \mathrm{e}+001.00000 \mathrm{e}-01$ 1.00000e-09 1.00000e-01

Element: 11903 \# of layers: 7

Kx Ky Kz Ss Por

$1.03214 \mathrm{e}+011.03214 \mathrm{e}+011.03214 \mathrm{e}+001.00000 \mathrm{e}-092.12000 \mathrm{e}-01$ $1.03214 \mathrm{e}+011.03214 \mathrm{e}+011.03214 \mathrm{e}+001.00000 \mathrm{e}-092.12000 \mathrm{e}-01$

$1.03214 \mathrm{e}+011.03214 \mathrm{e}+011.03214 \mathrm{e}+001.00000 \mathrm{e}-092.12000 \mathrm{e}-01$

$1.03214 \mathrm{e}+011.03214 \mathrm{e}+01 \quad 1.03214 \mathrm{e}+001.00000 \mathrm{e}-092.12000 \mathrm{e}-01$

$1.03214 \mathrm{e}+011.03214 \mathrm{e}+011.03214 \mathrm{e}+001.00000 \mathrm{e}-092.12000 \mathrm{e}-01$

$1.00000 \mathrm{e}-051.00000 \mathrm{e}-05$ 1.00000e-06 1.00000e-09 1.00000e-01

$1.00000 \mathrm{e}+001.00000 \mathrm{e}+001.00000 \mathrm{e}-01$ 1.00000e-09 1.00000e-01

Element: 11904 \# of layers: 7

Kx Ky Kz Ss Por 
$1.08862 \mathrm{e}+011.08862 \mathrm{e}+01$ 1.08862e+00 1.00000e-09 2.12000e-01 $1.08862 \mathrm{e}+011.08862 \mathrm{e}+011.08862 \mathrm{e}+001.00000 \mathrm{e}-092.12000 \mathrm{e}-01$ $1.08862 \mathrm{e}+011.08862 \mathrm{e}+011.08862 \mathrm{e}+001.00000 \mathrm{e}-092.12000 \mathrm{e}-01$ $1.08862 \mathrm{e}+011.08862 \mathrm{e}+011.08862 \mathrm{e}+001.00000 \mathrm{e}-092.12000 \mathrm{e}-01$ $1.08862 \mathrm{e}+011.08862 \mathrm{e}+011.08862 \mathrm{e}+001.00000 \mathrm{e}-092.12000 \mathrm{e}-01$ $1.00000 \mathrm{e}-051.00000 \mathrm{e}-051.00000 \mathrm{e}-061.00000 \mathrm{e}-091.00000 \mathrm{e}-01$ $1.00000 \mathrm{e}+001.00000 \mathrm{e}+001.00000 \mathrm{e}-01$ 1.00000e-09 1.00000e-01 Element: 11905 \# of layers: 7

$\mathrm{Kx} \mathrm{Ky} \mathrm{Kz}$ Ss Por

$1.08862 \mathrm{e}+01$ 1.08862e+01 1.08862e+00 1.00000e-09 2.12000e-01 $1.08862 \mathrm{e}+011.08862 \mathrm{e}+011.08862 \mathrm{e}+001.00000 \mathrm{e}-092.12000 \mathrm{e}-01$ $1.08862 \mathrm{e}+011.08862 \mathrm{e}+011.08862 \mathrm{e}+001.00000 \mathrm{e}-092.12000 \mathrm{e}-01$ $1.08862 \mathrm{e}+011.08862 \mathrm{e}+011.08862 \mathrm{e}+001.00000 \mathrm{e}-092.12000 \mathrm{e}-01$ $1.08862 \mathrm{e}+01$ 1.08862e+01 1.08862e+00 1.00000e-09 2.12000e-01 $1.00000 \mathrm{e}-05$ 1.00000e-05 1.00000e-06 1.00000e-09 1.00000e-01 $1.00000 \mathrm{e}+001.00000 \mathrm{e}+001.00000 \mathrm{e}-011.00000 \mathrm{e}-091.00000 \mathrm{e}-01$ Element: 11906 \# of layers: 7

$\mathrm{Kx} \mathrm{Ky} \mathrm{Kz}$ Ss Por

$1.06353 \mathrm{e}+01$ 1.06353e+01 1.06353e+00 1.00000e-09 2.12000e-01 $1.06353 \mathrm{e}+01$ 1.06353e+01 1.06353e+00 1.00000e-09 2.12000e-01 $1.06353 \mathrm{e}+01$ 1.06353e+01 1.06353e+00 1.00000e-09 2.12000e-01 $1.06353 \mathrm{e}+011.06353 \mathrm{e}+01$ 1.06353e+00 1.00000e-09 2.12000e-01 $1.06353 \mathrm{e}+01$ 1.06353e+01 1.06353e+00 1.00000e-09 2.12000e-01 $1.00000 \mathrm{e}-05$ 1.00000e-05 1.00000e-06 1.00000e-09 1.00000e-01 $1.00000 \mathrm{e}+001.00000 \mathrm{e}+001.00000 \mathrm{e}-011.00000 \mathrm{e}-091.00000 \mathrm{e}-01$ Element: 11907 \# of layers: 7

$\mathrm{Kx} \mathrm{Ky} \mathrm{Kz}$ Ss Por

$1.08221 \mathrm{e}+011.08221 \mathrm{e}+011.08221 \mathrm{e}+001.00000 \mathrm{e}-092.12000 \mathrm{e}-01$ $1.08221 \mathrm{e}+011.08221 \mathrm{e}+011.08221 \mathrm{e}+001.00000 \mathrm{e}-092.12000 \mathrm{e}-01$ $1.08221 \mathrm{e}+011.08221 \mathrm{e}+011.08221 \mathrm{e}+001.00000 \mathrm{e}-092.12000 \mathrm{e}-01$ $1.08221 \mathrm{e}+011.08221 \mathrm{e}+011.08221 \mathrm{e}+001.00000 \mathrm{e}-092.12000 \mathrm{e}-01$ $1.08221 \mathrm{e}+011.08221 \mathrm{e}+011.08221 \mathrm{e}+001.00000 \mathrm{e}-092.12000 \mathrm{e}-01$ $1.00000 \mathrm{e}-05$ 1.00000e-05 1.00000e-06 1.00000e-09 1.00000e-01 $1.00000 \mathrm{e}+001.00000 \mathrm{e}+001.00000 \mathrm{e}-011.00000 \mathrm{e}-091.00000 \mathrm{e}-01$ Element: 11908 \# of layers: 7

$\mathrm{Kx} \mathrm{Ky} \mathrm{Kz}$ Ss Por

$1.03214 \mathrm{e}+011.03214 \mathrm{e}+011.03214 \mathrm{e}+001.00000 \mathrm{e}-092.12000 \mathrm{e}-01$ $1.03214 \mathrm{e}+011.03214 \mathrm{e}+011.03214 \mathrm{e}+001.00000 \mathrm{e}-092.12000 \mathrm{e}-01$ $1.03214 \mathrm{e}+011.03214 \mathrm{e}+011.03214 \mathrm{e}+001.00000 \mathrm{e}-092.12000 \mathrm{e}-01$ $1.03214 \mathrm{e}+011.03214 \mathrm{e}+011.03214 \mathrm{e}+001.00000 \mathrm{e}-092.12000 \mathrm{e}-01$ $1.03214 \mathrm{e}+011.03214 \mathrm{e}+011.03214 \mathrm{e}+001.00000 \mathrm{e}-092.12000 \mathrm{e}-01$ $1.00000 \mathrm{e}-05$ 1.00000e-05 1.00000e-06 1.00000e-09 1.00000e-01 $1.00000 \mathrm{e}+001.00000 \mathrm{e}+001.00000 \mathrm{e}-011.00000 \mathrm{e}-091.00000 \mathrm{e}-01$ Element: 11909 \# of layers: 7

$\mathrm{Kx} \mathrm{Ky} \mathrm{Kz}$ Ss Por

6.52424e+00 6.52424e+00 6.52424e-01 1.00000e-09 2.12000e-01 
$6.52424 \mathrm{e}+006.52424 \mathrm{e}+006.52424 \mathrm{e}-011.00000 \mathrm{e}-092.12000 \mathrm{e}-01$ $6.52424 \mathrm{e}+006.52424 \mathrm{e}+006.52424 \mathrm{e}-011.00000 \mathrm{e}-092.12000 \mathrm{e}-01$ $6.52424 \mathrm{e}+006.52424 \mathrm{e}+006.52424 \mathrm{e}-011.00000 \mathrm{e}-092.12000 \mathrm{e}-01$ $6.52424 \mathrm{e}+006.52424 \mathrm{e}+00 \quad 6.52424 \mathrm{e}-011.00000 \mathrm{e}-092.12000 \mathrm{e}-01$ $1.00000 \mathrm{e}-05$ 1.00000e-05 1.00000e-06 1.00000e-09 1.00000e-01 $1.00000 \mathrm{e}+001.00000 \mathrm{e}+001.00000 \mathrm{e}-011.00000 \mathrm{e}-091.00000 \mathrm{e}-01$ Element: 11910 \# of layers: 7

Kx Ky Kz Ss Por

$6.52424 \mathrm{e}+006.52424 \mathrm{e}+006.52424 \mathrm{e}-01$ 1.00000e-09 2.12000e-01 $6.52424 \mathrm{e}+006.52424 \mathrm{e}+006.52424 \mathrm{e}-011.00000 \mathrm{e}-092.12000 \mathrm{e}-01$ $6.52424 \mathrm{e}+006.52424 \mathrm{e}+006.52424 \mathrm{e}-011.00000 \mathrm{e}-092.12000 \mathrm{e}-01$ $6.52424 \mathrm{e}+006.52424 \mathrm{e}+006.52424 \mathrm{e}-011.00000 \mathrm{e}-092.12000 \mathrm{e}-01$ $6.52424 \mathrm{e}+006.52424 \mathrm{e}+006.52424 \mathrm{e}-011.00000 \mathrm{e}-092.12000 \mathrm{e}-01$ $1.00000 \mathrm{e}-05$ 1.00000e-05 1.00000e-06 1.00000e-09 1.00000e-01 $1.00000 \mathrm{e}+001.00000 \mathrm{e}+001.00000 \mathrm{e}-011.00000 \mathrm{e}-091.00000 \mathrm{e}-01$ Element: 11911 \# of layers: 7

Kx Ky Kz Ss Por

$6.52424 \mathrm{e}+006.52424 \mathrm{e}+00$ 6.52424e-01 1.00000e-09 2.12000e-01 $6.52424 \mathrm{e}+006.52424 \mathrm{e}+006.52424 \mathrm{e}-011.00000 \mathrm{e}-092.12000 \mathrm{e}-01$ $6.52424 \mathrm{e}+006.52424 \mathrm{e}+006.52424 \mathrm{e}-011.00000 \mathrm{e}-092.12000 \mathrm{e}-01$ $6.52424 \mathrm{e}+006.52424 \mathrm{e}+006.52424 \mathrm{e}-011.00000 \mathrm{e}-092.12000 \mathrm{e}-01$ $6.52424 \mathrm{e}+006.52424 \mathrm{e}+006.52424 \mathrm{e}-011.00000 \mathrm{e}-092.12000 \mathrm{e}-01$ $1.00000 \mathrm{e}-05$ 1.00000e-05 1.00000e-06 1.00000e-09 1.00000e-01 $1.00000 \mathrm{e}+001.00000 \mathrm{e}+001.00000 \mathrm{e}-011.00000 \mathrm{e}-091.00000 \mathrm{e}-01$ Element: 11912 \# of layers: 7

Kx Ky Kz Ss Por

$6.52424 \mathrm{e}+006.52424 \mathrm{e}+00$ 6.52424e-01 1.00000e-09 2.12000e-01 $6.52424 \mathrm{e}+006.52424 \mathrm{e}+006.52424 \mathrm{e}-011.00000 \mathrm{e}-092.12000 \mathrm{e}-01$ $6.52424 \mathrm{e}+006.52424 \mathrm{e}+006.52424 \mathrm{e}-011.00000 \mathrm{e}-092.12000 \mathrm{e}-01$ $6.52424 \mathrm{e}+006.52424 \mathrm{e}+006.52424 \mathrm{e}-011.00000 \mathrm{e}-092.12000 \mathrm{e}-01$ $6.52424 \mathrm{e}+006.52424 \mathrm{e}+006.52424 \mathrm{e}-011.00000 \mathrm{e}-092.12000 \mathrm{e}-01$ $1.00000 \mathrm{e}-05$ 1.00000e-05 1.00000e-06 1.00000e-09 1.00000e-01 $1.00000 \mathrm{e}+001.00000 \mathrm{e}+001.00000 \mathrm{e}-011.00000 \mathrm{e}-091.00000 \mathrm{e}-01$ Element: 11913 \# of layers: 7

Kx Ky Kz Ss Por

$6.52424 \mathrm{e}+006.52424 \mathrm{e}+006.52424 \mathrm{e}-01$ 1.00000e-09 2.12000e-01 $6.52424 \mathrm{e}+006.52424 \mathrm{e}+006.52424 \mathrm{e}-011.00000 \mathrm{e}-092.12000 \mathrm{e}-01$ $6.52424 \mathrm{e}+006.52424 \mathrm{e}+006.52424 \mathrm{e}-011.00000 \mathrm{e}-092.12000 \mathrm{e}-01$ $6.52424 \mathrm{e}+006.52424 \mathrm{e}+006.52424 \mathrm{e}-011.00000 \mathrm{e}-092.12000 \mathrm{e}-01$ $6.52424 \mathrm{e}+006.52424 \mathrm{e}+006.52424 \mathrm{e}-011.00000 \mathrm{e}-092.12000 \mathrm{e}-01$ $1.00000 \mathrm{e}-05$ 1.00000e-05 1.00000e-06 1.00000e-09 1.00000e-01 $1.00000 \mathrm{e}+001.00000 \mathrm{e}+001.00000 \mathrm{e}-011.00000 \mathrm{e}-091.00000 \mathrm{e}-01$ Element: 11914 \# of layers: 7

Kx Ky Kz Ss Por

$6.52424 \mathrm{e}+006.52424 \mathrm{e}+006.52424 \mathrm{e}-011.00000 \mathrm{e}-092.12000 \mathrm{e}-01$ $6.52424 \mathrm{e}+006.52424 \mathrm{e}+006.52424 \mathrm{e}-011.00000 \mathrm{e}-092.12000 \mathrm{e}-01$ 
$6.52424 \mathrm{e}+006.52424 \mathrm{e}+006.52424 \mathrm{e}-011.00000 \mathrm{e}-092.12000 \mathrm{e}-01$ $6.52424 \mathrm{e}+006.52424 \mathrm{e}+006.52424 \mathrm{e}-011.00000 \mathrm{e}-092.12000 \mathrm{e}-01$ $6.52424 \mathrm{e}+006.52424 \mathrm{e}+006.52424 \mathrm{e}-011.00000 \mathrm{e}-092.12000 \mathrm{e}-01$ $1.00000 \mathrm{e}-05$ 1.00000e-05 1.00000e-06 1.00000e-09 1.00000e-01 $1.00000 \mathrm{e}+001.00000 \mathrm{e}+001.00000 \mathrm{e}-011.00000 \mathrm{e}-091.00000 \mathrm{e}-01$ Element: 11915 \# of layers: 7

Kx Ky Kz Ss Por

$6.52424 \mathrm{e}+006.52424 \mathrm{e}+00$ 6.52424e-01 1.00000e-09 2.12000e-01 $6.52424 \mathrm{e}+006.52424 \mathrm{e}+006.52424 \mathrm{e}-011.00000 \mathrm{e}-092.12000 \mathrm{e}-01$ $6.52424 \mathrm{e}+006.52424 \mathrm{e}+006.52424 \mathrm{e}-011.00000 \mathrm{e}-092.12000 \mathrm{e}-01$ $6.52424 \mathrm{e}+006.52424 \mathrm{e}+006.52424 \mathrm{e}-011.00000 \mathrm{e}-092.12000 \mathrm{e}-01$ $6.52424 \mathrm{e}+006.52424 \mathrm{e}+006.52424 \mathrm{e}-011.00000 \mathrm{e}-092.12000 \mathrm{e}-01$ $1.00000 \mathrm{e}-05$ 1.00000e-05 1.00000e-06 1.00000e-09 1.00000e-01 $1.00000 \mathrm{e}+001.00000 \mathrm{e}+001.00000 \mathrm{e}-011.00000 \mathrm{e}-091.00000 \mathrm{e}-01$ Element: 11916 \# of layers: 7

Kx Ky Kz Ss Por

$6.52424 \mathrm{e}+006.52424 \mathrm{e}+006.52424 \mathrm{e}-011.00000 \mathrm{e}-092.12000 \mathrm{e}-01$ $6.52424 \mathrm{e}+006.52424 \mathrm{e}+006.52424 \mathrm{e}-011.00000 \mathrm{e}-092.12000 \mathrm{e}-01$ $6.52424 \mathrm{e}+006.52424 \mathrm{e}+006.52424 \mathrm{e}-011.00000 \mathrm{e}-092.12000 \mathrm{e}-01$ $6.52424 \mathrm{e}+006.52424 \mathrm{e}+006.52424 \mathrm{e}-011.00000 \mathrm{e}-092.12000 \mathrm{e}-01$ $6.52424 \mathrm{e}+006.52424 \mathrm{e}+006.52424 \mathrm{e}-011.00000 \mathrm{e}-092.12000 \mathrm{e}-01$ $1.00000 \mathrm{e}-05$ 1.00000e-05 1.00000e-06 1.00000e-09 1.00000e-01 $1.00000 \mathrm{e}+001.00000 \mathrm{e}+001.00000 \mathrm{e}-011.00000 \mathrm{e}-091.00000 \mathrm{e}-01$ Element: 11917 \# of layers: 7

Kx Ky Kz Ss Por

$6.52424 \mathrm{e}+006.52424 \mathrm{e}+006.52424 \mathrm{e}-011.00000 \mathrm{e}-092.12000 \mathrm{e}-01$ $6.52424 \mathrm{e}+006.52424 \mathrm{e}+006.52424 \mathrm{e}-011.00000 \mathrm{e}-092.12000 \mathrm{e}-01$ $6.52424 \mathrm{e}+006.52424 \mathrm{e}+006.52424 \mathrm{e}-011.00000 \mathrm{e}-092.12000 \mathrm{e}-01$ $6.52424 \mathrm{e}+006.52424 \mathrm{e}+00 \quad 6.52424 \mathrm{e}-011.00000 \mathrm{e}-092.12000 \mathrm{e}-01$ $6.52424 \mathrm{e}+006.52424 \mathrm{e}+006.52424 \mathrm{e}-011.00000 \mathrm{e}-092.12000 \mathrm{e}-01$ $1.00000 \mathrm{e}-051.00000 \mathrm{e}-05$ 1.00000e-06 1.00000e-09 1.00000e-01 $1.00000 \mathrm{e}+001.00000 \mathrm{e}+001.00000 \mathrm{e}-011.00000 \mathrm{e}-091.00000 \mathrm{e}-01$ Element: 11918 \# of layers: 7

Kx Ky Kz Ss Por

$6.52424 \mathrm{e}+006.52424 \mathrm{e}+006.52424 \mathrm{e}-011.00000 \mathrm{e}-092.12000 \mathrm{e}-01$ $6.52424 \mathrm{e}+006.52424 \mathrm{e}+006.52424 \mathrm{e}-011.00000 \mathrm{e}-092.12000 \mathrm{e}-01$ $6.52424 \mathrm{e}+006.52424 \mathrm{e}+006.52424 \mathrm{e}-011.00000 \mathrm{e}-092.12000 \mathrm{e}-01$ $6.52424 \mathrm{e}+006.52424 \mathrm{e}+006.52424 \mathrm{e}-011.00000 \mathrm{e}-092.12000 \mathrm{e}-01$ $6.52424 \mathrm{e}+006.52424 \mathrm{e}+006.52424 \mathrm{e}-011.00000 \mathrm{e}-092.12000 \mathrm{e}-01$ $1.00000 \mathrm{e}-05$ 1.00000e-05 1.00000e-06 1.00000e-09 1.00000e-01 $1.00000 \mathrm{e}+001.00000 \mathrm{e}+001.00000 \mathrm{e}-011.00000 \mathrm{e}-091.00000 \mathrm{e}-01$ Element: 11919 \# of layers: 7

Kx Ky Kz Ss Por

$3.24862 \mathrm{e}+003.24862 \mathrm{e}+00$ 3.24862e-01 1.00000e-09 2.12000e-01 $3.24862 \mathrm{e}+003.24862 \mathrm{e}+003.24862 \mathrm{e}-01$ 1.00000e-09 2.12000e-01 $3.24862 \mathrm{e}+003.24862 \mathrm{e}+003.24862 \mathrm{e}-01$ 1.00000e-09 2.12000e-01 
$3.24862 \mathrm{e}+003.24862 \mathrm{e}+003.24862 \mathrm{e}-01$ 1.00000e-09 2.12000e-01 $3.24862 \mathrm{e}+003.24862 \mathrm{e}+003.24862 \mathrm{e}-01$ 1.00000e-09 2.12000e-01 $1.00000 \mathrm{e}-05$ 1.00000e-05 1.00000e-06 1.00000e-09 1.00000e-01 $1.00000 \mathrm{e}+001.00000 \mathrm{e}+001.00000 \mathrm{e}-011.00000 \mathrm{e}-091.00000 \mathrm{e}-01$ Element: 11920 \# of layers: 7

Kx Ky Kz Ss Por

$3.24862 \mathrm{e}+003.24862 \mathrm{e}+00$ 3.24862e-01 1.00000e-09 2.12000e-01 $3.24862 \mathrm{e}+003.24862 \mathrm{e}+003.24862 \mathrm{e}-01$ 1.00000e-09 2.12000e-01 $3.24862 \mathrm{e}+003.24862 \mathrm{e}+003.24862 \mathrm{e}-01$ 1.00000e-09 2.12000e-01 $3.24862 \mathrm{e}+003.24862 \mathrm{e}+003.24862 \mathrm{e}-01$ 1.00000e-09 2.12000e-01 $3.24862 \mathrm{e}+003.24862 \mathrm{e}+003.24862 \mathrm{e}-01$ 1.00000e-09 2.12000e-01 $1.00000 \mathrm{e}-05$ 1.00000e-05 1.00000e-06 1.00000e-09 1.00000e-01 $1.00000 \mathrm{e}+001.00000 \mathrm{e}+001.00000 \mathrm{e}-011.00000 \mathrm{e}-091.00000 \mathrm{e}-01$ Element: 11921 \# of layers: 7

Kx Ky Kz Ss Por

$3.24862 \mathrm{e}+003.24862 \mathrm{e}+00$ 3.24862e-01 1.00000e-09 2.12000e-01 $3.24862 \mathrm{e}+003.24862 \mathrm{e}+003.24862 \mathrm{e}-01$ 1.00000e-09 2.12000e-01 $3.24862 \mathrm{e}+003.24862 \mathrm{e}+003.24862 \mathrm{e}-01$ 1.00000e-09 2.12000e-01 $3.24862 \mathrm{e}+003.24862 \mathrm{e}+003.24862 \mathrm{e}-01$ 1.00000e-09 2.12000e-01 $3.24862 \mathrm{e}+003.24862 \mathrm{e}+003.24862 \mathrm{e}-01$ 1.00000e-09 2.12000e-01 $1.00000 \mathrm{e}-05$ 1.00000e-05 1.00000e-06 1.00000e-09 1.00000e-01 $1.00000 \mathrm{e}+001.00000 \mathrm{e}+001.00000 \mathrm{e}-011.00000 \mathrm{e}-091.00000 \mathrm{e}-01$ Element: 11922 \# of layers: 7

Kx Ky Kz Ss Por

$3.24862 \mathrm{e}+003.24862 \mathrm{e}+00$ 3.24862e-01 1.00000e-09 2.12000e-01 $3.24862 \mathrm{e}+003.24862 \mathrm{e}+003.24862 \mathrm{e}-01$ 1.00000e-09 2.12000e-01 $3.24862 \mathrm{e}+003.24862 \mathrm{e}+003.24862 \mathrm{e}-011.00000 \mathrm{e}-092.12000 \mathrm{e}-01$ $3.24862 \mathrm{e}+003.24862 \mathrm{e}+003.24862 \mathrm{e}-011.00000 \mathrm{e}-092.12000 \mathrm{e}-01$ $3.24862 \mathrm{e}+003.24862 \mathrm{e}+003.24862 \mathrm{e}-01$ 1.00000e-09 2.12000e-01 $1.00000 \mathrm{e}-05$ 1.00000e-05 1.00000e-06 1.00000e-09 1.00000e-01 $1.00000 \mathrm{e}+001.00000 \mathrm{e}+001.00000 \mathrm{e}-011.00000 \mathrm{e}-091.00000 \mathrm{e}-01$ Element: 11923 \# of layers: 7

Kx Ky Kz Ss Por

$3.24862 \mathrm{e}+003.24862 \mathrm{e}+003.24862 \mathrm{e}-01$ 1.00000e-09 2.12000e-01 $3.24862 \mathrm{e}+003.24862 \mathrm{e}+003.24862 \mathrm{e}-01$ 1.00000e-09 2.12000e-01 $3.24862 \mathrm{e}+003.24862 \mathrm{e}+003.24862 \mathrm{e}-01$ 1.00000e-09 2.12000e-01 $3.24862 \mathrm{e}+003.24862 \mathrm{e}+003.24862 \mathrm{e}-011.00000 \mathrm{e}-092.12000 \mathrm{e}-01$ $3.24862 \mathrm{e}+003.24862 \mathrm{e}+003.24862 \mathrm{e}-01$ 1.00000e-09 2.12000e-01 $1.00000 \mathrm{e}-05$ 1.00000e-05 1.00000e-06 1.00000e-09 1.00000e-01 $1.00000 \mathrm{e}+001.00000 \mathrm{e}+001.00000 \mathrm{e}-011.00000 \mathrm{e}-091.00000 \mathrm{e}-01$ Element: 11924 \# of layers: 7

Kx Ky Kz Ss Por

$6.52424 \mathrm{e}+006.52424 \mathrm{e}+006.52424 \mathrm{e}-011.00000 \mathrm{e}-092.12000 \mathrm{e}-01$ $6.52424 \mathrm{e}+006.52424 \mathrm{e}+006.52424 \mathrm{e}-011.00000 \mathrm{e}-092.12000 \mathrm{e}-01$ $6.52424 \mathrm{e}+006.52424 \mathrm{e}+006.52424 \mathrm{e}-011.00000 \mathrm{e}-092.12000 \mathrm{e}-01$ $6.52424 \mathrm{e}+006.52424 \mathrm{e}+006.52424 \mathrm{e}-01$ 1.00000e-09 2.12000e-01 
6.52424e+00 6.52424e+00 6.52424e-01 1.00000e-09 2.12000e-01 $1.00000 \mathrm{e}-05$ 1.00000e-05 1.00000e-06 1.00000e-09 1.00000e-01 $1.00000 \mathrm{e}+001.00000 \mathrm{e}+001.00000 \mathrm{e}-011.00000 \mathrm{e}-09$ 1.00000e-01 Element: 11925 \# of layers: 7

$\mathrm{Kx} \mathrm{Ky} \mathrm{Kz}$ Ss Por

$6.52424 \mathrm{e}+006.52424 \mathrm{e}+006.52424 \mathrm{e}-01$ 1.00000e-09 2.12000e-01

$6.52424 \mathrm{e}+006.52424 \mathrm{e}+006.52424 \mathrm{e}-01$ 1.00000e-09 2.12000e-01

$6.52424 \mathrm{e}+006.52424 \mathrm{e}+006.52424 \mathrm{e}-01$ 1.00000e-09 2.12000e-01

$6.52424 \mathrm{e}+006.52424 \mathrm{e}+006.52424 \mathrm{e}-01$ 1.00000e-09 2.12000e-01

$6.52424 \mathrm{e}+006.52424 \mathrm{e}+006.52424 \mathrm{e}-01$ 1.00000e-09 2.12000e-01

$1.00000 \mathrm{e}-05$ 1.00000e-05 1.00000e-06 1.00000e-09 1.00000e-01

$1.00000 \mathrm{e}+001.00000 \mathrm{e}+001.00000 \mathrm{e}-011.00000 \mathrm{e}-091.00000 \mathrm{e}-01$

Element: 11926 \# of layers: 7

$\mathrm{Kx} \mathrm{Ky} \mathrm{Kz}$ Ss Por

3.24862e+00 3.24862e+00 3.24862e-01 1.00000e-09 2.12000e-01

$3.24862 \mathrm{e}+003.24862 \mathrm{e}+00$ 3.24862e-01 1.00000e-09 2.12000e-01

3.24862e+00 3.24862e+00 3.24862e-01 1.00000e-09 2.12000e-01

3.24862e+00 3.24862e+00 3.24862e-01 1.00000e-09 2.12000e-01

3.24862e+00 3.24862e+00 3.24862e-01 1.00000e-09 2.12000e-01

$1.00000 \mathrm{e}-05$ 1.00000e-05 1.00000e-06 1.00000e-09 1.00000e-01

$1.00000 \mathrm{e}+001.00000 \mathrm{e}+001.00000 \mathrm{e}-011.00000 \mathrm{e}-091.00000 \mathrm{e}-01$

Element: 11927 \# of layers: 7

$\mathrm{Kx} \mathrm{Ky} \mathrm{Kz}$ Ss Por

3.24862e+00 3.24862e+00 3.24862e-01 1.00000e-09 2.12000e-01

$3.24862 \mathrm{e}+003.24862 \mathrm{e}+00$ 3.24862e-01 1.00000e-09 2.12000e-01

$3.24862 \mathrm{e}+00$ 3.24862e+00 3.24862e-01 1.00000e-09 2.12000e-01

$3.24862 \mathrm{e}+003.24862 \mathrm{e}+00$ 3.24862e-01 1.00000e-09 2.12000e-01

3.24862e+00 3.24862e+00 3.24862e-01 1.00000e-09 2.12000e-01

$1.00000 \mathrm{e}-05$ 1.00000e-05 1.00000e-06 1.00000e-09 1.00000e-01

$1.00000 \mathrm{e}+001.00000 \mathrm{e}+001.00000 \mathrm{e}-011.00000 \mathrm{e}-091.00000 \mathrm{e}-01$

Element: 11928 \# of layers: 7

$\mathrm{Kx} \mathrm{Ky} \mathrm{Kz}$ Ss Por

3.24862e+00 3.24862e+00 3.24862e-01 1.00000e-09 2.12000e-01

$3.24862 \mathrm{e}+003.24862 \mathrm{e}+00$ 3.24862e-01 1.00000e-09 2.12000e-01

3.24862e+00 3.24862e+00 3.24862e-01 1.00000e-09 2.12000e-01

$3.24862 \mathrm{e}+00$ 3.24862e+00 3.24862e-01 1.00000e-09 2.12000e-01

$3.24862 \mathrm{e}+003.24862 \mathrm{e}+00$ 3.24862e-01 1.00000e-09 2.12000e-01

$1.00000 \mathrm{e}-05$ 1.00000e-05 1.00000e-06 1.00000e-09 1.00000e-01

$1.00000 \mathrm{e}+001.00000 \mathrm{e}+001.00000 \mathrm{e}-01$ 1.00000e-09 1.00000e-01

Element: 11929 \# of layers: 7

$\mathrm{Kx} \mathrm{Ky} \mathrm{Kz}$ Ss Por

3.24862e+00 3.24862e+00 3.24862e-01 1.00000e-09 2.12000e-01

3.24862e+00 3.24862e+00 3.24862e-01 1.00000e-09 2.12000e-01

3.24862e+00 3.24862e+00 3.24862e-01 1.00000e-09 2.12000e-01

$3.24862 \mathrm{e}+00$ 3.24862e+00 3.24862e-01 1.00000e-09 2.12000e-01

$3.24862 \mathrm{e}+003.24862 \mathrm{e}+00$ 3.24862e-01 1.00000e-09 2.12000e-01 
$1.00000 \mathrm{e}-05$ 1.00000e-05 1.00000e-06 1.00000e-09 1.00000e-01 $1.00000 \mathrm{e}+001.00000 \mathrm{e}+001.00000 \mathrm{e}-01$ 1.00000e-09 1.00000e-01 Element: 11930 \# of layers: 7

Kx Ky Kz Ss Por

3.24862e+00 3.24862e+00 3.24862e-01 1.00000e-09 2.12000e-01 $3.24862 \mathrm{e}+003.24862 \mathrm{e}+00$ 3.24862e-01 1.00000e-09 2.12000e-01 3.24862e+00 3.24862e+00 3.24862e-01 1.00000e-09 2.12000e-01 $3.24862 \mathrm{e}+003.24862 \mathrm{e}+00$ 3.24862e-01 1.00000e-09 2.12000e-01 $3.24862 \mathrm{e}+003.24862 \mathrm{e}+00$ 3.24862e-01 1.00000e-09 2.12000e-01 $1.00000 \mathrm{e}-05$ 1.00000e-05 1.00000e-06 1.00000e-09 1.00000e-01 $1.00000 \mathrm{e}+001.00000 \mathrm{e}+001.00000 \mathrm{e}-011.00000 \mathrm{e}-091.00000 \mathrm{e}-01$ Element: 11931 \# of layers: 7

$\mathrm{Kx} \mathrm{Ky} \mathrm{Kz}$ Ss Por

3.24862e+00 3.24862e+00 3.24862e-01 1.00000e-09 2.12000e-01 3.24862e+00 3.24862e+00 3.24862e-01 1.00000e-09 2.12000e-01 $3.24862 \mathrm{e}+003.24862 \mathrm{e}+00$ 3.24862e-01 1.00000e-09 2.12000e-01 $3.24862 \mathrm{e}+003.24862 \mathrm{e}+00$ 3.24862e-01 1.00000e-09 2.12000e-01 3.24862e+00 3.24862e+00 3.24862e-01 1.00000e-09 2.12000e-01 $1.00000 \mathrm{e}-051.00000 \mathrm{e}-051.00000 \mathrm{e}-061.00000 \mathrm{e}-091.00000 \mathrm{e}-01$ $1.00000 \mathrm{e}+001.00000 \mathrm{e}+001.00000 \mathrm{e}-011.00000 \mathrm{e}-09$ 1.00000e-01 Element: 11932 \# of layers: 7

$\mathrm{Kx} \mathrm{Ky} \mathrm{Kz}$ Ss Por

3.24862e+00 3.24862e+00 3.24862e-01 1.00000e-09 2.12000e-01 $3.24862 \mathrm{e}+00$ 3.24862e+00 3.24862e-01 1.00000e-09 2.12000e-01 $3.24862 \mathrm{e}+003.24862 \mathrm{e}+00$ 3.24862e-01 1.00000e-09 2.12000e-01 $3.24862 \mathrm{e}+003.24862 \mathrm{e}+00$ 3.24862e-01 1.00000e-09 2.12000e-01 $3.24862 \mathrm{e}+003.24862 \mathrm{e}+00$ 3.24862e-01 1.00000e-09 2.12000e-01 $1.00000 \mathrm{e}-05$ 1.00000e-05 1.00000e-06 1.00000e-09 1.00000e-01 $1.00000 \mathrm{e}+001.00000 \mathrm{e}+001.00000 \mathrm{e}-011.00000 \mathrm{e}-091.00000 \mathrm{e}-01$ Element: 11933 \# of layers: 7

$\mathrm{Kx} \mathrm{Ky} \mathrm{Kz}$ Ss Por

3.24862e+00 3.24862e+00 3.24862e-01 1.00000e-09 2.12000e-01 $3.24862 \mathrm{e}+003.24862 \mathrm{e}+00$ 3.24862e-01 1.00000e-09 2.12000e-01 $3.24862 \mathrm{e}+00$ 3.24862e+00 3.24862e-01 1.00000e-09 2.12000e-01 3.24862e+00 3.24862e+00 3.24862e-01 1.00000e-09 2.12000e-01 3.24862e+00 3.24862e+00 3.24862e-01 1.00000e-09 2.12000e-01 $1.00000 \mathrm{e}-05$ 1.00000e-05 1.00000e-06 1.00000e-09 1.00000e-01 $1.00000 \mathrm{e}+001.00000 \mathrm{e}+001.00000 \mathrm{e}-011.00000 \mathrm{e}-091.00000 \mathrm{e}-01$ Element: 11934 \# of layers: 7

$\mathrm{Kx} \mathrm{Ky} \mathrm{Kz}$ Ss Por

3.24862e+00 3.24862e+00 3.24862e-01 1.00000e-09 2.12000e-01 $3.24862 \mathrm{e}+00$ 3.24862e+00 3.24862e-01 1.00000e-09 2.12000e-01 $3.24862 \mathrm{e}+003.24862 \mathrm{e}+00$ 3.24862e-01 1.00000e-09 2.12000e-01 3.24862e+00 3.24862e+00 3.24862e-01 1.00000e-09 2.12000e-01 3.24862e+00 3.24862e+00 3.24862e-01 1.00000e-09 2.12000e-01 $1.00000 \mathrm{e}-05$ 1.00000e-05 1.00000e-06 1.00000e-09 1.00000e-01 
$1.00000 \mathrm{e}+001.00000 \mathrm{e}+001.00000 \mathrm{e}-011.00000 \mathrm{e}-091.00000 \mathrm{e}-01$ Element: 11935 \# of layers: 7

$\mathrm{Kx} \mathrm{Ky} \mathrm{Kz}$ Ss Por

3.24862e+00 3.24862e+00 3.24862e-01 1.00000e-09 2.12000e-01

3.24862e+00 3.24862e+00 3.24862e-01 1.00000e-09 2.12000e-01

$3.24862 \mathrm{e}+003.24862 \mathrm{e}+00$ 3.24862e-01 1.00000e-09 2.12000e-01

$3.24862 \mathrm{e}+003.24862 \mathrm{e}+00$ 3.24862e-01 1.00000e-09 2.12000e-01

$3.24862 \mathrm{e}+003.24862 \mathrm{e}+003.24862 \mathrm{e}-01$ 1.00000e-09 2.12000e-01

$1.00000 \mathrm{e}-05$ 1.00000e-05 1.00000e-06 1.00000e-09 1.00000e-01

$1.00000 \mathrm{e}+001.00000 \mathrm{e}+001.00000 \mathrm{e}-011.00000 \mathrm{e}-091.00000 \mathrm{e}-01$

Element: 11936 \# of layers: 7

$\mathrm{Kx} \mathrm{Ky} \mathrm{Kz}$ Ss Por

3.24862e+00 3.24862e+00 3.24862e-01 1.00000e-09 2.12000e-01

$3.24862 \mathrm{e}+00$ 3.24862e+00 3.24862e-01 1.00000e-09 2.12000e-01

3.24862e+00 3.24862e+00 3.24862e-01 1.00000e-09 2.12000e-01

$3.24862 \mathrm{e}+003.24862 \mathrm{e}+003.24862 \mathrm{e}-01$ 1.00000e-09 2.12000e-01

3.24862e+00 3.24862e+00 3.24862e-01 1.00000e-09 2.12000e-01

$1.00000 \mathrm{e}-05$ 1.00000e-05 1.00000e-06 1.00000e-09 1.00000e-01

$1.00000 \mathrm{e}+001.00000 \mathrm{e}+001.00000 \mathrm{e}-01$ 1.00000e-09 1.00000e-01

Element: 11937 \# of layers: 7

$\mathrm{Kx} \mathrm{Ky} \mathrm{Kz}$ Ss Por

3.24862e+00 3.24862e+00 3.24862e-01 1.00000e-09 2.12000e-01

3.24862e+00 3.24862e+00 3.24862e-01 1.00000e-09 2.12000e-01

$3.24862 \mathrm{e}+00$ 3.24862e+00 3.24862e-01 1.00000e-09 2.12000e-01

$3.24862 \mathrm{e}+003.24862 \mathrm{e}+00$ 3.24862e-01 1.00000e-09 2.12000e-01

$3.24862 \mathrm{e}+003.24862 \mathrm{e}+00$ 3.24862e-01 1.00000e-09 2.12000e-01

$1.00000 \mathrm{e}-05$ 1.00000e-05 1.00000e-06 1.00000e-09 1.00000e-01

$1.00000 \mathrm{e}+001.00000 \mathrm{e}+001.00000 \mathrm{e}-011.00000 \mathrm{e}-091.00000 \mathrm{e}-01$

Element: 11938 \# of layers: 7

$\mathrm{Kx} \mathrm{Ky} \mathrm{Kz}$ Ss Por

3.33817e+00 3.33817e+00 3.33817e-01 1.00000e-09 2.12000e-01 3.33817e+00 3.33817e+00 3.33817e-01 1.00000e-09 2.12000e-01 $3.33817 \mathrm{e}+003.33817 \mathrm{e}+00$ 3.33817e-01 1.00000e-09 2.12000e-01 $3.33817 \mathrm{e}+00$ 3.33817e+00 3.33817e-01 1.00000e-09 2.12000e-01 $3.33817 \mathrm{e}+003.33817 \mathrm{e}+00$ 3.33817e-01 1.00000e-09 2.12000e-01 $1.00000 \mathrm{e}-05$ 1.00000e-05 1.00000e-06 1.00000e-09 1.00000e-01 $1.00000 \mathrm{e}+001.00000 \mathrm{e}+001.00000 \mathrm{e}-011.00000 \mathrm{e}-091.00000 \mathrm{e}-01$ Element: 11939 \# of layers: 7

$\mathrm{Kx} \mathrm{Ky} \mathrm{Kz}$ Ss Por

3.33817e+00 3.33817e+00 3.33817e-01 1.00000e-09 2.12000e-01 $3.33817 \mathrm{e}+003.33817 \mathrm{e}+00$ 3.33817e-01 1.00000e-09 2.12000e-01 $3.33817 \mathrm{e}+003.33817 \mathrm{e}+00$ 3.33817e-01 1.00000e-09 2.12000e-01 $3.33817 \mathrm{e}+003.33817 \mathrm{e}+00$ 3.33817e-01 1.00000e-09 2.12000e-01 3.33817e+00 3.33817e+00 3.33817e-01 1.00000e-09 2.12000e-01 $1.00000 \mathrm{e}-05$ 1.00000e-05 1.00000e-06 1.00000e-09 1.00000e-01 $1.00000 \mathrm{e}+001.00000 \mathrm{e}+001.00000 \mathrm{e}-011.00000 \mathrm{e}-091.00000 \mathrm{e}-01$ 
Element: 11940 \# of layers: 7

Kx Ky Kz Ss Por

3.33817e+00 3.33817e+00 3.33817e-01 1.00000e-09 2.12000e-01

$3.33817 \mathrm{e}+003.33817 \mathrm{e}+003.33817 \mathrm{e}-011.00000 \mathrm{e}-092.12000 \mathrm{e}-01$

$3.33817 \mathrm{e}+003.33817 \mathrm{e}+003.33817 \mathrm{e}-011.00000 \mathrm{e}-092.12000 \mathrm{e}-01$

$3.33817 \mathrm{e}+003.33817 \mathrm{e}+003.33817 \mathrm{e}-011.00000 \mathrm{e}-092.12000 \mathrm{e}-01$

$3.33817 \mathrm{e}+003.33817 \mathrm{e}+003.33817 \mathrm{e}-01$ 1.00000e-09 2.12000e-01

$1.00000 \mathrm{e}-05$ 1.00000e-05 1.00000e-06 1.00000e-09 1.00000e-01

$1.00000 \mathrm{e}+001.00000 \mathrm{e}+001.00000 \mathrm{e}-011.00000 \mathrm{e}-091.00000 \mathrm{e}-01$

Element: 11941 \# of layers: 7

Kx Ky Kz Ss Por

$3.24862 \mathrm{e}+003.24862 \mathrm{e}+00$ 3.24862e-01 1.00000e-09 2.12000e-01

$3.24862 \mathrm{e}+003.24862 \mathrm{e}+003.24862 \mathrm{e}-01$ 1.00000e-09 2.12000e-01

$3.24862 \mathrm{e}+003.24862 \mathrm{e}+003.24862 \mathrm{e}-011.00000 \mathrm{e}-092.12000 \mathrm{e}-01$

$3.24862 \mathrm{e}+003.24862 \mathrm{e}+003.24862 \mathrm{e}-011.00000 \mathrm{e}-092.12000 \mathrm{e}-01$

$3.24862 \mathrm{e}+003.24862 \mathrm{e}+003.24862 \mathrm{e}-01$ 1.00000e-09 2.12000e-01

$1.00000 \mathrm{e}-05$ 1.00000e-05 1.00000e-06 1.00000e-09 1.00000e-01

$1.00000 \mathrm{e}+001.00000 \mathrm{e}+001.00000 \mathrm{e}-011.00000 \mathrm{e}-091.00000 \mathrm{e}-01$

Element: 11942 \# of layers: 7

Kx Ky Kz Ss Por

$3.24862 \mathrm{e}+003.24862 \mathrm{e}+003.24862 \mathrm{e}-01$ 1.00000e-09 2.12000e-01

$3.24862 \mathrm{e}+003.24862 \mathrm{e}+003.24862 \mathrm{e}-01$ 1.00000e-09 2.12000e-01

$3.24862 \mathrm{e}+003.24862 \mathrm{e}+003.24862 \mathrm{e}-011.00000 \mathrm{e}-092.12000 \mathrm{e}-01$

$3.24862 \mathrm{e}+003.24862 \mathrm{e}+003.24862 \mathrm{e}-011.00000 \mathrm{e}-092.12000 \mathrm{e}-01$

$3.24862 \mathrm{e}+003.24862 \mathrm{e}+003.24862 \mathrm{e}-01$ 1.00000e-09 2.12000e-01

$1.00000 \mathrm{e}-05$ 1.00000e-05 1.00000e-06 1.00000e-09 1.00000e-01

$1.00000 \mathrm{e}+001.00000 \mathrm{e}+001.00000 \mathrm{e}-011.00000 \mathrm{e}-091.00000 \mathrm{e}-01$

Element: 11943 \# of layers: 7

Kx Ky Kz Ss Por

$3.24862 \mathrm{e}+003.24862 \mathrm{e}+00$ 3.24862e-01 1.00000e-09 2.12000e-01

$3.24862 \mathrm{e}+003.24862 \mathrm{e}+003.24862 \mathrm{e}-01$ 1.00000e-09 2.12000e-01

$3.24862 \mathrm{e}+003.24862 \mathrm{e}+003.24862 \mathrm{e}-01$ 1.00000e-09 2.12000e-01

$3.24862 \mathrm{e}+003.24862 \mathrm{e}+003.24862 \mathrm{e}-011.00000 \mathrm{e}-092.12000 \mathrm{e}-01$

$3.24862 \mathrm{e}+003.24862 \mathrm{e}+003.24862 \mathrm{e}-01$ 1.00000e-09 2.12000e-01

$1.00000 \mathrm{e}-05$ 1.00000e-05 1.00000e-06 1.00000e-09 1.00000e-01

$1.00000 \mathrm{e}+001.00000 \mathrm{e}+001.00000 \mathrm{e}-011.00000 \mathrm{e}-091.00000 \mathrm{e}-01$

Element: 11944 \# of layers: 7

Kx Ky Kz Ss Por

$3.24862 \mathrm{e}+003.24862 \mathrm{e}+00$ 3.24862e-01 1.00000e-09 2.12000e-01

$3.24862 \mathrm{e}+003.24862 \mathrm{e}+003.24862 \mathrm{e}-01$ 1.00000e-09 2.12000e-01

$3.24862 \mathrm{e}+003.24862 \mathrm{e}+003.24862 \mathrm{e}-01$ 1.00000e-09 2.12000e-01

$3.24862 \mathrm{e}+003.24862 \mathrm{e}+003.24862 \mathrm{e}-01$ 1.00000e-09 2.12000e-01

$3.24862 \mathrm{e}+003.24862 \mathrm{e}+003.24862 \mathrm{e}-01$ 1.00000e-09 2.12000e-01

$1.00000 \mathrm{e}-05$ 1.00000e-05 1.00000e-06 1.00000e-09 1.00000e-01

$1.00000 \mathrm{e}+001.00000 \mathrm{e}+001.00000 \mathrm{e}-011.00000 \mathrm{e}-091.00000 \mathrm{e}-01$

Element: 11945 \# of layers: 7 
$\mathrm{Kx} \mathrm{Ky} \mathrm{Kz}$ Ss Por

3.33817e+00 3.33817e+00 3.33817e-01 1.00000e-09 2.12000e-01 $3.33817 \mathrm{e}+003.33817 \mathrm{e}+00$ 3.33817e-01 1.00000e-09 2.12000e-01 $3.33817 \mathrm{e}+00$ 3.33817e+00 3.33817e-01 1.00000e-09 2.12000e-01 $3.33817 \mathrm{e}+003.33817 \mathrm{e}+00$ 3.33817e-01 1.00000e-09 2.12000e-01 $3.33817 \mathrm{e}+003.33817 \mathrm{e}+00$ 3.33817e-01 1.00000e-09 2.12000e-01 1.00000e-05 1.00000e-05 1.00000e-06 1.00000e-09 1.00000e-01 $1.00000 \mathrm{e}+001.00000 \mathrm{e}+001.00000 \mathrm{e}-01$ 1.00000e-09 1.00000e-01 Element: 11946 \# of layers: 7

$\mathrm{Kx} \mathrm{Ky} \mathrm{Kz}$ Ss Por

3.33817e+00 3.33817e+00 3.33817e-01 1.00000e-09 2.12000e-01 $3.33817 \mathrm{e}+003.33817 \mathrm{e}+00$ 3.33817e-01 1.00000e-09 2.12000e-01 $3.33817 \mathrm{e}+003.33817 \mathrm{e}+00$ 3.33817e-01 1.00000e-09 2.12000e-01 $3.33817 \mathrm{e}+003.33817 \mathrm{e}+00$ 3.33817e-01 1.00000e-09 2.12000e-01 $3.33817 \mathrm{e}+003.33817 \mathrm{e}+00$ 3.33817e-01 1.00000e-09 2.12000e-01 $1.00000 \mathrm{e}-05$ 1.00000e-05 1.00000e-06 1.00000e-09 1.00000e-01 $1.00000 \mathrm{e}+001.00000 \mathrm{e}+001.00000 \mathrm{e}-01$ 1.00000e-09 1.00000e-01 Element: 11947 \# of layers: 7

$\mathrm{Kx} \mathrm{Ky} \mathrm{Kz}$ Ss Por

3.33817e+00 3.33817e+00 3.33817e-01 1.00000e-09 2.12000e-01 $3.33817 \mathrm{e}+003.33817 \mathrm{e}+00$ 3.33817e-01 1.00000e-09 2.12000e-01 3.33817e+00 3.33817e+00 3.33817e-01 1.00000e-09 2.12000e-01 3.33817e+00 3.33817e+00 3.33817e-01 1.00000e-09 2.12000e-01 $3.33817 \mathrm{e}+00$ 3.33817e+00 3.33817e-01 1.00000e-09 2.12000e-01 $1.00000 \mathrm{e}-05$ 1.00000e-05 1.00000e-06 1.00000e-09 1.00000e-01 $1.00000 \mathrm{e}+001.00000 \mathrm{e}+001.00000 \mathrm{e}-01$ 1.00000e-09 1.00000e-01 Element: 11948 \# of layers: 7

$\mathrm{Kx} \mathrm{Ky} \mathrm{Kz}$ Ss Por

3.33817e+00 3.33817e+00 3.33817e-01 1.00000e-09 2.12000e-01 $3.33817 \mathrm{e}+00$ 3.33817e+00 3.33817e-01 1.00000e-09 2.12000e-01 $3.33817 \mathrm{e}+003.33817 \mathrm{e}+00$ 3.33817e-01 1.00000e-09 2.12000e-01 $3.33817 \mathrm{e}+00$ 3.33817e+00 3.33817e-01 1.00000e-09 2.12000e-01 $3.33817 \mathrm{e}+003.33817 \mathrm{e}+00$ 3.33817e-01 1.00000e-09 2.12000e-01 $1.00000 \mathrm{e}-05$ 1.00000e-05 1.00000e-06 1.00000e-09 1.00000e-01 $1.00000 \mathrm{e}+001.00000 \mathrm{e}+001.00000 \mathrm{e}-011.00000 \mathrm{e}-091.00000 \mathrm{e}-01$ Element: 11949 \# of layers: 7

Kx Ky Kz Ss Por

3.33817e+00 3.33817e+00 3.33817e-01 1.00000e-09 2.12000e-01 $3.33817 \mathrm{e}+00$ 3.33817e+00 3.33817e-01 1.00000e-09 2.12000e-01 3.33817e+00 3.33817e+00 3.33817e-01 1.00000e-09 2.12000e-01 $3.33817 \mathrm{e}+003.33817 \mathrm{e}+00$ 3.33817e-01 1.00000e-09 2.12000e-01 $3.33817 \mathrm{e}+00$ 3.33817e+00 3.33817e-01 1.00000e-09 2.12000e-01 $1.00000 \mathrm{e}-05$ 1.00000e-05 1.00000e-06 1.00000e-09 1.00000e-01 $1.00000 \mathrm{e}+001.00000 \mathrm{e}+001.00000 \mathrm{e}-01$ 1.00000e-09 1.00000e-01 Element: 11950 \# of layers: 7

Kx Ky Kz Ss Por 
$3.33817 \mathrm{e}+003.33817 \mathrm{e}+00$ 3.33817e-01 1.00000e-09 2.12000e-01 $3.33817 \mathrm{e}+003.33817 \mathrm{e}+003.33817 \mathrm{e}-011.00000 \mathrm{e}-092.12000 \mathrm{e}-01$ $3.33817 \mathrm{e}+003.33817 \mathrm{e}+003.33817 \mathrm{e}-01$ 1.00000e-09 2.12000e-01 $3.33817 \mathrm{e}+003.33817 \mathrm{e}+003.33817 \mathrm{e}-011.00000 \mathrm{e}-092.12000 \mathrm{e}-01$ $3.33817 \mathrm{e}+003.33817 \mathrm{e}+003.33817 \mathrm{e}-01$ 1.00000e-09 2.12000e-01 $1.00000 \mathrm{e}-05$ 1.00000e-05 1.00000e-06 1.00000e-09 1.00000e-01 $1.00000 \mathrm{e}+001.00000 \mathrm{e}+001.00000 \mathrm{e}-011.00000 \mathrm{e}-091.00000 \mathrm{e}-01$ Element: 11951 \# of layers: 7

Kx Ky Kz Ss Por

$3.33817 \mathrm{e}+003.33817 \mathrm{e}+00$ 3.33817e-01 1.00000e-09 2.12000e-01 $3.33817 \mathrm{e}+003.33817 \mathrm{e}+003.33817 \mathrm{e}-01$ 1.00000e-09 2.12000e-01 $3.33817 \mathrm{e}+003.33817 \mathrm{e}+003.33817 \mathrm{e}-011.00000 \mathrm{e}-092.12000 \mathrm{e}-01$ $3.33817 \mathrm{e}+003.33817 \mathrm{e}+003.33817 \mathrm{e}-01$ 1.00000e-09 2.12000e-01 $3.33817 \mathrm{e}+003.33817 \mathrm{e}+003.33817 \mathrm{e}-01$ 1.00000e-09 2.12000e-01 $1.00000 \mathrm{e}-05$ 1.00000e-05 1.00000e-06 1.00000e-09 1.00000e-01 $1.00000 \mathrm{e}+001.00000 \mathrm{e}+001.00000 \mathrm{e}-011.00000 \mathrm{e}-091.00000 \mathrm{e}-01$ Element: 11952 \# of layers: 7

Kx Ky Kz Ss Por

$3.33817 \mathrm{e}+003.33817 \mathrm{e}+00$ 3.33817e-01 1.00000e-09 2.12000e-01 $3.33817 \mathrm{e}+003.33817 \mathrm{e}+003.33817 \mathrm{e}-01$ 1.00000e-09 2.12000e-01 $3.33817 \mathrm{e}+003.33817 \mathrm{e}+003.33817 \mathrm{e}-011.00000 \mathrm{e}-092.12000 \mathrm{e}-01$ $3.33817 \mathrm{e}+003.33817 \mathrm{e}+00$ 3.33817e-01 1.00000e-09 2.12000e-01 $3.33817 \mathrm{e}+003.33817 \mathrm{e}+003.33817 \mathrm{e}-01$ 1.00000e-09 2.12000e-01 $1.00000 \mathrm{e}-05$ 1.00000e-05 1.00000e-06 1.00000e-09 1.00000e-01 $1.00000 \mathrm{e}+001.00000 \mathrm{e}+001.00000 \mathrm{e}-011.00000 \mathrm{e}-091.00000 \mathrm{e}-01$ Element: 11953 \# of layers: 7

Kx Ky Kz Ss Por

$3.33817 \mathrm{e}+003.33817 \mathrm{e}+00$ 3.33817e-01 1.00000e-09 2.12000e-01 $3.33817 \mathrm{e}+003.33817 \mathrm{e}+003.33817 \mathrm{e}-011.00000 \mathrm{e}-092.12000 \mathrm{e}-01$ $3.33817 \mathrm{e}+003.33817 \mathrm{e}+003.33817 \mathrm{e}-01$ 1.00000e-09 2.12000e-01 $3.33817 \mathrm{e}+003.33817 \mathrm{e}+003.33817 \mathrm{e}-01$ 1.00000e-09 2.12000e-01 $3.33817 \mathrm{e}+003.33817 \mathrm{e}+003.33817 \mathrm{e}-01$ 1.00000e-09 2.12000e-01 $1.00000 \mathrm{e}-05$ 1.00000e-05 1.00000e-06 1.00000e-09 1.00000e-01 $1.00000 \mathrm{e}+001.00000 \mathrm{e}+001.00000 \mathrm{e}-011.00000 \mathrm{e}-091.00000 \mathrm{e}-01$ Element: 11954 \# of layers: 7

Kx Ky Kz Ss Por $3.33817 \mathrm{e}+003.33817 \mathrm{e}+00$ 3.33817e-01 1.00000e-09 2.12000e-01 $3.33817 \mathrm{e}+003.33817 \mathrm{e}+003.33817 \mathrm{e}-011.00000 \mathrm{e}-09$ 2.12000e-01 $3.33817 \mathrm{e}+003.33817 \mathrm{e}+003.33817 \mathrm{e}-01$ 1.00000e-09 2.12000e-01 $3.33817 \mathrm{e}+003.33817 \mathrm{e}+003.33817 \mathrm{e}-011.00000 \mathrm{e}-092.12000 \mathrm{e}-01$ $3.33817 \mathrm{e}+003.33817 \mathrm{e}+003.33817 \mathrm{e}-01$ 1.00000e-09 2.12000e-01 $1.00000 \mathrm{e}-05$ 1.00000e-05 1.00000e-06 1.00000e-09 1.00000e-01 $1.00000 \mathrm{e}+001.00000 \mathrm{e}+001.00000 \mathrm{e}-011.00000 \mathrm{e}-091.00000 \mathrm{e}-01$ Element: 11955 \# of layers: 7

Kx Ky Kz Ss Por 3.33817e+00 3.33817e+00 3.33817e-01 1.00000e-09 2.12000e-01 
$3.33817 \mathrm{e}+003.33817 \mathrm{e}+00$ 3.33817e-01 1.00000e-09 2.12000e-01 $3.33817 \mathrm{e}+003.33817 \mathrm{e}+003.33817 \mathrm{e}-01$ 1.00000e-09 2.12000e-01 $3.33817 \mathrm{e}+003.33817 \mathrm{e}+003.33817 \mathrm{e}-01$ 1.00000e-09 2.12000e-01 $3.33817 \mathrm{e}+003.33817 \mathrm{e}+003.33817 \mathrm{e}-011.00000 \mathrm{e}-092.12000 \mathrm{e}-01$ $1.00000 \mathrm{e}-05$ 1.00000e-05 1.00000e-06 1.00000e-09 1.00000e-01 $1.00000 \mathrm{e}+001.00000 \mathrm{e}+001.00000 \mathrm{e}-011.00000 \mathrm{e}-091.00000 \mathrm{e}-01$ Element: 11956 \# of layers: 7

Kx Ky Kz Ss Por

5.58912e+00 5.58912e+00 5.58912e-01 1.00000e-09 2.12000e-01

$5.58912 \mathrm{e}+00$ 5.58912e+00 5.58912e-01 1.00000e-09 2.12000e-01 $5.58912 \mathrm{e}+005.58912 \mathrm{e}+00$ 5.58912e-01 1.00000e-09 2.12000e-01 $5.58912 \mathrm{e}+005.58912 \mathrm{e}+00$ 5.58912e-01 1.00000e-09 2.12000e-01 $5.58912 \mathrm{e}+005.58912 \mathrm{e}+00$ 5.58912e-01 1.00000e-09 2.12000e-01 $1.00000 \mathrm{e}-05$ 1.00000e-05 1.00000e-06 1.00000e-09 1.00000e-01 $1.00000 \mathrm{e}+001.00000 \mathrm{e}+001.00000 \mathrm{e}-011.00000 \mathrm{e}-091.00000 \mathrm{e}-01$ Element: 11957 \# of layers: 7

Kx Ky Kz Ss Por

5.58912e+00 5.58912e+00 5.58912e-01 1.00000e-09 2.12000e-01 $5.58912 \mathrm{e}+005.58912 \mathrm{e}+005.58912 \mathrm{e}-011.00000 \mathrm{e}-092.12000 \mathrm{e}-01$ $5.58912 \mathrm{e}+005.58912 \mathrm{e}+00$ 5.58912e-01 1.00000e-09 2.12000e-01 $5.58912 \mathrm{e}+00$ 5.58912e+00 5.58912e-01 1.00000e-09 2.12000e-01 $5.58912 \mathrm{e}+005.58912 \mathrm{e}+00$ 5.58912e-01 1.00000e-09 2.12000e-01 $1.00000 \mathrm{e}-05$ 1.00000e-05 1.00000e-06 1.00000e-09 1.00000e-01 $1.00000 \mathrm{e}+001.00000 \mathrm{e}+001.00000 \mathrm{e}-011.00000 \mathrm{e}-091.00000 \mathrm{e}-01$ Element: 11958 \# of layers: 7

Kx Ky Kz Ss Por

$5.58912 \mathrm{e}+00$ 5.58912e+00 5.58912e-01 1.00000e-09 2.12000e-01 $5.58912 \mathrm{e}+005.58912 \mathrm{e}+00$ 5.58912e-01 1.00000e-09 2.12000e-01 $5.58912 \mathrm{e}+00$ 5.58912e+00 5.58912e-01 1.00000e-09 2.12000e-01 $5.58912 \mathrm{e}+005.58912 \mathrm{e}+00$ 5.58912e-01 1.00000e-09 2.12000e-01 $5.58912 \mathrm{e}+005.58912 \mathrm{e}+00$ 5.58912e-01 1.00000e-09 2.12000e-01 $1.00000 \mathrm{e}-05$ 1.00000e-05 1.00000e-06 1.00000e-09 1.00000e-01 $1.00000 \mathrm{e}+001.00000 \mathrm{e}+001.00000 \mathrm{e}-011.00000 \mathrm{e}-091.00000 \mathrm{e}-01$ Element: 11959 \# of layers: 7

Kx Ky Kz Ss Por

$3.33817 \mathrm{e}+003.33817 \mathrm{e}+00$ 3.33817e-01 1.00000e-09 2.12000e-01 $3.33817 \mathrm{e}+003.33817 \mathrm{e}+003.33817 \mathrm{e}-011.00000 \mathrm{e}-09$ 2.12000e-01 $3.33817 \mathrm{e}+003.33817 \mathrm{e}+003.33817 \mathrm{e}-01$ 1.00000e-09 2.12000e-01 $3.33817 \mathrm{e}+003.33817 \mathrm{e}+003.33817 \mathrm{e}-01$ 1.00000e-09 2.12000e-01 $3.33817 \mathrm{e}+003.33817 \mathrm{e}+003.33817 \mathrm{e}-01$ 1.00000e-09 2.12000e-01 $1.00000 \mathrm{e}-05$ 1.00000e-05 1.00000e-06 1.00000e-09 1.00000e-01 $1.00000 \mathrm{e}+001.00000 \mathrm{e}+001.00000 \mathrm{e}-011.00000 \mathrm{e}-091.00000 \mathrm{e}-01$ Element: 11960 \# of layers: 7

Kx Ky Kz Ss Por $3.33817 \mathrm{e}+003.33817 \mathrm{e}+00$ 3.33817e-01 1.00000e-09 2.12000e-01 $3.33817 \mathrm{e}+003.33817 \mathrm{e}+003.33817 \mathrm{e}-01$ 1.00000e-09 2.12000e-01 
$3.33817 \mathrm{e}+003.33817 \mathrm{e}+00$ 3.33817e-01 1.00000e-09 2.12000e-01 $3.33817 \mathrm{e}+003.33817 \mathrm{e}+003.33817 \mathrm{e}-01$ 1.00000e-09 2.12000e-01 $3.33817 \mathrm{e}+003.33817 \mathrm{e}+003.33817 \mathrm{e}-01$ 1.00000e-09 2.12000e-01 $1.00000 \mathrm{e}-05$ 1.00000e-05 1.00000e-06 1.00000e-09 1.00000e-01 $1.00000 \mathrm{e}+001.00000 \mathrm{e}+001.00000 \mathrm{e}-011.00000 \mathrm{e}-091.00000 \mathrm{e}-01$ Element: 11961 \# of layers: 7

Kx Ky Kz Ss Por

$3.33817 \mathrm{e}+003.33817 \mathrm{e}+00$ 3.33817e-01 1.00000e-09 2.12000e-01 $3.33817 \mathrm{e}+003.33817 \mathrm{e}+003.33817 \mathrm{e}-011.00000 \mathrm{e}-092.12000 \mathrm{e}-01$ $3.33817 \mathrm{e}+003.33817 \mathrm{e}+003.33817 \mathrm{e}-011.00000 \mathrm{e}-092.12000 \mathrm{e}-01$ $3.33817 \mathrm{e}+003.33817 \mathrm{e}+00$ 3.33817e-01 1.00000e-09 2.12000e-01 $3.33817 \mathrm{e}+003.33817 \mathrm{e}+003.33817 \mathrm{e}-01$ 1.00000e-09 2.12000e-01 $1.00000 \mathrm{e}-05$ 1.00000e-05 1.00000e-06 1.00000e-09 1.00000e-01 $1.00000 \mathrm{e}+001.00000 \mathrm{e}+001.00000 \mathrm{e}-011.00000 \mathrm{e}-091.00000 \mathrm{e}-01$ Element: 11962 \# of layers: 7

Kx Ky Kz Ss Por

3.33817e+00 3.33817e+00 3.33817e-01 1.00000e-09 2.12000e-01 $3.33817 \mathrm{e}+003.33817 \mathrm{e}+003.33817 \mathrm{e}-011.00000 \mathrm{e}-092.12000 \mathrm{e}-01$ $3.33817 \mathrm{e}+003.33817 \mathrm{e}+003.33817 \mathrm{e}-011.00000 \mathrm{e}-092.12000 \mathrm{e}-01$ $3.33817 \mathrm{e}+003.33817 \mathrm{e}+003.33817 \mathrm{e}-011.00000 \mathrm{e}-092.12000 \mathrm{e}-01$ $3.33817 \mathrm{e}+003.33817 \mathrm{e}+003.33817 \mathrm{e}-01$ 1.00000e-09 2.12000e-01 $1.00000 \mathrm{e}-05$ 1.00000e-05 1.00000e-06 1.00000e-09 1.00000e-01 $1.00000 \mathrm{e}+001.00000 \mathrm{e}+001.00000 \mathrm{e}-011.00000 \mathrm{e}-091.00000 \mathrm{e}-01$ Element: 11963 \# of layers: 7

Kx Ky Kz Ss Por

$5.58912 \mathrm{e}+00$ 5.58912e+00 5.58912e-01 1.00000e-09 2.12000e-01 $5.58912 \mathrm{e}+005.58912 \mathrm{e}+00$ 5.58912e-01 1.00000e-09 2.12000e-01 $5.58912 \mathrm{e}+005.58912 \mathrm{e}+00$ 5.58912e-01 1.00000e-09 2.12000e-01 $5.58912 \mathrm{e}+005.58912 \mathrm{e}+00$ 5.58912e-01 1.00000e-09 2.12000e-01 $5.58912 \mathrm{e}+005.58912 \mathrm{e}+005.58912 \mathrm{e}-011.00000 \mathrm{e}-092.12000 \mathrm{e}-01$ $1.00000 \mathrm{e}-05$ 1.00000e-05 1.00000e-06 1.00000e-09 1.00000e-01 $1.00000 \mathrm{e}+001.00000 \mathrm{e}+001.00000 \mathrm{e}-011.00000 \mathrm{e}-091.00000 \mathrm{e}-01$ Element: 11964 \# of layers: 7

Kx Ky Kz Ss Por

$5.58912 \mathrm{e}+00$ 5.58912e+00 5.58912e-01 1.00000e-09 2.12000e-01 $5.58912 \mathrm{e}+005.58912 \mathrm{e}+00$ 5.58912e-01 1.00000e-09 2.12000e-01 $5.58912 \mathrm{e}+005.58912 \mathrm{e}+00$ 5.58912e-01 1.00000e-09 2.12000e-01 $5.58912 \mathrm{e}+005.58912 \mathrm{e}+00$ 5.58912e-01 1.00000e-09 2.12000e-01 $5.58912 \mathrm{e}+00$ 5.58912e+00 5.58912e-01 1.00000e-09 2.12000e-01 $1.00000 \mathrm{e}-05$ 1.00000e-05 1.00000e-06 1.00000e-09 1.00000e-01 $1.00000 \mathrm{e}+001.00000 \mathrm{e}+001.00000 \mathrm{e}-011.00000 \mathrm{e}-091.00000 \mathrm{e}-01$ Element: 11965 \# of layers: 7

Kx Ky Kz Ss Por

$5.58912 \mathrm{e}+00$ 5.58912e+00 5.58912e-01 1.00000e-09 2.12000e-01 $5.58912 \mathrm{e}+005.58912 \mathrm{e}+00$ 5.58912e-01 1.00000e-09 2.12000e-01 $5.58912 \mathrm{e}+005.58912 \mathrm{e}+00$ 5.58912e-01 1.00000e-09 2.12000e-01 
$5.58912 \mathrm{e}+00$ 5.58912e+00 5.58912e-01 1.00000e-09 2.12000e-01 $5.58912 \mathrm{e}+005.58912 \mathrm{e}+00$ 5.58912e-01 1.00000e-09 2.12000e-01 $1.00000 \mathrm{e}-05$ 1.00000e-05 1.00000e-06 1.00000e-09 1.00000e-01 $1.00000 \mathrm{e}+001.00000 \mathrm{e}+001.00000 \mathrm{e}-011.00000 \mathrm{e}-091.00000 \mathrm{e}-01$ Element: 11966 \# of layers: 7

Kx Ky Kz Ss Por

$5.58912 \mathrm{e}+00$ 5.58912e+00 5.58912e-01 1.00000e-09 2.12000e-01 $5.58912 \mathrm{e}+005.58912 \mathrm{e}+00$ 5.58912e-01 1.00000e-09 2.12000e-01 $5.58912 \mathrm{e}+005.58912 \mathrm{e}+00$ 5.58912e-01 1.00000e-09 2.12000e-01 $5.58912 \mathrm{e}+00$ 5.58912e+00 5.58912e-01 1.00000e-09 2.12000e-01 $5.58912 \mathrm{e}+005.58912 \mathrm{e}+00$ 5.58912e-01 1.00000e-09 2.12000e-01 $1.00000 \mathrm{e}-05$ 1.00000e-05 1.00000e-06 1.00000e-09 1.00000e-01 $1.00000 \mathrm{e}+001.00000 \mathrm{e}+001.00000 \mathrm{e}-011.00000 \mathrm{e}-091.00000 \mathrm{e}-01$ Element: 11967 \# of layers: 7

Kx Ky Kz Ss Por

$5.58912 \mathrm{e}+00$ 5.58912e+00 5.58912e-01 1.00000e-09 2.12000e-01 $5.58912 \mathrm{e}+005.58912 \mathrm{e}+00$ 5.58912e-01 1.00000e-09 2.12000e-01 $5.58912 \mathrm{e}+005.58912 \mathrm{e}+00$ 5.58912e-01 1.00000e-09 2.12000e-01 $5.58912 \mathrm{e}+005.58912 \mathrm{e}+005.58912 \mathrm{e}-011.00000 \mathrm{e}-092.12000 \mathrm{e}-01$ $5.58912 \mathrm{e}+005.58912 \mathrm{e}+00$ 5.58912e-01 1.00000e-09 2.12000e-01 $1.00000 \mathrm{e}-05$ 1.00000e-05 1.00000e-06 1.00000e-09 1.00000e-01 $1.00000 \mathrm{e}+001.00000 \mathrm{e}+001.00000 \mathrm{e}-011.00000 \mathrm{e}-091.00000 \mathrm{e}-01$ Element: 11968 \# of layers: 7

Kx Ky Kz Ss Por

$5.58912 \mathrm{e}+00$ 5.58912e+00 5.58912e-01 1.00000e-09 2.12000e-01 5.58912e+00 5.58912e+00 5.58912e-01 1.00000e-09 2.12000e-01 $5.58912 \mathrm{e}+005.58912 \mathrm{e}+00$ 5.58912e-01 1.00000e-09 2.12000e-01 $5.58912 \mathrm{e}+005.58912 \mathrm{e}+00$ 5.58912e-01 1.00000e-09 2.12000e-01 $5.58912 \mathrm{e}+005.58912 \mathrm{e}+00$ 5.58912e-01 1.00000e-09 2.12000e-01 $1.00000 \mathrm{e}-05$ 1.00000e-05 1.00000e-06 1.00000e-09 1.00000e-01 $1.00000 \mathrm{e}+001.00000 \mathrm{e}+001.00000 \mathrm{e}-011.00000 \mathrm{e}-091.00000 \mathrm{e}-01$ Element: 11969 \# of layers: 7

Kx Ky Kz Ss Por

$5.58912 \mathrm{e}+00$ 5.58912e+00 5.58912e-01 1.00000e-09 2.12000e-01

$5.58912 \mathrm{e}+005.58912 \mathrm{e}+00$ 5.58912e-01 1.00000e-09 2.12000e-01 $5.58912 \mathrm{e}+005.58912 \mathrm{e}+00$ 5.58912e-01 1.00000e-09 2.12000e-01 $5.58912 \mathrm{e}+005.58912 \mathrm{e}+00$ 5.58912e-01 1.00000e-09 2.12000e-01 $5.58912 \mathrm{e}+005.58912 \mathrm{e}+00$ 5.58912e-01 1.00000e-09 2.12000e-01 $1.00000 \mathrm{e}-05$ 1.00000e-05 1.00000e-06 1.00000e-09 1.00000e-01 $1.00000 \mathrm{e}+001.00000 \mathrm{e}+001.00000 \mathrm{e}-011.00000 \mathrm{e}-091.00000 \mathrm{e}-01$ Element: 11970 \# of layers: 7

Kx Ky Kz Ss Por

$5.58912 \mathrm{e}+00$ 5.58912e+00 5.58912e-01 1.00000e-09 2.12000e-01 $5.58912 \mathrm{e}+005.58912 \mathrm{e}+00$ 5.58912e-01 1.00000e-09 2.12000e-01 $5.58912 \mathrm{e}+005.58912 \mathrm{e}+00$ 5.58912e-01 1.00000e-09 2.12000e-01 $5.58912 \mathrm{e}+005.58912 \mathrm{e}+00$ 5.58912e-01 1.00000e-09 2.12000e-01 
$5.58912 \mathrm{e}+00$ 5.58912e+00 5.58912e-01 1.00000e-09 2.12000e-01 $1.00000 \mathrm{e}-05$ 1.00000e-05 1.00000e-06 1.00000e-09 1.00000e-01 $1.00000 \mathrm{e}+001.00000 \mathrm{e}+001.00000 \mathrm{e}-011.00000 \mathrm{e}-091.00000 \mathrm{e}-01$ Element: 11971 \# of layers: 7

Kx Ky Kz Ss Por

$5.58912 \mathrm{e}+00$ 5.58912e+00 5.58912e-01 1.00000e-09 2.12000e-01 $5.58912 \mathrm{e}+005.58912 \mathrm{e}+00$ 5.58912e-01 1.00000e-09 2.12000e-01 $5.58912 \mathrm{e}+005.58912 \mathrm{e}+00$ 5.58912e-01 1.00000e-09 2.12000e-01 $5.58912 \mathrm{e}+005.58912 \mathrm{e}+005.58912 \mathrm{e}-011.00000 \mathrm{e}-092.12000 \mathrm{e}-01$ $5.58912 \mathrm{e}+00$ 5.58912e+00 5.58912e-01 1.00000e-09 2.12000e-01 $1.00000 \mathrm{e}-05$ 1.00000e-05 1.00000e-06 1.00000e-09 1.00000e-01 $1.00000 \mathrm{e}+001.00000 \mathrm{e}+001.00000 \mathrm{e}-011.00000 \mathrm{e}-091.00000 \mathrm{e}-01$ Element: 11972 \# of layers: 7

Kx Ky Kz Ss Por

$5.58912 \mathrm{e}+00$ 5.58912e+00 5.58912e-01 1.00000e-09 2.12000e-01 $5.58912 \mathrm{e}+005.58912 \mathrm{e}+00$ 5.58912e-01 1.00000e-09 2.12000e-01 $5.58912 \mathrm{e}+005.58912 \mathrm{e}+005.58912 \mathrm{e}-011.00000 \mathrm{e}-092.12000 \mathrm{e}-01$ $5.58912 \mathrm{e}+005.58912 \mathrm{e}+00$ 5.58912e-01 1.00000e-09 2.12000e-01 $5.58912 \mathrm{e}+005.58912 \mathrm{e}+005.58912 \mathrm{e}-011.00000 \mathrm{e}-092.12000 \mathrm{e}-01$ $1.00000 \mathrm{e}-05$ 1.00000e-05 1.00000e-06 1.00000e-09 1.00000e-01 $1.00000 \mathrm{e}+001.00000 \mathrm{e}+001.00000 \mathrm{e}-011.00000 \mathrm{e}-091.00000 \mathrm{e}-01$ Element: 11973 \# of layers: 7

Kx Ky Kz Ss Por

$6.52424 \mathrm{e}+006.52424 \mathrm{e}+006.52424 \mathrm{e}-01$ 1.00000e-09 2.12000e-01 $6.52424 \mathrm{e}+006.52424 \mathrm{e}+006.52424 \mathrm{e}-011.00000 \mathrm{e}-092.12000 \mathrm{e}-01$ $6.52424 \mathrm{e}+006.52424 \mathrm{e}+006.52424 \mathrm{e}-011.00000 \mathrm{e}-092.12000 \mathrm{e}-01$ $6.52424 \mathrm{e}+006.52424 \mathrm{e}+006.52424 \mathrm{e}-011.00000 \mathrm{e}-092.12000 \mathrm{e}-01$ $6.52424 \mathrm{e}+006.52424 \mathrm{e}+006.52424 \mathrm{e}-011.00000 \mathrm{e}-092.12000 \mathrm{e}-01$ $1.00000 \mathrm{e}-05$ 1.00000e-05 1.00000e-06 1.00000e-09 1.00000e-01 $1.00000 \mathrm{e}+001.00000 \mathrm{e}+001.00000 \mathrm{e}-011.00000 \mathrm{e}-091.00000 \mathrm{e}-01$ Element: 11974 \# of layers: 7

Kx Ky Kz Ss Por

$6.52424 \mathrm{e}+006.52424 \mathrm{e}+006.52424 \mathrm{e}-01$ 1.00000e-09 2.12000e-01 $6.52424 \mathrm{e}+006.52424 \mathrm{e}+006.52424 \mathrm{e}-011.00000 \mathrm{e}-092.12000 \mathrm{e}-01$ $6.52424 \mathrm{e}+006.52424 \mathrm{e}+006.52424 \mathrm{e}-011.00000 \mathrm{e}-092.12000 \mathrm{e}-01$ $6.52424 \mathrm{e}+006.52424 \mathrm{e}+006.52424 \mathrm{e}-011.00000 \mathrm{e}-092.12000 \mathrm{e}-01$ $6.52424 \mathrm{e}+006.52424 \mathrm{e}+006.52424 \mathrm{e}-011.00000 \mathrm{e}-092.12000 \mathrm{e}-01$ $1.00000 \mathrm{e}-05$ 1.00000e-05 1.00000e-06 1.00000e-09 1.00000e-01 $1.00000 \mathrm{e}+001.00000 \mathrm{e}+001.00000 \mathrm{e}-011.00000 \mathrm{e}-091.00000 \mathrm{e}-01$ Element: 11975 \# of layers: 7

Kx Ky Kz Ss Por

$6.52424 \mathrm{e}+006.52424 \mathrm{e}+006.52424 \mathrm{e}-011.00000 \mathrm{e}-092.12000 \mathrm{e}-01$ $6.52424 \mathrm{e}+006.52424 \mathrm{e}+006.52424 \mathrm{e}-011.00000 \mathrm{e}-092.12000 \mathrm{e}-01$ $6.52424 \mathrm{e}+006.52424 \mathrm{e}+006.52424 \mathrm{e}-011.00000 \mathrm{e}-092.12000 \mathrm{e}-01$ $6.52424 \mathrm{e}+006.52424 \mathrm{e}+006.52424 \mathrm{e}-011.00000 \mathrm{e}-092.12000 \mathrm{e}-01$ $6.52424 \mathrm{e}+006.52424 \mathrm{e}+006.52424 \mathrm{e}-011.00000 \mathrm{e}-092.12000 \mathrm{e}-01$ 
$1.00000 \mathrm{e}-05$ 1.00000e-05 1.00000e-06 1.00000e-09 1.00000e-01 $1.00000 \mathrm{e}+001.00000 \mathrm{e}+001.00000 \mathrm{e}-01$ 1.00000e-09 1.00000e-01 Element: 11976 \# of layers: 7

Kx Ky Kz Ss Por

6.52424e+00 6.52424e+00 6.52424e-01 1.00000e-09 2.12000e-01 $6.52424 \mathrm{e}+006.52424 \mathrm{e}+006.52424 \mathrm{e}-01$ 1.00000e-09 2.12000e-01 $6.52424 \mathrm{e}+006.52424 \mathrm{e}+00 \quad 6.52424 \mathrm{e}-01$ 1.00000e-09 2.12000e-01 $6.52424 \mathrm{e}+006.52424 \mathrm{e}+006.52424 \mathrm{e}-01$ 1.00000e-09 2.12000e-01 $6.52424 \mathrm{e}+006.52424 \mathrm{e}+006.52424 \mathrm{e}-01$ 1.00000e-09 2.12000e-01 $1.00000 \mathrm{e}-05$ 1.00000e-05 1.00000e-06 1.00000e-09 1.00000e-01 $1.00000 \mathrm{e}+001.00000 \mathrm{e}+001.00000 \mathrm{e}-011.00000 \mathrm{e}-091.00000 \mathrm{e}-01$ Element: 11977 \# of layers: 7

$\mathrm{Kx} \mathrm{Ky} \mathrm{Kz}$ Ss Por

$6.52424 \mathrm{e}+006.52424 \mathrm{e}+006.52424 \mathrm{e}-01$ 1.00000e-09 2.12000e-01 $6.52424 \mathrm{e}+006.52424 \mathrm{e}+006.52424 \mathrm{e}-01$ 1.00000e-09 2.12000e-01 $6.52424 \mathrm{e}+006.52424 \mathrm{e}+006.52424 \mathrm{e}-01$ 1.00000e-09 2.12000e-01 $6.52424 \mathrm{e}+006.52424 \mathrm{e}+006.52424 \mathrm{e}-01$ 1.00000e-09 2.12000e-01 $6.52424 \mathrm{e}+006.52424 \mathrm{e}+006.52424 \mathrm{e}-01$ 1.00000e-09 2.12000e-01 $1.00000 \mathrm{e}-051.00000 \mathrm{e}-051.00000 \mathrm{e}-061.00000 \mathrm{e}-091.00000 \mathrm{e}-01$ $1.00000 \mathrm{e}+001.00000 \mathrm{e}+001.00000 \mathrm{e}-011.00000 \mathrm{e}-09$ 1.00000e-01 Element: 11978 \# of layers: 7

$\mathrm{Kx} \mathrm{Ky} \mathrm{Kz}$ Ss Por

5.58912e+00 5.58912e+00 5.58912e-01 1.00000e-09 2.12000e-01 $5.58912 \mathrm{e}+00$ 5.58912e+00 5.58912e-01 1.00000e-09 2.12000e-01 $5.58912 \mathrm{e}+00$ 5.58912e+00 5.58912e-01 1.00000e-09 2.12000e-01 $5.58912 \mathrm{e}+005.58912 \mathrm{e}+00$ 5.58912e-01 1.00000e-09 2.12000e-01 $5.58912 \mathrm{e}+00$ 5.58912e+00 5.58912e-01 1.00000e-09 2.12000e-01 $1.00000 \mathrm{e}-05$ 1.00000e-05 1.00000e-06 1.00000e-09 1.00000e-01 $1.00000 \mathrm{e}+001.00000 \mathrm{e}+001.00000 \mathrm{e}-011.00000 \mathrm{e}-091.00000 \mathrm{e}-01$ Element: 11979 \# of layers: 7

$\mathrm{Kx} \mathrm{Ky} \mathrm{Kz}$ Ss Por

5.58912e+00 5.58912e+00 5.58912e-01 1.00000e-09 2.12000e-01 $5.58912 \mathrm{e}+00$ 5.58912e+00 5.58912e-01 1.00000e-09 2.12000e-01 5.58912e+00 5.58912e+00 5.58912e-01 1.00000e-09 2.12000e-01 $5.58912 \mathrm{e}+00$ 5.58912e+00 5.58912e-01 1.00000e-09 2.12000e-01 $5.58912 \mathrm{e}+005.58912 \mathrm{e}+00$ 5.58912e-01 1.00000e-09 2.12000e-01 $1.00000 \mathrm{e}-051.00000 \mathrm{e}-05$ 1.00000e-06 1.00000e-09 1.00000e-01 $1.00000 \mathrm{e}+001.00000 \mathrm{e}+001.00000 \mathrm{e}-011.00000 \mathrm{e}-091.00000 \mathrm{e}-01$ Element: 11980 \# of layers: 7

$\mathrm{Kx} \mathrm{Ky} \mathrm{Kz}$ Ss Por

6.52424e+00 6.52424e+00 6.52424e-01 1.00000e-09 2.12000e-01 $6.52424 \mathrm{e}+006.52424 \mathrm{e}+006.52424 \mathrm{e}-01$ 1.00000e-09 2.12000e-01 $6.52424 \mathrm{e}+006.52424 \mathrm{e}+006.52424 \mathrm{e}-01$ 1.00000e-09 2.12000e-01 $6.52424 \mathrm{e}+006.52424 \mathrm{e}+006.52424 \mathrm{e}-01$ 1.00000e-09 2.12000e-01 $6.52424 \mathrm{e}+006.52424 \mathrm{e}+006.52424 \mathrm{e}-01$ 1.00000e-09 2.12000e-01 $1.00000 \mathrm{e}-05$ 1.00000e-05 1.00000e-06 1.00000e-09 1.00000e-01 
$1.00000 \mathrm{e}+001.00000 \mathrm{e}+001.00000 \mathrm{e}-011.00000 \mathrm{e}-091.00000 \mathrm{e}-01$ Element: 11981 \# of layers: 7

Kx Ky Kz Ss Por

$6.52424 \mathrm{e}+006.52424 \mathrm{e}+00$ 6.52424e-01 1.00000e-09 2.12000e-01

$6.52424 \mathrm{e}+006.52424 \mathrm{e}+006.52424 \mathrm{e}-01$ 1.00000e-09 2.12000e-01

$6.52424 \mathrm{e}+006.52424 \mathrm{e}+006.52424 \mathrm{e}-01$ 1.00000e-09 2.12000e-01

$6.52424 \mathrm{e}+006.52424 \mathrm{e}+006.52424 \mathrm{e}-01$ 1.00000e-09 2.12000e-01

$6.52424 \mathrm{e}+006.52424 \mathrm{e}+006.52424 \mathrm{e}-01$ 1.00000e-09 2.12000e-01

$1.00000 \mathrm{e}-05$ 1.00000e-05 1.00000e-06 1.00000e-09 1.00000e-01

$1.00000 \mathrm{e}+001.00000 \mathrm{e}+001.00000 \mathrm{e}-011.00000 \mathrm{e}-091.00000 \mathrm{e}-01$

Element: 11982 \# of layers: 7

$\mathrm{Kx} \mathrm{Ky} \mathrm{Kz}$ Ss Por

3.24862e+00 3.24862e+00 3.24862e-01 1.00000e-09 2.12000e-01

$3.24862 \mathrm{e}+00$ 3.24862e+00 3.24862e-01 1.00000e-09 2.12000e-01

3.24862e+00 3.24862e+00 3.24862e-01 1.00000e-09 2.12000e-01

$3.24862 \mathrm{e}+003.24862 \mathrm{e}+003.24862 \mathrm{e}-01$ 1.00000e-09 2.12000e-01

3.24862e+00 3.24862e+00 3.24862e-01 1.00000e-09 2.12000e-01

$1.00000 \mathrm{e}-05$ 1.00000e-05 1.00000e-06 1.00000e-09 1.00000e-01

$1.00000 \mathrm{e}+001.00000 \mathrm{e}+001.00000 \mathrm{e}-011.00000 \mathrm{e}-091.00000 \mathrm{e}-01$

Element: 11983 \# of layers: 7

$\mathrm{Kx} \mathrm{Ky} \mathrm{Kz}$ Ss Por

3.24862e+00 3.24862e+00 3.24862e-01 1.00000e-09 2.12000e-01

3.24862e+00 3.24862e+00 3.24862e-01 1.00000e-09 2.12000e-01

$3.24862 \mathrm{e}+00$ 3.24862e+00 3.24862e-01 1.00000e-09 2.12000e-01

$3.24862 \mathrm{e}+003.24862 \mathrm{e}+00$ 3.24862e-01 1.00000e-09 2.12000e-01

$3.24862 \mathrm{e}+003.24862 \mathrm{e}+00$ 3.24862e-01 1.00000e-09 2.12000e-01

$1.00000 \mathrm{e}-05$ 1.00000e-05 1.00000e-06 1.00000e-09 1.00000e-01

$1.00000 \mathrm{e}+001.00000 \mathrm{e}+001.00000 \mathrm{e}-011.00000 \mathrm{e}-09$ 1.00000e-01

Element: 11984 \# of layers: 7

$\mathrm{Kx} \mathrm{Ky} \mathrm{Kz}$ Ss Por

3.24862e+00 3.24862e+00 3.24862e-01 1.00000e-09 2.12000e-01

3.24862e+00 3.24862e+00 3.24862e-01 1.00000e-09 2.12000e-01

$3.24862 \mathrm{e}+003.24862 \mathrm{e}+00$ 3.24862e-01 1.00000e-09 2.12000e-01

$3.24862 \mathrm{e}+00$ 3.24862e+00 3.24862e-01 1.00000e-09 2.12000e-01

$3.24862 \mathrm{e}+00$ 3.24862e+00 3.24862e-01 1.00000e-09 2.12000e-01

$1.00000 \mathrm{e}-05$ 1.00000e-05 1.00000e-06 1.00000e-09 1.00000e-01

$1.00000 \mathrm{e}+001.00000 \mathrm{e}+001.00000 \mathrm{e}-011.00000 \mathrm{e}-091.00000 \mathrm{e}-01$

Element: 11985 \# of layers: 7

$\mathrm{Kx} \mathrm{Ky} \mathrm{Kz}$ Ss Por

3.33817e+00 3.33817e+00 3.33817e-01 1.00000e-09 2.12000e-01

$3.33817 \mathrm{e}+003.33817 \mathrm{e}+00$ 3.33817e-01 1.00000e-09 2.12000e-01

$3.33817 \mathrm{e}+003.33817 \mathrm{e}+00$ 3.33817e-01 1.00000e-09 2.12000e-01

3.33817e+00 3.33817e+00 3.33817e-01 1.00000e-09 2.12000e-01

3.33817e+00 3.33817e+00 3.33817e-01 1.00000e-09 2.12000e-01

$1.00000 \mathrm{e}-05$ 1.00000e-05 1.00000e-06 1.00000e-09 1.00000e-01

$1.00000 \mathrm{e}+001.00000 \mathrm{e}+001.00000 \mathrm{e}-011.00000 \mathrm{e}-091.00000 \mathrm{e}-01$ 
Element: 11986 \# of layers: 7

$\mathrm{Kx} \mathrm{Ky} \mathrm{Kz}$ Ss Por

3.33817e+00 3.33817e+00 3.33817e-01 1.00000e-09 2.12000e-01

$3.33817 \mathrm{e}+00$ 3.33817e+00 3.33817e-01 1.00000e-09 2.12000e-01

3.33817e+00 3.33817e+00 3.33817e-01 1.00000e-09 2.12000e-01

$3.33817 \mathrm{e}+003.33817 \mathrm{e}+00$ 3.33817e-01 1.00000e-09 2.12000e-01

$3.33817 \mathrm{e}+00$ 3.33817e+00 3.33817e-01 1.00000e-09 2.12000e-01

$1.00000 \mathrm{e}-05$ 1.00000e-05 1.00000e-06 1.00000e-09 1.00000e-01

$1.00000 \mathrm{e}+001.00000 \mathrm{e}+001.00000 \mathrm{e}-011.00000 \mathrm{e}-091.00000 \mathrm{e}-01$

Element: 11987 \# of layers: 7

$\mathrm{Kx} \mathrm{Ky} \mathrm{Kz}$ Ss Por

5.58912e+00 5.58912e+00 5.58912e-01 1.00000e-09 2.12000e-01

$5.58912 \mathrm{e}+00$ 5.58912e+00 5.58912e-01 1.00000e-09 2.12000e-01

$5.58912 \mathrm{e}+005.58912 \mathrm{e}+00$ 5.58912e-01 1.00000e-09 2.12000e-01

$5.58912 \mathrm{e}+005.58912 \mathrm{e}+00$ 5.58912e-01 1.00000e-09 2.12000e-01

$5.58912 \mathrm{e}+005.58912 \mathrm{e}+00$ 5.58912e-01 1.00000e-09 2.12000e-01

$1.00000 \mathrm{e}-05$ 1.00000e-05 1.00000e-06 1.00000e-09 1.00000e-01

$1.00000 \mathrm{e}+001.00000 \mathrm{e}+001.00000 \mathrm{e}-01$ 1.00000e-09 1.00000e-01

Element: 11988 \# of layers: 7

$\mathrm{Kx} \mathrm{Ky} \mathrm{Kz}$ Ss Por

6.52424e+00 6.52424e+00 6.52424e-01 1.00000e-09 2.12000e-01

$6.52424 \mathrm{e}+006.52424 \mathrm{e}+00$ 6.52424e-01 1.00000e-09 2.12000e-01

$6.52424 \mathrm{e}+006.52424 \mathrm{e}+006.52424 \mathrm{e}-01$ 1.00000e-09 2.12000e-01

$6.52424 \mathrm{e}+006.52424 \mathrm{e}+006.52424 \mathrm{e}-01$ 1.00000e-09 2.12000e-01

$6.52424 \mathrm{e}+006.52424 \mathrm{e}+006.52424 \mathrm{e}-01$ 1.00000e-09 2.12000e-01

$1.00000 \mathrm{e}-05$ 1.00000e-05 1.00000e-06 1.00000e-09 1.00000e-01

$1.00000 \mathrm{e}+001.00000 \mathrm{e}+001.00000 \mathrm{e}-011.00000 \mathrm{e}-091.00000 \mathrm{e}-01$

Element: 11989 \# of layers: 7

$\mathrm{Kx} \mathrm{Ky} \mathrm{Kz}$ Ss Por

3.24862e+00 3.24862e+00 3.24862e-01 1.00000e-09 2.12000e-01

$3.24862 \mathrm{e}+003.24862 \mathrm{e}+00$ 3.24862e-01 1.00000e-09 2.12000e-01

$3.24862 \mathrm{e}+00$ 3.24862e+00 3.24862e-01 1.00000e-09 2.12000e-01

$3.24862 \mathrm{e}+003.24862 \mathrm{e}+003.24862 \mathrm{e}-01$ 1.00000e-09 2.12000e-01

$3.24862 \mathrm{e}+00$ 3.24862e+00 3.24862e-01 1.00000e-09 2.12000e-01

$1.00000 \mathrm{e}-05$ 1.00000e-05 1.00000e-06 1.00000e-09 1.00000e-01

$1.00000 \mathrm{e}+001.00000 \mathrm{e}+001.00000 \mathrm{e}-011.00000 \mathrm{e}-091.00000 \mathrm{e}-01$

Element: 11990 \# of layers: 7

$\mathrm{Kx} \mathrm{Ky} \mathrm{Kz}$ Ss Por

3.69863e+00 3.69863e+00 3.69863e-01 1.00000e-09 2.12000e-01

$3.69863 \mathrm{e}+003.69863 \mathrm{e}+00$ 3.69863e-01 1.00000e-09 2.12000e-01

$3.69863 \mathrm{e}+003.69863 \mathrm{e}+00$ 3.69863e-01 1.00000e-09 2.12000e-01

$3.69863 \mathrm{e}+003.69863 \mathrm{e}+00$ 3.69863e-01 1.00000e-09 2.12000e-01

$3.69863 \mathrm{e}+00$ 3.69863e+00 3.69863e-01 1.00000e-09 2.12000e-01

$1.00000 \mathrm{e}-051.00000 \mathrm{e}-051.00000 \mathrm{e}-061.00000 \mathrm{e}-091.00000 \mathrm{e}-01$

$1.00000 \mathrm{e}+001.00000 \mathrm{e}+001.00000 \mathrm{e}-011.00000 \mathrm{e}-091.00000 \mathrm{e}-01$

Element: 11991 \# of layers: 7 
$\mathrm{Kx} \mathrm{Ky} \mathrm{Kz}$ Ss Por

3.69863e+00 3.69863e+00 3.69863e-01 1.00000e-09 2.12000e-01

$3.69863 \mathrm{e}+003.69863 \mathrm{e}+00$ 3.69863e-01 1.00000e-09 2.12000e-01

$3.69863 \mathrm{e}+003.69863 \mathrm{e}+003.69863 \mathrm{e}-01$ 1.00000e-09 2.12000e-01

$3.69863 \mathrm{e}+003.69863 \mathrm{e}+00$ 3.69863e-01 1.00000e-09 2.12000e-01

$3.69863 \mathrm{e}+00$ 3.69863e+00 3.69863e-01 1.00000e-09 2.12000e-01

$1.00000 \mathrm{e}-05$ 1.00000e-05 1.00000e-06 1.00000e-09 1.00000e-01

$1.00000 \mathrm{e}+001.00000 \mathrm{e}+001.00000 \mathrm{e}-011.00000 \mathrm{e}-091.00000 \mathrm{e}-01$

Element: 11992 \# of layers: 7

$\mathrm{Kx} \mathrm{Ky} \mathrm{Kz}$ Ss Por

3.69863e+00 3.69863e+00 3.69863e-01 1.00000e-09 2.12000e-01

$3.69863 \mathrm{e}+003.69863 \mathrm{e}+00$ 3.69863e-01 1.00000e-09 2.12000e-01

$3.69863 \mathrm{e}+003.69863 \mathrm{e}+003.69863 \mathrm{e}-01$ 1.00000e-09 2.12000e-01

$3.69863 \mathrm{e}+00$ 3.69863e+00 3.69863e-01 1.00000e-09 2.12000e-01

$3.69863 \mathrm{e}+003.69863 \mathrm{e}+00$ 3.69863e-01 1.00000e-09 2.12000e-01

$1.00000 \mathrm{e}-05$ 1.00000e-05 1.00000e-06 1.00000e-09 1.00000e-01

$1.00000 \mathrm{e}+001.00000 \mathrm{e}+001.00000 \mathrm{e}-011.00000 \mathrm{e}-091.00000 \mathrm{e}-01$

Element: 11993 \# of layers: 7

$\mathrm{Kx} \mathrm{Ky} \mathrm{Kz}$ Ss Por

3.69863e+00 3.69863e+00 3.69863e-01 1.00000e-09 2.12000e-01

$3.69863 \mathrm{e}+003.69863 \mathrm{e}+00$ 3.69863e-01 1.00000e-09 2.12000e-01

$3.69863 \mathrm{e}+003.69863 \mathrm{e}+00$ 3.69863e-01 1.00000e-09 2.12000e-01

3.69863e+00 3.69863e+00 3.69863e-01 1.00000e-09 2.12000e-01

$3.69863 \mathrm{e}+003.69863 \mathrm{e}+00$ 3.69863e-01 1.00000e-09 2.12000e-01

$1.00000 \mathrm{e}-05$ 1.00000e-05 1.00000e-06 1.00000e-09 1.00000e-01

$1.00000 \mathrm{e}+001.00000 \mathrm{e}+001.00000 \mathrm{e}-01$ 1.00000e-09 1.00000e-01

Element: 11994 \# of layers: 7

$\mathrm{Kx} \mathrm{Ky} \mathrm{Kz}$ Ss Por

3.69863e+00 3.69863e+00 3.69863e-01 1.00000e-09 2.12000e-01

$3.69863 \mathrm{e}+00$ 3.69863e+00 3.69863e-01 1.00000e-09 2.12000e-01

$3.69863 \mathrm{e}+003.69863 \mathrm{e}+00$ 3.69863e-01 1.00000e-09 2.12000e-01

$3.69863 \mathrm{e}+00$ 3.69863e+00 3.69863e-01 1.00000e-09 2.12000e-01

$3.69863 \mathrm{e}+003.69863 \mathrm{e}+00$ 3.69863e-01 1.00000e-09 2.12000e-01

$1.00000 \mathrm{e}-05$ 1.00000e-05 1.00000e-06 1.00000e-09 1.00000e-01

$1.00000 \mathrm{e}+001.00000 \mathrm{e}+001.00000 \mathrm{e}-011.00000 \mathrm{e}-091.00000 \mathrm{e}-01$

Element: 11995 \# of layers: 7

Kx Ky Kz Ss Por

3.69863e+00 3.69863e+00 3.69863e-01 1.00000e-09 2.12000e-01

$3.69863 \mathrm{e}+00$ 3.69863e+00 3.69863e-01 1.00000e-09 2.12000e-01

$3.69863 \mathrm{e}+003.69863 \mathrm{e}+00$ 3.69863e-01 1.00000e-09 2.12000e-01

$3.69863 \mathrm{e}+003.69863 \mathrm{e}+00$ 3.69863e-01 1.00000e-09 2.12000e-01

$3.69863 \mathrm{e}+003.69863 \mathrm{e}+00$ 3.69863e-01 1.00000e-09 2.12000e-01

$1.00000 \mathrm{e}-05$ 1.00000e-05 1.00000e-06 1.00000e-09 1.00000e-01

$1.00000 \mathrm{e}+001.00000 \mathrm{e}+001.00000 \mathrm{e}-01$ 1.00000e-09 1.00000e-01

Element: 11996 \# of layers: 7

Kx Ky Kz Ss Por 
$3.69863 \mathrm{e}+003.69863 \mathrm{e}+00$ 3.69863e-01 1.00000e-09 2.12000e-01 $3.69863 \mathrm{e}+003.69863 \mathrm{e}+003.69863 \mathrm{e}-01$ 1.00000e-09 2.12000e-01 $3.69863 \mathrm{e}+003.69863 \mathrm{e}+00$ 3.69863e-01 1.00000e-09 2.12000e-01 $3.69863 \mathrm{e}+003.69863 \mathrm{e}+003.69863 \mathrm{e}-01$ 1.00000e-09 2.12000e-01 $3.69863 \mathrm{e}+00$ 3.69863e+00 3.69863e-01 1.00000e-09 2.12000e-01 $1.00000 \mathrm{e}-05$ 1.00000e-05 1.00000e-06 1.00000e-09 1.00000e-01 $1.00000 \mathrm{e}+001.00000 \mathrm{e}+00$ 1.00000e-01 1.00000e-09 1.00000e-01 Element: 11997 \# of layers: 7

$\mathrm{Kx} \mathrm{Ky} \mathrm{Kz}$ Ss Por

3.69863e+00 3.69863e+00 3.69863e-01 1.00000e-09 2.12000e-01 $3.69863 \mathrm{e}+003.69863 \mathrm{e}+00$ 3.69863e-01 1.00000e-09 2.12000e-01 $3.69863 \mathrm{e}+003.69863 \mathrm{e}+003.69863 \mathrm{e}-01$ 1.00000e-09 2.12000e-01 $3.69863 \mathrm{e}+003.69863 \mathrm{e}+00$ 3.69863e-01 1.00000e-09 2.12000e-01 $3.69863 \mathrm{e}+00$ 3.69863e+00 3.69863e-01 1.00000e-09 2.12000e-01 $1.00000 \mathrm{e}-05$ 1.00000e-05 1.00000e-06 1.00000e-09 1.00000e-01 $1.00000 \mathrm{e}+001.00000 \mathrm{e}+001.00000 \mathrm{e}-011.00000 \mathrm{e}-091.00000 \mathrm{e}-01$ Element: 11998 \# of layers: 7

$\mathrm{Kx} \mathrm{Ky} \mathrm{Kz}$ Ss Por

3.69863e+00 3.69863e+00 3.69863e-01 1.00000e-09 2.12000e-01 $3.69863 \mathrm{e}+003.69863 \mathrm{e}+00$ 3.69863e-01 1.00000e-09 2.12000e-01 $3.69863 \mathrm{e}+003.69863 \mathrm{e}+00$ 3.69863e-01 1.00000e-09 2.12000e-01 $3.69863 \mathrm{e}+003.69863 \mathrm{e}+00$ 3.69863e-01 1.00000e-09 2.12000e-01 3.69863e+00 3.69863e+00 3.69863e-01 1.00000e-09 2.12000e-01 $1.00000 \mathrm{e}-05$ 1.00000e-05 1.00000e-06 1.00000e-09 1.00000e-01 $1.00000 \mathrm{e}+001.00000 \mathrm{e}+001.00000 \mathrm{e}-011.00000 \mathrm{e}-091.00000 \mathrm{e}-01$ Element: 11999 \# of layers: 7

$\mathrm{Kx} \mathrm{Ky} \mathrm{Kz}$ Ss Por

3.69863e+00 3.69863e+00 3.69863e-01 1.00000e-09 2.12000e-01 $3.69863 \mathrm{e}+003.69863 \mathrm{e}+00$ 3.69863e-01 1.00000e-09 2.12000e-01 $3.69863 \mathrm{e}+00$ 3.69863e+00 3.69863e-01 1.00000e-09 2.12000e-01 $3.69863 \mathrm{e}+00$ 3.69863e+00 3.69863e-01 1.00000e-09 2.12000e-01 $3.69863 \mathrm{e}+003.69863 \mathrm{e}+003.69863 \mathrm{e}-01$ 1.00000e-09 2.12000e-01 $1.00000 \mathrm{e}-05$ 1.00000e-05 1.00000e-06 1.00000e-09 1.00000e-01 $1.00000 \mathrm{e}+001.00000 \mathrm{e}+001.00000 \mathrm{e}-011.00000 \mathrm{e}-091.00000 \mathrm{e}-01$ Element: 12000 \# of layers: 7

$\mathrm{Kx} \mathrm{Ky} \mathrm{Kz}$ Ss Por

4.32122e+00 4.32122e+00 4.32122e-01 1.00000e-09 2.12000e-01 4.32122e+00 4.32122e+00 4.32122e-01 1.00000e-09 2.12000e-01 4.32122e+00 4.32122e+00 4.32122e-01 1.00000e-09 2.12000e-01 4.32122e+00 4.32122e+00 4.32122e-01 1.00000e-09 2.12000e-01 $4.32122 \mathrm{e}+004.32122 \mathrm{e}+004.32122 \mathrm{e}-01$ 1.00000e-09 2.12000e-01 $1.00000 \mathrm{e}-05$ 1.00000e-05 1.00000e-06 1.00000e-09 1.00000e-01 $1.00000 \mathrm{e}+001.00000 \mathrm{e}+001.00000 \mathrm{e}-011.00000 \mathrm{e}-091.00000 \mathrm{e}-01$ Element: 12001 \# of layers: 7

$\mathrm{Kx} \mathrm{Ky} \mathrm{Kz}$ Ss Por 4.32122e+00 4.32122e+00 4.32122e-01 1.00000e-09 2.12000e-01 
$4.32122 \mathrm{e}+004.32122 \mathrm{e}+00$ 4.32122e-01 1.00000e-09 2.12000e-01 $4.32122 \mathrm{e}+004.32122 \mathrm{e}+004.32122 \mathrm{e}-011.00000 \mathrm{e}-092.12000 \mathrm{e}-01$ $4.32122 \mathrm{e}+004.32122 \mathrm{e}+00$ 4.32122e-01 1.00000e-09 2.12000e-01 $4.32122 \mathrm{e}+004.32122 \mathrm{e}+004.32122 \mathrm{e}-011.00000 \mathrm{e}-092.12000 \mathrm{e}-01$ $1.00000 \mathrm{e}-05$ 1.00000e-05 1.00000e-06 1.00000e-09 1.00000e-01 $1.00000 \mathrm{e}+001.00000 \mathrm{e}+001.00000 \mathrm{e}-011.00000 \mathrm{e}-091.00000 \mathrm{e}-01$ Element: 12002 \# of layers: 7

Kx Ky Kz Ss Por

4.32122e+00 4.32122e+00 4.32122e-01 1.00000e-09 2.12000e-01 $4.32122 \mathrm{e}+004.32122 \mathrm{e}+004.32122 \mathrm{e}-011.00000 \mathrm{e}-092.12000 \mathrm{e}-01$ $4.32122 \mathrm{e}+004.32122 \mathrm{e}+004.32122 \mathrm{e}-011.00000 \mathrm{e}-09$ 2.12000e-01 $4.32122 \mathrm{e}+004.32122 \mathrm{e}+004.32122 \mathrm{e}-011.00000 \mathrm{e}-09$ 2.12000e-01 $4.32122 \mathrm{e}+004.32122 \mathrm{e}+00$ 4.32122e-01 1.00000e-09 2.12000e-01 $1.00000 \mathrm{e}-05$ 1.00000e-05 1.00000e-06 1.00000e-09 1.00000e-01 $1.00000 \mathrm{e}+001.00000 \mathrm{e}+001.00000 \mathrm{e}-011.00000 \mathrm{e}-091.00000 \mathrm{e}-01$ Element: 12003 \# of layers: 7

Kx Ky Kz Ss Por

4.32122e+00 4.32122e+00 4.32122e-01 1.00000e-09 2.12000e-01 $4.32122 \mathrm{e}+004.32122 \mathrm{e}+004.32122 \mathrm{e}-011.00000 \mathrm{e}-092.12000 \mathrm{e}-01$ $4.32122 \mathrm{e}+004.32122 \mathrm{e}+004.32122 \mathrm{e}-011.00000 \mathrm{e}-09$ 2.12000e-01 $4.32122 \mathrm{e}+004.32122 \mathrm{e}+004.32122 \mathrm{e}-011.00000 \mathrm{e}-09$ 2.12000e-01 $4.32122 \mathrm{e}+004.32122 \mathrm{e}+00$ 4.32122e-01 1.00000e-09 2.12000e-01 $1.00000 \mathrm{e}-05$ 1.00000e-05 1.00000e-06 1.00000e-09 1.00000e-01 $1.00000 \mathrm{e}+001.00000 \mathrm{e}+001.00000 \mathrm{e}-011.00000 \mathrm{e}-091.00000 \mathrm{e}-01$ Element: 12004 \# of layers: 7

Kx Ky Kz Ss Por

$4.32122 \mathrm{e}+00$ 4.32122e+00 4.32122e-01 1.00000e-09 2.12000e-01 $4.32122 \mathrm{e}+004.32122 \mathrm{e}+004.32122 \mathrm{e}-011.00000 \mathrm{e}-09$ 2.12000e-01 $4.32122 \mathrm{e}+004.32122 \mathrm{e}+00$ 4.32122e-01 1.00000e-09 2.12000e-01 $4.32122 \mathrm{e}+004.32122 \mathrm{e}+004.32122 \mathrm{e}-01$ 1.00000e-09 2.12000e-01 $4.32122 \mathrm{e}+004.32122 \mathrm{e}+00$ 4.32122e-01 1.00000e-09 2.12000e-01 $1.00000 \mathrm{e}-05$ 1.00000e-05 1.00000e-06 1.00000e-09 1.00000e-01 $1.00000 \mathrm{e}+001.00000 \mathrm{e}+001.00000 \mathrm{e}-011.00000 \mathrm{e}-091.00000 \mathrm{e}-01$ Element: 12005 \# of layers: 7

Kx Ky Kz Ss Por

$3.69863 \mathrm{e}+003.69863 \mathrm{e}+00$ 3.69863e-01 1.00000e-09 2.12000e-01 $3.69863 \mathrm{e}+003.69863 \mathrm{e}+003.69863 \mathrm{e}-01$ 1.00000e-09 2.12000e-01 $3.69863 \mathrm{e}+003.69863 \mathrm{e}+003.69863 \mathrm{e}-01$ 1.00000e-09 2.12000e-01 $3.69863 \mathrm{e}+003.69863 \mathrm{e}+003.69863 \mathrm{e}-01$ 1.00000e-09 2.12000e-01 $3.69863 \mathrm{e}+003.69863 \mathrm{e}+003.69863 \mathrm{e}-01$ 1.00000e-09 2.12000e-01 $1.00000 \mathrm{e}-05$ 1.00000e-05 1.00000e-06 1.00000e-09 1.00000e-01 $1.00000 \mathrm{e}+001.00000 \mathrm{e}+001.00000 \mathrm{e}-011.00000 \mathrm{e}-091.00000 \mathrm{e}-01$ Element: 12006 \# of layers: 7

Kx Ky Kz Ss Por $3.69863 \mathrm{e}+003.69863 \mathrm{e}+00$ 3.69863e-01 1.00000e-09 2.12000e-01 $3.69863 \mathrm{e}+003.69863 \mathrm{e}+003.69863 \mathrm{e}-01$ 1.00000e-09 2.12000e-01 
$3.69863 \mathrm{e}+003.69863 \mathrm{e}+00$ 3.69863e-01 1.00000e-09 2.12000e-01 $3.69863 \mathrm{e}+003.69863 \mathrm{e}+003.69863 \mathrm{e}-01$ 1.00000e-09 2.12000e-01 $3.69863 \mathrm{e}+003.69863 \mathrm{e}+003.69863 \mathrm{e}-01$ 1.00000e-09 2.12000e-01 $1.00000 \mathrm{e}-05$ 1.00000e-05 1.00000e-06 1.00000e-09 1.00000e-01 $1.00000 \mathrm{e}+001.00000 \mathrm{e}+001.00000 \mathrm{e}-011.00000 \mathrm{e}-091.00000 \mathrm{e}-01$ Element: 12007 \# of layers: 7

Kx Ky Kz Ss Por

4.32122e+00 4.32122e+00 4.32122e-01 1.00000e-09 2.12000e-01 $4.32122 \mathrm{e}+004.32122 \mathrm{e}+004.32122 \mathrm{e}-011.00000 \mathrm{e}-092.12000 \mathrm{e}-01$ $4.32122 \mathrm{e}+004.32122 \mathrm{e}+004.32122 \mathrm{e}-011.00000 \mathrm{e}-092.12000 \mathrm{e}-01$ $4.32122 \mathrm{e}+004.32122 \mathrm{e}+00$ 4.32122e-01 1.00000e-09 2.12000e-01 $4.32122 \mathrm{e}+004.32122 \mathrm{e}+00$ 4.32122e-01 1.00000e-09 2.12000e-01 $1.00000 \mathrm{e}-05$ 1.00000e-05 1.00000e-06 1.00000e-09 1.00000e-01 $1.00000 \mathrm{e}+001.00000 \mathrm{e}+001.00000 \mathrm{e}-011.00000 \mathrm{e}-091.00000 \mathrm{e}-01$ Element: 12008 \# of layers: 7

Kx Ky Kz Ss Por

$4.32122 \mathrm{e}+00$ 4.32122e+00 4.32122e-01 1.00000e-09 2.12000e-01 $4.32122 \mathrm{e}+004.32122 \mathrm{e}+004.32122 \mathrm{e}-011.00000 \mathrm{e}-09$ 2.12000e-01 $4.32122 \mathrm{e}+004.32122 \mathrm{e}+00$ 4.32122e-01 1.00000e-09 2.12000e-01 $4.32122 \mathrm{e}+004.32122 \mathrm{e}+004.32122 \mathrm{e}-011.00000 \mathrm{e}-092.12000 \mathrm{e}-01$ $4.32122 \mathrm{e}+004.32122 \mathrm{e}+00$ 4.32122e-01 1.00000e-09 2.12000e-01 $1.00000 \mathrm{e}-05$ 1.00000e-05 1.00000e-06 1.00000e-09 1.00000e-01 $1.00000 \mathrm{e}+001.00000 \mathrm{e}+001.00000 \mathrm{e}-011.00000 \mathrm{e}-091.00000 \mathrm{e}-01$ Element: 12009 \# of layers: 6

Kx Ky Kz Ss Por

$4.32122 \mathrm{e}+00$ 4.32122e+00 4.32122e-01 1.00000e-09 2.12000e-01 $4.32122 \mathrm{e}+004.32122 \mathrm{e}+00$ 4.32122e-01 1.00000e-09 2.12000e-01 $4.32122 \mathrm{e}+004.32122 \mathrm{e}+00$ 4.32122e-01 1.00000e-09 2.12000e-01 $4.32122 \mathrm{e}+004.32122 \mathrm{e}+00$ 4.32122e-01 1.00000e-09 2.12000e-01 $1.00000 \mathrm{e}-05$ 1.00000e-05 1.00000e-06 1.00000e-09 1.00000e-01 $1.00000 \mathrm{e}+001.00000 \mathrm{e}+001.00000 \mathrm{e}-011.00000 \mathrm{e}-091.00000 \mathrm{e}-01$ Element: 12010 \# of layers: 6

Kx Ky Kz Ss Por

4.32122e+00 4.32122e+00 4.32122e-01 1.00000e-09 2.12000e-01 $4.32122 \mathrm{e}+004.32122 \mathrm{e}+004.32122 \mathrm{e}-011.00000 \mathrm{e}-092.12000 \mathrm{e}-01$ $4.32122 \mathrm{e}+004.32122 \mathrm{e}+00$ 4.32122e-01 1.00000e-09 2.12000e-01 $4.32122 \mathrm{e}+004.32122 \mathrm{e}+00$ 4.32122e-01 1.00000e-09 2.12000e-01 $1.00000 \mathrm{e}-05$ 1.00000e-05 1.00000e-06 1.00000e-09 1.00000e-01 $1.00000 \mathrm{e}+001.00000 \mathrm{e}+001.00000 \mathrm{e}-011.00000 \mathrm{e}-091.00000 \mathrm{e}-01$ Element: 12011 \# of layers: 6

Kx Ky Kz Ss Por

4.32122e+00 4.32122e+00 4.32122e-01 1.00000e-09 2.12000e-01 $4.32122 \mathrm{e}+004.32122 \mathrm{e}+004.32122 \mathrm{e}-011.00000 \mathrm{e}-09$ 2.12000e-01 $4.32122 \mathrm{e}+004.32122 \mathrm{e}+004.32122 \mathrm{e}-011.00000 \mathrm{e}-092.12000 \mathrm{e}-01$ $4.32122 \mathrm{e}+004.32122 \mathrm{e}+00$ 4.32122e-01 1.00000e-09 2.12000e-01 $1.00000 \mathrm{e}-05$ 1.00000e-05 1.00000e-06 1.00000e-09 1.00000e-01 
$1.00000 \mathrm{e}+001.00000 \mathrm{e}+00$ 1.00000e-01 1.00000e-09 1.00000e-01

Element: 12012 \# of layers: 6

Kx Ky Kz Ss Por

4.32122e+00 4.32122e+00 4.32122e-01 1.00000e-09 2.12000e-01

4.32122e+00 4.32122e+00 4.32122e-01 1.00000e-09 2.12000e-01

$4.32122 \mathrm{e}+004.32122 \mathrm{e}+00$ 4.32122e-01 1.00000e-09 2.12000e-01

4.32122e+00 4.32122e+00 4.32122e-01 1.00000e-09 2.12000e-01

$1.00000 \mathrm{e}-05$ 1.00000e-05 1.00000e-06 1.00000e-09 1.00000e-01

$1.00000 \mathrm{e}+001.00000 \mathrm{e}+001.00000 \mathrm{e}-011.00000 \mathrm{e}-09$ 1.00000e-01

Element: 12013 \# of layers: 6

$\mathrm{Kx} \mathrm{Ky} \mathrm{Kz}$ Ss Por

4.32122e+00 4.32122e+00 4.32122e-01 1.00000e-09 2.12000e-01

$4.32122 \mathrm{e}+00$ 4.32122e+00 4.32122e-01 1.00000e-09 2.12000e-01

4.32122e+00 4.32122e+00 4.32122e-01 1.00000e-09 2.12000e-01

4.32122e+00 4.32122e+00 4.32122e-01 1.00000e-09 2.12000e-01

$1.00000 \mathrm{e}-05$ 1.00000e-05 1.00000e-06 1.00000e-09 1.00000e-01

$1.00000 \mathrm{e}+001.00000 \mathrm{e}+001.00000 \mathrm{e}-01$ 1.00000e-09 1.00000e-01

Element: 12014 \# of layers: 7

$\mathrm{Kx} \mathrm{Ky} \mathrm{Kz}$ Ss Por

4.32122e+00 4.32122e+00 4.32122e-01 1.00000e-09 2.12000e-01 $4.32122 \mathrm{e}+004.32122 \mathrm{e}+00$ 4.32122e-01 1.00000e-09 2.12000e-01

4.32122e+00 4.32122e+00 4.32122e-01 1.00000e-09 2.12000e-01

4.32122e+00 4.32122e+00 4.32122e-01 1.00000e-09 2.12000e-01

$4.32122 \mathrm{e}+004.32122 \mathrm{e}+004.32122 \mathrm{e}-01$ 1.00000e-09 2.12000e-01

$1.00000 \mathrm{e}-05$ 1.00000e-05 1.00000e-06 1.00000e-09 1.00000e-01

$1.00000 \mathrm{e}+001.00000 \mathrm{e}+001.00000 \mathrm{e}-01$ 1.00000e-09 1.00000e-01

Element: 12015 \# of layers: 7

$\mathrm{Kx} \mathrm{Ky} \mathrm{Kz}$ Ss Por

4.32122e+00 4.32122e+00 4.32122e-01 1.00000e-09 2.12000e-01

4.32122e+00 4.32122e+00 4.32122e-01 1.00000e-09 2.12000e-01

4.32122e+00 4.32122e+00 4.32122e-01 1.00000e-09 2.12000e-01

$4.32122 \mathrm{e}+00$ 4.32122e+00 4.32122e-01 1.00000e-09 2.12000e-01

$4.32122 \mathrm{e}+004.32122 \mathrm{e}+00$ 4.32122e-01 1.00000e-09 2.12000e-01

$1.00000 \mathrm{e}-051.00000 \mathrm{e}-051.00000 \mathrm{e}-061.00000 \mathrm{e}-091.00000 \mathrm{e}-01$

$1.00000 \mathrm{e}+001.00000 \mathrm{e}+001.00000 \mathrm{e}-011.00000 \mathrm{e}-091.00000 \mathrm{e}-01$

Element: 12016 \# of layers: 6

Kx Ky Kz Ss Por

4.32122e+00 4.32122e+00 4.32122e-01 1.00000e-09 2.12000e-01

4.32122e+00 4.32122e+00 4.32122e-01 1.00000e-09 2.12000e-01

4.32122e+00 4.32122e+00 4.32122e-01 1.00000e-09 2.12000e-01

$4.32122 \mathrm{e}+004.32122 \mathrm{e}+004.32122 \mathrm{e}-01$ 1.00000e-09 2.12000e-01

$1.00000 \mathrm{e}-05$ 1.00000e-05 1.00000e-06 1.00000e-09 1.00000e-01

$1.00000 \mathrm{e}+001.00000 \mathrm{e}+001.00000 \mathrm{e}-01$ 1.00000e-09 1.00000e-01

Element: 12017 \# of layers: 6

Kx Ky Kz Ss Por

4.32122e+00 4.32122e+00 4.32122e-01 1.00000e-09 2.12000e-01 
4.32122e+00 4.32122e+00 4.32122e-01 1.00000e-09 2.12000e-01 4.32122e+00 4.32122e+00 4.32122e-01 1.00000e-09 2.12000e-01 4.32122e+00 4.32122e+00 4.32122e-01 1.00000e-09 2.12000e-01 $1.00000 \mathrm{e}-05$ 1.00000e-05 1.00000e-06 1.00000e-09 1.00000e-01 $1.00000 \mathrm{e}+001.00000 \mathrm{e}+00$ 1.00000e-01 1.00000e-09 1.00000e-01 Element: 12018 \# of layers: 6

$\mathrm{Kx} \mathrm{Ky} \mathrm{Kz}$ Ss Por

4.32122e+00 4.32122e+00 4.32122e-01 1.00000e-09 2.12000e-01 $4.32122 \mathrm{e}+004.32122 \mathrm{e}+00$ 4.32122e-01 1.00000e-09 2.12000e-01 $4.32122 \mathrm{e}+004.32122 \mathrm{e}+00$ 4.32122e-01 1.00000e-09 2.12000e-01 $4.32122 \mathrm{e}+00$ 4.32122e+00 4.32122e-01 1.00000e-09 2.12000e-01 $1.00000 \mathrm{e}-05$ 1.00000e-05 1.00000e-06 1.00000e-09 1.00000e-01 $1.00000 \mathrm{e}+001.00000 \mathrm{e}+001.00000 \mathrm{e}-011.00000 \mathrm{e}-091.00000 \mathrm{e}-01$ Element: 12019 \# of layers: 6

$\mathrm{Kx} \mathrm{Ky} \mathrm{Kz}$ Ss Por

3.66825e+00 3.66825e+00 3.66825e-01 1.00000e-09 2.12000e-01 $3.66825 \mathrm{e}+003.66825 \mathrm{e}+003.66825 \mathrm{e}-01$ 1.00000e-09 2.12000e-01 $3.66825 \mathrm{e}+003.66825 \mathrm{e}+003.66825 \mathrm{e}-01$ 1.00000e-09 2.12000e-01 $3.66825 \mathrm{e}+003.66825 \mathrm{e}+003.66825 \mathrm{e}-01$ 1.00000e-09 2.12000e-01 $1.00000 \mathrm{e}-05$ 1.00000e-05 1.00000e-06 1.00000e-09 1.00000e-01 $1.00000 \mathrm{e}+001.00000 \mathrm{e}+001.00000 \mathrm{e}-011.00000 \mathrm{e}-091.00000 \mathrm{e}-01$ Element: 12020 \# of layers: 6

$\mathrm{Kx} \mathrm{Ky} \mathrm{Kz}$ Ss Por

3.66825e+00 3.66825e+00 3.66825e-01 1.00000e-09 2.12000e-01 $3.66825 \mathrm{e}+003.66825 \mathrm{e}+003.66825 \mathrm{e}-01$ 1.00000e-09 2.12000e-01 $3.66825 \mathrm{e}+003.66825 \mathrm{e}+003.66825 \mathrm{e}-01$ 1.00000e-09 2.12000e-01 $3.66825 \mathrm{e}+003.66825 \mathrm{e}+00$ 3.66825e-01 1.00000e-09 2.12000e-01 $1.00000 \mathrm{e}-05$ 1.00000e-05 1.00000e-06 1.00000e-09 1.00000e-01 $1.00000 \mathrm{e}+001.00000 \mathrm{e}+001.00000 \mathrm{e}-011.00000 \mathrm{e}-091.00000 \mathrm{e}-01$ Element: 12021 \# of layers: 7

$\mathrm{Kx} \mathrm{Ky} \mathrm{Kz}$ Ss Por

$3.66825 \mathrm{e}+003.66825 \mathrm{e}+00$ 3.66825e-01 1.00000e-09 2.12000e-01 $3.66825 \mathrm{e}+003.66825 \mathrm{e}+003.66825 \mathrm{e}-01$ 1.00000e-09 2.12000e-01 $3.66825 \mathrm{e}+003.66825 \mathrm{e}+003.66825 \mathrm{e}-01$ 1.00000e-09 2.12000e-01 $3.66825 \mathrm{e}+003.66825 \mathrm{e}+003.66825 \mathrm{e}-01$ 1.00000e-09 2.12000e-01 $3.66825 \mathrm{e}+003.66825 \mathrm{e}+003.66825 \mathrm{e}-01$ 1.00000e-09 2.12000e-01 $1.00000 \mathrm{e}-05$ 1.00000e-05 1.00000e-06 1.00000e-09 1.00000e-01 $1.00000 \mathrm{e}+001.00000 \mathrm{e}+001.00000 \mathrm{e}-011.00000 \mathrm{e}-091.00000 \mathrm{e}-01$ Element: 12022 \# of layers: 7

$\mathrm{Kx} \mathrm{Ky} \mathrm{Kz}$ Ss Por 4.32122e+00 4.32122e+00 4.32122e-01 1.00000e-09 2.12000e-01 4.32122e+00 4.32122e+00 4.32122e-01 1.00000e-09 2.12000e-01 4.32122e+00 4.32122e+00 4.32122e-01 1.00000e-09 2.12000e-01 4.32122e+00 4.32122e+00 4.32122e-01 1.00000e-09 2.12000e-01 4.32122e+00 4.32122e+00 4.32122e-01 1.00000e-09 2.12000e-01 $1.00000 \mathrm{e}-05$ 1.00000e-05 1.00000e-06 1.00000e-09 1.00000e-01 
$1.00000 \mathrm{e}+001.00000 \mathrm{e}+001.00000 \mathrm{e}-01$ 1.00000e-09 1.00000e-01

Element: 12023 \# of layers: 7

Kx Ky Kz Ss Por

4.32122e+00 4.32122e+00 4.32122e-01 1.00000e-09 2.12000e-01

4.32122e+00 4.32122e+00 4.32122e-01 1.00000e-09 2.12000e-01

4.32122e+00 4.32122e+00 4.32122e-01 1.00000e-09 2.12000e-01

4.32122e+00 4.32122e+00 4.32122e-01 1.00000e-09 2.12000e-01

$4.32122 \mathrm{e}+004.32122 \mathrm{e}+00$ 4.32122e-01 1.00000e-09 2.12000e-01

$1.00000 \mathrm{e}-05$ 1.00000e-05 1.00000e-06 1.00000e-09 1.00000e-01

$1.00000 \mathrm{e}+001.00000 \mathrm{e}+001.00000 \mathrm{e}-01$ 1.00000e-09 1.00000e-01

Element: 12024 \# of layers: 6

$\mathrm{Kx} \mathrm{Ky} \mathrm{Kz}$ Ss Por

4.32122e+00 4.32122e+00 4.32122e-01 1.00000e-09 2.12000e-01

4.32122e+00 4.32122e+00 4.32122e-01 1.00000e-09 2.12000e-01

4.32122e+00 4.32122e+00 4.32122e-01 1.00000e-09 2.12000e-01

$4.32122 \mathrm{e}+004.32122 \mathrm{e}+004.32122 \mathrm{e}-01$ 1.00000e-09 2.12000e-01

$1.00000 \mathrm{e}-05$ 1.00000e-05 1.00000e-06 1.00000e-09 1.00000e-01

$1.00000 \mathrm{e}+001.00000 \mathrm{e}+001.00000 \mathrm{e}-01$ 1.00000e-09 1.00000e-01

Element: 12025 \# of layers: 6

$\mathrm{Kx} \mathrm{Ky} \mathrm{Kz}$ Ss Por

4.32122e+00 4.32122e+00 4.32122e-01 1.00000e-09 2.12000e-01

4.32122e+00 4.32122e+00 4.32122e-01 1.00000e-09 2.12000e-01

4.32122e+00 4.32122e+00 4.32122e-01 1.00000e-09 2.12000e-01

4.32122e+00 4.32122e+00 4.32122e-01 1.00000e-09 2.12000e-01

$1.00000 \mathrm{e}-05$ 1.00000e-05 1.00000e-06 1.00000e-09 1.00000e-01

$1.00000 \mathrm{e}+001.00000 \mathrm{e}+001.00000 \mathrm{e}-011.00000 \mathrm{e}-091.00000 \mathrm{e}-01$

Element: 12026 \# of layers: 6

$\mathrm{Kx} \mathrm{Ky} \mathrm{Kz}$ Ss Por

$3.66825 \mathrm{e}+00$ 3.66825e+00 3.66825e-01 1.00000e-09 2.12000e-01

$3.66825 \mathrm{e}+003.66825 \mathrm{e}+00$ 3.66825e-01 1.00000e-09 2.12000e-01

$3.66825 \mathrm{e}+003.66825 \mathrm{e}+00$ 3.66825e-01 1.00000e-09 2.12000e-01

$3.66825 \mathrm{e}+003.66825 \mathrm{e}+003.66825 \mathrm{e}-01$ 1.00000e-09 2.12000e-01

$1.00000 \mathrm{e}-05$ 1.00000e-05 1.00000e-06 1.00000e-09 1.00000e-01

$1.00000 \mathrm{e}+001.00000 \mathrm{e}+001.00000 \mathrm{e}-011.00000 \mathrm{e}-091.00000 \mathrm{e}-01$

Element: 12027 \# of layers: 6

$\mathrm{Kx} \mathrm{Ky} \mathrm{Kz}$ Ss Por

3.66825e+00 3.66825e+00 3.66825e-01 1.00000e-09 2.12000e-01

$3.66825 \mathrm{e}+003.66825 \mathrm{e}+003.66825 \mathrm{e}-01$ 1.00000e-09 2.12000e-01

$3.66825 \mathrm{e}+003.66825 \mathrm{e}+003.66825 \mathrm{e}-01$ 1.00000e-09 2.12000e-01

$3.66825 \mathrm{e}+003.66825 \mathrm{e}+003.66825 \mathrm{e}-01$ 1.00000e-09 2.12000e-01

$1.00000 \mathrm{e}-05$ 1.00000e-05 1.00000e-06 1.00000e-09 1.00000e-01

$1.00000 \mathrm{e}+001.00000 \mathrm{e}+001.00000 \mathrm{e}-011.00000 \mathrm{e}-091.00000 \mathrm{e}-01$

Element: 12028 \# of layers: 6

$\mathrm{Kx} \mathrm{Ky} \mathrm{Kz}$ Ss Por

3.66825e+00 3.66825e+00 3.66825e-01 1.00000e-09 2.12000e-01

$3.66825 \mathrm{e}+003.66825 \mathrm{e}+003.66825 \mathrm{e}-01$ 1.00000e-09 2.12000e-01 
$3.66825 \mathrm{e}+003.66825 \mathrm{e}+003.66825 \mathrm{e}-01$ 1.00000e-09 2.12000e-01 $3.66825 \mathrm{e}+003.66825 \mathrm{e}+003.66825 \mathrm{e}-01$ 1.00000e-09 2.12000e-01 $1.00000 \mathrm{e}-05$ 1.00000e-05 1.00000e-06 1.00000e-09 1.00000e-01 $1.00000 \mathrm{e}+001.00000 \mathrm{e}+001.00000 \mathrm{e}-011.00000 \mathrm{e}-091.00000 \mathrm{e}-01$ Element: 12029 \# of layers: 6

$\mathrm{Kx} \mathrm{Ky} \mathrm{Kz}$ Ss Por

$3.66825 \mathrm{e}+003.66825 \mathrm{e}+00$ 3.66825e-01 1.00000e-09 2.12000e-01 $3.66825 \mathrm{e}+003.66825 \mathrm{e}+00$ 3.66825e-01 1.00000e-09 2.12000e-01 $3.66825 \mathrm{e}+003.66825 \mathrm{e}+003.66825 \mathrm{e}-01$ 1.00000e-09 2.12000e-01 $3.66825 \mathrm{e}+003.66825 \mathrm{e}+003.66825 \mathrm{e}-01$ 1.00000e-09 2.12000e-01 $1.00000 \mathrm{e}-05$ 1.00000e-05 1.00000e-06 1.00000e-09 1.00000e-01 $1.00000 \mathrm{e}+001.00000 \mathrm{e}+001.00000 \mathrm{e}-011.00000 \mathrm{e}-091.00000 \mathrm{e}-01$ Element: 12030 \# of layers: 7

$\mathrm{Kx} \mathrm{Ky} \mathrm{Kz}$ Ss Por

3.66825e+00 3.66825e+00 3.66825e-01 1.00000e-09 2.12000e-01 $3.66825 \mathrm{e}+003.66825 \mathrm{e}+003.66825 \mathrm{e}-01$ 1.00000e-09 2.12000e-01 $3.66825 \mathrm{e}+003.66825 \mathrm{e}+003.66825 \mathrm{e}-01$ 1.00000e-09 2.12000e-01 $3.66825 \mathrm{e}+003.66825 \mathrm{e}+003.66825 \mathrm{e}-01$ 1.00000e-09 2.12000e-01 $3.66825 \mathrm{e}+003.66825 \mathrm{e}+003.66825 \mathrm{e}-01$ 1.00000e-09 2.12000e-01 $1.00000 \mathrm{e}-05$ 1.00000e-05 1.00000e-06 1.00000e-09 1.00000e-01 $1.00000 \mathrm{e}+001.00000 \mathrm{e}+001.00000 \mathrm{e}-011.00000 \mathrm{e}-091.00000 \mathrm{e}-01$ Element: 12031 \# of layers: 7

$\mathrm{Kx} \mathrm{Ky} \mathrm{Kz}$ Ss Por

3.66825e+00 3.66825e+00 3.66825e-01 1.00000e-09 2.12000e-01 $3.66825 \mathrm{e}+003.66825 \mathrm{e}+003.66825 \mathrm{e}-01$ 1.00000e-09 2.12000e-01 $3.66825 \mathrm{e}+003.66825 \mathrm{e}+003.66825 \mathrm{e}-01$ 1.00000e-09 2.12000e-01 $3.66825 \mathrm{e}+003.66825 \mathrm{e}+003.66825 \mathrm{e}-01$ 1.00000e-09 2.12000e-01 $3.66825 \mathrm{e}+003.66825 \mathrm{e}+003.66825 \mathrm{e}-01$ 1.00000e-09 2.12000e-01 $1.00000 \mathrm{e}-05$ 1.00000e-05 1.00000e-06 1.00000e-09 1.00000e-01 $1.00000 \mathrm{e}+001.00000 \mathrm{e}+001.00000 \mathrm{e}-011.00000 \mathrm{e}-091.00000 \mathrm{e}-01$ Element: 12032 \# of layers: 7

$\mathrm{Kx} \mathrm{Ky} \mathrm{Kz}$ Ss Por

3.66825e+00 3.66825e+00 3.66825e-01 1.00000e-09 2.12000e-01 $3.66825 \mathrm{e}+003.66825 \mathrm{e}+00$ 3.66825e-01 1.00000e-09 2.12000e-01 $3.66825 \mathrm{e}+003.66825 \mathrm{e}+003.66825 \mathrm{e}-01$ 1.00000e-09 2.12000e-01 $3.66825 \mathrm{e}+003.66825 \mathrm{e}+003.66825 \mathrm{e}-01$ 1.00000e-09 2.12000e-01 $3.66825 \mathrm{e}+003.66825 \mathrm{e}+003.66825 \mathrm{e}-01$ 1.00000e-09 2.12000e-01 $1.00000 \mathrm{e}-05$ 1.00000e-05 1.00000e-06 1.00000e-09 1.00000e-01 $1.00000 \mathrm{e}+001.00000 \mathrm{e}+001.00000 \mathrm{e}-01$ 1.00000e-09 1.00000e-01 Element: 12033 \# of layers: 6

$\mathrm{Kx} \mathrm{Ky} \mathrm{Kz}$ Ss Por 3.66825e+00 3.66825e+00 3.66825e-01 1.00000e-09 2.12000e-01 $3.66825 \mathrm{e}+003.66825 \mathrm{e}+00$ 3.66825e-01 1.00000e-09 2.12000e-01 $3.66825 \mathrm{e}+003.66825 \mathrm{e}+003.66825 \mathrm{e}-01$ 1.00000e-09 2.12000e-01 $3.66825 \mathrm{e}+003.66825 \mathrm{e}+003.66825 \mathrm{e}-01$ 1.00000e-09 2.12000e-01 $1.00000 \mathrm{e}-05$ 1.00000e-05 1.00000e-06 1.00000e-09 1.00000e-01 
$1.00000 \mathrm{e}+001.00000 \mathrm{e}+00$ 1.00000e-01 1.00000e-09 1.00000e-01

Element: 12034 \# of layers: 6

Kx Ky Kz Ss Por

$3.66825 \mathrm{e}+00$ 3.66825e+00 3.66825e-01 1.00000e-09 2.12000e-01

$3.66825 \mathrm{e}+003.66825 \mathrm{e}+003.66825 \mathrm{e}-01$ 1.00000e-09 2.12000e-01

$3.66825 \mathrm{e}+003.66825 \mathrm{e}+00$ 3.66825e-01 1.00000e-09 2.12000e-01

$3.66825 \mathrm{e}+003.66825 \mathrm{e}+003.66825 \mathrm{e}-01$ 1.00000e-09 2.12000e-01

$1.00000 \mathrm{e}-05$ 1.00000e-05 1.00000e-06 1.00000e-09 1.00000e-01

$1.00000 \mathrm{e}+001.00000 \mathrm{e}+001.00000 \mathrm{e}-011.00000 \mathrm{e}-091.00000 \mathrm{e}-01$

Element: 12035 \# of layers: 7

$\mathrm{Kx} \mathrm{Ky} \mathrm{Kz}$ Ss Por

$3.66825 \mathrm{e}+003.66825 \mathrm{e}+00$ 3.66825e-01 1.00000e-09 2.12000e-01

$3.66825 \mathrm{e}+003.66825 \mathrm{e}+003.66825 \mathrm{e}-01$ 1.00000e-09 2.12000e-01

$3.66825 \mathrm{e}+003.66825 \mathrm{e}+003.66825 \mathrm{e}-01$ 1.00000e-09 2.12000e-01

$3.66825 \mathrm{e}+003.66825 \mathrm{e}+003.66825 \mathrm{e}-01$ 1.00000e-09 2.12000e-01

$3.66825 \mathrm{e}+003.66825 \mathrm{e}+003.66825 \mathrm{e}-01$ 1.00000e-09 2.12000e-01

$1.00000 \mathrm{e}-05$ 1.00000e-05 1.00000e-06 1.00000e-09 1.00000e-01

$1.00000 \mathrm{e}+001.00000 \mathrm{e}+001.00000 \mathrm{e}-01$ 1.00000e-09 1.00000e-01

Element: 12036 \# of layers: 7

$\mathrm{Kx} \mathrm{Ky} \mathrm{Kz}$ Ss Por

3.66825e+00 3.66825e+00 3.66825e-01 1.00000e-09 2.12000e-01

$3.66825 \mathrm{e}+003.66825 \mathrm{e}+00$ 3.66825e-01 1.00000e-09 2.12000e-01

$3.66825 \mathrm{e}+003.66825 \mathrm{e}+003.66825 \mathrm{e}-01$ 1.00000e-09 2.12000e-01

$3.66825 \mathrm{e}+003.66825 \mathrm{e}+003.66825 \mathrm{e}-01$ 1.00000e-09 2.12000e-01

$3.66825 \mathrm{e}+003.66825 \mathrm{e}+003.66825 \mathrm{e}-01$ 1.00000e-09 2.12000e-01

$1.00000 \mathrm{e}-05$ 1.00000e-05 1.00000e-06 1.00000e-09 1.00000e-01

$1.00000 \mathrm{e}+001.00000 \mathrm{e}+001.00000 \mathrm{e}-011.00000 \mathrm{e}-09$ 1.00000e-01

Element: 12037 \# of layers: 7

Kx Ky Kz Ss Por

3.71888e+00 3.71888e+00 3.71888e-01 1.00000e-09 2.12000e-01

$3.71888 \mathrm{e}+003.71888 \mathrm{e}+00$ 3.71888e-01 1.00000e-09 2.12000e-01

$3.71888 \mathrm{e}+003.71888 \mathrm{e}+00$ 3.71888e-01 1.00000e-09 2.12000e-01

$3.71888 \mathrm{e}+003.71888 \mathrm{e}+00$ 3.71888e-01 1.00000e-09 2.12000e-01

$3.71888 \mathrm{e}+003.71888 \mathrm{e}+00$ 3.71888e-01 1.00000e-09 2.12000e-01

$1.00000 \mathrm{e}-05$ 1.00000e-05 1.00000e-06 1.00000e-09 1.00000e-01

$1.00000 \mathrm{e}+001.00000 \mathrm{e}+001.00000 \mathrm{e}-011.00000 \mathrm{e}-09$ 1.00000e-01

Element: 12038 \# of layers: 7

Kx Ky Kz Ss Por

3.71888e+00 3.71888e+00 3.71888e-01 1.00000e-09 2.12000e-01

3.71888e+00 3.71888e+00 3.71888e-01 1.00000e-09 2.12000e-01

$3.71888 \mathrm{e}+003.71888 \mathrm{e}+00$ 3.71888e-01 1.00000e-09 2.12000e-01

$3.71888 \mathrm{e}+003.71888 \mathrm{e}+00$ 3.71888e-01 1.00000e-09 2.12000e-01

$3.71888 \mathrm{e}+00$ 3.71888e+00 3.71888e-01 1.00000e-09 2.12000e-01

$1.00000 \mathrm{e}-05$ 1.00000e-05 1.00000e-06 1.00000e-09 1.00000e-01

$1.00000 \mathrm{e}+001.00000 \mathrm{e}+001.00000 \mathrm{e}-01$ 1.00000e-09 1.00000e-01

Element: 12039 \# of layers: 7 
$\mathrm{Kx} \mathrm{Ky} \mathrm{Kz}$ Ss Por

3.71888e+00 3.71888e+00 3.71888e-01 1.00000e-09 2.12000e-01

$3.71888 \mathrm{e}+003.71888 \mathrm{e}+00$ 3.71888e-01 1.00000e-09 2.12000e-01

$3.71888 \mathrm{e}+003.71888 \mathrm{e}+00$ 3.71888e-01 1.00000e-09 2.12000e-01

$3.71888 \mathrm{e}+003.71888 \mathrm{e}+00$ 3.71888e-01 1.00000e-09 2.12000e-01

$3.71888 \mathrm{e}+003.71888 \mathrm{e}+003.71888 \mathrm{e}-01$ 1.00000e-09 2.12000e-01

$1.00000 \mathrm{e}-05$ 1.00000e-05 1.00000e-06 1.00000e-09 1.00000e-01

$1.00000 \mathrm{e}+001.00000 \mathrm{e}+001.00000 \mathrm{e}-01$ 1.00000e-09 1.00000e-01

Element: 12040 \# of layers: 7

$\mathrm{Kx} \mathrm{Ky} \mathrm{Kz}$ Ss Por

3.66825e+00 3.66825e+00 3.66825e-01 1.00000e-09 2.12000e-01

$3.66825 \mathrm{e}+003.66825 \mathrm{e}+003.66825 \mathrm{e}-01$ 1.00000e-09 2.12000e-01

$3.66825 \mathrm{e}+003.66825 \mathrm{e}+003.66825 \mathrm{e}-01$ 1.00000e-09 2.12000e-01

$3.66825 \mathrm{e}+003.66825 \mathrm{e}+003.66825 \mathrm{e}-01$ 1.00000e-09 2.12000e-01

$3.66825 \mathrm{e}+003.66825 \mathrm{e}+003.66825 \mathrm{e}-01$ 1.00000e-09 2.12000e-01

$1.00000 \mathrm{e}-05$ 1.00000e-05 1.00000e-06 1.00000e-09 1.00000e-01

$1.00000 \mathrm{e}+001.00000 \mathrm{e}+001.00000 \mathrm{e}-01$ 1.00000e-09 1.00000e-01

Element: 12041 \# of layers: 7

$\mathrm{Kx} \mathrm{Ky} \mathrm{Kz}$ Ss Por

3.66825e+00 3.66825e+00 3.66825e-01 1.00000e-09 2.12000e-01

$3.66825 \mathrm{e}+003.66825 \mathrm{e}+003.66825 \mathrm{e}-01$ 1.00000e-09 2.12000e-01

$3.66825 \mathrm{e}+003.66825 \mathrm{e}+00$ 3.66825e-01 1.00000e-09 2.12000e-01

$3.66825 \mathrm{e}+003.66825 \mathrm{e}+00$ 3.66825e-01 1.00000e-09 2.12000e-01

$3.66825 \mathrm{e}+003.66825 \mathrm{e}+003.66825 \mathrm{e}-01$ 1.00000e-09 2.12000e-01

$1.00000 \mathrm{e}-051.00000 \mathrm{e}-05$ 1.00000e-06 1.00000e-09 1.00000e-01

$1.00000 \mathrm{e}+001.00000 \mathrm{e}+001.00000 \mathrm{e}-01$ 1.00000e-09 1.00000e-01

Element: 12042 \# of layers: 7

$\mathrm{Kx} \mathrm{Ky} \mathrm{Kz}$ Ss Por

$3.66825 \mathrm{e}+00$ 3.66825e+00 3.66825e-01 1.00000e-09 2.12000e-01

$3.66825 \mathrm{e}+003.66825 \mathrm{e}+00$ 3.66825e-01 1.00000e-09 2.12000e-01

$3.66825 \mathrm{e}+003.66825 \mathrm{e}+003.66825 \mathrm{e}-01$ 1.00000e-09 2.12000e-01

$3.66825 \mathrm{e}+003.66825 \mathrm{e}+00$ 3.66825e-01 1.00000e-09 2.12000e-01

$3.66825 \mathrm{e}+003.66825 \mathrm{e}+003.66825 \mathrm{e}-01$ 1.00000e-09 2.12000e-01

$1.00000 \mathrm{e}-05$ 1.00000e-05 1.00000e-06 1.00000e-09 1.00000e-01

$1.00000 \mathrm{e}+001.00000 \mathrm{e}+001.00000 \mathrm{e}-011.00000 \mathrm{e}-091.00000 \mathrm{e}-01$

Element: 12043 \# of layers: 7

Kx Ky Kz Ss Por

$3.66825 \mathrm{e}+00$ 3.66825e+00 3.66825e-01 1.00000e-09 2.12000e-01

$3.66825 \mathrm{e}+003.66825 \mathrm{e}+003.66825 \mathrm{e}-01$ 1.00000e-09 2.12000e-01

$3.66825 \mathrm{e}+003.66825 \mathrm{e}+003.66825 \mathrm{e}-01$ 1.00000e-09 2.12000e-01

$3.66825 \mathrm{e}+003.66825 \mathrm{e}+003.66825 \mathrm{e}-01$ 1.00000e-09 2.12000e-01

$3.66825 \mathrm{e}+003.66825 \mathrm{e}+00$ 3.66825e-01 1.00000e-09 2.12000e-01

$1.00000 \mathrm{e}-051.00000 \mathrm{e}-051.00000 \mathrm{e}-061.00000 \mathrm{e}-091.00000 \mathrm{e}-01$

$1.00000 \mathrm{e}+001.00000 \mathrm{e}+001.00000 \mathrm{e}-011.00000 \mathrm{e}-091.00000 \mathrm{e}-01$

Element: 12044 \# of layers: 7

Kx Ky Kz Ss Por 
$3.71888 \mathrm{e}+003.71888 \mathrm{e}+00$ 3.71888e-01 1.00000e-09 2.12000e-01 $3.71888 \mathrm{e}+003.71888 \mathrm{e}+003.71888 \mathrm{e}-011.00000 \mathrm{e}-092.12000 \mathrm{e}-01$ $3.71888 \mathrm{e}+003.71888 \mathrm{e}+003.71888 \mathrm{e}-01$ 1.00000e-09 2.12000e-01 $3.71888 \mathrm{e}+003.71888 \mathrm{e}+003.71888 \mathrm{e}-011.00000 \mathrm{e}-092.12000 \mathrm{e}-01$ $3.71888 \mathrm{e}+003.71888 \mathrm{e}+003.71888 \mathrm{e}-01$ 1.00000e-09 2.12000e-01 $1.00000 \mathrm{e}-05$ 1.00000e-05 1.00000e-06 1.00000e-09 1.00000e-01 $1.00000 \mathrm{e}+001.00000 \mathrm{e}+001.00000 \mathrm{e}-011.00000 \mathrm{e}-091.00000 \mathrm{e}-01$ Element: 12045 \# of layers: 7

Kx Ky Kz Ss Por

$3.71888 \mathrm{e}+003.71888 \mathrm{e}+00$ 3.71888e-01 1.00000e-09 2.12000e-01 $3.71888 \mathrm{e}+003.71888 \mathrm{e}+003.71888 \mathrm{e}-01$ 1.00000e-09 2.12000e-01 $3.71888 \mathrm{e}+003.71888 \mathrm{e}+003.71888 \mathrm{e}-01$ 1.00000e-09 2.12000e-01 $3.71888 \mathrm{e}+003.71888 \mathrm{e}+003.71888 \mathrm{e}-011.00000 \mathrm{e}-092.12000 \mathrm{e}-01$ $3.71888 \mathrm{e}+003.71888 \mathrm{e}+003.71888 \mathrm{e}-01$ 1.00000e-09 2.12000e-01 $1.00000 \mathrm{e}-05$ 1.00000e-05 1.00000e-06 1.00000e-09 1.00000e-01 $1.00000 \mathrm{e}+001.00000 \mathrm{e}+001.00000 \mathrm{e}-011.00000 \mathrm{e}-091.00000 \mathrm{e}-01$ Element: 12046 \# of layers: 7

Kx Ky Kz Ss Por

$3.71888 \mathrm{e}+003.71888 \mathrm{e}+00$ 3.71888e-01 1.00000e-09 2.12000e-01

$3.71888 \mathrm{e}+003.71888 \mathrm{e}+003.71888 \mathrm{e}-011.00000 \mathrm{e}-092.12000 \mathrm{e}-01$

$3.71888 \mathrm{e}+003.71888 \mathrm{e}+003.71888 \mathrm{e}-011.00000 \mathrm{e}-092.12000 \mathrm{e}-01$

$3.71888 \mathrm{e}+003.71888 \mathrm{e}+003.71888 \mathrm{e}-011.00000 \mathrm{e}-092.12000 \mathrm{e}-01$ $3.71888 \mathrm{e}+003.71888 \mathrm{e}+003.71888 \mathrm{e}-01$ 1.00000e-09 2.12000e-01 $1.00000 \mathrm{e}-05$ 1.00000e-05 1.00000e-06 1.00000e-09 1.00000e-01 $1.00000 \mathrm{e}+001.00000 \mathrm{e}+001.00000 \mathrm{e}-011.00000 \mathrm{e}-091.00000 \mathrm{e}-01$ Element: 12047 \# of layers: 7

Kx Ky Kz Ss Por

$3.71888 \mathrm{e}+003.71888 \mathrm{e}+00$ 3.71888e-01 1.00000e-09 2.12000e-01 $3.71888 \mathrm{e}+003.71888 \mathrm{e}+003.71888 \mathrm{e}-011.00000 \mathrm{e}-092.12000 \mathrm{e}-01$ $3.71888 \mathrm{e}+003.71888 \mathrm{e}+003.71888 \mathrm{e}-011.00000 \mathrm{e}-092.12000 \mathrm{e}-01$ $3.71888 \mathrm{e}+003.71888 \mathrm{e}+003.71888 \mathrm{e}-01$ 1.00000e-09 2.12000e-01 $3.71888 \mathrm{e}+003.71888 \mathrm{e}+003.71888 \mathrm{e}-01$ 1.00000e-09 2.12000e-01 $1.00000 \mathrm{e}-05$ 1.00000e-05 1.00000e-06 1.00000e-09 1.00000e-01 $1.00000 \mathrm{e}+001.00000 \mathrm{e}+001.00000 \mathrm{e}-011.00000 \mathrm{e}-091.00000 \mathrm{e}-01$ Element: 12048 \# of layers: 7

Kx Ky Kz Ss Por

$3.71888 \mathrm{e}+003.71888 \mathrm{e}+00$ 3.71888e-01 1.00000e-09 2.12000e-01 $3.71888 \mathrm{e}+003.71888 \mathrm{e}+003.71888 \mathrm{e}-01$ 1.00000e-09 2.12000e-01 $3.71888 \mathrm{e}+003.71888 \mathrm{e}+003.71888 \mathrm{e}-011.00000 \mathrm{e}-092.12000 \mathrm{e}-01$ $3.71888 \mathrm{e}+003.71888 \mathrm{e}+003.71888 \mathrm{e}-011.00000 \mathrm{e}-092.12000 \mathrm{e}-01$ $3.71888 \mathrm{e}+003.71888 \mathrm{e}+003.71888 \mathrm{e}-01$ 1.00000e-09 2.12000e-01 $1.00000 \mathrm{e}-05$ 1.00000e-05 1.00000e-06 1.00000e-09 1.00000e-01 $1.00000 \mathrm{e}+001.00000 \mathrm{e}+001.00000 \mathrm{e}-011.00000 \mathrm{e}-091.00000 \mathrm{e}-01$ Element: 12049 \# of layers: 7

Kx Ky Kz Ss Por

3.71888e+00 3.71888e+00 3.71888e-01 1.00000e-09 2.12000e-01 
$3.71888 \mathrm{e}+003.71888 \mathrm{e}+00$ 3.71888e-01 1.00000e-09 2.12000e-01 $3.71888 \mathrm{e}+003.71888 \mathrm{e}+003.71888 \mathrm{e}-011.00000 \mathrm{e}-092.12000 \mathrm{e}-01$ $3.71888 \mathrm{e}+003.71888 \mathrm{e}+003.71888 \mathrm{e}-01$ 1.00000e-09 2.12000e-01 $3.71888 \mathrm{e}+003.71888 \mathrm{e}+003.71888 \mathrm{e}-01$ 1.00000e-09 2.12000e-01 $1.00000 \mathrm{e}-05$ 1.00000e-05 1.00000e-06 1.00000e-09 1.00000e-01 $1.00000 \mathrm{e}+001.00000 \mathrm{e}+001.00000 \mathrm{e}-011.00000 \mathrm{e}-091.00000 \mathrm{e}-01$ Element: 12050 \# of layers: 7

Kx Ky Kz Ss Por

$3.71888 \mathrm{e}+003.71888 \mathrm{e}+00$ 3.71888e-01 1.00000e-09 2.12000e-01 $3.71888 \mathrm{e}+003.71888 \mathrm{e}+003.71888 \mathrm{e}-011.00000 \mathrm{e}-092.12000 \mathrm{e}-01$ $3.71888 \mathrm{e}+003.71888 \mathrm{e}+003.71888 \mathrm{e}-011.00000 \mathrm{e}-092.12000 \mathrm{e}-01$ $3.71888 \mathrm{e}+003.71888 \mathrm{e}+003.71888 \mathrm{e}-01$ 1.00000e-09 2.12000e-01 $3.71888 \mathrm{e}+003.71888 \mathrm{e}+003.71888 \mathrm{e}-011.00000 \mathrm{e}-092.12000 \mathrm{e}-01$ $1.00000 \mathrm{e}-05$ 1.00000e-05 1.00000e-06 1.00000e-09 1.00000e-01 $1.00000 \mathrm{e}+001.00000 \mathrm{e}+001.00000 \mathrm{e}-011.00000 \mathrm{e}-091.00000 \mathrm{e}-01$ Element: 12051 \# of layers: 7

Kx Ky Kz Ss Por

$3.71888 \mathrm{e}+003.71888 \mathrm{e}+00$ 3.71888e-01 1.00000e-09 2.12000e-01 $3.71888 \mathrm{e}+003.71888 \mathrm{e}+003.71888 \mathrm{e}-011.00000 \mathrm{e}-092.12000 \mathrm{e}-01$ $3.71888 \mathrm{e}+003.71888 \mathrm{e}+003.71888 \mathrm{e}-01$ 1.00000e-09 2.12000e-01 $3.71888 \mathrm{e}+003.71888 \mathrm{e}+003.71888 \mathrm{e}-011.00000 \mathrm{e}-092.12000 \mathrm{e}-01$ $3.71888 \mathrm{e}+003.71888 \mathrm{e}+00$ 3.71888e-01 1.00000e-09 2.12000e-01 $1.00000 \mathrm{e}-05$ 1.00000e-05 1.00000e-06 1.00000e-09 1.00000e-01 $1.00000 \mathrm{e}+001.00000 \mathrm{e}+001.00000 \mathrm{e}-011.00000 \mathrm{e}-091.00000 \mathrm{e}-01$ Element: 12052 \# of layers: 7

Kx Ky Kz Ss Por

$3.71888 \mathrm{e}+003.71888 \mathrm{e}+00$ 3.71888e-01 1.00000e-09 2.12000e-01

$3.71888 \mathrm{e}+003.71888 \mathrm{e}+003.71888 \mathrm{e}-01$ 1.00000e-09 2.12000e-01

$3.71888 \mathrm{e}+003.71888 \mathrm{e}+003.71888 \mathrm{e}-01$ 1.00000e-09 2.12000e-01

$3.71888 \mathrm{e}+003.71888 \mathrm{e}+00$ 3.71888e-01 1.00000e-09 2.12000e-01 $3.71888 \mathrm{e}+003.71888 \mathrm{e}+003.71888 \mathrm{e}-01$ 1.00000e-09 2.12000e-01 $1.00000 \mathrm{e}-05$ 1.00000e-05 1.00000e-06 1.00000e-09 1.00000e-01 $1.00000 \mathrm{e}+001.00000 \mathrm{e}+001.00000 \mathrm{e}-011.00000 \mathrm{e}-091.00000 \mathrm{e}-01$ Element: 12053 \# of layers: 7

Kx Ky Kz Ss Por

$3.71888 \mathrm{e}+003.71888 \mathrm{e}+00$ 3.71888e-01 1.00000e-09 2.12000e-01 $3.71888 \mathrm{e}+003.71888 \mathrm{e}+003.71888 \mathrm{e}-01$ 1.00000e-09 2.12000e-01 $3.71888 \mathrm{e}+003.71888 \mathrm{e}+003.71888 \mathrm{e}-01$ 1.00000e-09 2.12000e-01 $3.71888 \mathrm{e}+003.71888 \mathrm{e}+003.71888 \mathrm{e}-01$ 1.00000e-09 2.12000e-01 $3.71888 \mathrm{e}+003.71888 \mathrm{e}+003.71888 \mathrm{e}-01$ 1.00000e-09 2.12000e-01 $1.00000 \mathrm{e}-05$ 1.00000e-05 1.00000e-06 1.00000e-09 1.00000e-01 $1.00000 \mathrm{e}+001.00000 \mathrm{e}+001.00000 \mathrm{e}-011.00000 \mathrm{e}-091.00000 \mathrm{e}-01$ Element: 12054 \# of layers: 7

Kx Ky Kz Ss Por $3.69863 \mathrm{e}+003.69863 \mathrm{e}+00$ 3.69863e-01 1.00000e-09 2.12000e-01 $3.69863 \mathrm{e}+003.69863 \mathrm{e}+003.69863 \mathrm{e}-01$ 1.00000e-09 2.12000e-01 
$3.69863 \mathrm{e}+003.69863 \mathrm{e}+00$ 3.69863e-01 1.00000e-09 2.12000e-01 $3.69863 \mathrm{e}+003.69863 \mathrm{e}+003.69863 \mathrm{e}-01$ 1.00000e-09 2.12000e-01 $3.69863 \mathrm{e}+003.69863 \mathrm{e}+003.69863 \mathrm{e}-01$ 1.00000e-09 2.12000e-01 $1.00000 \mathrm{e}-05$ 1.00000e-05 1.00000e-06 1.00000e-09 1.00000e-01 $1.00000 \mathrm{e}+001.00000 \mathrm{e}+001.00000 \mathrm{e}-011.00000 \mathrm{e}-091.00000 \mathrm{e}-01$ Element: 12055 \# of layers: 7

Kx Ky Kz Ss Por

$3.69863 \mathrm{e}+003.69863 \mathrm{e}+00$ 3.69863e-01 1.00000e-09 2.12000e-01 $3.69863 \mathrm{e}+003.69863 \mathrm{e}+003.69863 \mathrm{e}-011.00000 \mathrm{e}-092.12000 \mathrm{e}-01$ $3.69863 \mathrm{e}+003.69863 \mathrm{e}+003.69863 \mathrm{e}-011.00000 \mathrm{e}-092.12000 \mathrm{e}-01$ $3.69863 \mathrm{e}+003.69863 \mathrm{e}+003.69863 \mathrm{e}-011.00000 \mathrm{e}-092.12000 \mathrm{e}-01$ $3.69863 \mathrm{e}+003.69863 \mathrm{e}+003.69863 \mathrm{e}-01$ 1.00000e-09 2.12000e-01 $1.00000 \mathrm{e}-05$ 1.00000e-05 1.00000e-06 1.00000e-09 1.00000e-01 $1.00000 \mathrm{e}+001.00000 \mathrm{e}+001.00000 \mathrm{e}-011.00000 \mathrm{e}-091.00000 \mathrm{e}-01$ Element: 12056 \# of layers: 7

Kx Ky Kz Ss Por

$3.69863 \mathrm{e}+003.69863 \mathrm{e}+00$ 3.69863e-01 1.00000e-09 2.12000e-01 $3.69863 \mathrm{e}+003.69863 \mathrm{e}+003.69863 \mathrm{e}-011.00000 \mathrm{e}-092.12000 \mathrm{e}-01$ $3.69863 \mathrm{e}+003.69863 \mathrm{e}+003.69863 \mathrm{e}-011.00000 \mathrm{e}-092.12000 \mathrm{e}-01$ $3.69863 \mathrm{e}+003.69863 \mathrm{e}+003.69863 \mathrm{e}-011.00000 \mathrm{e}-092.12000 \mathrm{e}-01$ $3.69863 \mathrm{e}+003.69863 \mathrm{e}+003.69863 \mathrm{e}-01$ 1.00000e-09 2.12000e-01 $1.00000 \mathrm{e}-05$ 1.00000e-05 1.00000e-06 1.00000e-09 1.00000e-01 $1.00000 \mathrm{e}+001.00000 \mathrm{e}+001.00000 \mathrm{e}-011.00000 \mathrm{e}-091.00000 \mathrm{e}-01$ Element: 12057 \# of layers: 7

Kx Ky Kz Ss Por $3.69863 \mathrm{e}+003.69863 \mathrm{e}+00$ 3.69863e-01 1.00000e-09 2.12000e-01 $3.69863 \mathrm{e}+003.69863 \mathrm{e}+003.69863 \mathrm{e}-01$ 1.00000e-09 2.12000e-01 $3.69863 \mathrm{e}+003.69863 \mathrm{e}+003.69863 \mathrm{e}-01$ 1.00000e-09 2.12000e-01 $3.69863 \mathrm{e}+003.69863 \mathrm{e}+003.69863 \mathrm{e}-01$ 1.00000e-09 2.12000e-01 $3.69863 \mathrm{e}+003.69863 \mathrm{e}+003.69863 \mathrm{e}-01$ 1.00000e-09 2.12000e-01 $1.00000 \mathrm{e}-05$ 1.00000e-05 1.00000e-06 1.00000e-09 1.00000e-01 $1.00000 \mathrm{e}+001.00000 \mathrm{e}+001.00000 \mathrm{e}-011.00000 \mathrm{e}-091.00000 \mathrm{e}-01$ Element: 12058 \# of layers: 7

Kx Ky Kz Ss Por

$3.69863 \mathrm{e}+003.69863 \mathrm{e}+00$ 3.69863e-01 1.00000e-09 2.12000e-01 $3.69863 \mathrm{e}+003.69863 \mathrm{e}+003.69863 \mathrm{e}-011.00000 \mathrm{e}-092.12000 \mathrm{e}-01$ $3.69863 \mathrm{e}+003.69863 \mathrm{e}+003.69863 \mathrm{e}-01$ 1.00000e-09 2.12000e-01 $3.69863 \mathrm{e}+003.69863 \mathrm{e}+003.69863 \mathrm{e}-01$ 1.00000e-09 2.12000e-01 $3.69863 \mathrm{e}+003.69863 \mathrm{e}+003.69863 \mathrm{e}-01$ 1.00000e-09 2.12000e-01 $1.00000 \mathrm{e}-05$ 1.00000e-05 1.00000e-06 1.00000e-09 1.00000e-01 $1.00000 \mathrm{e}+001.00000 \mathrm{e}+001.00000 \mathrm{e}-011.00000 \mathrm{e}-091.00000 \mathrm{e}-01$ Element: 12059 \# of layers: 7

Kx Ky Kz Ss Por $3.71888 \mathrm{e}+003.71888 \mathrm{e}+00$ 3.71888e-01 1.00000e-09 2.12000e-01 $3.71888 \mathrm{e}+003.71888 \mathrm{e}+003.71888 \mathrm{e}-01$ 1.00000e-09 2.12000e-01 $3.71888 \mathrm{e}+003.71888 \mathrm{e}+003.71888 \mathrm{e}-01$ 1.00000e-09 2.12000e-01 
$3.71888 \mathrm{e}+003.71888 \mathrm{e}+003.71888 \mathrm{e}-01$ 1.00000e-09 2.12000e-01 $3.71888 \mathrm{e}+003.71888 \mathrm{e}+003.71888 \mathrm{e}-01$ 1.00000e-09 2.12000e-01 $1.00000 \mathrm{e}-05$ 1.00000e-05 1.00000e-06 1.00000e-09 1.00000e-01 $1.00000 \mathrm{e}+001.00000 \mathrm{e}+001.00000 \mathrm{e}-011.00000 \mathrm{e}-091.00000 \mathrm{e}-01$ Element: 12060 \# of layers: 7

Kx Ky Kz Ss Por

$3.71888 \mathrm{e}+003.71888 \mathrm{e}+00$ 3.71888e-01 1.00000e-09 2.12000e-01 $3.71888 \mathrm{e}+003.71888 \mathrm{e}+003.71888 \mathrm{e}-011.00000 \mathrm{e}-092.12000 \mathrm{e}-01$ $3.71888 \mathrm{e}+003.71888 \mathrm{e}+003.71888 \mathrm{e}-011.00000 \mathrm{e}-092.12000 \mathrm{e}-01$ $3.71888 \mathrm{e}+003.71888 \mathrm{e}+003.71888 \mathrm{e}-011.00000 \mathrm{e}-092.12000 \mathrm{e}-01$ $3.71888 \mathrm{e}+003.71888 \mathrm{e}+003.71888 \mathrm{e}-01$ 1.00000e-09 2.12000e-01 $1.00000 \mathrm{e}-05$ 1.00000e-05 1.00000e-06 1.00000e-09 1.00000e-01 $1.00000 \mathrm{e}+001.00000 \mathrm{e}+001.00000 \mathrm{e}-011.00000 \mathrm{e}-091.00000 \mathrm{e}-01$ Element: 12061 \# of layers: 7

Kx Ky Kz Ss Por

$3.69863 \mathrm{e}+003.69863 \mathrm{e}+00$ 3.69863e-01 1.00000e-09 2.12000e-01 $3.69863 \mathrm{e}+003.69863 \mathrm{e}+003.69863 \mathrm{e}-011.00000 \mathrm{e}-09$ 2.12000e-01 $3.69863 \mathrm{e}+003.69863 \mathrm{e}+003.69863 \mathrm{e}-01$ 1.00000e-09 2.12000e-01 $3.69863 \mathrm{e}+003.69863 \mathrm{e}+003.69863 \mathrm{e}-011.00000 \mathrm{e}-092.12000 \mathrm{e}-01$ $3.69863 \mathrm{e}+003.69863 \mathrm{e}+003.69863 \mathrm{e}-01$ 1.00000e-09 2.12000e-01 $1.00000 \mathrm{e}-05$ 1.00000e-05 1.00000e-06 1.00000e-09 1.00000e-01 $1.00000 \mathrm{e}+001.00000 \mathrm{e}+001.00000 \mathrm{e}-011.00000 \mathrm{e}-091.00000 \mathrm{e}-01$ Element: 12062 \# of layers: 7

Kx Ky Kz Ss Por

$3.69863 \mathrm{e}+003.69863 \mathrm{e}+00$ 3.69863e-01 1.00000e-09 2.12000e-01 $3.69863 \mathrm{e}+003.69863 \mathrm{e}+003.69863 \mathrm{e}-01$ 1.00000e-09 2.12000e-01 $3.69863 \mathrm{e}+003.69863 \mathrm{e}+003.69863 \mathrm{e}-011.00000 \mathrm{e}-092.12000 \mathrm{e}-01$ $3.69863 \mathrm{e}+003.69863 \mathrm{e}+003.69863 \mathrm{e}-011.00000 \mathrm{e}-09$ 2.12000e-01 $3.69863 \mathrm{e}+003.69863 \mathrm{e}+003.69863 \mathrm{e}-01$ 1.00000e-09 2.12000e-01 $1.00000 \mathrm{e}-05$ 1.00000e-05 1.00000e-06 1.00000e-09 1.00000e-01 $1.00000 \mathrm{e}+001.00000 \mathrm{e}+001.00000 \mathrm{e}-011.00000 \mathrm{e}-091.00000 \mathrm{e}-01$ Element: 12063 \# of layers: 7

Kx Ky Kz Ss Por

$4.32122 \mathrm{e}+00$ 4.32122e+00 4.32122e-01 1.00000e-09 2.12000e-01 $4.32122 \mathrm{e}+004.32122 \mathrm{e}+004.32122 \mathrm{e}-011.00000 \mathrm{e}-09$ 2.12000e-01 $4.32122 \mathrm{e}+004.32122 \mathrm{e}+00$ 4.32122e-01 1.00000e-09 2.12000e-01 $4.32122 \mathrm{e}+004.32122 \mathrm{e}+004.32122 \mathrm{e}-011.00000 \mathrm{e}-092.12000 \mathrm{e}-01$ $4.32122 \mathrm{e}+004.32122 \mathrm{e}+00$ 4.32122e-01 1.00000e-09 2.12000e-01 $1.00000 \mathrm{e}-05$ 1.00000e-05 1.00000e-06 1.00000e-09 1.00000e-01 $1.00000 \mathrm{e}+001.00000 \mathrm{e}+001.00000 \mathrm{e}-011.00000 \mathrm{e}-091.00000 \mathrm{e}-01$ Element: 12064 \# of layers: 7

Kx Ky Kz Ss Por

$4.32122 \mathrm{e}+00$ 4.32122e+00 4.32122e-01 1.00000e-09 2.12000e-01 $4.32122 \mathrm{e}+004.32122 \mathrm{e}+004.32122 \mathrm{e}-011.00000 \mathrm{e}-092.12000 \mathrm{e}-01$ $4.32122 \mathrm{e}+004.32122 \mathrm{e}+004.32122 \mathrm{e}-011.00000 \mathrm{e}-09$ 2.12000e-01 $4.32122 \mathrm{e}+004.32122 \mathrm{e}+004.32122 \mathrm{e}-01$ 1.00000e-09 2.12000e-01 
4.32122e+00 4.32122e+00 4.32122e-01 1.00000e-09 2.12000e-01 $1.00000 \mathrm{e}-05$ 1.00000e-05 1.00000e-06 1.00000e-09 1.00000e-01 $1.00000 \mathrm{e}+001.00000 \mathrm{e}+00$ 1.00000e-01 1.00000e-09 1.00000e-01 Element: 12065 \# of layers: 7

$\mathrm{Kx} \mathrm{Ky} \mathrm{Kz}$ Ss Por

4.32122e+00 4.32122e+00 4.32122e-01 1.00000e-09 2.12000e-01 4.32122e+00 4.32122e+00 4.32122e-01 1.00000e-09 2.12000e-01 $4.32122 \mathrm{e}+00$ 4.32122e+00 4.32122e-01 1.00000e-09 2.12000e-01 4.32122e+00 4.32122e+00 4.32122e-01 1.00000e-09 2.12000e-01 $4.32122 \mathrm{e}+004.32122 \mathrm{e}+00$ 4.32122e-01 1.00000e-09 2.12000e-01 $1.00000 \mathrm{e}-05$ 1.00000e-05 1.00000e-06 1.00000e-09 1.00000e-01 $1.00000 \mathrm{e}+001.00000 \mathrm{e}+001.00000 \mathrm{e}-01$ 1.00000e-09 1.00000e-01 Element: 12066 \# of layers: 7

$\mathrm{Kx} \mathrm{Ky} \mathrm{Kz}$ Ss Por

$3.66825 \mathrm{e}+003.66825 \mathrm{e}+00$ 3.66825e-01 1.00000e-09 2.12000e-01 $3.66825 \mathrm{e}+003.66825 \mathrm{e}+003.66825 \mathrm{e}-01$ 1.00000e-09 2.12000e-01 $3.66825 \mathrm{e}+003.66825 \mathrm{e}+003.66825 \mathrm{e}-01$ 1.00000e-09 2.12000e-01 $3.66825 \mathrm{e}+003.66825 \mathrm{e}+003.66825 \mathrm{e}-01$ 1.00000e-09 2.12000e-01 $3.66825 \mathrm{e}+003.66825 \mathrm{e}+00$ 3.66825e-01 1.00000e-09 2.12000e-01 $1.00000 \mathrm{e}-05$ 1.00000e-05 1.00000e-06 1.00000e-09 1.00000e-01 $1.00000 \mathrm{e}+001.00000 \mathrm{e}+001.00000 \mathrm{e}-011.00000 \mathrm{e}-091.00000 \mathrm{e}-01$ Element: 12067 \# of layers: 7

$\mathrm{Kx} \mathrm{Ky} \mathrm{Kz}$ Ss Por

3.66825e+00 3.66825e+00 3.66825e-01 1.00000e-09 2.12000e-01 $3.66825 \mathrm{e}+003.66825 \mathrm{e}+003.66825 \mathrm{e}-01$ 1.00000e-09 2.12000e-01 $3.66825 \mathrm{e}+003.66825 \mathrm{e}+003.66825 \mathrm{e}-01$ 1.00000e-09 2.12000e-01 $3.66825 \mathrm{e}+003.66825 \mathrm{e}+003.66825 \mathrm{e}-01$ 1.00000e-09 2.12000e-01 $3.66825 \mathrm{e}+003.66825 \mathrm{e}+00$ 3.66825e-01 1.00000e-09 2.12000e-01 $1.00000 \mathrm{e}-051.00000 \mathrm{e}-05$ 1.00000e-06 1.00000e-09 1.00000e-01 $1.00000 \mathrm{e}+001.00000 \mathrm{e}+001.00000 \mathrm{e}-011.00000 \mathrm{e}-091.00000 \mathrm{e}-01$ Element: 12068 \# of layers: 7

$\mathrm{Kx} \mathrm{Ky} \mathrm{Kz}$ Ss Por

3.71888e+00 3.71888e+00 3.71888e-01 1.00000e-09 2.12000e-01 $3.71888 \mathrm{e}+003.71888 \mathrm{e}+00$ 3.71888e-01 1.00000e-09 2.12000e-01 $3.71888 \mathrm{e}+003.71888 \mathrm{e}+00$ 3.71888e-01 1.00000e-09 2.12000e-01 $3.71888 \mathrm{e}+003.71888 \mathrm{e}+00$ 3.71888e-01 1.00000e-09 2.12000e-01 $3.71888 \mathrm{e}+003.71888 \mathrm{e}+00$ 3.71888e-01 1.00000e-09 2.12000e-01 $1.00000 \mathrm{e}-05$ 1.00000e-05 1.00000e-06 1.00000e-09 1.00000e-01 $1.00000 \mathrm{e}+001.00000 \mathrm{e}+001.00000 \mathrm{e}-01$ 1.00000e-09 1.00000e-01 Element: 12069 \# of layers: 7

$\mathrm{Kx} \mathrm{Ky} \mathrm{Kz}$ Ss Por

3.69863e+00 3.69863e+00 3.69863e-01 1.00000e-09 2.12000e-01 $3.69863 \mathrm{e}+003.69863 \mathrm{e}+00$ 3.69863e-01 1.00000e-09 2.12000e-01 3.69863e+00 3.69863e+00 3.69863e-01 1.00000e-09 2.12000e-01 $3.69863 \mathrm{e}+003.69863 \mathrm{e}+00$ 3.69863e-01 1.00000e-09 2.12000e-01 $3.69863 e+003.69863 e+003.69863 e-01$ 1.00000e-09 2.12000e-01 
$1.00000 \mathrm{e}-05$ 1.00000e-05 1.00000e-06 1.00000e-09 1.00000e-01 $1.00000 \mathrm{e}+001.00000 \mathrm{e}+001.00000 \mathrm{e}-01$ 1.00000e-09 1.00000e-01 Element: 12070 \# of layers: 7

Kx Ky Kz Ss Por

4.32122e+00 4.32122e+00 4.32122e-01 1.00000e-09 2.12000e-01 $4.32122 \mathrm{e}+004.32122 \mathrm{e}+00$ 4.32122e-01 1.00000e-09 2.12000e-01 $4.32122 \mathrm{e}+00$ 4.32122e+00 4.32122e-01 1.00000e-09 2.12000e-01 $4.32122 \mathrm{e}+00$ 4.32122e+00 4.32122e-01 1.00000e-09 2.12000e-01 4.32122e+00 4.32122e+00 4.32122e-01 1.00000e-09 2.12000e-01 $1.00000 \mathrm{e}-05$ 1.00000e-05 1.00000e-06 1.00000e-09 1.00000e-01 $1.00000 \mathrm{e}+001.00000 \mathrm{e}+001.00000 \mathrm{e}-011.00000 \mathrm{e}-091.00000 \mathrm{e}-01$ Element: 12071 \# of layers: 6

$\mathrm{Kx} \mathrm{Ky} \mathrm{Kz}$ Ss Por

5.06373e+00 5.06373e+00 5.06373e-01 1.00000e-09 2.12000e-01 5.06373e+00 5.06373e+00 5.06373e-01 1.00000e-09 2.12000e-01 5.06373e+00 5.06373e+00 5.06373e-01 1.00000e-09 2.12000e-01 5.06373e+00 5.06373e+00 5.06373e-01 1.00000e-09 2.12000e-01 $1.00000 \mathrm{e}-05$ 1.00000e-05 1.00000e-06 1.00000e-09 1.00000e-01 $1.00000 \mathrm{e}+001.00000 \mathrm{e}+001.00000 \mathrm{e}-01$ 1.00000e-09 1.00000e-01 Element: 12072 \# of layers: 6

$\mathrm{Kx} \mathrm{Ky} \mathrm{Kz}$ Ss Por

5.06373e+00 5.06373e+00 5.06373e-01 1.00000e-09 2.12000e-01 5.06373e+00 5.06373e+00 5.06373e-01 1.00000e-09 2.12000e-01 $5.06373 \mathrm{e}+00$ 5.06373e+00 5.06373e-01 1.00000e-09 2.12000e-01 $5.06373 \mathrm{e}+00$ 5.06373e+00 5.06373e-01 1.00000e-09 2.12000e-01 $1.00000 \mathrm{e}-051.00000 \mathrm{e}-051.00000 \mathrm{e}-061.00000 \mathrm{e}-091.00000 \mathrm{e}-01$ $1.00000 \mathrm{e}+001.00000 \mathrm{e}+001.00000 \mathrm{e}-011.00000 \mathrm{e}-09$ 1.00000e-01 Element: 12073 \# of layers: 6

Kx Ky Kz Ss Por 5.06373e+00 5.06373e+00 5.06373e-01 1.00000e-09 2.12000e-01 5.06373e+00 5.06373e+00 5.06373e-01 1.00000e-09 2.12000e-01 5.06373e+00 5.06373e+00 5.06373e-01 1.00000e-09 2.12000e-01 $5.06373 \mathrm{e}+00$ 5.06373e+00 5.06373e-01 1.00000e-09 2.12000e-01 $1.00000 \mathrm{e}-05$ 1.00000e-05 1.00000e-06 1.00000e-09 1.00000e-01 $1.00000 \mathrm{e}+001.00000 \mathrm{e}+001.00000 \mathrm{e}-011.00000 \mathrm{e}-091.00000 \mathrm{e}-01$ Element: 12074 \# of layers: 5

Kx Ky Kz Ss Por 5.06373e+00 5.06373e+00 5.06373e-01 1.00000e-09 2.12000e-01 5.06373e+00 5.06373e+00 5.06373e-01 1.00000e-09 2.12000e-01 5.06373e+00 5.06373e+00 5.06373e-01 1.00000e-09 2.12000e-01 $1.00000 \mathrm{e}-05$ 1.00000e-05 1.00000e-06 1.00000e-09 1.00000e-01 $1.00000 \mathrm{e}+001.00000 \mathrm{e}+001.00000 \mathrm{e}-011.00000 \mathrm{e}-091.00000 \mathrm{e}-01$ Element: 12075 \# of layers: 5

$\mathrm{Kx} \mathrm{Ky} \mathrm{Kz}$ Ss Por 5.06373e+00 5.06373e+00 5.06373e-01 1.00000e-09 2.12000e-01 $5.06373 \mathrm{e}+00$ 5.06373e+00 5.06373e-01 1.00000e-09 2.12000e-01 
5.06373e+00 5.06373e+00 5.06373e-01 1.00000e-09 2.12000e-01 $1.00000 \mathrm{e}-05$ 1.00000e-05 1.00000e-06 1.00000e-09 1.00000e-01

$1.00000 \mathrm{e}+001.00000 \mathrm{e}+00$ 1.00000e-01 1.00000e-09 1.00000e-01

Element: 12076 \# of layers: 5

$\mathrm{Kx} \mathrm{Ky} \mathrm{Kz}$ Ss Por

5.06373e+00 5.06373e+00 5.06373e-01 1.00000e-09 2.12000e-01

$5.06373 \mathrm{e}+00$ 5.06373e+00 5.06373e-01 1.00000e-09 2.12000e-01

$5.06373 \mathrm{e}+00$ 5.06373e+00 5.06373e-01 1.00000e-09 2.12000e-01

$1.00000 \mathrm{e}-051.00000 \mathrm{e}-051.00000 \mathrm{e}-061.00000 \mathrm{e}-091.00000 \mathrm{e}-01$

$1.00000 \mathrm{e}+001.00000 \mathrm{e}+00$ 1.00000e-01 1.00000e-09 1.00000e-01

Element: 12077 \# of layers: 6

Kx Ky Kz Ss Por

5.06373e+00 5.06373e+00 5.06373e-01 1.00000e-09 2.12000e-01

5.06373e+00 5.06373e+00 5.06373e-01 1.00000e-09 2.12000e-01

5.06373e+00 5.06373e+00 5.06373e-01 1.00000e-09 2.12000e-01

5.06373e+00 5.06373e+00 5.06373e-01 1.00000e-09 2.12000e-01

$1.00000 \mathrm{e}-05$ 1.00000e-05 1.00000e-06 1.00000e-09 1.00000e-01

$1.00000 \mathrm{e}+001.00000 \mathrm{e}+001.00000 \mathrm{e}-01$ 1.00000e-09 1.00000e-01

Element: 12078 \# of layers: 6

Kx Ky Kz Ss Por

5.06373e+00 5.06373e+00 5.06373e-01 1.00000e-09 2.12000e-01

5.06373e+00 5.06373e+00 5.06373e-01 1.00000e-09 2.12000e-01

5.06373e+00 5.06373e+00 5.06373e-01 1.00000e-09 2.12000e-01

5.06373e+00 5.06373e+00 5.06373e-01 1.00000e-09 2.12000e-01

$1.00000 \mathrm{e}-05$ 1.00000e-05 1.00000e-06 1.00000e-09 1.00000e-01

$1.00000 \mathrm{e}+001.00000 \mathrm{e}+001.00000 \mathrm{e}-01$ 1.00000e-09 1.00000e-01

Element: 12079 \# of layers: 5

$\mathrm{Kx} \mathrm{Ky} \mathrm{Kz}$ Ss Por

5.06373e+00 5.06373e+00 5.06373e-01 1.00000e-09 2.12000e-01

5.06373e+00 5.06373e+00 5.06373e-01 1.00000e-09 2.12000e-01

5.06373e+00 5.06373e+00 5.06373e-01 1.00000e-09 2.12000e-01

$1.00000 \mathrm{e}-05$ 1.00000e-05 1.00000e-06 1.00000e-09 1.00000e-01

$1.00000 \mathrm{e}+001.00000 \mathrm{e}+001.00000 \mathrm{e}-011.00000 \mathrm{e}-091.00000 \mathrm{e}-01$

Element: 12080 \# of layers: 6

$\mathrm{Kx} \mathrm{Ky} \mathrm{Kz}$ Ss Por

5.06373e+00 5.06373e+00 5.06373e-01 1.00000e-09 2.12000e-01

5.06373e+00 5.06373e+00 5.06373e-01 1.00000e-09 2.12000e-01

$5.06373 \mathrm{e}+00$ 5.06373e+00 5.06373e-01 1.00000e-09 2.12000e-01

5.06373e+00 5.06373e+00 5.06373e-01 1.00000e-09 2.12000e-01

$1.00000 \mathrm{e}-05$ 1.00000e-05 1.00000e-06 1.00000e-09 1.00000e-01

$1.00000 \mathrm{e}+001.00000 \mathrm{e}+001.00000 \mathrm{e}-011.00000 \mathrm{e}-091.00000 \mathrm{e}-01$

Element: 12081 \# of layers: 6

$\mathrm{Kx} \mathrm{Ky} \mathrm{Kz}$ Ss Por

6.33704e+00 6.33704e+00 6.33704e-01 1.00000e-09 2.12000e-01

$6.33704 \mathrm{e}+006.33704 \mathrm{e}+006.33704 \mathrm{e}-01$ 1.00000e-09 2.12000e-01

$6.33704 \mathrm{e}+006.33704 \mathrm{e}+006.33704 \mathrm{e}-01$ 1.00000e-09 2.12000e-01 
6.33704e+00 6.33704e+00 6.33704e-01 1.00000e-09 2.12000e-01 $1.00000 \mathrm{e}-05$ 1.00000e-05 1.00000e-06 1.00000e-09 1.00000e-01 $1.00000 \mathrm{e}+001.00000 \mathrm{e}+001.00000 \mathrm{e}-011.00000 \mathrm{e}-09$ 1.00000e-01 Element: 12082 \# of layers: 6

$\mathrm{Kx} \mathrm{Ky} \mathrm{Kz}$ Ss Por

6.33704e+00 6.33704e+00 6.33704e-01 1.00000e-09 2.12000e-01 $6.33704 \mathrm{e}+006.33704 \mathrm{e}+00$ 6.33704e-01 1.00000e-09 2.12000e-01 $6.33704 \mathrm{e}+006.33704 \mathrm{e}+006.33704 \mathrm{e}-01$ 1.00000e-09 2.12000e-01 $6.33704 \mathrm{e}+006.33704 \mathrm{e}+006.33704 \mathrm{e}-01$ 1.00000e-09 2.12000e-01 $1.00000 \mathrm{e}-05$ 1.00000e-05 1.00000e-06 1.00000e-09 1.00000e-01 $1.00000 \mathrm{e}+001.00000 \mathrm{e}+001.00000 \mathrm{e}-011.00000 \mathrm{e}-091.00000 \mathrm{e}-01$ Element: 12083 \# of layers: 5

$\mathrm{Kx} \mathrm{Ky} \mathrm{Kz}$ Ss Por

6.33704e+00 6.33704e+00 6.33704e-01 1.00000e-09 2.12000e-01 $6.33704 \mathrm{e}+006.33704 \mathrm{e}+00$ 6.33704e-01 1.00000e-09 2.12000e-01 $6.33704 \mathrm{e}+006.33704 \mathrm{e}+006.33704 \mathrm{e}-01$ 1.00000e-09 2.12000e-01 $1.00000 \mathrm{e}-05$ 1.00000e-05 1.00000e-06 1.00000e-09 1.00000e-01 $1.00000 \mathrm{e}+001.00000 \mathrm{e}+001.00000 \mathrm{e}-011.00000 \mathrm{e}-091.00000 \mathrm{e}-01$ Element: 12084 \# of layers: 5

$\mathrm{Kx} \mathrm{Ky} \mathrm{Kz}$ Ss Por

6.33704e+00 6.33704e+00 6.33704e-01 1.00000e-09 2.12000e-01 6.33704e+00 6.33704e+00 6.33704e-01 1.00000e-09 2.12000e-01 6.33704e+00 6.33704e+00 6.33704e-01 1.00000e-09 2.12000e-01 $1.00000 \mathrm{e}-05$ 1.00000e-05 1.00000e-06 1.00000e-09 1.00000e-01 $1.00000 \mathrm{e}+001.00000 \mathrm{e}+001.00000 \mathrm{e}-011.00000 \mathrm{e}-091.00000 \mathrm{e}-01$ Element: 12085 \# of layers: 5

$\mathrm{Kx} \mathrm{Ky} \mathrm{Kz}$ Ss Por

6.33704e+00 6.33704e+00 6.33704e-01 1.00000e-09 2.12000e-01 $6.33704 \mathrm{e}+006.33704 \mathrm{e}+00$ 6.33704e-01 1.00000e-09 2.12000e-01 6.33704e+00 6.33704e+00 6.33704e-01 1.00000e-09 2.12000e-01 $1.00000 \mathrm{e}-05$ 1.00000e-05 1.00000e-06 1.00000e-09 1.00000e-01 $1.00000 \mathrm{e}+001.00000 \mathrm{e}+001.00000 \mathrm{e}-01$ 1.00000e-09 1.00000e-01 Element: 12086 \# of layers: 5

$\mathrm{Kx} \mathrm{Ky} \mathrm{Kz}$ Ss Por

5.06373e+00 5.06373e+00 5.06373e-01 1.00000e-09 2.12000e-01 5.06373e+00 5.06373e+00 5.06373e-01 1.00000e-09 2.12000e-01 5.06373e+00 5.06373e+00 5.06373e-01 1.00000e-09 2.12000e-01 $1.00000 \mathrm{e}-05$ 1.00000e-05 1.00000e-06 1.00000e-09 1.00000e-01 $1.00000 \mathrm{e}+001.00000 \mathrm{e}+001.00000 \mathrm{e}-011.00000 \mathrm{e}-091.00000 \mathrm{e}-01$ Element: 12087 \# of layers: 5

$\mathrm{Kx} \mathrm{Ky} \mathrm{Kz}$ Ss Por 5.06373e+00 5.06373e+00 5.06373e-01 1.00000e-09 2.12000e-01 5.06373e+00 5.06373e+00 5.06373e-01 1.00000e-09 2.12000e-01 5.06373e+00 5.06373e+00 5.06373e-01 1.00000e-09 2.12000e-01 $1.00000 \mathrm{e}-05$ 1.00000e-05 1.00000e-06 1.00000e-09 1.00000e-01 $1.00000 \mathrm{e}+001.00000 \mathrm{e}+001.00000 \mathrm{e}-011.00000 \mathrm{e}-091.00000 \mathrm{e}-01$ 
Element: 12088 \# of layers: 5

Kx Ky Kz Ss Por

$6.33704 \mathrm{e}+006.33704 \mathrm{e}+00$ 6.33704e-01 1.00000e-09 2.12000e-01

$6.33704 \mathrm{e}+006.33704 \mathrm{e}+006.33704 \mathrm{e}-011.00000 \mathrm{e}-092.12000 \mathrm{e}-01$

$6.33704 \mathrm{e}+006.33704 \mathrm{e}+006.33704 \mathrm{e}-011.00000 \mathrm{e}-092.12000 \mathrm{e}-01$

$1.00000 \mathrm{e}-05$ 1.00000e-05 1.00000e-06 1.00000e-09 1.00000e-01

$1.00000 \mathrm{e}+001.00000 \mathrm{e}+001.00000 \mathrm{e}-011.00000 \mathrm{e}-091.00000 \mathrm{e}-01$

Element: 12089 \# of layers: 6

$\mathrm{Kx} \mathrm{Ky} \mathrm{Kz}$ Ss Por

$6.33704 \mathrm{e}+006.33704 \mathrm{e}+00$ 6.33704e-01 1.00000e-09 2.12000e-01

$6.33704 \mathrm{e}+006.33704 \mathrm{e}+006.33704 \mathrm{e}-011.00000 \mathrm{e}-092.12000 \mathrm{e}-01$

$6.33704 \mathrm{e}+006.33704 \mathrm{e}+006.33704 \mathrm{e}-011.00000 \mathrm{e}-092.12000 \mathrm{e}-01$

$6.33704 \mathrm{e}+006.33704 \mathrm{e}+006.33704 \mathrm{e}-011.00000 \mathrm{e}-092.12000 \mathrm{e}-01$

$1.00000 \mathrm{e}-05$ 1.00000e-05 1.00000e-06 1.00000e-09 1.00000e-01

$1.00000 \mathrm{e}+001.00000 \mathrm{e}+001.00000 \mathrm{e}-011.00000 \mathrm{e}-091.00000 \mathrm{e}-01$

Element: 12090 \# of layers: 6

Kx Ky Kz Ss Por

6.33704e+00 6.33704e+00 6.33704e-01 1.00000e-09 2.12000e-01

$6.33704 \mathrm{e}+006.33704 \mathrm{e}+006.33704 \mathrm{e}-011.00000 \mathrm{e}-092.12000 \mathrm{e}-01$

$6.33704 \mathrm{e}+006.33704 \mathrm{e}+006.33704 \mathrm{e}-011.00000 \mathrm{e}-092.12000 \mathrm{e}-01$

$6.33704 \mathrm{e}+006.33704 \mathrm{e}+006.33704 \mathrm{e}-01$ 1.00000e-09 2.12000e-01

$1.00000 \mathrm{e}-05$ 1.00000e-05 1.00000e-06 1.00000e-09 1.00000e-01

$1.00000 \mathrm{e}+001.00000 \mathrm{e}+001.00000 \mathrm{e}-011.00000 \mathrm{e}-091.00000 \mathrm{e}-01$

Element: 12091 \# of layers: 6

Kx Ky Kz Ss Por

$6.33704 \mathrm{e}+006.33704 \mathrm{e}+00$ 6.33704e-01 1.00000e-09 2.12000e-01

$6.33704 \mathrm{e}+006.33704 \mathrm{e}+006.33704 \mathrm{e}-011.00000 \mathrm{e}-092.12000 \mathrm{e}-01$

$6.33704 \mathrm{e}+006.33704 \mathrm{e}+006.33704 \mathrm{e}-011.00000 \mathrm{e}-092.12000 \mathrm{e}-01$

$6.33704 \mathrm{e}+006.33704 \mathrm{e}+006.33704 \mathrm{e}-011.00000 \mathrm{e}-092.12000 \mathrm{e}-01$

$1.00000 \mathrm{e}-05$ 1.00000e-05 1.00000e-06 1.00000e-09 1.00000e-01

$1.00000 \mathrm{e}+001.00000 \mathrm{e}+001.00000 \mathrm{e}-011.00000 \mathrm{e}-091.00000 \mathrm{e}-01$

Element: 12092 \# of layers: 5

Kx Ky Kz Ss Por

$6.33704 \mathrm{e}+006.33704 \mathrm{e}+00$ 6.33704e-01 1.00000e-09 2.12000e-01

$6.33704 \mathrm{e}+006.33704 \mathrm{e}+006.33704 \mathrm{e}-011.00000 \mathrm{e}-092.12000 \mathrm{e}-01$

$6.33704 \mathrm{e}+006.33704 \mathrm{e}+006.33704 \mathrm{e}-01$ 1.00000e-09 2.12000e-01

$1.00000 \mathrm{e}-05$ 1.00000e-05 1.00000e-06 1.00000e-09 1.00000e-01

$1.00000 \mathrm{e}+001.00000 \mathrm{e}+001.00000 \mathrm{e}-011.00000 \mathrm{e}-091.00000 \mathrm{e}-01$

Element: 12093 \# of layers: 5

Kx Ky Kz Ss Por

$6.33704 \mathrm{e}+006.33704 \mathrm{e}+006.33704 \mathrm{e}-011.00000 \mathrm{e}-092.12000 \mathrm{e}-01$

$6.33704 \mathrm{e}+006.33704 \mathrm{e}+006.33704 \mathrm{e}-011.00000 \mathrm{e}-09$ 2.12000e-01

$6.33704 \mathrm{e}+006.33704 \mathrm{e}+006.33704 \mathrm{e}-011.00000 \mathrm{e}-09$ 2.12000e-01

$1.00000 \mathrm{e}-05$ 1.00000e-05 1.00000e-06 1.00000e-09 1.00000e-01

$1.00000 \mathrm{e}+001.00000 \mathrm{e}+001.00000 \mathrm{e}-011.00000 \mathrm{e}-091.00000 \mathrm{e}-01$

Element: 12094 \# of layers: 5 
$\mathrm{Kx} \mathrm{Ky} \mathrm{Kz}$ Ss Por

6.33704e+00 6.33704e+00 6.33704e-01 1.00000e-09 2.12000e-01

$6.33704 \mathrm{e}+006.33704 \mathrm{e}+006.33704 \mathrm{e}-01$ 1.00000e-09 2.12000e-01

$6.33704 \mathrm{e}+006.33704 \mathrm{e}+006.33704 \mathrm{e}-01$ 1.00000e-09 2.12000e-01

$1.00000 \mathrm{e}-05$ 1.00000e-05 1.00000e-06 1.00000e-09 1.00000e-01

$1.00000 \mathrm{e}+001.00000 \mathrm{e}+001.00000 \mathrm{e}-011.00000 \mathrm{e}-09$ 1.00000e-01

Element: 12095 \# of layers: 5

Kx Ky Kz Ss Por

6.33704e+00 6.33704e+00 6.33704e-01 1.00000e-09 2.12000e-01

$6.33704 \mathrm{e}+006.33704 \mathrm{e}+00$ 6.33704e-01 1.00000e-09 2.12000e-01

$6.33704 \mathrm{e}+006.33704 \mathrm{e}+006.33704 \mathrm{e}-01$ 1.00000e-09 2.12000e-01

$1.00000 \mathrm{e}-05$ 1.00000e-05 1.00000e-06 1.00000e-09 1.00000e-01

$1.00000 \mathrm{e}+001.00000 \mathrm{e}+00$ 1.00000e-01 1.00000e-09 1.00000e-01

Element: 12096 \# of layers: 5

$\mathrm{Kx} \mathrm{Ky} \mathrm{Kz}$ Ss Por

6.33704e+00 6.33704e+00 6.33704e-01 1.00000e-09 2.12000e-01

$6.33704 \mathrm{e}+006.33704 \mathrm{e}+00$ 6.33704e-01 1.00000e-09 2.12000e-01

$6.33704 \mathrm{e}+006.33704 \mathrm{e}+006.33704 \mathrm{e}-01$ 1.00000e-09 2.12000e-01

$1.00000 \mathrm{e}-051.00000 \mathrm{e}-05$ 1.00000e-06 1.00000e-09 1.00000e-01

$1.00000 \mathrm{e}+001.00000 \mathrm{e}+001.00000 \mathrm{e}-01$ 1.00000e-09 1.00000e-01

Element: 12097 \# of layers: 5

$\mathrm{Kx} \mathrm{Ky} \mathrm{Kz}$ Ss Por

6.33704e+00 6.33704e+00 6.33704e-01 1.00000e-09 2.12000e-01

$6.33704 \mathrm{e}+006.33704 \mathrm{e}+00$ 6.33704e-01 1.00000e-09 2.12000e-01

6.33704e+00 6.33704e+00 6.33704e-01 1.00000e-09 2.12000e-01

$1.00000 \mathrm{e}-05$ 1.00000e-05 1.00000e-06 1.00000e-09 1.00000e-01

$1.00000 \mathrm{e}+001.00000 \mathrm{e}+001.00000 \mathrm{e}-011.00000 \mathrm{e}-091.00000 \mathrm{e}-01$

Element: 12098 \# of layers: 5

$\mathrm{Kx} \mathrm{Ky} \mathrm{Kz}$ Ss Por

6.33704e+00 6.33704e+00 6.33704e-01 1.00000e-09 2.12000e-01

$6.33704 \mathrm{e}+006.33704 \mathrm{e}+00$ 6.33704e-01 1.00000e-09 2.12000e-01

$6.33704 \mathrm{e}+006.33704 \mathrm{e}+006.33704 \mathrm{e}-01$ 1.00000e-09 2.12000e-01

$1.00000 \mathrm{e}-05$ 1.00000e-05 1.00000e-06 1.00000e-09 1.00000e-01

$1.00000 \mathrm{e}+001.00000 \mathrm{e}+00$ 1.00000e-01 1.00000e-09 1.00000e-01

Element: 12099 \# of layers: 5

$\mathrm{Kx} \mathrm{Ky} \mathrm{Kz}$ Ss Por

6.33704e+00 6.33704e+00 6.33704e-01 1.00000e-09 2.12000e-01

6.33704e+00 6.33704e+00 6.33704e-01 1.00000e-09 2.12000e-01

$6.33704 \mathrm{e}+006.33704 \mathrm{e}+006.33704 \mathrm{e}-01$ 1.00000e-09 2.12000e-01

$1.00000 \mathrm{e}-05$ 1.00000e-05 1.00000e-06 1.00000e-09 1.00000e-01

$1.00000 \mathrm{e}+001.00000 \mathrm{e}+001.00000 \mathrm{e}-011.00000 \mathrm{e}-091.00000 \mathrm{e}-01$

Element: 12100 \# of layers: 5

$\mathrm{Kx} \mathrm{Ky} \mathrm{Kz}$ Ss Por

6.62617e+00 6.62617e+00 6.62617e-01 1.00000e-09 2.12000e-01

$6.62617 \mathrm{e}+00$ 6.62617e+00 6.62617e-01 1.00000e-09 2.12000e-01

$6.62617 \mathrm{e}+00$ 6.62617e+00 6.62617e-01 1.00000e-09 2.12000e-01 
$1.00000 \mathrm{e}-05$ 1.00000e-05 1.00000e-06 1.00000e-09 1.00000e-01 $1.00000 \mathrm{e}+001.00000 \mathrm{e}+001.00000 \mathrm{e}-011.00000 \mathrm{e}-091.00000 \mathrm{e}-01$ Element: 12101 \# of layers: 5

Kx Ky Kz Ss Por

6.62617e+00 6.62617e+00 6.62617e-01 1.00000e-09 2.12000e-01 $6.62617 \mathrm{e}+006.62617 \mathrm{e}+00$ 6.62617e-01 1.00000e-09 2.12000e-01 $6.62617 \mathrm{e}+006.62617 \mathrm{e}+00$ 6.62617e-01 1.00000e-09 2.12000e-01 $1.00000 \mathrm{e}-05$ 1.00000e-05 1.00000e-06 1.00000e-09 1.00000e-01 $1.00000 \mathrm{e}+001.00000 \mathrm{e}+001.00000 \mathrm{e}-011.00000 \mathrm{e}-091.00000 \mathrm{e}-01$ Element: 12102 \# of layers: 5

$\mathrm{Kx} \mathrm{Ky} \mathrm{Kz}$ Ss Por

6.62617e+00 6.62617e+00 6.62617e-01 1.00000e-09 2.12000e-01 6.62617e+00 6.62617e+00 6.62617e-01 1.00000e-09 2.12000e-01 6.62617e+00 6.62617e+00 6.62617e-01 1.00000e-09 2.12000e-01 $1.00000 \mathrm{e}-05$ 1.00000e-05 1.00000e-06 1.00000e-09 1.00000e-01 $1.00000 \mathrm{e}+001.00000 \mathrm{e}+001.00000 \mathrm{e}-011.00000 \mathrm{e}-091.00000 \mathrm{e}-01$ Element: 12103 \# of layers: 5

$\mathrm{Kx} \mathrm{Ky} \mathrm{Kz}$ Ss Por

6.33704e+00 6.33704e+00 6.33704e-01 1.00000e-09 2.12000e-01 $6.33704 \mathrm{e}+006.33704 \mathrm{e}+00$ 6.33704e-01 1.00000e-09 2.12000e-01 $6.33704 \mathrm{e}+00 \quad 6.33704 \mathrm{e}+00 \quad 6.33704 \mathrm{e}-01$ 1.00000e-09 2.12000e-01 $1.00000 \mathrm{e}-051.00000 \mathrm{e}-05$ 1.00000e-06 1.00000e-09 1.00000e-01 $1.00000 \mathrm{e}+001.00000 \mathrm{e}+001.00000 \mathrm{e}-01$ 1.00000e-09 1.00000e-01 Element: 12104 \# of layers: 5

Kx Ky Kz Ss Por

6.33704e+00 6.33704e+00 6.33704e-01 1.00000e-09 2.12000e-01 $6.33704 \mathrm{e}+006.33704 \mathrm{e}+00$ 6.33704e-01 1.00000e-09 2.12000e-01 $6.33704 \mathrm{e}+006.33704 \mathrm{e}+006.33704 \mathrm{e}-01$ 1.00000e-09 2.12000e-01 $1.00000 \mathrm{e}-05$ 1.00000e-05 1.00000e-06 1.00000e-09 1.00000e-01 $1.00000 \mathrm{e}+001.00000 \mathrm{e}+001.00000 \mathrm{e}-011.00000 \mathrm{e}-091.00000 \mathrm{e}-01$ Element: 12105 \# of layers: 5

$\mathrm{Kx} \mathrm{Ky} \mathrm{Kz}$ Ss Por

6.33704e+00 6.33704e+00 6.33704e-01 1.00000e-09 2.12000e-01 6.33704e+00 6.33704e+00 6.33704e-01 1.00000e-09 2.12000e-01 $6.33704 \mathrm{e}+006.33704 \mathrm{e}+006.33704 \mathrm{e}-01$ 1.00000e-09 2.12000e-01 1.00000e-05 1.00000e-05 1.00000e-06 1.00000e-09 1.00000e-01 $1.00000 \mathrm{e}+001.00000 \mathrm{e}+001.00000 \mathrm{e}-011.00000 \mathrm{e}-091.00000 \mathrm{e}-01$ Element: 12106 \# of layers: 5

$\mathrm{Kx} \mathrm{Ky} \mathrm{Kz}$ Ss Por

6.33704e+00 6.33704e+00 6.33704e-01 1.00000e-09 2.12000e-01 $6.33704 \mathrm{e}+006.33704 \mathrm{e}+00$ 6.33704e-01 1.00000e-09 2.12000e-01 $6.33704 \mathrm{e}+006.33704 \mathrm{e}+00$ 6.33704e-01 1.00000e-09 2.12000e-01 $1.00000 \mathrm{e}-05$ 1.00000e-05 1.00000e-06 1.00000e-09 1.00000e-01 $1.00000 \mathrm{e}+001.00000 \mathrm{e}+001.00000 \mathrm{e}-01$ 1.00000e-09 1.00000e-01 Element: 12107 \# of layers: 5

Kx Ky Kz Ss Por 
$6.62617 \mathrm{e}+006.62617 \mathrm{e}+00$ 6.62617e-01 1.00000e-09 2.12000e-01 $6.62617 \mathrm{e}+006.62617 \mathrm{e}+006.62617 \mathrm{e}-011.00000 \mathrm{e}-092.12000 \mathrm{e}-01$ $6.62617 \mathrm{e}+006.62617 \mathrm{e}+00$ 6.62617e-01 1.00000e-09 2.12000e-01 $1.00000 \mathrm{e}-05$ 1.00000e-05 1.00000e-06 1.00000e-09 1.00000e-01 $1.00000 \mathrm{e}+001.00000 \mathrm{e}+001.00000 \mathrm{e}-011.00000 \mathrm{e}-091.00000 \mathrm{e}-01$ Element: 12108 \# of layers: 5

Kx Ky Kz Ss Por

$6.62617 \mathrm{e}+006.62617 \mathrm{e}+00$ 6.62617e-01 1.00000e-09 2.12000e-01 $6.62617 \mathrm{e}+006.62617 \mathrm{e}+006.62617 \mathrm{e}-011.00000 \mathrm{e}-092.12000 \mathrm{e}-01$ $6.62617 \mathrm{e}+006.62617 \mathrm{e}+006.62617 \mathrm{e}-011.00000 \mathrm{e}-09$ 2.12000e-01 $1.00000 \mathrm{e}-05$ 1.00000e-05 1.00000e-06 1.00000e-09 1.00000e-01 $1.00000 \mathrm{e}+001.00000 \mathrm{e}+001.00000 \mathrm{e}-011.00000 \mathrm{e}-091.00000 \mathrm{e}-01$ Element: 12109 \# of layers: 4

Kx Ky Kz Ss Por

6.62617e+00 6.62617e+00 6.62617e-01 1.00000e-09 2.12000e-01 $6.62617 \mathrm{e}+006.62617 \mathrm{e}+006.62617 \mathrm{e}-011.00000 \mathrm{e}-092.12000 \mathrm{e}-01$ $1.00000 \mathrm{e}-05$ 1.00000e-05 1.00000e-06 1.00000e-09 1.00000e-01 $1.00000 \mathrm{e}+001.00000 \mathrm{e}+001.00000 \mathrm{e}-011.00000 \mathrm{e}-091.00000 \mathrm{e}-01$ Element: 12110 \# of layers: 5

Kx Ky Kz Ss Por

$6.62617 \mathrm{e}+00$ 6.62617e+00 6.62617e-01 1.00000e-09 2.12000e-01 $6.62617 \mathrm{e}+006.62617 \mathrm{e}+006.62617 \mathrm{e}-011.00000 \mathrm{e}-092.12000 \mathrm{e}-01$ $6.62617 \mathrm{e}+006.62617 \mathrm{e}+00$ 6.62617e-01 1.00000e-09 2.12000e-01 $1.00000 \mathrm{e}-05$ 1.00000e-05 1.00000e-06 1.00000e-09 1.00000e-01 $1.00000 \mathrm{e}+001.00000 \mathrm{e}+001.00000 \mathrm{e}-011.00000 \mathrm{e}-091.00000 \mathrm{e}-01$ Element: 12111 \# of layers: 5

Kx Ky Kz Ss Por

$6.62617 \mathrm{e}+006.62617 \mathrm{e}+00$ 6.62617e-01 1.00000e-09 2.12000e-01 $6.62617 \mathrm{e}+006.62617 \mathrm{e}+00$ 6.62617e-01 1.00000e-09 2.12000e-01 $6.62617 \mathrm{e}+006.62617 \mathrm{e}+00$ 6.62617e-01 1.00000e-09 2.12000e-01 $1.00000 \mathrm{e}-05$ 1.00000e-05 1.00000e-06 1.00000e-09 1.00000e-01 $1.00000 \mathrm{e}+001.00000 \mathrm{e}+001.00000 \mathrm{e}-011.00000 \mathrm{e}-091.00000 \mathrm{e}-01$ Element: 12112 \# of layers: 5

Kx Ky Kz Ss Por $6.62617 \mathrm{e}+00$ 6.62617e+00 6.62617e-01 1.00000e-09 2.12000e-01 $6.62617 \mathrm{e}+006.62617 \mathrm{e}+006.62617 \mathrm{e}-011.00000 \mathrm{e}-092.12000 \mathrm{e}-01$ $6.62617 \mathrm{e}+006.62617 \mathrm{e}+006.62617 \mathrm{e}-01$ 1.00000e-09 2.12000e-01 $1.00000 \mathrm{e}-05$ 1.00000e-05 1.00000e-06 1.00000e-09 1.00000e-01 $1.00000 \mathrm{e}+001.00000 \mathrm{e}+001.00000 \mathrm{e}-011.00000 \mathrm{e}-091.00000 \mathrm{e}-01$ Element: 12113 \# of layers: 5

Kx Ky Kz Ss Por $6.62617 \mathrm{e}+006.62617 \mathrm{e}+00$ 6.62617e-01 1.00000e-09 2.12000e-01 $6.62617 \mathrm{e}+006.62617 \mathrm{e}+006.62617 \mathrm{e}-011.00000 \mathrm{e}-092.12000 \mathrm{e}-01$ $6.62617 \mathrm{e}+006.62617 \mathrm{e}+00$ 6.62617e-01 1.00000e-09 2.12000e-01 $1.00000 \mathrm{e}-051.00000 \mathrm{e}-051.00000 \mathrm{e}-061.00000 \mathrm{e}-091.00000 \mathrm{e}-01$ $1.00000 \mathrm{e}+001.00000 \mathrm{e}+001.00000 \mathrm{e}-011.00000 \mathrm{e}-091.00000 \mathrm{e}-01$ 
Element: 12114 \# of layers: 5

Kx Ky Kz Ss Por

6.62617e+00 6.62617e+00 6.62617e-01 1.00000e-09 2.12000e-01

$6.62617 \mathrm{e}+006.62617 \mathrm{e}+00$ 6.62617e-01 1.00000e-09 2.12000e-01

$6.62617 \mathrm{e}+006.62617 \mathrm{e}+006.62617 \mathrm{e}-011.00000 \mathrm{e}-092.12000 \mathrm{e}-01$

$1.00000 \mathrm{e}-05$ 1.00000e-05 1.00000e-06 1.00000e-09 1.00000e-01

$1.00000 \mathrm{e}+001.00000 \mathrm{e}+001.00000 \mathrm{e}-011.00000 \mathrm{e}-091.00000 \mathrm{e}-01$

Element: 12115 \# of layers: 5

Kx Ky Kz Ss Por

$6.62617 \mathrm{e}+006.62617 \mathrm{e}+00$ 6.62617e-01 1.00000e-09 2.12000e-01

$6.62617 \mathrm{e}+006.62617 \mathrm{e}+006.62617 \mathrm{e}-011.00000 \mathrm{e}-092.12000 \mathrm{e}-01$

$6.62617 \mathrm{e}+006.62617 \mathrm{e}+006.62617 \mathrm{e}-011.00000 \mathrm{e}-092.12000 \mathrm{e}-01$

$1.00000 \mathrm{e}-05$ 1.00000e-05 1.00000e-06 1.00000e-09 1.00000e-01

$1.00000 \mathrm{e}+001.00000 \mathrm{e}+001.00000 \mathrm{e}-011.00000 \mathrm{e}-091.00000 \mathrm{e}-01$

Element: 12116 \# of layers: 5

Kx Ky Kz Ss Por

$6.62617 \mathrm{e}+006.62617 \mathrm{e}+00$ 6.62617e-01 1.00000e-09 2.12000e-01

$6.62617 \mathrm{e}+006.62617 \mathrm{e}+006.62617 \mathrm{e}-011.00000 \mathrm{e}-092.12000 \mathrm{e}-01$

$6.62617 \mathrm{e}+006.62617 \mathrm{e}+006.62617 \mathrm{e}-011.00000 \mathrm{e}-092.12000 \mathrm{e}-01$

$1.00000 \mathrm{e}-05$ 1.00000e-05 1.00000e-06 1.00000e-09 1.00000e-01

$1.00000 \mathrm{e}+001.00000 \mathrm{e}+001.00000 \mathrm{e}-011.00000 \mathrm{e}-091.00000 \mathrm{e}-01$

Element: 12117 \# of layers: 5

Kx Ky Kz Ss Por

$6.62617 \mathrm{e}+00$ 6.62617e+00 6.62617e-01 1.00000e-09 2.12000e-01

$6.62617 \mathrm{e}+006.62617 \mathrm{e}+00$ 6.62617e-01 1.00000e-09 2.12000e-01

$6.62617 \mathrm{e}+006.62617 \mathrm{e}+00$ 6.62617e-01 1.00000e-09 2.12000e-01

$1.00000 \mathrm{e}-05$ 1.00000e-05 1.00000e-06 1.00000e-09 1.00000e-01

$1.00000 \mathrm{e}+001.00000 \mathrm{e}+001.00000 \mathrm{e}-011.00000 \mathrm{e}-091.00000 \mathrm{e}-01$

Element: 12118 \# of layers: 5

Kx Ky Kz Ss Por

4.88913e+00 4.88913e+00 4.88913e-01 1.00000e-09 2.12000e-01

$4.88913 \mathrm{e}+004.88913 \mathrm{e}+004.88913 \mathrm{e}-01$ 1.00000e-09 2.12000e-01

$4.88913 \mathrm{e}+004.88913 \mathrm{e}+00$ 4.88913e-01 1.00000e-09 2.12000e-01

$1.00000 \mathrm{e}-05$ 1.00000e-05 1.00000e-06 1.00000e-09 1.00000e-01

$1.00000 \mathrm{e}+001.00000 \mathrm{e}+001.00000 \mathrm{e}-011.00000 \mathrm{e}-091.00000 \mathrm{e}-01$

Element: 12119 \# of layers: 5

Kx Ky Kz Ss Por

4.88913e+00 4.88913e+00 4.88913e-01 1.00000e-09 2.12000e-01

$4.88913 \mathrm{e}+004.88913 \mathrm{e}+00$ 4.88913e-01 1.00000e-09 2.12000e-01

$4.88913 \mathrm{e}+00$ 4.88913e+00 4.88913e-01 1.00000e-09 2.12000e-01

$1.00000 \mathrm{e}-05$ 1.00000e-05 1.00000e-06 1.00000e-09 1.00000e-01

$1.00000 \mathrm{e}+001.00000 \mathrm{e}+001.00000 \mathrm{e}-011.00000 \mathrm{e}-091.00000 \mathrm{e}-01$

Element: 12120 \# of layers: 5

Kx Ky Kz Ss Por

4.88913e+00 4.88913e+00 4.88913e-01 1.00000e-09 2.12000e-01

$4.88913 \mathrm{e}+004.88913 \mathrm{e}+004.88913 \mathrm{e}-01$ 1.00000e-09 2.12000e-01 
4.88913e+00 4.88913e+00 4.88913e-01 1.00000e-09 2.12000e-01 $1.00000 \mathrm{e}-05$ 1.00000e-05 1.00000e-06 1.00000e-09 1.00000e-01 $1.00000 \mathrm{e}+001.00000 \mathrm{e}+00$ 1.00000e-01 1.00000e-09 1.00000e-01 Element: 12121 \# of layers: 5

$\mathrm{Kx} \mathrm{Ky} \mathrm{Kz}$ Ss Por

6.62617e+00 6.62617e+00 6.62617e-01 1.00000e-09 2.12000e-01 $6.62617 \mathrm{e}+006.62617 \mathrm{e}+00$ 6.62617e-01 1.00000e-09 2.12000e-01 $6.62617 \mathrm{e}+006.62617 \mathrm{e}+006.62617 \mathrm{e}-01$ 1.00000e-09 2.12000e-01 $1.00000 \mathrm{e}-05$ 1.00000e-05 1.00000e-06 1.00000e-09 1.00000e-01 $1.00000 \mathrm{e}+001.00000 \mathrm{e}+00$ 1.00000e-01 1.00000e-09 1.00000e-01 Element: 12122 \# of layers: 5

$\mathrm{Kx} \mathrm{Ky} \mathrm{Kz}$ Ss Por

6.62617e+00 6.62617e+00 6.62617e-01 1.00000e-09 2.12000e-01 6.62617e+00 6.62617e+00 6.62617e-01 1.00000e-09 2.12000e-01 6.62617e+00 6.62617e+00 6.62617e-01 1.00000e-09 2.12000e-01 $1.00000 \mathrm{e}-05$ 1.00000e-05 1.00000e-06 1.00000e-09 1.00000e-01 $1.00000 \mathrm{e}+001.00000 \mathrm{e}+001.00000 \mathrm{e}-011.00000 \mathrm{e}-091.00000 \mathrm{e}-01$ Element: 12123 \# of layers: 5

$\mathrm{Kx} \mathrm{Ky} \mathrm{Kz}$ Ss Por

6.62617e+00 6.62617e+00 6.62617e-01 1.00000e-09 2.12000e-01 $6.62617 \mathrm{e}+00$ 6.62617e+00 6.62617e-01 1.00000e-09 2.12000e-01 6.62617e+00 6.62617e+00 6.62617e-01 1.00000e-09 2.12000e-01 $1.00000 \mathrm{e}-05$ 1.00000e-05 1.00000e-06 1.00000e-09 1.00000e-01 $1.00000 \mathrm{e}+001.00000 \mathrm{e}+001.00000 \mathrm{e}-011.00000 \mathrm{e}-09$ 1.00000e-01 Element: 12124 \# of layers: 5

$\mathrm{Kx} \mathrm{Ky} \mathrm{Kz}$ Ss Por

6.62617e+00 6.62617e+00 6.62617e-01 1.00000e-09 2.12000e-01 6.62617e+00 6.62617e+00 6.62617e-01 1.00000e-09 2.12000e-01 $6.62617 \mathrm{e}+006.62617 \mathrm{e}+00$ 6.62617e-01 1.00000e-09 2.12000e-01 $1.00000 \mathrm{e}-05$ 1.00000e-05 1.00000e-06 1.00000e-09 1.00000e-01 $1.00000 \mathrm{e}+001.00000 \mathrm{e}+001.00000 \mathrm{e}-011.00000 \mathrm{e}-091.00000 \mathrm{e}-01$ Element: 12125 \# of layers: 5

Kx Ky Kz Ss Por

4.88913e+00 4.88913e+00 4.88913e-01 1.00000e-09 2.12000e-01 4.88913e+00 4.88913e+00 4.88913e-01 1.00000e-09 2.12000e-01 4.88913e+00 4.88913e+00 4.88913e-01 1.00000e-09 2.12000e-01 $1.00000 \mathrm{e}-05$ 1.00000e-05 1.00000e-06 1.00000e-09 1.00000e-01 $1.00000 \mathrm{e}+001.00000 \mathrm{e}+001.00000 \mathrm{e}-011.00000 \mathrm{e}-091.00000 \mathrm{e}-01$ Element: 12126 \# of layers: 5

$\mathrm{Kx} \mathrm{Ky} \mathrm{Kz}$ Ss Por 4.88913e+00 4.88913e+00 4.88913e-01 1.00000e-09 2.12000e-01 $4.88913 \mathrm{e}+00$ 4.88913e+00 4.88913e-01 1.00000e-09 2.12000e-01 $4.88913 \mathrm{e}+00$ 4.88913e+00 4.88913e-01 1.00000e-09 2.12000e-01 $1.00000 \mathrm{e}-05$ 1.00000e-05 1.00000e-06 1.00000e-09 1.00000e-01 $1.00000 \mathrm{e}+001.00000 \mathrm{e}+00$ 1.00000e-01 1.00000e-09 1.00000e-01 Element: 12127 \# of layers: 6 
Kx Ky Kz Ss Por

4.88913e+00 4.88913e+00 4.88913e-01 1.00000e-09 2.12000e-01

$4.88913 \mathrm{e}+004.88913 \mathrm{e}+00$ 4.88913e-01 1.00000e-09 2.12000e-01

$4.88913 \mathrm{e}+004.88913 \mathrm{e}+004.88913 \mathrm{e}-01$ 1.00000e-09 2.12000e-01

$4.88913 \mathrm{e}+004.88913 \mathrm{e}+00$ 4.88913e-01 1.00000e-09 2.12000e-01

$1.00000 \mathrm{e}-05$ 1.00000e-05 1.00000e-06 1.00000e-09 1.00000e-01

$1.00000 \mathrm{e}+001.00000 \mathrm{e}+001.00000 \mathrm{e}-011.00000 \mathrm{e}-091.00000 \mathrm{e}-01$

Element: 12128 \# of layers: 6

Kx Ky Kz Ss Por

4.88913e+00 4.88913e+00 4.88913e-01 1.00000e-09 2.12000e-01

$4.88913 \mathrm{e}+004.88913 \mathrm{e}+00$ 4.88913e-01 1.00000e-09 2.12000e-01

$4.88913 \mathrm{e}+004.88913 \mathrm{e}+00$ 4.88913e-01 1.00000e-09 2.12000e-01

$4.88913 \mathrm{e}+004.88913 \mathrm{e}+00$ 4.88913e-01 1.00000e-09 2.12000e-01

$1.00000 \mathrm{e}-05$ 1.00000e-05 1.00000e-06 1.00000e-09 1.00000e-01

$1.00000 \mathrm{e}+001.00000 \mathrm{e}+001.00000 \mathrm{e}-011.00000 \mathrm{e}-091.00000 \mathrm{e}-01$

Element: 12129 \# of layers: 6

Kx Ky Kz Ss Por

4.88913e+00 4.88913e+00 4.88913e-01 1.00000e-09 2.12000e-01

$4.88913 \mathrm{e}+004.88913 \mathrm{e}+00$ 4.88913e-01 1.00000e-09 2.12000e-01

$4.88913 \mathrm{e}+004.88913 \mathrm{e}+00$ 4.88913e-01 1.00000e-09 2.12000e-01

$4.88913 \mathrm{e}+004.88913 \mathrm{e}+004.88913 \mathrm{e}-011.00000 \mathrm{e}-09$ 2.12000e-01

$1.00000 \mathrm{e}-05$ 1.00000e-05 1.00000e-06 1.00000e-09 1.00000e-01

$1.00000 \mathrm{e}+001.00000 \mathrm{e}+001.00000 \mathrm{e}-011.00000 \mathrm{e}-091.00000 \mathrm{e}-01$

Element: 12130 \# of layers: 5

Kx Ky Kz Ss Por

4.88913e+00 4.88913e+00 4.88913e-01 1.00000e-09 2.12000e-01

$4.88913 \mathrm{e}+004.88913 \mathrm{e}+004.88913 \mathrm{e}-01$ 1.00000e-09 2.12000e-01

$4.88913 \mathrm{e}+004.88913 \mathrm{e}+004.88913 \mathrm{e}-01$ 1.00000e-09 2.12000e-01

$1.00000 \mathrm{e}-05$ 1.00000e-05 1.00000e-06 1.00000e-09 1.00000e-01

$1.00000 \mathrm{e}+001.00000 \mathrm{e}+001.00000 \mathrm{e}-011.00000 \mathrm{e}-091.00000 \mathrm{e}-01$

Element: 12131 \# of layers: 5

Kx Ky Kz Ss Por

4.88913e+00 4.88913e+00 4.88913e-01 1.00000e-09 2.12000e-01

$4.88913 \mathrm{e}+004.88913 \mathrm{e}+00$ 4.88913e-01 1.00000e-09 2.12000e-01

$4.88913 \mathrm{e}+004.88913 \mathrm{e}+00$ 4.88913e-01 1.00000e-09 2.12000e-01

$1.00000 \mathrm{e}-05$ 1.00000e-05 1.00000e-06 1.00000e-09 1.00000e-01

$1.00000 \mathrm{e}+001.00000 \mathrm{e}+001.00000 \mathrm{e}-011.00000 \mathrm{e}-091.00000 \mathrm{e}-01$

Element: 12132 \# of layers: 5

Kx Ky Kz Ss Por

4.88913e+00 4.88913e+00 4.88913e-01 1.00000e-09 2.12000e-01

$4.88913 \mathrm{e}+004.88913 \mathrm{e}+00$ 4.88913e-01 1.00000e-09 2.12000e-01

$4.88913 \mathrm{e}+004.88913 \mathrm{e}+00$ 4.88913e-01 1.00000e-09 2.12000e-01

$1.00000 \mathrm{e}-05$ 1.00000e-05 1.00000e-06 1.00000e-09 1.00000e-01

$1.00000 \mathrm{e}+001.00000 \mathrm{e}+001.00000 \mathrm{e}-011.00000 \mathrm{e}-091.00000 \mathrm{e}-01$

Element: 12133 \# of layers: 5

Kx Ky Kz Ss Por 
4.88913e+00 4.88913e+00 4.88913e-01 1.00000e-09 2.12000e-01 4.88913e+00 4.88913e+00 4.88913e-01 1.00000e-09 2.12000e-01 4.88913e+00 4.88913e+00 4.88913e-01 1.00000e-09 2.12000e-01 $1.00000 \mathrm{e}-05$ 1.00000e-05 1.00000e-06 1.00000e-09 1.00000e-01 $1.00000 \mathrm{e}+001.00000 \mathrm{e}+001.00000 \mathrm{e}-01$ 1.00000e-09 1.00000e-01 Element: 12134 \# of layers: 6

$\mathrm{Kx} \mathrm{Ky} \mathrm{Kz}$ Ss Por

4.88913e+00 4.88913e+00 4.88913e-01 1.00000e-09 2.12000e-01 4.88913e+00 4.88913e+00 4.88913e-01 1.00000e-09 2.12000e-01 4.88913e+00 4.88913e+00 4.88913e-01 1.00000e-09 2.12000e-01 4.88913e+00 4.88913e+00 4.88913e-01 1.00000e-09 2.12000e-01 $1.00000 \mathrm{e}-05$ 1.00000e-05 1.00000e-06 1.00000e-09 1.00000e-01 $1.00000 \mathrm{e}+001.00000 \mathrm{e}+00$ 1.00000e-01 1.00000e-09 1.00000e-01 Element: 12135 \# of layers: 6

$\mathrm{Kx} \mathrm{Ky} \mathrm{Kz}$ Ss Por

5.06373e+00 5.06373e+00 5.06373e-01 1.00000e-09 2.12000e-01 5.06373e+00 5.06373e+00 5.06373e-01 1.00000e-09 2.12000e-01 5.06373e+00 5.06373e+00 5.06373e-01 1.00000e-09 2.12000e-01 5.06373e+00 5.06373e+00 5.06373e-01 1.00000e-09 2.12000e-01 $1.00000 \mathrm{e}-05$ 1.00000e-05 1.00000e-06 1.00000e-09 1.00000e-01 $1.00000 \mathrm{e}+001.00000 \mathrm{e}+001.00000 \mathrm{e}-011.00000 \mathrm{e}-091.00000 \mathrm{e}-01$ Element: 12136 \# of layers: 6

$\mathrm{Kx} \mathrm{Ky} \mathrm{Kz}$ Ss Por

5.06373e+00 5.06373e+00 5.06373e-01 1.00000e-09 2.12000e-01 5.06373e+00 5.06373e+00 5.06373e-01 1.00000e-09 2.12000e-01 5.06373e+00 5.06373e+00 5.06373e-01 1.00000e-09 2.12000e-01 5.06373e+00 5.06373e+00 5.06373e-01 1.00000e-09 2.12000e-01 $1.00000 \mathrm{e}-05$ 1.00000e-05 1.00000e-06 1.00000e-09 1.00000e-01 $1.00000 \mathrm{e}+001.00000 \mathrm{e}+001.00000 \mathrm{e}-011.00000 \mathrm{e}-091.00000 \mathrm{e}-01$ Element: 12137 \# of layers: 5

$\mathrm{Kx} \mathrm{Ky} \mathrm{Kz}$ Ss Por

5.06373e+00 5.06373e+00 5.06373e-01 1.00000e-09 2.12000e-01 $5.06373 \mathrm{e}+00$ 5.06373e+00 5.06373e-01 1.00000e-09 2.12000e-01 5.06373e+00 5.06373e+00 5.06373e-01 1.00000e-09 2.12000e-01 $1.00000 \mathrm{e}-05$ 1.00000e-05 1.00000e-06 1.00000e-09 1.00000e-01 $1.00000 \mathrm{e}+001.00000 \mathrm{e}+001.00000 \mathrm{e}-011.00000 \mathrm{e}-091.00000 \mathrm{e}-01$ Element: 12138 \# of layers: 5

$\mathrm{Kx} \mathrm{Ky} \mathrm{Kz}$ Ss Por

5.06373e+00 5.06373e+00 5.06373e-01 1.00000e-09 2.12000e-01 5.06373e+00 5.06373e+00 5.06373e-01 1.00000e-09 2.12000e-01 5.06373e+00 5.06373e+00 5.06373e-01 1.00000e-09 2.12000e-01 $1.00000 \mathrm{e}-05$ 1.00000e-05 1.00000e-06 1.00000e-09 1.00000e-01 $1.00000 \mathrm{e}+001.00000 \mathrm{e}+001.00000 \mathrm{e}-01$ 1.00000e-09 1.00000e-01 Element: 12139 \# of layers: 5

$\mathrm{Kx} \mathrm{Ky} \mathrm{Kz}$ Ss Por 5.06373e+00 5.06373e+00 5.06373e-01 1.00000e-09 2.12000e-01 
5.06373e+00 5.06373e+00 5.06373e-01 1.00000e-09 2.12000e-01 $5.06373 \mathrm{e}+00$ 5.06373e+00 5.06373e-01 1.00000e-09 2.12000e-01 $1.00000 \mathrm{e}-05$ 1.00000e-05 1.00000e-06 1.00000e-09 1.00000e-01 $1.00000 \mathrm{e}+001.00000 \mathrm{e}+001.00000 \mathrm{e}-011.00000 \mathrm{e}-091.00000 \mathrm{e}-01$ Element: 12140 \# of layers: 5

Kx Ky Kz Ss Por

4.88913e+00 4.88913e+00 4.88913e-01 1.00000e-09 2.12000e-01 $4.88913 \mathrm{e}+004.88913 \mathrm{e}+00$ 4.88913e-01 1.00000e-09 2.12000e-01 $4.88913 \mathrm{e}+00$ 4.88913e+00 4.88913e-01 1.00000e-09 2.12000e-01 $1.00000 \mathrm{e}-05$ 1.00000e-05 1.00000e-06 1.00000e-09 1.00000e-01 $1.00000 \mathrm{e}+001.00000 \mathrm{e}+001.00000 \mathrm{e}-011.00000 \mathrm{e}-091.00000 \mathrm{e}-01$ Element: 12141 \# of layers: 5

Kx Ky Kz Ss Por

4.88913e+00 4.88913e+00 4.88913e-01 1.00000e-09 2.12000e-01 $4.88913 \mathrm{e}+004.88913 \mathrm{e}+00$ 4.88913e-01 1.00000e-09 2.12000e-01 $4.88913 \mathrm{e}+004.88913 \mathrm{e}+00$ 4.88913e-01 1.00000e-09 2.12000e-01 $1.00000 \mathrm{e}-05$ 1.00000e-05 1.00000e-06 1.00000e-09 1.00000e-01 $1.00000 \mathrm{e}+001.00000 \mathrm{e}+001.00000 \mathrm{e}-011.00000 \mathrm{e}-091.00000 \mathrm{e}-01$ Element: 12142 \# of layers: 5

Kx Ky Kz Ss Por

5.06373e+00 5.06373e+00 5.06373e-01 1.00000e-09 2.12000e-01 $5.06373 \mathrm{e}+00$ 5.06373e+00 5.06373e-01 1.00000e-09 2.12000e-01 $5.06373 \mathrm{e}+00$ 5.06373e+00 5.06373e-01 1.00000e-09 2.12000e-01 $1.00000 \mathrm{e}-05$ 1.00000e-05 1.00000e-06 1.00000e-09 1.00000e-01 $1.00000 \mathrm{e}+001.00000 \mathrm{e}+001.00000 \mathrm{e}-011.00000 \mathrm{e}-091.00000 \mathrm{e}-01$ Element: 12143 \# of layers: 5

Kx Ky Kz Ss Por

5.06373e+00 5.06373e+00 5.06373e-01 1.00000e-09 2.12000e-01 $5.06373 \mathrm{e}+005.06373 \mathrm{e}+00$ 5.06373e-01 1.00000e-09 2.12000e-01 5.06373e+00 5.06373e+00 5.06373e-01 1.00000e-09 2.12000e-01 $1.00000 \mathrm{e}-05$ 1.00000e-05 1.00000e-06 1.00000e-09 1.00000e-01 $1.00000 \mathrm{e}+001.00000 \mathrm{e}+001.00000 \mathrm{e}-011.00000 \mathrm{e}-091.00000 \mathrm{e}-01$ Element: 12144 \# of layers: 5

Kx Ky Kz Ss Por

$6.33704 \mathrm{e}+006.33704 \mathrm{e}+00$ 6.33704e-01 1.00000e-09 2.12000e-01 $6.33704 \mathrm{e}+006.33704 \mathrm{e}+00$ 6.33704e-01 1.00000e-09 2.12000e-01 $6.33704 \mathrm{e}+006.33704 \mathrm{e}+006.33704 \mathrm{e}-011.00000 \mathrm{e}-092.12000 \mathrm{e}-01$ $1.00000 \mathrm{e}-05$ 1.00000e-05 1.00000e-06 1.00000e-09 1.00000e-01 $1.00000 \mathrm{e}+001.00000 \mathrm{e}+001.00000 \mathrm{e}-011.00000 \mathrm{e}-091.00000 \mathrm{e}-01$ Element: 12145 \# of layers: 5

Kx Ky Kz Ss Por

$6.33704 \mathrm{e}+006.33704 \mathrm{e}+00$ 6.33704e-01 1.00000e-09 2.12000e-01 $6.33704 \mathrm{e}+006.33704 \mathrm{e}+006.33704 \mathrm{e}-011.00000 \mathrm{e}-092.12000 \mathrm{e}-01$ $6.33704 \mathrm{e}+006.33704 \mathrm{e}+006.33704 \mathrm{e}-01$ 1.00000e-09 2.12000e-01 $1.00000 \mathrm{e}-05$ 1.00000e-05 1.00000e-06 1.00000e-09 1.00000e-01 $1.00000 \mathrm{e}+001.00000 \mathrm{e}+001.00000 \mathrm{e}-011.00000 \mathrm{e}-091.00000 \mathrm{e}-01$ 
Element: 12146 \# of layers: 5

Kx Ky Kz Ss Por

$6.33704 \mathrm{e}+006.33704 \mathrm{e}+00$ 6.33704e-01 1.00000e-09 2.12000e-01

$6.33704 \mathrm{e}+006.33704 \mathrm{e}+006.33704 \mathrm{e}-011.00000 \mathrm{e}-09$ 2.12000e-01

$6.33704 \mathrm{e}+006.33704 \mathrm{e}+006.33704 \mathrm{e}-011.00000 \mathrm{e}-092.12000 \mathrm{e}-01$

$1.00000 \mathrm{e}-05$ 1.00000e-05 1.00000e-06 1.00000e-09 1.00000e-01

$1.00000 \mathrm{e}+001.00000 \mathrm{e}+001.00000 \mathrm{e}-011.00000 \mathrm{e}-091.00000 \mathrm{e}-01$

Element: 12147 \# of layers: 5

Kx Ky Kz Ss Por

$6.62617 \mathrm{e}+006.62617 \mathrm{e}+00$ 6.62617e-01 1.00000e-09 2.12000e-01

$6.62617 \mathrm{e}+006.62617 \mathrm{e}+006.62617 \mathrm{e}-011.00000 \mathrm{e}-092.12000 \mathrm{e}-01$

$6.62617 \mathrm{e}+006.62617 \mathrm{e}+006.62617 \mathrm{e}-011.00000 \mathrm{e}-092.12000 \mathrm{e}-01$

$1.00000 \mathrm{e}-05$ 1.00000e-05 1.00000e-06 1.00000e-09 1.00000e-01

$1.00000 \mathrm{e}+001.00000 \mathrm{e}+001.00000 \mathrm{e}-011.00000 \mathrm{e}-091.00000 \mathrm{e}-01$

Element: 12148 \# of layers: 5

Kx Ky Kz Ss Por

$6.62617 \mathrm{e}+006.62617 \mathrm{e}+00$ 6.62617e-01 1.00000e-09 2.12000e-01

$6.62617 \mathrm{e}+006.62617 \mathrm{e}+006.62617 \mathrm{e}-011.00000 \mathrm{e}-092.12000 \mathrm{e}-01$

$6.62617 \mathrm{e}+006.62617 \mathrm{e}+006.62617 \mathrm{e}-011.00000 \mathrm{e}-092.12000 \mathrm{e}-01$

$1.00000 \mathrm{e}-05$ 1.00000e-05 1.00000e-06 1.00000e-09 1.00000e-01

$1.00000 \mathrm{e}+001.00000 \mathrm{e}+001.00000 \mathrm{e}-011.00000 \mathrm{e}-091.00000 \mathrm{e}-01$

Element: 12149 \# of layers: 5

Kx Ky Kz Ss Por

4.88913e+00 4.88913e+00 4.88913e-01 1.00000e-09 2.12000e-01

$4.88913 \mathrm{e}+004.88913 \mathrm{e}+004.88913 \mathrm{e}-011.00000 \mathrm{e}-09$ 2.12000e-01

$4.88913 \mathrm{e}+004.88913 \mathrm{e}+00$ 4.88913e-01 1.00000e-09 2.12000e-01

$1.00000 \mathrm{e}-05$ 1.00000e-05 1.00000e-06 1.00000e-09 1.00000e-01

$1.00000 \mathrm{e}+001.00000 \mathrm{e}+001.00000 \mathrm{e}-011.00000 \mathrm{e}-091.00000 \mathrm{e}-01$

Element: 12150 \# of layers: 5

Kx Ky Kz Ss Por

5.06373e+00 5.06373e+00 5.06373e-01 1.00000e-09 2.12000e-01

$5.06373 \mathrm{e}+00$ 5.06373e+00 5.06373e-01 1.00000e-09 2.12000e-01

$5.06373 \mathrm{e}+00$ 5.06373e+00 5.06373e-01 1.00000e-09 2.12000e-01

$1.00000 \mathrm{e}-05$ 1.00000e-05 1.00000e-06 1.00000e-09 1.00000e-01

$1.00000 \mathrm{e}+001.00000 \mathrm{e}+001.00000 \mathrm{e}-011.00000 \mathrm{e}-091.00000 \mathrm{e}-01$

Element: 12151 \# of layers: 5

Kx Ky Kz Ss Por

$6.33704 \mathrm{e}+006.33704 \mathrm{e}+00$ 6.33704e-01 1.00000e-09 2.12000e-01

$6.33704 \mathrm{e}+006.33704 \mathrm{e}+006.33704 \mathrm{e}-011.00000 \mathrm{e}-092.12000 \mathrm{e}-01$

$6.33704 \mathrm{e}+006.33704 \mathrm{e}+006.33704 \mathrm{e}-011.00000 \mathrm{e}-092.12000 \mathrm{e}-01$

$1.00000 \mathrm{e}-05$ 1.00000e-05 1.00000e-06 1.00000e-09 1.00000e-01

$1.00000 \mathrm{e}+001.00000 \mathrm{e}+001.00000 \mathrm{e}-011.00000 \mathrm{e}-091.00000 \mathrm{e}-01$

Element: 12152 \# of layers: 6

Kx Ky Kz Ss Por

7.96202e+00 7.96202e+00 7.96202e-01 1.00000e-09 2.12000e-01

$7.96202 \mathrm{e}+007.96202 \mathrm{e}+00$ 7.96202e-01 1.00000e-09 2.12000e-01 
$7.96202 \mathrm{e}+00$ 7.96202e+00 7.96202e-01 1.00000e-09 2.12000e-01 $7.96202 \mathrm{e}+007.96202 \mathrm{e}+00$ 7.96202e-01 1.00000e-09 2.12000e-01 $1.00000 \mathrm{e}-05$ 1.00000e-05 1.00000e-06 1.00000e-09 1.00000e-01 $1.00000 \mathrm{e}+001.00000 \mathrm{e}+001.00000 \mathrm{e}-011.00000 \mathrm{e}-091.00000 \mathrm{e}-01$ Element: 12153 \# of layers: 6

Kx Ky Kz Ss Por

7.96202e+00 7.96202e+00 7.96202e-01 1.00000e-09 2.12000e-01

$7.96202 \mathrm{e}+007.96202 \mathrm{e}+007.96202 \mathrm{e}-011.00000 \mathrm{e}-092.12000 \mathrm{e}-01$

$7.96202 \mathrm{e}+007.96202 \mathrm{e}+00$ 7.96202e-01 1.00000e-09 2.12000e-01

$7.96202 \mathrm{e}+00$ 7.96202e+00 7.96202e-01 1.00000e-09 2.12000e-01

$1.00000 \mathrm{e}-05$ 1.00000e-05 1.00000e-06 1.00000e-09 1.00000e-01

$1.00000 \mathrm{e}+001.00000 \mathrm{e}+001.00000 \mathrm{e}-011.00000 \mathrm{e}-091.00000 \mathrm{e}-01$

Element: 12154 \# of layers: 4

Kx Ky Kz Ss Por

7.96202e+00 7.96202e+00 7.96202e-01 1.00000e-09 2.12000e-01

$7.96202 \mathrm{e}+00$ 7.96202e+00 7.96202e-01 1.00000e-09 2.12000e-01

$1.00000 \mathrm{e}-05$ 1.00000e-05 1.00000e-06 1.00000e-09 1.00000e-01

$1.00000 \mathrm{e}+001.00000 \mathrm{e}+001.00000 \mathrm{e}-011.00000 \mathrm{e}-091.00000 \mathrm{e}-01$

Element: 12155 \# of layers: 4

Kx Ky Kz Ss Por

$7.96202 \mathrm{e}+007.96202 \mathrm{e}+00$ 7.96202e-01 1.00000e-09 2.12000e-01

$7.96202 \mathrm{e}+007.96202 \mathrm{e}+00$ 7.96202e-01 1.00000e-09 2.12000e-01

$1.00000 \mathrm{e}-05$ 1.00000e-05 1.00000e-06 1.00000e-09 1.00000e-01

$1.00000 \mathrm{e}+001.00000 \mathrm{e}+001.00000 \mathrm{e}-011.00000 \mathrm{e}-091.00000 \mathrm{e}-01$

Element: 12156 \# of layers: 4

Kx Ky Kz Ss Por

7.96202e+00 7.96202e+00 7.96202e-01 1.00000e-09 2.12000e-01

$7.96202 \mathrm{e}+007.96202 \mathrm{e}+00$ 7.96202e-01 1.00000e-09 2.12000e-01

$1.00000 \mathrm{e}-05$ 1.00000e-05 1.00000e-06 1.00000e-09 1.00000e-01

$1.00000 \mathrm{e}+001.00000 \mathrm{e}+001.00000 \mathrm{e}-011.00000 \mathrm{e}-091.00000 \mathrm{e}-01$

Element: 12157 \# of layers: 4

Kx Ky Kz Ss Por

7.96202e+00 7.96202e+00 7.96202e-01 1.00000e-09 2.12000e-01

$7.96202 \mathrm{e}+007.96202 \mathrm{e}+00$ 7.96202e-01 1.00000e-09 2.12000e-01

$1.00000 \mathrm{e}-05$ 1.00000e-05 1.00000e-06 1.00000e-09 1.00000e-01

$1.00000 \mathrm{e}+001.00000 \mathrm{e}+001.00000 \mathrm{e}-011.00000 \mathrm{e}-091.00000 \mathrm{e}-01$

Element: 12158 \# of layers: 5

Kx Ky Kz Ss Por

$7.96202 \mathrm{e}+00$ 7.96202e+00 7.96202e-01 1.00000e-09 2.12000e-01

$7.96202 \mathrm{e}+00$ 7.96202e+00 7.96202e-01 1.00000e-09 2.12000e-01

7.96202e+00 7.96202e+00 7.96202e-01 1.00000e-09 2.12000e-01

$1.00000 \mathrm{e}-05$ 1.00000e-05 1.00000e-06 1.00000e-09 1.00000e-01

$1.00000 \mathrm{e}+001.00000 \mathrm{e}+001.00000 \mathrm{e}-011.00000 \mathrm{e}-091.00000 \mathrm{e}-01$

Element: 12159 \# of layers: 5

Kx Ky Kz Ss Por

7.96202e+00 7.96202e+00 7.96202e-01 1.00000e-09 2.12000e-01 
$7.96202 \mathrm{e}+00$ 7.96202e+00 7.96202e-01 1.00000e-09 2.12000e-01 $7.96202 \mathrm{e}+007.96202 \mathrm{e}+00$ 7.96202e-01 1.00000e-09 2.12000e-01 $1.00000 \mathrm{e}-05$ 1.00000e-05 1.00000e-06 1.00000e-09 1.00000e-01 $1.00000 \mathrm{e}+001.00000 \mathrm{e}+001.00000 \mathrm{e}-011.00000 \mathrm{e}-091.00000 \mathrm{e}-01$ Element: 12160 \# of layers: 5

Kx Ky Kz Ss Por

7.96202e+00 7.96202e+00 7.96202e-01 1.00000e-09 2.12000e-01

$7.96202 \mathrm{e}+007.96202 \mathrm{e}+007.96202 \mathrm{e}-011.00000 \mathrm{e}-092.12000 \mathrm{e}-01$ $7.96202 \mathrm{e}+007.96202 \mathrm{e}+00$ 7.96202e-01 1.00000e-09 2.12000e-01 $1.00000 \mathrm{e}-05$ 1.00000e-05 1.00000e-06 1.00000e-09 1.00000e-01 $1.00000 \mathrm{e}+001.00000 \mathrm{e}+001.00000 \mathrm{e}-011.00000 \mathrm{e}-091.00000 \mathrm{e}-01$ Element: 12161 \# of layers: 4

Kx Ky Kz Ss Por

7.96202e+00 7.96202e+00 7.96202e-01 1.00000e-09 2.12000e-01 $7.96202 \mathrm{e}+007.96202 \mathrm{e}+00$ 7.96202e-01 1.00000e-09 2.12000e-01 $1.00000 \mathrm{e}-05$ 1.00000e-05 1.00000e-06 1.00000e-09 1.00000e-01 $1.00000 \mathrm{e}+001.00000 \mathrm{e}+001.00000 \mathrm{e}-011.00000 \mathrm{e}-091.00000 \mathrm{e}-01$ Element: 12162 \# of layers: 4

Kx Ky Kz Ss Por

$1.36429 \mathrm{e}+011.36429 \mathrm{e}+011.36429 \mathrm{e}+00$ 1.00000e-09 2.12000e-01 $1.36429 \mathrm{e}+011.36429 \mathrm{e}+011.36429 \mathrm{e}+001.00000 \mathrm{e}-092.12000 \mathrm{e}-01$ $1.00000 \mathrm{e}-05$ 1.00000e-05 1.00000e-06 1.00000e-09 1.00000e-01 $1.00000 \mathrm{e}+001.00000 \mathrm{e}+001.00000 \mathrm{e}-011.00000 \mathrm{e}-091.00000 \mathrm{e}-01$ Element: 12163 \# of layers: 4

Kx Ky Kz Ss Por

$1.36429 \mathrm{e}+011.36429 \mathrm{e}+011.36429 \mathrm{e}+00$ 1.00000e-09 2.12000e-01 $1.36429 \mathrm{e}+011.36429 \mathrm{e}+011.36429 \mathrm{e}+001.00000 \mathrm{e}-092.12000 \mathrm{e}-01$ $1.00000 \mathrm{e}-051.00000 \mathrm{e}-05$ 1.00000e-06 1.00000e-09 1.00000e-01 $1.00000 \mathrm{e}+001.00000 \mathrm{e}+001.00000 \mathrm{e}-011.00000 \mathrm{e}-091.00000 \mathrm{e}-01$ Element: 12164 \# of layers: 4

Kx Ky Kz Ss Por

$1.36429 \mathrm{e}+011.36429 \mathrm{e}+011.36429 \mathrm{e}+00$ 1.00000e-09 2.12000e-01 $1.36429 \mathrm{e}+011.36429 \mathrm{e}+011.36429 \mathrm{e}+001.00000 \mathrm{e}-092.12000 \mathrm{e}-01$ $1.00000 \mathrm{e}-05$ 1.00000e-05 1.00000e-06 1.00000e-09 1.00000e-01 $1.00000 \mathrm{e}+001.00000 \mathrm{e}+001.00000 \mathrm{e}-011.00000 \mathrm{e}-091.00000 \mathrm{e}-01$ Element: 12165 \# of layers: 4

Kx Ky Kz Ss Por $1.36429 \mathrm{e}+011.36429 \mathrm{e}+011.36429 \mathrm{e}+00$ 1.00000e-09 2.12000e-01 $1.36429 \mathrm{e}+011.36429 \mathrm{e}+011.36429 \mathrm{e}+001.00000 \mathrm{e}-092.12000 \mathrm{e}-01$ $1.00000 \mathrm{e}-05$ 1.00000e-05 1.00000e-06 1.00000e-09 1.00000e-01 $1.00000 \mathrm{e}+001.00000 \mathrm{e}+001.00000 \mathrm{e}-011.00000 \mathrm{e}-091.00000 \mathrm{e}-01$ Element: 12166 \# of layers: 4

Kx Ky Kz Ss Por $1.36429 \mathrm{e}+01$ 1.36429e+01 1.36429e+00 1.00000e-09 2.12000e-01 $1.36429 \mathrm{e}+011.36429 \mathrm{e}+011.36429 \mathrm{e}+001.00000 \mathrm{e}-092.12000 \mathrm{e}-01$ $1.00000 \mathrm{e}-05$ 1.00000e-05 1.00000e-06 1.00000e-09 1.00000e-01 
$1.00000 \mathrm{e}+001.00000 \mathrm{e}+00$ 1.00000e-01 1.00000e-09 1.00000e-01

Element: 12167 \# of layers: 4

$\mathrm{Kx} \mathrm{Ky} \mathrm{Kz}$ Ss Por

7.96202e+00 7.96202e+00 7.96202e-01 1.00000e-09 2.12000e-01

$7.96202 \mathrm{e}+00$ 7.96202e+00 7.96202e-01 1.00000e-09 2.12000e-01

$1.00000 \mathrm{e}-05$ 1.00000e-05 1.00000e-06 1.00000e-09 1.00000e-01

$1.00000 \mathrm{e}+001.00000 \mathrm{e}+001.00000 \mathrm{e}-01$ 1.00000e-09 1.00000e-01

Element: 12168 \# of layers: 4

$\mathrm{Kx} \mathrm{Ky} \mathrm{Kz}$ Ss Por

7.96202e+00 7.96202e+00 7.96202e-01 1.00000e-09 2.12000e-01

$7.96202 \mathrm{e}+00$ 7.96202e+00 7.96202e-01 1.00000e-09 2.12000e-01

$1.00000 \mathrm{e}-05$ 1.00000e-05 1.00000e-06 1.00000e-09 1.00000e-01

$1.00000 \mathrm{e}+001.00000 \mathrm{e}+001.00000 \mathrm{e}-01$ 1.00000e-09 1.00000e-01

Element: 12169 \# of layers: 4

$\mathrm{Kx} \mathrm{Ky} \mathrm{Kz}$ Ss Por

$1.36429 \mathrm{e}+01$ 1.36429e+01 1.36429e+00 1.00000e-09 2.12000e-01

$1.36429 \mathrm{e}+01$ 1.36429e+01 1.36429e+00 1.00000e-09 2.12000e-01

$1.00000 \mathrm{e}-05$ 1.00000e-05 1.00000e-06 1.00000e-09 1.00000e-01

$1.00000 \mathrm{e}+001.00000 \mathrm{e}+001.00000 \mathrm{e}-01$ 1.00000e-09 1.00000e-01

Element: 12170 \# of layers: 4

Kx Ky Kz Ss Por

$1.36429 \mathrm{e}+01$ 1.36429e+01 1.36429e+00 1.00000e-09 2.12000e-01

$1.36429 \mathrm{e}+01$ 1.36429e+01 1.36429e+00 1.00000e-09 2.12000e-01

$1.00000 \mathrm{e}-05$ 1.00000e-05 1.00000e-06 1.00000e-09 1.00000e-01

$1.00000 \mathrm{e}+001.00000 \mathrm{e}+001.00000 \mathrm{e}-011.00000 \mathrm{e}-091.00000 \mathrm{e}-01$

Element: 12171 \# of layers: 4

$\mathrm{Kx} \mathrm{Ky} \mathrm{Kz}$ Ss Por

$1.36429 \mathrm{e}+01$ 1.36429e+01 1.36429e+00 1.00000e-09 2.12000e-01

$1.36429 \mathrm{e}+01$ 1.36429e+01 1.36429e+00 1.00000e-09 2.12000e-01

$1.00000 \mathrm{e}-05$ 1.00000e-05 1.00000e-06 1.00000e-09 1.00000e-01

$1.00000 \mathrm{e}+001.00000 \mathrm{e}+001.00000 \mathrm{e}-011.00000 \mathrm{e}-091.00000 \mathrm{e}-01$

Element: 12172 \# of layers: 4

Kx Ky Kz Ss Por

$1.36429 \mathrm{e}+01$ 1.36429e+01 1.36429e+00 1.00000e-09 2.12000e-01

$1.36429 \mathrm{e}+01$ 1.36429e+01 1.36429e+00 1.00000e-09 2.12000e-01

$1.00000 \mathrm{e}-05$ 1.00000e-05 1.00000e-06 1.00000e-09 1.00000e-01

$1.00000 \mathrm{e}+001.00000 \mathrm{e}+001.00000 \mathrm{e}-011.00000 \mathrm{e}-091.00000 \mathrm{e}-01$

Element: 12173 \# of layers: 4

$\mathrm{Kx} \mathrm{Ky} \mathrm{Kz}$ Ss Por

$1.36429 \mathrm{e}+01$ 1.36429e+01 1.36429e+00 1.00000e-09 2.12000e-01

$1.36429 \mathrm{e}+01$ 1.36429e+01 1.36429e+00 1.00000e-09 2.12000e-01

$1.00000 \mathrm{e}-05$ 1.00000e-05 1.00000e-06 1.00000e-09 1.00000e-01

$1.00000 \mathrm{e}+001.00000 \mathrm{e}+001.00000 \mathrm{e}-01$ 1.00000e-09 1.00000e-01

Element: 12174 \# of layers: 4

$\mathrm{Kx} \mathrm{Ky} \mathrm{Kz}$ Ss Por

$1.36429 \mathrm{e}+01$ 1.36429e+01 1.36429e+00 1.00000e-09 2.12000e-01 
$1.36429 \mathrm{e}+01$ 1.36429e+01 1.36429e+00 1.00000e-09 2.12000e-01 $1.00000 \mathrm{e}-05$ 1.00000e-05 1.00000e-06 1.00000e-09 1.00000e-01

$1.00000 \mathrm{e}+001.00000 \mathrm{e}+001.00000 \mathrm{e}-011.00000 \mathrm{e}-09$ 1.00000e-01

Element: 12175 \# of layers: 4

$\mathrm{Kx} \mathrm{Ky} \mathrm{Kz}$ Ss Por

$1.36429 \mathrm{e}+01$ 1.36429e+01 1.36429e+00 1.00000e-09 2.12000e-01

$1.36429 \mathrm{e}+01$ 1.36429e+01 1.36429e+00 1.00000e-09 2.12000e-01

$1.00000 \mathrm{e}-05$ 1.00000e-05 1.00000e-06 1.00000e-09 1.00000e-01

$1.00000 \mathrm{e}+001.00000 \mathrm{e}+001.00000 \mathrm{e}-011.00000 \mathrm{e}-091.00000 \mathrm{e}-01$

Element: 12176 \# of layers: 4

$\mathrm{Kx} \mathrm{Ky} \mathrm{Kz}$ Ss Por

$1.36429 \mathrm{e}+01$ 1.36429e+01 1.36429e+00 1.00000e-09 2.12000e-01

$1.36429 \mathrm{e}+01$ 1.36429e+01 1.36429e+00 1.00000e-09 2.12000e-01

$1.00000 \mathrm{e}-05$ 1.00000e-05 1.00000e-06 1.00000e-09 1.00000e-01

$1.00000 \mathrm{e}+001.00000 \mathrm{e}+001.00000 \mathrm{e}-01$ 1.00000e-09 1.00000e-01

Element: 12177 \# of layers: 4

$\mathrm{Kx} \mathrm{Ky} \mathrm{Kz}$ Ss Por

$1.36429 \mathrm{e}+01$ 1.36429e+01 1.36429e+00 1.00000e-09 2.12000e-01

$1.36429 \mathrm{e}+01$ 1.36429e+01 1.36429e+00 1.00000e-09 2.12000e-01

$1.00000 \mathrm{e}-051.00000 \mathrm{e}-05$ 1.00000e-06 1.00000e-09 1.00000e-01

$1.00000 \mathrm{e}+001.00000 \mathrm{e}+001.00000 \mathrm{e}-011.00000 \mathrm{e}-091.00000 \mathrm{e}-01$

Element: 12178 \# of layers: 4

$\mathrm{Kx} \mathrm{Ky} \mathrm{Kz}$ Ss Por

$1.36429 \mathrm{e}+01$ 1.36429e+01 1.36429e+00 1.00000e-09 2.12000e-01

$1.36429 \mathrm{e}+01$ 1.36429e+01 1.36429e+00 1.00000e-09 2.12000e-01

$1.00000 \mathrm{e}-05$ 1.00000e-05 1.00000e-06 1.00000e-09 1.00000e-01

$1.00000 \mathrm{e}+001.00000 \mathrm{e}+001.00000 \mathrm{e}-01$ 1.00000e-09 1.00000e-01

Element: 12179 \# of layers: 4

Kx Ky Kz Ss Por

$1.36429 \mathrm{e}+01$ 1.36429e+01 1.36429e+00 1.00000e-09 2.12000e-01

$1.36429 \mathrm{e}+01$ 1.36429e+01 1.36429e+00 1.00000e-09 2.12000e-01

$1.00000 \mathrm{e}-05$ 1.00000e-05 1.00000e-06 1.00000e-09 1.00000e-01

$1.00000 \mathrm{e}+001.00000 \mathrm{e}+001.00000 \mathrm{e}-011.00000 \mathrm{e}-091.00000 \mathrm{e}-01$

Element: 12180 \# of layers: 4

$\mathrm{Kx} \mathrm{Ky} \mathrm{Kz}$ Ss Por

$1.36429 \mathrm{e}+01$ 1.36429e+01 1.36429e+00 1.00000e-09 2.12000e-01

$1.36429 \mathrm{e}+011.36429 \mathrm{e}+011.36429 \mathrm{e}+001.00000 \mathrm{e}-092.12000 \mathrm{e}-01$

$1.00000 \mathrm{e}-05$ 1.00000e-05 1.00000e-06 1.00000e-09 1.00000e-01

$1.00000 \mathrm{e}+001.00000 \mathrm{e}+001.00000 \mathrm{e}-011.00000 \mathrm{e}-091.00000 \mathrm{e}-01$

Element: 12181 \# of layers: 4

Kx Ky Kz Ss Por

$1.69883 e+011.69883 e+011.69883 e+001.00000 e-092.12000 e-01$

$1.69883 \mathrm{e}+01$ 1.69883e+01 1.69883e+00 1.00000e-09 2.12000e-01

$1.00000 \mathrm{e}-05$ 1.00000e-05 1.00000e-06 1.00000e-09 1.00000e-01

$1.00000 \mathrm{e}+001.00000 \mathrm{e}+001.00000 \mathrm{e}-011.00000 \mathrm{e}-09$ 1.00000e-01

Element: 12182 \# of layers: 4 
$\mathrm{Kx} \mathrm{Ky} \mathrm{Kz} \mathrm{Ss} \mathrm{Por}$

$1.69883 e+011.69883 e+01$ 1.69883e+00 1.00000e-09 2.12000e-01

$1.69883 \mathrm{e}+011.69883 \mathrm{e}+01$ 1.69883e+00 1.00000e-09 2.12000e-01

$1.00000 \mathrm{e}-05$ 1.00000e-05 1.00000e-06 1.00000e-09 1.00000e-01

$1.00000 \mathrm{e}+001.00000 \mathrm{e}+001.00000 \mathrm{e}-01$ 1.00000e-09 1.00000e-01

Element: 12183 \# of layers: 4

$\mathrm{Kx} \mathrm{Ky} \mathrm{Kz}$ Ss Por

$1.69883 e+011.69883 e+011.69883 e+001.00000 e-092.12000 e-01$

$1.69883 \mathrm{e}+01$ 1.69883e+01 1.69883e+00 1.00000e-09 2.12000e-01

$1.00000 \mathrm{e}-05$ 1.00000e-05 1.00000e-06 1.00000e-09 1.00000e-01

$1.00000 \mathrm{e}+001.00000 \mathrm{e}+001.00000 \mathrm{e}-011.00000 \mathrm{e}-091.00000 \mathrm{e}-01$

Element: 12184 \# of layers: 4

$\mathrm{Kx} \mathrm{Ky} \mathrm{Kz}$ Ss Por

$1.36429 \mathrm{e}+01$ 1.36429e+01 1.36429e+00 1.00000e-09 2.12000e-01

$1.36429 \mathrm{e}+01$ 1.36429e+01 1.36429e+00 1.00000e-09 2.12000e-01

$1.00000 \mathrm{e}-05$ 1.00000e-05 1.00000e-06 1.00000e-09 1.00000e-01

$1.00000 \mathrm{e}+001.00000 \mathrm{e}+001.00000 \mathrm{e}-011.00000 \mathrm{e}-091.00000 \mathrm{e}-01$

Element: 12185 \# of layers: 4

$\mathrm{Kx} \mathrm{Ky} \mathrm{Kz}$ Ss Por

$1.36429 \mathrm{e}+01$ 1.36429e+01 1.36429e+00 1.00000e-09 2.12000e-01

$1.36429 \mathrm{e}+01$ 1.36429e+01 1.36429e+00 1.00000e-09 2.12000e-01

$1.00000 \mathrm{e}-05$ 1.00000e-05 1.00000e-06 1.00000e-09 1.00000e-01

$1.00000 \mathrm{e}+001.00000 \mathrm{e}+001.00000 \mathrm{e}-01$ 1.00000e-09 1.00000e-01

Element: 12186 \# of layers: 4

$\mathrm{Kx} \mathrm{Ky} \mathrm{Kz}$ Ss Por

$1.36429 \mathrm{e}+01$ 1.36429e+01 1.36429e+00 1.00000e-09 2.12000e-01

$1.36429 \mathrm{e}+01$ 1.36429e+01 1.36429e+00 1.00000e-09 2.12000e-01

$1.00000 \mathrm{e}-051.00000 \mathrm{e}-051.00000 \mathrm{e}-061.00000 \mathrm{e}-091.00000 \mathrm{e}-01$

$1.00000 \mathrm{e}+001.00000 \mathrm{e}+001.00000 \mathrm{e}-011.00000 \mathrm{e}-091.00000 \mathrm{e}-01$

Element: 12187 \# of layers: 4

$\mathrm{Kx} \mathrm{Ky} \mathrm{Kz}$ Ss Por

$1.36429 \mathrm{e}+01$ 1.36429e+01 1.36429e+00 1.00000e-09 2.12000e-01

$1.36429 \mathrm{e}+011.36429 \mathrm{e}+01 \quad 1.36429 \mathrm{e}+001.00000 \mathrm{e}-092.12000 \mathrm{e}-01$

$1.00000 \mathrm{e}-05$ 1.00000e-05 1.00000e-06 1.00000e-09 1.00000e-01

$1.00000 \mathrm{e}+001.00000 \mathrm{e}+001.00000 \mathrm{e}-011.00000 \mathrm{e}-091.00000 \mathrm{e}-01$

Element: 12188 \# of layers: 4

$\mathrm{Kx} \mathrm{Ky} \mathrm{Kz}$ Ss Por

$1.69883 \mathrm{e}+01$ 1.69883e+01 1.69883e+00 1.00000e-09 2.12000e-01

$1.69883 \mathrm{e}+01$ 1.69883e+01 1.69883e+00 1.00000e-09 2.12000e-01

$1.00000 \mathrm{e}-05$ 1.00000e-05 1.00000e-06 1.00000e-09 1.00000e-01

$1.00000 \mathrm{e}+001.00000 \mathrm{e}+001.00000 \mathrm{e}-011.00000 \mathrm{e}-091.00000 \mathrm{e}-01$

Element: 12189 \# of layers: 4

$\mathrm{Kx} \mathrm{Ky} \mathrm{Kz}$ Ss Por

1.69883e+01 1.69883e+01 1.69883e+00 1.00000e-09 2.12000e-01

$1.69883 \mathrm{e}+01$ 1.69883e+01 1.69883e+00 1.00000e-09 2.12000e-01

1.00000e-05 1.00000e-05 1.00000e-06 1.00000e-09 1.00000e-01 
$1.00000 \mathrm{e}+001.00000 \mathrm{e}+00$ 1.00000e-01 1.00000e-09 1.00000e-01

Element: 12190 \# of layers: 4

Kx Ky Kz Ss Por

$1.69883 e+011.69883 e+011.69883 e+001.00000 e-092.12000 e-01$

$1.69883 \mathrm{e}+011.69883 \mathrm{e}+01$ 1.69883e+00 1.00000e-09 2.12000e-01

$1.00000 \mathrm{e}-05$ 1.00000e-05 1.00000e-06 1.00000e-09 1.00000e-01

$1.00000 \mathrm{e}+001.00000 \mathrm{e}+001.00000 \mathrm{e}-01$ 1.00000e-09 1.00000e-01

Element: 12191 \# of layers: 4

$\mathrm{Kx} \mathrm{Ky} \mathrm{Kz}$ Ss Por

$1.69883 \mathrm{e}+01$ 1.69883e+01 1.69883e+00 1.00000e-09 2.12000e-01

$1.69883 \mathrm{e}+01$ 1.69883e+01 1.69883e+00 1.00000e-09 2.12000e-01

$1.00000 \mathrm{e}-05$ 1.00000e-05 1.00000e-06 1.00000e-09 1.00000e-01

$1.00000 \mathrm{e}+001.00000 \mathrm{e}+001.00000 \mathrm{e}-011.00000 \mathrm{e}-09$ 1.00000e-01

Element: 12192 \# of layers: 4

$\mathrm{Kx} \mathrm{Ky} \mathrm{Kz}$ Ss Por

$1.69883 \mathrm{e}+01$ 1.69883e+01 1.69883e+00 1.00000e-09 2.12000e-01

$1.69883 \mathrm{e}+011.69883 \mathrm{e}+01$ 1.69883e+00 1.00000e-09 2.12000e-01

$1.00000 \mathrm{e}-05$ 1.00000e-05 1.00000e-06 1.00000e-09 1.00000e-01

$1.00000 \mathrm{e}+001.00000 \mathrm{e}+001.00000 \mathrm{e}-01$ 1.00000e-09 1.00000e-01

Element: 12193 \# of layers: 4

$\mathrm{Kx} \mathrm{Ky} \mathrm{Kz}$ Ss Por

$1.69883 \mathrm{e}+01$ 1.69883e+01 1.69883e+00 1.00000e-09 2.12000e-01

$1.69883 \mathrm{e}+01$ 1.69883e+01 1.69883e+00 1.00000e-09 2.12000e-01

$1.00000 \mathrm{e}-05$ 1.00000e-05 1.00000e-06 1.00000e-09 1.00000e-01

$1.00000 \mathrm{e}+001.00000 \mathrm{e}+001.00000 \mathrm{e}-011.00000 \mathrm{e}-091.00000 \mathrm{e}-01$

Element: 12194 \# of layers: 4

Kx Ky Kz Ss Por

$1.69883 e+011.69883 e+011.69883 e+001.00000 e-092.12000 e-01$

$1.69883 \mathrm{e}+011.69883 \mathrm{e}+011.69883 \mathrm{e}+001.00000 \mathrm{e}-092.12000 \mathrm{e}-01$

$1.00000 \mathrm{e}-05$ 1.00000e-05 1.00000e-06 1.00000e-09 1.00000e-01

$1.00000 \mathrm{e}+001.00000 \mathrm{e}+001.00000 \mathrm{e}-011.00000 \mathrm{e}-091.00000 \mathrm{e}-01$

Element: 12195 \# of layers: 4

Kx Ky Kz Ss Por

$1.69883 \mathrm{e}+01$ 1.69883e+01 1.69883e+00 1.00000e-09 2.12000e-01

$1.69883 \mathrm{e}+01$ 1.69883e+01 1.69883e+00 1.00000e-09 2.12000e-01

$1.00000 \mathrm{e}-05$ 1.00000e-05 1.00000e-06 1.00000e-09 1.00000e-01

$1.00000 \mathrm{e}+001.00000 \mathrm{e}+001.00000 \mathrm{e}-011.00000 \mathrm{e}-091.00000 \mathrm{e}-01$

Element: 12196 \# of layers: 4

$\mathrm{Kx} \mathrm{Ky} \mathrm{Kz}$ Ss Por

$1.69883 \mathrm{e}+01$ 1.69883e+01 1.69883e+00 1.00000e-09 2.12000e-01

$1.69883 \mathrm{e}+01$ 1.69883e+01 1.69883e+00 1.00000e-09 2.12000e-01

$1.00000 \mathrm{e}-05$ 1.00000e-05 1.00000e-06 1.00000e-09 1.00000e-01

$1.00000 \mathrm{e}+001.00000 \mathrm{e}+001.00000 \mathrm{e}-01$ 1.00000e-09 1.00000e-01

Element: 12197 \# of layers: 4

$\mathrm{Kx} \mathrm{Ky} \mathrm{Kz}$ Ss Por

$1.69883 e+011.69883 e+011.69883 e+001.00000 e-092.12000 e-01$ 
$1.69883 \mathrm{e}+01$ 1.69883e+01 1.69883e+00 1.00000e-09 2.12000e-01 $1.00000 \mathrm{e}-05$ 1.00000e-05 1.00000e-06 1.00000e-09 1.00000e-01

$1.00000 \mathrm{e}+001.00000 \mathrm{e}+001.00000 \mathrm{e}-011.00000 \mathrm{e}-09$ 1.00000e-01

Element: 12198 \# of layers: 4

$\mathrm{Kx} \mathrm{Ky} \mathrm{Kz}$ Ss Por

$1.69883 \mathrm{e}+01$ 1.69883e+01 1.69883e+00 1.00000e-09 2.12000e-01

$1.69883 \mathrm{e}+011.69883 \mathrm{e}+01$ 1.69883e+00 1.00000e-09 2.12000e-01

$1.00000 \mathrm{e}-05$ 1.00000e-05 1.00000e-06 1.00000e-09 1.00000e-01

$1.00000 \mathrm{e}+001.00000 \mathrm{e}+001.00000 \mathrm{e}-011.00000 \mathrm{e}-091.00000 \mathrm{e}-01$

Element: 12199 \# of layers: 4

$\mathrm{Kx} \mathrm{Ky} \mathrm{Kz}$ Ss Por

$1.12433 \mathrm{e}+01$ 1.12433e+01 1.12433e+00 1.00000e-09 2.12000e-01

$1.12433 \mathrm{e}+01$ 1.12433e+01 1.12433e+00 1.00000e-09 2.12000e-01

$1.00000 \mathrm{e}-05$ 1.00000e-05 1.00000e-06 1.00000e-09 1.00000e-01

$1.00000 \mathrm{e}+001.00000 \mathrm{e}+001.00000 \mathrm{e}-01$ 1.00000e-09 1.00000e-01

Element: 12200 \# of layers: 4

$\mathrm{Kx} \mathrm{Ky} \mathrm{Kz}$ Ss Por

$1.12433 \mathrm{e}+01$ 1.12433e+01 1.12433e+00 1.00000e-09 2.12000e-01

$1.12433 \mathrm{e}+01$ 1.12433e+01 1.12433e+00 1.00000e-09 2.12000e-01

1.00000e-05 1.00000e-05 1.00000e-06 1.00000e-09 1.00000e-01

$1.00000 \mathrm{e}+001.00000 \mathrm{e}+001.00000 \mathrm{e}-011.00000 \mathrm{e}-091.00000 \mathrm{e}-01$

Element: 12201 \# of layers: 4

$\mathrm{Kx} \mathrm{Ky} \mathrm{Kz}$ Ss Por

$1.12433 \mathrm{e}+01$ 1.12433e+01 1.12433e+00 1.00000e-09 2.12000e-01

$1.12433 \mathrm{e}+011.12433 \mathrm{e}+011.12433 \mathrm{e}+001.00000 \mathrm{e}-092.12000 \mathrm{e}-01$

$1.00000 \mathrm{e}-05$ 1.00000e-05 1.00000e-06 1.00000e-09 1.00000e-01

$1.00000 \mathrm{e}+001.00000 \mathrm{e}+001.00000 \mathrm{e}-011.00000 \mathrm{e}-09$ 1.00000e-01

Element: 12202 \# of layers: 4

Kx Ky Kz Ss Por

$1.69883 \mathrm{e}+01$ 1.69883e+01 1.69883e+00 1.00000e-09 2.12000e-01

$1.69883 \mathrm{e}+01$ 1.69883e+01 1.69883e+00 1.00000e-09 2.12000e-01

$1.00000 \mathrm{e}-05$ 1.00000e-05 1.00000e-06 1.00000e-09 1.00000e-01

$1.00000 \mathrm{e}+001.00000 \mathrm{e}+001.00000 \mathrm{e}-011.00000 \mathrm{e}-091.00000 \mathrm{e}-01$

Element: 12203 \# of layers: 4

$\mathrm{Kx} \mathrm{Ky} \mathrm{Kz}$ Ss Por

$1.69883 e+011.69883 e+01$ 1.69883e+00 1.00000e-09 2.12000e-01

$1.69883 \mathrm{e}+01$ 1.69883e+01 1.69883e+00 1.00000e-09 2.12000e-01

$1.00000 \mathrm{e}-05$ 1.00000e-05 1.00000e-06 1.00000e-09 1.00000e-01

$1.00000 \mathrm{e}+001.00000 \mathrm{e}+001.00000 \mathrm{e}-01$ 1.00000e-09 1.00000e-01

Element: 12204 \# of layers: 4

$\mathrm{Kx} \mathrm{Ky} \mathrm{Kz}$ Ss Por

$1.69883 \mathrm{e}+01$ 1.69883e+01 1.69883e+00 1.00000e-09 2.12000e-01

$1.69883 \mathrm{e}+01$ 1.69883e+01 1.69883e+00 1.00000e-09 2.12000e-01

$1.00000 \mathrm{e}-05$ 1.00000e-05 1.00000e-06 1.00000e-09 1.00000e-01

$1.00000 \mathrm{e}+001.00000 \mathrm{e}+001.00000 \mathrm{e}-011.00000 \mathrm{e}-09$ 1.00000e-01

Element: 12205 \# of layers: 4 
$\mathrm{Kx} \mathrm{Ky} \mathrm{Kz} \mathrm{Ss} \mathrm{Por}$

$1.69883 e+011.69883 e+01$ 1.69883e+00 1.00000e-09 2.12000e-01

$1.69883 \mathrm{e}+011.69883 \mathrm{e}+01$ 1.69883e+00 1.00000e-09 2.12000e-01

$1.00000 \mathrm{e}-05$ 1.00000e-05 1.00000e-06 1.00000e-09 1.00000e-01

$1.00000 \mathrm{e}+001.00000 \mathrm{e}+001.00000 \mathrm{e}-01$ 1.00000e-09 1.00000e-01

Element: 12206 \# of layers: 4

$\mathrm{Kx} \mathrm{Ky} \mathrm{Kz}$ Ss Por

$1.12433 \mathrm{e}+01$ 1.12433e+01 1.12433e+00 1.00000e-09 2.12000e-01

$1.12433 \mathrm{e}+01$ 1.12433e+01 1.12433e+00 1.00000e-09 2.12000e-01

$1.00000 \mathrm{e}-051.00000 \mathrm{e}-05$ 1.00000e-06 1.00000e-09 1.00000e-01

$1.00000 \mathrm{e}+001.00000 \mathrm{e}+001.00000 \mathrm{e}-01$ 1.00000e-09 1.00000e-01

Element: 12207 \# of layers: 4

$\mathrm{Kx} \mathrm{Ky} \mathrm{Kz}$ Ss Por

$1.12433 \mathrm{e}+01$ 1.12433e+01 1.12433e+00 1.00000e-09 2.12000e-01

$1.12433 \mathrm{e}+011.12433 \mathrm{e}+01$ 1.12433e+00 1.00000e-09 2.12000e-01

$1.00000 \mathrm{e}-05$ 1.00000e-05 1.00000e-06 1.00000e-09 1.00000e-01

$1.00000 \mathrm{e}+001.00000 \mathrm{e}+001.00000 \mathrm{e}-01$ 1.00000e-09 1.00000e-01

Element: 12208 \# of layers: 4

$\mathrm{Kx} \mathrm{Ky} \mathrm{Kz}$ Ss Por

1.12433e+01 1.12433e+01 1.12433e+00 1.00000e-09 2.12000e-01

$1.12433 \mathrm{e}+01$ 1.12433e+01 1.12433e+00 1.00000e-09 2.12000e-01

$1.00000 \mathrm{e}-05$ 1.00000e-05 1.00000e-06 1.00000e-09 1.00000e-01

$1.00000 \mathrm{e}+001.00000 \mathrm{e}+001.00000 \mathrm{e}-01$ 1.00000e-09 1.00000e-01

Element: 12209 \# of layers: 4

Kx Ky Kz Ss Por

$1.12433 \mathrm{e}+01$ 1.12433e+01 1.12433e+00 1.00000e-09 2.12000e-01

$1.12433 \mathrm{e}+01$ 1.12433e+01 1.12433e+00 1.00000e-09 2.12000e-01

$1.00000 \mathrm{e}-051.00000 \mathrm{e}-051.00000 \mathrm{e}-061.00000 \mathrm{e}-091.00000 \mathrm{e}-01$

$1.00000 \mathrm{e}+001.00000 \mathrm{e}+001.00000 \mathrm{e}-011.00000 \mathrm{e}-091.00000 \mathrm{e}-01$

Element: 12210 \# of layers: 4

$\mathrm{Kx} \mathrm{Ky} \mathrm{Kz}$ Ss Por

$1.12433 \mathrm{e}+01$ 1.12433e+01 1.12433e+00 1.00000e-09 2.12000e-01

$1.12433 \mathrm{e}+011.12433 \mathrm{e}+01$ 1.12433e+00 1.00000e-09 2.12000e-01

$1.00000 \mathrm{e}-05$ 1.00000e-05 1.00000e-06 1.00000e-09 1.00000e-01

$1.00000 \mathrm{e}+001.00000 \mathrm{e}+001.00000 \mathrm{e}-011.00000 \mathrm{e}-091.00000 \mathrm{e}-01$

Element: 12211 \# of layers: 4

Kx Ky Kz Ss Por

$1.12433 \mathrm{e}+01$ 1.12433e+01 1.12433e+00 1.00000e-09 2.12000e-01

$1.12433 \mathrm{e}+01$ 1.12433e+01 1.12433e+00 1.00000e-09 2.12000e-01

$1.00000 \mathrm{e}-05$ 1.00000e-05 1.00000e-06 1.00000e-09 1.00000e-01

$1.00000 \mathrm{e}+001.00000 \mathrm{e}+001.00000 \mathrm{e}-011.00000 \mathrm{e}-091.00000 \mathrm{e}-01$

Element: 12212 \# of layers: 4

$\mathrm{Kx} \mathrm{Ky} \mathrm{Kz}$ Ss Por

$1.12433 \mathrm{e}+01$ 1.12433e+01 1.12433e+00 1.00000e-09 2.12000e-01

$1.12433 \mathrm{e}+01$ 1.12433e+01 1.12433e+00 1.00000e-09 2.12000e-01

$1.00000 \mathrm{e}-05$ 1.00000e-05 1.00000e-06 1.00000e-09 1.00000e-01 
$1.00000 \mathrm{e}+001.00000 \mathrm{e}+00$ 1.00000e-01 1.00000e-09 1.00000e-01

Element: 12213 \# of layers: 4

Kx Ky Kz Ss Por

$1.12433 \mathrm{e}+01$ 1.12433e+01 1.12433e+00 1.00000e-09 2.12000e-01

$1.12433 \mathrm{e}+011.12433 \mathrm{e}+01$ 1.12433e+00 1.00000e-09 2.12000e-01

$1.00000 \mathrm{e}-05$ 1.00000e-05 1.00000e-06 1.00000e-09 1.00000e-01

$1.00000 \mathrm{e}+001.00000 \mathrm{e}+001.00000 \mathrm{e}-01$ 1.00000e-09 1.00000e-01

Element: 12214 \# of layers: 4

$\mathrm{Kx} \mathrm{Ky} \mathrm{Kz}$ Ss Por

1.12433e+01 1.12433e+01 1.12433e+00 1.00000e-09 2.12000e-01

$1.12433 \mathrm{e}+01$ 1.12433e+01 1.12433e+00 1.00000e-09 2.12000e-01

$1.00000 \mathrm{e}-05$ 1.00000e-05 1.00000e-06 1.00000e-09 1.00000e-01

$1.00000 \mathrm{e}+001.00000 \mathrm{e}+001.00000 \mathrm{e}-011.00000 \mathrm{e}-09$ 1.00000e-01

Element: 12215 \# of layers: 4

$\mathrm{Kx} \mathrm{Ky} \mathrm{Kz}$ Ss Por

$1.12433 \mathrm{e}+01$ 1.12433e+01 1.12433e+00 1.00000e-09 2.12000e-01

$1.12433 \mathrm{e}+011.12433 \mathrm{e}+01$ 1.12433e+00 1.00000e-09 2.12000e-01

$1.00000 \mathrm{e}-05$ 1.00000e-05 1.00000e-06 1.00000e-09 1.00000e-01

$1.00000 \mathrm{e}+001.00000 \mathrm{e}+001.00000 \mathrm{e}-01$ 1.00000e-09 1.00000e-01

Element: 12216 \# of layers: 4

$\mathrm{Kx} \mathrm{Ky} \mathrm{Kz}$ Ss Por

7.96202e+00 7.96202e+00 7.96202e-01 1.00000e-09 2.12000e-01

7.96202e+00 7.96202e+00 7.96202e-01 1.00000e-09 2.12000e-01

$1.00000 \mathrm{e}-05$ 1.00000e-05 1.00000e-06 1.00000e-09 1.00000e-01

$1.00000 \mathrm{e}+001.00000 \mathrm{e}+001.00000 \mathrm{e}-011.00000 \mathrm{e}-091.00000 \mathrm{e}-01$

Element: 12217 \# of layers: 5

$\mathrm{Kx} \mathrm{Ky} \mathrm{Kz}$ Ss Por

7.96202e+00 7.96202e+00 7.96202e-01 1.00000e-09 2.12000e-01

$7.96202 \mathrm{e}+00$ 7.96202e+00 7.96202e-01 1.00000e-09 2.12000e-01

7.96202e+00 7.96202e+00 7.96202e-01 1.00000e-09 2.12000e-01

$1.00000 \mathrm{e}-05$ 1.00000e-05 1.00000e-06 1.00000e-09 1.00000e-01

$1.00000 \mathrm{e}+001.00000 \mathrm{e}+001.00000 \mathrm{e}-01$ 1.00000e-09 1.00000e-01

Element: 12218 \# of layers: 4

$\mathrm{Kx} \mathrm{Ky} \mathrm{Kz}$ Ss Por

7.96202e+00 7.96202e+00 7.96202e-01 1.00000e-09 2.12000e-01

$7.96202 \mathrm{e}+00$ 7.96202e+00 7.96202e-01 1.00000e-09 2.12000e-01

$1.00000 \mathrm{e}-05$ 1.00000e-05 1.00000e-06 1.00000e-09 1.00000e-01

$1.00000 \mathrm{e}+001.00000 \mathrm{e}+001.00000 \mathrm{e}-011.00000 \mathrm{e}-09$ 1.00000e-01

Element: 12219 \# of layers: 4

$\mathrm{Kx} \mathrm{Ky} \mathrm{Kz}$ Ss Por

7.96202e+00 7.96202e+00 7.96202e-01 1.00000e-09 2.12000e-01

7.96202e+00 7.96202e+00 7.96202e-01 1.00000e-09 2.12000e-01

$1.00000 \mathrm{e}-05$ 1.00000e-05 1.00000e-06 1.00000e-09 1.00000e-01

$1.00000 \mathrm{e}+001.00000 \mathrm{e}+001.00000 \mathrm{e}-01$ 1.00000e-09 1.00000e-01

Element: 12220 \# of layers: 4

Kx Ky Kz Ss Por 
$7.96202 \mathrm{e}+00$ 7.96202e+00 7.96202e-01 1.00000e-09 2.12000e-01 $7.96202 \mathrm{e}+007.96202 \mathrm{e}+00$ 7.96202e-01 1.00000e-09 2.12000e-01 $1.00000 \mathrm{e}-05$ 1.00000e-05 1.00000e-06 1.00000e-09 1.00000e-01 $1.00000 \mathrm{e}+001.00000 \mathrm{e}+001.00000 \mathrm{e}-011.00000 \mathrm{e}-091.00000 \mathrm{e}-01$ Element: 12221 \# of layers: 4

Kx Ky Kz Ss Por

$1.12433 \mathrm{e}+011.12433 \mathrm{e}+01$ 1.12433e+00 1.00000e-09 2.12000e-01 $1.12433 \mathrm{e}+011.12433 \mathrm{e}+011.12433 \mathrm{e}+00$ 1.00000e-09 2.12000e-01 $1.00000 \mathrm{e}-05$ 1.00000e-05 1.00000e-06 1.00000e-09 1.00000e-01 $1.00000 \mathrm{e}+001.00000 \mathrm{e}+001.00000 \mathrm{e}-011.00000 \mathrm{e}-091.00000 \mathrm{e}-01$ Element: 12222 \# of layers: 4

Kx Ky Kz Ss Por

$1.12433 \mathrm{e}+011.12433 \mathrm{e}+01$ 1.12433e+00 1.00000e-09 2.12000e-01 $1.12433 \mathrm{e}+011.12433 \mathrm{e}+011.12433 \mathrm{e}+00$ 1.00000e-09 2.12000e-01 $1.00000 \mathrm{e}-05$ 1.00000e-05 1.00000e-06 1.00000e-09 1.00000e-01 $1.00000 \mathrm{e}+001.00000 \mathrm{e}+001.00000 \mathrm{e}-011.00000 \mathrm{e}-091.00000 \mathrm{e}-01$ Element: 12223 \# of layers: 4

Kx Ky Kz Ss Por

7.96202e+00 7.96202e+00 7.96202e-01 1.00000e-09 2.12000e-01 $7.96202 \mathrm{e}+007.96202 \mathrm{e}+00$ 7.96202e-01 1.00000e-09 2.12000e-01 $1.00000 \mathrm{e}-05$ 1.00000e-05 1.00000e-06 1.00000e-09 1.00000e-01 $1.00000 \mathrm{e}+001.00000 \mathrm{e}+001.00000 \mathrm{e}-011.00000 \mathrm{e}-091.00000 \mathrm{e}-01$ Element: 12224 \# of layers: 4

Kx Ky Kz Ss Por

$7.96202 \mathrm{e}+007.96202 \mathrm{e}+00$ 7.96202e-01 1.00000e-09 2.12000e-01 $7.96202 \mathrm{e}+007.96202 \mathrm{e}+00$ 7.96202e-01 1.00000e-09 2.12000e-01 $1.00000 \mathrm{e}-05$ 1.00000e-05 1.00000e-06 1.00000e-09 1.00000e-01 $1.00000 \mathrm{e}+001.00000 \mathrm{e}+001.00000 \mathrm{e}-011.00000 \mathrm{e}-091.00000 \mathrm{e}-01$ Element: 12225 \# of layers: 4

Kx Ky Kz Ss Por

$1.36429 \mathrm{e}+011.36429 \mathrm{e}+011.36429 \mathrm{e}+00$ 1.00000e-09 2.12000e-01 $1.36429 \mathrm{e}+011.36429 \mathrm{e}+011.36429 \mathrm{e}+001.00000 \mathrm{e}-092.12000 \mathrm{e}-01$ $1.00000 \mathrm{e}-05$ 1.00000e-05 1.00000e-06 1.00000e-09 1.00000e-01 $1.00000 \mathrm{e}+001.00000 \mathrm{e}+001.00000 \mathrm{e}-011.00000 \mathrm{e}-091.00000 \mathrm{e}-01$ Element: 12226 \# of layers: 4

Kx Ky Kz Ss Por $1.36429 \mathrm{e}+011.36429 \mathrm{e}+011.36429 \mathrm{e}+00$ 1.00000e-09 2.12000e-01 $1.36429 \mathrm{e}+011.36429 \mathrm{e}+011.36429 \mathrm{e}+00$ 1.00000e-09 2.12000e-01 $1.00000 \mathrm{e}-05$ 1.00000e-05 1.00000e-06 1.00000e-09 1.00000e-01 $1.00000 \mathrm{e}+001.00000 \mathrm{e}+001.00000 \mathrm{e}-011.00000 \mathrm{e}-091.00000 \mathrm{e}-01$ Element: 12227 \# of layers: 4

Kx Ky Kz Ss Por $1.36429 \mathrm{e}+011.36429 \mathrm{e}+011.36429 \mathrm{e}+00$ 1.00000e-09 2.12000e-01 $1.36429 \mathrm{e}+011.36429 \mathrm{e}+011.36429 \mathrm{e}+001.00000 \mathrm{e}-092.12000 \mathrm{e}-01$ $1.00000 \mathrm{e}-05$ 1.00000e-05 1.00000e-06 1.00000e-09 1.00000e-01 $1.00000 \mathrm{e}+001.00000 \mathrm{e}+001.00000 \mathrm{e}-011.00000 \mathrm{e}-091.00000 \mathrm{e}-01$ 
Element: 12228 \# of layers: 4

Kx Ky Kz Ss Por

$1.69883 \mathrm{e}+011.69883 \mathrm{e}+011.69883 \mathrm{e}+00$ 1.00000e-09 2.12000e-01

$1.69883 \mathrm{e}+011.69883 \mathrm{e}+011.69883 \mathrm{e}+001.00000 \mathrm{e}-092.12000 \mathrm{e}-01$

$1.00000 \mathrm{e}-05$ 1.00000e-05 1.00000e-06 1.00000e-09 1.00000e-01

$1.00000 \mathrm{e}+001.00000 \mathrm{e}+001.00000 \mathrm{e}-011.00000 \mathrm{e}-091.00000 \mathrm{e}-01$

Element: 12229 \# of layers: 4

Kx Ky Kz Ss Por

$1.69883 \mathrm{e}+011.69883 \mathrm{e}+011.69883 \mathrm{e}+00$ 1.00000e-09 2.12000e-01

$1.69883 \mathrm{e}+011.69883 \mathrm{e}+011.69883 \mathrm{e}+00$ 1.00000e-09 2.12000e-01

$1.00000 \mathrm{e}-05$ 1.00000e-05 1.00000e-06 1.00000e-09 1.00000e-01

$1.00000 \mathrm{e}+001.00000 \mathrm{e}+001.00000 \mathrm{e}-011.00000 \mathrm{e}-091.00000 \mathrm{e}-01$

Element: 12230 \# of layers: 4

Kx Ky Kz Ss Por

$1.12433 \mathrm{e}+011.12433 \mathrm{e}+01$ 1.12433e+00 1.00000e-09 2.12000e-01

$1.12433 \mathrm{e}+011.12433 \mathrm{e}+011.12433 \mathrm{e}+00$ 1.00000e-09 2.12000e-01

$1.00000 \mathrm{e}-05$ 1.00000e-05 1.00000e-06 1.00000e-09 1.00000e-01

$1.00000 \mathrm{e}+001.00000 \mathrm{e}+001.00000 \mathrm{e}-011.00000 \mathrm{e}-091.00000 \mathrm{e}-01$

Element: 12231 \# of layers: 4

Kx Ky Kz Ss Por

7.96202e+00 7.96202e+00 7.96202e-01 1.00000e-09 2.12000e-01

$7.96202 \mathrm{e}+007.96202 \mathrm{e}+00$ 7.96202e-01 1.00000e-09 2.12000e-01

$1.00000 \mathrm{e}-05$ 1.00000e-05 1.00000e-06 1.00000e-09 1.00000e-01

$1.00000 \mathrm{e}+001.00000 \mathrm{e}+001.00000 \mathrm{e}-011.00000 \mathrm{e}-091.00000 \mathrm{e}-01$

Element: 12232 \# of layers: 4

Kx Ky Kz Ss Por

$1.36429 \mathrm{e}+011.36429 \mathrm{e}+011.36429 \mathrm{e}+00$ 1.00000e-09 2.12000e-01

$1.36429 \mathrm{e}+011.36429 \mathrm{e}+011.36429 \mathrm{e}+001.00000 \mathrm{e}-092.12000 \mathrm{e}-01$

$1.00000 \mathrm{e}-05$ 1.00000e-05 1.00000e-06 1.00000e-09 1.00000e-01

$1.00000 \mathrm{e}+001.00000 \mathrm{e}+001.00000 \mathrm{e}-011.00000 \mathrm{e}-091.00000 \mathrm{e}-01$

Element: 12233 \# of layers: 4

Kx Ky Kz Ss Por

$1.76959 \mathrm{e}+011.76959 \mathrm{e}+011.76959 \mathrm{e}+00$ 1.00000e-09 2.12000e-01

$1.76959 \mathrm{e}+011.76959 \mathrm{e}+011.76959 \mathrm{e}+00$ 1.00000e-09 2.12000e-01

$1.00000 \mathrm{e}-05$ 1.00000e-05 1.00000e-06 1.00000e-09 1.00000e-01

$1.00000 \mathrm{e}+001.00000 \mathrm{e}+001.00000 \mathrm{e}-011.00000 \mathrm{e}-091.00000 \mathrm{e}-01$

Element: 12234 \# of layers: 4

Kx Ky Kz Ss Por

$1.76959 \mathrm{e}+011.76959 \mathrm{e}+01$ 1.76959e+00 1.00000e-09 2.12000e-01

$1.76959 \mathrm{e}+011.76959 \mathrm{e}+011.76959 \mathrm{e}+00$ 1.00000e-09 2.12000e-01

$1.00000 \mathrm{e}-051.00000 \mathrm{e}-05$ 1.00000e-06 1.00000e-09 1.00000e-01

$1.00000 \mathrm{e}+001.00000 \mathrm{e}+001.00000 \mathrm{e}-011.00000 \mathrm{e}-091.00000 \mathrm{e}-01$

Element: 12235 \# of layers: 4

Kx Ky Kz Ss Por

$1.76959 \mathrm{e}+011.76959 \mathrm{e}+011.76959 \mathrm{e}+00$ 1.00000e-09 2.12000e-01

$1.76959 \mathrm{e}+011.76959 \mathrm{e}+011.76959 \mathrm{e}+00$ 1.00000e-09 2.12000e-01 
$1.00000 \mathrm{e}-05$ 1.00000e-05 1.00000e-06 1.00000e-09 1.00000e-01 $1.00000 \mathrm{e}+001.00000 \mathrm{e}+001.00000 \mathrm{e}-01$ 1.00000e-09 1.00000e-01 Element: 12236 \# of layers: 4

Kx Ky Kz Ss Por

$1.76959 \mathrm{e}+01$ 1.76959e+01 1.76959e+00 1.00000e-09 2.12000e-01

$1.76959 \mathrm{e}+01$ 1.76959e+01 1.76959e+00 1.00000e-09 2.12000e-01

$1.00000 \mathrm{e}-05$ 1.00000e-05 1.00000e-06 1.00000e-09 1.00000e-01

$1.00000 \mathrm{e}+001.00000 \mathrm{e}+001.00000 \mathrm{e}-01$ 1.00000e-09 1.00000e-01

Element: 12237 \# of layers: 4

$\mathrm{Kx} \mathrm{Ky} \mathrm{Kz}$ Ss Por

1.76959e+01 1.76959e+01 1.76959e+00 1.00000e-09 2.12000e-01

$1.76959 \mathrm{e}+01$ 1.76959e+01 1.76959e+00 1.00000e-09 2.12000e-01

$1.00000 \mathrm{e}-05$ 1.00000e-05 1.00000e-06 1.00000e-09 1.00000e-01

$1.00000 \mathrm{e}+001.00000 \mathrm{e}+001.00000 \mathrm{e}-011.00000 \mathrm{e}-09$ 1.00000e-01

Element: 12238 \# of layers: 4

Kx Ky Kz Ss Por

$1.76959 \mathrm{e}+01$ 1.76959e+01 1.76959e+00 1.00000e-09 2.12000e-01

$1.76959 \mathrm{e}+01$ 1.76959e+01 1.76959e+00 1.00000e-09 2.12000e-01

$1.00000 \mathrm{e}-05$ 1.00000e-05 1.00000e-06 1.00000e-09 1.00000e-01

$1.00000 \mathrm{e}+001.00000 \mathrm{e}+001.00000 \mathrm{e}-011.00000 \mathrm{e}-09$ 1.00000e-01

Element: 12239 \# of layers: 4

$\mathrm{Kx} \mathrm{Ky} \mathrm{Kz}$ Ss Por

$1.76959 \mathrm{e}+01$ 1.76959e+01 1.76959e+00 1.00000e-09 2.12000e-01

$1.76959 \mathrm{e}+01$ 1.76959e+01 1.76959e+00 1.00000e-09 2.12000e-01

$1.00000 \mathrm{e}-05$ 1.00000e-05 1.00000e-06 1.00000e-09 1.00000e-01

$1.00000 \mathrm{e}+001.00000 \mathrm{e}+001.00000 \mathrm{e}-01$ 1.00000e-09 1.00000e-01

Element: 12240 \# of layers: 4

$\mathrm{Kx} \mathrm{Ky} \mathrm{Kz}$ Ss Por

$1.76959 \mathrm{e}+01$ 1.76959e+01 1.76959e+00 1.00000e-09 2.12000e-01

$1.76959 \mathrm{e}+01$ 1.76959e+01 1.76959e+00 1.00000e-09 2.12000e-01

$1.00000 \mathrm{e}-05$ 1.00000e-05 1.00000e-06 1.00000e-09 1.00000e-01

$1.00000 \mathrm{e}+001.00000 \mathrm{e}+001.00000 \mathrm{e}-011.00000 \mathrm{e}-091.00000 \mathrm{e}-01$

Element: 12241 \# of layers: 4

$\mathrm{Kx} \mathrm{Ky} \mathrm{Kz}$ Ss Por

$1.76959 \mathrm{e}+01$ 1.76959e+01 1.76959e+00 1.00000e-09 2.12000e-01

$1.76959 \mathrm{e}+01$ 1.76959e+01 1.76959e+00 1.00000e-09 2.12000e-01

$1.00000 \mathrm{e}-05$ 1.00000e-05 1.00000e-06 1.00000e-09 1.00000e-01

$1.00000 \mathrm{e}+001.00000 \mathrm{e}+001.00000 \mathrm{e}-011.00000 \mathrm{e}-091.00000 \mathrm{e}-01$

Element: 12242 \# of layers: 4

$\mathrm{Kx} \mathrm{Ky} \mathrm{Kz}$ Ss Por

$1.76959 e+01$ 1.76959e+01 1.76959e+00 1.00000e-09 2.12000e-01

$1.76959 \mathrm{e}+01$ 1.76959e+01 1.76959e+00 1.00000e-09 2.12000e-01

$1.00000 \mathrm{e}-05$ 1.00000e-05 1.00000e-06 1.00000e-09 1.00000e-01

$1.00000 \mathrm{e}+001.00000 \mathrm{e}+001.00000 \mathrm{e}-01$ 1.00000e-09 1.00000e-01

Element: 12243 \# of layers: 4

Kx Ky Kz Ss Por 
$2.05587 \mathrm{e}+012.05587 \mathrm{e}+012.05587 \mathrm{e}+00$ 1.00000e-09 2.12000e-01 $2.05587 \mathrm{e}+012.05587 \mathrm{e}+012.05587 \mathrm{e}+00$ 1.00000e-09 2.12000e-01 $1.00000 \mathrm{e}-05$ 1.00000e-05 1.00000e-06 1.00000e-09 1.00000e-01 $1.00000 \mathrm{e}+001.00000 \mathrm{e}+001.00000 \mathrm{e}-011.00000 \mathrm{e}-091.00000 \mathrm{e}-01$ Element: 12244 \# of layers: 5

Kx Ky Kz Ss Por

$2.05587 \mathrm{e}+012.05587 \mathrm{e}+012.05587 \mathrm{e}+00$ 1.00000e-09 2.12000e-01 $2.05587 \mathrm{e}+012.05587 \mathrm{e}+012.05587 \mathrm{e}+001.00000 \mathrm{e}-092.12000 \mathrm{e}-01$ $2.05587 \mathrm{e}+012.05587 \mathrm{e}+012.05587 \mathrm{e}+001.00000 \mathrm{e}-092.12000 \mathrm{e}-01$ $1.00000 \mathrm{e}-05$ 1.00000e-05 1.00000e-06 1.00000e-09 1.00000e-01 $1.00000 \mathrm{e}+001.00000 \mathrm{e}+001.00000 \mathrm{e}-011.00000 \mathrm{e}-091.00000 \mathrm{e}-01$ Element: 12245 \# of layers: 5

Kx Ky Kz Ss Por

$2.05587 \mathrm{e}+012.05587 \mathrm{e}+012.05587 \mathrm{e}+00$ 1.00000e-09 2.12000e-01 $2.05587 \mathrm{e}+012.05587 \mathrm{e}+012.05587 \mathrm{e}+001.00000 \mathrm{e}-092.12000 \mathrm{e}-01$ $2.05587 \mathrm{e}+012.05587 \mathrm{e}+012.05587 \mathrm{e}+00$ 1.00000e-09 2.12000e-01 $1.00000 \mathrm{e}-05$ 1.00000e-05 1.00000e-06 1.00000e-09 1.00000e-01 $1.00000 \mathrm{e}+001.00000 \mathrm{e}+001.00000 \mathrm{e}-011.00000 \mathrm{e}-091.00000 \mathrm{e}-01$ Element: 12246 \# of layers: 5

Kx Ky Kz Ss Por

$2.05587 \mathrm{e}+012.05587 \mathrm{e}+012.05587 \mathrm{e}+00$ 1.00000e-09 2.12000e-01 $2.05587 \mathrm{e}+012.05587 \mathrm{e}+012.05587 \mathrm{e}+001.00000 \mathrm{e}-092.12000 \mathrm{e}-01$ $2.05587 \mathrm{e}+012.05587 \mathrm{e}+012.05587 \mathrm{e}+00$ 1.00000e-09 2.12000e-01 $1.00000 \mathrm{e}-05$ 1.00000e-05 1.00000e-06 1.00000e-09 1.00000e-01 $1.00000 \mathrm{e}+001.00000 \mathrm{e}+001.00000 \mathrm{e}-011.00000 \mathrm{e}-091.00000 \mathrm{e}-01$ Element: 12247 \# of layers: 4

Kx Ky Kz Ss Por

$2.05587 \mathrm{e}+012.05587 \mathrm{e}+012.05587 \mathrm{e}+00$ 1.00000e-09 2.12000e-01 $2.05587 \mathrm{e}+012.05587 \mathrm{e}+012.05587 \mathrm{e}+001.00000 \mathrm{e}-092.12000 \mathrm{e}-01$ $1.00000 \mathrm{e}-05$ 1.00000e-05 1.00000e-06 1.00000e-09 1.00000e-01 $1.00000 \mathrm{e}+001.00000 \mathrm{e}+001.00000 \mathrm{e}-011.00000 \mathrm{e}-091.00000 \mathrm{e}-01$ Element: 12248 \# of layers: 4

Kx Ky Kz Ss Por

$1.76959 \mathrm{e}+011.76959 \mathrm{e}+011.76959 \mathrm{e}+00$ 1.00000e-09 2.12000e-01 $1.76959 \mathrm{e}+011.76959 \mathrm{e}+011.76959 \mathrm{e}+001.00000 \mathrm{e}-092.12000 \mathrm{e}-01$ $1.00000 \mathrm{e}-05$ 1.00000e-05 1.00000e-06 1.00000e-09 1.00000e-01 $1.00000 \mathrm{e}+001.00000 \mathrm{e}+001.00000 \mathrm{e}-011.00000 \mathrm{e}-091.00000 \mathrm{e}-01$ Element: 12249 \# of layers: 4

Kx Ky Kz Ss Por

$1.76959 \mathrm{e}+011.76959 \mathrm{e}+01$ 1.76959e+00 1.00000e-09 2.12000e-01 $1.76959 \mathrm{e}+011.76959 \mathrm{e}+011.76959 \mathrm{e}+00$ 1.00000e-09 2.12000e-01 $1.00000 \mathrm{e}-05$ 1.00000e-05 1.00000e-06 1.00000e-09 1.00000e-01 $1.00000 \mathrm{e}+001.00000 \mathrm{e}+001.00000 \mathrm{e}-011.00000 \mathrm{e}-091.00000 \mathrm{e}-01$ Element: 12250 \# of layers: 4

Kx Ky Kz Ss Por $2.05587 \mathrm{e}+012.05587 \mathrm{e}+012.05587 \mathrm{e}+00$ 1.00000e-09 2.12000e-01 
$2.05587 \mathrm{e}+012.05587 \mathrm{e}+012.05587 \mathrm{e}+00$ 1.00000e-09 2.12000e-01 $1.00000 \mathrm{e}-05$ 1.00000e-05 1.00000e-06 1.00000e-09 1.00000e-01 $1.00000 \mathrm{e}+001.00000 \mathrm{e}+001.00000 \mathrm{e}-011.00000 \mathrm{e}-091.00000 \mathrm{e}-01$

Element: 12251 \# of layers: 4

$\mathrm{Kx} \mathrm{Ky} \mathrm{Kz}$ Ss Por

$2.05587 \mathrm{e}+012.05587 \mathrm{e}+012.05587 \mathrm{e}+00$ 1.00000e-09 2.12000e-01

$2.05587 \mathrm{e}+012.05587 \mathrm{e}+012.05587 \mathrm{e}+00$ 1.00000e-09 2.12000e-01

$1.00000 \mathrm{e}-05$ 1.00000e-05 1.00000e-06 1.00000e-09 1.00000e-01

$1.00000 \mathrm{e}+001.00000 \mathrm{e}+001.00000 \mathrm{e}-011.00000 \mathrm{e}-091.00000 \mathrm{e}-01$

Element: 12252 \# of layers: 4

Kx Ky Kz Ss Por

$2.05587 \mathrm{e}+012.05587 \mathrm{e}+012.05587 \mathrm{e}+00$ 1.00000e-09 2.12000e-01

$2.05587 \mathrm{e}+012.05587 \mathrm{e}+012.05587 \mathrm{e}+001.00000 \mathrm{e}-092.12000 \mathrm{e}-01$

$1.00000 \mathrm{e}-05$ 1.00000e-05 1.00000e-06 1.00000e-09 1.00000e-01

$1.00000 \mathrm{e}+001.00000 \mathrm{e}+001.00000 \mathrm{e}-01$ 1.00000e-09 1.00000e-01

Element: 12253 \# of layers: 4

$\mathrm{Kx} \mathrm{Ky} \mathrm{Kz}$ Ss Por

$2.05587 \mathrm{e}+012.05587 \mathrm{e}+012.05587 \mathrm{e}+00$ 1.00000e-09 2.12000e-01

$2.05587 \mathrm{e}+012.05587 \mathrm{e}+012.05587 \mathrm{e}+00$ 1.00000e-09 2.12000e-01

$1.00000 \mathrm{e}-05$ 1.00000e-05 1.00000e-06 1.00000e-09 1.00000e-01

$1.00000 \mathrm{e}+001.00000 \mathrm{e}+001.00000 \mathrm{e}-011.00000 \mathrm{e}-091.00000 \mathrm{e}-01$

Element: 12254 \# of layers: 4

$\mathrm{Kx} \mathrm{Ky} \mathrm{Kz}$ Ss Por

$2.05587 \mathrm{e}+012.05587 \mathrm{e}+012.05587 \mathrm{e}+00$ 1.00000e-09 2.12000e-01

$2.05587 \mathrm{e}+012.05587 \mathrm{e}+012.05587 \mathrm{e}+001.00000 \mathrm{e}-092.12000 \mathrm{e}-01$

$1.00000 \mathrm{e}-05$ 1.00000e-05 1.00000e-06 1.00000e-09 1.00000e-01

$1.00000 \mathrm{e}+001.00000 \mathrm{e}+001.00000 \mathrm{e}-011.00000 \mathrm{e}-091.00000 \mathrm{e}-01$

Element: 12255 \# of layers: 4

Kx Ky Kz Ss Por

$2.05587 \mathrm{e}+012.05587 \mathrm{e}+012.05587 \mathrm{e}+00$ 1.00000e-09 2.12000e-01

$2.05587 \mathrm{e}+012.05587 \mathrm{e}+012.05587 \mathrm{e}+00$ 1.00000e-09 2.12000e-01

$1.00000 \mathrm{e}-05$ 1.00000e-05 1.00000e-06 1.00000e-09 1.00000e-01

$1.00000 \mathrm{e}+001.00000 \mathrm{e}+001.00000 \mathrm{e}-011.00000 \mathrm{e}-091.00000 \mathrm{e}-01$

Element: 12256 \# of layers: 4

$\mathrm{Kx} \mathrm{Ky} \mathrm{Kz}$ Ss Por

$2.05587 \mathrm{e}+012.05587 \mathrm{e}+012.05587 \mathrm{e}+00$ 1.00000e-09 2.12000e-01

$2.05587 \mathrm{e}+012.05587 \mathrm{e}+012.05587 \mathrm{e}+001.00000 \mathrm{e}-092.12000 \mathrm{e}-01$

$1.00000 \mathrm{e}-05$ 1.00000e-05 1.00000e-06 1.00000e-09 1.00000e-01

$1.00000 \mathrm{e}+001.00000 \mathrm{e}+00$ 1.00000e-01 1.00000e-09 1.00000e-01

Element: 12257 \# of layers: 4

Kx Ky Kz Ss Por

2.05587e+01 2.05587e+01 2.05587e+00 1.00000e-09 2.12000e-01

$2.05587 \mathrm{e}+012.05587 \mathrm{e}+012.05587 \mathrm{e}+00$ 1.00000e-09 2.12000e-01

$1.00000 \mathrm{e}-05$ 1.00000e-05 1.00000e-06 1.00000e-09 1.00000e-01

$1.00000 \mathrm{e}+001.00000 \mathrm{e}+001.00000 \mathrm{e}-011.00000 \mathrm{e}-09$ 1.00000e-01

Element: 12258 \# of layers: 4 
$\mathrm{Kx} \mathrm{Ky} \mathrm{Kz}$ Ss Por

$2.05587 \mathrm{e}+012.05587 \mathrm{e}+012.05587 \mathrm{e}+00$ 1.00000e-09 2.12000e-01

$2.05587 \mathrm{e}+012.05587 \mathrm{e}+012.05587 \mathrm{e}+00$ 1.00000e-09 2.12000e-01

$1.00000 \mathrm{e}-05$ 1.00000e-05 1.00000e-06 1.00000e-09 1.00000e-01

$1.00000 \mathrm{e}+001.00000 \mathrm{e}+001.00000 \mathrm{e}-01$ 1.00000e-09 1.00000e-01

Element: 12259 \# of layers: 4

Kx Ky Kz Ss Por

2.05587e+01 2.05587e+01 2.05587e+00 1.00000e-09 2.12000e-01

$2.05587 \mathrm{e}+012.05587 \mathrm{e}+012.05587 \mathrm{e}+001.00000 \mathrm{e}-092.12000 \mathrm{e}-01$

$1.00000 \mathrm{e}-05$ 1.00000e-05 1.00000e-06 1.00000e-09 1.00000e-01

$1.00000 \mathrm{e}+001.00000 \mathrm{e}+001.00000 \mathrm{e}-011.00000 \mathrm{e}-091.00000 \mathrm{e}-01$

Element: 12260 \# of layers: 4

$\mathrm{Kx} \mathrm{Ky} \mathrm{Kz}$ Ss Por

$2.05587 \mathrm{e}+012.05587 \mathrm{e}+012.05587 \mathrm{e}+00$ 1.00000e-09 2.12000e-01

$2.05587 \mathrm{e}+012.05587 \mathrm{e}+012.05587 \mathrm{e}+001.00000 \mathrm{e}-092.12000 \mathrm{e}-01$

$1.00000 \mathrm{e}-05$ 1.00000e-05 1.00000e-06 1.00000e-09 1.00000e-01

$1.00000 \mathrm{e}+001.00000 \mathrm{e}+001.00000 \mathrm{e}-01$ 1.00000e-09 1.00000e-01

Element: 12261 \# of layers: 5

$\mathrm{Kx} \mathrm{Ky} \mathrm{Kz}$ Ss Por

$2.05587 \mathrm{e}+012.05587 \mathrm{e}+012.05587 \mathrm{e}+00$ 1.00000e-09 2.12000e-01

$2.05587 \mathrm{e}+012.05587 \mathrm{e}+012.05587 \mathrm{e}+00$ 1.00000e-09 2.12000e-01

$1.00000 \mathrm{e}-05$ 1.00000e-05 1.00000e-06 1.00000e-09 1.00000e-01

$1.00000 \mathrm{e}+001.00000 \mathrm{e}+001.00000 \mathrm{e}-011.00000 \mathrm{e}-091.00000 \mathrm{e}-01$

1.00000e-06 1.00000e-06 1.00000e-06 1.00000e-09 5.00000e-02

Element: 12262 \# of layers: 5

$\mathrm{Kx} \mathrm{Ky} \mathrm{Kz}$ Ss Por

9.92001e+01 9.92001e+01 9.92001e+00 1.00000e-09 2.12000e-01

$9.92001 \mathrm{e}+01$ 9.92001e+01 9.92001e+00 1.00000e-09 2.12000e-01

$1.00000 \mathrm{e}-05$ 1.00000e-05 1.00000e-06 1.00000e-09 1.00000e-01

$1.00000 \mathrm{e}+001.00000 \mathrm{e}+001.00000 \mathrm{e}-011.00000 \mathrm{e}-091.00000 \mathrm{e}-01$

1.00000e-06 1.00000e-06 1.00000e-06 1.00000e-09 5.00000e-02

Element: 12263 \# of layers: 5

Kx Ky Kz Ss Por

9.92001e+01 9.92001e+01 9.92001e+00 1.00000e-09 2.12000e-01

$9.92001 \mathrm{e}+019.92001 \mathrm{e}+019.92001 \mathrm{e}+001.00000 \mathrm{e}-092.12000 \mathrm{e}-01$

$1.00000 \mathrm{e}-05$ 1.00000e-05 1.00000e-06 1.00000e-09 1.00000e-01

$1.00000 \mathrm{e}+001.00000 \mathrm{e}+001.00000 \mathrm{e}-011.00000 \mathrm{e}-091.00000 \mathrm{e}-01$

1.00000e-06 1.00000e-06 1.00000e-06 1.00000e-09 5.00000e-02

Element: 12264 \# of layers: 5

$\mathrm{Kx} \mathrm{Ky} \mathrm{Kz}$ Ss Por

9.92001e+01 9.92001e+01 9.92001e+00 1.00000e-09 2.12000e-01

$9.92001 \mathrm{e}+019.92001 \mathrm{e}+019.92001 \mathrm{e}+001.00000 \mathrm{e}-092.12000 \mathrm{e}-01$

$1.00000 \mathrm{e}-05$ 1.00000e-05 1.00000e-06 1.00000e-09 1.00000e-01

$1.00000 \mathrm{e}+001.00000 \mathrm{e}+001.00000 \mathrm{e}-011.00000 \mathrm{e}-091.00000 \mathrm{e}-01$

1.00000e-06 1.00000e-06 1.00000e-06 1.00000e-09 5.00000e-02

Element: 12265 \# of layers: 4 
$\mathrm{Kx} \mathrm{Ky} \mathrm{Kz}$ Ss Por

$2.05587 \mathrm{e}+012.05587 \mathrm{e}+012.05587 \mathrm{e}+00$ 1.00000e-09 2.12000e-01

$2.05587 \mathrm{e}+012.05587 \mathrm{e}+012.05587 \mathrm{e}+00$ 1.00000e-09 2.12000e-01

$1.00000 \mathrm{e}-05$ 1.00000e-05 1.00000e-06 1.00000e-09 1.00000e-01

$1.00000 \mathrm{e}+001.00000 \mathrm{e}+001.00000 \mathrm{e}-01$ 1.00000e-09 1.00000e-01

Element: 12266 \# of layers: 4

Kx Ky Kz Ss Por

2.05587e+01 2.05587e+01 2.05587e+00 1.00000e-09 2.12000e-01

$2.05587 \mathrm{e}+012.05587 \mathrm{e}+012.05587 \mathrm{e}+001.00000 \mathrm{e}-092.12000 \mathrm{e}-01$

$1.00000 \mathrm{e}-05$ 1.00000e-05 1.00000e-06 1.00000e-09 1.00000e-01

$1.00000 \mathrm{e}+001.00000 \mathrm{e}+001.00000 \mathrm{e}-01$ 1.00000e-09 1.00000e-01

Element: 12267 \# of layers: 4

$\mathrm{Kx} \mathrm{Ky} \mathrm{Kz}$ Ss Por

$2.05587 \mathrm{e}+012.05587 \mathrm{e}+012.05587 \mathrm{e}+00$ 1.00000e-09 2.12000e-01

$2.05587 \mathrm{e}+012.05587 \mathrm{e}+012.05587 \mathrm{e}+001.00000 \mathrm{e}-092.12000 \mathrm{e}-01$

$1.00000 \mathrm{e}-05$ 1.00000e-05 1.00000e-06 1.00000e-09 1.00000e-01

$1.00000 \mathrm{e}+001.00000 \mathrm{e}+001.00000 \mathrm{e}-011.00000 \mathrm{e}-091.00000 \mathrm{e}-01$

Element: 12268 \# of layers: 4

$\mathrm{Kx} \mathrm{Ky} \mathrm{Kz}$ Ss Por

$2.05587 \mathrm{e}+012.05587 \mathrm{e}+012.05587 \mathrm{e}+00$ 1.00000e-09 2.12000e-01

$2.05587 \mathrm{e}+012.05587 \mathrm{e}+012.05587 \mathrm{e}+00$ 1.00000e-09 2.12000e-01

$1.00000 \mathrm{e}-05$ 1.00000e-05 1.00000e-06 1.00000e-09 1.00000e-01

$1.00000 \mathrm{e}+001.00000 \mathrm{e}+001.00000 \mathrm{e}-01$ 1.00000e-09 1.00000e-01

Element: 12269 \# of layers: 5

Kx Ky Kz Ss Por

$9.92001 \mathrm{e}+019.92001 \mathrm{e}+019.92001 \mathrm{e}+001.00000 \mathrm{e}-092.12000 \mathrm{e}-01$

9.92001e+01 9.92001e+01 9.92001e+00 1.00000e-09 2.12000e-01

$1.00000 \mathrm{e}-05$ 1.00000e-05 1.00000e-06 1.00000e-09 1.00000e-01

$1.00000 \mathrm{e}+001.00000 \mathrm{e}+001.00000 \mathrm{e}-011.00000 \mathrm{e}-091.00000 \mathrm{e}-01$

1.00000e-06 1.00000e-06 1.00000e-06 1.00000e-09 5.00000e-02

Element: 12270 \# of layers: 5

$\mathrm{Kx} \mathrm{Ky} \mathrm{Kz}$ Ss Por

9.92001e+01 9.92001e+01 9.92001e+00 1.00000e-09 2.12000e-01

$9.92001 \mathrm{e}+019.92001 \mathrm{e}+019.92001 \mathrm{e}+001.00000 \mathrm{e}-092.12000 \mathrm{e}-01$

$1.00000 \mathrm{e}-051.00000 \mathrm{e}-05$ 1.00000e-06 1.00000e-09 1.00000e-01

$1.00000 \mathrm{e}+001.00000 \mathrm{e}+001.00000 \mathrm{e}-011.00000 \mathrm{e}-091.00000 \mathrm{e}-01$

1.00000e-06 1.00000e-06 1.00000e-06 1.00000e-09 5.00000e-02

Element: 12271 \# of layers: 5

$\mathrm{Kx} \mathrm{Ky} \mathrm{Kz}$ Ss Por

9.92001e+01 9.92001e+01 9.92001e+00 1.00000e-09 2.12000e-01

$9.92001 \mathrm{e}+019.92001 \mathrm{e}+019.92001 \mathrm{e}+001.00000 \mathrm{e}-092.12000 \mathrm{e}-01$

$1.00000 \mathrm{e}-05$ 1.00000e-05 1.00000e-06 1.00000e-09 1.00000e-01

$1.00000 \mathrm{e}+001.00000 \mathrm{e}+001.00000 \mathrm{e}-011.00000 \mathrm{e}-091.00000 \mathrm{e}-01$

1.00000e-06 1.00000e-06 1.00000e-06 1.00000e-09 5.00000e-02

Element: 12272 \# of layers: 5

Kx Ky Kz Ss Por 
$9.92001 \mathrm{e}+019.92001 \mathrm{e}+01$ 9.92001e+00 1.00000e-09 2.12000e-01 $9.92001 \mathrm{e}+019.92001 \mathrm{e}+019.92001 \mathrm{e}+001.00000 \mathrm{e}-092.12000 \mathrm{e}-01$ $1.00000 \mathrm{e}-05$ 1.00000e-05 1.00000e-06 1.00000e-09 1.00000e-01

$1.00000 \mathrm{e}+001.00000 \mathrm{e}+001.00000 \mathrm{e}-011.00000 \mathrm{e}-091.00000 \mathrm{e}-01$ 1.00000e-06 1.00000e-06 1.00000e-06 1.00000e-09 5.00000e-02

Element: 12273 \# of layers: 5

Kx Ky Kz Ss Por

$9.92001 \mathrm{e}+019.92001 \mathrm{e}+019.92001 \mathrm{e}+00$ 1.00000e-09 2.12000e-01

$9.92001 \mathrm{e}+019.92001 \mathrm{e}+019.92001 \mathrm{e}+001.00000 \mathrm{e}-092.12000 \mathrm{e}-01$

$1.00000 \mathrm{e}-05$ 1.00000e-05 1.00000e-06 1.00000e-09 1.00000e-01

$1.00000 \mathrm{e}+001.00000 \mathrm{e}+001.00000 \mathrm{e}-011.00000 \mathrm{e}-091.00000 \mathrm{e}-01$

$1.00000 \mathrm{e}-06$ 1.00000e-06 1.00000e-06 1.00000e-09 5.00000e-02

Element: 12274 \# of layers: 5

Kx Ky Kz Ss Por

$9.92001 \mathrm{e}+019.92001 \mathrm{e}+01$ 9.92001e+00 1.00000e-09 2.12000e-01

$9.92001 \mathrm{e}+019.92001 \mathrm{e}+019.92001 \mathrm{e}+001.00000 \mathrm{e}-092.12000 \mathrm{e}-01$

$1.00000 \mathrm{e}-05$ 1.00000e-05 1.00000e-06 1.00000e-09 1.00000e-01

$1.00000 \mathrm{e}+001.00000 \mathrm{e}+001.00000 \mathrm{e}-011.00000 \mathrm{e}-091.00000 \mathrm{e}-01$

$1.00000 \mathrm{e}-06$ 1.00000e-06 1.00000e-06 1.00000e-09 5.00000e-02

Element: 12275 \# of layers: 5

Kx Ky Kz Ss Por

$9.92001 \mathrm{e}+019.92001 \mathrm{e}+01$ 9.92001e+00 1.00000e-09 2.12000e-01

$9.92001 \mathrm{e}+019.92001 \mathrm{e}+019.92001 \mathrm{e}+001.00000 \mathrm{e}-092.12000 \mathrm{e}-01$

$1.00000 \mathrm{e}-05$ 1.00000e-05 1.00000e-06 1.00000e-09 1.00000e-01

$1.00000 \mathrm{e}+001.00000 \mathrm{e}+001.00000 \mathrm{e}-011.00000 \mathrm{e}-091.00000 \mathrm{e}-01$

$1.00000 \mathrm{e}-06$ 1.00000e-06 1.00000e-06 1.00000e-09 5.00000e-02

Element: 12276 \# of layers: 5

Kx Ky Kz Ss Por

$9.92001 \mathrm{e}+019.92001 \mathrm{e}+019.92001 \mathrm{e}+001.00000 \mathrm{e}-092.12000 \mathrm{e}-01$

$9.92001 \mathrm{e}+019.92001 \mathrm{e}+019.92001 \mathrm{e}+001.00000 \mathrm{e}-092.12000 \mathrm{e}-01$

$1.00000 \mathrm{e}-05$ 1.00000e-05 1.00000e-06 1.00000e-09 1.00000e-01

$1.00000 \mathrm{e}+001.00000 \mathrm{e}+001.00000 \mathrm{e}-011.00000 \mathrm{e}-091.00000 \mathrm{e}-01$

1.00000e-06 1.00000e-06 1.00000e-06 1.00000e-09 5.00000e-02

Element: 12277 \# of layers: 5

Kx Ky Kz Ss Por

$9.92001 \mathrm{e}+019.92001 \mathrm{e}+01$ 9.92001e+00 1.00000e-09 2.12000e-01

$9.92001 \mathrm{e}+019.92001 \mathrm{e}+019.92001 \mathrm{e}+001.00000 \mathrm{e}-092.12000 \mathrm{e}-01$

$1.00000 \mathrm{e}-05$ 1.00000e-05 1.00000e-06 1.00000e-09 1.00000e-01

$1.00000 \mathrm{e}+001.00000 \mathrm{e}+001.00000 \mathrm{e}-011.00000 \mathrm{e}-091.00000 \mathrm{e}-01$

$1.00000 \mathrm{e}-06$ 1.00000e-06 1.00000e-06 1.00000e-09 5.00000e-02

Element: 12278 \# of layers: 6

Kx Ky Kz Ss Por

$9.92001 \mathrm{e}+019.92001 \mathrm{e}+01$ 9.92001e+00 1.00000e-09 2.12000e-01

$9.92001 \mathrm{e}+019.92001 \mathrm{e}+019.92001 \mathrm{e}+001.00000 \mathrm{e}-092.12000 \mathrm{e}-01$

$9.92001 \mathrm{e}+019.92001 \mathrm{e}+019.92001 \mathrm{e}+001.00000 \mathrm{e}-092.12000 \mathrm{e}-01$

$1.00000 \mathrm{e}-05$ 1.00000e-05 1.00000e-06 1.00000e-09 1.00000e-01 
$1.00000 \mathrm{e}+001.00000 \mathrm{e}+001.00000 \mathrm{e}-011.00000 \mathrm{e}-091.00000 \mathrm{e}-01$ 1.00000e-06 1.00000e-06 1.00000e-06 1.00000e-09 5.00000e-02

Element: 12279 \# of layers: 5

Kx Ky Kz Ss Por

9.92001e+01 9.92001e+01 9.92001e+00 1.00000e-09 2.12000e-01

$9.92001 \mathrm{e}+019.92001 \mathrm{e}+019.92001 \mathrm{e}+001.00000 \mathrm{e}-092.12000 \mathrm{e}-01$

$1.00000 \mathrm{e}-05$ 1.00000e-05 1.00000e-06 1.00000e-09 1.00000e-01

$1.00000 \mathrm{e}+001.00000 \mathrm{e}+001.00000 \mathrm{e}-011.00000 \mathrm{e}-091.00000 \mathrm{e}-01$

1.00000e-06 1.00000e-06 1.00000e-06 1.00000e-09 5.00000e-02

Element: 12280 \# of layers: 5

$\mathrm{Kx} \mathrm{Ky} \mathrm{Kz}$ Ss Por

$2.02867 \mathrm{e}+012.02867 \mathrm{e}+012.02867 \mathrm{e}+00$ 1.00000e-09 2.12000e-01

$2.02867 \mathrm{e}+012.02867 \mathrm{e}+012.02867 \mathrm{e}+00$ 1.00000e-09 2.12000e-01

$1.00000 \mathrm{e}-05$ 1.00000e-05 1.00000e-06 1.00000e-09 1.00000e-01

$1.00000 \mathrm{e}+001.00000 \mathrm{e}+001.00000 \mathrm{e}-011.00000 \mathrm{e}-091.00000 \mathrm{e}-01$

1.00000e-06 1.00000e-06 1.00000e-06 1.00000e-09 5.00000e-02

Element: 12281 \# of layers: 5

$\mathrm{Kx} \mathrm{Ky} \mathrm{Kz}$ Ss Por

2.02867e+01 2.02867e+01 2.02867e+00 1.00000e-09 2.12000e-01

$2.02867 \mathrm{e}+012.02867 \mathrm{e}+012.02867 \mathrm{e}+00$ 1.00000e-09 2.12000e-01

$1.00000 \mathrm{e}-05$ 1.00000e-05 1.00000e-06 1.00000e-09 1.00000e-01

$1.00000 \mathrm{e}+001.00000 \mathrm{e}+001.00000 \mathrm{e}-011.00000 \mathrm{e}-091.00000 \mathrm{e}-01$

1.00000e-06 1.00000e-06 1.00000e-06 1.00000e-09 5.00000e-02

Element: 12282 \# of layers: 4

$\mathrm{Kx} \mathrm{Ky} \mathrm{Kz}$ Ss Por

$2.02867 \mathrm{e}+012.02867 \mathrm{e}+012.02867 \mathrm{e}+001.00000 \mathrm{e}-092.12000 \mathrm{e}-01$

$2.02867 \mathrm{e}+012.02867 \mathrm{e}+012.02867 \mathrm{e}+00$ 1.00000e-09 2.12000e-01

$1.00000 \mathrm{e}-05$ 1.00000e-05 1.00000e-06 1.00000e-09 1.00000e-01

$1.00000 \mathrm{e}+001.00000 \mathrm{e}+001.00000 \mathrm{e}-011.00000 \mathrm{e}-091.00000 \mathrm{e}-01$

Element: 12283 \# of layers: 4

$\mathrm{Kx} \mathrm{Ky} \mathrm{Kz}$ Ss Por

9.92001e+01 9.92001e+01 9.92001e+00 1.00000e-09 2.12000e-01

$9.92001 \mathrm{e}+019.92001 \mathrm{e}+019.92001 \mathrm{e}+001.00000 \mathrm{e}-092.12000 \mathrm{e}-01$

$1.00000 \mathrm{e}-05$ 1.00000e-05 1.00000e-06 1.00000e-09 1.00000e-01

$1.00000 \mathrm{e}+001.00000 \mathrm{e}+001.00000 \mathrm{e}-01$ 1.00000e-09 1.00000e-01

Element: 12284 \# of layers: 6

Kx Ky Kz Ss Por

9.92001e+01 9.92001e+01 9.92001e+00 1.00000e-09 2.12000e-01

$9.92001 \mathrm{e}+019.92001 \mathrm{e}+01$ 9.92001e+00 1.00000e-09 2.12000e-01

$9.92001 \mathrm{e}+019.92001 \mathrm{e}+019.92001 \mathrm{e}+001.00000 \mathrm{e}-092.12000 \mathrm{e}-01$

$1.00000 \mathrm{e}-05$ 1.00000e-05 1.00000e-06 1.00000e-09 1.00000e-01

$1.00000 \mathrm{e}+001.00000 \mathrm{e}+001.00000 \mathrm{e}-011.00000 \mathrm{e}-091.00000 \mathrm{e}-01$

1.00000e-06 1.00000e-06 1.00000e-06 1.00000e-09 5.00000e-02

Element: 12285 \# of layers: 6

$\mathrm{Kx} \mathrm{Ky} \mathrm{Kz}$ Ss Por

9.92001e+01 9.92001e+01 9.92001e+00 1.00000e-09 2.12000e-01 
$9.92001 \mathrm{e}+019.92001 \mathrm{e}+01$ 9.92001e+00 1.00000e-09 2.12000e-01 $9.92001 \mathrm{e}+019.92001 \mathrm{e}+019.92001 \mathrm{e}+001.00000 \mathrm{e}-092.12000 \mathrm{e}-01$ $1.00000 \mathrm{e}-05$ 1.00000e-05 1.00000e-06 1.00000e-09 1.00000e-01 $1.00000 \mathrm{e}+001.00000 \mathrm{e}+001.00000 \mathrm{e}-011.00000 \mathrm{e}-091.00000 \mathrm{e}-01$ $1.00000 \mathrm{e}-06$ 1.00000e-06 1.00000e-06 1.00000e-09 5.00000e-02

Element: 12286 \# of layers: 5

Kx Ky Kz Ss Por

$9.92001 \mathrm{e}+019.92001 \mathrm{e}+019.92001 \mathrm{e}+00$ 1.00000e-09 2.12000e-01

$9.92001 \mathrm{e}+019.92001 \mathrm{e}+019.92001 \mathrm{e}+001.00000 \mathrm{e}-092.12000 \mathrm{e}-01$ $1.00000 \mathrm{e}-05$ 1.00000e-05 1.00000e-06 1.00000e-09 1.00000e-01 $1.00000 \mathrm{e}+001.00000 \mathrm{e}+001.00000 \mathrm{e}-011.00000 \mathrm{e}-091.00000 \mathrm{e}-01$ $1.00000 \mathrm{e}-06$ 1.00000e-06 1.00000e-06 1.00000e-09 5.00000e-02 Element: 12287 \# of layers: 4

Kx Ky Kz Ss Por

$2.02867 \mathrm{e}+012.02867 \mathrm{e}+012.02867 \mathrm{e}+00$ 1.00000e-09 2.12000e-01 $2.02867 \mathrm{e}+012.02867 \mathrm{e}+012.02867 \mathrm{e}+001.00000 \mathrm{e}-092.12000 \mathrm{e}-01$ $1.00000 \mathrm{e}-05$ 1.00000e-05 1.00000e-06 1.00000e-09 1.00000e-01 $1.00000 \mathrm{e}+001.00000 \mathrm{e}+001.00000 \mathrm{e}-011.00000 \mathrm{e}-091.00000 \mathrm{e}-01$ Element: 12288 \# of layers: 4

Kx Ky Kz Ss Por $2.02867 \mathrm{e}+012.02867 \mathrm{e}+012.02867 \mathrm{e}+00$ 1.00000e-09 2.12000e-01 $2.02867 \mathrm{e}+012.02867 \mathrm{e}+012.02867 \mathrm{e}+00$ 1.00000e-09 2.12000e-01 $1.00000 \mathrm{e}-05$ 1.00000e-05 1.00000e-06 1.00000e-09 1.00000e-01 $1.00000 \mathrm{e}+001.00000 \mathrm{e}+001.00000 \mathrm{e}-011.00000 \mathrm{e}-091.00000 \mathrm{e}-01$ Element: 12289 \# of layers: 4

Kx Ky Kz Ss Por

$2.02867 \mathrm{e}+012.02867 \mathrm{e}+012.02867 \mathrm{e}+00$ 1.00000e-09 2.12000e-01 $2.02867 \mathrm{e}+012.02867 \mathrm{e}+012.02867 \mathrm{e}+001.00000 \mathrm{e}-092.12000 \mathrm{e}-01$ $1.00000 \mathrm{e}-05$ 1.00000e-05 1.00000e-06 1.00000e-09 1.00000e-01 $1.00000 \mathrm{e}+001.00000 \mathrm{e}+001.00000 \mathrm{e}-011.00000 \mathrm{e}-091.00000 \mathrm{e}-01$ Element: 12290 \# of layers: 4

Kx Ky Kz Ss Por $2.02867 \mathrm{e}+012.02867 \mathrm{e}+012.02867 \mathrm{e}+00$ 1.00000e-09 2.12000e-01 $2.02867 \mathrm{e}+012.02867 \mathrm{e}+012.02867 \mathrm{e}+001.00000 \mathrm{e}-092.12000 \mathrm{e}-01$ $1.00000 \mathrm{e}-05$ 1.00000e-05 1.00000e-06 1.00000e-09 1.00000e-01 $1.00000 \mathrm{e}+001.00000 \mathrm{e}+001.00000 \mathrm{e}-011.00000 \mathrm{e}-091.00000 \mathrm{e}-01$ Element: 12291 \# of layers: 4

Kx Ky Kz Ss Por $2.02867 \mathrm{e}+012.02867 \mathrm{e}+012.02867 \mathrm{e}+00$ 1.00000e-09 2.12000e-01 $2.02867 \mathrm{e}+012.02867 \mathrm{e}+012.02867 \mathrm{e}+001.00000 \mathrm{e}-092.12000 \mathrm{e}-01$ $1.00000 \mathrm{e}-051.00000 \mathrm{e}-05$ 1.00000e-06 1.00000e-09 1.00000e-01 $1.00000 \mathrm{e}+001.00000 \mathrm{e}+001.00000 \mathrm{e}-011.00000 \mathrm{e}-091.00000 \mathrm{e}-01$ Element: 12292 \# of layers: 4

Kx Ky Kz Ss Por $2.02867 \mathrm{e}+012.02867 \mathrm{e}+012.02867 \mathrm{e}+00$ 1.00000e-09 2.12000e-01 $2.02867 \mathrm{e}+012.02867 \mathrm{e}+012.02867 \mathrm{e}+001.00000 \mathrm{e}-092.12000 \mathrm{e}-01$ 
$1.00000 \mathrm{e}-05$ 1.00000e-05 1.00000e-06 1.00000e-09 1.00000e-01 $1.00000 \mathrm{e}+001.00000 \mathrm{e}+001.00000 \mathrm{e}-01$ 1.00000e-09 1.00000e-01 Element: 12293 \# of layers: 4

Kx Ky Kz Ss Por

$2.02867 \mathrm{e}+012.02867 \mathrm{e}+012.02867 \mathrm{e}+00$ 1.00000e-09 2.12000e-01 $2.02867 \mathrm{e}+012.02867 \mathrm{e}+012.02867 \mathrm{e}+00$ 1.00000e-09 2.12000e-01 $1.00000 \mathrm{e}-05$ 1.00000e-05 1.00000e-06 1.00000e-09 1.00000e-01 $1.00000 \mathrm{e}+001.00000 \mathrm{e}+001.00000 \mathrm{e}-01$ 1.00000e-09 1.00000e-01 Element: 12294 \# of layers: 4

$\mathrm{Kx} \mathrm{Ky} \mathrm{Kz}$ Ss Por

$2.02867 \mathrm{e}+012.02867 \mathrm{e}+012.02867 \mathrm{e}+00$ 1.00000e-09 2.12000e-01 $2.02867 \mathrm{e}+012.02867 \mathrm{e}+012.02867 \mathrm{e}+001.00000 \mathrm{e}-092.12000 \mathrm{e}-01$ $1.00000 \mathrm{e}-05$ 1.00000e-05 1.00000e-06 1.00000e-09 1.00000e-01 $1.00000 \mathrm{e}+001.00000 \mathrm{e}+001.00000 \mathrm{e}-011.00000 \mathrm{e}-09$ 1.00000e-01 Element: 12295 \# of layers: 4

Kx Ky Kz Ss Por

$2.02867 \mathrm{e}+012.02867 \mathrm{e}+012.02867 \mathrm{e}+00$ 1.00000e-09 2.12000e-01 $2.02867 \mathrm{e}+012.02867 \mathrm{e}+012.02867 \mathrm{e}+001.00000 \mathrm{e}-092.12000 \mathrm{e}-01$ $1.00000 \mathrm{e}-05$ 1.00000e-05 1.00000e-06 1.00000e-09 1.00000e-01 $1.00000 \mathrm{e}+001.00000 \mathrm{e}+001.00000 \mathrm{e}-011.00000 \mathrm{e}-091.00000 \mathrm{e}-01$ Element: 12296 \# of layers: 4

$\mathrm{Kx} \mathrm{Ky} \mathrm{Kz}$ Ss Por

$2.02867 \mathrm{e}+012.02867 \mathrm{e}+012.02867 \mathrm{e}+00$ 1.00000e-09 2.12000e-01 $2.02867 \mathrm{e}+012.02867 \mathrm{e}+012.02867 \mathrm{e}+001.00000 \mathrm{e}-092.12000 \mathrm{e}-01$ $1.00000 \mathrm{e}-051.00000 \mathrm{e}-05$ 1.00000e-06 1.00000e-09 1.00000e-01 $1.00000 \mathrm{e}+001.00000 \mathrm{e}+001.00000 \mathrm{e}-01$ 1.00000e-09 1.00000e-01 Element: 12297 \# of layers: 4

$\mathrm{Kx} \mathrm{Ky} \mathrm{Kz}$ Ss Por

$1.76959 \mathrm{e}+01$ 1.76959e+01 1.76959e+00 1.00000e-09 2.12000e-01

$1.76959 \mathrm{e}+01$ 1.76959e+01 1.76959e+00 1.00000e-09 2.12000e-01 $1.00000 \mathrm{e}-05$ 1.00000e-05 1.00000e-06 1.00000e-09 1.00000e-01 $1.00000 \mathrm{e}+001.00000 \mathrm{e}+001.00000 \mathrm{e}-011.00000 \mathrm{e}-091.00000 \mathrm{e}-01$ Element: 12298 \# of layers: 4

$\mathrm{Kx} \mathrm{Ky} \mathrm{Kz}$ Ss Por

$1.76959 \mathrm{e}+01$ 1.76959e+01 1.76959e+00 1.00000e-09 2.12000e-01 $1.76959 \mathrm{e}+01$ 1.76959e+01 1.76959e+00 1.00000e-09 2.12000e-01 1.00000e-05 1.00000e-05 1.00000e-06 1.00000e-09 1.00000e-01 $1.00000 \mathrm{e}+001.00000 \mathrm{e}+001.00000 \mathrm{e}-011.00000 \mathrm{e}-091.00000 \mathrm{e}-01$ Element: 12299 \# of layers: 4

$\mathrm{Kx} \mathrm{Ky} \mathrm{Kz}$ Ss Por

$1.76959 e+01$ 1.76959e+01 1.76959e+00 1.00000e-09 2.12000e-01 $1.76959 \mathrm{e}+01$ 1.76959e+01 1.76959e+00 1.00000e-09 2.12000e-01 $1.00000 \mathrm{e}-05$ 1.00000e-05 1.00000e-06 1.00000e-09 1.00000e-01 $1.00000 \mathrm{e}+001.00000 \mathrm{e}+001.00000 \mathrm{e}-011.00000 \mathrm{e}-091.00000 \mathrm{e}-01$ Element: 12300 \# of layers: 4

Kx Ky Kz Ss Por 
$1.76959 \mathrm{e}+011.76959 \mathrm{e}+011.76959 \mathrm{e}+00$ 1.00000e-09 2.12000e-01 $1.76959 \mathrm{e}+011.76959 \mathrm{e}+011.76959 \mathrm{e}+00$ 1.00000e-09 2.12000e-01 $1.00000 \mathrm{e}-05$ 1.00000e-05 1.00000e-06 1.00000e-09 1.00000e-01 $1.00000 \mathrm{e}+001.00000 \mathrm{e}+001.00000 \mathrm{e}-011.00000 \mathrm{e}-091.00000 \mathrm{e}-01$ Element: 12301 \# of layers: 4

Kx Ky Kz Ss Por

$1.76959 \mathrm{e}+011.76959 \mathrm{e}+01$ 1.76959e+00 1.00000e-09 2.12000e-01 $1.76959 \mathrm{e}+011.76959 \mathrm{e}+011.76959 \mathrm{e}+001.00000 \mathrm{e}-092.12000 \mathrm{e}-01$ $1.00000 \mathrm{e}-05$ 1.00000e-05 1.00000e-06 1.00000e-09 1.00000e-01 $1.00000 \mathrm{e}+001.00000 \mathrm{e}+001.00000 \mathrm{e}-011.00000 \mathrm{e}-091.00000 \mathrm{e}-01$ Element: 12302 \# of layers: 4

Kx Ky Kz Ss Por

$2.02867 \mathrm{e}+012.02867 \mathrm{e}+012.02867 \mathrm{e}+00$ 1.00000e-09 2.12000e-01 $2.02867 \mathrm{e}+012.02867 \mathrm{e}+012.02867 \mathrm{e}+001.00000 \mathrm{e}-092.12000 \mathrm{e}-01$ $1.00000 \mathrm{e}-05$ 1.00000e-05 1.00000e-06 1.00000e-09 1.00000e-01 $1.00000 \mathrm{e}+001.00000 \mathrm{e}+001.00000 \mathrm{e}-011.00000 \mathrm{e}-091.00000 \mathrm{e}-01$ Element: 12303 \# of layers: 4

Kx Ky Kz Ss Por

$2.02867 \mathrm{e}+012.02867 \mathrm{e}+012.02867 \mathrm{e}+00$ 1.00000e-09 2.12000e-01 $2.02867 \mathrm{e}+012.02867 \mathrm{e}+012.02867 \mathrm{e}+001.00000 \mathrm{e}-092.12000 \mathrm{e}-01$ $1.00000 \mathrm{e}-05$ 1.00000e-05 1.00000e-06 1.00000e-09 1.00000e-01 $1.00000 \mathrm{e}+001.00000 \mathrm{e}+001.00000 \mathrm{e}-011.00000 \mathrm{e}-091.00000 \mathrm{e}-01$ Element: 12304 \# of layers: 4

Kx Ky Kz Ss Por

$1.76959 \mathrm{e}+011.76959 \mathrm{e}+011.76959 \mathrm{e}+00$ 1.00000e-09 2.12000e-01

$1.76959 \mathrm{e}+011.76959 \mathrm{e}+011.76959 \mathrm{e}+00$ 1.00000e-09 2.12000e-01 $1.00000 \mathrm{e}-05$ 1.00000e-05 1.00000e-06 1.00000e-09 1.00000e-01 $1.00000 \mathrm{e}+001.00000 \mathrm{e}+001.00000 \mathrm{e}-011.00000 \mathrm{e}-091.00000 \mathrm{e}-01$ Element: 12305 \# of layers: 4

Kx Ky Kz Ss Por

$1.76959 \mathrm{e}+011.76959 \mathrm{e}+011.76959 \mathrm{e}+00$ 1.00000e-09 2.12000e-01 $1.76959 \mathrm{e}+011.76959 \mathrm{e}+011.76959 \mathrm{e}+00$ 1.00000e-09 2.12000e-01 $1.00000 \mathrm{e}-05$ 1.00000e-05 1.00000e-06 1.00000e-09 1.00000e-01 $1.00000 \mathrm{e}+001.00000 \mathrm{e}+001.00000 \mathrm{e}-011.00000 \mathrm{e}-091.00000 \mathrm{e}-01$ Element: 12306 \# of layers: 4

Kx Ky Kz Ss Por $2.05587 \mathrm{e}+012.05587 \mathrm{e}+012.05587 \mathrm{e}+00$ 1.00000e-09 2.12000e-01 $2.05587 \mathrm{e}+012.05587 \mathrm{e}+012.05587 \mathrm{e}+001.00000 \mathrm{e}-092.12000 \mathrm{e}-01$ $1.00000 \mathrm{e}-05$ 1.00000e-05 1.00000e-06 1.00000e-09 1.00000e-01 $1.00000 \mathrm{e}+001.00000 \mathrm{e}+001.00000 \mathrm{e}-011.00000 \mathrm{e}-091.00000 \mathrm{e}-01$ Element: 12307 \# of layers: 5

Kx Ky Kz Ss Por $2.05587 \mathrm{e}+012.05587 \mathrm{e}+012.05587 \mathrm{e}+00$ 1.00000e-09 2.12000e-01 $2.05587 \mathrm{e}+012.05587 \mathrm{e}+012.05587 \mathrm{e}+001.00000 \mathrm{e}-092.12000 \mathrm{e}-01$ $2.05587 \mathrm{e}+012.05587 \mathrm{e}+012.05587 \mathrm{e}+001.00000 \mathrm{e}-092.12000 \mathrm{e}-01$ $1.00000 \mathrm{e}-05$ 1.00000e-05 1.00000e-06 1.00000e-09 1.00000e-01 
$1.00000 \mathrm{e}+001.00000 \mathrm{e}+00$ 1.00000e-01 1.00000e-09 1.00000e-01

Element: 12308 \# of layers: 5

Kx Ky Kz Ss Por

$2.05587 \mathrm{e}+012.05587 \mathrm{e}+012.05587 \mathrm{e}+00$ 1.00000e-09 2.12000e-01

$2.05587 \mathrm{e}+012.05587 \mathrm{e}+012.05587 \mathrm{e}+001.00000 \mathrm{e}-092.12000 \mathrm{e}-01$

$2.05587 \mathrm{e}+012.05587 \mathrm{e}+012.05587 \mathrm{e}+001.00000 \mathrm{e}-09$ 2.12000e-01

$1.00000 \mathrm{e}-05$ 1.00000e-05 1.00000e-06 1.00000e-09 1.00000e-01

$1.00000 \mathrm{e}+001.00000 \mathrm{e}+001.00000 \mathrm{e}-011.00000 \mathrm{e}-091.00000 \mathrm{e}-01$

Element: 12309 \# of layers: 6

$\mathrm{Kx} \mathrm{Ky} \mathrm{Kz}$ Ss Por

9.92001e+01 9.92001e+01 9.92001e+00 1.00000e-09 2.12000e-01

$9.92001 \mathrm{e}+019.92001 \mathrm{e}+019.92001 \mathrm{e}+001.00000 \mathrm{e}-092.12000 \mathrm{e}-01$

$9.92001 \mathrm{e}+01$ 9.92001e+01 9.92001e+00 1.00000e-09 2.12000e-01

$1.00000 \mathrm{e}-05$ 1.00000e-05 1.00000e-06 1.00000e-09 1.00000e-01

$1.00000 \mathrm{e}+001.00000 \mathrm{e}+001.00000 \mathrm{e}-011.00000 \mathrm{e}-091.00000 \mathrm{e}-01$

1.00000e-06 1.00000e-06 1.00000e-06 1.00000e-09 5.00000e-02

Element: 12310 \# of layers: 4

$\mathrm{Kx} \mathrm{Ky} \mathrm{Kz}$ Ss Por

9.92001e+01 9.92001e+01 9.92001e+00 1.00000e-09 2.12000e-01

$9.92001 \mathrm{e}+019.92001 \mathrm{e}+019.92001 \mathrm{e}+001.00000 \mathrm{e}-092.12000 \mathrm{e}-01$

$1.00000 \mathrm{e}-05$ 1.00000e-05 1.00000e-06 1.00000e-09 1.00000e-01

$1.00000 \mathrm{e}+001.00000 \mathrm{e}+001.00000 \mathrm{e}-011.00000 \mathrm{e}-091.00000 \mathrm{e}-01$

Element: 12311 \# of layers: 4

Kx Ky Kz Ss Por

$2.02867 \mathrm{e}+012.02867 \mathrm{e}+012.02867 \mathrm{e}+00$ 1.00000e-09 2.12000e-01

$2.02867 \mathrm{e}+012.02867 \mathrm{e}+012.02867 \mathrm{e}+00$ 1.00000e-09 2.12000e-01

$1.00000 \mathrm{e}-05$ 1.00000e-05 1.00000e-06 1.00000e-09 1.00000e-01

$1.00000 \mathrm{e}+001.00000 \mathrm{e}+001.00000 \mathrm{e}-01$ 1.00000e-09 1.00000e-01

Element: 12312 \# of layers: 4

$\mathrm{Kx} \mathrm{Ky} \mathrm{Kz}$ Ss Por

$1.76959 \mathrm{e}+01$ 1.76959e+01 1.76959e+00 1.00000e-09 2.12000e-01

$1.76959 \mathrm{e}+01$ 1.76959e+01 1.76959e+00 1.00000e-09 2.12000e-01

$1.00000 \mathrm{e}-05$ 1.00000e-05 1.00000e-06 1.00000e-09 1.00000e-01

$1.00000 \mathrm{e}+001.00000 \mathrm{e}+001.00000 \mathrm{e}-01$ 1.00000e-09 1.00000e-01

Element: 12313 \# of layers: 4

Kx Ky Kz Ss Por

$2.05587 \mathrm{e}+012.05587 \mathrm{e}+012.05587 \mathrm{e}+00$ 1.00000e-09 2.12000e-01

$2.05587 \mathrm{e}+012.05587 \mathrm{e}+012.05587 \mathrm{e}+00$ 1.00000e-09 2.12000e-01

$1.00000 \mathrm{e}-05$ 1.00000e-05 1.00000e-06 1.00000e-09 1.00000e-01

$1.00000 \mathrm{e}+001.00000 \mathrm{e}+001.00000 \mathrm{e}-01$ 1.00000e-09 1.00000e-01

Element: 12314 \# of layers: 4

Kx Ky Kz Ss Por

3.10732e+01 3.10732e+01 3.10732e+00 1.00000e-09 2.12000e-01

3.10732e+01 3.10732e+01 3.10732e+00 1.00000e-09 2.12000e-01

$1.00000 \mathrm{e}-05$ 1.00000e-05 1.00000e-06 1.00000e-09 1.00000e-01

$1.00000 \mathrm{e}+001.00000 \mathrm{e}+001.00000 \mathrm{e}-011.00000 \mathrm{e}-091.00000 \mathrm{e}-01$ 
Element: 12315 \# of layers: 4

Kx Ky Kz Ss Por

$3.10732 \mathrm{e}+013.10732 \mathrm{e}+013.10732 \mathrm{e}+00$ 1.00000e-09 2.12000e-01

$3.10732 \mathrm{e}+013.10732 \mathrm{e}+013.10732 \mathrm{e}+001.00000 \mathrm{e}-092.12000 \mathrm{e}-01$

$1.00000 \mathrm{e}-05$ 1.00000e-05 1.00000e-06 1.00000e-09 1.00000e-01

$1.00000 \mathrm{e}+001.00000 \mathrm{e}+001.00000 \mathrm{e}-011.00000 \mathrm{e}-091.00000 \mathrm{e}-01$

Element: 12316 \# of layers: 4

Kx Ky Kz Ss Por

3.10732e+01 3.10732e+01 3.10732e+00 1.00000e-09 2.12000e-01

$3.10732 \mathrm{e}+013.10732 \mathrm{e}+013.10732 \mathrm{e}+001.00000 \mathrm{e}-092.12000 \mathrm{e}-01$

$1.00000 \mathrm{e}-05$ 1.00000e-05 1.00000e-06 1.00000e-09 1.00000e-01

$1.00000 \mathrm{e}+001.00000 \mathrm{e}+001.00000 \mathrm{e}-011.00000 \mathrm{e}-091.00000 \mathrm{e}-01$

Element: 12317 \# of layers: 3

Kx Ky Kz Ss Por

3.10732e+01 3.10732e+01 3.10732e+00 1.00000e-09 2.12000e-01

$1.00000 \mathrm{e}-05$ 1.00000e-05 1.00000e-06 1.00000e-09 1.00000e-01

$1.00000 \mathrm{e}+001.00000 \mathrm{e}+001.00000 \mathrm{e}-011.00000 \mathrm{e}-091.00000 \mathrm{e}-01$

Element: 12318 \# of layers: 3

Kx Ky Kz Ss Por

$3.10732 \mathrm{e}+013.10732 \mathrm{e}+013.10732 \mathrm{e}+00$ 1.00000e-09 2.12000e-01

$1.00000 \mathrm{e}-05$ 1.00000e-05 1.00000e-06 1.00000e-09 1.00000e-01

$1.00000 \mathrm{e}+001.00000 \mathrm{e}+001.00000 \mathrm{e}-011.00000 \mathrm{e}-091.00000 \mathrm{e}-01$

Element: 12319 \# of layers: 3

Kx Ky Kz Ss Por

3.10732e+01 3.10732e+01 3.10732e+00 1.00000e-09 2.12000e-01

$1.00000 \mathrm{e}-05$ 1.00000e-05 1.00000e-06 1.00000e-09 1.00000e-01

$1.00000 \mathrm{e}+001.00000 \mathrm{e}+001.00000 \mathrm{e}-011.00000 \mathrm{e}-091.00000 \mathrm{e}-01$

Element: 12320 \# of layers: 4

Kx Ky Kz Ss Por

$3.10732 \mathrm{e}+013.10732 \mathrm{e}+013.10732 \mathrm{e}+00$ 1.00000e-09 2.12000e-01

$3.10732 \mathrm{e}+013.10732 \mathrm{e}+013.10732 \mathrm{e}+001.00000 \mathrm{e}-092.12000 \mathrm{e}-01$

$1.00000 \mathrm{e}-05$ 1.00000e-05 1.00000e-06 1.00000e-09 1.00000e-01

$1.00000 \mathrm{e}+001.00000 \mathrm{e}+001.00000 \mathrm{e}-011.00000 \mathrm{e}-091.00000 \mathrm{e}-01$

Element: 12321 \# of layers: 4

Kx Ky Kz Ss Por

$3.10732 \mathrm{e}+013.10732 \mathrm{e}+013.10732 \mathrm{e}+00$ 1.00000e-09 2.12000e-01

$3.10732 \mathrm{e}+013.10732 \mathrm{e}+013.10732 \mathrm{e}+00$ 1.00000e-09 2.12000e-01

$1.00000 \mathrm{e}-05$ 1.00000e-05 1.00000e-06 1.00000e-09 1.00000e-01

$1.00000 \mathrm{e}+001.00000 \mathrm{e}+001.00000 \mathrm{e}-011.00000 \mathrm{e}-091.00000 \mathrm{e}-01$

Element: 12322 \# of layers: 4

Kx Ky Kz Ss Por

3.10732e+01 3.10732e+01 3.10732e+00 1.00000e-09 2.12000e-01

$3.10732 \mathrm{e}+013.10732 \mathrm{e}+013.10732 \mathrm{e}+00$ 1.00000e-09 2.12000e-01

$1.00000 \mathrm{e}-05$ 1.00000e-05 1.00000e-06 1.00000e-09 1.00000e-01

$1.00000 \mathrm{e}+001.00000 \mathrm{e}+001.00000 \mathrm{e}-011.00000 \mathrm{e}-091.00000 \mathrm{e}-01$

Element: 12323 \# of layers: 3 
Kx Ky Kz Ss Por

3.10732e+01 3.10732e+01 3.10732e+00 1.00000e-09 2.12000e-01

$1.00000 \mathrm{e}-05$ 1.00000e-05 1.00000e-06 1.00000e-09 1.00000e-01

$1.00000 \mathrm{e}+001.00000 \mathrm{e}+001.00000 \mathrm{e}-011.00000 \mathrm{e}-091.00000 \mathrm{e}-01$

Element: 12324 \# of layers: 3

$\mathrm{Kx} \mathrm{Ky} \mathrm{Kz}$ Ss Por

2.29325e+02 2.29325e+02 2.29325e+01 1.00000e-09 2.12000e-01

$1.00000 \mathrm{e}-05$ 1.00000e-05 1.00000e-06 1.00000e-09 1.00000e-01

$1.00000 \mathrm{e}+001.00000 \mathrm{e}+001.00000 \mathrm{e}-01$ 1.00000e-09 1.00000e-01

Element: 12325 \# of layers: 4

Kx Ky Kz Ss Por

5.73910e+03 5.73910e+03 5.73910e+02 1.00000e-09 7.00000e-02

$2.29325 \mathrm{e}+02$ 2.29325e+02 2.29325e+01 1.00000e-09 2.12000e-01

$1.00000 \mathrm{e}-05$ 1.00000e-05 1.00000e-06 1.00000e-09 1.00000e-01

$1.00000 \mathrm{e}+001.00000 \mathrm{e}+001.00000 \mathrm{e}-01$ 1.00000e-09 1.00000e-01

Element: 12326 \# of layers: 4

Kx Ky Kz Ss Por

5.73910e+03 5.73910e+03 5.73910e+02 1.00000e-09 7.00000e-02

$2.29325 \mathrm{e}+02$ 2.29325e+02 2.29325e+01 1.00000e-09 2.12000e-01

$1.00000 \mathrm{e}-05$ 1.00000e-05 1.00000e-06 1.00000e-09 1.00000e-01

$1.00000 \mathrm{e}+001.00000 \mathrm{e}+001.00000 \mathrm{e}-011.00000 \mathrm{e}-091.00000 \mathrm{e}-01$

Element: 12327 \# of layers: 5

Kx Ky Kz Ss Por

5.73910e+03 5.73910e+03 5.73910e+02 1.00000e-09 7.00000e-02

$2.29325 \mathrm{e}+02$ 2.29325e+02 2.29325e+01 1.00000e-09 2.12000e-01

$1.00000 \mathrm{e}-05$ 1.00000e-05 1.00000e-06 1.00000e-09 1.00000e-01

$1.00000 \mathrm{e}+001.00000 \mathrm{e}+001.00000 \mathrm{e}-011.00000 \mathrm{e}-091.00000 \mathrm{e}-01$

1.00000e-06 1.00000e-06 1.00000e-06 1.00000e-09 5.00000e-02

Element: 12328 \# of layers: 4

$\mathrm{Kx} \mathrm{Ky} \mathrm{Kz}$ Ss Por

2.29325e+02 2.29325e+02 2.29325e+01 1.00000e-09 2.12000e-01

$1.00000 \mathrm{e}-051.00000 \mathrm{e}-051.00000 \mathrm{e}-061.00000 \mathrm{e}-091.00000 \mathrm{e}-01$

$1.00000 \mathrm{e}+001.00000 \mathrm{e}+001.00000 \mathrm{e}-011.00000 \mathrm{e}-091.00000 \mathrm{e}-01$

1.00000e-06 1.00000e-06 1.00000e-06 1.00000e-09 5.00000e-02

Element: 12329 \# of layers: 4

Kx Ky Kz Ss Por

3.10732e+01 3.10732e+01 3.10732e+00 1.00000e-09 2.12000e-01

$1.00000 \mathrm{e}-05$ 1.00000e-05 1.00000e-06 1.00000e-09 1.00000e-01

$1.00000 \mathrm{e}+001.00000 \mathrm{e}+001.00000 \mathrm{e}-011.00000 \mathrm{e}-091.00000 \mathrm{e}-01$

1.00000e-06 1.00000e-06 1.00000e-06 1.00000e-09 5.00000e-02

Element: 12330 \# of layers: 3

Kx Ky Kz Ss Por

3.10732e+01 3.10732e+01 3.10732e+00 1.00000e-09 2.12000e-01

$1.00000 \mathrm{e}-05$ 1.00000e-05 1.00000e-06 1.00000e-09 1.00000e-01

$1.00000 \mathrm{e}+001.00000 \mathrm{e}+001.00000 \mathrm{e}-01$ 1.00000e-09 1.00000e-01

Element: 12331 \# of layers: 3 
$\mathrm{Kx} \mathrm{Ky} \mathrm{Kz}$ Ss Por

2.29325e+02 2.29325e+02 2.29325e+01 1.00000e-09 2.12000e-01

$1.00000 \mathrm{e}-05$ 1.00000e-05 1.00000e-06 1.00000e-09 1.00000e-01

$1.00000 \mathrm{e}+001.00000 \mathrm{e}+001.00000 \mathrm{e}-011.00000 \mathrm{e}-091.00000 \mathrm{e}-01$

Element: 12332 \# of layers: 5

$\mathrm{Kx} \mathrm{Ky} \mathrm{Kz}$ Ss Por

5.73910e+03 5.73910e+03 5.73910e+02 1.00000e-09 7.00000e-02

$2.29325 \mathrm{e}+02$ 2.29325e+02 2.29325e+01 1.00000e-09 2.12000e-01

$1.00000 \mathrm{e}-05$ 1.00000e-05 1.00000e-06 1.00000e-09 1.00000e-01

$1.00000 \mathrm{e}+001.00000 \mathrm{e}+001.00000 \mathrm{e}-01$ 1.00000e-09 1.00000e-01

1.00000e-06 1.00000e-06 1.00000e-06 1.00000e-09 5.00000e-02

Element: 12333 \# of layers: 5

$\mathrm{Kx} \mathrm{Ky} \mathrm{Kz}$ Ss Por

5.73910e+03 5.73910e+03 5.73910e+02 1.00000e-09 7.00000e-02

$2.29325 \mathrm{e}+022.29325 \mathrm{e}+02$ 2.29325e+01 1.00000e-09 2.12000e-01

$1.00000 \mathrm{e}-05$ 1.00000e-05 1.00000e-06 1.00000e-09 1.00000e-01

$1.00000 \mathrm{e}+001.00000 \mathrm{e}+001.00000 \mathrm{e}-011.00000 \mathrm{e}-091.00000 \mathrm{e}-01$

1.00000e-06 1.00000e-06 1.00000e-06 1.00000e-09 5.00000e-02

Element: 12334 \# of layers: 5

Kx Ky Kz Ss Por

5.73910e+03 5.73910e+03 5.73910e+02 1.00000e-09 7.00000e-02

$2.29325 \mathrm{e}+02$ 2.29325e+02 2.29325e+01 1.00000e-09 2.12000e-01

$1.00000 \mathrm{e}-05$ 1.00000e-05 1.00000e-06 1.00000e-09 1.00000e-01

$1.00000 \mathrm{e}+001.00000 \mathrm{e}+001.00000 \mathrm{e}-011.00000 \mathrm{e}-091.00000 \mathrm{e}-01$

$1.00000 \mathrm{e}-06$ 1.00000e-06 1.00000e-06 1.00000e-09 5.00000e-02

Element: 12335 \# of layers: 5

Kx Ky Kz Ss Por

5.73910e+03 5.73910e+03 5.73910e+02 1.00000e-09 7.00000e-02

$2.29325 \mathrm{e}+02$ 2.29325e+02 2.29325e+01 1.00000e-09 2.12000e-01

$1.00000 \mathrm{e}-05$ 1.00000e-05 1.00000e-06 1.00000e-09 1.00000e-01

$1.00000 \mathrm{e}+001.00000 \mathrm{e}+001.00000 \mathrm{e}-01$ 1.00000e-09 1.00000e-01

1.00000e-06 1.00000e-06 1.00000e-06 1.00000e-09 5.00000e-02

Element: 12336 \# of layers: 5

$\mathrm{Kx} \mathrm{Ky} \mathrm{Kz}$ Ss Por

5.73910e+03 5.73910e+03 5.73910e+02 1.00000e-09 7.00000e-02

$2.29325 \mathrm{e}+02$ 2.29325e+02 2.29325e+01 1.00000e-09 2.12000e-01

1.00000e-05 1.00000e-05 1.00000e-06 1.00000e-09 1.00000e-01

$1.00000 \mathrm{e}+001.00000 \mathrm{e}+001.00000 \mathrm{e}-011.00000 \mathrm{e}-091.00000 \mathrm{e}-01$

1.00000e-06 1.00000e-06 1.00000e-06 1.00000e-09 5.00000e-02

Element: 12337 \# of layers: 5

Kx Ky Kz Ss Por

5.73910e+03 5.73910e+03 5.73910e+02 1.00000e-09 7.00000e-02

$2.29325 \mathrm{e}+02$ 2.29325e+02 2.29325e+01 1.00000e-09 2.12000e-01

$1.00000 \mathrm{e}-05$ 1.00000e-05 1.00000e-06 1.00000e-09 1.00000e-01

$1.00000 \mathrm{e}+001.00000 \mathrm{e}+001.00000 \mathrm{e}-011.00000 \mathrm{e}-091.00000 \mathrm{e}-01$

$1.00000 \mathrm{e}-06$ 1.00000e-06 1.00000e-06 1.00000e-09 5.00000e-02 
Element: 12338 \# of layers: 5

$\mathrm{Kx} \mathrm{Ky} \mathrm{Kz}$ Ss Por

5.73910e+03 5.73910e+03 5.73910e+02 1.00000e-09 7.00000e-02

$2.29325 \mathrm{e}+02$ 2.29325e+02 2.29325e+01 1.00000e-09 2.12000e-01

$1.00000 \mathrm{e}-05$ 1.00000e-05 1.00000e-06 1.00000e-09 1.00000e-01

$1.00000 \mathrm{e}+001.00000 \mathrm{e}+001.00000 \mathrm{e}-011.00000 \mathrm{e}-091.00000 \mathrm{e}-01$

1.00000e-06 1.00000e-06 1.00000e-06 1.00000e-09 5.00000e-02

Element: 12339 \# of layers: 5

$\mathrm{Kx} \mathrm{Ky} \mathrm{Kz}$ Ss Por

5.73910e+03 5.73910e+03 5.73910e+02 1.00000e-09 7.00000e-02

$2.29325 \mathrm{e}+02$ 2.29325e+02 2.29325e+01 1.00000e-09 2.12000e-01

$1.00000 \mathrm{e}-05$ 1.00000e-05 1.00000e-06 1.00000e-09 1.00000e-01

$1.00000 \mathrm{e}+001.00000 \mathrm{e}+001.00000 \mathrm{e}-011.00000 \mathrm{e}-091.00000 \mathrm{e}-01$

1.00000e-06 1.00000e-06 1.00000e-06 1.00000e-09 5.00000e-02

Element: 12340 \# of layers: 5

Kx Ky Kz Ss Por

5.73910e+03 5.73910e+03 5.73910e+02 1.00000e-09 7.00000e-02

$2.29325 \mathrm{e}+02$ 2.29325e+02 2.29325e+01 1.00000e-09 2.12000e-01

$1.00000 \mathrm{e}-05$ 1.00000e-05 1.00000e-06 1.00000e-09 1.00000e-01

$1.00000 \mathrm{e}+001.00000 \mathrm{e}+001.00000 \mathrm{e}-011.00000 \mathrm{e}-091.00000 \mathrm{e}-01$

$1.00000 \mathrm{e}-06$ 1.00000e-06 1.00000e-06 1.00000e-09 5.00000e-02

Element: 12341 \# of layers: 5

$\mathrm{Kx} \mathrm{Ky} \mathrm{Kz}$ Ss Por

2.93816e+03 2.93816e+03 2.93816e+02 1.00000e-09 7.00000e-02

$1.17398 \mathrm{e}+02$ 1.17398e+02 1.17399e+01 1.00000e-09 2.12000e-01

$1.00000 \mathrm{e}-05$ 1.00000e-05 1.00000e-06 1.00000e-09 1.00000e-01

$1.00000 \mathrm{e}+001.00000 \mathrm{e}+001.00000 \mathrm{e}-011.00000 \mathrm{e}-091.00000 \mathrm{e}-01$

1.00000e-06 1.00000e-06 1.00000e-06 1.00000e-09 5.00000e-02

Element: 12342 \# of layers: 5

$\mathrm{Kx} \mathrm{Ky} \mathrm{Kz}$ Ss Por

5.73910e+03 5.73910e+03 5.73910e+02 1.00000e-09 7.00000e-02

$2.29325 \mathrm{e}+02$ 2.29325e+02 2.29325e+01 1.00000e-09 2.12000e-01

$1.00000 \mathrm{e}-05$ 1.00000e-05 1.00000e-06 1.00000e-09 1.00000e-01

$1.00000 \mathrm{e}+001.00000 \mathrm{e}+001.00000 \mathrm{e}-011.00000 \mathrm{e}-091.00000 \mathrm{e}-01$

1.00000e-06 1.00000e-06 1.00000e-06 1.00000e-09 5.00000e-02

Element: 12343 \# of layers: 5

Kx Ky Kz Ss Por

5.73910e+03 5.73910e+03 5.73910e+02 1.00000e-09 7.00000e-02

$2.29325 \mathrm{e}+02$ 2.29325e+02 2.29325e+01 1.00000e-09 2.12000e-01

$1.00000 \mathrm{e}-05$ 1.00000e-05 1.00000e-06 1.00000e-09 1.00000e-01

$1.00000 \mathrm{e}+001.00000 \mathrm{e}+001.00000 \mathrm{e}-011.00000 \mathrm{e}-091.00000 \mathrm{e}-01$

1.00000e-06 1.00000e-06 1.00000e-06 1.00000e-09 5.00000e-02

Element: 12344 \# of layers: 5

$\mathrm{Kx} \mathrm{Ky} \mathrm{Kz}$ Ss Por

5.73910e+03 5.73910e+03 5.73910e+02 1.00000e-09 7.00000e-02

$2.29325 \mathrm{e}+02$ 2.29325e+02 2.29325e+01 1.00000e-09 2.12000e-01 
$1.00000 \mathrm{e}-05$ 1.00000e-05 1.00000e-06 1.00000e-09 1.00000e-01 $1.00000 \mathrm{e}+001.00000 \mathrm{e}+001.00000 \mathrm{e}-01$ 1.00000e-09 1.00000e-01 1.00000e-06 1.00000e-06 1.00000e-06 1.00000e-09 5.00000e-02

Element: 12345 \# of layers: 5

Kx Ky Kz Ss Por

5.73910e+03 5.73910e+03 5.73910e+02 1.00000e-09 7.00000e-02

$2.29325 \mathrm{e}+02$ 2.29325e+02 2.29325e+01 1.00000e-09 2.12000e-01

$1.00000 \mathrm{e}-05$ 1.00000e-05 1.00000e-06 1.00000e-09 1.00000e-01

$1.00000 \mathrm{e}+001.00000 \mathrm{e}+001.00000 \mathrm{e}-011.00000 \mathrm{e}-091.00000 \mathrm{e}-01$

1.00000e-06 1.00000e-06 1.00000e-06 1.00000e-09 5.00000e-02

Element: 12346 \# of layers: 5

Kx Ky Kz Ss Por

2.93816e+03 2.93816e+03 2.93816e+02 1.00000e-09 7.00000e-02

$1.17398 \mathrm{e}+02$ 1.17398e+02 1.17399e+01 1.00000e-09 2.12000e-01

$1.00000 \mathrm{e}-05$ 1.00000e-05 1.00000e-06 1.00000e-09 1.00000e-01

$1.00000 \mathrm{e}+001.00000 \mathrm{e}+001.00000 \mathrm{e}-011.00000 \mathrm{e}-091.00000 \mathrm{e}-01$

1.00000e-06 1.00000e-06 1.00000e-06 1.00000e-09 5.00000e-02

Element: 12347 \# of layers: 5

$\mathrm{Kx} \mathrm{Ky} \mathrm{Kz}$ Ss Por

2.93816e+03 2.93816e+03 2.93816e+02 1.00000e-09 7.00000e-02

$1.17398 \mathrm{e}+021.17398 \mathrm{e}+02 \quad 1.17399 \mathrm{e}+01$ 1.00000e-09 2.12000e-01

$1.00000 \mathrm{e}-05$ 1.00000e-05 1.00000e-06 1.00000e-09 1.00000e-01

$1.00000 \mathrm{e}+001.00000 \mathrm{e}+001.00000 \mathrm{e}-011.00000 \mathrm{e}-091.00000 \mathrm{e}-01$

1.00000e-06 1.00000e-06 1.00000e-06 1.00000e-09 5.00000e-02

Element: 12348 \# of layers: 5

$\mathrm{Kx} \mathrm{Ky} \mathrm{Kz}$ Ss Por

$2.93816 \mathrm{e}+032.93816 \mathrm{e}+03$ 2.93816e+02 1.00000e-09 7.00000e-02

$1.17398 \mathrm{e}+02$ 1.17398e+02 1.17399e+01 1.00000e-09 2.12000e-01

$1.00000 \mathrm{e}-05$ 1.00000e-05 1.00000e-06 1.00000e-09 1.00000e-01

$1.00000 \mathrm{e}+001.00000 \mathrm{e}+001.00000 \mathrm{e}-011.00000 \mathrm{e}-091.00000 \mathrm{e}-01$

1.00000e-06 1.00000e-06 1.00000e-06 1.00000e-09 5.00000e-02

Element: 12349 \# of layers: 5

Kx Ky Kz Ss Por

$2.93816 \mathrm{e}+032.93816 \mathrm{e}+032.93816 \mathrm{e}+02$ 1.00000e-09 7.00000e-02

$1.17398 \mathrm{e}+02$ 1.17398e+02 1.17399e+01 1.00000e-09 2.12000e-01

1.00000e-05 1.00000e-05 1.00000e-06 1.00000e-09 1.00000e-01

$1.00000 \mathrm{e}+001.00000 \mathrm{e}+001.00000 \mathrm{e}-011.00000 \mathrm{e}-091.00000 \mathrm{e}-01$

1.00000e-06 1.00000e-06 1.00000e-06 1.00000e-09 5.00000e-02

Element: 12350 \# of layers: 5

$\mathrm{Kx} \mathrm{Ky} \mathrm{Kz}$ Ss Por

$2.93816 \mathrm{e}+03$ 2.93816e+03 2.93816e+02 1.00000e-09 7.00000e-02

$1.17398 \mathrm{e}+02$ 1.17398e+02 1.17399e+01 1.00000e-09 2.12000e-01

$1.00000 \mathrm{e}-05$ 1.00000e-05 1.00000e-06 1.00000e-09 1.00000e-01

$1.00000 \mathrm{e}+001.00000 \mathrm{e}+001.00000 \mathrm{e}-011.00000 \mathrm{e}-091.00000 \mathrm{e}-01$

1.00000e-06 1.00000e-06 1.00000e-06 1.00000e-09 5.00000e-02

Element: 12351 \# of layers: 5 
$\mathrm{Kx} \mathrm{Ky} \mathrm{Kz}$ Ss Por

2.93816e+03 2.93816e+03 2.93816e+02 1.00000e-09 7.00000e-02

$1.17398 \mathrm{e}+02$ 1.17398e+02 1.17399e+01 1.00000e-09 2.12000e-01

$1.00000 \mathrm{e}-05$ 1.00000e-05 1.00000e-06 1.00000e-09 1.00000e-01

$1.00000 \mathrm{e}+001.00000 \mathrm{e}+001.00000 \mathrm{e}-011.00000 \mathrm{e}-091.00000 \mathrm{e}-01$

1.00000e-06 1.00000e-06 1.00000e-06 1.00000e-09 5.00000e-02

Element: 12352 \# of layers: 4

$\mathrm{Kx} \mathrm{Ky} \mathrm{Kz}$ Ss Por

$3.92588 \mathrm{e}+02$ 3.92588e+02 3.92588e+01 1.00000e-09 2.12000e-01

$1.00000 \mathrm{e}-05$ 1.00000e-05 1.00000e-06 1.00000e-09 1.00000e-01

$1.00000 \mathrm{e}+001.00000 \mathrm{e}+001.00000 \mathrm{e}-011.00000 \mathrm{e}-091.00000 \mathrm{e}-01$

1.00000e-06 1.00000e-06 1.00000e-06 1.00000e-09 5.00000e-02

Element: 12353 \# of layers: 4

$\mathrm{Kx} \mathrm{Ky} \mathrm{Kz}$ Ss Por

3.92588e+02 3.92588e+02 3.92588e+01 1.00000e-09 2.12000e-01

$1.00000 \mathrm{e}-05$ 1.00000e-05 1.00000e-06 1.00000e-09 1.00000e-01

$1.00000 \mathrm{e}+001.00000 \mathrm{e}+001.00000 \mathrm{e}-011.00000 \mathrm{e}-091.00000 \mathrm{e}-01$

1.00000e-06 1.00000e-06 1.00000e-06 1.00000e-09 5.00000e-02

Element: 12354 \# of layers: 4

$\mathrm{Kx} \mathrm{Ky} \mathrm{Kz}$ Ss Por

3.92588e+02 3.92588e+02 3.92588e+01 1.00000e-09 2.12000e-01

$1.00000 \mathrm{e}-05$ 1.00000e-05 1.00000e-06 1.00000e-09 1.00000e-01

$1.00000 \mathrm{e}+001.00000 \mathrm{e}+001.00000 \mathrm{e}-011.00000 \mathrm{e}-091.00000 \mathrm{e}-01$

1.00000e-06 1.00000e-06 1.00000e-06 1.00000e-09 5.00000e-02

Element: 12355 \# of layers: 5

$\mathrm{Kx} \mathrm{Ky} \mathrm{Kz}$ Ss Por

2.93816e+03 2.93816e+03 2.93816e+02 1.00000e-09 7.00000e-02

$1.17398 \mathrm{e}+02$ 1.17398e+02 1.17399e+01 1.00000e-09 2.12000e-01

$1.00000 \mathrm{e}-05$ 1.00000e-05 1.00000e-06 1.00000e-09 1.00000e-01

$1.00000 \mathrm{e}+001.00000 \mathrm{e}+001.00000 \mathrm{e}-011.00000 \mathrm{e}-091.00000 \mathrm{e}-01$

1.00000e-06 1.00000e-06 1.00000e-06 1.00000e-09 5.00000e-02

Element: 12356 \# of layers: 5

$\mathrm{Kx} \mathrm{Ky} \mathrm{Kz}$ Ss Por

2.93816e+03 2.93816e+03 2.93816e+02 1.00000e-09 7.00000e-02

$1.17398 \mathrm{e}+02$ 1.17398e+02 1.17399e+01 1.00000e-09 2.12000e-01

$1.00000 \mathrm{e}-05$ 1.00000e-05 1.00000e-06 1.00000e-09 1.00000e-01

$1.00000 \mathrm{e}+001.00000 \mathrm{e}+001.00000 \mathrm{e}-011.00000 \mathrm{e}-091.00000 \mathrm{e}-01$

1.00000e-06 1.00000e-06 1.00000e-06 1.00000e-09 5.00000e-02

Element: 12357 \# of layers: 5

$\mathrm{Kx} \mathrm{Ky} \mathrm{Kz}$ Ss Por

2.93816e+03 2.93816e+03 2.93816e+02 1.00000e-09 7.00000e-02

$1.17398 \mathrm{e}+02$ 1.17398e+02 1.17399e+01 1.00000e-09 2.12000e-01

$1.00000 \mathrm{e}-05$ 1.00000e-05 1.00000e-06 1.00000e-09 1.00000e-01

$1.00000 \mathrm{e}+001.00000 \mathrm{e}+001.00000 \mathrm{e}-011.00000 \mathrm{e}-091.00000 \mathrm{e}-01$

1.00000e-06 1.00000e-06 1.00000e-06 1.00000e-09 5.00000e-02

Element: 12358 \# of layers: 5 
$\mathrm{Kx} \mathrm{Ky} \mathrm{Kz}$ Ss Por

2.93816e+03 2.93816e+03 2.93816e+02 1.00000e-09 7.00000e-02

$1.17398 \mathrm{e}+02$ 1.17398e+02 1.17399e+01 1.00000e-09 2.12000e-01

$1.00000 \mathrm{e}-05$ 1.00000e-05 1.00000e-06 1.00000e-09 1.00000e-01

$1.00000 \mathrm{e}+001.00000 \mathrm{e}+001.00000 \mathrm{e}-011.00000 \mathrm{e}-091.00000 \mathrm{e}-01$

1.00000e-06 1.00000e-06 1.00000e-06 1.00000e-09 5.00000e-02

Element: 12359 \# of layers: 4

$\mathrm{Kx} \mathrm{Ky} \mathrm{Kz}$ Ss Por

$3.92588 \mathrm{e}+02$ 3.92588e+02 3.92588e+01 1.00000e-09 2.12000e-01

$1.00000 \mathrm{e}-05$ 1.00000e-05 1.00000e-06 1.00000e-09 1.00000e-01

$1.00000 \mathrm{e}+001.00000 \mathrm{e}+001.00000 \mathrm{e}-011.00000 \mathrm{e}-091.00000 \mathrm{e}-01$

1.00000e-06 1.00000e-06 1.00000e-06 1.00000e-09 5.00000e-02

Element: 12360 \# of layers: 4

$\mathrm{Kx} \mathrm{Ky} \mathrm{Kz}$ Ss Por

3.92588e+02 3.92588e+02 3.92588e+01 1.00000e-09 2.12000e-01

$1.00000 \mathrm{e}-05$ 1.00000e-05 1.00000e-06 1.00000e-09 1.00000e-01

$1.00000 \mathrm{e}+001.00000 \mathrm{e}+001.00000 \mathrm{e}-011.00000 \mathrm{e}-091.00000 \mathrm{e}-01$

1.00000e-06 1.00000e-06 1.00000e-06 1.00000e-09 5.00000e-02

Element: 12361 \# of layers: 5

$\mathrm{Kx} \mathrm{Ky} \mathrm{Kz}$ Ss Por

3.92588e+02 3.92588e+02 3.92588e+01 1.00000e-09 2.12000e-01

$3.92588 \mathrm{e}+02$ 3.92588e+02 3.92588e+01 1.00000e-09 2.12000e-01

$1.00000 \mathrm{e}-05$ 1.00000e-05 1.00000e-06 1.00000e-09 1.00000e-01

$1.00000 \mathrm{e}+001.00000 \mathrm{e}+001.00000 \mathrm{e}-011.00000 \mathrm{e}-091.00000 \mathrm{e}-01$

1.00000e-06 1.00000e-06 1.00000e-06 1.00000e-09 5.00000e-02

Element: 12362 \# of layers: 4

$\mathrm{Kx} \mathrm{Ky} \mathrm{Kz}$ Ss Por

3.92588e+02 3.92588e+02 3.92588e+01 1.00000e-09 2.12000e-01

$1.00000 \mathrm{e}-051.00000 \mathrm{e}-05$ 1.00000e-06 1.00000e-09 1.00000e-01

$1.00000 \mathrm{e}+001.00000 \mathrm{e}+001.00000 \mathrm{e}-011.00000 \mathrm{e}-091.00000 \mathrm{e}-01$

1.00000e-06 1.00000e-06 1.00000e-06 1.00000e-09 5.00000e-02

Element: 12363 \# of layers: 4

$\mathrm{Kx} \mathrm{Ky} \mathrm{Kz}$ Ss Por

$3.92588 \mathrm{e}+02$ 3.92588e+02 3.92588e+01 1.00000e-09 2.12000e-01

$1.00000 \mathrm{e}-05$ 1.00000e-05 1.00000e-06 1.00000e-09 1.00000e-01

$1.00000 \mathrm{e}+001.00000 \mathrm{e}+001.00000 \mathrm{e}-011.00000 \mathrm{e}-091.00000 \mathrm{e}-01$

1.00000e-06 1.00000e-06 1.00000e-06 1.00000e-09 5.00000e-02

Element: 12364 \# of layers: 4

$\mathrm{Kx} \mathrm{Ky} \mathrm{Kz}$ Ss Por

3.92588e+02 3.92588e+02 3.92588e+01 1.00000e-09 2.12000e-01

$1.00000 \mathrm{e}-05$ 1.00000e-05 1.00000e-06 1.00000e-09 1.00000e-01

$1.00000 \mathrm{e}+001.00000 \mathrm{e}+001.00000 \mathrm{e}-011.00000 \mathrm{e}-091.00000 \mathrm{e}-01$

1.00000e-06 1.00000e-06 1.00000e-06 1.00000e-09 5.00000e-02

Element: 12365 \# of layers: 4

$\mathrm{Kx} \mathrm{Ky} \mathrm{Kz}$ Ss Por

3.92588e+02 3.92588e+02 3.92588e+01 1.00000e-09 2.12000e-01 
$1.00000 \mathrm{e}-05$ 1.00000e-05 1.00000e-06 1.00000e-09 1.00000e-01 $1.00000 \mathrm{e}+001.00000 \mathrm{e}+001.00000 \mathrm{e}-01$ 1.00000e-09 1.00000e-01 1.00000e-06 1.00000e-06 1.00000e-06 1.00000e-09 5.00000e-02

Element: 12366 \# of layers: 4

$\mathrm{Kx} \mathrm{Ky} \mathrm{Kz}$ Ss Por

3.92588e+02 3.92588e+02 3.92588e+01 1.00000e-09 2.12000e-01 1.00000e-05 1.00000e-05 1.00000e-06 1.00000e-09 1.00000e-01

$1.00000 \mathrm{e}+001.00000 \mathrm{e}+001.00000 \mathrm{e}-011.00000 \mathrm{e}-091.00000 \mathrm{e}-01$ 1.00000e-06 1.00000e-06 1.00000e-06 1.00000e-09 5.00000e-02

Element: 12367 \# of layers: 4

$\mathrm{Kx} \mathrm{Ky} \mathrm{Kz}$ Ss Por

3.92588e+02 3.92588e+02 3.92588e+01 1.00000e-09 2.12000e-01 $1.00000 \mathrm{e}-05$ 1.00000e-05 1.00000e-06 1.00000e-09 1.00000e-01 $1.00000 \mathrm{e}+001.00000 \mathrm{e}+001.00000 \mathrm{e}-011.00000 \mathrm{e}-091.00000 \mathrm{e}-01$ 1.00000e-06 1.00000e-06 1.00000e-06 1.00000e-09 5.00000e-02

Element: 12368 \# of layers: 4

$\mathrm{Kx} \mathrm{Ky} \mathrm{Kz}$ Ss Por

3.92588e+02 3.92588e+02 3.92588e+01 1.00000e-09 2.12000e-01 $1.00000 \mathrm{e}-05$ 1.00000e-05 1.00000e-06 1.00000e-09 1.00000e-01 $1.00000 \mathrm{e}+001.00000 \mathrm{e}+001.00000 \mathrm{e}-011.00000 \mathrm{e}-091.00000 \mathrm{e}-01$ 1.00000e-06 1.00000e-06 1.00000e-06 1.00000e-09 5.00000e-02 Element: 12369 \# of layers: 4

$\mathrm{Kx} \mathrm{Ky} \mathrm{Kz}$ Ss Por

3.10732e+01 3.10732e+01 3.10732e+00 1.00000e-09 2.12000e-01 $1.00000 \mathrm{e}-05$ 1.00000e-05 1.00000e-06 1.00000e-09 1.00000e-01 $1.00000 \mathrm{e}+001.00000 \mathrm{e}+001.00000 \mathrm{e}-011.00000 \mathrm{e}-091.00000 \mathrm{e}-01$ 1.00000e-06 1.00000e-06 1.00000e-06 1.00000e-09 5.00000e-02 Element: 12370 \# of layers: 4

Kx Ky Kz Ss Por

3.10732e+01 3.10732e+01 3.10732e+00 1.00000e-09 2.12000e-01 $3.10732 \mathrm{e}+013.10732 \mathrm{e}+013.10732 \mathrm{e}+00$ 1.00000e-09 2.12000e-01 $1.00000 \mathrm{e}-051.00000 \mathrm{e}-05$ 1.00000e-06 1.00000e-09 1.00000e-01 $1.00000 \mathrm{e}+001.00000 \mathrm{e}+001.00000 \mathrm{e}-011.00000 \mathrm{e}-091.00000 \mathrm{e}-01$ Element: 12371 \# of layers: 3

$\mathrm{Kx} \mathrm{Ky} \mathrm{Kz}$ Ss Por

3.10732e+01 3.10732e+01 3.10732e+00 1.00000e-09 2.12000e-01 $1.00000 \mathrm{e}-05$ 1.00000e-05 1.00000e-06 1.00000e-09 1.00000e-01 $1.00000 \mathrm{e}+001.00000 \mathrm{e}+001.00000 \mathrm{e}-011.00000 \mathrm{e}-09$ 1.00000e-01 Element: 12372 \# of layers: 3

$\mathrm{Kx} \mathrm{Ky} \mathrm{Kz}$ Ss Por

3.10732e+01 3.10732e+01 3.10732e+00 1.00000e-09 2.12000e-01 $1.00000 \mathrm{e}-05$ 1.00000e-05 1.00000e-06 1.00000e-09 1.00000e-01 $1.00000 \mathrm{e}+001.00000 \mathrm{e}+001.00000 \mathrm{e}-011.00000 \mathrm{e}-091.00000 \mathrm{e}-01$ Element: 12373 \# of layers: 4

$\mathrm{Kx} \mathrm{Ky} \mathrm{Kz}$ Ss Por 3.10732e+01 3.10732e+01 3.10732e+00 1.00000e-09 2.12000e-01 
$1.00000 \mathrm{e}-05$ 1.00000e-05 1.00000e-06 1.00000e-09 1.00000e-01 $1.00000 \mathrm{e}+001.00000 \mathrm{e}+001.00000 \mathrm{e}-01$ 1.00000e-09 1.00000e-01 1.00000e-06 1.00000e-06 1.00000e-06 1.00000e-09 5.00000e-02

Element: 12374 \# of layers: 4

$\mathrm{Kx} \mathrm{Ky} \mathrm{Kz}$ Ss Por

3.92588e+02 3.92588e+02 3.92588e+01 1.00000e-09 2.12000e-01 $1.00000 \mathrm{e}-05$ 1.00000e-05 1.00000e-06 1.00000e-09 1.00000e-01

$1.00000 \mathrm{e}+001.00000 \mathrm{e}+001.00000 \mathrm{e}-011.00000 \mathrm{e}-091.00000 \mathrm{e}-01$ 1.00000e-06 1.00000e-06 1.00000e-06 1.00000e-09 5.00000e-02

Element: 12375 \# of layers: 4

$\mathrm{Kx} \mathrm{Ky} \mathrm{Kz}$ Ss Por

3.92588e+02 3.92588e+02 3.92588e+01 1.00000e-09 2.12000e-01 $1.00000 \mathrm{e}-05$ 1.00000e-05 1.00000e-06 1.00000e-09 1.00000e-01 $1.00000 \mathrm{e}+001.00000 \mathrm{e}+001.00000 \mathrm{e}-011.00000 \mathrm{e}-091.00000 \mathrm{e}-01$ 1.00000e-06 1.00000e-06 1.00000e-06 1.00000e-09 5.00000e-02 Element: 12376 \# of layers: 4

$\mathrm{Kx} \mathrm{Ky} \mathrm{Kz}$ Ss Por

3.10732e+01 3.10732e+01 3.10732e+00 1.00000e-09 2.12000e-01 $1.00000 \mathrm{e}-05$ 1.00000e-05 1.00000e-06 1.00000e-09 1.00000e-01 $1.00000 \mathrm{e}+001.00000 \mathrm{e}+001.00000 \mathrm{e}-011.00000 \mathrm{e}-091.00000 \mathrm{e}-01$ 1.00000e-06 1.00000e-06 1.00000e-06 1.00000e-09 5.00000e-02 Element: 12377 \# of layers: 4

Kx Ky Kz Ss Por

3.10732e+01 3.10732e+01 3.10732e+00 1.00000e-09 2.12000e-01 $1.00000 \mathrm{e}-05$ 1.00000e-05 1.00000e-06 1.00000e-09 1.00000e-01 $1.00000 \mathrm{e}+001.00000 \mathrm{e}+001.00000 \mathrm{e}-011.00000 \mathrm{e}-091.00000 \mathrm{e}-01$ 1.00000e-06 1.00000e-06 1.00000e-06 1.00000e-09 5.00000e-02 Element: 12378 \# of layers: 4

$\mathrm{Kx} \mathrm{Ky} \mathrm{Kz}$ Ss Por

$2.29325 \mathrm{e}+02$ 2.29325e+02 2.29325e+01 1.00000e-09 2.12000e-01 $1.00000 \mathrm{e}-05$ 1.00000e-05 1.00000e-06 1.00000e-09 1.00000e-01 $1.00000 \mathrm{e}+001.00000 \mathrm{e}+001.00000 \mathrm{e}-011.00000 \mathrm{e}-091.00000 \mathrm{e}-01$ 1.00000e-06 1.00000e-06 1.00000e-06 1.00000e-09 5.00000e-02 Element: 12379 \# of layers: 5

$\mathrm{Kx} \mathrm{Ky} \mathrm{Kz}$ Ss Por

5.73910e+03 5.73910e+03 5.73910e+02 1.00000e-09 7.00000e-02 $2.29325 \mathrm{e}+02$ 2.29325e+02 2.29325e+01 1.00000e-09 2.12000e-01 $1.00000 \mathrm{e}-05$ 1.00000e-05 1.00000e-06 1.00000e-09 1.00000e-01 $1.00000 \mathrm{e}+001.00000 \mathrm{e}+001.00000 \mathrm{e}-011.00000 \mathrm{e}-091.00000 \mathrm{e}-01$ 1.00000e-06 1.00000e-06 1.00000e-06 1.00000e-09 5.00000e-02 Element: 12380 \# of layers: 5

Kx Ky Kz Ss Por

5.73910e+03 5.73910e+03 5.73910e+02 1.00000e-09 7.00000e-02 $2.29325 \mathrm{e}+02$ 2.29325e+02 2.29325e+01 1.00000e-09 2.12000e-01 $1.00000 \mathrm{e}-05$ 1.00000e-05 1.00000e-06 1.00000e-09 1.00000e-01 $1.00000 \mathrm{e}+001.00000 \mathrm{e}+001.00000 \mathrm{e}-011.00000 \mathrm{e}-091.00000 \mathrm{e}-01$ 
1.00000e-06 1.00000e-06 1.00000e-06 1.00000e-09 5.00000e-02

Element: 12381 \# of layers: 5

Kx Ky Kz Ss Por

$2.93816 \mathrm{e}+032.93816 \mathrm{e}+03$ 2.93816e+02 1.00000e-09 7.00000e-02

$1.17398 \mathrm{e}+02$ 1.17398e+02 1.17399e+01 1.00000e-09 2.12000e-01

$1.00000 \mathrm{e}-05$ 1.00000e-05 1.00000e-06 1.00000e-09 1.00000e-01

$1.00000 \mathrm{e}+001.00000 \mathrm{e}+001.00000 \mathrm{e}-011.00000 \mathrm{e}-091.00000 \mathrm{e}-01$

1.00000e-06 1.00000e-06 1.00000e-06 1.00000e-09 5.00000e-02

Element: 12382 \# of layers: 4

$\mathrm{Kx} \mathrm{Ky} \mathrm{Kz}$ Ss Por

1.17398e+02 1.17398e+02 1.17399e+01 1.00000e-09 2.12000e-01

$1.00000 \mathrm{e}-05$ 1.00000e-05 1.00000e-06 1.00000e-09 1.00000e-01

$1.00000 \mathrm{e}+001.00000 \mathrm{e}+001.00000 \mathrm{e}-011.00000 \mathrm{e}-091.00000 \mathrm{e}-01$

1.00000e-06 1.00000e-06 1.00000e-06 1.00000e-09 5.00000e-02

Element: 12383 \# of layers: 4

Kx Ky Kz Ss Por

3.92588e+02 3.92588e+02 3.92588e+01 1.00000e-09 2.12000e-01

$1.00000 \mathrm{e}-05$ 1.00000e-05 1.00000e-06 1.00000e-09 1.00000e-01

$1.00000 \mathrm{e}+001.00000 \mathrm{e}+001.00000 \mathrm{e}-011.00000 \mathrm{e}-091.00000 \mathrm{e}-01$

1.00000e-06 1.00000e-06 1.00000e-06 1.00000e-09 5.00000e-02

Element: 12384 \# of layers: 4

$\mathrm{Kx} \mathrm{Ky} \mathrm{Kz}$ Ss Por

3.10732e+01 3.10732e+01 3.10732e+00 1.00000e-09 2.12000e-01

$1.00000 \mathrm{e}-05$ 1.00000e-05 1.00000e-06 1.00000e-09 1.00000e-01

$1.00000 \mathrm{e}+001.00000 \mathrm{e}+001.00000 \mathrm{e}-011.00000 \mathrm{e}-091.00000 \mathrm{e}-01$

1.00000e-06 1.00000e-06 1.00000e-06 1.00000e-09 5.00000e-02

Element: 12385 \# of layers: 4

$\mathrm{Kx} \mathrm{Ky} \mathrm{Kz}$ Ss Por

$2.29325 \mathrm{e}+02$ 2.29325e+02 2.29325e+01 1.00000e-09 2.12000e-01

$1.00000 \mathrm{e}-05$ 1.00000e-05 1.00000e-06 1.00000e-09 1.00000e-01

$1.00000 \mathrm{e}+001.00000 \mathrm{e}+001.00000 \mathrm{e}-01$ 1.00000e-09 1.00000e-01

1.00000e-06 1.00000e-06 1.00000e-06 1.00000e-09 5.00000e-02

Element: 12386 \# of layers: 5

$\mathrm{Kx} \mathrm{Ky} \mathrm{Kz}$ Ss Por

$1.04516 \mathrm{e}+041.04516 \mathrm{e}+04$ 1.04516e+03 1.00000e-09 7.00000e-02

$4.17631 \mathrm{e}+02$ 4.17631e+02 4.17631e+01 1.00000e-09 2.12000e-01

1.00000e-05 1.00000e-05 1.00000e-06 1.00000e-09 1.00000e-01

$1.00000 \mathrm{e}+001.00000 \mathrm{e}+001.00000 \mathrm{e}-011.00000 \mathrm{e}-091.00000 \mathrm{e}-01$

1.00000e-06 1.00000e-06 1.00000e-06 1.00000e-09 5.00000e-02

Element: 12387 \# of layers: 5

$\mathrm{Kx} \mathrm{Ky} \mathrm{Kz}$ Ss Por

$1.04516 \mathrm{e}+04$ 1.04516e+04 1.04516e+03 1.00000e-09 7.00000e-02

4.17631e+02 4.17631e+02 4.17631e+01 1.00000e-09 2.12000e-01

$1.00000 \mathrm{e}-05$ 1.00000e-05 1.00000e-06 1.00000e-09 1.00000e-01

$1.00000 \mathrm{e}+001.00000 \mathrm{e}+001.00000 \mathrm{e}-011.00000 \mathrm{e}-091.00000 \mathrm{e}-01$

$1.00000 \mathrm{e}-06$ 1.00000e-06 1.00000e-06 1.00000e-09 5.00000e-02 
Element: 12388 \# of layers: 5

Kx Ky Kz Ss Por

$1.04516 \mathrm{e}+041.04516 \mathrm{e}+041.04516 \mathrm{e}+03$ 1.00000e-09 7.00000e-02

$4.17631 \mathrm{e}+024.17631 \mathrm{e}+024.17631 \mathrm{e}+011.00000 \mathrm{e}-092.12000 \mathrm{e}-01$

$1.00000 \mathrm{e}-05$ 1.00000e-05 1.00000e-06 1.00000e-09 1.00000e-01

$1.00000 \mathrm{e}+001.00000 \mathrm{e}+001.00000 \mathrm{e}-011.00000 \mathrm{e}-091.00000 \mathrm{e}-01$

$1.00000 \mathrm{e}-06$ 1.00000e-06 1.00000e-06 1.00000e-09 5.00000e-02

Element: 12389 \# of layers: 5

Kx Ky Kz Ss Por

$1.04516 \mathrm{e}+041.04516 \mathrm{e}+041.04516 \mathrm{e}+03$ 1.00000e-09 7.00000e-02

$4.17631 \mathrm{e}+02 \quad 4.17631 \mathrm{e}+024.17631 \mathrm{e}+011.00000 \mathrm{e}-092.12000 \mathrm{e}-01$

$1.00000 \mathrm{e}-05$ 1.00000e-05 1.00000e-06 1.00000e-09 1.00000e-01

$1.00000 \mathrm{e}+001.00000 \mathrm{e}+001.00000 \mathrm{e}-011.00000 \mathrm{e}-091.00000 \mathrm{e}-01$

$1.00000 \mathrm{e}-06$ 1.00000e-06 1.00000e-06 1.00000e-09 5.00000e-02

Element: 12390 \# of layers: 5

Kx Ky Kz Ss Por

$1.04516 \mathrm{e}+041.04516 \mathrm{e}+041.04516 \mathrm{e}+03$ 1.00000e-09 7.00000e-02

$4.17631 \mathrm{e}+02 \quad 4.17631 \mathrm{e}+024.17631 \mathrm{e}+01$ 1.00000e-09 2.12000e-01

$1.00000 \mathrm{e}-05$ 1.00000e-05 1.00000e-06 1.00000e-09 1.00000e-01

$1.00000 \mathrm{e}+001.00000 \mathrm{e}+001.00000 \mathrm{e}-011.00000 \mathrm{e}-091.00000 \mathrm{e}-01$

1.00000e-06 1.00000e-06 1.00000e-06 1.00000e-09 5.00000e-02

Element: 12391 \# of layers: 7

Kx Ky Kz Ss Por

$1.45742 \mathrm{e}+011.45742 \mathrm{e}+011.45742 \mathrm{e}+00$ 1.00000e-09 2.12000e-01

$1.45742 \mathrm{e}+011.45742 \mathrm{e}+011.45742 \mathrm{e}+001.00000 \mathrm{e}-092.12000 \mathrm{e}-01$

$1.45742 \mathrm{e}+011.45742 \mathrm{e}+011.45742 \mathrm{e}+001.00000 \mathrm{e}-092.12000 \mathrm{e}-01$

$1.45742 \mathrm{e}+011.45742 \mathrm{e}+011.45742 \mathrm{e}+001.00000 \mathrm{e}-092.12000 \mathrm{e}-01$

$1.45742 \mathrm{e}+011.45742 \mathrm{e}+011.45742 \mathrm{e}+001.00000 \mathrm{e}-092.12000 \mathrm{e}-01$

$1.00000 \mathrm{e}-051.00000 \mathrm{e}-05$ 1.00000e-06 1.00000e-09 1.00000e-01

$1.00000 \mathrm{e}+001.00000 \mathrm{e}+001.00000 \mathrm{e}-011.00000 \mathrm{e}-091.00000 \mathrm{e}-01$

Element: 12392 \# of layers: 7

Kx Ky Kz Ss Por

$1.45742 \mathrm{e}+011.45742 \mathrm{e}+011.45742 \mathrm{e}+00$ 1.00000e-09 2.12000e-01

$1.45742 \mathrm{e}+011.45742 \mathrm{e}+011.45742 \mathrm{e}+001.00000 \mathrm{e}-092.12000 \mathrm{e}-01$

$1.45742 \mathrm{e}+011.45742 \mathrm{e}+011.45742 \mathrm{e}+001.00000 \mathrm{e}-092.12000 \mathrm{e}-01$

$1.45742 \mathrm{e}+011.45742 \mathrm{e}+011.45742 \mathrm{e}+001.00000 \mathrm{e}-092.12000 \mathrm{e}-01$

$1.45742 \mathrm{e}+011.45742 \mathrm{e}+011.45742 \mathrm{e}+001.00000 \mathrm{e}-092.12000 \mathrm{e}-01$

$1.00000 \mathrm{e}-05$ 1.00000e-05 1.00000e-06 1.00000e-09 1.00000e-01

$1.00000 \mathrm{e}+001.00000 \mathrm{e}+001.00000 \mathrm{e}-011.00000 \mathrm{e}-091.00000 \mathrm{e}-01$

Element: 12393 \# of layers: 7

Kx Ky Kz Ss Por

$1.45742 \mathrm{e}+011.45742 \mathrm{e}+011.45742 \mathrm{e}+00$ 1.00000e-09 2.12000e-01

$1.45742 \mathrm{e}+011.45742 \mathrm{e}+011.45742 \mathrm{e}+001.00000 \mathrm{e}-092.12000 \mathrm{e}-01$

$1.45742 \mathrm{e}+011.45742 \mathrm{e}+011.45742 \mathrm{e}+001.00000 \mathrm{e}-092.12000 \mathrm{e}-01$

$1.45742 \mathrm{e}+011.45742 \mathrm{e}+011.45742 \mathrm{e}+001.00000 \mathrm{e}-092.12000 \mathrm{e}-01$

$1.45742 \mathrm{e}+011.45742 \mathrm{e}+011.45742 \mathrm{e}+001.00000 \mathrm{e}-092.12000 \mathrm{e}-01$ 
$1.00000 \mathrm{e}-05$ 1.00000e-05 1.00000e-06 1.00000e-09 1.00000e-01 $1.00000 \mathrm{e}+001.00000 \mathrm{e}+001.00000 \mathrm{e}-01$ 1.00000e-09 1.00000e-01 Element: 12394 \# of layers: 7

Kx Ky Kz Ss Por

$1.45742 \mathrm{e}+011.45742 \mathrm{e}+011.45742 \mathrm{e}+001.00000 \mathrm{e}-092.12000 \mathrm{e}-01$ $1.45742 \mathrm{e}+01$ 1.45742e+01 1.45742e+00 1.00000e-09 2.12000e-01 $1.45742 \mathrm{e}+01$ 1.45742e+01 1.45742e+00 1.00000e-09 2.12000e-01 $1.45742 \mathrm{e}+011.45742 \mathrm{e}+011.45742 \mathrm{e}+001.00000 \mathrm{e}-092.12000 \mathrm{e}-01$ $1.45742 \mathrm{e}+01$ 1.45742e+01 1.45742e+00 1.00000e-09 2.12000e-01 $1.00000 \mathrm{e}-05$ 1.00000e-05 1.00000e-06 1.00000e-09 1.00000e-01 $1.00000 \mathrm{e}+001.00000 \mathrm{e}+001.00000 \mathrm{e}-01$ 1.00000e-09 1.00000e-01 Element: 12395 \# of layers: 7

Kx Ky Kz Ss Por

1.45742e+01 1.45742e+01 1.45742e+00 1.00000e-09 2.12000e-01 $1.45742 \mathrm{e}+01$ 1.45742e+01 1.45742e+00 1.00000e-09 2.12000e-01 $1.45742 \mathrm{e}+011.45742 \mathrm{e}+01$ 1.45742e+00 1.00000e-09 2.12000e-01 $1.45742 \mathrm{e}+011.45742 \mathrm{e}+01$ 1.45742e+00 1.00000e-09 2.12000e-01 $1.45742 \mathrm{e}+01$ 1.45742e+01 1.45742e+00 1.00000e-09 2.12000e-01 $1.00000 \mathrm{e}-05$ 1.00000e-05 1.00000e-06 1.00000e-09 1.00000e-01 $1.00000 \mathrm{e}+001.00000 \mathrm{e}+001.00000 \mathrm{e}-011.00000 \mathrm{e}-09$ 1.00000e-01 Element: 12396 \# of layers: 7

$\mathrm{Kx} \mathrm{Ky} \mathrm{Kz}$ Ss Por

$1.57791 \mathrm{e}+01$ 1.57791e+01 1.57791e+00 1.00000e-09 2.12000e-01 $1.57791 \mathrm{e}+011.57791 \mathrm{e}+011.57791 \mathrm{e}+001.00000 \mathrm{e}-092.12000 \mathrm{e}-01$ $1.57791 \mathrm{e}+011.57791 \mathrm{e}+011.57791 \mathrm{e}+001.00000 \mathrm{e}-092.12000 \mathrm{e}-01$ $1.57791 \mathrm{e}+011.57791 \mathrm{e}+01$ 1.57791e+00 1.00000e-09 2.12000e-01 $1.57791 \mathrm{e}+011.57791 \mathrm{e}+011.57791 \mathrm{e}+001.00000 \mathrm{e}-092.12000 \mathrm{e}-01$ $1.00000 \mathrm{e}-05$ 1.00000e-05 1.00000e-06 1.00000e-09 1.00000e-01 $1.00000 \mathrm{e}+001.00000 \mathrm{e}+001.00000 \mathrm{e}-011.00000 \mathrm{e}-091.00000 \mathrm{e}-01$ Element: 12397 \# of layers: 7

$\mathrm{Kx} \mathrm{Ky} \mathrm{Kz}$ Ss Por

$1.57791 \mathrm{e}+011.57791 \mathrm{e}+01$ 1.57791e+00 1.00000e-09 2.12000e-01 $1.57791 \mathrm{e}+011.57791 \mathrm{e}+011.57791 \mathrm{e}+001.00000 \mathrm{e}-092.12000 \mathrm{e}-01$ $1.57791 \mathrm{e}+011.57791 \mathrm{e}+011.57791 \mathrm{e}+001.00000 \mathrm{e}-092.12000 \mathrm{e}-01$ $1.57791 \mathrm{e}+011.57791 \mathrm{e}+011.57791 \mathrm{e}+001.00000 \mathrm{e}-092.12000 \mathrm{e}-01$ $1.57791 \mathrm{e}+011.57791 \mathrm{e}+011.57791 \mathrm{e}+001.00000 \mathrm{e}-092.12000 \mathrm{e}-01$ $1.00000 \mathrm{e}-05$ 1.00000e-05 1.00000e-06 1.00000e-09 1.00000e-01 $1.00000 \mathrm{e}+001.00000 \mathrm{e}+001.00000 \mathrm{e}-011.00000 \mathrm{e}-091.00000 \mathrm{e}-01$ Element: 12398 \# of layers: 7

$\mathrm{Kx} \mathrm{Ky} \mathrm{Kz}$ Ss Por

$1.57791 \mathrm{e}+01$ 1.57791e+01 1.57791e+00 1.00000e-09 2.12000e-01 $1.57791 \mathrm{e}+011.57791 \mathrm{e}+011.57791 \mathrm{e}+001.00000 \mathrm{e}-092.12000 \mathrm{e}-01$ $1.57791 \mathrm{e}+011.57791 \mathrm{e}+011.57791 \mathrm{e}+001.00000 \mathrm{e}-092.12000 \mathrm{e}-01$ $1.57791 \mathrm{e}+011.57791 \mathrm{e}+011.57791 \mathrm{e}+001.00000 \mathrm{e}-092.12000 \mathrm{e}-01$ $1.57791 \mathrm{e}+011.57791 \mathrm{e}+011.57791 \mathrm{e}+001.00000 \mathrm{e}-092.12000 \mathrm{e}-01$ $1.00000 \mathrm{e}-05$ 1.00000e-05 1.00000e-06 1.00000e-09 1.00000e-01 
$1.00000 \mathrm{e}+001.00000 \mathrm{e}+001.00000 \mathrm{e}-011.00000 \mathrm{e}-091.00000 \mathrm{e}-01$

Element: 12399 \# of layers: 7

Kx Ky Kz Ss Por

$1.57791 \mathrm{e}+01$ 1.57791e+01 1.57791e+00 1.00000e-09 2.12000e-01

$1.57791 \mathrm{e}+011.57791 \mathrm{e}+011.57791 \mathrm{e}+001.00000 \mathrm{e}-092.12000 \mathrm{e}-01$

$1.57791 \mathrm{e}+011.57791 \mathrm{e}+011.57791 \mathrm{e}+001.00000 \mathrm{e}-092.12000 \mathrm{e}-01$

$1.57791 \mathrm{e}+011.57791 \mathrm{e}+011.57791 \mathrm{e}+001.00000 \mathrm{e}-092.12000 \mathrm{e}-01$

$1.57791 \mathrm{e}+011.57791 \mathrm{e}+011.57791 \mathrm{e}+001.00000 \mathrm{e}-092.12000 \mathrm{e}-01$

$1.00000 \mathrm{e}-051.00000 \mathrm{e}-051.00000 \mathrm{e}-061.00000 \mathrm{e}-091.00000 \mathrm{e}-01$

$1.00000 \mathrm{e}+001.00000 \mathrm{e}+001.00000 \mathrm{e}-011.00000 \mathrm{e}-091.00000 \mathrm{e}-01$

Element: 12400 \# of layers: 7

Kx Ky Kz Ss Por

$1.57791 \mathrm{e}+01$ 1.57791e+01 1.57791e+00 1.00000e-09 2.12000e-01

$1.57791 \mathrm{e}+011.57791 \mathrm{e}+011.57791 \mathrm{e}+001.00000 \mathrm{e}-092.12000 \mathrm{e}-01$

$1.57791 \mathrm{e}+011.57791 \mathrm{e}+011.57791 \mathrm{e}+001.00000 \mathrm{e}-092.12000 \mathrm{e}-01$

$1.57791 \mathrm{e}+011.57791 \mathrm{e}+011.57791 \mathrm{e}+001.00000 \mathrm{e}-092.12000 \mathrm{e}-01$

$1.57791 \mathrm{e}+011.57791 \mathrm{e}+01$ 1.57791e+00 1.00000e-09 2.12000e-01

$1.00000 \mathrm{e}-051.00000 \mathrm{e}-051.00000 \mathrm{e}-061.00000 \mathrm{e}-091.00000 \mathrm{e}-01$

$1.00000 \mathrm{e}+001.00000 \mathrm{e}+001.00000 \mathrm{e}-01$ 1.00000e-09 1.00000e-01

Element: 12401 \# of layers: 7

$\mathrm{Kx} \mathrm{Ky} \mathrm{Kz}$ Ss Por

$1.45742 \mathrm{e}+01$ 1.45742e+01 1.45742e+00 1.00000e-09 2.12000e-01

$1.45742 \mathrm{e}+01$ 1.45742e+01 1.45742e+00 1.00000e-09 2.12000e-01

$1.45742 \mathrm{e}+011.45742 \mathrm{e}+011.45742 \mathrm{e}+001.00000 \mathrm{e}-092.12000 \mathrm{e}-01$

$1.45742 \mathrm{e}+011.45742 \mathrm{e}+011.45742 \mathrm{e}+001.00000 \mathrm{e}-092.12000 \mathrm{e}-01$

$1.45742 \mathrm{e}+011.45742 \mathrm{e}+01$ 1.45742e+00 1.00000e-09 2.12000e-01

$1.00000 \mathrm{e}-05$ 1.00000e-05 1.00000e-06 1.00000e-09 1.00000e-01

$1.00000 \mathrm{e}+001.00000 \mathrm{e}+001.00000 \mathrm{e}-01$ 1.00000e-09 1.00000e-01

Element: 12402 \# of layers: 7

$\mathrm{Kx} \mathrm{Ky} \mathrm{Kz}$ Ss Por

1.45742e+01 1.45742e+01 1.45742e+00 1.00000e-09 2.12000e-01

$1.45742 \mathrm{e}+01$ 1.45742e+01 1.45742e+00 1.00000e-09 2.12000e-01

$1.45742 \mathrm{e}+011.45742 \mathrm{e}+01$ 1.45742e+00 1.00000e-09 2.12000e-01

$1.45742 \mathrm{e}+011.45742 \mathrm{e}+01$ 1.45742e+00 1.00000e-09 2.12000e-01

$1.45742 \mathrm{e}+01$ 1.45742e+01 1.45742e+00 1.00000e-09 2.12000e-01

$1.00000 \mathrm{e}-05$ 1.00000e-05 1.00000e-06 1.00000e-09 1.00000e-01

$1.00000 \mathrm{e}+001.00000 \mathrm{e}+001.00000 \mathrm{e}-011.00000 \mathrm{e}-091.00000 \mathrm{e}-01$

Element: 12403 \# of layers: 7

$\mathrm{Kx} \mathrm{Ky} \mathrm{Kz}$ Ss Por

$1.57791 \mathrm{e}+011.57791 \mathrm{e}+01$ 1.57791e+00 1.00000e-09 2.12000e-01

$1.57791 \mathrm{e}+011.57791 \mathrm{e}+011.57791 \mathrm{e}+001.00000 \mathrm{e}-092.12000 \mathrm{e}-01$

$1.57791 \mathrm{e}+011.57791 \mathrm{e}+01$ 1.57791e+00 1.00000e-09 2.12000e-01

$1.57791 \mathrm{e}+011.57791 \mathrm{e}+01$ 1.57791e+00 1.00000e-09 2.12000e-01

$1.57791 \mathrm{e}+01$ 1.57791e+01 1.57791e+00 1.00000e-09 2.12000e-01

$1.00000 \mathrm{e}-05$ 1.00000e-05 1.00000e-06 1.00000e-09 1.00000e-01

$1.00000 \mathrm{e}+001.00000 \mathrm{e}+001.00000 \mathrm{e}-011.00000 \mathrm{e}-091.00000 \mathrm{e}-01$ 
Element: 12404 \# of layers: 7

Kx Ky Kz Ss Por

$1.57791 \mathrm{e}+011.57791 \mathrm{e}+011.57791 \mathrm{e}+00$ 1.00000e-09 2.12000e-01

$1.57791 \mathrm{e}+011.57791 \mathrm{e}+011.57791 \mathrm{e}+001.00000 \mathrm{e}-092.12000 \mathrm{e}-01$

$1.57791 \mathrm{e}+011.57791 \mathrm{e}+011.57791 \mathrm{e}+001.00000 \mathrm{e}-092.12000 \mathrm{e}-01$

$1.57791 \mathrm{e}+011.57791 \mathrm{e}+011.57791 \mathrm{e}+001.00000 \mathrm{e}-092.12000 \mathrm{e}-01$

$1.57791 \mathrm{e}+011.57791 \mathrm{e}+011.57791 \mathrm{e}+001.00000 \mathrm{e}-092.12000 \mathrm{e}-01$

$1.00000 \mathrm{e}-05$ 1.00000e-05 1.00000e-06 1.00000e-09 1.00000e-01

$1.00000 \mathrm{e}+001.00000 \mathrm{e}+001.00000 \mathrm{e}-011.00000 \mathrm{e}-091.00000 \mathrm{e}-01$

Element: 12405 \# of layers: 7

Kx Ky Kz Ss Por

$1.57791 \mathrm{e}+011.57791 \mathrm{e}+011.57791 \mathrm{e}+00$ 1.00000e-09 2.12000e-01

$1.57791 \mathrm{e}+011.57791 \mathrm{e}+011.57791 \mathrm{e}+001.00000 \mathrm{e}-092.12000 \mathrm{e}-01$

$1.57791 \mathrm{e}+011.57791 \mathrm{e}+011.57791 \mathrm{e}+001.00000 \mathrm{e}-092.12000 \mathrm{e}-01$

$1.57791 \mathrm{e}+011.57791 \mathrm{e}+011.57791 \mathrm{e}+001.00000 \mathrm{e}-092.12000 \mathrm{e}-01$

$1.57791 \mathrm{e}+011.57791 \mathrm{e}+011.57791 \mathrm{e}+001.00000 \mathrm{e}-092.12000 \mathrm{e}-01$

$1.00000 \mathrm{e}-05$ 1.00000e-05 1.00000e-06 1.00000e-09 1.00000e-01

$1.00000 \mathrm{e}+001.00000 \mathrm{e}+001.00000 \mathrm{e}-011.00000 \mathrm{e}-091.00000 \mathrm{e}-01$

Element: 12406 \# of layers: 7

Kx Ky Kz Ss Por

$1.57791 \mathrm{e}+011.57791 \mathrm{e}+011.57791 \mathrm{e}+00$ 1.00000e-09 2.12000e-01

$1.57791 \mathrm{e}+011.57791 \mathrm{e}+011.57791 \mathrm{e}+001.00000 \mathrm{e}-092.12000 \mathrm{e}-01$

$1.57791 \mathrm{e}+011.57791 \mathrm{e}+011.57791 \mathrm{e}+001.00000 \mathrm{e}-092.12000 \mathrm{e}-01$

$1.57791 \mathrm{e}+011.57791 \mathrm{e}+011.57791 \mathrm{e}+001.00000 \mathrm{e}-092.12000 \mathrm{e}-01$

$1.57791 \mathrm{e}+011.57791 \mathrm{e}+011.57791 \mathrm{e}+001.00000 \mathrm{e}-092.12000 \mathrm{e}-01$

$1.00000 \mathrm{e}-05$ 1.00000e-05 1.00000e-06 1.00000e-09 1.00000e-01

$1.00000 \mathrm{e}+001.00000 \mathrm{e}+001.00000 \mathrm{e}-011.00000 \mathrm{e}-091.00000 \mathrm{e}-01$

Element: 12407 \# of layers: 7

Kx Ky Kz Ss Por

$1.57791 \mathrm{e}+011.57791 \mathrm{e}+011.57791 \mathrm{e}+00$ 1.00000e-09 2.12000e-01

$1.57791 \mathrm{e}+011.57791 \mathrm{e}+011.57791 \mathrm{e}+001.00000 \mathrm{e}-092.12000 \mathrm{e}-01$

$1.57791 \mathrm{e}+011.57791 \mathrm{e}+011.57791 \mathrm{e}+001.00000 \mathrm{e}-092.12000 \mathrm{e}-01$

$1.57791 \mathrm{e}+011.57791 \mathrm{e}+011.57791 \mathrm{e}+001.00000 \mathrm{e}-092.12000 \mathrm{e}-01$

$1.57791 \mathrm{e}+011.57791 \mathrm{e}+011.57791 \mathrm{e}+001.00000 \mathrm{e}-092.12000 \mathrm{e}-01$

$1.00000 \mathrm{e}-05$ 1.00000e-05 1.00000e-06 1.00000e-09 1.00000e-01

$1.00000 \mathrm{e}+001.00000 \mathrm{e}+001.00000 \mathrm{e}-011.00000 \mathrm{e}-091.00000 \mathrm{e}-01$

Element: 12408 \# of layers: 7

Kx Ky Kz Ss Por

$1.57791 \mathrm{e}+011.57791 \mathrm{e}+011.57791 \mathrm{e}+00$ 1.00000e-09 2.12000e-01

$1.57791 \mathrm{e}+011.57791 \mathrm{e}+011.57791 \mathrm{e}+001.00000 \mathrm{e}-092.12000 \mathrm{e}-01$

$1.57791 \mathrm{e}+011.57791 \mathrm{e}+011.57791 \mathrm{e}+001.00000 \mathrm{e}-092.12000 \mathrm{e}-01$

$1.57791 \mathrm{e}+011.57791 \mathrm{e}+011.57791 \mathrm{e}+001.00000 \mathrm{e}-092.12000 \mathrm{e}-01$

$1.57791 \mathrm{e}+011.57791 \mathrm{e}+011.57791 \mathrm{e}+001.00000 \mathrm{e}-092.12000 \mathrm{e}-01$

$1.00000 \mathrm{e}-05$ 1.00000e-05 1.00000e-06 1.00000e-09 1.00000e-01

$1.00000 \mathrm{e}+001.00000 \mathrm{e}+001.00000 \mathrm{e}-011.00000 \mathrm{e}-091.00000 \mathrm{e}-01$

Element: 12409 \# of layers: 7 
Kx Ky Kz Ss Por

$1.57791 \mathrm{e}+011.57791 \mathrm{e}+01$ 1.57791e+00 1.00000e-09 2.12000e-01

$1.57791 \mathrm{e}+011.57791 \mathrm{e}+011.57791 \mathrm{e}+001.00000 \mathrm{e}-092.12000 \mathrm{e}-01$

$1.57791 \mathrm{e}+011.57791 \mathrm{e}+011.57791 \mathrm{e}+001.00000 \mathrm{e}-092.12000 \mathrm{e}-01$

$1.57791 \mathrm{e}+011.57791 \mathrm{e}+01$ 1.57791e+00 1.00000e-09 2.12000e-01

$1.57791 \mathrm{e}+011.57791 \mathrm{e}+011.57791 \mathrm{e}+001.00000 \mathrm{e}-092.12000 \mathrm{e}-01$

$1.00000 \mathrm{e}-05$ 1.00000e-05 1.00000e-06 1.00000e-09 1.00000e-01

$1.00000 \mathrm{e}+001.00000 \mathrm{e}+001.00000 \mathrm{e}-01$ 1.00000e-09 1.00000e-01

Element: 12410 \# of layers: 7

$\mathrm{Kx} \mathrm{Ky} \mathrm{Kz}$ Ss Por

$1.57791 \mathrm{e}+011.57791 \mathrm{e}+01$ 1.57791e+00 1.00000e-09 2.12000e-01

$1.57791 \mathrm{e}+011.57791 \mathrm{e}+011.57791 \mathrm{e}+001.00000 \mathrm{e}-092.12000 \mathrm{e}-01$

$1.57791 \mathrm{e}+011.57791 \mathrm{e}+011.57791 \mathrm{e}+001.00000 \mathrm{e}-092.12000 \mathrm{e}-01$

$1.57791 \mathrm{e}+011.57791 \mathrm{e}+011.57791 \mathrm{e}+001.00000 \mathrm{e}-092.12000 \mathrm{e}-01$

$1.57791 \mathrm{e}+011.57791 \mathrm{e}+01$ 1.57791e+00 1.00000e-09 2.12000e-01

$1.00000 \mathrm{e}-05$ 1.00000e-05 1.00000e-06 1.00000e-09 1.00000e-01

$1.00000 \mathrm{e}+001.00000 \mathrm{e}+001.00000 \mathrm{e}-01$ 1.00000e-09 1.00000e-01

Element: 12411 \# of layers: 7

$\mathrm{Kx} \mathrm{Ky} \mathrm{Kz}$ Ss Por

$1.57791 \mathrm{e}+011.57791 \mathrm{e}+011.57791 \mathrm{e}+001.00000 \mathrm{e}-092.12000 \mathrm{e}-01$

$1.57791 \mathrm{e}+011.57791 \mathrm{e}+011.57791 \mathrm{e}+001.00000 \mathrm{e}-092.12000 \mathrm{e}-01$

$1.57791 \mathrm{e}+011.57791 \mathrm{e}+01$ 1.57791e+00 1.00000e-09 2.12000e-01

$1.57791 \mathrm{e}+011.57791 \mathrm{e}+01$ 1.57791e+00 1.00000e-09 2.12000e-01

$1.57791 \mathrm{e}+011.57791 \mathrm{e}+011.57791 \mathrm{e}+001.00000 \mathrm{e}-092.12000 \mathrm{e}-01$

$1.00000 \mathrm{e}-05$ 1.00000e-05 1.00000e-06 1.00000e-09 1.00000e-01

$1.00000 \mathrm{e}+001.00000 \mathrm{e}+001.00000 \mathrm{e}-01$ 1.00000e-09 1.00000e-01

Element: 12412 \# of layers: 7

$\mathrm{Kx} \mathrm{Ky} \mathrm{Kz}$ Ss Por

$1.57791 \mathrm{e}+011.57791 \mathrm{e}+011.57791 \mathrm{e}+001.00000 \mathrm{e}-092.12000 \mathrm{e}-01$

$1.57791 \mathrm{e}+011.57791 \mathrm{e}+01$ 1.57791e+00 1.00000e-09 2.12000e-01

$1.57791 \mathrm{e}+011.57791 \mathrm{e}+01$ 1.57791e+00 1.00000e-09 2.12000e-01

$1.57791 \mathrm{e}+011.57791 \mathrm{e}+011.57791 \mathrm{e}+001.00000 \mathrm{e}-092.12000 \mathrm{e}-01$

$1.57791 \mathrm{e}+011.57791 \mathrm{e}+011.57791 \mathrm{e}+001.00000 \mathrm{e}-092.12000 \mathrm{e}-01$

$1.00000 \mathrm{e}-05$ 1.00000e-05 1.00000e-06 1.00000e-09 1.00000e-01

$1.00000 \mathrm{e}+001.00000 \mathrm{e}+001.00000 \mathrm{e}-011.00000 \mathrm{e}-091.00000 \mathrm{e}-01$

Element: 12413 \# of layers: 7

Kx Ky Kz Ss Por

$1.57791 \mathrm{e}+011.57791 \mathrm{e}+01$ 1.57791e+00 1.00000e-09 2.12000e-01

$1.57791 \mathrm{e}+011.57791 \mathrm{e}+01$ 1.57791e+00 1.00000e-09 2.12000e-01

$1.57791 \mathrm{e}+011.57791 \mathrm{e}+011.57791 \mathrm{e}+001.00000 \mathrm{e}-092.12000 \mathrm{e}-01$

$1.57791 \mathrm{e}+011.57791 \mathrm{e}+011.57791 \mathrm{e}+001.00000 \mathrm{e}-092.12000 \mathrm{e}-01$

$1.57791 \mathrm{e}+011.57791 \mathrm{e}+01$ 1.57791e+00 1.00000e-09 2.12000e-01

$1.00000 \mathrm{e}-05$ 1.00000e-05 1.00000e-06 1.00000e-09 1.00000e-01

$1.00000 \mathrm{e}+001.00000 \mathrm{e}+001.00000 \mathrm{e}-01$ 1.00000e-09 1.00000e-01

Element: 12414 \# of layers: 7

Kx Ky Kz Ss Por 
$1.57791 \mathrm{e}+011.57791 \mathrm{e}+01$ 1.57791e+00 1.00000e-09 2.12000e-01 $1.57791 \mathrm{e}+011.57791 \mathrm{e}+011.57791 \mathrm{e}+001.00000 \mathrm{e}-092.12000 \mathrm{e}-01$ $1.57791 \mathrm{e}+011.57791 \mathrm{e}+011.57791 \mathrm{e}+001.00000 \mathrm{e}-092.12000 \mathrm{e}-01$ $1.57791 \mathrm{e}+011.57791 \mathrm{e}+011.57791 \mathrm{e}+001.00000 \mathrm{e}-092.12000 \mathrm{e}-01$ $1.57791 \mathrm{e}+011.57791 \mathrm{e}+01$ 1.57791e+00 1.00000e-09 2.12000e-01 $1.00000 \mathrm{e}-05$ 1.00000e-05 1.00000e-06 1.00000e-09 1.00000e-01 $1.00000 \mathrm{e}+001.00000 \mathrm{e}+001.00000 \mathrm{e}-011.00000 \mathrm{e}-091.00000 \mathrm{e}-01$ Element: 12415 \# of layers: 7

$\mathrm{Kx} \mathrm{Ky} \mathrm{Kz}$ Ss Por

$1.32049 \mathrm{e}+01$ 1.32049e+01 1.32049e+00 1.00000e-09 2.12000e-01 $1.32049 \mathrm{e}+01$ 1.32049e+01 1.32049e+00 1.00000e-09 2.12000e-01 $1.32049 \mathrm{e}+01$ 1.32049e+01 1.32049e+00 1.00000e-09 2.12000e-01 $1.32049 \mathrm{e}+01$ 1.32049e+01 1.32049e+00 1.00000e-09 2.12000e-01 $1.32049 \mathrm{e}+01$ 1.32049e+01 1.32049e+00 1.00000e-09 2.12000e-01 $1.00000 \mathrm{e}-05$ 1.00000e-05 1.00000e-06 1.00000e-09 1.00000e-01 $1.00000 \mathrm{e}+001.00000 \mathrm{e}+001.00000 \mathrm{e}-011.00000 \mathrm{e}-091.00000 \mathrm{e}-01$ Element: 12416 \# of layers: 7

$\mathrm{Kx} \mathrm{Ky} \mathrm{Kz}$ Ss Por

1.32049e+01 1.32049e+01 1.32049e+00 1.00000e-09 2.12000e-01 $1.32049 \mathrm{e}+01$ 1.32049e+01 1.32049e+00 1.00000e-09 2.12000e-01 $1.32049 \mathrm{e}+01$ 1.32049e+01 1.32049e+00 1.00000e-09 2.12000e-01 $1.32049 \mathrm{e}+01$ 1.32049e+01 1.32049e+00 1.00000e-09 2.12000e-01 $1.32049 \mathrm{e}+01$ 1.32049e+01 1.32049e+00 1.00000e-09 2.12000e-01 $1.00000 \mathrm{e}-05$ 1.00000e-05 1.00000e-06 1.00000e-09 1.00000e-01 $1.00000 \mathrm{e}+001.00000 \mathrm{e}+001.00000 \mathrm{e}-011.00000 \mathrm{e}-091.00000 \mathrm{e}-01$ Element: 12417 \# of layers: 7

$\mathrm{Kx} \mathrm{Ky} \mathrm{Kz}$ Ss Por

$1.32049 \mathrm{e}+01$ 1.32049e+01 1.32049e+00 1.00000e-09 2.12000e-01 $1.32049 \mathrm{e}+01$ 1.32049e+01 1.32049e+00 1.00000e-09 2.12000e-01 $1.32049 \mathrm{e}+01$ 1.32049e+01 1.32049e+00 1.00000e-09 2.12000e-01 $1.32049 \mathrm{e}+01$ 1.32049e+01 1.32049e+00 1.00000e-09 2.12000e-01 $1.32049 \mathrm{e}+01$ 1.32049e+01 1.32049e+00 1.00000e-09 2.12000e-01 $1.00000 \mathrm{e}-05$ 1.00000e-05 1.00000e-06 1.00000e-09 1.00000e-01 $1.00000 \mathrm{e}+001.00000 \mathrm{e}+001.00000 \mathrm{e}-011.00000 \mathrm{e}-091.00000 \mathrm{e}-01$ Element: 12418 \# of layers: 7

Kx Ky Kz Ss Por

$1.57791 \mathrm{e}+011.57791 \mathrm{e}+01$ 1.57791e+00 1.00000e-09 2.12000e-01 $1.57791 \mathrm{e}+011.57791 \mathrm{e}+011.57791 \mathrm{e}+001.00000 \mathrm{e}-092.12000 \mathrm{e}-01$ $1.57791 \mathrm{e}+011.57791 \mathrm{e}+011.57791 \mathrm{e}+001.00000 \mathrm{e}-092.12000 \mathrm{e}-01$ $1.57791 \mathrm{e}+011.57791 \mathrm{e}+011.57791 \mathrm{e}+001.00000 \mathrm{e}-092.12000 \mathrm{e}-01$ $1.57791 \mathrm{e}+011.57791 \mathrm{e}+011.57791 \mathrm{e}+001.00000 \mathrm{e}-092.12000 \mathrm{e}-01$ $1.00000 \mathrm{e}-05$ 1.00000e-05 1.00000e-06 1.00000e-09 1.00000e-01 $1.00000 \mathrm{e}+001.00000 \mathrm{e}+001.00000 \mathrm{e}-011.00000 \mathrm{e}-091.00000 \mathrm{e}-01$ Element: 12419 \# of layers: 7

Kx Ky Kz Ss Por

$1.57791 \mathrm{e}+011.57791 \mathrm{e}+011.57791 \mathrm{e}+001.00000 \mathrm{e}-092.12000 \mathrm{e}-01$ 
$1.57791 \mathrm{e}+011.57791 \mathrm{e}+01$ 1.57791e+00 1.00000e-09 2.12000e-01 $1.57791 \mathrm{e}+011.57791 \mathrm{e}+011.57791 \mathrm{e}+001.00000 \mathrm{e}-092.12000 \mathrm{e}-01$ $1.57791 \mathrm{e}+011.57791 \mathrm{e}+011.57791 \mathrm{e}+001.00000 \mathrm{e}-092.12000 \mathrm{e}-01$ $1.57791 \mathrm{e}+011.57791 \mathrm{e}+011.57791 \mathrm{e}+001.00000 \mathrm{e}-092.12000 \mathrm{e}-01$ $1.00000 \mathrm{e}-05$ 1.00000e-05 1.00000e-06 1.00000e-09 1.00000e-01 $1.00000 \mathrm{e}+001.00000 \mathrm{e}+001.00000 \mathrm{e}-011.00000 \mathrm{e}-091.00000 \mathrm{e}-01$ Element: 12420 \# of layers: 7

Kx Ky Kz Ss Por

$1.57791 \mathrm{e}+01$ 1.57791e+01 1.57791e+00 1.00000e-09 2.12000e-01 $1.57791 \mathrm{e}+011.57791 \mathrm{e}+011.57791 \mathrm{e}+001.00000 \mathrm{e}-092.12000 \mathrm{e}-01$ $1.57791 \mathrm{e}+011.57791 \mathrm{e}+011.57791 \mathrm{e}+001.00000 \mathrm{e}-092.12000 \mathrm{e}-01$ $1.57791 \mathrm{e}+011.57791 \mathrm{e}+011.57791 \mathrm{e}+001.00000 \mathrm{e}-092.12000 \mathrm{e}-01$ $1.57791 \mathrm{e}+011.57791 \mathrm{e}+011.57791 \mathrm{e}+001.00000 \mathrm{e}-092.12000 \mathrm{e}-01$ $1.00000 \mathrm{e}-05$ 1.00000e-05 1.00000e-06 1.00000e-09 1.00000e-01 $1.00000 \mathrm{e}+001.00000 \mathrm{e}+001.00000 \mathrm{e}-01$ 1.00000e-09 1.00000e-01 Element: 12421 \# of layers: 7

$\mathrm{Kx} \mathrm{Ky} \mathrm{Kz}$ Ss Por

$1.57791 \mathrm{e}+011.57791 \mathrm{e}+01$ 1.57791e+00 1.00000e-09 2.12000e-01 $1.57791 \mathrm{e}+011.57791 \mathrm{e}+01$ 1.57791e+00 1.00000e-09 2.12000e-01 $1.57791 \mathrm{e}+011.57791 \mathrm{e}+011.57791 \mathrm{e}+001.00000 \mathrm{e}-092.12000 \mathrm{e}-01$ $1.57791 \mathrm{e}+011.57791 \mathrm{e}+011.57791 \mathrm{e}+001.00000 \mathrm{e}-092.12000 \mathrm{e}-01$ $1.57791 \mathrm{e}+01$ 1.57791e+01 1.57791e+00 1.00000e-09 2.12000e-01 $1.00000 \mathrm{e}-05$ 1.00000e-05 1.00000e-06 1.00000e-09 1.00000e-01 $1.00000 \mathrm{e}+001.00000 \mathrm{e}+001.00000 \mathrm{e}-011.00000 \mathrm{e}-09$ 1.00000e-01 Element: 12422 \# of layers: 7

$\mathrm{Kx} \mathrm{Ky} \mathrm{Kz}$ Ss Por

$1.32049 \mathrm{e}+01$ 1.32049e+01 1.32049e+00 1.00000e-09 2.12000e-01 $1.32049 \mathrm{e}+01$ 1.32049e+01 1.32049e+00 1.00000e-09 2.12000e-01 $1.32049 \mathrm{e}+01$ 1.32049e+01 1.32049e+00 1.00000e-09 2.12000e-01 $1.32049 \mathrm{e}+01$ 1.32049e+01 1.32049e+00 1.00000e-09 2.12000e-01 $1.32049 \mathrm{e}+01$ 1.32049e+01 1.32049e+00 1.00000e-09 2.12000e-01 $1.00000 \mathrm{e}-05$ 1.00000e-05 1.00000e-06 1.00000e-09 1.00000e-01 $1.00000 \mathrm{e}+001.00000 \mathrm{e}+001.00000 \mathrm{e}-011.00000 \mathrm{e}-091.00000 \mathrm{e}-01$ Element: 12423 \# of layers: 7

$\mathrm{Kx} \mathrm{Ky} \mathrm{Kz}$ Ss Por

$1.32049 \mathrm{e}+01$ 1.32049e+01 1.32049e+00 1.00000e-09 2.12000e-01 $1.32049 \mathrm{e}+01$ 1.32049e+01 1.32049e+00 1.00000e-09 2.12000e-01 $1.32049 \mathrm{e}+01$ 1.32049e+01 1.32049e+00 1.00000e-09 2.12000e-01 $1.32049 \mathrm{e}+01$ 1.32049e+01 1.32049e+00 1.00000e-09 2.12000e-01 $1.32049 \mathrm{e}+01$ 1.32049e+01 1.32049e+00 1.00000e-09 2.12000e-01 $1.00000 \mathrm{e}-05$ 1.00000e-05 1.00000e-06 1.00000e-09 1.00000e-01 $1.00000 \mathrm{e}+001.00000 \mathrm{e}+001.00000 \mathrm{e}-011.00000 \mathrm{e}-091.00000 \mathrm{e}-01$ Element: 12424 \# of layers: 7

$\mathrm{Kx} \mathrm{Ky} \mathrm{Kz}$ Ss Por

$1.32049 \mathrm{e}+01$ 1.32049e+01 1.32049e+00 1.00000e-09 2.12000e-01 $1.32049 \mathrm{e}+01$ 1.32049e+01 1.32049e+00 1.00000e-09 2.12000e-01 
1.32049e+01 1.32049e+01 1.32049e+00 1.00000e-09 2.12000e-01 $1.32049 \mathrm{e}+01$ 1.32049e+01 1.32049e+00 1.00000e-09 2.12000e-01 $1.32049 \mathrm{e}+01$ 1.32049e+01 1.32049e+00 1.00000e-09 2.12000e-01 $1.00000 \mathrm{e}-05$ 1.00000e-05 1.00000e-06 1.00000e-09 1.00000e-01 $1.00000 \mathrm{e}+001.00000 \mathrm{e}+001.00000 \mathrm{e}-01$ 1.00000e-09 1.00000e-01 Element: 12425 \# of layers: 7

$\mathrm{Kx} \mathrm{Ky} \mathrm{Kz}$ Ss Por

$1.32049 \mathrm{e}+01$ 1.32049e+01 1.32049e+00 1.00000e-09 2.12000e-01 $1.32049 \mathrm{e}+01$ 1.32049e+01 1.32049e+00 1.00000e-09 2.12000e-01 $1.32049 \mathrm{e}+01$ 1.32049e+01 1.32049e+00 1.00000e-09 2.12000e-01 $1.32049 \mathrm{e}+01$ 1.32049e+01 1.32049e+00 1.00000e-09 2.12000e-01 $1.32049 \mathrm{e}+01$ 1.32049e+01 1.32049e+00 1.00000e-09 2.12000e-01 $1.00000 \mathrm{e}-051.00000 \mathrm{e}-05$ 1.00000e-06 1.00000e-09 1.00000e-01 $1.00000 \mathrm{e}+001.00000 \mathrm{e}+001.00000 \mathrm{e}-011.00000 \mathrm{e}-09$ 1.00000e-01 Element: 12426 \# of layers: 7

Kx Ky Kz Ss Por

$1.32049 \mathrm{e}+01$ 1.32049e+01 1.32049e+00 1.00000e-09 2.12000e-01 $1.32049 \mathrm{e}+01$ 1.32049e+01 1.32049e+00 1.00000e-09 2.12000e-01 $1.32049 \mathrm{e}+01$ 1.32049e+01 1.32049e+00 1.00000e-09 2.12000e-01 $1.32049 \mathrm{e}+01$ 1.32049e+01 1.32049e+00 1.00000e-09 2.12000e-01 $1.32049 \mathrm{e}+01$ 1.32049e+01 1.32049e+00 1.00000e-09 2.12000e-01 $1.00000 \mathrm{e}-05$ 1.00000e-05 1.00000e-06 1.00000e-09 1.00000e-01 $1.00000 \mathrm{e}+001.00000 \mathrm{e}+001.00000 \mathrm{e}-01$ 1.00000e-09 1.00000e-01 Element: 12427 \# of layers: 7

Kx Ky Kz Ss Por

$1.32049 \mathrm{e}+01$ 1.32049e+01 1.32049e+00 1.00000e-09 2.12000e-01 $1.32049 \mathrm{e}+01$ 1.32049e+01 1.32049e+00 1.00000e-09 2.12000e-01 $1.32049 \mathrm{e}+01$ 1.32049e+01 1.32049e+00 1.00000e-09 2.12000e-01 $1.32049 \mathrm{e}+01$ 1.32049e+01 1.32049e+00 1.00000e-09 2.12000e-01 $1.32049 \mathrm{e}+01$ 1.32049e+01 1.32049e+00 1.00000e-09 2.12000e-01 $1.00000 \mathrm{e}-05$ 1.00000e-05 1.00000e-06 1.00000e-09 1.00000e-01 $1.00000 \mathrm{e}+001.00000 \mathrm{e}+001.00000 \mathrm{e}-01$ 1.00000e-09 1.00000e-01 Element: 12428 \# of layers: 7

$\mathrm{Kx} \mathrm{Ky} \mathrm{Kz}$ Ss Por

$1.32049 \mathrm{e}+01$ 1.32049e+01 1.32049e+00 1.00000e-09 2.12000e-01 $1.32049 \mathrm{e}+01$ 1.32049e+01 1.32049e+00 1.00000e-09 2.12000e-01 $1.32049 \mathrm{e}+01$ 1.32049e+01 1.32049e+00 1.00000e-09 2.12000e-01 $1.32049 \mathrm{e}+01$ 1.32049e+01 1.32049e+00 1.00000e-09 2.12000e-01 $1.32049 \mathrm{e}+01$ 1.32049e+01 1.32049e+00 1.00000e-09 2.12000e-01 $1.00000 \mathrm{e}-05$ 1.00000e-05 1.00000e-06 1.00000e-09 1.00000e-01 $1.00000 \mathrm{e}+001.00000 \mathrm{e}+001.00000 \mathrm{e}-011.00000 \mathrm{e}-091.00000 \mathrm{e}-01$ Element: 12429 \# of layers: 7

$\mathrm{Kx} \mathrm{Ky} \mathrm{Kz}$ Ss Por

$1.32049 \mathrm{e}+01$ 1.32049e+01 1.32049e+00 1.00000e-09 2.12000e-01 $1.32049 \mathrm{e}+01$ 1.32049e+01 1.32049e+00 1.00000e-09 2.12000e-01 $1.32049 \mathrm{e}+01$ 1.32049e+01 1.32049e+00 1.00000e-09 2.12000e-01 
$1.32049 \mathrm{e}+01$ 1.32049e+01 1.32049e+00 1.00000e-09 2.12000e-01 $1.32049 \mathrm{e}+01$ 1.32049e+01 1.32049e+00 1.00000e-09 2.12000e-01 $1.00000 \mathrm{e}-05$ 1.00000e-05 1.00000e-06 1.00000e-09 1.00000e-01

$1.00000 \mathrm{e}+001.00000 \mathrm{e}+001.00000 \mathrm{e}-011.00000 \mathrm{e}-091.00000 \mathrm{e}-01$ Element: 12430 \# of layers: 7

$\mathrm{Kx} \mathrm{Ky} \mathrm{Kz}$ Ss Por

$1.32049 \mathrm{e}+01$ 1.32049e+01 1.32049e+00 1.00000e-09 2.12000e-01 $1.32049 \mathrm{e}+01$ 1.32049e+01 1.32049e+00 1.00000e-09 2.12000e-01 $1.32049 \mathrm{e}+01$ 1.32049e+01 1.32049e+00 1.00000e-09 2.12000e-01 $1.32049 \mathrm{e}+01$ 1.32049e+01 1.32049e+00 1.00000e-09 2.12000e-01 $1.32049 \mathrm{e}+01$ 1.32049e+01 1.32049e+00 1.00000e-09 2.12000e-01 $1.00000 \mathrm{e}-05$ 1.00000e-05 1.00000e-06 1.00000e-09 1.00000e-01 $1.00000 \mathrm{e}+001.00000 \mathrm{e}+001.00000 \mathrm{e}-01$ 1.00000e-09 1.00000e-01 Element: 12431 \# of layers: 7

Kx Ky Kz Ss Por

$1.32049 \mathrm{e}+01$ 1.32049e+01 1.32049e+00 1.00000e-09 2.12000e-01 $1.32049 \mathrm{e}+01$ 1.32049e+01 1.32049e+00 1.00000e-09 2.12000e-01 $1.32049 \mathrm{e}+01$ 1.32049e+01 1.32049e+00 1.00000e-09 2.12000e-01 $1.32049 \mathrm{e}+01$ 1.32049e+01 1.32049e+00 1.00000e-09 2.12000e-01 $1.32049 \mathrm{e}+01$ 1.32049e+01 1.32049e+00 1.00000e-09 2.12000e-01 $1.00000 \mathrm{e}-05$ 1.00000e-05 1.00000e-06 1.00000e-09 1.00000e-01 $1.00000 \mathrm{e}+001.00000 \mathrm{e}+001.00000 \mathrm{e}-01$ 1.00000e-09 1.00000e-01 Element: 12432 \# of layers: 7

Kx Ky Kz Ss Por

$1.32049 \mathrm{e}+01$ 1.32049e+01 1.32049e+00 1.00000e-09 2.12000e-01 $1.32049 \mathrm{e}+01$ 1.32049e+01 1.32049e+00 1.00000e-09 2.12000e-01 $1.32049 \mathrm{e}+01$ 1.32049e+01 1.32049e+00 1.00000e-09 2.12000e-01 $1.32049 \mathrm{e}+01$ 1.32049e+01 1.32049e+00 1.00000e-09 2.12000e-01 $1.32049 \mathrm{e}+01$ 1.32049e+01 1.32049e+00 1.00000e-09 2.12000e-01 $1.00000 \mathrm{e}-05$ 1.00000e-05 1.00000e-06 1.00000e-09 1.00000e-01 $1.00000 \mathrm{e}+001.00000 \mathrm{e}+001.00000 \mathrm{e}-01$ 1.00000e-09 1.00000e-01 Element: 12433 \# of layers: 7

Kx Ky Kz Ss Por

8.18995e+00 8.18995e+00 8.18995e-01 1.00000e-09 2.12000e-01 8.18995e+00 8.18995e+00 8.18995e-01 1.00000e-09 2.12000e-01 8.18995e+00 8.18995e+00 8.18995e-01 1.00000e-09 2.12000e-01 8.18995e+00 8.18995e+00 8.18995e-01 1.00000e-09 2.12000e-01 8.18995e+00 8.18995e+00 8.18995e-01 1.00000e-09 2.12000e-01 $1.00000 \mathrm{e}-05$ 1.00000e-05 1.00000e-06 1.00000e-09 1.00000e-01 $1.00000 \mathrm{e}+001.00000 \mathrm{e}+00$ 1.00000e-01 1.00000e-09 1.00000e-01 Element: 12434 \# of layers: 7

$\mathrm{Kx} \mathrm{Ky} \mathrm{Kz}$ Ss Por

8.18995e+00 8.18995e+00 8.18995e-01 1.00000e-09 2.12000e-01 8.18995e+00 8.18995e+00 8.18995e-01 1.00000e-09 2.12000e-01 8.18995e+00 8.18995e+00 8.18995e-01 1.00000e-09 2.12000e-01 $8.18995 \mathrm{e}+00$ 8.18995e+00 8.18995e-01 1.00000e-09 2.12000e-01 
$8.18995 \mathrm{e}+00$ 8.18995e+00 8.18995e-01 1.00000e-09 2.12000e-01 $1.00000 \mathrm{e}-05$ 1.00000e-05 1.00000e-06 1.00000e-09 1.00000e-01 $1.00000 \mathrm{e}+001.00000 \mathrm{e}+001.00000 \mathrm{e}-011.00000 \mathrm{e}-091.00000 \mathrm{e}-01$ Element: 12435 \# of layers: 7

Kx Ky Kz Ss Por

8.18995e+00 8.18995e+00 8.18995e-01 1.00000e-09 2.12000e-01

$8.18995 \mathrm{e}+008.18995 \mathrm{e}+00$ 8.18995e-01 1.00000e-09 2.12000e-01

$8.18995 \mathrm{e}+00$ 8.18995e+00 8.18995e-01 1.00000e-09 2.12000e-01

$8.18995 \mathrm{e}+008.18995 \mathrm{e}+00$ 8.18995e-01 1.00000e-09 2.12000e-01

$8.18995 \mathrm{e}+00$ 8.18995e+00 8.18995e-01 1.00000e-09 2.12000e-01

$1.00000 \mathrm{e}-05$ 1.00000e-05 1.00000e-06 1.00000e-09 1.00000e-01

$1.00000 \mathrm{e}+001.00000 \mathrm{e}+001.00000 \mathrm{e}-011.00000 \mathrm{e}-091.00000 \mathrm{e}-01$

Element: 12436 \# of layers: 7

Kx Ky Kz Ss Por

$1.32049 \mathrm{e}+011.32049 \mathrm{e}+011.32049 \mathrm{e}+00$ 1.00000e-09 2.12000e-01

$1.32049 \mathrm{e}+011.32049 \mathrm{e}+011.32049 \mathrm{e}+00$ 1.00000e-09 2.12000e-01

$1.32049 \mathrm{e}+011.32049 \mathrm{e}+011.32049 \mathrm{e}+001.00000 \mathrm{e}-092.12000 \mathrm{e}-01$

$1.32049 \mathrm{e}+011.32049 \mathrm{e}+011.32049 \mathrm{e}+00$ 1.00000e-09 2.12000e-01

$1.32049 \mathrm{e}+011.32049 \mathrm{e}+011.32049 \mathrm{e}+00$ 1.00000e-09 2.12000e-01

$1.00000 \mathrm{e}-05$ 1.00000e-05 1.00000e-06 1.00000e-09 1.00000e-01

$1.00000 \mathrm{e}+001.00000 \mathrm{e}+001.00000 \mathrm{e}-011.00000 \mathrm{e}-091.00000 \mathrm{e}-01$

Element: 12437 \# of layers: 7

Kx Ky Kz Ss Por

$1.32049 \mathrm{e}+011.32049 \mathrm{e}+011.32049 \mathrm{e}+00$ 1.00000e-09 2.12000e-01

$1.32049 \mathrm{e}+011.32049 \mathrm{e}+011.32049 \mathrm{e}+001.00000 \mathrm{e}-092.12000 \mathrm{e}-01$

$1.32049 \mathrm{e}+011.32049 \mathrm{e}+011.32049 \mathrm{e}+001.00000 \mathrm{e}-092.12000 \mathrm{e}-01$

$1.32049 \mathrm{e}+011.32049 \mathrm{e}+011.32049 \mathrm{e}+00$ 1.00000e-09 2.12000e-01

$1.32049 \mathrm{e}+011.32049 \mathrm{e}+011.32049 \mathrm{e}+001.00000 \mathrm{e}-092.12000 \mathrm{e}-01$

$1.00000 \mathrm{e}-05$ 1.00000e-05 1.00000e-06 1.00000e-09 1.00000e-01

$1.00000 \mathrm{e}+001.00000 \mathrm{e}+001.00000 \mathrm{e}-011.00000 \mathrm{e}-091.00000 \mathrm{e}-01$

Element: 12438 \# of layers: 7

Kx Ky Kz Ss Por

$1.32049 \mathrm{e}+011.32049 \mathrm{e}+011.32049 \mathrm{e}+00$ 1.00000e-09 2.12000e-01

$1.32049 \mathrm{e}+011.32049 \mathrm{e}+011.32049 \mathrm{e}+001.00000 \mathrm{e}-092.12000 \mathrm{e}-01$

$1.32049 \mathrm{e}+011.32049 \mathrm{e}+011.32049 \mathrm{e}+001.00000 \mathrm{e}-092.12000 \mathrm{e}-01$

$1.32049 \mathrm{e}+011.32049 \mathrm{e}+011.32049 \mathrm{e}+00$ 1.00000e-09 2.12000e-01

$1.32049 \mathrm{e}+011.32049 \mathrm{e}+011.32049 \mathrm{e}+00$ 1.00000e-09 2.12000e-01

$1.00000 \mathrm{e}-05$ 1.00000e-05 1.00000e-06 1.00000e-09 1.00000e-01

$1.00000 \mathrm{e}+001.00000 \mathrm{e}+001.00000 \mathrm{e}-011.00000 \mathrm{e}-091.00000 \mathrm{e}-01$

Element: 12439 \# of layers: 7

Kx Ky Kz Ss Por

$1.32049 \mathrm{e}+011.32049 \mathrm{e}+011.32049 \mathrm{e}+00$ 1.00000e-09 2.12000e-01

$1.32049 \mathrm{e}+011.32049 \mathrm{e}+011.32049 \mathrm{e}+00$ 1.00000e-09 2.12000e-01

$1.32049 \mathrm{e}+011.32049 \mathrm{e}+011.32049 \mathrm{e}+001.00000 \mathrm{e}-092.12000 \mathrm{e}-01$

$1.32049 \mathrm{e}+011.32049 \mathrm{e}+011.32049 \mathrm{e}+00$ 1.00000e-09 2.12000e-01

$1.32049 \mathrm{e}+011.32049 \mathrm{e}+01$ 1.32049e+00 1.00000e-09 2.12000e-01 
$1.00000 \mathrm{e}-05$ 1.00000e-05 1.00000e-06 1.00000e-09 1.00000e-01 $1.00000 \mathrm{e}+001.00000 \mathrm{e}+001.00000 \mathrm{e}-011.00000 \mathrm{e}-091.00000 \mathrm{e}-01$ Element: 12440 \# of layers: 7

Kx Ky Kz Ss Por

8.18995e+00 8.18995e+00 8.18995e-01 1.00000e-09 2.12000e-01

8.18995e+00 8.18995e+00 8.18995e-01 1.00000e-09 2.12000e-01

8.18995e+00 8.18995e+00 8.18995e-01 1.00000e-09 2.12000e-01

8.18995e+00 8.18995e+00 8.18995e-01 1.00000e-09 2.12000e-01

$8.18995 \mathrm{e}+00$ 8.18995e+00 8.18995e-01 1.00000e-09 2.12000e-01

$1.00000 \mathrm{e}-05$ 1.00000e-05 1.00000e-06 1.00000e-09 1.00000e-01

$1.00000 \mathrm{e}+001.00000 \mathrm{e}+001.00000 \mathrm{e}-01$ 1.00000e-09 1.00000e-01

Element: 12441 \# of layers: 7

Kx Ky Kz Ss Por

8.18995e+00 8.18995e+00 8.18995e-01 1.00000e-09 2.12000e-01

8.18995e+00 8.18995e+00 8.18995e-01 1.00000e-09 2.12000e-01

8.18995e+00 8.18995e+00 8.18995e-01 1.00000e-09 2.12000e-01

8.18995e+00 8.18995e+00 8.18995e-01 1.00000e-09 2.12000e-01

8.18995e+00 8.18995e+00 8.18995e-01 1.00000e-09 2.12000e-01

$1.00000 \mathrm{e}-051.00000 \mathrm{e}-05$ 1.00000e-06 1.00000e-09 1.00000e-01

$1.00000 \mathrm{e}+001.00000 \mathrm{e}+001.00000 \mathrm{e}-011.00000 \mathrm{e}-091.00000 \mathrm{e}-01$

Element: 12442 \# of layers: 7

$\mathrm{Kx} \mathrm{Ky} \mathrm{Kz}$ Ss Por

8.18995e+00 8.18995e+00 8.18995e-01 1.00000e-09 2.12000e-01

8.18995e+00 8.18995e+00 8.18995e-01 1.00000e-09 2.12000e-01

$8.18995 \mathrm{e}+00$ 8.18995e+00 8.18995e-01 1.00000e-09 2.12000e-01

8.18995e+00 8.18995e+00 8.18995e-01 1.00000e-09 2.12000e-01

$8.18995 \mathrm{e}+00$ 8.18995e+00 8.18995e-01 1.00000e-09 2.12000e-01

$1.00000 \mathrm{e}-05$ 1.00000e-05 1.00000e-06 1.00000e-09 1.00000e-01

$1.00000 \mathrm{e}+001.00000 \mathrm{e}+001.00000 \mathrm{e}-011.00000 \mathrm{e}-091.00000 \mathrm{e}-01$

Element: 12443 \# of layers: 7

$\mathrm{Kx} \mathrm{Ky} \mathrm{Kz}$ Ss Por

8.18995e+00 8.18995e+00 8.18995e-01 1.00000e-09 2.12000e-01

8.18995e+00 8.18995e+00 8.18995e-01 1.00000e-09 2.12000e-01

8.18995e+00 8.18995e+00 8.18995e-01 1.00000e-09 2.12000e-01

8.18995e+00 8.18995e+00 8.18995e-01 1.00000e-09 2.12000e-01

8.18995e+00 8.18995e+00 8.18995e-01 1.00000e-09 2.12000e-01

1.00000e-05 1.00000e-05 1.00000e-06 1.00000e-09 1.00000e-01

$1.00000 \mathrm{e}+001.00000 \mathrm{e}+001.00000 \mathrm{e}-011.00000 \mathrm{e}-091.00000 \mathrm{e}-01$

Element: 12444 \# of layers: 7

$\mathrm{Kx} \mathrm{Ky} \mathrm{Kz}$ Ss Por

$1.45742 \mathrm{e}+01$ 1.45742e+01 1.45742e+00 1.00000e-09 2.12000e-01 $1.45742 \mathrm{e}+01$ 1.45742e+01 1.45742e+00 1.00000e-09 2.12000e-01 $1.45742 \mathrm{e}+011.45742 \mathrm{e}+01$ 1.45742e+00 1.00000e-09 2.12000e-01 $1.45742 \mathrm{e}+011.45742 \mathrm{e}+011.45742 \mathrm{e}+001.00000 \mathrm{e}-092.12000 \mathrm{e}-01$ $1.45742 \mathrm{e}+011.45742 \mathrm{e}+01 \quad 1.45742 \mathrm{e}+001.00000 \mathrm{e}-092.12000 \mathrm{e}-01$ $1.00000 \mathrm{e}-05$ 1.00000e-05 1.00000e-06 1.00000e-09 1.00000e-01 
$1.00000 \mathrm{e}+001.00000 \mathrm{e}+001.00000 \mathrm{e}-011.00000 \mathrm{e}-091.00000 \mathrm{e}-01$

Element: 12445 \# of layers: 7

Kx Ky Kz Ss Por

$1.45742 \mathrm{e}+01$ 1.45742e+01 1.45742e+00 1.00000e-09 2.12000e-01

$1.45742 \mathrm{e}+011.45742 \mathrm{e}+01$ 1.45742e+00 1.00000e-09 2.12000e-01

$1.45742 \mathrm{e}+01$ 1.45742e+01 1.45742e+00 1.00000e-09 2.12000e-01

$1.45742 \mathrm{e}+011.45742 \mathrm{e}+01$ 1.45742e+00 1.00000e-09 2.12000e-01

$1.45742 \mathrm{e}+01$ 1.45742e+01 1.45742e+00 1.00000e-09 2.12000e-01

$1.00000 \mathrm{e}-05$ 1.00000e-05 1.00000e-06 1.00000e-09 1.00000e-01

$1.00000 \mathrm{e}+001.00000 \mathrm{e}+001.00000 \mathrm{e}-011.00000 \mathrm{e}-091.00000 \mathrm{e}-01$

Element: 12446 \# of layers: 7

Kx Ky Kz Ss Por

8.18995e+00 8.18995e+00 8.18995e-01 1.00000e-09 2.12000e-01

8.18995e+00 8.18995e+00 8.18995e-01 1.00000e-09 2.12000e-01

8.18995e+00 8.18995e+00 8.18995e-01 1.00000e-09 2.12000e-01

8.18995e+00 8.18995e+00 8.18995e-01 1.00000e-09 2.12000e-01

8.18995e+00 8.18995e+00 8.18995e-01 1.00000e-09 2.12000e-01

$1.00000 \mathrm{e}-05$ 1.00000e-05 1.00000e-06 1.00000e-09 1.00000e-01

$1.00000 \mathrm{e}+001.00000 \mathrm{e}+001.00000 \mathrm{e}-01$ 1.00000e-09 1.00000e-01

Element: 12447 \# of layers: 7

$\mathrm{Kx} \mathrm{Ky} \mathrm{Kz}$ Ss Por

$1.45742 \mathrm{e}+01$ 1.45742e+01 1.45742e+00 1.00000e-09 2.12000e-01

$1.45742 \mathrm{e}+01$ 1.45742e+01 1.45742e+00 1.00000e-09 2.12000e-01

$1.45742 \mathrm{e}+011.45742 \mathrm{e}+011.45742 \mathrm{e}+001.00000 \mathrm{e}-092.12000 \mathrm{e}-01$

$1.45742 \mathrm{e}+011.45742 \mathrm{e}+011.45742 \mathrm{e}+001.00000 \mathrm{e}-092.12000 \mathrm{e}-01$

$1.45742 \mathrm{e}+011.45742 \mathrm{e}+01$ 1.45742e+00 1.00000e-09 2.12000e-01

$1.00000 \mathrm{e}-05$ 1.00000e-05 1.00000e-06 1.00000e-09 1.00000e-01

$1.00000 \mathrm{e}+001.00000 \mathrm{e}+001.00000 \mathrm{e}-01$ 1.00000e-09 1.00000e-01

Element: 12448 \# of layers: 7

$\mathrm{Kx} \mathrm{Ky} \mathrm{Kz}$ Ss Por

1.45742e+01 1.45742e+01 1.45742e+00 1.00000e-09 2.12000e-01

$1.45742 \mathrm{e}+01$ 1.45742e+01 1.45742e+00 1.00000e-09 2.12000e-01

$1.45742 \mathrm{e}+011.45742 \mathrm{e}+01$ 1.45742e+00 1.00000e-09 2.12000e-01

$1.45742 \mathrm{e}+011.45742 \mathrm{e}+01$ 1.45742e+00 1.00000e-09 2.12000e-01

$1.45742 \mathrm{e}+01$ 1.45742e+01 1.45742e+00 1.00000e-09 2.12000e-01

$1.00000 \mathrm{e}-05$ 1.00000e-05 1.00000e-06 1.00000e-09 1.00000e-01

$1.00000 \mathrm{e}+001.00000 \mathrm{e}+001.00000 \mathrm{e}-011.00000 \mathrm{e}-091.00000 \mathrm{e}-01$

Element: 12449 \# of layers: 7

$\mathrm{Kx} \mathrm{Ky} \mathrm{Kz}$ Ss Por

$1.57791 \mathrm{e}+011.57791 \mathrm{e}+01$ 1.57791e+00 1.00000e-09 2.12000e-01

$1.57791 \mathrm{e}+011.57791 \mathrm{e}+011.57791 \mathrm{e}+001.00000 \mathrm{e}-092.12000 \mathrm{e}-01$

$1.57791 \mathrm{e}+011.57791 \mathrm{e}+01$ 1.57791e+00 1.00000e-09 2.12000e-01

$1.57791 \mathrm{e}+011.57791 \mathrm{e}+011.57791 \mathrm{e}+001.00000 \mathrm{e}-092.12000 \mathrm{e}-01$

$1.57791 \mathrm{e}+01$ 1.57791e+01 1.57791e+00 1.00000e-09 2.12000e-01

$1.00000 \mathrm{e}-05$ 1.00000e-05 1.00000e-06 1.00000e-09 1.00000e-01

$1.00000 \mathrm{e}+001.00000 \mathrm{e}+001.00000 \mathrm{e}-011.00000 \mathrm{e}-091.00000 \mathrm{e}-01$ 
Element: 12450 \# of layers: 7

Kx Ky Kz Ss Por

$1.57791 \mathrm{e}+011.57791 \mathrm{e}+011.57791 \mathrm{e}+00$ 1.00000e-09 2.12000e-01

$1.57791 \mathrm{e}+011.57791 \mathrm{e}+011.57791 \mathrm{e}+001.00000 \mathrm{e}-092.12000 \mathrm{e}-01$

$1.57791 \mathrm{e}+011.57791 \mathrm{e}+011.57791 \mathrm{e}+001.00000 \mathrm{e}-092.12000 \mathrm{e}-01$

$1.57791 \mathrm{e}+011.57791 \mathrm{e}+011.57791 \mathrm{e}+001.00000 \mathrm{e}-092.12000 \mathrm{e}-01$

$1.57791 \mathrm{e}+011.57791 \mathrm{e}+011.57791 \mathrm{e}+001.00000 \mathrm{e}-092.12000 \mathrm{e}-01$

$1.00000 \mathrm{e}-05$ 1.00000e-05 1.00000e-06 1.00000e-09 1.00000e-01

$1.00000 \mathrm{e}+001.00000 \mathrm{e}+001.00000 \mathrm{e}-011.00000 \mathrm{e}-091.00000 \mathrm{e}-01$

Element: 12451 \# of layers: 7

Kx Ky Kz Ss Por

$1.57791 \mathrm{e}+011.57791 \mathrm{e}+011.57791 \mathrm{e}+00$ 1.00000e-09 2.12000e-01

$1.57791 \mathrm{e}+011.57791 \mathrm{e}+011.57791 \mathrm{e}+001.00000 \mathrm{e}-092.12000 \mathrm{e}-01$

$1.57791 \mathrm{e}+011.57791 \mathrm{e}+011.57791 \mathrm{e}+001.00000 \mathrm{e}-092.12000 \mathrm{e}-01$

$1.57791 \mathrm{e}+011.57791 \mathrm{e}+011.57791 \mathrm{e}+001.00000 \mathrm{e}-092.12000 \mathrm{e}-01$

$1.57791 \mathrm{e}+011.57791 \mathrm{e}+011.57791 \mathrm{e}+001.00000 \mathrm{e}-092.12000 \mathrm{e}-01$

$1.00000 \mathrm{e}-05$ 1.00000e-05 1.00000e-06 1.00000e-09 1.00000e-01

$1.00000 \mathrm{e}+001.00000 \mathrm{e}+001.00000 \mathrm{e}-011.00000 \mathrm{e}-091.00000 \mathrm{e}-01$

Element: 12452 \# of layers: 7

Kx Ky Kz Ss Por

$1.32049 \mathrm{e}+011.32049 \mathrm{e}+01$ 1.32049e+00 1.00000e-09 2.12000e-01

$1.32049 \mathrm{e}+011.32049 \mathrm{e}+011.32049 \mathrm{e}+00$ 1.00000e-09 2.12000e-01

$1.32049 \mathrm{e}+011.32049 \mathrm{e}+011.32049 \mathrm{e}+00$ 1.00000e-09 2.12000e-01

$1.32049 \mathrm{e}+011.32049 \mathrm{e}+011.32049 \mathrm{e}+00$ 1.00000e-09 2.12000e-01

$1.32049 \mathrm{e}+011.32049 \mathrm{e}+011.32049 \mathrm{e}+001.00000 \mathrm{e}-092.12000 \mathrm{e}-01$

$1.00000 \mathrm{e}-05$ 1.00000e-05 1.00000e-06 1.00000e-09 1.00000e-01

$1.00000 \mathrm{e}+001.00000 \mathrm{e}+001.00000 \mathrm{e}-011.00000 \mathrm{e}-091.00000 \mathrm{e}-01$

Element: 12453 \# of layers: 7

Kx Ky Kz Ss Por

$1.32049 \mathrm{e}+011.32049 \mathrm{e}+011.32049 \mathrm{e}+00$ 1.00000e-09 2.12000e-01

$1.32049 \mathrm{e}+011.32049 \mathrm{e}+011.32049 \mathrm{e}+001.00000 \mathrm{e}-092.12000 \mathrm{e}-01$

$1.32049 \mathrm{e}+011.32049 \mathrm{e}+011.32049 \mathrm{e}+001.00000 \mathrm{e}-092.12000 \mathrm{e}-01$

$1.32049 \mathrm{e}+011.32049 \mathrm{e}+011.32049 \mathrm{e}+00$ 1.00000e-09 2.12000e-01

$1.32049 \mathrm{e}+011.32049 \mathrm{e}+011.32049 \mathrm{e}+001.00000 \mathrm{e}-092.12000 \mathrm{e}-01$

$1.00000 \mathrm{e}-05$ 1.00000e-05 1.00000e-06 1.00000e-09 1.00000e-01

$1.00000 \mathrm{e}+001.00000 \mathrm{e}+001.00000 \mathrm{e}-011.00000 \mathrm{e}-091.00000 \mathrm{e}-01$

Element: 12454 \# of layers: 7

Kx Ky Kz Ss Por

8.18995e+00 8.18995e+00 8.18995e-01 1.00000e-09 2.12000e-01

$8.18995 \mathrm{e}+00$ 8.18995e+00 8.18995e-01 1.00000e-09 2.12000e-01

$8.18995 \mathrm{e}+008.18995 \mathrm{e}+00$ 8.18995e-01 1.00000e-09 2.12000e-01

$8.18995 \mathrm{e}+00$ 8.18995e+00 8.18995e-01 1.00000e-09 2.12000e-01

$8.18995 \mathrm{e}+00$ 8.18995e+00 8.18995e-01 1.00000e-09 2.12000e-01

$1.00000 \mathrm{e}-05$ 1.00000e-05 1.00000e-06 1.00000e-09 1.00000e-01

$1.00000 \mathrm{e}+001.00000 \mathrm{e}+001.00000 \mathrm{e}-011.00000 \mathrm{e}-091.00000 \mathrm{e}-01$

Element: 12455 \# of layers: 7 
$\mathrm{Kx} \mathrm{Ky} \mathrm{Kz} \mathrm{Ss} \mathrm{Por}$

$1.45742 \mathrm{e}+01$ 1.45742e+01 1.45742e+00 1.00000e-09 2.12000e-01

$1.45742 \mathrm{e}+011.45742 \mathrm{e}+011.45742 \mathrm{e}+001.00000 \mathrm{e}-092.12000 \mathrm{e}-01$

$1.45742 \mathrm{e}+011.45742 \mathrm{e}+011.45742 \mathrm{e}+001.00000 \mathrm{e}-092.12000 \mathrm{e}-01$

$1.45742 \mathrm{e}+011.45742 \mathrm{e}+01$ 1.45742e+00 1.00000e-09 2.12000e-01

$1.45742 \mathrm{e}+01$ 1.45742e+01 1.45742e+00 1.00000e-09 2.12000e-01

$1.00000 \mathrm{e}-05$ 1.00000e-05 1.00000e-06 1.00000e-09 1.00000e-01

$1.00000 \mathrm{e}+001.00000 \mathrm{e}+001.00000 \mathrm{e}-01$ 1.00000e-09 1.00000e-01

Element: 12456 \# of layers: 7

$\mathrm{Kx} \mathrm{Ky} \mathrm{Kz}$ Ss Por

$1.57791 \mathrm{e}+011.57791 \mathrm{e}+01$ 1.57791e+00 1.00000e-09 2.12000e-01

$1.57791 \mathrm{e}+011.57791 \mathrm{e}+011.57791 \mathrm{e}+001.00000 \mathrm{e}-092.12000 \mathrm{e}-01$

$1.57791 \mathrm{e}+011.57791 \mathrm{e}+011.57791 \mathrm{e}+001.00000 \mathrm{e}-092.12000 \mathrm{e}-01$

$1.57791 \mathrm{e}+011.57791 \mathrm{e}+011.57791 \mathrm{e}+001.00000 \mathrm{e}-092.12000 \mathrm{e}-01$

$1.57791 \mathrm{e}+011.57791 \mathrm{e}+011.57791 \mathrm{e}+001.00000 \mathrm{e}-092.12000 \mathrm{e}-01$

$1.00000 \mathrm{e}-05$ 1.00000e-05 1.00000e-06 1.00000e-09 1.00000e-01

$1.00000 \mathrm{e}+001.00000 \mathrm{e}+001.00000 \mathrm{e}-011.00000 \mathrm{e}-091.00000 \mathrm{e}-01$

Element: 12457 \# of layers: 7

$\mathrm{Kx} \mathrm{Ky} \mathrm{Kz}$ Ss Por

$1.53629 \mathrm{e}+01$ 1.53629e+01 1.53629e+00 1.00000e-09 2.12000e-01

$1.53629 \mathrm{e}+011.53629 \mathrm{e}+01$ 1.53629e+00 1.00000e-09 2.12000e-01

$1.53629 \mathrm{e}+01$ 1.53629e+01 1.53629e+00 1.00000e-09 2.12000e-01

$1.53629 \mathrm{e}+01$ 1.53629e+01 1.53629e+00 1.00000e-09 2.12000e-01

$1.53629 \mathrm{e}+011.53629 \mathrm{e}+01 \quad 1.53629 \mathrm{e}+001.00000 \mathrm{e}-092.12000 \mathrm{e}-01$

$1.00000 \mathrm{e}-05$ 1.00000e-05 1.00000e-06 1.00000e-09 1.00000e-01

$1.00000 \mathrm{e}+001.00000 \mathrm{e}+001.00000 \mathrm{e}-01$ 1.00000e-09 1.00000e-01

Element: 12458 \# of layers: 7

$\mathrm{Kx} \mathrm{Ky} \mathrm{Kz}$ Ss Por

$1.53629 \mathrm{e}+01$ 1.53629e+01 1.53629e+00 1.00000e-09 2.12000e-01

$1.53629 \mathrm{e}+01$ 1.53629e+01 1.53629e+00 1.00000e-09 2.12000e-01

$1.53629 \mathrm{e}+01$ 1.53629e+01 1.53629e+00 1.00000e-09 2.12000e-01

$1.53629 \mathrm{e}+01$ 1.53629e+01 1.53629e+00 1.00000e-09 2.12000e-01

$1.53629 \mathrm{e}+011.53629 \mathrm{e}+011.53629 \mathrm{e}+001.00000 \mathrm{e}-092.12000 \mathrm{e}-01$

$1.00000 \mathrm{e}-051.00000 \mathrm{e}-051.00000 \mathrm{e}-061.00000 \mathrm{e}-091.00000 \mathrm{e}-01$

$1.00000 \mathrm{e}+001.00000 \mathrm{e}+001.00000 \mathrm{e}-01$ 1.00000e-09 1.00000e-01

Element: 12459 \# of layers: 7

Kx Ky Kz Ss Por

$1.53629 \mathrm{e}+01$ 1.53629e+01 1.53629e+00 1.00000e-09 2.12000e-01

$1.53629 \mathrm{e}+01$ 1.53629e+01 1.53629e+00 1.00000e-09 2.12000e-01

$1.53629 \mathrm{e}+01$ 1.53629e+01 1.53629e+00 1.00000e-09 2.12000e-01

$1.53629 \mathrm{e}+011.53629 \mathrm{e}+01$ 1.53629e+00 1.00000e-09 2.12000e-01

$1.53629 \mathrm{e}+01$ 1.53629e+01 1.53629e+00 1.00000e-09 2.12000e-01

$1.00000 \mathrm{e}-05$ 1.00000e-05 1.00000e-06 1.00000e-09 1.00000e-01

$1.00000 \mathrm{e}+001.00000 \mathrm{e}+001.00000 \mathrm{e}-01$ 1.00000e-09 1.00000e-01

Element: 12460 \# of layers: 7

Kx Ky Kz Ss Por 
$1.53629 \mathrm{e}+01$ 1.53629e+01 1.53629e+00 1.00000e-09 2.12000e-01 $1.53629 \mathrm{e}+01$ 1.53629e+01 1.53629e+00 1.00000e-09 2.12000e-01 $1.53629 \mathrm{e}+011.53629 \mathrm{e}+01$ 1.53629e+00 1.00000e-09 2.12000e-01 $1.53629 \mathrm{e}+011.53629 \mathrm{e}+011.53629 \mathrm{e}+001.00000 \mathrm{e}-092.12000 \mathrm{e}-01$ $1.53629 \mathrm{e}+01$ 1.53629e+01 1.53629e+00 1.00000e-09 2.12000e-01 $1.00000 \mathrm{e}-051.00000 \mathrm{e}-05$ 1.00000e-06 1.00000e-09 1.00000e-01 $1.00000 \mathrm{e}+001.00000 \mathrm{e}+001.00000 \mathrm{e}-01$ 1.00000e-09 1.00000e-01 Element: 12461 \# of layers: 7

$\mathrm{Kx} \mathrm{Ky} \mathrm{Kz}$ Ss Por

$1.53629 \mathrm{e}+01$ 1.53629e+01 1.53629e+00 1.00000e-09 2.12000e-01 $1.53629 \mathrm{e}+01$ 1.53629e+01 1.53629e+00 1.00000e-09 2.12000e-01 $1.53629 \mathrm{e}+011.53629 \mathrm{e}+011.53629 \mathrm{e}+001.00000 \mathrm{e}-092.12000 \mathrm{e}-01$ $1.53629 \mathrm{e}+01$ 1.53629e+01 1.53629e+00 1.00000e-09 2.12000e-01 $1.53629 \mathrm{e}+01$ 1.53629e+01 1.53629e+00 1.00000e-09 2.12000e-01 $1.00000 \mathrm{e}-05$ 1.00000e-05 1.00000e-06 1.00000e-09 1.00000e-01 $1.00000 \mathrm{e}+001.00000 \mathrm{e}+001.00000 \mathrm{e}-011.00000 \mathrm{e}-091.00000 \mathrm{e}-01$ Element: 12462 \# of layers: 7

$\mathrm{Kx} \mathrm{Ky} \mathrm{Kz}$ Ss Por

$1.53629 \mathrm{e}+01$ 1.53629e+01 1.53629e+00 1.00000e-09 2.12000e-01 $1.53629 \mathrm{e}+01$ 1.53629e+01 1.53629e+00 1.00000e-09 2.12000e-01 $1.53629 \mathrm{e}+01$ 1.53629e+01 1.53629e+00 1.00000e-09 2.12000e-01 $1.53629 \mathrm{e}+01$ 1.53629e+01 1.53629e+00 1.00000e-09 2.12000e-01 $1.53629 \mathrm{e}+01$ 1.53629e+01 1.53629e+00 1.00000e-09 2.12000e-01 $1.00000 \mathrm{e}-05$ 1.00000e-05 1.00000e-06 1.00000e-09 1.00000e-01 $1.00000 \mathrm{e}+001.00000 \mathrm{e}+001.00000 \mathrm{e}-011.00000 \mathrm{e}-091.00000 \mathrm{e}-01$ Element: 12463 \# of layers: 7

$\mathrm{Kx} \mathrm{Ky} \mathrm{Kz}$ Ss Por

$1.53629 \mathrm{e}+01$ 1.53629e+01 1.53629e+00 1.00000e-09 2.12000e-01 $1.53629 \mathrm{e}+011.53629 \mathrm{e}+011.53629 \mathrm{e}+001.00000 \mathrm{e}-092.12000 \mathrm{e}-01$ $1.53629 \mathrm{e}+01$ 1.53629e+01 1.53629e+00 1.00000e-09 2.12000e-01 $1.53629 \mathrm{e}+01$ 1.53629e+01 1.53629e+00 1.00000e-09 2.12000e-01 $1.53629 \mathrm{e}+01$ 1.53629e+01 1.53629e+00 1.00000e-09 2.12000e-01 $1.00000 \mathrm{e}-05$ 1.00000e-05 1.00000e-06 1.00000e-09 1.00000e-01 $1.00000 \mathrm{e}+001.00000 \mathrm{e}+001.00000 \mathrm{e}-011.00000 \mathrm{e}-091.00000 \mathrm{e}-01$ Element: 12464 \# of layers: 7

$\mathrm{Kx} \mathrm{Ky} \mathrm{Kz}$ Ss Por

$1.53629 \mathrm{e}+01$ 1.53629e+01 1.53629e+00 1.00000e-09 2.12000e-01 $1.53629 \mathrm{e}+011.53629 \mathrm{e}+011.53629 \mathrm{e}+001.00000 \mathrm{e}-092.12000 \mathrm{e}-01$ $1.53629 \mathrm{e}+011.53629 \mathrm{e}+01$ 1.53629e+00 1.00000e-09 2.12000e-01 $1.53629 \mathrm{e}+011.53629 \mathrm{e}+01$ 1.53629e+00 1.00000e-09 2.12000e-01 $1.53629 \mathrm{e}+01$ 1.53629e+01 1.53629e+00 1.00000e-09 2.12000e-01 $1.00000 \mathrm{e}-05$ 1.00000e-05 1.00000e-06 1.00000e-09 1.00000e-01 $1.00000 \mathrm{e}+001.00000 \mathrm{e}+001.00000 \mathrm{e}-011.00000 \mathrm{e}-091.00000 \mathrm{e}-01$ Element: 12465 \# of layers: 7

$\mathrm{Kx} \mathrm{Ky} \mathrm{Kz} \mathrm{Ss} \mathrm{Por}$

$1.53629 e+01$ 1.53629e+01 1.53629e+00 1.00000e-09 2.12000e-01 
$1.53629 \mathrm{e}+01$ 1.53629e+01 1.53629e+00 1.00000e-09 2.12000e-01 $1.53629 \mathrm{e}+01$ 1.53629e+01 1.53629e+00 1.00000e-09 2.12000e-01 $1.53629 \mathrm{e}+011.53629 \mathrm{e}+01$ 1.53629e+00 1.00000e-09 2.12000e-01 $1.53629 \mathrm{e}+011.53629 \mathrm{e}+011.53629 \mathrm{e}+001.00000 \mathrm{e}-092.12000 \mathrm{e}-01$ $1.00000 \mathrm{e}-05$ 1.00000e-05 1.00000e-06 1.00000e-09 1.00000e-01 $1.00000 \mathrm{e}+001.00000 \mathrm{e}+001.00000 \mathrm{e}-011.00000 \mathrm{e}-091.00000 \mathrm{e}-01$ Element: 12466 \# of layers: 7

$\mathrm{Kx} \mathrm{Ky} \mathrm{Kz}$ Ss Por

$1.53629 \mathrm{e}+01$ 1.53629e+01 1.53629e+00 1.00000e-09 2.12000e-01 $1.53629 \mathrm{e}+01$ 1.53629e+01 1.53629e+00 1.00000e-09 2.12000e-01 $1.53629 \mathrm{e}+01$ 1.53629e+01 1.53629e+00 1.00000e-09 2.12000e-01 $1.53629 \mathrm{e}+011.53629 \mathrm{e}+011.53629 \mathrm{e}+001.00000 \mathrm{e}-092.12000 \mathrm{e}-01$ $1.53629 \mathrm{e}+01$ 1.53629e+01 1.53629e+00 1.00000e-09 2.12000e-01 $1.00000 \mathrm{e}-05$ 1.00000e-05 1.00000e-06 1.00000e-09 1.00000e-01 $1.00000 \mathrm{e}+001.00000 \mathrm{e}+001.00000 \mathrm{e}-01$ 1.00000e-09 1.00000e-01 Element: 12467 \# of layers: 7

$\mathrm{Kx} \mathrm{Ky} \mathrm{Kz}$ Ss Por

1.59337e+01 1.59337e+01 1.59337e+00 1.00000e-09 2.12000e-01 $1.59337 \mathrm{e}+01$ 1.59337e+01 1.59337e+00 1.00000e-09 2.12000e-01 $1.59337 \mathrm{e}+01$ 1.59337e+01 1.59337e+00 1.00000e-09 2.12000e-01 $1.59337 \mathrm{e}+01$ 1.59337e+01 1.59337e+00 1.00000e-09 2.12000e-01 $1.59337 \mathrm{e}+01$ 1.59337e+01 1.59337e+00 1.00000e-09 2.12000e-01 $1.00000 \mathrm{e}-05$ 1.00000e-05 1.00000e-06 1.00000e-09 1.00000e-01 $1.00000 \mathrm{e}+001.00000 \mathrm{e}+001.00000 \mathrm{e}-011.00000 \mathrm{e}-09$ 1.00000e-01 Element: 12468 \# of layers: 7

$\mathrm{Kx} \mathrm{Ky} \mathrm{Kz}$ Ss Por

$1.59337 \mathrm{e}+01$ 1.59337e+01 1.59337e+00 1.00000e-09 2.12000e-01 $1.59337 \mathrm{e}+01$ 1.59337e+01 1.59337e+00 1.00000e-09 2.12000e-01 $1.59337 \mathrm{e}+01$ 1.59337e+01 1.59337e+00 1.00000e-09 2.12000e-01 $1.59337 \mathrm{e}+01$ 1.59337e+01 1.59337e+00 1.00000e-09 2.12000e-01 $1.59337 \mathrm{e}+01$ 1.59337e+01 1.59337e+00 1.00000e-09 2.12000e-01 $1.00000 \mathrm{e}-05$ 1.00000e-05 1.00000e-06 1.00000e-09 1.00000e-01 $1.00000 \mathrm{e}+001.00000 \mathrm{e}+001.00000 \mathrm{e}-011.00000 \mathrm{e}-091.00000 \mathrm{e}-01$ Element: 12469 \# of layers: 7

$\mathrm{Kx} \mathrm{Ky} \mathrm{Kz}$ Ss Por

1.59337e+01 1.59337e+01 1.59337e+00 1.00000e-09 2.12000e-01 $1.59337 \mathrm{e}+01$ 1.59337e+01 1.59337e+00 1.00000e-09 2.12000e-01 $1.59337 \mathrm{e}+01$ 1.59337e+01 1.59337e+00 1.00000e-09 2.12000e-01 $1.59337 \mathrm{e}+01$ 1.59337e+01 1.59337e+00 1.00000e-09 2.12000e-01 $1.59337 \mathrm{e}+01$ 1.59337e+01 1.59337e+00 1.00000e-09 2.12000e-01 $1.00000 \mathrm{e}-05$ 1.00000e-05 1.00000e-06 1.00000e-09 1.00000e-01 $1.00000 \mathrm{e}+001.00000 \mathrm{e}+001.00000 \mathrm{e}-011.00000 \mathrm{e}-091.00000 \mathrm{e}-01$ Element: 12470 \# of layers: 7

$\mathrm{Kx} \mathrm{Ky} \mathrm{Kz}$ Ss Por

1.59337e+01 1.59337e+01 1.59337e+00 1.00000e-09 2.12000e-01 $1.59337 \mathrm{e}+01$ 1.59337e+01 1.59337e+00 1.00000e-09 2.12000e-01 
$1.59337 \mathrm{e}+01$ 1.59337e+01 1.59337e+00 1.00000e-09 2.12000e-01 $1.59337 \mathrm{e}+01$ 1.59337e+01 1.59337e+00 1.00000e-09 2.12000e-01 $1.59337 \mathrm{e}+01$ 1.59337e+01 1.59337e+00 1.00000e-09 2.12000e-01 $1.00000 \mathrm{e}-05$ 1.00000e-05 1.00000e-06 1.00000e-09 1.00000e-01 $1.00000 \mathrm{e}+001.00000 \mathrm{e}+001.00000 \mathrm{e}-01$ 1.00000e-09 1.00000e-01 Element: 12471 \# of layers: 7

Kx Ky Kz Ss Por

1.59337e+01 1.59337e+01 1.59337e+00 1.00000e-09 2.12000e-01 $1.59337 \mathrm{e}+01$ 1.59337e+01 1.59337e+00 1.00000e-09 2.12000e-01 $1.59337 \mathrm{e}+01$ 1.59337e+01 1.59337e+00 1.00000e-09 2.12000e-01 $1.59337 \mathrm{e}+01$ 1.59337e+01 1.59337e+00 1.00000e-09 2.12000e-01 $1.59337 \mathrm{e}+01$ 1.59337e+01 1.59337e+00 1.00000e-09 2.12000e-01 $1.00000 \mathrm{e}-051.00000 \mathrm{e}-05$ 1.00000e-06 1.00000e-09 1.00000e-01 $1.00000 \mathrm{e}+001.00000 \mathrm{e}+001.00000 \mathrm{e}-01$ 1.00000e-09 1.00000e-01 Element: 12472 \# of layers: 7

Kx Ky Kz Ss Por

$1.53629 \mathrm{e}+01$ 1.53629e+01 1.53629e+00 1.00000e-09 2.12000e-01 $1.53629 \mathrm{e}+011.53629 \mathrm{e}+01$ 1.53629e+00 1.00000e-09 2.12000e-01 $1.53629 \mathrm{e}+01$ 1.53629e+01 1.53629e+00 1.00000e-09 2.12000e-01 $1.53629 \mathrm{e}+01$ 1.53629e+01 1.53629e+00 1.00000e-09 2.12000e-01 $1.53629 \mathrm{e}+01$ 1.53629e+01 1.53629e+00 1.00000e-09 2.12000e-01 $1.00000 \mathrm{e}-05$ 1.00000e-05 1.00000e-06 1.00000e-09 1.00000e-01 $1.00000 \mathrm{e}+001.00000 \mathrm{e}+001.00000 \mathrm{e}-01$ 1.00000e-09 1.00000e-01 Element: 12473 \# of layers: 7

Kx Ky Kz Ss Por

$1.53629 \mathrm{e}+01$ 1.53629e+01 1.53629e+00 1.00000e-09 2.12000e-01 $1.53629 \mathrm{e}+011.53629 \mathrm{e}+011.53629 \mathrm{e}+001.00000 \mathrm{e}-092.12000 \mathrm{e}-01$ $1.53629 \mathrm{e}+01$ 1.53629e+01 1.53629e+00 1.00000e-09 2.12000e-01 $1.53629 \mathrm{e}+011.53629 \mathrm{e}+011.53629 \mathrm{e}+001.00000 \mathrm{e}-092.12000 \mathrm{e}-01$ $1.53629 \mathrm{e}+01$ 1.53629e+01 1.53629e+00 1.00000e-09 2.12000e-01 $1.00000 \mathrm{e}-05$ 1.00000e-05 1.00000e-06 1.00000e-09 1.00000e-01 $1.00000 \mathrm{e}+001.00000 \mathrm{e}+001.00000 \mathrm{e}-01$ 1.00000e-09 1.00000e-01 Element: 12474 \# of layers: 7

$\mathrm{Kx} \mathrm{Ky} \mathrm{Kz}$ Ss Por

1.59337e+01 1.59337e+01 1.59337e+00 1.00000e-09 2.12000e-01 1.59337e+01 1.59337e+01 1.59337e+00 1.00000e-09 2.12000e-01 $1.59337 \mathrm{e}+01$ 1.59337e+01 1.59337e+00 1.00000e-09 2.12000e-01 $1.59337 \mathrm{e}+01$ 1.59337e+01 1.59337e+00 1.00000e-09 2.12000e-01 $1.59337 \mathrm{e}+01$ 1.59337e+01 1.59337e+00 1.00000e-09 2.12000e-01 $1.00000 \mathrm{e}-05$ 1.00000e-05 1.00000e-06 1.00000e-09 1.00000e-01 $1.00000 \mathrm{e}+001.00000 \mathrm{e}+001.00000 \mathrm{e}-011.00000 \mathrm{e}-091.00000 \mathrm{e}-01$ Element: 12475 \# of layers: 7

$\mathrm{Kx} \mathrm{Ky} \mathrm{Kz}$ Ss Por

1.59337e+01 1.59337e+01 1.59337e+00 1.00000e-09 2.12000e-01 $1.59337 \mathrm{e}+01$ 1.59337e+01 1.59337e+00 1.00000e-09 2.12000e-01 $1.59337 \mathrm{e}+01$ 1.59337e+01 1.59337e+00 1.00000e-09 2.12000e-01 
$1.59337 \mathrm{e}+01$ 1.59337e+01 1.59337e+00 1.00000e-09 2.12000e-01 $1.59337 \mathrm{e}+01$ 1.59337e+01 1.59337e+00 1.00000e-09 2.12000e-01 $1.00000 \mathrm{e}-05$ 1.00000e-05 1.00000e-06 1.00000e-09 1.00000e-01 $1.00000 \mathrm{e}+001.00000 \mathrm{e}+001.00000 \mathrm{e}-011.00000 \mathrm{e}-091.00000 \mathrm{e}-01$ Element: 12476 \# of layers: 7

$\mathrm{Kx} \mathrm{Ky} \mathrm{Kz}$ Ss Por

$1.59337 \mathrm{e}+01$ 1.59337e+01 1.59337e+00 1.00000e-09 2.12000e-01 $1.59337 \mathrm{e}+01$ 1.59337e+01 1.59337e+00 1.00000e-09 2.12000e-01 $1.59337 \mathrm{e}+01$ 1.59337e+01 1.59337e+00 1.00000e-09 2.12000e-01 $1.59337 \mathrm{e}+01$ 1.59337e+01 1.59337e+00 1.00000e-09 2.12000e-01 $1.59337 \mathrm{e}+01$ 1.59337e+01 1.59337e+00 1.00000e-09 2.12000e-01 $1.00000 \mathrm{e}-05$ 1.00000e-05 1.00000e-06 1.00000e-09 1.00000e-01 $1.00000 \mathrm{e}+001.00000 \mathrm{e}+001.00000 \mathrm{e}-01$ 1.00000e-09 1.00000e-01 Element: 12477 \# of layers: 7

$\mathrm{Kx} \mathrm{Ky} \mathrm{Kz}$ Ss Por

1.59337e+01 1.59337e+01 1.59337e+00 1.00000e-09 2.12000e-01 $1.59337 \mathrm{e}+01$ 1.59337e+01 1.59337e+00 1.00000e-09 2.12000e-01 $1.59337 \mathrm{e}+01$ 1.59337e+01 1.59337e+00 1.00000e-09 2.12000e-01 $1.59337 \mathrm{e}+01$ 1.59337e+01 1.59337e+00 1.00000e-09 2.12000e-01 $1.59337 \mathrm{e}+01$ 1.59337e+01 1.59337e+00 1.00000e-09 2.12000e-01 $1.00000 \mathrm{e}-05$ 1.00000e-05 1.00000e-06 1.00000e-09 1.00000e-01 $1.00000 \mathrm{e}+001.00000 \mathrm{e}+001.00000 \mathrm{e}-01$ 1.00000e-09 1.00000e-01 Element: 12478 \# of layers: 7

Kx Ky Kz Ss Por

$1.59337 \mathrm{e}+01$ 1.59337e+01 1.59337e+00 1.00000e-09 2.12000e-01 $1.59337 \mathrm{e}+01$ 1.59337e+01 1.59337e+00 1.00000e-09 2.12000e-01 $1.59337 \mathrm{e}+01$ 1.59337e+01 1.59337e+00 1.00000e-09 2.12000e-01 $1.59337 \mathrm{e}+01$ 1.59337e+01 1.59337e+00 1.00000e-09 2.12000e-01 $1.59337 \mathrm{e}+01$ 1.59337e+01 1.59337e+00 1.00000e-09 2.12000e-01 $1.00000 \mathrm{e}-05$ 1.00000e-05 1.00000e-06 1.00000e-09 1.00000e-01 $1.00000 \mathrm{e}+001.00000 \mathrm{e}+001.00000 \mathrm{e}-011.00000 \mathrm{e}-091.00000 \mathrm{e}-01$ Element: 12479 \# of layers: 7

Kx Ky Kz Ss Por

1.59337e+01 1.59337e+01 1.59337e+00 1.00000e-09 2.12000e-01 $1.59337 \mathrm{e}+011.59337 \mathrm{e}+01$ 1.59337e+00 1.00000e-09 2.12000e-01 $1.59337 \mathrm{e}+01$ 1.59337e+01 1.59337e+00 1.00000e-09 2.12000e-01 $1.59337 \mathrm{e}+01$ 1.59337e+01 1.59337e+00 1.00000e-09 2.12000e-01 $1.59337 \mathrm{e}+01$ 1.59337e+01 1.59337e+00 1.00000e-09 2.12000e-01 $1.00000 \mathrm{e}-05$ 1.00000e-05 1.00000e-06 1.00000e-09 1.00000e-01 $1.00000 \mathrm{e}+001.00000 \mathrm{e}+001.00000 \mathrm{e}-01$ 1.00000e-09 1.00000e-01 Element: 12480 \# of layers: 7

Kx Ky Kz Ss Por

$1.59337 \mathrm{e}+01$ 1.59337e+01 1.59337e+00 1.00000e-09 2.12000e-01 1.59337e+01 1.59337e+01 1.59337e+00 1.00000e-09 2.12000e-01 $1.59337 \mathrm{e}+01$ 1.59337e+01 1.59337e+00 1.00000e-09 2.12000e-01 $1.59337 \mathrm{e}+01$ 1.59337e+01 1.59337e+00 1.00000e-09 2.12000e-01 
$1.59337 \mathrm{e}+01$ 1.59337e+01 1.59337e+00 1.00000e-09 2.12000e-01 $1.00000 \mathrm{e}-05$ 1.00000e-05 1.00000e-06 1.00000e-09 1.00000e-01 $1.00000 \mathrm{e}+001.00000 \mathrm{e}+001.00000 \mathrm{e}-011.00000 \mathrm{e}-09$ 1.00000e-01 Element: 12481 \# of layers: 7

$\mathrm{Kx} \mathrm{Ky} \mathrm{Kz}$ Ss Por

1.59337e+01 1.59337e+01 1.59337e+00 1.00000e-09 2.12000e-01 $1.59337 \mathrm{e}+01$ 1.59337e+01 1.59337e+00 1.00000e-09 2.12000e-01 $1.59337 \mathrm{e}+01$ 1.59337e+01 1.59337e+00 1.00000e-09 2.12000e-01 $1.59337 \mathrm{e}+01$ 1.59337e+01 1.59337e+00 1.00000e-09 2.12000e-01 $1.59337 \mathrm{e}+01$ 1.59337e+01 1.59337e+00 1.00000e-09 2.12000e-01 $1.00000 \mathrm{e}-05$ 1.00000e-05 1.00000e-06 1.00000e-09 1.00000e-01 $1.00000 \mathrm{e}+001.00000 \mathrm{e}+001.00000 \mathrm{e}-01$ 1.00000e-09 1.00000e-01 Element: 12482 \# of layers: 7

$\mathrm{Kx} \mathrm{Ky} \mathrm{Kz}$ Ss Por

1.59337e+01 1.59337e+01 1.59337e+00 1.00000e-09 2.12000e-01 $1.59337 \mathrm{e}+01$ 1.59337e+01 1.59337e+00 1.00000e-09 2.12000e-01 $1.59337 \mathrm{e}+01$ 1.59337e+01 1.59337e+00 1.00000e-09 2.12000e-01 $1.59337 \mathrm{e}+01$ 1.59337e+01 1.59337e+00 1.00000e-09 2.12000e-01 $1.59337 \mathrm{e}+01$ 1.59337e+01 1.59337e+00 1.00000e-09 2.12000e-01 $1.00000 \mathrm{e}-05$ 1.00000e-05 1.00000e-06 1.00000e-09 1.00000e-01 $1.00000 \mathrm{e}+001.00000 \mathrm{e}+001.00000 \mathrm{e}-011.00000 \mathrm{e}-091.00000 \mathrm{e}-01$ Element: 12483 \# of layers: 7

$\mathrm{Kx} \mathrm{Ky} \mathrm{Kz}$ Ss Por

$1.59337 \mathrm{e}+01$ 1.59337e+01 1.59337e+00 1.00000e-09 2.12000e-01 $1.59337 \mathrm{e}+01$ 1.59337e+01 1.59337e+00 1.00000e-09 2.12000e-01 $1.59337 \mathrm{e}+01$ 1.59337e+01 1.59337e+00 1.00000e-09 2.12000e-01 $1.59337 \mathrm{e}+01$ 1.59337e+01 1.59337e+00 1.00000e-09 2.12000e-01 $1.59337 \mathrm{e}+01$ 1.59337e+01 1.59337e+00 1.00000e-09 2.12000e-01 $1.00000 \mathrm{e}-05$ 1.00000e-05 1.00000e-06 1.00000e-09 1.00000e-01 $1.00000 \mathrm{e}+001.00000 \mathrm{e}+001.00000 \mathrm{e}-011.00000 \mathrm{e}-091.00000 \mathrm{e}-01$ Element: 12484 \# of layers: 7

$\mathrm{Kx} \mathrm{Ky} \mathrm{Kz}$ Ss Por

1.59337e+01 1.59337e+01 1.59337e+00 1.00000e-09 2.12000e-01 $1.59337 \mathrm{e}+01$ 1.59337e+01 1.59337e+00 1.00000e-09 2.12000e-01 $1.59337 \mathrm{e}+011.59337 \mathrm{e}+01$ 1.59337e+00 1.00000e-09 2.12000e-01 $1.59337 \mathrm{e}+01$ 1.59337e+01 1.59337e+00 1.00000e-09 2.12000e-01 $1.59337 \mathrm{e}+01$ 1.59337e+01 1.59337e+00 1.00000e-09 2.12000e-01 $1.00000 \mathrm{e}-05$ 1.00000e-05 1.00000e-06 1.00000e-09 1.00000e-01 $1.00000 \mathrm{e}+001.00000 \mathrm{e}+001.00000 \mathrm{e}-011.00000 \mathrm{e}-091.00000 \mathrm{e}-01$ Element: 12485 \# of layers: 7

$\mathrm{Kx} \mathrm{Ky} \mathrm{Kz}$ Ss Por

1.59337e+01 1.59337e+01 1.59337e+00 1.00000e-09 2.12000e-01 $1.59337 \mathrm{e}+01$ 1.59337e+01 1.59337e+00 1.00000e-09 2.12000e-01 1.59337e+01 1.59337e+01 1.59337e+00 1.00000e-09 2.12000e-01 $1.59337 \mathrm{e}+01$ 1.59337e+01 1.59337e+00 1.00000e-09 2.12000e-01 $1.59337 \mathrm{e}+01$ 1.59337e+01 1.59337e+00 1.00000e-09 2.12000e-01 
$1.00000 \mathrm{e}-05$ 1.00000e-05 1.00000e-06 1.00000e-09 1.00000e-01 $1.00000 \mathrm{e}+001.00000 \mathrm{e}+001.00000 \mathrm{e}-01$ 1.00000e-09 1.00000e-01 Element: 12486 \# of layers: 7

Kx Ky Kz Ss Por

6.02090e+00 6.02090e+00 6.02090e-01 1.00000e-09 2.12000e-01 $6.02090 \mathrm{e}+00$ 6.02090e+00 6.02090e-01 1.00000e-09 2.12000e-01 $6.02090 \mathrm{e}+00$ 6.02090e+00 6.02090e-01 1.00000e-09 2.12000e-01 $6.02090 \mathrm{e}+00$ 6.02090e+00 6.02090e-01 1.00000e-09 2.12000e-01 6.02090e+00 6.02090e+00 6.02090e-01 1.00000e-09 2.12000e-01 $1.00000 \mathrm{e}-05$ 1.00000e-05 1.00000e-06 1.00000e-09 1.00000e-01 $1.00000 \mathrm{e}+001.00000 \mathrm{e}+001.00000 \mathrm{e}-01$ 1.00000e-09 1.00000e-01 Element: 12487 \# of layers: 7

$\mathrm{Kx} \mathrm{Ky} \mathrm{Kz}$ Ss Por

6.02090e+00 6.02090e+00 6.02090e-01 1.00000e-09 2.12000e-01 6.02090e+00 6.02090e+00 6.02090e-01 1.00000e-09 2.12000e-01 $6.02090 \mathrm{e}+006.02090 \mathrm{e}+006.02090 \mathrm{e}-01$ 1.00000e-09 2.12000e-01 $6.02090 \mathrm{e}+006.02090 \mathrm{e}+00$ 6.02090e-01 1.00000e-09 2.12000e-01 6.02090e+00 6.02090e+00 6.02090e-01 1.00000e-09 2.12000e-01 $1.00000 \mathrm{e}-05$ 1.00000e-05 1.00000e-06 1.00000e-09 1.00000e-01 $1.00000 \mathrm{e}+001.00000 \mathrm{e}+001.00000 \mathrm{e}-011.00000 \mathrm{e}-09$ 1.00000e-01 Element: 12488 \# of layers: 7

$\mathrm{Kx} \mathrm{Ky} \mathrm{Kz}$ Ss Por 6.02090e+00 6.02090e+00 6.02090e-01 1.00000e-09 2.12000e-01 6.02090e+00 6.02090e+00 6.02090e-01 1.00000e-09 2.12000e-01 $6.02090 \mathrm{e}+006.02090 \mathrm{e}+00$ 6.02090e-01 1.00000e-09 2.12000e-01 $6.02090 \mathrm{e}+006.02090 \mathrm{e}+00$ 6.02090e-01 1.00000e-09 2.12000e-01 $6.02090 \mathrm{e}+00$ 6.02090e+00 6.02090e-01 1.00000e-09 2.12000e-01 $1.00000 \mathrm{e}-05$ 1.00000e-05 1.00000e-06 1.00000e-09 1.00000e-01 $1.00000 \mathrm{e}+001.00000 \mathrm{e}+001.00000 \mathrm{e}-011.00000 \mathrm{e}-091.00000 \mathrm{e}-01$ Element: 12489 \# of layers: 7

$\mathrm{Kx} \mathrm{Ky} \mathrm{Kz}$ Ss Por

$1.59337 \mathrm{e}+01$ 1.59337e+01 1.59337e+00 1.00000e-09 2.12000e-01 $1.59337 \mathrm{e}+01$ 1.59337e+01 1.59337e+00 1.00000e-09 2.12000e-01 $1.59337 \mathrm{e}+01$ 1.59337e+01 1.59337e+00 1.00000e-09 2.12000e-01 $1.59337 \mathrm{e}+011.59337 \mathrm{e}+01$ 1.59337e+00 1.00000e-09 2.12000e-01 $1.59337 \mathrm{e}+01$ 1.59337e+01 1.59337e+00 1.00000e-09 2.12000e-01 $1.00000 \mathrm{e}-05$ 1.00000e-05 1.00000e-06 1.00000e-09 1.00000e-01 $1.00000 \mathrm{e}+001.00000 \mathrm{e}+001.00000 \mathrm{e}-011.00000 \mathrm{e}-091.00000 \mathrm{e}-01$ Element: 12490 \# of layers: 7

$\mathrm{Kx} \mathrm{Ky} \mathrm{Kz}$ Ss Por

$1.59337 \mathrm{e}+01$ 1.59337e+01 1.59337e+00 1.00000e-09 2.12000e-01 $1.59337 \mathrm{e}+01$ 1.59337e+01 1.59337e+00 1.00000e-09 2.12000e-01 $1.59337 \mathrm{e}+01$ 1.59337e+01 1.59337e+00 1.00000e-09 2.12000e-01 $1.59337 \mathrm{e}+01$ 1.59337e+01 1.59337e+00 1.00000e-09 2.12000e-01 $1.59337 \mathrm{e}+01$ 1.59337e+01 1.59337e+00 1.00000e-09 2.12000e-01 $1.00000 \mathrm{e}-05$ 1.00000e-05 1.00000e-06 1.00000e-09 1.00000e-01 
$1.00000 \mathrm{e}+001.00000 \mathrm{e}+00$ 1.00000e-01 1.00000e-09 1.00000e-01

Element: 12491 \# of layers: 7

Kx Ky Kz Ss Por

1.59337e+01 1.59337e+01 1.59337e+00 1.00000e-09 2.12000e-01

$1.59337 \mathrm{e}+01$ 1.59337e+01 1.59337e+00 1.00000e-09 2.12000e-01

$1.59337 \mathrm{e}+01$ 1.59337e+01 1.59337e+00 1.00000e-09 2.12000e-01

$1.59337 \mathrm{e}+01$ 1.59337e+01 1.59337e+00 1.00000e-09 2.12000e-01

$1.59337 \mathrm{e}+01$ 1.59337e+01 1.59337e+00 1.00000e-09 2.12000e-01

$1.00000 \mathrm{e}-05$ 1.00000e-05 1.00000e-06 1.00000e-09 1.00000e-01

$1.00000 \mathrm{e}+001.00000 \mathrm{e}+001.00000 \mathrm{e}-011.00000 \mathrm{e}-091.00000 \mathrm{e}-01$

Element: 12492 \# of layers: 7

Kx Ky Kz Ss Por

1.59337e+01 1.59337e+01 1.59337e+00 1.00000e-09 2.12000e-01

$1.59337 \mathrm{e}+01$ 1.59337e+01 1.59337e+00 1.00000e-09 2.12000e-01

$1.59337 \mathrm{e}+01$ 1.59337e+01 1.59337e+00 1.00000e-09 2.12000e-01

$1.59337 \mathrm{e}+01$ 1.59337e+01 1.59337e+00 1.00000e-09 2.12000e-01

$1.59337 \mathrm{e}+01$ 1.59337e+01 1.59337e+00 1.00000e-09 2.12000e-01

$1.00000 \mathrm{e}-05$ 1.00000e-05 1.00000e-06 1.00000e-09 1.00000e-01

$1.00000 \mathrm{e}+001.00000 \mathrm{e}+001.00000 \mathrm{e}-01$ 1.00000e-09 1.00000e-01

Element: 12493 \# of layers: 7

$\mathrm{Kx} \mathrm{Ky} \mathrm{Kz}$ Ss Por

6.02090e+00 6.02090e+00 6.02090e-01 1.00000e-09 2.12000e-01

$6.02090 \mathrm{e}+006.02090 \mathrm{e}+00$ 6.02090e-01 1.00000e-09 2.12000e-01

6.02090e+00 6.02090e+00 6.02090e-01 1.00000e-09 2.12000e-01

$6.02090 \mathrm{e}+006.02090 \mathrm{e}+00$ 6.02090e-01 1.00000e-09 2.12000e-01

$6.02090 \mathrm{e}+006.02090 \mathrm{e}+006.02090 \mathrm{e}-01$ 1.00000e-09 2.12000e-01

$1.00000 \mathrm{e}-05$ 1.00000e-05 1.00000e-06 1.00000e-09 1.00000e-01

$1.00000 \mathrm{e}+001.00000 \mathrm{e}+001.00000 \mathrm{e}-01$ 1.00000e-09 1.00000e-01

Element: 12494 \# of layers: 7

$\mathrm{Kx} \mathrm{Ky} \mathrm{Kz}$ Ss Por

6.02090e+00 6.02090e+00 6.02090e-01 1.00000e-09 2.12000e-01

$6.02090 \mathrm{e}+00$ 6.02090e+00 6.02090e-01 1.00000e-09 2.12000e-01

$6.02090 \mathrm{e}+006.02090 \mathrm{e}+00$ 6.02090e-01 1.00000e-09 2.12000e-01

$6.02090 \mathrm{e}+00$ 6.02090e+00 6.02090e-01 1.00000e-09 2.12000e-01

6.02090e+00 6.02090e+00 6.02090e-01 1.00000e-09 2.12000e-01

$1.00000 \mathrm{e}-05$ 1.00000e-05 1.00000e-06 1.00000e-09 1.00000e-01

$1.00000 \mathrm{e}+001.00000 \mathrm{e}+001.00000 \mathrm{e}-011.00000 \mathrm{e}-091.00000 \mathrm{e}-01$

Element: 12495 \# of layers: 7

$\mathrm{Kx} \mathrm{Ky} \mathrm{Kz}$ Ss Por

6.02090e+00 6.02090e+00 6.02090e-01 1.00000e-09 2.12000e-01

$6.02090 \mathrm{e}+006.02090 \mathrm{e}+00$ 6.02090e-01 1.00000e-09 2.12000e-01

$6.02090 \mathrm{e}+006.02090 \mathrm{e}+00$ 6.02090e-01 1.00000e-09 2.12000e-01

$6.02090 \mathrm{e}+006.02090 \mathrm{e}+00$ 6.02090e-01 1.00000e-09 2.12000e-01

$6.02090 \mathrm{e}+006.02090 \mathrm{e}+00$ 6.02090e-01 1.00000e-09 2.12000e-01

$1.00000 \mathrm{e}-05$ 1.00000e-05 1.00000e-06 1.00000e-09 1.00000e-01

$1.00000 \mathrm{e}+001.00000 \mathrm{e}+001.00000 \mathrm{e}-011.00000 \mathrm{e}-091.00000 \mathrm{e}-01$ 
Element: 12496 \# of layers: 7

Kx Ky Kz Ss Por

$6.02090 \mathrm{e}+006.02090 \mathrm{e}+00$ 6.02090e-01 1.00000e-09 2.12000e-01

$6.02090 \mathrm{e}+006.02090 \mathrm{e}+00$ 6.02090e-01 1.00000e-09 2.12000e-01

$6.02090 \mathrm{e}+006.02090 \mathrm{e}+006.02090 \mathrm{e}-011.00000 \mathrm{e}-092.12000 \mathrm{e}-01$

$6.02090 \mathrm{e}+006.02090 \mathrm{e}+00$ 6.02090e-01 1.00000e-09 2.12000e-01

$6.02090 \mathrm{e}+006.02090 \mathrm{e}+00$ 6.02090e-01 1.00000e-09 2.12000e-01

$1.00000 \mathrm{e}-05$ 1.00000e-05 1.00000e-06 1.00000e-09 1.00000e-01

$1.00000 \mathrm{e}+001.00000 \mathrm{e}+001.00000 \mathrm{e}-011.00000 \mathrm{e}-091.00000 \mathrm{e}-01$

Element: 12497 \# of layers: 7

Kx Ky Kz Ss Por

$6.02090 \mathrm{e}+006.02090 \mathrm{e}+00$ 6.02090e-01 1.00000e-09 2.12000e-01

$6.02090 \mathrm{e}+006.02090 \mathrm{e}+006.02090 \mathrm{e}-011.00000 \mathrm{e}-092.12000 \mathrm{e}-01$

$6.02090 \mathrm{e}+006.02090 \mathrm{e}+00$ 6.02090e-01 1.00000e-09 2.12000e-01

$6.02090 \mathrm{e}+006.02090 \mathrm{e}+006.02090 \mathrm{e}-011.00000 \mathrm{e}-092.12000 \mathrm{e}-01$

$6.02090 \mathrm{e}+006.02090 \mathrm{e}+00$ 6.02090e-01 1.00000e-09 2.12000e-01

$1.00000 \mathrm{e}-05$ 1.00000e-05 1.00000e-06 1.00000e-09 1.00000e-01

$1.00000 \mathrm{e}+001.00000 \mathrm{e}+001.00000 \mathrm{e}-011.00000 \mathrm{e}-091.00000 \mathrm{e}-01$

Element: 12498 \# of layers: 7

Kx Ky Kz Ss Por

$6.02090 \mathrm{e}+006.02090 \mathrm{e}+00$ 6.02090e-01 1.00000e-09 2.12000e-01

$6.02090 \mathrm{e}+006.02090 \mathrm{e}+006.02090 \mathrm{e}-011.00000 \mathrm{e}-092.12000 \mathrm{e}-01$

$6.02090 \mathrm{e}+006.02090 \mathrm{e}+00$ 6.02090e-01 1.00000e-09 2.12000e-01

$6.02090 \mathrm{e}+006.02090 \mathrm{e}+00$ 6.02090e-01 1.00000e-09 2.12000e-01

$6.02090 \mathrm{e}+006.02090 \mathrm{e}+00$ 6.02090e-01 1.00000e-09 2.12000e-01

$1.00000 \mathrm{e}-05$ 1.00000e-05 1.00000e-06 1.00000e-09 1.00000e-01

$1.00000 \mathrm{e}+001.00000 \mathrm{e}+001.00000 \mathrm{e}-011.00000 \mathrm{e}-091.00000 \mathrm{e}-01$

Element: 12499 \# of layers: 7

Kx Ky Kz Ss Por

$6.02090 \mathrm{e}+006.02090 \mathrm{e}+00$ 6.02090e-01 1.00000e-09 2.12000e-01

$6.02090 \mathrm{e}+006.02090 \mathrm{e}+00$ 6.02090e-01 1.00000e-09 2.12000e-01

$6.02090 \mathrm{e}+006.02090 \mathrm{e}+00$ 6.02090e-01 1.00000e-09 2.12000e-01

$6.02090 \mathrm{e}+006.02090 \mathrm{e}+00$ 6.02090e-01 1.00000e-09 2.12000e-01

$6.02090 \mathrm{e}+006.02090 \mathrm{e}+00$ 6.02090e-01 1.00000e-09 2.12000e-01

$1.00000 \mathrm{e}-05$ 1.00000e-05 1.00000e-06 1.00000e-09 1.00000e-01

$1.00000 \mathrm{e}+001.00000 \mathrm{e}+001.00000 \mathrm{e}-011.00000 \mathrm{e}-091.00000 \mathrm{e}-01$

Element: 12500 \# of layers: 7

Kx Ky Kz Ss Por

$6.02090 \mathrm{e}+006.02090 \mathrm{e}+00$ 6.02090e-01 1.00000e-09 2.12000e-01

$6.02090 \mathrm{e}+006.02090 \mathrm{e}+00$ 6.02090e-01 1.00000e-09 2.12000e-01

$6.02090 \mathrm{e}+006.02090 \mathrm{e}+00$ 6.02090e-01 1.00000e-09 2.12000e-01

$6.02090 \mathrm{e}+006.02090 \mathrm{e}+00$ 6.02090e-01 1.00000e-09 2.12000e-01

$6.02090 \mathrm{e}+006.02090 \mathrm{e}+00$ 6.02090e-01 1.00000e-09 2.12000e-01

$1.00000 \mathrm{e}-05$ 1.00000e-05 1.00000e-06 1.00000e-09 1.00000e-01

$1.00000 \mathrm{e}+001.00000 \mathrm{e}+001.00000 \mathrm{e}-011.00000 \mathrm{e}-091.00000 \mathrm{e}-01$

Element: 12501 \# of layers: 7 
$\mathrm{Kx} \mathrm{Ky} \mathrm{Kz}$ Ss Por

6.02090e+00 6.02090e+00 6.02090e-01 1.00000e-09 2.12000e-01

6.02090e+00 6.02090e+00 6.02090e-01 1.00000e-09 2.12000e-01

$6.02090 \mathrm{e}+006.02090 \mathrm{e}+00$ 6.02090e-01 1.00000e-09 2.12000e-01

6.02090e+00 6.02090e+00 6.02090e-01 1.00000e-09 2.12000e-01

$6.02090 \mathrm{e}+00$ 6.02090e+00 6.02090e-01 1.00000e-09 2.12000e-01

1.00000e-05 1.00000e-05 1.00000e-06 1.00000e-09 1.00000e-01

$1.00000 \mathrm{e}+001.00000 \mathrm{e}+001.00000 \mathrm{e}-01$ 1.00000e-09 1.00000e-01

Element: 12502 \# of layers: 7

$\mathrm{Kx} \mathrm{Ky} \mathrm{Kz}$ Ss Por

6.02090e+00 6.02090e+00 6.02090e-01 1.00000e-09 2.12000e-01

$6.02090 \mathrm{e}+00$ 6.02090e+00 6.02090e-01 1.00000e-09 2.12000e-01

$6.02090 \mathrm{e}+006.02090 \mathrm{e}+00$ 6.02090e-01 1.00000e-09 2.12000e-01

$6.02090 \mathrm{e}+006.02090 \mathrm{e}+00$ 6.02090e-01 1.00000e-09 2.12000e-01

6.02090e+00 6.02090e+00 6.02090e-01 1.00000e-09 2.12000e-01

$1.00000 \mathrm{e}-05$ 1.00000e-05 1.00000e-06 1.00000e-09 1.00000e-01

$1.00000 \mathrm{e}+001.00000 \mathrm{e}+001.00000 \mathrm{e}-01$ 1.00000e-09 1.00000e-01

Element: 12503 \# of layers: 7

$\mathrm{Kx} \mathrm{Ky} \mathrm{Kz}$ Ss Por

6.02090e+00 6.02090e+00 6.02090e-01 1.00000e-09 2.12000e-01

$6.02090 \mathrm{e}+006.02090 \mathrm{e}+00$ 6.02090e-01 1.00000e-09 2.12000e-01

6.02090e+00 6.02090e+00 6.02090e-01 1.00000e-09 2.12000e-01

$6.02090 \mathrm{e}+006.02090 \mathrm{e}+00$ 6.02090e-01 1.00000e-09 2.12000e-01

$6.02090 \mathrm{e}+00$ 6.02090e+00 6.02090e-01 1.00000e-09 2.12000e-01

$1.00000 \mathrm{e}-05$ 1.00000e-05 1.00000e-06 1.00000e-09 1.00000e-01

$1.00000 \mathrm{e}+001.00000 \mathrm{e}+001.00000 \mathrm{e}-01$ 1.00000e-09 1.00000e-01

Element: 12504 \# of layers: 7

$\mathrm{Kx} \mathrm{Ky} \mathrm{Kz}$ Ss Por

$1.09460 \mathrm{e}+011.09460 \mathrm{e}+011.09460 \mathrm{e}+001.00000 \mathrm{e}-092.12000 \mathrm{e}-01$

$1.09460 \mathrm{e}+011.09460 \mathrm{e}+011.09460 \mathrm{e}+001.00000 \mathrm{e}-092.12000 \mathrm{e}-01$

$1.09460 \mathrm{e}+011.09460 \mathrm{e}+011.09460 \mathrm{e}+001.00000 \mathrm{e}-092.12000 \mathrm{e}-01$

$1.09460 \mathrm{e}+011.09460 \mathrm{e}+011.09460 \mathrm{e}+001.00000 \mathrm{e}-092.12000 \mathrm{e}-01$

$1.09460 \mathrm{e}+011.09460 \mathrm{e}+011.09460 \mathrm{e}+001.00000 \mathrm{e}-092.12000 \mathrm{e}-01$

$1.00000 \mathrm{e}-05$ 1.00000e-05 1.00000e-06 1.00000e-09 1.00000e-01

$1.00000 \mathrm{e}+001.00000 \mathrm{e}+001.00000 \mathrm{e}-011.00000 \mathrm{e}-091.00000 \mathrm{e}-01$

Element: 12505 \# of layers: 7

Kx Ky Kz Ss Por

$1.09460 \mathrm{e}+011.09460 \mathrm{e}+011.09460 \mathrm{e}+001.00000 \mathrm{e}-092.12000 \mathrm{e}-01$ $1.09460 \mathrm{e}+011.09460 \mathrm{e}+011.09460 \mathrm{e}+001.00000 \mathrm{e}-092.12000 \mathrm{e}-01$

$1.09460 \mathrm{e}+011.09460 \mathrm{e}+011.09460 \mathrm{e}+001.00000 \mathrm{e}-092.12000 \mathrm{e}-01$

$1.09460 \mathrm{e}+011.09460 \mathrm{e}+011.09460 \mathrm{e}+001.00000 \mathrm{e}-092.12000 \mathrm{e}-01$

$1.09460 \mathrm{e}+011.09460 \mathrm{e}+011.09460 \mathrm{e}+001.00000 \mathrm{e}-092.12000 \mathrm{e}-01$

$1.00000 \mathrm{e}-05$ 1.00000e-05 1.00000e-06 1.00000e-09 1.00000e-01

$1.00000 \mathrm{e}+001.00000 \mathrm{e}+001.00000 \mathrm{e}-01$ 1.00000e-09 1.00000e-01

Element: 12506 \# of layers: 7

Kx Ky Kz Ss Por 
$1.09460 \mathrm{e}+011.09460 \mathrm{e}+011.09460 \mathrm{e}+001.00000 \mathrm{e}-092.12000 \mathrm{e}-01$ $1.09460 \mathrm{e}+011.09460 \mathrm{e}+011.09460 \mathrm{e}+001.00000 \mathrm{e}-092.12000 \mathrm{e}-01$ $1.09460 \mathrm{e}+011.09460 \mathrm{e}+011.09460 \mathrm{e}+001.00000 \mathrm{e}-092.12000 \mathrm{e}-01$ $1.09460 \mathrm{e}+011.09460 \mathrm{e}+011.09460 \mathrm{e}+001.00000 \mathrm{e}-092.12000 \mathrm{e}-01$ $1.09460 \mathrm{e}+011.09460 \mathrm{e}+011.09460 \mathrm{e}+001.00000 \mathrm{e}-092.12000 \mathrm{e}-01$ $1.00000 \mathrm{e}-05$ 1.00000e-05 1.00000e-06 1.00000e-09 1.00000e-01 $1.00000 \mathrm{e}+001.00000 \mathrm{e}+001.00000 \mathrm{e}-011.00000 \mathrm{e}-091.00000 \mathrm{e}-01$ Element: 12507 \# of layers: 7

$\mathrm{Kx} \mathrm{Ky} \mathrm{Kz}$ Ss Por

6.02090e+00 6.02090e+00 6.02090e-01 1.00000e-09 2.12000e-01 6.02090e+00 6.02090e+00 6.02090e-01 1.00000e-09 2.12000e-01 $6.02090 \mathrm{e}+006.02090 \mathrm{e}+00 \quad 6.02090 \mathrm{e}-01$ 1.00000e-09 2.12000e-01 6.02090e+00 6.02090e+00 6.02090e-01 1.00000e-09 2.12000e-01 6.02090e+00 6.02090e+00 6.02090e-01 1.00000e-09 2.12000e-01 $1.00000 \mathrm{e}-05$ 1.00000e-05 1.00000e-06 1.00000e-09 1.00000e-01 $1.00000 \mathrm{e}+001.00000 \mathrm{e}+001.00000 \mathrm{e}-011.00000 \mathrm{e}-091.00000 \mathrm{e}-01$ Element: 12508 \# of layers: 7

$\mathrm{Kx} \mathrm{Ky} \mathrm{Kz}$ Ss Por 6.02090e+00 6.02090e+00 6.02090e-01 1.00000e-09 2.12000e-01 $6.02090 \mathrm{e}+006.02090 \mathrm{e}+00$ 6.02090e-01 1.00000e-09 2.12000e-01 $6.02090 \mathrm{e}+006.02090 \mathrm{e}+00$ 6.02090e-01 1.00000e-09 2.12000e-01 6.02090e+00 6.02090e+00 6.02090e-01 1.00000e-09 2.12000e-01 6.02090e+00 6.02090e+00 6.02090e-01 1.00000e-09 2.12000e-01 $1.00000 \mathrm{e}-05$ 1.00000e-05 1.00000e-06 1.00000e-09 1.00000e-01 $1.00000 \mathrm{e}+001.00000 \mathrm{e}+001.00000 \mathrm{e}-011.00000 \mathrm{e}-091.00000 \mathrm{e}-01$ Element: 12509 \# of layers: 7

$\mathrm{Kx} \mathrm{Ky} \mathrm{Kz}$ Ss Por

6.02090e+00 6.02090e+00 6.02090e-01 1.00000e-09 2.12000e-01 $6.02090 \mathrm{e}+006.02090 \mathrm{e}+00$ 6.02090e-01 1.00000e-09 2.12000e-01 6.02090e+00 6.02090e+00 6.02090e-01 1.00000e-09 2.12000e-01 $6.02090 \mathrm{e}+00$ 6.02090e+00 6.02090e-01 1.00000e-09 2.12000e-01 6.02090e+00 6.02090e+00 6.02090e-01 1.00000e-09 2.12000e-01 $1.00000 \mathrm{e}-05$ 1.00000e-05 1.00000e-06 1.00000e-09 1.00000e-01 $1.00000 \mathrm{e}+001.00000 \mathrm{e}+001.00000 \mathrm{e}-011.00000 \mathrm{e}-091.00000 \mathrm{e}-01$ Element: 12510 \# of layers: 7

$\mathrm{Kx} \mathrm{Ky} \mathrm{Kz}$ Ss Por

6.02090e+00 6.02090e+00 6.02090e-01 1.00000e-09 2.12000e-01 $6.02090 \mathrm{e}+006.02090 \mathrm{e}+00$ 6.02090e-01 1.00000e-09 2.12000e-01 $6.02090 \mathrm{e}+006.02090 \mathrm{e}+00$ 6.02090e-01 1.00000e-09 2.12000e-01 $6.02090 \mathrm{e}+006.02090 \mathrm{e}+006.02090 \mathrm{e}-01$ 1.00000e-09 2.12000e-01 6.02090e+00 6.02090e+00 6.02090e-01 1.00000e-09 2.12000e-01 $1.00000 \mathrm{e}-05$ 1.00000e-05 1.00000e-06 1.00000e-09 1.00000e-01 $1.00000 \mathrm{e}+001.00000 \mathrm{e}+001.00000 \mathrm{e}-01$ 1.00000e-09 1.00000e-01 Element: 12511 \# of layers: 7

$\mathrm{Kx} \mathrm{Ky} \mathrm{Kz}$ Ss Por

$1.09460 \mathrm{e}+011.09460 \mathrm{e}+01$ 1.09460e+00 1.00000e-09 2.12000e-01 
$1.09460 \mathrm{e}+011.09460 \mathrm{e}+01$ 1.09460e+00 1.00000e-09 2.12000e-01 $1.09460 \mathrm{e}+011.09460 \mathrm{e}+011.09460 \mathrm{e}+001.00000 \mathrm{e}-092.12000 \mathrm{e}-01$ $1.09460 \mathrm{e}+011.09460 \mathrm{e}+011.09460 \mathrm{e}+001.00000 \mathrm{e}-092.12000 \mathrm{e}-01$ $1.09460 \mathrm{e}+011.09460 \mathrm{e}+011.09460 \mathrm{e}+001.00000 \mathrm{e}-092.12000 \mathrm{e}-01$ $1.00000 \mathrm{e}-05$ 1.00000e-05 1.00000e-06 1.00000e-09 1.00000e-01 $1.00000 \mathrm{e}+001.00000 \mathrm{e}+001.00000 \mathrm{e}-011.00000 \mathrm{e}-091.00000 \mathrm{e}-01$ Element: 12512 \# of layers: 7

$\mathrm{Kx} \mathrm{Ky} \mathrm{Kz}$ Ss Por

$1.09460 \mathrm{e}+011.09460 \mathrm{e}+011.09460 \mathrm{e}+001.00000 \mathrm{e}-092.12000 \mathrm{e}-01$ $1.09460 \mathrm{e}+011.09460 \mathrm{e}+011.09460 \mathrm{e}+001.00000 \mathrm{e}-092.12000 \mathrm{e}-01$ $1.09460 \mathrm{e}+011.09460 \mathrm{e}+011.09460 \mathrm{e}+001.00000 \mathrm{e}-092.12000 \mathrm{e}-01$ $1.09460 \mathrm{e}+011.09460 \mathrm{e}+011.09460 \mathrm{e}+001.00000 \mathrm{e}-092.12000 \mathrm{e}-01$ $1.09460 \mathrm{e}+011.09460 \mathrm{e}+011.09460 \mathrm{e}+001.00000 \mathrm{e}-092.12000 \mathrm{e}-01$ $1.00000 \mathrm{e}-05$ 1.00000e-05 1.00000e-06 1.00000e-09 1.00000e-01 $1.00000 \mathrm{e}+001.00000 \mathrm{e}+001.00000 \mathrm{e}-01$ 1.00000e-09 1.00000e-01 Element: 12513 \# of layers: 7

$\mathrm{Kx} \mathrm{Ky} \mathrm{Kz}$ Ss Por $1.09460 \mathrm{e}+01$ 1.09460e+01 1.09460e+00 1.00000e-09 2.12000e-01 $1.09460 \mathrm{e}+011.09460 \mathrm{e}+011.09460 \mathrm{e}+001.00000 \mathrm{e}-092.12000 \mathrm{e}-01$ $1.09460 \mathrm{e}+011.09460 \mathrm{e}+01 \quad 1.09460 \mathrm{e}+001.00000 \mathrm{e}-092.12000 \mathrm{e}-01$ $1.09460 \mathrm{e}+011.09460 \mathrm{e}+011.09460 \mathrm{e}+001.00000 \mathrm{e}-092.12000 \mathrm{e}-01$ $1.09460 \mathrm{e}+011.09460 \mathrm{e}+011.09460 \mathrm{e}+001.00000 \mathrm{e}-092.12000 \mathrm{e}-01$ $1.00000 \mathrm{e}-051.00000 \mathrm{e}-05$ 1.00000e-06 1.00000e-09 1.00000e-01 $1.00000 \mathrm{e}+001.00000 \mathrm{e}+001.00000 \mathrm{e}-011.00000 \mathrm{e}-09$ 1.00000e-01 Element: 12514 \# of layers: 7

$\mathrm{Kx} \mathrm{Ky} \mathrm{Kz}$ Ss Por

$1.09460 \mathrm{e}+011.09460 \mathrm{e}+011.09460 \mathrm{e}+001.00000 \mathrm{e}-092.12000 \mathrm{e}-01$ $1.09460 \mathrm{e}+011.09460 \mathrm{e}+011.09460 \mathrm{e}+001.00000 \mathrm{e}-092.12000 \mathrm{e}-01$ $1.09460 \mathrm{e}+011.09460 \mathrm{e}+011.09460 \mathrm{e}+001.00000 \mathrm{e}-092.12000 \mathrm{e}-01$ $1.09460 \mathrm{e}+011.09460 \mathrm{e}+011.09460 \mathrm{e}+001.00000 \mathrm{e}-092.12000 \mathrm{e}-01$ $1.09460 \mathrm{e}+011.09460 \mathrm{e}+011.09460 \mathrm{e}+001.00000 \mathrm{e}-092.12000 \mathrm{e}-01$ $1.00000 \mathrm{e}-05$ 1.00000e-05 1.00000e-06 1.00000e-09 1.00000e-01 $1.00000 \mathrm{e}+001.00000 \mathrm{e}+001.00000 \mathrm{e}-011.00000 \mathrm{e}-091.00000 \mathrm{e}-01$ Element: 12515 \# of layers: 7

$\mathrm{Kx} \mathrm{Ky} \mathrm{Kz}$ Ss Por

$1.09460 \mathrm{e}+011.09460 \mathrm{e}+011.09460 \mathrm{e}+001.00000 \mathrm{e}-092.12000 \mathrm{e}-01$ $1.09460 \mathrm{e}+011.09460 \mathrm{e}+011.09460 \mathrm{e}+001.00000 \mathrm{e}-092.12000 \mathrm{e}-01$ $1.09460 \mathrm{e}+011.09460 \mathrm{e}+011.09460 \mathrm{e}+001.00000 \mathrm{e}-092.12000 \mathrm{e}-01$ $1.09460 \mathrm{e}+011.09460 \mathrm{e}+011.09460 \mathrm{e}+001.00000 \mathrm{e}-092.12000 \mathrm{e}-01$ $1.09460 \mathrm{e}+011.09460 \mathrm{e}+011.09460 \mathrm{e}+001.00000 \mathrm{e}-092.12000 \mathrm{e}-01$ $1.00000 \mathrm{e}-05$ 1.00000e-05 1.00000e-06 1.00000e-09 1.00000e-01 $1.00000 \mathrm{e}+001.00000 \mathrm{e}+001.00000 \mathrm{e}-011.00000 \mathrm{e}-091.00000 \mathrm{e}-01$ Element: 12516 \# of layers: 7

$\mathrm{Kx} \mathrm{Ky} \mathrm{Kz}$ Ss Por $1.09460 \mathrm{e}+011.09460 \mathrm{e}+011.09460 \mathrm{e}+001.00000 \mathrm{e}-092.12000 \mathrm{e}-01$ $1.09460 \mathrm{e}+011.09460 \mathrm{e}+011.09460 \mathrm{e}+001.00000 \mathrm{e}-092.12000 \mathrm{e}-01$ 
$1.09460 \mathrm{e}+011.09460 \mathrm{e}+011.09460 \mathrm{e}+001.00000 \mathrm{e}-092.12000 \mathrm{e}-01$ $1.09460 \mathrm{e}+011.09460 \mathrm{e}+011.09460 \mathrm{e}+001.00000 \mathrm{e}-092.12000 \mathrm{e}-01$ $1.09460 \mathrm{e}+011.09460 \mathrm{e}+011.09460 \mathrm{e}+001.00000 \mathrm{e}-092.12000 \mathrm{e}-01$ $1.00000 \mathrm{e}-05$ 1.00000e-05 1.00000e-06 1.00000e-09 1.00000e-01 $1.00000 \mathrm{e}+001.00000 \mathrm{e}+001.00000 \mathrm{e}-01$ 1.00000e-09 1.00000e-01 Element: 12517 \# of layers: 7

$\mathrm{Kx} \mathrm{Ky} \mathrm{Kz}$ Ss Por

$1.09460 \mathrm{e}+011.09460 \mathrm{e}+011.09460 \mathrm{e}+001.00000 \mathrm{e}-092.12000 \mathrm{e}-01$ $1.09460 \mathrm{e}+011.09460 \mathrm{e}+011.09460 \mathrm{e}+001.00000 \mathrm{e}-092.12000 \mathrm{e}-01$ $1.09460 \mathrm{e}+011.09460 \mathrm{e}+011.09460 \mathrm{e}+001.00000 \mathrm{e}-092.12000 \mathrm{e}-01$ $1.09460 \mathrm{e}+011.09460 \mathrm{e}+011.09460 \mathrm{e}+001.00000 \mathrm{e}-092.12000 \mathrm{e}-01$ $1.09460 \mathrm{e}+011.09460 \mathrm{e}+011.09460 \mathrm{e}+001.00000 \mathrm{e}-092.12000 \mathrm{e}-01$ $1.00000 \mathrm{e}-051.00000 \mathrm{e}-051.00000 \mathrm{e}-061.00000 \mathrm{e}-091.00000 \mathrm{e}-01$ $1.00000 \mathrm{e}+001.00000 \mathrm{e}+001.00000 \mathrm{e}-011.00000 \mathrm{e}-09$ 1.00000e-01 Element: 12518 \# of layers: 7

Kx Ky Kz Ss Por

$1.09460 \mathrm{e}+011.09460 \mathrm{e}+011.09460 \mathrm{e}+00$ 1.00000e-09 2.12000e-01 $1.09460 \mathrm{e}+011.09460 \mathrm{e}+011.09460 \mathrm{e}+001.00000 \mathrm{e}-092.12000 \mathrm{e}-01$ $1.09460 \mathrm{e}+011.09460 \mathrm{e}+011.09460 \mathrm{e}+001.00000 \mathrm{e}-092.12000 \mathrm{e}-01$ $1.09460 \mathrm{e}+011.09460 \mathrm{e}+011.09460 \mathrm{e}+001.00000 \mathrm{e}-092.12000 \mathrm{e}-01$ $1.09460 \mathrm{e}+011.09460 \mathrm{e}+011.09460 \mathrm{e}+001.00000 \mathrm{e}-092.12000 \mathrm{e}-01$ $1.00000 \mathrm{e}-05$ 1.00000e-05 1.00000e-06 1.00000e-09 1.00000e-01 $1.00000 \mathrm{e}+001.00000 \mathrm{e}+001.00000 \mathrm{e}-01$ 1.00000e-09 1.00000e-01 Element: 12519 \# of layers: 7

Kx Ky Kz Ss Por $1.09460 \mathrm{e}+011.09460 \mathrm{e}+011.09460 \mathrm{e}+001.00000 \mathrm{e}-092.12000 \mathrm{e}-01$ $1.09460 \mathrm{e}+011.09460 \mathrm{e}+011.09460 \mathrm{e}+001.00000 \mathrm{e}-092.12000 \mathrm{e}-01$ $1.09460 \mathrm{e}+011.09460 \mathrm{e}+011.09460 \mathrm{e}+001.00000 \mathrm{e}-092.12000 \mathrm{e}-01$ $1.09460 \mathrm{e}+011.09460 \mathrm{e}+011.09460 \mathrm{e}+001.00000 \mathrm{e}-092.12000 \mathrm{e}-01$ $1.09460 \mathrm{e}+011.09460 \mathrm{e}+011.09460 \mathrm{e}+001.00000 \mathrm{e}-092.12000 \mathrm{e}-01$ $1.00000 \mathrm{e}-05$ 1.00000e-05 1.00000e-06 1.00000e-09 1.00000e-01 $1.00000 \mathrm{e}+001.00000 \mathrm{e}+001.00000 \mathrm{e}-01$ 1.00000e-09 1.00000e-01 Element: 12520 \# of layers: 7

$\mathrm{Kx} \mathrm{Ky} \mathrm{Kz}$ Ss Por $1.09460 \mathrm{e}+011.09460 \mathrm{e}+011.09460 \mathrm{e}+001.00000 \mathrm{e}-092.12000 \mathrm{e}-01$ $1.09460 \mathrm{e}+011.09460 \mathrm{e}+011.09460 \mathrm{e}+001.00000 \mathrm{e}-092.12000 \mathrm{e}-01$ $1.09460 \mathrm{e}+011.09460 \mathrm{e}+011.09460 \mathrm{e}+001.00000 \mathrm{e}-092.12000 \mathrm{e}-01$ $1.09460 \mathrm{e}+011.09460 \mathrm{e}+011.09460 \mathrm{e}+001.00000 \mathrm{e}-092.12000 \mathrm{e}-01$ $1.09460 \mathrm{e}+011.09460 \mathrm{e}+011.09460 \mathrm{e}+001.00000 \mathrm{e}-092.12000 \mathrm{e}-01$ $1.00000 \mathrm{e}-05$ 1.00000e-05 1.00000e-06 1.00000e-09 1.00000e-01 $1.00000 \mathrm{e}+001.00000 \mathrm{e}+001.00000 \mathrm{e}-011.00000 \mathrm{e}-091.00000 \mathrm{e}-01$ Element: 12521 \# of layers: 7

$\mathrm{Kx} \mathrm{Ky} \mathrm{Kz}$ Ss Por

$1.53629 \mathrm{e}+01$ 1.53629e+01 1.53629e+00 1.00000e-09 2.12000e-01 $1.53629 \mathrm{e}+01$ 1.53629e+01 1.53629e+00 1.00000e-09 2.12000e-01 $1.53629 \mathrm{e}+011.53629 \mathrm{e}+01$ 1.53629e+00 1.00000e-09 2.12000e-01 
$1.53629 \mathrm{e}+01$ 1.53629e+01 1.53629e+00 1.00000e-09 2.12000e-01 $1.53629 \mathrm{e}+01$ 1.53629e+01 1.53629e+00 1.00000e-09 2.12000e-01 $1.00000 \mathrm{e}-05$ 1.00000e-05 1.00000e-06 1.00000e-09 1.00000e-01 $1.00000 \mathrm{e}+001.00000 \mathrm{e}+001.00000 \mathrm{e}-011.00000 \mathrm{e}-091.00000 \mathrm{e}-01$ Element: 12522 \# of layers: 7

$\mathrm{Kx} \mathrm{Ky} \mathrm{Kz}$ Ss Por

$1.53629 \mathrm{e}+01$ 1.53629e+01 1.53629e+00 1.00000e-09 2.12000e-01 $1.53629 \mathrm{e}+011.53629 \mathrm{e}+011.53629 \mathrm{e}+001.00000 \mathrm{e}-092.12000 \mathrm{e}-01$ $1.53629 \mathrm{e}+01$ 1.53629e+01 1.53629e+00 1.00000e-09 2.12000e-01 $1.53629 \mathrm{e}+01$ 1.53629e+01 1.53629e+00 1.00000e-09 2.12000e-01 $1.53629 \mathrm{e}+011.53629 \mathrm{e}+01$ 1.53629e+00 1.00000e-09 2.12000e-01 $1.00000 \mathrm{e}-05$ 1.00000e-05 1.00000e-06 1.00000e-09 1.00000e-01 $1.00000 \mathrm{e}+001.00000 \mathrm{e}+001.00000 \mathrm{e}-01$ 1.00000e-09 1.00000e-01 Element: 12523 \# of layers: 7

$\mathrm{Kx} \mathrm{Ky} \mathrm{Kz}$ Ss Por

$1.53629 \mathrm{e}+01$ 1.53629e+01 1.53629e+00 1.00000e-09 2.12000e-01 $1.53629 \mathrm{e}+01$ 1.53629e+01 1.53629e+00 1.00000e-09 2.12000e-01 $1.53629 \mathrm{e}+011.53629 \mathrm{e}+011.53629 \mathrm{e}+001.00000 \mathrm{e}-092.12000 \mathrm{e}-01$ $1.53629 \mathrm{e}+01$ 1.53629e+01 1.53629e+00 1.00000e-09 2.12000e-01 $1.53629 \mathrm{e}+01$ 1.53629e+01 1.53629e+00 1.00000e-09 2.12000e-01 $1.00000 \mathrm{e}-05$ 1.00000e-05 1.00000e-06 1.00000e-09 1.00000e-01 $1.00000 \mathrm{e}+001.00000 \mathrm{e}+001.00000 \mathrm{e}-01$ 1.00000e-09 1.00000e-01 Element: 12524 \# of layers: 7

Kx Ky Kz Ss Por

$1.53629 \mathrm{e}+01$ 1.53629e+01 1.53629e+00 1.00000e-09 2.12000e-01 $1.53629 \mathrm{e}+011.53629 \mathrm{e}+01$ 1.53629e+00 1.00000e-09 2.12000e-01 $1.53629 \mathrm{e}+011.53629 \mathrm{e}+01$ 1.53629e+00 1.00000e-09 2.12000e-01 $1.53629 \mathrm{e}+01$ 1.53629e+01 1.53629e+00 1.00000e-09 2.12000e-01 $1.53629 \mathrm{e}+011.53629 \mathrm{e}+011.53629 \mathrm{e}+001.00000 \mathrm{e}-092.12000 \mathrm{e}-01$ $1.00000 \mathrm{e}-05$ 1.00000e-05 1.00000e-06 1.00000e-09 1.00000e-01 $1.00000 \mathrm{e}+001.00000 \mathrm{e}+001.00000 \mathrm{e}-01$ 1.00000e-09 1.00000e-01 Element: 12525 \# of layers: 7

Kx Ky Kz Ss Por

$1.53629 \mathrm{e}+01$ 1.53629e+01 1.53629e+00 1.00000e-09 2.12000e-01 $1.53629 \mathrm{e}+011.53629 \mathrm{e}+011.53629 \mathrm{e}+001.00000 \mathrm{e}-092.12000 \mathrm{e}-01$ $1.53629 \mathrm{e}+011.53629 \mathrm{e}+01$ 1.53629e+00 1.00000e-09 2.12000e-01 $1.53629 \mathrm{e}+011.53629 \mathrm{e}+011.53629 \mathrm{e}+001.00000 \mathrm{e}-092.12000 \mathrm{e}-01$ $1.53629 \mathrm{e}+011.53629 \mathrm{e}+011.53629 \mathrm{e}+001.00000 \mathrm{e}-092.12000 \mathrm{e}-01$ $1.00000 \mathrm{e}-05$ 1.00000e-05 1.00000e-06 1.00000e-09 1.00000e-01 $1.00000 \mathrm{e}+001.00000 \mathrm{e}+00$ 1.00000e-01 1.00000e-09 1.00000e-01 Element: 12526 \# of layers: 7

$\mathrm{Kx} \mathrm{Ky} \mathrm{Kz}$ Ss Por $1.09460 \mathrm{e}+011.09460 \mathrm{e}+011.09460 \mathrm{e}+001.00000 \mathrm{e}-092.12000 \mathrm{e}-01$ $1.09460 \mathrm{e}+01$ 1.09460e+01 1.09460e+00 1.00000e-09 2.12000e-01 $1.09460 \mathrm{e}+011.09460 \mathrm{e}+011.09460 \mathrm{e}+001.00000 \mathrm{e}-092.12000 \mathrm{e}-01$ $1.09460 \mathrm{e}+011.09460 \mathrm{e}+011.09460 \mathrm{e}+001.00000 \mathrm{e}-092.12000 \mathrm{e}-01$ 
$1.09460 \mathrm{e}+011.09460 \mathrm{e}+011.09460 \mathrm{e}+001.00000 \mathrm{e}-092.12000 \mathrm{e}-01$ $1.00000 \mathrm{e}-05$ 1.00000e-05 1.00000e-06 1.00000e-09 1.00000e-01

$1.00000 \mathrm{e}+001.00000 \mathrm{e}+001.00000 \mathrm{e}-011.00000 \mathrm{e}-09$ 1.00000e-01

Element: 12527 \# of layers: 7

$\mathrm{Kx} \mathrm{Ky} \mathrm{Kz}$ Ss Por

$1.09460 \mathrm{e}+01$ 1.09460e+01 1.09460e+00 1.00000e-09 2.12000e-01 $1.09460 \mathrm{e}+011.09460 \mathrm{e}+011.09460 \mathrm{e}+001.00000 \mathrm{e}-092.12000 \mathrm{e}-01$ $1.09460 \mathrm{e}+011.09460 \mathrm{e}+011.09460 \mathrm{e}+001.00000 \mathrm{e}-092.12000 \mathrm{e}-01$ $1.09460 \mathrm{e}+011.09460 \mathrm{e}+011.09460 \mathrm{e}+001.00000 \mathrm{e}-092.12000 \mathrm{e}-01$ $1.09460 \mathrm{e}+011.09460 \mathrm{e}+011.09460 \mathrm{e}+001.00000 \mathrm{e}-092.12000 \mathrm{e}-01$ $1.00000 \mathrm{e}-05$ 1.00000e-05 1.00000e-06 1.00000e-09 1.00000e-01 $1.00000 \mathrm{e}+001.00000 \mathrm{e}+001.00000 \mathrm{e}-01$ 1.00000e-09 1.00000e-01 Element: 12528 \# of layers: 7

$\mathrm{Kx} \mathrm{Ky} \mathrm{Kz}$ Ss Por

$1.53629 \mathrm{e}+01$ 1.53629e+01 1.53629e+00 1.00000e-09 2.12000e-01 $1.53629 \mathrm{e}+011.53629 \mathrm{e}+011.53629 \mathrm{e}+001.00000 \mathrm{e}-092.12000 \mathrm{e}-01$ $1.53629 \mathrm{e}+011.53629 \mathrm{e}+01$ 1.53629e+00 1.00000e-09 2.12000e-01 $1.53629 \mathrm{e}+011.53629 \mathrm{e}+01$ 1.53629e+00 1.00000e-09 2.12000e-01 $1.53629 \mathrm{e}+01$ 1.53629e+01 1.53629e+00 1.00000e-09 2.12000e-01 $1.00000 \mathrm{e}-05$ 1.00000e-05 1.00000e-06 1.00000e-09 1.00000e-01 $1.00000 \mathrm{e}+001.00000 \mathrm{e}+001.00000 \mathrm{e}-011.00000 \mathrm{e}-091.00000 \mathrm{e}-01$ Element: 12529 \# of layers: 7

$\mathrm{Kx} \mathrm{Ky} \mathrm{Kz}$ Ss Por

$1.53629 \mathrm{e}+01$ 1.53629e+01 1.53629e+00 1.00000e-09 2.12000e-01 $1.53629 \mathrm{e}+011.53629 \mathrm{e}+011.53629 \mathrm{e}+001.00000 \mathrm{e}-092.12000 \mathrm{e}-01$ $1.53629 \mathrm{e}+01$ 1.53629e+01 1.53629e+00 1.00000e-09 2.12000e-01 $1.53629 \mathrm{e}+011.53629 \mathrm{e}+011.53629 \mathrm{e}+001.00000 \mathrm{e}-092.12000 \mathrm{e}-01$ $1.53629 \mathrm{e}+01$ 1.53629e+01 1.53629e+00 1.00000e-09 2.12000e-01 $1.00000 \mathrm{e}-05$ 1.00000e-05 1.00000e-06 1.00000e-09 1.00000e-01 $1.00000 \mathrm{e}+001.00000 \mathrm{e}+001.00000 \mathrm{e}-011.00000 \mathrm{e}-091.00000 \mathrm{e}-01$ Element: 12530 \# of layers: 7

$\mathrm{Kx} \mathrm{Ky} \mathrm{Kz}$ Ss Por

1.59337e+01 1.59337e+01 1.59337e+00 1.00000e-09 2.12000e-01 $1.59337 \mathrm{e}+01$ 1.59337e+01 1.59337e+00 1.00000e-09 2.12000e-01 $1.59337 \mathrm{e}+011.59337 \mathrm{e}+01$ 1.59337e+00 1.00000e-09 2.12000e-01 $1.59337 \mathrm{e}+01$ 1.59337e+01 1.59337e+00 1.00000e-09 2.12000e-01 $1.59337 \mathrm{e}+01$ 1.59337e+01 1.59337e+00 1.00000e-09 2.12000e-01 $1.00000 \mathrm{e}-05$ 1.00000e-05 1.00000e-06 1.00000e-09 1.00000e-01 $1.00000 \mathrm{e}+001.00000 \mathrm{e}+001.00000 \mathrm{e}-011.00000 \mathrm{e}-091.00000 \mathrm{e}-01$ Element: 12531 \# of layers: 7

Kx Ky Kz Ss Por

1.59337e+01 1.59337e+01 1.59337e+00 1.00000e-09 2.12000e-01 $1.59337 \mathrm{e}+01$ 1.59337e+01 1.59337e+00 1.00000e-09 2.12000e-01 1.59337e+01 1.59337e+01 1.59337e+00 1.00000e-09 2.12000e-01 $1.59337 \mathrm{e}+01$ 1.59337e+01 1.59337e+00 1.00000e-09 2.12000e-01 $1.59337 \mathrm{e}+01$ 1.59337e+01 1.59337e+00 1.00000e-09 2.12000e-01 
$1.00000 \mathrm{e}-05$ 1.00000e-05 1.00000e-06 1.00000e-09 1.00000e-01 $1.00000 \mathrm{e}+001.00000 \mathrm{e}+001.00000 \mathrm{e}-01$ 1.00000e-09 1.00000e-01 Element: 12532 \# of layers: 7

Kx Ky Kz Ss Por

$1.59337 \mathrm{e}+01$ 1.59337e+01 1.59337e+00 1.00000e-09 2.12000e-01 $1.59337 \mathrm{e}+01$ 1.59337e+01 1.59337e+00 1.00000e-09 2.12000e-01 $1.59337 \mathrm{e}+01$ 1.59337e+01 1.59337e+00 1.00000e-09 2.12000e-01 $1.59337 \mathrm{e}+01$ 1.59337e+01 1.59337e+00 1.00000e-09 2.12000e-01 $1.59337 \mathrm{e}+01$ 1.59337e+01 1.59337e+00 1.00000e-09 2.12000e-01 $1.00000 \mathrm{e}-05$ 1.00000e-05 1.00000e-06 1.00000e-09 1.00000e-01 $1.00000 \mathrm{e}+001.00000 \mathrm{e}+001.00000 \mathrm{e}-011.00000 \mathrm{e}-091.00000 \mathrm{e}-01$ Element: 12533 \# of layers: 7

$\mathrm{Kx} \mathrm{Ky} \mathrm{Kz}$ Ss Por

6.02090e+00 6.02090e+00 6.02090e-01 1.00000e-09 2.12000e-01 6.02090e+00 6.02090e+00 6.02090e-01 1.00000e-09 2.12000e-01 $6.02090 \mathrm{e}+006.02090 \mathrm{e}+006.02090 \mathrm{e}-01$ 1.00000e-09 2.12000e-01 $6.02090 \mathrm{e}+006.02090 \mathrm{e}+00$ 6.02090e-01 1.00000e-09 2.12000e-01 6.02090e+00 6.02090e+00 6.02090e-01 1.00000e-09 2.12000e-01 $1.00000 \mathrm{e}-05$ 1.00000e-05 1.00000e-06 1.00000e-09 1.00000e-01 $1.00000 \mathrm{e}+001.00000 \mathrm{e}+001.00000 \mathrm{e}-011.00000 \mathrm{e}-09$ 1.00000e-01 Element: 12534 \# of layers: 7

$\mathrm{Kx} \mathrm{Ky} \mathrm{Kz}$ Ss Por 6.02090e+00 6.02090e+00 6.02090e-01 1.00000e-09 2.12000e-01 6.02090e+00 6.02090e+00 6.02090e-01 1.00000e-09 2.12000e-01 $6.02090 \mathrm{e}+006.02090 \mathrm{e}+00$ 6.02090e-01 1.00000e-09 2.12000e-01 $6.02090 \mathrm{e}+006.02090 \mathrm{e}+00$ 6.02090e-01 1.00000e-09 2.12000e-01 $6.02090 \mathrm{e}+00$ 6.02090e+00 6.02090e-01 1.00000e-09 2.12000e-01 $1.00000 \mathrm{e}-05$ 1.00000e-05 1.00000e-06 1.00000e-09 1.00000e-01 $1.00000 \mathrm{e}+001.00000 \mathrm{e}+001.00000 \mathrm{e}-011.00000 \mathrm{e}-091.00000 \mathrm{e}-01$ Element: 12535 \# of layers: 7

$\mathrm{Kx} \mathrm{Ky} \mathrm{Kz}$ Ss Por

$1.09460 \mathrm{e}+01$ 1.09460e+01 1.09460e+00 1.00000e-09 2.12000e-01 $1.09460 \mathrm{e}+011.09460 \mathrm{e}+011.09460 \mathrm{e}+001.00000 \mathrm{e}-092.12000 \mathrm{e}-01$ $1.09460 \mathrm{e}+011.09460 \mathrm{e}+011.09460 \mathrm{e}+001.00000 \mathrm{e}-092.12000 \mathrm{e}-01$ $1.09460 \mathrm{e}+011.09460 \mathrm{e}+011.09460 \mathrm{e}+001.00000 \mathrm{e}-092.12000 \mathrm{e}-01$ $1.09460 \mathrm{e}+011.09460 \mathrm{e}+011.09460 \mathrm{e}+001.00000 \mathrm{e}-092.12000 \mathrm{e}-01$ 1.00000e-05 1.00000e-05 1.00000e-06 1.00000e-09 1.00000e-01 $1.00000 \mathrm{e}+001.00000 \mathrm{e}+001.00000 \mathrm{e}-011.00000 \mathrm{e}-091.00000 \mathrm{e}-01$ Element: 12536 \# of layers: 7

$\mathrm{Kx} \mathrm{Ky} \mathrm{Kz}$ Ss Por

$1.53629 \mathrm{e}+01$ 1.53629e+01 1.53629e+00 1.00000e-09 2.12000e-01 $1.53629 \mathrm{e}+01$ 1.53629e+01 1.53629e+00 1.00000e-09 2.12000e-01 $1.53629 \mathrm{e}+011.53629 \mathrm{e}+01$ 1.53629e+00 1.00000e-09 2.12000e-01 $1.53629 \mathrm{e}+01$ 1.53629e+01 1.53629e+00 1.00000e-09 2.12000e-01 $1.53629 \mathrm{e}+011.53629 \mathrm{e}+01 \quad 1.53629 \mathrm{e}+001.00000 \mathrm{e}-092.12000 \mathrm{e}-01$ $1.00000 \mathrm{e}-05$ 1.00000e-05 1.00000e-06 1.00000e-09 1.00000e-01 
$1.00000 \mathrm{e}+001.00000 \mathrm{e}+00$ 1.00000e-01 1.00000e-09 1.00000e-01

Element: 12537 \# of layers: 7

Kx Ky Kz Ss Por

1.59337e+01 1.59337e+01 1.59337e+00 1.00000e-09 2.12000e-01

$1.59337 \mathrm{e}+01$ 1.59337e+01 1.59337e+00 1.00000e-09 2.12000e-01

$1.59337 \mathrm{e}+01$ 1.59337e+01 1.59337e+00 1.00000e-09 2.12000e-01

$1.59337 \mathrm{e}+01$ 1.59337e+01 1.59337e+00 1.00000e-09 2.12000e-01

$1.59337 \mathrm{e}+01$ 1.59337e+01 1.59337e+00 1.00000e-09 2.12000e-01

$1.00000 \mathrm{e}-05$ 1.00000e-05 1.00000e-06 1.00000e-09 1.00000e-01

$1.00000 \mathrm{e}+001.00000 \mathrm{e}+001.00000 \mathrm{e}-011.00000 \mathrm{e}-091.00000 \mathrm{e}-01$

Element: 12538 \# of layers: 7

Kx Ky Kz Ss Por

$1.36994 \mathrm{e}+01$ 1.36994e+01 1.36994e+00 1.00000e-09 2.12000e-01

$1.36994 \mathrm{e}+011.36994 \mathrm{e}+01$ 1.36994e+00 1.00000e-09 2.12000e-01

$1.36994 \mathrm{e}+01$ 1.36994e+01 1.36994e+00 1.00000e-09 2.12000e-01

$1.36994 \mathrm{e}+011.36994 \mathrm{e}+011.36994 \mathrm{e}+001.00000 \mathrm{e}-092.12000 \mathrm{e}-01$

$1.36994 \mathrm{e}+011.36994 \mathrm{e}+011.36994 \mathrm{e}+001.00000 \mathrm{e}-092.12000 \mathrm{e}-01$

$1.00000 \mathrm{e}-05$ 1.00000e-05 1.00000e-06 1.00000e-09 1.00000e-01

$1.00000 \mathrm{e}+001.00000 \mathrm{e}+001.00000 \mathrm{e}-01$ 1.00000e-09 1.00000e-01

Element: 12539 \# of layers: 7

$\mathrm{Kx} \mathrm{Ky} \mathrm{Kz}$ Ss Por

$1.36994 \mathrm{e}+01$ 1.36994e+01 1.36994e+00 1.00000e-09 2.12000e-01

$1.36994 \mathrm{e}+01$ 1.36994e+01 1.36994e+00 1.00000e-09 2.12000e-01

$1.36994 \mathrm{e}+011.36994 \mathrm{e}+011.36994 \mathrm{e}+001.00000 \mathrm{e}-092.12000 \mathrm{e}-01$

$1.36994 \mathrm{e}+011.36994 \mathrm{e}+011.36994 \mathrm{e}+001.00000 \mathrm{e}-092.12000 \mathrm{e}-01$

$1.36994 \mathrm{e}+01$ 1.36994e+01 1.36994e+00 1.00000e-09 2.12000e-01

$1.00000 \mathrm{e}-05$ 1.00000e-05 1.00000e-06 1.00000e-09 1.00000e-01

$1.00000 \mathrm{e}+001.00000 \mathrm{e}+001.00000 \mathrm{e}-01$ 1.00000e-09 1.00000e-01

Element: 12540 \# of layers: 7

$\mathrm{Kx} \mathrm{Ky} \mathrm{Kz}$ Ss Por

$1.36994 \mathrm{e}+01$ 1.36994e+01 1.36994e+00 1.00000e-09 2.12000e-01

$1.36994 \mathrm{e}+01$ 1.36994e+01 1.36994e+00 1.00000e-09 2.12000e-01

$1.36994 \mathrm{e}+011.36994 \mathrm{e}+011.36994 \mathrm{e}+001.00000 \mathrm{e}-092.12000 \mathrm{e}-01$

$1.36994 \mathrm{e}+011.36994 \mathrm{e}+01$ 1.36994e+00 1.00000e-09 2.12000e-01

$1.36994 \mathrm{e}+011.36994 \mathrm{e}+01 \quad 1.36994 \mathrm{e}+001.00000 \mathrm{e}-092.12000 \mathrm{e}-01$

1.00000e-05 1.00000e-05 1.00000e-06 1.00000e-09 1.00000e-01

$1.00000 \mathrm{e}+001.00000 \mathrm{e}+001.00000 \mathrm{e}-011.00000 \mathrm{e}-091.00000 \mathrm{e}-01$

Element: 12541 \# of layers: 7

$\mathrm{Kx} \mathrm{Ky} \mathrm{Kz}$ Ss Por

$1.36994 \mathrm{e}+011.36994 \mathrm{e}+01$ 1.36994e+00 1.00000e-09 2.12000e-01

$1.36994 \mathrm{e}+011.36994 \mathrm{e}+011.36994 \mathrm{e}+001.00000 \mathrm{e}-092.12000 \mathrm{e}-01$

$1.36994 \mathrm{e}+011.36994 \mathrm{e}+011.36994 \mathrm{e}+001.00000 \mathrm{e}-092.12000 \mathrm{e}-01$

$1.36994 \mathrm{e}+011.36994 \mathrm{e}+011.36994 \mathrm{e}+001.00000 \mathrm{e}-092.12000 \mathrm{e}-01$

$1.36994 \mathrm{e}+01$ 1.36994e+01 1.36994e+00 1.00000e-09 2.12000e-01

$1.00000 \mathrm{e}-05$ 1.00000e-05 1.00000e-06 1.00000e-09 1.00000e-01

$1.00000 \mathrm{e}+001.00000 \mathrm{e}+001.00000 \mathrm{e}-011.00000 \mathrm{e}-091.00000 \mathrm{e}-01$ 
Element: 12542 \# of layers: 7

Kx Ky Kz Ss Por

$1.36994 \mathrm{e}+011.36994 \mathrm{e}+011.36994 \mathrm{e}+00$ 1.00000e-09 2.12000e-01

$1.36994 \mathrm{e}+011.36994 \mathrm{e}+011.36994 \mathrm{e}+001.00000 \mathrm{e}-092.12000 \mathrm{e}-01$

$1.36994 \mathrm{e}+011.36994 \mathrm{e}+011.36994 \mathrm{e}+001.00000 \mathrm{e}-092.12000 \mathrm{e}-01$

$1.36994 \mathrm{e}+011.36994 \mathrm{e}+011.36994 \mathrm{e}+001.00000 \mathrm{e}-092.12000 \mathrm{e}-01$

$1.36994 \mathrm{e}+011.36994 \mathrm{e}+011.36994 \mathrm{e}+001.00000 \mathrm{e}-092.12000 \mathrm{e}-01$

$1.00000 \mathrm{e}-05$ 1.00000e-05 1.00000e-06 1.00000e-09 1.00000e-01

$1.00000 \mathrm{e}+001.00000 \mathrm{e}+001.00000 \mathrm{e}-011.00000 \mathrm{e}-091.00000 \mathrm{e}-01$

Element: 12543 \# of layers: 7

Kx Ky Kz Ss Por

$1.36994 \mathrm{e}+011.36994 \mathrm{e}+011.36994 \mathrm{e}+00$ 1.00000e-09 2.12000e-01

$1.36994 \mathrm{e}+011.36994 \mathrm{e}+011.36994 \mathrm{e}+001.00000 \mathrm{e}-092.12000 \mathrm{e}-01$

$1.36994 \mathrm{e}+011.36994 \mathrm{e}+011.36994 \mathrm{e}+001.00000 \mathrm{e}-092.12000 \mathrm{e}-01$

$1.36994 \mathrm{e}+011.36994 \mathrm{e}+011.36994 \mathrm{e}+001.00000 \mathrm{e}-092.12000 \mathrm{e}-01$

$1.36994 \mathrm{e}+011.36994 \mathrm{e}+011.36994 \mathrm{e}+001.00000 \mathrm{e}-092.12000 \mathrm{e}-01$

$1.00000 \mathrm{e}-05$ 1.00000e-05 1.00000e-06 1.00000e-09 1.00000e-01

$1.00000 \mathrm{e}+001.00000 \mathrm{e}+001.00000 \mathrm{e}-011.00000 \mathrm{e}-091.00000 \mathrm{e}-01$

Element: 12544 \# of layers: 7

Kx Ky Kz Ss Por

$1.36994 \mathrm{e}+011.36994 \mathrm{e}+011.36994 \mathrm{e}+00$ 1.00000e-09 2.12000e-01

$1.36994 \mathrm{e}+011.36994 \mathrm{e}+011.36994 \mathrm{e}+001.00000 \mathrm{e}-092.12000 \mathrm{e}-01$

$1.36994 \mathrm{e}+011.36994 \mathrm{e}+011.36994 \mathrm{e}+001.00000 \mathrm{e}-092.12000 \mathrm{e}-01$

$1.36994 \mathrm{e}+011.36994 \mathrm{e}+011.36994 \mathrm{e}+001.00000 \mathrm{e}-092.12000 \mathrm{e}-01$

$1.36994 \mathrm{e}+011.36994 \mathrm{e}+011.36994 \mathrm{e}+001.00000 \mathrm{e}-092.12000 \mathrm{e}-01$

$1.00000 \mathrm{e}-05$ 1.00000e-05 1.00000e-06 1.00000e-09 1.00000e-01

$1.00000 \mathrm{e}+001.00000 \mathrm{e}+001.00000 \mathrm{e}-011.00000 \mathrm{e}-091.00000 \mathrm{e}-01$

Element: 12545 \# of layers: 7

Kx Ky Kz Ss Por

$1.36994 \mathrm{e}+011.36994 \mathrm{e}+011.36994 \mathrm{e}+00$ 1.00000e-09 2.12000e-01

$1.36994 \mathrm{e}+011.36994 \mathrm{e}+011.36994 \mathrm{e}+001.00000 \mathrm{e}-092.12000 \mathrm{e}-01$

$1.36994 \mathrm{e}+011.36994 \mathrm{e}+011.36994 \mathrm{e}+001.00000 \mathrm{e}-092.12000 \mathrm{e}-01$

$1.36994 \mathrm{e}+011.36994 \mathrm{e}+011.36994 \mathrm{e}+001.00000 \mathrm{e}-092.12000 \mathrm{e}-01$

$1.36994 \mathrm{e}+011.36994 \mathrm{e}+011.36994 \mathrm{e}+001.00000 \mathrm{e}-092.12000 \mathrm{e}-01$

$1.00000 \mathrm{e}-05$ 1.00000e-05 1.00000e-06 1.00000e-09 1.00000e-01

$1.00000 \mathrm{e}+001.00000 \mathrm{e}+001.00000 \mathrm{e}-011.00000 \mathrm{e}-091.00000 \mathrm{e}-01$

Element: 12546 \# of layers: 7

Kx Ky Kz Ss Por

$1.36994 \mathrm{e}+011.36994 \mathrm{e}+011.36994 \mathrm{e}+00$ 1.00000e-09 2.12000e-01

$1.36994 \mathrm{e}+011.36994 \mathrm{e}+011.36994 \mathrm{e}+001.00000 \mathrm{e}-092.12000 \mathrm{e}-01$

$1.36994 \mathrm{e}+011.36994 \mathrm{e}+011.36994 \mathrm{e}+001.00000 \mathrm{e}-092.12000 \mathrm{e}-01$

$1.36994 \mathrm{e}+011.36994 \mathrm{e}+011.36994 \mathrm{e}+001.00000 \mathrm{e}-092.12000 \mathrm{e}-01$

$1.36994 \mathrm{e}+011.36994 \mathrm{e}+011.36994 \mathrm{e}+001.00000 \mathrm{e}-092.12000 \mathrm{e}-01$

$1.00000 \mathrm{e}-05$ 1.00000e-05 1.00000e-06 1.00000e-09 1.00000e-01

$1.00000 \mathrm{e}+001.00000 \mathrm{e}+001.00000 \mathrm{e}-011.00000 \mathrm{e}-091.00000 \mathrm{e}-01$

Element: 12547 \# of layers: 7 
$\mathrm{Kx} \mathrm{Ky} \mathrm{Kz}$ Ss Por

$1.36994 \mathrm{e}+01$ 1.36994e+01 1.36994e+00 1.00000e-09 2.12000e-01

$1.36994 \mathrm{e}+011.36994 \mathrm{e}+011.36994 \mathrm{e}+001.00000 \mathrm{e}-092.12000 \mathrm{e}-01$

$1.36994 \mathrm{e}+011.36994 \mathrm{e}+011.36994 \mathrm{e}+001.00000 \mathrm{e}-092.12000 \mathrm{e}-01$

$1.36994 \mathrm{e}+011.36994 \mathrm{e}+01$ 1.36994e+00 1.00000e-09 2.12000e-01

$1.36994 \mathrm{e}+011.36994 \mathrm{e}+011.36994 \mathrm{e}+001.00000 \mathrm{e}-092.12000 \mathrm{e}-01$

$1.00000 \mathrm{e}-05$ 1.00000e-05 1.00000e-06 1.00000e-09 1.00000e-01

$1.00000 \mathrm{e}+001.00000 \mathrm{e}+001.00000 \mathrm{e}-01$ 1.00000e-09 1.00000e-01

Element: 12548 \# of layers: 7

$\mathrm{Kx} \mathrm{Ky} \mathrm{Kz}$ Ss Por

9.48373e+00 9.48373e+00 9.48373e-01 1.00000e-09 2.12000e-01

$9.48373 e+009.48373 e+00$ 9.48373e-01 1.00000e-09 2.12000e-01

9.48373e+00 9.48373e+00 9.48373e-01 1.00000e-09 2.12000e-01

9.48373e+00 9.48373e+00 9.48373e-01 1.00000e-09 2.12000e-01

9.48373e+00 9.48373e+00 9.48373e-01 1.00000e-09 2.12000e-01

$1.00000 \mathrm{e}-05$ 1.00000e-05 1.00000e-06 1.00000e-09 1.00000e-01

$1.00000 \mathrm{e}+001.00000 \mathrm{e}+001.00000 \mathrm{e}-01$ 1.00000e-09 1.00000e-01

Element: 12549 \# of layers: 7

$\mathrm{Kx} \mathrm{Ky} \mathrm{Kz}$ Ss Por

9.48373e+00 9.48373e+00 9.48373e-01 1.00000e-09 2.12000e-01

$9.48373 e+00$ 9.48373e+00 9.48373e-01 1.00000e-09 2.12000e-01

9.48373e+00 9.48373e+00 9.48373e-01 1.00000e-09 2.12000e-01

9.48373e+00 9.48373e+00 9.48373e-01 1.00000e-09 2.12000e-01

9.48373e+00 9.48373e+00 9.48373e-01 1.00000e-09 2.12000e-01

$1.00000 \mathrm{e}-05$ 1.00000e-05 1.00000e-06 1.00000e-09 1.00000e-01

$1.00000 \mathrm{e}+001.00000 \mathrm{e}+001.00000 \mathrm{e}-01$ 1.00000e-09 1.00000e-01

Element: 12550 \# of layers: 7

$\mathrm{Kx} \mathrm{Ky} \mathrm{Kz} \mathrm{Ss} \mathrm{Por}$

9.48373e+00 9.48373e+00 9.48373e-01 1.00000e-09 2.12000e-01

9.48373e+00 9.48373e+00 9.48373e-01 1.00000e-09 2.12000e-01

9.48373e+00 9.48373e+00 9.48373e-01 1.00000e-09 2.12000e-01

9.48373e+00 9.48373e+00 9.48373e-01 1.00000e-09 2.12000e-01

9.48373e+00 9.48373e+00 9.48373e-01 1.00000e-09 2.12000e-01

$1.00000 \mathrm{e}-05$ 1.00000e-05 1.00000e-06 1.00000e-09 1.00000e-01

$1.00000 \mathrm{e}+001.00000 \mathrm{e}+001.00000 \mathrm{e}-01$ 1.00000e-09 1.00000e-01

Element: 12551 \# of layers: 7

Kx Ky Kz Ss Por

9.48373e+00 9.48373e+00 9.48373e-01 1.00000e-09 2.12000e-01

9.48373e+00 9.48373e+00 9.48373e-01 1.00000e-09 2.12000e-01

9.48373e+00 9.48373e+00 9.48373e-01 1.00000e-09 2.12000e-01

9.48373e+00 9.48373e+00 9.48373e-01 1.00000e-09 2.12000e-01

9.48373e+00 9.48373e+00 9.48373e-01 1.00000e-09 2.12000e-01

$1.00000 \mathrm{e}-05$ 1.00000e-05 1.00000e-06 1.00000e-09 1.00000e-01

$1.00000 \mathrm{e}+001.00000 \mathrm{e}+001.00000 \mathrm{e}-01$ 1.00000e-09 1.00000e-01

Element: 12552 \# of layers: 7

Kx Ky Kz Ss Por 
9.48373e+00 9.48373e+00 9.48373e-01 1.00000e-09 2.12000e-01 9.48373e+00 9.48373e+00 9.48373e-01 1.00000e-09 2.12000e-01 9.48373e+00 9.48373e+00 9.48373e-01 1.00000e-09 2.12000e-01 $9.48373 e+009.48373 e+00$ 9.48373e-01 1.00000e-09 2.12000e-01 9.48373e+00 9.48373e+00 9.48373e-01 1.00000e-09 2.12000e-01 $1.00000 \mathrm{e}-05$ 1.00000e-05 1.00000e-06 1.00000e-09 1.00000e-01 $1.00000 \mathrm{e}+001.00000 \mathrm{e}+001.00000 \mathrm{e}-011.00000 \mathrm{e}-091.00000 \mathrm{e}-01$ Element: 12553 \# of layers: 7

$\mathrm{Kx} \mathrm{Ky} \mathrm{Kz}$ Ss Por

$1.36994 \mathrm{e}+01$ 1.36994e+01 1.36994e+00 1.00000e-09 2.12000e-01 $1.36994 \mathrm{e}+01$ 1.36994e+01 1.36994e+00 1.00000e-09 2.12000e-01 $1.36994 \mathrm{e}+011.36994 \mathrm{e}+011.36994 \mathrm{e}+001.00000 \mathrm{e}-092.12000 \mathrm{e}-01$ $1.36994 \mathrm{e}+011.36994 \mathrm{e}+01$ 1.36994e+00 1.00000e-09 2.12000e-01 $1.36994 \mathrm{e}+011.36994 \mathrm{e}+011.36994 \mathrm{e}+001.00000 \mathrm{e}-092.12000 \mathrm{e}-01$ $1.00000 \mathrm{e}-05$ 1.00000e-05 1.00000e-06 1.00000e-09 1.00000e-01 $1.00000 \mathrm{e}+001.00000 \mathrm{e}+001.00000 \mathrm{e}-011.00000 \mathrm{e}-091.00000 \mathrm{e}-01$ Element: 12554 \# of layers: 7

$\mathrm{Kx} \mathrm{Ky} \mathrm{Kz}$ Ss Por

$1.36994 \mathrm{e}+01$ 1.36994e+01 1.36994e+00 1.00000e-09 2.12000e-01 $1.36994 \mathrm{e}+01$ 1.36994e+01 1.36994e+00 1.00000e-09 2.12000e-01 $1.36994 \mathrm{e}+011.36994 \mathrm{e}+011.36994 \mathrm{e}+001.00000 \mathrm{e}-092.12000 \mathrm{e}-01$ $1.36994 \mathrm{e}+011.36994 \mathrm{e}+01$ 1.36994e+00 1.00000e-09 2.12000e-01 $1.36994 \mathrm{e}+01$ 1.36994e+01 1.36994e+00 1.00000e-09 2.12000e-01 $1.00000 \mathrm{e}-05$ 1.00000e-05 1.00000e-06 1.00000e-09 1.00000e-01 $1.00000 \mathrm{e}+001.00000 \mathrm{e}+001.00000 \mathrm{e}-011.00000 \mathrm{e}-091.00000 \mathrm{e}-01$ Element: 12555 \# of layers: 7

$\mathrm{Kx} \mathrm{Ky} \mathrm{Kz}$ Ss Por 9.48373e+00 9.48373e+00 9.48373e-01 1.00000e-09 2.12000e-01 $9.48373 \mathrm{e}+00$ 9.48373e+00 9.48373e-01 1.00000e-09 2.12000e-01 9.48373e+00 9.48373e+00 9.48373e-01 1.00000e-09 2.12000e-01 9.48373e+00 9.48373e+00 9.48373e-01 1.00000e-09 2.12000e-01 9.48373e+00 9.48373e+00 9.48373e-01 1.00000e-09 2.12000e-01 $1.00000 \mathrm{e}-05$ 1.00000e-05 1.00000e-06 1.00000e-09 1.00000e-01 $1.00000 \mathrm{e}+001.00000 \mathrm{e}+001.00000 \mathrm{e}-011.00000 \mathrm{e}-091.00000 \mathrm{e}-01$ Element: 12556 \# of layers: 7

$\mathrm{Kx} \mathrm{Ky} \mathrm{Kz}$ Ss Por 9.48373e+00 9.48373e+00 9.48373e-01 1.00000e-09 2.12000e-01 $9.48373 e+00$ 9.48373e+00 9.48373e-01 1.00000e-09 2.12000e-01 9.48373e+00 9.48373e+00 9.48373e-01 1.00000e-09 2.12000e-01 9.48373e+00 9.48373e+00 9.48373e-01 1.00000e-09 2.12000e-01 9.48373e+00 9.48373e+00 9.48373e-01 1.00000e-09 2.12000e-01 $1.00000 \mathrm{e}-05$ 1.00000e-05 1.00000e-06 1.00000e-09 1.00000e-01 $1.00000 \mathrm{e}+001.00000 \mathrm{e}+001.00000 \mathrm{e}-011.00000 \mathrm{e}-091.00000 \mathrm{e}-01$ Element: 12557 \# of layers: 7

$\mathrm{Kx} \mathrm{Ky} \mathrm{Kz}$ Ss Por 9.48373e+00 9.48373e+00 9.48373e-01 1.00000e-09 2.12000e-01 
9.48373e+00 9.48373e+00 9.48373e-01 1.00000e-09 2.12000e-01 9.48373e+00 9.48373e+00 9.48373e-01 1.00000e-09 2.12000e-01 9.48373e+00 9.48373e+00 9.48373e-01 1.00000e-09 2.12000e-01 $9.48373 \mathrm{e}+00$ 9.48373e+00 9.48373e-01 1.00000e-09 2.12000e-01 $1.00000 \mathrm{e}-05$ 1.00000e-05 1.00000e-06 1.00000e-09 1.00000e-01 $1.00000 \mathrm{e}+001.00000 \mathrm{e}+001.00000 \mathrm{e}-011.00000 \mathrm{e}-091.00000 \mathrm{e}-01$ Element: 12558 \# of layers: 7

$\mathrm{Kx} \mathrm{Ky} \mathrm{Kz}$ Ss Por

9.48373e+00 9.48373e+00 9.48373e-01 1.00000e-09 2.12000e-01

9.48373e+00 9.48373e+00 9.48373e-01 1.00000e-09 2.12000e-01

9.48373e+00 9.48373e+00 9.48373e-01 1.00000e-09 2.12000e-01

9.48373e+00 9.48373e+00 9.48373e-01 1.00000e-09 2.12000e-01

9.48373e+00 9.48373e+00 9.48373e-01 1.00000e-09 2.12000e-01

$1.00000 \mathrm{e}-05$ 1.00000e-05 1.00000e-06 1.00000e-09 1.00000e-01

$1.00000 \mathrm{e}+001.00000 \mathrm{e}+001.00000 \mathrm{e}-01$ 1.00000e-09 1.00000e-01

Element: 12559 \# of layers: 7

$\mathrm{Kx} \mathrm{Ky} \mathrm{Kz}$ Ss Por

9.48373e+00 9.48373e+00 9.48373e-01 1.00000e-09 2.12000e-01

9.48373e+00 9.48373e+00 9.48373e-01 1.00000e-09 2.12000e-01

9.48373e+00 9.48373e+00 9.48373e-01 1.00000e-09 2.12000e-01

$9.48373 e+00$ 9.48373e+00 9.48373e-01 1.00000e-09 2.12000e-01

9.48373e+00 9.48373e+00 9.48373e-01 1.00000e-09 2.12000e-01

$1.00000 \mathrm{e}-05$ 1.00000e-05 1.00000e-06 1.00000e-09 1.00000e-01

$1.00000 \mathrm{e}+001.00000 \mathrm{e}+001.00000 \mathrm{e}-011.00000 \mathrm{e}-09$ 1.00000e-01

Element: 12560 \# of layers: 7

$\mathrm{Kx} \mathrm{Ky} \mathrm{Kz}$ Ss Por

9.48373e+00 9.48373e+00 9.48373e-01 1.00000e-09 2.12000e-01

9.48373e+00 9.48373e+00 9.48373e-01 1.00000e-09 2.12000e-01

$9.48373 e+009.48373 e+00$ 9.48373e-01 1.00000e-09 2.12000e-01

$9.48373 \mathrm{e}+00$ 9.48373e+00 9.48373e-01 1.00000e-09 2.12000e-01

9.48373e+00 9.48373e+00 9.48373e-01 1.00000e-09 2.12000e-01

$1.00000 \mathrm{e}-05$ 1.00000e-05 1.00000e-06 1.00000e-09 1.00000e-01

$1.00000 \mathrm{e}+001.00000 \mathrm{e}+001.00000 \mathrm{e}-011.00000 \mathrm{e}-091.00000 \mathrm{e}-01$

Element: 12561 \# of layers: 7

$\mathrm{Kx} \mathrm{Ky} \mathrm{Kz}$ Ss Por

9.48373e+00 9.48373e+00 9.48373e-01 1.00000e-09 2.12000e-01

9.48373e+00 9.48373e+00 9.48373e-01 1.00000e-09 2.12000e-01

$9.48373 e+00$ 9.48373e+00 9.48373e-01 1.00000e-09 2.12000e-01

9.48373e+00 9.48373e+00 9.48373e-01 1.00000e-09 2.12000e-01

9.48373e+00 9.48373e+00 9.48373e-01 1.00000e-09 2.12000e-01

$1.00000 \mathrm{e}-05$ 1.00000e-05 1.00000e-06 1.00000e-09 1.00000e-01

$1.00000 \mathrm{e}+001.00000 \mathrm{e}+001.00000 \mathrm{e}-011.00000 \mathrm{e}-091.00000 \mathrm{e}-01$

Element: 12562 \# of layers: 7

$\mathrm{Kx} \mathrm{Ky} \mathrm{Kz}$ Ss Por

9.48373e+00 9.48373e+00 9.48373e-01 1.00000e-09 2.12000e-01

$9.48373 e+00$ 9.48373e+00 9.48373e-01 1.00000e-09 2.12000e-01 
9.48373e+00 9.48373e+00 9.48373e-01 1.00000e-09 2.12000e-01 9.48373e+00 9.48373e+00 9.48373e-01 1.00000e-09 2.12000e-01 9.48373e+00 9.48373e+00 9.48373e-01 1.00000e-09 2.12000e-01 $1.00000 \mathrm{e}-05$ 1.00000e-05 1.00000e-06 1.00000e-09 1.00000e-01 $1.00000 \mathrm{e}+001.00000 \mathrm{e}+001.00000 \mathrm{e}-011.00000 \mathrm{e}-091.00000 \mathrm{e}-01$ Element: 12563 \# of layers: 7

$\mathrm{Kx} \mathrm{Ky} \mathrm{Kz}$ Ss Por

9.48373e+00 9.48373e+00 9.48373e-01 1.00000e-09 2.12000e-01

9.48373e+00 9.48373e+00 9.48373e-01 1.00000e-09 2.12000e-01

9.48373e+00 9.48373e+00 9.48373e-01 1.00000e-09 2.12000e-01

9.48373e+00 9.48373e+00 9.48373e-01 1.00000e-09 2.12000e-01

9.48373e+00 9.48373e+00 9.48373e-01 1.00000e-09 2.12000e-01

$1.00000 \mathrm{e}-05$ 1.00000e-05 1.00000e-06 1.00000e-09 1.00000e-01

$1.00000 \mathrm{e}+001.00000 \mathrm{e}+001.00000 \mathrm{e}-011.00000 \mathrm{e}-091.00000 \mathrm{e}-01$

Element: 12564 \# of layers: 7

Kx Ky Kz Ss Por

9.48373e+00 9.48373e+00 9.48373e-01 1.00000e-09 2.12000e-01

9.48373e+00 9.48373e+00 9.48373e-01 1.00000e-09 2.12000e-01

9.48373e+00 9.48373e+00 9.48373e-01 1.00000e-09 2.12000e-01

9.48373e+00 9.48373e+00 9.48373e-01 1.00000e-09 2.12000e-01

$9.48373 e+00$ 9.48373e+00 9.48373e-01 1.00000e-09 2.12000e-01

$1.00000 \mathrm{e}-051.00000 \mathrm{e}-051.00000 \mathrm{e}-061.00000 \mathrm{e}-091.00000 \mathrm{e}-01$

$1.00000 \mathrm{e}+001.00000 \mathrm{e}+001.00000 \mathrm{e}-01$ 1.00000e-09 1.00000e-01

Element: 12565 \# of layers: 7

Kx Ky Kz Ss Por

9.48373e+00 9.48373e+00 9.48373e-01 1.00000e-09 2.12000e-01

9.48373e+00 9.48373e+00 9.48373e-01 1.00000e-09 2.12000e-01

9.48373e+00 9.48373e+00 9.48373e-01 1.00000e-09 2.12000e-01

$9.48373 e+009.48373 e+00$ 9.48373e-01 1.00000e-09 2.12000e-01

9.48373e+00 9.48373e+00 9.48373e-01 1.00000e-09 2.12000e-01

$1.00000 \mathrm{e}-05$ 1.00000e-05 1.00000e-06 1.00000e-09 1.00000e-01

$1.00000 \mathrm{e}+001.00000 \mathrm{e}+001.00000 \mathrm{e}-01$ 1.00000e-09 1.00000e-01

Element: 12566 \# of layers: 7

$\mathrm{Kx} \mathrm{Ky} \mathrm{Kz}$ Ss Por

9.48373e+00 9.48373e+00 9.48373e-01 1.00000e-09 2.12000e-01

9.48373e+00 9.48373e+00 9.48373e-01 1.00000e-09 2.12000e-01

9.48373e+00 9.48373e+00 9.48373e-01 1.00000e-09 2.12000e-01

$9.48373 e+00$ 9.48373e+00 9.48373e-01 1.00000e-09 2.12000e-01

9.48373e+00 9.48373e+00 9.48373e-01 1.00000e-09 2.12000e-01

$1.00000 \mathrm{e}-05$ 1.00000e-05 1.00000e-06 1.00000e-09 1.00000e-01

$1.00000 \mathrm{e}+001.00000 \mathrm{e}+001.00000 \mathrm{e}-011.00000 \mathrm{e}-091.00000 \mathrm{e}-01$

Element: 12567 \# of layers: 7

$\mathrm{Kx} \mathrm{Ky} \mathrm{Kz}$ Ss Por

4.98228e+00 4.98228e+00 4.98228e-01 1.00000e-09 2.12000e-01

4.98228e+00 4.98228e+00 4.98228e-01 1.00000e-09 2.12000e-01

$4.98228 \mathrm{e}+004.98228 \mathrm{e}+00$ 4.98228e-01 1.00000e-09 2.12000e-01 
$4.98228 \mathrm{e}+004.98228 \mathrm{e}+00$ 4.98228e-01 1.00000e-09 2.12000e-01 $4.98228 \mathrm{e}+004.98228 \mathrm{e}+004.98228 \mathrm{e}-011.00000 \mathrm{e}-092.12000 \mathrm{e}-01$ $1.00000 \mathrm{e}-05$ 1.00000e-05 1.00000e-06 1.00000e-09 1.00000e-01 $1.00000 \mathrm{e}+001.00000 \mathrm{e}+001.00000 \mathrm{e}-011.00000 \mathrm{e}-091.00000 \mathrm{e}-01$ Element: 12568 \# of layers: 7

Kx Ky Kz Ss Por

$4.98228 \mathrm{e}+004.98228 \mathrm{e}+004.98228 \mathrm{e}-01$ 1.00000e-09 2.12000e-01 $4.98228 \mathrm{e}+004.98228 \mathrm{e}+004.98228 \mathrm{e}-011.00000 \mathrm{e}-092.12000 \mathrm{e}-01$ $4.98228 \mathrm{e}+004.98228 \mathrm{e}+004.98228 \mathrm{e}-011.00000 \mathrm{e}-092.12000 \mathrm{e}-01$ $4.98228 \mathrm{e}+004.98228 \mathrm{e}+004.98228 \mathrm{e}-01$ 1.00000e-09 2.12000e-01 $4.98228 \mathrm{e}+004.98228 \mathrm{e}+004.98228 \mathrm{e}-01$ 1.00000e-09 2.12000e-01 $1.00000 \mathrm{e}-05$ 1.00000e-05 1.00000e-06 1.00000e-09 1.00000e-01 $1.00000 \mathrm{e}+001.00000 \mathrm{e}+001.00000 \mathrm{e}-011.00000 \mathrm{e}-091.00000 \mathrm{e}-01$ Element: 12569 \# of layers: 7

Kx Ky Kz Ss Por $4.98228 \mathrm{e}+004.98228 \mathrm{e}+00$ 4.98228e-01 1.00000e-09 2.12000e-01 $4.98228 \mathrm{e}+004.98228 \mathrm{e}+004.98228 \mathrm{e}-011.00000 \mathrm{e}-092.12000 \mathrm{e}-01$ $4.98228 \mathrm{e}+004.98228 \mathrm{e}+004.98228 \mathrm{e}-01$ 1.00000e-09 2.12000e-01 $4.98228 \mathrm{e}+004.98228 \mathrm{e}+004.98228 \mathrm{e}-011.00000 \mathrm{e}-092.12000 \mathrm{e}-01$ $4.98228 \mathrm{e}+004.98228 \mathrm{e}+004.98228 \mathrm{e}-01$ 1.00000e-09 2.12000e-01 $1.00000 \mathrm{e}-05$ 1.00000e-05 1.00000e-06 1.00000e-09 1.00000e-01 $1.00000 \mathrm{e}+001.00000 \mathrm{e}+001.00000 \mathrm{e}-011.00000 \mathrm{e}-091.00000 \mathrm{e}-01$ Element: 12570 \# of layers: 7

Kx Ky Kz Ss Por

9.48373e+00 9.48373e+00 9.48373e-01 1.00000e-09 2.12000e-01 $9.48373 \mathrm{e}+00$ 9.48373e+00 9.48373e-01 1.00000e-09 2.12000e-01 $9.48373 \mathrm{e}+00$ 9.48373e+00 9.48373e-01 1.00000e-09 2.12000e-01 $9.48373 \mathrm{e}+00$ 9.48373e+00 9.48373e-01 1.00000e-09 2.12000e-01 $9.48373 \mathrm{e}+00$ 9.48373e+00 9.48373e-01 1.00000e-09 2.12000e-01 $1.00000 \mathrm{e}-05$ 1.00000e-05 1.00000e-06 1.00000e-09 1.00000e-01 $1.00000 \mathrm{e}+001.00000 \mathrm{e}+001.00000 \mathrm{e}-011.00000 \mathrm{e}-091.00000 \mathrm{e}-01$ Element: 12571 \# of layers: 7

Kx Ky Kz Ss Por

9.48373e+00 9.48373e+00 9.48373e-01 1.00000e-09 2.12000e-01 $9.48373 \mathrm{e}+00$ 9.48373e+00 9.48373e-01 1.00000e-09 2.12000e-01 $9.48373 \mathrm{e}+00$ 9.48373e+00 9.48373e-01 1.00000e-09 2.12000e-01 $9.48373 \mathrm{e}+00$ 9.48373e+00 9.48373e-01 1.00000e-09 2.12000e-01 $9.48373 \mathrm{e}+00$ 9.48373e+00 9.48373e-01 1.00000e-09 2.12000e-01 $1.00000 \mathrm{e}-05$ 1.00000e-05 1.00000e-06 1.00000e-09 1.00000e-01 $1.00000 \mathrm{e}+001.00000 \mathrm{e}+001.00000 \mathrm{e}-011.00000 \mathrm{e}-091.00000 \mathrm{e}-01$ Element: 12572 \# of layers: 7

Kx Ky Kz Ss Por 9.48373e+00 9.48373e+00 9.48373e-01 1.00000e-09 2.12000e-01 $9.48373 \mathrm{e}+00$ 9.48373e+00 9.48373e-01 1.00000e-09 2.12000e-01 $9.48373 \mathrm{e}+00$ 9.48373e+00 9.48373e-01 1.00000e-09 2.12000e-01 $9.48373 e+00$ 9.48373e+00 9.48373e-01 1.00000e-09 2.12000e-01 
9.48373e+00 9.48373e+00 9.48373e-01 1.00000e-09 2.12000e-01 $1.00000 \mathrm{e}-05$ 1.00000e-05 1.00000e-06 1.00000e-09 1.00000e-01 $1.00000 \mathrm{e}+001.00000 \mathrm{e}+001.00000 \mathrm{e}-011.00000 \mathrm{e}-09$ 1.00000e-01 Element: 12573 \# of layers: 7

$\mathrm{Kx} \mathrm{Ky} \mathrm{Kz}$ Ss Por

9.48373e+00 9.48373e+00 9.48373e-01 1.00000e-09 2.12000e-01 9.48373e+00 9.48373e+00 9.48373e-01 1.00000e-09 2.12000e-01 9.48373e+00 9.48373e+00 9.48373e-01 1.00000e-09 2.12000e-01 $9.48373 e+00$ 9.48373e+00 9.48373e-01 1.00000e-09 2.12000e-01 9.48373e+00 9.48373e+00 9.48373e-01 1.00000e-09 2.12000e-01 $1.00000 \mathrm{e}-05$ 1.00000e-05 1.00000e-06 1.00000e-09 1.00000e-01 $1.00000 \mathrm{e}+001.00000 \mathrm{e}+001.00000 \mathrm{e}-011.00000 \mathrm{e}-091.00000 \mathrm{e}-01$ Element: 12574 \# of layers: 7

$\mathrm{Kx} \mathrm{Ky} \mathrm{Kz}$ Ss Por

4.98228e+00 4.98228e+00 4.98228e-01 1.00000e-09 2.12000e-01 $4.98228 \mathrm{e}+004.98228 \mathrm{e}+00$ 4.98228e-01 1.00000e-09 2.12000e-01 $4.98228 \mathrm{e}+00$ 4.98228e+00 4.98228e-01 1.00000e-09 2.12000e-01 $4.98228 \mathrm{e}+004.98228 \mathrm{e}+00$ 4.98228e-01 1.00000e-09 2.12000e-01 $4.98228 \mathrm{e}+004.98228 \mathrm{e}+00$ 4.98228e-01 1.00000e-09 2.12000e-01 $1.00000 \mathrm{e}-05$ 1.00000e-05 1.00000e-06 1.00000e-09 1.00000e-01 $1.00000 \mathrm{e}+001.00000 \mathrm{e}+001.00000 \mathrm{e}-011.00000 \mathrm{e}-091.00000 \mathrm{e}-01$ Element: 12575 \# of layers: 7

$\mathrm{Kx} \mathrm{Ky} \mathrm{Kz}$ Ss Por

4.98228e+00 4.98228e+00 4.98228e-01 1.00000e-09 2.12000e-01 $4.98228 \mathrm{e}+004.98228 \mathrm{e}+00$ 4.98228e-01 1.00000e-09 2.12000e-01 $4.98228 \mathrm{e}+004.98228 \mathrm{e}+00$ 4.98228e-01 1.00000e-09 2.12000e-01 4.98228e+00 4.98228e+00 4.98228e-01 1.00000e-09 2.12000e-01 $4.98228 \mathrm{e}+00$ 4.98228e+00 4.98228e-01 1.00000e-09 2.12000e-01 $1.00000 \mathrm{e}-05$ 1.00000e-05 1.00000e-06 1.00000e-09 1.00000e-01 $1.00000 \mathrm{e}+001.00000 \mathrm{e}+001.00000 \mathrm{e}-011.00000 \mathrm{e}-091.00000 \mathrm{e}-01$ Element: 12576 \# of layers: 7

$\mathrm{Kx} \mathrm{Ky} \mathrm{Kz}$ Ss Por

4.98228e+00 4.98228e+00 4.98228e-01 1.00000e-09 2.12000e-01 $4.98228 \mathrm{e}+00$ 4.98228e+00 4.98228e-01 1.00000e-09 2.12000e-01 4.98228e+00 4.98228e+00 4.98228e-01 1.00000e-09 2.12000e-01 $4.98228 \mathrm{e}+004.98228 \mathrm{e}+00$ 4.98228e-01 1.00000e-09 2.12000e-01 $4.98228 \mathrm{e}+004.98228 \mathrm{e}+00$ 4.98228e-01 1.00000e-09 2.12000e-01 $1.00000 \mathrm{e}-05$ 1.00000e-05 1.00000e-06 1.00000e-09 1.00000e-01 $1.00000 \mathrm{e}+001.00000 \mathrm{e}+001.00000 \mathrm{e}-01$ 1.00000e-09 1.00000e-01 Element: 12577 \# of layers: 7

$\mathrm{Kx} \mathrm{Ky} \mathrm{Kz}$ Ss Por

4.98228e+00 4.98228e+00 4.98228e-01 1.00000e-09 2.12000e-01 $4.98228 \mathrm{e}+004.98228 \mathrm{e}+00$ 4.98228e-01 1.00000e-09 2.12000e-01 $4.98228 \mathrm{e}+00$ 4.98228e+00 4.98228e-01 1.00000e-09 2.12000e-01 $4.98228 \mathrm{e}+004.98228 \mathrm{e}+00$ 4.98228e-01 1.00000e-09 2.12000e-01 $4.98228 \mathrm{e}+004.98228 \mathrm{e}+00$ 4.98228e-01 1.00000e-09 2.12000e-01 
$1.00000 \mathrm{e}-05$ 1.00000e-05 1.00000e-06 1.00000e-09 1.00000e-01 $1.00000 \mathrm{e}+001.00000 \mathrm{e}+001.00000 \mathrm{e}-01$ 1.00000e-09 1.00000e-01 Element: 12578 \# of layers: 7

Kx Ky Kz Ss Por

4.98228e+00 4.98228e+00 4.98228e-01 1.00000e-09 2.12000e-01 $4.98228 \mathrm{e}+004.98228 \mathrm{e}+00$ 4.98228e-01 1.00000e-09 2.12000e-01 $4.98228 \mathrm{e}+00$ 4.98228e+00 4.98228e-01 1.00000e-09 2.12000e-01 $4.98228 \mathrm{e}+00$ 4.98228e+00 4.98228e-01 1.00000e-09 2.12000e-01 $4.98228 \mathrm{e}+004.98228 \mathrm{e}+00$ 4.98228e-01 1.00000e-09 2.12000e-01 $1.00000 \mathrm{e}-05$ 1.00000e-05 1.00000e-06 1.00000e-09 1.00000e-01 $1.00000 \mathrm{e}+001.00000 \mathrm{e}+001.00000 \mathrm{e}-011.00000 \mathrm{e}-091.00000 \mathrm{e}-01$ Element: 12579 \# of layers: 7

$\mathrm{Kx} \mathrm{Ky} \mathrm{Kz}$ Ss Por

4.98228e+00 4.98228e+00 4.98228e-01 1.00000e-09 2.12000e-01 4.98228e+00 4.98228e+00 4.98228e-01 1.00000e-09 2.12000e-01 $4.98228 \mathrm{e}+004.98228 \mathrm{e}+00$ 4.98228e-01 1.00000e-09 2.12000e-01 $4.98228 \mathrm{e}+004.98228 \mathrm{e}+004.98228 \mathrm{e}-01$ 1.00000e-09 2.12000e-01 $4.98228 \mathrm{e}+00$ 4.98228e+00 4.98228e-01 1.00000e-09 2.12000e-01 $1.00000 \mathrm{e}-05$ 1.00000e-05 1.00000e-06 1.00000e-09 1.00000e-01 $1.00000 \mathrm{e}+001.00000 \mathrm{e}+001.00000 \mathrm{e}-011.00000 \mathrm{e}-091.00000 \mathrm{e}-01$ Element: 12580 \# of layers: 7

$\mathrm{Kx} \mathrm{Ky} \mathrm{Kz}$ Ss Por

4.98228e+00 4.98228e+00 4.98228e-01 1.00000e-09 2.12000e-01 $4.98228 \mathrm{e}+00$ 4.98228e+00 4.98228e-01 1.00000e-09 2.12000e-01 $4.98228 \mathrm{e}+004.98228 \mathrm{e}+00$ 4.98228e-01 1.00000e-09 2.12000e-01 4.98228e+00 4.98228e+00 4.98228e-01 1.00000e-09 2.12000e-01 $4.98228 \mathrm{e}+004.98228 \mathrm{e}+00$ 4.98228e-01 1.00000e-09 2.12000e-01 $1.00000 \mathrm{e}-05$ 1.00000e-05 1.00000e-06 1.00000e-09 1.00000e-01 $1.00000 \mathrm{e}+001.00000 \mathrm{e}+001.00000 \mathrm{e}-011.00000 \mathrm{e}-091.00000 \mathrm{e}-01$ Element: 12581 \# of layers: 7

$\mathrm{Kx} \mathrm{Ky} \mathrm{Kz}$ Ss Por

4.98228e+00 4.98228e+00 4.98228e-01 1.00000e-09 2.12000e-01 $4.98228 \mathrm{e}+004.98228 \mathrm{e}+00$ 4.98228e-01 1.00000e-09 2.12000e-01 $4.98228 \mathrm{e}+00$ 4.98228e+00 4.98228e-01 1.00000e-09 2.12000e-01 $4.98228 \mathrm{e}+00$ 4.98228e+00 4.98228e-01 1.00000e-09 2.12000e-01 $4.98228 \mathrm{e}+00$ 4.98228e+00 4.98228e-01 1.00000e-09 2.12000e-01 1.00000e-05 1.00000e-05 1.00000e-06 1.00000e-09 1.00000e-01 $1.00000 \mathrm{e}+001.00000 \mathrm{e}+001.00000 \mathrm{e}-011.00000 \mathrm{e}-091.00000 \mathrm{e}-01$ Element: 12582 \# of layers: 7

$\mathrm{Kx} \mathrm{Ky} \mathrm{Kz}$ Ss Por 4.98228e+00 4.98228e+00 4.98228e-01 1.00000e-09 2.12000e-01 $4.98228 \mathrm{e}+00$ 4.98228e+00 4.98228e-01 1.00000e-09 2.12000e-01 4.98228e+00 4.98228e+00 4.98228e-01 1.00000e-09 2.12000e-01 $4.98228 \mathrm{e}+00$ 4.98228e+00 4.98228e-01 1.00000e-09 2.12000e-01 $4.98228 \mathrm{e}+004.98228 \mathrm{e}+00$ 4.98228e-01 1.00000e-09 2.12000e-01 $1.00000 \mathrm{e}-05$ 1.00000e-05 1.00000e-06 1.00000e-09 1.00000e-01 
$1.00000 \mathrm{e}+001.00000 \mathrm{e}+00$ 1.00000e-01 1.00000e-09 1.00000e-01 Element: 12583 \# of layers: 7

Kx Ky Kz Ss Por

4.98228e+00 4.98228e+00 4.98228e-01 1.00000e-09 2.12000e-01

4.98228e+00 4.98228e+00 4.98228e-01 1.00000e-09 2.12000e-01

$4.98228 \mathrm{e}+004.98228 \mathrm{e}+00$ 4.98228e-01 1.00000e-09 2.12000e-01

$4.98228 \mathrm{e}+00$ 4.98228e+00 4.98228e-01 1.00000e-09 2.12000e-01

$4.98228 \mathrm{e}+004.98228 \mathrm{e}+00$ 4.98228e-01 1.00000e-09 2.12000e-01

$1.00000 \mathrm{e}-05$ 1.00000e-05 1.00000e-06 1.00000e-09 1.00000e-01

$1.00000 \mathrm{e}+001.00000 \mathrm{e}+001.00000 \mathrm{e}-011.00000 \mathrm{e}-091.00000 \mathrm{e}-01$

Element: 12584 \# of layers: 7

$\mathrm{Kx} \mathrm{Ky} \mathrm{Kz}$ Ss Por

4.98228e+00 4.98228e+00 4.98228e-01 1.00000e-09 2.12000e-01

4.98228e+00 4.98228e+00 4.98228e-01 1.00000e-09 2.12000e-01

$4.98228 \mathrm{e}+004.98228 \mathrm{e}+00$ 4.98228e-01 1.00000e-09 2.12000e-01

$4.98228 \mathrm{e}+004.98228 \mathrm{e}+00$ 4.98228e-01 1.00000e-09 2.12000e-01

4.98228e+00 4.98228e+00 4.98228e-01 1.00000e-09 2.12000e-01

$1.00000 \mathrm{e}-05$ 1.00000e-05 1.00000e-06 1.00000e-09 1.00000e-01

$1.00000 \mathrm{e}+001.00000 \mathrm{e}+001.00000 \mathrm{e}-011.00000 \mathrm{e}-091.00000 \mathrm{e}-01$

Element: 12585 \# of layers: 7

Kx Ky Kz Ss Por

4.47782e+00 4.47782e+00 4.47782e-01 1.00000e-09 2.12000e-01

4.47782e+00 4.47782e+00 4.47782e-01 1.00000e-09 2.12000e-01

4.47782e+00 4.47782e+00 4.47782e-01 1.00000e-09 2.12000e-01

$4.47782 \mathrm{e}+004.47782 \mathrm{e}+00$ 4.47782e-01 1.00000e-09 2.12000e-01

4.47782e+00 4.47782e+00 4.47782e-01 1.00000e-09 2.12000e-01

$1.00000 \mathrm{e}-05$ 1.00000e-05 1.00000e-06 1.00000e-09 1.00000e-01

$1.00000 \mathrm{e}+001.00000 \mathrm{e}+001.00000 \mathrm{e}-011.00000 \mathrm{e}-091.00000 \mathrm{e}-01$

Element: 12586 \# of layers: 7

$\mathrm{Kx} \mathrm{Ky} \mathrm{Kz}$ Ss Por

4.47782e+00 4.47782e+00 4.47782e-01 1.00000e-09 2.12000e-01

4.47782e+00 4.47782e+00 4.47782e-01 1.00000e-09 2.12000e-01

4.47782e+00 4.47782e+00 4.47782e-01 1.00000e-09 2.12000e-01

4.47782e+00 4.47782e+00 4.47782e-01 1.00000e-09 2.12000e-01

4.47782e+00 4.47782e+00 4.47782e-01 1.00000e-09 2.12000e-01

$1.00000 \mathrm{e}-05$ 1.00000e-05 1.00000e-06 1.00000e-09 1.00000e-01

$1.00000 \mathrm{e}+001.00000 \mathrm{e}+001.00000 \mathrm{e}-011.00000 \mathrm{e}-091.00000 \mathrm{e}-01$

Element: 12587 \# of layers: 7

$\mathrm{Kx} \mathrm{Ky} \mathrm{Kz}$ Ss Por

4.47782e+00 4.47782e+00 4.47782e-01 1.00000e-09 2.12000e-01

$4.47782 \mathrm{e}+004.47782 \mathrm{e}+004.47782 \mathrm{e}-01$ 1.00000e-09 2.12000e-01

$4.47782 \mathrm{e}+004.47782 \mathrm{e}+00$ 4.47782e-01 1.00000e-09 2.12000e-01

4.47782e+00 4.47782e+00 4.47782e-01 1.00000e-09 2.12000e-01

4.47782e+00 4.47782e+00 4.47782e-01 1.00000e-09 2.12000e-01

$1.00000 \mathrm{e}-05$ 1.00000e-05 1.00000e-06 1.00000e-09 1.00000e-01

$1.00000 \mathrm{e}+001.00000 \mathrm{e}+001.00000 \mathrm{e}-011.00000 \mathrm{e}-091.00000 \mathrm{e}-01$ 
Element: 12588 \# of layers: 7

Kx Ky Kz Ss Por

4.98228e+00 4.98228e+00 4.98228e-01 1.00000e-09 2.12000e-01

$4.98228 \mathrm{e}+004.98228 \mathrm{e}+004.98228 \mathrm{e}-011.00000 \mathrm{e}-09$ 2.12000e-01

$4.98228 \mathrm{e}+004.98228 \mathrm{e}+004.98228 \mathrm{e}-011.00000 \mathrm{e}-092.12000 \mathrm{e}-01$

$4.98228 \mathrm{e}+004.98228 \mathrm{e}+004.98228 \mathrm{e}-01$ 1.00000e-09 2.12000e-01

$4.98228 \mathrm{e}+004.98228 \mathrm{e}+004.98228 \mathrm{e}-01$ 1.00000e-09 2.12000e-01

$1.00000 \mathrm{e}-05$ 1.00000e-05 1.00000e-06 1.00000e-09 1.00000e-01

$1.00000 \mathrm{e}+001.00000 \mathrm{e}+001.00000 \mathrm{e}-011.00000 \mathrm{e}-091.00000 \mathrm{e}-01$

Element: 12589 \# of layers: 7

Kx Ky Kz Ss Por

$4.98228 \mathrm{e}+004.98228 \mathrm{e}+00$ 4.98228e-01 1.00000e-09 2.12000e-01

$4.98228 \mathrm{e}+004.98228 \mathrm{e}+004.98228 \mathrm{e}-01$ 1.00000e-09 2.12000e-01

$4.98228 \mathrm{e}+004.98228 \mathrm{e}+004.98228 \mathrm{e}-011.00000 \mathrm{e}-092.12000 \mathrm{e}-01$

$4.98228 \mathrm{e}+004.98228 \mathrm{e}+004.98228 \mathrm{e}-01$ 1.00000e-09 2.12000e-01

$4.98228 \mathrm{e}+004.98228 \mathrm{e}+004.98228 \mathrm{e}-01$ 1.00000e-09 2.12000e-01

$1.00000 \mathrm{e}-05$ 1.00000e-05 1.00000e-06 1.00000e-09 1.00000e-01

$1.00000 \mathrm{e}+001.00000 \mathrm{e}+001.00000 \mathrm{e}-011.00000 \mathrm{e}-091.00000 \mathrm{e}-01$

Element: 12590 \# of layers: 7

Kx Ky Kz Ss Por

$4.98228 \mathrm{e}+004.98228 \mathrm{e}+00$ 4.98228e-01 1.00000e-09 2.12000e-01

$4.98228 \mathrm{e}+004.98228 \mathrm{e}+004.98228 \mathrm{e}-011.00000 \mathrm{e}-092.12000 \mathrm{e}-01$

$4.98228 \mathrm{e}+004.98228 \mathrm{e}+004.98228 \mathrm{e}-01$ 1.00000e-09 2.12000e-01

$4.98228 \mathrm{e}+004.98228 \mathrm{e}+004.98228 \mathrm{e}-011.00000 \mathrm{e}-092.12000 \mathrm{e}-01$

$4.98228 \mathrm{e}+004.98228 \mathrm{e}+004.98228 \mathrm{e}-011.00000 \mathrm{e}-092.12000 \mathrm{e}-01$

$1.00000 \mathrm{e}-05$ 1.00000e-05 1.00000e-06 1.00000e-09 1.00000e-01

$1.00000 \mathrm{e}+001.00000 \mathrm{e}+001.00000 \mathrm{e}-011.00000 \mathrm{e}-091.00000 \mathrm{e}-01$

Element: 12591 \# of layers: 7

Kx Ky Kz Ss Por

$4.98228 \mathrm{e}+004.98228 \mathrm{e}+004.98228 \mathrm{e}-01$ 1.00000e-09 2.12000e-01

$4.98228 \mathrm{e}+004.98228 \mathrm{e}+004.98228 \mathrm{e}-011.00000 \mathrm{e}-092.12000 \mathrm{e}-01$

$4.98228 \mathrm{e}+004.98228 \mathrm{e}+004.98228 \mathrm{e}-01$ 1.00000e-09 2.12000e-01

$4.98228 \mathrm{e}+004.98228 \mathrm{e}+004.98228 \mathrm{e}-011.00000 \mathrm{e}-092.12000 \mathrm{e}-01$

$4.98228 \mathrm{e}+004.98228 \mathrm{e}+004.98228 \mathrm{e}-01$ 1.00000e-09 2.12000e-01

$1.00000 \mathrm{e}-05$ 1.00000e-05 1.00000e-06 1.00000e-09 1.00000e-01

$1.00000 \mathrm{e}+001.00000 \mathrm{e}+001.00000 \mathrm{e}-011.00000 \mathrm{e}-091.00000 \mathrm{e}-01$

Element: 12592 \# of layers: 7

Kx Ky Kz Ss Por

4.47782e+00 4.47782e+00 4.47782e-01 1.00000e-09 2.12000e-01

$4.47782 \mathrm{e}+004.47782 \mathrm{e}+004.47782 \mathrm{e}-01$ 1.00000e-09 2.12000e-01

$4.47782 \mathrm{e}+004.47782 \mathrm{e}+004.47782 \mathrm{e}-011.00000 \mathrm{e}-092.12000 \mathrm{e}-01$

$4.47782 \mathrm{e}+004.47782 \mathrm{e}+004.47782 \mathrm{e}-01$ 1.00000e-09 2.12000e-01

$4.47782 \mathrm{e}+004.47782 \mathrm{e}+00$ 4.47782e-01 1.00000e-09 2.12000e-01

$1.00000 \mathrm{e}-05$ 1.00000e-05 1.00000e-06 1.00000e-09 1.00000e-01

$1.00000 \mathrm{e}+001.00000 \mathrm{e}+001.00000 \mathrm{e}-011.00000 \mathrm{e}-091.00000 \mathrm{e}-01$

Element: 12593 \# of layers: 7 
Kx Ky Kz Ss Por

4.47782e+00 4.47782e+00 4.47782e-01 1.00000e-09 2.12000e-01

4.47782e+00 4.47782e+00 4.47782e-01 1.00000e-09 2.12000e-01

$4.47782 \mathrm{e}+00$ 4.47782e+00 4.47782e-01 1.00000e-09 2.12000e-01

4.47782e+00 4.47782e+00 4.47782e-01 1.00000e-09 2.12000e-01

4.47782e+00 4.47782e+00 4.47782e-01 1.00000e-09 2.12000e-01

$1.00000 \mathrm{e}-05$ 1.00000e-05 1.00000e-06 1.00000e-09 1.00000e-01

$1.00000 \mathrm{e}+001.00000 \mathrm{e}+001.00000 \mathrm{e}-01$ 1.00000e-09 1.00000e-01

Element: 12594 \# of layers: 7

$\mathrm{Kx} \mathrm{Ky} \mathrm{Kz}$ Ss Por

4.47782e+00 4.47782e+00 4.47782e-01 1.00000e-09 2.12000e-01

$4.47782 \mathrm{e}+004.47782 \mathrm{e}+00$ 4.47782e-01 1.00000e-09 2.12000e-01

4.47782e+00 4.47782e+00 4.47782e-01 1.00000e-09 2.12000e-01

4.47782e+00 4.47782e+00 4.47782e-01 1.00000e-09 2.12000e-01

4.47782e+00 4.47782e+00 4.47782e-01 1.00000e-09 2.12000e-01

$1.00000 \mathrm{e}-05$ 1.00000e-05 1.00000e-06 1.00000e-09 1.00000e-01

$1.00000 \mathrm{e}+001.00000 \mathrm{e}+001.00000 \mathrm{e}-01$ 1.00000e-09 1.00000e-01

Element: 12595 \# of layers: 7

$\mathrm{Kx} \mathrm{Ky} \mathrm{Kz}$ Ss Por

4.47782e+00 4.47782e+00 4.47782e-01 1.00000e-09 2.12000e-01

$4.47782 \mathrm{e}+004.47782 \mathrm{e}+00$ 4.47782e-01 1.00000e-09 2.12000e-01

$4.47782 \mathrm{e}+00$ 4.47782e+00 4.47782e-01 1.00000e-09 2.12000e-01

4.47782e+00 4.47782e+00 4.47782e-01 1.00000e-09 2.12000e-01

$4.47782 \mathrm{e}+004.47782 \mathrm{e}+00$ 4.47782e-01 1.00000e-09 2.12000e-01

$1.00000 \mathrm{e}-05$ 1.00000e-05 1.00000e-06 1.00000e-09 1.00000e-01

$1.00000 \mathrm{e}+001.00000 \mathrm{e}+001.00000 \mathrm{e}-01$ 1.00000e-09 1.00000e-01

Element: 12596 \# of layers: 7

$\mathrm{Kx} \mathrm{Ky} \mathrm{Kz} \mathrm{Ss} \mathrm{Por}$

4.47782e+00 4.47782e+00 4.47782e-01 1.00000e-09 2.12000e-01 $4.47782 \mathrm{e}+00$ 4.47782e+00 4.47782e-01 1.00000e-09 2.12000e-01

4.47782e+00 4.47782e+00 4.47782e-01 1.00000e-09 2.12000e-01

4.47782e+00 4.47782e+00 4.47782e-01 1.00000e-09 2.12000e-01

$4.47782 \mathrm{e}+004.47782 \mathrm{e}+00$ 4.47782e-01 1.00000e-09 2.12000e-01

$1.00000 \mathrm{e}-051.00000 \mathrm{e}-051.00000 \mathrm{e}-061.00000 \mathrm{e}-091.00000 \mathrm{e}-01$

$1.00000 \mathrm{e}+001.00000 \mathrm{e}+001.00000 \mathrm{e}-011.00000 \mathrm{e}-091.00000 \mathrm{e}-01$

Element: 12597 \# of layers: 7

$\mathrm{Kx} \mathrm{Ky} \mathrm{Kz}$ Ss Por

4.47782e+00 4.47782e+00 4.47782e-01 1.00000e-09 2.12000e-01

4.47782e+00 4.47782e+00 4.47782e-01 1.00000e-09 2.12000e-01

4.47782e+00 4.47782e+00 4.47782e-01 1.00000e-09 2.12000e-01

$4.47782 \mathrm{e}+004.47782 \mathrm{e}+004.47782 \mathrm{e}-01$ 1.00000e-09 2.12000e-01

4.47782e+00 4.47782e+00 4.47782e-01 1.00000e-09 2.12000e-01

$1.00000 \mathrm{e}-05$ 1.00000e-05 1.00000e-06 1.00000e-09 1.00000e-01

$1.00000 \mathrm{e}+001.00000 \mathrm{e}+001.00000 \mathrm{e}-01$ 1.00000e-09 1.00000e-01

Element: 12598 \# of layers: 7

Kx Ky Kz Ss Por 
4.47782e+00 4.47782e+00 4.47782e-01 1.00000e-09 2.12000e-01 4.47782e+00 4.47782e+00 4.47782e-01 1.00000e-09 2.12000e-01 4.47782e+00 4.47782e+00 4.47782e-01 1.00000e-09 2.12000e-01 $4.47782 \mathrm{e}+00$ 4.47782e+00 4.47782e-01 1.00000e-09 2.12000e-01 4.47782e+00 4.47782e+00 4.47782e-01 1.00000e-09 2.12000e-01 $1.00000 \mathrm{e}-05$ 1.00000e-05 1.00000e-06 1.00000e-09 1.00000e-01 $1.00000 \mathrm{e}+001.00000 \mathrm{e}+001.00000 \mathrm{e}-011.00000 \mathrm{e}-091.00000 \mathrm{e}-01$ Element: 12599 \# of layers: 7

$\mathrm{Kx} \mathrm{Ky} \mathrm{Kz}$ Ss Por

4.47782e+00 4.47782e+00 4.47782e-01 1.00000e-09 2.12000e-01 4.47782e+00 4.47782e+00 4.47782e-01 1.00000e-09 2.12000e-01 $4.47782 \mathrm{e}+00$ 4.47782e+00 4.47782e-01 1.00000e-09 2.12000e-01 4.47782e+00 4.47782e+00 4.47782e-01 1.00000e-09 2.12000e-01 4.47782e+00 4.47782e+00 4.47782e-01 1.00000e-09 2.12000e-01 $1.00000 \mathrm{e}-05$ 1.00000e-05 1.00000e-06 1.00000e-09 1.00000e-01 $1.00000 \mathrm{e}+001.00000 \mathrm{e}+001.00000 \mathrm{e}-011.00000 \mathrm{e}-091.00000 \mathrm{e}-01$ Element: 12600 \# of layers: 7

$\mathrm{Kx} \mathrm{Ky} \mathrm{Kz}$ Ss Por

4.47782e+00 4.47782e+00 4.47782e-01 1.00000e-09 2.12000e-01 $4.47782 \mathrm{e}+004.47782 \mathrm{e}+00$ 4.47782e-01 1.00000e-09 2.12000e-01 $4.47782 \mathrm{e}+004.47782 \mathrm{e}+00$ 4.47782e-01 1.00000e-09 2.12000e-01 4.47782e+00 4.47782e+00 4.47782e-01 1.00000e-09 2.12000e-01 4.47782e+00 4.47782e+00 4.47782e-01 1.00000e-09 2.12000e-01 $1.00000 \mathrm{e}-05$ 1.00000e-05 1.00000e-06 1.00000e-09 1.00000e-01 $1.00000 \mathrm{e}+001.00000 \mathrm{e}+001.00000 \mathrm{e}-011.00000 \mathrm{e}-091.00000 \mathrm{e}-01$ Element: 12601 \# of layers: 7

$\mathrm{Kx} \mathrm{Ky} \mathrm{Kz}$ Ss Por

4.47782e+00 4.47782e+00 4.47782e-01 1.00000e-09 2.12000e-01 $4.47782 \mathrm{e}+004.47782 \mathrm{e}+00$ 4.47782e-01 1.00000e-09 2.12000e-01 $4.47782 \mathrm{e}+00$ 4.47782e+00 4.47782e-01 1.00000e-09 2.12000e-01 4.47782e+00 4.47782e+00 4.47782e-01 1.00000e-09 2.12000e-01 4.47782e+00 4.47782e+00 4.47782e-01 1.00000e-09 2.12000e-01 $1.00000 \mathrm{e}-05$ 1.00000e-05 1.00000e-06 1.00000e-09 1.00000e-01 $1.00000 \mathrm{e}+001.00000 \mathrm{e}+001.00000 \mathrm{e}-011.00000 \mathrm{e}-091.00000 \mathrm{e}-01$ Element: 12602 \# of layers: 7

$\mathrm{Kx} \mathrm{Ky} \mathrm{Kz}$ Ss Por

$1.36994 \mathrm{e}+01$ 1.36994e+01 1.36994e+00 1.00000e-09 2.12000e-01 $1.36994 \mathrm{e}+011.36994 \mathrm{e}+011.36994 \mathrm{e}+001.00000 \mathrm{e}-092.12000 \mathrm{e}-01$ $1.36994 \mathrm{e}+011.36994 \mathrm{e}+011.36994 \mathrm{e}+001.00000 \mathrm{e}-092.12000 \mathrm{e}-01$ $1.36994 \mathrm{e}+011.36994 \mathrm{e}+011.36994 \mathrm{e}+001.00000 \mathrm{e}-092.12000 \mathrm{e}-01$ $1.36994 \mathrm{e}+01$ 1.36994e+01 1.36994e+00 1.00000e-09 2.12000e-01 $1.00000 \mathrm{e}-05$ 1.00000e-05 1.00000e-06 1.00000e-09 1.00000e-01 $1.00000 \mathrm{e}+001.00000 \mathrm{e}+001.00000 \mathrm{e}-01$ 1.00000e-09 1.00000e-01 Element: 12603 \# of layers: 7

$\mathrm{Kx} \mathrm{Ky} \mathrm{Kz}$ Ss Por $1.36994 \mathrm{e}+01$ 1.36994e+01 1.36994e+00 1.00000e-09 2.12000e-01 
$1.36994 \mathrm{e}+011.36994 \mathrm{e}+01$ 1.36994e+00 1.00000e-09 2.12000e-01 $1.36994 \mathrm{e}+01$ 1.36994e+01 1.36994e+00 1.00000e-09 2.12000e-01 $1.36994 \mathrm{e}+011.36994 \mathrm{e}+011.36994 \mathrm{e}+001.00000 \mathrm{e}-092.12000 \mathrm{e}-01$ $1.36994 \mathrm{e}+011.36994 \mathrm{e}+011.36994 \mathrm{e}+001.00000 \mathrm{e}-092.12000 \mathrm{e}-01$ $1.00000 \mathrm{e}-05$ 1.00000e-05 1.00000e-06 1.00000e-09 1.00000e-01 $1.00000 \mathrm{e}+001.00000 \mathrm{e}+001.00000 \mathrm{e}-011.00000 \mathrm{e}-091.00000 \mathrm{e}-01$ Element: 12604 \# of layers: 7

Kx Ky Kz Ss Por

$1.36994 \mathrm{e}+01$ 1.36994e+01 1.36994e+00 1.00000e-09 2.12000e-01

$1.36994 \mathrm{e}+011.36994 \mathrm{e}+011.36994 \mathrm{e}+001.00000 \mathrm{e}-092.12000 \mathrm{e}-01$ $1.36994 \mathrm{e}+01$ 1.36994e+01 1.36994e+00 1.00000e-09 2.12000e-01 $1.36994 \mathrm{e}+011.36994 \mathrm{e}+011.36994 \mathrm{e}+001.00000 \mathrm{e}-092.12000 \mathrm{e}-01$ $1.36994 \mathrm{e}+011.36994 \mathrm{e}+011.36994 \mathrm{e}+001.00000 \mathrm{e}-092.12000 \mathrm{e}-01$ $1.00000 \mathrm{e}-05$ 1.00000e-05 1.00000e-06 1.00000e-09 1.00000e-01 $1.00000 \mathrm{e}+001.00000 \mathrm{e}+001.00000 \mathrm{e}-01$ 1.00000e-09 1.00000e-01 Element: 12605 \# of layers: 7

$\mathrm{Kx} \mathrm{Ky} \mathrm{Kz}$ Ss Por

$1.36994 \mathrm{e}+01$ 1.36994e+01 1.36994e+00 1.00000e-09 2.12000e-01 $1.36994 \mathrm{e}+01$ 1.36994e+01 1.36994e+00 1.00000e-09 2.12000e-01 $1.36994 \mathrm{e}+011.36994 \mathrm{e}+01 \quad 1.36994 \mathrm{e}+001.00000 \mathrm{e}-092.12000 \mathrm{e}-01$ $1.36994 \mathrm{e}+011.36994 \mathrm{e}+011.36994 \mathrm{e}+001.00000 \mathrm{e}-092.12000 \mathrm{e}-01$ $1.36994 \mathrm{e}+011.36994 \mathrm{e}+01$ 1.36994e+00 1.00000e-09 2.12000e-01 $1.00000 \mathrm{e}-05$ 1.00000e-05 1.00000e-06 1.00000e-09 1.00000e-01 $1.00000 \mathrm{e}+001.00000 \mathrm{e}+001.00000 \mathrm{e}-011.00000 \mathrm{e}-09$ 1.00000e-01 Element: 12606 \# of layers: 7

$\mathrm{Kx} \mathrm{Ky} \mathrm{Kz}$ Ss Por

$1.36994 \mathrm{e}+01$ 1.36994e+01 1.36994e+00 1.00000e-09 2.12000e-01 $1.36994 \mathrm{e}+011.36994 \mathrm{e}+011.36994 \mathrm{e}+001.00000 \mathrm{e}-092.12000 \mathrm{e}-01$ $1.36994 \mathrm{e}+011.36994 \mathrm{e}+011.36994 \mathrm{e}+001.00000 \mathrm{e}-092.12000 \mathrm{e}-01$ $1.36994 \mathrm{e}+011.36994 \mathrm{e}+011.36994 \mathrm{e}+001.00000 \mathrm{e}-092.12000 \mathrm{e}-01$ $1.36994 \mathrm{e}+011.36994 \mathrm{e}+01 \quad 1.36994 \mathrm{e}+001.00000 \mathrm{e}-092.12000 \mathrm{e}-01$ $1.00000 \mathrm{e}-05$ 1.00000e-05 1.00000e-06 1.00000e-09 1.00000e-01 $1.00000 \mathrm{e}+001.00000 \mathrm{e}+001.00000 \mathrm{e}-011.00000 \mathrm{e}-091.00000 \mathrm{e}-01$ Element: 12607 \# of layers: 7

$\mathrm{Kx} \mathrm{Ky} \mathrm{Kz}$ Ss Por

4.47782e+00 4.47782e+00 4.47782e-01 1.00000e-09 2.12000e-01 $4.47782 \mathrm{e}+004.47782 \mathrm{e}+00$ 4.47782e-01 1.00000e-09 2.12000e-01 $4.47782 \mathrm{e}+004.47782 \mathrm{e}+00$ 4.47782e-01 1.00000e-09 2.12000e-01 4.47782e+00 4.47782e+00 4.47782e-01 1.00000e-09 2.12000e-01 4.47782e+00 4.47782e+00 4.47782e-01 1.00000e-09 2.12000e-01 $1.00000 \mathrm{e}-05$ 1.00000e-05 1.00000e-06 1.00000e-09 1.00000e-01 $1.00000 \mathrm{e}+001.00000 \mathrm{e}+001.00000 \mathrm{e}-011.00000 \mathrm{e}-091.00000 \mathrm{e}-01$ Element: 12608 \# of layers: 7

$\mathrm{Kx} \mathrm{Ky} \mathrm{Kz}$ Ss Por

4.47782e+00 4.47782e+00 4.47782e-01 1.00000e-09 2.12000e-01 $4.47782 \mathrm{e}+004.47782 \mathrm{e}+00$ 4.47782e-01 1.00000e-09 2.12000e-01 
4.47782e+00 4.47782e+00 4.47782e-01 1.00000e-09 2.12000e-01 4.47782e+00 4.47782e+00 4.47782e-01 1.00000e-09 2.12000e-01 4.47782e+00 4.47782e+00 4.47782e-01 1.00000e-09 2.12000e-01 $1.00000 \mathrm{e}-05$ 1.00000e-05 1.00000e-06 1.00000e-09 1.00000e-01 $1.00000 \mathrm{e}+001.00000 \mathrm{e}+001.00000 \mathrm{e}-011.00000 \mathrm{e}-091.00000 \mathrm{e}-01$ Element: 12609 \# of layers: 7

$\mathrm{Kx} \mathrm{Ky} \mathrm{Kz}$ Ss Por

$1.36994 \mathrm{e}+01$ 1.36994e+01 1.36994e+00 1.00000e-09 2.12000e-01 $1.36994 \mathrm{e}+011.36994 \mathrm{e}+01$ 1.36994e+00 1.00000e-09 2.12000e-01 $1.36994 \mathrm{e}+011.36994 \mathrm{e}+011.36994 \mathrm{e}+001.00000 \mathrm{e}-092.12000 \mathrm{e}-01$ $1.36994 \mathrm{e}+01$ 1.36994e+01 1.36994e+00 1.00000e-09 2.12000e-01 $1.36994 \mathrm{e}+011.36994 \mathrm{e}+01 \quad 1.36994 \mathrm{e}+001.00000 \mathrm{e}-092.12000 \mathrm{e}-01$ $1.00000 \mathrm{e}-05$ 1.00000e-05 1.00000e-06 1.00000e-09 1.00000e-01 $1.00000 \mathrm{e}+001.00000 \mathrm{e}+001.00000 \mathrm{e}-011.00000 \mathrm{e}-091.00000 \mathrm{e}-01$ Element: 12610 \# of layers: 7

Kx Ky Kz Ss Por

$1.36994 \mathrm{e}+011.36994 \mathrm{e}+01$ 1.36994e+00 1.00000e-09 2.12000e-01 $1.36994 \mathrm{e}+01$ 1.36994e+01 1.36994e+00 1.00000e-09 2.12000e-01 $1.36994 \mathrm{e}+01$ 1.36994e+01 1.36994e+00 1.00000e-09 2.12000e-01 $1.36994 \mathrm{e}+011.36994 \mathrm{e}+01 \quad 1.36994 \mathrm{e}+001.00000 \mathrm{e}-092.12000 \mathrm{e}-01$ $1.36994 \mathrm{e}+011.36994 \mathrm{e}+011.36994 \mathrm{e}+001.00000 \mathrm{e}-092.12000 \mathrm{e}-01$ $1.00000 \mathrm{e}-05$ 1.00000e-05 1.00000e-06 1.00000e-09 1.00000e-01 $1.00000 \mathrm{e}+001.00000 \mathrm{e}+001.00000 \mathrm{e}-01$ 1.00000e-09 1.00000e-01 Element: 12611 \# of layers: 7

Kx Ky Kz Ss Por

9.48373e+00 9.48373e+00 9.48373e-01 1.00000e-09 2.12000e-01 9.48373e+00 9.48373e+00 9.48373e-01 1.00000e-09 2.12000e-01 9.48373e+00 9.48373e+00 9.48373e-01 1.00000e-09 2.12000e-01 $9.48373 e+00$ 9.48373e+00 9.48373e-01 1.00000e-09 2.12000e-01 9.48373e+00 9.48373e+00 9.48373e-01 1.00000e-09 2.12000e-01 $1.00000 \mathrm{e}-05$ 1.00000e-05 1.00000e-06 1.00000e-09 1.00000e-01 $1.00000 \mathrm{e}+001.00000 \mathrm{e}+001.00000 \mathrm{e}-01$ 1.00000e-09 1.00000e-01 Element: 12612 \# of layers: 7

$\mathrm{Kx} \mathrm{Ky} \mathrm{Kz}$ Ss Por

9.48373e+00 9.48373e+00 9.48373e-01 1.00000e-09 2.12000e-01 9.48373e+00 9.48373e+00 9.48373e-01 1.00000e-09 2.12000e-01 $9.48373 e+00$ 9.48373e+00 9.48373e-01 1.00000e-09 2.12000e-01 $9.48373 e+00$ 9.48373e+00 9.48373e-01 1.00000e-09 2.12000e-01 9.48373e+00 9.48373e+00 9.48373e-01 1.00000e-09 2.12000e-01 $1.00000 \mathrm{e}-05$ 1.00000e-05 1.00000e-06 1.00000e-09 1.00000e-01 $1.00000 \mathrm{e}+001.00000 \mathrm{e}+001.00000 \mathrm{e}-011.00000 \mathrm{e}-091.00000 \mathrm{e}-01$ Element: 12613 \# of layers: 7

$\mathrm{Kx} \mathrm{Ky} \mathrm{Kz}$ Ss Por

9.48373e+00 9.48373e+00 9.48373e-01 1.00000e-09 2.12000e-01 9.48373e+00 9.48373e+00 9.48373e-01 1.00000e-09 2.12000e-01 $9.48373 e+00$ 9.48373e+00 9.48373e-01 1.00000e-09 2.12000e-01 
9.48373e+00 9.48373e+00 9.48373e-01 1.00000e-09 2.12000e-01 9.48373e+00 9.48373e+00 9.48373e-01 1.00000e-09 2.12000e-01 $1.00000 \mathrm{e}-05$ 1.00000e-05 1.00000e-06 1.00000e-09 1.00000e-01 $1.00000 \mathrm{e}+001.00000 \mathrm{e}+001.00000 \mathrm{e}-011.00000 \mathrm{e}-091.00000 \mathrm{e}-01$ Element: 12614 \# of layers: 7

$\mathrm{Kx} \mathrm{Ky} \mathrm{Kz}$ Ss Por

4.98228e+00 4.98228e+00 4.98228e-01 1.00000e-09 2.12000e-01 $4.98228 \mathrm{e}+004.98228 \mathrm{e}+00$ 4.98228e-01 1.00000e-09 2.12000e-01 $4.98228 \mathrm{e}+00$ 4.98228e+00 4.98228e-01 1.00000e-09 2.12000e-01 4.98228e+00 4.98228e+00 4.98228e-01 1.00000e-09 2.12000e-01 $4.98228 \mathrm{e}+004.98228 \mathrm{e}+00$ 4.98228e-01 1.00000e-09 2.12000e-01 $1.00000 \mathrm{e}-05$ 1.00000e-05 1.00000e-06 1.00000e-09 1.00000e-01 $1.00000 \mathrm{e}+001.00000 \mathrm{e}+001.00000 \mathrm{e}-01$ 1.00000e-09 1.00000e-01 Element: 12615 \# of layers: 7

$\mathrm{Kx} \mathrm{Ky} \mathrm{Kz}$ Ss Por

4.98228e+00 4.98228e+00 4.98228e-01 1.00000e-09 2.12000e-01 $4.98228 \mathrm{e}+00$ 4.98228e+00 4.98228e-01 1.00000e-09 2.12000e-01 $4.98228 \mathrm{e}+00$ 4.98228e+00 4.98228e-01 1.00000e-09 2.12000e-01 4.98228e+00 4.98228e+00 4.98228e-01 1.00000e-09 2.12000e-01 $4.98228 \mathrm{e}+004.98228 \mathrm{e}+004.98228 \mathrm{e}-01$ 1.00000e-09 2.12000e-01 $1.00000 \mathrm{e}-05$ 1.00000e-05 1.00000e-06 1.00000e-09 1.00000e-01 $1.00000 \mathrm{e}+001.00000 \mathrm{e}+001.00000 \mathrm{e}-01$ 1.00000e-09 1.00000e-01 Element: 12616 \# of layers: 7

Kx Ky Kz Ss Por

4.47782e+00 4.47782e+00 4.47782e-01 1.00000e-09 2.12000e-01 $4.47782 \mathrm{e}+004.47782 \mathrm{e}+00$ 4.47782e-01 1.00000e-09 2.12000e-01 $4.47782 \mathrm{e}+004.47782 \mathrm{e}+00$ 4.47782e-01 1.00000e-09 2.12000e-01 $4.47782 \mathrm{e}+004.47782 \mathrm{e}+004.47782 \mathrm{e}-01$ 1.00000e-09 2.12000e-01 $4.47782 \mathrm{e}+004.47782 \mathrm{e}+00$ 4.47782e-01 1.00000e-09 2.12000e-01 $1.00000 \mathrm{e}-051.00000 \mathrm{e}-051.00000 \mathrm{e}-061.00000 \mathrm{e}-091.00000 \mathrm{e}-01$ $1.00000 \mathrm{e}+001.00000 \mathrm{e}+001.00000 \mathrm{e}-011.00000 \mathrm{e}-091.00000 \mathrm{e}-01$ Element: 12617 \# of layers: 7

Kx Ky Kz Ss Por

$1.36994 \mathrm{e}+011.36994 \mathrm{e}+01$ 1.36994e+00 1.00000e-09 2.12000e-01 $1.36994 \mathrm{e}+011.36994 \mathrm{e}+01$ 1.36994e+00 1.00000e-09 2.12000e-01 $1.36994 \mathrm{e}+011.36994 \mathrm{e}+011.36994 \mathrm{e}+001.00000 \mathrm{e}-092.12000 \mathrm{e}-01$ $1.36994 \mathrm{e}+011.36994 \mathrm{e}+011.36994 \mathrm{e}+001.00000 \mathrm{e}-092.12000 \mathrm{e}-01$ $1.36994 \mathrm{e}+011.36994 \mathrm{e}+011.36994 \mathrm{e}+001.00000 \mathrm{e}-092.12000 \mathrm{e}-01$ $1.00000 \mathrm{e}-05$ 1.00000e-05 1.00000e-06 1.00000e-09 1.00000e-01 $1.00000 \mathrm{e}+001.00000 \mathrm{e}+001.00000 \mathrm{e}-01$ 1.00000e-09 1.00000e-01 Element: 12618 \# of layers: 7

Kx Ky Kz Ss Por 9.48373e+00 9.48373e+00 9.48373e-01 1.00000e-09 2.12000e-01 9.48373e+00 9.48373e+00 9.48373e-01 1.00000e-09 2.12000e-01 $9.48373 \mathrm{e}+00$ 9.48373e+00 9.48373e-01 1.00000e-09 2.12000e-01 $9.48373 e+00$ 9.48373e+00 9.48373e-01 1.00000e-09 2.12000e-01 
9.48373e+00 9.48373e+00 9.48373e-01 1.00000e-09 2.12000e-01 $1.00000 \mathrm{e}-05$ 1.00000e-05 1.00000e-06 1.00000e-09 1.00000e-01 $1.00000 \mathrm{e}+001.00000 \mathrm{e}+001.00000 \mathrm{e}-011.00000 \mathrm{e}-09$ 1.00000e-01 Element: 12619 \# of layers: 7

$\mathrm{Kx} \mathrm{Ky} \mathrm{Kz}$ Ss Por

$1.06983 \mathrm{e}+01$ 1.06983e+01 1.06983e+00 1.00000e-09 2.12000e-01 $1.06983 \mathrm{e}+011.06983 \mathrm{e}+01$ 1.06983e+00 1.00000e-09 2.12000e-01 $1.06983 \mathrm{e}+011.06983 \mathrm{e}+011.06983 \mathrm{e}+001.00000 \mathrm{e}-092.12000 \mathrm{e}-01$ $1.06983 \mathrm{e}+011.06983 \mathrm{e}+01$ 1.06983e+00 1.00000e-09 2.12000e-01 $1.06983 \mathrm{e}+01$ 1.06983e+01 1.06983e+00 1.00000e-09 2.12000e-01 $1.00000 \mathrm{e}-05$ 1.00000e-05 1.00000e-06 1.00000e-09 1.00000e-01 $1.00000 \mathrm{e}+001.00000 \mathrm{e}+001.00000 \mathrm{e}-011.00000 \mathrm{e}-091.00000 \mathrm{e}-01$ Element: 12620 \# of layers: 7

$\mathrm{Kx} \mathrm{Ky} \mathrm{Kz}$ Ss Por

$1.06983 \mathrm{e}+01$ 1.06983e+01 1.06983e+00 1.00000e-09 2.12000e-01 $1.06983 \mathrm{e}+011.06983 \mathrm{e}+011.06983 \mathrm{e}+001.00000 \mathrm{e}-092.12000 \mathrm{e}-01$ $1.06983 \mathrm{e}+011.06983 \mathrm{e}+01$ 1.06983e+00 1.00000e-09 2.12000e-01 $1.06983 \mathrm{e}+011.06983 \mathrm{e}+01$ 1.06983e+00 1.00000e-09 2.12000e-01 $1.06983 \mathrm{e}+01$ 1.06983e+01 1.06983e+00 1.00000e-09 2.12000e-01 $1.00000 \mathrm{e}-05$ 1.00000e-05 1.00000e-06 1.00000e-09 1.00000e-01 $1.00000 \mathrm{e}+001.00000 \mathrm{e}+001.00000 \mathrm{e}-011.00000 \mathrm{e}-091.00000 \mathrm{e}-01$ Element: 12621 \# of layers: 7

$\mathrm{Kx} \mathrm{Ky} \mathrm{Kz}$ Ss Por $1.06983 \mathrm{e}+01$ 1.06983e+01 1.06983e+00 1.00000e-09 2.12000e-01 $1.06983 \mathrm{e}+011.06983 \mathrm{e}+011.06983 \mathrm{e}+001.00000 \mathrm{e}-092.12000 \mathrm{e}-01$ $1.06983 \mathrm{e}+011.06983 \mathrm{e}+01$ 1.06983e+00 1.00000e-09 2.12000e-01 $1.06983 \mathrm{e}+011.06983 \mathrm{e}+011.06983 \mathrm{e}+001.00000 \mathrm{e}-092.12000 \mathrm{e}-01$ $1.06983 \mathrm{e}+011.06983 \mathrm{e}+01$ 1.06983e+00 1.00000e-09 2.12000e-01 $1.00000 \mathrm{e}-05$ 1.00000e-05 1.00000e-06 1.00000e-09 1.00000e-01 $1.00000 \mathrm{e}+001.00000 \mathrm{e}+001.00000 \mathrm{e}-011.00000 \mathrm{e}-091.00000 \mathrm{e}-01$ Element: 12622 \# of layers: 7

$\mathrm{Kx} \mathrm{Ky} \mathrm{Kz}$ Ss Por

$1.06983 \mathrm{e}+01$ 1.06983e+01 1.06983e+00 1.00000e-09 2.12000e-01 $1.06983 \mathrm{e}+01$ 1.06983e+01 1.06983e+00 1.00000e-09 2.12000e-01 $1.06983 \mathrm{e}+011.06983 \mathrm{e}+011.06983 \mathrm{e}+001.00000 \mathrm{e}-092.12000 \mathrm{e}-01$ $1.06983 \mathrm{e}+011.06983 \mathrm{e}+01$ 1.06983e+00 1.00000e-09 2.12000e-01 $1.06983 \mathrm{e}+01$ 1.06983e+01 1.06983e+00 1.00000e-09 2.12000e-01 $1.00000 \mathrm{e}-05$ 1.00000e-05 1.00000e-06 1.00000e-09 1.00000e-01 $1.00000 \mathrm{e}+001.00000 \mathrm{e}+001.00000 \mathrm{e}-01$ 1.00000e-09 1.00000e-01 Element: 12623 \# of layers: 7

$\mathrm{Kx} \mathrm{Ky} \mathrm{Kz}$ Ss Por $1.06983 \mathrm{e}+01$ 1.06983e+01 1.06983e+00 1.00000e-09 2.12000e-01 $1.06983 \mathrm{e}+01$ 1.06983e+01 1.06983e+00 1.00000e-09 2.12000e-01 $1.06983 \mathrm{e}+01$ 1.06983e+01 1.06983e+00 1.00000e-09 2.12000e-01 $1.06983 \mathrm{e}+01$ 1.06983e+01 1.06983e+00 1.00000e-09 2.12000e-01 $1.06983 \mathrm{e}+011.06983 \mathrm{e}+011.06983 \mathrm{e}+001.00000 \mathrm{e}-092.12000 \mathrm{e}-01$ 
$1.00000 \mathrm{e}-05$ 1.00000e-05 1.00000e-06 1.00000e-09 1.00000e-01 $1.00000 \mathrm{e}+001.00000 \mathrm{e}+001.00000 \mathrm{e}-01$ 1.00000e-09 1.00000e-01 Element: 12624 \# of layers: 7

Kx Ky Kz Ss Por

$1.06983 \mathrm{e}+01$ 1.06983e+01 1.06983e+00 1.00000e-09 2.12000e-01 $1.06983 \mathrm{e}+011.06983 \mathrm{e}+011.06983 \mathrm{e}+001.00000 \mathrm{e}-092.12000 \mathrm{e}-01$ $1.06983 \mathrm{e}+01$ 1.06983e+01 1.06983e+00 1.00000e-09 2.12000e-01 $1.06983 \mathrm{e}+011.06983 \mathrm{e}+011.06983 \mathrm{e}+001.00000 \mathrm{e}-092.12000 \mathrm{e}-01$ $1.06983 \mathrm{e}+01$ 1.06983e+01 1.06983e+00 1.00000e-09 2.12000e-01 $1.00000 \mathrm{e}-05$ 1.00000e-05 1.00000e-06 1.00000e-09 1.00000e-01 $1.00000 \mathrm{e}+001.00000 \mathrm{e}+001.00000 \mathrm{e}-011.00000 \mathrm{e}-091.00000 \mathrm{e}-01$ Element: 12625 \# of layers: 7

$\mathrm{Kx} \mathrm{Ky} \mathrm{Kz}$ Ss Por

$1.06983 \mathrm{e}+01$ 1.06983e+01 1.06983e+00 1.00000e-09 2.12000e-01 $1.06983 \mathrm{e}+01$ 1.06983e+01 1.06983e+00 1.00000e-09 2.12000e-01 $1.06983 \mathrm{e}+011.06983 \mathrm{e}+011.06983 \mathrm{e}+001.00000 \mathrm{e}-092.12000 \mathrm{e}-01$ $1.06983 \mathrm{e}+011.06983 \mathrm{e}+011.06983 \mathrm{e}+001.00000 \mathrm{e}-092.12000 \mathrm{e}-01$ $1.06983 \mathrm{e}+011.06983 \mathrm{e}+01$ 1.06983e+00 1.00000e-09 2.12000e-01 $1.00000 \mathrm{e}-051.00000 \mathrm{e}-05$ 1.00000e-06 1.00000e-09 1.00000e-01 $1.00000 \mathrm{e}+001.00000 \mathrm{e}+001.00000 \mathrm{e}-011.00000 \mathrm{e}-091.00000 \mathrm{e}-01$ Element: 12626 \# of layers: 7

$\mathrm{Kx} \mathrm{Ky} \mathrm{Kz}$ Ss Por

$1.06983 \mathrm{e}+01$ 1.06983e+01 1.06983e+00 1.00000e-09 2.12000e-01 $1.06983 \mathrm{e}+011.06983 \mathrm{e}+011.06983 \mathrm{e}+001.00000 \mathrm{e}-092.12000 \mathrm{e}-01$ $1.06983 \mathrm{e}+011.06983 \mathrm{e}+011.06983 \mathrm{e}+001.00000 \mathrm{e}-092.12000 \mathrm{e}-01$ $1.06983 \mathrm{e}+01$ 1.06983e+01 1.06983e+00 1.00000e-09 2.12000e-01 $1.06983 \mathrm{e}+011.06983 \mathrm{e}+011.06983 \mathrm{e}+001.00000 \mathrm{e}-092.12000 \mathrm{e}-01$ $1.00000 \mathrm{e}-05$ 1.00000e-05 1.00000e-06 1.00000e-09 1.00000e-01 $1.00000 \mathrm{e}+001.00000 \mathrm{e}+001.00000 \mathrm{e}-011.00000 \mathrm{e}-091.00000 \mathrm{e}-01$ Element: 12627 \# of layers: 7

$\mathrm{Kx} \mathrm{Ky} \mathrm{Kz}$ Ss Por

$1.06983 \mathrm{e}+01$ 1.06983e+01 1.06983e+00 1.00000e-09 2.12000e-01 $1.06983 \mathrm{e}+011.06983 \mathrm{e}+011.06983 \mathrm{e}+001.00000 \mathrm{e}-092.12000 \mathrm{e}-01$ $1.06983 \mathrm{e}+01$ 1.06983e+01 1.06983e+00 1.00000e-09 2.12000e-01 $1.06983 \mathrm{e}+011.06983 \mathrm{e}+011.06983 \mathrm{e}+001.00000 \mathrm{e}-092.12000 \mathrm{e}-01$ $1.06983 \mathrm{e}+01$ 1.06983e+01 1.06983e+00 1.00000e-09 2.12000e-01 $1.00000 \mathrm{e}-05$ 1.00000e-05 1.00000e-06 1.00000e-09 1.00000e-01 $1.00000 \mathrm{e}+001.00000 \mathrm{e}+001.00000 \mathrm{e}-011.00000 \mathrm{e}-091.00000 \mathrm{e}-01$ Element: 12628 \# of layers: 7

$\mathrm{Kx} \mathrm{Ky} \mathrm{Kz}$ Ss Por $1.06983 e+01$ 1.06983e+01 1.06983e+00 1.00000e-09 2.12000e-01 $1.06983 \mathrm{e}+011.06983 \mathrm{e}+01 \quad 1.06983 \mathrm{e}+001.00000 \mathrm{e}-092.12000 \mathrm{e}-01$ $1.06983 \mathrm{e}+011.06983 \mathrm{e}+011.06983 \mathrm{e}+001.00000 \mathrm{e}-092.12000 \mathrm{e}-01$ $1.06983 \mathrm{e}+01$ 1.06983e+01 1.06983e+00 1.00000e-09 2.12000e-01 $1.06983 \mathrm{e}+011.06983 \mathrm{e}+01$ 1.06983e+00 1.00000e-09 2.12000e-01 $1.00000 \mathrm{e}-05$ 1.00000e-05 1.00000e-06 1.00000e-09 1.00000e-01 
$1.00000 \mathrm{e}+001.00000 \mathrm{e}+00$ 1.00000e-01 1.00000e-09 1.00000e-01

Element: 12629 \# of layers: 7

$\mathrm{Kx} \mathrm{Ky} \mathrm{Kz}$ Ss Por

$1.29436 \mathrm{e}+01$ 1.29436e+01 1.29436e+00 1.00000e-09 2.12000e-01

$1.29436 \mathrm{e}+011.29436 \mathrm{e}+011.29436 \mathrm{e}+001.00000 \mathrm{e}-092.12000 \mathrm{e}-01$

$1.29436 \mathrm{e}+011.29436 \mathrm{e}+011.29436 \mathrm{e}+001.00000 \mathrm{e}-092.12000 \mathrm{e}-01$

$1.29436 \mathrm{e}+01$ 1.29436e+01 1.29436e+00 1.00000e-09 2.12000e-01

$1.29436 \mathrm{e}+011.29436 \mathrm{e}+01 \quad 1.29436 \mathrm{e}+001.00000 \mathrm{e}-092.12000 \mathrm{e}-01$

$1.00000 \mathrm{e}-051.00000 \mathrm{e}-051.00000 \mathrm{e}-061.00000 \mathrm{e}-091.00000 \mathrm{e}-01$

$1.00000 \mathrm{e}+001.00000 \mathrm{e}+001.00000 \mathrm{e}-011.00000 \mathrm{e}-091.00000 \mathrm{e}-01$

Element: 12630 \# of layers: 7

Kx Ky Kz Ss Por

$1.29436 \mathrm{e}+01$ 1.29436e+01 1.29436e+00 1.00000e-09 2.12000e-01

$1.29436 \mathrm{e}+011.29436 \mathrm{e}+011.29436 \mathrm{e}+001.00000 \mathrm{e}-092.12000 \mathrm{e}-01$

$1.29436 \mathrm{e}+011.29436 \mathrm{e}+011.29436 \mathrm{e}+001.00000 \mathrm{e}-092.12000 \mathrm{e}-01$

$1.29436 \mathrm{e}+011.29436 \mathrm{e}+011.29436 \mathrm{e}+001.00000 \mathrm{e}-092.12000 \mathrm{e}-01$

$1.29436 \mathrm{e}+011.29436 \mathrm{e}+011.29436 \mathrm{e}+001.00000 \mathrm{e}-092.12000 \mathrm{e}-01$

$1.00000 \mathrm{e}-05$ 1.00000e-05 1.00000e-06 1.00000e-09 1.00000e-01

$1.00000 \mathrm{e}+001.00000 \mathrm{e}+001.00000 \mathrm{e}-01$ 1.00000e-09 1.00000e-01

Element: 12631 \# of layers: 7

$\mathrm{Kx} \mathrm{Ky} \mathrm{Kz}$ Ss Por

$1.29436 \mathrm{e}+01$ 1.29436e+01 1.29436e+00 1.00000e-09 2.12000e-01

$1.29436 \mathrm{e}+01$ 1.29436e+01 1.29436e+00 1.00000e-09 2.12000e-01

$1.29436 \mathrm{e}+011.29436 \mathrm{e}+011.29436 \mathrm{e}+001.00000 \mathrm{e}-092.12000 \mathrm{e}-01$

$1.29436 \mathrm{e}+011.29436 \mathrm{e}+011.29436 \mathrm{e}+001.00000 \mathrm{e}-092.12000 \mathrm{e}-01$

$1.29436 \mathrm{e}+011.29436 \mathrm{e}+01$ 1.29436e+00 1.00000e-09 2.12000e-01

$1.00000 \mathrm{e}-05$ 1.00000e-05 1.00000e-06 1.00000e-09 1.00000e-01

$1.00000 \mathrm{e}+001.00000 \mathrm{e}+001.00000 \mathrm{e}-011.00000 \mathrm{e}-091.00000 \mathrm{e}-01$

Element: 12632 \# of layers: 7

$\mathrm{Kx} \mathrm{Ky} \mathrm{Kz}$ Ss Por

$1.29436 \mathrm{e}+01$ 1.29436e+01 1.29436e+00 1.00000e-09 2.12000e-01

$1.29436 \mathrm{e}+01$ 1.29436e+01 1.29436e+00 1.00000e-09 2.12000e-01

$1.29436 \mathrm{e}+011.29436 \mathrm{e}+011.29436 \mathrm{e}+001.00000 \mathrm{e}-092.12000 \mathrm{e}-01$

$1.29436 \mathrm{e}+011.29436 \mathrm{e}+011.29436 \mathrm{e}+001.00000 \mathrm{e}-092.12000 \mathrm{e}-01$

$1.29436 \mathrm{e}+011.29436 \mathrm{e}+011.29436 \mathrm{e}+001.00000 \mathrm{e}-092.12000 \mathrm{e}-01$

$1.00000 \mathrm{e}-05$ 1.00000e-05 1.00000e-06 1.00000e-09 1.00000e-01

$1.00000 \mathrm{e}+001.00000 \mathrm{e}+001.00000 \mathrm{e}-011.00000 \mathrm{e}-091.00000 \mathrm{e}-01$

Element: 12633 \# of layers: 7

$\mathrm{Kx} \mathrm{Ky} \mathrm{Kz}$ Ss Por

$1.29436 \mathrm{e}+011.29436 \mathrm{e}+011.29436 \mathrm{e}+001.00000 \mathrm{e}-092.12000 \mathrm{e}-01$

$1.29436 \mathrm{e}+011.29436 \mathrm{e}+01 \quad 1.29436 \mathrm{e}+001.00000 \mathrm{e}-092.12000 \mathrm{e}-01$

$1.29436 \mathrm{e}+011.29436 \mathrm{e}+01 \quad 1.29436 \mathrm{e}+001.00000 \mathrm{e}-092.12000 \mathrm{e}-01$

$1.29436 \mathrm{e}+011.29436 \mathrm{e}+01$ 1.29436e+00 1.00000e-09 2.12000e-01

$1.29436 \mathrm{e}+01$ 1.29436e+01 1.29436e+00 1.00000e-09 2.12000e-01

$1.00000 \mathrm{e}-05$ 1.00000e-05 1.00000e-06 1.00000e-09 1.00000e-01

$1.00000 \mathrm{e}+001.00000 \mathrm{e}+001.00000 \mathrm{e}-011.00000 \mathrm{e}-091.00000 \mathrm{e}-01$ 
Element: 12634 \# of layers: 7

Kx Ky Kz Ss Por

$1.06983 \mathrm{e}+011.06983 \mathrm{e}+011.06983 \mathrm{e}+00$ 1.00000e-09 2.12000e-01

$1.06983 \mathrm{e}+011.06983 \mathrm{e}+011.06983 \mathrm{e}+001.00000 \mathrm{e}-092.12000 \mathrm{e}-01$

$1.06983 \mathrm{e}+011.06983 \mathrm{e}+011.06983 \mathrm{e}+001.00000 \mathrm{e}-092.12000 \mathrm{e}-01$

$1.06983 \mathrm{e}+011.06983 \mathrm{e}+011.06983 \mathrm{e}+001.00000 \mathrm{e}-092.12000 \mathrm{e}-01$

$1.06983 \mathrm{e}+011.06983 \mathrm{e}+011.06983 \mathrm{e}+00$ 1.00000e-09 2.12000e-01

$1.00000 \mathrm{e}-05$ 1.00000e-05 1.00000e-06 1.00000e-09 1.00000e-01

$1.00000 \mathrm{e}+001.00000 \mathrm{e}+001.00000 \mathrm{e}-011.00000 \mathrm{e}-091.00000 \mathrm{e}-01$

Element: 12635 \# of layers: 7

Kx Ky Kz Ss Por

$1.06983 \mathrm{e}+011.06983 \mathrm{e}+011.06983 \mathrm{e}+00$ 1.00000e-09 2.12000e-01

$1.06983 \mathrm{e}+011.06983 \mathrm{e}+011.06983 \mathrm{e}+001.00000 \mathrm{e}-092.12000 \mathrm{e}-01$

$1.06983 \mathrm{e}+011.06983 \mathrm{e}+011.06983 \mathrm{e}+001.00000 \mathrm{e}-092.12000 \mathrm{e}-01$

$1.06983 \mathrm{e}+011.06983 \mathrm{e}+011.06983 \mathrm{e}+00$ 1.00000e-09 2.12000e-01

$1.06983 \mathrm{e}+011.06983 \mathrm{e}+011.06983 \mathrm{e}+001.00000 \mathrm{e}-092.12000 \mathrm{e}-01$

$1.00000 \mathrm{e}-05$ 1.00000e-05 1.00000e-06 1.00000e-09 1.00000e-01

$1.00000 \mathrm{e}+001.00000 \mathrm{e}+001.00000 \mathrm{e}-011.00000 \mathrm{e}-091.00000 \mathrm{e}-01$

Element: 12636 \# of layers: 7

Kx Ky Kz Ss Por

$1.29436 \mathrm{e}+011.29436 \mathrm{e}+011.29436 \mathrm{e}+00$ 1.00000e-09 2.12000e-01

$1.29436 \mathrm{e}+011.29436 \mathrm{e}+011.29436 \mathrm{e}+001.00000 \mathrm{e}-092.12000 \mathrm{e}-01$

$1.29436 \mathrm{e}+011.29436 \mathrm{e}+011.29436 \mathrm{e}+001.00000 \mathrm{e}-092.12000 \mathrm{e}-01$

$1.29436 \mathrm{e}+011.29436 \mathrm{e}+011.29436 \mathrm{e}+001.00000 \mathrm{e}-092.12000 \mathrm{e}-01$

$1.29436 \mathrm{e}+011.29436 \mathrm{e}+011.29436 \mathrm{e}+001.00000 \mathrm{e}-092.12000 \mathrm{e}-01$

$1.00000 \mathrm{e}-05$ 1.00000e-05 1.00000e-06 1.00000e-09 1.00000e-01

$1.00000 \mathrm{e}+001.00000 \mathrm{e}+001.00000 \mathrm{e}-011.00000 \mathrm{e}-091.00000 \mathrm{e}-01$

Element: 12637 \# of layers: 7

Kx Ky Kz Ss Por

$1.29436 \mathrm{e}+011.29436 \mathrm{e}+011.29436 \mathrm{e}+00$ 1.00000e-09 2.12000e-01

$1.29436 \mathrm{e}+011.29436 \mathrm{e}+011.29436 \mathrm{e}+001.00000 \mathrm{e}-092.12000 \mathrm{e}-01$

$1.29436 \mathrm{e}+011.29436 \mathrm{e}+011.29436 \mathrm{e}+001.00000 \mathrm{e}-092.12000 \mathrm{e}-01$

$1.29436 \mathrm{e}+011.29436 \mathrm{e}+011.29436 \mathrm{e}+001.00000 \mathrm{e}-092.12000 \mathrm{e}-01$

$1.29436 \mathrm{e}+011.29436 \mathrm{e}+011.29436 \mathrm{e}+001.00000 \mathrm{e}-092.12000 \mathrm{e}-01$

$1.00000 \mathrm{e}-05$ 1.00000e-05 1.00000e-06 1.00000e-09 1.00000e-01

$1.00000 \mathrm{e}+001.00000 \mathrm{e}+001.00000 \mathrm{e}-011.00000 \mathrm{e}-091.00000 \mathrm{e}-01$

Element: 12638 \# of layers: 7

Kx Ky Kz Ss Por

$1.29436 \mathrm{e}+011.29436 \mathrm{e}+011.29436 \mathrm{e}+00$ 1.00000e-09 2.12000e-01

$1.29436 \mathrm{e}+011.29436 \mathrm{e}+011.29436 \mathrm{e}+001.00000 \mathrm{e}-092.12000 \mathrm{e}-01$

$1.29436 \mathrm{e}+011.29436 \mathrm{e}+011.29436 \mathrm{e}+001.00000 \mathrm{e}-092.12000 \mathrm{e}-01$

$1.29436 \mathrm{e}+011.29436 \mathrm{e}+011.29436 \mathrm{e}+001.00000 \mathrm{e}-092.12000 \mathrm{e}-01$

$1.29436 \mathrm{e}+011.29436 \mathrm{e}+011.29436 \mathrm{e}+001.00000 \mathrm{e}-092.12000 \mathrm{e}-01$

$1.00000 \mathrm{e}-05$ 1.00000e-05 1.00000e-06 1.00000e-09 1.00000e-01

$1.00000 \mathrm{e}+001.00000 \mathrm{e}+001.00000 \mathrm{e}-011.00000 \mathrm{e}-091.00000 \mathrm{e}-01$

Element: 12639 \# of layers: 7 
$\mathrm{Kx} \mathrm{Ky} \mathrm{Kz}$ Ss Por

$1.29436 \mathrm{e}+01$ 1.29436e+01 1.29436e+00 1.00000e-09 2.12000e-01

$1.29436 \mathrm{e}+011.29436 \mathrm{e}+011.29436 \mathrm{e}+001.00000 \mathrm{e}-092.12000 \mathrm{e}-01$

$1.29436 \mathrm{e}+011.29436 \mathrm{e}+01 \quad 1.29436 \mathrm{e}+00$ 1.00000e-09 2.12000e-01

$1.29436 \mathrm{e}+011.29436 \mathrm{e}+011.29436 \mathrm{e}+001.00000 \mathrm{e}-092.12000 \mathrm{e}-01$

$1.29436 \mathrm{e}+011.29436 \mathrm{e}+01 \quad 1.29436 \mathrm{e}+001.00000 \mathrm{e}-092.12000 \mathrm{e}-01$

$1.00000 \mathrm{e}-05$ 1.00000e-05 1.00000e-06 1.00000e-09 1.00000e-01

$1.00000 \mathrm{e}+001.00000 \mathrm{e}+001.00000 \mathrm{e}-01$ 1.00000e-09 1.00000e-01

Element: 12640 \# of layers: 7

$\mathrm{Kx} \mathrm{Ky} \mathrm{Kz}$ Ss Por

$1.29436 \mathrm{e}+01$ 1.29436e+01 1.29436e+00 1.00000e-09 2.12000e-01

$1.29436 \mathrm{e}+011.29436 \mathrm{e}+011.29436 \mathrm{e}+001.00000 \mathrm{e}-092.12000 \mathrm{e}-01$

$1.29436 \mathrm{e}+011.29436 \mathrm{e}+011.29436 \mathrm{e}+001.00000 \mathrm{e}-092.12000 \mathrm{e}-01$

$1.29436 \mathrm{e}+011.29436 \mathrm{e}+011.29436 \mathrm{e}+001.00000 \mathrm{e}-092.12000 \mathrm{e}-01$

$1.29436 \mathrm{e}+011.29436 \mathrm{e}+011.29436 \mathrm{e}+001.00000 \mathrm{e}-092.12000 \mathrm{e}-01$

$1.00000 \mathrm{e}-05$ 1.00000e-05 1.00000e-06 1.00000e-09 1.00000e-01

$1.00000 \mathrm{e}+001.00000 \mathrm{e}+001.00000 \mathrm{e}-011.00000 \mathrm{e}-091.00000 \mathrm{e}-01$

Element: 12641 \# of layers: 7

$\mathrm{Kx} \mathrm{Ky} \mathrm{Kz}$ Ss Por

$1.29436 \mathrm{e}+011.29436 \mathrm{e}+01$ 1.29436e+00 1.00000e-09 2.12000e-01

$1.29436 \mathrm{e}+011.29436 \mathrm{e}+011.29436 \mathrm{e}+001.00000 \mathrm{e}-092.12000 \mathrm{e}-01$

$1.29436 \mathrm{e}+01$ 1.29436e+01 1.29436e+00 1.00000e-09 2.12000e-01

$1.29436 \mathrm{e}+01$ 1.29436e+01 1.29436e+00 1.00000e-09 2.12000e-01

$1.29436 \mathrm{e}+011.29436 \mathrm{e}+01 \quad 1.29436 \mathrm{e}+001.00000 \mathrm{e}-092.12000 \mathrm{e}-01$

$1.00000 \mathrm{e}-05$ 1.00000e-05 1.00000e-06 1.00000e-09 1.00000e-01

$1.00000 \mathrm{e}+001.00000 \mathrm{e}+001.00000 \mathrm{e}-01$ 1.00000e-09 1.00000e-01

Element: 12642 \# of layers: 7

$\mathrm{Kx} \mathrm{Ky} \mathrm{Kz}$ Ss Por

$1.29436 \mathrm{e}+011.29436 \mathrm{e}+011.29436 \mathrm{e}+001.00000 \mathrm{e}-092.12000 \mathrm{e}-01$

$1.29436 \mathrm{e}+011.29436 \mathrm{e}+011.29436 \mathrm{e}+001.00000 \mathrm{e}-092.12000 \mathrm{e}-01$

$1.29436 \mathrm{e}+011.29436 \mathrm{e}+011.29436 \mathrm{e}+001.00000 \mathrm{e}-092.12000 \mathrm{e}-01$

$1.29436 \mathrm{e}+011.29436 \mathrm{e}+01$ 1.29436e+00 1.00000e-09 2.12000e-01

$1.29436 \mathrm{e}+011.29436 \mathrm{e}+011.29436 \mathrm{e}+001.00000 \mathrm{e}-092.12000 \mathrm{e}-01$

$1.00000 \mathrm{e}-05$ 1.00000e-05 1.00000e-06 1.00000e-09 1.00000e-01

$1.00000 \mathrm{e}+001.00000 \mathrm{e}+001.00000 \mathrm{e}-011.00000 \mathrm{e}-091.00000 \mathrm{e}-01$

Element: 12643 \# of layers: 7

Kx Ky Kz Ss Por

$1.29436 \mathrm{e}+011.29436 \mathrm{e}+011.29436 \mathrm{e}+001.00000 \mathrm{e}-092.12000 \mathrm{e}-01$

$1.29436 \mathrm{e}+011.29436 \mathrm{e}+011.29436 \mathrm{e}+001.00000 \mathrm{e}-092.12000 \mathrm{e}-01$

$1.29436 \mathrm{e}+011.29436 \mathrm{e}+011.29436 \mathrm{e}+001.00000 \mathrm{e}-092.12000 \mathrm{e}-01$

$1.29436 \mathrm{e}+011.29436 \mathrm{e}+01 \quad 1.29436 \mathrm{e}+001.00000 \mathrm{e}-092.12000 \mathrm{e}-01$

$1.29436 \mathrm{e}+011.29436 \mathrm{e}+01$ 1.29436e+00 1.00000e-09 2.12000e-01

$1.00000 \mathrm{e}-051.00000 \mathrm{e}-05$ 1.00000e-06 1.00000e-09 1.00000e-01

$1.00000 \mathrm{e}+001.00000 \mathrm{e}+001.00000 \mathrm{e}-01$ 1.00000e-09 1.00000e-01

Element: 12644 \# of layers: 7

Kx Ky Kz Ss Por 
$1.29436 \mathrm{e}+01$ 1.29436e+01 1.29436e+00 1.00000e-09 2.12000e-01 $1.29436 \mathrm{e}+01$ 1.29436e+01 1.29436e+00 1.00000e-09 2.12000e-01 $1.29436 \mathrm{e}+011.29436 \mathrm{e}+011.29436 \mathrm{e}+001.00000 \mathrm{e}-092.12000 \mathrm{e}-01$ $1.29436 \mathrm{e}+011.29436 \mathrm{e}+011.29436 \mathrm{e}+001.00000 \mathrm{e}-092.12000 \mathrm{e}-01$ $1.29436 \mathrm{e}+011.29436 \mathrm{e}+011.29436 \mathrm{e}+001.00000 \mathrm{e}-092.12000 \mathrm{e}-01$ $1.00000 \mathrm{e}-051.00000 \mathrm{e}-05$ 1.00000e-06 1.00000e-09 1.00000e-01 $1.00000 \mathrm{e}+001.00000 \mathrm{e}+001.00000 \mathrm{e}-01$ 1.00000e-09 1.00000e-01 Element: 12645 \# of layers: 7

$\mathrm{Kx} \mathrm{Ky} \mathrm{Kz}$ Ss Por

$1.29436 \mathrm{e}+01$ 1.29436e+01 1.29436e+00 1.00000e-09 2.12000e-01 $1.29436 \mathrm{e}+01$ 1.29436e+01 1.29436e+00 1.00000e-09 2.12000e-01 $1.29436 \mathrm{e}+011.29436 \mathrm{e}+011.29436 \mathrm{e}+001.00000 \mathrm{e}-092.12000 \mathrm{e}-01$ $1.29436 \mathrm{e}+011.29436 \mathrm{e}+011.29436 \mathrm{e}+001.00000 \mathrm{e}-092.12000 \mathrm{e}-01$ $1.29436 \mathrm{e}+011.29436 \mathrm{e}+011.29436 \mathrm{e}+001.00000 \mathrm{e}-092.12000 \mathrm{e}-01$ $1.00000 \mathrm{e}-051.00000 \mathrm{e}-051.00000 \mathrm{e}-061.00000 \mathrm{e}-091.00000 \mathrm{e}-01$ $1.00000 \mathrm{e}+001.00000 \mathrm{e}+001.00000 \mathrm{e}-011.00000 \mathrm{e}-091.00000 \mathrm{e}-01$ Element: 12646 \# of layers: 7

$\mathrm{Kx} \mathrm{Ky} \mathrm{Kz}$ Ss Por

$1.29436 \mathrm{e}+01$ 1.29436e+01 1.29436e+00 1.00000e-09 2.12000e-01 $1.29436 \mathrm{e}+011.29436 \mathrm{e}+011.29436 \mathrm{e}+001.00000 \mathrm{e}-092.12000 \mathrm{e}-01$ $1.29436 \mathrm{e}+011.29436 \mathrm{e}+011.29436 \mathrm{e}+001.00000 \mathrm{e}-092.12000 \mathrm{e}-01$ $1.29436 \mathrm{e}+011.29436 \mathrm{e}+011.29436 \mathrm{e}+001.00000 \mathrm{e}-092.12000 \mathrm{e}-01$ $1.29436 \mathrm{e}+01$ 1.29436e+01 1.29436e+00 1.00000e-09 2.12000e-01 $1.00000 \mathrm{e}-05$ 1.00000e-05 1.00000e-06 1.00000e-09 1.00000e-01 $1.00000 \mathrm{e}+001.00000 \mathrm{e}+001.00000 \mathrm{e}-011.00000 \mathrm{e}-091.00000 \mathrm{e}-01$ Element: 12647 \# of layers: 7

$\mathrm{Kx} \mathrm{Ky} \mathrm{Kz}$ Ss Por

$1.29436 \mathrm{e}+011.29436 \mathrm{e}+011.29436 \mathrm{e}+001.00000 \mathrm{e}-092.12000 \mathrm{e}-01$ $1.29436 \mathrm{e}+011.29436 \mathrm{e}+011.29436 \mathrm{e}+001.00000 \mathrm{e}-092.12000 \mathrm{e}-01$ $1.29436 \mathrm{e}+011.29436 \mathrm{e}+011.29436 \mathrm{e}+001.00000 \mathrm{e}-092.12000 \mathrm{e}-01$ $1.29436 \mathrm{e}+011.29436 \mathrm{e}+01 \quad 1.29436 \mathrm{e}+001.00000 \mathrm{e}-092.12000 \mathrm{e}-01$ $1.29436 \mathrm{e}+011.29436 \mathrm{e}+011.29436 \mathrm{e}+00$ 1.00000e-09 2.12000e-01 $1.00000 \mathrm{e}-05$ 1.00000e-05 1.00000e-06 1.00000e-09 1.00000e-01 $1.00000 \mathrm{e}+001.00000 \mathrm{e}+001.00000 \mathrm{e}-011.00000 \mathrm{e}-091.00000 \mathrm{e}-01$ Element: 12648 \# of layers: 7

$\mathrm{Kx} \mathrm{Ky} \mathrm{Kz}$ Ss Por

$1.13999 \mathrm{e}+01$ 1.13999e+01 1.13999e+00 1.00000e-09 2.12000e-01 $1.13999 \mathrm{e}+01$ 1.13999e+01 1.13999e+00 1.00000e-09 2.12000e-01 $1.13999 \mathrm{e}+01$ 1.13999e+01 1.13999e+00 1.00000e-09 2.12000e-01 $1.13999 \mathrm{e}+01$ 1.13999e+01 1.13999e+00 1.00000e-09 2.12000e-01 $1.13999 \mathrm{e}+01$ 1.13999e+01 1.13999e+00 1.00000e-09 2.12000e-01 $1.00000 \mathrm{e}-05$ 1.00000e-05 1.00000e-06 1.00000e-09 1.00000e-01 $1.00000 \mathrm{e}+001.00000 \mathrm{e}+001.00000 \mathrm{e}-011.00000 \mathrm{e}-091.00000 \mathrm{e}-01$ Element: 12649 \# of layers: 7

$\mathrm{Kx} \mathrm{Ky} \mathrm{Kz}$ Ss Por

$1.13999 \mathrm{e}+01$ 1.13999e+01 1.13999e+00 1.00000e-09 2.12000e-01 
1.13999e+01 1.13999e+01 1.13999e+00 1.00000e-09 2.12000e-01 $1.13999 \mathrm{e}+01$ 1.13999e+01 1.13999e+00 1.00000e-09 2.12000e-01 $1.13999 \mathrm{e}+01$ 1.13999e+01 1.13999e+00 1.00000e-09 2.12000e-01 $1.13999 \mathrm{e}+01$ 1.13999e+01 1.13999e+00 1.00000e-09 2.12000e-01 $1.00000 \mathrm{e}-05$ 1.00000e-05 1.00000e-06 1.00000e-09 1.00000e-01 $1.00000 \mathrm{e}+001.00000 \mathrm{e}+001.00000 \mathrm{e}-011.00000 \mathrm{e}-091.00000 \mathrm{e}-01$ Element: 12650 \# of layers: 7

Kx Ky Kz Ss Por

$1.13999 \mathrm{e}+01$ 1.13999e+01 1.13999e+00 1.00000e-09 2.12000e-01 $1.13999 \mathrm{e}+01$ 1.13999e+01 1.13999e+00 1.00000e-09 2.12000e-01 $1.13999 \mathrm{e}+01$ 1.13999e+01 1.13999e+00 1.00000e-09 2.12000e-01 $1.13999 \mathrm{e}+01$ 1.13999e+01 1.13999e+00 1.00000e-09 2.12000e-01 $1.13999 \mathrm{e}+01$ 1.13999e+01 1.13999e+00 1.00000e-09 2.12000e-01 $1.00000 \mathrm{e}-05$ 1.00000e-05 1.00000e-06 1.00000e-09 1.00000e-01 $1.00000 \mathrm{e}+001.00000 \mathrm{e}+001.00000 \mathrm{e}-01$ 1.00000e-09 1.00000e-01 Element: 12651 \# of layers: 7

$\mathrm{Kx} \mathrm{Ky} \mathrm{Kz}$ Ss Por

$1.29436 \mathrm{e}+01$ 1.29436e+01 1.29436e+00 1.00000e-09 2.12000e-01 $1.29436 \mathrm{e}+01$ 1.29436e+01 1.29436e+00 1.00000e-09 2.12000e-01 $1.29436 \mathrm{e}+011.29436 \mathrm{e}+01 \quad 1.29436 \mathrm{e}+001.00000 \mathrm{e}-092.12000 \mathrm{e}-01$ $1.29436 \mathrm{e}+011.29436 \mathrm{e}+011.29436 \mathrm{e}+001.00000 \mathrm{e}-092.12000 \mathrm{e}-01$ $1.29436 \mathrm{e}+01$ 1.29436e+01 1.29436e+00 1.00000e-09 2.12000e-01 $1.00000 \mathrm{e}-05$ 1.00000e-05 1.00000e-06 1.00000e-09 1.00000e-01 $1.00000 \mathrm{e}+001.00000 \mathrm{e}+001.00000 \mathrm{e}-011.00000 \mathrm{e}-09$ 1.00000e-01 Element: 12652 \# of layers: 7

$\mathrm{Kx} \mathrm{Ky} \mathrm{Kz}$ Ss Por

$1.29436 \mathrm{e}+011.29436 \mathrm{e}+011.29436 \mathrm{e}+001.00000 \mathrm{e}-092.12000 \mathrm{e}-01$ $1.29436 \mathrm{e}+011.29436 \mathrm{e}+011.29436 \mathrm{e}+001.00000 \mathrm{e}-092.12000 \mathrm{e}-01$ $1.29436 \mathrm{e}+011.29436 \mathrm{e}+011.29436 \mathrm{e}+001.00000 \mathrm{e}-092.12000 \mathrm{e}-01$ $1.29436 \mathrm{e}+011.29436 \mathrm{e}+011.29436 \mathrm{e}+001.00000 \mathrm{e}-092.12000 \mathrm{e}-01$ $1.29436 \mathrm{e}+011.29436 \mathrm{e}+01 \quad 1.29436 \mathrm{e}+00 \quad 1.00000 \mathrm{e}-092.12000 \mathrm{e}-01$ $1.00000 \mathrm{e}-05$ 1.00000e-05 1.00000e-06 1.00000e-09 1.00000e-01 $1.00000 \mathrm{e}+001.00000 \mathrm{e}+001.00000 \mathrm{e}-011.00000 \mathrm{e}-091.00000 \mathrm{e}-01$ Element: 12653 \# of layers: 7

$\mathrm{Kx} \mathrm{Ky} \mathrm{Kz}$ Ss Por

$1.29436 \mathrm{e}+011.29436 \mathrm{e}+011.29436 \mathrm{e}+001.00000 \mathrm{e}-09$ 2.12000e-01 $1.29436 \mathrm{e}+011.29436 \mathrm{e}+011.29436 \mathrm{e}+001.00000 \mathrm{e}-092.12000 \mathrm{e}-01$ $1.29436 \mathrm{e}+011.29436 \mathrm{e}+011.29436 \mathrm{e}+001.00000 \mathrm{e}-092.12000 \mathrm{e}-01$ $1.29436 \mathrm{e}+011.29436 \mathrm{e}+011.29436 \mathrm{e}+001.00000 \mathrm{e}-092.12000 \mathrm{e}-01$ $1.29436 \mathrm{e}+011.29436 \mathrm{e}+011.29436 \mathrm{e}+001.00000 \mathrm{e}-092.12000 \mathrm{e}-01$ $1.00000 \mathrm{e}-05$ 1.00000e-05 1.00000e-06 1.00000e-09 1.00000e-01 $1.00000 \mathrm{e}+001.00000 \mathrm{e}+001.00000 \mathrm{e}-011.00000 \mathrm{e}-091.00000 \mathrm{e}-01$ Element: 12654 \# of layers: 7

$\mathrm{Kx} \mathrm{Ky} \mathrm{Kz}$ Ss Por

$1.29436 \mathrm{e}+01$ 1.29436e+01 1.29436e+00 1.00000e-09 2.12000e-01 $1.29436 \mathrm{e}+011.29436 \mathrm{e}+011.29436 \mathrm{e}+001.00000 \mathrm{e}-092.12000 \mathrm{e}-01$ 
$1.29436 \mathrm{e}+01$ 1.29436e+01 1.29436e+00 1.00000e-09 2.12000e-01 $1.29436 \mathrm{e}+01$ 1.29436e+01 1.29436e+00 1.00000e-09 2.12000e-01 $1.29436 \mathrm{e}+011.29436 \mathrm{e}+01 \quad 1.29436 \mathrm{e}+001.00000 \mathrm{e}-092.12000 \mathrm{e}-01$ $1.00000 \mathrm{e}-05$ 1.00000e-05 1.00000e-06 1.00000e-09 1.00000e-01 $1.00000 \mathrm{e}+001.00000 \mathrm{e}+001.00000 \mathrm{e}-01$ 1.00000e-09 1.00000e-01 Element: 12655 \# of layers: 7

$\mathrm{Kx} \mathrm{Ky} \mathrm{Kz}$ Ss Por

$1.13999 \mathrm{e}+01$ 1.13999e+01 1.13999e+00 1.00000e-09 2.12000e-01 $1.13999 \mathrm{e}+01$ 1.13999e+01 1.13999e+00 1.00000e-09 2.12000e-01 $1.13999 \mathrm{e}+01$ 1.13999e+01 1.13999e+00 1.00000e-09 2.12000e-01 $1.13999 \mathrm{e}+01$ 1.13999e+01 1.13999e+00 1.00000e-09 2.12000e-01 $1.13999 \mathrm{e}+01$ 1.13999e+01 1.13999e+00 1.00000e-09 2.12000e-01 $1.00000 \mathrm{e}-05$ 1.00000e-05 1.00000e-06 1.00000e-09 1.00000e-01 $1.00000 \mathrm{e}+001.00000 \mathrm{e}+001.00000 \mathrm{e}-011.00000 \mathrm{e}-09$ 1.00000e-01 Element: 12656 \# of layers: 7

Kx Ky Kz Ss Por

$1.13999 \mathrm{e}+01$ 1.13999e+01 1.13999e+00 1.00000e-09 2.12000e-01 $1.13999 \mathrm{e}+01$ 1.13999e+01 1.13999e+00 1.00000e-09 2.12000e-01 $1.13999 \mathrm{e}+01$ 1.13999e+01 1.13999e+00 1.00000e-09 2.12000e-01 $1.13999 \mathrm{e}+01$ 1.13999e+01 1.13999e+00 1.00000e-09 2.12000e-01 $1.13999 \mathrm{e}+01$ 1.13999e+01 1.13999e+00 1.00000e-09 2.12000e-01 $1.00000 \mathrm{e}-05$ 1.00000e-05 1.00000e-06 1.00000e-09 1.00000e-01 $1.00000 \mathrm{e}+001.00000 \mathrm{e}+001.00000 \mathrm{e}-01$ 1.00000e-09 1.00000e-01 Element: 12657 \# of layers: 7

Kx Ky Kz Ss Por

$1.13999 \mathrm{e}+01$ 1.13999e+01 1.13999e+00 1.00000e-09 2.12000e-01 $1.13999 \mathrm{e}+01$ 1.13999e+01 1.13999e+00 1.00000e-09 2.12000e-01 $1.13999 \mathrm{e}+01$ 1.13999e+01 1.13999e+00 1.00000e-09 2.12000e-01 $1.13999 \mathrm{e}+01$ 1.13999e+01 1.13999e+00 1.00000e-09 2.12000e-01 $1.13999 \mathrm{e}+01$ 1.13999e+01 1.13999e+00 1.00000e-09 2.12000e-01 $1.00000 \mathrm{e}-05$ 1.00000e-05 1.00000e-06 1.00000e-09 1.00000e-01 $1.00000 \mathrm{e}+001.00000 \mathrm{e}+001.00000 \mathrm{e}-01$ 1.00000e-09 1.00000e-01 Element: 12658 \# of layers: 7

$\mathrm{Kx} \mathrm{Ky} \mathrm{Kz}$ Ss Por

$1.13999 \mathrm{e}+01$ 1.13999e+01 1.13999e+00 1.00000e-09 2.12000e-01

$1.13999 \mathrm{e}+01$ 1.13999e+01 1.13999e+00 1.00000e-09 2.12000e-01

$1.13999 \mathrm{e}+01$ 1.13999e+01 1.13999e+00 1.00000e-09 2.12000e-01

$1.13999 \mathrm{e}+01$ 1.13999e+01 1.13999e+00 1.00000e-09 2.12000e-01

$1.13999 \mathrm{e}+01$ 1.13999e+01 1.13999e+00 1.00000e-09 2.12000e-01 $1.00000 \mathrm{e}-05$ 1.00000e-05 1.00000e-06 1.00000e-09 1.00000e-01

$1.00000 \mathrm{e}+001.00000 \mathrm{e}+001.00000 \mathrm{e}-011.00000 \mathrm{e}-091.00000 \mathrm{e}-01$ Element: 12659 \# of layers: 7

$\mathrm{Kx} \mathrm{Ky} \mathrm{Kz}$ Ss Por

1.13999e+01 1.13999e+01 1.13999e+00 1.00000e-09 2.12000e-01 $1.13999 \mathrm{e}+01$ 1.13999e+01 1.13999e+00 1.00000e-09 2.12000e-01 $1.13999 \mathrm{e}+01$ 1.13999e+01 1.13999e+00 1.00000e-09 2.12000e-01 
$1.13999 \mathrm{e}+01$ 1.13999e+01 1.13999e+00 1.00000e-09 2.12000e-01 $1.13999 \mathrm{e}+01$ 1.13999e+01 1.13999e+00 1.00000e-09 2.12000e-01 $1.00000 \mathrm{e}-051.00000 \mathrm{e}-05$ 1.00000e-06 1.00000e-09 1.00000e-01 $1.00000 \mathrm{e}+001.00000 \mathrm{e}+001.00000 \mathrm{e}-011.00000 \mathrm{e}-091.00000 \mathrm{e}-01$ Element: 12660 \# of layers: 7

$\mathrm{Kx} \mathrm{Ky} \mathrm{Kz}$ Ss Por

$1.13999 \mathrm{e}+01$ 1.13999e+01 1.13999e+00 1.00000e-09 2.12000e-01 $1.13999 \mathrm{e}+01$ 1.13999e+01 1.13999e+00 1.00000e-09 2.12000e-01 $1.13999 \mathrm{e}+01$ 1.13999e+01 1.13999e+00 1.00000e-09 2.12000e-01 $1.13999 \mathrm{e}+01$ 1.13999e+01 1.13999e+00 1.00000e-09 2.12000e-01 $1.13999 \mathrm{e}+01$ 1.13999e+01 1.13999e+00 1.00000e-09 2.12000e-01 $1.00000 \mathrm{e}-05$ 1.00000e-05 1.00000e-06 1.00000e-09 1.00000e-01 $1.00000 \mathrm{e}+001.00000 \mathrm{e}+001.00000 \mathrm{e}-01$ 1.00000e-09 1.00000e-01 Element: 12661 \# of layers: 7

$\mathrm{Kx} \mathrm{Ky} \mathrm{Kz}$ Ss Por

$1.13999 \mathrm{e}+01$ 1.13999e+01 1.13999e+00 1.00000e-09 2.12000e-01 $1.13999 \mathrm{e}+01$ 1.13999e+01 1.13999e+00 1.00000e-09 2.12000e-01 $1.13999 \mathrm{e}+01$ 1.13999e+01 1.13999e+00 1.00000e-09 2.12000e-01 $1.13999 \mathrm{e}+01$ 1.13999e+01 1.13999e+00 1.00000e-09 2.12000e-01 $1.13999 \mathrm{e}+01$ 1.13999e+01 1.13999e+00 1.00000e-09 2.12000e-01 $1.00000 \mathrm{e}-05$ 1.00000e-05 1.00000e-06 1.00000e-09 1.00000e-01 $1.00000 \mathrm{e}+001.00000 \mathrm{e}+001.00000 \mathrm{e}-01$ 1.00000e-09 1.00000e-01 Element: 12662 \# of layers: 7

Kx Ky Kz Ss Por

$1.13999 \mathrm{e}+01$ 1.13999e+01 1.13999e+00 1.00000e-09 2.12000e-01 $1.13999 \mathrm{e}+01$ 1.13999e+01 1.13999e+00 1.00000e-09 2.12000e-01 $1.13999 \mathrm{e}+01$ 1.13999e+01 1.13999e+00 1.00000e-09 2.12000e-01 $1.13999 \mathrm{e}+01$ 1.13999e+01 1.13999e+00 1.00000e-09 2.12000e-01 $1.13999 \mathrm{e}+01$ 1.13999e+01 1.13999e+00 1.00000e-09 2.12000e-01 $1.00000 \mathrm{e}-05$ 1.00000e-05 1.00000e-06 1.00000e-09 1.00000e-01 $1.00000 \mathrm{e}+001.00000 \mathrm{e}+001.00000 \mathrm{e}-011.00000 \mathrm{e}-091.00000 \mathrm{e}-01$ Element: 12663 \# of layers: 7

Kx Ky Kz Ss Por

$1.13999 \mathrm{e}+01$ 1.13999e+01 1.13999e+00 1.00000e-09 2.12000e-01 $1.13999 \mathrm{e}+01$ 1.13999e+01 1.13999e+00 1.00000e-09 2.12000e-01 $1.13999 \mathrm{e}+01$ 1.13999e+01 1.13999e+00 1.00000e-09 2.12000e-01 $1.13999 \mathrm{e}+01$ 1.13999e+01 1.13999e+00 1.00000e-09 2.12000e-01 $1.13999 \mathrm{e}+01$ 1.13999e+01 1.13999e+00 1.00000e-09 2.12000e-01 $1.00000 \mathrm{e}-05$ 1.00000e-05 1.00000e-06 1.00000e-09 1.00000e-01 $1.00000 \mathrm{e}+001.00000 \mathrm{e}+00$ 1.00000e-01 1.00000e-09 1.00000e-01 Element: 12664 \# of layers: 7

$\mathrm{Kx} \mathrm{Ky} \mathrm{Kz}$ Ss Por

$1.13999 \mathrm{e}+01$ 1.13999e+01 1.13999e+00 1.00000e-09 2.12000e-01 $1.13999 \mathrm{e}+01$ 1.13999e+01 1.13999e+00 1.00000e-09 2.12000e-01 $1.13999 \mathrm{e}+01$ 1.13999e+01 1.13999e+00 1.00000e-09 2.12000e-01 $1.13999 \mathrm{e}+01$ 1.13999e+01 1.13999e+00 1.00000e-09 2.12000e-01 
$1.13999 \mathrm{e}+01$ 1.13999e+01 1.13999e+00 1.00000e-09 2.12000e-01 $1.00000 \mathrm{e}-05$ 1.00000e-05 1.00000e-06 1.00000e-09 1.00000e-01 $1.00000 \mathrm{e}+001.00000 \mathrm{e}+001.00000 \mathrm{e}-011.00000 \mathrm{e}-09$ 1.00000e-01 Element: 12665 \# of layers: 7

$\mathrm{Kx} \mathrm{Ky} \mathrm{Kz}$ Ss Por

$1.13999 \mathrm{e}+01$ 1.13999e+01 1.13999e+00 1.00000e-09 2.12000e-01

$1.13999 \mathrm{e}+01$ 1.13999e+01 1.13999e+00 1.00000e-09 2.12000e-01

$1.13999 \mathrm{e}+01$ 1.13999e+01 1.13999e+00 1.00000e-09 2.12000e-01

$1.13999 \mathrm{e}+01$ 1.13999e+01 1.13999e+00 1.00000e-09 2.12000e-01

$1.13999 \mathrm{e}+01$ 1.13999e+01 1.13999e+00 1.00000e-09 2.12000e-01 $1.00000 \mathrm{e}-05$ 1.00000e-05 1.00000e-06 1.00000e-09 1.00000e-01

$1.00000 \mathrm{e}+001.00000 \mathrm{e}+001.00000 \mathrm{e}-011.00000 \mathrm{e}-091.00000 \mathrm{e}-01$

Element: 12666 \# of layers: 7

$\mathrm{Kx} \mathrm{Ky} \mathrm{Kz}$ Ss Por

6.94747e+00 6.94747e+00 6.94747e-01 1.00000e-09 2.12000e-01 $6.94747 \mathrm{e}+006.94747 \mathrm{e}+00$ 6.94747e-01 1.00000e-09 2.12000e-01 6.94747e+00 6.94747e+00 6.94747e-01 1.00000e-09 2.12000e-01 6.94747e+00 6.94747e+00 6.94747e-01 1.00000e-09 2.12000e-01 6.94747e+00 6.94747e+00 6.94747e-01 1.00000e-09 2.12000e-01 $1.00000 \mathrm{e}-05$ 1.00000e-05 1.00000e-06 1.00000e-09 1.00000e-01 $1.00000 \mathrm{e}+001.00000 \mathrm{e}+001.00000 \mathrm{e}-011.00000 \mathrm{e}-091.00000 \mathrm{e}-01$ Element: 12667 \# of layers: 7

$\mathrm{Kx} \mathrm{Ky} \mathrm{Kz}$ Ss Por

6.94747e+00 6.94747e+00 6.94747e-01 1.00000e-09 2.12000e-01 $6.94747 \mathrm{e}+00$ 6.94747e+00 6.94747e-01 1.00000e-09 2.12000e-01 6.94747e+00 6.94747e+00 6.94747e-01 1.00000e-09 2.12000e-01 6.94747e+00 6.94747e+00 6.94747e-01 1.00000e-09 2.12000e-01 6.94747e+00 6.94747e+00 6.94747e-01 1.00000e-09 2.12000e-01 $1.00000 \mathrm{e}-05$ 1.00000e-05 1.00000e-06 1.00000e-09 1.00000e-01 $1.00000 \mathrm{e}+001.00000 \mathrm{e}+001.00000 \mathrm{e}-011.00000 \mathrm{e}-091.00000 \mathrm{e}-01$ Element: 12668 \# of layers: 7

$\mathrm{Kx} \mathrm{Ky} \mathrm{Kz}$ Ss Por

6.94747e+00 6.94747e+00 6.94747e-01 1.00000e-09 2.12000e-01 6.94747e+00 6.94747e+00 6.94747e-01 1.00000e-09 2.12000e-01 6.94747e+00 6.94747e+00 6.94747e-01 1.00000e-09 2.12000e-01 6.94747e+00 6.94747e+00 6.94747e-01 1.00000e-09 2.12000e-01 $6.94747 \mathrm{e}+006.94747 \mathrm{e}+00$ 6.94747e-01 1.00000e-09 2.12000e-01 $1.00000 \mathrm{e}-05$ 1.00000e-05 1.00000e-06 1.00000e-09 1.00000e-01 $1.00000 \mathrm{e}+001.00000 \mathrm{e}+001.00000 \mathrm{e}-01$ 1.00000e-09 1.00000e-01 Element: 12669 \# of layers: 7

Kx Ky Kz Ss Por

1.13999e+01 1.13999e+01 1.13999e+00 1.00000e-09 2.12000e-01 $1.13999 \mathrm{e}+01$ 1.13999e+01 1.13999e+00 1.00000e-09 2.12000e-01 1.13999e+01 1.13999e+01 1.13999e+00 1.00000e-09 2.12000e-01 $1.13999 \mathrm{e}+01$ 1.13999e+01 1.13999e+00 1.00000e-09 2.12000e-01 $1.13999 \mathrm{e}+01$ 1.13999e+01 1.13999e+00 1.00000e-09 2.12000e-01 
$1.00000 \mathrm{e}-05$ 1.00000e-05 1.00000e-06 1.00000e-09 1.00000e-01 $1.00000 \mathrm{e}+001.00000 \mathrm{e}+001.00000 \mathrm{e}-011.00000 \mathrm{e}-091.00000 \mathrm{e}-01$ Element: 12670 \# of layers: 7

Kx Ky Kz Ss Por

$1.13999 \mathrm{e}+01$ 1.13999e+01 1.13999e+00 1.00000e-09 2.12000e-01 $1.13999 \mathrm{e}+01$ 1.13999e+01 1.13999e+00 1.00000e-09 2.12000e-01 $1.13999 \mathrm{e}+01$ 1.13999e+01 1.13999e+00 1.00000e-09 2.12000e-01 $1.13999 \mathrm{e}+01$ 1.13999e+01 1.13999e+00 1.00000e-09 2.12000e-01 $1.13999 \mathrm{e}+01$ 1.13999e+01 1.13999e+00 1.00000e-09 2.12000e-01 $1.00000 \mathrm{e}-05$ 1.00000e-05 1.00000e-06 1.00000e-09 1.00000e-01 $1.00000 \mathrm{e}+001.00000 \mathrm{e}+001.00000 \mathrm{e}-011.00000 \mathrm{e}-091.00000 \mathrm{e}-01$ Element: 12671 \# of layers: 7

Kx Ky Kz Ss Por

1.13999e+01 1.13999e+01 1.13999e+00 1.00000e-09 2.12000e-01 $1.13999 \mathrm{e}+01$ 1.13999e+01 1.13999e+00 1.00000e-09 2.12000e-01 $1.13999 \mathrm{e}+01$ 1.13999e+01 1.13999e+00 1.00000e-09 2.12000e-01 $1.13999 \mathrm{e}+01$ 1.13999e+01 1.13999e+00 1.00000e-09 2.12000e-01 $1.13999 \mathrm{e}+011.13999 \mathrm{e}+01$ 1.13999e+00 1.00000e-09 2.12000e-01 $1.00000 \mathrm{e}-05$ 1.00000e-05 1.00000e-06 1.00000e-09 1.00000e-01 $1.00000 \mathrm{e}+001.00000 \mathrm{e}+001.00000 \mathrm{e}-011.00000 \mathrm{e}-09$ 1.00000e-01 Element: 12672 \# of layers: 7

$\mathrm{Kx} \mathrm{Ky} \mathrm{Kz}$ Ss Por

1.13999e+01 1.13999e+01 1.13999e+00 1.00000e-09 2.12000e-01 $1.13999 \mathrm{e}+01$ 1.13999e+01 1.13999e+00 1.00000e-09 2.12000e-01 $1.13999 \mathrm{e}+011.13999 \mathrm{e}+01$ 1.13999e+00 1.00000e-09 2.12000e-01 $1.13999 \mathrm{e}+01$ 1.13999e+01 1.13999e+00 1.00000e-09 2.12000e-01 $1.13999 \mathrm{e}+01$ 1.13999e+01 1.13999e+00 1.00000e-09 2.12000e-01 $1.00000 \mathrm{e}-05$ 1.00000e-05 1.00000e-06 1.00000e-09 1.00000e-01 $1.00000 \mathrm{e}+001.00000 \mathrm{e}+001.00000 \mathrm{e}-011.00000 \mathrm{e}-091.00000 \mathrm{e}-01$ Element: 12673 \# of layers: 7

$\mathrm{Kx} \mathrm{Ky} \mathrm{Kz}$ Ss Por

6.94747e+00 6.94747e+00 6.94747e-01 1.00000e-09 2.12000e-01 $6.94747 \mathrm{e}+006.94747 \mathrm{e}+00$ 6.94747e-01 1.00000e-09 2.12000e-01 6.94747e+00 6.94747e+00 6.94747e-01 1.00000e-09 2.12000e-01 6.94747e+00 6.94747e+00 6.94747e-01 1.00000e-09 2.12000e-01 6.94747e+00 6.94747e+00 6.94747e-01 1.00000e-09 2.12000e-01 1.00000e-05 1.00000e-05 1.00000e-06 1.00000e-09 1.00000e-01 $1.00000 \mathrm{e}+001.00000 \mathrm{e}+001.00000 \mathrm{e}-011.00000 \mathrm{e}-091.00000 \mathrm{e}-01$ Element: 12674 \# of layers: 7

$\mathrm{Kx} \mathrm{Ky} \mathrm{Kz}$ Ss Por 6.94747e+00 6.94747e+00 6.94747e-01 1.00000e-09 2.12000e-01 6.94747e+00 6.94747e+00 6.94747e-01 1.00000e-09 2.12000e-01 $6.94747 \mathrm{e}+00$ 6.94747e+00 6.94747e-01 1.00000e-09 2.12000e-01 6.94747e+00 6.94747e+00 6.94747e-01 1.00000e-09 2.12000e-01 $6.94747 \mathrm{e}+006.94747 \mathrm{e}+006.94747 \mathrm{e}-01$ 1.00000e-09 2.12000e-01 1.00000e-05 1.00000e-05 1.00000e-06 1.00000e-09 1.00000e-01 
$1.00000 \mathrm{e}+001.00000 \mathrm{e}+001.00000 \mathrm{e}-01$ 1.00000e-09 1.00000e-01 Element: 12675 \# of layers: 7

$\mathrm{Kx} \mathrm{Ky} \mathrm{Kz}$ Ss Por

6.94747e+00 6.94747e+00 6.94747e-01 1.00000e-09 2.12000e-01 6.94747e+00 6.94747e+00 6.94747e-01 1.00000e-09 2.12000e-01 6.94747e+00 6.94747e+00 6.94747e-01 1.00000e-09 2.12000e-01 6.94747e+00 6.94747e+00 6.94747e-01 1.00000e-09 2.12000e-01 6.94747e+00 6.94747e+00 6.94747e-01 1.00000e-09 2.12000e-01 $1.00000 \mathrm{e}-05$ 1.00000e-05 1.00000e-06 1.00000e-09 1.00000e-01 $1.00000 \mathrm{e}+001.00000 \mathrm{e}+00$ 1.00000e-01 1.00000e-09 1.00000e-01 Element: 12676 \# of layers: 7

Kx Ky Kz Ss Por

6.94747e+00 6.94747e+00 6.94747e-01 1.00000e-09 2.12000e-01 6.94747e+00 6.94747e+00 6.94747e-01 1.00000e-09 2.12000e-01 6.94747e+00 6.94747e+00 6.94747e-01 1.00000e-09 2.12000e-01 $6.94747 \mathrm{e}+006.94747 \mathrm{e}+00$ 6.94747e-01 1.00000e-09 2.12000e-01 6.94747e+00 6.94747e+00 6.94747e-01 1.00000e-09 2.12000e-01 $1.00000 \mathrm{e}-05$ 1.00000e-05 1.00000e-06 1.00000e-09 1.00000e-01 $1.00000 \mathrm{e}+001.00000 \mathrm{e}+001.00000 \mathrm{e}-01$ 1.00000e-09 1.00000e-01 Element: 12677 \# of layers: 7

Kx Ky Kz Ss Por

6.94747e+00 6.94747e+00 6.94747e-01 1.00000e-09 2.12000e-01 6.94747e+00 6.94747e+00 6.94747e-01 1.00000e-09 2.12000e-01 6.94747e+00 6.94747e+00 6.94747e-01 1.00000e-09 2.12000e-01 $6.94747 \mathrm{e}+00$ 6.94747e+00 6.94747e-01 1.00000e-09 2.12000e-01 6.94747e+00 6.94747e+00 6.94747e-01 1.00000e-09 2.12000e-01 $1.00000 \mathrm{e}-05$ 1.00000e-05 1.00000e-06 1.00000e-09 1.00000e-01 $1.00000 \mathrm{e}+001.00000 \mathrm{e}+001.00000 \mathrm{e}-01$ 1.00000e-09 1.00000e-01 Element: 12678 \# of layers: 7

$\mathrm{Kx} \mathrm{Ky} \mathrm{Kz}$ Ss Por

6.94747e+00 6.94747e+00 6.94747e-01 1.00000e-09 2.12000e-01 6.94747e+00 6.94747e+00 6.94747e-01 1.00000e-09 2.12000e-01 $6.94747 \mathrm{e}+006.94747 \mathrm{e}+00$ 6.94747e-01 1.00000e-09 2.12000e-01 6.94747e+00 6.94747e+00 6.94747e-01 1.00000e-09 2.12000e-01 6.94747e+00 6.94747e+00 6.94747e-01 1.00000e-09 2.12000e-01 1.00000e-05 1.00000e-05 1.00000e-06 1.00000e-09 1.00000e-01 $1.00000 \mathrm{e}+001.00000 \mathrm{e}+001.00000 \mathrm{e}-011.00000 \mathrm{e}-091.00000 \mathrm{e}-01$ Element: 12679 \# of layers: 7

$\mathrm{Kx} \mathrm{Ky} \mathrm{Kz}$ Ss Por

6.94747e+00 6.94747e+00 6.94747e-01 1.00000e-09 2.12000e-01 6.94747e+00 6.94747e+00 6.94747e-01 1.00000e-09 2.12000e-01 6.94747e+00 6.94747e+00 6.94747e-01 1.00000e-09 2.12000e-01 6.94747e+00 6.94747e+00 6.94747e-01 1.00000e-09 2.12000e-01 6.94747e+00 6.94747e+00 6.94747e-01 1.00000e-09 2.12000e-01 $1.00000 \mathrm{e}-051.00000 \mathrm{e}-05$ 1.00000e-06 1.00000e-09 1.00000e-01 $1.00000 \mathrm{e}+001.00000 \mathrm{e}+001.00000 \mathrm{e}-011.00000 \mathrm{e}-091.00000 \mathrm{e}-01$ 
Element: 12680 \# of layers: 7

Kx Ky Kz Ss Por

$6.94747 \mathrm{e}+006.94747 \mathrm{e}+00$ 6.94747e-01 1.00000e-09 2.12000e-01

$6.94747 \mathrm{e}+006.94747 \mathrm{e}+00$ 6.94747e-01 1.00000e-09 2.12000e-01

$6.94747 \mathrm{e}+006.94747 \mathrm{e}+006.94747 \mathrm{e}-011.00000 \mathrm{e}-092.12000 \mathrm{e}-01$

$6.94747 \mathrm{e}+006.94747 \mathrm{e}+006.94747 \mathrm{e}-011.00000 \mathrm{e}-092.12000 \mathrm{e}-01$

$6.94747 \mathrm{e}+006.94747 \mathrm{e}+006.94747 \mathrm{e}-011.00000 \mathrm{e}-092.12000 \mathrm{e}-01$

$1.00000 \mathrm{e}-05$ 1.00000e-05 1.00000e-06 1.00000e-09 1.00000e-01

$1.00000 \mathrm{e}+001.00000 \mathrm{e}+001.00000 \mathrm{e}-011.00000 \mathrm{e}-091.00000 \mathrm{e}-01$

Element: 12681 \# of layers: 7

Kx Ky Kz Ss Por

$6.94747 \mathrm{e}+006.94747 \mathrm{e}+00$ 6.94747e-01 1.00000e-09 2.12000e-01

$6.94747 \mathrm{e}+006.94747 \mathrm{e}+00$ 6.94747e-01 1.00000e-09 2.12000e-01

$6.94747 \mathrm{e}+006.94747 \mathrm{e}+006.94747 \mathrm{e}-011.00000 \mathrm{e}-092.12000 \mathrm{e}-01$

$6.94747 \mathrm{e}+006.94747 \mathrm{e}+00$ 6.94747e-01 1.00000e-09 2.12000e-01

$6.94747 \mathrm{e}+006.94747 \mathrm{e}+006.94747 \mathrm{e}-011.00000 \mathrm{e}-092.12000 \mathrm{e}-01$

$1.00000 \mathrm{e}-05$ 1.00000e-05 1.00000e-06 1.00000e-09 1.00000e-01

$1.00000 \mathrm{e}+001.00000 \mathrm{e}+001.00000 \mathrm{e}-011.00000 \mathrm{e}-091.00000 \mathrm{e}-01$

Element: 12682 \# of layers: 7

Kx Ky Kz Ss Por

$6.94747 \mathrm{e}+006.94747 \mathrm{e}+00$ 6.94747e-01 1.00000e-09 2.12000e-01

$6.94747 \mathrm{e}+006.94747 \mathrm{e}+006.94747 \mathrm{e}-011.00000 \mathrm{e}-092.12000 \mathrm{e}-01$

$6.94747 \mathrm{e}+006.94747 \mathrm{e}+006.94747 \mathrm{e}-011.00000 \mathrm{e}-092.12000 \mathrm{e}-01$

$6.94747 \mathrm{e}+006.94747 \mathrm{e}+006.94747 \mathrm{e}-011.00000 \mathrm{e}-092.12000 \mathrm{e}-01$

$6.94747 \mathrm{e}+006.94747 \mathrm{e}+006.94747 \mathrm{e}-011.00000 \mathrm{e}-09$ 2.12000e-01

$1.00000 \mathrm{e}-05$ 1.00000e-05 1.00000e-06 1.00000e-09 1.00000e-01

$1.00000 \mathrm{e}+001.00000 \mathrm{e}+001.00000 \mathrm{e}-011.00000 \mathrm{e}-091.00000 \mathrm{e}-01$

Element: 12683 \# of layers: 7

Kx Ky Kz Ss Por

$1.06983 \mathrm{e}+011.06983 \mathrm{e}+011.06983 \mathrm{e}+00$ 1.00000e-09 2.12000e-01

$1.06983 \mathrm{e}+011.06983 \mathrm{e}+011.06983 \mathrm{e}+001.00000 \mathrm{e}-092.12000 \mathrm{e}-01$

$1.06983 \mathrm{e}+011.06983 \mathrm{e}+011.06983 \mathrm{e}+001.00000 \mathrm{e}-092.12000 \mathrm{e}-01$

$1.06983 \mathrm{e}+011.06983 \mathrm{e}+011.06983 \mathrm{e}+001.00000 \mathrm{e}-092.12000 \mathrm{e}-01$

$1.06983 \mathrm{e}+011.06983 \mathrm{e}+011.06983 \mathrm{e}+001.00000 \mathrm{e}-092.12000 \mathrm{e}-01$

$1.00000 \mathrm{e}-05$ 1.00000e-05 1.00000e-06 1.00000e-09 1.00000e-01

$1.00000 \mathrm{e}+001.00000 \mathrm{e}+001.00000 \mathrm{e}-011.00000 \mathrm{e}-091.00000 \mathrm{e}-01$

Element: 12684 \# of layers: 7

Kx Ky Kz Ss Por

$1.06983 \mathrm{e}+011.06983 \mathrm{e}+01$ 1.06983e+00 1.00000e-09 2.12000e-01

$1.06983 \mathrm{e}+011.06983 \mathrm{e}+011.06983 \mathrm{e}+00$ 1.00000e-09 2.12000e-01

$1.06983 \mathrm{e}+011.06983 \mathrm{e}+011.06983 \mathrm{e}+001.00000 \mathrm{e}-092.12000 \mathrm{e}-01$

$1.06983 \mathrm{e}+011.06983 \mathrm{e}+011.06983 \mathrm{e}+001.00000 \mathrm{e}-092.12000 \mathrm{e}-01$

$1.06983 \mathrm{e}+011.06983 \mathrm{e}+011.06983 \mathrm{e}+001.00000 \mathrm{e}-092.12000 \mathrm{e}-01$

$1.00000 \mathrm{e}-05$ 1.00000e-05 1.00000e-06 1.00000e-09 1.00000e-01

$1.00000 \mathrm{e}+001.00000 \mathrm{e}+001.00000 \mathrm{e}-011.00000 \mathrm{e}-091.00000 \mathrm{e}-01$

Element: 12685 \# of layers: 7 
$\mathrm{Kx} \mathrm{Ky} \mathrm{Kz} \mathrm{Ss} \mathrm{Por}$

$1.06983 \mathrm{e}+01$ 1.06983e+01 1.06983e+00 1.00000e-09 2.12000e-01

$1.06983 \mathrm{e}+011.06983 \mathrm{e}+01$ 1.06983e+00 1.00000e-09 2.12000e-01

$1.06983 \mathrm{e}+011.06983 \mathrm{e}+011.06983 \mathrm{e}+001.00000 \mathrm{e}-092.12000 \mathrm{e}-01$

$1.06983 \mathrm{e}+011.06983 \mathrm{e}+01$ 1.06983e+00 1.00000e-09 2.12000e-01

$1.06983 \mathrm{e}+01$ 1.06983e+01 1.06983e+00 1.00000e-09 2.12000e-01

$1.00000 \mathrm{e}-05$ 1.00000e-05 1.00000e-06 1.00000e-09 1.00000e-01

$1.00000 \mathrm{e}+001.00000 \mathrm{e}+001.00000 \mathrm{e}-01$ 1.00000e-09 1.00000e-01

Element: 12686 \# of layers: 7

$\mathrm{Kx} \mathrm{Ky} \mathrm{Kz}$ Ss Por

$1.06983 \mathrm{e}+01$ 1.06983e+01 1.06983e+00 1.00000e-09 2.12000e-01

$1.06983 \mathrm{e}+011.06983 \mathrm{e}+011.06983 \mathrm{e}+001.00000 \mathrm{e}-092.12000 \mathrm{e}-01$

$1.06983 \mathrm{e}+01$ 1.06983e+01 1.06983e+00 1.00000e-09 2.12000e-01

$1.06983 \mathrm{e}+01$ 1.06983e+01 1.06983e+00 1.00000e-09 2.12000e-01

$1.06983 \mathrm{e}+01$ 1.06983e+01 1.06983e+00 1.00000e-09 2.12000e-01

$1.00000 \mathrm{e}-05$ 1.00000e-05 1.00000e-06 1.00000e-09 1.00000e-01

$1.00000 \mathrm{e}+001.00000 \mathrm{e}+001.00000 \mathrm{e}-011.00000 \mathrm{e}-091.00000 \mathrm{e}-01$

Element: 12687 \# of layers: 7

$\mathrm{Kx} \mathrm{Ky} \mathrm{Kz}$ Ss Por

$1.06983 \mathrm{e}+01$ 1.06983e+01 1.06983e+00 1.00000e-09 2.12000e-01

$1.06983 \mathrm{e}+011.06983 \mathrm{e}+011.06983 \mathrm{e}+001.00000 \mathrm{e}-092.12000 \mathrm{e}-01$

$1.06983 \mathrm{e}+01$ 1.06983e+01 1.06983e+00 1.00000e-09 2.12000e-01

$1.06983 \mathrm{e}+01$ 1.06983e+01 1.06983e+00 1.00000e-09 2.12000e-01

$1.06983 \mathrm{e}+011.06983 \mathrm{e}+01$ 1.06983e+00 1.00000e-09 2.12000e-01

$1.00000 \mathrm{e}-05$ 1.00000e-05 1.00000e-06 1.00000e-09 1.00000e-01

$1.00000 \mathrm{e}+001.00000 \mathrm{e}+001.00000 \mathrm{e}-01$ 1.00000e-09 1.00000e-01

Element: 12688 \# of layers: 7

$\mathrm{Kx} \mathrm{Ky} \mathrm{Kz}$ Ss Por

6.94747e+00 6.94747e+00 6.94747e-01 1.00000e-09 2.12000e-01

6.94747e+00 6.94747e+00 6.94747e-01 1.00000e-09 2.12000e-01

6.94747e+00 6.94747e+00 6.94747e-01 1.00000e-09 2.12000e-01

6.94747e+00 6.94747e+00 6.94747e-01 1.00000e-09 2.12000e-01

$6.94747 \mathrm{e}+006.94747 \mathrm{e}+00$ 6.94747e-01 1.00000e-09 2.12000e-01

$1.00000 \mathrm{e}-051.00000 \mathrm{e}-051.00000 \mathrm{e}-061.00000 \mathrm{e}-091.00000 \mathrm{e}-01$

$1.00000 \mathrm{e}+001.00000 \mathrm{e}+001.00000 \mathrm{e}-01$ 1.00000e-09 1.00000e-01

Element: 12689 \# of layers: 7

Kx Ky Kz Ss Por

6.94747e+00 6.94747e+00 6.94747e-01 1.00000e-09 2.12000e-01 6.94747e+00 6.94747e+00 6.94747e-01 1.00000e-09 2.12000e-01 6.94747e+00 6.94747e+00 6.94747e-01 1.00000e-09 2.12000e-01 6.94747e+00 6.94747e+00 6.94747e-01 1.00000e-09 2.12000e-01 $6.94747 \mathrm{e}+006.94747 \mathrm{e}+00$ 6.94747e-01 1.00000e-09 2.12000e-01 $1.00000 \mathrm{e}-05$ 1.00000e-05 1.00000e-06 1.00000e-09 1.00000e-01 $1.00000 \mathrm{e}+001.00000 \mathrm{e}+001.00000 \mathrm{e}-01$ 1.00000e-09 1.00000e-01 Element: 12690 \# of layers: 7

Kx Ky Kz Ss Por 
$1.06983 \mathrm{e}+01$ 1.06983e+01 1.06983e+00 1.00000e-09 2.12000e-01 $1.06983 \mathrm{e}+01$ 1.06983e+01 1.06983e+00 1.00000e-09 2.12000e-01 $1.06983 \mathrm{e}+011.06983 \mathrm{e}+01$ 1.06983e+00 1.00000e-09 2.12000e-01 $1.06983 \mathrm{e}+011.06983 \mathrm{e}+011.06983 \mathrm{e}+001.00000 \mathrm{e}-092.12000 \mathrm{e}-01$ $1.06983 \mathrm{e}+011.06983 \mathrm{e}+01$ 1.06983e+00 1.00000e-09 2.12000e-01 $1.00000 \mathrm{e}-05$ 1.00000e-05 1.00000e-06 1.00000e-09 1.00000e-01 $1.00000 \mathrm{e}+001.00000 \mathrm{e}+00$ 1.00000e-01 1.00000e-09 1.00000e-01

Element: 12691 \# of layers: 7

$\mathrm{Kx} \mathrm{Ky} \mathrm{Kz}$ Ss Por

$1.06983 \mathrm{e}+01$ 1.06983e+01 1.06983e+00 1.00000e-09 2.12000e-01 $1.06983 \mathrm{e}+01$ 1.06983e+01 1.06983e+00 1.00000e-09 2.12000e-01 $1.06983 \mathrm{e}+011.06983 \mathrm{e}+011.06983 \mathrm{e}+001.00000 \mathrm{e}-092.12000 \mathrm{e}-01$ $1.06983 \mathrm{e}+01$ 1.06983e+01 1.06983e+00 1.00000e-09 2.12000e-01 $1.06983 \mathrm{e}+01$ 1.06983e+01 1.06983e+00 1.00000e-09 2.12000e-01 $1.00000 \mathrm{e}-051.00000 \mathrm{e}-051.00000 \mathrm{e}-061.00000 \mathrm{e}-091.00000 \mathrm{e}-01$ $1.00000 \mathrm{e}+001.00000 \mathrm{e}+001.00000 \mathrm{e}-011.00000 \mathrm{e}-091.00000 \mathrm{e}-01$ Element: 12692 \# of layers: 7

$\mathrm{Kx} \mathrm{Ky} \mathrm{Kz}$ Ss Por

$1.29436 \mathrm{e}+01$ 1.29436e+01 1.29436e+00 1.00000e-09 2.12000e-01 $1.29436 \mathrm{e}+011.29436 \mathrm{e}+011.29436 \mathrm{e}+001.00000 \mathrm{e}-092.12000 \mathrm{e}-01$ $1.29436 \mathrm{e}+011.29436 \mathrm{e}+011.29436 \mathrm{e}+001.00000 \mathrm{e}-092.12000 \mathrm{e}-01$ $1.29436 \mathrm{e}+011.29436 \mathrm{e}+011.29436 \mathrm{e}+001.00000 \mathrm{e}-092.12000 \mathrm{e}-01$ $1.29436 \mathrm{e}+01$ 1.29436e+01 1.29436e+00 1.00000e-09 2.12000e-01 $1.00000 \mathrm{e}-05$ 1.00000e-05 1.00000e-06 1.00000e-09 1.00000e-01 $1.00000 \mathrm{e}+001.00000 \mathrm{e}+001.00000 \mathrm{e}-011.00000 \mathrm{e}-091.00000 \mathrm{e}-01$ Element: 12693 \# of layers: 7

$\mathrm{Kx} \mathrm{Ky} \mathrm{Kz}$ Ss Por

$1.29436 \mathrm{e}+011.29436 \mathrm{e}+011.29436 \mathrm{e}+001.00000 \mathrm{e}-092.12000 \mathrm{e}-01$ $1.29436 \mathrm{e}+011.29436 \mathrm{e}+011.29436 \mathrm{e}+001.00000 \mathrm{e}-092.12000 \mathrm{e}-01$ $1.29436 \mathrm{e}+011.29436 \mathrm{e}+011.29436 \mathrm{e}+001.00000 \mathrm{e}-092.12000 \mathrm{e}-01$ $1.29436 \mathrm{e}+011.29436 \mathrm{e}+01 \quad 1.29436 \mathrm{e}+001.00000 \mathrm{e}-092.12000 \mathrm{e}-01$ $1.29436 \mathrm{e}+011.29436 \mathrm{e}+011.29436 \mathrm{e}+00$ 1.00000e-09 2.12000e-01 $1.00000 \mathrm{e}-05$ 1.00000e-05 1.00000e-06 1.00000e-09 1.00000e-01 $1.00000 \mathrm{e}+001.00000 \mathrm{e}+001.00000 \mathrm{e}-011.00000 \mathrm{e}-09$ 1.00000e-01 Element: 12694 \# of layers: 7

$\mathrm{Kx} \mathrm{Ky} \mathrm{Kz}$ Ss Por

$1.29436 \mathrm{e}+01$ 1.29436e+01 1.29436e+00 1.00000e-09 2.12000e-01 $1.29436 \mathrm{e}+011.29436 \mathrm{e}+011.29436 \mathrm{e}+001.00000 \mathrm{e}-092.12000 \mathrm{e}-01$ $1.29436 \mathrm{e}+011.29436 \mathrm{e}+011.29436 \mathrm{e}+001.00000 \mathrm{e}-092.12000 \mathrm{e}-01$ $1.29436 \mathrm{e}+011.29436 \mathrm{e}+011.29436 \mathrm{e}+001.00000 \mathrm{e}-092.12000 \mathrm{e}-01$ $1.29436 \mathrm{e}+011.29436 \mathrm{e}+01$ 1.29436e+00 1.00000e-09 2.12000e-01 $1.00000 \mathrm{e}-05$ 1.00000e-05 1.00000e-06 1.00000e-09 1.00000e-01 $1.00000 \mathrm{e}+001.00000 \mathrm{e}+001.00000 \mathrm{e}-011.00000 \mathrm{e}-091.00000 \mathrm{e}-01$ Element: 12695 \# of layers: 7

$\mathrm{Kx} \mathrm{Ky} \mathrm{Kz}$ Ss Por

$1.13999 \mathrm{e}+01$ 1.13999e+01 1.13999e+00 1.00000e-09 2.12000e-01 
1.13999e+01 1.13999e+01 1.13999e+00 1.00000e-09 2.12000e-01 $1.13999 \mathrm{e}+01$ 1.13999e+01 1.13999e+00 1.00000e-09 2.12000e-01 $1.13999 \mathrm{e}+01$ 1.13999e+01 1.13999e+00 1.00000e-09 2.12000e-01 $1.13999 \mathrm{e}+01$ 1.13999e+01 1.13999e+00 1.00000e-09 2.12000e-01 $1.00000 \mathrm{e}-05$ 1.00000e-05 1.00000e-06 1.00000e-09 1.00000e-01 $1.00000 \mathrm{e}+001.00000 \mathrm{e}+001.00000 \mathrm{e}-011.00000 \mathrm{e}-091.00000 \mathrm{e}-01$ Element: 12696 \# of layers: 7

Kx Ky Kz Ss Por

$1.13999 \mathrm{e}+01$ 1.13999e+01 1.13999e+00 1.00000e-09 2.12000e-01 $1.13999 \mathrm{e}+01$ 1.13999e+01 1.13999e+00 1.00000e-09 2.12000e-01 $1.13999 \mathrm{e}+01$ 1.13999e+01 1.13999e+00 1.00000e-09 2.12000e-01 $1.13999 \mathrm{e}+01$ 1.13999e+01 1.13999e+00 1.00000e-09 2.12000e-01 $1.13999 \mathrm{e}+01$ 1.13999e+01 1.13999e+00 1.00000e-09 2.12000e-01 $1.00000 \mathrm{e}-05$ 1.00000e-05 1.00000e-06 1.00000e-09 1.00000e-01 $1.00000 \mathrm{e}+001.00000 \mathrm{e}+001.00000 \mathrm{e}-01$ 1.00000e-09 1.00000e-01 Element: 12697 \# of layers: 7

$\mathrm{Kx} \mathrm{Ky} \mathrm{Kz}$ Ss Por

6.94747e+00 6.94747e+00 6.94747e-01 1.00000e-09 2.12000e-01 6.94747e+00 6.94747e+00 6.94747e-01 1.00000e-09 2.12000e-01 6.94747e+00 6.94747e+00 6.94747e-01 1.00000e-09 2.12000e-01 $6.94747 \mathrm{e}+00$ 6.94747e+00 6.94747e-01 1.00000e-09 2.12000e-01 6.94747e+00 6.94747e+00 6.94747e-01 1.00000e-09 2.12000e-01 $1.00000 \mathrm{e}-05$ 1.00000e-05 1.00000e-06 1.00000e-09 1.00000e-01 $1.00000 \mathrm{e}+001.00000 \mathrm{e}+001.00000 \mathrm{e}-011.00000 \mathrm{e}-09$ 1.00000e-01

Element: 12698 \# of layers: 7

$\mathrm{Kx} \mathrm{Ky} \mathrm{Kz}$ Ss Por

$1.06983 \mathrm{e}+01$ 1.06983e+01 1.06983e+00 1.00000e-09 2.12000e-01 $1.06983 \mathrm{e}+011.06983 \mathrm{e}+01$ 1.06983e+00 1.00000e-09 2.12000e-01 $1.06983 \mathrm{e}+011.06983 \mathrm{e}+011.06983 \mathrm{e}+001.00000 \mathrm{e}-092.12000 \mathrm{e}-01$ $1.06983 \mathrm{e}+01$ 1.06983e+01 1.06983e+00 1.00000e-09 2.12000e-01 $1.06983 \mathrm{e}+01$ 1.06983e+01 1.06983e+00 1.00000e-09 2.12000e-01 1.00000e-05 1.00000e-05 1.00000e-06 1.00000e-09 1.00000e-01 $1.00000 \mathrm{e}+001.00000 \mathrm{e}+001.00000 \mathrm{e}-011.00000 \mathrm{e}-091.00000 \mathrm{e}-01$ Element: 12699 \# of layers: 7

$\mathrm{Kx} \mathrm{Ky} \mathrm{Kz}$ Ss Por

$1.29436 \mathrm{e}+011.29436 \mathrm{e}+011.29436 \mathrm{e}+001.00000 \mathrm{e}-09$ 2.12000e-01 $1.29436 \mathrm{e}+011.29436 \mathrm{e}+011.29436 \mathrm{e}+001.00000 \mathrm{e}-092.12000 \mathrm{e}-01$ $1.29436 \mathrm{e}+011.29436 \mathrm{e}+011.29436 \mathrm{e}+001.00000 \mathrm{e}-092.12000 \mathrm{e}-01$ $1.29436 \mathrm{e}+011.29436 \mathrm{e}+011.29436 \mathrm{e}+001.00000 \mathrm{e}-092.12000 \mathrm{e}-01$ $1.29436 \mathrm{e}+011.29436 \mathrm{e}+011.29436 \mathrm{e}+001.00000 \mathrm{e}-092.12000 \mathrm{e}-01$ $1.00000 \mathrm{e}-05$ 1.00000e-05 1.00000e-06 1.00000e-09 1.00000e-01 $1.00000 \mathrm{e}+001.00000 \mathrm{e}+001.00000 \mathrm{e}-011.00000 \mathrm{e}-091.00000 \mathrm{e}-01$ Element: 12700 \# of layers: 7

$\mathrm{Kx} \mathrm{Ky} \mathrm{Kz}$ Ss Por $1.08277 \mathrm{e}+01$ 1.08277e+01 1.08277e+00 1.00000e-09 2.12000e-01 $1.08277 \mathrm{e}+01$ 1.08277e+01 1.08277e+00 1.00000e-09 2.12000e-01 
1.08277e+01 1.08277e+01 1.08277e+00 1.00000e-09 2.12000e-01 $1.08277 \mathrm{e}+01$ 1.08277e+01 1.08277e+00 1.00000e-09 2.12000e-01 $1.08277 \mathrm{e}+011.08277 \mathrm{e}+01$ 1.08277e+00 1.00000e-09 2.12000e-01 $1.00000 \mathrm{e}-05$ 1.00000e-05 1.00000e-06 1.00000e-09 1.00000e-01 $1.00000 \mathrm{e}+001.00000 \mathrm{e}+001.00000 \mathrm{e}-01$ 1.00000e-09 1.00000e-01 Element: 12701 \# of layers: 7

$\mathrm{Kx} \mathrm{Ky} \mathrm{Kz}$ Ss Por

$1.08277 \mathrm{e}+01$ 1.08277e+01 1.08277e+00 1.00000e-09 2.12000e-01 $1.08277 \mathrm{e}+01$ 1.08277e+01 1.08277e+00 1.00000e-09 2.12000e-01 $1.08277 \mathrm{e}+01$ 1.08277e+01 1.08277e+00 1.00000e-09 2.12000e-01 $1.08277 \mathrm{e}+01$ 1.08277e+01 1.08277e+00 1.00000e-09 2.12000e-01 $1.08277 \mathrm{e}+011.08277 \mathrm{e}+01$ 1.08277e+00 1.00000e-09 2.12000e-01 $1.00000 \mathrm{e}-05$ 1.00000e-05 1.00000e-06 1.00000e-09 1.00000e-01 $1.00000 \mathrm{e}+001.00000 \mathrm{e}+001.00000 \mathrm{e}-011.00000 \mathrm{e}-09$ 1.00000e-01 Element: 12702 \# of layers: 7

Kx Ky Kz Ss Por

$1.08277 \mathrm{e}+01$ 1.08277e+01 1.08277e+00 1.00000e-09 2.12000e-01 $1.08277 \mathrm{e}+011.08277 \mathrm{e}+01$ 1.08277e+00 1.00000e-09 2.12000e-01 $1.08277 \mathrm{e}+01$ 1.08277e+01 1.08277e+00 1.00000e-09 2.12000e-01 $1.08277 \mathrm{e}+01$ 1.08277e+01 1.08277e+00 1.00000e-09 2.12000e-01 $1.08277 \mathrm{e}+011.08277 \mathrm{e}+01$ 1.08277e+00 1.00000e-09 2.12000e-01 $1.00000 \mathrm{e}-05$ 1.00000e-05 1.00000e-06 1.00000e-09 1.00000e-01 $1.00000 \mathrm{e}+001.00000 \mathrm{e}+001.00000 \mathrm{e}-01$ 1.00000e-09 1.00000e-01 Element: 12703 \# of layers: 7

Kx Ky Kz Ss Por

$1.08277 \mathrm{e}+01$ 1.08277e+01 1.08277e+00 1.00000e-09 2.12000e-01 $1.08277 \mathrm{e}+011.08277 \mathrm{e}+01$ 1.08277e+00 1.00000e-09 2.12000e-01 $1.08277 \mathrm{e}+011.08277 \mathrm{e}+01$ 1.08277e+00 1.00000e-09 2.12000e-01 $1.08277 \mathrm{e}+01$ 1.08277e+01 1.08277e+00 1.00000e-09 2.12000e-01 $1.08277 \mathrm{e}+01$ 1.08277e+01 1.08277e+00 1.00000e-09 2.12000e-01 $1.00000 \mathrm{e}-05$ 1.00000e-05 1.00000e-06 1.00000e-09 1.00000e-01 $1.00000 \mathrm{e}+001.00000 \mathrm{e}+001.00000 \mathrm{e}-011.00000 \mathrm{e}-091.00000 \mathrm{e}-01$ Element: 12704 \# of layers: 7

$\mathrm{Kx} \mathrm{Ky} \mathrm{Kz}$ Ss Por

$1.08277 \mathrm{e}+01$ 1.08277e+01 1.08277e+00 1.00000e-09 2.12000e-01 $1.08277 \mathrm{e}+01$ 1.08277e+01 1.08277e+00 1.00000e-09 2.12000e-01 $1.08277 \mathrm{e}+011.08277 \mathrm{e}+01$ 1.08277e+00 1.00000e-09 2.12000e-01 $1.08277 \mathrm{e}+011.08277 \mathrm{e}+01$ 1.08277e+00 1.00000e-09 2.12000e-01 $1.08277 \mathrm{e}+011.08277 \mathrm{e}+01$ 1.08277e+00 1.00000e-09 2.12000e-01 $1.00000 \mathrm{e}-05$ 1.00000e-05 1.00000e-06 1.00000e-09 1.00000e-01 $1.00000 \mathrm{e}+001.00000 \mathrm{e}+001.00000 \mathrm{e}-011.00000 \mathrm{e}-091.00000 \mathrm{e}-01$ Element: 12705 \# of layers: 7

$\mathrm{Kx} \mathrm{Ky} \mathrm{Kz}$ Ss Por

1.08277e+01 1.08277e+01 1.08277e+00 1.00000e-09 2.12000e-01 $1.08277 \mathrm{e}+011.08277 \mathrm{e}+01$ 1.08277e+00 1.00000e-09 2.12000e-01 $1.08277 \mathrm{e}+01$ 1.08277e+01 1.08277e+00 1.00000e-09 2.12000e-01 
$1.08277 \mathrm{e}+01$ 1.08277e+01 1.08277e+00 1.00000e-09 2.12000e-01 $1.08277 \mathrm{e}+01$ 1.08277e+01 1.08277e+00 1.00000e-09 2.12000e-01 $1.00000 \mathrm{e}-05$ 1.00000e-05 1.00000e-06 1.00000e-09 1.00000e-01 $1.00000 \mathrm{e}+001.00000 \mathrm{e}+001.00000 \mathrm{e}-011.00000 \mathrm{e}-091.00000 \mathrm{e}-01$ Element: 12706 \# of layers: 7

$\mathrm{Kx} \mathrm{Ky} \mathrm{Kz}$ Ss Por

$1.08277 \mathrm{e}+01$ 1.08277e+01 1.08277e+00 1.00000e-09 2.12000e-01 $1.08277 \mathrm{e}+011.08277 \mathrm{e}+01$ 1.08277e+00 1.00000e-09 2.12000e-01 $1.08277 \mathrm{e}+01$ 1.08277e+01 1.08277e+00 1.00000e-09 2.12000e-01 $1.08277 \mathrm{e}+011.08277 \mathrm{e}+01$ 1.08277e+00 1.00000e-09 2.12000e-01 $1.08277 \mathrm{e}+01$ 1.08277e+01 1.08277e+00 1.00000e-09 2.12000e-01 $1.00000 \mathrm{e}-05$ 1.00000e-05 1.00000e-06 1.00000e-09 1.00000e-01 $1.00000 \mathrm{e}+001.00000 \mathrm{e}+001.00000 \mathrm{e}-01$ 1.00000e-09 1.00000e-01 Element: 12707 \# of layers: 7

$\mathrm{Kx} \mathrm{Ky} \mathrm{Kz}$ Ss Por

$1.08277 \mathrm{e}+01$ 1.08277e+01 1.08277e+00 1.00000e-09 2.12000e-01 $1.08277 \mathrm{e}+01$ 1.08277e+01 1.08277e+00 1.00000e-09 2.12000e-01 $1.08277 \mathrm{e}+011.08277 \mathrm{e}+01$ 1.08277e+00 1.00000e-09 2.12000e-01 $1.08277 \mathrm{e}+01$ 1.08277e+01 1.08277e+00 1.00000e-09 2.12000e-01 $1.08277 \mathrm{e}+01$ 1.08277e+01 1.08277e+00 1.00000e-09 2.12000e-01 $1.00000 \mathrm{e}-05$ 1.00000e-05 1.00000e-06 1.00000e-09 1.00000e-01 $1.00000 \mathrm{e}+001.00000 \mathrm{e}+001.00000 \mathrm{e}-01$ 1.00000e-09 1.00000e-01 Element: 12708 \# of layers: 7

$\mathrm{Kx} \mathrm{Ky} \mathrm{Kz}$ Ss Por

$1.08277 \mathrm{e}+01$ 1.08277e+01 1.08277e+00 1.00000e-09 2.12000e-01 $1.08277 \mathrm{e}+011.08277 \mathrm{e}+01$ 1.08277e+00 1.00000e-09 2.12000e-01 $1.08277 \mathrm{e}+011.08277 \mathrm{e}+01$ 1.08277e+00 1.00000e-09 2.12000e-01 $1.08277 \mathrm{e}+01$ 1.08277e+01 1.08277e+00 1.00000e-09 2.12000e-01 $1.08277 \mathrm{e}+011.08277 \mathrm{e}+01$ 1.08277e+00 1.00000e-09 2.12000e-01 1.00000e-05 1.00000e-05 1.00000e-06 1.00000e-09 1.00000e-01 $1.00000 \mathrm{e}+001.00000 \mathrm{e}+001.00000 \mathrm{e}-01$ 1.00000e-09 1.00000e-01 Element: 12709 \# of layers: 7

Kx Ky Kz Ss Por

$1.08277 \mathrm{e}+01$ 1.08277e+01 1.08277e+00 1.00000e-09 2.12000e-01 $1.08277 \mathrm{e}+01$ 1.08277e+01 1.08277e+00 1.00000e-09 2.12000e-01 $1.08277 \mathrm{e}+011.08277 \mathrm{e}+01$ 1.08277e+00 1.00000e-09 2.12000e-01 $1.08277 \mathrm{e}+011.08277 \mathrm{e}+01$ 1.08277e+00 1.00000e-09 2.12000e-01 $1.08277 \mathrm{e}+011.08277 \mathrm{e}+01$ 1.08277e+00 1.00000e-09 2.12000e-01 $1.00000 \mathrm{e}-05$ 1.00000e-05 1.00000e-06 1.00000e-09 1.00000e-01 $1.00000 \mathrm{e}+001.00000 \mathrm{e}+001.00000 \mathrm{e}-01$ 1.00000e-09 1.00000e-01 Element: 12710 \# of layers: 7

Kx Ky Kz Ss Por

$1.13396 \mathrm{e}+01$ 1.13396e+01 1.13396e+00 1.00000e-09 2.12000e-01 $1.13396 \mathrm{e}+01$ 1.13396e+01 1.13396e+00 1.00000e-09 2.12000e-01 $1.13396 \mathrm{e}+01$ 1.13396e+01 1.13396e+00 1.00000e-09 2.12000e-01 $1.13396 \mathrm{e}+011.13396 \mathrm{e}+011.13396 \mathrm{e}+001.00000 \mathrm{e}-092.12000 \mathrm{e}-01$ 
$1.13396 \mathrm{e}+01$ 1.13396e+01 1.13396e+00 1.00000e-09 2.12000e-01 $1.00000 \mathrm{e}-05$ 1.00000e-05 1.00000e-06 1.00000e-09 1.00000e-01

$1.00000 \mathrm{e}+001.00000 \mathrm{e}+001.00000 \mathrm{e}-011.00000 \mathrm{e}-09$ 1.00000e-01

Element: 12711 \# of layers: 7

Kx Ky Kz Ss Por

$1.13396 \mathrm{e}+01$ 1.13396e+01 1.13396e+00 1.00000e-09 2.12000e-01

$1.13396 \mathrm{e}+011.13396 \mathrm{e}+011.13396 \mathrm{e}+001.00000 \mathrm{e}-092.12000 \mathrm{e}-01$

$1.13396 \mathrm{e}+011.13396 \mathrm{e}+011.13396 \mathrm{e}+001.00000 \mathrm{e}-092.12000 \mathrm{e}-01$

$1.13396 \mathrm{e}+011.13396 \mathrm{e}+011.13396 \mathrm{e}+001.00000 \mathrm{e}-092.12000 \mathrm{e}-01$

$1.13396 \mathrm{e}+01$ 1.13396e+01 1.13396e+00 1.00000e-09 2.12000e-01

$1.00000 \mathrm{e}-05$ 1.00000e-05 1.00000e-06 1.00000e-09 1.00000e-01

$1.00000 \mathrm{e}+001.00000 \mathrm{e}+001.00000 \mathrm{e}-011.00000 \mathrm{e}-091.00000 \mathrm{e}-01$

Element: 12712 \# of layers: 7

$\mathrm{Kx} \mathrm{Ky} \mathrm{Kz}$ Ss Por

$1.13396 \mathrm{e}+01$ 1.13396e+01 1.13396e+00 1.00000e-09 2.12000e-01

$1.13396 \mathrm{e}+011.13396 \mathrm{e}+011.13396 \mathrm{e}+001.00000 \mathrm{e}-092.12000 \mathrm{e}-01$

$1.13396 \mathrm{e}+011.13396 \mathrm{e}+011.13396 \mathrm{e}+001.00000 \mathrm{e}-092.12000 \mathrm{e}-01$

$1.13396 \mathrm{e}+011.13396 \mathrm{e}+011.13396 \mathrm{e}+001.00000 \mathrm{e}-092.12000 \mathrm{e}-01$

$1.13396 \mathrm{e}+01$ 1.13396e+01 1.13396e+00 1.00000e-09 2.12000e-01

$1.00000 \mathrm{e}-05$ 1.00000e-05 1.00000e-06 1.00000e-09 1.00000e-01

$1.00000 \mathrm{e}+001.00000 \mathrm{e}+001.00000 \mathrm{e}-011.00000 \mathrm{e}-091.00000 \mathrm{e}-01$

Element: 12713 \# of layers: 7

Kx Ky Kz Ss Por

1.13396e+01 1.13396e+01 1.13396e+00 1.00000e-09 2.12000e-01

$1.13396 \mathrm{e}+011.13396 \mathrm{e}+011.13396 \mathrm{e}+001.00000 \mathrm{e}-092.12000 \mathrm{e}-01$

$1.13396 \mathrm{e}+011.13396 \mathrm{e}+011.13396 \mathrm{e}+001.00000 \mathrm{e}-092.12000 \mathrm{e}-01$

$1.13396 \mathrm{e}+011.13396 \mathrm{e}+01$ 1.13396e+00 1.00000e-09 2.12000e-01

$1.13396 \mathrm{e}+011.13396 \mathrm{e}+011.13396 \mathrm{e}+001.00000 \mathrm{e}-092.12000 \mathrm{e}-01$

$1.00000 \mathrm{e}-05$ 1.00000e-05 1.00000e-06 1.00000e-09 1.00000e-01

$1.00000 \mathrm{e}+001.00000 \mathrm{e}+001.00000 \mathrm{e}-011.00000 \mathrm{e}-091.00000 \mathrm{e}-01$

Element: 12714 \# of layers: 7

Kx Ky Kz Ss Por

$1.13396 \mathrm{e}+01$ 1.13396e+01 1.13396e+00 1.00000e-09 2.12000e-01

$1.13396 \mathrm{e}+011.13396 \mathrm{e}+011.13396 \mathrm{e}+001.00000 \mathrm{e}-092.12000 \mathrm{e}-01$

$1.13396 \mathrm{e}+011.13396 \mathrm{e}+01$ 1.13396e+00 1.00000e-09 2.12000e-01

$1.13396 \mathrm{e}+011.13396 \mathrm{e}+01$ 1.13396e+00 1.00000e-09 2.12000e-01

$1.13396 \mathrm{e}+011.13396 \mathrm{e}+011.13396 \mathrm{e}+001.00000 \mathrm{e}-092.12000 \mathrm{e}-01$

$1.00000 \mathrm{e}-05$ 1.00000e-05 1.00000e-06 1.00000e-09 1.00000e-01

$1.00000 \mathrm{e}+001.00000 \mathrm{e}+001.00000 \mathrm{e}-01$ 1.00000e-09 1.00000e-01

Element: 12715 \# of layers: 7

Kx Ky Kz Ss Por

$1.08277 \mathrm{e}+01$ 1.08277e+01 1.08277e+00 1.00000e-09 2.12000e-01 $1.08277 \mathrm{e}+01$ 1.08277e+01 1.08277e+00 1.00000e-09 2.12000e-01 1.08277e+01 1.08277e+01 1.08277e+00 1.00000e-09 2.12000e-01 $1.08277 \mathrm{e}+01$ 1.08277e+01 1.08277e+00 1.00000e-09 2.12000e-01 $1.08277 \mathrm{e}+01$ 1.08277e+01 1.08277e+00 1.00000e-09 2.12000e-01 
$1.00000 \mathrm{e}-05$ 1.00000e-05 1.00000e-06 1.00000e-09 1.00000e-01 $1.00000 \mathrm{e}+001.00000 \mathrm{e}+001.00000 \mathrm{e}-01$ 1.00000e-09 1.00000e-01 Element: 12716 \# of layers: 7

Kx Ky Kz Ss Por

$1.08277 \mathrm{e}+01$ 1.08277e+01 1.08277e+00 1.00000e-09 2.12000e-01 $1.08277 \mathrm{e}+01$ 1.08277e+01 1.08277e+00 1.00000e-09 2.12000e-01 $1.08277 \mathrm{e}+01$ 1.08277e+01 1.08277e+00 1.00000e-09 2.12000e-01 $1.08277 \mathrm{e}+011.08277 \mathrm{e}+01$ 1.08277e+00 1.00000e-09 2.12000e-01 $1.08277 \mathrm{e}+01$ 1.08277e+01 1.08277e+00 1.00000e-09 2.12000e-01 $1.00000 \mathrm{e}-05$ 1.00000e-05 1.00000e-06 1.00000e-09 1.00000e-01 $1.00000 \mathrm{e}+001.00000 \mathrm{e}+001.00000 \mathrm{e}-01$ 1.00000e-09 1.00000e-01 Element: 12717 \# of layers: 7

Kx Ky Kz Ss Por

$1.13396 \mathrm{e}+01$ 1.13396e+01 1.13396e+00 1.00000e-09 2.12000e-01 $1.13396 \mathrm{e}+01$ 1.13396e+01 1.13396e+00 1.00000e-09 2.12000e-01 $1.13396 \mathrm{e}+011.13396 \mathrm{e}+011.13396 \mathrm{e}+001.00000 \mathrm{e}-092.12000 \mathrm{e}-01$ $1.13396 \mathrm{e}+011.13396 \mathrm{e}+011.13396 \mathrm{e}+001.00000 \mathrm{e}-092.12000 \mathrm{e}-01$ $1.13396 \mathrm{e}+01$ 1.13396e+01 1.13396e+00 1.00000e-09 2.12000e-01 $1.00000 \mathrm{e}-05$ 1.00000e-05 1.00000e-06 1.00000e-09 1.00000e-01 $1.00000 \mathrm{e}+001.00000 \mathrm{e}+001.00000 \mathrm{e}-011.00000 \mathrm{e}-09$ 1.00000e-01 Element: 12718 \# of layers: 7

$\mathrm{Kx} \mathrm{Ky} \mathrm{Kz}$ Ss Por

$1.13396 \mathrm{e}+01$ 1.13396e+01 1.13396e+00 1.00000e-09 2.12000e-01 $1.13396 \mathrm{e}+011.13396 \mathrm{e}+01$ 1.13396e+00 1.00000e-09 2.12000e-01 $1.13396 \mathrm{e}+011.13396 \mathrm{e}+011.13396 \mathrm{e}+001.00000 \mathrm{e}-092.12000 \mathrm{e}-01$ $1.13396 \mathrm{e}+01$ 1.13396e+01 1.13396e+00 1.00000e-09 2.12000e-01 $1.13396 \mathrm{e}+011.13396 \mathrm{e}+011.13396 \mathrm{e}+001.00000 \mathrm{e}-092.12000 \mathrm{e}-01$ $1.00000 \mathrm{e}-05$ 1.00000e-05 1.00000e-06 1.00000e-09 1.00000e-01 $1.00000 \mathrm{e}+001.00000 \mathrm{e}+001.00000 \mathrm{e}-011.00000 \mathrm{e}-091.00000 \mathrm{e}-01$ Element: 12719 \# of layers: 7

$\mathrm{Kx} \mathrm{Ky} \mathrm{Kz}$ Ss Por

$1.13396 \mathrm{e}+01$ 1.13396e+01 1.13396e+00 1.00000e-09 2.12000e-01 $1.13396 \mathrm{e}+011.13396 \mathrm{e}+011.13396 \mathrm{e}+001.00000 \mathrm{e}-092.12000 \mathrm{e}-01$ $1.13396 \mathrm{e}+011.13396 \mathrm{e}+01$ 1.13396e+00 1.00000e-09 2.12000e-01 $1.13396 \mathrm{e}+011.13396 \mathrm{e}+011.13396 \mathrm{e}+001.00000 \mathrm{e}-092.12000 \mathrm{e}-01$ $1.13396 \mathrm{e}+011.13396 \mathrm{e}+011.13396 \mathrm{e}+001.00000 \mathrm{e}-092.12000 \mathrm{e}-01$ $1.00000 \mathrm{e}-05$ 1.00000e-05 1.00000e-06 1.00000e-09 1.00000e-01 $1.00000 \mathrm{e}+001.00000 \mathrm{e}+001.00000 \mathrm{e}-011.00000 \mathrm{e}-091.00000 \mathrm{e}-01$ Element: 12720 \# of layers: 7

Kx Ky Kz Ss Por

$1.13396 \mathrm{e}+01$ 1.13396e+01 1.13396e+00 1.00000e-09 2.12000e-01 $1.13396 \mathrm{e}+01$ 1.13396e+01 1.13396e+00 1.00000e-09 2.12000e-01 $1.13396 \mathrm{e}+011.13396 \mathrm{e}+01$ 1.13396e+00 1.00000e-09 2.12000e-01 $1.13396 \mathrm{e}+01$ 1.13396e+01 1.13396e+00 1.00000e-09 2.12000e-01 $1.13396 \mathrm{e}+011.13396 \mathrm{e}+011.13396 \mathrm{e}+001.00000 \mathrm{e}-092.12000 \mathrm{e}-01$ $1.00000 \mathrm{e}-05$ 1.00000e-05 1.00000e-06 1.00000e-09 1.00000e-01 
$1.00000 \mathrm{e}+001.00000 \mathrm{e}+00$ 1.00000e-01 1.00000e-09 1.00000e-01

Element: 12721 \# of layers: 7

Kx Ky Kz Ss Por

$1.13396 \mathrm{e}+01$ 1.13396e+01 1.13396e+00 1.00000e-09 2.12000e-01

$1.13396 \mathrm{e}+01$ 1.13396e+01 1.13396e+00 1.00000e-09 2.12000e-01

$1.13396 \mathrm{e}+01$ 1.13396e+01 1.13396e+00 1.00000e-09 2.12000e-01

$1.13396 \mathrm{e}+011.13396 \mathrm{e}+011.13396 \mathrm{e}+001.00000 \mathrm{e}-092.12000 \mathrm{e}-01$

$1.13396 \mathrm{e}+011.13396 \mathrm{e}+011.13396 \mathrm{e}+001.00000 \mathrm{e}-092.12000 \mathrm{e}-01$

$1.00000 \mathrm{e}-05$ 1.00000e-05 1.00000e-06 1.00000e-09 1.00000e-01

$1.00000 \mathrm{e}+001.00000 \mathrm{e}+001.00000 \mathrm{e}-011.00000 \mathrm{e}-091.00000 \mathrm{e}-01$

Element: 12722 \# of layers: 7

Kx Ky Kz Ss Por

$1.13396 \mathrm{e}+01$ 1.13396e+01 1.13396e+00 1.00000e-09 2.12000e-01

$1.13396 \mathrm{e}+01$ 1.13396e+01 1.13396e+00 1.00000e-09 2.12000e-01

$1.13396 \mathrm{e}+01$ 1.13396e+01 1.13396e+00 1.00000e-09 2.12000e-01

$1.13396 \mathrm{e}+011.13396 \mathrm{e}+011.13396 \mathrm{e}+001.00000 \mathrm{e}-092.12000 \mathrm{e}-01$

$1.13396 \mathrm{e}+011.13396 \mathrm{e}+011.13396 \mathrm{e}+001.00000 \mathrm{e}-092.12000 \mathrm{e}-01$

$1.00000 \mathrm{e}-05$ 1.00000e-05 1.00000e-06 1.00000e-09 1.00000e-01

$1.00000 \mathrm{e}+001.00000 \mathrm{e}+001.00000 \mathrm{e}-01$ 1.00000e-09 1.00000e-01

Element: 12723 \# of layers: 7

$\mathrm{Kx} \mathrm{Ky} \mathrm{Kz}$ Ss Por

$1.13396 \mathrm{e}+01$ 1.13396e+01 1.13396e+00 1.00000e-09 2.12000e-01

$1.13396 \mathrm{e}+01$ 1.13396e+01 1.13396e+00 1.00000e-09 2.12000e-01

$1.13396 \mathrm{e}+011.13396 \mathrm{e}+01$ 1.13396e+00 1.00000e-09 2.12000e-01

$1.13396 \mathrm{e}+011.13396 \mathrm{e}+011.13396 \mathrm{e}+001.00000 \mathrm{e}-092.12000 \mathrm{e}-01$

$1.13396 \mathrm{e}+01$ 1.13396e+01 1.13396e+00 1.00000e-09 2.12000e-01

$1.00000 \mathrm{e}-05$ 1.00000e-05 1.00000e-06 1.00000e-09 1.00000e-01

$1.00000 \mathrm{e}+001.00000 \mathrm{e}+001.00000 \mathrm{e}-01$ 1.00000e-09 1.00000e-01

Element: 12724 \# of layers: 7

$\mathrm{Kx} \mathrm{Ky} \mathrm{Kz}$ Ss Por

1.13396e+01 1.13396e+01 1.13396e+00 1.00000e-09 2.12000e-01

$1.13396 \mathrm{e}+01$ 1.13396e+01 1.13396e+00 1.00000e-09 2.12000e-01

$1.13396 \mathrm{e}+011.13396 \mathrm{e}+011.13396 \mathrm{e}+001.00000 \mathrm{e}-092.12000 \mathrm{e}-01$

$1.13396 \mathrm{e}+01$ 1.13396e+01 1.13396e+00 1.00000e-09 2.12000e-01

$1.13396 \mathrm{e}+01$ 1.13396e+01 1.13396e+00 1.00000e-09 2.12000e-01

1.00000e-05 1.00000e-05 1.00000e-06 1.00000e-09 1.00000e-01

$1.00000 \mathrm{e}+001.00000 \mathrm{e}+001.00000 \mathrm{e}-011.00000 \mathrm{e}-091.00000 \mathrm{e}-01$

Element: 12725 \# of layers: 7

$\mathrm{Kx} \mathrm{Ky} \mathrm{Kz}$ Ss Por

$1.13396 \mathrm{e}+01$ 1.13396e+01 1.13396e+00 1.00000e-09 2.12000e-01

$1.13396 \mathrm{e}+01$ 1.13396e+01 1.13396e+00 1.00000e-09 2.12000e-01

$1.13396 \mathrm{e}+01$ 1.13396e+01 1.13396e+00 1.00000e-09 2.12000e-01

$1.13396 \mathrm{e}+01$ 1.13396e+01 1.13396e+00 1.00000e-09 2.12000e-01

$1.13396 \mathrm{e}+01$ 1.13396e+01 1.13396e+00 1.00000e-09 2.12000e-01

$1.00000 \mathrm{e}-05$ 1.00000e-05 1.00000e-06 1.00000e-09 1.00000e-01

$1.00000 \mathrm{e}+001.00000 \mathrm{e}+001.00000 \mathrm{e}-011.00000 \mathrm{e}-091.00000 \mathrm{e}-01$ 
Element: 12726 \# of layers: 7

Kx Ky Kz Ss Por

$1.13396 \mathrm{e}+011.13396 \mathrm{e}+011.13396 \mathrm{e}+00$ 1.00000e-09 2.12000e-01

$1.13396 \mathrm{e}+011.13396 \mathrm{e}+011.13396 \mathrm{e}+001.00000 \mathrm{e}-092.12000 \mathrm{e}-01$

$1.13396 \mathrm{e}+011.13396 \mathrm{e}+011.13396 \mathrm{e}+001.00000 \mathrm{e}-092.12000 \mathrm{e}-01$

$1.13396 \mathrm{e}+011.13396 \mathrm{e}+011.13396 \mathrm{e}+001.00000 \mathrm{e}-092.12000 \mathrm{e}-01$

$1.13396 \mathrm{e}+011.13396 \mathrm{e}+011.13396 \mathrm{e}+001.00000 \mathrm{e}-092.12000 \mathrm{e}-01$

$1.00000 \mathrm{e}-05$ 1.00000e-05 1.00000e-06 1.00000e-09 1.00000e-01

$1.00000 \mathrm{e}+001.00000 \mathrm{e}+001.00000 \mathrm{e}-011.00000 \mathrm{e}-091.00000 \mathrm{e}-01$

Element: 12727 \# of layers: 7

Kx Ky Kz Ss Por

$1.13396 \mathrm{e}+011.13396 \mathrm{e}+011.13396 \mathrm{e}+00$ 1.00000e-09 2.12000e-01

$1.13396 \mathrm{e}+011.13396 \mathrm{e}+011.13396 \mathrm{e}+00$ 1.00000e-09 2.12000e-01

$1.13396 \mathrm{e}+011.13396 \mathrm{e}+011.13396 \mathrm{e}+001.00000 \mathrm{e}-092.12000 \mathrm{e}-01$

$1.13396 \mathrm{e}+011.13396 \mathrm{e}+011.13396 \mathrm{e}+001.00000 \mathrm{e}-092.12000 \mathrm{e}-01$

$1.13396 \mathrm{e}+011.13396 \mathrm{e}+011.13396 \mathrm{e}+001.00000 \mathrm{e}-092.12000 \mathrm{e}-01$

$1.00000 \mathrm{e}-05$ 1.00000e-05 1.00000e-06 1.00000e-09 1.00000e-01

$1.00000 \mathrm{e}+001.00000 \mathrm{e}+001.00000 \mathrm{e}-011.00000 \mathrm{e}-091.00000 \mathrm{e}-01$

Element: 12728 \# of layers: 7

Kx Ky Kz Ss Por

$1.13396 \mathrm{e}+011.13396 \mathrm{e}+011.13396 \mathrm{e}+00$ 1.00000e-09 2.12000e-01

$1.13396 \mathrm{e}+011.13396 \mathrm{e}+011.13396 \mathrm{e}+001.00000 \mathrm{e}-092.12000 \mathrm{e}-01$

$1.13396 \mathrm{e}+011.13396 \mathrm{e}+011.13396 \mathrm{e}+00$ 1.00000e-09 2.12000e-01

$1.13396 \mathrm{e}+011.13396 \mathrm{e}+011.13396 \mathrm{e}+001.00000 \mathrm{e}-092.12000 \mathrm{e}-01$

$1.13396 \mathrm{e}+011.13396 \mathrm{e}+011.13396 \mathrm{e}+001.00000 \mathrm{e}-092.12000 \mathrm{e}-01$

$1.00000 \mathrm{e}-05$ 1.00000e-05 1.00000e-06 1.00000e-09 1.00000e-01

$1.00000 \mathrm{e}+001.00000 \mathrm{e}+001.00000 \mathrm{e}-011.00000 \mathrm{e}-091.00000 \mathrm{e}-01$

Element: 12729 \# of layers: 7

Kx Ky Kz Ss Por

8.83594e+00 8.83594e+00 8.83594e-01 1.00000e-09 2.12000e-01

$8.83594 \mathrm{e}+008.83594 \mathrm{e}+008.83594 \mathrm{e}-01$ 1.00000e-09 2.12000e-01

$8.83594 \mathrm{e}+008.83594 \mathrm{e}+008.83594 \mathrm{e}-01$ 1.00000e-09 2.12000e-01

$8.83594 \mathrm{e}+008.83594 \mathrm{e}+008.83594 \mathrm{e}-011.00000 \mathrm{e}-092.12000 \mathrm{e}-01$

$8.83594 \mathrm{e}+008.83594 \mathrm{e}+00$ 8.83594e-01 1.00000e-09 2.12000e-01

$1.00000 \mathrm{e}-05$ 1.00000e-05 1.00000e-06 1.00000e-09 1.00000e-01

$1.00000 \mathrm{e}+001.00000 \mathrm{e}+001.00000 \mathrm{e}-011.00000 \mathrm{e}-091.00000 \mathrm{e}-01$

Element: 12730 \# of layers: 7

Kx Ky Kz Ss Por

$8.83594 \mathrm{e}+008.83594 \mathrm{e}+00$ 8.83594e-01 1.00000e-09 2.12000e-01

$8.83594 \mathrm{e}+008.83594 \mathrm{e}+00$ 8.83594e-01 1.00000e-09 2.12000e-01

$8.83594 \mathrm{e}+008.83594 \mathrm{e}+008.83594 \mathrm{e}-01$ 1.00000e-09 2.12000e-01

$8.83594 \mathrm{e}+008.83594 \mathrm{e}+008.83594 \mathrm{e}-01$ 1.00000e-09 2.12000e-01

$8.83594 \mathrm{e}+008.83594 \mathrm{e}+00$ 8.83594e-01 1.00000e-09 2.12000e-01

$1.00000 \mathrm{e}-05$ 1.00000e-05 1.00000e-06 1.00000e-09 1.00000e-01

$1.00000 \mathrm{e}+001.00000 \mathrm{e}+001.00000 \mathrm{e}-011.00000 \mathrm{e}-091.00000 \mathrm{e}-01$

Element: 12731 \# of layers: 7 
$\mathrm{Kx} \mathrm{Ky} \mathrm{Kz}$ Ss Por

8.83594e+00 8.83594e+00 8.83594e-01 1.00000e-09 2.12000e-01 $8.83594 \mathrm{e}+00$ 8.83594e+00 8.83594e-01 1.00000e-09 2.12000e-01 $8.83594 \mathrm{e}+008.83594 \mathrm{e}+008.83594 \mathrm{e}-01$ 1.00000e-09 2.12000e-01 8.83594e+00 8.83594e+00 8.83594e-01 1.00000e-09 2.12000e-01 $8.83594 \mathrm{e}+00$ 8.83594e+00 8.83594e-01 1.00000e-09 2.12000e-01 $1.00000 \mathrm{e}-05$ 1.00000e-05 1.00000e-06 1.00000e-09 1.00000e-01 $1.00000 \mathrm{e}+001.00000 \mathrm{e}+001.00000 \mathrm{e}-011.00000 \mathrm{e}-091.00000 \mathrm{e}-01$ Element: 12732 \# of layers: 7

$\mathrm{Kx} \mathrm{Ky} \mathrm{Kz}$ Ss Por

$1.13396 \mathrm{e}+01$ 1.13396e+01 1.13396e+00 1.00000e-09 2.12000e-01 $1.13396 \mathrm{e}+01$ 1.13396e+01 1.13396e+00 1.00000e-09 2.12000e-01 $1.13396 \mathrm{e}+011.13396 \mathrm{e}+01$ 1.13396e+00 1.00000e-09 2.12000e-01 $1.13396 \mathrm{e}+01$ 1.13396e+01 1.13396e+00 1.00000e-09 2.12000e-01 $1.13396 \mathrm{e}+011.13396 \mathrm{e}+011.13396 \mathrm{e}+001.00000 \mathrm{e}-092.12000 \mathrm{e}-01$ $1.00000 \mathrm{e}-05$ 1.00000e-05 1.00000e-06 1.00000e-09 1.00000e-01 $1.00000 \mathrm{e}+001.00000 \mathrm{e}+001.00000 \mathrm{e}-01$ 1.00000e-09 1.00000e-01 Element: 12733 \# of layers: 7

$\mathrm{Kx} \mathrm{Ky} \mathrm{Kz}$ Ss Por

$1.13396 \mathrm{e}+01$ 1.13396e+01 1.13396e+00 1.00000e-09 2.12000e-01 $1.13396 \mathrm{e}+011.13396 \mathrm{e}+011.13396 \mathrm{e}+001.00000 \mathrm{e}-092.12000 \mathrm{e}-01$ $1.13396 \mathrm{e}+01$ 1.13396e+01 1.13396e+00 1.00000e-09 2.12000e-01 $1.13396 \mathrm{e}+01$ 1.13396e+01 1.13396e+00 1.00000e-09 2.12000e-01 $1.13396 \mathrm{e}+011.13396 \mathrm{e}+011.13396 \mathrm{e}+001.00000 \mathrm{e}-092.12000 \mathrm{e}-01$ $1.00000 \mathrm{e}-05$ 1.00000e-05 1.00000e-06 1.00000e-09 1.00000e-01 $1.00000 \mathrm{e}+001.00000 \mathrm{e}+001.00000 \mathrm{e}-01$ 1.00000e-09 1.00000e-01 Element: 12734 \# of layers: 7

$\mathrm{Kx} \mathrm{Ky} \mathrm{Kz}$ Ss Por

$1.13396 \mathrm{e}+01$ 1.13396e+01 1.13396e+00 1.00000e-09 2.12000e-01 $1.13396 \mathrm{e}+01$ 1.13396e+01 1.13396e+00 1.00000e-09 2.12000e-01 $1.13396 \mathrm{e}+01$ 1.13396e+01 1.13396e+00 1.00000e-09 2.12000e-01 $1.13396 \mathrm{e}+01$ 1.13396e+01 1.13396e+00 1.00000e-09 2.12000e-01 $1.13396 \mathrm{e}+011.13396 \mathrm{e}+011.13396 \mathrm{e}+001.00000 \mathrm{e}-092.12000 \mathrm{e}-01$ $1.00000 \mathrm{e}-05$ 1.00000e-05 1.00000e-06 1.00000e-09 1.00000e-01 $1.00000 \mathrm{e}+001.00000 \mathrm{e}+001.00000 \mathrm{e}-01$ 1.00000e-09 1.00000e-01 Element: 12735 \# of layers: 7

Kx Ky Kz Ss Por

$1.13396 \mathrm{e}+01$ 1.13396e+01 1.13396e+00 1.00000e-09 2.12000e-01 $1.13396 \mathrm{e}+01$ 1.13396e+01 1.13396e+00 1.00000e-09 2.12000e-01 $1.13396 \mathrm{e}+01$ 1.13396e+01 1.13396e+00 1.00000e-09 2.12000e-01 $1.13396 \mathrm{e}+011.13396 \mathrm{e}+01$ 1.13396e+00 1.00000e-09 2.12000e-01 $1.13396 \mathrm{e}+01$ 1.13396e+01 1.13396e+00 1.00000e-09 2.12000e-01 $1.00000 \mathrm{e}-05$ 1.00000e-05 1.00000e-06 1.00000e-09 1.00000e-01 $1.00000 \mathrm{e}+001.00000 \mathrm{e}+001.00000 \mathrm{e}-01$ 1.00000e-09 1.00000e-01 Element: 12736 \# of layers: 7

Kx Ky Kz Ss Por 
8.83594e+00 8.83594e+00 8.83594e-01 1.00000e-09 2.12000e-01 $8.83594 \mathrm{e}+00$ 8.83594e+00 8.83594e-01 1.00000e-09 2.12000e-01 $8.83594 \mathrm{e}+008.83594 \mathrm{e}+008.83594 \mathrm{e}-01$ 1.00000e-09 2.12000e-01 $8.83594 \mathrm{e}+00$ 8.83594e+00 8.83594e-01 1.00000e-09 2.12000e-01 $8.83594 \mathrm{e}+008.83594 \mathrm{e}+008.83594 \mathrm{e}-01$ 1.00000e-09 2.12000e-01 $1.00000 \mathrm{e}-05$ 1.00000e-05 1.00000e-06 1.00000e-09 1.00000e-01 $1.00000 \mathrm{e}+001.00000 \mathrm{e}+001.00000 \mathrm{e}-01$ 1.00000e-09 1.00000e-01 Element: 12737 \# of layers: 7

$\mathrm{Kx} \mathrm{Ky} \mathrm{Kz}$ Ss Por

8.83594e+00 8.83594e+00 8.83594e-01 1.00000e-09 2.12000e-01 $8.83594 \mathrm{e}+008.83594 \mathrm{e}+00$ 8.83594e-01 1.00000e-09 2.12000e-01 $8.83594 \mathrm{e}+00$ 8.83594e+00 8.83594e-01 1.00000e-09 2.12000e-01 8.83594e+00 8.83594e+00 8.83594e-01 1.00000e-09 2.12000e-01 $8.83594 \mathrm{e}+008.83594 \mathrm{e}+008.83594 \mathrm{e}-01$ 1.00000e-09 2.12000e-01 $1.00000 \mathrm{e}-05$ 1.00000e-05 1.00000e-06 1.00000e-09 1.00000e-01 $1.00000 \mathrm{e}+001.00000 \mathrm{e}+001.00000 \mathrm{e}-011.00000 \mathrm{e}-091.00000 \mathrm{e}-01$ Element: 12738 \# of layers: 7

$\mathrm{Kx} \mathrm{Ky} \mathrm{Kz}$ Ss Por

8.83594e+00 8.83594e+00 8.83594e-01 1.00000e-09 2.12000e-01 $8.83594 \mathrm{e}+008.83594 \mathrm{e}+00$ 8.83594e-01 1.00000e-09 2.12000e-01 $8.83594 \mathrm{e}+008.83594 \mathrm{e}+008.83594 \mathrm{e}-01$ 1.00000e-09 2.12000e-01 8.83594e+00 8.83594e+00 8.83594e-01 1.00000e-09 2.12000e-01 $8.83594 \mathrm{e}+00$ 8.83594e+00 8.83594e-01 1.00000e-09 2.12000e-01 $1.00000 \mathrm{e}-05$ 1.00000e-05 1.00000e-06 1.00000e-09 1.00000e-01 $1.00000 \mathrm{e}+001.00000 \mathrm{e}+001.00000 \mathrm{e}-011.00000 \mathrm{e}-091.00000 \mathrm{e}-01$ Element: 12739 \# of layers: 7

$\mathrm{Kx} \mathrm{Ky} \mathrm{Kz}$ Ss Por

8.83594e+00 8.83594e+00 8.83594e-01 1.00000e-09 2.12000e-01 $8.83594 \mathrm{e}+008.83594 \mathrm{e}+008.83594 \mathrm{e}-01$ 1.00000e-09 2.12000e-01 8.83594e+00 8.83594e+00 8.83594e-01 1.00000e-09 2.12000e-01 8.83594e+00 8.83594e+00 8.83594e-01 1.00000e-09 2.12000e-01 $8.83594 \mathrm{e}+00$ 8.83594e+00 8.83594e-01 1.00000e-09 2.12000e-01 $1.00000 \mathrm{e}-05$ 1.00000e-05 1.00000e-06 1.00000e-09 1.00000e-01 $1.00000 \mathrm{e}+001.00000 \mathrm{e}+001.00000 \mathrm{e}-01$ 1.00000e-09 1.00000e-01 Element: 12740 \# of layers: 7

$\mathrm{Kx} \mathrm{Ky} \mathrm{Kz}$ Ss Por

8.83594e+00 8.83594e+00 8.83594e-01 1.00000e-09 2.12000e-01 $8.83594 \mathrm{e}+00$ 8.83594e+00 8.83594e-01 1.00000e-09 2.12000e-01 $8.83594 \mathrm{e}+008.83594 \mathrm{e}+00$ 8.83594e-01 1.00000e-09 2.12000e-01 $8.83594 \mathrm{e}+00$ 8.83594e+00 8.83594e-01 1.00000e-09 2.12000e-01 $8.83594 \mathrm{e}+008.83594 \mathrm{e}+008.83594 \mathrm{e}-01$ 1.00000e-09 2.12000e-01 $1.00000 \mathrm{e}-05$ 1.00000e-05 1.00000e-06 1.00000e-09 1.00000e-01 $1.00000 \mathrm{e}+001.00000 \mathrm{e}+001.00000 \mathrm{e}-01$ 1.00000e-09 1.00000e-01 Element: 12741 \# of layers: 7

$\mathrm{Kx} \mathrm{Ky} \mathrm{Kz}$ Ss Por

8.83594e+00 8.83594e+00 8.83594e-01 1.00000e-09 2.12000e-01 
8.83594e+00 8.83594e+00 8.83594e-01 1.00000e-09 2.12000e-01 $8.83594 \mathrm{e}+00$ 8.83594e+00 8.83594e-01 1.00000e-09 2.12000e-01 $8.83594 \mathrm{e}+008.83594 \mathrm{e}+008.83594 \mathrm{e}-01$ 1.00000e-09 2.12000e-01 $8.83594 \mathrm{e}+008.83594 \mathrm{e}+008.83594 \mathrm{e}-01$ 1.00000e-09 2.12000e-01 $1.00000 \mathrm{e}-05$ 1.00000e-05 1.00000e-06 1.00000e-09 1.00000e-01 $1.00000 \mathrm{e}+001.00000 \mathrm{e}+001.00000 \mathrm{e}-011.00000 \mathrm{e}-091.00000 \mathrm{e}-01$ Element: 12742 \# of layers: 7

$\mathrm{Kx} \mathrm{Ky} \mathrm{Kz}$ Ss Por

8.83594e+00 8.83594e+00 8.83594e-01 1.00000e-09 2.12000e-01 $8.83594 \mathrm{e}+00$ 8.83594e+00 8.83594e-01 1.00000e-09 2.12000e-01 $8.83594 \mathrm{e}+008.83594 \mathrm{e}+00 \quad 8.83594 \mathrm{e}-01$ 1.00000e-09 2.12000e-01 $8.83594 \mathrm{e}+008.83594 \mathrm{e}+00 \quad 8.83594 \mathrm{e}-01$ 1.00000e-09 2.12000e-01 $8.83594 \mathrm{e}+00$ 8.83594e+00 8.83594e-01 1.00000e-09 2.12000e-01 $1.00000 \mathrm{e}-05$ 1.00000e-05 1.00000e-06 1.00000e-09 1.00000e-01 $1.00000 \mathrm{e}+001.00000 \mathrm{e}+001.00000 \mathrm{e}-011.00000 \mathrm{e}-091.00000 \mathrm{e}-01$ Element: 12743 \# of layers: 7

$\mathrm{Kx} \mathrm{Ky} \mathrm{Kz}$ Ss Por

8.83594e+00 8.83594e+00 8.83594e-01 1.00000e-09 2.12000e-01 $8.83594 \mathrm{e}+008.83594 \mathrm{e}+00$ 8.83594e-01 1.00000e-09 2.12000e-01 $8.83594 \mathrm{e}+008.83594 \mathrm{e}+008.83594 \mathrm{e}-01$ 1.00000e-09 2.12000e-01 $8.83594 \mathrm{e}+00$ 8.83594e+00 8.83594e-01 1.00000e-09 2.12000e-01 $8.83594 \mathrm{e}+00$ 8.83594e+00 8.83594e-01 1.00000e-09 2.12000e-01 $1.00000 \mathrm{e}-051.00000 \mathrm{e}-051.00000 \mathrm{e}-061.00000 \mathrm{e}-091.00000 \mathrm{e}-01$ $1.00000 \mathrm{e}+001.00000 \mathrm{e}+001.00000 \mathrm{e}-011.00000 \mathrm{e}-091.00000 \mathrm{e}-01$ Element: 12744 \# of layers: 7

Kx Ky Kz Ss Por

8.83594e+00 8.83594e+00 8.83594e-01 1.00000e-09 2.12000e-01 $8.83594 \mathrm{e}+00$ 8.83594e+00 8.83594e-01 1.00000e-09 2.12000e-01 $8.83594 \mathrm{e}+008.83594 \mathrm{e}+008.83594 \mathrm{e}-01$ 1.00000e-09 2.12000e-01 8.83594e+00 8.83594e+00 8.83594e-01 1.00000e-09 2.12000e-01 $8.83594 \mathrm{e}+00$ 8.83594e+00 8.83594e-01 1.00000e-09 2.12000e-01 $1.00000 \mathrm{e}-05$ 1.00000e-05 1.00000e-06 1.00000e-09 1.00000e-01 $1.00000 \mathrm{e}+001.00000 \mathrm{e}+001.00000 \mathrm{e}-011.00000 \mathrm{e}-091.00000 \mathrm{e}-01$ Element: 12745 \# of layers: 7

$\mathrm{Kx} \mathrm{Ky} \mathrm{Kz}$ Ss Por

8.83594e+00 8.83594e+00 8.83594e-01 1.00000e-09 2.12000e-01 $8.83594 \mathrm{e}+008.83594 \mathrm{e}+008.83594 \mathrm{e}-01$ 1.00000e-09 2.12000e-01 $8.83594 \mathrm{e}+00$ 8.83594e+00 8.83594e-01 1.00000e-09 2.12000e-01 $8.83594 \mathrm{e}+008.83594 \mathrm{e}+00$ 8.83594e-01 1.00000e-09 2.12000e-01 $8.83594 \mathrm{e}+00$ 8.83594e+00 8.83594e-01 1.00000e-09 2.12000e-01 $1.00000 \mathrm{e}-05$ 1.00000e-05 1.00000e-06 1.00000e-09 1.00000e-01 $1.00000 \mathrm{e}+001.00000 \mathrm{e}+001.00000 \mathrm{e}-011.00000 \mathrm{e}-091.00000 \mathrm{e}-01$ Element: 12746 \# of layers: 7

$\mathrm{Kx} \mathrm{Ky} \mathrm{Kz}$ Ss Por 8.83594e+00 8.83594e+00 8.83594e-01 1.00000e-09 2.12000e-01 $8.83594 \mathrm{e}+008.83594 \mathrm{e}+008.83594 \mathrm{e}-01$ 1.00000e-09 2.12000e-01 
8.83594e+00 8.83594e+00 8.83594e-01 1.00000e-09 2.12000e-01 $8.83594 \mathrm{e}+008.83594 \mathrm{e}+008.83594 \mathrm{e}-01$ 1.00000e-09 2.12000e-01 $8.83594 \mathrm{e}+008.83594 \mathrm{e}+008.83594 \mathrm{e}-01$ 1.00000e-09 2.12000e-01 $1.00000 \mathrm{e}-05$ 1.00000e-05 1.00000e-06 1.00000e-09 1.00000e-01 $1.00000 \mathrm{e}+001.00000 \mathrm{e}+001.00000 \mathrm{e}-011.00000 \mathrm{e}-091.00000 \mathrm{e}-01$ Element: 12747 \# of layers: 7

$\mathrm{Kx} \mathrm{Ky} \mathrm{Kz}$ Ss Por

$1.04080 \mathrm{e}+011.04080 \mathrm{e}+011.04080 \mathrm{e}+001.00000 \mathrm{e}-092.12000 \mathrm{e}-01$ $1.04080 \mathrm{e}+011.04080 \mathrm{e}+011.04080 \mathrm{e}+001.00000 \mathrm{e}-092.12000 \mathrm{e}-01$ $1.04080 \mathrm{e}+011.04080 \mathrm{e}+011.04080 \mathrm{e}+001.00000 \mathrm{e}-092.12000 \mathrm{e}-01$ $1.04080 \mathrm{e}+011.04080 \mathrm{e}+011.04080 \mathrm{e}+001.00000 \mathrm{e}-092.12000 \mathrm{e}-01$ $1.04080 \mathrm{e}+011.04080 \mathrm{e}+011.04080 \mathrm{e}+001.00000 \mathrm{e}-092.12000 \mathrm{e}-01$ $1.00000 \mathrm{e}-05$ 1.00000e-05 1.00000e-06 1.00000e-09 1.00000e-01 $1.00000 \mathrm{e}+001.00000 \mathrm{e}+001.00000 \mathrm{e}-011.00000 \mathrm{e}-091.00000 \mathrm{e}-01$ Element: 12748 \# of layers: 7

Kx Ky Kz Ss Por

$1.04080 \mathrm{e}+011.04080 \mathrm{e}+011.04080 \mathrm{e}+001.00000 \mathrm{e}-092.12000 \mathrm{e}-01$ $1.04080 \mathrm{e}+011.04080 \mathrm{e}+011.04080 \mathrm{e}+001.00000 \mathrm{e}-092.12000 \mathrm{e}-01$ $1.04080 \mathrm{e}+011.04080 \mathrm{e}+011.04080 \mathrm{e}+001.00000 \mathrm{e}-092.12000 \mathrm{e}-01$ $1.04080 \mathrm{e}+011.04080 \mathrm{e}+011.04080 \mathrm{e}+001.00000 \mathrm{e}-092.12000 \mathrm{e}-01$ $1.04080 \mathrm{e}+011.04080 \mathrm{e}+011.04080 \mathrm{e}+001.00000 \mathrm{e}-092.12000 \mathrm{e}-01$ $1.00000 \mathrm{e}-05$ 1.00000e-05 1.00000e-06 1.00000e-09 1.00000e-01 $1.00000 \mathrm{e}+001.00000 \mathrm{e}+001.00000 \mathrm{e}-01$ 1.00000e-09 1.00000e-01 Element: 12749 \# of layers: 7

$\mathrm{Kx} \mathrm{Ky} \mathrm{Kz}$ Ss Por $1.04080 \mathrm{e}+011.04080 \mathrm{e}+011.04080 \mathrm{e}+001.00000 \mathrm{e}-092.12000 \mathrm{e}-01$ $1.04080 \mathrm{e}+011.04080 \mathrm{e}+011.04080 \mathrm{e}+001.00000 \mathrm{e}-092.12000 \mathrm{e}-01$ $1.04080 \mathrm{e}+011.04080 \mathrm{e}+011.04080 \mathrm{e}+001.00000 \mathrm{e}-092.12000 \mathrm{e}-01$ $1.04080 \mathrm{e}+011.04080 \mathrm{e}+011.04080 \mathrm{e}+001.00000 \mathrm{e}-092.12000 \mathrm{e}-01$ $1.04080 \mathrm{e}+011.04080 \mathrm{e}+011.04080 \mathrm{e}+001.00000 \mathrm{e}-092.12000 \mathrm{e}-01$ $1.00000 \mathrm{e}-051.00000 \mathrm{e}-051.00000 \mathrm{e}-061.00000 \mathrm{e}-091.00000 \mathrm{e}-01$ $1.00000 \mathrm{e}+001.00000 \mathrm{e}+001.00000 \mathrm{e}-01$ 1.00000e-09 1.00000e-01 Element: 12750 \# of layers: 7

$\mathrm{Kx} \mathrm{Ky} \mathrm{Kz}$ Ss Por

8.83594e+00 8.83594e+00 8.83594e-01 1.00000e-09 2.12000e-01 $8.83594 \mathrm{e}+00$ 8.83594e+00 8.83594e-01 1.00000e-09 2.12000e-01 $8.83594 \mathrm{e}+008.83594 \mathrm{e}+008.83594 \mathrm{e}-01$ 1.00000e-09 2.12000e-01 $8.83594 \mathrm{e}+008.83594 \mathrm{e}+008.83594 \mathrm{e}-01$ 1.00000e-09 2.12000e-01 $8.83594 \mathrm{e}+008.83594 \mathrm{e}+00$ 8.83594e-01 1.00000e-09 2.12000e-01 $1.00000 \mathrm{e}-05$ 1.00000e-05 1.00000e-06 1.00000e-09 1.00000e-01 $1.00000 \mathrm{e}+001.00000 \mathrm{e}+001.00000 \mathrm{e}-011.00000 \mathrm{e}-091.00000 \mathrm{e}-01$ Element: 12751 \# of layers: 7

$\mathrm{Kx} \mathrm{Ky} \mathrm{Kz}$ Ss Por

8.83594e+00 8.83594e+00 8.83594e-01 1.00000e-09 2.12000e-01 $8.83594 \mathrm{e}+008.83594 \mathrm{e}+008.83594 \mathrm{e}-01$ 1.00000e-09 2.12000e-01 $8.83594 \mathrm{e}+00$ 8.83594e+00 8.83594e-01 1.00000e-09 2.12000e-01 
$8.83594 \mathrm{e}+008.83594 \mathrm{e}+008.83594 \mathrm{e}-01$ 1.00000e-09 2.12000e-01 $8.83594 \mathrm{e}+008.83594 \mathrm{e}+00$ 8.83594e-01 1.00000e-09 2.12000e-01 $1.00000 \mathrm{e}-051.00000 \mathrm{e}-05$ 1.00000e-06 1.00000e-09 1.00000e-01 $1.00000 \mathrm{e}+001.00000 \mathrm{e}+001.00000 \mathrm{e}-011.00000 \mathrm{e}-091.00000 \mathrm{e}-01$ Element: 12752 \# of layers: 7

Kx Ky Kz Ss Por

$8.83594 \mathrm{e}+008.83594 \mathrm{e}+00$ 8.83594e-01 1.00000e-09 2.12000e-01 $8.83594 \mathrm{e}+008.83594 \mathrm{e}+008.83594 \mathrm{e}-01$ 1.00000e-09 2.12000e-01 $8.83594 \mathrm{e}+008.83594 \mathrm{e}+008.83594 \mathrm{e}-011.00000 \mathrm{e}-092.12000 \mathrm{e}-01$ $8.83594 \mathrm{e}+008.83594 \mathrm{e}+00$ 8.83594e-01 1.00000e-09 2.12000e-01 $8.83594 \mathrm{e}+008.83594 \mathrm{e}+00$ 8.83594e-01 1.00000e-09 2.12000e-01 $1.00000 \mathrm{e}-05$ 1.00000e-05 1.00000e-06 1.00000e-09 1.00000e-01 $1.00000 \mathrm{e}+001.00000 \mathrm{e}+001.00000 \mathrm{e}-011.00000 \mathrm{e}-091.00000 \mathrm{e}-01$ Element: 12753 \# of layers: 7

Kx Ky Kz Ss Por $8.83594 \mathrm{e}+008.83594 \mathrm{e}+00$ 8.83594e-01 1.00000e-09 2.12000e-01 $8.83594 \mathrm{e}+008.83594 \mathrm{e}+00$ 8.83594e-01 1.00000e-09 2.12000e-01 $8.83594 \mathrm{e}+008.83594 \mathrm{e}+008.83594 \mathrm{e}-011.00000 \mathrm{e}-092.12000 \mathrm{e}-01$ $8.83594 \mathrm{e}+008.83594 \mathrm{e}+00$ 8.83594e-01 1.00000e-09 2.12000e-01 $8.83594 \mathrm{e}+008.83594 \mathrm{e}+008.83594 \mathrm{e}-011.00000 \mathrm{e}-092.12000 \mathrm{e}-01$ $1.00000 \mathrm{e}-05$ 1.00000e-05 1.00000e-06 1.00000e-09 1.00000e-01 $1.00000 \mathrm{e}+001.00000 \mathrm{e}+001.00000 \mathrm{e}-011.00000 \mathrm{e}-091.00000 \mathrm{e}-01$ Element: 12754 \# of layers: 7

Kx Ky Kz Ss Por

$1.04080 \mathrm{e}+011.04080 \mathrm{e}+011.04080 \mathrm{e}+001.00000 \mathrm{e}-092.12000 \mathrm{e}-01$ $1.04080 \mathrm{e}+011.04080 \mathrm{e}+011.04080 \mathrm{e}+001.00000 \mathrm{e}-092.12000 \mathrm{e}-01$ $1.04080 \mathrm{e}+011.04080 \mathrm{e}+011.04080 \mathrm{e}+001.00000 \mathrm{e}-092.12000 \mathrm{e}-01$ $1.04080 \mathrm{e}+011.04080 \mathrm{e}+011.04080 \mathrm{e}+001.00000 \mathrm{e}-092.12000 \mathrm{e}-01$ $1.04080 \mathrm{e}+011.04080 \mathrm{e}+011.04080 \mathrm{e}+001.00000 \mathrm{e}-092.12000 \mathrm{e}-01$ $1.00000 \mathrm{e}-05$ 1.00000e-05 1.00000e-06 1.00000e-09 1.00000e-01 $1.00000 \mathrm{e}+001.00000 \mathrm{e}+001.00000 \mathrm{e}-011.00000 \mathrm{e}-091.00000 \mathrm{e}-01$ Element: 12755 \# of layers: 7

Kx Ky Kz Ss Por $1.04080 \mathrm{e}+011.04080 \mathrm{e}+011.04080 \mathrm{e}+00$ 1.00000e-09 2.12000e-01 $1.04080 \mathrm{e}+011.04080 \mathrm{e}+011.04080 \mathrm{e}+001.00000 \mathrm{e}-092.12000 \mathrm{e}-01$ $1.04080 \mathrm{e}+011.04080 \mathrm{e}+011.04080 \mathrm{e}+001.00000 \mathrm{e}-092.12000 \mathrm{e}-01$ $1.04080 \mathrm{e}+011.04080 \mathrm{e}+011.04080 \mathrm{e}+001.00000 \mathrm{e}-092.12000 \mathrm{e}-01$ $1.04080 \mathrm{e}+011.04080 \mathrm{e}+011.04080 \mathrm{e}+001.00000 \mathrm{e}-092.12000 \mathrm{e}-01$ $1.00000 \mathrm{e}-05$ 1.00000e-05 1.00000e-06 1.00000e-09 1.00000e-01 $1.00000 \mathrm{e}+001.00000 \mathrm{e}+001.00000 \mathrm{e}-011.00000 \mathrm{e}-091.00000 \mathrm{e}-01$ Element: 12756 \# of layers: 7

Kx Ky Kz Ss Por $1.04080 \mathrm{e}+011.04080 \mathrm{e}+011.04080 \mathrm{e}+00$ 1.00000e-09 2.12000e-01 $1.04080 \mathrm{e}+011.04080 \mathrm{e}+011.04080 \mathrm{e}+001.00000 \mathrm{e}-092.12000 \mathrm{e}-01$ $1.04080 \mathrm{e}+011.04080 \mathrm{e}+011.04080 \mathrm{e}+001.00000 \mathrm{e}-092.12000 \mathrm{e}-01$ $1.04080 \mathrm{e}+011.04080 \mathrm{e}+011.04080 \mathrm{e}+001.00000 \mathrm{e}-092.12000 \mathrm{e}-01$ 
$1.04080 \mathrm{e}+011.04080 \mathrm{e}+011.04080 \mathrm{e}+001.00000 \mathrm{e}-092.12000 \mathrm{e}-01$ $1.00000 \mathrm{e}-05$ 1.00000e-05 1.00000e-06 1.00000e-09 1.00000e-01

$1.00000 \mathrm{e}+001.00000 \mathrm{e}+001.00000 \mathrm{e}-011.00000 \mathrm{e}-09$ 1.00000e-01

Element: 12757 \# of layers: 7

$\mathrm{Kx} \mathrm{Ky} \mathrm{Kz}$ Ss Por

$1.04080 \mathrm{e}+011.04080 \mathrm{e}+011.04080 \mathrm{e}+001.00000 \mathrm{e}-092.12000 \mathrm{e}-01$

$1.04080 \mathrm{e}+011.04080 \mathrm{e}+011.04080 \mathrm{e}+001.00000 \mathrm{e}-092.12000 \mathrm{e}-01$

$1.04080 \mathrm{e}+011.04080 \mathrm{e}+011.04080 \mathrm{e}+001.00000 \mathrm{e}-092.12000 \mathrm{e}-01$

$1.04080 \mathrm{e}+011.04080 \mathrm{e}+011.04080 \mathrm{e}+001.00000 \mathrm{e}-092.12000 \mathrm{e}-01$

$1.04080 \mathrm{e}+011.04080 \mathrm{e}+011.04080 \mathrm{e}+001.00000 \mathrm{e}-092.12000 \mathrm{e}-01$

$1.00000 \mathrm{e}-05$ 1.00000e-05 1.00000e-06 1.00000e-09 1.00000e-01

$1.00000 \mathrm{e}+001.00000 \mathrm{e}+001.00000 \mathrm{e}-011.00000 \mathrm{e}-091.00000 \mathrm{e}-01$

Element: 12758 \# of layers: 7

$\mathrm{Kx} \mathrm{Ky} \mathrm{Kz}$ Ss Por

$1.04080 \mathrm{e}+011.04080 \mathrm{e}+011.04080 \mathrm{e}+001.00000 \mathrm{e}-092.12000 \mathrm{e}-01$

$1.04080 \mathrm{e}+011.04080 \mathrm{e}+011.04080 \mathrm{e}+001.00000 \mathrm{e}-092.12000 \mathrm{e}-01$

$1.04080 \mathrm{e}+011.04080 \mathrm{e}+011.04080 \mathrm{e}+001.00000 \mathrm{e}-092.12000 \mathrm{e}-01$

$1.04080 \mathrm{e}+011.04080 \mathrm{e}+011.04080 \mathrm{e}+001.00000 \mathrm{e}-092.12000 \mathrm{e}-01$

$1.04080 \mathrm{e}+011.04080 \mathrm{e}+011.04080 \mathrm{e}+001.00000 \mathrm{e}-092.12000 \mathrm{e}-01$

$1.00000 \mathrm{e}-05$ 1.00000e-05 1.00000e-06 1.00000e-09 1.00000e-01

$1.00000 \mathrm{e}+001.00000 \mathrm{e}+001.00000 \mathrm{e}-011.00000 \mathrm{e}-091.00000 \mathrm{e}-01$

Element: 12759 \# of layers: 7

$\mathrm{Kx} \mathrm{Ky} \mathrm{Kz}$ Ss Por

$1.04080 \mathrm{e}+011.04080 \mathrm{e}+011.04080 \mathrm{e}+001.00000 \mathrm{e}-092.12000 \mathrm{e}-01$

$1.04080 \mathrm{e}+011.04080 \mathrm{e}+011.04080 \mathrm{e}+001.00000 \mathrm{e}-092.12000 \mathrm{e}-01$

$1.04080 \mathrm{e}+011.04080 \mathrm{e}+011.04080 \mathrm{e}+001.00000 \mathrm{e}-092.12000 \mathrm{e}-01$

$1.04080 \mathrm{e}+011.04080 \mathrm{e}+011.04080 \mathrm{e}+001.00000 \mathrm{e}-092.12000 \mathrm{e}-01$

$1.04080 \mathrm{e}+011.04080 \mathrm{e}+011.04080 \mathrm{e}+001.00000 \mathrm{e}-092.12000 \mathrm{e}-01$

$1.00000 \mathrm{e}-05$ 1.00000e-05 1.00000e-06 1.00000e-09 1.00000e-01

$1.00000 \mathrm{e}+001.00000 \mathrm{e}+001.00000 \mathrm{e}-011.00000 \mathrm{e}-091.00000 \mathrm{e}-01$

Element: 12760 \# of layers: 7

$\mathrm{Kx} \mathrm{Ky} \mathrm{Kz}$ Ss Por

$1.04080 \mathrm{e}+01$ 1.04080e+01 1.04080e+00 1.00000e-09 2.12000e-01

$1.04080 \mathrm{e}+011.04080 \mathrm{e}+011.04080 \mathrm{e}+001.00000 \mathrm{e}-092.12000 \mathrm{e}-01$

$1.04080 \mathrm{e}+011.04080 \mathrm{e}+01 \quad 1.04080 \mathrm{e}+001.00000 \mathrm{e}-092.12000 \mathrm{e}-01$

$1.04080 \mathrm{e}+011.04080 \mathrm{e}+011.04080 \mathrm{e}+001.00000 \mathrm{e}-092.12000 \mathrm{e}-01$

$1.04080 \mathrm{e}+011.04080 \mathrm{e}+011.04080 \mathrm{e}+001.00000 \mathrm{e}-092.12000 \mathrm{e}-01$

$1.00000 \mathrm{e}-05$ 1.00000e-05 1.00000e-06 1.00000e-09 1.00000e-01

$1.00000 \mathrm{e}+001.00000 \mathrm{e}+001.00000 \mathrm{e}-01$ 1.00000e-09 1.00000e-01

Element: 12761 \# of layers: 7

$\mathrm{Kx} \mathrm{Ky} \mathrm{Kz}$ Ss Por

$1.04080 \mathrm{e}+01$ 1.04080e+01 1.04080e+00 1.00000e-09 2.12000e-01 $1.04080 \mathrm{e}+011.04080 \mathrm{e}+011.04080 \mathrm{e}+001.00000 \mathrm{e}-092.12000 \mathrm{e}-01$ $1.04080 \mathrm{e}+011.04080 \mathrm{e}+01$ 1.04080e+00 1.00000e-09 2.12000e-01 $1.04080 \mathrm{e}+011.04080 \mathrm{e}+011.04080 \mathrm{e}+001.00000 \mathrm{e}-092.12000 \mathrm{e}-01$ $1.04080 \mathrm{e}+011.04080 \mathrm{e}+011.04080 \mathrm{e}+001.00000 \mathrm{e}-092.12000 \mathrm{e}-01$ 
$1.00000 \mathrm{e}-05$ 1.00000e-05 1.00000e-06 1.00000e-09 1.00000e-01 $1.00000 \mathrm{e}+001.00000 \mathrm{e}+001.00000 \mathrm{e}-01$ 1.00000e-09 1.00000e-01 Element: 12762 \# of layers: 7

Kx Ky Kz Ss Por

$1.04080 \mathrm{e}+011.04080 \mathrm{e}+011.04080 \mathrm{e}+001.00000 \mathrm{e}-092.12000 \mathrm{e}-01$ $1.04080 \mathrm{e}+011.04080 \mathrm{e}+011.04080 \mathrm{e}+001.00000 \mathrm{e}-092.12000 \mathrm{e}-01$ $1.04080 \mathrm{e}+011.04080 \mathrm{e}+011.04080 \mathrm{e}+001.00000 \mathrm{e}-092.12000 \mathrm{e}-01$ $1.04080 \mathrm{e}+011.04080 \mathrm{e}+01 \quad 1.04080 \mathrm{e}+001.00000 \mathrm{e}-092.12000 \mathrm{e}-01$ $1.04080 \mathrm{e}+011.04080 \mathrm{e}+011.04080 \mathrm{e}+001.00000 \mathrm{e}-092.12000 \mathrm{e}-01$ $1.00000 \mathrm{e}-05$ 1.00000e-05 1.00000e-06 1.00000e-09 1.00000e-01 $1.00000 \mathrm{e}+001.00000 \mathrm{e}+001.00000 \mathrm{e}-011.00000 \mathrm{e}-091.00000 \mathrm{e}-01$ Element: 12763 \# of layers: 7

Kx Ky Kz Ss Por

$1.04080 \mathrm{e}+01$ 1.04080e+01 1.04080e+00 1.00000e-09 2.12000e-01 $1.04080 \mathrm{e}+011.04080 \mathrm{e}+011.04080 \mathrm{e}+001.00000 \mathrm{e}-092.12000 \mathrm{e}-01$ $1.04080 \mathrm{e}+011.04080 \mathrm{e}+011.04080 \mathrm{e}+001.00000 \mathrm{e}-092.12000 \mathrm{e}-01$ $1.04080 \mathrm{e}+011.04080 \mathrm{e}+01 \quad 1.04080 \mathrm{e}+001.00000 \mathrm{e}-092.12000 \mathrm{e}-01$ $1.04080 \mathrm{e}+011.04080 \mathrm{e}+011.04080 \mathrm{e}+001.00000 \mathrm{e}-092.12000 \mathrm{e}-01$ $1.00000 \mathrm{e}-05$ 1.00000e-05 1.00000e-06 1.00000e-09 1.00000e-01 $1.00000 \mathrm{e}+001.00000 \mathrm{e}+001.00000 \mathrm{e}-011.00000 \mathrm{e}-09$ 1.00000e-01 Element: 12764 \# of layers: 7

$\mathrm{Kx} \mathrm{Ky} \mathrm{Kz}$ Ss Por

$1.08277 \mathrm{e}+01$ 1.08277e+01 1.08277e+00 1.00000e-09 2.12000e-01 $1.08277 \mathrm{e}+011.08277 \mathrm{e}+01$ 1.08277e+00 1.00000e-09 2.12000e-01 $1.08277 \mathrm{e}+011.08277 \mathrm{e}+01$ 1.08277e+00 1.00000e-09 2.12000e-01 $1.08277 \mathrm{e}+01$ 1.08277e+01 1.08277e+00 1.00000e-09 2.12000e-01 $1.08277 \mathrm{e}+01$ 1.08277e+01 1.08277e+00 1.00000e-09 2.12000e-01 $1.00000 \mathrm{e}-05$ 1.00000e-05 1.00000e-06 1.00000e-09 1.00000e-01 $1.00000 \mathrm{e}+001.00000 \mathrm{e}+001.00000 \mathrm{e}-011.00000 \mathrm{e}-091.00000 \mathrm{e}-01$ Element: 12765 \# of layers: 7

$\mathrm{Kx} \mathrm{Ky} \mathrm{Kz}$ Ss Por

$1.08277 \mathrm{e}+01$ 1.08277e+01 1.08277e+00 1.00000e-09 2.12000e-01 $1.08277 \mathrm{e}+011.08277 \mathrm{e}+01$ 1.08277e+00 1.00000e-09 2.12000e-01 $1.08277 \mathrm{e}+01$ 1.08277e+01 1.08277e+00 1.00000e-09 2.12000e-01 $1.08277 \mathrm{e}+011.08277 \mathrm{e}+01$ 1.08277e+00 1.00000e-09 2.12000e-01 $1.08277 \mathrm{e}+01$ 1.08277e+01 1.08277e+00 1.00000e-09 2.12000e-01 $1.00000 \mathrm{e}-05$ 1.00000e-05 1.00000e-06 1.00000e-09 1.00000e-01 $1.00000 \mathrm{e}+001.00000 \mathrm{e}+001.00000 \mathrm{e}-011.00000 \mathrm{e}-091.00000 \mathrm{e}-01$ Element: 12766 \# of layers: 7

$\mathrm{Kx} \mathrm{Ky} \mathrm{Kz}$ Ss Por $1.08277 \mathrm{e}+01$ 1.08277e+01 1.08277e+00 1.00000e-09 2.12000e-01 $1.08277 \mathrm{e}+011.08277 \mathrm{e}+01$ 1.08277e+00 1.00000e-09 2.12000e-01 $1.08277 \mathrm{e}+011.08277 \mathrm{e}+01$ 1.08277e+00 1.00000e-09 2.12000e-01 1.08277e+01 1.08277e+01 1.08277e+00 1.00000e-09 2.12000e-01 $1.08277 \mathrm{e}+011.08277 \mathrm{e}+01$ 1.08277e+00 1.00000e-09 2.12000e-01 $1.00000 \mathrm{e}-05$ 1.00000e-05 1.00000e-06 1.00000e-09 1.00000e-01 
$1.00000 \mathrm{e}+001.00000 \mathrm{e}+00$ 1.00000e-01 1.00000e-09 1.00000e-01

Element: 12767 \# of layers: 7

Kx Ky Kz Ss Por

$1.08277 \mathrm{e}+01$ 1.08277e+01 1.08277e+00 1.00000e-09 2.12000e-01

$1.08277 \mathrm{e}+01$ 1.08277e+01 1.08277e+00 1.00000e-09 2.12000e-01

$1.08277 \mathrm{e}+011.08277 \mathrm{e}+01$ 1.08277e+00 1.00000e-09 2.12000e-01

$1.08277 \mathrm{e}+011.08277 \mathrm{e}+01$ 1.08277e+00 1.00000e-09 2.12000e-01

$1.08277 \mathrm{e}+01$ 1.08277e+01 1.08277e+00 1.00000e-09 2.12000e-01

$1.00000 \mathrm{e}-05$ 1.00000e-05 1.00000e-06 1.00000e-09 1.00000e-01

$1.00000 \mathrm{e}+001.00000 \mathrm{e}+001.00000 \mathrm{e}-011.00000 \mathrm{e}-091.00000 \mathrm{e}-01$

Element: 12768 \# of layers: 7

Kx Ky Kz Ss Por

$1.08277 \mathrm{e}+01$ 1.08277e+01 1.08277e+00 1.00000e-09 2.12000e-01

$1.08277 \mathrm{e}+01$ 1.08277e+01 1.08277e+00 1.00000e-09 2.12000e-01

$1.08277 \mathrm{e}+01$ 1.08277e+01 1.08277e+00 1.00000e-09 2.12000e-01

$1.08277 \mathrm{e}+01$ 1.08277e+01 1.08277e+00 1.00000e-09 2.12000e-01

$1.08277 \mathrm{e}+011.08277 \mathrm{e}+01$ 1.08277e+00 1.00000e-09 2.12000e-01

$1.00000 \mathrm{e}-05$ 1.00000e-05 1.00000e-06 1.00000e-09 1.00000e-01

$1.00000 \mathrm{e}+001.00000 \mathrm{e}+001.00000 \mathrm{e}-01$ 1.00000e-09 1.00000e-01

Element: 12769 \# of layers: 7

$\mathrm{Kx} \mathrm{Ky} \mathrm{Kz}$ Ss Por

$1.04080 \mathrm{e}+01$ 1.04080e+01 1.04080e+00 1.00000e-09 2.12000e-01

$1.04080 \mathrm{e}+011.04080 \mathrm{e}+011.04080 \mathrm{e}+001.00000 \mathrm{e}-092.12000 \mathrm{e}-01$

$1.04080 \mathrm{e}+011.04080 \mathrm{e}+011.04080 \mathrm{e}+001.00000 \mathrm{e}-092.12000 \mathrm{e}-01$

$1.04080 \mathrm{e}+011.04080 \mathrm{e}+011.04080 \mathrm{e}+001.00000 \mathrm{e}-092.12000 \mathrm{e}-01$

$1.04080 \mathrm{e}+011.04080 \mathrm{e}+011.04080 \mathrm{e}+001.00000 \mathrm{e}-092.12000 \mathrm{e}-01$

$1.00000 \mathrm{e}-05$ 1.00000e-05 1.00000e-06 1.00000e-09 1.00000e-01

$1.00000 \mathrm{e}+001.00000 \mathrm{e}+001.00000 \mathrm{e}-01$ 1.00000e-09 1.00000e-01

Element: 12770 \# of layers: 7

$\mathrm{Kx} \mathrm{Ky} \mathrm{Kz}$ Ss Por

$1.04080 \mathrm{e}+011.04080 \mathrm{e}+011.04080 \mathrm{e}+001.00000 \mathrm{e}-092.12000 \mathrm{e}-01$

$1.04080 \mathrm{e}+011.04080 \mathrm{e}+011.04080 \mathrm{e}+001.00000 \mathrm{e}-092.12000 \mathrm{e}-01$

$1.04080 \mathrm{e}+011.04080 \mathrm{e}+011.04080 \mathrm{e}+001.00000 \mathrm{e}-092.12000 \mathrm{e}-01$

$1.04080 \mathrm{e}+011.04080 \mathrm{e}+011.04080 \mathrm{e}+001.00000 \mathrm{e}-092.12000 \mathrm{e}-01$

$1.04080 \mathrm{e}+011.04080 \mathrm{e}+011.04080 \mathrm{e}+001.00000 \mathrm{e}-092.12000 \mathrm{e}-01$

$1.00000 \mathrm{e}-05$ 1.00000e-05 1.00000e-06 1.00000e-09 1.00000e-01

$1.00000 \mathrm{e}+001.00000 \mathrm{e}+001.00000 \mathrm{e}-011.00000 \mathrm{e}-091.00000 \mathrm{e}-01$

Element: 12771 \# of layers: 7

$\mathrm{Kx} \mathrm{Ky} \mathrm{Kz}$ Ss Por

$1.08277 \mathrm{e}+01$ 1.08277e+01 1.08277e+00 1.00000e-09 2.12000e-01

$1.08277 \mathrm{e}+01$ 1.08277e+01 1.08277e+00 1.00000e-09 2.12000e-01

$1.08277 \mathrm{e}+01$ 1.08277e+01 1.08277e+00 1.00000e-09 2.12000e-01

$1.08277 \mathrm{e}+01$ 1.08277e+01 1.08277e+00 1.00000e-09 2.12000e-01

1.08277e+01 1.08277e+01 1.08277e+00 1.00000e-09 2.12000e-01

$1.00000 \mathrm{e}-05$ 1.00000e-05 1.00000e-06 1.00000e-09 1.00000e-01

$1.00000 \mathrm{e}+001.00000 \mathrm{e}+001.00000 \mathrm{e}-011.00000 \mathrm{e}-091.00000 \mathrm{e}-01$ 
Element: 12772 \# of layers: 7

Kx Ky Kz Ss Por

$1.08277 \mathrm{e}+011.08277 \mathrm{e}+011.08277 \mathrm{e}+00$ 1.00000e-09 2.12000e-01

$1.08277 \mathrm{e}+011.08277 \mathrm{e}+011.08277 \mathrm{e}+001.00000 \mathrm{e}-092.12000 \mathrm{e}-01$

$1.08277 \mathrm{e}+011.08277 \mathrm{e}+011.08277 \mathrm{e}+001.00000 \mathrm{e}-092.12000 \mathrm{e}-01$

$1.08277 \mathrm{e}+011.08277 \mathrm{e}+011.08277 \mathrm{e}+001.00000 \mathrm{e}-092.12000 \mathrm{e}-01$

$1.08277 \mathrm{e}+011.08277 \mathrm{e}+011.08277 \mathrm{e}+00$ 1.00000e-09 2.12000e-01

$1.00000 \mathrm{e}-05$ 1.00000e-05 1.00000e-06 1.00000e-09 1.00000e-01

$1.00000 \mathrm{e}+001.00000 \mathrm{e}+001.00000 \mathrm{e}-011.00000 \mathrm{e}-091.00000 \mathrm{e}-01$

Element: 12773 \# of layers: 7

Kx Ky Kz Ss Por

$1.13396 \mathrm{e}+011.13396 \mathrm{e}+011.13396 \mathrm{e}+00$ 1.00000e-09 2.12000e-01

$1.13396 \mathrm{e}+011.13396 \mathrm{e}+011.13396 \mathrm{e}+001.00000 \mathrm{e}-092.12000 \mathrm{e}-01$

$1.13396 \mathrm{e}+011.13396 \mathrm{e}+011.13396 \mathrm{e}+001.00000 \mathrm{e}-092.12000 \mathrm{e}-01$

$1.13396 \mathrm{e}+011.13396 \mathrm{e}+011.13396 \mathrm{e}+001.00000 \mathrm{e}-092.12000 \mathrm{e}-01$

$1.13396 \mathrm{e}+011.13396 \mathrm{e}+011.13396 \mathrm{e}+001.00000 \mathrm{e}-092.12000 \mathrm{e}-01$

$1.00000 \mathrm{e}-05$ 1.00000e-05 1.00000e-06 1.00000e-09 1.00000e-01

$1.00000 \mathrm{e}+001.00000 \mathrm{e}+001.00000 \mathrm{e}-011.00000 \mathrm{e}-091.00000 \mathrm{e}-01$

Element: 12774 \# of layers: 7

Kx Ky Kz Ss Por

$1.13396 \mathrm{e}+011.13396 \mathrm{e}+011.13396 \mathrm{e}+00$ 1.00000e-09 2.12000e-01

$1.13396 \mathrm{e}+011.13396 \mathrm{e}+011.13396 \mathrm{e}+001.00000 \mathrm{e}-092.12000 \mathrm{e}-01$

$1.13396 \mathrm{e}+011.13396 \mathrm{e}+011.13396 \mathrm{e}+00$ 1.00000e-09 2.12000e-01

$1.13396 \mathrm{e}+011.13396 \mathrm{e}+011.13396 \mathrm{e}+001.00000 \mathrm{e}-092.12000 \mathrm{e}-01$

$1.13396 \mathrm{e}+011.13396 \mathrm{e}+011.13396 \mathrm{e}+001.00000 \mathrm{e}-092.12000 \mathrm{e}-01$

$1.00000 \mathrm{e}-05$ 1.00000e-05 1.00000e-06 1.00000e-09 1.00000e-01

$1.00000 \mathrm{e}+001.00000 \mathrm{e}+001.00000 \mathrm{e}-011.00000 \mathrm{e}-091.00000 \mathrm{e}-01$

Element: 12775 \# of layers: 7

Kx Ky Kz Ss Por

$1.13396 \mathrm{e}+011.13396 \mathrm{e}+011.13396 \mathrm{e}+00$ 1.00000e-09 2.12000e-01

$1.13396 \mathrm{e}+011.13396 \mathrm{e}+011.13396 \mathrm{e}+001.00000 \mathrm{e}-092.12000 \mathrm{e}-01$

$1.13396 \mathrm{e}+011.13396 \mathrm{e}+011.13396 \mathrm{e}+00$ 1.00000e-09 2.12000e-01

$1.13396 \mathrm{e}+011.13396 \mathrm{e}+011.13396 \mathrm{e}+00$ 1.00000e-09 2.12000e-01

$1.13396 \mathrm{e}+011.13396 \mathrm{e}+011.13396 \mathrm{e}+001.00000 \mathrm{e}-092.12000 \mathrm{e}-01$

$1.00000 \mathrm{e}-05$ 1.00000e-05 1.00000e-06 1.00000e-09 1.00000e-01

$1.00000 \mathrm{e}+001.00000 \mathrm{e}+001.00000 \mathrm{e}-011.00000 \mathrm{e}-091.00000 \mathrm{e}-01$

Element: 12776 \# of layers: 7

Kx Ky Kz Ss Por

$8.83594 \mathrm{e}+008.83594 \mathrm{e}+00$ 8.83594e-01 1.00000e-09 2.12000e-01

$8.83594 \mathrm{e}+008.83594 \mathrm{e}+00$ 8.83594e-01 1.00000e-09 2.12000e-01

$8.83594 \mathrm{e}+008.83594 \mathrm{e}+00$ 8.83594e-01 1.00000e-09 2.12000e-01

$8.83594 \mathrm{e}+008.83594 \mathrm{e}+00$ 8.83594e-01 1.00000e-09 2.12000e-01

$8.83594 \mathrm{e}+008.83594 \mathrm{e}+00$ 8.83594e-01 1.00000e-09 2.12000e-01

$1.00000 \mathrm{e}-05$ 1.00000e-05 1.00000e-06 1.00000e-09 1.00000e-01

$1.00000 \mathrm{e}+001.00000 \mathrm{e}+001.00000 \mathrm{e}-011.00000 \mathrm{e}-091.00000 \mathrm{e}-01$

Element: 12777 \# of layers: 7 
$\mathrm{Kx} \mathrm{Ky} \mathrm{Kz}$ Ss Por

8.83594e+00 8.83594e+00 8.83594e-01 1.00000e-09 2.12000e-01 $8.83594 \mathrm{e}+008.83594 \mathrm{e}+008.83594 \mathrm{e}-01$ 1.00000e-09 2.12000e-01 $8.83594 \mathrm{e}+008.83594 \mathrm{e}+008.83594 \mathrm{e}-01$ 1.00000e-09 2.12000e-01 8.83594e+00 8.83594e+00 8.83594e-01 1.00000e-09 2.12000e-01 $8.83594 \mathrm{e}+008.83594 \mathrm{e}+008.83594 \mathrm{e}-01$ 1.00000e-09 2.12000e-01 $1.00000 \mathrm{e}-05$ 1.00000e-05 1.00000e-06 1.00000e-09 1.00000e-01 $1.00000 \mathrm{e}+001.00000 \mathrm{e}+001.00000 \mathrm{e}-011.00000 \mathrm{e}-091.00000 \mathrm{e}-01$ Element: 12778 \# of layers: 7

$\mathrm{Kx} \mathrm{Ky} \mathrm{Kz}$ Ss Por

$1.04080 \mathrm{e}+01$ 1.04080e+01 1.04080e+00 1.00000e-09 2.12000e-01 $1.04080 \mathrm{e}+011.04080 \mathrm{e}+01 \quad 1.04080 \mathrm{e}+001.00000 \mathrm{e}-092.12000 \mathrm{e}-01$ $1.04080 \mathrm{e}+011.04080 \mathrm{e}+01$ 1.04080e+00 1.00000e-09 2.12000e-01 $1.04080 \mathrm{e}+011.04080 \mathrm{e}+011.04080 \mathrm{e}+001.00000 \mathrm{e}-092.12000 \mathrm{e}-01$ $1.04080 \mathrm{e}+011.04080 \mathrm{e}+011.04080 \mathrm{e}+001.00000 \mathrm{e}-092.12000 \mathrm{e}-01$ $1.00000 \mathrm{e}-05$ 1.00000e-05 1.00000e-06 1.00000e-09 1.00000e-01 $1.00000 \mathrm{e}+001.00000 \mathrm{e}+001.00000 \mathrm{e}-01$ 1.00000e-09 1.00000e-01 Element: 12779 \# of layers: 7

$\mathrm{Kx} \mathrm{Ky} \mathrm{Kz}$ Ss Por

$1.08277 \mathrm{e}+01$ 1.08277e+01 1.08277e+00 1.00000e-09 2.12000e-01 $1.08277 \mathrm{e}+011.08277 \mathrm{e}+01$ 1.08277e+00 1.00000e-09 2.12000e-01 $1.08277 \mathrm{e}+01$ 1.08277e+01 1.08277e+00 1.00000e-09 2.12000e-01 $1.08277 \mathrm{e}+01$ 1.08277e+01 1.08277e+00 1.00000e-09 2.12000e-01 $1.08277 \mathrm{e}+011.08277 \mathrm{e}+01$ 1.08277e+00 1.00000e-09 2.12000e-01 $1.00000 \mathrm{e}-05$ 1.00000e-05 1.00000e-06 1.00000e-09 1.00000e-01 $1.00000 \mathrm{e}+001.00000 \mathrm{e}+001.00000 \mathrm{e}-011.00000 \mathrm{e}-091.00000 \mathrm{e}-01$ Element: 12780 \# of layers: 7

$\mathrm{Kx} \mathrm{Ky} \mathrm{Kz}$ Ss Por

$1.13396 \mathrm{e}+01$ 1.13396e+01 1.13396e+00 1.00000e-09 2.12000e-01 $1.13396 \mathrm{e}+01$ 1.13396e+01 1.13396e+00 1.00000e-09 2.12000e-01 $1.13396 \mathrm{e}+01$ 1.13396e+01 1.13396e+00 1.00000e-09 2.12000e-01 $1.13396 \mathrm{e}+011.13396 \mathrm{e}+01$ 1.13396e+00 1.00000e-09 2.12000e-01 $1.13396 \mathrm{e}+011.13396 \mathrm{e}+011.13396 \mathrm{e}+001.00000 \mathrm{e}-092.12000 \mathrm{e}-01$ $1.00000 \mathrm{e}-05$ 1.00000e-05 1.00000e-06 1.00000e-09 1.00000e-01 $1.00000 \mathrm{e}+001.00000 \mathrm{e}+001.00000 \mathrm{e}-01$ 1.00000e-09 1.00000e-01 Element: 12781 \# of layers: 7

Kx Ky Kz Ss Por

5.77925e+00 5.77925e+00 5.77925e-01 1.00000e-09 2.12000e-01 $5.77925 \mathrm{e}+00$ 5.77925e+00 5.77925e-01 1.00000e-09 2.12000e-01 5.77925e+00 5.77925e+00 5.77925e-01 1.00000e-09 2.12000e-01 $5.77925 \mathrm{e}+00$ 5.77925e+00 5.77925e-01 1.00000e-09 2.12000e-01 $5.77925 \mathrm{e}+005.77925 \mathrm{e}+00$ 5.77925e-01 1.00000e-09 2.12000e-01 $1.00000 \mathrm{e}-051.00000 \mathrm{e}-051.00000 \mathrm{e}-061.00000 \mathrm{e}-091.00000 \mathrm{e}-01$ $1.00000 \mathrm{e}+001.00000 \mathrm{e}+001.00000 \mathrm{e}-01$ 1.00000e-09 1.00000e-01 Element: 12782 \# of layers: 7

Kx Ky Kz Ss Por 
$5.77925 \mathrm{e}+00$ 5.77925e+00 5.77925e-01 1.00000e-09 2.12000e-01 $5.77925 \mathrm{e}+005.77925 \mathrm{e}+005.77925 \mathrm{e}-011.00000 \mathrm{e}-092.12000 \mathrm{e}-01$ $5.77925 \mathrm{e}+005.77925 \mathrm{e}+00$ 5.77925e-01 1.00000e-09 2.12000e-01 $5.77925 \mathrm{e}+005.77925 \mathrm{e}+00$ 5.77925e-01 1.00000e-09 2.12000e-01 $5.77925 \mathrm{e}+00$ 5.77925e+00 5.77925e-01 1.00000e-09 2.12000e-01 $1.00000 \mathrm{e}-05$ 1.00000e-05 1.00000e-06 1.00000e-09 1.00000e-01 $1.00000 \mathrm{e}+001.00000 \mathrm{e}+001.00000 \mathrm{e}-011.00000 \mathrm{e}-091.00000 \mathrm{e}-01$ Element: 12783 \# of layers: 7

$\mathrm{Kx} \mathrm{Ky} \mathrm{Kz}$ Ss Por

5.77925e+00 5.77925e+00 5.77925e-01 1.00000e-09 2.12000e-01 $5.77925 \mathrm{e}+005.77925 \mathrm{e}+00$ 5.77925e-01 1.00000e-09 2.12000e-01 $5.77925 \mathrm{e}+00$ 5.77925e+00 5.77925e-01 1.00000e-09 2.12000e-01 $5.77925 \mathrm{e}+005.77925 \mathrm{e}+005.77925 \mathrm{e}-011.00000 \mathrm{e}-092.12000 \mathrm{e}-01$ $5.77925 \mathrm{e}+00$ 5.77925e+00 5.77925e-01 1.00000e-09 2.12000e-01 $1.00000 \mathrm{e}-05$ 1.00000e-05 1.00000e-06 1.00000e-09 1.00000e-01 $1.00000 \mathrm{e}+001.00000 \mathrm{e}+001.00000 \mathrm{e}-011.00000 \mathrm{e}-091.00000 \mathrm{e}-01$ Element: 12784 \# of layers: 7

Kx Ky Kz Ss Por

$5.77925 \mathrm{e}+00$ 5.77925e+00 5.77925e-01 1.00000e-09 2.12000e-01

$5.77925 \mathrm{e}+005.77925 \mathrm{e}+00$ 5.77925e-01 1.00000e-09 2.12000e-01

$5.77925 \mathrm{e}+005.77925 \mathrm{e}+00$ 5.77925e-01 1.00000e-09 2.12000e-01

$5.77925 \mathrm{e}+005.77925 \mathrm{e}+00$ 5.77925e-01 1.00000e-09 2.12000e-01

$5.77925 \mathrm{e}+005.77925 \mathrm{e}+00$ 5.77925e-01 1.00000e-09 2.12000e-01 $1.00000 \mathrm{e}-05$ 1.00000e-05 1.00000e-06 1.00000e-09 1.00000e-01 $1.00000 \mathrm{e}+001.00000 \mathrm{e}+001.00000 \mathrm{e}-011.00000 \mathrm{e}-091.00000 \mathrm{e}-01$ Element: 12785 \# of layers: 7

Kx Ky Kz Ss Por

$5.77925 \mathrm{e}+00$ 5.77925e+00 5.77925e-01 1.00000e-09 2.12000e-01 $5.77925 \mathrm{e}+00$ 5.77925e+00 5.77925e-01 1.00000e-09 2.12000e-01 $5.77925 \mathrm{e}+005.77925 \mathrm{e}+00$ 5.77925e-01 1.00000e-09 2.12000e-01 $5.77925 \mathrm{e}+00$ 5.77925e+00 5.77925e-01 1.00000e-09 2.12000e-01 $5.77925 \mathrm{e}+00$ 5.77925e+00 5.77925e-01 1.00000e-09 2.12000e-01 $1.00000 \mathrm{e}-05$ 1.00000e-05 1.00000e-06 1.00000e-09 1.00000e-01 $1.00000 \mathrm{e}+001.00000 \mathrm{e}+001.00000 \mathrm{e}-011.00000 \mathrm{e}-091.00000 \mathrm{e}-01$ Element: 12786 \# of layers: 7

Kx Ky Kz Ss Por

$5.77925 \mathrm{e}+00$ 5.77925e+00 5.77925e-01 1.00000e-09 2.12000e-01 $5.77925 \mathrm{e}+005.77925 \mathrm{e}+00$ 5.77925e-01 1.00000e-09 2.12000e-01 $5.77925 \mathrm{e}+005.77925 \mathrm{e}+005.77925 \mathrm{e}-011.00000 \mathrm{e}-092.12000 \mathrm{e}-01$ $5.77925 \mathrm{e}+005.77925 \mathrm{e}+00$ 5.77925e-01 1.00000e-09 2.12000e-01 $5.77925 \mathrm{e}+00$ 5.77925e+00 5.77925e-01 1.00000e-09 2.12000e-01 $1.00000 \mathrm{e}-05$ 1.00000e-05 1.00000e-06 1.00000e-09 1.00000e-01 $1.00000 \mathrm{e}+001.00000 \mathrm{e}+001.00000 \mathrm{e}-011.00000 \mathrm{e}-091.00000 \mathrm{e}-01$ Element: 12787 \# of layers: 7

Kx Ky Kz Ss Por

5.77925e+00 5.77925e+00 5.77925e-01 1.00000e-09 2.12000e-01 
$5.77925 \mathrm{e}+00$ 5.77925e+00 5.77925e-01 1.00000e-09 2.12000e-01 $5.77925 \mathrm{e}+005.77925 \mathrm{e}+00$ 5.77925e-01 1.00000e-09 2.12000e-01 $5.77925 \mathrm{e}+005.77925 \mathrm{e}+00$ 5.77925e-01 1.00000e-09 2.12000e-01 $5.77925 \mathrm{e}+005.77925 \mathrm{e}+00$ 5.77925e-01 1.00000e-09 2.12000e-01 $1.00000 \mathrm{e}-05$ 1.00000e-05 1.00000e-06 1.00000e-09 1.00000e-01 $1.00000 \mathrm{e}+001.00000 \mathrm{e}+001.00000 \mathrm{e}-011.00000 \mathrm{e}-091.00000 \mathrm{e}-01$ Element: 12788 \# of layers: 7

Kx Ky Kz Ss Por

$5.77925 \mathrm{e}+00$ 5.77925e+00 5.77925e-01 1.00000e-09 2.12000e-01 $5.77925 \mathrm{e}+00$ 5.77925e+00 5.77925e-01 1.00000e-09 2.12000e-01 $5.77925 \mathrm{e}+005.77925 \mathrm{e}+00$ 5.77925e-01 1.00000e-09 2.12000e-01 $5.77925 \mathrm{e}+005.77925 \mathrm{e}+00$ 5.77925e-01 1.00000e-09 2.12000e-01 $5.77925 \mathrm{e}+005.77925 \mathrm{e}+00$ 5.77925e-01 1.00000e-09 2.12000e-01 $1.00000 \mathrm{e}-05$ 1.00000e-05 1.00000e-06 1.00000e-09 1.00000e-01 $1.00000 \mathrm{e}+001.00000 \mathrm{e}+001.00000 \mathrm{e}-011.00000 \mathrm{e}-091.00000 \mathrm{e}-01$ Element: 12789 \# of layers: 7

Kx Ky Kz Ss Por

$5.77925 \mathrm{e}+00$ 5.77925e+00 5.77925e-01 1.00000e-09 2.12000e-01 $5.77925 \mathrm{e}+005.77925 \mathrm{e}+005.77925 \mathrm{e}-011.00000 \mathrm{e}-092.12000 \mathrm{e}-01$ $5.77925 \mathrm{e}+005.77925 \mathrm{e}+00$ 5.77925e-01 1.00000e-09 2.12000e-01 $5.77925 \mathrm{e}+005.77925 \mathrm{e}+00$ 5.77925e-01 1.00000e-09 2.12000e-01 $5.77925 \mathrm{e}+005.77925 \mathrm{e}+00$ 5.77925e-01 1.00000e-09 2.12000e-01 $1.00000 \mathrm{e}-05$ 1.00000e-05 1.00000e-06 1.00000e-09 1.00000e-01 $1.00000 \mathrm{e}+001.00000 \mathrm{e}+001.00000 \mathrm{e}-011.00000 \mathrm{e}-091.00000 \mathrm{e}-01$ Element: 12790 \# of layers: 7

Kx Ky Kz Ss Por

$5.77925 \mathrm{e}+00$ 5.77925e+00 5.77925e-01 1.00000e-09 2.12000e-01 $5.77925 \mathrm{e}+005.77925 \mathrm{e}+00$ 5.77925e-01 1.00000e-09 2.12000e-01 $5.77925 \mathrm{e}+005.77925 \mathrm{e}+00$ 5.77925e-01 1.00000e-09 2.12000e-01 $5.77925 \mathrm{e}+005.77925 \mathrm{e}+00$ 5.77925e-01 1.00000e-09 2.12000e-01 $5.77925 \mathrm{e}+00$ 5.77925e+00 5.77925e-01 1.00000e-09 2.12000e-01 $1.00000 \mathrm{e}-05$ 1.00000e-05 1.00000e-06 1.00000e-09 1.00000e-01 $1.00000 \mathrm{e}+001.00000 \mathrm{e}+001.00000 \mathrm{e}-011.00000 \mathrm{e}-091.00000 \mathrm{e}-01$ Element: 12791 \# of layers: 7

Kx Ky Kz Ss Por

$3.41647 \mathrm{e}+003.41647 \mathrm{e}+003.41647 \mathrm{e}-01$ 1.00000e-09 2.12000e-01 $3.41647 \mathrm{e}+003.41647 \mathrm{e}+003.41647 \mathrm{e}-011.00000 \mathrm{e}-092.12000 \mathrm{e}-01$ $3.41647 \mathrm{e}+003.41647 \mathrm{e}+003.41647 \mathrm{e}-01$ 1.00000e-09 2.12000e-01 $3.41647 \mathrm{e}+003.41647 \mathrm{e}+003.41647 \mathrm{e}-01$ 1.00000e-09 2.12000e-01 $3.41647 \mathrm{e}+003.41647 \mathrm{e}+003.41647 \mathrm{e}-01$ 1.00000e-09 2.12000e-01 $1.00000 \mathrm{e}-05$ 1.00000e-05 1.00000e-06 1.00000e-09 1.00000e-01 $1.00000 \mathrm{e}+001.00000 \mathrm{e}+001.00000 \mathrm{e}-011.00000 \mathrm{e}-091.00000 \mathrm{e}-01$ Element: 12792 \# of layers: 7

Kx Ky Kz Ss Por

$3.41647 \mathrm{e}+003.41647 \mathrm{e}+00$ 3.41647e-01 1.00000e-09 2.12000e-01 $3.41647 \mathrm{e}+003.41647 \mathrm{e}+003.41647 \mathrm{e}-01$ 1.00000e-09 2.12000e-01 
$3.41647 \mathrm{e}+003.41647 \mathrm{e}+003.41647 \mathrm{e}-01$ 1.00000e-09 2.12000e-01 $3.41647 \mathrm{e}+003.41647 \mathrm{e}+003.41647 \mathrm{e}-01$ 1.00000e-09 2.12000e-01 $3.41647 \mathrm{e}+003.41647 \mathrm{e}+003.41647 \mathrm{e}-01$ 1.00000e-09 2.12000e-01 $1.00000 \mathrm{e}-05$ 1.00000e-05 1.00000e-06 1.00000e-09 1.00000e-01 $1.00000 \mathrm{e}+001.00000 \mathrm{e}+001.00000 \mathrm{e}-011.00000 \mathrm{e}-091.00000 \mathrm{e}-01$ Element: 12793 \# of layers: 7

Kx Ky Kz Ss Por

$3.41647 \mathrm{e}+003.41647 \mathrm{e}+00$ 3.41647e-01 1.00000e-09 2.12000e-01 $3.41647 \mathrm{e}+003.41647 \mathrm{e}+003.41647 \mathrm{e}-011.00000 \mathrm{e}-092.12000 \mathrm{e}-01$ $3.41647 \mathrm{e}+003.41647 \mathrm{e}+003.41647 \mathrm{e}-011.00000 \mathrm{e}-092.12000 \mathrm{e}-01$ $3.41647 \mathrm{e}+003.41647 \mathrm{e}+003.41647 \mathrm{e}-011.00000 \mathrm{e}-092.12000 \mathrm{e}-01$ $3.41647 \mathrm{e}+003.41647 \mathrm{e}+003.41647 \mathrm{e}-01$ 1.00000e-09 2.12000e-01 $1.00000 \mathrm{e}-05$ 1.00000e-05 1.00000e-06 1.00000e-09 1.00000e-01 $1.00000 \mathrm{e}+001.00000 \mathrm{e}+001.00000 \mathrm{e}-011.00000 \mathrm{e}-091.00000 \mathrm{e}-01$ Element: 12794 \# of layers: 7

Kx Ky Kz Ss Por

$3.41647 \mathrm{e}+003.41647 \mathrm{e}+00$ 3.41647e-01 1.00000e-09 2.12000e-01 $3.41647 \mathrm{e}+003.41647 \mathrm{e}+003.41647 \mathrm{e}-011.00000 \mathrm{e}-092.12000 \mathrm{e}-01$ $3.41647 \mathrm{e}+003.41647 \mathrm{e}+003.41647 \mathrm{e}-01$ 1.00000e-09 2.12000e-01 $3.41647 \mathrm{e}+003.41647 \mathrm{e}+003.41647 \mathrm{e}-011.00000 \mathrm{e}-092.12000 \mathrm{e}-01$ $3.41647 \mathrm{e}+003.41647 \mathrm{e}+003.41647 \mathrm{e}-01$ 1.00000e-09 2.12000e-01 $1.00000 \mathrm{e}-05$ 1.00000e-05 1.00000e-06 1.00000e-09 1.00000e-01 $1.00000 \mathrm{e}+001.00000 \mathrm{e}+001.00000 \mathrm{e}-011.00000 \mathrm{e}-091.00000 \mathrm{e}-01$ Element: 12795 \# of layers: 7

Kx Ky Kz Ss Por

$3.41647 \mathrm{e}+003.41647 \mathrm{e}+003.41647 \mathrm{e}-011.00000 \mathrm{e}-092.12000 \mathrm{e}-01$ $3.41647 \mathrm{e}+003.41647 \mathrm{e}+003.41647 \mathrm{e}-01$ 1.00000e-09 2.12000e-01 $3.41647 \mathrm{e}+003.41647 \mathrm{e}+003.41647 \mathrm{e}-011.00000 \mathrm{e}-092.12000 \mathrm{e}-01$ $3.41647 \mathrm{e}+003.41647 \mathrm{e}+003.41647 \mathrm{e}-011.00000 \mathrm{e}-09$ 2.12000e-01 $3.41647 \mathrm{e}+003.41647 \mathrm{e}+003.41647 \mathrm{e}-011.00000 \mathrm{e}-092.12000 \mathrm{e}-01$ $1.00000 \mathrm{e}-05$ 1.00000e-05 1.00000e-06 1.00000e-09 1.00000e-01 $1.00000 \mathrm{e}+001.00000 \mathrm{e}+001.00000 \mathrm{e}-011.00000 \mathrm{e}-091.00000 \mathrm{e}-01$ Element: 12796 \# of layers: 7

$\mathrm{Kx} \mathrm{Ky} \mathrm{Kz}$ Ss Por

5.77925e+00 5.77925e+00 5.77925e-01 1.00000e-09 2.12000e-01 5.77925e+00 5.77925e+00 5.77925e-01 1.00000e-09 2.12000e-01 $5.77925 \mathrm{e}+005.77925 \mathrm{e}+00$ 5.77925e-01 1.00000e-09 2.12000e-01 $5.77925 \mathrm{e}+005.77925 \mathrm{e}+00$ 5.77925e-01 1.00000e-09 2.12000e-01 $5.77925 \mathrm{e}+00$ 5.77925e+00 5.77925e-01 1.00000e-09 2.12000e-01 $1.00000 \mathrm{e}-05$ 1.00000e-05 1.00000e-06 1.00000e-09 1.00000e-01 $1.00000 \mathrm{e}+001.00000 \mathrm{e}+001.00000 \mathrm{e}-011.00000 \mathrm{e}-091.00000 \mathrm{e}-01$ Element: 12797 \# of layers: 7

$\mathrm{Kx} \mathrm{Ky} \mathrm{Kz}$ Ss Por

5.77925e+00 5.77925e+00 5.77925e-01 1.00000e-09 2.12000e-01 $5.77925 \mathrm{e}+005.77925 \mathrm{e}+00$ 5.77925e-01 1.00000e-09 2.12000e-01 $5.77925 \mathrm{e}+00$ 5.77925e+00 5.77925e-01 1.00000e-09 2.12000e-01 
$5.77925 \mathrm{e}+00$ 5.77925e+00 5.77925e-01 1.00000e-09 2.12000e-01 $5.77925 \mathrm{e}+00$ 5.77925e+00 5.77925e-01 1.00000e-09 2.12000e-01 $1.00000 \mathrm{e}-05$ 1.00000e-05 1.00000e-06 1.00000e-09 1.00000e-01 $1.00000 \mathrm{e}+001.00000 \mathrm{e}+001.00000 \mathrm{e}-011.00000 \mathrm{e}-091.00000 \mathrm{e}-01$ Element: 12798 \# of layers: 7

Kx Ky Kz Ss Por

$3.41647 \mathrm{e}+003.41647 \mathrm{e}+003.41647 \mathrm{e}-01$ 1.00000e-09 2.12000e-01 $3.41647 \mathrm{e}+003.41647 \mathrm{e}+003.41647 \mathrm{e}-011.00000 \mathrm{e}-092.12000 \mathrm{e}-01$ $3.41647 \mathrm{e}+003.41647 \mathrm{e}+003.41647 \mathrm{e}-011.00000 \mathrm{e}-092.12000 \mathrm{e}-01$ $3.41647 \mathrm{e}+003.41647 \mathrm{e}+003.41647 \mathrm{e}-011.00000 \mathrm{e}-092.12000 \mathrm{e}-01$ $3.41647 \mathrm{e}+003.41647 \mathrm{e}+003.41647 \mathrm{e}-01$ 1.00000e-09 2.12000e-01 $1.00000 \mathrm{e}-05$ 1.00000e-05 1.00000e-06 1.00000e-09 1.00000e-01 $1.00000 \mathrm{e}+001.00000 \mathrm{e}+001.00000 \mathrm{e}-011.00000 \mathrm{e}-091.00000 \mathrm{e}-01$ Element: 12799 \# of layers: 7

Kx Ky Kz Ss Por

$3.41647 \mathrm{e}+003.41647 \mathrm{e}+00$ 3.41647e-01 1.00000e-09 2.12000e-01 $3.41647 \mathrm{e}+003.41647 \mathrm{e}+003.41647 \mathrm{e}-011.00000 \mathrm{e}-092.12000 \mathrm{e}-01$ $3.41647 \mathrm{e}+003.41647 \mathrm{e}+003.41647 \mathrm{e}-011.00000 \mathrm{e}-092.12000 \mathrm{e}-01$ $3.41647 \mathrm{e}+003.41647 \mathrm{e}+003.41647 \mathrm{e}-01$ 1.00000e-09 2.12000e-01 $3.41647 \mathrm{e}+003.41647 \mathrm{e}+003.41647 \mathrm{e}-011.00000 \mathrm{e}-09$ 2.12000e-01 $1.00000 \mathrm{e}-05$ 1.00000e-05 1.00000e-06 1.00000e-09 1.00000e-01 $1.00000 \mathrm{e}+001.00000 \mathrm{e}+001.00000 \mathrm{e}-011.00000 \mathrm{e}-091.00000 \mathrm{e}-01$ Element: 12800 \# of layers: 7

Kx Ky Kz Ss Por

$3.41647 \mathrm{e}+003.41647 \mathrm{e}+00$ 3.41647e-01 1.00000e-09 2.12000e-01 $3.41647 \mathrm{e}+003.41647 \mathrm{e}+003.41647 \mathrm{e}-011.00000 \mathrm{e}-092.12000 \mathrm{e}-01$ $3.41647 \mathrm{e}+003.41647 \mathrm{e}+003.41647 \mathrm{e}-01$ 1.00000e-09 2.12000e-01 $3.41647 \mathrm{e}+003.41647 \mathrm{e}+003.41647 \mathrm{e}-011.00000 \mathrm{e}-092.12000 \mathrm{e}-01$ $3.41647 \mathrm{e}+003.41647 \mathrm{e}+003.41647 \mathrm{e}-011.00000 \mathrm{e}-09$ 2.12000e-01 $1.00000 \mathrm{e}-05$ 1.00000e-05 1.00000e-06 1.00000e-09 1.00000e-01 $1.00000 \mathrm{e}+001.00000 \mathrm{e}+001.00000 \mathrm{e}-011.00000 \mathrm{e}-091.00000 \mathrm{e}-01$ Element: 12801 \# of layers: 7

Kx Ky Kz Ss Por

$3.41647 \mathrm{e}+003.41647 \mathrm{e}+003.41647 \mathrm{e}-011.00000 \mathrm{e}-092.12000 \mathrm{e}-01$ $3.41647 \mathrm{e}+003.41647 \mathrm{e}+003.41647 \mathrm{e}-011.00000 \mathrm{e}-092.12000 \mathrm{e}-01$ $3.41647 \mathrm{e}+003.41647 \mathrm{e}+003.41647 \mathrm{e}-011.00000 \mathrm{e}-092.12000 \mathrm{e}-01$ $3.41647 \mathrm{e}+003.41647 \mathrm{e}+003.41647 \mathrm{e}-011.00000 \mathrm{e}-092.12000 \mathrm{e}-01$ $3.41647 \mathrm{e}+003.41647 \mathrm{e}+003.41647 \mathrm{e}-011.00000 \mathrm{e}-09$ 2.12000e-01 $1.00000 \mathrm{e}-05$ 1.00000e-05 1.00000e-06 1.00000e-09 1.00000e-01 $1.00000 \mathrm{e}+001.00000 \mathrm{e}+001.00000 \mathrm{e}-011.00000 \mathrm{e}-091.00000 \mathrm{e}-01$ Element: 12802 \# of layers: 7

Kx Ky Kz Ss Por

$3.41647 \mathrm{e}+003.41647 \mathrm{e}+003.41647 \mathrm{e}-011.00000 \mathrm{e}-092.12000 \mathrm{e}-01$ $3.41647 \mathrm{e}+003.41647 \mathrm{e}+003.41647 \mathrm{e}-011.00000 \mathrm{e}-092.12000 \mathrm{e}-01$ $3.41647 \mathrm{e}+003.41647 \mathrm{e}+003.41647 \mathrm{e}-01$ 1.00000e-09 2.12000e-01 $3.41647 \mathrm{e}+003.41647 \mathrm{e}+003.41647 \mathrm{e}-01$ 1.00000e-09 2.12000e-01 
3.41647e+00 3.41647e+00 3.41647e-01 1.00000e-09 2.12000e-01 $1.00000 \mathrm{e}-05$ 1.00000e-05 1.00000e-06 1.00000e-09 1.00000e-01

$1.00000 \mathrm{e}+001.00000 \mathrm{e}+001.00000 \mathrm{e}-01$ 1.00000e-09 1.00000e-01

Element: 12803 \# of layers: 7

$\mathrm{Kx} \mathrm{Ky} \mathrm{Kz}$ Ss Por

3.41647e+00 3.41647e+00 3.41647e-01 1.00000e-09 2.12000e-01

3.41647e+00 3.41647e+00 3.41647e-01 1.00000e-09 2.12000e-01

$3.41647 \mathrm{e}+003.41647 \mathrm{e}+003.41647 \mathrm{e}-01$ 1.00000e-09 2.12000e-01

$3.41647 \mathrm{e}+003.41647 \mathrm{e}+003.41647 \mathrm{e}-01$ 1.00000e-09 2.12000e-01

$3.41647 \mathrm{e}+003.41647 \mathrm{e}+00$ 3.41647e-01 1.00000e-09 2.12000e-01

$1.00000 \mathrm{e}-05$ 1.00000e-05 1.00000e-06 1.00000e-09 1.00000e-01

$1.00000 \mathrm{e}+001.00000 \mathrm{e}+001.00000 \mathrm{e}-011.00000 \mathrm{e}-091.00000 \mathrm{e}-01$

Element: 12804 \# of layers: 7

$\mathrm{Kx} \mathrm{Ky} \mathrm{Kz}$ Ss Por

3.41647e+00 3.41647e+00 3.41647e-01 1.00000e-09 2.12000e-01

$3.41647 \mathrm{e}+003.41647 \mathrm{e}+00$ 3.41647e-01 1.00000e-09 2.12000e-01

3.41647e+00 3.41647e+00 3.41647e-01 1.00000e-09 2.12000e-01

$3.41647 \mathrm{e}+00$ 3.41647e+00 3.41647e-01 1.00000e-09 2.12000e-01

3.41647e+00 3.41647e+00 3.41647e-01 1.00000e-09 2.12000e-01

$1.00000 \mathrm{e}-05$ 1.00000e-05 1.00000e-06 1.00000e-09 1.00000e-01

$1.00000 \mathrm{e}+001.00000 \mathrm{e}+001.00000 \mathrm{e}-011.00000 \mathrm{e}-091.00000 \mathrm{e}-01$

Element: 12805 \# of layers: 7

$\mathrm{Kx} \mathrm{Ky} \mathrm{Kz}$ Ss Por

3.41647e+00 3.41647e+00 3.41647e-01 1.00000e-09 2.12000e-01

$3.41647 \mathrm{e}+003.41647 \mathrm{e}+00$ 3.41647e-01 1.00000e-09 2.12000e-01

$3.41647 \mathrm{e}+003.41647 \mathrm{e}+00$ 3.41647e-01 1.00000e-09 2.12000e-01

$3.41647 \mathrm{e}+003.41647 \mathrm{e}+00$ 3.41647e-01 1.00000e-09 2.12000e-01

3.41647e+00 3.41647e+00 3.41647e-01 1.00000e-09 2.12000e-01

$1.00000 \mathrm{e}-05$ 1.00000e-05 1.00000e-06 1.00000e-09 1.00000e-01

$1.00000 \mathrm{e}+001.00000 \mathrm{e}+001.00000 \mathrm{e}-011.00000 \mathrm{e}-091.00000 \mathrm{e}-01$

Element: 12806 \# of layers: 7

$\mathrm{Kx} \mathrm{Ky} \mathrm{Kz}$ Ss Por

3.41647e+00 3.41647e+00 3.41647e-01 1.00000e-09 2.12000e-01

$3.41647 \mathrm{e}+003.41647 \mathrm{e}+00$ 3.41647e-01 1.00000e-09 2.12000e-01

$3.41647 \mathrm{e}+003.41647 \mathrm{e}+00$ 3.41647e-01 1.00000e-09 2.12000e-01

3.41647e+00 3.41647e+00 3.41647e-01 1.00000e-09 2.12000e-01

$3.41647 \mathrm{e}+003.41647 \mathrm{e}+00$ 3.41647e-01 1.00000e-09 2.12000e-01

$1.00000 \mathrm{e}-05$ 1.00000e-05 1.00000e-06 1.00000e-09 1.00000e-01

$1.00000 \mathrm{e}+001.00000 \mathrm{e}+001.00000 \mathrm{e}-01$ 1.00000e-09 1.00000e-01

Element: 12807 \# of layers: 7

Kx Ky Kz Ss Por

3.41647e+00 3.41647e+00 3.41647e-01 1.00000e-09 2.12000e-01

$3.41647 \mathrm{e}+003.41647 \mathrm{e}+00$ 3.41647e-01 1.00000e-09 2.12000e-01

3.41647e+00 3.41647e+00 3.41647e-01 1.00000e-09 2.12000e-01

$3.41647 \mathrm{e}+003.41647 \mathrm{e}+00$ 3.41647e-01 1.00000e-09 2.12000e-01

$3.41647 \mathrm{e}+003.41647 \mathrm{e}+00$ 3.41647e-01 1.00000e-09 2.12000e-01 
$1.00000 \mathrm{e}-05$ 1.00000e-05 1.00000e-06 1.00000e-09 1.00000e-01 $1.00000 \mathrm{e}+001.00000 \mathrm{e}+001.00000 \mathrm{e}-01$ 1.00000e-09 1.00000e-01 Element: 12808 \# of layers: 7

Kx Ky Kz Ss Por

3.41647e+00 3.41647e+00 3.41647e-01 1.00000e-09 2.12000e-01 $3.41647 \mathrm{e}+003.41647 \mathrm{e}+00$ 3.41647e-01 1.00000e-09 2.12000e-01 3.41647e+00 3.41647e+00 3.41647e-01 1.00000e-09 2.12000e-01 $3.41647 \mathrm{e}+003.41647 \mathrm{e}+003.41647 \mathrm{e}-01$ 1.00000e-09 2.12000e-01 3.41647e+00 3.41647e+00 3.41647e-01 1.00000e-09 2.12000e-01 $1.00000 \mathrm{e}-05$ 1.00000e-05 1.00000e-06 1.00000e-09 1.00000e-01 $1.00000 \mathrm{e}+001.00000 \mathrm{e}+001.00000 \mathrm{e}-011.00000 \mathrm{e}-091.00000 \mathrm{e}-01$ Element: 12809 \# of layers: 7

$\mathrm{Kx} \mathrm{Ky} \mathrm{Kz}$ Ss Por

3.41647e+00 3.41647e+00 3.41647e-01 1.00000e-09 2.12000e-01 3.41647e+00 3.41647e+00 3.41647e-01 1.00000e-09 2.12000e-01 $3.41647 \mathrm{e}+003.41647 \mathrm{e}+003.41647 \mathrm{e}-01$ 1.00000e-09 2.12000e-01 $3.41647 \mathrm{e}+003.41647 \mathrm{e}+003.41647 \mathrm{e}-01$ 1.00000e-09 2.12000e-01 $3.41647 \mathrm{e}+00$ 3.41647e+00 3.41647e-01 1.00000e-09 2.12000e-01 $1.00000 \mathrm{e}-05$ 1.00000e-05 1.00000e-06 1.00000e-09 1.00000e-01 $1.00000 \mathrm{e}+001.00000 \mathrm{e}+001.00000 \mathrm{e}-011.00000 \mathrm{e}-091.00000 \mathrm{e}-01$ Element: 12810 \# of layers: 7

$\mathrm{Kx} \mathrm{Ky} \mathrm{Kz}$ Ss Por

$2.92664 \mathrm{e}+002.92664 \mathrm{e}+00$ 2.92664e-01 1.00000e-09 2.12000e-01 $2.92664 \mathrm{e}+002.92664 \mathrm{e}+002.92664 \mathrm{e}-01$ 1.00000e-09 2.12000e-01 $2.92664 \mathrm{e}+002.92664 \mathrm{e}+00 \quad 2.92664 \mathrm{e}-011.00000 \mathrm{e}-092.12000 \mathrm{e}-01$ $2.92664 \mathrm{e}+002.92664 \mathrm{e}+002.92664 \mathrm{e}-01$ 1.00000e-09 2.12000e-01 $2.92664 \mathrm{e}+002.92664 \mathrm{e}+002.92664 \mathrm{e}-01 \quad 1.00000 \mathrm{e}-092.12000 \mathrm{e}-01$ $1.00000 \mathrm{e}-05$ 1.00000e-05 1.00000e-06 1.00000e-09 1.00000e-01 $1.00000 \mathrm{e}+001.00000 \mathrm{e}+001.00000 \mathrm{e}-011.00000 \mathrm{e}-091.00000 \mathrm{e}-01$ Element: 12811 \# of layers: 7

$\mathrm{Kx} \mathrm{Ky} \mathrm{Kz}$ Ss Por

$2.92664 \mathrm{e}+002.92664 \mathrm{e}+002.92664 \mathrm{e}-01$ 1.00000e-09 2.12000e-01 $2.92664 \mathrm{e}+002.92664 \mathrm{e}+002.92664 \mathrm{e}-01$ 1.00000e-09 2.12000e-01 $2.92664 \mathrm{e}+002.92664 \mathrm{e}+002.92664 \mathrm{e}-01$ 1.00000e-09 2.12000e-01 $2.92664 \mathrm{e}+002.92664 \mathrm{e}+002.92664 \mathrm{e}-01$ 1.00000e-09 2.12000e-01 $2.92664 \mathrm{e}+002.92664 \mathrm{e}+002.92664 \mathrm{e}-01$ 1.00000e-09 2.12000e-01 $1.00000 \mathrm{e}-05$ 1.00000e-05 1.00000e-06 1.00000e-09 1.00000e-01 $1.00000 \mathrm{e}+001.00000 \mathrm{e}+001.00000 \mathrm{e}-011.00000 \mathrm{e}-091.00000 \mathrm{e}-01$ Element: 12812 \# of layers: 7

$\mathrm{Kx} \mathrm{Ky} \mathrm{Kz}$ Ss Por $2.92664 \mathrm{e}+002.92664 \mathrm{e}+00$ 2.92664e-01 1.00000e-09 2.12000e-01 $2.92664 \mathrm{e}+002.92664 \mathrm{e}+002.92664 \mathrm{e}-01$ 1.00000e-09 2.12000e-01 $2.92664 \mathrm{e}+002.92664 \mathrm{e}+002.92664 \mathrm{e}-01$ 1.00000e-09 2.12000e-01 $2.92664 \mathrm{e}+002.92664 \mathrm{e}+002.92664 \mathrm{e}-01$ 1.00000e-09 2.12000e-01 $2.92664 \mathrm{e}+002.92664 \mathrm{e}+002.92664 \mathrm{e}-01$ 1.00000e-09 2.12000e-01 $1.00000 \mathrm{e}-05$ 1.00000e-05 1.00000e-06 1.00000e-09 1.00000e-01 
$1.00000 \mathrm{e}+001.00000 \mathrm{e}+001.00000 \mathrm{e}-01$ 1.00000e-09 1.00000e-01 Element: 12813 \# of layers: 7

Kx Ky Kz Ss Por

3.41647e+00 3.41647e+00 3.41647e-01 1.00000e-09 2.12000e-01

$3.41647 \mathrm{e}+003.41647 \mathrm{e}+00$ 3.41647e-01 1.00000e-09 2.12000e-01

$3.41647 \mathrm{e}+003.41647 \mathrm{e}+00$ 3.41647e-01 1.00000e-09 2.12000e-01

3.41647e+00 3.41647e+00 3.41647e-01 1.00000e-09 2.12000e-01

$3.41647 \mathrm{e}+003.41647 \mathrm{e}+00$ 3.41647e-01 1.00000e-09 2.12000e-01

$1.00000 \mathrm{e}-05$ 1.00000e-05 1.00000e-06 1.00000e-09 1.00000e-01

$1.00000 \mathrm{e}+001.00000 \mathrm{e}+001.00000 \mathrm{e}-011.00000 \mathrm{e}-091.00000 \mathrm{e}-01$

Element: 12814 \# of layers: 7

Kx Ky Kz Ss Por

3.41647e+00 3.41647e+00 3.41647e-01 1.00000e-09 2.12000e-01

$3.41647 \mathrm{e}+003.41647 \mathrm{e}+003.41647 \mathrm{e}-01$ 1.00000e-09 2.12000e-01

3.41647e+00 3.41647e+00 3.41647e-01 1.00000e-09 2.12000e-01

$3.41647 \mathrm{e}+003.41647 \mathrm{e}+003.41647 \mathrm{e}-01$ 1.00000e-09 2.12000e-01

$3.41647 \mathrm{e}+00$ 3.41647e+00 3.41647e-01 1.00000e-09 2.12000e-01

$1.00000 \mathrm{e}-05$ 1.00000e-05 1.00000e-06 1.00000e-09 1.00000e-01

$1.00000 \mathrm{e}+001.00000 \mathrm{e}+001.00000 \mathrm{e}-011.00000 \mathrm{e}-091.00000 \mathrm{e}-01$

Element: 12815 \# of layers: 7

$\mathrm{Kx} \mathrm{Ky} \mathrm{Kz}$ Ss Por

3.41647e+00 3.41647e+00 3.41647e-01 1.00000e-09 2.12000e-01

3.41647e+00 3.41647e+00 3.41647e-01 1.00000e-09 2.12000e-01

$3.41647 \mathrm{e}+003.41647 \mathrm{e}+00$ 3.41647e-01 1.00000e-09 2.12000e-01

$3.41647 \mathrm{e}+003.41647 \mathrm{e}+00$ 3.41647e-01 1.00000e-09 2.12000e-01

$3.41647 \mathrm{e}+003.41647 \mathrm{e}+00$ 3.41647e-01 1.00000e-09 2.12000e-01

$1.00000 \mathrm{e}-05$ 1.00000e-05 1.00000e-06 1.00000e-09 1.00000e-01

$1.00000 \mathrm{e}+001.00000 \mathrm{e}+001.00000 \mathrm{e}-01$ 1.00000e-09 1.00000e-01

Element: 12816 \# of layers: 7

$\mathrm{Kx} \mathrm{Ky} \mathrm{Kz}$ Ss Por

3.41647e+00 3.41647e+00 3.41647e-01 1.00000e-09 2.12000e-01

3.41647e+00 3.41647e+00 3.41647e-01 1.00000e-09 2.12000e-01

$3.41647 \mathrm{e}+003.41647 \mathrm{e}+00$ 3.41647e-01 1.00000e-09 2.12000e-01

3.41647e+00 3.41647e+00 3.41647e-01 1.00000e-09 2.12000e-01

$3.41647 \mathrm{e}+003.41647 \mathrm{e}+003.41647 \mathrm{e}-01$ 1.00000e-09 2.12000e-01

$1.00000 \mathrm{e}-05$ 1.00000e-05 1.00000e-06 1.00000e-09 1.00000e-01

$1.00000 \mathrm{e}+001.00000 \mathrm{e}+001.00000 \mathrm{e}-01$ 1.00000e-09 1.00000e-01

Element: 12817 \# of layers: 7

$\mathrm{Kx} \mathrm{Ky} \mathrm{Kz}$ Ss Por

$2.92664 \mathrm{e}+002.92664 \mathrm{e}+002.92664 \mathrm{e}-01$ 1.00000e-09 2.12000e-01

$2.92664 \mathrm{e}+002.92664 \mathrm{e}+002.92664 \mathrm{e}-01$ 1.00000e-09 2.12000e-01

$2.92664 \mathrm{e}+002.92664 \mathrm{e}+002.92664 \mathrm{e}-01$ 1.00000e-09 2.12000e-01

$2.92664 \mathrm{e}+002.92664 \mathrm{e}+002.92664 \mathrm{e}-01$ 1.00000e-09 2.12000e-01

$2.92664 \mathrm{e}+002.92664 \mathrm{e}+002.92664 \mathrm{e}-01$ 1.00000e-09 2.12000e-01 $1.00000 \mathrm{e}-05$ 1.00000e-05 1.00000e-06 1.00000e-09 1.00000e-01

$1.00000 \mathrm{e}+001.00000 \mathrm{e}+001.00000 \mathrm{e}-011.00000 \mathrm{e}-091.00000 \mathrm{e}-01$ 
Element: 12818 \# of layers: 7

Kx Ky Kz Ss Por

$2.92664 \mathrm{e}+002.92664 \mathrm{e}+002.92664 \mathrm{e}-01$ 1.00000e-09 2.12000e-01

$2.92664 \mathrm{e}+002.92664 \mathrm{e}+002.92664 \mathrm{e}-011.00000 \mathrm{e}-092.12000 \mathrm{e}-01$

$2.92664 \mathrm{e}+002.92664 \mathrm{e}+002.92664 \mathrm{e}-011.00000 \mathrm{e}-092.12000 \mathrm{e}-01$

$2.92664 \mathrm{e}+002.92664 \mathrm{e}+002.92664 \mathrm{e}-011.00000 \mathrm{e}-092.12000 \mathrm{e}-01$

$2.92664 \mathrm{e}+002.92664 \mathrm{e}+002.92664 \mathrm{e}-011.00000 \mathrm{e}-092.12000 \mathrm{e}-01$

$1.00000 \mathrm{e}-05$ 1.00000e-05 1.00000e-06 1.00000e-09 1.00000e-01

$1.00000 \mathrm{e}+001.00000 \mathrm{e}+001.00000 \mathrm{e}-011.00000 \mathrm{e}-091.00000 \mathrm{e}-01$

Element: 12819 \# of layers: 7

Kx Ky Kz Ss Por

$2.92664 \mathrm{e}+002.92664 \mathrm{e}+002.92664 \mathrm{e}-01$ 1.00000e-09 2.12000e-01

$2.92664 \mathrm{e}+002.92664 \mathrm{e}+002.92664 \mathrm{e}-011.00000 \mathrm{e}-092.12000 \mathrm{e}-01$

$2.92664 \mathrm{e}+002.92664 \mathrm{e}+002.92664 \mathrm{e}-011.00000 \mathrm{e}-092.12000 \mathrm{e}-01$

$2.92664 \mathrm{e}+002.92664 \mathrm{e}+002.92664 \mathrm{e}-011.00000 \mathrm{e}-092.12000 \mathrm{e}-01$

$2.92664 \mathrm{e}+002.92664 \mathrm{e}+002.92664 \mathrm{e}-011.00000 \mathrm{e}-092.12000 \mathrm{e}-01$

$1.00000 \mathrm{e}-05$ 1.00000e-05 1.00000e-06 1.00000e-09 1.00000e-01

$1.00000 \mathrm{e}+001.00000 \mathrm{e}+001.00000 \mathrm{e}-011.00000 \mathrm{e}-091.00000 \mathrm{e}-01$

Element: 12820 \# of layers: 7

Kx Ky Kz Ss Por

$2.92664 \mathrm{e}+002.92664 \mathrm{e}+002.92664 \mathrm{e}-011.00000 \mathrm{e}-092.12000 \mathrm{e}-01$

$2.92664 \mathrm{e}+002.92664 \mathrm{e}+002.92664 \mathrm{e}-011.00000 \mathrm{e}-092.12000 \mathrm{e}-01$

$2.92664 \mathrm{e}+002.92664 \mathrm{e}+002.92664 \mathrm{e}-011.00000 \mathrm{e}-092.12000 \mathrm{e}-01$

$2.92664 \mathrm{e}+002.92664 \mathrm{e}+002.92664 \mathrm{e}-011.00000 \mathrm{e}-092.12000 \mathrm{e}-01$

$2.92664 \mathrm{e}+002.92664 \mathrm{e}+002.92664 \mathrm{e}-011.00000 \mathrm{e}-092.12000 \mathrm{e}-01$

$1.00000 \mathrm{e}-05$ 1.00000e-05 1.00000e-06 1.00000e-09 1.00000e-01

$1.00000 \mathrm{e}+001.00000 \mathrm{e}+001.00000 \mathrm{e}-011.00000 \mathrm{e}-091.00000 \mathrm{e}-01$

Element: 12821 \# of layers: 7

Kx Ky Kz Ss Por

$2.92664 \mathrm{e}+002.92664 \mathrm{e}+002.92664 \mathrm{e}-01$ 1.00000e-09 2.12000e-01

$2.92664 \mathrm{e}+002.92664 \mathrm{e}+002.92664 \mathrm{e}-011.00000 \mathrm{e}-092.12000 \mathrm{e}-01$

$2.92664 \mathrm{e}+002.92664 \mathrm{e}+002.92664 \mathrm{e}-011.00000 \mathrm{e}-092.12000 \mathrm{e}-01$

$2.92664 \mathrm{e}+002.92664 \mathrm{e}+002.92664 \mathrm{e}-011.00000 \mathrm{e}-092.12000 \mathrm{e}-01$

$2.92664 \mathrm{e}+002.92664 \mathrm{e}+002.92664 \mathrm{e}-011.00000 \mathrm{e}-092.12000 \mathrm{e}-01$

$1.00000 \mathrm{e}-05$ 1.00000e-05 1.00000e-06 1.00000e-09 1.00000e-01

$1.00000 \mathrm{e}+001.00000 \mathrm{e}+001.00000 \mathrm{e}-011.00000 \mathrm{e}-091.00000 \mathrm{e}-01$

Element: 12822 \# of layers: 7

Kx Ky Kz Ss Por

$2.92664 \mathrm{e}+002.92664 \mathrm{e}+002.92664 \mathrm{e}-011.00000 \mathrm{e}-092.12000 \mathrm{e}-01$

$2.92664 \mathrm{e}+002.92664 \mathrm{e}+002.92664 \mathrm{e}-011.00000 \mathrm{e}-092.12000 \mathrm{e}-01$

$2.92664 \mathrm{e}+002.92664 \mathrm{e}+002.92664 \mathrm{e}-011.00000 \mathrm{e}-092.12000 \mathrm{e}-01$

$2.92664 \mathrm{e}+002.92664 \mathrm{e}+002.92664 \mathrm{e}-011.00000 \mathrm{e}-092.12000 \mathrm{e}-01$

$2.92664 \mathrm{e}+002.92664 \mathrm{e}+002.92664 \mathrm{e}-011.00000 \mathrm{e}-092.12000 \mathrm{e}-01$

$1.00000 \mathrm{e}-05$ 1.00000e-05 1.00000e-06 1.00000e-09 1.00000e-01

$1.00000 \mathrm{e}+001.00000 \mathrm{e}+001.00000 \mathrm{e}-011.00000 \mathrm{e}-091.00000 \mathrm{e}-01$

Element: 12823 \# of layers: 7 
$\mathrm{Kx} \mathrm{Ky} \mathrm{Kz}$ Ss Por

$2.92664 \mathrm{e}+002.92664 \mathrm{e}+002.92664 \mathrm{e}-01$ 1.00000e-09 2.12000e-01

$2.92664 \mathrm{e}+002.92664 \mathrm{e}+002.92664 \mathrm{e}-01$ 1.00000e-09 2.12000e-01

$2.92664 \mathrm{e}+002.92664 \mathrm{e}+002.92664 \mathrm{e}-01$ 1.00000e-09 2.12000e-01

$2.92664 \mathrm{e}+002.92664 \mathrm{e}+002.92664 \mathrm{e}-01$ 1.00000e-09 2.12000e-01

$2.92664 \mathrm{e}+002.92664 \mathrm{e}+002.92664 \mathrm{e}-01$ 1.00000e-09 2.12000e-01

1.00000e-05 1.00000e-05 1.00000e-06 1.00000e-09 1.00000e-01

$1.00000 \mathrm{e}+001.00000 \mathrm{e}+001.00000 \mathrm{e}-01$ 1.00000e-09 1.00000e-01

Element: 12824 \# of layers: 7

$\mathrm{Kx} \mathrm{Ky} \mathrm{Kz}$ Ss Por

$2.92664 \mathrm{e}+002.92664 \mathrm{e}+00$ 2.92664e-01 1.00000e-09 2.12000e-01

$2.92664 \mathrm{e}+002.92664 \mathrm{e}+002.92664 \mathrm{e}-01$ 1.00000e-09 2.12000e-01

$2.92664 \mathrm{e}+002.92664 \mathrm{e}+002.92664 \mathrm{e}-01$ 1.00000e-09 2.12000e-01

$2.92664 \mathrm{e}+002.92664 \mathrm{e}+002.92664 \mathrm{e}-01$ 1.00000e-09 2.12000e-01

$2.92664 \mathrm{e}+002.92664 \mathrm{e}+002.92664 \mathrm{e}-01$ 1.00000e-09 2.12000e-01

$1.00000 \mathrm{e}-05$ 1.00000e-05 1.00000e-06 1.00000e-09 1.00000e-01

$1.00000 \mathrm{e}+001.00000 \mathrm{e}+001.00000 \mathrm{e}-01$ 1.00000e-09 1.00000e-01

Element: 12825 \# of layers: 7

$\mathrm{Kx} \mathrm{Ky} \mathrm{Kz}$ Ss Por

$2.92664 \mathrm{e}+002.92664 \mathrm{e}+002.92664 \mathrm{e}-01$ 1.00000e-09 2.12000e-01

$2.92664 \mathrm{e}+002.92664 \mathrm{e}+002.92664 \mathrm{e}-01$ 1.00000e-09 2.12000e-01

$2.92664 \mathrm{e}+002.92664 \mathrm{e}+00$ 2.92664e-01 1.00000e-09 2.12000e-01

$2.92664 \mathrm{e}+002.92664 \mathrm{e}+00$ 2.92664e-01 1.00000e-09 2.12000e-01

$2.92664 \mathrm{e}+002.92664 \mathrm{e}+002.92664 \mathrm{e}-01$ 1.00000e-09 2.12000e-01

$1.00000 \mathrm{e}-05$ 1.00000e-05 1.00000e-06 1.00000e-09 1.00000e-01

$1.00000 \mathrm{e}+001.00000 \mathrm{e}+001.00000 \mathrm{e}-01$ 1.00000e-09 1.00000e-01

Element: 12826 \# of layers: 7

$\mathrm{Kx} \mathrm{Ky} \mathrm{Kz}$ Ss Por

$2.92664 \mathrm{e}+002.92664 \mathrm{e}+00$ 2.92664e-01 1.00000e-09 2.12000e-01

$2.92664 \mathrm{e}+002.92664 \mathrm{e}+002.92664 \mathrm{e}-01$ 1.00000e-09 2.12000e-01

$2.92664 \mathrm{e}+002.92664 \mathrm{e}+002.92664 \mathrm{e}-01$ 1.00000e-09 2.12000e-01

$2.92664 \mathrm{e}+002.92664 \mathrm{e}+002.92664 \mathrm{e}-01$ 1.00000e-09 2.12000e-01

$2.92664 \mathrm{e}+002.92664 \mathrm{e}+002.92664 \mathrm{e}-01$ 1.00000e-09 2.12000e-01

$1.00000 \mathrm{e}-05$ 1.00000e-05 1.00000e-06 1.00000e-09 1.00000e-01

$1.00000 \mathrm{e}+001.00000 \mathrm{e}+001.00000 \mathrm{e}-01$ 1.00000e-09 1.00000e-01

Element: 12827 \# of layers: 7

$\mathrm{Kx} \mathrm{Ky} \mathrm{Kz}$ Ss Por

$2.92664 \mathrm{e}+002.92664 \mathrm{e}+00$ 2.92664e-01 1.00000e-09 2.12000e-01

$2.92664 \mathrm{e}+002.92664 \mathrm{e}+002.92664 \mathrm{e}-01$ 1.00000e-09 2.12000e-01

$2.92664 \mathrm{e}+002.92664 \mathrm{e}+002.92664 \mathrm{e}-01$ 1.00000e-09 2.12000e-01

$2.92664 \mathrm{e}+002.92664 \mathrm{e}+002.92664 \mathrm{e}-01$ 1.00000e-09 2.12000e-01

$2.92664 \mathrm{e}+002.92664 \mathrm{e}+002.92664 \mathrm{e}-01$ 1.00000e-09 2.12000e-01

$1.00000 \mathrm{e}-051.00000 \mathrm{e}-051.00000 \mathrm{e}-061.00000 \mathrm{e}-091.00000 \mathrm{e}-01$

$1.00000 \mathrm{e}+001.00000 \mathrm{e}+001.00000 \mathrm{e}-01$ 1.00000e-09 1.00000e-01

Element: 12828 \# of layers: 7

Kx Ky Kz Ss Por 
$3.49500 \mathrm{e}+003.49500 \mathrm{e}+003.49500 \mathrm{e}-01$ 1.00000e-09 2.12000e-01 $3.49500 \mathrm{e}+003.49500 \mathrm{e}+00 \quad 3.49500 \mathrm{e}-01$ 1.00000e-09 2.12000e-01 $3.49500 \mathrm{e}+003.49500 \mathrm{e}+003.49500 \mathrm{e}-01$ 1.00000e-09 2.12000e-01 $3.49500 \mathrm{e}+003.49500 \mathrm{e}+003.49500 \mathrm{e}-01$ 1.00000e-09 2.12000e-01 $3.49500 \mathrm{e}+003.49500 \mathrm{e}+00$ 3.49500e-01 1.00000e-09 2.12000e-01 $1.00000 \mathrm{e}-05$ 1.00000e-05 1.00000e-06 1.00000e-09 1.00000e-01 $1.00000 \mathrm{e}+001.00000 \mathrm{e}+00$ 1.00000e-01 1.00000e-09 1.00000e-01 Element: 12829 \# of layers: 7

$\mathrm{Kx} \mathrm{Ky} \mathrm{Kz}$ Ss Por

3.49500e+00 3.49500e+00 3.49500e-01 1.00000e-09 2.12000e-01 $3.49500 \mathrm{e}+003.49500 \mathrm{e}+003.49500 \mathrm{e}-01$ 1.00000e-09 2.12000e-01 $3.49500 \mathrm{e}+003.49500 \mathrm{e}+003.49500 \mathrm{e}-01$ 1.00000e-09 2.12000e-01 $3.49500 \mathrm{e}+003.49500 \mathrm{e}+003.49500 \mathrm{e}-01$ 1.00000e-09 2.12000e-01 $3.49500 \mathrm{e}+003.49500 \mathrm{e}+00$ 3.49500e-01 1.00000e-09 2.12000e-01 $1.00000 \mathrm{e}-05$ 1.00000e-05 1.00000e-06 1.00000e-09 1.00000e-01 $1.00000 \mathrm{e}+001.00000 \mathrm{e}+001.00000 \mathrm{e}-011.00000 \mathrm{e}-091.00000 \mathrm{e}-01$ Element: 12830 \# of layers: 7

$\mathrm{Kx} \mathrm{Ky} \mathrm{Kz}$ Ss Por

3.49500e+00 3.49500e+00 3.49500e-01 1.00000e-09 2.12000e-01 $3.49500 \mathrm{e}+003.49500 \mathrm{e}+003.49500 \mathrm{e}-01$ 1.00000e-09 2.12000e-01 $3.49500 \mathrm{e}+003.49500 \mathrm{e}+003.49500 \mathrm{e}-01$ 1.00000e-09 2.12000e-01 $3.49500 \mathrm{e}+003.49500 \mathrm{e}+003.49500 \mathrm{e}-01$ 1.00000e-09 2.12000e-01 $3.49500 \mathrm{e}+003.49500 \mathrm{e}+003.49500 \mathrm{e}-01$ 1.00000e-09 2.12000e-01 $1.00000 \mathrm{e}-051.00000 \mathrm{e}-05$ 1.00000e-06 1.00000e-09 1.00000e-01 $1.00000 \mathrm{e}+001.00000 \mathrm{e}+001.00000 \mathrm{e}-011.00000 \mathrm{e}-091.00000 \mathrm{e}-01$ Element: 12831 \# of layers: 7

$\mathrm{Kx} \mathrm{Ky} \mathrm{Kz}$ Ss Por

$2.92664 \mathrm{e}+002.92664 \mathrm{e}+00$ 2.92664e-01 1.00000e-09 2.12000e-01 $2.92664 \mathrm{e}+002.92664 \mathrm{e}+002.92664 \mathrm{e}-01 \quad 1.00000 \mathrm{e}-092.12000 \mathrm{e}-01$ $2.92664 \mathrm{e}+002.92664 \mathrm{e}+002.92664 \mathrm{e}-01$ 1.00000e-09 2.12000e-01 $2.92664 \mathrm{e}+002.92664 \mathrm{e}+002.92664 \mathrm{e}-01$ 1.00000e-09 2.12000e-01 $2.92664 \mathrm{e}+002.92664 \mathrm{e}+002.92664 \mathrm{e}-01$ 1.00000e-09 2.12000e-01 $1.00000 \mathrm{e}-05$ 1.00000e-05 1.00000e-06 1.00000e-09 1.00000e-01 $1.00000 \mathrm{e}+001.00000 \mathrm{e}+001.00000 \mathrm{e}-011.00000 \mathrm{e}-09$ 1.00000e-01 Element: 12832 \# of layers: 7

$\mathrm{Kx} \mathrm{Ky} \mathrm{Kz}$ Ss Por

$2.92664 \mathrm{e}+002.92664 \mathrm{e}+002.92664 \mathrm{e}-01$ 1.00000e-09 2.12000e-01 $2.92664 \mathrm{e}+002.92664 \mathrm{e}+002.92664 \mathrm{e}-01$ 1.00000e-09 2.12000e-01 $2.92664 \mathrm{e}+002.92664 \mathrm{e}+002.92664 \mathrm{e}-01$ 1.00000e-09 2.12000e-01 $2.92664 \mathrm{e}+002.92664 \mathrm{e}+002.92664 \mathrm{e}-01$ 1.00000e-09 2.12000e-01 $2.92664 \mathrm{e}+002.92664 \mathrm{e}+002.92664 \mathrm{e}-01$ 1.00000e-09 2.12000e-01 $1.00000 \mathrm{e}-05$ 1.00000e-05 1.00000e-06 1.00000e-09 1.00000e-01 $1.00000 \mathrm{e}+001.00000 \mathrm{e}+001.00000 \mathrm{e}-011.00000 \mathrm{e}-091.00000 \mathrm{e}-01$ Element: 12833 \# of layers: 7

$\mathrm{Kx} \mathrm{Ky} \mathrm{Kz}$ Ss Por 2.92664e+00 2.92664e+00 2.92664e-01 1.00000e-09 2.12000e-01 
$2.92664 \mathrm{e}+002.92664 \mathrm{e}+002.92664 \mathrm{e}-011.00000 \mathrm{e}-092.12000 \mathrm{e}-01$ $2.92664 \mathrm{e}+002.92664 \mathrm{e}+002.92664 \mathrm{e}-011.00000 \mathrm{e}-092.12000 \mathrm{e}-01$ $2.92664 \mathrm{e}+002.92664 \mathrm{e}+002.92664 \mathrm{e}-011.00000 \mathrm{e}-092.12000 \mathrm{e}-01$ $2.92664 \mathrm{e}+002.92664 \mathrm{e}+002.92664 \mathrm{e}-011.00000 \mathrm{e}-092.12000 \mathrm{e}-01$ $1.00000 \mathrm{e}-05$ 1.00000e-05 1.00000e-06 1.00000e-09 1.00000e-01 $1.00000 \mathrm{e}+001.00000 \mathrm{e}+001.00000 \mathrm{e}-011.00000 \mathrm{e}-091.00000 \mathrm{e}-01$ Element: 12834 \# of layers: 7

Kx Ky Kz Ss Por

$2.92664 \mathrm{e}+002.92664 \mathrm{e}+002.92664 \mathrm{e}-011.00000 \mathrm{e}-092.12000 \mathrm{e}-01$ $2.92664 \mathrm{e}+002.92664 \mathrm{e}+002.92664 \mathrm{e}-011.00000 \mathrm{e}-092.12000 \mathrm{e}-01$ $2.92664 \mathrm{e}+002.92664 \mathrm{e}+002.92664 \mathrm{e}-011.00000 \mathrm{e}-092.12000 \mathrm{e}-01$ $2.92664 \mathrm{e}+002.92664 \mathrm{e}+002.92664 \mathrm{e}-011.00000 \mathrm{e}-092.12000 \mathrm{e}-01$ $2.92664 \mathrm{e}+002.92664 \mathrm{e}+002.92664 \mathrm{e}-011.00000 \mathrm{e}-092.12000 \mathrm{e}-01$ $1.00000 \mathrm{e}-05$ 1.00000e-05 1.00000e-06 1.00000e-09 1.00000e-01 $1.00000 \mathrm{e}+001.00000 \mathrm{e}+001.00000 \mathrm{e}-011.00000 \mathrm{e}-091.00000 \mathrm{e}-01$ Element: 12835 \# of layers: 7

Kx Ky Kz Ss Por

$3.49500 \mathrm{e}+003.49500 \mathrm{e}+00$ 3.49500e-01 1.00000e-09 2.12000e-01 $3.49500 \mathrm{e}+003.49500 \mathrm{e}+003.49500 \mathrm{e}-011.00000 \mathrm{e}-092.12000 \mathrm{e}-01$ $3.49500 \mathrm{e}+003.49500 \mathrm{e}+003.49500 \mathrm{e}-01$ 1.00000e-09 2.12000e-01 $3.49500 \mathrm{e}+003.49500 \mathrm{e}+003.49500 \mathrm{e}-011.00000 \mathrm{e}-092.12000 \mathrm{e}-01$ $3.49500 \mathrm{e}+003.49500 \mathrm{e}+003.49500 \mathrm{e}-011.00000 \mathrm{e}-092.12000 \mathrm{e}-01$ $1.00000 \mathrm{e}-05$ 1.00000e-05 1.00000e-06 1.00000e-09 1.00000e-01 $1.00000 \mathrm{e}+001.00000 \mathrm{e}+001.00000 \mathrm{e}-011.00000 \mathrm{e}-091.00000 \mathrm{e}-01$ Element: 12836 \# of layers: 7

Kx Ky Kz Ss Por

$3.49500 \mathrm{e}+003.49500 \mathrm{e}+00$ 3.49500e-01 1.00000e-09 2.12000e-01 $3.49500 \mathrm{e}+003.49500 \mathrm{e}+003.49500 \mathrm{e}-011.00000 \mathrm{e}-092.12000 \mathrm{e}-01$ $3.49500 \mathrm{e}+003.49500 \mathrm{e}+003.49500 \mathrm{e}-011.00000 \mathrm{e}-092.12000 \mathrm{e}-01$ $3.49500 \mathrm{e}+003.49500 \mathrm{e}+003.49500 \mathrm{e}-011.00000 \mathrm{e}-092.12000 \mathrm{e}-01$ $3.49500 \mathrm{e}+003.49500 \mathrm{e}+003.49500 \mathrm{e}-01$ 1.00000e-09 2.12000e-01 $1.00000 \mathrm{e}-05$ 1.00000e-05 1.00000e-06 1.00000e-09 1.00000e-01 $1.00000 \mathrm{e}+001.00000 \mathrm{e}+001.00000 \mathrm{e}-011.00000 \mathrm{e}-091.00000 \mathrm{e}-01$ Element: 12837 \# of layers: 7

Kx Ky Kz Ss Por

$3.49500 \mathrm{e}+003.49500 \mathrm{e}+003.49500 \mathrm{e}-01$ 1.00000e-09 2.12000e-01 $3.49500 \mathrm{e}+003.49500 \mathrm{e}+003.49500 \mathrm{e}-011.00000 \mathrm{e}-092.12000 \mathrm{e}-01$ $3.49500 \mathrm{e}+003.49500 \mathrm{e}+003.49500 \mathrm{e}-011.00000 \mathrm{e}-092.12000 \mathrm{e}-01$ $3.49500 \mathrm{e}+003.49500 \mathrm{e}+003.49500 \mathrm{e}-011.00000 \mathrm{e}-092.12000 \mathrm{e}-01$ $3.49500 \mathrm{e}+003.49500 \mathrm{e}+003.49500 \mathrm{e}-011.00000 \mathrm{e}-092.12000 \mathrm{e}-01$ $1.00000 \mathrm{e}-05$ 1.00000e-05 1.00000e-06 1.00000e-09 1.00000e-01 $1.00000 \mathrm{e}+001.00000 \mathrm{e}+001.00000 \mathrm{e}-011.00000 \mathrm{e}-091.00000 \mathrm{e}-01$ Element: 12838 \# of layers: 7

Kx Ky Kz Ss Por

$3.49500 \mathrm{e}+003.49500 \mathrm{e}+003.49500 \mathrm{e}-01$ 1.00000e-09 2.12000e-01 $3.49500 \mathrm{e}+003.49500 \mathrm{e}+003.49500 \mathrm{e}-01$ 1.00000e-09 2.12000e-01 
$3.49500 \mathrm{e}+003.49500 \mathrm{e}+003.49500 \mathrm{e}-011.00000 \mathrm{e}-092.12000 \mathrm{e}-01$ $3.49500 \mathrm{e}+003.49500 \mathrm{e}+003.49500 \mathrm{e}-011.00000 \mathrm{e}-092.12000 \mathrm{e}-01$ $3.49500 \mathrm{e}+003.49500 \mathrm{e}+003.49500 \mathrm{e}-01$ 1.00000e-09 2.12000e-01 $1.00000 \mathrm{e}-05$ 1.00000e-05 1.00000e-06 1.00000e-09 1.00000e-01 $1.00000 \mathrm{e}+001.00000 \mathrm{e}+001.00000 \mathrm{e}-011.00000 \mathrm{e}-091.00000 \mathrm{e}-01$ Element: 12839 \# of layers: 7

Kx Ky Kz Ss Por

$3.49500 \mathrm{e}+003.49500 \mathrm{e}+003.49500 \mathrm{e}-01$ 1.00000e-09 2.12000e-01 $3.49500 \mathrm{e}+003.49500 \mathrm{e}+003.49500 \mathrm{e}-011.00000 \mathrm{e}-092.12000 \mathrm{e}-01$ $3.49500 \mathrm{e}+003.49500 \mathrm{e}+003.49500 \mathrm{e}-011.00000 \mathrm{e}-092.12000 \mathrm{e}-01$ $3.49500 \mathrm{e}+003.49500 \mathrm{e}+003.49500 \mathrm{e}-011.00000 \mathrm{e}-092.12000 \mathrm{e}-01$ $3.49500 \mathrm{e}+003.49500 \mathrm{e}+003.49500 \mathrm{e}-01$ 1.00000e-09 2.12000e-01 $1.00000 \mathrm{e}-05$ 1.00000e-05 1.00000e-06 1.00000e-09 1.00000e-01 $1.00000 \mathrm{e}+001.00000 \mathrm{e}+001.00000 \mathrm{e}-011.00000 \mathrm{e}-091.00000 \mathrm{e}-01$ Element: 12840 \# of layers: 7

Kx Ky Kz Ss Por

$3.49500 \mathrm{e}+003.49500 \mathrm{e}+003.49500 \mathrm{e}-01$ 1.00000e-09 2.12000e-01 $3.49500 \mathrm{e}+003.49500 \mathrm{e}+003.49500 \mathrm{e}-011.00000 \mathrm{e}-092.12000 \mathrm{e}-01$ $3.49500 \mathrm{e}+003.49500 \mathrm{e}+003.49500 \mathrm{e}-011.00000 \mathrm{e}-092.12000 \mathrm{e}-01$ $3.49500 \mathrm{e}+003.49500 \mathrm{e}+003.49500 \mathrm{e}-011.00000 \mathrm{e}-092.12000 \mathrm{e}-01$ $3.49500 \mathrm{e}+003.49500 \mathrm{e}+003.49500 \mathrm{e}-011.00000 \mathrm{e}-092.12000 \mathrm{e}-01$ $1.00000 \mathrm{e}-05$ 1.00000e-05 1.00000e-06 1.00000e-09 1.00000e-01 $1.00000 \mathrm{e}+001.00000 \mathrm{e}+001.00000 \mathrm{e}-011.00000 \mathrm{e}-091.00000 \mathrm{e}-01$ Element: 12841 \# of layers: 7

Kx Ky Kz Ss Por

$3.49500 \mathrm{e}+003.49500 \mathrm{e}+003.49500 \mathrm{e}-011.00000 \mathrm{e}-092.12000 \mathrm{e}-01$ $3.49500 \mathrm{e}+003.49500 \mathrm{e}+003.49500 \mathrm{e}-01$ 1.00000e-09 2.12000e-01 $3.49500 \mathrm{e}+003.49500 \mathrm{e}+003.49500 \mathrm{e}-011.00000 \mathrm{e}-092.12000 \mathrm{e}-01$ $3.49500 \mathrm{e}+003.49500 \mathrm{e}+003.49500 \mathrm{e}-011.00000 \mathrm{e}-092.12000 \mathrm{e}-01$ $3.49500 \mathrm{e}+003.49500 \mathrm{e}+003.49500 \mathrm{e}-011.00000 \mathrm{e}-092.12000 \mathrm{e}-01$ $1.00000 \mathrm{e}-05$ 1.00000e-05 1.00000e-06 1.00000e-09 1.00000e-01 $1.00000 \mathrm{e}+001.00000 \mathrm{e}+001.00000 \mathrm{e}-011.00000 \mathrm{e}-091.00000 \mathrm{e}-01$ Element: 12842 \# of layers: 7

Kx Ky Kz Ss Por

$3.49500 \mathrm{e}+003.49500 \mathrm{e}+003.49500 \mathrm{e}-01$ 1.00000e-09 2.12000e-01 $3.49500 \mathrm{e}+003.49500 \mathrm{e}+003.49500 \mathrm{e}-011.00000 \mathrm{e}-092.12000 \mathrm{e}-01$ $3.49500 \mathrm{e}+003.49500 \mathrm{e}+003.49500 \mathrm{e}-011.00000 \mathrm{e}-092.12000 \mathrm{e}-01$ $3.49500 \mathrm{e}+003.49500 \mathrm{e}+003.49500 \mathrm{e}-01$ 1.00000e-09 2.12000e-01 $3.49500 \mathrm{e}+003.49500 \mathrm{e}+003.49500 \mathrm{e}-01$ 1.00000e-09 2.12000e-01 $1.00000 \mathrm{e}-05$ 1.00000e-05 1.00000e-06 1.00000e-09 1.00000e-01 $1.00000 \mathrm{e}+001.00000 \mathrm{e}+001.00000 \mathrm{e}-011.00000 \mathrm{e}-091.00000 \mathrm{e}-01$ Element: 12843 \# of layers: 7

Kx Ky Kz Ss Por

$3.49500 \mathrm{e}+003.49500 \mathrm{e}+003.49500 \mathrm{e}-011.00000 \mathrm{e}-092.12000 \mathrm{e}-01$ $3.49500 \mathrm{e}+003.49500 \mathrm{e}+003.49500 \mathrm{e}-011.00000 \mathrm{e}-092.12000 \mathrm{e}-01$ $3.49500 \mathrm{e}+003.49500 \mathrm{e}+003.49500 \mathrm{e}-01$ 1.00000e-09 2.12000e-01 
$3.49500 \mathrm{e}+003.49500 \mathrm{e}+003.49500 \mathrm{e}-011.00000 \mathrm{e}-092.12000 \mathrm{e}-01$ $3.49500 \mathrm{e}+003.49500 \mathrm{e}+003.49500 \mathrm{e}-01$ 1.00000e-09 2.12000e-01 $1.00000 \mathrm{e}-05$ 1.00000e-05 1.00000e-06 1.00000e-09 1.00000e-01 $1.00000 \mathrm{e}+001.00000 \mathrm{e}+001.00000 \mathrm{e}-011.00000 \mathrm{e}-091.00000 \mathrm{e}-01$ Element: 12844 \# of layers: 7

Kx Ky Kz Ss Por

$3.49500 \mathrm{e}+003.49500 \mathrm{e}+003.49500 \mathrm{e}-01$ 1.00000e-09 2.12000e-01 $3.49500 \mathrm{e}+003.49500 \mathrm{e}+003.49500 \mathrm{e}-011.00000 \mathrm{e}-092.12000 \mathrm{e}-01$ $3.49500 \mathrm{e}+003.49500 \mathrm{e}+003.49500 \mathrm{e}-011.00000 \mathrm{e}-092.12000 \mathrm{e}-01$ $3.49500 \mathrm{e}+003.49500 \mathrm{e}+003.49500 \mathrm{e}-011.00000 \mathrm{e}-092.12000 \mathrm{e}-01$ $3.49500 \mathrm{e}+003.49500 \mathrm{e}+003.49500 \mathrm{e}-01$ 1.00000e-09 2.12000e-01 $1.00000 \mathrm{e}-05$ 1.00000e-05 1.00000e-06 1.00000e-09 1.00000e-01 $1.00000 \mathrm{e}+001.00000 \mathrm{e}+001.00000 \mathrm{e}-011.00000 \mathrm{e}-091.00000 \mathrm{e}-01$ Element: 12845 \# of layers: 7

Kx Ky Kz Ss Por

$5.77925 \mathrm{e}+00$ 5.77925e+00 5.77925e-01 1.00000e-09 2.12000e-01 $5.77925 \mathrm{e}+005.77925 \mathrm{e}+00$ 5.77925e-01 1.00000e-09 2.12000e-01 $5.77925 \mathrm{e}+005.77925 \mathrm{e}+005.77925 \mathrm{e}-011.00000 \mathrm{e}-092.12000 \mathrm{e}-01$ $5.77925 \mathrm{e}+005.77925 \mathrm{e}+005.77925 \mathrm{e}-011.00000 \mathrm{e}-092.12000 \mathrm{e}-01$ $5.77925 \mathrm{e}+00$ 5.77925e+00 5.77925e-01 1.00000e-09 2.12000e-01 $1.00000 \mathrm{e}-05$ 1.00000e-05 1.00000e-06 1.00000e-09 1.00000e-01 $1.00000 \mathrm{e}+001.00000 \mathrm{e}+001.00000 \mathrm{e}-011.00000 \mathrm{e}-091.00000 \mathrm{e}-01$ Element: 12846 \# of layers: 7

Kx Ky Kz Ss Por

$5.77925 \mathrm{e}+00$ 5.77925e+00 5.77925e-01 1.00000e-09 2.12000e-01 $5.77925 \mathrm{e}+005.77925 \mathrm{e}+00$ 5.77925e-01 1.00000e-09 2.12000e-01 $5.77925 \mathrm{e}+005.77925 \mathrm{e}+00$ 5.77925e-01 1.00000e-09 2.12000e-01 $5.77925 \mathrm{e}+005.77925 \mathrm{e}+00$ 5.77925e-01 1.00000e-09 2.12000e-01 $5.77925 \mathrm{e}+005.77925 \mathrm{e}+00$ 5.77925e-01 1.00000e-09 2.12000e-01 $1.00000 \mathrm{e}-05$ 1.00000e-05 1.00000e-06 1.00000e-09 1.00000e-01 $1.00000 \mathrm{e}+001.00000 \mathrm{e}+001.00000 \mathrm{e}-011.00000 \mathrm{e}-091.00000 \mathrm{e}-01$ Element: 12847 \# of layers: 7

Kx Ky Kz Ss Por

$5.77925 \mathrm{e}+00$ 5.77925e+00 5.77925e-01 1.00000e-09 2.12000e-01 $5.77925 \mathrm{e}+005.77925 \mathrm{e}+00$ 5.77925e-01 1.00000e-09 2.12000e-01 $5.77925 \mathrm{e}+005.77925 \mathrm{e}+00$ 5.77925e-01 1.00000e-09 2.12000e-01 $5.77925 \mathrm{e}+005.77925 \mathrm{e}+00$ 5.77925e-01 1.00000e-09 2.12000e-01 $5.77925 \mathrm{e}+005.77925 \mathrm{e}+00$ 5.77925e-01 1.00000e-09 2.12000e-01 $1.00000 \mathrm{e}-05$ 1.00000e-05 1.00000e-06 1.00000e-09 1.00000e-01 $1.00000 \mathrm{e}+001.00000 \mathrm{e}+001.00000 \mathrm{e}-011.00000 \mathrm{e}-091.00000 \mathrm{e}-01$ Element: 12848 \# of layers: 7

Kx Ky Kz Ss Por

$5.77925 \mathrm{e}+00$ 5.77925e+00 5.77925e-01 1.00000e-09 2.12000e-01 $5.77925 \mathrm{e}+005.77925 \mathrm{e}+00$ 5.77925e-01 1.00000e-09 2.12000e-01 $5.77925 \mathrm{e}+005.77925 \mathrm{e}+00$ 5.77925e-01 1.00000e-09 2.12000e-01 $5.77925 \mathrm{e}+005.77925 \mathrm{e}+00$ 5.77925e-01 1.00000e-09 2.12000e-01 
$5.77925 \mathrm{e}+00$ 5.77925e+00 5.77925e-01 1.00000e-09 2.12000e-01 $1.00000 \mathrm{e}-05$ 1.00000e-05 1.00000e-06 1.00000e-09 1.00000e-01 $1.00000 \mathrm{e}+001.00000 \mathrm{e}+001.00000 \mathrm{e}-011.00000 \mathrm{e}-091.00000 \mathrm{e}-01$ Element: 12849 \# of layers: 7

Kx Ky Kz Ss Por

$5.77925 \mathrm{e}+00$ 5.77925e+00 5.77925e-01 1.00000e-09 2.12000e-01

$5.77925 \mathrm{e}+005.77925 \mathrm{e}+00$ 5.77925e-01 1.00000e-09 2.12000e-01

$5.77925 \mathrm{e}+005.77925 \mathrm{e}+00$ 5.77925e-01 1.00000e-09 2.12000e-01

$5.77925 \mathrm{e}+005.77925 \mathrm{e}+005.77925 \mathrm{e}-011.00000 \mathrm{e}-092.12000 \mathrm{e}-01$

$5.77925 \mathrm{e}+00$ 5.77925e+00 5.77925e-01 1.00000e-09 2.12000e-01

$1.00000 \mathrm{e}-05$ 1.00000e-05 1.00000e-06 1.00000e-09 1.00000e-01

$1.00000 \mathrm{e}+001.00000 \mathrm{e}+001.00000 \mathrm{e}-011.00000 \mathrm{e}-091.00000 \mathrm{e}-01$

Element: 12850 \# of layers: 7

Kx Ky Kz Ss Por

$3.49500 \mathrm{e}+003.49500 \mathrm{e}+00$ 3.49500e-01 1.00000e-09 2.12000e-01

$3.49500 \mathrm{e}+003.49500 \mathrm{e}+003.49500 \mathrm{e}-011.00000 \mathrm{e}-092.12000 \mathrm{e}-01$

$3.49500 \mathrm{e}+003.49500 \mathrm{e}+003.49500 \mathrm{e}-011.00000 \mathrm{e}-092.12000 \mathrm{e}-01$

$3.49500 \mathrm{e}+003.49500 \mathrm{e}+003.49500 \mathrm{e}-011.00000 \mathrm{e}-092.12000 \mathrm{e}-01$

$3.49500 \mathrm{e}+003.49500 \mathrm{e}+003.49500 \mathrm{e}-011.00000 \mathrm{e}-092.12000 \mathrm{e}-01$

$1.00000 \mathrm{e}-05$ 1.00000e-05 1.00000e-06 1.00000e-09 1.00000e-01

$1.00000 \mathrm{e}+001.00000 \mathrm{e}+001.00000 \mathrm{e}-011.00000 \mathrm{e}-091.00000 \mathrm{e}-01$

Element: 12851 \# of layers: 7

Kx Ky Kz Ss Por

$3.49500 \mathrm{e}+003.49500 \mathrm{e}+00$ 3.49500e-01 1.00000e-09 2.12000e-01

$3.49500 \mathrm{e}+003.49500 \mathrm{e}+003.49500 \mathrm{e}-011.00000 \mathrm{e}-092.12000 \mathrm{e}-01$

$3.49500 \mathrm{e}+003.49500 \mathrm{e}+003.49500 \mathrm{e}-011.00000 \mathrm{e}-092.12000 \mathrm{e}-01$

$3.49500 \mathrm{e}+003.49500 \mathrm{e}+003.49500 \mathrm{e}-011.00000 \mathrm{e}-092.12000 \mathrm{e}-01$

$3.49500 \mathrm{e}+003.49500 \mathrm{e}+003.49500 \mathrm{e}-011.00000 \mathrm{e}-09$ 2.12000e-01

$1.00000 \mathrm{e}-05$ 1.00000e-05 1.00000e-06 1.00000e-09 1.00000e-01

$1.00000 \mathrm{e}+001.00000 \mathrm{e}+001.00000 \mathrm{e}-011.00000 \mathrm{e}-091.00000 \mathrm{e}-01$

Element: 12852 \# of layers: 7

Kx Ky Kz Ss Por

$5.77925 \mathrm{e}+005.77925 \mathrm{e}+00$ 5.77925e-01 1.00000e-09 2.12000e-01

$5.77925 \mathrm{e}+005.77925 \mathrm{e}+00$ 5.77925e-01 1.00000e-09 2.12000e-01

$5.77925 \mathrm{e}+005.77925 \mathrm{e}+00$ 5.77925e-01 1.00000e-09 2.12000e-01

$5.77925 \mathrm{e}+005.77925 \mathrm{e}+00$ 5.77925e-01 1.00000e-09 2.12000e-01

$5.77925 \mathrm{e}+005.77925 \mathrm{e}+00$ 5.77925e-01 1.00000e-09 2.12000e-01

$1.00000 \mathrm{e}-05$ 1.00000e-05 1.00000e-06 1.00000e-09 1.00000e-01

$1.00000 \mathrm{e}+001.00000 \mathrm{e}+001.00000 \mathrm{e}-011.00000 \mathrm{e}-091.00000 \mathrm{e}-01$

Element: 12853 \# of layers: 7

Kx Ky Kz Ss Por

$5.77925 \mathrm{e}+00$ 5.77925e+00 5.77925e-01 1.00000e-09 2.12000e-01

$5.77925 \mathrm{e}+005.77925 \mathrm{e}+00$ 5.77925e-01 1.00000e-09 2.12000e-01

$5.77925 \mathrm{e}+005.77925 \mathrm{e}+00$ 5.77925e-01 1.00000e-09 2.12000e-01

$5.77925 \mathrm{e}+005.77925 \mathrm{e}+00$ 5.77925e-01 1.00000e-09 2.12000e-01

$5.77925 \mathrm{e}+005.77925 \mathrm{e}+00$ 5.77925e-01 1.00000e-09 2.12000e-01 
$1.00000 \mathrm{e}-05$ 1.00000e-05 1.00000e-06 1.00000e-09 1.00000e-01 $1.00000 \mathrm{e}+001.00000 \mathrm{e}+001.00000 \mathrm{e}-011.00000 \mathrm{e}-091.00000 \mathrm{e}-01$ Element: 12854 \# of layers: 7

Kx Ky Kz Ss Por

$3.41647 \mathrm{e}+003.41647 \mathrm{e}+00$ 3.41647e-01 1.00000e-09 2.12000e-01

$3.41647 \mathrm{e}+003.41647 \mathrm{e}+003.41647 \mathrm{e}-011.00000 \mathrm{e}-092.12000 \mathrm{e}-01$

$3.41647 \mathrm{e}+003.41647 \mathrm{e}+003.41647 \mathrm{e}-011.00000 \mathrm{e}-092.12000 \mathrm{e}-01$

$3.41647 \mathrm{e}+003.41647 \mathrm{e}+003.41647 \mathrm{e}-011.00000 \mathrm{e}-092.12000 \mathrm{e}-01$

$3.41647 \mathrm{e}+003.41647 \mathrm{e}+003.41647 \mathrm{e}-01$ 1.00000e-09 2.12000e-01

$1.00000 \mathrm{e}-05$ 1.00000e-05 1.00000e-06 1.00000e-09 1.00000e-01

$1.00000 \mathrm{e}+001.00000 \mathrm{e}+001.00000 \mathrm{e}-011.00000 \mathrm{e}-091.00000 \mathrm{e}-01$

Element: 12855 \# of layers: 7

Kx Ky Kz Ss Por

$3.41647 \mathrm{e}+003.41647 \mathrm{e}+003.41647 \mathrm{e}-01$ 1.00000e-09 2.12000e-01

$3.41647 \mathrm{e}+003.41647 \mathrm{e}+003.41647 \mathrm{e}-01$ 1.00000e-09 2.12000e-01

$3.41647 \mathrm{e}+003.41647 \mathrm{e}+003.41647 \mathrm{e}-011.00000 \mathrm{e}-092.12000 \mathrm{e}-01$

$3.41647 \mathrm{e}+003.41647 \mathrm{e}+003.41647 \mathrm{e}-011.00000 \mathrm{e}-092.12000 \mathrm{e}-01$

$3.41647 \mathrm{e}+003.41647 \mathrm{e}+003.41647 \mathrm{e}-01$ 1.00000e-09 2.12000e-01

$1.00000 \mathrm{e}-05$ 1.00000e-05 1.00000e-06 1.00000e-09 1.00000e-01

$1.00000 \mathrm{e}+001.00000 \mathrm{e}+001.00000 \mathrm{e}-011.00000 \mathrm{e}-091.00000 \mathrm{e}-01$

Element: 12856 \# of layers: 7

Kx Ky Kz Ss Por

$3.41647 \mathrm{e}+003.41647 \mathrm{e}+00$ 3.41647e-01 1.00000e-09 2.12000e-01

$3.41647 \mathrm{e}+003.41647 \mathrm{e}+003.41647 \mathrm{e}-011.00000 \mathrm{e}-092.12000 \mathrm{e}-01$

$3.41647 \mathrm{e}+003.41647 \mathrm{e}+003.41647 \mathrm{e}-011.00000 \mathrm{e}-092.12000 \mathrm{e}-01$

$3.41647 \mathrm{e}+003.41647 \mathrm{e}+003.41647 \mathrm{e}-01$ 1.00000e-09 2.12000e-01

$3.41647 \mathrm{e}+003.41647 \mathrm{e}+003.41647 \mathrm{e}-011.00000 \mathrm{e}-092.12000 \mathrm{e}-01$

$1.00000 \mathrm{e}-05$ 1.00000e-05 1.00000e-06 1.00000e-09 1.00000e-01

$1.00000 \mathrm{e}+001.00000 \mathrm{e}+001.00000 \mathrm{e}-011.00000 \mathrm{e}-091.00000 \mathrm{e}-01$

Element: 12857 \# of layers: 7

Kx Ky Kz Ss Por

$2.92664 \mathrm{e}+002.92664 \mathrm{e}+002.92664 \mathrm{e}-01$ 1.00000e-09 2.12000e-01

$2.92664 \mathrm{e}+002.92664 \mathrm{e}+002.92664 \mathrm{e}-011.00000 \mathrm{e}-092.12000 \mathrm{e}-01$

$2.92664 \mathrm{e}+002.92664 \mathrm{e}+002.92664 \mathrm{e}-011.00000 \mathrm{e}-092.12000 \mathrm{e}-01$

$2.92664 \mathrm{e}+002.92664 \mathrm{e}+002.92664 \mathrm{e}-011.00000 \mathrm{e}-092.12000 \mathrm{e}-01$

$2.92664 \mathrm{e}+002.92664 \mathrm{e}+002.92664 \mathrm{e}-011.00000 \mathrm{e}-092.12000 \mathrm{e}-01$ $1.00000 \mathrm{e}-05$ 1.00000e-05 1.00000e-06 1.00000e-09 1.00000e-01

$1.00000 \mathrm{e}+001.00000 \mathrm{e}+001.00000 \mathrm{e}-011.00000 \mathrm{e}-091.00000 \mathrm{e}-01$

Element: 12858 \# of layers: 7

Kx Ky Kz Ss Por

$2.92664 \mathrm{e}+002.92664 \mathrm{e}+002.92664 \mathrm{e}-01$ 1.00000e-09 2.12000e-01

$2.92664 \mathrm{e}+002.92664 \mathrm{e}+002.92664 \mathrm{e}-011.00000 \mathrm{e}-092.12000 \mathrm{e}-01$

$2.92664 \mathrm{e}+002.92664 \mathrm{e}+002.92664 \mathrm{e}-011.00000 \mathrm{e}-092.12000 \mathrm{e}-01$

$2.92664 \mathrm{e}+002.92664 \mathrm{e}+002.92664 \mathrm{e}-011.00000 \mathrm{e}-092.12000 \mathrm{e}-01$

$2.92664 \mathrm{e}+002.92664 \mathrm{e}+002.92664 \mathrm{e}-011.00000 \mathrm{e}-092.12000 \mathrm{e}-01$

$1.00000 \mathrm{e}-05$ 1.00000e-05 1.00000e-06 1.00000e-09 1.00000e-01 
$1.00000 \mathrm{e}+001.00000 \mathrm{e}+001.00000 \mathrm{e}-011.00000 \mathrm{e}-091.00000 \mathrm{e}-01$ Element: 12859 \# of layers: 7

$\mathrm{Kx} \mathrm{Ky} \mathrm{Kz}$ Ss Por

3.49500e+00 3.49500e+00 3.49500e-01 1.00000e-09 2.12000e-01

$3.49500 \mathrm{e}+003.49500 \mathrm{e}+003.49500 \mathrm{e}-01$ 1.00000e-09 2.12000e-01

$3.49500 \mathrm{e}+003.49500 \mathrm{e}+00$ 3.49500e-01 1.00000e-09 2.12000e-01

$3.49500 \mathrm{e}+003.49500 \mathrm{e}+00$ 3.49500e-01 1.00000e-09 2.12000e-01

$3.49500 \mathrm{e}+003.49500 \mathrm{e}+003.49500 \mathrm{e}-01$ 1.00000e-09 2.12000e-01

$1.00000 \mathrm{e}-05$ 1.00000e-05 1.00000e-06 1.00000e-09 1.00000e-01

$1.00000 \mathrm{e}+001.00000 \mathrm{e}+001.00000 \mathrm{e}-011.00000 \mathrm{e}-091.00000 \mathrm{e}-01$

Element: 12860 \# of layers: 7

Kx Ky Kz Ss Por

5.77925e+00 5.77925e+00 5.77925e-01 1.00000e-09 2.12000e-01

$5.77925 \mathrm{e}+005.77925 \mathrm{e}+00$ 5.77925e-01 1.00000e-09 2.12000e-01

$5.77925 \mathrm{e}+005.77925 \mathrm{e}+00$ 5.77925e-01 1.00000e-09 2.12000e-01

$5.77925 \mathrm{e}+005.77925 \mathrm{e}+00$ 5.77925e-01 1.00000e-09 2.12000e-01

$5.77925 \mathrm{e}+00$ 5.77925e+00 5.77925e-01 1.00000e-09 2.12000e-01

$1.00000 \mathrm{e}-05$ 1.00000e-05 1.00000e-06 1.00000e-09 1.00000e-01

$1.00000 \mathrm{e}+001.00000 \mathrm{e}+001.00000 \mathrm{e}-01$ 1.00000e-09 1.00000e-01

Element: 12861 \# of layers: 7

$\mathrm{Kx} \mathrm{Ky} \mathrm{Kz}$ Ss Por

3.41647e+00 3.41647e+00 3.41647e-01 1.00000e-09 2.12000e-01

3.41647e+00 3.41647e+00 3.41647e-01 1.00000e-09 2.12000e-01

$3.41647 \mathrm{e}+003.41647 \mathrm{e}+00$ 3.41647e-01 1.00000e-09 2.12000e-01

$3.41647 \mathrm{e}+003.41647 \mathrm{e}+00$ 3.41647e-01 1.00000e-09 2.12000e-01

$3.41647 \mathrm{e}+003.41647 \mathrm{e}+00$ 3.41647e-01 1.00000e-09 2.12000e-01

$1.00000 \mathrm{e}-05$ 1.00000e-05 1.00000e-06 1.00000e-09 1.00000e-01

$1.00000 \mathrm{e}+001.00000 \mathrm{e}+001.00000 \mathrm{e}-01$ 1.00000e-09 1.00000e-01

Element: 12862 \# of layers: 7

$\mathrm{Kx} \mathrm{Ky} \mathrm{Kz}$ Ss Por

$2.64268 \mathrm{e}+002.64268 \mathrm{e}+00$ 2.64268e-01 1.00000e-09 2.12000e-01

$2.64268 \mathrm{e}+002.64268 \mathrm{e}+00$ 2.64268e-01 1.00000e-09 2.12000e-01

$2.64268 \mathrm{e}+002.64268 \mathrm{e}+002.64268 \mathrm{e}-01$ 1.00000e-09 2.12000e-01

$2.64268 \mathrm{e}+002.64268 \mathrm{e}+00$ 2.64268e-01 1.00000e-09 2.12000e-01

$2.64268 \mathrm{e}+002.64268 \mathrm{e}+002.64268 \mathrm{e}-01$ 1.00000e-09 2.12000e-01

$1.00000 \mathrm{e}-05$ 1.00000e-05 1.00000e-06 1.00000e-09 1.00000e-01

$1.00000 \mathrm{e}+001.00000 \mathrm{e}+001.00000 \mathrm{e}-011.00000 \mathrm{e}-091.00000 \mathrm{e}-01$

Element: 12863 \# of layers: 7

$\mathrm{Kx} \mathrm{Ky} \mathrm{Kz}$ Ss Por

$2.64268 \mathrm{e}+00$ 2.64268e+00 2.64268e-01 1.00000e-09 2.12000e-01

$2.64268 \mathrm{e}+002.64268 \mathrm{e}+00$ 2.64268e-01 1.00000e-09 2.12000e-01

$2.64268 \mathrm{e}+002.64268 \mathrm{e}+00$ 2.64268e-01 1.00000e-09 2.12000e-01

$2.64268 \mathrm{e}+002.64268 \mathrm{e}+00$ 2.64268e-01 1.00000e-09 2.12000e-01

2.64268e+00 2.64268e+00 2.64268e-01 1.00000e-09 2.12000e-01 $1.00000 \mathrm{e}-05$ 1.00000e-05 1.00000e-06 1.00000e-09 1.00000e-01

$1.00000 \mathrm{e}+001.00000 \mathrm{e}+001.00000 \mathrm{e}-011.00000 \mathrm{e}-091.00000 \mathrm{e}-01$ 
Element: 12864 \# of layers: 7

Kx Ky Kz Ss Por

$2.64268 \mathrm{e}+002.64268 \mathrm{e}+00$ 2.64268e-01 1.00000e-09 2.12000e-01

$2.64268 \mathrm{e}+002.64268 \mathrm{e}+002.64268 \mathrm{e}-011.00000 \mathrm{e}-092.12000 \mathrm{e}-01$

$2.64268 \mathrm{e}+002.64268 \mathrm{e}+002.64268 \mathrm{e}-011.00000 \mathrm{e}-092.12000 \mathrm{e}-01$

$2.64268 \mathrm{e}+002.64268 \mathrm{e}+002.64268 \mathrm{e}-011.00000 \mathrm{e}-092.12000 \mathrm{e}-01$

$2.64268 \mathrm{e}+002.64268 \mathrm{e}+002.64268 \mathrm{e}-011.00000 \mathrm{e}-092.12000 \mathrm{e}-01$

$1.00000 \mathrm{e}-05$ 1.00000e-05 1.00000e-06 1.00000e-09 1.00000e-01

$1.00000 \mathrm{e}+001.00000 \mathrm{e}+001.00000 \mathrm{e}-011.00000 \mathrm{e}-091.00000 \mathrm{e}-01$

Element: 12865 \# of layers: 7

Kx Ky Kz Ss Por

$2.64268 \mathrm{e}+002.64268 \mathrm{e}+002.64268 \mathrm{e}-01$ 1.00000e-09 2.12000e-01

$2.64268 \mathrm{e}+002.64268 \mathrm{e}+002.64268 \mathrm{e}-011.00000 \mathrm{e}-092.12000 \mathrm{e}-01$

$2.64268 \mathrm{e}+002.64268 \mathrm{e}+002.64268 \mathrm{e}-011.00000 \mathrm{e}-092.12000 \mathrm{e}-01$

$2.64268 \mathrm{e}+002.64268 \mathrm{e}+002.64268 \mathrm{e}-011.00000 \mathrm{e}-092.12000 \mathrm{e}-01$

$2.64268 \mathrm{e}+002.64268 \mathrm{e}+002.64268 \mathrm{e}-011.00000 \mathrm{e}-092.12000 \mathrm{e}-01$

$1.00000 \mathrm{e}-05$ 1.00000e-05 1.00000e-06 1.00000e-09 1.00000e-01

$1.00000 \mathrm{e}+001.00000 \mathrm{e}+001.00000 \mathrm{e}-011.00000 \mathrm{e}-091.00000 \mathrm{e}-01$

Element: 12866 \# of layers: 7

Kx Ky Kz Ss Por

$2.64268 \mathrm{e}+002.64268 \mathrm{e}+002.64268 \mathrm{e}-01$ 1.00000e-09 2.12000e-01

$2.64268 \mathrm{e}+002.64268 \mathrm{e}+002.64268 \mathrm{e}-011.00000 \mathrm{e}-092.12000 \mathrm{e}-01$

$2.64268 \mathrm{e}+002.64268 \mathrm{e}+002.64268 \mathrm{e}-011.00000 \mathrm{e}-092.12000 \mathrm{e}-01$

$2.64268 \mathrm{e}+002.64268 \mathrm{e}+002.64268 \mathrm{e}-011.00000 \mathrm{e}-092.12000 \mathrm{e}-01$

$2.64268 \mathrm{e}+002.64268 \mathrm{e}+002.64268 \mathrm{e}-011.00000 \mathrm{e}-092.12000 \mathrm{e}-01$

$1.00000 \mathrm{e}-05$ 1.00000e-05 1.00000e-06 1.00000e-09 1.00000e-01

$1.00000 \mathrm{e}+001.00000 \mathrm{e}+001.00000 \mathrm{e}-011.00000 \mathrm{e}-091.00000 \mathrm{e}-01$

Element: 12867 \# of layers: 7

Kx Ky Kz Ss Por

$2.64268 \mathrm{e}+002.64268 \mathrm{e}+002.64268 \mathrm{e}-011.00000 \mathrm{e}-092.12000 \mathrm{e}-01$

$2.64268 \mathrm{e}+002.64268 \mathrm{e}+002.64268 \mathrm{e}-011.00000 \mathrm{e}-092.12000 \mathrm{e}-01$

$2.64268 \mathrm{e}+002.64268 \mathrm{e}+002.64268 \mathrm{e}-011.00000 \mathrm{e}-092.12000 \mathrm{e}-01$

$2.64268 \mathrm{e}+002.64268 \mathrm{e}+002.64268 \mathrm{e}-011.00000 \mathrm{e}-092.12000 \mathrm{e}-01$

$2.64268 \mathrm{e}+002.64268 \mathrm{e}+002.64268 \mathrm{e}-01$ 1.00000e-09 2.12000e-01

$1.00000 \mathrm{e}-05$ 1.00000e-05 1.00000e-06 1.00000e-09 1.00000e-01

$1.00000 \mathrm{e}+001.00000 \mathrm{e}+001.00000 \mathrm{e}-011.00000 \mathrm{e}-091.00000 \mathrm{e}-01$

Element: 12868 \# of layers: 7

Kx Ky Kz Ss Por

$2.64268 \mathrm{e}+002.64268 \mathrm{e}+002.64268 \mathrm{e}-01$ 1.00000e-09 2.12000e-01

$2.64268 \mathrm{e}+002.64268 \mathrm{e}+002.64268 \mathrm{e}-011.00000 \mathrm{e}-092.12000 \mathrm{e}-01$

$2.64268 \mathrm{e}+002.64268 \mathrm{e}+002.64268 \mathrm{e}-011.00000 \mathrm{e}-092.12000 \mathrm{e}-01$

$2.64268 \mathrm{e}+002.64268 \mathrm{e}+002.64268 \mathrm{e}-011.00000 \mathrm{e}-092.12000 \mathrm{e}-01$

$2.64268 \mathrm{e}+002.64268 \mathrm{e}+002.64268 \mathrm{e}-011.00000 \mathrm{e}-092.12000 \mathrm{e}-01$

$1.00000 \mathrm{e}-05$ 1.00000e-05 1.00000e-06 1.00000e-09 1.00000e-01

$1.00000 \mathrm{e}+001.00000 \mathrm{e}+001.00000 \mathrm{e}-011.00000 \mathrm{e}-091.00000 \mathrm{e}-01$

Element: 12869 \# of layers: 7 
$\mathrm{Kx} \mathrm{Ky} \mathrm{Kz}$ Ss Por

2.64268e+00 2.64268e+00 2.64268e-01 1.00000e-09 2.12000e-01

$2.64268 \mathrm{e}+002.64268 \mathrm{e}+00$ 2.64268e-01 1.00000e-09 2.12000e-01

$2.64268 \mathrm{e}+002.64268 \mathrm{e}+00$ 2.64268e-01 1.00000e-09 2.12000e-01

$2.64268 \mathrm{e}+002.64268 \mathrm{e}+00$ 2.64268e-01 1.00000e-09 2.12000e-01

$2.64268 \mathrm{e}+002.64268 \mathrm{e}+002.64268 \mathrm{e}-01$ 1.00000e-09 2.12000e-01

$1.00000 \mathrm{e}-05$ 1.00000e-05 1.00000e-06 1.00000e-09 1.00000e-01

$1.00000 \mathrm{e}+001.00000 \mathrm{e}+001.00000 \mathrm{e}-01$ 1.00000e-09 1.00000e-01

Element: 12870 \# of layers: 7

$\mathrm{Kx} \mathrm{Ky} \mathrm{Kz}$ Ss Por

$2.64268 \mathrm{e}+00$ 2.64268e+00 2.64268e-01 1.00000e-09 2.12000e-01

$2.64268 \mathrm{e}+002.64268 \mathrm{e}+002.64268 \mathrm{e}-01$ 1.00000e-09 2.12000e-01

$2.64268 \mathrm{e}+002.64268 \mathrm{e}+002.64268 \mathrm{e}-01$ 1.00000e-09 2.12000e-01

$2.64268 \mathrm{e}+002.64268 \mathrm{e}+00$ 2.64268e-01 1.00000e-09 2.12000e-01

$2.64268 \mathrm{e}+002.64268 \mathrm{e}+00$ 2.64268e-01 1.00000e-09 2.12000e-01

$1.00000 \mathrm{e}-05$ 1.00000e-05 1.00000e-06 1.00000e-09 1.00000e-01

$1.00000 \mathrm{e}+001.00000 \mathrm{e}+001.00000 \mathrm{e}-01$ 1.00000e-09 1.00000e-01

Element: 12871 \# of layers: 7

$\mathrm{Kx} \mathrm{Ky} \mathrm{Kz}$ Ss Por

$2.64268 \mathrm{e}+002.64268 \mathrm{e}+00$ 2.64268e-01 1.00000e-09 2.12000e-01

$2.64268 \mathrm{e}+002.64268 \mathrm{e}+00$ 2.64268e-01 1.00000e-09 2.12000e-01

$2.64268 \mathrm{e}+002.64268 \mathrm{e}+00$ 2.64268e-01 1.00000e-09 2.12000e-01

$2.64268 \mathrm{e}+002.64268 \mathrm{e}+00$ 2.64268e-01 1.00000e-09 2.12000e-01

$2.64268 \mathrm{e}+002.64268 \mathrm{e}+00$ 2.64268e-01 1.00000e-09 2.12000e-01

$1.00000 \mathrm{e}-05$ 1.00000e-05 1.00000e-06 1.00000e-09 1.00000e-01

$1.00000 \mathrm{e}+001.00000 \mathrm{e}+001.00000 \mathrm{e}-01$ 1.00000e-09 1.00000e-01

Element: 12872 \# of layers: 7

$\mathrm{Kx} \mathrm{Ky} \mathrm{Kz}$ Ss Por

$2.06113 \mathrm{e}+00$ 2.06113e+00 2.06113e-01 1.00000e-09 2.12000e-01

$2.06113 \mathrm{e}+00$ 2.06113e+00 2.06113e-01 1.00000e-09 2.12000e-01

$2.06113 \mathrm{e}+002.06113 \mathrm{e}+00$ 2.06113e-01 1.00000e-09 2.12000e-01

$2.06113 \mathrm{e}+00$ 2.06113e+00 2.06113e-01 1.00000e-09 2.12000e-01

$2.06113 \mathrm{e}+002.06113 \mathrm{e}+002.06113 \mathrm{e}-01$ 1.00000e-09 2.12000e-01

$1.00000 \mathrm{e}-05$ 1.00000e-05 1.00000e-06 1.00000e-09 1.00000e-01

$1.00000 \mathrm{e}+001.00000 \mathrm{e}+001.00000 \mathrm{e}-01$ 1.00000e-09 1.00000e-01

Element: 12873 \# of layers: 7

Kx Ky Kz Ss Por

2.06113e+00 2.06113e+00 2.06113e-01 1.00000e-09 2.12000e-01

$2.06113 \mathrm{e}+002.06113 \mathrm{e}+00$ 2.06113e-01 1.00000e-09 2.12000e-01

$2.06113 \mathrm{e}+002.06113 \mathrm{e}+00$ 2.06113e-01 1.00000e-09 2.12000e-01

$2.06113 \mathrm{e}+002.06113 \mathrm{e}+00$ 2.06113e-01 1.00000e-09 2.12000e-01

$2.06113 \mathrm{e}+002.06113 \mathrm{e}+00$ 2.06113e-01 1.00000e-09 2.12000e-01

$1.00000 \mathrm{e}-05$ 1.00000e-05 1.00000e-06 1.00000e-09 1.00000e-01

$1.00000 \mathrm{e}+001.00000 \mathrm{e}+001.00000 \mathrm{e}-01$ 1.00000e-09 1.00000e-01

Element: 12874 \# of layers: 7

Kx Ky Kz Ss Por 
$2.06113 \mathrm{e}+002.06113 \mathrm{e}+00$ 2.06113e-01 1.00000e-09 2.12000e-01 $2.06113 \mathrm{e}+002.06113 \mathrm{e}+002.06113 \mathrm{e}-011.00000 \mathrm{e}-092.12000 \mathrm{e}-01$ $2.06113 \mathrm{e}+002.06113 \mathrm{e}+002.06113 \mathrm{e}-01$ 1.00000e-09 2.12000e-01 $2.06113 \mathrm{e}+002.06113 \mathrm{e}+002.06113 \mathrm{e}-011.00000 \mathrm{e}-092.12000 \mathrm{e}-01$ $2.06113 \mathrm{e}+002.06113 \mathrm{e}+002.06113 \mathrm{e}-011.00000 \mathrm{e}-092.12000 \mathrm{e}-01$ $1.00000 \mathrm{e}-05$ 1.00000e-05 1.00000e-06 1.00000e-09 1.00000e-01 $1.00000 \mathrm{e}+001.00000 \mathrm{e}+001.00000 \mathrm{e}-011.00000 \mathrm{e}-091.00000 \mathrm{e}-01$ Element: 12875 \# of layers: 7

Kx Ky Kz Ss Por

$2.06113 \mathrm{e}+002.06113 \mathrm{e}+00$ 2.06113e-01 1.00000e-09 2.12000e-01 $2.06113 \mathrm{e}+002.06113 \mathrm{e}+002.06113 \mathrm{e}-011.00000 \mathrm{e}-092.12000 \mathrm{e}-01$ $2.06113 \mathrm{e}+002.06113 \mathrm{e}+002.06113 \mathrm{e}-011.00000 \mathrm{e}-092.12000 \mathrm{e}-01$ $2.06113 \mathrm{e}+002.06113 \mathrm{e}+002.06113 \mathrm{e}-011.00000 \mathrm{e}-092.12000 \mathrm{e}-01$ $2.06113 \mathrm{e}+002.06113 \mathrm{e}+002.06113 \mathrm{e}-011.00000 \mathrm{e}-092.12000 \mathrm{e}-01$ $1.00000 \mathrm{e}-05$ 1.00000e-05 1.00000e-06 1.00000e-09 1.00000e-01 $1.00000 \mathrm{e}+001.00000 \mathrm{e}+001.00000 \mathrm{e}-011.00000 \mathrm{e}-091.00000 \mathrm{e}-01$ Element: 12876 \# of layers: 7

Kx Ky Kz Ss Por

$2.06113 \mathrm{e}+002.06113 \mathrm{e}+00$ 2.06113e-01 1.00000e-09 2.12000e-01 $2.06113 \mathrm{e}+002.06113 \mathrm{e}+002.06113 \mathrm{e}-011.00000 \mathrm{e}-092.12000 \mathrm{e}-01$ $2.06113 \mathrm{e}+002.06113 \mathrm{e}+002.06113 \mathrm{e}-011.00000 \mathrm{e}-092.12000 \mathrm{e}-01$ $2.06113 \mathrm{e}+002.06113 \mathrm{e}+002.06113 \mathrm{e}-01$ 1.00000e-09 2.12000e-01 $2.06113 \mathrm{e}+002.06113 \mathrm{e}+002.06113 \mathrm{e}-01$ 1.00000e-09 2.12000e-01 $1.00000 \mathrm{e}-05$ 1.00000e-05 1.00000e-06 1.00000e-09 1.00000e-01 $1.00000 \mathrm{e}+001.00000 \mathrm{e}+001.00000 \mathrm{e}-011.00000 \mathrm{e}-091.00000 \mathrm{e}-01$ Element: 12877 \# of layers: 7

Kx Ky Kz Ss Por

$2.64268 \mathrm{e}+002.64268 \mathrm{e}+002.64268 \mathrm{e}-011.00000 \mathrm{e}-092.12000 \mathrm{e}-01$ $2.64268 \mathrm{e}+002.64268 \mathrm{e}+002.64268 \mathrm{e}-011.00000 \mathrm{e}-092.12000 \mathrm{e}-01$ $2.64268 \mathrm{e}+002.64268 \mathrm{e}+002.64268 \mathrm{e}-011.00000 \mathrm{e}-092.12000 \mathrm{e}-01$ $2.64268 \mathrm{e}+002.64268 \mathrm{e}+002.64268 \mathrm{e}-011.00000 \mathrm{e}-092.12000 \mathrm{e}-01$ $2.64268 \mathrm{e}+002.64268 \mathrm{e}+002.64268 \mathrm{e}-011.00000 \mathrm{e}-092.12000 \mathrm{e}-01$ $1.00000 \mathrm{e}-05$ 1.00000e-05 1.00000e-06 1.00000e-09 1.00000e-01 $1.00000 \mathrm{e}+001.00000 \mathrm{e}+001.00000 \mathrm{e}-011.00000 \mathrm{e}-091.00000 \mathrm{e}-01$ Element: 12878 \# of layers: 7

Kx Ky Kz Ss Por

$2.64268 \mathrm{e}+002.64268 \mathrm{e}+002.64268 \mathrm{e}-01$ 1.00000e-09 2.12000e-01 $2.64268 \mathrm{e}+002.64268 \mathrm{e}+002.64268 \mathrm{e}-011.00000 \mathrm{e}-092.12000 \mathrm{e}-01$ $2.64268 \mathrm{e}+002.64268 \mathrm{e}+002.64268 \mathrm{e}-01$ 1.00000e-09 2.12000e-01 $2.64268 \mathrm{e}+002.64268 \mathrm{e}+002.64268 \mathrm{e}-011.00000 \mathrm{e}-092.12000 \mathrm{e}-01$ $2.64268 \mathrm{e}+002.64268 \mathrm{e}+002.64268 \mathrm{e}-011.00000 \mathrm{e}-092.12000 \mathrm{e}-01$ $1.00000 \mathrm{e}-05$ 1.00000e-05 1.00000e-06 1.00000e-09 1.00000e-01 $1.00000 \mathrm{e}+001.00000 \mathrm{e}+001.00000 \mathrm{e}-011.00000 \mathrm{e}-091.00000 \mathrm{e}-01$ Element: 12879 \# of layers: 7

Kx Ky Kz Ss Por 2.06113e+00 2.06113e+00 2.06113e-01 1.00000e-09 2.12000e-01 
$2.06113 \mathrm{e}+002.06113 \mathrm{e}+00$ 2.06113e-01 1.00000e-09 2.12000e-01 $2.06113 \mathrm{e}+002.06113 \mathrm{e}+002.06113 \mathrm{e}-011.00000 \mathrm{e}-092.12000 \mathrm{e}-01$ $2.06113 \mathrm{e}+002.06113 \mathrm{e}+002.06113 \mathrm{e}-01$ 1.00000e-09 2.12000e-01 $2.06113 \mathrm{e}+002.06113 \mathrm{e}+002.06113 \mathrm{e}-011.00000 \mathrm{e}-092.12000 \mathrm{e}-01$ $1.00000 \mathrm{e}-05$ 1.00000e-05 1.00000e-06 1.00000e-09 1.00000e-01 $1.00000 \mathrm{e}+001.00000 \mathrm{e}+001.00000 \mathrm{e}-011.00000 \mathrm{e}-091.00000 \mathrm{e}-01$ Element: 12880 \# of layers: 7

Kx Ky Kz Ss Por

2.06113e+00 2.06113e+00 2.06113e-01 1.00000e-09 2.12000e-01 $2.06113 \mathrm{e}+002.06113 \mathrm{e}+002.06113 \mathrm{e}-011.00000 \mathrm{e}-092.12000 \mathrm{e}-01$ $2.06113 \mathrm{e}+002.06113 \mathrm{e}+002.06113 \mathrm{e}-011.00000 \mathrm{e}-092.12000 \mathrm{e}-01$ $2.06113 \mathrm{e}+002.06113 \mathrm{e}+002.06113 \mathrm{e}-011.00000 \mathrm{e}-092.12000 \mathrm{e}-01$ $2.06113 \mathrm{e}+002.06113 \mathrm{e}+002.06113 \mathrm{e}-01$ 1.00000e-09 2.12000e-01 $1.00000 \mathrm{e}-05$ 1.00000e-05 1.00000e-06 1.00000e-09 1.00000e-01 $1.00000 \mathrm{e}+001.00000 \mathrm{e}+001.00000 \mathrm{e}-011.00000 \mathrm{e}-091.00000 \mathrm{e}-01$ Element: 12881 \# of layers: 6

Kx Ky Kz Ss Por

2.06113e+00 2.06113e+00 2.06113e-01 1.00000e-09 2.12000e-01 $2.06113 \mathrm{e}+002.06113 \mathrm{e}+002.06113 \mathrm{e}-011.00000 \mathrm{e}-092.12000 \mathrm{e}-01$ $2.06113 \mathrm{e}+002.06113 \mathrm{e}+002.06113 \mathrm{e}-01$ 1.00000e-09 2.12000e-01 $2.06113 \mathrm{e}+002.06113 \mathrm{e}+002.06113 \mathrm{e}-011.00000 \mathrm{e}-092.12000 \mathrm{e}-01$ $1.00000 \mathrm{e}-05$ 1.00000e-05 1.00000e-06 1.00000e-09 1.00000e-01 $1.00000 \mathrm{e}+001.00000 \mathrm{e}+001.00000 \mathrm{e}-011.00000 \mathrm{e}-091.00000 \mathrm{e}-01$ Element: 12882 \# of layers: 6

Kx Ky Kz Ss Por

$2.06113 \mathrm{e}+002.06113 \mathrm{e}+00$ 2.06113e-01 1.00000e-09 2.12000e-01 $2.06113 \mathrm{e}+002.06113 \mathrm{e}+002.06113 \mathrm{e}-011.00000 \mathrm{e}-092.12000 \mathrm{e}-01$ $2.06113 \mathrm{e}+002.06113 \mathrm{e}+002.06113 \mathrm{e}-011.00000 \mathrm{e}-092.12000 \mathrm{e}-01$ $2.06113 \mathrm{e}+002.06113 \mathrm{e}+002.06113 \mathrm{e}-011.00000 \mathrm{e}-092.12000 \mathrm{e}-01$ $1.00000 \mathrm{e}-05$ 1.00000e-05 1.00000e-06 1.00000e-09 1.00000e-01 $1.00000 \mathrm{e}+001.00000 \mathrm{e}+001.00000 \mathrm{e}-011.00000 \mathrm{e}-091.00000 \mathrm{e}-01$ Element: 12883 \# of layers: 6

Kx Ky Kz Ss Por

$2.06113 \mathrm{e}+002.06113 \mathrm{e}+002$ 2.06113e-01 1.00000e-09 2.12000e-01 $2.06113 \mathrm{e}+002.06113 \mathrm{e}+002.06113 \mathrm{e}-011.00000 \mathrm{e}-092.12000 \mathrm{e}-01$ $2.06113 \mathrm{e}+002.06113 \mathrm{e}+002.06113 \mathrm{e}-011.00000 \mathrm{e}-092.12000 \mathrm{e}-01$ $2.06113 \mathrm{e}+002.06113 \mathrm{e}+002.06113 \mathrm{e}-011.00000 \mathrm{e}-092.12000 \mathrm{e}-01$ $1.00000 \mathrm{e}-05$ 1.00000e-05 1.00000e-06 1.00000e-09 1.00000e-01 $1.00000 \mathrm{e}+001.00000 \mathrm{e}+001.00000 \mathrm{e}-011.00000 \mathrm{e}-091.00000 \mathrm{e}-01$ Element: 12884 \# of layers: 6

Kx Ky Kz Ss Por

$2.06113 \mathrm{e}+002.06113 \mathrm{e}+002$ 2.06113e-01 1.00000e-09 2.12000e-01 $2.06113 \mathrm{e}+002.06113 \mathrm{e}+002.06113 \mathrm{e}-011.00000 \mathrm{e}-092.12000 \mathrm{e}-01$ $2.06113 \mathrm{e}+002.06113 \mathrm{e}+002.06113 \mathrm{e}-011.00000 \mathrm{e}-092.12000 \mathrm{e}-01$ $2.06113 \mathrm{e}+002.06113 \mathrm{e}+002.06113 \mathrm{e}-01$ 1.00000e-09 2.12000e-01 $1.00000 \mathrm{e}-05$ 1.00000e-05 1.00000e-06 1.00000e-09 1.00000e-01 
$1.00000 \mathrm{e}+001.00000 \mathrm{e}+001.00000 \mathrm{e}-01$ 1.00000e-09 1.00000e-01

Element: 12885 \# of layers: 6

Kx Ky Kz Ss Por

$2.06113 \mathrm{e}+00$ 2.06113e+00 2.06113e-01 1.00000e-09 2.12000e-01

$2.06113 \mathrm{e}+002.06113 \mathrm{e}+00$ 2.06113e-01 1.00000e-09 2.12000e-01

$2.06113 \mathrm{e}+002.06113 \mathrm{e}+00$ 2.06113e-01 1.00000e-09 2.12000e-01

$2.06113 \mathrm{e}+00$ 2.06113e+00 2.06113e-01 1.00000e-09 2.12000e-01

$1.00000 \mathrm{e}-05$ 1.00000e-05 1.00000e-06 1.00000e-09 1.00000e-01

$1.00000 \mathrm{e}+001.00000 \mathrm{e}+001.00000 \mathrm{e}-011.00000 \mathrm{e}-091.00000 \mathrm{e}-01$

Element: 12886 \# of layers: 7

$\mathrm{Kx} \mathrm{Ky} \mathrm{Kz}$ Ss Por

$2.06113 \mathrm{e}+00$ 2.06113e+00 2.06113e-01 1.00000e-09 2.12000e-01

$2.06113 \mathrm{e}+002.06113 \mathrm{e}+00$ 2.06113e-01 1.00000e-09 2.12000e-01

$2.06113 \mathrm{e}+002.06113 \mathrm{e}+00$ 2.06113e-01 1.00000e-09 2.12000e-01

$2.06113 \mathrm{e}+002.06113 \mathrm{e}+00$ 2.06113e-01 1.00000e-09 2.12000e-01

$2.06113 \mathrm{e}+002.06113 \mathrm{e}+00$ 2.06113e-01 1.00000e-09 2.12000e-01

$1.00000 \mathrm{e}-05$ 1.00000e-05 1.00000e-06 1.00000e-09 1.00000e-01

$1.00000 \mathrm{e}+001.00000 \mathrm{e}+001.00000 \mathrm{e}-01$ 1.00000e-09 1.00000e-01

Element: 12887 \# of layers: 7

$\mathrm{Kx} \mathrm{Ky} \mathrm{Kz}$ Ss Por

2.06113e+00 2.06113e+00 2.06113e-01 1.00000e-09 2.12000e-01

$2.06113 \mathrm{e}+00$ 2.06113e+00 2.06113e-01 1.00000e-09 2.12000e-01

$2.06113 \mathrm{e}+002.06113 \mathrm{e}+00$ 2.06113e-01 1.00000e-09 2.12000e-01

$2.06113 \mathrm{e}+002.06113 \mathrm{e}+00$ 2.06113e-01 1.00000e-09 2.12000e-01

$2.06113 \mathrm{e}+002.06113 \mathrm{e}+002.06113 \mathrm{e}-01$ 1.00000e-09 2.12000e-01

$1.00000 \mathrm{e}-05$ 1.00000e-05 1.00000e-06 1.00000e-09 1.00000e-01

$1.00000 \mathrm{e}+001.00000 \mathrm{e}+001.00000 \mathrm{e}-011.00000 \mathrm{e}-091.00000 \mathrm{e}-01$

Element: 12888 \# of layers: 6

$\mathrm{Kx} \mathrm{Ky} \mathrm{Kz}$ Ss Por

2.06113e+00 2.06113e+00 2.06113e-01 1.00000e-09 2.12000e-01

$2.06113 \mathrm{e}+002.06113 \mathrm{e}+00$ 2.06113e-01 1.00000e-09 2.12000e-01

$2.06113 \mathrm{e}+00$ 2.06113e+00 2.06113e-01 1.00000e-09 2.12000e-01

$2.06113 \mathrm{e}+002.06113 \mathrm{e}+002.06113 \mathrm{e}-01$ 1.00000e-09 2.12000e-01

$1.00000 \mathrm{e}-05$ 1.00000e-05 1.00000e-06 1.00000e-09 1.00000e-01

$1.00000 \mathrm{e}+001.00000 \mathrm{e}+001.00000 \mathrm{e}-011.00000 \mathrm{e}-091.00000 \mathrm{e}-01$

Element: 12889 \# of layers: 6

Kx Ky Kz Ss Por

2.06113e+00 2.06113e+00 2.06113e-01 1.00000e-09 2.12000e-01

$2.06113 \mathrm{e}+002.06113 \mathrm{e}+00$ 2.06113e-01 1.00000e-09 2.12000e-01

$2.06113 \mathrm{e}+002.06113 \mathrm{e}+00$ 2.06113e-01 1.00000e-09 2.12000e-01

$2.06113 \mathrm{e}+002.06113 \mathrm{e}+00$ 2.06113e-01 1.00000e-09 2.12000e-01

$1.00000 \mathrm{e}-05$ 1.00000e-05 1.00000e-06 1.00000e-09 1.00000e-01

$1.00000 \mathrm{e}+001.00000 \mathrm{e}+001.00000 \mathrm{e}-011.00000 \mathrm{e}-091.00000 \mathrm{e}-01$

Element: 12890 \# of layers: 6

$\mathrm{Kx} \mathrm{Ky} \mathrm{Kz}$ Ss Por

2.06113e+00 2.06113e+00 2.06113e-01 1.00000e-09 2.12000e-01 
$2.06113 \mathrm{e}+002.06113 \mathrm{e}+00$ 2.06113e-01 1.00000e-09 2.12000e-01 $2.06113 \mathrm{e}+002.06113 \mathrm{e}+002.06113 \mathrm{e}-01$ 1.00000e-09 2.12000e-01 $2.06113 \mathrm{e}+002.06113 \mathrm{e}+002.06113 \mathrm{e}-01$ 1.00000e-09 2.12000e-01 $1.00000 \mathrm{e}-05$ 1.00000e-05 1.00000e-06 1.00000e-09 1.00000e-01 $1.00000 \mathrm{e}+001.00000 \mathrm{e}+001.00000 \mathrm{e}-011.00000 \mathrm{e}-091.00000 \mathrm{e}-01$ Element: 12891 \# of layers: 6

Kx Ky Kz Ss Por

$2.11405 \mathrm{e}+002.11405 \mathrm{e}+002.11405 \mathrm{e}-01$ 1.00000e-09 2.12000e-01 $2.11405 \mathrm{e}+002.11405 \mathrm{e}+002.11405 \mathrm{e}-01$ 1.00000e-09 2.12000e-01 $2.11405 \mathrm{e}+002.11405 \mathrm{e}+002.11405 \mathrm{e}-011.00000 \mathrm{e}-092.12000 \mathrm{e}-01$ $2.11405 \mathrm{e}+002.11405 \mathrm{e}+00$ 2.11405e-01 1.00000e-09 2.12000e-01 $1.00000 \mathrm{e}-05$ 1.00000e-05 1.00000e-06 1.00000e-09 1.00000e-01 $1.00000 \mathrm{e}+001.00000 \mathrm{e}+001.00000 \mathrm{e}-011.00000 \mathrm{e}-091.00000 \mathrm{e}-01$ Element: 12892 \# of layers: 6

Kx Ky Kz Ss Por

$2.11405 \mathrm{e}+002.11405 \mathrm{e}+00$ 2.11405e-01 1.00000e-09 2.12000e-01 $2.11405 \mathrm{e}+002.11405 \mathrm{e}+002.11405 \mathrm{e}-01$ 1.00000e-09 2.12000e-01 $2.11405 \mathrm{e}+002.11405 \mathrm{e}+002.11405 \mathrm{e}-011.00000 \mathrm{e}-092.12000 \mathrm{e}-01$ $2.11405 \mathrm{e}+002.11405 \mathrm{e}+00$ 2.11405e-01 1.00000e-09 2.12000e-01 $1.00000 \mathrm{e}-05$ 1.00000e-05 1.00000e-06 1.00000e-09 1.00000e-01 $1.00000 \mathrm{e}+001.00000 \mathrm{e}+001.00000 \mathrm{e}-011.00000 \mathrm{e}-091.00000 \mathrm{e}-01$ Element: 12893 \# of layers: 7

$\mathrm{Kx} \mathrm{Ky} \mathrm{Kz}$ Ss Por

$2.11405 \mathrm{e}+002.11405 \mathrm{e}+00$ 2.11405e-01 1.00000e-09 2.12000e-01 $2.11405 \mathrm{e}+002.11405 \mathrm{e}+002.11405 \mathrm{e}-01$ 1.00000e-09 2.12000e-01 $2.11405 \mathrm{e}+002.11405 \mathrm{e}+002.11405 \mathrm{e}-011.00000 \mathrm{e}-092.12000 \mathrm{e}-01$ $2.11405 \mathrm{e}+002.11405 \mathrm{e}+002.11405 \mathrm{e}-011.00000 \mathrm{e}-092.12000 \mathrm{e}-01$ $2.11405 \mathrm{e}+002.11405 \mathrm{e}+00$ 2.11405e-01 1.00000e-09 2.12000e-01 $1.00000 \mathrm{e}-05$ 1.00000e-05 1.00000e-06 1.00000e-09 1.00000e-01 $1.00000 \mathrm{e}+001.00000 \mathrm{e}+001.00000 \mathrm{e}-011.00000 \mathrm{e}-091.00000 \mathrm{e}-01$ Element: 12894 \# of layers: 7

Kx Ky Kz Ss Por

$2.06113 \mathrm{e}+002.06113 \mathrm{e}+00$ 2.06113e-01 1.00000e-09 2.12000e-01 $2.06113 \mathrm{e}+002.06113 \mathrm{e}+002.06113 \mathrm{e}-011.00000 \mathrm{e}-092.12000 \mathrm{e}-01$ $2.06113 \mathrm{e}+002.06113 \mathrm{e}+002.06113 \mathrm{e}-01$ 1.00000e-09 2.12000e-01 $2.06113 \mathrm{e}+002.06113 \mathrm{e}+002.06113 \mathrm{e}-01$ 1.00000e-09 2.12000e-01 $2.06113 \mathrm{e}+002.06113 \mathrm{e}+002.06113 \mathrm{e}-011.00000 \mathrm{e}-092.12000 \mathrm{e}-01$ $1.00000 \mathrm{e}-05$ 1.00000e-05 1.00000e-06 1.00000e-09 1.00000e-01 $1.00000 \mathrm{e}+001.00000 \mathrm{e}+001.00000 \mathrm{e}-011.00000 \mathrm{e}-091.00000 \mathrm{e}-01$ Element: 12895 \# of layers: 7

Kx Ky Kz Ss Por

$2.06113 \mathrm{e}+002.06113 \mathrm{e}+002.06113 \mathrm{e}-011.00000 \mathrm{e}-092.12000 \mathrm{e}-01$ $2.06113 \mathrm{e}+002.06113 \mathrm{e}+002.06113 \mathrm{e}-011.00000 \mathrm{e}-092.12000 \mathrm{e}-01$ $2.06113 \mathrm{e}+002.06113 \mathrm{e}+002.06113 \mathrm{e}-011.00000 \mathrm{e}-092.12000 \mathrm{e}-01$ $2.06113 \mathrm{e}+002.06113 \mathrm{e}+002.06113 \mathrm{e}-011.00000 \mathrm{e}-092.12000 \mathrm{e}-01$ $2.06113 \mathrm{e}+002.06113 \mathrm{e}+002.06113 \mathrm{e}-01$ 1.00000e-09 2.12000e-01 
$1.00000 \mathrm{e}-05$ 1.00000e-05 1.00000e-06 1.00000e-09 1.00000e-01 $1.00000 \mathrm{e}+001.00000 \mathrm{e}+001.00000 \mathrm{e}-011.00000 \mathrm{e}-091.00000 \mathrm{e}-01$ Element: 12896 \# of layers: 6

Kx Ky Kz Ss Por

2.06113e+00 2.06113e+00 2.06113e-01 1.00000e-09 2.12000e-01 $2.06113 \mathrm{e}+002.06113 \mathrm{e}+00$ 2.06113e-01 1.00000e-09 2.12000e-01 $2.06113 \mathrm{e}+002.06113 \mathrm{e}+00$ 2.06113e-01 1.00000e-09 2.12000e-01 $2.06113 \mathrm{e}+002.06113 \mathrm{e}+002.06113 \mathrm{e}-01$ 1.00000e-09 2.12000e-01 $1.00000 \mathrm{e}-051.00000 \mathrm{e}-051.00000 \mathrm{e}-061.00000 \mathrm{e}-091.00000 \mathrm{e}-01$ $1.00000 \mathrm{e}+001.00000 \mathrm{e}+00$ 1.00000e-01 1.00000e-09 1.00000e-01 Element: 12897 \# of layers: 6

Kx Ky Kz Ss Por

2.06113e+00 2.06113e+00 2.06113e-01 1.00000e-09 2.12000e-01 $2.06113 \mathrm{e}+002.06113 \mathrm{e}+00$ 2.06113e-01 1.00000e-09 2.12000e-01 $2.06113 \mathrm{e}+002.06113 \mathrm{e}+00$ 2.06113e-01 1.00000e-09 2.12000e-01 $2.06113 \mathrm{e}+002.06113 \mathrm{e}+00$ 2.06113e-01 1.00000e-09 2.12000e-01 $1.00000 \mathrm{e}-05$ 1.00000e-05 1.00000e-06 1.00000e-09 1.00000e-01 $1.00000 \mathrm{e}+001.00000 \mathrm{e}+001.00000 \mathrm{e}-011.00000 \mathrm{e}-091.00000 \mathrm{e}-01$ Element: 12898 \# of layers: 6

$\mathrm{Kx} \mathrm{Ky} \mathrm{Kz}$ Ss Por

2.11405e+00 2.11405e+00 2.11405e-01 1.00000e-09 2.12000e-01 2.11405e+00 2.11405e+00 2.11405e-01 1.00000e-09 2.12000e-01 $2.11405 \mathrm{e}+002.11405 \mathrm{e}+00$ 2.11405e-01 1.00000e-09 2.12000e-01 $2.11405 \mathrm{e}+002.11405 \mathrm{e}+00$ 2.11405e-01 1.00000e-09 2.12000e-01 $1.00000 \mathrm{e}-05$ 1.00000e-05 1.00000e-06 1.00000e-09 1.00000e-01 $1.00000 \mathrm{e}+001.00000 \mathrm{e}+001.00000 \mathrm{e}-011.00000 \mathrm{e}-091.00000 \mathrm{e}-01$ Element: 12899 \# of layers: 6

$\mathrm{Kx} \mathrm{Ky} \mathrm{Kz}$ Ss Por

$2.11405 \mathrm{e}+00$ 2.11405e+00 2.11405e-01 1.00000e-09 2.12000e-01 $2.11405 \mathrm{e}+00$ 2.11405e+00 2.11405e-01 1.00000e-09 2.12000e-01 $2.11405 \mathrm{e}+002.11405 \mathrm{e}+00$ 2.11405e-01 1.00000e-09 2.12000e-01 $2.11405 \mathrm{e}+002.11405 \mathrm{e}+00$ 2.11405e-01 1.00000e-09 2.12000e-01 $1.00000 \mathrm{e}-05$ 1.00000e-05 1.00000e-06 1.00000e-09 1.00000e-01 $1.00000 \mathrm{e}+001.00000 \mathrm{e}+001.00000 \mathrm{e}-011.00000 \mathrm{e}-091.00000 \mathrm{e}-01$ Element: 12900 \# of layers: 6

$\mathrm{Kx} \mathrm{Ky} \mathrm{Kz}$ Ss Por

2.11405e+00 2.11405e+00 2.11405e-01 1.00000e-09 2.12000e-01 $2.11405 \mathrm{e}+002.11405 \mathrm{e}+00$ 2.11405e-01 1.00000e-09 2.12000e-01 $2.11405 \mathrm{e}+002.11405 \mathrm{e}+00$ 2.11405e-01 1.00000e-09 2.12000e-01 $2.11405 \mathrm{e}+002.11405 \mathrm{e}+00$ 2.11405e-01 1.00000e-09 2.12000e-01 $1.00000 \mathrm{e}-05$ 1.00000e-05 1.00000e-06 1.00000e-09 1.00000e-01 $1.00000 \mathrm{e}+001.00000 \mathrm{e}+001.00000 \mathrm{e}-011.00000 \mathrm{e}-091.00000 \mathrm{e}-01$ Element: 12901 \# of layers: 6

$\mathrm{Kx} \mathrm{Ky} \mathrm{Kz}$ Ss Por

2.11405e+00 2.11405e+00 2.11405e-01 1.00000e-09 2.12000e-01 $2.11405 \mathrm{e}+002.11405 \mathrm{e}+00$ 2.11405e-01 1.00000e-09 2.12000e-01 
$2.11405 \mathrm{e}+002.11405 \mathrm{e}+002.11405 \mathrm{e}-01$ 1.00000e-09 2.12000e-01 $2.11405 \mathrm{e}+002.11405 \mathrm{e}+002.11405 \mathrm{e}-01$ 1.00000e-09 2.12000e-01 $1.00000 \mathrm{e}-05$ 1.00000e-05 1.00000e-06 1.00000e-09 1.00000e-01 $1.00000 \mathrm{e}+001.00000 \mathrm{e}+001.00000 \mathrm{e}-011.00000 \mathrm{e}-091.00000 \mathrm{e}-01$ Element: 12902 \# of layers: 7

Kx Ky Kz Ss Por

$2.11405 \mathrm{e}+002.11405 \mathrm{e}+002.11405 \mathrm{e}-01$ 1.00000e-09 2.12000e-01 $2.11405 \mathrm{e}+002.11405 \mathrm{e}+002.11405 \mathrm{e}-011.00000 \mathrm{e}-092.12000 \mathrm{e}-01$ $2.11405 \mathrm{e}+002.11405 \mathrm{e}+002.11405 \mathrm{e}-011.00000 \mathrm{e}-092.12000 \mathrm{e}-01$ $2.11405 \mathrm{e}+002.11405 \mathrm{e}+002.11405 \mathrm{e}-011.00000 \mathrm{e}-092.12000 \mathrm{e}-01$ $2.11405 \mathrm{e}+002.11405 \mathrm{e}+002.11405 \mathrm{e}-011.00000 \mathrm{e}-092.12000 \mathrm{e}-01$ $1.00000 \mathrm{e}-05$ 1.00000e-05 1.00000e-06 1.00000e-09 1.00000e-01 $1.00000 \mathrm{e}+001.00000 \mathrm{e}+001.00000 \mathrm{e}-011.00000 \mathrm{e}-091.00000 \mathrm{e}-01$ Element: 12903 \# of layers: 7

Kx Ky Kz Ss Por

$2.11405 \mathrm{e}+002.11405 \mathrm{e}+00$ 2.11405e-01 1.00000e-09 2.12000e-01 $2.11405 \mathrm{e}+002.11405 \mathrm{e}+002.11405 \mathrm{e}-011.00000 \mathrm{e}-092.12000 \mathrm{e}-01$ $2.11405 \mathrm{e}+002.11405 \mathrm{e}+002.11405 \mathrm{e}-011.00000 \mathrm{e}-092.12000 \mathrm{e}-01$ $2.11405 \mathrm{e}+002.11405 \mathrm{e}+002.11405 \mathrm{e}-011.00000 \mathrm{e}-092.12000 \mathrm{e}-01$ $2.11405 \mathrm{e}+002.11405 \mathrm{e}+002.11405 \mathrm{e}-011.00000 \mathrm{e}-092.12000 \mathrm{e}-01$ $1.00000 \mathrm{e}-05$ 1.00000e-05 1.00000e-06 1.00000e-09 1.00000e-01 $1.00000 \mathrm{e}+001.00000 \mathrm{e}+001.00000 \mathrm{e}-011.00000 \mathrm{e}-091.00000 \mathrm{e}-01$ Element: 12904 \# of layers: 7

Kx Ky Kz Ss Por

$2.11405 \mathrm{e}+002.11405 \mathrm{e}+00$ 2.11405e-01 1.00000e-09 2.12000e-01 $2.11405 \mathrm{e}+002.11405 \mathrm{e}+002.11405 \mathrm{e}-01$ 1.00000e-09 2.12000e-01 $2.11405 \mathrm{e}+002.11405 \mathrm{e}+002.11405 \mathrm{e}-011.00000 \mathrm{e}-092.12000 \mathrm{e}-01$ $2.11405 \mathrm{e}+002.11405 \mathrm{e}+002.11405 \mathrm{e}-011.00000 \mathrm{e}-092.12000 \mathrm{e}-01$ $2.11405 \mathrm{e}+002.11405 \mathrm{e}+002.11405 \mathrm{e}-011.00000 \mathrm{e}-092.12000 \mathrm{e}-01$ $1.00000 \mathrm{e}-05$ 1.00000e-05 1.00000e-06 1.00000e-09 1.00000e-01 $1.00000 \mathrm{e}+001.00000 \mathrm{e}+001.00000 \mathrm{e}-011.00000 \mathrm{e}-091.00000 \mathrm{e}-01$ Element: 12905 \# of layers: 6

Kx Ky Kz Ss Por

$2.11405 \mathrm{e}+002.11405 \mathrm{e}+002.11405 \mathrm{e}-01$ 1.00000e-09 2.12000e-01 $2.11405 \mathrm{e}+002.11405 \mathrm{e}+002.11405 \mathrm{e}-01$ 1.00000e-09 2.12000e-01 $2.11405 \mathrm{e}+002.11405 \mathrm{e}+002.11405 \mathrm{e}-011.00000 \mathrm{e}-092.12000 \mathrm{e}-01$ $2.11405 \mathrm{e}+002.11405 \mathrm{e}+002.11405 \mathrm{e}-011.00000 \mathrm{e}-092.12000 \mathrm{e}-01$ $1.00000 \mathrm{e}-05$ 1.00000e-05 1.00000e-06 1.00000e-09 1.00000e-01 $1.00000 \mathrm{e}+001.00000 \mathrm{e}+001.00000 \mathrm{e}-011.00000 \mathrm{e}-091.00000 \mathrm{e}-01$ Element: 12906 \# of layers: 6

Kx Ky Kz Ss Por

$2.11405 \mathrm{e}+002.11405 \mathrm{e}+002.11405 \mathrm{e}-01$ 1.00000e-09 2.12000e-01 $2.11405 \mathrm{e}+002.11405 \mathrm{e}+002.11405 \mathrm{e}-011.00000 \mathrm{e}-092.12000 \mathrm{e}-01$ $2.11405 \mathrm{e}+002.11405 \mathrm{e}+002.11405 \mathrm{e}-011.00000 \mathrm{e}-092.12000 \mathrm{e}-01$ $2.11405 \mathrm{e}+002.11405 \mathrm{e}+002.11405 \mathrm{e}-01$ 1.00000e-09 2.12000e-01 $1.00000 \mathrm{e}-05$ 1.00000e-05 1.00000e-06 1.00000e-09 1.00000e-01 
$1.00000 \mathrm{e}+001.00000 \mathrm{e}+00$ 1.00000e-01 1.00000e-09 1.00000e-01

Element: 12907 \# of layers: 6

$\mathrm{Kx} \mathrm{Ky} \mathrm{Kz}$ Ss Por

$2.11405 \mathrm{e}+00$ 2.11405e+00 2.11405e-01 1.00000e-09 2.12000e-01

$2.11405 \mathrm{e}+002.11405 \mathrm{e}+00$ 2.11405e-01 1.00000e-09 2.12000e-01

$2.11405 \mathrm{e}+002.11405 \mathrm{e}+00$ 2.11405e-01 1.00000e-09 2.12000e-01

$2.11405 \mathrm{e}+002.11405 \mathrm{e}+00$ 2.11405e-01 1.00000e-09 2.12000e-01

$1.00000 \mathrm{e}-05$ 1.00000e-05 1.00000e-06 1.00000e-09 1.00000e-01

$1.00000 \mathrm{e}+001.00000 \mathrm{e}+001.00000 \mathrm{e}-011.00000 \mathrm{e}-091.00000 \mathrm{e}-01$

Element: 12908 \# of layers: 7

$\mathrm{Kx} \mathrm{Ky} \mathrm{Kz}$ Ss Por

2.11405e+00 2.11405e+00 2.11405e-01 1.00000e-09 2.12000e-01

$2.11405 \mathrm{e}+002.11405 \mathrm{e}+00$ 2.11405e-01 1.00000e-09 2.12000e-01

$2.11405 \mathrm{e}+002.11405 \mathrm{e}+00$ 2.11405e-01 1.00000e-09 2.12000e-01

$2.11405 \mathrm{e}+002.11405 \mathrm{e}+002.11405 \mathrm{e}-01$ 1.00000e-09 2.12000e-01

$2.11405 \mathrm{e}+002.11405 \mathrm{e}+00$ 2.11405e-01 1.00000e-09 2.12000e-01

$1.00000 \mathrm{e}-05$ 1.00000e-05 1.00000e-06 1.00000e-09 1.00000e-01

$1.00000 \mathrm{e}+001.00000 \mathrm{e}+001.00000 \mathrm{e}-01$ 1.00000e-09 1.00000e-01

Element: 12909 \# of layers: 7

Kx Ky Kz Ss Por

$1.77184 \mathrm{e}+001.77184 \mathrm{e}+00$ 1.77185e-01 1.00000e-09 2.12000e-01

$1.77184 \mathrm{e}+001.77184 \mathrm{e}+00$ 1.77185e-01 1.00000e-09 2.12000e-01

$1.77184 \mathrm{e}+001.77184 \mathrm{e}+00$ 1.77185e-01 1.00000e-09 2.12000e-01

$1.77184 \mathrm{e}+001.77184 \mathrm{e}+001.77185 \mathrm{e}-01$ 1.00000e-09 2.12000e-01

$1.77184 \mathrm{e}+001.77184 \mathrm{e}+001.77185 \mathrm{e}-011.00000 \mathrm{e}-092.12000 \mathrm{e}-01$

$1.00000 \mathrm{e}-05$ 1.00000e-05 1.00000e-06 1.00000e-09 1.00000e-01

$1.00000 \mathrm{e}+001.00000 \mathrm{e}+001.00000 \mathrm{e}-011.00000 \mathrm{e}-091.00000 \mathrm{e}-01$

Element: 12910 \# of layers: 7

Kx Ky Kz Ss Por

$1.77184 \mathrm{e}+001.77184 \mathrm{e}+00$ 1.77185e-01 1.00000e-09 2.12000e-01

$1.77184 \mathrm{e}+001.77184 \mathrm{e}+00$ 1.77185e-01 1.00000e-09 2.12000e-01

$1.77184 \mathrm{e}+001.77184 \mathrm{e}+001.77185 \mathrm{e}-011.00000 \mathrm{e}-092.12000 \mathrm{e}-01$

$1.77184 \mathrm{e}+001.77184 \mathrm{e}+001.77185 \mathrm{e}-011.00000 \mathrm{e}-092.12000 \mathrm{e}-01$

$1.77184 \mathrm{e}+001.77184 \mathrm{e}+001.77185 \mathrm{e}-01$ 1.00000e-09 2.12000e-01

$1.00000 \mathrm{e}-05$ 1.00000e-05 1.00000e-06 1.00000e-09 1.00000e-01

$1.00000 \mathrm{e}+001.00000 \mathrm{e}+001.00000 \mathrm{e}-011.00000 \mathrm{e}-091.00000 \mathrm{e}-01$

Element: 12911 \# of layers: 7

$\mathrm{Kx} \mathrm{Ky} \mathrm{Kz}$ Ss Por

$1.77184 \mathrm{e}+001.77184 \mathrm{e}+00$ 1.77185e-01 1.00000e-09 2.12000e-01

$1.77184 \mathrm{e}+001.77184 \mathrm{e}+00$ 1.77185e-01 1.00000e-09 2.12000e-01

$1.77184 \mathrm{e}+001.77184 \mathrm{e}+001.77185 \mathrm{e}-011.00000 \mathrm{e}-092.12000 \mathrm{e}-01$

$1.77184 \mathrm{e}+001.77184 \mathrm{e}+00$ 1.77185e-01 1.00000e-09 2.12000e-01

$1.77184 \mathrm{e}+001.77184 \mathrm{e}+00$ 1.77185e-01 1.00000e-09 2.12000e-01

$1.00000 \mathrm{e}-05$ 1.00000e-05 1.00000e-06 1.00000e-09 1.00000e-01

$1.00000 \mathrm{e}+001.00000 \mathrm{e}+001.00000 \mathrm{e}-01$ 1.00000e-09 1.00000e-01

Element: 12912 \# of layers: 7 
$\mathrm{Kx} \mathrm{Ky} \mathrm{Kz}$ Ss Por

2.11405e+00 2.11405e+00 2.11405e-01 1.00000e-09 2.12000e-01

$2.11405 \mathrm{e}+002.11405 \mathrm{e}+00$ 2.11405e-01 1.00000e-09 2.12000e-01

$2.11405 \mathrm{e}+00$ 2.11405e+00 2.11405e-01 1.00000e-09 2.12000e-01

$2.11405 \mathrm{e}+002.11405 \mathrm{e}+00$ 2.11405e-01 1.00000e-09 2.12000e-01

$2.11405 \mathrm{e}+002.11405 \mathrm{e}+00$ 2.11405e-01 1.00000e-09 2.12000e-01

$1.00000 \mathrm{e}-05$ 1.00000e-05 1.00000e-06 1.00000e-09 1.00000e-01

$1.00000 \mathrm{e}+001.00000 \mathrm{e}+001.00000 \mathrm{e}-011.00000 \mathrm{e}-091.00000 \mathrm{e}-01$

Element: 12913 \# of layers: 6

$\mathrm{Kx} \mathrm{Ky} \mathrm{Kz}$ Ss Por

$2.11405 \mathrm{e}+00$ 2.11405e+00 2.11405e-01 1.00000e-09 2.12000e-01

$2.11405 \mathrm{e}+00$ 2.11405e+00 2.11405e-01 1.00000e-09 2.12000e-01

$2.11405 \mathrm{e}+002.11405 \mathrm{e}+00$ 2.11405e-01 1.00000e-09 2.12000e-01

$2.11405 \mathrm{e}+002.11405 \mathrm{e}+00$ 2.11405e-01 1.00000e-09 2.12000e-01

$1.00000 \mathrm{e}-05$ 1.00000e-05 1.00000e-06 1.00000e-09 1.00000e-01

$1.00000 \mathrm{e}+001.00000 \mathrm{e}+001.00000 \mathrm{e}-011.00000 \mathrm{e}-091.00000 \mathrm{e}-01$

Element: 12914 \# of layers: 6

$\mathrm{Kx} \mathrm{Ky} \mathrm{Kz}$ Ss Por

2.11405e+00 2.11405e+00 2.11405e-01 1.00000e-09 2.12000e-01

$2.11405 \mathrm{e}+002.11405 \mathrm{e}+00$ 2.11405e-01 1.00000e-09 2.12000e-01

$2.11405 \mathrm{e}+002.11405 \mathrm{e}+002.11405 \mathrm{e}-01$ 1.00000e-09 2.12000e-01

2.11405e+00 2.11405e+00 2.11405e-01 1.00000e-09 2.12000e-01

$1.00000 \mathrm{e}-05$ 1.00000e-05 1.00000e-06 1.00000e-09 1.00000e-01

$1.00000 \mathrm{e}+001.00000 \mathrm{e}+001.00000 \mathrm{e}-011.00000 \mathrm{e}-09$ 1.00000e-01

Element: 12915 \# of layers: 7

$\mathrm{Kx} \mathrm{Ky} \mathrm{Kz}$ Ss Por

2.11405e+00 2.11405e+00 2.11405e-01 1.00000e-09 2.12000e-01

$2.11405 \mathrm{e}+002.11405 \mathrm{e}+00$ 2.11405e-01 1.00000e-09 2.12000e-01

$2.11405 \mathrm{e}+002.11405 \mathrm{e}+00$ 2.11405e-01 1.00000e-09 2.12000e-01

$2.11405 \mathrm{e}+00$ 2.11405e+00 2.11405e-01 1.00000e-09 2.12000e-01

$2.11405 \mathrm{e}+002.11405 \mathrm{e}+00$ 2.11405e-01 1.00000e-09 2.12000e-01

$1.00000 \mathrm{e}-05$ 1.00000e-05 1.00000e-06 1.00000e-09 1.00000e-01

$1.00000 \mathrm{e}+001.00000 \mathrm{e}+001.00000 \mathrm{e}-011.00000 \mathrm{e}-091.00000 \mathrm{e}-01$

Element: 12916 \# of layers: 7

$\mathrm{Kx} \mathrm{Ky} \mathrm{Kz}$ Ss Por

$1.77184 \mathrm{e}+001.77184 \mathrm{e}+00$ 1.77185e-01 1.00000e-09 2.12000e-01

$1.77184 \mathrm{e}+001.77184 \mathrm{e}+001.77185 \mathrm{e}-011.00000 \mathrm{e}-092.12000 \mathrm{e}-01$

$1.77184 \mathrm{e}+001.77184 \mathrm{e}+001.77185 \mathrm{e}-011.00000 \mathrm{e}-092.12000 \mathrm{e}-01$

$1.77184 \mathrm{e}+001.77184 \mathrm{e}+00$ 1.77185e-01 1.00000e-09 2.12000e-01

$1.77184 \mathrm{e}+001.77184 \mathrm{e}+00$ 1.77185e-01 1.00000e-09 2.12000e-01

$1.00000 \mathrm{e}-05$ 1.00000e-05 1.00000e-06 1.00000e-09 1.00000e-01

$1.00000 \mathrm{e}+001.00000 \mathrm{e}+001.00000 \mathrm{e}-011.00000 \mathrm{e}-09$ 1.00000e-01

Element: 12917 \# of layers: 7

$\mathrm{Kx} \mathrm{Ky} \mathrm{Kz}$ Ss Por

$1.77184 \mathrm{e}+001.77184 \mathrm{e}+00$ 1.77185e-01 1.00000e-09 2.12000e-01

$1.77184 \mathrm{e}+001.77184 \mathrm{e}+001.77185 \mathrm{e}-011.00000 \mathrm{e}-092.12000 \mathrm{e}-01$ 
$1.77184 \mathrm{e}+001.77184 \mathrm{e}+001.77185 \mathrm{e}-011.00000 \mathrm{e}-092.12000 \mathrm{e}-01$ $1.77184 \mathrm{e}+001.77184 \mathrm{e}+001.77185 \mathrm{e}-011.00000 \mathrm{e}-092.12000 \mathrm{e}-01$ $1.77184 \mathrm{e}+001.77184 \mathrm{e}+001.77185 \mathrm{e}-011.00000 \mathrm{e}-092.12000 \mathrm{e}-01$ $1.00000 \mathrm{e}-05$ 1.00000e-05 1.00000e-06 1.00000e-09 1.00000e-01 $1.00000 \mathrm{e}+001.00000 \mathrm{e}+001.00000 \mathrm{e}-011.00000 \mathrm{e}-091.00000 \mathrm{e}-01$ Element: 12918 \# of layers: 7

Kx Ky Kz Ss Por

$1.77184 \mathrm{e}+001.77184 \mathrm{e}+00$ 1.77185e-01 1.00000e-09 2.12000e-01

$1.77184 \mathrm{e}+001.77184 \mathrm{e}+001.77185 \mathrm{e}-011.00000 \mathrm{e}-092.12000 \mathrm{e}-01$

$1.77184 \mathrm{e}+001.77184 \mathrm{e}+001.77185 \mathrm{e}-011.00000 \mathrm{e}-092.12000 \mathrm{e}-01$ $1.77184 \mathrm{e}+001.77184 \mathrm{e}+001.77185 \mathrm{e}-011.00000 \mathrm{e}-092.12000 \mathrm{e}-01$ $1.77184 \mathrm{e}+001.77184 \mathrm{e}+001.77185 \mathrm{e}-011.00000 \mathrm{e}-092.12000 \mathrm{e}-01$ $1.00000 \mathrm{e}-05$ 1.00000e-05 1.00000e-06 1.00000e-09 1.00000e-01 $1.00000 \mathrm{e}+001.00000 \mathrm{e}+001.00000 \mathrm{e}-011.00000 \mathrm{e}-091.00000 \mathrm{e}-01$ Element: 12919 \# of layers: 7

Kx Ky Kz Ss Por

$1.77184 \mathrm{e}+001.77184 \mathrm{e}+00$ 1.77185e-01 1.00000e-09 2.12000e-01 $1.77184 \mathrm{e}+001.77184 \mathrm{e}+001.77185 \mathrm{e}-011.00000 \mathrm{e}-092.12000 \mathrm{e}-01$ $1.77184 \mathrm{e}+001.77184 \mathrm{e}+001.77185 \mathrm{e}-011.00000 \mathrm{e}-092.12000 \mathrm{e}-01$ $1.77184 \mathrm{e}+001.77184 \mathrm{e}+001.77185 \mathrm{e}-011.00000 \mathrm{e}-092.12000 \mathrm{e}-01$ $1.77184 \mathrm{e}+001.77184 \mathrm{e}+001.77185 \mathrm{e}-011.00000 \mathrm{e}-092.12000 \mathrm{e}-01$ $1.00000 \mathrm{e}-05$ 1.00000e-05 1.00000e-06 1.00000e-09 1.00000e-01 $1.00000 \mathrm{e}+001.00000 \mathrm{e}+001.00000 \mathrm{e}-011.00000 \mathrm{e}-091.00000 \mathrm{e}-01$ Element: 12920 \# of layers: 7

Kx Ky Kz Ss Por

$1.77184 \mathrm{e}+001.77184 \mathrm{e}+00$ 1.77185e-01 1.00000e-09 2.12000e-01

$1.77184 \mathrm{e}+001.77184 \mathrm{e}+001.77185 \mathrm{e}-011.00000 \mathrm{e}-092.12000 \mathrm{e}-01$

$1.77184 \mathrm{e}+001.77184 \mathrm{e}+001.77185 \mathrm{e}-011.00000 \mathrm{e}-092.12000 \mathrm{e}-01$

$1.77184 \mathrm{e}+001.77184 \mathrm{e}+001.77185 \mathrm{e}-011.00000 \mathrm{e}-092.12000 \mathrm{e}-01$

$1.77184 \mathrm{e}+001.77184 \mathrm{e}+001.77185 \mathrm{e}-011.00000 \mathrm{e}-092.12000 \mathrm{e}-01$ $1.00000 \mathrm{e}-05$ 1.00000e-05 1.00000e-06 1.00000e-09 1.00000e-01 $1.00000 \mathrm{e}+001.00000 \mathrm{e}+001.00000 \mathrm{e}-011.00000 \mathrm{e}-091.00000 \mathrm{e}-01$ Element: 12921 \# of layers: 7

Kx Ky Kz Ss Por

$1.77184 \mathrm{e}+001.77184 \mathrm{e}+00$ 1.77185e-01 1.00000e-09 2.12000e-01

$1.77184 \mathrm{e}+001.77184 \mathrm{e}+001.77185 \mathrm{e}-011.00000 \mathrm{e}-092.12000 \mathrm{e}-01$

$1.77184 \mathrm{e}+001.77184 \mathrm{e}+001.77185 \mathrm{e}-011.00000 \mathrm{e}-092.12000 \mathrm{e}-01$

$1.77184 \mathrm{e}+001.77184 \mathrm{e}+001.77185 \mathrm{e}-011.00000 \mathrm{e}-092.12000 \mathrm{e}-01$

$1.77184 \mathrm{e}+001.77184 \mathrm{e}+001.77185 \mathrm{e}-011.00000 \mathrm{e}-092.12000 \mathrm{e}-01$ $1.00000 \mathrm{e}-05$ 1.00000e-05 1.00000e-06 1.00000e-09 1.00000e-01 $1.00000 \mathrm{e}+001.00000 \mathrm{e}+001.00000 \mathrm{e}-011.00000 \mathrm{e}-091.00000 \mathrm{e}-01$ Element: 12922 \# of layers: 7

Kx Ky Kz Ss Por

$1.77184 \mathrm{e}+001.77184 \mathrm{e}+00$ 1.77185e-01 1.00000e-09 2.12000e-01

$1.77184 \mathrm{e}+001.77184 \mathrm{e}+001.77185 \mathrm{e}-011.00000 \mathrm{e}-092.12000 \mathrm{e}-01$

$1.77184 \mathrm{e}+001.77184 \mathrm{e}+001.77185 \mathrm{e}-011.00000 \mathrm{e}-092.12000 \mathrm{e}-01$ 
$1.77184 \mathrm{e}+001.77184 \mathrm{e}+001.77185 \mathrm{e}-011.00000 \mathrm{e}-092.12000 \mathrm{e}-01$ $1.77184 \mathrm{e}+001.77184 \mathrm{e}+001.77185 \mathrm{e}-011.00000 \mathrm{e}-092.12000 \mathrm{e}-01$ $1.00000 \mathrm{e}-05$ 1.00000e-05 1.00000e-06 1.00000e-09 1.00000e-01 $1.00000 \mathrm{e}+001.00000 \mathrm{e}+001.00000 \mathrm{e}-011.00000 \mathrm{e}-091.00000 \mathrm{e}-01$ Element: 12923 \# of layers: 7

Kx Ky Kz Ss Por

$1.77184 \mathrm{e}+001.77184 \mathrm{e}+00$ 1.77185e-01 1.00000e-09 2.12000e-01

$1.77184 \mathrm{e}+001.77184 \mathrm{e}+001.77185 \mathrm{e}-011.00000 \mathrm{e}-092.12000 \mathrm{e}-01$

$1.77184 \mathrm{e}+001.77184 \mathrm{e}+001.77185 \mathrm{e}-011.00000 \mathrm{e}-092.12000 \mathrm{e}-01$

$1.77184 \mathrm{e}+001.77184 \mathrm{e}+001.77185 \mathrm{e}-011.00000 \mathrm{e}-092.12000 \mathrm{e}-01$

$1.77184 \mathrm{e}+001.77184 \mathrm{e}+001.77185 \mathrm{e}-011.00000 \mathrm{e}-09$ 2.12000e-01

$1.00000 \mathrm{e}-05$ 1.00000e-05 1.00000e-06 1.00000e-09 1.00000e-01

$1.00000 \mathrm{e}+001.00000 \mathrm{e}+001.00000 \mathrm{e}-011.00000 \mathrm{e}-091.00000 \mathrm{e}-01$

Element: 12924 \# of layers: 7

Kx Ky Kz Ss Por

$1.77184 \mathrm{e}+001.77184 \mathrm{e}+00$ 1.77185e-01 1.00000e-09 2.12000e-01

$1.77184 \mathrm{e}+001.77184 \mathrm{e}+001.77185 \mathrm{e}-011.00000 \mathrm{e}-092.12000 \mathrm{e}-01$

$1.77184 \mathrm{e}+001.77184 \mathrm{e}+001.77185 \mathrm{e}-011.00000 \mathrm{e}-092.12000 \mathrm{e}-01$

$1.77184 \mathrm{e}+001.77184 \mathrm{e}+001.77185 \mathrm{e}-011.00000 \mathrm{e}-092.12000 \mathrm{e}-01$

$1.77184 \mathrm{e}+001.77184 \mathrm{e}+001.77185 \mathrm{e}-011.00000 \mathrm{e}-092.12000 \mathrm{e}-01$

$1.00000 \mathrm{e}-05$ 1.00000e-05 1.00000e-06 1.00000e-09 1.00000e-01

$1.00000 \mathrm{e}+001.00000 \mathrm{e}+001.00000 \mathrm{e}-011.00000 \mathrm{e}-091.00000 \mathrm{e}-01$

Element: 12925 \# of layers: 7

Kx Ky Kz Ss Por

$1.77184 \mathrm{e}+001.77184 \mathrm{e}+00$ 1.77185e-01 1.00000e-09 2.12000e-01

$1.77184 \mathrm{e}+001.77184 \mathrm{e}+001.77185 \mathrm{e}-011.00000 \mathrm{e}-092.12000 \mathrm{e}-01$

$1.77184 \mathrm{e}+001.77184 \mathrm{e}+001.77185 \mathrm{e}-011.00000 \mathrm{e}-092.12000 \mathrm{e}-01$

$1.77184 \mathrm{e}+001.77184 \mathrm{e}+001.77185 \mathrm{e}-011.00000 \mathrm{e}-092.12000 \mathrm{e}-01$

$1.77184 \mathrm{e}+001.77184 \mathrm{e}+001.77185 \mathrm{e}-011.00000 \mathrm{e}-092.12000 \mathrm{e}-01$

$1.00000 \mathrm{e}-05$ 1.00000e-05 1.00000e-06 1.00000e-09 1.00000e-01

$1.00000 \mathrm{e}+001.00000 \mathrm{e}+001.00000 \mathrm{e}-011.00000 \mathrm{e}-091.00000 \mathrm{e}-01$

Element: 12926 \# of layers: 7

Kx Ky Kz Ss Por

$2.64268 \mathrm{e}+002.64268 \mathrm{e}+002.64268 \mathrm{e}-011.00000 \mathrm{e}-092.12000 \mathrm{e}-01$

$2.64268 \mathrm{e}+002.64268 \mathrm{e}+002.64268 \mathrm{e}-011.00000 \mathrm{e}-092.12000 \mathrm{e}-01$

$2.64268 \mathrm{e}+002.64268 \mathrm{e}+002.64268 \mathrm{e}-01$ 1.00000e-09 2.12000e-01

$2.64268 \mathrm{e}+002.64268 \mathrm{e}+002.64268 \mathrm{e}-011.00000 \mathrm{e}-092.12000 \mathrm{e}-01$

$2.64268 \mathrm{e}+002.64268 \mathrm{e}+002.64268 \mathrm{e}-011.00000 \mathrm{e}-092.12000 \mathrm{e}-01$

$1.00000 \mathrm{e}-05$ 1.00000e-05 1.00000e-06 1.00000e-09 1.00000e-01

$1.00000 \mathrm{e}+001.00000 \mathrm{e}+001.00000 \mathrm{e}-011.00000 \mathrm{e}-091.00000 \mathrm{e}-01$

Element: 12927 \# of layers: 7

Kx Ky Kz Ss Por

$2.64268 \mathrm{e}+002.64268 \mathrm{e}+002.64268 \mathrm{e}-011.00000 \mathrm{e}-092.12000 \mathrm{e}-01$

$2.64268 \mathrm{e}+002.64268 \mathrm{e}+002.64268 \mathrm{e}-011.00000 \mathrm{e}-092.12000 \mathrm{e}-01$

$2.64268 \mathrm{e}+002.64268 \mathrm{e}+002.64268 \mathrm{e}-011.00000 \mathrm{e}-092.12000 \mathrm{e}-01$

$2.64268 \mathrm{e}+002.64268 \mathrm{e}+002.64268 \mathrm{e}-01$ 1.00000e-09 2.12000e-01 
$2.64268 \mathrm{e}+00$ 2.64268e+00 2.64268e-01 1.00000e-09 2.12000e-01 $1.00000 \mathrm{e}-05$ 1.00000e-05 1.00000e-06 1.00000e-09 1.00000e-01 $1.00000 \mathrm{e}+001.00000 \mathrm{e}+001.00000 \mathrm{e}-01$ 1.00000e-09 1.00000e-01 Element: 12928 \# of layers: 7

$\mathrm{Kx} \mathrm{Ky} \mathrm{Kz}$ Ss Por

$2.64268 \mathrm{e}+002.64268 \mathrm{e}+00$ 2.64268e-01 1.00000e-09 2.12000e-01 $2.64268 \mathrm{e}+002.64268 \mathrm{e}+00$ 2.64268e-01 1.00000e-09 2.12000e-01 $2.64268 \mathrm{e}+002.64268 \mathrm{e}+00$ 2.64268e-01 1.00000e-09 2.12000e-01 $2.64268 \mathrm{e}+002.64268 \mathrm{e}+00$ 2.64268e-01 1.00000e-09 2.12000e-01 $2.64268 \mathrm{e}+002.64268 \mathrm{e}+00$ 2.64268e-01 1.00000e-09 2.12000e-01 $1.00000 \mathrm{e}-05$ 1.00000e-05 1.00000e-06 1.00000e-09 1.00000e-01 $1.00000 \mathrm{e}+001.00000 \mathrm{e}+001.00000 \mathrm{e}-011.00000 \mathrm{e}-091.00000 \mathrm{e}-01$ Element: 12929 \# of layers: 7

$\mathrm{Kx} \mathrm{Ky} \mathrm{Kz}$ Ss Por

$2.64268 \mathrm{e}+002.64268 \mathrm{e}+00$ 2.64268e-01 1.00000e-09 2.12000e-01 $2.64268 \mathrm{e}+002.64268 \mathrm{e}+002.64268 \mathrm{e}-01$ 1.00000e-09 2.12000e-01 $2.64268 \mathrm{e}+002.64268 \mathrm{e}+00$ 2.64268e-01 1.00000e-09 2.12000e-01 $2.64268 \mathrm{e}+002.64268 \mathrm{e}+002.64268 \mathrm{e}-01$ 1.00000e-09 2.12000e-01 $2.64268 \mathrm{e}+002.64268 \mathrm{e}+00$ 2.64268e-01 1.00000e-09 2.12000e-01 $1.00000 \mathrm{e}-05$ 1.00000e-05 1.00000e-06 1.00000e-09 1.00000e-01 $1.00000 \mathrm{e}+001.00000 \mathrm{e}+001.00000 \mathrm{e}-011.00000 \mathrm{e}-091.00000 \mathrm{e}-01$ Element: 12930 \# of layers: 7

$\mathrm{Kx} \mathrm{Ky} \mathrm{Kz}$ Ss Por

2.64268e+00 2.64268e+00 2.64268e-01 1.00000e-09 2.12000e-01 $2.64268 \mathrm{e}+002.64268 \mathrm{e}+00$ 2.64268e-01 1.00000e-09 2.12000e-01 $2.64268 \mathrm{e}+002.64268 \mathrm{e}+00$ 2.64268e-01 1.00000e-09 2.12000e-01 $2.64268 \mathrm{e}+002.64268 \mathrm{e}+00$ 2.64268e-01 1.00000e-09 2.12000e-01 $2.64268 \mathrm{e}+002.64268 \mathrm{e}+00$ 2.64268e-01 1.00000e-09 2.12000e-01 $1.00000 \mathrm{e}-05$ 1.00000e-05 1.00000e-06 1.00000e-09 1.00000e-01 $1.00000 \mathrm{e}+001.00000 \mathrm{e}+001.00000 \mathrm{e}-011.00000 \mathrm{e}-091.00000 \mathrm{e}-01$ Element: 12931 \# of layers: 7

$\mathrm{Kx} \mathrm{Ky} \mathrm{Kz}$ Ss Por

$1.77184 \mathrm{e}+001.77184 \mathrm{e}+00$ 1.77185e-01 1.00000e-09 2.12000e-01 $1.77184 \mathrm{e}+001.77184 \mathrm{e}+00$ 1.77185e-01 1.00000e-09 2.12000e-01 $1.77184 \mathrm{e}+001.77184 \mathrm{e}+00$ 1.77185e-01 1.00000e-09 2.12000e-01 $1.77184 \mathrm{e}+001.77184 \mathrm{e}+001.77185 \mathrm{e}-011.00000 \mathrm{e}-092.12000 \mathrm{e}-01$ $1.77184 \mathrm{e}+001.77184 \mathrm{e}+001.77185 \mathrm{e}-011.00000 \mathrm{e}-092.12000 \mathrm{e}-01$ $1.00000 \mathrm{e}-05$ 1.00000e-05 1.00000e-06 1.00000e-09 1.00000e-01 $1.00000 \mathrm{e}+001.00000 \mathrm{e}+001.00000 \mathrm{e}-01$ 1.00000e-09 1.00000e-01 Element: 12932 \# of layers: 7

Kx Ky Kz Ss Por

$1.77184 \mathrm{e}+001.77184 \mathrm{e}+00$ 1.77185e-01 1.00000e-09 2.12000e-01 $1.77184 \mathrm{e}+001.77184 \mathrm{e}+00$ 1.77185e-01 1.00000e-09 2.12000e-01 $1.77184 \mathrm{e}+001.77184 \mathrm{e}+001.77185 \mathrm{e}-011.00000 \mathrm{e}-092.12000 \mathrm{e}-01$ $1.77184 \mathrm{e}+001.77184 \mathrm{e}+001.77185 \mathrm{e}-01$ 1.00000e-09 2.12000e-01 $1.77184 \mathrm{e}+001.77184 \mathrm{e}+001.77185 \mathrm{e}-011.00000 \mathrm{e}-092.12000 \mathrm{e}-01$ 
$1.00000 \mathrm{e}-05$ 1.00000e-05 1.00000e-06 1.00000e-09 1.00000e-01 $1.00000 \mathrm{e}+001.00000 \mathrm{e}+001.00000 \mathrm{e}-01$ 1.00000e-09 1.00000e-01 Element: 12933 \# of layers: 7

Kx Ky Kz Ss Por

2.64268e+00 2.64268e+00 2.64268e-01 1.00000e-09 2.12000e-01

$2.64268 \mathrm{e}+002.64268 \mathrm{e}+00$ 2.64268e-01 1.00000e-09 2.12000e-01

$2.64268 \mathrm{e}+002.64268 \mathrm{e}+00$ 2.64268e-01 1.00000e-09 2.12000e-01

$2.64268 \mathrm{e}+002.64268 \mathrm{e}+00$ 2.64268e-01 1.00000e-09 2.12000e-01

$2.64268 \mathrm{e}+002.64268 \mathrm{e}+002.64268 \mathrm{e}-01$ 1.00000e-09 2.12000e-01

$1.00000 \mathrm{e}-05$ 1.00000e-05 1.00000e-06 1.00000e-09 1.00000e-01

$1.00000 \mathrm{e}+001.00000 \mathrm{e}+001.00000 \mathrm{e}-01$ 1.00000e-09 1.00000e-01

Element: 12934 \# of layers: 7

$\mathrm{Kx} \mathrm{Ky} \mathrm{Kz}$ Ss Por

$2.64268 \mathrm{e}+002.64268 \mathrm{e}+00$ 2.64268e-01 1.00000e-09 2.12000e-01

$2.64268 \mathrm{e}+002.64268 \mathrm{e}+00$ 2.64268e-01 1.00000e-09 2.12000e-01

$2.64268 \mathrm{e}+002.64268 \mathrm{e}+00$ 2.64268e-01 1.00000e-09 2.12000e-01

$2.64268 \mathrm{e}+002.64268 \mathrm{e}+00$ 2.64268e-01 1.00000e-09 2.12000e-01

$2.64268 \mathrm{e}+002.64268 \mathrm{e}+002.64268 \mathrm{e}-01$ 1.00000e-09 2.12000e-01

$1.00000 \mathrm{e}-05$ 1.00000e-05 1.00000e-06 1.00000e-09 1.00000e-01

$1.00000 \mathrm{e}+001.00000 \mathrm{e}+001.00000 \mathrm{e}-011.00000 \mathrm{e}-09$ 1.00000e-01

Element: 12935 \# of layers: 7

$\mathrm{Kx} \mathrm{Ky} \mathrm{Kz}$ Ss Por

$2.06113 \mathrm{e}+002.06113 \mathrm{e}+00$ 2.06113e-01 1.00000e-09 2.12000e-01

$2.06113 \mathrm{e}+002.06113 \mathrm{e}+002.06113 \mathrm{e}-01$ 1.00000e-09 2.12000e-01

$2.06113 \mathrm{e}+002.06113 \mathrm{e}+00$ 2.06113e-01 1.00000e-09 2.12000e-01

$2.06113 \mathrm{e}+002.06113 \mathrm{e}+00$ 2.06113e-01 1.00000e-09 2.12000e-01

$2.06113 \mathrm{e}+002.06113 \mathrm{e}+00$ 2.06113e-01 1.00000e-09 2.12000e-01

$1.00000 \mathrm{e}-05$ 1.00000e-05 1.00000e-06 1.00000e-09 1.00000e-01

$1.00000 \mathrm{e}+001.00000 \mathrm{e}+001.00000 \mathrm{e}-011.00000 \mathrm{e}-091.00000 \mathrm{e}-01$

Element: 12936 \# of layers: 7

$\mathrm{Kx} \mathrm{Ky} \mathrm{Kz}$ Ss Por

$2.06113 \mathrm{e}+002.06113 \mathrm{e}+00$ 2.06113e-01 1.00000e-09 2.12000e-01

$2.06113 \mathrm{e}+002.06113 \mathrm{e}+002.06113 \mathrm{e}-01$ 1.00000e-09 2.12000e-01

$2.06113 \mathrm{e}+002.06113 \mathrm{e}+00$ 2.06113e-01 1.00000e-09 2.12000e-01

$2.06113 \mathrm{e}+002.06113 \mathrm{e}+00$ 2.06113e-01 1.00000e-09 2.12000e-01

$2.06113 \mathrm{e}+002.06113 \mathrm{e}+00$ 2.06113e-01 1.00000e-09 2.12000e-01

1.00000e-05 1.00000e-05 1.00000e-06 1.00000e-09 1.00000e-01

$1.00000 \mathrm{e}+001.00000 \mathrm{e}+001.00000 \mathrm{e}-011.00000 \mathrm{e}-09$ 1.00000e-01

Element: 12937 \# of layers: 7

$\mathrm{Kx} \mathrm{Ky} \mathrm{Kz}$ Ss Por

2.06113e+00 2.06113e+00 2.06113e-01 1.00000e-09 2.12000e-01

$2.06113 \mathrm{e}+002.06113 \mathrm{e}+00$ 2.06113e-01 1.00000e-09 2.12000e-01

$2.06113 \mathrm{e}+00$ 2.06113e+00 2.06113e-01 1.00000e-09 2.12000e-01

$2.06113 \mathrm{e}+00$ 2.06113e+00 2.06113e-01 1.00000e-09 2.12000e-01

$2.06113 \mathrm{e}+002.06113 \mathrm{e}+00$ 2.06113e-01 1.00000e-09 2.12000e-01

$1.00000 \mathrm{e}-05$ 1.00000e-05 1.00000e-06 1.00000e-09 1.00000e-01 
$1.00000 \mathrm{e}+001.00000 \mathrm{e}+001.00000 \mathrm{e}-01$ 1.00000e-09 1.00000e-01 Element: 12938 \# of layers: 7

$\mathrm{Kx} \mathrm{Ky} \mathrm{Kz}$ Ss Por

$2.11405 \mathrm{e}+00$ 2.11405e+00 2.11405e-01 1.00000e-09 2.12000e-01

$2.11405 \mathrm{e}+002.11405 \mathrm{e}+00$ 2.11405e-01 1.00000e-09 2.12000e-01

$2.11405 \mathrm{e}+002.11405 \mathrm{e}+00$ 2.11405e-01 1.00000e-09 2.12000e-01

$2.11405 \mathrm{e}+00$ 2.11405e+00 2.11405e-01 1.00000e-09 2.12000e-01

$2.11405 \mathrm{e}+002.11405 \mathrm{e}+00$ 2.11405e-01 1.00000e-09 2.12000e-01

$1.00000 \mathrm{e}-05$ 1.00000e-05 1.00000e-06 1.00000e-09 1.00000e-01

$1.00000 \mathrm{e}+001.00000 \mathrm{e}+001.00000 \mathrm{e}-011.00000 \mathrm{e}-091.00000 \mathrm{e}-01$

Element: 12939 \# of layers: 7

Kx Ky Kz Ss Por

2.11405e+00 2.11405e+00 2.11405e-01 1.00000e-09 2.12000e-01

$2.11405 \mathrm{e}+002.11405 \mathrm{e}+00$ 2.11405e-01 1.00000e-09 2.12000e-01

$2.11405 \mathrm{e}+002.11405 \mathrm{e}+00$ 2.11405e-01 1.00000e-09 2.12000e-01

$2.11405 \mathrm{e}+002.11405 \mathrm{e}+00$ 2.11405e-01 1.00000e-09 2.12000e-01

$2.11405 \mathrm{e}+002.11405 \mathrm{e}+002.11405 \mathrm{e}-01$ 1.00000e-09 2.12000e-01 $1.00000 \mathrm{e}-05$ 1.00000e-05 1.00000e-06 1.00000e-09 1.00000e-01

$1.00000 \mathrm{e}+001.00000 \mathrm{e}+001.00000 \mathrm{e}-011.00000 \mathrm{e}-091.00000 \mathrm{e}-01$

Element: 12940 \# of layers: 7

$\mathrm{Kx} \mathrm{Ky} \mathrm{Kz}$ Ss Por

$1.77184 \mathrm{e}+001.77184 \mathrm{e}+00$ 1.77185e-01 1.00000e-09 2.12000e-01

$1.77184 \mathrm{e}+001.77184 \mathrm{e}+00$ 1.77185e-01 1.00000e-09 2.12000e-01

$1.77184 \mathrm{e}+001.77184 \mathrm{e}+001.77185 \mathrm{e}-011.00000 \mathrm{e}-092.12000 \mathrm{e}-01$

$1.77184 \mathrm{e}+001.77184 \mathrm{e}+001.77185 \mathrm{e}-011.00000 \mathrm{e}-092.12000 \mathrm{e}-01$

$1.77184 \mathrm{e}+001.77184 \mathrm{e}+001.77185 \mathrm{e}-011.00000 \mathrm{e}-092.12000 \mathrm{e}-01$

$1.00000 \mathrm{e}-05$ 1.00000e-05 1.00000e-06 1.00000e-09 1.00000e-01

$1.00000 \mathrm{e}+001.00000 \mathrm{e}+001.00000 \mathrm{e}-011.00000 \mathrm{e}-091.00000 \mathrm{e}-01$

Element: 12941 \# of layers: 7

$\mathrm{Kx} \mathrm{Ky} \mathrm{Kz}$ Ss Por

$2.64268 \mathrm{e}+002.64268 \mathrm{e}+00$ 2.64268e-01 1.00000e-09 2.12000e-01

$2.64268 \mathrm{e}+002.64268 \mathrm{e}+00$ 2.64268e-01 1.00000e-09 2.12000e-01

$2.64268 \mathrm{e}+002.64268 \mathrm{e}+002.64268 \mathrm{e}-01$ 1.00000e-09 2.12000e-01

$2.64268 \mathrm{e}+002.64268 \mathrm{e}+00$ 2.64268e-01 1.00000e-09 2.12000e-01

$2.64268 \mathrm{e}+002.64268 \mathrm{e}+00$ 2.64268e-01 1.00000e-09 2.12000e-01

$1.00000 \mathrm{e}-05$ 1.00000e-05 1.00000e-06 1.00000e-09 1.00000e-01

$1.00000 \mathrm{e}+001.00000 \mathrm{e}+001.00000 \mathrm{e}-011.00000 \mathrm{e}-091.00000 \mathrm{e}-01$

Element: 12942 \# of layers: 7

$\mathrm{Kx} \mathrm{Ky} \mathrm{Kz}$ Ss Por

$2.06113 \mathrm{e}+00$ 2.06113e+00 2.06113e-01 1.00000e-09 2.12000e-01

$2.06113 \mathrm{e}+002.06113 \mathrm{e}+00$ 2.06113e-01 1.00000e-09 2.12000e-01

$2.06113 \mathrm{e}+002.06113 \mathrm{e}+00$ 2.06113e-01 1.00000e-09 2.12000e-01

$2.06113 \mathrm{e}+00$ 2.06113e+00 2.06113e-01 1.00000e-09 2.12000e-01

$2.06113 \mathrm{e}+002.06113 \mathrm{e}+00$ 2.06113e-01 1.00000e-09 2.12000e-01 $1.00000 \mathrm{e}-05$ 1.00000e-05 1.00000e-06 1.00000e-09 1.00000e-01

$1.00000 \mathrm{e}+001.00000 \mathrm{e}+001.00000 \mathrm{e}-011.00000 \mathrm{e}-091.00000 \mathrm{e}-01$ 
Element: 12943 \# of layers: 6

$\mathrm{Kx} \mathrm{Ky} \mathrm{Kz}$ Ss Por

$2.59318 \mathrm{e}+002.59318 \mathrm{e}+002.59318 \mathrm{e}-01$ 1.00000e-09 2.12000e-01

$2.59318 \mathrm{e}+002.59318 \mathrm{e}+00$ 2.59318e-01 1.00000e-09 2.12000e-01

$2.59318 \mathrm{e}+002.59318 \mathrm{e}+00$ 2.59318e-01 1.00000e-09 2.12000e-01

$2.59318 \mathrm{e}+002.59318 \mathrm{e}+002.59318 \mathrm{e}-01$ 1.00000e-09 2.12000e-01

$1.00000 \mathrm{e}-05$ 1.00000e-05 1.00000e-06 1.00000e-09 1.00000e-01

$1.00000 \mathrm{e}+001.00000 \mathrm{e}+001.00000 \mathrm{e}-011.00000 \mathrm{e}-091.00000 \mathrm{e}-01$

Element: 12944 \# of layers: 5

$\mathrm{Kx} \mathrm{Ky} \mathrm{Kz}$ Ss Por

$2.59318 \mathrm{e}+002.59318 \mathrm{e}+00$ 2.59318e-01 1.00000e-09 2.12000e-01

$2.59318 \mathrm{e}+002.59318 \mathrm{e}+002.59318 \mathrm{e}-01$ 1.00000e-09 2.12000e-01

$2.59318 \mathrm{e}+002.59318 \mathrm{e}+002.59318 \mathrm{e}-01$ 1.00000e-09 2.12000e-01

$1.00000 \mathrm{e}-05$ 1.00000e-05 1.00000e-06 1.00000e-09 1.00000e-01

$1.00000 \mathrm{e}+001.00000 \mathrm{e}+001.00000 \mathrm{e}-01$ 1.00000e-09 1.00000e-01

Element: 12945 \# of layers: 5

$\mathrm{Kx} \mathrm{Ky} \mathrm{Kz}$ Ss Por

$2.59318 \mathrm{e}+002.59318 \mathrm{e}+00$ 2.59318e-01 1.00000e-09 2.12000e-01

$2.59318 \mathrm{e}+002.59318 \mathrm{e}+00$ 2.59318e-01 1.00000e-09 2.12000e-01

$2.59318 \mathrm{e}+002.59318 \mathrm{e}+002.59318 \mathrm{e}-01$ 1.00000e-09 2.12000e-01

$1.00000 \mathrm{e}-05$ 1.00000e-05 1.00000e-06 1.00000e-09 1.00000e-01

$1.00000 \mathrm{e}+001.00000 \mathrm{e}+001.00000 \mathrm{e}-011.00000 \mathrm{e}-091.00000 \mathrm{e}-01$

Element: 12946 \# of layers: 5

Kx Ky Kz Ss Por

$2.59318 \mathrm{e}+00$ 2.59318e+00 2.59318e-01 1.00000e-09 2.12000e-01

$2.59318 \mathrm{e}+002.59318 \mathrm{e}+002.59318 \mathrm{e}-01$ 1.00000e-09 2.12000e-01

$2.59318 \mathrm{e}+002.59318 \mathrm{e}+00$ 2.59318e-01 1.00000e-09 2.12000e-01

$1.00000 \mathrm{e}-05$ 1.00000e-05 1.00000e-06 1.00000e-09 1.00000e-01

$1.00000 \mathrm{e}+001.00000 \mathrm{e}+001.00000 \mathrm{e}-011.00000 \mathrm{e}-091.00000 \mathrm{e}-01$

Element: 12947 \# of layers: 5

$\mathrm{Kx} \mathrm{Ky} \mathrm{Kz}$ Ss Por

$2.59318 \mathrm{e}+002.59318 \mathrm{e}+00$ 2.59318e-01 1.00000e-09 2.12000e-01

$2.59318 \mathrm{e}+002.59318 \mathrm{e}+002.59318 \mathrm{e}-01$ 1.00000e-09 2.12000e-01

$2.59318 \mathrm{e}+002.59318 \mathrm{e}+00$ 2.59318e-01 1.00000e-09 2.12000e-01

$1.00000 \mathrm{e}-05$ 1.00000e-05 1.00000e-06 1.00000e-09 1.00000e-01

$1.00000 \mathrm{e}+001.00000 \mathrm{e}+001.00000 \mathrm{e}-011.00000 \mathrm{e}-09$ 1.00000e-01

Element: 12948 \# of layers: 5

$\mathrm{Kx} \mathrm{Ky} \mathrm{Kz}$ Ss Por

$2.59318 \mathrm{e}+002.59318 \mathrm{e}+00$ 2.59318e-01 1.00000e-09 2.12000e-01

$2.59318 \mathrm{e}+002.59318 \mathrm{e}+002.59318 \mathrm{e}-01$ 1.00000e-09 2.12000e-01

$2.59318 \mathrm{e}+002.59318 \mathrm{e}+00$ 2.59318e-01 1.00000e-09 2.12000e-01

$1.00000 \mathrm{e}-05$ 1.00000e-05 1.00000e-06 1.00000e-09 1.00000e-01

$1.00000 \mathrm{e}+001.00000 \mathrm{e}+001.00000 \mathrm{e}-011.00000 \mathrm{e}-091.00000 \mathrm{e}-01$

Element: 12949 \# of layers: 6

$\mathrm{Kx} \mathrm{Ky} \mathrm{Kz}$ Ss Por

2.59318e+00 2.59318e+00 2.59318e-01 1.00000e-09 2.12000e-01 
$2.59318 \mathrm{e}+002.59318 \mathrm{e}+002.59318 \mathrm{e}-011.00000 \mathrm{e}-092.12000 \mathrm{e}-01$ $2.59318 \mathrm{e}+002.59318 \mathrm{e}+002.59318 \mathrm{e}-011.00000 \mathrm{e}-092.12000 \mathrm{e}-01$ $2.59318 \mathrm{e}+002.59318 \mathrm{e}+002.59318 \mathrm{e}-011.00000 \mathrm{e}-092.12000 \mathrm{e}-01$ $1.00000 \mathrm{e}-05$ 1.00000e-05 1.00000e-06 1.00000e-09 1.00000e-01 $1.00000 \mathrm{e}+001.00000 \mathrm{e}+001.00000 \mathrm{e}-011.00000 \mathrm{e}-091.00000 \mathrm{e}-01$ Element: 12950 \# of layers: 6

Kx Ky Kz Ss Por

$2.59318 \mathrm{e}+002.59318 \mathrm{e}+002.59318 \mathrm{e}-011.00000 \mathrm{e}-092.12000 \mathrm{e}-01$ $2.59318 \mathrm{e}+002.59318 \mathrm{e}+002.59318 \mathrm{e}-011.00000 \mathrm{e}-092.12000 \mathrm{e}-01$ $2.59318 \mathrm{e}+002.59318 \mathrm{e}+002.59318 \mathrm{e}-011.00000 \mathrm{e}-092.12000 \mathrm{e}-01$ $2.59318 \mathrm{e}+002.59318 \mathrm{e}+002.59318 \mathrm{e}-011.00000 \mathrm{e}-092.12000 \mathrm{e}-01$ $1.00000 \mathrm{e}-05$ 1.00000e-05 1.00000e-06 1.00000e-09 1.00000e-01 $1.00000 \mathrm{e}+001.00000 \mathrm{e}+001.00000 \mathrm{e}-011.00000 \mathrm{e}-091.00000 \mathrm{e}-01$ Element: 12951 \# of layers: 5

Kx Ky Kz Ss Por

$2.59318 \mathrm{e}+002.59318 \mathrm{e}+002.59318 \mathrm{e}-011.00000 \mathrm{e}-092.12000 \mathrm{e}-01$ $2.59318 \mathrm{e}+002.59318 \mathrm{e}+002.59318 \mathrm{e}-011.00000 \mathrm{e}-092.12000 \mathrm{e}-01$ $2.59318 \mathrm{e}+002.59318 \mathrm{e}+002.59318 \mathrm{e}-011.00000 \mathrm{e}-092.12000 \mathrm{e}-01$ $1.00000 \mathrm{e}-05$ 1.00000e-05 1.00000e-06 1.00000e-09 1.00000e-01 $1.00000 \mathrm{e}+001.00000 \mathrm{e}+001.00000 \mathrm{e}-011.00000 \mathrm{e}-091.00000 \mathrm{e}-01$ Element: 12952 \# of layers: 5

Kx Ky Kz Ss Por

$2.59318 \mathrm{e}+002.59318 \mathrm{e}+002.59318 \mathrm{e}-011.00000 \mathrm{e}-092.12000 \mathrm{e}-01$ $2.59318 \mathrm{e}+002.59318 \mathrm{e}+002.59318 \mathrm{e}-011.00000 \mathrm{e}-092.12000 \mathrm{e}-01$ $2.59318 \mathrm{e}+002.59318 \mathrm{e}+002.59318 \mathrm{e}-011.00000 \mathrm{e}-092.12000 \mathrm{e}-01$ $1.00000 \mathrm{e}-05$ 1.00000e-05 1.00000e-06 1.00000e-09 1.00000e-01 $1.00000 \mathrm{e}+001.00000 \mathrm{e}+001.00000 \mathrm{e}-011.00000 \mathrm{e}-091.00000 \mathrm{e}-01$ Element: 12953 \# of layers: 5

Kx Ky Kz Ss Por

$6.29834 \mathrm{e}+006.29834 \mathrm{e}+00$ 6.29834e-01 1.00000e-09 2.12000e-01 $6.29834 \mathrm{e}+006.29834 \mathrm{e}+006.29834 \mathrm{e}-011.00000 \mathrm{e}-092.12000 \mathrm{e}-01$ $6.29834 \mathrm{e}+006.29834 \mathrm{e}+00$ 6.29834e-01 1.00000e-09 2.12000e-01 $1.00000 \mathrm{e}-05$ 1.00000e-05 1.00000e-06 1.00000e-09 1.00000e-01 $1.00000 \mathrm{e}+001.00000 \mathrm{e}+001.00000 \mathrm{e}-011.00000 \mathrm{e}-091.00000 \mathrm{e}-01$ Element: 12954 \# of layers: 5

Kx Ky Kz Ss Por

$6.29834 \mathrm{e}+006.29834 \mathrm{e}+00$ 6.29834e-01 1.00000e-09 2.12000e-01 $6.29834 \mathrm{e}+006.29834 \mathrm{e}+00$ 6.29834e-01 1.00000e-09 2.12000e-01 $6.29834 \mathrm{e}+006.29834 \mathrm{e}+006.29834 \mathrm{e}-01$ 1.00000e-09 2.12000e-01 $1.00000 \mathrm{e}-05$ 1.00000e-05 1.00000e-06 1.00000e-09 1.00000e-01 $1.00000 \mathrm{e}+001.00000 \mathrm{e}+001.00000 \mathrm{e}-011.00000 \mathrm{e}-091.00000 \mathrm{e}-01$ Element: 12955 \# of layers: 5

Kx Ky Kz Ss Por

$6.29834 \mathrm{e}+006.29834 \mathrm{e}+00$ 6.29834e-01 1.00000e-09 2.12000e-01 $6.29834 \mathrm{e}+006.29834 \mathrm{e}+006.29834 \mathrm{e}-011.00000 \mathrm{e}-092.12000 \mathrm{e}-01$ $6.29834 \mathrm{e}+006.29834 \mathrm{e}+006.29834 \mathrm{e}-01$ 1.00000e-09 2.12000e-01 
$1.00000 \mathrm{e}-05$ 1.00000e-05 1.00000e-06 1.00000e-09 1.00000e-01 $1.00000 \mathrm{e}+001.00000 \mathrm{e}+001.00000 \mathrm{e}-01$ 1.00000e-09 1.00000e-01 Element: 12956 \# of layers: 5

Kx Ky Kz Ss Por

6.29834e+00 6.29834e+00 6.29834e-01 1.00000e-09 2.12000e-01 $6.29834 \mathrm{e}+006.29834 \mathrm{e}+00$ 6.29834e-01 1.00000e-09 2.12000e-01 $6.29834 \mathrm{e}+006.29834 \mathrm{e}+00$ 6.29834e-01 1.00000e-09 2.12000e-01 $1.00000 \mathrm{e}-05$ 1.00000e-05 1.00000e-06 1.00000e-09 1.00000e-01 $1.00000 \mathrm{e}+001.00000 \mathrm{e}+001.00000 \mathrm{e}-011.00000 \mathrm{e}-091.00000 \mathrm{e}-01$ Element: 12957 \# of layers: 5

$\mathrm{Kx} \mathrm{Ky} \mathrm{Kz}$ Ss Por

6.29834e+00 6.29834e+00 6.29834e-01 1.00000e-09 2.12000e-01 $6.29834 \mathrm{e}+006.29834 \mathrm{e}+006.29834 \mathrm{e}-01$ 1.00000e-09 2.12000e-01 $6.29834 \mathrm{e}+006.29834 \mathrm{e}+006.29834 \mathrm{e}-01$ 1.00000e-09 2.12000e-01 $1.00000 \mathrm{e}-05$ 1.00000e-05 1.00000e-06 1.00000e-09 1.00000e-01 $1.00000 \mathrm{e}+001.00000 \mathrm{e}+001.00000 \mathrm{e}-011.00000 \mathrm{e}-091.00000 \mathrm{e}-01$ Element: 12958 \# of layers: 5

$\mathrm{Kx} \mathrm{Ky} \mathrm{Kz}$ Ss Por

$2.59318 \mathrm{e}+00$ 2.59318e+00 2.59318e-01 1.00000e-09 2.12000e-01 $2.59318 \mathrm{e}+002.59318 \mathrm{e}+00$ 2.59318e-01 1.00000e-09 2.12000e-01 $2.59318 \mathrm{e}+002.59318 \mathrm{e}+00$ 2.59318e-01 1.00000e-09 2.12000e-01 $1.00000 \mathrm{e}-05$ 1.00000e-05 1.00000e-06 1.00000e-09 1.00000e-01 $1.00000 \mathrm{e}+001.00000 \mathrm{e}+001.00000 \mathrm{e}-01$ 1.00000e-09 1.00000e-01 Element: 12959 \# of layers: 5

Kx Ky Kz Ss Por

$2.59318 \mathrm{e}+002.59318 \mathrm{e}+00$ 2.59318e-01 1.00000e-09 2.12000e-01 $2.59318 \mathrm{e}+002.59318 \mathrm{e}+00$ 2.59318e-01 1.00000e-09 2.12000e-01 $2.59318 \mathrm{e}+002.59318 \mathrm{e}+00$ 2.59318e-01 1.00000e-09 2.12000e-01 $1.00000 \mathrm{e}-05$ 1.00000e-05 1.00000e-06 1.00000e-09 1.00000e-01 $1.00000 \mathrm{e}+001.00000 \mathrm{e}+001.00000 \mathrm{e}-011.00000 \mathrm{e}-091.00000 \mathrm{e}-01$ Element: 12960 \# of layers: 5

$\mathrm{Kx} \mathrm{Ky} \mathrm{Kz}$ Ss Por

6.29834e+00 6.29834e+00 6.29834e-01 1.00000e-09 2.12000e-01 6.29834e+00 6.29834e+00 6.29834e-01 1.00000e-09 2.12000e-01 $6.29834 \mathrm{e}+006.29834 \mathrm{e}+006.29834 \mathrm{e}-01$ 1.00000e-09 2.12000e-01 $1.00000 \mathrm{e}-05$ 1.00000e-05 1.00000e-06 1.00000e-09 1.00000e-01 $1.00000 \mathrm{e}+001.00000 \mathrm{e}+001.00000 \mathrm{e}-011.00000 \mathrm{e}-091.00000 \mathrm{e}-01$ Element: 12961 \# of layers: 5

$\mathrm{Kx} \mathrm{Ky} \mathrm{Kz}$ Ss Por

6.29834e+00 6.29834e+00 6.29834e-01 1.00000e-09 2.12000e-01 $6.29834 \mathrm{e}+006.29834 \mathrm{e}+00$ 6.29834e-01 1.00000e-09 2.12000e-01 $6.29834 \mathrm{e}+006.29834 \mathrm{e}+00$ 6.29834e-01 1.00000e-09 2.12000e-01 $1.00000 \mathrm{e}-05$ 1.00000e-05 1.00000e-06 1.00000e-09 1.00000e-01 $1.00000 \mathrm{e}+001.00000 \mathrm{e}+001.00000 \mathrm{e}-01$ 1.00000e-09 1.00000e-01 Element: 12962 \# of layers: 4

Kx Ky Kz Ss Por 
$6.29834 \mathrm{e}+006.29834 \mathrm{e}+00$ 6.29834e-01 1.00000e-09 2.12000e-01 $6.29834 \mathrm{e}+006.29834 \mathrm{e}+00$ 6.29834e-01 1.00000e-09 2.12000e-01 $1.00000 \mathrm{e}-05$ 1.00000e-05 1.00000e-06 1.00000e-09 1.00000e-01 $1.00000 \mathrm{e}+001.00000 \mathrm{e}+001.00000 \mathrm{e}-011.00000 \mathrm{e}-091.00000 \mathrm{e}-01$ Element: 12963 \# of layers: 4

Kx Ky Kz Ss Por

$6.29834 \mathrm{e}+006.29834 \mathrm{e}+00$ 6.29834e-01 1.00000e-09 2.12000e-01 $6.29834 \mathrm{e}+006.29834 \mathrm{e}+006.29834 \mathrm{e}-01$ 1.00000e-09 2.12000e-01 $1.00000 \mathrm{e}-05$ 1.00000e-05 1.00000e-06 1.00000e-09 1.00000e-01 $1.00000 \mathrm{e}+001.00000 \mathrm{e}+001.00000 \mathrm{e}-011.00000 \mathrm{e}-091.00000 \mathrm{e}-01$ Element: 12964 \# of layers: 4

Kx Ky Kz Ss Por

$6.29834 \mathrm{e}+006.29834 \mathrm{e}+00$ 6.29834e-01 1.00000e-09 2.12000e-01 $6.29834 \mathrm{e}+006.29834 \mathrm{e}+006.29834 \mathrm{e}-01$ 1.00000e-09 2.12000e-01 $1.00000 \mathrm{e}-05$ 1.00000e-05 1.00000e-06 1.00000e-09 1.00000e-01 $1.00000 \mathrm{e}+001.00000 \mathrm{e}+001.00000 \mathrm{e}-011.00000 \mathrm{e}-09$ 1.00000e-01 Element: 12965 \# of layers: 4

Kx Ky Kz Ss Por

$6.29834 \mathrm{e}+006.29834 \mathrm{e}+00$ 6.29834e-01 1.00000e-09 2.12000e-01 $6.29834 \mathrm{e}+006.29834 \mathrm{e}+006.29834 \mathrm{e}-011.00000 \mathrm{e}-092.12000 \mathrm{e}-01$ $1.00000 \mathrm{e}-05$ 1.00000e-05 1.00000e-06 1.00000e-09 1.00000e-01 $1.00000 \mathrm{e}+001.00000 \mathrm{e}+001.00000 \mathrm{e}-011.00000 \mathrm{e}-091.00000 \mathrm{e}-01$ Element: 12966 \# of layers: 4

Kx Ky Kz Ss Por $6.29834 \mathrm{e}+006.29834 \mathrm{e}+00$ 6.29834e-01 1.00000e-09 2.12000e-01 $6.29834 \mathrm{e}+006.29834 \mathrm{e}+006.29834 \mathrm{e}-01$ 1.00000e-09 2.12000e-01 $1.00000 \mathrm{e}-05$ 1.00000e-05 1.00000e-06 1.00000e-09 1.00000e-01 $1.00000 \mathrm{e}+001.00000 \mathrm{e}+001.00000 \mathrm{e}-011.00000 \mathrm{e}-091.00000 \mathrm{e}-01$ Element: 12967 \# of layers: 5

Kx Ky Kz Ss Por

$6.29834 \mathrm{e}+006.29834 \mathrm{e}+00$ 6.29834e-01 1.00000e-09 2.12000e-01 $6.29834 \mathrm{e}+006.29834 \mathrm{e}+006.29834 \mathrm{e}-01$ 1.00000e-09 2.12000e-01 $6.29834 \mathrm{e}+006.29834 \mathrm{e}+00$ 6.29834e-01 1.00000e-09 2.12000e-01 $1.00000 \mathrm{e}-05$ 1.00000e-05 1.00000e-06 1.00000e-09 1.00000e-01 $1.00000 \mathrm{e}+001.00000 \mathrm{e}+001.00000 \mathrm{e}-011.00000 \mathrm{e}-091.00000 \mathrm{e}-01$ Element: 12968 \# of layers: 5

Kx Ky Kz Ss Por $6.29834 \mathrm{e}+006.29834 \mathrm{e}+00$ 6.29834e-01 1.00000e-09 2.12000e-01 $6.29834 \mathrm{e}+006.29834 \mathrm{e}+00$ 6.29834e-01 1.00000e-09 2.12000e-01 $6.29834 \mathrm{e}+006.29834 \mathrm{e}+00$ 6.29834e-01 1.00000e-09 2.12000e-01 $1.00000 \mathrm{e}-05$ 1.00000e-05 1.00000e-06 1.00000e-09 1.00000e-01 $1.00000 \mathrm{e}+001.00000 \mathrm{e}+001.00000 \mathrm{e}-011.00000 \mathrm{e}-091.00000 \mathrm{e}-01$ Element: 12969 \# of layers: 4

Kx Ky Kz Ss Por $6.29834 \mathrm{e}+006.29834 \mathrm{e}+00$ 6.29834e-01 1.00000e-09 2.12000e-01 $6.29834 \mathrm{e}+006.29834 \mathrm{e}+006.29834 \mathrm{e}-01$ 1.00000e-09 2.12000e-01 
$1.00000 \mathrm{e}-05$ 1.00000e-05 1.00000e-06 1.00000e-09 1.00000e-01 $1.00000 \mathrm{e}+001.00000 \mathrm{e}+001.00000 \mathrm{e}-01$ 1.00000e-09 1.00000e-01 Element: 12970 \# of layers: 4

Kx Ky Kz Ss Por

6.29834e+00 6.29834e+00 6.29834e-01 1.00000e-09 2.12000e-01 $6.29834 \mathrm{e}+006.29834 \mathrm{e}+006.29834 \mathrm{e}-01$ 1.00000e-09 2.12000e-01 1.00000e-05 1.00000e-05 1.00000e-06 1.00000e-09 1.00000e-01 $1.00000 \mathrm{e}+001.00000 \mathrm{e}+001.00000 \mathrm{e}-01$ 1.00000e-09 1.00000e-01 Element: 12971 \# of layers: 4

$\mathrm{Kx} \mathrm{Ky} \mathrm{Kz}$ Ss Por

6.29834e+00 6.29834e+00 6.29834e-01 1.00000e-09 2.12000e-01 $6.29834 \mathrm{e}+006.29834 \mathrm{e}+006.29834 \mathrm{e}-01$ 1.00000e-09 2.12000e-01 $1.00000 \mathrm{e}-05$ 1.00000e-05 1.00000e-06 1.00000e-09 1.00000e-01 $1.00000 \mathrm{e}+001.00000 \mathrm{e}+001.00000 \mathrm{e}-011.00000 \mathrm{e}-09$ 1.00000e-01 Element: 12972 \# of layers: 4

Kx Ky Kz Ss Por

$1.17459 \mathrm{e}+01$ 1.17459e+01 1.17459e+00 1.00000e-09 2.12000e-01 $1.17459 \mathrm{e}+011.17459 \mathrm{e}+01$ 1.17459e+00 1.00000e-09 2.12000e-01 $1.00000 \mathrm{e}-051.00000 \mathrm{e}-051.00000 \mathrm{e}-061.00000 \mathrm{e}-091.00000 \mathrm{e}-01$ $1.00000 \mathrm{e}+001.00000 \mathrm{e}+001.00000 \mathrm{e}-011.00000 \mathrm{e}-091.00000 \mathrm{e}-01$ Element: 12973 \# of layers: 4

$\mathrm{Kx} \mathrm{Ky} \mathrm{Kz}$ Ss Por

$1.17459 \mathrm{e}+01$ 1.17459e+01 1.17459e+00 1.00000e-09 2.12000e-01 $1.17459 \mathrm{e}+01$ 1.17459e+01 1.17459e+00 1.00000e-09 2.12000e-01 $1.00000 \mathrm{e}-05$ 1.00000e-05 1.00000e-06 1.00000e-09 1.00000e-01 $1.00000 \mathrm{e}+001.00000 \mathrm{e}+001.00000 \mathrm{e}-01$ 1.00000e-09 1.00000e-01 Element: 12974 \# of layers: 5

$\mathrm{Kx} \mathrm{Ky} \mathrm{Kz}$ Ss Por

1.17459e+01 1.17459e+01 1.17459e+00 1.00000e-09 2.12000e-01 $1.17459 \mathrm{e}+01$ 1.17459e+01 1.17459e+00 1.00000e-09 2.12000e-01 $1.17459 \mathrm{e}+01$ 1.17459e+01 1.17459e+00 1.00000e-09 2.12000e-01 $1.00000 \mathrm{e}-05$ 1.00000e-05 1.00000e-06 1.00000e-09 1.00000e-01 $1.00000 \mathrm{e}+001.00000 \mathrm{e}+001.00000 \mathrm{e}-011.00000 \mathrm{e}-091.00000 \mathrm{e}-01$ Element: 12975 \# of layers: 5

$\mathrm{Kx} \mathrm{Ky} \mathrm{Kz}$ Ss Por

6.29834e+00 6.29834e+00 6.29834e-01 1.00000e-09 2.12000e-01 $6.29834 \mathrm{e}+006.29834 \mathrm{e}+006.29834 \mathrm{e}-01$ 1.00000e-09 2.12000e-01 $6.29834 \mathrm{e}+006.29834 \mathrm{e}+006.29834 \mathrm{e}-01$ 1.00000e-09 2.12000e-01 $1.00000 \mathrm{e}-05$ 1.00000e-05 1.00000e-06 1.00000e-09 1.00000e-01 $1.00000 \mathrm{e}+001.00000 \mathrm{e}+001.00000 \mathrm{e}-01$ 1.00000e-09 1.00000e-01 Element: 12976 \# of layers: 5

$\mathrm{Kx} \mathrm{Ky} \mathrm{Kz}$ Ss Por 6.29834e+00 6.29834e+00 6.29834e-01 1.00000e-09 2.12000e-01 $6.29834 \mathrm{e}+006.29834 \mathrm{e}+00$ 6.29834e-01 1.00000e-09 2.12000e-01 $6.29834 \mathrm{e}+006.29834 \mathrm{e}+006.29834 \mathrm{e}-01$ 1.00000e-09 2.12000e-01 $1.00000 \mathrm{e}-05$ 1.00000e-05 1.00000e-06 1.00000e-09 1.00000e-01 
$1.00000 \mathrm{e}+001.00000 \mathrm{e}+00$ 1.00000e-01 1.00000e-09 1.00000e-01

Element: 12977 \# of layers: 4

Kx Ky Kz Ss Por

6.29834e+00 6.29834e+00 6.29834e-01 1.00000e-09 2.12000e-01

$6.29834 \mathrm{e}+006.29834 \mathrm{e}+006.29834 \mathrm{e}-01$ 1.00000e-09 2.12000e-01

$1.00000 \mathrm{e}-05$ 1.00000e-05 1.00000e-06 1.00000e-09 1.00000e-01

$1.00000 \mathrm{e}+001.00000 \mathrm{e}+001.00000 \mathrm{e}-01$ 1.00000e-09 1.00000e-01

Element: 12978 \# of layers: 4

$\mathrm{Kx} \mathrm{Ky} \mathrm{Kz}$ Ss Por

$6.29834 \mathrm{e}+006.29834 \mathrm{e}+00$ 6.29834e-01 1.00000e-09 2.12000e-01

$6.29834 \mathrm{e}+006.29834 \mathrm{e}+006.29834 \mathrm{e}-01$ 1.00000e-09 2.12000e-01

$1.00000 \mathrm{e}-05$ 1.00000e-05 1.00000e-06 1.00000e-09 1.00000e-01

$1.00000 \mathrm{e}+001.00000 \mathrm{e}+001.00000 \mathrm{e}-01$ 1.00000e-09 1.00000e-01

Element: 12979 \# of layers: 4

Kx Ky Kz Ss Por

$1.17459 \mathrm{e}+01$ 1.17459e+01 1.17459e+00 1.00000e-09 2.12000e-01

$1.17459 \mathrm{e}+01$ 1.17459e+01 1.17459e+00 1.00000e-09 2.12000e-01

$1.00000 \mathrm{e}-05$ 1.00000e-05 1.00000e-06 1.00000e-09 1.00000e-01

$1.00000 \mathrm{e}+001.00000 \mathrm{e}+001.00000 \mathrm{e}-011.00000 \mathrm{e}-091.00000 \mathrm{e}-01$

Element: 12980 \# of layers: 5

$\mathrm{Kx} \mathrm{Ky} \mathrm{Kz}$ Ss Por

$1.17459 \mathrm{e}+01$ 1.17459e+01 1.17459e+00 1.00000e-09 2.12000e-01

$1.17459 \mathrm{e}+01$ 1.17459e+01 1.17459e+00 1.00000e-09 2.12000e-01

$1.00000 \mathrm{e}-05$ 1.00000e-05 1.00000e-06 1.00000e-09 1.00000e-01

$1.00000 \mathrm{e}+001.00000 \mathrm{e}+001.00000 \mathrm{e}-011.00000 \mathrm{e}-091.00000 \mathrm{e}-01$

1.00000e-06 1.00000e-06 1.00000e-06 1.00000e-09 5.00000e-02

Element: 12981 \# of layers: 5

$\mathrm{Kx} \mathrm{Ky} \mathrm{Kz}$ Ss Por

1.17459e+01 1.17459e+01 1.17459e+00 1.00000e-09 2.12000e-01

$1.17459 \mathrm{e}+01$ 1.17459e+01 1.17459e+00 1.00000e-09 2.12000e-01

$1.00000 \mathrm{e}-05$ 1.00000e-05 1.00000e-06 1.00000e-09 1.00000e-01

$1.00000 \mathrm{e}+001.00000 \mathrm{e}+001.00000 \mathrm{e}-011.00000 \mathrm{e}-091.00000 \mathrm{e}-01$

1.00000e-06 1.00000e-06 1.00000e-06 1.00000e-09 5.00000e-02

Element: 12982 \# of layers: 4

$\mathrm{Kx} \mathrm{Ky} \mathrm{Kz}$ Ss Por

$1.17459 \mathrm{e}+01$ 1.17459e+01 1.17459e+00 1.00000e-09 2.12000e-01

$1.17459 \mathrm{e}+011.17459 \mathrm{e}+011.17459 \mathrm{e}+001.00000 \mathrm{e}-092.12000 \mathrm{e}-01$

$1.00000 \mathrm{e}-05$ 1.00000e-05 1.00000e-06 1.00000e-09 1.00000e-01

$1.00000 \mathrm{e}+001.00000 \mathrm{e}+001.00000 \mathrm{e}-01$ 1.00000e-09 1.00000e-01

Element: 12983 \# of layers: 4

Kx Ky Kz Ss Por

$1.17459 \mathrm{e}+01$ 1.17459e+01 1.17459e+00 1.00000e-09 2.12000e-01

$1.17459 \mathrm{e}+01$ 1.17459e+01 1.17459e+00 1.00000e-09 2.12000e-01

$1.00000 \mathrm{e}-05$ 1.00000e-05 1.00000e-06 1.00000e-09 1.00000e-01

$1.00000 \mathrm{e}+001.00000 \mathrm{e}+001.00000 \mathrm{e}-01$ 1.00000e-09 1.00000e-01

Element: 12984 \# of layers: 4 
Kx Ky Kz Ss Por

$1.17459 \mathrm{e}+01$ 1.17459e+01 1.17459e+00 1.00000e-09 2.12000e-01

$1.17459 \mathrm{e}+01$ 1.17459e+01 1.17459e+00 1.00000e-09 2.12000e-01

$1.00000 \mathrm{e}-05$ 1.00000e-05 1.00000e-06 1.00000e-09 1.00000e-01

$1.00000 \mathrm{e}+001.00000 \mathrm{e}+001.00000 \mathrm{e}-01$ 1.00000e-09 1.00000e-01

Element: 12985 \# of layers: 4

$\mathrm{Kx} \mathrm{Ky} \mathrm{Kz}$ Ss Por

$1.17459 \mathrm{e}+01$ 1.17459e+01 1.17459e+00 1.00000e-09 2.12000e-01

$1.17459 \mathrm{e}+01$ 1.17459e+01 1.17459e+00 1.00000e-09 2.12000e-01

$1.00000 \mathrm{e}-05$ 1.00000e-05 1.00000e-06 1.00000e-09 1.00000e-01

$1.00000 \mathrm{e}+001.00000 \mathrm{e}+001.00000 \mathrm{e}-01$ 1.00000e-09 1.00000e-01

Element: 12986 \# of layers: 4

$\mathrm{Kx} \mathrm{Ky} \mathrm{Kz}$ Ss Por

$1.17459 \mathrm{e}+01$ 1.17459e+01 1.17459e+00 1.00000e-09 2.12000e-01

$1.17459 \mathrm{e}+01$ 1.17459e+01 1.17459e+00 1.00000e-09 2.12000e-01

$1.00000 \mathrm{e}-05$ 1.00000e-05 1.00000e-06 1.00000e-09 1.00000e-01

$1.00000 \mathrm{e}+001.00000 \mathrm{e}+001.00000 \mathrm{e}-01$ 1.00000e-09 1.00000e-01

Element: 12987 \# of layers: 4

$\mathrm{Kx} \mathrm{Ky} \mathrm{Kz}$ Ss Por

$1.17459 \mathrm{e}+01$ 1.17459e+01 1.17459e+00 1.00000e-09 2.12000e-01

$1.17459 \mathrm{e}+01$ 1.17459e+01 1.17459e+00 1.00000e-09 2.12000e-01

$1.00000 \mathrm{e}-05$ 1.00000e-05 1.00000e-06 1.00000e-09 1.00000e-01

$1.00000 \mathrm{e}+001.00000 \mathrm{e}+001.00000 \mathrm{e}-01$ 1.00000e-09 1.00000e-01

Element: 12988 \# of layers: 5

Kx Ky Kz Ss Por

$1.17459 \mathrm{e}+01$ 1.17459e+01 1.17459e+00 1.00000e-09 2.12000e-01

$1.17459 \mathrm{e}+01$ 1.17459e+01 1.17459e+00 1.00000e-09 2.12000e-01

$1.17459 \mathrm{e}+01$ 1.17459e+01 1.17459e+00 1.00000e-09 2.12000e-01

$1.00000 \mathrm{e}-05$ 1.00000e-05 1.00000e-06 1.00000e-09 1.00000e-01

$1.00000 \mathrm{e}+001.00000 \mathrm{e}+001.00000 \mathrm{e}-01$ 1.00000e-09 1.00000e-01

Element: 12989 \# of layers: 5

Kx Ky Kz Ss Por

$1.17459 \mathrm{e}+01$ 1.17459e+01 1.17459e+00 1.00000e-09 2.12000e-01

$1.17459 \mathrm{e}+01$ 1.17459e+01 1.17459e+00 1.00000e-09 2.12000e-01

$1.17459 \mathrm{e}+01$ 1.17459e+01 1.17459e+00 1.00000e-09 2.12000e-01

$1.00000 \mathrm{e}-05$ 1.00000e-05 1.00000e-06 1.00000e-09 1.00000e-01

$1.00000 \mathrm{e}+001.00000 \mathrm{e}+001.00000 \mathrm{e}-011.00000 \mathrm{e}-091.00000 \mathrm{e}-01$

Element: 12990 \# of layers: 5

Kx Ky Kz Ss Por

4.77753e+00 4.77753e+00 4.77753e-01 1.00000e-09 2.12000e-01

4.77753e+00 4.77753e+00 4.77753e-01 1.00000e-09 2.12000e-01

4.77753e+00 4.77753e+00 4.77753e-01 1.00000e-09 2.12000e-01

$1.00000 \mathrm{e}-05$ 1.00000e-05 1.00000e-06 1.00000e-09 1.00000e-01

$1.00000 \mathrm{e}+001.00000 \mathrm{e}+001.00000 \mathrm{e}-01$ 1.00000e-09 1.00000e-01

Element: 12991 \# of layers: 5

Kx Ky Kz Ss Por 
4.77753e+00 4.77753e+00 4.77753e-01 1.00000e-09 2.12000e-01

4.77753e+00 4.77753e+00 4.77753e-01 1.00000e-09 2.12000e-01

4.77753e+00 4.77753e+00 4.77753e-01 1.00000e-09 2.12000e-01

$1.00000 \mathrm{e}-05$ 1.00000e-05 1.00000e-06 1.00000e-09 1.00000e-01

$1.00000 \mathrm{e}+001.00000 \mathrm{e}+001.00000 \mathrm{e}-01$ 1.00000e-09 1.00000e-01

Element: 12992 \# of layers: 5

$\mathrm{Kx} \mathrm{Ky} \mathrm{Kz}$ Ss Por

4.77753e+00 4.77753e+00 4.77753e-01 1.00000e-09 2.12000e-01

4.77753e+00 4.77753e+00 4.77753e-01 1.00000e-09 2.12000e-01

4.77753e+00 4.77753e+00 4.77753e-01 1.00000e-09 2.12000e-01

$1.00000 \mathrm{e}-05$ 1.00000e-05 1.00000e-06 1.00000e-09 1.00000e-01

$1.00000 \mathrm{e}+001.00000 \mathrm{e}+001.00000 \mathrm{e}-011.00000 \mathrm{e}-091.00000 \mathrm{e}-01$

Element: 12993 \# of layers: 5

$\mathrm{Kx} \mathrm{Ky} \mathrm{Kz}$ Ss Por

$1.17459 \mathrm{e}+01$ 1.17459e+01 1.17459e+00 1.00000e-09 2.12000e-01

$1.17459 \mathrm{e}+011.17459 \mathrm{e}+011.17459 \mathrm{e}+001.00000 \mathrm{e}-092.12000 \mathrm{e}-01$

$1.17459 \mathrm{e}+01$ 1.17459e+01 1.17459e+00 1.00000e-09 2.12000e-01

$1.00000 \mathrm{e}-05$ 1.00000e-05 1.00000e-06 1.00000e-09 1.00000e-01

$1.00000 \mathrm{e}+001.00000 \mathrm{e}+001.00000 \mathrm{e}-01$ 1.00000e-09 1.00000e-01

Element: 12994 \# of layers: 5

Kx Ky Kz Ss Por

$1.17459 \mathrm{e}+01$ 1.17459e+01 1.17459e+00 1.00000e-09 2.12000e-01

$1.17459 \mathrm{e}+01$ 1.17459e+01 1.17459e+00 1.00000e-09 2.12000e-01

$1.17459 \mathrm{e}+01$ 1.17459e+01 1.17459e+00 1.00000e-09 2.12000e-01

$1.00000 \mathrm{e}-05$ 1.00000e-05 1.00000e-06 1.00000e-09 1.00000e-01

$1.00000 \mathrm{e}+001.00000 \mathrm{e}+001.00000 \mathrm{e}-01$ 1.00000e-09 1.00000e-01

Element: 12995 \# of layers: 5

$\mathrm{Kx} \mathrm{Ky} \mathrm{Kz}$ Ss Por

1.17459e+01 1.17459e+01 1.17459e+00 1.00000e-09 2.12000e-01

$1.17459 \mathrm{e}+01$ 1.17459e+01 1.17459e+00 1.00000e-09 2.12000e-01

$1.17459 \mathrm{e}+01$ 1.17459e+01 1.17459e+00 1.00000e-09 2.12000e-01

$1.00000 \mathrm{e}-05$ 1.00000e-05 1.00000e-06 1.00000e-09 1.00000e-01

$1.00000 \mathrm{e}+001.00000 \mathrm{e}+001.00000 \mathrm{e}-011.00000 \mathrm{e}-091.00000 \mathrm{e}-01$

Element: 12996 \# of layers: 5

$\mathrm{Kx} \mathrm{Ky} \mathrm{Kz}$ Ss Por

$1.17459 \mathrm{e}+01$ 1.17459e+01 1.17459e+00 1.00000e-09 2.12000e-01

$1.17459 \mathrm{e}+011.17459 \mathrm{e}+011.17459 \mathrm{e}+001.00000 \mathrm{e}-092.12000 \mathrm{e}-01$

$1.17459 \mathrm{e}+011.17459 \mathrm{e}+011.17459 \mathrm{e}+001.00000 \mathrm{e}-092.12000 \mathrm{e}-01$

$1.00000 \mathrm{e}-051.00000 \mathrm{e}-051.00000 \mathrm{e}-061.00000 \mathrm{e}-091.00000 \mathrm{e}-01$

$1.00000 \mathrm{e}+001.00000 \mathrm{e}+001.00000 \mathrm{e}-01$ 1.00000e-09 1.00000e-01

Element: 12997 \# of layers: 5

Kx Ky Kz Ss Por

4.77753e+00 4.77753e+00 4.77753e-01 1.00000e-09 2.12000e-01

4.77753e+00 4.77753e+00 4.77753e-01 1.00000e-09 2.12000e-01

$4.77753 \mathrm{e}+004.77753 \mathrm{e}+00$ 4.77753e-01 1.00000e-09 2.12000e-01

$1.00000 \mathrm{e}-05$ 1.00000e-05 1.00000e-06 1.00000e-09 1.00000e-01 
$1.00000 \mathrm{e}+001.00000 \mathrm{e}+00$ 1.00000e-01 1.00000e-09 1.00000e-01

Element: 12998 \# of layers: 5

Kx Ky Kz Ss Por

4.77753e+00 4.77753e+00 4.77753e-01 1.00000e-09 2.12000e-01

4.77753e+00 4.77753e+00 4.77753e-01 1.00000e-09 2.12000e-01

4.77753e+00 4.77753e+00 4.77753e-01 1.00000e-09 2.12000e-01

$1.00000 \mathrm{e}-05$ 1.00000e-05 1.00000e-06 1.00000e-09 1.00000e-01

$1.00000 \mathrm{e}+001.00000 \mathrm{e}+001.00000 \mathrm{e}-011.00000 \mathrm{e}-091.00000 \mathrm{e}-01$

Element: 12999 \# of layers: 6

$\mathrm{Kx} \mathrm{Ky} \mathrm{Kz}$ Ss Por

4.77753e+00 4.77753e+00 4.77753e-01 1.00000e-09 2.12000e-01

$4.77753 \mathrm{e}+004.77753 \mathrm{e}+00$ 4.77753e-01 1.00000e-09 2.12000e-01

$4.77753 \mathrm{e}+004.77753 \mathrm{e}+00$ 4.77753e-01 1.00000e-09 2.12000e-01

4.77753e+00 4.77753e+00 4.77753e-01 1.00000e-09 2.12000e-01

$1.00000 \mathrm{e}-05$ 1.00000e-05 1.00000e-06 1.00000e-09 1.00000e-01

$1.00000 \mathrm{e}+001.00000 \mathrm{e}+001.00000 \mathrm{e}-011.00000 \mathrm{e}-091.00000 \mathrm{e}-01$

Element: 13000 \# of layers: 6

$\mathrm{Kx} \mathrm{Ky} \mathrm{Kz}$ Ss Por

4.77753e+00 4.77753e+00 4.77753e-01 1.00000e-09 2.12000e-01

4.77753e+00 4.77753e+00 4.77753e-01 1.00000e-09 2.12000e-01

4.77753e+00 4.77753e+00 4.77753e-01 1.00000e-09 2.12000e-01

4.77753e+00 4.77753e+00 4.77753e-01 1.00000e-09 2.12000e-01

$1.00000 \mathrm{e}-051.00000 \mathrm{e}-051.00000 \mathrm{e}-061.00000 \mathrm{e}-091.00000 \mathrm{e}-01$

$1.00000 \mathrm{e}+001.00000 \mathrm{e}+001.00000 \mathrm{e}-011.00000 \mathrm{e}-091.00000 \mathrm{e}-01$

Element: 13001 \# of layers: 6

Kx Ky Kz Ss Por

4.77753e+00 4.77753e+00 4.77753e-01 1.00000e-09 2.12000e-01

4.77753e+00 4.77753e+00 4.77753e-01 1.00000e-09 2.12000e-01

$4.77753 \mathrm{e}+00$ 4.77753e+00 4.77753e-01 1.00000e-09 2.12000e-01

4.77753e+00 4.77753e+00 4.77753e-01 1.00000e-09 2.12000e-01

$1.00000 \mathrm{e}-05$ 1.00000e-05 1.00000e-06 1.00000e-09 1.00000e-01

$1.00000 \mathrm{e}+001.00000 \mathrm{e}+001.00000 \mathrm{e}-011.00000 \mathrm{e}-091.00000 \mathrm{e}-01$

Element: 13002 \# of layers: 5

$\mathrm{Kx} \mathrm{Ky} \mathrm{Kz}$ Ss Por

4.77753e+00 4.77753e+00 4.77753e-01 1.00000e-09 2.12000e-01

4.77753e+00 4.77753e+00 4.77753e-01 1.00000e-09 2.12000e-01

4.77753e+00 4.77753e+00 4.77753e-01 1.00000e-09 2.12000e-01

$1.00000 \mathrm{e}-05$ 1.00000e-05 1.00000e-06 1.00000e-09 1.00000e-01

$1.00000 \mathrm{e}+001.00000 \mathrm{e}+001.00000 \mathrm{e}-01$ 1.00000e-09 1.00000e-01

Element: 13003 \# of layers: 5

Kx Ky Kz Ss Por

4.77753e+00 4.77753e+00 4.77753e-01 1.00000e-09 2.12000e-01

4.77753e+00 4.77753e+00 4.77753e-01 1.00000e-09 2.12000e-01

4.77753e+00 4.77753e+00 4.77753e-01 1.00000e-09 2.12000e-01

$1.00000 \mathrm{e}-051.00000 \mathrm{e}-051.00000 \mathrm{e}-061.00000 \mathrm{e}-091.00000 \mathrm{e}-01$

$1.00000 \mathrm{e}+001.00000 \mathrm{e}+001.00000 \mathrm{e}-011.00000 \mathrm{e}-091.00000 \mathrm{e}-01$ 
Element: 13004 \# of layers: 5

$\mathrm{Kx} \mathrm{Ky} \mathrm{Kz}$ Ss Por

4.77753e+00 4.77753e+00 4.77753e-01 1.00000e-09 2.12000e-01

$4.77753 \mathrm{e}+00$ 4.77753e+00 4.77753e-01 1.00000e-09 2.12000e-01

4.77753e+00 4.77753e+00 4.77753e-01 1.00000e-09 2.12000e-01

$1.00000 \mathrm{e}-05$ 1.00000e-05 1.00000e-06 1.00000e-09 1.00000e-01

$1.00000 \mathrm{e}+001.00000 \mathrm{e}+00$ 1.00000e-01 1.00000e-09 1.00000e-01

Element: 13005 \# of layers: 5

$\mathrm{Kx} \mathrm{Ky} \mathrm{Kz}$ Ss Por

4.77753e+00 4.77753e+00 4.77753e-01 1.00000e-09 2.12000e-01

$4.77753 \mathrm{e}+00$ 4.77753e+00 4.77753e-01 1.00000e-09 2.12000e-01

$4.77753 \mathrm{e}+00$ 4.77753e+00 4.77753e-01 1.00000e-09 2.12000e-01

$1.00000 \mathrm{e}-05$ 1.00000e-05 1.00000e-06 1.00000e-09 1.00000e-01

$1.00000 \mathrm{e}+001.00000 \mathrm{e}+001.00000 \mathrm{e}-011.00000 \mathrm{e}-091.00000 \mathrm{e}-01$

Element: 13006 \# of layers: 6

Kx Ky Kz Ss Por

4.77753e+00 4.77753e+00 4.77753e-01 1.00000e-09 2.12000e-01

4.77753e+00 4.77753e+00 4.77753e-01 1.00000e-09 2.12000e-01

4.77753e+00 4.77753e+00 4.77753e-01 1.00000e-09 2.12000e-01

$4.77753 \mathrm{e}+00$ 4.77753e+00 4.77753e-01 1.00000e-09 2.12000e-01

$1.00000 \mathrm{e}-05$ 1.00000e-05 1.00000e-06 1.00000e-09 1.00000e-01

$1.00000 \mathrm{e}+001.00000 \mathrm{e}+001.00000 \mathrm{e}-01$ 1.00000e-09 1.00000e-01

Element: 13007 \# of layers: 6

Kx Ky Kz Ss Por

$2.59318 \mathrm{e}+002.59318 \mathrm{e}+00$ 2.59318e-01 1.00000e-09 2.12000e-01

$2.59318 \mathrm{e}+002.59318 \mathrm{e}+002.59318 \mathrm{e}-01$ 1.00000e-09 2.12000e-01

$2.59318 \mathrm{e}+002.59318 \mathrm{e}+002.59318 \mathrm{e}-01$ 1.00000e-09 2.12000e-01

$2.59318 \mathrm{e}+002.59318 \mathrm{e}+00$ 2.59318e-01 1.00000e-09 2.12000e-01

$1.00000 \mathrm{e}-05$ 1.00000e-05 1.00000e-06 1.00000e-09 1.00000e-01

$1.00000 \mathrm{e}+001.00000 \mathrm{e}+001.00000 \mathrm{e}-011.00000 \mathrm{e}-091.00000 \mathrm{e}-01$

Element: 13008 \# of layers: 6

$\mathrm{Kx} \mathrm{Ky} \mathrm{Kz}$ Ss Por

$2.59318 \mathrm{e}+002.59318 \mathrm{e}+00$ 2.59318e-01 1.00000e-09 2.12000e-01

$2.59318 \mathrm{e}+002.59318 \mathrm{e}+00$ 2.59318e-01 1.00000e-09 2.12000e-01

$2.59318 \mathrm{e}+002.59318 \mathrm{e}+002.59318 \mathrm{e}-01$ 1.00000e-09 2.12000e-01

$2.59318 \mathrm{e}+002.59318 \mathrm{e}+002.59318 \mathrm{e}-01$ 1.00000e-09 2.12000e-01

$1.00000 \mathrm{e}-05$ 1.00000e-05 1.00000e-06 1.00000e-09 1.00000e-01

$1.00000 \mathrm{e}+001.00000 \mathrm{e}+001.00000 \mathrm{e}-011.00000 \mathrm{e}-09$ 1.00000e-01

Element: 13009 \# of layers: 5

$\mathrm{Kx} \mathrm{Ky} \mathrm{Kz}$ Ss Por

$2.59318 \mathrm{e}+002.59318 \mathrm{e}+00$ 2.59318e-01 1.00000e-09 2.12000e-01

$2.59318 \mathrm{e}+002.59318 \mathrm{e}+002.59318 \mathrm{e}-01$ 1.00000e-09 2.12000e-01

$2.59318 \mathrm{e}+00$ 2.59318e+00 2.59318e-01 1.00000e-09 2.12000e-01

$1.00000 \mathrm{e}-05$ 1.00000e-05 1.00000e-06 1.00000e-09 1.00000e-01

$1.00000 \mathrm{e}+001.00000 \mathrm{e}+001.00000 \mathrm{e}-01$ 1.00000e-09 1.00000e-01

Element: 13010 \# of layers: 5 
$\mathrm{Kx} \mathrm{Ky} \mathrm{Kz}$ Ss Por

$2.59318 \mathrm{e}+00$ 2.59318e+00 2.59318e-01 1.00000e-09 2.12000e-01

$2.59318 \mathrm{e}+002.59318 \mathrm{e}+002.59318 \mathrm{e}-01$ 1.00000e-09 2.12000e-01

$2.59318 \mathrm{e}+002.59318 \mathrm{e}+002.59318 \mathrm{e}-01$ 1.00000e-09 2.12000e-01

$1.00000 \mathrm{e}-05$ 1.00000e-05 1.00000e-06 1.00000e-09 1.00000e-01

$1.00000 \mathrm{e}+001.00000 \mathrm{e}+001.00000 \mathrm{e}-01$ 1.00000e-09 1.00000e-01

Element: 13011 \# of layers: 5

Kx Ky Kz Ss Por

2.59318e+00 2.59318e+00 2.59318e-01 1.00000e-09 2.12000e-01

$2.59318 \mathrm{e}+002.59318 \mathrm{e}+00$ 2.59318e-01 1.00000e-09 2.12000e-01

$2.59318 \mathrm{e}+002.59318 \mathrm{e}+002.59318 \mathrm{e}-01$ 1.00000e-09 2.12000e-01

$1.00000 \mathrm{e}-05$ 1.00000e-05 1.00000e-06 1.00000e-09 1.00000e-01

$1.00000 \mathrm{e}+001.00000 \mathrm{e}+00$ 1.00000e-01 1.00000e-09 1.00000e-01

Element: 13012 \# of layers: 5

Kx Ky Kz Ss Por

4.77753e+00 4.77753e+00 4.77753e-01 1.00000e-09 2.12000e-01

4.77753e+00 4.77753e+00 4.77753e-01 1.00000e-09 2.12000e-01

4.77753e+00 4.77753e+00 4.77753e-01 1.00000e-09 2.12000e-01

$1.00000 \mathrm{e}-051.00000 \mathrm{e}-051.00000 \mathrm{e}-061.00000 \mathrm{e}-091.00000 \mathrm{e}-01$

$1.00000 \mathrm{e}+001.00000 \mathrm{e}+001.00000 \mathrm{e}-01$ 1.00000e-09 1.00000e-01

Element: 13013 \# of layers: 5

$\mathrm{Kx} \mathrm{Ky} \mathrm{Kz}$ Ss Por

4.77753e+00 4.77753e+00 4.77753e-01 1.00000e-09 2.12000e-01

4.77753e+00 4.77753e+00 4.77753e-01 1.00000e-09 2.12000e-01

4.77753e+00 4.77753e+00 4.77753e-01 1.00000e-09 2.12000e-01

$1.00000 \mathrm{e}-05$ 1.00000e-05 1.00000e-06 1.00000e-09 1.00000e-01

$1.00000 \mathrm{e}+001.00000 \mathrm{e}+001.00000 \mathrm{e}-011.00000 \mathrm{e}-091.00000 \mathrm{e}-01$

Element: 13014 \# of layers: 5

Kx Ky Kz Ss Por

2.59318e+00 2.59318e+00 2.59318e-01 1.00000e-09 2.12000e-01

$2.59318 \mathrm{e}+002.59318 \mathrm{e}+00$ 2.59318e-01 1.00000e-09 2.12000e-01

$2.59318 \mathrm{e}+00$ 2.59318e+00 2.59318e-01 1.00000e-09 2.12000e-01

$1.00000 \mathrm{e}-05$ 1.00000e-05 1.00000e-06 1.00000e-09 1.00000e-01

$1.00000 \mathrm{e}+001.00000 \mathrm{e}+001.00000 \mathrm{e}-01$ 1.00000e-09 1.00000e-01

Element: 13015 \# of layers: 5

Kx Ky Kz Ss Por

$2.59318 \mathrm{e}+002.59318 \mathrm{e}+002.59318 \mathrm{e}-01$ 1.00000e-09 2.12000e-01

$2.59318 \mathrm{e}+002.59318 \mathrm{e}+002.59318 \mathrm{e}-01$ 1.00000e-09 2.12000e-01

$2.59318 \mathrm{e}+002.59318 \mathrm{e}+00$ 2.59318e-01 1.00000e-09 2.12000e-01

$1.00000 \mathrm{e}-05$ 1.00000e-05 1.00000e-06 1.00000e-09 1.00000e-01

$1.00000 \mathrm{e}+001.00000 \mathrm{e}+001.00000 \mathrm{e}-011.00000 \mathrm{e}-091.00000 \mathrm{e}-01$

Element: 13016 \# of layers: 5

$\mathrm{Kx} \mathrm{Ky} \mathrm{Kz}$ Ss Por

6.29834e+00 6.29834e+00 6.29834e-01 1.00000e-09 2.12000e-01

$6.29834 \mathrm{e}+006.29834 \mathrm{e}+006.29834 \mathrm{e}-01$ 1.00000e-09 2.12000e-01

$6.29834 \mathrm{e}+006.29834 \mathrm{e}+006.29834 \mathrm{e}-01$ 1.00000e-09 2.12000e-01 
$1.00000 \mathrm{e}-05$ 1.00000e-05 1.00000e-06 1.00000e-09 1.00000e-01 $1.00000 \mathrm{e}+001.00000 \mathrm{e}+001.00000 \mathrm{e}-01$ 1.00000e-09 1.00000e-01 Element: 13017 \# of layers: 5

Kx Ky Kz Ss Por

6.29834e+00 6.29834e+00 6.29834e-01 1.00000e-09 2.12000e-01 $6.29834 \mathrm{e}+006.29834 \mathrm{e}+00$ 6.29834e-01 1.00000e-09 2.12000e-01 $6.29834 \mathrm{e}+006.29834 \mathrm{e}+00$ 6.29834e-01 1.00000e-09 2.12000e-01 $1.00000 \mathrm{e}-05$ 1.00000e-05 1.00000e-06 1.00000e-09 1.00000e-01 $1.00000 \mathrm{e}+001.00000 \mathrm{e}+001.00000 \mathrm{e}-011.00000 \mathrm{e}-091.00000 \mathrm{e}-01$ Element: 13018 \# of layers: 5

$\mathrm{Kx} \mathrm{Ky} \mathrm{Kz}$ Ss Por

6.29834e+00 6.29834e+00 6.29834e-01 1.00000e-09 2.12000e-01 $6.29834 \mathrm{e}+006.29834 \mathrm{e}+006.29834 \mathrm{e}-01$ 1.00000e-09 2.12000e-01 $6.29834 \mathrm{e}+006.29834 \mathrm{e}+006.29834 \mathrm{e}-01$ 1.00000e-09 2.12000e-01 $1.00000 \mathrm{e}-05$ 1.00000e-05 1.00000e-06 1.00000e-09 1.00000e-01 $1.00000 \mathrm{e}+001.00000 \mathrm{e}+001.00000 \mathrm{e}-011.00000 \mathrm{e}-091.00000 \mathrm{e}-01$ Element: 13019 \# of layers: 5

Kx Ky Kz Ss Por

$1.17459 \mathrm{e}+01$ 1.17459e+01 1.17459e+00 1.00000e-09 2.12000e-01

$1.17459 \mathrm{e}+01$ 1.17459e+01 1.17459e+00 1.00000e-09 2.12000e-01

$1.17459 \mathrm{e}+01$ 1.17459e+01 1.17459e+00 1.00000e-09 2.12000e-01 $1.00000 \mathrm{e}-05$ 1.00000e-05 1.00000e-06 1.00000e-09 1.00000e-01 $1.00000 \mathrm{e}+001.00000 \mathrm{e}+001.00000 \mathrm{e}-011.00000 \mathrm{e}-091.00000 \mathrm{e}-01$ Element: 13020 \# of layers: 5

Kx Ky Kz Ss Por

$1.17459 \mathrm{e}+01$ 1.17459e+01 1.17459e+00 1.00000e-09 2.12000e-01 $1.17459 \mathrm{e}+01$ 1.17459e+01 1.17459e+00 1.00000e-09 2.12000e-01 $1.17459 \mathrm{e}+011.17459 \mathrm{e}+01$ 1.17459e+00 1.00000e-09 2.12000e-01 1.00000e-05 1.00000e-05 1.00000e-06 1.00000e-09 1.00000e-01 $1.00000 \mathrm{e}+001.00000 \mathrm{e}+001.00000 \mathrm{e}-011.00000 \mathrm{e}-091.00000 \mathrm{e}-01$ Element: 13021 \# of layers: 5

$\mathrm{Kx} \mathrm{Ky} \mathrm{Kz}$ Ss Por

4.77753e+00 4.77753e+00 4.77753e-01 1.00000e-09 2.12000e-01 4.77753e+00 4.77753e+00 4.77753e-01 1.00000e-09 2.12000e-01 4.77753e+00 4.77753e+00 4.77753e-01 1.00000e-09 2.12000e-01 1.00000e-05 1.00000e-05 1.00000e-06 1.00000e-09 1.00000e-01 $1.00000 \mathrm{e}+001.00000 \mathrm{e}+001.00000 \mathrm{e}-011.00000 \mathrm{e}-091.00000 \mathrm{e}-01$ Element: 13022 \# of layers: 5

$\mathrm{Kx} \mathrm{Ky} \mathrm{Kz}$ Ss Por

$2.59318 \mathrm{e}+002.59318 \mathrm{e}+00$ 2.59318e-01 1.00000e-09 2.12000e-01 $2.59318 \mathrm{e}+002.59318 \mathrm{e}+00$ 2.59318e-01 1.00000e-09 2.12000e-01 $2.59318 \mathrm{e}+002.59318 \mathrm{e}+002.59318 \mathrm{e}-01$ 1.00000e-09 2.12000e-01 $1.00000 \mathrm{e}-05$ 1.00000e-05 1.00000e-06 1.00000e-09 1.00000e-01 $1.00000 \mathrm{e}+001.00000 \mathrm{e}+001.00000 \mathrm{e}-011.00000 \mathrm{e}-091.00000 \mathrm{e}-01$ Element: 13023 \# of layers: 5

Kx Ky Kz Ss Por 
$6.29834 \mathrm{e}+006.29834 \mathrm{e}+00$ 6.29834e-01 1.00000e-09 2.12000e-01 $6.29834 \mathrm{e}+006.29834 \mathrm{e}+00$ 6.29834e-01 1.00000e-09 2.12000e-01 $6.29834 \mathrm{e}+006.29834 \mathrm{e}+00$ 6.29834e-01 1.00000e-09 2.12000e-01 $1.00000 \mathrm{e}-05$ 1.00000e-05 1.00000e-06 1.00000e-09 1.00000e-01 $1.00000 \mathrm{e}+001.00000 \mathrm{e}+001.00000 \mathrm{e}-011.00000 \mathrm{e}-091.00000 \mathrm{e}-01$ Element: 13024 \# of layers: 4

Kx Ky Kz Ss Por

$1.48976 \mathrm{e}+011.48976 \mathrm{e}+011.48976 \mathrm{e}+00$ 1.00000e-09 2.12000e-01 $1.48976 \mathrm{e}+011.48976 \mathrm{e}+011.48976 \mathrm{e}+00$ 1.00000e-09 2.12000e-01 $1.00000 \mathrm{e}-051.00000 \mathrm{e}-05$ 1.00000e-06 1.00000e-09 1.00000e-01 $1.00000 \mathrm{e}+001.00000 \mathrm{e}+001.00000 \mathrm{e}-011.00000 \mathrm{e}-091.00000 \mathrm{e}-01$ Element: 13025 \# of layers: 4

Kx Ky Kz Ss Por

$1.48976 \mathrm{e}+011.48976 \mathrm{e}+011.48976 \mathrm{e}+00$ 1.00000e-09 2.12000e-01 $1.48976 \mathrm{e}+011.48976 \mathrm{e}+011.48976 \mathrm{e}+001.00000 \mathrm{e}-092.12000 \mathrm{e}-01$ $1.00000 \mathrm{e}-05$ 1.00000e-05 1.00000e-06 1.00000e-09 1.00000e-01 $1.00000 \mathrm{e}+001.00000 \mathrm{e}+001.00000 \mathrm{e}-011.00000 \mathrm{e}-091.00000 \mathrm{e}-01$ Element: 13026 \# of layers: 4

Kx Ky Kz Ss Por

$1.48976 \mathrm{e}+011.48976 \mathrm{e}+011.48976 \mathrm{e}+00$ 1.00000e-09 2.12000e-01 $1.48976 \mathrm{e}+011.48976 \mathrm{e}+011.48976 \mathrm{e}+001.00000 \mathrm{e}-092.12000 \mathrm{e}-01$ $1.00000 \mathrm{e}-05$ 1.00000e-05 1.00000e-06 1.00000e-09 1.00000e-01 $1.00000 \mathrm{e}+001.00000 \mathrm{e}+001.00000 \mathrm{e}-011.00000 \mathrm{e}-091.00000 \mathrm{e}-01$ Element: 13027 \# of layers: 4

Kx Ky Kz Ss Por $1.48976 \mathrm{e}+011.48976 \mathrm{e}+011.48976 \mathrm{e}+00$ 1.00000e-09 2.12000e-01 $1.48976 \mathrm{e}+011.48976 \mathrm{e}+011.48976 \mathrm{e}+001.00000 \mathrm{e}-092.12000 \mathrm{e}-01$ $1.00000 \mathrm{e}-051.00000 \mathrm{e}-05$ 1.00000e-06 1.00000e-09 1.00000e-01 $1.00000 \mathrm{e}+001.00000 \mathrm{e}+001.00000 \mathrm{e}-011.00000 \mathrm{e}-091.00000 \mathrm{e}-01$ Element: 13028 \# of layers: 4

Kx Ky Kz Ss Por

$1.48976 \mathrm{e}+011.48976 \mathrm{e}+011.48976 \mathrm{e}+00$ 1.00000e-09 2.12000e-01 $1.48976 \mathrm{e}+011.48976 \mathrm{e}+011.48976 \mathrm{e}+001.00000 \mathrm{e}-092.12000 \mathrm{e}-01$ $1.00000 \mathrm{e}-05$ 1.00000e-05 1.00000e-06 1.00000e-09 1.00000e-01 $1.00000 \mathrm{e}+001.00000 \mathrm{e}+001.00000 \mathrm{e}-011.00000 \mathrm{e}-091.00000 \mathrm{e}-01$ Element: 13029 \# of layers: 4

Kx Ky Kz Ss Por $1.48976 \mathrm{e}+011.48976 \mathrm{e}+011.48976 \mathrm{e}+00$ 1.00000e-09 2.12000e-01 $1.48976 \mathrm{e}+011.48976 \mathrm{e}+011.48976 \mathrm{e}+001.00000 \mathrm{e}-092.12000 \mathrm{e}-01$ $1.00000 \mathrm{e}-05$ 1.00000e-05 1.00000e-06 1.00000e-09 1.00000e-01 $1.00000 \mathrm{e}+001.00000 \mathrm{e}+001.00000 \mathrm{e}-011.00000 \mathrm{e}-091.00000 \mathrm{e}-01$ Element: 13030 \# of layers: 4

Kx Ky Kz Ss Por $1.48976 \mathrm{e}+011.48976 \mathrm{e}+011.48976 \mathrm{e}+00$ 1.00000e-09 2.12000e-01 $1.48976 \mathrm{e}+011.48976 \mathrm{e}+011.48976 \mathrm{e}+001.00000 \mathrm{e}-092.12000 \mathrm{e}-01$ $1.00000 \mathrm{e}-05$ 1.00000e-05 1.00000e-06 1.00000e-09 1.00000e-01 
$1.00000 \mathrm{e}+001.00000 \mathrm{e}+00$ 1.00000e-01 1.00000e-09 1.00000e-01

Element: 13031 \# of layers: 4

Kx Ky Kz Ss Por

$1.48976 \mathrm{e}+01$ 1.48976e+01 1.48976e+00 1.00000e-09 2.12000e-01

$1.48976 \mathrm{e}+011.48976 \mathrm{e}+01$ 1.48976e+00 1.00000e-09 2.12000e-01

$1.00000 \mathrm{e}-05$ 1.00000e-05 1.00000e-06 1.00000e-09 1.00000e-01

$1.00000 \mathrm{e}+001.00000 \mathrm{e}+001.00000 \mathrm{e}-01$ 1.00000e-09 1.00000e-01

Element: 13032 \# of layers: 4

$\mathrm{Kx} \mathrm{Ky} \mathrm{Kz}$ Ss Por

1.48976e+01 1.48976e+01 1.48976e+00 1.00000e-09 2.12000e-01

$1.48976 \mathrm{e}+01$ 1.48976e+01 1.48976e+00 1.00000e-09 2.12000e-01

$1.00000 \mathrm{e}-05$ 1.00000e-05 1.00000e-06 1.00000e-09 1.00000e-01

$1.00000 \mathrm{e}+001.00000 \mathrm{e}+001.00000 \mathrm{e}-01$ 1.00000e-09 1.00000e-01

Element: 13033 \# of layers: 4

$\mathrm{Kx} \mathrm{Ky} \mathrm{Kz}$ Ss Por

$1.48976 \mathrm{e}+01$ 1.48976e+01 1.48976e+00 1.00000e-09 2.12000e-01

$1.48976 \mathrm{e}+011.48976 \mathrm{e}+011.48976 \mathrm{e}+001.00000 \mathrm{e}-092.12000 \mathrm{e}-01$

$1.00000 \mathrm{e}-051.00000 \mathrm{e}-051.00000 \mathrm{e}-061.00000 \mathrm{e}-091.00000 \mathrm{e}-01$

$1.00000 \mathrm{e}+001.00000 \mathrm{e}+001.00000 \mathrm{e}-01$ 1.00000e-09 1.00000e-01

Element: 13034 \# of layers: 4

$\mathrm{Kx} \mathrm{Ky} \mathrm{Kz}$ Ss Por

$1.94841 \mathrm{e}+011.94841 \mathrm{e}+01$ 1.94841e+00 1.00000e-09 2.12000e-01

$1.94841 \mathrm{e}+011.94841 \mathrm{e}+01$ 1.94841e+00 1.00000e-09 2.12000e-01

$1.00000 \mathrm{e}-05$ 1.00000e-05 1.00000e-06 1.00000e-09 1.00000e-01

$1.00000 \mathrm{e}+001.00000 \mathrm{e}+001.00000 \mathrm{e}-011.00000 \mathrm{e}-091.00000 \mathrm{e}-01$

Element: 13035 \# of layers: 4

$\mathrm{Kx} \mathrm{Ky} \mathrm{Kz}$ Ss Por

$1.94841 \mathrm{e}+01$ 1.94841e+01 1.94841e+00 1.00000e-09 2.12000e-01

$1.94841 \mathrm{e}+011.94841 \mathrm{e}+011.94841 \mathrm{e}+001.00000 \mathrm{e}-092.12000 \mathrm{e}-01$

$1.00000 \mathrm{e}-05$ 1.00000e-05 1.00000e-06 1.00000e-09 1.00000e-01

$1.00000 \mathrm{e}+001.00000 \mathrm{e}+001.00000 \mathrm{e}-011.00000 \mathrm{e}-091.00000 \mathrm{e}-01$

Element: 13036 \# of layers: 4

Kx Ky Kz Ss Por

$1.94841 \mathrm{e}+01$ 1.94841e+01 1.94841e+00 1.00000e-09 2.12000e-01

$1.94841 \mathrm{e}+011.94841 \mathrm{e}+01$ 1.94841e+00 1.00000e-09 2.12000e-01

$1.00000 \mathrm{e}-05$ 1.00000e-05 1.00000e-06 1.00000e-09 1.00000e-01

$1.00000 \mathrm{e}+001.00000 \mathrm{e}+001.00000 \mathrm{e}-011.00000 \mathrm{e}-091.00000 \mathrm{e}-01$

Element: 13037 \# of layers: 4

$\mathrm{Kx} \mathrm{Ky} \mathrm{Kz}$ Ss Por

$1.94841 \mathrm{e}+011.94841 \mathrm{e}+01$ 1.94841e+00 1.00000e-09 2.12000e-01

$1.94841 \mathrm{e}+011.94841 \mathrm{e}+01$ 1.94841e+00 1.00000e-09 2.12000e-01

$1.00000 \mathrm{e}-05$ 1.00000e-05 1.00000e-06 1.00000e-09 1.00000e-01

$1.00000 \mathrm{e}+001.00000 \mathrm{e}+001.00000 \mathrm{e}-011.00000 \mathrm{e}-091.00000 \mathrm{e}-01$

Element: 13038 \# of layers: 4

$\mathrm{Kx} \mathrm{Ky} \mathrm{Kz}$ Ss Por

$1.94841 \mathrm{e}+011.94841 \mathrm{e}+011.94841 \mathrm{e}+001.00000 \mathrm{e}-092.12000 \mathrm{e}-01$ 
$1.94841 \mathrm{e}+01$ 1.94841e+01 1.94841e+00 1.00000e-09 2.12000e-01 $1.00000 \mathrm{e}-05$ 1.00000e-05 1.00000e-06 1.00000e-09 1.00000e-01

$1.00000 \mathrm{e}+001.00000 \mathrm{e}+001.00000 \mathrm{e}-01$ 1.00000e-09 1.00000e-01

Element: 13039 \# of layers: 4

$\mathrm{Kx} \mathrm{Ky} \mathrm{Kz}$ Ss Por

$1.48976 \mathrm{e}+01$ 1.48976e+01 1.48976e+00 1.00000e-09 2.12000e-01

$1.48976 \mathrm{e}+01$ 1.48976e+01 1.48976e+00 1.00000e-09 2.12000e-01

$1.00000 \mathrm{e}-05$ 1.00000e-05 1.00000e-06 1.00000e-09 1.00000e-01

$1.00000 \mathrm{e}+001.00000 \mathrm{e}+001.00000 \mathrm{e}-011.00000 \mathrm{e}-091.00000 \mathrm{e}-01$

Element: 13040 \# of layers: 4

$\mathrm{Kx} \mathrm{Ky} \mathrm{Kz}$ Ss Por

$1.48976 \mathrm{e}+01$ 1.48976e+01 1.48976e+00 1.00000e-09 2.12000e-01

$1.48976 \mathrm{e}+01$ 1.48976e+01 1.48976e+00 1.00000e-09 2.12000e-01

$1.00000 \mathrm{e}-05$ 1.00000e-05 1.00000e-06 1.00000e-09 1.00000e-01

$1.00000 \mathrm{e}+001.00000 \mathrm{e}+001.00000 \mathrm{e}-01$ 1.00000e-09 1.00000e-01

Element: 13041 \# of layers: 4

$\mathrm{Kx} \mathrm{Ky} \mathrm{Kz}$ Ss Por

$1.94841 \mathrm{e}+01$ 1.94841e+01 1.94841e+00 1.00000e-09 2.12000e-01

$1.94841 \mathrm{e}+01$ 1.94841e+01 1.94841e+00 1.00000e-09 2.12000e-01

$1.00000 \mathrm{e}-05$ 1.00000e-05 1.00000e-06 1.00000e-09 1.00000e-01

$1.00000 \mathrm{e}+001.00000 \mathrm{e}+001.00000 \mathrm{e}-011.00000 \mathrm{e}-091.00000 \mathrm{e}-01$

Element: 13042 \# of layers: 4

$\mathrm{Kx} \mathrm{Ky} \mathrm{Kz}$ Ss Por

$1.94841 \mathrm{e}+01$ 1.94841e+01 1.94841e+00 1.00000e-09 2.12000e-01

$1.94841 \mathrm{e}+011.94841 \mathrm{e}+011.94841 \mathrm{e}+001.00000 \mathrm{e}-092.12000 \mathrm{e}-01$

$1.00000 \mathrm{e}-05$ 1.00000e-05 1.00000e-06 1.00000e-09 1.00000e-01

$1.00000 \mathrm{e}+001.00000 \mathrm{e}+001.00000 \mathrm{e}-011.00000 \mathrm{e}-09$ 1.00000e-01

Element: 13043 \# of layers: 4

Kx Ky Kz Ss Por

$1.94841 \mathrm{e}+01$ 1.94841e+01 1.94841e+00 1.00000e-09 2.12000e-01

$1.94841 \mathrm{e}+011.94841 \mathrm{e}+011.94841 \mathrm{e}+001.00000 \mathrm{e}-092.12000 \mathrm{e}-01$

$1.00000 \mathrm{e}-05$ 1.00000e-05 1.00000e-06 1.00000e-09 1.00000e-01

$1.00000 \mathrm{e}+001.00000 \mathrm{e}+001.00000 \mathrm{e}-011.00000 \mathrm{e}-091.00000 \mathrm{e}-01$

Element: 13044 \# of layers: 5

$\mathrm{Kx} \mathrm{Ky} \mathrm{Kz}$ Ss Por

$1.94841 \mathrm{e}+011.94841 \mathrm{e}+01$ 1.94841e+00 1.00000e-09 2.12000e-01

$1.94841 \mathrm{e}+011.94841 \mathrm{e}+011.94841 \mathrm{e}+001.00000 \mathrm{e}-092.12000 \mathrm{e}-01$

$1.00000 \mathrm{e}-05$ 1.00000e-05 1.00000e-06 1.00000e-09 1.00000e-01

$1.00000 \mathrm{e}+001.00000 \mathrm{e}+001.00000 \mathrm{e}-011.00000 \mathrm{e}-091.00000 \mathrm{e}-01$

1.00000e-06 1.00000e-06 1.00000e-06 1.00000e-09 5.00000e-02

Element: 13045 \# of layers: 5

$\mathrm{Kx} \mathrm{Ky} \mathrm{Kz}$ Ss Por

$1.94841 \mathrm{e}+011.94841 \mathrm{e}+01$ 1.94841e+00 1.00000e-09 2.12000e-01

$1.94841 \mathrm{e}+01$ 1.94841e+01 1.94841e+00 1.00000e-09 2.12000e-01

$1.00000 \mathrm{e}-05$ 1.00000e-05 1.00000e-06 1.00000e-09 1.00000e-01

$1.00000 \mathrm{e}+001.00000 \mathrm{e}+001.00000 \mathrm{e}-011.00000 \mathrm{e}-091.00000 \mathrm{e}-01$ 
1.00000e-06 1.00000e-06 1.00000e-06 1.00000e-09 5.00000e-02

Element: 13046 \# of layers: 5

Kx Ky Kz Ss Por

$1.94841 \mathrm{e}+01$ 1.94841e+01 1.94841e+00 1.00000e-09 2.12000e-01

$1.94841 \mathrm{e}+01$ 1.94841e+01 1.94841e+00 1.00000e-09 2.12000e-01

$1.00000 \mathrm{e}-05$ 1.00000e-05 1.00000e-06 1.00000e-09 1.00000e-01

$1.00000 \mathrm{e}+001.00000 \mathrm{e}+001.00000 \mathrm{e}-011.00000 \mathrm{e}-091.00000 \mathrm{e}-01$

1.00000e-06 1.00000e-06 1.00000e-06 1.00000e-09 5.00000e-02

Element: 13047 \# of layers: 5

$\mathrm{Kx} \mathrm{Ky} \mathrm{Kz}$ Ss Por

$1.94841 \mathrm{e}+011.94841 \mathrm{e}+011.94841 \mathrm{e}+00$ 1.00000e-09 2.12000e-01

$1.94841 \mathrm{e}+011.94841 \mathrm{e}+011.94841 \mathrm{e}+001.00000 \mathrm{e}-092.12000 \mathrm{e}-01$

$1.00000 \mathrm{e}-051.00000 \mathrm{e}-05$ 1.00000e-06 1.00000e-09 1.00000e-01

$1.00000 \mathrm{e}+001.00000 \mathrm{e}+001.00000 \mathrm{e}-011.00000 \mathrm{e}-091.00000 \mathrm{e}-01$

1.00000e-06 1.00000e-06 1.00000e-06 1.00000e-09 5.00000e-02

Element: 13048 \# of layers: 5

$\mathrm{Kx} \mathrm{Ky} \mathrm{Kz}$ Ss Por

$1.94841 \mathrm{e}+01$ 1.94841e+01 1.94841e+00 1.00000e-09 2.12000e-01

$1.94841 \mathrm{e}+01$ 1.94841e+01 1.94841e+00 1.00000e-09 2.12000e-01

$1.00000 \mathrm{e}-05$ 1.00000e-05 1.00000e-06 1.00000e-09 1.00000e-01

$1.00000 \mathrm{e}+001.00000 \mathrm{e}+001.00000 \mathrm{e}-011.00000 \mathrm{e}-091.00000 \mathrm{e}-01$

1.00000e-06 1.00000e-06 1.00000e-06 1.00000e-09 5.00000e-02

Element: 13049 \# of layers: 4

Kx Ky Kz Ss Por

$1.94841 \mathrm{e}+01$ 1.94841e+01 1.94841e+00 1.00000e-09 2.12000e-01

$1.94841 \mathrm{e}+011.94841 \mathrm{e}+01$ 1.94841e+00 1.00000e-09 2.12000e-01

$1.00000 \mathrm{e}-05$ 1.00000e-05 1.00000e-06 1.00000e-09 1.00000e-01

$1.00000 \mathrm{e}+001.00000 \mathrm{e}+001.00000 \mathrm{e}-01$ 1.00000e-09 1.00000e-01

Element: 13050 \# of layers: 4

$\mathrm{Kx} \mathrm{Ky} \mathrm{Kz}$ Ss Por

$1.94841 \mathrm{e}+01$ 1.94841e+01 1.94841e+00 1.00000e-09 2.12000e-01

$1.94841 \mathrm{e}+011.94841 \mathrm{e}+011.94841 \mathrm{e}+00$ 1.00000e-09 2.12000e-01

$1.00000 \mathrm{e}-05$ 1.00000e-05 1.00000e-06 1.00000e-09 1.00000e-01

$1.00000 \mathrm{e}+001.00000 \mathrm{e}+001.00000 \mathrm{e}-011.00000 \mathrm{e}-091.00000 \mathrm{e}-01$

Element: 13051 \# of layers: 5

Kx Ky Kz Ss Por

$1.94841 \mathrm{e}+01$ 1.94841e+01 1.94841e+00 1.00000e-09 2.12000e-01

$1.94841 \mathrm{e}+011.94841 \mathrm{e}+011.94841 \mathrm{e}+001.00000 \mathrm{e}-092.12000 \mathrm{e}-01$

$1.00000 \mathrm{e}-051.00000 \mathrm{e}-051.00000 \mathrm{e}-061.00000 \mathrm{e}-091.00000 \mathrm{e}-01$

$1.00000 \mathrm{e}+001.00000 \mathrm{e}+001.00000 \mathrm{e}-011.00000 \mathrm{e}-091.00000 \mathrm{e}-01$

1.00000e-06 1.00000e-06 1.00000e-06 1.00000e-09 5.00000e-02

Element: 13052 \# of layers: 5

$\mathrm{Kx} \mathrm{Ky} \mathrm{Kz}$ Ss Por

1.94841e+01 1.94841e+01 1.94841e+00 1.00000e-09 2.12000e-01

$1.94841 \mathrm{e}+011.94841 \mathrm{e}+01$ 1.94841e+00 1.00000e-09 2.12000e-01

$1.00000 \mathrm{e}-05$ 1.00000e-05 1.00000e-06 1.00000e-09 1.00000e-01 
$1.00000 \mathrm{e}+001.00000 \mathrm{e}+001.00000 \mathrm{e}-011.00000 \mathrm{e}-091.00000 \mathrm{e}-01$ $1.00000 \mathrm{e}-06$ 1.00000e-06 1.00000e-06 1.00000e-09 5.00000e-02

Element: 13053 \# of layers: 6

Kx Ky Kz Ss Por

4.12276e+02 4.12276e+02 4.12276e+01 1.00000e-09 2.12000e-01 4.12276e+02 4.12276e+02 4.12276e+01 1.00000e-09 2.12000e-01

$4.12276 \mathrm{e}+02$ 4.12276e+02 4.12276e+01 1.00000e-09 2.12000e-01 $1.00000 \mathrm{e}-05$ 1.00000e-05 1.00000e-06 1.00000e-09 1.00000e-01 $1.00000 \mathrm{e}+001.00000 \mathrm{e}+001.00000 \mathrm{e}-011.00000 \mathrm{e}-091.00000 \mathrm{e}-01$ 1.00000e-06 1.00000e-06 1.00000e-06 1.00000e-09 5.00000e-02 Element: 13054 \# of layers: 6

Kx Ky Kz Ss Por

4.12276e+02 4.12276e+02 4.12276e+01 1.00000e-09 2.12000e-01 4.12276e+02 4.12276e+02 4.12276e+01 1.00000e-09 2.12000e-01 4.12276e+02 4.12276e+02 4.12276e+01 1.00000e-09 2.12000e-01 $1.00000 \mathrm{e}-05$ 1.00000e-05 1.00000e-06 1.00000e-09 1.00000e-01 $1.00000 \mathrm{e}+001.00000 \mathrm{e}+001.00000 \mathrm{e}-011.00000 \mathrm{e}-091.00000 \mathrm{e}-01$ 1.00000e-06 1.00000e-06 1.00000e-06 1.00000e-09 5.00000e-02 Element: 13055 \# of layers: 6

$\mathrm{Kx} \mathrm{Ky} \mathrm{Kz}$ Ss Por

4.12276e+02 4.12276e+02 4.12276e+01 1.00000e-09 2.12000e-01 4.12276e+02 4.12276e+02 4.12276e+01 1.00000e-09 2.12000e-01 4.12276e+02 4.12276e+02 4.12276e+01 1.00000e-09 2.12000e-01 $1.00000 \mathrm{e}-051.00000 \mathrm{e}-05$ 1.00000e-06 1.00000e-09 1.00000e-01 $1.00000 \mathrm{e}+001.00000 \mathrm{e}+001.00000 \mathrm{e}-011.00000 \mathrm{e}-091.00000 \mathrm{e}-01$ 1.00000e-06 1.00000e-06 1.00000e-06 1.00000e-09 5.00000e-02

Element: 13056 \# of layers: 5

$\mathrm{Kx} \mathrm{Ky} \mathrm{Kz}$ Ss Por

$1.94841 \mathrm{e}+01$ 1.94841e+01 1.94841e+00 1.00000e-09 2.12000e-01 $1.94841 \mathrm{e}+011.94841 \mathrm{e}+011.94841 \mathrm{e}+001.00000 \mathrm{e}-092.12000 \mathrm{e}-01$ 1.00000e-05 1.00000e-05 1.00000e-06 1.00000e-09 1.00000e-01 $1.00000 \mathrm{e}+001.00000 \mathrm{e}+001.00000 \mathrm{e}-011.00000 \mathrm{e}-091.00000 \mathrm{e}-01$ 1.00000e-06 1.00000e-06 1.00000e-06 1.00000e-09 5.00000e-02 Element: 13057 \# of layers: 5

$\mathrm{Kx} \mathrm{Ky} \mathrm{Kz}$ Ss Por

$1.94841 \mathrm{e}+011.94841 \mathrm{e}+01$ 1.94841e+00 1.00000e-09 2.12000e-01 $1.94841 \mathrm{e}+011.94841 \mathrm{e}+011.94841 \mathrm{e}+001.00000 \mathrm{e}-092.12000 \mathrm{e}-01$ $1.00000 \mathrm{e}-05$ 1.00000e-05 1.00000e-06 1.00000e-09 1.00000e-01 $1.00000 \mathrm{e}+001.00000 \mathrm{e}+001.00000 \mathrm{e}-011.00000 \mathrm{e}-091.00000 \mathrm{e}-01$ 1.00000e-06 1.00000e-06 1.00000e-06 1.00000e-09 5.00000e-02 Element: 13058 \# of layers: 5

$\mathrm{Kx} \mathrm{Ky} \mathrm{Kz}$ Ss Por $1.94841 \mathrm{e}+011.94841 \mathrm{e}+01$ 1.94841e+00 1.00000e-09 2.12000e-01 $1.94841 \mathrm{e}+01$ 1.94841e+01 1.94841e+00 1.00000e-09 2.12000e-01 $1.00000 \mathrm{e}-051.00000 \mathrm{e}-05$ 1.00000e-06 1.00000e-09 1.00000e-01 $1.00000 \mathrm{e}+001.00000 \mathrm{e}+001.00000 \mathrm{e}-011.00000 \mathrm{e}-091.00000 \mathrm{e}-01$ 
1.00000e-06 1.00000e-06 1.00000e-06 1.00000e-09 5.00000e-02

Element: 13059 \# of layers: 5

Kx Ky Kz Ss Por

$1.94841 \mathrm{e}+01$ 1.94841e+01 1.94841e+00 1.00000e-09 2.12000e-01

$1.94841 \mathrm{e}+011.94841 \mathrm{e}+01$ 1.94841e+00 1.00000e-09 2.12000e-01

$1.00000 \mathrm{e}-05$ 1.00000e-05 1.00000e-06 1.00000e-09 1.00000e-01

$1.00000 \mathrm{e}+001.00000 \mathrm{e}+001.00000 \mathrm{e}-011.00000 \mathrm{e}-091.00000 \mathrm{e}-01$

1.00000e-06 1.00000e-06 1.00000e-06 1.00000e-09 5.00000e-02

Element: 13060 \# of layers: 5

$\mathrm{Kx} \mathrm{Ky} \mathrm{Kz}$ Ss Por

4.12276e+02 4.12276e+02 4.12276e+01 1.00000e-09 2.12000e-01

$4.12276 \mathrm{e}+02$ 4.12276e+02 4.12276e+01 1.00000e-09 2.12000e-01

$1.00000 \mathrm{e}-05$ 1.00000e-05 1.00000e-06 1.00000e-09 1.00000e-01

$1.00000 \mathrm{e}+001.00000 \mathrm{e}+001.00000 \mathrm{e}-011.00000 \mathrm{e}-091.00000 \mathrm{e}-01$

1.00000e-06 1.00000e-06 1.00000e-06 1.00000e-09 5.00000e-02

Element: 13061 \# of layers: 4

$\mathrm{Kx} \mathrm{Ky} \mathrm{Kz}$ Ss Por

4.12276e+02 4.12276e+02 4.12276e+01 1.00000e-09 2.12000e-01 $1.00000 \mathrm{e}-051.00000 \mathrm{e}-051.00000 \mathrm{e}-061.00000 \mathrm{e}-091.00000 \mathrm{e}-01$

$1.00000 \mathrm{e}+001.00000 \mathrm{e}+001.00000 \mathrm{e}-011.00000 \mathrm{e}-091.00000 \mathrm{e}-01$

1.00000e-06 1.00000e-06 1.00000e-06 1.00000e-09 5.00000e-02

Element: 13062 \# of layers: 4

$\mathrm{Kx} \mathrm{Ky} \mathrm{Kz}$ Ss Por

4.12276e+02 4.12276e+02 4.12276e+01 1.00000e-09 2.12000e-01

$1.00000 \mathrm{e}-05$ 1.00000e-05 1.00000e-06 1.00000e-09 1.00000e-01

$1.00000 \mathrm{e}+001.00000 \mathrm{e}+001.00000 \mathrm{e}-011.00000 \mathrm{e}-091.00000 \mathrm{e}-01$

1.00000e-06 1.00000e-06 1.00000e-06 1.00000e-09 5.00000e-02

Element: 13063 \# of layers: 4

$\mathrm{Kx} \mathrm{Ky} \mathrm{Kz}$ Ss Por

4.12276e+02 4.12276e+02 4.12276e+01 1.00000e-09 2.12000e-01

$1.00000 \mathrm{e}-05$ 1.00000e-05 1.00000e-06 1.00000e-09 1.00000e-01

$1.00000 \mathrm{e}+001.00000 \mathrm{e}+001.00000 \mathrm{e}-011.00000 \mathrm{e}-091.00000 \mathrm{e}-01$

1.00000e-06 1.00000e-06 1.00000e-06 1.00000e-09 5.00000e-02

Element: 13064 \# of layers: 5

$\mathrm{Kx} \mathrm{Ky} \mathrm{Kz}$ Ss Por

4.12276e+02 4.12276e+02 4.12276e+01 1.00000e-09 2.12000e-01

$4.12276 \mathrm{e}+02$ 4.12276e+02 4.12276e+01 1.00000e-09 2.12000e-01

$1.00000 \mathrm{e}-05$ 1.00000e-05 1.00000e-06 1.00000e-09 1.00000e-01

$1.00000 \mathrm{e}+001.00000 \mathrm{e}+001.00000 \mathrm{e}-011.00000 \mathrm{e}-091.00000 \mathrm{e}-01$

1.00000e-06 1.00000e-06 1.00000e-06 1.00000e-09 5.00000e-02

Element: 13065 \# of layers: 5

$\mathrm{Kx} \mathrm{Ky} \mathrm{Kz}$ Ss Por

4.12276e+02 4.12276e+02 4.12276e+01 1.00000e-09 2.12000e-01

4.12276e+02 4.12276e+02 4.12276e+01 1.00000e-09 2.12000e-01

$1.00000 \mathrm{e}-05$ 1.00000e-05 1.00000e-06 1.00000e-09 1.00000e-01

$1.00000 \mathrm{e}+001.00000 \mathrm{e}+001.00000 \mathrm{e}-011.00000 \mathrm{e}-091.00000 \mathrm{e}-01$ 
1.00000e-06 1.00000e-06 1.00000e-06 1.00000e-09 5.00000e-02

Element: 13066 \# of layers: 5

Kx Ky Kz Ss Por

4.12276e+02 4.12276e+02 4.12276e+01 1.00000e-09 2.12000e-01

4.12276e+02 4.12276e+02 4.12276e+01 1.00000e-09 2.12000e-01

$1.00000 \mathrm{e}-05$ 1.00000e-05 1.00000e-06 1.00000e-09 1.00000e-01

$1.00000 \mathrm{e}+001.00000 \mathrm{e}+001.00000 \mathrm{e}-011.00000 \mathrm{e}-091.00000 \mathrm{e}-01$

1.00000e-06 1.00000e-06 1.00000e-06 1.00000e-09 5.00000e-02

Element: 13067 \# of layers: 5

$\mathrm{Kx} \mathrm{Ky} \mathrm{Kz}$ Ss Por

4.12276e+02 4.12276e+02 4.12276e+01 1.00000e-09 2.12000e-01

$4.12276 \mathrm{e}+02$ 4.12276e+02 4.12276e+01 1.00000e-09 2.12000e-01

$1.00000 \mathrm{e}-051.00000 \mathrm{e}-051.00000 \mathrm{e}-061.00000 \mathrm{e}-091.00000 \mathrm{e}-01$

$1.00000 \mathrm{e}+001.00000 \mathrm{e}+001.00000 \mathrm{e}-011.00000 \mathrm{e}-091.00000 \mathrm{e}-01$

1.00000e-06 1.00000e-06 1.00000e-06 1.00000e-09 5.00000e-02

Element: 13068 \# of layers: 5

$\mathrm{Kx} \mathrm{Ky} \mathrm{Kz}$ Ss Por

4.12276e+02 4.12276e+02 4.12276e+01 1.00000e-09 2.12000e-01

4.12276e+02 4.12276e+02 4.12276e+01 1.00000e-09 2.12000e-01

$1.00000 \mathrm{e}-05$ 1.00000e-05 1.00000e-06 1.00000e-09 1.00000e-01

$1.00000 \mathrm{e}+001.00000 \mathrm{e}+001.00000 \mathrm{e}-011.00000 \mathrm{e}-091.00000 \mathrm{e}-01$

1.00000e-06 1.00000e-06 1.00000e-06 1.00000e-09 5.00000e-02

Element: 13069 \# of layers: 6

Kx Ky Kz Ss Por

4.12276e+02 4.12276e+02 4.12276e+01 1.00000e-09 2.12000e-01

4.12276e+02 4.12276e+02 4.12276e+01 1.00000e-09 2.12000e-01

4.12276e+02 4.12276e+02 4.12276e+01 1.00000e-09 2.12000e-01

$1.00000 \mathrm{e}-05$ 1.00000e-05 1.00000e-06 1.00000e-09 1.00000e-01

$1.00000 \mathrm{e}+001.00000 \mathrm{e}+001.00000 \mathrm{e}-011.00000 \mathrm{e}-091.00000 \mathrm{e}-01$

1.00000e-06 1.00000e-06 1.00000e-06 1.00000e-09 5.00000e-02

Element: 13070 \# of layers: 5

$\mathrm{Kx} \mathrm{Ky} \mathrm{Kz}$ Ss Por

4.12276e+02 4.12276e+02 4.12276e+01 1.00000e-09 2.12000e-01

4.12276e+02 4.12276e+02 4.12276e+01 1.00000e-09 2.12000e-01

$1.00000 \mathrm{e}-05$ 1.00000e-05 1.00000e-06 1.00000e-09 1.00000e-01

$1.00000 \mathrm{e}+001.00000 \mathrm{e}+001.00000 \mathrm{e}-011.00000 \mathrm{e}-091.00000 \mathrm{e}-01$

1.00000e-06 1.00000e-06 1.00000e-06 1.00000e-09 5.00000e-02

Element: 13071 \# of layers: 5

$\mathrm{Kx} \mathrm{Ky} \mathrm{Kz}$ Ss Por

$1.66285 \mathrm{e}+011.66285 \mathrm{e}+011.66285 \mathrm{e}+001.00000 \mathrm{e}-092.12000 \mathrm{e}-01$

$1.66285 \mathrm{e}+011.66285 \mathrm{e}+011.66285 \mathrm{e}+001.00000 \mathrm{e}-092.12000 \mathrm{e}-01$

$1.00000 \mathrm{e}-05$ 1.00000e-05 1.00000e-06 1.00000e-09 1.00000e-01

$1.00000 \mathrm{e}+001.00000 \mathrm{e}+001.00000 \mathrm{e}-011.00000 \mathrm{e}-091.00000 \mathrm{e}-01$

1.00000e-06 1.00000e-06 1.00000e-06 1.00000e-09 5.00000e-02

Element: 13072 \# of layers: 5

Kx Ky Kz Ss Por 
$1.66285 \mathrm{e}+011.66285 \mathrm{e}+01$ 1.66285e+00 1.00000e-09 2.12000e-01 $1.66285 \mathrm{e}+011.66285 \mathrm{e}+011.66285 \mathrm{e}+001.00000 \mathrm{e}-092.12000 \mathrm{e}-01$ $1.00000 \mathrm{e}-05$ 1.00000e-05 1.00000e-06 1.00000e-09 1.00000e-01

$1.00000 \mathrm{e}+001.00000 \mathrm{e}+001.00000 \mathrm{e}-011.00000 \mathrm{e}-091.00000 \mathrm{e}-01$ 1.00000e-06 1.00000e-06 1.00000e-06 1.00000e-09 5.00000e-02

Element: 13073 \# of layers: 5

$\mathrm{Kx} \mathrm{Ky} \mathrm{Kz}$ Ss Por

$1.66285 \mathrm{e}+011.66285 \mathrm{e}+011.66285 \mathrm{e}+001.00000 \mathrm{e}-092.12000 \mathrm{e}-01$ $1.66285 \mathrm{e}+011.66285 \mathrm{e}+011.66285 \mathrm{e}+001.00000 \mathrm{e}-092.12000 \mathrm{e}-01$ $1.00000 \mathrm{e}-05$ 1.00000e-05 1.00000e-06 1.00000e-09 1.00000e-01 $1.00000 \mathrm{e}+001.00000 \mathrm{e}+001.00000 \mathrm{e}-011.00000 \mathrm{e}-091.00000 \mathrm{e}-01$ 1.00000e-06 1.00000e-06 1.00000e-06 1.00000e-09 5.00000e-02 Element: 13074 \# of layers: 5

$\mathrm{Kx} \mathrm{Ky} \mathrm{Kz}$ Ss Por

4.12276e+02 4.12276e+02 4.12276e+01 1.00000e-09 2.12000e-01 $4.12276 \mathrm{e}+02$ 4.12276e+02 4.12276e+01 1.00000e-09 2.12000e-01 $1.00000 \mathrm{e}-05$ 1.00000e-05 1.00000e-06 1.00000e-09 1.00000e-01 $1.00000 \mathrm{e}+001.00000 \mathrm{e}+001.00000 \mathrm{e}-011.00000 \mathrm{e}-091.00000 \mathrm{e}-01$ 1.00000e-06 1.00000e-06 1.00000e-06 1.00000e-09 5.00000e-02 Element: 13075 \# of layers: 6

$\mathrm{Kx} \mathrm{Ky} \mathrm{Kz}$ Ss Por

4.12276e+02 4.12276e+02 4.12276e+01 1.00000e-09 2.12000e-01 4.12276e+02 4.12276e+02 4.12276e+01 1.00000e-09 2.12000e-01 4.12276e+02 4.12276e+02 4.12276e+01 1.00000e-09 2.12000e-01 $1.00000 \mathrm{e}-05$ 1.00000e-05 1.00000e-06 1.00000e-09 1.00000e-01 $1.00000 \mathrm{e}+001.00000 \mathrm{e}+001.00000 \mathrm{e}-011.00000 \mathrm{e}-091.00000 \mathrm{e}-01$ 1.00000e-06 1.00000e-06 1.00000e-06 1.00000e-09 5.00000e-02 Element: 13076 \# of layers: 6

Kx Ky Kz Ss Por

4.12276e+02 4.12276e+02 4.12276e+01 1.00000e-09 2.12000e-01 4.12276e+02 4.12276e+02 4.12276e+01 1.00000e-09 2.12000e-01 $4.12276 \mathrm{e}+02$ 4.12276e+02 4.12276e+01 1.00000e-09 2.12000e-01 $1.00000 \mathrm{e}-05$ 1.00000e-05 1.00000e-06 1.00000e-09 1.00000e-01 $1.00000 \mathrm{e}+001.00000 \mathrm{e}+001.00000 \mathrm{e}-011.00000 \mathrm{e}-091.00000 \mathrm{e}-01$ 1.00000e-06 1.00000e-06 1.00000e-06 1.00000e-09 5.00000e-02 Element: 13077 \# of layers: 5

$\mathrm{Kx} \mathrm{Ky} \mathrm{Kz}$ Ss Por

4.12276e+02 4.12276e+02 4.12276e+01 1.00000e-09 2.12000e-01 4.12276e+02 4.12276e+02 4.12276e+01 1.00000e-09 2.12000e-01 $1.00000 \mathrm{e}-05$ 1.00000e-05 1.00000e-06 1.00000e-09 1.00000e-01 $1.00000 \mathrm{e}+001.00000 \mathrm{e}+001.00000 \mathrm{e}-011.00000 \mathrm{e}-091.00000 \mathrm{e}-01$ 1.00000e-06 1.00000e-06 1.00000e-06 1.00000e-09 5.00000e-02 Element: 13078 \# of layers: 5

$\mathrm{Kx} \mathrm{Ky} \mathrm{Kz}$ Ss Por $1.66285 \mathrm{e}+01$ 1.66285e+01 1.66285e+00 1.00000e-09 2.12000e-01 $1.66285 \mathrm{e}+011.66285 \mathrm{e}+011.66285 \mathrm{e}+001.00000 \mathrm{e}-092.12000 \mathrm{e}-01$ 
$1.00000 \mathrm{e}-05$ 1.00000e-05 1.00000e-06 1.00000e-09 1.00000e-01 $1.00000 \mathrm{e}+001.00000 \mathrm{e}+001.00000 \mathrm{e}-01$ 1.00000e-09 1.00000e-01 1.00000e-06 1.00000e-06 1.00000e-06 1.00000e-09 5.00000e-02

Element: 13079 \# of layers: 5

$\mathrm{Kx} \mathrm{Ky} \mathrm{Kz}$ Ss Por

$1.66285 \mathrm{e}+011.66285 \mathrm{e}+011.66285 \mathrm{e}+001.00000 \mathrm{e}-092.12000 \mathrm{e}-01$

$1.66285 \mathrm{e}+011.66285 \mathrm{e}+011.66285 \mathrm{e}+001.00000 \mathrm{e}-092.12000 \mathrm{e}-01$

$1.00000 \mathrm{e}-05$ 1.00000e-05 1.00000e-06 1.00000e-09 1.00000e-01

$1.00000 \mathrm{e}+001.00000 \mathrm{e}+001.00000 \mathrm{e}-011.00000 \mathrm{e}-091.00000 \mathrm{e}-01$

1.00000e-06 1.00000e-06 1.00000e-06 1.00000e-09 5.00000e-02

Element: 13080 \# of layers: 5

Kx Ky Kz Ss Por

$1.66285 \mathrm{e}+011.66285 \mathrm{e}+01$ 1.66285e+00 1.00000e-09 2.12000e-01

$1.66285 \mathrm{e}+011.66285 \mathrm{e}+011.66285 \mathrm{e}+001.00000 \mathrm{e}-092.12000 \mathrm{e}-01$

$1.00000 \mathrm{e}-05$ 1.00000e-05 1.00000e-06 1.00000e-09 1.00000e-01

$1.00000 \mathrm{e}+001.00000 \mathrm{e}+001.00000 \mathrm{e}-011.00000 \mathrm{e}-091.00000 \mathrm{e}-01$

1.00000e-06 1.00000e-06 1.00000e-06 1.00000e-09 5.00000e-02

Element: 13081 \# of layers: 5

$\mathrm{Kx} \mathrm{Ky} \mathrm{Kz}$ Ss Por

$1.66285 \mathrm{e}+01$ 1.66285e+01 1.66285e+00 1.00000e-09 2.12000e-01

$1.66285 \mathrm{e}+011.66285 \mathrm{e}+011.66285 \mathrm{e}+001.00000 \mathrm{e}-092.12000 \mathrm{e}-01$

$1.00000 \mathrm{e}-05$ 1.00000e-05 1.00000e-06 1.00000e-09 1.00000e-01

$1.00000 \mathrm{e}+001.00000 \mathrm{e}+001.00000 \mathrm{e}-011.00000 \mathrm{e}-091.00000 \mathrm{e}-01$

1.00000e-06 1.00000e-06 1.00000e-06 1.00000e-09 5.00000e-02

Element: 13082 \# of layers: 4

$\mathrm{Kx} \mathrm{Ky} \mathrm{Kz}$ Ss Por

$1.66285 \mathrm{e}+011.66285 \mathrm{e}+011.66285 \mathrm{e}+001.00000 \mathrm{e}-092.12000 \mathrm{e}-01$

$1.66285 \mathrm{e}+011.66285 \mathrm{e}+011.66285 \mathrm{e}+001.00000 \mathrm{e}-092.12000 \mathrm{e}-01$

$1.00000 \mathrm{e}-05$ 1.00000e-05 1.00000e-06 1.00000e-09 1.00000e-01

$1.00000 \mathrm{e}+001.00000 \mathrm{e}+001.00000 \mathrm{e}-011.00000 \mathrm{e}-091.00000 \mathrm{e}-01$

Element: 13083 \# of layers: 5

$\mathrm{Kx} \mathrm{Ky} \mathrm{Kz}$ Ss Por

$1.66285 \mathrm{e}+011.66285 \mathrm{e}+011.66285 \mathrm{e}+001.00000 \mathrm{e}-092.12000 \mathrm{e}-01$

$1.66285 \mathrm{e}+011.66285 \mathrm{e}+01$ 1.66285e+00 1.00000e-09 2.12000e-01

$1.00000 \mathrm{e}-05$ 1.00000e-05 1.00000e-06 1.00000e-09 1.00000e-01

$1.00000 \mathrm{e}+001.00000 \mathrm{e}+001.00000 \mathrm{e}-011.00000 \mathrm{e}-091.00000 \mathrm{e}-01$

1.00000e-06 1.00000e-06 1.00000e-06 1.00000e-09 5.00000e-02

Element: 13084 \# of layers: 5

$\mathrm{Kx} \mathrm{Ky} \mathrm{Kz}$ Ss Por

$1.66285 \mathrm{e}+011.66285 \mathrm{e}+011.66285 \mathrm{e}+001.00000 \mathrm{e}-092.12000 \mathrm{e}-01$

$1.66285 \mathrm{e}+011.66285 \mathrm{e}+011.66285 \mathrm{e}+001.00000 \mathrm{e}-092.12000 \mathrm{e}-01$

$1.00000 \mathrm{e}-05$ 1.00000e-05 1.00000e-06 1.00000e-09 1.00000e-01

$1.00000 \mathrm{e}+001.00000 \mathrm{e}+001.00000 \mathrm{e}-011.00000 \mathrm{e}-091.00000 \mathrm{e}-01$

1.00000e-06 1.00000e-06 1.00000e-06 1.00000e-09 5.00000e-02

Element: 13085 \# of layers: 5

Kx Ky Kz Ss Por 
$1.66285 \mathrm{e}+011.66285 \mathrm{e}+01$ 1.66285e+00 1.00000e-09 2.12000e-01 $1.66285 \mathrm{e}+011.66285 \mathrm{e}+011.66285 \mathrm{e}+001.00000 \mathrm{e}-092.12000 \mathrm{e}-01$ $1.00000 \mathrm{e}-05$ 1.00000e-05 1.00000e-06 1.00000e-09 1.00000e-01

$1.00000 \mathrm{e}+001.00000 \mathrm{e}+001.00000 \mathrm{e}-011.00000 \mathrm{e}-091.00000 \mathrm{e}-01$ 1.00000e-06 1.00000e-06 1.00000e-06 1.00000e-09 5.00000e-02

Element: 13086 \# of layers: 5

$\mathrm{Kx} \mathrm{Ky} \mathrm{Kz}$ Ss Por

$1.66285 \mathrm{e}+011.66285 \mathrm{e}+011.66285 \mathrm{e}+001.00000 \mathrm{e}-092.12000 \mathrm{e}-01$

$1.66285 \mathrm{e}+011.66285 \mathrm{e}+011.66285 \mathrm{e}+001.00000 \mathrm{e}-092.12000 \mathrm{e}-01$

$1.00000 \mathrm{e}-05$ 1.00000e-05 1.00000e-06 1.00000e-09 1.00000e-01

$1.00000 \mathrm{e}+001.00000 \mathrm{e}+001.00000 \mathrm{e}-011.00000 \mathrm{e}-091.00000 \mathrm{e}-01$

1.00000e-06 1.00000e-06 1.00000e-06 1.00000e-09 5.00000e-02

Element: 13087 \# of layers: 4

$\mathrm{Kx} \mathrm{Ky} \mathrm{Kz}$ Ss Por

$1.66285 \mathrm{e}+011.66285 \mathrm{e}+01$ 1.66285e+00 1.00000e-09 2.12000e-01

$1.66285 \mathrm{e}+011.66285 \mathrm{e}+011.66285 \mathrm{e}+001.00000 \mathrm{e}-092.12000 \mathrm{e}-01$

$1.00000 \mathrm{e}-05$ 1.00000e-05 1.00000e-06 1.00000e-09 1.00000e-01

$1.00000 \mathrm{e}+001.00000 \mathrm{e}+001.00000 \mathrm{e}-01$ 1.00000e-09 1.00000e-01

Element: 13088 \# of layers: 4

Kx Ky Kz Ss Por

$1.48976 \mathrm{e}+01$ 1.48976e+01 1.48976e+00 1.00000e-09 2.12000e-01

$1.48976 \mathrm{e}+01$ 1.48976e+01 1.48976e+00 1.00000e-09 2.12000e-01

$1.00000 \mathrm{e}-05$ 1.00000e-05 1.00000e-06 1.00000e-09 1.00000e-01

$1.00000 \mathrm{e}+001.00000 \mathrm{e}+001.00000 \mathrm{e}-011.00000 \mathrm{e}-091.00000 \mathrm{e}-01$

Element: 13089 \# of layers: 4

$\mathrm{Kx} \mathrm{Ky} \mathrm{Kz}$ Ss Por

$1.48976 \mathrm{e}+01$ 1.48976e+01 1.48976e+00 1.00000e-09 2.12000e-01

$1.48976 \mathrm{e}+011.48976 \mathrm{e}+011.48976 \mathrm{e}+001.00000 \mathrm{e}-092.12000 \mathrm{e}-01$

$1.00000 \mathrm{e}-05$ 1.00000e-05 1.00000e-06 1.00000e-09 1.00000e-01

$1.00000 \mathrm{e}+001.00000 \mathrm{e}+001.00000 \mathrm{e}-011.00000 \mathrm{e}-091.00000 \mathrm{e}-01$

Element: 13090 \# of layers: 4

Kx Ky Kz Ss Por

$1.48976 \mathrm{e}+01$ 1.48976e+01 1.48976e+00 1.00000e-09 2.12000e-01

$1.48976 \mathrm{e}+011.48976 \mathrm{e}+011.48976 \mathrm{e}+001.00000 \mathrm{e}-092.12000 \mathrm{e}-01$

$1.00000 \mathrm{e}-05$ 1.00000e-05 1.00000e-06 1.00000e-09 1.00000e-01

$1.00000 \mathrm{e}+001.00000 \mathrm{e}+001.00000 \mathrm{e}-011.00000 \mathrm{e}-09$ 1.00000e-01

Element: 13091 \# of layers: 4

Kx Ky Kz Ss Por

$1.48976 \mathrm{e}+01$ 1.48976e+01 1.48976e+00 1.00000e-09 2.12000e-01

$1.48976 \mathrm{e}+011.48976 \mathrm{e}+011.48976 \mathrm{e}+001.00000 \mathrm{e}-092.12000 \mathrm{e}-01$

$1.00000 \mathrm{e}-05$ 1.00000e-05 1.00000e-06 1.00000e-09 1.00000e-01

$1.00000 \mathrm{e}+001.00000 \mathrm{e}+001.00000 \mathrm{e}-011.00000 \mathrm{e}-091.00000 \mathrm{e}-01$

Element: 13092 \# of layers: 4

$\mathrm{Kx} \mathrm{Ky} \mathrm{Kz}$ Ss Por

$1.48976 \mathrm{e}+01$ 1.48976e+01 1.48976e+00 1.00000e-09 2.12000e-01

$1.48976 \mathrm{e}+011.48976 \mathrm{e}+011.48976 \mathrm{e}+001.00000 \mathrm{e}-092.12000 \mathrm{e}-01$ 
$1.00000 \mathrm{e}-05$ 1.00000e-05 1.00000e-06 1.00000e-09 1.00000e-01 $1.00000 \mathrm{e}+001.00000 \mathrm{e}+001.00000 \mathrm{e}-01$ 1.00000e-09 1.00000e-01 Element: 13093 \# of layers: 5

Kx Ky Kz Ss Por

$1.66285 \mathrm{e}+011.66285 \mathrm{e}+011.66285 \mathrm{e}+001.00000 \mathrm{e}-092.12000 \mathrm{e}-01$

$1.66285 \mathrm{e}+011.66285 \mathrm{e}+011.66285 \mathrm{e}+001.00000 \mathrm{e}-092.12000 \mathrm{e}-01$ $1.00000 \mathrm{e}-05$ 1.00000e-05 1.00000e-06 1.00000e-09 1.00000e-01

$1.00000 \mathrm{e}+001.00000 \mathrm{e}+001.00000 \mathrm{e}-011.00000 \mathrm{e}-091.00000 \mathrm{e}-01$ 1.00000e-06 1.00000e-06 1.00000e-06 1.00000e-09 5.00000e-02

Element: 13094 \# of layers: 5

$\mathrm{Kx} \mathrm{Ky} \mathrm{Kz}$ Ss Por

$1.66285 \mathrm{e}+011.66285 \mathrm{e}+01$ 1.66285e+00 1.00000e-09 2.12000e-01

$1.66285 \mathrm{e}+011.66285 \mathrm{e}+011.66285 \mathrm{e}+001.00000 \mathrm{e}-092.12000 \mathrm{e}-01$

$1.00000 \mathrm{e}-05$ 1.00000e-05 1.00000e-06 1.00000e-09 1.00000e-01

$1.00000 \mathrm{e}+001.00000 \mathrm{e}+001.00000 \mathrm{e}-011.00000 \mathrm{e}-091.00000 \mathrm{e}-01$

1.00000e-06 1.00000e-06 1.00000e-06 1.00000e-09 5.00000e-02

Element: 13095 \# of layers: 4

Kx Ky Kz Ss Por

$1.48976 \mathrm{e}+01$ 1.48976e+01 1.48976e+00 1.00000e-09 2.12000e-01

$1.48976 \mathrm{e}+011.48976 \mathrm{e}+01 \quad 1.48976 \mathrm{e}+001.00000 \mathrm{e}-092.12000 \mathrm{e}-01$

$1.00000 \mathrm{e}-05$ 1.00000e-05 1.00000e-06 1.00000e-09 1.00000e-01

$1.00000 \mathrm{e}+001.00000 \mathrm{e}+001.00000 \mathrm{e}-01$ 1.00000e-09 1.00000e-01

Element: 13096 \# of layers: 4

Kx Ky Kz Ss Por

$1.48976 \mathrm{e}+01$ 1.48976e+01 1.48976e+00 1.00000e-09 2.12000e-01

$1.48976 \mathrm{e}+01$ 1.48976e+01 1.48976e+00 1.00000e-09 2.12000e-01

$1.00000 \mathrm{e}-05$ 1.00000e-05 1.00000e-06 1.00000e-09 1.00000e-01

$1.00000 \mathrm{e}+001.00000 \mathrm{e}+001.00000 \mathrm{e}-011.00000 \mathrm{e}-091.00000 \mathrm{e}-01$

Element: 13097 \# of layers: 4

$\mathrm{Kx} \mathrm{Ky} \mathrm{Kz}$ Ss Por

$1.94841 \mathrm{e}+01$ 1.94841e+01 1.94841e+00 1.00000e-09 2.12000e-01

$1.94841 \mathrm{e}+011.94841 \mathrm{e}+011.94841 \mathrm{e}+00$ 1.00000e-09 2.12000e-01

$1.00000 \mathrm{e}-05$ 1.00000e-05 1.00000e-06 1.00000e-09 1.00000e-01

$1.00000 \mathrm{e}+001.00000 \mathrm{e}+001.00000 \mathrm{e}-011.00000 \mathrm{e}-091.00000 \mathrm{e}-01$

Element: 13098 \# of layers: 4

$\mathrm{Kx} \mathrm{Ky} \mathrm{Kz}$ Ss Por

$1.94841 \mathrm{e}+01$ 1.94841e+01 1.94841e+00 1.00000e-09 2.12000e-01

$1.94841 \mathrm{e}+011.94841 \mathrm{e}+011.94841 \mathrm{e}+001.00000 \mathrm{e}-092.12000 \mathrm{e}-01$

$1.00000 \mathrm{e}-051.00000 \mathrm{e}-051.00000 \mathrm{e}-061.00000 \mathrm{e}-091.00000 \mathrm{e}-01$

$1.00000 \mathrm{e}+001.00000 \mathrm{e}+001.00000 \mathrm{e}-01$ 1.00000e-09 1.00000e-01

Element: 13099 \# of layers: 5

$\mathrm{Kx} \mathrm{Ky} \mathrm{Kz}$ Ss Por

$1.94841 \mathrm{e}+011.94841 \mathrm{e}+01$ 1.94841e+00 1.00000e-09 2.12000e-01

$1.94841 \mathrm{e}+01$ 1.94841e+01 1.94841e+00 1.00000e-09 2.12000e-01

$1.00000 \mathrm{e}-05$ 1.00000e-05 1.00000e-06 1.00000e-09 1.00000e-01

$1.00000 \mathrm{e}+001.00000 \mathrm{e}+001.00000 \mathrm{e}-011.00000 \mathrm{e}-091.00000 \mathrm{e}-01$ 
1.00000e-06 1.00000e-06 1.00000e-06 1.00000e-09 5.00000e-02

Element: 13100 \# of layers: 6

Kx Ky Kz Ss Por

4.12276e+02 4.12276e+02 4.12276e+01 1.00000e-09 2.12000e-01

4.12276e+02 4.12276e+02 4.12276e+01 1.00000e-09 2.12000e-01

$4.12276 \mathrm{e}+02$ 4.12276e+02 4.12276e+01 1.00000e-09 2.12000e-01

$1.00000 \mathrm{e}-05$ 1.00000e-05 1.00000e-06 1.00000e-09 1.00000e-01

$1.00000 \mathrm{e}+001.00000 \mathrm{e}+001.00000 \mathrm{e}-011.00000 \mathrm{e}-091.00000 \mathrm{e}-01$

1.00000e-06 1.00000e-06 1.00000e-06 1.00000e-09 5.00000e-02

Element: 13101 \# of layers: 5

$\mathrm{Kx} \mathrm{Ky} \mathrm{Kz}$ Ss Por

4.12276e+02 4.12276e+02 4.12276e+01 1.00000e-09 2.12000e-01

4.12276e+02 4.12276e+02 4.12276e+01 1.00000e-09 2.12000e-01

$1.00000 \mathrm{e}-05$ 1.00000e-05 1.00000e-06 1.00000e-09 1.00000e-01

$1.00000 \mathrm{e}+001.00000 \mathrm{e}+001.00000 \mathrm{e}-011.00000 \mathrm{e}-091.00000 \mathrm{e}-01$

1.00000e-06 1.00000e-06 1.00000e-06 1.00000e-09 5.00000e-02

Element: 13102 \# of layers: 5

$\mathrm{Kx} \mathrm{Ky} \mathrm{Kz}$ Ss Por

$1.66285 \mathrm{e}+01$ 1.66285e+01 1.66285e+00 1.00000e-09 2.12000e-01

$1.66285 \mathrm{e}+011.66285 \mathrm{e}+011.66285 \mathrm{e}+001.00000 \mathrm{e}-092.12000 \mathrm{e}-01$

$1.00000 \mathrm{e}-05$ 1.00000e-05 1.00000e-06 1.00000e-09 1.00000e-01

$1.00000 \mathrm{e}+001.00000 \mathrm{e}+001.00000 \mathrm{e}-011.00000 \mathrm{e}-091.00000 \mathrm{e}-01$

1.00000e-06 1.00000e-06 1.00000e-06 1.00000e-09 5.00000e-02

Element: 13103 \# of layers: 4

$\mathrm{Kx} \mathrm{Ky} \mathrm{Kz}$ Ss Por

$1.48976 \mathrm{e}+01$ 1.48976e+01 1.48976e+00 1.00000e-09 2.12000e-01

$1.48976 \mathrm{e}+01$ 1.48976e+01 1.48976e+00 1.00000e-09 2.12000e-01

$1.00000 \mathrm{e}-05$ 1.00000e-05 1.00000e-06 1.00000e-09 1.00000e-01

$1.00000 \mathrm{e}+001.00000 \mathrm{e}+001.00000 \mathrm{e}-011.00000 \mathrm{e}-091.00000 \mathrm{e}-01$

Element: 13104 \# of layers: 4

$\mathrm{Kx} \mathrm{Ky} \mathrm{Kz}$ Ss Por

$1.94841 \mathrm{e}+01$ 1.94841e+01 1.94841e+00 1.00000e-09 2.12000e-01

$1.94841 \mathrm{e}+011.94841 \mathrm{e}+011.94841 \mathrm{e}+001.00000 \mathrm{e}-092.12000 \mathrm{e}-01$

$1.00000 \mathrm{e}-05$ 1.00000e-05 1.00000e-06 1.00000e-09 1.00000e-01

$1.00000 \mathrm{e}+001.00000 \mathrm{e}+001.00000 \mathrm{e}-01$ 1.00000e-09 1.00000e-01

Element: 13105 \# of layers: 5

Kx Ky Kz Ss Por

$2.44580 \mathrm{e}+02$ 2.44580e+02 2.44580e+01 1.00000e-09 2.12000e-01

$2.44580 \mathrm{e}+02$ 2.44580e+02 2.44580e+01 1.00000e-09 2.12000e-01

$1.00000 \mathrm{e}-05$ 1.00000e-05 1.00000e-06 1.00000e-09 1.00000e-01

$1.00000 \mathrm{e}+001.00000 \mathrm{e}+001.00000 \mathrm{e}-011.00000 \mathrm{e}-091.00000 \mathrm{e}-01$

1.00000e-06 1.00000e-06 1.00000e-06 1.00000e-09 5.00000e-02

Element: 13106 \# of layers: 5

$\mathrm{Kx} \mathrm{Ky} \mathrm{Kz}$ Ss Por

$2.44580 \mathrm{e}+02$ 2.44580e+02 2.44580e+01 1.00000e-09 2.12000e-01

$2.44580 \mathrm{e}+02$ 2.44580e+02 2.44580e+01 1.00000e-09 2.12000e-01 
$1.00000 \mathrm{e}-05$ 1.00000e-05 1.00000e-06 1.00000e-09 1.00000e-01 $1.00000 \mathrm{e}+001.00000 \mathrm{e}+001.00000 \mathrm{e}-01$ 1.00000e-09 1.00000e-01 1.00000e-06 1.00000e-06 1.00000e-06 1.00000e-09 5.00000e-02

Element: 13107 \# of layers: 5

$\mathrm{Kx} \mathrm{Ky} \mathrm{Kz}$ Ss Por

$2.44580 \mathrm{e}+02$ 2.44580e+02 2.44580e+01 1.00000e-09 2.12000e-01

$2.44580 \mathrm{e}+02$ 2.44580e+02 2.44580e+01 1.00000e-09 2.12000e-01 $1.00000 \mathrm{e}-05$ 1.00000e-05 1.00000e-06 1.00000e-09 1.00000e-01

$1.00000 \mathrm{e}+001.00000 \mathrm{e}+001.00000 \mathrm{e}-011.00000 \mathrm{e}-091.00000 \mathrm{e}-01$ 1.00000e-06 1.00000e-06 1.00000e-06 1.00000e-09 5.00000e-02

Element: 13108 \# of layers: 5

$\mathrm{Kx} \mathrm{Ky} \mathrm{Kz}$ Ss Por

$2.44580 \mathrm{e}+02$ 2.44580e+02 2.44580e+01 1.00000e-09 2.12000e-01

$2.44580 \mathrm{e}+02$ 2.44580e+02 2.44580e+01 1.00000e-09 2.12000e-01 $1.00000 \mathrm{e}-05$ 1.00000e-05 1.00000e-06 1.00000e-09 1.00000e-01

$1.00000 \mathrm{e}+001.00000 \mathrm{e}+001.00000 \mathrm{e}-011.00000 \mathrm{e}-091.00000 \mathrm{e}-01$

1.00000e-06 1.00000e-06 1.00000e-06 1.00000e-09 5.00000e-02

Element: 13109 \# of layers: 5

$\mathrm{Kx} \mathrm{Ky} \mathrm{Kz}$ Ss Por

$2.44580 \mathrm{e}+02$ 2.44580e+02 2.44580e+01 1.00000e-09 2.12000e-01

$2.44580 \mathrm{e}+02$ 2.44580e+02 2.44580e+01 1.00000e-09 2.12000e-01

$1.00000 \mathrm{e}-05$ 1.00000e-05 1.00000e-06 1.00000e-09 1.00000e-01

$1.00000 \mathrm{e}+001.00000 \mathrm{e}+001.00000 \mathrm{e}-011.00000 \mathrm{e}-091.00000 \mathrm{e}-01$

1.00000e-06 1.00000e-06 1.00000e-06 1.00000e-09 5.00000e-02

Element: 13110 \# of layers: 5

$\mathrm{Kx} \mathrm{Ky} \mathrm{Kz}$ Ss Por

$2.44580 \mathrm{e}+02$ 2.44580e+02 2.44580e+01 1.00000e-09 2.12000e-01

$2.44580 \mathrm{e}+02$ 2.44580e+02 2.44580e+01 1.00000e-09 2.12000e-01

$1.00000 \mathrm{e}-05$ 1.00000e-05 1.00000e-06 1.00000e-09 1.00000e-01

$1.00000 \mathrm{e}+001.00000 \mathrm{e}+001.00000 \mathrm{e}-011.00000 \mathrm{e}-091.00000 \mathrm{e}-01$

1.00000e-06 1.00000e-06 1.00000e-06 1.00000e-09 5.00000e-02

Element: 13111 \# of layers: 5

$\mathrm{Kx} \mathrm{Ky} \mathrm{Kz}$ Ss Por

$2.44580 \mathrm{e}+02$ 2.44580e+02 2.44580e+01 1.00000e-09 2.12000e-01

$2.44580 \mathrm{e}+022.44580 \mathrm{e}+02$ 2.44580e+01 1.00000e-09 2.12000e-01

$1.00000 \mathrm{e}-05$ 1.00000e-05 1.00000e-06 1.00000e-09 1.00000e-01

$1.00000 \mathrm{e}+001.00000 \mathrm{e}+001.00000 \mathrm{e}-011.00000 \mathrm{e}-091.00000 \mathrm{e}-01$

1.00000e-06 1.00000e-06 1.00000e-06 1.00000e-09 5.00000e-02

Element: 13112 \# of layers: 5

$\mathrm{Kx} \mathrm{Ky} \mathrm{Kz}$ Ss Por

$2.44580 \mathrm{e}+02$ 2.44580e+02 2.44580e+01 1.00000e-09 2.12000e-01

$2.44580 \mathrm{e}+022.44580 \mathrm{e}+022.44580 \mathrm{e}+01$ 1.00000e-09 2.12000e-01

$1.00000 \mathrm{e}-05$ 1.00000e-05 1.00000e-06 1.00000e-09 1.00000e-01

$1.00000 \mathrm{e}+001.00000 \mathrm{e}+001.00000 \mathrm{e}-011.00000 \mathrm{e}-091.00000 \mathrm{e}-01$

1.00000e-06 1.00000e-06 1.00000e-06 1.00000e-09 5.00000e-02

Element: 13113 \# of layers: 5 
$\mathrm{Kx} \mathrm{Ky} \mathrm{Kz} \mathrm{Ss} \mathrm{Por}$

$2.44580 \mathrm{e}+02$ 2.44580e+02 2.44580e+01 1.00000e-09 2.12000e-01

$2.44580 \mathrm{e}+02$ 2.44580e+02 2.44580e+01 1.00000e-09 2.12000e-01

$1.00000 \mathrm{e}-05$ 1.00000e-05 1.00000e-06 1.00000e-09 1.00000e-01

$1.00000 \mathrm{e}+001.00000 \mathrm{e}+001.00000 \mathrm{e}-011.00000 \mathrm{e}-091.00000 \mathrm{e}-01$

1.00000e-06 1.00000e-06 1.00000e-06 1.00000e-09 5.00000e-02

Element: 13114 \# of layers: 5

Kx Ky Kz Ss Por

$2.44580 \mathrm{e}+02$ 2.44580e+02 2.44580e+01 1.00000e-09 2.12000e-01

$2.44580 \mathrm{e}+02$ 2.44580e+02 2.44580e+01 1.00000e-09 2.12000e-01

$1.00000 \mathrm{e}-05$ 1.00000e-05 1.00000e-06 1.00000e-09 1.00000e-01

$1.00000 \mathrm{e}+001.00000 \mathrm{e}+001.00000 \mathrm{e}-011.00000 \mathrm{e}-091.00000 \mathrm{e}-01$

1.00000e-06 1.00000e-06 1.00000e-06 1.00000e-09 5.00000e-02

Element: 13115 \# of layers: 5

$\mathrm{Kx} \mathrm{Ky} \mathrm{Kz}$ Ss Por

$1.01896 \mathrm{e}+031.01896 \mathrm{e}+03$ 1.01896e+02 1.00000e-09 2.12000e-01

$1.01896 \mathrm{e}+03$ 1.01896e+03 1.01896e+02 1.00000e-09 2.12000e-01

$1.00000 \mathrm{e}-05$ 1.00000e-05 1.00000e-06 1.00000e-09 1.00000e-01

$1.00000 \mathrm{e}+001.00000 \mathrm{e}+001.00000 \mathrm{e}-011.00000 \mathrm{e}-091.00000 \mathrm{e}-01$

1.00000e-06 1.00000e-06 1.00000e-06 1.00000e-09 5.00000e-02

Element: 13116 \# of layers: 6

$\mathrm{Kx} \mathrm{Ky} \mathrm{Kz}$ Ss Por

$1.01896 \mathrm{e}+03$ 1.01896e+03 1.01896e+02 1.00000e-09 2.12000e-01

$1.01896 \mathrm{e}+031.01896 \mathrm{e}+03$ 1.01896e+02 1.00000e-09 2.12000e-01

$1.01896 \mathrm{e}+03$ 1.01896e+03 1.01896e+02 1.00000e-09 2.12000e-01

$1.00000 \mathrm{e}-05$ 1.00000e-05 1.00000e-06 1.00000e-09 1.00000e-01

$1.00000 \mathrm{e}+001.00000 \mathrm{e}+001.00000 \mathrm{e}-011.00000 \mathrm{e}-091.00000 \mathrm{e}-01$

1.00000e-06 1.00000e-06 1.00000e-06 1.00000e-09 5.00000e-02

Element: 13117 \# of layers: 6

$\mathrm{Kx} \mathrm{Ky} \mathrm{Kz}$ Ss Por

$1.01896 \mathrm{e}+03$ 1.01896e+03 1.01896e+02 1.00000e-09 2.12000e-01

$1.01896 \mathrm{e}+031.01896 \mathrm{e}+03$ 1.01896e+02 1.00000e-09 2.12000e-01

$1.01896 \mathrm{e}+031.01896 \mathrm{e}+031.01896 \mathrm{e}+02$ 1.00000e-09 2.12000e-01

$1.00000 \mathrm{e}-05$ 1.00000e-05 1.00000e-06 1.00000e-09 1.00000e-01

$1.00000 \mathrm{e}+001.00000 \mathrm{e}+001.00000 \mathrm{e}-011.00000 \mathrm{e}-091.00000 \mathrm{e}-01$

1.00000e-06 1.00000e-06 1.00000e-06 1.00000e-09 5.00000e-02

Element: 13118 \# of layers: 6

$\mathrm{Kx} \mathrm{Ky} \mathrm{Kz}$ Ss Por

$1.01896 \mathrm{e}+031.01896 \mathrm{e}+03$ 1.01896e+02 1.00000e-09 2.12000e-01

$1.01896 \mathrm{e}+031.01896 \mathrm{e}+03$ 1.01896e+02 1.00000e-09 2.12000e-01

$1.01896 \mathrm{e}+031.01896 \mathrm{e}+03$ 1.01896e+02 1.00000e-09 2.12000e-01

$1.00000 \mathrm{e}-05$ 1.00000e-05 1.00000e-06 1.00000e-09 1.00000e-01

$1.00000 \mathrm{e}+001.00000 \mathrm{e}+001.00000 \mathrm{e}-011.00000 \mathrm{e}-091.00000 \mathrm{e}-01$

1.00000e-06 1.00000e-06 1.00000e-06 1.00000e-09 5.00000e-02

Element: 13119 \# of layers: 5

Kx Ky Kz Ss Por 
$1.01896 \mathrm{e}+03$ 1.01896e+03 1.01896e+02 1.00000e-09 2.12000e-01 $1.01896 \mathrm{e}+031.01896 \mathrm{e}+03$ 1.01896e+02 1.00000e-09 2.12000e-01 $1.00000 \mathrm{e}-05$ 1.00000e-05 1.00000e-06 1.00000e-09 1.00000e-01

$1.00000 \mathrm{e}+001.00000 \mathrm{e}+001.00000 \mathrm{e}-011.00000 \mathrm{e}-091.00000 \mathrm{e}-01$ 1.00000e-06 1.00000e-06 1.00000e-06 1.00000e-09 5.00000e-02

Element: 13120 \# of layers: 5

$\mathrm{Kx} \mathrm{Ky} \mathrm{Kz}$ Ss Por

$2.44580 \mathrm{e}+02$ 2.44580e+02 2.44580e+01 1.00000e-09 2.12000e-01

$2.44580 \mathrm{e}+02$ 2.44580e+02 2.44580e+01 1.00000e-09 2.12000e-01

$1.00000 \mathrm{e}-05$ 1.00000e-05 1.00000e-06 1.00000e-09 1.00000e-01

$1.00000 \mathrm{e}+001.00000 \mathrm{e}+001.00000 \mathrm{e}-011.00000 \mathrm{e}-091.00000 \mathrm{e}-01$

1.00000e-06 1.00000e-06 1.00000e-06 1.00000e-09 5.00000e-02

Element: 13121 \# of layers: 5

$\mathrm{Kx} \mathrm{Ky} \mathrm{Kz}$ Ss Por

$2.44580 \mathrm{e}+02$ 2.44580e+02 2.44580e+01 1.00000e-09 2.12000e-01

$2.44580 \mathrm{e}+022.44580 \mathrm{e}+022.44580 \mathrm{e}+01$ 1.00000e-09 2.12000e-01

$1.00000 \mathrm{e}-05$ 1.00000e-05 1.00000e-06 1.00000e-09 1.00000e-01

$1.00000 \mathrm{e}+001.00000 \mathrm{e}+001.00000 \mathrm{e}-011.00000 \mathrm{e}-091.00000 \mathrm{e}-01$

1.00000e-06 1.00000e-06 1.00000e-06 1.00000e-09 5.00000e-02

Element: 13122 \# of layers: 5

$\mathrm{Kx} \mathrm{Ky} \mathrm{Kz}$ Ss Por

$1.01896 \mathrm{e}+03$ 1.01896e+03 1.01896e+02 1.00000e-09 2.12000e-01

$1.01896 \mathrm{e}+031.01896 \mathrm{e}+03$ 1.01896e+02 1.00000e-09 2.12000e-01

$1.00000 \mathrm{e}-05$ 1.00000e-05 1.00000e-06 1.00000e-09 1.00000e-01

$1.00000 \mathrm{e}+001.00000 \mathrm{e}+001.00000 \mathrm{e}-011.00000 \mathrm{e}-091.00000 \mathrm{e}-01$

1.00000e-06 1.00000e-06 1.00000e-06 1.00000e-09 5.00000e-02

Element: 13123 \# of layers: 5

$\mathrm{Kx} \mathrm{Ky} \mathrm{Kz}$ Ss Por

$1.01896 \mathrm{e}+03$ 1.01896e+03 1.01896e+02 1.00000e-09 2.12000e-01

$1.01896 \mathrm{e}+03$ 1.01896e+03 1.01896e+02 1.00000e-09 2.12000e-01

$1.00000 \mathrm{e}-05$ 1.00000e-05 1.00000e-06 1.00000e-09 1.00000e-01

$1.00000 \mathrm{e}+001.00000 \mathrm{e}+001.00000 \mathrm{e}-011.00000 \mathrm{e}-091.00000 \mathrm{e}-01$

1.00000e-06 1.00000e-06 1.00000e-06 1.00000e-09 5.00000e-02

Element: 13124 \# of layers: 5

$\mathrm{Kx} \mathrm{Ky} \mathrm{Kz}$ Ss Por

$1.01896 \mathrm{e}+03$ 1.01896e+03 1.01896e+02 1.00000e-09 2.12000e-01

$1.01896 \mathrm{e}+031.01896 \mathrm{e}+031.01896 \mathrm{e}+021.00000 \mathrm{e}-092.12000 \mathrm{e}-01$

$1.00000 \mathrm{e}-05$ 1.00000e-05 1.00000e-06 1.00000e-09 1.00000e-01

$1.00000 \mathrm{e}+001.00000 \mathrm{e}+001.00000 \mathrm{e}-011.00000 \mathrm{e}-091.00000 \mathrm{e}-01$

1.00000e-06 1.00000e-06 1.00000e-06 1.00000e-09 5.00000e-02

Element: 13125 \# of layers: 5

$\mathrm{Kx} \mathrm{Ky} \mathrm{Kz}$ Ss Por

$1.01896 \mathrm{e}+03$ 1.01896e+03 1.01896e+02 1.00000e-09 2.12000e-01

$1.01896 \mathrm{e}+03$ 1.01896e+03 1.01896e+02 1.00000e-09 2.12000e-01

$1.00000 \mathrm{e}-05$ 1.00000e-05 1.00000e-06 1.00000e-09 1.00000e-01

$1.00000 \mathrm{e}+001.00000 \mathrm{e}+001.00000 \mathrm{e}-011.00000 \mathrm{e}-091.00000 \mathrm{e}-01$ 
1.00000e-06 1.00000e-06 1.00000e-06 1.00000e-09 5.00000e-02

Element: 13126 \# of layers: 5

Kx Ky Kz Ss Por

$1.01896 \mathrm{e}+03$ 1.01896e+03 1.01896e+02 1.00000e-09 2.12000e-01

$1.01896 \mathrm{e}+031.01896 \mathrm{e}+03$ 1.01896e+02 1.00000e-09 2.12000e-01

$1.00000 \mathrm{e}-05$ 1.00000e-05 1.00000e-06 1.00000e-09 1.00000e-01

$1.00000 \mathrm{e}+001.00000 \mathrm{e}+001.00000 \mathrm{e}-011.00000 \mathrm{e}-091.00000 \mathrm{e}-01$

1.00000e-06 1.00000e-06 1.00000e-06 1.00000e-09 5.00000e-02

Element: 13127 \# of layers: 5

$\mathrm{Kx} \mathrm{Ky} \mathrm{Kz}$ Ss Por

$1.01896 \mathrm{e}+03$ 1.01896e+03 1.01896e+02 1.00000e-09 2.12000e-01

$1.01896 \mathrm{e}+031.01896 \mathrm{e}+031.01896 \mathrm{e}+02$ 1.00000e-09 2.12000e-01

$1.00000 \mathrm{e}-051.00000 \mathrm{e}-05$ 1.00000e-06 1.00000e-09 1.00000e-01

$1.00000 \mathrm{e}+001.00000 \mathrm{e}+001.00000 \mathrm{e}-011.00000 \mathrm{e}-091.00000 \mathrm{e}-01$

1.00000e-06 1.00000e-06 1.00000e-06 1.00000e-09 5.00000e-02

Element: 13128 \# of layers: 5

$\mathrm{Kx} \mathrm{Ky} \mathrm{Kz}$ Ss Por

$1.01896 \mathrm{e}+031.01896 \mathrm{e}+03$ 1.01896e+02 1.00000e-09 2.12000e-01

$1.01896 \mathrm{e}+031.01896 \mathrm{e}+03$ 1.01896e+02 1.00000e-09 2.12000e-01

$1.00000 \mathrm{e}-05$ 1.00000e-05 1.00000e-06 1.00000e-09 1.00000e-01

$1.00000 \mathrm{e}+001.00000 \mathrm{e}+001.00000 \mathrm{e}-011.00000 \mathrm{e}-091.00000 \mathrm{e}-01$

1.00000e-06 1.00000e-06 1.00000e-06 1.00000e-09 5.00000e-02

Element: 13129 \# of layers: 5

Kx Ky Kz Ss Por

$1.01896 \mathrm{e}+03$ 1.01896e+03 1.01896e+02 1.00000e-09 2.12000e-01

$1.01896 \mathrm{e}+031.01896 \mathrm{e}+03$ 1.01896e+02 1.00000e-09 2.12000e-01

$1.00000 \mathrm{e}-05$ 1.00000e-05 1.00000e-06 1.00000e-09 1.00000e-01

$1.00000 \mathrm{e}+001.00000 \mathrm{e}+001.00000 \mathrm{e}-011.00000 \mathrm{e}-091.00000 \mathrm{e}-01$

1.00000e-06 1.00000e-06 1.00000e-06 1.00000e-09 5.00000e-02

Element: 13130 \# of layers: 5

$\mathrm{Kx} \mathrm{Ky} \mathrm{Kz}$ Ss Por

$1.01896 \mathrm{e}+03$ 1.01896e+03 1.01896e+02 1.00000e-09 2.12000e-01

$1.01896 \mathrm{e}+031.01896 \mathrm{e}+031.01896 \mathrm{e}+02$ 1.00000e-09 2.12000e-01

$1.00000 \mathrm{e}-05$ 1.00000e-05 1.00000e-06 1.00000e-09 1.00000e-01

$1.00000 \mathrm{e}+001.00000 \mathrm{e}+001.00000 \mathrm{e}-011.00000 \mathrm{e}-091.00000 \mathrm{e}-01$

1.00000e-06 1.00000e-06 1.00000e-06 1.00000e-09 5.00000e-02

Element: 13131 \# of layers: 5

Kx Ky Kz Ss Por

$1.01896 \mathrm{e}+03$ 1.01896e+03 1.01896e+02 1.00000e-09 2.12000e-01

$1.01896 \mathrm{e}+031.01896 \mathrm{e}+031.01896 \mathrm{e}+021.00000 \mathrm{e}-092.12000 \mathrm{e}-01$

$1.00000 \mathrm{e}-05$ 1.00000e-05 1.00000e-06 1.00000e-09 1.00000e-01

$1.00000 \mathrm{e}+001.00000 \mathrm{e}+001.00000 \mathrm{e}-011.00000 \mathrm{e}-091.00000 \mathrm{e}-01$

1.00000e-06 1.00000e-06 1.00000e-06 1.00000e-09 5.00000e-02

Element: 13132 \# of layers: 5

$\mathrm{Kx} \mathrm{Ky} \mathrm{Kz}$ Ss Por

$1.01896 \mathrm{e}+03$ 1.01896e+03 1.01896e+02 1.00000e-09 2.12000e-01 
$1.01896 \mathrm{e}+03$ 1.01896e+03 1.01896e+02 1.00000e-09 2.12000e-01 $1.00000 \mathrm{e}-05$ 1.00000e-05 1.00000e-06 1.00000e-09 1.00000e-01 $1.00000 \mathrm{e}+001.00000 \mathrm{e}+001.00000 \mathrm{e}-011.00000 \mathrm{e}-091.00000 \mathrm{e}-01$ 1.00000e-06 1.00000e-06 1.00000e-06 1.00000e-09 5.00000e-02 Element: 13133 \# of layers: 5

$\mathrm{Kx} \mathrm{Ky} \mathrm{Kz}$ Ss Por

$1.01896 \mathrm{e}+03$ 1.01896e+03 1.01896e+02 1.00000e-09 2.12000e-01 $1.01896 \mathrm{e}+03$ 1.01896e+03 1.01896e+02 1.00000e-09 2.12000e-01 $1.00000 \mathrm{e}-051.00000 \mathrm{e}-051.00000 \mathrm{e}-061.00000 \mathrm{e}-091.00000 \mathrm{e}-01$ $1.00000 \mathrm{e}+001.00000 \mathrm{e}+001.00000 \mathrm{e}-01$ 1.00000e-09 1.00000e-01 1.00000e-06 1.00000e-06 1.00000e-06 1.00000e-09 5.00000e-02 Element: 13134 \# of layers: 5

$\mathrm{Kx} \mathrm{Ky} \mathrm{Kz}$ Ss Por

$1.23818 \mathrm{e}+03$ 1.23818e+03 1.23818e+02 1.00000e-09 2.12000e-01 $1.23818 \mathrm{e}+031.23818 \mathrm{e}+03$ 1.23818e+02 1.00000e-09 2.12000e-01 $1.00000 \mathrm{e}-05$ 1.00000e-05 1.00000e-06 1.00000e-09 1.00000e-01 $1.00000 \mathrm{e}+001.00000 \mathrm{e}+001.00000 \mathrm{e}-011.00000 \mathrm{e}-091.00000 \mathrm{e}-01$ 1.00000e-06 1.00000e-06 1.00000e-06 1.00000e-09 5.00000e-02 Element: 13135 \# of layers: 5

$\mathrm{Kx} \mathrm{Ky} \mathrm{Kz}$ Ss Por

$1.23818 \mathrm{e}+03$ 1.23818e+03 1.23818e+02 1.00000e-09 2.12000e-01 $1.23818 \mathrm{e}+031.23818 \mathrm{e}+03$ 1.23818e+02 1.00000e-09 2.12000e-01 $1.00000 \mathrm{e}-051.00000 \mathrm{e}-05$ 1.00000e-06 1.00000e-09 1.00000e-01 $1.00000 \mathrm{e}+001.00000 \mathrm{e}+001.00000 \mathrm{e}-011.00000 \mathrm{e}-091.00000 \mathrm{e}-01$ $1.00000 \mathrm{e}-06$ 1.00000e-06 1.00000e-06 1.00000e-09 5.00000e-02 Element: 13136 \# of layers: 5

Kx Ky Kz Ss Por

$1.23818 \mathrm{e}+03$ 1.23818e+03 1.23818e+02 1.00000e-09 2.12000e-01 $1.23818 \mathrm{e}+03$ 1.23818e+03 1.23818e+02 1.00000e-09 2.12000e-01 $1.00000 \mathrm{e}-05$ 1.00000e-05 1.00000e-06 1.00000e-09 1.00000e-01 $1.00000 \mathrm{e}+001.00000 \mathrm{e}+001.00000 \mathrm{e}-01$ 1.00000e-09 1.00000e-01 1.00000e-06 1.00000e-06 1.00000e-06 1.00000e-09 5.00000e-02 Element: 13137 \# of layers: 5

$\mathrm{Kx} \mathrm{Ky} \mathrm{Kz}$ Ss Por $1.01896 \mathrm{e}+03$ 1.01896e+03 1.01896e+02 1.00000e-09 2.12000e-01 $1.01896 \mathrm{e}+031.01896 \mathrm{e}+03$ 1.01896e+02 1.00000e-09 2.12000e-01 $1.00000 \mathrm{e}-05$ 1.00000e-05 1.00000e-06 1.00000e-09 1.00000e-01 $1.00000 \mathrm{e}+001.00000 \mathrm{e}+001.00000 \mathrm{e}-011.00000 \mathrm{e}-091.00000 \mathrm{e}-01$ 1.00000e-06 1.00000e-06 1.00000e-06 1.00000e-09 5.00000e-02 Element: 13138 \# of layers: 5

Kx Ky Kz Ss Por $1.01896 \mathrm{e}+03$ 1.01896e+03 1.01896e+02 1.00000e-09 2.12000e-01 $1.01896 \mathrm{e}+031.01896 \mathrm{e}+03$ 1.01896e+02 1.00000e-09 2.12000e-01 $1.00000 \mathrm{e}-05$ 1.00000e-05 1.00000e-06 1.00000e-09 1.00000e-01 $1.00000 \mathrm{e}+001.00000 \mathrm{e}+001.00000 \mathrm{e}-011.00000 \mathrm{e}-091.00000 \mathrm{e}-01$ $1.00000 \mathrm{e}-06$ 1.00000e-06 1.00000e-06 1.00000e-09 5.00000e-02 
Element: 13139 \# of layers: 5

Kx Ky Kz Ss Por

$1.01896 \mathrm{e}+031.01896 \mathrm{e}+03$ 1.01896e+02 1.00000e-09 2.12000e-01

$1.01896 \mathrm{e}+031.01896 \mathrm{e}+031.01896 \mathrm{e}+021.00000 \mathrm{e}-092.12000 \mathrm{e}-01$

$1.00000 \mathrm{e}-05$ 1.00000e-05 1.00000e-06 1.00000e-09 1.00000e-01

$1.00000 \mathrm{e}+001.00000 \mathrm{e}+001.00000 \mathrm{e}-011.00000 \mathrm{e}-091.00000 \mathrm{e}-01$

$1.00000 \mathrm{e}-06$ 1.00000e-06 1.00000e-06 1.00000e-09 5.00000e-02

Element: 13140 \# of layers: 5

Kx Ky Kz Ss Por

$1.01896 \mathrm{e}+03$ 1.01896e+03 1.01896e+02 1.00000e-09 2.12000e-01

$1.01896 \mathrm{e}+031.01896 \mathrm{e}+031.01896 \mathrm{e}+021.00000 \mathrm{e}-092.12000 \mathrm{e}-01$

$1.00000 \mathrm{e}-05$ 1.00000e-05 1.00000e-06 1.00000e-09 1.00000e-01

$1.00000 \mathrm{e}+001.00000 \mathrm{e}+001.00000 \mathrm{e}-011.00000 \mathrm{e}-091.00000 \mathrm{e}-01$

$1.00000 \mathrm{e}-06$ 1.00000e-06 1.00000e-06 1.00000e-09 5.00000e-02

Element: 13141 \# of layers: 5

Kx Ky Kz Ss Por

$1.23818 \mathrm{e}+03$ 1.23818e+03 1.23818e+02 1.00000e-09 2.12000e-01

$1.23818 \mathrm{e}+031.23818 \mathrm{e}+03 \quad 1.23818 \mathrm{e}+021.00000 \mathrm{e}-092.12000 \mathrm{e}-01$

$1.00000 \mathrm{e}-05$ 1.00000e-05 1.00000e-06 1.00000e-09 1.00000e-01

$1.00000 \mathrm{e}+001.00000 \mathrm{e}+001.00000 \mathrm{e}-011.00000 \mathrm{e}-091.00000 \mathrm{e}-01$

$1.00000 \mathrm{e}-06$ 1.00000e-06 1.00000e-06 1.00000e-09 5.00000e-02

Element: 13142 \# of layers: 5

Kx Ky Kz Ss Por

$1.23818 \mathrm{e}+03$ 1.23818e+03 1.23818e+02 1.00000e-09 2.12000e-01

$1.23818 \mathrm{e}+03$ 1.23818e+03 1.23818e+02 1.00000e-09 2.12000e-01

$1.00000 \mathrm{e}-05$ 1.00000e-05 1.00000e-06 1.00000e-09 1.00000e-01

$1.00000 \mathrm{e}+001.00000 \mathrm{e}+001.00000 \mathrm{e}-011.00000 \mathrm{e}-091.00000 \mathrm{e}-01$

$1.00000 \mathrm{e}-061.00000 \mathrm{e}-06$ 1.00000e-06 1.00000e-09 5.00000e-02

Element: 13143 \# of layers: 5

Kx Ky Kz Ss Por

$1.23818 \mathrm{e}+03$ 1.23818e+03 1.23818e+02 1.00000e-09 2.12000e-01

$1.23818 \mathrm{e}+03 \quad 1.23818 \mathrm{e}+03 \quad 1.23818 \mathrm{e}+021.00000 \mathrm{e}-092.12000 \mathrm{e}-01$

$1.00000 \mathrm{e}-05$ 1.00000e-05 1.00000e-06 1.00000e-09 1.00000e-01

$1.00000 \mathrm{e}+001.00000 \mathrm{e}+001.00000 \mathrm{e}-011.00000 \mathrm{e}-091.00000 \mathrm{e}-01$

$1.00000 \mathrm{e}-06$ 1.00000e-06 1.00000e-06 1.00000e-09 5.00000e-02

Element: 13144 \# of layers: 5

Kx Ky Kz Ss Por

$1.23818 \mathrm{e}+03$ 1.23818e+03 1.23818e+02 1.00000e-09 2.12000e-01

$1.23818 \mathrm{e}+031.23818 \mathrm{e}+03 \quad 1.23818 \mathrm{e}+021.00000 \mathrm{e}-092.12000 \mathrm{e}-01$

$1.00000 \mathrm{e}-05$ 1.00000e-05 1.00000e-06 1.00000e-09 1.00000e-01

$1.00000 \mathrm{e}+001.00000 \mathrm{e}+001.00000 \mathrm{e}-011.00000 \mathrm{e}-091.00000 \mathrm{e}-01$

$1.00000 \mathrm{e}-06$ 1.00000e-06 1.00000e-06 1.00000e-09 5.00000e-02

Element: 13145 \# of layers: 5

Kx Ky Kz Ss Por

$1.23818 \mathrm{e}+03$ 1.23818e+03 1.23818e+02 1.00000e-09 2.12000e-01

$1.23818 \mathrm{e}+03$ 1.23818e+03 1.23818e+02 1.00000e-09 2.12000e-01 
$1.00000 \mathrm{e}-05$ 1.00000e-05 1.00000e-06 1.00000e-09 1.00000e-01 $1.00000 \mathrm{e}+001.00000 \mathrm{e}+001.00000 \mathrm{e}-011.00000 \mathrm{e}-091.00000 \mathrm{e}-01$ 1.00000e-06 1.00000e-06 1.00000e-06 1.00000e-09 5.00000e-02

Element: 13146 \# of layers: 5

$\mathrm{Kx} \mathrm{Ky} \mathrm{Kz}$ Ss Por

$1.23818 \mathrm{e}+03$ 1.23818e+03 1.23818e+02 1.00000e-09 2.12000e-01

$1.23818 \mathrm{e}+031.23818 \mathrm{e}+03$ 1.23818e+02 1.00000e-09 2.12000e-01

$1.00000 \mathrm{e}-05$ 1.00000e-05 1.00000e-06 1.00000e-09 1.00000e-01

$1.00000 \mathrm{e}+001.00000 \mathrm{e}+001.00000 \mathrm{e}-011.00000 \mathrm{e}-091.00000 \mathrm{e}-01$

1.00000e-06 1.00000e-06 1.00000e-06 1.00000e-09 5.00000e-02

Element: 13147 \# of layers: 5

Kx Ky Kz Ss Por

$1.23818 \mathrm{e}+03$ 1.23818e+03 1.23818e+02 1.00000e-09 2.12000e-01

$1.23818 \mathrm{e}+031.23818 \mathrm{e}+03$ 1.23818e+02 1.00000e-09 2.12000e-01

$1.00000 \mathrm{e}-05$ 1.00000e-05 1.00000e-06 1.00000e-09 1.00000e-01

$1.00000 \mathrm{e}+001.00000 \mathrm{e}+001.00000 \mathrm{e}-011.00000 \mathrm{e}-091.00000 \mathrm{e}-01$

1.00000e-06 1.00000e-06 1.00000e-06 1.00000e-09 5.00000e-02

Element: 13148 \# of layers: 5

$\mathrm{Kx} \mathrm{Ky} \mathrm{Kz}$ Ss Por

$1.23818 \mathrm{e}+03$ 1.23818e+03 1.23818e+02 1.00000e-09 2.12000e-01

$1.23818 \mathrm{e}+031.23818 \mathrm{e}+03 \quad 1.23818 \mathrm{e}+02$ 1.00000e-09 2.12000e-01

$1.00000 \mathrm{e}-05$ 1.00000e-05 1.00000e-06 1.00000e-09 1.00000e-01

$1.00000 \mathrm{e}+001.00000 \mathrm{e}+001.00000 \mathrm{e}-011.00000 \mathrm{e}-091.00000 \mathrm{e}-01$

1.00000e-06 1.00000e-06 1.00000e-06 1.00000e-09 5.00000e-02

Element: 13149 \# of layers: 5

$\mathrm{Kx} \mathrm{Ky} \mathrm{Kz}$ Ss Por

$1.23818 \mathrm{e}+03$ 1.23818e+03 1.23818e+02 1.00000e-09 2.12000e-01

$1.23818 \mathrm{e}+031.23818 \mathrm{e}+03$ 1.23818e+02 1.00000e-09 2.12000e-01

$1.00000 \mathrm{e}-051.00000 \mathrm{e}-05$ 1.00000e-06 1.00000e-09 1.00000e-01

$1.00000 \mathrm{e}+001.00000 \mathrm{e}+001.00000 \mathrm{e}-011.00000 \mathrm{e}-091.00000 \mathrm{e}-01$

1.00000e-06 1.00000e-06 1.00000e-06 1.00000e-09 5.00000e-02

Element: 13150 \# of layers: 5

Kx Ky Kz Ss Por

$1.23818 \mathrm{e}+03$ 1.23818e+03 1.23818e+02 1.00000e-09 2.12000e-01

$1.23818 \mathrm{e}+031.23818 \mathrm{e}+03$ 1.23818e+02 1.00000e-09 2.12000e-01

$1.00000 \mathrm{e}-05$ 1.00000e-05 1.00000e-06 1.00000e-09 1.00000e-01

$1.00000 \mathrm{e}+001.00000 \mathrm{e}+001.00000 \mathrm{e}-011.00000 \mathrm{e}-091.00000 \mathrm{e}-01$

1.00000e-06 1.00000e-06 1.00000e-06 1.00000e-09 5.00000e-02

Element: 13151 \# of layers: 5

$\mathrm{Kx} \mathrm{Ky} \mathrm{Kz}$ Ss Por

$1.23818 \mathrm{e}+03$ 1.23818e+03 1.23818e+02 1.00000e-09 2.12000e-01

$1.23818 \mathrm{e}+03$ 1.23818e+03 1.23818e+02 1.00000e-09 2.12000e-01

$1.00000 \mathrm{e}-051.00000 \mathrm{e}-05$ 1.00000e-06 1.00000e-09 1.00000e-01

$1.00000 \mathrm{e}+001.00000 \mathrm{e}+001.00000 \mathrm{e}-011.00000 \mathrm{e}-091.00000 \mathrm{e}-01$

1.00000e-06 1.00000e-06 1.00000e-06 1.00000e-09 5.00000e-02

Element: 13152 \# of layers: 5 
Kx Ky Kz Ss Por

$1.17891 \mathrm{e}+03$ 1.17891e+03 1.17891e+02 1.00000e-09 2.12000e-01

$1.17891 \mathrm{e}+03$ 1.17891e+03 1.17891e+02 1.00000e-09 2.12000e-01

$1.00000 \mathrm{e}-05$ 1.00000e-05 1.00000e-06 1.00000e-09 1.00000e-01

$1.00000 \mathrm{e}+001.00000 \mathrm{e}+001.00000 \mathrm{e}-011.00000 \mathrm{e}-091.00000 \mathrm{e}-01$

1.00000e-06 1.00000e-06 1.00000e-06 1.00000e-09 5.00000e-02

Element: 13153 \# of layers: 5

Kx Ky Kz Ss Por

1.17891e+03 1.17891e+03 1.17891e+02 1.00000e-09 2.12000e-01

$1.17891 \mathrm{e}+031.17891 \mathrm{e}+03$ 1.17891e+02 1.00000e-09 2.12000e-01

$1.00000 \mathrm{e}-05$ 1.00000e-05 1.00000e-06 1.00000e-09 1.00000e-01

$1.00000 \mathrm{e}+001.00000 \mathrm{e}+001.00000 \mathrm{e}-011.00000 \mathrm{e}-091.00000 \mathrm{e}-01$

1.00000e-06 1.00000e-06 1.00000e-06 1.00000e-09 5.00000e-02

Element: 13154 \# of layers: 5

Kx Ky Kz Ss Por

$1.17891 \mathrm{e}+03$ 1.17891e+03 1.17891e+02 1.00000e-09 2.12000e-01

$1.17891 \mathrm{e}+03$ 1.17891e+03 1.17891e+02 1.00000e-09 2.12000e-01

$1.00000 \mathrm{e}-05$ 1.00000e-05 1.00000e-06 1.00000e-09 1.00000e-01

$1.00000 \mathrm{e}+001.00000 \mathrm{e}+001.00000 \mathrm{e}-011.00000 \mathrm{e}-091.00000 \mathrm{e}-01$

1.00000e-06 1.00000e-06 1.00000e-06 1.00000e-09 5.00000e-02

Element: 13155 \# of layers: 5

$\mathrm{Kx} \mathrm{Ky} \mathrm{Kz}$ Ss Por

$1.23818 \mathrm{e}+03$ 1.23818e+03 1.23818e+02 1.00000e-09 2.12000e-01

$1.23818 \mathrm{e}+031.23818 \mathrm{e}+03$ 1.23818e+02 1.00000e-09 2.12000e-01

$1.00000 \mathrm{e}-05$ 1.00000e-05 1.00000e-06 1.00000e-09 1.00000e-01

$1.00000 \mathrm{e}+001.00000 \mathrm{e}+001.00000 \mathrm{e}-011.00000 \mathrm{e}-091.00000 \mathrm{e}-01$

1.00000e-06 1.00000e-06 1.00000e-06 1.00000e-09 5.00000e-02

Element: 13156 \# of layers: 5

Kx Ky Kz Ss Por

$1.23818 \mathrm{e}+03$ 1.23818e+03 1.23818e+02 1.00000e-09 2.12000e-01

$1.23818 \mathrm{e}+031.23818 \mathrm{e}+03$ 1.23818e+02 1.00000e-09 2.12000e-01

$1.00000 \mathrm{e}-05$ 1.00000e-05 1.00000e-06 1.00000e-09 1.00000e-01

$1.00000 \mathrm{e}+001.00000 \mathrm{e}+001.00000 \mathrm{e}-011.00000 \mathrm{e}-091.00000 \mathrm{e}-01$

1.00000e-06 1.00000e-06 1.00000e-06 1.00000e-09 5.00000e-02

Element: 13157 \# of layers: 5

Kx Ky Kz Ss Por

$1.23818 \mathrm{e}+03$ 1.23818e+03 1.23818e+02 1.00000e-09 2.12000e-01

$1.23818 \mathrm{e}+031.23818 \mathrm{e}+03$ 1.23818e+02 1.00000e-09 2.12000e-01

$1.00000 \mathrm{e}-05$ 1.00000e-05 1.00000e-06 1.00000e-09 1.00000e-01

$1.00000 \mathrm{e}+001.00000 \mathrm{e}+001.00000 \mathrm{e}-011.00000 \mathrm{e}-091.00000 \mathrm{e}-01$

1.00000e-06 1.00000e-06 1.00000e-06 1.00000e-09 5.00000e-02

Element: 13158 \# of layers: 5

$\mathrm{Kx} \mathrm{Ky} \mathrm{Kz}$ Ss Por

$1.23818 \mathrm{e}+03$ 1.23818e+03 1.23818e+02 1.00000e-09 2.12000e-01

$1.23818 \mathrm{e}+03$ 1.23818e+03 1.23818e+02 1.00000e-09 2.12000e-01

$1.00000 \mathrm{e}-05$ 1.00000e-05 1.00000e-06 1.00000e-09 1.00000e-01 
$1.00000 \mathrm{e}+001.00000 \mathrm{e}+001.00000 \mathrm{e}-011.00000 \mathrm{e}-091.00000 \mathrm{e}-01$ 1.00000e-06 1.00000e-06 1.00000e-06 1.00000e-09 5.00000e-02

Element: 13159 \# of layers: 4

Kx Ky Kz Ss Por

$1.17891 \mathrm{e}+031.17891 \mathrm{e}+03$ 1.17891e+02 1.00000e-09 2.12000e-01 $1.00000 \mathrm{e}-05$ 1.00000e-05 1.00000e-06 1.00000e-09 1.00000e-01 $1.00000 \mathrm{e}+001.00000 \mathrm{e}+001.00000 \mathrm{e}-011.00000 \mathrm{e}-091.00000 \mathrm{e}-01$ 1.00000e-06 1.00000e-06 1.00000e-06 1.00000e-09 5.00000e-02

Element: 13160 \# of layers: 4

$\mathrm{Kx} \mathrm{Ky} \mathrm{Kz}$ Ss Por

$1.17891 \mathrm{e}+03$ 1.17891e+03 1.17891e+02 1.00000e-09 2.12000e-01 $1.00000 \mathrm{e}-05$ 1.00000e-05 1.00000e-06 1.00000e-09 1.00000e-01

$1.00000 \mathrm{e}+001.00000 \mathrm{e}+001.00000 \mathrm{e}-011.00000 \mathrm{e}-091.00000 \mathrm{e}-01$ 1.00000e-06 1.00000e-06 1.00000e-06 1.00000e-09 5.00000e-02

Element: 13161 \# of layers: 4

Kx Ky Kz Ss Por

$1.17891 \mathrm{e}+03$ 1.17891e+03 1.17891e+02 1.00000e-09 2.12000e-01 $1.00000 \mathrm{e}-05$ 1.00000e-05 1.00000e-06 1.00000e-09 1.00000e-01 $1.00000 \mathrm{e}+001.00000 \mathrm{e}+001.00000 \mathrm{e}-011.00000 \mathrm{e}-091.00000 \mathrm{e}-01$ 1.00000e-06 1.00000e-06 1.00000e-06 1.00000e-09 5.00000e-02

Element: 13162 \# of layers: 4

$\mathrm{Kx} \mathrm{Ky} \mathrm{Kz}$ Ss Por

$1.17891 \mathrm{e}+03$ 1.17891e+03 1.17891e+02 1.00000e-09 2.12000e-01 $1.00000 \mathrm{e}-05$ 1.00000e-05 1.00000e-06 1.00000e-09 1.00000e-01

$1.00000 \mathrm{e}+001.00000 \mathrm{e}+001.00000 \mathrm{e}-011.00000 \mathrm{e}-091.00000 \mathrm{e}-01$ 1.00000e-06 1.00000e-06 1.00000e-06 1.00000e-09 5.00000e-02

Element: 13163 \# of layers: 4

$\mathrm{Kx} \mathrm{Ky} \mathrm{Kz}$ Ss Por

$1.17891 \mathrm{e}+03$ 1.17891e+03 1.17891e+02 1.00000e-09 2.12000e-01 $1.00000 \mathrm{e}-05$ 1.00000e-05 1.00000e-06 1.00000e-09 1.00000e-01 $1.00000 \mathrm{e}+001.00000 \mathrm{e}+001.00000 \mathrm{e}-01$ 1.00000e-09 1.00000e-01 1.00000e-06 1.00000e-06 1.00000e-06 1.00000e-09 5.00000e-02 Element: 13164 \# of layers: 4

$\mathrm{Kx} \mathrm{Ky} \mathrm{Kz}$ Ss Por

$1.17891 \mathrm{e}+03$ 1.17891e+03 1.17891e+02 1.00000e-09 2.12000e-01 $1.00000 \mathrm{e}-05$ 1.00000e-05 1.00000e-06 1.00000e-09 1.00000e-01 $1.00000 \mathrm{e}+001.00000 \mathrm{e}+001.00000 \mathrm{e}-011.00000 \mathrm{e}-091.00000 \mathrm{e}-01$ $1.00000 \mathrm{e}-06$ 1.00000e-06 1.00000e-06 1.00000e-09 5.00000e-02 Element: 13165 \# of layers: 4

Kx Ky Kz Ss Por

$1.17891 \mathrm{e}+03$ 1.17891e+03 1.17891e+02 1.00000e-09 2.12000e-01 $1.00000 \mathrm{e}-05$ 1.00000e-05 1.00000e-06 1.00000e-09 1.00000e-01 $1.00000 \mathrm{e}+001.00000 \mathrm{e}+001.00000 \mathrm{e}-011.00000 \mathrm{e}-091.00000 \mathrm{e}-01$ 1.00000e-06 1.00000e-06 1.00000e-06 1.00000e-09 5.00000e-02 Element: 13166 \# of layers: 4

Kx Ky Kz Ss Por 
$1.17891 \mathrm{e}+03$ 1.17891e+03 1.17891e+02 1.00000e-09 2.12000e-01 $1.00000 \mathrm{e}-05$ 1.00000e-05 1.00000e-06 1.00000e-09 1.00000e-01 $1.00000 \mathrm{e}+001.00000 \mathrm{e}+001.00000 \mathrm{e}-011.00000 \mathrm{e}-091.00000 \mathrm{e}-01$ 1.00000e-06 1.00000e-06 1.00000e-06 1.00000e-09 5.00000e-02 Element: 13167 \# of layers: 4

Kx Ky Kz Ss Por

$1.17891 \mathrm{e}+03$ 1.17891e+03 1.17891e+02 1.00000e-09 2.12000e-01 $1.00000 \mathrm{e}-05$ 1.00000e-05 1.00000e-06 1.00000e-09 1.00000e-01 $1.00000 \mathrm{e}+001.00000 \mathrm{e}+001.00000 \mathrm{e}-011.00000 \mathrm{e}-091.00000 \mathrm{e}-01$ 1.00000e-06 1.00000e-06 1.00000e-06 1.00000e-09 5.00000e-02 Element: 13168 \# of layers: 5

Kx Ky Kz Ss Por

$1.17891 \mathrm{e}+03$ 1.17891e+03 1.17891e+02 1.00000e-09 2.12000e-01 $1.17891 \mathrm{e}+03$ 1.17891e+03 1.17891e+02 1.00000e-09 2.12000e-01 $1.00000 \mathrm{e}-05$ 1.00000e-05 1.00000e-06 1.00000e-09 1.00000e-01 $1.00000 \mathrm{e}+001.00000 \mathrm{e}+001.00000 \mathrm{e}-011.00000 \mathrm{e}-091.00000 \mathrm{e}-01$ 1.00000e-06 1.00000e-06 1.00000e-06 1.00000e-09 5.00000e-02 Element: 13169 \# of layers: 5

$\mathrm{Kx} \mathrm{Ky} \mathrm{Kz}$ Ss Por

$2.44580 \mathrm{e}+02$ 2.44580e+02 2.44580e+01 1.00000e-09 2.12000e-01 $2.44580 \mathrm{e}+02$ 2.44580e+02 2.44580e+01 1.00000e-09 2.12000e-01 $1.00000 \mathrm{e}-05$ 1.00000e-05 1.00000e-06 1.00000e-09 1.00000e-01 $1.00000 \mathrm{e}+001.00000 \mathrm{e}+001.00000 \mathrm{e}-011.00000 \mathrm{e}-091.00000 \mathrm{e}-01$ 1.00000e-06 1.00000e-06 1.00000e-06 1.00000e-09 5.00000e-02

Element: 13170 \# of layers: 5

$\mathrm{Kx} \mathrm{Ky} \mathrm{Kz}$ Ss Por

$2.44580 \mathrm{e}+02$ 2.44580e+02 2.44580e+01 1.00000e-09 2.12000e-01 $2.44580 \mathrm{e}+02$ 2.44580e+02 2.44580e+01 1.00000e-09 2.12000e-01 $1.00000 \mathrm{e}-051.00000 \mathrm{e}-05$ 1.00000e-06 1.00000e-09 1.00000e-01 $1.00000 \mathrm{e}+001.00000 \mathrm{e}+001.00000 \mathrm{e}-011.00000 \mathrm{e}-091.00000 \mathrm{e}-01$ 1.00000e-06 1.00000e-06 1.00000e-06 1.00000e-09 5.00000e-02 Element: 13171 \# of layers: 5

Kx Ky Kz Ss Por

$2.44580 \mathrm{e}+02$ 2.44580e+02 2.44580e+01 1.00000e-09 2.12000e-01

$2.44580 \mathrm{e}+022.44580 \mathrm{e}+02$ 2.44580e+01 1.00000e-09 2.12000e-01 $1.00000 \mathrm{e}-05$ 1.00000e-05 1.00000e-06 1.00000e-09 1.00000e-01 $1.00000 \mathrm{e}+001.00000 \mathrm{e}+001.00000 \mathrm{e}-011.00000 \mathrm{e}-091.00000 \mathrm{e}-01$ 1.00000e-06 1.00000e-06 1.00000e-06 1.00000e-09 5.00000e-02 Element: 13172 \# of layers: 5

$\mathrm{Kx} \mathrm{Ky} \mathrm{Kz}$ Ss Por

$2.44580 \mathrm{e}+02$ 2.44580e+02 2.44580e+01 1.00000e-09 2.12000e-01 $2.44580 \mathrm{e}+02$ 2.44580e+02 2.44580e+01 1.00000e-09 2.12000e-01 $1.00000 \mathrm{e}-05$ 1.00000e-05 1.00000e-06 1.00000e-09 1.00000e-01 $1.00000 \mathrm{e}+001.00000 \mathrm{e}+001.00000 \mathrm{e}-011.00000 \mathrm{e}-091.00000 \mathrm{e}-01$ 1.00000e-06 1.00000e-06 1.00000e-06 1.00000e-09 5.00000e-02 Element: 13173 \# of layers: 4 
$\mathrm{Kx} \mathrm{Ky} \mathrm{Kz} \mathrm{Ss} \mathrm{Por}$

$2.44580 \mathrm{e}+02$ 2.44580e+02 2.44580e+01 1.00000e-09 2.12000e-01 $1.00000 \mathrm{e}-05$ 1.00000e-05 1.00000e-06 1.00000e-09 1.00000e-01

$1.00000 \mathrm{e}+001.00000 \mathrm{e}+001.00000 \mathrm{e}-011.00000 \mathrm{e}-091.00000 \mathrm{e}-01$ 1.00000e-06 1.00000e-06 1.00000e-06 1.00000e-09 5.00000e-02

Element: 13174 \# of layers: 4

$\mathrm{Kx} \mathrm{Ky} \mathrm{Kz}$ Ss Por

$1.17891 \mathrm{e}+03$ 1.17891e+03 1.17891e+02 1.00000e-09 2.12000e-01 $1.00000 \mathrm{e}-05$ 1.00000e-05 1.00000e-06 1.00000e-09 1.00000e-01

$1.00000 \mathrm{e}+001.00000 \mathrm{e}+001.00000 \mathrm{e}-01$ 1.00000e-09 1.00000e-01 1.00000e-06 1.00000e-06 1.00000e-06 1.00000e-09 5.00000e-02

Element: 13175 \# of layers: 4

Kx Ky Kz Ss Por

$1.17891 \mathrm{e}+031.17891 \mathrm{e}+03$ 1.17891e+02 1.00000e-09 2.12000e-01 $1.00000 \mathrm{e}-051.00000 \mathrm{e}-051.00000 \mathrm{e}-061.00000 \mathrm{e}-091.00000 \mathrm{e}-01$

$1.00000 \mathrm{e}+001.00000 \mathrm{e}+001.00000 \mathrm{e}-011.00000 \mathrm{e}-091.00000 \mathrm{e}-01$

1.00000e-06 1.00000e-06 1.00000e-06 1.00000e-09 5.00000e-02

Element: 13176 \# of layers: 5

$\mathrm{Kx} \mathrm{Ky} \mathrm{Kz}$ Ss Por

$2.44580 \mathrm{e}+02$ 2.44580e+02 2.44580e+01 1.00000e-09 2.12000e-01

$2.44580 \mathrm{e}+02$ 2.44580e+02 2.44580e+01 1.00000e-09 2.12000e-01

$1.00000 \mathrm{e}-05$ 1.00000e-05 1.00000e-06 1.00000e-09 1.00000e-01

$1.00000 \mathrm{e}+001.00000 \mathrm{e}+001.00000 \mathrm{e}-011.00000 \mathrm{e}-091.00000 \mathrm{e}-01$

1.00000e-06 1.00000e-06 1.00000e-06 1.00000e-09 5.00000e-02

Element: 13177 \# of layers: 5

$\mathrm{Kx} \mathrm{Ky} \mathrm{Kz}$ Ss Por

$2.44580 \mathrm{e}+02$ 2.44580e+02 2.44580e+01 1.00000e-09 2.12000e-01

$2.44580 \mathrm{e}+02$ 2.44580e+02 2.44580e+01 1.00000e-09 2.12000e-01

$1.00000 \mathrm{e}-05$ 1.00000e-05 1.00000e-06 1.00000e-09 1.00000e-01

$1.00000 \mathrm{e}+001.00000 \mathrm{e}+001.00000 \mathrm{e}-011.00000 \mathrm{e}-091.00000 \mathrm{e}-01$

1.00000e-06 1.00000e-06 1.00000e-06 1.00000e-09 5.00000e-02

Element: 13178 \# of layers: 5

Kx Ky Kz Ss Por

$1.01896 \mathrm{e}+03$ 1.01896e+03 1.01896e+02 1.00000e-09 2.12000e-01

$1.01896 \mathrm{e}+031.01896 \mathrm{e}+03$ 1.01896e+02 1.00000e-09 2.12000e-01

$1.00000 \mathrm{e}-05$ 1.00000e-05 1.00000e-06 1.00000e-09 1.00000e-01

$1.00000 \mathrm{e}+001.00000 \mathrm{e}+001.00000 \mathrm{e}-011.00000 \mathrm{e}-091.00000 \mathrm{e}-01$

1.00000e-06 1.00000e-06 1.00000e-06 1.00000e-09 5.00000e-02

Element: 13179 \# of layers: 6

$\mathrm{Kx} \mathrm{Ky} \mathrm{Kz}$ Ss Por

$1.01896 \mathrm{e}+03$ 1.01896e+03 1.01896e+02 1.00000e-09 2.12000e-01

$1.01896 \mathrm{e}+031.01896 \mathrm{e}+03$ 1.01896e+02 1.00000e-09 2.12000e-01

$1.01896 \mathrm{e}+031.01896 \mathrm{e}+03$ 1.01896e+02 1.00000e-09 2.12000e-01

$1.00000 \mathrm{e}-051.00000 \mathrm{e}-05$ 1.00000e-06 1.00000e-09 1.00000e-01

$1.00000 \mathrm{e}+001.00000 \mathrm{e}+001.00000 \mathrm{e}-011.00000 \mathrm{e}-091.00000 \mathrm{e}-01$

$1.00000 \mathrm{e}-06$ 1.00000e-06 1.00000e-06 1.00000e-09 5.00000e-02 
Element: 13180 \# of layers: 6

Kx Ky Kz Ss Por

$1.01896 \mathrm{e}+031.01896 \mathrm{e}+03$ 1.01896e+02 1.00000e-09 2.12000e-01

$1.01896 \mathrm{e}+031.01896 \mathrm{e}+031.01896 \mathrm{e}+021.00000 \mathrm{e}-092.12000 \mathrm{e}-01$

$1.01896 \mathrm{e}+031.01896 \mathrm{e}+031.01896 \mathrm{e}+021.00000 \mathrm{e}-092.12000 \mathrm{e}-01$

$1.00000 \mathrm{e}-05$ 1.00000e-05 1.00000e-06 1.00000e-09 1.00000e-01

$1.00000 \mathrm{e}+001.00000 \mathrm{e}+001.00000 \mathrm{e}-011.00000 \mathrm{e}-091.00000 \mathrm{e}-01$

$1.00000 \mathrm{e}-06$ 1.00000e-06 1.00000e-06 1.00000e-09 5.00000e-02

Element: 13181 \# of layers: 6

Kx Ky Kz Ss Por

$1.23818 \mathrm{e}+03$ 1.23818e+03 1.23818e+02 1.00000e-09 2.12000e-01

$1.23818 \mathrm{e}+03 \quad 1.23818 \mathrm{e}+03 \quad 1.23818 \mathrm{e}+02$ 1.00000e-09 2.12000e-01

$1.23818 \mathrm{e}+03 \quad 1.23818 \mathrm{e}+03 \quad 1.23818 \mathrm{e}+021.00000 \mathrm{e}-092.12000 \mathrm{e}-01$

$1.00000 \mathrm{e}-05$ 1.00000e-05 1.00000e-06 1.00000e-09 1.00000e-01

$1.00000 \mathrm{e}+001.00000 \mathrm{e}+001.00000 \mathrm{e}-011.00000 \mathrm{e}-091.00000 \mathrm{e}-01$

$1.00000 \mathrm{e}-06$ 1.00000e-06 1.00000e-06 1.00000e-09 5.00000e-02

Element: 13182 \# of layers: 6

Kx Ky Kz Ss Por

$1.23818 \mathrm{e}+03$ 1.23818e+03 1.23818e+02 1.00000e-09 2.12000e-01

$1.23818 \mathrm{e}+031.23818 \mathrm{e}+03 \quad 1.23818 \mathrm{e}+021.00000 \mathrm{e}-092.12000 \mathrm{e}-01$

$1.23818 \mathrm{e}+03 \quad 1.23818 \mathrm{e}+03 \quad 1.23818 \mathrm{e}+021.00000 \mathrm{e}-092.12000 \mathrm{e}-01$

$1.00000 \mathrm{e}-05$ 1.00000e-05 1.00000e-06 1.00000e-09 1.00000e-01

$1.00000 \mathrm{e}+001.00000 \mathrm{e}+001.00000 \mathrm{e}-011.00000 \mathrm{e}-091.00000 \mathrm{e}-01$

$1.00000 \mathrm{e}-06$ 1.00000e-06 1.00000e-06 1.00000e-09 5.00000e-02

Element: 13183 \# of layers: 6

Kx Ky Kz Ss Por

$1.17891 \mathrm{e}+03$ 1.17891e+03 1.17891e+02 1.00000e-09 2.12000e-01

$1.17891 \mathrm{e}+031.17891 \mathrm{e}+031.17891 \mathrm{e}+021.00000 \mathrm{e}-092.12000 \mathrm{e}-01$

$1.17891 \mathrm{e}+03$ 1.17891e+03 1.17891e+02 1.00000e-09 2.12000e-01

$1.00000 \mathrm{e}-05$ 1.00000e-05 1.00000e-06 1.00000e-09 1.00000e-01

$1.00000 \mathrm{e}+001.00000 \mathrm{e}+001.00000 \mathrm{e}-011.00000 \mathrm{e}-091.00000 \mathrm{e}-01$

$1.00000 \mathrm{e}-06$ 1.00000e-06 1.00000e-06 1.00000e-09 5.00000e-02

Element: 13184 \# of layers: 5

Kx Ky Kz Ss Por

$2.44580 \mathrm{e}+022.44580 \mathrm{e}+022.44580 \mathrm{e}+01$ 1.00000e-09 2.12000e-01

$2.44580 \mathrm{e}+02 \quad 2.44580 \mathrm{e}+022.44580 \mathrm{e}+011.00000 \mathrm{e}-092.12000 \mathrm{e}-01$

$1.00000 \mathrm{e}-05$ 1.00000e-05 1.00000e-06 1.00000e-09 1.00000e-01

$1.00000 \mathrm{e}+001.00000 \mathrm{e}+001.00000 \mathrm{e}-011.00000 \mathrm{e}-091.00000 \mathrm{e}-01$

$1.00000 \mathrm{e}-06$ 1.00000e-06 1.00000e-06 1.00000e-09 5.00000e-02

Element: 13185 \# of layers: 5

Kx Ky Kz Ss Por

$1.01896 \mathrm{e}+031.01896 \mathrm{e}+03$ 1.01896e+02 1.00000e-09 2.12000e-01 $1.01896 \mathrm{e}+031.01896 \mathrm{e}+031.01896 \mathrm{e}+021.00000 \mathrm{e}-092.12000 \mathrm{e}-01$ $1.00000 \mathrm{e}-05$ 1.00000e-05 1.00000e-06 1.00000e-09 1.00000e-01 $1.00000 \mathrm{e}+001.00000 \mathrm{e}+001.00000 \mathrm{e}-011.00000 \mathrm{e}-091.00000 \mathrm{e}-01$ $1.00000 \mathrm{e}-06$ 1.00000e-06 1.00000e-06 1.00000e-09 5.00000e-02 
Element: 13186 \# of layers: 5

Kx Ky Kz Ss Por

$1.96166 \mathrm{e}+021.96166 \mathrm{e}+021.96166 \mathrm{e}+011.00000 \mathrm{e}-092.12000 \mathrm{e}-01$

$1.96166 \mathrm{e}+021.96166 \mathrm{e}+021.96166 \mathrm{e}+011.00000 \mathrm{e}-092.12000 \mathrm{e}-01$

$1.00000 \mathrm{e}-05$ 1.00000e-05 1.00000e-06 1.00000e-09 1.00000e-01

$1.00000 \mathrm{e}+001.00000 \mathrm{e}+001.00000 \mathrm{e}-011.00000 \mathrm{e}-091.00000 \mathrm{e}-01$

$1.00000 \mathrm{e}-06$ 1.00000e-06 1.00000e-06 1.00000e-09 5.00000e-02

Element: 13187 \# of layers: 5

$\mathrm{Kx} \mathrm{Ky} \mathrm{Kz}$ Ss Por

$1.96166 \mathrm{e}+021.96166 \mathrm{e}+021.96166 \mathrm{e}+011.00000 \mathrm{e}-092.12000 \mathrm{e}-01$

$1.96166 \mathrm{e}+021.96166 \mathrm{e}+021.96166 \mathrm{e}+011.00000 \mathrm{e}-092.12000 \mathrm{e}-01$

$1.00000 \mathrm{e}-05$ 1.00000e-05 1.00000e-06 1.00000e-09 1.00000e-01

$1.00000 \mathrm{e}+001.00000 \mathrm{e}+001.00000 \mathrm{e}-011.00000 \mathrm{e}-091.00000 \mathrm{e}-01$

$1.00000 \mathrm{e}-06$ 1.00000e-06 1.00000e-06 1.00000e-09 5.00000e-02

Element: 13188 \# of layers: 5

Kx Ky Kz Ss Por

$1.96166 \mathrm{e}+021.96166 \mathrm{e}+021.96166 \mathrm{e}+011.00000 \mathrm{e}-092.12000 \mathrm{e}-01$

$1.96166 \mathrm{e}+021.96166 \mathrm{e}+021.96166 \mathrm{e}+011.00000 \mathrm{e}-092.12000 \mathrm{e}-01$

$1.00000 \mathrm{e}-05$ 1.00000e-05 1.00000e-06 1.00000e-09 1.00000e-01

$1.00000 \mathrm{e}+001.00000 \mathrm{e}+001.00000 \mathrm{e}-011.00000 \mathrm{e}-091.00000 \mathrm{e}-01$

$1.00000 \mathrm{e}-06$ 1.00000e-06 1.00000e-06 1.00000e-09 5.00000e-02

Element: 13189 \# of layers: 5

Kx Ky Kz Ss Por

$1.96166 \mathrm{e}+021.96166 \mathrm{e}+021.96166 \mathrm{e}+011.00000 \mathrm{e}-092.12000 \mathrm{e}-01$

$1.96166 \mathrm{e}+021.96166 \mathrm{e}+021.96166 \mathrm{e}+011.00000 \mathrm{e}-092.12000 \mathrm{e}-01$

$1.00000 \mathrm{e}-05$ 1.00000e-05 1.00000e-06 1.00000e-09 1.00000e-01

$1.00000 \mathrm{e}+001.00000 \mathrm{e}+001.00000 \mathrm{e}-011.00000 \mathrm{e}-091.00000 \mathrm{e}-01$

$1.00000 \mathrm{e}-06$ 1.00000e-06 1.00000e-06 1.00000e-09 5.00000e-02

Element: 13190 \# of layers: 6

Kx Ky Kz Ss Por

$4.90946 \mathrm{e}+03$ 4.90946e+03 4.90946e+02 1.00000e-09 7.00000e-02

$1.96166 \mathrm{e}+021.96166 \mathrm{e}+021.96166 \mathrm{e}+011.00000 \mathrm{e}-092.12000 \mathrm{e}-01$

$1.96166 \mathrm{e}+021.96166 \mathrm{e}+021.96166 \mathrm{e}+011.00000 \mathrm{e}-092.12000 \mathrm{e}-01$

$1.00000 \mathrm{e}-05$ 1.00000e-05 1.00000e-06 1.00000e-09 1.00000e-01

$1.00000 \mathrm{e}+001.00000 \mathrm{e}+001.00000 \mathrm{e}-011.00000 \mathrm{e}-091.00000 \mathrm{e}-01$

$1.00000 \mathrm{e}-06$ 1.00000e-06 1.00000e-06 1.00000e-09 5.00000e-02

Element: 13191 \# of layers: 5

Kx Ky Kz Ss Por

$1.96166 \mathrm{e}+021.96166 \mathrm{e}+021.96166 \mathrm{e}+01$ 1.00000e-09 2.12000e-01

$1.96166 \mathrm{e}+021.96166 \mathrm{e}+021.96166 \mathrm{e}+011.00000 \mathrm{e}-092.12000 \mathrm{e}-01$

$1.00000 \mathrm{e}-05$ 1.00000e-05 1.00000e-06 1.00000e-09 1.00000e-01

$1.00000 \mathrm{e}+001.00000 \mathrm{e}+001.00000 \mathrm{e}-011.00000 \mathrm{e}-091.00000 \mathrm{e}-01$

$1.00000 \mathrm{e}-06$ 1.00000e-06 1.00000e-06 1.00000e-09 5.00000e-02

Element: 13192 \# of layers: 5

Kx Ky Kz Ss Por

$1.96166 \mathrm{e}+021.96166 \mathrm{e}+021.96166 \mathrm{e}+01$ 1.00000e-09 2.12000e-01 
$1.96166 \mathrm{e}+02$ 1.96166e+02 1.96166e+01 1.00000e-09 2.12000e-01 $1.00000 \mathrm{e}-05$ 1.00000e-05 1.00000e-06 1.00000e-09 1.00000e-01 $1.00000 \mathrm{e}+001.00000 \mathrm{e}+001.00000 \mathrm{e}-011.00000 \mathrm{e}-091.00000 \mathrm{e}-01$ 1.00000e-06 1.00000e-06 1.00000e-06 1.00000e-09 5.00000e-02 Element: 13193 \# of layers: 5

$\mathrm{Kx} \mathrm{Ky} \mathrm{Kz}$ Ss Por

$1.96166 \mathrm{e}+02$ 1.96166e+02 1.96166e+01 1.00000e-09 2.12000e-01 $1.96166 \mathrm{e}+02$ 1.96166e+02 1.96166e+01 1.00000e-09 2.12000e-01 $1.00000 \mathrm{e}-051.00000 \mathrm{e}-051.00000 \mathrm{e}-061.00000 \mathrm{e}-091.00000 \mathrm{e}-01$ $1.00000 \mathrm{e}+001.00000 \mathrm{e}+001.00000 \mathrm{e}-01$ 1.00000e-09 1.00000e-01 1.00000e-06 1.00000e-06 1.00000e-06 1.00000e-09 5.00000e-02

Element: 13194 \# of layers: 5

$\mathrm{Kx} \mathrm{Ky} \mathrm{Kz}$ Ss Por

$1.96166 \mathrm{e}+02$ 1.96166e+02 1.96166e+01 1.00000e-09 2.12000e-01 $1.96166 \mathrm{e}+021.96166 \mathrm{e}+021.96166 \mathrm{e}+01$ 1.00000e-09 2.12000e-01 1.00000e-05 1.00000e-05 1.00000e-06 1.00000e-09 1.00000e-01 $1.00000 \mathrm{e}+001.00000 \mathrm{e}+001.00000 \mathrm{e}-011.00000 \mathrm{e}-091.00000 \mathrm{e}-01$ 1.00000e-06 1.00000e-06 1.00000e-06 1.00000e-09 5.00000e-02 Element: 13195 \# of layers: 5

Kx Ky Kz Ss Por

$1.64324 \mathrm{e}+03$ 1.64324e+03 1.64324e+02 1.00000e-09 7.00000e-02 6.56587e+01 6.56587e+01 6.56587e+00 1.00000e-09 2.12000e-01 $1.00000 \mathrm{e}-05$ 1.00000e-05 1.00000e-06 1.00000e-09 1.00000e-01 $1.00000 \mathrm{e}+001.00000 \mathrm{e}+001.00000 \mathrm{e}-011.00000 \mathrm{e}-091.00000 \mathrm{e}-01$ $1.00000 \mathrm{e}-06$ 1.00000e-06 1.00000e-06 1.00000e-09 5.00000e-02 Element: 13196 \# of layers: 6

$\mathrm{Kx} \mathrm{Ky} \mathrm{Kz}$ Ss Por 4.90946e+03 4.90946e+03 4.90946e+02 1.00000e-09 7.00000e-02 $4.90946 \mathrm{e}+03$ 4.90946e+03 4.90946e+02 1.00000e-09 7.00000e-02 $1.96166 \mathrm{e}+02$ 1.96166e+02 1.96166e+01 1.00000e-09 2.12000e-01 $1.00000 \mathrm{e}-05$ 1.00000e-05 1.00000e-06 1.00000e-09 1.00000e-01 $1.00000 \mathrm{e}+001.00000 \mathrm{e}+001.00000 \mathrm{e}-011.00000 \mathrm{e}-091.00000 \mathrm{e}-01$ $1.00000 \mathrm{e}-06$ 1.00000e-06 1.00000e-06 1.00000e-09 5.00000e-02 Element: 13197 \# of layers: 5

$\mathrm{Kx} \mathrm{Ky} \mathrm{Kz}$ Ss Por

4.90946e+03 4.90946e+03 4.90946e+02 1.00000e-09 7.00000e-02 $1.96166 \mathrm{e}+021.96166 \mathrm{e}+021.96166 \mathrm{e}+01$ 1.00000e-09 2.12000e-01 $1.00000 \mathrm{e}-05$ 1.00000e-05 1.00000e-06 1.00000e-09 1.00000e-01 $1.00000 \mathrm{e}+001.00000 \mathrm{e}+001.00000 \mathrm{e}-011.00000 \mathrm{e}-091.00000 \mathrm{e}-01$ 1.00000e-06 1.00000e-06 1.00000e-06 1.00000e-09 5.00000e-02 Element: 13198 \# of layers: 6

$\mathrm{Kx} \mathrm{Ky} \mathrm{Kz}$ Ss Por $1.64324 \mathrm{e}+031.64324 \mathrm{e}+03$ 1.64324e+02 1.00000e-09 7.00000e-02 $1.64324 \mathrm{e}+031.64324 \mathrm{e}+03$ 1.64324e+02 1.00000e-09 7.00000e-02 $6.56587 \mathrm{e}+016.56587 \mathrm{e}+016.56587 \mathrm{e}+00$ 1.00000e-09 2.12000e-01 $1.00000 \mathrm{e}-05$ 1.00000e-05 1.00000e-06 1.00000e-09 1.00000e-01 
$1.00000 \mathrm{e}+001.00000 \mathrm{e}+001.00000 \mathrm{e}-011.00000 \mathrm{e}-091.00000 \mathrm{e}-01$ 1.00000e-06 1.00000e-06 1.00000e-06 1.00000e-09 5.00000e-02

Element: 13199 \# of layers: 5

Kx Ky Kz Ss Por

$1.64324 \mathrm{e}+031.64324 \mathrm{e}+03$ 1.64324e+02 1.00000e-09 7.00000e-02

$6.56587 \mathrm{e}+016.56587 \mathrm{e}+016.56587 \mathrm{e}+00$ 1.00000e-09 2.12000e-01

$1.00000 \mathrm{e}-05$ 1.00000e-05 1.00000e-06 1.00000e-09 1.00000e-01

$1.00000 \mathrm{e}+001.00000 \mathrm{e}+001.00000 \mathrm{e}-011.00000 \mathrm{e}-091.00000 \mathrm{e}-01$

$1.00000 \mathrm{e}-06$ 1.00000e-06 1.00000e-06 1.00000e-09 5.00000e-02

Element: 13200 \# of layers: 6

$\mathrm{Kx} \mathrm{Ky} \mathrm{Kz}$ Ss Por

3.09187e+03 3.09187e+03 3.09187e+02 1.00000e-09 7.00000e-02

$1.23541 \mathrm{e}+02$ 1.23541e+02 1.23541e+01 1.00000e-09 2.12000e-01

$1.23541 \mathrm{e}+021.23541 \mathrm{e}+02$ 1.23541e+01 1.00000e-09 2.12000e-01

$1.00000 \mathrm{e}-05$ 1.00000e-05 1.00000e-06 1.00000e-09 1.00000e-01

$1.00000 \mathrm{e}+001.00000 \mathrm{e}+001.00000 \mathrm{e}-011.00000 \mathrm{e}-091.00000 \mathrm{e}-01$

1.00000e-06 1.00000e-06 1.00000e-06 1.00000e-09 5.00000e-02

Element: 13201 \# of layers: 5

$\mathrm{Kx} \mathrm{Ky} \mathrm{Kz}$ Ss Por

$1.23541 \mathrm{e}+02$ 1.23541e+02 1.23541e+01 1.00000e-09 2.12000e-01

$1.23541 \mathrm{e}+021.23541 \mathrm{e}+02$ 1.23541e+01 1.00000e-09 2.12000e-01

$1.00000 \mathrm{e}-05$ 1.00000e-05 1.00000e-06 1.00000e-09 1.00000e-01

$1.00000 \mathrm{e}+001.00000 \mathrm{e}+001.00000 \mathrm{e}-011.00000 \mathrm{e}-091.00000 \mathrm{e}-01$

1.00000e-06 1.00000e-06 1.00000e-06 1.00000e-09 5.00000e-02

Element: 13202 \# of layers: 5

$\mathrm{Kx} \mathrm{Ky} \mathrm{Kz}$ Ss Por

$1.23541 \mathrm{e}+02$ 1.23541e+02 1.23541e+01 1.00000e-09 2.12000e-01

$1.23541 \mathrm{e}+021.23541 \mathrm{e}+021.23541 \mathrm{e}+01$ 1.00000e-09 2.12000e-01

$1.00000 \mathrm{e}-05$ 1.00000e-05 1.00000e-06 1.00000e-09 1.00000e-01

$1.00000 \mathrm{e}+001.00000 \mathrm{e}+001.00000 \mathrm{e}-011.00000 \mathrm{e}-091.00000 \mathrm{e}-01$

1.00000e-06 1.00000e-06 1.00000e-06 1.00000e-09 5.00000e-02

Element: 13203 \# of layers: 5

Kx Ky Kz Ss Por

$1.23541 \mathrm{e}+02$ 1.23541e+02 1.23541e+01 1.00000e-09 2.12000e-01

$1.23541 \mathrm{e}+021.23541 \mathrm{e}+02$ 1.23541e+01 1.00000e-09 2.12000e-01

$1.00000 \mathrm{e}-05$ 1.00000e-05 1.00000e-06 1.00000e-09 1.00000e-01

$1.00000 \mathrm{e}+001.00000 \mathrm{e}+001.00000 \mathrm{e}-011.00000 \mathrm{e}-091.00000 \mathrm{e}-01$

1.00000e-06 1.00000e-06 1.00000e-06 1.00000e-09 5.00000e-02

Element: 13204 \# of layers: 6

Kx Ky Kz Ss Por

3.09187e+03 3.09187e+03 3.09187e+02 1.00000e-09 7.00000e-02

$1.23541 \mathrm{e}+021.23541 \mathrm{e}+02$ 1.23541e+01 1.00000e-09 2.12000e-01

$1.23541 \mathrm{e}+021.23541 \mathrm{e}+021.23541 \mathrm{e}+01$ 1.00000e-09 2.12000e-01

$1.00000 \mathrm{e}-05$ 1.00000e-05 1.00000e-06 1.00000e-09 1.00000e-01

$1.00000 \mathrm{e}+001.00000 \mathrm{e}+001.00000 \mathrm{e}-011.00000 \mathrm{e}-091.00000 \mathrm{e}-01$

$1.00000 \mathrm{e}-06$ 1.00000e-06 1.00000e-06 1.00000e-09 5.00000e-02 
Element: 13205 \# of layers: 5

$\mathrm{Kx} \mathrm{Ky} \mathrm{Kz}$ Ss Por

$1.23541 \mathrm{e}+021.23541 \mathrm{e}+02$ 1.23541e+01 1.00000e-09 2.12000e-01

$1.23541 \mathrm{e}+021.23541 \mathrm{e}+021.23541 \mathrm{e}+01$ 1.00000e-09 2.12000e-01

$1.00000 \mathrm{e}-05$ 1.00000e-05 1.00000e-06 1.00000e-09 1.00000e-01

$1.00000 \mathrm{e}+001.00000 \mathrm{e}+001.00000 \mathrm{e}-011.00000 \mathrm{e}-091.00000 \mathrm{e}-01$

1.00000e-06 1.00000e-06 1.00000e-06 1.00000e-09 5.00000e-02

Element: 13206 \# of layers: 5

$\mathrm{Kx} \mathrm{Ky} \mathrm{Kz}$ Ss Por

$1.96166 \mathrm{e}+02$ 1.96166e+02 1.96166e+01 1.00000e-09 2.12000e-01

$1.96166 \mathrm{e}+02$ 1.96166e+02 1.96166e+01 1.00000e-09 2.12000e-01

$1.00000 \mathrm{e}-05$ 1.00000e-05 1.00000e-06 1.00000e-09 1.00000e-01

$1.00000 \mathrm{e}+001.00000 \mathrm{e}+001.00000 \mathrm{e}-011.00000 \mathrm{e}-091.00000 \mathrm{e}-01$

1.00000e-06 1.00000e-06 1.00000e-06 1.00000e-09 5.00000e-02

Element: 13207 \# of layers: 5

Kx Ky Kz Ss Por

$1.96166 \mathrm{e}+02$ 1.96166e+02 1.96166e+01 1.00000e-09 2.12000e-01

$1.96166 \mathrm{e}+021.96166 \mathrm{e}+02$ 1.96166e+01 1.00000e-09 2.12000e-01

$1.00000 \mathrm{e}-05$ 1.00000e-05 1.00000e-06 1.00000e-09 1.00000e-01

$1.00000 \mathrm{e}+001.00000 \mathrm{e}+001.00000 \mathrm{e}-011.00000 \mathrm{e}-091.00000 \mathrm{e}-01$

1.00000e-06 1.00000e-06 1.00000e-06 1.00000e-09 5.00000e-02

Element: 13208 \# of layers: 5

$\mathrm{Kx} \mathrm{Ky} \mathrm{Kz}$ Ss Por

$1.96166 \mathrm{e}+02$ 1.96166e+02 1.96166e+01 1.00000e-09 2.12000e-01

$1.96166 \mathrm{e}+02$ 1.96166e+02 1.96166e+01 1.00000e-09 2.12000e-01

$1.00000 \mathrm{e}-05$ 1.00000e-05 1.00000e-06 1.00000e-09 1.00000e-01

$1.00000 \mathrm{e}+001.00000 \mathrm{e}+001.00000 \mathrm{e}-011.00000 \mathrm{e}-091.00000 \mathrm{e}-01$

1.00000e-06 1.00000e-06 1.00000e-06 1.00000e-09 5.00000e-02

Element: 13209 \# of layers: 5

$\mathrm{Kx} \mathrm{Ky} \mathrm{Kz}$ Ss Por

$1.96166 \mathrm{e}+02$ 1.96166e+02 1.96166e+01 1.00000e-09 2.12000e-01

$1.96166 \mathrm{e}+02$ 1.96166e+02 1.96166e+01 1.00000e-09 2.12000e-01

$1.00000 \mathrm{e}-05$ 1.00000e-05 1.00000e-06 1.00000e-09 1.00000e-01

$1.00000 \mathrm{e}+001.00000 \mathrm{e}+001.00000 \mathrm{e}-011.00000 \mathrm{e}-091.00000 \mathrm{e}-01$

1.00000e-06 1.00000e-06 1.00000e-06 1.00000e-09 5.00000e-02

Element: 13210 \# of layers: 6

Kx Ky Kz Ss Por

4.90946e+03 4.90946e+03 4.90946e+02 1.00000e-09 7.00000e-02

$1.96166 \mathrm{e}+021.96166 \mathrm{e}+021.96166 \mathrm{e}+01$ 1.00000e-09 2.12000e-01

$1.96166 \mathrm{e}+021.96166 \mathrm{e}+021.96166 \mathrm{e}+01$ 1.00000e-09 2.12000e-01

$1.00000 \mathrm{e}-05$ 1.00000e-05 1.00000e-06 1.00000e-09 1.00000e-01

$1.00000 \mathrm{e}+001.00000 \mathrm{e}+001.00000 \mathrm{e}-011.00000 \mathrm{e}-091.00000 \mathrm{e}-01$

1.00000e-06 1.00000e-06 1.00000e-06 1.00000e-09 5.00000e-02

Element: 13211 \# of layers: 5

$\mathrm{Kx} \mathrm{Ky} \mathrm{Kz}$ Ss Por

$1.23541 \mathrm{e}+02$ 1.23541e+02 1.23541e+01 1.00000e-09 2.12000e-01 
$1.23541 \mathrm{e}+02$ 1.23541e+02 1.23541e+01 1.00000e-09 2.12000e-01 $1.00000 \mathrm{e}-05$ 1.00000e-05 1.00000e-06 1.00000e-09 1.00000e-01 $1.00000 \mathrm{e}+001.00000 \mathrm{e}+001.00000 \mathrm{e}-011.00000 \mathrm{e}-091.00000 \mathrm{e}-01$ $1.00000 \mathrm{e}-06$ 1.00000e-06 1.00000e-06 1.00000e-09 5.00000e-02 Element: 13212 \# of layers: 5

$\mathrm{Kx} \mathrm{Ky} \mathrm{Kz}$ Ss Por

$1.96166 \mathrm{e}+02$ 1.96166e+02 1.96166e+01 1.00000e-09 2.12000e-01 $1.96166 \mathrm{e}+02$ 1.96166e+02 1.96166e+01 1.00000e-09 2.12000e-01 $1.00000 \mathrm{e}-051.00000 \mathrm{e}-051.00000 \mathrm{e}-061.00000 \mathrm{e}-091.00000 \mathrm{e}-01$ $1.00000 \mathrm{e}+001.00000 \mathrm{e}+001.00000 \mathrm{e}-01$ 1.00000e-09 1.00000e-01 1.00000e-06 1.00000e-06 1.00000e-06 1.00000e-09 5.00000e-02 Element: 13213 \# of layers: 7

$\mathrm{Kx} \mathrm{Ky} \mathrm{Kz}$ Ss Por

7.23413e+00 7.23413e+00 7.23413e-01 1.00000e-09 2.12000e-01 7.23413e+00 7.23413e+00 7.23413e-01 1.00000e-09 2.12000e-01 $7.23413 \mathrm{e}+00$ 7.23413e+00 7.23413e-01 1.00000e-09 2.12000e-01 7.23413e+00 7.23413e+00 7.23413e-01 1.00000e-09 2.12000e-01 7.23413e+00 7.23413e+00 7.23413e-01 1.00000e-09 2.12000e-01 $1.00000 \mathrm{e}-05$ 1.00000e-05 1.00000e-06 1.00000e-09 1.00000e-01 $1.00000 \mathrm{e}+001.00000 \mathrm{e}+001.00000 \mathrm{e}-011.00000 \mathrm{e}-09$ 1.00000e-01 Element: 13214 \# of layers: 7

$\mathrm{Kx} \mathrm{Ky} \mathrm{Kz}$ Ss Por

7.23413e+00 7.23413e+00 7.23413e-01 1.00000e-09 2.12000e-01 $7.23413 \mathrm{e}+00$ 7.23413e+00 7.23413e-01 1.00000e-09 2.12000e-01 $7.23413 \mathrm{e}+00$ 7.23413e+00 7.23413e-01 1.00000e-09 2.12000e-01 $7.23413 \mathrm{e}+00$ 7.23413e+00 7.23413e-01 1.00000e-09 2.12000e-01 $7.23413 \mathrm{e}+00$ 7.23413e+00 7.23413e-01 1.00000e-09 2.12000e-01 $1.00000 \mathrm{e}-05$ 1.00000e-05 1.00000e-06 1.00000e-09 1.00000e-01 $1.00000 \mathrm{e}+001.00000 \mathrm{e}+001.00000 \mathrm{e}-011.00000 \mathrm{e}-091.00000 \mathrm{e}-01$ Element: 13215 \# of layers: 7

$\mathrm{Kx} \mathrm{Ky} \mathrm{Kz}$ Ss Por

7.23413e+00 7.23413e+00 7.23413e-01 1.00000e-09 2.12000e-01 $7.23413 \mathrm{e}+00$ 7.23413e+00 7.23413e-01 1.00000e-09 2.12000e-01 7.23413e+00 7.23413e+00 7.23413e-01 1.00000e-09 2.12000e-01 7.23413e+00 7.23413e+00 7.23413e-01 1.00000e-09 2.12000e-01 $7.23413 \mathrm{e}+00$ 7.23413e+00 7.23413e-01 1.00000e-09 2.12000e-01 $1.00000 \mathrm{e}-05$ 1.00000e-05 1.00000e-06 1.00000e-09 1.00000e-01 $1.00000 \mathrm{e}+001.00000 \mathrm{e}+001.00000 \mathrm{e}-01$ 1.00000e-09 1.00000e-01 Element: 13216 \# of layers: 7

$\mathrm{Kx} \mathrm{Ky} \mathrm{Kz}$ Ss Por

7.23413e+00 7.23413e+00 7.23413e-01 1.00000e-09 2.12000e-01 $7.23413 \mathrm{e}+00$ 7.23413e+00 7.23413e-01 1.00000e-09 2.12000e-01 $7.23413 \mathrm{e}+00$ 7.23413e+00 7.23413e-01 1.00000e-09 2.12000e-01 7.23413e+00 7.23413e+00 7.23413e-01 1.00000e-09 2.12000e-01 7.23413e+00 7.23413e+00 7.23413e-01 1.00000e-09 2.12000e-01 $1.00000 \mathrm{e}-05$ 1.00000e-05 1.00000e-06 1.00000e-09 1.00000e-01 
$1.00000 \mathrm{e}+001.00000 \mathrm{e}+001.00000 \mathrm{e}-011.00000 \mathrm{e}-091.00000 \mathrm{e}-01$ Element: 13217 \# of layers: 7

Kx Ky Kz Ss Por

7.23413e+00 7.23413e+00 7.23413e-01 1.00000e-09 2.12000e-01

7.23413e+00 7.23413e+00 7.23413e-01 1.00000e-09 2.12000e-01

$7.23413 \mathrm{e}+00$ 7.23413e+00 7.23413e-01 1.00000e-09 2.12000e-01

7.23413e+00 7.23413e+00 7.23413e-01 1.00000e-09 2.12000e-01

$7.23413 \mathrm{e}+00$ 7.23413e+00 7.23413e-01 1.00000e-09 2.12000e-01

$1.00000 \mathrm{e}-05$ 1.00000e-05 1.00000e-06 1.00000e-09 1.00000e-01

$1.00000 \mathrm{e}+001.00000 \mathrm{e}+00$ 1.00000e-01 1.00000e-09 1.00000e-01

Element: 13218 \# of layers: 7

Kx Ky Kz Ss Por

5.89310e+00 5.89310e+00 5.89310e-01 1.00000e-09 2.12000e-01

$5.89310 \mathrm{e}+005.89310 \mathrm{e}+005.89310 \mathrm{e}-01$ 1.00000e-09 2.12000e-01

$5.89310 \mathrm{e}+005.89310 \mathrm{e}+005.89310 \mathrm{e}-01$ 1.00000e-09 2.12000e-01

$5.89310 \mathrm{e}+005.89310 \mathrm{e}+005.89310 \mathrm{e}-01$ 1.00000e-09 2.12000e-01

$5.89310 \mathrm{e}+005.89310 \mathrm{e}+00$ 5.89310e-01 1.00000e-09 2.12000e-01

$1.00000 \mathrm{e}-051.00000 \mathrm{e}-051.00000 \mathrm{e}-061.00000 \mathrm{e}-091.00000 \mathrm{e}-01$

$1.00000 \mathrm{e}+001.00000 \mathrm{e}+001.00000 \mathrm{e}-01$ 1.00000e-09 1.00000e-01

Element: 13219 \# of layers: 7

$\mathrm{Kx} \mathrm{Ky} \mathrm{Kz}$ Ss Por

5.89310e+00 5.89310e+00 5.89310e-01 1.00000e-09 2.12000e-01

$5.89310 \mathrm{e}+005.89310 \mathrm{e}+005.89310 \mathrm{e}-011.00000 \mathrm{e}-092.12000 \mathrm{e}-01$

$5.89310 \mathrm{e}+00$ 5.89310e+00 5.89310e-01 1.00000e-09 2.12000e-01

$5.89310 \mathrm{e}+00$ 5.89310e+00 5.89310e-01 1.00000e-09 2.12000e-01

$5.89310 \mathrm{e}+005.89310 \mathrm{e}+005.89310 \mathrm{e}-01$ 1.00000e-09 2.12000e-01

$1.00000 \mathrm{e}-05$ 1.00000e-05 1.00000e-06 1.00000e-09 1.00000e-01

$1.00000 \mathrm{e}+001.00000 \mathrm{e}+001.00000 \mathrm{e}-01$ 1.00000e-09 1.00000e-01

Element: 13220 \# of layers: 7

$\mathrm{Kx} \mathrm{Ky} \mathrm{Kz}$ Ss Por

5.89310e+00 5.89310e+00 5.89310e-01 1.00000e-09 2.12000e-01

$5.89310 \mathrm{e}+005.89310 \mathrm{e}+00$ 5.89310e-01 1.00000e-09 2.12000e-01

$5.89310 \mathrm{e}+005.89310 \mathrm{e}+00$ 5.89310e-01 1.00000e-09 2.12000e-01

$5.89310 \mathrm{e}+005.89310 \mathrm{e}+00$ 5.89310e-01 1.00000e-09 2.12000e-01

$5.89310 \mathrm{e}+005.89310 \mathrm{e}+005.89310 \mathrm{e}-01$ 1.00000e-09 2.12000e-01

$1.00000 \mathrm{e}-05$ 1.00000e-05 1.00000e-06 1.00000e-09 1.00000e-01

$1.00000 \mathrm{e}+001.00000 \mathrm{e}+001.00000 \mathrm{e}-011.00000 \mathrm{e}-091.00000 \mathrm{e}-01$

Element: 13221 \# of layers: 7

$\mathrm{Kx} \mathrm{Ky} \mathrm{Kz}$ Ss Por

$5.89310 \mathrm{e}+005.89310 \mathrm{e}+00$ 5.89310e-01 1.00000e-09 2.12000e-01

$5.89310 \mathrm{e}+005.89310 \mathrm{e}+00$ 5.89310e-01 1.00000e-09 2.12000e-01

$5.89310 \mathrm{e}+005.89310 \mathrm{e}+00$ 5.89310e-01 1.00000e-09 2.12000e-01

$5.89310 \mathrm{e}+005.89310 \mathrm{e}+005.89310 \mathrm{e}-01$ 1.00000e-09 2.12000e-01

$5.89310 \mathrm{e}+005.89310 \mathrm{e}+00$ 5.89310e-01 1.00000e-09 2.12000e-01

$1.00000 \mathrm{e}-05$ 1.00000e-05 1.00000e-06 1.00000e-09 1.00000e-01

$1.00000 \mathrm{e}+001.00000 \mathrm{e}+001.00000 \mathrm{e}-011.00000 \mathrm{e}-091.00000 \mathrm{e}-01$ 
Element: 13222 \# of layers: 7

$\mathrm{Kx} \mathrm{Ky} \mathrm{Kz} \mathrm{Ss} \mathrm{Por}$

5.89310e+00 5.89310e+00 5.89310e-01 1.00000e-09 2.12000e-01

$5.89310 \mathrm{e}+00$ 5.89310e+00 5.89310e-01 1.00000e-09 2.12000e-01

$5.89310 \mathrm{e}+005.89310 \mathrm{e}+00$ 5.89310e-01 1.00000e-09 2.12000e-01

$5.89310 \mathrm{e}+005.89310 \mathrm{e}+00$ 5.89310e-01 1.00000e-09 2.12000e-01

$5.89310 \mathrm{e}+00$ 5.89310e+00 5.89310e-01 1.00000e-09 2.12000e-01

$1.00000 \mathrm{e}-05$ 1.00000e-05 1.00000e-06 1.00000e-09 1.00000e-01

$1.00000 \mathrm{e}+001.00000 \mathrm{e}+001.00000 \mathrm{e}-011.00000 \mathrm{e}-09$ 1.00000e-01

Element: 13223 \# of layers: 7

Kx Ky Kz Ss Por

7.23413e+00 7.23413e+00 7.23413e-01 1.00000e-09 2.12000e-01

7.23413e+00 7.23413e+00 7.23413e-01 1.00000e-09 2.12000e-01

$7.23413 \mathrm{e}+00$ 7.23413e+00 7.23413e-01 1.00000e-09 2.12000e-01

7.23413e+00 7.23413e+00 7.23413e-01 1.00000e-09 2.12000e-01

$7.23413 \mathrm{e}+00$ 7.23413e+00 7.23413e-01 1.00000e-09 2.12000e-01

$1.00000 \mathrm{e}-05$ 1.00000e-05 1.00000e-06 1.00000e-09 1.00000e-01

$1.00000 \mathrm{e}+001.00000 \mathrm{e}+001.00000 \mathrm{e}-01$ 1.00000e-09 1.00000e-01

Element: 13224 \# of layers: 7

$\mathrm{Kx} \mathrm{Ky} \mathrm{Kz}$ Ss Por

7.23413e+00 7.23413e+00 7.23413e-01 1.00000e-09 2.12000e-01

7.23413e+00 7.23413e+00 7.23413e-01 1.00000e-09 2.12000e-01

7.23413e+00 7.23413e+00 7.23413e-01 1.00000e-09 2.12000e-01

$7.23413 \mathrm{e}+00$ 7.23413e+00 7.23413e-01 1.00000e-09 2.12000e-01

$7.23413 \mathrm{e}+007.23413 \mathrm{e}+00$ 7.23413e-01 1.00000e-09 2.12000e-01

$1.00000 \mathrm{e}-05$ 1.00000e-05 1.00000e-06 1.00000e-09 1.00000e-01

$1.00000 \mathrm{e}+001.00000 \mathrm{e}+001.00000 \mathrm{e}-011.00000 \mathrm{e}-091.00000 \mathrm{e}-01$

Element: 13225 \# of layers: 7

Kx Ky Kz Ss Por

5.89310e+00 5.89310e+00 5.89310e-01 1.00000e-09 2.12000e-01

$5.89310 \mathrm{e}+005.89310 \mathrm{e}+005.89310 \mathrm{e}-01$ 1.00000e-09 2.12000e-01

$5.89310 \mathrm{e}+005.89310 \mathrm{e}+00$ 5.89310e-01 1.00000e-09 2.12000e-01

$5.89310 \mathrm{e}+005.89310 \mathrm{e}+005.89310 \mathrm{e}-01$ 1.00000e-09 2.12000e-01

$5.89310 \mathrm{e}+005.89310 \mathrm{e}+00$ 5.89310e-01 1.00000e-09 2.12000e-01

$1.00000 \mathrm{e}-05$ 1.00000e-05 1.00000e-06 1.00000e-09 1.00000e-01

$1.00000 \mathrm{e}+001.00000 \mathrm{e}+001.00000 \mathrm{e}-01$ 1.00000e-09 1.00000e-01

Element: 13226 \# of layers: 7

$\mathrm{Kx} \mathrm{Ky} \mathrm{Kz}$ Ss Por

$5.89310 \mathrm{e}+005.89310 \mathrm{e}+005.89310 \mathrm{e}-011.00000 \mathrm{e}-092.12000 \mathrm{e}-01$

$5.89310 \mathrm{e}+005.89310 \mathrm{e}+005.89310 \mathrm{e}-01$ 1.00000e-09 2.12000e-01

$5.89310 \mathrm{e}+005.89310 \mathrm{e}+00$ 5.89310e-01 1.00000e-09 2.12000e-01

$5.89310 \mathrm{e}+005.89310 \mathrm{e}+00$ 5.89310e-01 1.00000e-09 2.12000e-01

$5.89310 \mathrm{e}+00$ 5.89310e+00 5.89310e-01 1.00000e-09 2.12000e-01

$1.00000 \mathrm{e}-051.00000 \mathrm{e}-051.00000 \mathrm{e}-061.00000 \mathrm{e}-091.00000 \mathrm{e}-01$

$1.00000 \mathrm{e}+001.00000 \mathrm{e}+001.00000 \mathrm{e}-01$ 1.00000e-09 1.00000e-01

Element: 13227 \# of layers: 7 


\section{Kx Ky Kz Ss Por}

$5.89310 \mathrm{e}+00$ 5.89310e+00 5.89310e-01 1.00000e-09 2.12000e-01

$5.89310 \mathrm{e}+005.89310 \mathrm{e}+005.89310 \mathrm{e}-01$ 1.00000e-09 2.12000e-01

$5.89310 \mathrm{e}+00$ 5.89310e+00 5.89310e-01 1.00000e-09 2.12000e-01

$5.89310 \mathrm{e}+005.89310 \mathrm{e}+00$ 5.89310e-01 1.00000e-09 2.12000e-01

$5.89310 \mathrm{e}+005.89310 \mathrm{e}+00$ 5.89310e-01 1.00000e-09 2.12000e-01

$1.00000 \mathrm{e}-05$ 1.00000e-05 1.00000e-06 1.00000e-09 1.00000e-01

$1.00000 \mathrm{e}+001.00000 \mathrm{e}+001.00000 \mathrm{e}-011.00000 \mathrm{e}-091.00000 \mathrm{e}-01$

Element: 13228 \# of layers: 7

$\mathrm{Kx} \mathrm{Ky} \mathrm{Kz}$ Ss Por

5.89310e+00 5.89310e+00 5.89310e-01 1.00000e-09 2.12000e-01

$5.89310 \mathrm{e}+005.89310 \mathrm{e}+005.89310 \mathrm{e}-011.00000 \mathrm{e}-092.12000 \mathrm{e}-01$

$5.89310 \mathrm{e}+005.89310 \mathrm{e}+005.89310 \mathrm{e}-011.00000 \mathrm{e}-092.12000 \mathrm{e}-01$

$5.89310 \mathrm{e}+005.89310 \mathrm{e}+005.89310 \mathrm{e}-01$ 1.00000e-09 2.12000e-01

$5.89310 \mathrm{e}+005.89310 \mathrm{e}+00$ 5.89310e-01 1.00000e-09 2.12000e-01 1.00000e-05 1.00000e-05 1.00000e-06 1.00000e-09 1.00000e-01

$1.00000 \mathrm{e}+001.00000 \mathrm{e}+001.00000 \mathrm{e}-01$ 1.00000e-09 1.00000e-01

Element: 13229 \# of layers: 7

$\mathrm{Kx} \mathrm{Ky} \mathrm{Kz}$ Ss Por

5.89310e+00 5.89310e+00 5.89310e-01 1.00000e-09 2.12000e-01

$5.89310 \mathrm{e}+00$ 5.89310e+00 5.89310e-01 1.00000e-09 2.12000e-01

$5.89310 \mathrm{e}+00$ 5.89310e+00 5.89310e-01 1.00000e-09 2.12000e-01

$5.89310 \mathrm{e}+005.89310 \mathrm{e}+005.89310 \mathrm{e}-01$ 1.00000e-09 2.12000e-01

$5.89310 \mathrm{e}+005.89310 \mathrm{e}+005.89310 \mathrm{e}-01$ 1.00000e-09 2.12000e-01

$1.00000 \mathrm{e}-051.00000 \mathrm{e}-05$ 1.00000e-06 1.00000e-09 1.00000e-01

$1.00000 \mathrm{e}+001.00000 \mathrm{e}+001.00000 \mathrm{e}-01$ 1.00000e-09 1.00000e-01

Element: 13230 \# of layers: 7

$\mathrm{Kx} \mathrm{Ky} \mathrm{Kz}$ Ss Por

5.89310e+00 5.89310e+00 5.89310e-01 1.00000e-09 2.12000e-01

$5.89310 \mathrm{e}+005.89310 \mathrm{e}+00$ 5.89310e-01 1.00000e-09 2.12000e-01

$5.89310 \mathrm{e}+005.89310 \mathrm{e}+005.89310 \mathrm{e}-01$ 1.00000e-09 2.12000e-01

$5.89310 \mathrm{e}+005.89310 \mathrm{e}+00$ 5.89310e-01 1.00000e-09 2.12000e-01

$5.89310 \mathrm{e}+005.89310 \mathrm{e}+005.89310 \mathrm{e}-01$ 1.00000e-09 2.12000e-01

$1.00000 \mathrm{e}-05$ 1.00000e-05 1.00000e-06 1.00000e-09 1.00000e-01

$1.00000 \mathrm{e}+001.00000 \mathrm{e}+001.00000 \mathrm{e}-011.00000 \mathrm{e}-091.00000 \mathrm{e}-01$

Element: 13231 \# of layers: 7

Kx Ky Kz Ss Por

5.89310e+00 5.89310e+00 5.89310e-01 1.00000e-09 2.12000e-01

$5.89310 \mathrm{e}+00$ 5.89310e+00 5.89310e-01 1.00000e-09 2.12000e-01

$5.89310 \mathrm{e}+005.89310 \mathrm{e}+005.89310 \mathrm{e}-01$ 1.00000e-09 2.12000e-01

$5.89310 \mathrm{e}+005.89310 \mathrm{e}+00$ 5.89310e-01 1.00000e-09 2.12000e-01

$5.89310 \mathrm{e}+005.89310 \mathrm{e}+00$ 5.89310e-01 1.00000e-09 2.12000e-01

$1.00000 \mathrm{e}-05$ 1.00000e-05 1.00000e-06 1.00000e-09 1.00000e-01

$1.00000 \mathrm{e}+001.00000 \mathrm{e}+001.00000 \mathrm{e}-01$ 1.00000e-09 1.00000e-01

Element: 13232 \# of layers: 7

Kx Ky Kz Ss Por 
$5.89310 \mathrm{e}+005.89310 \mathrm{e}+00$ 5.89310e-01 1.00000e-09 2.12000e-01 $5.89310 \mathrm{e}+005.89310 \mathrm{e}+005.89310 \mathrm{e}-011.00000 \mathrm{e}-092.12000 \mathrm{e}-01$ $5.89310 \mathrm{e}+005.89310 \mathrm{e}+00$ 5.89310e-01 1.00000e-09 2.12000e-01 $5.89310 \mathrm{e}+005.89310 \mathrm{e}+005.89310 \mathrm{e}-011.00000 \mathrm{e}-092.12000 \mathrm{e}-01$ $5.89310 \mathrm{e}+005.89310 \mathrm{e}+00$ 5.89310e-01 1.00000e-09 2.12000e-01 $1.00000 \mathrm{e}-05$ 1.00000e-05 1.00000e-06 1.00000e-09 1.00000e-01 $1.00000 \mathrm{e}+001.00000 \mathrm{e}+001.00000 \mathrm{e}-011.00000 \mathrm{e}-091.00000 \mathrm{e}-01$ Element: 13233 \# of layers: 7

Kx Ky Kz Ss Por

$5.89310 \mathrm{e}+005.89310 \mathrm{e}+00$ 5.89310e-01 1.00000e-09 2.12000e-01 $5.89310 \mathrm{e}+005.89310 \mathrm{e}+005.89310 \mathrm{e}-011.00000 \mathrm{e}-092.12000 \mathrm{e}-01$ $5.89310 \mathrm{e}+005.89310 \mathrm{e}+005.89310 \mathrm{e}-011.00000 \mathrm{e}-092.12000 \mathrm{e}-01$ $5.89310 \mathrm{e}+005.89310 \mathrm{e}+005.89310 \mathrm{e}-011.00000 \mathrm{e}-092.12000 \mathrm{e}-01$ $5.89310 \mathrm{e}+005.89310 \mathrm{e}+00$ 5.89310e-01 1.00000e-09 2.12000e-01 $1.00000 \mathrm{e}-05$ 1.00000e-05 1.00000e-06 1.00000e-09 1.00000e-01 $1.00000 \mathrm{e}+001.00000 \mathrm{e}+001.00000 \mathrm{e}-011.00000 \mathrm{e}-091.00000 \mathrm{e}-01$ Element: 13234 \# of layers: 7

Kx Ky Kz Ss Por

$5.89310 \mathrm{e}+005.89310 \mathrm{e}+00$ 5.89310e-01 1.00000e-09 2.12000e-01 $5.89310 \mathrm{e}+005.89310 \mathrm{e}+005.89310 \mathrm{e}-011.00000 \mathrm{e}-092.12000 \mathrm{e}-01$ $5.89310 \mathrm{e}+005.89310 \mathrm{e}+005.89310 \mathrm{e}-011.00000 \mathrm{e}-092.12000 \mathrm{e}-01$ $5.89310 \mathrm{e}+005.89310 \mathrm{e}+005.89310 \mathrm{e}-011.00000 \mathrm{e}-092.12000 \mathrm{e}-01$ $5.89310 \mathrm{e}+005.89310 \mathrm{e}+005.89310 \mathrm{e}-011.00000 \mathrm{e}-092.12000 \mathrm{e}-01$ $1.00000 \mathrm{e}-05$ 1.00000e-05 1.00000e-06 1.00000e-09 1.00000e-01 $1.00000 \mathrm{e}+001.00000 \mathrm{e}+001.00000 \mathrm{e}-011.00000 \mathrm{e}-091.00000 \mathrm{e}-01$ Element: 13235 \# of layers: 7

Kx Ky Kz Ss Por

$5.89310 \mathrm{e}+005.89310 \mathrm{e}+00$ 5.89310e-01 1.00000e-09 2.12000e-01 $5.89310 \mathrm{e}+005.89310 \mathrm{e}+00$ 5.89310e-01 1.00000e-09 2.12000e-01 $5.89310 \mathrm{e}+005.89310 \mathrm{e}+005.89310 \mathrm{e}-011.00000 \mathrm{e}-092.12000 \mathrm{e}-01$ $5.89310 \mathrm{e}+005.89310 \mathrm{e}+005.89310 \mathrm{e}-011.00000 \mathrm{e}-092.12000 \mathrm{e}-01$ $5.89310 \mathrm{e}+005.89310 \mathrm{e}+00$ 5.89310e-01 1.00000e-09 2.12000e-01 $1.00000 \mathrm{e}-05$ 1.00000e-05 1.00000e-06 1.00000e-09 1.00000e-01 $1.00000 \mathrm{e}+001.00000 \mathrm{e}+001.00000 \mathrm{e}-011.00000 \mathrm{e}-091.00000 \mathrm{e}-01$ Element: 13236 \# of layers: 7

Kx Ky Kz Ss Por

$5.89310 \mathrm{e}+005.89310 \mathrm{e}+00$ 5.89310e-01 1.00000e-09 2.12000e-01 $5.89310 \mathrm{e}+005.89310 \mathrm{e}+005.89310 \mathrm{e}-011.00000 \mathrm{e}-092.12000 \mathrm{e}-01$ $5.89310 \mathrm{e}+005.89310 \mathrm{e}+005.89310 \mathrm{e}-011.00000 \mathrm{e}-092.12000 \mathrm{e}-01$ $5.89310 \mathrm{e}+005.89310 \mathrm{e}+005.89310 \mathrm{e}-011.00000 \mathrm{e}-092.12000 \mathrm{e}-01$ $5.89310 \mathrm{e}+005.89310 \mathrm{e}+00$ 5.89310e-01 1.00000e-09 2.12000e-01 $1.00000 \mathrm{e}-05$ 1.00000e-05 1.00000e-06 1.00000e-09 1.00000e-01 $1.00000 \mathrm{e}+001.00000 \mathrm{e}+001.00000 \mathrm{e}-011.00000 \mathrm{e}-091.00000 \mathrm{e}-01$ Element: 13237 \# of layers: 7

Kx Ky Kz Ss Por

6.15793e+00 6.15793e+00 6.15793e-01 1.00000e-09 2.12000e-01 
$6.15793 \mathrm{e}+00$ 6.15793e+00 6.15793e-01 1.00000e-09 2.12000e-01 $6.15793 \mathrm{e}+00$ 6.15793e+00 6.15793e-01 1.00000e-09 2.12000e-01 $6.15793 \mathrm{e}+006.15793 \mathrm{e}+00$ 6.15793e-01 1.00000e-09 2.12000e-01 $6.15793 \mathrm{e}+006.15793 \mathrm{e}+00$ 6.15793e-01 1.00000e-09 2.12000e-01 $1.00000 \mathrm{e}-05$ 1.00000e-05 1.00000e-06 1.00000e-09 1.00000e-01 $1.00000 \mathrm{e}+001.00000 \mathrm{e}+001.00000 \mathrm{e}-011.00000 \mathrm{e}-091.00000 \mathrm{e}-01$ Element: 13238 \# of layers: 7

Kx Ky Kz Ss Por

6.15793e+00 6.15793e+00 6.15793e-01 1.00000e-09 2.12000e-01 $6.15793 \mathrm{e}+006.15793 \mathrm{e}+00$ 6.15793e-01 1.00000e-09 2.12000e-01 $6.15793 \mathrm{e}+00$ 6.15793e+00 6.15793e-01 1.00000e-09 2.12000e-01 $6.15793 \mathrm{e}+00$ 6.15793e+00 6.15793e-01 1.00000e-09 2.12000e-01 $6.15793 \mathrm{e}+006.15793 \mathrm{e}+00$ 6.15793e-01 1.00000e-09 2.12000e-01 $1.00000 \mathrm{e}-05$ 1.00000e-05 1.00000e-06 1.00000e-09 1.00000e-01 $1.00000 \mathrm{e}+001.00000 \mathrm{e}+001.00000 \mathrm{e}-011.00000 \mathrm{e}-091.00000 \mathrm{e}-01$ Element: 13239 \# of layers: 7

Kx Ky Kz Ss Por

6.15793e+00 6.15793e+00 6.15793e-01 1.00000e-09 2.12000e-01 $6.15793 \mathrm{e}+006.15793 \mathrm{e}+00$ 6.15793e-01 1.00000e-09 2.12000e-01 $6.15793 \mathrm{e}+006.15793 \mathrm{e}+00$ 6.15793e-01 1.00000e-09 2.12000e-01 $6.15793 \mathrm{e}+00$ 6.15793e+00 6.15793e-01 1.00000e-09 2.12000e-01 $6.15793 \mathrm{e}+006.15793 \mathrm{e}+00$ 6.15793e-01 1.00000e-09 2.12000e-01 $1.00000 \mathrm{e}-05$ 1.00000e-05 1.00000e-06 1.00000e-09 1.00000e-01 $1.00000 \mathrm{e}+001.00000 \mathrm{e}+001.00000 \mathrm{e}-011.00000 \mathrm{e}-091.00000 \mathrm{e}-01$ Element: 13240 \# of layers: 7

Kx Ky Kz Ss Por

$5.89310 \mathrm{e}+005.89310 \mathrm{e}+00$ 5.89310e-01 1.00000e-09 2.12000e-01 $5.89310 \mathrm{e}+005.89310 \mathrm{e}+005.89310 \mathrm{e}-011.00000 \mathrm{e}-092.12000 \mathrm{e}-01$ $5.89310 \mathrm{e}+005.89310 \mathrm{e}+00$ 5.89310e-01 1.00000e-09 2.12000e-01 $5.89310 \mathrm{e}+005.89310 \mathrm{e}+005.89310 \mathrm{e}-011.00000 \mathrm{e}-092.12000 \mathrm{e}-01$ $5.89310 \mathrm{e}+005.89310 \mathrm{e}+00$ 5.89310e-01 1.00000e-09 2.12000e-01 $1.00000 \mathrm{e}-05$ 1.00000e-05 1.00000e-06 1.00000e-09 1.00000e-01 $1.00000 \mathrm{e}+001.00000 \mathrm{e}+001.00000 \mathrm{e}-011.00000 \mathrm{e}-09$ 1.00000e-01 Element: 13241 \# of layers: 7

Kx Ky Kz Ss Por

$5.89310 \mathrm{e}+005.89310 \mathrm{e}+00$ 5.89310e-01 1.00000e-09 2.12000e-01 $5.89310 \mathrm{e}+005.89310 \mathrm{e}+005.89310 \mathrm{e}-011.00000 \mathrm{e}-092.12000 \mathrm{e}-01$ $5.89310 \mathrm{e}+005.89310 \mathrm{e}+00$ 5.89310e-01 1.00000e-09 2.12000e-01 $5.89310 \mathrm{e}+005.89310 \mathrm{e}+005.89310 \mathrm{e}-011.00000 \mathrm{e}-092.12000 \mathrm{e}-01$ $5.89310 \mathrm{e}+005.89310 \mathrm{e}+00$ 5.89310e-01 1.00000e-09 2.12000e-01 $1.00000 \mathrm{e}-05$ 1.00000e-05 1.00000e-06 1.00000e-09 1.00000e-01 $1.00000 \mathrm{e}+001.00000 \mathrm{e}+001.00000 \mathrm{e}-011.00000 \mathrm{e}-091.00000 \mathrm{e}-01$ Element: 13242 \# of layers: 7

Kx Ky Kz Ss Por

$5.89310 \mathrm{e}+00$ 5.89310e+00 5.89310e-01 1.00000e-09 2.12000e-01 $5.89310 \mathrm{e}+005.89310 \mathrm{e}+00$ 5.89310e-01 1.00000e-09 2.12000e-01 
$5.89310 \mathrm{e}+005.89310 \mathrm{e}+00$ 5.89310e-01 1.00000e-09 2.12000e-01 $5.89310 \mathrm{e}+005.89310 \mathrm{e}+005.89310 \mathrm{e}-011.00000 \mathrm{e}-092.12000 \mathrm{e}-01$ $5.89310 \mathrm{e}+005.89310 \mathrm{e}+00$ 5.89310e-01 1.00000e-09 2.12000e-01 $1.00000 \mathrm{e}-05$ 1.00000e-05 1.00000e-06 1.00000e-09 1.00000e-01 $1.00000 \mathrm{e}+001.00000 \mathrm{e}+001.00000 \mathrm{e}-011.00000 \mathrm{e}-091.00000 \mathrm{e}-01$ Element: 13243 \# of layers: 7

Kx Ky Kz Ss Por

$5.89310 \mathrm{e}+00$ 5.89310e+00 5.89310e-01 1.00000e-09 2.12000e-01 $5.89310 \mathrm{e}+005.89310 \mathrm{e}+005.89310 \mathrm{e}-011.00000 \mathrm{e}-092.12000 \mathrm{e}-01$ $5.89310 \mathrm{e}+005.89310 \mathrm{e}+005.89310 \mathrm{e}-011.00000 \mathrm{e}-092.12000 \mathrm{e}-01$ $5.89310 \mathrm{e}+005.89310 \mathrm{e}+005.89310 \mathrm{e}-011.00000 \mathrm{e}-092.12000 \mathrm{e}-01$ $5.89310 \mathrm{e}+005.89310 \mathrm{e}+00$ 5.89310e-01 1.00000e-09 2.12000e-01 $1.00000 \mathrm{e}-05$ 1.00000e-05 1.00000e-06 1.00000e-09 1.00000e-01 $1.00000 \mathrm{e}+001.00000 \mathrm{e}+001.00000 \mathrm{e}-011.00000 \mathrm{e}-091.00000 \mathrm{e}-01$ Element: 13244 \# of layers: 7

Kx Ky Kz Ss Por

6.15793e+00 6.15793e+00 6.15793e-01 1.00000e-09 2.12000e-01 $6.15793 \mathrm{e}+006.15793 \mathrm{e}+00$ 6.15793e-01 1.00000e-09 2.12000e-01 $6.15793 \mathrm{e}+006.15793 \mathrm{e}+00$ 6.15793e-01 1.00000e-09 2.12000e-01 $6.15793 \mathrm{e}+006.15793 \mathrm{e}+00$ 6.15793e-01 1.00000e-09 2.12000e-01 $6.15793 \mathrm{e}+00$ 6.15793e+00 6.15793e-01 1.00000e-09 2.12000e-01 $1.00000 \mathrm{e}-05$ 1.00000e-05 1.00000e-06 1.00000e-09 1.00000e-01 $1.00000 \mathrm{e}+001.00000 \mathrm{e}+001.00000 \mathrm{e}-011.00000 \mathrm{e}-091.00000 \mathrm{e}-01$ Element: 13245 \# of layers: 7

Kx Ky Kz Ss Por

6.15793e+00 6.15793e+00 6.15793e-01 1.00000e-09 2.12000e-01 $6.15793 \mathrm{e}+006.15793 \mathrm{e}+00$ 6.15793e-01 1.00000e-09 2.12000e-01 $6.15793 \mathrm{e}+006.15793 \mathrm{e}+00$ 6.15793e-01 1.00000e-09 2.12000e-01 $6.15793 \mathrm{e}+006.15793 \mathrm{e}+00$ 6.15793e-01 1.00000e-09 2.12000e-01 $6.15793 \mathrm{e}+006.15793 \mathrm{e}+00$ 6.15793e-01 1.00000e-09 2.12000e-01 $1.00000 \mathrm{e}-05$ 1.00000e-05 1.00000e-06 1.00000e-09 1.00000e-01 $1.00000 \mathrm{e}+001.00000 \mathrm{e}+001.00000 \mathrm{e}-011.00000 \mathrm{e}-091.00000 \mathrm{e}-01$ Element: 13246 \# of layers: 7

Kx Ky Kz Ss Por

6.15793e+00 6.15793e+00 6.15793e-01 1.00000e-09 2.12000e-01 $6.15793 \mathrm{e}+006.15793 \mathrm{e}+00$ 6.15793e-01 1.00000e-09 2.12000e-01 $6.15793 \mathrm{e}+006.15793 \mathrm{e}+00$ 6.15793e-01 1.00000e-09 2.12000e-01 $6.15793 \mathrm{e}+006.15793 \mathrm{e}+00$ 6.15793e-01 1.00000e-09 2.12000e-01 $6.15793 \mathrm{e}+006.15793 \mathrm{e}+00$ 6.15793e-01 1.00000e-09 2.12000e-01 $1.00000 \mathrm{e}-05$ 1.00000e-05 1.00000e-06 1.00000e-09 1.00000e-01 $1.00000 \mathrm{e}+001.00000 \mathrm{e}+001.00000 \mathrm{e}-011.00000 \mathrm{e}-091.00000 \mathrm{e}-01$ Element: 13247 \# of layers: 7

$\mathrm{Kx} \mathrm{Ky} \mathrm{Kz}$ Ss Por

6.15793e+00 6.15793e+00 6.15793e-01 1.00000e-09 2.12000e-01 6.15793e+00 6.15793e+00 6.15793e-01 1.00000e-09 2.12000e-01 $6.15793 e+006.15793 e+006.15793 e-01$ 1.00000e-09 2.12000e-01 
$6.15793 \mathrm{e}+00$ 6.15793e+00 6.15793e-01 1.00000e-09 2.12000e-01 $6.15793 \mathrm{e}+006.15793 \mathrm{e}+00$ 6.15793e-01 1.00000e-09 2.12000e-01 $1.00000 \mathrm{e}-05$ 1.00000e-05 1.00000e-06 1.00000e-09 1.00000e-01 $1.00000 \mathrm{e}+001.00000 \mathrm{e}+001.00000 \mathrm{e}-011.00000 \mathrm{e}-091.00000 \mathrm{e}-01$ Element: 13248 \# of layers: 7

Kx Ky Kz Ss Por

6.15793e+00 6.15793e+00 6.15793e-01 1.00000e-09 2.12000e-01 $6.15793 \mathrm{e}+00$ 6.15793e+00 6.15793e-01 1.00000e-09 2.12000e-01 $6.15793 \mathrm{e}+006.15793 \mathrm{e}+00$ 6.15793e-01 1.00000e-09 2.12000e-01 $6.15793 \mathrm{e}+006.15793 \mathrm{e}+00$ 6.15793e-01 1.00000e-09 2.12000e-01 $6.15793 \mathrm{e}+006.15793 \mathrm{e}+00$ 6.15793e-01 1.00000e-09 2.12000e-01 $1.00000 \mathrm{e}-05$ 1.00000e-05 1.00000e-06 1.00000e-09 1.00000e-01 $1.00000 \mathrm{e}+001.00000 \mathrm{e}+001.00000 \mathrm{e}-011.00000 \mathrm{e}-091.00000 \mathrm{e}-01$ Element: 13249 \# of layers: 7

Kx Ky Kz Ss Por

6.15793e+00 6.15793e+00 6.15793e-01 1.00000e-09 2.12000e-01 $6.15793 \mathrm{e}+006.15793 \mathrm{e}+00$ 6.15793e-01 1.00000e-09 2.12000e-01 $6.15793 \mathrm{e}+006.15793 \mathrm{e}+00$ 6.15793e-01 1.00000e-09 2.12000e-01 $6.15793 \mathrm{e}+006.15793 \mathrm{e}+00$ 6.15793e-01 1.00000e-09 2.12000e-01 $6.15793 \mathrm{e}+006.15793 \mathrm{e}+00$ 6.15793e-01 1.00000e-09 2.12000e-01 $1.00000 \mathrm{e}-05$ 1.00000e-05 1.00000e-06 1.00000e-09 1.00000e-01 $1.00000 \mathrm{e}+001.00000 \mathrm{e}+001.00000 \mathrm{e}-011.00000 \mathrm{e}-091.00000 \mathrm{e}-01$ Element: 13250 \# of layers: 7

Kx Ky Kz Ss Por

$6.15793 \mathrm{e}+006.15793 \mathrm{e}+00$ 6.15793e-01 1.00000e-09 2.12000e-01 $6.15793 \mathrm{e}+00$ 6.15793e+00 6.15793e-01 1.00000e-09 2.12000e-01 $6.15793 \mathrm{e}+006.15793 \mathrm{e}+00$ 6.15793e-01 1.00000e-09 2.12000e-01 $6.15793 \mathrm{e}+006.15793 \mathrm{e}+00$ 6.15793e-01 1.00000e-09 2.12000e-01 $6.15793 \mathrm{e}+006.15793 \mathrm{e}+00$ 6.15793e-01 1.00000e-09 2.12000e-01 $1.00000 \mathrm{e}-05$ 1.00000e-05 1.00000e-06 1.00000e-09 1.00000e-01 $1.00000 \mathrm{e}+001.00000 \mathrm{e}+001.00000 \mathrm{e}-011.00000 \mathrm{e}-091.00000 \mathrm{e}-01$ Element: 13251 \# of layers: 7

Kx Ky Kz Ss Por

6.15793e+00 6.15793e+00 6.15793e-01 1.00000e-09 2.12000e-01 $6.15793 \mathrm{e}+006.15793 \mathrm{e}+00$ 6.15793e-01 1.00000e-09 2.12000e-01 $6.15793 \mathrm{e}+006.15793 \mathrm{e}+00$ 6.15793e-01 1.00000e-09 2.12000e-01 $6.15793 \mathrm{e}+006.15793 \mathrm{e}+00$ 6.15793e-01 1.00000e-09 2.12000e-01 $6.15793 \mathrm{e}+006.15793 \mathrm{e}+00$ 6.15793e-01 1.00000e-09 2.12000e-01 $1.00000 \mathrm{e}-05$ 1.00000e-05 1.00000e-06 1.00000e-09 1.00000e-01 $1.00000 \mathrm{e}+001.00000 \mathrm{e}+001.00000 \mathrm{e}-011.00000 \mathrm{e}-091.00000 \mathrm{e}-01$ Element: 13252 \# of layers: 7

Kx Ky Kz Ss Por

6.15793e+00 6.15793e+00 6.15793e-01 1.00000e-09 2.12000e-01 $6.15793 \mathrm{e}+006.15793 \mathrm{e}+00$ 6.15793e-01 1.00000e-09 2.12000e-01 $6.15793 \mathrm{e}+006.15793 \mathrm{e}+00$ 6.15793e-01 1.00000e-09 2.12000e-01 $6.15793 \mathrm{e}+006.15793 \mathrm{e}+00$ 6.15793e-01 1.00000e-09 2.12000e-01 
6.15793e+00 6.15793e+00 6.15793e-01 1.00000e-09 2.12000e-01 $1.00000 \mathrm{e}-05$ 1.00000e-05 1.00000e-06 1.00000e-09 1.00000e-01 $1.00000 \mathrm{e}+001.00000 \mathrm{e}+001.00000 \mathrm{e}-011.00000 \mathrm{e}-091.00000 \mathrm{e}-01$ Element: 13253 \# of layers: 7

$\mathrm{Kx} \mathrm{Ky} \mathrm{Kz}$ Ss Por

6.15793e+00 6.15793e+00 6.15793e-01 1.00000e-09 2.12000e-01 $6.15793 e+006.15793 e+00$ 6.15793e-01 1.00000e-09 2.12000e-01 $6.15793 \mathrm{e}+00$ 6.15793e+00 6.15793e-01 1.00000e-09 2.12000e-01 6.15793e+00 6.15793e+00 6.15793e-01 1.00000e-09 2.12000e-01 $6.15793 \mathrm{e}+00$ 6.15793e+00 6.15793e-01 1.00000e-09 2.12000e-01 $1.00000 \mathrm{e}-05$ 1.00000e-05 1.00000e-06 1.00000e-09 1.00000e-01 $1.00000 \mathrm{e}+001.00000 \mathrm{e}+001.00000 \mathrm{e}-01$ 1.00000e-09 1.00000e-01 Element: 13254 \# of layers: 7

$\mathrm{Kx} \mathrm{Ky} \mathrm{Kz}$ Ss Por

6.15793e+00 6.15793e+00 6.15793e-01 1.00000e-09 2.12000e-01 $6.15793 e+006.15793 e+00$ 6.15793e-01 1.00000e-09 2.12000e-01 6.15793e+00 6.15793e+00 6.15793e-01 1.00000e-09 2.12000e-01 6.15793e+00 6.15793e+00 6.15793e-01 1.00000e-09 2.12000e-01 6.15793e+00 6.15793e+00 6.15793e-01 1.00000e-09 2.12000e-01 1.00000e-05 1.00000e-05 1.00000e-06 1.00000e-09 1.00000e-01 $1.00000 \mathrm{e}+001.00000 \mathrm{e}+001.00000 \mathrm{e}-011.00000 \mathrm{e}-091.00000 \mathrm{e}-01$ Element: 13255 \# of layers: 7

$\mathrm{Kx} \mathrm{Ky} \mathrm{Kz}$ Ss Por

5.96465e+00 5.96465e+00 5.96465e-01 1.00000e-09 2.12000e-01 $5.96465 \mathrm{e}+00$ 5.96465e+00 5.96465e-01 1.00000e-09 2.12000e-01 5.96465e+00 5.96465e+00 5.96465e-01 1.00000e-09 2.12000e-01 5.96465e+00 5.96465e+00 5.96465e-01 1.00000e-09 2.12000e-01 $5.96465 \mathrm{e}+00$ 5.96465e+00 5.96465e-01 1.00000e-09 2.12000e-01 $1.00000 \mathrm{e}-05$ 1.00000e-05 1.00000e-06 1.00000e-09 1.00000e-01 $1.00000 \mathrm{e}+001.00000 \mathrm{e}+001.00000 \mathrm{e}-011.00000 \mathrm{e}-091.00000 \mathrm{e}-01$ Element: 13256 \# of layers: 7

$\mathrm{Kx} \mathrm{Ky} \mathrm{Kz}$ Ss Por

5.96465e+00 5.96465e+00 5.96465e-01 1.00000e-09 2.12000e-01 5.96465e+00 5.96465e+00 5.96465e-01 1.00000e-09 2.12000e-01 $5.96465 \mathrm{e}+005.96465 \mathrm{e}+00$ 5.96465e-01 1.00000e-09 2.12000e-01 5.96465e+00 5.96465e+00 5.96465e-01 1.00000e-09 2.12000e-01 $5.96465 \mathrm{e}+00$ 5.96465e+00 5.96465e-01 1.00000e-09 2.12000e-01 $1.00000 \mathrm{e}-05$ 1.00000e-05 1.00000e-06 1.00000e-09 1.00000e-01 $1.00000 \mathrm{e}+001.00000 \mathrm{e}+001.00000 \mathrm{e}-01$ 1.00000e-09 1.00000e-01 Element: 13257 \# of layers: 7

$\mathrm{Kx} \mathrm{Ky} \mathrm{Kz}$ Ss Por

5.96465e+00 5.96465e+00 5.96465e-01 1.00000e-09 2.12000e-01 5.96465e+00 5.96465e+00 5.96465e-01 1.00000e-09 2.12000e-01 5.96465e+00 5.96465e+00 5.96465e-01 1.00000e-09 2.12000e-01 $5.96465 \mathrm{e}+00$ 5.96465e+00 5.96465e-01 1.00000e-09 2.12000e-01 $5.96465 \mathrm{e}+00$ 5.96465e+00 5.96465e-01 1.00000e-09 2.12000e-01 
$1.00000 \mathrm{e}-05$ 1.00000e-05 1.00000e-06 1.00000e-09 1.00000e-01 $1.00000 \mathrm{e}+001.00000 \mathrm{e}+001.00000 \mathrm{e}-01$ 1.00000e-09 1.00000e-01 Element: 13258 \# of layers: 7

Kx Ky Kz Ss Por

6.15793e+00 6.15793e+00 6.15793e-01 1.00000e-09 2.12000e-01 $6.15793 \mathrm{e}+00$ 6.15793e+00 6.15793e-01 1.00000e-09 2.12000e-01 $6.15793 e+006.15793 e+00$ 6.15793e-01 1.00000e-09 2.12000e-01 $6.15793 \mathrm{e}+00$ 6.15793e+00 6.15793e-01 1.00000e-09 2.12000e-01 6.15793e+00 6.15793e+00 6.15793e-01 1.00000e-09 2.12000e-01 1.00000e-05 1.00000e-05 1.00000e-06 1.00000e-09 1.00000e-01 $1.00000 \mathrm{e}+001.00000 \mathrm{e}+001.00000 \mathrm{e}-011.00000 \mathrm{e}-091.00000 \mathrm{e}-01$ Element: 13259 \# of layers: 7

Kx Ky Kz Ss Por

6.15793e+00 6.15793e+00 6.15793e-01 1.00000e-09 2.12000e-01 6.15793e+00 6.15793e+00 6.15793e-01 1.00000e-09 2.12000e-01 $6.15793 e+006.15793 e+00$ 6.15793e-01 1.00000e-09 2.12000e-01 6.15793e+00 6.15793e+00 6.15793e-01 1.00000e-09 2.12000e-01 6.15793e+00 6.15793e+00 6.15793e-01 1.00000e-09 2.12000e-01 $1.00000 \mathrm{e}-05$ 1.00000e-05 1.00000e-06 1.00000e-09 1.00000e-01 $1.00000 \mathrm{e}+001.00000 \mathrm{e}+001.00000 \mathrm{e}-011.00000 \mathrm{e}-09$ 1.00000e-01 Element: 13260 \# of layers: 7

$\mathrm{Kx} \mathrm{Ky} \mathrm{Kz}$ Ss Por

6.15793e+00 6.15793e+00 6.15793e-01 1.00000e-09 2.12000e-01 6.15793e+00 6.15793e+00 6.15793e-01 1.00000e-09 2.12000e-01 $6.15793 \mathrm{e}+00$ 6.15793e+00 6.15793e-01 1.00000e-09 2.12000e-01 6.15793e+00 6.15793e+00 6.15793e-01 1.00000e-09 2.12000e-01 $6.15793 \mathrm{e}+006.15793 \mathrm{e}+00$ 6.15793e-01 1.00000e-09 2.12000e-01 $1.00000 \mathrm{e}-05$ 1.00000e-05 1.00000e-06 1.00000e-09 1.00000e-01 $1.00000 \mathrm{e}+001.00000 \mathrm{e}+001.00000 \mathrm{e}-011.00000 \mathrm{e}-091.00000 \mathrm{e}-01$ Element: 13261 \# of layers: 7

$\mathrm{Kx} \mathrm{Ky} \mathrm{Kz}$ Ss Por

6.15793e+00 6.15793e+00 6.15793e-01 1.00000e-09 2.12000e-01 6.15793e+00 6.15793e+00 6.15793e-01 1.00000e-09 2.12000e-01 6.15793e+00 6.15793e+00 6.15793e-01 1.00000e-09 2.12000e-01 6.15793e+00 6.15793e+00 6.15793e-01 1.00000e-09 2.12000e-01 6.15793e+00 6.15793e+00 6.15793e-01 1.00000e-09 2.12000e-01 1.00000e-05 1.00000e-05 1.00000e-06 1.00000e-09 1.00000e-01 $1.00000 \mathrm{e}+001.00000 \mathrm{e}+001.00000 \mathrm{e}-011.00000 \mathrm{e}-091.00000 \mathrm{e}-01$ Element: 13262 \# of layers: 7

$\mathrm{Kx} \mathrm{Ky} \mathrm{Kz}$ Ss Por

5.96465e+00 5.96465e+00 5.96465e-01 1.00000e-09 2.12000e-01 $5.96465 \mathrm{e}+00$ 5.96465e+00 5.96465e-01 1.00000e-09 2.12000e-01 $5.96465 \mathrm{e}+00$ 5.96465e+00 5.96465e-01 1.00000e-09 2.12000e-01 $5.96465 \mathrm{e}+00$ 5.96465e+00 5.96465e-01 1.00000e-09 2.12000e-01 $5.96465 \mathrm{e}+00$ 5.96465e+00 5.96465e-01 1.00000e-09 2.12000e-01 $1.00000 \mathrm{e}-05$ 1.00000e-05 1.00000e-06 1.00000e-09 1.00000e-01 
$1.00000 \mathrm{e}+001.00000 \mathrm{e}+00$ 1.00000e-01 1.00000e-09 1.00000e-01 Element: 13263 \# of layers: 7

$\mathrm{Kx} \mathrm{Ky} \mathrm{Kz}$ Ss Por

5.96465e+00 5.96465e+00 5.96465e-01 1.00000e-09 2.12000e-01

5.96465e+00 5.96465e+00 5.96465e-01 1.00000e-09 2.12000e-01

5.96465e+00 5.96465e+00 5.96465e-01 1.00000e-09 2.12000e-01

5.96465e+00 5.96465e+00 5.96465e-01 1.00000e-09 2.12000e-01

$5.96465 \mathrm{e}+005.96465 \mathrm{e}+00$ 5.96465e-01 1.00000e-09 2.12000e-01

$1.00000 \mathrm{e}-05$ 1.00000e-05 1.00000e-06 1.00000e-09 1.00000e-01

$1.00000 \mathrm{e}+001.00000 \mathrm{e}+001.00000 \mathrm{e}-01$ 1.00000e-09 1.00000e-01

Element: 13264 \# of layers: 7

Kx Ky Kz Ss Por

5.96465e+00 5.96465e+00 5.96465e-01 1.00000e-09 2.12000e-01

5.96465e+00 5.96465e+00 5.96465e-01 1.00000e-09 2.12000e-01

5.96465e+00 5.96465e+00 5.96465e-01 1.00000e-09 2.12000e-01

$5.96465 \mathrm{e}+00$ 5.96465e+00 5.96465e-01 1.00000e-09 2.12000e-01

$5.96465 \mathrm{e}+00$ 5.96465e+00 5.96465e-01 1.00000e-09 2.12000e-01

$1.00000 \mathrm{e}-05$ 1.00000e-05 1.00000e-06 1.00000e-09 1.00000e-01

$1.00000 \mathrm{e}+001.00000 \mathrm{e}+001.00000 \mathrm{e}-01$ 1.00000e-09 1.00000e-01

Element: 13265 \# of layers: 7

Kx Ky Kz Ss Por

5.96465e+00 5.96465e+00 5.96465e-01 1.00000e-09 2.12000e-01

5.96465e+00 5.96465e+00 5.96465e-01 1.00000e-09 2.12000e-01

$5.96465 \mathrm{e}+005.96465 \mathrm{e}+00$ 5.96465e-01 1.00000e-09 2.12000e-01

$5.96465 \mathrm{e}+00$ 5.96465e+00 5.96465e-01 1.00000e-09 2.12000e-01

5.96465e+00 5.96465e+00 5.96465e-01 1.00000e-09 2.12000e-01

$1.00000 \mathrm{e}-05$ 1.00000e-05 1.00000e-06 1.00000e-09 1.00000e-01

$1.00000 \mathrm{e}+001.00000 \mathrm{e}+001.00000 \mathrm{e}-01$ 1.00000e-09 1.00000e-01

Element: 13266 \# of layers: 7

$\mathrm{Kx} \mathrm{Ky} \mathrm{Kz}$ Ss Por

7.23413e+00 7.23413e+00 7.23413e-01 1.00000e-09 2.12000e-01

7.23413e+00 7.23413e+00 7.23413e-01 1.00000e-09 2.12000e-01

$7.23413 \mathrm{e}+00$ 7.23413e+00 7.23413e-01 1.00000e-09 2.12000e-01

$7.23413 \mathrm{e}+00$ 7.23413e+00 7.23413e-01 1.00000e-09 2.12000e-01

7.23413e+00 7.23413e+00 7.23413e-01 1.00000e-09 2.12000e-01

$1.00000 \mathrm{e}-05$ 1.00000e-05 1.00000e-06 1.00000e-09 1.00000e-01

$1.00000 \mathrm{e}+001.00000 \mathrm{e}+001.00000 \mathrm{e}-011.00000 \mathrm{e}-091.00000 \mathrm{e}-01$

Element: 13267 \# of layers: 7

$\mathrm{Kx} \mathrm{Ky} \mathrm{Kz}$ Ss Por

7.23413e+00 7.23413e+00 7.23413e-01 1.00000e-09 2.12000e-01

$7.23413 \mathrm{e}+00$ 7.23413e+00 7.23413e-01 1.00000e-09 2.12000e-01

$7.23413 \mathrm{e}+00$ 7.23413e+00 7.23413e-01 1.00000e-09 2.12000e-01

$7.23413 \mathrm{e}+00$ 7.23413e+00 7.23413e-01 1.00000e-09 2.12000e-01

7.23413e+00 7.23413e+00 7.23413e-01 1.00000e-09 2.12000e-01

$1.00000 \mathrm{e}-05$ 1.00000e-05 1.00000e-06 1.00000e-09 1.00000e-01

$1.00000 \mathrm{e}+001.00000 \mathrm{e}+001.00000 \mathrm{e}-011.00000 \mathrm{e}-091.00000 \mathrm{e}-01$ 
Element: 13268 \# of layers: 7

$\mathrm{Kx} \mathrm{Ky} \mathrm{Kz}$ Ss Por

5.96465e+00 5.96465e+00 5.96465e-01 1.00000e-09 2.12000e-01

$5.96465 \mathrm{e}+00$ 5.96465e+00 5.96465e-01 1.00000e-09 2.12000e-01

5.96465e+00 5.96465e+00 5.96465e-01 1.00000e-09 2.12000e-01

$5.96465 \mathrm{e}+005.96465 \mathrm{e}+00$ 5.96465e-01 1.00000e-09 2.12000e-01

$5.96465 \mathrm{e}+00$ 5.96465e+00 5.96465e-01 1.00000e-09 2.12000e-01

$1.00000 \mathrm{e}-05$ 1.00000e-05 1.00000e-06 1.00000e-09 1.00000e-01

$1.00000 \mathrm{e}+001.00000 \mathrm{e}+001.00000 \mathrm{e}-011.00000 \mathrm{e}-091.00000 \mathrm{e}-01$

Element: 13269 \# of layers: 7

$\mathrm{Kx} \mathrm{Ky} \mathrm{Kz}$ Ss Por

7.23413e+00 7.23413e+00 7.23413e-01 1.00000e-09 2.12000e-01

7.23413e+00 7.23413e+00 7.23413e-01 1.00000e-09 2.12000e-01

$7.23413 \mathrm{e}+00$ 7.23413e+00 7.23413e-01 1.00000e-09 2.12000e-01

7.23413e+00 7.23413e+00 7.23413e-01 1.00000e-09 2.12000e-01

$7.23413 \mathrm{e}+00$ 7.23413e+00 7.23413e-01 1.00000e-09 2.12000e-01

$1.00000 \mathrm{e}-05$ 1.00000e-05 1.00000e-06 1.00000e-09 1.00000e-01

$1.00000 \mathrm{e}+001.00000 \mathrm{e}+001.00000 \mathrm{e}-01$ 1.00000e-09 1.00000e-01

Element: 13270 \# of layers: 7

$\mathrm{Kx} \mathrm{Ky} \mathrm{Kz}$ Ss Por

7.23413e+00 7.23413e+00 7.23413e-01 1.00000e-09 2.12000e-01

7.23413e+00 7.23413e+00 7.23413e-01 1.00000e-09 2.12000e-01

7.23413e+00 7.23413e+00 7.23413e-01 1.00000e-09 2.12000e-01

$7.23413 \mathrm{e}+00$ 7.23413e+00 7.23413e-01 1.00000e-09 2.12000e-01

$7.23413 \mathrm{e}+007.23413 \mathrm{e}+00$ 7.23413e-01 1.00000e-09 2.12000e-01

$1.00000 \mathrm{e}-05$ 1.00000e-05 1.00000e-06 1.00000e-09 1.00000e-01

$1.00000 \mathrm{e}+001.00000 \mathrm{e}+001.00000 \mathrm{e}-011.00000 \mathrm{e}-091.00000 \mathrm{e}-01$

Element: 13271 \# of layers: 7

Kx Ky Kz Ss Por

5.89310e+00 5.89310e+00 5.89310e-01 1.00000e-09 2.12000e-01

$5.89310 \mathrm{e}+005.89310 \mathrm{e}+005.89310 \mathrm{e}-01$ 1.00000e-09 2.12000e-01

$5.89310 \mathrm{e}+005.89310 \mathrm{e}+00$ 5.89310e-01 1.00000e-09 2.12000e-01

$5.89310 \mathrm{e}+005.89310 \mathrm{e}+00$ 5.89310e-01 1.00000e-09 2.12000e-01

$5.89310 \mathrm{e}+005.89310 \mathrm{e}+00$ 5.89310e-01 1.00000e-09 2.12000e-01

$1.00000 \mathrm{e}-05$ 1.00000e-05 1.00000e-06 1.00000e-09 1.00000e-01

$1.00000 \mathrm{e}+001.00000 \mathrm{e}+001.00000 \mathrm{e}-01$ 1.00000e-09 1.00000e-01

Element: 13272 \# of layers: 7

$\mathrm{Kx} \mathrm{Ky} \mathrm{Kz}$ Ss Por

$5.89310 \mathrm{e}+005.89310 \mathrm{e}+005.89310 \mathrm{e}-011.00000 \mathrm{e}-092.12000 \mathrm{e}-01$

$5.89310 \mathrm{e}+005.89310 \mathrm{e}+005.89310 \mathrm{e}-01$ 1.00000e-09 2.12000e-01

$5.89310 \mathrm{e}+005.89310 \mathrm{e}+00$ 5.89310e-01 1.00000e-09 2.12000e-01

$5.89310 \mathrm{e}+005.89310 \mathrm{e}+00$ 5.89310e-01 1.00000e-09 2.12000e-01

$5.89310 \mathrm{e}+00$ 5.89310e+00 5.89310e-01 1.00000e-09 2.12000e-01

$1.00000 \mathrm{e}-05$ 1.00000e-05 1.00000e-06 1.00000e-09 1.00000e-01

$1.00000 \mathrm{e}+001.00000 \mathrm{e}+001.00000 \mathrm{e}-01$ 1.00000e-09 1.00000e-01

Element: 13273 \# of layers: 7 
Kx Ky Kz Ss Por

5.89310e+00 5.89310e+00 5.89310e-01 1.00000e-09 2.12000e-01

$5.89310 \mathrm{e}+00$ 5.89310e+00 5.89310e-01 1.00000e-09 2.12000e-01

$5.89310 \mathrm{e}+00$ 5.89310e+00 5.89310e-01 1.00000e-09 2.12000e-01

$5.89310 \mathrm{e}+005.89310 \mathrm{e}+00$ 5.89310e-01 1.00000e-09 2.12000e-01

$5.89310 \mathrm{e}+005.89310 \mathrm{e}+005.89310 \mathrm{e}-01$ 1.00000e-09 2.12000e-01

$1.00000 \mathrm{e}-05$ 1.00000e-05 1.00000e-06 1.00000e-09 1.00000e-01

$1.00000 \mathrm{e}+001.00000 \mathrm{e}+001.00000 \mathrm{e}-011.00000 \mathrm{e}-091.00000 \mathrm{e}-01$

Element: 13274 \# of layers: 7

$\mathrm{Kx} \mathrm{Ky} \mathrm{Kz}$ Ss Por

6.15793e+00 6.15793e+00 6.15793e-01 1.00000e-09 2.12000e-01

6.15793e+00 6.15793e+00 6.15793e-01 1.00000e-09 2.12000e-01

6.15793e+00 6.15793e+00 6.15793e-01 1.00000e-09 2.12000e-01

6.15793e+00 6.15793e+00 6.15793e-01 1.00000e-09 2.12000e-01

6.15793e+00 6.15793e+00 6.15793e-01 1.00000e-09 2.12000e-01

$1.00000 \mathrm{e}-05$ 1.00000e-05 1.00000e-06 1.00000e-09 1.00000e-01

$1.00000 \mathrm{e}+001.00000 \mathrm{e}+001.00000 \mathrm{e}-011.00000 \mathrm{e}-091.00000 \mathrm{e}-01$

Element: 13275 \# of layers: 7

$\mathrm{Kx} \mathrm{Ky} \mathrm{Kz}$ Ss Por

6.15793e+00 6.15793e+00 6.15793e-01 1.00000e-09 2.12000e-01

6.15793e+00 6.15793e+00 6.15793e-01 1.00000e-09 2.12000e-01

6.15793e+00 6.15793e+00 6.15793e-01 1.00000e-09 2.12000e-01

6.15793e+00 6.15793e+00 6.15793e-01 1.00000e-09 2.12000e-01

6.15793e+00 6.15793e+00 6.15793e-01 1.00000e-09 2.12000e-01

$1.00000 \mathrm{e}-05$ 1.00000e-05 1.00000e-06 1.00000e-09 1.00000e-01

$1.00000 \mathrm{e}+001.00000 \mathrm{e}+001.00000 \mathrm{e}-01$ 1.00000e-09 1.00000e-01

Element: 13276 \# of layers: 7

$\mathrm{Kx} \mathrm{Ky} \mathrm{Kz}$ Ss Por

5.96465e+00 5.96465e+00 5.96465e-01 1.00000e-09 2.12000e-01

5.96465e+00 5.96465e+00 5.96465e-01 1.00000e-09 2.12000e-01

5.96465e+00 5.96465e+00 5.96465e-01 1.00000e-09 2.12000e-01

5.96465e+00 5.96465e+00 5.96465e-01 1.00000e-09 2.12000e-01

$5.96465 \mathrm{e}+005.96465 \mathrm{e}+00$ 5.96465e-01 1.00000e-09 2.12000e-01

$1.00000 \mathrm{e}-051.00000 \mathrm{e}-051.00000 \mathrm{e}-061.00000 \mathrm{e}-091.00000 \mathrm{e}-01$

$1.00000 \mathrm{e}+001.00000 \mathrm{e}+001.00000 \mathrm{e}-01$ 1.00000e-09 1.00000e-01

Element: 13277 \# of layers: 7

Kx Ky Kz Ss Por

7.23413e+00 7.23413e+00 7.23413e-01 1.00000e-09 2.12000e-01

7.23413e+00 7.23413e+00 7.23413e-01 1.00000e-09 2.12000e-01

7.23413e+00 7.23413e+00 7.23413e-01 1.00000e-09 2.12000e-01

$7.23413 \mathrm{e}+00$ 7.23413e+00 7.23413e-01 1.00000e-09 2.12000e-01

$7.23413 \mathrm{e}+00$ 7.23413e+00 7.23413e-01 1.00000e-09 2.12000e-01

$1.00000 \mathrm{e}-051.00000 \mathrm{e}-051.00000 \mathrm{e}-061.00000 \mathrm{e}-091.00000 \mathrm{e}-01$

$1.00000 \mathrm{e}+001.00000 \mathrm{e}+001.00000 \mathrm{e}-01$ 1.00000e-09 1.00000e-01

Element: 13278 \# of layers: 7

Kx Ky Kz Ss Por 
$5.89310 \mathrm{e}+005.89310 \mathrm{e}+00$ 5.89310e-01 1.00000e-09 2.12000e-01 $5.89310 \mathrm{e}+005.89310 \mathrm{e}+005.89310 \mathrm{e}-011.00000 \mathrm{e}-092.12000 \mathrm{e}-01$ $5.89310 \mathrm{e}+005.89310 \mathrm{e}+00$ 5.89310e-01 1.00000e-09 2.12000e-01 $5.89310 \mathrm{e}+005.89310 \mathrm{e}+005.89310 \mathrm{e}-011.00000 \mathrm{e}-092.12000 \mathrm{e}-01$ $5.89310 \mathrm{e}+005.89310 \mathrm{e}+00$ 5.89310e-01 1.00000e-09 2.12000e-01 $1.00000 \mathrm{e}-05$ 1.00000e-05 1.00000e-06 1.00000e-09 1.00000e-01 $1.00000 \mathrm{e}+001.00000 \mathrm{e}+001.00000 \mathrm{e}-011.00000 \mathrm{e}-091.00000 \mathrm{e}-01$ Element: 13279 \# of layers: 7

Kx Ky Kz Ss Por

$4.47085 \mathrm{e}+004.47085 \mathrm{e}+004.47085 \mathrm{e}-01$ 1.00000e-09 2.12000e-01 $4.47085 \mathrm{e}+004.47085 \mathrm{e}+004.47085 \mathrm{e}-011.00000 \mathrm{e}-092.12000 \mathrm{e}-01$ $4.47085 \mathrm{e}+004.47085 \mathrm{e}+004.47085 \mathrm{e}-011.00000 \mathrm{e}-092.12000 \mathrm{e}-01$ $4.47085 \mathrm{e}+004.47085 \mathrm{e}+004.47085 \mathrm{e}-01$ 1.00000e-09 2.12000e-01 $4.47085 \mathrm{e}+004.47085 \mathrm{e}+004.47085 \mathrm{e}-01$ 1.00000e-09 2.12000e-01 $1.00000 \mathrm{e}-05$ 1.00000e-05 1.00000e-06 1.00000e-09 1.00000e-01 $1.00000 \mathrm{e}+001.00000 \mathrm{e}+001.00000 \mathrm{e}-011.00000 \mathrm{e}-09$ 1.00000e-01 Element: 13280 \# of layers: 7

Kx Ky Kz Ss Por

$4.47085 \mathrm{e}+004.47085 \mathrm{e}+00$ 4.47085e-01 1.00000e-09 2.12000e-01 $4.47085 \mathrm{e}+004.47085 \mathrm{e}+004.47085 \mathrm{e}-011.00000 \mathrm{e}-092.12000 \mathrm{e}-01$ $4.47085 \mathrm{e}+004.47085 \mathrm{e}+004.47085 \mathrm{e}-011.00000 \mathrm{e}-092.12000 \mathrm{e}-01$ $4.47085 \mathrm{e}+004.47085 \mathrm{e}+004.47085 \mathrm{e}-011.00000 \mathrm{e}-092.12000 \mathrm{e}-01$ $4.47085 \mathrm{e}+004.47085 \mathrm{e}+00$ 4.47085e-01 1.00000e-09 2.12000e-01 $1.00000 \mathrm{e}-05$ 1.00000e-05 1.00000e-06 1.00000e-09 1.00000e-01 $1.00000 \mathrm{e}+001.00000 \mathrm{e}+001.00000 \mathrm{e}-011.00000 \mathrm{e}-091.00000 \mathrm{e}-01$ Element: 13281 \# of layers: 7

Kx Ky Kz Ss Por

$4.47085 \mathrm{e}+004.47085 \mathrm{e}+004.47085 \mathrm{e}-01$ 1.00000e-09 2.12000e-01 $4.47085 \mathrm{e}+004.47085 \mathrm{e}+004.47085 \mathrm{e}-01$ 1.00000e-09 2.12000e-01 $4.47085 \mathrm{e}+004.47085 \mathrm{e}+004.47085 \mathrm{e}-011.00000 \mathrm{e}-092.12000 \mathrm{e}-01$ $4.47085 \mathrm{e}+004.47085 \mathrm{e}+004.47085 \mathrm{e}-011.00000 \mathrm{e}-092.12000 \mathrm{e}-01$ $4.47085 \mathrm{e}+004.47085 \mathrm{e}+004.47085 \mathrm{e}-01$ 1.00000e-09 2.12000e-01 $1.00000 \mathrm{e}-05$ 1.00000e-05 1.00000e-06 1.00000e-09 1.00000e-01 $1.00000 \mathrm{e}+001.00000 \mathrm{e}+001.00000 \mathrm{e}-011.00000 \mathrm{e}-091.00000 \mathrm{e}-01$ Element: 13282 \# of layers: 7

Kx Ky Kz Ss Por $4.47085 \mathrm{e}+004.47085 \mathrm{e}+00$ 4.47085e-01 1.00000e-09 2.12000e-01 $4.47085 \mathrm{e}+004.47085 \mathrm{e}+004.47085 \mathrm{e}-01$ 1.00000e-09 2.12000e-01 $4.47085 \mathrm{e}+004.47085 \mathrm{e}+004.47085 \mathrm{e}-01$ 1.00000e-09 2.12000e-01 $4.47085 \mathrm{e}+004.47085 \mathrm{e}+004.47085 \mathrm{e}-01$ 1.00000e-09 2.12000e-01 $4.47085 \mathrm{e}+004.47085 \mathrm{e}+004.47085 \mathrm{e}-01$ 1.00000e-09 2.12000e-01 $1.00000 \mathrm{e}-05$ 1.00000e-05 1.00000e-06 1.00000e-09 1.00000e-01 $1.00000 \mathrm{e}+001.00000 \mathrm{e}+001.00000 \mathrm{e}-011.00000 \mathrm{e}-091.00000 \mathrm{e}-01$ Element: 13283 \# of layers: 7

Kx Ky Kz Ss Por

4.47085e+00 4.47085e+00 4.47085e-01 1.00000e-09 2.12000e-01 
4.47085e+00 4.47085e+00 4.47085e-01 1.00000e-09 2.12000e-01 4.47085e+00 4.47085e+00 4.47085e-01 1.00000e-09 2.12000e-01 4.47085e+00 4.47085e+00 4.47085e-01 1.00000e-09 2.12000e-01 $4.47085 \mathrm{e}+00$ 4.47085e+00 4.47085e-01 1.00000e-09 2.12000e-01 $1.00000 \mathrm{e}-05$ 1.00000e-05 1.00000e-06 1.00000e-09 1.00000e-01 $1.00000 \mathrm{e}+001.00000 \mathrm{e}+001.00000 \mathrm{e}-011.00000 \mathrm{e}-091.00000 \mathrm{e}-01$ Element: 13284 \# of layers: 7

$\mathrm{Kx} \mathrm{Ky} \mathrm{Kz}$ Ss Por

4.47085e+00 4.47085e+00 4.47085e-01 1.00000e-09 2.12000e-01 $4.47085 \mathrm{e}+004.47085 \mathrm{e}+00$ 4.47085e-01 1.00000e-09 2.12000e-01 4.47085e+00 4.47085e+00 4.47085e-01 1.00000e-09 2.12000e-01 $4.47085 \mathrm{e}+004.47085 \mathrm{e}+00$ 4.47085e-01 1.00000e-09 2.12000e-01 $4.47085 \mathrm{e}+00$ 4.47085e+00 4.47085e-01 1.00000e-09 2.12000e-01 $1.00000 \mathrm{e}-05$ 1.00000e-05 1.00000e-06 1.00000e-09 1.00000e-01 $1.00000 \mathrm{e}+001.00000 \mathrm{e}+001.00000 \mathrm{e}-01$ 1.00000e-09 1.00000e-01 Element: 13285 \# of layers: 7

$\mathrm{Kx} \mathrm{Ky} \mathrm{Kz}$ Ss Por

4.47085e+00 4.47085e+00 4.47085e-01 1.00000e-09 2.12000e-01 4.47085e+00 4.47085e+00 4.47085e-01 1.00000e-09 2.12000e-01 $4.47085 \mathrm{e}+004.47085 \mathrm{e}+00$ 4.47085e-01 1.00000e-09 2.12000e-01 $4.47085 \mathrm{e}+004.47085 \mathrm{e}+00$ 4.47085e-01 1.00000e-09 2.12000e-01 $4.47085 \mathrm{e}+00$ 4.47085e+00 4.47085e-01 1.00000e-09 2.12000e-01 $1.00000 \mathrm{e}-05$ 1.00000e-05 1.00000e-06 1.00000e-09 1.00000e-01 $1.00000 \mathrm{e}+001.00000 \mathrm{e}+001.00000 \mathrm{e}-011.00000 \mathrm{e}-09$ 1.00000e-01 Element: 13286 \# of layers: 7

$\mathrm{Kx} \mathrm{Ky} \mathrm{Kz}$ Ss Por

4.47085e+00 4.47085e+00 4.47085e-01 1.00000e-09 2.12000e-01 $4.47085 \mathrm{e}+00$ 4.47085e+00 4.47085e-01 1.00000e-09 2.12000e-01 $4.47085 \mathrm{e}+00$ 4.47085e+00 4.47085e-01 1.00000e-09 2.12000e-01 $4.47085 \mathrm{e}+00$ 4.47085e+00 4.47085e-01 1.00000e-09 2.12000e-01 $4.47085 \mathrm{e}+00$ 4.47085e+00 4.47085e-01 1.00000e-09 2.12000e-01 $1.00000 \mathrm{e}-05$ 1.00000e-05 1.00000e-06 1.00000e-09 1.00000e-01 $1.00000 \mathrm{e}+001.00000 \mathrm{e}+001.00000 \mathrm{e}-011.00000 \mathrm{e}-091.00000 \mathrm{e}-01$ Element: 13287 \# of layers: 7

$\mathrm{Kx} \mathrm{Ky} \mathrm{Kz}$ Ss Por

4.47085e+00 4.47085e+00 4.47085e-01 1.00000e-09 2.12000e-01 $4.47085 \mathrm{e}+004.47085 \mathrm{e}+00$ 4.47085e-01 1.00000e-09 2.12000e-01 $4.47085 \mathrm{e}+004.47085 \mathrm{e}+00$ 4.47085e-01 1.00000e-09 2.12000e-01 $4.47085 \mathrm{e}+004.47085 \mathrm{e}+00$ 4.47085e-01 1.00000e-09 2.12000e-01 4.47085e+00 4.47085e+00 4.47085e-01 1.00000e-09 2.12000e-01 $1.00000 \mathrm{e}-05$ 1.00000e-05 1.00000e-06 1.00000e-09 1.00000e-01 $1.00000 \mathrm{e}+001.00000 \mathrm{e}+001.00000 \mathrm{e}-011.00000 \mathrm{e}-09$ 1.00000e-01 Element: 13288 \# of layers: 7

$\mathrm{Kx} \mathrm{Ky} \mathrm{Kz}$ Ss Por 4.47085e+00 4.47085e+00 4.47085e-01 1.00000e-09 2.12000e-01 $4.47085 \mathrm{e}+004.47085 \mathrm{e}+00$ 4.47085e-01 1.00000e-09 2.12000e-01 
4.47085e+00 4.47085e+00 4.47085e-01 1.00000e-09 2.12000e-01 4.47085e+00 4.47085e+00 4.47085e-01 1.00000e-09 2.12000e-01 4.47085e+00 4.47085e+00 4.47085e-01 1.00000e-09 2.12000e-01 $1.00000 \mathrm{e}-05$ 1.00000e-05 1.00000e-06 1.00000e-09 1.00000e-01 $1.00000 \mathrm{e}+001.00000 \mathrm{e}+001.00000 \mathrm{e}-01$ 1.00000e-09 1.00000e-01 Element: 13289 \# of layers: 7

$\mathrm{Kx} \mathrm{Ky} \mathrm{Kz}$ Ss Por

4.16034e+00 4.16034e+00 4.16034e-01 1.00000e-09 2.12000e-01 $4.16034 \mathrm{e}+004.16034 \mathrm{e}+004.16034 \mathrm{e}-01$ 1.00000e-09 2.12000e-01 $4.16034 \mathrm{e}+004.16034 \mathrm{e}+004.16034 \mathrm{e}-01$ 1.00000e-09 2.12000e-01 $4.16034 \mathrm{e}+004.16034 \mathrm{e}+004.16034 \mathrm{e}-01$ 1.00000e-09 2.12000e-01 $4.16034 \mathrm{e}+004.16034 \mathrm{e}+00 \quad 4.16034 \mathrm{e}-01$ 1.00000e-09 2.12000e-01 $1.00000 \mathrm{e}-05$ 1.00000e-05 1.00000e-06 1.00000e-09 1.00000e-01 $1.00000 \mathrm{e}+001.00000 \mathrm{e}+001.00000 \mathrm{e}-011.00000 \mathrm{e}-091.00000 \mathrm{e}-01$ Element: 13290 \# of layers: 7

Kx Ky Kz Ss Por

4.16034e+00 4.16034e+00 4.16034e-01 1.00000e-09 2.12000e-01 $4.16034 \mathrm{e}+004.16034 \mathrm{e}+004.16034 \mathrm{e}-01$ 1.00000e-09 2.12000e-01 $4.16034 \mathrm{e}+004.16034 \mathrm{e}+004.16034 \mathrm{e}-01$ 1.00000e-09 2.12000e-01 $4.16034 \mathrm{e}+004.16034 \mathrm{e}+00 \quad 4.16034 \mathrm{e}-01$ 1.00000e-09 2.12000e-01 $4.16034 \mathrm{e}+004.16034 \mathrm{e}+00 \quad 4.16034 \mathrm{e}-01$ 1.00000e-09 2.12000e-01 $1.00000 \mathrm{e}-05$ 1.00000e-05 1.00000e-06 1.00000e-09 1.00000e-01 $1.00000 \mathrm{e}+001.00000 \mathrm{e}+001.00000 \mathrm{e}-01$ 1.00000e-09 1.00000e-01 Element: 13291 \# of layers: 7

$\mathrm{Kx} \mathrm{Ky} \mathrm{Kz}$ Ss Por

4.16034e+00 4.16034e+00 4.16034e-01 1.00000e-09 2.12000e-01 4.16034e+00 4.16034e+00 4.16034e-01 1.00000e-09 2.12000e-01 $4.16034 \mathrm{e}+004.16034 \mathrm{e}+004.16034 \mathrm{e}-01$ 1.00000e-09 2.12000e-01 $4.16034 \mathrm{e}+004.16034 \mathrm{e}+00$ 4.16034e-01 1.00000e-09 2.12000e-01 4.16034e+00 4.16034e+00 4.16034e-01 1.00000e-09 2.12000e-01 $1.00000 \mathrm{e}-05$ 1.00000e-05 1.00000e-06 1.00000e-09 1.00000e-01 $1.00000 \mathrm{e}+001.00000 \mathrm{e}+001.00000 \mathrm{e}-01$ 1.00000e-09 1.00000e-01 Element: 13292 \# of layers: 7

$\mathrm{Kx} \mathrm{Ky} \mathrm{Kz}$ Ss Por

4.16034e+00 4.16034e+00 4.16034e-01 1.00000e-09 2.12000e-01 $4.16034 \mathrm{e}+004.16034 \mathrm{e}+004.16034 \mathrm{e}-01$ 1.00000e-09 2.12000e-01 $4.16034 \mathrm{e}+004.16034 \mathrm{e}+004.16034 \mathrm{e}-01$ 1.00000e-09 2.12000e-01 $4.16034 \mathrm{e}+004.16034 \mathrm{e}+004.16034 \mathrm{e}-01$ 1.00000e-09 2.12000e-01 $4.16034 \mathrm{e}+004.16034 \mathrm{e}+00$ 4.16034e-01 1.00000e-09 2.12000e-01 $1.00000 \mathrm{e}-05$ 1.00000e-05 1.00000e-06 1.00000e-09 1.00000e-01 $1.00000 \mathrm{e}+001.00000 \mathrm{e}+001.00000 \mathrm{e}-011.00000 \mathrm{e}-091.00000 \mathrm{e}-01$ Element: 13293 \# of layers: 7

$\mathrm{Kx} \mathrm{Ky} \mathrm{Kz}$ Ss Por

4.16034e+00 4.16034e+00 4.16034e-01 1.00000e-09 2.12000e-01 $4.16034 \mathrm{e}+004.16034 \mathrm{e}+00$ 4.16034e-01 1.00000e-09 2.12000e-01 $4.16034 \mathrm{e}+004.16034 \mathrm{e}+004.16034 \mathrm{e}-01$ 1.00000e-09 2.12000e-01 
$4.16034 \mathrm{e}+004.16034 \mathrm{e}+00$ 4.16034e-01 1.00000e-09 2.12000e-01 $4.16034 \mathrm{e}+004.16034 \mathrm{e}+004.16034 \mathrm{e}-01$ 1.00000e-09 2.12000e-01 $1.00000 \mathrm{e}-05$ 1.00000e-05 1.00000e-06 1.00000e-09 1.00000e-01 $1.00000 \mathrm{e}+001.00000 \mathrm{e}+001.00000 \mathrm{e}-011.00000 \mathrm{e}-091.00000 \mathrm{e}-01$ Element: 13294 \# of layers: 7

Kx Ky Kz Ss Por

$4.47085 \mathrm{e}+004.47085 \mathrm{e}+004.47085 \mathrm{e}-01$ 1.00000e-09 2.12000e-01 $4.47085 \mathrm{e}+004.47085 \mathrm{e}+004.47085 \mathrm{e}-011.00000 \mathrm{e}-092.12000 \mathrm{e}-01$ $4.47085 \mathrm{e}+004.47085 \mathrm{e}+004.47085 \mathrm{e}-011.00000 \mathrm{e}-092.12000 \mathrm{e}-01$ $4.47085 \mathrm{e}+004.47085 \mathrm{e}+004.47085 \mathrm{e}-011.00000 \mathrm{e}-092.12000 \mathrm{e}-01$ $4.47085 \mathrm{e}+004.47085 \mathrm{e}+004.47085 \mathrm{e}-01$ 1.00000e-09 2.12000e-01 $1.00000 \mathrm{e}-05$ 1.00000e-05 1.00000e-06 1.00000e-09 1.00000e-01 $1.00000 \mathrm{e}+001.00000 \mathrm{e}+001.00000 \mathrm{e}-011.00000 \mathrm{e}-091.00000 \mathrm{e}-01$ Element: 13295 \# of layers: 7

Kx Ky Kz Ss Por

$4.47085 \mathrm{e}+004.47085 \mathrm{e}+00$ 4.47085e-01 1.00000e-09 2.12000e-01 $4.47085 \mathrm{e}+004.47085 \mathrm{e}+004.47085 \mathrm{e}-011.00000 \mathrm{e}-092.12000 \mathrm{e}-01$ $4.47085 \mathrm{e}+004.47085 \mathrm{e}+004.47085 \mathrm{e}-011.00000 \mathrm{e}-092.12000 \mathrm{e}-01$ $4.47085 \mathrm{e}+004.47085 \mathrm{e}+004.47085 \mathrm{e}-01$ 1.00000e-09 2.12000e-01 $4.47085 \mathrm{e}+004.47085 \mathrm{e}+004.47085 \mathrm{e}-01$ 1.00000e-09 2.12000e-01 $1.00000 \mathrm{e}-05$ 1.00000e-05 1.00000e-06 1.00000e-09 1.00000e-01 $1.00000 \mathrm{e}+001.00000 \mathrm{e}+001.00000 \mathrm{e}-011.00000 \mathrm{e}-091.00000 \mathrm{e}-01$ Element: 13296 \# of layers: 7

Kx Ky Kz Ss Por

$4.16034 \mathrm{e}+004.16034 \mathrm{e}+004.16034 \mathrm{e}-01$ 1.00000e-09 2.12000e-01 $4.16034 \mathrm{e}+004.16034 \mathrm{e}+004.16034 \mathrm{e}-011.00000 \mathrm{e}-092.12000 \mathrm{e}-01$ $4.16034 \mathrm{e}+004.16034 \mathrm{e}+004.16034 \mathrm{e}-011.00000 \mathrm{e}-092.12000 \mathrm{e}-01$ $4.16034 \mathrm{e}+004.16034 \mathrm{e}+004.16034 \mathrm{e}-011.00000 \mathrm{e}-092.12000 \mathrm{e}-01$ $4.16034 \mathrm{e}+004.16034 \mathrm{e}+004.16034 \mathrm{e}-011.00000 \mathrm{e}-092.12000 \mathrm{e}-01$ $1.00000 \mathrm{e}-05$ 1.00000e-05 1.00000e-06 1.00000e-09 1.00000e-01 $1.00000 \mathrm{e}+001.00000 \mathrm{e}+001.00000 \mathrm{e}-011.00000 \mathrm{e}-091.00000 \mathrm{e}-01$ Element: 13297 \# of layers: 7

Kx Ky Kz Ss Por

$4.16034 \mathrm{e}+004.16034 \mathrm{e}+004.16034 \mathrm{e}-01$ 1.00000e-09 2.12000e-01 $4.16034 \mathrm{e}+004.16034 \mathrm{e}+004.16034 \mathrm{e}-011.00000 \mathrm{e}-092.12000 \mathrm{e}-01$ $4.16034 \mathrm{e}+004.16034 \mathrm{e}+004.16034 \mathrm{e}-011.00000 \mathrm{e}-092.12000 \mathrm{e}-01$ $4.16034 \mathrm{e}+004.16034 \mathrm{e}+004.16034 \mathrm{e}-011.00000 \mathrm{e}-092.12000 \mathrm{e}-01$ $4.16034 \mathrm{e}+004.16034 \mathrm{e}+00$ 4.16034e-01 1.00000e-09 2.12000e-01 $1.00000 \mathrm{e}-05$ 1.00000e-05 1.00000e-06 1.00000e-09 1.00000e-01 $1.00000 \mathrm{e}+001.00000 \mathrm{e}+001.00000 \mathrm{e}-011.00000 \mathrm{e}-091.00000 \mathrm{e}-01$ Element: 13298 \# of layers: 7

Kx Ky Kz Ss Por

$4.16034 \mathrm{e}+004.16034 \mathrm{e}+00$ 4.16034e-01 1.00000e-09 2.12000e-01 $4.16034 \mathrm{e}+004.16034 \mathrm{e}+004.16034 \mathrm{e}-011.00000 \mathrm{e}-092.12000 \mathrm{e}-01$ $4.16034 \mathrm{e}+004.16034 \mathrm{e}+004.16034 \mathrm{e}-011.00000 \mathrm{e}-092.12000 \mathrm{e}-01$ $4.16034 \mathrm{e}+004.16034 \mathrm{e}+004.16034 \mathrm{e}-01$ 1.00000e-09 2.12000e-01 
4.16034e+00 4.16034e+00 4.16034e-01 1.00000e-09 2.12000e-01 $1.00000 \mathrm{e}-05$ 1.00000e-05 1.00000e-06 1.00000e-09 1.00000e-01 $1.00000 \mathrm{e}+001.00000 \mathrm{e}+001.00000 \mathrm{e}-011.00000 \mathrm{e}-091.00000 \mathrm{e}-01$ Element: 13299 \# of layers: 7

$\mathrm{Kx} \mathrm{Ky} \mathrm{Kz}$ Ss Por

4.16034e+00 4.16034e+00 4.16034e-01 1.00000e-09 2.12000e-01 $4.16034 \mathrm{e}+004.16034 \mathrm{e}+00$ 4.16034e-01 1.00000e-09 2.12000e-01 $4.16034 \mathrm{e}+004.16034 \mathrm{e}+004.16034 \mathrm{e}-01$ 1.00000e-09 2.12000e-01 $4.16034 \mathrm{e}+004.16034 \mathrm{e}+004.16034 \mathrm{e}-01$ 1.00000e-09 2.12000e-01 $4.16034 \mathrm{e}+004.16034 \mathrm{e}+004.16034 \mathrm{e}-01$ 1.00000e-09 2.12000e-01 $1.00000 \mathrm{e}-05$ 1.00000e-05 1.00000e-06 1.00000e-09 1.00000e-01 $1.00000 \mathrm{e}+001.00000 \mathrm{e}+001.00000 \mathrm{e}-011.00000 \mathrm{e}-091.00000 \mathrm{e}-01$ Element: 13300 \# of layers: 7

$\mathrm{Kx} \mathrm{Ky} \mathrm{Kz}$ Ss Por

4.16034e+00 4.16034e+00 4.16034e-01 1.00000e-09 2.12000e-01 $4.16034 \mathrm{e}+004.16034 \mathrm{e}+004.16034 \mathrm{e}-01$ 1.00000e-09 2.12000e-01 $4.16034 \mathrm{e}+004.16034 \mathrm{e}+004.16034 \mathrm{e}-01$ 1.00000e-09 2.12000e-01 $4.16034 \mathrm{e}+004.16034 \mathrm{e}+00$ 4.16034e-01 1.00000e-09 2.12000e-01 $4.16034 \mathrm{e}+004.16034 \mathrm{e}+004.16034 \mathrm{e}-01$ 1.00000e-09 2.12000e-01 $1.00000 \mathrm{e}-05$ 1.00000e-05 1.00000e-06 1.00000e-09 1.00000e-01 $1.00000 \mathrm{e}+001.00000 \mathrm{e}+001.00000 \mathrm{e}-011.00000 \mathrm{e}-091.00000 \mathrm{e}-01$ Element: 13301 \# of layers: 7

$\mathrm{Kx} \mathrm{Ky} \mathrm{Kz}$ Ss Por

4.16034e+00 4.16034e+00 4.16034e-01 1.00000e-09 2.12000e-01 $4.16034 \mathrm{e}+004.16034 \mathrm{e}+004.16034 \mathrm{e}-01$ 1.00000e-09 2.12000e-01 $4.16034 \mathrm{e}+004.16034 \mathrm{e}+004.16034 \mathrm{e}-01$ 1.00000e-09 2.12000e-01 $4.16034 \mathrm{e}+004.16034 \mathrm{e}+00$ 4.16034e-01 1.00000e-09 2.12000e-01 $4.16034 \mathrm{e}+004.16034 \mathrm{e}+004.16034 \mathrm{e}-01$ 1.00000e-09 2.12000e-01 $1.00000 \mathrm{e}-05$ 1.00000e-05 1.00000e-06 1.00000e-09 1.00000e-01 $1.00000 \mathrm{e}+001.00000 \mathrm{e}+001.00000 \mathrm{e}-011.00000 \mathrm{e}-091.00000 \mathrm{e}-01$ Element: 13302 \# of layers: 7

$\mathrm{Kx} \mathrm{Ky} \mathrm{Kz}$ Ss Por

4.16034e+00 4.16034e+00 4.16034e-01 1.00000e-09 2.12000e-01 $4.16034 \mathrm{e}+004.16034 \mathrm{e}+00$ 4.16034e-01 1.00000e-09 2.12000e-01 $4.16034 \mathrm{e}+004.16034 \mathrm{e}+004.16034 \mathrm{e}-01$ 1.00000e-09 2.12000e-01 $4.16034 \mathrm{e}+004.16034 \mathrm{e}+004.16034 \mathrm{e}-01$ 1.00000e-09 2.12000e-01 $4.16034 \mathrm{e}+004.16034 \mathrm{e}+004.16034 \mathrm{e}-01$ 1.00000e-09 2.12000e-01 $1.00000 \mathrm{e}-05$ 1.00000e-05 1.00000e-06 1.00000e-09 1.00000e-01 $1.00000 \mathrm{e}+001.00000 \mathrm{e}+001.00000 \mathrm{e}-01$ 1.00000e-09 1.00000e-01 Element: 13303 \# of layers: 7

$\mathrm{Kx} \mathrm{Ky} \mathrm{Kz}$ Ss Por

4.16034e+00 4.16034e+00 4.16034e-01 1.00000e-09 2.12000e-01 $4.16034 \mathrm{e}+00$ 4.16034e+00 4.16034e-01 1.00000e-09 2.12000e-01 $4.16034 \mathrm{e}+004.16034 \mathrm{e}+004.16034 \mathrm{e}-01$ 1.00000e-09 2.12000e-01 $4.16034 \mathrm{e}+004.16034 \mathrm{e}+004.16034 \mathrm{e}-01$ 1.00000e-09 2.12000e-01 $4.16034 \mathrm{e}+004.16034 \mathrm{e}+004.16034 \mathrm{e}-01$ 1.00000e-09 2.12000e-01 
$1.00000 \mathrm{e}-05$ 1.00000e-05 1.00000e-06 1.00000e-09 1.00000e-01 $1.00000 \mathrm{e}+001.00000 \mathrm{e}+001.00000 \mathrm{e}-01$ 1.00000e-09 1.00000e-01 Element: 13304 \# of layers: 7

$\mathrm{Kx} \mathrm{Ky} \mathrm{Kz}$ Ss Por

4.16034e+00 4.16034e+00 4.16034e-01 1.00000e-09 2.12000e-01 $4.16034 \mathrm{e}+004.16034 \mathrm{e}+004.16034 \mathrm{e}-01$ 1.00000e-09 2.12000e-01 $4.16034 \mathrm{e}+004.16034 \mathrm{e}+004.16034 \mathrm{e}-01$ 1.00000e-09 2.12000e-01 $4.16034 \mathrm{e}+004.16034 \mathrm{e}+00$ 4.16034e-01 1.00000e-09 2.12000e-01 $4.16034 \mathrm{e}+004.16034 \mathrm{e}+004.16034 \mathrm{e}-01$ 1.00000e-09 2.12000e-01 $1.00000 \mathrm{e}-05$ 1.00000e-05 1.00000e-06 1.00000e-09 1.00000e-01 $1.00000 \mathrm{e}+001.00000 \mathrm{e}+001.00000 \mathrm{e}-011.00000 \mathrm{e}-091.00000 \mathrm{e}-01$ Element: 13305 \# of layers: 7

$\mathrm{Kx} \mathrm{Ky} \mathrm{Kz}$ Ss Por

4.16034e+00 4.16034e+00 4.16034e-01 1.00000e-09 2.12000e-01 4.16034e+00 4.16034e+00 4.16034e-01 1.00000e-09 2.12000e-01 $4.16034 \mathrm{e}+004.16034 \mathrm{e}+004.16034 \mathrm{e}-01$ 1.00000e-09 2.12000e-01 $4.16034 \mathrm{e}+004.16034 \mathrm{e}+004.16034 \mathrm{e}-01$ 1.00000e-09 2.12000e-01 $4.16034 \mathrm{e}+004.16034 \mathrm{e}+004.16034 \mathrm{e}-01$ 1.00000e-09 2.12000e-01 $1.00000 \mathrm{e}-051.00000 \mathrm{e}-05$ 1.00000e-06 1.00000e-09 1.00000e-01 $1.00000 \mathrm{e}+001.00000 \mathrm{e}+001.00000 \mathrm{e}-011.00000 \mathrm{e}-09$ 1.00000e-01 Element: 13306 \# of layers: 7

$\mathrm{Kx} \mathrm{Ky} \mathrm{Kz}$ Ss Por

4.16034e+00 4.16034e+00 4.16034e-01 1.00000e-09 2.12000e-01 $4.16034 \mathrm{e}+004.16034 \mathrm{e}+004.16034 \mathrm{e}-01$ 1.00000e-09 2.12000e-01 $4.16034 \mathrm{e}+004.16034 \mathrm{e}+004.16034 \mathrm{e}-01$ 1.00000e-09 2.12000e-01 $4.16034 \mathrm{e}+004.16034 \mathrm{e}+004.16034 \mathrm{e}-01$ 1.00000e-09 2.12000e-01 $4.16034 \mathrm{e}+004.16034 \mathrm{e}+004.16034 \mathrm{e}-01$ 1.00000e-09 2.12000e-01 1.00000e-05 1.00000e-05 1.00000e-06 1.00000e-09 1.00000e-01 $1.00000 \mathrm{e}+001.00000 \mathrm{e}+001.00000 \mathrm{e}-011.00000 \mathrm{e}-091.00000 \mathrm{e}-01$ Element: 13307 \# of layers: 7

$\mathrm{Kx} \mathrm{Ky} \mathrm{Kz}$ Ss Por

4.16034e+00 4.16034e+00 4.16034e-01 1.00000e-09 2.12000e-01 $4.16034 \mathrm{e}+004.16034 \mathrm{e}+004.16034 \mathrm{e}-01$ 1.00000e-09 2.12000e-01 $4.16034 \mathrm{e}+004.16034 \mathrm{e}+004.16034 \mathrm{e}-01$ 1.00000e-09 2.12000e-01 $4.16034 \mathrm{e}+004.16034 \mathrm{e}+004.16034 \mathrm{e}-01$ 1.00000e-09 2.12000e-01 $4.16034 \mathrm{e}+004.16034 \mathrm{e}+00$ 4.16034e-01 1.00000e-09 2.12000e-01 1.00000e-05 1.00000e-05 1.00000e-06 1.00000e-09 1.00000e-01 $1.00000 \mathrm{e}+001.00000 \mathrm{e}+001.00000 \mathrm{e}-011.00000 \mathrm{e}-091.00000 \mathrm{e}-01$ Element: 13308 \# of layers: 7

$\mathrm{Kx} \mathrm{Ky} \mathrm{Kz}$ Ss Por 4.99848e+00 4.99848e+00 4.99848e-01 1.00000e-09 2.12000e-01 $4.99848 \mathrm{e}+00$ 4.99848e+00 4.99848e-01 1.00000e-09 2.12000e-01 4.99848e+00 4.99848e+00 4.99848e-01 1.00000e-09 2.12000e-01 $4.99848 \mathrm{e}+00$ 4.99848e+00 4.99848e-01 1.00000e-09 2.12000e-01 4.99848e+00 4.99848e+00 4.99848e-01 1.00000e-09 2.12000e-01 $1.00000 \mathrm{e}-05$ 1.00000e-05 1.00000e-06 1.00000e-09 1.00000e-01 
$1.00000 \mathrm{e}+001.00000 \mathrm{e}+00$ 1.00000e-01 1.00000e-09 1.00000e-01 Element: 13309 \# of layers: 7

Kx Ky Kz Ss Por

4.99848e+00 4.99848e+00 4.99848e-01 1.00000e-09 2.12000e-01 4.99848e+00 4.99848e+00 4.99848e-01 1.00000e-09 2.12000e-01 $4.99848 \mathrm{e}+004.99848 \mathrm{e}+00$ 4.99848e-01 1.00000e-09 2.12000e-01 4.99848e+00 4.99848e+00 4.99848e-01 1.00000e-09 2.12000e-01 $4.99848 \mathrm{e}+00$ 4.99848e+00 4.99848e-01 1.00000e-09 2.12000e-01 $1.00000 \mathrm{e}-05$ 1.00000e-05 1.00000e-06 1.00000e-09 1.00000e-01 $1.00000 \mathrm{e}+001.00000 \mathrm{e}+00$ 1.00000e-01 1.00000e-09 1.00000e-01 Element: 13310 \# of layers: 7

$\mathrm{Kx} \mathrm{Ky} \mathrm{Kz}$ Ss Por

4.99848e+00 4.99848e+00 4.99848e-01 1.00000e-09 2.12000e-01 4.99848e+00 4.99848e+00 4.99848e-01 1.00000e-09 2.12000e-01 $4.99848 \mathrm{e}+004.99848 \mathrm{e}+00$ 4.99848e-01 1.00000e-09 2.12000e-01 $4.99848 \mathrm{e}+004.99848 \mathrm{e}+00$ 4.99848e-01 1.00000e-09 2.12000e-01 $4.99848 \mathrm{e}+004.99848 \mathrm{e}+00$ 4.99848e-01 1.00000e-09 2.12000e-01 $1.00000 \mathrm{e}-05$ 1.00000e-05 1.00000e-06 1.00000e-09 1.00000e-01 $1.00000 \mathrm{e}+001.00000 \mathrm{e}+001.00000 \mathrm{e}-01$ 1.00000e-09 1.00000e-01 Element: 13311 \# of layers: 7

Kx Ky Kz Ss Por

4.16034e+00 4.16034e+00 4.16034e-01 1.00000e-09 2.12000e-01 4.16034e+00 4.16034e+00 4.16034e-01 1.00000e-09 2.12000e-01 $4.16034 \mathrm{e}+004.16034 \mathrm{e}+004.16034 \mathrm{e}-01$ 1.00000e-09 2.12000e-01 $4.16034 \mathrm{e}+004.16034 \mathrm{e}+004.16034 \mathrm{e}-01$ 1.00000e-09 2.12000e-01 $4.16034 \mathrm{e}+004.16034 \mathrm{e}+004.16034 \mathrm{e}-01$ 1.00000e-09 2.12000e-01 $1.00000 \mathrm{e}-05$ 1.00000e-05 1.00000e-06 1.00000e-09 1.00000e-01 $1.00000 \mathrm{e}+001.00000 \mathrm{e}+001.00000 \mathrm{e}-011.00000 \mathrm{e}-091.00000 \mathrm{e}-01$ Element: 13312 \# of layers: 7

$\mathrm{Kx} \mathrm{Ky} \mathrm{Kz}$ Ss Por

4.16034e+00 4.16034e+00 4.16034e-01 1.00000e-09 2.12000e-01 $4.16034 \mathrm{e}+004.16034 \mathrm{e}+004.16034 \mathrm{e}-01$ 1.00000e-09 2.12000e-01 $4.16034 \mathrm{e}+004.16034 \mathrm{e}+00 \quad 4.16034 \mathrm{e}-01$ 1.00000e-09 2.12000e-01 $4.16034 \mathrm{e}+004.16034 \mathrm{e}+004.16034 \mathrm{e}-01$ 1.00000e-09 2.12000e-01 $4.16034 \mathrm{e}+004.16034 \mathrm{e}+004.16034 \mathrm{e}-01$ 1.00000e-09 2.12000e-01 $1.00000 \mathrm{e}-05$ 1.00000e-05 1.00000e-06 1.00000e-09 1.00000e-01 $1.00000 \mathrm{e}+001.00000 \mathrm{e}+001.00000 \mathrm{e}-011.00000 \mathrm{e}-091.00000 \mathrm{e}-01$ Element: 13313 \# of layers: 7

$\mathrm{Kx} \mathrm{Ky} \mathrm{Kz}$ Ss Por

4.16034e+00 4.16034e+00 4.16034e-01 1.00000e-09 2.12000e-01 $4.16034 \mathrm{e}+004.16034 \mathrm{e}+004.16034 \mathrm{e}-01$ 1.00000e-09 2.12000e-01 $4.16034 \mathrm{e}+004.16034 \mathrm{e}+004.16034 \mathrm{e}-01$ 1.00000e-09 2.12000e-01 4.16034e+00 4.16034e+00 4.16034e-01 1.00000e-09 2.12000e-01 $4.16034 \mathrm{e}+004.16034 \mathrm{e}+004.16034 \mathrm{e}-01$ 1.00000e-09 2.12000e-01 $1.00000 \mathrm{e}-05$ 1.00000e-05 1.00000e-06 1.00000e-09 1.00000e-01 $1.00000 \mathrm{e}+001.00000 \mathrm{e}+001.00000 \mathrm{e}-011.00000 \mathrm{e}-091.00000 \mathrm{e}-01$ 
Element: 13314 \# of layers: 7

Kx Ky Kz Ss Por

$4.16034 \mathrm{e}+004.16034 \mathrm{e}+00$ 4.16034e-01 1.00000e-09 2.12000e-01

$4.16034 \mathrm{e}+004.16034 \mathrm{e}+004.16034 \mathrm{e}-011.00000 \mathrm{e}-09$ 2.12000e-01

$4.16034 \mathrm{e}+004.16034 \mathrm{e}+004.16034 \mathrm{e}-011.00000 \mathrm{e}-092.12000 \mathrm{e}-01$

$4.16034 \mathrm{e}+004.16034 \mathrm{e}+004.16034 \mathrm{e}-01$ 1.00000e-09 2.12000e-01

$4.16034 \mathrm{e}+004.16034 \mathrm{e}+004.16034 \mathrm{e}-011.00000 \mathrm{e}-092.12000 \mathrm{e}-01$

$1.00000 \mathrm{e}-05$ 1.00000e-05 1.00000e-06 1.00000e-09 1.00000e-01

$1.00000 \mathrm{e}+001.00000 \mathrm{e}+001.00000 \mathrm{e}-011.00000 \mathrm{e}-091.00000 \mathrm{e}-01$

Element: 13315 \# of layers: 7

Kx Ky Kz Ss Por

$4.99848 \mathrm{e}+004.99848 \mathrm{e}+00$ 4.99848e-01 1.00000e-09 2.12000e-01

$4.99848 \mathrm{e}+004.99848 \mathrm{e}+004.99848 \mathrm{e}-01$ 1.00000e-09 2.12000e-01

$4.99848 \mathrm{e}+004.99848 \mathrm{e}+004.99848 \mathrm{e}-011.00000 \mathrm{e}-092.12000 \mathrm{e}-01$

$4.99848 \mathrm{e}+004.99848 \mathrm{e}+004.99848 \mathrm{e}-01$ 1.00000e-09 2.12000e-01

$4.99848 \mathrm{e}+004.99848 \mathrm{e}+00$ 4.99848e-01 1.00000e-09 2.12000e-01

$1.00000 \mathrm{e}-05$ 1.00000e-05 1.00000e-06 1.00000e-09 1.00000e-01

$1.00000 \mathrm{e}+001.00000 \mathrm{e}+001.00000 \mathrm{e}-011.00000 \mathrm{e}-091.00000 \mathrm{e}-01$

Element: 13316 \# of layers: 7

Kx Ky Kz Ss Por

$4.99848 \mathrm{e}+004.99848 \mathrm{e}+00$ 4.99848e-01 1.00000e-09 2.12000e-01

$4.99848 \mathrm{e}+004.99848 \mathrm{e}+004.99848 \mathrm{e}-011.00000 \mathrm{e}-092.12000 \mathrm{e}-01$

$4.99848 \mathrm{e}+004.99848 \mathrm{e}+004.99848 \mathrm{e}-011.00000 \mathrm{e}-092.12000 \mathrm{e}-01$

$4.99848 \mathrm{e}+004.99848 \mathrm{e}+004.99848 \mathrm{e}-011.00000 \mathrm{e}-092.12000 \mathrm{e}-01$

$4.99848 \mathrm{e}+004.99848 \mathrm{e}+00$ 4.99848e-01 1.00000e-09 2.12000e-01

$1.00000 \mathrm{e}-05$ 1.00000e-05 1.00000e-06 1.00000e-09 1.00000e-01

$1.00000 \mathrm{e}+001.00000 \mathrm{e}+001.00000 \mathrm{e}-011.00000 \mathrm{e}-091.00000 \mathrm{e}-01$

Element: 13317 \# of layers: 7

Kx Ky Kz Ss Por

$4.99848 \mathrm{e}+004.99848 \mathrm{e}+00$ 4.99848e-01 1.00000e-09 2.12000e-01

$4.99848 \mathrm{e}+004.99848 \mathrm{e}+004.99848 \mathrm{e}-01$ 1.00000e-09 2.12000e-01

$4.99848 \mathrm{e}+004.99848 \mathrm{e}+004.99848 \mathrm{e}-01$ 1.00000e-09 2.12000e-01

$4.99848 \mathrm{e}+004.99848 \mathrm{e}+004.99848 \mathrm{e}-011.00000 \mathrm{e}-092.12000 \mathrm{e}-01$

$4.99848 \mathrm{e}+004.99848 \mathrm{e}+00$ 4.99848e-01 1.00000e-09 2.12000e-01

$1.00000 \mathrm{e}-05$ 1.00000e-05 1.00000e-06 1.00000e-09 1.00000e-01

$1.00000 \mathrm{e}+001.00000 \mathrm{e}+001.00000 \mathrm{e}-011.00000 \mathrm{e}-091.00000 \mathrm{e}-01$

Element: 13318 \# of layers: 7

Kx Ky Kz Ss Por

$4.99848 \mathrm{e}+004.99848 \mathrm{e}+00$ 4.99848e-01 1.00000e-09 2.12000e-01

$4.99848 \mathrm{e}+004.99848 \mathrm{e}+004.99848 \mathrm{e}-01$ 1.00000e-09 2.12000e-01

$4.99848 \mathrm{e}+004.99848 \mathrm{e}+004.99848 \mathrm{e}-01$ 1.00000e-09 2.12000e-01

$4.99848 \mathrm{e}+004.99848 \mathrm{e}+004.99848 \mathrm{e}-011.00000 \mathrm{e}-092.12000 \mathrm{e}-01$

$4.99848 \mathrm{e}+004.99848 \mathrm{e}+00$ 4.99848e-01 1.00000e-09 2.12000e-01

$1.00000 \mathrm{e}-05$ 1.00000e-05 1.00000e-06 1.00000e-09 1.00000e-01

$1.00000 \mathrm{e}+001.00000 \mathrm{e}+001.00000 \mathrm{e}-011.00000 \mathrm{e}-091.00000 \mathrm{e}-01$

Element: 13319 \# of layers: 7 
Kx Ky Kz Ss Por

4.99848e+00 4.99848e+00 4.99848e-01 1.00000e-09 2.12000e-01

4.99848e+00 4.99848e+00 4.99848e-01 1.00000e-09 2.12000e-01

$4.99848 \mathrm{e}+00$ 4.99848e+00 4.99848e-01 1.00000e-09 2.12000e-01

4.99848e+00 4.99848e+00 4.99848e-01 1.00000e-09 2.12000e-01

$4.99848 \mathrm{e}+004.99848 \mathrm{e}+00$ 4.99848e-01 1.00000e-09 2.12000e-01

$1.00000 \mathrm{e}-05$ 1.00000e-05 1.00000e-06 1.00000e-09 1.00000e-01

$1.00000 \mathrm{e}+001.00000 \mathrm{e}+001.00000 \mathrm{e}-01$ 1.00000e-09 1.00000e-01

Element: 13320 \# of layers: 7

$\mathrm{Kx} \mathrm{Ky} \mathrm{Kz}$ Ss Por

4.99848e+00 4.99848e+00 4.99848e-01 1.00000e-09 2.12000e-01

$4.99848 \mathrm{e}+00$ 4.99848e+00 4.99848e-01 1.00000e-09 2.12000e-01

4.99848e+00 4.99848e+00 4.99848e-01 1.00000e-09 2.12000e-01

4.99848e+00 4.99848e+00 4.99848e-01 1.00000e-09 2.12000e-01

4.99848e+00 4.99848e+00 4.99848e-01 1.00000e-09 2.12000e-01

$1.00000 \mathrm{e}-05$ 1.00000e-05 1.00000e-06 1.00000e-09 1.00000e-01

$1.00000 \mathrm{e}+001.00000 \mathrm{e}+001.00000 \mathrm{e}-011.00000 \mathrm{e}-091.00000 \mathrm{e}-01$

Element: 13321 \# of layers: 7

$\mathrm{Kx} \mathrm{Ky} \mathrm{Kz}$ Ss Por

4.99848e+00 4.99848e+00 4.99848e-01 1.00000e-09 2.12000e-01

$4.99848 \mathrm{e}+00$ 4.99848e+00 4.99848e-01 1.00000e-09 2.12000e-01

$4.99848 \mathrm{e}+00$ 4.99848e+00 4.99848e-01 1.00000e-09 2.12000e-01

4.99848e+00 4.99848e+00 4.99848e-01 1.00000e-09 2.12000e-01

4.99848e+00 4.99848e+00 4.99848e-01 1.00000e-09 2.12000e-01

$1.00000 \mathrm{e}-05$ 1.00000e-05 1.00000e-06 1.00000e-09 1.00000e-01

$1.00000 \mathrm{e}+001.00000 \mathrm{e}+001.00000 \mathrm{e}-01$ 1.00000e-09 1.00000e-01

Element: 13322 \# of layers: 7

$\mathrm{Kx} \mathrm{Ky} \mathrm{Kz}$ Ss Por

4.99848e+00 4.99848e+00 4.99848e-01 1.00000e-09 2.12000e-01

4.99848e+00 4.99848e+00 4.99848e-01 1.00000e-09 2.12000e-01

$4.99848 \mathrm{e}+004.99848 \mathrm{e}+00$ 4.99848e-01 1.00000e-09 2.12000e-01

4.99848e+00 4.99848e+00 4.99848e-01 1.00000e-09 2.12000e-01

$4.99848 \mathrm{e}+004.99848 \mathrm{e}+00$ 4.99848e-01 1.00000e-09 2.12000e-01

$1.00000 \mathrm{e}-05$ 1.00000e-05 1.00000e-06 1.00000e-09 1.00000e-01

$1.00000 \mathrm{e}+001.00000 \mathrm{e}+001.00000 \mathrm{e}-011.00000 \mathrm{e}-091.00000 \mathrm{e}-01$

Element: 13323 \# of layers: 7

Kx Ky Kz Ss Por

4.99848e+00 4.99848e+00 4.99848e-01 1.00000e-09 2.12000e-01

4.99848e+00 4.99848e+00 4.99848e-01 1.00000e-09 2.12000e-01

4.99848e+00 4.99848e+00 4.99848e-01 1.00000e-09 2.12000e-01

4.99848e+00 4.99848e+00 4.99848e-01 1.00000e-09 2.12000e-01

$4.99848 \mathrm{e}+00$ 4.99848e+00 4.99848e-01 1.00000e-09 2.12000e-01

$1.00000 \mathrm{e}-051.00000 \mathrm{e}-051.00000 \mathrm{e}-061.00000 \mathrm{e}-091.00000 \mathrm{e}-01$

$1.00000 \mathrm{e}+001.00000 \mathrm{e}+001.00000 \mathrm{e}-01$ 1.00000e-09 1.00000e-01

Element: 13324 \# of layers: 7

Kx Ky Kz Ss Por 
4.99848e+00 4.99848e+00 4.99848e-01 1.00000e-09 2.12000e-01 4.99848e+00 4.99848e+00 4.99848e-01 1.00000e-09 2.12000e-01 4.99848e+00 4.99848e+00 4.99848e-01 1.00000e-09 2.12000e-01 $4.99848 \mathrm{e}+00$ 4.99848e+00 4.99848e-01 1.00000e-09 2.12000e-01 4.99848e+00 4.99848e+00 4.99848e-01 1.00000e-09 2.12000e-01 $1.00000 \mathrm{e}-05$ 1.00000e-05 1.00000e-06 1.00000e-09 1.00000e-01 $1.00000 \mathrm{e}+001.00000 \mathrm{e}+001.00000 \mathrm{e}-01$ 1.00000e-09 1.00000e-01 Element: 13325 \# of layers: 7

$\mathrm{Kx} \mathrm{Ky} \mathrm{Kz}$ Ss Por

4.99848e+00 4.99848e+00 4.99848e-01 1.00000e-09 2.12000e-01 4.99848e+00 4.99848e+00 4.99848e-01 1.00000e-09 2.12000e-01 4.99848e+00 4.99848e+00 4.99848e-01 1.00000e-09 2.12000e-01 4.99848e+00 4.99848e+00 4.99848e-01 1.00000e-09 2.12000e-01 4.99848e+00 4.99848e+00 4.99848e-01 1.00000e-09 2.12000e-01 $1.00000 \mathrm{e}-05$ 1.00000e-05 1.00000e-06 1.00000e-09 1.00000e-01 $1.00000 \mathrm{e}+001.00000 \mathrm{e}+001.00000 \mathrm{e}-011.00000 \mathrm{e}-091.00000 \mathrm{e}-01$ Element: 13326 \# of layers: 7

Kx Ky Kz Ss Por

6.34941e+00 6.34941e+00 6.34941e-01 1.00000e-09 2.12000e-01 $6.34941 \mathrm{e}+006.34941 \mathrm{e}+00$ 6.34941e-01 1.00000e-09 2.12000e-01 $6.34941 \mathrm{e}+006.34941 \mathrm{e}+00$ 6.34941e-01 1.00000e-09 2.12000e-01 $6.34941 \mathrm{e}+00$ 6.34941e+00 6.34941e-01 1.00000e-09 2.12000e-01 6.34941e+00 6.34941e+00 6.34941e-01 1.00000e-09 2.12000e-01 $1.00000 \mathrm{e}-05$ 1.00000e-05 1.00000e-06 1.00000e-09 1.00000e-01 $1.00000 \mathrm{e}+001.00000 \mathrm{e}+001.00000 \mathrm{e}-011.00000 \mathrm{e}-091.00000 \mathrm{e}-01$ Element: 13327 \# of layers: 7

$\mathrm{Kx} \mathrm{Ky} \mathrm{Kz}$ Ss Por

6.34941e+00 6.34941e+00 6.34941e-01 1.00000e-09 2.12000e-01 $6.34941 \mathrm{e}+006.34941 \mathrm{e}+00$ 6.34941e-01 1.00000e-09 2.12000e-01 6.34941e+00 6.34941e+00 6.34941e-01 1.00000e-09 2.12000e-01 $6.34941 \mathrm{e}+006.34941 \mathrm{e}+00$ 6.34941e-01 1.00000e-09 2.12000e-01 $6.34941 \mathrm{e}+006.34941 \mathrm{e}+00$ 6.34941e-01 1.00000e-09 2.12000e-01 $1.00000 \mathrm{e}-05$ 1.00000e-05 1.00000e-06 1.00000e-09 1.00000e-01 $1.00000 \mathrm{e}+001.00000 \mathrm{e}+001.00000 \mathrm{e}-011.00000 \mathrm{e}-09$ 1.00000e-01 Element: 13328 \# of layers: 7

$\mathrm{Kx} \mathrm{Ky} \mathrm{Kz}$ Ss Por

6.34941e+00 6.34941e+00 6.34941e-01 1.00000e-09 2.12000e-01 6.34941e+00 6.34941e+00 6.34941e-01 1.00000e-09 2.12000e-01 6.34941e+00 6.34941e+00 6.34941e-01 1.00000e-09 2.12000e-01 6.34941e+00 6.34941e+00 6.34941e-01 1.00000e-09 2.12000e-01 $6.34941 \mathrm{e}+006.34941 \mathrm{e}+00$ 6.34941e-01 1.00000e-09 2.12000e-01 $1.00000 \mathrm{e}-05$ 1.00000e-05 1.00000e-06 1.00000e-09 1.00000e-01 $1.00000 \mathrm{e}+001.00000 \mathrm{e}+001.00000 \mathrm{e}-011.00000 \mathrm{e}-091.00000 \mathrm{e}-01$ Element: 13329 \# of layers: 7

$\mathrm{Kx} \mathrm{Ky} \mathrm{Kz}$ Ss Por 4.99848e+00 4.99848e+00 4.99848e-01 1.00000e-09 2.12000e-01 
4.99848e+00 4.99848e+00 4.99848e-01 1.00000e-09 2.12000e-01 4.99848e+00 4.99848e+00 4.99848e-01 1.00000e-09 2.12000e-01 4.99848e+00 4.99848e+00 4.99848e-01 1.00000e-09 2.12000e-01 $4.99848 \mathrm{e}+004.99848 \mathrm{e}+00$ 4.99848e-01 1.00000e-09 2.12000e-01 $1.00000 \mathrm{e}-05$ 1.00000e-05 1.00000e-06 1.00000e-09 1.00000e-01 $1.00000 \mathrm{e}+001.00000 \mathrm{e}+00$ 1.00000e-01 1.00000e-09 1.00000e-01 Element: 13330 \# of layers: 7

$\mathrm{Kx} \mathrm{Ky} \mathrm{Kz}$ Ss Por

4.99848e+00 4.99848e+00 4.99848e-01 1.00000e-09 2.12000e-01 $4.99848 \mathrm{e}+004.99848 \mathrm{e}+00$ 4.99848e-01 1.00000e-09 2.12000e-01 4.99848e+00 4.99848e+00 4.99848e-01 1.00000e-09 2.12000e-01 4.99848e+00 4.99848e+00 4.99848e-01 1.00000e-09 2.12000e-01 4.99848e+00 4.99848e+00 4.99848e-01 1.00000e-09 2.12000e-01 $1.00000 \mathrm{e}-05$ 1.00000e-05 1.00000e-06 1.00000e-09 1.00000e-01 $1.00000 \mathrm{e}+001.00000 \mathrm{e}+001.00000 \mathrm{e}-01$ 1.00000e-09 1.00000e-01 Element: 13331 \# of layers: 7

$\mathrm{Kx} \mathrm{Ky} \mathrm{Kz}$ Ss Por

4.99848e+00 4.99848e+00 4.99848e-01 1.00000e-09 2.12000e-01 4.99848e+00 4.99848e+00 4.99848e-01 1.00000e-09 2.12000e-01 $4.99848 \mathrm{e}+00$ 4.99848e+00 4.99848e-01 1.00000e-09 2.12000e-01 $4.99848 \mathrm{e}+00$ 4.99848e+00 4.99848e-01 1.00000e-09 2.12000e-01 4.99848e+00 4.99848e+00 4.99848e-01 1.00000e-09 2.12000e-01 $1.00000 \mathrm{e}-05$ 1.00000e-05 1.00000e-06 1.00000e-09 1.00000e-01 $1.00000 \mathrm{e}+001.00000 \mathrm{e}+001.00000 \mathrm{e}-011.00000 \mathrm{e}-09$ 1.00000e-01 Element: 13332 \# of layers: 7

$\mathrm{Kx} \mathrm{Ky} \mathrm{Kz}$ Ss Por

4.99848e+00 4.99848e+00 4.99848e-01 1.00000e-09 2.12000e-01 4.99848e+00 4.99848e+00 4.99848e-01 1.00000e-09 2.12000e-01 $4.99848 \mathrm{e}+00$ 4.99848e+00 4.99848e-01 1.00000e-09 2.12000e-01 4.99848e+00 4.99848e+00 4.99848e-01 1.00000e-09 2.12000e-01 4.99848e+00 4.99848e+00 4.99848e-01 1.00000e-09 2.12000e-01 1.00000e-05 1.00000e-05 1.00000e-06 1.00000e-09 1.00000e-01 $1.00000 \mathrm{e}+001.00000 \mathrm{e}+001.00000 \mathrm{e}-011.00000 \mathrm{e}-091.00000 \mathrm{e}-01$ Element: 13333 \# of layers: 7

$\mathrm{Kx} \mathrm{Ky} \mathrm{Kz}$ Ss Por

6.34941e+00 6.34941e+00 6.34941e-01 1.00000e-09 2.12000e-01 $6.34941 \mathrm{e}+006.34941 \mathrm{e}+00$ 6.34941e-01 1.00000e-09 2.12000e-01 6.34941e+00 6.34941e+00 6.34941e-01 1.00000e-09 2.12000e-01 6.34941e+00 6.34941e+00 6.34941e-01 1.00000e-09 2.12000e-01 6.34941e+00 6.34941e+00 6.34941e-01 1.00000e-09 2.12000e-01 $1.00000 \mathrm{e}-05$ 1.00000e-05 1.00000e-06 1.00000e-09 1.00000e-01 $1.00000 \mathrm{e}+001.00000 \mathrm{e}+001.00000 \mathrm{e}-011.00000 \mathrm{e}-09$ 1.00000e-01 Element: 13334 \# of layers: 7

$\mathrm{Kx} \mathrm{Ky} \mathrm{Kz}$ Ss Por

6.34941e+00 6.34941e+00 6.34941e-01 1.00000e-09 2.12000e-01 $6.34941 \mathrm{e}+006.34941 \mathrm{e}+00$ 6.34941e-01 1.00000e-09 2.12000e-01 
$6.34941 \mathrm{e}+006.34941 \mathrm{e}+00$ 6.34941e-01 1.00000e-09 2.12000e-01 $6.34941 \mathrm{e}+006.34941 \mathrm{e}+006.34941 \mathrm{e}-01$ 1.00000e-09 2.12000e-01 $6.34941 \mathrm{e}+006.34941 \mathrm{e}+00$ 6.34941e-01 1.00000e-09 2.12000e-01 $1.00000 \mathrm{e}-05$ 1.00000e-05 1.00000e-06 1.00000e-09 1.00000e-01 $1.00000 \mathrm{e}+001.00000 \mathrm{e}+001.00000 \mathrm{e}-011.00000 \mathrm{e}-091.00000 \mathrm{e}-01$ Element: 13335 \# of layers: 7

Kx Ky Kz Ss Por

$6.34941 \mathrm{e}+006.34941 \mathrm{e}+00$ 6.34941e-01 1.00000e-09 2.12000e-01 $6.34941 \mathrm{e}+006.34941 \mathrm{e}+006.34941 \mathrm{e}-011.00000 \mathrm{e}-092.12000 \mathrm{e}-01$ $6.34941 \mathrm{e}+006.34941 \mathrm{e}+006.34941 \mathrm{e}-011.00000 \mathrm{e}-092.12000 \mathrm{e}-01$ $6.34941 \mathrm{e}+006.34941 \mathrm{e}+006.34941 \mathrm{e}-01$ 1.00000e-09 2.12000e-01 $6.34941 \mathrm{e}+006.34941 \mathrm{e}+006.34941 \mathrm{e}-011.00000 \mathrm{e}-09$ 2.12000e-01 $1.00000 \mathrm{e}-05$ 1.00000e-05 1.00000e-06 1.00000e-09 1.00000e-01 $1.00000 \mathrm{e}+001.00000 \mathrm{e}+001.00000 \mathrm{e}-011.00000 \mathrm{e}-091.00000 \mathrm{e}-01$ Element: 13336 \# of layers: 7

Kx Ky Kz Ss Por

$6.34941 \mathrm{e}+006.34941 \mathrm{e}+00$ 6.34941e-01 1.00000e-09 2.12000e-01 $6.34941 \mathrm{e}+006.34941 \mathrm{e}+006.34941 \mathrm{e}-011.00000 \mathrm{e}-092.12000 \mathrm{e}-01$ $6.34941 \mathrm{e}+006.34941 \mathrm{e}+006.34941 \mathrm{e}-011.00000 \mathrm{e}-092.12000 \mathrm{e}-01$ $6.34941 \mathrm{e}+006.34941 \mathrm{e}+006.34941 \mathrm{e}-01$ 1.00000e-09 2.12000e-01 $6.34941 \mathrm{e}+006.34941 \mathrm{e}+006.34941 \mathrm{e}-011.00000 \mathrm{e}-09$ 2.12000e-01 $1.00000 \mathrm{e}-05$ 1.00000e-05 1.00000e-06 1.00000e-09 1.00000e-01 $1.00000 \mathrm{e}+001.00000 \mathrm{e}+001.00000 \mathrm{e}-011.00000 \mathrm{e}-091.00000 \mathrm{e}-01$ Element: 13337 \# of layers: 7

Kx Ky Kz Ss Por

$6.34941 \mathrm{e}+006.34941 \mathrm{e}+00$ 6.34941e-01 1.00000e-09 2.12000e-01 $6.34941 \mathrm{e}+006.34941 \mathrm{e}+006.34941 \mathrm{e}-011.00000 \mathrm{e}-092.12000 \mathrm{e}-01$ $6.34941 \mathrm{e}+006.34941 \mathrm{e}+006.34941 \mathrm{e}-011.00000 \mathrm{e}-092.12000 \mathrm{e}-01$ $6.34941 \mathrm{e}+006.34941 \mathrm{e}+006.34941 \mathrm{e}-011.00000 \mathrm{e}-092.12000 \mathrm{e}-01$ $6.34941 \mathrm{e}+006.34941 \mathrm{e}+006.34941 \mathrm{e}-011.00000 \mathrm{e}-092.12000 \mathrm{e}-01$ $1.00000 \mathrm{e}-05$ 1.00000e-05 1.00000e-06 1.00000e-09 1.00000e-01 $1.00000 \mathrm{e}+001.00000 \mathrm{e}+001.00000 \mathrm{e}-011.00000 \mathrm{e}-091.00000 \mathrm{e}-01$ Element: 13338 \# of layers: 7

Kx Ky Kz Ss Por

$6.34941 \mathrm{e}+006.34941 \mathrm{e}+00$ 6.34941e-01 1.00000e-09 2.12000e-01 $6.34941 \mathrm{e}+006.34941 \mathrm{e}+006.34941 \mathrm{e}-011.00000 \mathrm{e}-092.12000 \mathrm{e}-01$ $6.34941 \mathrm{e}+006.34941 \mathrm{e}+006.34941 \mathrm{e}-011.00000 \mathrm{e}-092.12000 \mathrm{e}-01$ $6.34941 \mathrm{e}+006.34941 \mathrm{e}+006.34941 \mathrm{e}-011.00000 \mathrm{e}-092.12000 \mathrm{e}-01$ $6.34941 \mathrm{e}+006.34941 \mathrm{e}+00$ 6.34941e-01 1.00000e-09 2.12000e-01 $1.00000 \mathrm{e}-05$ 1.00000e-05 1.00000e-06 1.00000e-09 1.00000e-01 $1.00000 \mathrm{e}+001.00000 \mathrm{e}+001.00000 \mathrm{e}-011.00000 \mathrm{e}-091.00000 \mathrm{e}-01$ Element: 13339 \# of layers: 7

Kx Ky Kz Ss Por $6.34941 \mathrm{e}+006.34941 \mathrm{e}+00$ 6.34941e-01 1.00000e-09 2.12000e-01 $6.34941 \mathrm{e}+006.34941 \mathrm{e}+006.34941 \mathrm{e}-011.00000 \mathrm{e}-09$ 2.12000e-01 $6.34941 \mathrm{e}+006.34941 \mathrm{e}+006.34941 \mathrm{e}-01$ 1.00000e-09 2.12000e-01 
$6.34941 \mathrm{e}+006.34941 \mathrm{e}+00$ 6.34941e-01 1.00000e-09 2.12000e-01 $6.34941 \mathrm{e}+006.34941 \mathrm{e}+006.34941 \mathrm{e}-01$ 1.00000e-09 2.12000e-01 $1.00000 \mathrm{e}-05$ 1.00000e-05 1.00000e-06 1.00000e-09 1.00000e-01 $1.00000 \mathrm{e}+001.00000 \mathrm{e}+001.00000 \mathrm{e}-011.00000 \mathrm{e}-091.00000 \mathrm{e}-01$ Element: 13340 \# of layers: 7

Kx Ky Kz Ss Por

$6.34941 \mathrm{e}+006.34941 \mathrm{e}+00$ 6.34941e-01 1.00000e-09 2.12000e-01 $6.34941 \mathrm{e}+006.34941 \mathrm{e}+006.34941 \mathrm{e}-011.00000 \mathrm{e}-092.12000 \mathrm{e}-01$ $6.34941 \mathrm{e}+006.34941 \mathrm{e}+006.34941 \mathrm{e}-011.00000 \mathrm{e}-092.12000 \mathrm{e}-01$ $6.34941 \mathrm{e}+006.34941 \mathrm{e}+006.34941 \mathrm{e}-011.00000 \mathrm{e}-092.12000 \mathrm{e}-01$ $6.34941 \mathrm{e}+006.34941 \mathrm{e}+006.34941 \mathrm{e}-01$ 1.00000e-09 2.12000e-01 $1.00000 \mathrm{e}-05$ 1.00000e-05 1.00000e-06 1.00000e-09 1.00000e-01 $1.00000 \mathrm{e}+001.00000 \mathrm{e}+001.00000 \mathrm{e}-011.00000 \mathrm{e}-091.00000 \mathrm{e}-01$ Element: 13341 \# of layers: 7

Kx Ky Kz Ss Por

$6.34941 \mathrm{e}+006.34941 \mathrm{e}+00$ 6.34941e-01 1.00000e-09 2.12000e-01 $6.34941 \mathrm{e}+006.34941 \mathrm{e}+00$ 6.34941e-01 1.00000e-09 2.12000e-01 $6.34941 \mathrm{e}+006.34941 \mathrm{e}+006.34941 \mathrm{e}-011.00000 \mathrm{e}-092.12000 \mathrm{e}-01$ $6.34941 \mathrm{e}+006.34941 \mathrm{e}+006.34941 \mathrm{e}-011.00000 \mathrm{e}-092.12000 \mathrm{e}-01$ $6.34941 \mathrm{e}+006.34941 \mathrm{e}+006.34941 \mathrm{e}-011.00000 \mathrm{e}-09$ 2.12000e-01 $1.00000 \mathrm{e}-05$ 1.00000e-05 1.00000e-06 1.00000e-09 1.00000e-01 $1.00000 \mathrm{e}+001.00000 \mathrm{e}+001.00000 \mathrm{e}-011.00000 \mathrm{e}-091.00000 \mathrm{e}-01$ Element: 13342 \# of layers: 7

Kx Ky Kz Ss Por

$6.34941 \mathrm{e}+006.34941 \mathrm{e}+00$ 6.34941e-01 1.00000e-09 2.12000e-01 $6.34941 \mathrm{e}+006.34941 \mathrm{e}+006.34941 \mathrm{e}-011.00000 \mathrm{e}-092.12000 \mathrm{e}-01$ $6.34941 \mathrm{e}+006.34941 \mathrm{e}+006.34941 \mathrm{e}-011.00000 \mathrm{e}-092.12000 \mathrm{e}-01$ $6.34941 \mathrm{e}+006.34941 \mathrm{e}+00$ 6.34941e-01 1.00000e-09 2.12000e-01 $6.34941 \mathrm{e}+006.34941 \mathrm{e}+006.34941 \mathrm{e}-011.00000 \mathrm{e}-092.12000 \mathrm{e}-01$ $1.00000 \mathrm{e}-05$ 1.00000e-05 1.00000e-06 1.00000e-09 1.00000e-01 $1.00000 \mathrm{e}+001.00000 \mathrm{e}+001.00000 \mathrm{e}-011.00000 \mathrm{e}-091.00000 \mathrm{e}-01$ Element: 13343 \# of layers: 7

Kx Ky Kz Ss Por

$4.47085 \mathrm{e}+004.47085 \mathrm{e}+00$ 4.47085e-01 1.00000e-09 2.12000e-01 $4.47085 \mathrm{e}+004.47085 \mathrm{e}+004.47085 \mathrm{e}-011.00000 \mathrm{e}-092.12000 \mathrm{e}-01$ $4.47085 \mathrm{e}+004.47085 \mathrm{e}+004.47085 \mathrm{e}-011.00000 \mathrm{e}-092.12000 \mathrm{e}-01$ $4.47085 \mathrm{e}+004.47085 \mathrm{e}+004.47085 \mathrm{e}-011.00000 \mathrm{e}-092.12000 \mathrm{e}-01$ $4.47085 \mathrm{e}+004.47085 \mathrm{e}+004.47085 \mathrm{e}-011.00000 \mathrm{e}-092.12000 \mathrm{e}-01$ $1.00000 \mathrm{e}-05$ 1.00000e-05 1.00000e-06 1.00000e-09 1.00000e-01 $1.00000 \mathrm{e}+001.00000 \mathrm{e}+001.00000 \mathrm{e}-011.00000 \mathrm{e}-091.00000 \mathrm{e}-01$ Element: 13344 \# of layers: 7

Kx Ky Kz Ss Por

$4.47085 \mathrm{e}+004.47085 \mathrm{e}+00$ 4.47085e-01 1.00000e-09 2.12000e-01 $4.47085 \mathrm{e}+004.47085 \mathrm{e}+004.47085 \mathrm{e}-011.00000 \mathrm{e}-092.12000 \mathrm{e}-01$ $4.47085 \mathrm{e}+004.47085 \mathrm{e}+004.47085 \mathrm{e}-011.00000 \mathrm{e}-092.12000 \mathrm{e}-01$ $4.47085 \mathrm{e}+004.47085 \mathrm{e}+004.47085 \mathrm{e}-01$ 1.00000e-09 2.12000e-01 
4.47085e+00 4.47085e+00 4.47085e-01 1.00000e-09 2.12000e-01 $1.00000 \mathrm{e}-05$ 1.00000e-05 1.00000e-06 1.00000e-09 1.00000e-01 $1.00000 \mathrm{e}+001.00000 \mathrm{e}+001.00000 \mathrm{e}-011.00000 \mathrm{e}-091.00000 \mathrm{e}-01$ Element: 13345 \# of layers: 7

$\mathrm{Kx} \mathrm{Ky} \mathrm{Kz}$ Ss Por

4.47085e+00 4.47085e+00 4.47085e-01 1.00000e-09 2.12000e-01 $4.47085 \mathrm{e}+004.47085 \mathrm{e}+00$ 4.47085e-01 1.00000e-09 2.12000e-01 $4.47085 \mathrm{e}+004.47085 \mathrm{e}+00$ 4.47085e-01 1.00000e-09 2.12000e-01 $4.47085 \mathrm{e}+00$ 4.47085e+00 4.47085e-01 1.00000e-09 2.12000e-01 $4.47085 \mathrm{e}+00$ 4.47085e+00 4.47085e-01 1.00000e-09 2.12000e-01 $1.00000 \mathrm{e}-05$ 1.00000e-05 1.00000e-06 1.00000e-09 1.00000e-01 $1.00000 \mathrm{e}+001.00000 \mathrm{e}+001.00000 \mathrm{e}-011.00000 \mathrm{e}-091.00000 \mathrm{e}-01$ Element: 13346 \# of layers: 7

$\mathrm{Kx} \mathrm{Ky} \mathrm{Kz}$ Ss Por

4.47085e+00 4.47085e+00 4.47085e-01 1.00000e-09 2.12000e-01 $4.47085 \mathrm{e}+004.47085 \mathrm{e}+004.47085 \mathrm{e}-01$ 1.00000e-09 2.12000e-01 $4.47085 \mathrm{e}+00$ 4.47085e+00 4.47085e-01 1.00000e-09 2.12000e-01 $4.47085 \mathrm{e}+00$ 4.47085e+00 4.47085e-01 1.00000e-09 2.12000e-01 4.47085e+00 4.47085e+00 4.47085e-01 1.00000e-09 2.12000e-01 $1.00000 \mathrm{e}-051.00000 \mathrm{e}-051.00000 \mathrm{e}-061.00000 \mathrm{e}-091.00000 \mathrm{e}-01$ $1.00000 \mathrm{e}+001.00000 \mathrm{e}+001.00000 \mathrm{e}-011.00000 \mathrm{e}-091.00000 \mathrm{e}-01$ Element: 13347 \# of layers: 7

$\mathrm{Kx} \mathrm{Ky} \mathrm{Kz}$ Ss Por

4.47085e+00 4.47085e+00 4.47085e-01 1.00000e-09 2.12000e-01 $4.47085 \mathrm{e}+004.47085 \mathrm{e}+00$ 4.47085e-01 1.00000e-09 2.12000e-01 $4.47085 \mathrm{e}+004.47085 \mathrm{e}+00$ 4.47085e-01 1.00000e-09 2.12000e-01 $4.47085 \mathrm{e}+004.47085 \mathrm{e}+00$ 4.47085e-01 1.00000e-09 2.12000e-01 $4.47085 \mathrm{e}+004.47085 \mathrm{e}+00$ 4.47085e-01 1.00000e-09 2.12000e-01 $1.00000 \mathrm{e}-05$ 1.00000e-05 1.00000e-06 1.00000e-09 1.00000e-01 $1.00000 \mathrm{e}+001.00000 \mathrm{e}+001.00000 \mathrm{e}-011.00000 \mathrm{e}-091.00000 \mathrm{e}-01$ Element: 13348 \# of layers: 7

$\mathrm{Kx} \mathrm{Ky} \mathrm{Kz}$ Ss Por

6.34941e+00 6.34941e+00 6.34941e-01 1.00000e-09 2.12000e-01 6.34941e+00 6.34941e+00 6.34941e-01 1.00000e-09 2.12000e-01 6.34941e+00 6.34941e+00 6.34941e-01 1.00000e-09 2.12000e-01 6.34941e+00 6.34941e+00 6.34941e-01 1.00000e-09 2.12000e-01 $6.34941 \mathrm{e}+006.34941 \mathrm{e}+00$ 6.34941e-01 1.00000e-09 2.12000e-01 $1.00000 \mathrm{e}-05$ 1.00000e-05 1.00000e-06 1.00000e-09 1.00000e-01 $1.00000 \mathrm{e}+001.00000 \mathrm{e}+001.00000 \mathrm{e}-01$ 1.00000e-09 1.00000e-01 Element: 13349 \# of layers: 7

Kx Ky Kz Ss Por

6.34941e+00 6.34941e+00 6.34941e-01 1.00000e-09 2.12000e-01 $6.34941 \mathrm{e}+006.34941 \mathrm{e}+00$ 6.34941e-01 1.00000e-09 2.12000e-01 6.34941e+00 6.34941e+00 6.34941e-01 1.00000e-09 2.12000e-01 $6.34941 \mathrm{e}+006.34941 \mathrm{e}+006.34941 \mathrm{e}-01$ 1.00000e-09 2.12000e-01 $6.34941 \mathrm{e}+006.34941 \mathrm{e}+00$ 6.34941e-01 1.00000e-09 2.12000e-01 
$1.00000 \mathrm{e}-05$ 1.00000e-05 1.00000e-06 1.00000e-09 1.00000e-01 $1.00000 \mathrm{e}+001.00000 \mathrm{e}+001.00000 \mathrm{e}-01$ 1.00000e-09 1.00000e-01 Element: 13350 \# of layers: 7

Kx Ky Kz Ss Por

4.47085e+00 4.47085e+00 4.47085e-01 1.00000e-09 2.12000e-01 $4.47085 \mathrm{e}+004.47085 \mathrm{e}+00$ 4.47085e-01 1.00000e-09 2.12000e-01 4.47085e+00 4.47085e+00 4.47085e-01 1.00000e-09 2.12000e-01 $4.47085 \mathrm{e}+004.47085 \mathrm{e}+00$ 4.47085e-01 1.00000e-09 2.12000e-01 $4.47085 \mathrm{e}+00$ 4.47085e+00 4.47085e-01 1.00000e-09 2.12000e-01 $1.00000 \mathrm{e}-05$ 1.00000e-05 1.00000e-06 1.00000e-09 1.00000e-01 $1.00000 \mathrm{e}+001.00000 \mathrm{e}+001.00000 \mathrm{e}-011.00000 \mathrm{e}-091.00000 \mathrm{e}-01$ Element: 13351 \# of layers: 7

$\mathrm{Kx} \mathrm{Ky} \mathrm{Kz}$ Ss Por

4.47085e+00 4.47085e+00 4.47085e-01 1.00000e-09 2.12000e-01 4.47085e+00 4.47085e+00 4.47085e-01 1.00000e-09 2.12000e-01 $4.47085 \mathrm{e}+004.47085 \mathrm{e}+004.47085 \mathrm{e}-01$ 1.00000e-09 2.12000e-01 $4.47085 \mathrm{e}+004.47085 \mathrm{e}+00$ 4.47085e-01 1.00000e-09 2.12000e-01 $4.47085 \mathrm{e}+004.47085 \mathrm{e}+004.47085 \mathrm{e}-01$ 1.00000e-09 2.12000e-01 $1.00000 \mathrm{e}-05$ 1.00000e-05 1.00000e-06 1.00000e-09 1.00000e-01 $1.00000 \mathrm{e}+001.00000 \mathrm{e}+001.00000 \mathrm{e}-011.00000 \mathrm{e}-09$ 1.00000e-01 Element: 13352 \# of layers: 7

$\mathrm{Kx} \mathrm{Ky} \mathrm{Kz}$ Ss Por

4.16034e+00 4.16034e+00 4.16034e-01 1.00000e-09 2.12000e-01 $4.16034 \mathrm{e}+004.16034 \mathrm{e}+004.16034 \mathrm{e}-01$ 1.00000e-09 2.12000e-01 $4.16034 \mathrm{e}+004.16034 \mathrm{e}+004.16034 \mathrm{e}-01$ 1.00000e-09 2.12000e-01 $4.16034 \mathrm{e}+004.16034 \mathrm{e}+004.16034 \mathrm{e}-01$ 1.00000e-09 2.12000e-01 $4.16034 \mathrm{e}+004.16034 \mathrm{e}+004.16034 \mathrm{e}-01$ 1.00000e-09 2.12000e-01 $1.00000 \mathrm{e}-05$ 1.00000e-05 1.00000e-06 1.00000e-09 1.00000e-01 $1.00000 \mathrm{e}+001.00000 \mathrm{e}+001.00000 \mathrm{e}-011.00000 \mathrm{e}-091.00000 \mathrm{e}-01$ Element: 13353 \# of layers: 7

$\mathrm{Kx} \mathrm{Ky} \mathrm{Kz}$ Ss Por

4.16034e+00 4.16034e+00 4.16034e-01 1.00000e-09 2.12000e-01 $4.16034 \mathrm{e}+004.16034 \mathrm{e}+004.16034 \mathrm{e}-01$ 1.00000e-09 2.12000e-01 $4.16034 \mathrm{e}+004.16034 \mathrm{e}+004.16034 \mathrm{e}-01$ 1.00000e-09 2.12000e-01 $4.16034 \mathrm{e}+004.16034 \mathrm{e}+004.16034 \mathrm{e}-01$ 1.00000e-09 2.12000e-01 $4.16034 \mathrm{e}+004.16034 \mathrm{e}+00$ 4.16034e-01 1.00000e-09 2.12000e-01 1.00000e-05 1.00000e-05 1.00000e-06 1.00000e-09 1.00000e-01 $1.00000 \mathrm{e}+001.00000 \mathrm{e}+001.00000 \mathrm{e}-011.00000 \mathrm{e}-091.00000 \mathrm{e}-01$ Element: 13354 \# of layers: 7

$\mathrm{Kx} \mathrm{Ky} \mathrm{Kz}$ Ss Por

4.16034e+00 4.16034e+00 4.16034e-01 1.00000e-09 2.12000e-01 $4.16034 \mathrm{e}+004.16034 \mathrm{e}+004.16034 \mathrm{e}-01$ 1.00000e-09 2.12000e-01 $4.16034 \mathrm{e}+004.16034 \mathrm{e}+004.16034 \mathrm{e}-01$ 1.00000e-09 2.12000e-01 $4.16034 \mathrm{e}+004.16034 \mathrm{e}+004.16034 \mathrm{e}-01$ 1.00000e-09 2.12000e-01 $4.16034 \mathrm{e}+004.16034 \mathrm{e}+004.16034 \mathrm{e}-01$ 1.00000e-09 2.12000e-01 $1.00000 \mathrm{e}-05$ 1.00000e-05 1.00000e-06 1.00000e-09 1.00000e-01 
$1.00000 \mathrm{e}+001.00000 \mathrm{e}+00$ 1.00000e-01 1.00000e-09 1.00000e-01 Element: 13355 \# of layers: 7

Kx Ky Kz Ss Por

4.99848e+00 4.99848e+00 4.99848e-01 1.00000e-09 2.12000e-01 4.99848e+00 4.99848e+00 4.99848e-01 1.00000e-09 2.12000e-01 $4.99848 \mathrm{e}+004.99848 \mathrm{e}+00$ 4.99848e-01 1.00000e-09 2.12000e-01 4.99848e+00 4.99848e+00 4.99848e-01 1.00000e-09 2.12000e-01 $4.99848 \mathrm{e}+00$ 4.99848e+00 4.99848e-01 1.00000e-09 2.12000e-01 $1.00000 \mathrm{e}-05$ 1.00000e-05 1.00000e-06 1.00000e-09 1.00000e-01 $1.00000 \mathrm{e}+001.00000 \mathrm{e}+00$ 1.00000e-01 1.00000e-09 1.00000e-01 Element: 13356 \# of layers: 7

$\mathrm{Kx} \mathrm{Ky} \mathrm{Kz}$ Ss Por

4.99848e+00 4.99848e+00 4.99848e-01 1.00000e-09 2.12000e-01 4.99848e+00 4.99848e+00 4.99848e-01 1.00000e-09 2.12000e-01 4.99848e+00 4.99848e+00 4.99848e-01 1.00000e-09 2.12000e-01 $4.99848 \mathrm{e}+004.99848 \mathrm{e}+00$ 4.99848e-01 1.00000e-09 2.12000e-01 $4.99848 \mathrm{e}+004.99848 \mathrm{e}+00$ 4.99848e-01 1.00000e-09 2.12000e-01 $1.00000 \mathrm{e}-05$ 1.00000e-05 1.00000e-06 1.00000e-09 1.00000e-01 $1.00000 \mathrm{e}+001.00000 \mathrm{e}+001.00000 \mathrm{e}-01$ 1.00000e-09 1.00000e-01 Element: 13357 \# of layers: 7

$\mathrm{Kx} \mathrm{Ky} \mathrm{Kz}$ Ss Por

6.34941e+00 6.34941e+00 6.34941e-01 1.00000e-09 2.12000e-01 $6.34941 \mathrm{e}+006.34941 \mathrm{e}+00$ 6.34941e-01 1.00000e-09 2.12000e-01 6.34941e+00 6.34941e+00 6.34941e-01 1.00000e-09 2.12000e-01 $6.34941 \mathrm{e}+006.34941 \mathrm{e}+00$ 6.34941e-01 1.00000e-09 2.12000e-01 $6.34941 \mathrm{e}+006.34941 \mathrm{e}+00$ 6.34941e-01 1.00000e-09 2.12000e-01 $1.00000 \mathrm{e}-05$ 1.00000e-05 1.00000e-06 1.00000e-09 1.00000e-01 $1.00000 \mathrm{e}+001.00000 \mathrm{e}+001.00000 \mathrm{e}-01$ 1.00000e-09 1.00000e-01 Element: 13358 \# of layers: 7

$\mathrm{Kx} \mathrm{Ky} \mathrm{Kz}$ Ss Por

4.47085e+00 4.47085e+00 4.47085e-01 1.00000e-09 2.12000e-01 4.47085e+00 4.47085e+00 4.47085e-01 1.00000e-09 2.12000e-01 $4.47085 \mathrm{e}+004.47085 \mathrm{e}+00$ 4.47085e-01 1.00000e-09 2.12000e-01 $4.47085 \mathrm{e}+00$ 4.47085e+00 4.47085e-01 1.00000e-09 2.12000e-01 4.47085e+00 4.47085e+00 4.47085e-01 1.00000e-09 2.12000e-01 $1.00000 \mathrm{e}-05$ 1.00000e-05 1.00000e-06 1.00000e-09 1.00000e-01 $1.00000 \mathrm{e}+001.00000 \mathrm{e}+001.00000 \mathrm{e}-011.00000 \mathrm{e}-091.00000 \mathrm{e}-01$ Element: 13359 \# of layers: 7

$\mathrm{Kx} \mathrm{Ky} \mathrm{Kz}$ Ss Por

4.16034e+00 4.16034e+00 4.16034e-01 1.00000e-09 2.12000e-01 $4.16034 \mathrm{e}+004.16034 \mathrm{e}+004.16034 \mathrm{e}-01$ 1.00000e-09 2.12000e-01 $4.16034 \mathrm{e}+004.16034 \mathrm{e}+004.16034 \mathrm{e}-01$ 1.00000e-09 2.12000e-01 4.16034e+00 4.16034e+00 4.16034e-01 1.00000e-09 2.12000e-01 4.16034e+00 4.16034e+00 4.16034e-01 1.00000e-09 2.12000e-01 $1.00000 \mathrm{e}-05$ 1.00000e-05 1.00000e-06 1.00000e-09 1.00000e-01 $1.00000 \mathrm{e}+001.00000 \mathrm{e}+001.00000 \mathrm{e}-011.00000 \mathrm{e}-091.00000 \mathrm{e}-01$ 
Element: 13360 \# of layers: 7

Kx Ky Kz Ss Por

4.42742e+00 4.42742e+00 4.42742e-01 1.00000e-09 2.12000e-01

$4.42742 \mathrm{e}+00 \quad 4.42742 \mathrm{e}+004.42742 \mathrm{e}-011.00000 \mathrm{e}-09$ 2.12000e-01

$4.42742 \mathrm{e}+00 \quad 4.42742 \mathrm{e}+004.42742 \mathrm{e}-011.00000 \mathrm{e}-09$ 2.12000e-01

$4.42742 \mathrm{e}+004.42742 \mathrm{e}+004.42742 \mathrm{e}-01$ 1.00000e-09 2.12000e-01

$4.42742 \mathrm{e}+00 \quad 4.42742 \mathrm{e}+004.42742 \mathrm{e}-01$ 1.00000e-09 2.12000e-01

$1.00000 \mathrm{e}-05$ 1.00000e-05 1.00000e-06 1.00000e-09 1.00000e-01

$1.00000 \mathrm{e}+001.00000 \mathrm{e}+001.00000 \mathrm{e}-011.00000 \mathrm{e}-091.00000 \mathrm{e}-01$

Element: 13361 \# of layers: 7

Kx Ky Kz Ss Por

4.42742e+00 4.42742e+00 4.42742e-01 1.00000e-09 2.12000e-01

$4.42742 \mathrm{e}+004.42742 \mathrm{e}+004.42742 \mathrm{e}-011.00000 \mathrm{e}-092.12000 \mathrm{e}-01$

$4.42742 \mathrm{e}+004.42742 \mathrm{e}+004.42742 \mathrm{e}-011.00000 \mathrm{e}-092.12000 \mathrm{e}-01$

$4.42742 \mathrm{e}+004.42742 \mathrm{e}+004.42742 \mathrm{e}-01$ 1.00000e-09 2.12000e-01

$4.42742 \mathrm{e}+004.42742 \mathrm{e}+00$ 4.42742e-01 1.00000e-09 2.12000e-01

$1.00000 \mathrm{e}-05$ 1.00000e-05 1.00000e-06 1.00000e-09 1.00000e-01

$1.00000 \mathrm{e}+001.00000 \mathrm{e}+001.00000 \mathrm{e}-011.00000 \mathrm{e}-091.00000 \mathrm{e}-01$

Element: 13362 \# of layers: 7

Kx Ky Kz Ss Por

$4.42742 \mathrm{e}+004.42742 \mathrm{e}+00$ 4.42742e-01 1.00000e-09 2.12000e-01

$4.42742 \mathrm{e}+004.42742 \mathrm{e}+004.42742 \mathrm{e}-011.00000 \mathrm{e}-092.12000 \mathrm{e}-01$

$4.42742 \mathrm{e}+004.42742 \mathrm{e}+004.42742 \mathrm{e}-011.00000 \mathrm{e}-092.12000 \mathrm{e}-01$

$4.42742 \mathrm{e}+004.42742 \mathrm{e}+004.42742 \mathrm{e}-011.00000 \mathrm{e}-092.12000 \mathrm{e}-01$

$4.42742 \mathrm{e}+004.42742 \mathrm{e}+004.42742 \mathrm{e}-011.00000 \mathrm{e}-092.12000 \mathrm{e}-01$

$1.00000 \mathrm{e}-05$ 1.00000e-05 1.00000e-06 1.00000e-09 1.00000e-01

$1.00000 \mathrm{e}+001.00000 \mathrm{e}+001.00000 \mathrm{e}-011.00000 \mathrm{e}-091.00000 \mathrm{e}-01$

Element: 13363 \# of layers: 7

Kx Ky Kz Ss Por

4.42742e+00 4.42742e+00 4.42742e-01 1.00000e-09 2.12000e-01

$4.42742 \mathrm{e}+004.42742 \mathrm{e}+004.42742 \mathrm{e}-011.00000 \mathrm{e}-092.12000 \mathrm{e}-01$

$4.42742 \mathrm{e}+004.42742 \mathrm{e}+004.42742 \mathrm{e}-01$ 1.00000e-09 2.12000e-01

$4.42742 \mathrm{e}+004.42742 \mathrm{e}+004.42742 \mathrm{e}-011.00000 \mathrm{e}-09$ 2.12000e-01

$4.42742 \mathrm{e}+00 \quad 4.42742 \mathrm{e}+00 \quad 4.42742 \mathrm{e}-01$ 1.00000e-09 2.12000e-01

$1.00000 \mathrm{e}-05$ 1.00000e-05 1.00000e-06 1.00000e-09 1.00000e-01

$1.00000 \mathrm{e}+001.00000 \mathrm{e}+001.00000 \mathrm{e}-011.00000 \mathrm{e}-091.00000 \mathrm{e}-01$

Element: 13364 \# of layers: 7

Kx Ky Kz Ss Por

4.42742e+00 4.42742e+00 4.42742e-01 1.00000e-09 2.12000e-01

$4.42742 \mathrm{e}+004.42742 \mathrm{e}+00$ 4.42742e-01 1.00000e-09 2.12000e-01

$4.42742 \mathrm{e}+004.42742 \mathrm{e}+004.42742 \mathrm{e}-011.00000 \mathrm{e}-09$ 2.12000e-01

$4.42742 \mathrm{e}+00 \quad 4.42742 \mathrm{e}+004.42742 \mathrm{e}-011.00000 \mathrm{e}-09$ 2.12000e-01

$4.42742 \mathrm{e}+00 \quad 4.42742 \mathrm{e}+00 \quad 4.42742 \mathrm{e}-01$ 1.00000e-09 2.12000e-01

$1.00000 \mathrm{e}-05$ 1.00000e-05 1.00000e-06 1.00000e-09 1.00000e-01

$1.00000 \mathrm{e}+001.00000 \mathrm{e}+001.00000 \mathrm{e}-011.00000 \mathrm{e}-091.00000 \mathrm{e}-01$

Element: 13365 \# of layers: 7 
Kx Ky Kz Ss Por

4.42742e+00 4.42742e+00 4.42742e-01 1.00000e-09 2.12000e-01

4.42742e+00 4.42742e+00 4.42742e-01 1.00000e-09 2.12000e-01

$4.42742 \mathrm{e}+004.42742 \mathrm{e}+00$ 4.42742e-01 1.00000e-09 2.12000e-01

4.42742e+00 4.42742e+00 4.42742e-01 1.00000e-09 2.12000e-01

4.42742e+00 4.42742e+00 4.42742e-01 1.00000e-09 2.12000e-01

$1.00000 \mathrm{e}-05$ 1.00000e-05 1.00000e-06 1.00000e-09 1.00000e-01

$1.00000 \mathrm{e}+001.00000 \mathrm{e}+001.00000 \mathrm{e}-011.00000 \mathrm{e}-091.00000 \mathrm{e}-01$

Element: 13366 \# of layers: 7

$\mathrm{Kx} \mathrm{Ky} \mathrm{Kz}$ Ss Por

4.42742e+00 4.42742e+00 4.42742e-01 1.00000e-09 2.12000e-01

$4.42742 \mathrm{e}+004.42742 \mathrm{e}+00$ 4.42742e-01 1.00000e-09 2.12000e-01

4.42742e+00 4.42742e+00 4.42742e-01 1.00000e-09 2.12000e-01

4.42742e+00 4.42742e+00 4.42742e-01 1.00000e-09 2.12000e-01

4.42742e+00 4.42742e+00 4.42742e-01 1.00000e-09 2.12000e-01

$1.00000 \mathrm{e}-05$ 1.00000e-05 1.00000e-06 1.00000e-09 1.00000e-01

$1.00000 \mathrm{e}+001.00000 \mathrm{e}+00$ 1.00000e-01 1.00000e-09 1.00000e-01

Element: 13367 \# of layers: 7

$\mathrm{Kx} \mathrm{Ky} \mathrm{Kz}$ Ss Por

4.42742e+00 4.42742e+00 4.42742e-01 1.00000e-09 2.12000e-01

$4.42742 \mathrm{e}+004.42742 \mathrm{e}+00$ 4.42742e-01 1.00000e-09 2.12000e-01

$4.42742 \mathrm{e}+00$ 4.42742e+00 4.42742e-01 1.00000e-09 2.12000e-01

4.42742e+00 4.42742e+00 4.42742e-01 1.00000e-09 2.12000e-01

$4.42742 \mathrm{e}+004.42742 \mathrm{e}+00$ 4.42742e-01 1.00000e-09 2.12000e-01

$1.00000 \mathrm{e}-05$ 1.00000e-05 1.00000e-06 1.00000e-09 1.00000e-01

$1.00000 \mathrm{e}+001.00000 \mathrm{e}+001.00000 \mathrm{e}-01$ 1.00000e-09 1.00000e-01

Element: 13368 \# of layers: 7

$\mathrm{Kx} \mathrm{Ky} \mathrm{Kz} \mathrm{Ss} \mathrm{Por}$

4.42742e+00 4.42742e+00 4.42742e-01 1.00000e-09 2.12000e-01 $4.42742 \mathrm{e}+004.42742 \mathrm{e}+00$ 4.42742e-01 1.00000e-09 2.12000e-01

4.42742e+00 4.42742e+00 4.42742e-01 1.00000e-09 2.12000e-01

$4.42742 \mathrm{e}+00$ 4.42742e+00 4.42742e-01 1.00000e-09 2.12000e-01

$4.42742 \mathrm{e}+004.42742 \mathrm{e}+00$ 4.42742e-01 1.00000e-09 2.12000e-01

$1.00000 \mathrm{e}-05$ 1.00000e-05 1.00000e-06 1.00000e-09 1.00000e-01

$1.00000 \mathrm{e}+001.00000 \mathrm{e}+001.00000 \mathrm{e}-011.00000 \mathrm{e}-091.00000 \mathrm{e}-01$

Element: 13369 \# of layers: 7

Kx Ky Kz Ss Por

4.42742e+00 4.42742e+00 4.42742e-01 1.00000e-09 2.12000e-01

4.42742e+00 4.42742e+00 4.42742e-01 1.00000e-09 2.12000e-01

4.42742e+00 4.42742e+00 4.42742e-01 1.00000e-09 2.12000e-01

$4.42742 \mathrm{e}+004.42742 \mathrm{e}+004.42742 \mathrm{e}-01$ 1.00000e-09 2.12000e-01

$4.42742 \mathrm{e}+004.42742 \mathrm{e}+00$ 4.42742e-01 1.00000e-09 2.12000e-01

$1.00000 \mathrm{e}-05$ 1.00000e-05 1.00000e-06 1.00000e-09 1.00000e-01

$1.00000 \mathrm{e}+001.00000 \mathrm{e}+001.00000 \mathrm{e}-01$ 1.00000e-09 1.00000e-01

Element: 13370 \# of layers: 7

Kx Ky Kz Ss Por 
$5.11841 \mathrm{e}+00$ 5.11841e+00 5.11841e-01 1.00000e-09 2.12000e-01 $5.11841 \mathrm{e}+005.11841 \mathrm{e}+00$ 5.11841e-01 1.00000e-09 2.12000e-01 $5.11841 \mathrm{e}+005.11841 \mathrm{e}+00$ 5.11841e-01 1.00000e-09 2.12000e-01 $5.11841 \mathrm{e}+005.11841 \mathrm{e}+00$ 5.11841e-01 1.00000e-09 2.12000e-01 $5.11841 \mathrm{e}+00$ 5.11841e+00 5.11841e-01 1.00000e-09 2.12000e-01 $1.00000 \mathrm{e}-05$ 1.00000e-05 1.00000e-06 1.00000e-09 1.00000e-01 $1.00000 \mathrm{e}+001.00000 \mathrm{e}+001.00000 \mathrm{e}-011.00000 \mathrm{e}-091.00000 \mathrm{e}-01$ Element: 13371 \# of layers: 7

Kx Ky Kz Ss Por

$5.11841 \mathrm{e}+00$ 5.11841e+00 5.11841e-01 1.00000e-09 2.12000e-01 $5.11841 \mathrm{e}+005.11841 \mathrm{e}+00$ 5.11841e-01 1.00000e-09 2.12000e-01 $5.11841 \mathrm{e}+005.11841 \mathrm{e}+00$ 5.11841e-01 1.00000e-09 2.12000e-01 $5.11841 \mathrm{e}+005.11841 \mathrm{e}+00$ 5.11841e-01 1.00000e-09 2.12000e-01 $5.11841 \mathrm{e}+00$ 5.11841e+00 5.11841e-01 1.00000e-09 2.12000e-01 $1.00000 \mathrm{e}-05$ 1.00000e-05 1.00000e-06 1.00000e-09 1.00000e-01 $1.00000 \mathrm{e}+001.00000 \mathrm{e}+001.00000 \mathrm{e}-011.00000 \mathrm{e}-091.00000 \mathrm{e}-01$ Element: 13372 \# of layers: 7

Kx Ky Kz Ss Por

$5.11841 \mathrm{e}+00$ 5.11841e+00 5.11841e-01 1.00000e-09 2.12000e-01 $5.11841 \mathrm{e}+005.11841 \mathrm{e}+00$ 5.11841e-01 1.00000e-09 2.12000e-01 $5.11841 \mathrm{e}+005.11841 \mathrm{e}+00$ 5.11841e-01 1.00000e-09 2.12000e-01 $5.11841 \mathrm{e}+005.11841 \mathrm{e}+005.11841 \mathrm{e}-011.00000 \mathrm{e}-092.12000 \mathrm{e}-01$ $5.11841 \mathrm{e}+005.11841 \mathrm{e}+005.11841 \mathrm{e}-011.00000 \mathrm{e}-092.12000 \mathrm{e}-01$ $1.00000 \mathrm{e}-05$ 1.00000e-05 1.00000e-06 1.00000e-09 1.00000e-01 $1.00000 \mathrm{e}+001.00000 \mathrm{e}+001.00000 \mathrm{e}-011.00000 \mathrm{e}-091.00000 \mathrm{e}-01$ Element: 13373 \# of layers: 7

Kx Ky Kz Ss Por

5.11841e+00 5.11841e+00 5.11841e-01 1.00000e-09 2.12000e-01 $5.11841 \mathrm{e}+005.11841 \mathrm{e}+00$ 5.11841e-01 1.00000e-09 2.12000e-01 $5.11841 \mathrm{e}+005.11841 \mathrm{e}+00$ 5.11841e-01 1.00000e-09 2.12000e-01 $5.11841 \mathrm{e}+005.11841 \mathrm{e}+00$ 5.11841e-01 1.00000e-09 2.12000e-01 $5.11841 \mathrm{e}+00$ 5.11841e+00 5.11841e-01 1.00000e-09 2.12000e-01 $1.00000 \mathrm{e}-05$ 1.00000e-05 1.00000e-06 1.00000e-09 1.00000e-01 $1.00000 \mathrm{e}+001.00000 \mathrm{e}+001.00000 \mathrm{e}-011.00000 \mathrm{e}-091.00000 \mathrm{e}-01$ Element: 13374 \# of layers: 7

Kx Ky Kz Ss Por

5.11841e+00 5.11841e+00 5.11841e-01 1.00000e-09 2.12000e-01 $5.11841 \mathrm{e}+005.11841 \mathrm{e}+00$ 5.11841e-01 1.00000e-09 2.12000e-01 $5.11841 \mathrm{e}+005.11841 \mathrm{e}+005.11841 \mathrm{e}-011.00000 \mathrm{e}-092.12000 \mathrm{e}-01$ $5.11841 \mathrm{e}+005.11841 \mathrm{e}+00$ 5.11841e-01 1.00000e-09 2.12000e-01 $5.11841 \mathrm{e}+00$ 5.11841e+00 5.11841e-01 1.00000e-09 2.12000e-01 $1.00000 \mathrm{e}-05$ 1.00000e-05 1.00000e-06 1.00000e-09 1.00000e-01 $1.00000 \mathrm{e}+001.00000 \mathrm{e}+001.00000 \mathrm{e}-011.00000 \mathrm{e}-091.00000 \mathrm{e}-01$ Element: 13375 \# of layers: 7

Kx Ky Kz Ss Por

4.42742e+00 4.42742e+00 4.42742e-01 1.00000e-09 2.12000e-01 
4.42742e+00 4.42742e+00 4.42742e-01 1.00000e-09 2.12000e-01 4.42742e+00 4.42742e+00 4.42742e-01 1.00000e-09 2.12000e-01 4.42742e+00 4.42742e+00 4.42742e-01 1.00000e-09 2.12000e-01 $4.42742 \mathrm{e}+00$ 4.42742e+00 4.42742e-01 1.00000e-09 2.12000e-01 $1.00000 \mathrm{e}-05$ 1.00000e-05 1.00000e-06 1.00000e-09 1.00000e-01 $1.00000 \mathrm{e}+001.00000 \mathrm{e}+001.00000 \mathrm{e}-011.00000 \mathrm{e}-091.00000 \mathrm{e}-01$ Element: 13376 \# of layers: 7

$\mathrm{Kx} \mathrm{Ky} \mathrm{Kz}$ Ss Por

4.42742e+00 4.42742e+00 4.42742e-01 1.00000e-09 2.12000e-01 $4.42742 \mathrm{e}+00$ 4.42742e+00 4.42742e-01 1.00000e-09 2.12000e-01 4.42742e+00 4.42742e+00 4.42742e-01 1.00000e-09 2.12000e-01 4.42742e+00 4.42742e+00 4.42742e-01 1.00000e-09 2.12000e-01 4.42742e+00 4.42742e+00 4.42742e-01 1.00000e-09 2.12000e-01 $1.00000 \mathrm{e}-05$ 1.00000e-05 1.00000e-06 1.00000e-09 1.00000e-01 $1.00000 \mathrm{e}+001.00000 \mathrm{e}+001.00000 \mathrm{e}-01$ 1.00000e-09 1.00000e-01 Element: 13377 \# of layers: 7

$\mathrm{Kx} \mathrm{Ky} \mathrm{Kz}$ Ss Por

5.11841e+00 5.11841e+00 5.11841e-01 1.00000e-09 2.12000e-01 5.11841e+00 5.11841e+00 5.11841e-01 1.00000e-09 2.12000e-01 $5.11841 \mathrm{e}+00$ 5.11841e+00 5.11841e-01 1.00000e-09 2.12000e-01 $5.11841 \mathrm{e}+00$ 5.11841e+00 5.11841e-01 1.00000e-09 2.12000e-01 5.11841e+00 5.11841e+00 5.11841e-01 1.00000e-09 2.12000e-01 $1.00000 \mathrm{e}-05$ 1.00000e-05 1.00000e-06 1.00000e-09 1.00000e-01 $1.00000 \mathrm{e}+001.00000 \mathrm{e}+001.00000 \mathrm{e}-011.00000 \mathrm{e}-09$ 1.00000e-01 Element: 13378 \# of layers: 7

$\mathrm{Kx} \mathrm{Ky} \mathrm{Kz}$ Ss Por

5.11841e+00 5.11841e+00 5.11841e-01 1.00000e-09 2.12000e-01 5.11841e+00 5.11841e+00 5.11841e-01 1.00000e-09 2.12000e-01 $5.11841 \mathrm{e}+00$ 5.11841e+00 5.11841e-01 1.00000e-09 2.12000e-01 5.11841e+00 5.11841e+00 5.11841e-01 1.00000e-09 2.12000e-01 $5.11841 \mathrm{e}+00$ 5.11841e+00 5.11841e-01 1.00000e-09 2.12000e-01 1.00000e-05 1.00000e-05 1.00000e-06 1.00000e-09 1.00000e-01 $1.00000 \mathrm{e}+001.00000 \mathrm{e}+001.00000 \mathrm{e}-011.00000 \mathrm{e}-091.00000 \mathrm{e}-01$ Element: 13379 \# of layers: 7

$\mathrm{Kx} \mathrm{Ky} \mathrm{Kz}$ Ss Por

5.11841e+00 5.11841e+00 5.11841e-01 1.00000e-09 2.12000e-01 $5.11841 \mathrm{e}+005.11841 \mathrm{e}+00$ 5.11841e-01 1.00000e-09 2.12000e-01 5.11841e+00 5.11841e+00 5.11841e-01 1.00000e-09 2.12000e-01 5.11841e+00 5.11841e+00 5.11841e-01 1.00000e-09 2.12000e-01 5.11841e+00 5.11841e+00 5.11841e-01 1.00000e-09 2.12000e-01 $1.00000 \mathrm{e}-05$ 1.00000e-05 1.00000e-06 1.00000e-09 1.00000e-01 $1.00000 \mathrm{e}+001.00000 \mathrm{e}+001.00000 \mathrm{e}-011.00000 \mathrm{e}-091.00000 \mathrm{e}-01$ Element: 13380 \# of layers: 7

$\mathrm{Kx} \mathrm{Ky} \mathrm{Kz}$ Ss Por

5.11841e+00 5.11841e+00 5.11841e-01 1.00000e-09 2.12000e-01 $5.11841 \mathrm{e}+00$ 5.11841e+00 5.11841e-01 1.00000e-09 2.12000e-01 
$5.11841 \mathrm{e}+00$ 5.11841e+00 5.11841e-01 1.00000e-09 2.12000e-01 $5.11841 \mathrm{e}+005.11841 \mathrm{e}+00$ 5.11841e-01 1.00000e-09 2.12000e-01 $5.11841 \mathrm{e}+005.11841 \mathrm{e}+00$ 5.11841e-01 1.00000e-09 2.12000e-01 $1.00000 \mathrm{e}-05$ 1.00000e-05 1.00000e-06 1.00000e-09 1.00000e-01 $1.00000 \mathrm{e}+001.00000 \mathrm{e}+001.00000 \mathrm{e}-011.00000 \mathrm{e}-091.00000 \mathrm{e}-01$ Element: 13381 \# of layers: 7

Kx Ky Kz Ss Por

5.11841e+00 5.11841e+00 5.11841e-01 1.00000e-09 2.12000e-01 $5.11841 \mathrm{e}+005.11841 \mathrm{e}+005.11841 \mathrm{e}-011.00000 \mathrm{e}-092.12000 \mathrm{e}-01$ $5.11841 \mathrm{e}+005.11841 \mathrm{e}+00$ 5.11841e-01 1.00000e-09 2.12000e-01 $5.11841 \mathrm{e}+005.11841 \mathrm{e}+00$ 5.11841e-01 1.00000e-09 2.12000e-01 $5.11841 \mathrm{e}+00$ 5.11841e+00 5.11841e-01 1.00000e-09 2.12000e-01 $1.00000 \mathrm{e}-05$ 1.00000e-05 1.00000e-06 1.00000e-09 1.00000e-01 $1.00000 \mathrm{e}+001.00000 \mathrm{e}+001.00000 \mathrm{e}-011.00000 \mathrm{e}-091.00000 \mathrm{e}-01$ Element: 13382 \# of layers: 7

Kx Ky Kz Ss Por

$5.11841 \mathrm{e}+00$ 5.11841e+00 5.11841e-01 1.00000e-09 2.12000e-01 $5.11841 \mathrm{e}+005.11841 \mathrm{e}+005.11841 \mathrm{e}-011.00000 \mathrm{e}-092.12000 \mathrm{e}-01$ $5.11841 \mathrm{e}+005.11841 \mathrm{e}+005.11841 \mathrm{e}-011.00000 \mathrm{e}-092.12000 \mathrm{e}-01$ $5.11841 \mathrm{e}+005.11841 \mathrm{e}+00$ 5.11841e-01 1.00000e-09 2.12000e-01 $5.11841 \mathrm{e}+00$ 5.11841e+00 5.11841e-01 1.00000e-09 2.12000e-01 $1.00000 \mathrm{e}-05$ 1.00000e-05 1.00000e-06 1.00000e-09 1.00000e-01 $1.00000 \mathrm{e}+001.00000 \mathrm{e}+001.00000 \mathrm{e}-011.00000 \mathrm{e}-091.00000 \mathrm{e}-01$ Element: 13383 \# of layers: 7

Kx Ky Kz Ss Por

$5.11841 \mathrm{e}+00$ 5.11841e+00 5.11841e-01 1.00000e-09 2.12000e-01 $5.11841 \mathrm{e}+005.11841 \mathrm{e}+00$ 5.11841e-01 1.00000e-09 2.12000e-01 $5.11841 \mathrm{e}+005.11841 \mathrm{e}+00$ 5.11841e-01 1.00000e-09 2.12000e-01 $5.11841 \mathrm{e}+005.11841 \mathrm{e}+00$ 5.11841e-01 1.00000e-09 2.12000e-01 $5.11841 \mathrm{e}+005.11841 \mathrm{e}+005.11841 \mathrm{e}-011.00000 \mathrm{e}-092.12000 \mathrm{e}-01$ $1.00000 \mathrm{e}-05$ 1.00000e-05 1.00000e-06 1.00000e-09 1.00000e-01 $1.00000 \mathrm{e}+001.00000 \mathrm{e}+001.00000 \mathrm{e}-011.00000 \mathrm{e}-091.00000 \mathrm{e}-01$ Element: 13384 \# of layers: 7

Kx Ky Kz Ss Por

$5.11841 \mathrm{e}+00$ 5.11841e+00 5.11841e-01 1.00000e-09 2.12000e-01 $5.11841 \mathrm{e}+005.11841 \mathrm{e}+005.11841 \mathrm{e}-011.00000 \mathrm{e}-092.12000 \mathrm{e}-01$ $5.11841 \mathrm{e}+005.11841 \mathrm{e}+00$ 5.11841e-01 1.00000e-09 2.12000e-01 $5.11841 \mathrm{e}+005.11841 \mathrm{e}+00$ 5.11841e-01 1.00000e-09 2.12000e-01 $5.11841 \mathrm{e}+005.11841 \mathrm{e}+00$ 5.11841e-01 1.00000e-09 2.12000e-01 $1.00000 \mathrm{e}-05$ 1.00000e-05 1.00000e-06 1.00000e-09 1.00000e-01 $1.00000 \mathrm{e}+001.00000 \mathrm{e}+001.00000 \mathrm{e}-011.00000 \mathrm{e}-091.00000 \mathrm{e}-01$ Element: 13385 \# of layers: 7

Kx Ky Kz Ss Por

$5.11841 \mathrm{e}+00$ 5.11841e+00 5.11841e-01 1.00000e-09 2.12000e-01 $5.11841 \mathrm{e}+005.11841 \mathrm{e}+00$ 5.11841e-01 1.00000e-09 2.12000e-01 $5.11841 \mathrm{e}+005.11841 \mathrm{e}+00$ 5.11841e-01 1.00000e-09 2.12000e-01 
$5.11841 \mathrm{e}+00$ 5.11841e+00 5.11841e-01 1.00000e-09 2.12000e-01 $5.11841 \mathrm{e}+005.11841 \mathrm{e}+005.11841 \mathrm{e}-011.00000 \mathrm{e}-092.12000 \mathrm{e}-01$ $1.00000 \mathrm{e}-05$ 1.00000e-05 1.00000e-06 1.00000e-09 1.00000e-01 $1.00000 \mathrm{e}+001.00000 \mathrm{e}+001.00000 \mathrm{e}-011.00000 \mathrm{e}-091.00000 \mathrm{e}-01$ Element: 13386 \# of layers: 7

Kx Ky Kz Ss Por

$5.11841 \mathrm{e}+00$ 5.11841e+00 5.11841e-01 1.00000e-09 2.12000e-01

$5.11841 \mathrm{e}+005.11841 \mathrm{e}+00$ 5.11841e-01 1.00000e-09 2.12000e-01

$5.11841 \mathrm{e}+005.11841 \mathrm{e}+00$ 5.11841e-01 1.00000e-09 2.12000e-01

$5.11841 \mathrm{e}+005.11841 \mathrm{e}+005.11841 \mathrm{e}-011.00000 \mathrm{e}-092.12000 \mathrm{e}-01$

$5.11841 \mathrm{e}+005.11841 \mathrm{e}+00$ 5.11841e-01 1.00000e-09 2.12000e-01 $1.00000 \mathrm{e}-05$ 1.00000e-05 1.00000e-06 1.00000e-09 1.00000e-01 $1.00000 \mathrm{e}+001.00000 \mathrm{e}+001.00000 \mathrm{e}-011.00000 \mathrm{e}-091.00000 \mathrm{e}-01$ Element: 13387 \# of layers: 7

Kx Ky Kz Ss Por

$5.11841 \mathrm{e}+00$ 5.11841e+00 5.11841e-01 1.00000e-09 2.12000e-01 $5.11841 \mathrm{e}+005.11841 \mathrm{e}+00$ 5.11841e-01 1.00000e-09 2.12000e-01 $5.11841 \mathrm{e}+005.11841 \mathrm{e}+005.11841 \mathrm{e}-011.00000 \mathrm{e}-092.12000 \mathrm{e}-01$ $5.11841 \mathrm{e}+005.11841 \mathrm{e}+00$ 5.11841e-01 1.00000e-09 2.12000e-01 $5.11841 \mathrm{e}+005.11841 \mathrm{e}+00$ 5.11841e-01 1.00000e-09 2.12000e-01 $1.00000 \mathrm{e}-05$ 1.00000e-05 1.00000e-06 1.00000e-09 1.00000e-01 $1.00000 \mathrm{e}+001.00000 \mathrm{e}+001.00000 \mathrm{e}-011.00000 \mathrm{e}-091.00000 \mathrm{e}-01$ Element: 13388 \# of layers: 7

Kx Ky Kz Ss Por

5.11841e+00 5.11841e+00 5.11841e-01 1.00000e-09 2.12000e-01 $5.11841 \mathrm{e}+005.11841 \mathrm{e}+00$ 5.11841e-01 1.00000e-09 2.12000e-01 $5.11841 \mathrm{e}+005.11841 \mathrm{e}+00$ 5.11841e-01 1.00000e-09 2.12000e-01 $5.11841 \mathrm{e}+005.11841 \mathrm{e}+00$ 5.11841e-01 1.00000e-09 2.12000e-01 $5.11841 \mathrm{e}+005.11841 \mathrm{e}+00$ 5.11841e-01 1.00000e-09 2.12000e-01 $1.00000 \mathrm{e}-05$ 1.00000e-05 1.00000e-06 1.00000e-09 1.00000e-01 $1.00000 \mathrm{e}+001.00000 \mathrm{e}+001.00000 \mathrm{e}-011.00000 \mathrm{e}-091.00000 \mathrm{e}-01$ Element: 13389 \# of layers: 7

Kx Ky Kz Ss Por $5.06711 \mathrm{e}+00$ 5.06711e+00 5.06711e-01 1.00000e-09 2.12000e-01 $5.06711 \mathrm{e}+005.06711 \mathrm{e}+00$ 5.06711e-01 1.00000e-09 2.12000e-01 $5.06711 \mathrm{e}+005.06711 \mathrm{e}+00$ 5.06711e-01 1.00000e-09 2.12000e-01 $5.06711 \mathrm{e}+005.06711 \mathrm{e}+00$ 5.06711e-01 1.00000e-09 2.12000e-01 $5.06711 \mathrm{e}+005.06711 \mathrm{e}+00$ 5.06711e-01 1.00000e-09 2.12000e-01 $1.00000 \mathrm{e}-05$ 1.00000e-05 1.00000e-06 1.00000e-09 1.00000e-01 $1.00000 \mathrm{e}+001.00000 \mathrm{e}+001.00000 \mathrm{e}-011.00000 \mathrm{e}-091.00000 \mathrm{e}-01$ Element: 13390 \# of layers: 7

$\mathrm{Kx} \mathrm{Ky} \mathrm{Kz}$ Ss Por

5.06711e+00 5.06711e+00 5.06711e-01 1.00000e-09 2.12000e-01 $5.06711 \mathrm{e}+005.06711 \mathrm{e}+00$ 5.06711e-01 1.00000e-09 2.12000e-01 $5.06711 \mathrm{e}+005.06711 \mathrm{e}+005.06711 \mathrm{e}-01$ 1.00000e-09 2.12000e-01 $5.06711 \mathrm{e}+00$ 5.06711e+00 5.06711e-01 1.00000e-09 2.12000e-01 
5.06711e+00 5.06711e+00 5.06711e-01 1.00000e-09 2.12000e-01 $1.00000 \mathrm{e}-05$ 1.00000e-05 1.00000e-06 1.00000e-09 1.00000e-01 $1.00000 \mathrm{e}+001.00000 \mathrm{e}+001.00000 \mathrm{e}-011.00000 \mathrm{e}-091.00000 \mathrm{e}-01$ Element: 13391 \# of layers: 7

$\mathrm{Kx} \mathrm{Ky} \mathrm{Kz}$ Ss Por

$5.06711 \mathrm{e}+005.06711 \mathrm{e}+00$ 5.06711e-01 1.00000e-09 2.12000e-01 $5.06711 \mathrm{e}+005.06711 \mathrm{e}+00$ 5.06711e-01 1.00000e-09 2.12000e-01 $5.06711 \mathrm{e}+005.06711 \mathrm{e}+00$ 5.06711e-01 1.00000e-09 2.12000e-01 $5.06711 \mathrm{e}+005.06711 \mathrm{e}+00$ 5.06711e-01 1.00000e-09 2.12000e-01 $5.06711 \mathrm{e}+005.06711 \mathrm{e}+005.06711 \mathrm{e}-01$ 1.00000e-09 2.12000e-01 $1.00000 \mathrm{e}-05$ 1.00000e-05 1.00000e-06 1.00000e-09 1.00000e-01 $1.00000 \mathrm{e}+001.00000 \mathrm{e}+001.00000 \mathrm{e}-011.00000 \mathrm{e}-091.00000 \mathrm{e}-01$ Element: 13392 \# of layers: 7

$\mathrm{Kx} \mathrm{Ky} \mathrm{Kz}$ Ss Por

5.11841e+00 5.11841e+00 5.11841e-01 1.00000e-09 2.12000e-01

$5.11841 \mathrm{e}+005.11841 \mathrm{e}+00$ 5.11841e-01 1.00000e-09 2.12000e-01

5.11841e+00 5.11841e+00 5.11841e-01 1.00000e-09 2.12000e-01

5.11841e+00 5.11841e+00 5.11841e-01 1.00000e-09 2.12000e-01

5.11841e+00 5.11841e+00 5.11841e-01 1.00000e-09 2.12000e-01 $1.00000 \mathrm{e}-05$ 1.00000e-05 1.00000e-06 1.00000e-09 1.00000e-01

$1.00000 \mathrm{e}+001.00000 \mathrm{e}+001.00000 \mathrm{e}-011.00000 \mathrm{e}-091.00000 \mathrm{e}-01$ Element: 13393 \# of layers: 7

Kx Ky Kz Ss Por

5.11841e+00 5.11841e+00 5.11841e-01 1.00000e-09 2.12000e-01

$5.11841 \mathrm{e}+00$ 5.11841e+00 5.11841e-01 1.00000e-09 2.12000e-01

5.11841e+00 5.11841e+00 5.11841e-01 1.00000e-09 2.12000e-01

5.11841e+00 5.11841e+00 5.11841e-01 1.00000e-09 2.12000e-01

$5.11841 \mathrm{e}+00$ 5.11841e+00 5.11841e-01 1.00000e-09 2.12000e-01

$1.00000 \mathrm{e}-05$ 1.00000e-05 1.00000e-06 1.00000e-09 1.00000e-01

$1.00000 \mathrm{e}+001.00000 \mathrm{e}+001.00000 \mathrm{e}-011.00000 \mathrm{e}-091.00000 \mathrm{e}-01$

Element: 13394 \# of layers: 7

Kx Ky Kz Ss Por

5.11841e+00 5.11841e+00 5.11841e-01 1.00000e-09 2.12000e-01

5.11841e+00 5.11841e+00 5.11841e-01 1.00000e-09 2.12000e-01

5.11841e+00 5.11841e+00 5.11841e-01 1.00000e-09 2.12000e-01

5.11841e+00 5.11841e+00 5.11841e-01 1.00000e-09 2.12000e-01

$5.11841 \mathrm{e}+005.11841 \mathrm{e}+00$ 5.11841e-01 1.00000e-09 2.12000e-01

$1.00000 \mathrm{e}-05$ 1.00000e-05 1.00000e-06 1.00000e-09 1.00000e-01

$1.00000 \mathrm{e}+001.00000 \mathrm{e}+001.00000 \mathrm{e}-01$ 1.00000e-09 1.00000e-01

Element: 13395 \# of layers: 7

Kx Ky Kz Ss Por

5.11841e+00 5.11841e+00 5.11841e-01 1.00000e-09 2.12000e-01

5.11841e+00 5.11841e+00 5.11841e-01 1.00000e-09 2.12000e-01

5.11841e+00 5.11841e+00 5.11841e-01 1.00000e-09 2.12000e-01

5.11841e+00 5.11841e+00 5.11841e-01 1.00000e-09 2.12000e-01

$5.11841 \mathrm{e}+00$ 5.11841e+00 5.11841e-01 1.00000e-09 2.12000e-01 
$1.00000 \mathrm{e}-05$ 1.00000e-05 1.00000e-06 1.00000e-09 1.00000e-01 $1.00000 \mathrm{e}+001.00000 \mathrm{e}+001.00000 \mathrm{e}-01$ 1.00000e-09 1.00000e-01 Element: 13396 \# of layers: 7

Kx Ky Kz Ss Por

5.06711e+00 5.06711e+00 5.06711e-01 1.00000e-09 2.12000e-01 $5.06711 \mathrm{e}+005.06711 \mathrm{e}+00$ 5.06711e-01 1.00000e-09 2.12000e-01 $5.06711 \mathrm{e}+005.06711 \mathrm{e}+00$ 5.06711e-01 1.00000e-09 2.12000e-01 $5.06711 \mathrm{e}+005.06711 \mathrm{e}+005.06711 \mathrm{e}-011.00000 \mathrm{e}-092.12000 \mathrm{e}-01$ $5.06711 \mathrm{e}+00$ 5.06711e+00 5.06711e-01 1.00000e-09 2.12000e-01 $1.00000 \mathrm{e}-05$ 1.00000e-05 1.00000e-06 1.00000e-09 1.00000e-01 $1.00000 \mathrm{e}+001.00000 \mathrm{e}+001.00000 \mathrm{e}-011.00000 \mathrm{e}-091.00000 \mathrm{e}-01$ Element: 13397 \# of layers: 7

$\mathrm{Kx} \mathrm{Ky} \mathrm{Kz}$ Ss Por

5.06711e+00 5.06711e+00 5.06711e-01 1.00000e-09 2.12000e-01 $5.06711 \mathrm{e}+005.06711 \mathrm{e}+005.06711 \mathrm{e}-01$ 1.00000e-09 2.12000e-01 $5.06711 \mathrm{e}+005.06711 \mathrm{e}+005.06711 \mathrm{e}-01$ 1.00000e-09 2.12000e-01 $5.06711 \mathrm{e}+005.06711 \mathrm{e}+005.06711 \mathrm{e}-011.00000 \mathrm{e}-092.12000 \mathrm{e}-01$ $5.06711 \mathrm{e}+005.06711 \mathrm{e}+00$ 5.06711e-01 1.00000e-09 2.12000e-01 $1.00000 \mathrm{e}-051.00000 \mathrm{e}-051.00000 \mathrm{e}-061.00000 \mathrm{e}-091.00000 \mathrm{e}-01$ $1.00000 \mathrm{e}+001.00000 \mathrm{e}+001.00000 \mathrm{e}-011.00000 \mathrm{e}-09$ 1.00000e-01 Element: 13398 \# of layers: 7

$\mathrm{Kx} \mathrm{Ky} \mathrm{Kz}$ Ss Por

5.06711e+00 5.06711e+00 5.06711e-01 1.00000e-09 2.12000e-01 $5.06711 \mathrm{e}+005.06711 \mathrm{e}+005.06711 \mathrm{e}-01$ 1.00000e-09 2.12000e-01 $5.06711 \mathrm{e}+005.06711 \mathrm{e}+00$ 5.06711e-01 1.00000e-09 2.12000e-01 $5.06711 \mathrm{e}+005.06711 \mathrm{e}+005.06711 \mathrm{e}-011.00000 \mathrm{e}-092.12000 \mathrm{e}-01$ $5.06711 \mathrm{e}+005.06711 \mathrm{e}+005.06711 \mathrm{e}-01$ 1.00000e-09 2.12000e-01 $1.00000 \mathrm{e}-05$ 1.00000e-05 1.00000e-06 1.00000e-09 1.00000e-01 $1.00000 \mathrm{e}+001.00000 \mathrm{e}+001.00000 \mathrm{e}-011.00000 \mathrm{e}-091.00000 \mathrm{e}-01$ Element: 13399 \# of layers: 7

$\mathrm{Kx} \mathrm{Ky} \mathrm{Kz}$ Ss Por

$5.06711 \mathrm{e}+00$ 5.06711e+00 5.06711e-01 1.00000e-09 2.12000e-01 $5.06711 \mathrm{e}+005.06711 \mathrm{e}+005.06711 \mathrm{e}-011.00000 \mathrm{e}-092.12000 \mathrm{e}-01$ $5.06711 \mathrm{e}+00$ 5.06711e+00 5.06711e-01 1.00000e-09 2.12000e-01 $5.06711 \mathrm{e}+005.06711 \mathrm{e}+00$ 5.06711e-01 1.00000e-09 2.12000e-01 $5.06711 \mathrm{e}+005.06711 \mathrm{e}+00$ 5.06711e-01 1.00000e-09 2.12000e-01 $1.00000 \mathrm{e}-05$ 1.00000e-05 1.00000e-06 1.00000e-09 1.00000e-01 $1.00000 \mathrm{e}+001.00000 \mathrm{e}+001.00000 \mathrm{e}-011.00000 \mathrm{e}-09$ 1.00000e-01 Element: 13400 \# of layers: 7

$\mathrm{Kx} \mathrm{Ky} \mathrm{Kz}$ Ss Por

5.06711e+00 5.06711e+00 5.06711e-01 1.00000e-09 2.12000e-01 $5.06711 \mathrm{e}+005.06711 \mathrm{e}+00$ 5.06711e-01 1.00000e-09 2.12000e-01 $5.06711 \mathrm{e}+00$ 5.06711e+00 5.06711e-01 1.00000e-09 2.12000e-01 5.06711e+00 5.06711e+00 5.06711e-01 1.00000e-09 2.12000e-01 $5.06711 \mathrm{e}+005.06711 \mathrm{e}+005.06711 \mathrm{e}-01$ 1.00000e-09 2.12000e-01 $1.00000 \mathrm{e}-05$ 1.00000e-05 1.00000e-06 1.00000e-09 1.00000e-01 
$1.00000 \mathrm{e}+001.00000 \mathrm{e}+001.00000 \mathrm{e}-01$ 1.00000e-09 1.00000e-01 Element: 13401 \# of layers: 7

Kx Ky Kz Ss Por

5.06711e+00 5.06711e+00 5.06711e-01 1.00000e-09 2.12000e-01

$5.06711 \mathrm{e}+005.06711 \mathrm{e}+00$ 5.06711e-01 1.00000e-09 2.12000e-01

$5.06711 \mathrm{e}+005.06711 \mathrm{e}+005.06711 \mathrm{e}-011.00000 \mathrm{e}-092.12000 \mathrm{e}-01$

$5.06711 \mathrm{e}+005.06711 \mathrm{e}+00$ 5.06711e-01 1.00000e-09 2.12000e-01

$5.06711 \mathrm{e}+005.06711 \mathrm{e}+00$ 5.06711e-01 1.00000e-09 2.12000e-01

$1.00000 \mathrm{e}-05$ 1.00000e-05 1.00000e-06 1.00000e-09 1.00000e-01

$1.00000 \mathrm{e}+001.00000 \mathrm{e}+001.00000 \mathrm{e}-01$ 1.00000e-09 1.00000e-01

Element: 13402 \# of layers: 7

Kx Ky Kz Ss Por

5.06711e+00 5.06711e+00 5.06711e-01 1.00000e-09 2.12000e-01

$5.06711 \mathrm{e}+005.06711 \mathrm{e}+00$ 5.06711e-01 1.00000e-09 2.12000e-01

$5.06711 \mathrm{e}+005.06711 \mathrm{e}+00$ 5.06711e-01 1.00000e-09 2.12000e-01

$5.06711 \mathrm{e}+005.06711 \mathrm{e}+005.06711 \mathrm{e}-01$ 1.00000e-09 2.12000e-01

$5.06711 \mathrm{e}+00$ 5.06711e+00 5.06711e-01 1.00000e-09 2.12000e-01

$1.00000 \mathrm{e}-05$ 1.00000e-05 1.00000e-06 1.00000e-09 1.00000e-01

$1.00000 \mathrm{e}+001.00000 \mathrm{e}+001.00000 \mathrm{e}-01$ 1.00000e-09 1.00000e-01

Element: 13403 \# of layers: 7

$\mathrm{Kx} \mathrm{Ky} \mathrm{Kz}$ Ss Por

5.06711e+00 5.06711e+00 5.06711e-01 1.00000e-09 2.12000e-01

$5.06711 \mathrm{e}+005.06711 \mathrm{e}+00$ 5.06711e-01 1.00000e-09 2.12000e-01

$5.06711 \mathrm{e}+005.06711 \mathrm{e}+00$ 5.06711e-01 1.00000e-09 2.12000e-01

$5.06711 \mathrm{e}+005.06711 \mathrm{e}+00$ 5.06711e-01 1.00000e-09 2.12000e-01

$5.06711 \mathrm{e}+00$ 5.06711e+00 5.06711e-01 1.00000e-09 2.12000e-01

$1.00000 \mathrm{e}-05$ 1.00000e-05 1.00000e-06 1.00000e-09 1.00000e-01

$1.00000 \mathrm{e}+001.00000 \mathrm{e}+001.00000 \mathrm{e}-01$ 1.00000e-09 1.00000e-01

Element: 13404 \# of layers: 7

$\mathrm{Kx} \mathrm{Ky} \mathrm{Kz}$ Ss Por

5.06711e+00 5.06711e+00 5.06711e-01 1.00000e-09 2.12000e-01

$5.06711 \mathrm{e}+005.06711 \mathrm{e}+005.06711 \mathrm{e}-01$ 1.00000e-09 2.12000e-01

$5.06711 \mathrm{e}+005.06711 \mathrm{e}+005.06711 \mathrm{e}-011.00000 \mathrm{e}-092.12000 \mathrm{e}-01$

$5.06711 \mathrm{e}+00$ 5.06711e+00 5.06711e-01 1.00000e-09 2.12000e-01

$5.06711 \mathrm{e}+005.06711 \mathrm{e}+005.06711 \mathrm{e}-01$ 1.00000e-09 2.12000e-01

$1.00000 \mathrm{e}-05$ 1.00000e-05 1.00000e-06 1.00000e-09 1.00000e-01

$1.00000 \mathrm{e}+001.00000 \mathrm{e}+001.00000 \mathrm{e}-011.00000 \mathrm{e}-091.00000 \mathrm{e}-01$

Element: 13405 \# of layers: 7

$\mathrm{Kx} \mathrm{Ky} \mathrm{Kz}$ Ss Por

5.06711e+00 5.06711e+00 5.06711e-01 1.00000e-09 2.12000e-01

$5.06711 \mathrm{e}+005.06711 \mathrm{e}+00$ 5.06711e-01 1.00000e-09 2.12000e-01

$5.06711 \mathrm{e}+005.06711 \mathrm{e}+00$ 5.06711e-01 1.00000e-09 2.12000e-01

5.06711e+00 5.06711e+00 5.06711e-01 1.00000e-09 2.12000e-01

$5.06711 \mathrm{e}+005.06711 \mathrm{e}+00$ 5.06711e-01 1.00000e-09 2.12000e-01

$1.00000 \mathrm{e}-05$ 1.00000e-05 1.00000e-06 1.00000e-09 1.00000e-01

$1.00000 \mathrm{e}+001.00000 \mathrm{e}+001.00000 \mathrm{e}-011.00000 \mathrm{e}-091.00000 \mathrm{e}-01$ 
Element: 13406 \# of layers: 7

$\mathrm{Kx} \mathrm{Ky} \mathrm{Kz}$ Ss Por

5.06711e+00 5.06711e+00 5.06711e-01 1.00000e-09 2.12000e-01

$5.06711 \mathrm{e}+005.06711 \mathrm{e}+005.06711 \mathrm{e}-011.00000 \mathrm{e}-092.12000 \mathrm{e}-01$

$5.06711 \mathrm{e}+005.06711 \mathrm{e}+00$ 5.06711e-01 1.00000e-09 2.12000e-01

$5.06711 \mathrm{e}+005.06711 \mathrm{e}+005.06711 \mathrm{e}-011.00000 \mathrm{e}-092.12000 \mathrm{e}-01$

$5.06711 \mathrm{e}+00$ 5.06711e+00 5.06711e-01 1.00000e-09 2.12000e-01

$1.00000 \mathrm{e}-05$ 1.00000e-05 1.00000e-06 1.00000e-09 1.00000e-01

$1.00000 \mathrm{e}+001.00000 \mathrm{e}+001.00000 \mathrm{e}-011.00000 \mathrm{e}-09$ 1.00000e-01

Element: 13407 \# of layers: 7

Kx Ky Kz Ss Por

4.81263e+00 4.81263e+00 4.81263e-01 1.00000e-09 2.12000e-01

$4.81263 \mathrm{e}+004.81263 \mathrm{e}+00$ 4.81263e-01 1.00000e-09 2.12000e-01

4.81263e+00 4.81263e+00 4.81263e-01 1.00000e-09 2.12000e-01

$4.81263 \mathrm{e}+00$ 4.81263e+00 4.81263e-01 1.00000e-09 2.12000e-01

$4.81263 \mathrm{e}+004.81263 \mathrm{e}+004.81263 \mathrm{e}-01$ 1.00000e-09 2.12000e-01

$1.00000 \mathrm{e}-05$ 1.00000e-05 1.00000e-06 1.00000e-09 1.00000e-01

$1.00000 \mathrm{e}+001.00000 \mathrm{e}+001.00000 \mathrm{e}-01$ 1.00000e-09 1.00000e-01

Element: 13408 \# of layers: 7

$\mathrm{Kx} \mathrm{Ky} \mathrm{Kz}$ Ss Por

4.81263e+00 4.81263e+00 4.81263e-01 1.00000e-09 2.12000e-01

4.81263e+00 4.81263e+00 4.81263e-01 1.00000e-09 2.12000e-01

4.81263e+00 4.81263e+00 4.81263e-01 1.00000e-09 2.12000e-01

$4.81263 \mathrm{e}+004.81263 \mathrm{e}+00$ 4.81263e-01 1.00000e-09 2.12000e-01

$4.81263 \mathrm{e}+004.81263 \mathrm{e}+00$ 4.81263e-01 1.00000e-09 2.12000e-01

$1.00000 \mathrm{e}-051.00000 \mathrm{e}-051.00000 \mathrm{e}-061.00000 \mathrm{e}-091.00000 \mathrm{e}-01$

$1.00000 \mathrm{e}+001.00000 \mathrm{e}+001.00000 \mathrm{e}-011.00000 \mathrm{e}-091.00000 \mathrm{e}-01$

Element: 13409 \# of layers: 7

Kx Ky Kz Ss Por

4.81263e+00 4.81263e+00 4.81263e-01 1.00000e-09 2.12000e-01

$4.81263 \mathrm{e}+004.81263 \mathrm{e}+00$ 4.81263e-01 1.00000e-09 2.12000e-01

$4.81263 \mathrm{e}+00$ 4.81263e+00 4.81263e-01 1.00000e-09 2.12000e-01

$4.81263 \mathrm{e}+004.81263 \mathrm{e}+00$ 4.81263e-01 1.00000e-09 2.12000e-01

4.81263e+00 4.81263e+00 4.81263e-01 1.00000e-09 2.12000e-01

$1.00000 \mathrm{e}-05$ 1.00000e-05 1.00000e-06 1.00000e-09 1.00000e-01

$1.00000 \mathrm{e}+001.00000 \mathrm{e}+001.00000 \mathrm{e}-011.00000 \mathrm{e}-091.00000 \mathrm{e}-01$

Element: 13410 \# of layers: 7

$\mathrm{Kx} \mathrm{Ky} \mathrm{Kz}$ Ss Por

$5.06711 \mathrm{e}+005.06711 \mathrm{e}+00$ 5.06711e-01 1.00000e-09 2.12000e-01

$5.06711 \mathrm{e}+005.06711 \mathrm{e}+005.06711 \mathrm{e}-011.00000 \mathrm{e}-092.12000 \mathrm{e}-01$

$5.06711 \mathrm{e}+005.06711 \mathrm{e}+00$ 5.06711e-01 1.00000e-09 2.12000e-01

$5.06711 \mathrm{e}+005.06711 \mathrm{e}+00$ 5.06711e-01 1.00000e-09 2.12000e-01

$5.06711 \mathrm{e}+005.06711 \mathrm{e}+00$ 5.06711e-01 1.00000e-09 2.12000e-01

$1.00000 \mathrm{e}-051.00000 \mathrm{e}-05$ 1.00000e-06 1.00000e-09 1.00000e-01

$1.00000 \mathrm{e}+001.00000 \mathrm{e}+001.00000 \mathrm{e}-011.00000 \mathrm{e}-091.00000 \mathrm{e}-01$

Element: 13411 \# of layers: 7 
$\mathrm{Kx} \mathrm{Ky} \mathrm{Kz} \mathrm{Ss} \mathrm{Por}$

5.06711e+00 5.06711e+00 5.06711e-01 1.00000e-09 2.12000e-01

$5.06711 \mathrm{e}+005.06711 \mathrm{e}+00$ 5.06711e-01 1.00000e-09 2.12000e-01

$5.06711 \mathrm{e}+005.06711 \mathrm{e}+005.06711 \mathrm{e}-011.00000 \mathrm{e}-092.12000 \mathrm{e}-01$

$5.06711 \mathrm{e}+005.06711 \mathrm{e}+00$ 5.06711e-01 1.00000e-09 2.12000e-01

$5.06711 \mathrm{e}+00$ 5.06711e+00 5.06711e-01 1.00000e-09 2.12000e-01

$1.00000 \mathrm{e}-05$ 1.00000e-05 1.00000e-06 1.00000e-09 1.00000e-01

$1.00000 \mathrm{e}+001.00000 \mathrm{e}+001.00000 \mathrm{e}-011.00000 \mathrm{e}-091.00000 \mathrm{e}-01$

Element: 13412 \# of layers: 7

$\mathrm{Kx} \mathrm{Ky} \mathrm{Kz}$ Ss Por

5.06711e+00 5.06711e+00 5.06711e-01 1.00000e-09 2.12000e-01

$5.06711 \mathrm{e}+005.06711 \mathrm{e}+005.06711 \mathrm{e}-011.00000 \mathrm{e}-092.12000 \mathrm{e}-01$

$5.06711 \mathrm{e}+005.06711 \mathrm{e}+005.06711 \mathrm{e}-011.00000 \mathrm{e}-092.12000 \mathrm{e}-01$

$5.06711 \mathrm{e}+00$ 5.06711e+00 5.06711e-01 1.00000e-09 2.12000e-01

$5.06711 \mathrm{e}+005.06711 \mathrm{e}+00$ 5.06711e-01 1.00000e-09 2.12000e-01

1.00000e-05 1.00000e-05 1.00000e-06 1.00000e-09 1.00000e-01

$1.00000 \mathrm{e}+001.00000 \mathrm{e}+001.00000 \mathrm{e}-01$ 1.00000e-09 1.00000e-01

Element: 13413 \# of layers: 7

$\mathrm{Kx} \mathrm{Ky} \mathrm{Kz}$ Ss Por

5.06711e+00 5.06711e+00 5.06711e-01 1.00000e-09 2.12000e-01

$5.06711 \mathrm{e}+005.06711 \mathrm{e}+005.06711 \mathrm{e}-01$ 1.00000e-09 2.12000e-01

$5.06711 \mathrm{e}+005.06711 \mathrm{e}+00$ 5.06711e-01 1.00000e-09 2.12000e-01

$5.06711 \mathrm{e}+005.06711 \mathrm{e}+00$ 5.06711e-01 1.00000e-09 2.12000e-01

$5.06711 \mathrm{e}+00$ 5.06711e+00 5.06711e-01 1.00000e-09 2.12000e-01

$1.00000 \mathrm{e}-05$ 1.00000e-05 1.00000e-06 1.00000e-09 1.00000e-01

$1.00000 \mathrm{e}+001.00000 \mathrm{e}+001.00000 \mathrm{e}-011.00000 \mathrm{e}-091.00000 \mathrm{e}-01$

Element: 13414 \# of layers: 7

$\mathrm{Kx} \mathrm{Ky} \mathrm{Kz}$ Ss Por

4.81263e+00 4.81263e+00 4.81263e-01 1.00000e-09 2.12000e-01

$4.81263 \mathrm{e}+004.81263 \mathrm{e}+00$ 4.81263e-01 1.00000e-09 2.12000e-01

$4.81263 \mathrm{e}+004.81263 \mathrm{e}+00$ 4.81263e-01 1.00000e-09 2.12000e-01

$4.81263 \mathrm{e}+004.81263 \mathrm{e}+00$ 4.81263e-01 1.00000e-09 2.12000e-01

$4.81263 \mathrm{e}+004.81263 \mathrm{e}+00$ 4.81263e-01 1.00000e-09 2.12000e-01

$1.00000 \mathrm{e}-05$ 1.00000e-05 1.00000e-06 1.00000e-09 1.00000e-01

$1.00000 \mathrm{e}+001.00000 \mathrm{e}+001.00000 \mathrm{e}-01$ 1.00000e-09 1.00000e-01

Element: 13415 \# of layers: 7

Kx Ky Kz Ss Por

4.81263e+00 4.81263e+00 4.81263e-01 1.00000e-09 2.12000e-01 4.81263e+00 4.81263e+00 4.81263e-01 1.00000e-09 2.12000e-01 $4.81263 \mathrm{e}+00$ 4.81263e+00 4.81263e-01 1.00000e-09 2.12000e-01 $4.81263 \mathrm{e}+004.81263 \mathrm{e}+00$ 4.81263e-01 1.00000e-09 2.12000e-01 $4.81263 \mathrm{e}+004.81263 \mathrm{e}+00$ 4.81263e-01 1.00000e-09 2.12000e-01 $1.00000 \mathrm{e}-05$ 1.00000e-05 1.00000e-06 1.00000e-09 1.00000e-01 $1.00000 \mathrm{e}+001.00000 \mathrm{e}+001.00000 \mathrm{e}-01$ 1.00000e-09 1.00000e-01 Element: 13416 \# of layers: 7

Kx Ky Kz Ss Por 
4.81263e+00 4.81263e+00 4.81263e-01 1.00000e-09 2.12000e-01 4.81263e+00 4.81263e+00 4.81263e-01 1.00000e-09 2.12000e-01 $4.81263 \mathrm{e}+00$ 4.81263e+00 4.81263e-01 1.00000e-09 2.12000e-01 $4.81263 \mathrm{e}+00$ 4.81263e+00 4.81263e-01 1.00000e-09 2.12000e-01 $4.81263 \mathrm{e}+004.81263 \mathrm{e}+00$ 4.81263e-01 1.00000e-09 2.12000e-01 $1.00000 \mathrm{e}-05$ 1.00000e-05 1.00000e-06 1.00000e-09 1.00000e-01 $1.00000 \mathrm{e}+001.00000 \mathrm{e}+00$ 1.00000e-01 1.00000e-09 1.00000e-01 Element: 13417 \# of layers: 7

$\mathrm{Kx} \mathrm{Ky} \mathrm{Kz}$ Ss Por

4.81263e+00 4.81263e+00 4.81263e-01 1.00000e-09 2.12000e-01 $4.81263 \mathrm{e}+004.81263 \mathrm{e}+00$ 4.81263e-01 1.00000e-09 2.12000e-01 $4.81263 \mathrm{e}+00$ 4.81263e+00 4.81263e-01 1.00000e-09 2.12000e-01 4.81263e+00 4.81263e+00 4.81263e-01 1.00000e-09 2.12000e-01 $4.81263 \mathrm{e}+00$ 4.81263e+00 4.81263e-01 1.00000e-09 2.12000e-01 $1.00000 \mathrm{e}-05$ 1.00000e-05 1.00000e-06 1.00000e-09 1.00000e-01 $1.00000 \mathrm{e}+001.00000 \mathrm{e}+001.00000 \mathrm{e}-011.00000 \mathrm{e}-091.00000 \mathrm{e}-01$ Element: 13418 \# of layers: 7

$\mathrm{Kx} \mathrm{Ky} \mathrm{Kz}$ Ss Por

4.81263e+00 4.81263e+00 4.81263e-01 1.00000e-09 2.12000e-01 $4.81263 \mathrm{e}+004.81263 \mathrm{e}+00$ 4.81263e-01 1.00000e-09 2.12000e-01 $4.81263 \mathrm{e}+004.81263 \mathrm{e}+00$ 4.81263e-01 1.00000e-09 2.12000e-01 4.81263e+00 4.81263e+00 4.81263e-01 1.00000e-09 2.12000e-01 4.81263e+00 4.81263e+00 4.81263e-01 1.00000e-09 2.12000e-01 $1.00000 \mathrm{e}-05$ 1.00000e-05 1.00000e-06 1.00000e-09 1.00000e-01 $1.00000 \mathrm{e}+001.00000 \mathrm{e}+001.00000 \mathrm{e}-011.00000 \mathrm{e}-091.00000 \mathrm{e}-01$ Element: 13419 \# of layers: 7

$\mathrm{Kx} \mathrm{Ky} \mathrm{Kz}$ Ss Por

4.81263e+00 4.81263e+00 4.81263e-01 1.00000e-09 2.12000e-01 $4.81263 \mathrm{e}+004.81263 \mathrm{e}+004.81263 \mathrm{e}-01$ 1.00000e-09 2.12000e-01 $4.81263 \mathrm{e}+00$ 4.81263e+00 4.81263e-01 1.00000e-09 2.12000e-01 $4.81263 \mathrm{e}+004.81263 \mathrm{e}+00$ 4.81263e-01 1.00000e-09 2.12000e-01 4.81263e+00 4.81263e+00 4.81263e-01 1.00000e-09 2.12000e-01 $1.00000 \mathrm{e}-05$ 1.00000e-05 1.00000e-06 1.00000e-09 1.00000e-01 $1.00000 \mathrm{e}+001.00000 \mathrm{e}+001.00000 \mathrm{e}-011.00000 \mathrm{e}-091.00000 \mathrm{e}-01$ Element: 13420 \# of layers: 7

$\mathrm{Kx} \mathrm{Ky} \mathrm{Kz}$ Ss Por

4.81263e+00 4.81263e+00 4.81263e-01 1.00000e-09 2.12000e-01 $4.81263 \mathrm{e}+004.81263 \mathrm{e}+00$ 4.81263e-01 1.00000e-09 2.12000e-01 $4.81263 \mathrm{e}+00$ 4.81263e+00 4.81263e-01 1.00000e-09 2.12000e-01 $4.81263 \mathrm{e}+00$ 4.81263e+00 4.81263e-01 1.00000e-09 2.12000e-01 $4.81263 \mathrm{e}+004.81263 \mathrm{e}+00$ 4.81263e-01 1.00000e-09 2.12000e-01 $1.00000 \mathrm{e}-05$ 1.00000e-05 1.00000e-06 1.00000e-09 1.00000e-01 $1.00000 \mathrm{e}+001.00000 \mathrm{e}+001.00000 \mathrm{e}-011.00000 \mathrm{e}-091.00000 \mathrm{e}-01$ Element: 13421 \# of layers: 7

$\mathrm{Kx} \mathrm{Ky} \mathrm{Kz}$ Ss Por 4.81263e+00 4.81263e+00 4.81263e-01 1.00000e-09 2.12000e-01 
4.81263e+00 4.81263e+00 4.81263e-01 1.00000e-09 2.12000e-01 4.81263e+00 4.81263e+00 4.81263e-01 1.00000e-09 2.12000e-01 $4.81263 \mathrm{e}+00$ 4.81263e+00 4.81263e-01 1.00000e-09 2.12000e-01 $4.81263 \mathrm{e}+00$ 4.81263e+00 4.81263e-01 1.00000e-09 2.12000e-01 $1.00000 \mathrm{e}-05$ 1.00000e-05 1.00000e-06 1.00000e-09 1.00000e-01 $1.00000 \mathrm{e}+001.00000 \mathrm{e}+001.00000 \mathrm{e}-011.00000 \mathrm{e}-091.00000 \mathrm{e}-01$ Element: 13422 \# of layers: 7

$\mathrm{Kx} \mathrm{Ky} \mathrm{Kz}$ Ss Por

4.81263e+00 4.81263e+00 4.81263e-01 1.00000e-09 2.12000e-01 $4.81263 \mathrm{e}+004.81263 \mathrm{e}+00$ 4.81263e-01 1.00000e-09 2.12000e-01 4.81263e+00 4.81263e+00 4.81263e-01 1.00000e-09 2.12000e-01 $4.81263 \mathrm{e}+00$ 4.81263e+00 4.81263e-01 1.00000e-09 2.12000e-01 $4.81263 \mathrm{e}+004.81263 \mathrm{e}+004.81263 \mathrm{e}-01$ 1.00000e-09 2.12000e-01 $1.00000 \mathrm{e}-05$ 1.00000e-05 1.00000e-06 1.00000e-09 1.00000e-01 $1.00000 \mathrm{e}+001.00000 \mathrm{e}+001.00000 \mathrm{e}-01$ 1.00000e-09 1.00000e-01 Element: 13423 \# of layers: 7

$\mathrm{Kx} \mathrm{Ky} \mathrm{Kz}$ Ss Por

4.81263e+00 4.81263e+00 4.81263e-01 1.00000e-09 2.12000e-01 4.81263e+00 4.81263e+00 4.81263e-01 1.00000e-09 2.12000e-01 $4.81263 \mathrm{e}+00$ 4.81263e+00 4.81263e-01 1.00000e-09 2.12000e-01 $4.81263 \mathrm{e}+004.81263 \mathrm{e}+00$ 4.81263e-01 1.00000e-09 2.12000e-01 4.81263e+00 4.81263e+00 4.81263e-01 1.00000e-09 2.12000e-01 $1.00000 \mathrm{e}-051.00000 \mathrm{e}-051.00000 \mathrm{e}-061.00000 \mathrm{e}-091.00000 \mathrm{e}-01$ $1.00000 \mathrm{e}+001.00000 \mathrm{e}+001.00000 \mathrm{e}-011.00000 \mathrm{e}-09$ 1.00000e-01 Element: 13424 \# of layers: 7

$\mathrm{Kx} \mathrm{Ky} \mathrm{Kz}$ Ss Por

4.42742e+00 4.42742e+00 4.42742e-01 1.00000e-09 2.12000e-01 4.42742e+00 4.42742e+00 4.42742e-01 1.00000e-09 2.12000e-01 $4.42742 \mathrm{e}+004.42742 \mathrm{e}+00$ 4.42742e-01 1.00000e-09 2.12000e-01 4.42742e+00 4.42742e+00 4.42742e-01 1.00000e-09 2.12000e-01 4.42742e+00 4.42742e+00 4.42742e-01 1.00000e-09 2.12000e-01 $1.00000 \mathrm{e}-05$ 1.00000e-05 1.00000e-06 1.00000e-09 1.00000e-01 $1.00000 \mathrm{e}+001.00000 \mathrm{e}+001.00000 \mathrm{e}-011.00000 \mathrm{e}-091.00000 \mathrm{e}-01$ Element: 13425 \# of layers: 7

$\mathrm{Kx} \mathrm{Ky} \mathrm{Kz}$ Ss Por

4.42742e+00 4.42742e+00 4.42742e-01 1.00000e-09 2.12000e-01 $4.42742 \mathrm{e}+004.42742 \mathrm{e}+00$ 4.42742e-01 1.00000e-09 2.12000e-01 4.42742e+00 4.42742e+00 4.42742e-01 1.00000e-09 2.12000e-01 4.42742e+00 4.42742e+00 4.42742e-01 1.00000e-09 2.12000e-01 4.42742e+00 4.42742e+00 4.42742e-01 1.00000e-09 2.12000e-01 $1.00000 \mathrm{e}-05$ 1.00000e-05 1.00000e-06 1.00000e-09 1.00000e-01 $1.00000 \mathrm{e}+001.00000 \mathrm{e}+001.00000 \mathrm{e}-011.00000 \mathrm{e}-091.00000 \mathrm{e}-01$ Element: 13426 \# of layers: 7

$\mathrm{Kx} \mathrm{Ky} \mathrm{Kz}$ Ss Por 4.42742e+00 4.42742e+00 4.42742e-01 1.00000e-09 2.12000e-01 $4.42742 \mathrm{e}+004.42742 \mathrm{e}+00$ 4.42742e-01 1.00000e-09 2.12000e-01 
4.42742e+00 4.42742e+00 4.42742e-01 1.00000e-09 2.12000e-01 4.42742e+00 4.42742e+00 4.42742e-01 1.00000e-09 2.12000e-01 4.42742e+00 4.42742e+00 4.42742e-01 1.00000e-09 2.12000e-01 $1.00000 \mathrm{e}-05$ 1.00000e-05 1.00000e-06 1.00000e-09 1.00000e-01 $1.00000 \mathrm{e}+001.00000 \mathrm{e}+001.00000 \mathrm{e}-01$ 1.00000e-09 1.00000e-01 Element: 13427 \# of layers: 7

$\mathrm{Kx} \mathrm{Ky} \mathrm{Kz}$ Ss Por

4.42742e+00 4.42742e+00 4.42742e-01 1.00000e-09 2.12000e-01 4.42742e+00 4.42742e+00 4.42742e-01 1.00000e-09 2.12000e-01 4.42742e+00 4.42742e+00 4.42742e-01 1.00000e-09 2.12000e-01 4.42742e+00 4.42742e+00 4.42742e-01 1.00000e-09 2.12000e-01 $4.42742 \mathrm{e}+00$ 4.42742e+00 4.42742e-01 1.00000e-09 2.12000e-01 $1.00000 \mathrm{e}-05$ 1.00000e-05 1.00000e-06 1.00000e-09 1.00000e-01 $1.00000 \mathrm{e}+001.00000 \mathrm{e}+001.00000 \mathrm{e}-011.00000 \mathrm{e}-091.00000 \mathrm{e}-01$ Element: 13428 \# of layers: 7

Kx Ky Kz Ss Por

4.42742e+00 4.42742e+00 4.42742e-01 1.00000e-09 2.12000e-01 4.42742e+00 4.42742e+00 4.42742e-01 1.00000e-09 2.12000e-01 4.42742e+00 4.42742e+00 4.42742e-01 1.00000e-09 2.12000e-01 $4.42742 \mathrm{e}+004.42742 \mathrm{e}+00$ 4.42742e-01 1.00000e-09 2.12000e-01 $4.42742 \mathrm{e}+004.42742 \mathrm{e}+00$ 4.42742e-01 1.00000e-09 2.12000e-01 $1.00000 \mathrm{e}-051.00000 \mathrm{e}-051.00000 \mathrm{e}-061.00000 \mathrm{e}-091.00000 \mathrm{e}-01$ $1.00000 \mathrm{e}+001.00000 \mathrm{e}+001.00000 \mathrm{e}-01$ 1.00000e-09 1.00000e-01 Element: 13429 \# of layers: 7

$\mathrm{Kx} \mathrm{Ky} \mathrm{Kz}$ Ss Por

4.81263e+00 4.81263e+00 4.81263e-01 1.00000e-09 2.12000e-01 $4.81263 \mathrm{e}+004.81263 \mathrm{e}+00$ 4.81263e-01 1.00000e-09 2.12000e-01 $4.81263 \mathrm{e}+004.81263 \mathrm{e}+00$ 4.81263e-01 1.00000e-09 2.12000e-01 $4.81263 \mathrm{e}+004.81263 \mathrm{e}+00$ 4.81263e-01 1.00000e-09 2.12000e-01 4.81263e+00 4.81263e+00 4.81263e-01 1.00000e-09 2.12000e-01 $1.00000 \mathrm{e}-05$ 1.00000e-05 1.00000e-06 1.00000e-09 1.00000e-01 $1.00000 \mathrm{e}+001.00000 \mathrm{e}+001.00000 \mathrm{e}-01$ 1.00000e-09 1.00000e-01 Element: 13430 \# of layers: 7

$\mathrm{Kx} \mathrm{Ky} \mathrm{Kz}$ Ss Por

4.81263e+00 4.81263e+00 4.81263e-01 1.00000e-09 2.12000e-01 4.81263e+00 4.81263e+00 4.81263e-01 1.00000e-09 2.12000e-01 $4.81263 \mathrm{e}+004.81263 \mathrm{e}+00$ 4.81263e-01 1.00000e-09 2.12000e-01 $4.81263 \mathrm{e}+004.81263 \mathrm{e}+00$ 4.81263e-01 1.00000e-09 2.12000e-01 $4.81263 \mathrm{e}+00$ 4.81263e+00 4.81263e-01 1.00000e-09 2.12000e-01 $1.00000 \mathrm{e}-05$ 1.00000e-05 1.00000e-06 1.00000e-09 1.00000e-01 $1.00000 \mathrm{e}+001.00000 \mathrm{e}+001.00000 \mathrm{e}-011.00000 \mathrm{e}-091.00000 \mathrm{e}-01$ Element: 13431 \# of layers: 7

$\mathrm{Kx} \mathrm{Ky} \mathrm{Kz}$ Ss Por

4.42742e+00 4.42742e+00 4.42742e-01 1.00000e-09 2.12000e-01 $4.42742 \mathrm{e}+00$ 4.42742e+00 4.42742e-01 1.00000e-09 2.12000e-01 4.42742e+00 4.42742e+00 4.42742e-01 1.00000e-09 2.12000e-01 
$4.42742 \mathrm{e}+004.42742 \mathrm{e}+00$ 4.42742e-01 1.00000e-09 2.12000e-01 $4.42742 \mathrm{e}+004.42742 \mathrm{e}+00$ 4.42742e-01 1.00000e-09 2.12000e-01 $1.00000 \mathrm{e}-05$ 1.00000e-05 1.00000e-06 1.00000e-09 1.00000e-01 $1.00000 \mathrm{e}+001.00000 \mathrm{e}+001.00000 \mathrm{e}-011.00000 \mathrm{e}-091.00000 \mathrm{e}-01$ Element: 13432 \# of layers: 7

Kx Ky Kz Ss Por

4.42742e+00 4.42742e+00 4.42742e-01 1.00000e-09 2.12000e-01 $4.42742 \mathrm{e}+004.42742 \mathrm{e}+004.42742 \mathrm{e}-011.00000 \mathrm{e}-092.12000 \mathrm{e}-01$ $4.42742 \mathrm{e}+004.42742 \mathrm{e}+004.42742 \mathrm{e}-011.00000 \mathrm{e}-092.12000 \mathrm{e}-01$ $4.42742 \mathrm{e}+004.42742 \mathrm{e}+004.42742 \mathrm{e}-011.00000 \mathrm{e}-092.12000 \mathrm{e}-01$ $4.42742 \mathrm{e}+004.42742 \mathrm{e}+004.42742 \mathrm{e}-01$ 1.00000e-09 2.12000e-01 $1.00000 \mathrm{e}-05$ 1.00000e-05 1.00000e-06 1.00000e-09 1.00000e-01 $1.00000 \mathrm{e}+001.00000 \mathrm{e}+001.00000 \mathrm{e}-011.00000 \mathrm{e}-091.00000 \mathrm{e}-01$ Element: 13433 \# of layers: 7

Kx Ky Kz Ss Por

$5.11841 \mathrm{e}+00$ 5.11841e+00 5.11841e-01 1.00000e-09 2.12000e-01 $5.11841 \mathrm{e}+005.11841 \mathrm{e}+00$ 5.11841e-01 1.00000e-09 2.12000e-01 $5.11841 \mathrm{e}+005.11841 \mathrm{e}+005.11841 \mathrm{e}-011.00000 \mathrm{e}-092.12000 \mathrm{e}-01$ $5.11841 \mathrm{e}+005.11841 \mathrm{e}+005.11841 \mathrm{e}-011.00000 \mathrm{e}-092.12000 \mathrm{e}-01$ $5.11841 \mathrm{e}+005.11841 \mathrm{e}+005.11841 \mathrm{e}-011.00000 \mathrm{e}-092.12000 \mathrm{e}-01$ $1.00000 \mathrm{e}-05$ 1.00000e-05 1.00000e-06 1.00000e-09 1.00000e-01 $1.00000 \mathrm{e}+001.00000 \mathrm{e}+001.00000 \mathrm{e}-011.00000 \mathrm{e}-091.00000 \mathrm{e}-01$ Element: 13434 \# of layers: 7

Kx Ky Kz Ss Por

5.11841e+00 5.11841e+00 5.11841e-01 1.00000e-09 2.12000e-01 $5.11841 \mathrm{e}+005.11841 \mathrm{e}+00$ 5.11841e-01 1.00000e-09 2.12000e-01 $5.11841 \mathrm{e}+005.11841 \mathrm{e}+00$ 5.11841e-01 1.00000e-09 2.12000e-01 $5.11841 \mathrm{e}+005.11841 \mathrm{e}+00$ 5.11841e-01 1.00000e-09 2.12000e-01 $5.11841 \mathrm{e}+00$ 5.11841e+00 5.11841e-01 1.00000e-09 2.12000e-01 $1.00000 \mathrm{e}-05$ 1.00000e-05 1.00000e-06 1.00000e-09 1.00000e-01 $1.00000 \mathrm{e}+001.00000 \mathrm{e}+001.00000 \mathrm{e}-011.00000 \mathrm{e}-091.00000 \mathrm{e}-01$ Element: 13435 \# of layers: 7

Kx Ky Kz Ss Por

$5.11841 \mathrm{e}+00$ 5.11841e+00 5.11841e-01 1.00000e-09 2.12000e-01 $5.11841 \mathrm{e}+005.11841 \mathrm{e}+00$ 5.11841e-01 1.00000e-09 2.12000e-01 $5.11841 \mathrm{e}+005.11841 \mathrm{e}+00$ 5.11841e-01 1.00000e-09 2.12000e-01 $5.11841 \mathrm{e}+005.11841 \mathrm{e}+00$ 5.11841e-01 1.00000e-09 2.12000e-01 $5.11841 \mathrm{e}+005.11841 \mathrm{e}+00$ 5.11841e-01 1.00000e-09 2.12000e-01 $1.00000 \mathrm{e}-05$ 1.00000e-05 1.00000e-06 1.00000e-09 1.00000e-01 $1.00000 \mathrm{e}+001.00000 \mathrm{e}+001.00000 \mathrm{e}-011.00000 \mathrm{e}-091.00000 \mathrm{e}-01$ Element: 13436 \# of layers: 7

Kx Ky Kz Ss Por

$5.06711 \mathrm{e}+00$ 5.06711e+00 5.06711e-01 1.00000e-09 2.12000e-01 $5.06711 \mathrm{e}+005.06711 \mathrm{e}+005.06711 \mathrm{e}-011.00000 \mathrm{e}-092.12000 \mathrm{e}-01$ $5.06711 \mathrm{e}+005.06711 \mathrm{e}+00$ 5.06711e-01 1.00000e-09 2.12000e-01 $5.06711 \mathrm{e}+005.06711 \mathrm{e}+00$ 5.06711e-01 1.00000e-09 2.12000e-01 
5.06711e+00 5.06711e+00 5.06711e-01 1.00000e-09 2.12000e-01 $1.00000 \mathrm{e}-05$ 1.00000e-05 1.00000e-06 1.00000e-09 1.00000e-01 $1.00000 \mathrm{e}+001.00000 \mathrm{e}+001.00000 \mathrm{e}-011.00000 \mathrm{e}-091.00000 \mathrm{e}-01$ Element: 13437 \# of layers: 7

$\mathrm{Kx} \mathrm{Ky} \mathrm{Kz}$ Ss Por

$5.06711 \mathrm{e}+005.06711 \mathrm{e}+00$ 5.06711e-01 1.00000e-09 2.12000e-01 $5.06711 \mathrm{e}+005.06711 \mathrm{e}+00$ 5.06711e-01 1.00000e-09 2.12000e-01 $5.06711 \mathrm{e}+005.06711 \mathrm{e}+00$ 5.06711e-01 1.00000e-09 2.12000e-01 $5.06711 \mathrm{e}+005.06711 \mathrm{e}+00$ 5.06711e-01 1.00000e-09 2.12000e-01 $5.06711 \mathrm{e}+005.06711 \mathrm{e}+005.06711 \mathrm{e}-01$ 1.00000e-09 2.12000e-01 $1.00000 \mathrm{e}-05$ 1.00000e-05 1.00000e-06 1.00000e-09 1.00000e-01 $1.00000 \mathrm{e}+001.00000 \mathrm{e}+001.00000 \mathrm{e}-011.00000 \mathrm{e}-091.00000 \mathrm{e}-01$ Element: 13438 \# of layers: 7

$\mathrm{Kx} \mathrm{Ky} \mathrm{Kz}$ Ss Por

4.81263e+00 4.81263e+00 4.81263e-01 1.00000e-09 2.12000e-01 $4.81263 \mathrm{e}+004.81263 \mathrm{e}+004.81263 \mathrm{e}-01$ 1.00000e-09 2.12000e-01 $4.81263 \mathrm{e}+004.81263 \mathrm{e}+00$ 4.81263e-01 1.00000e-09 2.12000e-01 $4.81263 \mathrm{e}+004.81263 \mathrm{e}+00$ 4.81263e-01 1.00000e-09 2.12000e-01 4.81263e+00 4.81263e+00 4.81263e-01 1.00000e-09 2.12000e-01 $1.00000 \mathrm{e}-05$ 1.00000e-05 1.00000e-06 1.00000e-09 1.00000e-01 $1.00000 \mathrm{e}+001.00000 \mathrm{e}+001.00000 \mathrm{e}-011.00000 \mathrm{e}-091.00000 \mathrm{e}-01$ Element: 13439 \# of layers: 7

$\mathrm{Kx} \mathrm{Ky} \mathrm{Kz}$ Ss Por

4.42742e+00 4.42742e+00 4.42742e-01 1.00000e-09 2.12000e-01 $4.42742 \mathrm{e}+004.42742 \mathrm{e}+00$ 4.42742e-01 1.00000e-09 2.12000e-01 $4.42742 \mathrm{e}+004.42742 \mathrm{e}+00$ 4.42742e-01 1.00000e-09 2.12000e-01 4.42742e+00 4.42742e+00 4.42742e-01 1.00000e-09 2.12000e-01 4.42742e+00 4.42742e+00 4.42742e-01 1.00000e-09 2.12000e-01 $1.00000 \mathrm{e}-05$ 1.00000e-05 1.00000e-06 1.00000e-09 1.00000e-01 $1.00000 \mathrm{e}+001.00000 \mathrm{e}+001.00000 \mathrm{e}-011.00000 \mathrm{e}-091.00000 \mathrm{e}-01$ Element: 13440 \# of layers: 7

$\mathrm{Kx} \mathrm{Ky} \mathrm{Kz}$ Ss Por

5.11841e+00 5.11841e+00 5.11841e-01 1.00000e-09 2.12000e-01 $5.11841 \mathrm{e}+00$ 5.11841e+00 5.11841e-01 1.00000e-09 2.12000e-01 5.11841e+00 5.11841e+00 5.11841e-01 1.00000e-09 2.12000e-01 5.11841e+00 5.11841e+00 5.11841e-01 1.00000e-09 2.12000e-01 $5.11841 \mathrm{e}+005.11841 \mathrm{e}+00$ 5.11841e-01 1.00000e-09 2.12000e-01 $1.00000 \mathrm{e}-05$ 1.00000e-05 1.00000e-06 1.00000e-09 1.00000e-01 $1.00000 \mathrm{e}+001.00000 \mathrm{e}+001.00000 \mathrm{e}-01$ 1.00000e-09 1.00000e-01 Element: 13441 \# of layers: 7

$\mathrm{Kx} \mathrm{Ky} \mathrm{Kz}$ Ss Por

5.58012e+00 5.58012e+00 5.58012e-01 1.00000e-09 2.12000e-01

$5.58012 \mathrm{e}+00$ 5.58012e+00 5.58012e-01 1.00000e-09 2.12000e-01

5.58012e+00 5.58012e+00 5.58012e-01 1.00000e-09 2.12000e-01

$5.58012 \mathrm{e}+005.58012 \mathrm{e}+005.58012 \mathrm{e}-01$ 1.00000e-09 2.12000e-01

$5.58012 \mathrm{e}+00$ 5.58012e+00 5.58012e-01 1.00000e-09 2.12000e-01 
$1.00000 \mathrm{e}-05$ 1.00000e-05 1.00000e-06 1.00000e-09 1.00000e-01 $1.00000 \mathrm{e}+001.00000 \mathrm{e}+001.00000 \mathrm{e}-011.00000 \mathrm{e}-091.00000 \mathrm{e}-01$ Element: 13442 \# of layers: 7

Kx Ky Kz Ss Por

$5.58012 \mathrm{e}+00$ 5.58012e+00 5.58012e-01 1.00000e-09 2.12000e-01

$5.58012 \mathrm{e}+005.58012 \mathrm{e}+005.58012 \mathrm{e}-011.00000 \mathrm{e}-092.12000 \mathrm{e}-01$

$5.58012 \mathrm{e}+005.58012 \mathrm{e}+00$ 5.58012e-01 1.00000e-09 2.12000e-01

$5.58012 \mathrm{e}+005.58012 \mathrm{e}+00$ 5.58012e-01 1.00000e-09 2.12000e-01

$5.58012 \mathrm{e}+005.58012 \mathrm{e}+00$ 5.58012e-01 1.00000e-09 2.12000e-01

$1.00000 \mathrm{e}-05$ 1.00000e-05 1.00000e-06 1.00000e-09 1.00000e-01

$1.00000 \mathrm{e}+001.00000 \mathrm{e}+001.00000 \mathrm{e}-011.00000 \mathrm{e}-091.00000 \mathrm{e}-01$

Element: 13443 \# of layers: 7

Kx Ky Kz Ss Por

$5.58012 \mathrm{e}+00$ 5.58012e+00 5.58012e-01 1.00000e-09 2.12000e-01

$5.58012 \mathrm{e}+005.58012 \mathrm{e}+005.58012 \mathrm{e}-011.00000 \mathrm{e}-092.12000 \mathrm{e}-01$

$5.58012 \mathrm{e}+005.58012 \mathrm{e}+00$ 5.58012e-01 1.00000e-09 2.12000e-01

$5.58012 \mathrm{e}+005.58012 \mathrm{e}+005.58012 \mathrm{e}-011.00000 \mathrm{e}-092.12000 \mathrm{e}-01$

$5.58012 \mathrm{e}+005.58012 \mathrm{e}+00$ 5.58012e-01 1.00000e-09 2.12000e-01

$1.00000 \mathrm{e}-05$ 1.00000e-05 1.00000e-06 1.00000e-09 1.00000e-01

$1.00000 \mathrm{e}+001.00000 \mathrm{e}+001.00000 \mathrm{e}-011.00000 \mathrm{e}-091.00000 \mathrm{e}-01$

Element: 13444 \# of layers: 7

Kx Ky Kz Ss Por

$5.58012 \mathrm{e}+00$ 5.58012e+00 5.58012e-01 1.00000e-09 2.12000e-01

$5.58012 \mathrm{e}+005.58012 \mathrm{e}+005.58012 \mathrm{e}-011.00000 \mathrm{e}-092.12000 \mathrm{e}-01$

$5.58012 \mathrm{e}+005.58012 \mathrm{e}+00$ 5.58012e-01 1.00000e-09 2.12000e-01

$5.58012 \mathrm{e}+005.58012 \mathrm{e}+005.58012 \mathrm{e}-011.00000 \mathrm{e}-092.12000 \mathrm{e}-01$

$5.58012 \mathrm{e}+005.58012 \mathrm{e}+00$ 5.58012e-01 1.00000e-09 2.12000e-01

$1.00000 \mathrm{e}-05$ 1.00000e-05 1.00000e-06 1.00000e-09 1.00000e-01

$1.00000 \mathrm{e}+001.00000 \mathrm{e}+001.00000 \mathrm{e}-011.00000 \mathrm{e}-091.00000 \mathrm{e}-01$

Element: 13445 \# of layers: 7

Kx Ky Kz Ss Por

$5.58012 \mathrm{e}+00$ 5.58012e+00 5.58012e-01 1.00000e-09 2.12000e-01

$5.58012 \mathrm{e}+005.58012 \mathrm{e}+00$ 5.58012e-01 1.00000e-09 2.12000e-01

$5.58012 \mathrm{e}+005.58012 \mathrm{e}+005.58012 \mathrm{e}-011.00000 \mathrm{e}-092.12000 \mathrm{e}-01$

$5.58012 \mathrm{e}+005.58012 \mathrm{e}+005.58012 \mathrm{e}-011.00000 \mathrm{e}-092.12000 \mathrm{e}-01$

$5.58012 \mathrm{e}+005.58012 \mathrm{e}+00$ 5.58012e-01 1.00000e-09 2.12000e-01 $1.00000 \mathrm{e}-05$ 1.00000e-05 1.00000e-06 1.00000e-09 1.00000e-01

$1.00000 \mathrm{e}+001.00000 \mathrm{e}+001.00000 \mathrm{e}-011.00000 \mathrm{e}-091.00000 \mathrm{e}-01$

Element: 13446 \# of layers: 7

Kx Ky Kz Ss Por

$5.58012 \mathrm{e}+00$ 5.58012e+00 5.58012e-01 1.00000e-09 2.12000e-01

$5.58012 \mathrm{e}+005.58012 \mathrm{e}+005.58012 \mathrm{e}-011.00000 \mathrm{e}-092.12000 \mathrm{e}-01$

$5.58012 \mathrm{e}+005.58012 \mathrm{e}+005.58012 \mathrm{e}-011.00000 \mathrm{e}-092.12000 \mathrm{e}-01$

$5.58012 \mathrm{e}+005.58012 \mathrm{e}+005.58012 \mathrm{e}-011.00000 \mathrm{e}-092.12000 \mathrm{e}-01$

$5.58012 \mathrm{e}+005.58012 \mathrm{e}+00$ 5.58012e-01 1.00000e-09 2.12000e-01

$1.00000 \mathrm{e}-05$ 1.00000e-05 1.00000e-06 1.00000e-09 1.00000e-01 
$1.00000 \mathrm{e}+001.00000 \mathrm{e}+001.00000 \mathrm{e}-011.00000 \mathrm{e}-091.00000 \mathrm{e}-01$ Element: 13447 \# of layers: 7

Kx Ky Kz Ss Por

5.58012e+00 5.58012e+00 5.58012e-01 1.00000e-09 2.12000e-01

5.58012e+00 5.58012e+00 5.58012e-01 1.00000e-09 2.12000e-01

$5.58012 \mathrm{e}+005.58012 \mathrm{e}+005.58012 \mathrm{e}-011.00000 \mathrm{e}-092.12000 \mathrm{e}-01$

5.58012e+00 5.58012e+00 5.58012e-01 1.00000e-09 2.12000e-01

$5.58012 \mathrm{e}+005.58012 \mathrm{e}+00$ 5.58012e-01 1.00000e-09 2.12000e-01

$1.00000 \mathrm{e}-05$ 1.00000e-05 1.00000e-06 1.00000e-09 1.00000e-01

$1.00000 \mathrm{e}+001.00000 \mathrm{e}+001.00000 \mathrm{e}-01$ 1.00000e-09 1.00000e-01

Element: 13448 \# of layers: 7

Kx Ky Kz Ss Por

5.58012e+00 5.58012e+00 5.58012e-01 1.00000e-09 2.12000e-01

$5.58012 \mathrm{e}+005.58012 \mathrm{e}+00$ 5.58012e-01 1.00000e-09 2.12000e-01

$5.58012 \mathrm{e}+005.58012 \mathrm{e}+00$ 5.58012e-01 1.00000e-09 2.12000e-01

$5.58012 \mathrm{e}+005.58012 \mathrm{e}+00$ 5.58012e-01 1.00000e-09 2.12000e-01

$5.58012 \mathrm{e}+00$ 5.58012e+00 5.58012e-01 1.00000e-09 2.12000e-01

$1.00000 \mathrm{e}-05$ 1.00000e-05 1.00000e-06 1.00000e-09 1.00000e-01

$1.00000 \mathrm{e}+001.00000 \mathrm{e}+001.00000 \mathrm{e}-01$ 1.00000e-09 1.00000e-01

Element: 13449 \# of layers: 7

$\mathrm{Kx} \mathrm{Ky} \mathrm{Kz}$ Ss Por

5.58012e+00 5.58012e+00 5.58012e-01 1.00000e-09 2.12000e-01

$5.58012 \mathrm{e}+005.58012 \mathrm{e}+00$ 5.58012e-01 1.00000e-09 2.12000e-01

$5.58012 \mathrm{e}+005.58012 \mathrm{e}+005.58012 \mathrm{e}-01$ 1.00000e-09 2.12000e-01

$5.58012 \mathrm{e}+00$ 5.58012e+00 5.58012e-01 1.00000e-09 2.12000e-01

$5.58012 \mathrm{e}+00$ 5.58012e+00 5.58012e-01 1.00000e-09 2.12000e-01

$1.00000 \mathrm{e}-05$ 1.00000e-05 1.00000e-06 1.00000e-09 1.00000e-01

$1.00000 \mathrm{e}+001.00000 \mathrm{e}+001.00000 \mathrm{e}-01$ 1.00000e-09 1.00000e-01

Element: 13450 \# of layers: 7

$\mathrm{Kx} \mathrm{Ky} \mathrm{Kz}$ Ss Por

5.58012e+00 5.58012e+00 5.58012e-01 1.00000e-09 2.12000e-01

$5.58012 \mathrm{e}+00$ 5.58012e+00 5.58012e-01 1.00000e-09 2.12000e-01

$5.58012 \mathrm{e}+005.58012 \mathrm{e}+005.58012 \mathrm{e}-01$ 1.00000e-09 2.12000e-01

5.58012e+00 5.58012e+00 5.58012e-01 1.00000e-09 2.12000e-01

$5.58012 \mathrm{e}+005.58012 \mathrm{e}+005.58012 \mathrm{e}-011.00000 \mathrm{e}-092.12000 \mathrm{e}-01$

$1.00000 \mathrm{e}-05$ 1.00000e-05 1.00000e-06 1.00000e-09 1.00000e-01

$1.00000 \mathrm{e}+001.00000 \mathrm{e}+001.00000 \mathrm{e}-011.00000 \mathrm{e}-091.00000 \mathrm{e}-01$

Element: 13451 \# of layers: 7

Kx Ky Kz Ss Por

5.72975e+00 5.72975e+00 5.72975e-01 1.00000e-09 2.12000e-01

$5.72975 \mathrm{e}+00$ 5.72975e+00 5.72975e-01 1.00000e-09 2.12000e-01

$5.72975 \mathrm{e}+00$ 5.72975e+00 5.72975e-01 1.00000e-09 2.12000e-01

$5.72975 \mathrm{e}+00$ 5.72975e+00 5.72975e-01 1.00000e-09 2.12000e-01

5.72975e+00 5.72975e+00 5.72975e-01 1.00000e-09 2.12000e-01

$1.00000 \mathrm{e}-05$ 1.00000e-05 1.00000e-06 1.00000e-09 1.00000e-01

$1.00000 \mathrm{e}+001.00000 \mathrm{e}+001.00000 \mathrm{e}-011.00000 \mathrm{e}-091.00000 \mathrm{e}-01$ 
Element: 13452 \# of layers: 7

Kx Ky Kz Ss Por

$5.72975 \mathrm{e}+00$ 5.72975e+00 5.72975e-01 1.00000e-09 2.12000e-01

$5.72975 \mathrm{e}+00$ 5.72975e+00 5.72975e-01 1.00000e-09 2.12000e-01

$5.72975 \mathrm{e}+005.72975 \mathrm{e}+00$ 5.72975e-01 1.00000e-09 2.12000e-01

$5.72975 \mathrm{e}+005.72975 \mathrm{e}+00$ 5.72975e-01 1.00000e-09 2.12000e-01

$5.72975 \mathrm{e}+00$ 5.72975e+00 5.72975e-01 1.00000e-09 2.12000e-01

$1.00000 \mathrm{e}-05$ 1.00000e-05 1.00000e-06 1.00000e-09 1.00000e-01

$1.00000 \mathrm{e}+001.00000 \mathrm{e}+001.00000 \mathrm{e}-011.00000 \mathrm{e}-091.00000 \mathrm{e}-01$

Element: 13453 \# of layers: 7

Kx Ky Kz Ss Por

$5.72975 \mathrm{e}+00$ 5.72975e+00 5.72975e-01 1.00000e-09 2.12000e-01

$5.72975 \mathrm{e}+005.72975 \mathrm{e}+00$ 5.72975e-01 1.00000e-09 2.12000e-01

$5.72975 \mathrm{e}+005.72975 \mathrm{e}+00$ 5.72975e-01 1.00000e-09 2.12000e-01

$5.72975 \mathrm{e}+005.72975 \mathrm{e}+00$ 5.72975e-01 1.00000e-09 2.12000e-01

$5.72975 \mathrm{e}+00$ 5.72975e+00 5.72975e-01 1.00000e-09 2.12000e-01

$1.00000 \mathrm{e}-05$ 1.00000e-05 1.00000e-06 1.00000e-09 1.00000e-01

$1.00000 \mathrm{e}+001.00000 \mathrm{e}+001.00000 \mathrm{e}-011.00000 \mathrm{e}-091.00000 \mathrm{e}-01$

Element: 13454 \# of layers: 7

Kx Ky Kz Ss Por

$5.72975 \mathrm{e}+00$ 5.72975e+00 5.72975e-01 1.00000e-09 2.12000e-01

$5.72975 \mathrm{e}+00$ 5.72975e+00 5.72975e-01 1.00000e-09 2.12000e-01

$5.72975 \mathrm{e}+005.72975 \mathrm{e}+00$ 5.72975e-01 1.00000e-09 2.12000e-01

$5.72975 \mathrm{e}+005.72975 \mathrm{e}+00$ 5.72975e-01 1.00000e-09 2.12000e-01

$5.72975 \mathrm{e}+00$ 5.72975e+00 5.72975e-01 1.00000e-09 2.12000e-01

$1.00000 \mathrm{e}-05$ 1.00000e-05 1.00000e-06 1.00000e-09 1.00000e-01

$1.00000 \mathrm{e}+001.00000 \mathrm{e}+001.00000 \mathrm{e}-011.00000 \mathrm{e}-091.00000 \mathrm{e}-01$

Element: 13455 \# of layers: 7

Kx Ky Kz Ss Por

$5.72975 \mathrm{e}+00$ 5.72975e+00 5.72975e-01 1.00000e-09 2.12000e-01

$5.72975 \mathrm{e}+00$ 5.72975e+00 5.72975e-01 1.00000e-09 2.12000e-01

$5.72975 \mathrm{e}+00$ 5.72975e+00 5.72975e-01 1.00000e-09 2.12000e-01

$5.72975 \mathrm{e}+00$ 5.72975e+00 5.72975e-01 1.00000e-09 2.12000e-01

$5.72975 \mathrm{e}+005.72975 \mathrm{e}+00$ 5.72975e-01 1.00000e-09 2.12000e-01

$1.00000 \mathrm{e}-05$ 1.00000e-05 1.00000e-06 1.00000e-09 1.00000e-01

$1.00000 \mathrm{e}+001.00000 \mathrm{e}+001.00000 \mathrm{e}-011.00000 \mathrm{e}-091.00000 \mathrm{e}-01$

Element: 13456 \# of layers: 7

Kx Ky Kz Ss Por

$5.58012 \mathrm{e}+00$ 5.58012e+00 5.58012e-01 1.00000e-09 2.12000e-01

$5.58012 \mathrm{e}+005.58012 \mathrm{e}+005.58012 \mathrm{e}-011.00000 \mathrm{e}-092.12000 \mathrm{e}-01$

$5.58012 \mathrm{e}+005.58012 \mathrm{e}+00$ 5.58012e-01 1.00000e-09 2.12000e-01

$5.58012 \mathrm{e}+005.58012 \mathrm{e}+005.58012 \mathrm{e}-011.00000 \mathrm{e}-092.12000 \mathrm{e}-01$

$5.58012 \mathrm{e}+005.58012 \mathrm{e}+00$ 5.58012e-01 1.00000e-09 2.12000e-01

$1.00000 \mathrm{e}-05$ 1.00000e-05 1.00000e-06 1.00000e-09 1.00000e-01

$1.00000 \mathrm{e}+001.00000 \mathrm{e}+001.00000 \mathrm{e}-011.00000 \mathrm{e}-091.00000 \mathrm{e}-01$

Element: 13457 \# of layers: 7 
$\mathrm{Kx} \mathrm{Ky} \mathrm{Kz} \mathrm{Ss} \mathrm{Por}$

5.58012e+00 5.58012e+00 5.58012e-01 1.00000e-09 2.12000e-01

$5.58012 \mathrm{e}+00$ 5.58012e+00 5.58012e-01 1.00000e-09 2.12000e-01

$5.58012 \mathrm{e}+00$ 5.58012e+00 5.58012e-01 1.00000e-09 2.12000e-01

5.58012e+00 5.58012e+00 5.58012e-01 1.00000e-09 2.12000e-01

$5.58012 \mathrm{e}+005.58012 \mathrm{e}+00$ 5.58012e-01 1.00000e-09 2.12000e-01

$1.00000 \mathrm{e}-05$ 1.00000e-05 1.00000e-06 1.00000e-09 1.00000e-01

$1.00000 \mathrm{e}+001.00000 \mathrm{e}+001.00000 \mathrm{e}-011.00000 \mathrm{e}-091.00000 \mathrm{e}-01$

Element: 13458 \# of layers: 7

$\mathrm{Kx} \mathrm{Ky} \mathrm{Kz}$ Ss Por

5.72975e+00 5.72975e+00 5.72975e-01 1.00000e-09 2.12000e-01

$5.72975 \mathrm{e}+005.72975 \mathrm{e}+00$ 5.72975e-01 1.00000e-09 2.12000e-01

$5.72975 \mathrm{e}+00$ 5.72975e+00 5.72975e-01 1.00000e-09 2.12000e-01

$5.72975 \mathrm{e}+00$ 5.72975e+00 5.72975e-01 1.00000e-09 2.12000e-01

5.72975e+00 5.72975e+00 5.72975e-01 1.00000e-09 2.12000e-01

$1.00000 \mathrm{e}-05$ 1.00000e-05 1.00000e-06 1.00000e-09 1.00000e-01

$1.00000 \mathrm{e}+001.00000 \mathrm{e}+001.00000 \mathrm{e}-01$ 1.00000e-09 1.00000e-01

Element: 13459 \# of layers: 7

$\mathrm{Kx} \mathrm{Ky} \mathrm{Kz}$ Ss Por

5.72975e+00 5.72975e+00 5.72975e-01 1.00000e-09 2.12000e-01

$5.72975 \mathrm{e}+005.72975 \mathrm{e}+00$ 5.72975e-01 1.00000e-09 2.12000e-01

5.72975e+00 5.72975e+00 5.72975e-01 1.00000e-09 2.12000e-01

$5.72975 \mathrm{e}+005.72975 \mathrm{e}+00$ 5.72975e-01 1.00000e-09 2.12000e-01

$5.72975 \mathrm{e}+00$ 5.72975e+00 5.72975e-01 1.00000e-09 2.12000e-01

$1.00000 \mathrm{e}-05$ 1.00000e-05 1.00000e-06 1.00000e-09 1.00000e-01

$1.00000 \mathrm{e}+001.00000 \mathrm{e}+001.00000 \mathrm{e}-01$ 1.00000e-09 1.00000e-01

Element: 13460 \# of layers: 7

$\mathrm{Kx} \mathrm{Ky} \mathrm{Kz}$ Ss Por

5.72975e+00 5.72975e+00 5.72975e-01 1.00000e-09 2.12000e-01

5.72975e+00 5.72975e+00 5.72975e-01 1.00000e-09 2.12000e-01

$5.72975 \mathrm{e}+005.72975 \mathrm{e}+00$ 5.72975e-01 1.00000e-09 2.12000e-01

5.72975e+00 5.72975e+00 5.72975e-01 1.00000e-09 2.12000e-01

$5.72975 \mathrm{e}+005.72975 \mathrm{e}+00$ 5.72975e-01 1.00000e-09 2.12000e-01

$1.00000 \mathrm{e}-05$ 1.00000e-05 1.00000e-06 1.00000e-09 1.00000e-01

$1.00000 \mathrm{e}+001.00000 \mathrm{e}+001.00000 \mathrm{e}-011.00000 \mathrm{e}-091.00000 \mathrm{e}-01$

Element: 13461 \# of layers: 7

Kx Ky Kz Ss Por

5.72975e+00 5.72975e+00 5.72975e-01 1.00000e-09 2.12000e-01

$5.72975 \mathrm{e}+005.72975 \mathrm{e}+00$ 5.72975e-01 1.00000e-09 2.12000e-01

$5.72975 \mathrm{e}+005.72975 \mathrm{e}+00$ 5.72975e-01 1.00000e-09 2.12000e-01

$5.72975 \mathrm{e}+005.72975 \mathrm{e}+00$ 5.72975e-01 1.00000e-09 2.12000e-01

5.72975e+00 5.72975e+00 5.72975e-01 1.00000e-09 2.12000e-01

$1.00000 \mathrm{e}-051.00000 \mathrm{e}-051.00000 \mathrm{e}-061.00000 \mathrm{e}-091.00000 \mathrm{e}-01$

$1.00000 \mathrm{e}+001.00000 \mathrm{e}+001.00000 \mathrm{e}-01$ 1.00000e-09 1.00000e-01

Element: 13462 \# of layers: 7

Kx Ky Kz Ss Por 
$5.72975 \mathrm{e}+00$ 5.72975e+00 5.72975e-01 1.00000e-09 2.12000e-01 $5.72975 \mathrm{e}+005.72975 \mathrm{e}+00$ 5.72975e-01 1.00000e-09 2.12000e-01 $5.72975 \mathrm{e}+005.72975 \mathrm{e}+00$ 5.72975e-01 1.00000e-09 2.12000e-01 $5.72975 \mathrm{e}+00$ 5.72975e+00 5.72975e-01 1.00000e-09 2.12000e-01 $5.72975 \mathrm{e}+00$ 5.72975e+00 5.72975e-01 1.00000e-09 2.12000e-01 $1.00000 \mathrm{e}-05$ 1.00000e-05 1.00000e-06 1.00000e-09 1.00000e-01 $1.00000 \mathrm{e}+001.00000 \mathrm{e}+001.00000 \mathrm{e}-011.00000 \mathrm{e}-091.00000 \mathrm{e}-01$ Element: 13463 \# of layers: 7

Kx Ky Kz Ss Por

$5.72975 \mathrm{e}+00$ 5.72975e+00 5.72975e-01 1.00000e-09 2.12000e-01 $5.72975 \mathrm{e}+00$ 5.72975e+00 5.72975e-01 1.00000e-09 2.12000e-01 $5.72975 \mathrm{e}+00$ 5.72975e+00 5.72975e-01 1.00000e-09 2.12000e-01 $5.72975 \mathrm{e}+005.72975 \mathrm{e}+00$ 5.72975e-01 1.00000e-09 2.12000e-01 $5.72975 \mathrm{e}+00$ 5.72975e+00 5.72975e-01 1.00000e-09 2.12000e-01 $1.00000 \mathrm{e}-05$ 1.00000e-05 1.00000e-06 1.00000e-09 1.00000e-01 $1.00000 \mathrm{e}+001.00000 \mathrm{e}+001.00000 \mathrm{e}-011.00000 \mathrm{e}-091.00000 \mathrm{e}-01$ Element: 13464 \# of layers: 7

Kx Ky Kz Ss Por

$5.72975 \mathrm{e}+00$ 5.72975e+00 5.72975e-01 1.00000e-09 2.12000e-01 $5.72975 \mathrm{e}+005.72975 \mathrm{e}+00$ 5.72975e-01 1.00000e-09 2.12000e-01 $5.72975 \mathrm{e}+00$ 5.72975e+00 5.72975e-01 1.00000e-09 2.12000e-01 $5.72975 \mathrm{e}+005.72975 \mathrm{e}+00$ 5.72975e-01 1.00000e-09 2.12000e-01 $5.72975 \mathrm{e}+00$ 5.72975e+00 5.72975e-01 1.00000e-09 2.12000e-01 $1.00000 \mathrm{e}-05$ 1.00000e-05 1.00000e-06 1.00000e-09 1.00000e-01 $1.00000 \mathrm{e}+001.00000 \mathrm{e}+001.00000 \mathrm{e}-011.00000 \mathrm{e}-091.00000 \mathrm{e}-01$ Element: 13465 \# of layers: 7

Kx Ky Kz Ss Por

5.72975e+00 5.72975e+00 5.72975e-01 1.00000e-09 2.12000e-01 $5.72975 \mathrm{e}+00$ 5.72975e+00 5.72975e-01 1.00000e-09 2.12000e-01 $5.72975 \mathrm{e}+005.72975 \mathrm{e}+00$ 5.72975e-01 1.00000e-09 2.12000e-01 $5.72975 \mathrm{e}+00$ 5.72975e+00 5.72975e-01 1.00000e-09 2.12000e-01 $5.72975 \mathrm{e}+005.72975 \mathrm{e}+00$ 5.72975e-01 1.00000e-09 2.12000e-01 $1.00000 \mathrm{e}-05$ 1.00000e-05 1.00000e-06 1.00000e-09 1.00000e-01 $1.00000 \mathrm{e}+001.00000 \mathrm{e}+001.00000 \mathrm{e}-011.00000 \mathrm{e}-091.00000 \mathrm{e}-01$ Element: 13466 \# of layers: 7

Kx Ky Kz Ss Por $5.72975 \mathrm{e}+00$ 5.72975e+00 5.72975e-01 1.00000e-09 2.12000e-01 $5.72975 \mathrm{e}+00$ 5.72975e+00 5.72975e-01 1.00000e-09 2.12000e-01 $5.72975 \mathrm{e}+005.72975 \mathrm{e}+00$ 5.72975e-01 1.00000e-09 2.12000e-01 $5.72975 \mathrm{e}+00$ 5.72975e+00 5.72975e-01 1.00000e-09 2.12000e-01 $5.72975 \mathrm{e}+00$ 5.72975e+00 5.72975e-01 1.00000e-09 2.12000e-01 $1.00000 \mathrm{e}-05$ 1.00000e-05 1.00000e-06 1.00000e-09 1.00000e-01 $1.00000 \mathrm{e}+001.00000 \mathrm{e}+001.00000 \mathrm{e}-011.00000 \mathrm{e}-091.00000 \mathrm{e}-01$ Element: 13467 \# of layers: 7

Kx Ky Kz Ss Por

5.72975e+00 5.72975e+00 5.72975e-01 1.00000e-09 2.12000e-01 
$5.72975 \mathrm{e}+00$ 5.72975e+00 5.72975e-01 1.00000e-09 2.12000e-01 $5.72975 \mathrm{e}+005.72975 \mathrm{e}+00$ 5.72975e-01 1.00000e-09 2.12000e-01 $5.72975 \mathrm{e}+005.72975 \mathrm{e}+00$ 5.72975e-01 1.00000e-09 2.12000e-01 $5.72975 \mathrm{e}+00$ 5.72975e+00 5.72975e-01 1.00000e-09 2.12000e-01 $1.00000 \mathrm{e}-05$ 1.00000e-05 1.00000e-06 1.00000e-09 1.00000e-01 $1.00000 \mathrm{e}+001.00000 \mathrm{e}+001.00000 \mathrm{e}-011.00000 \mathrm{e}-091.00000 \mathrm{e}-01$ Element: 13468 \# of layers: 7

Kx Ky Kz Ss Por

$5.72975 \mathrm{e}+00$ 5.72975e+00 5.72975e-01 1.00000e-09 2.12000e-01 $5.72975 \mathrm{e}+00$ 5.72975e+00 5.72975e-01 1.00000e-09 2.12000e-01 $5.72975 \mathrm{e}+00$ 5.72975e+00 5.72975e-01 1.00000e-09 2.12000e-01 $5.72975 \mathrm{e}+00$ 5.72975e+00 5.72975e-01 1.00000e-09 2.12000e-01 $5.72975 \mathrm{e}+005.72975 \mathrm{e}+00$ 5.72975e-01 1.00000e-09 2.12000e-01 $1.00000 \mathrm{e}-05$ 1.00000e-05 1.00000e-06 1.00000e-09 1.00000e-01 $1.00000 \mathrm{e}+001.00000 \mathrm{e}+001.00000 \mathrm{e}-011.00000 \mathrm{e}-091.00000 \mathrm{e}-01$ Element: 13469 \# of layers: 7

Kx Ky Kz Ss Por

5.72975e+00 5.72975e+00 5.72975e-01 1.00000e-09 2.12000e-01 $5.72975 \mathrm{e}+005.72975 \mathrm{e}+00$ 5.72975e-01 1.00000e-09 2.12000e-01 $5.72975 \mathrm{e}+005.72975 \mathrm{e}+00$ 5.72975e-01 1.00000e-09 2.12000e-01 $5.72975 \mathrm{e}+00$ 5.72975e+00 5.72975e-01 1.00000e-09 2.12000e-01 $5.72975 \mathrm{e}+00$ 5.72975e+00 5.72975e-01 1.00000e-09 2.12000e-01 $1.00000 \mathrm{e}-05$ 1.00000e-05 1.00000e-06 1.00000e-09 1.00000e-01 $1.00000 \mathrm{e}+001.00000 \mathrm{e}+001.00000 \mathrm{e}-011.00000 \mathrm{e}-091.00000 \mathrm{e}-01$ Element: 13470 \# of layers: 7

Kx Ky Kz Ss Por

$5.62287 \mathrm{e}+00$ 5.62287e+00 5.62287e-01 1.00000e-09 2.12000e-01 $5.62287 \mathrm{e}+005.62287 \mathrm{e}+005.62287 \mathrm{e}-011.00000 \mathrm{e}-092.12000 \mathrm{e}-01$ $5.62287 \mathrm{e}+005.62287 \mathrm{e}+00$ 5.62287e-01 1.00000e-09 2.12000e-01 $5.62287 \mathrm{e}+005.62287 \mathrm{e}+00$ 5.62287e-01 1.00000e-09 2.12000e-01 $5.62287 \mathrm{e}+005.62287 \mathrm{e}+00$ 5.62287e-01 1.00000e-09 2.12000e-01 $1.00000 \mathrm{e}-05$ 1.00000e-05 1.00000e-06 1.00000e-09 1.00000e-01 $1.00000 \mathrm{e}+001.00000 \mathrm{e}+001.00000 \mathrm{e}-011.00000 \mathrm{e}-091.00000 \mathrm{e}-01$ Element: 13471 \# of layers: 7

Kx Ky Kz Ss Por

$5.62287 \mathrm{e}+00$ 5.62287e+00 5.62287e-01 1.00000e-09 2.12000e-01 $5.62287 \mathrm{e}+005.62287 \mathrm{e}+00$ 5.62287e-01 1.00000e-09 2.12000e-01 $5.62287 \mathrm{e}+005.62287 \mathrm{e}+00$ 5.62287e-01 1.00000e-09 2.12000e-01 $5.62287 \mathrm{e}+005.62287 \mathrm{e}+005.62287 \mathrm{e}-011.00000 \mathrm{e}-092.12000 \mathrm{e}-01$ $5.62287 \mathrm{e}+005.62287 \mathrm{e}+00$ 5.62287e-01 1.00000e-09 2.12000e-01 $1.00000 \mathrm{e}-05$ 1.00000e-05 1.00000e-06 1.00000e-09 1.00000e-01 $1.00000 \mathrm{e}+001.00000 \mathrm{e}+001.00000 \mathrm{e}-011.00000 \mathrm{e}-091.00000 \mathrm{e}-01$ Element: 13472 \# of layers: 7

Kx Ky Kz Ss Por

$5.62287 \mathrm{e}+00$ 5.62287e+00 5.62287e-01 1.00000e-09 2.12000e-01 $5.62287 \mathrm{e}+00$ 5.62287e+00 5.62287e-01 1.00000e-09 2.12000e-01 
$5.62287 \mathrm{e}+00$ 5.62287e+00 5.62287e-01 1.00000e-09 2.12000e-01 $5.62287 \mathrm{e}+005.62287 \mathrm{e}+00$ 5.62287e-01 1.00000e-09 2.12000e-01 $5.62287 \mathrm{e}+005.62287 \mathrm{e}+00$ 5.62287e-01 1.00000e-09 2.12000e-01 $1.00000 \mathrm{e}-05$ 1.00000e-05 1.00000e-06 1.00000e-09 1.00000e-01 $1.00000 \mathrm{e}+001.00000 \mathrm{e}+001.00000 \mathrm{e}-011.00000 \mathrm{e}-091.00000 \mathrm{e}-01$ Element: 13473 \# of layers: 7

Kx Ky Kz Ss Por

5.72975e+00 5.72975e+00 5.72975e-01 1.00000e-09 2.12000e-01 $5.72975 \mathrm{e}+005.72975 \mathrm{e}+00$ 5.72975e-01 1.00000e-09 2.12000e-01 $5.72975 \mathrm{e}+00$ 5.72975e+00 5.72975e-01 1.00000e-09 2.12000e-01 $5.72975 \mathrm{e}+00$ 5.72975e+00 5.72975e-01 1.00000e-09 2.12000e-01 $5.72975 \mathrm{e}+00$ 5.72975e+00 5.72975e-01 1.00000e-09 2.12000e-01 $1.00000 \mathrm{e}-05$ 1.00000e-05 1.00000e-06 1.00000e-09 1.00000e-01 $1.00000 \mathrm{e}+001.00000 \mathrm{e}+001.00000 \mathrm{e}-011.00000 \mathrm{e}-091.00000 \mathrm{e}-01$ Element: 13474 \# of layers: 7

Kx Ky Kz Ss Por

$5.72975 \mathrm{e}+00$ 5.72975e+00 5.72975e-01 1.00000e-09 2.12000e-01 $5.72975 \mathrm{e}+005.72975 \mathrm{e}+005.72975 \mathrm{e}-011.00000 \mathrm{e}-092.12000 \mathrm{e}-01$ $5.72975 \mathrm{e}+005.72975 \mathrm{e}+005.72975 \mathrm{e}-011.00000 \mathrm{e}-092.12000 \mathrm{e}-01$ $5.72975 \mathrm{e}+005.72975 \mathrm{e}+00$ 5.72975e-01 1.00000e-09 2.12000e-01 $5.72975 \mathrm{e}+005.72975 \mathrm{e}+00$ 5.72975e-01 1.00000e-09 2.12000e-01 $1.00000 \mathrm{e}-05$ 1.00000e-05 1.00000e-06 1.00000e-09 1.00000e-01 $1.00000 \mathrm{e}+001.00000 \mathrm{e}+001.00000 \mathrm{e}-011.00000 \mathrm{e}-091.00000 \mathrm{e}-01$ Element: 13475 \# of layers: 7

Kx Ky Kz Ss Por

$5.72975 \mathrm{e}+00$ 5.72975e+00 5.72975e-01 1.00000e-09 2.12000e-01 $5.72975 \mathrm{e}+005.72975 \mathrm{e}+00$ 5.72975e-01 1.00000e-09 2.12000e-01 $5.72975 \mathrm{e}+005.72975 \mathrm{e}+00$ 5.72975e-01 1.00000e-09 2.12000e-01 $5.72975 \mathrm{e}+00$ 5.72975e+00 5.72975e-01 1.00000e-09 2.12000e-01 $5.72975 \mathrm{e}+00$ 5.72975e+00 5.72975e-01 1.00000e-09 2.12000e-01 $1.00000 \mathrm{e}-05$ 1.00000e-05 1.00000e-06 1.00000e-09 1.00000e-01 $1.00000 \mathrm{e}+001.00000 \mathrm{e}+001.00000 \mathrm{e}-011.00000 \mathrm{e}-091.00000 \mathrm{e}-01$ Element: 13476 \# of layers: 7

Kx Ky Kz Ss Por

$5.72975 \mathrm{e}+00$ 5.72975e+00 5.72975e-01 1.00000e-09 2.12000e-01 $5.72975 \mathrm{e}+00$ 5.72975e+00 5.72975e-01 1.00000e-09 2.12000e-01 $5.72975 \mathrm{e}+005.72975 \mathrm{e}+00$ 5.72975e-01 1.00000e-09 2.12000e-01 $5.72975 \mathrm{e}+005.72975 \mathrm{e}+00$ 5.72975e-01 1.00000e-09 2.12000e-01 $5.72975 \mathrm{e}+005.72975 \mathrm{e}+00$ 5.72975e-01 1.00000e-09 2.12000e-01 $1.00000 \mathrm{e}-05$ 1.00000e-05 1.00000e-06 1.00000e-09 1.00000e-01 $1.00000 \mathrm{e}+001.00000 \mathrm{e}+001.00000 \mathrm{e}-011.00000 \mathrm{e}-091.00000 \mathrm{e}-01$ Element: 13477 \# of layers: 7

Kx Ky Kz Ss Por

$5.62287 \mathrm{e}+00$ 5.62287e+00 5.62287e-01 1.00000e-09 2.12000e-01 $5.62287 \mathrm{e}+005.62287 \mathrm{e}+00$ 5.62287e-01 1.00000e-09 2.12000e-01 $5.62287 \mathrm{e}+005.62287 \mathrm{e}+00$ 5.62287e-01 1.00000e-09 2.12000e-01 
$5.62287 \mathrm{e}+00$ 5.62287e+00 5.62287e-01 1.00000e-09 2.12000e-01 $5.62287 \mathrm{e}+00$ 5.62287e+00 5.62287e-01 1.00000e-09 2.12000e-01 $1.00000 \mathrm{e}-05$ 1.00000e-05 1.00000e-06 1.00000e-09 1.00000e-01 $1.00000 \mathrm{e}+001.00000 \mathrm{e}+001.00000 \mathrm{e}-011.00000 \mathrm{e}-091.00000 \mathrm{e}-01$ Element: 13478 \# of layers: 7

Kx Ky Kz Ss Por

$5.62287 \mathrm{e}+00$ 5.62287e+00 5.62287e-01 1.00000e-09 2.12000e-01

$5.62287 \mathrm{e}+005.62287 \mathrm{e}+00$ 5.62287e-01 1.00000e-09 2.12000e-01

$5.62287 \mathrm{e}+005.62287 \mathrm{e}+005.62287 \mathrm{e}-011.00000 \mathrm{e}-092.12000 \mathrm{e}-01$

$5.62287 \mathrm{e}+005.62287 \mathrm{e}+00$ 5.62287e-01 1.00000e-09 2.12000e-01

$5.62287 \mathrm{e}+005.62287 \mathrm{e}+00$ 5.62287e-01 1.00000e-09 2.12000e-01 $1.00000 \mathrm{e}-05$ 1.00000e-05 1.00000e-06 1.00000e-09 1.00000e-01 $1.00000 \mathrm{e}+001.00000 \mathrm{e}+001.00000 \mathrm{e}-011.00000 \mathrm{e}-091.00000 \mathrm{e}-01$ Element: 13479 \# of layers: 7

Kx Ky Kz Ss Por

$5.62287 \mathrm{e}+00$ 5.62287e+00 5.62287e-01 1.00000e-09 2.12000e-01 $5.62287 \mathrm{e}+005.62287 \mathrm{e}+00$ 5.62287e-01 1.00000e-09 2.12000e-01 $5.62287 \mathrm{e}+005.62287 \mathrm{e}+00$ 5.62287e-01 1.00000e-09 2.12000e-01 $5.62287 \mathrm{e}+005.62287 \mathrm{e}+005.62287 \mathrm{e}-011.00000 \mathrm{e}-092.12000 \mathrm{e}-01$ $5.62287 \mathrm{e}+00$ 5.62287e+00 5.62287e-01 1.00000e-09 2.12000e-01 $1.00000 \mathrm{e}-05$ 1.00000e-05 1.00000e-06 1.00000e-09 1.00000e-01 $1.00000 \mathrm{e}+001.00000 \mathrm{e}+001.00000 \mathrm{e}-011.00000 \mathrm{e}-091.00000 \mathrm{e}-01$ Element: 13480 \# of layers: 7

Kx Ky Kz Ss Por

$5.62287 \mathrm{e}+00$ 5.62287e+00 5.62287e-01 1.00000e-09 2.12000e-01 $5.62287 \mathrm{e}+00$ 5.62287e+00 5.62287e-01 1.00000e-09 2.12000e-01 $5.62287 \mathrm{e}+005.62287 \mathrm{e}+00$ 5.62287e-01 1.00000e-09 2.12000e-01 $5.62287 \mathrm{e}+005.62287 \mathrm{e}+00$ 5.62287e-01 1.00000e-09 2.12000e-01 $5.62287 \mathrm{e}+005.62287 \mathrm{e}+00$ 5.62287e-01 1.00000e-09 2.12000e-01 $1.00000 \mathrm{e}-05$ 1.00000e-05 1.00000e-06 1.00000e-09 1.00000e-01 $1.00000 \mathrm{e}+001.00000 \mathrm{e}+001.00000 \mathrm{e}-011.00000 \mathrm{e}-091.00000 \mathrm{e}-01$ Element: 13481 \# of layers: 7

Kx Ky Kz Ss Por

$5.62287 \mathrm{e}+00$ 5.62287e+00 5.62287e-01 1.00000e-09 2.12000e-01 $5.62287 \mathrm{e}+005.62287 \mathrm{e}+005.62287 \mathrm{e}-011.00000 \mathrm{e}-092.12000 \mathrm{e}-01$ $5.62287 \mathrm{e}+005.62287 \mathrm{e}+00$ 5.62287e-01 1.00000e-09 2.12000e-01 $5.62287 \mathrm{e}+00$ 5.62287e+00 5.62287e-01 1.00000e-09 2.12000e-01 $5.62287 \mathrm{e}+00$ 5.62287e+00 5.62287e-01 1.00000e-09 2.12000e-01 $1.00000 \mathrm{e}-05$ 1.00000e-05 1.00000e-06 1.00000e-09 1.00000e-01 $1.00000 \mathrm{e}+001.00000 \mathrm{e}+001.00000 \mathrm{e}-011.00000 \mathrm{e}-091.00000 \mathrm{e}-01$ Element: 13482 \# of layers: 7

Kx Ky Kz Ss Por

$5.62287 \mathrm{e}+00$ 5.62287e+00 5.62287e-01 1.00000e-09 2.12000e-01 $5.62287 \mathrm{e}+005.62287 \mathrm{e}+00$ 5.62287e-01 1.00000e-09 2.12000e-01 $5.62287 \mathrm{e}+005.62287 \mathrm{e}+00$ 5.62287e-01 1.00000e-09 2.12000e-01 $5.62287 \mathrm{e}+005.62287 \mathrm{e}+00$ 5.62287e-01 1.00000e-09 2.12000e-01 
$5.62287 \mathrm{e}+00$ 5.62287e+00 5.62287e-01 1.00000e-09 2.12000e-01 $1.00000 \mathrm{e}-05$ 1.00000e-05 1.00000e-06 1.00000e-09 1.00000e-01 $1.00000 \mathrm{e}+001.00000 \mathrm{e}+001.00000 \mathrm{e}-011.00000 \mathrm{e}-091.00000 \mathrm{e}-01$ Element: 13483 \# of layers: 7

Kx Ky Kz Ss Por

$5.62287 \mathrm{e}+00$ 5.62287e+00 5.62287e-01 1.00000e-09 2.12000e-01 $5.62287 \mathrm{e}+005.62287 \mathrm{e}+00$ 5.62287e-01 1.00000e-09 2.12000e-01 $5.62287 \mathrm{e}+005.62287 \mathrm{e}+005.62287 \mathrm{e}-011.00000 \mathrm{e}-092.12000 \mathrm{e}-01$ $5.62287 \mathrm{e}+005.62287 \mathrm{e}+005.62287 \mathrm{e}-011.00000 \mathrm{e}-092.12000 \mathrm{e}-01$ $5.62287 \mathrm{e}+005.62287 \mathrm{e}+00$ 5.62287e-01 1.00000e-09 2.12000e-01 $1.00000 \mathrm{e}-05$ 1.00000e-05 1.00000e-06 1.00000e-09 1.00000e-01 $1.00000 \mathrm{e}+001.00000 \mathrm{e}+001.00000 \mathrm{e}-011.00000 \mathrm{e}-091.00000 \mathrm{e}-01$ Element: 13484 \# of layers: 7

Kx Ky Kz Ss Por

$5.62287 \mathrm{e}+00$ 5.62287e+00 5.62287e-01 1.00000e-09 2.12000e-01 $5.62287 \mathrm{e}+005.62287 \mathrm{e}+00$ 5.62287e-01 1.00000e-09 2.12000e-01 $5.62287 \mathrm{e}+005.62287 \mathrm{e}+005.62287 \mathrm{e}-011.00000 \mathrm{e}-092.12000 \mathrm{e}-01$ $5.62287 \mathrm{e}+005.62287 \mathrm{e}+005.62287 \mathrm{e}-011.00000 \mathrm{e}-092.12000 \mathrm{e}-01$ $5.62287 \mathrm{e}+005.62287 \mathrm{e}+00$ 5.62287e-01 1.00000e-09 2.12000e-01 $1.00000 \mathrm{e}-05$ 1.00000e-05 1.00000e-06 1.00000e-09 1.00000e-01 $1.00000 \mathrm{e}+001.00000 \mathrm{e}+001.00000 \mathrm{e}-011.00000 \mathrm{e}-091.00000 \mathrm{e}-01$ Element: 13485 \# of layers: 7

Kx Ky Kz Ss Por

$5.62287 \mathrm{e}+00$ 5.62287e+00 5.62287e-01 1.00000e-09 2.12000e-01 $5.62287 \mathrm{e}+005.62287 \mathrm{e}+00$ 5.62287e-01 1.00000e-09 2.12000e-01 $5.62287 \mathrm{e}+005.62287 \mathrm{e}+005.62287 \mathrm{e}-011.00000 \mathrm{e}-092.12000 \mathrm{e}-01$ $5.62287 \mathrm{e}+00$ 5.62287e+00 5.62287e-01 1.00000e-09 2.12000e-01 $5.62287 \mathrm{e}+005.62287 \mathrm{e}+00$ 5.62287e-01 1.00000e-09 2.12000e-01 $1.00000 \mathrm{e}-05$ 1.00000e-05 1.00000e-06 1.00000e-09 1.00000e-01 $1.00000 \mathrm{e}+001.00000 \mathrm{e}+001.00000 \mathrm{e}-011.00000 \mathrm{e}-091.00000 \mathrm{e}-01$ Element: 13486 \# of layers: 7

Kx Ky Kz Ss Por

$5.62287 \mathrm{e}+00$ 5.62287e+00 5.62287e-01 1.00000e-09 2.12000e-01 $5.62287 \mathrm{e}+005.62287 \mathrm{e}+00$ 5.62287e-01 1.00000e-09 2.12000e-01 $5.62287 \mathrm{e}+005.62287 \mathrm{e}+005.62287 \mathrm{e}-011.00000 \mathrm{e}-092.12000 \mathrm{e}-01$ $5.62287 \mathrm{e}+005.62287 \mathrm{e}+005.62287 \mathrm{e}-011.00000 \mathrm{e}-092.12000 \mathrm{e}-01$ $5.62287 \mathrm{e}+005.62287 \mathrm{e}+00$ 5.62287e-01 1.00000e-09 2.12000e-01 $1.00000 \mathrm{e}-05$ 1.00000e-05 1.00000e-06 1.00000e-09 1.00000e-01 $1.00000 \mathrm{e}+001.00000 \mathrm{e}+001.00000 \mathrm{e}-011.00000 \mathrm{e}-091.00000 \mathrm{e}-01$ Element: 13487 \# of layers: 7

Kx Ky Kz Ss Por

$5.62287 \mathrm{e}+00$ 5.62287e+00 5.62287e-01 1.00000e-09 2.12000e-01 $5.62287 \mathrm{e}+005.62287 \mathrm{e}+00$ 5.62287e-01 1.00000e-09 2.12000e-01 $5.62287 \mathrm{e}+005.62287 \mathrm{e}+00$ 5.62287e-01 1.00000e-09 2.12000e-01 $5.62287 \mathrm{e}+005.62287 \mathrm{e}+00$ 5.62287e-01 1.00000e-09 2.12000e-01 $5.62287 \mathrm{e}+00$ 5.62287e+00 5.62287e-01 1.00000e-09 2.12000e-01 
$1.00000 \mathrm{e}-05$ 1.00000e-05 1.00000e-06 1.00000e-09 1.00000e-01 $1.00000 \mathrm{e}+001.00000 \mathrm{e}+001.00000 \mathrm{e}-01$ 1.00000e-09 1.00000e-01 Element: 13488 \# of layers: 7

Kx Ky Kz Ss Por

5.73335e+00 5.73335e+00 5.73335e-01 1.00000e-09 2.12000e-01

5.73335e+00 5.73335e+00 5.73335e-01 1.00000e-09 2.12000e-01

5.73335e+00 5.73335e+00 5.73335e-01 1.00000e-09 2.12000e-01

$5.73335 \mathrm{e}+00$ 5.73335e+00 5.73335e-01 1.00000e-09 2.12000e-01

5.73335e+00 5.73335e+00 5.73335e-01 1.00000e-09 2.12000e-01

$1.00000 \mathrm{e}-05$ 1.00000e-05 1.00000e-06 1.00000e-09 1.00000e-01

$1.00000 \mathrm{e}+001.00000 \mathrm{e}+001.00000 \mathrm{e}-01$ 1.00000e-09 1.00000e-01

Element: 13489 \# of layers: 7

Kx Ky Kz Ss Por

5.73335e+00 5.73335e+00 5.73335e-01 1.00000e-09 2.12000e-01

5.73335e+00 5.73335e+00 5.73335e-01 1.00000e-09 2.12000e-01

$5.73335 \mathrm{e}+005.73335 \mathrm{e}+00$ 5.73335e-01 1.00000e-09 2.12000e-01

$5.73335 \mathrm{e}+00$ 5.73335e+00 5.73335e-01 1.00000e-09 2.12000e-01

$5.73335 \mathrm{e}+00$ 5.73335e+00 5.73335e-01 1.00000e-09 2.12000e-01

$1.00000 \mathrm{e}-051.00000 \mathrm{e}-05$ 1.00000e-06 1.00000e-09 1.00000e-01

$1.00000 \mathrm{e}+001.00000 \mathrm{e}+001.00000 \mathrm{e}-011.00000 \mathrm{e}-09$ 1.00000e-01

Element: 13490 \# of layers: 7

$\mathrm{Kx} \mathrm{Ky} \mathrm{Kz}$ Ss Por

5.73335e+00 5.73335e+00 5.73335e-01 1.00000e-09 2.12000e-01

5.73335e+00 5.73335e+00 5.73335e-01 1.00000e-09 2.12000e-01

$5.73335 \mathrm{e}+00$ 5.73335e+00 5.73335e-01 1.00000e-09 2.12000e-01

$5.73335 \mathrm{e}+00$ 5.73335e+00 5.73335e-01 1.00000e-09 2.12000e-01

$5.73335 \mathrm{e}+00$ 5.73335e+00 5.73335e-01 1.00000e-09 2.12000e-01

1.00000e-05 1.00000e-05 1.00000e-06 1.00000e-09 1.00000e-01

$1.00000 \mathrm{e}+001.00000 \mathrm{e}+001.00000 \mathrm{e}-011.00000 \mathrm{e}-091.00000 \mathrm{e}-01$

Element: 13491 \# of layers: 7

$\mathrm{Kx} \mathrm{Ky} \mathrm{Kz}$ Ss Por

5.62287e+00 5.62287e+00 5.62287e-01 1.00000e-09 2.12000e-01

$5.62287 \mathrm{e}+00$ 5.62287e+00 5.62287e-01 1.00000e-09 2.12000e-01

$5.62287 \mathrm{e}+00$ 5.62287e+00 5.62287e-01 1.00000e-09 2.12000e-01

$5.62287 \mathrm{e}+005.62287 \mathrm{e}+00$ 5.62287e-01 1.00000e-09 2.12000e-01

5.62287e+00 5.62287e+00 5.62287e-01 1.00000e-09 2.12000e-01 $1.00000 \mathrm{e}-05$ 1.00000e-05 1.00000e-06 1.00000e-09 1.00000e-01

$1.00000 \mathrm{e}+001.00000 \mathrm{e}+001.00000 \mathrm{e}-011.00000 \mathrm{e}-091.00000 \mathrm{e}-01$

Element: 13492 \# of layers: 7

$\mathrm{Kx} \mathrm{Ky} \mathrm{Kz}$ Ss Por

5.62287e+00 5.62287e+00 5.62287e-01 1.00000e-09 2.12000e-01

$5.62287 \mathrm{e}+00$ 5.62287e+00 5.62287e-01 1.00000e-09 2.12000e-01

$5.62287 \mathrm{e}+00$ 5.62287e+00 5.62287e-01 1.00000e-09 2.12000e-01

$5.62287 \mathrm{e}+005.62287 \mathrm{e}+00$ 5.62287e-01 1.00000e-09 2.12000e-01

$5.62287 \mathrm{e}+00$ 5.62287e+00 5.62287e-01 1.00000e-09 2.12000e-01

$1.00000 \mathrm{e}-05$ 1.00000e-05 1.00000e-06 1.00000e-09 1.00000e-01 
$1.00000 \mathrm{e}+001.00000 \mathrm{e}+001.00000 \mathrm{e}-011.00000 \mathrm{e}-091.00000 \mathrm{e}-01$ Element: 13493 \# of layers: 7

Kx Ky Kz Ss Por

5.62287e+00 5.62287e+00 5.62287e-01 1.00000e-09 2.12000e-01

5.62287e+00 5.62287e+00 5.62287e-01 1.00000e-09 2.12000e-01

$5.62287 \mathrm{e}+005.62287 \mathrm{e}+00$ 5.62287e-01 1.00000e-09 2.12000e-01

5.62287e+00 5.62287e+00 5.62287e-01 1.00000e-09 2.12000e-01

$5.62287 \mathrm{e}+005.62287 \mathrm{e}+00$ 5.62287e-01 1.00000e-09 2.12000e-01

$1.00000 \mathrm{e}-05$ 1.00000e-05 1.00000e-06 1.00000e-09 1.00000e-01

$1.00000 \mathrm{e}+001.00000 \mathrm{e}+001.00000 \mathrm{e}-01$ 1.00000e-09 1.00000e-01

Element: 13494 \# of layers: 7

Kx Ky Kz Ss Por

5.62287e+00 5.62287e+00 5.62287e-01 1.00000e-09 2.12000e-01

$5.62287 \mathrm{e}+005.62287 \mathrm{e}+00$ 5.62287e-01 1.00000e-09 2.12000e-01

5.62287e+00 5.62287e+00 5.62287e-01 1.00000e-09 2.12000e-01

$5.62287 \mathrm{e}+00$ 5.62287e+00 5.62287e-01 1.00000e-09 2.12000e-01

5.62287e+00 5.62287e+00 5.62287e-01 1.00000e-09 2.12000e-01

$1.00000 \mathrm{e}-05$ 1.00000e-05 1.00000e-06 1.00000e-09 1.00000e-01

$1.00000 \mathrm{e}+001.00000 \mathrm{e}+001.00000 \mathrm{e}-01$ 1.00000e-09 1.00000e-01

Element: 13495 \# of layers: 7

Kx Ky Kz Ss Por

5.73335e+00 5.73335e+00 5.73335e-01 1.00000e-09 2.12000e-01

5.73335e+00 5.73335e+00 5.73335e-01 1.00000e-09 2.12000e-01

5.73335e+00 5.73335e+00 5.73335e-01 1.00000e-09 2.12000e-01

$5.73335 \mathrm{e}+00$ 5.73335e+00 5.73335e-01 1.00000e-09 2.12000e-01

$5.73335 \mathrm{e}+00$ 5.73335e+00 5.73335e-01 1.00000e-09 2.12000e-01

$1.00000 \mathrm{e}-05$ 1.00000e-05 1.00000e-06 1.00000e-09 1.00000e-01

$1.00000 \mathrm{e}+001.00000 \mathrm{e}+001.00000 \mathrm{e}-01$ 1.00000e-09 1.00000e-01

Element: 13496 \# of layers: 7

$\mathrm{Kx} \mathrm{Ky} \mathrm{Kz}$ Ss Por

5.73335e+00 5.73335e+00 5.73335e-01 1.00000e-09 2.12000e-01

$5.73335 \mathrm{e}+005.73335 \mathrm{e}+00$ 5.73335e-01 1.00000e-09 2.12000e-01

$5.73335 \mathrm{e}+00$ 5.73335e+00 5.73335e-01 1.00000e-09 2.12000e-01

5.73335e+00 5.73335e+00 5.73335e-01 1.00000e-09 2.12000e-01

$5.73335 \mathrm{e}+00$ 5.73335e+00 5.73335e-01 1.00000e-09 2.12000e-01

$1.00000 \mathrm{e}-05$ 1.00000e-05 1.00000e-06 1.00000e-09 1.00000e-01

$1.00000 \mathrm{e}+001.00000 \mathrm{e}+001.00000 \mathrm{e}-011.00000 \mathrm{e}-091.00000 \mathrm{e}-01$

Element: 13497 \# of layers: 7

$\mathrm{Kx} \mathrm{Ky} \mathrm{Kz}$ Ss Por

5.73335e+00 5.73335e+00 5.73335e-01 1.00000e-09 2.12000e-01

5.73335e+00 5.73335e+00 5.73335e-01 1.00000e-09 2.12000e-01

5.73335e+00 5.73335e+00 5.73335e-01 1.00000e-09 2.12000e-01

5.73335e+00 5.73335e+00 5.73335e-01 1.00000e-09 2.12000e-01

5.73335e+00 5.73335e+00 5.73335e-01 1.00000e-09 2.12000e-01

$1.00000 \mathrm{e}-05$ 1.00000e-05 1.00000e-06 1.00000e-09 1.00000e-01

$1.00000 \mathrm{e}+001.00000 \mathrm{e}+001.00000 \mathrm{e}-011.00000 \mathrm{e}-091.00000 \mathrm{e}-01$ 
Element: 13498 \# of layers: 7

Kx Ky Kz Ss Por

$5.73335 \mathrm{e}+00$ 5.73335e+00 5.73335e-01 1.00000e-09 2.12000e-01

$5.73335 \mathrm{e}+00$ 5.73335e+00 5.73335e-01 1.00000e-09 2.12000e-01

$5.73335 \mathrm{e}+005.73335 \mathrm{e}+00$ 5.73335e-01 1.00000e-09 2.12000e-01

$5.73335 \mathrm{e}+005.73335 \mathrm{e}+00$ 5.73335e-01 1.00000e-09 2.12000e-01

$5.73335 \mathrm{e}+00$ 5.73335e+00 5.73335e-01 1.00000e-09 2.12000e-01

$1.00000 \mathrm{e}-05$ 1.00000e-05 1.00000e-06 1.00000e-09 1.00000e-01

$1.00000 \mathrm{e}+001.00000 \mathrm{e}+001.00000 \mathrm{e}-011.00000 \mathrm{e}-091.00000 \mathrm{e}-01$

Element: 13499 \# of layers: 7

Kx Ky Kz Ss Por

$5.73335 \mathrm{e}+00$ 5.73335e+00 5.73335e-01 1.00000e-09 2.12000e-01

$5.73335 \mathrm{e}+005.73335 \mathrm{e}+00$ 5.73335e-01 1.00000e-09 2.12000e-01

$5.73335 \mathrm{e}+005.73335 \mathrm{e}+00$ 5.73335e-01 1.00000e-09 2.12000e-01

$5.73335 \mathrm{e}+005.73335 \mathrm{e}+00$ 5.73335e-01 1.00000e-09 2.12000e-01

$5.73335 \mathrm{e}+00$ 5.73335e+00 5.73335e-01 1.00000e-09 2.12000e-01

$1.00000 \mathrm{e}-05$ 1.00000e-05 1.00000e-06 1.00000e-09 1.00000e-01

$1.00000 \mathrm{e}+001.00000 \mathrm{e}+001.00000 \mathrm{e}-011.00000 \mathrm{e}-091.00000 \mathrm{e}-01$

Element: 13500 \# of layers: 7

Kx Ky Kz Ss Por

$5.73335 \mathrm{e}+00$ 5.73335e+00 5.73335e-01 1.00000e-09 2.12000e-01

$5.73335 \mathrm{e}+005.73335 \mathrm{e}+00$ 5.73335e-01 1.00000e-09 2.12000e-01

$5.73335 \mathrm{e}+005.73335 \mathrm{e}+00$ 5.73335e-01 1.00000e-09 2.12000e-01

$5.73335 \mathrm{e}+005.73335 \mathrm{e}+00$ 5.73335e-01 1.00000e-09 2.12000e-01

$5.73335 \mathrm{e}+00$ 5.73335e+00 5.73335e-01 1.00000e-09 2.12000e-01

$1.00000 \mathrm{e}-05$ 1.00000e-05 1.00000e-06 1.00000e-09 1.00000e-01

$1.00000 \mathrm{e}+001.00000 \mathrm{e}+001.00000 \mathrm{e}-011.00000 \mathrm{e}-091.00000 \mathrm{e}-01$

Element: 13501 \# of layers: 7

Kx Ky Kz Ss Por

$5.73335 \mathrm{e}+00$ 5.73335e+00 5.73335e-01 1.00000e-09 2.12000e-01

$5.73335 \mathrm{e}+00$ 5.73335e+00 5.73335e-01 1.00000e-09 2.12000e-01

$5.73335 \mathrm{e}+005.73335 \mathrm{e}+00$ 5.73335e-01 1.00000e-09 2.12000e-01

$5.73335 \mathrm{e}+005.73335 \mathrm{e}+00$ 5.73335e-01 1.00000e-09 2.12000e-01

$5.73335 \mathrm{e}+005.73335 \mathrm{e}+00$ 5.73335e-01 1.00000e-09 2.12000e-01

$1.00000 \mathrm{e}-05$ 1.00000e-05 1.00000e-06 1.00000e-09 1.00000e-01

$1.00000 \mathrm{e}+001.00000 \mathrm{e}+001.00000 \mathrm{e}-011.00000 \mathrm{e}-091.00000 \mathrm{e}-01$

Element: 13502 \# of layers: 7

Kx Ky Kz Ss Por

$5.73335 \mathrm{e}+00$ 5.73335e+00 5.73335e-01 1.00000e-09 2.12000e-01

$5.73335 \mathrm{e}+005.73335 \mathrm{e}+00$ 5.73335e-01 1.00000e-09 2.12000e-01

$5.73335 \mathrm{e}+005.73335 \mathrm{e}+00$ 5.73335e-01 1.00000e-09 2.12000e-01

$5.73335 \mathrm{e}+005.73335 \mathrm{e}+00$ 5.73335e-01 1.00000e-09 2.12000e-01

$5.73335 \mathrm{e}+005.73335 \mathrm{e}+00$ 5.73335e-01 1.00000e-09 2.12000e-01

$1.00000 \mathrm{e}-05$ 1.00000e-05 1.00000e-06 1.00000e-09 1.00000e-01

$1.00000 \mathrm{e}+001.00000 \mathrm{e}+001.00000 \mathrm{e}-011.00000 \mathrm{e}-091.00000 \mathrm{e}-01$

Element: 13503 \# of layers: 7 
Kx Ky Kz Ss Por

5.73335e+00 5.73335e+00 5.73335e-01 1.00000e-09 2.12000e-01

$5.73335 \mathrm{e}+00$ 5.73335e+00 5.73335e-01 1.00000e-09 2.12000e-01

$5.73335 \mathrm{e}+00$ 5.73335e+00 5.73335e-01 1.00000e-09 2.12000e-01

5.73335e+00 5.73335e+00 5.73335e-01 1.00000e-09 2.12000e-01

$5.73335 \mathrm{e}+00$ 5.73335e+00 5.73335e-01 1.00000e-09 2.12000e-01

$1.00000 \mathrm{e}-05$ 1.00000e-05 1.00000e-06 1.00000e-09 1.00000e-01

$1.00000 \mathrm{e}+001.00000 \mathrm{e}+001.00000 \mathrm{e}-01$ 1.00000e-09 1.00000e-01

Element: 13504 \# of layers: 7

$\mathrm{Kx} \mathrm{Ky} \mathrm{Kz}$ Ss Por

5.73335e+00 5.73335e+00 5.73335e-01 1.00000e-09 2.12000e-01

$5.73335 \mathrm{e}+005.73335 \mathrm{e}+00$ 5.73335e-01 1.00000e-09 2.12000e-01

$5.73335 \mathrm{e}+00$ 5.73335e+00 5.73335e-01 1.00000e-09 2.12000e-01

5.73335e+00 5.73335e+00 5.73335e-01 1.00000e-09 2.12000e-01

5.73335e+00 5.73335e+00 5.73335e-01 1.00000e-09 2.12000e-01

$1.00000 \mathrm{e}-05$ 1.00000e-05 1.00000e-06 1.00000e-09 1.00000e-01

$1.00000 \mathrm{e}+001.00000 \mathrm{e}+001.00000 \mathrm{e}-011.00000 \mathrm{e}-091.00000 \mathrm{e}-01$

Element: 13505 \# of layers: 7

$\mathrm{Kx} \mathrm{Ky} \mathrm{Kz}$ Ss Por

5.58012e+00 5.58012e+00 5.58012e-01 1.00000e-09 2.12000e-01

$5.58012 \mathrm{e}+00$ 5.58012e+00 5.58012e-01 1.00000e-09 2.12000e-01

5.58012e+00 5.58012e+00 5.58012e-01 1.00000e-09 2.12000e-01

$5.58012 \mathrm{e}+005.58012 \mathrm{e}+00$ 5.58012e-01 1.00000e-09 2.12000e-01

$5.58012 \mathrm{e}+00$ 5.58012e+00 5.58012e-01 1.00000e-09 2.12000e-01

$1.00000 \mathrm{e}-05$ 1.00000e-05 1.00000e-06 1.00000e-09 1.00000e-01

$1.00000 \mathrm{e}+001.00000 \mathrm{e}+001.00000 \mathrm{e}-01$ 1.00000e-09 1.00000e-01

Element: 13506 \# of layers: 7

$\mathrm{Kx} \mathrm{Ky} \mathrm{Kz}$ Ss Por

5.58012e+00 5.58012e+00 5.58012e-01 1.00000e-09 2.12000e-01

5.58012e+00 5.58012e+00 5.58012e-01 1.00000e-09 2.12000e-01

$5.58012 \mathrm{e}+005.58012 \mathrm{e}+00$ 5.58012e-01 1.00000e-09 2.12000e-01

5.58012e+00 5.58012e+00 5.58012e-01 1.00000e-09 2.12000e-01

$5.58012 \mathrm{e}+005.58012 \mathrm{e}+00$ 5.58012e-01 1.00000e-09 2.12000e-01

$1.00000 \mathrm{e}-05$ 1.00000e-05 1.00000e-06 1.00000e-09 1.00000e-01

$1.00000 \mathrm{e}+001.00000 \mathrm{e}+001.00000 \mathrm{e}-01$ 1.00000e-09 1.00000e-01

Element: 13507 \# of layers: 7

Kx Ky Kz Ss Por

5.58012e+00 5.58012e+00 5.58012e-01 1.00000e-09 2.12000e-01

$5.58012 \mathrm{e}+005.58012 \mathrm{e}+005.58012 \mathrm{e}-011.00000 \mathrm{e}-092.12000 \mathrm{e}-01$

$5.58012 \mathrm{e}+005.58012 \mathrm{e}+00$ 5.58012e-01 1.00000e-09 2.12000e-01

$5.58012 \mathrm{e}+00$ 5.58012e+00 5.58012e-01 1.00000e-09 2.12000e-01

$5.58012 \mathrm{e}+00$ 5.58012e+00 5.58012e-01 1.00000e-09 2.12000e-01

$1.00000 \mathrm{e}-05$ 1.00000e-05 1.00000e-06 1.00000e-09 1.00000e-01

$1.00000 \mathrm{e}+001.00000 \mathrm{e}+001.00000 \mathrm{e}-01$ 1.00000e-09 1.00000e-01

Element: 13508 \# of layers: 7

Kx Ky Kz Ss Por 
$5.58012 \mathrm{e}+00$ 5.58012e+00 5.58012e-01 1.00000e-09 2.12000e-01 $5.58012 \mathrm{e}+005.58012 \mathrm{e}+005.58012 \mathrm{e}-011.00000 \mathrm{e}-092.12000 \mathrm{e}-01$ $5.58012 \mathrm{e}+005.58012 \mathrm{e}+00$ 5.58012e-01 1.00000e-09 2.12000e-01 $5.58012 \mathrm{e}+005.58012 \mathrm{e}+00$ 5.58012e-01 1.00000e-09 2.12000e-01 $5.58012 \mathrm{e}+005.58012 \mathrm{e}+00$ 5.58012e-01 1.00000e-09 2.12000e-01 $1.00000 \mathrm{e}-05$ 1.00000e-05 1.00000e-06 1.00000e-09 1.00000e-01 $1.00000 \mathrm{e}+001.00000 \mathrm{e}+001.00000 \mathrm{e}-011.00000 \mathrm{e}-091.00000 \mathrm{e}-01$ Element: 13509 \# of layers: 7

Kx Ky Kz Ss Por

$5.58012 \mathrm{e}+00$ 5.58012e+00 5.58012e-01 1.00000e-09 2.12000e-01 $5.58012 \mathrm{e}+005.58012 \mathrm{e}+005.58012 \mathrm{e}-011.00000 \mathrm{e}-092.12000 \mathrm{e}-01$ $5.58012 \mathrm{e}+005.58012 \mathrm{e}+00$ 5.58012e-01 1.00000e-09 2.12000e-01 $5.58012 \mathrm{e}+005.58012 \mathrm{e}+005.58012 \mathrm{e}-011.00000 \mathrm{e}-092.12000 \mathrm{e}-01$ $5.58012 \mathrm{e}+005.58012 \mathrm{e}+00$ 5.58012e-01 1.00000e-09 2.12000e-01 $1.00000 \mathrm{e}-05$ 1.00000e-05 1.00000e-06 1.00000e-09 1.00000e-01 $1.00000 \mathrm{e}+001.00000 \mathrm{e}+001.00000 \mathrm{e}-011.00000 \mathrm{e}-091.00000 \mathrm{e}-01$ Element: 13510 \# of layers: 7

Kx Ky Kz Ss Por

$5.73335 \mathrm{e}+00$ 5.73335e+00 5.73335e-01 1.00000e-09 2.12000e-01 $5.73335 \mathrm{e}+005.73335 \mathrm{e}+00$ 5.73335e-01 1.00000e-09 2.12000e-01 $5.73335 \mathrm{e}+005.73335 \mathrm{e}+00$ 5.73335e-01 1.00000e-09 2.12000e-01 $5.73335 \mathrm{e}+005.73335 \mathrm{e}+00$ 5.73335e-01 1.00000e-09 2.12000e-01 $5.73335 \mathrm{e}+005.73335 \mathrm{e}+00$ 5.73335e-01 1.00000e-09 2.12000e-01 $1.00000 \mathrm{e}-05$ 1.00000e-05 1.00000e-06 1.00000e-09 1.00000e-01 $1.00000 \mathrm{e}+001.00000 \mathrm{e}+001.00000 \mathrm{e}-011.00000 \mathrm{e}-091.00000 \mathrm{e}-01$ Element: 13511 \# of layers: 7

Kx Ky Kz Ss Por

$5.73335 \mathrm{e}+00$ 5.73335e+00 5.73335e-01 1.00000e-09 2.12000e-01 $5.73335 \mathrm{e}+00$ 5.73335e+00 5.73335e-01 1.00000e-09 2.12000e-01 $5.73335 \mathrm{e}+005.73335 \mathrm{e}+00$ 5.73335e-01 1.00000e-09 2.12000e-01 $5.73335 \mathrm{e}+00$ 5.73335e+00 5.73335e-01 1.00000e-09 2.12000e-01 $5.73335 \mathrm{e}+005.73335 \mathrm{e}+00$ 5.73335e-01 1.00000e-09 2.12000e-01 $1.00000 \mathrm{e}-05$ 1.00000e-05 1.00000e-06 1.00000e-09 1.00000e-01 $1.00000 \mathrm{e}+001.00000 \mathrm{e}+001.00000 \mathrm{e}-011.00000 \mathrm{e}-091.00000 \mathrm{e}-01$ Element: 13512 \# of layers: 7

Kx Ky Kz Ss Por $5.58012 \mathrm{e}+00$ 5.58012e+00 5.58012e-01 1.00000e-09 2.12000e-01 $5.58012 \mathrm{e}+005.58012 \mathrm{e}+00$ 5.58012e-01 1.00000e-09 2.12000e-01 $5.58012 \mathrm{e}+005.58012 \mathrm{e}+00$ 5.58012e-01 1.00000e-09 2.12000e-01 $5.58012 \mathrm{e}+005.58012 \mathrm{e}+005.58012 \mathrm{e}-011.00000 \mathrm{e}-092.12000 \mathrm{e}-01$ $5.58012 \mathrm{e}+005.58012 \mathrm{e}+00$ 5.58012e-01 1.00000e-09 2.12000e-01 $1.00000 \mathrm{e}-05$ 1.00000e-05 1.00000e-06 1.00000e-09 1.00000e-01 $1.00000 \mathrm{e}+001.00000 \mathrm{e}+001.00000 \mathrm{e}-011.00000 \mathrm{e}-091.00000 \mathrm{e}-01$ Element: 13513 \# of layers: 7

Kx Ky Kz Ss Por 5.58012e+00 5.58012e+00 5.58012e-01 1.00000e-09 2.12000e-01 
$5.58012 \mathrm{e}+00$ 5.58012e+00 5.58012e-01 1.00000e-09 2.12000e-01

$5.58012 \mathrm{e}+005.58012 \mathrm{e}+005.58012 \mathrm{e}-011.00000 \mathrm{e}-092.12000 \mathrm{e}-01$

$5.58012 \mathrm{e}+005.58012 \mathrm{e}+00$ 5.58012e-01 1.00000e-09 2.12000e-01

$5.58012 \mathrm{e}+00$ 5.58012e+00 5.58012e-01 1.00000e-09 2.12000e-01

$1.00000 \mathrm{e}-05$ 1.00000e-05 1.00000e-06 1.00000e-09 1.00000e-01

$1.00000 \mathrm{e}+001.00000 \mathrm{e}+001.00000 \mathrm{e}-011.00000 \mathrm{e}-091.00000 \mathrm{e}-01$

Element: 13514 \# of layers: 7

Kx Ky Kz Ss Por

$5.72975 \mathrm{e}+00$ 5.72975e+00 5.72975e-01 1.00000e-09 2.12000e-01

$5.72975 \mathrm{e}+00$ 5.72975e+00 5.72975e-01 1.00000e-09 2.12000e-01

$5.72975 \mathrm{e}+00$ 5.72975e+00 5.72975e-01 1.00000e-09 2.12000e-01

$5.72975 \mathrm{e}+00$ 5.72975e+00 5.72975e-01 1.00000e-09 2.12000e-01

$5.72975 \mathrm{e}+005.72975 \mathrm{e}+00$ 5.72975e-01 1.00000e-09 2.12000e-01

$1.00000 \mathrm{e}-05$ 1.00000e-05 1.00000e-06 1.00000e-09 1.00000e-01

$1.00000 \mathrm{e}+001.00000 \mathrm{e}+001.00000 \mathrm{e}-011.00000 \mathrm{e}-091.00000 \mathrm{e}-01$

Element: 13515 \# of layers: 7

Kx Ky Kz Ss Por

$5.72975 \mathrm{e}+00$ 5.72975e+00 5.72975e-01 1.00000e-09 2.12000e-01

$5.72975 \mathrm{e}+005.72975 \mathrm{e}+005.72975 \mathrm{e}-011.00000 \mathrm{e}-092.12000 \mathrm{e}-01$

$5.72975 \mathrm{e}+005.72975 \mathrm{e}+00$ 5.72975e-01 1.00000e-09 2.12000e-01

$5.72975 \mathrm{e}+00$ 5.72975e+00 5.72975e-01 1.00000e-09 2.12000e-01

$5.72975 \mathrm{e}+005.72975 \mathrm{e}+00$ 5.72975e-01 1.00000e-09 2.12000e-01

$1.00000 \mathrm{e}-05$ 1.00000e-05 1.00000e-06 1.00000e-09 1.00000e-01

$1.00000 \mathrm{e}+001.00000 \mathrm{e}+001.00000 \mathrm{e}-011.00000 \mathrm{e}-091.00000 \mathrm{e}-01$

Element: 13516 \# of layers: 7

Kx Ky Kz Ss Por

$5.72975 \mathrm{e}+00$ 5.72975e+00 5.72975e-01 1.00000e-09 2.12000e-01

$5.72975 \mathrm{e}+005.72975 \mathrm{e}+00$ 5.72975e-01 1.00000e-09 2.12000e-01

$5.72975 \mathrm{e}+00$ 5.72975e+00 5.72975e-01 1.00000e-09 2.12000e-01

$5.72975 \mathrm{e}+005.72975 \mathrm{e}+00$ 5.72975e-01 1.00000e-09 2.12000e-01

$5.72975 \mathrm{e}+00$ 5.72975e+00 5.72975e-01 1.00000e-09 2.12000e-01

$1.00000 \mathrm{e}-05$ 1.00000e-05 1.00000e-06 1.00000e-09 1.00000e-01

$1.00000 \mathrm{e}+001.00000 \mathrm{e}+001.00000 \mathrm{e}-011.00000 \mathrm{e}-091.00000 \mathrm{e}-01$

Element: 13517 \# of layers: 7

Kx Ky Kz Ss Por

$5.62287 \mathrm{e}+00$ 5.62287e+00 5.62287e-01 1.00000e-09 2.12000e-01

$5.62287 \mathrm{e}+005.62287 \mathrm{e}+00$ 5.62287e-01 1.00000e-09 2.12000e-01

$5.62287 \mathrm{e}+005.62287 \mathrm{e}+00$ 5.62287e-01 1.00000e-09 2.12000e-01

$5.62287 \mathrm{e}+005.62287 \mathrm{e}+005.62287 \mathrm{e}-011.00000 \mathrm{e}-092.12000 \mathrm{e}-01$

$5.62287 \mathrm{e}+005.62287 \mathrm{e}+00$ 5.62287e-01 1.00000e-09 2.12000e-01 $1.00000 \mathrm{e}-05$ 1.00000e-05 1.00000e-06 1.00000e-09 1.00000e-01

$1.00000 \mathrm{e}+001.00000 \mathrm{e}+001.00000 \mathrm{e}-011.00000 \mathrm{e}-091.00000 \mathrm{e}-01$

Element: 13518 \# of layers: 7

Kx Ky Kz Ss Por

$5.62287 \mathrm{e}+00$ 5.62287e+00 5.62287e-01 1.00000e-09 2.12000e-01

$5.62287 \mathrm{e}+00$ 5.62287e+00 5.62287e-01 1.00000e-09 2.12000e-01 
$5.62287 \mathrm{e}+00$ 5.62287e+00 5.62287e-01 1.00000e-09 2.12000e-01 $5.62287 \mathrm{e}+005.62287 \mathrm{e}+00$ 5.62287e-01 1.00000e-09 2.12000e-01 $5.62287 \mathrm{e}+00$ 5.62287e+00 5.62287e-01 1.00000e-09 2.12000e-01 $1.00000 \mathrm{e}-05$ 1.00000e-05 1.00000e-06 1.00000e-09 1.00000e-01 $1.00000 \mathrm{e}+001.00000 \mathrm{e}+001.00000 \mathrm{e}-011.00000 \mathrm{e}-091.00000 \mathrm{e}-01$ Element: 13519 \# of layers: 7

Kx Ky Kz Ss Por

$5.73335 \mathrm{e}+00$ 5.73335e+00 5.73335e-01 1.00000e-09 2.12000e-01 $5.73335 \mathrm{e}+005.73335 \mathrm{e}+00$ 5.73335e-01 1.00000e-09 2.12000e-01 $5.73335 \mathrm{e}+005.73335 \mathrm{e}+00$ 5.73335e-01 1.00000e-09 2.12000e-01 $5.73335 \mathrm{e}+005.73335 \mathrm{e}+00$ 5.73335e-01 1.00000e-09 2.12000e-01 $5.73335 \mathrm{e}+00$ 5.73335e+00 5.73335e-01 1.00000e-09 2.12000e-01 $1.00000 \mathrm{e}-05$ 1.00000e-05 1.00000e-06 1.00000e-09 1.00000e-01 $1.00000 \mathrm{e}+001.00000 \mathrm{e}+001.00000 \mathrm{e}-011.00000 \mathrm{e}-091.00000 \mathrm{e}-01$ Element: 13520 \# of layers: 7

Kx Ky Kz Ss Por

$5.58012 \mathrm{e}+00$ 5.58012e+00 5.58012e-01 1.00000e-09 2.12000e-01

$5.58012 \mathrm{e}+005.58012 \mathrm{e}+005.58012 \mathrm{e}-011.00000 \mathrm{e}-092.12000 \mathrm{e}-01$ $5.58012 \mathrm{e}+005.58012 \mathrm{e}+005.58012 \mathrm{e}-011.00000 \mathrm{e}-092.12000 \mathrm{e}-01$ $5.58012 \mathrm{e}+005.58012 \mathrm{e}+005.58012 \mathrm{e}-011.00000 \mathrm{e}-092.12000 \mathrm{e}-01$ $5.58012 \mathrm{e}+005.58012 \mathrm{e}+00$ 5.58012e-01 1.00000e-09 2.12000e-01 $1.00000 \mathrm{e}-05$ 1.00000e-05 1.00000e-06 1.00000e-09 1.00000e-01 $1.00000 \mathrm{e}+001.00000 \mathrm{e}+001.00000 \mathrm{e}-011.00000 \mathrm{e}-091.00000 \mathrm{e}-01$ Element: 13521 \# of layers: 7

Kx Ky Kz Ss Por

$5.72975 \mathrm{e}+00$ 5.72975e+00 5.72975e-01 1.00000e-09 2.12000e-01 $5.72975 \mathrm{e}+00$ 5.72975e+00 5.72975e-01 1.00000e-09 2.12000e-01 $5.72975 \mathrm{e}+005.72975 \mathrm{e}+00$ 5.72975e-01 1.00000e-09 2.12000e-01 $5.72975 \mathrm{e}+005.72975 \mathrm{e}+00$ 5.72975e-01 1.00000e-09 2.12000e-01 $5.72975 \mathrm{e}+00$ 5.72975e+00 5.72975e-01 1.00000e-09 2.12000e-01 $1.00000 \mathrm{e}-05$ 1.00000e-05 1.00000e-06 1.00000e-09 1.00000e-01 $1.00000 \mathrm{e}+001.00000 \mathrm{e}+001.00000 \mathrm{e}-011.00000 \mathrm{e}-091.00000 \mathrm{e}-01$ Element: 13522 \# of layers: 7

Kx Ky Kz Ss Por

$5.36412 \mathrm{e}+00$ 5.36412e+00 5.36412e-01 1.00000e-09 2.12000e-01 $5.36412 \mathrm{e}+005.36412 \mathrm{e}+005.36412 \mathrm{e}-011.00000 \mathrm{e}-092.12000 \mathrm{e}-01$ $5.36412 \mathrm{e}+005.36412 \mathrm{e}+00$ 5.36412e-01 1.00000e-09 2.12000e-01 $5.36412 \mathrm{e}+005.36412 \mathrm{e}+00$ 5.36412e-01 1.00000e-09 2.12000e-01 $5.36412 \mathrm{e}+005.36412 \mathrm{e}+00$ 5.36412e-01 1.00000e-09 2.12000e-01 $1.00000 \mathrm{e}-05$ 1.00000e-05 1.00000e-06 1.00000e-09 1.00000e-01 $1.00000 \mathrm{e}+001.00000 \mathrm{e}+001.00000 \mathrm{e}-011.00000 \mathrm{e}-091.00000 \mathrm{e}-01$ Element: 13523 \# of layers: 7

Kx Ky Kz Ss Por

$5.36412 \mathrm{e}+00$ 5.36412e+00 5.36412e-01 1.00000e-09 2.12000e-01 $5.36412 \mathrm{e}+005.36412 \mathrm{e}+00$ 5.36412e-01 1.00000e-09 2.12000e-01 $5.36412 \mathrm{e}+005.36412 \mathrm{e}+00$ 5.36412e-01 1.00000e-09 2.12000e-01 
$5.36412 \mathrm{e}+00$ 5.36412e+00 5.36412e-01 1.00000e-09 2.12000e-01 $5.36412 \mathrm{e}+005.36412 \mathrm{e}+00$ 5.36412e-01 1.00000e-09 2.12000e-01 $1.00000 \mathrm{e}-05$ 1.00000e-05 1.00000e-06 1.00000e-09 1.00000e-01 $1.00000 \mathrm{e}+001.00000 \mathrm{e}+001.00000 \mathrm{e}-011.00000 \mathrm{e}-091.00000 \mathrm{e}-01$ Element: 13524 \# of layers: 7

Kx Ky Kz Ss Por

5.36412e+00 5.36412e+00 5.36412e-01 1.00000e-09 2.12000e-01

$5.36412 \mathrm{e}+005.36412 \mathrm{e}+00$ 5.36412e-01 1.00000e-09 2.12000e-01

$5.36412 \mathrm{e}+005.36412 \mathrm{e}+005.36412 \mathrm{e}-011.00000 \mathrm{e}-092.12000 \mathrm{e}-01$

$5.36412 \mathrm{e}+005.36412 \mathrm{e}+00$ 5.36412e-01 1.00000e-09 2.12000e-01

$5.36412 \mathrm{e}+005.36412 \mathrm{e}+00$ 5.36412e-01 1.00000e-09 2.12000e-01 $1.00000 \mathrm{e}-05$ 1.00000e-05 1.00000e-06 1.00000e-09 1.00000e-01 $1.00000 \mathrm{e}+001.00000 \mathrm{e}+001.00000 \mathrm{e}-011.00000 \mathrm{e}-091.00000 \mathrm{e}-01$ Element: 13525 \# of layers: 7

Kx Ky Kz Ss Por

5.36412e+00 5.36412e+00 5.36412e-01 1.00000e-09 2.12000e-01 $5.36412 \mathrm{e}+005.36412 \mathrm{e}+00$ 5.36412e-01 1.00000e-09 2.12000e-01 $5.36412 \mathrm{e}+005.36412 \mathrm{e}+005.36412 \mathrm{e}-011.00000 \mathrm{e}-092.12000 \mathrm{e}-01$ $5.36412 \mathrm{e}+005.36412 \mathrm{e}+005.36412 \mathrm{e}-011.00000 \mathrm{e}-092.12000 \mathrm{e}-01$ $5.36412 \mathrm{e}+00$ 5.36412e+00 5.36412e-01 1.00000e-09 2.12000e-01 $1.00000 \mathrm{e}-05$ 1.00000e-05 1.00000e-06 1.00000e-09 1.00000e-01 $1.00000 \mathrm{e}+001.00000 \mathrm{e}+001.00000 \mathrm{e}-011.00000 \mathrm{e}-091.00000 \mathrm{e}-01$ Element: 13526 \# of layers: 7

Kx Ky Kz Ss Por

5.36412e+00 5.36412e+00 5.36412e-01 1.00000e-09 2.12000e-01 $5.36412 \mathrm{e}+00$ 5.36412e+00 5.36412e-01 1.00000e-09 2.12000e-01 $5.36412 \mathrm{e}+005.36412 \mathrm{e}+00$ 5.36412e-01 1.00000e-09 2.12000e-01 $5.36412 \mathrm{e}+005.36412 \mathrm{e}+00$ 5.36412e-01 1.00000e-09 2.12000e-01 $5.36412 \mathrm{e}+005.36412 \mathrm{e}+00$ 5.36412e-01 1.00000e-09 2.12000e-01 $1.00000 \mathrm{e}-05$ 1.00000e-05 1.00000e-06 1.00000e-09 1.00000e-01 $1.00000 \mathrm{e}+001.00000 \mathrm{e}+001.00000 \mathrm{e}-011.00000 \mathrm{e}-091.00000 \mathrm{e}-01$ Element: 13527 \# of layers: 7

Kx Ky Kz Ss Por

$5.36412 \mathrm{e}+00$ 5.36412e+00 5.36412e-01 1.00000e-09 2.12000e-01

$5.36412 \mathrm{e}+005.36412 \mathrm{e}+005.36412 \mathrm{e}-011.00000 \mathrm{e}-092.12000 \mathrm{e}-01$ $5.36412 \mathrm{e}+005.36412 \mathrm{e}+00$ 5.36412e-01 1.00000e-09 2.12000e-01 $5.36412 \mathrm{e}+005.36412 \mathrm{e}+00$ 5.36412e-01 1.00000e-09 2.12000e-01 5.36412e+00 5.36412e+00 5.36412e-01 1.00000e-09 2.12000e-01 $1.00000 \mathrm{e}-05$ 1.00000e-05 1.00000e-06 1.00000e-09 1.00000e-01 $1.00000 \mathrm{e}+001.00000 \mathrm{e}+001.00000 \mathrm{e}-011.00000 \mathrm{e}-091.00000 \mathrm{e}-01$ Element: 13528 \# of layers: 7

Kx Ky Kz Ss Por

$5.36412 \mathrm{e}+00$ 5.36412e+00 5.36412e-01 1.00000e-09 2.12000e-01 $5.36412 \mathrm{e}+005.36412 \mathrm{e}+005.36412 \mathrm{e}-011.00000 \mathrm{e}-092.12000 \mathrm{e}-01$ $5.36412 \mathrm{e}+005.36412 \mathrm{e}+00$ 5.36412e-01 1.00000e-09 2.12000e-01 $5.36412 \mathrm{e}+005.36412 \mathrm{e}+00$ 5.36412e-01 1.00000e-09 2.12000e-01 
5.36412e+00 5.36412e+00 5.36412e-01 1.00000e-09 2.12000e-01 $1.00000 \mathrm{e}-05$ 1.00000e-05 1.00000e-06 1.00000e-09 1.00000e-01 $1.00000 \mathrm{e}+001.00000 \mathrm{e}+001.00000 \mathrm{e}-011.00000 \mathrm{e}-091.00000 \mathrm{e}-01$ Element: 13529 \# of layers: 7

$\mathrm{Kx} \mathrm{Ky} \mathrm{Kz}$ Ss Por

5.36412e+00 5.36412e+00 5.36412e-01 1.00000e-09 2.12000e-01 $5.36412 \mathrm{e}+00$ 5.36412e+00 5.36412e-01 1.00000e-09 2.12000e-01 $5.36412 \mathrm{e}+00$ 5.36412e+00 5.36412e-01 1.00000e-09 2.12000e-01 5.36412e+00 5.36412e+00 5.36412e-01 1.00000e-09 2.12000e-01 $5.36412 \mathrm{e}+005.36412 \mathrm{e}+00$ 5.36412e-01 1.00000e-09 2.12000e-01 $1.00000 \mathrm{e}-05$ 1.00000e-05 1.00000e-06 1.00000e-09 1.00000e-01 $1.00000 \mathrm{e}+001.00000 \mathrm{e}+001.00000 \mathrm{e}-011.00000 \mathrm{e}-091.00000 \mathrm{e}-01$ Element: 13530 \# of layers: 7

$\mathrm{Kx} \mathrm{Ky} \mathrm{Kz}$ Ss Por

5.36412e+00 5.36412e+00 5.36412e-01 1.00000e-09 2.12000e-01 $5.36412 \mathrm{e}+005.36412 \mathrm{e}+00$ 5.36412e-01 1.00000e-09 2.12000e-01 5.36412e+00 5.36412e+00 5.36412e-01 1.00000e-09 2.12000e-01 5.36412e+00 5.36412e+00 5.36412e-01 1.00000e-09 2.12000e-01 5.36412e+00 5.36412e+00 5.36412e-01 1.00000e-09 2.12000e-01 $1.00000 \mathrm{e}-05$ 1.00000e-05 1.00000e-06 1.00000e-09 1.00000e-01 $1.00000 \mathrm{e}+001.00000 \mathrm{e}+001.00000 \mathrm{e}-011.00000 \mathrm{e}-091.00000 \mathrm{e}-01$ Element: 13531 \# of layers: 7

$\mathrm{Kx} \mathrm{Ky} \mathrm{Kz}$ Ss Por

5.36412e+00 5.36412e+00 5.36412e-01 1.00000e-09 2.12000e-01 $5.36412 \mathrm{e}+00$ 5.36412e+00 5.36412e-01 1.00000e-09 2.12000e-01 5.36412e+00 5.36412e+00 5.36412e-01 1.00000e-09 2.12000e-01 5.36412e+00 5.36412e+00 5.36412e-01 1.00000e-09 2.12000e-01 $5.36412 \mathrm{e}+00$ 5.36412e+00 5.36412e-01 1.00000e-09 2.12000e-01 $1.00000 \mathrm{e}-05$ 1.00000e-05 1.00000e-06 1.00000e-09 1.00000e-01 $1.00000 \mathrm{e}+001.00000 \mathrm{e}+001.00000 \mathrm{e}-011.00000 \mathrm{e}-091.00000 \mathrm{e}-01$ Element: 13532 \# of layers: 7

$\mathrm{Kx} \mathrm{Ky} \mathrm{Kz}$ Ss Por

3.32062e+00 3.32062e+00 3.32062e-01 1.00000e-09 2.12000e-01 3.32062e+00 3.32062e+00 3.32062e-01 1.00000e-09 2.12000e-01 $3.32062 \mathrm{e}+00$ 3.32062e+00 3.32062e-01 1.00000e-09 2.12000e-01 $3.32062 \mathrm{e}+00$ 3.32062e+00 3.32062e-01 1.00000e-09 2.12000e-01 $3.32062 \mathrm{e}+003.32062 \mathrm{e}+00$ 3.32062e-01 1.00000e-09 2.12000e-01 $1.00000 \mathrm{e}-05$ 1.00000e-05 1.00000e-06 1.00000e-09 1.00000e-01 $1.00000 \mathrm{e}+001.00000 \mathrm{e}+001.00000 \mathrm{e}-01$ 1.00000e-09 1.00000e-01 Element: 13533 \# of layers: 7

$\mathrm{Kx} \mathrm{Ky} \mathrm{Kz}$ Ss Por

3.32062e+00 3.32062e+00 3.32062e-01 1.00000e-09 2.12000e-01 3.32062e+00 3.32062e+00 3.32062e-01 1.00000e-09 2.12000e-01 3.32062e+00 3.32062e+00 3.32062e-01 1.00000e-09 2.12000e-01 $3.32062 \mathrm{e}+00$ 3.32062e+00 3.32062e-01 1.00000e-09 2.12000e-01 $3.32062 \mathrm{e}+003.32062 \mathrm{e}+00$ 3.32062e-01 1.00000e-09 2.12000e-01 
$1.00000 \mathrm{e}-05$ 1.00000e-05 1.00000e-06 1.00000e-09 1.00000e-01 $1.00000 \mathrm{e}+001.00000 \mathrm{e}+001.00000 \mathrm{e}-011.00000 \mathrm{e}-091.00000 \mathrm{e}-01$ Element: 13534 \# of layers: 7

Kx Ky Kz Ss Por

$3.32062 \mathrm{e}+00$ 3.32062e+00 3.32062e-01 1.00000e-09 2.12000e-01 $3.32062 \mathrm{e}+003.32062 \mathrm{e}+003.32062 \mathrm{e}-011.00000 \mathrm{e}-092.12000 \mathrm{e}-01$ $3.32062 \mathrm{e}+003.32062 \mathrm{e}+003.32062 \mathrm{e}-01$ 1.00000e-09 2.12000e-01 $3.32062 \mathrm{e}+003.32062 \mathrm{e}+003.32062 \mathrm{e}-01$ 1.00000e-09 2.12000e-01 $3.32062 \mathrm{e}+003.32062 \mathrm{e}+003.32062 \mathrm{e}-01$ 1.00000e-09 2.12000e-01 $1.00000 \mathrm{e}-05$ 1.00000e-05 1.00000e-06 1.00000e-09 1.00000e-01 $1.00000 \mathrm{e}+001.00000 \mathrm{e}+001.00000 \mathrm{e}-011.00000 \mathrm{e}-091.00000 \mathrm{e}-01$ Element: 13535 \# of layers: 7

Kx Ky Kz Ss Por

3.32062e+00 3.32062e+00 3.32062e-01 1.00000e-09 2.12000e-01 $3.32062 \mathrm{e}+003.32062 \mathrm{e}+003.32062 \mathrm{e}-01$ 1.00000e-09 2.12000e-01 $3.32062 \mathrm{e}+003.32062 \mathrm{e}+003.32062 \mathrm{e}-01$ 1.00000e-09 2.12000e-01 $3.32062 \mathrm{e}+003.32062 \mathrm{e}+003.32062 \mathrm{e}-01$ 1.00000e-09 2.12000e-01 $3.32062 \mathrm{e}+003.32062 \mathrm{e}+003.32062 \mathrm{e}-01$ 1.00000e-09 2.12000e-01 $1.00000 \mathrm{e}-05$ 1.00000e-05 1.00000e-06 1.00000e-09 1.00000e-01 $1.00000 \mathrm{e}+001.00000 \mathrm{e}+001.00000 \mathrm{e}-011.00000 \mathrm{e}-091.00000 \mathrm{e}-01$ Element: 13536 \# of layers: 7

Kx Ky Kz Ss Por

3.32062e+00 3.32062e+00 3.32062e-01 1.00000e-09 2.12000e-01 $3.32062 \mathrm{e}+003.32062 \mathrm{e}+003.32062 \mathrm{e}-01$ 1.00000e-09 2.12000e-01 $3.32062 \mathrm{e}+003.32062 \mathrm{e}+003.32062 \mathrm{e}-011.00000 \mathrm{e}-092.12000 \mathrm{e}-01$ $3.32062 \mathrm{e}+003.32062 \mathrm{e}+003.32062 \mathrm{e}-01$ 1.00000e-09 2.12000e-01 $3.32062 \mathrm{e}+003.32062 \mathrm{e}+003.32062 \mathrm{e}-01$ 1.00000e-09 2.12000e-01 $1.00000 \mathrm{e}-05$ 1.00000e-05 1.00000e-06 1.00000e-09 1.00000e-01 $1.00000 \mathrm{e}+001.00000 \mathrm{e}+001.00000 \mathrm{e}-011.00000 \mathrm{e}-091.00000 \mathrm{e}-01$ Element: 13537 \# of layers: 7

Kx Ky Kz Ss Por

$5.36412 \mathrm{e}+00$ 5.36412e+00 5.36412e-01 1.00000e-09 2.12000e-01 $5.36412 \mathrm{e}+005.36412 \mathrm{e}+00$ 5.36412e-01 1.00000e-09 2.12000e-01 $5.36412 \mathrm{e}+005.36412 \mathrm{e}+005.36412 \mathrm{e}-011.00000 \mathrm{e}-092.12000 \mathrm{e}-01$ $5.36412 \mathrm{e}+005.36412 \mathrm{e}+005.36412 \mathrm{e}-011.00000 \mathrm{e}-092.12000 \mathrm{e}-01$ $5.36412 \mathrm{e}+005.36412 \mathrm{e}+00$ 5.36412e-01 1.00000e-09 2.12000e-01 $1.00000 \mathrm{e}-05$ 1.00000e-05 1.00000e-06 1.00000e-09 1.00000e-01 $1.00000 \mathrm{e}+001.00000 \mathrm{e}+001.00000 \mathrm{e}-011.00000 \mathrm{e}-091.00000 \mathrm{e}-01$ Element: 13538 \# of layers: 7

Kx Ky Kz Ss Por

$5.36412 \mathrm{e}+00$ 5.36412e+00 5.36412e-01 1.00000e-09 2.12000e-01 $5.36412 \mathrm{e}+005.36412 \mathrm{e}+00$ 5.36412e-01 1.00000e-09 2.12000e-01 $5.36412 \mathrm{e}+005.36412 \mathrm{e}+00$ 5.36412e-01 1.00000e-09 2.12000e-01 $5.36412 \mathrm{e}+005.36412 \mathrm{e}+005.36412 \mathrm{e}-011.00000 \mathrm{e}-092.12000 \mathrm{e}-01$ $5.36412 \mathrm{e}+005.36412 \mathrm{e}+00$ 5.36412e-01 1.00000e-09 2.12000e-01 $1.00000 \mathrm{e}-05$ 1.00000e-05 1.00000e-06 1.00000e-09 1.00000e-01 
$1.00000 \mathrm{e}+001.00000 \mathrm{e}+001.00000 \mathrm{e}-011.00000 \mathrm{e}-091.00000 \mathrm{e}-01$ Element: 13539 \# of layers: 7

$\mathrm{Kx} \mathrm{Ky} \mathrm{Kz}$ Ss Por

3.32062e+00 3.32062e+00 3.32062e-01 1.00000e-09 2.12000e-01

$3.32062 \mathrm{e}+003.32062 \mathrm{e}+00$ 3.32062e-01 1.00000e-09 2.12000e-01

$3.32062 \mathrm{e}+003.32062 \mathrm{e}+00$ 3.32062e-01 1.00000e-09 2.12000e-01

$3.32062 \mathrm{e}+003.32062 \mathrm{e}+00$ 3.32062e-01 1.00000e-09 2.12000e-01

$3.32062 \mathrm{e}+003.32062 \mathrm{e}+00$ 3.32062e-01 1.00000e-09 2.12000e-01

$1.00000 \mathrm{e}-05$ 1.00000e-05 1.00000e-06 1.00000e-09 1.00000e-01

$1.00000 \mathrm{e}+001.00000 \mathrm{e}+001.00000 \mathrm{e}-011.00000 \mathrm{e}-091.00000 \mathrm{e}-01$

Element: 13540 \# of layers: 7

$\mathrm{Kx} \mathrm{Ky} \mathrm{Kz}$ Ss Por

3.32062e+00 3.32062e+00 3.32062e-01 1.00000e-09 2.12000e-01

$3.32062 \mathrm{e}+003.32062 \mathrm{e}+00$ 3.32062e-01 1.00000e-09 2.12000e-01

$3.32062 \mathrm{e}+003.32062 \mathrm{e}+00$ 3.32062e-01 1.00000e-09 2.12000e-01

$3.32062 \mathrm{e}+003.32062 \mathrm{e}+00$ 3.32062e-01 1.00000e-09 2.12000e-01

3.32062e+00 3.32062e+00 3.32062e-01 1.00000e-09 2.12000e-01

$1.00000 \mathrm{e}-051.00000 \mathrm{e}-051.00000 \mathrm{e}-061.00000 \mathrm{e}-091.00000 \mathrm{e}-01$

$1.00000 \mathrm{e}+001.00000 \mathrm{e}+001.00000 \mathrm{e}-01$ 1.00000e-09 1.00000e-01

Element: 13541 \# of layers: 7

$\mathrm{Kx} \mathrm{Ky} \mathrm{Kz}$ Ss Por

3.32062e+00 3.32062e+00 3.32062e-01 1.00000e-09 2.12000e-01

3.32062e+00 3.32062e+00 3.32062e-01 1.00000e-09 2.12000e-01

$3.32062 \mathrm{e}+00$ 3.32062e+00 3.32062e-01 1.00000e-09 2.12000e-01

$3.32062 \mathrm{e}+003.32062 \mathrm{e}+00$ 3.32062e-01 1.00000e-09 2.12000e-01

$3.32062 \mathrm{e}+003.32062 \mathrm{e}+00$ 3.32062e-01 1.00000e-09 2.12000e-01

$1.00000 \mathrm{e}-05$ 1.00000e-05 1.00000e-06 1.00000e-09 1.00000e-01

$1.00000 \mathrm{e}+001.00000 \mathrm{e}+001.00000 \mathrm{e}-011.00000 \mathrm{e}-091.00000 \mathrm{e}-01$

Element: 13542 \# of layers: 7

$\mathrm{Kx} \mathrm{Ky} \mathrm{Kz}$ Ss Por

3.32062e+00 3.32062e+00 3.32062e-01 1.00000e-09 2.12000e-01

3.32062e+00 3.32062e+00 3.32062e-01 1.00000e-09 2.12000e-01

$3.32062 \mathrm{e}+003.32062 \mathrm{e}+00$ 3.32062e-01 1.00000e-09 2.12000e-01

3.32062e+00 3.32062e+00 3.32062e-01 1.00000e-09 2.12000e-01

$3.32062 \mathrm{e}+003.32062 \mathrm{e}+00$ 3.32062e-01 1.00000e-09 2.12000e-01

$1.00000 \mathrm{e}-05$ 1.00000e-05 1.00000e-06 1.00000e-09 1.00000e-01

$1.00000 \mathrm{e}+001.00000 \mathrm{e}+001.00000 \mathrm{e}-01$ 1.00000e-09 1.00000e-01

Element: 13543 \# of layers: 7

$\mathrm{Kx} \mathrm{Ky} \mathrm{Kz}$ Ss Por

3.32062e+00 3.32062e+00 3.32062e-01 1.00000e-09 2.12000e-01

$3.32062 \mathrm{e}+003.32062 \mathrm{e}+00$ 3.32062e-01 1.00000e-09 2.12000e-01

3.32062e+00 3.32062e+00 3.32062e-01 1.00000e-09 2.12000e-01

$3.32062 \mathrm{e}+00$ 3.32062e+00 3.32062e-01 1.00000e-09 2.12000e-01

3.32062e+00 3.32062e+00 3.32062e-01 1.00000e-09 2.12000e-01

$1.00000 \mathrm{e}-05$ 1.00000e-05 1.00000e-06 1.00000e-09 1.00000e-01

$1.00000 \mathrm{e}+001.00000 \mathrm{e}+001.00000 \mathrm{e}-011.00000 \mathrm{e}-091.00000 \mathrm{e}-01$ 
Element: 13544 \# of layers: 7

$\mathrm{Kx} \mathrm{Ky} \mathrm{Kz}$ Ss Por

3.32062e+00 3.32062e+00 3.32062e-01 1.00000e-09 2.12000e-01

$3.32062 \mathrm{e}+003.32062 \mathrm{e}+00$ 3.32062e-01 1.00000e-09 2.12000e-01

3.32062e+00 3.32062e+00 3.32062e-01 1.00000e-09 2.12000e-01

$3.32062 \mathrm{e}+003.32062 \mathrm{e}+00$ 3.32062e-01 1.00000e-09 2.12000e-01

$3.32062 \mathrm{e}+003.32062 \mathrm{e}+00$ 3.32062e-01 1.00000e-09 2.12000e-01

$1.00000 \mathrm{e}-05$ 1.00000e-05 1.00000e-06 1.00000e-09 1.00000e-01

$1.00000 \mathrm{e}+001.00000 \mathrm{e}+001.00000 \mathrm{e}-011.00000 \mathrm{e}-091.00000 \mathrm{e}-01$

Element: 13545 \# of layers: 7

$\mathrm{Kx} \mathrm{Ky} \mathrm{Kz}$ Ss Por

3.32062e+00 3.32062e+00 3.32062e-01 1.00000e-09 2.12000e-01

$3.32062 \mathrm{e}+00$ 3.32062e+00 3.32062e-01 1.00000e-09 2.12000e-01

$3.32062 \mathrm{e}+003.32062 \mathrm{e}+00$ 3.32062e-01 1.00000e-09 2.12000e-01

3.32062e+00 3.32062e+00 3.32062e-01 1.00000e-09 2.12000e-01

3.32062e+00 3.32062e+00 3.32062e-01 1.00000e-09 2.12000e-01

$1.00000 \mathrm{e}-05$ 1.00000e-05 1.00000e-06 1.00000e-09 1.00000e-01

$1.00000 \mathrm{e}+001.00000 \mathrm{e}+001.00000 \mathrm{e}-011.00000 \mathrm{e}-091.00000 \mathrm{e}-01$

Element: 13546 \# of layers: 7

$\mathrm{Kx} \mathrm{Ky} \mathrm{Kz}$ Ss Por

3.32062e+00 3.32062e+00 3.32062e-01 1.00000e-09 2.12000e-01

3.32062e+00 3.32062e+00 3.32062e-01 1.00000e-09 2.12000e-01

3.32062e+00 3.32062e+00 3.32062e-01 1.00000e-09 2.12000e-01

$3.32062 \mathrm{e}+00$ 3.32062e+00 3.32062e-01 1.00000e-09 2.12000e-01

$3.32062 \mathrm{e}+003.32062 \mathrm{e}+00$ 3.32062e-01 1.00000e-09 2.12000e-01

$1.00000 \mathrm{e}-05$ 1.00000e-05 1.00000e-06 1.00000e-09 1.00000e-01

$1.00000 \mathrm{e}+001.00000 \mathrm{e}+001.00000 \mathrm{e}-011.00000 \mathrm{e}-091.00000 \mathrm{e}-01$

Element: 13547 \# of layers: 7

$\mathrm{Kx} \mathrm{Ky} \mathrm{Kz}$ Ss Por

3.32062e+00 3.32062e+00 3.32062e-01 1.00000e-09 2.12000e-01

$3.32062 \mathrm{e}+003.32062 \mathrm{e}+00$ 3.32062e-01 1.00000e-09 2.12000e-01

3.32062e+00 3.32062e+00 3.32062e-01 1.00000e-09 2.12000e-01

$3.32062 \mathrm{e}+003.32062 \mathrm{e}+00$ 3.32062e-01 1.00000e-09 2.12000e-01

$3.32062 \mathrm{e}+003.32062 \mathrm{e}+00$ 3.32062e-01 1.00000e-09 2.12000e-01

$1.00000 \mathrm{e}-05$ 1.00000e-05 1.00000e-06 1.00000e-09 1.00000e-01

$1.00000 \mathrm{e}+001.00000 \mathrm{e}+001.00000 \mathrm{e}-011.00000 \mathrm{e}-091.00000 \mathrm{e}-01$

Element: 13548 \# of layers: 7

$\mathrm{Kx} \mathrm{Ky} \mathrm{Kz}$ Ss Por

3.32062e+00 3.32062e+00 3.32062e-01 1.00000e-09 2.12000e-01

3.32062e+00 3.32062e+00 3.32062e-01 1.00000e-09 2.12000e-01

$3.32062 \mathrm{e}+00$ 3.32062e+00 3.32062e-01 1.00000e-09 2.12000e-01

$3.32062 \mathrm{e}+00$ 3.32062e+00 3.32062e-01 1.00000e-09 2.12000e-01

3.32062e+00 3.32062e+00 3.32062e-01 1.00000e-09 2.12000e-01

$1.00000 \mathrm{e}-05$ 1.00000e-05 1.00000e-06 1.00000e-09 1.00000e-01

$1.00000 \mathrm{e}+001.00000 \mathrm{e}+001.00000 \mathrm{e}-01$ 1.00000e-09 1.00000e-01

Element: 13549 \# of layers: 7 
$\mathrm{Kx} \mathrm{Ky} \mathrm{Kz}$ Ss Por

3.32062e+00 3.32062e+00 3.32062e-01 1.00000e-09 2.12000e-01

$3.32062 \mathrm{e}+00$ 3.32062e+00 3.32062e-01 1.00000e-09 2.12000e-01

$3.32062 \mathrm{e}+00$ 3.32062e+00 3.32062e-01 1.00000e-09 2.12000e-01

3.32062e+00 3.32062e+00 3.32062e-01 1.00000e-09 2.12000e-01

3.32062e+00 3.32062e+00 3.32062e-01 1.00000e-09 2.12000e-01

$1.00000 \mathrm{e}-05$ 1.00000e-05 1.00000e-06 1.00000e-09 1.00000e-01

$1.00000 \mathrm{e}+001.00000 \mathrm{e}+001.00000 \mathrm{e}-011.00000 \mathrm{e}-091.00000 \mathrm{e}-01$

Element: 13550 \# of layers: 7

$\mathrm{Kx} \mathrm{Ky} \mathrm{Kz}$ Ss Por

3.32062e+00 3.32062e+00 3.32062e-01 1.00000e-09 2.12000e-01

$3.32062 \mathrm{e}+003.32062 \mathrm{e}+00$ 3.32062e-01 1.00000e-09 2.12000e-01

$3.32062 \mathrm{e}+00$ 3.32062e+00 3.32062e-01 1.00000e-09 2.12000e-01

$3.32062 \mathrm{e}+00$ 3.32062e+00 3.32062e-01 1.00000e-09 2.12000e-01

3.32062e+00 3.32062e+00 3.32062e-01 1.00000e-09 2.12000e-01

$1.00000 \mathrm{e}-05$ 1.00000e-05 1.00000e-06 1.00000e-09 1.00000e-01

$1.00000 \mathrm{e}+001.00000 \mathrm{e}+001.00000 \mathrm{e}-01$ 1.00000e-09 1.00000e-01

Element: 13551 \# of layers: 7

$\mathrm{Kx} \mathrm{Ky} \mathrm{Kz}$ Ss Por

3.22724e+00 3.22724e+00 3.22724e-01 1.00000e-09 2.12000e-01

$3.22724 \mathrm{e}+003.22724 \mathrm{e}+003.22724 \mathrm{e}-01$ 1.00000e-09 2.12000e-01

$3.22724 \mathrm{e}+003.22724 \mathrm{e}+003.22724 \mathrm{e}-01$ 1.00000e-09 2.12000e-01

$3.22724 \mathrm{e}+003.22724 \mathrm{e}+003.22724 \mathrm{e}-01$ 1.00000e-09 2.12000e-01

$3.22724 \mathrm{e}+003.22724 \mathrm{e}+003.22724 \mathrm{e}-01$ 1.00000e-09 2.12000e-01

$1.00000 \mathrm{e}-051.00000 \mathrm{e}-05$ 1.00000e-06 1.00000e-09 1.00000e-01

$1.00000 \mathrm{e}+001.00000 \mathrm{e}+001.00000 \mathrm{e}-01$ 1.00000e-09 1.00000e-01

Element: 13552 \# of layers: 7

$\mathrm{Kx} \mathrm{Ky} \mathrm{Kz}$ Ss Por

$3.22724 \mathrm{e}+003.22724 \mathrm{e}+00$ 3.22724e-01 1.00000e-09 2.12000e-01

$3.22724 \mathrm{e}+003.22724 \mathrm{e}+003.22724 \mathrm{e}-01$ 1.00000e-09 2.12000e-01

$3.22724 \mathrm{e}+003.22724 \mathrm{e}+003.22724 \mathrm{e}-01$ 1.00000e-09 2.12000e-01

$3.22724 \mathrm{e}+003.22724 \mathrm{e}+00$ 3.22724e-01 1.00000e-09 2.12000e-01

$3.22724 \mathrm{e}+003.22724 \mathrm{e}+003.22724 \mathrm{e}-01$ 1.00000e-09 2.12000e-01

$1.00000 \mathrm{e}-05$ 1.00000e-05 1.00000e-06 1.00000e-09 1.00000e-01

$1.00000 \mathrm{e}+001.00000 \mathrm{e}+001.00000 \mathrm{e}-011.00000 \mathrm{e}-091.00000 \mathrm{e}-01$

Element: 13553 \# of layers: 7

Kx Ky Kz Ss Por

$3.22724 \mathrm{e}+003.22724 \mathrm{e}+00$ 3.22724e-01 1.00000e-09 2.12000e-01

$3.22724 \mathrm{e}+003.22724 \mathrm{e}+003.22724 \mathrm{e}-01$ 1.00000e-09 2.12000e-01

$3.22724 \mathrm{e}+003.22724 \mathrm{e}+003.22724 \mathrm{e}-01$ 1.00000e-09 2.12000e-01

$3.22724 \mathrm{e}+003.22724 \mathrm{e}+003.22724 \mathrm{e}-01$ 1.00000e-09 2.12000e-01

$3.22724 \mathrm{e}+003.22724 \mathrm{e}+003.22724 \mathrm{e}-01$ 1.00000e-09 2.12000e-01

$1.00000 \mathrm{e}-05$ 1.00000e-05 1.00000e-06 1.00000e-09 1.00000e-01

$1.00000 \mathrm{e}+001.00000 \mathrm{e}+001.00000 \mathrm{e}-01$ 1.00000e-09 1.00000e-01

Element: 13554 \# of layers: 7

Kx Ky Kz Ss Por 
$3.32062 \mathrm{e}+003.32062 \mathrm{e}+00$ 3.32062e-01 1.00000e-09 2.12000e-01 $3.32062 \mathrm{e}+003.32062 \mathrm{e}+003.32062 \mathrm{e}-01$ 1.00000e-09 2.12000e-01 $3.32062 \mathrm{e}+003.32062 \mathrm{e}+003.32062 \mathrm{e}-01$ 1.00000e-09 2.12000e-01 $3.32062 \mathrm{e}+003.32062 \mathrm{e}+003.32062 \mathrm{e}-01$ 1.00000e-09 2.12000e-01 $3.32062 \mathrm{e}+003.32062 \mathrm{e}+003.32062 \mathrm{e}-01$ 1.00000e-09 2.12000e-01 $1.00000 \mathrm{e}-05$ 1.00000e-05 1.00000e-06 1.00000e-09 1.00000e-01 $1.00000 \mathrm{e}+001.00000 \mathrm{e}+001.00000 \mathrm{e}-011.00000 \mathrm{e}-091.00000 \mathrm{e}-01$ Element: 13555 \# of layers: 7

Kx Ky Kz Ss Por

3.32062e+00 3.32062e+00 3.32062e-01 1.00000e-09 2.12000e-01 $3.32062 \mathrm{e}+003.32062 \mathrm{e}+003.32062 \mathrm{e}-01$ 1.00000e-09 2.12000e-01 $3.32062 \mathrm{e}+003.32062 \mathrm{e}+003.32062 \mathrm{e}-01$ 1.00000e-09 2.12000e-01 $3.32062 \mathrm{e}+003.32062 \mathrm{e}+003.32062 \mathrm{e}-01$ 1.00000e-09 2.12000e-01 $3.32062 \mathrm{e}+003.32062 \mathrm{e}+003.32062 \mathrm{e}-01$ 1.00000e-09 2.12000e-01 $1.00000 \mathrm{e}-05$ 1.00000e-05 1.00000e-06 1.00000e-09 1.00000e-01 $1.00000 \mathrm{e}+001.00000 \mathrm{e}+001.00000 \mathrm{e}-011.00000 \mathrm{e}-091.00000 \mathrm{e}-01$ Element: 13556 \# of layers: 7

Kx Ky Kz Ss Por

3.32062e+00 3.32062e+00 3.32062e-01 1.00000e-09 2.12000e-01 $3.32062 \mathrm{e}+003.32062 \mathrm{e}+003.32062 \mathrm{e}-01$ 1.00000e-09 2.12000e-01 $3.32062 \mathrm{e}+003.32062 \mathrm{e}+003.32062 \mathrm{e}-01$ 1.00000e-09 2.12000e-01 $3.32062 \mathrm{e}+003.32062 \mathrm{e}+003.32062 \mathrm{e}-01$ 1.00000e-09 2.12000e-01 $3.32062 \mathrm{e}+003.32062 \mathrm{e}+003.32062 \mathrm{e}-011.00000 \mathrm{e}-092.12000 \mathrm{e}-01$ $1.00000 \mathrm{e}-05$ 1.00000e-05 1.00000e-06 1.00000e-09 1.00000e-01 $1.00000 \mathrm{e}+001.00000 \mathrm{e}+001.00000 \mathrm{e}-011.00000 \mathrm{e}-091.00000 \mathrm{e}-01$ Element: 13557 \# of layers: 7

Kx Ky Kz Ss Por

3.32062e+00 3.32062e+00 3.32062e-01 1.00000e-09 2.12000e-01 $3.32062 \mathrm{e}+003.32062 \mathrm{e}+003.32062 \mathrm{e}-01$ 1.00000e-09 2.12000e-01 $3.32062 \mathrm{e}+003.32062 \mathrm{e}+003.32062 \mathrm{e}-01$ 1.00000e-09 2.12000e-01 $3.32062 \mathrm{e}+003.32062 \mathrm{e}+003.32062 \mathrm{e}-01$ 1.00000e-09 2.12000e-01 $3.32062 \mathrm{e}+003.32062 \mathrm{e}+003.32062 \mathrm{e}-01$ 1.00000e-09 2.12000e-01 $1.00000 \mathrm{e}-05$ 1.00000e-05 1.00000e-06 1.00000e-09 1.00000e-01 $1.00000 \mathrm{e}+001.00000 \mathrm{e}+001.00000 \mathrm{e}-011.00000 \mathrm{e}-091.00000 \mathrm{e}-01$ Element: 13558 \# of layers: 7

Kx Ky Kz Ss Por

$3.22724 \mathrm{e}+003.22724 \mathrm{e}+003.22724 \mathrm{e}-01$ 1.00000e-09 2.12000e-01 $3.22724 \mathrm{e}+003.22724 \mathrm{e}+003.22724 \mathrm{e}-011.00000 \mathrm{e}-092.12000 \mathrm{e}-01$ $3.22724 \mathrm{e}+003.22724 \mathrm{e}+003.22724 \mathrm{e}-01$ 1.00000e-09 2.12000e-01 $3.22724 \mathrm{e}+003.22724 \mathrm{e}+003.22724 \mathrm{e}-011.00000 \mathrm{e}-092.12000 \mathrm{e}-01$ $3.22724 \mathrm{e}+003.22724 \mathrm{e}+003.22724 \mathrm{e}-01$ 1.00000e-09 2.12000e-01 $1.00000 \mathrm{e}-05$ 1.00000e-05 1.00000e-06 1.00000e-09 1.00000e-01 $1.00000 \mathrm{e}+001.00000 \mathrm{e}+001.00000 \mathrm{e}-011.00000 \mathrm{e}-091.00000 \mathrm{e}-01$ Element: 13559 \# of layers: 7

Kx Ky Kz Ss Por

3.22724e+00 3.22724e+00 3.22724e-01 1.00000e-09 2.12000e-01 
$3.22724 \mathrm{e}+003.22724 \mathrm{e}+003.22724 \mathrm{e}-01$ 1.00000e-09 2.12000e-01 $3.22724 \mathrm{e}+003.22724 \mathrm{e}+003.22724 \mathrm{e}-01$ 1.00000e-09 2.12000e-01 $3.22724 \mathrm{e}+003.22724 \mathrm{e}+003.22724 \mathrm{e}-011.00000 \mathrm{e}-092.12000 \mathrm{e}-01$ $3.22724 \mathrm{e}+003.22724 \mathrm{e}+003.22724 \mathrm{e}-011.00000 \mathrm{e}-092.12000 \mathrm{e}-01$ $1.00000 \mathrm{e}-05$ 1.00000e-05 1.00000e-06 1.00000e-09 1.00000e-01 $1.00000 \mathrm{e}+001.00000 \mathrm{e}+001.00000 \mathrm{e}-011.00000 \mathrm{e}-091.00000 \mathrm{e}-01$ Element: 13560 \# of layers: 7

Kx Ky Kz Ss Por

$3.22724 \mathrm{e}+003.22724 \mathrm{e}+00$ 3.22724e-01 1.00000e-09 2.12000e-01 $3.22724 \mathrm{e}+003.22724 \mathrm{e}+003.22724 \mathrm{e}-011.00000 \mathrm{e}-092.12000 \mathrm{e}-01$ $3.22724 \mathrm{e}+003.22724 \mathrm{e}+003.22724 \mathrm{e}-011.00000 \mathrm{e}-092.12000 \mathrm{e}-01$ $3.22724 \mathrm{e}+003.22724 \mathrm{e}+003.22724 \mathrm{e}-011.00000 \mathrm{e}-092.12000 \mathrm{e}-01$ $3.22724 \mathrm{e}+003.22724 \mathrm{e}+003.22724 \mathrm{e}-01$ 1.00000e-09 2.12000e-01 $1.00000 \mathrm{e}-05$ 1.00000e-05 1.00000e-06 1.00000e-09 1.00000e-01 $1.00000 \mathrm{e}+001.00000 \mathrm{e}+001.00000 \mathrm{e}-011.00000 \mathrm{e}-091.00000 \mathrm{e}-01$ Element: 13561 \# of layers: 7

Kx Ky Kz Ss Por

$3.22724 \mathrm{e}+003.22724 \mathrm{e}+003.22724 \mathrm{e}-01$ 1.00000e-09 2.12000e-01 $3.22724 \mathrm{e}+003.22724 \mathrm{e}+003.22724 \mathrm{e}-011.00000 \mathrm{e}-092.12000 \mathrm{e}-01$ $3.22724 \mathrm{e}+003.22724 \mathrm{e}+003.22724 \mathrm{e}-011.00000 \mathrm{e}-092.12000 \mathrm{e}-01$ $3.22724 \mathrm{e}+003.22724 \mathrm{e}+003.22724 \mathrm{e}-011.00000 \mathrm{e}-092.12000 \mathrm{e}-01$ $3.22724 \mathrm{e}+003.22724 \mathrm{e}+003.22724 \mathrm{e}-011.00000 \mathrm{e}-092.12000 \mathrm{e}-01$ $1.00000 \mathrm{e}-05$ 1.00000e-05 1.00000e-06 1.00000e-09 1.00000e-01 $1.00000 \mathrm{e}+001.00000 \mathrm{e}+001.00000 \mathrm{e}-011.00000 \mathrm{e}-091.00000 \mathrm{e}-01$ Element: 13562 \# of layers: 7

Kx Ky Kz Ss Por

$3.22724 \mathrm{e}+003.22724 \mathrm{e}+00$ 3.22724e-01 1.00000e-09 2.12000e-01 $3.22724 \mathrm{e}+003.22724 \mathrm{e}+003.22724 \mathrm{e}-011.00000 \mathrm{e}-092.12000 \mathrm{e}-01$ $3.22724 \mathrm{e}+003.22724 \mathrm{e}+003.22724 \mathrm{e}-011.00000 \mathrm{e}-092.12000 \mathrm{e}-01$ $3.22724 \mathrm{e}+003.22724 \mathrm{e}+003.22724 \mathrm{e}-011.00000 \mathrm{e}-09$ 2.12000e-01 $3.22724 \mathrm{e}+003.22724 \mathrm{e}+003.22724 \mathrm{e}-01$ 1.00000e-09 2.12000e-01 $1.00000 \mathrm{e}-05$ 1.00000e-05 1.00000e-06 1.00000e-09 1.00000e-01 $1.00000 \mathrm{e}+001.00000 \mathrm{e}+001.00000 \mathrm{e}-011.00000 \mathrm{e}-091.00000 \mathrm{e}-01$ Element: 13563 \# of layers: 7

Kx Ky Kz Ss Por

$3.22724 \mathrm{e}+003.22724 \mathrm{e}+003.22724 \mathrm{e}-01$ 1.00000e-09 2.12000e-01 $3.22724 \mathrm{e}+003.22724 \mathrm{e}+003.22724 \mathrm{e}-011.00000 \mathrm{e}-092.12000 \mathrm{e}-01$ $3.22724 \mathrm{e}+003.22724 \mathrm{e}+003.22724 \mathrm{e}-011.00000 \mathrm{e}-092.12000 \mathrm{e}-01$ $3.22724 \mathrm{e}+003.22724 \mathrm{e}+003.22724 \mathrm{e}-01$ 1.00000e-09 2.12000e-01 $3.22724 \mathrm{e}+003.22724 \mathrm{e}+003.22724 \mathrm{e}-011.00000 \mathrm{e}-092.12000 \mathrm{e}-01$ $1.00000 \mathrm{e}-05$ 1.00000e-05 1.00000e-06 1.00000e-09 1.00000e-01 $1.00000 \mathrm{e}+001.00000 \mathrm{e}+001.00000 \mathrm{e}-011.00000 \mathrm{e}-091.00000 \mathrm{e}-01$ Element: 13564 \# of layers: 7

Kx Ky Kz Ss Por

$3.22724 \mathrm{e}+003.22724 \mathrm{e}+003.22724 \mathrm{e}-01$ 1.00000e-09 2.12000e-01 $3.22724 \mathrm{e}+003.22724 \mathrm{e}+003.22724 \mathrm{e}-01$ 1.00000e-09 2.12000e-01 
$3.22724 \mathrm{e}+003.22724 \mathrm{e}+003.22724 \mathrm{e}-01$ 1.00000e-09 2.12000e-01 $3.22724 \mathrm{e}+003.22724 \mathrm{e}+003.22724 \mathrm{e}-01$ 1.00000e-09 2.12000e-01 $3.22724 \mathrm{e}+003.22724 \mathrm{e}+003.22724 \mathrm{e}-01$ 1.00000e-09 2.12000e-01 $1.00000 \mathrm{e}-05$ 1.00000e-05 1.00000e-06 1.00000e-09 1.00000e-01 $1.00000 \mathrm{e}+001.00000 \mathrm{e}+001.00000 \mathrm{e}-011.00000 \mathrm{e}-091.00000 \mathrm{e}-01$ Element: 13565 \# of layers: 7

Kx Ky Kz Ss Por

$3.22724 \mathrm{e}+003.22724 \mathrm{e}+003.22724 \mathrm{e}-01$ 1.00000e-09 2.12000e-01 $3.22724 \mathrm{e}+003.22724 \mathrm{e}+003.22724 \mathrm{e}-011.00000 \mathrm{e}-092.12000 \mathrm{e}-01$ $3.22724 \mathrm{e}+003.22724 \mathrm{e}+003.22724 \mathrm{e}-011.00000 \mathrm{e}-092.12000 \mathrm{e}-01$ $3.22724 \mathrm{e}+003.22724 \mathrm{e}+003.22724 \mathrm{e}-011.00000 \mathrm{e}-092.12000 \mathrm{e}-01$ $3.22724 \mathrm{e}+003.22724 \mathrm{e}+003.22724 \mathrm{e}-011.00000 \mathrm{e}-092.12000 \mathrm{e}-01$ $1.00000 \mathrm{e}-05$ 1.00000e-05 1.00000e-06 1.00000e-09 1.00000e-01 $1.00000 \mathrm{e}+001.00000 \mathrm{e}+001.00000 \mathrm{e}-011.00000 \mathrm{e}-091.00000 \mathrm{e}-01$ Element: 13566 \# of layers: 7

Kx Ky Kz Ss Por

$3.22724 \mathrm{e}+003.22724 \mathrm{e}+003.22724 \mathrm{e}-01$ 1.00000e-09 2.12000e-01 $3.22724 \mathrm{e}+003.22724 \mathrm{e}+003.22724 \mathrm{e}-011.00000 \mathrm{e}-092.12000 \mathrm{e}-01$ $3.22724 \mathrm{e}+003.22724 \mathrm{e}+003.22724 \mathrm{e}-01$ 1.00000e-09 2.12000e-01 $3.22724 \mathrm{e}+003.22724 \mathrm{e}+003.22724 \mathrm{e}-011.00000 \mathrm{e}-092.12000 \mathrm{e}-01$ $3.22724 \mathrm{e}+003.22724 \mathrm{e}+003.22724 \mathrm{e}-01$ 1.00000e-09 2.12000e-01 $1.00000 \mathrm{e}-05$ 1.00000e-05 1.00000e-06 1.00000e-09 1.00000e-01 $1.00000 \mathrm{e}+001.00000 \mathrm{e}+001.00000 \mathrm{e}-011.00000 \mathrm{e}-091.00000 \mathrm{e}-01$ Element: 13567 \# of layers: 7

Kx Ky Kz Ss Por

$3.22724 \mathrm{e}+003.22724 \mathrm{e}+003.22724 \mathrm{e}-011.00000 \mathrm{e}-092.12000 \mathrm{e}-01$ $3.22724 \mathrm{e}+003.22724 \mathrm{e}+003.22724 \mathrm{e}-01$ 1.00000e-09 2.12000e-01 $3.22724 \mathrm{e}+003.22724 \mathrm{e}+003.22724 \mathrm{e}-011.00000 \mathrm{e}-092.12000 \mathrm{e}-01$ $3.22724 \mathrm{e}+003.22724 \mathrm{e}+003.22724 \mathrm{e}-011.00000 \mathrm{e}-09$ 2.12000e-01 $3.22724 \mathrm{e}+003.22724 \mathrm{e}+003.22724 \mathrm{e}-011.00000 \mathrm{e}-092.12000 \mathrm{e}-01$ $1.00000 \mathrm{e}-05$ 1.00000e-05 1.00000e-06 1.00000e-09 1.00000e-01 $1.00000 \mathrm{e}+001.00000 \mathrm{e}+001.00000 \mathrm{e}-011.00000 \mathrm{e}-091.00000 \mathrm{e}-01$ Element: 13568 \# of layers: 7

Kx Ky Kz Ss Por

$3.22724 \mathrm{e}+003.22724 \mathrm{e}+003.22724 \mathrm{e}-01$ 1.00000e-09 2.12000e-01 $3.22724 \mathrm{e}+003.22724 \mathrm{e}+003.22724 \mathrm{e}-011.00000 \mathrm{e}-092.12000 \mathrm{e}-01$ $3.22724 \mathrm{e}+003.22724 \mathrm{e}+003.22724 \mathrm{e}-011.00000 \mathrm{e}-092.12000 \mathrm{e}-01$ $3.22724 \mathrm{e}+003.22724 \mathrm{e}+003.22724 \mathrm{e}-01$ 1.00000e-09 2.12000e-01 $3.22724 \mathrm{e}+003.22724 \mathrm{e}+003.22724 \mathrm{e}-01$ 1.00000e-09 2.12000e-01 $1.00000 \mathrm{e}-05$ 1.00000e-05 1.00000e-06 1.00000e-09 1.00000e-01 $1.00000 \mathrm{e}+001.00000 \mathrm{e}+001.00000 \mathrm{e}-011.00000 \mathrm{e}-091.00000 \mathrm{e}-01$ Element: 13569 \# of layers: 7

Kx Ky Kz Ss Por

$3.45067 \mathrm{e}+003.45067 \mathrm{e}+00$ 3.45067e-01 1.00000e-09 2.12000e-01 $3.45067 \mathrm{e}+003.45067 \mathrm{e}+003.45067 \mathrm{e}-01$ 1.00000e-09 2.12000e-01 $3.45067 \mathrm{e}+003.45067 \mathrm{e}+003.45067 \mathrm{e}-01$ 1.00000e-09 2.12000e-01 
$3.45067 \mathrm{e}+003.45067 \mathrm{e}+003.45067 \mathrm{e}-01$ 1.00000e-09 2.12000e-01 $3.45067 \mathrm{e}+003.45067 \mathrm{e}+003.45067 \mathrm{e}-01$ 1.00000e-09 2.12000e-01 $1.00000 \mathrm{e}-05$ 1.00000e-05 1.00000e-06 1.00000e-09 1.00000e-01 $1.00000 \mathrm{e}+001.00000 \mathrm{e}+001.00000 \mathrm{e}-011.00000 \mathrm{e}-091.00000 \mathrm{e}-01$ Element: 13570 \# of layers: 7

Kx Ky Kz Ss Por

$3.45067 \mathrm{e}+003.45067 \mathrm{e}+00$ 3.45067e-01 1.00000e-09 2.12000e-01 $3.45067 \mathrm{e}+003.45067 \mathrm{e}+003.45067 \mathrm{e}-011.00000 \mathrm{e}-092.12000 \mathrm{e}-01$ $3.45067 \mathrm{e}+003.45067 \mathrm{e}+003.45067 \mathrm{e}-011.00000 \mathrm{e}-092.12000 \mathrm{e}-01$ $3.45067 \mathrm{e}+003.45067 \mathrm{e}+003.45067 \mathrm{e}-011.00000 \mathrm{e}-092.12000 \mathrm{e}-01$ $3.45067 \mathrm{e}+003.45067 \mathrm{e}+003.45067 \mathrm{e}-01$ 1.00000e-09 2.12000e-01 $1.00000 \mathrm{e}-05$ 1.00000e-05 1.00000e-06 1.00000e-09 1.00000e-01 $1.00000 \mathrm{e}+001.00000 \mathrm{e}+001.00000 \mathrm{e}-011.00000 \mathrm{e}-091.00000 \mathrm{e}-01$ Element: 13571 \# of layers: 7

Kx Ky Kz Ss Por

$3.45067 \mathrm{e}+003.45067 \mathrm{e}+00$ 3.45067e-01 1.00000e-09 2.12000e-01 $3.45067 \mathrm{e}+003.45067 \mathrm{e}+003.45067 \mathrm{e}-011.00000 \mathrm{e}-092.12000 \mathrm{e}-01$ $3.45067 \mathrm{e}+003.45067 \mathrm{e}+003.45067 \mathrm{e}-01$ 1.00000e-09 2.12000e-01 $3.45067 \mathrm{e}+003.45067 \mathrm{e}+003.45067 \mathrm{e}-011.00000 \mathrm{e}-092.12000 \mathrm{e}-01$ $3.45067 \mathrm{e}+003.45067 \mathrm{e}+003.45067 \mathrm{e}-01$ 1.00000e-09 2.12000e-01 $1.00000 \mathrm{e}-05$ 1.00000e-05 1.00000e-06 1.00000e-09 1.00000e-01 $1.00000 \mathrm{e}+001.00000 \mathrm{e}+001.00000 \mathrm{e}-011.00000 \mathrm{e}-091.00000 \mathrm{e}-01$ Element: 13572 \# of layers: 7

Kx Ky Kz Ss Por

$3.22724 \mathrm{e}+003.22724 \mathrm{e}+003.22724 \mathrm{e}-01$ 1.00000e-09 2.12000e-01 $3.22724 \mathrm{e}+003.22724 \mathrm{e}+003.22724 \mathrm{e}-01$ 1.00000e-09 2.12000e-01 $3.22724 \mathrm{e}+003.22724 \mathrm{e}+003.22724 \mathrm{e}-011.00000 \mathrm{e}-092.12000 \mathrm{e}-01$ $3.22724 \mathrm{e}+003.22724 \mathrm{e}+003.22724 \mathrm{e}-011.00000 \mathrm{e}-092.12000 \mathrm{e}-01$ $3.22724 \mathrm{e}+003.22724 \mathrm{e}+003.22724 \mathrm{e}-011.00000 \mathrm{e}-092.12000 \mathrm{e}-01$ $1.00000 \mathrm{e}-05$ 1.00000e-05 1.00000e-06 1.00000e-09 1.00000e-01 $1.00000 \mathrm{e}+001.00000 \mathrm{e}+001.00000 \mathrm{e}-011.00000 \mathrm{e}-091.00000 \mathrm{e}-01$ Element: 13573 \# of layers: 7

Kx Ky Kz Ss Por

$3.22724 \mathrm{e}+003.22724 \mathrm{e}+003.22724 \mathrm{e}-01$ 1.00000e-09 2.12000e-01 $3.22724 \mathrm{e}+003.22724 \mathrm{e}+003.22724 \mathrm{e}-011.00000 \mathrm{e}-092.12000 \mathrm{e}-01$ $3.22724 \mathrm{e}+003.22724 \mathrm{e}+003.22724 \mathrm{e}-011.00000 \mathrm{e}-092.12000 \mathrm{e}-01$ $3.22724 \mathrm{e}+003.22724 \mathrm{e}+003.22724 \mathrm{e}-011.00000 \mathrm{e}-092.12000 \mathrm{e}-01$ $3.22724 \mathrm{e}+003.22724 \mathrm{e}+003.22724 \mathrm{e}-011.00000 \mathrm{e}-092.12000 \mathrm{e}-01$ $1.00000 \mathrm{e}-05$ 1.00000e-05 1.00000e-06 1.00000e-09 1.00000e-01 $1.00000 \mathrm{e}+001.00000 \mathrm{e}+001.00000 \mathrm{e}-011.00000 \mathrm{e}-091.00000 \mathrm{e}-01$ Element: 13574 \# of layers: 7

Kx Ky Kz Ss Por

$3.22724 \mathrm{e}+003.22724 \mathrm{e}+00$ 3.22724e-01 1.00000e-09 2.12000e-01 $3.22724 \mathrm{e}+003.22724 \mathrm{e}+003.22724 \mathrm{e}-011.00000 \mathrm{e}-092.12000 \mathrm{e}-01$ $3.22724 \mathrm{e}+003.22724 \mathrm{e}+003.22724 \mathrm{e}-011.00000 \mathrm{e}-092.12000 \mathrm{e}-01$ $3.22724 \mathrm{e}+003.22724 \mathrm{e}+003.22724 \mathrm{e}-01$ 1.00000e-09 2.12000e-01 
$3.22724 \mathrm{e}+003.22724 \mathrm{e}+003.22724 \mathrm{e}-01$ 1.00000e-09 2.12000e-01 $1.00000 \mathrm{e}-05$ 1.00000e-05 1.00000e-06 1.00000e-09 1.00000e-01 $1.00000 \mathrm{e}+001.00000 \mathrm{e}+001.00000 \mathrm{e}-011.00000 \mathrm{e}-091.00000 \mathrm{e}-01$ Element: 13575 \# of layers: 7

Kx Ky Kz Ss Por

$3.22724 \mathrm{e}+003.22724 \mathrm{e}+003.22724 \mathrm{e}-01$ 1.00000e-09 2.12000e-01 $3.22724 \mathrm{e}+003.22724 \mathrm{e}+003.22724 \mathrm{e}-011.00000 \mathrm{e}-092.12000 \mathrm{e}-01$ $3.22724 \mathrm{e}+003.22724 \mathrm{e}+003.22724 \mathrm{e}-011.00000 \mathrm{e}-092.12000 \mathrm{e}-01$ $3.22724 \mathrm{e}+003.22724 \mathrm{e}+003.22724 \mathrm{e}-011.00000 \mathrm{e}-092.12000 \mathrm{e}-01$ $3.22724 \mathrm{e}+003.22724 \mathrm{e}+003.22724 \mathrm{e}-01$ 1.00000e-09 2.12000e-01 $1.00000 \mathrm{e}-05$ 1.00000e-05 1.00000e-06 1.00000e-09 1.00000e-01 $1.00000 \mathrm{e}+001.00000 \mathrm{e}+001.00000 \mathrm{e}-011.00000 \mathrm{e}-091.00000 \mathrm{e}-01$ Element: 13576 \# of layers: 7

Kx Ky Kz Ss Por

$3.45067 \mathrm{e}+003.45067 \mathrm{e}+00$ 3.45067e-01 1.00000e-09 2.12000e-01 $3.45067 \mathrm{e}+003.45067 \mathrm{e}+003.45067 \mathrm{e}-01$ 1.00000e-09 2.12000e-01 $3.45067 \mathrm{e}+003.45067 \mathrm{e}+003.45067 \mathrm{e}-011.00000 \mathrm{e}-092.12000 \mathrm{e}-01$ $3.45067 \mathrm{e}+003.45067 \mathrm{e}+003.45067 \mathrm{e}-01$ 1.00000e-09 2.12000e-01 $3.45067 \mathrm{e}+003.45067 \mathrm{e}+003.45067 \mathrm{e}-01$ 1.00000e-09 2.12000e-01 $1.00000 \mathrm{e}-05$ 1.00000e-05 1.00000e-06 1.00000e-09 1.00000e-01 $1.00000 \mathrm{e}+001.00000 \mathrm{e}+001.00000 \mathrm{e}-011.00000 \mathrm{e}-091.00000 \mathrm{e}-01$ Element: 13577 \# of layers: 7

Kx Ky Kz Ss Por

$3.45067 \mathrm{e}+003.45067 \mathrm{e}+00$ 3.45067e-01 1.00000e-09 2.12000e-01 $3.45067 \mathrm{e}+003.45067 \mathrm{e}+003.45067 \mathrm{e}-011.00000 \mathrm{e}-092.12000 \mathrm{e}-01$ $3.45067 \mathrm{e}+003.45067 \mathrm{e}+003.45067 \mathrm{e}-01$ 1.00000e-09 2.12000e-01 $3.45067 \mathrm{e}+003.45067 \mathrm{e}+003.45067 \mathrm{e}-01$ 1.00000e-09 2.12000e-01 $3.45067 \mathrm{e}+003.45067 \mathrm{e}+003.45067 \mathrm{e}-011.00000 \mathrm{e}-09$ 2.12000e-01 $1.00000 \mathrm{e}-05$ 1.00000e-05 1.00000e-06 1.00000e-09 1.00000e-01 $1.00000 \mathrm{e}+001.00000 \mathrm{e}+001.00000 \mathrm{e}-011.00000 \mathrm{e}-091.00000 \mathrm{e}-01$ Element: 13578 \# of layers: 7

Kx Ky Kz Ss Por

$3.45067 \mathrm{e}+003.45067 \mathrm{e}+00$ 3.45067e-01 1.00000e-09 2.12000e-01 $3.45067 \mathrm{e}+003.45067 \mathrm{e}+003.45067 \mathrm{e}-01$ 1.00000e-09 2.12000e-01 $3.45067 \mathrm{e}+003.45067 \mathrm{e}+003.45067 \mathrm{e}-01$ 1.00000e-09 2.12000e-01 $3.45067 \mathrm{e}+003.45067 \mathrm{e}+003.45067 \mathrm{e}-01$ 1.00000e-09 2.12000e-01 $3.45067 \mathrm{e}+003.45067 \mathrm{e}+003.45067 \mathrm{e}-01$ 1.00000e-09 2.12000e-01 $1.00000 \mathrm{e}-05$ 1.00000e-05 1.00000e-06 1.00000e-09 1.00000e-01 $1.00000 \mathrm{e}+001.00000 \mathrm{e}+001.00000 \mathrm{e}-011.00000 \mathrm{e}-091.00000 \mathrm{e}-01$ Element: 13579 \# of layers: 7

Kx Ky Kz Ss Por $3.45067 \mathrm{e}+003.45067 \mathrm{e}+00$ 3.45067e-01 1.00000e-09 2.12000e-01 $3.45067 \mathrm{e}+003.45067 \mathrm{e}+003.45067 \mathrm{e}-011.00000 \mathrm{e}-09$ 2.12000e-01 $3.45067 \mathrm{e}+003.45067 \mathrm{e}+003.45067 \mathrm{e}-01$ 1.00000e-09 2.12000e-01 $3.45067 \mathrm{e}+003.45067 \mathrm{e}+003.45067 \mathrm{e}-01$ 1.00000e-09 2.12000e-01 $3.45067 \mathrm{e}+003.45067 \mathrm{e}+003.45067 \mathrm{e}-01$ 1.00000e-09 2.12000e-01 
$1.00000 \mathrm{e}-05$ 1.00000e-05 1.00000e-06 1.00000e-09 1.00000e-01 $1.00000 \mathrm{e}+001.00000 \mathrm{e}+001.00000 \mathrm{e}-01$ 1.00000e-09 1.00000e-01 Element: 13580 \# of layers: 7

Kx Ky Kz Ss Por

3.45067e+00 3.45067e+00 3.45067e-01 1.00000e-09 2.12000e-01

$3.45067 \mathrm{e}+003.45067 \mathrm{e}+00$ 3.45067e-01 1.00000e-09 2.12000e-01

$3.45067 \mathrm{e}+003.45067 \mathrm{e}+00$ 3.45067e-01 1.00000e-09 2.12000e-01

$3.45067 \mathrm{e}+003.45067 \mathrm{e}+003.45067 \mathrm{e}-01$ 1.00000e-09 2.12000e-01

$3.45067 \mathrm{e}+003.45067 \mathrm{e}+003.45067 \mathrm{e}-01$ 1.00000e-09 2.12000e-01

$1.00000 \mathrm{e}-05$ 1.00000e-05 1.00000e-06 1.00000e-09 1.00000e-01

$1.00000 \mathrm{e}+001.00000 \mathrm{e}+001.00000 \mathrm{e}-01$ 1.00000e-09 1.00000e-01

Element: 13581 \# of layers: 7

Kx Ky Kz Ss Por

3.45067e+00 3.45067e+00 3.45067e-01 1.00000e-09 2.12000e-01

3.45067e+00 3.45067e+00 3.45067e-01 1.00000e-09 2.12000e-01

$3.45067 \mathrm{e}+003.45067 \mathrm{e}+00$ 3.45067e-01 1.00000e-09 2.12000e-01

$3.45067 \mathrm{e}+003.45067 \mathrm{e}+003.45067 \mathrm{e}-01$ 1.00000e-09 2.12000e-01

3.45067e+00 3.45067e+00 3.45067e-01 1.00000e-09 2.12000e-01

$1.00000 \mathrm{e}-05$ 1.00000e-05 1.00000e-06 1.00000e-09 1.00000e-01

$1.00000 \mathrm{e}+001.00000 \mathrm{e}+001.00000 \mathrm{e}-011.00000 \mathrm{e}-09$ 1.00000e-01

Element: 13582 \# of layers: 7

$\mathrm{Kx} \mathrm{Ky} \mathrm{Kz}$ Ss Por

3.45067e+00 3.45067e+00 3.45067e-01 1.00000e-09 2.12000e-01

$3.45067 \mathrm{e}+003.45067 \mathrm{e}+00$ 3.45067e-01 1.00000e-09 2.12000e-01

$3.45067 \mathrm{e}+003.45067 \mathrm{e}+00$ 3.45067e-01 1.00000e-09 2.12000e-01

$3.45067 \mathrm{e}+003.45067 \mathrm{e}+00$ 3.45067e-01 1.00000e-09 2.12000e-01

$3.45067 \mathrm{e}+003.45067 \mathrm{e}+00$ 3.45067e-01 1.00000e-09 2.12000e-01

$1.00000 \mathrm{e}-05$ 1.00000e-05 1.00000e-06 1.00000e-09 1.00000e-01

$1.00000 \mathrm{e}+001.00000 \mathrm{e}+001.00000 \mathrm{e}-011.00000 \mathrm{e}-091.00000 \mathrm{e}-01$

Element: 13583 \# of layers: 7

$\mathrm{Kx} \mathrm{Ky} \mathrm{Kz} \mathrm{Ss} \mathrm{Por}$

3.45067e+00 3.45067e+00 3.45067e-01 1.00000e-09 2.12000e-01

$3.45067 \mathrm{e}+003.45067 \mathrm{e}+00$ 3.45067e-01 1.00000e-09 2.12000e-01

$3.45067 \mathrm{e}+003.45067 \mathrm{e}+00$ 3.45067e-01 1.00000e-09 2.12000e-01

$3.45067 \mathrm{e}+003.45067 \mathrm{e}+003.45067 \mathrm{e}-01$ 1.00000e-09 2.12000e-01

3.45067e+00 3.45067e+00 3.45067e-01 1.00000e-09 2.12000e-01

1.00000e-05 1.00000e-05 1.00000e-06 1.00000e-09 1.00000e-01

$1.00000 \mathrm{e}+001.00000 \mathrm{e}+001.00000 \mathrm{e}-011.00000 \mathrm{e}-091.00000 \mathrm{e}-01$

Element: 13584 \# of layers: 7

$\mathrm{Kx} \mathrm{Ky} \mathrm{Kz}$ Ss Por

3.45067e+00 3.45067e+00 3.45067e-01 1.00000e-09 2.12000e-01

$3.45067 \mathrm{e}+00$ 3.45067e+00 3.45067e-01 1.00000e-09 2.12000e-01

$3.45067 \mathrm{e}+003.45067 \mathrm{e}+00$ 3.45067e-01 1.00000e-09 2.12000e-01

$3.45067 \mathrm{e}+003.45067 \mathrm{e}+003.45067 \mathrm{e}-01$ 1.00000e-09 2.12000e-01

$3.45067 \mathrm{e}+003.45067 \mathrm{e}+00$ 3.45067e-01 1.00000e-09 2.12000e-01

$1.00000 \mathrm{e}-05$ 1.00000e-05 1.00000e-06 1.00000e-09 1.00000e-01 
$1.00000 \mathrm{e}+001.00000 \mathrm{e}+001.00000 \mathrm{e}-011.00000 \mathrm{e}-091.00000 \mathrm{e}-01$ Element: 13585 \# of layers: 7

Kx Ky Kz Ss Por

3.45067e+00 3.45067e+00 3.45067e-01 1.00000e-09 2.12000e-01

$3.45067 \mathrm{e}+003.45067 \mathrm{e}+00$ 3.45067e-01 1.00000e-09 2.12000e-01

$3.45067 \mathrm{e}+00$ 3.45067e+00 3.45067e-01 1.00000e-09 2.12000e-01

$3.45067 \mathrm{e}+00$ 3.45067e+00 3.45067e-01 1.00000e-09 2.12000e-01

$3.45067 \mathrm{e}+003.45067 \mathrm{e}+00$ 3.45067e-01 1.00000e-09 2.12000e-01

$1.00000 \mathrm{e}-05$ 1.00000e-05 1.00000e-06 1.00000e-09 1.00000e-01

$1.00000 \mathrm{e}+001.00000 \mathrm{e}+001.00000 \mathrm{e}-01$ 1.00000e-09 1.00000e-01

Element: 13586 \# of layers: 7

Kx Ky Kz Ss Por

5.36412e+00 5.36412e+00 5.36412e-01 1.00000e-09 2.12000e-01

$5.36412 \mathrm{e}+005.36412 \mathrm{e}+00$ 5.36412e-01 1.00000e-09 2.12000e-01

$5.36412 \mathrm{e}+005.36412 \mathrm{e}+00$ 5.36412e-01 1.00000e-09 2.12000e-01

$5.36412 \mathrm{e}+005.36412 \mathrm{e}+00$ 5.36412e-01 1.00000e-09 2.12000e-01

$5.36412 \mathrm{e}+00$ 5.36412e+00 5.36412e-01 1.00000e-09 2.12000e-01

$1.00000 \mathrm{e}-05$ 1.00000e-05 1.00000e-06 1.00000e-09 1.00000e-01

$1.00000 \mathrm{e}+001.00000 \mathrm{e}+001.00000 \mathrm{e}-01$ 1.00000e-09 1.00000e-01

Element: 13587 \# of layers: 7

Kx Ky Kz Ss Por

5.36412e+00 5.36412e+00 5.36412e-01 1.00000e-09 2.12000e-01

$5.36412 \mathrm{e}+00$ 5.36412e+00 5.36412e-01 1.00000e-09 2.12000e-01

5.36412e+00 5.36412e+00 5.36412e-01 1.00000e-09 2.12000e-01

$5.36412 \mathrm{e}+00$ 5.36412e+00 5.36412e-01 1.00000e-09 2.12000e-01

5.36412e+00 5.36412e+00 5.36412e-01 1.00000e-09 2.12000e-01

$1.00000 \mathrm{e}-05$ 1.00000e-05 1.00000e-06 1.00000e-09 1.00000e-01

$1.00000 \mathrm{e}+001.00000 \mathrm{e}+001.00000 \mathrm{e}-01$ 1.00000e-09 1.00000e-01

Element: 13588 \# of layers: 7

$\mathrm{Kx} \mathrm{Ky} \mathrm{Kz}$ Ss Por

5.36412e+00 5.36412e+00 5.36412e-01 1.00000e-09 2.12000e-01

$5.36412 \mathrm{e}+00$ 5.36412e+00 5.36412e-01 1.00000e-09 2.12000e-01

$5.36412 \mathrm{e}+00$ 5.36412e+00 5.36412e-01 1.00000e-09 2.12000e-01

5.36412e+00 5.36412e+00 5.36412e-01 1.00000e-09 2.12000e-01

$5.36412 \mathrm{e}+00$ 5.36412e+00 5.36412e-01 1.00000e-09 2.12000e-01

$1.00000 \mathrm{e}-05$ 1.00000e-05 1.00000e-06 1.00000e-09 1.00000e-01

$1.00000 \mathrm{e}+001.00000 \mathrm{e}+001.00000 \mathrm{e}-011.00000 \mathrm{e}-091.00000 \mathrm{e}-01$

Element: 13589 \# of layers: 7

$\mathrm{Kx} \mathrm{Ky} \mathrm{Kz}$ Ss Por

5.36412e+00 5.36412e+00 5.36412e-01 1.00000e-09 2.12000e-01

$5.36412 \mathrm{e}+00$ 5.36412e+00 5.36412e-01 1.00000e-09 2.12000e-01

$5.36412 \mathrm{e}+00$ 5.36412e+00 5.36412e-01 1.00000e-09 2.12000e-01

5.36412e+00 5.36412e+00 5.36412e-01 1.00000e-09 2.12000e-01

$5.36412 \mathrm{e}+005.36412 \mathrm{e}+00$ 5.36412e-01 1.00000e-09 2.12000e-01 $1.00000 \mathrm{e}-05$ 1.00000e-05 1.00000e-06 1.00000e-09 1.00000e-01

$1.00000 \mathrm{e}+001.00000 \mathrm{e}+001.00000 \mathrm{e}-011.00000 \mathrm{e}-091.00000 \mathrm{e}-01$ 
Element: 13590 \# of layers: 7

$\mathrm{Kx} \mathrm{Ky} \mathrm{Kz}$ Ss Por

5.36412e+00 5.36412e+00 5.36412e-01 1.00000e-09 2.12000e-01

$5.36412 \mathrm{e}+00$ 5.36412e+00 5.36412e-01 1.00000e-09 2.12000e-01

5.36412e+00 5.36412e+00 5.36412e-01 1.00000e-09 2.12000e-01

$5.36412 \mathrm{e}+005.36412 \mathrm{e}+005.36412 \mathrm{e}-01$ 1.00000e-09 2.12000e-01

5.36412e+00 5.36412e+00 5.36412e-01 1.00000e-09 2.12000e-01

$1.00000 \mathrm{e}-05$ 1.00000e-05 1.00000e-06 1.00000e-09 1.00000e-01

$1.00000 \mathrm{e}+001.00000 \mathrm{e}+001.00000 \mathrm{e}-011.00000 \mathrm{e}-091.00000 \mathrm{e}-01$

Element: 13591 \# of layers: 7

$\mathrm{Kx} \mathrm{Ky} \mathrm{Kz}$ Ss Por

3.45067e+00 3.45067e+00 3.45067e-01 1.00000e-09 2.12000e-01

3.45067e+00 3.45067e+00 3.45067e-01 1.00000e-09 2.12000e-01

3.45067e+00 3.45067e+00 3.45067e-01 1.00000e-09 2.12000e-01

3.45067e+00 3.45067e+00 3.45067e-01 1.00000e-09 2.12000e-01

$3.45067 \mathrm{e}+003.45067 \mathrm{e}+003.45067 \mathrm{e}-01$ 1.00000e-09 2.12000e-01

$1.00000 \mathrm{e}-05$ 1.00000e-05 1.00000e-06 1.00000e-09 1.00000e-01

$1.00000 \mathrm{e}+001.00000 \mathrm{e}+001.00000 \mathrm{e}-01$ 1.00000e-09 1.00000e-01

Element: 13592 \# of layers: 7

$\mathrm{Kx} \mathrm{Ky} \mathrm{Kz}$ Ss Por

3.45067e+00 3.45067e+00 3.45067e-01 1.00000e-09 2.12000e-01

3.45067e+00 3.45067e+00 3.45067e-01 1.00000e-09 2.12000e-01

3.45067e+00 3.45067e+00 3.45067e-01 1.00000e-09 2.12000e-01

$3.45067 \mathrm{e}+003.45067 \mathrm{e}+00$ 3.45067e-01 1.00000e-09 2.12000e-01

$3.45067 \mathrm{e}+003.45067 \mathrm{e}+00$ 3.45067e-01 1.00000e-09 2.12000e-01

$1.00000 \mathrm{e}-05$ 1.00000e-05 1.00000e-06 1.00000e-09 1.00000e-01

$1.00000 \mathrm{e}+001.00000 \mathrm{e}+001.00000 \mathrm{e}-011.00000 \mathrm{e}-091.00000 \mathrm{e}-01$

Element: 13593 \# of layers: 7

Kx Ky Kz Ss Por

5.36412e+00 5.36412e+00 5.36412e-01 1.00000e-09 2.12000e-01

5.36412e+00 5.36412e+00 5.36412e-01 1.00000e-09 2.12000e-01

5.36412e+00 5.36412e+00 5.36412e-01 1.00000e-09 2.12000e-01

$5.36412 \mathrm{e}+005.36412 \mathrm{e}+00$ 5.36412e-01 1.00000e-09 2.12000e-01

5.36412e+00 5.36412e+00 5.36412e-01 1.00000e-09 2.12000e-01

$1.00000 \mathrm{e}-05$ 1.00000e-05 1.00000e-06 1.00000e-09 1.00000e-01

$1.00000 \mathrm{e}+001.00000 \mathrm{e}+001.00000 \mathrm{e}-011.00000 \mathrm{e}-091.00000 \mathrm{e}-01$

Element: 13594 \# of layers: 7

$\mathrm{Kx} \mathrm{Ky} \mathrm{Kz}$ Ss Por

5.36412e+00 5.36412e+00 5.36412e-01 1.00000e-09 2.12000e-01

5.36412e+00 5.36412e+00 5.36412e-01 1.00000e-09 2.12000e-01

$5.36412 \mathrm{e}+005.36412 \mathrm{e}+00$ 5.36412e-01 1.00000e-09 2.12000e-01

5.36412e+00 5.36412e+00 5.36412e-01 1.00000e-09 2.12000e-01

5.36412e+00 5.36412e+00 5.36412e-01 1.00000e-09 2.12000e-01

$1.00000 \mathrm{e}-05$ 1.00000e-05 1.00000e-06 1.00000e-09 1.00000e-01

$1.00000 \mathrm{e}+001.00000 \mathrm{e}+001.00000 \mathrm{e}-011.00000 \mathrm{e}-091.00000 \mathrm{e}-01$

Element: 13595 \# of layers: 7 
$\mathrm{Kx} \mathrm{Ky} \mathrm{Kz}$ Ss Por

3.32062e+00 3.32062e+00 3.32062e-01 1.00000e-09 2.12000e-01

$3.32062 \mathrm{e}+00$ 3.32062e+00 3.32062e-01 1.00000e-09 2.12000e-01

$3.32062 \mathrm{e}+00$ 3.32062e+00 3.32062e-01 1.00000e-09 2.12000e-01

3.32062e+00 3.32062e+00 3.32062e-01 1.00000e-09 2.12000e-01

3.32062e+00 3.32062e+00 3.32062e-01 1.00000e-09 2.12000e-01

$1.00000 \mathrm{e}-051.00000 \mathrm{e}-051.00000 \mathrm{e}-061.00000 \mathrm{e}-091.00000 \mathrm{e}-01$

$1.00000 \mathrm{e}+001.00000 \mathrm{e}+001.00000 \mathrm{e}-011.00000 \mathrm{e}-091.00000 \mathrm{e}-01$

Element: 13596 \# of layers: 7

$\mathrm{Kx} \mathrm{Ky} \mathrm{Kz}$ Ss Por

3.32062e+00 3.32062e+00 3.32062e-01 1.00000e-09 2.12000e-01

$3.32062 \mathrm{e}+003.32062 \mathrm{e}+00$ 3.32062e-01 1.00000e-09 2.12000e-01

$3.32062 \mathrm{e}+00$ 3.32062e+00 3.32062e-01 1.00000e-09 2.12000e-01

$3.32062 \mathrm{e}+00$ 3.32062e+00 3.32062e-01 1.00000e-09 2.12000e-01

3.32062e+00 3.32062e+00 3.32062e-01 1.00000e-09 2.12000e-01

$1.00000 \mathrm{e}-05$ 1.00000e-05 1.00000e-06 1.00000e-09 1.00000e-01

$1.00000 \mathrm{e}+001.00000 \mathrm{e}+001.00000 \mathrm{e}-01$ 1.00000e-09 1.00000e-01

Element: 13597 \# of layers: 7

$\mathrm{Kx} \mathrm{Ky} \mathrm{Kz}$ Ss Por

3.32062e+00 3.32062e+00 3.32062e-01 1.00000e-09 2.12000e-01

$3.32062 \mathrm{e}+003.32062 \mathrm{e}+00$ 3.32062e-01 1.00000e-09 2.12000e-01

3.32062e+00 3.32062e+00 3.32062e-01 1.00000e-09 2.12000e-01

3.32062e+00 3.32062e+00 3.32062e-01 1.00000e-09 2.12000e-01

$3.32062 \mathrm{e}+003.32062 \mathrm{e}+00$ 3.32062e-01 1.00000e-09 2.12000e-01

$1.00000 \mathrm{e}-05$ 1.00000e-05 1.00000e-06 1.00000e-09 1.00000e-01

$1.00000 \mathrm{e}+001.00000 \mathrm{e}+001.00000 \mathrm{e}-01$ 1.00000e-09 1.00000e-01

Element: 13598 \# of layers: 7

$\mathrm{Kx} \mathrm{Ky} \mathrm{Kz}$ Ss Por

$3.22724 \mathrm{e}+003.22724 \mathrm{e}+00$ 3.22724e-01 1.00000e-09 2.12000e-01

$3.22724 \mathrm{e}+003.22724 \mathrm{e}+003.22724 \mathrm{e}-01$ 1.00000e-09 2.12000e-01

$3.22724 \mathrm{e}+003.22724 \mathrm{e}+003.22724 \mathrm{e}-01$ 1.00000e-09 2.12000e-01

$3.22724 \mathrm{e}+003.22724 \mathrm{e}+00$ 3.22724e-01 1.00000e-09 2.12000e-01

$3.22724 \mathrm{e}+003.22724 \mathrm{e}+003.22724 \mathrm{e}-01$ 1.00000e-09 2.12000e-01

$1.00000 \mathrm{e}-05$ 1.00000e-05 1.00000e-06 1.00000e-09 1.00000e-01

$1.00000 \mathrm{e}+001.00000 \mathrm{e}+001.00000 \mathrm{e}-01$ 1.00000e-09 1.00000e-01

Element: 13599 \# of layers: 7

Kx Ky Kz Ss Por

$3.22724 \mathrm{e}+003.22724 \mathrm{e}+00$ 3.22724e-01 1.00000e-09 2.12000e-01

$3.22724 \mathrm{e}+003.22724 \mathrm{e}+003.22724 \mathrm{e}-01$ 1.00000e-09 2.12000e-01

$3.22724 \mathrm{e}+003.22724 \mathrm{e}+003.22724 \mathrm{e}-01$ 1.00000e-09 2.12000e-01

$3.22724 \mathrm{e}+003.22724 \mathrm{e}+003.22724 \mathrm{e}-01$ 1.00000e-09 2.12000e-01

$3.22724 \mathrm{e}+003.22724 \mathrm{e}+003.22724 \mathrm{e}-01$ 1.00000e-09 2.12000e-01

$1.00000 \mathrm{e}-05$ 1.00000e-05 1.00000e-06 1.00000e-09 1.00000e-01

$1.00000 \mathrm{e}+001.00000 \mathrm{e}+001.00000 \mathrm{e}-01$ 1.00000e-09 1.00000e-01

Element: 13600 \# of layers: 7

Kx Ky Kz Ss Por 
$3.45067 \mathrm{e}+003.45067 \mathrm{e}+003.45067 \mathrm{e}-01$ 1.00000e-09 2.12000e-01 $3.45067 \mathrm{e}+003.45067 \mathrm{e}+003.45067 \mathrm{e}-011.00000 \mathrm{e}-092.12000 \mathrm{e}-01$ $3.45067 \mathrm{e}+003.45067 \mathrm{e}+003.45067 \mathrm{e}-01$ 1.00000e-09 2.12000e-01 $3.45067 \mathrm{e}+003.45067 \mathrm{e}+003.45067 \mathrm{e}-011.00000 \mathrm{e}-092.12000 \mathrm{e}-01$ $3.45067 \mathrm{e}+003.45067 \mathrm{e}+003.45067 \mathrm{e}-01$ 1.00000e-09 2.12000e-01 $1.00000 \mathrm{e}-05$ 1.00000e-05 1.00000e-06 1.00000e-09 1.00000e-01 $1.00000 \mathrm{e}+001.00000 \mathrm{e}+001.00000 \mathrm{e}-011.00000 \mathrm{e}-091.00000 \mathrm{e}-01$ Element: 13601 \# of layers: 7

$\mathrm{Kx} \mathrm{Ky} \mathrm{Kz}$ Ss Por

5.36412e+00 5.36412e+00 5.36412e-01 1.00000e-09 2.12000e-01 $5.36412 \mathrm{e}+005.36412 \mathrm{e}+00$ 5.36412e-01 1.00000e-09 2.12000e-01 $5.36412 \mathrm{e}+00$ 5.36412e+00 5.36412e-01 1.00000e-09 2.12000e-01 $5.36412 \mathrm{e}+005.36412 \mathrm{e}+005.36412 \mathrm{e}-011.00000 \mathrm{e}-092.12000 \mathrm{e}-01$ $5.36412 \mathrm{e}+00$ 5.36412e+00 5.36412e-01 1.00000e-09 2.12000e-01 $1.00000 \mathrm{e}-05$ 1.00000e-05 1.00000e-06 1.00000e-09 1.00000e-01 $1.00000 \mathrm{e}+001.00000 \mathrm{e}+001.00000 \mathrm{e}-011.00000 \mathrm{e}-091.00000 \mathrm{e}-01$ Element: 13602 \# of layers: 7

Kx Ky Kz Ss Por

3.32062e+00 3.32062e+00 3.32062e-01 1.00000e-09 2.12000e-01 $3.32062 \mathrm{e}+003.32062 \mathrm{e}+003.32062 \mathrm{e}-01$ 1.00000e-09 2.12000e-01 $3.32062 \mathrm{e}+003.32062 \mathrm{e}+003.32062 \mathrm{e}-01$ 1.00000e-09 2.12000e-01 $3.32062 \mathrm{e}+003.32062 \mathrm{e}+003.32062 \mathrm{e}-01$ 1.00000e-09 2.12000e-01 $3.32062 \mathrm{e}+003.32062 \mathrm{e}+003.32062 \mathrm{e}-011.00000 \mathrm{e}-092.12000 \mathrm{e}-01$ $1.00000 \mathrm{e}-05$ 1.00000e-05 1.00000e-06 1.00000e-09 1.00000e-01 $1.00000 \mathrm{e}+001.00000 \mathrm{e}+001.00000 \mathrm{e}-011.00000 \mathrm{e}-091.00000 \mathrm{e}-01$ Element: 13603 \# of layers: 7

Kx Ky Kz Ss Por

$3.22409 \mathrm{e}+003.22409 \mathrm{e}+00$ 3.22409e-01 1.00000e-09 2.12000e-01 $3.22409 \mathrm{e}+003.22409 \mathrm{e}+003.22409 \mathrm{e}-01$ 1.00000e-09 2.12000e-01 $3.22409 \mathrm{e}+003.22409 \mathrm{e}+003.22409 \mathrm{e}-01$ 1.00000e-09 2.12000e-01 $3.22409 \mathrm{e}+003.22409 \mathrm{e}+003.22409 \mathrm{e}-01$ 1.00000e-09 2.12000e-01 $3.22409 \mathrm{e}+003.22409 \mathrm{e}+003.22409 \mathrm{e}-01$ 1.00000e-09 2.12000e-01 $1.00000 \mathrm{e}-05$ 1.00000e-05 1.00000e-06 1.00000e-09 1.00000e-01 $1.00000 \mathrm{e}+001.00000 \mathrm{e}+001.00000 \mathrm{e}-011.00000 \mathrm{e}-091.00000 \mathrm{e}-01$ Element: 13604 \# of layers: 7

Kx Ky Kz Ss Por

$3.22409 \mathrm{e}+003.22409 \mathrm{e}+00$ 3.22409e-01 1.00000e-09 2.12000e-01 $3.22409 \mathrm{e}+003.22409 \mathrm{e}+003.22409 \mathrm{e}-01$ 1.00000e-09 2.12000e-01 $3.22409 \mathrm{e}+003.22409 \mathrm{e}+003.22409 \mathrm{e}-01$ 1.00000e-09 2.12000e-01 $3.22409 \mathrm{e}+003.22409 \mathrm{e}+003.22409 \mathrm{e}-01$ 1.00000e-09 2.12000e-01 $3.22409 \mathrm{e}+003.22409 \mathrm{e}+00$ 3.22409e-01 1.00000e-09 2.12000e-01 $1.00000 \mathrm{e}-05$ 1.00000e-05 1.00000e-06 1.00000e-09 1.00000e-01 $1.00000 \mathrm{e}+001.00000 \mathrm{e}+001.00000 \mathrm{e}-011.00000 \mathrm{e}-091.00000 \mathrm{e}-01$ Element: 13605 \# of layers: 7

Kx Ky Kz Ss Por

3.22409e+00 3.22409e+00 3.22409e-01 1.00000e-09 2.12000e-01 
$3.22409 \mathrm{e}+003.22409 \mathrm{e}+00$ 3.22409e-01 1.00000e-09 2.12000e-01 $3.22409 \mathrm{e}+003.22409 \mathrm{e}+003.22409 \mathrm{e}-01$ 1.00000e-09 2.12000e-01 $3.22409 \mathrm{e}+003.22409 \mathrm{e}+003.22409 \mathrm{e}-01$ 1.00000e-09 2.12000e-01 $3.22409 \mathrm{e}+003.22409 \mathrm{e}+003.22409 \mathrm{e}-01$ 1.00000e-09 2.12000e-01 $1.00000 \mathrm{e}-05$ 1.00000e-05 1.00000e-06 1.00000e-09 1.00000e-01 $1.00000 \mathrm{e}+001.00000 \mathrm{e}+001.00000 \mathrm{e}-011.00000 \mathrm{e}-091.00000 \mathrm{e}-01$ Element: 13606 \# of layers: 7

Kx Ky Kz Ss Por

$3.22409 \mathrm{e}+003.22409 \mathrm{e}+00$ 3.22409e-01 1.00000e-09 2.12000e-01 $3.22409 \mathrm{e}+003.22409 \mathrm{e}+003.22409 \mathrm{e}-01$ 1.00000e-09 2.12000e-01 $3.22409 \mathrm{e}+003.22409 \mathrm{e}+003.22409 \mathrm{e}-01$ 1.00000e-09 2.12000e-01 $3.22409 \mathrm{e}+003.22409 \mathrm{e}+003.22409 \mathrm{e}-01$ 1.00000e-09 2.12000e-01 $3.22409 \mathrm{e}+003.22409 \mathrm{e}+003.22409 \mathrm{e}-01$ 1.00000e-09 2.12000e-01 $1.00000 \mathrm{e}-05$ 1.00000e-05 1.00000e-06 1.00000e-09 1.00000e-01 $1.00000 \mathrm{e}+001.00000 \mathrm{e}+001.00000 \mathrm{e}-011.00000 \mathrm{e}-091.00000 \mathrm{e}-01$ Element: 13607 \# of layers: 7

Kx Ky Kz Ss Por

$3.22409 \mathrm{e}+003.22409 \mathrm{e}+00$ 3.22409e-01 1.00000e-09 2.12000e-01 $3.22409 \mathrm{e}+003.22409 \mathrm{e}+003.22409 \mathrm{e}-01$ 1.00000e-09 2.12000e-01 $3.22409 \mathrm{e}+003.22409 \mathrm{e}+003.22409 \mathrm{e}-01$ 1.00000e-09 2.12000e-01 $3.22409 \mathrm{e}+003.22409 \mathrm{e}+003.22409 \mathrm{e}-01$ 1.00000e-09 2.12000e-01 $3.22409 \mathrm{e}+003.22409 \mathrm{e}+00$ 3.22409e-01 1.00000e-09 2.12000e-01 $1.00000 \mathrm{e}-05$ 1.00000e-05 1.00000e-06 1.00000e-09 1.00000e-01 $1.00000 \mathrm{e}+001.00000 \mathrm{e}+001.00000 \mathrm{e}-011.00000 \mathrm{e}-091.00000 \mathrm{e}-01$ Element: 13608 \# of layers: 7

Kx Ky Kz Ss Por

$3.22409 \mathrm{e}+003.22409 \mathrm{e}+00$ 3.22409e-01 1.00000e-09 2.12000e-01 $3.22409 \mathrm{e}+003.22409 \mathrm{e}+003.22409 \mathrm{e}-01$ 1.00000e-09 2.12000e-01 $3.22409 \mathrm{e}+003.22409 \mathrm{e}+003.22409 \mathrm{e}-01$ 1.00000e-09 2.12000e-01 $3.22409 \mathrm{e}+003.22409 \mathrm{e}+00$ 3.22409e-01 1.00000e-09 2.12000e-01 $3.22409 \mathrm{e}+003.22409 \mathrm{e}+00$ 3.22409e-01 1.00000e-09 2.12000e-01 $1.00000 \mathrm{e}-05$ 1.00000e-05 1.00000e-06 1.00000e-09 1.00000e-01 $1.00000 \mathrm{e}+001.00000 \mathrm{e}+001.00000 \mathrm{e}-011.00000 \mathrm{e}-091.00000 \mathrm{e}-01$ Element: 13609 \# of layers: 7

$\mathrm{Kx} \mathrm{Ky} \mathrm{Kz}$ Ss Por

$3.22409 \mathrm{e}+003.22409 \mathrm{e}+00$ 3.22409e-01 1.00000e-09 2.12000e-01 $3.22409 \mathrm{e}+003.22409 \mathrm{e}+003.22409 \mathrm{e}-01$ 1.00000e-09 2.12000e-01 $3.22409 \mathrm{e}+003.22409 \mathrm{e}+003.22409 \mathrm{e}-01$ 1.00000e-09 2.12000e-01 $3.22409 \mathrm{e}+003.22409 \mathrm{e}+003.22409 \mathrm{e}-01$ 1.00000e-09 2.12000e-01 $3.22409 \mathrm{e}+003.22409 \mathrm{e}+003.22409 \mathrm{e}-01$ 1.00000e-09 2.12000e-01 $1.00000 \mathrm{e}-05$ 1.00000e-05 1.00000e-06 1.00000e-09 1.00000e-01 $1.00000 \mathrm{e}+001.00000 \mathrm{e}+001.00000 \mathrm{e}-011.00000 \mathrm{e}-091.00000 \mathrm{e}-01$ Element: 13610 \# of layers: 7

Kx Ky Kz Ss Por

3.22409e+00 3.22409e+00 3.22409e-01 1.00000e-09 2.12000e-01 $3.22409 \mathrm{e}+003.22409 \mathrm{e}+003.22409 \mathrm{e}-01$ 1.00000e-09 2.12000e-01 
$3.22409 \mathrm{e}+003.22409 \mathrm{e}+00$ 3.22409e-01 1.00000e-09 2.12000e-01 $3.22409 \mathrm{e}+003.22409 \mathrm{e}+003.22409 \mathrm{e}-01$ 1.00000e-09 2.12000e-01 $3.22409 \mathrm{e}+003.22409 \mathrm{e}+00$ 3.22409e-01 1.00000e-09 2.12000e-01 $1.00000 \mathrm{e}-05$ 1.00000e-05 1.00000e-06 1.00000e-09 1.00000e-01 $1.00000 \mathrm{e}+001.00000 \mathrm{e}+001.00000 \mathrm{e}-011.00000 \mathrm{e}-091.00000 \mathrm{e}-01$ Element: 13611 \# of layers: 7

Kx Ky Kz Ss Por

3.22409e+00 3.22409e+00 3.22409e-01 1.00000e-09 2.12000e-01 $3.22409 \mathrm{e}+003.22409 \mathrm{e}+003.22409 \mathrm{e}-01$ 1.00000e-09 2.12000e-01 $3.22409 \mathrm{e}+003.22409 \mathrm{e}+003.22409 \mathrm{e}-01$ 1.00000e-09 2.12000e-01 $3.22409 \mathrm{e}+003.22409 \mathrm{e}+003.22409 \mathrm{e}-01$ 1.00000e-09 2.12000e-01 $3.22409 \mathrm{e}+003.22409 \mathrm{e}+003.22409 \mathrm{e}-01$ 1.00000e-09 2.12000e-01 $1.00000 \mathrm{e}-05$ 1.00000e-05 1.00000e-06 1.00000e-09 1.00000e-01 $1.00000 \mathrm{e}+001.00000 \mathrm{e}+001.00000 \mathrm{e}-011.00000 \mathrm{e}-091.00000 \mathrm{e}-01$ Element: 13612 \# of layers: 7

Kx Ky Kz Ss Por

$3.22409 \mathrm{e}+003.22409 \mathrm{e}+00$ 3.22409e-01 1.00000e-09 2.12000e-01 $3.22409 \mathrm{e}+003.22409 \mathrm{e}+003.22409 \mathrm{e}-01$ 1.00000e-09 2.12000e-01 $3.22409 \mathrm{e}+003.22409 \mathrm{e}+003.22409 \mathrm{e}-011.00000 \mathrm{e}-092.12000 \mathrm{e}-01$ $3.22409 \mathrm{e}+003.22409 \mathrm{e}+003.22409 \mathrm{e}-011.00000 \mathrm{e}-092.12000 \mathrm{e}-01$ $3.22409 \mathrm{e}+003.22409 \mathrm{e}+00$ 3.22409e-01 1.00000e-09 2.12000e-01 $1.00000 \mathrm{e}-05$ 1.00000e-05 1.00000e-06 1.00000e-09 1.00000e-01 $1.00000 \mathrm{e}+001.00000 \mathrm{e}+001.00000 \mathrm{e}-011.00000 \mathrm{e}-091.00000 \mathrm{e}-01$ Element: 13613 \# of layers: 7

Kx Ky Kz Ss Por

$1.79984 \mathrm{e}+001.79984 \mathrm{e}+00$ 1.79984e-01 1.00000e-09 2.12000e-01 $1.79984 \mathrm{e}+001.79984 \mathrm{e}+001.79984 \mathrm{e}-011.00000 \mathrm{e}-092.12000 \mathrm{e}-01$ $1.79984 \mathrm{e}+001.79984 \mathrm{e}+001.79984 \mathrm{e}-011.00000 \mathrm{e}-092.12000 \mathrm{e}-01$ $1.79984 \mathrm{e}+001.79984 \mathrm{e}+001.79984 \mathrm{e}-011.00000 \mathrm{e}-092.12000 \mathrm{e}-01$ $1.79984 \mathrm{e}+001.79984 \mathrm{e}+001.79984 \mathrm{e}-011.00000 \mathrm{e}-092.12000 \mathrm{e}-01$ $1.00000 \mathrm{e}-05$ 1.00000e-05 1.00000e-06 1.00000e-09 1.00000e-01 $1.00000 \mathrm{e}+001.00000 \mathrm{e}+001.00000 \mathrm{e}-011.00000 \mathrm{e}-091.00000 \mathrm{e}-01$ Element: 13614 \# of layers: 7

Kx Ky Kz Ss Por

$1.79984 \mathrm{e}+001.79984 \mathrm{e}+00$ 1.79984e-01 1.00000e-09 2.12000e-01 $1.79984 \mathrm{e}+001.79984 \mathrm{e}+001.79984 \mathrm{e}-011.00000 \mathrm{e}-092.12000 \mathrm{e}-01$ $1.79984 \mathrm{e}+001.79984 \mathrm{e}+00$ 1.79984e-01 1.00000e-09 2.12000e-01 $1.79984 \mathrm{e}+001.79984 \mathrm{e}+001.79984 \mathrm{e}-011.00000 \mathrm{e}-092.12000 \mathrm{e}-01$ $1.79984 \mathrm{e}+001.79984 \mathrm{e}+001.79984 \mathrm{e}-011.00000 \mathrm{e}-092.12000 \mathrm{e}-01$ $1.00000 \mathrm{e}-05$ 1.00000e-05 1.00000e-06 1.00000e-09 1.00000e-01 $1.00000 \mathrm{e}+001.00000 \mathrm{e}+001.00000 \mathrm{e}-011.00000 \mathrm{e}-091.00000 \mathrm{e}-01$ Element: 13615 \# of layers: 6

Kx Ky Kz Ss Por

$1.79984 \mathrm{e}+001.79984 \mathrm{e}+00$ 1.79984e-01 1.00000e-09 2.12000e-01 $1.79984 \mathrm{e}+001.79984 \mathrm{e}+001.79984 \mathrm{e}-011.00000 \mathrm{e}-092.12000 \mathrm{e}-01$ $1.79984 \mathrm{e}+001.79984 \mathrm{e}+001.79984 \mathrm{e}-011.00000 \mathrm{e}-092.12000 \mathrm{e}-01$ 
$1.79984 \mathrm{e}+001.79984 \mathrm{e}+00$ 1.79984e-01 1.00000e-09 2.12000e-01 $1.79984 \mathrm{e}+001.79984 \mathrm{e}+001.79984 \mathrm{e}-011.00000 \mathrm{e}-092.12000 \mathrm{e}-01$ $1.00000 \mathrm{e}+001.00000 \mathrm{e}+001.00000 \mathrm{e}-011.00000 \mathrm{e}-091.00000 \mathrm{e}-01$ Element: 13616 \# of layers: 6

Kx Ky Kz Ss Por

$1.79984 \mathrm{e}+001.79984 \mathrm{e}+00$ 1.79984e-01 1.00000e-09 2.12000e-01

$1.79984 \mathrm{e}+001.79984 \mathrm{e}+001.79984 \mathrm{e}-011.00000 \mathrm{e}-092.12000 \mathrm{e}-01$

$1.79984 \mathrm{e}+001.79984 \mathrm{e}+001.79984 \mathrm{e}-011.00000 \mathrm{e}-092.12000 \mathrm{e}-01$

$1.79984 \mathrm{e}+001.79984 \mathrm{e}+001.79984 \mathrm{e}-011.00000 \mathrm{e}-092.12000 \mathrm{e}-01$

$1.79984 \mathrm{e}+001.79984 \mathrm{e}+001.79984 \mathrm{e}-011.00000 \mathrm{e}-092.12000 \mathrm{e}-01$ $1.00000 \mathrm{e}+001.00000 \mathrm{e}+001.00000 \mathrm{e}-011.00000 \mathrm{e}-091.00000 \mathrm{e}-01$ Element: 13617 \# of layers: 6

Kx Ky Kz Ss Por

$1.79984 \mathrm{e}+001.79984 \mathrm{e}+00$ 1.79984e-01 1.00000e-09 2.12000e-01 $1.79984 \mathrm{e}+001.79984 \mathrm{e}+001.79984 \mathrm{e}-011.00000 \mathrm{e}-092.12000 \mathrm{e}-01$ $1.79984 \mathrm{e}+001.79984 \mathrm{e}+001.79984 \mathrm{e}-011.00000 \mathrm{e}-092.12000 \mathrm{e}-01$ $1.79984 \mathrm{e}+001.79984 \mathrm{e}+001.79984 \mathrm{e}-011.00000 \mathrm{e}-092.12000 \mathrm{e}-01$ $1.79984 \mathrm{e}+001.79984 \mathrm{e}+001.79984 \mathrm{e}-011.00000 \mathrm{e}-092.12000 \mathrm{e}-01$ $1.00000 \mathrm{e}+001.00000 \mathrm{e}+001.00000 \mathrm{e}-011.00000 \mathrm{e}-091.00000 \mathrm{e}-01$ Element: 13618 \# of layers: 7

Kx Ky Kz Ss Por

$3.22409 \mathrm{e}+003.22409 \mathrm{e}+00$ 3.22409e-01 1.00000e-09 2.12000e-01 $3.22409 \mathrm{e}+003.22409 \mathrm{e}+003.22409 \mathrm{e}-01$ 1.00000e-09 2.12000e-01 $3.22409 \mathrm{e}+003.22409 \mathrm{e}+003.22409 \mathrm{e}-01$ 1.00000e-09 2.12000e-01 $3.22409 \mathrm{e}+003.22409 \mathrm{e}+003.22409 \mathrm{e}-01$ 1.00000e-09 2.12000e-01 $3.22409 \mathrm{e}+003.22409 \mathrm{e}+00$ 3.22409e-01 1.00000e-09 2.12000e-01 $1.00000 \mathrm{e}-05$ 1.00000e-05 1.00000e-06 1.00000e-09 1.00000e-01 $1.00000 \mathrm{e}+001.00000 \mathrm{e}+001.00000 \mathrm{e}-011.00000 \mathrm{e}-091.00000 \mathrm{e}-01$ Element: 13619 \# of layers: 7

Kx Ky Kz Ss Por

$3.22409 \mathrm{e}+003.22409 \mathrm{e}+00$ 3.22409e-01 1.00000e-09 2.12000e-01 $3.22409 \mathrm{e}+003.22409 \mathrm{e}+003.22409 \mathrm{e}-01$ 1.00000e-09 2.12000e-01 $3.22409 \mathrm{e}+003.22409 \mathrm{e}+00$ 3.22409e-01 1.00000e-09 2.12000e-01 $3.22409 \mathrm{e}+003.22409 \mathrm{e}+003.22409 \mathrm{e}-01$ 1.00000e-09 2.12000e-01 $3.22409 \mathrm{e}+003.22409 \mathrm{e}+003.22409 \mathrm{e}-01$ 1.00000e-09 2.12000e-01 $1.00000 \mathrm{e}-05$ 1.00000e-05 1.00000e-06 1.00000e-09 1.00000e-01 $1.00000 \mathrm{e}+001.00000 \mathrm{e}+001.00000 \mathrm{e}-011.00000 \mathrm{e}-091.00000 \mathrm{e}-01$ Element: 13620 \# of layers: 7

Kx Ky Kz Ss Por

$1.79984 \mathrm{e}+001.79984 \mathrm{e}+00$ 1.79984e-01 1.00000e-09 2.12000e-01 $1.79984 \mathrm{e}+001.79984 \mathrm{e}+001.79984 \mathrm{e}-011.00000 \mathrm{e}-092.12000 \mathrm{e}-01$ $1.79984 \mathrm{e}+001.79984 \mathrm{e}+001.79984 \mathrm{e}-011.00000 \mathrm{e}-092.12000 \mathrm{e}-01$ $1.79984 \mathrm{e}+001.79984 \mathrm{e}+001.79984 \mathrm{e}-011.00000 \mathrm{e}-092.12000 \mathrm{e}-01$ $1.79984 \mathrm{e}+001.79984 \mathrm{e}+00$ 1.79984e-01 1.00000e-09 2.12000e-01 $1.00000 \mathrm{e}-05$ 1.00000e-05 1.00000e-06 1.00000e-09 1.00000e-01 $1.00000 \mathrm{e}+001.00000 \mathrm{e}+001.00000 \mathrm{e}-011.00000 \mathrm{e}-091.00000 \mathrm{e}-01$ 
Element: 13621 \# of layers: 7

$\mathrm{Kx} \mathrm{Ky} \mathrm{Kz}$ Ss Por

$1.79984 \mathrm{e}+001.79984 \mathrm{e}+001.79984 \mathrm{e}-01$ 1.00000e-09 2.12000e-01

$1.79984 \mathrm{e}+001.79984 \mathrm{e}+00 \quad 1.79984 \mathrm{e}-011.00000 \mathrm{e}-092.12000 \mathrm{e}-01$

$1.79984 \mathrm{e}+001.79984 \mathrm{e}+001.79984 \mathrm{e}-01$ 1.00000e-09 2.12000e-01

$1.79984 \mathrm{e}+001.79984 \mathrm{e}+001.79984 \mathrm{e}-01$ 1.00000e-09 2.12000e-01

$1.79984 \mathrm{e}+001.79984 \mathrm{e}+001.79984 \mathrm{e}-01$ 1.00000e-09 2.12000e-01

$1.00000 \mathrm{e}-05$ 1.00000e-05 1.00000e-06 1.00000e-09 1.00000e-01

$1.00000 \mathrm{e}+001.00000 \mathrm{e}+001.00000 \mathrm{e}-011.00000 \mathrm{e}-091.00000 \mathrm{e}-01$

Element: 13622 \# of layers: 7

$\mathrm{Kx} \mathrm{Ky} \mathrm{Kz}$ Ss Por

$1.79984 \mathrm{e}+00$ 1.79984e+00 1.79984e-01 1.00000e-09 2.12000e-01

$1.79984 \mathrm{e}+001.79984 \mathrm{e}+00$ 1.79984e-01 1.00000e-09 2.12000e-01

$1.79984 \mathrm{e}+001.79984 \mathrm{e}+001.79984 \mathrm{e}-01$ 1.00000e-09 2.12000e-01

$1.79984 \mathrm{e}+001.79984 \mathrm{e}+001.79984 \mathrm{e}-01$ 1.00000e-09 2.12000e-01

$1.79984 \mathrm{e}+001.79984 \mathrm{e}+00 \quad 1.79984 \mathrm{e}-01$ 1.00000e-09 2.12000e-01

$1.00000 \mathrm{e}-05$ 1.00000e-05 1.00000e-06 1.00000e-09 1.00000e-01

$1.00000 \mathrm{e}+001.00000 \mathrm{e}+001.00000 \mathrm{e}-011.00000 \mathrm{e}-091.00000 \mathrm{e}-01$

Element: 13623 \# of layers: 7

$\mathrm{Kx} \mathrm{Ky} \mathrm{Kz}$ Ss Por

$1.79984 \mathrm{e}+001.79984 \mathrm{e}+00$ 1.79984e-01 1.00000e-09 2.12000e-01

$1.79984 \mathrm{e}+00$ 1.79984e+00 1.79984e-01 1.00000e-09 2.12000e-01

$1.79984 \mathrm{e}+001.79984 \mathrm{e}+00$ 1.79984e-01 1.00000e-09 2.12000e-01

$1.79984 \mathrm{e}+001.79984 \mathrm{e}+001.79984 \mathrm{e}-01$ 1.00000e-09 2.12000e-01

$1.79984 \mathrm{e}+001.79984 \mathrm{e}+001.79984 \mathrm{e}-011.00000 \mathrm{e}-092.12000 \mathrm{e}-01$

$1.00000 \mathrm{e}-05$ 1.00000e-05 1.00000e-06 1.00000e-09 1.00000e-01

$1.00000 \mathrm{e}+001.00000 \mathrm{e}+001.00000 \mathrm{e}-011.00000 \mathrm{e}-091.00000 \mathrm{e}-01$

Element: 13624 \# of layers: 7

Kx Ky Kz Ss Por

1.79984e+00 1.79984e+00 1.79984e-01 1.00000e-09 2.12000e-01

$1.79984 \mathrm{e}+001.79984 \mathrm{e}+001.79984 \mathrm{e}-01$ 1.00000e-09 2.12000e-01

$1.79984 \mathrm{e}+001.79984 \mathrm{e}+00 \quad 1.79984 \mathrm{e}-01$ 1.00000e-09 2.12000e-01

$1.79984 \mathrm{e}+001.79984 \mathrm{e}+001.79984 \mathrm{e}-011.00000 \mathrm{e}-092.12000 \mathrm{e}-01$

$1.79984 \mathrm{e}+001.79984 \mathrm{e}+001.79984 \mathrm{e}-01$ 1.00000e-09 2.12000e-01

$1.00000 \mathrm{e}-05$ 1.00000e-05 1.00000e-06 1.00000e-09 1.00000e-01

$1.00000 \mathrm{e}+001.00000 \mathrm{e}+001.00000 \mathrm{e}-011.00000 \mathrm{e}-091.00000 \mathrm{e}-01$

Element: 13625 \# of layers: 6

$\mathrm{Kx} \mathrm{Ky} \mathrm{Kz}$ Ss Por

$1.79984 \mathrm{e}+001.79984 \mathrm{e}+00$ 1.79984e-01 1.00000e-09 2.12000e-01

$1.79984 \mathrm{e}+001.79984 \mathrm{e}+001.79984 \mathrm{e}-01$ 1.00000e-09 2.12000e-01

$1.79984 \mathrm{e}+001.79984 \mathrm{e}+001.79984 \mathrm{e}-01$ 1.00000e-09 2.12000e-01

$1.79984 \mathrm{e}+001.79984 \mathrm{e}+00$ 1.79984e-01 1.00000e-09 2.12000e-01

$1.79984 \mathrm{e}+001.79984 \mathrm{e}+00$ 1.79984e-01 1.00000e-09 2.12000e-01

$1.00000 \mathrm{e}+001.00000 \mathrm{e}+001.00000 \mathrm{e}-011.00000 \mathrm{e}-091.00000 \mathrm{e}-01$

Element: 13626 \# of layers: 6

Kx Ky Kz Ss Por 
$1.79984 \mathrm{e}+001.79984 \mathrm{e}+00$ 1.79984e-01 1.00000e-09 2.12000e-01 $1.79984 \mathrm{e}+001.79984 \mathrm{e}+00$ 1.79984e-01 1.00000e-09 2.12000e-01 $1.79984 \mathrm{e}+001.79984 \mathrm{e}+001.79984 \mathrm{e}-011.00000 \mathrm{e}-092.12000 \mathrm{e}-01$ $1.79984 \mathrm{e}+001.79984 \mathrm{e}+001.79984 \mathrm{e}-011.00000 \mathrm{e}-092.12000 \mathrm{e}-01$ $1.79984 \mathrm{e}+001.79984 \mathrm{e}+001.79984 \mathrm{e}-01$ 1.00000e-09 2.12000e-01 $1.00000 \mathrm{e}+001.00000 \mathrm{e}+001.00000 \mathrm{e}-011.00000 \mathrm{e}-091.00000 \mathrm{e}-01$ Element: 13627 \# of layers: 6

Kx Ky Kz Ss Por

$1.79984 \mathrm{e}+001.79984 \mathrm{e}+00$ 1.79984e-01 1.00000e-09 2.12000e-01 $1.79984 \mathrm{e}+001.79984 \mathrm{e}+001.79984 \mathrm{e}-01$ 1.00000e-09 2.12000e-01 $1.79984 \mathrm{e}+001.79984 \mathrm{e}+001.79984 \mathrm{e}-01$ 1.00000e-09 2.12000e-01 $1.79984 \mathrm{e}+001.79984 \mathrm{e}+001.79984 \mathrm{e}-011.00000 \mathrm{e}-092.12000 \mathrm{e}-01$ $1.79984 \mathrm{e}+001.79984 \mathrm{e}+001.79984 \mathrm{e}-011.00000 \mathrm{e}-092.12000 \mathrm{e}-01$ $1.00000 \mathrm{e}+001.00000 \mathrm{e}+001.00000 \mathrm{e}-01$ 1.00000e-09 1.00000e-01 Element: 13628 \# of layers: 6

Kx Ky Kz Ss Por

$1.79984 \mathrm{e}+00$ 1.79984e+00 1.79984e-01 1.00000e-09 2.12000e-01 $1.79984 \mathrm{e}+001.79984 \mathrm{e}+001.79984 \mathrm{e}-01$ 1.00000e-09 2.12000e-01 $1.79984 \mathrm{e}+001.79984 \mathrm{e}+001.79984 \mathrm{e}-01$ 1.00000e-09 2.12000e-01 $1.79984 \mathrm{e}+001.79984 \mathrm{e}+00 \quad 1.79984 \mathrm{e}-011.00000 \mathrm{e}-092.12000 \mathrm{e}-01$ $1.79984 \mathrm{e}+001.79984 \mathrm{e}+001.79984 \mathrm{e}-011.00000 \mathrm{e}-092.12000 \mathrm{e}-01$ $1.00000 \mathrm{e}+001.00000 \mathrm{e}+001.00000 \mathrm{e}-01$ 1.00000e-09 1.00000e-01 Element: 13629 \# of layers: 6

Kx Ky Kz Ss Por

$1.79984 \mathrm{e}+001.79984 \mathrm{e}+00$ 1.79984e-01 1.00000e-09 2.12000e-01 $1.79984 \mathrm{e}+001.79984 \mathrm{e}+001.79984 \mathrm{e}-01$ 1.00000e-09 2.12000e-01 $1.79984 \mathrm{e}+001.79984 \mathrm{e}+001.79984 \mathrm{e}-01$ 1.00000e-09 2.12000e-01 $1.79984 \mathrm{e}+001.79984 \mathrm{e}+001.79984 \mathrm{e}-01$ 1.00000e-09 2.12000e-01 $1.79984 \mathrm{e}+001.79984 \mathrm{e}+00 \quad 1.79984 \mathrm{e}-011.00000 \mathrm{e}-092.12000 \mathrm{e}-01$ $1.00000 \mathrm{e}+001.00000 \mathrm{e}+001.00000 \mathrm{e}-01$ 1.00000e-09 1.00000e-01 Element: 13630 \# of layers: 6

$\mathrm{Kx} \mathrm{Ky} \mathrm{Kz}$ Ss Por

$1.79984 \mathrm{e}+001.79984 \mathrm{e}+00$ 1.79984e-01 1.00000e-09 2.12000e-01 $1.79984 \mathrm{e}+001.79984 \mathrm{e}+00$ 1.79984e-01 1.00000e-09 2.12000e-01 $1.79984 \mathrm{e}+001.79984 \mathrm{e}+001.79984 \mathrm{e}-01$ 1.00000e-09 2.12000e-01 $1.79984 \mathrm{e}+001.79984 \mathrm{e}+001.79984 \mathrm{e}-011.00000 \mathrm{e}-092.12000 \mathrm{e}-01$ $1.79984 \mathrm{e}+001.79984 \mathrm{e}+001.79984 \mathrm{e}-011.00000 \mathrm{e}-092.12000 \mathrm{e}-01$ $1.00000 \mathrm{e}+001.00000 \mathrm{e}+001.00000 \mathrm{e}-01$ 1.00000e-09 1.00000e-01 Element: 13631 \# of layers: 6

$\mathrm{Kx} \mathrm{Ky} \mathrm{Kz}$ Ss Por

$1.79984 \mathrm{e}+001.79984 \mathrm{e}+00$ 1.79984e-01 1.00000e-09 2.12000e-01 $1.79984 \mathrm{e}+001.79984 \mathrm{e}+00$ 1.79984e-01 1.00000e-09 2.12000e-01 $1.79984 \mathrm{e}+001.79984 \mathrm{e}+001.79984 \mathrm{e}-01$ 1.00000e-09 2.12000e-01 $1.79984 \mathrm{e}+001.79984 \mathrm{e}+001.79984 \mathrm{e}-01$ 1.00000e-09 2.12000e-01 $1.79984 \mathrm{e}+001.79984 \mathrm{e}+001.79984 \mathrm{e}-011.00000 \mathrm{e}-092.12000 \mathrm{e}-01$ $1.00000 \mathrm{e}+001.00000 \mathrm{e}+001.00000 \mathrm{e}-011.00000 \mathrm{e}-091.00000 \mathrm{e}-01$ 
Element: 13632 \# of layers: 6

$\mathrm{Kx} \mathrm{Ky} \mathrm{Kz} \mathrm{Ss} \mathrm{Por}$

$1.68351 \mathrm{e}+001.68351 \mathrm{e}+00$ 1.68351e-01 1.00000e-09 2.12000e-01

$1.68351 \mathrm{e}+001.68351 \mathrm{e}+001.68351 \mathrm{e}-011.00000 \mathrm{e}-092.12000 \mathrm{e}-01$

$1.68351 \mathrm{e}+001.68351 \mathrm{e}+001.68351 \mathrm{e}-01$ 1.00000e-09 2.12000e-01

$1.68351 \mathrm{e}+001.68351 \mathrm{e}+00$ 1.68351e-01 1.00000e-09 2.12000e-01

$1.68351 \mathrm{e}+001.68351 \mathrm{e}+001.68351 \mathrm{e}-011.00000 \mathrm{e}-092.12000 \mathrm{e}-01$

$1.00000 \mathrm{e}+001.00000 \mathrm{e}+001.00000 \mathrm{e}-01$ 1.00000e-09 1.00000e-01

Element: 13633 \# of layers: 6

$\mathrm{Kx} \mathrm{Ky} \mathrm{Kz}$ Ss Por

$1.68351 \mathrm{e}+00$ 1.68351e+00 1.68351e-01 1.00000e-09 2.12000e-01

$1.68351 \mathrm{e}+001.68351 \mathrm{e}+001.68351 \mathrm{e}-011.00000 \mathrm{e}-092.12000 \mathrm{e}-01$

$1.68351 \mathrm{e}+001.68351 \mathrm{e}+001.68351 \mathrm{e}-011.00000 \mathrm{e}-092.12000 \mathrm{e}-01$

$1.68351 \mathrm{e}+001.68351 \mathrm{e}+001.68351 \mathrm{e}-011.00000 \mathrm{e}-092.12000 \mathrm{e}-01$

$1.68351 \mathrm{e}+001.68351 \mathrm{e}+001.68351 \mathrm{e}-01$ 1.00000e-09 2.12000e-01

$1.00000 \mathrm{e}+001.00000 \mathrm{e}+001.00000 \mathrm{e}-01$ 1.00000e-09 1.00000e-01

Element: 13634 \# of layers: 6

$\mathrm{Kx} \mathrm{Ky} \mathrm{Kz}$ Ss Por

$1.68351 \mathrm{e}+001.68351 \mathrm{e}+00$ 1.68351e-01 1.00000e-09 2.12000e-01

$1.68351 \mathrm{e}+001.68351 \mathrm{e}+001.68351 \mathrm{e}-01$ 1.00000e-09 2.12000e-01

$1.68351 \mathrm{e}+001.68351 \mathrm{e}+001.68351 \mathrm{e}-01$ 1.00000e-09 2.12000e-01

$1.68351 \mathrm{e}+001.68351 \mathrm{e}+00$ 1.68351e-01 1.00000e-09 2.12000e-01

$1.68351 \mathrm{e}+001.68351 \mathrm{e}+00$ 1.68351e-01 1.00000e-09 2.12000e-01

$1.00000 \mathrm{e}+001.00000 \mathrm{e}+001.00000 \mathrm{e}-01$ 1.00000e-09 1.00000e-01

Element: 13635 \# of layers: 6

$\mathrm{Kx} \mathrm{Ky} \mathrm{Kz}$ Ss Por

$1.79984 \mathrm{e}+001.79984 \mathrm{e}+00$ 1.79984e-01 1.00000e-09 2.12000e-01

$1.79984 \mathrm{e}+001.79984 \mathrm{e}+001.79984 \mathrm{e}-01$ 1.00000e-09 2.12000e-01

$1.79984 \mathrm{e}+001.79984 \mathrm{e}+00 \quad 1.79984 \mathrm{e}-011.00000 \mathrm{e}-092.12000 \mathrm{e}-01$

$1.79984 \mathrm{e}+001.79984 \mathrm{e}+00$ 1.79984e-01 1.00000e-09 2.12000e-01

$1.79984 \mathrm{e}+001.79984 \mathrm{e}+00 \quad 1.79984 \mathrm{e}-011.00000 \mathrm{e}-092.12000 \mathrm{e}-01$

$1.00000 \mathrm{e}+001.00000 \mathrm{e}+001.00000 \mathrm{e}-011.00000 \mathrm{e}-091.00000 \mathrm{e}-01$

Element: 13636 \# of layers: 6

$\mathrm{Kx} \mathrm{Ky} \mathrm{Kz}$ Ss Por

$1.79984 \mathrm{e}+001.79984 \mathrm{e}+00$ 1.79984e-01 1.00000e-09 2.12000e-01

$1.79984 \mathrm{e}+001.79984 \mathrm{e}+001.79984 \mathrm{e}-011.00000 \mathrm{e}-092.12000 \mathrm{e}-01$

$1.79984 \mathrm{e}+001.79984 \mathrm{e}+001.79984 \mathrm{e}-01$ 1.00000e-09 2.12000e-01

$1.79984 \mathrm{e}+001.79984 \mathrm{e}+001.79984 \mathrm{e}-01$ 1.00000e-09 2.12000e-01

$1.79984 \mathrm{e}+001.79984 \mathrm{e}+001.79984 \mathrm{e}-011.00000 \mathrm{e}-092.12000 \mathrm{e}-01$

$1.00000 \mathrm{e}+001.00000 \mathrm{e}+001.00000 \mathrm{e}-01$ 1.00000e-09 1.00000e-01

Element: 13637 \# of layers: 6

$\mathrm{Kx} \mathrm{Ky} \mathrm{Kz}$ Ss Por

1.79984e+00 1.79984e+00 1.79984e-01 1.00000e-09 2.12000e-01

$1.79984 \mathrm{e}+001.79984 \mathrm{e}+001.79984 \mathrm{e}-011.00000 \mathrm{e}-092.12000 \mathrm{e}-01$

$1.79984 \mathrm{e}+001.79984 \mathrm{e}+001.79984 \mathrm{e}-01$ 1.00000e-09 2.12000e-01

$1.79984 \mathrm{e}+001.79984 \mathrm{e}+00 \quad 1.79984 \mathrm{e}-01$ 1.00000e-09 2.12000e-01 
$1.79984 \mathrm{e}+001.79984 \mathrm{e}+00$ 1.79984e-01 1.00000e-09 2.12000e-01 $1.00000 \mathrm{e}+001.00000 \mathrm{e}+001.00000 \mathrm{e}-011.00000 \mathrm{e}-091.00000 \mathrm{e}-01$ Element: 13638 \# of layers: 6

Kx Ky Kz Ss Por

$1.79984 \mathrm{e}+001.79984 \mathrm{e}+00$ 1.79984e-01 1.00000e-09 2.12000e-01 $1.79984 \mathrm{e}+001.79984 \mathrm{e}+001.79984 \mathrm{e}-011.00000 \mathrm{e}-092.12000 \mathrm{e}-01$ $1.79984 \mathrm{e}+001.79984 \mathrm{e}+001.79984 \mathrm{e}-011.00000 \mathrm{e}-092.12000 \mathrm{e}-01$ $1.79984 \mathrm{e}+001.79984 \mathrm{e}+001.79984 \mathrm{e}-011.00000 \mathrm{e}-092.12000 \mathrm{e}-01$ $1.79984 \mathrm{e}+001.79984 \mathrm{e}+001.79984 \mathrm{e}-011.00000 \mathrm{e}-092.12000 \mathrm{e}-01$ $1.00000 \mathrm{e}+001.00000 \mathrm{e}+001.00000 \mathrm{e}-011.00000 \mathrm{e}-091.00000 \mathrm{e}-01$ Element: 13639 \# of layers: 6

Kx Ky Kz Ss Por

$1.68351 \mathrm{e}+001.68351 \mathrm{e}+00$ 1.68351e-01 1.00000e-09 2.12000e-01 $1.68351 \mathrm{e}+001.68351 \mathrm{e}+001.68351 \mathrm{e}-011.00000 \mathrm{e}-092.12000 \mathrm{e}-01$ $1.68351 \mathrm{e}+001.68351 \mathrm{e}+001.68351 \mathrm{e}-011.00000 \mathrm{e}-092.12000 \mathrm{e}-01$ $1.68351 \mathrm{e}+001.68351 \mathrm{e}+001.68351 \mathrm{e}-011.00000 \mathrm{e}-092.12000 \mathrm{e}-01$ $1.68351 \mathrm{e}+001.68351 \mathrm{e}+001.68351 \mathrm{e}-011.00000 \mathrm{e}-092.12000 \mathrm{e}-01$ $1.00000 \mathrm{e}+001.00000 \mathrm{e}+001.00000 \mathrm{e}-011.00000 \mathrm{e}-091.00000 \mathrm{e}-01$ Element: 13640 \# of layers: 6

Kx Ky Kz Ss Por

$1.68351 \mathrm{e}+001.68351 \mathrm{e}+001.68351 \mathrm{e}-011.00000 \mathrm{e}-092.12000 \mathrm{e}-01$ $1.68351 \mathrm{e}+001.68351 \mathrm{e}+001.68351 \mathrm{e}-011.00000 \mathrm{e}-092.12000 \mathrm{e}-01$ $1.68351 \mathrm{e}+001.68351 \mathrm{e}+001.68351 \mathrm{e}-011.00000 \mathrm{e}-092.12000 \mathrm{e}-01$ $1.68351 \mathrm{e}+001.68351 \mathrm{e}+001.68351 \mathrm{e}-011.00000 \mathrm{e}-092.12000 \mathrm{e}-01$ $1.68351 \mathrm{e}+001.68351 \mathrm{e}+001.68351 \mathrm{e}-011.00000 \mathrm{e}-092.12000 \mathrm{e}-01$ $1.00000 \mathrm{e}+001.00000 \mathrm{e}+001.00000 \mathrm{e}-011.00000 \mathrm{e}-091.00000 \mathrm{e}-01$ Element: 13641 \# of layers: 6

Kx Ky Kz Ss Por

$1.68351 \mathrm{e}+001.68351 \mathrm{e}+001.68351 \mathrm{e}-011.00000 \mathrm{e}-092.12000 \mathrm{e}-01$ $1.68351 \mathrm{e}+001.68351 \mathrm{e}+001.68351 \mathrm{e}-011.00000 \mathrm{e}-092.12000 \mathrm{e}-01$ $1.68351 \mathrm{e}+001.68351 \mathrm{e}+001.68351 \mathrm{e}-011.00000 \mathrm{e}-092.12000 \mathrm{e}-01$ $1.68351 \mathrm{e}+001.68351 \mathrm{e}+001.68351 \mathrm{e}-011.00000 \mathrm{e}-092.12000 \mathrm{e}-01$ $1.68351 \mathrm{e}+001.68351 \mathrm{e}+001.68351 \mathrm{e}-011.00000 \mathrm{e}-092.12000 \mathrm{e}-01$ $1.00000 \mathrm{e}+001.00000 \mathrm{e}+001.00000 \mathrm{e}-011.00000 \mathrm{e}-091.00000 \mathrm{e}-01$ Element: 13642 \# of layers: 6

Kx Ky Kz Ss Por

$1.68351 \mathrm{e}+001.68351 \mathrm{e}+001.68351 \mathrm{e}-011.00000 \mathrm{e}-092.12000 \mathrm{e}-01$ $1.68351 \mathrm{e}+001.68351 \mathrm{e}+001.68351 \mathrm{e}-011.00000 \mathrm{e}-092.12000 \mathrm{e}-01$ $1.68351 \mathrm{e}+001.68351 \mathrm{e}+001.68351 \mathrm{e}-011.00000 \mathrm{e}-092.12000 \mathrm{e}-01$ $1.68351 \mathrm{e}+001.68351 \mathrm{e}+001.68351 \mathrm{e}-011.00000 \mathrm{e}-092.12000 \mathrm{e}-01$ $1.68351 \mathrm{e}+001.68351 \mathrm{e}+001.68351 \mathrm{e}-011.00000 \mathrm{e}-092.12000 \mathrm{e}-01$ $1.00000 \mathrm{e}+001.00000 \mathrm{e}+001.00000 \mathrm{e}-011.00000 \mathrm{e}-091.00000 \mathrm{e}-01$ Element: 13643 \# of layers: 6

Kx Ky Kz Ss Por

$1.68351 \mathrm{e}+001.68351 \mathrm{e}+00$ 1.68351e-01 1.00000e-09 2.12000e-01 $1.68351 \mathrm{e}+001.68351 \mathrm{e}+001.68351 \mathrm{e}-011.00000 \mathrm{e}-092.12000 \mathrm{e}-01$ 
$1.68351 \mathrm{e}+001.68351 \mathrm{e}+00$ 1.68351e-01 1.00000e-09 2.12000e-01 $1.68351 \mathrm{e}+001.68351 \mathrm{e}+001.68351 \mathrm{e}-01$ 1.00000e-09 2.12000e-01 $1.68351 \mathrm{e}+001.68351 \mathrm{e}+001.68351 \mathrm{e}-011.00000 \mathrm{e}-092.12000 \mathrm{e}-01$ $1.00000 \mathrm{e}+001.00000 \mathrm{e}+001.00000 \mathrm{e}-011.00000 \mathrm{e}-091.00000 \mathrm{e}-01$ Element: 13644 \# of layers: 6

$\mathrm{Kx} \mathrm{Ky} \mathrm{Kz}$ Ss Por

$1.68351 \mathrm{e}+001.68351 \mathrm{e}+00$ 1.68351e-01 1.00000e-09 2.12000e-01

$1.68351 \mathrm{e}+001.68351 \mathrm{e}+001.68351 \mathrm{e}-011.00000 \mathrm{e}-092.12000 \mathrm{e}-01$

$1.68351 \mathrm{e}+001.68351 \mathrm{e}+001.68351 \mathrm{e}-011.00000 \mathrm{e}-092.12000 \mathrm{e}-01$

$1.68351 \mathrm{e}+001.68351 \mathrm{e}+001.68351 \mathrm{e}-011.00000 \mathrm{e}-092.12000 \mathrm{e}-01$

$1.68351 \mathrm{e}+001.68351 \mathrm{e}+001.68351 \mathrm{e}-011.00000 \mathrm{e}-092.12000 \mathrm{e}-01$

$1.00000 \mathrm{e}+001.00000 \mathrm{e}+001.00000 \mathrm{e}-01$ 1.00000e-09 1.00000e-01

Element: 13645 \# of layers: 6

$\mathrm{Kx} \mathrm{Ky} \mathrm{Kz}$ Ss Por

$1.68351 \mathrm{e}+001.68351 \mathrm{e}+00$ 1.68351e-01 1.00000e-09 2.12000e-01

$1.68351 \mathrm{e}+001.68351 \mathrm{e}+001.68351 \mathrm{e}-011.00000 \mathrm{e}-092.12000 \mathrm{e}-01$

$1.68351 \mathrm{e}+001.68351 \mathrm{e}+001.68351 \mathrm{e}-011.00000 \mathrm{e}-092.12000 \mathrm{e}-01$

$1.68351 \mathrm{e}+001.68351 \mathrm{e}+001.68351 \mathrm{e}-011.00000 \mathrm{e}-092.12000 \mathrm{e}-01$

$1.68351 \mathrm{e}+001.68351 \mathrm{e}+001.68351 \mathrm{e}-01$ 1.00000e-09 2.12000e-01

$1.00000 \mathrm{e}+001.00000 \mathrm{e}+001.00000 \mathrm{e}-01$ 1.00000e-09 1.00000e-01

Element: 13646 \# of layers: 6

$\mathrm{Kx} \mathrm{Ky} \mathrm{Kz}$ Ss Por

$1.68351 \mathrm{e}+001.68351 \mathrm{e}+00$ 1.68351e-01 1.00000e-09 2.12000e-01

$1.68351 \mathrm{e}+001.68351 \mathrm{e}+001.68351 \mathrm{e}-01$ 1.00000e-09 2.12000e-01

$1.68351 \mathrm{e}+001.68351 \mathrm{e}+001.68351 \mathrm{e}-011.00000 \mathrm{e}-092.12000 \mathrm{e}-01$

$1.68351 \mathrm{e}+001.68351 \mathrm{e}+001.68351 \mathrm{e}-011.00000 \mathrm{e}-092.12000 \mathrm{e}-01$

$1.68351 \mathrm{e}+001.68351 \mathrm{e}+001.68351 \mathrm{e}-011.00000 \mathrm{e}-092.12000 \mathrm{e}-01$

$1.00000 \mathrm{e}+001.00000 \mathrm{e}+001.00000 \mathrm{e}-01$ 1.00000e-09 1.00000e-01

Element: 13647 \# of layers: 6

$\mathrm{Kx} \mathrm{Ky} \mathrm{Kz}$ Ss Por

$1.68351 \mathrm{e}+001.68351 \mathrm{e}+00$ 1.68351e-01 1.00000e-09 2.12000e-01

$1.68351 \mathrm{e}+001.68351 \mathrm{e}+001.68351 \mathrm{e}-01$ 1.00000e-09 2.12000e-01

$1.68351 \mathrm{e}+001.68351 \mathrm{e}+001.68351 \mathrm{e}-011.00000 \mathrm{e}-092.12000 \mathrm{e}-01$

$1.68351 \mathrm{e}+001.68351 \mathrm{e}+001.68351 \mathrm{e}-011.00000 \mathrm{e}-092.12000 \mathrm{e}-01$

$1.68351 \mathrm{e}+001.68351 \mathrm{e}+001.68351 \mathrm{e}-011.00000 \mathrm{e}-092.12000 \mathrm{e}-01$

$1.00000 \mathrm{e}+001.00000 \mathrm{e}+001.00000 \mathrm{e}-01$ 1.00000e-09 1.00000e-01

Element: 13648 \# of layers: 6

$\mathrm{Kx} \mathrm{Ky} \mathrm{Kz}$ Ss Por

$1.68351 \mathrm{e}+001.68351 \mathrm{e}+00$ 1.68351e-01 1.00000e-09 2.12000e-01

$1.68351 \mathrm{e}+001.68351 \mathrm{e}+00$ 1.68351e-01 1.00000e-09 2.12000e-01

$1.68351 \mathrm{e}+001.68351 \mathrm{e}+001.68351 \mathrm{e}-01$ 1.00000e-09 2.12000e-01

$1.68351 \mathrm{e}+001.68351 \mathrm{e}+001.68351 \mathrm{e}-011.00000 \mathrm{e}-092.12000 \mathrm{e}-01$

$1.68351 \mathrm{e}+001.68351 \mathrm{e}+001.68351 \mathrm{e}-011.00000 \mathrm{e}-092.12000 \mathrm{e}-01$

$1.00000 \mathrm{e}+001.00000 \mathrm{e}+001.00000 \mathrm{e}-01$ 1.00000e-09 1.00000e-01

Element: 13649 \# of layers: 6

Kx Ky Kz Ss Por 
$1.68351 \mathrm{e}+001.68351 \mathrm{e}+00$ 1.68351e-01 1.00000e-09 2.12000e-01 $1.68351 \mathrm{e}+001.68351 \mathrm{e}+001.68351 \mathrm{e}-01$ 1.00000e-09 2.12000e-01 $1.68351 \mathrm{e}+001.68351 \mathrm{e}+001.68351 \mathrm{e}-01$ 1.00000e-09 2.12000e-01 $1.68351 \mathrm{e}+001.68351 \mathrm{e}+001.68351 \mathrm{e}-011.00000 \mathrm{e}-092.12000 \mathrm{e}-01$ $1.68351 \mathrm{e}+001.68351 \mathrm{e}+001.68351 \mathrm{e}-01$ 1.00000e-09 2.12000e-01 $1.00000 \mathrm{e}+001.00000 \mathrm{e}+001.00000 \mathrm{e}-011.00000 \mathrm{e}-091.00000 \mathrm{e}-01$ Element: 13650 \# of layers: 6

$\mathrm{Kx} \mathrm{Ky} \mathrm{Kz}$ Ss Por

$1.95192 \mathrm{e}+00$ 1.95192e+00 1.95192e-01 1.00000e-09 2.12000e-01 1.95192e+00 1.95192e+00 1.95192e-01 1.00000e-09 2.12000e-01 $1.95192 \mathrm{e}+00$ 1.95192e+00 1.95192e-01 1.00000e-09 2.12000e-01 $1.95192 \mathrm{e}+001.95192 \mathrm{e}+001.95192 \mathrm{e}-01$ 1.00000e-09 2.12000e-01 $1.95192 \mathrm{e}+00$ 1.95192e+00 1.95192e-01 1.00000e-09 2.12000e-01 $1.00000 \mathrm{e}+001.00000 \mathrm{e}+001.00000 \mathrm{e}-01$ 1.00000e-09 1.00000e-01 Element: 13651 \# of layers: 6

Kx Ky Kz Ss Por

1.95192e+00 1.95192e+00 1.95192e-01 1.00000e-09 2.12000e-01 1.95192e+00 1.95192e+00 1.95192e-01 1.00000e-09 2.12000e-01 $1.95192 \mathrm{e}+001.95192 \mathrm{e}+00$ 1.95192e-01 1.00000e-09 2.12000e-01 $1.95192 \mathrm{e}+00$ 1.95192e+00 1.95192e-01 1.00000e-09 2.12000e-01 $1.95192 \mathrm{e}+001.95192 \mathrm{e}+001.95192 \mathrm{e}-01$ 1.00000e-09 2.12000e-01 $1.00000 \mathrm{e}+001.00000 \mathrm{e}+001.00000 \mathrm{e}-01$ 1.00000e-09 1.00000e-01 Element: 13652 \# of layers: 7

$\mathrm{Kx} \mathrm{Ky} \mathrm{Kz}$ Ss Por

$1.95192 \mathrm{e}+00$ 1.95192e+00 1.95192e-01 1.00000e-09 2.12000e-01 $1.95192 \mathrm{e}+00$ 1.95192e+00 1.95192e-01 1.00000e-09 2.12000e-01 1.95192e+00 1.95192e+00 1.95192e-01 1.00000e-09 2.12000e-01 1.95192e+00 1.95192e+00 1.95192e-01 1.00000e-09 2.12000e-01 $1.95192 \mathrm{e}+001.95192 \mathrm{e}+00$ 1.95192e-01 1.00000e-09 2.12000e-01 $1.00000 \mathrm{e}-05$ 1.00000e-05 1.00000e-06 1.00000e-09 1.00000e-01 $1.00000 \mathrm{e}+001.00000 \mathrm{e}+00$ 1.00000e-01 1.00000e-09 1.00000e-01 Element: 13653 \# of layers: 6

Kx Ky Kz Ss Por

$1.68351 \mathrm{e}+001.68351 \mathrm{e}+00$ 1.68351e-01 1.00000e-09 2.12000e-01 $1.68351 \mathrm{e}+001.68351 \mathrm{e}+001.68351 \mathrm{e}-01$ 1.00000e-09 2.12000e-01 $1.68351 \mathrm{e}+001.68351 \mathrm{e}+001.68351 \mathrm{e}-01$ 1.00000e-09 2.12000e-01 $1.68351 \mathrm{e}+001.68351 \mathrm{e}+001.68351 \mathrm{e}-011.00000 \mathrm{e}-092.12000 \mathrm{e}-01$ $1.68351 \mathrm{e}+001.68351 \mathrm{e}+001.68351 \mathrm{e}-011.00000 \mathrm{e}-092.12000 \mathrm{e}-01$ $1.00000 \mathrm{e}+001.00000 \mathrm{e}+001.00000 \mathrm{e}-01$ 1.00000e-09 1.00000e-01 Element: 13654 \# of layers: 6

$\mathrm{Kx} \mathrm{Ky} \mathrm{Kz}$ Ss Por

$1.68351 \mathrm{e}+001.68351 \mathrm{e}+001.68351 \mathrm{e}-011.00000 \mathrm{e}-092.12000 \mathrm{e}-01$ $1.68351 \mathrm{e}+001.68351 \mathrm{e}+00$ 1.68351e-01 1.00000e-09 2.12000e-01 $1.68351 \mathrm{e}+001.68351 \mathrm{e}+00$ 1.68351e-01 1.00000e-09 2.12000e-01 $1.68351 \mathrm{e}+001.68351 \mathrm{e}+001.68351 \mathrm{e}-01$ 1.00000e-09 2.12000e-01 $1.68351 \mathrm{e}+001.68351 \mathrm{e}+001.68351 \mathrm{e}-011.00000 \mathrm{e}-092.12000 \mathrm{e}-01$ 
$1.00000 \mathrm{e}+001.00000 \mathrm{e}+001.00000 \mathrm{e}-011.00000 \mathrm{e}-091.00000 \mathrm{e}-01$

Element: 13655 \# of layers: 6

Kx Ky Kz Ss Por

$1.68351 \mathrm{e}+001.68351 \mathrm{e}+001.68351 \mathrm{e}-011.00000 \mathrm{e}-092.12000 \mathrm{e}-01$

$1.68351 \mathrm{e}+001.68351 \mathrm{e}+001.68351 \mathrm{e}-01$ 1.00000e-09 2.12000e-01

$1.68351 \mathrm{e}+001.68351 \mathrm{e}+001.68351 \mathrm{e}-011.00000 \mathrm{e}-092.12000 \mathrm{e}-01$

$1.68351 \mathrm{e}+001.68351 \mathrm{e}+001.68351 \mathrm{e}-011.00000 \mathrm{e}-092.12000 \mathrm{e}-01$

$1.68351 \mathrm{e}+001.68351 \mathrm{e}+001.68351 \mathrm{e}-011.00000 \mathrm{e}-092.12000 \mathrm{e}-01$

$1.00000 \mathrm{e}+001.00000 \mathrm{e}+001.00000 \mathrm{e}-01$ 1.00000e-09 1.00000e-01

Element: 13656 \# of layers: 6

Kx Ky Kz Ss Por

$1.68351 \mathrm{e}+001.68351 \mathrm{e}+001.68351 \mathrm{e}-011.00000 \mathrm{e}-092.12000 \mathrm{e}-01$

$1.68351 \mathrm{e}+001.68351 \mathrm{e}+001.68351 \mathrm{e}-011.00000 \mathrm{e}-092.12000 \mathrm{e}-01$

$1.68351 \mathrm{e}+001.68351 \mathrm{e}+001.68351 \mathrm{e}-01$ 1.00000e-09 2.12000e-01

$1.68351 \mathrm{e}+001.68351 \mathrm{e}+001.68351 \mathrm{e}-01$ 1.00000e-09 2.12000e-01

$1.68351 \mathrm{e}+001.68351 \mathrm{e}+001.68351 \mathrm{e}-011.00000 \mathrm{e}-092.12000 \mathrm{e}-01$

$1.00000 \mathrm{e}+001.00000 \mathrm{e}+00$ 1.00000e-01 1.00000e-09 1.00000e-01

Element: 13657 \# of layers: 7

$\mathrm{Kx} \mathrm{Ky} \mathrm{Kz}$ Ss Por

1.95192e+00 1.95192e+00 1.95192e-01 1.00000e-09 2.12000e-01

$1.95192 \mathrm{e}+001.95192 \mathrm{e}+00$ 1.95192e-01 1.00000e-09 2.12000e-01

$1.95192 \mathrm{e}+00$ 1.95192e+00 1.95192e-01 1.00000e-09 2.12000e-01

1.95192e+00 1.95192e+00 1.95192e-01 1.00000e-09 2.12000e-01

$1.95192 \mathrm{e}+001.95192 \mathrm{e}+00$ 1.95192e-01 1.00000e-09 2.12000e-01

$1.00000 \mathrm{e}-05$ 1.00000e-05 1.00000e-06 1.00000e-09 1.00000e-01

$1.00000 \mathrm{e}+001.00000 \mathrm{e}+001.00000 \mathrm{e}-01$ 1.00000e-09 1.00000e-01

Element: 13658 \# of layers: 7

$\mathrm{Kx} \mathrm{Ky} \mathrm{Kz}$ Ss Por

1.95192e+00 1.95192e+00 1.95192e-01 1.00000e-09 2.12000e-01

$1.95192 \mathrm{e}+00$ 1.95192e+00 1.95192e-01 1.00000e-09 2.12000e-01

$1.95192 \mathrm{e}+00$ 1.95192e+00 1.95192e-01 1.00000e-09 2.12000e-01

$1.95192 \mathrm{e}+001.95192 \mathrm{e}+00$ 1.95192e-01 1.00000e-09 2.12000e-01

$1.95192 \mathrm{e}+001.95192 \mathrm{e}+00$ 1.95192e-01 1.00000e-09 2.12000e-01

$1.00000 \mathrm{e}-05$ 1.00000e-05 1.00000e-06 1.00000e-09 1.00000e-01

$1.00000 \mathrm{e}+001.00000 \mathrm{e}+001.00000 \mathrm{e}-01$ 1.00000e-09 1.00000e-01

Element: 13659 \# of layers: 7

Kx Ky Kz Ss Por

1.95192e+00 1.95192e+00 1.95192e-01 1.00000e-09 2.12000e-01 $1.95192 \mathrm{e}+00$ 1.95192e+00 1.95192e-01 1.00000e-09 2.12000e-01 1.95192e+00 1.95192e+00 1.95192e-01 1.00000e-09 2.12000e-01 $1.95192 \mathrm{e}+001.95192 \mathrm{e}+00$ 1.95192e-01 1.00000e-09 2.12000e-01 $1.95192 \mathrm{e}+001.95192 \mathrm{e}+00$ 1.95192e-01 1.00000e-09 2.12000e-01 $1.00000 \mathrm{e}-05$ 1.00000e-05 1.00000e-06 1.00000e-09 1.00000e-01 $1.00000 \mathrm{e}+001.00000 \mathrm{e}+001.00000 \mathrm{e}-01$ 1.00000e-09 1.00000e-01 Element: 13660 \# of layers: 7

Kx Ky Kz Ss Por 
$1.95192 \mathrm{e}+001.95192 \mathrm{e}+00$ 1.95192e-01 1.00000e-09 2.12000e-01 $1.95192 \mathrm{e}+001.95192 \mathrm{e}+001.95192 \mathrm{e}-011.00000 \mathrm{e}-092.12000 \mathrm{e}-01$ $1.95192 \mathrm{e}+001.95192 \mathrm{e}+00$ 1.95192e-01 1.00000e-09 2.12000e-01 $1.95192 \mathrm{e}+001.95192 \mathrm{e}+001.95192 \mathrm{e}-011.00000 \mathrm{e}-092.12000 \mathrm{e}-01$ $1.95192 \mathrm{e}+001.95192 \mathrm{e}+001.95192 \mathrm{e}-011.00000 \mathrm{e}-092.12000 \mathrm{e}-01$ $1.00000 \mathrm{e}-05$ 1.00000e-05 1.00000e-06 1.00000e-09 1.00000e-01 $1.00000 \mathrm{e}+001.00000 \mathrm{e}+001.00000 \mathrm{e}-011.00000 \mathrm{e}-091.00000 \mathrm{e}-01$ Element: 13661 \# of layers: 7

$\mathrm{Kx} \mathrm{Ky} \mathrm{Kz}$ Ss Por

1.95192e+00 1.95192e+00 1.95192e-01 1.00000e-09 2.12000e-01 $1.95192 \mathrm{e}+00$ 1.95192e+00 1.95192e-01 1.00000e-09 2.12000e-01 $1.95192 \mathrm{e}+001.95192 \mathrm{e}+001.95192 \mathrm{e}-01$ 1.00000e-09 2.12000e-01 $1.95192 \mathrm{e}+001.95192 \mathrm{e}+001.95192 \mathrm{e}-011.00000 \mathrm{e}-092.12000 \mathrm{e}-01$ $1.95192 \mathrm{e}+001.95192 \mathrm{e}+001.95192 \mathrm{e}-011.00000 \mathrm{e}-092.12000 \mathrm{e}-01$ $1.00000 \mathrm{e}-05$ 1.00000e-05 1.00000e-06 1.00000e-09 1.00000e-01 $1.00000 \mathrm{e}+001.00000 \mathrm{e}+001.00000 \mathrm{e}-011.00000 \mathrm{e}-091.00000 \mathrm{e}-01$ Element: 13662 \# of layers: 7

Kx Ky Kz Ss Por

$1.95192 \mathrm{e}+001.95192 \mathrm{e}+00$ 1.95192e-01 1.00000e-09 2.12000e-01 $1.95192 \mathrm{e}+001.95192 \mathrm{e}+001.95192 \mathrm{e}-011.00000 \mathrm{e}-092.12000 \mathrm{e}-01$ $1.95192 \mathrm{e}+001.95192 \mathrm{e}+001.95192 \mathrm{e}-011.00000 \mathrm{e}-092.12000 \mathrm{e}-01$ $1.95192 \mathrm{e}+001.95192 \mathrm{e}+001.95192 \mathrm{e}-011.00000 \mathrm{e}-092.12000 \mathrm{e}-01$ $1.95192 \mathrm{e}+001.95192 \mathrm{e}+001.95192 \mathrm{e}-011.00000 \mathrm{e}-092.12000 \mathrm{e}-01$ $1.00000 \mathrm{e}-05$ 1.00000e-05 1.00000e-06 1.00000e-09 1.00000e-01 $1.00000 \mathrm{e}+001.00000 \mathrm{e}+001.00000 \mathrm{e}-011.00000 \mathrm{e}-091.00000 \mathrm{e}-01$ Element: 13663 \# of layers: 7

Kx Ky Kz Ss Por

$1.95192 \mathrm{e}+001.95192 \mathrm{e}+00$ 1.95192e-01 1.00000e-09 2.12000e-01 $1.95192 \mathrm{e}+001.95192 \mathrm{e}+001.95192 \mathrm{e}-011.00000 \mathrm{e}-092.12000 \mathrm{e}-01$ $1.95192 \mathrm{e}+001.95192 \mathrm{e}+001.95192 \mathrm{e}-011.00000 \mathrm{e}-092.12000 \mathrm{e}-01$ $1.95192 \mathrm{e}+001.95192 \mathrm{e}+001.95192 \mathrm{e}-011.00000 \mathrm{e}-092.12000 \mathrm{e}-01$ $1.95192 \mathrm{e}+001.95192 \mathrm{e}+001.95192 \mathrm{e}-011.00000 \mathrm{e}-09$ 2.12000e-01 $1.00000 \mathrm{e}-05$ 1.00000e-05 1.00000e-06 1.00000e-09 1.00000e-01 $1.00000 \mathrm{e}+001.00000 \mathrm{e}+001.00000 \mathrm{e}-011.00000 \mathrm{e}-091.00000 \mathrm{e}-01$ Element: 13664 \# of layers: 7

Kx Ky Kz Ss Por

$1.95192 \mathrm{e}+001.95192 \mathrm{e}+00$ 1.95192e-01 1.00000e-09 2.12000e-01 $1.95192 \mathrm{e}+001.95192 \mathrm{e}+00$ 1.95192e-01 1.00000e-09 2.12000e-01 $1.95192 \mathrm{e}+001.95192 \mathrm{e}+001.95192 \mathrm{e}-011.00000 \mathrm{e}-092.12000 \mathrm{e}-01$ $1.95192 \mathrm{e}+001.95192 \mathrm{e}+001.95192 \mathrm{e}-011.00000 \mathrm{e}-092.12000 \mathrm{e}-01$ $1.95192 \mathrm{e}+001.95192 \mathrm{e}+001.95192 \mathrm{e}-011.00000 \mathrm{e}-092.12000 \mathrm{e}-01$ $1.00000 \mathrm{e}-05$ 1.00000e-05 1.00000e-06 1.00000e-09 1.00000e-01 $1.00000 \mathrm{e}+001.00000 \mathrm{e}+001.00000 \mathrm{e}-011.00000 \mathrm{e}-091.00000 \mathrm{e}-01$ Element: 13665 \# of layers: 7

Kx Ky Kz Ss Por

$1.95192 \mathrm{e}+00$ 1.95192e+00 1.95192e-01 1.00000e-09 2.12000e-01 
$1.95192 \mathrm{e}+001.95192 \mathrm{e}+00$ 1.95192e-01 1.00000e-09 2.12000e-01 $1.95192 \mathrm{e}+001.95192 \mathrm{e}+001.95192 \mathrm{e}-011.00000 \mathrm{e}-092.12000 \mathrm{e}-01$ $1.95192 \mathrm{e}+001.95192 \mathrm{e}+00$ 1.95192e-01 1.00000e-09 2.12000e-01 $1.95192 \mathrm{e}+001.95192 \mathrm{e}+001.95192 \mathrm{e}-011.00000 \mathrm{e}-092.12000 \mathrm{e}-01$ $1.00000 \mathrm{e}-05$ 1.00000e-05 1.00000e-06 1.00000e-09 1.00000e-01 $1.00000 \mathrm{e}+001.00000 \mathrm{e}+001.00000 \mathrm{e}-011.00000 \mathrm{e}-091.00000 \mathrm{e}-01$ Element: 13666 \# of layers: 7

Kx Ky Kz Ss Por

$1.95192 \mathrm{e}+001.95192 \mathrm{e}+00$ 1.95192e-01 1.00000e-09 2.12000e-01 $1.95192 \mathrm{e}+001.95192 \mathrm{e}+001.95192 \mathrm{e}-011.00000 \mathrm{e}-092.12000 \mathrm{e}-01$ $1.95192 \mathrm{e}+001.95192 \mathrm{e}+001.95192 \mathrm{e}-011.00000 \mathrm{e}-092.12000 \mathrm{e}-01$ $1.95192 \mathrm{e}+001.95192 \mathrm{e}+001.95192 \mathrm{e}-011.00000 \mathrm{e}-092.12000 \mathrm{e}-01$ $1.95192 \mathrm{e}+001.95192 \mathrm{e}+001.95192 \mathrm{e}-011.00000 \mathrm{e}-092.12000 \mathrm{e}-01$ $1.00000 \mathrm{e}-05$ 1.00000e-05 1.00000e-06 1.00000e-09 1.00000e-01 $1.00000 \mathrm{e}+001.00000 \mathrm{e}+001.00000 \mathrm{e}-011.00000 \mathrm{e}-091.00000 \mathrm{e}-01$ Element: 13667 \# of layers: 7

Kx Ky Kz Ss Por

$3.22409 \mathrm{e}+003.22409 \mathrm{e}+00$ 3.22409e-01 1.00000e-09 2.12000e-01 $3.22409 \mathrm{e}+003.22409 \mathrm{e}+003.22409 \mathrm{e}-01$ 1.00000e-09 2.12000e-01 $3.22409 \mathrm{e}+003.22409 \mathrm{e}+003.22409 \mathrm{e}-01$ 1.00000e-09 2.12000e-01 $3.22409 \mathrm{e}+003.22409 \mathrm{e}+003.22409 \mathrm{e}-01$ 1.00000e-09 2.12000e-01 $3.22409 \mathrm{e}+003.22409 \mathrm{e}+00$ 3.22409e-01 1.00000e-09 2.12000e-01 $1.00000 \mathrm{e}-05$ 1.00000e-05 1.00000e-06 1.00000e-09 1.00000e-01 $1.00000 \mathrm{e}+001.00000 \mathrm{e}+001.00000 \mathrm{e}-011.00000 \mathrm{e}-091.00000 \mathrm{e}-01$ Element: 13668 \# of layers: 7

Kx Ky Kz Ss Por

$3.22409 \mathrm{e}+003.22409 \mathrm{e}+00$ 3.22409e-01 1.00000e-09 2.12000e-01 $3.22409 \mathrm{e}+003.22409 \mathrm{e}+00$ 3.22409e-01 1.00000e-09 2.12000e-01 $3.22409 \mathrm{e}+003.22409 \mathrm{e}+003.22409 \mathrm{e}-01$ 1.00000e-09 2.12000e-01 $3.22409 \mathrm{e}+003.22409 \mathrm{e}+003.22409 \mathrm{e}-01$ 1.00000e-09 2.12000e-01 $3.22409 \mathrm{e}+003.22409 \mathrm{e}+00$ 3.22409e-01 1.00000e-09 2.12000e-01 $1.00000 \mathrm{e}-05$ 1.00000e-05 1.00000e-06 1.00000e-09 1.00000e-01 $1.00000 \mathrm{e}+001.00000 \mathrm{e}+001.00000 \mathrm{e}-011.00000 \mathrm{e}-091.00000 \mathrm{e}-01$ Element: 13669 \# of layers: 7

Kx Ky Kz Ss Por

$3.22409 \mathrm{e}+003.22409 \mathrm{e}+00$ 3.22409e-01 1.00000e-09 2.12000e-01

$3.22409 \mathrm{e}+003.22409 \mathrm{e}+003.22409 \mathrm{e}-01$ 1.00000e-09 2.12000e-01 $3.22409 \mathrm{e}+003.22409 \mathrm{e}+003.22409 \mathrm{e}-01$ 1.00000e-09 2.12000e-01 $3.22409 \mathrm{e}+003.22409 \mathrm{e}+003.22409 \mathrm{e}-01$ 1.00000e-09 2.12000e-01 $3.22409 \mathrm{e}+003.22409 \mathrm{e}+003.22409 \mathrm{e}-01$ 1.00000e-09 2.12000e-01 $1.00000 \mathrm{e}-05$ 1.00000e-05 1.00000e-06 1.00000e-09 1.00000e-01 $1.00000 \mathrm{e}+001.00000 \mathrm{e}+001.00000 \mathrm{e}-011.00000 \mathrm{e}-091.00000 \mathrm{e}-01$ Element: 13670 \# of layers: 7

Kx Ky Kz Ss Por

$3.22409 \mathrm{e}+003.22409 \mathrm{e}+00$ 3.22409e-01 1.00000e-09 2.12000e-01 $3.22409 \mathrm{e}+003.22409 \mathrm{e}+00$ 3.22409e-01 1.00000e-09 2.12000e-01 
$3.22409 \mathrm{e}+003.22409 \mathrm{e}+00$ 3.22409e-01 1.00000e-09 2.12000e-01 $3.22409 \mathrm{e}+003.22409 \mathrm{e}+003.22409 \mathrm{e}-01$ 1.00000e-09 2.12000e-01 $3.22409 \mathrm{e}+003.22409 \mathrm{e}+00$ 3.22409e-01 1.00000e-09 2.12000e-01 $1.00000 \mathrm{e}-05$ 1.00000e-05 1.00000e-06 1.00000e-09 1.00000e-01 $1.00000 \mathrm{e}+001.00000 \mathrm{e}+001.00000 \mathrm{e}-011.00000 \mathrm{e}-091.00000 \mathrm{e}-01$ Element: 13671 \# of layers: 7

Kx Ky Kz Ss Por

3.22409e+00 3.22409e+00 3.22409e-01 1.00000e-09 2.12000e-01 $3.22409 \mathrm{e}+003.22409 \mathrm{e}+003.22409 \mathrm{e}-01$ 1.00000e-09 2.12000e-01 $3.22409 \mathrm{e}+003.22409 \mathrm{e}+003.22409 \mathrm{e}-01$ 1.00000e-09 2.12000e-01 $3.22409 \mathrm{e}+003.22409 \mathrm{e}+003.22409 \mathrm{e}-01$ 1.00000e-09 2.12000e-01 $3.22409 \mathrm{e}+003.22409 \mathrm{e}+003.22409 \mathrm{e}-01$ 1.00000e-09 2.12000e-01 $1.00000 \mathrm{e}-05$ 1.00000e-05 1.00000e-06 1.00000e-09 1.00000e-01 $1.00000 \mathrm{e}+001.00000 \mathrm{e}+001.00000 \mathrm{e}-011.00000 \mathrm{e}-091.00000 \mathrm{e}-01$ Element: 13672 \# of layers: 7

Kx Ky Kz Ss Por

$1.95192 \mathrm{e}+001.95192 \mathrm{e}+00$ 1.95192e-01 1.00000e-09 2.12000e-01 $1.95192 \mathrm{e}+001.95192 \mathrm{e}+00$ 1.95192e-01 1.00000e-09 2.12000e-01 $1.95192 \mathrm{e}+001.95192 \mathrm{e}+001.95192 \mathrm{e}-011.00000 \mathrm{e}-092.12000 \mathrm{e}-01$ $1.95192 \mathrm{e}+001.95192 \mathrm{e}+001.95192 \mathrm{e}-011.00000 \mathrm{e}-092.12000 \mathrm{e}-01$ $1.95192 \mathrm{e}+001.95192 \mathrm{e}+001.95192 \mathrm{e}-011.00000 \mathrm{e}-092.12000 \mathrm{e}-01$ $1.00000 \mathrm{e}-05$ 1.00000e-05 1.00000e-06 1.00000e-09 1.00000e-01 $1.00000 \mathrm{e}+001.00000 \mathrm{e}+001.00000 \mathrm{e}-011.00000 \mathrm{e}-091.00000 \mathrm{e}-01$ Element: 13673 \# of layers: 7

Kx Ky Kz Ss Por

$1.95192 \mathrm{e}+001.95192 \mathrm{e}+00$ 1.95192e-01 1.00000e-09 2.12000e-01 $1.95192 \mathrm{e}+001.95192 \mathrm{e}+001.95192 \mathrm{e}-011.00000 \mathrm{e}-092.12000 \mathrm{e}-01$ $1.95192 \mathrm{e}+001.95192 \mathrm{e}+001.95192 \mathrm{e}-011.00000 \mathrm{e}-092.12000 \mathrm{e}-01$ $1.95192 \mathrm{e}+001.95192 \mathrm{e}+001.95192 \mathrm{e}-011.00000 \mathrm{e}-092.12000 \mathrm{e}-01$ $1.95192 \mathrm{e}+001.95192 \mathrm{e}+001.95192 \mathrm{e}-011.00000 \mathrm{e}-092.12000 \mathrm{e}-01$ $1.00000 \mathrm{e}-05$ 1.00000e-05 1.00000e-06 1.00000e-09 1.00000e-01 $1.00000 \mathrm{e}+001.00000 \mathrm{e}+001.00000 \mathrm{e}-011.00000 \mathrm{e}-091.00000 \mathrm{e}-01$ Element: 13674 \# of layers: 7

Kx Ky Kz Ss Por

$3.22409 \mathrm{e}+003.22409 \mathrm{e}+00$ 3.22409e-01 1.00000e-09 2.12000e-01 $3.22409 \mathrm{e}+003.22409 \mathrm{e}+003.22409 \mathrm{e}-01$ 1.00000e-09 2.12000e-01 $3.22409 \mathrm{e}+003.22409 \mathrm{e}+003.22409 \mathrm{e}-01$ 1.00000e-09 2.12000e-01 $3.22409 \mathrm{e}+003.22409 \mathrm{e}+003.22409 \mathrm{e}-01$ 1.00000e-09 2.12000e-01 $3.22409 \mathrm{e}+003.22409 \mathrm{e}+00$ 3.22409e-01 1.00000e-09 2.12000e-01 $1.00000 \mathrm{e}-05$ 1.00000e-05 1.00000e-06 1.00000e-09 1.00000e-01 $1.00000 \mathrm{e}+001.00000 \mathrm{e}+001.00000 \mathrm{e}-011.00000 \mathrm{e}-091.00000 \mathrm{e}-01$ Element: 13675 \# of layers: 7

Kx Ky Kz Ss Por

$3.22409 \mathrm{e}+003.22409 \mathrm{e}+00$ 3.22409e-01 1.00000e-09 2.12000e-01 $3.22409 \mathrm{e}+003.22409 \mathrm{e}+00$ 3.22409e-01 1.00000e-09 2.12000e-01 $3.22409 \mathrm{e}+003.22409 \mathrm{e}+003.22409 \mathrm{e}-01$ 1.00000e-09 2.12000e-01 
$3.22409 \mathrm{e}+003.22409 \mathrm{e}+00$ 3.22409e-01 1.00000e-09 2.12000e-01 $3.22409 \mathrm{e}+003.22409 \mathrm{e}+00$ 3.22409e-01 1.00000e-09 2.12000e-01 $1.00000 \mathrm{e}-05$ 1.00000e-05 1.00000e-06 1.00000e-09 1.00000e-01 $1.00000 \mathrm{e}+001.00000 \mathrm{e}+001.00000 \mathrm{e}-011.00000 \mathrm{e}-091.00000 \mathrm{e}-01$ Element: 13676 \# of layers: 6

Kx Ky Kz Ss Por

$1.79984 \mathrm{e}+001.79984 \mathrm{e}+00$ 1.79984e-01 1.00000e-09 2.12000e-01

$1.79984 \mathrm{e}+001.79984 \mathrm{e}+001.79984 \mathrm{e}-011.00000 \mathrm{e}-092.12000 \mathrm{e}-01$

$1.79984 \mathrm{e}+001.79984 \mathrm{e}+001.79984 \mathrm{e}-011.00000 \mathrm{e}-092.12000 \mathrm{e}-01$

$1.79984 \mathrm{e}+001.79984 \mathrm{e}+001.79984 \mathrm{e}-011.00000 \mathrm{e}-092.12000 \mathrm{e}-01$

$1.79984 \mathrm{e}+001.79984 \mathrm{e}+001.79984 \mathrm{e}-011.00000 \mathrm{e}-09$ 2.12000e-01

$1.00000 \mathrm{e}+001.00000 \mathrm{e}+00$ 1.00000e-01 1.00000e-09 1.00000e-01

Element: 13677 \# of layers: 6

Kx Ky Kz Ss Por

$1.79984 \mathrm{e}+001.79984 \mathrm{e}+00$ 1.79984e-01 1.00000e-09 2.12000e-01

$1.79984 \mathrm{e}+001.79984 \mathrm{e}+001.79984 \mathrm{e}-011.00000 \mathrm{e}-092.12000 \mathrm{e}-01$

$1.79984 \mathrm{e}+001.79984 \mathrm{e}+001.79984 \mathrm{e}-011.00000 \mathrm{e}-092.12000 \mathrm{e}-01$

$1.79984 \mathrm{e}+001.79984 \mathrm{e}+001.79984 \mathrm{e}-011.00000 \mathrm{e}-092.12000 \mathrm{e}-01$

$1.79984 \mathrm{e}+001.79984 \mathrm{e}+001.79984 \mathrm{e}-011.00000 \mathrm{e}-092.12000 \mathrm{e}-01$

$1.00000 \mathrm{e}+001.00000 \mathrm{e}+001.00000 \mathrm{e}-011.00000 \mathrm{e}-091.00000 \mathrm{e}-01$

Element: 13678 \# of layers: 6

Kx Ky Kz Ss Por

$1.79984 \mathrm{e}+001.79984 \mathrm{e}+00$ 1.79984e-01 1.00000e-09 2.12000e-01

$1.79984 \mathrm{e}+001.79984 \mathrm{e}+00$ 1.79984e-01 1.00000e-09 2.12000e-01

$1.79984 \mathrm{e}+001.79984 \mathrm{e}+001.79984 \mathrm{e}-011.00000 \mathrm{e}-092.12000 \mathrm{e}-01$

$1.79984 \mathrm{e}+001.79984 \mathrm{e}+00$ 1.79984e-01 1.00000e-09 2.12000e-01

$1.79984 \mathrm{e}+001.79984 \mathrm{e}+001.79984 \mathrm{e}-011.00000 \mathrm{e}-092.12000 \mathrm{e}-01$

$1.00000 \mathrm{e}+001.00000 \mathrm{e}+001.00000 \mathrm{e}-011.00000 \mathrm{e}-091.00000 \mathrm{e}-01$

Element: 13679 \# of layers: 6

Kx Ky Kz Ss Por

$1.68351 \mathrm{e}+001.68351 \mathrm{e}+001.68351 \mathrm{e}-011.00000 \mathrm{e}-092.12000 \mathrm{e}-01$ $1.68351 \mathrm{e}+001.68351 \mathrm{e}+001.68351 \mathrm{e}-011.00000 \mathrm{e}-092.12000 \mathrm{e}-01$ $1.68351 \mathrm{e}+001.68351 \mathrm{e}+001.68351 \mathrm{e}-011.00000 \mathrm{e}-092.12000 \mathrm{e}-01$ $1.68351 \mathrm{e}+001.68351 \mathrm{e}+001.68351 \mathrm{e}-011.00000 \mathrm{e}-092.12000 \mathrm{e}-01$ $1.68351 \mathrm{e}+001.68351 \mathrm{e}+001.68351 \mathrm{e}-011.00000 \mathrm{e}-092.12000 \mathrm{e}-01$ $1.00000 \mathrm{e}+001.00000 \mathrm{e}+001.00000 \mathrm{e}-011.00000 \mathrm{e}-091.00000 \mathrm{e}-01$ Element: 13680 \# of layers: 6

Kx Ky Kz Ss Por

$1.68351 \mathrm{e}+001.68351 \mathrm{e}+00$ 1.68351e-01 1.00000e-09 2.12000e-01 $1.68351 \mathrm{e}+001.68351 \mathrm{e}+001.68351 \mathrm{e}-011.00000 \mathrm{e}-092.12000 \mathrm{e}-01$ $1.68351 \mathrm{e}+001.68351 \mathrm{e}+001.68351 \mathrm{e}-011.00000 \mathrm{e}-092.12000 \mathrm{e}-01$ $1.68351 \mathrm{e}+001.68351 \mathrm{e}+001.68351 \mathrm{e}-011.00000 \mathrm{e}-092.12000 \mathrm{e}-01$ $1.68351 \mathrm{e}+001.68351 \mathrm{e}+001.68351 \mathrm{e}-011.00000 \mathrm{e}-092.12000 \mathrm{e}-01$ $1.00000 \mathrm{e}+001.00000 \mathrm{e}+001.00000 \mathrm{e}-011.00000 \mathrm{e}-091.00000 \mathrm{e}-01$ Element: 13681 \# of layers: 7

Kx Ky Kz Ss Por 
$1.95192 \mathrm{e}+001.95192 \mathrm{e}+00$ 1.95192e-01 1.00000e-09 2.12000e-01 $1.95192 \mathrm{e}+001.95192 \mathrm{e}+001.95192 \mathrm{e}-011.00000 \mathrm{e}-092.12000 \mathrm{e}-01$ $1.95192 \mathrm{e}+001.95192 \mathrm{e}+00$ 1.95192e-01 1.00000e-09 2.12000e-01 $1.95192 \mathrm{e}+001.95192 \mathrm{e}+001.95192 \mathrm{e}-011.00000 \mathrm{e}-092.12000 \mathrm{e}-01$ $1.95192 \mathrm{e}+001.95192 \mathrm{e}+001.95192 \mathrm{e}-011.00000 \mathrm{e}-092.12000 \mathrm{e}-01$ $1.00000 \mathrm{e}-05$ 1.00000e-05 1.00000e-06 1.00000e-09 1.00000e-01 $1.00000 \mathrm{e}+001.00000 \mathrm{e}+001.00000 \mathrm{e}-011.00000 \mathrm{e}-091.00000 \mathrm{e}-01$ Element: 13682 \# of layers: 7

Kx Ky Kz Ss Por

$3.22409 \mathrm{e}+003.22409 \mathrm{e}+00$ 3.22409e-01 1.00000e-09 2.12000e-01 $3.22409 \mathrm{e}+003.22409 \mathrm{e}+003.22409 \mathrm{e}-01$ 1.00000e-09 2.12000e-01 $3.22409 \mathrm{e}+003.22409 \mathrm{e}+003.22409 \mathrm{e}-01$ 1.00000e-09 2.12000e-01 $3.22409 \mathrm{e}+003.22409 \mathrm{e}+003.22409 \mathrm{e}-01$ 1.00000e-09 2.12000e-01 $3.22409 \mathrm{e}+003.22409 \mathrm{e}+003.22409 \mathrm{e}-01$ 1.00000e-09 2.12000e-01 $1.00000 \mathrm{e}-05$ 1.00000e-05 1.00000e-06 1.00000e-09 1.00000e-01 $1.00000 \mathrm{e}+001.00000 \mathrm{e}+001.00000 \mathrm{e}-011.00000 \mathrm{e}-091.00000 \mathrm{e}-01$ Element: 13683 \# of layers: 6

Kx Ky Kz Ss Por

$1.79984 \mathrm{e}+001.79984 \mathrm{e}+00$ 1.79984e-01 1.00000e-09 2.12000e-01 $1.79984 \mathrm{e}+001.79984 \mathrm{e}+001.79984 \mathrm{e}-011.00000 \mathrm{e}-092.12000 \mathrm{e}-01$ $1.79984 \mathrm{e}+001.79984 \mathrm{e}+001.79984 \mathrm{e}-011.00000 \mathrm{e}-092.12000 \mathrm{e}-01$ $1.79984 \mathrm{e}+001.79984 \mathrm{e}+001.79984 \mathrm{e}-011.00000 \mathrm{e}-092.12000 \mathrm{e}-01$ $1.79984 \mathrm{e}+001.79984 \mathrm{e}+001.79984 \mathrm{e}-011.00000 \mathrm{e}-092.12000 \mathrm{e}-01$ $1.00000 \mathrm{e}+001.00000 \mathrm{e}+001.00000 \mathrm{e}-011.00000 \mathrm{e}-091.00000 \mathrm{e}-01$ Element: 13684 \# of layers: 7

Kx Ky Kz Ss Por

$1.82661 \mathrm{e}+001.82661 \mathrm{e}+00$ 1.82661e-01 1.00000e-09 2.12000e-01 $1.82661 \mathrm{e}+001.82661 \mathrm{e}+001.82661 \mathrm{e}-011.00000 \mathrm{e}-092.12000 \mathrm{e}-01$ $1.82661 \mathrm{e}+001.82661 \mathrm{e}+001.82661 \mathrm{e}-011.00000 \mathrm{e}-092.12000 \mathrm{e}-01$ $1.82661 \mathrm{e}+001.82661 \mathrm{e}+001.82661 \mathrm{e}-011.00000 \mathrm{e}-092.12000 \mathrm{e}-01$ $1.82661 \mathrm{e}+001.82661 \mathrm{e}+001.82661 \mathrm{e}-011.00000 \mathrm{e}-092.12000 \mathrm{e}-01$ $1.00000 \mathrm{e}-05$ 1.00000e-05 1.00000e-06 1.00000e-09 1.00000e-01 $1.00000 \mathrm{e}+001.00000 \mathrm{e}+001.00000 \mathrm{e}-011.00000 \mathrm{e}-091.00000 \mathrm{e}-01$ Element: 13685 \# of layers: 7

Kx Ky Kz Ss Por

$1.82661 \mathrm{e}+001.82661 \mathrm{e}+00$ 1.82661e-01 1.00000e-09 2.12000e-01 $1.82661 \mathrm{e}+001.82661 \mathrm{e}+001.82661 \mathrm{e}-011.00000 \mathrm{e}-092.12000 \mathrm{e}-01$ $1.82661 \mathrm{e}+001.82661 \mathrm{e}+001.82661 \mathrm{e}-011.00000 \mathrm{e}-092.12000 \mathrm{e}-01$ $1.82661 \mathrm{e}+001.82661 \mathrm{e}+001.82661 \mathrm{e}-011.00000 \mathrm{e}-092.12000 \mathrm{e}-01$ $1.82661 \mathrm{e}+001.82661 \mathrm{e}+001.82661 \mathrm{e}-011.00000 \mathrm{e}-092.12000 \mathrm{e}-01$ $1.00000 \mathrm{e}-05$ 1.00000e-05 1.00000e-06 1.00000e-09 1.00000e-01 $1.00000 \mathrm{e}+001.00000 \mathrm{e}+001.00000 \mathrm{e}-011.00000 \mathrm{e}-091.00000 \mathrm{e}-01$ Element: 13686 \# of layers: 7

Kx Ky Kz Ss Por

$1.82661 \mathrm{e}+001.82661 \mathrm{e}+00$ 1.82661e-01 1.00000e-09 2.12000e-01 $1.82661 \mathrm{e}+001.82661 \mathrm{e}+001.82661 \mathrm{e}-011.00000 \mathrm{e}-092.12000 \mathrm{e}-01$ 
$1.82661 \mathrm{e}+00$ 1.82661e+00 1.82661e-01 1.00000e-09 2.12000e-01 $1.82661 \mathrm{e}+001.82661 \mathrm{e}+001.82661 \mathrm{e}-01$ 1.00000e-09 2.12000e-01 $1.82661 \mathrm{e}+001.82661 \mathrm{e}+001.82661 \mathrm{e}-01$ 1.00000e-09 2.12000e-01 $1.00000 \mathrm{e}-05$ 1.00000e-05 1.00000e-06 1.00000e-09 1.00000e-01 $1.00000 \mathrm{e}+001.00000 \mathrm{e}+00$ 1.00000e-01 1.00000e-09 1.00000e-01 Element: 13687 \# of layers: 7

$\mathrm{Kx} \mathrm{Ky} \mathrm{Kz}$ Ss Por

$1.82661 \mathrm{e}+001.82661 \mathrm{e}+00$ 1.82661e-01 1.00000e-09 2.12000e-01 $1.82661 \mathrm{e}+001.82661 \mathrm{e}+001.82661 \mathrm{e}-01$ 1.00000e-09 2.12000e-01 $1.82661 \mathrm{e}+001.82661 \mathrm{e}+001.82661 \mathrm{e}-01$ 1.00000e-09 2.12000e-01 $1.82661 \mathrm{e}+001.82661 \mathrm{e}+001.82661 \mathrm{e}-01$ 1.00000e-09 2.12000e-01 $1.82661 \mathrm{e}+001.82661 \mathrm{e}+001.82661 \mathrm{e}-011.00000 \mathrm{e}-092.12000 \mathrm{e}-01$ $1.00000 \mathrm{e}-051.00000 \mathrm{e}-05$ 1.00000e-06 1.00000e-09 1.00000e-01 $1.00000 \mathrm{e}+001.00000 \mathrm{e}+001.00000 \mathrm{e}-01$ 1.00000e-09 1.00000e-01 Element: 13688 \# of layers: 7

$\mathrm{Kx} \mathrm{Ky} \mathrm{Kz}$ Ss Por

$1.82661 \mathrm{e}+001.82661 \mathrm{e}+00$ 1.82661e-01 1.00000e-09 2.12000e-01 $1.82661 \mathrm{e}+001.82661 \mathrm{e}+001.82661 \mathrm{e}-01$ 1.00000e-09 2.12000e-01 $1.82661 \mathrm{e}+001.82661 \mathrm{e}+001.82661 \mathrm{e}-011.00000 \mathrm{e}-092.12000 \mathrm{e}-01$ $1.82661 \mathrm{e}+001.82661 \mathrm{e}+001.82661 \mathrm{e}-011.00000 \mathrm{e}-092.12000 \mathrm{e}-01$ $1.82661 \mathrm{e}+001.82661 \mathrm{e}+001.82661 \mathrm{e}-011.00000 \mathrm{e}-092.12000 \mathrm{e}-01$ $1.00000 \mathrm{e}-051.00000 \mathrm{e}-051.00000 \mathrm{e}-061.00000 \mathrm{e}-091.00000 \mathrm{e}-01$ $1.00000 \mathrm{e}+001.00000 \mathrm{e}+001.00000 \mathrm{e}-01$ 1.00000e-09 1.00000e-01 Element: 13689 \# of layers: 7

$\mathrm{Kx} \mathrm{Ky} \mathrm{Kz}$ Ss Por

$1.82661 \mathrm{e}+001.82661 \mathrm{e}+00$ 1.82661e-01 1.00000e-09 2.12000e-01 $1.82661 \mathrm{e}+001.82661 \mathrm{e}+001.82661 \mathrm{e}-011.00000 \mathrm{e}-092.12000 \mathrm{e}-01$ $1.82661 \mathrm{e}+001.82661 \mathrm{e}+001.82661 \mathrm{e}-01$ 1.00000e-09 2.12000e-01 $1.82661 \mathrm{e}+001.82661 \mathrm{e}+001.82661 \mathrm{e}-011.00000 \mathrm{e}-092.12000 \mathrm{e}-01$ $1.82661 \mathrm{e}+001.82661 \mathrm{e}+001.82661 \mathrm{e}-011.00000 \mathrm{e}-092.12000 \mathrm{e}-01$ $1.00000 \mathrm{e}-05$ 1.00000e-05 1.00000e-06 1.00000e-09 1.00000e-01 $1.00000 \mathrm{e}+001.00000 \mathrm{e}+001.00000 \mathrm{e}-01$ 1.00000e-09 1.00000e-01 Element: 13690 \# of layers: 7

$\mathrm{Kx} \mathrm{Ky} \mathrm{Kz}$ Ss Por

$1.82661 \mathrm{e}+001.82661 \mathrm{e}+00$ 1.82661e-01 1.00000e-09 2.12000e-01 $1.82661 \mathrm{e}+001.82661 \mathrm{e}+001.82661 \mathrm{e}-01$ 1.00000e-09 2.12000e-01 $1.82661 \mathrm{e}+001.82661 \mathrm{e}+001.82661 \mathrm{e}-011.00000 \mathrm{e}-092.12000 \mathrm{e}-01$ $1.82661 \mathrm{e}+001.82661 \mathrm{e}+001.82661 \mathrm{e}-01$ 1.00000e-09 2.12000e-01 $1.82661 \mathrm{e}+001.82661 \mathrm{e}+001.82661 \mathrm{e}-01$ 1.00000e-09 2.12000e-01 $1.00000 \mathrm{e}-051.00000 \mathrm{e}-05$ 1.00000e-06 1.00000e-09 1.00000e-01 $1.00000 \mathrm{e}+001.00000 \mathrm{e}+001.00000 \mathrm{e}-011.00000 \mathrm{e}-091.00000 \mathrm{e}-01$ Element: 13691 \# of layers: 7

$\mathrm{Kx} \mathrm{Ky} \mathrm{Kz}$ Ss Por

1.82661e+00 1.82661e+00 1.82661e-01 1.00000e-09 2.12000e-01 $1.82661 \mathrm{e}+001.82661 \mathrm{e}+001.82661 \mathrm{e}-01$ 1.00000e-09 2.12000e-01 $1.82661 \mathrm{e}+001.82661 \mathrm{e}+001.82661 \mathrm{e}-01$ 1.00000e-09 2.12000e-01 
$1.82661 \mathrm{e}+001.82661 \mathrm{e}+001.82661 \mathrm{e}-011.00000 \mathrm{e}-092.12000 \mathrm{e}-01$ $1.82661 \mathrm{e}+001.82661 \mathrm{e}+001.82661 \mathrm{e}-011.00000 \mathrm{e}-092.12000 \mathrm{e}-01$ $1.00000 \mathrm{e}-05$ 1.00000e-05 1.00000e-06 1.00000e-09 1.00000e-01 $1.00000 \mathrm{e}+001.00000 \mathrm{e}+001.00000 \mathrm{e}-011.00000 \mathrm{e}-091.00000 \mathrm{e}-01$ Element: 13692 \# of layers: 7

Kx Ky Kz Ss Por

$1.82661 \mathrm{e}+001.82661 \mathrm{e}+001.82661 \mathrm{e}-011.00000 \mathrm{e}-092.12000 \mathrm{e}-01$ $1.82661 \mathrm{e}+001.82661 \mathrm{e}+001.82661 \mathrm{e}-011.00000 \mathrm{e}-092.12000 \mathrm{e}-01$ $1.82661 \mathrm{e}+001.82661 \mathrm{e}+001.82661 \mathrm{e}-011.00000 \mathrm{e}-092.12000 \mathrm{e}-01$ $1.82661 \mathrm{e}+001.82661 \mathrm{e}+001.82661 \mathrm{e}-011.00000 \mathrm{e}-092.12000 \mathrm{e}-01$ $1.82661 \mathrm{e}+001.82661 \mathrm{e}+001.82661 \mathrm{e}-011.00000 \mathrm{e}-092.12000 \mathrm{e}-01$ $1.00000 \mathrm{e}-05$ 1.00000e-05 1.00000e-06 1.00000e-09 1.00000e-01 $1.00000 \mathrm{e}+001.00000 \mathrm{e}+001.00000 \mathrm{e}-011.00000 \mathrm{e}-091.00000 \mathrm{e}-01$ Element: 13693 \# of layers: 7

Kx Ky Kz Ss Por

$1.82661 \mathrm{e}+001.82661 \mathrm{e}+00$ 1.82661e-01 1.00000e-09 2.12000e-01 $1.82661 \mathrm{e}+001.82661 \mathrm{e}+001.82661 \mathrm{e}-011.00000 \mathrm{e}-092.12000 \mathrm{e}-01$ $1.82661 \mathrm{e}+001.82661 \mathrm{e}+001.82661 \mathrm{e}-011.00000 \mathrm{e}-092.12000 \mathrm{e}-01$ $1.82661 \mathrm{e}+001.82661 \mathrm{e}+001.82661 \mathrm{e}-011.00000 \mathrm{e}-092.12000 \mathrm{e}-01$ $1.82661 \mathrm{e}+001.82661 \mathrm{e}+001.82661 \mathrm{e}-011.00000 \mathrm{e}-092.12000 \mathrm{e}-01$ $1.00000 \mathrm{e}-05$ 1.00000e-05 1.00000e-06 1.00000e-09 1.00000e-01 $1.00000 \mathrm{e}+001.00000 \mathrm{e}+001.00000 \mathrm{e}-011.00000 \mathrm{e}-091.00000 \mathrm{e}-01$ Element: 13694 \# of layers: 7

Kx Ky Kz Ss Por

3.37732e+00 3.37732e+00 3.37732e-01 1.00000e-09 2.12000e-01 $3.37732 \mathrm{e}+003.37732 \mathrm{e}+003.37732 \mathrm{e}-011.00000 \mathrm{e}-092.12000 \mathrm{e}-01$ $3.37732 \mathrm{e}+003.37732 \mathrm{e}+003.37732 \mathrm{e}-011.00000 \mathrm{e}-092.12000 \mathrm{e}-01$ $3.37732 \mathrm{e}+003.37732 \mathrm{e}+003.37732 \mathrm{e}-011.00000 \mathrm{e}-09$ 2.12000e-01 $3.37732 \mathrm{e}+003.37732 \mathrm{e}+003.37732 \mathrm{e}-01$ 1.00000e-09 2.12000e-01 $1.00000 \mathrm{e}-05$ 1.00000e-05 1.00000e-06 1.00000e-09 1.00000e-01 $1.00000 \mathrm{e}+001.00000 \mathrm{e}+001.00000 \mathrm{e}-011.00000 \mathrm{e}-091.00000 \mathrm{e}-01$ Element: 13695 \# of layers: 6

Kx Ky Kz Ss Por

3.37732e+00 3.37732e+00 3.37732e-01 1.00000e-09 2.12000e-01 $3.37732 \mathrm{e}+003.37732 \mathrm{e}+003.37732 \mathrm{e}-01$ 1.00000e-09 2.12000e-01 $3.37732 \mathrm{e}+003.37732 \mathrm{e}+003.37732 \mathrm{e}-01$ 1.00000e-09 2.12000e-01 $3.37732 \mathrm{e}+003.37732 \mathrm{e}+003.37732 \mathrm{e}-011.00000 \mathrm{e}-09$ 2.12000e-01 $1.00000 \mathrm{e}-05$ 1.00000e-05 1.00000e-06 1.00000e-09 1.00000e-01 $1.00000 \mathrm{e}+001.00000 \mathrm{e}+001.00000 \mathrm{e}-011.00000 \mathrm{e}-091.00000 \mathrm{e}-01$ Element: 13696 \# of layers: 6

Kx Ky Kz Ss Por

3.37732e+00 3.37732e+00 3.37732e-01 1.00000e-09 2.12000e-01 $3.37732 \mathrm{e}+003.37732 \mathrm{e}+003.37732 \mathrm{e}-011.00000 \mathrm{e}-092.12000 \mathrm{e}-01$ $3.37732 \mathrm{e}+003.37732 \mathrm{e}+00$ 3.37732e-01 1.00000e-09 2.12000e-01 $3.37732 \mathrm{e}+003.37732 \mathrm{e}+003.37732 \mathrm{e}-01$ 1.00000e-09 2.12000e-01 $1.00000 \mathrm{e}-05$ 1.00000e-05 1.00000e-06 1.00000e-09 1.00000e-01 
$1.00000 \mathrm{e}+001.00000 \mathrm{e}+001.00000 \mathrm{e}-011.00000 \mathrm{e}-091.00000 \mathrm{e}-01$ Element: 13697 \# of layers: 6

Kx Ky Kz Ss Por

3.37732e+00 3.37732e+00 3.37732e-01 1.00000e-09 2.12000e-01

3.37732e+00 3.37732e+00 3.37732e-01 1.00000e-09 2.12000e-01

3.37732e+00 3.37732e+00 3.37732e-01 1.00000e-09 2.12000e-01

3.37732e+00 3.37732e+00 3.37732e-01 1.00000e-09 2.12000e-01

$1.00000 \mathrm{e}-05$ 1.00000e-05 1.00000e-06 1.00000e-09 1.00000e-01

$1.00000 \mathrm{e}+001.00000 \mathrm{e}+001.00000 \mathrm{e}-011.00000 \mathrm{e}-091.00000 \mathrm{e}-01$

Element: 13698 \# of layers: 7

$\mathrm{Kx} \mathrm{Ky} \mathrm{Kz}$ Ss Por

3.37732e+00 3.37732e+00 3.37732e-01 1.00000e-09 2.12000e-01

3.37732e+00 3.37732e+00 3.37732e-01 1.00000e-09 2.12000e-01

3.37732e+00 3.37732e+00 3.37732e-01 1.00000e-09 2.12000e-01

3.37732e+00 3.37732e+00 3.37732e-01 1.00000e-09 2.12000e-01

3.37732e+00 3.37732e+00 3.37732e-01 1.00000e-09 2.12000e-01

$1.00000 \mathrm{e}-05$ 1.00000e-05 1.00000e-06 1.00000e-09 1.00000e-01

$1.00000 \mathrm{e}+001.00000 \mathrm{e}+001.00000 \mathrm{e}-01$ 1.00000e-09 1.00000e-01

Element: 13699 \# of layers: 7

$\mathrm{Kx} \mathrm{Ky} \mathrm{Kz}$ Ss Por

$1.82661 \mathrm{e}+001.82661 \mathrm{e}+00$ 1.82661e-01 1.00000e-09 2.12000e-01

$1.82661 \mathrm{e}+001.82661 \mathrm{e}+00$ 1.82661e-01 1.00000e-09 2.12000e-01

$1.82661 \mathrm{e}+001.82661 \mathrm{e}+00$ 1.82661e-01 1.00000e-09 2.12000e-01

$1.82661 \mathrm{e}+001.82661 \mathrm{e}+001.82661 \mathrm{e}-01$ 1.00000e-09 2.12000e-01

$1.82661 \mathrm{e}+001.82661 \mathrm{e}+001.82661 \mathrm{e}-011.00000 \mathrm{e}-092.12000 \mathrm{e}-01$

$1.00000 \mathrm{e}-051.00000 \mathrm{e}-05$ 1.00000e-06 1.00000e-09 1.00000e-01

$1.00000 \mathrm{e}+001.00000 \mathrm{e}+001.00000 \mathrm{e}-011.00000 \mathrm{e}-09$ 1.00000e-01

Element: 13700 \# of layers: 7

Kx Ky Kz Ss Por

$1.82661 \mathrm{e}+001.82661 \mathrm{e}+00$ 1.82661e-01 1.00000e-09 2.12000e-01

$1.82661 \mathrm{e}+001.82661 \mathrm{e}+001.82661 \mathrm{e}-01$ 1.00000e-09 2.12000e-01

$1.82661 \mathrm{e}+001.82661 \mathrm{e}+001.82661 \mathrm{e}-01$ 1.00000e-09 2.12000e-01

$1.82661 \mathrm{e}+001.82661 \mathrm{e}+001.82661 \mathrm{e}-011.00000 \mathrm{e}-092.12000 \mathrm{e}-01$

$1.82661 \mathrm{e}+001.82661 \mathrm{e}+001.82661 \mathrm{e}-011.00000 \mathrm{e}-092.12000 \mathrm{e}-01$

$1.00000 \mathrm{e}-05$ 1.00000e-05 1.00000e-06 1.00000e-09 1.00000e-01

$1.00000 \mathrm{e}+001.00000 \mathrm{e}+001.00000 \mathrm{e}-011.00000 \mathrm{e}-09$ 1.00000e-01

Element: 13701 \# of layers: 7

Kx Ky Kz Ss Por

3.37732e+00 3.37732e+00 3.37732e-01 1.00000e-09 2.12000e-01

3.37732e+00 3.37732e+00 3.37732e-01 1.00000e-09 2.12000e-01

3.37732e+00 3.37732e+00 3.37732e-01 1.00000e-09 2.12000e-01

$3.37732 \mathrm{e}+00$ 3.37732e+00 3.37732e-01 1.00000e-09 2.12000e-01

3.37732e+00 3.37732e+00 3.37732e-01 1.00000e-09 2.12000e-01

$1.00000 \mathrm{e}-05$ 1.00000e-05 1.00000e-06 1.00000e-09 1.00000e-01

$1.00000 \mathrm{e}+001.00000 \mathrm{e}+001.00000 \mathrm{e}-011.00000 \mathrm{e}-09$ 1.00000e-01

Element: 13702 \# of layers: 7 
$\mathrm{Kx} \mathrm{Ky} \mathrm{Kz}$ Ss Por

3.37732e+00 3.37732e+00 3.37732e-01 1.00000e-09 2.12000e-01

3.37732e+00 3.37732e+00 3.37732e-01 1.00000e-09 2.12000e-01

$3.37732 \mathrm{e}+00$ 3.37732e+00 3.37732e-01 1.00000e-09 2.12000e-01

3.37732e+00 3.37732e+00 3.37732e-01 1.00000e-09 2.12000e-01

$3.37732 \mathrm{e}+003.37732 \mathrm{e}+00$ 3.37732e-01 1.00000e-09 2.12000e-01

$1.00000 \mathrm{e}-05$ 1.00000e-05 1.00000e-06 1.00000e-09 1.00000e-01

$1.00000 \mathrm{e}+001.00000 \mathrm{e}+001.00000 \mathrm{e}-011.00000 \mathrm{e}-091.00000 \mathrm{e}-01$

Element: 13703 \# of layers: 6

$\mathrm{Kx} \mathrm{Ky} \mathrm{Kz}$ Ss Por

3.37732e+00 3.37732e+00 3.37732e-01 1.00000e-09 2.12000e-01

$3.37732 \mathrm{e}+003.37732 \mathrm{e}+00$ 3.37732e-01 1.00000e-09 2.12000e-01

3.37732e+00 3.37732e+00 3.37732e-01 1.00000e-09 2.12000e-01

$3.37732 \mathrm{e}+003.37732 \mathrm{e}+00$ 3.37732e-01 1.00000e-09 2.12000e-01

$1.00000 \mathrm{e}-051.00000 \mathrm{e}-051.00000 \mathrm{e}-061.00000 \mathrm{e}-091.00000 \mathrm{e}-01$

$1.00000 \mathrm{e}+001.00000 \mathrm{e}+001.00000 \mathrm{e}-011.00000 \mathrm{e}-091.00000 \mathrm{e}-01$

Element: 13704 \# of layers: 6

$\mathrm{Kx} \mathrm{Ky} \mathrm{Kz}$ Ss Por

3.37732e+00 3.37732e+00 3.37732e-01 1.00000e-09 2.12000e-01

3.37732e+00 3.37732e+00 3.37732e-01 1.00000e-09 2.12000e-01

$3.37732 \mathrm{e}+003.37732 \mathrm{e}+00$ 3.37732e-01 1.00000e-09 2.12000e-01

3.37732e+00 3.37732e+00 3.37732e-01 1.00000e-09 2.12000e-01

$1.00000 \mathrm{e}-051.00000 \mathrm{e}-051.00000 \mathrm{e}-061.00000 \mathrm{e}-091.00000 \mathrm{e}-01$

$1.00000 \mathrm{e}+001.00000 \mathrm{e}+001.00000 \mathrm{e}-011.00000 \mathrm{e}-091.00000 \mathrm{e}-01$

Element: 13705 \# of layers: 6

$\mathrm{Kx} \mathrm{Ky} \mathrm{Kz}$ Ss Por

3.37732e+00 3.37732e+00 3.37732e-01 1.00000e-09 2.12000e-01

3.37732e+00 3.37732e+00 3.37732e-01 1.00000e-09 2.12000e-01

$3.37732 \mathrm{e}+00$ 3.37732e+00 3.37732e-01 1.00000e-09 2.12000e-01

3.37732e+00 3.37732e+00 3.37732e-01 1.00000e-09 2.12000e-01

$1.00000 \mathrm{e}-05$ 1.00000e-05 1.00000e-06 1.00000e-09 1.00000e-01

$1.00000 \mathrm{e}+001.00000 \mathrm{e}+001.00000 \mathrm{e}-01$ 1.00000e-09 1.00000e-01

Element: 13706 \# of layers: 6

$\mathrm{Kx} \mathrm{Ky} \mathrm{Kz}$ Ss Por

3.37732e+00 3.37732e+00 3.37732e-01 1.00000e-09 2.12000e-01

3.37732e+00 3.37732e+00 3.37732e-01 1.00000e-09 2.12000e-01

$3.37732 \mathrm{e}+003.37732 \mathrm{e}+00$ 3.37732e-01 1.00000e-09 2.12000e-01

3.37732e+00 3.37732e+00 3.37732e-01 1.00000e-09 2.12000e-01

$1.00000 \mathrm{e}-05$ 1.00000e-05 1.00000e-06 1.00000e-09 1.00000e-01

$1.00000 \mathrm{e}+001.00000 \mathrm{e}+001.00000 \mathrm{e}-01$ 1.00000e-09 1.00000e-01

Element: 13707 \# of layers: 6

Kx Ky Kz Ss Por

3.37732e+00 3.37732e+00 3.37732e-01 1.00000e-09 2.12000e-01

3.37732e+00 3.37732e+00 3.37732e-01 1.00000e-09 2.12000e-01

3.37732e+00 3.37732e+00 3.37732e-01 1.00000e-09 2.12000e-01

$3.37732 \mathrm{e}+003.37732 \mathrm{e}+00$ 3.37732e-01 1.00000e-09 2.12000e-01 
$1.00000 \mathrm{e}-05$ 1.00000e-05 1.00000e-06 1.00000e-09 1.00000e-01 $1.00000 \mathrm{e}+001.00000 \mathrm{e}+001.00000 \mathrm{e}-01$ 1.00000e-09 1.00000e-01 Element: 13708 \# of layers: 7

Kx Ky Kz Ss Por

3.37732e+00 3.37732e+00 3.37732e-01 1.00000e-09 2.12000e-01 3.37732e+00 3.37732e+00 3.37732e-01 1.00000e-09 2.12000e-01 3.37732e+00 3.37732e+00 3.37732e-01 1.00000e-09 2.12000e-01 $3.37732 \mathrm{e}+00$ 3.37732e+00 3.37732e-01 1.00000e-09 2.12000e-01 3.37732e+00 3.37732e+00 3.37732e-01 1.00000e-09 2.12000e-01 $1.00000 \mathrm{e}-05$ 1.00000e-05 1.00000e-06 1.00000e-09 1.00000e-01 $1.00000 \mathrm{e}+001.00000 \mathrm{e}+001.00000 \mathrm{e}-011.00000 \mathrm{e}-091.00000 \mathrm{e}-01$ Element: 13709 \# of layers: 7

Kx Ky Kz Ss Por

3.37732e+00 3.37732e+00 3.37732e-01 1.00000e-09 2.12000e-01 3.37732e+00 3.37732e+00 3.37732e-01 1.00000e-09 2.12000e-01 $3.37732 \mathrm{e}+003.37732 \mathrm{e}+00$ 3.37732e-01 1.00000e-09 2.12000e-01 3.37732e+00 3.37732e+00 3.37732e-01 1.00000e-09 2.12000e-01 3.37732e+00 3.37732e+00 3.37732e-01 1.00000e-09 2.12000e-01 $1.00000 \mathrm{e}-051.00000 \mathrm{e}-051.00000 \mathrm{e}-061.00000 \mathrm{e}-091.00000 \mathrm{e}-01$ $1.00000 \mathrm{e}+001.00000 \mathrm{e}+001.00000 \mathrm{e}-011.00000 \mathrm{e}-091.00000 \mathrm{e}-01$ Element: 13710 \# of layers: 6

$\mathrm{Kx} \mathrm{Ky} \mathrm{Kz}$ Ss Por

3.37732e+00 3.37732e+00 3.37732e-01 1.00000e-09 2.12000e-01 3.37732e+00 3.37732e+00 3.37732e-01 1.00000e-09 2.12000e-01 $3.37732 \mathrm{e}+00$ 3.37732e+00 3.37732e-01 1.00000e-09 2.12000e-01 3.37732e+00 3.37732e+00 3.37732e-01 1.00000e-09 2.12000e-01 $1.00000 \mathrm{e}-05$ 1.00000e-05 1.00000e-06 1.00000e-09 1.00000e-01 $1.00000 \mathrm{e}+001.00000 \mathrm{e}+001.00000 \mathrm{e}-011.00000 \mathrm{e}-091.00000 \mathrm{e}-01$ Element: 13711 \# of layers: 6

$\mathrm{Kx} \mathrm{Ky} \mathrm{Kz}$ Ss Por

3.37732e+00 3.37732e+00 3.37732e-01 1.00000e-09 2.12000e-01 $3.37732 \mathrm{e}+003.37732 \mathrm{e}+00$ 3.37732e-01 1.00000e-09 2.12000e-01 $3.37732 \mathrm{e}+00$ 3.37732e+00 3.37732e-01 1.00000e-09 2.12000e-01 $3.37732 \mathrm{e}+003.37732 \mathrm{e}+00$ 3.37732e-01 1.00000e-09 2.12000e-01 $1.00000 \mathrm{e}-051.00000 \mathrm{e}-05$ 1.00000e-06 1.00000e-09 1.00000e-01 $1.00000 \mathrm{e}+001.00000 \mathrm{e}+00$ 1.00000e-01 1.00000e-09 1.00000e-01 Element: 13712 \# of layers: 6

Kx Ky Kz Ss Por

3.37732e+00 3.37732e+00 3.37732e-01 1.00000e-09 2.12000e-01 3.37732e+00 3.37732e+00 3.37732e-01 1.00000e-09 2.12000e-01 $3.37732 \mathrm{e}+00$ 3.37732e+00 3.37732e-01 1.00000e-09 2.12000e-01 $3.37732 \mathrm{e}+00$ 3.37732e+00 3.37732e-01 1.00000e-09 2.12000e-01 $1.00000 \mathrm{e}-05$ 1.00000e-05 1.00000e-06 1.00000e-09 1.00000e-01 $1.00000 \mathrm{e}+001.00000 \mathrm{e}+001.00000 \mathrm{e}-01$ 1.00000e-09 1.00000e-01 Element: 13713 \# of layers: 6

Kx Ky Kz Ss Por 
$7.11060 \mathrm{e}+007.11060 \mathrm{e}+00$ 7.11060e-01 1.00000e-09 2.12000e-01 $7.11060 \mathrm{e}+007.11060 \mathrm{e}+00$ 7.11060e-01 1.00000e-09 2.12000e-01 $7.11060 \mathrm{e}+007.11060 \mathrm{e}+00$ 7.11060e-01 1.00000e-09 2.12000e-01 $7.11060 \mathrm{e}+00$ 7.11060e+00 7.11060e-01 1.00000e-09 2.12000e-01 $1.00000 \mathrm{e}-05$ 1.00000e-05 1.00000e-06 1.00000e-09 1.00000e-01 $1.00000 \mathrm{e}+001.00000 \mathrm{e}+001.00000 \mathrm{e}-011.00000 \mathrm{e}-091.00000 \mathrm{e}-01$ Element: 13714 \# of layers: 6

Kx Ky Kz Ss Por

7.11060e+00 7.11060e+00 7.11060e-01 1.00000e-09 2.12000e-01

$7.11060 \mathrm{e}+007.11060 \mathrm{e}+00$ 7.11060e-01 1.00000e-09 2.12000e-01

$7.11060 \mathrm{e}+007.11060 \mathrm{e}+00$ 7.11060e-01 1.00000e-09 2.12000e-01

$7.11060 \mathrm{e}+007.11060 \mathrm{e}+00$ 7.11060e-01 1.00000e-09 2.12000e-01 $1.00000 \mathrm{e}-05$ 1.00000e-05 1.00000e-06 1.00000e-09 1.00000e-01 $1.00000 \mathrm{e}+001.00000 \mathrm{e}+001.00000 \mathrm{e}-011.00000 \mathrm{e}-091.00000 \mathrm{e}-01$ Element: 13715 \# of layers: 7

Kx Ky Kz Ss Por

7.11060e+00 7.11060e+00 7.11060e-01 1.00000e-09 2.12000e-01 $7.11060 \mathrm{e}+007.11060 \mathrm{e}+007.11060 \mathrm{e}-011.00000 \mathrm{e}-092.12000 \mathrm{e}-01$ $7.11060 \mathrm{e}+007.11060 \mathrm{e}+007.11060 \mathrm{e}-011.00000 \mathrm{e}-092.12000 \mathrm{e}-01$ $7.11060 \mathrm{e}+007.11060 \mathrm{e}+007.11060 \mathrm{e}-011.00000 \mathrm{e}-09$ 2.12000e-01 $7.11060 \mathrm{e}+007.11060 \mathrm{e}+00$ 7.11060e-01 1.00000e-09 2.12000e-01 $1.00000 \mathrm{e}-05$ 1.00000e-05 1.00000e-06 1.00000e-09 1.00000e-01 $1.00000 \mathrm{e}+001.00000 \mathrm{e}+001.00000 \mathrm{e}-011.00000 \mathrm{e}-091.00000 \mathrm{e}-01$ Element: 13716 \# of layers: 7

Kx Ky Kz Ss Por

3.37732e+00 3.37732e+00 3.37732e-01 1.00000e-09 2.12000e-01 $3.37732 \mathrm{e}+003.37732 \mathrm{e}+003.37732 \mathrm{e}-011.00000 \mathrm{e}-092.12000 \mathrm{e}-01$ $3.37732 \mathrm{e}+003.37732 \mathrm{e}+003.37732 \mathrm{e}-011.00000 \mathrm{e}-09$ 2.12000e-01 $3.37732 \mathrm{e}+003.37732 \mathrm{e}+003.37732 \mathrm{e}-011.00000 \mathrm{e}-092.12000 \mathrm{e}-01$ $3.37732 \mathrm{e}+003.37732 \mathrm{e}+00$ 3.37732e-01 1.00000e-09 2.12000e-01 $1.00000 \mathrm{e}-05$ 1.00000e-05 1.00000e-06 1.00000e-09 1.00000e-01 $1.00000 \mathrm{e}+001.00000 \mathrm{e}+001.00000 \mathrm{e}-011.00000 \mathrm{e}-091.00000 \mathrm{e}-01$ Element: 13717 \# of layers: 7

Kx Ky Kz Ss Por

3.37732e+00 3.37732e+00 3.37732e-01 1.00000e-09 2.12000e-01 $3.37732 \mathrm{e}+003.37732 \mathrm{e}+003.37732 \mathrm{e}-011.00000 \mathrm{e}-09$ 2.12000e-01 $3.37732 \mathrm{e}+003.37732 \mathrm{e}+003.37732 \mathrm{e}-011.00000 \mathrm{e}-09$ 2.12000e-01 $3.37732 \mathrm{e}+003.37732 \mathrm{e}+003.37732 \mathrm{e}-01$ 1.00000e-09 2.12000e-01 $3.37732 \mathrm{e}+003.37732 \mathrm{e}+003.37732 \mathrm{e}-01$ 1.00000e-09 2.12000e-01 $1.00000 \mathrm{e}-05$ 1.00000e-05 1.00000e-06 1.00000e-09 1.00000e-01 $1.00000 \mathrm{e}+001.00000 \mathrm{e}+001.00000 \mathrm{e}-011.00000 \mathrm{e}-091.00000 \mathrm{e}-01$ Element: 13718 \# of layers: 6

Kx Ky Kz Ss Por

3.37732e+00 3.37732e+00 3.37732e-01 1.00000e-09 2.12000e-01 $3.37732 \mathrm{e}+003.37732 \mathrm{e}+003.37732 \mathrm{e}-01$ 1.00000e-09 2.12000e-01 $3.37732 \mathrm{e}+003.37732 \mathrm{e}+003.37732 \mathrm{e}-01$ 1.00000e-09 2.12000e-01 
3.37732e+00 3.37732e+00 3.37732e-01 1.00000e-09 2.12000e-01 $1.00000 \mathrm{e}-05$ 1.00000e-05 1.00000e-06 1.00000e-09 1.00000e-01 $1.00000 \mathrm{e}+001.00000 \mathrm{e}+001.00000 \mathrm{e}-011.00000 \mathrm{e}-091.00000 \mathrm{e}-01$ Element: 13719 \# of layers: 6

Kx Ky Kz Ss Por

3.37732e+00 3.37732e+00 3.37732e-01 1.00000e-09 2.12000e-01 $3.37732 \mathrm{e}+003.37732 \mathrm{e}+003.37732 \mathrm{e}-011.00000 \mathrm{e}-092.12000 \mathrm{e}-01$ $3.37732 \mathrm{e}+003.37732 \mathrm{e}+003.37732 \mathrm{e}-01$ 1.00000e-09 2.12000e-01 $3.37732 \mathrm{e}+003.37732 \mathrm{e}+003.37732 \mathrm{e}-01$ 1.00000e-09 2.12000e-01 $1.00000 \mathrm{e}-05$ 1.00000e-05 1.00000e-06 1.00000e-09 1.00000e-01 $1.00000 \mathrm{e}+001.00000 \mathrm{e}+001.00000 \mathrm{e}-011.00000 \mathrm{e}-091.00000 \mathrm{e}-01$ Element: 13720 \# of layers: 6

Kx Ky Kz Ss Por

7.11060e+00 7.11060e+00 7.11060e-01 1.00000e-09 2.12000e-01 $7.11060 \mathrm{e}+007.11060 \mathrm{e}+00$ 7.11060e-01 1.00000e-09 2.12000e-01 $7.11060 \mathrm{e}+007.11060 \mathrm{e}+007.11060 \mathrm{e}-01$ 1.00000e-09 2.12000e-01 $7.11060 \mathrm{e}+007.11060 \mathrm{e}+007.11060 \mathrm{e}-01$ 1.00000e-09 2.12000e-01 $1.00000 \mathrm{e}-05$ 1.00000e-05 1.00000e-06 1.00000e-09 1.00000e-01 $1.00000 \mathrm{e}+001.00000 \mathrm{e}+001.00000 \mathrm{e}-011.00000 \mathrm{e}-091.00000 \mathrm{e}-01$ Element: 13721 \# of layers: 7

Kx Ky Kz Ss Por

7.11060e+00 7.11060e+00 7.11060e-01 1.00000e-09 2.12000e-01 $7.11060 \mathrm{e}+007.11060 \mathrm{e}+007.11060 \mathrm{e}-01$ 1.00000e-09 2.12000e-01 $7.11060 \mathrm{e}+007.11060 \mathrm{e}+007.11060 \mathrm{e}-011.00000 \mathrm{e}-092.12000 \mathrm{e}-01$ $7.11060 \mathrm{e}+007.11060 \mathrm{e}+007.11060 \mathrm{e}-011.00000 \mathrm{e}-092.12000 \mathrm{e}-01$ $1.00000 \mathrm{e}-05$ 1.00000e-05 1.00000e-06 1.00000e-09 1.00000e-01 $1.00000 \mathrm{e}+001.00000 \mathrm{e}+001.00000 \mathrm{e}-011.00000 \mathrm{e}-091.00000 \mathrm{e}-01$ $1.00000 \mathrm{e}-06$ 1.00000e-06 1.00000e-06 1.00000e-09 5.00000e-02 Element: 13722 \# of layers: 7

Kx Ky Kz Ss Por

7.11060e+00 7.11060e+00 7.11060e-01 1.00000e-09 2.12000e-01 $7.11060 \mathrm{e}+007.11060 \mathrm{e}+00$ 7.11060e-01 1.00000e-09 2.12000e-01 $7.11060 \mathrm{e}+007.11060 \mathrm{e}+00$ 7.11060e-01 1.00000e-09 2.12000e-01 $7.11060 \mathrm{e}+007.11060 \mathrm{e}+00$ 7.11060e-01 1.00000e-09 2.12000e-01 $1.00000 \mathrm{e}-05$ 1.00000e-05 1.00000e-06 1.00000e-09 1.00000e-01 $1.00000 \mathrm{e}+001.00000 \mathrm{e}+001.00000 \mathrm{e}-011.00000 \mathrm{e}-091.00000 \mathrm{e}-01$ $1.00000 \mathrm{e}-061.00000 \mathrm{e}-06$ 1.00000e-06 1.00000e-09 5.00000e-02 Element: 13723 \# of layers: 6

Kx Ky Kz Ss Por

7.11060e+00 7.11060e+00 7.11060e-01 1.00000e-09 2.12000e-01

$7.11060 \mathrm{e}+007.11060 \mathrm{e}+00$ 7.11060e-01 1.00000e-09 2.12000e-01

$7.11060 \mathrm{e}+007.11060 \mathrm{e}+00$ 7.11060e-01 1.00000e-09 2.12000e-01 $7.11060 \mathrm{e}+007.11060 \mathrm{e}+00$ 7.11060e-01 1.00000e-09 2.12000e-01 $1.00000 \mathrm{e}-05$ 1.00000e-05 1.00000e-06 1.00000e-09 1.00000e-01 $1.00000 \mathrm{e}+001.00000 \mathrm{e}+001.00000 \mathrm{e}-011.00000 \mathrm{e}-091.00000 \mathrm{e}-01$ Element: 13724 \# of layers: 6 
$\mathrm{Kx} \mathrm{Ky} \mathrm{Kz}$ Ss Por

7.11060e+00 7.11060e+00 7.11060e-01 1.00000e-09 2.12000e-01

7.11060e+00 7.11060e+00 7.11060e-01 1.00000e-09 2.12000e-01

$7.11060 \mathrm{e}+007.11060 \mathrm{e}+007.11060 \mathrm{e}-01$ 1.00000e-09 2.12000e-01

7.11060e+00 7.11060e+00 7.11060e-01 1.00000e-09 2.12000e-01

$7.11060 \mathrm{e}+007.11060 \mathrm{e}+00$ 7.11060e-01 1.00000e-09 2.12000e-01

$1.00000 \mathrm{e}+001.00000 \mathrm{e}+00$ 1.00000e-01 1.00000e-09 1.00000e-01

Element: 13725 \# of layers: 7

$\mathrm{Kx} \mathrm{Ky} \mathrm{Kz}$ Ss Por

7.11060e+00 7.11060e+00 7.11060e-01 1.00000e-09 2.12000e-01

$7.11060 \mathrm{e}+00$ 7.11060e+00 7.11060e-01 1.00000e-09 2.12000e-01

$7.11060 \mathrm{e}+007.11060 \mathrm{e}+007.11060 \mathrm{e}-01$ 1.00000e-09 2.12000e-01

7.11060e+00 7.11060e+00 7.11060e-01 1.00000e-09 2.12000e-01

$7.11060 \mathrm{e}+007.11060 \mathrm{e}+00$ 7.11060e-01 1.00000e-09 2.12000e-01

$1.00000 \mathrm{e}-05$ 1.00000e-05 1.00000e-06 1.00000e-09 1.00000e-01

$1.00000 \mathrm{e}+001.00000 \mathrm{e}+001.00000 \mathrm{e}-011.00000 \mathrm{e}-091.00000 \mathrm{e}-01$

Element: 13726 \# of layers: 7

$\mathrm{Kx} \mathrm{Ky} \mathrm{Kz}$ Ss Por

7.11060e+00 7.11060e+00 7.11060e-01 1.00000e-09 2.12000e-01

$7.11060 \mathrm{e}+00$ 7.11060e+00 7.11060e-01 1.00000e-09 2.12000e-01

$7.11060 \mathrm{e}+007.11060 \mathrm{e}+007.11060 \mathrm{e}-01$ 1.00000e-09 2.12000e-01

$7.11060 \mathrm{e}+00$ 7.11060e+00 7.11060e-01 1.00000e-09 2.12000e-01

7.11060e+00 7.11060e+00 7.11060e-01 1.00000e-09 2.12000e-01

$1.00000 \mathrm{e}-05$ 1.00000e-05 1.00000e-06 1.00000e-09 1.00000e-01

$1.00000 \mathrm{e}+001.00000 \mathrm{e}+001.00000 \mathrm{e}-011.00000 \mathrm{e}-091.00000 \mathrm{e}-01$

Element: 13727 \# of layers: 6

$\mathrm{Kx} \mathrm{Ky} \mathrm{Kz}$ Ss Por

7.11060e+00 7.11060e+00 7.11060e-01 1.00000e-09 2.12000e-01

$7.11060 \mathrm{e}+007.11060 \mathrm{e}+007.11060 \mathrm{e}-01$ 1.00000e-09 2.12000e-01

$7.11060 \mathrm{e}+007.11060 \mathrm{e}+00$ 7.11060e-01 1.00000e-09 2.12000e-01

$7.11060 \mathrm{e}+007.11060 \mathrm{e}+00$ 7.11060e-01 1.00000e-09 2.12000e-01

$1.00000 \mathrm{e}-05$ 1.00000e-05 1.00000e-06 1.00000e-09 1.00000e-01

$1.00000 \mathrm{e}+001.00000 \mathrm{e}+001.00000 \mathrm{e}-011.00000 \mathrm{e}-091.00000 \mathrm{e}-01$

Element: 13728 \# of layers: 6

$\mathrm{Kx} \mathrm{Ky} \mathrm{Kz}$ Ss Por

7.11060e+00 7.11060e+00 7.11060e-01 1.00000e-09 2.12000e-01

$7.11060 \mathrm{e}+007.11060 \mathrm{e}+007.11060 \mathrm{e}-01$ 1.00000e-09 2.12000e-01

7.11060e+00 7.11060e+00 7.11060e-01 1.00000e-09 2.12000e-01

7.11060e+00 7.11060e+00 7.11060e-01 1.00000e-09 2.12000e-01

$1.00000 \mathrm{e}-05$ 1.00000e-05 1.00000e-06 1.00000e-09 1.00000e-01

$1.00000 \mathrm{e}+001.00000 \mathrm{e}+001.00000 \mathrm{e}-011.00000 \mathrm{e}-091.00000 \mathrm{e}-01$

Element: 13729 \# of layers: 5

$\mathrm{Kx} \mathrm{Ky} \mathrm{Kz}$ Ss Por

7.11060e+00 7.11060e+00 7.11060e-01 1.00000e-09 2.12000e-01

7.11060e+00 7.11060e+00 7.11060e-01 1.00000e-09 2.12000e-01

$7.11060 \mathrm{e}+007.11060 \mathrm{e}+00$ 7.11060e-01 1.00000e-09 2.12000e-01 
$7.11060 \mathrm{e}+007.11060 \mathrm{e}+00$ 7.11060e-01 1.00000e-09 2.12000e-01 $1.00000 \mathrm{e}+001.00000 \mathrm{e}+001.00000 \mathrm{e}-011.00000 \mathrm{e}-091.00000 \mathrm{e}-01$ Element: 13730 \# of layers: 5

Kx Ky Kz Ss Por

7.11060e+00 7.11060e+00 7.11060e-01 1.00000e-09 2.12000e-01

$7.11060 \mathrm{e}+007.11060 \mathrm{e}+007.11060 \mathrm{e}-011.00000 \mathrm{e}-092.12000 \mathrm{e}-01$

$7.11060 \mathrm{e}+007.11060 \mathrm{e}+007.11060 \mathrm{e}-011.00000 \mathrm{e}-092.12000 \mathrm{e}-01$

$7.11060 \mathrm{e}+007.11060 \mathrm{e}+00$ 7.11060e-01 1.00000e-09 2.12000e-01

$1.00000 \mathrm{e}+001.00000 \mathrm{e}+00$ 1.00000e-01 1.00000e-09 1.00000e-01

Element: 13731 \# of layers: 6

Kx Ky Kz Ss Por

$2.71446 \mathrm{e}+002.71446 \mathrm{e}+002.71446 \mathrm{e}-01$ 1.00000e-09 2.12000e-01

$2.71446 \mathrm{e}+002.71446 \mathrm{e}+002.71446 \mathrm{e}-01$ 1.00000e-09 2.12000e-01

$2.71446 \mathrm{e}+002.71446 \mathrm{e}+002.71446 \mathrm{e}-011.00000 \mathrm{e}-092.12000 \mathrm{e}-01$

$2.71446 \mathrm{e}+002.71446 \mathrm{e}+002.71446 \mathrm{e}-011.00000 \mathrm{e}-092.12000 \mathrm{e}-01$

$2.71446 \mathrm{e}+002.71446 \mathrm{e}+002.71446 \mathrm{e}-011.00000 \mathrm{e}-092.12000 \mathrm{e}-01$

$1.00000 \mathrm{e}+001.00000 \mathrm{e}+001.00000 \mathrm{e}-011.00000 \mathrm{e}-091.00000 \mathrm{e}-01$

Element: 13732 \# of layers: 6

Kx Ky Kz Ss Por

$2.71446 \mathrm{e}+002.71446 \mathrm{e}+002.71446 \mathrm{e}-01$ 1.00000e-09 2.12000e-01

$2.71446 \mathrm{e}+002.71446 \mathrm{e}+002.71446 \mathrm{e}-011.00000 \mathrm{e}-092.12000 \mathrm{e}-01$

$2.71446 \mathrm{e}+002.71446 \mathrm{e}+00$ 2.71446e-01 1.00000e-09 2.12000e-01

$2.71446 \mathrm{e}+002.71446 \mathrm{e}+002.71446 \mathrm{e}-011.00000 \mathrm{e}-092.12000 \mathrm{e}-01$

$2.71446 \mathrm{e}+002.71446 \mathrm{e}+002.71446 \mathrm{e}-011.00000 \mathrm{e}-092.12000 \mathrm{e}-01$

$1.00000 \mathrm{e}+001.00000 \mathrm{e}+001.00000 \mathrm{e}-011.00000 \mathrm{e}-091.00000 \mathrm{e}-01$

Element: 13733 \# of layers: 6

Kx Ky Kz Ss Por

$2.71446 \mathrm{e}+002.71446 \mathrm{e}+002.71446 \mathrm{e}-01$ 1.00000e-09 2.12000e-01

$2.71446 \mathrm{e}+002.71446 \mathrm{e}+002.71446 \mathrm{e}-011.00000 \mathrm{e}-092.12000 \mathrm{e}-01$

$2.71446 \mathrm{e}+002.71446 \mathrm{e}+00$ 2.71446e-01 1.00000e-09 2.12000e-01

$2.71446 \mathrm{e}+002.71446 \mathrm{e}+002.71446 \mathrm{e}-011.00000 \mathrm{e}-092.12000 \mathrm{e}-01$

$2.71446 \mathrm{e}+002.71446 \mathrm{e}+002.71446 \mathrm{e}-01$ 1.00000e-09 2.12000e-01

$1.00000 \mathrm{e}+001.00000 \mathrm{e}+00$ 1.00000e-01 1.00000e-09 1.00000e-01

Element: 13734 \# of layers: 5

Kx Ky Kz Ss Por

7.11060e+00 7.11060e+00 7.11060e-01 1.00000e-09 2.12000e-01

$7.11060 \mathrm{e}+007.11060 \mathrm{e}+007.11060 \mathrm{e}-01$ 1.00000e-09 2.12000e-01

$7.11060 \mathrm{e}+007.11060 \mathrm{e}+00$ 7.11060e-01 1.00000e-09 2.12000e-01

$7.11060 \mathrm{e}+007.11060 \mathrm{e}+00$ 7.11060e-01 1.00000e-09 2.12000e-01

$1.00000 \mathrm{e}+001.00000 \mathrm{e}+00$ 1.00000e-01 1.00000e-09 1.00000e-01

Element: 13735 \# of layers: 6

Kx Ky Kz Ss Por

7.11060e+00 7.11060e+00 7.11060e-01 1.00000e-09 2.12000e-01

$7.11060 \mathrm{e}+007.11060 \mathrm{e}+007.11060 \mathrm{e}-011.00000 \mathrm{e}-092.12000 \mathrm{e}-01$

$7.11060 \mathrm{e}+007.11060 \mathrm{e}+00$ 7.11060e-01 1.00000e-09 2.12000e-01

$7.11060 \mathrm{e}+007.11060 \mathrm{e}+00$ 7.11060e-01 1.00000e-09 2.12000e-01 
$1.00000 \mathrm{e}-05$ 1.00000e-05 1.00000e-06 1.00000e-09 1.00000e-01 $1.00000 \mathrm{e}+001.00000 \mathrm{e}+001.00000 \mathrm{e}-011.00000 \mathrm{e}-091.00000 \mathrm{e}-01$ Element: 13736 \# of layers: 5

Kx Ky Kz Ss Por

7.11060e+00 7.11060e+00 7.11060e-01 1.00000e-09 2.12000e-01

$7.11060 \mathrm{e}+007.11060 \mathrm{e}+007.11060 \mathrm{e}-011.00000 \mathrm{e}-092.12000 \mathrm{e}-01$

$7.11060 \mathrm{e}+007.11060 \mathrm{e}+007.11060 \mathrm{e}-011.00000 \mathrm{e}-092.12000 \mathrm{e}-01$

$7.11060 \mathrm{e}+007.11060 \mathrm{e}+00$ 7.11060e-01 1.00000e-09 2.12000e-01

$1.00000 \mathrm{e}+001.00000 \mathrm{e}+00$ 1.00000e-01 1.00000e-09 1.00000e-01

Element: 13737 \# of layers: 5

Kx Ky Kz Ss Por

7.11060e+00 7.11060e+00 7.11060e-01 1.00000e-09 2.12000e-01

$7.11060 \mathrm{e}+007.11060 \mathrm{e}+007.11060 \mathrm{e}-011.00000 \mathrm{e}-092.12000 \mathrm{e}-01$

$7.11060 \mathrm{e}+007.11060 \mathrm{e}+007.11060 \mathrm{e}-011.00000 \mathrm{e}-09$ 2.12000e-01

$7.11060 \mathrm{e}+007.11060 \mathrm{e}+00$ 7.11060e-01 1.00000e-09 2.12000e-01

$1.00000 \mathrm{e}+001.00000 \mathrm{e}+00$ 1.00000e-01 1.00000e-09 1.00000e-01

Element: 13738 \# of layers: 6

Kx Ky Kz Ss Por

$2.71446 \mathrm{e}+002.71446 \mathrm{e}+00$ 2.71446e-01 1.00000e-09 2.12000e-01

$2.71446 \mathrm{e}+002.71446 \mathrm{e}+002.71446 \mathrm{e}-011.00000 \mathrm{e}-092.12000 \mathrm{e}-01$

$2.71446 \mathrm{e}+002.71446 \mathrm{e}+002.71446 \mathrm{e}-011.00000 \mathrm{e}-092.12000 \mathrm{e}-01$

$2.71446 \mathrm{e}+002.71446 \mathrm{e}+00$ 2.71446e-01 1.00000e-09 2.12000e-01

$2.71446 \mathrm{e}+002.71446 \mathrm{e}+002.71446 \mathrm{e}-011.00000 \mathrm{e}-092.12000 \mathrm{e}-01$

$1.00000 \mathrm{e}+001.00000 \mathrm{e}+001.00000 \mathrm{e}-011.00000 \mathrm{e}-091.00000 \mathrm{e}-01$

Element: 13739 \# of layers: 6

Kx Ky Kz Ss Por

$2.71446 \mathrm{e}+002.71446 \mathrm{e}+00$ 2.71446e-01 1.00000e-09 2.12000e-01

$2.71446 \mathrm{e}+002.71446 \mathrm{e}+002.71446 \mathrm{e}-011.00000 \mathrm{e}-092.12000 \mathrm{e}-01$

$2.71446 \mathrm{e}+002.71446 \mathrm{e}+002.71446 \mathrm{e}-011.00000 \mathrm{e}-092.12000 \mathrm{e}-01$

$2.71446 \mathrm{e}+002.71446 \mathrm{e}+002.71446 \mathrm{e}-011.00000 \mathrm{e}-092.12000 \mathrm{e}-01$

$2.71446 \mathrm{e}+002.71446 \mathrm{e}+002.71446 \mathrm{e}-011.00000 \mathrm{e}-092.12000 \mathrm{e}-01$

$1.00000 \mathrm{e}+001.00000 \mathrm{e}+001.00000 \mathrm{e}-011.00000 \mathrm{e}-091.00000 \mathrm{e}-01$

Element: 13740 \# of layers: 6

Kx Ky Kz Ss Por

$2.71446 \mathrm{e}+002.71446 \mathrm{e}+00$ 2.71446e-01 1.00000e-09 2.12000e-01

$2.71446 \mathrm{e}+002.71446 \mathrm{e}+002.71446 \mathrm{e}-011.00000 \mathrm{e}-092.12000 \mathrm{e}-01$

$2.71446 \mathrm{e}+002.71446 \mathrm{e}+002.71446 \mathrm{e}-011.00000 \mathrm{e}-092.12000 \mathrm{e}-01$

$2.71446 \mathrm{e}+002.71446 \mathrm{e}+002.71446 \mathrm{e}-01$ 1.00000e-09 2.12000e-01

$2.71446 \mathrm{e}+002.71446 \mathrm{e}+002.71446 \mathrm{e}-011.00000 \mathrm{e}-092.12000 \mathrm{e}-01$ $1.00000 \mathrm{e}+001.00000 \mathrm{e}+001.00000 \mathrm{e}-011.00000 \mathrm{e}-091.00000 \mathrm{e}-01$ Element: 13741 \# of layers: 6

Kx Ky Kz Ss Por

$2.71446 \mathrm{e}+002.71446 \mathrm{e}+00$ 2.71446e-01 1.00000e-09 2.12000e-01

$2.71446 \mathrm{e}+002.71446 \mathrm{e}+002.71446 \mathrm{e}-011.00000 \mathrm{e}-092.12000 \mathrm{e}-01$

$2.71446 \mathrm{e}+002.71446 \mathrm{e}+002.71446 \mathrm{e}-011.00000 \mathrm{e}-092.12000 \mathrm{e}-01$

$2.71446 \mathrm{e}+002.71446 \mathrm{e}+002.71446 \mathrm{e}-01$ 1.00000e-09 2.12000e-01 
$2.71446 \mathrm{e}+002.71446 \mathrm{e}+00$ 2.71446e-01 1.00000e-09 2.12000e-01 $1.00000 \mathrm{e}+001.00000 \mathrm{e}+001.00000 \mathrm{e}-011.00000 \mathrm{e}-091.00000 \mathrm{e}-01$ Element: 13742 \# of layers: 6

Kx Ky Kz Ss Por

$2.71446 \mathrm{e}+002.71446 \mathrm{e}+00$ 2.71446e-01 1.00000e-09 2.12000e-01

$2.71446 \mathrm{e}+002.71446 \mathrm{e}+002.71446 \mathrm{e}-011.00000 \mathrm{e}-092.12000 \mathrm{e}-01$

$2.71446 \mathrm{e}+002.71446 \mathrm{e}+002.71446 \mathrm{e}-011.00000 \mathrm{e}-092.12000 \mathrm{e}-01$

$2.71446 \mathrm{e}+002.71446 \mathrm{e}+002.71446 \mathrm{e}-011.00000 \mathrm{e}-092.12000 \mathrm{e}-01$

$2.71446 \mathrm{e}+002.71446 \mathrm{e}+002.71446 \mathrm{e}-011.00000 \mathrm{e}-092.12000 \mathrm{e}-01$

$1.00000 \mathrm{e}+001.00000 \mathrm{e}+001.00000 \mathrm{e}-011.00000 \mathrm{e}-091.00000 \mathrm{e}-01$

Element: 13743 \# of layers: 6

Kx Ky Kz Ss Por

$2.71446 \mathrm{e}+002.71446 \mathrm{e}+002.71446 \mathrm{e}-01$ 1.00000e-09 2.12000e-01

$2.71446 \mathrm{e}+002.71446 \mathrm{e}+002.71446 \mathrm{e}-011.00000 \mathrm{e}-092.12000 \mathrm{e}-01$

$2.71446 \mathrm{e}+002.71446 \mathrm{e}+002.71446 \mathrm{e}-011.00000 \mathrm{e}-092.12000 \mathrm{e}-01$

$2.71446 \mathrm{e}+002.71446 \mathrm{e}+002.71446 \mathrm{e}-011.00000 \mathrm{e}-092.12000 \mathrm{e}-01$

$2.71446 \mathrm{e}+002.71446 \mathrm{e}+002.71446 \mathrm{e}-011.00000 \mathrm{e}-092.12000 \mathrm{e}-01$

$1.00000 \mathrm{e}+001.00000 \mathrm{e}+001.00000 \mathrm{e}-011.00000 \mathrm{e}-091.00000 \mathrm{e}-01$

Element: 13744 \# of layers: 6

Kx Ky Kz Ss Por

$2.71446 \mathrm{e}+002.71446 \mathrm{e}+00$ 2.71446e-01 1.00000e-09 2.12000e-01

$2.71446 \mathrm{e}+002.71446 \mathrm{e}+002.71446 \mathrm{e}-011.00000 \mathrm{e}-092.12000 \mathrm{e}-01$

$2.71446 \mathrm{e}+002.71446 \mathrm{e}+002.71446 \mathrm{e}-011.00000 \mathrm{e}-092.12000 \mathrm{e}-01$

$2.71446 \mathrm{e}+002.71446 \mathrm{e}+002.71446 \mathrm{e}-011.00000 \mathrm{e}-092.12000 \mathrm{e}-01$

$2.71446 \mathrm{e}+002.71446 \mathrm{e}+002.71446 \mathrm{e}-011.00000 \mathrm{e}-092.12000 \mathrm{e}-01$

$1.00000 \mathrm{e}+001.00000 \mathrm{e}+001.00000 \mathrm{e}-011.00000 \mathrm{e}-091.00000 \mathrm{e}-01$

Element: 13745 \# of layers: 6

Kx Ky Kz Ss Por

$2.71446 \mathrm{e}+002.71446 \mathrm{e}+00$ 2.71446e-01 1.00000e-09 2.12000e-01

$2.71446 \mathrm{e}+002.71446 \mathrm{e}+00$ 2.71446e-01 1.00000e-09 2.12000e-01

$2.71446 \mathrm{e}+002.71446 \mathrm{e}+002.71446 \mathrm{e}-011.00000 \mathrm{e}-092.12000 \mathrm{e}-01$

$2.71446 \mathrm{e}+002.71446 \mathrm{e}+002.71446 \mathrm{e}-011.00000 \mathrm{e}-092.12000 \mathrm{e}-01$

$2.71446 \mathrm{e}+002.71446 \mathrm{e}+002.71446 \mathrm{e}-011.00000 \mathrm{e}-092.12000 \mathrm{e}-01$

$1.00000 \mathrm{e}+001.00000 \mathrm{e}+001.00000 \mathrm{e}-011.00000 \mathrm{e}-091.00000 \mathrm{e}-01$

Element: 13746 \# of layers: 6

Kx Ky Kz Ss Por

$2.71446 \mathrm{e}+002.71446 \mathrm{e}+002.71446 \mathrm{e}-011.00000 \mathrm{e}-092.12000 \mathrm{e}-01$

$2.71446 \mathrm{e}+002.71446 \mathrm{e}+002.71446 \mathrm{e}-01$ 1.00000e-09 2.12000e-01

$2.71446 \mathrm{e}+002.71446 \mathrm{e}+002.71446 \mathrm{e}-011.00000 \mathrm{e}-092.12000 \mathrm{e}-01$

$2.71446 \mathrm{e}+002.71446 \mathrm{e}+002.71446 \mathrm{e}-011.00000 \mathrm{e}-092.12000 \mathrm{e}-01$

$2.71446 \mathrm{e}+002.71446 \mathrm{e}+002.71446 \mathrm{e}-011.00000 \mathrm{e}-092.12000 \mathrm{e}-01$

$1.00000 \mathrm{e}+001.00000 \mathrm{e}+001.00000 \mathrm{e}-011.00000 \mathrm{e}-091.00000 \mathrm{e}-01$

Element: 13747 \# of layers: 6

Kx Ky Kz Ss Por

$2.71446 \mathrm{e}+002.71446 \mathrm{e}+002.71446 \mathrm{e}-01$ 1.00000e-09 2.12000e-01

$2.71446 \mathrm{e}+002.71446 \mathrm{e}+00$ 2.71446e-01 1.00000e-09 2.12000e-01 
$2.71446 \mathrm{e}+002.71446 \mathrm{e}+002.71446 \mathrm{e}-011.00000 \mathrm{e}-092.12000 \mathrm{e}-01$ $2.71446 \mathrm{e}+002.71446 \mathrm{e}+002.71446 \mathrm{e}-011.00000 \mathrm{e}-092.12000 \mathrm{e}-01$ $2.71446 \mathrm{e}+002.71446 \mathrm{e}+002.71446 \mathrm{e}-011.00000 \mathrm{e}-092.12000 \mathrm{e}-01$ $1.00000 \mathrm{e}+001.00000 \mathrm{e}+001.00000 \mathrm{e}-011.00000 \mathrm{e}-091.00000 \mathrm{e}-01$ Element: 13748 \# of layers: 6

Kx Ky Kz Ss Por

$1.82661 \mathrm{e}+001.82661 \mathrm{e}+001.82661 \mathrm{e}-011.00000 \mathrm{e}-092.12000 \mathrm{e}-01$ $1.82661 \mathrm{e}+001.82661 \mathrm{e}+001.82661 \mathrm{e}-011.00000 \mathrm{e}-092.12000 \mathrm{e}-01$ $1.82661 \mathrm{e}+001.82661 \mathrm{e}+001.82661 \mathrm{e}-011.00000 \mathrm{e}-092.12000 \mathrm{e}-01$ $1.82661 \mathrm{e}+001.82661 \mathrm{e}+001.82661 \mathrm{e}-011.00000 \mathrm{e}-092.12000 \mathrm{e}-01$ $1.82661 \mathrm{e}+001.82661 \mathrm{e}+001.82661 \mathrm{e}-011.00000 \mathrm{e}-092.12000 \mathrm{e}-01$ $1.00000 \mathrm{e}+001.00000 \mathrm{e}+001.00000 \mathrm{e}-011.00000 \mathrm{e}-091.00000 \mathrm{e}-01$ Element: 13749 \# of layers: 6

Kx Ky Kz Ss Por

$1.82661 \mathrm{e}+001.82661 \mathrm{e}+00$ 1.82661e-01 1.00000e-09 2.12000e-01 $1.82661 \mathrm{e}+001.82661 \mathrm{e}+001.82661 \mathrm{e}-011.00000 \mathrm{e}-092.12000 \mathrm{e}-01$ $1.82661 \mathrm{e}+001.82661 \mathrm{e}+001.82661 \mathrm{e}-011.00000 \mathrm{e}-092.12000 \mathrm{e}-01$ $1.82661 \mathrm{e}+001.82661 \mathrm{e}+001.82661 \mathrm{e}-011.00000 \mathrm{e}-092.12000 \mathrm{e}-01$ $1.82661 \mathrm{e}+001.82661 \mathrm{e}+001.82661 \mathrm{e}-011.00000 \mathrm{e}-092.12000 \mathrm{e}-01$ $1.00000 \mathrm{e}+001.00000 \mathrm{e}+001.00000 \mathrm{e}-011.00000 \mathrm{e}-091.00000 \mathrm{e}-01$ Element: 13750 \# of layers: 7

Kx Ky Kz Ss Por

$1.82661 \mathrm{e}+001.82661 \mathrm{e}+00$ 1.82661e-01 1.00000e-09 2.12000e-01 $1.82661 \mathrm{e}+001.82661 \mathrm{e}+001.82661 \mathrm{e}-011.00000 \mathrm{e}-092.12000 \mathrm{e}-01$ $1.82661 \mathrm{e}+001.82661 \mathrm{e}+001.82661 \mathrm{e}-011.00000 \mathrm{e}-092.12000 \mathrm{e}-01$ $1.82661 \mathrm{e}+001.82661 \mathrm{e}+001.82661 \mathrm{e}-011.00000 \mathrm{e}-092.12000 \mathrm{e}-01$ $1.82661 \mathrm{e}+001.82661 \mathrm{e}+001.82661 \mathrm{e}-011.00000 \mathrm{e}-092.12000 \mathrm{e}-01$ $1.00000 \mathrm{e}-05$ 1.00000e-05 1.00000e-06 1.00000e-09 1.00000e-01 $1.00000 \mathrm{e}+001.00000 \mathrm{e}+001.00000 \mathrm{e}-011.00000 \mathrm{e}-091.00000 \mathrm{e}-01$ Element: 13751 \# of layers: 7

Kx Ky Kz Ss Por

$1.82661 \mathrm{e}+001.82661 \mathrm{e}+001.82661 \mathrm{e}-011.00000 \mathrm{e}-092.12000 \mathrm{e}-01$ $1.82661 \mathrm{e}+001.82661 \mathrm{e}+001.82661 \mathrm{e}-011.00000 \mathrm{e}-092.12000 \mathrm{e}-01$ $1.82661 \mathrm{e}+001.82661 \mathrm{e}+001.82661 \mathrm{e}-011.00000 \mathrm{e}-092.12000 \mathrm{e}-01$ $1.82661 \mathrm{e}+001.82661 \mathrm{e}+001.82661 \mathrm{e}-011.00000 \mathrm{e}-092.12000 \mathrm{e}-01$ $1.82661 \mathrm{e}+001.82661 \mathrm{e}+001.82661 \mathrm{e}-011.00000 \mathrm{e}-092.12000 \mathrm{e}-01$ $1.00000 \mathrm{e}-05$ 1.00000e-05 1.00000e-06 1.00000e-09 1.00000e-01 $1.00000 \mathrm{e}+001.00000 \mathrm{e}+001.00000 \mathrm{e}-011.00000 \mathrm{e}-091.00000 \mathrm{e}-01$ Element: 13752 \# of layers: 6

Kx Ky Kz Ss Por

$1.82661 \mathrm{e}+001.82661 \mathrm{e}+001.82661 \mathrm{e}-011.00000 \mathrm{e}-092.12000 \mathrm{e}-01$ $1.82661 \mathrm{e}+001.82661 \mathrm{e}+001.82661 \mathrm{e}-011.00000 \mathrm{e}-092.12000 \mathrm{e}-01$ $1.82661 \mathrm{e}+001.82661 \mathrm{e}+001.82661 \mathrm{e}-011.00000 \mathrm{e}-092.12000 \mathrm{e}-01$ $1.82661 \mathrm{e}+001.82661 \mathrm{e}+001.82661 \mathrm{e}-011.00000 \mathrm{e}-092.12000 \mathrm{e}-01$ $1.82661 \mathrm{e}+001.82661 \mathrm{e}+001.82661 \mathrm{e}-011.00000 \mathrm{e}-092.12000 \mathrm{e}-01$ $1.00000 \mathrm{e}+001.00000 \mathrm{e}+001.00000 \mathrm{e}-011.00000 \mathrm{e}-091.00000 \mathrm{e}-01$ 
Element: 13753 \# of layers: 6

$\mathrm{Kx} \mathrm{Ky} \mathrm{Kz}$ Ss Por

$2.71446 \mathrm{e}+00$ 2.71446e+00 2.71446e-01 1.00000e-09 2.12000e-01

$2.71446 \mathrm{e}+002.71446 \mathrm{e}+00$ 2.71446e-01 1.00000e-09 2.12000e-01

$2.71446 \mathrm{e}+002.71446 \mathrm{e}+00$ 2.71446e-01 1.00000e-09 2.12000e-01

$2.71446 \mathrm{e}+002.71446 \mathrm{e}+00$ 2.71446e-01 1.00000e-09 2.12000e-01

$2.71446 \mathrm{e}+002.71446 \mathrm{e}+002.71446 \mathrm{e}-01$ 1.00000e-09 2.12000e-01

$1.00000 \mathrm{e}+001.00000 \mathrm{e}+001.00000 \mathrm{e}-01$ 1.00000e-09 1.00000e-01

Element: 13754 \# of layers: 6

$\mathrm{Kx} \mathrm{Ky} \mathrm{Kz}$ Ss Por

2.71446e+00 2.71446e+00 2.71446e-01 1.00000e-09 2.12000e-01

$2.71446 \mathrm{e}+002.71446 \mathrm{e}+00$ 2.71446e-01 1.00000e-09 2.12000e-01

$2.71446 \mathrm{e}+00$ 2.71446e+00 2.71446e-01 1.00000e-09 2.12000e-01

$2.71446 \mathrm{e}+002.71446 \mathrm{e}+00$ 2.71446e-01 1.00000e-09 2.12000e-01

$2.71446 \mathrm{e}+002.71446 \mathrm{e}+002.71446 \mathrm{e}-01$ 1.00000e-09 2.12000e-01

$1.00000 \mathrm{e}+001.00000 \mathrm{e}+001.00000 \mathrm{e}-01$ 1.00000e-09 1.00000e-01

Element: 13755 \# of layers: 6

$\mathrm{Kx} \mathrm{Ky} \mathrm{Kz}$ Ss Por

$1.82661 \mathrm{e}+001.82661 \mathrm{e}+00$ 1.82661e-01 1.00000e-09 2.12000e-01

$1.82661 \mathrm{e}+001.82661 \mathrm{e}+001.82661 \mathrm{e}-01$ 1.00000e-09 2.12000e-01

$1.82661 \mathrm{e}+001.82661 \mathrm{e}+001.82661 \mathrm{e}-01$ 1.00000e-09 2.12000e-01

$1.82661 \mathrm{e}+001.82661 \mathrm{e}+00$ 1.82661e-01 1.00000e-09 2.12000e-01

$1.82661 \mathrm{e}+001.82661 \mathrm{e}+00$ 1.82661e-01 1.00000e-09 2.12000e-01

$1.00000 \mathrm{e}+001.00000 \mathrm{e}+001.00000 \mathrm{e}-01$ 1.00000e-09 1.00000e-01

Element: 13756 \# of layers: 7

$\mathrm{Kx} \mathrm{Ky} \mathrm{Kz}$ Ss Por

$1.82661 \mathrm{e}+001.82661 \mathrm{e}+00$ 1.82661e-01 1.00000e-09 2.12000e-01

$1.82661 \mathrm{e}+001.82661 \mathrm{e}+001.82661 \mathrm{e}-011.00000 \mathrm{e}-092.12000 \mathrm{e}-01$

$1.82661 \mathrm{e}+001.82661 \mathrm{e}+001.82661 \mathrm{e}-011.00000 \mathrm{e}-092.12000 \mathrm{e}-01$

$1.82661 \mathrm{e}+001.82661 \mathrm{e}+00$ 1.82661e-01 1.00000e-09 2.12000e-01

$1.82661 \mathrm{e}+001.82661 \mathrm{e}+00$ 1.82661e-01 1.00000e-09 2.12000e-01

$1.00000 \mathrm{e}-05$ 1.00000e-05 1.00000e-06 1.00000e-09 1.00000e-01

$1.00000 \mathrm{e}+001.00000 \mathrm{e}+001.00000 \mathrm{e}-01$ 1.00000e-09 1.00000e-01

Element: 13757 \# of layers: 6

Kx Ky Kz Ss Por

3.37732e+00 3.37732e+00 3.37732e-01 1.00000e-09 2.12000e-01

$3.37732 \mathrm{e}+003.37732 \mathrm{e}+00$ 3.37732e-01 1.00000e-09 2.12000e-01

3.37732e+00 3.37732e+00 3.37732e-01 1.00000e-09 2.12000e-01

3.37732e+00 3.37732e+00 3.37732e-01 1.00000e-09 2.12000e-01

$1.00000 \mathrm{e}-05$ 1.00000e-05 1.00000e-06 1.00000e-09 1.00000e-01

$1.00000 \mathrm{e}+001.00000 \mathrm{e}+001.00000 \mathrm{e}-011.00000 \mathrm{e}-091.00000 \mathrm{e}-01$

Element: 13758 \# of layers: 6

Kx Ky Kz Ss Por

3.37732e+00 3.37732e+00 3.37732e-01 1.00000e-09 2.12000e-01

$3.37732 \mathrm{e}+003.37732 \mathrm{e}+00$ 3.37732e-01 1.00000e-09 2.12000e-01

$3.37732 \mathrm{e}+003.37732 \mathrm{e}+00$ 3.37732e-01 1.00000e-09 2.12000e-01 
3.37732e+00 3.37732e+00 3.37732e-01 1.00000e-09 2.12000e-01 $1.00000 \mathrm{e}-05$ 1.00000e-05 1.00000e-06 1.00000e-09 1.00000e-01 $1.00000 \mathrm{e}+001.00000 \mathrm{e}+001.00000 \mathrm{e}-011.00000 \mathrm{e}-091.00000 \mathrm{e}-01$ Element: 13759 \# of layers: 6

Kx Ky Kz Ss Por

3.37732e+00 3.37732e+00 3.37732e-01 1.00000e-09 2.12000e-01 $3.37732 \mathrm{e}+003.37732 \mathrm{e}+003.37732 \mathrm{e}-011.00000 \mathrm{e}-092.12000 \mathrm{e}-01$ $3.37732 \mathrm{e}+003.37732 \mathrm{e}+003.37732 \mathrm{e}-01$ 1.00000e-09 2.12000e-01 $3.37732 \mathrm{e}+003.37732 \mathrm{e}+003.37732 \mathrm{e}-01$ 1.00000e-09 2.12000e-01 $1.00000 \mathrm{e}-05$ 1.00000e-05 1.00000e-06 1.00000e-09 1.00000e-01 $1.00000 \mathrm{e}+001.00000 \mathrm{e}+001.00000 \mathrm{e}-011.00000 \mathrm{e}-091.00000 \mathrm{e}-01$ Element: 13760 \# of layers: 6

Kx Ky Kz Ss Por

7.11060e+00 7.11060e+00 7.11060e-01 1.00000e-09 2.12000e-01 $7.11060 \mathrm{e}+007.11060 \mathrm{e}+00$ 7.11060e-01 1.00000e-09 2.12000e-01 $7.11060 \mathrm{e}+007.11060 \mathrm{e}+007.11060 \mathrm{e}-01$ 1.00000e-09 2.12000e-01 $7.11060 \mathrm{e}+007.11060 \mathrm{e}+007.11060 \mathrm{e}-01$ 1.00000e-09 2.12000e-01 $1.00000 \mathrm{e}-05$ 1.00000e-05 1.00000e-06 1.00000e-09 1.00000e-01 $1.00000 \mathrm{e}+001.00000 \mathrm{e}+001.00000 \mathrm{e}-011.00000 \mathrm{e}-091.00000 \mathrm{e}-01$ Element: 13761 \# of layers: 6

Kx Ky Kz Ss Por

7.11060e+00 7.11060e+00 7.11060e-01 1.00000e-09 2.12000e-01 $7.11060 \mathrm{e}+007.11060 \mathrm{e}+007.11060 \mathrm{e}-011.00000 \mathrm{e}-092.12000 \mathrm{e}-01$ $7.11060 \mathrm{e}+007.11060 \mathrm{e}+007.11060 \mathrm{e}-011.00000 \mathrm{e}-092.12000 \mathrm{e}-01$ $7.11060 \mathrm{e}+007.11060 \mathrm{e}+007.11060 \mathrm{e}-011.00000 \mathrm{e}-092.12000 \mathrm{e}-01$ $1.00000 \mathrm{e}-05$ 1.00000e-05 1.00000e-06 1.00000e-09 1.00000e-01 $1.00000 \mathrm{e}+001.00000 \mathrm{e}+001.00000 \mathrm{e}-011.00000 \mathrm{e}-091.00000 \mathrm{e}-01$ Element: 13762 \# of layers: 6

Kx Ky Kz Ss Por

$2.71446 \mathrm{e}+002.71446 \mathrm{e}+00$ 2.71446e-01 1.00000e-09 2.12000e-01 $2.71446 \mathrm{e}+002.71446 \mathrm{e}+002.71446 \mathrm{e}-011.00000 \mathrm{e}-092.12000 \mathrm{e}-01$ $2.71446 \mathrm{e}+002.71446 \mathrm{e}+002.71446 \mathrm{e}-011.00000 \mathrm{e}-092.12000 \mathrm{e}-01$ $2.71446 \mathrm{e}+002.71446 \mathrm{e}+002.71446 \mathrm{e}-011.00000 \mathrm{e}-092.12000 \mathrm{e}-01$ $2.71446 \mathrm{e}+002.71446 \mathrm{e}+002.71446 \mathrm{e}-011.00000 \mathrm{e}-092.12000 \mathrm{e}-01$ $1.00000 \mathrm{e}+001.00000 \mathrm{e}+001.00000 \mathrm{e}-011.00000 \mathrm{e}-091.00000 \mathrm{e}-01$ Element: 13763 \# of layers: 7

Kx Ky Kz Ss Por

$1.82661 \mathrm{e}+001.82661 \mathrm{e}+00$ 1.82661e-01 1.00000e-09 2.12000e-01 $1.82661 \mathrm{e}+001.82661 \mathrm{e}+001.82661 \mathrm{e}-011.00000 \mathrm{e}-092.12000 \mathrm{e}-01$ $1.82661 \mathrm{e}+001.82661 \mathrm{e}+001.82661 \mathrm{e}-011.00000 \mathrm{e}-092.12000 \mathrm{e}-01$ $1.82661 \mathrm{e}+001.82661 \mathrm{e}+001.82661 \mathrm{e}-011.00000 \mathrm{e}-092.12000 \mathrm{e}-01$ $1.82661 \mathrm{e}+001.82661 \mathrm{e}+001.82661 \mathrm{e}-011.00000 \mathrm{e}-092.12000 \mathrm{e}-01$ $1.00000 \mathrm{e}-05$ 1.00000e-05 1.00000e-06 1.00000e-09 1.00000e-01 $1.00000 \mathrm{e}+001.00000 \mathrm{e}+001.00000 \mathrm{e}-011.00000 \mathrm{e}-091.00000 \mathrm{e}-01$ Element: 13764 \# of layers: 6

Kx Ky Kz Ss Por 
3.37732e+00 3.37732e+00 3.37732e-01 1.00000e-09 2.12000e-01 3.37732e+00 3.37732e+00 3.37732e-01 1.00000e-09 2.12000e-01 3.37732e+00 3.37732e+00 3.37732e-01 1.00000e-09 2.12000e-01 $3.37732 \mathrm{e}+00$ 3.37732e+00 3.37732e-01 1.00000e-09 2.12000e-01 $1.00000 \mathrm{e}-051.00000 \mathrm{e}-05$ 1.00000e-06 1.00000e-09 1.00000e-01 $1.00000 \mathrm{e}+001.00000 \mathrm{e}+001.00000 \mathrm{e}-011.00000 \mathrm{e}-091.00000 \mathrm{e}-01$ Element: 13765 \# of layers: 6

$\mathrm{Kx} \mathrm{Ky} \mathrm{Kz}$ Ss Por

8.91492e+00 8.91492e+00 8.91492e-01 1.00000e-09 2.12000e-01 8.91492e+00 8.91492e+00 8.91492e-01 1.00000e-09 2.12000e-01 8.91492e+00 8.91492e+00 8.91492e-01 1.00000e-09 2.12000e-01 8.91492e+00 8.91492e+00 8.91492e-01 1.00000e-09 2.12000e-01 $1.00000 \mathrm{e}-05$ 1.00000e-05 1.00000e-06 1.00000e-09 1.00000e-01 $1.00000 \mathrm{e}+001.00000 \mathrm{e}+001.00000 \mathrm{e}-01$ 1.00000e-09 1.00000e-01 Element: 13766 \# of layers: 5

Kx Ky Kz Ss Por

8.91492e+00 8.91492e+00 8.91492e-01 1.00000e-09 2.12000e-01 8.91492e+00 8.91492e+00 8.91492e-01 1.00000e-09 2.12000e-01 8.91492e+00 8.91492e+00 8.91492e-01 1.00000e-09 2.12000e-01 $1.00000 \mathrm{e}-05$ 1.00000e-05 1.00000e-06 1.00000e-09 1.00000e-01 $1.00000 \mathrm{e}+001.00000 \mathrm{e}+001.00000 \mathrm{e}-011.00000 \mathrm{e}-091.00000 \mathrm{e}-01$ Element: 13767 \# of layers: 5

Kx Ky Kz Ss Por

8.91492e+00 8.91492e+00 8.91492e-01 1.00000e-09 2.12000e-01 $8.91492 \mathrm{e}+008.91492 \mathrm{e}+00$ 8.91492e-01 1.00000e-09 2.12000e-01 8.91492e+00 8.91492e+00 8.91492e-01 1.00000e-09 2.12000e-01 $1.00000 \mathrm{e}-05$ 1.00000e-05 1.00000e-06 1.00000e-09 1.00000e-01 $1.00000 \mathrm{e}+001.00000 \mathrm{e}+001.00000 \mathrm{e}-01$ 1.00000e-09 1.00000e-01 Element: 13768 \# of layers: 5

$\mathrm{Kx} \mathrm{Ky} \mathrm{Kz}$ Ss Por

8.91492e+00 8.91492e+00 8.91492e-01 1.00000e-09 2.12000e-01 8.91492e+00 8.91492e+00 8.91492e-01 1.00000e-09 2.12000e-01 8.91492e+00 8.91492e+00 8.91492e-01 1.00000e-09 2.12000e-01 $1.00000 \mathrm{e}-051.00000 \mathrm{e}-051.00000 \mathrm{e}-061.00000 \mathrm{e}-091.00000 \mathrm{e}-01$ $1.00000 \mathrm{e}+001.00000 \mathrm{e}+001.00000 \mathrm{e}-01$ 1.00000e-09 1.00000e-01 Element: 13769 \# of layers: 5

Kx Ky Kz Ss Por

8.91492e+00 8.91492e+00 8.91492e-01 1.00000e-09 2.12000e-01 8.91492e+00 8.91492e+00 8.91492e-01 1.00000e-09 2.12000e-01 8.91492e+00 8.91492e+00 8.91492e-01 1.00000e-09 2.12000e-01 $1.00000 \mathrm{e}-05$ 1.00000e-05 1.00000e-06 1.00000e-09 1.00000e-01 $1.00000 \mathrm{e}+001.00000 \mathrm{e}+001.00000 \mathrm{e}-011.00000 \mathrm{e}-091.00000 \mathrm{e}-01$ Element: 13770 \# of layers: 5

$\mathrm{Kx} \mathrm{Ky} \mathrm{Kz}$ Ss Por 8.91492e+00 8.91492e+00 8.91492e-01 1.00000e-09 2.12000e-01 $8.91492 \mathrm{e}+008.91492 \mathrm{e}+00$ 8.91492e-01 1.00000e-09 2.12000e-01 
8.91492e+00 8.91492e+00 8.91492e-01 1.00000e-09 2.12000e-01 $1.00000 \mathrm{e}-05$ 1.00000e-05 1.00000e-06 1.00000e-09 1.00000e-01 $1.00000 \mathrm{e}+001.00000 \mathrm{e}+001.00000 \mathrm{e}-011.00000 \mathrm{e}-091.00000 \mathrm{e}-01$ Element: 13771 \# of layers: 6

$\mathrm{Kx} \mathrm{Ky} \mathrm{Kz}$ Ss Por

8.91492e+00 8.91492e+00 8.91492e-01 1.00000e-09 2.12000e-01 8.91492e+00 8.91492e+00 8.91492e-01 1.00000e-09 2.12000e-01 8.91492e+00 8.91492e+00 8.91492e-01 1.00000e-09 2.12000e-01 8.91492e+00 8.91492e+00 8.91492e-01 1.00000e-09 2.12000e-01 $1.00000 \mathrm{e}-05$ 1.00000e-05 1.00000e-06 1.00000e-09 1.00000e-01 $1.00000 \mathrm{e}+001.00000 \mathrm{e}+001.00000 \mathrm{e}-011.00000 \mathrm{e}-091.00000 \mathrm{e}-01$ Element: 13772 \# of layers: 6

$\mathrm{Kx} \mathrm{Ky} \mathrm{Kz}$ Ss Por

8.91492e+00 8.91492e+00 8.91492e-01 1.00000e-09 2.12000e-01 8.91492e+00 8.91492e+00 8.91492e-01 1.00000e-09 2.12000e-01 8.91492e+00 8.91492e+00 8.91492e-01 1.00000e-09 2.12000e-01 8.91492e+00 8.91492e+00 8.91492e-01 1.00000e-09 2.12000e-01 $1.00000 \mathrm{e}-05$ 1.00000e-05 1.00000e-06 1.00000e-09 1.00000e-01 $1.00000 \mathrm{e}+001.00000 \mathrm{e}+001.00000 \mathrm{e}-01$ 1.00000e-09 1.00000e-01 Element: 13773 \# of layers: 5

$\mathrm{Kx} \mathrm{Ky} \mathrm{Kz}$ Ss Por

8.91492e+00 8.91492e+00 8.91492e-01 1.00000e-09 2.12000e-01 8.91492e+00 8.91492e+00 8.91492e-01 1.00000e-09 2.12000e-01 8.91492e+00 8.91492e+00 8.91492e-01 1.00000e-09 2.12000e-01 $1.00000 \mathrm{e}-05$ 1.00000e-05 1.00000e-06 1.00000e-09 1.00000e-01 $1.00000 \mathrm{e}+001.00000 \mathrm{e}+001.00000 \mathrm{e}-011.00000 \mathrm{e}-091.00000 \mathrm{e}-01$ Element: 13774 \# of layers: 5

$\mathrm{Kx} \mathrm{Ky} \mathrm{Kz}$ Ss Por

8.91492e+00 8.91492e+00 8.91492e-01 1.00000e-09 2.12000e-01 8.91492e+00 8.91492e+00 8.91492e-01 1.00000e-09 2.12000e-01 8.91492e+00 8.91492e+00 8.91492e-01 1.00000e-09 2.12000e-01 1.00000e-05 1.00000e-05 1.00000e-06 1.00000e-09 1.00000e-01 $1.00000 \mathrm{e}+001.00000 \mathrm{e}+001.00000 \mathrm{e}-011.00000 \mathrm{e}-09$ 1.00000e-01 Element: 13775 \# of layers: 5

$\mathrm{Kx} \mathrm{Ky} \mathrm{Kz}$ Ss Por

$1.26106 \mathrm{e}+011.26106 \mathrm{e}+011.26106 \mathrm{e}+00$ 1.00000e-09 2.12000e-01 $1.26106 \mathrm{e}+011.26106 \mathrm{e}+011.26106 \mathrm{e}+001.00000 \mathrm{e}-092.12000 \mathrm{e}-01$ $1.26106 \mathrm{e}+011.26106 \mathrm{e}+011.26106 \mathrm{e}+001.00000 \mathrm{e}-092.12000 \mathrm{e}-01$ $1.00000 \mathrm{e}-051.00000 \mathrm{e}-051.00000 \mathrm{e}-061.00000 \mathrm{e}-091.00000 \mathrm{e}-01$ $1.00000 \mathrm{e}+001.00000 \mathrm{e}+001.00000 \mathrm{e}-011.00000 \mathrm{e}-091.00000 \mathrm{e}-01$ Element: 13776 \# of layers: 4

$\mathrm{Kx} \mathrm{Ky} \mathrm{Kz}$ Ss Por

$1.26106 \mathrm{e}+01$ 1.26106e+01 1.26106e+00 1.00000e-09 2.12000e-01 $1.26106 \mathrm{e}+01$ 1.26106e+01 1.26106e+00 1.00000e-09 2.12000e-01 $1.00000 \mathrm{e}-05$ 1.00000e-05 1.00000e-06 1.00000e-09 1.00000e-01 $1.00000 \mathrm{e}+001.00000 \mathrm{e}+001.00000 \mathrm{e}-011.00000 \mathrm{e}-091.00000 \mathrm{e}-01$ 
Element: 13777 \# of layers: 4

$\mathrm{Kx} \mathrm{Ky} \mathrm{Kz}$ Ss Por

$1.26106 \mathrm{e}+01$ 1.26106e+01 1.26106e+00 1.00000e-09 2.12000e-01

$1.26106 \mathrm{e}+011.26106 \mathrm{e}+011.26106 \mathrm{e}+001.00000 \mathrm{e}-092.12000 \mathrm{e}-01$

$1.00000 \mathrm{e}-05$ 1.00000e-05 1.00000e-06 1.00000e-09 1.00000e-01

$1.00000 \mathrm{e}+001.00000 \mathrm{e}+001.00000 \mathrm{e}-011.00000 \mathrm{e}-091.00000 \mathrm{e}-01$

Element: 13778 \# of layers: 5

Kx Ky Kz Ss Por

$1.26106 \mathrm{e}+011.26106 \mathrm{e}+011.26106 \mathrm{e}+001.00000 \mathrm{e}-092.12000 \mathrm{e}-01$

$1.26106 \mathrm{e}+011.26106 \mathrm{e}+011.26106 \mathrm{e}+001.00000 \mathrm{e}-092.12000 \mathrm{e}-01$

$1.00000 \mathrm{e}-05$ 1.00000e-05 1.00000e-06 1.00000e-09 1.00000e-01

$1.00000 \mathrm{e}+001.00000 \mathrm{e}+001.00000 \mathrm{e}-011.00000 \mathrm{e}-091.00000 \mathrm{e}-01$

1.00000e-06 1.00000e-06 1.00000e-06 1.00000e-09 5.00000e-02

Element: 13779 \# of layers: 5

Kx Ky Kz Ss Por

$1.26106 \mathrm{e}+01$ 1.26106e+01 1.26106e+00 1.00000e-09 2.12000e-01

$1.26106 \mathrm{e}+011.26106 \mathrm{e}+011.26106 \mathrm{e}+001.00000 \mathrm{e}-092.12000 \mathrm{e}-01$

$1.26106 \mathrm{e}+011.26106 \mathrm{e}+011.26106 \mathrm{e}+001.00000 \mathrm{e}-092.12000 \mathrm{e}-01$

$1.00000 \mathrm{e}-05$ 1.00000e-05 1.00000e-06 1.00000e-09 1.00000e-01

$1.00000 \mathrm{e}+001.00000 \mathrm{e}+001.00000 \mathrm{e}-011.00000 \mathrm{e}-091.00000 \mathrm{e}-01$

Element: 13780 \# of layers: 5

$\mathrm{Kx} \mathrm{Ky} \mathrm{Kz}$ Ss Por

8.91492e+00 8.91492e+00 8.91492e-01 1.00000e-09 2.12000e-01

8.91492e+00 8.91492e+00 8.91492e-01 1.00000e-09 2.12000e-01

$8.91492 \mathrm{e}+008.91492 \mathrm{e}+00$ 8.91492e-01 1.00000e-09 2.12000e-01

$1.00000 \mathrm{e}-05$ 1.00000e-05 1.00000e-06 1.00000e-09 1.00000e-01

$1.00000 \mathrm{e}+001.00000 \mathrm{e}+001.00000 \mathrm{e}-011.00000 \mathrm{e}-091.00000 \mathrm{e}-01$

Element: 13781 \# of layers: 5

Kx Ky Kz Ss Por

8.91492e+00 8.91492e+00 8.91492e-01 1.00000e-09 2.12000e-01

8.91492e+00 8.91492e+00 8.91492e-01 1.00000e-09 2.12000e-01

8.91492e+00 8.91492e+00 8.91492e-01 1.00000e-09 2.12000e-01

$1.00000 \mathrm{e}-051.00000 \mathrm{e}-05$ 1.00000e-06 1.00000e-09 1.00000e-01

$1.00000 \mathrm{e}+001.00000 \mathrm{e}+001.00000 \mathrm{e}-011.00000 \mathrm{e}-091.00000 \mathrm{e}-01$

Element: 13782 \# of layers: 5

$\mathrm{Kx} \mathrm{Ky} \mathrm{Kz}$ Ss Por

$1.26106 \mathrm{e}+01$ 1.26106e+01 1.26106e+00 1.00000e-09 2.12000e-01

$1.26106 \mathrm{e}+011.26106 \mathrm{e}+011.26106 \mathrm{e}+001.00000 \mathrm{e}-092.12000 \mathrm{e}-01$

$1.26106 \mathrm{e}+011.26106 \mathrm{e}+01$ 1.26106e+00 1.00000e-09 2.12000e-01

$1.00000 \mathrm{e}-05$ 1.00000e-05 1.00000e-06 1.00000e-09 1.00000e-01

$1.00000 \mathrm{e}+001.00000 \mathrm{e}+001.00000 \mathrm{e}-011.00000 \mathrm{e}-091.00000 \mathrm{e}-01$

Element: 13783 \# of layers: 5

Kx Ky Kz Ss Por

$1.26106 \mathrm{e}+01$ 1.26106e+01 1.26106e+00 1.00000e-09 2.12000e-01

$1.26106 \mathrm{e}+011.26106 \mathrm{e}+011.26106 \mathrm{e}+001.00000 \mathrm{e}-092.12000 \mathrm{e}-01$

$1.00000 \mathrm{e}-05$ 1.00000e-05 1.00000e-06 1.00000e-09 1.00000e-01 
$1.00000 \mathrm{e}+001.00000 \mathrm{e}+001.00000 \mathrm{e}-011.00000 \mathrm{e}-091.00000 \mathrm{e}-01$ 1.00000e-06 1.00000e-06 1.00000e-06 1.00000e-09 5.00000e-02

Element: 13784 \# of layers: 5

Kx Ky Kz Ss Por

$1.26106 \mathrm{e}+011.26106 \mathrm{e}+011.26106 \mathrm{e}+001.00000 \mathrm{e}-092.12000 \mathrm{e}-01$

$1.26106 \mathrm{e}+011.26106 \mathrm{e}+011.26106 \mathrm{e}+001.00000 \mathrm{e}-092.12000 \mathrm{e}-01$

$1.00000 \mathrm{e}-05$ 1.00000e-05 1.00000e-06 1.00000e-09 1.00000e-01

$1.00000 \mathrm{e}+001.00000 \mathrm{e}+001.00000 \mathrm{e}-011.00000 \mathrm{e}-091.00000 \mathrm{e}-01$

1.00000e-06 1.00000e-06 1.00000e-06 1.00000e-09 5.00000e-02

Element: 13785 \# of layers: 5

$\mathrm{Kx} \mathrm{Ky} \mathrm{Kz}$ Ss Por

$1.26106 \mathrm{e}+011.26106 \mathrm{e}+011.26106 \mathrm{e}+001.00000 \mathrm{e}-092.12000 \mathrm{e}-01$

$1.26106 \mathrm{e}+011.26106 \mathrm{e}+011.26106 \mathrm{e}+001.00000 \mathrm{e}-092.12000 \mathrm{e}-01$

$1.00000 \mathrm{e}-05$ 1.00000e-05 1.00000e-06 1.00000e-09 1.00000e-01

$1.00000 \mathrm{e}+001.00000 \mathrm{e}+001.00000 \mathrm{e}-011.00000 \mathrm{e}-091.00000 \mathrm{e}-01$

1.00000e-06 1.00000e-06 1.00000e-06 1.00000e-09 5.00000e-02

Element: 13786 \# of layers: 5

Kx Ky Kz Ss Por

$1.26106 \mathrm{e}+01$ 1.26106e+01 1.26106e+00 1.00000e-09 2.12000e-01

$1.26106 \mathrm{e}+011.26106 \mathrm{e}+01 \quad 1.26106 \mathrm{e}+001.00000 \mathrm{e}-092.12000 \mathrm{e}-01$

$1.00000 \mathrm{e}-05$ 1.00000e-05 1.00000e-06 1.00000e-09 1.00000e-01

$1.00000 \mathrm{e}+001.00000 \mathrm{e}+001.00000 \mathrm{e}-011.00000 \mathrm{e}-091.00000 \mathrm{e}-01$

1.00000e-06 1.00000e-06 1.00000e-06 1.00000e-09 5.00000e-02

Element: 13787 \# of layers: 5

Kx Ky Kz Ss Por

$1.26106 \mathrm{e}+011.26106 \mathrm{e}+011.26106 \mathrm{e}+001.00000 \mathrm{e}-092.12000 \mathrm{e}-01$

$1.26106 \mathrm{e}+011.26106 \mathrm{e}+011.26106 \mathrm{e}+001.00000 \mathrm{e}-092.12000 \mathrm{e}-01$

$1.00000 \mathrm{e}-05$ 1.00000e-05 1.00000e-06 1.00000e-09 1.00000e-01

$1.00000 \mathrm{e}+001.00000 \mathrm{e}+001.00000 \mathrm{e}-011.00000 \mathrm{e}-091.00000 \mathrm{e}-01$

1.00000e-06 1.00000e-06 1.00000e-06 1.00000e-09 5.00000e-02

Element: 13788 \# of layers: 5

$\mathrm{Kx} \mathrm{Ky} \mathrm{Kz}$ Ss Por

$1.26106 \mathrm{e}+01$ 1.26106e+01 1.26106e+00 1.00000e-09 2.12000e-01

$1.26106 \mathrm{e}+011.26106 \mathrm{e}+011.26106 \mathrm{e}+001.00000 \mathrm{e}-092.12000 \mathrm{e}-01$

$1.00000 \mathrm{e}-05$ 1.00000e-05 1.00000e-06 1.00000e-09 1.00000e-01

$1.00000 \mathrm{e}+001.00000 \mathrm{e}+001.00000 \mathrm{e}-011.00000 \mathrm{e}-091.00000 \mathrm{e}-01$

1.00000e-06 1.00000e-06 1.00000e-06 1.00000e-09 5.00000e-02

Element: 13789 \# of layers: 5

$\mathrm{Kx} \mathrm{Ky} \mathrm{Kz}$ Ss Por

$1.26106 \mathrm{e}+011.26106 \mathrm{e}+011.26106 \mathrm{e}+001.00000 \mathrm{e}-092.12000 \mathrm{e}-01$

$1.26106 \mathrm{e}+011.26106 \mathrm{e}+011.26106 \mathrm{e}+001.00000 \mathrm{e}-092.12000 \mathrm{e}-01$

$1.00000 \mathrm{e}-05$ 1.00000e-05 1.00000e-06 1.00000e-09 1.00000e-01

$1.00000 \mathrm{e}+001.00000 \mathrm{e}+001.00000 \mathrm{e}-011.00000 \mathrm{e}-091.00000 \mathrm{e}-01$

1.00000e-06 1.00000e-06 1.00000e-06 1.00000e-09 5.00000e-02

Element: 13790 \# of layers: 5

Kx Ky Kz Ss Por 
$1.26106 \mathrm{e}+011.26106 \mathrm{e}+011.26106 \mathrm{e}+001.00000 \mathrm{e}-092.12000 \mathrm{e}-01$ $1.26106 \mathrm{e}+011.26106 \mathrm{e}+011.26106 \mathrm{e}+001.00000 \mathrm{e}-092.12000 \mathrm{e}-01$ $1.00000 \mathrm{e}-051.00000 \mathrm{e}-05$ 1.00000e-06 1.00000e-09 1.00000e-01

$1.00000 \mathrm{e}+001.00000 \mathrm{e}+001.00000 \mathrm{e}-011.00000 \mathrm{e}-091.00000 \mathrm{e}-01$ 1.00000e-06 1.00000e-06 1.00000e-06 1.00000e-09 5.00000e-02

Element: 13791 \# of layers: 5

$\mathrm{Kx} \mathrm{Ky} \mathrm{Kz}$ Ss Por

$1.26106 \mathrm{e}+011.26106 \mathrm{e}+011.26106 \mathrm{e}+001.00000 \mathrm{e}-092.12000 \mathrm{e}-01$

$1.26106 \mathrm{e}+011.26106 \mathrm{e}+011.26106 \mathrm{e}+001.00000 \mathrm{e}-092.12000 \mathrm{e}-01$

$1.00000 \mathrm{e}-05$ 1.00000e-05 1.00000e-06 1.00000e-09 1.00000e-01

$1.00000 \mathrm{e}+001.00000 \mathrm{e}+001.00000 \mathrm{e}-011.00000 \mathrm{e}-091.00000 \mathrm{e}-01$

1.00000e-06 1.00000e-06 1.00000e-06 1.00000e-09 5.00000e-02

Element: 13792 \# of layers: 5

$\mathrm{Kx} \mathrm{Ky} \mathrm{Kz}$ Ss Por

$1.26106 \mathrm{e}+011.26106 \mathrm{e}+011.26106 \mathrm{e}+001.00000 \mathrm{e}-092.12000 \mathrm{e}-01$

$1.26106 \mathrm{e}+011.26106 \mathrm{e}+011.26106 \mathrm{e}+001.00000 \mathrm{e}-092.12000 \mathrm{e}-01$

$1.00000 \mathrm{e}-05$ 1.00000e-05 1.00000e-06 1.00000e-09 1.00000e-01

$1.00000 \mathrm{e}+001.00000 \mathrm{e}+001.00000 \mathrm{e}-011.00000 \mathrm{e}-091.00000 \mathrm{e}-01$

1.00000e-06 1.00000e-06 1.00000e-06 1.00000e-09 5.00000e-02

Element: 13793 \# of layers: 5

$\mathrm{Kx} \mathrm{Ky} \mathrm{Kz}$ Ss Por

$1.26106 \mathrm{e}+01$ 1.26106e+01 1.26106e+00 1.00000e-09 2.12000e-01

$1.26106 \mathrm{e}+011.26106 \mathrm{e}+011.26106 \mathrm{e}+001.00000 \mathrm{e}-092.12000 \mathrm{e}-01$

$1.00000 \mathrm{e}-05$ 1.00000e-05 1.00000e-06 1.00000e-09 1.00000e-01

$1.00000 \mathrm{e}+001.00000 \mathrm{e}+001.00000 \mathrm{e}-011.00000 \mathrm{e}-091.00000 \mathrm{e}-01$

1.00000e-06 1.00000e-06 1.00000e-06 1.00000e-09 5.00000e-02

Element: 13794 \# of layers: 5

$\mathrm{Kx} \mathrm{Ky} \mathrm{Kz}$ Ss Por

$1.23818 \mathrm{e}+01$ 1.23818e+01 1.23818e+00 1.00000e-09 2.12000e-01

$1.23818 \mathrm{e}+011.23818 \mathrm{e}+011.23818 \mathrm{e}+001.00000 \mathrm{e}-092.12000 \mathrm{e}-01$

$1.00000 \mathrm{e}-05$ 1.00000e-05 1.00000e-06 1.00000e-09 1.00000e-01

$1.00000 \mathrm{e}+001.00000 \mathrm{e}+001.00000 \mathrm{e}-011.00000 \mathrm{e}-091.00000 \mathrm{e}-01$

1.00000e-06 1.00000e-06 1.00000e-06 1.00000e-09 5.00000e-02

Element: 13795 \# of layers: 5

$\mathrm{Kx} \mathrm{Ky} \mathrm{Kz}$ Ss Por

$1.23818 \mathrm{e}+011.23818 \mathrm{e}+01$ 1.23818e+00 1.00000e-09 2.12000e-01

$1.23818 \mathrm{e}+011.23818 \mathrm{e}+011.23818 \mathrm{e}+001.00000 \mathrm{e}-092.12000 \mathrm{e}-01$

$1.00000 \mathrm{e}-05$ 1.00000e-05 1.00000e-06 1.00000e-09 1.00000e-01

$1.00000 \mathrm{e}+001.00000 \mathrm{e}+001.00000 \mathrm{e}-011.00000 \mathrm{e}-091.00000 \mathrm{e}-01$

1.00000e-06 1.00000e-06 1.00000e-06 1.00000e-09 5.00000e-02

Element: 13796 \# of layers: 5

Kx Ky Kz Ss Por

$1.23818 \mathrm{e}+01$ 1.23818e+01 1.23818e+00 1.00000e-09 2.12000e-01

$1.23818 \mathrm{e}+01$ 1.23818e+01 1.23818e+00 1.00000e-09 2.12000e-01

$1.00000 \mathrm{e}-05$ 1.00000e-05 1.00000e-06 1.00000e-09 1.00000e-01

$1.00000 \mathrm{e}+001.00000 \mathrm{e}+001.00000 \mathrm{e}-011.00000 \mathrm{e}-091.00000 \mathrm{e}-01$ 
1.00000e-06 1.00000e-06 1.00000e-06 1.00000e-09 5.00000e-02

Element: 13797 \# of layers: 5

Kx Ky Kz Ss Por

$1.26106 \mathrm{e}+011.26106 \mathrm{e}+011.26106 \mathrm{e}+001.00000 \mathrm{e}-092.12000 \mathrm{e}-01$

$1.26106 \mathrm{e}+011.26106 \mathrm{e}+011.26106 \mathrm{e}+001.00000 \mathrm{e}-092.12000 \mathrm{e}-01$

$1.00000 \mathrm{e}-05$ 1.00000e-05 1.00000e-06 1.00000e-09 1.00000e-01

$1.00000 \mathrm{e}+001.00000 \mathrm{e}+001.00000 \mathrm{e}-011.00000 \mathrm{e}-091.00000 \mathrm{e}-01$

1.00000e-06 1.00000e-06 1.00000e-06 1.00000e-09 5.00000e-02

Element: 13798 \# of layers: 5

$\mathrm{Kx} \mathrm{Ky} \mathrm{Kz}$ Ss Por

$1.26106 \mathrm{e}+01$ 1.26106e+01 1.26106e+00 1.00000e-09 2.12000e-01

$1.26106 \mathrm{e}+011.26106 \mathrm{e}+011.26106 \mathrm{e}+001.00000 \mathrm{e}-092.12000 \mathrm{e}-01$

$1.00000 \mathrm{e}-05$ 1.00000e-05 1.00000e-06 1.00000e-09 1.00000e-01

$1.00000 \mathrm{e}+001.00000 \mathrm{e}+001.00000 \mathrm{e}-011.00000 \mathrm{e}-091.00000 \mathrm{e}-01$

1.00000e-06 1.00000e-06 1.00000e-06 1.00000e-09 5.00000e-02

Element: 13799 \# of layers: 5

$\mathrm{Kx} \mathrm{Ky} \mathrm{Kz}$ Ss Por

$1.26106 \mathrm{e}+011.26106 \mathrm{e}+011.26106 \mathrm{e}+00$ 1.00000e-09 2.12000e-01

$1.26106 \mathrm{e}+011.26106 \mathrm{e}+011.26106 \mathrm{e}+001.00000 \mathrm{e}-092.12000 \mathrm{e}-01$

$1.00000 \mathrm{e}-05$ 1.00000e-05 1.00000e-06 1.00000e-09 1.00000e-01

$1.00000 \mathrm{e}+001.00000 \mathrm{e}+001.00000 \mathrm{e}-011.00000 \mathrm{e}-091.00000 \mathrm{e}-01$

1.00000e-06 1.00000e-06 1.00000e-06 1.00000e-09 5.00000e-02

Element: 13800 \# of layers: 5

Kx Ky Kz Ss Por

$1.26106 \mathrm{e}+011.26106 \mathrm{e}+011.26106 \mathrm{e}+001.00000 \mathrm{e}-092.12000 \mathrm{e}-01$

$1.26106 \mathrm{e}+011.26106 \mathrm{e}+011.26106 \mathrm{e}+001.00000 \mathrm{e}-092.12000 \mathrm{e}-01$

$1.00000 \mathrm{e}-05$ 1.00000e-05 1.00000e-06 1.00000e-09 1.00000e-01

$1.00000 \mathrm{e}+001.00000 \mathrm{e}+001.00000 \mathrm{e}-011.00000 \mathrm{e}-091.00000 \mathrm{e}-01$

1.00000e-06 1.00000e-06 1.00000e-06 1.00000e-09 5.00000e-02

Element: 13801 \# of layers: 5

$\mathrm{Kx} \mathrm{Ky} \mathrm{Kz}$ Ss Por

$1.23818 \mathrm{e}+011.23818 \mathrm{e}+01$ 1.23818e+00 1.00000e-09 2.12000e-01

$1.23818 \mathrm{e}+011.23818 \mathrm{e}+011.23818 \mathrm{e}+001.00000 \mathrm{e}-092.12000 \mathrm{e}-01$

$1.00000 \mathrm{e}-05$ 1.00000e-05 1.00000e-06 1.00000e-09 1.00000e-01

$1.00000 \mathrm{e}+001.00000 \mathrm{e}+001.00000 \mathrm{e}-011.00000 \mathrm{e}-091.00000 \mathrm{e}-01$

1.00000e-06 1.00000e-06 1.00000e-06 1.00000e-09 5.00000e-02

Element: 13802 \# of layers: 5

Kx Ky Kz Ss Por

$1.23818 \mathrm{e}+01$ 1.23818e+01 1.23818e+00 1.00000e-09 2.12000e-01

$1.23818 \mathrm{e}+01$ 1.23818e+01 1.23818e+00 1.00000e-09 2.12000e-01

$1.00000 \mathrm{e}-05$ 1.00000e-05 1.00000e-06 1.00000e-09 1.00000e-01

$1.00000 \mathrm{e}+001.00000 \mathrm{e}+001.00000 \mathrm{e}-011.00000 \mathrm{e}-091.00000 \mathrm{e}-01$

1.00000e-06 1.00000e-06 1.00000e-06 1.00000e-09 5.00000e-02

Element: 13803 \# of layers: 5

$\mathrm{Kx} \mathrm{Ky} \mathrm{Kz}$ Ss Por

$1.23818 \mathrm{e}+01$ 1.23818e+01 1.23818e+00 1.00000e-09 2.12000e-01 
$1.23818 \mathrm{e}+011.23818 \mathrm{e}+01$ 1.23818e+00 1.00000e-09 2.12000e-01 $1.00000 \mathrm{e}-05$ 1.00000e-05 1.00000e-06 1.00000e-09 1.00000e-01 $1.00000 \mathrm{e}+001.00000 \mathrm{e}+001.00000 \mathrm{e}-011.00000 \mathrm{e}-091.00000 \mathrm{e}-01$ 1.00000e-06 1.00000e-06 1.00000e-06 1.00000e-09 5.00000e-02 Element: 13804 \# of layers: 5

Kx Ky Kz Ss Por

$1.23818 \mathrm{e}+01$ 1.23818e+01 1.23818e+00 1.00000e-09 2.12000e-01 $1.23818 \mathrm{e}+01$ 1.23818e+01 1.23818e+00 1.00000e-09 2.12000e-01 $1.00000 \mathrm{e}-05$ 1.00000e-05 1.00000e-06 1.00000e-09 1.00000e-01 $1.00000 \mathrm{e}+001.00000 \mathrm{e}+001.00000 \mathrm{e}-01$ 1.00000e-09 1.00000e-01 1.00000e-06 1.00000e-06 1.00000e-06 1.00000e-09 5.00000e-02 Element: 13805 \# of layers: 5

$\mathrm{Kx} \mathrm{Ky} \mathrm{Kz}$ Ss Por

$1.23818 \mathrm{e}+01$ 1.23818e+01 1.23818e+00 1.00000e-09 2.12000e-01 $1.23818 \mathrm{e}+011.23818 \mathrm{e}+01$ 1.23818e+00 1.00000e-09 2.12000e-01 $1.00000 \mathrm{e}-05$ 1.00000e-05 1.00000e-06 1.00000e-09 1.00000e-01 $1.00000 \mathrm{e}+001.00000 \mathrm{e}+001.00000 \mathrm{e}-011.00000 \mathrm{e}-091.00000 \mathrm{e}-01$ 1.00000e-06 1.00000e-06 1.00000e-06 1.00000e-09 5.00000e-02 Element: 13806 \# of layers: 5

$\mathrm{Kx} \mathrm{Ky} \mathrm{Kz}$ Ss Por

$1.23818 \mathrm{e}+011.23818 \mathrm{e}+01$ 1.23818e+00 1.00000e-09 2.12000e-01 $1.23818 \mathrm{e}+01$ 1.23818e+01 1.23818e+00 1.00000e-09 2.12000e-01 $1.00000 \mathrm{e}-051.00000 \mathrm{e}-051.00000 \mathrm{e}-061.00000 \mathrm{e}-091.00000 \mathrm{e}-01$ $1.00000 \mathrm{e}+001.00000 \mathrm{e}+001.00000 \mathrm{e}-011.00000 \mathrm{e}-091.00000 \mathrm{e}-01$ $1.00000 \mathrm{e}-06$ 1.00000e-06 1.00000e-06 1.00000e-09 5.00000e-02 Element: 13807 \# of layers: 5

Kx Ky Kz Ss Por

$1.23818 \mathrm{e}+01$ 1.23818e+01 1.23818e+00 1.00000e-09 2.12000e-01 $1.23818 \mathrm{e}+01$ 1.23818e+01 1.23818e+00 1.00000e-09 2.12000e-01 $1.00000 \mathrm{e}-05$ 1.00000e-05 1.00000e-06 1.00000e-09 1.00000e-01 $1.00000 \mathrm{e}+001.00000 \mathrm{e}+001.00000 \mathrm{e}-01$ 1.00000e-09 1.00000e-01 1.00000e-06 1.00000e-06 1.00000e-06 1.00000e-09 5.00000e-02 Element: 13808 \# of layers: 5

$\mathrm{Kx} \mathrm{Ky} \mathrm{Kz}$ Ss Por

$1.23818 \mathrm{e}+01$ 1.23818e+01 1.23818e+00 1.00000e-09 2.12000e-01 $1.23818 \mathrm{e}+011.23818 \mathrm{e}+01$ 1.23818e+00 1.00000e-09 2.12000e-01 $1.00000 \mathrm{e}-05$ 1.00000e-05 1.00000e-06 1.00000e-09 1.00000e-01 $1.00000 \mathrm{e}+001.00000 \mathrm{e}+001.00000 \mathrm{e}-011.00000 \mathrm{e}-091.00000 \mathrm{e}-01$ 1.00000e-06 1.00000e-06 1.00000e-06 1.00000e-09 5.00000e-02 Element: 13809 \# of layers: 5

$\mathrm{Kx} \mathrm{Ky} \mathrm{Kz}$ Ss Por $1.23818 \mathrm{e}+011.23818 \mathrm{e}+01$ 1.23818e+00 1.00000e-09 2.12000e-01 $1.23818 \mathrm{e}+011.23818 \mathrm{e}+01$ 1.23818e+00 1.00000e-09 2.12000e-01 $1.00000 \mathrm{e}-05$ 1.00000e-05 1.00000e-06 1.00000e-09 1.00000e-01 $1.00000 \mathrm{e}+001.00000 \mathrm{e}+001.00000 \mathrm{e}-011.00000 \mathrm{e}-091.00000 \mathrm{e}-01$ $1.00000 \mathrm{e}-06$ 1.00000e-06 1.00000e-06 1.00000e-09 5.00000e-02 
Element: 13810 \# of layers: 6

Kx Ky Kz Ss Por

$1.23818 \mathrm{e}+011.23818 \mathrm{e}+011.23818 \mathrm{e}+00$ 1.00000e-09 2.12000e-01

$1.23818 \mathrm{e}+011.23818 \mathrm{e}+011.23818 \mathrm{e}+001.00000 \mathrm{e}-092.12000 \mathrm{e}-01$

$1.23818 \mathrm{e}+011.23818 \mathrm{e}+011.23818 \mathrm{e}+001.00000 \mathrm{e}-092.12000 \mathrm{e}-01$

$1.00000 \mathrm{e}-05$ 1.00000e-05 1.00000e-06 1.00000e-09 1.00000e-01

$1.00000 \mathrm{e}+001.00000 \mathrm{e}+001.00000 \mathrm{e}-011.00000 \mathrm{e}-091.00000 \mathrm{e}-01$

1.00000e-06 1.00000e-06 1.00000e-06 1.00000e-09 5.00000e-02

Element: 13811 \# of layers: 6

Kx Ky Kz Ss Por

$1.23818 \mathrm{e}+011.23818 \mathrm{e}+011.23818 \mathrm{e}+00$ 1.00000e-09 2.12000e-01

$1.23818 \mathrm{e}+011.23818 \mathrm{e}+011.23818 \mathrm{e}+001.00000 \mathrm{e}-092.12000 \mathrm{e}-01$

$1.23818 \mathrm{e}+011.23818 \mathrm{e}+011.23818 \mathrm{e}+001.00000 \mathrm{e}-092.12000 \mathrm{e}-01$

$1.00000 \mathrm{e}-05$ 1.00000e-05 1.00000e-06 1.00000e-09 1.00000e-01

$1.00000 \mathrm{e}+001.00000 \mathrm{e}+001.00000 \mathrm{e}-011.00000 \mathrm{e}-091.00000 \mathrm{e}-01$

$1.00000 \mathrm{e}-06$ 1.00000e-06 1.00000e-06 1.00000e-09 5.00000e-02

Element: 13812 \# of layers: 6

Kx Ky Kz Ss Por

$9.42658 \mathrm{e}+00$ 9.42658e+00 9.42658e-01 1.00000e-09 2.12000e-01

$9.42658 \mathrm{e}+009.42658 \mathrm{e}+00$ 9.42658e-01 1.00000e-09 2.12000e-01

$9.42658 \mathrm{e}+00$ 9.42658e+00 9.42658e-01 1.00000e-09 2.12000e-01

$1.00000 \mathrm{e}-05$ 1.00000e-05 1.00000e-06 1.00000e-09 1.00000e-01

$1.00000 \mathrm{e}+001.00000 \mathrm{e}+001.00000 \mathrm{e}-011.00000 \mathrm{e}-091.00000 \mathrm{e}-01$

$1.00000 \mathrm{e}-06$ 1.00000e-06 1.00000e-06 1.00000e-09 5.00000e-02

Element: 13813 \# of layers: 6

Kx Ky Kz Ss Por

$9.42658 \mathrm{e}+00$ 9.42658e+00 9.42658e-01 1.00000e-09 2.12000e-01

$9.42658 \mathrm{e}+00$ 9.42658e+00 9.42658e-01 1.00000e-09 2.12000e-01

$9.42658 \mathrm{e}+009.42658 \mathrm{e}+00$ 9.42658e-01 1.00000e-09 2.12000e-01

$1.00000 \mathrm{e}-05$ 1.00000e-05 1.00000e-06 1.00000e-09 1.00000e-01

$1.00000 \mathrm{e}+001.00000 \mathrm{e}+001.00000 \mathrm{e}-011.00000 \mathrm{e}-091.00000 \mathrm{e}-01$

$1.00000 \mathrm{e}-06$ 1.00000e-06 1.00000e-06 1.00000e-09 5.00000e-02

Element: 13814 \# of layers: 6

Kx Ky Kz Ss Por

$9.42658 \mathrm{e}+00$ 9.42658e+00 9.42658e-01 1.00000e-09 2.12000e-01

$9.42658 \mathrm{e}+009.42658 \mathrm{e}+00$ 9.42658e-01 1.00000e-09 2.12000e-01

$9.42658 \mathrm{e}+00$ 9.42658e+00 9.42658e-01 1.00000e-09 2.12000e-01

$1.00000 \mathrm{e}-05$ 1.00000e-05 1.00000e-06 1.00000e-09 1.00000e-01

$1.00000 \mathrm{e}+001.00000 \mathrm{e}+001.00000 \mathrm{e}-011.00000 \mathrm{e}-091.00000 \mathrm{e}-01$

1.00000e-06 1.00000e-06 1.00000e-06 1.00000e-09 5.00000e-02

Element: 13815 \# of layers: 6

Kx Ky Kz Ss Por

$1.23818 \mathrm{e}+011.23818 \mathrm{e}+011.23818 \mathrm{e}+00$ 1.00000e-09 2.12000e-01

$1.23818 \mathrm{e}+011.23818 \mathrm{e}+011.23818 \mathrm{e}+001.00000 \mathrm{e}-092.12000 \mathrm{e}-01$

$1.23818 \mathrm{e}+011.23818 \mathrm{e}+011.23818 \mathrm{e}+001.00000 \mathrm{e}-092.12000 \mathrm{e}-01$

$1.00000 \mathrm{e}-05$ 1.00000e-05 1.00000e-06 1.00000e-09 1.00000e-01 
$1.00000 \mathrm{e}+001.00000 \mathrm{e}+001.00000 \mathrm{e}-011.00000 \mathrm{e}-091.00000 \mathrm{e}-01$ $1.00000 \mathrm{e}-06$ 1.00000e-06 1.00000e-06 1.00000e-09 5.00000e-02

Element: 13816 \# of layers: 6

Kx Ky Kz Ss Por

$1.23818 \mathrm{e}+01$ 1.23818e+01 1.23818e+00 1.00000e-09 2.12000e-01

$1.23818 \mathrm{e}+011.23818 \mathrm{e}+01$ 1.23818e+00 1.00000e-09 2.12000e-01

$1.23818 \mathrm{e}+01$ 1.23818e+01 1.23818e+00 1.00000e-09 2.12000e-01

$1.00000 \mathrm{e}-05$ 1.00000e-05 1.00000e-06 1.00000e-09 1.00000e-01

$1.00000 \mathrm{e}+001.00000 \mathrm{e}+001.00000 \mathrm{e}-011.00000 \mathrm{e}-091.00000 \mathrm{e}-01$

1.00000e-06 1.00000e-06 1.00000e-06 1.00000e-09 5.00000e-02

Element: 13817 \# of layers: 6

Kx Ky Kz Ss Por

$1.23818 \mathrm{e}+01$ 1.23818e+01 1.23818e+00 1.00000e-09 2.12000e-01

$1.23818 \mathrm{e}+01$ 1.23818e+01 1.23818e+00 1.00000e-09 2.12000e-01

$1.23818 \mathrm{e}+011.23818 \mathrm{e}+011.23818 \mathrm{e}+001.00000 \mathrm{e}-092.12000 \mathrm{e}-01$

$1.00000 \mathrm{e}-05$ 1.00000e-05 1.00000e-06 1.00000e-09 1.00000e-01

$1.00000 \mathrm{e}+001.00000 \mathrm{e}+001.00000 \mathrm{e}-011.00000 \mathrm{e}-091.00000 \mathrm{e}-01$

1.00000e-06 1.00000e-06 1.00000e-06 1.00000e-09 5.00000e-02

Element: 13818 \# of layers: 6

$\mathrm{Kx} \mathrm{Ky} \mathrm{Kz}$ Ss Por

$1.23818 \mathrm{e}+01$ 1.23818e+01 1.23818e+00 1.00000e-09 2.12000e-01

$1.23818 \mathrm{e}+01$ 1.23818e+01 1.23818e+00 1.00000e-09 2.12000e-01

$1.23818 \mathrm{e}+01$ 1.23818e+01 1.23818e+00 1.00000e-09 2.12000e-01

$1.00000 \mathrm{e}-05$ 1.00000e-05 1.00000e-06 1.00000e-09 1.00000e-01

$1.00000 \mathrm{e}+001.00000 \mathrm{e}+001.00000 \mathrm{e}-011.00000 \mathrm{e}-091.00000 \mathrm{e}-01$

1.00000e-06 1.00000e-06 1.00000e-06 1.00000e-09 5.00000e-02

Element: 13819 \# of layers: 6

$\mathrm{Kx} \mathrm{Ky} \mathrm{Kz}$ Ss Por

9.42658e+00 9.42658e+00 9.42658e-01 1.00000e-09 2.12000e-01

$9.42658 \mathrm{e}+00$ 9.42658e+00 9.42658e-01 1.00000e-09 2.12000e-01

9.42658e+00 9.42658e+00 9.42658e-01 1.00000e-09 2.12000e-01

$1.00000 \mathrm{e}-05$ 1.00000e-05 1.00000e-06 1.00000e-09 1.00000e-01

$1.00000 \mathrm{e}+001.00000 \mathrm{e}+001.00000 \mathrm{e}-011.00000 \mathrm{e}-091.00000 \mathrm{e}-01$

1.00000e-06 1.00000e-06 1.00000e-06 1.00000e-09 5.00000e-02

Element: 13820 \# of layers: 6

$\mathrm{Kx} \mathrm{Ky} \mathrm{Kz}$ Ss Por

9.42658e+00 9.42658e+00 9.42658e-01 1.00000e-09 2.12000e-01

$9.42658 \mathrm{e}+00$ 9.42658e+00 9.42658e-01 1.00000e-09 2.12000e-01

9.42658e+00 9.42658e+00 9.42658e-01 1.00000e-09 2.12000e-01

$1.00000 \mathrm{e}-05$ 1.00000e-05 1.00000e-06 1.00000e-09 1.00000e-01

$1.00000 \mathrm{e}+001.00000 \mathrm{e}+001.00000 \mathrm{e}-011.00000 \mathrm{e}-091.00000 \mathrm{e}-01$

1.00000e-06 1.00000e-06 1.00000e-06 1.00000e-09 5.00000e-02

Element: 13821 \# of layers: 7

$\mathrm{Kx} \mathrm{Ky} \mathrm{Kz}$ Ss Por

9.42658e+00 9.42658e+00 9.42658e-01 1.00000e-09 2.12000e-01

$9.42658 \mathrm{e}+00$ 9.42658e+00 9.42658e-01 1.00000e-09 2.12000e-01 
9.42658e+00 9.42658e+00 9.42658e-01 1.00000e-09 2.12000e-01 $9.42658 \mathrm{e}+00$ 9.42658e+00 9.42658e-01 1.00000e-09 2.12000e-01 $1.00000 \mathrm{e}-05$ 1.00000e-05 1.00000e-06 1.00000e-09 1.00000e-01 $1.00000 \mathrm{e}+001.00000 \mathrm{e}+001.00000 \mathrm{e}-011.00000 \mathrm{e}-091.00000 \mathrm{e}-01$ 1.00000e-06 1.00000e-06 1.00000e-06 1.00000e-09 5.00000e-02

Element: 13822 \# of layers: 7

$\mathrm{Kx} \mathrm{Ky} \mathrm{Kz}$ Ss Por

9.42658e+00 9.42658e+00 9.42658e-01 1.00000e-09 2.12000e-01

$9.42658 \mathrm{e}+009.42658 \mathrm{e}+00$ 9.42658e-01 1.00000e-09 2.12000e-01

9.42658e+00 9.42658e+00 9.42658e-01 1.00000e-09 2.12000e-01

$9.42658 \mathrm{e}+00$ 9.42658e+00 9.42658e-01 1.00000e-09 2.12000e-01 $1.00000 \mathrm{e}-05$ 1.00000e-05 1.00000e-06 1.00000e-09 1.00000e-01

$1.00000 \mathrm{e}+001.00000 \mathrm{e}+001.00000 \mathrm{e}-011.00000 \mathrm{e}-091.00000 \mathrm{e}-01$ 1.00000e-06 1.00000e-06 1.00000e-06 1.00000e-09 5.00000e-02

Element: 13823 \# of layers: 6

Kx Ky Kz Ss Por

9.42658e+00 9.42658e+00 9.42658e-01 1.00000e-09 2.12000e-01

9.42658e+00 9.42658e+00 9.42658e-01 1.00000e-09 2.12000e-01

9.42658e+00 9.42658e+00 9.42658e-01 1.00000e-09 2.12000e-01

$9.42658 \mathrm{e}+00$ 9.42658e+00 9.42658e-01 1.00000e-09 2.12000e-01

$1.00000 \mathrm{e}-05$ 1.00000e-05 1.00000e-06 1.00000e-09 1.00000e-01

$1.00000 \mathrm{e}+001.00000 \mathrm{e}+001.00000 \mathrm{e}-011.00000 \mathrm{e}-091.00000 \mathrm{e}-01$

Element: 13824 \# of layers: 6

Kx Ky Kz Ss Por

9.42658e+00 9.42658e+00 9.42658e-01 1.00000e-09 2.12000e-01

9.42658e+00 9.42658e+00 9.42658e-01 1.00000e-09 2.12000e-01

9.42658e+00 9.42658e+00 9.42658e-01 1.00000e-09 2.12000e-01

$1.00000 \mathrm{e}-05$ 1.00000e-05 1.00000e-06 1.00000e-09 1.00000e-01

$1.00000 \mathrm{e}+001.00000 \mathrm{e}+001.00000 \mathrm{e}-011.00000 \mathrm{e}-091.00000 \mathrm{e}-01$

1.00000e-06 1.00000e-06 1.00000e-06 1.00000e-09 5.00000e-02

Element: 13825 \# of layers: 6

$\mathrm{Kx} \mathrm{Ky} \mathrm{Kz}$ Ss Por

9.42658e+00 9.42658e+00 9.42658e-01 1.00000e-09 2.12000e-01

$9.42658 \mathrm{e}+00$ 9.42658e+00 9.42658e-01 1.00000e-09 2.12000e-01

$9.42658 \mathrm{e}+009.42658 \mathrm{e}+00$ 9.42658e-01 1.00000e-09 2.12000e-01

$1.00000 \mathrm{e}-05$ 1.00000e-05 1.00000e-06 1.00000e-09 1.00000e-01

$1.00000 \mathrm{e}+001.00000 \mathrm{e}+001.00000 \mathrm{e}-011.00000 \mathrm{e}-091.00000 \mathrm{e}-01$

1.00000e-06 1.00000e-06 1.00000e-06 1.00000e-09 5.00000e-02

Element: 13826 \# of layers: 6

$\mathrm{Kx} \mathrm{Ky} \mathrm{Kz}$ Ss Por

9.42658e+00 9.42658e+00 9.42658e-01 1.00000e-09 2.12000e-01

$9.42658 \mathrm{e}+009.42658 \mathrm{e}+00$ 9.42658e-01 1.00000e-09 2.12000e-01

9.42658e+00 9.42658e+00 9.42658e-01 1.00000e-09 2.12000e-01

$1.00000 \mathrm{e}-05$ 1.00000e-05 1.00000e-06 1.00000e-09 1.00000e-01

$1.00000 \mathrm{e}+001.00000 \mathrm{e}+001.00000 \mathrm{e}-011.00000 \mathrm{e}-091.00000 \mathrm{e}-01$

$1.00000 \mathrm{e}-06$ 1.00000e-06 1.00000e-06 1.00000e-09 5.00000e-02 
Element: 13827 \# of layers: 6

$\mathrm{Kx} \mathrm{Ky} \mathrm{Kz}$ Ss Por

9.42658e+00 9.42658e+00 9.42658e-01 1.00000e-09 2.12000e-01

$9.42658 \mathrm{e}+00$ 9.42658e+00 9.42658e-01 1.00000e-09 2.12000e-01

9.42658e+00 9.42658e+00 9.42658e-01 1.00000e-09 2.12000e-01

$1.00000 \mathrm{e}-05$ 1.00000e-05 1.00000e-06 1.00000e-09 1.00000e-01

$1.00000 \mathrm{e}+001.00000 \mathrm{e}+001.00000 \mathrm{e}-011.00000 \mathrm{e}-091.00000 \mathrm{e}-01$

1.00000e-06 1.00000e-06 1.00000e-06 1.00000e-09 5.00000e-02

Element: 13828 \# of layers: 6

$\mathrm{Kx} \mathrm{Ky} \mathrm{Kz}$ Ss Por

9.42658e+00 9.42658e+00 9.42658e-01 1.00000e-09 2.12000e-01

$9.42658 \mathrm{e}+009.42658 \mathrm{e}+00$ 9.42658e-01 1.00000e-09 2.12000e-01

$9.42658 \mathrm{e}+009.42658 \mathrm{e}+00$ 9.42658e-01 1.00000e-09 2.12000e-01

9.42658e+00 9.42658e+00 9.42658e-01 1.00000e-09 2.12000e-01

$1.00000 \mathrm{e}-05$ 1.00000e-05 1.00000e-06 1.00000e-09 1.00000e-01

$1.00000 \mathrm{e}+001.00000 \mathrm{e}+001.00000 \mathrm{e}-011.00000 \mathrm{e}-091.00000 \mathrm{e}-01$

Element: 13829 \# of layers: 6

$\mathrm{Kx} \mathrm{Ky} \mathrm{Kz}$ Ss Por

8.91492e+00 8.91492e+00 8.91492e-01 1.00000e-09 2.12000e-01

$8.91492 \mathrm{e}+00$ 8.91492e+00 8.91492e-01 1.00000e-09 2.12000e-01

$8.91492 \mathrm{e}+008.91492 \mathrm{e}+00$ 8.91492e-01 1.00000e-09 2.12000e-01

8.91492e+00 8.91492e+00 8.91492e-01 1.00000e-09 2.12000e-01

$1.00000 \mathrm{e}-05$ 1.00000e-05 1.00000e-06 1.00000e-09 1.00000e-01

$1.00000 \mathrm{e}+001.00000 \mathrm{e}+001.00000 \mathrm{e}-011.00000 \mathrm{e}-091.00000 \mathrm{e}-01$

Element: 13830 \# of layers: 6

$\mathrm{Kx} \mathrm{Ky} \mathrm{Kz}$ Ss Por

8.91492e+00 8.91492e+00 8.91492e-01 1.00000e-09 2.12000e-01

$8.91492 \mathrm{e}+008.91492 \mathrm{e}+008.91492 \mathrm{e}-01$ 1.00000e-09 2.12000e-01

8.91492e+00 8.91492e+00 8.91492e-01 1.00000e-09 2.12000e-01

$8.91492 \mathrm{e}+008.91492 \mathrm{e}+008.91492 \mathrm{e}-01$ 1.00000e-09 2.12000e-01

$1.00000 \mathrm{e}-05$ 1.00000e-05 1.00000e-06 1.00000e-09 1.00000e-01

$1.00000 \mathrm{e}+001.00000 \mathrm{e}+001.00000 \mathrm{e}-011.00000 \mathrm{e}-091.00000 \mathrm{e}-01$

Element: 13831 \# of layers: 5

$\mathrm{Kx} \mathrm{Ky} \mathrm{Kz}$ Ss Por

8.91492e+00 8.91492e+00 8.91492e-01 1.00000e-09 2.12000e-01

8.91492e+00 8.91492e+00 8.91492e-01 1.00000e-09 2.12000e-01

8.91492e+00 8.91492e+00 8.91492e-01 1.00000e-09 2.12000e-01

$1.00000 \mathrm{e}-05$ 1.00000e-05 1.00000e-06 1.00000e-09 1.00000e-01

$1.00000 \mathrm{e}+001.00000 \mathrm{e}+001.00000 \mathrm{e}-01$ 1.00000e-09 1.00000e-01

Element: 13832 \# of layers: 5

$\mathrm{Kx} \mathrm{Ky} \mathrm{Kz}$ Ss Por

8.91492e+00 8.91492e+00 8.91492e-01 1.00000e-09 2.12000e-01

8.91492e+00 8.91492e+00 8.91492e-01 1.00000e-09 2.12000e-01

8.91492e+00 8.91492e+00 8.91492e-01 1.00000e-09 2.12000e-01 $1.00000 \mathrm{e}-051.00000 \mathrm{e}-051.00000 \mathrm{e}-061.00000 \mathrm{e}-091.00000 \mathrm{e}-01$

$1.00000 \mathrm{e}+001.00000 \mathrm{e}+001.00000 \mathrm{e}-011.00000 \mathrm{e}-091.00000 \mathrm{e}-01$ 
Element: 13833 \# of layers: 5

Kx Ky Kz Ss Por

8.91492e+00 8.91492e+00 8.91492e-01 1.00000e-09 2.12000e-01

$8.91492 \mathrm{e}+008.91492 \mathrm{e}+008.91492 \mathrm{e}-011.00000 \mathrm{e}-092.12000 \mathrm{e}-01$

$8.91492 \mathrm{e}+008.91492 \mathrm{e}+008.91492 \mathrm{e}-011.00000 \mathrm{e}-092.12000 \mathrm{e}-01$

$1.00000 \mathrm{e}-05$ 1.00000e-05 1.00000e-06 1.00000e-09 1.00000e-01

$1.00000 \mathrm{e}+001.00000 \mathrm{e}+001.00000 \mathrm{e}-011.00000 \mathrm{e}-091.00000 \mathrm{e}-01$

Element: 13834 \# of layers: 6

Kx Ky Kz Ss Por

$9.42658 \mathrm{e}+00$ 9.42658e+00 9.42658e-01 1.00000e-09 2.12000e-01

$9.42658 \mathrm{e}+009.42658 \mathrm{e}+00$ 9.42658e-01 1.00000e-09 2.12000e-01

9.42658e+00 9.42658e+00 9.42658e-01 1.00000e-09 2.12000e-01

$1.00000 \mathrm{e}-05$ 1.00000e-05 1.00000e-06 1.00000e-09 1.00000e-01

$1.00000 \mathrm{e}+001.00000 \mathrm{e}+001.00000 \mathrm{e}-011.00000 \mathrm{e}-091.00000 \mathrm{e}-01$

$1.00000 \mathrm{e}-06$ 1.00000e-06 1.00000e-06 1.00000e-09 5.00000e-02

Element: 13835 \# of layers: 6

Kx Ky Kz Ss Por

$9.42658 \mathrm{e}+00$ 9.42658e+00 9.42658e-01 1.00000e-09 2.12000e-01

$9.42658 \mathrm{e}+009.42658 \mathrm{e}+009.42658 \mathrm{e}-011.00000 \mathrm{e}-092.12000 \mathrm{e}-01$

$9.42658 \mathrm{e}+00$ 9.42658e+00 9.42658e-01 1.00000e-09 2.12000e-01

$1.00000 \mathrm{e}-05$ 1.00000e-05 1.00000e-06 1.00000e-09 1.00000e-01

$1.00000 \mathrm{e}+001.00000 \mathrm{e}+001.00000 \mathrm{e}-011.00000 \mathrm{e}-091.00000 \mathrm{e}-01$

$1.00000 \mathrm{e}-06$ 1.00000e-06 1.00000e-06 1.00000e-09 5.00000e-02

Element: 13836 \# of layers: 5

Kx Ky Kz Ss Por

$8.91492 \mathrm{e}+008.91492 \mathrm{e}+00$ 8.91492e-01 1.00000e-09 2.12000e-01

$8.91492 \mathrm{e}+008.91492 \mathrm{e}+00$ 8.91492e-01 1.00000e-09 2.12000e-01

$8.91492 \mathrm{e}+008.91492 \mathrm{e}+00$ 8.91492e-01 1.00000e-09 2.12000e-01

$1.00000 \mathrm{e}-05$ 1.00000e-05 1.00000e-06 1.00000e-09 1.00000e-01

$1.00000 \mathrm{e}+001.00000 \mathrm{e}+001.00000 \mathrm{e}-011.00000 \mathrm{e}-091.00000 \mathrm{e}-01$

Element: 13837 \# of layers: 5

Kx Ky Kz Ss Por

8.91492e+00 8.91492e+00 8.91492e-01 1.00000e-09 2.12000e-01

$8.91492 \mathrm{e}+008.91492 \mathrm{e}+008.91492 \mathrm{e}-011.00000 \mathrm{e}-092.12000 \mathrm{e}-01$

$8.91492 \mathrm{e}+008.91492 \mathrm{e}+00$ 8.91492e-01 1.00000e-09 2.12000e-01

$1.00000 \mathrm{e}-05$ 1.00000e-05 1.00000e-06 1.00000e-09 1.00000e-01

$1.00000 \mathrm{e}+001.00000 \mathrm{e}+001.00000 \mathrm{e}-011.00000 \mathrm{e}-091.00000 \mathrm{e}-01$

Element: 13838 \# of layers: 5

Kx Ky Kz Ss Por

$1.26106 \mathrm{e}+011.26106 \mathrm{e}+011.26106 \mathrm{e}+00$ 1.00000e-09 2.12000e-01

$1.26106 \mathrm{e}+011.26106 \mathrm{e}+011.26106 \mathrm{e}+001.00000 \mathrm{e}-092.12000 \mathrm{e}-01$

$1.26106 \mathrm{e}+011.26106 \mathrm{e}+011.26106 \mathrm{e}+001.00000 \mathrm{e}-092.12000 \mathrm{e}-01$

$1.00000 \mathrm{e}-05$ 1.00000e-05 1.00000e-06 1.00000e-09 1.00000e-01

$1.00000 \mathrm{e}+001.00000 \mathrm{e}+001.00000 \mathrm{e}-011.00000 \mathrm{e}-091.00000 \mathrm{e}-01$

Element: 13839 \# of layers: 5

Kx Ky Kz Ss Por 
$1.26106 \mathrm{e}+011.26106 \mathrm{e}+011.26106 \mathrm{e}+001.00000 \mathrm{e}-092.12000 \mathrm{e}-01$ $1.26106 \mathrm{e}+011.26106 \mathrm{e}+011.26106 \mathrm{e}+001.00000 \mathrm{e}-092.12000 \mathrm{e}-01$ $1.00000 \mathrm{e}-051.00000 \mathrm{e}-05$ 1.00000e-06 1.00000e-09 1.00000e-01

$1.00000 \mathrm{e}+001.00000 \mathrm{e}+001.00000 \mathrm{e}-011.00000 \mathrm{e}-091.00000 \mathrm{e}-01$ 1.00000e-06 1.00000e-06 1.00000e-06 1.00000e-09 5.00000e-02

Element: 13840 \# of layers: 5

$\mathrm{Kx} \mathrm{Ky} \mathrm{Kz}$ Ss Por

$1.26106 \mathrm{e}+011.26106 \mathrm{e}+011.26106 \mathrm{e}+001.00000 \mathrm{e}-092.12000 \mathrm{e}-01$

$1.26106 \mathrm{e}+011.26106 \mathrm{e}+011.26106 \mathrm{e}+001.00000 \mathrm{e}-092.12000 \mathrm{e}-01$

$1.00000 \mathrm{e}-05$ 1.00000e-05 1.00000e-06 1.00000e-09 1.00000e-01

$1.00000 \mathrm{e}+001.00000 \mathrm{e}+001.00000 \mathrm{e}-011.00000 \mathrm{e}-091.00000 \mathrm{e}-01$

1.00000e-06 1.00000e-06 1.00000e-06 1.00000e-09 5.00000e-02

Element: 13841 \# of layers: 5

$\mathrm{Kx} \mathrm{Ky} \mathrm{Kz}$ Ss Por

$1.23818 \mathrm{e}+011.23818 \mathrm{e}+01$ 1.23818e+00 1.00000e-09 2.12000e-01

$1.23818 \mathrm{e}+011.23818 \mathrm{e}+011.23818 \mathrm{e}+001.00000 \mathrm{e}-092.12000 \mathrm{e}-01$

$1.00000 \mathrm{e}-05$ 1.00000e-05 1.00000e-06 1.00000e-09 1.00000e-01

$1.00000 \mathrm{e}+001.00000 \mathrm{e}+001.00000 \mathrm{e}-011.00000 \mathrm{e}-091.00000 \mathrm{e}-01$

1.00000e-06 1.00000e-06 1.00000e-06 1.00000e-09 5.00000e-02

Element: 13842 \# of layers: 6

Kx Ky Kz Ss Por

$1.23818 \mathrm{e}+01$ 1.23818e+01 1.23818e+00 1.00000e-09 2.12000e-01

$1.23818 \mathrm{e}+01$ 1.23818e+01 1.23818e+00 1.00000e-09 2.12000e-01

$1.23818 \mathrm{e}+011.23818 \mathrm{e}+01 \quad 1.23818 \mathrm{e}+001.00000 \mathrm{e}-092.12000 \mathrm{e}-01$

$1.00000 \mathrm{e}-05$ 1.00000e-05 1.00000e-06 1.00000e-09 1.00000e-01

$1.00000 \mathrm{e}+001.00000 \mathrm{e}+001.00000 \mathrm{e}-011.00000 \mathrm{e}-091.00000 \mathrm{e}-01$

1.00000e-06 1.00000e-06 1.00000e-06 1.00000e-09 5.00000e-02

Element: 13843 \# of layers: 6

Kx Ky Kz Ss Por

9.42658e+00 9.42658e+00 9.42658e-01 1.00000e-09 2.12000e-01

9.42658e+00 9.42658e+00 9.42658e-01 1.00000e-09 2.12000e-01

9.42658e+00 9.42658e+00 9.42658e-01 1.00000e-09 2.12000e-01

$1.00000 \mathrm{e}-05$ 1.00000e-05 1.00000e-06 1.00000e-09 1.00000e-01

$1.00000 \mathrm{e}+001.00000 \mathrm{e}+001.00000 \mathrm{e}-011.00000 \mathrm{e}-091.00000 \mathrm{e}-01$

1.00000e-06 1.00000e-06 1.00000e-06 1.00000e-09 5.00000e-02

Element: 13844 \# of layers: 6

Kx Ky Kz Ss Por

8.91492e+00 8.91492e+00 8.91492e-01 1.00000e-09 2.12000e-01

8.91492e+00 8.91492e+00 8.91492e-01 1.00000e-09 2.12000e-01

8.91492e+00 8.91492e+00 8.91492e-01 1.00000e-09 2.12000e-01

$1.00000 \mathrm{e}-05$ 1.00000e-05 1.00000e-06 1.00000e-09 1.00000e-01

$1.00000 \mathrm{e}+001.00000 \mathrm{e}+001.00000 \mathrm{e}-011.00000 \mathrm{e}-091.00000 \mathrm{e}-01$

1.00000e-06 1.00000e-06 1.00000e-06 1.00000e-09 5.00000e-02

Element: 13845 \# of layers: 6

$\mathrm{Kx} \mathrm{Ky} \mathrm{Kz}$ Ss Por

$1.26106 \mathrm{e}+011.26106 \mathrm{e}+011.26106 \mathrm{e}+001.00000 \mathrm{e}-092.12000 \mathrm{e}-01$ 
$1.26106 \mathrm{e}+011.26106 \mathrm{e}+011.26106 \mathrm{e}+001.00000 \mathrm{e}-092.12000 \mathrm{e}-01$ $1.26106 \mathrm{e}+011.26106 \mathrm{e}+011.26106 \mathrm{e}+001.00000 \mathrm{e}-092.12000 \mathrm{e}-01$ $1.00000 \mathrm{e}-05$ 1.00000e-05 1.00000e-06 1.00000e-09 1.00000e-01

$1.00000 \mathrm{e}+001.00000 \mathrm{e}+001.00000 \mathrm{e}-011.00000 \mathrm{e}-091.00000 \mathrm{e}-01$ 1.00000e-06 1.00000e-06 1.00000e-06 1.00000e-09 5.00000e-02

Element: 13846 \# of layers: 5

$\mathrm{Kx} \mathrm{Ky} \mathrm{Kz}$ Ss Por

$2.57068 \mathrm{e}+022.57068 \mathrm{e}+02$ 2.57068e+01 1.00000e-09 2.12000e-01

$2.57068 \mathrm{e}+02$ 2.57068e+02 2.57068e+01 1.00000e-09 2.12000e-01

$1.00000 \mathrm{e}-05$ 1.00000e-05 1.00000e-06 1.00000e-09 1.00000e-01

$1.00000 \mathrm{e}+001.00000 \mathrm{e}+001.00000 \mathrm{e}-011.00000 \mathrm{e}-091.00000 \mathrm{e}-01$

1.00000e-06 1.00000e-06 1.00000e-06 1.00000e-09 5.00000e-02

Element: 13847 \# of layers: 5

$\mathrm{Kx} \mathrm{Ky} \mathrm{Kz}$ Ss Por

$2.57068 \mathrm{e}+022.57068 \mathrm{e}+02$ 2.57068e+01 1.00000e-09 2.12000e-01

$2.57068 \mathrm{e}+022.57068 \mathrm{e}+022.57068 \mathrm{e}+01$ 1.00000e-09 2.12000e-01

$1.00000 \mathrm{e}-05$ 1.00000e-05 1.00000e-06 1.00000e-09 1.00000e-01

$1.00000 \mathrm{e}+001.00000 \mathrm{e}+001.00000 \mathrm{e}-011.00000 \mathrm{e}-091.00000 \mathrm{e}-01$

1.00000e-06 1.00000e-06 1.00000e-06 1.00000e-09 5.00000e-02

Element: 13848 \# of layers: 5

$\mathrm{Kx} \mathrm{Ky} \mathrm{Kz}$ Ss Por

$2.57068 \mathrm{e}+02$ 2.57068e+02 2.57068e+01 1.00000e-09 2.12000e-01

$2.57068 \mathrm{e}+02$ 2.57068e+02 2.57068e+01 1.00000e-09 2.12000e-01

$1.00000 \mathrm{e}-05$ 1.00000e-05 1.00000e-06 1.00000e-09 1.00000e-01

$1.00000 \mathrm{e}+001.00000 \mathrm{e}+001.00000 \mathrm{e}-011.00000 \mathrm{e}-091.00000 \mathrm{e}-01$

1.00000e-06 1.00000e-06 1.00000e-06 1.00000e-09 5.00000e-02

Element: 13849 \# of layers: 5

$\mathrm{Kx} \mathrm{Ky} \mathrm{Kz}$ Ss Por

$2.57068 \mathrm{e}+022.57068 \mathrm{e}+02$ 2.57068e+01 1.00000e-09 2.12000e-01

$2.57068 \mathrm{e}+022.57068 \mathrm{e}+02$ 2.57068e+01 1.00000e-09 2.12000e-01

$1.00000 \mathrm{e}-05$ 1.00000e-05 1.00000e-06 1.00000e-09 1.00000e-01

$1.00000 \mathrm{e}+001.00000 \mathrm{e}+001.00000 \mathrm{e}-011.00000 \mathrm{e}-091.00000 \mathrm{e}-01$

1.00000e-06 1.00000e-06 1.00000e-06 1.00000e-09 5.00000e-02

Element: 13850 \# of layers: 5

$\mathrm{Kx} \mathrm{Ky} \mathrm{Kz}$ Ss Por

$2.57068 \mathrm{e}+02$ 2.57068e+02 2.57068e+01 1.00000e-09 2.12000e-01

$2.57068 \mathrm{e}+022.57068 \mathrm{e}+02$ 2.57068e+01 1.00000e-09 2.12000e-01

$1.00000 \mathrm{e}-05$ 1.00000e-05 1.00000e-06 1.00000e-09 1.00000e-01

$1.00000 \mathrm{e}+001.00000 \mathrm{e}+001.00000 \mathrm{e}-011.00000 \mathrm{e}-091.00000 \mathrm{e}-01$

1.00000e-06 1.00000e-06 1.00000e-06 1.00000e-09 5.00000e-02

Element: 13851 \# of layers: 5

$\mathrm{Kx} \mathrm{Ky} \mathrm{Kz}$ Ss Por

$2.57068 \mathrm{e}+02$ 2.57068e+02 2.57068e+01 1.00000e-09 2.12000e-01

$2.57068 \mathrm{e}+02$ 2.57068e+02 2.57068e+01 1.00000e-09 2.12000e-01

$1.00000 \mathrm{e}-05$ 1.00000e-05 1.00000e-06 1.00000e-09 1.00000e-01

$1.00000 \mathrm{e}+001.00000 \mathrm{e}+001.00000 \mathrm{e}-011.00000 \mathrm{e}-091.00000 \mathrm{e}-01$ 
1.00000e-06 1.00000e-06 1.00000e-06 1.00000e-09 5.00000e-02

Element: 13852 \# of layers: 5

$\mathrm{Kx} \mathrm{Ky} \mathrm{Kz}$ Ss Por

$2.57068 \mathrm{e}+02$ 2.57068e+02 2.57068e+01 1.00000e-09 2.12000e-01

$2.57068 \mathrm{e}+022.57068 \mathrm{e}+02$ 2.57068e+01 1.00000e-09 2.12000e-01

$1.00000 \mathrm{e}-05$ 1.00000e-05 1.00000e-06 1.00000e-09 1.00000e-01

$1.00000 \mathrm{e}+001.00000 \mathrm{e}+001.00000 \mathrm{e}-011.00000 \mathrm{e}-091.00000 \mathrm{e}-01$

1.00000e-06 1.00000e-06 1.00000e-06 1.00000e-09 5.00000e-02

Element: 13853 \# of layers: 5

$\mathrm{Kx} \mathrm{Ky} \mathrm{Kz}$ Ss Por

$2.57068 \mathrm{e}+02$ 2.57068e+02 2.57068e+01 1.00000e-09 2.12000e-01

$2.57068 \mathrm{e}+022.57068 \mathrm{e}+02 \quad 2.57068 \mathrm{e}+01$ 1.00000e-09 2.12000e-01

$1.00000 \mathrm{e}-05$ 1.00000e-05 1.00000e-06 1.00000e-09 1.00000e-01

$1.00000 \mathrm{e}+001.00000 \mathrm{e}+001.00000 \mathrm{e}-011.00000 \mathrm{e}-091.00000 \mathrm{e}-01$

1.00000e-06 1.00000e-06 1.00000e-06 1.00000e-09 5.00000e-02

Element: 13854 \# of layers: 5

$\mathrm{Kx} \mathrm{Ky} \mathrm{Kz}$ Ss Por

$2.57068 \mathrm{e}+02$ 2.57068e+02 2.57068e+01 1.00000e-09 2.12000e-01

$2.57068 \mathrm{e}+02$ 2.57068e+02 2.57068e+01 1.00000e-09 2.12000e-01

$1.00000 \mathrm{e}-05$ 1.00000e-05 1.00000e-06 1.00000e-09 1.00000e-01

$1.00000 \mathrm{e}+001.00000 \mathrm{e}+001.00000 \mathrm{e}-011.00000 \mathrm{e}-091.00000 \mathrm{e}-01$

$1.00000 \mathrm{e}-06$ 1.00000e-06 1.00000e-06 1.00000e-09 5.00000e-02

Element: 13855 \# of layers: 5

$\mathrm{Kx} \mathrm{Ky} \mathrm{Kz}$ Ss Por

$2.57068 \mathrm{e}+02$ 2.57068e+02 2.57068e+01 1.00000e-09 2.12000e-01

$2.57068 \mathrm{e}+022.57068 \mathrm{e}+02$ 2.57068e+01 1.00000e-09 2.12000e-01

$1.00000 \mathrm{e}-05$ 1.00000e-05 1.00000e-06 1.00000e-09 1.00000e-01

$1.00000 \mathrm{e}+001.00000 \mathrm{e}+001.00000 \mathrm{e}-011.00000 \mathrm{e}-091.00000 \mathrm{e}-01$

1.00000e-06 1.00000e-06 1.00000e-06 1.00000e-09 5.00000e-02

Element: 13856 \# of layers: 5

$\mathrm{Kx} \mathrm{Ky} \mathrm{Kz}$ Ss Por

$1.18361 \mathrm{e}+03$ 1.18361e+03 1.18362e+02 1.00000e-09 2.12000e-01

$1.18361 \mathrm{e}+031.18361 \mathrm{e}+03$ 1.18362e+02 1.00000e-09 2.12000e-01

$1.00000 \mathrm{e}-05$ 1.00000e-05 1.00000e-06 1.00000e-09 1.00000e-01

$1.00000 \mathrm{e}+001.00000 \mathrm{e}+001.00000 \mathrm{e}-011.00000 \mathrm{e}-091.00000 \mathrm{e}-01$

1.00000e-06 1.00000e-06 1.00000e-06 1.00000e-09 5.00000e-02

Element: 13857 \# of layers: 5

$\mathrm{Kx} \mathrm{Ky} \mathrm{Kz}$ Ss Por

$1.18361 \mathrm{e}+03$ 1.18361e+03 1.18362e+02 1.00000e-09 2.12000e-01

$1.18361 \mathrm{e}+031.18361 \mathrm{e}+03$ 1.18362e+02 1.00000e-09 2.12000e-01

$1.00000 \mathrm{e}-05$ 1.00000e-05 1.00000e-06 1.00000e-09 1.00000e-01

$1.00000 \mathrm{e}+001.00000 \mathrm{e}+001.00000 \mathrm{e}-011.00000 \mathrm{e}-091.00000 \mathrm{e}-01$

1.00000e-06 1.00000e-06 1.00000e-06 1.00000e-09 5.00000e-02

Element: 13858 \# of layers: 5

$\mathrm{Kx} \mathrm{Ky} \mathrm{Kz} \mathrm{Ss} \mathrm{Por}$

$1.18361 \mathrm{e}+03$ 1.18361e+03 1.18362e+02 1.00000e-09 2.12000e-01 
$1.18361 \mathrm{e}+03$ 1.18361e+03 1.18362e+02 1.00000e-09 2.12000e-01 $1.00000 \mathrm{e}-05$ 1.00000e-05 1.00000e-06 1.00000e-09 1.00000e-01

$1.00000 \mathrm{e}+001.00000 \mathrm{e}+001.00000 \mathrm{e}-011.00000 \mathrm{e}-091.00000 \mathrm{e}-01$

$1.00000 \mathrm{e}-06$ 1.00000e-06 1.00000e-06 1.00000e-09 5.00000e-02

Element: 13859 \# of layers: 5

$\mathrm{Kx} \mathrm{Ky} \mathrm{Kz}$ Ss Por

$1.18361 \mathrm{e}+03$ 1.18361e+03 1.18362e+02 1.00000e-09 2.12000e-01

$1.18361 \mathrm{e}+031.18361 \mathrm{e}+03$ 1.18362e+02 1.00000e-09 2.12000e-01

$1.00000 \mathrm{e}-05$ 1.00000e-05 1.00000e-06 1.00000e-09 1.00000e-01

$1.00000 \mathrm{e}+001.00000 \mathrm{e}+001.00000 \mathrm{e}-011.00000 \mathrm{e}-091.00000 \mathrm{e}-01$

1.00000e-06 1.00000e-06 1.00000e-06 1.00000e-09 5.00000e-02

Element: 13860 \# of layers: 5

Kx Ky Kz Ss Por

$1.18361 \mathrm{e}+03$ 1.18361e+03 1.18362e+02 1.00000e-09 2.12000e-01

$1.18361 \mathrm{e}+031.18361 \mathrm{e}+03$ 1.18362e+02 1.00000e-09 2.12000e-01

1.00000e-05 1.00000e-05 1.00000e-06 1.00000e-09 1.00000e-01

$1.00000 \mathrm{e}+001.00000 \mathrm{e}+001.00000 \mathrm{e}-011.00000 \mathrm{e}-091.00000 \mathrm{e}-01$

1.00000e-06 1.00000e-06 1.00000e-06 1.00000e-09 5.00000e-02

Element: 13861 \# of layers: 5

$\mathrm{Kx} \mathrm{Ky} \mathrm{Kz}$ Ss Por

$2.57068 \mathrm{e}+02$ 2.57068e+02 2.57068e+01 1.00000e-09 2.12000e-01

$2.57068 \mathrm{e}+02$ 2.57068e+02 2.57068e+01 1.00000e-09 2.12000e-01

$1.00000 \mathrm{e}-05$ 1.00000e-05 1.00000e-06 1.00000e-09 1.00000e-01

$1.00000 \mathrm{e}+001.00000 \mathrm{e}+001.00000 \mathrm{e}-011.00000 \mathrm{e}-091.00000 \mathrm{e}-01$

$1.00000 \mathrm{e}-06$ 1.00000e-06 1.00000e-06 1.00000e-09 5.00000e-02

Element: 13862 \# of layers: 5

$\mathrm{Kx} \mathrm{Ky} \mathrm{Kz}$ Ss Por

$2.57068 \mathrm{e}+022.57068 \mathrm{e}+02$ 2.57068e+01 1.00000e-09 2.12000e-01

$2.57068 \mathrm{e}+022.57068 \mathrm{e}+022.57068 \mathrm{e}+01$ 1.00000e-09 2.12000e-01

$1.00000 \mathrm{e}-05$ 1.00000e-05 1.00000e-06 1.00000e-09 1.00000e-01

$1.00000 \mathrm{e}+001.00000 \mathrm{e}+001.00000 \mathrm{e}-011.00000 \mathrm{e}-091.00000 \mathrm{e}-01$

1.00000e-06 1.00000e-06 1.00000e-06 1.00000e-09 5.00000e-02

Element: 13863 \# of layers: 5

Kx Ky Kz Ss Por

$1.18361 \mathrm{e}+03$ 1.18361e+03 1.18362e+02 1.00000e-09 2.12000e-01

$1.18361 \mathrm{e}+031.18361 \mathrm{e}+03$ 1.18362e+02 1.00000e-09 2.12000e-01

1.00000e-05 1.00000e-05 1.00000e-06 1.00000e-09 1.00000e-01

$1.00000 \mathrm{e}+001.00000 \mathrm{e}+001.00000 \mathrm{e}-011.00000 \mathrm{e}-091.00000 \mathrm{e}-01$

1.00000e-06 1.00000e-06 1.00000e-06 1.00000e-09 5.00000e-02

Element: 13864 \# of layers: 4

Kx Ky Kz Ss Por

$1.18361 \mathrm{e}+031.18361 \mathrm{e}+03$ 1.18362e+02 1.00000e-09 2.12000e-01

$1.00000 \mathrm{e}-05$ 1.00000e-05 1.00000e-06 1.00000e-09 1.00000e-01

$1.00000 \mathrm{e}+001.00000 \mathrm{e}+001.00000 \mathrm{e}-011.00000 \mathrm{e}-091.00000 \mathrm{e}-01$

1.00000e-06 1.00000e-06 1.00000e-06 1.00000e-09 5.00000e-02

Element: 13865 \# of layers: 4 
Kx Ky Kz Ss Por

$1.18361 \mathrm{e}+03$ 1.18361e+03 1.18362e+02 1.00000e-09 2.12000e-01

$1.00000 \mathrm{e}-05$ 1.00000e-05 1.00000e-06 1.00000e-09 1.00000e-01

$1.00000 \mathrm{e}+001.00000 \mathrm{e}+001.00000 \mathrm{e}-011.00000 \mathrm{e}-091.00000 \mathrm{e}-01$

1.00000e-06 1.00000e-06 1.00000e-06 1.00000e-09 5.00000e-02

Element: 13866 \# of layers: 4

$\mathrm{Kx} \mathrm{Ky} \mathrm{Kz}$ Ss Por

$1.18361 \mathrm{e}+03$ 1.18361e+03 1.18362e+02 1.00000e-09 2.12000e-01

$1.00000 \mathrm{e}-05$ 1.00000e-05 1.00000e-06 1.00000e-09 1.00000e-01

$1.00000 \mathrm{e}+001.00000 \mathrm{e}+001.00000 \mathrm{e}-01$ 1.00000e-09 1.00000e-01

1.00000e-06 1.00000e-06 1.00000e-06 1.00000e-09 5.00000e-02

Element: 13867 \# of layers: 4

$\mathrm{Kx} \mathrm{Ky} \mathrm{Kz}$ Ss Por

$1.18361 \mathrm{e}+03$ 1.18361e+03 1.18362e+02 1.00000e-09 2.12000e-01

$1.00000 \mathrm{e}-05$ 1.00000e-05 1.00000e-06 1.00000e-09 1.00000e-01

$1.00000 \mathrm{e}+001.00000 \mathrm{e}+001.00000 \mathrm{e}-011.00000 \mathrm{e}-091.00000 \mathrm{e}-01$

1.00000e-06 1.00000e-06 1.00000e-06 1.00000e-09 5.00000e-02

Element: 13868 \# of layers: 4

$\mathrm{Kx} \mathrm{Ky} \mathrm{Kz}$ Ss Por

$1.18361 \mathrm{e}+03$ 1.18361e+03 1.18362e+02 1.00000e-09 2.12000e-01

$1.00000 \mathrm{e}-05$ 1.00000e-05 1.00000e-06 1.00000e-09 1.00000e-01

$1.00000 \mathrm{e}+001.00000 \mathrm{e}+001.00000 \mathrm{e}-011.00000 \mathrm{e}-091.00000 \mathrm{e}-01$

1.00000e-06 1.00000e-06 1.00000e-06 1.00000e-09 5.00000e-02

Element: 13869 \# of layers: 4

Kx Ky Kz Ss Por

$1.18361 \mathrm{e}+031.18361 \mathrm{e}+03$ 1.18362e+02 1.00000e-09 2.12000e-01

$1.00000 \mathrm{e}-05$ 1.00000e-05 1.00000e-06 1.00000e-09 1.00000e-01

$1.00000 \mathrm{e}+001.00000 \mathrm{e}+001.00000 \mathrm{e}-011.00000 \mathrm{e}-091.00000 \mathrm{e}-01$

1.00000e-06 1.00000e-06 1.00000e-06 1.00000e-09 5.00000e-02

Element: 13870 \# of layers: 4

$\mathrm{Kx} \mathrm{Ky} \mathrm{Kz}$ Ss Por

$1.18361 \mathrm{e}+03$ 1.18361e+03 1.18362e+02 1.00000e-09 2.12000e-01

$1.00000 \mathrm{e}-05$ 1.00000e-05 1.00000e-06 1.00000e-09 1.00000e-01

$1.00000 \mathrm{e}+001.00000 \mathrm{e}+001.00000 \mathrm{e}-011.00000 \mathrm{e}-091.00000 \mathrm{e}-01$

1.00000e-06 1.00000e-06 1.00000e-06 1.00000e-09 5.00000e-02

Element: 13871 \# of layers: 4

Kx Ky Kz Ss Por

$1.18361 \mathrm{e}+031.18361 \mathrm{e}+03$ 1.18362e+02 1.00000e-09 2.12000e-01

$1.00000 \mathrm{e}-05$ 1.00000e-05 1.00000e-06 1.00000e-09 1.00000e-01

$1.00000 \mathrm{e}+001.00000 \mathrm{e}+001.00000 \mathrm{e}-011.00000 \mathrm{e}-091.00000 \mathrm{e}-01$

1.00000e-06 1.00000e-06 1.00000e-06 1.00000e-09 5.00000e-02

Element: 13872 \# of layers: 4

$\mathrm{Kx} \mathrm{Ky} \mathrm{Kz}$ Ss Por

1.18361e+03 1.18361e+03 1.18362e+02 1.00000e-09 2.12000e-01

$1.00000 \mathrm{e}-05$ 1.00000e-05 1.00000e-06 1.00000e-09 1.00000e-01

$1.00000 \mathrm{e}+001.00000 \mathrm{e}+001.00000 \mathrm{e}-011.00000 \mathrm{e}-091.00000 \mathrm{e}-01$ 
1.00000e-06 1.00000e-06 1.00000e-06 1.00000e-09 5.00000e-02

Element: 13873 \# of layers: 4

Kx Ky Kz Ss Por

$1.18361 \mathrm{e}+03$ 1.18361e+03 1.18362e+02 1.00000e-09 2.12000e-01

$1.00000 \mathrm{e}-05$ 1.00000e-05 1.00000e-06 1.00000e-09 1.00000e-01

$1.00000 \mathrm{e}+001.00000 \mathrm{e}+001.00000 \mathrm{e}-01$ 1.00000e-09 1.00000e-01

1.00000e-06 1.00000e-06 1.00000e-06 1.00000e-09 5.00000e-02

Element: 13874 \# of layers: 4

$\mathrm{Kx} \mathrm{Ky} \mathrm{Kz}$ Ss Por

$1.18361 \mathrm{e}+031.18361 \mathrm{e}+03$ 1.18362e+02 1.00000e-09 2.12000e-01

$1.00000 \mathrm{e}-05$ 1.00000e-05 1.00000e-06 1.00000e-09 1.00000e-01

$1.00000 \mathrm{e}+001.00000 \mathrm{e}+001.00000 \mathrm{e}-011.00000 \mathrm{e}-091.00000 \mathrm{e}-01$

1.00000e-06 1.00000e-06 1.00000e-06 1.00000e-09 5.00000e-02

Element: 13875 \# of layers: 4

$\mathrm{Kx} \mathrm{Ky} \mathrm{Kz}$ Ss Por

$1.28030 \mathrm{e}+031.28030 \mathrm{e}+03$ 1.28030e+02 1.00000e-09 2.12000e-01

$1.00000 \mathrm{e}-05$ 1.00000e-05 1.00000e-06 1.00000e-09 1.00000e-01

$1.00000 \mathrm{e}+001.00000 \mathrm{e}+001.00000 \mathrm{e}-011.00000 \mathrm{e}-091.00000 \mathrm{e}-01$

$1.00000 \mathrm{e}-06$ 1.00000e-06 1.00000e-06 1.00000e-09 5.00000e-02

Element: 13876 \# of layers: 4

$\mathrm{Kx} \mathrm{Ky} \mathrm{Kz}$ Ss Por

$1.28030 \mathrm{e}+031.28030 \mathrm{e}+031.28030 \mathrm{e}+021.00000 \mathrm{e}-092.12000 \mathrm{e}-01$

$1.00000 \mathrm{e}-05$ 1.00000e-05 1.00000e-06 1.00000e-09 1.00000e-01

$1.00000 \mathrm{e}+001.00000 \mathrm{e}+001.00000 \mathrm{e}-011.00000 \mathrm{e}-091.00000 \mathrm{e}-01$

$1.00000 \mathrm{e}-06$ 1.00000e-06 1.00000e-06 1.00000e-09 5.00000e-02

Element: 13877 \# of layers: 4

$\mathrm{Kx} \mathrm{Ky} \mathrm{Kz}$ Ss Por

$1.28030 \mathrm{e}+03$ 1.28030e+03 1.28030e+02 1.00000e-09 2.12000e-01

$1.00000 \mathrm{e}-05$ 1.00000e-05 1.00000e-06 1.00000e-09 1.00000e-01

$1.00000 \mathrm{e}+001.00000 \mathrm{e}+001.00000 \mathrm{e}-011.00000 \mathrm{e}-091.00000 \mathrm{e}-01$

$1.00000 \mathrm{e}-061.00000 \mathrm{e}-06$ 1.00000e-06 1.00000e-09 5.00000e-02

Element: 13878 \# of layers: 4

Kx Ky Kz Ss Por

$1.18361 \mathrm{e}+031.18361 \mathrm{e}+03$ 1.18362e+02 1.00000e-09 2.12000e-01

$1.00000 \mathrm{e}-051.00000 \mathrm{e}-051.00000 \mathrm{e}-061.00000 \mathrm{e}-091.00000 \mathrm{e}-01$

$1.00000 \mathrm{e}+001.00000 \mathrm{e}+001.00000 \mathrm{e}-011.00000 \mathrm{e}-091.00000 \mathrm{e}-01$

1.00000e-06 1.00000e-06 1.00000e-06 1.00000e-09 5.00000e-02

Element: 13879 \# of layers: 4

$\mathrm{Kx} \mathrm{Ky} \mathrm{Kz}$ Ss Por

$1.18361 \mathrm{e}+03$ 1.18361e+03 1.18362e+02 1.00000e-09 2.12000e-01

$1.00000 \mathrm{e}-05$ 1.00000e-05 1.00000e-06 1.00000e-09 1.00000e-01

$1.00000 \mathrm{e}+001.00000 \mathrm{e}+001.00000 \mathrm{e}-011.00000 \mathrm{e}-091.00000 \mathrm{e}-01$

1.00000e-06 1.00000e-06 1.00000e-06 1.00000e-09 5.00000e-02

Element: 13880 \# of layers: 4

$\mathrm{Kx} \mathrm{Ky} \mathrm{Kz}$ Ss Por

1.18361e+03 1.18361e+03 1.18362e+02 1.00000e-09 2.12000e-01 
$1.00000 \mathrm{e}-05$ 1.00000e-05 1.00000e-06 1.00000e-09 1.00000e-01 $1.00000 \mathrm{e}+001.00000 \mathrm{e}+001.00000 \mathrm{e}-01$ 1.00000e-09 1.00000e-01 1.00000e-06 1.00000e-06 1.00000e-06 1.00000e-09 5.00000e-02

Element: 13881 \# of layers: 4

$\mathrm{Kx} \mathrm{Ky} \mathrm{Kz}$ Ss Por

$1.18361 \mathrm{e}+031.18361 \mathrm{e}+03$ 1.18362e+02 1.00000e-09 2.12000e-01 $1.00000 \mathrm{e}-05$ 1.00000e-05 1.00000e-06 1.00000e-09 1.00000e-01

$1.00000 \mathrm{e}+001.00000 \mathrm{e}+001.00000 \mathrm{e}-011.00000 \mathrm{e}-091.00000 \mathrm{e}-01$ 1.00000e-06 1.00000e-06 1.00000e-06 1.00000e-09 5.00000e-02

Element: 13882 \# of layers: 2

$\mathrm{Kx} \mathrm{Ky} \mathrm{Kz}$ Ss Por

$1.28030 \mathrm{e}+03$ 1.28030e+03 1.28030e+02 1.00000e-09 2.12000e-01 1.00000e-06 1.00000e-06 1.00000e-06 1.00000e-09 5.00000e-02

Element: 13883 \# of layers: 2

$\mathrm{Kx} \mathrm{Ky} \mathrm{Kz}$ Ss Por

$1.28030 \mathrm{e}+031.28030 \mathrm{e}+03$ 1.28030e+02 1.00000e-09 2.12000e-01

1.00000e-06 1.00000e-06 1.00000e-06 1.00000e-09 5.00000e-02

Element: 13884 \# of layers: 2

$\mathrm{Kx} \mathrm{Ky} \mathrm{Kz}$ Ss Por

$1.28030 \mathrm{e}+031.28030 \mathrm{e}+03$ 1.28030e+02 1.00000e-09 2.12000e-01

1.00000e-06 1.00000e-06 1.00000e-06 1.00000e-09 5.00000e-02

Element: 13885 \# of layers: 2

$\mathrm{Kx} \mathrm{Ky} \mathrm{Kz}$ Ss Por

$1.28030 \mathrm{e}+031.28030 \mathrm{e}+03$ 1.28030e+02 1.00000e-09 2.12000e-01

1.00000e-06 1.00000e-06 1.00000e-06 1.00000e-09 5.00000e-02

Element: 13886 \# of layers: 2

$\mathrm{Kx} \mathrm{Ky} \mathrm{Kz}$ Ss Por

$1.28030 \mathrm{e}+031.28030 \mathrm{e}+03$ 1.28030e+02 1.00000e-09 2.12000e-01

1.00000e-06 1.00000e-06 1.00000e-06 1.00000e-09 5.00000e-02

Element: 13887 \# of layers: 2

$\mathrm{Kx} \mathrm{Ky} \mathrm{Kz}$ Ss Por

$1.28030 \mathrm{e}+031.28030 \mathrm{e}+03$ 1.28030e+02 1.00000e-09 2.12000e-01

1.00000e-06 1.00000e-06 1.00000e-06 1.00000e-09 5.00000e-02

Element: 13888 \# of layers: 2

$\mathrm{Kx} \mathrm{Ky} \mathrm{Kz}$ Ss Por

$1.28030 \mathrm{e}+03$ 1.28030e+03 1.28030e+02 1.00000e-09 2.12000e-01

1.00000e-06 1.00000e-06 1.00000e-06 1.00000e-09 5.00000e-02

Element: 13889 \# of layers: 2

$\mathrm{Kx} \mathrm{Ky} \mathrm{Kz}$ Ss Por

$1.28030 \mathrm{e}+03$ 1.28030e+03 1.28030e+02 1.00000e-09 2.12000e-01

1.00000e-06 1.00000e-06 1.00000e-06 1.00000e-09 5.00000e-02

Element: 13890 \# of layers: 2

$\mathrm{Kx} \mathrm{Ky} \mathrm{Kz}$ Ss Por

$1.28030 \mathrm{e}+031.28030 \mathrm{e}+03$ 1.28030e+02 1.00000e-09 2.12000e-01

1.00000e-06 1.00000e-06 1.00000e-06 1.00000e-09 5.00000e-02

Element: 13891 \# of layers: 3 
$\mathrm{Kx} \mathrm{Ky} \mathrm{Kz}$ Ss Por

$1.28030 \mathrm{e}+03$ 1.28030e+03 1.28030e+02 1.00000e-09 2.12000e-01

$1.28030 \mathrm{e}+03$ 1.28030e+03 1.28030e+02 1.00000e-09 2.12000e-01

1.00000e-06 1.00000e-06 1.00000e-06 1.00000e-09 5.00000e-02

Element: 13892 \# of layers: 3

$\mathrm{Kx} \mathrm{Ky} \mathrm{Kz}$ Ss Por

$1.28030 \mathrm{e}+03$ 1.28030e+03 1.28030e+02 1.00000e-09 2.12000e-01

$1.28030 \mathrm{e}+031.28030 \mathrm{e}+03 \quad 1.28030 \mathrm{e}+02$ 1.00000e-09 2.12000e-01

1.00000e-06 1.00000e-06 1.00000e-06 1.00000e-09 5.00000e-02

Element: 13893 \# of layers: 3

$\mathrm{Kx} \mathrm{Ky} \mathrm{Kz}$ Ss Por

7.04985e+02 7.04985e+02 7.04985e+01 1.00000e-09 2.12000e-01

$7.04985 \mathrm{e}+02$ 7.04985e+02 7.04985e+01 1.00000e-09 2.12000e-01

1.00000e-06 1.00000e-06 1.00000e-06 1.00000e-09 5.00000e-02

Element: 13894 \# of layers: 5

Kx Ky Kz Ss Por

7.04985e+02 7.04985e+02 7.04985e+01 1.00000e-09 2.12000e-01

$7.04985 \mathrm{e}+02$ 7.04985e+02 7.04985e+01 1.00000e-09 2.12000e-01

$1.00000 \mathrm{e}-05$ 1.00000e-05 1.00000e-06 1.00000e-09 1.00000e-01

$1.00000 \mathrm{e}+001.00000 \mathrm{e}+001.00000 \mathrm{e}-011.00000 \mathrm{e}-091.00000 \mathrm{e}-01$

1.00000e-06 1.00000e-06 1.00000e-06 1.00000e-09 5.00000e-02

Element: 13895 \# of layers: 5

$\mathrm{Kx} \mathrm{Ky} \mathrm{Kz}$ Ss Por

7.04985e+02 7.04985e+02 7.04985e+01 1.00000e-09 2.12000e-01

$7.04985 \mathrm{e}+02$ 7.04985e+02 7.04985e+01 1.00000e-09 2.12000e-01

$1.00000 \mathrm{e}-05$ 1.00000e-05 1.00000e-06 1.00000e-09 1.00000e-01

$1.00000 \mathrm{e}+001.00000 \mathrm{e}+001.00000 \mathrm{e}-011.00000 \mathrm{e}-091.00000 \mathrm{e}-01$

1.00000e-06 1.00000e-06 1.00000e-06 1.00000e-09 5.00000e-02

Element: 13896 \# of layers: 5

$\mathrm{Kx} \mathrm{Ky} \mathrm{Kz}$ Ss Por

$1.28030 \mathrm{e}+03$ 1.28030e+03 1.28030e+02 1.00000e-09 2.12000e-01

$1.28030 \mathrm{e}+031.28030 \mathrm{e}+03$ 1.28030e+02 1.00000e-09 2.12000e-01

$1.00000 \mathrm{e}-05$ 1.00000e-05 1.00000e-06 1.00000e-09 1.00000e-01

$1.00000 \mathrm{e}+001.00000 \mathrm{e}+001.00000 \mathrm{e}-011.00000 \mathrm{e}-091.00000 \mathrm{e}-01$

1.00000e-06 1.00000e-06 1.00000e-06 1.00000e-09 5.00000e-02

Element: 13897 \# of layers: 4

Kx Ky Kz Ss Por

$1.28030 \mathrm{e}+031.28030 \mathrm{e}+03$ 1.28030e+02 1.00000e-09 2.12000e-01

$1.00000 \mathrm{e}-05$ 1.00000e-05 1.00000e-06 1.00000e-09 1.00000e-01

$1.00000 \mathrm{e}+001.00000 \mathrm{e}+001.00000 \mathrm{e}-011.00000 \mathrm{e}-091.00000 \mathrm{e}-01$

1.00000e-06 1.00000e-06 1.00000e-06 1.00000e-09 5.00000e-02

Element: 13898 \# of layers: 5

$\mathrm{Kx} \mathrm{Ky} \mathrm{Kz}$ Ss Por

$1.28030 \mathrm{e}+03$ 1.28030e+03 1.28030e+02 1.00000e-09 2.12000e-01

$1.28030 \mathrm{e}+03$ 1.28030e+03 1.28030e+02 1.00000e-09 2.12000e-01

$1.00000 \mathrm{e}-05$ 1.00000e-05 1.00000e-06 1.00000e-09 1.00000e-01 
$1.00000 \mathrm{e}+001.00000 \mathrm{e}+001.00000 \mathrm{e}-011.00000 \mathrm{e}-091.00000 \mathrm{e}-01$ 1.00000e-06 1.00000e-06 1.00000e-06 1.00000e-09 5.00000e-02

Element: 13899 \# of layers: 5

Kx Ky Kz Ss Por

$1.28030 \mathrm{e}+031.28030 \mathrm{e}+03$ 1.28030e+02 1.00000e-09 2.12000e-01

$1.28030 \mathrm{e}+031.28030 \mathrm{e}+03$ 1.28030e+02 1.00000e-09 2.12000e-01

$1.00000 \mathrm{e}-05$ 1.00000e-05 1.00000e-06 1.00000e-09 1.00000e-01

$1.00000 \mathrm{e}+001.00000 \mathrm{e}+001.00000 \mathrm{e}-011.00000 \mathrm{e}-091.00000 \mathrm{e}-01$

1.00000e-06 1.00000e-06 1.00000e-06 1.00000e-09 5.00000e-02

Element: 13900 \# of layers: 3

$\mathrm{Kx} \mathrm{Ky} \mathrm{Kz}$ Ss Por

7.04985e+02 7.04985e+02 7.04985e+01 1.00000e-09 2.12000e-01

$7.04985 \mathrm{e}+02$ 7.04985e+02 7.04985e+01 1.00000e-09 2.12000e-01

1.00000e-06 1.00000e-06 1.00000e-06 1.00000e-09 5.00000e-02

Element: 13901 \# of layers: 5

$\mathrm{Kx} \mathrm{Ky} \mathrm{Kz}$ Ss Por

7.04985e+02 7.04985e+02 7.04985e+01 1.00000e-09 2.12000e-01

$7.04985 \mathrm{e}+02$ 7.04985e+02 7.04985e+01 1.00000e-09 2.12000e-01

$1.00000 \mathrm{e}-05$ 1.00000e-05 1.00000e-06 1.00000e-09 1.00000e-01

$1.00000 \mathrm{e}+001.00000 \mathrm{e}+001.00000 \mathrm{e}-011.00000 \mathrm{e}-091.00000 \mathrm{e}-01$

1.00000e-06 1.00000e-06 1.00000e-06 1.00000e-09 5.00000e-02

Element: 13902 \# of layers: 5

$\mathrm{Kx} \mathrm{Ky} \mathrm{Kz}$ Ss Por

7.04985e+02 7.04985e+02 7.04985e+01 1.00000e-09 2.12000e-01

$7.04985 \mathrm{e}+02$ 7.04985e+02 7.04985e+01 1.00000e-09 2.12000e-01

$1.00000 \mathrm{e}-05$ 1.00000e-05 1.00000e-06 1.00000e-09 1.00000e-01

$1.00000 \mathrm{e}+001.00000 \mathrm{e}+001.00000 \mathrm{e}-011.00000 \mathrm{e}-091.00000 \mathrm{e}-01$

1.00000e-06 1.00000e-06 1.00000e-06 1.00000e-09 5.00000e-02

Element: 13903 \# of layers: 5

$\mathrm{Kx} \mathrm{Ky} \mathrm{Kz}$ Ss Por

7.04985e+02 7.04985e+02 7.04985e+01 1.00000e-09 2.12000e-01

$7.04985 \mathrm{e}+02$ 7.04985e+02 7.04985e+01 1.00000e-09 2.12000e-01

$1.00000 \mathrm{e}-05$ 1.00000e-05 1.00000e-06 1.00000e-09 1.00000e-01

$1.00000 \mathrm{e}+001.00000 \mathrm{e}+001.00000 \mathrm{e}-011.00000 \mathrm{e}-091.00000 \mathrm{e}-01$

1.00000e-06 1.00000e-06 1.00000e-06 1.00000e-09 5.00000e-02

Element: 13904 \# of layers: 5

Kx Ky Kz Ss Por

7.04985e+02 7.04985e+02 7.04985e+01 1.00000e-09 2.12000e-01

$7.04985 \mathrm{e}+02$ 7.04985e+02 7.04985e+01 1.00000e-09 2.12000e-01

$1.00000 \mathrm{e}-05$ 1.00000e-05 1.00000e-06 1.00000e-09 1.00000e-01

$1.00000 \mathrm{e}+001.00000 \mathrm{e}+001.00000 \mathrm{e}-011.00000 \mathrm{e}-091.00000 \mathrm{e}-01$

1.00000e-06 1.00000e-06 1.00000e-06 1.00000e-09 5.00000e-02

Element: 13905 \# of layers: 5

$\mathrm{Kx} \mathrm{Ky} \mathrm{Kz}$ Ss Por

7.04985e+02 7.04985e+02 7.04985e+01 1.00000e-09 2.12000e-01

$7.04985 \mathrm{e}+02$ 7.04985e+02 7.04985e+01 1.00000e-09 2.12000e-01 
$1.00000 \mathrm{e}-05$ 1.00000e-05 1.00000e-06 1.00000e-09 1.00000e-01 $1.00000 \mathrm{e}+001.00000 \mathrm{e}+001.00000 \mathrm{e}-011.00000 \mathrm{e}-091.00000 \mathrm{e}-01$ 1.00000e-06 1.00000e-06 1.00000e-06 1.00000e-09 5.00000e-02

Element: 13906 \# of layers: 5

$\mathrm{Kx} \mathrm{Ky} \mathrm{Kz}$ Ss Por

7.04985e+02 7.04985e+02 7.04985e+01 1.00000e-09 2.12000e-01

$7.04985 \mathrm{e}+02$ 7.04985e+02 7.04985e+01 1.00000e-09 2.12000e-01

$1.00000 \mathrm{e}-05$ 1.00000e-05 1.00000e-06 1.00000e-09 1.00000e-01

$1.00000 \mathrm{e}+001.00000 \mathrm{e}+001.00000 \mathrm{e}-01$ 1.00000e-09 1.00000e-01

1.00000e-06 1.00000e-06 1.00000e-06 1.00000e-09 5.00000e-02

Element: 13907 \# of layers: 5

$\mathrm{Kx} \mathrm{Ky} \mathrm{Kz}$ Ss Por

7.04985e+02 7.04985e+02 7.04985e+01 1.00000e-09 2.12000e-01

$7.04985 \mathrm{e}+02$ 7.04985e+02 7.04985e+01 1.00000e-09 2.12000e-01

$1.00000 \mathrm{e}-05$ 1.00000e-05 1.00000e-06 1.00000e-09 1.00000e-01

$1.00000 \mathrm{e}+001.00000 \mathrm{e}+001.00000 \mathrm{e}-011.00000 \mathrm{e}-091.00000 \mathrm{e}-01$

1.00000e-06 1.00000e-06 1.00000e-06 1.00000e-09 5.00000e-02

Element: 13908 \# of layers: 5

$\mathrm{Kx} \mathrm{Ky} \mathrm{Kz}$ Ss Por

7.04985e+02 7.04985e+02 7.04985e+01 1.00000e-09 2.12000e-01

$7.04985 \mathrm{e}+02$ 7.04985e+02 7.04985e+01 1.00000e-09 2.12000e-01

$1.00000 \mathrm{e}-051.00000 \mathrm{e}-051.00000 \mathrm{e}-061.00000 \mathrm{e}-091.00000 \mathrm{e}-01$

$1.00000 \mathrm{e}+001.00000 \mathrm{e}+001.00000 \mathrm{e}-011.00000 \mathrm{e}-091.00000 \mathrm{e}-01$

1.00000e-06 1.00000e-06 1.00000e-06 1.00000e-09 5.00000e-02

Element: 13909 \# of layers: 5

$\mathrm{Kx} \mathrm{Ky} \mathrm{Kz}$ Ss Por

7.04985e+02 7.04985e+02 7.04985e+01 1.00000e-09 2.12000e-01

$7.04985 \mathrm{e}+02$ 7.04985e+02 7.04985e+01 1.00000e-09 2.12000e-01

$1.00000 \mathrm{e}-05$ 1.00000e-05 1.00000e-06 1.00000e-09 1.00000e-01

$1.00000 \mathrm{e}+001.00000 \mathrm{e}+001.00000 \mathrm{e}-011.00000 \mathrm{e}-091.00000 \mathrm{e}-01$

1.00000e-06 1.00000e-06 1.00000e-06 1.00000e-09 5.00000e-02

Element: 13910 \# of layers: 5

Kx Ky Kz Ss Por

$2.57068 \mathrm{e}+022.57068 \mathrm{e}+02$ 2.57068e+01 1.00000e-09 2.12000e-01

$2.57068 \mathrm{e}+022.57068 \mathrm{e}+02$ 2.57068e+01 1.00000e-09 2.12000e-01

$1.00000 \mathrm{e}-05$ 1.00000e-05 1.00000e-06 1.00000e-09 1.00000e-01

$1.00000 \mathrm{e}+001.00000 \mathrm{e}+001.00000 \mathrm{e}-011.00000 \mathrm{e}-091.00000 \mathrm{e}-01$

1.00000e-06 1.00000e-06 1.00000e-06 1.00000e-09 5.00000e-02

Element: 13911 \# of layers: 5

$\mathrm{Kx} \mathrm{Ky} \mathrm{Kz}$ Ss Por

$2.57068 \mathrm{e}+02$ 2.57068e+02 2.57068e+01 1.00000e-09 2.12000e-01

$2.57068 \mathrm{e}+022.57068 \mathrm{e}+02$ 2.57068e+01 1.00000e-09 2.12000e-01

$1.00000 \mathrm{e}-05$ 1.00000e-05 1.00000e-06 1.00000e-09 1.00000e-01

$1.00000 \mathrm{e}+001.00000 \mathrm{e}+001.00000 \mathrm{e}-011.00000 \mathrm{e}-091.00000 \mathrm{e}-01$

1.00000e-06 1.00000e-06 1.00000e-06 1.00000e-09 5.00000e-02

Element: 13912 \# of layers: 5 
$\mathrm{Kx} \mathrm{Ky} \mathrm{Kz} \mathrm{Ss} \mathrm{Por}$

$2.57068 \mathrm{e}+02$ 2.57068e+02 2.57068e+01 1.00000e-09 2.12000e-01

$2.57068 \mathrm{e}+022.57068 \mathrm{e}+02$ 2.57068e+01 1.00000e-09 2.12000e-01

$1.00000 \mathrm{e}-05$ 1.00000e-05 1.00000e-06 1.00000e-09 1.00000e-01

$1.00000 \mathrm{e}+001.00000 \mathrm{e}+001.00000 \mathrm{e}-011.00000 \mathrm{e}-091.00000 \mathrm{e}-01$

1.00000e-06 1.00000e-06 1.00000e-06 1.00000e-09 5.00000e-02

Element: 13913 \# of layers: 5

Kx Ky Kz Ss Por

$2.57068 \mathrm{e}+02$ 2.57068e+02 2.57068e+01 1.00000e-09 2.12000e-01

$2.57068 \mathrm{e}+022.57068 \mathrm{e}+022.57068 \mathrm{e}+01$ 1.00000e-09 2.12000e-01

$1.00000 \mathrm{e}-05$ 1.00000e-05 1.00000e-06 1.00000e-09 1.00000e-01

$1.00000 \mathrm{e}+001.00000 \mathrm{e}+001.00000 \mathrm{e}-011.00000 \mathrm{e}-091.00000 \mathrm{e}-01$

1.00000e-06 1.00000e-06 1.00000e-06 1.00000e-09 5.00000e-02

Element: 13914 \# of layers: 5

$\mathrm{Kx} \mathrm{Ky} \mathrm{Kz}$ Ss Por

$2.57068 \mathrm{e}+02$ 2.57068e+02 2.57068e+01 1.00000e-09 2.12000e-01

$2.57068 \mathrm{e}+022.57068 \mathrm{e}+02$ 2.57068e+01 1.00000e-09 2.12000e-01

$1.00000 \mathrm{e}-05$ 1.00000e-05 1.00000e-06 1.00000e-09 1.00000e-01

$1.00000 \mathrm{e}+001.00000 \mathrm{e}+001.00000 \mathrm{e}-011.00000 \mathrm{e}-091.00000 \mathrm{e}-01$

1.00000e-06 1.00000e-06 1.00000e-06 1.00000e-09 5.00000e-02

Element: 13915 \# of layers: 5

$\mathrm{Kx} \mathrm{Ky} \mathrm{Kz}$ Ss Por

7.04985e+02 7.04985e+02 7.04985e+01 1.00000e-09 2.12000e-01

$7.04985 \mathrm{e}+02$ 7.04985e+02 7.04985e+01 1.00000e-09 2.12000e-01

$1.00000 \mathrm{e}-05$ 1.00000e-05 1.00000e-06 1.00000e-09 1.00000e-01

$1.00000 \mathrm{e}+001.00000 \mathrm{e}+001.00000 \mathrm{e}-011.00000 \mathrm{e}-091.00000 \mathrm{e}-01$

1.00000e-06 1.00000e-06 1.00000e-06 1.00000e-09 5.00000e-02

Element: 13916 \# of layers: 5

Kx Ky Kz Ss Por

7.04985e+02 7.04985e+02 7.04985e+01 1.00000e-09 2.12000e-01

$7.04985 \mathrm{e}+02$ 7.04985e+02 7.04985e+01 1.00000e-09 2.12000e-01

$1.00000 \mathrm{e}-05$ 1.00000e-05 1.00000e-06 1.00000e-09 1.00000e-01

$1.00000 \mathrm{e}+001.00000 \mathrm{e}+001.00000 \mathrm{e}-011.00000 \mathrm{e}-091.00000 \mathrm{e}-01$

1.00000e-06 1.00000e-06 1.00000e-06 1.00000e-09 5.00000e-02

Element: 13917 \# of layers: 5

$\mathrm{Kx} \mathrm{Ky} \mathrm{Kz}$ Ss Por

$2.57068 \mathrm{e}+02$ 2.57068e+02 2.57068e+01 1.00000e-09 2.12000e-01

$2.57068 \mathrm{e}+02$ 2.57068e+02 2.57068e+01 1.00000e-09 2.12000e-01

$1.00000 \mathrm{e}-051.00000 \mathrm{e}-051.00000 \mathrm{e}-061.00000 \mathrm{e}-091.00000 \mathrm{e}-01$

$1.00000 \mathrm{e}+001.00000 \mathrm{e}+001.00000 \mathrm{e}-011.00000 \mathrm{e}-091.00000 \mathrm{e}-01$

1.00000e-06 1.00000e-06 1.00000e-06 1.00000e-09 5.00000e-02

Element: 13918 \# of layers: 5

$\mathrm{Kx} \mathrm{Ky} \mathrm{Kz}$ Ss Por

2.57068e+02 2.57068e+02 2.57068e+01 1.00000e-09 2.12000e-01

$2.57068 \mathrm{e}+022.57068 \mathrm{e}+02$ 2.57068e+01 1.00000e-09 2.12000e-01

$1.00000 \mathrm{e}-05$ 1.00000e-05 1.00000e-06 1.00000e-09 1.00000e-01 
$1.00000 \mathrm{e}+001.00000 \mathrm{e}+001.00000 \mathrm{e}-011.00000 \mathrm{e}-091.00000 \mathrm{e}-01$ 1.00000e-06 1.00000e-06 1.00000e-06 1.00000e-09 5.00000e-02

Element: 13919 \# of layers: 5

Kx Ky Kz Ss Por

$1.18361 \mathrm{e}+031.18361 \mathrm{e}+03$ 1.18362e+02 1.00000e-09 2.12000e-01

$1.18361 \mathrm{e}+031.18361 \mathrm{e}+03$ 1.18362e+02 1.00000e-09 2.12000e-01

$1.00000 \mathrm{e}-05$ 1.00000e-05 1.00000e-06 1.00000e-09 1.00000e-01

$1.00000 \mathrm{e}+001.00000 \mathrm{e}+001.00000 \mathrm{e}-011.00000 \mathrm{e}-091.00000 \mathrm{e}-01$

1.00000e-06 1.00000e-06 1.00000e-06 1.00000e-09 5.00000e-02

Element: 13920 \# of layers: 4

$\mathrm{Kx} \mathrm{Ky} \mathrm{Kz}$ Ss Por

$1.18361 \mathrm{e}+03$ 1.18361e+03 1.18362e+02 1.00000e-09 2.12000e-01

$1.00000 \mathrm{e}-05$ 1.00000e-05 1.00000e-06 1.00000e-09 1.00000e-01

$1.00000 \mathrm{e}+001.00000 \mathrm{e}+001.00000 \mathrm{e}-011.00000 \mathrm{e}-091.00000 \mathrm{e}-01$

1.00000e-06 1.00000e-06 1.00000e-06 1.00000e-09 5.00000e-02

Element: 13921 \# of layers: 4

$\mathrm{Kx} \mathrm{Ky} \mathrm{Kz}$ Ss Por

$1.18361 \mathrm{e}+031.18361 \mathrm{e}+03$ 1.18362e+02 1.00000e-09 2.12000e-01

$1.00000 \mathrm{e}-05$ 1.00000e-05 1.00000e-06 1.00000e-09 1.00000e-01

$1.00000 \mathrm{e}+001.00000 \mathrm{e}+001.00000 \mathrm{e}-011.00000 \mathrm{e}-091.00000 \mathrm{e}-01$

1.00000e-06 1.00000e-06 1.00000e-06 1.00000e-09 5.00000e-02

Element: 13922 \# of layers: 4

$\mathrm{Kx} \mathrm{Ky} \mathrm{Kz}$ Ss Por

$1.28030 \mathrm{e}+03$ 1.28030e+03 1.28030e+02 1.00000e-09 2.12000e-01

$1.00000 \mathrm{e}-05$ 1.00000e-05 1.00000e-06 1.00000e-09 1.00000e-01

$1.00000 \mathrm{e}+001.00000 \mathrm{e}+001.00000 \mathrm{e}-011.00000 \mathrm{e}-091.00000 \mathrm{e}-01$

1.00000e-06 1.00000e-06 1.00000e-06 1.00000e-09 5.00000e-02

Element: 13923 \# of layers: 5

Kx Ky Kz Ss Por

$1.28030 \mathrm{e}+031.28030 \mathrm{e}+03$ 1.28030e+02 1.00000e-09 2.12000e-01

$1.28030 \mathrm{e}+031.28030 \mathrm{e}+03$ 1.28030e+02 1.00000e-09 2.12000e-01

$1.00000 \mathrm{e}-05$ 1.00000e-05 1.00000e-06 1.00000e-09 1.00000e-01

$1.00000 \mathrm{e}+001.00000 \mathrm{e}+001.00000 \mathrm{e}-011.00000 \mathrm{e}-091.00000 \mathrm{e}-01$

1.00000e-06 1.00000e-06 1.00000e-06 1.00000e-09 5.00000e-02

Element: 13924 \# of layers: 5

Kx Ky Kz Ss Por

7.04985e+02 7.04985e+02 7.04985e+01 1.00000e-09 2.12000e-01

$7.04985 \mathrm{e}+02$ 7.04985e+02 7.04985e+01 1.00000e-09 2.12000e-01

$1.00000 \mathrm{e}-05$ 1.00000e-05 1.00000e-06 1.00000e-09 1.00000e-01

$1.00000 \mathrm{e}+001.00000 \mathrm{e}+001.00000 \mathrm{e}-011.00000 \mathrm{e}-091.00000 \mathrm{e}-01$

1.00000e-06 1.00000e-06 1.00000e-06 1.00000e-09 5.00000e-02

Element: 13925 \# of layers: 5

$\mathrm{Kx} \mathrm{Ky} \mathrm{Kz}$ Ss Por

2.57068e+02 2.57068e+02 2.57068e+01 1.00000e-09 2.12000e-01

$2.57068 \mathrm{e}+022.57068 \mathrm{e}+02 \quad 2.57068 \mathrm{e}+01$ 1.00000e-09 2.12000e-01

$1.00000 \mathrm{e}-05$ 1.00000e-05 1.00000e-06 1.00000e-09 1.00000e-01 
$1.00000 \mathrm{e}+001.00000 \mathrm{e}+001.00000 \mathrm{e}-011.00000 \mathrm{e}-091.00000 \mathrm{e}-01$ 1.00000e-06 1.00000e-06 1.00000e-06 1.00000e-09 5.00000e-02

Element: 13926 \# of layers: 5

Kx Ky Kz Ss Por

$1.18361 \mathrm{e}+031.18361 \mathrm{e}+03$ 1.18362e+02 1.00000e-09 2.12000e-01

$1.18361 \mathrm{e}+031.18361 \mathrm{e}+03$ 1.18362e+02 1.00000e-09 2.12000e-01

$1.00000 \mathrm{e}-05$ 1.00000e-05 1.00000e-06 1.00000e-09 1.00000e-01

$1.00000 \mathrm{e}+001.00000 \mathrm{e}+001.00000 \mathrm{e}-011.00000 \mathrm{e}-091.00000 \mathrm{e}-01$

1.00000e-06 1.00000e-06 1.00000e-06 1.00000e-09 5.00000e-02

Element: 13927 \# of layers: 4

$\mathrm{Kx} \mathrm{Ky} \mathrm{Kz}$ Ss Por

$1.40047 \mathrm{e}+03$ 1.40047e+03 1.40047e+02 1.00000e-09 2.12000e-01

$1.00000 \mathrm{e}-051.00000 \mathrm{e}-051.00000 \mathrm{e}-061.00000 \mathrm{e}-091.00000 \mathrm{e}-01$

$1.00000 \mathrm{e}+001.00000 \mathrm{e}+001.00000 \mathrm{e}-011.00000 \mathrm{e}-091.00000 \mathrm{e}-01$

1.00000e-06 1.00000e-06 1.00000e-06 1.00000e-09 5.00000e-02

Element: 13928 \# of layers: 4

$\mathrm{Kx} \mathrm{Ky} \mathrm{Kz}$ Ss Por

$1.40047 \mathrm{e}+03$ 1.40047e+03 1.40047e+02 1.00000e-09 2.12000e-01

$1.00000 \mathrm{e}-051.00000 \mathrm{e}-05$ 1.00000e-06 1.00000e-09 1.00000e-01

$1.00000 \mathrm{e}+001.00000 \mathrm{e}+001.00000 \mathrm{e}-011.00000 \mathrm{e}-091.00000 \mathrm{e}-01$

1.00000e-06 1.00000e-06 1.00000e-06 1.00000e-09 5.00000e-02

Element: 13929 \# of layers: 4

$\mathrm{Kx} \mathrm{Ky} \mathrm{Kz}$ Ss Por

1.40047e+03 1.40047e+03 1.40047e+02 1.00000e-09 2.12000e-01

$1.00000 \mathrm{e}-05$ 1.00000e-05 1.00000e-06 1.00000e-09 1.00000e-01

$1.00000 \mathrm{e}+001.00000 \mathrm{e}+001.00000 \mathrm{e}-011.00000 \mathrm{e}-091.00000 \mathrm{e}-01$

1.00000e-06 1.00000e-06 1.00000e-06 1.00000e-09 5.00000e-02

Element: 13930 \# of layers: 4

Kx Ky Kz Ss Por

1.40047e+03 1.40047e+03 1.40047e+02 1.00000e-09 2.12000e-01

$1.00000 \mathrm{e}-05$ 1.00000e-05 1.00000e-06 1.00000e-09 1.00000e-01

$1.00000 \mathrm{e}+001.00000 \mathrm{e}+001.00000 \mathrm{e}-011.00000 \mathrm{e}-091.00000 \mathrm{e}-01$

$1.00000 \mathrm{e}-06$ 1.00000e-06 1.00000e-06 1.00000e-09 5.00000e-02

Element: 13931 \# of layers: 4

$\mathrm{Kx} \mathrm{Ky} \mathrm{Kz}$ Ss Por

$1.40047 \mathrm{e}+03$ 1.40047e+03 1.40047e+02 1.00000e-09 2.12000e-01

$1.00000 \mathrm{e}-05$ 1.00000e-05 1.00000e-06 1.00000e-09 1.00000e-01

$1.00000 \mathrm{e}+001.00000 \mathrm{e}+001.00000 \mathrm{e}-011.00000 \mathrm{e}-091.00000 \mathrm{e}-01$

1.00000e-06 1.00000e-06 1.00000e-06 1.00000e-09 5.00000e-02

Element: 13932 \# of layers: 4

$\mathrm{Kx} \mathrm{Ky} \mathrm{Kz}$ Ss Por

$1.40047 \mathrm{e}+03$ 1.40047e+03 1.40047e+02 1.00000e-09 2.12000e-01

$1.00000 \mathrm{e}-051.00000 \mathrm{e}-05$ 1.00000e-06 1.00000e-09 1.00000e-01

$1.00000 \mathrm{e}+001.00000 \mathrm{e}+001.00000 \mathrm{e}-011.00000 \mathrm{e}-091.00000 \mathrm{e}-01$

1.00000e-06 1.00000e-06 1.00000e-06 1.00000e-09 5.00000e-02

Element: 13933 \# of layers: 4 
$\mathrm{Kx} \mathrm{Ky} \mathrm{Kz} \mathrm{Ss} \mathrm{Por}$

$1.40047 \mathrm{e}+03$ 1.40047e+03 1.40047e+02 1.00000e-09 2.12000e-01

$1.00000 \mathrm{e}-051.00000 \mathrm{e}-05$ 1.00000e-06 1.00000e-09 1.00000e-01

$1.00000 \mathrm{e}+001.00000 \mathrm{e}+001.00000 \mathrm{e}-011.00000 \mathrm{e}-091.00000 \mathrm{e}-01$

1.00000e-06 1.00000e-06 1.00000e-06 1.00000e-09 5.00000e-02

Element: 13934 \# of layers: 4

$\mathrm{Kx} \mathrm{Ky} \mathrm{Kz}$ Ss Por

$1.40047 \mathrm{e}+03$ 1.40047e+03 1.40047e+02 1.00000e-09 2.12000e-01

$1.00000 \mathrm{e}-051.00000 \mathrm{e}-051.00000 \mathrm{e}-061.00000 \mathrm{e}-091.00000 \mathrm{e}-01$

$1.00000 \mathrm{e}+001.00000 \mathrm{e}+001.00000 \mathrm{e}-011.00000 \mathrm{e}-091.00000 \mathrm{e}-01$

1.00000e-06 1.00000e-06 1.00000e-06 1.00000e-09 5.00000e-02

Element: 13935 \# of layers: 4

$\mathrm{Kx} \mathrm{Ky} \mathrm{Kz}$ Ss Por

$1.40047 \mathrm{e}+03$ 1.40047e+03 1.40047e+02 1.00000e-09 2.12000e-01

$1.00000 \mathrm{e}-05$ 1.00000e-05 1.00000e-06 1.00000e-09 1.00000e-01

$1.00000 \mathrm{e}+001.00000 \mathrm{e}+001.00000 \mathrm{e}-011.00000 \mathrm{e}-091.00000 \mathrm{e}-01$

1.00000e-06 1.00000e-06 1.00000e-06 1.00000e-09 5.00000e-02

Element: 13936 \# of layers: 5

$\mathrm{Kx} \mathrm{Ky} \mathrm{Kz}$ Ss Por

1.40047e+03 1.40047e+03 1.40047e+02 1.00000e-09 2.12000e-01

$1.40047 \mathrm{e}+03$ 1.40047e+03 1.40047e+02 1.00000e-09 2.12000e-01

$1.00000 \mathrm{e}-05$ 1.00000e-05 1.00000e-06 1.00000e-09 1.00000e-01

$1.00000 \mathrm{e}+001.00000 \mathrm{e}+001.00000 \mathrm{e}-011.00000 \mathrm{e}-091.00000 \mathrm{e}-01$

1.00000e-06 1.00000e-06 1.00000e-06 1.00000e-09 5.00000e-02

Element: 13937 \# of layers: 5

$\mathrm{Kx} \mathrm{Ky} \mathrm{Kz}$ Ss Por

$2.51240 \mathrm{e}+032.51240 \mathrm{e}+032.51240 \mathrm{e}+02$ 1.00000e-09 2.12000e-01

$2.51240 \mathrm{e}+032.51240 \mathrm{e}+032.51240 \mathrm{e}+02$ 1.00000e-09 2.12000e-01

$1.00000 \mathrm{e}-05$ 1.00000e-05 1.00000e-06 1.00000e-09 1.00000e-01

$1.00000 \mathrm{e}+001.00000 \mathrm{e}+001.00000 \mathrm{e}-011.00000 \mathrm{e}-091.00000 \mathrm{e}-01$

1.00000e-06 1.00000e-06 1.00000e-06 1.00000e-09 5.00000e-02

Element: 13938 \# of layers: 5

Kx Ky Kz Ss Por

$2.51240 \mathrm{e}+03$ 2.51240e+03 2.51240e+02 1.00000e-09 2.12000e-01

$2.51240 \mathrm{e}+032.51240 \mathrm{e}+032.51240 \mathrm{e}+02$ 1.00000e-09 2.12000e-01

$1.00000 \mathrm{e}-05$ 1.00000e-05 1.00000e-06 1.00000e-09 1.00000e-01

$1.00000 \mathrm{e}+001.00000 \mathrm{e}+001.00000 \mathrm{e}-011.00000 \mathrm{e}-091.00000 \mathrm{e}-01$

1.00000e-06 1.00000e-06 1.00000e-06 1.00000e-09 5.00000e-02

Element: 13939 \# of layers: 5

$\mathrm{Kx} \mathrm{Ky} \mathrm{Kz}$ Ss Por

$2.51240 \mathrm{e}+03$ 2.51240e+03 2.51240e+02 1.00000e-09 2.12000e-01

$2.51240 \mathrm{e}+032.51240 \mathrm{e}+032.51240 \mathrm{e}+02$ 1.00000e-09 2.12000e-01

$1.00000 \mathrm{e}-05$ 1.00000e-05 1.00000e-06 1.00000e-09 1.00000e-01

$1.00000 \mathrm{e}+001.00000 \mathrm{e}+001.00000 \mathrm{e}-011.00000 \mathrm{e}-091.00000 \mathrm{e}-01$

1.00000e-06 1.00000e-06 1.00000e-06 1.00000e-09 5.00000e-02

Element: 13940 \# of layers: 5 
$\mathrm{Kx} \mathrm{Ky} \mathrm{Kz}$ Ss Por

$2.51240 \mathrm{e}+032.51240 \mathrm{e}+032.51240 \mathrm{e}+02$ 1.00000e-09 2.12000e-01

$2.51240 \mathrm{e}+032.51240 \mathrm{e}+03$ 2.51240e+02 1.00000e-09 2.12000e-01

$1.00000 \mathrm{e}-05$ 1.00000e-05 1.00000e-06 1.00000e-09 1.00000e-01

$1.00000 \mathrm{e}+001.00000 \mathrm{e}+001.00000 \mathrm{e}-011.00000 \mathrm{e}-091.00000 \mathrm{e}-01$

1.00000e-06 1.00000e-06 1.00000e-06 1.00000e-09 5.00000e-02

Element: 13941 \# of layers: 5

Kx Ky Kz Ss Por

$2.51240 \mathrm{e}+032.51240 \mathrm{e}+032.51240 \mathrm{e}+02$ 1.00000e-09 2.12000e-01

$2.51240 \mathrm{e}+032.51240 \mathrm{e}+032.51240 \mathrm{e}+02$ 1.00000e-09 2.12000e-01

$1.00000 \mathrm{e}-05$ 1.00000e-05 1.00000e-06 1.00000e-09 1.00000e-01

$1.00000 \mathrm{e}+001.00000 \mathrm{e}+001.00000 \mathrm{e}-011.00000 \mathrm{e}-091.00000 \mathrm{e}-01$

1.00000e-06 1.00000e-06 1.00000e-06 1.00000e-09 5.00000e-02

Element: 13942 \# of layers: 4

$\mathrm{Kx} \mathrm{Ky} \mathrm{Kz}$ Ss Por

$1.40047 \mathrm{e}+03$ 1.40047e+03 1.40047e+02 1.00000e-09 2.12000e-01

$1.00000 \mathrm{e}-05$ 1.00000e-05 1.00000e-06 1.00000e-09 1.00000e-01

$1.00000 \mathrm{e}+001.00000 \mathrm{e}+001.00000 \mathrm{e}-011.00000 \mathrm{e}-091.00000 \mathrm{e}-01$

1.00000e-06 1.00000e-06 1.00000e-06 1.00000e-09 5.00000e-02

Element: 13943 \# of layers: 4

$\mathrm{Kx} \mathrm{Ky} \mathrm{Kz}$ Ss Por

$1.40047 \mathrm{e}+03$ 1.40047e+03 1.40047e+02 1.00000e-09 2.12000e-01

$1.00000 \mathrm{e}-05$ 1.00000e-05 1.00000e-06 1.00000e-09 1.00000e-01

$1.00000 \mathrm{e}+001.00000 \mathrm{e}+001.00000 \mathrm{e}-011.00000 \mathrm{e}-091.00000 \mathrm{e}-01$

1.00000e-06 1.00000e-06 1.00000e-06 1.00000e-09 5.00000e-02

Element: 13944 \# of layers: 5

$\mathrm{Kx} \mathrm{Ky} \mathrm{Kz}$ Ss Por

$2.51240 \mathrm{e}+03$ 2.51240e+03 2.51240e+02 1.00000e-09 2.12000e-01

$2.51240 \mathrm{e}+032.51240 \mathrm{e}+032.51240 \mathrm{e}+021.00000 \mathrm{e}-092.12000 \mathrm{e}-01$

$1.00000 \mathrm{e}-051.00000 \mathrm{e}-051.00000 \mathrm{e}-061.00000 \mathrm{e}-091.00000 \mathrm{e}-01$

$1.00000 \mathrm{e}+001.00000 \mathrm{e}+001.00000 \mathrm{e}-011.00000 \mathrm{e}-091.00000 \mathrm{e}-01$

1.00000e-06 1.00000e-06 1.00000e-06 1.00000e-09 5.00000e-02

Element: 13945 \# of layers: 5

$\mathrm{Kx} \mathrm{Ky} \mathrm{Kz}$ Ss Por

$2.51240 \mathrm{e}+032.51240 \mathrm{e}+032.51240 \mathrm{e}+02$ 1.00000e-09 2.12000e-01

$2.51240 \mathrm{e}+032.51240 \mathrm{e}+032.51240 \mathrm{e}+02$ 1.00000e-09 2.12000e-01

$1.00000 \mathrm{e}-05$ 1.00000e-05 1.00000e-06 1.00000e-09 1.00000e-01

$1.00000 \mathrm{e}+001.00000 \mathrm{e}+001.00000 \mathrm{e}-011.00000 \mathrm{e}-091.00000 \mathrm{e}-01$

1.00000e-06 1.00000e-06 1.00000e-06 1.00000e-09 5.00000e-02

Element: 13946 \# of layers: 5

$\mathrm{Kx} \mathrm{Ky} \mathrm{Kz}$ Ss Por

$2.51240 \mathrm{e}+03$ 2.51240e+03 2.51240e+02 1.00000e-09 2.12000e-01

$2.51240 \mathrm{e}+032.51240 \mathrm{e}+032.51240 \mathrm{e}+02$ 1.00000e-09 2.12000e-01

$1.00000 \mathrm{e}-051.00000 \mathrm{e}-05$ 1.00000e-06 1.00000e-09 1.00000e-01

$1.00000 \mathrm{e}+001.00000 \mathrm{e}+001.00000 \mathrm{e}-011.00000 \mathrm{e}-091.00000 \mathrm{e}-01$

$1.00000 \mathrm{e}-06$ 1.00000e-06 1.00000e-06 1.00000e-09 5.00000e-02 
Element: 13947 \# of layers: 5

$\mathrm{Kx} \mathrm{Ky} \mathrm{Kz}$ Ss Por

2.51240e+03 2.51240e+03 2.51240e+02 1.00000e-09 2.12000e-01

$2.51240 \mathrm{e}+032.51240 \mathrm{e}+032.51240 \mathrm{e}+02$ 1.00000e-09 2.12000e-01

$1.00000 \mathrm{e}-05$ 1.00000e-05 1.00000e-06 1.00000e-09 1.00000e-01

$1.00000 \mathrm{e}+001.00000 \mathrm{e}+001.00000 \mathrm{e}-011.00000 \mathrm{e}-091.00000 \mathrm{e}-01$

1.00000e-06 1.00000e-06 1.00000e-06 1.00000e-09 5.00000e-02

Element: 13948 \# of layers: 5

$\mathrm{Kx} \mathrm{Ky} \mathrm{Kz}$ Ss Por

$2.51240 \mathrm{e}+032.51240 \mathrm{e}+03$ 2.51240e+02 1.00000e-09 2.12000e-01

$2.51240 \mathrm{e}+032.51240 \mathrm{e}+032.51240 \mathrm{e}+02$ 1.00000e-09 2.12000e-01

$1.00000 \mathrm{e}-05$ 1.00000e-05 1.00000e-06 1.00000e-09 1.00000e-01

$1.00000 \mathrm{e}+001.00000 \mathrm{e}+001.00000 \mathrm{e}-011.00000 \mathrm{e}-091.00000 \mathrm{e}-01$

1.00000e-06 1.00000e-06 1.00000e-06 1.00000e-09 5.00000e-02

Element: 13949 \# of layers: 5

$\mathrm{Kx} \mathrm{Ky} \mathrm{Kz}$ Ss Por

$2.51240 \mathrm{e}+03$ 2.51240e+03 2.51240e+02 1.00000e-09 2.12000e-01

$2.51240 \mathrm{e}+032.51240 \mathrm{e}+032.51240 \mathrm{e}+02$ 1.00000e-09 2.12000e-01

$1.00000 \mathrm{e}-05$ 1.00000e-05 1.00000e-06 1.00000e-09 1.00000e-01

$1.00000 \mathrm{e}+001.00000 \mathrm{e}+001.00000 \mathrm{e}-011.00000 \mathrm{e}-091.00000 \mathrm{e}-01$

1.00000e-06 1.00000e-06 1.00000e-06 1.00000e-09 5.00000e-02

Element: 13950 \# of layers: 3

$\mathrm{Kx} \mathrm{Ky} \mathrm{Kz}$ Ss Por

$1.08641 \mathrm{e}+041.08641 \mathrm{e}+041.08641 \mathrm{e}+03$ 1.00000e-09 2.12000e-01

$1.08641 \mathrm{e}+041.08641 \mathrm{e}+041.08641 \mathrm{e}+03$ 1.00000e-09 2.12000e-01

1.00000e-06 1.00000e-06 1.00000e-06 1.00000e-09 5.00000e-02

Element: 13951 \# of layers: 3

$\mathrm{Kx} \mathrm{Ky} \mathrm{Kz} \mathrm{Ss} \mathrm{Por}$

$2.78331 \mathrm{e}+03$ 2.78331e+03 2.78331e+02 1.00000e-09 2.12000e-01

$2.78331 \mathrm{e}+03$ 2.78331e+03 2.78331e+02 1.00000e-09 2.12000e-01

1.00000e-06 1.00000e-06 1.00000e-06 1.00000e-09 5.00000e-02

Element: 13952 \# of layers: 2

Kx Ky Kz Ss Por

2.78331e+03 2.78331e+03 2.78331e+02 1.00000e-09 2.12000e-01

1.00000e-06 1.00000e-06 1.00000e-06 1.00000e-09 5.00000e-02

Element: 13953 \# of layers: 3

$\mathrm{Kx} \mathrm{Ky} \mathrm{Kz}$ Ss Por

$1.08641 \mathrm{e}+041.08641 \mathrm{e}+041.08641 \mathrm{e}+03$ 1.00000e-09 2.12000e-01

$1.08641 \mathrm{e}+041.08641 \mathrm{e}+041.08641 \mathrm{e}+03$ 1.00000e-09 2.12000e-01

1.00000e-06 1.00000e-06 1.00000e-06 1.00000e-09 5.00000e-02

Element: 13954 \# of layers: 3

$\mathrm{Kx} \mathrm{Ky} \mathrm{Kz}$ Ss Por

$1.08641 \mathrm{e}+041.08641 \mathrm{e}+041.08641 \mathrm{e}+03$ 1.00000e-09 2.12000e-01

$1.08641 \mathrm{e}+041.08641 \mathrm{e}+041.08641 \mathrm{e}+03$ 1.00000e-09 2.12000e-01

$1.00000 \mathrm{e}-06$ 1.00000e-06 1.00000e-06 1.00000e-09 5.00000e-02

Element: 13955 \# of layers: 2 
Kx Ky Kz Ss Por

2.78331e+03 2.78331e+03 2.78331e+02 1.00000e-09 2.12000e-01

1.00000e-06 1.00000e-06 1.00000e-06 1.00000e-09 5.00000e-02

Element: 13956 \# of layers: 2

$\mathrm{Kx} \mathrm{Ky} \mathrm{Kz}$ Ss Por

2.78331e+03 2.78331e+03 2.78331e+02 1.00000e-09 2.12000e-01

1.00000e-06 1.00000e-06 1.00000e-06 1.00000e-09 5.00000e-02

Element: 13957 \# of layers: 2

$\mathrm{Kx} \mathrm{Ky} \mathrm{Kz}$ Ss Por

$2.78331 \mathrm{e}+03$ 2.78331e+03 2.78331e+02 1.00000e-09 2.12000e-01

1.00000e-06 1.00000e-06 1.00000e-06 1.00000e-09 5.00000e-02

Element: 13958 \# of layers: 2

$\mathrm{Kx} \mathrm{Ky} \mathrm{Kz}$ Ss Por

$2.78331 \mathrm{e}+03$ 2.78331e+03 2.78331e+02 1.00000e-09 2.12000e-01

1.00000e-06 1.00000e-06 1.00000e-06 1.00000e-09 5.00000e-02

Element: 13959 \# of layers: 2

$\mathrm{Kx} \mathrm{Ky} \mathrm{Kz}$ Ss Por

2.78331e+03 2.78331e+03 2.78331e+02 1.00000e-09 2.12000e-01

1.00000e-06 1.00000e-06 1.00000e-06 1.00000e-09 5.00000e-02

Element: 13960 \# of layers: 2

$\mathrm{Kx} \mathrm{Ky} \mathrm{Kz}$ Ss Por

2.78331e+03 2.78331e+03 2.78331e+02 1.00000e-09 2.12000e-01

1.00000e-06 1.00000e-06 1.00000e-06 1.00000e-09 5.00000e-02

Element: 13961 \# of layers: 2

Kx Ky Kz Ss Por

$2.78331 \mathrm{e}+032.78331 \mathrm{e}+03$ 2.78331e+02 1.00000e-09 2.12000e-01

1.00000e-06 1.00000e-06 1.00000e-06 1.00000e-09 5.00000e-02

Element: 13962 \# of layers: 2

Kx Ky Kz Ss Por

2.78331e+03 2.78331e+03 2.78331e+02 1.00000e-09 2.12000e-01

$1.00000 \mathrm{e}-06$ 1.00000e-06 1.00000e-06 1.00000e-09 5.00000e-02

Element: 13963 \# of layers: 2

Kx Ky Kz Ss Por

2.78331e+03 2.78331e+03 2.78331e+02 1.00000e-09 2.12000e-01

1.00000e-06 1.00000e-06 1.00000e-06 1.00000e-09 5.00000e-02

Element: 13964 \# of layers: 2

Kx Ky Kz Ss Por

2.78331e+03 2.78331e+03 2.78331e+02 1.00000e-09 2.12000e-01

1.00000e-06 1.00000e-06 1.00000e-06 1.00000e-09 5.00000e-02

Element: 13965 \# of layers: 4

$\mathrm{Kx} \mathrm{Ky} \mathrm{Kz}$ Ss Por

$1.40047 \mathrm{e}+03$ 1.40047e+03 1.40047e+02 1.00000e-09 2.12000e-01

$1.00000 \mathrm{e}-051.00000 \mathrm{e}-051.00000 \mathrm{e}-061.00000 \mathrm{e}-091.00000 \mathrm{e}-01$

$1.00000 \mathrm{e}+001.00000 \mathrm{e}+001.00000 \mathrm{e}-011.00000 \mathrm{e}-091.00000 \mathrm{e}-01$

1.00000e-06 1.00000e-06 1.00000e-06 1.00000e-09 5.00000e-02

Element: 13966 \# of layers: 4 
$\mathrm{Kx} \mathrm{Ky} \mathrm{Kz} \mathrm{Ss} \mathrm{Por}$

$1.40047 \mathrm{e}+03$ 1.40047e+03 1.40047e+02 1.00000e-09 2.12000e-01

$1.00000 \mathrm{e}-05$ 1.00000e-05 1.00000e-06 1.00000e-09 1.00000e-01

$1.00000 \mathrm{e}+001.00000 \mathrm{e}+001.00000 \mathrm{e}-011.00000 \mathrm{e}-091.00000 \mathrm{e}-01$

1.00000e-06 1.00000e-06 1.00000e-06 1.00000e-09 5.00000e-02

Element: 13967 \# of layers: 4

$\mathrm{Kx} \mathrm{Ky} \mathrm{Kz}$ Ss Por

$1.40047 \mathrm{e}+03$ 1.40047e+03 1.40047e+02 1.00000e-09 2.12000e-01

$1.00000 \mathrm{e}-05$ 1.00000e-05 1.00000e-06 1.00000e-09 1.00000e-01

$1.00000 \mathrm{e}+001.00000 \mathrm{e}+001.00000 \mathrm{e}-01$ 1.00000e-09 1.00000e-01

1.00000e-06 1.00000e-06 1.00000e-06 1.00000e-09 5.00000e-02

Element: 13968 \# of layers: 4

$\mathrm{Kx} \mathrm{Ky} \mathrm{Kz}$ Ss Por

$1.40047 \mathrm{e}+031.40047 \mathrm{e}+03$ 1.40047e+02 1.00000e-09 2.12000e-01

$1.00000 \mathrm{e}-051.00000 \mathrm{e}-051.00000 \mathrm{e}-061.00000 \mathrm{e}-091.00000 \mathrm{e}-01$

$1.00000 \mathrm{e}+001.00000 \mathrm{e}+001.00000 \mathrm{e}-011.00000 \mathrm{e}-091.00000 \mathrm{e}-01$

1.00000e-06 1.00000e-06 1.00000e-06 1.00000e-09 5.00000e-02

Element: 13969 \# of layers: 4

$\mathrm{Kx} \mathrm{Ky} \mathrm{Kz}$ Ss Por

1.40047e+03 1.40047e+03 1.40047e+02 1.00000e-09 2.12000e-01

$1.00000 \mathrm{e}-05$ 1.00000e-05 1.00000e-06 1.00000e-09 1.00000e-01

$1.00000 \mathrm{e}+001.00000 \mathrm{e}+001.00000 \mathrm{e}-011.00000 \mathrm{e}-091.00000 \mathrm{e}-01$

1.00000e-06 1.00000e-06 1.00000e-06 1.00000e-09 5.00000e-02

Element: 13970 \# of layers: 2

Kx Ky Kz Ss Por

$2.78331 \mathrm{e}+032.78331 \mathrm{e}+03$ 2.78331e+02 1.00000e-09 2.12000e-01

1.00000e-06 1.00000e-06 1.00000e-06 1.00000e-09 5.00000e-02

Element: 13971 \# of layers: 2

Kx Ky Kz Ss Por

2.78331e+03 2.78331e+03 2.78331e+02 1.00000e-09 2.12000e-01

$1.00000 \mathrm{e}-06$ 1.00000e-06 1.00000e-06 1.00000e-09 5.00000e-02

Element: 13972 \# of layers: 4

Kx Ky Kz Ss Por

$1.40047 \mathrm{e}+03$ 1.40047e+03 1.40047e+02 1.00000e-09 2.12000e-01

$1.00000 \mathrm{e}-05$ 1.00000e-05 1.00000e-06 1.00000e-09 1.00000e-01

$1.00000 \mathrm{e}+001.00000 \mathrm{e}+001.00000 \mathrm{e}-011.00000 \mathrm{e}-091.00000 \mathrm{e}-01$

1.00000e-06 1.00000e-06 1.00000e-06 1.00000e-09 5.00000e-02

Element: 13973 \# of layers: 2

$\mathrm{Kx} \mathrm{Ky} \mathrm{Kz}$ Ss Por

$2.78331 \mathrm{e}+032.78331 \mathrm{e}+03$ 2.78331e+02 1.00000e-09 2.12000e-01

1.00000e-06 1.00000e-06 1.00000e-06 1.00000e-09 5.00000e-02

Element: 13974 \# of layers: 4

$\mathrm{Kx} \mathrm{Ky} \mathrm{Kz}$ Ss Por

1.40047e+03 1.40047e+03 1.40047e+02 1.00000e-09 2.12000e-01

$1.00000 \mathrm{e}-05$ 1.00000e-05 1.00000e-06 1.00000e-09 1.00000e-01

$1.00000 \mathrm{e}+001.00000 \mathrm{e}+001.00000 \mathrm{e}-011.00000 \mathrm{e}-091.00000 \mathrm{e}-01$ 
1.00000e-06 1.00000e-06 1.00000e-06 1.00000e-09 5.00000e-02

Element: 13975 \# of layers: 4

Kx Ky Kz Ss Por

$1.40047 \mathrm{e}+03$ 1.40047e+03 1.40047e+02 1.00000e-09 2.12000e-01

$1.00000 \mathrm{e}-05$ 1.00000e-05 1.00000e-06 1.00000e-09 1.00000e-01

$1.00000 \mathrm{e}+001.00000 \mathrm{e}+001.00000 \mathrm{e}-01$ 1.00000e-09 1.00000e-01

1.00000e-06 1.00000e-06 1.00000e-06 1.00000e-09 5.00000e-02

Element: 13976 \# of layers: 5

$\mathrm{Kx} \mathrm{Ky} \mathrm{Kz}$ Ss Por

$2.51240 \mathrm{e}+032.51240 \mathrm{e}+032.51240 \mathrm{e}+02$ 1.00000e-09 2.12000e-01

$2.51240 \mathrm{e}+032.51240 \mathrm{e}+032.51240 \mathrm{e}+02$ 1.00000e-09 2.12000e-01

$1.00000 \mathrm{e}-05$ 1.00000e-05 1.00000e-06 1.00000e-09 1.00000e-01

$1.00000 \mathrm{e}+001.00000 \mathrm{e}+001.00000 \mathrm{e}-011.00000 \mathrm{e}-091.00000 \mathrm{e}-01$

1.00000e-06 1.00000e-06 1.00000e-06 1.00000e-09 5.00000e-02

Element: 13977 \# of layers: 5

Kx Ky Kz Ss Por

$2.51240 \mathrm{e}+03$ 2.51240e+03 2.51240e+02 1.00000e-09 2.12000e-01

$2.51240 \mathrm{e}+032.51240 \mathrm{e}+032.51240 \mathrm{e}+02$ 1.00000e-09 2.12000e-01

$1.00000 \mathrm{e}-05$ 1.00000e-05 1.00000e-06 1.00000e-09 1.00000e-01

$1.00000 \mathrm{e}+001.00000 \mathrm{e}+001.00000 \mathrm{e}-011.00000 \mathrm{e}-091.00000 \mathrm{e}-01$

1.00000e-06 1.00000e-06 1.00000e-06 1.00000e-09 5.00000e-02

Element: 13978 \# of layers: 5

$\mathrm{Kx} \mathrm{Ky} \mathrm{Kz}$ Ss Por

$2.51240 \mathrm{e}+03$ 2.51240e+03 2.51240e+02 1.00000e-09 2.12000e-01

$2.51240 \mathrm{e}+032.51240 \mathrm{e}+032.51240 \mathrm{e}+021.00000 \mathrm{e}-092.12000 \mathrm{e}-01$

$1.00000 \mathrm{e}-05$ 1.00000e-05 1.00000e-06 1.00000e-09 1.00000e-01

$1.00000 \mathrm{e}+001.00000 \mathrm{e}+001.00000 \mathrm{e}-011.00000 \mathrm{e}-091.00000 \mathrm{e}-01$

1.00000e-06 1.00000e-06 1.00000e-06 1.00000e-09 5.00000e-02

Element: 13979 \# of layers: 3

$\mathrm{Kx} \mathrm{Ky} \mathrm{Kz}$ Ss Por

$1.08641 \mathrm{e}+041.08641 \mathrm{e}+041.08641 \mathrm{e}+03$ 1.00000e-09 2.12000e-01

$1.08641 \mathrm{e}+041.08641 \mathrm{e}+041.08641 \mathrm{e}+03$ 1.00000e-09 2.12000e-01

1.00000e-06 1.00000e-06 1.00000e-06 1.00000e-09 5.00000e-02

Element: 13980 \# of layers: 4

$\mathrm{Kx} \mathrm{Ky} \mathrm{Kz}$ Ss Por

$1.40047 \mathrm{e}+03$ 1.40047e+03 1.40047e+02 1.00000e-09 2.12000e-01

$1.00000 \mathrm{e}-051.00000 \mathrm{e}-05$ 1.00000e-06 1.00000e-09 1.00000e-01

$1.00000 \mathrm{e}+001.00000 \mathrm{e}+001.00000 \mathrm{e}-011.00000 \mathrm{e}-091.00000 \mathrm{e}-01$

1.00000e-06 1.00000e-06 1.00000e-06 1.00000e-09 5.00000e-02

Element: 13981 \# of layers: 7

$\mathrm{Kx} \mathrm{Ky} \mathrm{Kz}$ Ss Por

4.90735e+00 4.90735e+00 4.90735e-01 1.00000e-09 2.12000e-01

4.90735e+00 4.90735e+00 4.90735e-01 1.00000e-09 2.12000e-01

4.90735e+00 4.90735e+00 4.90735e-01 1.00000e-09 2.12000e-01

$4.90735 \mathrm{e}+004.90735 \mathrm{e}+00$ 4.90735e-01 1.00000e-09 2.12000e-01

$4.90735 \mathrm{e}+00$ 4.90735e+00 4.90735e-01 1.00000e-09 2.12000e-01 
$1.00000 \mathrm{e}-05$ 1.00000e-05 1.00000e-06 1.00000e-09 1.00000e-01 $1.00000 \mathrm{e}+001.00000 \mathrm{e}+001.00000 \mathrm{e}-01$ 1.00000e-09 1.00000e-01 Element: 13982 \# of layers: 7

Kx Ky Kz Ss Por

4.90735e+00 4.90735e+00 4.90735e-01 1.00000e-09 2.12000e-01 $4.90735 \mathrm{e}+004.90735 \mathrm{e}+00$ 4.90735e-01 1.00000e-09 2.12000e-01 $4.90735 \mathrm{e}+00$ 4.90735e+00 4.90735e-01 1.00000e-09 2.12000e-01 $4.90735 \mathrm{e}+00$ 4.90735e+00 4.90735e-01 1.00000e-09 2.12000e-01 $4.90735 \mathrm{e}+00$ 4.90735e+00 4.90735e-01 1.00000e-09 2.12000e-01 $1.00000 \mathrm{e}-05$ 1.00000e-05 1.00000e-06 1.00000e-09 1.00000e-01 $1.00000 \mathrm{e}+001.00000 \mathrm{e}+001.00000 \mathrm{e}-01$ 1.00000e-09 1.00000e-01 Element: 13983 \# of layers: 7

$\mathrm{Kx} \mathrm{Ky} \mathrm{Kz}$ Ss Por

4.90735e+00 4.90735e+00 4.90735e-01 1.00000e-09 2.12000e-01 4.90735e+00 4.90735e+00 4.90735e-01 1.00000e-09 2.12000e-01 $4.90735 \mathrm{e}+004.90735 \mathrm{e}+00$ 4.90735e-01 1.00000e-09 2.12000e-01 $4.90735 \mathrm{e}+004.90735 \mathrm{e}+004.90735 \mathrm{e}-01$ 1.00000e-09 2.12000e-01 $4.90735 \mathrm{e}+004.90735 \mathrm{e}+00$ 4.90735e-01 1.00000e-09 2.12000e-01 $1.00000 \mathrm{e}-05$ 1.00000e-05 1.00000e-06 1.00000e-09 1.00000e-01 $1.00000 \mathrm{e}+001.00000 \mathrm{e}+001.00000 \mathrm{e}-011.00000 \mathrm{e}-09$ 1.00000e-01 Element: 13984 \# of layers: 7

$\mathrm{Kx} \mathrm{Ky} \mathrm{Kz}$ Ss Por

4.90735e+00 4.90735e+00 4.90735e-01 1.00000e-09 2.12000e-01 $4.90735 \mathrm{e}+00$ 4.90735e+00 4.90735e-01 1.00000e-09 2.12000e-01 $4.90735 \mathrm{e}+004.90735 \mathrm{e}+00$ 4.90735e-01 1.00000e-09 2.12000e-01 4.90735e+00 4.90735e+00 4.90735e-01 1.00000e-09 2.12000e-01 $4.90735 \mathrm{e}+004.90735 \mathrm{e}+00$ 4.90735e-01 1.00000e-09 2.12000e-01 1.00000e-05 1.00000e-05 1.00000e-06 1.00000e-09 1.00000e-01 $1.00000 \mathrm{e}+001.00000 \mathrm{e}+001.00000 \mathrm{e}-011.00000 \mathrm{e}-091.00000 \mathrm{e}-01$ Element: 13985 \# of layers: 7

$\mathrm{Kx} \mathrm{Ky} \mathrm{Kz}$ Ss Por

4.90735e+00 4.90735e+00 4.90735e-01 1.00000e-09 2.12000e-01 $4.90735 \mathrm{e}+004.90735 \mathrm{e}+00$ 4.90735e-01 1.00000e-09 2.12000e-01 $4.90735 \mathrm{e}+00$ 4.90735e+00 4.90735e-01 1.00000e-09 2.12000e-01 $4.90735 \mathrm{e}+00$ 4.90735e+00 4.90735e-01 1.00000e-09 2.12000e-01 $4.90735 \mathrm{e}+00$ 4.90735e+00 4.90735e-01 1.00000e-09 2.12000e-01 1.00000e-05 1.00000e-05 1.00000e-06 1.00000e-09 1.00000e-01 $1.00000 \mathrm{e}+001.00000 \mathrm{e}+001.00000 \mathrm{e}-011.00000 \mathrm{e}-091.00000 \mathrm{e}-01$ Element: 13986 \# of layers: 7

$\mathrm{Kx} \mathrm{Ky} \mathrm{Kz}$ Ss Por

6.70942e+00 6.70942e+00 6.70942e-01 1.00000e-09 2.12000e-01 $6.70942 \mathrm{e}+00$ 6.70942e+00 6.70942e-01 1.00000e-09 2.12000e-01 6.70942e+00 6.70942e+00 6.70942e-01 1.00000e-09 2.12000e-01 6.70942e+00 6.70942e+00 6.70942e-01 1.00000e-09 2.12000e-01 6.70942e+00 6.70942e+00 6.70942e-01 1.00000e-09 2.12000e-01 $1.00000 \mathrm{e}-05$ 1.00000e-05 1.00000e-06 1.00000e-09 1.00000e-01 
$1.00000 \mathrm{e}+001.00000 \mathrm{e}+00$ 1.00000e-01 1.00000e-09 1.00000e-01 Element: 13987 \# of layers: 7

Kx Ky Kz Ss Por

6.70942e+00 6.70942e+00 6.70942e-01 1.00000e-09 2.12000e-01

6.70942e+00 6.70942e+00 6.70942e-01 1.00000e-09 2.12000e-01

$6.70942 \mathrm{e}+00$ 6.70942e+00 6.70942e-01 1.00000e-09 2.12000e-01

$6.70942 \mathrm{e}+00$ 6.70942e+00 6.70942e-01 1.00000e-09 2.12000e-01

$6.70942 \mathrm{e}+00$ 6.70942e+00 6.70942e-01 1.00000e-09 2.12000e-01

$1.00000 \mathrm{e}-05$ 1.00000e-05 1.00000e-06 1.00000e-09 1.00000e-01

$1.00000 \mathrm{e}+001.00000 \mathrm{e}+00$ 1.00000e-01 1.00000e-09 1.00000e-01

Element: 13988 \# of layers: 7

$\mathrm{Kx} \mathrm{Ky} \mathrm{Kz}$ Ss Por

6.70942e+00 6.70942e+00 6.70942e-01 1.00000e-09 2.12000e-01

6.70942e+00 6.70942e+00 6.70942e-01 1.00000e-09 2.12000e-01

6.70942e+00 6.70942e+00 6.70942e-01 1.00000e-09 2.12000e-01

$6.70942 \mathrm{e}+006.70942 \mathrm{e}+00$ 6.70942e-01 1.00000e-09 2.12000e-01

6.70942e+00 6.70942e+00 6.70942e-01 1.00000e-09 2.12000e-01

$1.00000 \mathrm{e}-05$ 1.00000e-05 1.00000e-06 1.00000e-09 1.00000e-01

$1.00000 \mathrm{e}+001.00000 \mathrm{e}+001.00000 \mathrm{e}-01$ 1.00000e-09 1.00000e-01

Element: 13989 \# of layers: 7

Kx Ky Kz Ss Por

6.70942e+00 6.70942e+00 6.70942e-01 1.00000e-09 2.12000e-01

6.70942e+00 6.70942e+00 6.70942e-01 1.00000e-09 2.12000e-01

6.70942e+00 6.70942e+00 6.70942e-01 1.00000e-09 2.12000e-01

6.70942e+00 6.70942e+00 6.70942e-01 1.00000e-09 2.12000e-01

6.70942e+00 6.70942e+00 6.70942e-01 1.00000e-09 2.12000e-01

$1.00000 \mathrm{e}-05$ 1.00000e-05 1.00000e-06 1.00000e-09 1.00000e-01

$1.00000 \mathrm{e}+001.00000 \mathrm{e}+001.00000 \mathrm{e}-011.00000 \mathrm{e}-091.00000 \mathrm{e}-01$

Element: 13990 \# of layers: 7

$\mathrm{Kx} \mathrm{Ky} \mathrm{Kz}$ Ss Por

6.70942e+00 6.70942e+00 6.70942e-01 1.00000e-09 2.12000e-01

6.70942e+00 6.70942e+00 6.70942e-01 1.00000e-09 2.12000e-01

6.70942e+00 6.70942e+00 6.70942e-01 1.00000e-09 2.12000e-01

6.70942e+00 6.70942e+00 6.70942e-01 1.00000e-09 2.12000e-01

$6.70942 \mathrm{e}+006.70942 \mathrm{e}+00$ 6.70942e-01 1.00000e-09 2.12000e-01

$1.00000 \mathrm{e}-05$ 1.00000e-05 1.00000e-06 1.00000e-09 1.00000e-01

$1.00000 \mathrm{e}+001.00000 \mathrm{e}+001.00000 \mathrm{e}-011.00000 \mathrm{e}-091.00000 \mathrm{e}-01$

Element: 13991 \# of layers: 7

$\mathrm{Kx} \mathrm{Ky} \mathrm{Kz}$ Ss Por

4.90735e+00 4.90735e+00 4.90735e-01 1.00000e-09 2.12000e-01 $4.90735 \mathrm{e}+00$ 4.90735e+00 4.90735e-01 1.00000e-09 2.12000e-01 $4.90735 \mathrm{e}+004.90735 \mathrm{e}+00$ 4.90735e-01 1.00000e-09 2.12000e-01 $4.90735 \mathrm{e}+00$ 4.90735e+00 4.90735e-01 1.00000e-09 2.12000e-01 4.90735e+00 4.90735e+00 4.90735e-01 1.00000e-09 2.12000e-01 $1.00000 \mathrm{e}-05$ 1.00000e-05 1.00000e-06 1.00000e-09 1.00000e-01

$1.00000 \mathrm{e}+001.00000 \mathrm{e}+001.00000 \mathrm{e}-011.00000 \mathrm{e}-091.00000 \mathrm{e}-01$ 
Element: 13992 \# of layers: 7

$\mathrm{Kx} \mathrm{Ky} \mathrm{Kz}$ Ss Por

4.90735e+00 4.90735e+00 4.90735e-01 1.00000e-09 2.12000e-01

$4.90735 \mathrm{e}+00$ 4.90735e+00 4.90735e-01 1.00000e-09 2.12000e-01

$4.90735 \mathrm{e}+00$ 4.90735e+00 4.90735e-01 1.00000e-09 2.12000e-01

4.90735e+00 4.90735e+00 4.90735e-01 1.00000e-09 2.12000e-01

$4.90735 \mathrm{e}+00$ 4.90735e+00 4.90735e-01 1.00000e-09 2.12000e-01

$1.00000 \mathrm{e}-05$ 1.00000e-05 1.00000e-06 1.00000e-09 1.00000e-01

$1.00000 \mathrm{e}+001.00000 \mathrm{e}+001.00000 \mathrm{e}-011.00000 \mathrm{e}-091.00000 \mathrm{e}-01$

Element: 13993 \# of layers: 7

$\mathrm{Kx} \mathrm{Ky} \mathrm{Kz}$ Ss Por

6.70942e+00 6.70942e+00 6.70942e-01 1.00000e-09 2.12000e-01

6.70942e+00 6.70942e+00 6.70942e-01 1.00000e-09 2.12000e-01

$6.70942 \mathrm{e}+00$ 6.70942e+00 6.70942e-01 1.00000e-09 2.12000e-01

6.70942e+00 6.70942e+00 6.70942e-01 1.00000e-09 2.12000e-01

6.70942e+00 6.70942e+00 6.70942e-01 1.00000e-09 2.12000e-01

$1.00000 \mathrm{e}-05$ 1.00000e-05 1.00000e-06 1.00000e-09 1.00000e-01

$1.00000 \mathrm{e}+001.00000 \mathrm{e}+001.00000 \mathrm{e}-01$ 1.00000e-09 1.00000e-01

Element: 13994 \# of layers: 7

$\mathrm{Kx} \mathrm{Ky} \mathrm{Kz}$ Ss Por

6.70942e+00 6.70942e+00 6.70942e-01 1.00000e-09 2.12000e-01

6.70942e+00 6.70942e+00 6.70942e-01 1.00000e-09 2.12000e-01

6.70942e+00 6.70942e+00 6.70942e-01 1.00000e-09 2.12000e-01

6.70942e+00 6.70942e+00 6.70942e-01 1.00000e-09 2.12000e-01

6.70942e+00 6.70942e+00 6.70942e-01 1.00000e-09 2.12000e-01

$1.00000 \mathrm{e}-05$ 1.00000e-05 1.00000e-06 1.00000e-09 1.00000e-01

$1.00000 \mathrm{e}+001.00000 \mathrm{e}+001.00000 \mathrm{e}-011.00000 \mathrm{e}-091.00000 \mathrm{e}-01$

Element: 13995 \# of layers: 7

Kx Ky Kz Ss Por

6.70942e+00 6.70942e+00 6.70942e-01 1.00000e-09 2.12000e-01

$6.70942 \mathrm{e}+00$ 6.70942e+00 6.70942e-01 1.00000e-09 2.12000e-01

6.70942e+00 6.70942e+00 6.70942e-01 1.00000e-09 2.12000e-01

6.70942e+00 6.70942e+00 6.70942e-01 1.00000e-09 2.12000e-01

6.70942e+00 6.70942e+00 6.70942e-01 1.00000e-09 2.12000e-01

$1.00000 \mathrm{e}-05$ 1.00000e-05 1.00000e-06 1.00000e-09 1.00000e-01

$1.00000 \mathrm{e}+001.00000 \mathrm{e}+001.00000 \mathrm{e}-011.00000 \mathrm{e}-091.00000 \mathrm{e}-01$

Element: 13996 \# of layers: 7

$\mathrm{Kx} \mathrm{Ky} \mathrm{Kz}$ Ss Por

6.70942e+00 6.70942e+00 6.70942e-01 1.00000e-09 2.12000e-01

6.70942e+00 6.70942e+00 6.70942e-01 1.00000e-09 2.12000e-01

$6.70942 \mathrm{e}+006.70942 \mathrm{e}+006.70942 \mathrm{e}-01$ 1.00000e-09 2.12000e-01

6.70942e+00 6.70942e+00 6.70942e-01 1.00000e-09 2.12000e-01

6.70942e+00 6.70942e+00 6.70942e-01 1.00000e-09 2.12000e-01

$1.00000 \mathrm{e}-051.00000 \mathrm{e}-05$ 1.00000e-06 1.00000e-09 1.00000e-01

$1.00000 \mathrm{e}+001.00000 \mathrm{e}+001.00000 \mathrm{e}-011.00000 \mathrm{e}-091.00000 \mathrm{e}-01$

Element: 13997 \# of layers: 7 
$\mathrm{Kx} \mathrm{Ky} \mathrm{Kz}$ Ss Por

6.70942e+00 6.70942e+00 6.70942e-01 1.00000e-09 2.12000e-01

6.70942e+00 6.70942e+00 6.70942e-01 1.00000e-09 2.12000e-01

$6.70942 \mathrm{e}+00$ 6.70942e+00 6.70942e-01 1.00000e-09 2.12000e-01

6.70942e+00 6.70942e+00 6.70942e-01 1.00000e-09 2.12000e-01

$6.70942 \mathrm{e}+006.70942 \mathrm{e}+00$ 6.70942e-01 1.00000e-09 2.12000e-01

$1.00000 \mathrm{e}-05$ 1.00000e-05 1.00000e-06 1.00000e-09 1.00000e-01

$1.00000 \mathrm{e}+001.00000 \mathrm{e}+001.00000 \mathrm{e}-011.00000 \mathrm{e}-091.00000 \mathrm{e}-01$

Element: 13998 \# of layers: 7

$\mathrm{Kx} \mathrm{Ky} \mathrm{Kz}$ Ss Por

6.70942e+00 6.70942e+00 6.70942e-01 1.00000e-09 2.12000e-01

$6.70942 \mathrm{e}+00$ 6.70942e+00 6.70942e-01 1.00000e-09 2.12000e-01

6.70942e+00 6.70942e+00 6.70942e-01 1.00000e-09 2.12000e-01

6.70942e+00 6.70942e+00 6.70942e-01 1.00000e-09 2.12000e-01

6.70942e+00 6.70942e+00 6.70942e-01 1.00000e-09 2.12000e-01

1.00000e-05 1.00000e-05 1.00000e-06 1.00000e-09 1.00000e-01

$1.00000 \mathrm{e}+001.00000 \mathrm{e}+001.00000 \mathrm{e}-01$ 1.00000e-09 1.00000e-01

Element: 13999 \# of layers: 7

$\mathrm{Kx} \mathrm{Ky} \mathrm{Kz}$ Ss Por

6.70942e+00 6.70942e+00 6.70942e-01 1.00000e-09 2.12000e-01

$6.70942 \mathrm{e}+00$ 6.70942e+00 6.70942e-01 1.00000e-09 2.12000e-01

6.70942e+00 6.70942e+00 6.70942e-01 1.00000e-09 2.12000e-01

6.70942e+00 6.70942e+00 6.70942e-01 1.00000e-09 2.12000e-01

6.70942e+00 6.70942e+00 6.70942e-01 1.00000e-09 2.12000e-01

$1.00000 \mathrm{e}-05$ 1.00000e-05 1.00000e-06 1.00000e-09 1.00000e-01

$1.00000 \mathrm{e}+001.00000 \mathrm{e}+001.00000 \mathrm{e}-011.00000 \mathrm{e}-091.00000 \mathrm{e}-01$

Element: 14000 \# of layers: 7

Kx Ky Kz Ss Por

6.70942e+00 6.70942e+00 6.70942e-01 1.00000e-09 2.12000e-01

$6.70942 \mathrm{e}+00$ 6.70942e+00 6.70942e-01 1.00000e-09 2.12000e-01

6.70942e+00 6.70942e+00 6.70942e-01 1.00000e-09 2.12000e-01

$6.70942 \mathrm{e}+00$ 6.70942e+00 6.70942e-01 1.00000e-09 2.12000e-01

$6.70942 \mathrm{e}+00$ 6.70942e+00 6.70942e-01 1.00000e-09 2.12000e-01

$1.00000 \mathrm{e}-05$ 1.00000e-05 1.00000e-06 1.00000e-09 1.00000e-01

$1.00000 \mathrm{e}+001.00000 \mathrm{e}+001.00000 \mathrm{e}-01$ 1.00000e-09 1.00000e-01

Element: 14001 \# of layers: 7

Kx Ky Kz Ss Por

6.70942e+00 6.70942e+00 6.70942e-01 1.00000e-09 2.12000e-01

6.70942e+00 6.70942e+00 6.70942e-01 1.00000e-09 2.12000e-01

6.70942e+00 6.70942e+00 6.70942e-01 1.00000e-09 2.12000e-01

6.70942e+00 6.70942e+00 6.70942e-01 1.00000e-09 2.12000e-01

6.70942e+00 6.70942e+00 6.70942e-01 1.00000e-09 2.12000e-01

$1.00000 \mathrm{e}-05$ 1.00000e-05 1.00000e-06 1.00000e-09 1.00000e-01

$1.00000 \mathrm{e}+001.00000 \mathrm{e}+001.00000 \mathrm{e}-01$ 1.00000e-09 1.00000e-01

Element: 14002 \# of layers: 7

Kx Ky Kz Ss Por 
$6.70942 \mathrm{e}+00$ 6.70942e+00 6.70942e-01 1.00000e-09 2.12000e-01 $6.70942 \mathrm{e}+006.70942 \mathrm{e}+00$ 6.70942e-01 1.00000e-09 2.12000e-01 $6.70942 \mathrm{e}+006.70942 \mathrm{e}+00$ 6.70942e-01 1.00000e-09 2.12000e-01 $6.70942 \mathrm{e}+006.70942 \mathrm{e}+00$ 6.70942e-01 1.00000e-09 2.12000e-01 $6.70942 \mathrm{e}+006.70942 \mathrm{e}+00$ 6.70942e-01 1.00000e-09 2.12000e-01 $1.00000 \mathrm{e}-05$ 1.00000e-05 1.00000e-06 1.00000e-09 1.00000e-01 $1.00000 \mathrm{e}+001.00000 \mathrm{e}+001.00000 \mathrm{e}-011.00000 \mathrm{e}-091.00000 \mathrm{e}-01$ Element: 14003 \# of layers: 7

Kx Ky Kz Ss Por

6.70942e+00 6.70942e+00 6.70942e-01 1.00000e-09 2.12000e-01 $6.70942 \mathrm{e}+006.70942 \mathrm{e}+00$ 6.70942e-01 1.00000e-09 2.12000e-01 $6.70942 \mathrm{e}+00$ 6.70942e+00 6.70942e-01 1.00000e-09 2.12000e-01 $6.70942 \mathrm{e}+006.70942 \mathrm{e}+00$ 6.70942e-01 1.00000e-09 2.12000e-01 $6.70942 \mathrm{e}+006.70942 \mathrm{e}+00$ 6.70942e-01 1.00000e-09 2.12000e-01 $1.00000 \mathrm{e}-05$ 1.00000e-05 1.00000e-06 1.00000e-09 1.00000e-01 $1.00000 \mathrm{e}+001.00000 \mathrm{e}+001.00000 \mathrm{e}-011.00000 \mathrm{e}-091.00000 \mathrm{e}-01$ Element: 14004 \# of layers: 7

Kx Ky Kz Ss Por

6.70942e+00 6.70942e+00 6.70942e-01 1.00000e-09 2.12000e-01

$6.70942 \mathrm{e}+006.70942 \mathrm{e}+00$ 6.70942e-01 1.00000e-09 2.12000e-01

$6.70942 \mathrm{e}+00$ 6.70942e+00 6.70942e-01 1.00000e-09 2.12000e-01

$6.70942 \mathrm{e}+006.70942 \mathrm{e}+00$ 6.70942e-01 1.00000e-09 2.12000e-01

$6.70942 \mathrm{e}+006.70942 \mathrm{e}+00$ 6.70942e-01 1.00000e-09 2.12000e-01 $1.00000 \mathrm{e}-05$ 1.00000e-05 1.00000e-06 1.00000e-09 1.00000e-01 $1.00000 \mathrm{e}+001.00000 \mathrm{e}+001.00000 \mathrm{e}-011.00000 \mathrm{e}-091.00000 \mathrm{e}-01$ Element: 14005 \# of layers: 7

Kx Ky Kz Ss Por

5.11526e+00 5.11526e+00 5.11526e-01 1.00000e-09 2.12000e-01 $5.11526 \mathrm{e}+005.11526 \mathrm{e}+00$ 5.11526e-01 1.00000e-09 2.12000e-01 $5.11526 \mathrm{e}+005.11526 \mathrm{e}+00$ 5.11526e-01 1.00000e-09 2.12000e-01 $5.11526 \mathrm{e}+00$ 5.11526e+00 5.11526e-01 1.00000e-09 2.12000e-01 $5.11526 \mathrm{e}+005.11526 \mathrm{e}+00$ 5.11526e-01 1.00000e-09 2.12000e-01 $1.00000 \mathrm{e}-05$ 1.00000e-05 1.00000e-06 1.00000e-09 1.00000e-01 $1.00000 \mathrm{e}+001.00000 \mathrm{e}+001.00000 \mathrm{e}-011.00000 \mathrm{e}-091.00000 \mathrm{e}-01$ Element: 14006 \# of layers: 7

Kx Ky Kz Ss Por

$5.11526 \mathrm{e}+00$ 5.11526e+00 5.11526e-01 1.00000e-09 2.12000e-01 $5.11526 \mathrm{e}+005.11526 \mathrm{e}+00$ 5.11526e-01 1.00000e-09 2.12000e-01 $5.11526 \mathrm{e}+005.11526 \mathrm{e}+00$ 5.11526e-01 1.00000e-09 2.12000e-01 $5.11526 \mathrm{e}+005.11526 \mathrm{e}+00$ 5.11526e-01 1.00000e-09 2.12000e-01 $5.11526 \mathrm{e}+005.11526 \mathrm{e}+00$ 5.11526e-01 1.00000e-09 2.12000e-01 $1.00000 \mathrm{e}-05$ 1.00000e-05 1.00000e-06 1.00000e-09 1.00000e-01 $1.00000 \mathrm{e}+001.00000 \mathrm{e}+001.00000 \mathrm{e}-011.00000 \mathrm{e}-091.00000 \mathrm{e}-01$ Element: 14007 \# of layers: 7

Kx Ky Kz Ss Por

5.11526e+00 5.11526e+00 5.11526e-01 1.00000e-09 2.12000e-01 
$5.11526 \mathrm{e}+00$ 5.11526e+00 5.11526e-01 1.00000e-09 2.12000e-01 $5.11526 \mathrm{e}+005.11526 \mathrm{e}+005.11526 \mathrm{e}-011.00000 \mathrm{e}-092.12000 \mathrm{e}-01$ $5.11526 \mathrm{e}+005.11526 \mathrm{e}+00$ 5.11526e-01 1.00000e-09 2.12000e-01 $5.11526 \mathrm{e}+005.11526 \mathrm{e}+00$ 5.11526e-01 1.00000e-09 2.12000e-01 $1.00000 \mathrm{e}-05$ 1.00000e-05 1.00000e-06 1.00000e-09 1.00000e-01 $1.00000 \mathrm{e}+001.00000 \mathrm{e}+001.00000 \mathrm{e}-011.00000 \mathrm{e}-091.00000 \mathrm{e}-01$ Element: 14008 \# of layers: 7

Kx Ky Kz Ss Por

6.70942e+00 6.70942e+00 6.70942e-01 1.00000e-09 2.12000e-01 $6.70942 \mathrm{e}+006.70942 \mathrm{e}+00$ 6.70942e-01 1.00000e-09 2.12000e-01 $6.70942 \mathrm{e}+006.70942 \mathrm{e}+00$ 6.70942e-01 1.00000e-09 2.12000e-01 $6.70942 \mathrm{e}+006.70942 \mathrm{e}+00$ 6.70942e-01 1.00000e-09 2.12000e-01 $6.70942 \mathrm{e}+006.70942 \mathrm{e}+00$ 6.70942e-01 1.00000e-09 2.12000e-01 $1.00000 \mathrm{e}-05$ 1.00000e-05 1.00000e-06 1.00000e-09 1.00000e-01 $1.00000 \mathrm{e}+001.00000 \mathrm{e}+001.00000 \mathrm{e}-011.00000 \mathrm{e}-091.00000 \mathrm{e}-01$ Element: 14009 \# of layers: 7

Kx Ky Kz Ss Por

6.70942e+00 6.70942e+00 6.70942e-01 1.00000e-09 2.12000e-01 $6.70942 \mathrm{e}+006.70942 \mathrm{e}+00$ 6.70942e-01 1.00000e-09 2.12000e-01 $6.70942 \mathrm{e}+006.70942 \mathrm{e}+00$ 6.70942e-01 1.00000e-09 2.12000e-01 $6.70942 \mathrm{e}+00$ 6.70942e+00 6.70942e-01 1.00000e-09 2.12000e-01 $6.70942 \mathrm{e}+006.70942 \mathrm{e}+00$ 6.70942e-01 1.00000e-09 2.12000e-01 $1.00000 \mathrm{e}-05$ 1.00000e-05 1.00000e-06 1.00000e-09 1.00000e-01 $1.00000 \mathrm{e}+001.00000 \mathrm{e}+001.00000 \mathrm{e}-011.00000 \mathrm{e}-091.00000 \mathrm{e}-01$ Element: 14010 \# of layers: 7

Kx Ky Kz Ss Por

6.70942e+00 6.70942e+00 6.70942e-01 1.00000e-09 2.12000e-01 $6.70942 \mathrm{e}+006.70942 \mathrm{e}+00$ 6.70942e-01 1.00000e-09 2.12000e-01 $6.70942 \mathrm{e}+00$ 6.70942e+00 6.70942e-01 1.00000e-09 2.12000e-01 $6.70942 \mathrm{e}+006.70942 \mathrm{e}+00$ 6.70942e-01 1.00000e-09 2.12000e-01 $6.70942 \mathrm{e}+006.70942 \mathrm{e}+00$ 6.70942e-01 1.00000e-09 2.12000e-01 $1.00000 \mathrm{e}-05$ 1.00000e-05 1.00000e-06 1.00000e-09 1.00000e-01 $1.00000 \mathrm{e}+001.00000 \mathrm{e}+001.00000 \mathrm{e}-011.00000 \mathrm{e}-091.00000 \mathrm{e}-01$ Element: 14011 \# of layers: 7

Kx Ky Kz Ss Por

6.70942e+00 6.70942e+00 6.70942e-01 1.00000e-09 2.12000e-01 $6.70942 \mathrm{e}+006.70942 \mathrm{e}+00$ 6.70942e-01 1.00000e-09 2.12000e-01 $6.70942 \mathrm{e}+006.70942 \mathrm{e}+00$ 6.70942e-01 1.00000e-09 2.12000e-01 $6.70942 \mathrm{e}+006.70942 \mathrm{e}+00$ 6.70942e-01 1.00000e-09 2.12000e-01 $6.70942 \mathrm{e}+006.70942 \mathrm{e}+00$ 6.70942e-01 1.00000e-09 2.12000e-01 $1.00000 \mathrm{e}-05$ 1.00000e-05 1.00000e-06 1.00000e-09 1.00000e-01 $1.00000 \mathrm{e}+001.00000 \mathrm{e}+001.00000 \mathrm{e}-011.00000 \mathrm{e}-091.00000 \mathrm{e}-01$ Element: 14012 \# of layers: 7

Kx Ky Kz Ss Por

5.11526e+00 5.11526e+00 5.11526e-01 1.00000e-09 2.12000e-01 $5.11526 \mathrm{e}+00$ 5.11526e+00 5.11526e-01 1.00000e-09 2.12000e-01 
$5.11526 \mathrm{e}+00$ 5.11526e+00 5.11526e-01 1.00000e-09 2.12000e-01 $5.11526 \mathrm{e}+005.11526 \mathrm{e}+00$ 5.11526e-01 1.00000e-09 2.12000e-01 $5.11526 \mathrm{e}+005.11526 \mathrm{e}+00$ 5.11526e-01 1.00000e-09 2.12000e-01 $1.00000 \mathrm{e}-05$ 1.00000e-05 1.00000e-06 1.00000e-09 1.00000e-01 $1.00000 \mathrm{e}+001.00000 \mathrm{e}+001.00000 \mathrm{e}-011.00000 \mathrm{e}-091.00000 \mathrm{e}-01$ Element: 14013 \# of layers: 7

Kx Ky Kz Ss Por

5.11526e+00 5.11526e+00 5.11526e-01 1.00000e-09 2.12000e-01 $5.11526 \mathrm{e}+005.11526 \mathrm{e}+005.11526 \mathrm{e}-011.00000 \mathrm{e}-092.12000 \mathrm{e}-01$ $5.11526 \mathrm{e}+005.11526 \mathrm{e}+00$ 5.11526e-01 1.00000e-09 2.12000e-01 $5.11526 \mathrm{e}+005.11526 \mathrm{e}+00$ 5.11526e-01 1.00000e-09 2.12000e-01 $5.11526 \mathrm{e}+005.11526 \mathrm{e}+00$ 5.11526e-01 1.00000e-09 2.12000e-01 $1.00000 \mathrm{e}-05$ 1.00000e-05 1.00000e-06 1.00000e-09 1.00000e-01 $1.00000 \mathrm{e}+001.00000 \mathrm{e}+001.00000 \mathrm{e}-011.00000 \mathrm{e}-091.00000 \mathrm{e}-01$ Element: 14014 \# of layers: 7

Kx Ky Kz Ss Por

$5.11526 \mathrm{e}+00$ 5.11526e+00 5.11526e-01 1.00000e-09 2.12000e-01 $5.11526 \mathrm{e}+005.11526 \mathrm{e}+005.11526 \mathrm{e}-011.00000 \mathrm{e}-092.12000 \mathrm{e}-01$ $5.11526 \mathrm{e}+005.11526 \mathrm{e}+005.11526 \mathrm{e}-011.00000 \mathrm{e}-092.12000 \mathrm{e}-01$ $5.11526 \mathrm{e}+00$ 5.11526e+00 5.11526e-01 1.00000e-09 2.12000e-01 $5.11526 \mathrm{e}+00$ 5.11526e+00 5.11526e-01 1.00000e-09 2.12000e-01 $1.00000 \mathrm{e}-05$ 1.00000e-05 1.00000e-06 1.00000e-09 1.00000e-01 $1.00000 \mathrm{e}+001.00000 \mathrm{e}+001.00000 \mathrm{e}-011.00000 \mathrm{e}-091.00000 \mathrm{e}-01$ Element: 14015 \# of layers: 7

Kx Ky Kz Ss Por

$5.11526 \mathrm{e}+00$ 5.11526e+00 5.11526e-01 1.00000e-09 2.12000e-01 $5.11526 \mathrm{e}+005.11526 \mathrm{e}+00$ 5.11526e-01 1.00000e-09 2.12000e-01 $5.11526 \mathrm{e}+005.11526 \mathrm{e}+00$ 5.11526e-01 1.00000e-09 2.12000e-01 $5.11526 \mathrm{e}+005.11526 \mathrm{e}+00$ 5.11526e-01 1.00000e-09 2.12000e-01 $5.11526 \mathrm{e}+00$ 5.11526e+00 5.11526e-01 1.00000e-09 2.12000e-01 $1.00000 \mathrm{e}-05$ 1.00000e-05 1.00000e-06 1.00000e-09 1.00000e-01 $1.00000 \mathrm{e}+001.00000 \mathrm{e}+001.00000 \mathrm{e}-011.00000 \mathrm{e}-091.00000 \mathrm{e}-01$ Element: 14016 \# of layers: 7

Kx Ky Kz Ss Por

$2.85959 \mathrm{e}+002.85959 \mathrm{e}+00$ 2.85959e-01 1.00000e-09 2.12000e-01 $2.85959 \mathrm{e}+002.85959 \mathrm{e}+002.85959 \mathrm{e}-011.00000 \mathrm{e}-092.12000 \mathrm{e}-01$ $2.85959 \mathrm{e}+002.85959 \mathrm{e}+002.85959 \mathrm{e}-01$ 1.00000e-09 2.12000e-01 $2.85959 \mathrm{e}+002.85959 \mathrm{e}+002.85959 \mathrm{e}-01$ 1.00000e-09 2.12000e-01 $2.85959 \mathrm{e}+002.85959 \mathrm{e}+002.85959 \mathrm{e}-01$ 1.00000e-09 2.12000e-01 $1.00000 \mathrm{e}-05$ 1.00000e-05 1.00000e-06 1.00000e-09 1.00000e-01 $1.00000 \mathrm{e}+001.00000 \mathrm{e}+001.00000 \mathrm{e}-011.00000 \mathrm{e}-091.00000 \mathrm{e}-01$ Element: 14017 \# of layers: 7

Kx Ky Kz Ss Por

$5.11526 \mathrm{e}+00$ 5.11526e+00 5.11526e-01 1.00000e-09 2.12000e-01 $5.11526 \mathrm{e}+005.11526 \mathrm{e}+00$ 5.11526e-01 1.00000e-09 2.12000e-01 $5.11526 \mathrm{e}+005.11526 \mathrm{e}+00$ 5.11526e-01 1.00000e-09 2.12000e-01 
$5.11526 \mathrm{e}+00$ 5.11526e+00 5.11526e-01 1.00000e-09 2.12000e-01 $5.11526 \mathrm{e}+005.11526 \mathrm{e}+00$ 5.11526e-01 1.00000e-09 2.12000e-01 $1.00000 \mathrm{e}-05$ 1.00000e-05 1.00000e-06 1.00000e-09 1.00000e-01 $1.00000 \mathrm{e}+001.00000 \mathrm{e}+001.00000 \mathrm{e}-011.00000 \mathrm{e}-091.00000 \mathrm{e}-01$ Element: 14018 \# of layers: 7

Kx Ky Kz Ss Por

$5.11526 \mathrm{e}+00$ 5.11526e+00 5.11526e-01 1.00000e-09 2.12000e-01

$5.11526 \mathrm{e}+005.11526 \mathrm{e}+00$ 5.11526e-01 1.00000e-09 2.12000e-01

$5.11526 \mathrm{e}+005.11526 \mathrm{e}+005.11526 \mathrm{e}-011.00000 \mathrm{e}-092.12000 \mathrm{e}-01$

$5.11526 \mathrm{e}+005.11526 \mathrm{e}+00$ 5.11526e-01 1.00000e-09 2.12000e-01

$5.11526 \mathrm{e}+005.11526 \mathrm{e}+00$ 5.11526e-01 1.00000e-09 2.12000e-01 $1.00000 \mathrm{e}-05$ 1.00000e-05 1.00000e-06 1.00000e-09 1.00000e-01 $1.00000 \mathrm{e}+001.00000 \mathrm{e}+001.00000 \mathrm{e}-011.00000 \mathrm{e}-091.00000 \mathrm{e}-01$ Element: 14019 \# of layers: 7

Kx Ky Kz Ss Por

$5.11526 \mathrm{e}+00$ 5.11526e+00 5.11526e-01 1.00000e-09 2.12000e-01 $5.11526 \mathrm{e}+005.11526 \mathrm{e}+00$ 5.11526e-01 1.00000e-09 2.12000e-01 $5.11526 \mathrm{e}+005.11526 \mathrm{e}+005.11526 \mathrm{e}-011.00000 \mathrm{e}-092.12000 \mathrm{e}-01$ $5.11526 \mathrm{e}+005.11526 \mathrm{e}+005.11526 \mathrm{e}-011.00000 \mathrm{e}-092.12000 \mathrm{e}-01$ $5.11526 \mathrm{e}+005.11526 \mathrm{e}+00$ 5.11526e-01 1.00000e-09 2.12000e-01 $1.00000 \mathrm{e}-05$ 1.00000e-05 1.00000e-06 1.00000e-09 1.00000e-01 $1.00000 \mathrm{e}+001.00000 \mathrm{e}+001.00000 \mathrm{e}-011.00000 \mathrm{e}-091.00000 \mathrm{e}-01$ Element: 14020 \# of layers: 7

Kx Ky Kz Ss Por

$2.85959 \mathrm{e}+002.85959 \mathrm{e}+002.85959 \mathrm{e}-011.00000 \mathrm{e}-092.12000 \mathrm{e}-01$ $2.85959 \mathrm{e}+002.85959 \mathrm{e}+002.85959 \mathrm{e}-01$ 1.00000e-09 2.12000e-01 $2.85959 \mathrm{e}+002.85959 \mathrm{e}+002.85959 \mathrm{e}-011.00000 \mathrm{e}-092.12000 \mathrm{e}-01$ $2.85959 \mathrm{e}+002.85959 \mathrm{e}+002.85959 \mathrm{e}-01$ 1.00000e-09 2.12000e-01 $2.85959 \mathrm{e}+002.85959 \mathrm{e}+002.85959 \mathrm{e}-01$ 1.00000e-09 2.12000e-01 $1.00000 \mathrm{e}-05$ 1.00000e-05 1.00000e-06 1.00000e-09 1.00000e-01 $1.00000 \mathrm{e}+001.00000 \mathrm{e}+001.00000 \mathrm{e}-011.00000 \mathrm{e}-091.00000 \mathrm{e}-01$ Element: 14021 \# of layers: 7

Kx Ky Kz Ss Por

$2.85959 \mathrm{e}+002.85959 \mathrm{e}+002.85959 \mathrm{e}-01$ 1.00000e-09 2.12000e-01 $2.85959 \mathrm{e}+002.85959 \mathrm{e}+002.85959 \mathrm{e}-01$ 1.00000e-09 2.12000e-01 $2.85959 \mathrm{e}+002.85959 \mathrm{e}+002.85959 \mathrm{e}-01$ 1.00000e-09 2.12000e-01 $2.85959 \mathrm{e}+002.85959 \mathrm{e}+002.85959 \mathrm{e}-01$ 1.00000e-09 2.12000e-01 $2.85959 \mathrm{e}+002.85959 \mathrm{e}+002.85959 \mathrm{e}-01$ 1.00000e-09 2.12000e-01 $1.00000 \mathrm{e}-05$ 1.00000e-05 1.00000e-06 1.00000e-09 1.00000e-01 $1.00000 \mathrm{e}+001.00000 \mathrm{e}+001.00000 \mathrm{e}-011.00000 \mathrm{e}-091.00000 \mathrm{e}-01$ Element: 14022 \# of layers: 7

Kx Ky Kz Ss Por

$2.85959 \mathrm{e}+002.85959 \mathrm{e}+002.85959 \mathrm{e}-01$ 1.00000e-09 2.12000e-01 $2.85959 \mathrm{e}+002.85959 \mathrm{e}+002.85959 \mathrm{e}-011.00000 \mathrm{e}-092.12000 \mathrm{e}-01$ $2.85959 \mathrm{e}+002.85959 \mathrm{e}+002.85959 \mathrm{e}-01$ 1.00000e-09 2.12000e-01 $2.85959 \mathrm{e}+002.85959 \mathrm{e}+002.85959 \mathrm{e}-01$ 1.00000e-09 2.12000e-01 
$2.85959 \mathrm{e}+002.85959 \mathrm{e}+00$ 2.85959e-01 1.00000e-09 2.12000e-01 $1.00000 \mathrm{e}-05$ 1.00000e-05 1.00000e-06 1.00000e-09 1.00000e-01 $1.00000 \mathrm{e}+001.00000 \mathrm{e}+001.00000 \mathrm{e}-011.00000 \mathrm{e}-091.00000 \mathrm{e}-01$ Element: 14023 \# of layers: 7

Kx Ky Kz Ss Por

$2.85959 \mathrm{e}+002.85959 \mathrm{e}+002.85959 \mathrm{e}-01$ 1.00000e-09 2.12000e-01 $2.85959 \mathrm{e}+002.85959 \mathrm{e}+002.85959 \mathrm{e}-01$ 1.00000e-09 2.12000e-01 $2.85959 \mathrm{e}+002.85959 \mathrm{e}+002.85959 \mathrm{e}-01$ 1.00000e-09 2.12000e-01 $2.85959 \mathrm{e}+002.85959 \mathrm{e}+002.85959 \mathrm{e}-011.00000 \mathrm{e}-092.12000 \mathrm{e}-01$ $2.85959 \mathrm{e}+002.85959 \mathrm{e}+002.85959 \mathrm{e}-01$ 1.00000e-09 2.12000e-01 $1.00000 \mathrm{e}-05$ 1.00000e-05 1.00000e-06 1.00000e-09 1.00000e-01 $1.00000 \mathrm{e}+001.00000 \mathrm{e}+001.00000 \mathrm{e}-011.00000 \mathrm{e}-091.00000 \mathrm{e}-01$ Element: 14024 \# of layers: 7

Kx Ky Kz Ss Por

$4.90735 \mathrm{e}+004.90735 \mathrm{e}+00$ 4.90735e-01 1.00000e-09 2.12000e-01 $4.90735 \mathrm{e}+004.90735 \mathrm{e}+00$ 4.90735e-01 1.00000e-09 2.12000e-01 $4.90735 \mathrm{e}+004.90735 \mathrm{e}+004.90735 \mathrm{e}-011.00000 \mathrm{e}-092.12000 \mathrm{e}-01$ $4.90735 \mathrm{e}+004.90735 \mathrm{e}+00$ 4.90735e-01 1.00000e-09 2.12000e-01 $4.90735 \mathrm{e}+004.90735 \mathrm{e}+004.90735 \mathrm{e}-011.00000 \mathrm{e}-092.12000 \mathrm{e}-01$ $1.00000 \mathrm{e}-05$ 1.00000e-05 1.00000e-06 1.00000e-09 1.00000e-01 $1.00000 \mathrm{e}+001.00000 \mathrm{e}+001.00000 \mathrm{e}-011.00000 \mathrm{e}-091.00000 \mathrm{e}-01$ Element: 14025 \# of layers: 7

Kx Ky Kz Ss Por

$4.90735 \mathrm{e}+004.90735 \mathrm{e}+00$ 4.90735e-01 1.00000e-09 2.12000e-01 $4.90735 \mathrm{e}+004.90735 \mathrm{e}+004.90735 \mathrm{e}-011.00000 \mathrm{e}-09$ 2.12000e-01 $4.90735 \mathrm{e}+004.90735 \mathrm{e}+00$ 4.90735e-01 1.00000e-09 2.12000e-01 $4.90735 \mathrm{e}+004.90735 \mathrm{e}+004.90735 \mathrm{e}-011.00000 \mathrm{e}-092.12000 \mathrm{e}-01$ $4.90735 \mathrm{e}+004.90735 \mathrm{e}+00$ 4.90735e-01 1.00000e-09 2.12000e-01 $1.00000 \mathrm{e}-05$ 1.00000e-05 1.00000e-06 1.00000e-09 1.00000e-01 $1.00000 \mathrm{e}+001.00000 \mathrm{e}+001.00000 \mathrm{e}-011.00000 \mathrm{e}-091.00000 \mathrm{e}-01$ Element: 14026 \# of layers: 7

Kx Ky Kz Ss Por

$2.85959 \mathrm{e}+002.85959 \mathrm{e}+002.85959 \mathrm{e}-01$ 1.00000e-09 2.12000e-01 $2.85959 \mathrm{e}+002.85959 \mathrm{e}+002.85959 \mathrm{e}-01$ 1.00000e-09 2.12000e-01 $2.85959 \mathrm{e}+002.85959 \mathrm{e}+002.85959 \mathrm{e}-01$ 1.00000e-09 2.12000e-01 $2.85959 \mathrm{e}+002.85959 \mathrm{e}+002.85959 \mathrm{e}-011.00000 \mathrm{e}-092.12000 \mathrm{e}-01$ $2.85959 \mathrm{e}+002.85959 \mathrm{e}+002.85959 \mathrm{e}-01$ 1.00000e-09 2.12000e-01 $1.00000 \mathrm{e}-05$ 1.00000e-05 1.00000e-06 1.00000e-09 1.00000e-01 $1.00000 \mathrm{e}+001.00000 \mathrm{e}+001.00000 \mathrm{e}-011.00000 \mathrm{e}-091.00000 \mathrm{e}-01$ Element: 14027 \# of layers: 7

Kx Ky Kz Ss Por

$2.85959 \mathrm{e}+002.85959 \mathrm{e}+002.85959 \mathrm{e}-01$ 1.00000e-09 2.12000e-01 $2.85959 \mathrm{e}+002.85959 \mathrm{e}+002.85959 \mathrm{e}-01$ 1.00000e-09 2.12000e-01 $2.85959 \mathrm{e}+002.85959 \mathrm{e}+002.85959 \mathrm{e}-01$ 1.00000e-09 2.12000e-01 $2.85959 \mathrm{e}+002.85959 \mathrm{e}+002.85959 \mathrm{e}-01$ 1.00000e-09 2.12000e-01 $2.85959 \mathrm{e}+002.85959 \mathrm{e}+002.85959 \mathrm{e}-01$ 1.00000e-09 2.12000e-01 
$1.00000 \mathrm{e}-05$ 1.00000e-05 1.00000e-06 1.00000e-09 1.00000e-01 $1.00000 \mathrm{e}+001.00000 \mathrm{e}+001.00000 \mathrm{e}-01$ 1.00000e-09 1.00000e-01 Element: 14028 \# of layers: 7

Kx Ky Kz Ss Por

4.90735e+00 4.90735e+00 4.90735e-01 1.00000e-09 2.12000e-01 $4.90735 \mathrm{e}+004.90735 \mathrm{e}+00$ 4.90735e-01 1.00000e-09 2.12000e-01 $4.90735 \mathrm{e}+004.90735 \mathrm{e}+00$ 4.90735e-01 1.00000e-09 2.12000e-01 $4.90735 \mathrm{e}+00$ 4.90735e+00 4.90735e-01 1.00000e-09 2.12000e-01 $4.90735 \mathrm{e}+00$ 4.90735e+00 4.90735e-01 1.00000e-09 2.12000e-01 $1.00000 \mathrm{e}-05$ 1.00000e-05 1.00000e-06 1.00000e-09 1.00000e-01 $1.00000 \mathrm{e}+001.00000 \mathrm{e}+001.00000 \mathrm{e}-01$ 1.00000e-09 1.00000e-01 Element: 14029 \# of layers: 7

$\mathrm{Kx} \mathrm{Ky} \mathrm{Kz}$ Ss Por

4.90735e+00 4.90735e+00 4.90735e-01 1.00000e-09 2.12000e-01 4.90735e+00 4.90735e+00 4.90735e-01 1.00000e-09 2.12000e-01 $4.90735 \mathrm{e}+004.90735 \mathrm{e}+00$ 4.90735e-01 1.00000e-09 2.12000e-01 $4.90735 \mathrm{e}+004.90735 \mathrm{e}+00$ 4.90735e-01 1.00000e-09 2.12000e-01 $4.90735 \mathrm{e}+00$ 4.90735e+00 4.90735e-01 1.00000e-09 2.12000e-01 $1.00000 \mathrm{e}-05$ 1.00000e-05 1.00000e-06 1.00000e-09 1.00000e-01 $1.00000 \mathrm{e}+001.00000 \mathrm{e}+001.00000 \mathrm{e}-011.00000 \mathrm{e}-091.00000 \mathrm{e}-01$ Element: 14030 \# of layers: 7

$\mathrm{Kx} \mathrm{Ky} \mathrm{Kz}$ Ss Por

6.70942e+00 6.70942e+00 6.70942e-01 1.00000e-09 2.12000e-01 6.70942e+00 6.70942e+00 6.70942e-01 1.00000e-09 2.12000e-01 $6.70942 \mathrm{e}+00$ 6.70942e+00 6.70942e-01 1.00000e-09 2.12000e-01 6.70942e+00 6.70942e+00 6.70942e-01 1.00000e-09 2.12000e-01 $6.70942 \mathrm{e}+006.70942 \mathrm{e}+00$ 6.70942e-01 1.00000e-09 2.12000e-01 $1.00000 \mathrm{e}-05$ 1.00000e-05 1.00000e-06 1.00000e-09 1.00000e-01 $1.00000 \mathrm{e}+001.00000 \mathrm{e}+001.00000 \mathrm{e}-011.00000 \mathrm{e}-091.00000 \mathrm{e}-01$ Element: 14031 \# of layers: 7

$\mathrm{Kx} \mathrm{Ky} \mathrm{Kz}$ Ss Por

6.70942e+00 6.70942e+00 6.70942e-01 1.00000e-09 2.12000e-01 $6.70942 \mathrm{e}+00$ 6.70942e+00 6.70942e-01 1.00000e-09 2.12000e-01 $6.70942 \mathrm{e}+006.70942 \mathrm{e}+00$ 6.70942e-01 1.00000e-09 2.12000e-01 $6.70942 \mathrm{e}+00$ 6.70942e+00 6.70942e-01 1.00000e-09 2.12000e-01 6.70942e+00 6.70942e+00 6.70942e-01 1.00000e-09 2.12000e-01 $1.00000 \mathrm{e}-05$ 1.00000e-05 1.00000e-06 1.00000e-09 1.00000e-01 $1.00000 \mathrm{e}+001.00000 \mathrm{e}+001.00000 \mathrm{e}-011.00000 \mathrm{e}-091.00000 \mathrm{e}-01$ Element: 14032 \# of layers: 7

$\mathrm{Kx} \mathrm{Ky} \mathrm{Kz}$ Ss Por

6.70942e+00 6.70942e+00 6.70942e-01 1.00000e-09 2.12000e-01 $6.70942 \mathrm{e}+00$ 6.70942e+00 6.70942e-01 1.00000e-09 2.12000e-01 6.70942e+00 6.70942e+00 6.70942e-01 1.00000e-09 2.12000e-01 6.70942e+00 6.70942e+00 6.70942e-01 1.00000e-09 2.12000e-01 6.70942e+00 6.70942e+00 6.70942e-01 1.00000e-09 2.12000e-01 $1.00000 \mathrm{e}-05$ 1.00000e-05 1.00000e-06 1.00000e-09 1.00000e-01 
$1.00000 \mathrm{e}+001.00000 \mathrm{e}+001.00000 \mathrm{e}-01$ 1.00000e-09 1.00000e-01 Element: 14033 \# of layers: 7

Kx Ky Kz Ss Por

5.11526e+00 5.11526e+00 5.11526e-01 1.00000e-09 2.12000e-01

5.11526e+00 5.11526e+00 5.11526e-01 1.00000e-09 2.12000e-01

5.11526e+00 5.11526e+00 5.11526e-01 1.00000e-09 2.12000e-01

5.11526e+00 5.11526e+00 5.11526e-01 1.00000e-09 2.12000e-01

$5.11526 \mathrm{e}+005.11526 \mathrm{e}+00$ 5.11526e-01 1.00000e-09 2.12000e-01

$1.00000 \mathrm{e}-05$ 1.00000e-05 1.00000e-06 1.00000e-09 1.00000e-01

$1.00000 \mathrm{e}+001.00000 \mathrm{e}+001.00000 \mathrm{e}-011.00000 \mathrm{e}-091.00000 \mathrm{e}-01$

Element: 14034 \# of layers: 7

Kx Ky Kz Ss Por

5.11526e+00 5.11526e+00 5.11526e-01 1.00000e-09 2.12000e-01

$5.11526 \mathrm{e}+005.11526 \mathrm{e}+00$ 5.11526e-01 1.00000e-09 2.12000e-01

5.11526e+00 5.11526e+00 5.11526e-01 1.00000e-09 2.12000e-01

$5.11526 \mathrm{e}+005.11526 \mathrm{e}+00$ 5.11526e-01 1.00000e-09 2.12000e-01

$5.11526 \mathrm{e}+00$ 5.11526e+00 5.11526e-01 1.00000e-09 2.12000e-01

$1.00000 \mathrm{e}-05$ 1.00000e-05 1.00000e-06 1.00000e-09 1.00000e-01

$1.00000 \mathrm{e}+001.00000 \mathrm{e}+001.00000 \mathrm{e}-01$ 1.00000e-09 1.00000e-01

Element: 14035 \# of layers: 7

$\mathrm{Kx} \mathrm{Ky} \mathrm{Kz}$ Ss Por

2.85959e+00 2.85959e+00 2.85959e-01 1.00000e-09 2.12000e-01

$2.85959 \mathrm{e}+00$ 2.85959e+00 2.85959e-01 1.00000e-09 2.12000e-01

$2.85959 \mathrm{e}+002.85959 \mathrm{e}+00$ 2.85959e-01 1.00000e-09 2.12000e-01

$2.85959 \mathrm{e}+002.85959 \mathrm{e}+00$ 2.85959e-01 1.00000e-09 2.12000e-01

$2.85959 \mathrm{e}+002.85959 \mathrm{e}+00$ 2.85959e-01 1.00000e-09 2.12000e-01

$1.00000 \mathrm{e}-05$ 1.00000e-05 1.00000e-06 1.00000e-09 1.00000e-01

$1.00000 \mathrm{e}+001.00000 \mathrm{e}+001.00000 \mathrm{e}-01$ 1.00000e-09 1.00000e-01

Element: 14036 \# of layers: 7

$\mathrm{Kx} \mathrm{Ky} \mathrm{Kz}$ Ss Por

4.90735e+00 4.90735e+00 4.90735e-01 1.00000e-09 2.12000e-01 4.90735e+00 4.90735e+00 4.90735e-01 1.00000e-09 2.12000e-01 $4.90735 \mathrm{e}+004.90735 \mathrm{e}+00$ 4.90735e-01 1.00000e-09 2.12000e-01 $4.90735 \mathrm{e}+00$ 4.90735e+00 4.90735e-01 1.00000e-09 2.12000e-01 $4.90735 \mathrm{e}+004.90735 \mathrm{e}+00$ 4.90735e-01 1.00000e-09 2.12000e-01 $1.00000 \mathrm{e}-05$ 1.00000e-05 1.00000e-06 1.00000e-09 1.00000e-01

$1.00000 \mathrm{e}+001.00000 \mathrm{e}+001.00000 \mathrm{e}-011.00000 \mathrm{e}-091.00000 \mathrm{e}-01$ Element: 14037 \# of layers: 7

$\mathrm{Kx} \mathrm{Ky} \mathrm{Kz}$ Ss Por

6.70942e+00 6.70942e+00 6.70942e-01 1.00000e-09 2.12000e-01

6.70942e+00 6.70942e+00 6.70942e-01 1.00000e-09 2.12000e-01

6.70942e+00 6.70942e+00 6.70942e-01 1.00000e-09 2.12000e-01

6.70942e+00 6.70942e+00 6.70942e-01 1.00000e-09 2.12000e-01

6.70942e+00 6.70942e+00 6.70942e-01 1.00000e-09 2.12000e-01 $1.00000 \mathrm{e}-05$ 1.00000e-05 1.00000e-06 1.00000e-09 1.00000e-01

$1.00000 \mathrm{e}+001.00000 \mathrm{e}+001.00000 \mathrm{e}-011.00000 \mathrm{e}-091.00000 \mathrm{e}-01$ 
Element: 14038 \# of layers: 7

Kx Ky Kz Ss Por

7.11128e+00 7.11128e+00 7.11128e-01 1.00000e-09 2.12000e-01

$7.11128 \mathrm{e}+007.11128 \mathrm{e}+007.11128 \mathrm{e}-011.00000 \mathrm{e}-092.12000 \mathrm{e}-01$

$7.11128 \mathrm{e}+007.11128 \mathrm{e}+007.11128 \mathrm{e}-011.00000 \mathrm{e}-092.12000 \mathrm{e}-01$

$7.11128 \mathrm{e}+007.11128 \mathrm{e}+007.11128 \mathrm{e}-011.00000 \mathrm{e}-092.12000 \mathrm{e}-01$

$7.11128 \mathrm{e}+00$ 7.11128e+00 7.11128e-01 1.00000e-09 2.12000e-01

$1.00000 \mathrm{e}-05$ 1.00000e-05 1.00000e-06 1.00000e-09 1.00000e-01

$1.00000 \mathrm{e}+001.00000 \mathrm{e}+001.00000 \mathrm{e}-011.00000 \mathrm{e}-091.00000 \mathrm{e}-01$

Element: 14039 \# of layers: 7

Kx Ky Kz Ss Por

7.11128e+00 7.11128e+00 7.11128e-01 1.00000e-09 2.12000e-01

$7.11128 \mathrm{e}+007.11128 \mathrm{e}+00$ 7.11128e-01 1.00000e-09 2.12000e-01

$7.11128 \mathrm{e}+007.11128 \mathrm{e}+007.11128 \mathrm{e}-011.00000 \mathrm{e}-09$ 2.12000e-01

$7.11128 \mathrm{e}+007.11128 \mathrm{e}+00$ 7.11128e-01 1.00000e-09 2.12000e-01

$7.11128 \mathrm{e}+00$ 7.11128e+00 7.11128e-01 1.00000e-09 2.12000e-01

$1.00000 \mathrm{e}-05$ 1.00000e-05 1.00000e-06 1.00000e-09 1.00000e-01

$1.00000 \mathrm{e}+001.00000 \mathrm{e}+001.00000 \mathrm{e}-011.00000 \mathrm{e}-091.00000 \mathrm{e}-01$

Element: 14040 \# of layers: 7

Kx Ky Kz Ss Por

$7.11128 \mathrm{e}+00$ 7.11128e+00 7.11128e-01 1.00000e-09 2.12000e-01

$7.11128 \mathrm{e}+00$ 7.11128e+00 7.11128e-01 1.00000e-09 2.12000e-01

$7.11128 \mathrm{e}+007.11128 \mathrm{e}+007.11128 \mathrm{e}-01$ 1.00000e-09 2.12000e-01

$7.11128 \mathrm{e}+007.11128 \mathrm{e}+007.11128 \mathrm{e}-011.00000 \mathrm{e}-092.12000 \mathrm{e}-01$

$7.11128 \mathrm{e}+007.11128 \mathrm{e}+00$ 7.11128e-01 1.00000e-09 2.12000e-01

$1.00000 \mathrm{e}-05$ 1.00000e-05 1.00000e-06 1.00000e-09 1.00000e-01

$1.00000 \mathrm{e}+001.00000 \mathrm{e}+001.00000 \mathrm{e}-011.00000 \mathrm{e}-091.00000 \mathrm{e}-01$

Element: 14041 \# of layers: 7

Kx Ky Kz Ss Por

$7.11128 \mathrm{e}+00$ 7.11128e+00 7.11128e-01 1.00000e-09 2.12000e-01

$7.11128 \mathrm{e}+007.11128 \mathrm{e}+007.11128 \mathrm{e}-011.00000 \mathrm{e}-092.12000 \mathrm{e}-01$

$7.11128 \mathrm{e}+007.11128 \mathrm{e}+007.11128 \mathrm{e}-011.00000 \mathrm{e}-092.12000 \mathrm{e}-01$

$7.11128 \mathrm{e}+007.11128 \mathrm{e}+007.11128 \mathrm{e}-011.00000 \mathrm{e}-092.12000 \mathrm{e}-01$

$7.11128 \mathrm{e}+007.11128 \mathrm{e}+00$ 7.11128e-01 1.00000e-09 2.12000e-01

$1.00000 \mathrm{e}-05$ 1.00000e-05 1.00000e-06 1.00000e-09 1.00000e-01

$1.00000 \mathrm{e}+001.00000 \mathrm{e}+001.00000 \mathrm{e}-011.00000 \mathrm{e}-091.00000 \mathrm{e}-01$

Element: 14042 \# of layers: 7

Kx Ky Kz Ss Por

7.11128e+00 7.11128e+00 7.11128e-01 1.00000e-09 2.12000e-01

$7.11128 \mathrm{e}+007.11128 \mathrm{e}+007.11128 \mathrm{e}-011.00000 \mathrm{e}-092.12000 \mathrm{e}-01$

$7.11128 \mathrm{e}+007.11128 \mathrm{e}+00$ 7.11128e-01 1.00000e-09 2.12000e-01

$7.11128 \mathrm{e}+007.11128 \mathrm{e}+00$ 7.11128e-01 1.00000e-09 2.12000e-01

$7.11128 \mathrm{e}+00$ 7.11128e+00 7.11128e-01 1.00000e-09 2.12000e-01

$1.00000 \mathrm{e}-05$ 1.00000e-05 1.00000e-06 1.00000e-09 1.00000e-01

$1.00000 \mathrm{e}+001.00000 \mathrm{e}+001.00000 \mathrm{e}-011.00000 \mathrm{e}-091.00000 \mathrm{e}-01$

Element: 14043 \# of layers: 7 
Kx Ky Kz Ss Por

7.11128e+00 7.11128e+00 7.11128e-01 1.00000e-09 2.12000e-01

$7.11128 \mathrm{e}+00$ 7.11128e+00 7.11128e-01 1.00000e-09 2.12000e-01

$7.11128 \mathrm{e}+00$ 7.11128e+00 7.11128e-01 1.00000e-09 2.12000e-01

7.11128e+00 7.11128e+00 7.11128e-01 1.00000e-09 2.12000e-01

7.11128e+00 7.11128e+00 7.11128e-01 1.00000e-09 2.12000e-01

$1.00000 \mathrm{e}-05$ 1.00000e-05 1.00000e-06 1.00000e-09 1.00000e-01

$1.00000 \mathrm{e}+001.00000 \mathrm{e}+001.00000 \mathrm{e}-011.00000 \mathrm{e}-091.00000 \mathrm{e}-01$

Element: 14044 \# of layers: 7

$\mathrm{Kx} \mathrm{Ky} \mathrm{Kz}$ Ss Por

7.11128e+00 7.11128e+00 7.11128e-01 1.00000e-09 2.12000e-01

$7.11128 \mathrm{e}+00$ 7.11128e+00 7.11128e-01 1.00000e-09 2.12000e-01

$7.11128 \mathrm{e}+00$ 7.11128e+00 7.11128e-01 1.00000e-09 2.12000e-01

$7.11128 \mathrm{e}+00$ 7.11128e+00 7.11128e-01 1.00000e-09 2.12000e-01

7.11128e+00 7.11128e+00 7.11128e-01 1.00000e-09 2.12000e-01

$1.00000 \mathrm{e}-05$ 1.00000e-05 1.00000e-06 1.00000e-09 1.00000e-01

$1.00000 \mathrm{e}+001.00000 \mathrm{e}+001.00000 \mathrm{e}-01$ 1.00000e-09 1.00000e-01

Element: 14045 \# of layers: 7

$\mathrm{Kx} \mathrm{Ky} \mathrm{Kz}$ Ss Por

7.11128e+00 7.11128e+00 7.11128e-01 1.00000e-09 2.12000e-01

7.11128e+00 7.11128e+00 7.11128e-01 1.00000e-09 2.12000e-01

7.11128e+00 7.11128e+00 7.11128e-01 1.00000e-09 2.12000e-01

7.11128e+00 7.11128e+00 7.11128e-01 1.00000e-09 2.12000e-01

$7.11128 \mathrm{e}+00$ 7.11128e+00 7.11128e-01 1.00000e-09 2.12000e-01

$1.00000 \mathrm{e}-05$ 1.00000e-05 1.00000e-06 1.00000e-09 1.00000e-01

$1.00000 \mathrm{e}+001.00000 \mathrm{e}+001.00000 \mathrm{e}-01$ 1.00000e-09 1.00000e-01

Element: 14046 \# of layers: 7

$\mathrm{Kx} \mathrm{Ky} \mathrm{Kz}$ Ss Por

7.11128e+00 7.11128e+00 7.11128e-01 1.00000e-09 2.12000e-01

7.11128e+00 7.11128e+00 7.11128e-01 1.00000e-09 2.12000e-01

$7.11128 \mathrm{e}+00$ 7.11128e+00 7.11128e-01 1.00000e-09 2.12000e-01

$7.11128 \mathrm{e}+00$ 7.11128e+00 7.11128e-01 1.00000e-09 2.12000e-01

$7.11128 \mathrm{e}+007.11128 \mathrm{e}+00$ 7.11128e-01 1.00000e-09 2.12000e-01

$1.00000 \mathrm{e}-05$ 1.00000e-05 1.00000e-06 1.00000e-09 1.00000e-01

$1.00000 \mathrm{e}+001.00000 \mathrm{e}+001.00000 \mathrm{e}-011.00000 \mathrm{e}-091.00000 \mathrm{e}-01$

Element: 14047 \# of layers: 7

Kx Ky Kz Ss Por

7.11128e+00 7.11128e+00 7.11128e-01 1.00000e-09 2.12000e-01

7.11128e+00 7.11128e+00 7.11128e-01 1.00000e-09 2.12000e-01

7.11128e+00 7.11128e+00 7.11128e-01 1.00000e-09 2.12000e-01

$7.11128 \mathrm{e}+00$ 7.11128e+00 7.11128e-01 1.00000e-09 2.12000e-01

7.11128e+00 7.11128e+00 7.11128e-01 1.00000e-09 2.12000e-01 $1.00000 \mathrm{e}-05$ 1.00000e-05 1.00000e-06 1.00000e-09 1.00000e-01

$1.00000 \mathrm{e}+001.00000 \mathrm{e}+001.00000 \mathrm{e}-01$ 1.00000e-09 1.00000e-01

Element: 14048 \# of layers: 7

Kx Ky Kz Ss Por 
7.37003e+00 7.37003e+00 7.37003e-01 1.00000e-09 2.12000e-01

$7.37003 \mathrm{e}+00$ 7.37003e+00 7.37003e-01 1.00000e-09 2.12000e-01

$7.37003 \mathrm{e}+00$ 7.37003e+00 7.37003e-01 1.00000e-09 2.12000e-01

$7.37003 \mathrm{e}+00$ 7.37003e+00 7.37003e-01 1.00000e-09 2.12000e-01

$7.37003 \mathrm{e}+00$ 7.37003e+00 7.37003e-01 1.00000e-09 2.12000e-01

$1.00000 \mathrm{e}-05$ 1.00000e-05 1.00000e-06 1.00000e-09 1.00000e-01

$1.00000 \mathrm{e}+001.00000 \mathrm{e}+001.00000 \mathrm{e}-011.00000 \mathrm{e}-091.00000 \mathrm{e}-01$

Element: 14049 \# of layers: 7

$\mathrm{Kx} \mathrm{Ky} \mathrm{Kz}$ Ss Por

7.37003e+00 7.37003e+00 7.37003e-01 1.00000e-09 2.12000e-01

$7.37003 \mathrm{e}+00$ 7.37003e+00 7.37003e-01 1.00000e-09 2.12000e-01

$7.37003 \mathrm{e}+00$ 7.37003e+00 7.37003e-01 1.00000e-09 2.12000e-01

$7.37003 \mathrm{e}+00$ 7.37003e+00 7.37003e-01 1.00000e-09 2.12000e-01

$7.37003 \mathrm{e}+00$ 7.37003e+00 7.37003e-01 1.00000e-09 2.12000e-01

$1.00000 \mathrm{e}-05$ 1.00000e-05 1.00000e-06 1.00000e-09 1.00000e-01

$1.00000 \mathrm{e}+001.00000 \mathrm{e}+001.00000 \mathrm{e}-011.00000 \mathrm{e}-091.00000 \mathrm{e}-01$

Element: 14050 \# of layers: 7

Kx Ky Kz Ss Por

7.37003e+00 7.37003e+00 7.37003e-01 1.00000e-09 2.12000e-01

$7.37003 \mathrm{e}+00$ 7.37003e+00 7.37003e-01 1.00000e-09 2.12000e-01

$7.37003 \mathrm{e}+00$ 7.37003e+00 7.37003e-01 1.00000e-09 2.12000e-01

$7.37003 \mathrm{e}+00$ 7.37003e+00 7.37003e-01 1.00000e-09 2.12000e-01

$7.37003 \mathrm{e}+00$ 7.37003e+00 7.37003e-01 1.00000e-09 2.12000e-01

$1.00000 \mathrm{e}-05$ 1.00000e-05 1.00000e-06 1.00000e-09 1.00000e-01

$1.00000 \mathrm{e}+001.00000 \mathrm{e}+001.00000 \mathrm{e}-011.00000 \mathrm{e}-091.00000 \mathrm{e}-01$

Element: 14051 \# of layers: 7

Kx Ky Kz Ss Por

7.37003e+00 7.37003e+00 7.37003e-01 1.00000e-09 2.12000e-01

$7.37003 \mathrm{e}+00$ 7.37003e+00 7.37003e-01 1.00000e-09 2.12000e-01

$7.37003 \mathrm{e}+00$ 7.37003e+00 7.37003e-01 1.00000e-09 2.12000e-01

$7.37003 \mathrm{e}+00$ 7.37003e+00 7.37003e-01 1.00000e-09 2.12000e-01

$7.37003 \mathrm{e}+00$ 7.37003e+00 7.37003e-01 1.00000e-09 2.12000e-01

$1.00000 \mathrm{e}-05$ 1.00000e-05 1.00000e-06 1.00000e-09 1.00000e-01

$1.00000 \mathrm{e}+001.00000 \mathrm{e}+001.00000 \mathrm{e}-011.00000 \mathrm{e}-091.00000 \mathrm{e}-01$

Element: 14052 \# of layers: 7

Kx Ky Kz Ss Por

7.37003e+00 7.37003e+00 7.37003e-01 1.00000e-09 2.12000e-01

$7.37003 \mathrm{e}+00$ 7.37003e+00 7.37003e-01 1.00000e-09 2.12000e-01

$7.37003 \mathrm{e}+00$ 7.37003e+00 7.37003e-01 1.00000e-09 2.12000e-01

$7.37003 \mathrm{e}+00$ 7.37003e+00 7.37003e-01 1.00000e-09 2.12000e-01

$7.37003 \mathrm{e}+00$ 7.37003e+00 7.37003e-01 1.00000e-09 2.12000e-01

$1.00000 \mathrm{e}-05$ 1.00000e-05 1.00000e-06 1.00000e-09 1.00000e-01

$1.00000 \mathrm{e}+001.00000 \mathrm{e}+001.00000 \mathrm{e}-011.00000 \mathrm{e}-091.00000 \mathrm{e}-01$

Element: 14053 \# of layers: 7

Kx Ky Kz Ss Por

7.11128e+00 7.11128e+00 7.11128e-01 1.00000e-09 2.12000e-01 
$7.11128 \mathrm{e}+007.11128 \mathrm{e}+00$ 7.11128e-01 1.00000e-09 2.12000e-01 $7.11128 \mathrm{e}+007.11128 \mathrm{e}+007.11128 \mathrm{e}-01$ 1.00000e-09 2.12000e-01 $7.11128 \mathrm{e}+007.11128 \mathrm{e}+00$ 7.11128e-01 1.00000e-09 2.12000e-01 $7.11128 \mathrm{e}+00$ 7.11128e+00 7.11128e-01 1.00000e-09 2.12000e-01 $1.00000 \mathrm{e}-05$ 1.00000e-05 1.00000e-06 1.00000e-09 1.00000e-01 $1.00000 \mathrm{e}+001.00000 \mathrm{e}+001.00000 \mathrm{e}-011.00000 \mathrm{e}-091.00000 \mathrm{e}-01$ Element: 14054 \# of layers: 7

Kx Ky Kz Ss Por

7.11128e+00 7.11128e+00 7.11128e-01 1.00000e-09 2.12000e-01 $7.11128 \mathrm{e}+007.11128 \mathrm{e}+007.11128 \mathrm{e}-01$ 1.00000e-09 2.12000e-01 $7.11128 \mathrm{e}+007.11128 \mathrm{e}+007.11128 \mathrm{e}-011.00000 \mathrm{e}-092.12000 \mathrm{e}-01$ $7.11128 \mathrm{e}+007.11128 \mathrm{e}+007.11128 \mathrm{e}-011.00000 \mathrm{e}-09$ 2.12000e-01 $7.11128 \mathrm{e}+007.11128 \mathrm{e}+00$ 7.11128e-01 1.00000e-09 2.12000e-01 $1.00000 \mathrm{e}-05$ 1.00000e-05 1.00000e-06 1.00000e-09 1.00000e-01 $1.00000 \mathrm{e}+001.00000 \mathrm{e}+001.00000 \mathrm{e}-011.00000 \mathrm{e}-091.00000 \mathrm{e}-01$ Element: 14055 \# of layers: 7

Kx Ky Kz Ss Por

7.37003e+00 7.37003e+00 7.37003e-01 1.00000e-09 2.12000e-01 $7.37003 \mathrm{e}+00$ 7.37003e+00 7.37003e-01 1.00000e-09 2.12000e-01 $7.37003 \mathrm{e}+00$ 7.37003e+00 7.37003e-01 1.00000e-09 2.12000e-01 $7.37003 \mathrm{e}+00$ 7.37003e+00 7.37003e-01 1.00000e-09 2.12000e-01 7.37003e+00 7.37003e+00 7.37003e-01 1.00000e-09 2.12000e-01 $1.00000 \mathrm{e}-05$ 1.00000e-05 1.00000e-06 1.00000e-09 1.00000e-01 $1.00000 \mathrm{e}+001.00000 \mathrm{e}+001.00000 \mathrm{e}-011.00000 \mathrm{e}-091.00000 \mathrm{e}-01$ Element: 14056 \# of layers: 7

Kx Ky Kz Ss Por

7.37003e+00 7.37003e+00 7.37003e-01 1.00000e-09 2.12000e-01 $7.37003 \mathrm{e}+00$ 7.37003e+00 7.37003e-01 1.00000e-09 2.12000e-01 $7.37003 \mathrm{e}+00$ 7.37003e+00 7.37003e-01 1.00000e-09 2.12000e-01 $7.37003 \mathrm{e}+00$ 7.37003e+00 7.37003e-01 1.00000e-09 2.12000e-01 $7.37003 \mathrm{e}+00$ 7.37003e+00 7.37003e-01 1.00000e-09 2.12000e-01 $1.00000 \mathrm{e}-05$ 1.00000e-05 1.00000e-06 1.00000e-09 1.00000e-01 $1.00000 \mathrm{e}+001.00000 \mathrm{e}+001.00000 \mathrm{e}-011.00000 \mathrm{e}-091.00000 \mathrm{e}-01$ Element: 14057 \# of layers: 7

Kx Ky Kz Ss Por

7.37003e+00 7.37003e+00 7.37003e-01 1.00000e-09 2.12000e-01 $7.37003 \mathrm{e}+00$ 7.37003e+00 7.37003e-01 1.00000e-09 2.12000e-01 $7.37003 \mathrm{e}+00$ 7.37003e+00 7.37003e-01 1.00000e-09 2.12000e-01 $7.37003 \mathrm{e}+00$ 7.37003e+00 7.37003e-01 1.00000e-09 2.12000e-01 $7.37003 \mathrm{e}+00$ 7.37003e+00 7.37003e-01 1.00000e-09 2.12000e-01 $1.00000 \mathrm{e}-05$ 1.00000e-05 1.00000e-06 1.00000e-09 1.00000e-01 $1.00000 \mathrm{e}+001.00000 \mathrm{e}+001.00000 \mathrm{e}-011.00000 \mathrm{e}-091.00000 \mathrm{e}-01$ Element: 14058 \# of layers: 7

Kx Ky Kz Ss Por

7.37003e+00 7.37003e+00 7.37003e-01 1.00000e-09 2.12000e-01 $7.37003 \mathrm{e}+00$ 7.37003e+00 7.37003e-01 1.00000e-09 2.12000e-01 
7.37003e+00 7.37003e+00 7.37003e-01 1.00000e-09 2.12000e-01 $7.37003 \mathrm{e}+00$ 7.37003e+00 7.37003e-01 1.00000e-09 2.12000e-01 $7.37003 \mathrm{e}+00$ 7.37003e+00 7.37003e-01 1.00000e-09 2.12000e-01 $1.00000 \mathrm{e}-05$ 1.00000e-05 1.00000e-06 1.00000e-09 1.00000e-01 $1.00000 \mathrm{e}+001.00000 \mathrm{e}+001.00000 \mathrm{e}-011.00000 \mathrm{e}-091.00000 \mathrm{e}-01$ Element: 14059 \# of layers: 7

Kx Ky Kz Ss Por

7.37003e+00 7.37003e+00 7.37003e-01 1.00000e-09 2.12000e-01 $7.37003 \mathrm{e}+00$ 7.37003e+00 7.37003e-01 1.00000e-09 2.12000e-01

$7.37003 \mathrm{e}+00$ 7.37003e+00 7.37003e-01 1.00000e-09 2.12000e-01 $7.37003 \mathrm{e}+00$ 7.37003e+00 7.37003e-01 1.00000e-09 2.12000e-01 $7.37003 \mathrm{e}+00$ 7.37003e+00 7.37003e-01 1.00000e-09 2.12000e-01 $1.00000 \mathrm{e}-05$ 1.00000e-05 1.00000e-06 1.00000e-09 1.00000e-01 $1.00000 \mathrm{e}+001.00000 \mathrm{e}+001.00000 \mathrm{e}-011.00000 \mathrm{e}-091.00000 \mathrm{e}-01$ Element: 14060 \# of layers: 7

Kx Ky Kz Ss Por

7.37003e+00 7.37003e+00 7.37003e-01 1.00000e-09 2.12000e-01 $7.37003 \mathrm{e}+00$ 7.37003e+00 7.37003e-01 1.00000e-09 2.12000e-01 $7.37003 \mathrm{e}+00$ 7.37003e+00 7.37003e-01 1.00000e-09 2.12000e-01 $7.37003 \mathrm{e}+00$ 7.37003e+00 7.37003e-01 1.00000e-09 2.12000e-01 $7.37003 \mathrm{e}+00$ 7.37003e+00 7.37003e-01 1.00000e-09 2.12000e-01 $1.00000 \mathrm{e}-05$ 1.00000e-05 1.00000e-06 1.00000e-09 1.00000e-01 $1.00000 \mathrm{e}+001.00000 \mathrm{e}+001.00000 \mathrm{e}-011.00000 \mathrm{e}-091.00000 \mathrm{e}-01$ Element: 14061 \# of layers: 7

Kx Ky Kz Ss Por

7.37003e+00 7.37003e+00 7.37003e-01 1.00000e-09 2.12000e-01

$7.37003 \mathrm{e}+007.37003 \mathrm{e}+00$ 7.37003e-01 1.00000e-09 2.12000e-01

$7.37003 \mathrm{e}+00$ 7.37003e+00 7.37003e-01 1.00000e-09 2.12000e-01

$7.37003 \mathrm{e}+00$ 7.37003e+00 7.37003e-01 1.00000e-09 2.12000e-01 $7.37003 \mathrm{e}+00$ 7.37003e+00 7.37003e-01 1.00000e-09 2.12000e-01 $1.00000 \mathrm{e}-05$ 1.00000e-05 1.00000e-06 1.00000e-09 1.00000e-01 $1.00000 \mathrm{e}+001.00000 \mathrm{e}+001.00000 \mathrm{e}-011.00000 \mathrm{e}-091.00000 \mathrm{e}-01$ Element: 14062 \# of layers: 7

Kx Ky Kz Ss Por

7.37003e+00 7.37003e+00 7.37003e-01 1.00000e-09 2.12000e-01 $7.37003 \mathrm{e}+00$ 7.37003e+00 7.37003e-01 1.00000e-09 2.12000e-01 $7.37003 \mathrm{e}+00$ 7.37003e+00 7.37003e-01 1.00000e-09 2.12000e-01 $7.37003 \mathrm{e}+00$ 7.37003e+00 7.37003e-01 1.00000e-09 2.12000e-01 $7.37003 \mathrm{e}+00$ 7.37003e+00 7.37003e-01 1.00000e-09 2.12000e-01 $1.00000 \mathrm{e}-05$ 1.00000e-05 1.00000e-06 1.00000e-09 1.00000e-01 $1.00000 \mathrm{e}+001.00000 \mathrm{e}+001.00000 \mathrm{e}-011.00000 \mathrm{e}-091.00000 \mathrm{e}-01$ Element: 14063 \# of layers: 7

Kx Ky Kz Ss Por

7.37003e+00 7.37003e+00 7.37003e-01 1.00000e-09 2.12000e-01 $7.37003 \mathrm{e}+00$ 7.37003e+00 7.37003e-01 1.00000e-09 2.12000e-01 $7.37003 \mathrm{e}+00$ 7.37003e+00 7.37003e-01 1.00000e-09 2.12000e-01 
7.37003e+00 7.37003e+00 7.37003e-01 1.00000e-09 2.12000e-01 7.37003e+00 7.37003e+00 7.37003e-01 1.00000e-09 2.12000e-01 $1.00000 \mathrm{e}-05$ 1.00000e-05 1.00000e-06 1.00000e-09 1.00000e-01 $1.00000 \mathrm{e}+001.00000 \mathrm{e}+001.00000 \mathrm{e}-011.00000 \mathrm{e}-091.00000 \mathrm{e}-01$ Element: 14064 \# of layers: 7

Kx Ky Kz Ss Por

7.37003e+00 7.37003e+00 7.37003e-01 1.00000e-09 2.12000e-01 $7.37003 \mathrm{e}+00$ 7.37003e+00 7.37003e-01 1.00000e-09 2.12000e-01 $7.37003 \mathrm{e}+007.37003 \mathrm{e}+00$ 7.37003e-01 1.00000e-09 2.12000e-01 $7.37003 \mathrm{e}+00$ 7.37003e+00 7.37003e-01 1.00000e-09 2.12000e-01 $7.37003 \mathrm{e}+00$ 7.37003e+00 7.37003e-01 1.00000e-09 2.12000e-01 $1.00000 \mathrm{e}-05$ 1.00000e-05 1.00000e-06 1.00000e-09 1.00000e-01 $1.00000 \mathrm{e}+001.00000 \mathrm{e}+001.00000 \mathrm{e}-011.00000 \mathrm{e}-091.00000 \mathrm{e}-01$ Element: 14065 \# of layers: 7

Kx Ky Kz Ss Por

7.37003e+00 7.37003e+00 7.37003e-01 1.00000e-09 2.12000e-01 $7.37003 \mathrm{e}+00$ 7.37003e+00 7.37003e-01 1.00000e-09 2.12000e-01 $7.37003 \mathrm{e}+00$ 7.37003e+00 7.37003e-01 1.00000e-09 2.12000e-01 $7.37003 \mathrm{e}+00$ 7.37003e+00 7.37003e-01 1.00000e-09 2.12000e-01 $7.37003 \mathrm{e}+00$ 7.37003e+00 7.37003e-01 1.00000e-09 2.12000e-01 $1.00000 \mathrm{e}-05$ 1.00000e-05 1.00000e-06 1.00000e-09 1.00000e-01 $1.00000 \mathrm{e}+001.00000 \mathrm{e}+001.00000 \mathrm{e}-011.00000 \mathrm{e}-091.00000 \mathrm{e}-01$ Element: 14066 \# of layers: 7

Kx Ky Kz Ss Por

7.37003e+00 7.37003e+00 7.37003e-01 1.00000e-09 2.12000e-01 $7.37003 \mathrm{e}+00$ 7.37003e+00 7.37003e-01 1.00000e-09 2.12000e-01 $7.37003 \mathrm{e}+007.37003 \mathrm{e}+00$ 7.37003e-01 1.00000e-09 2.12000e-01 $7.37003 \mathrm{e}+007.37003 \mathrm{e}+007.37003 \mathrm{e}-011.00000 \mathrm{e}-092.12000 \mathrm{e}-01$ $7.37003 \mathrm{e}+00$ 7.37003e+00 7.37003e-01 1.00000e-09 2.12000e-01 $1.00000 \mathrm{e}-05$ 1.00000e-05 1.00000e-06 1.00000e-09 1.00000e-01 $1.00000 \mathrm{e}+001.00000 \mathrm{e}+001.00000 \mathrm{e}-011.00000 \mathrm{e}-091.00000 \mathrm{e}-01$ Element: 14067 \# of layers: 7

Kx Ky Kz Ss Por

$8.20390 \mathrm{e}+008.20390 \mathrm{e}+00$ 8.20390e-01 1.00000e-09 2.12000e-01 $8.20390 \mathrm{e}+008.20390 \mathrm{e}+008.20390 \mathrm{e}-01$ 1.00000e-09 2.12000e-01 $8.20390 \mathrm{e}+008.20390 \mathrm{e}+008.20390 \mathrm{e}-01$ 1.00000e-09 2.12000e-01 $8.20390 \mathrm{e}+008.20390 \mathrm{e}+008.20390 \mathrm{e}-011.00000 \mathrm{e}-092.12000 \mathrm{e}-01$ $8.20390 \mathrm{e}+008.20390 \mathrm{e}+00$ 8.20390e-01 1.00000e-09 2.12000e-01 $1.00000 \mathrm{e}-05$ 1.00000e-05 1.00000e-06 1.00000e-09 1.00000e-01 $1.00000 \mathrm{e}+001.00000 \mathrm{e}+001.00000 \mathrm{e}-011.00000 \mathrm{e}-091.00000 \mathrm{e}-01$ Element: 14068 \# of layers: 7

Kx Ky Kz Ss Por

$8.20390 \mathrm{e}+00$ 8.20390e+00 8.20390e-01 1.00000e-09 2.12000e-01 $8.20390 \mathrm{e}+008.20390 \mathrm{e}+00$ 8.20390e-01 1.00000e-09 2.12000e-01 $8.20390 \mathrm{e}+008.20390 \mathrm{e}+008.20390 \mathrm{e}-011.00000 \mathrm{e}-092.12000 \mathrm{e}-01$ $8.20390 \mathrm{e}+008.20390 \mathrm{e}+00$ 8.20390e-01 1.00000e-09 2.12000e-01 
$8.20390 \mathrm{e}+00$ 8.20390e+00 8.20390e-01 1.00000e-09 2.12000e-01 $1.00000 \mathrm{e}-05$ 1.00000e-05 1.00000e-06 1.00000e-09 1.00000e-01 $1.00000 \mathrm{e}+001.00000 \mathrm{e}+001.00000 \mathrm{e}-011.00000 \mathrm{e}-09$ 1.00000e-01 Element: 14069 \# of layers: 7

$\mathrm{Kx} \mathrm{Ky} \mathrm{Kz}$ Ss Por

8.20390e+00 8.20390e+00 8.20390e-01 1.00000e-09 2.12000e-01 $8.20390 \mathrm{e}+00$ 8.20390e+00 8.20390e-01 1.00000e-09 2.12000e-01 $8.20390 \mathrm{e}+00$ 8.20390e+00 8.20390e-01 1.00000e-09 2.12000e-01 $8.20390 \mathrm{e}+00$ 8.20390e+00 8.20390e-01 1.00000e-09 2.12000e-01 $8.20390 \mathrm{e}+008.20390 \mathrm{e}+00$ 8.20390e-01 1.00000e-09 2.12000e-01 $1.00000 \mathrm{e}-05$ 1.00000e-05 1.00000e-06 1.00000e-09 1.00000e-01 $1.00000 \mathrm{e}+001.00000 \mathrm{e}+001.00000 \mathrm{e}-01$ 1.00000e-09 1.00000e-01 Element: 14070 \# of layers: 7

$\mathrm{Kx} \mathrm{Ky} \mathrm{Kz}$ Ss Por

7.37003e+00 7.37003e+00 7.37003e-01 1.00000e-09 2.12000e-01 7.37003e+00 7.37003e+00 7.37003e-01 1.00000e-09 2.12000e-01 7.37003e+00 7.37003e+00 7.37003e-01 1.00000e-09 2.12000e-01 7.37003e+00 7.37003e+00 7.37003e-01 1.00000e-09 2.12000e-01 7.37003e+00 7.37003e+00 7.37003e-01 1.00000e-09 2.12000e-01 $1.00000 \mathrm{e}-05$ 1.00000e-05 1.00000e-06 1.00000e-09 1.00000e-01 $1.00000 \mathrm{e}+001.00000 \mathrm{e}+001.00000 \mathrm{e}-011.00000 \mathrm{e}-091.00000 \mathrm{e}-01$ Element: 14071 \# of layers: 7

$\mathrm{Kx} \mathrm{Ky} \mathrm{Kz}$ Ss Por

7.37003e+00 7.37003e+00 7.37003e-01 1.00000e-09 2.12000e-01 $7.37003 \mathrm{e}+00$ 7.37003e+00 7.37003e-01 1.00000e-09 2.12000e-01 7.37003e+00 7.37003e+00 7.37003e-01 1.00000e-09 2.12000e-01 7.37003e+00 7.37003e+00 7.37003e-01 1.00000e-09 2.12000e-01 7.37003e+00 7.37003e+00 7.37003e-01 1.00000e-09 2.12000e-01 $1.00000 \mathrm{e}-05$ 1.00000e-05 1.00000e-06 1.00000e-09 1.00000e-01 $1.00000 \mathrm{e}+001.00000 \mathrm{e}+001.00000 \mathrm{e}-011.00000 \mathrm{e}-091.00000 \mathrm{e}-01$ Element: 14072 \# of layers: 7

$\mathrm{Kx} \mathrm{Ky} \mathrm{Kz}$ Ss Por

7.37003e+00 7.37003e+00 7.37003e-01 1.00000e-09 2.12000e-01 7.37003e+00 7.37003e+00 7.37003e-01 1.00000e-09 2.12000e-01 7.37003e+00 7.37003e+00 7.37003e-01 1.00000e-09 2.12000e-01 7.37003e+00 7.37003e+00 7.37003e-01 1.00000e-09 2.12000e-01 7.37003e+00 7.37003e+00 7.37003e-01 1.00000e-09 2.12000e-01 $1.00000 \mathrm{e}-05$ 1.00000e-05 1.00000e-06 1.00000e-09 1.00000e-01 $1.00000 \mathrm{e}+001.00000 \mathrm{e}+001.00000 \mathrm{e}-01$ 1.00000e-09 1.00000e-01 Element: 14073 \# of layers: 7

$\mathrm{Kx} \mathrm{Ky} \mathrm{Kz}$ Ss Por

7.37003e+00 7.37003e+00 7.37003e-01 1.00000e-09 2.12000e-01 7.37003e+00 7.37003e+00 7.37003e-01 1.00000e-09 2.12000e-01 7.37003e+00 7.37003e+00 7.37003e-01 1.00000e-09 2.12000e-01 7.37003e+00 7.37003e+00 7.37003e-01 1.00000e-09 2.12000e-01 $7.37003 e+007.37003 e+00$ 7.37003e-01 1.00000e-09 2.12000e-01 
$1.00000 \mathrm{e}-05$ 1.00000e-05 1.00000e-06 1.00000e-09 1.00000e-01 $1.00000 \mathrm{e}+001.00000 \mathrm{e}+001.00000 \mathrm{e}-01$ 1.00000e-09 1.00000e-01 Element: 14074 \# of layers: 7

Kx Ky Kz Ss Por

8.20390e+00 8.20390e+00 8.20390e-01 1.00000e-09 2.12000e-01 $8.20390 \mathrm{e}+008.20390 \mathrm{e}+00$ 8.20390e-01 1.00000e-09 2.12000e-01 $8.20390 \mathrm{e}+00$ 8.20390e+00 8.20390e-01 1.00000e-09 2.12000e-01 $8.20390 \mathrm{e}+00$ 8.20390e+00 8.20390e-01 1.00000e-09 2.12000e-01 $8.20390 \mathrm{e}+00$ 8.20390e+00 8.20390e-01 1.00000e-09 2.12000e-01 $1.00000 \mathrm{e}-05$ 1.00000e-05 1.00000e-06 1.00000e-09 1.00000e-01 $1.00000 \mathrm{e}+001.00000 \mathrm{e}+001.00000 \mathrm{e}-011.00000 \mathrm{e}-091.00000 \mathrm{e}-01$ Element: 14075 \# of layers: 7

$\mathrm{Kx} \mathrm{Ky} \mathrm{Kz}$ Ss Por

8.20390e+00 8.20390e+00 8.20390e-01 1.00000e-09 2.12000e-01 8.20390e+00 8.20390e+00 8.20390e-01 1.00000e-09 2.12000e-01 $8.20390 \mathrm{e}+00$ 8.20390e+00 8.20390e-01 1.00000e-09 2.12000e-01 $8.20390 \mathrm{e}+00$ 8.20390e+00 8.20390e-01 1.00000e-09 2.12000e-01 8.20390e+00 8.20390e+00 8.20390e-01 1.00000e-09 2.12000e-01 $1.00000 \mathrm{e}-05$ 1.00000e-05 1.00000e-06 1.00000e-09 1.00000e-01 $1.00000 \mathrm{e}+001.00000 \mathrm{e}+001.00000 \mathrm{e}-011.00000 \mathrm{e}-091.00000 \mathrm{e}-01$ Element: 14076 \# of layers: 7

$\mathrm{Kx} \mathrm{Ky} \mathrm{Kz}$ Ss Por

8.20390e+00 8.20390e+00 8.20390e-01 1.00000e-09 2.12000e-01 $8.20390 \mathrm{e}+00$ 8.20390e+00 8.20390e-01 1.00000e-09 2.12000e-01 $8.20390 \mathrm{e}+008.20390 \mathrm{e}+00$ 8.20390e-01 1.00000e-09 2.12000e-01 $8.20390 \mathrm{e}+008.20390 \mathrm{e}+00$ 8.20390e-01 1.00000e-09 2.12000e-01 $8.20390 \mathrm{e}+008.20390 \mathrm{e}+00$ 8.20390e-01 1.00000e-09 2.12000e-01 $1.00000 \mathrm{e}-05$ 1.00000e-05 1.00000e-06 1.00000e-09 1.00000e-01 $1.00000 \mathrm{e}+001.00000 \mathrm{e}+001.00000 \mathrm{e}-011.00000 \mathrm{e}-091.00000 \mathrm{e}-01$ Element: 14077 \# of layers: 7

$\mathrm{Kx} \mathrm{Ky} \mathrm{Kz}$ Ss Por

8.20390e+00 8.20390e+00 8.20390e-01 1.00000e-09 2.12000e-01 $8.20390 \mathrm{e}+00$ 8.20390e+00 8.20390e-01 1.00000e-09 2.12000e-01 $8.20390 \mathrm{e}+008.20390 \mathrm{e}+00$ 8.20390e-01 1.00000e-09 2.12000e-01 8.20390e+00 8.20390e+00 8.20390e-01 1.00000e-09 2.12000e-01 8.20390e+00 8.20390e+00 8.20390e-01 1.00000e-09 2.12000e-01 $1.00000 \mathrm{e}-05$ 1.00000e-05 1.00000e-06 1.00000e-09 1.00000e-01 $1.00000 \mathrm{e}+001.00000 \mathrm{e}+001.00000 \mathrm{e}-011.00000 \mathrm{e}-091.00000 \mathrm{e}-01$ Element: 14078 \# of layers: 7

$\mathrm{Kx} \mathrm{Ky} \mathrm{Kz}$ Ss Por

7.75929e+00 7.75929e+00 7.75929e-01 1.00000e-09 2.12000e-01 $7.75929 \mathrm{e}+00$ 7.75929e+00 7.75929e-01 1.00000e-09 2.12000e-01 7.75929e+00 7.75929e+00 7.75929e-01 1.00000e-09 2.12000e-01 7.75929e+00 7.75929e+00 7.75929e-01 1.00000e-09 2.12000e-01 $7.75929 \mathrm{e}+00$ 7.75929e+00 7.75929e-01 1.00000e-09 2.12000e-01 $1.00000 \mathrm{e}-05$ 1.00000e-05 1.00000e-06 1.00000e-09 1.00000e-01 
$1.00000 \mathrm{e}+001.00000 \mathrm{e}+001.00000 \mathrm{e}-01$ 1.00000e-09 1.00000e-01 Element: 14079 \# of layers: 7

$\mathrm{Kx} \mathrm{Ky} \mathrm{Kz}$ Ss Por

8.20390e+00 8.20390e+00 8.20390e-01 1.00000e-09 2.12000e-01

$8.20390 \mathrm{e}+008.20390 \mathrm{e}+00$ 8.20390e-01 1.00000e-09 2.12000e-01

$8.20390 \mathrm{e}+008.20390 \mathrm{e}+00$ 8.20390e-01 1.00000e-09 2.12000e-01

$8.20390 \mathrm{e}+00$ 8.20390e+00 8.20390e-01 1.00000e-09 2.12000e-01

$8.20390 \mathrm{e}+008.20390 \mathrm{e}+008.20390 \mathrm{e}-01$ 1.00000e-09 2.12000e-01

$1.00000 \mathrm{e}-051.00000 \mathrm{e}-051.00000 \mathrm{e}-061.00000 \mathrm{e}-091.00000 \mathrm{e}-01$

$1.00000 \mathrm{e}+001.00000 \mathrm{e}+001.00000 \mathrm{e}-011.00000 \mathrm{e}-091.00000 \mathrm{e}-01$

Element: 14080 \# of layers: 7

$\mathrm{Kx} \mathrm{Ky} \mathrm{Kz}$ Ss Por

8.20390e+00 8.20390e+00 8.20390e-01 1.00000e-09 2.12000e-01

$8.20390 \mathrm{e}+00$ 8.20390e+00 8.20390e-01 1.00000e-09 2.12000e-01

8.20390e+00 8.20390e+00 8.20390e-01 1.00000e-09 2.12000e-01

8.20390e+00 8.20390e+00 8.20390e-01 1.00000e-09 2.12000e-01

$8.20390 \mathrm{e}+00$ 8.20390e+00 8.20390e-01 1.00000e-09 2.12000e-01

$1.00000 \mathrm{e}-05$ 1.00000e-05 1.00000e-06 1.00000e-09 1.00000e-01

$1.00000 \mathrm{e}+001.00000 \mathrm{e}+001.00000 \mathrm{e}-011.00000 \mathrm{e}-091.00000 \mathrm{e}-01$

Element: 14081 \# of layers: 7

$\mathrm{Kx} \mathrm{Ky} \mathrm{Kz}$ Ss Por

8.20390e+00 8.20390e+00 8.20390e-01 1.00000e-09 2.12000e-01

$8.20390 \mathrm{e}+008.20390 \mathrm{e}+00$ 8.20390e-01 1.00000e-09 2.12000e-01

$8.20390 \mathrm{e}+00$ 8.20390e+00 8.20390e-01 1.00000e-09 2.12000e-01

$8.20390 \mathrm{e}+00$ 8.20390e+00 8.20390e-01 1.00000e-09 2.12000e-01

$8.20390 \mathrm{e}+008.20390 \mathrm{e}+008.20390 \mathrm{e}-01$ 1.00000e-09 2.12000e-01

$1.00000 \mathrm{e}-05$ 1.00000e-05 1.00000e-06 1.00000e-09 1.00000e-01

$1.00000 \mathrm{e}+001.00000 \mathrm{e}+001.00000 \mathrm{e}-011.00000 \mathrm{e}-091.00000 \mathrm{e}-01$

Element: 14082 \# of layers: 7

$\mathrm{Kx} \mathrm{Ky} \mathrm{Kz}$ Ss Por

7.75929e+00 7.75929e+00 7.75929e-01 1.00000e-09 2.12000e-01

7.75929e+00 7.75929e+00 7.75929e-01 1.00000e-09 2.12000e-01

$7.75929 \mathrm{e}+00$ 7.75929e+00 7.75929e-01 1.00000e-09 2.12000e-01

7.75929e+00 7.75929e+00 7.75929e-01 1.00000e-09 2.12000e-01

$7.75929 \mathrm{e}+00$ 7.75929e+00 7.75929e-01 1.00000e-09 2.12000e-01

$1.00000 \mathrm{e}-05$ 1.00000e-05 1.00000e-06 1.00000e-09 1.00000e-01

$1.00000 \mathrm{e}+001.00000 \mathrm{e}+001.00000 \mathrm{e}-011.00000 \mathrm{e}-091.00000 \mathrm{e}-01$

Element: 14083 \# of layers: 7

$\mathrm{Kx} \mathrm{Ky} \mathrm{Kz}$ Ss Por

7.75929e+00 7.75929e+00 7.75929e-01 1.00000e-09 2.12000e-01

$7.75929 \mathrm{e}+00$ 7.75929e+00 7.75929e-01 1.00000e-09 2.12000e-01

$7.75929 \mathrm{e}+00$ 7.75929e+00 7.75929e-01 1.00000e-09 2.12000e-01

7.75929e+00 7.75929e+00 7.75929e-01 1.00000e-09 2.12000e-01

7.75929e+00 7.75929e+00 7.75929e-01 1.00000e-09 2.12000e-01

$1.00000 \mathrm{e}-05$ 1.00000e-05 1.00000e-06 1.00000e-09 1.00000e-01

$1.00000 \mathrm{e}+001.00000 \mathrm{e}+001.00000 \mathrm{e}-011.00000 \mathrm{e}-091.00000 \mathrm{e}-01$ 
Element: 14084 \# of layers: 7

$\mathrm{Kx} \mathrm{Ky} \mathrm{Kz}$ Ss Por

7.75929e+00 7.75929e+00 7.75929e-01 1.00000e-09 2.12000e-01

$7.75929 \mathrm{e}+00$ 7.75929e+00 7.75929e-01 1.00000e-09 2.12000e-01

7.75929e+00 7.75929e+00 7.75929e-01 1.00000e-09 2.12000e-01

7.75929e+00 7.75929e+00 7.75929e-01 1.00000e-09 2.12000e-01

$7.75929 \mathrm{e}+00$ 7.75929e+00 7.75929e-01 1.00000e-09 2.12000e-01

$1.00000 \mathrm{e}-05$ 1.00000e-05 1.00000e-06 1.00000e-09 1.00000e-01

$1.00000 \mathrm{e}+001.00000 \mathrm{e}+001.00000 \mathrm{e}-011.00000 \mathrm{e}-091.00000 \mathrm{e}-01$

Element: 14085 \# of layers: 7

$\mathrm{Kx} \mathrm{Ky} \mathrm{Kz}$ Ss Por

7.75929e+00 7.75929e+00 7.75929e-01 1.00000e-09 2.12000e-01

7.75929e+00 7.75929e+00 7.75929e-01 1.00000e-09 2.12000e-01

$7.75929 \mathrm{e}+00$ 7.75929e+00 7.75929e-01 1.00000e-09 2.12000e-01

7.75929e+00 7.75929e+00 7.75929e-01 1.00000e-09 2.12000e-01

$7.75929 \mathrm{e}+00$ 7.75929e+00 7.75929e-01 1.00000e-09 2.12000e-01

$1.00000 \mathrm{e}-05$ 1.00000e-05 1.00000e-06 1.00000e-09 1.00000e-01

$1.00000 \mathrm{e}+001.00000 \mathrm{e}+001.00000 \mathrm{e}-011.00000 \mathrm{e}-091.00000 \mathrm{e}-01$

Element: 14086 \# of layers: 7

$\mathrm{Kx} \mathrm{Ky} \mathrm{Kz}$ Ss Por

7.75929e+00 7.75929e+00 7.75929e-01 1.00000e-09 2.12000e-01

7.75929e+00 7.75929e+00 7.75929e-01 1.00000e-09 2.12000e-01

7.75929e+00 7.75929e+00 7.75929e-01 1.00000e-09 2.12000e-01

$7.75929 \mathrm{e}+00$ 7.75929e+00 7.75929e-01 1.00000e-09 2.12000e-01

7.75929e+00 7.75929e+00 7.75929e-01 1.00000e-09 2.12000e-01

$1.00000 \mathrm{e}-05$ 1.00000e-05 1.00000e-06 1.00000e-09 1.00000e-01

$1.00000 \mathrm{e}+001.00000 \mathrm{e}+001.00000 \mathrm{e}-011.00000 \mathrm{e}-091.00000 \mathrm{e}-01$

Element: 14087 \# of layers: 7

$\mathrm{Kx} \mathrm{Ky} \mathrm{Kz}$ Ss Por

7.11128e+00 7.11128e+00 7.11128e-01 1.00000e-09 2.12000e-01

$7.11128 \mathrm{e}+00$ 7.11128e+00 7.11128e-01 1.00000e-09 2.12000e-01

$7.11128 \mathrm{e}+00$ 7.11128e+00 7.11128e-01 1.00000e-09 2.12000e-01

$7.11128 \mathrm{e}+007.11128 \mathrm{e}+00$ 7.11128e-01 1.00000e-09 2.12000e-01

7.11128e+00 7.11128e+00 7.11128e-01 1.00000e-09 2.12000e-01

$1.00000 \mathrm{e}-05$ 1.00000e-05 1.00000e-06 1.00000e-09 1.00000e-01

$1.00000 \mathrm{e}+001.00000 \mathrm{e}+001.00000 \mathrm{e}-011.00000 \mathrm{e}-091.00000 \mathrm{e}-01$

Element: 14088 \# of layers: 7

$\mathrm{Kx} \mathrm{Ky} \mathrm{Kz}$ Ss Por

7.11128e+00 7.11128e+00 7.11128e-01 1.00000e-09 2.12000e-01

7.11128e+00 7.11128e+00 7.11128e-01 1.00000e-09 2.12000e-01

$7.11128 \mathrm{e}+00$ 7.11128e+00 7.11128e-01 1.00000e-09 2.12000e-01

$7.11128 \mathrm{e}+00$ 7.11128e+00 7.11128e-01 1.00000e-09 2.12000e-01

7.11128e+00 7.11128e+00 7.11128e-01 1.00000e-09 2.12000e-01

$1.00000 \mathrm{e}-051.00000 \mathrm{e}-05$ 1.00000e-06 1.00000e-09 1.00000e-01

$1.00000 \mathrm{e}+001.00000 \mathrm{e}+001.00000 \mathrm{e}-011.00000 \mathrm{e}-09$ 1.00000e-01

Element: 14089 \# of layers: 7 
Kx Ky Kz Ss Por

7.11128e+00 7.11128e+00 7.11128e-01 1.00000e-09 2.12000e-01

$7.11128 \mathrm{e}+00$ 7.11128e+00 7.11128e-01 1.00000e-09 2.12000e-01

$7.11128 \mathrm{e}+00$ 7.11128e+00 7.11128e-01 1.00000e-09 2.12000e-01

7.11128e+00 7.11128e+00 7.11128e-01 1.00000e-09 2.12000e-01

7.11128e+00 7.11128e+00 7.11128e-01 1.00000e-09 2.12000e-01

$1.00000 \mathrm{e}-05$ 1.00000e-05 1.00000e-06 1.00000e-09 1.00000e-01

$1.00000 \mathrm{e}+001.00000 \mathrm{e}+001.00000 \mathrm{e}-011.00000 \mathrm{e}-091.00000 \mathrm{e}-01$

Element: 14090 \# of layers: 7

$\mathrm{Kx} \mathrm{Ky} \mathrm{Kz}$ Ss Por

7.11128e+00 7.11128e+00 7.11128e-01 1.00000e-09 2.12000e-01

$7.11128 \mathrm{e}+00$ 7.11128e+00 7.11128e-01 1.00000e-09 2.12000e-01

$7.11128 \mathrm{e}+00$ 7.11128e+00 7.11128e-01 1.00000e-09 2.12000e-01

$7.11128 \mathrm{e}+00$ 7.11128e+00 7.11128e-01 1.00000e-09 2.12000e-01

7.11128e+00 7.11128e+00 7.11128e-01 1.00000e-09 2.12000e-01

$1.00000 \mathrm{e}-05$ 1.00000e-05 1.00000e-06 1.00000e-09 1.00000e-01

$1.00000 \mathrm{e}+001.00000 \mathrm{e}+001.00000 \mathrm{e}-011.00000 \mathrm{e}-091.00000 \mathrm{e}-01$

Element: 14091 \# of layers: 7

$\mathrm{Kx} \mathrm{Ky} \mathrm{Kz}$ Ss Por

7.11128e+00 7.11128e+00 7.11128e-01 1.00000e-09 2.12000e-01

7.11128e+00 7.11128e+00 7.11128e-01 1.00000e-09 2.12000e-01

7.11128e+00 7.11128e+00 7.11128e-01 1.00000e-09 2.12000e-01

7.11128e+00 7.11128e+00 7.11128e-01 1.00000e-09 2.12000e-01

$7.11128 \mathrm{e}+00$ 7.11128e+00 7.11128e-01 1.00000e-09 2.12000e-01

$1.00000 \mathrm{e}-05$ 1.00000e-05 1.00000e-06 1.00000e-09 1.00000e-01

$1.00000 \mathrm{e}+001.00000 \mathrm{e}+001.00000 \mathrm{e}-01$ 1.00000e-09 1.00000e-01

Element: 14092 \# of layers: 7

$\mathrm{Kx} \mathrm{Ky} \mathrm{Kz}$ Ss Por

7.75929e+00 7.75929e+00 7.75929e-01 1.00000e-09 2.12000e-01

7.75929e+00 7.75929e+00 7.75929e-01 1.00000e-09 2.12000e-01

$7.75929 \mathrm{e}+00$ 7.75929e+00 7.75929e-01 1.00000e-09 2.12000e-01

7.75929e+00 7.75929e+00 7.75929e-01 1.00000e-09 2.12000e-01

$7.75929 \mathrm{e}+00$ 7.75929e+00 7.75929e-01 1.00000e-09 2.12000e-01

$1.00000 \mathrm{e}-05$ 1.00000e-05 1.00000e-06 1.00000e-09 1.00000e-01

$1.00000 \mathrm{e}+001.00000 \mathrm{e}+001.00000 \mathrm{e}-011.00000 \mathrm{e}-091.00000 \mathrm{e}-01$

Element: 14093 \# of layers: 7

Kx Ky Kz Ss Por

7.75929e+00 7.75929e+00 7.75929e-01 1.00000e-09 2.12000e-01

7.75929e+00 7.75929e+00 7.75929e-01 1.00000e-09 2.12000e-01

7.75929e+00 7.75929e+00 7.75929e-01 1.00000e-09 2.12000e-01

$7.75929 \mathrm{e}+00$ 7.75929e+00 7.75929e-01 1.00000e-09 2.12000e-01

$7.75929 \mathrm{e}+00$ 7.75929e+00 7.75929e-01 1.00000e-09 2.12000e-01

$1.00000 \mathrm{e}-051.00000 \mathrm{e}-051.00000 \mathrm{e}-061.00000 \mathrm{e}-091.00000 \mathrm{e}-01$

$1.00000 \mathrm{e}+001.00000 \mathrm{e}+001.00000 \mathrm{e}-01$ 1.00000e-09 1.00000e-01

Element: 14094 \# of layers: 7

Kx Ky Kz Ss Por 
$7.11128 \mathrm{e}+007.11128 \mathrm{e}+00$ 7.11128e-01 1.00000e-09 2.12000e-01 $7.11128 \mathrm{e}+007.11128 \mathrm{e}+007.11128 \mathrm{e}-01$ 1.00000e-09 2.12000e-01 $7.11128 \mathrm{e}+007.11128 \mathrm{e}+00$ 7.11128e-01 1.00000e-09 2.12000e-01 $7.11128 \mathrm{e}+007.11128 \mathrm{e}+007.11128 \mathrm{e}-011.00000 \mathrm{e}-092.12000 \mathrm{e}-01$ $7.11128 \mathrm{e}+00$ 7.11128e+00 7.11128e-01 1.00000e-09 2.12000e-01 $1.00000 \mathrm{e}-05$ 1.00000e-05 1.00000e-06 1.00000e-09 1.00000e-01 $1.00000 \mathrm{e}+001.00000 \mathrm{e}+001.00000 \mathrm{e}-011.00000 \mathrm{e}-091.00000 \mathrm{e}-01$ Element: 14095 \# of layers: 7

Kx Ky Kz Ss Por

7.11128e+00 7.11128e+00 7.11128e-01 1.00000e-09 2.12000e-01 $7.11128 \mathrm{e}+007.11128 \mathrm{e}+007.11128 \mathrm{e}-011.00000 \mathrm{e}-092.12000 \mathrm{e}-01$ $7.11128 \mathrm{e}+007.11128 \mathrm{e}+007.11128 \mathrm{e}-011.00000 \mathrm{e}-09$ 2.12000e-01 $7.11128 \mathrm{e}+007.11128 \mathrm{e}+007.11128 \mathrm{e}-011.00000 \mathrm{e}-092.12000 \mathrm{e}-01$ $7.11128 \mathrm{e}+007.11128 \mathrm{e}+007.11128 \mathrm{e}-011.00000 \mathrm{e}-09$ 2.12000e-01 $1.00000 \mathrm{e}-05$ 1.00000e-05 1.00000e-06 1.00000e-09 1.00000e-01 $1.00000 \mathrm{e}+001.00000 \mathrm{e}+001.00000 \mathrm{e}-011.00000 \mathrm{e}-091.00000 \mathrm{e}-01$ Element: 14096 \# of layers: 7

Kx Ky Kz Ss Por

7.37003e+00 7.37003e+00 7.37003e-01 1.00000e-09 2.12000e-01 $7.37003 \mathrm{e}+00$ 7.37003e+00 7.37003e-01 1.00000e-09 2.12000e-01 $7.37003 \mathrm{e}+00$ 7.37003e+00 7.37003e-01 1.00000e-09 2.12000e-01 $7.37003 \mathrm{e}+00$ 7.37003e+00 7.37003e-01 1.00000e-09 2.12000e-01 $7.37003 \mathrm{e}+00$ 7.37003e+00 7.37003e-01 1.00000e-09 2.12000e-01 $1.00000 \mathrm{e}-05$ 1.00000e-05 1.00000e-06 1.00000e-09 1.00000e-01 $1.00000 \mathrm{e}+001.00000 \mathrm{e}+001.00000 \mathrm{e}-011.00000 \mathrm{e}-091.00000 \mathrm{e}-01$ Element: 14097 \# of layers: 7

Kx Ky Kz Ss Por

7.37003e+00 7.37003e+00 7.37003e-01 1.00000e-09 2.12000e-01 $7.37003 \mathrm{e}+00$ 7.37003e+00 7.37003e-01 1.00000e-09 2.12000e-01 $7.37003 \mathrm{e}+00$ 7.37003e+00 7.37003e-01 1.00000e-09 2.12000e-01 $7.37003 \mathrm{e}+00$ 7.37003e+00 7.37003e-01 1.00000e-09 2.12000e-01 $7.37003 \mathrm{e}+00$ 7.37003e+00 7.37003e-01 1.00000e-09 2.12000e-01 $1.00000 \mathrm{e}-05$ 1.00000e-05 1.00000e-06 1.00000e-09 1.00000e-01 $1.00000 \mathrm{e}+001.00000 \mathrm{e}+001.00000 \mathrm{e}-011.00000 \mathrm{e}-091.00000 \mathrm{e}-01$ Element: 14098 \# of layers: 7

Kx Ky Kz Ss Por

7.37003e+00 7.37003e+00 7.37003e-01 1.00000e-09 2.12000e-01 $7.37003 \mathrm{e}+00$ 7.37003e+00 7.37003e-01 1.00000e-09 2.12000e-01 $7.37003 \mathrm{e}+00$ 7.37003e+00 7.37003e-01 1.00000e-09 2.12000e-01 $7.37003 \mathrm{e}+00$ 7.37003e+00 7.37003e-01 1.00000e-09 2.12000e-01 $7.37003 \mathrm{e}+00$ 7.37003e+00 7.37003e-01 1.00000e-09 2.12000e-01 $1.00000 \mathrm{e}-05$ 1.00000e-05 1.00000e-06 1.00000e-09 1.00000e-01 $1.00000 \mathrm{e}+001.00000 \mathrm{e}+001.00000 \mathrm{e}-011.00000 \mathrm{e}-091.00000 \mathrm{e}-01$ Element: 14099 \# of layers: 7

Kx Ky Kz Ss Por

8.20390e+00 8.20390e+00 8.20390e-01 1.00000e-09 2.12000e-01 
$8.20390 \mathrm{e}+008.20390 \mathrm{e}+008.20390 \mathrm{e}-01$ 1.00000e-09 2.12000e-01 $8.20390 \mathrm{e}+008.20390 \mathrm{e}+008.20390 \mathrm{e}-011.00000 \mathrm{e}-092.12000 \mathrm{e}-01$ $8.20390 \mathrm{e}+008.20390 \mathrm{e}+00$ 8.20390e-01 1.00000e-09 2.12000e-01 $8.20390 \mathrm{e}+008.20390 \mathrm{e}+00$ 8.20390e-01 1.00000e-09 2.12000e-01 $1.00000 \mathrm{e}-05$ 1.00000e-05 1.00000e-06 1.00000e-09 1.00000e-01 $1.00000 \mathrm{e}+001.00000 \mathrm{e}+001.00000 \mathrm{e}-011.00000 \mathrm{e}-091.00000 \mathrm{e}-01$ Element: 14100 \# of layers: 7

Kx Ky Kz Ss Por

$8.20390 \mathrm{e}+008.20390 \mathrm{e}+00$ 8.20390e-01 1.00000e-09 2.12000e-01 $8.20390 \mathrm{e}+008.20390 \mathrm{e}+008.20390 \mathrm{e}-011.00000 \mathrm{e}-092.12000 \mathrm{e}-01$ $8.20390 \mathrm{e}+008.20390 \mathrm{e}+008.20390 \mathrm{e}-01$ 1.00000e-09 2.12000e-01 $8.20390 \mathrm{e}+008.20390 \mathrm{e}+008.20390 \mathrm{e}-01$ 1.00000e-09 2.12000e-01 $8.20390 \mathrm{e}+008.20390 \mathrm{e}+00$ 8.20390e-01 1.00000e-09 2.12000e-01 $1.00000 \mathrm{e}-05$ 1.00000e-05 1.00000e-06 1.00000e-09 1.00000e-01 $1.00000 \mathrm{e}+001.00000 \mathrm{e}+001.00000 \mathrm{e}-011.00000 \mathrm{e}-091.00000 \mathrm{e}-01$ Element: 14101 \# of layers: 7

Kx Ky Kz Ss Por

7.75929e+00 7.75929e+00 7.75929e-01 1.00000e-09 2.12000e-01 $7.75929 \mathrm{e}+007.75929 \mathrm{e}+00$ 7.75929e-01 1.00000e-09 2.12000e-01 $7.75929 \mathrm{e}+007.75929 \mathrm{e}+00$ 7.75929e-01 1.00000e-09 2.12000e-01 $7.75929 \mathrm{e}+007.75929 \mathrm{e}+007.75929 \mathrm{e}-011.00000 \mathrm{e}-092.12000 \mathrm{e}-01$ $7.75929 \mathrm{e}+00$ 7.75929e+00 7.75929e-01 1.00000e-09 2.12000e-01 $1.00000 \mathrm{e}-05$ 1.00000e-05 1.00000e-06 1.00000e-09 1.00000e-01 $1.00000 \mathrm{e}+001.00000 \mathrm{e}+001.00000 \mathrm{e}-011.00000 \mathrm{e}-091.00000 \mathrm{e}-01$ Element: 14102 \# of layers: 7

Kx Ky Kz Ss Por

7.11128e+00 7.11128e+00 7.11128e-01 1.00000e-09 2.12000e-01 $7.11128 \mathrm{e}+007.11128 \mathrm{e}+007.11128 \mathrm{e}-011.00000 \mathrm{e}-092.12000 \mathrm{e}-01$ $7.11128 \mathrm{e}+007.11128 \mathrm{e}+00$ 7.11128e-01 1.00000e-09 2.12000e-01 $7.11128 \mathrm{e}+007.11128 \mathrm{e}+00$ 7.11128e-01 1.00000e-09 2.12000e-01 $7.11128 \mathrm{e}+007.11128 \mathrm{e}+00$ 7.11128e-01 1.00000e-09 2.12000e-01 $1.00000 \mathrm{e}-05$ 1.00000e-05 1.00000e-06 1.00000e-09 1.00000e-01 $1.00000 \mathrm{e}+001.00000 \mathrm{e}+001.00000 \mathrm{e}-011.00000 \mathrm{e}-091.00000 \mathrm{e}-01$ Element: 14103 \# of layers: 7

Kx Ky Kz Ss Por

7.37003e+00 7.37003e+00 7.37003e-01 1.00000e-09 2.12000e-01 $7.37003 \mathrm{e}+007.37003 \mathrm{e}+00$ 7.37003e-01 1.00000e-09 2.12000e-01 $7.37003 \mathrm{e}+00$ 7.37003e+00 7.37003e-01 1.00000e-09 2.12000e-01 $7.37003 \mathrm{e}+00$ 7.37003e+00 7.37003e-01 1.00000e-09 2.12000e-01 $7.37003 \mathrm{e}+00$ 7.37003e+00 7.37003e-01 1.00000e-09 2.12000e-01 $1.00000 \mathrm{e}-05$ 1.00000e-05 1.00000e-06 1.00000e-09 1.00000e-01 $1.00000 \mathrm{e}+001.00000 \mathrm{e}+001.00000 \mathrm{e}-011.00000 \mathrm{e}-091.00000 \mathrm{e}-01$ Element: 14104 \# of layers: 7

Kx Ky Kz Ss Por

$5.59745 \mathrm{e}+00$ 5.59745e+00 5.59745e-01 1.00000e-09 2.12000e-01 $5.59745 \mathrm{e}+005.59745 \mathrm{e}+00$ 5.59745e-01 1.00000e-09 2.12000e-01 
$5.59745 \mathrm{e}+005.59745 \mathrm{e}+00$ 5.59745e-01 1.00000e-09 2.12000e-01 $5.59745 \mathrm{e}+005.59745 \mathrm{e}+00$ 5.59745e-01 1.00000e-09 2.12000e-01 $5.59745 \mathrm{e}+005.59745 \mathrm{e}+00$ 5.59745e-01 1.00000e-09 2.12000e-01 $1.00000 \mathrm{e}-05$ 1.00000e-05 1.00000e-06 1.00000e-09 1.00000e-01 $1.00000 \mathrm{e}+001.00000 \mathrm{e}+001.00000 \mathrm{e}-011.00000 \mathrm{e}-091.00000 \mathrm{e}-01$ Element: 14105 \# of layers: 7

Kx Ky Kz Ss Por

$5.59745 \mathrm{e}+00$ 5.59745e+00 5.59745e-01 1.00000e-09 2.12000e-01 $5.59745 \mathrm{e}+005.59745 \mathrm{e}+005.59745 \mathrm{e}-011.00000 \mathrm{e}-092.12000 \mathrm{e}-01$ $5.59745 \mathrm{e}+005.59745 \mathrm{e}+005.59745 \mathrm{e}-011.00000 \mathrm{e}-092.12000 \mathrm{e}-01$ $5.59745 \mathrm{e}+005.59745 \mathrm{e}+005.59745 \mathrm{e}-011.00000 \mathrm{e}-092.12000 \mathrm{e}-01$ $5.59745 \mathrm{e}+005.59745 \mathrm{e}+00$ 5.59745e-01 1.00000e-09 2.12000e-01 $1.00000 \mathrm{e}-05$ 1.00000e-05 1.00000e-06 1.00000e-09 1.00000e-01 $1.00000 \mathrm{e}+001.00000 \mathrm{e}+001.00000 \mathrm{e}-011.00000 \mathrm{e}-091.00000 \mathrm{e}-01$ Element: 14106 \# of layers: 7

Kx Ky Kz Ss Por

$5.59745 \mathrm{e}+00$ 5.59745e+00 5.59745e-01 1.00000e-09 2.12000e-01

$5.59745 \mathrm{e}+005.59745 \mathrm{e}+005.59745 \mathrm{e}-011.00000 \mathrm{e}-092.12000 \mathrm{e}-01$ $5.59745 \mathrm{e}+005.59745 \mathrm{e}+005.59745 \mathrm{e}-011.00000 \mathrm{e}-092.12000 \mathrm{e}-01$ $5.59745 \mathrm{e}+005.59745 \mathrm{e}+00$ 5.59745e-01 1.00000e-09 2.12000e-01 $5.59745 \mathrm{e}+005.59745 \mathrm{e}+00$ 5.59745e-01 1.00000e-09 2.12000e-01 $1.00000 \mathrm{e}-05$ 1.00000e-05 1.00000e-06 1.00000e-09 1.00000e-01 $1.00000 \mathrm{e}+001.00000 \mathrm{e}+001.00000 \mathrm{e}-011.00000 \mathrm{e}-091.00000 \mathrm{e}-01$ Element: 14107 \# of layers: 7

Kx Ky Kz Ss Por

$5.59745 \mathrm{e}+00$ 5.59745e+00 5.59745e-01 1.00000e-09 2.12000e-01 $5.59745 \mathrm{e}+005.59745 \mathrm{e}+00$ 5.59745e-01 1.00000e-09 2.12000e-01 $5.59745 \mathrm{e}+005.59745 \mathrm{e}+005.59745 \mathrm{e}-011.00000 \mathrm{e}-092.12000 \mathrm{e}-01$ $5.59745 \mathrm{e}+005.59745 \mathrm{e}+005.59745 \mathrm{e}-011.00000 \mathrm{e}-092.12000 \mathrm{e}-01$ $5.59745 \mathrm{e}+005.59745 \mathrm{e}+00$ 5.59745e-01 1.00000e-09 2.12000e-01 $1.00000 \mathrm{e}-05$ 1.00000e-05 1.00000e-06 1.00000e-09 1.00000e-01 $1.00000 \mathrm{e}+001.00000 \mathrm{e}+001.00000 \mathrm{e}-011.00000 \mathrm{e}-091.00000 \mathrm{e}-01$ Element: 14108 \# of layers: 7

$\mathrm{Kx} \mathrm{Ky} \mathrm{Kz}$ Ss Por

5.59745e+00 5.59745e+00 5.59745e-01 1.00000e-09 2.12000e-01 $5.59745 \mathrm{e}+005.59745 \mathrm{e}+00$ 5.59745e-01 1.00000e-09 2.12000e-01 $5.59745 \mathrm{e}+005.59745 \mathrm{e}+00$ 5.59745e-01 1.00000e-09 2.12000e-01 $5.59745 \mathrm{e}+005.59745 \mathrm{e}+00$ 5.59745e-01 1.00000e-09 2.12000e-01 $5.59745 \mathrm{e}+00$ 5.59745e+00 5.59745e-01 1.00000e-09 2.12000e-01 $1.00000 \mathrm{e}-05$ 1.00000e-05 1.00000e-06 1.00000e-09 1.00000e-01 $1.00000 \mathrm{e}+001.00000 \mathrm{e}+001.00000 \mathrm{e}-011.00000 \mathrm{e}-091.00000 \mathrm{e}-01$ Element: 14109 \# of layers: 7

$\mathrm{Kx} \mathrm{Ky} \mathrm{Kz}$ Ss Por

5.59745e+00 5.59745e+00 5.59745e-01 1.00000e-09 2.12000e-01 $5.59745 \mathrm{e}+005.59745 \mathrm{e}+00$ 5.59745e-01 1.00000e-09 2.12000e-01 $5.59745 \mathrm{e}+00$ 5.59745e+00 5.59745e-01 1.00000e-09 2.12000e-01 
$5.59745 \mathrm{e}+005.59745 \mathrm{e}+00$ 5.59745e-01 1.00000e-09 2.12000e-01 $5.59745 \mathrm{e}+005.59745 \mathrm{e}+00$ 5.59745e-01 1.00000e-09 2.12000e-01 $1.00000 \mathrm{e}-05$ 1.00000e-05 1.00000e-06 1.00000e-09 1.00000e-01 $1.00000 \mathrm{e}+001.00000 \mathrm{e}+001.00000 \mathrm{e}-011.00000 \mathrm{e}-091.00000 \mathrm{e}-01$ Element: 14110 \# of layers: 7

Kx Ky Kz Ss Por

$5.59745 \mathrm{e}+00$ 5.59745e+00 5.59745e-01 1.00000e-09 2.12000e-01 $5.59745 \mathrm{e}+005.59745 \mathrm{e}+005.59745 \mathrm{e}-011.00000 \mathrm{e}-092.12000 \mathrm{e}-01$ $5.59745 \mathrm{e}+005.59745 \mathrm{e}+005.59745 \mathrm{e}-011.00000 \mathrm{e}-092.12000 \mathrm{e}-01$ $5.59745 \mathrm{e}+005.59745 \mathrm{e}+005.59745 \mathrm{e}-011.00000 \mathrm{e}-092.12000 \mathrm{e}-01$ $5.59745 \mathrm{e}+005.59745 \mathrm{e}+00$ 5.59745e-01 1.00000e-09 2.12000e-01 $1.00000 \mathrm{e}-05$ 1.00000e-05 1.00000e-06 1.00000e-09 1.00000e-01 $1.00000 \mathrm{e}+001.00000 \mathrm{e}+001.00000 \mathrm{e}-011.00000 \mathrm{e}-091.00000 \mathrm{e}-01$ Element: 14111 \# of layers: 7

Kx Ky Kz Ss Por

$5.59745 \mathrm{e}+00$ 5.59745e+00 5.59745e-01 1.00000e-09 2.12000e-01 $5.59745 \mathrm{e}+005.59745 \mathrm{e}+005.59745 \mathrm{e}-011.00000 \mathrm{e}-092.12000 \mathrm{e}-01$ $5.59745 \mathrm{e}+005.59745 \mathrm{e}+00$ 5.59745e-01 1.00000e-09 2.12000e-01 $5.59745 \mathrm{e}+005.59745 \mathrm{e}+005.59745 \mathrm{e}-011.00000 \mathrm{e}-092.12000 \mathrm{e}-01$ $5.59745 \mathrm{e}+005.59745 \mathrm{e}+00$ 5.59745e-01 1.00000e-09 2.12000e-01 $1.00000 \mathrm{e}-05$ 1.00000e-05 1.00000e-06 1.00000e-09 1.00000e-01 $1.00000 \mathrm{e}+001.00000 \mathrm{e}+001.00000 \mathrm{e}-011.00000 \mathrm{e}-091.00000 \mathrm{e}-01$ Element: 14112 \# of layers: 7

Kx Ky Kz Ss Por

$5.59745 \mathrm{e}+00$ 5.59745e+00 5.59745e-01 1.00000e-09 2.12000e-01 $5.59745 \mathrm{e}+005.59745 \mathrm{e}+005.59745 \mathrm{e}-011.00000 \mathrm{e}-092.12000 \mathrm{e}-01$ $5.59745 \mathrm{e}+005.59745 \mathrm{e}+00$ 5.59745e-01 1.00000e-09 2.12000e-01 $5.59745 \mathrm{e}+005.59745 \mathrm{e}+00$ 5.59745e-01 1.00000e-09 2.12000e-01 $5.59745 \mathrm{e}+005.59745 \mathrm{e}+00$ 5.59745e-01 1.00000e-09 2.12000e-01 $1.00000 \mathrm{e}-05$ 1.00000e-05 1.00000e-06 1.00000e-09 1.00000e-01 $1.00000 \mathrm{e}+001.00000 \mathrm{e}+001.00000 \mathrm{e}-011.00000 \mathrm{e}-091.00000 \mathrm{e}-01$ Element: 14113 \# of layers: 7

Kx Ky Kz Ss Por

$5.59745 \mathrm{e}+005.59745 \mathrm{e}+00$ 5.59745e-01 1.00000e-09 2.12000e-01 $5.59745 \mathrm{e}+005.59745 \mathrm{e}+005.59745 \mathrm{e}-011.00000 \mathrm{e}-092.12000 \mathrm{e}-01$ $5.59745 \mathrm{e}+005.59745 \mathrm{e}+00$ 5.59745e-01 1.00000e-09 2.12000e-01 $5.59745 \mathrm{e}+005.59745 \mathrm{e}+00$ 5.59745e-01 1.00000e-09 2.12000e-01 $5.59745 \mathrm{e}+005.59745 \mathrm{e}+00$ 5.59745e-01 1.00000e-09 2.12000e-01 $1.00000 \mathrm{e}-05$ 1.00000e-05 1.00000e-06 1.00000e-09 1.00000e-01 $1.00000 \mathrm{e}+001.00000 \mathrm{e}+001.00000 \mathrm{e}-011.00000 \mathrm{e}-091.00000 \mathrm{e}-01$ Element: 14114 \# of layers: 7

Kx Ky Kz Ss Por

$5.49259 \mathrm{e}+00$ 5.49259e+00 5.49259e-01 1.00000e-09 2.12000e-01 $5.49259 \mathrm{e}+005.49259 \mathrm{e}+00$ 5.49259e-01 1.00000e-09 2.12000e-01 $5.49259 \mathrm{e}+005.49259 \mathrm{e}+00$ 5.49259e-01 1.00000e-09 2.12000e-01 $5.49259 \mathrm{e}+00$ 5.49259e+00 5.49259e-01 1.00000e-09 2.12000e-01 
5.49259e+00 5.49259e+00 5.49259e-01 1.00000e-09 2.12000e-01 $1.00000 \mathrm{e}-05$ 1.00000e-05 1.00000e-06 1.00000e-09 1.00000e-01 $1.00000 \mathrm{e}+001.00000 \mathrm{e}+001.00000 \mathrm{e}-01$ 1.00000e-09 1.00000e-01 Element: 14115 \# of layers: 7

$\mathrm{Kx} \mathrm{Ky} \mathrm{Kz}$ Ss Por

5.49259e+00 5.49259e+00 5.49259e-01 1.00000e-09 2.12000e-01 5.49259e+00 5.49259e+00 5.49259e-01 1.00000e-09 2.12000e-01 5.49259e+00 5.49259e+00 5.49259e-01 1.00000e-09 2.12000e-01 5.49259e+00 5.49259e+00 5.49259e-01 1.00000e-09 2.12000e-01 5.49259e+00 5.49259e+00 5.49259e-01 1.00000e-09 2.12000e-01 $1.00000 \mathrm{e}-05$ 1.00000e-05 1.00000e-06 1.00000e-09 1.00000e-01 $1.00000 \mathrm{e}+001.00000 \mathrm{e}+001.00000 \mathrm{e}-011.00000 \mathrm{e}-091.00000 \mathrm{e}-01$ Element: 14116 \# of layers: 7

$\mathrm{Kx} \mathrm{Ky} \mathrm{Kz}$ Ss Por

5.49259e+00 5.49259e+00 5.49259e-01 1.00000e-09 2.12000e-01 $5.49259 \mathrm{e}+00$ 5.49259e+00 5.49259e-01 1.00000e-09 2.12000e-01 5.49259e+00 5.49259e+00 5.49259e-01 1.00000e-09 2.12000e-01 5.49259e+00 5.49259e+00 5.49259e-01 1.00000e-09 2.12000e-01 5.49259e+00 5.49259e+00 5.49259e-01 1.00000e-09 2.12000e-01 $1.00000 \mathrm{e}-05$ 1.00000e-05 1.00000e-06 1.00000e-09 1.00000e-01 $1.00000 \mathrm{e}+001.00000 \mathrm{e}+001.00000 \mathrm{e}-011.00000 \mathrm{e}-091.00000 \mathrm{e}-01$ Element: 14117 \# of layers: 7

$\mathrm{Kx} \mathrm{Ky} \mathrm{Kz}$ Ss Por

5.49259e+00 5.49259e+00 5.49259e-01 1.00000e-09 2.12000e-01 $5.49259 \mathrm{e}+00$ 5.49259e+00 5.49259e-01 1.00000e-09 2.12000e-01 5.49259e+00 5.49259e+00 5.49259e-01 1.00000e-09 2.12000e-01 5.49259e+00 5.49259e+00 5.49259e-01 1.00000e-09 2.12000e-01 5.49259e+00 5.49259e+00 5.49259e-01 1.00000e-09 2.12000e-01 $1.00000 \mathrm{e}-05$ 1.00000e-05 1.00000e-06 1.00000e-09 1.00000e-01 $1.00000 \mathrm{e}+001.00000 \mathrm{e}+001.00000 \mathrm{e}-011.00000 \mathrm{e}-091.00000 \mathrm{e}-01$ Element: 14118 \# of layers: 7

$\mathrm{Kx} \mathrm{Ky} \mathrm{Kz}$ Ss Por

5.49259e+00 5.49259e+00 5.49259e-01 1.00000e-09 2.12000e-01 $5.49259 \mathrm{e}+00$ 5.49259e+00 5.49259e-01 1.00000e-09 2.12000e-01 5.49259e+00 5.49259e+00 5.49259e-01 1.00000e-09 2.12000e-01 5.49259e+00 5.49259e+00 5.49259e-01 1.00000e-09 2.12000e-01 $5.49259 \mathrm{e}+00$ 5.49259e+00 5.49259e-01 1.00000e-09 2.12000e-01 $1.00000 \mathrm{e}-05$ 1.00000e-05 1.00000e-06 1.00000e-09 1.00000e-01 $1.00000 \mathrm{e}+001.00000 \mathrm{e}+001.00000 \mathrm{e}-01$ 1.00000e-09 1.00000e-01 Element: 14119 \# of layers: 7

Kx Ky Kz Ss Por

5.59745e+00 5.59745e+00 5.59745e-01 1.00000e-09 2.12000e-01 $5.59745 \mathrm{e}+00$ 5.59745e+00 5.59745e-01 1.00000e-09 2.12000e-01 5.59745e+00 5.59745e+00 5.59745e-01 1.00000e-09 2.12000e-01 $5.59745 \mathrm{e}+005.59745 \mathrm{e}+00$ 5.59745e-01 1.00000e-09 2.12000e-01 $5.59745 \mathrm{e}+00$ 5.59745e+00 5.59745e-01 1.00000e-09 2.12000e-01 
$1.00000 \mathrm{e}-05$ 1.00000e-05 1.00000e-06 1.00000e-09 1.00000e-01 $1.00000 \mathrm{e}+001.00000 \mathrm{e}+001.00000 \mathrm{e}-01$ 1.00000e-09 1.00000e-01 Element: 14120 \# of layers: 7

Kx Ky Kz Ss Por

5.59745e+00 5.59745e+00 5.59745e-01 1.00000e-09 2.12000e-01

$5.59745 \mathrm{e}+00$ 5.59745e+00 5.59745e-01 1.00000e-09 2.12000e-01

$5.59745 \mathrm{e}+00$ 5.59745e+00 5.59745e-01 1.00000e-09 2.12000e-01

$5.59745 \mathrm{e}+00$ 5.59745e+00 5.59745e-01 1.00000e-09 2.12000e-01

$5.59745 \mathrm{e}+00$ 5.59745e+00 5.59745e-01 1.00000e-09 2.12000e-01

$1.00000 \mathrm{e}-05$ 1.00000e-05 1.00000e-06 1.00000e-09 1.00000e-01

$1.00000 \mathrm{e}+001.00000 \mathrm{e}+001.00000 \mathrm{e}-011.00000 \mathrm{e}-091.00000 \mathrm{e}-01$

Element: 14121 \# of layers: 7

Kx Ky Kz Ss Por

5.49259e+00 5.49259e+00 5.49259e-01 1.00000e-09 2.12000e-01

5.49259e+00 5.49259e+00 5.49259e-01 1.00000e-09 2.12000e-01

$5.49259 \mathrm{e}+00$ 5.49259e+00 5.49259e-01 1.00000e-09 2.12000e-01

5.49259e+00 5.49259e+00 5.49259e-01 1.00000e-09 2.12000e-01

5.49259e+00 5.49259e+00 5.49259e-01 1.00000e-09 2.12000e-01

$1.00000 \mathrm{e}-051.00000 \mathrm{e}-05$ 1.00000e-06 1.00000e-09 1.00000e-01

$1.00000 \mathrm{e}+001.00000 \mathrm{e}+001.00000 \mathrm{e}-011.00000 \mathrm{e}-091.00000 \mathrm{e}-01$

Element: 14122 \# of layers: 7

$\mathrm{Kx} \mathrm{Ky} \mathrm{Kz}$ Ss Por

5.49259e+00 5.49259e+00 5.49259e-01 1.00000e-09 2.12000e-01

5.49259e+00 5.49259e+00 5.49259e-01 1.00000e-09 2.12000e-01

$5.49259 \mathrm{e}+00$ 5.49259e+00 5.49259e-01 1.00000e-09 2.12000e-01

5.49259e+00 5.49259e+00 5.49259e-01 1.00000e-09 2.12000e-01

5.49259e+00 5.49259e+00 5.49259e-01 1.00000e-09 2.12000e-01

1.00000e-05 1.00000e-05 1.00000e-06 1.00000e-09 1.00000e-01

$1.00000 \mathrm{e}+001.00000 \mathrm{e}+001.00000 \mathrm{e}-011.00000 \mathrm{e}-091.00000 \mathrm{e}-01$

Element: 14123 \# of layers: 7

$\mathrm{Kx} \mathrm{Ky} \mathrm{Kz}$ Ss Por

5.49259e+00 5.49259e+00 5.49259e-01 1.00000e-09 2.12000e-01

$5.49259 \mathrm{e}+00$ 5.49259e+00 5.49259e-01 1.00000e-09 2.12000e-01

$5.49259 \mathrm{e}+00$ 5.49259e+00 5.49259e-01 1.00000e-09 2.12000e-01

5.49259e+00 5.49259e+00 5.49259e-01 1.00000e-09 2.12000e-01

5.49259e+00 5.49259e+00 5.49259e-01 1.00000e-09 2.12000e-01

1.00000e-05 1.00000e-05 1.00000e-06 1.00000e-09 1.00000e-01

$1.00000 \mathrm{e}+001.00000 \mathrm{e}+001.00000 \mathrm{e}-011.00000 \mathrm{e}-091.00000 \mathrm{e}-01$

Element: 14124 \# of layers: 7

$\mathrm{Kx} \mathrm{Ky} \mathrm{Kz}$ Ss Por

5.49259e+00 5.49259e+00 5.49259e-01 1.00000e-09 2.12000e-01

5.49259e+00 5.49259e+00 5.49259e-01 1.00000e-09 2.12000e-01

5.49259e+00 5.49259e+00 5.49259e-01 1.00000e-09 2.12000e-01

5.49259e+00 5.49259e+00 5.49259e-01 1.00000e-09 2.12000e-01

5.49259e+00 5.49259e+00 5.49259e-01 1.00000e-09 2.12000e-01

$1.00000 \mathrm{e}-05$ 1.00000e-05 1.00000e-06 1.00000e-09 1.00000e-01 
$1.00000 \mathrm{e}+001.00000 \mathrm{e}+00$ 1.00000e-01 1.00000e-09 1.00000e-01 Element: 14125 \# of layers: 7

Kx Ky Kz Ss Por

5.49259e+00 5.49259e+00 5.49259e-01 1.00000e-09 2.12000e-01

5.49259e+00 5.49259e+00 5.49259e-01 1.00000e-09 2.12000e-01

5.49259e+00 5.49259e+00 5.49259e-01 1.00000e-09 2.12000e-01

5.49259e+00 5.49259e+00 5.49259e-01 1.00000e-09 2.12000e-01

5.49259e+00 5.49259e+00 5.49259e-01 1.00000e-09 2.12000e-01

$1.00000 \mathrm{e}-05$ 1.00000e-05 1.00000e-06 1.00000e-09 1.00000e-01

$1.00000 \mathrm{e}+001.00000 \mathrm{e}+001.00000 \mathrm{e}-01$ 1.00000e-09 1.00000e-01

Element: 14126 \# of layers: 6

Kx Ky Kz Ss Por

5.49259e+00 5.49259e+00 5.49259e-01 1.00000e-09 2.12000e-01

5.49259e+00 5.49259e+00 5.49259e-01 1.00000e-09 2.12000e-01

5.49259e+00 5.49259e+00 5.49259e-01 1.00000e-09 2.12000e-01

$5.49259 \mathrm{e}+005.49259 \mathrm{e}+00$ 5.49259e-01 1.00000e-09 2.12000e-01

5.49259e+00 5.49259e+00 5.49259e-01 1.00000e-09 2.12000e-01

$1.00000 \mathrm{e}+001.00000 \mathrm{e}+001.00000 \mathrm{e}-01$ 1.00000e-09 1.00000e-01

Element: 14127 \# of layers: 7

$\mathrm{Kx} \mathrm{Ky} \mathrm{Kz}$ Ss Por

5.49259e+00 5.49259e+00 5.49259e-01 1.00000e-09 2.12000e-01

5.49259e+00 5.49259e+00 5.49259e-01 1.00000e-09 2.12000e-01

5.49259e+00 5.49259e+00 5.49259e-01 1.00000e-09 2.12000e-01

5.49259e+00 5.49259e+00 5.49259e-01 1.00000e-09 2.12000e-01

$5.49259 \mathrm{e}+00$ 5.49259e+00 5.49259e-01 1.00000e-09 2.12000e-01

$1.00000 \mathrm{e}-05$ 1.00000e-05 1.00000e-06 1.00000e-09 1.00000e-01

$1.00000 \mathrm{e}+001.00000 \mathrm{e}+001.00000 \mathrm{e}-011.00000 \mathrm{e}-091.00000 \mathrm{e}-01$

Element: 14128 \# of layers: 7

$\mathrm{Kx} \mathrm{Ky} \mathrm{Kz}$ Ss Por

5.49259e+00 5.49259e+00 5.49259e-01 1.00000e-09 2.12000e-01

5.49259e+00 5.49259e+00 5.49259e-01 1.00000e-09 2.12000e-01

5.49259e+00 5.49259e+00 5.49259e-01 1.00000e-09 2.12000e-01

$5.49259 \mathrm{e}+005.49259 \mathrm{e}+00$ 5.49259e-01 1.00000e-09 2.12000e-01

5.49259e+00 5.49259e+00 5.49259e-01 1.00000e-09 2.12000e-01

$1.00000 \mathrm{e}-05$ 1.00000e-05 1.00000e-06 1.00000e-09 1.00000e-01

$1.00000 \mathrm{e}+001.00000 \mathrm{e}+001.00000 \mathrm{e}-011.00000 \mathrm{e}-091.00000 \mathrm{e}-01$

Element: 14129 \# of layers: 7

$\mathrm{Kx} \mathrm{Ky} \mathrm{Kz}$ Ss Por

5.49259e+00 5.49259e+00 5.49259e-01 1.00000e-09 2.12000e-01

5.49259e+00 5.49259e+00 5.49259e-01 1.00000e-09 2.12000e-01

$5.49259 \mathrm{e}+005.49259 \mathrm{e}+00$ 5.49259e-01 1.00000e-09 2.12000e-01

$5.49259 \mathrm{e}+005.49259 \mathrm{e}+00$ 5.49259e-01 1.00000e-09 2.12000e-01

5.49259e+00 5.49259e+00 5.49259e-01 1.00000e-09 2.12000e-01

$1.00000 \mathrm{e}-051.00000 \mathrm{e}-051.00000 \mathrm{e}-061.00000 \mathrm{e}-091.00000 \mathrm{e}-01$

$1.00000 \mathrm{e}+001.00000 \mathrm{e}+001.00000 \mathrm{e}-01$ 1.00000e-09 1.00000e-01

Element: 14130 \# of layers: 7 
$\mathrm{Kx} \mathrm{Ky} \mathrm{Kz} \mathrm{Ss} \mathrm{Por}$

5.49259e+00 5.49259e+00 5.49259e-01 1.00000e-09 2.12000e-01

5.49259e+00 5.49259e+00 5.49259e-01 1.00000e-09 2.12000e-01

$5.49259 \mathrm{e}+00$ 5.49259e+00 5.49259e-01 1.00000e-09 2.12000e-01

5.49259e+00 5.49259e+00 5.49259e-01 1.00000e-09 2.12000e-01

$5.49259 \mathrm{e}+00$ 5.49259e+00 5.49259e-01 1.00000e-09 2.12000e-01

$1.00000 \mathrm{e}-05$ 1.00000e-05 1.00000e-06 1.00000e-09 1.00000e-01

$1.00000 \mathrm{e}+001.00000 \mathrm{e}+001.00000 \mathrm{e}-011.00000 \mathrm{e}-091.00000 \mathrm{e}-01$

Element: 14131 \# of layers: 6

$\mathrm{Kx} \mathrm{Ky} \mathrm{Kz}$ Ss Por

5.49259e+00 5.49259e+00 5.49259e-01 1.00000e-09 2.12000e-01

5.49259e+00 5.49259e+00 5.49259e-01 1.00000e-09 2.12000e-01

$5.49259 \mathrm{e}+005.49259 \mathrm{e}+00$ 5.49259e-01 1.00000e-09 2.12000e-01

5.49259e+00 5.49259e+00 5.49259e-01 1.00000e-09 2.12000e-01

5.49259e+00 5.49259e+00 5.49259e-01 1.00000e-09 2.12000e-01

$1.00000 \mathrm{e}+001.00000 \mathrm{e}+001.00000 \mathrm{e}-01$ 1.00000e-09 1.00000e-01

Element: 14132 \# of layers: 6

$\mathrm{Kx} \mathrm{Ky} \mathrm{Kz}$ Ss Por

5.49259e+00 5.49259e+00 5.49259e-01 1.00000e-09 2.12000e-01

5.49259e+00 5.49259e+00 5.49259e-01 1.00000e-09 2.12000e-01

5.49259e+00 5.49259e+00 5.49259e-01 1.00000e-09 2.12000e-01

5.49259e+00 5.49259e+00 5.49259e-01 1.00000e-09 2.12000e-01

$5.49259 \mathrm{e}+005.49259 \mathrm{e}+00$ 5.49259e-01 1.00000e-09 2.12000e-01

$1.00000 \mathrm{e}+001.00000 \mathrm{e}+001.00000 \mathrm{e}-01$ 1.00000e-09 1.00000e-01

Element: 14133 \# of layers: 6

$\mathrm{Kx} \mathrm{Ky} \mathrm{Kz}$ Ss Por

$5.45794 \mathrm{e}+005.45794 \mathrm{e}+005.45794 \mathrm{e}-01$ 1.00000e-09 2.12000e-01

$5.45794 \mathrm{e}+005.45794 \mathrm{e}+00$ 5.45794e-01 1.00000e-09 2.12000e-01

$5.45794 \mathrm{e}+005.45794 \mathrm{e}+005.45794 \mathrm{e}-011.00000 \mathrm{e}-092.12000 \mathrm{e}-01$

$5.45794 \mathrm{e}+005.45794 \mathrm{e}+005.45794 \mathrm{e}-011.00000 \mathrm{e}-092.12000 \mathrm{e}-01$

$5.45794 \mathrm{e}+005.45794 \mathrm{e}+005.45794 \mathrm{e}-01$ 1.00000e-09 2.12000e-01

$1.00000 \mathrm{e}+001.00000 \mathrm{e}+001.00000 \mathrm{e}-01$ 1.00000e-09 1.00000e-01

Element: 14134 \# of layers: 6

$\mathrm{Kx} \mathrm{Ky} \mathrm{Kz}$ Ss Por

$5.45794 \mathrm{e}+005.45794 \mathrm{e}+005.45794 \mathrm{e}-01$ 1.00000e-09 2.12000e-01

$5.45794 \mathrm{e}+005.45794 \mathrm{e}+005.45794 \mathrm{e}-011.00000 \mathrm{e}-092.12000 \mathrm{e}-01$

$5.45794 \mathrm{e}+005.45794 \mathrm{e}+005.45794 \mathrm{e}-01$ 1.00000e-09 2.12000e-01

$5.45794 \mathrm{e}+005.45794 \mathrm{e}+00$ 5.45794e-01 1.00000e-09 2.12000e-01

$5.45794 \mathrm{e}+005.45794 \mathrm{e}+00$ 5.45794e-01 1.00000e-09 2.12000e-01

$1.00000 \mathrm{e}+001.00000 \mathrm{e}+001.00000 \mathrm{e}-01$ 1.00000e-09 1.00000e-01

Element: 14135 \# of layers: 6

$\mathrm{Kx} \mathrm{Ky} \mathrm{Kz}$ Ss Por

5.45794e+00 5.45794e+00 5.45794e-01 1.00000e-09 2.12000e-01

$5.45794 \mathrm{e}+005.45794 \mathrm{e}+005.45794 \mathrm{e}-011.00000 \mathrm{e}-092.12000 \mathrm{e}-01$

$5.45794 \mathrm{e}+005.45794 \mathrm{e}+005.45794 \mathrm{e}-011.00000 \mathrm{e}-092.12000 \mathrm{e}-01$

$5.45794 \mathrm{e}+005.45794 \mathrm{e}+00$ 5.45794e-01 1.00000e-09 2.12000e-01 
$5.45794 \mathrm{e}+005.45794 \mathrm{e}+00$ 5.45794e-01 1.00000e-09 2.12000e-01 $1.00000 \mathrm{e}+001.00000 \mathrm{e}+001.00000 \mathrm{e}-01$ 1.00000e-09 1.00000e-01 Element: 14136 \# of layers: 6

Kx Ky Kz Ss Por

5.49259e+00 5.49259e+00 5.49259e-01 1.00000e-09 2.12000e-01

5.49259e+00 5.49259e+00 5.49259e-01 1.00000e-09 2.12000e-01

5.49259e+00 5.49259e+00 5.49259e-01 1.00000e-09 2.12000e-01

$5.49259 \mathrm{e}+00$ 5.49259e+00 5.49259e-01 1.00000e-09 2.12000e-01

5.49259e+00 5.49259e+00 5.49259e-01 1.00000e-09 2.12000e-01

$1.00000 \mathrm{e}+001.00000 \mathrm{e}+001.00000 \mathrm{e}-011.00000 \mathrm{e}-091.00000 \mathrm{e}-01$

Element: 14137 \# of layers: 7

Kx Ky Kz Ss Por

5.49259e+00 5.49259e+00 5.49259e-01 1.00000e-09 2.12000e-01

5.49259e+00 5.49259e+00 5.49259e-01 1.00000e-09 2.12000e-01

5.49259e+00 5.49259e+00 5.49259e-01 1.00000e-09 2.12000e-01

$5.49259 \mathrm{e}+005.49259 \mathrm{e}+00$ 5.49259e-01 1.00000e-09 2.12000e-01

5.49259e+00 5.49259e+00 5.49259e-01 1.00000e-09 2.12000e-01

$1.00000 \mathrm{e}-05$ 1.00000e-05 1.00000e-06 1.00000e-09 1.00000e-01

$1.00000 \mathrm{e}+001.00000 \mathrm{e}+001.00000 \mathrm{e}-01$ 1.00000e-09 1.00000e-01

Element: 14138 \# of layers: 6

$\mathrm{Kx} \mathrm{Ky} \mathrm{Kz}$ Ss Por

5.49259e+00 5.49259e+00 5.49259e-01 1.00000e-09 2.12000e-01

5.49259e+00 5.49259e+00 5.49259e-01 1.00000e-09 2.12000e-01

5.49259e+00 5.49259e+00 5.49259e-01 1.00000e-09 2.12000e-01

$5.49259 \mathrm{e}+00$ 5.49259e+00 5.49259e-01 1.00000e-09 2.12000e-01

5.49259e+00 5.49259e+00 5.49259e-01 1.00000e-09 2.12000e-01

$1.00000 \mathrm{e}+001.00000 \mathrm{e}+001.00000 \mathrm{e}-011.00000 \mathrm{e}-091.00000 \mathrm{e}-01$

Element: 14139 \# of layers: 6

$\mathrm{Kx} \mathrm{Ky} \mathrm{Kz}$ Ss Por

5.49259e+00 5.49259e+00 5.49259e-01 1.00000e-09 2.12000e-01

5.49259e+00 5.49259e+00 5.49259e-01 1.00000e-09 2.12000e-01

5.49259e+00 5.49259e+00 5.49259e-01 1.00000e-09 2.12000e-01

$5.49259 \mathrm{e}+005.49259 \mathrm{e}+00$ 5.49259e-01 1.00000e-09 2.12000e-01

5.49259e+00 5.49259e+00 5.49259e-01 1.00000e-09 2.12000e-01

$1.00000 \mathrm{e}+001.00000 \mathrm{e}+001.00000 \mathrm{e}-01$ 1.00000e-09 1.00000e-01

Element: 14140 \# of layers: 6

Kx Ky Kz Ss Por

5.45794e+00 5.45794e+00 5.45794e-01 1.00000e-09 2.12000e-01

$5.45794 \mathrm{e}+005.45794 \mathrm{e}+005.45794 \mathrm{e}-011.00000 \mathrm{e}-092.12000 \mathrm{e}-01$

$5.45794 \mathrm{e}+005.45794 \mathrm{e}+00$ 5.45794e-01 1.00000e-09 2.12000e-01

$5.45794 \mathrm{e}+005.45794 \mathrm{e}+005.45794 \mathrm{e}-011.00000 \mathrm{e}-092.12000 \mathrm{e}-01$

$5.45794 \mathrm{e}+00$ 5.45794e+00 5.45794e-01 1.00000e-09 2.12000e-01

$1.00000 \mathrm{e}+001.00000 \mathrm{e}+001.00000 \mathrm{e}-011.00000 \mathrm{e}-091.00000 \mathrm{e}-01$

Element: 14141 \# of layers: 6

$\mathrm{Kx} \mathrm{Ky} \mathrm{Kz}$ Ss Por

5.45794e+00 5.45794e+00 5.45794e-01 1.00000e-09 2.12000e-01 
$5.45794 \mathrm{e}+00$ 5.45794e+00 5.45794e-01 1.00000e-09 2.12000e-01 $5.45794 \mathrm{e}+005.45794 \mathrm{e}+005.45794 \mathrm{e}-011.00000 \mathrm{e}-092.12000 \mathrm{e}-01$ $5.45794 \mathrm{e}+005.45794 \mathrm{e}+005.45794 \mathrm{e}-011.00000 \mathrm{e}-092.12000 \mathrm{e}-01$ $5.45794 \mathrm{e}+005.45794 \mathrm{e}+005.45794 \mathrm{e}-011.00000 \mathrm{e}-092.12000 \mathrm{e}-01$ $1.00000 \mathrm{e}+001.00000 \mathrm{e}+001.00000 \mathrm{e}-011.00000 \mathrm{e}-091.00000 \mathrm{e}-01$ Element: 14142 \# of layers: 6

Kx Ky Kz Ss Por

$5.45794 \mathrm{e}+00$ 5.45794e+00 5.45794e-01 1.00000e-09 2.12000e-01 $5.45794 \mathrm{e}+005.45794 \mathrm{e}+005.45794 \mathrm{e}-011.00000 \mathrm{e}-092.12000 \mathrm{e}-01$ $5.45794 \mathrm{e}+005.45794 \mathrm{e}+005.45794 \mathrm{e}-011.00000 \mathrm{e}-092.12000 \mathrm{e}-01$ $5.45794 \mathrm{e}+005.45794 \mathrm{e}+005.45794 \mathrm{e}-011.00000 \mathrm{e}-092.12000 \mathrm{e}-01$ $5.45794 \mathrm{e}+005.45794 \mathrm{e}+005.45794 \mathrm{e}-011.00000 \mathrm{e}-092.12000 \mathrm{e}-01$ $1.00000 \mathrm{e}+001.00000 \mathrm{e}+001.00000 \mathrm{e}-011.00000 \mathrm{e}-091.00000 \mathrm{e}-01$ Element: 14143 \# of layers: 6

Kx Ky Kz Ss Por

$5.45794 \mathrm{e}+00$ 5.45794e+00 5.45794e-01 1.00000e-09 2.12000e-01 $5.45794 \mathrm{e}+005.45794 \mathrm{e}+005.45794 \mathrm{e}-011.00000 \mathrm{e}-092.12000 \mathrm{e}-01$ $5.45794 \mathrm{e}+005.45794 \mathrm{e}+00$ 5.45794e-01 1.00000e-09 2.12000e-01 $5.45794 \mathrm{e}+005.45794 \mathrm{e}+00$ 5.45794e-01 1.00000e-09 2.12000e-01 $5.45794 \mathrm{e}+005.45794 \mathrm{e}+005.45794 \mathrm{e}-011.00000 \mathrm{e}-092.12000 \mathrm{e}-01$ $1.00000 \mathrm{e}+001.00000 \mathrm{e}+001.00000 \mathrm{e}-011.00000 \mathrm{e}-091.00000 \mathrm{e}-01$ Element: 14144 \# of layers: 6

Kx Ky Kz Ss Por

$7.47714 \mathrm{e}+007.47714 \mathrm{e}+00$ 7.47714e-01 1.00000e-09 2.12000e-01

$7.47714 \mathrm{e}+007.47714 \mathrm{e}+007.47714 \mathrm{e}-011.00000 \mathrm{e}-092.12000 \mathrm{e}-01$ $7.47714 \mathrm{e}+007.47714 \mathrm{e}+007.47714 \mathrm{e}-011.00000 \mathrm{e}-092.12000 \mathrm{e}-01$ $7.47714 \mathrm{e}+007.47714 \mathrm{e}+007.47714 \mathrm{e}-011.00000 \mathrm{e}-092.12000 \mathrm{e}-01$ $7.47714 \mathrm{e}+007.47714 \mathrm{e}+007.47714 \mathrm{e}-011.00000 \mathrm{e}-092.12000 \mathrm{e}-01$ $1.00000 \mathrm{e}+001.00000 \mathrm{e}+00$ 1.00000e-01 1.00000e-09 1.00000e-01 Element: 14145 \# of layers: 6

Kx Ky Kz Ss Por

$5.45794 \mathrm{e}+00$ 5.45794e+00 5.45794e-01 1.00000e-09 2.12000e-01 $5.45794 \mathrm{e}+005.45794 \mathrm{e}+005.45794 \mathrm{e}-011.00000 \mathrm{e}-092.12000 \mathrm{e}-01$ $5.45794 \mathrm{e}+005.45794 \mathrm{e}+00$ 5.45794e-01 1.00000e-09 2.12000e-01 $5.45794 \mathrm{e}+005.45794 \mathrm{e}+005.45794 \mathrm{e}-011.00000 \mathrm{e}-092.12000 \mathrm{e}-01$ $5.45794 \mathrm{e}+005.45794 \mathrm{e}+00$ 5.45794e-01 1.00000e-09 2.12000e-01 $1.00000 \mathrm{e}+001.00000 \mathrm{e}+001.00000 \mathrm{e}-011.00000 \mathrm{e}-091.00000 \mathrm{e}-01$ Element: 14146 \# of layers: 6

Kx Ky Kz Ss Por

$5.45794 \mathrm{e}+005.45794 \mathrm{e}+00$ 5.45794e-01 1.00000e-09 2.12000e-01 $5.45794 \mathrm{e}+005.45794 \mathrm{e}+005.45794 \mathrm{e}-011.00000 \mathrm{e}-092.12000 \mathrm{e}-01$ $5.45794 \mathrm{e}+005.45794 \mathrm{e}+005.45794 \mathrm{e}-011.00000 \mathrm{e}-092.12000 \mathrm{e}-01$ $5.45794 \mathrm{e}+005.45794 \mathrm{e}+005.45794 \mathrm{e}-011.00000 \mathrm{e}-092.12000 \mathrm{e}-01$ $5.45794 \mathrm{e}+005.45794 \mathrm{e}+005.45794 \mathrm{e}-011.00000 \mathrm{e}-092.12000 \mathrm{e}-01$ $1.00000 \mathrm{e}+001.00000 \mathrm{e}+001.00000 \mathrm{e}-011.00000 \mathrm{e}-091.00000 \mathrm{e}-01$ Element: 14147 \# of layers: 6 
$\mathrm{Kx} \mathrm{Ky} \mathrm{Kz} \mathrm{Ss} \mathrm{Por}$

5.45794e+00 5.45794e+00 5.45794e-01 1.00000e-09 2.12000e-01

$5.45794 \mathrm{e}+005.45794 \mathrm{e}+00$ 5.45794e-01 1.00000e-09 2.12000e-01

$5.45794 \mathrm{e}+005.45794 \mathrm{e}+00$ 5.45794e-01 1.00000e-09 2.12000e-01

$5.45794 \mathrm{e}+005.45794 \mathrm{e}+005.45794 \mathrm{e}-011.00000 \mathrm{e}-092.12000 \mathrm{e}-01$

$5.45794 \mathrm{e}+005.45794 \mathrm{e}+00$ 5.45794e-01 1.00000e-09 2.12000e-01

$1.00000 \mathrm{e}+001.00000 \mathrm{e}+001.00000 \mathrm{e}-01$ 1.00000e-09 1.00000e-01

Element: 14148 \# of layers: 7

$\mathrm{Kx} \mathrm{Ky} \mathrm{Kz}$ Ss Por

$7.47714 \mathrm{e}+007.47714 \mathrm{e}+007.47714 \mathrm{e}-01$ 1.00000e-09 2.12000e-01

$7.47714 \mathrm{e}+007.47714 \mathrm{e}+007.47714 \mathrm{e}-01$ 1.00000e-09 2.12000e-01

$7.47714 \mathrm{e}+007.47714 \mathrm{e}+007.47714 \mathrm{e}-011.00000 \mathrm{e}-092.12000 \mathrm{e}-01$

$7.47714 \mathrm{e}+007.47714 \mathrm{e}+007.47714 \mathrm{e}-01$ 1.00000e-09 2.12000e-01

$7.47714 \mathrm{e}+007.47714 \mathrm{e}+007.47714 \mathrm{e}-01$ 1.00000e-09 2.12000e-01

$1.00000 \mathrm{e}-05$ 1.00000e-05 1.00000e-06 1.00000e-09 1.00000e-01

$1.00000 \mathrm{e}+001.00000 \mathrm{e}+001.00000 \mathrm{e}-011.00000 \mathrm{e}-091.00000 \mathrm{e}-01$

Element: 14149 \# of layers: 7

$\mathrm{Kx} \mathrm{Ky} \mathrm{Kz}$ Ss Por

7.47714e+00 7.47714e+00 7.47714e-01 1.00000e-09 2.12000e-01

$7.47714 \mathrm{e}+007.47714 \mathrm{e}+007.47714 \mathrm{e}-01$ 1.00000e-09 2.12000e-01

$7.47714 \mathrm{e}+007.47714 \mathrm{e}+007.47714 \mathrm{e}-01$ 1.00000e-09 2.12000e-01

$7.47714 \mathrm{e}+007.47714 \mathrm{e}+007.47714 \mathrm{e}-01$ 1.00000e-09 2.12000e-01

$7.47714 \mathrm{e}+007.47714 \mathrm{e}+007.47714 \mathrm{e}-01$ 1.00000e-09 2.12000e-01

$1.00000 \mathrm{e}-05$ 1.00000e-05 1.00000e-06 1.00000e-09 1.00000e-01

$1.00000 \mathrm{e}+001.00000 \mathrm{e}+001.00000 \mathrm{e}-011.00000 \mathrm{e}-091.00000 \mathrm{e}-01$

Element: 14150 \# of layers: 6

$\mathrm{Kx} \mathrm{Ky} \mathrm{Kz}$ Ss Por

7.47714e+00 7.47714e+00 7.47714e-01 1.00000e-09 2.12000e-01

$7.47714 \mathrm{e}+007.47714 \mathrm{e}+007.47714 \mathrm{e}-011.00000 \mathrm{e}-092.12000 \mathrm{e}-01$

$7.47714 \mathrm{e}+007.47714 \mathrm{e}+007.47714 \mathrm{e}-01$ 1.00000e-09 2.12000e-01

$7.47714 \mathrm{e}+007.47714 \mathrm{e}+007.47714 \mathrm{e}-01$ 1.00000e-09 2.12000e-01

$7.47714 \mathrm{e}+007.47714 \mathrm{e}+007.47714 \mathrm{e}-01$ 1.00000e-09 2.12000e-01

$1.00000 \mathrm{e}+001.00000 \mathrm{e}+001.00000 \mathrm{e}-01$ 1.00000e-09 1.00000e-01

Element: 14151 \# of layers: 7

Kx Ky Kz Ss Por

$7.47714 \mathrm{e}+007.47714 \mathrm{e}+007.47714 \mathrm{e}-01$ 1.00000e-09 2.12000e-01

$7.47714 \mathrm{e}+007.47714 \mathrm{e}+007.47714 \mathrm{e}-01$ 1.00000e-09 2.12000e-01

$7.47714 \mathrm{e}+007.47714 \mathrm{e}+007.47714 \mathrm{e}-01$ 1.00000e-09 2.12000e-01

$7.47714 \mathrm{e}+007.47714 \mathrm{e}+007.47714 \mathrm{e}-01$ 1.00000e-09 2.12000e-01

$7.47714 \mathrm{e}+007.47714 \mathrm{e}+007.47714 \mathrm{e}-01$ 1.00000e-09 2.12000e-01

$1.00000 \mathrm{e}-05$ 1.00000e-05 1.00000e-06 1.00000e-09 1.00000e-01

$1.00000 \mathrm{e}+001.00000 \mathrm{e}+001.00000 \mathrm{e}-011.00000 \mathrm{e}-091.00000 \mathrm{e}-01$

Element: 14152 \# of layers: 7

$\mathrm{Kx} \mathrm{Ky} \mathrm{Kz}$ Ss Por

7.47714e+00 7.47714e+00 7.47714e-01 1.00000e-09 2.12000e-01

$7.47714 \mathrm{e}+007.47714 \mathrm{e}+007.47714 \mathrm{e}-011.00000 \mathrm{e}-092.12000 \mathrm{e}-01$ 
$7.47714 \mathrm{e}+007.47714 \mathrm{e}+00$ 7.47714e-01 1.00000e-09 2.12000e-01 $7.47714 \mathrm{e}+007.47714 \mathrm{e}+007.47714 \mathrm{e}-011.00000 \mathrm{e}-092.12000 \mathrm{e}-01$ $7.47714 \mathrm{e}+007.47714 \mathrm{e}+00$ 7.47714e-01 1.00000e-09 2.12000e-01 $1.00000 \mathrm{e}-05$ 1.00000e-05 1.00000e-06 1.00000e-09 1.00000e-01 $1.00000 \mathrm{e}+001.00000 \mathrm{e}+001.00000 \mathrm{e}-011.00000 \mathrm{e}-091.00000 \mathrm{e}-01$ Element: 14153 \# of layers: 7

Kx Ky Kz Ss Por

$5.59745 \mathrm{e}+00$ 5.59745e+00 5.59745e-01 1.00000e-09 2.12000e-01 $5.59745 \mathrm{e}+005.59745 \mathrm{e}+005.59745 \mathrm{e}-011.00000 \mathrm{e}-092.12000 \mathrm{e}-01$ $5.59745 \mathrm{e}+005.59745 \mathrm{e}+005.59745 \mathrm{e}-011.00000 \mathrm{e}-092.12000 \mathrm{e}-01$ $5.59745 \mathrm{e}+005.59745 \mathrm{e}+005.59745 \mathrm{e}-011.00000 \mathrm{e}-092.12000 \mathrm{e}-01$ $5.59745 \mathrm{e}+005.59745 \mathrm{e}+00$ 5.59745e-01 1.00000e-09 2.12000e-01 $1.00000 \mathrm{e}-05$ 1.00000e-05 1.00000e-06 1.00000e-09 1.00000e-01 $1.00000 \mathrm{e}+001.00000 \mathrm{e}+001.00000 \mathrm{e}-011.00000 \mathrm{e}-091.00000 \mathrm{e}-01$ Element: 14154 \# of layers: 7

Kx Ky Kz Ss Por

$5.59745 \mathrm{e}+00$ 5.59745e+00 5.59745e-01 1.00000e-09 2.12000e-01

$5.59745 \mathrm{e}+005.59745 \mathrm{e}+005.59745 \mathrm{e}-011.00000 \mathrm{e}-092.12000 \mathrm{e}-01$ $5.59745 \mathrm{e}+005.59745 \mathrm{e}+005.59745 \mathrm{e}-011.00000 \mathrm{e}-092.12000 \mathrm{e}-01$ $5.59745 \mathrm{e}+005.59745 \mathrm{e}+00$ 5.59745e-01 1.00000e-09 2.12000e-01 $5.59745 \mathrm{e}+005.59745 \mathrm{e}+00$ 5.59745e-01 1.00000e-09 2.12000e-01 $1.00000 \mathrm{e}-05$ 1.00000e-05 1.00000e-06 1.00000e-09 1.00000e-01 $1.00000 \mathrm{e}+001.00000 \mathrm{e}+001.00000 \mathrm{e}-011.00000 \mathrm{e}-091.00000 \mathrm{e}-01$ Element: 14155 \# of layers: 7

Kx Ky Kz Ss Por

$5.59745 \mathrm{e}+00$ 5.59745e+00 5.59745e-01 1.00000e-09 2.12000e-01 $5.59745 \mathrm{e}+005.59745 \mathrm{e}+005.59745 \mathrm{e}-011.00000 \mathrm{e}-092.12000 \mathrm{e}-01$ $5.59745 \mathrm{e}+005.59745 \mathrm{e}+005.59745 \mathrm{e}-011.00000 \mathrm{e}-092.12000 \mathrm{e}-01$ $5.59745 \mathrm{e}+005.59745 \mathrm{e}+00$ 5.59745e-01 1.00000e-09 2.12000e-01 $5.59745 \mathrm{e}+005.59745 \mathrm{e}+00$ 5.59745e-01 1.00000e-09 2.12000e-01 $1.00000 \mathrm{e}-05$ 1.00000e-05 1.00000e-06 1.00000e-09 1.00000e-01 $1.00000 \mathrm{e}+001.00000 \mathrm{e}+001.00000 \mathrm{e}-011.00000 \mathrm{e}-091.00000 \mathrm{e}-01$ Element: 14156 \# of layers: 7

$\mathrm{Kx} \mathrm{Ky} \mathrm{Kz}$ Ss Por

5.59745e+00 5.59745e+00 5.59745e-01 1.00000e-09 2.12000e-01 $5.59745 \mathrm{e}+005.59745 \mathrm{e}+00$ 5.59745e-01 1.00000e-09 2.12000e-01 $5.59745 \mathrm{e}+005.59745 \mathrm{e}+00$ 5.59745e-01 1.00000e-09 2.12000e-01 $5.59745 \mathrm{e}+005.59745 \mathrm{e}+00$ 5.59745e-01 1.00000e-09 2.12000e-01 $5.59745 \mathrm{e}+00$ 5.59745e+00 5.59745e-01 1.00000e-09 2.12000e-01 $1.00000 \mathrm{e}-05$ 1.00000e-05 1.00000e-06 1.00000e-09 1.00000e-01 $1.00000 \mathrm{e}+001.00000 \mathrm{e}+001.00000 \mathrm{e}-011.00000 \mathrm{e}-091.00000 \mathrm{e}-01$ Element: 14157 \# of layers: 7

$\mathrm{Kx} \mathrm{Ky} \mathrm{Kz}$ Ss Por

5.59745e+00 5.59745e+00 5.59745e-01 1.00000e-09 2.12000e-01 $5.59745 \mathrm{e}+005.59745 \mathrm{e}+00$ 5.59745e-01 1.00000e-09 2.12000e-01 $5.59745 \mathrm{e}+00$ 5.59745e+00 5.59745e-01 1.00000e-09 2.12000e-01 
$5.59745 \mathrm{e}+005.59745 \mathrm{e}+00$ 5.59745e-01 1.00000e-09 2.12000e-01 $5.59745 \mathrm{e}+005.59745 \mathrm{e}+00$ 5.59745e-01 1.00000e-09 2.12000e-01 $1.00000 \mathrm{e}-05$ 1.00000e-05 1.00000e-06 1.00000e-09 1.00000e-01 $1.00000 \mathrm{e}+001.00000 \mathrm{e}+001.00000 \mathrm{e}-011.00000 \mathrm{e}-091.00000 \mathrm{e}-01$ Element: 14158 \# of layers: 7

Kx Ky Kz Ss Por

7.47714e+00 7.47714e+00 7.47714e-01 1.00000e-09 2.12000e-01

$7.47714 \mathrm{e}+007.47714 \mathrm{e}+007.47714 \mathrm{e}-011.00000 \mathrm{e}-092.12000 \mathrm{e}-01$ $7.47714 \mathrm{e}+007.47714 \mathrm{e}+007.47714 \mathrm{e}-011.00000 \mathrm{e}-092.12000 \mathrm{e}-01$ $7.47714 \mathrm{e}+007.47714 \mathrm{e}+007.47714 \mathrm{e}-011.00000 \mathrm{e}-092.12000 \mathrm{e}-01$ $7.47714 \mathrm{e}+007.47714 \mathrm{e}+007.47714 \mathrm{e}-011.00000 \mathrm{e}-092.12000 \mathrm{e}-01$ $1.00000 \mathrm{e}-05$ 1.00000e-05 1.00000e-06 1.00000e-09 1.00000e-01 $1.00000 \mathrm{e}+001.00000 \mathrm{e}+001.00000 \mathrm{e}-011.00000 \mathrm{e}-091.00000 \mathrm{e}-01$ Element: 14159 \# of layers: 7

Kx Ky Kz Ss Por

7.47714e+00 7.47714e+00 7.47714e-01 1.00000e-09 2.12000e-01 $7.47714 \mathrm{e}+007.47714 \mathrm{e}+007.47714 \mathrm{e}-011.00000 \mathrm{e}-092.12000 \mathrm{e}-01$ $7.47714 \mathrm{e}+007.47714 \mathrm{e}+007.47714 \mathrm{e}-011.00000 \mathrm{e}-092.12000 \mathrm{e}-01$ $7.47714 \mathrm{e}+007.47714 \mathrm{e}+007.47714 \mathrm{e}-011.00000 \mathrm{e}-092.12000 \mathrm{e}-01$ $7.47714 \mathrm{e}+007.47714 \mathrm{e}+007.47714 \mathrm{e}-011.00000 \mathrm{e}-092.12000 \mathrm{e}-01$ $1.00000 \mathrm{e}-05$ 1.00000e-05 1.00000e-06 1.00000e-09 1.00000e-01 $1.00000 \mathrm{e}+001.00000 \mathrm{e}+001.00000 \mathrm{e}-011.00000 \mathrm{e}-091.00000 \mathrm{e}-01$ Element: 14160 \# of layers: 7

Kx Ky Kz Ss Por

$5.59745 \mathrm{e}+00$ 5.59745e+00 5.59745e-01 1.00000e-09 2.12000e-01 $5.59745 \mathrm{e}+005.59745 \mathrm{e}+005.59745 \mathrm{e}-011.00000 \mathrm{e}-092.12000 \mathrm{e}-01$ $5.59745 \mathrm{e}+005.59745 \mathrm{e}+00$ 5.59745e-01 1.00000e-09 2.12000e-01 $5.59745 \mathrm{e}+005.59745 \mathrm{e}+00$ 5.59745e-01 1.00000e-09 2.12000e-01 $5.59745 \mathrm{e}+005.59745 \mathrm{e}+00$ 5.59745e-01 1.00000e-09 2.12000e-01 $1.00000 \mathrm{e}-05$ 1.00000e-05 1.00000e-06 1.00000e-09 1.00000e-01 $1.00000 \mathrm{e}+001.00000 \mathrm{e}+001.00000 \mathrm{e}-011.00000 \mathrm{e}-091.00000 \mathrm{e}-01$ Element: 14161 \# of layers: 7

Kx Ky Kz Ss Por

$5.59745 \mathrm{e}+005.59745 \mathrm{e}+00$ 5.59745e-01 1.00000e-09 2.12000e-01 $5.59745 \mathrm{e}+005.59745 \mathrm{e}+005.59745 \mathrm{e}-011.00000 \mathrm{e}-092.12000 \mathrm{e}-01$ $5.59745 \mathrm{e}+005.59745 \mathrm{e}+00$ 5.59745e-01 1.00000e-09 2.12000e-01 $5.59745 \mathrm{e}+005.59745 \mathrm{e}+00$ 5.59745e-01 1.00000e-09 2.12000e-01 $5.59745 \mathrm{e}+005.59745 \mathrm{e}+00$ 5.59745e-01 1.00000e-09 2.12000e-01 $1.00000 \mathrm{e}-05$ 1.00000e-05 1.00000e-06 1.00000e-09 1.00000e-01 $1.00000 \mathrm{e}+001.00000 \mathrm{e}+001.00000 \mathrm{e}-011.00000 \mathrm{e}-091.00000 \mathrm{e}-01$ Element: 14162 \# of layers: 7

Kx Ky Kz Ss Por

$5.49259 \mathrm{e}+00$ 5.49259e+00 5.49259e-01 1.00000e-09 2.12000e-01 $5.49259 \mathrm{e}+005.49259 \mathrm{e}+00$ 5.49259e-01 1.00000e-09 2.12000e-01 $5.49259 \mathrm{e}+005.49259 \mathrm{e}+00$ 5.49259e-01 1.00000e-09 2.12000e-01 $5.49259 \mathrm{e}+00$ 5.49259e+00 5.49259e-01 1.00000e-09 2.12000e-01 
5.49259e+00 5.49259e+00 5.49259e-01 1.00000e-09 2.12000e-01 $1.00000 \mathrm{e}-05$ 1.00000e-05 1.00000e-06 1.00000e-09 1.00000e-01 $1.00000 \mathrm{e}+001.00000 \mathrm{e}+00$ 1.00000e-01 1.00000e-09 1.00000e-01 Element: 14163 \# of layers: 7

$\mathrm{Kx} \mathrm{Ky} \mathrm{Kz}$ Ss Por

5.49259e+00 5.49259e+00 5.49259e-01 1.00000e-09 2.12000e-01 5.49259e+00 5.49259e+00 5.49259e-01 1.00000e-09 2.12000e-01 5.49259e+00 5.49259e+00 5.49259e-01 1.00000e-09 2.12000e-01 5.49259e+00 5.49259e+00 5.49259e-01 1.00000e-09 2.12000e-01 5.49259e+00 5.49259e+00 5.49259e-01 1.00000e-09 2.12000e-01 $1.00000 \mathrm{e}-05$ 1.00000e-05 1.00000e-06 1.00000e-09 1.00000e-01 $1.00000 \mathrm{e}+001.00000 \mathrm{e}+001.00000 \mathrm{e}-011.00000 \mathrm{e}-091.00000 \mathrm{e}-01$ Element: 14164 \# of layers: 7

$\mathrm{Kx} \mathrm{Ky} \mathrm{Kz}$ Ss Por

5.49259e+00 5.49259e+00 5.49259e-01 1.00000e-09 2.12000e-01 $5.49259 \mathrm{e}+00$ 5.49259e+00 5.49259e-01 1.00000e-09 2.12000e-01 $5.49259 \mathrm{e}+00$ 5.49259e+00 5.49259e-01 1.00000e-09 2.12000e-01 5.49259e+00 5.49259e+00 5.49259e-01 1.00000e-09 2.12000e-01 5.49259e+00 5.49259e+00 5.49259e-01 1.00000e-09 2.12000e-01 $1.00000 \mathrm{e}-05$ 1.00000e-05 1.00000e-06 1.00000e-09 1.00000e-01 $1.00000 \mathrm{e}+001.00000 \mathrm{e}+001.00000 \mathrm{e}-011.00000 \mathrm{e}-091.00000 \mathrm{e}-01$ Element: 14165 \# of layers: 6

$\mathrm{Kx} \mathrm{Ky} \mathrm{Kz}$ Ss Por

5.45794e+00 5.45794e+00 5.45794e-01 1.00000e-09 2.12000e-01 $5.45794 \mathrm{e}+005.45794 \mathrm{e}+00$ 5.45794e-01 1.00000e-09 2.12000e-01 $5.45794 \mathrm{e}+005.45794 \mathrm{e}+00$ 5.45794e-01 1.00000e-09 2.12000e-01 $5.45794 \mathrm{e}+005.45794 \mathrm{e}+005.45794 \mathrm{e}-011.00000 \mathrm{e}-092.12000 \mathrm{e}-01$ $5.45794 \mathrm{e}+005.45794 \mathrm{e}+00$ 5.45794e-01 1.00000e-09 2.12000e-01 $1.00000 \mathrm{e}+001.00000 \mathrm{e}+001.00000 \mathrm{e}-01$ 1.00000e-09 1.00000e-01 Element: 14166 \# of layers: 7

$\mathrm{Kx} \mathrm{Ky} \mathrm{Kz}$ Ss Por

5.45794e+00 5.45794e+00 5.45794e-01 1.00000e-09 2.12000e-01 $5.45794 \mathrm{e}+005.45794 \mathrm{e}+005.45794 \mathrm{e}-01$ 1.00000e-09 2.12000e-01 $5.45794 \mathrm{e}+005.45794 \mathrm{e}+005.45794 \mathrm{e}-011.00000 \mathrm{e}-092.12000 \mathrm{e}-01$ $5.45794 \mathrm{e}+005.45794 \mathrm{e}+005.45794 \mathrm{e}-01$ 1.00000e-09 2.12000e-01 $5.45794 \mathrm{e}+005.45794 \mathrm{e}+005.45794 \mathrm{e}-011.00000 \mathrm{e}-092.12000 \mathrm{e}-01$ $1.00000 \mathrm{e}-05$ 1.00000e-05 1.00000e-06 1.00000e-09 1.00000e-01 $1.00000 \mathrm{e}+001.00000 \mathrm{e}+001.00000 \mathrm{e}-011.00000 \mathrm{e}-09$ 1.00000e-01 Element: 14167 \# of layers: 7

Kx Ky Kz Ss Por

7.47714e+00 7.47714e+00 7.47714e-01 1.00000e-09 2.12000e-01 $7.47714 \mathrm{e}+007.47714 \mathrm{e}+007.47714 \mathrm{e}-01$ 1.00000e-09 2.12000e-01 $7.47714 \mathrm{e}+007.47714 \mathrm{e}+00$ 7.47714e-01 1.00000e-09 2.12000e-01 $7.47714 \mathrm{e}+007.47714 \mathrm{e}+007.47714 \mathrm{e}-01$ 1.00000e-09 2.12000e-01 $7.47714 \mathrm{e}+007.47714 \mathrm{e}+007.47714 \mathrm{e}-01$ 1.00000e-09 2.12000e-01 $1.00000 \mathrm{e}-05$ 1.00000e-05 1.00000e-06 1.00000e-09 1.00000e-01 
$1.00000 \mathrm{e}+001.00000 \mathrm{e}+001.00000 \mathrm{e}-01$ 1.00000e-09 1.00000e-01 Element: 14168 \# of layers: 7

Kx Ky Kz Ss Por

5.59745e+00 5.59745e+00 5.59745e-01 1.00000e-09 2.12000e-01

$5.59745 \mathrm{e}+005.59745 \mathrm{e}+00$ 5.59745e-01 1.00000e-09 2.12000e-01

5.59745e+00 5.59745e+00 5.59745e-01 1.00000e-09 2.12000e-01

$5.59745 \mathrm{e}+00$ 5.59745e+00 5.59745e-01 1.00000e-09 2.12000e-01

$5.59745 \mathrm{e}+005.59745 \mathrm{e}+00$ 5.59745e-01 1.00000e-09 2.12000e-01

$1.00000 \mathrm{e}-05$ 1.00000e-05 1.00000e-06 1.00000e-09 1.00000e-01

$1.00000 \mathrm{e}+001.00000 \mathrm{e}+001.00000 \mathrm{e}-01$ 1.00000e-09 1.00000e-01

Element: 14169 \# of layers: 7

$\mathrm{Kx} \mathrm{Ky} \mathrm{Kz}$ Ss Por

5.49259e+00 5.49259e+00 5.49259e-01 1.00000e-09 2.12000e-01

5.49259e+00 5.49259e+00 5.49259e-01 1.00000e-09 2.12000e-01

5.49259e+00 5.49259e+00 5.49259e-01 1.00000e-09 2.12000e-01

$5.49259 \mathrm{e}+00$ 5.49259e+00 5.49259e-01 1.00000e-09 2.12000e-01

5.49259e+00 5.49259e+00 5.49259e-01 1.00000e-09 2.12000e-01

$1.00000 \mathrm{e}-05$ 1.00000e-05 1.00000e-06 1.00000e-09 1.00000e-01

$1.00000 \mathrm{e}+001.00000 \mathrm{e}+001.00000 \mathrm{e}-011.00000 \mathrm{e}-091.00000 \mathrm{e}-01$

Element: 14170 \# of layers: 7

$\mathrm{Kx} \mathrm{Ky} \mathrm{Kz}$ Ss Por

5.48854e+00 5.48854e+00 5.48854e-01 1.00000e-09 2.12000e-01

$5.48854 \mathrm{e}+005.48854 \mathrm{e}+005.48854 \mathrm{e}-011.00000 \mathrm{e}-092.12000 \mathrm{e}-01$

$5.48854 \mathrm{e}+005.48854 \mathrm{e}+005.48854 \mathrm{e}-011.00000 \mathrm{e}-092.12000 \mathrm{e}-01$

$5.48854 \mathrm{e}+005.48854 \mathrm{e}+005.48854 \mathrm{e}-011.00000 \mathrm{e}-092.12000 \mathrm{e}-01$

$5.48854 \mathrm{e}+005.48854 \mathrm{e}+00$ 5.48854e-01 1.00000e-09 2.12000e-01

$1.00000 \mathrm{e}-05$ 1.00000e-05 1.00000e-06 1.00000e-09 1.00000e-01

$1.00000 \mathrm{e}+001.00000 \mathrm{e}+001.00000 \mathrm{e}-01$ 1.00000e-09 1.00000e-01

Element: 14171 \# of layers: 7

$\mathrm{Kx} \mathrm{Ky} \mathrm{Kz}$ Ss Por

$5.48854 \mathrm{e}+005.48854 \mathrm{e}+005.48854 \mathrm{e}-011.00000 \mathrm{e}-092.12000 \mathrm{e}-01$

$5.48854 \mathrm{e}+005.48854 \mathrm{e}+00$ 5.48854e-01 1.00000e-09 2.12000e-01

$5.48854 \mathrm{e}+005.48854 \mathrm{e}+005.48854 \mathrm{e}-011.00000 \mathrm{e}-092.12000 \mathrm{e}-01$

$5.48854 \mathrm{e}+005.48854 \mathrm{e}+005.48854 \mathrm{e}-011.00000 \mathrm{e}-092.12000 \mathrm{e}-01$

$5.48854 \mathrm{e}+005.48854 \mathrm{e}+005.48854 \mathrm{e}-011.00000 \mathrm{e}-092.12000 \mathrm{e}-01$

$1.00000 \mathrm{e}-05$ 1.00000e-05 1.00000e-06 1.00000e-09 1.00000e-01

$1.00000 \mathrm{e}+001.00000 \mathrm{e}+001.00000 \mathrm{e}-011.00000 \mathrm{e}-091.00000 \mathrm{e}-01$

Element: 14172 \# of layers: 7

$\mathrm{Kx} \mathrm{Ky} \mathrm{Kz}$ Ss Por

5.48854e+00 5.48854e+00 5.48854e-01 1.00000e-09 2.12000e-01

$5.48854 \mathrm{e}+005.48854 \mathrm{e}+00$ 5.48854e-01 1.00000e-09 2.12000e-01

$5.48854 \mathrm{e}+005.48854 \mathrm{e}+00$ 5.48854e-01 1.00000e-09 2.12000e-01

$5.48854 \mathrm{e}+00$ 5.48854e+00 5.48854e-01 1.00000e-09 2.12000e-01

$5.48854 \mathrm{e}+005.48854 \mathrm{e}+00$ 5.48854e-01 1.00000e-09 2.12000e-01

$1.00000 \mathrm{e}-05$ 1.00000e-05 1.00000e-06 1.00000e-09 1.00000e-01

$1.00000 \mathrm{e}+001.00000 \mathrm{e}+001.00000 \mathrm{e}-011.00000 \mathrm{e}-091.00000 \mathrm{e}-01$ 
Element: 14173 \# of layers: 6

$\mathrm{Kx} \mathrm{Ky} \mathrm{Kz} \mathrm{Ss} \mathrm{Por}$

$5.48854 \mathrm{e}+00$ 5.48854e+00 5.48854e-01 1.00000e-09 2.12000e-01

$5.48854 \mathrm{e}+005.48854 \mathrm{e}+005.48854 \mathrm{e}-011.00000 \mathrm{e}-092.12000 \mathrm{e}-01$

$5.48854 \mathrm{e}+005.48854 \mathrm{e}+005.48854 \mathrm{e}-01$ 1.00000e-09 2.12000e-01

$5.48854 \mathrm{e}+00$ 5.48854e+00 5.48854e-01 1.00000e-09 2.12000e-01

$5.48854 \mathrm{e}+005.48854 \mathrm{e}+005.48854 \mathrm{e}-011.00000 \mathrm{e}-092.12000 \mathrm{e}-01$

$1.00000 \mathrm{e}+001.00000 \mathrm{e}+001.00000 \mathrm{e}-01$ 1.00000e-09 1.00000e-01

Element: 14174 \# of layers: 6

$\mathrm{Kx} \mathrm{Ky} \mathrm{Kz}$ Ss Por

$5.48854 \mathrm{e}+00$ 5.48854e+00 5.48854e-01 1.00000e-09 2.12000e-01

$5.48854 \mathrm{e}+005.48854 \mathrm{e}+005.48854 \mathrm{e}-011.00000 \mathrm{e}-092.12000 \mathrm{e}-01$

$5.48854 \mathrm{e}+005.48854 \mathrm{e}+005.48854 \mathrm{e}-01$ 1.00000e-09 2.12000e-01

$5.48854 \mathrm{e}+00$ 5.48854e+00 5.48854e-01 1.00000e-09 2.12000e-01

$5.48854 \mathrm{e}+005.48854 \mathrm{e}+00$ 5.48854e-01 1.00000e-09 2.12000e-01

$1.00000 \mathrm{e}+001.00000 \mathrm{e}+001.00000 \mathrm{e}-01$ 1.00000e-09 1.00000e-01

Element: 14175 \# of layers: 6

$\mathrm{Kx} \mathrm{Ky} \mathrm{Kz}$ Ss Por

5.48854e+00 5.48854e+00 5.48854e-01 1.00000e-09 2.12000e-01

$5.48854 \mathrm{e}+005.48854 \mathrm{e}+00$ 5.48854e-01 1.00000e-09 2.12000e-01

$5.48854 \mathrm{e}+005.48854 \mathrm{e}+005.48854 \mathrm{e}-01$ 1.00000e-09 2.12000e-01

$5.48854 \mathrm{e}+005.48854 \mathrm{e}+00$ 5.48854e-01 1.00000e-09 2.12000e-01

$5.48854 \mathrm{e}+005.48854 \mathrm{e}+00$ 5.48854e-01 1.00000e-09 2.12000e-01

$1.00000 \mathrm{e}+001.00000 \mathrm{e}+001.00000 \mathrm{e}-011.00000 \mathrm{e}-091.00000 \mathrm{e}-01$

Element: 14176 \# of layers: 6

$\mathrm{Kx} \mathrm{Ky} \mathrm{Kz}$ Ss Por

5.48854e+00 5.48854e+00 5.48854e-01 1.00000e-09 2.12000e-01

$5.48854 \mathrm{e}+005.48854 \mathrm{e}+005.48854 \mathrm{e}-011.00000 \mathrm{e}-092.12000 \mathrm{e}-01$

$5.48854 \mathrm{e}+005.48854 \mathrm{e}+005.48854 \mathrm{e}-011.00000 \mathrm{e}-092.12000 \mathrm{e}-01$

$5.48854 \mathrm{e}+005.48854 \mathrm{e}+005.48854 \mathrm{e}-011.00000 \mathrm{e}-092.12000 \mathrm{e}-01$

$5.48854 \mathrm{e}+005.48854 \mathrm{e}+00$ 5.48854e-01 1.00000e-09 2.12000e-01

$1.00000 \mathrm{e}+001.00000 \mathrm{e}+001.00000 \mathrm{e}-01$ 1.00000e-09 1.00000e-01

Element: 14177 \# of layers: 6

$\mathrm{Kx} \mathrm{Ky} \mathrm{Kz} \mathrm{Ss} \mathrm{Por}$

5.48854e+00 5.48854e+00 5.48854e-01 1.00000e-09 2.12000e-01

$5.48854 \mathrm{e}+005.48854 \mathrm{e}+00$ 5.48854e-01 1.00000e-09 2.12000e-01

$5.48854 \mathrm{e}+005.48854 \mathrm{e}+005.48854 \mathrm{e}-011.00000 \mathrm{e}-092.12000 \mathrm{e}-01$

$5.48854 \mathrm{e}+005.48854 \mathrm{e}+005.48854 \mathrm{e}-011.00000 \mathrm{e}-092.12000 \mathrm{e}-01$

$5.48854 \mathrm{e}+005.48854 \mathrm{e}+00$ 5.48854e-01 1.00000e-09 2.12000e-01

$1.00000 \mathrm{e}+001.00000 \mathrm{e}+001.00000 \mathrm{e}-01$ 1.00000e-09 1.00000e-01

Element: 14178 \# of layers: 6

$\mathrm{Kx} \mathrm{Ky} \mathrm{Kz}$ Ss Por

5.48854e+00 5.48854e+00 5.48854e-01 1.00000e-09 2.12000e-01

$5.48854 \mathrm{e}+005.48854 \mathrm{e}+005.48854 \mathrm{e}-01$ 1.00000e-09 2.12000e-01

$5.48854 \mathrm{e}+005.48854 \mathrm{e}+005.48854 \mathrm{e}-011.00000 \mathrm{e}-092.12000 \mathrm{e}-01$

$5.48854 \mathrm{e}+005.48854 \mathrm{e}+00$ 5.48854e-01 1.00000e-09 2.12000e-01 
5.48854e+00 5.48854e+00 5.48854e-01 1.00000e-09 2.12000e-01 $1.00000 \mathrm{e}+001.00000 \mathrm{e}+001.00000 \mathrm{e}-01$ 1.00000e-09 1.00000e-01 Element: 14179 \# of layers: 7

Kx Ky Kz Ss Por

5.48854e+00 5.48854e+00 5.48854e-01 1.00000e-09 2.12000e-01

$5.48854 \mathrm{e}+005.48854 \mathrm{e}+00$ 5.48854e-01 1.00000e-09 2.12000e-01

$5.48854 \mathrm{e}+005.48854 \mathrm{e}+00$ 5.48854e-01 1.00000e-09 2.12000e-01

$5.48854 \mathrm{e}+005.48854 \mathrm{e}+005.48854 \mathrm{e}-01$ 1.00000e-09 2.12000e-01

$5.48854 \mathrm{e}+005.48854 \mathrm{e}+005.48854 \mathrm{e}-01$ 1.00000e-09 2.12000e-01

$1.00000 \mathrm{e}-05$ 1.00000e-05 1.00000e-06 1.00000e-09 1.00000e-01

$1.00000 \mathrm{e}+001.00000 \mathrm{e}+001.00000 \mathrm{e}-01$ 1.00000e-09 1.00000e-01

Element: 14180 \# of layers: 7

Kx Ky Kz Ss Por

4.65962e+00 4.65962e+00 4.65962e-01 1.00000e-09 2.12000e-01

4.65962e+00 4.65962e+00 4.65962e-01 1.00000e-09 2.12000e-01

$4.65962 \mathrm{e}+004.65962 \mathrm{e}+00$ 4.65962e-01 1.00000e-09 2.12000e-01

$4.65962 \mathrm{e}+004.65962 \mathrm{e}+00$ 4.65962e-01 1.00000e-09 2.12000e-01

$4.65962 \mathrm{e}+00$ 4.65962e+00 4.65962e-01 1.00000e-09 2.12000e-01

$1.00000 \mathrm{e}-05$ 1.00000e-05 1.00000e-06 1.00000e-09 1.00000e-01

$1.00000 \mathrm{e}+001.00000 \mathrm{e}+001.00000 \mathrm{e}-011.00000 \mathrm{e}-091.00000 \mathrm{e}-01$

Element: 14181 \# of layers: 7

$\mathrm{Kx} \mathrm{Ky} \mathrm{Kz}$ Ss Por

4.65962e+00 4.65962e+00 4.65962e-01 1.00000e-09 2.12000e-01

4.65962e+00 4.65962e+00 4.65962e-01 1.00000e-09 2.12000e-01

$4.65962 \mathrm{e}+004.65962 \mathrm{e}+00$ 4.65962e-01 1.00000e-09 2.12000e-01

$4.65962 \mathrm{e}+004.65962 \mathrm{e}+00$ 4.65962e-01 1.00000e-09 2.12000e-01

$4.65962 \mathrm{e}+004.65962 \mathrm{e}+00$ 4.65962e-01 1.00000e-09 2.12000e-01

1.00000e-05 1.00000e-05 1.00000e-06 1.00000e-09 1.00000e-01

$1.00000 \mathrm{e}+001.00000 \mathrm{e}+001.00000 \mathrm{e}-011.00000 \mathrm{e}-091.00000 \mathrm{e}-01$

Element: 14182 \# of layers: 6

$\mathrm{Kx} \mathrm{Ky} \mathrm{Kz}$ Ss Por

4.65962e+00 4.65962e+00 4.65962e-01 1.00000e-09 2.12000e-01

$4.65962 \mathrm{e}+004.65962 \mathrm{e}+00$ 4.65962e-01 1.00000e-09 2.12000e-01

$4.65962 \mathrm{e}+004.65962 \mathrm{e}+00$ 4.65962e-01 1.00000e-09 2.12000e-01

$4.65962 \mathrm{e}+004.65962 \mathrm{e}+00$ 4.65962e-01 1.00000e-09 2.12000e-01

4.65962e+00 4.65962e+00 4.65962e-01 1.00000e-09 2.12000e-01

$1.00000 \mathrm{e}+001.00000 \mathrm{e}+001.00000 \mathrm{e}-01$ 1.00000e-09 1.00000e-01

Element: 14183 \# of layers: 6

$\mathrm{Kx} \mathrm{Ky} \mathrm{Kz}$ Ss Por

4.65962e+00 4.65962e+00 4.65962e-01 1.00000e-09 2.12000e-01

$4.65962 \mathrm{e}+004.65962 \mathrm{e}+00$ 4.65962e-01 1.00000e-09 2.12000e-01

$4.65962 \mathrm{e}+004.65962 \mathrm{e}+00$ 4.65962e-01 1.00000e-09 2.12000e-01

4.65962e+00 4.65962e+00 4.65962e-01 1.00000e-09 2.12000e-01

4.65962e+00 4.65962e+00 4.65962e-01 1.00000e-09 2.12000e-01

$1.00000 \mathrm{e}+001.00000 \mathrm{e}+001.00000 \mathrm{e}-01$ 1.00000e-09 1.00000e-01

Element: 14184 \# of layers: 6 
$\mathrm{Kx} \mathrm{Ky} \mathrm{Kz}$ Ss Por

4.65962e+00 4.65962e+00 4.65962e-01 1.00000e-09 2.12000e-01

4.65962e+00 4.65962e+00 4.65962e-01 1.00000e-09 2.12000e-01

$4.65962 \mathrm{e}+004.65962 \mathrm{e}+00$ 4.65962e-01 1.00000e-09 2.12000e-01

4.65962e+00 4.65962e+00 4.65962e-01 1.00000e-09 2.12000e-01

$4.65962 \mathrm{e}+004.65962 \mathrm{e}+00$ 4.65962e-01 1.00000e-09 2.12000e-01

$1.00000 \mathrm{e}+001.00000 \mathrm{e}+001.00000 \mathrm{e}-01$ 1.00000e-09 1.00000e-01

Element: 14185 \# of layers: 6

$\mathrm{Kx} \mathrm{Ky} \mathrm{Kz}$ Ss Por

$5.48854 \mathrm{e}+005.48854 \mathrm{e}+005.48854 \mathrm{e}-011.00000 \mathrm{e}-092.12000 \mathrm{e}-01$

$5.48854 \mathrm{e}+005.48854 \mathrm{e}+00$ 5.48854e-01 1.00000e-09 2.12000e-01

$5.48854 \mathrm{e}+005.48854 \mathrm{e}+005.48854 \mathrm{e}-011.00000 \mathrm{e}-092.12000 \mathrm{e}-01$

$5.48854 \mathrm{e}+005.48854 \mathrm{e}+005.48854 \mathrm{e}-011.00000 \mathrm{e}-092.12000 \mathrm{e}-01$

$5.48854 \mathrm{e}+005.48854 \mathrm{e}+005.48854 \mathrm{e}-011.00000 \mathrm{e}-092.12000 \mathrm{e}-01$

$1.00000 \mathrm{e}+001.00000 \mathrm{e}+00$ 1.00000e-01 1.00000e-09 1.00000e-01

Element: 14186 \# of layers: 6

$\mathrm{Kx} \mathrm{Ky} \mathrm{Kz}$ Ss Por

$5.48854 \mathrm{e}+005.48854 \mathrm{e}+005.48854 \mathrm{e}-011.00000 \mathrm{e}-092.12000 \mathrm{e}-01$

$5.48854 \mathrm{e}+005.48854 \mathrm{e}+00$ 5.48854e-01 1.00000e-09 2.12000e-01

$5.48854 \mathrm{e}+005.48854 \mathrm{e}+005.48854 \mathrm{e}-011.00000 \mathrm{e}-092.12000 \mathrm{e}-01$

$5.48854 \mathrm{e}+005.48854 \mathrm{e}+00$ 5.48854e-01 1.00000e-09 2.12000e-01

$5.48854 \mathrm{e}+005.48854 \mathrm{e}+00$ 5.48854e-01 1.00000e-09 2.12000e-01

$1.00000 \mathrm{e}+001.00000 \mathrm{e}+001.00000 \mathrm{e}-01$ 1.00000e-09 1.00000e-01

Element: 14187 \# of layers: 6

Kx Ky Kz Ss Por

4.65962e+00 4.65962e+00 4.65962e-01 1.00000e-09 2.12000e-01

$4.65962 \mathrm{e}+004.65962 \mathrm{e}+00$ 4.65962e-01 1.00000e-09 2.12000e-01

4.65962e+00 4.65962e+00 4.65962e-01 1.00000e-09 2.12000e-01

$4.65962 \mathrm{e}+004.65962 \mathrm{e}+00$ 4.65962e-01 1.00000e-09 2.12000e-01

$4.65962 \mathrm{e}+00$ 4.65962e+00 4.65962e-01 1.00000e-09 2.12000e-01

$1.00000 \mathrm{e}+001.00000 \mathrm{e}+001.00000 \mathrm{e}-01$ 1.00000e-09 1.00000e-01

Element: 14188 \# of layers: 7

$\mathrm{Kx} \mathrm{Ky} \mathrm{Kz}$ Ss Por

4.65962e+00 4.65962e+00 4.65962e-01 1.00000e-09 2.12000e-01

$4.65962 \mathrm{e}+004.65962 \mathrm{e}+00$ 4.65962e-01 1.00000e-09 2.12000e-01

4.65962e+00 4.65962e+00 4.65962e-01 1.00000e-09 2.12000e-01

$4.65962 \mathrm{e}+004.65962 \mathrm{e}+00$ 4.65962e-01 1.00000e-09 2.12000e-01

$4.65962 \mathrm{e}+004.65962 \mathrm{e}+00$ 4.65962e-01 1.00000e-09 2.12000e-01

$1.00000 \mathrm{e}-05$ 1.00000e-05 1.00000e-06 1.00000e-09 1.00000e-01

$1.00000 \mathrm{e}+001.00000 \mathrm{e}+001.00000 \mathrm{e}-01$ 1.00000e-09 1.00000e-01

Element: 14189 \# of layers: 7

$\mathrm{Kx} \mathrm{Ky} \mathrm{Kz}$ Ss Por

4.65962e+00 4.65962e+00 4.65962e-01 1.00000e-09 2.12000e-01

4.65962e+00 4.65962e+00 4.65962e-01 1.00000e-09 2.12000e-01

4.65962e+00 4.65962e+00 4.65962e-01 1.00000e-09 2.12000e-01

$4.65962 \mathrm{e}+004.65962 \mathrm{e}+00$ 4.65962e-01 1.00000e-09 2.12000e-01 
4.65962e+00 4.65962e+00 4.65962e-01 1.00000e-09 2.12000e-01 $1.00000 \mathrm{e}-05$ 1.00000e-05 1.00000e-06 1.00000e-09 1.00000e-01 $1.00000 \mathrm{e}+001.00000 \mathrm{e}+00$ 1.00000e-01 1.00000e-09 1.00000e-01 Element: 14190 \# of layers: 7

$\mathrm{Kx} \mathrm{Ky} \mathrm{Kz}$ Ss Por

4.65962e+00 4.65962e+00 4.65962e-01 1.00000e-09 2.12000e-01 $4.65962 \mathrm{e}+004.65962 \mathrm{e}+00$ 4.65962e-01 1.00000e-09 2.12000e-01 $4.65962 \mathrm{e}+00$ 4.65962e+00 4.65962e-01 1.00000e-09 2.12000e-01 4.65962e+00 4.65962e+00 4.65962e-01 1.00000e-09 2.12000e-01 $4.65962 \mathrm{e}+004.65962 \mathrm{e}+00$ 4.65962e-01 1.00000e-09 2.12000e-01 $1.00000 \mathrm{e}-051.00000 \mathrm{e}-05$ 1.00000e-06 1.00000e-09 1.00000e-01 $1.00000 \mathrm{e}+001.00000 \mathrm{e}+001.00000 \mathrm{e}-01$ 1.00000e-09 1.00000e-01 Element: 14191 \# of layers: 6

$\mathrm{Kx} \mathrm{Ky} \mathrm{Kz}$ Ss Por

4.65962e+00 4.65962e+00 4.65962e-01 1.00000e-09 2.12000e-01 $4.65962 \mathrm{e}+004.65962 \mathrm{e}+00$ 4.65962e-01 1.00000e-09 2.12000e-01 $4.65962 \mathrm{e}+00$ 4.65962e+00 4.65962e-01 1.00000e-09 2.12000e-01 4.65962e+00 4.65962e+00 4.65962e-01 1.00000e-09 2.12000e-01 4.65962e+00 4.65962e+00 4.65962e-01 1.00000e-09 2.12000e-01 $1.00000 \mathrm{e}+001.00000 \mathrm{e}+001.00000 \mathrm{e}-01$ 1.00000e-09 1.00000e-01 Element: 14192 \# of layers: 6

$\mathrm{Kx} \mathrm{Ky} \mathrm{Kz}$ Ss Por

4.65962e+00 4.65962e+00 4.65962e-01 1.00000e-09 2.12000e-01 $4.65962 \mathrm{e}+004.65962 \mathrm{e}+00$ 4.65962e-01 1.00000e-09 2.12000e-01 $4.65962 \mathrm{e}+004.65962 \mathrm{e}+00$ 4.65962e-01 1.00000e-09 2.12000e-01 4.65962e+00 4.65962e+00 4.65962e-01 1.00000e-09 2.12000e-01 4.65962e+00 4.65962e+00 4.65962e-01 1.00000e-09 2.12000e-01 $1.00000 \mathrm{e}+001.00000 \mathrm{e}+001.00000 \mathrm{e}-01$ 1.00000e-09 1.00000e-01 Element: 14193 \# of layers: 6

$\mathrm{Kx} \mathrm{Ky} \mathrm{Kz}$ Ss Por

4.65962e+00 4.65962e+00 4.65962e-01 1.00000e-09 2.12000e-01 4.65962e+00 4.65962e+00 4.65962e-01 1.00000e-09 2.12000e-01 $4.65962 \mathrm{e}+004.65962 \mathrm{e}+00$ 4.65962e-01 1.00000e-09 2.12000e-01 $4.65962 \mathrm{e}+00$ 4.65962e+00 4.65962e-01 1.00000e-09 2.12000e-01 4.65962e+00 4.65962e+00 4.65962e-01 1.00000e-09 2.12000e-01 $1.00000 \mathrm{e}+001.00000 \mathrm{e}+001.00000 \mathrm{e}-01$ 1.00000e-09 1.00000e-01 Element: 14194 \# of layers: 6

$\mathrm{Kx} \mathrm{Ky} \mathrm{Kz}$ Ss Por

4.65962e+00 4.65962e+00 4.65962e-01 1.00000e-09 2.12000e-01 4.65962e+00 4.65962e+00 4.65962e-01 1.00000e-09 2.12000e-01 $4.65962 \mathrm{e}+004.65962 \mathrm{e}+00$ 4.65962e-01 1.00000e-09 2.12000e-01 $4.65962 \mathrm{e}+004.65962 \mathrm{e}+00$ 4.65962e-01 1.00000e-09 2.12000e-01 $4.65962 \mathrm{e}+00$ 4.65962e+00 4.65962e-01 1.00000e-09 2.12000e-01 $1.00000 \mathrm{e}+001.00000 \mathrm{e}+001.00000 \mathrm{e}-01$ 1.00000e-09 1.00000e-01 Element: 14195 \# of layers: 6

Kx Ky Kz Ss Por 
4.65962e+00 4.65962e+00 4.65962e-01 1.00000e-09 2.12000e-01 4.65962e+00 4.65962e+00 4.65962e-01 1.00000e-09 2.12000e-01 4.65962e+00 4.65962e+00 4.65962e-01 1.00000e-09 2.12000e-01 $4.65962 \mathrm{e}+00$ 4.65962e+00 4.65962e-01 1.00000e-09 2.12000e-01 4.65962e+00 4.65962e+00 4.65962e-01 1.00000e-09 2.12000e-01 $1.00000 \mathrm{e}+001.00000 \mathrm{e}+001.00000 \mathrm{e}-011.00000 \mathrm{e}-091.00000 \mathrm{e}-01$ Element: 14196 \# of layers: 6

$\mathrm{Kx} \mathrm{Ky} \mathrm{Kz}$ Ss Por

4.65962e+00 4.65962e+00 4.65962e-01 1.00000e-09 2.12000e-01 $4.65962 \mathrm{e}+004.65962 \mathrm{e}+00$ 4.65962e-01 1.00000e-09 2.12000e-01 $4.65962 \mathrm{e}+004.65962 \mathrm{e}+00$ 4.65962e-01 1.00000e-09 2.12000e-01 4.65962e+00 4.65962e+00 4.65962e-01 1.00000e-09 2.12000e-01 $4.65962 \mathrm{e}+00$ 4.65962e+00 4.65962e-01 1.00000e-09 2.12000e-01 $1.00000 \mathrm{e}+001.00000 \mathrm{e}+001.00000 \mathrm{e}-01$ 1.00000e-09 1.00000e-01 Element: 14197 \# of layers: 6

Kx Ky Kz Ss Por

4.65962e+00 4.65962e+00 4.65962e-01 1.00000e-09 2.12000e-01 4.65962e+00 4.65962e+00 4.65962e-01 1.00000e-09 2.12000e-01 4.65962e+00 4.65962e+00 4.65962e-01 1.00000e-09 2.12000e-01 $4.65962 \mathrm{e}+004.65962 \mathrm{e}+00$ 4.65962e-01 1.00000e-09 2.12000e-01 $4.65962 \mathrm{e}+00$ 4.65962e+00 4.65962e-01 1.00000e-09 2.12000e-01 $1.00000 \mathrm{e}+001.00000 \mathrm{e}+001.00000 \mathrm{e}-01$ 1.00000e-09 1.00000e-01 Element: 14198 \# of layers: 6

Kx Ky Kz Ss Por

4.65962e+00 4.65962e+00 4.65962e-01 1.00000e-09 2.12000e-01 4.65962e+00 4.65962e+00 4.65962e-01 1.00000e-09 2.12000e-01 4.65962e+00 4.65962e+00 4.65962e-01 1.00000e-09 2.12000e-01 4.65962e+00 4.65962e+00 4.65962e-01 1.00000e-09 2.12000e-01 $4.65962 \mathrm{e}+004.65962 \mathrm{e}+00$ 4.65962e-01 1.00000e-09 2.12000e-01 $1.00000 \mathrm{e}+001.00000 \mathrm{e}+001.00000 \mathrm{e}-01$ 1.00000e-09 1.00000e-01 Element: 14199 \# of layers: 6

$\mathrm{Kx} \mathrm{Ky} \mathrm{Kz}$ Ss Por

5.19469e+00 5.19469e+00 5.19469e-01 1.00000e-09 2.12000e-01 5.19469e+00 5.19469e+00 5.19469e-01 1.00000e-09 2.12000e-01 5.19469e+00 5.19469e+00 5.19469e-01 1.00000e-09 2.12000e-01 5.19469e+00 5.19469e+00 5.19469e-01 1.00000e-09 2.12000e-01 $5.19469 \mathrm{e}+00$ 5.19469e+00 5.19469e-01 1.00000e-09 2.12000e-01 $1.00000 \mathrm{e}+001.00000 \mathrm{e}+00$ 1.00000e-01 1.00000e-09 1.00000e-01 Element: 14200 \# of layers: 6

$\mathrm{Kx} \mathrm{Ky} \mathrm{Kz}$ Ss Por

5.19469e+00 5.19469e+00 5.19469e-01 1.00000e-09 2.12000e-01 5.19469e+00 5.19469e+00 5.19469e-01 1.00000e-09 2.12000e-01 5.19469e+00 5.19469e+00 5.19469e-01 1.00000e-09 2.12000e-01 5.19469e+00 5.19469e+00 5.19469e-01 1.00000e-09 2.12000e-01 5.19469e+00 5.19469e+00 5.19469e-01 1.00000e-09 2.12000e-01 $1.00000 \mathrm{e}+001.00000 \mathrm{e}+001.00000 \mathrm{e}-011.00000 \mathrm{e}-091.00000 \mathrm{e}-01$ 
Element: 14201 \# of layers: 6

$\mathrm{Kx} \mathrm{Ky} \mathrm{Kz}$ Ss Por

5.19469e+00 5.19469e+00 5.19469e-01 1.00000e-09 2.12000e-01

5.19469e+00 5.19469e+00 5.19469e-01 1.00000e-09 2.12000e-01

5.19469e+00 5.19469e+00 5.19469e-01 1.00000e-09 2.12000e-01

5.19469e+00 5.19469e+00 5.19469e-01 1.00000e-09 2.12000e-01

5.19469e+00 5.19469e+00 5.19469e-01 1.00000e-09 2.12000e-01

$1.00000 \mathrm{e}+001.00000 \mathrm{e}+001.00000 \mathrm{e}-01$ 1.00000e-09 1.00000e-01

Element: 14202 \# of layers: 6

$\mathrm{Kx} \mathrm{Ky} \mathrm{Kz}$ Ss Por

4.65962e+00 4.65962e+00 4.65962e-01 1.00000e-09 2.12000e-01

$4.65962 \mathrm{e}+004.65962 \mathrm{e}+00$ 4.65962e-01 1.00000e-09 2.12000e-01

$4.65962 \mathrm{e}+00$ 4.65962e+00 4.65962e-01 1.00000e-09 2.12000e-01

4.65962e+00 4.65962e+00 4.65962e-01 1.00000e-09 2.12000e-01

4.65962e+00 4.65962e+00 4.65962e-01 1.00000e-09 2.12000e-01

$1.00000 \mathrm{e}+001.00000 \mathrm{e}+001.00000 \mathrm{e}-01$ 1.00000e-09 1.00000e-01

Element: 14203 \# of layers: 6

$\mathrm{Kx} \mathrm{Ky} \mathrm{Kz}$ Ss Por

4.65962e+00 4.65962e+00 4.65962e-01 1.00000e-09 2.12000e-01

$4.65962 \mathrm{e}+004.65962 \mathrm{e}+00$ 4.65962e-01 1.00000e-09 2.12000e-01

$4.65962 \mathrm{e}+004.65962 \mathrm{e}+00$ 4.65962e-01 1.00000e-09 2.12000e-01

$4.65962 \mathrm{e}+00$ 4.65962e+00 4.65962e-01 1.00000e-09 2.12000e-01

4.65962e+00 4.65962e+00 4.65962e-01 1.00000e-09 2.12000e-01

$1.00000 \mathrm{e}+001.00000 \mathrm{e}+001.00000 \mathrm{e}-01$ 1.00000e-09 1.00000e-01

Element: 14204 \# of layers: 6

$\mathrm{Kx} \mathrm{Ky} \mathrm{Kz}$ Ss Por

4.65962e+00 4.65962e+00 4.65962e-01 1.00000e-09 2.12000e-01

$4.65962 \mathrm{e}+004.65962 \mathrm{e}+00$ 4.65962e-01 1.00000e-09 2.12000e-01

$4.65962 \mathrm{e}+004.65962 \mathrm{e}+00$ 4.65962e-01 1.00000e-09 2.12000e-01

$4.65962 \mathrm{e}+00$ 4.65962e+00 4.65962e-01 1.00000e-09 2.12000e-01

4.65962e+00 4.65962e+00 4.65962e-01 1.00000e-09 2.12000e-01

$1.00000 \mathrm{e}+001.00000 \mathrm{e}+001.00000 \mathrm{e}-01$ 1.00000e-09 1.00000e-01

Element: 14205 \# of layers: 6

$\mathrm{Kx} \mathrm{Ky} \mathrm{Kz}$ Ss Por

4.65962e+00 4.65962e+00 4.65962e-01 1.00000e-09 2.12000e-01

$4.65962 \mathrm{e}+004.65962 \mathrm{e}+00$ 4.65962e-01 1.00000e-09 2.12000e-01

$4.65962 \mathrm{e}+004.65962 \mathrm{e}+00$ 4.65962e-01 1.00000e-09 2.12000e-01

$4.65962 \mathrm{e}+004.65962 \mathrm{e}+00$ 4.65962e-01 1.00000e-09 2.12000e-01

4.65962e+00 4.65962e+00 4.65962e-01 1.00000e-09 2.12000e-01

$1.00000 \mathrm{e}+001.00000 \mathrm{e}+001.00000 \mathrm{e}-01$ 1.00000e-09 1.00000e-01

Element: 14206 \# of layers: 6

$\mathrm{Kx} \mathrm{Ky} \mathrm{Kz}$ Ss Por

5.19469e+00 5.19469e+00 5.19469e-01 1.00000e-09 2.12000e-01

5.19469e+00 5.19469e+00 5.19469e-01 1.00000e-09 2.12000e-01

5.19469e+00 5.19469e+00 5.19469e-01 1.00000e-09 2.12000e-01

$5.19469 \mathrm{e}+00$ 5.19469e+00 5.19469e-01 1.00000e-09 2.12000e-01 
5.19469e+00 5.19469e+00 5.19469e-01 1.00000e-09 2.12000e-01 $1.00000 \mathrm{e}+001.00000 \mathrm{e}+001.00000 \mathrm{e}-011.00000 \mathrm{e}-091.00000 \mathrm{e}-01$ Element: 14207 \# of layers: 6

Kx Ky Kz Ss Por

5.19469e+00 5.19469e+00 5.19469e-01 1.00000e-09 2.12000e-01

$5.19469 \mathrm{e}+00$ 5.19469e+00 5.19469e-01 1.00000e-09 2.12000e-01

$5.19469 \mathrm{e}+00$ 5.19469e+00 5.19469e-01 1.00000e-09 2.12000e-01

$5.19469 \mathrm{e}+00$ 5.19469e+00 5.19469e-01 1.00000e-09 2.12000e-01

$5.19469 \mathrm{e}+00$ 5.19469e+00 5.19469e-01 1.00000e-09 2.12000e-01 $1.00000 \mathrm{e}+001.00000 \mathrm{e}+001.00000 \mathrm{e}-011.00000 \mathrm{e}-091.00000 \mathrm{e}-01$ Element: 14208 \# of layers: 6

Kx Ky Kz Ss Por

5.19469e+00 5.19469e+00 5.19469e-01 1.00000e-09 2.12000e-01

$5.19469 \mathrm{e}+00$ 5.19469e+00 5.19469e-01 1.00000e-09 2.12000e-01

$5.19469 \mathrm{e}+00$ 5.19469e+00 5.19469e-01 1.00000e-09 2.12000e-01

$5.19469 \mathrm{e}+00$ 5.19469e+00 5.19469e-01 1.00000e-09 2.12000e-01

$5.19469 \mathrm{e}+00$ 5.19469e+00 5.19469e-01 1.00000e-09 2.12000e-01 $1.00000 \mathrm{e}+001.00000 \mathrm{e}+001.00000 \mathrm{e}-011.00000 \mathrm{e}-091.00000 \mathrm{e}-01$

Element: 14209 \# of layers: 6

Kx Ky Kz Ss Por

5.19469e+00 5.19469e+00 5.19469e-01 1.00000e-09 2.12000e-01

$5.19469 \mathrm{e}+00$ 5.19469e+00 5.19469e-01 1.00000e-09 2.12000e-01

$5.19469 \mathrm{e}+00$ 5.19469e+00 5.19469e-01 1.00000e-09 2.12000e-01

$5.19469 \mathrm{e}+00$ 5.19469e+00 5.19469e-01 1.00000e-09 2.12000e-01

$5.19469 \mathrm{e}+00$ 5.19469e+00 5.19469e-01 1.00000e-09 2.12000e-01 $1.00000 \mathrm{e}+001.00000 \mathrm{e}+00$ 1.00000e-01 1.00000e-09 1.00000e-01

Element: 14210 \# of layers: 6

Kx Ky Kz Ss Por

5.48269e+00 5.48269e+00 5.48269e-01 1.00000e-09 2.12000e-01

$5.48269 \mathrm{e}+005.48269 \mathrm{e}+00$ 5.48269e-01 1.00000e-09 2.12000e-01

$5.48269 \mathrm{e}+005.48269 \mathrm{e}+005.48269 \mathrm{e}-011.00000 \mathrm{e}-092.12000 \mathrm{e}-01$

$5.48269 \mathrm{e}+005.48269 \mathrm{e}+00$ 5.48269e-01 1.00000e-09 2.12000e-01

$5.48269 \mathrm{e}+005.48269 \mathrm{e}+00$ 5.48269e-01 1.00000e-09 2.12000e-01

$1.00000 \mathrm{e}+001.00000 \mathrm{e}+001.00000 \mathrm{e}-011.00000 \mathrm{e}-091.00000 \mathrm{e}-01$

Element: 14211 \# of layers: 6

Kx Ky Kz Ss Por

5.19469e+00 5.19469e+00 5.19469e-01 1.00000e-09 2.12000e-01

$5.19469 \mathrm{e}+005.19469 \mathrm{e}+00$ 5.19469e-01 1.00000e-09 2.12000e-01

$5.19469 \mathrm{e}+00$ 5.19469e+00 5.19469e-01 1.00000e-09 2.12000e-01

$5.19469 \mathrm{e}+00$ 5.19469e+00 5.19469e-01 1.00000e-09 2.12000e-01

$5.19469 \mathrm{e}+00$ 5.19469e+00 5.19469e-01 1.00000e-09 2.12000e-01

$1.00000 \mathrm{e}+001.00000 \mathrm{e}+001.00000 \mathrm{e}-011.00000 \mathrm{e}-091.00000 \mathrm{e}-01$

Element: 14212 \# of layers: 6

Kx Ky Kz Ss Por

5.19469e+00 5.19469e+00 5.19469e-01 1.00000e-09 2.12000e-01

$5.19469 \mathrm{e}+00$ 5.19469e+00 5.19469e-01 1.00000e-09 2.12000e-01 
5.19469e+00 5.19469e+00 5.19469e-01 1.00000e-09 2.12000e-01 $5.19469 \mathrm{e}+00$ 5.19469e+00 5.19469e-01 1.00000e-09 2.12000e-01 $5.19469 \mathrm{e}+00$ 5.19469e+00 5.19469e-01 1.00000e-09 2.12000e-01 $1.00000 \mathrm{e}+001.00000 \mathrm{e}+00$ 1.00000e-01 1.00000e-09 1.00000e-01 Element: 14213 \# of layers: 6

Kx Ky Kz Ss Por

5.19469e+00 5.19469e+00 5.19469e-01 1.00000e-09 2.12000e-01

$5.19469 \mathrm{e}+00$ 5.19469e+00 5.19469e-01 1.00000e-09 2.12000e-01

$5.19469 \mathrm{e}+00$ 5.19469e+00 5.19469e-01 1.00000e-09 2.12000e-01

$5.19469 \mathrm{e}+00$ 5.19469e+00 5.19469e-01 1.00000e-09 2.12000e-01

$5.19469 \mathrm{e}+005.19469 \mathrm{e}+00$ 5.19469e-01 1.00000e-09 2.12000e-01

$1.00000 \mathrm{e}+001.00000 \mathrm{e}+00$ 1.00000e-01 1.00000e-09 1.00000e-01

Element: 14214 \# of layers: 6

Kx Ky Kz Ss Por

$5.48269 \mathrm{e}+005.48269 \mathrm{e}+00$ 5.48269e-01 1.00000e-09 2.12000e-01

$5.48269 \mathrm{e}+005.48269 \mathrm{e}+00$ 5.48269e-01 1.00000e-09 2.12000e-01

$5.48269 \mathrm{e}+005.48269 \mathrm{e}+00$ 5.48269e-01 1.00000e-09 2.12000e-01

$5.48269 \mathrm{e}+005.48269 \mathrm{e}+00$ 5.48269e-01 1.00000e-09 2.12000e-01

$5.48269 \mathrm{e}+005.48269 \mathrm{e}+00$ 5.48269e-01 1.00000e-09 2.12000e-01

$1.00000 \mathrm{e}+001.00000 \mathrm{e}+001.00000 \mathrm{e}-011.00000 \mathrm{e}-091.00000 \mathrm{e}-01$

Element: 14215 \# of layers: 6

Kx Ky Kz Ss Por

$5.48269 \mathrm{e}+005.48269 \mathrm{e}+00$ 5.48269e-01 1.00000e-09 2.12000e-01

$5.48269 \mathrm{e}+005.48269 \mathrm{e}+00$ 5.48269e-01 1.00000e-09 2.12000e-01

$5.48269 \mathrm{e}+005.48269 \mathrm{e}+00$ 5.48269e-01 1.00000e-09 2.12000e-01

$5.48269 \mathrm{e}+00$ 5.48269e+00 5.48269e-01 1.00000e-09 2.12000e-01

$5.48269 \mathrm{e}+005.48269 \mathrm{e}+00$ 5.48269e-01 1.00000e-09 2.12000e-01

$1.00000 \mathrm{e}+001.00000 \mathrm{e}+001.00000 \mathrm{e}-011.00000 \mathrm{e}-091.00000 \mathrm{e}-01$

Element: 14216 \# of layers: 6

Kx Ky Kz Ss Por

5.48269e+00 5.48269e+00 5.48269e-01 1.00000e-09 2.12000e-01

$5.48269 \mathrm{e}+005.48269 \mathrm{e}+00$ 5.48269e-01 1.00000e-09 2.12000e-01

$5.48269 \mathrm{e}+005.48269 \mathrm{e}+005.48269 \mathrm{e}-011.00000 \mathrm{e}-092.12000 \mathrm{e}-01$

$5.48269 \mathrm{e}+005.48269 \mathrm{e}+00$ 5.48269e-01 1.00000e-09 2.12000e-01

$5.48269 \mathrm{e}+005.48269 \mathrm{e}+00$ 5.48269e-01 1.00000e-09 2.12000e-01

$1.00000 \mathrm{e}+001.00000 \mathrm{e}+001.00000 \mathrm{e}-011.00000 \mathrm{e}-091.00000 \mathrm{e}-01$

Element: 14217 \# of layers: 6

Kx Ky Kz Ss Por

$5.48269 \mathrm{e}+00$ 5.48269e+00 5.48269e-01 1.00000e-09 2.12000e-01

$5.48269 \mathrm{e}+005.48269 \mathrm{e}+00$ 5.48269e-01 1.00000e-09 2.12000e-01

$5.48269 \mathrm{e}+005.48269 \mathrm{e}+00$ 5.48269e-01 1.00000e-09 2.12000e-01

$5.48269 \mathrm{e}+005.48269 \mathrm{e}+00$ 5.48269e-01 1.00000e-09 2.12000e-01

$5.48269 \mathrm{e}+005.48269 \mathrm{e}+00$ 5.48269e-01 1.00000e-09 2.12000e-01

$1.00000 \mathrm{e}+001.00000 \mathrm{e}+001.00000 \mathrm{e}-011.00000 \mathrm{e}-091.00000 \mathrm{e}-01$

Element: 14218 \# of layers: 6

Kx Ky Kz Ss Por 
$5.48269 \mathrm{e}+005.48269 \mathrm{e}+00$ 5.48269e-01 1.00000e-09 2.12000e-01 $5.48269 \mathrm{e}+005.48269 \mathrm{e}+005.48269 \mathrm{e}-011.00000 \mathrm{e}-092.12000 \mathrm{e}-01$ $5.48269 \mathrm{e}+005.48269 \mathrm{e}+00$ 5.48269e-01 1.00000e-09 2.12000e-01 $5.48269 \mathrm{e}+005.48269 \mathrm{e}+00$ 5.48269e-01 1.00000e-09 2.12000e-01 $5.48269 \mathrm{e}+005.48269 \mathrm{e}+00$ 5.48269e-01 1.00000e-09 2.12000e-01 $1.00000 \mathrm{e}+001.00000 \mathrm{e}+001.00000 \mathrm{e}-011.00000 \mathrm{e}-091.00000 \mathrm{e}-01$ Element: 14219 \# of layers: 6

Kx Ky Kz Ss Por

$5.48854 \mathrm{e}+005.48854 \mathrm{e}+00$ 5.48854e-01 1.00000e-09 2.12000e-01

$5.48854 \mathrm{e}+005.48854 \mathrm{e}+005.48854 \mathrm{e}-011.00000 \mathrm{e}-092.12000 \mathrm{e}-01$ $5.48854 \mathrm{e}+005.48854 \mathrm{e}+005.48854 \mathrm{e}-011.00000 \mathrm{e}-092.12000 \mathrm{e}-01$ $5.48854 \mathrm{e}+005.48854 \mathrm{e}+005.48854 \mathrm{e}-011.00000 \mathrm{e}-092.12000 \mathrm{e}-01$ $5.48854 \mathrm{e}+005.48854 \mathrm{e}+005.48854 \mathrm{e}-011.00000 \mathrm{e}-092.12000 \mathrm{e}-01$ $1.00000 \mathrm{e}+001.00000 \mathrm{e}+001.00000 \mathrm{e}-011.00000 \mathrm{e}-091.00000 \mathrm{e}-01$ Element: 14220 \# of layers: 6

Kx Ky Kz Ss Por

$5.48854 \mathrm{e}+005.48854 \mathrm{e}+00$ 5.48854e-01 1.00000e-09 2.12000e-01

$5.48854 \mathrm{e}+005.48854 \mathrm{e}+005.48854 \mathrm{e}-011.00000 \mathrm{e}-092.12000 \mathrm{e}-01$

$5.48854 \mathrm{e}+005.48854 \mathrm{e}+005.48854 \mathrm{e}-011.00000 \mathrm{e}-092.12000 \mathrm{e}-01$

$5.48854 \mathrm{e}+005.48854 \mathrm{e}+005.48854 \mathrm{e}-011.00000 \mathrm{e}-092.12000 \mathrm{e}-01$

$5.48854 \mathrm{e}+005.48854 \mathrm{e}+005.48854 \mathrm{e}-011.00000 \mathrm{e}-092.12000 \mathrm{e}-01$ $1.00000 \mathrm{e}+001.00000 \mathrm{e}+001.00000 \mathrm{e}-011.00000 \mathrm{e}-091.00000 \mathrm{e}-01$ Element: 14221 \# of layers: 6

Kx Ky Kz Ss Por

$5.48854 \mathrm{e}+005.48854 \mathrm{e}+00$ 5.48854e-01 1.00000e-09 2.12000e-01 $5.48854 \mathrm{e}+005.48854 \mathrm{e}+005.48854 \mathrm{e}-011.00000 \mathrm{e}-092.12000 \mathrm{e}-01$ $5.48854 \mathrm{e}+005.48854 \mathrm{e}+005.48854 \mathrm{e}-011.00000 \mathrm{e}-092.12000 \mathrm{e}-01$ $5.48854 \mathrm{e}+005.48854 \mathrm{e}+005.48854 \mathrm{e}-011.00000 \mathrm{e}-092.12000 \mathrm{e}-01$ $5.48854 \mathrm{e}+005.48854 \mathrm{e}+005.48854 \mathrm{e}-011.00000 \mathrm{e}-092.12000 \mathrm{e}-01$ $1.00000 \mathrm{e}+001.00000 \mathrm{e}+001.00000 \mathrm{e}-011.00000 \mathrm{e}-091.00000 \mathrm{e}-01$ Element: 14222 \# of layers: 6

Kx Ky Kz Ss Por

$5.48854 \mathrm{e}+005.48854 \mathrm{e}+00$ 5.48854e-01 1.00000e-09 2.12000e-01 $5.48854 \mathrm{e}+005.48854 \mathrm{e}+005.48854 \mathrm{e}-011.00000 \mathrm{e}-092.12000 \mathrm{e}-01$ $5.48854 \mathrm{e}+005.48854 \mathrm{e}+005.48854 \mathrm{e}-011.00000 \mathrm{e}-092.12000 \mathrm{e}-01$ $5.48854 \mathrm{e}+005.48854 \mathrm{e}+005.48854 \mathrm{e}-011.00000 \mathrm{e}-092.12000 \mathrm{e}-01$ $5.48854 \mathrm{e}+005.48854 \mathrm{e}+005.48854 \mathrm{e}-011.00000 \mathrm{e}-092.12000 \mathrm{e}-01$ $1.00000 \mathrm{e}+001.00000 \mathrm{e}+001.00000 \mathrm{e}-011.00000 \mathrm{e}-091.00000 \mathrm{e}-01$ Element: 14223 \# of layers: 6

Kx Ky Kz Ss Por

$5.48854 \mathrm{e}+005.48854 \mathrm{e}+00$ 5.48854e-01 1.00000e-09 2.12000e-01 $5.48854 \mathrm{e}+005.48854 \mathrm{e}+005.48854 \mathrm{e}-011.00000 \mathrm{e}-092.12000 \mathrm{e}-01$ $5.48854 \mathrm{e}+005.48854 \mathrm{e}+005.48854 \mathrm{e}-011.00000 \mathrm{e}-092.12000 \mathrm{e}-01$ $5.48854 \mathrm{e}+005.48854 \mathrm{e}+005.48854 \mathrm{e}-011.00000 \mathrm{e}-092.12000 \mathrm{e}-01$ $5.48854 \mathrm{e}+005.48854 \mathrm{e}+00$ 5.48854e-01 1.00000e-09 2.12000e-01 $1.00000 \mathrm{e}+001.00000 \mathrm{e}+001.00000 \mathrm{e}-011.00000 \mathrm{e}-091.00000 \mathrm{e}-01$ 
Element: 14224 \# of layers: 6

$\mathrm{Kx} \mathrm{Ky} \mathrm{Kz} \mathrm{Ss} \mathrm{Por}$

5.48269e+00 5.48269e+00 5.48269e-01 1.00000e-09 2.12000e-01

$5.48269 \mathrm{e}+00$ 5.48269e+00 5.48269e-01 1.00000e-09 2.12000e-01

5.48269e+00 5.48269e+00 5.48269e-01 1.00000e-09 2.12000e-01

5.48269e+00 5.48269e+00 5.48269e-01 1.00000e-09 2.12000e-01

$5.48269 \mathrm{e}+00$ 5.48269e+00 5.48269e-01 1.00000e-09 2.12000e-01

$1.00000 \mathrm{e}+001.00000 \mathrm{e}+001.00000 \mathrm{e}-01$ 1.00000e-09 1.00000e-01

Element: 14225 \# of layers: 6

$\mathrm{Kx} \mathrm{Ky} \mathrm{Kz} \mathrm{Ss} \mathrm{Por}$

5.48269e+00 5.48269e+00 5.48269e-01 1.00000e-09 2.12000e-01

$5.48269 \mathrm{e}+005.48269 \mathrm{e}+00$ 5.48269e-01 1.00000e-09 2.12000e-01

$5.48269 \mathrm{e}+00$ 5.48269e+00 5.48269e-01 1.00000e-09 2.12000e-01

$5.48269 \mathrm{e}+00$ 5.48269e+00 5.48269e-01 1.00000e-09 2.12000e-01

5.48269e+00 5.48269e+00 5.48269e-01 1.00000e-09 2.12000e-01

$1.00000 \mathrm{e}+001.00000 \mathrm{e}+001.00000 \mathrm{e}-01$ 1.00000e-09 1.00000e-01

Element: 14226 \# of layers: 6

$\mathrm{Kx} \mathrm{Ky} \mathrm{Kz}$ Ss Por

5.48854e+00 5.48854e+00 5.48854e-01 1.00000e-09 2.12000e-01

$5.48854 \mathrm{e}+005.48854 \mathrm{e}+00$ 5.48854e-01 1.00000e-09 2.12000e-01

$5.48854 \mathrm{e}+005.48854 \mathrm{e}+005.48854 \mathrm{e}-01$ 1.00000e-09 2.12000e-01

$5.48854 \mathrm{e}+005.48854 \mathrm{e}+00$ 5.48854e-01 1.00000e-09 2.12000e-01

$5.48854 \mathrm{e}+005.48854 \mathrm{e}+00$ 5.48854e-01 1.00000e-09 2.12000e-01

$1.00000 \mathrm{e}+001.00000 \mathrm{e}+001.00000 \mathrm{e}-011.00000 \mathrm{e}-091.00000 \mathrm{e}-01$

Element: 14227 \# of layers: 6

$\mathrm{Kx} \mathrm{Ky} \mathrm{Kz}$ Ss Por

5.48854e+00 5.48854e+00 5.48854e-01 1.00000e-09 2.12000e-01

$5.48854 \mathrm{e}+005.48854 \mathrm{e}+005.48854 \mathrm{e}-011.00000 \mathrm{e}-092.12000 \mathrm{e}-01$

$5.48854 \mathrm{e}+005.48854 \mathrm{e}+005.48854 \mathrm{e}-011.00000 \mathrm{e}-092.12000 \mathrm{e}-01$

$5.48854 \mathrm{e}+005.48854 \mathrm{e}+005.48854 \mathrm{e}-011.00000 \mathrm{e}-092.12000 \mathrm{e}-01$

$5.48854 \mathrm{e}+005.48854 \mathrm{e}+00$ 5.48854e-01 1.00000e-09 2.12000e-01

$1.00000 \mathrm{e}+001.00000 \mathrm{e}+001.00000 \mathrm{e}-01$ 1.00000e-09 1.00000e-01

Element: 14228 \# of layers: 6

$\mathrm{Kx} \mathrm{Ky} \mathrm{Kz}$ Ss Por

4.65962e+00 4.65962e+00 4.65962e-01 1.00000e-09 2.12000e-01

$4.65962 \mathrm{e}+004.65962 \mathrm{e}+00$ 4.65962e-01 1.00000e-09 2.12000e-01

$4.65962 \mathrm{e}+004.65962 \mathrm{e}+00$ 4.65962e-01 1.00000e-09 2.12000e-01

$4.65962 \mathrm{e}+004.65962 \mathrm{e}+00$ 4.65962e-01 1.00000e-09 2.12000e-01

4.65962e+00 4.65962e+00 4.65962e-01 1.00000e-09 2.12000e-01

$1.00000 \mathrm{e}+001.00000 \mathrm{e}+001.00000 \mathrm{e}-01$ 1.00000e-09 1.00000e-01

Element: 14229 \# of layers: 6

$\mathrm{Kx} \mathrm{Ky} \mathrm{Kz}$ Ss Por

4.65962e+00 4.65962e+00 4.65962e-01 1.00000e-09 2.12000e-01

4.65962e+00 4.65962e+00 4.65962e-01 1.00000e-09 2.12000e-01

$4.65962 \mathrm{e}+004.65962 \mathrm{e}+00$ 4.65962e-01 1.00000e-09 2.12000e-01

$4.65962 \mathrm{e}+004.65962 \mathrm{e}+00$ 4.65962e-01 1.00000e-09 2.12000e-01 
4.65962e+00 4.65962e+00 4.65962e-01 1.00000e-09 2.12000e-01 $1.00000 \mathrm{e}+001.00000 \mathrm{e}+001.00000 \mathrm{e}-01$ 1.00000e-09 1.00000e-01 Element: 14230 \# of layers: 6

Kx Ky Kz Ss Por

4.65962e+00 4.65962e+00 4.65962e-01 1.00000e-09 2.12000e-01 $4.65962 \mathrm{e}+004.65962 \mathrm{e}+00$ 4.65962e-01 1.00000e-09 2.12000e-01 $4.65962 \mathrm{e}+004.65962 \mathrm{e}+00$ 4.65962e-01 1.00000e-09 2.12000e-01 $4.65962 \mathrm{e}+00$ 4.65962e+00 4.65962e-01 1.00000e-09 2.12000e-01 4.65962e+00 4.65962e+00 4.65962e-01 1.00000e-09 2.12000e-01 $1.00000 \mathrm{e}+001.00000 \mathrm{e}+001.00000 \mathrm{e}-01$ 1.00000e-09 1.00000e-01 Element: 14231 \# of layers: 6

Kx Ky Kz Ss Por

5.19469e+00 5.19469e+00 5.19469e-01 1.00000e-09 2.12000e-01 5.19469e+00 5.19469e+00 5.19469e-01 1.00000e-09 2.12000e-01 5.19469e+00 5.19469e+00 5.19469e-01 1.00000e-09 2.12000e-01 5.19469e+00 5.19469e+00 5.19469e-01 1.00000e-09 2.12000e-01 5.19469e+00 5.19469e+00 5.19469e-01 1.00000e-09 2.12000e-01 $1.00000 \mathrm{e}+001.00000 \mathrm{e}+001.00000 \mathrm{e}-01$ 1.00000e-09 1.00000e-01 Element: 14232 \# of layers: 6

$\mathrm{Kx} \mathrm{Ky} \mathrm{Kz}$ Ss Por

5.19469e+00 5.19469e+00 5.19469e-01 1.00000e-09 2.12000e-01 5.19469e+00 5.19469e+00 5.19469e-01 1.00000e-09 2.12000e-01 5.19469e+00 5.19469e+00 5.19469e-01 1.00000e-09 2.12000e-01 5.19469e+00 5.19469e+00 5.19469e-01 1.00000e-09 2.12000e-01 $5.19469 \mathrm{e}+00$ 5.19469e+00 5.19469e-01 1.00000e-09 2.12000e-01 $1.00000 \mathrm{e}+001.00000 \mathrm{e}+001.00000 \mathrm{e}-011.00000 \mathrm{e}-091.00000 \mathrm{e}-01$ Element: 14233 \# of layers: 6

$\mathrm{Kx} \mathrm{Ky} \mathrm{Kz}$ Ss Por

5.48269e+00 5.48269e+00 5.48269e-01 1.00000e-09 2.12000e-01 $5.48269 \mathrm{e}+00$ 5.48269e+00 5.48269e-01 1.00000e-09 2.12000e-01 5.48269e+00 5.48269e+00 5.48269e-01 1.00000e-09 2.12000e-01 $5.48269 \mathrm{e}+005.48269 \mathrm{e}+00$ 5.48269e-01 1.00000e-09 2.12000e-01 $5.48269 \mathrm{e}+005.48269 \mathrm{e}+00$ 5.48269e-01 1.00000e-09 2.12000e-01 $1.00000 \mathrm{e}+001.00000 \mathrm{e}+00$ 1.00000e-01 1.00000e-09 1.00000e-01 Element: 14234 \# of layers: 6

$\mathrm{Kx} \mathrm{Ky} \mathrm{Kz}$ Ss Por

5.48854e+00 5.48854e+00 5.48854e-01 1.00000e-09 2.12000e-01 $5.48854 \mathrm{e}+005.48854 \mathrm{e}+005.48854 \mathrm{e}-011.00000 \mathrm{e}-092.12000 \mathrm{e}-01$ $5.48854 \mathrm{e}+005.48854 \mathrm{e}+00$ 5.48854e-01 1.00000e-09 2.12000e-01 $5.48854 \mathrm{e}+005.48854 \mathrm{e}+005.48854 \mathrm{e}-01$ 1.00000e-09 2.12000e-01 $5.48854 \mathrm{e}+005.48854 \mathrm{e}+00 \quad 5.48854 \mathrm{e}-011.00000 \mathrm{e}-092.12000 \mathrm{e}-01$ $1.00000 \mathrm{e}+001.00000 \mathrm{e}+001.00000 \mathrm{e}-011.00000 \mathrm{e}-091.00000 \mathrm{e}-01$ Element: 14235 \# of layers: 6

$\mathrm{Kx} \mathrm{Ky} \mathrm{Kz}$ Ss Por 4.65962e+00 4.65962e+00 4.65962e-01 1.00000e-09 2.12000e-01 $4.65962 \mathrm{e}+004.65962 \mathrm{e}+00$ 4.65962e-01 1.00000e-09 2.12000e-01 
$4.65962 \mathrm{e}+004.65962 \mathrm{e}+00$ 4.65962e-01 1.00000e-09 2.12000e-01 $4.65962 \mathrm{e}+004.65962 \mathrm{e}+004.65962 \mathrm{e}-011.00000 \mathrm{e}-092.12000 \mathrm{e}-01$ $4.65962 \mathrm{e}+004.65962 \mathrm{e}+004.65962 \mathrm{e}-011.00000 \mathrm{e}-09$ 2.12000e-01 $1.00000 \mathrm{e}+001.00000 \mathrm{e}+001.00000 \mathrm{e}-011.00000 \mathrm{e}-091.00000 \mathrm{e}-01$ Element: 14236 \# of layers: 7

Kx Ky Kz Ss Por

3.35032e+00 3.35032e+00 3.35032e-01 1.00000e-09 2.12000e-01 $3.35032 \mathrm{e}+003.35032 \mathrm{e}+003.35032 \mathrm{e}-01$ 1.00000e-09 2.12000e-01 $3.35032 \mathrm{e}+003.35032 \mathrm{e}+003.35032 \mathrm{e}-011.00000 \mathrm{e}-092.12000 \mathrm{e}-01$ $3.35032 \mathrm{e}+003.35032 \mathrm{e}+003.35032 \mathrm{e}-011.00000 \mathrm{e}-092.12000 \mathrm{e}-01$ $3.35032 \mathrm{e}+003.35032 \mathrm{e}+003.35032 \mathrm{e}-01$ 1.00000e-09 2.12000e-01 $1.00000 \mathrm{e}-05$ 1.00000e-05 1.00000e-06 1.00000e-09 1.00000e-01 $1.00000 \mathrm{e}+001.00000 \mathrm{e}+001.00000 \mathrm{e}-011.00000 \mathrm{e}-091.00000 \mathrm{e}-01$ Element: 14237 \# of layers: 7

Kx Ky Kz Ss Por

3.35032e+00 3.35032e+00 3.35032e-01 1.00000e-09 2.12000e-01 $3.35032 \mathrm{e}+003.35032 \mathrm{e}+003.35032 \mathrm{e}-01$ 1.00000e-09 2.12000e-01 $3.35032 \mathrm{e}+003.35032 \mathrm{e}+003.35032 \mathrm{e}-01$ 1.00000e-09 2.12000e-01 $3.35032 \mathrm{e}+003.35032 \mathrm{e}+003.35032 \mathrm{e}-01$ 1.00000e-09 2.12000e-01 $3.35032 \mathrm{e}+003.35032 \mathrm{e}+003.35032 \mathrm{e}-011.00000 \mathrm{e}-092.12000 \mathrm{e}-01$ $1.00000 \mathrm{e}-05$ 1.00000e-05 1.00000e-06 1.00000e-09 1.00000e-01 $1.00000 \mathrm{e}+001.00000 \mathrm{e}+001.00000 \mathrm{e}-011.00000 \mathrm{e}-091.00000 \mathrm{e}-01$ Element: 14238 \# of layers: 7

Kx Ky Kz Ss Por $3.35032 \mathrm{e}+003.35032 \mathrm{e}+003.35032 \mathrm{e}-01$ 1.00000e-09 2.12000e-01 $3.35032 \mathrm{e}+003.35032 \mathrm{e}+003.35032 \mathrm{e}-011.00000 \mathrm{e}-092.12000 \mathrm{e}-01$ $3.35032 \mathrm{e}+003.35032 \mathrm{e}+003.35032 \mathrm{e}-01$ 1.00000e-09 2.12000e-01 $3.35032 \mathrm{e}+003.35032 \mathrm{e}+003.35032 \mathrm{e}-01$ 1.00000e-09 2.12000e-01 $3.35032 \mathrm{e}+003.35032 \mathrm{e}+003.35032 \mathrm{e}-011.00000 \mathrm{e}-092.12000 \mathrm{e}-01$ $1.00000 \mathrm{e}-05$ 1.00000e-05 1.00000e-06 1.00000e-09 1.00000e-01 $1.00000 \mathrm{e}+001.00000 \mathrm{e}+001.00000 \mathrm{e}-011.00000 \mathrm{e}-091.00000 \mathrm{e}-01$ Element: 14239 \# of layers: 6

Kx Ky Kz Ss Por

3.35032e+00 3.35032e+00 3.35032e-01 1.00000e-09 2.12000e-01 $3.35032 \mathrm{e}+003.35032 \mathrm{e}+003.35032 \mathrm{e}-011.00000 \mathrm{e}-092.12000 \mathrm{e}-01$ $3.35032 \mathrm{e}+003.35032 \mathrm{e}+003.35032 \mathrm{e}-01$ 1.00000e-09 2.12000e-01 $3.35032 \mathrm{e}+003.35032 \mathrm{e}+003.35032 \mathrm{e}-01$ 1.00000e-09 2.12000e-01 $3.35032 \mathrm{e}+003.35032 \mathrm{e}+003.35032 \mathrm{e}-01$ 1.00000e-09 2.12000e-01 $1.00000 \mathrm{e}+001.00000 \mathrm{e}+001.00000 \mathrm{e}-011.00000 \mathrm{e}-091.00000 \mathrm{e}-01$ Element: 14240 \# of layers: 6

Kx Ky Kz Ss Por

3.35032e+00 3.35032e+00 3.35032e-01 1.00000e-09 2.12000e-01 $3.35032 \mathrm{e}+003.35032 \mathrm{e}+003.35032 \mathrm{e}-01$ 1.00000e-09 2.12000e-01 $3.35032 \mathrm{e}+003.35032 \mathrm{e}+003.35032 \mathrm{e}-011.00000 \mathrm{e}-092.12000 \mathrm{e}-01$ $3.35032 \mathrm{e}+003.35032 \mathrm{e}+003.35032 \mathrm{e}-01$ 1.00000e-09 2.12000e-01 $3.35032 \mathrm{e}+003.35032 \mathrm{e}+003.35032 \mathrm{e}-01$ 1.00000e-09 2.12000e-01 
$1.00000 \mathrm{e}+001.00000 \mathrm{e}+00$ 1.00000e-01 1.00000e-09 1.00000e-01

Element: 14241 \# of layers: 6

Kx Ky Kz Ss Por

3.35032e+00 3.35032e+00 3.35032e-01 1.00000e-09 2.12000e-01

$3.35032 \mathrm{e}+003.35032 \mathrm{e}+00$ 3.35032e-01 1.00000e-09 2.12000e-01

$3.35032 \mathrm{e}+003.35032 \mathrm{e}+00$ 3.35032e-01 1.00000e-09 2.12000e-01

3.35032e+00 3.35032e+00 3.35032e-01 1.00000e-09 2.12000e-01

$3.35032 \mathrm{e}+003.35032 \mathrm{e}+003.35032 \mathrm{e}-01$ 1.00000e-09 2.12000e-01

$1.00000 \mathrm{e}+001.00000 \mathrm{e}+001.00000 \mathrm{e}-011.00000 \mathrm{e}-091.00000 \mathrm{e}-01$

Element: 14242 \# of layers: 6

$\mathrm{Kx} \mathrm{Ky} \mathrm{Kz}$ Ss Por

3.35032e+00 3.35032e+00 3.35032e-01 1.00000e-09 2.12000e-01

$3.35032 \mathrm{e}+00$ 3.35032e+00 3.35032e-01 1.00000e-09 2.12000e-01

$3.35032 \mathrm{e}+00$ 3.35032e+00 3.35032e-01 1.00000e-09 2.12000e-01

3.35032e+00 3.35032e+00 3.35032e-01 1.00000e-09 2.12000e-01

$3.35032 \mathrm{e}+003.35032 \mathrm{e}+00$ 3.35032e-01 1.00000e-09 2.12000e-01

$1.00000 \mathrm{e}+001.00000 \mathrm{e}+001.00000 \mathrm{e}-011.00000 \mathrm{e}-091.00000 \mathrm{e}-01$

Element: 14243 \# of layers: 6

$\mathrm{Kx} \mathrm{Ky} \mathrm{Kz}$ Ss Por

3.35032e+00 3.35032e+00 3.35032e-01 1.00000e-09 2.12000e-01

$3.35032 \mathrm{e}+003.35032 \mathrm{e}+003.35032 \mathrm{e}-01$ 1.00000e-09 2.12000e-01

3.35032e+00 3.35032e+00 3.35032e-01 1.00000e-09 2.12000e-01

3.35032e+00 3.35032e+00 3.35032e-01 1.00000e-09 2.12000e-01

$3.35032 \mathrm{e}+00$ 3.35032e+00 3.35032e-01 1.00000e-09 2.12000e-01

$1.00000 \mathrm{e}+001.00000 \mathrm{e}+001.00000 \mathrm{e}-011.00000 \mathrm{e}-091.00000 \mathrm{e}-01$

Element: 14244 \# of layers: 6

$\mathrm{Kx} \mathrm{Ky} \mathrm{Kz}$ Ss Por

3.35032e+00 3.35032e+00 3.35032e-01 1.00000e-09 2.12000e-01

$3.35032 \mathrm{e}+00$ 3.35032e+00 3.35032e-01 1.00000e-09 2.12000e-01

$3.35032 \mathrm{e}+00$ 3.35032e+00 3.35032e-01 1.00000e-09 2.12000e-01

$3.35032 \mathrm{e}+003.35032 \mathrm{e}+00$ 3.35032e-01 1.00000e-09 2.12000e-01

3.35032e+00 3.35032e+00 3.35032e-01 1.00000e-09 2.12000e-01

$1.00000 \mathrm{e}+001.00000 \mathrm{e}+001.00000 \mathrm{e}-01$ 1.00000e-09 1.00000e-01

Element: 14245 \# of layers: 7

$\mathrm{Kx} \mathrm{Ky} \mathrm{Kz}$ Ss Por

3.35032e+00 3.35032e+00 3.35032e-01 1.00000e-09 2.12000e-01

3.35032e+00 3.35032e+00 3.35032e-01 1.00000e-09 2.12000e-01

$3.35032 \mathrm{e}+003.35032 \mathrm{e}+00$ 3.35032e-01 1.00000e-09 2.12000e-01

3.35032e+00 3.35032e+00 3.35032e-01 1.00000e-09 2.12000e-01

3.35032e+00 3.35032e+00 3.35032e-01 1.00000e-09 2.12000e-01

1.00000e-05 1.00000e-05 1.00000e-06 1.00000e-09 1.00000e-01

$1.00000 \mathrm{e}+001.00000 \mathrm{e}+001.00000 \mathrm{e}-011.00000 \mathrm{e}-091.00000 \mathrm{e}-01$

Element: 14246 \# of layers: 7

$\mathrm{Kx} \mathrm{Ky} \mathrm{Kz}$ Ss Por

$1.89573 \mathrm{e}+00$ 1.89573e+00 1.89573e-01 1.00000e-09 2.12000e-01

$1.89573 \mathrm{e}+001.89573 \mathrm{e}+00$ 1.89573e-01 1.00000e-09 2.12000e-01 
$1.89573 \mathrm{e}+00$ 1.89573e+00 1.89573e-01 1.00000e-09 2.12000e-01 $1.89573 \mathrm{e}+00$ 1.89573e+00 1.89573e-01 1.00000e-09 2.12000e-01 $1.89573 \mathrm{e}+00$ 1.89573e+00 1.89573e-01 1.00000e-09 2.12000e-01 $1.00000 \mathrm{e}-05$ 1.00000e-05 1.00000e-06 1.00000e-09 1.00000e-01 $1.00000 \mathrm{e}+001.00000 \mathrm{e}+001.00000 \mathrm{e}-01$ 1.00000e-09 1.00000e-01 Element: 14247 \# of layers: 7

$\mathrm{Kx} \mathrm{Ky} \mathrm{Kz}$ Ss Por

$1.89573 e+00$ 1.89573e+00 1.89573e-01 1.00000e-09 2.12000e-01 $1.89573 \mathrm{e}+00$ 1.89573e+00 1.89573e-01 1.00000e-09 2.12000e-01 $1.89573 \mathrm{e}+00$ 1.89573e+00 1.89573e-01 1.00000e-09 2.12000e-01 $1.89573 \mathrm{e}+00$ 1.89573e+00 1.89573e-01 1.00000e-09 2.12000e-01 $1.89573 \mathrm{e}+001.89573 \mathrm{e}+001.89573 \mathrm{e}-01$ 1.00000e-09 2.12000e-01 $1.00000 \mathrm{e}-051.00000 \mathrm{e}-05$ 1.00000e-06 1.00000e-09 1.00000e-01 $1.00000 \mathrm{e}+001.00000 \mathrm{e}+001.00000 \mathrm{e}-01$ 1.00000e-09 1.00000e-01 Element: 14248 \# of layers: 6

Kx Ky Kz Ss Por

$1.89573 \mathrm{e}+00$ 1.89573e+00 1.89573e-01 1.00000e-09 2.12000e-01 $1.89573 \mathrm{e}+00$ 1.89573e+00 1.89573e-01 1.00000e-09 2.12000e-01 $1.89573 \mathrm{e}+00$ 1.89573e+00 1.89573e-01 1.00000e-09 2.12000e-01 $1.89573 \mathrm{e}+001.89573 \mathrm{e}+00$ 1.89573e-01 1.00000e-09 2.12000e-01 $1.89573 \mathrm{e}+001.89573 \mathrm{e}+00$ 1.89573e-01 1.00000e-09 2.12000e-01 $1.00000 \mathrm{e}+001.00000 \mathrm{e}+001.00000 \mathrm{e}-01$ 1.00000e-09 1.00000e-01 Element: 14249 \# of layers: 6

Kx Ky Kz Ss Por

$1.89573 \mathrm{e}+00$ 1.89573e+00 1.89573e-01 1.00000e-09 2.12000e-01 $1.89573 \mathrm{e}+00$ 1.89573e+00 1.89573e-01 1.00000e-09 2.12000e-01 $1.89573 \mathrm{e}+001.89573 \mathrm{e}+00$ 1.89573e-01 1.00000e-09 2.12000e-01 $1.89573 \mathrm{e}+00$ 1.89573e+00 1.89573e-01 1.00000e-09 2.12000e-01 $1.89573 \mathrm{e}+001.89573 \mathrm{e}+00$ 1.89573e-01 1.00000e-09 2.12000e-01 $1.00000 \mathrm{e}+001.00000 \mathrm{e}+001.00000 \mathrm{e}-011.00000 \mathrm{e}-091.00000 \mathrm{e}-01$ Element: 14250 \# of layers: 6

$\mathrm{Kx} \mathrm{Ky} \mathrm{Kz}$ Ss Por

$1.89573 \mathrm{e}+00$ 1.89573e+00 1.89573e-01 1.00000e-09 2.12000e-01 $1.89573 \mathrm{e}+00$ 1.89573e+00 1.89573e-01 1.00000e-09 2.12000e-01 $1.89573 \mathrm{e}+00$ 1.89573e+00 1.89573e-01 1.00000e-09 2.12000e-01 $1.89573 \mathrm{e}+001.89573 \mathrm{e}+00$ 1.89573e-01 1.00000e-09 2.12000e-01 $1.89573 \mathrm{e}+001.89573 \mathrm{e}+00$ 1.89573e-01 1.00000e-09 2.12000e-01 $1.00000 \mathrm{e}+001.00000 \mathrm{e}+001.00000 \mathrm{e}-011.00000 \mathrm{e}-091.00000 \mathrm{e}-01$ Element: 14251 \# of layers: 6

$\mathrm{Kx} \mathrm{Ky} \mathrm{Kz}$ Ss Por

3.35032e+00 3.35032e+00 3.35032e-01 1.00000e-09 2.12000e-01 $3.35032 \mathrm{e}+00$ 3.35032e+00 3.35032e-01 1.00000e-09 2.12000e-01 $3.35032 \mathrm{e}+003.35032 \mathrm{e}+00$ 3.35032e-01 1.00000e-09 2.12000e-01 3.35032e+00 3.35032e+00 3.35032e-01 1.00000e-09 2.12000e-01 $3.35032 \mathrm{e}+00$ 3.35032e+00 3.35032e-01 1.00000e-09 2.12000e-01 $1.00000 \mathrm{e}+001.00000 \mathrm{e}+001.00000 \mathrm{e}-011.00000 \mathrm{e}-091.00000 \mathrm{e}-01$ 
Element: 14252 \# of layers: 6

$\mathrm{Kx} \mathrm{Ky} \mathrm{Kz}$ Ss Por

3.35032e+00 3.35032e+00 3.35032e-01 1.00000e-09 2.12000e-01

$3.35032 \mathrm{e}+00$ 3.35032e+00 3.35032e-01 1.00000e-09 2.12000e-01

3.35032e+00 3.35032e+00 3.35032e-01 1.00000e-09 2.12000e-01

$3.35032 \mathrm{e}+003.35032 \mathrm{e}+00$ 3.35032e-01 1.00000e-09 2.12000e-01

3.35032e+00 3.35032e+00 3.35032e-01 1.00000e-09 2.12000e-01

$1.00000 \mathrm{e}+001.00000 \mathrm{e}+001.00000 \mathrm{e}-01$ 1.00000e-09 1.00000e-01

Element: 14253 \# of layers: 6

$\mathrm{Kx} \mathrm{Ky} \mathrm{Kz}$ Ss Por

1.89573e+00 1.89573e+00 1.89573e-01 1.00000e-09 2.12000e-01

$1.89573 \mathrm{e}+001.89573 \mathrm{e}+00$ 1.89573e-01 1.00000e-09 2.12000e-01

$1.89573 \mathrm{e}+00$ 1.89573e+00 1.89573e-01 1.00000e-09 2.12000e-01

$1.89573 \mathrm{e}+00$ 1.89573e+00 1.89573e-01 1.00000e-09 2.12000e-01

$1.89573 \mathrm{e}+00$ 1.89573e+00 1.89573e-01 1.00000e-09 2.12000e-01

$1.00000 \mathrm{e}+001.00000 \mathrm{e}+001.00000 \mathrm{e}-01$ 1.00000e-09 1.00000e-01

Element: 14254 \# of layers: 7

$\mathrm{Kx} \mathrm{Ky} \mathrm{Kz}$ Ss Por

$1.89573 \mathrm{e}+00$ 1.89573e+00 1.89573e-01 1.00000e-09 2.12000e-01

$1.89573 \mathrm{e}+001.89573 \mathrm{e}+00$ 1.89573e-01 1.00000e-09 2.12000e-01

$1.89573 \mathrm{e}+001.89573 \mathrm{e}+00$ 1.89573e-01 1.00000e-09 2.12000e-01

$1.89573 \mathrm{e}+00$ 1.89573e+00 1.89573e-01 1.00000e-09 2.12000e-01

$1.89573 \mathrm{e}+00$ 1.89573e+00 1.89573e-01 1.00000e-09 2.12000e-01

$1.00000 \mathrm{e}-05$ 1.00000e-05 1.00000e-06 1.00000e-09 1.00000e-01

$1.00000 \mathrm{e}+001.00000 \mathrm{e}+001.00000 \mathrm{e}-011.00000 \mathrm{e}-091.00000 \mathrm{e}-01$

Element: 14255 \# of layers: 7

$\mathrm{Kx} \mathrm{Ky} \mathrm{Kz}$ Ss Por

1.89573e+00 1.89573e+00 1.89573e-01 1.00000e-09 2.12000e-01

$1.89573 \mathrm{e}+001.89573 \mathrm{e}+00$ 1.89573e-01 1.00000e-09 2.12000e-01

$1.89573 \mathrm{e}+00$ 1.89573e+00 1.89573e-01 1.00000e-09 2.12000e-01

$1.89573 \mathrm{e}+001.89573 \mathrm{e}+00$ 1.89573e-01 1.00000e-09 2.12000e-01

$1.89573 \mathrm{e}+00$ 1.89573e+00 1.89573e-01 1.00000e-09 2.12000e-01

$1.00000 \mathrm{e}-05$ 1.00000e-05 1.00000e-06 1.00000e-09 1.00000e-01

$1.00000 \mathrm{e}+001.00000 \mathrm{e}+001.00000 \mathrm{e}-011.00000 \mathrm{e}-091.00000 \mathrm{e}-01$

Element: 14256 \# of layers: 7

Kx Ky Kz Ss Por

$1.89573 e+001.89573 e+00$ 1.89573e-01 1.00000e-09 2.12000e-01

$1.89573 \mathrm{e}+00$ 1.89573e+00 1.89573e-01 1.00000e-09 2.12000e-01

$1.89573 \mathrm{e}+00$ 1.89573e+00 1.89573e-01 1.00000e-09 2.12000e-01

$1.89573 \mathrm{e}+00$ 1.89573e+00 1.89573e-01 1.00000e-09 2.12000e-01

$1.89573 \mathrm{e}+001.89573 \mathrm{e}+00$ 1.89573e-01 1.00000e-09 2.12000e-01

$1.00000 \mathrm{e}-05$ 1.00000e-05 1.00000e-06 1.00000e-09 1.00000e-01

$1.00000 \mathrm{e}+001.00000 \mathrm{e}+001.00000 \mathrm{e}-01$ 1.00000e-09 1.00000e-01

Element: 14257 \# of layers: 6

$\mathrm{Kx} \mathrm{Ky} \mathrm{Kz}$ Ss Por

$1.89573 e+00$ 1.89573e+00 1.89573e-01 1.00000e-09 2.12000e-01 
$1.89573 \mathrm{e}+00$ 1.89573e+00 1.89573e-01 1.00000e-09 2.12000e-01 $1.89573 \mathrm{e}+00$ 1.89573e+00 1.89573e-01 1.00000e-09 2.12000e-01 $1.89573 \mathrm{e}+00$ 1.89573e+00 1.89573e-01 1.00000e-09 2.12000e-01 $1.89573 \mathrm{e}+00$ 1.89573e+00 1.89573e-01 1.00000e-09 2.12000e-01 $1.00000 \mathrm{e}+001.00000 \mathrm{e}+001.00000 \mathrm{e}-011.00000 \mathrm{e}-091.00000 \mathrm{e}-01$ Element: 14258 \# of layers: 6

$\mathrm{Kx} \mathrm{Ky} \mathrm{Kz}$ Ss Por

$1.89573 \mathrm{e}+00$ 1.89573e+00 1.89573e-01 1.00000e-09 2.12000e-01 $1.89573 \mathrm{e}+00$ 1.89573e+00 1.89573e-01 1.00000e-09 2.12000e-01 $1.89573 \mathrm{e}+00$ 1.89573e+00 1.89573e-01 1.00000e-09 2.12000e-01 $1.89573 \mathrm{e}+00$ 1.89573e+00 1.89573e-01 1.00000e-09 2.12000e-01 $1.89573 \mathrm{e}+001.89573 \mathrm{e}+001.89573 \mathrm{e}-01$ 1.00000e-09 2.12000e-01 $1.00000 \mathrm{e}+001.00000 \mathrm{e}+001.00000 \mathrm{e}-01$ 1.00000e-09 1.00000e-01 Element: 14259 \# of layers: 6

$\mathrm{Kx} \mathrm{Ky} \mathrm{Kz}$ Ss Por

$1.89573 \mathrm{e}+00$ 1.89573e+00 1.89573e-01 1.00000e-09 2.12000e-01 $1.89573 \mathrm{e}+00$ 1.89573e+00 1.89573e-01 1.00000e-09 2.12000e-01 $1.89573 \mathrm{e}+00$ 1.89573e+00 1.89573e-01 1.00000e-09 2.12000e-01 $1.89573 \mathrm{e}+00$ 1.89573e+00 1.89573e-01 1.00000e-09 2.12000e-01 $1.89573 \mathrm{e}+00$ 1.89573e+00 1.89573e-01 1.00000e-09 2.12000e-01 $1.00000 \mathrm{e}+001.00000 \mathrm{e}+001.00000 \mathrm{e}-011.00000 \mathrm{e}-091.00000 \mathrm{e}-01$ Element: 14260 \# of layers: 6

$\mathrm{Kx} \mathrm{Ky} \mathrm{Kz}$ Ss Por

$1.89573 \mathrm{e}+00$ 1.89573e+00 1.89573e-01 1.00000e-09 2.12000e-01 $1.89573 \mathrm{e}+001.89573 \mathrm{e}+00$ 1.89573e-01 1.00000e-09 2.12000e-01 $1.89573 \mathrm{e}+00$ 1.89573e+00 1.89573e-01 1.00000e-09 2.12000e-01 $1.89573 \mathrm{e}+00$ 1.89573e+00 1.89573e-01 1.00000e-09 2.12000e-01 $1.89573 \mathrm{e}+001.89573 \mathrm{e}+00$ 1.89573e-01 1.00000e-09 2.12000e-01 $1.00000 \mathrm{e}+001.00000 \mathrm{e}+001.00000 \mathrm{e}-011.00000 \mathrm{e}-091.00000 \mathrm{e}-01$ Element: 14261 \# of layers: 6

$\mathrm{Kx} \mathrm{Ky} \mathrm{Kz}$ Ss Por

$1.89573 e+00$ 1.89573e+00 1.89573e-01 1.00000e-09 2.12000e-01 $1.89573 \mathrm{e}+001.89573 \mathrm{e}+00$ 1.89573e-01 1.00000e-09 2.12000e-01 $1.89573 \mathrm{e}+00$ 1.89573e+00 1.89573e-01 1.00000e-09 2.12000e-01 $1.89573 \mathrm{e}+00$ 1.89573e+00 1.89573e-01 1.00000e-09 2.12000e-01 $1.89573 \mathrm{e}+00$ 1.89573e+00 1.89573e-01 1.00000e-09 2.12000e-01 $1.00000 \mathrm{e}+001.00000 \mathrm{e}+001.00000 \mathrm{e}-01$ 1.00000e-09 1.00000e-01 Element: 14262 \# of layers: 6

$\mathrm{Kx} \mathrm{Ky} \mathrm{Kz}$ Ss Por

$1.89573 \mathrm{e}+00$ 1.89573e+00 1.89573e-01 1.00000e-09 2.12000e-01 $1.89573 \mathrm{e}+001.89573 \mathrm{e}+00$ 1.89573e-01 1.00000e-09 2.12000e-01 $1.89573 \mathrm{e}+001.89573 \mathrm{e}+00$ 1.89573e-01 1.00000e-09 2.12000e-01 $1.89573 \mathrm{e}+00$ 1.89573e+00 1.89573e-01 1.00000e-09 2.12000e-01 $1.89573 \mathrm{e}+00$ 1.89573e+00 1.89573e-01 1.00000e-09 2.12000e-01 $1.00000 \mathrm{e}+001.00000 \mathrm{e}+001.00000 \mathrm{e}-01$ 1.00000e-09 1.00000e-01 Element: 14263 \# of layers: 6 
$\mathrm{Kx} \mathrm{Ky} \mathrm{Kz}$ Ss Por

$1.89573 \mathrm{e}+00$ 1.89573e+00 1.89573e-01 1.00000e-09 2.12000e-01

$1.89573 \mathrm{e}+00$ 1.89573e+00 1.89573e-01 1.00000e-09 2.12000e-01

$1.89573 \mathrm{e}+00$ 1.89573e+00 1.89573e-01 1.00000e-09 2.12000e-01

$1.89573 \mathrm{e}+00$ 1.89573e+00 1.89573e-01 1.00000e-09 2.12000e-01

$1.89573 \mathrm{e}+00$ 1.89573e+00 1.89573e-01 1.00000e-09 2.12000e-01

$1.00000 \mathrm{e}+001.00000 \mathrm{e}+001.00000 \mathrm{e}-01$ 1.00000e-09 1.00000e-01

Element: 14264 \# of layers: 6

$\mathrm{Kx} \mathrm{Ky} \mathrm{Kz}$ Ss Por

1.89573e+00 1.89573e+00 1.89573e-01 1.00000e-09 2.12000e-01

$1.89573 \mathrm{e}+00$ 1.89573e+00 1.89573e-01 1.00000e-09 2.12000e-01

$1.89573 \mathrm{e}+00$ 1.89573e+00 1.89573e-01 1.00000e-09 2.12000e-01

$1.89573 \mathrm{e}+00$ 1.89573e+00 1.89573e-01 1.00000e-09 2.12000e-01

$1.89573 \mathrm{e}+001.89573 \mathrm{e}+00$ 1.89573e-01 1.00000e-09 2.12000e-01

$1.00000 \mathrm{e}+001.00000 \mathrm{e}+001.00000 \mathrm{e}-01$ 1.00000e-09 1.00000e-01

Element: 14265 \# of layers: 6

$\mathrm{Kx} \mathrm{Ky} \mathrm{Kz}$ Ss Por

3.46372e+00 3.46372e+00 3.46372e-01 1.00000e-09 2.12000e-01

$3.46372 \mathrm{e}+003.46372 \mathrm{e}+003.46372 \mathrm{e}-01$ 1.00000e-09 2.12000e-01

$3.46372 \mathrm{e}+003.46372 \mathrm{e}+00$ 3.46372e-01 1.00000e-09 2.12000e-01

$3.46372 \mathrm{e}+003.46372 \mathrm{e}+00$ 3.46372e-01 1.00000e-09 2.12000e-01

$3.46372 \mathrm{e}+00$ 3.46372e+00 3.46372e-01 1.00000e-09 2.12000e-01

$1.00000 \mathrm{e}+001.00000 \mathrm{e}+001.00000 \mathrm{e}-011.00000 \mathrm{e}-091.00000 \mathrm{e}-01$

Element: 14266 \# of layers: 6

Kx Ky Kz Ss Por

3.46372e+00 3.46372e+00 3.46372e-01 1.00000e-09 2.12000e-01

$3.46372 \mathrm{e}+003.46372 \mathrm{e}+00$ 3.46372e-01 1.00000e-09 2.12000e-01

3.46372e+00 3.46372e+00 3.46372e-01 1.00000e-09 2.12000e-01

$3.46372 \mathrm{e}+003.46372 \mathrm{e}+00$ 3.46372e-01 1.00000e-09 2.12000e-01

$3.46372 \mathrm{e}+003.46372 \mathrm{e}+00$ 3.46372e-01 1.00000e-09 2.12000e-01

$1.00000 \mathrm{e}+001.00000 \mathrm{e}+001.00000 \mathrm{e}-011.00000 \mathrm{e}-091.00000 \mathrm{e}-01$

Element: 14267 \# of layers: 6

Kx Ky Kz Ss Por

3.46372e+00 3.46372e+00 3.46372e-01 1.00000e-09 2.12000e-01

$3.46372 \mathrm{e}+003.46372 \mathrm{e}+00$ 3.46372e-01 1.00000e-09 2.12000e-01

$3.46372 \mathrm{e}+003.46372 \mathrm{e}+00$ 3.46372e-01 1.00000e-09 2.12000e-01

$3.46372 \mathrm{e}+003.46372 \mathrm{e}+00$ 3.46372e-01 1.00000e-09 2.12000e-01

3.46372e+00 3.46372e+00 3.46372e-01 1.00000e-09 2.12000e-01

$1.00000 \mathrm{e}+001.00000 \mathrm{e}+001.00000 \mathrm{e}-01$ 1.00000e-09 1.00000e-01

Element: 14268 \# of layers: 6

$\mathrm{Kx} \mathrm{Ky} \mathrm{Kz}$ Ss Por

$1.89573 \mathrm{e}+00$ 1.89573e+00 1.89573e-01 1.00000e-09 2.12000e-01

$1.89573 \mathrm{e}+00$ 1.89573e+00 1.89573e-01 1.00000e-09 2.12000e-01

$1.89573 \mathrm{e}+00$ 1.89573e+00 1.89573e-01 1.00000e-09 2.12000e-01

$1.89573 \mathrm{e}+001.89573 \mathrm{e}+00$ 1.89573e-01 1.00000e-09 2.12000e-01

$1.89573 \mathrm{e}+001.89573 \mathrm{e}+00$ 1.89573e-01 1.00000e-09 2.12000e-01 
$1.00000 \mathrm{e}+001.00000 \mathrm{e}+00$ 1.00000e-01 1.00000e-09 1.00000e-01

Element: 14269 \# of layers: 6

Kx Ky Kz Ss Por

$1.89573 \mathrm{e}+00$ 1.89573e+00 1.89573e-01 1.00000e-09 2.12000e-01

$1.89573 \mathrm{e}+00$ 1.89573e+00 1.89573e-01 1.00000e-09 2.12000e-01

$1.89573 \mathrm{e}+00$ 1.89573e+00 1.89573e-01 1.00000e-09 2.12000e-01

$1.89573 \mathrm{e}+00$ 1.89573e+00 1.89573e-01 1.00000e-09 2.12000e-01

$1.89573 \mathrm{e}+001.89573 \mathrm{e}+00$ 1.89573e-01 1.00000e-09 2.12000e-01

$1.00000 \mathrm{e}+001.00000 \mathrm{e}+001.00000 \mathrm{e}-01$ 1.00000e-09 1.00000e-01

Element: 14270 \# of layers: 6

$\mathrm{Kx} \mathrm{Ky} \mathrm{Kz}$ Ss Por

$1.89573 e+001.89573 e+00$ 1.89573e-01 1.00000e-09 2.12000e-01

$1.89573 \mathrm{e}+00$ 1.89573e+00 1.89573e-01 1.00000e-09 2.12000e-01

$1.89573 \mathrm{e}+00$ 1.89573e+00 1.89573e-01 1.00000e-09 2.12000e-01

$1.89573 \mathrm{e}+00$ 1.89573e+00 1.89573e-01 1.00000e-09 2.12000e-01

$1.89573 \mathrm{e}+001.89573 \mathrm{e}+00$ 1.89573e-01 1.00000e-09 2.12000e-01

$1.00000 \mathrm{e}+001.00000 \mathrm{e}+001.00000 \mathrm{e}-011.00000 \mathrm{e}-091.00000 \mathrm{e}-01$

Element: 14271 \# of layers: 6

$\mathrm{Kx} \mathrm{Ky} \mathrm{Kz}$ Ss Por

1.89573e+00 1.89573e+00 1.89573e-01 1.00000e-09 2.12000e-01

$1.89573 \mathrm{e}+001.89573 \mathrm{e}+00$ 1.89573e-01 1.00000e-09 2.12000e-01

$1.89573 \mathrm{e}+00$ 1.89573e+00 1.89573e-01 1.00000e-09 2.12000e-01

$1.89573 \mathrm{e}+00$ 1.89573e+00 1.89573e-01 1.00000e-09 2.12000e-01

$1.89573 \mathrm{e}+00$ 1.89573e+00 1.89573e-01 1.00000e-09 2.12000e-01

$1.00000 \mathrm{e}+001.00000 \mathrm{e}+001.00000 \mathrm{e}-011.00000 \mathrm{e}-091.00000 \mathrm{e}-01$

Element: 14272 \# of layers: 6

$\mathrm{Kx} \mathrm{Ky} \mathrm{Kz}$ Ss Por

3.46372e+00 3.46372e+00 3.46372e-01 1.00000e-09 2.12000e-01

$3.46372 \mathrm{e}+003.46372 \mathrm{e}+00$ 3.46372e-01 1.00000e-09 2.12000e-01

$3.46372 \mathrm{e}+003.46372 \mathrm{e}+00$ 3.46372e-01 1.00000e-09 2.12000e-01

$3.46372 \mathrm{e}+003.46372 \mathrm{e}+00$ 3.46372e-01 1.00000e-09 2.12000e-01

$3.46372 \mathrm{e}+003.46372 \mathrm{e}+00$ 3.46372e-01 1.00000e-09 2.12000e-01

$1.00000 \mathrm{e}+001.00000 \mathrm{e}+001.00000 \mathrm{e}-01$ 1.00000e-09 1.00000e-01

Element: 14273 \# of layers: 6

$\mathrm{Kx} \mathrm{Ky} \mathrm{Kz}$ Ss Por

3.46372e+00 3.46372e+00 3.46372e-01 1.00000e-09 2.12000e-01

$3.46372 \mathrm{e}+003.46372 \mathrm{e}+00$ 3.46372e-01 1.00000e-09 2.12000e-01

$3.46372 \mathrm{e}+003.46372 \mathrm{e}+00$ 3.46372e-01 1.00000e-09 2.12000e-01

3.46372e+00 3.46372e+00 3.46372e-01 1.00000e-09 2.12000e-01

$3.46372 \mathrm{e}+003.46372 \mathrm{e}+00$ 3.46372e-01 1.00000e-09 2.12000e-01

$1.00000 \mathrm{e}+001.00000 \mathrm{e}+001.00000 \mathrm{e}-011.00000 \mathrm{e}-091.00000 \mathrm{e}-01$

Element: 14274 \# of layers: 6

$\mathrm{Kx} \mathrm{Ky} \mathrm{Kz}$ Ss Por

3.46372e+00 3.46372e+00 3.46372e-01 1.00000e-09 2.12000e-01

3.46372e+00 3.46372e+00 3.46372e-01 1.00000e-09 2.12000e-01

$3.46372 \mathrm{e}+003.46372 \mathrm{e}+00$ 3.46372e-01 1.00000e-09 2.12000e-01 
$3.46372 \mathrm{e}+003.46372 \mathrm{e}+003.46372 \mathrm{e}-01$ 1.00000e-09 2.12000e-01 $3.46372 \mathrm{e}+003.46372 \mathrm{e}+003.46372 \mathrm{e}-01$ 1.00000e-09 2.12000e-01 $1.00000 \mathrm{e}+001.00000 \mathrm{e}+001.00000 \mathrm{e}-011.00000 \mathrm{e}-091.00000 \mathrm{e}-01$ Element: 14275 \# of layers: 6

Kx Ky Kz Ss Por

3.46372e+00 3.46372e+00 3.46372e-01 1.00000e-09 2.12000e-01 $3.46372 \mathrm{e}+003.46372 \mathrm{e}+003.46372 \mathrm{e}-011.00000 \mathrm{e}-092.12000 \mathrm{e}-01$ $3.46372 \mathrm{e}+003.46372 \mathrm{e}+003.46372 \mathrm{e}-01$ 1.00000e-09 2.12000e-01 $3.46372 \mathrm{e}+003.46372 \mathrm{e}+003.46372 \mathrm{e}-011.00000 \mathrm{e}-092.12000 \mathrm{e}-01$ $3.46372 \mathrm{e}+003.46372 \mathrm{e}+003.46372 \mathrm{e}-011.00000 \mathrm{e}-092.12000 \mathrm{e}-01$ $1.00000 \mathrm{e}+001.00000 \mathrm{e}+001.00000 \mathrm{e}-011.00000 \mathrm{e}-091.00000 \mathrm{e}-01$ Element: 14276 \# of layers: 6

Kx Ky Kz Ss Por

4.86663e+00 4.86663e+00 4.86663e-01 1.00000e-09 2.12000e-01 $4.86663 \mathrm{e}+004.86663 \mathrm{e}+004.86663 \mathrm{e}-01$ 1.00000e-09 2.12000e-01 $4.86663 \mathrm{e}+004.86663 \mathrm{e}+00$ 4.86663e-01 1.00000e-09 2.12000e-01 $4.86663 \mathrm{e}+004.86663 \mathrm{e}+004.86663 \mathrm{e}-011.00000 \mathrm{e}-092.12000 \mathrm{e}-01$ $4.86663 \mathrm{e}+004.86663 \mathrm{e}+00$ 4.86663e-01 1.00000e-09 2.12000e-01 $1.00000 \mathrm{e}+001.00000 \mathrm{e}+001.00000 \mathrm{e}-011.00000 \mathrm{e}-091.00000 \mathrm{e}-01$ Element: 14277 \# of layers: 6

Kx Ky Kz Ss Por

3.46372e+00 3.46372e+00 3.46372e-01 1.00000e-09 2.12000e-01 $3.46372 \mathrm{e}+003.46372 \mathrm{e}+003.46372 \mathrm{e}-011.00000 \mathrm{e}-092.12000 \mathrm{e}-01$ $3.46372 \mathrm{e}+003.46372 \mathrm{e}+003.46372 \mathrm{e}-011.00000 \mathrm{e}-092.12000 \mathrm{e}-01$ $3.46372 \mathrm{e}+003.46372 \mathrm{e}+003.46372 \mathrm{e}-011.00000 \mathrm{e}-092.12000 \mathrm{e}-01$ $3.46372 \mathrm{e}+003.46372 \mathrm{e}+003.46372 \mathrm{e}-01$ 1.00000e-09 2.12000e-01 $1.00000 \mathrm{e}+001.00000 \mathrm{e}+001.00000 \mathrm{e}-011.00000 \mathrm{e}-091.00000 \mathrm{e}-01$ Element: 14278 \# of layers: 6

Kx Ky Kz Ss Por

3.46372e+00 3.46372e+00 3.46372e-01 1.00000e-09 2.12000e-01

$3.46372 \mathrm{e}+003.46372 \mathrm{e}+003.46372 \mathrm{e}-011.00000 \mathrm{e}-092.12000 \mathrm{e}-01$ $3.46372 \mathrm{e}+003.46372 \mathrm{e}+003.46372 \mathrm{e}-011.00000 \mathrm{e}-092.12000 \mathrm{e}-01$ $3.46372 \mathrm{e}+003.46372 \mathrm{e}+003.46372 \mathrm{e}-01$ 1.00000e-09 2.12000e-01 $3.46372 \mathrm{e}+003.46372 \mathrm{e}+003.46372 \mathrm{e}-01$ 1.00000e-09 2.12000e-01 $1.00000 \mathrm{e}+001.00000 \mathrm{e}+001.00000 \mathrm{e}-011.00000 \mathrm{e}-091.00000 \mathrm{e}-01$ Element: 14279 \# of layers: 6

Kx Ky Kz Ss Por

3.46372e+00 3.46372e+00 3.46372e-01 1.00000e-09 2.12000e-01 $3.46372 \mathrm{e}+003.46372 \mathrm{e}+003.46372 \mathrm{e}-01$ 1.00000e-09 2.12000e-01 $3.46372 \mathrm{e}+003.46372 \mathrm{e}+003.46372 \mathrm{e}-011.00000 \mathrm{e}-092.12000 \mathrm{e}-01$ $3.46372 \mathrm{e}+003.46372 \mathrm{e}+003.46372 \mathrm{e}-01$ 1.00000e-09 2.12000e-01 $3.46372 \mathrm{e}+003.46372 \mathrm{e}+003.46372 \mathrm{e}-011.00000 \mathrm{e}-092.12000 \mathrm{e}-01$ $1.00000 \mathrm{e}+001.00000 \mathrm{e}+001.00000 \mathrm{e}-011.00000 \mathrm{e}-091.00000 \mathrm{e}-01$ Element: 14280 \# of layers: 6

Kx Ky Kz Ss Por

4.86663e+00 4.86663e+00 4.86663e-01 1.00000e-09 2.12000e-01 
4.86663e+00 4.86663e+00 4.86663e-01 1.00000e-09 2.12000e-01 $4.86663 \mathrm{e}+00$ 4.86663e+00 4.86663e-01 1.00000e-09 2.12000e-01 4.86663e+00 4.86663e+00 4.86663e-01 1.00000e-09 2.12000e-01 $4.86663 \mathrm{e}+004.86663 \mathrm{e}+00$ 4.86663e-01 1.00000e-09 2.12000e-01 $1.00000 \mathrm{e}+001.00000 \mathrm{e}+001.00000 \mathrm{e}-011.00000 \mathrm{e}-091.00000 \mathrm{e}-01$ Element: 14281 \# of layers: 6

$\mathrm{Kx} \mathrm{Ky} \mathrm{Kz}$ Ss Por

4.86663e+00 4.86663e+00 4.86663e-01 1.00000e-09 2.12000e-01 $4.86663 \mathrm{e}+004.86663 \mathrm{e}+00$ 4.86663e-01 1.00000e-09 2.12000e-01 $4.86663 \mathrm{e}+004.86663 \mathrm{e}+00$ 4.86663e-01 1.00000e-09 2.12000e-01 $4.86663 \mathrm{e}+004.86663 \mathrm{e}+00$ 4.86663e-01 1.00000e-09 2.12000e-01 $4.86663 \mathrm{e}+004.86663 \mathrm{e}+00$ 4.86663e-01 1.00000e-09 2.12000e-01 $1.00000 \mathrm{e}+001.00000 \mathrm{e}+00$ 1.00000e-01 1.00000e-09 1.00000e-01 Element: 14282 \# of layers: 6

$\mathrm{Kx} \mathrm{Ky} \mathrm{Kz}$ Ss Por

4.86663e+00 4.86663e+00 4.86663e-01 1.00000e-09 2.12000e-01 $4.86663 \mathrm{e}+00$ 4.86663e+00 4.86663e-01 1.00000e-09 2.12000e-01

$4.86663 \mathrm{e}+00$ 4.86663e+00 4.86663e-01 1.00000e-09 2.12000e-01 4.86663e+00 4.86663e+00 4.86663e-01 1.00000e-09 2.12000e-01 $4.86663 \mathrm{e}+004.86663 \mathrm{e}+00$ 4.86663e-01 1.00000e-09 2.12000e-01 $1.00000 \mathrm{e}+001.00000 \mathrm{e}+001.00000 \mathrm{e}-011.00000 \mathrm{e}-091.00000 \mathrm{e}-01$ Element: 14283 \# of layers: 6

$\mathrm{Kx} \mathrm{Ky} \mathrm{Kz}$ Ss Por

4.86663e+00 4.86663e+00 4.86663e-01 1.00000e-09 2.12000e-01 $4.86663 \mathrm{e}+004.86663 \mathrm{e}+00$ 4.86663e-01 1.00000e-09 2.12000e-01 $4.86663 \mathrm{e}+00$ 4.86663e+00 4.86663e-01 1.00000e-09 2.12000e-01 4.86663e+00 4.86663e+00 4.86663e-01 1.00000e-09 2.12000e-01 4.86663e+00 4.86663e+00 4.86663e-01 1.00000e-09 2.12000e-01 $1.00000 \mathrm{e}+001.00000 \mathrm{e}+001.00000 \mathrm{e}-011.00000 \mathrm{e}-091.00000 \mathrm{e}-01$ Element: 14284 \# of layers: 6

$\mathrm{Kx} \mathrm{Ky} \mathrm{Kz}$ Ss Por

4.86663e+00 4.86663e+00 4.86663e-01 1.00000e-09 2.12000e-01 $4.86663 \mathrm{e}+004.86663 \mathrm{e}+00$ 4.86663e-01 1.00000e-09 2.12000e-01 $4.86663 \mathrm{e}+00$ 4.86663e+00 4.86663e-01 1.00000e-09 2.12000e-01 4.86663e+00 4.86663e+00 4.86663e-01 1.00000e-09 2.12000e-01 $4.86663 \mathrm{e}+00$ 4.86663e+00 4.86663e-01 1.00000e-09 2.12000e-01 $1.00000 \mathrm{e}+001.00000 \mathrm{e}+001.00000 \mathrm{e}-011.00000 \mathrm{e}-091.00000 \mathrm{e}-01$ Element: 14285 \# of layers: 6

$\mathrm{Kx} \mathrm{Ky} \mathrm{Kz}$ Ss Por

3.35032e+00 3.35032e+00 3.35032e-01 1.00000e-09 2.12000e-01 $3.35032 \mathrm{e}+003.35032 \mathrm{e}+00$ 3.35032e-01 1.00000e-09 2.12000e-01 $3.35032 \mathrm{e}+003.35032 \mathrm{e}+00$ 3.35032e-01 1.00000e-09 2.12000e-01 $3.35032 \mathrm{e}+00$ 3.35032e+00 3.35032e-01 1.00000e-09 2.12000e-01 3.35032e+00 3.35032e+00 3.35032e-01 1.00000e-09 2.12000e-01 $1.00000 \mathrm{e}+001.00000 \mathrm{e}+001.00000 \mathrm{e}-01$ 1.00000e-09 1.00000e-01 Element: 14286 \# of layers: 6 
$\mathrm{Kx} \mathrm{Ky} \mathrm{Kz}$ Ss Por

3.35032e+00 3.35032e+00 3.35032e-01 1.00000e-09 2.12000e-01

$3.35032 \mathrm{e}+00$ 3.35032e+00 3.35032e-01 1.00000e-09 2.12000e-01

$3.35032 \mathrm{e}+00$ 3.35032e+00 3.35032e-01 1.00000e-09 2.12000e-01

3.35032e+00 3.35032e+00 3.35032e-01 1.00000e-09 2.12000e-01

$3.35032 \mathrm{e}+003.35032 \mathrm{e}+00$ 3.35032e-01 1.00000e-09 2.12000e-01

$1.00000 \mathrm{e}+001.00000 \mathrm{e}+001.00000 \mathrm{e}-01$ 1.00000e-09 1.00000e-01

Element: 14287 \# of layers: 6

$\mathrm{Kx} \mathrm{Ky} \mathrm{Kz}$ Ss Por

3.35032e+00 3.35032e+00 3.35032e-01 1.00000e-09 2.12000e-01

$3.35032 \mathrm{e}+003.35032 \mathrm{e}+00$ 3.35032e-01 1.00000e-09 2.12000e-01

$3.35032 \mathrm{e}+003.35032 \mathrm{e}+00$ 3.35032e-01 1.00000e-09 2.12000e-01

$3.35032 \mathrm{e}+003.35032 \mathrm{e}+00$ 3.35032e-01 1.00000e-09 2.12000e-01

$3.35032 \mathrm{e}+003.35032 \mathrm{e}+00$ 3.35032e-01 1.00000e-09 2.12000e-01

$1.00000 \mathrm{e}+001.00000 \mathrm{e}+00$ 1.00000e-01 1.00000e-09 1.00000e-01

Element: 14288 \# of layers: 6

$\mathrm{Kx} \mathrm{Ky} \mathrm{Kz}$ Ss Por

3.35032e+00 3.35032e+00 3.35032e-01 1.00000e-09 2.12000e-01

$3.35032 \mathrm{e}+003.35032 \mathrm{e}+00$ 3.35032e-01 1.00000e-09 2.12000e-01

3.35032e+00 3.35032e+00 3.35032e-01 1.00000e-09 2.12000e-01

$3.35032 \mathrm{e}+003.35032 \mathrm{e}+00$ 3.35032e-01 1.00000e-09 2.12000e-01

3.35032e+00 3.35032e+00 3.35032e-01 1.00000e-09 2.12000e-01

$1.00000 \mathrm{e}+001.00000 \mathrm{e}+001.00000 \mathrm{e}-01$ 1.00000e-09 1.00000e-01

Element: 14289 \# of layers: 6

Kx Ky Kz Ss Por

3.35032e+00 3.35032e+00 3.35032e-01 1.00000e-09 2.12000e-01

3.35032e+00 3.35032e+00 3.35032e-01 1.00000e-09 2.12000e-01

3.35032e+00 3.35032e+00 3.35032e-01 1.00000e-09 2.12000e-01

$3.35032 \mathrm{e}+003.35032 \mathrm{e}+003.35032 \mathrm{e}-01$ 1.00000e-09 2.12000e-01

3.35032e+00 3.35032e+00 3.35032e-01 1.00000e-09 2.12000e-01

$1.00000 \mathrm{e}+001.00000 \mathrm{e}+001.00000 \mathrm{e}-011.00000 \mathrm{e}-091.00000 \mathrm{e}-01$

Element: 14290 \# of layers: 6

Kx Ky Kz Ss Por

4.86663e+00 4.86663e+00 4.86663e-01 1.00000e-09 2.12000e-01

4.86663e+00 4.86663e+00 4.86663e-01 1.00000e-09 2.12000e-01

$4.86663 \mathrm{e}+00$ 4.86663e+00 4.86663e-01 1.00000e-09 2.12000e-01

$4.86663 \mathrm{e}+004.86663 \mathrm{e}+00$ 4.86663e-01 1.00000e-09 2.12000e-01

$4.86663 \mathrm{e}+004.86663 \mathrm{e}+00$ 4.86663e-01 1.00000e-09 2.12000e-01

$1.00000 \mathrm{e}+001.00000 \mathrm{e}+001.00000 \mathrm{e}-01$ 1.00000e-09 1.00000e-01

Element: 14291 \# of layers: 6

Kx Ky Kz Ss Por

4.86663e+00 4.86663e+00 4.86663e-01 1.00000e-09 2.12000e-01

4.86663e+00 4.86663e+00 4.86663e-01 1.00000e-09 2.12000e-01

4.86663e+00 4.86663e+00 4.86663e-01 1.00000e-09 2.12000e-01

4.86663e+00 4.86663e+00 4.86663e-01 1.00000e-09 2.12000e-01

$4.86663 \mathrm{e}+004.86663 \mathrm{e}+00$ 4.86663e-01 1.00000e-09 2.12000e-01 
$1.00000 \mathrm{e}+001.00000 \mathrm{e}+00$ 1.00000e-01 1.00000e-09 1.00000e-01

Element: 14292 \# of layers: 6

Kx Ky Kz Ss Por

3.35032e+00 3.35032e+00 3.35032e-01 1.00000e-09 2.12000e-01

3.35032e+00 3.35032e+00 3.35032e-01 1.00000e-09 2.12000e-01

$3.35032 \mathrm{e}+003.35032 \mathrm{e}+00$ 3.35032e-01 1.00000e-09 2.12000e-01

3.35032e+00 3.35032e+00 3.35032e-01 1.00000e-09 2.12000e-01

$3.35032 \mathrm{e}+003.35032 \mathrm{e}+003.35032 \mathrm{e}-01$ 1.00000e-09 2.12000e-01

$1.00000 \mathrm{e}+001.00000 \mathrm{e}+001.00000 \mathrm{e}-01$ 1.00000e-09 1.00000e-01

Element: 14293 \# of layers: 6

$\mathrm{Kx} \mathrm{Ky} \mathrm{Kz}$ Ss Por

3.35032e+00 3.35032e+00 3.35032e-01 1.00000e-09 2.12000e-01

3.35032e+00 3.35032e+00 3.35032e-01 1.00000e-09 2.12000e-01

$3.35032 \mathrm{e}+003.35032 \mathrm{e}+00$ 3.35032e-01 1.00000e-09 2.12000e-01

3.35032e+00 3.35032e+00 3.35032e-01 1.00000e-09 2.12000e-01

$3.35032 \mathrm{e}+003.35032 \mathrm{e}+00$ 3.35032e-01 1.00000e-09 2.12000e-01

$1.00000 \mathrm{e}+001.00000 \mathrm{e}+001.00000 \mathrm{e}-01$ 1.00000e-09 1.00000e-01

Element: 14294 \# of layers: 6

$\mathrm{Kx} \mathrm{Ky} \mathrm{Kz}$ Ss Por

1.89573e+00 1.89573e+00 1.89573e-01 1.00000e-09 2.12000e-01

$1.89573 \mathrm{e}+001.89573 \mathrm{e}+00$ 1.89573e-01 1.00000e-09 2.12000e-01

$1.89573 \mathrm{e}+00$ 1.89573e+00 1.89573e-01 1.00000e-09 2.12000e-01

$1.89573 \mathrm{e}+00$ 1.89573e+00 1.89573e-01 1.00000e-09 2.12000e-01

$1.89573 \mathrm{e}+00$ 1.89573e+00 1.89573e-01 1.00000e-09 2.12000e-01

$1.00000 \mathrm{e}+001.00000 \mathrm{e}+001.00000 \mathrm{e}-011.00000 \mathrm{e}-091.00000 \mathrm{e}-01$

Element: 14295 \# of layers: 6

$\mathrm{Kx} \mathrm{Ky} \mathrm{Kz}$ Ss Por

1.89573e+00 1.89573e+00 1.89573e-01 1.00000e-09 2.12000e-01

$1.89573 \mathrm{e}+001.89573 \mathrm{e}+00$ 1.89573e-01 1.00000e-09 2.12000e-01

$1.89573 \mathrm{e}+00$ 1.89573e+00 1.89573e-01 1.00000e-09 2.12000e-01

$1.89573 \mathrm{e}+00$ 1.89573e+00 1.89573e-01 1.00000e-09 2.12000e-01

$1.89573 \mathrm{e}+00$ 1.89573e+00 1.89573e-01 1.00000e-09 2.12000e-01

$1.00000 \mathrm{e}+001.00000 \mathrm{e}+001.00000 \mathrm{e}-01$ 1.00000e-09 1.00000e-01

Element: 14296 \# of layers: 6

$\mathrm{Kx} \mathrm{Ky} \mathrm{Kz}$ Ss Por

$1.89573 \mathrm{e}+00$ 1.89573e+00 1.89573e-01 1.00000e-09 2.12000e-01

$1.89573 \mathrm{e}+001.89573 \mathrm{e}+00$ 1.89573e-01 1.00000e-09 2.12000e-01

$1.89573 \mathrm{e}+001.89573 \mathrm{e}+00$ 1.89573e-01 1.00000e-09 2.12000e-01

$1.89573 \mathrm{e}+00$ 1.89573e+00 1.89573e-01 1.00000e-09 2.12000e-01

$1.89573 \mathrm{e}+00$ 1.89573e+00 1.89573e-01 1.00000e-09 2.12000e-01

$1.00000 \mathrm{e}+001.00000 \mathrm{e}+001.00000 \mathrm{e}-01$ 1.00000e-09 1.00000e-01

Element: 14297 \# of layers: 6

$\mathrm{Kx} \mathrm{Ky} \mathrm{Kz}$ Ss Por

3.46372e+00 3.46372e+00 3.46372e-01 1.00000e-09 2.12000e-01

$3.46372 \mathrm{e}+003.46372 \mathrm{e}+003.46372 \mathrm{e}-01$ 1.00000e-09 2.12000e-01

$3.46372 \mathrm{e}+003.46372 \mathrm{e}+00$ 3.46372e-01 1.00000e-09 2.12000e-01 
$3.46372 \mathrm{e}+003.46372 \mathrm{e}+003.46372 \mathrm{e}-01$ 1.00000e-09 2.12000e-01 $3.46372 \mathrm{e}+003.46372 \mathrm{e}+003.46372 \mathrm{e}-01$ 1.00000e-09 2.12000e-01 $1.00000 \mathrm{e}+001.00000 \mathrm{e}+001.00000 \mathrm{e}-011.00000 \mathrm{e}-091.00000 \mathrm{e}-01$ Element: 14298 \# of layers: 6

Kx Ky Kz Ss Por

3.46372e+00 3.46372e+00 3.46372e-01 1.00000e-09 2.12000e-01 $3.46372 \mathrm{e}+003.46372 \mathrm{e}+003.46372 \mathrm{e}-011.00000 \mathrm{e}-092.12000 \mathrm{e}-01$ $3.46372 \mathrm{e}+003.46372 \mathrm{e}+003.46372 \mathrm{e}-01$ 1.00000e-09 2.12000e-01 $3.46372 \mathrm{e}+003.46372 \mathrm{e}+003.46372 \mathrm{e}-011.00000 \mathrm{e}-092.12000 \mathrm{e}-01$ $3.46372 \mathrm{e}+003.46372 \mathrm{e}+003.46372 \mathrm{e}-011.00000 \mathrm{e}-092.12000 \mathrm{e}-01$ $1.00000 \mathrm{e}+001.00000 \mathrm{e}+001.00000 \mathrm{e}-011.00000 \mathrm{e}-091.00000 \mathrm{e}-01$ Element: 14299 \# of layers: 6

Kx Ky Kz Ss Por

4.86663e+00 4.86663e+00 4.86663e-01 1.00000e-09 2.12000e-01 $4.86663 \mathrm{e}+004.86663 \mathrm{e}+00$ 4.86663e-01 1.00000e-09 2.12000e-01 $4.86663 \mathrm{e}+004.86663 \mathrm{e}+00$ 4.86663e-01 1.00000e-09 2.12000e-01 $4.86663 \mathrm{e}+004.86663 \mathrm{e}+004.86663 \mathrm{e}-011.00000 \mathrm{e}-092.12000 \mathrm{e}-01$ $4.86663 \mathrm{e}+004.86663 \mathrm{e}+00$ 4.86663e-01 1.00000e-09 2.12000e-01 $1.00000 \mathrm{e}+001.00000 \mathrm{e}+001.00000 \mathrm{e}-011.00000 \mathrm{e}-091.00000 \mathrm{e}-01$ Element: 14300 \# of layers: 6

Kx Ky Kz Ss Por

3.35032e+00 3.35032e+00 3.35032e-01 1.00000e-09 2.12000e-01 $3.35032 \mathrm{e}+003.35032 \mathrm{e}+003.35032 \mathrm{e}-011.00000 \mathrm{e}-092.12000 \mathrm{e}-01$ $3.35032 \mathrm{e}+003.35032 \mathrm{e}+003.35032 \mathrm{e}-01$ 1.00000e-09 2.12000e-01 $3.35032 \mathrm{e}+003.35032 \mathrm{e}+003.35032 \mathrm{e}-011.00000 \mathrm{e}-092.12000 \mathrm{e}-01$ $3.35032 \mathrm{e}+003.35032 \mathrm{e}+003.35032 \mathrm{e}-011.00000 \mathrm{e}-092.12000 \mathrm{e}-01$ $1.00000 \mathrm{e}+001.00000 \mathrm{e}+001.00000 \mathrm{e}-011.00000 \mathrm{e}-091.00000 \mathrm{e}-01$ Element: 14301 \# of layers: 6

Kx Ky Kz Ss Por

$1.89573 \mathrm{e}+001.89573 \mathrm{e}+00$ 1.89573e-01 1.00000e-09 2.12000e-01 $1.89573 \mathrm{e}+001.89573 \mathrm{e}+00$ 1.89573e-01 1.00000e-09 2.12000e-01 $1.89573 \mathrm{e}+001.89573 \mathrm{e}+00$ 1.89573e-01 1.00000e-09 2.12000e-01 $1.89573 \mathrm{e}+001.89573 \mathrm{e}+001.89573 \mathrm{e}-011.00000 \mathrm{e}-092.12000 \mathrm{e}-01$ $1.89573 \mathrm{e}+001.89573 \mathrm{e}+001.89573 \mathrm{e}-011.00000 \mathrm{e}-092.12000 \mathrm{e}-01$ $1.00000 \mathrm{e}+001.00000 \mathrm{e}+001.00000 \mathrm{e}-011.00000 \mathrm{e}-091.00000 \mathrm{e}-01$ Element: 14302 \# of layers: 7

Kx Ky Kz Ss Por

$1.57179 \mathrm{e}+001.57179 \mathrm{e}+00$ 1.57179e-01 1.00000e-09 2.12000e-01 $1.57179 \mathrm{e}+001.57179 \mathrm{e}+00$ 1.57179e-01 1.00000e-09 2.12000e-01 $1.57179 \mathrm{e}+001.57179 \mathrm{e}+00$ 1.57179e-01 1.00000e-09 2.12000e-01 $1.57179 \mathrm{e}+001.57179 \mathrm{e}+00$ 1.57179e-01 1.00000e-09 2.12000e-01 $1.57179 \mathrm{e}+001.57179 \mathrm{e}+001.57179 \mathrm{e}-011.00000 \mathrm{e}-092.12000 \mathrm{e}-01$ $1.00000 \mathrm{e}-05$ 1.00000e-05 1.00000e-06 1.00000e-09 1.00000e-01 $1.00000 \mathrm{e}+001.00000 \mathrm{e}+001.00000 \mathrm{e}-011.00000 \mathrm{e}-091.00000 \mathrm{e}-01$ Element: 14303 \# of layers: 7

Kx Ky Kz Ss Por 
$1.57179 \mathrm{e}+001.57179 \mathrm{e}+00$ 1.57179e-01 1.00000e-09 2.12000e-01 $1.57179 \mathrm{e}+001.57179 \mathrm{e}+00$ 1.57179e-01 1.00000e-09 2.12000e-01 $1.57179 \mathrm{e}+001.57179 \mathrm{e}+00$ 1.57179e-01 1.00000e-09 2.12000e-01 $1.57179 \mathrm{e}+001.57179 \mathrm{e}+00$ 1.57179e-01 1.00000e-09 2.12000e-01 $1.57179 \mathrm{e}+001.57179 \mathrm{e}+00$ 1.57179e-01 1.00000e-09 2.12000e-01 $1.00000 \mathrm{e}-05$ 1.00000e-05 1.00000e-06 1.00000e-09 1.00000e-01 $1.00000 \mathrm{e}+001.00000 \mathrm{e}+00$ 1.00000e-01 1.00000e-09 1.00000e-01 Element: 14304 \# of layers: 6

$\mathrm{Kx} \mathrm{Ky} \mathrm{Kz}$ Ss Por

$1.57179 \mathrm{e}+001.57179 \mathrm{e}+00$ 1.57179e-01 1.00000e-09 2.12000e-01 $1.57179 \mathrm{e}+001.57179 \mathrm{e}+00$ 1.57179e-01 1.00000e-09 2.12000e-01 $1.57179 \mathrm{e}+001.57179 \mathrm{e}+001.57179 \mathrm{e}-01$ 1.00000e-09 2.12000e-01 $1.57179 \mathrm{e}+001.57179 \mathrm{e}+00$ 1.57179e-01 1.00000e-09 2.12000e-01 $1.57179 \mathrm{e}+001.57179 \mathrm{e}+001.57179 \mathrm{e}-01$ 1.00000e-09 2.12000e-01 $1.00000 \mathrm{e}+001.00000 \mathrm{e}+001.00000 \mathrm{e}-01$ 1.00000e-09 1.00000e-01 Element: 14305 \# of layers: 6

$\mathrm{Kx} \mathrm{Ky} \mathrm{Kz}$ Ss Por

$1.57179 \mathrm{e}+001.57179 \mathrm{e}+00$ 1.57179e-01 1.00000e-09 2.12000e-01 $1.57179 \mathrm{e}+001.57179 \mathrm{e}+001.57179 \mathrm{e}-01$ 1.00000e-09 2.12000e-01 $1.57179 \mathrm{e}+001.57179 \mathrm{e}+00$ 1.57179e-01 1.00000e-09 2.12000e-01 $1.57179 \mathrm{e}+001.57179 \mathrm{e}+001.57179 \mathrm{e}-01$ 1.00000e-09 2.12000e-01 $1.57179 \mathrm{e}+001.57179 \mathrm{e}+00$ 1.57179e-01 1.00000e-09 2.12000e-01 $1.00000 \mathrm{e}+001.00000 \mathrm{e}+001.00000 \mathrm{e}-01$ 1.00000e-09 1.00000e-01 Element: 14306 \# of layers: 6

Kx Ky Kz Ss Por

$1.57179 \mathrm{e}+001.57179 \mathrm{e}+00$ 1.57179e-01 1.00000e-09 2.12000e-01 $1.57179 \mathrm{e}+001.57179 \mathrm{e}+00$ 1.57179e-01 1.00000e-09 2.12000e-01 $1.57179 \mathrm{e}+001.57179 \mathrm{e}+00$ 1.57179e-01 1.00000e-09 2.12000e-01 $1.57179 \mathrm{e}+001.57179 \mathrm{e}+00$ 1.57179e-01 1.00000e-09 2.12000e-01 $1.57179 \mathrm{e}+001.57179 \mathrm{e}+001.57179 \mathrm{e}-011.00000 \mathrm{e}-092.12000 \mathrm{e}-01$ $1.00000 \mathrm{e}+001.00000 \mathrm{e}+001.00000 \mathrm{e}-01$ 1.00000e-09 1.00000e-01 Element: 14307 \# of layers: 6

Kx Ky Kz Ss Por

1.57179e+00 1.57179e+00 1.57179e-01 1.00000e-09 2.12000e-01 $1.57179 \mathrm{e}+001.57179 \mathrm{e}+00$ 1.57179e-01 1.00000e-09 2.12000e-01 $1.57179 \mathrm{e}+001.57179 \mathrm{e}+00$ 1.57179e-01 1.00000e-09 2.12000e-01 $1.57179 \mathrm{e}+001.57179 \mathrm{e}+00$ 1.57179e-01 1.00000e-09 2.12000e-01 $1.57179 \mathrm{e}+001.57179 \mathrm{e}+001.57179 \mathrm{e}-01$ 1.00000e-09 2.12000e-01 $1.00000 \mathrm{e}+001.00000 \mathrm{e}+001.00000 \mathrm{e}-01$ 1.00000e-09 1.00000e-01 Element: 14308 \# of layers: 6

$\mathrm{Kx} \mathrm{Ky} \mathrm{Kz}$ Ss Por

$1.57179 \mathrm{e}+00$ 1.57179e+00 1.57179e-01 1.00000e-09 2.12000e-01 $1.57179 \mathrm{e}+00$ 1.57179e+00 1.57179e-01 1.00000e-09 2.12000e-01 $1.57179 \mathrm{e}+001.57179 \mathrm{e}+00$ 1.57179e-01 1.00000e-09 2.12000e-01 $1.57179 \mathrm{e}+001.57179 \mathrm{e}+00$ 1.57179e-01 1.00000e-09 2.12000e-01 $1.57179 \mathrm{e}+001.57179 \mathrm{e}+00$ 1.57179e-01 1.00000e-09 2.12000e-01 
$1.00000 \mathrm{e}+001.00000 \mathrm{e}+00$ 1.00000e-01 1.00000e-09 1.00000e-01

Element: 14309 \# of layers: 6

Kx Ky Kz Ss Por

$1.57179 \mathrm{e}+00$ 1.57179e+00 1.57179e-01 1.00000e-09 2.12000e-01

$1.57179 \mathrm{e}+001.57179 \mathrm{e}+00$ 1.57179e-01 1.00000e-09 2.12000e-01

$1.57179 \mathrm{e}+001.57179 \mathrm{e}+001.57179 \mathrm{e}-01$ 1.00000e-09 2.12000e-01

$1.57179 \mathrm{e}+001.57179 \mathrm{e}+001.57179 \mathrm{e}-01$ 1.00000e-09 2.12000e-01

$1.57179 \mathrm{e}+001.57179 \mathrm{e}+00 \quad 1.57179 \mathrm{e}-01 \quad 1.00000 \mathrm{e}-092.12000 \mathrm{e}-01$

$1.00000 \mathrm{e}+001.00000 \mathrm{e}+001.00000 \mathrm{e}-011.00000 \mathrm{e}-091.00000 \mathrm{e}-01$

Element: 14310 \# of layers: 6

$\mathrm{Kx} \mathrm{Ky} \mathrm{Kz}$ Ss Por

$1.57179 \mathrm{e}+001.57179 \mathrm{e}+00$ 1.57179e-01 1.00000e-09 2.12000e-01

$1.57179 \mathrm{e}+001.57179 \mathrm{e}+00$ 1.57179e-01 1.00000e-09 2.12000e-01

$1.57179 \mathrm{e}+001.57179 \mathrm{e}+00$ 1.57179e-01 1.00000e-09 2.12000e-01

$1.57179 \mathrm{e}+001.57179 \mathrm{e}+00$ 1.57179e-01 1.00000e-09 2.12000e-01

$1.57179 \mathrm{e}+001.57179 \mathrm{e}+001.57179 \mathrm{e}-01$ 1.00000e-09 2.12000e-01

$1.00000 \mathrm{e}+001.00000 \mathrm{e}+00$ 1.00000e-01 1.00000e-09 1.00000e-01

Element: 14311 \# of layers: 6

$\mathrm{Kx} \mathrm{Ky} \mathrm{Kz}$ Ss Por

$1.57179 \mathrm{e}+001.57179 \mathrm{e}+00$ 1.57179e-01 1.00000e-09 2.12000e-01

$1.57179 \mathrm{e}+001.57179 \mathrm{e}+00$ 1.57179e-01 1.00000e-09 2.12000e-01

$1.57179 \mathrm{e}+00$ 1.57179e+00 1.57179e-01 1.00000e-09 2.12000e-01

$1.57179 \mathrm{e}+001.57179 \mathrm{e}+00$ 1.57179e-01 1.00000e-09 2.12000e-01

$1.57179 \mathrm{e}+001.57179 \mathrm{e}+00$ 1.57179e-01 1.00000e-09 2.12000e-01

$1.00000 \mathrm{e}+001.00000 \mathrm{e}+001.00000 \mathrm{e}-011.00000 \mathrm{e}-091.00000 \mathrm{e}-01$

Element: 14312 \# of layers: 6

$\mathrm{Kx} \mathrm{Ky} \mathrm{Kz}$ Ss Por

$1.70704 \mathrm{e}+001.70704 \mathrm{e}+00$ 1.70704e-01 1.00000e-09 2.12000e-01

$1.70704 \mathrm{e}+001.70704 \mathrm{e}+001.70704 \mathrm{e}-011.00000 \mathrm{e}-092.12000 \mathrm{e}-01$

$1.70704 \mathrm{e}+001.70704 \mathrm{e}+001.70704 \mathrm{e}-01$ 1.00000e-09 2.12000e-01

$1.70704 \mathrm{e}+001.70704 \mathrm{e}+001.70704 \mathrm{e}-01$ 1.00000e-09 2.12000e-01

$1.70704 \mathrm{e}+001.70704 \mathrm{e}+001.70704 \mathrm{e}-011.00000 \mathrm{e}-092.12000 \mathrm{e}-01$

$1.00000 \mathrm{e}+001.00000 \mathrm{e}+001.00000 \mathrm{e}-01$ 1.00000e-09 1.00000e-01

Element: 14313 \# of layers: 6

$\mathrm{Kx} \mathrm{Ky} \mathrm{Kz}$ Ss Por

$1.70704 \mathrm{e}+001.70704 \mathrm{e}+00$ 1.70704e-01 1.00000e-09 2.12000e-01

$1.70704 \mathrm{e}+001.70704 \mathrm{e}+001.70704 \mathrm{e}-011.00000 \mathrm{e}-092.12000 \mathrm{e}-01$

$1.70704 \mathrm{e}+001.70704 \mathrm{e}+001.70704 \mathrm{e}-01$ 1.00000e-09 2.12000e-01

$1.70704 \mathrm{e}+001.70704 \mathrm{e}+001.70704 \mathrm{e}-01$ 1.00000e-09 2.12000e-01

$1.70704 \mathrm{e}+001.70704 \mathrm{e}+00$ 1.70704e-01 1.00000e-09 2.12000e-01

$1.00000 \mathrm{e}+001.00000 \mathrm{e}+001.00000 \mathrm{e}-01$ 1.00000e-09 1.00000e-01

Element: 14314 \# of layers: 7

$\mathrm{Kx} \mathrm{Ky} \mathrm{Kz}$ Ss Por

$1.70704 \mathrm{e}+001.70704 \mathrm{e}+00$ 1.70704e-01 1.00000e-09 2.12000e-01

$1.70704 \mathrm{e}+001.70704 \mathrm{e}+001.70704 \mathrm{e}-01$ 1.00000e-09 2.12000e-01

$1.70704 \mathrm{e}+001.70704 \mathrm{e}+001.70704 \mathrm{e}-011.00000 \mathrm{e}-092.12000 \mathrm{e}-01$ 
$1.70704 \mathrm{e}+001.70704 \mathrm{e}+00$ 1.70704e-01 1.00000e-09 2.12000e-01 $1.70704 \mathrm{e}+001.70704 \mathrm{e}+001.70704 \mathrm{e}-011.00000 \mathrm{e}-092.12000 \mathrm{e}-01$ $1.00000 \mathrm{e}-05$ 1.00000e-05 1.00000e-06 1.00000e-09 1.00000e-01 $1.00000 \mathrm{e}+001.00000 \mathrm{e}+001.00000 \mathrm{e}-011.00000 \mathrm{e}-091.00000 \mathrm{e}-01$ Element: 14315 \# of layers: 7

Kx Ky Kz Ss Por

$1.70704 \mathrm{e}+001.70704 \mathrm{e}+00$ 1.70704e-01 1.00000e-09 2.12000e-01 $1.70704 \mathrm{e}+001.70704 \mathrm{e}+001.70704 \mathrm{e}-011.00000 \mathrm{e}-092.12000 \mathrm{e}-01$ $1.70704 \mathrm{e}+001.70704 \mathrm{e}+001.70704 \mathrm{e}-011.00000 \mathrm{e}-092.12000 \mathrm{e}-01$ $1.70704 \mathrm{e}+001.70704 \mathrm{e}+001.70704 \mathrm{e}-011.00000 \mathrm{e}-092.12000 \mathrm{e}-01$ $1.70704 \mathrm{e}+001.70704 \mathrm{e}+001.70704 \mathrm{e}-011.00000 \mathrm{e}-092.12000 \mathrm{e}-01$ $1.00000 \mathrm{e}-05$ 1.00000e-05 1.00000e-06 1.00000e-09 1.00000e-01 $1.00000 \mathrm{e}+001.00000 \mathrm{e}+001.00000 \mathrm{e}-011.00000 \mathrm{e}-091.00000 \mathrm{e}-01$ Element: 14316 \# of layers: 6

Kx Ky Kz Ss Por

$1.70704 \mathrm{e}+001.70704 \mathrm{e}+00$ 1.70704e-01 1.00000e-09 2.12000e-01 $1.70704 \mathrm{e}+001.70704 \mathrm{e}+001.70704 \mathrm{e}-011.00000 \mathrm{e}-092.12000 \mathrm{e}-01$ $1.70704 \mathrm{e}+001.70704 \mathrm{e}+001.70704 \mathrm{e}-011.00000 \mathrm{e}-092.12000 \mathrm{e}-01$ $1.70704 \mathrm{e}+001.70704 \mathrm{e}+001.70704 \mathrm{e}-011.00000 \mathrm{e}-092.12000 \mathrm{e}-01$ $1.70704 \mathrm{e}+001.70704 \mathrm{e}+001.70704 \mathrm{e}-011.00000 \mathrm{e}-092.12000 \mathrm{e}-01$ $1.00000 \mathrm{e}+001.00000 \mathrm{e}+001.00000 \mathrm{e}-011.00000 \mathrm{e}-091.00000 \mathrm{e}-01$ Element: 14317 \# of layers: 6

Kx Ky Kz Ss Por

$1.57179 \mathrm{e}+001.57179 \mathrm{e}+00$ 1.57179e-01 1.00000e-09 2.12000e-01 $1.57179 \mathrm{e}+001.57179 \mathrm{e}+001.57179 \mathrm{e}-011.00000 \mathrm{e}-092.12000 \mathrm{e}-01$ $1.57179 \mathrm{e}+001.57179 \mathrm{e}+001.57179 \mathrm{e}-011.00000 \mathrm{e}-092.12000 \mathrm{e}-01$ $1.57179 \mathrm{e}+001.57179 \mathrm{e}+001.57179 \mathrm{e}-011.00000 \mathrm{e}-092.12000 \mathrm{e}-01$ $1.57179 \mathrm{e}+001.57179 \mathrm{e}+001.57179 \mathrm{e}-011.00000 \mathrm{e}-092.12000 \mathrm{e}-01$ $1.00000 \mathrm{e}+001.00000 \mathrm{e}+001.00000 \mathrm{e}-011.00000 \mathrm{e}-091.00000 \mathrm{e}-01$ Element: 14318 \# of layers: 6

Kx Ky Kz Ss Por

$1.57179 \mathrm{e}+001.57179 \mathrm{e}+00$ 1.57179e-01 1.00000e-09 2.12000e-01 $1.57179 \mathrm{e}+001.57179 \mathrm{e}+001.57179 \mathrm{e}-011.00000 \mathrm{e}-092.12000 \mathrm{e}-01$ $1.57179 \mathrm{e}+001.57179 \mathrm{e}+001.57179 \mathrm{e}-011.00000 \mathrm{e}-092.12000 \mathrm{e}-01$ $1.57179 \mathrm{e}+001.57179 \mathrm{e}+001.57179 \mathrm{e}-011.00000 \mathrm{e}-092.12000 \mathrm{e}-01$ $1.57179 \mathrm{e}+001.57179 \mathrm{e}+001.57179 \mathrm{e}-011.00000 \mathrm{e}-092.12000 \mathrm{e}-01$ $1.00000 \mathrm{e}+001.00000 \mathrm{e}+001.00000 \mathrm{e}-011.00000 \mathrm{e}-091.00000 \mathrm{e}-01$ Element: 14319 \# of layers: 6

Kx Ky Kz Ss Por

$1.70704 \mathrm{e}+001.70704 \mathrm{e}+00$ 1.70704e-01 1.00000e-09 2.12000e-01 $1.70704 \mathrm{e}+001.70704 \mathrm{e}+001.70704 \mathrm{e}-011.00000 \mathrm{e}-092.12000 \mathrm{e}-01$ $1.70704 \mathrm{e}+001.70704 \mathrm{e}+001.70704 \mathrm{e}-011.00000 \mathrm{e}-092.12000 \mathrm{e}-01$ $1.70704 \mathrm{e}+001.70704 \mathrm{e}+001.70704 \mathrm{e}-011.00000 \mathrm{e}-092.12000 \mathrm{e}-01$ $1.70704 \mathrm{e}+001.70704 \mathrm{e}+001.70704 \mathrm{e}-011.00000 \mathrm{e}-092.12000 \mathrm{e}-01$ $1.00000 \mathrm{e}+001.00000 \mathrm{e}+001.00000 \mathrm{e}-011.00000 \mathrm{e}-091.00000 \mathrm{e}-01$ Element: 14320 \# of layers: 6 
$\mathrm{Kx} \mathrm{Ky} \mathrm{Kz} \mathrm{Ss} \mathrm{Por}$

1.70704e+00 1.70704e+00 1.70704e-01 1.00000e-09 2.12000e-01

$1.70704 \mathrm{e}+001.70704 \mathrm{e}+001.70704 \mathrm{e}-01$ 1.00000e-09 2.12000e-01

$1.70704 \mathrm{e}+001.70704 \mathrm{e}+001.70704 \mathrm{e}-011.00000 \mathrm{e}-092.12000 \mathrm{e}-01$

$1.70704 \mathrm{e}+001.70704 \mathrm{e}+001.70704 \mathrm{e}-01$ 1.00000e-09 2.12000e-01

$1.70704 \mathrm{e}+001.70704 \mathrm{e}+001.70704 \mathrm{e}-011.00000 \mathrm{e}-092.12000 \mathrm{e}-01$

$1.00000 \mathrm{e}+001.00000 \mathrm{e}+00$ 1.00000e-01 1.00000e-09 1.00000e-01

Element: 14321 \# of layers: 6

$\mathrm{Kx} \mathrm{Ky} \mathrm{Kz}$ Ss Por

$1.70704 \mathrm{e}+00$ 1.70704e+00 1.70704e-01 1.00000e-09 2.12000e-01

$1.70704 \mathrm{e}+001.70704 \mathrm{e}+001.70704 \mathrm{e}-01$ 1.00000e-09 2.12000e-01

$1.70704 \mathrm{e}+001.70704 \mathrm{e}+001.70704 \mathrm{e}-011.00000 \mathrm{e}-092.12000 \mathrm{e}-01$

$1.70704 \mathrm{e}+001.70704 \mathrm{e}+001.70704 \mathrm{e}-011.00000 \mathrm{e}-092.12000 \mathrm{e}-01$

$1.70704 \mathrm{e}+001.70704 \mathrm{e}+001.70704 \mathrm{e}-01$ 1.00000e-09 2.12000e-01

$1.00000 \mathrm{e}+001.00000 \mathrm{e}+001.00000 \mathrm{e}-01$ 1.00000e-09 1.00000e-01

Element: 14322 \# of layers: 6

$\mathrm{Kx} \mathrm{Ky} \mathrm{Kz}$ Ss Por

$1.70704 \mathrm{e}+001.70704 \mathrm{e}+00$ 1.70704e-01 1.00000e-09 2.12000e-01

$1.70704 \mathrm{e}+001.70704 \mathrm{e}+001.70704 \mathrm{e}-01$ 1.00000e-09 2.12000e-01

$1.70704 \mathrm{e}+001.70704 \mathrm{e}+001.70704 \mathrm{e}-011.00000 \mathrm{e}-092.12000 \mathrm{e}-01$

$1.70704 \mathrm{e}+001.70704 \mathrm{e}+001.70704 \mathrm{e}-011.00000 \mathrm{e}-092.12000 \mathrm{e}-01$

$1.70704 \mathrm{e}+001.70704 \mathrm{e}+00$ 1.70704e-01 1.00000e-09 2.12000e-01

$1.00000 \mathrm{e}+001.00000 \mathrm{e}+001.00000 \mathrm{e}-011.00000 \mathrm{e}-091.00000 \mathrm{e}-01$

Element: 14323 \# of layers: 6

$\mathrm{Kx} \mathrm{Ky} \mathrm{Kz}$ Ss Por

$1.70704 \mathrm{e}+001.70704 \mathrm{e}+00$ 1.70704e-01 1.00000e-09 2.12000e-01

$1.70704 \mathrm{e}+001.70704 \mathrm{e}+001.70704 \mathrm{e}-011.00000 \mathrm{e}-092.12000 \mathrm{e}-01$

$1.70704 \mathrm{e}+001.70704 \mathrm{e}+001.70704 \mathrm{e}-01$ 1.00000e-09 2.12000e-01

$1.70704 \mathrm{e}+001.70704 \mathrm{e}+001.70704 \mathrm{e}-011.00000 \mathrm{e}-092.12000 \mathrm{e}-01$

$1.70704 \mathrm{e}+001.70704 \mathrm{e}+00$ 1.70704e-01 1.00000e-09 2.12000e-01

$1.00000 \mathrm{e}+001.00000 \mathrm{e}+001.00000 \mathrm{e}-011.00000 \mathrm{e}-091.00000 \mathrm{e}-01$

Element: 14324 \# of layers: 6

Kx Ky Kz Ss Por

$1.70704 \mathrm{e}+001.70704 \mathrm{e}+00$ 1.70704e-01 1.00000e-09 2.12000e-01

$1.70704 \mathrm{e}+001.70704 \mathrm{e}+001.70704 \mathrm{e}-01$ 1.00000e-09 2.12000e-01

$1.70704 \mathrm{e}+001.70704 \mathrm{e}+001.70704 \mathrm{e}-01$ 1.00000e-09 2.12000e-01

$1.70704 \mathrm{e}+001.70704 \mathrm{e}+001.70704 \mathrm{e}-011.00000 \mathrm{e}-092.12000 \mathrm{e}-01$

$1.70704 \mathrm{e}+001.70704 \mathrm{e}+001.70704 \mathrm{e}-011.00000 \mathrm{e}-092.12000 \mathrm{e}-01$

$1.00000 \mathrm{e}+001.00000 \mathrm{e}+001.00000 \mathrm{e}-011.00000 \mathrm{e}-091.00000 \mathrm{e}-01$

Element: 14325 \# of layers: 6

$\mathrm{Kx} \mathrm{Ky} \mathrm{Kz}$ Ss Por

$1.70704 \mathrm{e}+001.70704 \mathrm{e}+00$ 1.70704e-01 1.00000e-09 2.12000e-01

$1.70704 \mathrm{e}+001.70704 \mathrm{e}+00$ 1.70704e-01 1.00000e-09 2.12000e-01

$1.70704 \mathrm{e}+001.70704 \mathrm{e}+00$ 1.70704e-01 1.00000e-09 2.12000e-01

$1.70704 \mathrm{e}+001.70704 \mathrm{e}+001.70704 \mathrm{e}-011.00000 \mathrm{e}-092.12000 \mathrm{e}-01$

$1.70704 \mathrm{e}+001.70704 \mathrm{e}+001.70704 \mathrm{e}-011.00000 \mathrm{e}-092.12000 \mathrm{e}-01$ 
$1.00000 \mathrm{e}+001.00000 \mathrm{e}+001.00000 \mathrm{e}-01$ 1.00000e-09 1.00000e-01 Element: 14326 \# of layers: 7

Kx Ky Kz Ss Por

$1.70704 \mathrm{e}+001.70704 \mathrm{e}+00$ 1.70704e-01 1.00000e-09 2.12000e-01

$1.70704 \mathrm{e}+001.70704 \mathrm{e}+001.70704 \mathrm{e}-01$ 1.00000e-09 2.12000e-01

$1.70704 \mathrm{e}+001.70704 \mathrm{e}+001.70704 \mathrm{e}-01$ 1.00000e-09 2.12000e-01

$1.70704 \mathrm{e}+001.70704 \mathrm{e}+001.70704 \mathrm{e}-01$ 1.00000e-09 2.12000e-01

$1.70704 \mathrm{e}+001.70704 \mathrm{e}+001.70704 \mathrm{e}-011.00000 \mathrm{e}-092.12000 \mathrm{e}-01$

$1.00000 \mathrm{e}-05$ 1.00000e-05 1.00000e-06 1.00000e-09 1.00000e-01

$1.00000 \mathrm{e}+001.00000 \mathrm{e}+001.00000 \mathrm{e}-011.00000 \mathrm{e}-091.00000 \mathrm{e}-01$

Element: 14327 \# of layers: 7

Kx Ky Kz Ss Por

$1.70704 \mathrm{e}+001.70704 \mathrm{e}+00$ 1.70704e-01 1.00000e-09 2.12000e-01

$1.70704 \mathrm{e}+001.70704 \mathrm{e}+001.70704 \mathrm{e}-01$ 1.00000e-09 2.12000e-01

$1.70704 \mathrm{e}+001.70704 \mathrm{e}+001.70704 \mathrm{e}-01$ 1.00000e-09 2.12000e-01

$1.70704 \mathrm{e}+001.70704 \mathrm{e}+001.70704 \mathrm{e}-011.00000 \mathrm{e}-092.12000 \mathrm{e}-01$

$1.70704 \mathrm{e}+001.70704 \mathrm{e}+001.70704 \mathrm{e}-01$ 1.00000e-09 2.12000e-01

$1.00000 \mathrm{e}-05$ 1.00000e-05 1.00000e-06 1.00000e-09 1.00000e-01

$1.00000 \mathrm{e}+001.00000 \mathrm{e}+001.00000 \mathrm{e}-01$ 1.00000e-09 1.00000e-01

Element: 14328 \# of layers: 6

$\mathrm{Kx} \mathrm{Ky} \mathrm{Kz}$ Ss Por

1.70704e+00 1.70704e+00 1.70704e-01 1.00000e-09 2.12000e-01

$1.70704 \mathrm{e}+001.70704 \mathrm{e}+001.70704 \mathrm{e}-01$ 1.00000e-09 2.12000e-01

$1.70704 \mathrm{e}+001.70704 \mathrm{e}+001.70704 \mathrm{e}-011.00000 \mathrm{e}-092.12000 \mathrm{e}-01$

$1.70704 \mathrm{e}+001.70704 \mathrm{e}+001.70704 \mathrm{e}-011.00000 \mathrm{e}-092.12000 \mathrm{e}-01$

$1.70704 \mathrm{e}+001.70704 \mathrm{e}+001.70704 \mathrm{e}-01$ 1.00000e-09 2.12000e-01

$1.00000 \mathrm{e}+001.00000 \mathrm{e}+001.00000 \mathrm{e}-011.00000 \mathrm{e}-091.00000 \mathrm{e}-01$

Element: 14329 \# of layers: 6

Kx Ky Kz Ss Por

$1.70704 \mathrm{e}+001.70704 \mathrm{e}+00$ 1.70704e-01 1.00000e-09 2.12000e-01

$1.70704 \mathrm{e}+001.70704 \mathrm{e}+001.70704 \mathrm{e}-01$ 1.00000e-09 2.12000e-01

$1.70704 \mathrm{e}+001.70704 \mathrm{e}+001.70704 \mathrm{e}-01$ 1.00000e-09 2.12000e-01

$1.70704 \mathrm{e}+001.70704 \mathrm{e}+001.70704 \mathrm{e}-011.00000 \mathrm{e}-092.12000 \mathrm{e}-01$

$1.70704 \mathrm{e}+001.70704 \mathrm{e}+001.70704 \mathrm{e}-01$ 1.00000e-09 2.12000e-01

$1.00000 \mathrm{e}+001.00000 \mathrm{e}+001.00000 \mathrm{e}-01$ 1.00000e-09 1.00000e-01

Element: 14330 \# of layers: 6

Kx Ky Kz Ss Por

$1.70704 \mathrm{e}+001.70704 \mathrm{e}+00$ 1.70704e-01 1.00000e-09 2.12000e-01

$1.70704 \mathrm{e}+001.70704 \mathrm{e}+001.70704 \mathrm{e}-011.00000 \mathrm{e}-092.12000 \mathrm{e}-01$

$1.70704 \mathrm{e}+001.70704 \mathrm{e}+001.70704 \mathrm{e}-01$ 1.00000e-09 2.12000e-01

$1.70704 \mathrm{e}+001.70704 \mathrm{e}+001.70704 \mathrm{e}-011.00000 \mathrm{e}-092.12000 \mathrm{e}-01$

$1.70704 \mathrm{e}+001.70704 \mathrm{e}+001.70704 \mathrm{e}-011.00000 \mathrm{e}-092.12000 \mathrm{e}-01$

$1.00000 \mathrm{e}+001.00000 \mathrm{e}+001.00000 \mathrm{e}-01$ 1.00000e-09 1.00000e-01

Element: 14331 \# of layers: 7

$\mathrm{Kx} \mathrm{Ky} \mathrm{Kz}$ Ss Por

$1.80398 \mathrm{e}+00$ 1.80398e+00 1.80398e-01 1.00000e-09 2.12000e-01 
$1.80398 \mathrm{e}+001.80398 \mathrm{e}+00$ 1.80398e-01 1.00000e-09 2.12000e-01 $1.80398 \mathrm{e}+001.80398 \mathrm{e}+001.80398 \mathrm{e}-011.00000 \mathrm{e}-092.12000 \mathrm{e}-01$ $1.80398 \mathrm{e}+001.80398 \mathrm{e}+00$ 1.80398e-01 1.00000e-09 2.12000e-01 $1.80398 \mathrm{e}+001.80398 \mathrm{e}+001.80398 \mathrm{e}-011.00000 \mathrm{e}-092.12000 \mathrm{e}-01$ $1.00000 \mathrm{e}+001.00000 \mathrm{e}+001.00000 \mathrm{e}-011.00000 \mathrm{e}-091.00000 \mathrm{e}-01$ $1.00000 \mathrm{e}-06$ 1.00000e-06 1.00000e-06 1.00000e-09 5.00000e-02 Element: 14332 \# of layers: 6

Kx Ky Kz Ss Por

$1.80398 \mathrm{e}+001.80398 \mathrm{e}+00$ 1.80398e-01 1.00000e-09 2.12000e-01 $1.80398 \mathrm{e}+001.80398 \mathrm{e}+001.80398 \mathrm{e}-01$ 1.00000e-09 2.12000e-01 $1.80398 \mathrm{e}+001.80398 \mathrm{e}+001.80398 \mathrm{e}-011.00000 \mathrm{e}-092.12000 \mathrm{e}-01$ $1.80398 \mathrm{e}+001.80398 \mathrm{e}+001.80398 \mathrm{e}-011.00000 \mathrm{e}-092.12000 \mathrm{e}-01$ $1.80398 \mathrm{e}+001.80398 \mathrm{e}+001.80398 \mathrm{e}-011.00000 \mathrm{e}-092.12000 \mathrm{e}-01$ $1.00000 \mathrm{e}+001.00000 \mathrm{e}+001.00000 \mathrm{e}-011.00000 \mathrm{e}-091.00000 \mathrm{e}-01$ Element: 14333 \# of layers: 6

Kx Ky Kz Ss Por

$1.80398 \mathrm{e}+001.80398 \mathrm{e}+00$ 1.80398e-01 1.00000e-09 2.12000e-01 $1.80398 \mathrm{e}+001.80398 \mathrm{e}+00$ 1.80398e-01 1.00000e-09 2.12000e-01 $1.80398 \mathrm{e}+001.80398 \mathrm{e}+001.80398 \mathrm{e}-011.00000 \mathrm{e}-092.12000 \mathrm{e}-01$ $1.80398 \mathrm{e}+001.80398 \mathrm{e}+001.80398 \mathrm{e}-011.00000 \mathrm{e}-092.12000 \mathrm{e}-01$ $1.80398 \mathrm{e}+001.80398 \mathrm{e}+001.80398 \mathrm{e}-011.00000 \mathrm{e}-092.12000 \mathrm{e}-01$ $1.00000 \mathrm{e}+001.00000 \mathrm{e}+001.00000 \mathrm{e}-011.00000 \mathrm{e}-091.00000 \mathrm{e}-01$ Element: 14334 \# of layers: 6

Kx Ky Kz Ss Por

$1.70704 \mathrm{e}+001.70704 \mathrm{e}+00$ 1.70704e-01 1.00000e-09 2.12000e-01 $1.70704 \mathrm{e}+001.70704 \mathrm{e}+001.70704 \mathrm{e}-011.00000 \mathrm{e}-092.12000 \mathrm{e}-01$ $1.70704 \mathrm{e}+001.70704 \mathrm{e}+001.70704 \mathrm{e}-011.00000 \mathrm{e}-092.12000 \mathrm{e}-01$ $1.70704 \mathrm{e}+001.70704 \mathrm{e}+001.70704 \mathrm{e}-011.00000 \mathrm{e}-092.12000 \mathrm{e}-01$ $1.70704 \mathrm{e}+001.70704 \mathrm{e}+001.70704 \mathrm{e}-011.00000 \mathrm{e}-092.12000 \mathrm{e}-01$ $1.00000 \mathrm{e}+001.00000 \mathrm{e}+001.00000 \mathrm{e}-011.00000 \mathrm{e}-091.00000 \mathrm{e}-01$ Element: 14335 \# of layers: 6

Kx Ky Kz Ss Por

$1.70704 \mathrm{e}+001.70704 \mathrm{e}+00$ 1.70704e-01 1.00000e-09 2.12000e-01 $1.70704 \mathrm{e}+001.70704 \mathrm{e}+001.70704 \mathrm{e}-011.00000 \mathrm{e}-092.12000 \mathrm{e}-01$ $1.70704 \mathrm{e}+001.70704 \mathrm{e}+001.70704 \mathrm{e}-011.00000 \mathrm{e}-092.12000 \mathrm{e}-01$ $1.70704 \mathrm{e}+001.70704 \mathrm{e}+001.70704 \mathrm{e}-011.00000 \mathrm{e}-092.12000 \mathrm{e}-01$ $1.70704 \mathrm{e}+001.70704 \mathrm{e}+001.70704 \mathrm{e}-011.00000 \mathrm{e}-092.12000 \mathrm{e}-01$ $1.00000 \mathrm{e}+001.00000 \mathrm{e}+001.00000 \mathrm{e}-011.00000 \mathrm{e}-091.00000 \mathrm{e}-01$ Element: 14336 \# of layers: 6

Kx Ky Kz Ss Por

$1.70704 \mathrm{e}+001.70704 \mathrm{e}+00$ 1.70704e-01 1.00000e-09 2.12000e-01 $1.70704 \mathrm{e}+001.70704 \mathrm{e}+001.70704 \mathrm{e}-011.00000 \mathrm{e}-092.12000 \mathrm{e}-01$ $1.70704 \mathrm{e}+001.70704 \mathrm{e}+001.70704 \mathrm{e}-011.00000 \mathrm{e}-092.12000 \mathrm{e}-01$ $1.70704 \mathrm{e}+001.70704 \mathrm{e}+001.70704 \mathrm{e}-011.00000 \mathrm{e}-092.12000 \mathrm{e}-01$ $1.70704 \mathrm{e}+001.70704 \mathrm{e}+001.70704 \mathrm{e}-011.00000 \mathrm{e}-092.12000 \mathrm{e}-01$ $1.00000 \mathrm{e}+001.00000 \mathrm{e}+001.00000 \mathrm{e}-011.00000 \mathrm{e}-091.00000 \mathrm{e}-01$ 
Element: 14337 \# of layers: 6

$\mathrm{Kx} \mathrm{Ky} \mathrm{Kz} \mathrm{Ss} \mathrm{Por}$

$1.70704 \mathrm{e}+001.70704 \mathrm{e}+00$ 1.70704e-01 1.00000e-09 2.12000e-01

$1.70704 \mathrm{e}+001.70704 \mathrm{e}+001.70704 \mathrm{e}-011.00000 \mathrm{e}-092.12000 \mathrm{e}-01$

$1.70704 \mathrm{e}+001.70704 \mathrm{e}+001.70704 \mathrm{e}-011.00000 \mathrm{e}-092.12000 \mathrm{e}-01$

$1.70704 \mathrm{e}+001.70704 \mathrm{e}+001.70704 \mathrm{e}-01$ 1.00000e-09 2.12000e-01

$1.70704 \mathrm{e}+001.70704 \mathrm{e}+001.70704 \mathrm{e}-011.00000 \mathrm{e}-092.12000 \mathrm{e}-01$

$1.00000 \mathrm{e}+001.00000 \mathrm{e}+001.00000 \mathrm{e}-01$ 1.00000e-09 1.00000e-01

Element: 14338 \# of layers: 5

$\mathrm{Kx} \mathrm{Ky} \mathrm{Kz}$ Ss Por

$1.80398 \mathrm{e}+001.80398 \mathrm{e}+00$ 1.80398e-01 1.00000e-09 2.12000e-01

$1.80398 \mathrm{e}+001.80398 \mathrm{e}+00$ 1.80398e-01 1.00000e-09 2.12000e-01

$1.80398 \mathrm{e}+001.80398 \mathrm{e}+001.80398 \mathrm{e}-01$ 1.00000e-09 2.12000e-01

$1.80398 \mathrm{e}+00$ 1.80398e+00 1.80398e-01 1.00000e-09 2.12000e-01

$1.80398 \mathrm{e}+00$ 1.80398e+00 1.80398e-01 1.00000e-09 2.12000e-01

Element: 14339 \# of layers: 5

$\mathrm{Kx} \mathrm{Ky} \mathrm{Kz}$ Ss Por

$1.80398 \mathrm{e}+00$ 1.80398e+00 1.80398e-01 1.00000e-09 2.12000e-01

$1.80398 \mathrm{e}+001.80398 \mathrm{e}+00$ 1.80398e-01 1.00000e-09 2.12000e-01

$1.80398 \mathrm{e}+001.80398 \mathrm{e}+00$ 1.80398e-01 1.00000e-09 2.12000e-01

$1.80398 \mathrm{e}+001.80398 \mathrm{e}+00$ 1.80398e-01 1.00000e-09 2.12000e-01

$1.80398 \mathrm{e}+00$ 1.80398e+00 1.80398e-01 1.00000e-09 2.12000e-01

Element: 14340 \# of layers: 6

Kx Ky Kz Ss Por

$1.80398 \mathrm{e}+001.80398 \mathrm{e}+00$ 1.80398e-01 1.00000e-09 2.12000e-01

$1.80398 \mathrm{e}+001.80398 \mathrm{e}+00$ 1.80398e-01 1.00000e-09 2.12000e-01

$1.80398 \mathrm{e}+001.80398 \mathrm{e}+00$ 1.80398e-01 1.00000e-09 2.12000e-01

$1.80398 \mathrm{e}+00$ 1.80398e+00 1.80398e-01 1.00000e-09 2.12000e-01

$1.80398 \mathrm{e}+001.80398 \mathrm{e}+00$ 1.80398e-01 1.00000e-09 2.12000e-01

1.00000e-06 1.00000e-06 1.00000e-06 1.00000e-09 5.00000e-02

Element: 14341 \# of layers: 6

Kx Ky Kz Ss Por

$1.80398 \mathrm{e}+001.80398 \mathrm{e}+00$ 1.80398e-01 1.00000e-09 2.12000e-01

$1.80398 \mathrm{e}+00$ 1.80398e+00 1.80398e-01 1.00000e-09 2.12000e-01

$1.80398 \mathrm{e}+001.80398 \mathrm{e}+00$ 1.80398e-01 1.00000e-09 2.12000e-01

$1.80398 \mathrm{e}+001.80398 \mathrm{e}+00$ 1.80398e-01 1.00000e-09 2.12000e-01

$1.80398 \mathrm{e}+001.80398 \mathrm{e}+00$ 1.80398e-01 1.00000e-09 2.12000e-01

1.00000e-06 1.00000e-06 1.00000e-06 1.00000e-09 5.00000e-02

Element: 14342 \# of layers: 5

$\mathrm{Kx} \mathrm{Ky} \mathrm{Kz}$ Ss Por

$1.89994 \mathrm{e}+001.89994 \mathrm{e}+00$ 1.89994e-01 1.00000e-09 2.12000e-01

$1.89994 \mathrm{e}+001.89994 \mathrm{e}+00$ 1.89994e-01 1.00000e-09 2.12000e-01

$1.89994 \mathrm{e}+001.89994 \mathrm{e}+00$ 1.89994e-01 1.00000e-09 2.12000e-01

$1.89994 \mathrm{e}+001.89994 \mathrm{e}+00$ 1.89994e-01 1.00000e-09 2.12000e-01

$1.89994 \mathrm{e}+001.89994 \mathrm{e}+00$ 1.89994e-01 1.00000e-09 2.12000e-01

Element: 14343 \# of layers: 5 
$\mathrm{Kx} \mathrm{Ky} \mathrm{Kz}$ Ss Por

$1.80398 \mathrm{e}+00$ 1.80398e+00 1.80398e-01 1.00000e-09 2.12000e-01

$1.80398 \mathrm{e}+001.80398 \mathrm{e}+00$ 1.80398e-01 1.00000e-09 2.12000e-01

$1.80398 \mathrm{e}+00$ 1.80398e+00 1.80398e-01 1.00000e-09 2.12000e-01

$1.80398 \mathrm{e}+001.80398 \mathrm{e}+00$ 1.80398e-01 1.00000e-09 2.12000e-01

$1.80398 \mathrm{e}+00$ 1.80398e+00 1.80398e-01 1.00000e-09 2.12000e-01

Element: 14344 \# of layers: 5

$\mathrm{Kx} \mathrm{Ky} \mathrm{Kz}$ Ss Por

$1.80398 \mathrm{e}+00$ 1.80398e+00 1.80398e-01 1.00000e-09 2.12000e-01

$1.80398 \mathrm{e}+00$ 1.80398e+00 1.80398e-01 1.00000e-09 2.12000e-01

$1.80398 \mathrm{e}+001.80398 \mathrm{e}+00$ 1.80398e-01 1.00000e-09 2.12000e-01

$1.80398 \mathrm{e}+001.80398 \mathrm{e}+00$ 1.80398e-01 1.00000e-09 2.12000e-01

$1.80398 \mathrm{e}+001.80398 \mathrm{e}+00$ 1.80398e-01 1.00000e-09 2.12000e-01

Element: 14345 \# of layers: 5

$\mathrm{Kx} \mathrm{Ky} \mathrm{Kz}$ Ss Por

$1.80398 \mathrm{e}+00$ 1.80398e+00 1.80398e-01 1.00000e-09 2.12000e-01

$1.80398 \mathrm{e}+001.80398 \mathrm{e}+00$ 1.80398e-01 1.00000e-09 2.12000e-01

$1.80398 \mathrm{e}+001.80398 \mathrm{e}+00$ 1.80398e-01 1.00000e-09 2.12000e-01

$1.80398 \mathrm{e}+001.80398 \mathrm{e}+00$ 1.80398e-01 1.00000e-09 2.12000e-01

$1.80398 \mathrm{e}+00$ 1.80398e+00 1.80398e-01 1.00000e-09 2.12000e-01

Element: 14346 \# of layers: 6

$\mathrm{Kx} \mathrm{Ky} \mathrm{Kz}$ Ss Por

$1.89994 \mathrm{e}+001.89994 \mathrm{e}+001.89994 \mathrm{e}-01$ 1.00000e-09 2.12000e-01

$1.89994 \mathrm{e}+001.89994 \mathrm{e}+001.89994 \mathrm{e}-011.00000 \mathrm{e}-092.12000 \mathrm{e}-01$

$1.89994 \mathrm{e}+001.89994 \mathrm{e}+001.89994 \mathrm{e}-011.00000 \mathrm{e}-092.12000 \mathrm{e}-01$

$1.89994 \mathrm{e}+001.89994 \mathrm{e}+001.89994 \mathrm{e}-01$ 1.00000e-09 2.12000e-01

$1.89994 \mathrm{e}+001.89994 \mathrm{e}+001.89994 \mathrm{e}-01$ 1.00000e-09 2.12000e-01

$1.00000 \mathrm{e}+001.00000 \mathrm{e}+001.00000 \mathrm{e}-011.00000 \mathrm{e}-091.00000 \mathrm{e}-01$

Element: 14347 \# of layers: 6

$\mathrm{Kx} \mathrm{Ky} \mathrm{Kz}$ Ss Por

$1.89994 \mathrm{e}+001.89994 \mathrm{e}+001.89994 \mathrm{e}-01$ 1.00000e-09 2.12000e-01

$1.89994 \mathrm{e}+001.89994 \mathrm{e}+001.89994 \mathrm{e}-01$ 1.00000e-09 2.12000e-01

$1.89994 \mathrm{e}+001.89994 \mathrm{e}+001.89994 \mathrm{e}-011.00000 \mathrm{e}-092.12000 \mathrm{e}-01$

$1.89994 \mathrm{e}+001.89994 \mathrm{e}+001.89994 \mathrm{e}-011.00000 \mathrm{e}-092.12000 \mathrm{e}-01$

$1.89994 \mathrm{e}+001.89994 \mathrm{e}+001.89994 \mathrm{e}-01$ 1.00000e-09 2.12000e-01

$1.00000 \mathrm{e}+001.00000 \mathrm{e}+001.00000 \mathrm{e}-01$ 1.00000e-09 1.00000e-01

Element: 14348 \# of layers: 5

$\mathrm{Kx} \mathrm{Ky} \mathrm{Kz}$ Ss Por

$1.89994 \mathrm{e}+001.89994 \mathrm{e}+00$ 1.89994e-01 1.00000e-09 2.12000e-01

$1.89994 \mathrm{e}+001.89994 \mathrm{e}+001.89994 \mathrm{e}-01$ 1.00000e-09 2.12000e-01

$1.89994 \mathrm{e}+001.89994 \mathrm{e}+001.89994 \mathrm{e}-011.00000 \mathrm{e}-092.12000 \mathrm{e}-01$

$1.89994 \mathrm{e}+001.89994 \mathrm{e}+00 \quad 1.89994 \mathrm{e}-011.00000 \mathrm{e}-092.12000 \mathrm{e}-01$

$1.89994 \mathrm{e}+001.89994 \mathrm{e}+00$ 1.89994e-01 1.00000e-09 2.12000e-01

Element: 14349 \# of layers: 6

$\mathrm{Kx} \mathrm{Ky} \mathrm{Kz}$ Ss Por

$1.89994 \mathrm{e}+001.89994 \mathrm{e}+00$ 1.89994e-01 1.00000e-09 2.12000e-01 
$1.89994 \mathrm{e}+001.89994 \mathrm{e}+001.89994 \mathrm{e}-011.00000 \mathrm{e}-092.12000 \mathrm{e}-01$ $1.89994 \mathrm{e}+001.89994 \mathrm{e}+001.89994 \mathrm{e}-011.00000 \mathrm{e}-092.12000 \mathrm{e}-01$ $1.89994 \mathrm{e}+001.89994 \mathrm{e}+001.89994 \mathrm{e}-011.00000 \mathrm{e}-092.12000 \mathrm{e}-01$ $1.89994 \mathrm{e}+001.89994 \mathrm{e}+001.89994 \mathrm{e}-011.00000 \mathrm{e}-092.12000 \mathrm{e}-01$ $1.00000 \mathrm{e}+001.00000 \mathrm{e}+001.00000 \mathrm{e}-011.00000 \mathrm{e}-091.00000 \mathrm{e}-01$ Element: 14350 \# of layers: 6

Kx Ky Kz Ss Por

$1.89994 \mathrm{e}+001.89994 \mathrm{e}+00$ 1.89994e-01 1.00000e-09 2.12000e-01 $1.89994 \mathrm{e}+001.89994 \mathrm{e}+001.89994 \mathrm{e}-011.00000 \mathrm{e}-092.12000 \mathrm{e}-01$ $1.89994 \mathrm{e}+001.89994 \mathrm{e}+001.89994 \mathrm{e}-011.00000 \mathrm{e}-092.12000 \mathrm{e}-01$ $1.89994 \mathrm{e}+001.89994 \mathrm{e}+001.89994 \mathrm{e}-011.00000 \mathrm{e}-092.12000 \mathrm{e}-01$ $1.89994 \mathrm{e}+001.89994 \mathrm{e}+001.89994 \mathrm{e}-011.00000 \mathrm{e}-092.12000 \mathrm{e}-01$ $1.00000 \mathrm{e}+001.00000 \mathrm{e}+001.00000 \mathrm{e}-011.00000 \mathrm{e}-091.00000 \mathrm{e}-01$ Element: 14351 \# of layers: 6

Kx Ky Kz Ss Por

$1.57179 \mathrm{e}+001.57179 \mathrm{e}+00$ 1.57179e-01 1.00000e-09 2.12000e-01 $1.57179 \mathrm{e}+001.57179 \mathrm{e}+001.57179 \mathrm{e}-011.00000 \mathrm{e}-092.12000 \mathrm{e}-01$ $1.57179 \mathrm{e}+001.57179 \mathrm{e}+001.57179 \mathrm{e}-011.00000 \mathrm{e}-092.12000 \mathrm{e}-01$ $1.57179 \mathrm{e}+001.57179 \mathrm{e}+001.57179 \mathrm{e}-011.00000 \mathrm{e}-092.12000 \mathrm{e}-01$ $1.57179 \mathrm{e}+001.57179 \mathrm{e}+001.57179 \mathrm{e}-011.00000 \mathrm{e}-092.12000 \mathrm{e}-01$ $1.00000 \mathrm{e}+001.00000 \mathrm{e}+001.00000 \mathrm{e}-011.00000 \mathrm{e}-091.00000 \mathrm{e}-01$ Element: 14352 \# of layers: 6

$\mathrm{Kx} \mathrm{Ky} \mathrm{Kz}$ Ss Por

$1.57179 \mathrm{e}+001.57179 \mathrm{e}+00$ 1.57179e-01 1.00000e-09 2.12000e-01 $1.57179 \mathrm{e}+001.57179 \mathrm{e}+001.57179 \mathrm{e}-011.00000 \mathrm{e}-092.12000 \mathrm{e}-01$ $1.57179 \mathrm{e}+001.57179 \mathrm{e}+001.57179 \mathrm{e}-011.00000 \mathrm{e}-092.12000 \mathrm{e}-01$ $1.57179 \mathrm{e}+001.57179 \mathrm{e}+001.57179 \mathrm{e}-011.00000 \mathrm{e}-092.12000 \mathrm{e}-01$ $1.57179 \mathrm{e}+001.57179 \mathrm{e}+00$ 1.57179e-01 1.00000e-09 2.12000e-01 $1.00000 \mathrm{e}+001.00000 \mathrm{e}+00$ 1.00000e-01 1.00000e-09 1.00000e-01 Element: 14353 \# of layers: 6

Kx Ky Kz Ss Por

$1.57179 \mathrm{e}+001.57179 \mathrm{e}+00$ 1.57179e-01 1.00000e-09 2.12000e-01 $1.57179 \mathrm{e}+001.57179 \mathrm{e}+001.57179 \mathrm{e}-011.00000 \mathrm{e}-092.12000 \mathrm{e}-01$ $1.57179 \mathrm{e}+001.57179 \mathrm{e}+001.57179 \mathrm{e}-011.00000 \mathrm{e}-092.12000 \mathrm{e}-01$ $1.57179 \mathrm{e}+001.57179 \mathrm{e}+001.57179 \mathrm{e}-011.00000 \mathrm{e}-092.12000 \mathrm{e}-01$ $1.57179 \mathrm{e}+001.57179 \mathrm{e}+00$ 1.57179e-01 1.00000e-09 2.12000e-01 $1.00000 \mathrm{e}+001.00000 \mathrm{e}+001.00000 \mathrm{e}-011.00000 \mathrm{e}-091.00000 \mathrm{e}-01$ Element: 14354 \# of layers: 6

Kx Ky Kz Ss Por

$1.57179 \mathrm{e}+001.57179 \mathrm{e}+00$ 1.57179e-01 1.00000e-09 2.12000e-01 $1.57179 \mathrm{e}+001.57179 \mathrm{e}+001.57179 \mathrm{e}-011.00000 \mathrm{e}-092.12000 \mathrm{e}-01$ $1.57179 \mathrm{e}+001.57179 \mathrm{e}+001.57179 \mathrm{e}-011.00000 \mathrm{e}-092.12000 \mathrm{e}-01$ $1.57179 \mathrm{e}+001.57179 \mathrm{e}+001.57179 \mathrm{e}-011.00000 \mathrm{e}-092.12000 \mathrm{e}-01$ $1.57179 \mathrm{e}+001.57179 \mathrm{e}+00$ 1.57179e-01 1.00000e-09 2.12000e-01 $1.00000 \mathrm{e}+001.00000 \mathrm{e}+001.00000 \mathrm{e}-011.00000 \mathrm{e}-091.00000 \mathrm{e}-01$ Element: 14355 \# of layers: 6 
Kx Ky Kz Ss Por

1.57179e+00 1.57179e+00 1.57179e-01 1.00000e-09 2.12000e-01

$1.57179 \mathrm{e}+001.57179 \mathrm{e}+00$ 1.57179e-01 1.00000e-09 2.12000e-01

$1.57179 \mathrm{e}+001.57179 \mathrm{e}+00$ 1.57179e-01 1.00000e-09 2.12000e-01

$1.57179 \mathrm{e}+001.57179 \mathrm{e}+00$ 1.57179e-01 1.00000e-09 2.12000e-01

$1.57179 \mathrm{e}+001.57179 \mathrm{e}+00$ 1.57179e-01 1.00000e-09 2.12000e-01

$1.00000 \mathrm{e}+001.00000 \mathrm{e}+00$ 1.00000e-01 1.00000e-09 1.00000e-01

Element: 14356 \# of layers: 6

$\mathrm{Kx} \mathrm{Ky} \mathrm{Kz}$ Ss Por

$1.89994 \mathrm{e}+001.89994 \mathrm{e}+00$ 1.89994e-01 1.00000e-09 2.12000e-01

$1.89994 \mathrm{e}+001.89994 \mathrm{e}+001.89994 \mathrm{e}-011.00000 \mathrm{e}-092.12000 \mathrm{e}-01$

$1.89994 \mathrm{e}+001.89994 \mathrm{e}+001.89994 \mathrm{e}-011.00000 \mathrm{e}-092.12000 \mathrm{e}-01$

$1.89994 \mathrm{e}+001.89994 \mathrm{e}+001.89994 \mathrm{e}-011.00000 \mathrm{e}-092.12000 \mathrm{e}-01$

$1.89994 \mathrm{e}+001.89994 \mathrm{e}+001.89994 \mathrm{e}-01$ 1.00000e-09 2.12000e-01

$1.00000 \mathrm{e}+001.00000 \mathrm{e}+001.00000 \mathrm{e}-01$ 1.00000e-09 1.00000e-01

Element: 14357 \# of layers: 6

$\mathrm{Kx} \mathrm{Ky} \mathrm{Kz}$ Ss Por

$1.89994 \mathrm{e}+001.89994 \mathrm{e}+00$ 1.89994e-01 1.00000e-09 2.12000e-01

$1.89994 \mathrm{e}+001.89994 \mathrm{e}+001.89994 \mathrm{e}-011.00000 \mathrm{e}-092.12000 \mathrm{e}-01$

$1.89994 \mathrm{e}+001.89994 \mathrm{e}+001.89994 \mathrm{e}-011.00000 \mathrm{e}-092.12000 \mathrm{e}-01$

$1.89994 \mathrm{e}+001.89994 \mathrm{e}+001.89994 \mathrm{e}-011.00000 \mathrm{e}-092.12000 \mathrm{e}-01$

$1.89994 \mathrm{e}+001.89994 \mathrm{e}+00$ 1.89994e-01 1.00000e-09 2.12000e-01

$1.00000 \mathrm{e}+001.00000 \mathrm{e}+001.00000 \mathrm{e}-01$ 1.00000e-09 1.00000e-01

Element: 14358 \# of layers: 6

Kx Ky Kz Ss Por

$1.57179 \mathrm{e}+001.57179 \mathrm{e}+00$ 1.57179e-01 1.00000e-09 2.12000e-01

$1.57179 \mathrm{e}+001.57179 \mathrm{e}+00$ 1.57179e-01 1.00000e-09 2.12000e-01

$1.57179 \mathrm{e}+001.57179 \mathrm{e}+00$ 1.57179e-01 1.00000e-09 2.12000e-01

$1.57179 \mathrm{e}+001.57179 \mathrm{e}+00$ 1.57179e-01 1.00000e-09 2.12000e-01

$1.57179 \mathrm{e}+001.57179 \mathrm{e}+00$ 1.57179e-01 1.00000e-09 2.12000e-01

$1.00000 \mathrm{e}+001.00000 \mathrm{e}+001.00000 \mathrm{e}-01$ 1.00000e-09 1.00000e-01

Element: 14359 \# of layers: 6

Kx Ky Kz Ss Por

1.57179e+00 1.57179e+00 1.57179e-01 1.00000e-09 2.12000e-01

$1.57179 \mathrm{e}+001.57179 \mathrm{e}+00$ 1.57179e-01 1.00000e-09 2.12000e-01

$1.57179 \mathrm{e}+001.57179 \mathrm{e}+00$ 1.57179e-01 1.00000e-09 2.12000e-01

$1.57179 \mathrm{e}+001.57179 \mathrm{e}+00$ 1.57179e-01 1.00000e-09 2.12000e-01

$1.57179 \mathrm{e}+001.57179 \mathrm{e}+001.57179 \mathrm{e}-01$ 1.00000e-09 2.12000e-01

$1.00000 \mathrm{e}+001.00000 \mathrm{e}+001.00000 \mathrm{e}-01$ 1.00000e-09 1.00000e-01

Element: 14360 \# of layers: 6

$\mathrm{Kx} \mathrm{Ky} \mathrm{Kz}$ Ss Por

$1.70704 \mathrm{e}+001.70704 \mathrm{e}+00$ 1.70704e-01 1.00000e-09 2.12000e-01

$1.70704 \mathrm{e}+001.70704 \mathrm{e}+00$ 1.70704e-01 1.00000e-09 2.12000e-01

$1.70704 \mathrm{e}+001.70704 \mathrm{e}+001.70704 \mathrm{e}-01$ 1.00000e-09 2.12000e-01

$1.70704 \mathrm{e}+001.70704 \mathrm{e}+001.70704 \mathrm{e}-011.00000 \mathrm{e}-092.12000 \mathrm{e}-01$

$1.70704 \mathrm{e}+001.70704 \mathrm{e}+001.70704 \mathrm{e}-011.00000 \mathrm{e}-092.12000 \mathrm{e}-01$ 
$1.00000 \mathrm{e}+001.00000 \mathrm{e}+001.00000 \mathrm{e}-011.00000 \mathrm{e}-091.00000 \mathrm{e}-01$

Element: 14361 \# of layers: 6

Kx Ky Kz Ss Por

$1.70704 \mathrm{e}+001.70704 \mathrm{e}+00$ 1.70704e-01 1.00000e-09 2.12000e-01

$1.70704 \mathrm{e}+001.70704 \mathrm{e}+001.70704 \mathrm{e}-01$ 1.00000e-09 2.12000e-01

$1.70704 \mathrm{e}+001.70704 \mathrm{e}+001.70704 \mathrm{e}-01$ 1.00000e-09 2.12000e-01

$1.70704 \mathrm{e}+001.70704 \mathrm{e}+001.70704 \mathrm{e}-01$ 1.00000e-09 2.12000e-01

$1.70704 \mathrm{e}+001.70704 \mathrm{e}+001.70704 \mathrm{e}-011.00000 \mathrm{e}-092.12000 \mathrm{e}-01$

$1.00000 \mathrm{e}+001.00000 \mathrm{e}+001.00000 \mathrm{e}-011.00000 \mathrm{e}-091.00000 \mathrm{e}-01$

Element: 14362 \# of layers: 6

$\mathrm{Kx} \mathrm{Ky} \mathrm{Kz}$ Ss Por

$1.70704 \mathrm{e}+001.70704 \mathrm{e}+00$ 1.70704e-01 1.00000e-09 2.12000e-01

$1.70704 \mathrm{e}+001.70704 \mathrm{e}+001.70704 \mathrm{e}-01$ 1.00000e-09 2.12000e-01

$1.70704 \mathrm{e}+001.70704 \mathrm{e}+001.70704 \mathrm{e}-01$ 1.00000e-09 2.12000e-01

$1.70704 \mathrm{e}+001.70704 \mathrm{e}+001.70704 \mathrm{e}-01$ 1.00000e-09 2.12000e-01

$1.70704 \mathrm{e}+001.70704 \mathrm{e}+001.70704 \mathrm{e}-01$ 1.00000e-09 2.12000e-01

$1.00000 \mathrm{e}+001.00000 \mathrm{e}+00$ 1.00000e-01 1.00000e-09 1.00000e-01

Element: 14363 \# of layers: 6

$\mathrm{Kx} \mathrm{Ky} \mathrm{Kz}$ Ss Por

$1.80398 \mathrm{e}+001.80398 \mathrm{e}+00$ 1.80398e-01 1.00000e-09 2.12000e-01

$1.80398 \mathrm{e}+001.80398 \mathrm{e}+00$ 1.80398e-01 1.00000e-09 2.12000e-01

$1.80398 \mathrm{e}+00$ 1.80398e+00 1.80398e-01 1.00000e-09 2.12000e-01

$1.80398 \mathrm{e}+001.80398 \mathrm{e}+00$ 1.80398e-01 1.00000e-09 2.12000e-01

$1.80398 \mathrm{e}+001.80398 \mathrm{e}+00$ 1.80398e-01 1.00000e-09 2.12000e-01

$1.00000 \mathrm{e}+001.00000 \mathrm{e}+001.00000 \mathrm{e}-011.00000 \mathrm{e}-091.00000 \mathrm{e}-01$

Element: 14364 \# of layers: 6

$\mathrm{Kx} \mathrm{Ky} \mathrm{Kz}$ Ss Por

1.80398e+00 1.80398e+00 1.80398e-01 1.00000e-09 2.12000e-01

$1.80398 \mathrm{e}+001.80398 \mathrm{e}+00$ 1.80398e-01 1.00000e-09 2.12000e-01

$1.80398 \mathrm{e}+00$ 1.80398e+00 1.80398e-01 1.00000e-09 2.12000e-01

$1.80398 \mathrm{e}+00$ 1.80398e+00 1.80398e-01 1.00000e-09 2.12000e-01

$1.80398 \mathrm{e}+00$ 1.80398e+00 1.80398e-01 1.00000e-09 2.12000e-01

$1.00000 \mathrm{e}+001.00000 \mathrm{e}+001.00000 \mathrm{e}-01$ 1.00000e-09 1.00000e-01

Element: 14365 \# of layers: 6

$\mathrm{Kx} \mathrm{Ky} \mathrm{Kz}$ Ss Por

$1.89994 \mathrm{e}+00$ 1.89994e+00 1.89994e-01 1.00000e-09 2.12000e-01

$1.89994 \mathrm{e}+001.89994 \mathrm{e}+001.89994 \mathrm{e}-011.00000 \mathrm{e}-092.12000 \mathrm{e}-01$

$1.89994 \mathrm{e}+001.89994 \mathrm{e}+001.89994 \mathrm{e}-01$ 1.00000e-09 2.12000e-01

$1.89994 \mathrm{e}+001.89994 \mathrm{e}+001.89994 \mathrm{e}-01$ 1.00000e-09 2.12000e-01

$1.89994 \mathrm{e}+001.89994 \mathrm{e}+001.89994 \mathrm{e}-01$ 1.00000e-09 2.12000e-01

$1.00000 \mathrm{e}+001.00000 \mathrm{e}+001.00000 \mathrm{e}-01$ 1.00000e-09 1.00000e-01

Element: 14366 \# of layers: 6

$\mathrm{Kx} \mathrm{Ky} \mathrm{Kz}$ Ss Por

$1.57179 \mathrm{e}+00$ 1.57179e+00 1.57179e-01 1.00000e-09 2.12000e-01

$1.57179 \mathrm{e}+001.57179 \mathrm{e}+00$ 1.57179e-01 1.00000e-09 2.12000e-01

$1.57179 \mathrm{e}+001.57179 \mathrm{e}+00$ 1.57179e-01 1.00000e-09 2.12000e-01 
$1.57179 \mathrm{e}+001.57179 \mathrm{e}+00$ 1.57179e-01 1.00000e-09 2.12000e-01 $1.57179 \mathrm{e}+001.57179 \mathrm{e}+001.57179 \mathrm{e}-011.00000 \mathrm{e}-092.12000 \mathrm{e}-01$ $1.00000 \mathrm{e}+001.00000 \mathrm{e}+00$ 1.00000e-01 1.00000e-09 1.00000e-01 Element: 14367 \# of layers: 6

$\mathrm{Kx} \mathrm{Ky} \mathrm{Kz}$ Ss Por

$1.70704 \mathrm{e}+00$ 1.70704e+00 1.70704e-01 1.00000e-09 2.12000e-01 $1.70704 \mathrm{e}+001.70704 \mathrm{e}+001.70704 \mathrm{e}-01$ 1.00000e-09 2.12000e-01 $1.70704 \mathrm{e}+001.70704 \mathrm{e}+001.70704 \mathrm{e}-011.00000 \mathrm{e}-092.12000 \mathrm{e}-01$ $1.70704 \mathrm{e}+001.70704 \mathrm{e}+001.70704 \mathrm{e}-01$ 1.00000e-09 2.12000e-01 $1.70704 \mathrm{e}+001.70704 \mathrm{e}+001.70704 \mathrm{e}-01$ 1.00000e-09 2.12000e-01 $1.00000 \mathrm{e}+001.00000 \mathrm{e}+001.00000 \mathrm{e}-01$ 1.00000e-09 1.00000e-01 Element: 14368 \# of layers: 6

$\mathrm{Kx} \mathrm{Ky} \mathrm{Kz}$ Ss Por

$2.02734 \mathrm{e}+002.02734 \mathrm{e}+002.02734 \mathrm{e}-01$ 1.00000e-09 2.12000e-01 $2.02734 \mathrm{e}+002.02734 \mathrm{e}+002.02734 \mathrm{e}-01$ 1.00000e-09 2.12000e-01 $2.02734 \mathrm{e}+002.02734 \mathrm{e}+002.02734 \mathrm{e}-01$ 1.00000e-09 2.12000e-01 $2.02734 \mathrm{e}+002.02734 \mathrm{e}+00 \quad 2.02734 \mathrm{e}-01 \quad 1.00000 \mathrm{e}-092.12000 \mathrm{e}-01$ $2.02734 \mathrm{e}+002.02734 \mathrm{e}+002.02734 \mathrm{e}-01$ 1.00000e-09 2.12000e-01 $1.00000 \mathrm{e}+001.00000 \mathrm{e}+001.00000 \mathrm{e}-01$ 1.00000e-09 1.00000e-01 Element: 14369 \# of layers: 6

$\mathrm{Kx} \mathrm{Ky} \mathrm{Kz}$ Ss Por

2.02734e+00 2.02734e+00 2.02734e-01 1.00000e-09 2.12000e-01 $2.02734 \mathrm{e}+002.02734 \mathrm{e}+002.02734 \mathrm{e}-01$ 1.00000e-09 2.12000e-01 $2.02734 \mathrm{e}+002.02734 \mathrm{e}+002.02734 \mathrm{e}-01$ 1.00000e-09 2.12000e-01 $2.02734 \mathrm{e}+002.02734 \mathrm{e}+00 \quad 2.02734 \mathrm{e}-011.00000 \mathrm{e}-092.12000 \mathrm{e}-01$ $2.02734 \mathrm{e}+002.02734 \mathrm{e}+002.02734 \mathrm{e}-01$ 1.00000e-09 2.12000e-01 $1.00000 \mathrm{e}+001.00000 \mathrm{e}+001.00000 \mathrm{e}-01$ 1.00000e-09 1.00000e-01 Element: 14370 \# of layers: 6

$\mathrm{Kx} \mathrm{Ky} \mathrm{Kz}$ Ss Por

2.02734e+00 2.02734e+00 2.02734e-01 1.00000e-09 2.12000e-01 $2.02734 \mathrm{e}+002.02734 \mathrm{e}+002.02734 \mathrm{e}-01$ 1.00000e-09 2.12000e-01 $2.02734 \mathrm{e}+002.02734 \mathrm{e}+002.02734 \mathrm{e}-01$ 1.00000e-09 2.12000e-01 $2.02734 \mathrm{e}+002.02734 \mathrm{e}+002.02734 \mathrm{e}-011.00000 \mathrm{e}-092.12000 \mathrm{e}-01$ $2.02734 \mathrm{e}+002.02734 \mathrm{e}+002.02734 \mathrm{e}-011.00000 \mathrm{e}-092.12000 \mathrm{e}-01$ $1.00000 \mathrm{e}+001.00000 \mathrm{e}+001.00000 \mathrm{e}-01$ 1.00000e-09 1.00000e-01 Element: 14371 \# of layers: 6

Kx Ky Kz Ss Por

$2.02734 \mathrm{e}+002.02734 \mathrm{e}+00$ 2.02734e-01 1.00000e-09 2.12000e-01 $2.02734 \mathrm{e}+002.02734 \mathrm{e}+002.02734 \mathrm{e}-01$ 1.00000e-09 2.12000e-01 $2.02734 \mathrm{e}+002.02734 \mathrm{e}+002.02734 \mathrm{e}-01$ 1.00000e-09 2.12000e-01 $2.02734 \mathrm{e}+002.02734 \mathrm{e}+002.02734 \mathrm{e}-01$ 1.00000e-09 2.12000e-01 $2.02734 \mathrm{e}+002.02734 \mathrm{e}+002.02734 \mathrm{e}-01$ 1.00000e-09 2.12000e-01 $1.00000 \mathrm{e}+001.00000 \mathrm{e}+001.00000 \mathrm{e}-01$ 1.00000e-09 1.00000e-01 Element: 14372 \# of layers: 6

$\mathrm{Kx} \mathrm{Ky} \mathrm{Kz}$ Ss Por 2.02734e+00 2.02734e+00 2.02734e-01 1.00000e-09 2.12000e-01 
$2.02734 \mathrm{e}+002.02734 \mathrm{e}+002.02734 \mathrm{e}-01$ 1.00000e-09 2.12000e-01 $2.02734 \mathrm{e}+002.02734 \mathrm{e}+002.02734 \mathrm{e}-01$ 1.00000e-09 2.12000e-01 $2.02734 \mathrm{e}+002.02734 \mathrm{e}+002.02734 \mathrm{e}-01$ 1.00000e-09 2.12000e-01 $2.02734 \mathrm{e}+002.02734 \mathrm{e}+002.02734 \mathrm{e}-01$ 1.00000e-09 2.12000e-01 $1.00000 \mathrm{e}+001.00000 \mathrm{e}+001.00000 \mathrm{e}-01$ 1.00000e-09 1.00000e-01 Element: 14373 \# of layers: 6

$\mathrm{Kx} \mathrm{Ky} \mathrm{Kz}$ Ss Por

$2.02734 \mathrm{e}+002.02734 \mathrm{e}+00$ 2.02734e-01 1.00000e-09 2.12000e-01 $2.02734 \mathrm{e}+002.02734 \mathrm{e}+002.02734 \mathrm{e}-01$ 1.00000e-09 2.12000e-01 $2.02734 \mathrm{e}+002.02734 \mathrm{e}+002.02734 \mathrm{e}-01$ 1.00000e-09 2.12000e-01 $2.02734 \mathrm{e}+002.02734 \mathrm{e}+002.02734 \mathrm{e}-01$ 1.00000e-09 2.12000e-01 $2.02734 \mathrm{e}+002.02734 \mathrm{e}+002.02734 \mathrm{e}-01 \quad 1.00000 \mathrm{e}-092.12000 \mathrm{e}-01$ $1.00000 \mathrm{e}+001.00000 \mathrm{e}+001.00000 \mathrm{e}-01$ 1.00000e-09 1.00000e-01 Element: 14374 \# of layers: 6

$\mathrm{Kx} \mathrm{Ky} \mathrm{Kz}$ Ss Por

$2.02734 \mathrm{e}+002.02734 \mathrm{e}+002.02734 \mathrm{e}-01$ 1.00000e-09 2.12000e-01 $2.02734 \mathrm{e}+002.02734 \mathrm{e}+002.02734 \mathrm{e}-01$ 1.00000e-09 2.12000e-01 $2.02734 \mathrm{e}+002.02734 \mathrm{e}+002.02734 \mathrm{e}-01$ 1.00000e-09 2.12000e-01 $2.02734 \mathrm{e}+002.02734 \mathrm{e}+002.02734 \mathrm{e}-01$ 1.00000e-09 2.12000e-01 $2.02734 \mathrm{e}+002.02734 \mathrm{e}+002.02734 \mathrm{e}-01$ 1.00000e-09 2.12000e-01 $1.00000 \mathrm{e}+001.00000 \mathrm{e}+001.00000 \mathrm{e}-01$ 1.00000e-09 1.00000e-01 Element: 14375 \# of layers: 6

$\mathrm{Kx} \mathrm{Ky} \mathrm{Kz}$ Ss Por

2.02734e+00 2.02734e+00 2.02734e-01 1.00000e-09 2.12000e-01 $2.02734 \mathrm{e}+002.02734 \mathrm{e}+002.02734 \mathrm{e}-01$ 1.00000e-09 2.12000e-01 $2.02734 \mathrm{e}+002.02734 \mathrm{e}+002.02734 \mathrm{e}-01$ 1.00000e-09 2.12000e-01 $2.02734 \mathrm{e}+002.02734 \mathrm{e}+002.02734 \mathrm{e}-01$ 1.00000e-09 2.12000e-01 $2.02734 \mathrm{e}+002.02734 \mathrm{e}+002.02734 \mathrm{e}-01$ 1.00000e-09 2.12000e-01 $1.00000 \mathrm{e}+001.00000 \mathrm{e}+001.00000 \mathrm{e}-011.00000 \mathrm{e}-091.00000 \mathrm{e}-01$ Element: 14376 \# of layers: 6

$\mathrm{Kx} \mathrm{Ky} \mathrm{Kz} \mathrm{Ss} \mathrm{Por}$

$2.02734 \mathrm{e}+00$ 2.02734e+00 2.02734e-01 1.00000e-09 2.12000e-01 $2.02734 \mathrm{e}+002.02734 \mathrm{e}+002.02734 \mathrm{e}-01 \quad 1.00000 \mathrm{e}-092.12000 \mathrm{e}-01$ $2.02734 \mathrm{e}+002.02734 \mathrm{e}+002.02734 \mathrm{e}-01$ 1.00000e-09 2.12000e-01 $2.02734 \mathrm{e}+002.02734 \mathrm{e}+002.02734 \mathrm{e}-01$ 1.00000e-09 2.12000e-01 $2.02734 \mathrm{e}+002.02734 \mathrm{e}+002.02734 \mathrm{e}-01 \quad 1.00000 \mathrm{e}-092.12000 \mathrm{e}-01$ $1.00000 \mathrm{e}+001.00000 \mathrm{e}+001.00000 \mathrm{e}-01$ 1.00000e-09 1.00000e-01 Element: 14377 \# of layers: 6

$\mathrm{Kx} \mathrm{Ky} \mathrm{Kz}$ Ss Por

$2.02734 \mathrm{e}+002.02734 \mathrm{e}+00$ 2.02734e-01 1.00000e-09 2.12000e-01 $2.02734 \mathrm{e}+002.02734 \mathrm{e}+002.02734 \mathrm{e}-01$ 1.00000e-09 2.12000e-01 $2.02734 \mathrm{e}+002.02734 \mathrm{e}+002.02734 \mathrm{e}-01$ 1.00000e-09 2.12000e-01 $2.02734 \mathrm{e}+002.02734 \mathrm{e}+002.02734 \mathrm{e}-01$ 1.00000e-09 2.12000e-01 $2.02734 \mathrm{e}+002.02734 \mathrm{e}+002.02734 \mathrm{e}-01$ 1.00000e-09 2.12000e-01 $1.00000 \mathrm{e}+001.00000 \mathrm{e}+001.00000 \mathrm{e}-011.00000 \mathrm{e}-091.00000 \mathrm{e}-01$ Element: 14378 \# of layers: 5 
$\mathrm{Kx} \mathrm{Ky} \mathrm{Kz}$ Ss Por

4.67807e+00 4.67807e+00 4.67807e-01 1.00000e-09 2.12000e-01

4.67807e+00 4.67807e+00 4.67807e-01 1.00000e-09 2.12000e-01

4.67807e+00 4.67807e+00 4.67807e-01 1.00000e-09 2.12000e-01

$4.67807 \mathrm{e}+00$ 4.67807e+00 4.67807e-01 1.00000e-09 2.12000e-01

$1.00000 \mathrm{e}+001.00000 \mathrm{e}+001.00000 \mathrm{e}-01$ 1.00000e-09 1.00000e-01

Element: 14379 \# of layers: 5

Kx Ky Kz Ss Por

4.67807e+00 4.67807e+00 4.67807e-01 1.00000e-09 2.12000e-01

4.67807e+00 4.67807e+00 4.67807e-01 1.00000e-09 2.12000e-01

4.67807e+00 4.67807e+00 4.67807e-01 1.00000e-09 2.12000e-01

$4.67807 \mathrm{e}+004.67807 \mathrm{e}+00$ 4.67807e-01 1.00000e-09 2.12000e-01

$1.00000 \mathrm{e}+001.00000 \mathrm{e}+00$ 1.00000e-01 1.00000e-09 1.00000e-01

Element: 14380 \# of layers: 5

$\mathrm{Kx} \mathrm{Ky} \mathrm{Kz}$ Ss Por

4.67807e+00 4.67807e+00 4.67807e-01 1.00000e-09 2.12000e-01

$4.67807 \mathrm{e}+00$ 4.67807e+00 4.67807e-01 1.00000e-09 2.12000e-01

4.67807e+00 4.67807e+00 4.67807e-01 1.00000e-09 2.12000e-01

4.67807e+00 4.67807e+00 4.67807e-01 1.00000e-09 2.12000e-01

$1.00000 \mathrm{e}+001.00000 \mathrm{e}+001.00000 \mathrm{e}-01$ 1.00000e-09 1.00000e-01

Element: 14381 \# of layers: 6

$\mathrm{Kx} \mathrm{Ky} \mathrm{Kz}$ Ss Por

4.67807e+00 4.67807e+00 4.67807e-01 1.00000e-09 2.12000e-01

4.67807e+00 4.67807e+00 4.67807e-01 1.00000e-09 2.12000e-01

$4.67807 \mathrm{e}+004.67807 \mathrm{e}+00$ 4.67807e-01 1.00000e-09 2.12000e-01

4.67807e+00 4.67807e+00 4.67807e-01 1.00000e-09 2.12000e-01

$1.00000 \mathrm{e}+001.00000 \mathrm{e}+001.00000 \mathrm{e}-011.00000 \mathrm{e}-091.00000 \mathrm{e}-01$

1.00000e-06 1.00000e-06 1.00000e-06 1.00000e-09 5.00000e-02

Element: 14382 \# of layers: 6

$\mathrm{Kx} \mathrm{Ky} \mathrm{Kz}$ Ss Por

4.67807e+00 4.67807e+00 4.67807e-01 1.00000e-09 2.12000e-01

4.67807e+00 4.67807e+00 4.67807e-01 1.00000e-09 2.12000e-01

$4.67807 \mathrm{e}+004.67807 \mathrm{e}+00$ 4.67807e-01 1.00000e-09 2.12000e-01

4.67807e+00 4.67807e+00 4.67807e-01 1.00000e-09 2.12000e-01

4.67807e+00 4.67807e+00 4.67807e-01 1.00000e-09 2.12000e-01

$1.00000 \mathrm{e}+001.00000 \mathrm{e}+001.00000 \mathrm{e}-01$ 1.00000e-09 1.00000e-01

Element: 14383 \# of layers: 6

$\mathrm{Kx} \mathrm{Ky} \mathrm{Kz}$ Ss Por

$2.02734 \mathrm{e}+002.02734 \mathrm{e}+002.02734 \mathrm{e}-01$ 1.00000e-09 2.12000e-01

$2.02734 \mathrm{e}+002.02734 \mathrm{e}+002.02734 \mathrm{e}-01$ 1.00000e-09 2.12000e-01

$2.02734 \mathrm{e}+002.02734 \mathrm{e}+002.02734 \mathrm{e}-01$ 1.00000e-09 2.12000e-01

$2.02734 \mathrm{e}+002.02734 \mathrm{e}+002.02734 \mathrm{e}-01$ 1.00000e-09 2.12000e-01

$2.02734 \mathrm{e}+002.02734 \mathrm{e}+002.02734 \mathrm{e}-01$ 1.00000e-09 2.12000e-01

$1.00000 \mathrm{e}+001.00000 \mathrm{e}+001.00000 \mathrm{e}-011.00000 \mathrm{e}-091.00000 \mathrm{e}-01$

Element: 14384 \# of layers: 6

Kx Ky Kz Ss Por 
$2.02734 \mathrm{e}+002.02734 \mathrm{e}+002.02734 \mathrm{e}-01$ 1.00000e-09 2.12000e-01 $2.02734 \mathrm{e}+002.02734 \mathrm{e}+002.02734 \mathrm{e}-01 \quad 1.00000 \mathrm{e}-092.12000 \mathrm{e}-01$ $2.02734 \mathrm{e}+002.02734 \mathrm{e}+002.02734 \mathrm{e}-01$ 1.00000e-09 2.12000e-01 $2.02734 \mathrm{e}+002.02734 \mathrm{e}+002.02734 \mathrm{e}-01$ 1.00000e-09 2.12000e-01 $2.02734 \mathrm{e}+002.02734 \mathrm{e}+002.02734 \mathrm{e}-01$ 1.00000e-09 2.12000e-01 $1.00000 \mathrm{e}+001.00000 \mathrm{e}+001.00000 \mathrm{e}-01$ 1.00000e-09 1.00000e-01 Element: 14385 \# of layers: 5

$\mathrm{Kx} \mathrm{Ky} \mathrm{Kz}$ Ss Por

4.67807e+00 4.67807e+00 4.67807e-01 1.00000e-09 2.12000e-01 4.67807e+00 4.67807e+00 4.67807e-01 1.00000e-09 2.12000e-01 $4.67807 \mathrm{e}+004.67807 \mathrm{e}+00$ 4.67807e-01 1.00000e-09 2.12000e-01 $4.67807 \mathrm{e}+004.67807 \mathrm{e}+00$ 4.67807e-01 1.00000e-09 2.12000e-01 $1.00000 \mathrm{e}+001.00000 \mathrm{e}+001.00000 \mathrm{e}-01$ 1.00000e-09 1.00000e-01 Element: 14386 \# of layers: 7

$\mathrm{Kx} \mathrm{Ky} \mathrm{Kz}$ Ss Por

4.67807e+00 4.67807e+00 4.67807e-01 1.00000e-09 2.12000e-01 4.67807e+00 4.67807e+00 4.67807e-01 1.00000e-09 2.12000e-01 $4.67807 \mathrm{e}+00$ 4.67807e+00 4.67807e-01 1.00000e-09 2.12000e-01 4.67807e+00 4.67807e+00 4.67807e-01 1.00000e-09 2.12000e-01 $4.67807 \mathrm{e}+00$ 4.67807e+00 4.67807e-01 1.00000e-09 2.12000e-01 $1.00000 \mathrm{e}+001.00000 \mathrm{e}+001.00000 \mathrm{e}-011.00000 \mathrm{e}-091.00000 \mathrm{e}-01$ 1.00000e-06 1.00000e-06 1.00000e-06 1.00000e-09 5.00000e-02

Element: 14387 \# of layers: 7

Kx Ky Kz Ss Por

4.67807e+00 4.67807e+00 4.67807e-01 1.00000e-09 2.12000e-01 4.67807e+00 4.67807e+00 4.67807e-01 1.00000e-09 2.12000e-01 4.67807e+00 4.67807e+00 4.67807e-01 1.00000e-09 2.12000e-01 4.67807e+00 4.67807e+00 4.67807e-01 1.00000e-09 2.12000e-01 1.00000e-05 1.00000e-05 1.00000e-06 1.00000e-09 1.00000e-01 $1.00000 \mathrm{e}+001.00000 \mathrm{e}+001.00000 \mathrm{e}-011.00000 \mathrm{e}-091.00000 \mathrm{e}-01$ 1.00000e-06 1.00000e-06 1.00000e-06 1.00000e-09 5.00000e-02 Element: 14388 \# of layers: 7

Kx Ky Kz Ss Por

4.67807e+00 4.67807e+00 4.67807e-01 1.00000e-09 2.12000e-01 $4.67807 \mathrm{e}+00$ 4.67807e+00 4.67807e-01 1.00000e-09 2.12000e-01 $4.67807 \mathrm{e}+004.67807 \mathrm{e}+00$ 4.67807e-01 1.00000e-09 2.12000e-01 $4.67807 \mathrm{e}+004.67807 \mathrm{e}+00$ 4.67807e-01 1.00000e-09 2.12000e-01 $1.00000 \mathrm{e}-05$ 1.00000e-05 1.00000e-06 1.00000e-09 1.00000e-01 $1.00000 \mathrm{e}+001.00000 \mathrm{e}+001.00000 \mathrm{e}-011.00000 \mathrm{e}-091.00000 \mathrm{e}-01$ 1.00000e-06 1.00000e-06 1.00000e-06 1.00000e-09 5.00000e-02 Element: 14389 \# of layers: 7

Kx Ky Kz Ss Por

4.67807e+00 4.67807e+00 4.67807e-01 1.00000e-09 2.12000e-01 4.67807e+00 4.67807e+00 4.67807e-01 1.00000e-09 2.12000e-01 4.67807e+00 4.67807e+00 4.67807e-01 1.00000e-09 2.12000e-01 $4.67807 e+004.67807 e+00$ 4.67807e-01 1.00000e-09 2.12000e-01 
$1.00000 \mathrm{e}-05$ 1.00000e-05 1.00000e-06 1.00000e-09 1.00000e-01 $1.00000 \mathrm{e}+001.00000 \mathrm{e}+001.00000 \mathrm{e}-011.00000 \mathrm{e}-091.00000 \mathrm{e}-01$ $1.00000 \mathrm{e}-06$ 1.00000e-06 1.00000e-06 1.00000e-09 5.00000e-02 Element: 14390 \# of layers: 7

Kx Ky Kz Ss Por

$4.67807 \mathrm{e}+004.67807 \mathrm{e}+00$ 4.67807e-01 1.00000e-09 2.12000e-01 $4.67807 \mathrm{e}+004.67807 \mathrm{e}+004.67807 \mathrm{e}-011.00000 \mathrm{e}-092.12000 \mathrm{e}-01$ $4.67807 \mathrm{e}+004.67807 \mathrm{e}+004.67807 \mathrm{e}-011.00000 \mathrm{e}-092.12000 \mathrm{e}-01$ $4.67807 \mathrm{e}+004.67807 \mathrm{e}+00$ 4.67807e-01 1.00000e-09 2.12000e-01 $1.00000 \mathrm{e}-05$ 1.00000e-05 1.00000e-06 1.00000e-09 1.00000e-01 $1.00000 \mathrm{e}+001.00000 \mathrm{e}+001.00000 \mathrm{e}-011.00000 \mathrm{e}-091.00000 \mathrm{e}-01$ $1.00000 \mathrm{e}-06$ 1.00000e-06 1.00000e-06 1.00000e-09 5.00000e-02 Element: 14391 \# of layers: 6

Kx Ky Kz Ss Por

4.67807e+00 4.67807e+00 4.67807e-01 1.00000e-09 2.12000e-01 $4.67807 \mathrm{e}+004.67807 \mathrm{e}+00$ 4.67807e-01 1.00000e-09 2.12000e-01 $4.67807 \mathrm{e}+004.67807 \mathrm{e}+00$ 4.67807e-01 1.00000e-09 2.12000e-01 $4.67807 \mathrm{e}+004.67807 \mathrm{e}+004.67807 \mathrm{e}-011.00000 \mathrm{e}-092.12000 \mathrm{e}-01$ $1.00000 \mathrm{e}+001.00000 \mathrm{e}+001.00000 \mathrm{e}-011.00000 \mathrm{e}-091.00000 \mathrm{e}-01$ $1.00000 \mathrm{e}-06$ 1.00000e-06 1.00000e-06 1.00000e-09 5.00000e-02 Element: 14392 \# of layers: 7

Kx Ky Kz Ss Por

$4.67807 \mathrm{e}+004.67807 \mathrm{e}+00$ 4.67807e-01 1.00000e-09 2.12000e-01 $4.67807 \mathrm{e}+004.67807 \mathrm{e}+004.67807 \mathrm{e}-011.00000 \mathrm{e}-092.12000 \mathrm{e}-01$ $4.67807 \mathrm{e}+004.67807 \mathrm{e}+004.67807 \mathrm{e}-011.00000 \mathrm{e}-092.12000 \mathrm{e}-01$ $4.67807 \mathrm{e}+004.67807 \mathrm{e}+004.67807 \mathrm{e}-011.00000 \mathrm{e}-092.12000 \mathrm{e}-01$ $4.67807 \mathrm{e}+004.67807 \mathrm{e}+004.67807 \mathrm{e}-011.00000 \mathrm{e}-092.12000 \mathrm{e}-01$ $1.00000 \mathrm{e}+001.00000 \mathrm{e}+001.00000 \mathrm{e}-011.00000 \mathrm{e}-091.00000 \mathrm{e}-01$ $1.00000 \mathrm{e}-06$ 1.00000e-06 1.00000e-06 1.00000e-09 5.00000e-02 Element: 14393 \# of layers: 7

Kx Ky Kz Ss Por

$4.67807 \mathrm{e}+004.67807 \mathrm{e}+00$ 4.67807e-01 1.00000e-09 2.12000e-01 $4.67807 \mathrm{e}+004.67807 \mathrm{e}+004.67807 \mathrm{e}-01$ 1.00000e-09 2.12000e-01 $4.67807 \mathrm{e}+004.67807 \mathrm{e}+004.67807 \mathrm{e}-011.00000 \mathrm{e}-092.12000 \mathrm{e}-01$ $4.67807 \mathrm{e}+004.67807 \mathrm{e}+004.67807 \mathrm{e}-011.00000 \mathrm{e}-092.12000 \mathrm{e}-01$ $4.67807 \mathrm{e}+004.67807 \mathrm{e}+004.67807 \mathrm{e}-011.00000 \mathrm{e}-092.12000 \mathrm{e}-01$ $1.00000 \mathrm{e}+001.00000 \mathrm{e}+001.00000 \mathrm{e}-011.00000 \mathrm{e}-091.00000 \mathrm{e}-01$ $1.00000 \mathrm{e}-06$ 1.00000e-06 1.00000e-06 1.00000e-09 5.00000e-02 Element: 14394 \# of layers: 7

Kx Ky Kz Ss Por $4.67807 \mathrm{e}+004.67807 \mathrm{e}+00$ 4.67807e-01 1.00000e-09 2.12000e-01 $4.67807 \mathrm{e}+004.67807 \mathrm{e}+00$ 4.67807e-01 1.00000e-09 2.12000e-01 $4.67807 \mathrm{e}+004.67807 \mathrm{e}+004.67807 \mathrm{e}-011.00000 \mathrm{e}-092.12000 \mathrm{e}-01$ $4.67807 \mathrm{e}+004.67807 \mathrm{e}+00$ 4.67807e-01 1.00000e-09 2.12000e-01 $1.00000 \mathrm{e}-05$ 1.00000e-05 1.00000e-06 1.00000e-09 1.00000e-01 $1.00000 \mathrm{e}+001.00000 \mathrm{e}+001.00000 \mathrm{e}-011.00000 \mathrm{e}-091.00000 \mathrm{e}-01$ 
1.00000e-06 1.00000e-06 1.00000e-06 1.00000e-09 5.00000e-02

Element: 14395 \# of layers: 5

Kx Ky Kz Ss Por

4.67807e+00 4.67807e+00 4.67807e-01 1.00000e-09 2.12000e-01

4.67807e+00 4.67807e+00 4.67807e-01 1.00000e-09 2.12000e-01

4.67807e+00 4.67807e+00 4.67807e-01 1.00000e-09 2.12000e-01

4.67807e+00 4.67807e+00 4.67807e-01 1.00000e-09 2.12000e-01

1.00000e-06 1.00000e-06 1.00000e-06 1.00000e-09 5.00000e-02

Element: 14396 \# of layers: 5

$\mathrm{Kx} \mathrm{Ky} \mathrm{Kz}$ Ss Por

4.67807e+00 4.67807e+00 4.67807e-01 1.00000e-09 2.12000e-01

4.67807e+00 4.67807e+00 4.67807e-01 1.00000e-09 2.12000e-01

4.67807e+00 4.67807e+00 4.67807e-01 1.00000e-09 2.12000e-01

4.67807e+00 4.67807e+00 4.67807e-01 1.00000e-09 2.12000e-01

1.00000e-06 1.00000e-06 1.00000e-06 1.00000e-09 5.00000e-02

Element: 14397 \# of layers: 5

$\mathrm{Kx} \mathrm{Ky} \mathrm{Kz}$ Ss Por

$2.59138 \mathrm{e}+00$ 2.59138e+00 2.59138e-01 1.00000e-09 2.12000e-01

$2.59138 \mathrm{e}+002.59138 \mathrm{e}+00$ 2.59138e-01 1.00000e-09 2.12000e-01

$2.59138 \mathrm{e}+002.59138 \mathrm{e}+00$ 2.59138e-01 1.00000e-09 2.12000e-01

$2.59138 \mathrm{e}+002.59138 \mathrm{e}+00$ 2.59138e-01 1.00000e-09 2.12000e-01

1.00000e-06 1.00000e-06 1.00000e-06 1.00000e-09 5.00000e-02

Element: 14398 \# of layers: 5

Kx Ky Kz Ss Por

$2.59138 \mathrm{e}+00$ 2.59138e+00 2.59138e-01 1.00000e-09 2.12000e-01

$2.59138 \mathrm{e}+002.59138 \mathrm{e}+00$ 2.59138e-01 1.00000e-09 2.12000e-01

$2.59138 \mathrm{e}+002.59138 \mathrm{e}+00$ 2.59138e-01 1.00000e-09 2.12000e-01

$2.59138 \mathrm{e}+002.59138 \mathrm{e}+00$ 2.59138e-01 1.00000e-09 2.12000e-01

1.00000e-06 1.00000e-06 1.00000e-06 1.00000e-09 5.00000e-02

Element: 14399 \# of layers: 6

$\mathrm{Kx} \mathrm{Ky} \mathrm{Kz}$ Ss Por

$2.59138 \mathrm{e}+002.59138 \mathrm{e}+00$ 2.59138e-01 1.00000e-09 2.12000e-01

$2.59138 \mathrm{e}+002.59138 \mathrm{e}+002.59138 \mathrm{e}-01$ 1.00000e-09 2.12000e-01

$2.59138 \mathrm{e}+002.59138 \mathrm{e}+00$ 2.59138e-01 1.00000e-09 2.12000e-01

$2.59138 \mathrm{e}+002.59138 \mathrm{e}+00$ 2.59138e-01 1.00000e-09 2.12000e-01

$2.59138 \mathrm{e}+002.59138 \mathrm{e}+002.59138 \mathrm{e}-01$ 1.00000e-09 2.12000e-01

1.00000e-06 1.00000e-06 1.00000e-06 1.00000e-09 5.00000e-02

Element: 14400 \# of layers: 7

$\mathrm{Kx} \mathrm{Ky} \mathrm{Kz}$ Ss Por

4.67807e+00 4.67807e+00 4.67807e-01 1.00000e-09 2.12000e-01

$4.67807 \mathrm{e}+00$ 4.67807e+00 4.67807e-01 1.00000e-09 2.12000e-01

$4.67807 \mathrm{e}+00$ 4.67807e+00 4.67807e-01 1.00000e-09 2.12000e-01

$4.67807 \mathrm{e}+00$ 4.67807e+00 4.67807e-01 1.00000e-09 2.12000e-01

4.67807e+00 4.67807e+00 4.67807e-01 1.00000e-09 2.12000e-01

$1.00000 \mathrm{e}+001.00000 \mathrm{e}+001.00000 \mathrm{e}-011.00000 \mathrm{e}-091.00000 \mathrm{e}-01$

$1.00000 \mathrm{e}-06$ 1.00000e-06 1.00000e-06 1.00000e-09 5.00000e-02 
Element: 14401 \# of layers: 7

$\mathrm{Kx} \mathrm{Ky} \mathrm{Kz}$ Ss Por

4.67807e+00 4.67807e+00 4.67807e-01 1.00000e-09 2.12000e-01

$4.67807 \mathrm{e}+00$ 4.67807e+00 4.67807e-01 1.00000e-09 2.12000e-01

4.67807e+00 4.67807e+00 4.67807e-01 1.00000e-09 2.12000e-01

4.67807e+00 4.67807e+00 4.67807e-01 1.00000e-09 2.12000e-01

4.67807e+00 4.67807e+00 4.67807e-01 1.00000e-09 2.12000e-01

$1.00000 \mathrm{e}+001.00000 \mathrm{e}+001.00000 \mathrm{e}-011.00000 \mathrm{e}-091.00000 \mathrm{e}-01$

1.00000e-06 1.00000e-06 1.00000e-06 1.00000e-09 5.00000e-02

Element: 14402 \# of layers: 5

$\mathrm{Kx} \mathrm{Ky} \mathrm{Kz}$ Ss Por

4.67807e+00 4.67807e+00 4.67807e-01 1.00000e-09 2.12000e-01

4.67807e+00 4.67807e+00 4.67807e-01 1.00000e-09 2.12000e-01

4.67807e+00 4.67807e+00 4.67807e-01 1.00000e-09 2.12000e-01

4.67807e+00 4.67807e+00 4.67807e-01 1.00000e-09 2.12000e-01

1.00000e-06 1.00000e-06 1.00000e-06 1.00000e-09 5.00000e-02

Element: 14403 \# of layers: 5

$\mathrm{Kx} \mathrm{Ky} \mathrm{Kz}$ Ss Por

4.67807e+00 4.67807e+00 4.67807e-01 1.00000e-09 2.12000e-01

4.67807e+00 4.67807e+00 4.67807e-01 1.00000e-09 2.12000e-01

$4.67807 \mathrm{e}+004.67807 \mathrm{e}+00$ 4.67807e-01 1.00000e-09 2.12000e-01

4.67807e+00 4.67807e+00 4.67807e-01 1.00000e-09 2.12000e-01

$1.00000 \mathrm{e}-06$ 1.00000e-06 1.00000e-06 1.00000e-09 5.00000e-02

Element: 14404 \# of layers: 6

Kx Ky Kz Ss Por

2.59138e+00 2.59138e+00 2.59138e-01 1.00000e-09 2.12000e-01

2.59138e+00 2.59138e+00 2.59138e-01 1.00000e-09 2.12000e-01

$2.59138 \mathrm{e}+002.59138 \mathrm{e}+002.59138 \mathrm{e}-01$ 1.00000e-09 2.12000e-01

$2.59138 \mathrm{e}+002.59138 \mathrm{e}+00$ 2.59138e-01 1.00000e-09 2.12000e-01

$2.59138 \mathrm{e}+00$ 2.59138e+00 2.59138e-01 1.00000e-09 2.12000e-01

1.00000e-06 1.00000e-06 1.00000e-06 1.00000e-09 5.00000e-02

Element: 14405 \# of layers: 5

Kx Ky Kz Ss Por

2.59138e+00 2.59138e+00 2.59138e-01 1.00000e-09 2.12000e-01

$2.59138 \mathrm{e}+00$ 2.59138e+00 2.59138e-01 1.00000e-09 2.12000e-01

$2.59138 \mathrm{e}+002.59138 \mathrm{e}+002.59138 \mathrm{e}-01$ 1.00000e-09 2.12000e-01

$2.59138 \mathrm{e}+002.59138 \mathrm{e}+002.59138 \mathrm{e}-01$ 1.00000e-09 2.12000e-01

1.00000e-06 1.00000e-06 1.00000e-06 1.00000e-09 5.00000e-02

Element: 14406 \# of layers: 5

$\mathrm{Kx} \mathrm{Ky} \mathrm{Kz}$ Ss Por

$2.59138 \mathrm{e}+002.59138 \mathrm{e}+00$ 2.59138e-01 1.00000e-09 2.12000e-01

$2.59138 \mathrm{e}+002.59138 \mathrm{e}+00$ 2.59138e-01 1.00000e-09 2.12000e-01

$2.59138 \mathrm{e}+00$ 2.59138e+00 2.59138e-01 1.00000e-09 2.12000e-01

2.59138e+00 2.59138e+00 2.59138e-01 1.00000e-09 2.12000e-01

1.00000e-06 1.00000e-06 1.00000e-06 1.00000e-09 5.00000e-02

Element: 14407 \# of layers: 5 
$\mathrm{Kx} \mathrm{Ky} \mathrm{Kz}$ Ss Por

$2.59138 \mathrm{e}+002.59138 \mathrm{e}+00$ 2.59138e-01 1.00000e-09 2.12000e-01

$2.59138 \mathrm{e}+002.59138 \mathrm{e}+00$ 2.59138e-01 1.00000e-09 2.12000e-01

$2.59138 \mathrm{e}+00$ 2.59138e+00 2.59138e-01 1.00000e-09 2.12000e-01

$2.59138 \mathrm{e}+002.59138 \mathrm{e}+00$ 2.59138e-01 1.00000e-09 2.12000e-01

1.00000e-06 1.00000e-06 1.00000e-06 1.00000e-09 5.00000e-02

Element: 14408 \# of layers: 6

$\mathrm{Kx} \mathrm{Ky} \mathrm{Kz}$ Ss Por

$2.13914 \mathrm{e}+002.13914 \mathrm{e}+002.13914 \mathrm{e}-01$ 1.00000e-09 2.12000e-01

$2.13914 \mathrm{e}+002.13914 \mathrm{e}+002.13914 \mathrm{e}-01$ 1.00000e-09 2.12000e-01

$2.13914 \mathrm{e}+002.13914 \mathrm{e}+002.13914 \mathrm{e}-01$ 1.00000e-09 2.12000e-01

$2.13914 \mathrm{e}+002.13914 \mathrm{e}+002.13914 \mathrm{e}-01 \quad 1.00000 \mathrm{e}-092.12000 \mathrm{e}-01$

$2.13914 \mathrm{e}+002.13914 \mathrm{e}+002.13914 \mathrm{e}-01$ 1.00000e-09 2.12000e-01

1.00000e-06 1.00000e-06 1.00000e-06 1.00000e-09 5.00000e-02

Element: 14409 \# of layers: 6

Kx Ky Kz Ss Por

2.59138e+00 2.59138e+00 2.59138e-01 1.00000e-09 2.12000e-01

$2.59138 \mathrm{e}+002.59138 \mathrm{e}+00$ 2.59138e-01 1.00000e-09 2.12000e-01

$2.59138 \mathrm{e}+002.59138 \mathrm{e}+00$ 2.59138e-01 1.00000e-09 2.12000e-01

$2.59138 \mathrm{e}+002.59138 \mathrm{e}+00$ 2.59138e-01 1.00000e-09 2.12000e-01

$2.59138 \mathrm{e}+002.59138 \mathrm{e}+00$ 2.59138e-01 1.00000e-09 2.12000e-01

1.00000e-06 1.00000e-06 1.00000e-06 1.00000e-09 5.00000e-02

Element: 14410 \# of layers: 6

Kx Ky Kz Ss Por

$2.59138 \mathrm{e}+00$ 2.59138e+00 2.59138e-01 1.00000e-09 2.12000e-01

$2.59138 \mathrm{e}+002.59138 \mathrm{e}+00$ 2.59138e-01 1.00000e-09 2.12000e-01

$2.59138 \mathrm{e}+002.59138 \mathrm{e}+00$ 2.59138e-01 1.00000e-09 2.12000e-01

$2.59138 \mathrm{e}+002.59138 \mathrm{e}+00$ 2.59138e-01 1.00000e-09 2.12000e-01

$2.59138 \mathrm{e}+002.59138 \mathrm{e}+00$ 2.59138e-01 1.00000e-09 2.12000e-01

1.00000e-06 1.00000e-06 1.00000e-06 1.00000e-09 5.00000e-02

Element: 14411 \# of layers: 6

$\mathrm{Kx} \mathrm{Ky} \mathrm{Kz}$ Ss Por

$2.59138 \mathrm{e}+002.59138 \mathrm{e}+00$ 2.59138e-01 1.00000e-09 2.12000e-01

$2.59138 \mathrm{e}+00$ 2.59138e+00 2.59138e-01 1.00000e-09 2.12000e-01

$2.59138 \mathrm{e}+002.59138 \mathrm{e}+002.59138 \mathrm{e}-01$ 1.00000e-09 2.12000e-01

$2.59138 \mathrm{e}+002.59138 \mathrm{e}+00$ 2.59138e-01 1.00000e-09 2.12000e-01

$2.59138 \mathrm{e}+002.59138 \mathrm{e}+002.59138 \mathrm{e}-01$ 1.00000e-09 2.12000e-01

1.00000e-06 1.00000e-06 1.00000e-06 1.00000e-09 5.00000e-02

Element: 14412 \# of layers: 6

$\mathrm{Kx} \mathrm{Ky} \mathrm{Kz}$ Ss Por

$2.13914 \mathrm{e}+002.13914 \mathrm{e}+00$ 2.13914e-01 1.00000e-09 2.12000e-01

$2.13914 \mathrm{e}+002.13914 \mathrm{e}+002.13914 \mathrm{e}-01$ 1.00000e-09 2.12000e-01

2.13914e+00 2.13914e+00 2.13914e-01 1.00000e-09 2.12000e-01

2.13914e+00 2.13914e+00 2.13914e-01 1.00000e-09 2.12000e-01

$2.13914 \mathrm{e}+002.13914 \mathrm{e}+002.13914 \mathrm{e}-01$ 1.00000e-09 2.12000e-01

$1.00000 \mathrm{e}-06$ 1.00000e-06 1.00000e-06 1.00000e-09 5.00000e-02 
Element: 14413 \# of layers: 6

$\mathrm{Kx} \mathrm{Ky} \mathrm{Kz}$ Ss Por

$2.13914 \mathrm{e}+002.13914 \mathrm{e}+002.13914 \mathrm{e}-01$ 1.00000e-09 2.12000e-01

$2.13914 \mathrm{e}+002.13914 \mathrm{e}+002.13914 \mathrm{e}-01$ 1.00000e-09 2.12000e-01

$2.13914 \mathrm{e}+002.13914 \mathrm{e}+002.13914 \mathrm{e}-01$ 1.00000e-09 2.12000e-01

$2.13914 \mathrm{e}+002.13914 \mathrm{e}+002.13914 \mathrm{e}-01$ 1.00000e-09 2.12000e-01

$2.13914 \mathrm{e}+002.13914 \mathrm{e}+002.13914 \mathrm{e}-01 \quad 1.00000 \mathrm{e}-092.12000 \mathrm{e}-01$

1.00000e-06 1.00000e-06 1.00000e-06 1.00000e-09 5.00000e-02

Element: 14414 \# of layers: 6

$\mathrm{Kx} \mathrm{Ky} \mathrm{Kz}$ Ss Por

$2.13914 \mathrm{e}+00$ 2.13914e+00 2.13914e-01 1.00000e-09 2.12000e-01

$2.13914 \mathrm{e}+002.13914 \mathrm{e}+002.13914 \mathrm{e}-01$ 1.00000e-09 2.12000e-01

$2.13914 \mathrm{e}+002.13914 \mathrm{e}+002.13914 \mathrm{e}-01$ 1.00000e-09 2.12000e-01

$2.13914 \mathrm{e}+002.13914 \mathrm{e}+002.13914 \mathrm{e}-01$ 1.00000e-09 2.12000e-01

$2.13914 \mathrm{e}+002.13914 \mathrm{e}+002.13914 \mathrm{e}-01$ 1.00000e-09 2.12000e-01 1.00000e-06 1.00000e-06 1.00000e-06 1.00000e-09 5.00000e-02

Element: 14415 \# of layers: 6

$\mathrm{Kx} \mathrm{Ky} \mathrm{Kz}$ Ss Por

2.13914e+00 2.13914e+00 2.13914e-01 1.00000e-09 2.12000e-01

$2.13914 \mathrm{e}+002.13914 \mathrm{e}+002.13914 \mathrm{e}-01$ 1.00000e-09 2.12000e-01

$2.13914 \mathrm{e}+002.13914 \mathrm{e}+002.13914 \mathrm{e}-01$ 1.00000e-09 2.12000e-01

$2.13914 \mathrm{e}+002.13914 \mathrm{e}+00$ 2.13914e-01 1.00000e-09 2.12000e-01

$2.13914 \mathrm{e}+002.13914 \mathrm{e}+002.13914 \mathrm{e}-01$ 1.00000e-09 2.12000e-01

1.00000e-06 1.00000e-06 1.00000e-06 1.00000e-09 5.00000e-02

Element: 14416 \# of layers: 6

$\mathrm{Kx} \mathrm{Ky} \mathrm{Kz}$ Ss Por

$2.13914 \mathrm{e}+002.13914 \mathrm{e}+002.13914 \mathrm{e}-01$ 1.00000e-09 2.12000e-01

$2.13914 \mathrm{e}+002.13914 \mathrm{e}+002.13914 \mathrm{e}-01$ 1.00000e-09 2.12000e-01

$2.13914 \mathrm{e}+002.13914 \mathrm{e}+002.13914 \mathrm{e}-01$ 1.00000e-09 2.12000e-01

$2.13914 \mathrm{e}+002.13914 \mathrm{e}+002.13914 \mathrm{e}-01$ 1.00000e-09 2.12000e-01

$2.13914 \mathrm{e}+002.13914 \mathrm{e}+002.13914 \mathrm{e}-01$ 1.00000e-09 2.12000e-01

1.00000e-06 1.00000e-06 1.00000e-06 1.00000e-09 5.00000e-02

Element: 14417 \# of layers: 6

$\mathrm{Kx} \mathrm{Ky} \mathrm{Kz}$ Ss Por

$2.02734 \mathrm{e}+002.02734 \mathrm{e}+002.02734 \mathrm{e}-01$ 1.00000e-09 2.12000e-01

$2.02734 \mathrm{e}+002.02734 \mathrm{e}+002.02734 \mathrm{e}-01 \quad 1.00000 \mathrm{e}-092.12000 \mathrm{e}-01$

$2.02734 \mathrm{e}+002.02734 \mathrm{e}+002.02734 \mathrm{e}-01$ 1.00000e-09 2.12000e-01

$2.02734 \mathrm{e}+002.02734 \mathrm{e}+002.02734 \mathrm{e}-01$ 1.00000e-09 2.12000e-01

$2.02734 \mathrm{e}+002.02734 \mathrm{e}+002.02734 \mathrm{e}-01$ 1.00000e-09 2.12000e-01

$1.00000 \mathrm{e}+001.00000 \mathrm{e}+001.00000 \mathrm{e}-01$ 1.00000e-09 1.00000e-01

Element: 14418 \# of layers: 6

$\mathrm{Kx} \mathrm{Ky} \mathrm{Kz}$ Ss Por

2.02734e+00 2.02734e+00 2.02734e-01 1.00000e-09 2.12000e-01

$2.02734 \mathrm{e}+002.02734 \mathrm{e}+00$ 2.02734e-01 1.00000e-09 2.12000e-01

$2.02734 \mathrm{e}+002.02734 \mathrm{e}+002.02734 \mathrm{e}-01$ 1.00000e-09 2.12000e-01

$2.02734 \mathrm{e}+002.02734 \mathrm{e}+002.02734 \mathrm{e}-011.00000 \mathrm{e}-092.12000 \mathrm{e}-01$ 
$2.02734 \mathrm{e}+002.02734 \mathrm{e}+002.02734 \mathrm{e}-011.00000 \mathrm{e}-092.12000 \mathrm{e}-01$ $1.00000 \mathrm{e}+001.00000 \mathrm{e}+001.00000 \mathrm{e}-011.00000 \mathrm{e}-091.00000 \mathrm{e}-01$ Element: 14419 \# of layers: 6

Kx Ky Kz Ss Por

$2.02734 \mathrm{e}+002.02734 \mathrm{e}+002.02734 \mathrm{e}-011.00000 \mathrm{e}-092.12000 \mathrm{e}-01$ $2.02734 \mathrm{e}+002.02734 \mathrm{e}+002.02734 \mathrm{e}-011.00000 \mathrm{e}-092.12000 \mathrm{e}-01$ $2.02734 \mathrm{e}+002.02734 \mathrm{e}+002.02734 \mathrm{e}-011.00000 \mathrm{e}-092.12000 \mathrm{e}-01$ $2.02734 \mathrm{e}+002.02734 \mathrm{e}+002.02734 \mathrm{e}-011.00000 \mathrm{e}-092.12000 \mathrm{e}-01$ $2.02734 \mathrm{e}+002.02734 \mathrm{e}+002.02734 \mathrm{e}-011.00000 \mathrm{e}-092.12000 \mathrm{e}-01$ $1.00000 \mathrm{e}+001.00000 \mathrm{e}+001.00000 \mathrm{e}-011.00000 \mathrm{e}-091.00000 \mathrm{e}-01$ Element: 14420 \# of layers: 6

Kx Ky Kz Ss Por

$2.02734 \mathrm{e}+002.02734 \mathrm{e}+002.02734 \mathrm{e}-011.00000 \mathrm{e}-092.12000 \mathrm{e}-01$ $2.02734 \mathrm{e}+002.02734 \mathrm{e}+002.02734 \mathrm{e}-011.00000 \mathrm{e}-092.12000 \mathrm{e}-01$ $2.02734 \mathrm{e}+002.02734 \mathrm{e}+002.02734 \mathrm{e}-011.00000 \mathrm{e}-092.12000 \mathrm{e}-01$ $2.02734 \mathrm{e}+002.02734 \mathrm{e}+002.02734 \mathrm{e}-011.00000 \mathrm{e}-092.12000 \mathrm{e}-01$ $2.02734 \mathrm{e}+002.02734 \mathrm{e}+002.02734 \mathrm{e}-011.00000 \mathrm{e}-092.12000 \mathrm{e}-01$ $1.00000 \mathrm{e}+001.00000 \mathrm{e}+001.00000 \mathrm{e}-011.00000 \mathrm{e}-091.00000 \mathrm{e}-01$ Element: 14421 \# of layers: 6

Kx Ky Kz Ss Por

$2.02734 \mathrm{e}+002.02734 \mathrm{e}+002.02734 \mathrm{e}-011.00000 \mathrm{e}-092.12000 \mathrm{e}-01$ $2.02734 \mathrm{e}+002.02734 \mathrm{e}+002.02734 \mathrm{e}-011.00000 \mathrm{e}-092.12000 \mathrm{e}-01$ $2.02734 \mathrm{e}+002.02734 \mathrm{e}+002.02734 \mathrm{e}-011.00000 \mathrm{e}-092.12000 \mathrm{e}-01$ $2.02734 \mathrm{e}+002.02734 \mathrm{e}+002.02734 \mathrm{e}-011.00000 \mathrm{e}-092.12000 \mathrm{e}-01$ $2.02734 \mathrm{e}+002.02734 \mathrm{e}+002.02734 \mathrm{e}-011.00000 \mathrm{e}-092.12000 \mathrm{e}-01$ $1.00000 \mathrm{e}+001.00000 \mathrm{e}+001.00000 \mathrm{e}-011.00000 \mathrm{e}-091.00000 \mathrm{e}-01$ Element: 14422 \# of layers: 6

Kx Ky Kz Ss Por

$2.13914 \mathrm{e}+002.13914 \mathrm{e}+002.13914 \mathrm{e}-01$ 1.00000e-09 2.12000e-01 $2.13914 \mathrm{e}+002.13914 \mathrm{e}+002.13914 \mathrm{e}-011.00000 \mathrm{e}-092.12000 \mathrm{e}-01$ $2.13914 \mathrm{e}+002.13914 \mathrm{e}+002.13914 \mathrm{e}-011.00000 \mathrm{e}-092.12000 \mathrm{e}-01$ $2.13914 \mathrm{e}+002.13914 \mathrm{e}+002.13914 \mathrm{e}-011.00000 \mathrm{e}-092.12000 \mathrm{e}-01$ $2.13914 \mathrm{e}+002.13914 \mathrm{e}+002.13914 \mathrm{e}-01$ 1.00000e-09 2.12000e-01 $1.00000 \mathrm{e}-06$ 1.00000e-06 1.00000e-06 1.00000e-09 5.00000e-02 Element: 14423 \# of layers: 6

Kx Ky Kz Ss Por

$2.13914 \mathrm{e}+002.13914 \mathrm{e}+002.13914 \mathrm{e}-01$ 1.00000e-09 2.12000e-01 $2.13914 \mathrm{e}+002.13914 \mathrm{e}+002.13914 \mathrm{e}-011.00000 \mathrm{e}-092.12000 \mathrm{e}-01$ $2.13914 \mathrm{e}+002.13914 \mathrm{e}+002.13914 \mathrm{e}-01$ 1.00000e-09 2.12000e-01 $2.13914 \mathrm{e}+002.13914 \mathrm{e}+002.13914 \mathrm{e}-011.00000 \mathrm{e}-092.12000 \mathrm{e}-01$ $2.13914 \mathrm{e}+002.13914 \mathrm{e}+002.13914 \mathrm{e}-011.00000 \mathrm{e}-092.12000 \mathrm{e}-01$ $1.00000 \mathrm{e}-06$ 1.00000e-06 1.00000e-06 1.00000e-09 5.00000e-02 Element: 14424 \# of layers: 6

$\mathrm{Kx} \mathrm{Ky} \mathrm{Kz}$ Ss Por

$2.02734 \mathrm{e}+002.02734 \mathrm{e}+00$ 2.02734e-01 1.00000e-09 2.12000e-01 $2.02734 \mathrm{e}+002.02734 \mathrm{e}+002.02734 \mathrm{e}-011.00000 \mathrm{e}-092.12000 \mathrm{e}-01$ 
$2.02734 \mathrm{e}+002.02734 \mathrm{e}+002.02734 \mathrm{e}-01$ 1.00000e-09 2.12000e-01 $2.02734 \mathrm{e}+002.02734 \mathrm{e}+002.02734 \mathrm{e}-01 \quad 1.00000 \mathrm{e}-092.12000 \mathrm{e}-01$ $2.02734 \mathrm{e}+002.02734 \mathrm{e}+002.02734 \mathrm{e}-01$ 1.00000e-09 2.12000e-01 $1.00000 \mathrm{e}+001.00000 \mathrm{e}+001.00000 \mathrm{e}-01$ 1.00000e-09 1.00000e-01 Element: 14425 \# of layers: 6

$\mathrm{Kx} \mathrm{Ky} \mathrm{Kz}$ Ss Por

$2.02734 \mathrm{e}+002.02734 \mathrm{e}+00$ 2.02734e-01 1.00000e-09 2.12000e-01 $2.02734 \mathrm{e}+002.02734 \mathrm{e}+002.02734 \mathrm{e}-01$ 1.00000e-09 2.12000e-01 $2.02734 \mathrm{e}+002.02734 \mathrm{e}+002.02734 \mathrm{e}-01$ 1.00000e-09 2.12000e-01 $2.02734 \mathrm{e}+002.02734 \mathrm{e}+00 \quad 2.02734 \mathrm{e}-01 \quad 1.00000 \mathrm{e}-092.12000 \mathrm{e}-01$ $2.02734 \mathrm{e}+002.02734 \mathrm{e}+002.02734 \mathrm{e}-01$ 1.00000e-09 2.12000e-01 $1.00000 \mathrm{e}+001.00000 \mathrm{e}+001.00000 \mathrm{e}-011.00000 \mathrm{e}-091.00000 \mathrm{e}-01$ Element: 14426 \# of layers: 6

$\mathrm{Kx} \mathrm{Ky} \mathrm{Kz}$ Ss Por

4.67807e+00 4.67807e+00 4.67807e-01 1.00000e-09 2.12000e-01 $4.67807 \mathrm{e}+004.67807 \mathrm{e}+00$ 4.67807e-01 1.00000e-09 2.12000e-01 4.67807e+00 4.67807e+00 4.67807e-01 1.00000e-09 2.12000e-01 $4.67807 \mathrm{e}+00$ 4.67807e+00 4.67807e-01 1.00000e-09 2.12000e-01 4.67807e+00 4.67807e+00 4.67807e-01 1.00000e-09 2.12000e-01 $1.00000 \mathrm{e}+001.00000 \mathrm{e}+001.00000 \mathrm{e}-01$ 1.00000e-09 1.00000e-01 Element: 14427 \# of layers: 6

$\mathrm{Kx} \mathrm{Ky} \mathrm{Kz}$ Ss Por

4.67807e+00 4.67807e+00 4.67807e-01 1.00000e-09 2.12000e-01 4.67807e+00 4.67807e+00 4.67807e-01 1.00000e-09 2.12000e-01 $4.67807 \mathrm{e}+004.67807 \mathrm{e}+00$ 4.67807e-01 1.00000e-09 2.12000e-01 4.67807e+00 4.67807e+00 4.67807e-01 1.00000e-09 2.12000e-01 $1.00000 \mathrm{e}+001.00000 \mathrm{e}+001.00000 \mathrm{e}-011.00000 \mathrm{e}-091.00000 \mathrm{e}-01$ 1.00000e-06 1.00000e-06 1.00000e-06 1.00000e-09 5.00000e-02

Element: 14428 \# of layers: 6

$\mathrm{Kx} \mathrm{Ky} \mathrm{Kz}$ Ss Por

4.67807e+00 4.67807e+00 4.67807e-01 1.00000e-09 2.12000e-01 $4.67807 \mathrm{e}+00$ 4.67807e+00 4.67807e-01 1.00000e-09 2.12000e-01 $4.67807 \mathrm{e}+004.67807 \mathrm{e}+00$ 4.67807e-01 1.00000e-09 2.12000e-01 $4.67807 \mathrm{e}+00$ 4.67807e+00 4.67807e-01 1.00000e-09 2.12000e-01 $1.00000 \mathrm{e}+001.00000 \mathrm{e}+001.00000 \mathrm{e}-011.00000 \mathrm{e}-091.00000 \mathrm{e}-01$ 1.00000e-06 1.00000e-06 1.00000e-06 1.00000e-09 5.00000e-02 Element: 14429 \# of layers: 5

Kx Ky Kz Ss Por

$2.59138 \mathrm{e}+002.59138 \mathrm{e}+00$ 2.59138e-01 1.00000e-09 2.12000e-01 $2.59138 \mathrm{e}+002.59138 \mathrm{e}+00$ 2.59138e-01 1.00000e-09 2.12000e-01 $2.59138 \mathrm{e}+002.59138 \mathrm{e}+00$ 2.59138e-01 1.00000e-09 2.12000e-01 $2.59138 \mathrm{e}+002.59138 \mathrm{e}+00$ 2.59138e-01 1.00000e-09 2.12000e-01 1.00000e-06 1.00000e-06 1.00000e-06 1.00000e-09 5.00000e-02 Element: 14430 \# of layers: 6

$\mathrm{Kx} \mathrm{Ky} \mathrm{Kz}$ Ss Por 2.59138e+00 2.59138e+00 2.59138e-01 1.00000e-09 2.12000e-01 
$2.59138 \mathrm{e}+002.59138 \mathrm{e}+002.59138 \mathrm{e}-011.00000 \mathrm{e}-092.12000 \mathrm{e}-01$ $2.59138 \mathrm{e}+002.59138 \mathrm{e}+002.59138 \mathrm{e}-011.00000 \mathrm{e}-092.12000 \mathrm{e}-01$ $2.59138 \mathrm{e}+002.59138 \mathrm{e}+002.59138 \mathrm{e}-01$ 1.00000e-09 2.12000e-01 $2.59138 \mathrm{e}+002.59138 \mathrm{e}+002.59138 \mathrm{e}-011.00000 \mathrm{e}-092.12000 \mathrm{e}-01$ $1.00000 \mathrm{e}-06$ 1.00000e-06 1.00000e-06 1.00000e-09 5.00000e-02

Element: 14431 \# of layers: 6

Kx Ky Kz Ss Por

$2.13914 \mathrm{e}+002.13914 \mathrm{e}+002.13914 \mathrm{e}-01$ 1.00000e-09 2.12000e-01

$2.13914 \mathrm{e}+002.13914 \mathrm{e}+002.13914 \mathrm{e}-011.00000 \mathrm{e}-092.12000 \mathrm{e}-01$

$2.13914 \mathrm{e}+002.13914 \mathrm{e}+002.13914 \mathrm{e}-011.00000 \mathrm{e}-092.12000 \mathrm{e}-01$

$2.13914 \mathrm{e}+002.13914 \mathrm{e}+002.13914 \mathrm{e}-011.00000 \mathrm{e}-092.12000 \mathrm{e}-01$

$2.13914 \mathrm{e}+002.13914 \mathrm{e}+002.13914 \mathrm{e}-011.00000 \mathrm{e}-092.12000 \mathrm{e}-01$

$1.00000 \mathrm{e}-06$ 1.00000e-06 1.00000e-06 1.00000e-09 5.00000e-02

Element: 14432 \# of layers: 7

Kx Ky Kz Ss Por

$2.02734 \mathrm{e}+002.02734 \mathrm{e}+002.02734 \mathrm{e}-011.00000 \mathrm{e}-092.12000 \mathrm{e}-01$

$2.02734 \mathrm{e}+002.02734 \mathrm{e}+002.02734 \mathrm{e}-011.00000 \mathrm{e}-092.12000 \mathrm{e}-01$

$2.02734 \mathrm{e}+002.02734 \mathrm{e}+002.02734 \mathrm{e}-011.00000 \mathrm{e}-092.12000 \mathrm{e}-01$

$2.02734 \mathrm{e}+002.02734 \mathrm{e}+002.02734 \mathrm{e}-011.00000 \mathrm{e}-092.12000 \mathrm{e}-01$

$2.02734 \mathrm{e}+002.02734 \mathrm{e}+002.02734 \mathrm{e}-011.00000 \mathrm{e}-092.12000 \mathrm{e}-01$

$1.00000 \mathrm{e}+001.00000 \mathrm{e}+001.00000 \mathrm{e}-011.00000 \mathrm{e}-091.00000 \mathrm{e}-01$

$1.00000 \mathrm{e}-06$ 1.00000e-06 1.00000e-06 1.00000e-09 5.00000e-02

Element: 14433 \# of layers: 7

Kx Ky Kz Ss Por

$4.67807 \mathrm{e}+00$ 4.67807e+00 4.67807e-01 1.00000e-09 2.12000e-01

$4.67807 \mathrm{e}+004.67807 \mathrm{e}+004.67807 \mathrm{e}-011.00000 \mathrm{e}-092.12000 \mathrm{e}-01$

$4.67807 \mathrm{e}+004.67807 \mathrm{e}+004.67807 \mathrm{e}-011.00000 \mathrm{e}-092.12000 \mathrm{e}-01$

$4.67807 \mathrm{e}+004.67807 \mathrm{e}+00$ 4.67807e-01 1.00000e-09 2.12000e-01

$4.67807 \mathrm{e}+004.67807 \mathrm{e}+00$ 4.67807e-01 1.00000e-09 2.12000e-01

$1.00000 \mathrm{e}+001.00000 \mathrm{e}+001.00000 \mathrm{e}-011.00000 \mathrm{e}-091.00000 \mathrm{e}-01$

$1.00000 \mathrm{e}-06$ 1.00000e-06 1.00000e-06 1.00000e-09 5.00000e-02

Element: 14434 \# of layers: 7

Kx Ky Kz Ss Por

9.16107e+00 9.16107e+00 9.16107e-01 1.00000e-09 2.12000e-01

$9.16107 \mathrm{e}+009.16107 \mathrm{e}+00$ 9.16107e-01 1.00000e-09 2.12000e-01

$9.16107 \mathrm{e}+009.16107 \mathrm{e}+00$ 9.16107e-01 1.00000e-09 2.12000e-01

$9.16107 \mathrm{e}+009.16107 \mathrm{e}+00$ 9.16107e-01 1.00000e-09 2.12000e-01

$1.00000 \mathrm{e}-05$ 1.00000e-05 1.00000e-06 1.00000e-09 1.00000e-01

$1.00000 \mathrm{e}+001.00000 \mathrm{e}+001.00000 \mathrm{e}-011.00000 \mathrm{e}-091.00000 \mathrm{e}-01$

$1.00000 \mathrm{e}-06$ 1.00000e-06 1.00000e-06 1.00000e-09 5.00000e-02

Element: 14435 \# of layers: 6

Kx Ky Kz Ss Por

$9.16107 \mathrm{e}+00$ 9.16107e+00 9.16107e-01 1.00000e-09 2.12000e-01

$9.16107 \mathrm{e}+009.16107 \mathrm{e}+00$ 9.16107e-01 1.00000e-09 2.12000e-01

$9.16107 \mathrm{e}+00$ 9.16107e+00 9.16107e-01 1.00000e-09 2.12000e-01

$1.00000 \mathrm{e}-05$ 1.00000e-05 1.00000e-06 1.00000e-09 1.00000e-01 
$1.00000 \mathrm{e}+001.00000 \mathrm{e}+001.00000 \mathrm{e}-011.00000 \mathrm{e}-091.00000 \mathrm{e}-01$ $1.00000 \mathrm{e}-06$ 1.00000e-06 1.00000e-06 1.00000e-09 5.00000e-02

Element: 14436 \# of layers: 6

Kx Ky Kz Ss Por

9.16107e+00 9.16107e+00 9.16107e-01 1.00000e-09 2.12000e-01

$9.16107 \mathrm{e}+009.16107 \mathrm{e}+00$ 9.16107e-01 1.00000e-09 2.12000e-01

$9.16107 \mathrm{e}+00$ 9.16107e+00 9.16107e-01 1.00000e-09 2.12000e-01 $1.00000 \mathrm{e}-05$ 1.00000e-05 1.00000e-06 1.00000e-09 1.00000e-01

$1.00000 \mathrm{e}+001.00000 \mathrm{e}+001.00000 \mathrm{e}-011.00000 \mathrm{e}-091.00000 \mathrm{e}-01$ $1.00000 \mathrm{e}-06$ 1.00000e-06 1.00000e-06 1.00000e-09 5.00000e-02

Element: 14437 \# of layers: 6

Kx Ky Kz Ss Por

9.16107e+00 9.16107e+00 9.16107e-01 1.00000e-09 2.12000e-01

$9.16107 \mathrm{e}+009.16107 \mathrm{e}+00$ 9.16107e-01 1.00000e-09 2.12000e-01

$9.16107 \mathrm{e}+009.16107 \mathrm{e}+00$ 9.16107e-01 1.00000e-09 2.12000e-01 $1.00000 \mathrm{e}-05$ 1.00000e-05 1.00000e-06 1.00000e-09 1.00000e-01

$1.00000 \mathrm{e}+001.00000 \mathrm{e}+001.00000 \mathrm{e}-011.00000 \mathrm{e}-091.00000 \mathrm{e}-01$ 1.00000e-06 1.00000e-06 1.00000e-06 1.00000e-09 5.00000e-02

Element: 14438 \# of layers: 6

Kx Ky Kz Ss Por

9.16107e+00 9.16107e+00 9.16107e-01 1.00000e-09 2.12000e-01

$9.16107 \mathrm{e}+009.16107 \mathrm{e}+00$ 9.16107e-01 1.00000e-09 2.12000e-01

$9.16107 \mathrm{e}+00$ 9.16107e+00 9.16107e-01 1.00000e-09 2.12000e-01 $1.00000 \mathrm{e}-05$ 1.00000e-05 1.00000e-06 1.00000e-09 1.00000e-01

$1.00000 \mathrm{e}+001.00000 \mathrm{e}+001.00000 \mathrm{e}-011.00000 \mathrm{e}-091.00000 \mathrm{e}-01$ $1.00000 \mathrm{e}-06$ 1.00000e-06 1.00000e-06 1.00000e-09 5.00000e-02

Element: 14439 \# of layers: 6

Kx Ky Kz Ss Por

9.16107e+00 9.16107e+00 9.16107e-01 1.00000e-09 2.12000e-01

$9.16107 \mathrm{e}+009.16107 \mathrm{e}+00$ 9.16107e-01 1.00000e-09 2.12000e-01

$9.16107 \mathrm{e}+00$ 9.16107e+00 9.16107e-01 1.00000e-09 2.12000e-01

$1.00000 \mathrm{e}-05$ 1.00000e-05 1.00000e-06 1.00000e-09 1.00000e-01

$1.00000 \mathrm{e}+001.00000 \mathrm{e}+001.00000 \mathrm{e}-011.00000 \mathrm{e}-091.00000 \mathrm{e}-01$

$1.00000 \mathrm{e}-061.00000 \mathrm{e}-06$ 1.00000e-06 1.00000e-09 5.00000e-02

Element: 14440 \# of layers: 7

Kx Ky Kz Ss Por

9.16107e+00 9.16107e+00 9.16107e-01 1.00000e-09 2.12000e-01

$9.16107 \mathrm{e}+00$ 9.16107e+00 9.16107e-01 1.00000e-09 2.12000e-01

$9.16107 \mathrm{e}+009.16107 \mathrm{e}+00$ 9.16107e-01 1.00000e-09 2.12000e-01

$9.16107 \mathrm{e}+00$ 9.16107e+00 9.16107e-01 1.00000e-09 2.12000e-01 $1.00000 \mathrm{e}-05$ 1.00000e-05 1.00000e-06 1.00000e-09 1.00000e-01

$1.00000 \mathrm{e}+001.00000 \mathrm{e}+001.00000 \mathrm{e}-011.00000 \mathrm{e}-091.00000 \mathrm{e}-01$ $1.00000 \mathrm{e}-06$ 1.00000e-06 1.00000e-06 1.00000e-09 5.00000e-02

Element: 14441 \# of layers: 7

Kx Ky Kz Ss Por

9.16107e+00 9.16107e+00 9.16107e-01 1.00000e-09 2.12000e-01 
$9.16107 \mathrm{e}+00$ 9.16107e+00 9.16107e-01 1.00000e-09 2.12000e-01 $9.16107 \mathrm{e}+009.16107 \mathrm{e}+00$ 9.16107e-01 1.00000e-09 2.12000e-01 $9.16107 \mathrm{e}+00$ 9.16107e+00 9.16107e-01 1.00000e-09 2.12000e-01 $1.00000 \mathrm{e}-05$ 1.00000e-05 1.00000e-06 1.00000e-09 1.00000e-01 $1.00000 \mathrm{e}+001.00000 \mathrm{e}+001.00000 \mathrm{e}-011.00000 \mathrm{e}-091.00000 \mathrm{e}-01$ $1.00000 \mathrm{e}-061.00000 \mathrm{e}-06$ 1.00000e-06 1.00000e-09 5.00000e-02 Element: 14442 \# of layers: 6

Kx Ky Kz Ss Por

9.16107e+00 9.16107e+00 9.16107e-01 1.00000e-09 2.12000e-01 $9.16107 \mathrm{e}+009.16107 \mathrm{e}+00$ 9.16107e-01 1.00000e-09 2.12000e-01 $9.16107 \mathrm{e}+00$ 9.16107e+00 9.16107e-01 1.00000e-09 2.12000e-01 $1.00000 \mathrm{e}-05$ 1.00000e-05 1.00000e-06 1.00000e-09 1.00000e-01 $1.00000 \mathrm{e}+001.00000 \mathrm{e}+001.00000 \mathrm{e}-011.00000 \mathrm{e}-091.00000 \mathrm{e}-01$ $1.00000 \mathrm{e}-06$ 1.00000e-06 1.00000e-06 1.00000e-09 5.00000e-02 Element: 14443 \# of layers: 6

Kx Ky Kz Ss Por

$9.16107 \mathrm{e}+00$ 9.16107e+00 9.16107e-01 1.00000e-09 2.12000e-01 $9.16107 \mathrm{e}+009.16107 \mathrm{e}+00$ 9.16107e-01 1.00000e-09 2.12000e-01 $9.16107 \mathrm{e}+009.16107 \mathrm{e}+00$ 9.16107e-01 1.00000e-09 2.12000e-01 $1.00000 \mathrm{e}-05$ 1.00000e-05 1.00000e-06 1.00000e-09 1.00000e-01 $1.00000 \mathrm{e}+001.00000 \mathrm{e}+001.00000 \mathrm{e}-011.00000 \mathrm{e}-091.00000 \mathrm{e}-01$ $1.00000 \mathrm{e}-06$ 1.00000e-06 1.00000e-06 1.00000e-09 5.00000e-02

Element: 14444 \# of layers: 6

Kx Ky Kz Ss Por

$7.51426 \mathrm{e}+007.51426 \mathrm{e}+007.51426 \mathrm{e}-011.00000 \mathrm{e}-092.12000 \mathrm{e}-01$ $7.51426 \mathrm{e}+007.51426 \mathrm{e}+007.51426 \mathrm{e}-011.00000 \mathrm{e}-092.12000 \mathrm{e}-01$ $7.51426 \mathrm{e}+007.51426 \mathrm{e}+00$ 7.51426e-01 1.00000e-09 2.12000e-01 $1.00000 \mathrm{e}-051.00000 \mathrm{e}-05$ 1.00000e-06 1.00000e-09 1.00000e-01 $1.00000 \mathrm{e}+001.00000 \mathrm{e}+001.00000 \mathrm{e}-011.00000 \mathrm{e}-091.00000 \mathrm{e}-01$ $1.00000 \mathrm{e}-06$ 1.00000e-06 1.00000e-06 1.00000e-09 5.00000e-02

Element: 14445 \# of layers: 6

Kx Ky Kz Ss Por

7.51426e+00 7.51426e+00 7.51426e-01 1.00000e-09 2.12000e-01 $7.51426 \mathrm{e}+007.51426 \mathrm{e}+007.51426 \mathrm{e}-011.00000 \mathrm{e}-092.12000 \mathrm{e}-01$ $7.51426 \mathrm{e}+007.51426 \mathrm{e}+007.51426 \mathrm{e}-011.00000 \mathrm{e}-092.12000 \mathrm{e}-01$ $1.00000 \mathrm{e}-05$ 1.00000e-05 1.00000e-06 1.00000e-09 1.00000e-01 $1.00000 \mathrm{e}+001.00000 \mathrm{e}+001.00000 \mathrm{e}-011.00000 \mathrm{e}-091.00000 \mathrm{e}-01$ $1.00000 \mathrm{e}-06$ 1.00000e-06 1.00000e-06 1.00000e-09 5.00000e-02 Element: 14446 \# of layers: 4

Kx Ky Kz Ss Por

7.51426e+00 7.51426e+00 7.51426e-01 1.00000e-09 2.12000e-01

$7.51426 \mathrm{e}+007.51426 \mathrm{e}+007.51426 \mathrm{e}-011.00000 \mathrm{e}-092.12000 \mathrm{e}-01$

$7.51426 \mathrm{e}+007.51426 \mathrm{e}+00$ 7.51426e-01 1.00000e-09 2.12000e-01 1.00000e-06 1.00000e-06 1.00000e-06 1.00000e-09 5.00000e-02 Element: 14447 \# of layers: 4

Kx Ky Kz Ss Por 
$7.51426 \mathrm{e}+007.51426 \mathrm{e}+00$ 7.51426e-01 1.00000e-09 2.12000e-01

$7.51426 \mathrm{e}+007.51426 \mathrm{e}+007.51426 \mathrm{e}-011.00000 \mathrm{e}-092.12000 \mathrm{e}-01$

$7.51426 \mathrm{e}+007.51426 \mathrm{e}+007.51426 \mathrm{e}-011.00000 \mathrm{e}-092.12000 \mathrm{e}-01$

$1.00000 \mathrm{e}-06$ 1.00000e-06 1.00000e-06 1.00000e-09 5.00000e-02

Element: 14448 \# of layers: 4

$\mathrm{Kx} \mathrm{Ky} \mathrm{Kz}$ Ss Por

7.51426e+00 7.51426e+00 7.51426e-01 1.00000e-09 2.12000e-01

$7.51426 \mathrm{e}+007.51426 \mathrm{e}+007.51426 \mathrm{e}-011.00000 \mathrm{e}-092.12000 \mathrm{e}-01$

$7.51426 \mathrm{e}+007.51426 \mathrm{e}+00$ 7.51426e-01 1.00000e-09 2.12000e-01

$1.00000 \mathrm{e}-06$ 1.00000e-06 1.00000e-06 1.00000e-09 5.00000e-02

Element: 14449 \# of layers: 6

Kx Ky Kz Ss Por

9.16107e+00 9.16107e+00 9.16107e-01 1.00000e-09 2.12000e-01

$9.16107 \mathrm{e}+009.16107 \mathrm{e}+00$ 9.16107e-01 1.00000e-09 2.12000e-01

$9.16107 \mathrm{e}+009.16107 \mathrm{e}+00$ 9.16107e-01 1.00000e-09 2.12000e-01

$1.00000 \mathrm{e}-05$ 1.00000e-05 1.00000e-06 1.00000e-09 1.00000e-01

$1.00000 \mathrm{e}+001.00000 \mathrm{e}+001.00000 \mathrm{e}-011.00000 \mathrm{e}-091.00000 \mathrm{e}-01$

$1.00000 \mathrm{e}-06$ 1.00000e-06 1.00000e-06 1.00000e-09 5.00000e-02

Element: 14450 \# of layers: 6

Kx Ky Kz Ss Por

9.16107e+00 9.16107e+00 9.16107e-01 1.00000e-09 2.12000e-01

$9.16107 \mathrm{e}+009.16107 \mathrm{e}+00$ 9.16107e-01 1.00000e-09 2.12000e-01

$9.16107 \mathrm{e}+009.16107 \mathrm{e}+00$ 9.16107e-01 1.00000e-09 2.12000e-01

$1.00000 \mathrm{e}-05$ 1.00000e-05 1.00000e-06 1.00000e-09 1.00000e-01

$1.00000 \mathrm{e}+001.00000 \mathrm{e}+001.00000 \mathrm{e}-011.00000 \mathrm{e}-091.00000 \mathrm{e}-01$

$1.00000 \mathrm{e}-06$ 1.00000e-06 1.00000e-06 1.00000e-09 5.00000e-02

Element: 14451 \# of layers: 4

Kx Ky Kz Ss Por

$7.51426 \mathrm{e}+007.51426 \mathrm{e}+007.51426 \mathrm{e}-011.00000 \mathrm{e}-092.12000 \mathrm{e}-01$

$7.51426 \mathrm{e}+007.51426 \mathrm{e}+007.51426 \mathrm{e}-011.00000 \mathrm{e}-092.12000 \mathrm{e}-01$

$7.51426 \mathrm{e}+007.51426 \mathrm{e}+007.51426 \mathrm{e}-011.00000 \mathrm{e}-092.12000 \mathrm{e}-01$

$1.00000 \mathrm{e}-06$ 1.00000e-06 1.00000e-06 1.00000e-09 5.00000e-02

Element: 14452 \# of layers: 6

Kx Ky Kz Ss Por

7.51426e+00 7.51426e+00 7.51426e-01 1.00000e-09 2.12000e-01

$7.51426 \mathrm{e}+007.51426 \mathrm{e}+007.51426 \mathrm{e}-011.00000 \mathrm{e}-092.12000 \mathrm{e}-01$

$7.51426 \mathrm{e}+007.51426 \mathrm{e}+007.51426 \mathrm{e}-011.00000 \mathrm{e}-092.12000 \mathrm{e}-01$

$1.00000 \mathrm{e}-05$ 1.00000e-05 1.00000e-06 1.00000e-09 1.00000e-01

$1.00000 \mathrm{e}+001.00000 \mathrm{e}+001.00000 \mathrm{e}-011.00000 \mathrm{e}-091.00000 \mathrm{e}-01$

$1.00000 \mathrm{e}-06$ 1.00000e-06 1.00000e-06 1.00000e-09 5.00000e-02

Element: 14453 \# of layers: 5

Kx Ky Kz Ss Por

7.51426e+00 7.51426e+00 7.51426e-01 1.00000e-09 2.12000e-01

$7.51426 \mathrm{e}+007.51426 \mathrm{e}+00$ 7.51426e-01 1.00000e-09 2.12000e-01 $1.00000 \mathrm{e}-05$ 1.00000e-05 1.00000e-06 1.00000e-09 1.00000e-01

$1.00000 \mathrm{e}+001.00000 \mathrm{e}+001.00000 \mathrm{e}-011.00000 \mathrm{e}-091.00000 \mathrm{e}-01$ 
1.00000e-06 1.00000e-06 1.00000e-06 1.00000e-09 5.00000e-02

Element: 14454 \# of layers: 5

Kx Ky Kz Ss Por

7.51426e+00 7.51426e+00 7.51426e-01 1.00000e-09 2.12000e-01

7.51426e+00 7.51426e+00 7.51426e-01 1.00000e-09 2.12000e-01

$1.00000 \mathrm{e}-05$ 1.00000e-05 1.00000e-06 1.00000e-09 1.00000e-01

$1.00000 \mathrm{e}+001.00000 \mathrm{e}+001.00000 \mathrm{e}-011.00000 \mathrm{e}-091.00000 \mathrm{e}-01$

1.00000e-06 1.00000e-06 1.00000e-06 1.00000e-09 5.00000e-02

Element: 14455 \# of layers: 3

$\mathrm{Kx} \mathrm{Ky} \mathrm{Kz}$ Ss Por

7.51426e+00 7.51426e+00 7.51426e-01 1.00000e-09 2.12000e-01

$7.51426 \mathrm{e}+00$ 7.51426e+00 7.51426e-01 1.00000e-09 2.12000e-01

1.00000e-06 1.00000e-06 1.00000e-06 1.00000e-09 5.00000e-02

Element: 14456 \# of layers: 3

$\mathrm{Kx} \mathrm{Ky} \mathrm{Kz}$ Ss Por

7.51426e+00 7.51426e+00 7.51426e-01 1.00000e-09 2.12000e-01

$7.51426 \mathrm{e}+00$ 7.51426e+00 7.51426e-01 1.00000e-09 2.12000e-01

1.00000e-06 1.00000e-06 1.00000e-06 1.00000e-09 5.00000e-02

Element: 14457 \# of layers: 3

$\mathrm{Kx} \mathrm{Ky} \mathrm{Kz}$ Ss Por

7.51426e+00 7.51426e+00 7.51426e-01 1.00000e-09 2.12000e-01

7.51426e+00 7.51426e+00 7.51426e-01 1.00000e-09 2.12000e-01

$1.00000 \mathrm{e}-06$ 1.00000e-06 1.00000e-06 1.00000e-09 5.00000e-02

Element: 14458 \# of layers: 4

Kx Ky Kz Ss Por

7.51426e+00 7.51426e+00 7.51426e-01 1.00000e-09 2.12000e-01

7.51426e+00 7.51426e+00 7.51426e-01 1.00000e-09 2.12000e-01

$7.51426 \mathrm{e}+00$ 7.51426e+00 7.51426e-01 1.00000e-09 2.12000e-01

1.00000e-06 1.00000e-06 1.00000e-06 1.00000e-09 5.00000e-02

Element: 14459 \# of layers: 4

$\mathrm{Kx} \mathrm{Ky} \mathrm{Kz}$ Ss Por

7.51426e+00 7.51426e+00 7.51426e-01 1.00000e-09 2.12000e-01

$7.51426 \mathrm{e}+007.51426 \mathrm{e}+007.51426 \mathrm{e}-01$ 1.00000e-09 2.12000e-01

7.51426e+00 7.51426e+00 7.51426e-01 1.00000e-09 2.12000e-01

1.00000e-06 1.00000e-06 1.00000e-06 1.00000e-09 5.00000e-02

Element: 14460 \# of layers: 3

Kx Ky Kz Ss Por

7.51426e+00 7.51426e+00 7.51426e-01 1.00000e-09 2.12000e-01

$7.51426 \mathrm{e}+007.51426 \mathrm{e}+00$ 7.51426e-01 1.00000e-09 2.12000e-01

1.00000e-06 1.00000e-06 1.00000e-06 1.00000e-09 5.00000e-02

Element: 14461 \# of layers: 3

$\mathrm{Kx} \mathrm{Ky} \mathrm{Kz}$ Ss Por

7.51426e+00 7.51426e+00 7.51426e-01 1.00000e-09 2.12000e-01

$7.51426 \mathrm{e}+00$ 7.51426e+00 7.51426e-01 1.00000e-09 2.12000e-01

1.00000e-06 1.00000e-06 1.00000e-06 1.00000e-09 5.00000e-02

Element: 14462 \# of layers: 3 
$\mathrm{Kx} \mathrm{Ky} \mathrm{Kz}$ Ss Por

7.51426e+00 7.51426e+00 7.51426e-01 1.00000e-09 2.12000e-01

7.51426e+00 7.51426e+00 7.51426e-01 1.00000e-09 2.12000e-01

1.00000e-06 1.00000e-06 1.00000e-06 1.00000e-09 5.00000e-02

Element: 14463 \# of layers: 3

$\mathrm{Kx} \mathrm{Ky} \mathrm{Kz}$ Ss Por

6.09808e+00 6.09808e+00 6.09808e-01 1.00000e-09 2.12000e-01

$6.09808 \mathrm{e}+006.09808 \mathrm{e}+00$ 6.09808e-01 1.00000e-09 2.12000e-01

1.00000e-06 1.00000e-06 1.00000e-06 1.00000e-09 5.00000e-02

Element: 14464 \# of layers: 3

$\mathrm{Kx} \mathrm{Ky} \mathrm{Kz}$ Ss Por

6.09808e+00 6.09808e+00 6.09808e-01 1.00000e-09 2.12000e-01

$6.09808 \mathrm{e}+006.09808 \mathrm{e}+006.09808 \mathrm{e}-01$ 1.00000e-09 2.12000e-01

1.00000e-06 1.00000e-06 1.00000e-06 1.00000e-09 5.00000e-02

Element: 14465 \# of layers: 4

$\mathrm{Kx} \mathrm{Ky} \mathrm{Kz}$ Ss Por

6.09808e+00 6.09808e+00 6.09808e-01 1.00000e-09 2.12000e-01

$6.09808 \mathrm{e}+006.09808 \mathrm{e}+00$ 6.09808e-01 1.00000e-09 2.12000e-01

$6.09808 \mathrm{e}+006.09808 \mathrm{e}+00$ 6.09808e-01 1.00000e-09 2.12000e-01

1.00000e-06 1.00000e-06 1.00000e-06 1.00000e-09 5.00000e-02

Element: 14466 \# of layers: 4

$\mathrm{Kx} \mathrm{Ky} \mathrm{Kz}$ Ss Por

7.51426e+00 7.51426e+00 7.51426e-01 1.00000e-09 2.12000e-01

$7.51426 \mathrm{e}+00$ 7.51426e+00 7.51426e-01 1.00000e-09 2.12000e-01

$7.51426 \mathrm{e}+007.51426 \mathrm{e}+007.51426 \mathrm{e}-01$ 1.00000e-09 2.12000e-01

1.00000e-06 1.00000e-06 1.00000e-06 1.00000e-09 5.00000e-02

Element: 14467 \# of layers: 4

$\mathrm{Kx} \mathrm{Ky} \mathrm{Kz}$ Ss Por

7.51426e+00 7.51426e+00 7.51426e-01 1.00000e-09 2.12000e-01

$7.51426 \mathrm{e}+00$ 7.51426e+00 7.51426e-01 1.00000e-09 2.12000e-01

$7.51426 \mathrm{e}+007.51426 \mathrm{e}+00$ 7.51426e-01 1.00000e-09 2.12000e-01

1.00000e-06 1.00000e-06 1.00000e-06 1.00000e-09 5.00000e-02

Element: 14468 \# of layers: 3

$\mathrm{Kx} \mathrm{Ky} \mathrm{Kz}$ Ss Por

7.51426e+00 7.51426e+00 7.51426e-01 1.00000e-09 2.12000e-01

7.51426e+00 7.51426e+00 7.51426e-01 1.00000e-09 2.12000e-01

1.00000e-06 1.00000e-06 1.00000e-06 1.00000e-09 5.00000e-02

Element: 14469 \# of layers: 3

$\mathrm{Kx} \mathrm{Ky} \mathrm{Kz}$ Ss Por

7.51426e+00 7.51426e+00 7.51426e-01 1.00000e-09 2.12000e-01

$7.51426 \mathrm{e}+00$ 7.51426e+00 7.51426e-01 1.00000e-09 2.12000e-01

1.00000e-06 1.00000e-06 1.00000e-06 1.00000e-09 5.00000e-02

Element: 14470 \# of layers: 3

$\mathrm{Kx} \mathrm{Ky} \mathrm{Kz}$ Ss Por

6.09808e+00 6.09808e+00 6.09808e-01 1.00000e-09 2.12000e-01

$6.09808 \mathrm{e}+00$ 6.09808e+00 6.09808e-01 1.00000e-09 2.12000e-01 
1.00000e-06 1.00000e-06 1.00000e-06 1.00000e-09 5.00000e-02

Element: 14471 \# of layers: 3

$\mathrm{Kx} \mathrm{Ky} \mathrm{Kz}$ Ss Por

6.09808e+00 6.09808e+00 6.09808e-01 1.00000e-09 2.12000e-01

$6.09808 \mathrm{e}+006.09808 \mathrm{e}+00$ 6.09808e-01 1.00000e-09 2.12000e-01

1.00000e-06 1.00000e-06 1.00000e-06 1.00000e-09 5.00000e-02

Element: 14472 \# of layers: 3

$\mathrm{Kx} \mathrm{Ky} \mathrm{Kz} \mathrm{Ss} \mathrm{Por}$

6.09808e+00 6.09808e+00 6.09808e-01 1.00000e-09 2.12000e-01

$6.09808 \mathrm{e}+006.09808 \mathrm{e}+00$ 6.09808e-01 1.00000e-09 2.12000e-01

1.00000e-06 1.00000e-06 1.00000e-06 1.00000e-09 5.00000e-02

Element: 14473 \# of layers: 3

$\mathrm{Kx} \mathrm{Ky} \mathrm{Kz}$ Ss Por

6.09808e+00 6.09808e+00 6.09808e-01 1.00000e-09 2.12000e-01

$6.09808 \mathrm{e}+006.09808 \mathrm{e}+00$ 6.09808e-01 1.00000e-09 2.12000e-01

1.00000e-06 1.00000e-06 1.00000e-06 1.00000e-09 5.00000e-02

Element: 14474 \# of layers: 4

$\mathrm{Kx} \mathrm{Ky} \mathrm{Kz}$ Ss Por

4.22244e+00 4.22244e+00 4.22244e-01 1.00000e-09 2.12000e-01

$4.22244 \mathrm{e}+004.22244 \mathrm{e}+00 \quad 4.22244 \mathrm{e}-01$ 1.00000e-09 2.12000e-01

$4.22244 \mathrm{e}+00 \quad 4.22244 \mathrm{e}+00 \quad 4.22244 \mathrm{e}-01$ 1.00000e-09 2.12000e-01

$1.00000 \mathrm{e}-06$ 1.00000e-06 1.00000e-06 1.00000e-09 5.00000e-02

Element: 14475 \# of layers: 4

$\mathrm{Kx} \mathrm{Ky} \mathrm{Kz}$ Ss Por

6.09808e+00 6.09808e+00 6.09808e-01 1.00000e-09 2.12000e-01

$6.09808 \mathrm{e}+006.09808 \mathrm{e}+00$ 6.09808e-01 1.00000e-09 2.12000e-01

$6.09808 \mathrm{e}+006.09808 \mathrm{e}+006.09808 \mathrm{e}-01$ 1.00000e-09 2.12000e-01

1.00000e-06 1.00000e-06 1.00000e-06 1.00000e-09 5.00000e-02

Element: 14476 \# of layers: 4

$\mathrm{Kx} \mathrm{Ky} \mathrm{Kz}$ Ss Por

6.09808e+00 6.09808e+00 6.09808e-01 1.00000e-09 2.12000e-01

$6.09808 \mathrm{e}+006.09808 \mathrm{e}+00$ 6.09808e-01 1.00000e-09 2.12000e-01

$6.09808 \mathrm{e}+006.09808 \mathrm{e}+00$ 6.09808e-01 1.00000e-09 2.12000e-01

1.00000e-06 1.00000e-06 1.00000e-06 1.00000e-09 5.00000e-02

Element: 14477 \# of layers: 4

$\mathrm{Kx} \mathrm{Ky} \mathrm{Kz}$ Ss Por

6.09808e+00 6.09808e+00 6.09808e-01 1.00000e-09 2.12000e-01

$6.09808 \mathrm{e}+006.09808 \mathrm{e}+00$ 6.09808e-01 1.00000e-09 2.12000e-01

$6.09808 \mathrm{e}+006.09808 \mathrm{e}+00$ 6.09808e-01 1.00000e-09 2.12000e-01

1.00000e-06 1.00000e-06 1.00000e-06 1.00000e-09 5.00000e-02

Element: 14478 \# of layers: 5

$\mathrm{Kx} \mathrm{Ky} \mathrm{Kz}$ Ss Por

4.22244e+00 4.22244e+00 4.22244e-01 1.00000e-09 2.12000e-01

$4.22244 \mathrm{e}+004.22244 \mathrm{e}+00$ 4.22244e-01 1.00000e-09 2.12000e-01

$4.22244 \mathrm{e}+004.22244 \mathrm{e}+004.22244 \mathrm{e}-01$ 1.00000e-09 2.12000e-01

$4.22244 \mathrm{e}+004.22244 \mathrm{e}+004.22244 \mathrm{e}-01$ 1.00000e-09 2.12000e-01 
1.00000e-06 1.00000e-06 1.00000e-06 1.00000e-09 5.00000e-02

Element: 14479 \# of layers: 4

$\mathrm{Kx} \mathrm{Ky} \mathrm{Kz}$ Ss Por

$4.22244 \mathrm{e}+004.22244 \mathrm{e}+00$ 4.22244e-01 1.00000e-09 2.12000e-01

4.22244e+00 4.22244e+00 4.22244e-01 1.00000e-09 2.12000e-01

$4.22244 \mathrm{e}+004.22244 \mathrm{e}+004.22244 \mathrm{e}-01$ 1.00000e-09 2.12000e-01

1.00000e-06 1.00000e-06 1.00000e-06 1.00000e-09 5.00000e-02

Element: 14480 \# of layers: 4

$\mathrm{Kx} \mathrm{Ky} \mathrm{Kz}$ Ss Por

4.22244e+00 4.22244e+00 4.22244e-01 1.00000e-09 2.12000e-01

$4.22244 \mathrm{e}+004.22244 \mathrm{e}+004.22244 \mathrm{e}-01$ 1.00000e-09 2.12000e-01

$4.22244 \mathrm{e}+004.22244 \mathrm{e}+004.22244 \mathrm{e}-01$ 1.00000e-09 2.12000e-01

1.00000e-06 1.00000e-06 1.00000e-06 1.00000e-09 5.00000e-02

Element: 14481 \# of layers: 5

$\mathrm{Kx} \mathrm{Ky} \mathrm{Kz}$ Ss Por

4.22244e+00 4.22244e+00 4.22244e-01 1.00000e-09 2.12000e-01

$4.22244 \mathrm{e}+004.22244 \mathrm{e}+00$ 4.22244e-01 1.00000e-09 2.12000e-01

$4.22244 \mathrm{e}+004.22244 \mathrm{e}+00$ 4.22244e-01 1.00000e-09 2.12000e-01

$4.22244 \mathrm{e}+004.22244 \mathrm{e}+004.22244 \mathrm{e}-01$ 1.00000e-09 2.12000e-01

1.00000e-06 1.00000e-06 1.00000e-06 1.00000e-09 5.00000e-02

Element: 14482 \# of layers: 5

$\mathrm{Kx} \mathrm{Ky} \mathrm{Kz}$ Ss Por

4.22244e+00 4.22244e+00 4.22244e-01 1.00000e-09 2.12000e-01

$4.22244 \mathrm{e}+004.22244 \mathrm{e}+004.22244 \mathrm{e}-01$ 1.00000e-09 2.12000e-01

$4.22244 \mathrm{e}+00$ 4.22244e+00 4.22244e-01 1.00000e-09 2.12000e-01

4.22244e+00 4.22244e+00 4.22244e-01 1.00000e-09 2.12000e-01

1.00000e-06 1.00000e-06 1.00000e-06 1.00000e-09 5.00000e-02

Element: 14483 \# of layers: 5

Kx Ky Kz Ss Por

9.16107e+00 9.16107e+00 9.16107e-01 1.00000e-09 2.12000e-01

9.16107e+00 9.16107e+00 9.16107e-01 1.00000e-09 2.12000e-01

9.16107e+00 9.16107e+00 9.16107e-01 1.00000e-09 2.12000e-01

9.16107e+00 9.16107e+00 9.16107e-01 1.00000e-09 2.12000e-01

1.00000e-06 1.00000e-06 1.00000e-06 1.00000e-09 5.00000e-02

Element: 14484 \# of layers: 5

$\mathrm{Kx} \mathrm{Ky} \mathrm{Kz}$ Ss Por

9.16107e+00 9.16107e+00 9.16107e-01 1.00000e-09 2.12000e-01

9.16107e+00 9.16107e+00 9.16107e-01 1.00000e-09 2.12000e-01

9.16107e+00 9.16107e+00 9.16107e-01 1.00000e-09 2.12000e-01

9.16107e+00 9.16107e+00 9.16107e-01 1.00000e-09 2.12000e-01

1.00000e-06 1.00000e-06 1.00000e-06 1.00000e-09 5.00000e-02

Element: 14485 \# of layers: 4

$\mathrm{Kx} \mathrm{Ky} \mathrm{Kz}$ Ss Por

9.16107e+00 9.16107e+00 9.16107e-01 1.00000e-09 2.12000e-01

9.16107e+00 9.16107e+00 9.16107e-01 1.00000e-09 2.12000e-01

9.16107e+00 9.16107e+00 9.16107e-01 1.00000e-09 2.12000e-01 
1.00000e-06 1.00000e-06 1.00000e-06 1.00000e-09 5.00000e-02

Element: 14486 \# of layers: 4

Kx Ky Kz Ss Por

9.16107e+00 9.16107e+00 9.16107e-01 1.00000e-09 2.12000e-01

9.16107e+00 9.16107e+00 9.16107e-01 1.00000e-09 2.12000e-01

9.16107e+00 9.16107e+00 9.16107e-01 1.00000e-09 2.12000e-01

1.00000e-06 1.00000e-06 1.00000e-06 1.00000e-09 5.00000e-02

Element: 14487 \# of layers: 4

$\mathrm{Kx} \mathrm{Ky} \mathrm{Kz}$ Ss Por

9.16107e+00 9.16107e+00 9.16107e-01 1.00000e-09 2.12000e-01

9.16107e+00 9.16107e+00 9.16107e-01 1.00000e-09 2.12000e-01

$9.16107 \mathrm{e}+00$ 9.16107e+00 9.16107e-01 1.00000e-09 2.12000e-01

1.00000e-06 1.00000e-06 1.00000e-06 1.00000e-09 5.00000e-02

Element: 14488 \# of layers: 4

$\mathrm{Kx} \mathrm{Ky} \mathrm{Kz}$ Ss Por

4.22244e+00 4.22244e+00 4.22244e-01 1.00000e-09 2.12000e-01

$4.22244 \mathrm{e}+004.22244 \mathrm{e}+00$ 4.22244e-01 1.00000e-09 2.12000e-01

$4.22244 \mathrm{e}+004.22244 \mathrm{e}+004.22244 \mathrm{e}-01$ 1.00000e-09 2.12000e-01

1.00000e-06 1.00000e-06 1.00000e-06 1.00000e-09 5.00000e-02

Element: 14489 \# of layers: 4

$\mathrm{Kx} \mathrm{Ky} \mathrm{Kz}$ Ss Por

4.22244e+00 4.22244e+00 4.22244e-01 1.00000e-09 2.12000e-01

$4.22244 \mathrm{e}+004.22244 \mathrm{e}+004.22244 \mathrm{e}-01$ 1.00000e-09 2.12000e-01

$4.22244 \mathrm{e}+004.22244 \mathrm{e}+004.22244 \mathrm{e}-01$ 1.00000e-09 2.12000e-01

1.00000e-06 1.00000e-06 1.00000e-06 1.00000e-09 5.00000e-02

Element: 14490 \# of layers: 4

$\mathrm{Kx} \mathrm{Ky} \mathrm{Kz}$ Ss Por

9.16107e+00 9.16107e+00 9.16107e-01 1.00000e-09 2.12000e-01

9.16107e+00 9.16107e+00 9.16107e-01 1.00000e-09 2.12000e-01

9.16107e+00 9.16107e+00 9.16107e-01 1.00000e-09 2.12000e-01

$1.00000 \mathrm{e}-06$ 1.00000e-06 1.00000e-06 1.00000e-09 5.00000e-02

Element: 14491 \# of layers: 4

Kx Ky Kz Ss Por

9.16107e+00 9.16107e+00 9.16107e-01 1.00000e-09 2.12000e-01

9.16107e+00 9.16107e+00 9.16107e-01 1.00000e-09 2.12000e-01

9.16107e+00 9.16107e+00 9.16107e-01 1.00000e-09 2.12000e-01

1.00000e-06 1.00000e-06 1.00000e-06 1.00000e-09 5.00000e-02

Element: 14492 \# of layers: 4

$\mathrm{Kx} \mathrm{Ky} \mathrm{Kz}$ Ss Por

7.51426e+00 7.51426e+00 7.51426e-01 1.00000e-09 2.12000e-01

$7.51426 \mathrm{e}+007.51426 \mathrm{e}+007.51426 \mathrm{e}-01$ 1.00000e-09 2.12000e-01

$7.51426 \mathrm{e}+007.51426 \mathrm{e}+007.51426 \mathrm{e}-01$ 1.00000e-09 2.12000e-01

1.00000e-06 1.00000e-06 1.00000e-06 1.00000e-09 5.00000e-02

Element: 14493 \# of layers: 4

$\mathrm{Kx} \mathrm{Ky} \mathrm{Kz}$ Ss Por

7.51426e+00 7.51426e+00 7.51426e-01 1.00000e-09 2.12000e-01 
$7.51426 \mathrm{e}+007.51426 \mathrm{e}+00$ 7.51426e-01 1.00000e-09 2.12000e-01 $7.51426 \mathrm{e}+007.51426 \mathrm{e}+00$ 7.51426e-01 1.00000e-09 2.12000e-01 $1.00000 \mathrm{e}-06$ 1.00000e-06 1.00000e-06 1.00000e-09 5.00000e-02

Element: 14494 \# of layers: 4

Kx Ky Kz Ss Por

7.51426e+00 7.51426e+00 7.51426e-01 1.00000e-09 2.12000e-01

$7.51426 \mathrm{e}+007.51426 \mathrm{e}+007.51426 \mathrm{e}-011.00000 \mathrm{e}-092.12000 \mathrm{e}-01$

$7.51426 \mathrm{e}+007.51426 \mathrm{e}+007.51426 \mathrm{e}-011.00000 \mathrm{e}-092.12000 \mathrm{e}-01$ $1.00000 \mathrm{e}-06$ 1.00000e-06 1.00000e-06 1.00000e-09 5.00000e-02

Element: 14495 \# of layers: 4

Kx Ky Kz Ss Por

$6.09808 \mathrm{e}+00$ 6.09808e+00 6.09808e-01 1.00000e-09 2.12000e-01 $6.09808 \mathrm{e}+006.09808 \mathrm{e}+00$ 6.09808e-01 1.00000e-09 2.12000e-01 $6.09808 \mathrm{e}+006.09808 \mathrm{e}+00$ 6.09808e-01 1.00000e-09 2.12000e-01 $1.00000 \mathrm{e}-06$ 1.00000e-06 1.00000e-06 1.00000e-09 5.00000e-02

Element: 14496 \# of layers: 4

Kx Ky Kz Ss Por

$6.09808 \mathrm{e}+00$ 6.09808e+00 6.09808e-01 1.00000e-09 2.12000e-01

$6.09808 \mathrm{e}+006.09808 \mathrm{e}+006.09808 \mathrm{e}-011.00000 \mathrm{e}-092.12000 \mathrm{e}-01$

$6.09808 \mathrm{e}+006.09808 \mathrm{e}+00$ 6.09808e-01 1.00000e-09 2.12000e-01 $1.00000 \mathrm{e}-06$ 1.00000e-06 1.00000e-06 1.00000e-09 5.00000e-02

Element: 14497 \# of layers: 4

Kx Ky Kz Ss Por

$4.22244 \mathrm{e}+004.22244 \mathrm{e}+00$ 4.22244e-01 1.00000e-09 2.12000e-01 $4.22244 \mathrm{e}+004.22244 \mathrm{e}+004.22244 \mathrm{e}-011.00000 \mathrm{e}-092.12000 \mathrm{e}-01$ $4.22244 \mathrm{e}+004.22244 \mathrm{e}+00$ 4.22244e-01 1.00000e-09 2.12000e-01 $1.00000 \mathrm{e}-06$ 1.00000e-06 1.00000e-06 1.00000e-09 5.00000e-02 Element: 14498 \# of layers: 4

Kx Ky Kz Ss Por

$9.16107 \mathrm{e}+00$ 9.16107e+00 9.16107e-01 1.00000e-09 2.12000e-01

$9.16107 e+009.16107 e+009.16107 e-011.00000 e-092.12000 e-01$

$9.16107 \mathrm{e}+00$ 9.16107e+00 9.16107e-01 1.00000e-09 2.12000e-01 $1.00000 \mathrm{e}-06$ 1.00000e-06 1.00000e-06 1.00000e-09 5.00000e-02

Element: 14499 \# of layers: 4

Kx Ky Kz Ss Por

7.51426e+00 7.51426e+00 7.51426e-01 1.00000e-09 2.12000e-01

$7.51426 \mathrm{e}+007.51426 \mathrm{e}+00$ 7.51426e-01 1.00000e-09 2.12000e-01

$7.51426 \mathrm{e}+007.51426 \mathrm{e}+00$ 7.51426e-01 1.00000e-09 2.12000e-01

$1.00000 \mathrm{e}-06$ 1.00000e-06 1.00000e-06 1.00000e-09 5.00000e-02

Element: 14500 \# of layers: 5

Kx Ky Kz Ss Por

$8.92099 \mathrm{e}+01$ 8.92099e+01 8.92099e+00 1.00000e-09 2.12000e-01

$8.92099 \mathrm{e}+018.92099 \mathrm{e}+018.92099 \mathrm{e}+00$ 1.00000e-09 2.12000e-01 $1.00000 \mathrm{e}-05$ 1.00000e-05 1.00000e-06 1.00000e-09 1.00000e-01 $1.00000 \mathrm{e}+001.00000 \mathrm{e}+001.00000 \mathrm{e}-011.00000 \mathrm{e}-091.00000 \mathrm{e}-01$ $1.00000 \mathrm{e}-06$ 1.00000e-06 1.00000e-06 1.00000e-09 5.00000e-02 
Element: 14501 \# of layers: 5

Kx Ky Kz Ss Por

$8.92099 \mathrm{e}+018.92099 \mathrm{e}+01$ 8.92099e+00 1.00000e-09 2.12000e-01

$8.92099 \mathrm{e}+018.92099 \mathrm{e}+018.92099 \mathrm{e}+001.00000 \mathrm{e}-092.12000 \mathrm{e}-01$

$1.00000 \mathrm{e}-05$ 1.00000e-05 1.00000e-06 1.00000e-09 1.00000e-01

$1.00000 \mathrm{e}+001.00000 \mathrm{e}+001.00000 \mathrm{e}-011.00000 \mathrm{e}-091.00000 \mathrm{e}-01$

$1.00000 \mathrm{e}-06$ 1.00000e-06 1.00000e-06 1.00000e-09 5.00000e-02

Element: 14502 \# of layers: 3

Kx Ky Kz Ss Por

$8.92099 \mathrm{e}+01$ 8.92099e+01 8.92099e+00 1.00000e-09 2.12000e-01

$8.92099 \mathrm{e}+018.92099 \mathrm{e}+018.92099 \mathrm{e}+00$ 1.00000e-09 2.12000e-01

$1.00000 \mathrm{e}-06$ 1.00000e-06 1.00000e-06 1.00000e-09 5.00000e-02

Element: 14503 \# of layers: 3

Kx Ky Kz Ss Por

$8.92099 \mathrm{e}+018.92099 \mathrm{e}+01$ 8.92099e+00 1.00000e-09 2.12000e-01

$8.92099 \mathrm{e}+01$ 8.92099e+01 8.92099e+00 1.00000e-09 2.12000e-01

$1.00000 \mathrm{e}-06$ 1.00000e-06 1.00000e-06 1.00000e-09 5.00000e-02

Element: 14504 \# of layers: 3

Kx Ky Kz Ss Por

$8.92099 \mathrm{e}+01$ 8.92099e+01 8.92099e+00 1.00000e-09 2.12000e-01

$8.92099 \mathrm{e}+01$ 8.92099e+01 8.92099e+00 1.00000e-09 2.12000e-01

$1.00000 \mathrm{e}-06$ 1.00000e-06 1.00000e-06 1.00000e-09 5.00000e-02

Element: 14505 \# of layers: 3

Kx Ky Kz Ss Por

$8.92099 \mathrm{e}+018.92099 \mathrm{e}+01$ 8.92099e+00 1.00000e-09 2.12000e-01

$8.92099 \mathrm{e}+018.92099 \mathrm{e}+018.92099 \mathrm{e}+00$ 1.00000e-09 2.12000e-01

$1.00000 \mathrm{e}-06$ 1.00000e-06 1.00000e-06 1.00000e-09 5.00000e-02

Element: 14506 \# of layers: 3

Kx Ky Kz Ss Por

$8.92099 \mathrm{e}+01$ 8.92099e+01 8.92099e+00 1.00000e-09 2.12000e-01

$8.92099 \mathrm{e}+018.92099 \mathrm{e}+018.92099 \mathrm{e}+001.00000 \mathrm{e}-092.12000 \mathrm{e}-01$

1.00000e-06 1.00000e-06 1.00000e-06 1.00000e-09 5.00000e-02

Element: 14507 \# of layers: 3

Kx Ky Kz Ss Por

$8.92099 \mathrm{e}+018.92099 \mathrm{e}+018.92099 \mathrm{e}+00$ 1.00000e-09 2.12000e-01

$8.92099 \mathrm{e}+018.92099 \mathrm{e}+018.92099 \mathrm{e}+00$ 1.00000e-09 2.12000e-01

$1.00000 \mathrm{e}-06$ 1.00000e-06 1.00000e-06 1.00000e-09 5.00000e-02

Element: 14508 \# of layers: 3

Kx Ky Kz Ss Por

$8.92099 \mathrm{e}+01$ 8.92099e+01 8.92099e+00 1.00000e-09 2.12000e-01

$8.92099 \mathrm{e}+018.92099 \mathrm{e}+018.92099 \mathrm{e}+00$ 1.00000e-09 2.12000e-01

$1.00000 \mathrm{e}-06$ 1.00000e-06 1.00000e-06 1.00000e-09 5.00000e-02

Element: 14509 \# of layers: 3

Kx Ky Kz Ss Por

$8.92099 \mathrm{e}+018.92099 \mathrm{e}+01$ 8.92099e+00 1.00000e-09 2.12000e-01

$8.92099 \mathrm{e}+018.92099 \mathrm{e}+018.92099 \mathrm{e}+00$ 1.00000e-09 2.12000e-01 
1.00000e-06 1.00000e-06 1.00000e-06 1.00000e-09 5.00000e-02

Element: 14510 \# of layers: 3

$\mathrm{Kx} \mathrm{Ky} \mathrm{Kz}$ Ss Por

8.85439e+02 8.85439e+02 8.85439e+01 1.00000e-09 2.12000e-01

$8.85439 \mathrm{e}+02$ 8.85439e+02 8.85439e+01 1.00000e-09 2.12000e-01

1.00000e-06 1.00000e-06 1.00000e-06 1.00000e-09 5.00000e-02

Element: 14511 \# of layers: 4

Kx Ky Kz Ss Por

8.85439e+02 8.85439e+02 8.85439e+01 1.00000e-09 2.12000e-01

8.85439e+02 8.85439e+02 8.85439e+01 1.00000e-09 2.12000e-01

$8.85439 \mathrm{e}+02$ 8.85439e+02 8.85439e+01 1.00000e-09 2.12000e-01

1.00000e-06 1.00000e-06 1.00000e-06 1.00000e-09 5.00000e-02

Element: 14512 \# of layers: 4

$\mathrm{Kx} \mathrm{Ky} \mathrm{Kz}$ Ss Por

8.85439e+02 8.85439e+02 8.85439e+01 1.00000e-09 2.12000e-01

$8.85439 \mathrm{e}+02$ 8.85439e+02 8.85439e+01 1.00000e-09 2.12000e-01

$8.85439 \mathrm{e}+02$ 8.85439e+02 8.85439e+01 1.00000e-09 2.12000e-01

1.00000e-06 1.00000e-06 1.00000e-06 1.00000e-09 5.00000e-02

Element: 14513 \# of layers: 4

$\mathrm{Kx} \mathrm{Ky} \mathrm{Kz}$ Ss Por

8.85439e+02 8.85439e+02 8.85439e+01 1.00000e-09 2.12000e-01

$8.85439 \mathrm{e}+02$ 8.85439e+02 8.85439e+01 1.00000e-09 2.12000e-01

$8.85439 \mathrm{e}+02$ 8.85439e+02 8.85439e+01 1.00000e-09 2.12000e-01

1.00000e-06 1.00000e-06 1.00000e-06 1.00000e-09 5.00000e-02

Element: 14514 \# of layers: 3

$\mathrm{Kx} \mathrm{Ky} \mathrm{Kz}$ Ss Por

8.85439e+02 8.85439e+02 8.85439e+01 1.00000e-09 2.12000e-01

$8.85439 \mathrm{e}+02$ 8.85439e+02 8.85439e+01 1.00000e-09 2.12000e-01

1.00000e-06 1.00000e-06 1.00000e-06 1.00000e-09 5.00000e-02

Element: 14515 \# of layers: 3

$\mathrm{Kx} \mathrm{Ky} \mathrm{Kz}$ Ss Por

8.92099e+01 8.92099e+01 8.92099e+00 1.00000e-09 2.12000e-01

$8.92099 \mathrm{e}+018.92099 \mathrm{e}+018.92099 \mathrm{e}+00$ 1.00000e-09 2.12000e-01

$1.00000 \mathrm{e}-06$ 1.00000e-06 1.00000e-06 1.00000e-09 5.00000e-02

Element: 14516 \# of layers: 3

$\mathrm{Kx} \mathrm{Ky} \mathrm{Kz}$ Ss Por

8.92099e+01 8.92099e+01 8.92099e+00 1.00000e-09 2.12000e-01

$8.92099 \mathrm{e}+018.92099 \mathrm{e}+018.92099 \mathrm{e}+001.00000 \mathrm{e}-092.12000 \mathrm{e}-01$

1.00000e-06 1.00000e-06 1.00000e-06 1.00000e-09 5.00000e-02

Element: 14517 \# of layers: 3

$\mathrm{Kx} \mathrm{Ky} \mathrm{Kz}$ Ss Por

8.85439e+02 8.85439e+02 8.85439e+01 1.00000e-09 2.12000e-01

$8.85439 \mathrm{e}+02$ 8.85439e+02 8.85439e+01 1.00000e-09 2.12000e-01

1.00000e-06 1.00000e-06 1.00000e-06 1.00000e-09 5.00000e-02

Element: 14518 \# of layers: 3

Kx Ky Kz Ss Por 
8.85439e+02 8.85439e+02 8.85439e+01 1.00000e-09 2.12000e-01 8.85439e+02 8.85439e+02 8.85439e+01 1.00000e-09 2.12000e-01 1.00000e-06 1.00000e-06 1.00000e-06 1.00000e-09 5.00000e-02

Element: 14519 \# of layers: 2

$\mathrm{Kx} \mathrm{Ky} \mathrm{Kz}$ Ss Por

8.85439e+02 8.85439e+02 8.85439e+01 1.00000e-09 2.12000e-01 1.00000e-06 1.00000e-06 1.00000e-06 1.00000e-09 5.00000e-02

Element: 14520 \# of layers: 2

$\mathrm{Kx} \mathrm{Ky} \mathrm{Kz}$ Ss Por

8.85439e+02 8.85439e+02 8.85439e+01 1.00000e-09 2.12000e-01 1.00000e-06 1.00000e-06 1.00000e-06 1.00000e-09 5.00000e-02

Element: 14521 \# of layers: 2

$\mathrm{Kx} \mathrm{Ky} \mathrm{Kz}$ Ss Por

8.85439e+02 8.85439e+02 8.85439e+01 1.00000e-09 2.12000e-01 1.00000e-06 1.00000e-06 1.00000e-06 1.00000e-09 5.00000e-02

Element: 14522 \# of layers: 3

$\mathrm{Kx} \mathrm{Ky} \mathrm{Kz}$ Ss Por

8.85439e+02 8.85439e+02 8.85439e+01 1.00000e-09 2.12000e-01 $8.85439 \mathrm{e}+02$ 8.85439e+02 8.85439e+01 1.00000e-09 2.12000e-01 1.00000e-06 1.00000e-06 1.00000e-06 1.00000e-09 5.00000e-02

Element: 14523 \# of layers: 3

$\mathrm{Kx} \mathrm{Ky} \mathrm{Kz}$ Ss Por

8.85439e+02 8.85439e+02 8.85439e+01 1.00000e-09 2.12000e-01

$8.85439 \mathrm{e}+02$ 8.85439e+02 8.85439e+01 1.00000e-09 2.12000e-01 $1.00000 \mathrm{e}-06$ 1.00000e-06 1.00000e-06 1.00000e-09 5.00000e-02

Element: 14524 \# of layers: 3

$\mathrm{Kx} \mathrm{Ky} \mathrm{Kz}$ Ss Por

8.85439e+02 8.85439e+02 8.85439e+01 1.00000e-09 2.12000e-01

$8.85439 \mathrm{e}+02$ 8.85439e+02 8.85439e+01 1.00000e-09 2.12000e-01

1.00000e-06 1.00000e-06 1.00000e-06 1.00000e-09 5.00000e-02

Element: 14525 \# of layers: 3

$\mathrm{Kx} \mathrm{Ky} \mathrm{Kz}$ Ss Por

8.85439e+02 8.85439e+02 8.85439e+01 1.00000e-09 2.12000e-01

$8.85439 \mathrm{e}+02$ 8.85439e+02 8.85439e+01 1.00000e-09 2.12000e-01

1.00000e-06 1.00000e-06 1.00000e-06 1.00000e-09 5.00000e-02

Element: 14526 \# of layers: 2

Kx Ky Kz Ss Por

8.85439e+02 8.85439e+02 8.85439e+01 1.00000e-09 2.12000e-01 1.00000e-06 1.00000e-06 1.00000e-06 1.00000e-09 5.00000e-02

Element: 14527 \# of layers: 3

$\mathrm{Kx} \mathrm{Ky} \mathrm{Kz}$ Ss Por

3.80573e+01 3.80573e+01 3.80573e+00 1.00000e-09 2.12000e-01

$3.80573 \mathrm{e}+013.80573 \mathrm{e}+013.80573 \mathrm{e}+00$ 1.00000e-09 2.12000e-01

$1.00000 \mathrm{e}-06$ 1.00000e-06 1.00000e-06 1.00000e-09 5.00000e-02

Element: 14528 \# of layers: 3

Kx Ky Kz Ss Por 
8.85439e+02 8.85439e+02 8.85439e+01 1.00000e-09 2.12000e-01 8.85439e+02 8.85439e+02 8.85439e+01 1.00000e-09 2.12000e-01 1.00000e-06 1.00000e-06 1.00000e-06 1.00000e-09 5.00000e-02

Element: 14529 \# of layers: 3

$\mathrm{Kx} \mathrm{Ky} \mathrm{Kz}$ Ss Por

8.85439e+02 8.85439e+02 8.85439e+01 1.00000e-09 2.12000e-01

$8.85439 \mathrm{e}+02$ 8.85439e+02 8.85439e+01 1.00000e-09 2.12000e-01

1.00000e-06 1.00000e-06 1.00000e-06 1.00000e-09 5.00000e-02

Element: 14530 \# of layers: 3

$\mathrm{Kx} \mathrm{Ky} \mathrm{Kz}$ Ss Por

8.85439e+02 8.85439e+02 8.85439e+01 1.00000e-09 2.12000e-01

$8.85439 \mathrm{e}+02$ 8.85439e+02 8.85439e+01 1.00000e-09 2.12000e-01

1.00000e-06 1.00000e-06 1.00000e-06 1.00000e-09 5.00000e-02

Element: 14531 \# of layers: 3

$\mathrm{Kx} \mathrm{Ky} \mathrm{Kz}$ Ss Por

8.85439e+02 8.85439e+02 8.85439e+01 1.00000e-09 2.12000e-01

8.85439e+02 8.85439e+02 8.85439e+01 1.00000e-09 2.12000e-01

1.00000e-06 1.00000e-06 1.00000e-06 1.00000e-09 5.00000e-02

Element: 14532 \# of layers: 3

$\mathrm{Kx} \mathrm{Ky} \mathrm{Kz}$ Ss Por

3.80573e+01 3.80573e+01 3.80573e+00 1.00000e-09 2.12000e-01

$3.80573 \mathrm{e}+013.80573 \mathrm{e}+013.80573 \mathrm{e}+00$ 1.00000e-09 2.12000e-01

1.00000e-06 1.00000e-06 1.00000e-06 1.00000e-09 5.00000e-02

Element: 14533 \# of layers: 3

$\mathrm{Kx} \mathrm{Ky} \mathrm{Kz}$ Ss Por

8.29165e+00 8.29165e+00 8.29165e-01 1.00000e-09 2.12000e-01

$8.29165 \mathrm{e}+00$ 8.29165e+00 8.29165e-01 1.00000e-09 2.12000e-01

1.00000e-06 1.00000e-06 1.00000e-06 1.00000e-09 5.00000e-02

Element: 14534 \# of layers: 3

$\mathrm{Kx} \mathrm{Ky} \mathrm{Kz}$ Ss Por

8.29165e+00 8.29165e+00 8.29165e-01 1.00000e-09 2.12000e-01

8.29165e+00 8.29165e+00 8.29165e-01 1.00000e-09 2.12000e-01

1.00000e-06 1.00000e-06 1.00000e-06 1.00000e-09 5.00000e-02

Element: 14535 \# of layers: 3

$\mathrm{Kx} \mathrm{Ky} \mathrm{Kz}$ Ss Por

3.80573e+01 3.80573e+01 3.80573e+00 1.00000e-09 2.12000e-01

$3.80573 \mathrm{e}+013.80573 \mathrm{e}+013.80573 \mathrm{e}+00$ 1.00000e-09 2.12000e-01

1.00000e-06 1.00000e-06 1.00000e-06 1.00000e-09 5.00000e-02

Element: 14536 \# of layers: 4

$\mathrm{Kx} \mathrm{Ky} \mathrm{Kz}$ Ss Por

3.80573e+01 3.80573e+01 3.80573e+00 1.00000e-09 2.12000e-01

$3.80573 \mathrm{e}+013.80573 \mathrm{e}+013.80573 \mathrm{e}+001.00000 \mathrm{e}-092.12000 \mathrm{e}-01$

$3.80573 \mathrm{e}+013.80573 \mathrm{e}+01$ 3.80573e+00 1.00000e-09 2.12000e-01

1.00000e-06 1.00000e-06 1.00000e-06 1.00000e-09 5.00000e-02

Element: 14537 \# of layers: 3

Kx Ky Kz Ss Por 
$8.29165 \mathrm{e}+008.29165 \mathrm{e}+00$ 8.29165e-01 1.00000e-09 2.12000e-01 $8.29165 \mathrm{e}+008.29165 \mathrm{e}+00$ 8.29165e-01 1.00000e-09 2.12000e-01 $1.00000 \mathrm{e}-06$ 1.00000e-06 1.00000e-06 1.00000e-09 5.00000e-02

Element: 14538 \# of layers: 3

Kx Ky Kz Ss Por

$8.29165 \mathrm{e}+008.29165 \mathrm{e}+00$ 8.29165e-01 1.00000e-09 2.12000e-01

$8.29165 \mathrm{e}+008.29165 \mathrm{e}+00$ 8.29165e-01 1.00000e-09 2.12000e-01 $1.00000 \mathrm{e}-06$ 1.00000e-06 1.00000e-06 1.00000e-09 5.00000e-02

Element: 14539 \# of layers: 3

Kx Ky Kz Ss Por

$8.29165 \mathrm{e}+008.29165 \mathrm{e}+00$ 8.29165e-01 1.00000e-09 2.12000e-01

$8.29165 \mathrm{e}+008.29165 \mathrm{e}+00$ 8.29165e-01 1.00000e-09 2.12000e-01

$1.00000 \mathrm{e}-06$ 1.00000e-06 1.00000e-06 1.00000e-09 5.00000e-02

Element: 14540 \# of layers: 3

Kx Ky Kz Ss Por

$8.29165 \mathrm{e}+008.29165 \mathrm{e}+00$ 8.29165e-01 1.00000e-09 2.12000e-01

$8.29165 \mathrm{e}+008.29165 \mathrm{e}+00$ 8.29165e-01 1.00000e-09 2.12000e-01

$1.00000 \mathrm{e}-06$ 1.00000e-06 1.00000e-06 1.00000e-09 5.00000e-02

Element: 14541 \# of layers: 3

Kx Ky Kz Ss Por

$8.29165 \mathrm{e}+008.29165 \mathrm{e}+00$ 8.29165e-01 1.00000e-09 2.12000e-01

$8.29165 \mathrm{e}+008.29165 \mathrm{e}+00$ 8.29165e-01 1.00000e-09 2.12000e-01

$1.00000 \mathrm{e}-06$ 1.00000e-06 1.00000e-06 1.00000e-09 5.00000e-02

Element: 14542 \# of layers: 3

Kx Ky Kz Ss Por

$8.29165 \mathrm{e}+008.29165 \mathrm{e}+00$ 8.29165e-01 1.00000e-09 2.12000e-01

$8.29165 \mathrm{e}+008.29165 \mathrm{e}+00$ 8.29165e-01 1.00000e-09 2.12000e-01

$1.00000 \mathrm{e}-06$ 1.00000e-06 1.00000e-06 1.00000e-09 5.00000e-02

Element: 14543 \# of layers: 3

Kx Ky Kz Ss Por

$8.92099 \mathrm{e}+01$ 8.92099e+01 8.92099e+00 1.00000e-09 2.12000e-01

$8.92099 \mathrm{e}+018.92099 \mathrm{e}+018.92099 \mathrm{e}+00$ 1.00000e-09 2.12000e-01

$1.00000 \mathrm{e}-06$ 1.00000e-06 1.00000e-06 1.00000e-09 5.00000e-02

Element: 14544 \# of layers: 3

Kx Ky Kz Ss Por

$8.92099 \mathrm{e}+01$ 8.92099e+01 8.92099e+00 1.00000e-09 2.12000e-01

$8.92099 \mathrm{e}+01$ 8.92099e+01 8.92099e+00 1.00000e-09 2.12000e-01

$1.00000 \mathrm{e}-06$ 1.00000e-06 1.00000e-06 1.00000e-09 5.00000e-02

Element: 14545 \# of layers: 3

Kx Ky Kz Ss Por

$8.92099 \mathrm{e}+018.92099 \mathrm{e}+018.92099 \mathrm{e}+00$ 1.00000e-09 2.12000e-01

$8.92099 \mathrm{e}+018.92099 \mathrm{e}+018.92099 \mathrm{e}+00$ 1.00000e-09 2.12000e-01

$1.00000 \mathrm{e}-06$ 1.00000e-06 1.00000e-06 1.00000e-09 5.00000e-02

Element: 14546 \# of layers: 3

Kx Ky Kz Ss Por

8.92099e+01 8.92099e+01 8.92099e+00 1.00000e-09 2.12000e-01 
$8.92099 \mathrm{e}+018.92099 \mathrm{e}+018.92099 \mathrm{e}+00$ 1.00000e-09 2.12000e-01 1.00000e-06 1.00000e-06 1.00000e-06 1.00000e-09 5.00000e-02

Element: 14547 \# of layers: 3

Kx Ky Kz Ss Por

8.92099e+01 8.92099e+01 8.92099e+00 1.00000e-09 2.12000e-01

$8.92099 \mathrm{e}+018.92099 \mathrm{e}+018.92099 \mathrm{e}+00$ 1.00000e-09 2.12000e-01

1.00000e-06 1.00000e-06 1.00000e-06 1.00000e-09 5.00000e-02

Element: 14548 \# of layers: 3

$\mathrm{Kx} \mathrm{Ky} \mathrm{Kz}$ Ss Por

8.29165e+00 8.29165e+00 8.29165e-01 1.00000e-09 2.12000e-01

8.29165e+00 8.29165e+00 8.29165e-01 1.00000e-09 2.12000e-01

1.00000e-06 1.00000e-06 1.00000e-06 1.00000e-09 5.00000e-02

Element: 14549 \# of layers: 3

$\mathrm{Kx} \mathrm{Ky} \mathrm{Kz}$ Ss Por

8.29165e+00 8.29165e+00 8.29165e-01 1.00000e-09 2.12000e-01

$8.29165 \mathrm{e}+00$ 8.29165e+00 8.29165e-01 1.00000e-09 2.12000e-01

1.00000e-06 1.00000e-06 1.00000e-06 1.00000e-09 5.00000e-02

Element: 14550 \# of layers: 3

$\mathrm{Kx} \mathrm{Ky} \mathrm{Kz}$ Ss Por

8.92099e+01 8.92099e+01 8.92099e+00 1.00000e-09 2.12000e-01

8.92099e+01 8.92099e+01 8.92099e+00 1.00000e-09 2.12000e-01

1.00000e-06 1.00000e-06 1.00000e-06 1.00000e-09 5.00000e-02

Element: 14551 \# of layers: 3

Kx Ky Kz Ss Por

8.92099e+01 8.92099e+01 8.92099e+00 1.00000e-09 2.12000e-01

$8.92099 \mathrm{e}+018.92099 \mathrm{e}+018.92099 \mathrm{e}+001.00000 \mathrm{e}-092.12000 \mathrm{e}-01$

$1.00000 \mathrm{e}-06$ 1.00000e-06 1.00000e-06 1.00000e-09 5.00000e-02

Element: 14552 \# of layers: 3

Kx Ky Kz Ss Por

8.85439e+02 8.85439e+02 8.85439e+01 1.00000e-09 2.12000e-01

$8.85439 \mathrm{e}+02$ 8.85439e+02 8.85439e+01 1.00000e-09 2.12000e-01

1.00000e-06 1.00000e-06 1.00000e-06 1.00000e-09 5.00000e-02

Element: 14553 \# of layers: 4

$\mathrm{Kx} \mathrm{Ky} \mathrm{Kz}$ Ss Por

8.85439e+02 8.85439e+02 8.85439e+01 1.00000e-09 2.12000e-01

8.85439e+02 8.85439e+02 8.85439e+01 1.00000e-09 2.12000e-01

$8.85439 \mathrm{e}+02$ 8.85439e+02 8.85439e+01 1.00000e-09 2.12000e-01

1.00000e-06 1.00000e-06 1.00000e-06 1.00000e-09 5.00000e-02

Element: 14554 \# of layers: 4

$\mathrm{Kx} \mathrm{Ky} \mathrm{Kz}$ Ss Por

8.85439e+02 8.85439e+02 8.85439e+01 1.00000e-09 2.12000e-01

$8.85439 \mathrm{e}+02$ 8.85439e+02 8.85439e+01 1.00000e-09 2.12000e-01

$8.85439 \mathrm{e}+02$ 8.85439e+02 8.85439e+01 1.00000e-09 2.12000e-01

$1.00000 \mathrm{e}-06$ 1.00000e-06 1.00000e-06 1.00000e-09 5.00000e-02

Element: 14555 \# of layers: 4

Kx Ky Kz Ss Por 
$3.80573 \mathrm{e}+013.80573 \mathrm{e}+01$ 3.80573e+00 1.00000e-09 2.12000e-01 $3.80573 \mathrm{e}+013.80573 \mathrm{e}+013.80573 \mathrm{e}+00$ 1.00000e-09 2.12000e-01 $3.80573 \mathrm{e}+013.80573 \mathrm{e}+013.80573 \mathrm{e}+00$ 1.00000e-09 2.12000e-01 1.00000e-06 1.00000e-06 1.00000e-06 1.00000e-09 5.00000e-02

Element: 14556 \# of layers: 3

$\mathrm{Kx} \mathrm{Ky} \mathrm{Kz}$ Ss Por

3.80573e+01 3.80573e+01 3.80573e+00 1.00000e-09 2.12000e-01

$3.80573 \mathrm{e}+013.80573 \mathrm{e}+013.80573 \mathrm{e}+001.00000 \mathrm{e}-092.12000 \mathrm{e}-01$

1.00000e-06 1.00000e-06 1.00000e-06 1.00000e-09 5.00000e-02

Element: 14557 \# of layers: 3

$\mathrm{Kx} \mathrm{Ky} \mathrm{Kz}$ Ss Por

8.29165e+00 8.29165e+00 8.29165e-01 1.00000e-09 2.12000e-01

8.29165e+00 8.29165e+00 8.29165e-01 1.00000e-09 2.12000e-01

1.00000e-06 1.00000e-06 1.00000e-06 1.00000e-09 5.00000e-02

Element: 14558 \# of layers: 3

Kx Ky Kz Ss Por

8.92099e+01 8.92099e+01 8.92099e+00 1.00000e-09 2.12000e-01

$8.92099 \mathrm{e}+018.92099 \mathrm{e}+018.92099 \mathrm{e}+00$ 1.00000e-09 2.12000e-01 1.00000e-06 1.00000e-06 1.00000e-06 1.00000e-09 5.00000e-02

Element: 14559 \# of layers: 3

$\mathrm{Kx} \mathrm{Ky} \mathrm{Kz}$ Ss Por

8.85439e+02 8.85439e+02 8.85439e+01 1.00000e-09 2.12000e-01

$8.85439 \mathrm{e}+02$ 8.85439e+02 8.85439e+01 1.00000e-09 2.12000e-01

1.00000e-06 1.00000e-06 1.00000e-06 1.00000e-09 5.00000e-02

Element: 14560 \# of layers: 2

$\mathrm{Kx} \mathrm{Ky} \mathrm{Kz}$ Ss Por

$1.28905 \mathrm{e}+02$ 1.28905e+02 1.28905e+01 1.00000e-09 2.12000e-01

1.00000e-06 1.00000e-06 1.00000e-06 1.00000e-09 5.00000e-02

Element: 14561 \# of layers: 2

$\mathrm{Kx} \mathrm{Ky} \mathrm{Kz}$ Ss Por

$1.28905 \mathrm{e}+02$ 1.28905e+02 1.28905e+01 1.00000e-09 2.12000e-01

1.00000e-06 1.00000e-06 1.00000e-06 1.00000e-09 5.00000e-02

Element: 14562 \# of layers: 2

$\mathrm{Kx} \mathrm{Ky} \mathrm{Kz}$ Ss Por

$1.28905 \mathrm{e}+02$ 1.28905e+02 1.28905e+01 1.00000e-09 2.12000e-01

1.00000e-06 1.00000e-06 1.00000e-06 1.00000e-09 5.00000e-02

Element: 14563 \# of layers: 2

$\mathrm{Kx} \mathrm{Ky} \mathrm{Kz}$ Ss Por

$1.28905 \mathrm{e}+02$ 1.28905e+02 1.28905e+01 1.00000e-09 2.12000e-01

1.00000e-06 1.00000e-06 1.00000e-06 1.00000e-09 5.00000e-02

Element: 14564 \# of layers: 2

$\mathrm{Kx} \mathrm{Ky} \mathrm{Kz}$ Ss Por

$1.28905 \mathrm{e}+02$ 1.28905e+02 1.28905e+01 1.00000e-09 2.12000e-01

1.00000e-06 1.00000e-06 1.00000e-06 1.00000e-09 5.00000e-02

Element: 14565 \# of layers: 6

Kx Ky Kz Ss Por 
6.26886e+01 6.26886e+01 6.26886e+00 1.00000e-09 2.12000e-01 6.26886e+01 6.26886e+01 6.26886e+00 1.00000e-09 2.12000e-01 $6.26886 \mathrm{e}+016.26886 \mathrm{e}+016.26886 \mathrm{e}+00$ 1.00000e-09 2.12000e-01 $6.26886 \mathrm{e}+016.26886 \mathrm{e}+016.26886 \mathrm{e}+001.00000 \mathrm{e}-092.12000 \mathrm{e}-01$ $1.00000 \mathrm{e}-02$ 1.00000e-02 1.00000e-03 1.00000e-09 1.00000e-01 $1.00000 \mathrm{e}+001.00000 \mathrm{e}+001.00000 \mathrm{e}-011.00000 \mathrm{e}-091.00000 \mathrm{e}-01$ Element: 14566 \# of layers: 6

$\mathrm{Kx} \mathrm{Ky} \mathrm{Kz}$ Ss Por

6.26886e+01 6.26886e+01 6.26886e+00 1.00000e-09 2.12000e-01

$6.26886 \mathrm{e}+016.26886 \mathrm{e}+016.26886 \mathrm{e}+00$ 1.00000e-09 2.12000e-01 $6.26886 \mathrm{e}+016.26886 \mathrm{e}+016.26886 \mathrm{e}+00$ 1.00000e-09 2.12000e-01 $6.26886 \mathrm{e}+016.26886 \mathrm{e}+016.26886 \mathrm{e}+001.00000 \mathrm{e}-092.12000 \mathrm{e}-01$ $1.00000 \mathrm{e}-02$ 1.00000e-02 1.00000e-03 1.00000e-09 1.00000e-01 $1.00000 \mathrm{e}+001.00000 \mathrm{e}+001.00000 \mathrm{e}-011.00000 \mathrm{e}-09$ 1.00000e-01 Element: 14567 \# of layers: 6

Kx Ky Kz Ss Por

6.26886e+01 6.26886e+01 6.26886e+00 1.00000e-09 2.12000e-01

$6.26886 \mathrm{e}+016.26886 \mathrm{e}+016.26886 \mathrm{e}+00$ 1.00000e-09 2.12000e-01 $6.26886 \mathrm{e}+016.26886 \mathrm{e}+01$ 6.26886e+00 1.00000e-09 2.12000e-01 $6.26886 \mathrm{e}+016.26886 \mathrm{e}+016.26886 \mathrm{e}+00$ 1.00000e-09 2.12000e-01 $1.00000 \mathrm{e}-02$ 1.00000e-02 1.00000e-03 1.00000e-09 1.00000e-01 $1.00000 \mathrm{e}+001.00000 \mathrm{e}+001.00000 \mathrm{e}-011.00000 \mathrm{e}-091.00000 \mathrm{e}-01$ Element: 14568 \# of layers: 6

Kx Ky Kz Ss Por

$6.26886 \mathrm{e}+016.26886 \mathrm{e}+016.26886 \mathrm{e}+00$ 1.00000e-09 2.12000e-01 $6.26886 \mathrm{e}+016.26886 \mathrm{e}+016.26886 \mathrm{e}+001.00000 \mathrm{e}-092.12000 \mathrm{e}-01$ $6.26886 \mathrm{e}+016.26886 \mathrm{e}+016.26886 \mathrm{e}+00$ 1.00000e-09 2.12000e-01 $6.26886 \mathrm{e}+016.26886 \mathrm{e}+016.26886 \mathrm{e}+00$ 1.00000e-09 2.12000e-01 $1.00000 \mathrm{e}-02$ 1.00000e-02 1.00000e-03 1.00000e-09 1.00000e-01 $1.00000 \mathrm{e}+001.00000 \mathrm{e}+001.00000 \mathrm{e}-011.00000 \mathrm{e}-091.00000 \mathrm{e}-01$ Element: 14569 \# of layers: 6

$\mathrm{Kx} \mathrm{Ky} \mathrm{Kz}$ Ss Por

6.26886e+01 6.26886e+01 6.26886e+00 1.00000e-09 2.12000e-01 $6.26886 \mathrm{e}+016.26886 \mathrm{e}+016.26886 \mathrm{e}+001.00000 \mathrm{e}-092.12000 \mathrm{e}-01$ $6.26886 \mathrm{e}+016.26886 \mathrm{e}+016.26886 \mathrm{e}+00$ 1.00000e-09 2.12000e-01 $6.26886 \mathrm{e}+016.26886 \mathrm{e}+016.26886 \mathrm{e}+001.00000 \mathrm{e}-09$ 2.12000e-01 1.00000e-02 1.00000e-02 1.00000e-03 1.00000e-09 1.00000e-01 $1.00000 \mathrm{e}+001.00000 \mathrm{e}+001.00000 \mathrm{e}-011.00000 \mathrm{e}-091.00000 \mathrm{e}-01$ Element: 14570 \# of layers: 6

$\mathrm{Kx} \mathrm{Ky} \mathrm{Kz}$ Ss Por

6.26886e+01 6.26886e+01 6.26886e+00 1.00000e-09 2.12000e-01 $6.26886 \mathrm{e}+016.26886 \mathrm{e}+016.26886 \mathrm{e}+001.00000 \mathrm{e}-092.12000 \mathrm{e}-01$ 6.26886e+01 6.26886e+01 6.26886e+00 1.00000e-09 2.12000e-01 6.26886e+01 6.26886e+01 6.26886e+00 1.00000e-09 2.12000e-01 $1.00000 \mathrm{e}-02$ 1.00000e-02 1.00000e-03 1.00000e-09 1.00000e-01 $1.00000 \mathrm{e}+001.00000 \mathrm{e}+001.00000 \mathrm{e}-011.00000 \mathrm{e}-091.00000 \mathrm{e}-01$ 
Element: 14571 \# of layers: 6

Kx Ky Kz Ss Por

$6.26886 \mathrm{e}+016.26886 \mathrm{e}+016.26886 \mathrm{e}+00$ 1.00000e-09 2.12000e-01

$6.26886 \mathrm{e}+016.26886 \mathrm{e}+016.26886 \mathrm{e}+001.00000 \mathrm{e}-092.12000 \mathrm{e}-01$

$6.26886 \mathrm{e}+016.26886 \mathrm{e}+016.26886 \mathrm{e}+001.00000 \mathrm{e}-092.12000 \mathrm{e}-01$

$6.26886 \mathrm{e}+016.26886 \mathrm{e}+016.26886 \mathrm{e}+001.00000 \mathrm{e}-092.12000 \mathrm{e}-01$

$1.00000 \mathrm{e}-021.00000 \mathrm{e}-02$ 1.00000e-03 1.00000e-09 1.00000e-01

$1.00000 \mathrm{e}+001.00000 \mathrm{e}+001.00000 \mathrm{e}-011.00000 \mathrm{e}-091.00000 \mathrm{e}-01$

Element: 14572 \# of layers: 6

Kx Ky Kz Ss Por

$8.75944 \mathrm{e}+018.75944 \mathrm{e}+018.75944 \mathrm{e}+00$ 1.00000e-09 2.12000e-01

$8.75944 \mathrm{e}+018.75944 \mathrm{e}+018.75944 \mathrm{e}+001.00000 \mathrm{e}-092.12000 \mathrm{e}-01$

$8.75944 \mathrm{e}+018.75944 \mathrm{e}+018.75944 \mathrm{e}+001.00000 \mathrm{e}-092.12000 \mathrm{e}-01$

$8.75944 \mathrm{e}+018.75944 \mathrm{e}+018.75944 \mathrm{e}+001.00000 \mathrm{e}-092.12000 \mathrm{e}-01$

$1.00000 \mathrm{e}-02$ 1.00000e-02 1.00000e-03 1.00000e-09 1.00000e-01

$1.00000 \mathrm{e}+001.00000 \mathrm{e}+00$ 1.00000e-01 1.00000e-09 1.00000e-01

Element: 14573 \# of layers: 6

Kx Ky Kz Ss Por

$8.75944 \mathrm{e}+01$ 8.75944e+01 8.75944e+00 1.00000e-09 2.12000e-01

$8.75944 \mathrm{e}+018.75944 \mathrm{e}+018.75944 \mathrm{e}+001.00000 \mathrm{e}-092.12000 \mathrm{e}-01$

$8.75944 \mathrm{e}+018.75944 \mathrm{e}+018.75944 \mathrm{e}+001.00000 \mathrm{e}-092.12000 \mathrm{e}-01$

$8.75944 \mathrm{e}+018.75944 \mathrm{e}+018.75944 \mathrm{e}+00$ 1.00000e-09 2.12000e-01

$1.00000 \mathrm{e}-02$ 1.00000e-02 1.00000e-03 1.00000e-09 1.00000e-01

$1.00000 \mathrm{e}+001.00000 \mathrm{e}+001.00000 \mathrm{e}-011.00000 \mathrm{e}-091.00000 \mathrm{e}-01$

Element: 14574 \# of layers: 6

Kx Ky Kz Ss Por

$8.75944 \mathrm{e}+01$ 8.75944e+01 8.75944e+00 1.00000e-09 2.12000e-01

$8.75944 \mathrm{e}+018.75944 \mathrm{e}+018.75944 \mathrm{e}+001.00000 \mathrm{e}-092.12000 \mathrm{e}-01$

$8.75944 \mathrm{e}+018.75944 \mathrm{e}+018.75944 \mathrm{e}+001.00000 \mathrm{e}-092.12000 \mathrm{e}-01$

$8.75944 \mathrm{e}+018.75944 \mathrm{e}+018.75944 \mathrm{e}+00$ 1.00000e-09 2.12000e-01

$1.00000 \mathrm{e}-021.00000 \mathrm{e}-02$ 1.00000e-03 1.00000e-09 1.00000e-01

$1.00000 \mathrm{e}+001.00000 \mathrm{e}+001.00000 \mathrm{e}-011.00000 \mathrm{e}-091.00000 \mathrm{e}-01$

Element: 14575 \# of layers: 6

Kx Ky Kz Ss Por

$8.75944 \mathrm{e}+018.75944 \mathrm{e}+018.75944 \mathrm{e}+00$ 1.00000e-09 2.12000e-01

$8.75944 \mathrm{e}+018.75944 \mathrm{e}+018.75944 \mathrm{e}+001.00000 \mathrm{e}-092.12000 \mathrm{e}-01$

$8.75944 \mathrm{e}+018.75944 \mathrm{e}+018.75944 \mathrm{e}+00$ 1.00000e-09 2.12000e-01

$8.75944 \mathrm{e}+018.75944 \mathrm{e}+018.75944 \mathrm{e}+00$ 1.00000e-09 2.12000e-01

$1.00000 \mathrm{e}-02$ 1.00000e-02 1.00000e-03 1.00000e-09 1.00000e-01

$1.00000 \mathrm{e}+001.00000 \mathrm{e}+001.00000 \mathrm{e}-011.00000 \mathrm{e}-091.00000 \mathrm{e}-01$

Element: 14576 \# of layers: 6

Kx Ky Kz Ss Por

$8.75944 \mathrm{e}+018.75944 \mathrm{e}+018.75944 \mathrm{e}+00$ 1.00000e-09 2.12000e-01

$8.75944 \mathrm{e}+018.75944 \mathrm{e}+018.75944 \mathrm{e}+001.00000 \mathrm{e}-092.12000 \mathrm{e}-01$

$8.75944 \mathrm{e}+018.75944 \mathrm{e}+018.75944 \mathrm{e}+001.00000 \mathrm{e}-092.12000 \mathrm{e}-01$

$8.75944 \mathrm{e}+018.75944 \mathrm{e}+018.75944 \mathrm{e}+001.00000 \mathrm{e}-092.12000 \mathrm{e}-01$ 
$1.00000 \mathrm{e}-02$ 1.00000e-02 1.00000e-03 1.00000e-09 1.00000e-01 $1.00000 \mathrm{e}+001.00000 \mathrm{e}+001.00000 \mathrm{e}-01$ 1.00000e-09 1.00000e-01 Element: 14577 \# of layers: 6

Kx Ky Kz Ss Por

8.75944e+01 8.75944e+01 8.75944e+00 1.00000e-09 2.12000e-01

$8.75944 \mathrm{e}+018.75944 \mathrm{e}+018.75944 \mathrm{e}+001.00000 \mathrm{e}-092.12000 \mathrm{e}-01$

$8.75944 \mathrm{e}+018.75944 \mathrm{e}+018.75944 \mathrm{e}+001.00000 \mathrm{e}-092.12000 \mathrm{e}-01$

$8.75944 \mathrm{e}+018.75944 \mathrm{e}+018.75944 \mathrm{e}+001.00000 \mathrm{e}-092.12000 \mathrm{e}-01$

$1.00000 \mathrm{e}-02$ 1.00000e-02 1.00000e-03 1.00000e-09 1.00000e-01

$1.00000 \mathrm{e}+001.00000 \mathrm{e}+001.00000 \mathrm{e}-011.00000 \mathrm{e}-091.00000 \mathrm{e}-01$

Element: 14578 \# of layers: 6

Kx Ky Kz Ss Por

8.75944e+01 8.75944e+01 8.75944e+00 1.00000e-09 2.12000e-01

$8.75944 \mathrm{e}+018.75944 \mathrm{e}+018.75944 \mathrm{e}+00$ 1.00000e-09 2.12000e-01

$8.75944 \mathrm{e}+018.75944 \mathrm{e}+018.75944 \mathrm{e}+00$ 1.00000e-09 2.12000e-01

$8.75944 \mathrm{e}+018.75944 \mathrm{e}+018.75944 \mathrm{e}+00$ 1.00000e-09 2.12000e-01

$1.00000 \mathrm{e}-021.00000 \mathrm{e}-021.00000 \mathrm{e}-031.00000 \mathrm{e}-091.00000 \mathrm{e}-01$

$1.00000 \mathrm{e}+001.00000 \mathrm{e}+001.00000 \mathrm{e}-011.00000 \mathrm{e}-091.00000 \mathrm{e}-01$

Element: 14579 \# of layers: 7

$\mathrm{Kx} \mathrm{Ky} \mathrm{Kz}$ Ss Por

8.00950e+01 8.00950e+01 8.00950e+00 1.00000e-09 2.12000e-01

$8.00950 \mathrm{e}+018.00950 \mathrm{e}+018.00950 \mathrm{e}+001.00000 \mathrm{e}-092.12000 \mathrm{e}-01$

$8.00950 \mathrm{e}+018.00950 \mathrm{e}+018.00950 \mathrm{e}+001.00000 \mathrm{e}-092.12000 \mathrm{e}-01$

$8.00950 \mathrm{e}+018.00950 \mathrm{e}+018.00950 \mathrm{e}+001.00000 \mathrm{e}-092.12000 \mathrm{e}-01$

$8.00950 \mathrm{e}+018.00950 \mathrm{e}+018.00950 \mathrm{e}+001.00000 \mathrm{e}-092.12000 \mathrm{e}-01$

$1.00000 \mathrm{e}-02$ 1.00000e-02 1.00000e-03 1.00000e-09 1.00000e-01

$1.00000 \mathrm{e}+001.00000 \mathrm{e}+001.00000 \mathrm{e}-011.00000 \mathrm{e}-091.00000 \mathrm{e}-01$

Element: 14580 \# of layers: 6

Kx Ky Kz Ss Por

$8.00950 \mathrm{e}+018.00950 \mathrm{e}+018.00950 \mathrm{e}+001.00000 \mathrm{e}-092.12000 \mathrm{e}-01$

$8.00950 \mathrm{e}+018.00950 \mathrm{e}+018.00950 \mathrm{e}+001.00000 \mathrm{e}-092.12000 \mathrm{e}-01$

$8.00950 \mathrm{e}+018.00950 \mathrm{e}+018.00950 \mathrm{e}+00$ 1.00000e-09 2.12000e-01

$8.00950 \mathrm{e}+018.00950 \mathrm{e}+018.00950 \mathrm{e}+00$ 1.00000e-09 2.12000e-01

$1.00000 \mathrm{e}-021.00000 \mathrm{e}-021.00000 \mathrm{e}-031.00000 \mathrm{e}-091.00000 \mathrm{e}-01$

$1.00000 \mathrm{e}+001.00000 \mathrm{e}+001.00000 \mathrm{e}-011.00000 \mathrm{e}-091.00000 \mathrm{e}-01$

Element: 14581 \# of layers: 6

Kx Ky Kz Ss Por

8.00950e+01 8.00950e+01 8.00950e+00 1.00000e-09 2.12000e-01

$8.00950 \mathrm{e}+018.00950 \mathrm{e}+018.00950 \mathrm{e}+001.00000 \mathrm{e}-092.12000 \mathrm{e}-01$

$8.00950 \mathrm{e}+018.00950 \mathrm{e}+018.00950 \mathrm{e}+001.00000 \mathrm{e}-092.12000 \mathrm{e}-01$

$8.00950 \mathrm{e}+018.00950 \mathrm{e}+018.00950 \mathrm{e}+00$ 1.00000e-09 2.12000e-01

$1.00000 \mathrm{e}-02$ 1.00000e-02 1.00000e-03 1.00000e-09 1.00000e-01

$1.00000 \mathrm{e}+001.00000 \mathrm{e}+001.00000 \mathrm{e}-011.00000 \mathrm{e}-091.00000 \mathrm{e}-01$

Element: 14582 \# of layers: 7

$\mathrm{Kx} \mathrm{Ky} \mathrm{Kz}$ Ss Por

8.00950e+01 8.00950e+01 8.00950e+00 1.00000e-09 2.12000e-01 
8.00950e+01 8.00950e+01 8.00950e+00 1.00000e-09 2.12000e-01 $8.00950 \mathrm{e}+018.00950 \mathrm{e}+018.00950 \mathrm{e}+001.00000 \mathrm{e}-092.12000 \mathrm{e}-01$ $8.00950 \mathrm{e}+018.00950 \mathrm{e}+018.00950 \mathrm{e}+00$ 1.00000e-09 2.12000e-01 $8.00950 \mathrm{e}+018.00950 \mathrm{e}+018.00950 \mathrm{e}+001.00000 \mathrm{e}-092.12000 \mathrm{e}-01$ $1.00000 \mathrm{e}-02$ 1.00000e-02 1.00000e-03 1.00000e-09 1.00000e-01 $1.00000 \mathrm{e}+001.00000 \mathrm{e}+001.00000 \mathrm{e}-011.00000 \mathrm{e}-091.00000 \mathrm{e}-01$ Element: 14583 \# of layers: 7

Kx Ky Kz Ss Por

8.00950e+01 8.00950e+01 8.00950e+00 1.00000e-09 2.12000e-01 $8.00950 \mathrm{e}+018.00950 \mathrm{e}+018.00950 \mathrm{e}+001.00000 \mathrm{e}-092.12000 \mathrm{e}-01$ $8.00950 \mathrm{e}+018.00950 \mathrm{e}+018.00950 \mathrm{e}+00$ 1.00000e-09 2.12000e-01 $8.00950 \mathrm{e}+018.00950 \mathrm{e}+018.00950 \mathrm{e}+001.00000 \mathrm{e}-092.12000 \mathrm{e}-01$ $8.00950 \mathrm{e}+018.00950 \mathrm{e}+018.00950 \mathrm{e}+001.00000 \mathrm{e}-09$ 2.12000e-01 1.00000e-02 1.00000e-02 1.00000e-03 1.00000e-09 1.00000e-01 $1.00000 \mathrm{e}+001.00000 \mathrm{e}+001.00000 \mathrm{e}-01$ 1.00000e-09 1.00000e-01 Element: 14584 \# of layers: 6

$\mathrm{Kx} \mathrm{Ky} \mathrm{Kz}$ Ss Por 8.00950e+01 8.00950e+01 8.00950e+00 1.00000e-09 2.12000e-01 $8.00950 \mathrm{e}+018.00950 \mathrm{e}+018.00950 \mathrm{e}+001.00000 \mathrm{e}-092.12000 \mathrm{e}-01$ $8.00950 \mathrm{e}+018.00950 \mathrm{e}+018.00950 \mathrm{e}+001.00000 \mathrm{e}-092.12000 \mathrm{e}-01$ $8.00950 \mathrm{e}+018.00950 \mathrm{e}+018.00950 \mathrm{e}+001.00000 \mathrm{e}-092.12000 \mathrm{e}-01$ $1.00000 \mathrm{e}-02$ 1.00000e-02 1.00000e-03 1.00000e-09 1.00000e-01 $1.00000 \mathrm{e}+001.00000 \mathrm{e}+001.00000 \mathrm{e}-011.00000 \mathrm{e}-091.00000 \mathrm{e}-01$ Element: 14585 \# of layers: 7

$\mathrm{Kx} \mathrm{Ky} \mathrm{Kz}$ Ss Por $8.00950 \mathrm{e}+018.00950 \mathrm{e}+018.00950 \mathrm{e}+001.00000 \mathrm{e}-092.12000 \mathrm{e}-01$ $8.00950 \mathrm{e}+018.00950 \mathrm{e}+018.00950 \mathrm{e}+001.00000 \mathrm{e}-092.12000 \mathrm{e}-01$ $8.00950 \mathrm{e}+018.00950 \mathrm{e}+018.00950 \mathrm{e}+001.00000 \mathrm{e}-092.12000 \mathrm{e}-01$ $8.00950 \mathrm{e}+018.00950 \mathrm{e}+018.00950 \mathrm{e}+001.00000 \mathrm{e}-092.12000 \mathrm{e}-01$ $8.00950 \mathrm{e}+018.00950 \mathrm{e}+018.00950 \mathrm{e}+001.00000 \mathrm{e}-09$ 2.12000e-01 $1.00000 \mathrm{e}-02$ 1.00000e-02 1.00000e-03 1.00000e-09 1.00000e-01 $1.00000 \mathrm{e}+001.00000 \mathrm{e}+001.00000 \mathrm{e}-01$ 1.00000e-09 1.00000e-01 Element: 14586 \# of layers: 5

$\mathrm{Kx} \mathrm{Ky} \mathrm{Kz}$ Ss Por $1.08423 \mathrm{e}+02$ 1.08423e+02 1.08423e+01 1.00000e-09 2.12000e-01 $1.08423 \mathrm{e}+02$ 1.08423e+02 1.08423e+01 1.00000e-09 2.12000e-01 $1.08423 \mathrm{e}+021.08423 \mathrm{e}+02$ 1.08423e+01 1.00000e-09 2.12000e-01 $1.00000 \mathrm{e}-02$ 1.00000e-02 1.00000e-03 1.00000e-09 1.00000e-01 $1.00000 \mathrm{e}+001.00000 \mathrm{e}+001.00000 \mathrm{e}-011.00000 \mathrm{e}-091.00000 \mathrm{e}-01$ Element: 14587 \# of layers: 5

$\mathrm{Kx} \mathrm{Ky} \mathrm{Kz}$ Ss Por $1.08423 \mathrm{e}+02$ 1.08423e+02 1.08423e+01 1.00000e-09 2.12000e-01 $1.08423 \mathrm{e}+02$ 1.08423e+02 1.08423e+01 1.00000e-09 2.12000e-01 1.08423e+02 1.08423e+02 1.08423e+01 1.00000e-09 2.12000e-01 $1.00000 \mathrm{e}-02$ 1.00000e-02 1.00000e-03 1.00000e-09 1.00000e-01 $1.00000 \mathrm{e}+001.00000 \mathrm{e}+001.00000 \mathrm{e}-011.00000 \mathrm{e}-091.00000 \mathrm{e}-01$ 
Element: 14588 \# of layers: 5

Kx Ky Kz Ss Por

$1.08423 \mathrm{e}+021.08423 \mathrm{e}+021.08423 \mathrm{e}+01$ 1.00000e-09 2.12000e-01

$1.08423 \mathrm{e}+021.08423 \mathrm{e}+021.08423 \mathrm{e}+011.00000 \mathrm{e}-092.12000 \mathrm{e}-01$

$1.08423 \mathrm{e}+021.08423 \mathrm{e}+021.08423 \mathrm{e}+011.00000 \mathrm{e}-092.12000 \mathrm{e}-01$

$1.00000 \mathrm{e}-02$ 1.00000e-02 1.00000e-03 1.00000e-09 1.00000e-01

$1.00000 \mathrm{e}+001.00000 \mathrm{e}+001.00000 \mathrm{e}-011.00000 \mathrm{e}-091.00000 \mathrm{e}-01$

Element: 14589 \# of layers: 6

Kx Ky Kz Ss Por

$1.08423 \mathrm{e}+021.08423 \mathrm{e}+021.08423 \mathrm{e}+01$ 1.00000e-09 2.12000e-01

$1.08423 \mathrm{e}+021.08423 \mathrm{e}+021.08423 \mathrm{e}+011.00000 \mathrm{e}-092.12000 \mathrm{e}-01$

$1.08423 \mathrm{e}+02 \quad 1.08423 \mathrm{e}+02 \quad 1.08423 \mathrm{e}+01$ 1.00000e-09 2.12000e-01

$1.08423 \mathrm{e}+021.08423 \mathrm{e}+021.08423 \mathrm{e}+011.00000 \mathrm{e}-092.12000 \mathrm{e}-01$

$1.00000 \mathrm{e}-021.00000 \mathrm{e}-02$ 1.00000e-03 1.00000e-09 1.00000e-01

$1.00000 \mathrm{e}+001.00000 \mathrm{e}+001.00000 \mathrm{e}-011.00000 \mathrm{e}-091.00000 \mathrm{e}-01$

Element: 14590 \# of layers: 5

Kx Ky Kz Ss Por

$1.08423 \mathrm{e}+02$ 1.08423e+02 1.08423e+01 1.00000e-09 2.12000e-01

$1.08423 \mathrm{e}+021.08423 \mathrm{e}+021.08423 \mathrm{e}+011.00000 \mathrm{e}-092.12000 \mathrm{e}-01$

$1.08423 \mathrm{e}+021.08423 \mathrm{e}+02 \quad 1.08423 \mathrm{e}+011.00000 \mathrm{e}-092.12000 \mathrm{e}-01$

$1.00000 \mathrm{e}-021.00000 \mathrm{e}-021.00000 \mathrm{e}-031.00000 \mathrm{e}-091.00000 \mathrm{e}-01$

$1.00000 \mathrm{e}+001.00000 \mathrm{e}+001.00000 \mathrm{e}-011.00000 \mathrm{e}-091.00000 \mathrm{e}-01$

Element: 14591 \# of layers: 5

Kx Ky Kz Ss Por

$1.08423 \mathrm{e}+02 \quad 1.08423 \mathrm{e}+021.08423 \mathrm{e}+01$ 1.00000e-09 2.12000e-01

$1.08423 \mathrm{e}+021.08423 \mathrm{e}+021.08423 \mathrm{e}+011.00000 \mathrm{e}-092.12000 \mathrm{e}-01$

$1.08423 \mathrm{e}+021.08423 \mathrm{e}+021.08423 \mathrm{e}+011.00000 \mathrm{e}-092.12000 \mathrm{e}-01$

$1.00000 \mathrm{e}-021.00000 \mathrm{e}-02$ 1.00000e-03 1.00000e-09 1.00000e-01

$1.00000 \mathrm{e}+001.00000 \mathrm{e}+001.00000 \mathrm{e}-011.00000 \mathrm{e}-091.00000 \mathrm{e}-01$

Element: 14592 \# of layers: 5

Kx Ky Kz Ss Por

$1.08423 \mathrm{e}+021.08423 \mathrm{e}+021.08423 \mathrm{e}+01$ 1.00000e-09 2.12000e-01

$1.08423 \mathrm{e}+02 \quad 1.08423 \mathrm{e}+02 \quad 1.08423 \mathrm{e}+01$ 1.00000e-09 2.12000e-01

$1.08423 \mathrm{e}+021.08423 \mathrm{e}+021.08423 \mathrm{e}+011.00000 \mathrm{e}-092.12000 \mathrm{e}-01$

$1.00000 \mathrm{e}-021.00000 \mathrm{e}-02$ 1.00000e-03 1.00000e-09 1.00000e-01

$1.00000 \mathrm{e}+001.00000 \mathrm{e}+001.00000 \mathrm{e}-011.00000 \mathrm{e}-091.00000 \mathrm{e}-01$

Element: 14593 \# of layers: 5

Kx Ky Kz Ss Por

$2.11853 \mathrm{e}+02$ 2.11853e+02 2.11853e+01 1.00000e-09 2.12000e-01

$2.11853 \mathrm{e}+022.11853 \mathrm{e}+022.11853 \mathrm{e}+01$ 1.00000e-09 2.12000e-01

$2.11853 \mathrm{e}+022.11853 \mathrm{e}+022.11853 \mathrm{e}+01$ 1.00000e-09 2.12000e-01

$1.00000 \mathrm{e}-02$ 1.00000e-02 1.00000e-03 1.00000e-09 1.00000e-01

$1.00000 \mathrm{e}+001.00000 \mathrm{e}+001.00000 \mathrm{e}-011.00000 \mathrm{e}-091.00000 \mathrm{e}-01$

Element: 14594 \# of layers: 5

Kx Ky Kz Ss Por

2.11853e+02 2.11853e+02 2.11853e+01 1.00000e-09 2.12000e-01 
$2.11853 \mathrm{e}+022.11853 \mathrm{e}+022.11853 \mathrm{e}+01$ 1.00000e-09 2.12000e-01 $2.11853 \mathrm{e}+022.11853 \mathrm{e}+022.11853 \mathrm{e}+01$ 1.00000e-09 2.12000e-01 $1.00000 \mathrm{e}-02$ 1.00000e-02 1.00000e-03 1.00000e-09 1.00000e-01 $1.00000 \mathrm{e}+001.00000 \mathrm{e}+001.00000 \mathrm{e}-011.00000 \mathrm{e}-091.00000 \mathrm{e}-01$ Element: 14595 \# of layers: 5

Kx Ky Kz Ss Por

$2.11853 \mathrm{e}+02$ 2.11853e+02 2.11853e+01 1.00000e-09 2.12000e-01 $2.11853 \mathrm{e}+022.11853 \mathrm{e}+022.11853 \mathrm{e}+01$ 1.00000e-09 2.12000e-01 $2.11853 \mathrm{e}+022.11853 \mathrm{e}+022.11853 \mathrm{e}+01$ 1.00000e-09 2.12000e-01 $1.00000 \mathrm{e}-021.00000 \mathrm{e}-02$ 1.00000e-03 1.00000e-09 1.00000e-01 $1.00000 \mathrm{e}+001.00000 \mathrm{e}+001.00000 \mathrm{e}-011.00000 \mathrm{e}-091.00000 \mathrm{e}-01$ Element: 14596 \# of layers: 5

Kx Ky Kz Ss Por

$2.11853 \mathrm{e}+022.11853 \mathrm{e}+022.11853 \mathrm{e}+01$ 1.00000e-09 2.12000e-01 $2.11853 \mathrm{e}+022.11853 \mathrm{e}+022.11853 \mathrm{e}+01$ 1.00000e-09 2.12000e-01 $2.11853 \mathrm{e}+022.11853 \mathrm{e}+022.11853 \mathrm{e}+01$ 1.00000e-09 2.12000e-01 $1.00000 \mathrm{e}-02$ 1.00000e-02 1.00000e-03 1.00000e-09 1.00000e-01 $1.00000 \mathrm{e}+001.00000 \mathrm{e}+001.00000 \mathrm{e}-011.00000 \mathrm{e}-091.00000 \mathrm{e}-01$ Element: 14597 \# of layers: 5

Kx Ky Kz Ss Por

$2.11853 \mathrm{e}+02$ 2.11853e+02 2.11853e+01 1.00000e-09 2.12000e-01 $2.11853 \mathrm{e}+022.11853 \mathrm{e}+022.11853 \mathrm{e}+01$ 1.00000e-09 2.12000e-01 $2.11853 \mathrm{e}+022.11853 \mathrm{e}+022.11853 \mathrm{e}+01$ 1.00000e-09 2.12000e-01 $1.00000 \mathrm{e}-02$ 1.00000e-02 1.00000e-03 1.00000e-09 1.00000e-01 $1.00000 \mathrm{e}+001.00000 \mathrm{e}+001.00000 \mathrm{e}-011.00000 \mathrm{e}-091.00000 \mathrm{e}-01$ Element: 14598 \# of layers: 5

Kx Ky Kz Ss Por

$2.11853 \mathrm{e}+02$ 2.11853e+02 2.11853e+01 1.00000e-09 2.12000e-01 $2.11853 \mathrm{e}+022.11853 \mathrm{e}+022.11853 \mathrm{e}+01$ 1.00000e-09 2.12000e-01 $2.11853 \mathrm{e}+022.11853 \mathrm{e}+022.11853 \mathrm{e}+01$ 1.00000e-09 2.12000e-01 $1.00000 \mathrm{e}-021.00000 \mathrm{e}-02$ 1.00000e-03 1.00000e-09 1.00000e-01 $1.00000 \mathrm{e}+001.00000 \mathrm{e}+001.00000 \mathrm{e}-011.00000 \mathrm{e}-091.00000 \mathrm{e}-01$ Element: 14599 \# of layers: 5

Kx Ky Kz Ss Por

$2.11853 \mathrm{e}+022.11853 \mathrm{e}+022.11853 \mathrm{e}+01$ 1.00000e-09 2.12000e-01 $2.11853 \mathrm{e}+022.11853 \mathrm{e}+022.11853 \mathrm{e}+01$ 1.00000e-09 2.12000e-01 $2.11853 \mathrm{e}+02$ 2.11853e+02 2.11853e+01 1.00000e-09 2.12000e-01 $1.00000 \mathrm{e}-02$ 1.00000e-02 1.00000e-03 1.00000e-09 1.00000e-01 $1.00000 \mathrm{e}+001.00000 \mathrm{e}+001.00000 \mathrm{e}-011.00000 \mathrm{e}-091.00000 \mathrm{e}-01$ Element: 14600 \# of layers: 4

Kx Ky Kz Ss Por 3.50332e+02 3.50332e+02 3.50332e+01 1.00000e-09 2.12000e-01 $3.50332 \mathrm{e}+023.50332 \mathrm{e}+023.50332 \mathrm{e}+01$ 1.00000e-09 2.12000e-01 $1.00000 \mathrm{e}-021.00000 \mathrm{e}-02$ 1.00000e-03 1.00000e-09 1.00000e-01 $1.00000 \mathrm{e}+001.00000 \mathrm{e}+001.00000 \mathrm{e}-011.00000 \mathrm{e}-091.00000 \mathrm{e}-01$ Element: 14601 \# of layers: 4 
Kx Ky Kz Ss Por

3.50332e+02 3.50332e+02 3.50332e+01 1.00000e-09 2.12000e-01

$3.50332 \mathrm{e}+02$ 3.50332e+02 3.50332e+01 1.00000e-09 2.12000e-01

$1.00000 \mathrm{e}-02$ 1.00000e-02 1.00000e-03 1.00000e-09 1.00000e-01

$1.00000 \mathrm{e}+001.00000 \mathrm{e}+001.00000 \mathrm{e}-01$ 1.00000e-09 1.00000e-01

Element: 14602 \# of layers: 4

Kx Ky Kz Ss Por

3.50332e+02 3.50332e+02 3.50332e+01 1.00000e-09 2.12000e-01

$3.50332 \mathrm{e}+02$ 3.50332e+02 3.50332e+01 1.00000e-09 2.12000e-01

$1.00000 \mathrm{e}-02$ 1.00000e-02 1.00000e-03 1.00000e-09 1.00000e-01

$1.00000 \mathrm{e}+001.00000 \mathrm{e}+001.00000 \mathrm{e}-011.00000 \mathrm{e}-091.00000 \mathrm{e}-01$

Element: 14603 \# of layers: 4

$\mathrm{Kx} \mathrm{Ky} \mathrm{Kz}$ Ss Por

3.50332e+02 3.50332e+02 3.50332e+01 1.00000e-09 2.12000e-01

3.50332e+02 3.50332e+02 3.50332e+01 1.00000e-09 2.12000e-01

$1.00000 \mathrm{e}-02$ 1.00000e-02 1.00000e-03 1.00000e-09 1.00000e-01

$1.00000 \mathrm{e}+001.00000 \mathrm{e}+001.00000 \mathrm{e}-01$ 1.00000e-09 1.00000e-01

Element: 14604 \# of layers: 4

$\mathrm{Kx} \mathrm{Ky} \mathrm{Kz}$ Ss Por

3.50332e+02 3.50332e+02 3.50332e+01 1.00000e-09 2.12000e-01

$3.50332 \mathrm{e}+02$ 3.50332e+02 3.50332e+01 1.00000e-09 2.12000e-01

$1.00000 \mathrm{e}-02$ 1.00000e-02 1.00000e-03 1.00000e-09 1.00000e-01

$1.00000 \mathrm{e}+001.00000 \mathrm{e}+001.00000 \mathrm{e}-01$ 1.00000e-09 1.00000e-01

Element: 14605 \# of layers: 4

Kx Ky Kz Ss Por

3.50332e+02 3.50332e+02 3.50332e+01 1.00000e-09 2.12000e-01

$3.50332 \mathrm{e}+023.50332 \mathrm{e}+02$ 3.50332e+01 1.00000e-09 2.12000e-01

$1.00000 \mathrm{e}-02$ 1.00000e-02 1.00000e-03 1.00000e-09 1.00000e-01

$1.00000 \mathrm{e}+001.00000 \mathrm{e}+001.00000 \mathrm{e}-011.00000 \mathrm{e}-091.00000 \mathrm{e}-01$

Element: 14606 \# of layers: 4

$\mathrm{Kx} \mathrm{Ky} \mathrm{Kz}$ Ss Por

3.50332e+02 3.50332e+02 3.50332e+01 1.00000e-09 2.12000e-01

$3.50332 \mathrm{e}+02$ 3.50332e+02 3.50332e+01 1.00000e-09 2.12000e-01

$1.00000 \mathrm{e}-02$ 1.00000e-02 1.00000e-03 1.00000e-09 1.00000e-01

$1.00000 \mathrm{e}+001.00000 \mathrm{e}+001.00000 \mathrm{e}-011.00000 \mathrm{e}-091.00000 \mathrm{e}-01$

Element: 14607 \# of layers: 5

Kx Ky Kz Ss Por

$1.75985 \mathrm{e}+02$ 1.75985e+02 1.75985e+01 1.00000e-09 2.12000e-01

$1.75985 \mathrm{e}+02$ 1.75985e+02 1.75985e+01 1.00000e-09 2.12000e-01

$1.75985 \mathrm{e}+02$ 1.75985e+02 1.75985e+01 1.00000e-09 2.12000e-01

$1.00000 \mathrm{e}-02$ 1.00000e-02 1.00000e-03 1.00000e-09 1.00000e-01

$1.00000 \mathrm{e}+001.00000 \mathrm{e}+001.00000 \mathrm{e}-011.00000 \mathrm{e}-091.00000 \mathrm{e}-01$

Element: 14608 \# of layers: 6

$\mathrm{Kx} \mathrm{Ky} \mathrm{Kz}$ Ss Por

4.40445e+03 4.40445e+03 4.40445e+02 1.00000e-09 7.00000e-02

$1.75985 \mathrm{e}+02$ 1.75985e+02 1.75985e+01 1.00000e-09 2.12000e-01 
$1.75985 \mathrm{e}+021.75985 \mathrm{e}+021.75985 \mathrm{e}+01$ 1.00000e-09 2.12000e-01 $1.75985 \mathrm{e}+021.75985 \mathrm{e}+021.75985 \mathrm{e}+011.00000 \mathrm{e}-092.12000 \mathrm{e}-01$ $1.00000 \mathrm{e}-02$ 1.00000e-02 1.00000e-03 1.00000e-09 1.00000e-01 $1.00000 \mathrm{e}+001.00000 \mathrm{e}+001.00000 \mathrm{e}-011.00000 \mathrm{e}-091.00000 \mathrm{e}-01$ Element: 14609 \# of layers: 5

Kx Ky Kz Ss Por

$4.40445 \mathrm{e}+03$ 4.40445e+03 4.40445e+02 1.00000e-09 7.00000e-02 $4.40445 \mathrm{e}+03$ 4.40445e+03 4.40445e+02 1.00000e-09 7.00000e-02 $1.75985 \mathrm{e}+02 \quad 1.75985 \mathrm{e}+021.75985 \mathrm{e}+01$ 1.00000e-09 2.12000e-01 $1.00000 \mathrm{e}-021.00000 \mathrm{e}-02$ 1.00000e-03 1.00000e-09 1.00000e-01 $1.00000 \mathrm{e}+001.00000 \mathrm{e}+001.00000 \mathrm{e}-011.00000 \mathrm{e}-091.00000 \mathrm{e}-01$

Element: 14610 \# of layers: 5

Kx Ky Kz Ss Por

$4.40445 \mathrm{e}+03$ 4.40445e+03 4.40445e+02 1.00000e-09 7.00000e-02 $1.75985 \mathrm{e}+021.75985 \mathrm{e}+021.75985 \mathrm{e}+011.00000 \mathrm{e}-092.12000 \mathrm{e}-01$ $1.75985 \mathrm{e}+02 \quad 1.75985 \mathrm{e}+02 \quad 1.75985 \mathrm{e}+01$ 1.00000e-09 2.12000e-01 $1.00000 \mathrm{e}-021.00000 \mathrm{e}-02$ 1.00000e-03 1.00000e-09 1.00000e-01 $1.00000 \mathrm{e}+001.00000 \mathrm{e}+001.00000 \mathrm{e}-011.00000 \mathrm{e}-091.00000 \mathrm{e}-01$ Element: 14611 \# of layers: 4

Kx Ky Kz Ss Por

$1.75985 \mathrm{e}+02 \quad 1.75985 \mathrm{e}+02$ 1.75985e+01 1.00000e-09 2.12000e-01 $1.75985 \mathrm{e}+021.75985 \mathrm{e}+02 \quad 1.75985 \mathrm{e}+011.00000 \mathrm{e}-092.12000 \mathrm{e}-01$ $1.00000 \mathrm{e}-02$ 1.00000e-02 1.00000e-03 1.00000e-09 1.00000e-01 $1.00000 \mathrm{e}+001.00000 \mathrm{e}+001.00000 \mathrm{e}-011.00000 \mathrm{e}-091.00000 \mathrm{e}-01$ Element: 14612 \# of layers: 4

Kx Ky Kz Ss Por

$4.40445 \mathrm{e}+03$ 4.40445e+03 4.40445e+02 1.00000e-09 7.00000e-02 $1.75985 \mathrm{e}+02 \quad 1.75985 \mathrm{e}+02 \quad 1.75985 \mathrm{e}+011.00000 \mathrm{e}-092.12000 \mathrm{e}-01$ $1.00000 \mathrm{e}-021.00000 \mathrm{e}-021.00000 \mathrm{e}-031.00000 \mathrm{e}-091.00000 \mathrm{e}-01$ $1.00000 \mathrm{e}+001.00000 \mathrm{e}+001.00000 \mathrm{e}-011.00000 \mathrm{e}-091.00000 \mathrm{e}-01$ Element: 14613 \# of layers: 5

Kx Ky Kz Ss Por

$4.40445 \mathrm{e}+03$ 4.40445e+03 4.40445e+02 1.00000e-09 7.00000e-02 $1.75985 \mathrm{e}+021.75985 \mathrm{e}+02 \quad 1.75985 \mathrm{e}+011.00000 \mathrm{e}-092.12000 \mathrm{e}-01$ $1.75985 \mathrm{e}+02 \quad 1.75985 \mathrm{e}+021.75985 \mathrm{e}+01$ 1.00000e-09 2.12000e-01 $1.00000 \mathrm{e}-02$ 1.00000e-02 1.00000e-03 1.00000e-09 1.00000e-01 $1.00000 \mathrm{e}+001.00000 \mathrm{e}+001.00000 \mathrm{e}-011.00000 \mathrm{e}-091.00000 \mathrm{e}-01$ Element: 14614 \# of layers: 4

Kx Ky Kz Ss Por

$5.73856 \mathrm{e}+02$ 5.73856e+02 5.73856e+01 1.00000e-09 7.00000e-02 $2.29302 \mathrm{e}+012.29302 \mathrm{e}+012.29302 \mathrm{e}+00$ 1.00000e-09 2.12000e-01 $1.00000 \mathrm{e}-02$ 1.00000e-02 1.00000e-03 1.00000e-09 1.00000e-01 $1.00000 \mathrm{e}+001.00000 \mathrm{e}+001.00000 \mathrm{e}-011.00000 \mathrm{e}-091.00000 \mathrm{e}-01$ Element: 14615 \# of layers: 5

$\mathrm{Kx} \mathrm{Ky} \mathrm{Kz}$ Ss Por

5.73856e+02 5.73856e+02 5.73856e+01 1.00000e-09 7.00000e-02 
$5.73856 \mathrm{e}+02$ 5.73856e +02 5.73856e+01 1.00000e-09 7.00000e-02 $2.29302 \mathrm{e}+012.29302 \mathrm{e}+012.29302 \mathrm{e}+001.00000 \mathrm{e}-092.12000 \mathrm{e}-01$ $1.00000 \mathrm{e}-021.00000 \mathrm{e}-02$ 1.00000e-03 1.00000e-09 1.00000e-01 $1.00000 \mathrm{e}+001.00000 \mathrm{e}+001.00000 \mathrm{e}-011.00000 \mathrm{e}-091.00000 \mathrm{e}-01$ Element: 14616 \# of layers: 4

Kx Ky Kz Ss Por

$5.73856 \mathrm{e}+02$ 5.73856e+02 5.73856e+01 1.00000e-09 7.00000e-02 $2.29302 \mathrm{e}+012.29302 \mathrm{e}+012.29302 \mathrm{e}+001.00000 \mathrm{e}-092.12000 \mathrm{e}-01$ $1.00000 \mathrm{e}-021.00000 \mathrm{e}-02$ 1.00000e-03 1.00000e-09 1.00000e-01 $1.00000 \mathrm{e}+001.00000 \mathrm{e}+001.00000 \mathrm{e}-011.00000 \mathrm{e}-091.00000 \mathrm{e}-01$ Element: 14617 \# of layers: 4

Kx Ky Kz Ss Por

$5.73856 \mathrm{e}+02$ 5.73856e+02 5.73856e+01 1.00000e-09 7.00000e-02 $2.29302 \mathrm{e}+012.29302 \mathrm{e}+012.29302 \mathrm{e}+00$ 1.00000e-09 2.12000e-01 $1.00000 \mathrm{e}-02$ 1.00000e-02 1.00000e-03 1.00000e-09 1.00000e-01 $1.00000 \mathrm{e}+001.00000 \mathrm{e}+001.00000 \mathrm{e}-011.00000 \mathrm{e}-091.00000 \mathrm{e}-01$ Element: 14618 \# of layers: 5

Kx Ky Kz Ss Por

$5.73856 \mathrm{e}+02$ 5.73856e+02 5.73856e+01 1.00000e-09 7.00000e-02 $5.73856 \mathrm{e}+025.73856 \mathrm{e}+025.73856 \mathrm{e}+01$ 1.00000e-09 7.00000e-02 $2.29302 \mathrm{e}+012.29302 \mathrm{e}+012.29302 \mathrm{e}+001.00000 \mathrm{e}-092.12000 \mathrm{e}-01$ $1.00000 \mathrm{e}-02$ 1.00000e-02 1.00000e-03 1.00000e-09 1.00000e-01 $1.00000 \mathrm{e}+001.00000 \mathrm{e}+001.00000 \mathrm{e}-011.00000 \mathrm{e}-091.00000 \mathrm{e}-01$ Element: 14619 \# of layers: 4

Kx Ky Kz Ss Por

$5.73856 \mathrm{e}+02$ 5.73856e+02 5.73856e+01 1.00000e-09 7.00000e-02 $2.29302 \mathrm{e}+012.29302 \mathrm{e}+012.29302 \mathrm{e}+00$ 1.00000e-09 2.12000e-01 $1.00000 \mathrm{e}-021.00000 \mathrm{e}-02$ 1.00000e-03 1.00000e-09 1.00000e-01 $1.00000 \mathrm{e}+001.00000 \mathrm{e}+001.00000 \mathrm{e}-011.00000 \mathrm{e}-091.00000 \mathrm{e}-01$ Element: 14620 \# of layers: 5

Kx Ky Kz Ss Por

$5.73856 \mathrm{e}+025.73856 \mathrm{e}+025.73856 \mathrm{e}+01$ 1.00000e-09 7.00000e-02 $5.73856 \mathrm{e}+025.73856 \mathrm{e}+025.73856 \mathrm{e}+01$ 1.00000e-09 7.00000e-02 $2.29302 \mathrm{e}+012.29302 \mathrm{e}+012.29302 \mathrm{e}+001.00000 \mathrm{e}-092.12000 \mathrm{e}-01$ $1.00000 \mathrm{e}-02$ 1.00000e-02 1.00000e-03 1.00000e-09 1.00000e-01 $1.00000 \mathrm{e}+001.00000 \mathrm{e}+001.00000 \mathrm{e}-011.00000 \mathrm{e}-091.00000 \mathrm{e}-01$ Element: 14621 \# of layers: 4

Kx Ky Kz Ss Por

$2.36017 \mathrm{e}+022.36017 \mathrm{e}+022.36017 \mathrm{e}+01$ 1.00000e-09 7.00000e-02 $9.43040 \mathrm{e}+00$ 9.43040e+00 9.43040e-01 1.00000e-09 2.12000e-01 $1.00000 \mathrm{e}-021.00000 \mathrm{e}-02$ 1.00000e-03 1.00000e-09 1.00000e-01 $1.00000 \mathrm{e}+001.00000 \mathrm{e}+001.00000 \mathrm{e}-011.00000 \mathrm{e}-091.00000 \mathrm{e}-01$ Element: 14622 \# of layers: 4

Kx Ky Kz Ss Por $2.36017 \mathrm{e}+022.36017 \mathrm{e}+022.36017 \mathrm{e}+01$ 1.00000e-09 7.00000e-02 $9.43040 \mathrm{e}+00$ 9.43040e+00 9.43040e-01 1.00000e-09 2.12000e-01 
$1.00000 \mathrm{e}-02$ 1.00000e-02 1.00000e-03 1.00000e-09 1.00000e-01 $1.00000 \mathrm{e}+001.00000 \mathrm{e}+001.00000 \mathrm{e}-01$ 1.00000e-09 1.00000e-01 Element: 14623 \# of layers: 4

Kx Ky Kz Ss Por

2.36017e+02 2.36017e+02 2.36017e+01 1.00000e-09 7.00000e-02

$9.43040 \mathrm{e}+009.43040 \mathrm{e}+009.43040 \mathrm{e}-01$ 1.00000e-09 2.12000e-01

$1.00000 \mathrm{e}-02$ 1.00000e-02 1.00000e-03 1.00000e-09 1.00000e-01

$1.00000 \mathrm{e}+001.00000 \mathrm{e}+001.00000 \mathrm{e}-01$ 1.00000e-09 1.00000e-01

Element: 14624 \# of layers: 4

$\mathrm{Kx} \mathrm{Ky} \mathrm{Kz}$ Ss Por

2.36017e+02 2.36017e+02 2.36017e+01 1.00000e-09 7.00000e-02

$9.43040 \mathrm{e}+00$ 9.43040e+00 9.43040e-01 1.00000e-09 2.12000e-01

$1.00000 \mathrm{e}-02$ 1.00000e-02 1.00000e-03 1.00000e-09 1.00000e-01

$1.00000 \mathrm{e}+001.00000 \mathrm{e}+001.00000 \mathrm{e}-011.00000 \mathrm{e}-091.00000 \mathrm{e}-01$

Element: 14625 \# of layers: 4

Kx Ky Kz Ss Por

2.36017e+02 2.36017e+02 2.36017e+01 1.00000e-09 7.00000e-02

$9.43040 \mathrm{e}+00$ 9.43040e+00 9.43040e-01 1.00000e-09 2.12000e-01

$1.00000 \mathrm{e}-02$ 1.00000e-02 1.00000e-03 1.00000e-09 1.00000e-01

$1.00000 \mathrm{e}+001.00000 \mathrm{e}+001.00000 \mathrm{e}-011.00000 \mathrm{e}-091.00000 \mathrm{e}-01$

Element: 14626 \# of layers: 4

$\mathrm{Kx} \mathrm{Ky} \mathrm{Kz}$ Ss Por

2.36017e+02 2.36017e+02 2.36017e+01 1.00000e-09 7.00000e-02

9.43040e+00 9.43040e+00 9.43040e-01 1.00000e-09 2.12000e-01

$1.00000 \mathrm{e}-021.00000 \mathrm{e}-02$ 1.00000e-03 1.00000e-09 1.00000e-01

$1.00000 \mathrm{e}+001.00000 \mathrm{e}+001.00000 \mathrm{e}-01$ 1.00000e-09 1.00000e-01

Element: 14627 \# of layers: 4

$\mathrm{Kx} \mathrm{Ky} \mathrm{Kz}$ Ss Por

2.36017e+02 2.36017e+02 2.36017e+01 1.00000e-09 7.00000e-02

$9.43040 \mathrm{e}+00$ 9.43040e+00 9.43040e-01 1.00000e-09 2.12000e-01

1.00000e-02 1.00000e-02 1.00000e-03 1.00000e-09 1.00000e-01

$1.00000 \mathrm{e}+001.00000 \mathrm{e}+001.00000 \mathrm{e}-011.00000 \mathrm{e}-091.00000 \mathrm{e}-01$

Element: 14628 \# of layers: 4

$\mathrm{Kx} \mathrm{Ky} \mathrm{Kz}$ Ss Por

5.98147e+01 5.98147e+01 5.98147e+00 1.00000e-09 7.00000e-02

$2.39000 \mathrm{e}+002.39000 \mathrm{e}+00$ 2.39000e-01 1.00000e-09 2.12000e-01

$1.00000 \mathrm{e}-02$ 1.00000e-02 1.00000e-03 1.00000e-09 1.00000e-01

$1.00000 \mathrm{e}+001.00000 \mathrm{e}+001.00000 \mathrm{e}-011.00000 \mathrm{e}-09$ 1.00000e-01

Element: 14629 \# of layers: 4

$\mathrm{Kx} \mathrm{Ky} \mathrm{Kz}$ Ss Por

5.98147e+01 5.98147e+01 5.98147e+00 1.00000e-09 7.00000e-02

$2.39000 \mathrm{e}+002.39000 \mathrm{e}+002.39000 \mathrm{e}-01$ 1.00000e-09 2.12000e-01

$1.00000 \mathrm{e}-02$ 1.00000e-02 1.00000e-03 1.00000e-09 1.00000e-01

$1.00000 \mathrm{e}+001.00000 \mathrm{e}+001.00000 \mathrm{e}-01$ 1.00000e-09 1.00000e-01

Element: 14631 \# of layers: 4

Kx Ky Kz Ss Por 
5.98147e+01 5.98147e+01 5.98147e+00 1.00000e-09 7.00000e-02 $2.39000 \mathrm{e}+002.39000 \mathrm{e}+002.39000 \mathrm{e}-01$ 1.00000e-09 2.12000e-01 1.00000e-02 1.00000e-02 1.00000e-03 1.00000e-09 1.00000e-01 $1.00000 \mathrm{e}+001.00000 \mathrm{e}+001.00000 \mathrm{e}-011.00000 \mathrm{e}-091.00000 \mathrm{e}-01$ Element: 14632 \# of layers: 4

$\mathrm{Kx} \mathrm{Ky} \mathrm{Kz}$ Ss Por

5.98147e+01 5.98147e+01 5.98147e+00 1.00000e-09 7.00000e-02 $2.39000 \mathrm{e}+002.39000 \mathrm{e}+002.39000 \mathrm{e}-01$ 1.00000e-09 2.12000e-01 $1.00000 \mathrm{e}-02$ 1.00000e-02 1.00000e-03 1.00000e-09 1.00000e-01 $1.00000 \mathrm{e}+001.00000 \mathrm{e}+001.00000 \mathrm{e}-01$ 1.00000e-09 1.00000e-01 Element: 14633 \# of layers: 4

Kx Ky Kz Ss Por

5.98147e+01 5.98147e+01 5.98147e+00 1.00000e-09 7.00000e-02 $2.39000 \mathrm{e}+002.39000 \mathrm{e}+002.39000 \mathrm{e}-01$ 1.00000e-09 2.12000e-01 $1.00000 \mathrm{e}-02$ 1.00000e-02 1.00000e-03 1.00000e-09 1.00000e-01 $1.00000 \mathrm{e}+001.00000 \mathrm{e}+001.00000 \mathrm{e}-011.00000 \mathrm{e}-091.00000 \mathrm{e}-01$ Element: 14634 \# of layers: 4

Kx Ky Kz Ss Por

5.98147e+01 5.98147e+01 5.98147e+00 1.00000e-09 7.00000e-02 $2.39000 \mathrm{e}+002.39000 \mathrm{e}+002.39000 \mathrm{e}-01$ 1.00000e-09 2.12000e-01 $1.00000 \mathrm{e}-02$ 1.00000e-02 1.00000e-03 1.00000e-09 1.00000e-01 $1.00000 \mathrm{e}+001.00000 \mathrm{e}+001.00000 \mathrm{e}-01$ 1.00000e-09 1.00000e-01 Element: 14635 \# of layers: 4

Kx Ky Kz Ss Por

5.98147e+01 5.98147e+01 5.98147e+00 1.00000e-09 7.00000e-02 $2.39000 \mathrm{e}+002.39000 \mathrm{e}+00$ 2.39000e-01 1.00000e-09 2.12000e-01 $1.00000 \mathrm{e}-02$ 1.00000e-02 1.00000e-03 1.00000e-09 1.00000e-01 $1.00000 \mathrm{e}+001.00000 \mathrm{e}+001.00000 \mathrm{e}-011.00000 \mathrm{e}-091.00000 \mathrm{e}-01$

Element: 14636 \# of layers: 5

$\mathrm{Kx} \mathrm{Ky} \mathrm{Kz}$ Ss Por

2.86194e+02 2.86194e+02 2.86194e+01 1.00000e-09 7.00000e-02 $1.14354 \mathrm{e}+011.14354 \mathrm{e}+011.14354 \mathrm{e}+001.00000 \mathrm{e}-092.12000 \mathrm{e}-01$ $1.14354 \mathrm{e}+011.14354 \mathrm{e}+01 \quad 1.14354 \mathrm{e}+001.00000 \mathrm{e}-092.12000 \mathrm{e}-01$ $1.00000 \mathrm{e}-02$ 1.00000e-02 1.00000e-03 1.00000e-09 1.00000e-01 $1.00000 \mathrm{e}+001.00000 \mathrm{e}+001.00000 \mathrm{e}-01$ 1.00000e-09 1.00000e-01 Element: 14637 \# of layers: 4

Kx Ky Kz Ss Por

$2.86194 \mathrm{e}+022.86194 \mathrm{e}+02$ 2.86194e+01 1.00000e-09 7.00000e-02 $1.14354 \mathrm{e}+011.14354 \mathrm{e}+011.14354 \mathrm{e}+001.00000 \mathrm{e}-092.12000 \mathrm{e}-01$ $1.00000 \mathrm{e}-02$ 1.00000e-02 1.00000e-03 1.00000e-09 1.00000e-01 $1.00000 \mathrm{e}+001.00000 \mathrm{e}+001.00000 \mathrm{e}-011.00000 \mathrm{e}-091.00000 \mathrm{e}-01$ Element: 14638 \# of layers: 5

$\mathrm{Kx} \mathrm{Ky} \mathrm{Kz}$ Ss Por

$2.86194 \mathrm{e}+02$ 2.86194e+02 2.86194e+01 1.00000e-09 7.00000e-02 $2.86194 \mathrm{e}+022.86194 \mathrm{e}+02$ 2.86194e+01 1.00000e-09 7.00000e-02 $1.14354 \mathrm{e}+011.14354 \mathrm{e}+011.14354 \mathrm{e}+001.00000 \mathrm{e}-092.12000 \mathrm{e}-01$ 
$1.00000 \mathrm{e}-02$ 1.00000e-02 1.00000e-03 1.00000e-09 1.00000e-01 $1.00000 \mathrm{e}+001.00000 \mathrm{e}+001.00000 \mathrm{e}-01$ 1.00000e-09 1.00000e-01 Element: 14639 \# of layers: 5

Kx Ky Kz Ss Por

2.86194e+02 2.86194e+02 2.86194e+01 1.00000e-09 7.00000e-02 $1.14354 \mathrm{e}+011.14354 \mathrm{e}+011.14354 \mathrm{e}+001.00000 \mathrm{e}-092.12000 \mathrm{e}-01$ $1.14354 \mathrm{e}+011.14354 \mathrm{e}+011.14354 \mathrm{e}+001.00000 \mathrm{e}-092.12000 \mathrm{e}-01$ $1.00000 \mathrm{e}-02$ 1.00000e-02 1.00000e-03 1.00000e-09 1.00000e-01 $1.00000 \mathrm{e}+001.00000 \mathrm{e}+001.00000 \mathrm{e}-011.00000 \mathrm{e}-091.00000 \mathrm{e}-01$ Element: 14640 \# of layers: 4

$\mathrm{Kx} \mathrm{Ky} \mathrm{Kz}$ Ss Por

2.86194e+02 2.86194e+02 2.86194e+01 1.00000e-09 7.00000e-02 $1.14354 \mathrm{e}+011.14354 \mathrm{e}+011.14354 \mathrm{e}+001.00000 \mathrm{e}-092.12000 \mathrm{e}-01$ 1.00000e-02 1.00000e-02 1.00000e-03 1.00000e-09 1.00000e-01 $1.00000 \mathrm{e}+001.00000 \mathrm{e}+001.00000 \mathrm{e}-01$ 1.00000e-09 1.00000e-01 Element: 14641 \# of layers: 5

$\mathrm{Kx} \mathrm{Ky} \mathrm{Kz}$ Ss Por

$2.86194 \mathrm{e}+02$ 2.86194e+02 2.86194e+01 1.00000e-09 7.00000e-02 $2.86194 \mathrm{e}+02$ 2.86194e+02 2.86194e+01 1.00000e-09 7.00000e-02 $1.14354 \mathrm{e}+011.14354 \mathrm{e}+01 \quad 1.14354 \mathrm{e}+001.00000 \mathrm{e}-092.12000 \mathrm{e}-01$ $1.00000 \mathrm{e}-02$ 1.00000e-02 1.00000e-03 1.00000e-09 1.00000e-01 $1.00000 \mathrm{e}+001.00000 \mathrm{e}+001.00000 \mathrm{e}-011.00000 \mathrm{e}-091.00000 \mathrm{e}-01$ Element: 14642 \# of layers: 5

$\mathrm{Kx} \mathrm{Ky} \mathrm{Kz}$ Ss Por

$2.86194 \mathrm{e}+02$ 2.86194e+02 2.86194e+01 1.00000e-09 7.00000e-02

$2.86194 \mathrm{e}+022.86194 \mathrm{e}+02$ 2.86194e+01 1.00000e-09 7.00000e-02

$1.14354 \mathrm{e}+011.14354 \mathrm{e}+011.14354 \mathrm{e}+001.00000 \mathrm{e}-092.12000 \mathrm{e}-01$ $1.00000 \mathrm{e}-02$ 1.00000e-02 1.00000e-03 1.00000e-09 1.00000e-01

$1.00000 \mathrm{e}+001.00000 \mathrm{e}+001.00000 \mathrm{e}-011.00000 \mathrm{e}-091.00000 \mathrm{e}-01$ Element: 14643 \# of layers: 5

$\mathrm{Kx} \mathrm{Ky} \mathrm{Kz}$ Ss Por

4.35769e+02 4.35769e+02 4.35769e+01 1.00000e-09 7.00000e-02 4.35769e+02 4.35769e+02 4.35769e+01 1.00000e-09 7.00000e-02 $1.74120 \mathrm{e}+011.74120 \mathrm{e}+011.74120 \mathrm{e}+001.00000 \mathrm{e}-09$ 2.12000e-01 $1.00000 \mathrm{e}-02$ 1.00000e-02 1.00000e-03 1.00000e-09 1.00000e-01 $1.00000 \mathrm{e}+001.00000 \mathrm{e}+001.00000 \mathrm{e}-011.00000 \mathrm{e}-091.00000 \mathrm{e}-01$ Element: 14644 \# of layers: 5

Kx Ky Kz Ss Por

4.35769e+02 4.35769e+02 4.35769e+01 1.00000e-09 7.00000e-02 4.35769e+02 4.35769e+02 4.35769e+01 1.00000e-09 7.00000e-02 $1.74120 \mathrm{e}+011.74120 \mathrm{e}+01 \quad 1.74120 \mathrm{e}+001.00000 \mathrm{e}-092.12000 \mathrm{e}-01$ $1.00000 \mathrm{e}-02$ 1.00000e-02 1.00000e-03 1.00000e-09 1.00000e-01 $1.00000 \mathrm{e}+001.00000 \mathrm{e}+001.00000 \mathrm{e}-011.00000 \mathrm{e}-091.00000 \mathrm{e}-01$ Element: 14645 \# of layers: 5

$\mathrm{Kx} \mathrm{Ky} \mathrm{Kz}$ Ss Por

4.35769e+02 4.35769e+02 4.35769e+01 1.00000e-09 7.00000e-02 
4.35769e+02 4.35769e+02 4.35769e+01 1.00000e-09 7.00000e-02 $1.74120 \mathrm{e}+011.74120 \mathrm{e}+011.74120 \mathrm{e}+001.00000 \mathrm{e}-092.12000 \mathrm{e}-01$ $1.00000 \mathrm{e}-02$ 1.00000e-02 1.00000e-03 1.00000e-09 1.00000e-01 $1.00000 \mathrm{e}+001.00000 \mathrm{e}+001.00000 \mathrm{e}-011.00000 \mathrm{e}-091.00000 \mathrm{e}-01$ Element: 14646 \# of layers: 4

$\mathrm{Kx} \mathrm{Ky} \mathrm{Kz}$ Ss Por

4.35769e+02 4.35769e+02 4.35769e+01 1.00000e-09 7.00000e-02 $1.74120 \mathrm{e}+011.74120 \mathrm{e}+01 \quad 1.74120 \mathrm{e}+001.00000 \mathrm{e}-092.12000 \mathrm{e}-01$ $1.00000 \mathrm{e}-02$ 1.00000e-02 1.00000e-03 1.00000e-09 1.00000e-01 $1.00000 \mathrm{e}+001.00000 \mathrm{e}+001.00000 \mathrm{e}-011.00000 \mathrm{e}-091.00000 \mathrm{e}-01$ Element: 14647 \# of layers: 4

Kx Ky Kz Ss Por

4.35769e+02 4.35769e+02 4.35769e+01 1.00000e-09 7.00000e-02 $1.74120 \mathrm{e}+011.74120 \mathrm{e}+011.74120 \mathrm{e}+001.00000 \mathrm{e}-092.12000 \mathrm{e}-01$ $1.00000 \mathrm{e}-02$ 1.00000e-02 1.00000e-03 1.00000e-09 1.00000e-01 $1.00000 \mathrm{e}+001.00000 \mathrm{e}+001.00000 \mathrm{e}-011.00000 \mathrm{e}-091.00000 \mathrm{e}-01$ Element: 14648 \# of layers: 4

$\mathrm{Kx} \mathrm{Ky} \mathrm{Kz}$ Ss Por

4.35769e+02 4.35769e+02 4.35769e+01 1.00000e-09 7.00000e-02 $1.74120 \mathrm{e}+011.74120 \mathrm{e}+011.74120 \mathrm{e}+001.00000 \mathrm{e}-092.12000 \mathrm{e}-01$ $1.00000 \mathrm{e}-02$ 1.00000e-02 1.00000e-03 1.00000e-09 1.00000e-01 $1.00000 \mathrm{e}+001.00000 \mathrm{e}+001.00000 \mathrm{e}-01$ 1.00000e-09 1.00000e-01 Element: 14649 \# of layers: 4

Kx Ky Kz Ss Por

4.35769e+02 4.35769e+02 4.35769e+01 1.00000e-09 7.00000e-02 $1.74120 \mathrm{e}+011.74120 \mathrm{e}+011.74120 \mathrm{e}+001.00000 \mathrm{e}-092.12000 \mathrm{e}-01$ $1.00000 \mathrm{e}-02$ 1.00000e-02 1.00000e-03 1.00000e-09 1.00000e-01 $1.00000 \mathrm{e}+001.00000 \mathrm{e}+001.00000 \mathrm{e}-01$ 1.00000e-09 1.00000e-01

Element: 14650 \# of layers: 4

$\mathrm{Kx} \mathrm{Ky} \mathrm{Kz}$ Ss Por

8.38372e+01 8.38372e+01 8.38372e+00 1.00000e-09 7.00000e-02 3.34987e+00 3.34987e+00 3.34987e-01 1.00000e-09 2.12000e-01 1.00000e-02 1.00000e-02 1.00000e-03 1.00000e-09 1.00000e-01 $1.00000 \mathrm{e}+001.00000 \mathrm{e}+001.00000 \mathrm{e}-011.00000 \mathrm{e}-091.00000 \mathrm{e}-01$ Element: 14651 \# of layers: 4

Kx Ky Kz Ss Por 8.38372e+01 8.38372e+01 8.38372e+00 1.00000e-09 7.00000e-02 $3.34987 \mathrm{e}+003.34987 \mathrm{e}+00$ 3.34987e-01 1.00000e-09 2.12000e-01 $1.00000 \mathrm{e}-02$ 1.00000e-02 1.00000e-03 1.00000e-09 1.00000e-01 $1.00000 \mathrm{e}+001.00000 \mathrm{e}+001.00000 \mathrm{e}-01$ 1.00000e-09 1.00000e-01 Element: 14652 \# of layers: 4

$\mathrm{Kx} \mathrm{Ky} \mathrm{Kz}$ Ss Por

8.38372e+01 8.38372e+01 8.38372e+00 1.00000e-09 7.00000e-02 3.34987e+00 3.34987e+00 3.34987e-01 1.00000e-09 2.12000e-01 1.00000e-02 1.00000e-02 1.00000e-03 1.00000e-09 1.00000e-01 $1.00000 \mathrm{e}+001.00000 \mathrm{e}+001.00000 \mathrm{e}-011.00000 \mathrm{e}-091.00000 \mathrm{e}-01$ 
Element: 14653 \# of layers: 4

Kx Ky Kz Ss Por

8.38372e+01 8.38372e+01 8.38372e+00 1.00000e-09 7.00000e-02

$3.34987 \mathrm{e}+003.34987 \mathrm{e}+003.34987 \mathrm{e}-01$ 1.00000e-09 2.12000e-01

$1.00000 \mathrm{e}-02$ 1.00000e-02 1.00000e-03 1.00000e-09 1.00000e-01

$1.00000 \mathrm{e}+001.00000 \mathrm{e}+001.00000 \mathrm{e}-011.00000 \mathrm{e}-091.00000 \mathrm{e}-01$

Element: 14654 \# of layers: 4

Kx Ky Kz Ss Por

8.38372e+01 8.38372e+01 8.38372e+00 1.00000e-09 7.00000e-02

$3.34987 \mathrm{e}+003.34987 \mathrm{e}+003.34987 \mathrm{e}-01$ 1.00000e-09 2.12000e-01

$1.00000 \mathrm{e}-021.00000 \mathrm{e}-02$ 1.00000e-03 1.00000e-09 1.00000e-01

$1.00000 \mathrm{e}+001.00000 \mathrm{e}+00$ 1.00000e-01 1.00000e-09 1.00000e-01

Element: 14655 \# of layers: 4

Kx Ky Kz Ss Por

8.38372e+01 8.38372e+01 8.38372e+00 1.00000e-09 7.00000e-02

$3.34987 \mathrm{e}+003.34987 \mathrm{e}+00$ 3.34987e-01 1.00000e-09 2.12000e-01

$1.00000 \mathrm{e}-02$ 1.00000e-02 1.00000e-03 1.00000e-09 1.00000e-01

$1.00000 \mathrm{e}+001.00000 \mathrm{e}+001.00000 \mathrm{e}-011.00000 \mathrm{e}-091.00000 \mathrm{e}-01$

Element: 14656 \# of layers: 4

Kx Ky Kz Ss Por

8.38372e+01 8.38372e+01 8.38372e+00 1.00000e-09 7.00000e-02

$3.34987 \mathrm{e}+003.34987 \mathrm{e}+003.34987 \mathrm{e}-011.00000 \mathrm{e}-092.12000 \mathrm{e}-01$

$1.00000 \mathrm{e}-02$ 1.00000e-02 1.00000e-03 1.00000e-09 1.00000e-01

$1.00000 \mathrm{e}+001.00000 \mathrm{e}+001.00000 \mathrm{e}-011.00000 \mathrm{e}-091.00000 \mathrm{e}-01$

Element: 14657 \# of layers: 3

Kx Ky Kz Ss Por

7.07429e+01 7.07429e+01 7.07429e+00 1.00000e-09 7.00000e-02

$1.00000 \mathrm{e}-02$ 1.00000e-02 1.00000e-03 1.00000e-09 1.00000e-01

$1.00000 \mathrm{e}+001.00000 \mathrm{e}+001.00000 \mathrm{e}-011.00000 \mathrm{e}-091.00000 \mathrm{e}-01$

Element: 14658 \# of layers: 3

Kx Ky Kz Ss Por

7.07429e+01 7.07429e+01 7.07429e+00 1.00000e-09 7.00000e-02

$1.00000 \mathrm{e}-021.00000 \mathrm{e}-02$ 1.00000e-03 1.00000e-09 1.00000e-01

$1.00000 \mathrm{e}+001.00000 \mathrm{e}+001.00000 \mathrm{e}-011.00000 \mathrm{e}-091.00000 \mathrm{e}-01$

Element: 14659 \# of layers: 3

Kx Ky Kz Ss Por

7.07429e+01 7.07429e+01 7.07429e+00 1.00000e-09 7.00000e-02

$1.00000 \mathrm{e}-021.00000 \mathrm{e}-021.00000 \mathrm{e}-031.00000 \mathrm{e}-091.00000 \mathrm{e}-01$

$1.00000 \mathrm{e}+001.00000 \mathrm{e}+001.00000 \mathrm{e}-011.00000 \mathrm{e}-091.00000 \mathrm{e}-01$

Element: 14660 \# of layers: 3

Kx Ky Kz Ss Por

7.07429e+01 7.07429e+01 7.07429e+00 1.00000e-09 7.00000e-02 $1.00000 \mathrm{e}-021.00000 \mathrm{e}-02$ 1.00000e-03 1.00000e-09 1.00000e-01

$1.00000 \mathrm{e}+001.00000 \mathrm{e}+001.00000 \mathrm{e}-011.00000 \mathrm{e}-091.00000 \mathrm{e}-01$

Element: 14661 \# of layers: 3

Kx Ky Kz Ss Por 
7.07429e+01 7.07429e+01 7.07429e+00 1.00000e-09 7.00000e-02 $1.00000 \mathrm{e}-02$ 1.00000e-02 1.00000e-03 1.00000e-09 1.00000e-01

$1.00000 \mathrm{e}+001.00000 \mathrm{e}+001.00000 \mathrm{e}-011.00000 \mathrm{e}-09$ 1.00000e-01

Element: 14662 \# of layers: 3

$\mathrm{Kx} \mathrm{Ky} \mathrm{Kz}$ Ss Por

7.07429e+01 7.07429e+01 7.07429e+00 1.00000e-09 7.00000e-02

1.00000e-02 1.00000e-02 1.00000e-03 1.00000e-09 1.00000e-01

$1.00000 \mathrm{e}+001.00000 \mathrm{e}+001.00000 \mathrm{e}-01$ 1.00000e-09 1.00000e-01

Element: 14663 \# of layers: 3

$\mathrm{Kx} \mathrm{Ky} \mathrm{Kz}$ Ss Por

7.07429e+01 7.07429e+01 7.07429e+00 1.00000e-09 7.00000e-02

$1.00000 \mathrm{e}-02$ 1.00000e-02 1.00000e-03 1.00000e-09 1.00000e-01

$1.00000 \mathrm{e}+001.00000 \mathrm{e}+001.00000 \mathrm{e}-011.00000 \mathrm{e}-09$ 1.00000e-01

Element: 14664 \# of layers: 3

Kx Ky Kz Ss Por

5.80577e+01 5.80577e+01 5.80577e+00 1.00000e-09 7.00000e-02

$1.00000 \mathrm{e}-01$ 1.00000e-01 1.00000e-02 1.00000e-09 1.00000e-01

$1.00000 \mathrm{e}+001.00000 \mathrm{e}+001.00000 \mathrm{e}-01$ 1.00000e-09 1.00000e-01

Element: 14665 \# of layers: 3

$\mathrm{Kx} \mathrm{Ky} \mathrm{Kz}$ Ss Por

5.80577e+01 5.80577e+01 5.80577e+00 1.00000e-09 7.00000e-02

$1.00000 \mathrm{e}-011.00000 \mathrm{e}-011.00000 \mathrm{e}-021.00000 \mathrm{e}-091.00000 \mathrm{e}-01$

$1.00000 \mathrm{e}+001.00000 \mathrm{e}+001.00000 \mathrm{e}-01$ 1.00000e-09 1.00000e-01

Element: 14666 \# of layers: 3

Kx Ky Kz Ss Por

5.80577e+01 5.80577e+01 5.80577e+00 1.00000e-09 7.00000e-02

$1.00000 \mathrm{e}-011.00000 \mathrm{e}-011.00000 \mathrm{e}-021.00000 \mathrm{e}-091.00000 \mathrm{e}-01$

$1.00000 \mathrm{e}+001.00000 \mathrm{e}+001.00000 \mathrm{e}-01$ 1.00000e-09 1.00000e-01

Element: 14667 \# of layers: 3

$\mathrm{Kx} \mathrm{Ky} \mathrm{Kz}$ Ss Por

5.80577e+01 5.80577e+01 5.80577e+00 1.00000e-09 7.00000e-02

$1.00000 \mathrm{e}-01$ 1.00000e-01 1.00000e-02 1.00000e-09 1.00000e-01

$1.00000 \mathrm{e}+001.00000 \mathrm{e}+001.00000 \mathrm{e}-011.00000 \mathrm{e}-091.00000 \mathrm{e}-01$

Element: 14668 \# of layers: 3

$\mathrm{Kx} \mathrm{Ky} \mathrm{Kz}$ Ss Por

5.80577e+01 5.80577e+01 5.80577e+00 1.00000e-09 7.00000e-02

$1.00000 \mathrm{e}-01$ 1.00000e-01 1.00000e-02 1.00000e-09 1.00000e-01

$1.00000 \mathrm{e}+001.00000 \mathrm{e}+001.00000 \mathrm{e}-011.00000 \mathrm{e}-09$ 1.00000e-01

Element: 14669 \# of layers: 3

$\mathrm{Kx} \mathrm{Ky} \mathrm{Kz}$ Ss Por

5.80577e+01 5.80577e+01 5.80577e+00 1.00000e-09 7.00000e-02

$1.00000 \mathrm{e}-011.00000 \mathrm{e}-011.00000 \mathrm{e}-021.00000 \mathrm{e}-091.00000 \mathrm{e}-01$

$1.00000 \mathrm{e}+001.00000 \mathrm{e}+001.00000 \mathrm{e}-01$ 1.00000e-09 1.00000e-01

Element: 14670 \# of layers: 3

Kx Ky Kz Ss Por

5.80577e+01 5.80577e+01 5.80577e+00 1.00000e-09 7.00000e-02 
$1.00000 \mathrm{e}-01$ 1.00000e-01 1.00000e-02 1.00000e-09 1.00000e-01

$1.00000 \mathrm{e}+001.00000 \mathrm{e}+001.00000 \mathrm{e}-01$ 1.00000e-09 1.00000e-01

Element: 14671 \# of layers: 3

Kx Ky Kz Ss Por

$5.20030 \mathrm{e}+015.20030 \mathrm{e}+015.20030 \mathrm{e}+001.00000 \mathrm{e}-097.00000 \mathrm{e}-02$

$1.00000 \mathrm{e}-02$ 1.00000e-02 1.00000e-03 1.00000e-09 1.00000e-01

$1.00000 \mathrm{e}+001.00000 \mathrm{e}+001.00000 \mathrm{e}-011.00000 \mathrm{e}-091.00000 \mathrm{e}-01$

Element: 14672 \# of layers: 3

$\mathrm{Kx} \mathrm{Ky} \mathrm{Kz}$ Ss Por

$5.20030 \mathrm{e}+015.20030 \mathrm{e}+015.20030 \mathrm{e}+001.00000 \mathrm{e}-09$ 7.00000e-02

$1.00000 \mathrm{e}-02$ 1.00000e-02 1.00000e-03 1.00000e-09 1.00000e-01

$1.00000 \mathrm{e}+001.00000 \mathrm{e}+001.00000 \mathrm{e}-01$ 1.00000e-09 1.00000e-01

Element: 14673 \# of layers: 3

$\mathrm{Kx} \mathrm{Ky} \mathrm{Kz}$ Ss Por

$5.20030 \mathrm{e}+015.20030 \mathrm{e}+015.20030 \mathrm{e}+001.00000 \mathrm{e}-09$ 7.00000e-02

$1.00000 \mathrm{e}-02$ 1.00000e-02 1.00000e-03 1.00000e-09 1.00000e-01

$1.00000 \mathrm{e}+001.00000 \mathrm{e}+001.00000 \mathrm{e}-011.00000 \mathrm{e}-091.00000 \mathrm{e}-01$

Element: 14674 \# of layers: 3

$\mathrm{Kx} \mathrm{Ky} \mathrm{Kz}$ Ss Por

5.20030e+01 5.20030e+01 5.20030e+00 1.00000e-09 7.00000e-02

$1.00000 \mathrm{e}-02$ 1.00000e-02 1.00000e-03 1.00000e-09 1.00000e-01

$1.00000 \mathrm{e}+001.00000 \mathrm{e}+001.00000 \mathrm{e}-01$ 1.00000e-09 1.00000e-01

Element: 14675 \# of layers: 3

Kx Ky Kz Ss Por

5.20030e+01 5.20030e+01 5.20030e+00 1.00000e-09 7.00000e-02

$1.00000 \mathrm{e}-02$ 1.00000e-02 1.00000e-03 1.00000e-09 1.00000e-01

$1.00000 \mathrm{e}+001.00000 \mathrm{e}+001.00000 \mathrm{e}-011.00000 \mathrm{e}-091.00000 \mathrm{e}-01$

Element: 14676 \# of layers: 3

$\mathrm{Kx} \mathrm{Ky} \mathrm{Kz}$ Ss Por

$5.20030 \mathrm{e}+015.20030 \mathrm{e}+015.20030 \mathrm{e}+001.00000 \mathrm{e}-09$ 7.00000e-02

$1.00000 \mathrm{e}-02$ 1.00000e-02 1.00000e-03 1.00000e-09 1.00000e-01

$1.00000 \mathrm{e}+001.00000 \mathrm{e}+001.00000 \mathrm{e}-01$ 1.00000e-09 1.00000e-01

Element: 14677 \# of layers: 3

$\mathrm{Kx} \mathrm{Ky} \mathrm{Kz}$ Ss Por

$5.20030 \mathrm{e}+015.20030 \mathrm{e}+015.20030 \mathrm{e}+00$ 1.00000e-09 7.00000e-02

1.00000e-02 1.00000e-02 1.00000e-03 1.00000e-09 1.00000e-01

$1.00000 \mathrm{e}+001.00000 \mathrm{e}+001.00000 \mathrm{e}-011.00000 \mathrm{e}-091.00000 \mathrm{e}-01$

Element: 14678 \# of layers: 3

$\mathrm{Kx} \mathrm{Ky} \mathrm{Kz}$ Ss Por

4.82026e+01 4.82026e+01 4.82026e+00 1.00000e-09 7.00000e-02

$1.00000 \mathrm{e}-02$ 1.00000e-02 1.00000e-03 1.00000e-09 1.00000e-01

$1.00000 \mathrm{e}+001.00000 \mathrm{e}+001.00000 \mathrm{e}-011.00000 \mathrm{e}-091.00000 \mathrm{e}-01$

Element: 14679 \# of layers: 3

$\mathrm{Kx} \mathrm{Ky} \mathrm{Kz}$ Ss Por

4.82026e+01 4.82026e+01 4.82026e+00 1.00000e-09 7.00000e-02

$1.00000 \mathrm{e}-02$ 1.00000e-02 1.00000e-03 1.00000e-09 1.00000e-01 
$1.00000 \mathrm{e}+001.00000 \mathrm{e}+00$ 1.00000e-01 1.00000e-09 1.00000e-01

Element: 14680 \# of layers: 3

$\mathrm{Kx} \mathrm{Ky} \mathrm{Kz}$ Ss Por

$2.28764 \mathrm{e}+012.28764 \mathrm{e}+012.28764 \mathrm{e}+001.00000 \mathrm{e}-09$ 7.00000e-02

$1.00000 \mathrm{e}-02$ 1.00000e-02 1.00000e-03 1.00000e-09 1.00000e-01

$1.00000 \mathrm{e}+001.00000 \mathrm{e}+001.00000 \mathrm{e}-011.00000 \mathrm{e}-091.00000 \mathrm{e}-01$

Element: 14681 \# of layers: 3

$\mathrm{Kx} \mathrm{Ky} \mathrm{Kz}$ Ss Por

4.82026e+01 4.82026e+01 4.82026e+00 1.00000e-09 7.00000e-02

$1.00000 \mathrm{e}-02$ 1.00000e-02 1.00000e-03 1.00000e-09 1.00000e-01

$1.00000 \mathrm{e}+001.00000 \mathrm{e}+001.00000 \mathrm{e}-011.00000 \mathrm{e}-091.00000 \mathrm{e}-01$

Element: 14682 \# of layers: 3

$\mathrm{Kx} \mathrm{Ky} \mathrm{Kz}$ Ss Por

4.82026e+01 4.82026e+01 4.82026e+00 1.00000e-09 7.00000e-02 $1.00000 \mathrm{e}-02$ 1.00000e-02 1.00000e-03 1.00000e-09 1.00000e-01

$1.00000 \mathrm{e}+001.00000 \mathrm{e}+001.00000 \mathrm{e}-011.00000 \mathrm{e}-091.00000 \mathrm{e}-01$

Element: 14683 \# of layers: 3

$\mathrm{Kx} \mathrm{Ky} \mathrm{Kz}$ Ss Por

$2.28764 \mathrm{e}+012.28764 \mathrm{e}+012.28764 \mathrm{e}+00$ 1.00000e-09 7.00000e-02

$1.00000 \mathrm{e}-02$ 1.00000e-02 1.00000e-03 1.00000e-09 1.00000e-01

$1.00000 \mathrm{e}+001.00000 \mathrm{e}+001.00000 \mathrm{e}-011.00000 \mathrm{e}-091.00000 \mathrm{e}-01$

Element: 14684 \# of layers: 3

$\mathrm{Kx} \mathrm{Ky} \mathrm{Kz}$ Ss Por

4.82026e+01 4.82026e+01 4.82026e+00 1.00000e-09 7.00000e-02

$1.00000 \mathrm{e}-021.00000 \mathrm{e}-02$ 1.00000e-03 1.00000e-09 1.00000e-01

$1.00000 \mathrm{e}+001.00000 \mathrm{e}+001.00000 \mathrm{e}-01$ 1.00000e-09 1.00000e-01

Element: 14685 \# of layers: 3

$\mathrm{Kx} \mathrm{Ky} \mathrm{Kz}$ Ss Por

5.53313e+01 5.53313e+01 5.53313e+00 1.00000e-09 7.00000e-02

$1.00000 \mathrm{e}-02$ 1.00000e-02 1.00000e-03 1.00000e-09 1.00000e-01

$1.00000 \mathrm{e}+001.00000 \mathrm{e}+001.00000 \mathrm{e}-011.00000 \mathrm{e}-091.00000 \mathrm{e}-01$

Element: 14686 \# of layers: 3

Kx Ky Kz Ss Por

5.53313e+01 5.53313e+01 5.53313e+00 1.00000e-09 7.00000e-02

$1.00000 \mathrm{e}-02$ 1.00000e-02 1.00000e-03 1.00000e-09 1.00000e-01

$1.00000 \mathrm{e}+001.00000 \mathrm{e}+001.00000 \mathrm{e}-011.00000 \mathrm{e}-091.00000 \mathrm{e}-01$

Element: 14687 \# of layers: 3

Kx Ky Kz Ss Por

5.53313e+01 5.53313e+01 5.53313e+00 1.00000e-09 7.00000e-02 $1.00000 \mathrm{e}-02$ 1.00000e-02 1.00000e-03 1.00000e-09 1.00000e-01

$1.00000 \mathrm{e}+001.00000 \mathrm{e}+001.00000 \mathrm{e}-011.00000 \mathrm{e}-091.00000 \mathrm{e}-01$

Element: 14688 \# of layers: 3

$\mathrm{Kx} \mathrm{Ky} \mathrm{Kz}$ Ss Por

5.53313e+01 5.53313e+01 5.53313e+00 1.00000e-09 7.00000e-02

$1.00000 \mathrm{e}-021.00000 \mathrm{e}-021.00000 \mathrm{e}-031.00000 \mathrm{e}-091.00000 \mathrm{e}-01$

$1.00000 \mathrm{e}+001.00000 \mathrm{e}+001.00000 \mathrm{e}-011.00000 \mathrm{e}-091.00000 \mathrm{e}-01$ 
Element: 14689 \# of layers: 3

Kx Ky Kz Ss Por

5.53313e+01 5.53313e+01 5.53313e+00 1.00000e-09 7.00000e-02

$1.00000 \mathrm{e}-021.00000 \mathrm{e}-02$ 1.00000e-03 1.00000e-09 1.00000e-01

$1.00000 \mathrm{e}+001.00000 \mathrm{e}+001.00000 \mathrm{e}-011.00000 \mathrm{e}-091.00000 \mathrm{e}-01$

Element: 14690 \# of layers: 3

Kx Ky Kz Ss Por

$1.05066 \mathrm{e}+02 \quad 1.05066 \mathrm{e}+021.05066 \mathrm{e}+01$ 1.00000e-09 7.00000e-02

$1.00000 \mathrm{e}-02$ 1.00000e-02 1.00000e-03 1.00000e-09 1.00000e-01

$1.00000 \mathrm{e}+001.00000 \mathrm{e}+001.00000 \mathrm{e}-011.00000 \mathrm{e}-091.00000 \mathrm{e}-01$

Element: 14691 \# of layers: 3

Kx Ky Kz Ss Por

$1.05066 \mathrm{e}+021.05066 \mathrm{e}+021.05066 \mathrm{e}+011.00000 \mathrm{e}-097.00000 \mathrm{e}-02$

$1.00000 \mathrm{e}-021.00000 \mathrm{e}-02$ 1.00000e-03 1.00000e-09 1.00000e-01

$1.00000 \mathrm{e}+001.00000 \mathrm{e}+001.00000 \mathrm{e}-011.00000 \mathrm{e}-091.00000 \mathrm{e}-01$

Element: 14692 \# of layers: 3

Kx Ky Kz Ss Por

$2.55866 \mathrm{e}+022.55866 \mathrm{e}+022.55866 \mathrm{e}+01$ 1.00000e-09 7.00000e-02

$1.00000 \mathrm{e}-021.00000 \mathrm{e}-02$ 1.00000e-03 1.00000e-09 1.00000e-01

$1.00000 \mathrm{e}+001.00000 \mathrm{e}+001.00000 \mathrm{e}-011.00000 \mathrm{e}-091.00000 \mathrm{e}-01$

Element: 14693 \# of layers: 3

Kx Ky Kz Ss Por

$2.55866 \mathrm{e}+022.55866 \mathrm{e}+022.55866 \mathrm{e}+01$ 1.00000e-09 7.00000e-02

$1.00000 \mathrm{e}-021.00000 \mathrm{e}-02$ 1.00000e-03 1.00000e-09 1.00000e-01

$1.00000 \mathrm{e}+001.00000 \mathrm{e}+001.00000 \mathrm{e}-011.00000 \mathrm{e}-091.00000 \mathrm{e}-01$

Element: 14694 \# of layers: 3

Kx Ky Kz Ss Por

$2.55866 \mathrm{e}+022.55866 \mathrm{e}+022.55866 \mathrm{e}+01$ 1.00000e-09 7.00000e-02

$1.00000 \mathrm{e}-021.00000 \mathrm{e}-02$ 1.00000e-03 1.00000e-09 1.00000e-01

$1.00000 \mathrm{e}+001.00000 \mathrm{e}+001.00000 \mathrm{e}-011.00000 \mathrm{e}-091.00000 \mathrm{e}-01$

Element: 14695 \# of layers: 3

Kx Ky Kz Ss Por

$2.55866 \mathrm{e}+022.55866 \mathrm{e}+022.55866 \mathrm{e}+01$ 1.00000e-09 7.00000e-02

$1.00000 \mathrm{e}-021.00000 \mathrm{e}-021.00000 \mathrm{e}-031.00000 \mathrm{e}-091.00000 \mathrm{e}-01$

$1.00000 \mathrm{e}+001.00000 \mathrm{e}+001.00000 \mathrm{e}-011.00000 \mathrm{e}-091.00000 \mathrm{e}-01$

Element: 14696 \# of layers: 3

Kx Ky Kz Ss Por

$2.55866 \mathrm{e}+022.55866 \mathrm{e}+022.55866 \mathrm{e}+01$ 1.00000e-09 7.00000e-02

$1.00000 \mathrm{e}-021.00000 \mathrm{e}-02$ 1.00000e-03 1.00000e-09 1.00000e-01

$1.00000 \mathrm{e}+001.00000 \mathrm{e}+001.00000 \mathrm{e}-011.00000 \mathrm{e}-091.00000 \mathrm{e}-01$

Element: 14697 \# of layers: 3

Kx Ky Kz Ss Por

$2.55866 \mathrm{e}+022.55866 \mathrm{e}+022.55866 \mathrm{e}+01$ 1.00000e-09 7.00000e-02

$1.00000 \mathrm{e}-02$ 1.00000e-02 1.00000e-03 1.00000e-09 1.00000e-01

$1.00000 \mathrm{e}+001.00000 \mathrm{e}+001.00000 \mathrm{e}-011.00000 \mathrm{e}-091.00000 \mathrm{e}-01$

Element: 14698 \# of layers: 3 
Kx Ky Kz Ss Por

$2.55866 \mathrm{e}+02$ 2.55866e+02 2.55866e+01 1.00000e-09 7.00000e-02

$1.00000 \mathrm{e}-02$ 1.00000e-02 1.00000e-03 1.00000e-09 1.00000e-01

$1.00000 \mathrm{e}+001.00000 \mathrm{e}+001.00000 \mathrm{e}-011.00000 \mathrm{e}-091.00000 \mathrm{e}-01$

Element: 14699 \# of layers: 4

$\mathrm{Kx} \mathrm{Ky} \mathrm{Kz}$ Ss Por

4.93721e+02 4.93721e+02 4.93721e+01 1.00000e-09 7.00000e-02

$4.93721 \mathrm{e}+024.93721 \mathrm{e}+024.93721 \mathrm{e}+01$ 1.00000e-09 7.00000e-02

$1.00000 \mathrm{e}-02$ 1.00000e-02 1.00000e-03 1.00000e-09 1.00000e-01

$1.00000 \mathrm{e}+001.00000 \mathrm{e}+001.00000 \mathrm{e}-011.00000 \mathrm{e}-091.00000 \mathrm{e}-01$

Element: 14700 \# of layers: 4

$\mathrm{Kx} \mathrm{Ky} \mathrm{Kz}$ Ss Por

4.93721e+02 4.93721e+02 4.93721e+01 1.00000e-09 7.00000e-02

4.93721e+02 4.93721e+02 4.93721e+01 1.00000e-09 7.00000e-02

$1.00000 \mathrm{e}-021.00000 \mathrm{e}-021.00000 \mathrm{e}-031.00000 \mathrm{e}-091.00000 \mathrm{e}-01$

$1.00000 \mathrm{e}+001.00000 \mathrm{e}+001.00000 \mathrm{e}-011.00000 \mathrm{e}-091.00000 \mathrm{e}-01$

Element: 14701 \# of layers: 3

$\mathrm{Kx} \mathrm{Ky} \mathrm{Kz}$ Ss Por

4.93721e+02 4.93721e+02 4.93721e+01 1.00000e-09 7.00000e-02

$1.00000 \mathrm{e}-02$ 1.00000e-02 1.00000e-03 1.00000e-09 1.00000e-01

$1.00000 \mathrm{e}+001.00000 \mathrm{e}+001.00000 \mathrm{e}-011.00000 \mathrm{e}-091.00000 \mathrm{e}-01$

Element: 14702 \# of layers: 3

$\mathrm{Kx} \mathrm{Ky} \mathrm{Kz}$ Ss Por

4.93721e+02 4.93721e+02 4.93721e+01 1.00000e-09 7.00000e-02

$1.00000 \mathrm{e}-02$ 1.00000e-02 1.00000e-03 1.00000e-09 1.00000e-01

$1.00000 \mathrm{e}+001.00000 \mathrm{e}+001.00000 \mathrm{e}-01$ 1.00000e-09 1.00000e-01

Element: 14703 \# of layers: 3

$\mathrm{Kx} \mathrm{Ky} \mathrm{Kz}$ Ss Por

4.93721e+02 4.93721e+02 4.93721e+01 1.00000e-09 7.00000e-02

$1.00000 \mathrm{e}-02$ 1.00000e-02 1.00000e-03 1.00000e-09 1.00000e-01

$1.00000 \mathrm{e}+001.00000 \mathrm{e}+001.00000 \mathrm{e}-011.00000 \mathrm{e}-091.00000 \mathrm{e}-01$

Element: 14704 \# of layers: 3

Kx Ky Kz Ss Por

4.93721e+02 4.93721e+02 4.93721e+01 1.00000e-09 7.00000e-02 $1.00000 \mathrm{e}-02$ 1.00000e-02 1.00000e-03 1.00000e-09 1.00000e-01

$1.00000 \mathrm{e}+001.00000 \mathrm{e}+001.00000 \mathrm{e}-011.00000 \mathrm{e}-091.00000 \mathrm{e}-01$

Element: 14705 \# of layers: 3

Kx Ky Kz Ss Por

4.93721e+02 4.93721e+02 4.93721e+01 1.00000e-09 7.00000e-02 $1.00000 \mathrm{e}-02$ 1.00000e-02 1.00000e-03 1.00000e-09 1.00000e-01

$1.00000 \mathrm{e}+001.00000 \mathrm{e}+001.00000 \mathrm{e}-011.00000 \mathrm{e}-091.00000 \mathrm{e}-01$

Element: 14706 \# of layers: 8

$\mathrm{Kx} \mathrm{Ky} \mathrm{Kz}$ Ss Por

2.49568e+02 2.49568e+02 2.49568e+01 1.00000e-09 7.00000e-02

$2.49568 \mathrm{e}+02$ 2.49568e+02 2.49568e+01 1.00000e-09 7.00000e-02

$2.49568 \mathrm{e}+02$ 2.49568e+02 2.49568e+01 1.00000e-09 7.00000e-02 
2.49568e+02 2.49568e+02 2.49568e+01 1.00000e-09 7.00000e-02 9.97176e+00 9.97176e+00 9.97176e-01 1.00000e-09 2.12000e-01 9.97176e+00 9.97176e+00 9.97176e-01 1.00000e-09 2.12000e-01 $1.00000 \mathrm{e}-02$ 1.00000e-02 1.00000e-03 1.00000e-09 1.00000e-01 $1.00000 \mathrm{e}+001.00000 \mathrm{e}+001.00000 \mathrm{e}-011.00000 \mathrm{e}-091.00000 \mathrm{e}-01$ Element: 14707 \# of layers: 8

$\mathrm{Kx} \mathrm{Ky} \mathrm{Kz}$ Ss Por

$2.49568 \mathrm{e}+02$ 2.49568e+02 2.49568e+01 1.00000e-09 7.00000e-02 $2.49568 \mathrm{e}+022.49568 \mathrm{e}+02 \quad 2.49568 \mathrm{e}+01$ 1.00000e-09 7.00000e-02

$2.49568 \mathrm{e}+02$ 2.49568e+02 2.49568e+01 1.00000e-09 7.00000e-02 $2.49568 \mathrm{e}+02$ 2.49568e+02 2.49568e+01 1.00000e-09 7.00000e-02 $9.97176 \mathrm{e}+00$ 9.97176e+00 9.97176e-01 1.00000e-09 2.12000e-01 9.97176e+00 9.97176e+00 9.97176e-01 1.00000e-09 2.12000e-01 $1.00000 \mathrm{e}-02$ 1.00000e-02 1.00000e-03 1.00000e-09 1.00000e-01 $1.00000 \mathrm{e}+001.00000 \mathrm{e}+001.00000 \mathrm{e}-01$ 1.00000e-09 1.00000e-01 Element: 14708 \# of layers: 6

$\mathrm{Kx} \mathrm{Ky} \mathrm{Kz}$ Ss Por

2.24313e+02 2.24313e+02 2.24313e+01 1.00000e-09 7.00000e-02 $2.24313 \mathrm{e}+02$ 2.24313e+02 2.24313e+01 1.00000e-09 7.00000e-02 $2.24313 \mathrm{e}+02$ 2.24313e+02 2.24313e+01 1.00000e-09 7.00000e-02 $8.96262 \mathrm{e}+008.96262 \mathrm{e}+008.96262 \mathrm{e}-01$ 1.00000e-09 2.12000e-01 $1.00000 \mathrm{e}-021.00000 \mathrm{e}-021.00000 \mathrm{e}-031.00000 \mathrm{e}-091.00000 \mathrm{e}-01$ $1.00000 \mathrm{e}+001.00000 \mathrm{e}+001.00000 \mathrm{e}-011.00000 \mathrm{e}-091.00000 \mathrm{e}-01$ Element: 14709 \# of layers: 7

$\mathrm{Kx} \mathrm{Ky} \mathrm{Kz}$ Ss Por

$2.49568 \mathrm{e}+02$ 2.49568e+02 2.49568e+01 1.00000e-09 7.00000e-02 $2.49568 \mathrm{e}+02$ 2.49568e+02 2.49568e+01 1.00000e-09 7.00000e-02 $2.49568 \mathrm{e}+02$ 2.49568e+02 2.49568e+01 1.00000e-09 7.00000e-02 9.97176e+00 9.97176e+00 9.97176e-01 1.00000e-09 2.12000e-01 9.97176e+00 9.97176e+00 9.97176e-01 1.00000e-09 2.12000e-01 $1.00000 \mathrm{e}-02$ 1.00000e-02 1.00000e-03 1.00000e-09 1.00000e-01 $1.00000 \mathrm{e}+001.00000 \mathrm{e}+001.00000 \mathrm{e}-011.00000 \mathrm{e}-091.00000 \mathrm{e}-01$ Element: 14710 \# of layers: 7

$\mathrm{Kx} \mathrm{Ky} \mathrm{Kz}$ Ss Por

$2.49568 \mathrm{e}+02$ 2.49568e+02 2.49568e+01 1.00000e-09 7.00000e-02 $2.49568 \mathrm{e}+02$ 2.49568e+02 2.49568e+01 1.00000e-09 7.00000e-02 $2.49568 \mathrm{e}+022.49568 \mathrm{e}+02$ 2.49568e+01 1.00000e-09 7.00000e-02 $9.97176 \mathrm{e}+009.97176 \mathrm{e}+00$ 9.97176e-01 1.00000e-09 2.12000e-01 9.97176e+00 9.97176e+00 9.97176e-01 1.00000e-09 2.12000e-01 1.00000e-02 1.00000e-02 1.00000e-03 1.00000e-09 1.00000e-01 $1.00000 \mathrm{e}+001.00000 \mathrm{e}+001.00000 \mathrm{e}-011.00000 \mathrm{e}-091.00000 \mathrm{e}-01$ Element: 14711 \# of layers: 6

$\mathrm{Kx} \mathrm{Ky} \mathrm{Kz}$ Ss Por

2.49568e+02 2.49568e+02 2.49568e+01 1.00000e-09 7.00000e-02 $2.49568 \mathrm{e}+02$ 2.49568e+02 2.49568e+01 1.00000e-09 7.00000e-02 $9.97176 \mathrm{e}+00$ 9.97176e+00 9.97176e-01 1.00000e-09 2.12000e-01 
9.97176e+00 9.97176e+00 9.97176e-01 1.00000e-09 2.12000e-01 $1.00000 \mathrm{e}-02$ 1.00000e-02 1.00000e-03 1.00000e-09 1.00000e-01 $1.00000 \mathrm{e}+001.00000 \mathrm{e}+001.00000 \mathrm{e}-011.00000 \mathrm{e}-09$ 1.00000e-01 Element: 14712 \# of layers: 6

$\mathrm{Kx} \mathrm{Ky} \mathrm{Kz}$ Ss Por

2.24313e+02 2.24313e+02 2.24313e+01 1.00000e-09 7.00000e-02 $2.24313 \mathrm{e}+02$ 2.24313e+02 2.24313e+01 1.00000e-09 7.00000e-02 8.96262e+00 8.96262e+00 8.96262e-01 1.00000e-09 2.12000e-01 8.96262e+00 8.96262e+00 8.96262e-01 1.00000e-09 2.12000e-01 $1.00000 \mathrm{e}-02$ 1.00000e-02 1.00000e-03 1.00000e-09 1.00000e-01 $1.00000 \mathrm{e}+001.00000 \mathrm{e}+001.00000 \mathrm{e}-011.00000 \mathrm{e}-091.00000 \mathrm{e}-01$ Element: 14713 \# of layers: 8

Kx Ky Kz Ss Por

$1.97770 \mathrm{e}+02$ 1.97770e+02 1.97770e+01 1.00000e-09 7.00000e-02 $1.97770 \mathrm{e}+02$ 1.97770e+02 1.97770e+01 1.00000e-09 7.00000e-02 $1.97770 \mathrm{e}+021.97770 \mathrm{e}+02 \quad 1.97770 \mathrm{e}+01$ 1.00000e-09 7.00000e-02 7.90217e+00 7.90217e+00 7.90217e-01 1.00000e-09 2.12000e-01 7.90217e+00 7.90217e+00 7.90217e-01 1.00000e-09 2.12000e-01 $1.00000 \mathrm{e}-02$ 1.00000e-02 1.00000e-03 1.00000e-09 1.00000e-01 $1.00000 \mathrm{e}+001.00000 \mathrm{e}+001.00000 \mathrm{e}-011.00000 \mathrm{e}-091.00000 \mathrm{e}-01$ 1.00000e-06 1.00000e-06 1.00000e-06 1.00000e-09 5.00000e-02 Element: 14714 \# of layers: 8

$\mathrm{Kx} \mathrm{Ky} \mathrm{Kz}$ Ss Por

$1.97770 \mathrm{e}+02$ 1.97770e+02 1.97770e+01 1.00000e-09 7.00000e-02 $1.97770 \mathrm{e}+02$ 1.97770e+02 1.97770e+01 1.00000e-09 7.00000e-02 $1.97770 \mathrm{e}+02$ 1.97770e+02 1.97770e+01 1.00000e-09 7.00000e-02 7.90217e+00 7.90217e+00 7.90217e-01 1.00000e-09 2.12000e-01 $7.90217 \mathrm{e}+00$ 7.90217e+00 7.90217e-01 1.00000e-09 2.12000e-01 $1.00000 \mathrm{e}-02$ 1.00000e-02 1.00000e-03 1.00000e-09 1.00000e-01 $1.00000 \mathrm{e}+001.00000 \mathrm{e}+001.00000 \mathrm{e}-011.00000 \mathrm{e}-091.00000 \mathrm{e}-01$ 1.00000e-06 1.00000e-06 1.00000e-06 1.00000e-09 5.00000e-02 Element: 14715 \# of layers: 8

Kx Ky Kz Ss Por

$1.91219 \mathrm{e}+02$ 1.91219e+02 1.91219e+01 1.00000e-09 7.00000e-02 $1.91219 \mathrm{e}+02$ 1.91219e+02 1.91219e+01 1.00000e-09 7.00000e-02 $1.91219 \mathrm{e}+02$ 1.91219e+02 1.91219e+01 1.00000e-09 7.00000e-02 $7.64049 \mathrm{e}+00$ 7.64049e+00 7.64049e-01 1.00000e-09 2.12000e-01 $7.64049 \mathrm{e}+00$ 7.64049e+00 7.64049e-01 1.00000e-09 2.12000e-01 $1.00000 \mathrm{e}-02$ 1.00000e-02 1.00000e-03 1.00000e-09 1.00000e-01 $1.00000 \mathrm{e}+001.00000 \mathrm{e}+001.00000 \mathrm{e}-011.00000 \mathrm{e}-091.00000 \mathrm{e}-01$ 1.00000e-06 1.00000e-06 1.00000e-06 1.00000e-09 5.00000e-02 Element: 14716 \# of layers: 8

$\mathrm{Kx} \mathrm{Ky} \mathrm{Kz}$ Ss Por

1.97770e+02 1.97770e+02 1.97770e+01 1.00000e-09 7.00000e-02 $1.97770 \mathrm{e}+02$ 1.97770e+02 1.97770e+01 1.00000e-09 7.00000e-02 $1.97770 \mathrm{e}+021.97770 \mathrm{e}+021.97770 \mathrm{e}+01$ 1.00000e-09 7.00000e-02 
7.90217e+00 7.90217e+00 7.90217e-01 1.00000e-09 2.12000e-01 7.90217e+00 7.90217e+00 7.90217e-01 1.00000e-09 2.12000e-01 $1.00000 \mathrm{e}-02$ 1.00000e-02 1.00000e-03 1.00000e-09 1.00000e-01 $1.00000 \mathrm{e}+001.00000 \mathrm{e}+001.00000 \mathrm{e}-011.00000 \mathrm{e}-091.00000 \mathrm{e}-01$ $1.00000 \mathrm{e}-06$ 1.00000e-06 1.00000e-06 1.00000e-09 5.00000e-02 Element: 14717 \# of layers: 8

Kx Ky Kz Ss Por

$1.97770 \mathrm{e}+02$ 1.97770e+02 1.97770e+01 1.00000e-09 7.00000e-02 $1.97770 \mathrm{e}+021.97770 \mathrm{e}+021.97770 \mathrm{e}+011.00000 \mathrm{e}-097.00000 \mathrm{e}-02$ $1.97770 \mathrm{e}+021.97770 \mathrm{e}+021.97770 \mathrm{e}+011.00000 \mathrm{e}-097.00000 \mathrm{e}-02$ $7.90217 \mathrm{e}+007.90217 \mathrm{e}+00$ 7.90217e-01 1.00000e-09 2.12000e-01 $7.90217 \mathrm{e}+00$ 7.90217e+00 7.90217e-01 1.00000e-09 2.12000e-01 $1.00000 \mathrm{e}-02$ 1.00000e-02 1.00000e-03 1.00000e-09 1.00000e-01 $1.00000 \mathrm{e}+001.00000 \mathrm{e}+001.00000 \mathrm{e}-011.00000 \mathrm{e}-091.00000 \mathrm{e}-01$ $1.00000 \mathrm{e}-06$ 1.00000e-06 1.00000e-06 1.00000e-09 5.00000e-02 Element: 14718 \# of layers: 8

Kx Ky Kz Ss Por

$1.97770 \mathrm{e}+021.97770 \mathrm{e}+02$ 1.97770e+01 1.00000e-09 7.00000e-02 $1.97770 \mathrm{e}+021.97770 \mathrm{e}+021.97770 \mathrm{e}+011.00000 \mathrm{e}-097.00000 \mathrm{e}-02$ $1.97770 \mathrm{e}+021.97770 \mathrm{e}+021.97770 \mathrm{e}+011.00000 \mathrm{e}-097.00000 \mathrm{e}-02$ $7.90217 \mathrm{e}+007.90217 \mathrm{e}+00$ 7.90217e-01 1.00000e-09 2.12000e-01 7.90217e+00 7.90217e+00 7.90217e-01 1.00000e-09 2.12000e-01 $1.00000 \mathrm{e}-02$ 1.00000e-02 1.00000e-03 1.00000e-09 1.00000e-01 $1.00000 \mathrm{e}+001.00000 \mathrm{e}+001.00000 \mathrm{e}-011.00000 \mathrm{e}-091.00000 \mathrm{e}-01$ $1.00000 \mathrm{e}-061.00000 \mathrm{e}-06$ 1.00000e-06 1.00000e-09 5.00000e-02 Element: 14719 \# of layers: 8

Kx Ky Kz Ss Por

$1.97770 \mathrm{e}+021.97770 \mathrm{e}+021.97770 \mathrm{e}+01$ 1.00000e-09 7.00000e-02 $1.97770 \mathrm{e}+021.97770 \mathrm{e}+021.97770 \mathrm{e}+011.00000 \mathrm{e}-097.00000 \mathrm{e}-02$ $1.97770 \mathrm{e}+021.97770 \mathrm{e}+021.97770 \mathrm{e}+011.00000 \mathrm{e}-097.00000 \mathrm{e}-02$ $7.90217 \mathrm{e}+00$ 7.90217e+00 7.90217e-01 1.00000e-09 2.12000e-01 $7.90217 \mathrm{e}+00$ 7.90217e+00 7.90217e-01 1.00000e-09 2.12000e-01 $1.00000 \mathrm{e}-021.00000 \mathrm{e}-02$ 1.00000e-03 1.00000e-09 1.00000e-01 $1.00000 \mathrm{e}+001.00000 \mathrm{e}+001.00000 \mathrm{e}-011.00000 \mathrm{e}-091.00000 \mathrm{e}-01$ $1.00000 \mathrm{e}-06$ 1.00000e-06 1.00000e-06 1.00000e-09 5.00000e-02 Element: 14720 \# of layers: 7

Kx Ky Kz Ss Por

$1.41115 \mathrm{e}+021.41115 \mathrm{e}+021.41115 \mathrm{e}+01$ 1.00000e-09 7.00000e-02 $1.41115 \mathrm{e}+021.41115 \mathrm{e}+021.41115 \mathrm{e}+011.00000 \mathrm{e}-097.00000 \mathrm{e}-02$ $1.41115 \mathrm{e}+021.41115 \mathrm{e}+021.41115 \mathrm{e}+011.00000 \mathrm{e}-097.00000 \mathrm{e}-02$ $5.63839 \mathrm{e}+00$ 5.63839e+00 5.63839e-01 1.00000e-09 2.12000e-01 $1.00000 \mathrm{e}-021.00000 \mathrm{e}-02$ 1.00000e-03 1.00000e-09 1.00000e-01 $1.00000 \mathrm{e}+001.00000 \mathrm{e}+001.00000 \mathrm{e}-011.00000 \mathrm{e}-091.00000 \mathrm{e}-01$ $1.00000 \mathrm{e}-06$ 1.00000e-06 1.00000e-06 1.00000e-09 5.00000e-02 Element: 14721 \# of layers: 8

Kx Ky Kz Ss Por 
1.33213e+02 1.33213e+02 1.33213e+01 1.00000e-09 7.00000e-02 1.33213e+02 1.33213e+02 1.33213e+01 1.00000e-09 7.00000e-02 $1.33213 \mathrm{e}+02$ 1.33213e+02 1.33213e+01 1.00000e-09 7.00000e-02 $1.33213 \mathrm{e}+02$ 1.33213e+02 1.33213e+01 1.00000e-09 7.00000e-02 $5.32271 \mathrm{e}+00$ 5.32271e+00 5.32271e-01 1.00000e-09 2.12000e-01 $1.00000 \mathrm{e}-02$ 1.00000e-02 1.00000e-03 1.00000e-09 1.00000e-01 $1.00000 \mathrm{e}+001.00000 \mathrm{e}+001.00000 \mathrm{e}-011.00000 \mathrm{e}-091.00000 \mathrm{e}-01$ 1.00000e-06 1.00000e-06 1.00000e-06 1.00000e-09 5.00000e-02 Element: 14722 \# of layers: 7

$\mathrm{Kx} \mathrm{Ky} \mathrm{Kz}$ Ss Por

1.33213e+02 1.33213e+02 1.33213e+01 1.00000e-09 7.00000e-02 $1.33213 \mathrm{e}+02$ 1.33213e+02 1.33213e+01 1.00000e-09 7.00000e-02 $1.33213 \mathrm{e}+02$ 1.33213e+02 1.33213e+01 1.00000e-09 7.00000e-02 $5.32271 \mathrm{e}+005.32271 \mathrm{e}+00$ 5.32271e-01 1.00000e-09 2.12000e-01 $1.00000 \mathrm{e}-02$ 1.00000e-02 1.00000e-03 1.00000e-09 1.00000e-01 $1.00000 \mathrm{e}+001.00000 \mathrm{e}+001.00000 \mathrm{e}-011.00000 \mathrm{e}-091.00000 \mathrm{e}-01$ 1.00000e-06 1.00000e-06 1.00000e-06 1.00000e-09 5.00000e-02 Element: 14723 \# of layers: 8

$\mathrm{Kx} \mathrm{Ky} \mathrm{Kz}$ Ss Por

$5.84794 \mathrm{e}+015.84794 \mathrm{e}+015.84794 \mathrm{e}+001.00000 \mathrm{e}-09$ 7.00000e-02 $5.84794 \mathrm{e}+015.84794 \mathrm{e}+015.84794 \mathrm{e}+001.00000 \mathrm{e}-09$ 7.00000e-02 $5.84794 \mathrm{e}+015.84794 \mathrm{e}+015.84794 \mathrm{e}+001.00000 \mathrm{e}-097.00000 \mathrm{e}-02$ $5.84794 \mathrm{e}+015.84794 \mathrm{e}+015.84794 \mathrm{e}+00$ 1.00000e-09 7.00000e-02 $2.33667 \mathrm{e}+00$ 2.33667e+00 2.33667e-01 1.00000e-09 2.12000e-01 $1.00000 \mathrm{e}-02$ 1.00000e-02 1.00000e-03 1.00000e-09 1.00000e-01 $1.00000 \mathrm{e}+001.00000 \mathrm{e}+001.00000 \mathrm{e}-011.00000 \mathrm{e}-091.00000 \mathrm{e}-01$ 1.00000e-06 1.00000e-06 1.00000e-06 1.00000e-09 5.00000e-02 Element: 14724 \# of layers: 8

Kx Ky Kz Ss Por

1.33213e+02 1.33213e+02 1.33213e+01 1.00000e-09 7.00000e-02 $1.33213 \mathrm{e}+02$ 1.33213e+02 1.33213e+01 1.00000e-09 7.00000e-02 $1.33213 \mathrm{e}+02$ 1.33213e+02 1.33213e+01 1.00000e-09 7.00000e-02 $1.33213 \mathrm{e}+021.33213 \mathrm{e}+02$ 1.33213e+01 1.00000e-09 7.00000e-02 5.32271e+00 5.32271e+00 5.32271e-01 1.00000e-09 2.12000e-01 $1.00000 \mathrm{e}-02$ 1.00000e-02 1.00000e-03 1.00000e-09 1.00000e-01 $1.00000 \mathrm{e}+001.00000 \mathrm{e}+001.00000 \mathrm{e}-011.00000 \mathrm{e}-091.00000 \mathrm{e}-01$ 1.00000e-06 1.00000e-06 1.00000e-06 1.00000e-09 5.00000e-02 Element: 14725 \# of layers: 8

$\mathrm{Kx} \mathrm{Ky} \mathrm{Kz}$ Ss Por

1.33213e+02 1.33213e+02 1.33213e+01 1.00000e-09 7.00000e-02 $1.33213 \mathrm{e}+02$ 1.33213e+02 1.33213e+01 1.00000e-09 7.00000e-02 $1.33213 \mathrm{e}+02$ 1.33213e+02 1.33213e+01 1.00000e-09 7.00000e-02 1.33213e+02 1.33213e+02 1.33213e+01 1.00000e-09 7.00000e-02 $5.32271 \mathrm{e}+005.32271 \mathrm{e}+00$ 5.32271e-01 1.00000e-09 2.12000e-01 $1.00000 \mathrm{e}-02$ 1.00000e-02 1.00000e-03 1.00000e-09 1.00000e-01 $1.00000 \mathrm{e}+001.00000 \mathrm{e}+001.00000 \mathrm{e}-011.00000 \mathrm{e}-091.00000 \mathrm{e}-01$ 
1.00000e-06 1.00000e-06 1.00000e-06 1.00000e-09 5.00000e-02

Element: 14726 \# of layers: 7

$\mathrm{Kx} \mathrm{Ky} \mathrm{Kz}$ Ss Por

5.84794e+01 5.84794e+01 5.84794e+00 1.00000e-09 7.00000e-02

$5.84794 \mathrm{e}+015.84794 \mathrm{e}+015.84794 \mathrm{e}+001.00000 \mathrm{e}-09$ 7.00000e-02

$5.84794 \mathrm{e}+015.84794 \mathrm{e}+015.84794 \mathrm{e}+00$ 1.00000e-09 7.00000e-02

$2.33667 \mathrm{e}+00$ 2.33667e+00 2.33667e-01 1.00000e-09 2.12000e-01

$1.00000 \mathrm{e}-02$ 1.00000e-02 1.00000e-03 1.00000e-09 1.00000e-01

$1.00000 \mathrm{e}+001.00000 \mathrm{e}+001.00000 \mathrm{e}-011.00000 \mathrm{e}-091.00000 \mathrm{e}-01$

1.00000e-06 1.00000e-06 1.00000e-06 1.00000e-09 5.00000e-02

Element: 14727 \# of layers: 9

Kx Ky Kz Ss Por

5.95462e+01 5.95462e+01 5.95462e+00 1.00000e-09 7.00000e-02

$5.95462 \mathrm{e}+015.95462 \mathrm{e}+015.95462 \mathrm{e}+001.00000 \mathrm{e}-09$ 7.00000e-02

$5.95462 \mathrm{e}+015.95462 \mathrm{e}+015.95462 \mathrm{e}+001.00000 \mathrm{e}-09$ 7.00000e-02

$5.95462 \mathrm{e}+015.95462 \mathrm{e}+015.95462 \mathrm{e}+001.00000 \mathrm{e}-09$ 7.00000e-02

5.00000e-04 5.00000e-04 5.00000e-05 1.00000e-09 1.00000e-01

$2.37920 \mathrm{e}+002.37920 \mathrm{e}+002.37920 \mathrm{e}-01$ 1.00000e-09 2.12000e-01

$2.37920 \mathrm{e}+002.37920 \mathrm{e}+00$ 2.37920e-01 1.00000e-09 2.12000e-01

$1.00000 \mathrm{e}-02$ 1.00000e-02 1.00000e-03 1.00000e-09 1.00000e-01

$1.00000 \mathrm{e}+001.00000 \mathrm{e}+001.00000 \mathrm{e}-011.00000 \mathrm{e}-091.00000 \mathrm{e}-01$

Element: 14728 \# of layers: 9

$\mathrm{Kx} \mathrm{Ky} \mathrm{Kz}$ Ss Por

6.30141e+01 6.30141e+01 6.30141e+00 1.00000e-09 7.00000e-02

$6.30141 \mathrm{e}+016.30141 \mathrm{e}+016.30141 \mathrm{e}+001.00000 \mathrm{e}-09$ 7.00000e-02

$6.30141 \mathrm{e}+016.30141 \mathrm{e}+016.30141 \mathrm{e}+00$ 1.00000e-09 7.00000e-02

$6.30141 \mathrm{e}+016.30141 \mathrm{e}+016.30141 \mathrm{e}+001.00000 \mathrm{e}-09$ 7.00000e-02

5.00000e-04 5.00000e-04 5.00000e-05 1.00000e-09 1.00000e-01

$2.51780 \mathrm{e}+002.51780 \mathrm{e}+002.51780 \mathrm{e}-011.00000 \mathrm{e}-092.12000 \mathrm{e}-01$

$2.51780 \mathrm{e}+002.51780 \mathrm{e}+002.51780 \mathrm{e}-01$ 1.00000e-09 2.12000e-01

$1.00000 \mathrm{e}-02$ 1.00000e-02 1.00000e-03 1.00000e-09 1.00000e-01

$1.00000 \mathrm{e}+001.00000 \mathrm{e}+001.00000 \mathrm{e}-01$ 1.00000e-09 1.00000e-01

Element: 14729 \# of layers: 8

$\mathrm{Kx} \mathrm{Ky} \mathrm{Kz}$ Ss Por

6.30141e+01 6.30141e+01 6.30141e+00 1.00000e-09 7.00000e-02

$6.30141 \mathrm{e}+016.30141 \mathrm{e}+016.30141 \mathrm{e}+00$ 1.00000e-09 7.00000e-02

$6.30141 \mathrm{e}+016.30141 \mathrm{e}+016.30141 \mathrm{e}+00$ 1.00000e-09 7.00000e-02

$6.30141 \mathrm{e}+016.30141 \mathrm{e}+016.30141 \mathrm{e}+00$ 1.00000e-09 7.00000e-02

$2.51780 \mathrm{e}+002.51780 \mathrm{e}+002.51780 \mathrm{e}-01$ 1.00000e-09 2.12000e-01

$2.51780 \mathrm{e}+002.51780 \mathrm{e}+002.51780 \mathrm{e}-01$ 1.00000e-09 2.12000e-01

1.00000e-02 1.00000e-02 1.00000e-03 1.00000e-09 1.00000e-01

$1.00000 \mathrm{e}+001.00000 \mathrm{e}+001.00000 \mathrm{e}-011.00000 \mathrm{e}-091.00000 \mathrm{e}-01$

Element: 14730 \# of layers: 7

$\mathrm{Kx} \mathrm{Ky} \mathrm{Kz}$ Ss Por

6.86931e+01 6.86931e+01 6.86931e+00 1.00000e-09 7.00000e-02

$6.86931 \mathrm{e}+016.86931 \mathrm{e}+016.86931 \mathrm{e}+001.00000 \mathrm{e}-09$ 7.00000e-02 
$6.86931 \mathrm{e}+016.86931 \mathrm{e}+016.86931 \mathrm{e}+00$ 1.00000e-09 7.00000e-02 $2.74483 \mathrm{e}+00$ 2.74483e+00 2.74483e-01 1.00000e-09 2.12000e-01 $2.74483 \mathrm{e}+002.74483 \mathrm{e}+00$ 2.74483e-01 1.00000e-09 2.12000e-01 $1.00000 \mathrm{e}-02$ 1.00000e-02 1.00000e-03 1.00000e-09 1.00000e-01 $1.00000 \mathrm{e}+001.00000 \mathrm{e}+001.00000 \mathrm{e}-011.00000 \mathrm{e}-091.00000 \mathrm{e}-01$ Element: 14731 \# of layers: 7

$\mathrm{Kx} \mathrm{Ky} \mathrm{Kz}$ Ss Por

6.30141e+01 6.30141e+01 6.30141e+00 1.00000e-09 7.00000e-02 $6.30141 \mathrm{e}+016.30141 \mathrm{e}+016.30141 \mathrm{e}+00$ 1.00000e-09 7.00000e-02 $6.30141 \mathrm{e}+016.30141 \mathrm{e}+016.30141 \mathrm{e}+00$ 1.00000e-09 7.00000e-02 $2.51780 \mathrm{e}+002.51780 \mathrm{e}+002.51780 \mathrm{e}-01$ 1.00000e-09 2.12000e-01 $2.51780 \mathrm{e}+002.51780 \mathrm{e}+002.51780 \mathrm{e}-01$ 1.00000e-09 2.12000e-01 $1.00000 \mathrm{e}-02$ 1.00000e-02 1.00000e-03 1.00000e-09 1.00000e-01 $1.00000 \mathrm{e}+001.00000 \mathrm{e}+001.00000 \mathrm{e}-01$ 1.00000e-09 1.00000e-01 Element: 14732 \# of layers: 7

Kx Ky Kz Ss Por

6.30141e+01 6.30141e+01 6.30141e+00 1.00000e-09 7.00000e-02 $6.30141 \mathrm{e}+016.30141 \mathrm{e}+016.30141 \mathrm{e}+00$ 1.00000e-09 7.00000e-02 6.30141e+01 6.30141e+01 6.30141e+00 1.00000e-09 7.00000e-02 $2.51780 \mathrm{e}+002.51780 \mathrm{e}+002.51780 \mathrm{e}-01$ 1.00000e-09 2.12000e-01 $2.51780 \mathrm{e}+002.51780 \mathrm{e}+002.51780 \mathrm{e}-01$ 1.00000e-09 2.12000e-01 $1.00000 \mathrm{e}-02$ 1.00000e-02 1.00000e-03 1.00000e-09 1.00000e-01 $1.00000 \mathrm{e}+001.00000 \mathrm{e}+001.00000 \mathrm{e}-01$ 1.00000e-09 1.00000e-01 Element: 14733 \# of layers: 7

Kx Ky Kz Ss Por

6.30141e+01 6.30141e+01 6.30141e+00 1.00000e-09 7.00000e-02 $6.30141 \mathrm{e}+016.30141 \mathrm{e}+016.30141 \mathrm{e}+001.00000 \mathrm{e}-09$ 7.00000e-02 $6.30141 \mathrm{e}+016.30141 \mathrm{e}+016.30141 \mathrm{e}+00$ 1.00000e-09 7.00000e-02 $2.51780 \mathrm{e}+002.51780 \mathrm{e}+002.51780 \mathrm{e}-01$ 1.00000e-09 2.12000e-01 $2.51780 \mathrm{e}+002.51780 \mathrm{e}+002.51780 \mathrm{e}-01$ 1.00000e-09 2.12000e-01 1.00000e-02 1.00000e-02 1.00000e-03 1.00000e-09 1.00000e-01 $1.00000 \mathrm{e}+001.00000 \mathrm{e}+001.00000 \mathrm{e}-011.00000 \mathrm{e}-091.00000 \mathrm{e}-01$ Element: 14734 \# of layers: 9

$\mathrm{Kx} \mathrm{Ky} \mathrm{Kz}$ Ss Por

7.59011e+01 7.59011e+01 7.59011e+00 1.00000e-09 7.00000e-02 $7.59011 \mathrm{e}+017.59011 \mathrm{e}+017.59011 \mathrm{e}+001.00000 \mathrm{e}-09$ 7.00000e-02 $7.59011 \mathrm{e}+017.59011 \mathrm{e}+017.59011 \mathrm{e}+001.00000 \mathrm{e}-09$ 7.00000e-02 5.00000e-04 5.00000e-04 5.00000e-05 1.00000e-09 1.00000e-01 5.00000e-04 5.00000e-04 5.00000e-05 1.00000e-09 1.00000e-01 $3.03284 \mathrm{e}+003.03284 \mathrm{e}+003.03284 \mathrm{e}-01$ 1.00000e-09 2.12000e-01 $3.03284 \mathrm{e}+003.03284 \mathrm{e}+003.03284 \mathrm{e}-01$ 1.00000e-09 2.12000e-01 $1.00000 \mathrm{e}-02$ 1.00000e-02 1.00000e-03 1.00000e-09 1.00000e-01 $1.00000 \mathrm{e}+001.00000 \mathrm{e}+001.00000 \mathrm{e}-01$ 1.00000e-09 1.00000e-01 Element: 14735 \# of layers: 9

$\mathrm{Kx} \mathrm{Ky} \mathrm{Kz}$ Ss Por

7.59011e+01 7.59011e+01 7.59011e+00 1.00000e-09 7.00000e-02 
7.59011e+01 7.59011e+01 7.59011e+00 1.00000e-09 7.00000e-02 $7.59011 \mathrm{e}+017.59011 \mathrm{e}+01$ 7.59011e+00 1.00000e-09 7.00000e-02 5.00000e-04 5.00000e-04 5.00000e-05 1.00000e-09 1.00000e-01 5.00000e-04 5.00000e-04 5.00000e-05 1.00000e-09 1.00000e-01 $3.03284 \mathrm{e}+003.03284 \mathrm{e}+003.03284 \mathrm{e}-01$ 1.00000e-09 2.12000e-01 $3.03284 \mathrm{e}+003.03284 \mathrm{e}+003.03284 \mathrm{e}-01$ 1.00000e-09 2.12000e-01 $1.00000 \mathrm{e}-02$ 1.00000e-02 1.00000e-03 1.00000e-09 1.00000e-01 $1.00000 \mathrm{e}+001.00000 \mathrm{e}+001.00000 \mathrm{e}-011.00000 \mathrm{e}-091.00000 \mathrm{e}-01$ Element: 14736 \# of layers: 9

$\mathrm{Kx} \mathrm{Ky} \mathrm{Kz}$ Ss Por

8.90188e+01 8.90188e+01 8.90188e+00 1.00000e-09 7.00000e-02 $8.90188 \mathrm{e}+018.90188 \mathrm{e}+018.90188 \mathrm{e}+001.00000 \mathrm{e}-09$ 7.00000e-02 $8.90188 \mathrm{e}+018.90188 \mathrm{e}+018.90188 \mathrm{e}+00$ 1.00000e-09 7.00000e-02 5.00000e-04 5.00000e-04 5.00000e-05 1.00000e-09 1.00000e-01 5.00000e-04 5.00000e-04 5.00000e-05 1.00000e-09 1.00000e-01

$3.55688 \mathrm{e}+003.55688 \mathrm{e}+003.55688 \mathrm{e}-01$ 1.00000e-09 2.12000e-01 $3.55688 \mathrm{e}+003.55688 \mathrm{e}+00$ 3.55688e-01 1.00000e-09 2.12000e-01 $1.00000 \mathrm{e}-02$ 1.00000e-02 1.00000e-03 1.00000e-09 1.00000e-01 $1.00000 \mathrm{e}+001.00000 \mathrm{e}+001.00000 \mathrm{e}-01$ 1.00000e-09 1.00000e-01 Element: 14737 \# of layers: 9

$\mathrm{Kx} \mathrm{Ky} \mathrm{Kz}$ Ss Por

7.59011e+01 7.59011e+01 7.59011e+00 1.00000e-09 7.00000e-02 $7.59011 \mathrm{e}+017.59011 \mathrm{e}+017.59011 \mathrm{e}+001.00000 \mathrm{e}-09$ 7.00000e-02 $7.59011 \mathrm{e}+017.59011 \mathrm{e}+017.59011 \mathrm{e}+001.00000 \mathrm{e}-09$ 7.00000e-02 5.00000e-04 5.00000e-04 5.00000e-05 1.00000e-09 1.00000e-01 5.00000e-04 5.00000e-04 5.00000e-05 1.00000e-09 1.00000e-01 $3.03284 \mathrm{e}+003.03284 \mathrm{e}+003.03284 \mathrm{e}-01$ 1.00000e-09 2.12000e-01 $3.03284 \mathrm{e}+003.03284 \mathrm{e}+003.03284 \mathrm{e}-01$ 1.00000e-09 2.12000e-01 $1.00000 \mathrm{e}-021.00000 \mathrm{e}-02$ 1.00000e-03 1.00000e-09 1.00000e-01 $1.00000 \mathrm{e}+001.00000 \mathrm{e}+001.00000 \mathrm{e}-011.00000 \mathrm{e}-091.00000 \mathrm{e}-01$ Element: 14738 \# of layers: 9

$\mathrm{Kx} \mathrm{Ky} \mathrm{Kz}$ Ss Por

7.59011e+01 7.59011e+01 7.59011e+00 1.00000e-09 7.00000e-02 7.59011e+01 7.59011e+01 7.59011e+00 1.00000e-09 7.00000e-02 $7.59011 \mathrm{e}+017.59011 \mathrm{e}+017.59011 \mathrm{e}+001.00000 \mathrm{e}-09$ 7.00000e-02 5.00000e-04 5.00000e-04 5.00000e-05 1.00000e-09 1.00000e-01 5.00000e-04 5.00000e-04 5.00000e-05 1.00000e-09 1.00000e-01 $3.03284 \mathrm{e}+003.03284 \mathrm{e}+003.03284 \mathrm{e}-011.00000 \mathrm{e}-092.12000 \mathrm{e}-01$ $3.03284 \mathrm{e}+003.03284 \mathrm{e}+003.03284 \mathrm{e}-01$ 1.00000e-09 2.12000e-01 $1.00000 \mathrm{e}-02$ 1.00000e-02 1.00000e-03 1.00000e-09 1.00000e-01 $1.00000 \mathrm{e}+001.00000 \mathrm{e}+001.00000 \mathrm{e}-011.00000 \mathrm{e}-091.00000 \mathrm{e}-01$ Element: 14739 \# of layers: 9

$\mathrm{Kx} \mathrm{Ky} \mathrm{Kz}$ Ss Por

7.59011e+01 7.59011e+01 7.59011e+00 1.00000e-09 7.00000e-02 $7.59011 \mathrm{e}+017.59011 \mathrm{e}+017.59011 \mathrm{e}+001.00000 \mathrm{e}-09$ 7.00000e-02 $7.59011 \mathrm{e}+017.59011 \mathrm{e}+017.59011 \mathrm{e}+001.00000 \mathrm{e}-09$ 7.00000e-02 
5.00000e-04 5.00000e-04 5.00000e-05 1.00000e-09 1.00000e-01 5.00000e-04 5.00000e-04 5.00000e-05 1.00000e-09 1.00000e-01 $3.03284 \mathrm{e}+003.03284 \mathrm{e}+003.03284 \mathrm{e}-01$ 1.00000e-09 2.12000e-01 $3.03284 \mathrm{e}+003.03284 \mathrm{e}+003.03284 \mathrm{e}-01$ 1.00000e-09 2.12000e-01 $1.00000 \mathrm{e}-02$ 1.00000e-02 1.00000e-03 1.00000e-09 1.00000e-01 $1.00000 \mathrm{e}+001.00000 \mathrm{e}+001.00000 \mathrm{e}-011.00000 \mathrm{e}-091.00000 \mathrm{e}-01$ Element: 14740 \# of layers: 9

Kx Ky Kz Ss Por

8.90188e+01 8.90188e+01 8.90188e+00 1.00000e-09 7.00000e-02 $8.90188 \mathrm{e}+018.90188 \mathrm{e}+018.90188 \mathrm{e}+00$ 1.00000e-09 7.00000e-02 8.90188e+01 8.90188e+01 8.90188e+00 1.00000e-09 7.00000e-02 5.00000e-04 5.00000e-04 5.00000e-05 1.00000e-09 1.00000e-01 5.00000e-04 5.00000e-04 5.00000e-05 1.00000e-09 1.00000e-01

$3.55688 \mathrm{e}+003.55688 \mathrm{e}+003.55688 \mathrm{e}-01$ 1.00000e-09 2.12000e-01 $3.55688 \mathrm{e}+003.55688 \mathrm{e}+00$ 3.55688e-01 1.00000e-09 2.12000e-01 $1.00000 \mathrm{e}-02$ 1.00000e-02 1.00000e-03 1.00000e-09 1.00000e-01 $1.00000 \mathrm{e}+001.00000 \mathrm{e}+001.00000 \mathrm{e}-011.00000 \mathrm{e}-091.00000 \mathrm{e}-01$ Element: 14741 \# of layers: 8

$\mathrm{Kx} \mathrm{Ky} \mathrm{Kz}$ Ss Por

4.25885e+01 4.25885e+01 4.25885e+00 1.00000e-09 7.00000e-02 $4.25885 \mathrm{e}+014.25885 \mathrm{e}+014.25885 \mathrm{e}+001.00000 \mathrm{e}-09$ 7.00000e-02 $5.00000 \mathrm{e}-04$ 5.00000e-04 5.00000e-05 1.00000e-09 1.00000e-01 5.00000e-04 5.00000e-04 5.00000e-05 1.00000e-09 1.00000e-01 $1.70169 \mathrm{e}+001.70169 \mathrm{e}+00$ 1.70169e-01 1.00000e-09 2.12000e-01 $1.70169 \mathrm{e}+001.70169 \mathrm{e}+00 \quad 1.70169 \mathrm{e}-011.00000 \mathrm{e}-092.12000 \mathrm{e}-01$ $1.00000 \mathrm{e}-02$ 1.00000e-02 1.00000e-03 1.00000e-09 1.00000e-01 $1.00000 \mathrm{e}+001.00000 \mathrm{e}+001.00000 \mathrm{e}-011.00000 \mathrm{e}-091.00000 \mathrm{e}-01$ Element: 14742 \# of layers: 8

$\mathrm{Kx} \mathrm{Ky} \mathrm{Kz}$ Ss Por

4.25885e+01 4.25885e+01 4.25885e+00 1.00000e-09 7.00000e-02 $4.25885 \mathrm{e}+014.25885 \mathrm{e}+014.25885 \mathrm{e}+00$ 1.00000e-09 7.00000e-02 5.00000e-04 5.00000e-04 5.00000e-05 1.00000e-09 1.00000e-01 5.00000e-04 5.00000e-04 5.00000e-05 1.00000e-09 1.00000e-01

$1.70169 \mathrm{e}+001.70169 \mathrm{e}+00$ 1.70169e-01 1.00000e-09 2.12000e-01 $1.70169 \mathrm{e}+001.70169 \mathrm{e}+00$ 1.70169e-01 1.00000e-09 2.12000e-01 1.00000e-02 1.00000e-02 1.00000e-03 1.00000e-09 1.00000e-01 $1.00000 \mathrm{e}+001.00000 \mathrm{e}+001.00000 \mathrm{e}-011.00000 \mathrm{e}-091.00000 \mathrm{e}-01$ Element: 14743 \# of layers: 8

$\mathrm{Kx} \mathrm{Ky} \mathrm{Kz}$ Ss Por

4.25885e+01 4.25885e+01 4.25885e+00 1.00000e-09 7.00000e-02 $4.25885 \mathrm{e}+014.25885 \mathrm{e}+014.25885 \mathrm{e}+001.00000 \mathrm{e}-09$ 7.00000e-02 5.00000e-04 5.00000e-04 5.00000e-05 1.00000e-09 1.00000e-01 5.00000e-04 5.00000e-04 5.00000e-05 1.00000e-09 1.00000e-01 $1.70169 \mathrm{e}+00$ 1.70169e+00 1.70169e-01 1.00000e-09 2.12000e-01 $1.70169 \mathrm{e}+001.70169 \mathrm{e}+001.70169 \mathrm{e}-01$ 1.00000e-09 2.12000e-01 $1.00000 \mathrm{e}-02$ 1.00000e-02 1.00000e-03 1.00000e-09 1.00000e-01 
$1.00000 \mathrm{e}+001.00000 \mathrm{e}+00$ 1.00000e-01 1.00000e-09 1.00000e-01

Element: 14744 \# of layers: 8

$\mathrm{Kx} \mathrm{Ky} \mathrm{Kz}$ Ss Por

4.25885e+01 4.25885e+01 4.25885e+00 1.00000e-09 7.00000e-02

$4.25885 \mathrm{e}+014.25885 \mathrm{e}+014.25885 \mathrm{e}+001.00000 \mathrm{e}-09$ 7.00000e-02

5.00000e-04 5.00000e-04 5.00000e-05 1.00000e-09 1.00000e-01

5.00000e-04 5.00000e-04 5.00000e-05 1.00000e-09 1.00000e-01

$1.70169 \mathrm{e}+001.70169 \mathrm{e}+00$ 1.70169e-01 1.00000e-09 2.12000e-01

$1.70169 \mathrm{e}+001.70169 \mathrm{e}+00$ 1.70169e-01 1.00000e-09 2.12000e-01

$1.00000 \mathrm{e}-02$ 1.00000e-02 1.00000e-03 1.00000e-09 1.00000e-01

$1.00000 \mathrm{e}+001.00000 \mathrm{e}+001.00000 \mathrm{e}-011.00000 \mathrm{e}-091.00000 \mathrm{e}-01$

Element: 14745 \# of layers: 8

$\mathrm{Kx} \mathrm{Ky} \mathrm{Kz}$ Ss Por

4.25885e+01 4.25885e+01 4.25885e+00 1.00000e-09 7.00000e-02

$4.25885 \mathrm{e}+014.25885 \mathrm{e}+014.25885 \mathrm{e}+001.00000 \mathrm{e}-09$ 7.00000e-02

5.00000e-04 5.00000e-04 5.00000e-05 1.00000e-09 1.00000e-01

5.00000e-04 5.00000e-04 5.00000e-05 1.00000e-09 1.00000e-01

$1.70169 \mathrm{e}+001.70169 \mathrm{e}+00$ 1.70169e-01 1.00000e-09 2.12000e-01

$1.70169 \mathrm{e}+001.70169 \mathrm{e}+00$ 1.70169e-01 1.00000e-09 2.12000e-01

$1.00000 \mathrm{e}-02$ 1.00000e-02 1.00000e-03 1.00000e-09 1.00000e-01

$1.00000 \mathrm{e}+001.00000 \mathrm{e}+001.00000 \mathrm{e}-011.00000 \mathrm{e}-091.00000 \mathrm{e}-01$

Element: 14746 \# of layers: 8

$\mathrm{Kx} \mathrm{Ky} \mathrm{Kz}$ Ss Por

4.25885e+01 4.25885e+01 4.25885e+00 1.00000e-09 7.00000e-02

$4.25885 \mathrm{e}+014.25885 \mathrm{e}+014.25885 \mathrm{e}+001.00000 \mathrm{e}-09$ 7.00000e-02

5.00000e-04 5.00000e-04 5.00000e-05 1.00000e-09 1.00000e-01

5.00000e-04 5.00000e-04 5.00000e-05 1.00000e-09 1.00000e-01

$1.70169 \mathrm{e}+001.70169 \mathrm{e}+00$ 1.70169e-01 1.00000e-09 2.12000e-01

$1.70169 \mathrm{e}+001.70169 \mathrm{e}+00$ 1.70169e-01 1.00000e-09 2.12000e-01

$1.00000 \mathrm{e}-02$ 1.00000e-02 1.00000e-03 1.00000e-09 1.00000e-01

$1.00000 \mathrm{e}+001.00000 \mathrm{e}+001.00000 \mathrm{e}-011.00000 \mathrm{e}-091.00000 \mathrm{e}-01$

Element: 14747 \# of layers: 8

Kx Ky Kz Ss Por

4.25885e+01 4.25885e+01 4.25885e+00 1.00000e-09 7.00000e-02

$4.25885 \mathrm{e}+014.25885 \mathrm{e}+014.25885 \mathrm{e}+00$ 1.00000e-09 7.00000e-02

5.00000e-04 5.00000e-04 5.00000e-05 1.00000e-09 1.00000e-01

5.00000e-04 5.00000e-04 5.00000e-05 1.00000e-09 1.00000e-01

$1.70169 \mathrm{e}+001.70169 \mathrm{e}+001.70169 \mathrm{e}-01$ 1.00000e-09 2.12000e-01

$1.70169 \mathrm{e}+001.70169 \mathrm{e}+00$ 1.70169e-01 1.00000e-09 2.12000e-01

$1.00000 \mathrm{e}-02$ 1.00000e-02 1.00000e-03 1.00000e-09 1.00000e-01

$1.00000 \mathrm{e}+001.00000 \mathrm{e}+001.00000 \mathrm{e}-011.00000 \mathrm{e}-091.00000 \mathrm{e}-01$

Element: 14748 \# of layers: 9

$\mathrm{Kx} \mathrm{Ky} \mathrm{Kz}$ Ss Por

3.73609e+01 3.73609e+01 3.73609e+00 1.00000e-09 7.00000e-02

$3.73609 \mathrm{e}+013.73609 \mathrm{e}+013.73609 \mathrm{e}+001.00000 \mathrm{e}-09$ 7.00000e-02

5.00000e-04 5.00000e-04 5.00000e-05 1.00000e-09 1.00000e-01 
5.00000e-04 5.00000e-04 5.00000e-05 1.00000e-09 1.00000e-01 $1.49279 \mathrm{e}+001.49279 \mathrm{e}+00$ 1.49279e-01 1.00000e-09 2.12000e-01 $1.49279 \mathrm{e}+001.49279 \mathrm{e}+00$ 1.49279e-01 1.00000e-09 2.12000e-01 $1.49279 \mathrm{e}+001.49279 \mathrm{e}+001.49279 \mathrm{e}-01$ 1.00000e-09 2.12000e-01 $1.00000 \mathrm{e}-02$ 1.00000e-02 1.00000e-03 1.00000e-09 1.00000e-01 $1.00000 \mathrm{e}+001.00000 \mathrm{e}+001.00000 \mathrm{e}-011.00000 \mathrm{e}-091.00000 \mathrm{e}-01$ Element: 14749 \# of layers: 9

Kx Ky Kz Ss Por

3.73609e+01 3.73609e+01 3.73609e+00 1.00000e-09 7.00000e-02 $3.73609 \mathrm{e}+013.73609 \mathrm{e}+013.73609 \mathrm{e}+00$ 1.00000e-09 7.00000e-02 $3.73609 \mathrm{e}+013.73609 \mathrm{e}+013.73609 \mathrm{e}+00$ 1.00000e-09 7.00000e-02 5.00000e-04 5.00000e-04 5.00000e-05 1.00000e-09 1.00000e-01 5.00000e-04 5.00000e-04 5.00000e-05 1.00000e-09 1.00000e-01 $1.49279 \mathrm{e}+00$ 1.49279e+00 1.49279e-01 1.00000e-09 2.12000e-01 $1.49279 \mathrm{e}+001.49279 \mathrm{e}+00$ 1.49279e-01 1.00000e-09 2.12000e-01 $1.00000 \mathrm{e}-02$ 1.00000e-02 1.00000e-03 1.00000e-09 1.00000e-01 $1.00000 \mathrm{e}+001.00000 \mathrm{e}+001.00000 \mathrm{e}-011.00000 \mathrm{e}-091.00000 \mathrm{e}-01$ Element: 14750 \# of layers: 10

$\mathrm{Kx} \mathrm{Ky} \mathrm{Kz}$ Ss Por

3.73609e+01 3.73609e+01 3.73609e+00 1.00000e-09 7.00000e-02 $3.73609 \mathrm{e}+013.73609 \mathrm{e}+013.73609 \mathrm{e}+001.00000 \mathrm{e}-09$ 7.00000e-02 $3.73609 \mathrm{e}+013.73609 \mathrm{e}+013.73609 \mathrm{e}+001.00000 \mathrm{e}-09$ 7.00000e-02 5.00000e-04 5.00000e-04 5.00000e-05 1.00000e-09 1.00000e-01 5.00000e-04 5.00000e-04 5.00000e-05 1.00000e-09 1.00000e-01 $1.49279 \mathrm{e}+001.49279 \mathrm{e}+00$ 1.49279e-01 1.00000e-09 2.12000e-01 $1.49279 \mathrm{e}+00$ 1.49279e+00 1.49279e-01 1.00000e-09 2.12000e-01 $1.49279 \mathrm{e}+00$ 1.49279e+00 1.49279e-01 1.00000e-09 2.12000e-01 1.00000e-02 1.00000e-02 1.00000e-03 1.00000e-09 1.00000e-01 $1.00000 \mathrm{e}+001.00000 \mathrm{e}+001.00000 \mathrm{e}-011.00000 \mathrm{e}-091.00000 \mathrm{e}-01$ Element: 14751 \# of layers: 8

$\mathrm{Kx} \mathrm{Ky} \mathrm{Kz}$ Ss Por

3.73609e+01 3.73609e+01 3.73609e+00 1.00000e-09 7.00000e-02 $3.73609 \mathrm{e}+013.73609 \mathrm{e}+013.73609 \mathrm{e}+00$ 1.00000e-09 7.00000e-02 5.00000e-04 5.00000e-04 5.00000e-05 1.00000e-09 1.00000e-01 5.00000e-04 5.00000e-04 5.00000e-05 1.00000e-09 1.00000e-01 $1.49279 \mathrm{e}+00$ 1.49279e+00 1.49279e-01 1.00000e-09 2.12000e-01 $1.49279 \mathrm{e}+001.49279 \mathrm{e}+001.49279 \mathrm{e}-01$ 1.00000e-09 2.12000e-01 1.00000e-02 1.00000e-02 1.00000e-03 1.00000e-09 1.00000e-01 $1.00000 \mathrm{e}+001.00000 \mathrm{e}+001.00000 \mathrm{e}-011.00000 \mathrm{e}-091.00000 \mathrm{e}-01$ Element: 14752 \# of layers: 9

Kx Ky Kz Ss Por

3.73609e+01 3.73609e+01 3.73609e+00 1.00000e-09 7.00000e-02 $3.73609 \mathrm{e}+013.73609 \mathrm{e}+013.73609 \mathrm{e}+001.00000 \mathrm{e}-09$ 7.00000e-02 5.00000e-04 5.00000e-04 5.00000e-05 1.00000e-09 1.00000e-01 5.00000e-04 5.00000e-04 5.00000e-05 1.00000e-09 1.00000e-01 $1.49279 \mathrm{e}+001.49279 \mathrm{e}+00$ 1.49279e-01 1.00000e-09 2.12000e-01 
$1.49279 \mathrm{e}+001.49279 \mathrm{e}+00$ 1.49279e-01 1.00000e-09 2.12000e-01 $1.49279 \mathrm{e}+001.49279 \mathrm{e}+00$ 1.49279e-01 1.00000e-09 2.12000e-01 $1.00000 \mathrm{e}-02$ 1.00000e-02 1.00000e-03 1.00000e-09 1.00000e-01 $1.00000 \mathrm{e}+001.00000 \mathrm{e}+001.00000 \mathrm{e}-011.00000 \mathrm{e}-091.00000 \mathrm{e}-01$ Element: 14753 \# of layers: 8

Kx Ky Kz Ss Por

$3.73609 \mathrm{e}+013.73609 \mathrm{e}+013.73609 \mathrm{e}+00$ 1.00000e-09 7.00000e-02 $3.73609 \mathrm{e}+013.73609 \mathrm{e}+013.73609 \mathrm{e}+001.00000 \mathrm{e}-09$ 7.00000e-02 5.00000e-04 5.00000e-04 5.00000e-05 1.00000e-09 1.00000e-01 5.00000e-04 5.00000e-04 5.00000e-05 1.00000e-09 1.00000e-01 $1.49279 \mathrm{e}+001.49279 \mathrm{e}+00$ 1.49279e-01 1.00000e-09 2.12000e-01 $1.49279 \mathrm{e}+001.49279 \mathrm{e}+00$ 1.49279e-01 1.00000e-09 2.12000e-01 $1.00000 \mathrm{e}-02$ 1.00000e-02 1.00000e-03 1.00000e-09 1.00000e-01 $1.00000 \mathrm{e}+001.00000 \mathrm{e}+001.00000 \mathrm{e}-011.00000 \mathrm{e}-091.00000 \mathrm{e}-01$ Element: 14754 \# of layers: 9

Kx Ky Kz Ss Por

$3.73609 \mathrm{e}+013.73609 \mathrm{e}+013.73609 \mathrm{e}+00$ 1.00000e-09 7.00000e-02

$3.73609 \mathrm{e}+013.73609 \mathrm{e}+013.73609 \mathrm{e}+001.00000 \mathrm{e}-09$ 7.00000e-02 $5.00000 \mathrm{e}-04$ 5.00000e-04 5.00000e-05 1.00000e-09 1.00000e-01 5.00000e-04 5.00000e-04 5.00000e-05 1.00000e-09 1.00000e-01 $1.49279 \mathrm{e}+001.49279 \mathrm{e}+001.49279 \mathrm{e}-011.00000 \mathrm{e}-092.12000 \mathrm{e}-01$ $1.49279 \mathrm{e}+001.49279 \mathrm{e}+001.49279 \mathrm{e}-011.00000 \mathrm{e}-092.12000 \mathrm{e}-01$ $1.49279 \mathrm{e}+001.49279 \mathrm{e}+00$ 1.49279e-01 1.00000e-09 2.12000e-01 $1.00000 \mathrm{e}-021.00000 \mathrm{e}-02$ 1.00000e-03 1.00000e-09 1.00000e-01 $1.00000 \mathrm{e}+001.00000 \mathrm{e}+001.00000 \mathrm{e}-011.00000 \mathrm{e}-091.00000 \mathrm{e}-01$ Element: 14755 \# of layers: 8

Kx Ky Kz Ss Por

$2.34756 \mathrm{e}+012.34756 \mathrm{e}+012.34756 \mathrm{e}+00$ 1.00000e-09 7.00000e-02 $2.34756 \mathrm{e}+012.34756 \mathrm{e}+012.34756 \mathrm{e}+001.00000 \mathrm{e}-09$ 7.00000e-02 $2.34756 \mathrm{e}+012.34756 \mathrm{e}+012.34756 \mathrm{e}+001.00000 \mathrm{e}-097.00000 \mathrm{e}-02$ 5.00000e-04 5.00000e-04 5.00000e-05 1.00000e-09 1.00000e-01 5.00000e-04 5.00000e-04 5.00000e-05 1.00000e-09 1.00000e-01 9.38022e-01 9.38022e-01 9.38023e-02 1.00000e-09 2.12000e-01 $1.00000 \mathrm{e}-021.00000 \mathrm{e}-02$ 1.00000e-03 1.00000e-09 1.00000e-01 $1.00000 \mathrm{e}+001.00000 \mathrm{e}+001.00000 \mathrm{e}-011.00000 \mathrm{e}-091.00000 \mathrm{e}-01$ Element: 14756 \# of layers: 8

Kx Ky Kz Ss Por

$2.34756 \mathrm{e}+012.34756 \mathrm{e}+012.34756 \mathrm{e}+00$ 1.00000e-09 7.00000e-02 $2.34756 \mathrm{e}+012.34756 \mathrm{e}+012.34756 \mathrm{e}+001.00000 \mathrm{e}-09$ 7.00000e-02 $2.34756 \mathrm{e}+012.34756 \mathrm{e}+012.34756 \mathrm{e}+001.00000 \mathrm{e}-09$ 7.00000e-02 5.00000e-04 5.00000e-04 5.00000e-05 1.00000e-09 1.00000e-01 5.00000e-04 5.00000e-04 5.00000e-05 1.00000e-09 1.00000e-01 9.38022e-01 9.38022e-01 9.38023e-02 1.00000e-09 2.12000e-01 $1.00000 \mathrm{e}-02$ 1.00000e-02 1.00000e-03 1.00000e-09 1.00000e-01 $1.00000 \mathrm{e}+001.00000 \mathrm{e}+001.00000 \mathrm{e}-011.00000 \mathrm{e}-091.00000 \mathrm{e}-01$ Element: 14757 \# of layers: 8 
$\mathrm{Kx} \mathrm{Ky} \mathrm{Kz}$ Ss Por

$2.34756 \mathrm{e}+012.34756 \mathrm{e}+012.34756 \mathrm{e}+001.00000 \mathrm{e}-09$ 7.00000e-02

$2.34756 \mathrm{e}+012.34756 \mathrm{e}+012.34756 \mathrm{e}+001.00000 \mathrm{e}-09$ 7.00000e-02

$2.34756 \mathrm{e}+012.34756 \mathrm{e}+012.34756 \mathrm{e}+001.00000 \mathrm{e}-09$ 7.00000e-02

5.00000e-04 5.00000e-04 5.00000e-05 1.00000e-09 1.00000e-01

5.00000e-04 5.00000e-04 5.00000e-05 1.00000e-09 1.00000e-01

9.38022e-01 9.38022e-01 9.38023e-02 1.00000e-09 2.12000e-01

$1.00000 \mathrm{e}-02$ 1.00000e-02 1.00000e-03 1.00000e-09 1.00000e-01

$1.00000 \mathrm{e}+001.00000 \mathrm{e}+001.00000 \mathrm{e}-011.00000 \mathrm{e}-091.00000 \mathrm{e}-01$

Element: 14758 \# of layers: 8

Kx Ky Kz Ss Por

$2.34756 \mathrm{e}+012.34756 \mathrm{e}+012.34756 \mathrm{e}+00$ 1.00000e-09 7.00000e-02

$2.34756 \mathrm{e}+012.34756 \mathrm{e}+012.34756 \mathrm{e}+001.00000 \mathrm{e}-09$ 7.00000e-02

$2.34756 \mathrm{e}+012.34756 \mathrm{e}+012.34756 \mathrm{e}+001.00000 \mathrm{e}-09$ 7.00000e-02

5.00000e-04 5.00000e-04 5.00000e-05 1.00000e-09 1.00000e-01

5.00000e-04 5.00000e-04 5.00000e-05 1.00000e-09 1.00000e-01

9.38022e-01 9.38022e-01 9.38023e-02 1.00000e-09 2.12000e-01

$1.00000 \mathrm{e}-02$ 1.00000e-02 1.00000e-03 1.00000e-09 1.00000e-01

$1.00000 \mathrm{e}+001.00000 \mathrm{e}+001.00000 \mathrm{e}-01$ 1.00000e-09 1.00000e-01

Element: 14759 \# of layers: 7

Kx Ky Kz Ss Por

2.34756e+01 2.34756e+01 2.34756e+00 1.00000e-09 7.00000e-02

$2.34756 \mathrm{e}+012.34756 \mathrm{e}+012.34756 \mathrm{e}+00$ 1.00000e-09 7.00000e-02

$2.34756 \mathrm{e}+012.34756 \mathrm{e}+012.34756 \mathrm{e}+00$ 1.00000e-09 7.00000e-02

5.00000e-04 5.00000e-04 5.00000e-05 1.00000e-09 1.00000e-01

9.38022e-01 9.38022e-01 9.38023e-02 1.00000e-09 2.12000e-01

$1.00000 \mathrm{e}-02$ 1.00000e-02 1.00000e-03 1.00000e-09 1.00000e-01

$1.00000 \mathrm{e}+001.00000 \mathrm{e}+001.00000 \mathrm{e}-01$ 1.00000e-09 1.00000e-01

Element: 14760 \# of layers: 7

$\mathrm{Kx} \mathrm{Ky} \mathrm{Kz}$ Ss Por

$2.34756 \mathrm{e}+012.34756 \mathrm{e}+012.34756 \mathrm{e}+00$ 1.00000e-09 7.00000e-02

$2.34756 \mathrm{e}+012.34756 \mathrm{e}+012.34756 \mathrm{e}+001.00000 \mathrm{e}-09$ 7.00000e-02

5.00000e-04 5.00000e-04 5.00000e-05 1.00000e-09 1.00000e-01

5.00000e-04 5.00000e-04 5.00000e-05 1.00000e-09 1.00000e-01

9.38022e-01 9.38022e-01 9.38023e-02 1.00000e-09 2.12000e-01

$1.00000 \mathrm{e}-02$ 1.00000e-02 1.00000e-03 1.00000e-09 1.00000e-01

$1.00000 \mathrm{e}+001.00000 \mathrm{e}+001.00000 \mathrm{e}-011.00000 \mathrm{e}-091.00000 \mathrm{e}-01$

Element: 14761 \# of layers: 7

$\mathrm{Kx} \mathrm{Ky} \mathrm{Kz}$ Ss Por

$2.34756 \mathrm{e}+012.34756 \mathrm{e}+012.34756 \mathrm{e}+00$ 1.00000e-09 7.00000e-02

$2.34756 \mathrm{e}+012.34756 \mathrm{e}+012.34756 \mathrm{e}+001.00000 \mathrm{e}-09$ 7.00000e-02

$2.34756 \mathrm{e}+012.34756 \mathrm{e}+012.34756 \mathrm{e}+001.00000 \mathrm{e}-09$ 7.00000e-02

5.00000e-04 5.00000e-04 5.00000e-05 1.00000e-09 1.00000e-01

9.38022e-01 9.38022e-01 9.38023e-02 1.00000e-09 2.12000e-01

$1.00000 \mathrm{e}-02$ 1.00000e-02 1.00000e-03 1.00000e-09 1.00000e-01

$1.00000 \mathrm{e}+001.00000 \mathrm{e}+001.00000 \mathrm{e}-011.00000 \mathrm{e}-091.00000 \mathrm{e}-01$ 
Element: 14762 \# of layers: 7

$\mathrm{Kx} \mathrm{Ky} \mathrm{Kz}$ Ss Por

2.34269e+01 2.34269e+01 2.34269e+00 1.00000e-09 7.00000e-02

$2.34269 \mathrm{e}+012.34269 \mathrm{e}+012.34269 \mathrm{e}+001.00000 \mathrm{e}-09$ 7.00000e-02

$2.34269 \mathrm{e}+012.34269 \mathrm{e}+012.34269 \mathrm{e}+00$ 1.00000e-09 7.00000e-02

9.36065e-01 9.36065e-01 9.36065e-02 1.00000e-09 2.12000e-01

9.36065e-01 9.36065e-01 9.36065e-02 1.00000e-09 2.12000e-01

$1.00000 \mathrm{e}-02$ 1.00000e-02 1.00000e-03 1.00000e-09 1.00000e-01

$1.00000 \mathrm{e}+001.00000 \mathrm{e}+001.00000 \mathrm{e}-011.00000 \mathrm{e}-091.00000 \mathrm{e}-01$

Element: 14763 \# of layers: 7

$\mathrm{Kx} \mathrm{Ky} \mathrm{Kz}$ Ss Por

$2.34269 \mathrm{e}+012.34269 \mathrm{e}+012.34269 \mathrm{e}+00$ 1.00000e-09 7.00000e-02

$2.34269 \mathrm{e}+012.34269 \mathrm{e}+012.34269 \mathrm{e}+00$ 1.00000e-09 7.00000e-02

$2.34269 \mathrm{e}+012.34269 \mathrm{e}+012.34269 \mathrm{e}+00$ 1.00000e-09 7.00000e-02

9.36065e-01 9.36065e-01 9.36065e-02 1.00000e-09 2.12000e-01

9.36065e-01 9.36065e-01 9.36065e-02 1.00000e-09 2.12000e-01

$1.00000 \mathrm{e}-02$ 1.00000e-02 1.00000e-03 1.00000e-09 1.00000e-01

$1.00000 \mathrm{e}+001.00000 \mathrm{e}+001.00000 \mathrm{e}-01$ 1.00000e-09 1.00000e-01

Element: 14764 \# of layers: 7

$\mathrm{Kx} \mathrm{Ky} \mathrm{Kz}$ Ss Por

2.34269e+01 2.34269e+01 2.34269e+00 1.00000e-09 7.00000e-02

$2.34269 \mathrm{e}+012.34269 \mathrm{e}+012.34269 \mathrm{e}+00$ 1.00000e-09 7.00000e-02

$2.34269 \mathrm{e}+012.34269 \mathrm{e}+012.34269 \mathrm{e}+00$ 1.00000e-09 7.00000e-02

9.36065e-01 9.36065e-01 9.36065e-02 1.00000e-09 2.12000e-01

9.36065e-01 9.36065e-01 9.36065e-02 1.00000e-09 2.12000e-01

$1.00000 \mathrm{e}-02$ 1.00000e-02 1.00000e-03 1.00000e-09 1.00000e-01

$1.00000 \mathrm{e}+001.00000 \mathrm{e}+001.00000 \mathrm{e}-011.00000 \mathrm{e}-09$ 1.00000e-01

Element: 14765 \# of layers: 7

$\mathrm{Kx} \mathrm{Ky} \mathrm{Kz}$ Ss Por

$2.34269 \mathrm{e}+012.34269 \mathrm{e}+012.34269 \mathrm{e}+00$ 1.00000e-09 7.00000e-02

$2.34269 \mathrm{e}+012.34269 \mathrm{e}+012.34269 \mathrm{e}+00$ 1.00000e-09 7.00000e-02

$2.34269 \mathrm{e}+012.34269 \mathrm{e}+012.34269 \mathrm{e}+00$ 1.00000e-09 7.00000e-02

9.36065e-01 9.36065e-01 9.36065e-02 1.00000e-09 2.12000e-01

9.36065e-01 9.36065e-01 9.36065e-02 1.00000e-09 2.12000e-01

$1.00000 \mathrm{e}-02$ 1.00000e-02 1.00000e-03 1.00000e-09 1.00000e-01

$1.00000 \mathrm{e}+001.00000 \mathrm{e}+001.00000 \mathrm{e}-011.00000 \mathrm{e}-091.00000 \mathrm{e}-01$

Element: 14766 \# of layers: 7

Kx Ky Kz Ss Por

2.34269e+01 2.34269e+01 2.34269e+00 1.00000e-09 7.00000e-02

$2.34269 \mathrm{e}+012.34269 \mathrm{e}+012.34269 \mathrm{e}+00$ 1.00000e-09 7.00000e-02

$2.34269 \mathrm{e}+012.34269 \mathrm{e}+012.34269 \mathrm{e}+00$ 1.00000e-09 7.00000e-02

9.36065e-01 9.36065e-01 9.36065e-02 1.00000e-09 2.12000e-01

9.36065e-01 9.36065e-01 9.36065e-02 1.00000e-09 2.12000e-01

$1.00000 \mathrm{e}-02$ 1.00000e-02 1.00000e-03 1.00000e-09 1.00000e-01

$1.00000 \mathrm{e}+001.00000 \mathrm{e}+001.00000 \mathrm{e}-01$ 1.00000e-09 1.00000e-01

Element: 14767 \# of layers: 7 
Kx Ky Kz Ss Por

$2.34269 \mathrm{e}+012.34269 \mathrm{e}+012.34269 \mathrm{e}+00$ 1.00000e-09 7.00000e-02

$2.34269 \mathrm{e}+012.34269 \mathrm{e}+012.34269 \mathrm{e}+001.00000 \mathrm{e}-09$ 7.00000e-02

$2.34269 \mathrm{e}+012.34269 \mathrm{e}+012.34269 \mathrm{e}+001.00000 \mathrm{e}-09$ 7.00000e-02

9.36065e-01 9.36065e-01 9.36065e-02 1.00000e-09 2.12000e-01

9.36065e-01 9.36065e-01 9.36065e-02 1.00000e-09 2.12000e-01

$1.00000 \mathrm{e}-021.00000 \mathrm{e}-02$ 1.00000e-03 $1.00000 \mathrm{e}-091.00000 \mathrm{e}-01$

$1.00000 \mathrm{e}+001.00000 \mathrm{e}+001.00000 \mathrm{e}-011.00000 \mathrm{e}-091.00000 \mathrm{e}-01$

Element: 14768 \# of layers: 7

Kx Ky Kz Ss Por

$2.34269 \mathrm{e}+012.34269 \mathrm{e}+012.34269 \mathrm{e}+00$ 1.00000e-09 7.00000e-02

$2.34269 \mathrm{e}+012.34269 \mathrm{e}+012.34269 \mathrm{e}+001.00000 \mathrm{e}-09$ 7.00000e-02

$2.34269 \mathrm{e}+012.34269 \mathrm{e}+012.34269 \mathrm{e}+00$ 1.00000e-09 7.00000e-02

9.36065e-01 9.36065e-01 9.36065e-02 1.00000e-09 2.12000e-01

9.36065e-01 9.36065e-01 9.36065e-02 1.00000e-09 2.12000e-01

$1.00000 \mathrm{e}-021.00000 \mathrm{e}-02$ 1.00000e-03 1.00000e-09 1.00000e-01

$1.00000 \mathrm{e}+001.00000 \mathrm{e}+001.00000 \mathrm{e}-011.00000 \mathrm{e}-091.00000 \mathrm{e}-01$

Element: 14769 \# of layers: 9

Kx Ky Kz Ss Por

$2.37747 \mathrm{e}+012.37747 \mathrm{e}+012.37747 \mathrm{e}+00$ 1.00000e-09 7.00000e-02

$2.37747 \mathrm{e}+012.37747 \mathrm{e}+012.37747 \mathrm{e}+001.00000 \mathrm{e}-09$ 7.00000e-02

5.00000e-04 5.00000e-04 5.00000e-05 1.00000e-09 1.00000e-01

5.00000e-04 5.00000e-04 5.00000e-05 1.00000e-09 1.00000e-01

9.49948e-01 9.49948e-01 9.49948e-02 1.00000e-09 2.12000e-01

9.49948e-01 9.49948e-01 9.49948e-02 1.00000e-09 2.12000e-01

9.49948e-01 9.49948e-01 9.49948e-02 1.00000e-09 2.12000e-01

$1.00000 \mathrm{e}-02$ 1.00000e-02 1.00000e-03 1.00000e-09 1.00000e-01

$1.00000 \mathrm{e}+001.00000 \mathrm{e}+001.00000 \mathrm{e}-011.00000 \mathrm{e}-091.00000 \mathrm{e}-01$

Element: 14770 \# of layers: 10

Kx Ky Kz Ss Por

$2.37747 \mathrm{e}+012.37747 \mathrm{e}+012.37747 \mathrm{e}+00$ 1.00000e-09 7.00000e-02

$2.37747 \mathrm{e}+012.37747 \mathrm{e}+012.37747 \mathrm{e}+001.00000 \mathrm{e}-09$ 7.00000e-02

5.00000e-04 5.00000e-04 5.00000e-05 1.00000e-09 1.00000e-01

5.00000e-04 5.00000e-04 5.00000e-05 1.00000e-09 1.00000e-01

9.49948e-01 9.49948e-01 9.49948e-02 1.00000e-09 2.12000e-01

9.49948e-01 9.49948e-01 9.49948e-02 1.00000e-09 2.12000e-01

9.49948e-01 9.49948e-01 9.49948e-02 1.00000e-09 2.12000e-01

9.49948e-01 9.49948e-01 9.49948e-02 1.00000e-09 2.12000e-01

$1.00000 \mathrm{e}-02$ 1.00000e-02 1.00000e-03 1.00000e-09 1.00000e-01

$1.00000 \mathrm{e}+001.00000 \mathrm{e}+001.00000 \mathrm{e}-011.00000 \mathrm{e}-091.00000 \mathrm{e}-01$

Element: 14771 \# of layers: 10

Kx Ky Kz Ss Por

$2.37747 \mathrm{e}+012.37747 \mathrm{e}+012.37747 \mathrm{e}+00$ 1.00000e-09 7.00000e-02

$2.37747 \mathrm{e}+012.37747 \mathrm{e}+012.37747 \mathrm{e}+001.00000 \mathrm{e}-09$ 7.00000e-02

5.00000e-04 5.00000e-04 5.00000e-05 1.00000e-09 1.00000e-01

5.00000e-04 5.00000e-04 5.00000e-05 1.00000e-09 1.00000e-01 
9.49948e-01 9.49948e-01 9.49948e-02 1.00000e-09 2.12000e-01 9.49948e-01 9.49948e-01 9.49948e-02 1.00000e-09 2.12000e-01 9.49948e-01 9.49948e-01 9.49948e-02 1.00000e-09 2.12000e-01 9.49948e-01 9.49948e-01 9.49948e-02 1.00000e-09 2.12000e-01 $1.00000 \mathrm{e}-02$ 1.00000e-02 1.00000e-03 1.00000e-09 1.00000e-01 $1.00000 \mathrm{e}+001.00000 \mathrm{e}+001.00000 \mathrm{e}-011.00000 \mathrm{e}-091.00000 \mathrm{e}-01$ Element: 14772 \# of layers: 10

Kx Ky Kz Ss Por

$2.37747 \mathrm{e}+012.37747 \mathrm{e}+012.37747 \mathrm{e}+00$ 1.00000e-09 7.00000e-02

$2.37747 \mathrm{e}+012.37747 \mathrm{e}+012.37747 \mathrm{e}+00$ 1.00000e-09 7.00000e-02

5.00000e-04 5.00000e-04 5.00000e-05 1.00000e-09 1.00000e-01

5.00000e-04 5.00000e-04 5.00000e-05 1.00000e-09 1.00000e-01

9.49948e-01 9.49948e-01 9.49948e-02 1.00000e-09 2.12000e-01

9.49948e-01 9.49948e-01 9.49948e-02 1.00000e-09 2.12000e-01

9.49948e-01 9.49948e-01 9.49948e-02 1.00000e-09 2.12000e-01

9.49948e-01 9.49948e-01 9.49948e-02 1.00000e-09 2.12000e-01

$1.00000 \mathrm{e}-02$ 1.00000e-02 1.00000e-03 1.00000e-09 1.00000e-01

$1.00000 \mathrm{e}+001.00000 \mathrm{e}+001.00000 \mathrm{e}-011.00000 \mathrm{e}-091.00000 \mathrm{e}-01$

Element: 14773 \# of layers: 9

$\mathrm{Kx} \mathrm{Ky} \mathrm{Kz}$ Ss Por

2.37747e+01 2.37747e+01 2.37747e+00 1.00000e-09 7.00000e-02

$2.37747 \mathrm{e}+012.37747 \mathrm{e}+012.37747 \mathrm{e}+00$ 1.00000e-09 7.00000e-02

5.00000e-04 5.00000e-04 5.00000e-05 1.00000e-09 1.00000e-01

5.00000e-04 5.00000e-04 5.00000e-05 1.00000e-09 1.00000e-01

9.49948e-01 9.49948e-01 9.49948e-02 1.00000e-09 2.12000e-01

9.49948e-01 9.49948e-01 9.49948e-02 1.00000e-09 2.12000e-01

9.49948e-01 9.49948e-01 9.49948e-02 1.00000e-09 2.12000e-01

$1.00000 \mathrm{e}-02$ 1.00000e-02 1.00000e-03 1.00000e-09 1.00000e-01

$1.00000 \mathrm{e}+001.00000 \mathrm{e}+001.00000 \mathrm{e}-011.00000 \mathrm{e}-091.00000 \mathrm{e}-01$

Element: 14774 \# of layers: 9

$\mathrm{Kx} \mathrm{Ky} \mathrm{Kz}$ Ss Por

2.37747e+01 2.37747e+01 2.37747e+00 1.00000e-09 7.00000e-02

$2.37747 \mathrm{e}+012.37747 \mathrm{e}+012.37747 \mathrm{e}+00$ 1.00000e-09 7.00000e-02

5.00000e-04 5.00000e-04 5.00000e-05 1.00000e-09 1.00000e-01

5.00000e-04 5.00000e-04 5.00000e-05 1.00000e-09 1.00000e-01

9.49948e-01 9.49948e-01 9.49948e-02 1.00000e-09 2.12000e-01

9.49948e-01 9.49948e-01 9.49948e-02 1.00000e-09 2.12000e-01

9.49948e-01 9.49948e-01 9.49948e-02 1.00000e-09 2.12000e-01

$1.00000 \mathrm{e}-02$ 1.00000e-02 1.00000e-03 1.00000e-09 1.00000e-01

$1.00000 \mathrm{e}+001.00000 \mathrm{e}+001.00000 \mathrm{e}-01$ 1.00000e-09 1.00000e-01

Element: 14775 \# of layers: 9

$\mathrm{Kx} \mathrm{Ky} \mathrm{Kz}$ Ss Por

2.37747e+01 2.37747e+01 2.37747e+00 1.00000e-09 7.00000e-02

2.37747e+01 2.37747e+01 2.37747e+00 1.00000e-09 7.00000e-02

5.00000e-04 5.00000e-04 5.00000e-05 1.00000e-09 1.00000e-01

5.00000e-04 5.00000e-04 5.00000e-05 1.00000e-09 1.00000e-01 
9.49948e-01 9.49948e-01 9.49948e-02 1.00000e-09 2.12000e-01 9.49948e-01 9.49948e-01 9.49948e-02 1.00000e-09 2.12000e-01 9.49948e-01 9.49948e-01 9.49948e-02 1.00000e-09 2.12000e-01 $1.00000 \mathrm{e}-021.00000 \mathrm{e}-02$ 1.00000e-03 1.00000e-09 1.00000e-01 $1.00000 \mathrm{e}+001.00000 \mathrm{e}+001.00000 \mathrm{e}-011.00000 \mathrm{e}-091.00000 \mathrm{e}-01$ Element: 14776 \# of layers: 9

Kx Ky Kz Ss Por

$2.46631 \mathrm{e}+012.46631 \mathrm{e}+012.46631 \mathrm{e}+00$ 1.00000e-09 7.00000e-02

$2.46631 \mathrm{e}+012.46631 \mathrm{e}+012.46631 \mathrm{e}+001.00000 \mathrm{e}-09$ 7.00000e-02

$5.00000 \mathrm{e}-04$ 5.00000e-04 5.00000e-05 1.00000e-09 1.00000e-01

5.00000e-04 5.00000e-04 5.00000e-05 1.00000e-09 1.00000e-01 9.85431e-01 9.85431e-01 9.85431e-02 1.00000e-09 2.12000e-01

9.85431e-01 9.85431e-01 9.85431e-02 1.00000e-09 2.12000e-01

9.85431e-01 9.85431e-01 9.85431e-02 1.00000e-09 2.12000e-01

9.85431e-01 9.85431e-01 9.85431e-02 1.00000e-09 2.12000e-01

$1.00000 \mathrm{e}-021.00000 \mathrm{e}-02$ 1.00000e-03 1.00000e-09 1.00000e-01

Element: 14777 \# of layers: 10

Kx Ky Kz Ss Por

$2.46631 \mathrm{e}+012.46631 \mathrm{e}+012.46631 \mathrm{e}+00$ 1.00000e-09 7.00000e-02

$2.46631 \mathrm{e}+012.46631 \mathrm{e}+012.46631 \mathrm{e}+001.00000 \mathrm{e}-097.00000 \mathrm{e}-02$ 5.00000e-04 5.00000e-04 5.00000e-05 1.00000e-09 1.00000e-01 5.00000e-04 5.00000e-04 5.00000e-05 1.00000e-09 1.00000e-01 9.85431e-01 9.85431e-01 9.85431e-02 1.00000e-09 2.12000e-01 9.85431e-01 9.85431e-01 9.85431e-02 1.00000e-09 2.12000e-01 9.85431e-01 9.85431e-01 9.85431e-02 1.00000e-09 2.12000e-01 9.85431e-01 9.85431e-01 9.85431e-02 1.00000e-09 2.12000e-01 9.85431e-01 9.85431e-01 9.85431e-02 1.00000e-09 2.12000e-01 $1.00000 \mathrm{e}-021.00000 \mathrm{e}-02$ 1.00000e-03 1.00000e-09 1.00000e-01 Element: 14778 \# of layers: 9

Kx Ky Kz Ss Por

$2.46631 \mathrm{e}+012.46631 \mathrm{e}+012.46631 \mathrm{e}+00$ 1.00000e-09 7.00000e-02 $2.46631 \mathrm{e}+012.46631 \mathrm{e}+012.46631 \mathrm{e}+001.00000 \mathrm{e}-097.00000 \mathrm{e}-02$ 5.00000e-04 5.00000e-04 5.00000e-05 1.00000e-09 1.00000e-01 5.00000e-04 5.00000e-04 5.00000e-05 1.00000e-09 1.00000e-01 9.85431e-01 9.85431e-01 9.85431e-02 1.00000e-09 2.12000e-01 9.85431e-01 9.85431e-01 9.85431e-02 1.00000e-09 2.12000e-01 9.85431e-01 9.85431e-01 9.85431e-02 1.00000e-09 2.12000e-01 9.85431e-01 9.85431e-01 9.85431e-02 1.00000e-09 2.12000e-01 $1.00000 \mathrm{e}-02$ 1.00000e-02 1.00000e-03 1.00000e-09 1.00000e-01 Element: 14779 \# of layers: 10

Kx Ky Kz Ss Por $2.46631 \mathrm{e}+012.46631 \mathrm{e}+012.46631 \mathrm{e}+00$ 1.00000e-09 7.00000e-02 $2.46631 \mathrm{e}+012.46631 \mathrm{e}+012.46631 \mathrm{e}+001.00000 \mathrm{e}-097.00000 \mathrm{e}-02$ 5.00000e-04 5.00000e-04 5.00000e-05 1.00000e-09 1.00000e-01 5.00000e-04 5.00000e-04 5.00000e-05 1.00000e-09 1.00000e-01 9.85431e-01 9.85431e-01 9.85431e-02 1.00000e-09 2.12000e-01 
9.85431e-01 9.85431e-01 9.85431e-02 1.00000e-09 2.12000e-01 9.85431e-01 9.85431e-01 9.85431e-02 1.00000e-09 2.12000e-01 9.85431e-01 9.85431e-01 9.85431e-02 1.00000e-09 2.12000e-01 9.85431e-01 9.85431e-01 9.85431e-02 1.00000e-09 2.12000e-01 1.00000e-02 1.00000e-02 1.00000e-03 1.00000e-09 1.00000e-01 Element: 14780 \# of layers: 9

$\mathrm{Kx} \mathrm{Ky} \mathrm{Kz}$ Ss Por

$2.46631 \mathrm{e}+012.46631 \mathrm{e}+012.46631 \mathrm{e}+00$ 1.00000e-09 7.00000e-02

$2.46631 \mathrm{e}+012.46631 \mathrm{e}+012.46631 \mathrm{e}+001.00000 \mathrm{e}-097.00000 \mathrm{e}-02$

5.00000e-04 5.00000e-04 5.00000e-05 1.00000e-09 1.00000e-01

5.00000e-04 5.00000e-04 5.00000e-05 1.00000e-09 1.00000e-01

9.85431e-01 9.85431e-01 9.85431e-02 1.00000e-09 2.12000e-01

9.85431e-01 9.85431e-01 9.85431e-02 1.00000e-09 2.12000e-01

9.85431e-01 9.85431e-01 9.85431e-02 1.00000e-09 2.12000e-01

9.85431e-01 9.85431e-01 9.85431e-02 1.00000e-09 2.12000e-01

1.00000e-02 1.00000e-02 1.00000e-03 1.00000e-09 1.00000e-01

Element: 14781 \# of layers: 9

$\mathrm{Kx} \mathrm{Ky} \mathrm{Kz}$ Ss Por

$2.46631 \mathrm{e}+012.46631 \mathrm{e}+012.46631 \mathrm{e}+00$ 1.00000e-09 7.00000e-02

$2.46631 \mathrm{e}+012.46631 \mathrm{e}+012.46631 \mathrm{e}+001.00000 \mathrm{e}-09$ 7.00000e-02

5.00000e-04 5.00000e-04 5.00000e-05 1.00000e-09 1.00000e-01

5.00000e-04 5.00000e-04 5.00000e-05 1.00000e-09 1.00000e-01

9.85431e-01 9.85431e-01 9.85431e-02 1.00000e-09 2.12000e-01

9.85431e-01 9.85431e-01 9.85431e-02 1.00000e-09 2.12000e-01

9.85431e-01 9.85431e-01 9.85431e-02 1.00000e-09 2.12000e-01

9.85431e-01 9.85431e-01 9.85431e-02 1.00000e-09 2.12000e-01

$1.00000 \mathrm{e}-02$ 1.00000e-02 1.00000e-03 1.00000e-09 1.00000e-01

Element: 14782 \# of layers: 9

$\mathrm{Kx} \mathrm{Ky} \mathrm{Kz}$ Ss Por

$2.46631 \mathrm{e}+012.46631 \mathrm{e}+012.46631 \mathrm{e}+001.00000 \mathrm{e}-09$ 7.00000e-02

$2.46631 \mathrm{e}+012.46631 \mathrm{e}+012.46631 \mathrm{e}+001.00000 \mathrm{e}-09$ 7.00000e-02

5.00000e-04 5.00000e-04 5.00000e-05 1.00000e-09 1.00000e-01

5.00000e-04 5.00000e-04 5.00000e-05 1.00000e-09 1.00000e-01

9.85431e-01 9.85431e-01 9.85431e-02 1.00000e-09 2.12000e-01

9.85431e-01 9.85431e-01 9.85431e-02 1.00000e-09 2.12000e-01

9.85431e-01 9.85431e-01 9.85431e-02 1.00000e-09 2.12000e-01

9.85431e-01 9.85431e-01 9.85431e-02 1.00000e-09 2.12000e-01

$1.00000 \mathrm{e}-02$ 1.00000e-02 1.00000e-03 1.00000e-09 1.00000e-01

Element: 14783 \# of layers: 7

$\mathrm{Kx} \mathrm{Ky} \mathrm{Kz}$ Ss Por

3.93710e+01 3.93710e+01 3.93710e+00 1.00000e-09 7.00000e-02

5.00000e-04 5.00000e-04 5.00000e-05 1.00000e-09 1.00000e-01

$1.57314 \mathrm{e}+001.57314 \mathrm{e}+001.57314 \mathrm{e}-011.00000 \mathrm{e}-092.12000 \mathrm{e}-01$

$1.57314 \mathrm{e}+001.57314 \mathrm{e}+001.57314 \mathrm{e}-011.00000 \mathrm{e}-092.12000 \mathrm{e}-01$

$1.57314 \mathrm{e}+001.57314 \mathrm{e}+001.57314 \mathrm{e}-01 \quad 1.00000 \mathrm{e}-092.12000 \mathrm{e}-01$

$1.57314 \mathrm{e}+001.57314 \mathrm{e}+00 \quad 1.57314 \mathrm{e}-01 \quad 1.00000 \mathrm{e}-092.12000 \mathrm{e}-01$ 
$1.57314 \mathrm{e}+001.57314 \mathrm{e}+00$ 1.57314e-01 1.00000e-09 2.12000e-01 Element: 14784 \# of layers: 7

Kx Ky Kz Ss Por

3.93710e+01 3.93710e+01 3.93710e+00 1.00000e-09 7.00000e-02 5.00000e-04 5.00000e-04 5.00000e-05 1.00000e-09 1.00000e-01

$1.57314 \mathrm{e}+001.57314 \mathrm{e}+001.57314 \mathrm{e}-011.00000 \mathrm{e}-092.12000 \mathrm{e}-01$

$1.57314 \mathrm{e}+001.57314 \mathrm{e}+001.57314 \mathrm{e}-011.00000 \mathrm{e}-092.12000 \mathrm{e}-01$

$1.57314 \mathrm{e}+001.57314 \mathrm{e}+001.57314 \mathrm{e}-011.00000 \mathrm{e}-092.12000 \mathrm{e}-01$

$1.57314 \mathrm{e}+001.57314 \mathrm{e}+001.57314 \mathrm{e}-011.00000 \mathrm{e}-092.12000 \mathrm{e}-01$

$1.57314 \mathrm{e}+001.57314 \mathrm{e}+001.57314 \mathrm{e}-01$ 1.00000e-09 2.12000e-01

Element: 14785 \# of layers: 8

Kx Ky Kz Ss Por

$3.93710 \mathrm{e}+013.93710 \mathrm{e}+013.93710 \mathrm{e}+001.00000 \mathrm{e}-09$ 7.00000e-02

5.00000e-04 5.00000e-04 5.00000e-05 1.00000e-09 1.00000e-01

5.00000e-04 5.00000e-04 5.00000e-05 1.00000e-09 1.00000e-01

$1.57314 \mathrm{e}+001.57314 \mathrm{e}+001.57314 \mathrm{e}-011.00000 \mathrm{e}-092.12000 \mathrm{e}-01$

$1.57314 \mathrm{e}+001.57314 \mathrm{e}+00 \quad 1.57314 \mathrm{e}-011.00000 \mathrm{e}-092.12000 \mathrm{e}-01$

$1.57314 \mathrm{e}+001.57314 \mathrm{e}+001.57314 \mathrm{e}-011.00000 \mathrm{e}-092.12000 \mathrm{e}-01$

$1.57314 \mathrm{e}+001.57314 \mathrm{e}+001.57314 \mathrm{e}-01$ 1.00000e-09 2.12000e-01

$1.57314 \mathrm{e}+001.57314 \mathrm{e}+00 \quad 1.57314 \mathrm{e}-011.00000 \mathrm{e}-092.12000 \mathrm{e}-01$

Element: 14786 \# of layers: 8

$\mathrm{Kx} \mathrm{Ky} \mathrm{Kz}$ Ss Por

3.12683e+01 3.12683e+01 3.12683e+00 1.00000e-09 7.00000e-02 5.00000e-04 5.00000e-04 5.00000e-05 1.00000e-09 1.00000e-01

5.00000e-04 5.00000e-04 5.00000e-05 1.00000e-09 1.00000e-01

$1.24936 \mathrm{e}+001.24936 \mathrm{e}+001.24936 \mathrm{e}-01$ 1.00000e-09 2.12000e-01

$1.24936 \mathrm{e}+001.24936 \mathrm{e}+001.24936 \mathrm{e}-01$ 1.00000e-09 2.12000e-01

$1.24936 \mathrm{e}+001.24936 \mathrm{e}+00$ 1.24936e-01 1.00000e-09 2.12000e-01

$1.24936 \mathrm{e}+001.24936 \mathrm{e}+00$ 1.24936e-01 1.00000e-09 2.12000e-01

$1.24936 \mathrm{e}+00$ 1.24936e+00 1.24936e-01 1.00000e-09 2.12000e-01

Element: 14787 \# of layers: 8

$\mathrm{Kx} \mathrm{Ky} \mathrm{Kz}$ Ss Por

3.93710e+01 3.93710e+01 3.93710e+00 1.00000e-09 7.00000e-02

5.00000e-04 5.00000e-04 5.00000e-05 1.00000e-09 1.00000e-01

5.00000e-04 5.00000e-04 5.00000e-05 1.00000e-09 1.00000e-01

$1.57314 \mathrm{e}+001.57314 \mathrm{e}+001.57314 \mathrm{e}-011.00000 \mathrm{e}-092.12000 \mathrm{e}-01$

$1.57314 \mathrm{e}+001.57314 \mathrm{e}+001.57314 \mathrm{e}-011.00000 \mathrm{e}-092.12000 \mathrm{e}-01$

$1.57314 \mathrm{e}+001.57314 \mathrm{e}+001.57314 \mathrm{e}-011.00000 \mathrm{e}-092.12000 \mathrm{e}-01$

$1.57314 \mathrm{e}+001.57314 \mathrm{e}+001.57314 \mathrm{e}-011.00000 \mathrm{e}-092.12000 \mathrm{e}-01$

$1.57314 \mathrm{e}+001.57314 \mathrm{e}+001.57314 \mathrm{e}-01$ 1.00000e-09 2.12000e-01

Element: 14788 \# of layers: 8

$\mathrm{Kx} \mathrm{Ky} \mathrm{Kz}$ Ss Por

$3.93710 \mathrm{e}+013.93710 \mathrm{e}+013.93710 \mathrm{e}+001.00000 \mathrm{e}-09$ 7.00000e-02

5.00000e-04 5.00000e-04 5.00000e-05 1.00000e-09 1.00000e-01

5.00000e-04 5.00000e-04 5.00000e-05 1.00000e-09 1.00000e-01

$1.57314 \mathrm{e}+001.57314 \mathrm{e}+001.57314 \mathrm{e}-011.00000 \mathrm{e}-092.12000 \mathrm{e}-01$ 
$1.57314 \mathrm{e}+001.57314 \mathrm{e}+001.57314 \mathrm{e}-011.00000 \mathrm{e}-092.12000 \mathrm{e}-01$ $1.57314 \mathrm{e}+001.57314 \mathrm{e}+001.57314 \mathrm{e}-01$ 1.00000e-09 2.12000e-01 $1.57314 \mathrm{e}+001.57314 \mathrm{e}+001.57314 \mathrm{e}-011.00000 \mathrm{e}-092.12000 \mathrm{e}-01$ $1.57314 \mathrm{e}+001.57314 \mathrm{e}+00 \quad 1.57314 \mathrm{e}-011.00000 \mathrm{e}-092.12000 \mathrm{e}-01$ Element: 14789 \# of layers: 8

$\mathrm{Kx} \mathrm{Ky} \mathrm{Kz}$ Ss Por

3.12683e+01 3.12683e+01 3.12683e+00 1.00000e-09 7.00000e-02 5.00000e-04 5.00000e-04 5.00000e-05 1.00000e-09 1.00000e-01 5.00000e-04 5.00000e-04 5.00000e-05 1.00000e-09 1.00000e-01 $1.24936 \mathrm{e}+001.24936 \mathrm{e}+00$ 1.24936e-01 1.00000e-09 2.12000e-01 $1.24936 \mathrm{e}+001.24936 \mathrm{e}+00$ 1.24936e-01 1.00000e-09 2.12000e-01 $1.24936 \mathrm{e}+001.24936 \mathrm{e}+001.24936 \mathrm{e}-01$ 1.00000e-09 2.12000e-01 $1.24936 \mathrm{e}+001.24936 \mathrm{e}+001.24936 \mathrm{e}-01$ 1.00000e-09 2.12000e-01 $1.24936 \mathrm{e}+001.24936 \mathrm{e}+00$ 1.24936e-01 1.00000e-09 2.12000e-01 Element: 14790 \# of layers: 8

Kx Ky Kz Ss Por

5.53989e+01 5.53989e+01 5.53989e+00 1.00000e-09 7.00000e-02 5.00000e-04 5.00000e-04 5.00000e-05 1.00000e-09 1.00000e-01 5.00000e-04 5.00000e-04 5.00000e-05 1.00000e-09 1.00000e-01 $2.21353 \mathrm{e}+002.21353 \mathrm{e}+00$ 2.21353e-01 1.00000e-09 2.12000e-01 $2.21353 \mathrm{e}+002.21353 \mathrm{e}+00$ 2.21353e-01 1.00000e-09 2.12000e-01 $2.21353 \mathrm{e}+00$ 2.21353e+00 2.21353e-01 1.00000e-09 2.12000e-01 $2.21353 \mathrm{e}+00$ 2.21353e+00 2.21353e-01 1.00000e-09 2.12000e-01 $2.21353 \mathrm{e}+00$ 2.21353e+00 2.21353e-01 1.00000e-09 2.12000e-01 Element: 14791 \# of layers: 8

$\mathrm{Kx} \mathrm{Ky} \mathrm{Kz}$ Ss Por

5.53989e+01 5.53989e+01 5.53989e+00 1.00000e-09 7.00000e-02 5.00000e-04 5.00000e-04 5.00000e-05 1.00000e-09 1.00000e-01 5.00000e-04 5.00000e-04 5.00000e-05 1.00000e-09 1.00000e-01 $2.21353 \mathrm{e}+00$ 2.21353e+00 2.21353e-01 1.00000e-09 2.12000e-01 $2.21353 \mathrm{e}+002.21353 \mathrm{e}+00$ 2.21353e-01 1.00000e-09 2.12000e-01 $2.21353 \mathrm{e}+00$ 2.21353e+00 2.21353e-01 1.00000e-09 2.12000e-01 $2.21353 \mathrm{e}+002.21353 \mathrm{e}+00$ 2.21353e-01 1.00000e-09 2.12000e-01 $2.21353 \mathrm{e}+00$ 2.21353e+00 2.21353e-01 1.00000e-09 2.12000e-01 Element: 14792 \# of layers: 8

$\mathrm{Kx} \mathrm{Ky} \mathrm{Kz}$ Ss Por

5.53989e+01 5.53989e+01 5.53989e+00 1.00000e-09 7.00000e-02 5.00000e-04 5.00000e-04 5.00000e-05 1.00000e-09 1.00000e-01 5.00000e-04 5.00000e-04 5.00000e-05 1.00000e-09 1.00000e-01 $2.21353 \mathrm{e}+00$ 2.21353e+00 2.21353e-01 1.00000e-09 2.12000e-01 $2.21353 \mathrm{e}+002.21353 \mathrm{e}+00$ 2.21353e-01 1.00000e-09 2.12000e-01 $2.21353 \mathrm{e}+002.21353 \mathrm{e}+00$ 2.21353e-01 1.00000e-09 2.12000e-01 $2.21353 \mathrm{e}+00$ 2.21353e+00 2.21353e-01 1.00000e-09 2.12000e-01 $2.21353 \mathrm{e}+00$ 2.21353e+00 2.21353e-01 1.00000e-09 2.12000e-01 Element: 14793 \# of layers: 8

Kx Ky Kz Ss Por 
5.53989e+01 5.53989e+01 5.53989e+00 1.00000e-09 7.00000e-02 5.00000e-04 5.00000e-04 5.00000e-05 1.00000e-09 1.00000e-01 5.00000e-04 5.00000e-04 5.00000e-05 1.00000e-09 1.00000e-01

$2.21353 \mathrm{e}+002.21353 \mathrm{e}+00$ 2.21353e-01 1.00000e-09 2.12000e-01 $2.21353 \mathrm{e}+00$ 2.21353e+00 2.21353e-01 1.00000e-09 2.12000e-01 $2.21353 \mathrm{e}+002.21353 \mathrm{e}+00$ 2.21353e-01 1.00000e-09 2.12000e-01 $2.21353 \mathrm{e}+00$ 2.21353e+00 2.21353e-01 1.00000e-09 2.12000e-01 $2.21353 \mathrm{e}+00$ 2.21353e+00 2.21353e-01 1.00000e-09 2.12000e-01 Element: 14794 \# of layers: 8

$\mathrm{Kx} \mathrm{Ky} \mathrm{Kz}$ Ss Por

5.53989e+01 5.53989e+01 5.53989e+00 1.00000e-09 7.00000e-02 $5.53989 \mathrm{e}+015.53989 \mathrm{e}+015.53989 \mathrm{e}+001.00000 \mathrm{e}-09$ 7.00000e-02 5.00000e-04 5.00000e-04 5.00000e-05 1.00000e-09 1.00000e-01

$2.21353 \mathrm{e}+002.21353 \mathrm{e}+00$ 2.21353e-01 1.00000e-09 2.12000e-01 $2.21353 \mathrm{e}+00$ 2.21353e+00 2.21353e-01 1.00000e-09 2.12000e-01 $2.21353 \mathrm{e}+002.21353 \mathrm{e}+00$ 2.21353e-01 1.00000e-09 2.12000e-01 $2.21353 \mathrm{e}+00$ 2.21353e+00 2.21353e-01 1.00000e-09 2.12000e-01 $2.21353 \mathrm{e}+00$ 2.21353e+00 2.21353e-01 1.00000e-09 2.12000e-01 Element: 14795 \# of layers: 9

Kx Ky Kz Ss Por

6.67740e+01 6.67740e+01 6.67740e+00 1.00000e-09 7.00000e-02 6.67740e+01 6.67740e+01 6.67740e+00 1.00000e-09 7.00000e-02 $5.00000 \mathrm{e}-04$ 5.00000e-04 5.00000e-05 1.00000e-09 1.00000e-01 5.00000e-04 5.00000e-04 5.00000e-05 1.00000e-09 1.00000e-01

$2.66811 \mathrm{e}+002.66811 \mathrm{e}+002.66811 \mathrm{e}-011.00000 \mathrm{e}-092.12000 \mathrm{e}-01$

$2.66811 \mathrm{e}+002.66811 \mathrm{e}+002.66811 \mathrm{e}-01$ 1.00000e-09 2.12000e-01

$2.66811 \mathrm{e}+002.66811 \mathrm{e}+002.66811 \mathrm{e}-01$ 1.00000e-09 2.12000e-01

$2.66811 \mathrm{e}+002.66811 \mathrm{e}+002.66811 \mathrm{e}-01$ 1.00000e-09 2.12000e-01

$2.66811 \mathrm{e}+002.66811 \mathrm{e}+002.66811 \mathrm{e}-01$ 1.00000e-09 2.12000e-01

Element: 14796 \# of layers: 8

$\mathrm{Kx} \mathrm{Ky} \mathrm{Kz}$ Ss Por

5.53989e+01 5.53989e+01 5.53989e+00 1.00000e-09 7.00000e-02 $5.53989 \mathrm{e}+015.53989 \mathrm{e}+015.53989 \mathrm{e}+001.00000 \mathrm{e}-09$ 7.00000e-02 5.00000e-04 5.00000e-04 5.00000e-05 1.00000e-09 1.00000e-01

$2.21353 \mathrm{e}+002.21353 \mathrm{e}+00$ 2.21353e-01 1.00000e-09 2.12000e-01

$2.21353 \mathrm{e}+00$ 2.21353e+00 2.21353e-01 1.00000e-09 2.12000e-01

$2.21353 \mathrm{e}+002.21353 \mathrm{e}+00$ 2.21353e-01 1.00000e-09 2.12000e-01 $2.21353 \mathrm{e}+002.21353 \mathrm{e}+00$ 2.21353e-01 1.00000e-09 2.12000e-01

$2.21353 \mathrm{e}+00$ 2.21353e+00 2.21353e-01 1.00000e-09 2.12000e-01

Element: 14797 \# of layers: 4

$\mathrm{Kx} \mathrm{Ky} \mathrm{Kz}$ Ss Por

$2.43018 \mathrm{e}+02$ 2.43018e+02 2.43018e+01 1.00000e-09 7.00000e-02

9.71031e+00 9.71031e+00 9.71031e-01 1.00000e-09 2.12000e-01

$1.00000 \mathrm{e}-02$ 1.00000e-02 1.00000e-03 1.00000e-09 1.00000e-01

$1.00000 \mathrm{e}+001.00000 \mathrm{e}+001.00000 \mathrm{e}-011.00000 \mathrm{e}-09$ 1.00000e-01

Element: 14798 \# of layers: 4 
$\mathrm{Kx} \mathrm{Ky} \mathrm{Kz} \mathrm{Ss} \mathrm{Por}$

2.43018e+02 2.43018e+02 2.43018e+01 1.00000e-09 7.00000e-02

9.71031e+00 9.71031e+00 9.71031e-01 1.00000e-09 2.12000e-01

$1.00000 \mathrm{e}-02$ 1.00000e-02 1.00000e-03 1.00000e-09 1.00000e-01

$1.00000 \mathrm{e}+001.00000 \mathrm{e}+001.00000 \mathrm{e}-01$ 1.00000e-09 1.00000e-01

Element: 14799 \# of layers: 4

Kx Ky Kz Ss Por

1.66117e+02 1.66117e+02 1.66117e+01 1.00000e-09 7.00000e-02

6.63764e+00 6.63764e+00 6.63764e-01 1.00000e-09 2.12000e-01

$1.00000 \mathrm{e}-02$ 1.00000e-02 1.00000e-03 1.00000e-09 1.00000e-01

$1.00000 \mathrm{e}+001.00000 \mathrm{e}+001.00000 \mathrm{e}-011.00000 \mathrm{e}-091.00000 \mathrm{e}-01$

Element: 14800 \# of layers: 7

$\mathrm{Kx} \mathrm{Ky} \mathrm{Kz}$ Ss Por

3.45759e+02 3.45759e+02 3.45759e+01 1.00000e-09 7.00000e-02

3.45759e+02 3.45759e+02 3.45759e+01 1.00000e-09 7.00000e-02

$1.38151 \mathrm{e}+011.38151 \mathrm{e}+011.38151 \mathrm{e}+001.00000 \mathrm{e}-092.12000 \mathrm{e}-01$

$1.38151 \mathrm{e}+011.38151 \mathrm{e}+011.38151 \mathrm{e}+001.00000 \mathrm{e}-092.12000 \mathrm{e}-01$

$1.38151 \mathrm{e}+011.38151 \mathrm{e}+011.38151 \mathrm{e}+001.00000 \mathrm{e}-092.12000 \mathrm{e}-01$

$1.00000 \mathrm{e}-02$ 1.00000e-02 1.00000e-03 1.00000e-09 1.00000e-01

$1.00000 \mathrm{e}+001.00000 \mathrm{e}+001.00000 \mathrm{e}-011.00000 \mathrm{e}-091.00000 \mathrm{e}-01$

Element: 14801 \# of layers: 4

$\mathrm{Kx} \mathrm{Ky} \mathrm{Kz}$ Ss Por

3.45759e+02 3.45759e+02 3.45759e+01 1.00000e-09 7.00000e-02

$1.38151 \mathrm{e}+011.38151 \mathrm{e}+011.38151 \mathrm{e}+001.00000 \mathrm{e}-092.12000 \mathrm{e}-01$

$1.00000 \mathrm{e}-02$ 1.00000e-02 1.00000e-03 1.00000e-09 1.00000e-01

$1.00000 \mathrm{e}+001.00000 \mathrm{e}+001.00000 \mathrm{e}-01$ 1.00000e-09 1.00000e-01

Element: 14802 \# of layers: 7

$\mathrm{Kx} \mathrm{Ky} \mathrm{Kz} \mathrm{Ss} \mathrm{Por}$

2.02779e+02 2.02779e+02 2.02779e+01 1.00000e-09 7.00000e-02

$2.02779 \mathrm{e}+02$ 2.02779e+02 2.02779e+01 1.00000e-09 7.00000e-02

$8.10220 \mathrm{e}+008.10220 \mathrm{e}+00$ 8.10220e-01 1.00000e-09 2.12000e-01

$8.10220 \mathrm{e}+00$ 8.10220e+00 8.10220e-01 1.00000e-09 2.12000e-01

$8.10220 \mathrm{e}+008.10220 \mathrm{e}+008.10220 \mathrm{e}-01$ 1.00000e-09 2.12000e-01

$1.00000 \mathrm{e}-02$ 1.00000e-02 1.00000e-03 1.00000e-09 1.00000e-01

$1.00000 \mathrm{e}+001.00000 \mathrm{e}+001.00000 \mathrm{e}-011.00000 \mathrm{e}-091.00000 \mathrm{e}-01$

Element: 14803 \# of layers: 4

$\mathrm{Kx} \mathrm{Ky} \mathrm{Kz}$ Ss Por

2.02779e+02 2.02779e+02 2.02779e+01 1.00000e-09 7.00000e-02

$8.10220 \mathrm{e}+008.10220 \mathrm{e}+008.10220 \mathrm{e}-01$ 1.00000e-09 2.12000e-01

$1.00000 \mathrm{e}-02$ 1.00000e-02 1.00000e-03 1.00000e-09 1.00000e-01

$1.00000 \mathrm{e}+001.00000 \mathrm{e}+001.00000 \mathrm{e}-011.00000 \mathrm{e}-091.00000 \mathrm{e}-01$

Element: 14804 \# of layers: 5

$\mathrm{Kx} \mathrm{Ky} \mathrm{Kz}$ Ss Por

3.31036e+02 3.31036e+02 3.31036e+01 1.00000e-09 7.00000e-02

$1.32269 \mathrm{e}+01$ 1.32269e+01 1.32269e+00 1.00000e-09 2.12000e-01

$1.00000 \mathrm{e}-02$ 1.00000e-02 1.00000e-03 1.00000e-09 1.00000e-01 
$1.00000 \mathrm{e}+001.00000 \mathrm{e}+001.00000 \mathrm{e}-011.00000 \mathrm{e}-091.00000 \mathrm{e}-01$ 1.00000e-06 1.00000e-06 1.00000e-06 1.00000e-09 5.00000e-02

Element: 14805 \# of layers: 5

Kx Ky Kz Ss Por

3.31036e+02 3.31036e+02 3.31036e+01 1.00000e-09 7.00000e-02 $1.32269 \mathrm{e}+01$ 1.32269e+01 1.32269e+00 1.00000e-09 2.12000e-01 $1.00000 \mathrm{e}-02$ 1.00000e-02 1.00000e-03 1.00000e-09 1.00000e-01 $1.00000 \mathrm{e}+001.00000 \mathrm{e}+001.00000 \mathrm{e}-011.00000 \mathrm{e}-091.00000 \mathrm{e}-01$ 1.00000e-06 1.00000e-06 1.00000e-06 1.00000e-09 5.00000e-02

Element: 14806 \# of layers: 5

$\mathrm{Kx} \mathrm{Ky} \mathrm{Kz}$ Ss Por

3.28523e+02 3.28523e+02 3.28523e+01 1.00000e-09 7.00000e-02

$1.31266 \mathrm{e}+011.31266 \mathrm{e}+011.31266 \mathrm{e}+001.00000 \mathrm{e}-092.12000 \mathrm{e}-01$ $1.00000 \mathrm{e}-02$ 1.00000e-02 1.00000e-03 1.00000e-09 1.00000e-01 $1.00000 \mathrm{e}+001.00000 \mathrm{e}+001.00000 \mathrm{e}-011.00000 \mathrm{e}-091.00000 \mathrm{e}-01$ 1.00000e-06 1.00000e-06 1.00000e-06 1.00000e-09 5.00000e-02

Element: 14807 \# of layers: 4

$\mathrm{Kx} \mathrm{Ky} \mathrm{Kz}$ Ss Por

3.04970e+02 3.04970e+02 3.04970e+01 1.00000e-09 7.00000e-02 $1.21856 \mathrm{e}+011.21856 \mathrm{e}+01 \quad 1.21856 \mathrm{e}+001.00000 \mathrm{e}-092.12000 \mathrm{e}-01$ $1.00000 \mathrm{e}-02$ 1.00000e-02 1.00000e-03 1.00000e-09 1.00000e-01 $1.00000 \mathrm{e}+001.00000 \mathrm{e}+001.00000 \mathrm{e}-011.00000 \mathrm{e}-091.00000 \mathrm{e}-01$ Element: 14808 \# of layers: 5

Kx Ky Kz Ss Por

3.31036e+02 3.31036e+02 3.31036e+01 1.00000e-09 7.00000e-02 $1.32269 \mathrm{e}+011.32269 \mathrm{e}+011.32269 \mathrm{e}+001.00000 \mathrm{e}-092.12000 \mathrm{e}-01$ $1.00000 \mathrm{e}-02$ 1.00000e-02 1.00000e-03 1.00000e-09 1.00000e-01 $1.00000 \mathrm{e}+001.00000 \mathrm{e}+001.00000 \mathrm{e}-011.00000 \mathrm{e}-091.00000 \mathrm{e}-01$ 1.00000e-06 1.00000e-06 1.00000e-06 1.00000e-09 5.00000e-02 Element: 14809 \# of layers: 4

$\mathrm{Kx} \mathrm{Ky} \mathrm{Kz}$ Ss Por

3.07223e+02 3.07223e+02 3.07223e+01 1.00000e-09 7.00000e-02 $1.22756 \mathrm{e}+011.22756 \mathrm{e}+011.22756 \mathrm{e}+001.00000 \mathrm{e}-092.12000 \mathrm{e}-01$ $1.00000 \mathrm{e}-02$ 1.00000e-02 1.00000e-03 1.00000e-09 1.00000e-01 $1.00000 \mathrm{e}+001.00000 \mathrm{e}+001.00000 \mathrm{e}-01$ 1.00000e-09 1.00000e-01 Element: 14810 \# of layers: 4

Kx Ky Kz Ss Por

3.07223e+02 3.07223e+02 3.07223e+01 1.00000e-09 7.00000e-02 $1.22756 \mathrm{e}+011.22756 \mathrm{e}+011.22756 \mathrm{e}+001.00000 \mathrm{e}-092.12000 \mathrm{e}-01$ $1.00000 \mathrm{e}-02$ 1.00000e-02 1.00000e-03 1.00000e-09 1.00000e-01 $1.00000 \mathrm{e}+001.00000 \mathrm{e}+001.00000 \mathrm{e}-011.00000 \mathrm{e}-091.00000 \mathrm{e}-01$ Element: 14811 \# of layers: 5

$\mathrm{Kx} \mathrm{Ky} \mathrm{Kz}$ Ss Por

2.31539e+02 2.31539e+02 2.31539e+01 1.00000e-09 7.00000e-02 9.25152e+00 9.25152e+00 9.25152e-01 1.00000e-09 2.12000e-01 $1.00000 \mathrm{e}-02$ 1.00000e-02 1.00000e-03 1.00000e-09 1.00000e-01 
$1.00000 \mathrm{e}+001.00000 \mathrm{e}+001.00000 \mathrm{e}-011.00000 \mathrm{e}-091.00000 \mathrm{e}-01$ $1.00000 \mathrm{e}-06$ 1.00000e-06 1.00000e-06 1.00000e-09 5.00000e-02

Element: 14812 \# of layers: 4

Kx Ky Kz Ss Por

2.31539e+02 2.31539e+02 2.31539e+01 1.00000e-09 7.00000e-02

$9.25152 \mathrm{e}+00$ 9.25152e+00 9.25152e-01 1.00000e-09 2.12000e-01

$1.00000 \mathrm{e}-02$ 1.00000e-02 1.00000e-03 1.00000e-09 1.00000e-01

$1.00000 \mathrm{e}+001.00000 \mathrm{e}+001.00000 \mathrm{e}-011.00000 \mathrm{e}-091.00000 \mathrm{e}-01$

Element: 14813 \# of layers: 4

$\mathrm{Kx} \mathrm{Ky} \mathrm{Kz}$ Ss Por

2.93176e+02 2.93176e+02 2.93176e+01 1.00000e-09 7.00000e-02

$1.17142 \mathrm{e}+011.17142 \mathrm{e}+01$ 1.17142e+00 1.00000e-09 2.12000e-01

$1.00000 \mathrm{e}-02$ 1.00000e-02 1.00000e-03 1.00000e-09 1.00000e-01

$1.00000 \mathrm{e}+001.00000 \mathrm{e}+001.00000 \mathrm{e}-011.00000 \mathrm{e}-091.00000 \mathrm{e}-01$

Element: 14814 \# of layers: 4

$\mathrm{Kx} \mathrm{Ky} \mathrm{Kz}$ Ss Por

3.02358e+02 3.02358e+02 3.02358e+01 1.00000e-09 7.00000e-02

$1.20812 \mathrm{e}+011.20812 \mathrm{e}+011.20812 \mathrm{e}+001.00000 \mathrm{e}-092.12000 \mathrm{e}-01$

$1.00000 \mathrm{e}-02$ 1.00000e-02 1.00000e-03 1.00000e-09 1.00000e-01

$1.00000 \mathrm{e}+001.00000 \mathrm{e}+001.00000 \mathrm{e}-011.00000 \mathrm{e}-091.00000 \mathrm{e}-01$ 
geo_CA 


\begin{tabular}{|c|c|c|c|c|c|c|c|c|c|c|c|c|}
\hline \multicolumn{13}{|c|}{ Top elevation picks for hydrogeologic units in the System Assessment Capability model (some picks were subsequently revised for later models) } \\
\hline & \multicolumn{3}{|c|}{$-9999=$ no information, not deep enough } & & & & & & & & & \\
\hline & & & & & & & & & & \\
\hline & \multicolumn{3}{|c|}{$-2222=$ uncertain if unit present } & & & & & & & & & \\
\hline \multicolumn{13}{|c|}{ Elevations $(m)$ of hydrogeologic unit tops and bottoms based on NAVD88 sea level datum } \\
\hline \multicolumn{13}{|c|}{\begin{tabular}{l|l|l} 
Coordinates in state plane meters NAD83 & \\
\end{tabular}} \\
\hline & & & surf elev (top 1) & Top 2 & Top 3 & Top 4 & Top 5 & Top 6 & Top 7 & Top 8 & Top 9 & Top 10 \\
\hline Well number & EASTING & NORTHING & & & & & & & & & & (basalt) \\
\hline $1199-14-14$ & 593916.2 & 103642.0 & 108.2 & -1111.0 & -1111.0 & -1111.0 & -1111.0 & -1111.0 & -1111.0 & 99.1 & -1111.0 & 78.4 \\
\hline 1199-20-17 & 594749.5 & 105381.3 & 108.2 & -1111.0 & -1111.0 & -1111.0 & -1111.0 & 100.7 & 87.9 & 82.4 & -1111.0 & 67.1 \\
\hline $1199-22-11 \mathrm{~A}$ & 593083.8 & 105977.6 & 123.1 & -1111.0 & -1111.0 & -1111.0 & 102.8 & 98.5 & 95.5 & 90.3 & -1111.0 & 81.5 \\
\hline 1199-33-18D & 595031.9 & 109334.2 & 111.3 & -1111.0 & -1111.0 & -1111.0 & 101.0 & 98.8 & 86.3 & -9999.0 & -9999.0 & -9999.0 \\
\hline $1199-34-13$ & 593589.6 & 109695.0 & 120.1 & -1111.0 & -1111.0 & -1111.0 & 104.3 & 98.2 & -9999.0 & -9999.0 & -9999.0 & -9999.0 \\
\hline 1199-39-16B & 594374.4 & 111165.5 & 113.1 & -1111.0 & -1111.0 & -1111.0 & 101.3 & 94.9 & 89.7 & 86.6 & -9999.0 & -9999.0 \\
\hline 1199-40-16A & 594414.9 & 111559.6 & 118.9 & -1111.0 & -1111.0 & -1111.0 & 103.1 & 101.6 & -9999.0 & -9999.0 & -9999.0 & -9999.0 \\
\hline 199-B2-12 & 565368.0 & 145364.0 & 133.9 & -2222.0 & -1111.0 & -1111.0 & 103.7 & -2222.0 & -2222.0 & -2222.0 & -2222.0 & -2222.0 \\
\hline 199-B3-2 & 565847.6 & 145326.1 & 135.0 & -1111.0 & -1111.0 & -1111.0 & 118.7 & 89.4 & 55.9 & 20.8 & -41.7 & -63.9 \\
\hline 199-B3-46 & 565899.8 & 145369.3 & 134.4 & -1111.0 & -1111.0 & -1111.0 & 119.0 & -2222.0 & -2222.0 & -2222.0 & -2222.0 & -2222.0 \\
\hline 199-B4-3 & 565295.6 & 144771.1 & 140.5 & -1111.0 & -1111.0 & -1111.0 & 120.2 & -2222.0 & -2222.0 & -2222.0 & -2222.0 & -2222.0 \\
\hline 199-B4-9 & 565395.8 & 144564.2 & 143.8 & -1111.0 & -1111.0 & -1111.0 & 117.1 & -2222.0 & -2222.0 & -2222.0 & -2222.0 & -2222.0 \\
\hline 199-B9-2 & 565535.0 & 144078.3 & 151.5 & -1111.0 & -1111.0 & -1111.0 & 124.1 & -2222.0 & -2222.0 & -2222.0 & -2222.0 & -2222.0 \\
\hline 199-D2-5 & 573812.3 & 151148.2 & 140.2 & -1111.0 & -1111.0 & -1111.0 & 125.4 & 115.0 & -9999.0 & -9999.0 & -9999.0 & -9999.0 \\
\hline 199-D2-6 & 573000.2 & 151119.9 & 142.3 & -1111.0 & -1111.0 & -1111.0 & -1111.0 & 111.9 & -9999.0 & -9999.0 & -9999.0 & -9999.0 \\
\hline 199-D5-12 & 573840.0 & 151557.0 & 143.4 & -2222.0 & -1111.0 & -1111.0 & 128.4 & -2222.0 & -2222.0 & -2222.0 & -2222.0 & -2222.0 \\
\hline 199-D5-19 & 573849.1 & 151243.2 & 140.8 & -1111.0 & -1111.0 & -1111.0 & -1111.0 & 113.2 & -9999.0 & -9999.0 & -9999.0 & -9999.0 \\
\hline 199-D8-2 & 573693.0 & 152350.0 & 135.7 & -2222.0 & -1111.0 & -1111.0 & 119.3 & -2222.0 & -2222.0 & -2222.0 & -2222.0 & -2222.0 \\
\hline 199-D8-53 & 573889.9 & 152452.3 & 132.9 & -1111.0 & -1111.0 & -1111.0 & 119.6 & 113.2 & -9999.0 & -9999.0 & -9999.0 & -9999.0 \\
\hline 199-D8-55 & 573621.1 & 152364.6 & 133.8 & -1111.0 & -1111.0 & -1111.0 & 112.9 & -2222.0 & -2222.0 & -2222.0 & -2222.0 & -2222.0 \\
\hline 199-D8-6 & 573434.7 & 152060.8 & 145.1 & -1111.0 & -1111.0 & -1111.0 & 128.1 & 115.6 & -9999.0 & -9999.0 & -9999.0 & -9999.0 \\
\hline 199-F5-43B & 581170.9 & 147960.4 & 119.5 & -1111.0 & -1111.0 & -1111.0 & -1111.0 & 107.4 & -9999.0 & -9999.0 & -9999.0 & -9999.0 \\
\hline 199-F7-1 & 579687.2 & 147022.4 & 118.8 & -1111.0 & -1111.0 & -1111.0 & -2222.0 & 112.6 & -2222.0 & -2222.0 & -2222.0 & -2222.0 \\
\hline $199-\mathrm{H} 3-1$ & 577645.0 & 152438.0 & 129.1 & -2222.0 & -1111.0 & -1111.0 & 112.3 & -2222.0 & -2222.0 & -2222.0 & -2222.0 & -2222.0 \\
\hline $199-\mathrm{H} 3-2 \mathrm{C}$ & 577632.0 & 152750.0 & 128.0 & -2222.0 & -1111.0 & -1111.0 & 109.5 & -2222.0 & -2222.0 & -2222.0 & -2222.0 & -2222.0 \\
\hline $199-\mathrm{H} 4-1$ & 578148.0 & 152654.0 & 126.5 & -2222.0 & -1111.0 & -1111.0 & 111.6 & -2222.0 & -2222.0 & -2222.0 & -2222.0 & -2222.0 \\
\hline $199-\mathrm{H} 4-10$ & 577827.2 & 153155.8 & 1231 & -11110 & -1111.0 & -11110 & -111.0 & 1119 & -99990 & -99990 & -99990 & -99990 \\
\hline $199-\mathrm{H} 4-12 \mathrm{C}$ & 578011.8 & 152919.8 & 125.9 & -1111.0 & -1111.0 & -1111.0 & -1111.0 & 108.6 & 72.0 & 58.3 & -9999.0 & -9999.0 \\
\hline $199-\mathrm{H} 4-15 \mathrm{C}$ & 577907.7 & 153060.0 & 123.9 & -1111.0 & -1111.0 & -1111.0 & 111.0 & 100.7 & 64.1 & 58.0 & -1111.0 & 29.3 \\
\hline $199-\mathrm{H} 4-2$ & 578093.6 & 152501.5 & 128.4 & -1111.0 & -1111.0 & -1111.0 & -1111.0 & 109.8 & 71.1 & 51.6 & -1111.0 & 27.2 \\
\hline $199-\mathrm{H} 4-3$ & 577940.5 & 152858.5 & 128.1 & -1111.0 & -1111.0 & -1111.0 & 113.8 & 112.3 & -9999.0 & -9999.0 & -9999.0 & -9999.0 \\
\hline 199-H4-46 & 577883.9 & 152439.9 & 129.2 & -1111.0 & -1111.0 & -1111.0 & -1111.0 & 110.7 & -9999.0 & -9999.0 & -9999.0 & -9999.0 \\
\hline $199-\mathrm{H} 4-47$ & 577891.2 & 152553.3 & 129.2 & -1111.0 & -1111.0 & -1111.0 & -1111.0 & 113.8 & -9999.0 & -9999.0 & -9999.0 & -9999.0 \\
\hline 199-H5-1A & 577650.1 & 152257.7 & 128.0 & -1111.0 & -1111.0 & -1111.0 & -1111.0 & 112.3 & -9999.0 & -9999.0 & -9999.0 & -9999.0 \\
\hline $199-\mathrm{K}-10$ & 568912.8 & 146628.1 & 142.2 & -1111.0 & -1111.0 & -1111.0 & 134.2 & 92.7 & -9999.0 & -9999.0 & -9999.0 & -9999.0 \\
\hline $199-K-11$ & 568938.0 & 146617.8 & $\begin{array}{l}14 L . L \\
142.5\end{array}$ & -1111.0 & -1111.0 & -1111.0 & 135.1 & 91.8 & -9999.0 & -9999.0 & -9999.0 & -9999.0 \\
\hline $199-K-12$ & 568894.7 & 146661.3 & 142.2 & -1111.0 & -1111.0 & -1111.0 & 132.1 & -9999.0 & -9999.0 & -9999.0 & -9999.0 & -9999.0 \\
\hline 199-K-32B & 569012.4 & 147004.8 & 135.7 & -1111.0 & -1111.0 & -1111.0 & 125.7 & 95.2 & -9999.0 & -9999.0 & -9999.0 & -9999.0 \\
\hline $199-\mathrm{K}-35$ & 568832.3 & 146110.7 & 150.9 & -1111.0 & -1111.0 & -1111.0 & 128.4 & $\begin{array}{l}-9999.0 \\
\end{array}$ & -9999.0 & -9999.0 & -9999.0 & -9999.0 \\
\hline $199-\mathrm{N}-14$ & 571713.1 & 150243.4 & 138.1 & -1111.0 & -1111.0 & -1111.0 & 121.4 & -9999.0 & -9999.0 & -9999.0 & -9999.0 & -9999.0 \\
\hline $199-\mathrm{N}-16$ & 571281.4 & 149441.8 & 139.0 & -1111.0 & -1111.0 & -1111.0 & 123.2 & -9999.0 & -9999.0 & -9999.0 & -9999.0 & -9999.0 \\
\hline $199-\mathrm{N}-17$ & 571277.0 & 149713.0 & 140.8 & -2222.0 & -1111.0 & -1111.0 & 125.4 & -2222.0 & -2222.0 & -2222.0 & -2222.0 & -2222.0 \\
\hline $199-\mathrm{N}-2$ & 571476.0 & 149859.0 & 140.2 & -2222.0 & -1111.0 & -1111.0 & 120.5 & -2222.0 & -2222.0 & -2222.0 & -2222.0 & -2222.0 \\
\hline $199-\mathrm{N}-26$ & 571057.0 & 149410.0 & 139.1 & -2222.0 & -1111.0 & ת11119 & 126.3 & -2222.0 & -2222.0 & -2222.0 & -2222.0 & -2222.0 \\
\hline
\end{tabular}




\begin{tabular}{|c|c|c|c|c|c|c|c|c|c|c|c|c|}
\hline & & & surf elev (top 1) & Top 2 & Top 3 & Top 4 & Top 5 & Top 6 & Top 7 & Top 8 & Top 9 & Top 10 \\
\hline Well number & EASTING & NORTHING & & & & & & & & & & (basalt) \\
\hline 199-N-37 & 571969.0 & 149830.0 & 139.4 & -2222.0 & -1111.0 & -1111.0 & 125.4 & -2222.0 & -2222.0 & -2222.0 & -2222.0 & -2222.0 \\
\hline $199-\mathrm{N}-39$ & 572038.0 & 149884.0 & 138.9 & -2222.0 & -1111.0 & -1111.0 & 125.1 & -2222.0 & -2222.0 & -2222.0 & -2222.0 & -2222.0 \\
\hline $199-\mathrm{N}-44$ & 572181.0 & 149805.0 & 140.8 & -2222.0 & -1111.0 & -1111.0 & 126.9 & -2222.0 & -2222.0 & -2222.0 & -2222.0 & -2222.0 \\
\hline $199-\mathrm{N}-50$ & 572090.9 & 150298.8 & 138.1 & -1111.0 & -1111.0 & -1111.0 & 120.2 & -9999.0 & -9999.0 & -9999.0 & -9999.0 & -9999.0 \\
\hline $199-\mathrm{N}-69$ & 571483.9 & 149804.8 & 139.6 & -1111.0 & -1111.0 & -1111.0 & 120.5 & 109.8 & -9999.0 & -9999.0 & -9999.0 & -9999.0 \\
\hline $199-\mathrm{N}-70$ & 572042.0 & 149878.0 & 137.8 & -1111.0 & -1111.0 & -1111.0 & 125.1 & 107.4 & -9999.0 & -9999.0 & -9999.0 & -9999.0 \\
\hline $199-\mathrm{N}-77$ & 571309.8 & 149243.0 & 139.9 & -1111.0 & -1111.0 & -1111.0 & 121.1 & 110.4 & -9999.0 & -9999.0 & -9999.0 & -9999.0 \\
\hline 299-E13-20 & 573609.6 & 134312.7 & 226.4 & -1111.0 & -1111.0 & -1111.0 & 131.5 & 104.0 & 85.7 & 80.9 & 71.4 & 49.2 \\
\hline 299-E16-1 & 575782.7 & 135219.9 & 212.3 & -1111.0 & -1111.0 & -1111.0 & 128.6 & -1111.0 & -1111.0 & 110.3 & 90.8 & 68.3 \\
\hline 299-E17-21 & 574107.0 & 134894.2 & 226.3 & -2222.0 & -1111.0 & -1111.0 & 124.4 & -1111.0 & -1111.0 & 109.7 & 91.7 & -9999.0 \\
\hline 299-E17-6 & 575113.1 & 135108.2 & 219.8 & -2222.0 & -1111.0 & -1111.0 & 121.9 & -1111.0 & -1111.0 & 107.9 & 90.2 & -9999.0 \\
\hline 299-E19-1 & 572819.7 & 135085.6 & 224.2 & -1111.0 & -1111.0 & -1111.0 & 113.4 & -1111.0 & -1111.0 & 110.3 & 92.0 & 66.5 \\
\hline 299-E23-2 & 573709.4 & 135671.7 & 219.5 & -2222.0 & -1111.0 & -1111.0 & 102.7 & -1111.0 & -1111.0 & -1111.0 & 102.7 & 88.1 \\
\hline 299-E24-7 & 574406.5 & 135560.5 & 218.2 & -2222.0 & -1111.0 & -1111.0 & -1111.0 & -1111.0 & -1111.0 & -1111.0 & 99.4 & 82.6 \\
\hline 299-E24-8 & 574546.8 & 136271.8 & 209.7 & -2222.0 & -1111.0 & -1111.0 & -1111.0 & -1111.0 & -1111.0 & -1111.0 & 101.2 & 95.7 \\
\hline 299-E25-1000 & 576478.4 & 135757.6 & 205.5 & -2222.0 & -1111.0 & -1111.0 & -1111.0 & -1111.0 & -1111.0 & -1111.0 & 94.8 & 89.0 \\
\hline $299-E 25-2$ & 575513.8 & 136061.9 & 205.7 & -2222.0 & -1111.0 & -1111.0 & -1111.0 & -1111.0 & -1111.0 & -1111.0 & 111.9 & 96.0 \\
\hline 299-E25-28 & 576011.8 & 136111.7 & 201.8 & -2222.0 & -1111.0 & -1111.0 & -1111.0 & -1111.0 & -1111.0 & -1111.0 & 112.8 & 98.1 \\
\hline 299-E25-32 & 576382.4 & 136044.3 & 204.7 & -2222.0 & -1111.0 & -1111.0 & -1111.0 & -1111.0 & -1111.0 & -1111.0 & 111.3 & 97.8 \\
\hline 299-E26-8 & 575522.2 & 136687.2 & 188.8 & -1111.0 & -1111.0 & -1111.0 & -1111.0 & -1111.0 & -1111.0 & -1111.0 & 128.7 & 115.0 \\
\hline 299-E27-1 & 574515.1 & 136536.8 & 207.3 & -2222.0 & -1111.0 & -1111.0 & -1111.0 & -1111.0 & -1111.0 & -1111.0 & -1111.0 & 102.4 \\
\hline 299-E27-11 & 574652.9 & 137062.7 & 196.3 & -2222.0 & -1111.0 & -1111.0 & -1111.0 & -1111.0 & -1111.0 & -1111.0 & -1111.0 & 116.4 \\
\hline 299-E27-15 & 575095.3 & 136630.4 & 199.2 & -2222.0 & -1111.0 & -1111.0 & -1111.0 & -1111.0 & -1111.0 & -1111.0 & -9999.0 & -9999.0 \\
\hline 299-E27-17 & 574547.3 & 137122.0 & 193.6 & -2222.0 & -1111.0 & -1111.0 & -1111.0 & -1111.0 & -1111.0 & -1111.0 & -1111.0 & 118.9 \\
\hline 299-E28-16 & 573136.7 & 136562.6 & 214.3 & -1111.0 & -1111.0 & -1111.0 & -1111.0 & -1111.0 & -1111.0 & -1111.0 & 125.0 & -9999.0 \\
\hline 299-E28-22 & 574041.4 & 136320.8 & 213.5 & -1111.0 & -1111.0 & -1111.0 & -1111.0 & -1111.0 & -1111.0 & -1111.0 & 115.3 & 98.2 \\
\hline 299-E28-26 & 572941.6 & 137024.0 & 209.4 & -2222.0 & -1111.0 & -1111.0 & -1111.0 & -1111.0 & -1111.0 & -1111.0 & 118.3 & 110.3 \\
\hline 299-E28-27 & 573226.8 & 137070.1 & 207.4 & -1111.0 & -1111.0 & -1111.0 & -1111.0 & -1111.0 & -1111.0 & -1111.0 & 122.9 & -9999.0 \\
\hline 299-E32-4 & 572603.7 & 137187.2 & 209.0 & -1111.0 & -1111.0 & -1111.0 & -1111.0 & -1111.0 & -1111.0 & -1111.0 & -1111.0 & -9999.0 \\
\hline 299-E33-12 & 573780.5 & 137632.2 & 190.0 & -1111.0 & -1111.0 & -1111.0 & -1111.0 & -1111.0 & -1111.0 & -1111.0 & -1111.0 & 120.5 \\
\hline 299-E33-14 & 573985.6 & 137567.2 & 189.6 & -2222.0 & -1111.0 & -1111.0 & -1111.0 & -1111.0 & -1111.0 & -1111.0 & -1111.0 & 120.4 \\
\hline 299-E33-16 & 573791.7 & 137465.3 & 195.0 & -2222.0 & -1111.0 & -1111.0 & -1111.0 & -1111.0 & -1111.0 & -1111.0 & -1111.0 & 118.0 \\
\hline 299-E33-18 & 573779.2 & 137386.1 & 198.4 & -2222.0 & -1111.0 & -1111.0 & -1111.0 & -1111.0 & -1111.0 & -1111.0 & -1111.0 & 118.3 \\
\hline 299-E33-19 & 573847.6 & 137422.7 & 194.5 & -2222.0 & -1111.0 & -1111.0 & -1111.0 & -1111.0 & -1111.0 & -1111.0 & -1111.0 & 122.5 \\
\hline 299-E33-20 & 573847.6 & 137397.9 & 195.1 & -2222.0 & -1111.0 & -1111.0 & -1111.0 & -1111.0 & -1111.0 & -1111.0 & -1111.0 & 121.0 \\
\hline 299-E33-28 & 573226.4 & 137375.0 & 202.5 & -1111.0 & -1111.0 & -1111.0 & -1111.0 & -1111.0 & -1111.0 & -1111.0 & -1111.0 & 118.3 \\
\hline 299-E33-29 & 573227.9 & 137231.2 & 205.4 & -1111.0 & -1111.0 & -1111.0 & -1111.0 & -1111.0 & -1111.0 & -1111.0 & -1111.0 & 118.0 \\
\hline 299-E33-30 & 572923.8 & 137467.8 & 202.3 & -1111.0 & -1111.0 & -1111.0 & -1111.0 & -1111.0 & -1111.0 & -1111.0 & -1111.0 & 119.0 \\
\hline 299-E33-33 & 574080.1 & 137301.9 & 195.3 & -2222.0 & -1111.0 & -1111.0 & -1111.0 & -1111.0 & -1111.0 & -1111.0 & -1111.0 & 118.6 \\
\hline 299-E33-34 & 573104.5 & 137740.4 & 193.2 & -2222.0 & -1111.0 & -1111.0 & -1111.0 & -1111.0 & -1111.0 & -1111.0 & -1111.0 & 120.7 \\
\hline 299-E33-35 & 573220.8 & 137605.1 & 196.2 & -2222.0 & -1111.0 & -1111.0 & -1111.0 & -1111.0 & -1111.0 & -1111.0 & -1111.0 & 119.8 \\
\hline 299-E33-37 & 574091.5 & 137185.4 & 199.2 & -2222.0 & -1111.0 & -1111.0 & -1111.0 & -1111.0 & -1111.0 & -1111.0 & -1111.0 & 117.3 \\
\hline 299-E33-41 & 573707.2 & 137369.9 & 199.6 & -2222.0 & 132.0 & -1111.0 & -1111.0 & -1111.0 & -1111.0 & -1111.0 & -1111.0 & 119.5 \\
\hline 299-E33-42 & 573521.0 & 137424.4 & 199.4 & -2222.0 & -1111.0 & -1111.0 & -1111.0 & -1111.0 & -1111.0 & -1111.0 & -1111.0 & 118.9 \\
\hline 299-E33-43 & 573523.2 & 137325.4 & 201.9 & -2222.0 & 134.1 & -1111.0 & -1111.0 & -1111.0 & -1111.0 & -1111.0 & -1111.0 & 116.4 \\
\hline 299-E34-11 & 574176.2 & 137581.8 & 188.4 & -2222.0 & -1111.0 & -1111.0 & -1111.0 & -1111.0 & -1111.0 & -1111.0 & -1111.0 & 122.5 \\
\hline 299-E34-2 & 574634.8 & 137220.7 & 192.3 & -1111.0 & -1111.0 & -1111.0 & -1111.0 & -1111.0 & -1111.0 & -1111.0 & -1111.0 & 119.9 \\
\hline 299-E34-3 & 575110.3 & 137301.4 & 186.4 & -1111.0 & -1111.0 & -1111.0 & -1111.0 & -1111.0 & -1111.0 & -1111.0 & -1111.0 & 122.3 \\
\hline 299-E34-6 & 574462.3 & 137740.7 & 182.2 & -1111.0 & -1111.0 & -1111.0 & -1111.0 & -1111.0 & -1111.0 & -1111.0 & -1111.0 & 115.0 \\
\hline 299-E35-1 & 575459.7 & 137465.0 & 182.5 & -2222.0 & -1111.0 & -1111.0 & -1111.0 & -1111.0 & -1111.0 & -1111.0 & -1111.0 & 124.1 \\
\hline 299-W10-13 & 566027.4 & 136606.8 & 213.1 & 180.5 & 179.0 & -111क. & 171.4 & -9999.0 & -9999.0 & -9999.0 & -9999.0 & -9999.0 \\
\hline
\end{tabular}




\begin{tabular}{|c|c|c|c|c|c|c|c|c|c|c|c|c|}
\hline & & & surf elev (top 1) & Top 2 & Top 3 & Top 4 & Top 5 & Top 6 & Top 7 & Top 8 & Top 9 & Top 10 \\
\hline Well number & EASTING & NORTHING & & & & & & & & & & (basalt) \\
\hline 299-W10-14 & 566017.2 & 136608.9 & 213.2 & 177.5 & 174.4 & -1111.0 & 169.9 & -1111.0 & -1111.0 & 76.9 & -9999.0 & -9999.0 \\
\hline 299-W11-2 & 567406.3 & 136671.0 & 217.0 & 184.2 & 179.9 & -1111.0 & 172.9 & -1111.0 & -1111.0 & 89.1 & 83.9 & 62.9 \\
\hline 299-W11-26 & 567044.7 & 136563.7 & 211.5 & 186.6 & 180.8 & 172.3 & 169.9 & -1111.0 & -1111.0 & 87.0 & 81.8 & 58.9 \\
\hline 299-W14-7 & 567034.2 & 135654.5 & 206.7 & -1111.0 & 168.6 & -1111.0 & 167.4 & -1111.0 & -1111.0 & 78.4 & 62.9 & 49.5 \\
\hline 299-W14-8A & 568011.1 & 135685.7 & 221.0 & 174.7 & 170.2 & -1111.0 & 165.3 & -1111.0 & -1111.0 & 87.9 & 85.7 & 58.6 \\
\hline 299-W15-14 & 566092.9 & 135648.0 & 212.8 & -1111.0 & 164.1 & 160.1 & 156.8 & -1111.0 & -1111.0 & 74.2 & 59.2 & 41.2 \\
\hline 299-W15-15 & 566088.8 & 135751.5 & 212.7 & 171.1 & 168.0 & -1111.0 & 160.4 & -9999.0 & -9999.0 & -9999.0 & -9999.0 & -9999.0 \\
\hline 299-W15-16 & 566307.0 & 135733.6 & 208.8 & 168.6 & 167.1 & 161.0 & 158.0 & -9999.0 & -9999.0 & -9999.0 & -9999.0 & -9999.0 \\
\hline 299-W15-18 & 566308.7 & 135561.8 & 209.0 & -1111.0 & 168.9 & 164.4 & 158.3 & -9999.0 & -9999.0 & -9999.0 & -9999.0 & -9999.0 \\
\hline 299-W15-5 & 566735.0 & 135511.7 & 204.2 & 171.7 & 168.3 & -1111.0 & 162.5 & -1111.0 & -1111.0 & 75.7 & 69.6 & 45.2 \\
\hline 299-W18-21 & 566097.7 & 134978.7 & 203.8 & 168.3 & 163.8 & -1111.0 & 160.7 & -9999.0 & -9999.0 & -9999.0 & -9999.0 & -9999.0 \\
\hline 299-W18-22 & 566088.6 & 134990.2 & 203.8 & 168.3 & 162.2 & -1111.0 & 159.2 & -1111.0 & -1111.0 & 68.7 & -9999.0 & -9999.0 \\
\hline 299-W18-23 & 566084.5 & 135342.4 & 212.4 & 164.4 & 161.6 & -1111.0 & 158.3 & -9999.0 & -9999.0 & -9999.0 & -9999.0 & -9999.0 \\
\hline 299-W18-24 & 566370.8 & 135346.3 & 208.6 & 168.3 & 166.8 & 160.7 & 156.1 & -9999.0 & -9999.0 & -9999.0 & -9999.0 & -9999.0 \\
\hline 299-W19-10 & 567036.8 & 134800.3 & 207.9 & 166.2 & 160.1 & -1111.0 & 156.8 & -1111.0 & -1111.0 & 69.0 & 61.0 & 39.7 \\
\hline 299-W19-4 & 567949.9 & 135350.8 & 217.3 & 167.1 & 158.3 & 144.3 & 139.1 & -1111.0 & -1111.0 & 84.2 & 81.2 & 54.0 \\
\hline 299-W21-1 & 568143.4 & 134396.3 & 213.1 & 161.0 & 153.1 & -1111.0 & 144.6 & -9999.0 & -9999.0 & -9999.0 & -9999.0 & -9999.0 \\
\hline 299-W22-24 & 567648.2 & 134410.9 & 210.3 & 168.9 & 155.8 & 143.6 & 140.6 & -1111.0 & -1111.0 & 91.8 & 78.1 & 39.7 \\
\hline 299-W6-1 & 567214.1 & 137510.1 & 214.0 & -1111.0 & 200.6 & 196.7 & 184.5 & -1111.0 & -1111.0 & 88.5 & 84.5 & 75.7 \\
\hline 299-W6-2 & 566938.4 & 137351.0 & 211.1 & -1111.0 & 195.2 & 186.0 & 184.5 & -9999.0 & -9999.0 & -9999.0 & -9999.0 & -9999.0 \\
\hline 299-W7-1 & 565932.0 & 137647.1 & 210.5 & 193.3 & 190.3 & 178.1 & 168.9 & -9999.0 & -9999.0 & -9999.0 & -9999.0 & -9999.0 \\
\hline 299-W7-2 & 566302.8 & 137638.5 & 205.9 & 196.4 & 193.3 & 181.1 & 179.6 & -9999.0 & -9999.0 & -9999.0 & -9999.0 & -9999.0 \\
\hline 299-W7-4 & 566408.8 & 137308.2 & 204.7 & -1111.0 & 190.6 & 183.0 & 175.3 & -9999.0 & -9999.0 & -9999.0 & -9999.0 & -9999.0 \\
\hline 299-W7-5 & 566476.0 & 137635.7 & 205.1 & -1111.0 & 195.5 & -1111.0 & 183.3 & -9999.0 & -9999.0 & -9999.0 & -9999.0 & -9999.0 \\
\hline 299-W7-6 & 566658.1 & 137636.3 & 206.8 & -1111.0 & 201.9 & -1111.0 & 185.1 & -9999.0 & -9999.0 & -9999.0 & -9999.0 & -9999.0 \\
\hline 299-W8-1 & 565749.4 & 137646.6 & 213.8 & -1111.0 & 186.9 & 178.1 & 168.9 & -9999.0 & -9999.0 & -9999.0 & -9999.0 & -9999.0 \\
\hline 3099-45-18A & 594993.9 & 113197.7 & 110.0 & -1111.0 & -2222.0 & -1111.0 & -1111.0 & 99.8 & -9999.0 & -9999.0 & -9999.0 & -9999.0 \\
\hline 3099-47-18A & 594897.0 & 113699.4 & 114.0 & -1111.0 & -2222.0 & -1111.0 & -1111.0 & 101.9 & 78.4 & 70.5 & -1111.0 & 61.4 \\
\hline $399-1-16 C$ & 594312.0 & 116410.4 & 116.5 & -1111.0 & -2222.0 & -1111.0 & 103.7 & -1111.0 & -1111.0 & 81.8 & -1111.0 & 65.1 \\
\hline $399-1-17 \mathrm{C}$ & 594104.7 & 116409.2 & 115.3 & -1111.0 & -2222.0 & -1111.0 & 116.2 & -1111.0 & -1111.0 & 81.5 & 66.7 & 65.7 \\
\hline $399-1-18 \mathrm{C}$ & 593872.3 & 117294.6 & 118.3 & -1111.0 & -2222.0 & -1111.0 & 103.7 & -1111.0 & -1111.0 & 83.3 & 81.2 & 75.4 \\
\hline $399-1-9$ & 594254.0 & 116330.4 & 117.3 & -1111.0 & -2222.0 & -1111.0 & 101.9 & -1111.0 & -1111.0 & 82.4 & 66.3 & 65.3 \\
\hline 399-3-3 & 594049.6 & 115804.8 & 121.2 & -1111.0 & -2222.0 & -1111.0 & 104.6 & 90.6 & 78.7 & 74.5 & -9999.0 & -9999.0 \\
\hline $399-4-5$ & 594128.3 & 115638.5 & 122.5 & -1111.0 & -2222.0 & -1111.0 & 104.6 & 97.9 & 90.9 & 79.6 & -1111.0 & 64.1 \\
\hline $399-4-7$ & 594603.2 & 115492.6 & 114.9 & -1111.0 & -2222.0 & -1111.0 & 103.7 & -1111.0 & -1111.0 & 79.9 & -9999.0 & -9999.0 \\
\hline $399-5-2$ & 592814.5 & 115454.7 & 119.1 & -1111.0 & -2222.0 & -1111.0 & 105.5 & 99.1 & 93.7 & 70.2 & -1111.0 & 62.3 \\
\hline $399-8-1$ & 593632.2 & 116332.0 & 120.8 & -1111.0 & -2222.0 & -1111.0 & 101.0 & -9999.0 & -9999.0 & -9999.0 & -9999.0 & -9999.0 \\
\hline 399-8-2 & 593202.4 & 116300.4 & 120.7 & -1111.0 & -2222.0 & -1111.0 & 105.9 & 100.4 & 88.2 & -9999.0 & -9999.0 & -9999.0 \\
\hline $399-8-3$ & 593626.1 & 116683.6 & 119.8 & -1111.0 & -2222.0 & -1111.0 & 102.8 & 94.0 & -9999.0 & -9999.0 & -9999.0 & -9999.0 \\
\hline $399-8-5 C$ & 593386.1 & 116573.6 & 121.2 & -1111.0 & -1111.0 & -1111.0 & 102.5 & 99.8 & 94.0 & 72.0 & 66.0 & 62.6 \\
\hline 499-S1-7A & 587653.5 & 123190.8 & 168.9 & -1111.0 & -2222.0 & -1111.0 & 112.6 & -9999.0 & -9999.0 & -9999.0 & -9999.0 & -9999.0 \\
\hline 499-S1-7B & 587653.5 & 123206.3 & 168.9 & -1111.0 & -2222.0 & -1111.0 & 112.6 & -1111.0 & -1111.0 & 66.8 & 26.6 & -11.5 \\
\hline 499-S1-8J & 587524.7 & 123292.8 & 166.4 & -1111.0 & -2222.0 & -1111.0 & 112.6 & -1111.0 & -1111.0 & 68.1 & -9999.0 & -9999.0 \\
\hline 699-101-48C & 575222.9 & 154411.0 & 118.3 & -1111.0 & -1111.0 & -1111.0 & -1111.0 & 104.6 & -9999.0 & -9999.0 & -9999.0 & -9999.0 \\
\hline $699-10-30 A$ & 580608.1 & 126498.4 & 168.4 & -1111.0 & -2222.0 & 101.0 & 90.3 & 62.9 & 61.0 & 50.7 & 46.1 & 14.1 \\
\hline 699-10-54A & 573581.7 & 126562.3 & 157.4 & -1111.0 & -1111.0 & -1111.0 & 129.0 & -1111.0 & -1111.0 & 105.5 & -1111.0 & 94.3 \\
\hline 699-10-54B & 573554.1 & 126564.3 & 157.4 & -1111.0 & -1111.0 & -1111.0 & 129.3 & -1111.0 & -1111.0 & 106.5 & -1111.0 & 94.3 \\
\hline 699-107-79 & 565826.4 & 156065.7 & 200.9 & -1111.0 & -2222.0 & -1111.0 & 198.2 & 183.0 & 167.7 & 112.6 & -1111.0 & 94.0 \\
\hline 699-10-E12 & 593296.2 & 126696.6 & 131.3 & -1111.0 & -1111.0 & -1111.0 & 108.0 & 90.6 & 62.9 & 42.5 & 28.7 & 24.2 \\
\hline 699-11-23A & 582892.6 & 126708.1 & 166.1 & -1111.0 & -2222.0 & 94.0 & 80.2 & 25.4 & 8.6 & -20.3 & -40.1 & -9999.0 \\
\hline $699-11-29$ & 581155.3 & 126937.2 & 166.1 & -1111.0 & -2222.0 & $-222 \beta_{8} \mathrm{ag}$ & -2222.0 & -2222.0 & -2222.0 & -2222.0 & -2222.0 & -49.0 \\
\hline
\end{tabular}




\begin{tabular}{|c|c|c|c|c|c|c|c|c|c|c|c|c|}
\hline & & & surf elev (top 1) & Top 2 & Top 3 & Top 4 & Top 5 & Top 6 & Top 7 & Top 8 & Top 9 & Top 10 \\
\hline Well number & EASTING & NORTHING & & & & & & & & & & (basalt) \\
\hline 699-11-45A & 576279.0 & 126806.6 & 176.2 & -1111.0 & -1111.0 & -1111.0 & 125.7 & -1111.0 & -1111.0 & 108.6 & 96.7 & 64.4 \\
\hline 699-1-18 & 584529.8 & 123948.9 & 164.0 & -1111.0 & -1111.0 & -1111.0 & 126.9 & -2222.0 & -2222.0 & 65.9 & -9999.0 & -9999.0 \\
\hline 699-11-E4E & 590984.6 & 126738.2 & 134.4 & -1111.0 & -1111.0 & -1111.0 & 100.7 & 63.5 & 45.2 & 36.1 & 8.6 & -6.0 \\
\hline 699-11-E8B & 592319.3 & 126746.1 & 136.9 & -1111.0 & -1111.0 & -1111.0 & 105.9 & 79.9 & 76.9 & 40.3 & 28.1 & 20.5 \\
\hline $699-12-18$ & 584370.9 & 127282.1 & 167.2 & -1111.0 & -2222.0 & 84.5 & -2222.0 & -2222.0 & -2222.0 & -2222.0 & -2222.0 & -56.3 \\
\hline $699-12-1 A$ & 589563.2 & 127103.5 & 134.7 & -1111.0 & -2222.0 & -1111.0 & 116.5 & 59.2 & 43.7 & 9.8 & -5.7 & -17.6 \\
\hline 699-13-26 & 581844.8 & 127490.0 & 156.2 & -1111.0 & 122.0 & 94.3 & 88.2 & -2222.0 & -2222.0 & -2222.0 & -2222.0 & -70.6 \\
\hline $699-13-2 B$ & 589354.0 & 127336.0 & 135.0 & -1111.0 & -1111.0 & -1111.0 & 107.4 & -2222.0 & -2222.0 & -2222.0 & -2222.0 & -2222.0 \\
\hline 699-13-64 & 570415.9 & 127309.0 & 168.2 & -1111.0 & -1111.0 & -1111.0 & 162.8 & -1111.0 & -1111.0 & 157.1 & 137.6 & 120.2 \\
\hline 699-14-38 & 578401.9 & 127742.6 & 157.0 & -1111.0 & -2222.0 & 103.1 & 88.2 & -2222.0 & -2222.0 & 56.8 & 41.5 & 29.0 \\
\hline 699-14-E3E & 590766.0 & 127680.0 & 136.4 & -1111.0 & -1111.0 & -1111.0 & 106.2 & -2222.0 & -2222.0 & -2222.0 & -2222.0 & -2222.0 \\
\hline 699-14-E6P & 591594.0 & 127703.0 & 140.8 & -1111.0 & -1111.0 & -1111.0 & 99.5 & 63.6 & 56.0 & 49.9 & -2222.0 & -2222.0 \\
\hline 699-15-15A & 585350.7 & 128021.2 & 166.7 & -2222.0 & 121.7 & 101.6 & -2222.0 & -2222.0 & -2222.0 & -2222.0 & -2222.0 & -48.7 \\
\hline $699-15-26$ & 581770.3 & 127963.5 & 159.7 & -1111.0 & 122.6 & 91.2 & 74.5 & -9999.0 & -9999.0 & -9999.0 & -9999.0 & -9999.0 \\
\hline 699-15-E13 & 593789.2 & 128199.9 & 125.6 & -1111.0 & -1111.0 & 104.9 & 102.7 & 91.5 & 71.7 & 59.5 & -1111.0 & 33.6 \\
\hline $699-16-23$ & 582942.2 & 128371.6 & 169.0 & -1111.0 & -2222.0 & 96.7 & 79.9 & 32.7 & 12.9 & -3.6 & -32.5 & -50.2 \\
\hline 699-16-30A & 580619.8 & 128448.6 & 164.6 & -1111.0 & 132.1 & 100.1 & 76.0 & 4.0 & -26.4 & -38.6 & -64.5 & -92.3 \\
\hline 699-16-E4A & 591005.0 & 128299.4 & 141.0 & -1111.0 & -1111.0 & -2222.0 & 114.1 & -1111.0 & -1111.0 & 75.7 & 54.3 & 48.2 \\
\hline 699-17-15 & 585274.3 & 128611.5 & 163.1 & -1111.0 & -2222.0 & 94.3 & 88.2 & 37.9 & 34.8 & -18.5 & -24.6 & -40.8 \\
\hline $699-17-26 \mathrm{~A}$ & 581882.0 & 128581.0 & 159.5 & -2222.0 & 125.4 & 98.5 & -9999.0 & -9999.0 & -9999.0 & -9999.0 & -9999.0 & -9999.0 \\
\hline $699-17-26 \mathrm{~F}$ & 581953.7 & 128803.0 & 158.3 & -1111.0 & -2222.0 & 96.7 & 78.4 & 28.1 & -9999.0 & -9999.0 & -9999.0 & -9999.0 \\
\hline 699-17-26G & 581974.8 & 128826.4 & 158.3 & -1111.0 & -2222.0 & 81.8 & 75.7 & 29.0 & 11.4 & -25.8 & -35.0 & -57.2 \\
\hline $699-17-47$ & 575489.8 & 128765.2 & 176.1 & -1111.0 & -1111.0 & -1111.0 & 122.3 & 110.1 & 96.4 & 83.0 & 80.6 & 73.5 \\
\hline $699-17-5$ & 588557.9 & 128811.8 & 132.0 & -1111.0 & -2222.0 & 112.3 & 103.4 & -9999.0 & -9999.0 & -9999.0 & -9999.0 & -9999.0 \\
\hline $699-17-70$ & 568571.9 & 128635.7 & 171.6 & -1111.0 & -1111.0 & -1111.0 & 160.7 & -1111.0 & -1111.0 & 106.5 & 100.0 & 90.3 \\
\hline 699-18-21 & 583565.2 & 128871.6 & 163.8 & -1111.0 & -2222.0 & 93.0 & 88.5 & 36.7 & 19.9 & -6.0 & -30.4 & -48.7 \\
\hline 699-18-25E & 582325.0 & 128840.7 & 158.9 & -1111.0 & -2222.0 & 96.1 & -2222.0 & -2222.0 & -2222.0 & -2222.0 & -2222.0 & -62.4 \\
\hline $699-19-23$ & 582904.3 & 129373.2 & 163.3 & -1111.0 & -2222.0 & 93.0 & 85.1 & 36.4 & 16.5 & -4.8 & -27.7 & -42.0 \\
\hline 699-19-27 & 581748.4 & 129278.1 & 160.4 & -1111.0 & -2222.0 & 82.4 & 79.3 & 30.6 & 3.1 & -7.5 & -39.8 & -55.1 \\
\hline 699-19-34A & 579666.3 & 129156.4 & 163.3 & -1111.0 & -2222.0 & 96.1 & 90.0 & 50.4 & 19.9 & -20.9 & -28.9 & -51.4 \\
\hline 699-19-58 & 572133.5 & 129298.8 & 174.7 & -1111.0 & -1111.0 & -1111.0 & 130.2 & -1111.0 & -1111.0 & 117.7 & -1111.0 & 113.2 \\
\hline 699-19-88 & 563131.1 & 129413.9 & 196.3 & -1111.0 & 179.0 & -1111.0 & 177.8 & -1111.0 & -1111.0 & 95.2 & -1111.0 & 90.3 \\
\hline $699-20-18 \mathrm{~A}$ & 584316.8 & 129473.4 & 162.2 & -1111.0 & -2222.0 & 97.6 & 94.6 & 50.4 & 41.2 & 10.8 & -8.8 & -21.9 \\
\hline $699-20-20$ & 583518.5 & 129714.3 & 153.9 & -9999.0 & -2222.0 & -9999.0 & -9999.0 & -9999.0 & -9999.0 & -9999.0 & -9999.0 & -9999.0 \\
\hline $699-20-25$ & 582322.1 & 129739.3 & 158.7 & -1111.0 & -2222.0 & 88.2 & -2222.0 & -2222.0 & -2222.0 & -2222.0 & -2222.0 & -43.2 \\
\hline 699-20-39 & 577999.0 & 129729.0 & 164.8 & -1111.0 & 132.1 & -1111.0 & 116.8 & 62.6 & 19.9 & 10.8 & -11.5 & -22.7 \\
\hline 699-20-82 & 564812.0 & 129505.0 & 188.1 & -1111.0 & -1111.0 & -1111.0 & 167.4 & -1111.0 & -1111.0 & 82.9 & -1111.0 & 95.4 \\
\hline 699-20-E12 & 593592.9 & 129735.3 & 133.3 & -1111.0 & 114.4 & 109.8 & 103.7 & -1111.0 & -1111.0 & 56.5 & -1111.0 & 33.6 \\
\hline 699-20-E2 & 590665.1 & 129722.0 & 142.0 & -1111.0 & 122.3 & 102.8 & 96.1 & 50.7 & 47.6 & 28.7 & 4.7 & -4.2 \\
\hline 699-21-17 & 584791.6 & 129855.4 & 160.6 & -1111.0 & -2222.0 & 99.5 & 93.4 & 42.8 & 33.6 & 11.1 & -1.1 & -27.0 \\
\hline 699-21-30B & 580817.8 & 129982.9 & 164.2 & -1111.0 & -2222.0 & 96.7 & 92.1 & 26.6 & 11.4 & -10.0 & -25.2 & -52.9 \\
\hline $699-22-23$ & 582991.9 & 130342.7 & 156.4 & -1111.0 & -2222.0 & 91.8 & 85.7 & 41.5 & 15.6 & 1.9 & -28.6 & -39.2 \\
\hline $699-2-3$ & 588851.7 & 124186.7 & 145.4 & -1111.0 & -1111.0 & -1111.0 & 117.4 & -9999.0 & -9999.0 & -9999.0 & -9999.0 & -9999.0 \\
\hline 699-23-33 & 579924.1 & 130629.2 & 168.3 & -1111.0 & 123.8 & 108.6 & 98.6 & -2222.0 & -2222.0 & -2222.0 & -2222.0 & -20.0 \\
\hline $699-2-33 A$ & 580097.6 & 124130.5 & 163.4 & -1111.0 & -1111.0 & -1111.0 & 126.6 & 105.2 & 96.7 & 58.0 & 43.4 & 26.6 \\
\hline 699-24-1P & 590390.4 & 130712.6 & 144.7 & -1111.0 & 124.1 & 102.5 & 94.0 & 55.3 & 42.5 & 28.4 & -1111.0 & 5.6 \\
\hline $699-24-33$ & 579720.1 & 130768.4 & 159.7 & -9999.0 & -2222.0 & -9999.0 & -9999.0 & -9999.0 & -9999.0 & -9999.0 & -9999.0 & -9999.0 \\
\hline 699-24-34A & 579522.7 & 130669.4 & 162.8 & -9999.0 & -2222.0 & -9999.0 & -9999.0 & -9999.0 & -9999.0 & -9999.0 & -9999.0 & -9999.0 \\
\hline $699-24-35$ & 579176.8 & 130915.0 & 164.3 & -9999.0 & -2222.0 & -9999.0 & -9999.0 & -9999.0 & -9999.0 & -9999.0 & -9999.0 & -9999.0 \\
\hline 699-24-46 & 575785.7 & 130793.8 & 180.1 & -1111.0 & 132.4 & -1111.0 & 117.1 & 77.5 & 72.9 & 60.7 & -3.3 & -23.7 \\
\hline $699-25-20$ & 583892.3 & 130998.9 & 159.1 & -1111.0 & -2222.0 & -222p.9ae 4 & -2222.0 & -2222.0 & -2222.0 & -2222.0 & -2222.0 & -57.2 \\
\hline
\end{tabular}




\begin{tabular}{|c|c|c|c|c|c|c|c|c|c|c|c|c|}
\hline & & & surf elev (top 1) & Top 2 & Top 3 & Top 4 & Top 5 & Top 6 & Top 7 & Top 8 & Top 9 & Top 10 \\
\hline Well number & EASTING & NORTHING & & & & & & & & & & (basalt) \\
\hline $699-25-26$ & 582044.5 & 131061.7 & 157.1 & -1111.0 & 127.5 & 98.5 & -2222.0 & -2222.0 & -2222.0 & -2222.0 & -2222.0 & -26.7 \\
\hline $699-25-31$ & 580462.1 & 131178.0 & 155.9 & -1111.0 & 123.2 & -1111.0 & 108.0 & -2222.0 & -2222.0 & -2222.0 & -2222.0 & -13.9 \\
\hline $699-25-33 \mathrm{~A}$ & 579712.2 & 131224.6 & 161.1 & -1111.0 & 112.7 & -1111.0 & 104.9 & -9999.0 & -9999.0 & -9999.0 & -9999.0 & -9999.0 \\
\hline $699-25-55$ & 573083.0 & 131206.0 & 206.3 & -1111.0 & 140.0 & -1111.0 & 125.4 & -9999.0 & -9999.0 & -9999.0 & -9999.0 & -9999.0 \\
\hline $699-25-70$ & 568544.9 & 131171.7 & 191.7 & 153.1 & 153.1 & -1111.0 & 136.3 & -9999.0 & -9999.0 & -9999.0 & -9999.0 & -9999.0 \\
\hline $699-25-80$ & 565675.8 & 131106.0 & 188.1 & $\frac{150.1}{-1111.0}$ & $\frac{105.1}{180.5}$ & -1111.0 & $\begin{array}{l}176.6 \\
176.6\end{array}$ & -1111.0 & -1111.0 & -1111.0 & -1111.0 & 155.2 \\
\hline $699-26-15 \mathrm{C}$ & 585473.6 & 131359.3 & 135.4 & -1111.0 & 114.7 & 105.2 & 91.8 & 30.0 & 12.3 & -6.9 & -41.7 & -48.1 \\
\hline $699-26-29 \mathrm{~A}$ & 581065.4 & 131544.7 & 157.6 & -1111.0 & -2222.0 & 97.6 & -2222.0 & -2222.0 & -2222.0 & -2222.0 & -2222.0 & -57.8 \\
\hline $699-26-35 \mathrm{C}$ & 579332.0 & 131341.8 & 162.2 & -1111.0 & 120.5 & 100.7 & -9999.0 & -9999.0 & -9999.0 & -9999.0 & -9999.0 & -9999.0 \\
\hline $699-26-51$ & 574357.9 & 131260.0 & 205.7 & -1111.0 & -2222.0 & 133.6 & 127.5 & -9999.0 & -9999.0 & -9999.0 & -9999.0 & -9999.0 \\
\hline 699-26-83A & 564532.1 & 131300.4 & 194.2 & -1111.0 & -2222.0 & 174.7 & 171.7 & -1111.0 & -1111.0 & 132.7 & 113.8 & 92.1 \\
\hline $699-26-89$ & 562778.7 & 131375.1 & 199.0 & -1111.0 & 190.9 & 166.8 & 158.3 & -1111.0 & -1111.0 & 108.0 & 85.1 & 52.8 \\
\hline $699-2-7$ & 587844.8 & 123980.0 & 156.1 & -1111.0 & -2222.0 & -1111.0 & 119.0 & -9999.0 & -9999.0 & -9999.0 & -9999.0 & -9999.0 \\
\hline $699-28-23$ & 582807.1 & 132004.3 & 161.1 & -1111.0 & 128.4 & 94.9 & 82.7 & 19.0 & 6.8 & -10.0 & -31.3 & -47.8 \\
\hline $699-28-30$ & 580816.7 & 131991.7 & 162.1 & -1111.0 & 134.2 & 99.1 & -2222.0 & -2222.0 & -2222.0 & -31.6 & -37.7 & -52.6 \\
\hline $699-28-40$ & 577621.0 & 131932.0 & 170.6 & -1111.0 & 137.9 & -1111.0 & 116.5 & 75.6 & 71.0 & 55.8 & 29.0 & -9999.0 \\
\hline $699-28-52 A$ & 574188.0 & 132111.0 & 208.6 & -1111.0 & 134.8 & -1111.0 & 128.7 & 81.2 & 47.8 & 26.1 & 10.6 & 0.2 \\
\hline 699-29-4 & 588701.2 & 132255.3 & 148.7 & -9999.0 & -2222.0 & -9999.0 & -9999.0 & -9999.0 & -9999.0 & -9999.0 & -9999.0 & -9999.0 \\
\hline $699-29-70 \mathrm{C}$ & 568494.2 & 132246.6 & 192.9 & -1111.0 & 153.4 & -1111.0 & 148.2 & -1111.0 & -1111.0 & 81.8 & 65.9 & 28.1 \\
\hline $699-29-78$ & 566211.6 & 132413.6 & $\begin{array}{l}197.2 \\
197\end{array}$ & -1111.0 & 160.7 & -1111.0 & $\begin{array}{l}140.2 \\
147.9\end{array}$ & -2222.0 & -2222.0 & 64.1 & 40.9 & 19.0 \\
\hline $699-29-83$ & 564510.0 & 132372.3 & 189.9 & -1111.0 & 170.2 & -1111.0 & 156.8 & -1111.0 & -1111.0 & 76.6 & 53.7 & 21.4 \\
\hline 699-2-E14 & 594061.3 & 124028.4 & 118.5 & -1111.0 & -1111.0 & -1111.0 & 99.8 & 76.9 & 66.2 & 49.5 & 35.7 & 22.0 \\
\hline $699-2-E 19$ & 595692.0 & $\frac{1240<.4}{124133.0}$ & $\begin{array}{l}117.0 \\
117.0\end{array}$ & $\frac{-11110}{-2222.0}$ & $\frac{-11111.0}{-111.0}$ & -1111.0 & 99.8 & -2222.0 & -2222.0 & -2222.0 & $\frac{30.1}{-2222.0}$ & -2222.0 \\
\hline $699-30-25 C$ & 582358.4 & 132593.5 & 165.4 & -1111.0 & 122.3 & 93.7 & -2222.0 & -2222.0 & -2222.0 & -2222.0 & -2222.0 & -42.9 \\
\hline 699-31-11 & 586434.4 & 133040.5 & 146.8 & -1111.0 & -2222.0 & 99.5 & -2222.0 & -2222.0 & -2222.0 & -2222.0 & -2222.0 & -22.2 \\
\hline 699-31-17 & 584799.4 & 132968.5 & 133.8 & -1111.0 & -2222.0 & 93.7 & -2222.0 & -2222.0 & -2222.0 & -2222.0 & -2222.0 & -34.1 \\
\hline 699-31-31 & 580551.7 & 132794.2 & 161.3 & -1111.0 & 125.7 & 101.3 & 76.9 & 31.2 & -9.1 & -20.3 & -30.7 & -9999.0 \\
\hline 699-31-53A & 573754.0 & 132962.0 & 215.6 & -2222.0 & -1111.0 & -2222.0 & 129.9 & -2222.0 & -2222.0 & -2222.0 & -2222.0 & -2222.0 \\
\hline 699-31-53B & 573758.4 & 132975.1 & 215.7 & -1111.0 & -1111.0 & -1111.0 & 123.2 & 87.0 & -9999.0 & -9999.0 & -9999.0 & -9999.0 \\
\hline 699-31-65 & 569981.0 & 132777.0 & 208.6 & -2222.0 & -1111.0 & -2222.0 & 145.2 & -2222.0 & -2222.0 & -2222.0 & -2222.0 & -2222.0 \\
\hline 699-31-8 & 587395.4 & 132928.0 & 145.1 & -1111.0 & 123.2 & 98.8 & -2222.0 & -2222.0 & -2222.0 & -2222.0 & -2222.0 & -18.5 \\
\hline $699-32-22 B$ & 583199.8 & 133240.1 & 156.8 & -1111.0 & -2222.0 & 89.4 & 83.3 & 30.0 & 19.3 & 4.0 & -24.9 & -34.1 \\
\hline $699-32-26$ & 581891.2 & 133145.9 & 158.5 & -1111.0 & 141.2 & 97.0 & -2222.0 & -2222.0 & -2222.0 & -2222.0 & -2222.0 & -36.2 \\
\hline $699-32-32$ & 580298.6 & 133206.9 & 158.7 & -1111.0 & 135.1 & -1111.0 & 87.9 & -2222.0 & -2222.0 & 5.6 & -16.7 & -55.7 \\
\hline $699-32-42$ & 576691.0 & 133385.0 & 156.9 & -2222.0 & -1111.0 & -2222.0 & 122.0 & -2222.0 & -2222.0 & -2222.0 & -2222.0 & -2222.0 \\
\hline $699-32-62$ & 571009.6 & 133215.9 & 215.5 & -1111.0 & -1111.0 & -1111.0 & 148.2 & -1111.0 & -1111.0 & 93.7 & 73.2 & -9999.0 \\
\hline $699-32-72 \mathrm{~A}$ & 567942.7 & 133362.6 & 203.6 & -1111.0 & 149.4 & -1111.0 & 130.8 & -1111.0 & -1111.0 & 78.1 & 67.1 & 30.3 \\
\hline 699-32-77 & 566416.8 & 133152.5 & 199.3 & 168.3 & 160.7 & -1111.0 & 157.7 & -9999.0 & -9999.0 & -9999.0 & -9999.0 & -9999.0 \\
\hline $699-33-14$ & 585534.3 & 133606.9 & 143.3 & -1111.0 & 129.9 & 104.0 & -2222.0 & -2222.0 & -2222.0 & -2222.0 & -2222.0 & -23.1 \\
\hline $699-33-21 \mathrm{~A}$ & 583372.6 & 133484.0 & 152.2 & -1111.0 & 133.6 & 101.6 & -2222.0 & -2222.0 & -2222.0 & -2222.0 & -2222.0 & -34.4 \\
\hline 699-33-42 & 577020.0 & 133484.0 & 157.3 & -1111.0 & -1111.0 & -1111.0 & 123.5 & -9999.0 & -9999.0 & -9999.0 & -9999.0 & -9999.0 \\
\hline $699-33-56$ & 572922.7 & 133627.2 & 218.6 & -1111.0 & -1111.0 & -1111.0 & 132.4 & 97.6 & -9999.0 & -9999.0 & -9999.0 & -9999.0 \\
\hline $699-33-6$ & 588013.4 & 133424.0 & 153.3 & -1111.0 & -2222.0 & 101.0 & 93.4 & 73.2 & 58.3 & 11.1 & -10.3 & -11.5 \\
\hline $699-34-20$ & 583653.0 & 133721.6 & 152.5 & -1111.0 & 109.2 & 92.4 & -2222.0 & -2222.0 & -2222.0 & -2222.0 & -2222.0 & -30.4 \\
\hline $699-34-41 B$ & 577338.0 & 133914.0 & 174.0 & -1111.0 & -1111.0 & -1111.0 & 122.9 & -9999.0 & -9999.0 & -9999.0 & -9999.0 & -9999.0 \\
\hline $699-3-45$ & 576204.8 & 124401.3 & 153.6 & -1111.0 & -1111.0 & -1111.0 & 122.6 & -1111.0 & -1111.0 & -1111.0 & -1111.0 & 113.8 \\
\hline $699-34-8$ & 587504.3 & 133900.1 & 148.1 & -1111.0 & -2222.0 & 100.7 & -2222.0 & -2222.0 & -2222.0 & -2222.0 & -2222.0 & -2222.0 \\
\hline 699-34-88 & 563011.5 & 133950.3 & 192.6 & -1111.0 & 170.5 & 165.9 & 157.1 & -1111.0 & -1111.0 & 64.1 & 33.6 & -6.0 \\
\hline $699-35-19 A$ & 584084.9 & 134090.3 & 144.4 & -1111.0 & -2222.0 & 101.3 & -2222.0 & -2222.0 & -2222.0 & -2222.0 & -2222.0 & -22.5 \\
\hline $699-35-28$ & 581287.1 & 134019.4 & 162.3 & -1111.0 & 145.2 & 93.0 & 87.0 & 38.2 & 25.0 & 23.0 & 3.3 & -24.9 \\
\hline $699-35-3$ & 588963.0 & 134190.0 & 148.2 & -2222.0 & 130.8 & 103р & 98.8 & 77.2 & 69.6 & -9999.0 & -2222.0 & 8.6 \\
\hline
\end{tabular}




\begin{tabular}{|c|c|c|c|c|c|c|c|c|c|c|c|c|}
\hline & & & surf elev (top 1) & Top 2 & Top 3 & Top 4 & Top 5 & Top 6 & Top 7 & Top 8 & Top 9 & Top 10 \\
\hline Well number & EASTING & NORTHING & & & & & & & & & & (basalt) \\
\hline 699-35-3B & 589070.9 & 134275.9 & 146.2 & -1111.0 & -2222.0 & -1111.0 & 101.6 & 94.0 & 87.9 & 37.6 & -9999.0 & 26.9 \\
\hline $699-35-6$ & 588025.7 & 134320.9 & 153.2 & -1111.0 & 129.6 & 102.5 & 99.5 & 76.9 & 70.5 & 18.7 & -1111.0 & 2.5 \\
\hline $699-35-66$ & 569856.0 & 134094.0 & 221.7 & -2222.0 & -1111.0 & -2222.0 & 129.9 & -1111.0 & -1111.0 & 100.2 & 85.9 & -9999.0 \\
\hline $699-35-70$ & 568566.0 & 133988.0 & 211.3 & -2222.0 & 145.5 & -1111.0 & 136.3 & -9999.0 & -9999.0 & -9999.0 & -9999.0 & -9999.0 \\
\hline 699-35-78B & 566047.3 & 134278.6 & 201.2 & 169.2 & 159.5 & -1111.0 & 156.4 & -1111.0 & -1111.0 & 74.5 & 52.5 & 25.1 \\
\hline $699-35-9$ & 587123.0 & 134096.1 & 152.3 & -1111.0 & 117.7 & 103.1 & -9999.0 & -9999.0 & -9999.0 & -9999.0 & -9999.0 & -9999.0 \\
\hline 699-36-10 & 586772.3 & 134605.0 & 160.3 & -1111.0 & 123.2 & 101.9 & 94.0 & 76.9 & 71.1 & 16.2 & 5.6 & -5.7 \\
\hline 699-36-17 & 584706.7 & 134613.0 & 134.1 & -1111.0 & -2222.0 & 100.1 & 90.9 & 40.6 & 25.4 & 8.6 & -2222.0 & -11.2 \\
\hline 699-36-27 & 581805.3 & 134445.7 & 162.1 & -1111.0 & 143.0 & 98.8 & 91.5 & 36.7 & 24.5 & -3.0 & -12.1 & -18.8 \\
\hline 699-36-46P & 575995.0 & 134518.0 & 215.3 & -2222.0 & -1111.0 & -2222.0 & 126.0 & 106.5 & 73.8 & 64.1 & 58.6 & 57.4 \\
\hline 699-36-58A & 572251.7 & 134536.2 & 224.3 & -1111.0 & -2222.0 & -1111.0 & 130.8 & -9999.0 & -9999.0 & -9999.0 & -9999.0 & -9999.0 \\
\hline 699-36-61B & 571401.2 & 134586.9 & 228.4 & -1111.0 & -1111.0 & -1111.0 & 136.9 & -1111.0 & -1111.0 & 105.9 & 86.0 & 62.0 \\
\hline $699-36-93$ & 561549.9 & 134415.6 & 196.3 & -1111.0 & 165.0 & -1111.0 & 155.8 & -1111.0 & -1111.0 & 81.5 & 14.4 & -12.4 \\
\hline $699-36-E 3$ & 590776.9 & 134348.2 & 141.8 & -1111.0 & 115.3 & 106.2 & 94.3 & -2222.0 & -2222.0 & 62.3 & 45.2 & 43.7 \\
\hline 699-37-36 & 578974.0 & 134722.5 & 165.5 & -1111.0 & 140.0 & 119.0 & 116.2 & 105.4 & 81.2 & 41.6 & -1111.0 & 38.3 \\
\hline $699-37-43$ & 576828.5 & 134782.5 & 210.4 & -1111.0 & 136.9 & 124.1 & 121.4 & 106.2 & 89.4 & 81.8 & 68.1 & 55.9 \\
\hline $699-37-47 A$ & 575557.0 & 134893.3 & 218.4 & -1111.0 & -1111.0 & -1111.0 & 131.7 & -1111.0 & -1111.0 & 107.3 & 84.7 & 61.0 \\
\hline 699-37-82B & 564903.7 & 134733.4 & 193.9 & 172.0 & 171.7 & -1111.0 & 161.0 & -1111.0 & -1111.0 & 72.0 & 44.9 & 11.4 \\
\hline $699-37-84$ & 564246.8 & 134768.4 & 193.2 & -1111.0 & 172.9 & 174.1 & 170.8 & -1111.0 & -1111.0 & 64.7 & 37.6 & 5.9 \\
\hline $699-37-92$ & 561920.4 & 134597.2 & 196.6 & -1111.0 & 182.4 & 161.0 & 150.7 & -1111.0 & -1111.0 & 62.6 & 35.1 & -8.1 \\
\hline 699-37-E4 & 590996.3 & 135407.5 & 118.0 & -1111.0 & -2222.0 & -1111.0 & 102.2 & -9999.0 & -9999.0 & -9999.0 & -9999.0 & -9999.0 \\
\hline 699-38-15 & 585475.3 & 134951.3 & 137.7 & -1111.0 & -2222.0 & 102.2 & 99.1 & 39.7 & 36.7 & 13.2 & 3.1 & -5.4 \\
\hline 699-38-19 & 584256.0 & 135160.3 & 140.6 & -1111.0 & 126.3 & 101.9 & -2222.0 & -2222.0 & -2222.0 & -2222.0 & -2222.0 & -7.8 \\
\hline 699-38-3 & 589025.7 & 135121.9 & 151.7 & -1111.0 & -2222.0 & -1111.0 & 100.1 & 98.5 & -1111.0 & -1111.0 & -1111.0 & 88.8 \\
\hline 699-38-34A & 579491.0 & 135149.0 & 162.2 & -2222.0 & -1111.0 & 127.5 & 125.7 & 108.9 & 95.8 & -1111.0 & 78.4 & 54.3 \\
\hline 699-38-61 & 571219.1 & 134997.3 & 227.3 & -2222.0 & -2222.0 & -2222.0 & 132.0 & -2222.0 & -2222.0 & -9999.0 & -9999.0 & -9999.0 \\
\hline 699-38-65 & 570090.2 & 135039.8 & 229.6 & -1111.0 & 144.6 & -1111.0 & 144.0 & -1111.0 & -1111.0 & 109.4 & 94.2 & 69.2 \\
\hline $699-38-70$ & 568501.0 & 135089.0 & 216.7 & -2222.0 & 160.7 & -2222.0 & 156.1 & -2222.0 & -2222.0 & -2222.0 & -2222.0 & -2222.0 \\
\hline 699-38-8A & 587567.0 & 135238.7 & 146.3 & -1111.0 & -2222.0 & 100.1 & 80.2 & -2222.0 & -2222.0 & -2222.0 & -2222.0 & 23.9 \\
\hline $699-38-9$ & 587292.6 & 135020.8 & 152.7 & -1111.0 & -2222.0 & 108.0 & -2222.0 & -2222.0 & -2222.0 & -2222.0 & -2222.0 & 7.7 \\
\hline 699-38-E0 & 590010.2 & 135026.6 & 143.1 & -1111.0 & -2222.0 & -1111.0 & 100.1 & 89.4 & 84.8 & -1111.0 & -1111.0 & 78.7 \\
\hline 699-39-103 & 558481.2 & 135431.4 & 271.3 & -1111.0 & -1111.0 & -1111.0 & -1111.0 & -1111.0 & -1111.0 & -1111.0 & -1111.0 & 230.2 \\
\hline $699-39-23$ & 582841.7 & 135297.8 & 145.0 & -1111.0 & 130.8 & 106.5 & 97.3 & 51.6 & 47.0 & 18.1 & 2.8 & -3.6 \\
\hline 699-39-39 & 578052.4 & 135391.6 & 163.9 & -2222.0 & -2222.0 & -2222.0 & -1111.0 & -1111.0 & -1111.0 & 127.4 & -9999.0 & -9999.0 \\
\hline $699-39-79$ & 565890.9 & 135411.9 & 205.1 & 180.2 & 167.7 & -1111.0 & 160.1 & -2222.0 & -2222.0 & -2222.0 & -2222.0 & -2222.0 \\
\hline 699-39-7A & 587816.0 & 135441.0 & 149.3 & -2222.0 & -1111.0 & 108.3 & -1111.0 & -1111.0 & -1111.0 & -1111.0 & -1111.0 & 104.0 \\
\hline 699-39-7B & 587805.7 & 135431.7 & 149.2 & -1111.0 & -1111.0 & 107.7 & -1111.0 & -1111.0 & -1111.0 & -1111.0 & -1111.0 & 105.9 \\
\hline 699-39-E2 & 590532.0 & 135451.0 & 124.3 & -1111.0 & 111.9 & -1111.0 & 98.0 & 86.0 & 77.2 & 74.2 & -1111.0 & 68.1 \\
\hline $699-40-0$ & 589891.9 & 135820.1 & 128.2 & -1111.0 & -2222.0 & 107.7 & 94.0 & 87.9 & 68.1 & 36.1 & -1111.0 & 33.0 \\
\hline $699-40-1$ & 589721.9 & 135665.5 & 133.7 & -1111.0 & -2222.0 & -1111.0 & 101.3 & 92.1 & 82.7 & 47.9 & -1111.0 & 38.5 \\
\hline $699-40-12 \mathrm{~B}$ & 586325.3 & 135637.2 & 157.1 & -1111.0 & 125.1 & 108.9 & 101.6 & 89.4 & 40.6 & 30.0 & -1111.0 & 16.2 \\
\hline $699-40-13$ & 585939.4 & 135649.9 & 154.7 & -1111.0 & 120.2 & 107.1 & 101.0 & 87.0 & 74.2 & 39.1 & -2222.0 & 7.1 \\
\hline $699-40-2$ & 589133.0 & 135805.7 & 140.6 & -1111.0 & -2222.0 & -1111.0 & 109.2 & 94.0 & 89.4 & 49.8 & -1111.0 & 33.3 \\
\hline $699-40-20$ & 583830.2 & 135678.1 & 145.2 & -1111.0 & 130.5 & 103.4 & -2222.0 & -2222.0 & -2222.0 & -2222.0 & -2222.0 & -0.5 \\
\hline 699-40-32 & 580007.9 & 135575.8 & 159.2 & -1111.0 & -1111.0 & -1111.0 & -1111.0 & -1111.0 & -1111.0 & 119.3 & 82.3 & 61.6 \\
\hline $699-40-33 \mathrm{~A}$ & 579680.9 & 135822.4 & 157.9 & -1111.0 & -1111.0 & -1111.0 & -1111.0 & -1111.0 & -1111.0 & 123.8 & 82.1 & 74.2 \\
\hline $699-40-33 \mathrm{C}$ & 579682.6 & 135827.0 & 158.4 & -1111.0 & -1111.0 & -1111.0 & -1111.0 & -1111.0 & -1111.0 & 125.0 & 95.7 & 73.2 \\
\hline 699-40-36 & 578789.2 & 135633.8 & 160.9 & -1111.0 & -1111.0 & -1111.0 & -1111.0 & -1111.0 & -1111.0 & 126.6 & 101.2 & 78.9 \\
\hline $699-40-39$ & 577938.0 & 135646.0 & 165.3 & -1111.0 & -1111.0 & -1111.0 & -1111.0 & -1111.0 & -1111.0 & 128.4 & 104.2 & -9999.0 \\
\hline 699-40-40A & 577680.1 & 135594.1 & 164.9 & -1111.0 & -1111.0 & -1111.0 & -1111.0 & -1111.0 & -1111.0 & 129.2 & 106.4 & -9999.0 \\
\hline $699-40-62$ & 571164.3 & 135764.4 & 228.0 & -1111.0 & -1111.0 & -111p.8qe & 132.3 & -1111.0 & -1111.0 & 114.0 & -9999.0 & -9999.0 \\
\hline
\end{tabular}




\begin{tabular}{|c|c|c|c|c|c|c|c|c|c|c|c|c|}
\hline & & & surf elev (top 1) & Top 2 & Top 3 & Top 4 & Top 5 & Top 6 & Top 7 & Top 8 & Top 9 & Top 10 \\
\hline Well number & EASTING & NORTHING & & & & & & & & & & (basalt) \\
\hline $699-40-80$ & 565517.3 & 135547.7 & 199.9 & 173.2 & 173.2 & -1111.0 & 154.6 & -1111.0 & -1111.0 & 66.5 & 51.0 & 33.9 \\
\hline $699-40-84$ & 564246.0 & 135751.3 & 194.5 & 174.1 & 169.6 & 167.1 & 161.6 & -1111.0 & -1111.0 & 72.9 & 50.7 & 13.2 \\
\hline $699-41-10$ & 586962.4 & 136133.8 & 152.0 & -1111.0 & -2222.0 & -2222.0 & -2222.0 & -2222.0 & -2222.0 & -2222.0 & -2222.0 & 69.6 \\
\hline 699-41-11 & 586650.2 & 136024.8 & 155.5 & -1111.0 & -2222.0 & 103.1 & 100.1 & 71.1 & -1111.0 & 58.9 & -1111.0 & 40.6 \\
\hline $699-41-20$ & 583876.4 & 136149.8 & 147.7 & -1111.0 & 118.3 & 97.0 & 100.0 & -2222.0 & -2222.0 & 31.5 & 7.1 & 6.2 \\
\hline 699-41-23 & 582921.9 & 135903.0 & 142.0 & -9999.0 & -9999.0 & -9999.0 & -9999.0 & -9999.0 & -9999.0 & -9999.0 & -9999.0 & -9999.0 \\
\hline 699-41-31 & 580525.6 & 136002.0 & 153.0 & -2222.0 & 130.2 & 113.5 & 101.3 & -9999.0 & -9999.0 & -9999.0 & -9999.0 & -9999.0 \\
\hline 699-41-35 & 579079.7 & 135947.4 & 158.5 & -1111.0 & -1111.0 & -1111.0 & -1111.0 & -1111.0 & -1111.0 & 128.0 & 106.1 & 83.5 \\
\hline $699-41-40$ & 577614.0 & 135996.0 & 166.5 & -1111.0 & -1111.0 & -1111.0 & -1111.0 & -1111.0 & -1111.0 & 129.2 & 116.1 & -9999.0 \\
\hline $699-41-42$ & 577122.0 & 136068.0 & 196.2 & -1111.0 & -1111.0 & -1111.0 & -1111.0 & -1111.0 & -1111.0 & 126.6 & 119.5 & 94.2 \\
\hline $699-42-10$ & 586950.9 & 136267.3 & 150.4 & -1111.0 & -2222.0 & 101.0 & -1111.0 & 99.5 & -1111.0 & -1111.0 & -1111.0 & 89.7 \\
\hline $699-42-12 A$ & 586331.2 & 136445.4 & 156.7 & -1111.0 & 143.0 & -1111.0 & 118.0 & 93.7 & 86.0 & 72.3 & -1111.0 & 57.7 \\
\hline $699-42-21$ & 583404.8 & 136195.6 & 140.6 & -1111.0 & 121.4 & -2222.0 & 105.5 & -2222.0 & -2222.0 & 27.2 & 22.6 & 1.3 \\
\hline $699-42-29$ & 581045.1 & 136427.0 & 138.3 & -1111.0 & 115.3 & 105.5 & 102.5 & 64.7 & 50.7 & 25.1 & 20.5 & 7.7 \\
\hline $699-42-3$ & 588908.6 & 136319.2 & 135.3 & -1111.0 & 108.9 & 101.3 & 86.0 & 78.4 & 65.3 & 19.0 & -1111.0 & 17.2 \\
\hline $699-42-30$ & 580786.0 & 136213.8 & 146.5 & -1111.0 & 124.7 & -1111.0 & 108.0 & -2222.0 & -2222.0 & 66.4 & 34.1 & 17.1 \\
\hline $699-42-37$ & 578476.8 & 136247.2 & 158.2 & -1111.0 & -1111.0 & -1111.0 & -1111.0 & -1111.0 & -1111.0 & 131.1 & 118.6 & 82.3 \\
\hline $699-42-39 A$ & 577857.1 & 136251.8 & 170.1 & -2222.0 & -2222.0 & -2222.0 & -1111.0 & -1111.0 & -1111.0 & 128.0 & 117.3 & -9999.0 \\
\hline 699-42-39B & 577859.0 & 136236.4 & 170.2 & -2222.0 & -2222.0 & -2222.0 & -1111.0 & -1111.0 & -1111.0 & 129.2 & 117.0 & -9999.0 \\
\hline $699-42-40 \mathrm{~A}$ & 577638.1 & 136421.8 & 166.4 & -1111.0 & -2222.0 & -1111.0 & -1111.0 & -1111.0 & -1111.0 & 127.8 & 123.2 & -9999.0 \\
\hline $699-42-40 \mathrm{C}$ & 577644.4 & 136417.9 & 166.4 & -1111.0 & -1111.0 & -1111.0 & -1111.0 & -1111.0 & -1111.0 & 127.8 & 123.8 & 100.4 \\
\hline $699-42-42 A$ & 577088.0 & 136290.1 & 189.0 & -1111.0 & -1111.0 & -1111.0 & -1111.0 & -1111.0 & -1111.0 & 126.3 & 120.7 & 91.4 \\
\hline 699-42-42B & 576998.1 & 136433.9 & 177.7 & -1111.0 & -1111.0 & -1111.0 & -1111.0 & -1111.0 & -1111.0 & 130.2 & 122.2 & -9999.0 \\
\hline 699-42-E9B & 592466.5 & 136265.2 & 116.9 & -1111.0 & -2222.0 & 90.6 & 81.5 & 73.8 & 70.8 & 61.7 & -1111.0 & 49.5 \\
\hline 699-43-104 & 558106.1 & 136543.7 & 233.5 & -1111.0 & -2222.0 & 197.9 & 188.8 & -1111.0 & -1111.0 & 141.8 & 124.7 & 118.0 \\
\hline 699-43-18 & 584394.1 & 136576.1 & 157.1 & -1111.0 & 128.1 & -2222.0 & 100.7 & -1111.0 & 51.0 & 33.0 & -9999.0 & 19.3 \\
\hline $699-43-2$ & 589431.3 & 136739.8 & 123.2 & -1111.0 & -2222.0 & 105.9 & -2222.0 & -2222.0 & -2222.0 & -2222.0 & -2222.0 & 22.3 \\
\hline $699-43-23$ & 582978.2 & 136713.8 & 158.1 & -1111.0 & 128.7 & -1111.0 & 102.8 & 60.1 & 57.1 & -1111.0 & -1111.0 & 15.9 \\
\hline 699-43-41E & 577479.0 & 136594.0 & 168.0 & -2222.0 & -1111.0 & -2222.0 & -1111.0 & -1111.0 & -1111.0 & 130.5 & -9999.0 & -9999.0 \\
\hline 699-43-41F & 577479.0 & 136579.0 & 168.0 & -2222.0 & -1111.0 & -2222.0 & -1111.0 & -1111.0 & -1111.0 & 130.8 & -9999.0 & -9999.0 \\
\hline 699-43-41G & 577466.4 & 136586.6 & 167.9 & -1111.0 & -2222.0 & -1111.0 & -1111.0 & -1111.0 & -1111.0 & 131.8 & 125.7 & -9999.0 \\
\hline 699-43-42 & 577146.0 & 136628.0 & 173.4 & -2222.0 & -1111.0 & -2222.0 & -1111.0 & -1111.0 & -1111.0 & 126.0 & 125.0 & 107.6 \\
\hline $699-43-42 \mathrm{~J}$ & 577006.0 & 136452.0 & 177.2 & -2222.0 & -1111.0 & -2222.0 & -1111.0 & -1111.0 & -1111.0 & 130.2 & -9999.0 & -9999.0 \\
\hline $699-43-42 \mathrm{~K}$ & 576997.2 & 136445.0 & 177.1 & -1111.0 & -2222.0 & -1111.0 & -1111.0 & -1111.0 & -1111.0 & 129.2 & 121.9 & 101.2 \\
\hline $699-43-43$ & 576728.5 & 136576.3 & 176.5 & -1111.0 & -1111.0 & -1111.0 & -1111.0 & -1111.0 & -1111.0 & -1111.0 & 123.7 & -9999.0 \\
\hline $699-43-8$ & 587596.5 & 136704.1 & 144.0 & -1111.0 & 114.4 & 110.1 & 105.2 & 78.1 & -1111.0 & -1111.0 & -1111.0 & 66.5 \\
\hline $699-43-84$ & 564184.5 & 136656.2 & 193.2 & 174.7 & 174.4 & 164.7 & 160.7 & -1111.0 & -1111.0 & 61.0 & 47.0 & 22.3 \\
\hline $699-43-89$ & 562917.3 & 136620.0 & 196.3 & 172.0 & 167.1 & 162.5 & 154.6 & -9999.0 & -9999.0 & -9999.0 & -9999.0 & -9999.0 \\
\hline 699-43-9 & 587245.5 & 136505.4 & 149.1 & -1111.0 & -1111.0 & -1111.0 & -1111.0 & -1111.0 & -1111.0 & -1111.0 & -1111.0 & 100.7 \\
\hline 699-44-16 & 584912.1 & 137002.4 & 135.7 & -1111.0 & -2222.0 & 95.5 & 94.0 & 77.2 & 74.2 & 34.5 & -1111.0 & 30.9 \\
\hline 699-44-39B & 577960.6 & 136727.4 & 156.4 & -2222.0 & -2222.0 & -2222.0 & -1111.0 & -2222.0 & -2222.0 & -1111.0 & 118.3 & 103.9 \\
\hline 699-44-42 & 577099.3 & 136833.6 & 176.5 & -1111.0 & -1111.0 & -1111.0 & -1111.0 & -1111.0 & -1111.0 & -1111.0 & 127.8 & -9999.0 \\
\hline 699-44-43B & 576673.0 & 136897.0 & 176.9 & -2222.0 & -1111.0 & -2222.0 & -1111.0 & -1111.0 & -1111.0 & -1111.0 & 129.3 & -9999.0 \\
\hline $699-44-64$ & 570458.0 & 136895.0 & 221.4 & -2222.0 & -1111.0 & -2222.0 & 139.6 & -1111.0 & -1111.0 & 111.3 & 104.5 & 87.2 \\
\hline $699-44-7$ & 587839.6 & 136982.2 & 132.4 & -1111.0 & -2222.0 & 105.9 & 76.9 & 73.8 & 47.9 & 31.2 & -1111.0 & 5.0 \\
\hline $699-45-24$ & 582552.3 & 137231.6 & 155.5 & -1111.0 & 130.5 & 107.7 & 106.2 & -1111.0 & -2222.0 & -1111.0 & -1111.0 & 27.5 \\
\hline $699-45-26$ & 582081.8 & 137280.0 & 158.0 & -1111.0 & 136.0 & 107.1 & 102.5 & -2222.0 & -2222.0 & -2222.0 & -2222.0 & 22.3 \\
\hline $699-45-42$ & 577057.0 & 137287.0 & 176.3 & -2222.0 & -1111.0 & -1111.0 & -1111.0 & -1111.0 & -1111.0 & -1111.0 & 123.5 & 118.3 \\
\hline $699-45-78$ & 566027.0 & 137045.0 & 209.5 & -2222.0 & 183.3 & 174.1 & -2222.0 & -2222.0 & -2222.0 & -2222.0 & -2222.0 & -2222.0 \\
\hline 699-46-15 & 585429.8 & 137428.3 & 135.0 & -1111.0 & -1111.0 & -1111.0 & -1111.0 & -1111.0 & -1111.0 & -1111.0 & -1111.0 & 126.9 \\
\hline 699-46-21B & 583604.1 & 137556.9 & 159.1 & -1111.0 & -2222.0 & 136-مar & 122.3 & 79.3 & 62.6 & -9999.0 & -9999.0 & -9999.0 \\
\hline
\end{tabular}




\begin{tabular}{|c|c|c|c|c|c|c|c|c|c|c|c|c|}
\hline & & & surf elev (top 1) & Top 2 & Top 3 & Top 4 & Top 5 & Top 6 & Top 7 & Top 8 & Top 9 & Top 10 \\
\hline Well number & EASTING & NORTHING & & & & & & & & & & (basalt) \\
\hline 699-46-21C & 583480.3 & 137640.3 & 158.5 & -1111.0 & -2222.0 & 136.9 & 123.5 & -9999.0 & -9999.0 & -9999.0 & -9999.0 & -9999.0 \\
\hline $699-46-3$ & 588822.7 & 137688.4 & 115.7 & -1111.0 & -1111.0 & 103.1 & 91.2 & 75.7 & 72.6 & -2222.0 & -2222.0 & 24.8 \\
\hline $699-46-31$ & 580570.6 & 137585.8 & 145.2 & -1111.0 & -2222.0 & -1111.0 & -1111.0 & -1111.0 & -1111.0 & 74.4 & 46.9 & 28.7 \\
\hline $699-46-32$ & 580265.5 & 137574.7 & 143.3 & -1111.0 & -2222.0 & -1111.0 & -1111.0 & -1111.0 & -1111.0 & 118.6 & 90.5 & 83.2 \\
\hline $699-46-33$ & 579960.5 & 137564.1 & 142.8 & -1111.0 & -2222.0 & -1111.0 & -1111.0 & -1111.0 & -1111.0 & -1111.0 & 136.6 & 125.6 \\
\hline $699-46-5$ & 588470.4 & 137484.9 & 116.3 & -1111.0 & -2222.0 & 105.2 & 83.9 & 73.5 & 61.4 & 32.1 & -1111.0 & 18.1 \\
\hline $699-46-85 B$ & 564038.4 & 137389.0 & 241.4 & -1111.0 & 177.8 & 173.8 & 158.6 & -1111.0 & -1111.0 & 69.3 & 57.1 & 26.9 \\
\hline $699-47-24$ & 582598.4 & 137703.6 & 157.7 & -1111.0 & 141.8 & -1111.0 & 108.3 & 55.1 & -1111.0 & -1111.0 & -1111.0 & 35.0 \\
\hline 699-47-35A & 579312.5 & 137780.1 & 145.2 & -1111.0 & -1111.0 & -1111.0 & -1111.0 & -1111.0 & -1111.0 & -1111.0 & 134.2 & 115.0 \\
\hline $699-47-35 \mathrm{~B}$ & 579313.0 & 137793.0 & 145.3 & -2222.0 & -1111.0 & -1111.0 & -1111.0 & -1111.0 & -1111.0 & -1111.0 & 135.4 & 114.9 \\
\hline $699-47-42$ & 577156.3 & 137907.0 & 142.4 & -2222.0 & -1111.0 & -2222.0 & 126.8 & -1111.0 & -1111.0 & -1111.0 & 123.4 & 121.0 \\
\hline $699-47-60$ & 571474.4 & 137968.7 & 198.1 & -1111.0 & -1111.0 & -1111.0 & -1111.0 & -1111.0 & -1111.0 & -1111.0 & 130.2 & 112.2 \\
\hline $699-47-92$ & 561959.3 & 137899.2 & 246.0 & -1111.0 & 193.6 & 192.1 & 168.3 & -1111.0 & -1111.0 & 78.4 & 51.3 & 21.4 \\
\hline $699-48-18$ & 584426.5 & 138726.3 & 129.2 & -1111.0 & -2222.0 & 107.1 & -9999.0 & -9999.0 & -9999.0 & -9999.0 & -9999.0 & -9999.0 \\
\hline $699-48-22$ & 583116.0 & 138129.4 & 157.3 & -1111.0 & 122.0 & -1111.0 & 109.8 & -1111.0 & -1111.0 & 65.0 & -1111.0 & 44.3 \\
\hline $699-48-27$ & 581721.9 & 138265.3 & 160.1 & -1111.0 & -2222.0 & 107.7 & 106.2 & 57.7 & -2222.0 & -2222.0 & -1111.0 & 40.0 \\
\hline $699-48-71$ & 568351.0 & 138045.0 & 209.9 & -2222.0 & -1111.0 & -1111.0 & 158.6 & -2222.0 & -2222.0 & -2222.0 & -2222.0 & -2222.0 \\
\hline 699-48-77A & 566415.0 & 137965.0 & 205.9 & -2222.0 & 199.1 & 186.0 & -2222.0 & -9999.0 & -9999.0 & -9999.0 & -9999.0 & -9999.0 \\
\hline $699-48-77 \mathrm{C}$ & 566469.0 & 138086.8 & 205.4 & -1111.0 & 202.5 & 186.6 & 181.1 & -1111.0 & -1111.0 & -1111.0 & 118.0 & 69.0 \\
\hline 699-48-77D & 566433.3 & 138119.3 & 204.5 & -1111.0 & 203.7 & 187.5 & 180.2 & -9999.0 & -9999.0 & -9999.0 & -9999.0 & -9999.0 \\
\hline $699-49-100 \mathrm{C}$ & 559303.7 & 138503.2 & 241.7 & -1111.0 & 180.8 & -1111.0 & 173.2 & -1111.0 & -1111.0 & -1111.0 & -1111.0 & 117.7 \\
\hline $699-49-13 A$ & 586062.4 & 138407.0 & 125.0 & -1111.0 & -2222.0 & 99.1 & -9999.0 & -9999.0 & -9999.0 & -9999.0 & -9999.0 & -9999.0 \\
\hline $699-49-13 B$ & 586043.3 & 138383.1 & 125.3 & -1111.0 & $\frac{-22222.0}{-222.0}$ & 103.1 & -9999.0 & -9999.0 & -9999.0 & -9999.0 & -9999.0 & -9999.0 \\
\hline $699-49-13 C$ & 586024.5 & 138359.3 & 125.9 & -1111.0 & -2222.0 & 107.7 & -9999.0 & -9999.0 & -9999.0 & -9999.0 & -9999.0 & -9999.0 \\
\hline 699-49-13E & 586042.8 & 138386.5 & 126.8 & -1111.0 & -2222.0 & 104.6 & -9999.0 & -9999.0 & -9999.0 & -9999.0 & -9999.0 & -9999.0 \\
\hline $699-49-21$ & 583634.0 & 138555.7 & 150.4 & -1111.0 & -1111.0 & -1111.0 & -1111.0 & -1111.0 & -1111.0 & -1111.0 & -1111.0 & 118.7 \\
\hline 699-49-31 & 580539.2 & 138316.5 & 159.6 & -2222.0 & -1111.0 & -1111.0 & -1111.0 & 55.6 & 45.7 & -9999.0 & -9999.0 & 41.1 \\
\hline 699-49-32B & 580175.4 & 138299.2 & 156.4 & -2222.0 & -1111.0 & -1111.0 & -1111.0 & -1111.0 & -1111.0 & 135.3 & 110.6 & 104.5 \\
\hline $699-49-33$ & 579776.9 & 138286.8 & 152.9 & -1111.0 & -1111.0 & -1111.0 & -1111.0 & -1111.0 & -1111.0 & -1111.0 & 134.4 & 130.8 \\
\hline 699-49-57B & 572536.5 & 138381.0 & 169.6 & -2222.0 & -2222.0 & -1111.0 & -1111.0 & -1111.0 & -1111.0 & -1111.0 & $\frac{1111 .}{-111.0}$ & 119.5 \\
\hline $699-49-79$ & 565771.1 & 138271.1 & 210.0 & -1111.0 & 188.1 & 183.6 & 180.5 & -9999.0 & -9999.0 & -9999.0 & -9999.0 & -9999.0 \\
\hline $699-50-30$ & 580792.0 & 138827.0 & 161.4 & -2222.0 & -1111.0 & -1111.0 & 135.1 & 119.0 & 111.0 & 65.7 & 50.0 & 48.9 \\
\hline $699-50-42$ & 577112.0 & 138791.0 & 142.5 & -2222.0 & -1111.0 & -1111.0 & -1111.0 & -1111.0 & -1111.0 & -1111.0 & 130.8 & 122.5 \\
\hline $699-50-85$ & 564130.2 & 138669.3 & 225.2 & -1111.0 & 198.2 & 189.7 & 161.6 & -1111.0 & -1111.0 & 82.4 & 64.7 & 46.4 \\
\hline 699-50-96 & 560496.9 & 138598.9 & 243.8 & -1111.0 & -2222.0 & -1111.0 & 172.9 & -1111.0 & -1111.0 & 73.5 & 53.1 & 26.0 \\
\hline 699-50-99 & 559790.2 & 138597.6 & 241.7 & -1111.0 & -2222.0 & -1111.0 & 171.7 & -1111.0 & -1111.0 & 102.8 & 102.2 & 99.1 \\
\hline $699-51-19$ & 584151.5 & 138981.1 & 129.2 & -1111.0 & -2222.0 & 110.4 & -1111.0 & -1111.0 & -1111.0 & -1111.0 & $\frac{10<.2}{-1111.0}$ & 105.5 \\
\hline $699-51-75$ & 566978.1 & 138906.3 & 195.5 & -1111.0 & -1111.0 & -1111.0 & 131.8 & -1111.0 & -1111.0 & -1111.0 & -1111.0 & 82.4 \\
\hline 699-52-17 & 584669.1 & 139407.2 & 121.5 & -1111.0 & -2222.0 & 93.7 & 87.6 & 78.4 & 72.3 & 29.7 & -1111.0 & 15.9 \\
\hline $699-52-54$ & 573254.2 & 139193.2 & 173.1 & -1111.0 & -2222.0 & -1111.0 & -1111.0 & -1111.0 & -1111.0 & -1111.0 & -1111.0 & 123.2 \\
\hline $699-52-57$ & 572761.3 & 139115.3 & 171.3 & -9999.0 & -9999.0 & -9999.0 & -9999.0 & -9999.0 & -9999.0 & -9999.0 & -9999.0 & -9999.0 \\
\hline 699-53-55A & 573115.9 & 139631.9 & 175.9 & -1111.0 & -1111.0 & -1111.0 & -1111.0 & -1111.0 & -1111.0 & -1111.0 & -1111.0 & 86.3 \\
\hline 699-54-15A & 585187.1 & 139833.1 & 123.2 & -1111.0 & -1111.0 & -1111.0 & 94.0 & -2222.0 & -2222.0 & 34.2 & -1111.0 & 21.7 \\
\hline 699-54-18C & 584471.5 & 139998.6 & 122.6 & -1111.0 & -2222.0 & 90.6 & 83.0 & 62.6 & 41.8 & 32.1 & 19.0 & 16.8 \\
\hline $699-54-45 A$ & 576316.0 & 140007.0 & 150.8 & -2222.0 & -1111.0 & -1111.0 & 119.9 & -2222.0 & -2222.0 & -2222.0 & -2222.0 & -2222.0 \\
\hline $699-54-48$ & 575356.0 & 139822.0 & 139.6 & -2222.0 & -1111.0 & -1111.0 & 120.2 & -2222.0 & -2222.0 & -2222.0 & -2222.0 & -2222.0 \\
\hline $699-55-44$ & 576569.0 & 140391.0 & 158.7 & -2222.0 & -1111.0 & -1111.0 & 128.4 & -2222.0 & -2222.0 & -2222.0 & -2222.0 & -2222.0 \\
\hline 699-55-50A & 574642.3 & 140245.0 & 135.0 & -1111.0 & -1111.0 & -1111.0 & -1111.0 & -1111.0 & -1111.0 & -1111.0 & 111.6 & 105.5 \\
\hline 699-55-50B & 574641.7 & 140215.3 & 135.0 & -1111.0 & -2222.0 & -1111.0 & -1111.0 & -1111.0 & -1111.0 & -1111.0 & 113.2 & 107.7 \\
\hline 699-55-60A & 571563.0 & 140267.4 & 174.7 & -9999.0 & -2222.0 & -9999.0 & -9999.0 & -9999.0 & -9999.0 & -9999.0 & $\begin{array}{l}110.2 \\
-9999.0\end{array}$ & -9999.0 \\
\hline $699-55-70$ & 568560.0 & 140328.0 & 173.6 & -2222.0 & -1111.0 & -2228.90 & 158.9 & -2222.0 & -2222.0 & -2222.0 & -2222.0 & -2222.0 \\
\hline
\end{tabular}




\begin{tabular}{|c|c|c|c|c|c|c|c|c|c|c|c|c|}
\hline & & & surf elev (top 1) & Top 2 & Top 3 & Top 4 & Top 5 & Top 6 & Top 7 & Top 8 & Top 9 & Top 10 \\
\hline Well number & EASTING & NORTHING & & & & & & & & & & (basalt) \\
\hline 699-55-76 & 566723.4 & 140225.8 & 177.7 & -1111.0 & -1111.0 & -1111.0 & 142.1 & -1111.0 & -1111.0 & -1111.0 & -1111.0 & 110.7 \\
\hline $699-55-89$ & 562886.6 & 140199.5 & 188.1 & -1111.0 & 152.5 & -1111.0 & 150.4 & -9999.0 & -9999.0 & -9999.0 & -9999.0 & -9999.0 \\
\hline 699-55-95 & 560944.7 & 140231.1 & 236.8 & -1111.0 & 203.7 & -1111.0 & 196.1 & -1111.0 & -1111.0 & 117.4 & 100.7 & 81.8 \\
\hline 699-56-26A & 582038.4 & 140508.3 & 124.7 & -1111.0 & -2222.0 & -1111.0 & -1111.0 & -1111.0 & -1111.0 & -1111.0 & -1111.0 & 124.7 \\
\hline $699-56-53$ & 573794.2 & 140650.7 & 132.3 & -1111.0 & -1111.0 & -1111.0 & -1111.0 & -1111.0 & -1111.0 & -1111.0 & -1111.0 & 102.8 \\
\hline 699-57-83A & 564582.8 & 140825.1 & 176.2 & -1111.0 & -1111.0 & -1111.0 & 164.7 & -1111.0 & -1111.0 & 115.3 & 94.9 & 72.6 \\
\hline $699-58-40$ & 577542.2 & 141095.7 & 226.2 & -1111.0 & -2222.0 & -1111.0 & -1111.0 & -1111.0 & -1111.0 & -1111.0 & -1111.0 & 227.2 \\
\hline $699-58-41 \mathrm{~A}$ & 577531.1 & 141153.3 & 215.2 & -1111.0 & -2222.0 & -1111.0 & -1111.0 & -1111.0 & -1111.0 & -1111.0 & -1111.0 & 216.2 \\
\hline 699-59-80B & 565637.0 & 141574.0 & 178.0 & -2222.0 & -1111.0 & -1111.0 & 154.9 & -2222.0 & -2222.0 & -2222.0 & -2222.0 & -2222.0 \\
\hline 699-60-32 & 580115.1 & 141902.0 & 129.5 & -1111.0 & -2222.0 & -1111.0 & -1111.0 & 110.7 & -1111.0 & -1111.0 & -1111.0 & 106.5 \\
\hline $699-60-57$ & 572623.5 & 141870.3 & 143.1 & -1111.0 & -1111.0 & -1111.0 & -1111.0 & -1111.0 & -1111.0 & -1111.0 & -1111.0 & 100.1 \\
\hline 699-61-16A & 585100.9 & 142243.1 & 125.6 & -1111.0 & -2222.0 & 126.6 & -1111.0 & 109.2 & 64.1 & 55.6 & -1111.0 & 34.2 \\
\hline 699-61-55A & 573011.0 & 141983.8 & 140.7 & -1111.0 & -2222.0 & -1111.0 & -1111.0 & -1111.0 & -1111.0 & 139.1 & -1111.0 & 138.2 \\
\hline 699-61-62 & 570914.9 & 141921.7 & 151.5 & -1111.0 & -1111.0 & -1111.0 & -1111.0 & -1111.0 & -1111.0 & -1111.0 & -1111.0 & 98.5 \\
\hline 699-61-66 & 569787.6 & 142008.0 & 159.1 & -1111.0 & -1111.0 & -1111.0 & 111.3 & -1111.0 & -1111.0 & -1111.0 & -1111.0 & 94.3 \\
\hline $699-62-43 \mathrm{C}$ & 576869.4 & 142486.5 & 130.8 & -1111.0 & -2222.0 & -1111.0 & -1111.0 & 111.3 & -9999.0 & -9999.0 & -9999.0 & -9999.0 \\
\hline $699-62-43 F$ & 576858.1 & 142481.1 & 129.0 & -1111.0 & -2222.0 & -1111.0 & -1111.0 & 108.6 & -9999.0 & -9999.0 & -9999.0 & -9999.0 \\
\hline $699-6-2 A$ & 589311.7 & 125194.4 & 141.6 & -1111.0 & -1111.0 & -1111.0 & 119.3 & 57.4 & 36.7 & 21.4 & -9.7 & -22.8 \\
\hline 699-63-25A & 582315.5 & 142798.0 & 120.4 & -1111.0 & -2222.0 & -1111.0 & 102.5 & 97.3 & -9999.0 & -9999.0 & -9999.0 & -9999.0 \\
\hline 699-63-55 & 573094.4 & 142562.3 & 130.1 & -1111.0 & -1111.0 & -1111.0 & -1111.0 & 106.2 & 104.3 & -1111.0 & -1111.0 & 97.0 \\
\hline 699-63-58 & 572262.7 & 142583.1 & 149.9 & -1111.0 & -2222.0 & -1111.0 & 117.4 & -1111.0 & -1111.0 & -1111.0 & -1111.0 & 114.4 \\
\hline 699-63-89 & 562901.0 & 142577.1 & 156.2 & -1111.0 & -2222.0 & -1111.0 & 123.5 & -1111.0 & -1111.0 & -1111.0 & -1111.0 & 102.8 \\
\hline 699-63-90 & 562367.2 & 142612.4 & 155.4 & -1111.0 & -1111.0 & -1111.0 & 120.8 & -1111.0 & -1111.0 & -1111.0 & -1111.0 & 83.9 \\
\hline 699-63-92 & 561559.7 & 142637.4 & 151.5 & -1111.0 & -2222.0 & -1111.0 & -1111.0 & -1111.0 & -1111.0 & -1111.0 & -1111.0 & 105.9 \\
\hline 699-63-95 & 560914.6 & 142650.8 & 147.5 & -1111.0 & -1111.0 & -1111.0 & -1111.0 & -1111.0 & -1111.0 & -1111.0 & -1111.0 & 125.7 \\
\hline 699-64-27 & 581375.5 & 142946.1 & 126.2 & -1111.0 & -2222.0 & -1111.0 & 104.3 & -9999.0 & -9999.0 & -9999.0 & -9999.0 & -9999.0 \\
\hline 699-64-62 & 571055.8 & 142913.9 & 152.4 & -9999.0 & -9999.0 & -9999.0 & -9999.0 & -9999.0 & -9999.0 & -9999.0 & -9999.0 & -9999.0 \\
\hline $699-65-50$ & 574590.8 & 143187.9 & 142.3 & -1111.0 & -1111.0 & -1111.0 & 112.6 & 111.9 & 41.2 & -0.8 & -1111.0 & -32.8 \\
\hline $699-65-83$ & 564590.5 & 143249.1 & 147.8 & -1111.0 & -2222.0 & -1111.0 & 122.3 & -2222.0 & -2222.0 & -2222.0 & -2222.0 & -2222.0 \\
\hline 699-65-95 & 560815.4 & 143192.9 & 137.8 & -1111.0 & -1111.0 & -1111.0 & 133.0 & -1111.0 & -1111.0 & -1111.0 & -1111.0 & 121.7 \\
\hline $699-66-23$ & 582864.8 & 143617.2 & 118.6 & -1111.0 & -2222.0 & -1111.0 & -1111.0 & 107.4 & -9999.0 & -9999.0 & -9999.0 & -9999.0 \\
\hline 699-66-38 & 578294.0 & 143607.7 & 132.9 & -1111.0 & -2222.0 & -1111.0 & 126.0 & 115.3 & -9999.0 & -9999.0 & -9999.0 & -9999.0 \\
\hline 699-66-91 & 562174.8 & 143476.8 & 142.3 & -1111.0 & -1111.0 & -1111.0 & 126.6 & -2222.0 & -2222.0 & -2222.0 & -2222.0 & 113.8 \\
\hline $699-67-51$ & 574178.9 & 143933.2 & 159.7 & -1111.0 & -1111.0 & -1111.0 & 113.5 & 115.0 & -9999.0 & -9999.0 & -9999.0 & -9999.0 \\
\hline $699-67-86$ & 563661.6 & 143873.0 & 143.9 & -1111.0 & -2222.0 & -1111.0 & 108.3 & -2222.0 & -2222.0 & -2222.0 & -2222.0 & -2222.0 \\
\hline 699-67-98 & 559944.0 & 143714.7 & 139.0 & -2222.0 & -2222.0 & -1111.0 & 120.9 & 99.8 & -1111.0 & -1111.0 & 94.7 & 82.8 \\
\hline 699-69-45 & 576157.4 & 144556.3 & 148.1 & -1111.0 & -1111.0 & -1111.0 & 121.4 & 108.6 & -9999.0 & -9999.0 & -9999.0 & -9999.0 \\
\hline 699-70-17 & 584591.6 & 144960.5 & 269.4 & -1111.0 & -2222.0 & 270.4 & -1111.0 & -1111.0 & 92.4 & 57.4 & -1111.0 & 37.0 \\
\hline 699-71-30 & 580603.3 & 145226.9 & 121.9 & -1111.0 & -1111.0 & -1111.0 & 113.5 & 111.4 & 81.5 & -9999.0 & -9999.0 & -9999.0 \\
\hline 699-71-52 & 573907.9 & 145214.8 & 159.4 & -1111.0 & -1111.0 & -1111.0 & 122.3 & 113.8 & -9999.0 & -9999.0 & -9999.0 & -9999.0 \\
\hline 699-71-77 & 566402.0 & 145098.6 & 143.9 & -1111.0 & -1111.0 & -1111.0 & 112.9 & 90.9 & 56.2 & -9999.0 & -9999.0 & -9999.0 \\
\hline $699-72-73$ & 567551.5 & 145418.8 & 146.9 & -1111.0 & -1111.0 & -1111.0 & 122.3 & 97.0 & -9999.0 & -9999.0 & -9999.0 & -9999.0 \\
\hline 699-72-92 & 561839.4 & 145359.8 & 137.8 & -1111.0 & -1111.0 & -1111.0 & 92.4 & -9999.0 & -9999.0 & -9999.0 & -9999.0 & -9999.0 \\
\hline 699-73-61 & 571420.8 & 145781.5 & 161.8 & -1111.0 & -2222.0 & -1111.0 & 118.7 & -9999.0 & -9999.0 & -9999.0 & -9999.0 & -9999.0 \\
\hline 699-74-44 & 576393.1 & 146098.8 & 135.6 & -1111.0 & -2222.0 & -1111.0 & -1111.0 & 113.8 & -9999.0 & -9999.0 & -9999.0 & -9999.0 \\
\hline 699-74-48 & 575237.0 & 146307.0 & 148.6 & -2222.0 & -1111.0 & -1111.0 & 129.0 & 111.2 & -9999.0 & -9999.0 & -9999.0 & -9999.0 \\
\hline 699-77-36 & 578847.2 & 146868.9 & 125.6 & -1111.0 & -1111.0 & -1111.0 & -1111.0 & 112.9 & -9999.0 & -9999.0 & -9999.0 & -9999.0 \\
\hline $699-77-54$ & 573386.0 & 146854.8 & 146.5 & -1111.0 & -1111.0 & -1111.0 & 119.9 & 101.0 & -9999.0 & -9999.0 & -9999.0 & -9999.0 \\
\hline 699-80-43P & 576703.9 & 147729.9 & 126.2 & -1111.0 & -1111.0 & -1111.0 & -1111.0 & 113.2 & 82.7 & 40.0 & 18.7 & -6.9 \\
\hline 699-81-58 & 572185.0 & 148173.0 & 134.0 & -2222.0 & -1111.0 & -1111.0 & 115.0 & 105.5 & 89.7 & -9999.0 & -9999.0 & -9999.0 \\
\hline 699-81-62 & 570943.0 & 148103.1 & 134.4 & -1111.0 & -1111.0 & -111p.gor & 124.7 & 104.0 & 27.5 & 13.2 & -21.3 & -25.5 \\
\hline
\end{tabular}




\begin{tabular}{|c|c|c|c|c|c|c|c|c|c|c|c|c|}
\hline & & & surf elev (top 1) & Top 2 & Top 3 & Top 4 & Top 5 & Top 6 & Top 7 & Top 8 & Top 9 & Top 10 \\
\hline Well number & EASTING & NORTHING & & & & & & & & & & (basalt) \\
\hline $699-8-17$ & 584675.0 & 126017.9 & 159.2 & -1111.0 & 128.4 & 102.5 & -9999.0 & -9999.0 & -9999.0 & -9999.0 & -9999.0 & -9999.0 \\
\hline $699-8-25$ & 582299.0 & 125935.6 & 155.1 & -1111.0 & -1111.0 & -1111.0 & 115.7 & -9999.0 & -9999.0 & -9999.0 & -9999.0 & -9999.0 \\
\hline 699-8-32 & 580385.0 & 125978.7 & 168.9 & -1111.0 & -2222.0 & -1111.0 & 117.4 & -9999.0 & -9999.0 & -9999.0 & -9999.0 & -9999.0 \\
\hline $699-83-47$ & 575492.0 & 148705.2 & 132.6 & -1111.0 & -1111.0 & -1111.0 & -1111.0 & 109.2 & -9999.0 & -9999.0 & -9999.0 & -9999.0 \\
\hline 699-84-35A & 579193.1 & 149093.7 & 121.9 & -1111.0 & -1111.0 & -1111.0 & -1111.0 & 112.3 & 92.4 & 34.5 & -1111.0 & 12.9 \\
\hline $699-84-59$ & 571758.0 & 149179.8 & 140.2 & -1111.0 & -1111.0 & -1111.0 & 123.2 & 108.3 & 38.2 & 18.7 & -15.8 & -18.5 \\
\hline 699-84-62A & 570868.5 & 149074.4 & 137.5 & -1111.0 & -1111.0 & -1111.0 & 123.2 & 105.5 & -2222.0 & 4.4 & -17.9 & -19.4 \\
\hline $699-86-60$ & 571624.6 & 149601.1 & 138.1 & -1111.0 & -1111.0 & -1111.0 & 126.0 & 109.8 & 51.9 & 41.5 & -8.8 & -19.4 \\
\hline $699-86-64$ & 570334.0 & 149615.9 & 123.1 & -1111.0 & -1111.0 & -1111.0 & 93.7 & 106.5 & 41.8 & 33.9 & -13.6 & -15.2 \\
\hline $699-87-55$ & 572969.8 & 149904.0 & 139.8 & -1111.0 & -1111.0 & -1111.0 & 128.4 & -9999.0 & -9999.0 & -9999.0 & -9999.0 & -9999.0 \\
\hline 699-89-35 & 579121.0 & 150543.0 & 121.4 & -2222.0 & -1111.0 & -1111.0 & -1111.0 & 105.2 & -9999.0 & -9999.0 & -9999.0 & -9999.0 \\
\hline 699-92-14 & 585599.3 & 151643.2 & 262.7 & -1111.0 & -2222.0 & 262.8 & -1111.0 & 201.3 & 89.1 & -1111.0 & -1111.0 & 84.2 \\
\hline 699-93-48A & 575094.1 & 151795.3 & 133.2 & -1111.0 & -2222.0 & -1111.0 & -1111.0 & 112.9 & -9999.0 & -9999.0 & -9999.0 & -9999.0 \\
\hline $699-96-43$ & 576761.5 & 152605.3 & 128.3 & -1111.0 & -1111.0 & -1111.0 & -1111.0 & 115.9 & -9999.0 & -9999.0 & -9999.0 & -9999.0 \\
\hline 699-96-49 & 574851.3 & 152858.1 & 127.7 & -1111.0 & -1111.0 & -1111.0 & -1111.0 & 110.4 & -9999.0 & -9999.0 & -9999.0 & -9999.0 \\
\hline $699-97-43$ & 576671.9 & 153090.3 & 128.3 & -1111.0 & -1111.0 & -1111.0 & -1111.0 & 115.6 & -9999.0 & -9999.0 & -9999.0 & -9999.0 \\
\hline 699-9-E2 & 590618.6 & 126132.2 & 127.9 & -1111.0 & -1111.0 & -1111.0 & 114.7 & 70.5 & 44.6 & 32.4 & 3.4 & -0.2 \\
\hline 699-9-E5A & 591479.5 & 126312.2 & 138.4 & -1111.0 & -1111.0 & -1111.0 & 108.9 & -2222.0 & 77.2 & 14.4 & 3.7 & -5.7 \\
\hline 699-LANDFILL & 588935.1 & 112939.2 & 146.9 & -1111.0 & -2222.0 & -1111.0 & 121.7 & -1111.0 & -1111.0 & 86.3 & -1111.0 & 72.3 \\
\hline 699-ORV-1 & 588018.4 & 113866.6 & 143.9 & -1111.0 & -2222.0 & -1111.0 & 122.0 & -1111.0 & -1111.0 & 96.7 & -1111.0 & 83.9 \\
\hline 699-ORV-2 & 588735.5 & 114089.5 & 138.7 & -1111.0 & -2222.0 & -1111.0 & 121.4 & -1111.0 & -1111.0 & 90.9 & -1111.0 & 78.7 \\
\hline 699-S11-E12A & 593576.4 & 120173.5 & 111.3 & -1111.0 & -1111.0 & -1111.0 & 95.8 & 77.2 & 68.1 & 58.9 & -1111.0 & 48.2 \\
\hline 699-S11-E12B & 593602.6 & 120187.4 & 111.3 & -1111.0 & -2222.0 & -1111.0 & 95.5 & 78.7 & 68.1 & 58.9 & -1111.0 & 46.7 \\
\hline 699-S12-29 & 580739.6 & 119809.6 & 148.4 & -1111.0 & -2222.0 & -1111.0 & -1111.0 & -1111.0 & -1111.0 & 111.6 & -1111.0 & 94.9 \\
\hline 699-S12-3 & 589286.1 & 119631.8 & 132.7 & -1111.0 & -1111.0 & -1111.0 & 119.9 & 100.7 & -9999.0 & -9999.0 & -9999.0 & -9999.0 \\
\hline 699-S14-20A & 583920.0 & 119087.0 & 150.5 & -2222.0 & -1111.0 & -1111.0 & 120.5 & -2222.0 & -2222.0 & -2222.0 & -2222.0 & -2222.0 \\
\hline 699-S18-E2A & 590573.5 & 117895.2 & 132.6 & -1111.0 & -1111.0 & -1111.0 & 109.8 & -1111.0 & -1111.0 & 71.1 & -1111.0 & 58.0 \\
\hline 699-S19-11 & 586583.0 & 117799.0 & 147.5 & -2222.0 & -1111.0 & -1111.0 & 119.6 & -2222.0 & -2222.0 & -2222.0 & -2222.0 & -2222.0 \\
\hline 699-S19-E13 & 593835.0 & 117605.0 & 120.3 & -2222.0 & -1111.0 & -1111.0 & 97.3 & -2222.0 & -2222.0 & -2222.0 & -2222.0 & -2222.0 \\
\hline 699-S22-E9C & 592689.0 & 116752.6 & 113.1 & -1111.0 & -1111.0 & -1111.0 & 106.5 & 100.4 & 79.0 & 68.7 & 66.0 & 62.3 \\
\hline 699-S2-34B & 580454.3 & 122885.8 & 164.6 & -1111.0 & -2222.0 & -1111.0 & 127.5 & -1111.0 & -1111.0 & 84.8 & 66.5 & 60.4 \\
\hline 699-S24-19 & 584069.0 & 116258.9 & 130.1 & -1111.0 & -1111.0 & -1111.0 & 123.8 & -1111.0 & -1111.0 & 117.7 & -1111.0 & 117.4 \\
\hline 699-S27-E14 & 594114.1 & 115212.7 & 121.8 & -1111.0 & -2222.0 & -1111.0 & 103.7 & 97.9 & 83.3 & 72.6 & -9999.0 & -9999.0 \\
\hline 699-S27-E9C & 592720.9 & 115324.8 & 118.3 & -1111.0 & -1111.0 & -1111.0 & 110.1 & 96.7 & 79.3 & 66.8 & -1111.0 & 60.1 \\
\hline 699-S28-E0 & 590005.3 & 114963.2 & 136.7 & -1111.0 & -2222.0 & -1111.0 & 104.0 & -1111.0 & -1111.0 & 80.6 & -1111.0 & 69.7 \\
\hline 699-S29-E12 & 593626.0 & 114569.0 & 118.3 & -2222.0 & -1111.0 & -1111.0 & 104.3 & -2222.0 & -2222.0 & -2222.0 & -2222.0 & -2222.0 \\
\hline 699-S29-E16C & 594742.4 & 114730.5 & 114.9 & -1111.0 & -1111.0 & -1111.0 & 98.2 & -1111.0 & -1111.0 & 80.8 & 66.4 & 62.6 \\
\hline 699-S30-E15A & 594470.9 & 114308.4 & 122.0 & -1111.0 & -2222.0 & -1111.0 & 102.2 & -9999.0 & -9999.0 & -9999.0 & -9999.0 & -9999.0 \\
\hline 699-S30-E15C & 594366.0 & 114269.0 & 121.9 & -2222.0 & -1111.0 & -1111.0 & 101.9 & -2222.0 & -2222.0 & -2222.0 & -2222.0 & -2222.0 \\
\hline 699-S31-1 & 589749.3 & 114213.3 & 139.6 & -1111.0 & -1111.0 & -1111.0 & 119.0 & -1111.0 & -1111.0 & 84.2 & -1111.0 & 73.2 \\
\hline 699-S3-25 & 582460.3 & 122586.1 & 159.7 & -1111.0 & -1111.0 & -1111.0 & 119.6 & -9999.0 & -9999.0 & -9999.0 & -9999.0 & -9999.0 \\
\hline 699-S3-E12 & 593586.2 & 122551.4 & 121.0 & -1111.0 & -1111.0 & -1111.0 & 108.9 & 77.8 & 71.4 & 59.5 & -1111.0 & 46.1 \\
\hline 699-S4-E16 & 594988.3 & 122405.2 & 105.2 & -1111.0 & -1111.0 & -1111.0 & 97.9 & 84.2 & 75.4 & 58.3 & -1111.0 & 50.4 \\
\hline 699-S51-2 & 589201.7 & 108013.4 & 117.7 & -1111.0 & -2222.0 & -1111.0 & -1111.0 & 101.0 & 91.2 & 87.3 & -1111.0 & 65.9 \\
\hline 699-S6-E14A & 594262.4 & 121569.4 & 114.6 & -1111.0 & -1111.0 & -1111.0 & 105.2 & 62.0 & -1111.0 & 58.3 & -1111.0 & 56.2 \\
\hline 699-S6-E4C & 591055.7 & 121668.5 & 132.0 & -1111.0 & -1111.0 & -1111.0 & 115.6 & 70.5 & 49.2 & 43.1 & -1111.0 & 32.7 \\
\hline 699-S7-34 & 579430.7 & 121503.4 & 160.6 & -1111.0 & -1111.0 & -1111.0 & 133.6 & -1111.0 & -1111.0 & -1111.0 & -1111.0 & 117.7 \\
\hline 699-S8-19 & 584225.9 & 120963.7 & 153.6 & -1111.0 & -1111.0 & -1111.0 & 120.5 & -9999.0 & -9999.0 & -9999.0 & -9999.0 & -9999.0 \\
\hline
\end{tabular}

Page 10 
u1top_elev 


$\begin{array}{ll}\text { ncols } & 389 \\ \text { nrows } & 437 \\ \text { xllcorner } & 545925 \\ \text { yllcorner } & 100925 \\ \text { cellsize } & 150\end{array}$

NODATA_value -9999

-9999 -9999 -9999 -9999 -9999 -9999 -9999 -9999 -9999 -9999 -9999 -9999 -9999 -9999 -9999 -9999 -9999 -9999 -9999 -9999 -9999 -9999 -9999 -9999 -9999 -9999 -9999 -9999 -9999 -9999 -999 -9999 -9999 -9999 -9999 -9999 -9999 -9999 -9999 -9999 -9999 -9999 -9999 -9999 -9999 -9999 -9999 -9999 -9999 -9999 -9999 -9999 -9999 -9999 -9999 -9999 -9999 -9999 -9999 -9999 -9999

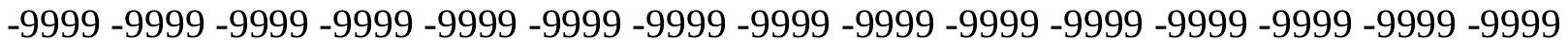
-9999 -9999 -9999 -9999 -9999 -9999 -9999 -9999 -9999 -9999 -9999 -9999 -9999 -9999 -9999 -9999 -9999 -9999 -9999 -9999 -9999 -9999 -9999 -9999 -9999 -9999 -9999 -9999 -9999 -9999 -9999 -9999 -9999 -9999 -9999 -9999 -9999 -9999 -9999 -9999 -9999 -9999 -9999 -9999 - 9999 -9999 -9999 -9999 -9999 -9999 -9999 -9999 -9999 -9999 -9999 -9999 -9999 -9999 -9999 -9999

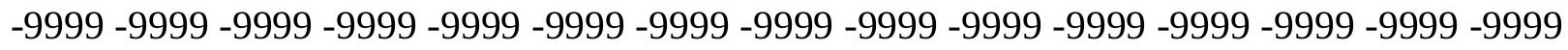
-9999 -9999 -9999 -9999 -9999 -9999 -9999 -9999 -9999 -9999 -9999 -9999 -9999 -9999 -9999 -9999 -9999 -9999 -9999 -9999 -9999 -9999 -9999 -9999 -9999 -9999 -9999 -9999 -9999 -9999 -999 -9999 -9999 -9999 -9999 -9999 -9999 -9999 -9999 -9999 -9999 -9999 -9999 -9999 -9999 -9999 -9999 -9999 -9999 -9999 -9999 -9999 -9999 -9999 -9999 -9999 -9999 -9999 -9999 -9999 -9999 -9999 -9999 -9999 -9999 -9999 -9999 -9999 -9999 -9999 -9999 -9999 -9999 -9999 -9999 -9999 -9999 -9999 -9999 -9999 -9999 -9999 -9999 -9999 -9999 -9999 -9999 -9999 -9999 -9999 -9999 -9999 -9999 -9999 -9999 -9999 -9999 -9999 -9999 -9999 -9999 -9999 -9999 -9999 -9999 -9999 -9999 -9999 -9999 -9999 -9999 -9999 -9999 -9999 -9999 -9999 -9999 -9999 -9999 -9999 -9999 -9999 -9999 -9999 -9999 -9999 -9999 -9999 -9999 -9999 -9999 -9999 -9999 -9999 -9999 -9999 -9999 -9999 -9999 -9999 -9999 -9999 -9999 -9999 -9999 -9999 -9999 -9999 -9999 -9999 -9999 -9999 -9999 -9999 -9999 -9999 -9999 -9999 -9999 -9999 -9999 -9999 -9999 -9999 -9999 -9999 -9999 -9999 -9999 -9999 -9999 -9999 -9999 -9999 -9999 -9999 -9999 -9999 -9999 -9999 -9999 -9999 -9999 -9999 -9999 -9999 -9999 -9999 -9999 -9999 -9999 -9999 -9999 -9999 -9999 -9999 -9999 -9999 -9999 -9999 -9999 -9999 -9999 -9999 -9999 -9999 -9999 -9999 -9999 -9999 -999 -9999 -9999 -9999 -9999 -9999 -9999 -9999 -9999 -9999 -9999 -9999 -9999 -9999 -9999 -9999 -9999 -9999 -9999 -9999 -9999 -9999 -9999 -9999 -9999 -9999 -9999 -9999 -9999 -9999 -

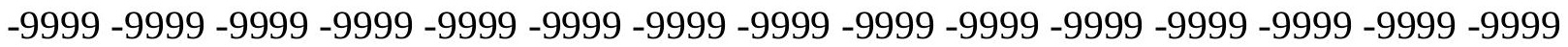
-9999 -9999 -9999 -9999 -9999 -9999 -9999 -9999 -9999 -9999 -9999 -9999 -9999 -9999 -9999 -9999 -9999 -9999 -9999 -9999 -9999 -9999 -9999 -9999 -9999 -9999 -9999 -9999 -9999 -9999 -

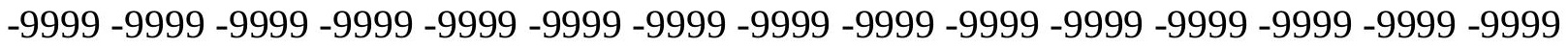

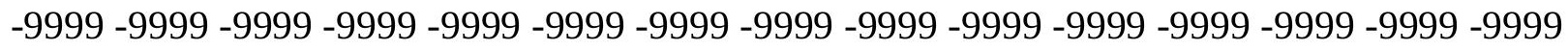
-9999 -9999 -9999 -9999 -9999 -9999 -9999 -9999 -9999 -9999 -9999 -9999 -9999 - 9999 - -9999 -9999 -9999 -9999 -9999 -9999 -9999 -9999 -9999 -9999 -9999 -9999 -9999 -9999 - 9999 - -999 -9999 -9999 -9999 -9999 -9999 -9999 -9999 -9999 -9999 -9999 -9999 -9999 -9999 -9999 -9999 -

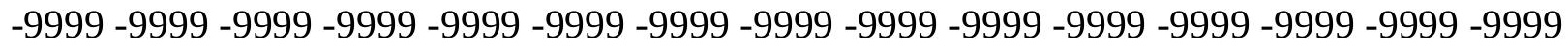

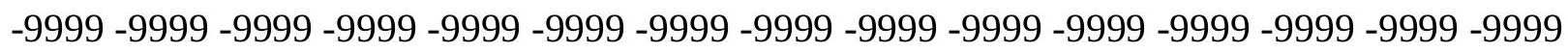
-9999 -9999 -9999 -9999 -9999 -9999 -9999 -9999 -9999 -9999 -9999 -9999 -9999 -9999 -9999 -9999 -9999 -9999 -9999 -9999 -9999 -9999 -9999 -9999-9999 -9999 -9999 -9999 -9999 -9999 -9999 -9999 -9999 -9999 -9999 -9999 -9999 -9999 -9999 -9999 -9999 -9999 -9999 -9999 -9999 -

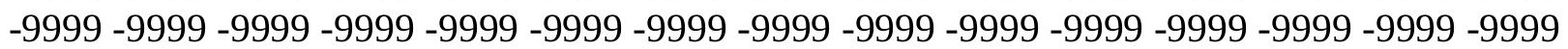


-9999 -9999 -9999 -9999 -9999 -9999 -9999 -9999 -9999 -9999 -9999 -9999 -9999 -9999 -9999 -9999 -9999 -9999 -9999 -9999 -9999 -9999 -9999 -9999 -9999 -9999 -9999 -9999 -9999 -9999 -

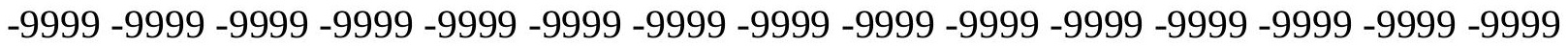
-9999 -9999 -9999 -9999 -9999 -9999 -9999 -9999 -9999 -9999 -9999 -9999 -9999 -9999 -9999 -9999 -9999 -9999 -9999 -9999 -9999 -9999 -9999 -9999-9999 -9999 -9999 -9999 -9999 -9999 -9999 -9999 -9999 -9999 -9999 -9999 -9999 -9999 -9999 -9999 -9999 -9999 -9999 -9999 -9999 -9999 -9999 -9999 -9999 -9999 -9999 -9999 -9999 -9999 -9999 -9999 -9999 -9999 -9999 -9999

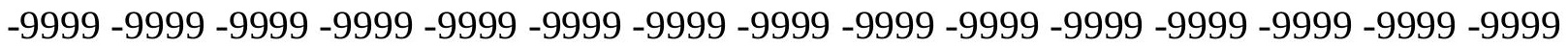

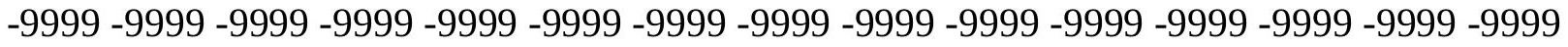
-9999 -9999 -9999 -9999 -9999 -9999 -9999 -9999 -9999 -9999 -9999 -9999 -9999 -9999 -9999 -9999 -9999 -9999 -9999 -9999 -9999 -9999 -9999 -9999 -9999 -9999 -9999 -9999 -9999 -9999 -9999 -9999 -9999 -9999 -9999 -9999 -9999 -9999 -9999 -9999 -9999 -9999 -9999 -9999 -9999 -9999 -9999 -9999 -9999 -9999 -9999 -9999 -9999 -9999 -9999 -9999 -9999 -9999 -9999 -9999 -9999 -9999 -9999 -9999 -9999 -9999 -9999 -9999 -9999 -9999 -9999 -9999 -9999 - 9999 -9999 -9999 -9999 -9999 -9999 -9999 -9999 -9999 -9999 -9999 -9999 -9999 -9999 -9999 -9999

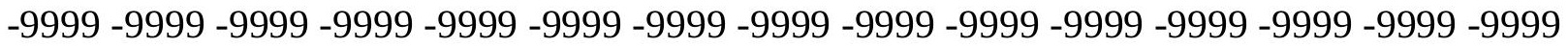
-9999 -9999 -9999 -9999 -9999 -9999 -9999 -9999 -9999 -9999 -9999 -9999 -9999 -9999 -9999 -9999 -9999 -9999 -9999 -9999 -9999 -9999 -9999 -9999 -9999 -9999 -9999 -9999 -9999 -9999 -9999 -9999 -9999 -9999 -9999 -9999 -9999 -9999 -9999 -9999 -9999 -9999 -9999 -9999 -9999 -

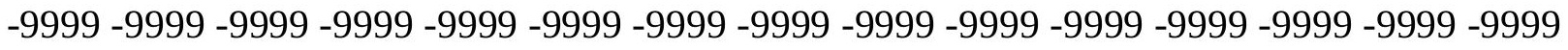

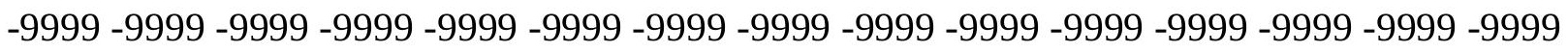
-9999 -9999 -9999 -9999 -9999 -9999 -9999 -9999 -9999 -9999 -9999 -9999 -9999 -9999 -9999 -9999 -9999 -9999 -9999 -9999 -9999 -9999 -9999 -9999 -9999 -9999 -9999 -9999 -9999 -9999 -9999 -9999 -9999 -9999 -9999 -9999 -9999 -9999 -9999 -9999 -9999 -9999 -9999 -9999 -9999 -

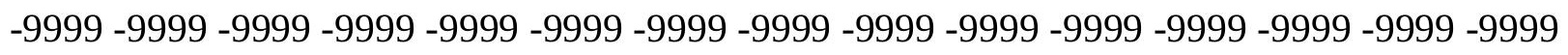
-9999 -9999 -9999 -9999 -9999 -9999 -9999 -9999 -9999 -9999 -9999 -9999 -9999 -9999 -9999 -9999 -9999 -9999 -9999 -9999 -9999 -9999 -9999 -9999 -9999 -9999 -9999 -9999 -9999 -9999 -

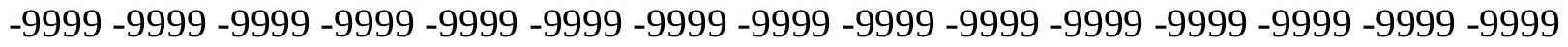
-9999 -9999 -9999 -9999 -9999 -9999 -9999 -9999 -9999 -9999 -9999 -9999 -9999 -9999 -9999 -9999 -9999 -9999 -9999 -9999 -9999 -9999 -9999 -9999 -9999 -9999 -9999 -9999 -9999 -999 -9999 -9999 -9999 -9999 -9999 -9999 -9999 -9999 -9999 -9999 -9999 -9999 -9999 -9999 -9999 -9999 -9999 -9999 -9999 -9999 -9999 -9999 -9999 -9999 -9999 -9999 -9999 -9999 -9999 -9999 -

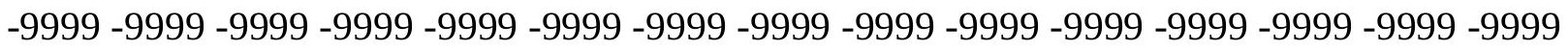

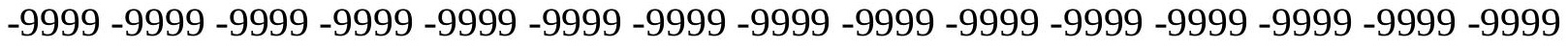

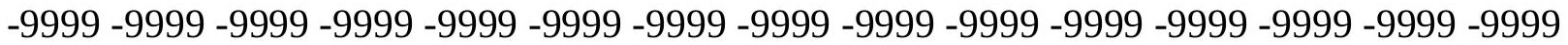

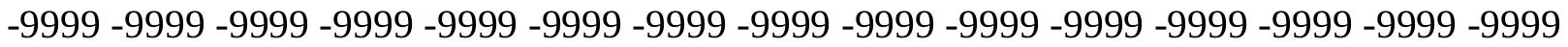

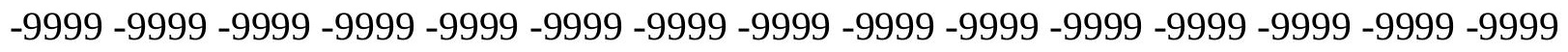

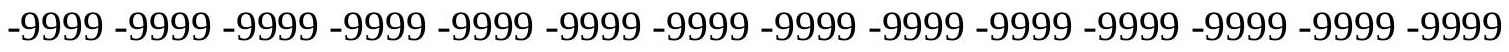
-9999 -9999 -9999 -9999 -9999 -9999 -9999 -9999 -9999 -9999 -9999 -9999 -9999 -9999 -9999 -9999 -9999 -9999 -9999 -9999 -9999 -9999 -9999 -9999 -9999 -9999 -9999 -9999 -9999 -9999 -

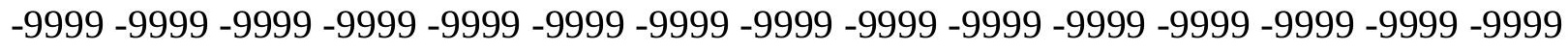

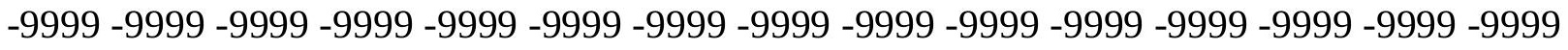
-9999 -9999 -9999 -9999 -9999 -9999 -9999 -9999 -9999 -9999 -9999 -9999 -9999 -9999 -9999 -9999 -9999 -9999 -9999 -9999 -9999 -9999 -9999 -9999-9999 -9999 -9999 -9999 -9999 -9999 -9999 -9999 -9999 -9999 -9999 -9999 -9999 -9999 -9999 -9999 -9999 -9999 -9999 -9999 -9999 -

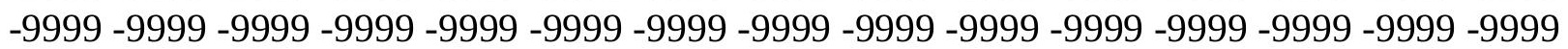


-9999 -9999 -9999 -9999 -9999 -9999 -9999 -9999 -9999 -9999 -9999 -9999 -9999 -9999 -9999 -9999 -9999 -9999 -9999 -9999 -9999 -9999 -9999 -9999 -9999 -9999 -9999 -9999 -9999 -9999 -9999 -9999 -9999 -9999 -9999 -9999 -9999 -9999 -9999 -9999 -9999 -9999 -9999 -9999 - 9999 -9999 -9999 -9999 -9999 -9999 -9999 -9999 -9999 -9999 -9999 -9999 -9999 -9999 -9999 -9999 -9999 -9999 -9999 -9999 -9999 -9999 -9999 -9999 -9999 -9999 -9999 -9999 -9999 -9999 -9999 -9999 -9999 -9999 -9999 -9999 -9999 -9999 -9999 -9999 -9999 -9999 -9999 -9999 -9999 -9999 -9999 -9999 -9999 -9999 -9999 -9999 -9999 -9999 -9999 -9999 -9999 -9999 -9999 -9999 -9999

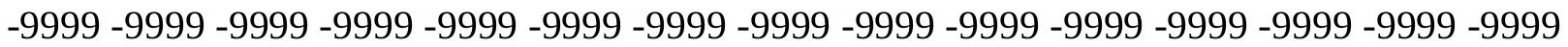
-9999 -9999 -9999 -9999 -9999 -9999 -9999 -9999 -9999 -9999 -9999 -9999 -9999 -9999 -9999 -9999 -9999 -9999 -9999 -9999 -9999 -9999 -9999 -9999 -9999 -9999 -9999 -9999 -9999 -9999

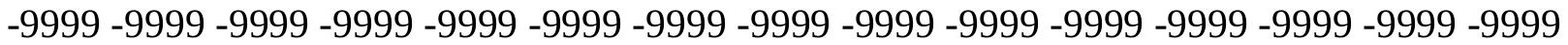
-9999 -9999 -9999 -9999 -9999 -9999 -9999 -9999 -9999 -9999 -9999 -9999 -9999 -9999 -9999 -9999 -9999 -9999 -9999 -9999 -9999 -9999 -9999 -9999 -9999 -9999 -9999 -9999 -9999 -9999 -

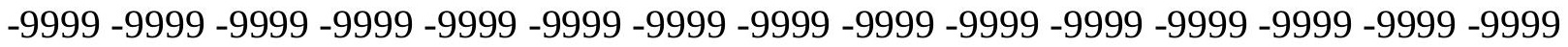
-9999 -9999 -9999 -9999 -9999 -9999 -9999 -9999 -9999 -9999 -9999 -9999 -9999 -9999 -9999

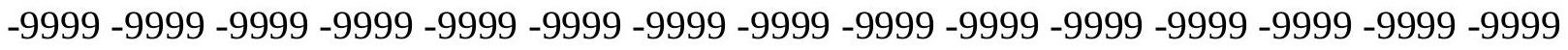
-9999 -9999 -9999 -9999 -9999 -9999 -9999 -9999 -9999 -9999 -9999 -9999 -9999 -9999 -9999 -9999 -9999 -9999 -9999 -9999 -9999 -9999 -9999 -9999 -9999 -9999 -9999 -9999 -9999 - -999 -9999 -9999 -9999 -9999 -9999 -9999 -9999 -9999 -9999 -9999 -9999 -9999 -9999 -9999 -9999 -9999 -9999 -9999 -9999 -9999 -9999 -9999 -9999 -9999 -9999 -9999 -9999 -9999 -9999 -9999 -9999 -9999 -9999 -9999 -9999 -9999 -9999 -9999 -9999 -9999 -9999 -9999 -9999 -9999 -9999 -999 -9999 -9999 -9999 -9999 -9999 -9999 -9999 -9999 -9999 -9999 -9999 -9999 -9999 -9999 -9999 -9999 -9999 -9999 -9999 -9999 -9999 -9999 -9999 -9999 -9999 -9999 -9999 -9999 -9999 -9999 -9999 -9999 -9999 -9999 -9999 -9999 -9999 -9999 -9999 -9999 -9999 -9999 -9999 -9999 -9999 -9999 -9999 -9999 -9999 -9999 -9999 -9999 -9999 -9999 -9999 -9999 -9999 -9999 -9999 -9999 -9999 -9999 -9999 -9999 -9999 -9999 -9999 -9999 -9999 -9999 -9999 -9999 -9999 -9999 -9999 -9999 -9999 -9999 -9999 -9999 -9999 -9999 -9999 -9999 -9999 -9999 -9999 -9999 -9999 -9999 -9999 -9999 -9999 -9999 -9999 -9999 -9999 -9999 -9999 -9999 -9999 -9999 -9999 -9999 -9999 -9999 -9999 -9999 -9999 -9999 -9999 -9999 -9999 -9999 -9999 -9999 -9999 -9999 -9999 -9999 -9999 -9999 -9999 -9999 -9999 -9999 -9999 -9999 -9999 -9999 -9999 -9999 -9999 -9999 -999 -9999 -9999 -9999 -9999 -9999 -9999 -9999 -9999 -9999 -9999 -9999 -9999 -9999 -9999 -9999 -9999 -9999 -9999 -9999 -9999 -9999 -9999 -9999 -9999 -9999 -9999 -9999 -9999 -9999 -9999 -

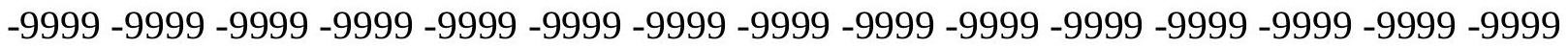

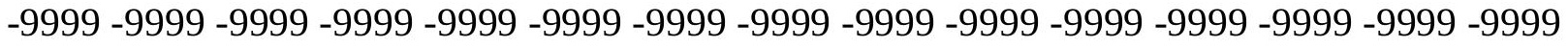

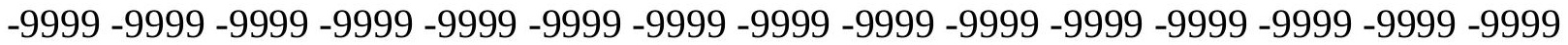
-9999 -9999 -9999 -9999 -9999 -9999 -9999 -9999 -9999 -9999 -9999 -9999 -9999 -9999 -9999

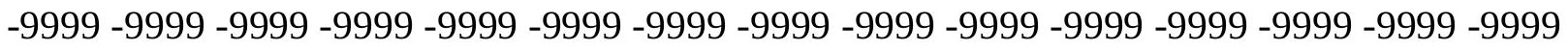

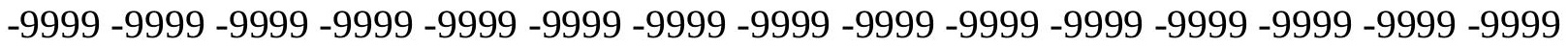

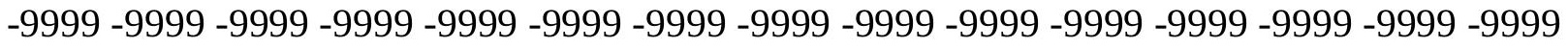
-9999 -9999 -9999 -9999 -9999 -9999 -9999 -9999 -9999 -9999 -9999 -9999 -9999 -9999 -9999 -

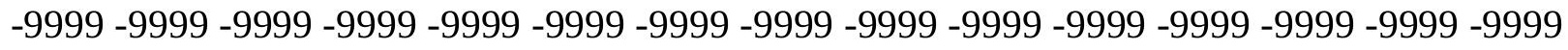

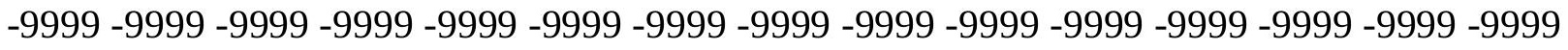
-9999 -9999 -9999 -9999 -9999 -9999 -9999 -9999 -9999 -9999 -9999 -9999 -9999 -9999 -9999 -9999 -9999 -9999 -9999 -9999 -9999 -9999 -9999 -9999 -9999 -9999 -9999 -9999 - -9999 -9999 -9999 -9999 -9999 -9999 -9999 -9999 -9999 -9999 -9999 -9999 -9999 -9999 -9999 -9999 -

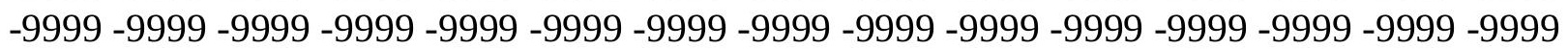


-9999 -9999 -9999 -9999 -9999 -9999 -9999 -9999 -9999 -9999 -9999 -9999 -9999 -9999 -9999 -9999 -9999 -9999 -9999 -9999 -9999 -9999 -9999 -9999 -9999 -9999 -9999 -9999 -9999 -9999 -9999 -9999 -9999 -9999 -9999 -9999 -9999 -9999 -9999 -9999 -9999 -9999 -9999 -9999 - 9999 -9999 -9999 -9999 -9999 -9999 -9999 -9999 -9999 -9999 -9999 -9999 -9999 -9999 -9999 -9999 -9999 -9999 -9999 -9999 -9999 -9999 -9999 -9999 -9999-9999 -9999 -9999 -9999 -9999 -9999 -9999 -9999 -9999 -9999 -9999 -9999 -9999 -9999 -9999 -9999 -9999 -9999 -9999 -9999 -9999 -9999 -9999 -9999 -9999 -9999 -9999 -9999 -9999 -9999 -9999 -9999 -9999 -9999 -9999 -9999

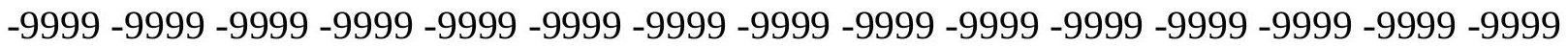

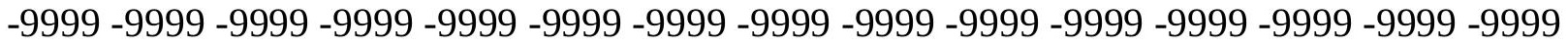
-9999 -9999 -9999 -9999 -9999 -9999 -9999 -9999 -9999 -9999 -9999 -9999 -9999 -9999 -9999

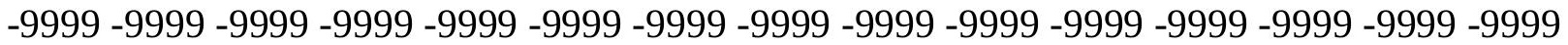
-9999 -9999 -9999 -9999 -9999 -9999 -9999 -9999 -9999 -9999 -9999 -9999 -9999 -9999 -9999 -9999 -9999 -9999 -9999 -9999 -9999 -9999 -9999 -9999 -9999 -9999 -9999 -9999 -9999 -9999 -

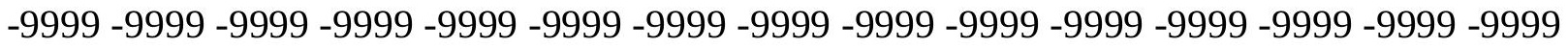
-9999 -9999 -9999 -9999 -9999 -9999 -9999 -9999 -9999 -9999 -9999 -9999 -9999 -9999 -9999

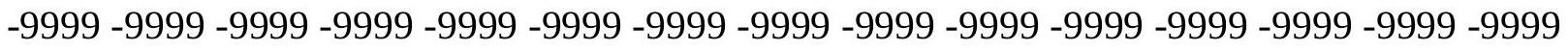
-9999 -9999 -9999 -9999 -9999 -9999 -9999 -9999 -9999 -9999 -9999 -9999 -9999 -9999 -9999 -9999 -9999 -9999 -9999 -9999 -9999 -9999 -9999 -9999 -9999 -9999 -9999 -9999 -9999 -9999 -9999 -9999 -9999 -9999 -9999 -9999 -9999 -9999 -9999 -9999 -9999 -9999 -9999 -9999 -9999 -9999 -9999 -9999 -9999 -9999 -9999 -9999 -9999 -9999 -9999 -9999 -9999 -9999 -9999 -9999 -9999 -9999 -9999 -9999 -9999 -9999 -9999 -9999 -9999 -9999 -9999 -9999 -9999 -9999 -9999 -999 -9999 -9999 -9999 -9999 -9999 -9999 -9999 -9999 -9999 -9999 -9999 -9999 -9999 -9999 -9999 -9999 -9999 -9999 -9999 -9999 -9999 -9999 -9999 -9999 -9999 -9999 -9999 -9999 -9999 -9999 -9999 -9999 -9999 -9999 -9999 -9999 -9999 -9999 -9999 -9999 -9999 -9999 -9999 -9999 -9999 -9999 -9999 -9999 -9999 -9999 -9999 -9999 -9999 -9999 -9999 -9999 -9999 -9999 -9999 -9999 -9999 -9999 -9999 -9999 -9999 -9999 -9999 -9999 -9999 -9999 -9999 -9999 -9999 -9999 -9999 -9999 -9999 -9999 -9999 -9999 -9999 -9999 -9999 -9999 -9999 -9999 -9999 -9999 -9999 -9999 -9999 -9999 -9999 -9999 -9999 -9999 -9999 -9999 -9999 -9999 -9999 -9999 -9999 -9999 -9999 -9999 -9999 -9999 -9999 -9999 -9999 -9999 -9999 -9999 -9999 -9999 -9999 -9999 -9999 -9999 -9999 -9999 -9999 -9999 -9999 -9999 -9999 -9999 -9999 -9999 -9999 -9999 -9999 -999 -9999 -9999 -9999 -9999 -9999 -9999 -9999 -9999 -9999 -9999 -9999 -9999 -9999 -9999 -9999 -9999 -9999 -9999 -9999 -9999 -9999 -9999 -9999 -9999 -9999 -9999 -9999 -9999 -9999 -9999 -

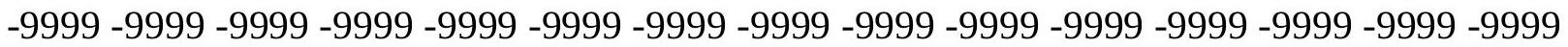

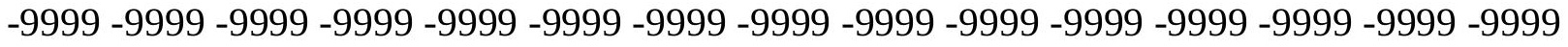

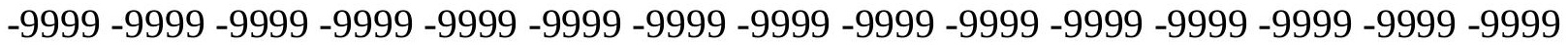
-9999 -9999 -9999 -9999 -9999 -9999 -9999 -9999 -9999 -9999 -9999 -9999 -9999 -9999 -9999

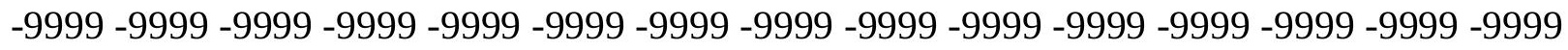

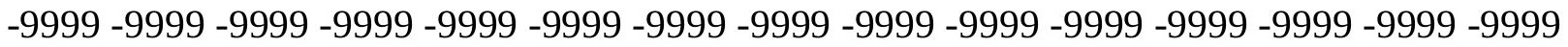
-9999 -9999 -9999 -9999 -9999 -9999 -9999 -9999 -9999 -9999 -9999 -9999 -9999 -9999 -9999 -9999 -9999 -9999 -9999 -9999 -9999 -9999 -9999 -9999 -9999 -9999 -9999 -9999 -9999 -9999 -

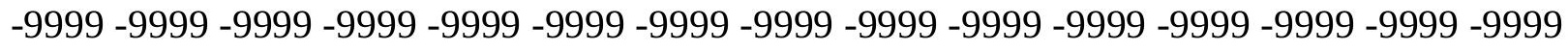

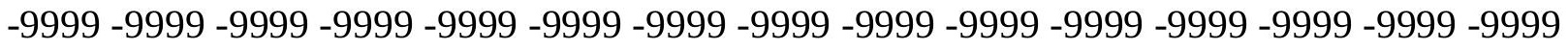
-9999 -9999 -9999 -9999 -9999 -9999 -9999 -9999 -9999 -9999 -9999 -9999 -9999 -9999 -9999 -9999 -9999 -9999 -9999 -9999 -9999 -9999 -9999 -9999-9999 -9999 -9999 -9999 -9999 -9999 -9999 -9999 -9999 -9999 -9999 -9999 -9999 -9999 -9999 -9999 -9999 -9999 -9999 -9999 -9999 -

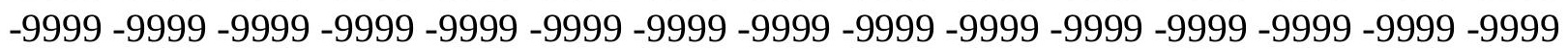


-9999 -9999 -9999 -9999 -9999 -9999 -9999 -9999 -9999 -9999 -9999 -9999 -9999 -9999 -9999 -9999 -9999 -9999 -9999 -9999 -9999 -9999 -9999 -9999 -9999 -9999 -9999 -9999 -9999 -9999 -9999 -9999 -9999 -9999 -9999 -9999 -9999 -9999 -9999 -9999 -9999 -9999 -9999 -9999 - 9999 -9999 -9999 -9999 -9999 -9999 -9999 -9999 -9999 -9999 -9999 -9999 -9999 -9999 -9999

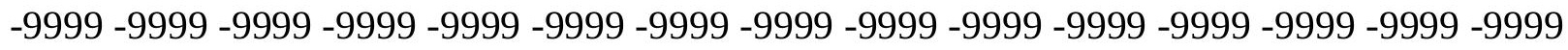
-9999 -9999 -9999 -9999 -9999 -9999 -9999 -9999 -9999 -9999 -9999 -9999 -9999 -9999 -9999 -9999 -9999 -9999 -9999 -9999 -9999 -9999 -9999 -9999 -9999 -9999 -9999 -9999 -9999 -9999

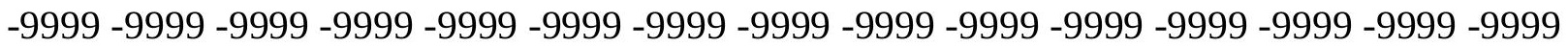

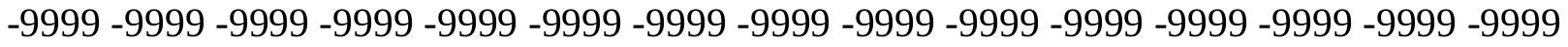
-9999 -9999 -9999 -9999 -9999 -9999 -9999 -9999 -9999 -9999 -9999 -9999 -9999 -9999 -9999 -9999 -9999 -9999 -9999 -9999 -9999 -9999 -9999 -9999 -9999 -9999 -9999 -9999 -9999 -9999 -9999 -9999 -9999 -9999 -9999 -9999 -9999 -9999 -9999 -9999 -9999 -9999 -9999 -9999 -9999 -9999 -9999 -9999 -9999 -9999 -9999 -9999 -9999 -9999 -9999 -9999 -9999 -9999 -9999 -9999 -

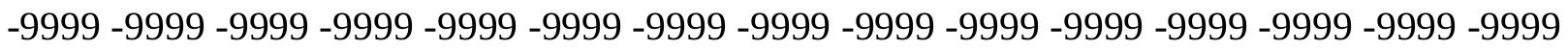
-9999 -9999 -9999 -9999 -9999 -9999 -9999 -9999 -9999 -9999 -9999 -9999 -9999 -9999 -9999 -

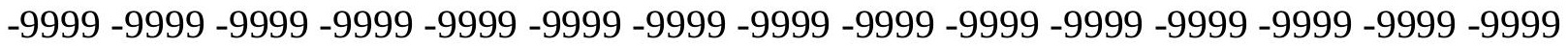
-9999 -9999 -9999 -9999 -9999 -9999 -9999 -9999 -9999 -9999 -9999 -9999 -9999 -9999 -9999 -9999 -9999 -9999 -9999 -9999 -9999 -9999 -9999 -9999 -9999 -9999 -9999 -9999 -9999 -9999 -9999 -9999 -9999 -9999 -9999 -9999 -9999 -9999 -9999 -9999 -9999 -9999 -9999 -9999 -9999 -

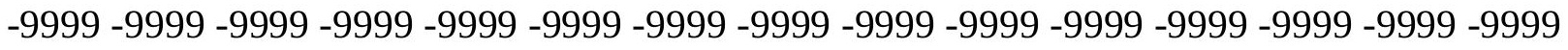
-9999 -9999 -9999 -9999 -9999 -9999 -9999 -9999 -9999 -9999 -9999 -9999 -9999 -9999 -9999

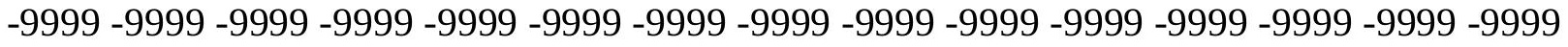
-9999 -9999 -9999 -9999 -9999 -9999 -9999 -9999 -9999 -9999 -9999 -9999 -9999 -9999 -9999 -9999 -9999 -9999 -9999 -9999 -9999 -9999 -9999 -9999 -9999 -9999 -9999 -9999 -9999 -9999 -9999 -9999 -9999 -9999 -9999 -9999 -9999 -9999 -9999 -9999 -9999 -9999 -9999 -9999 -9999 -9999 -9999 -9999 -9999 -9999 -9999 -9999 -9999 -9999 -9999 -9999 -9999 -9999 -9999 -9999 -9999 -9999 -9999 -9999 -9999 -9999 -9999 -9999 -9999 -9999 -9999 -9999 -9999 -9999 -9999 -9999 -9999 -9999 -9999 -9999 -9999 -9999 -9999 -9999 -9999 -9999 -9999 -9999 -9999 -9999 -9999 -9999 -9999 -9999 -9999 -9999 -9999 -9999 -9999 -9999 -9999 -9999 -9999 -9999 -9999 -9999 -9999 -9999 -9999 -9999 -9999 -9999 -9999 -9999 -9999 -9999 -9999 -9999 -9999 -9999 -9999 -9999 -9999 -9999 -9999 -9999 -9999 -9999 -9999 -9999 -9999 -9999 -9999 -9999 -9999 -9999 -9999 -9999 -9999 -9999 -9999 -9999 -9999 -9999 -9999 -9999 -9999 -9999 -9999 -

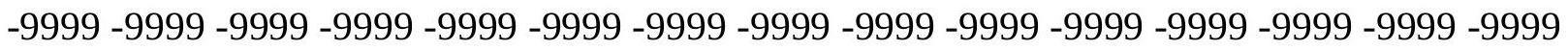

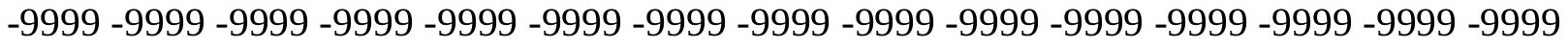
-9999 -9999 -9999 -9999 -9999 -9999 -9999 -9999 -9999 -9999 -9999 -9999 -9999 -9999 -9999 -

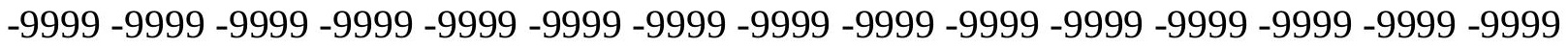

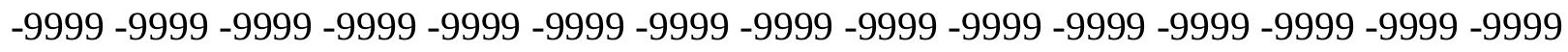

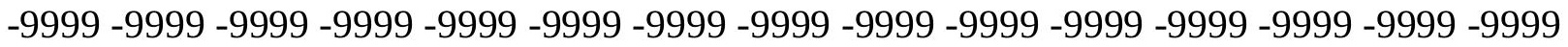

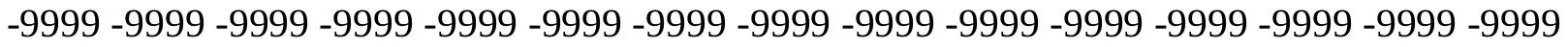
-9999 -9999 -9999 -9999 -9999 -9999 -9999 -9999 -9999 -9999 -9999 -9999 -9999 -9999 -9999 -

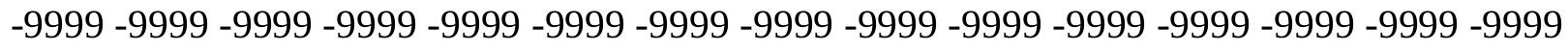

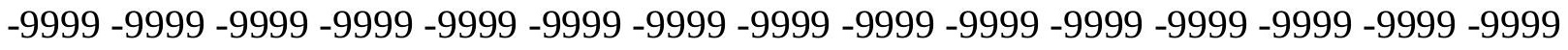
-9999 -9999 -9999 -9999 -9999 -9999 -9999 -9999 -9999 -9999 -9999 -9999 -9999 -9999 -9999 -9999 -9999 -9999 -9999 -9999 -9999 -9999 -9999 -9999-9999 -9999 -9999 -9999 -9999 -9999 -9999 -9999 -9999 -9999 -9999 -9999 -9999 -9999 -9999 -9999 -9999 -9999 -9999 -9999 -9999 -

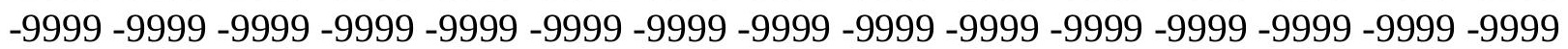


-9999 -9999 -9999 -9999 -9999 -9999 -9999 -9999 -9999 -9999 -9999 -9999 -9999 -9999 -9999 -9999 -9999 -9999 -9999 -9999 -9999 -9999 -9999 -9999 -9999 -9999 -9999 -9999 -9999 -9999 -9999 -9999 -9999 -9999 -9999 -9999 -9999 -9999 -9999 -9999 -9999 -9999 -9999 -9999 - 9999 -9999 -9999 -9999 -9999 -9999 -9999 -9999 -9999 -9999 -9999 -9999 -9999 -9999 -9999 -9999 -9999 -9999 -9999 -9999 -9999 -9999 -9999 -9999 -9999 -9999 -9999 -9999 -9999 -9999 -9999 -9999 -9999 -9999 -9999 -9999 -9999 -9999 -9999 -9999 -9999 -9999 -9999 -9999 -9999 -9999 -9999 -9999 -9999 -9999 -9999 -9999 -9999 -9999 -9999 -9999 -9999 -9999 -9999 -9999 -9999

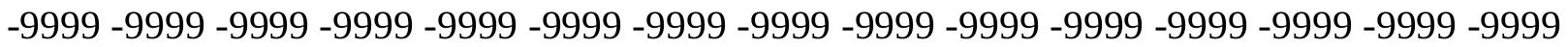

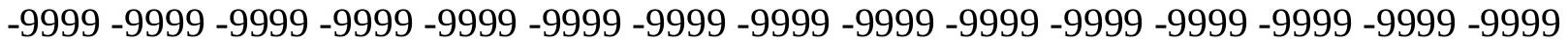
-9999 -9999 -9999 -9999 -9999 -9999 -9999 -9999 -9999 -9999 -9999 -9999 -9999 -9999 -9999 -9999 -9999 -9999 -9999 -9999 -9999 -9999 -9999 -9999 -9999 -9999 -9999 -9999 -9999 -9999 -9999 -9999 -9999 -9999 -9999 -9999 -9999 -9999 -9999 -9999 -9999 -9999 -9999 -9999 -9999 -9999 -9999 -9999 -9999 -9999 -9999 -9999 -9999 -9999 -9999 -9999 -9999 -9999 -9999 -9999 -9999 -9999 -9999 -9999 -9999 -9999 -9999 -9999 -9999 -9999 -9999 -9999 -9999 -9999 -9999 -9999 -9999 -9999 -9999 -9999 -9999 -9999 -9999 -9999 -9999 -9999 -9999 -9999 -9999 -

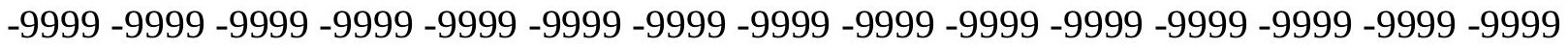
-9999 -9999 -9999 -9999 -9999 -9999 -9999 -9999 -9999 -9999 -9999 -9999 -9999 -9999 -9999 -9999 -9999 -9999 -9999 -9999 -9999 -9999 -9999 -9999 -9999 -9999 -9999 -9999 -9999 -9999 -9999 -9999 -9999 -9999 -9999 -9999 -9999 -9999 -9999 -9999 -9999 -9999 -9999 -9999 -9999 -9999 -9999 -9999 -9999 -9999 -9999 -9999 -9999 -9999 -9999 -9999 -9999 -9999 -9999 -9999 -9999 -9999 -9999 -9999 -9999 -9999 -9999 -9999 -9999 -9999 -9999 -9999 -9999 -9999 -9999 -999 -9999 -9999 -9999 -9999 -9999 -9999 -9999 -9999 -9999 -9999 -9999 -9999 -9999 -9999 -9999 -9999 -9999 -9999 -9999 -9999 -9999 -9999 -9999 -9999 -9999 -9999 -9999 -9999 -9999 -9999 -9999 -9999 -9999 -9999 -9999 -9999 -9999 -9999 -9999 -9999 -9999 -9999 -9999 -9999 -9999 -9999 -9999 -9999 -9999 -9999 -9999 -9999 -9999 -9999 -9999 -9999 -9999 -9999 -9999 -9999 -9999 -9999 -9999 -9999 -9999 -9999 -9999 -9999 -9999 -9999 -9999 -9999 -9999 -9999 -9999 -9999 -9999 -9999 -9999 -9999 -9999 -9999 -9999 -9999 -9999 -9999 -9999 -9999 -9999 -9999 -9999 -9999 -9999 -9999 -9999 -9999 -9999 -9999 -9999 -9999 -9999 -9999 -9999 -9999 -9999 -9999 -9999 -9999 -9999 -9999 -9999 -9999 -9999 -9999 -9999 -9999 -9999 -9999 -9999 -9999 -9999 -9999 -9999 -9999 -9999 -9999 -9999 -9999 -9999 -9999 -9999 -9999 -9999 -9999 -999 -9999 -9999 -9999 -9999 -9999 -9999 -9999 -9999 -9999 -9999 -9999 -9999 -9999 -9999 -9999 -9999 -9999 -9999 -9999 -9999 -9999 -9999 -9999 -9999 -9999 -9999 -9999 -9999 -9999 -9999 -

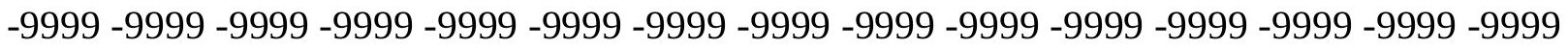

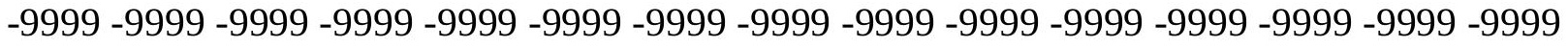

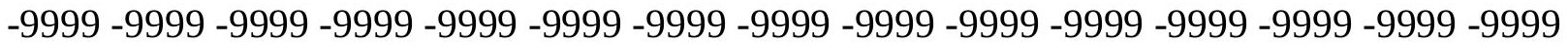
-9999 -9999 -9999 -9999 -9999 -9999 -9999 -9999 -9999 -9999 -9999 -9999 -9999 -9999 -9999 -9999 -9999 -9999 -9999 -9999 -9999 -9999 -9999 -9999 -9999 -9999 -9999 -9999 -9999 -

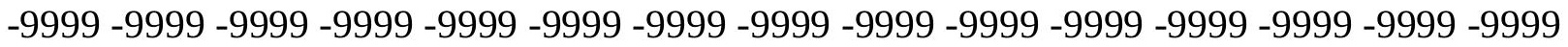
-9999 -9999 -9999 -9999 -9999 -9999 -9999 -9999 -9999 -9999 -9999 -9999 -9999 -9999 -9999 -9999 -9999 -9999 -9999 -9999 -9999 -9999 -9999 -9999 -9999 -9999 -9999 -9999 -9999 -9999 -

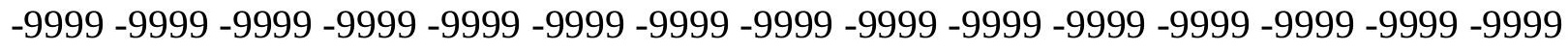

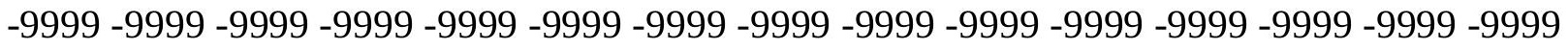
-9999 -9999 -9999 -9999 -9999 -9999 -9999 -9999 -9999 -9999 -9999 -9999 -9999 -9999 -9999 -9999 -9999 -9999 -9999 -9999 -9999 -9999 -9999 -9999-9999 -9999 -9999 -9999 -9999 -9999 -9999 -9999 -9999 -9999 -9999 -9999 -9999 -9999 -9999 -9999 -9999 -9999 -9999 -9999 -9999 -

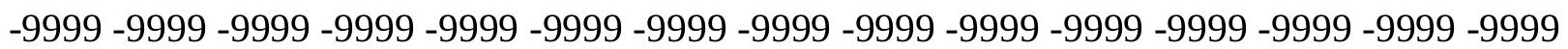


-9999 -9999 -9999 -9999 -9999 -9999 -9999 -9999 -9999 -9999 -9999 -9999 -9999 -9999 -9999 -9999 -9999 -9999 -9999 -9999 -9999 -9999 -9999 -9999 -9999 -9999 -9999 -9999 -9999 -9999 -

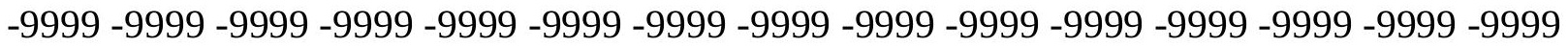
-9999 -9999 -9999 -9999 -9999 -9999 -9999 -9999 -9999 -9999 -9999 -9999 -9999 -9999 -9999 -9999 -9999 -9999 -9999 -9999 -9999 -9999 -9999 -9999-9999 -9999 -9999 -9999 -9999 -9999 -9999 -9999 -9999 -9999 -9999 -9999 -9999 -9999 -9999 -9999 -9999 -9999 -9999 -9999 -9999 -9999 -9999 -9999 -9999 -9999 -9999 -9999 -9999 -9999 -9999 -9999 -9999 -9999 -9999 -9999

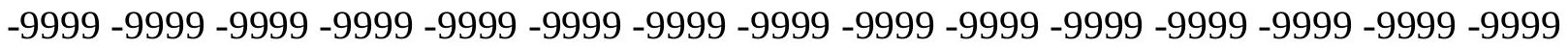

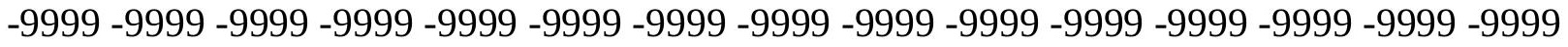
-9999 -9999 -9999 -9999 -9999 -9999 -9999 -9999 -9999 -9999 -9999 -9999 -9999 -9999 -9999 -9999 -9999 -9999 -9999 -9999 -9999 -9999 -9999 -9999 -9999 -9999 -9999 -9999 -9999 -9999 -9999 -9999 -9999 -9999 -9999 -9999 -9999 -9999 -9999 -9999 -9999 -9999 -9999 -9999 -9999 -9999 -9999 -9999 -9999 -9999 -9999 -9999 -9999 -9999 -9999 -9999 -9999 -9999 -9999 -9999 -9999 -9999 -9999 -9999 -9999 -9999 -9999 -9999 -9999 -9999 -9999 -9999 -9999 -9999 -9999 -9999 -9999 -9999 -9999 -9999 -9999 -9999 -9999 -9999 -9999 -9999 -9999 -9999 -9999 -9999 -

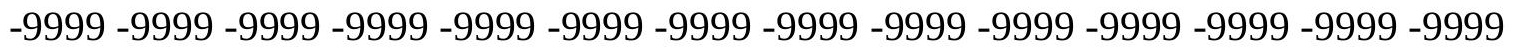
-9999 -9999 -9999 -9999 -9999 -9999 -9999 -9999 -9999 -9999 -9999 -9999 -9999 -9999 -9999 -9999 -9999 -9999 -9999 -9999 -9999 -9999 -9999 -9999 -9999 -9999 -9999 -9999 -9999 -9999 -9999 -9999 -9999 -9999 -9999 -9999 -9999 -9999 -9999 -9999 -9999 -9999 -9999 -9999 -9999 -

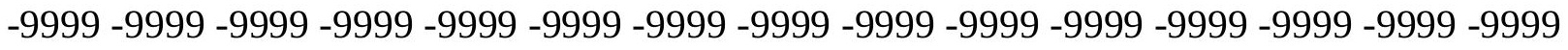

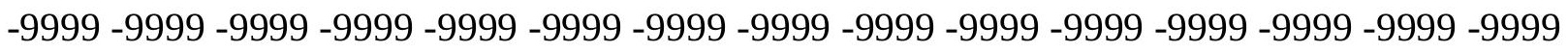
-9999 -9999 -9999 -9999 -9999 -9999 -9999 -9999 -9999 -9999 -9999 -9999 -9999 -9999 - 9999 -9999 -9999 -9999 -9999 -9999 -9999 -9999 -9999 -9999 -9999 -9999 -9999 -9999 -9999 -9999 -9999 -9999 -9999 -9999 -9999 -9999 -9999 -9999 -9999 -9999 -9999 -9999 -9999 -9999 -9999 -

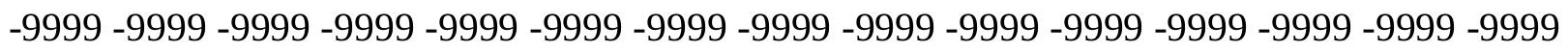
-9999 -9999 -9999 -9999 -9999 -9999 -9999 -9999 -9999 -9999 -9999 -9999 -9999 -9999 -9999 -9999 -9999 -9999 -9999 -9999 -9999 -9999 -9999 -9999 -9999 -9999 -9999 -9999 -9999 -9999 -

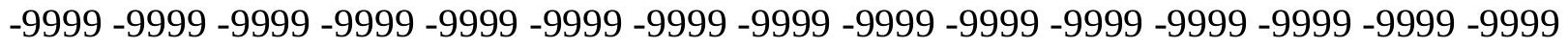
-9999 -9999 -9999 -9999 -9999 -9999 -9999 -9999 -9999 -9999 -9999 -9999 -9999 -9999 -9999 -9999 -9999 -9999 -9999 -9999 -9999 -9999 -9999 -9999 -9999 -9999 -9999 -9999 -9999 -999 -

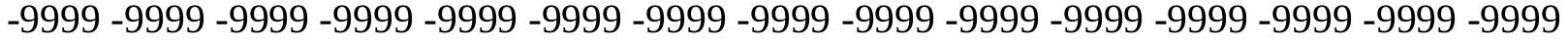
-9999 -9999 -9999 -9999 -9999 -9999 -9999 -9999 -9999 -9999 -9999 -9999 -9999 -9999 -9999 -

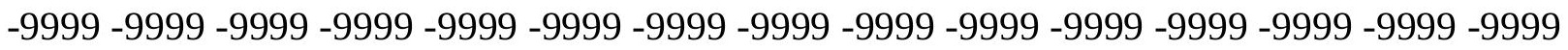

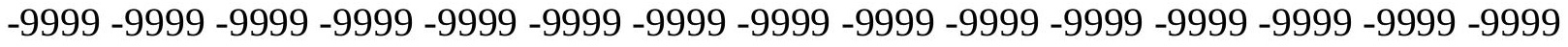

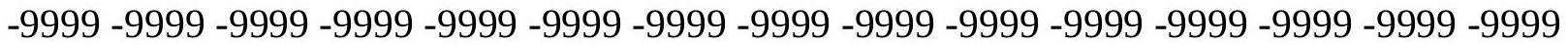
-9999 -9999 -9999 -9999 -9999 -9999 -9999 -9999 -9999 -9999 -9999 -9999 -9999 -9999 -9999 -

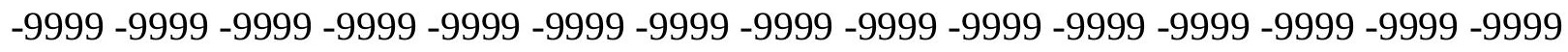

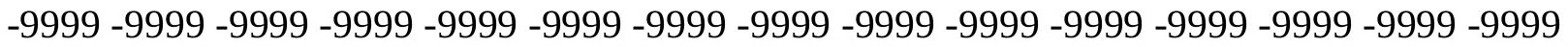
-9999 -9999 -9999 -9999 -9999 -9999 -9999 -9999 -9999 -9999 -9999 -9999 -9999 - 9999 - -999 -9999 -9999 -9999 -9999 -9999 -9999 -9999 -9999 -9999 -9999 -9999 -9999 -9999 -9999 -9999 -

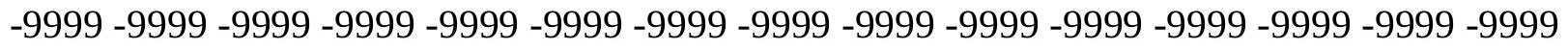

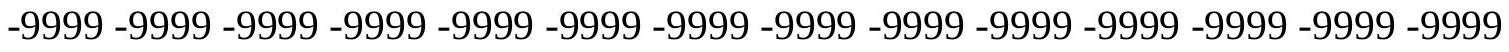
-9999 -9999 -9999 -9999 -9999 -9999 -9999 -9999 -9999 -9999 -9999 -9999 -9999 -9999 -9999 -9999 -9999 -9999 -9999 -9999 -9999 -9999 -9999 -9999-9999 -9999 -9999 -9999 -9999 -9999 -9999 -9999 -9999 -9999 -9999 -9999 -9999 -9999 -9999 -9999 -9999 -9999 -9999 -9999 -9999 -

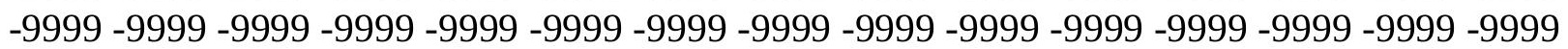


-9999 -9999 -9999 -9999 -9999 -9999 -9999 -9999 -9999 -9999 -9999 -9999 -9999 -9999 -9999 -9999 -9999 -9999 -9999 -9999 -9999 -9999 -9999 -9999 -9999 -9999 -9999 -9999 -9999 -9999 -

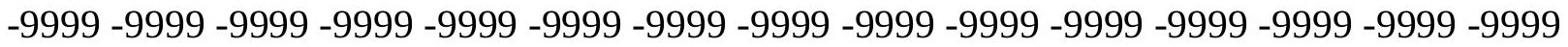
-9999 -9999 -9999 -9999 -9999 -9999 -9999 -9999 -9999 -9999 -9999 -9999 -9999 -9999 -9999 -9999 -9999 -9999 -9999 -9999 -9999 -9999 -9999 -9999-9999 -9999 -9999 -9999 -9999 -9999 -9999 -9999 -9999 -9999 -9999 -9999 -9999 -9999 -9999 -9999 -9999 -9999 -9999 -9999 -9999 -9999 -9999 -9999 -9999 -9999 -9999 -9999 -9999 -9999 -9999 -9999 -9999 -9999 -9999 -9999

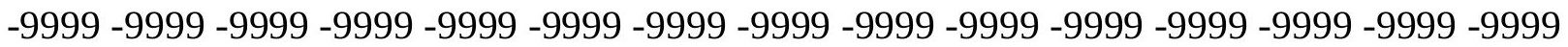

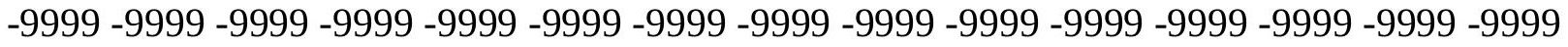
-9999 -9999 -9999 -9999 -9999 -9999 -9999 -9999 -9999 -9999 -9999 -9999 -9999 -9999 -9999 -9999 -9999 -9999 -9999 -9999 -9999 -9999 -9999 -9999 -9999 -9999 -9999 -9999 -9999 -9999 -9999 -9999 -9999 -9999 -9999 -9999 -9999 -9999 -9999 -9999 -9999 -9999 -9999 -9999 -9999 -9999 -9999 -9999 -9999 -9999 -9999 -9999 -9999 -9999 -9999 -9999 -9999 -9999 -9999 -9999 -

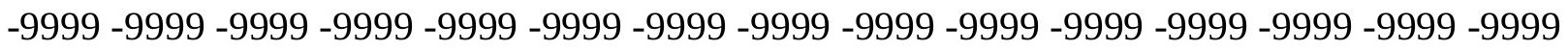
-9999 -9999 -9999 -9999 -9999 -9999 -9999 -9999 -9999 -9999 -9999 -9999 -9999 -9999 -9999 -

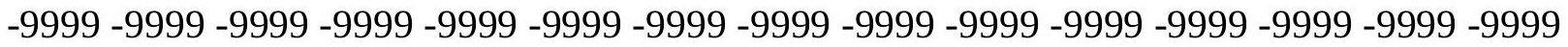
-9999 -9999 -9999 -9999 -9999 -9999 -9999 -9999 -9999 -9999 -9999 -9999 -9999 -9999 -9999 -9999 -9999 -9999 -9999 -9999 -9999 -9999 -9999 -9999 -9999 -9999 -9999 -9999 -9999 -9999 -9999 -9999 -9999 -9999 -9999 -9999 -9999 -9999 -9999 -9999 -9999 -9999 -9999 -9999 -9999 -

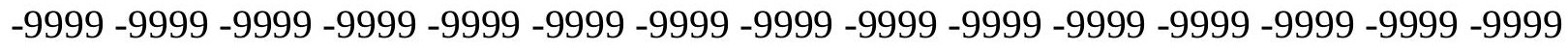

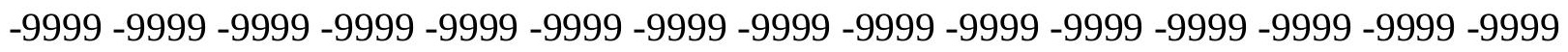
-9999 -9999 -9999 -9999 -9999 -9999 -9999 -9999 -9999 -9999 -9999 -9999 -9999 -9999 -9999 -9999 -9999 -9999 -9999 -9999 -9999 -9999 -9999 -9999 -9999 -9999 -9999 -9999 -9999 -9999 -9999 -9999 -9999 -9999 -9999 -9999 -9999 -9999 -9999 -9999 -9999 -9999 -9999 -9999 -

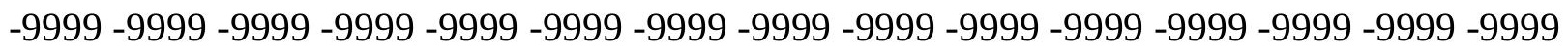
-9999 -9999 -9999 -9999 -9999 -9999 -9999 -9999 -9999 -9999 -9999 -9999 -9999 -9999 -9999 -9999 -9999 -9999 -9999 -9999 -9999 -9999 -9999 -9999 -9999 -9999 -9999 -9999 -9999 -9999 -

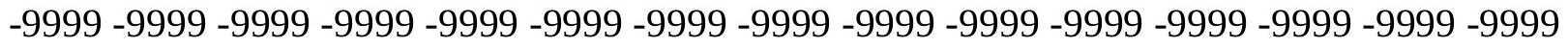
-9999 -9999 -9999 -9999 -9999 -9999 -9999 -9999 -9999 -9999 -9999 -9999 -9999 -9999 -9999 -9999 -9999 -9999 -9999 -9999 -9999 -9999 -9999 -9999 -9999 -9999 -9999 -9999 -9999 -999 -

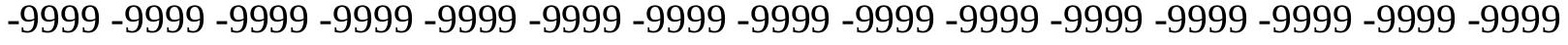
-9999 -9999 -9999 -9999 -9999 -9999 -9999 -9999 -9999 -9999 -9999 -9999 -9999 -9999 -9999 -

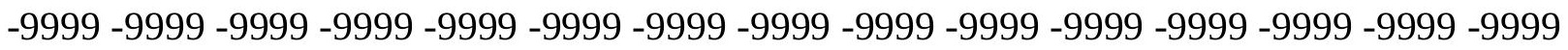

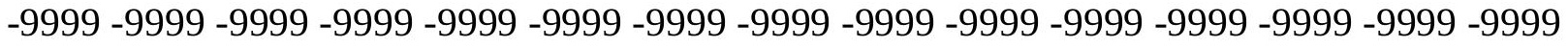

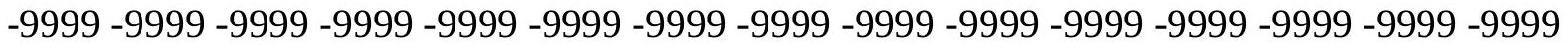

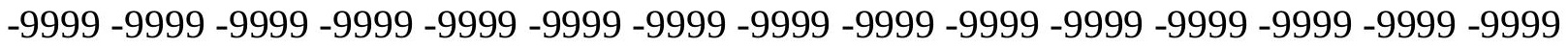

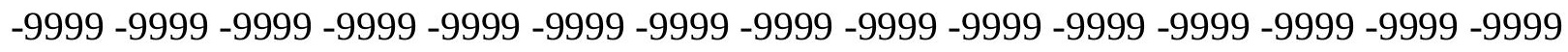

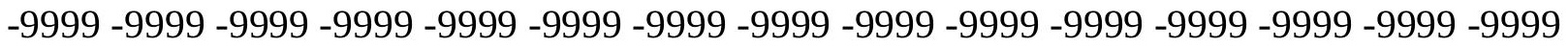

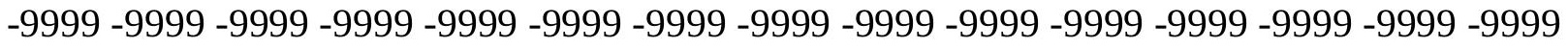
-9999 -9999 -9999 -9999 -9999 -9999 -9999 -9999 -9999 -9999 -9999 -9999 -9999 -9999 -9999 -

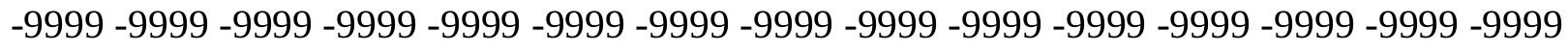

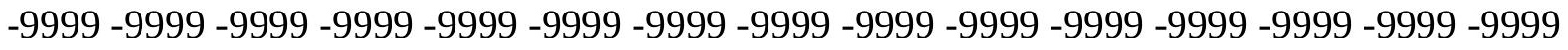
-9999 -9999 -9999 -9999 -9999 -9999 -9999 -9999 -9999 -9999 -9999 -9999 -9999 -9999 -9999 -9999 -9999 -9999 -9999 -9999 -9999 -9999 -9999 -9999-9999 -9999 -9999 -9999 -9999 -9999 -9999 -9999 -9999 -9999 -9999 -9999 -9999 -9999 -9999 -9999 -9999 -9999 -9999 -9999 -9999 -

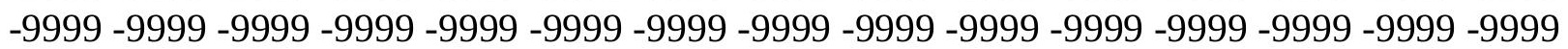


-9999 -9999 -9999 -9999 -9999 -9999 -9999 -9999 -9999 -9999 -9999 -9999 -9999 -9999 -9999 -9999 -9999 -9999 -9999 -9999 -9999 -9999 -9999 -9999 -9999 -9999 -9999 -9999 -9999 -

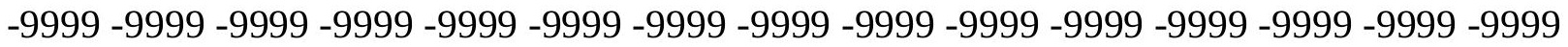
-9999 -9999 -9999 -9999 -9999 -9999 -9999 -9999 -9999 -9999 -9999 -9999 -9999 -9999 -9999 -9999 -9999 -9999 -9999 -9999 -9999 -9999 -9999 -9999 -9999 -9999 -9999 -9999 -9999 -9999 -9999 -9999 -9999 -9999 -9999 -9999 -9999 -9999 -9999 -9999 -9999 -9999 -9999 -9999 -9999 -9999 -9999 -9999 -9999 -9999 -9999 -9999 -9999 -9999 -9999 -9999 -9999 -9999 -9999 -9999

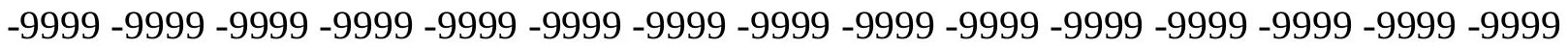

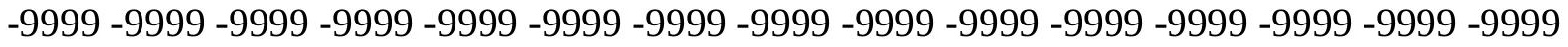
-9999 -9999 -9999 -9999 -9999 -9999 -9999 -9999 -9999 -9999 -9999 -9999 -9999 -9999 -9999 -9999 -9999 -9999 -9999 -9999 -9999 -9999 -9999 -9999 -9999 -9999 -9999 -9999 -9999 -9999 -9999 -9999 -9999 -9999 -9999 -9999 -9999 -9999 -9999 -9999 -9999 -9999 -9999 -9999 -9999 -9999 -9999 -9999 -9999 -9999 -9999 -9999 -9999 -9999 -9999 -9999 -9999 -9999 -9999 -9999 -9999 -9999 -9999 -9999 -9999 -9999 -9999 -9999 -9999 -9999 -9999 -9999 -9999 -9999 -9999 -9999 -9999 -9999 -9999 -9999 -9999 -9999 -9999 -9999 -9999 -9999 -9999 -9999 -9999 -9999 -

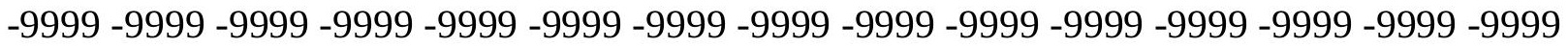
-9999 -9999 -9999 -9999 -9999 -9999 -9999 -9999 -9999 -9999 -9999 -9999 -9999 -9999 -9999 -9999 -9999 -9999 -9999 -9999 -9999 -9999 -9999 -9999 -9999 -9999 -9999 -9999 -9999 - 9999 -9999 -9999 -9999 -9999 -9999 -9999 -9999 -9999 -9999 -9999 -9999 -9999 -9999 -9999 -9999 -

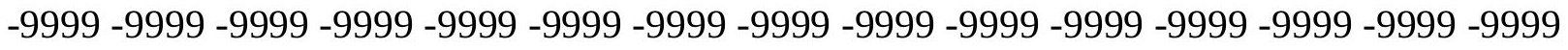

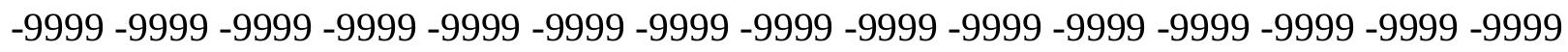

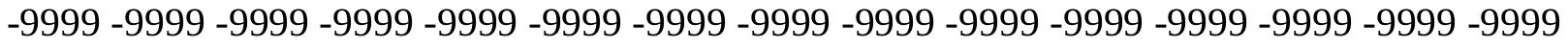
-9999 -9999 -9999 -9999 -9999 -9999 -9999 -9999 -9999 -9999 -9999 -9999 -9999 -9999 -9999 -9999 -9999 -9999 -9999 -9999 -9999 -9999 -9999 -9999 -9999 -9999 -9999 -9999 -9999 -9999 -

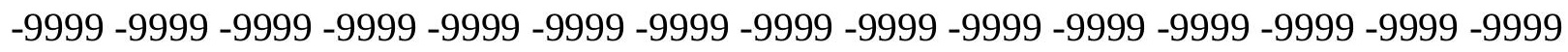
-9999 -9999 -9999 -9999 -9999 -9999 -9999 -9999 -9999 -9999 -9999 -9999 -9999 -9999 -9999 -9999 -9999 -9999 -9999 -9999 -9999 -9999 -9999 -9999 -9999 -9999 -9999 -9999 -9999 -9999 -9999 -9999 -9999 -9999 -9999 -9999 -9999 -9999 -9999 -9999 -9999 -9999 -9999 -9999 -9999 -9999 -9999 -9999 -9999 -9999 -9999 -9999 -9999 -9999 -9999 -9999 -9999 -9999 -9999 -9999 -9999 -9999 -9999 -9999 -9999 -9999 -9999 -9999 -9999 -9999 -9999 -9999 -9999 -999 -

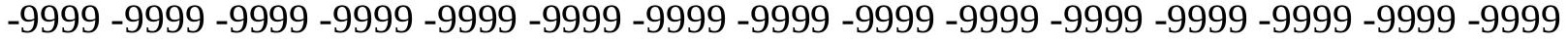
-9999 -9999 -9999 -9999 -9999 -9999 -9999 -9999 -9999 -9999 -9999 -9999 -9999 -9999 -9999 -

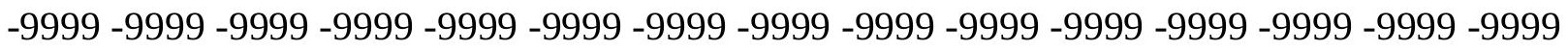

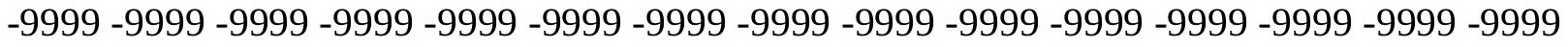

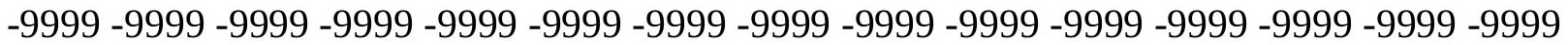

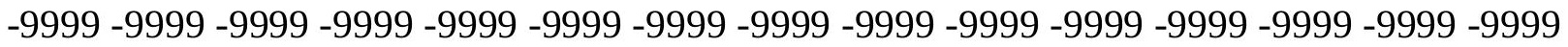

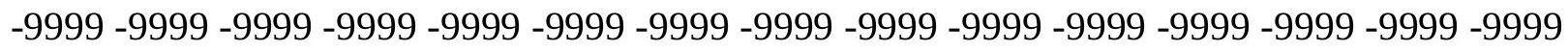

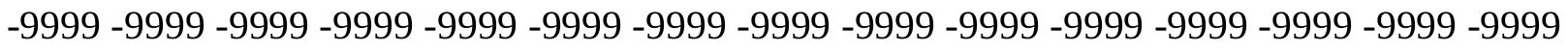

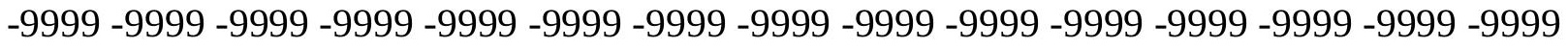
-9999 -9999 -9999 -9999 -9999 -9999 -9999 -9999 -9999 -9999 -9999 -9999 -9999 -9999 -9999 -

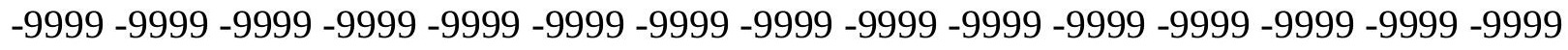

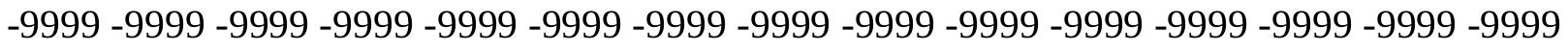
-9999 -9999 -9999 -9999 -9999 -9999 -9999 -9999 -9999 -9999 -9999 -9999 -9999 -9999 -9999 -9999 -9999 -9999 -9999 -9999 -9999 -9999 -9999 -9999-9999 -9999 -9999 -9999 -9999 -9999 -9999 -9999 -9999 -9999 -9999 -9999 -9999 -9999 -9999 -9999 -9999 -9999 -9999 -9999 -9999 -

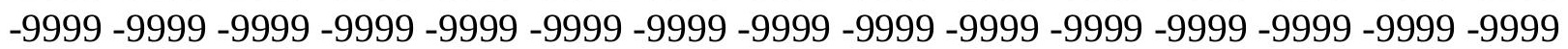


-9999 -9999 -9999 -9999 -9999 -9999 -9999 -9999 -9999 -9999 -9999 -9999 -9999 -9999 -9999 -9999 -9999 -9999 -9999 -9999 -9999 -9999 -9999 -9999 -9999 -9999 -9999 -9999 -9999 -9999 -

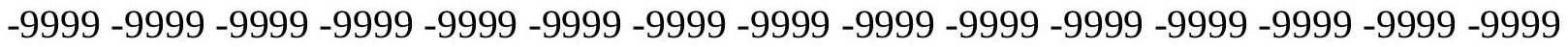
-9999 -9999 -9999 -9999 -9999 -9999 -9999 -9999 -9999 -9999 -9999 -9999 -9999 -9999 -9999 -9999 -9999 -9999 -9999 -9999 -9999 -9999 -9999 -9999-9999 -9999 -9999 -9999 -9999 -9999 -9999 -9999 -9999 -9999 -9999 -9999 -9999 -9999 -9999 -9999 -9999 -9999 -9999 -9999 -9999 -

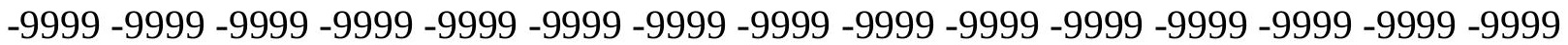
-9999 -9999 -9999 -9999 -9999 -9999 -9999 -9999 -9999 -9999 -9999 -9999 -9999 -9999 -9999 -9999 -9999 -9999 -9999 -9999 -9999 -9999 -9999 -9999 -9999 -9999 -9999 -9999 -9999 -9999 -9999 -9999 -9999 -9999 -9999 -9999 -9999 -9999 -9999 -9999 -9999 -9999 -9999 -9999 -9999 -9999 -9999 -9999 -9999 -9999 -9999 -9999 -9999 -9999 -9999 -9999 -9999 -9999 -9999 -9999 -9999 -9999 -9999 -9999 -9999 -9999 -9999 -9999 -9999 -9999 -9999 -9999 -9999 -9999 -9999 -9999 -9999 -9999 -9999 -9999 -9999 -9999 -9999 -9999 -9999 -9999 -9999 -9999 -9999 -9999 -9999 -9999 -9999 -9999 -9999 -9999 -9999 -9999 -9999 -9999 -9999 -9999 -9999 -9999 -9999 -9999 -9999 -9999 -9999 -9999 -9999 -9999 -9999 -9999 -9999 -9999 -9999 -9999 -9999 -

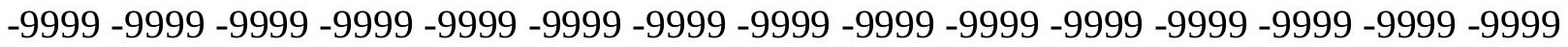
-9999 -9999 -9999 -9999 -9999 -9999 -9999 -9999 -9999 -9999 -9999 -9999 -9999 -9999 -9999 -9999 -9999 -9999 -9999 -9999 -9999 -9999 -9999 -9999 -9999 -9999 -9999 -9999 -9999 -9999 -9999 -9999 -9999 -9999 -9999 -9999 -9999 -9999 -9999 -9999 -9999 -9999 -9999 -9999 -9999 -

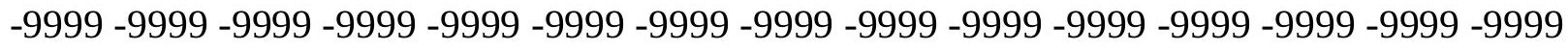

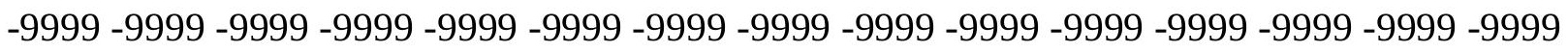
-9999 -9999 -9999 -9999 -9999 -9999 -9999 -9999 -9999 -9999 -9999 -9999 -9999 -9999 - 9999 -9999 -9999 -9999 -9999 -9999 -9999 -9999 -9999 -9999 -9999 -9999 -9999 -9999 -9999 -9999 -9999 -9999 -9999 -9999 -9999 -9999 -9999 -9999 -9999 -9999 -9999 -9999 -9999 -9999 -9999 -

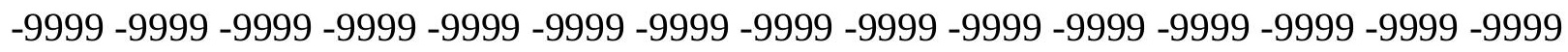
-9999 -9999 -9999 -9999 -9999 -9999 -9999 -9999 -9999 -9999 -9999 -9999 -9999 -9999 -9999 -9999 -9999 -9999 -9999 -9999 -9999 -9999 -9999 -9999 -9999 -9999 -9999 -9999 -9999 -9999 -

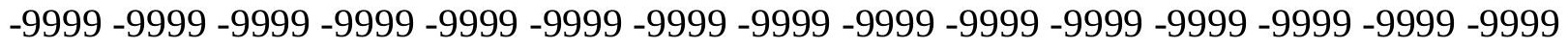
-9999 -9999 -9999 -9999 -9999 -9999 -9999 -9999 -9999 -9999 -9999 -9999 -9999 -9999 -9999 -9999 -9999 -9999 -9999 -9999 -9999 -9999 -9999 -9999 -9999 -9999 -9999 -9999 -9999 -999 -9999 -9999 -9999 -9999 -9999 -9999 -9999 -9999 -9999 -9999 -9999 -9999 -9999 -9999 -9999 -9999 -9999 -9999 -9999 -9999 -9999 -9999 -9999 -9999 -9999 -9999 -9999 -9999 -9999 -9999 -

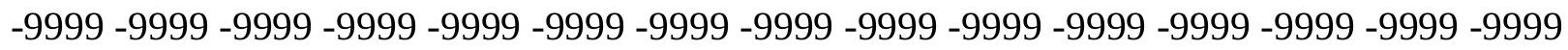

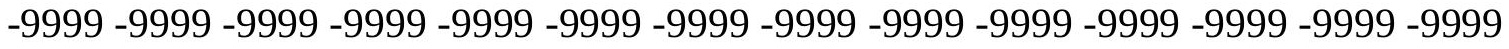
-9999 -9999 -9999 -9999 -9999 -9999 -9999 -9999 -9999 -9999 -9999 -9999 -9999 -9999 -9999

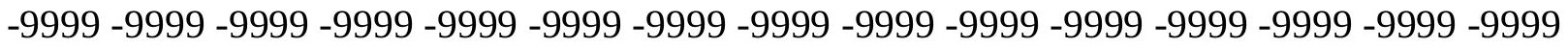

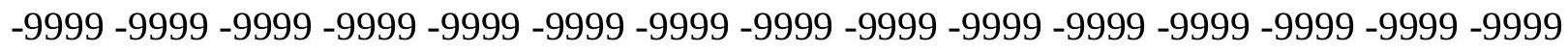

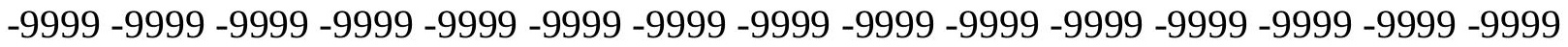

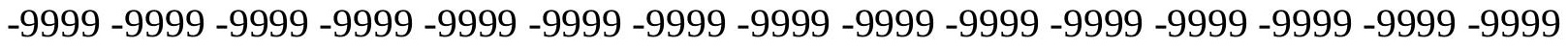
-9999 -9999 -9999 -9999 -9999 -9999 -9999 -9999 -9999 -9999 -9999 -9999 -9999 -9999 -9999 -

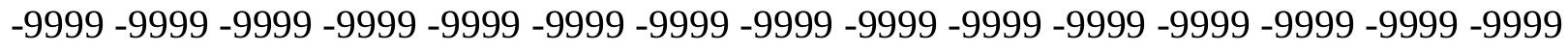

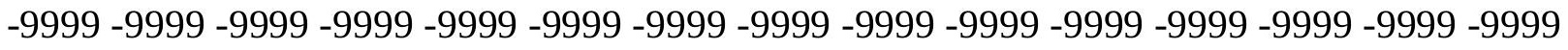
-9999 -9999 -9999 -9999 -9999 -9999 -9999 -9999 -9999 -9999 -9999 -9999 -9999 -9999 -9999 -9999 -9999 -9999 -9999 -9999 -9999 -9999 -9999 -9999-9999 -9999 -9999 -9999 -9999 -9999 -9999 -9999 -9999 -9999 -9999 -9999 -9999 -9999 -9999 -9999 -9999 -9999 -9999 -9999 -9999 -

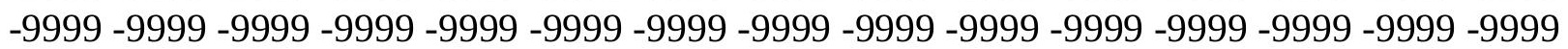


-9999 -9999 -9999 -9999 -9999 -9999 -9999 -9999 -9999 -9999 -9999 -9999 -9999 -9999 -9999 -9999 -9999 -9999 -9999 -9999 -9999 -9999 -9999 -9999 -9999 -9999 -9999 -9999 -9999 -9999 -

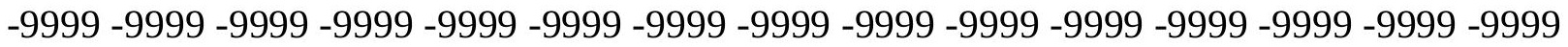
-9999 -9999 -9999 -9999 -9999 -9999 -9999 -9999 -9999 -9999 -9999 -9999 -9999 -9999 -9999 -9999 -9999 -9999 -9999 -9999 -9999 -9999 -9999 -9999-9999 -9999 -9999 -9999 -9999 -9999 -9999 -9999 -9999 -9999 -9999 -9999 -9999 -9999 -9999 -9999 -9999 -9999 -9999 -9999 -9999 -9999 -9999 -9999 -9999 -9999 -9999 -9999 -9999 -9999 -9999 -9999 -9999 -9999 -9999 -9999

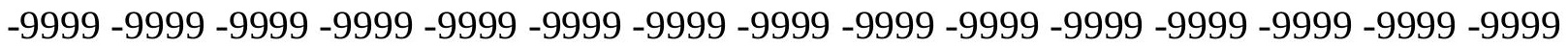

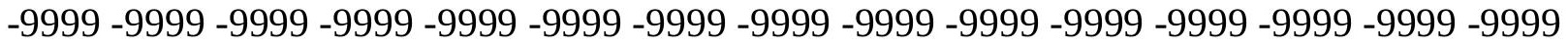
-9999 -9999 -9999 -9999 -9999 -9999 -9999 -9999 -9999 -9999 -9999 -9999 -9999 -9999 -9999 -9999 -9999 -9999 -9999 -9999 -9999 -9999 -9999 -9999 -9999 -9999 -9999 -9999 -9999 -9999 -9999 -9999 -9999 -9999 -9999 -9999 -9999 -9999 -9999 -9999 -9999 -9999 -9999 -9999 -9999 -9999 -9999 -9999 -9999 -9999 -9999 -9999 -9999 -9999 -9999 -9999 -9999 -9999 -9999 -9999 -9999 -9999 -9999 -9999 -9999 -9999 -9999 -9999 -9999 -9999 -9999 -9999 -9999 -9999 -9999 -9999 -9999 -9999 -9999 -9999 -9999 -9999 -9999 -9999 -9999 -9999 -9999 -9999 -9999

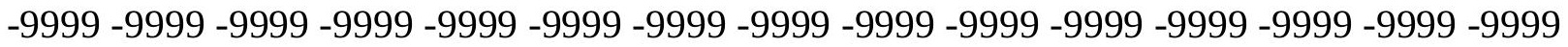
-9999 -9999 -9999 -9999 -9999 -9999 -9999 -9999 -9999 -9999 -9999 -9999 -9999 -9999 -9999 -9999 -9999 -9999 -9999 -9999 -9999 -9999 -9999 -9999 -9999 -9999 -9999 -9999 -9999 -9999 -9999 -9999 -9999 -9999 -9999 -9999 -9999 -9999 -9999 -9999 -9999 -9999 -9999 -9999 -9999 -

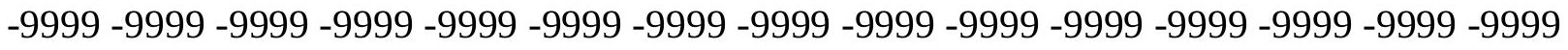

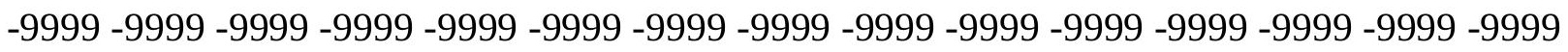
-9999 -9999 -9999 -9999 -9999 -9999 -9999 -9999 -9999 -9999 -9999 -9999 -9999 -9999 -9999 -9999 -9999 -9999 -9999 -9999 -9999 -9999 -9999 -9999 -9999 -9999 -9999 -9999 -9999 -9999 -9999 -9999 -9999 -9999 -9999 -9999 -9999 -9999 -9999 -9999 -9999 -9999 -9999 -9999 -9999 -

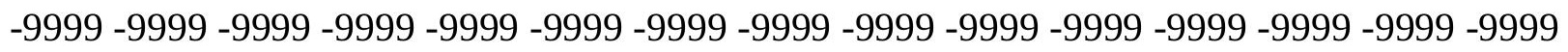
-9999 -9999 -9999 -9999 -9999 -9999 -9999 -9999 -9999 -9999 -9999 -9999 -9999 -9999 -9999 -9999 -9999 -9999 -9999 -9999 -9999 -9999 -9999 -9999 -9999 -9999 -9999 -9999 -9999 -9999 -

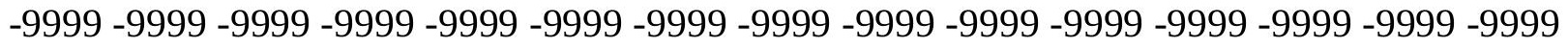
-9999 -9999 -9999 -9999 -9999 -9999 -9999 -9999 -9999 -9999 -9999 -9999 -9999 -9999 -9999 -9999 -9999 -9999 -9999 -9999 -9999 -9999 -9999 -9999 -9999 -9999 -9999 -9999 -9999 -999 -9999 -9999 -9999 -9999 -9999 -9999 -9999 -9999 -9999 -9999 -9999 -9999 -9999 -9999 -9999 -9999 -9999 -9999 -9999 -9999 -9999 -9999 -9999 -9999 -9999 -9999 -9999 -9999 -9999 -9999 -

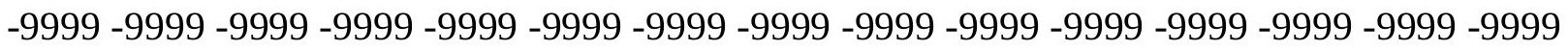

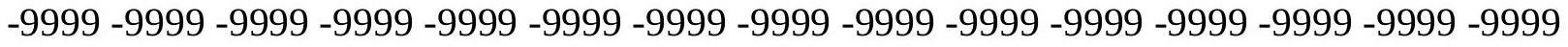

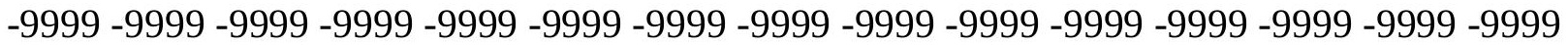

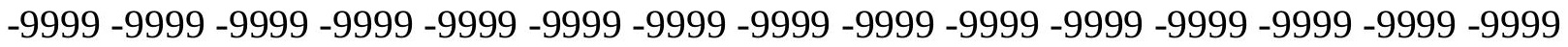

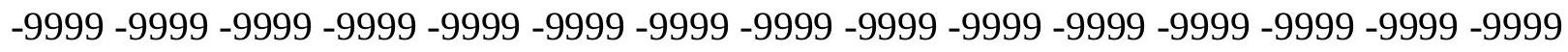

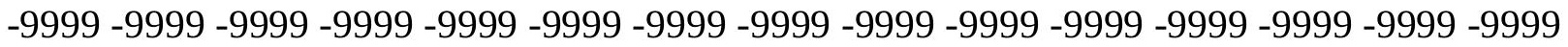
-9999 -9999 -9999 -9999 -9999 -9999 -9999 -9999 -9999 -9999 -9999 -9999 -9999 - 9999 - -999 -9999 -9999 -9999 -9999 -9999 -9999 -9999 -9999 -9999 -9999 -9999 -9999 -9999 -9999 - -999 -

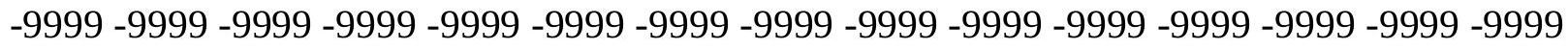

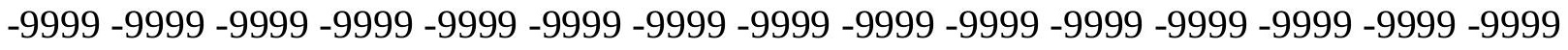
-9999 -9999 -9999 -9999 -9999 -9999 -9999 -9999 -9999 -9999 -9999 -9999 -9999 -9999 -9999 -9999 -9999 -9999 -9999 -9999 -9999 -9999 -9999 -9999-9999 -9999 -9999 -9999 -9999 -9999 -9999 -9999 -9999 -9999 -9999 -9999 -9999 -9999 -9999 -9999 -9999 -9999 -9999 -9999 -9999 -

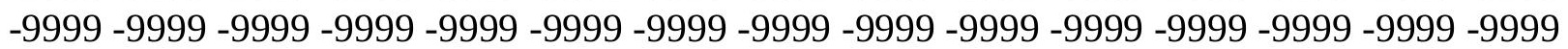


-9999 -9999 -9999 -9999 -9999 -9999 -9999 -9999 -9999 -9999 -9999 -9999 -9999 -9999 -9999 -9999 -9999 -9999 -9999 -9999 -9999 -9999 -9999 -9999 -9999 -9999 -9999 -9999 -9999 -9999 -9999 -9999 -9999 -9999 -9999 -9999 -9999 -9999 -9999 -9999 -9999 -9999 -9999 -9999 -9999 -9999 -9999 -9999 -9999 -9999 -9999 -9999 -9999 -9999 -9999 -9999 -9999 -9999 -9999 -9999 -9999 -9999 -9999 -9999 -9999 -9999 -9999 -9999 -9999 -9999 -9999 -9999 -9999 -9999 -9999 -9999 -9999 -9999 -9999 -9999 -9999 -9999 -9999 -9999 -9999 -9999 -9999 -9999 -9999 -9999 -9999 -9999 -9999 -9999 -9999 -9999 -9999 -9999 -9999 -9999 -9999 -9999 -9999 -9999 -9999 -

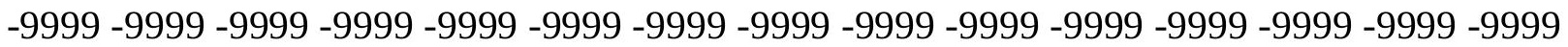
-9999 -9999 -9999 -9999 -9999 -9999 -9999 -9999 -9999 -9999 -9999 -9999 -9999 -9999 -9999 -9999 -9999 -9999 -9999 -9999 -9999 -9999 -9999 -9999 -9999 -9999 -9999 -9999 -9999 -9999 -

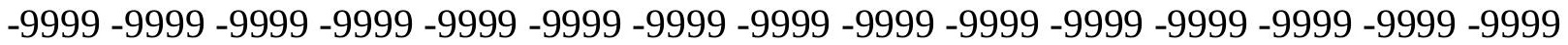
-9999 -9999 -9999 -9999 -9999 -9999 -9999 -9999 -9999 -9999 -9999 -9999 -9999 -9999 -9999 -9999 -9999 -9999 -9999 -9999 -9999 -9999 -9999 -9999 -9999 -9999 -9999 -9999 -9999 -9999 -9999 -9999 -9999 -9999 -9999 -9999 -9999 -9999 -9999 -9999 -9999 -9999 -9999 -9999 -9999 -9999 -9999 -9999 -9999 -9999 -9999 -9999 -9999 -9999 -9999 -9999 -9999 -9999 -9999 -9999

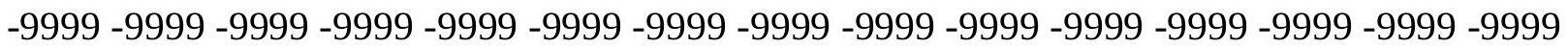
-9999 -9999 -9999 -9999 -9999 -9999 -9999 -9999 -9999 -9999 -9999 -9999 -9999 -9999 -9999 -9999 -9999 -9999 -9999 -9999 -9999 -9999 -9999 -9999 -9999 -9999 -9999 -9999 -9999 -9999 -9999 -9999 -9999 -9999 -9999 -9999 -9999 -9999 -9999 -9999 -9999 -9999 -9999 -9999 -9999 -9999 -9999 -9999 -9999 -9999 -9999 -9999 -9999 -9999 -9999 -9999 -9999 -9999 -9999 -9999 -9999 -9999 -9999 -9999 -9999 -9999 -9999 -9999 -9999 -9999 -9999 -9999 -9999 -9999 -9999 -9999 -9999 -9999 -9999 -9999 -9999 -9999 -9999 -9999 -9999 -9999 -9999 -9999 -9999 -9999 -9999 -9999 -9999 -9999 -9999 -9999 -9999 -9999 -9999 -9999 -9999 -9999 -9999 -9999 -9999 -9999 -9999 -9999 -9999 -9999 -9999 -9999 -9999 -9999 -9999 -9999 -9999 -9999 -9999 -9999 -9999 -9999 -9999 -9999 -9999 -9999 -9999 -9999 -9999 -9999 -9999 -9999 -9999 -9999 -9999 -9999 -9999 -9999 -9999 -9999 -9999 -9999 -9999 -9999 -9999 -9999 -9999 -9999 -9999 -9999 -9999 -9999 -9999 -9999 -9999 -9999 -9999 -9999 -9999 -9999 -9999 -9999 -9999 -9999 -9999 -9999 -9999 -9999 -9999 -9999 -9999 -9999 -9999 -9999 -9999 -9999 -9999 -9999 -9999

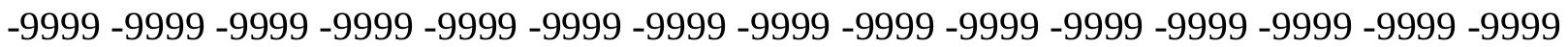
-9999 -9999 -9999 -9999 -9999 -9999 -9999 -9999 -9999 -9999 -9999 -9999 -9999 -9999 -9999 -9999 -9999 -9999 -9999 -9999 -9999 -9999 -9999 -9999 -9999 -9999 -9999 -9999 -9999 -9999 -

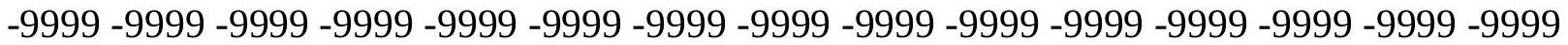
-9999 -9999 -9999 -9999 -9999 -9999 -9999 -9999 -9999 -9999 -9999 -9999 -9999 -9999 -9999 -9999 -9999 -9999 -9999 -9999 -9999 -9999 -9999 -9999 -9999 -9999 -9999 -9999 -9999 -9999 -9999 -9999 -9999 -9999 -9999 -9999 -9999 -9999 -9999 -9999 -9999 -9999 -9999 -9999 -9999 -9999 -9999 -9999 -9999 -9999 -9999 -9999 -9999 -9999 -9999 -9999 -9999 -9999 -9999 -9999 -9999 -9999 -9999 -9999 -9999 -9999 -9999 -9999 -9999 -9999 -9999 -9999 -9999 -9999 -9999

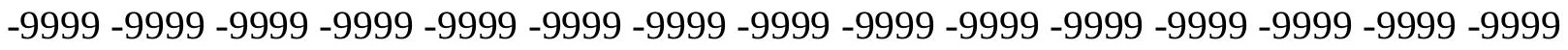
-9999 -9999 -9999 -9999 -9999 -9999 -9999 -9999 -9999 -9999 -9999 -9999 -9999 -9999 -9999 -9999 -9999 -9999 -9999 -9999 -9999 -9999 -9999 -9999 -9999 -9999 -9999 -9999 -9999 -9999 -9999 -9999 -9999 -9999 -9999 -9999 -9999 -9999 -9999 -9999 -9999 -9999 -9999 -9999 -9999 -999 -9999 -9999 -9999 -9999 -9999 -9999 -9999 -9999 -9999 -9999 -9999 -9999 -9999 -9999 -9999 -9999 -9999 -9999 -9999 -9999 -9999 -9999 -9999 -9999 -9999 -9999 -9999 -9999 -9999 -9999 -9999 -9999 -9999 -9999 -9999 -9999 -9999 -9999 -9999 -9999 -9999 -9999 -9999 -9999 -9999 -9999 -9999 -9999 -9999 -9999 -9999 -9999 -9999 -9999 -9999 -9999 -9999 -9999 -9999 -9999 -9999 -9999 -9999 -9999 -9999 -9999 -9999 -9999 -9999 -9999 -9999 -9999 -9999 -9999 
-9999 -9999 -9999 -9999 -9999 -9999 -9999 -9999 -9999 -9999 -9999 -9999 -9999 -9999 -9999 -9999 -9999 -9999 -9999 -9999 -9999 -9999 -9999 -9999 -9999 -9999 -9999 -9999 -9999 -9999 -

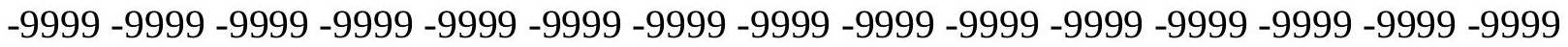
-9999 -9999 -9999 -9999 -9999 -9999 -9999 -9999 -9999 -9999 -9999 -9999 -9999 -9999 -9999 -9999 -9999 -9999 -9999 -9999 -9999 -9999 -9999 -9999-9999 -9999 -9999 -9999 -9999 -9999 -9999 -9999 -9999 -9999 -9999 -9999 -9999 -9999 -9999 -9999 -9999 -9999 -9999 -9999 -9999 -9999 -9999 -9999 -9999 -9999 -9999 -9999 -9999 -9999 -9999 -9999 -9999 -9999 -9999 -9999

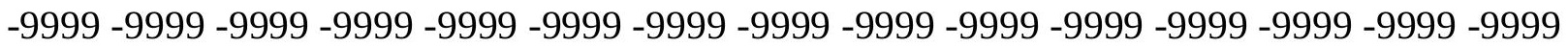

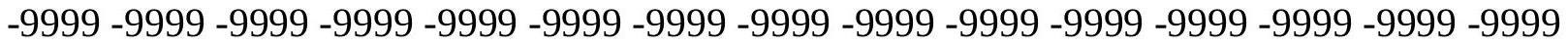
-9999 -9999 -9999 -9999 -9999 -9999 -9999 -9999 -9999 -9999 -9999 -9999 -9999 -9999 -9999 -9999 -9999 -9999 -9999 -9999 -9999 -9999 -9999 -9999 -9999 -9999 -9999 -9999 -9999 -9999 -9999 -9999 -9999 -9999 -9999 -9999 -9999 -9999 -9999 -9999 -9999 -9999 -9999 -9999 -9999 -9999 -9999 -9999 -9999 -9999 -9999 -9999 -9999 -9999 -9999 -9999 -9999 -9999 -9999 -9999 -

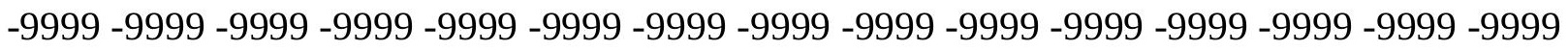
-9999 -9999 -9999 -9999 -9999 -9999 -9999 -9999 -9999 -9999 -9999 -9999 -9999 -9999 -9999 -

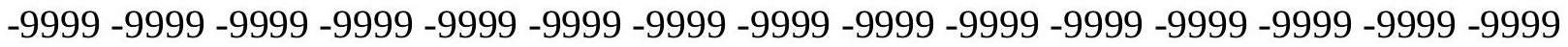
-9999 -9999 -9999 -9999 -9999 -9999 -9999 -9999 -9999 -9999 -9999 -9999 -9999 -9999 -9999 -9999 -9999 -9999 -9999 -9999 -9999 -9999 -9999 -9999 -9999 -9999 -9999 -9999 -9999 -9999 -9999 -9999 -9999 -9999 -9999 -9999 -9999 -9999 -9999 -9999 -9999 -9999 -9999 -9999 -9999 -

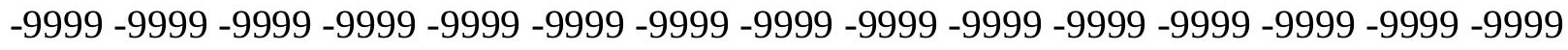

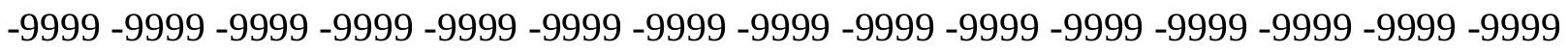

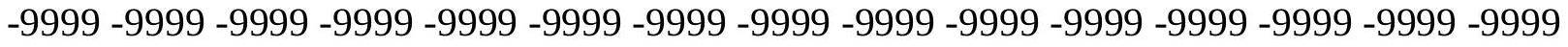
-9999 -9999 -9999 -9999 -9999 -9999 -9999 -9999 -9999 -9999 -9999 -9999 -9999 -9999 -9999 -9999 -9999 -9999 -9999 -9999 -9999 -9999 -9999 -9999 -9999 -9999 -9999 -9999 -9999 -9999 -

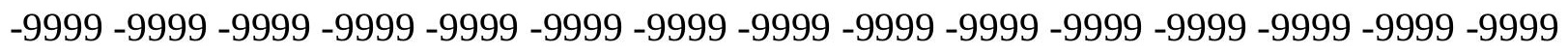
-9999 -9999 -9999 -9999 -9999 -9999 -9999 -9999 -9999 -9999 -9999 -9999 -9999 -9999 -9999 -9999 -9999 -9999 -9999 -9999 -9999 -9999 -9999 -9999 -9999 -9999 -9999 -9999 -9999 -

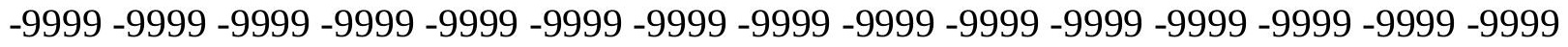
-9999 -9999 -9999 -9999 -9999 -9999 -9999 -9999 -9999 -9999 -9999 -9999 -9999 -9999 -9999 -9999 -9999 -9999 -9999 -9999 -9999 -9999 -9999 -9999 -9999 -9999 -9999 -9999 -9999 -999 -

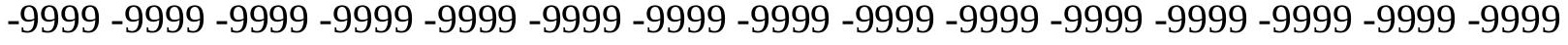
-9999 -9999 -9999 -9999 -9999 -9999 -9999 -9999 -9999 -9999 -9999 -9999 -9999 -9999 -9999 -

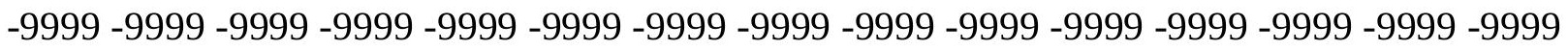

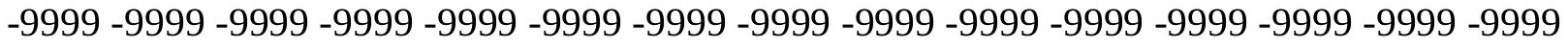

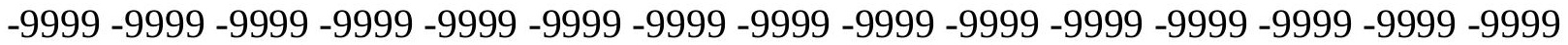
-9999 -9999 -9999 -9999 -9999 -9999 -9999 -9999 -9999 -9999 -9999 -9999 -9999 -9999 -9999

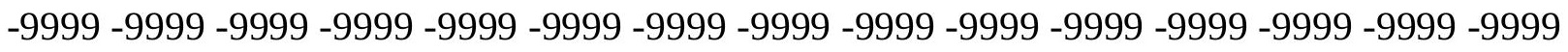

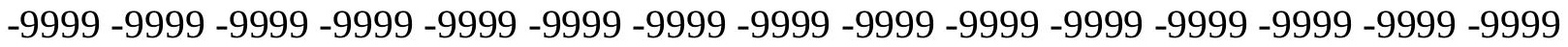
-9999 -9999 -9999 -9999 -9999 -9999 -9999 -9999 -9999 -9999 -9999 -9999 -9999 - 9999 - -999 -9999 -9999 -9999 -9999 -9999 -9999 -9999 -9999 -9999 -9999 -9999 -9999 -9999 -9999 -9999 -

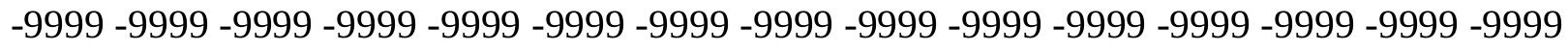

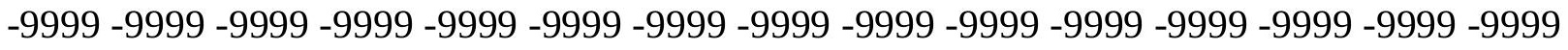
-9999 -9999 -9999 -9999 -9999 -9999 -9999 -9999 -9999 -9999 -9999 -9999 -9999 -9999 -9999 -9999 -9999 -9999 -9999 -9999 -9999 -9999 -9999 -9999-9999 -9999 -9999 -9999 -9999 -9999 -9999 -9999 -9999 -9999 -9999 -9999 -9999 -9999 -9999 -9999 -9999 -9999 -9999 -9999 -9999 -

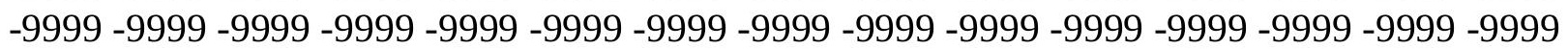


-9999 -9999 -9999 -9999 -9999 -9999 -9999 -9999 -9999 -9999 -9999 -9999 -9999 -9999 -9999 -9999 -9999 -9999 -9999 -9999 -9999 -9999 -9999 -9999 -9999 -9999 -9999 -9999 -9999 -9999 -9999 -9999 -9999 -9999 -9999 -9999 -9999 -9999 -9999 -9999 -9999 -9999 -9999 -9999 - 9999 -9999 -9999 -9999 -9999 -9999 -9999 -9999 -9999 -9999 -9999 -9999 -9999 -9999 -9999 -9999 -9999 -9999 -9999 -9999 -9999 -9999 -9999 -9999 -9999 -9999 -9999 -9999 -9999 -9999 - -9999 -9999 -9999 -9999 -9999 -9999 -9999 -9999 -9999 -9999 -9999 -9999 -9999 -9999 -9999 -9999 -9999 -9999 -9999 -9999 -9999 -9999 -9999 -9999 -9999 -9999 -9999 -9999 -9999 -9999

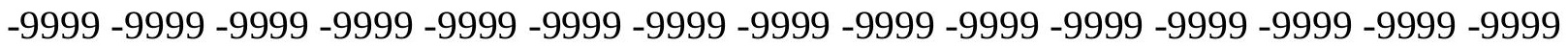

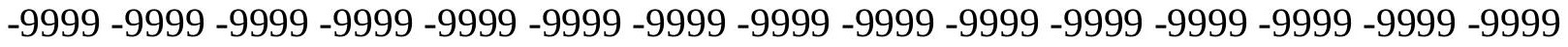
-9999 -9999 -9999 -9999 -9999 -9999 -9999 -9999 -9999 -9999 -9999 -9999 -9999 -9999 -9999

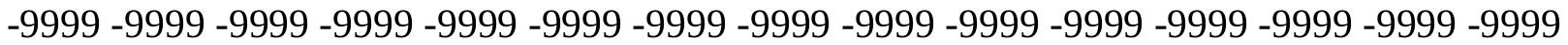
-9999 -9999 -9999 -9999 -9999 -9999 -9999 -9999 -9999 -9999 -9999 -9999 -9999 -9999 -9999 -9999 -9999 -9999 -9999 -9999 -9999 -9999 -9999 -9999 -9999 -9999 -9999 -9999 -9999 -9999 -9999 -9999 -9999 -9999 -9999 -9999 -9999 -9999 -9999 -9999 -9999 -9999 -9999 -9999 - -9999 -9999 -9999 -9999 -9999 -9999 -9999 -9999 -9999 -9999 -9999 -9999 -9999 -9999 -9999 -9999

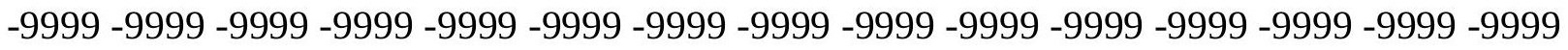
-9999 -9999 -9999 -9999 -9999 -9999 -9999 -9999 -9999 -9999 -9999 -9999 -9999 -9999 -9999 -9999 -9999 -9999 -9999 -9999 -9999 -9999 -9999 -9999 -9999 -9999 -9999 -9999 -9999 -9999 -9999 -9999 -9999 -9999 -9999 -9999 -9999 -9999 -9999 -9999 -9999 -9999 -9999 -9999 -9999 -

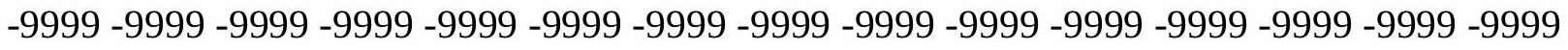
-9999 -9999 -9999 -9999 -9999 -9999 -9999 -9999 -9999 -9999 -9999 -9999 -9999 -9999 -9999 -999 -9999 -9999 -9999 -9999 -9999 -9999 -9999 -9999 -9999 -9999 -9999 -9999 -9999 -9999 -9999 -9999 -9999 -9999 -9999 -9999 -9999 -9999 -9999 -9999 -9999 -9999 -9999 -9999 -9999 -9999 -9999 -9999 -9999 -9999 -9999 -9999 -9999 -9999 -9999 -9999 -9999 -9999 -9999 -9999 -9999 -9999 -9999 -9999 -9999 -9999 -9999 -9999 -9999 -9999 -9999 -9999 -9999 -9999 -9999 -9999 -9999 -9999 -9999 -9999 -9999 -9999 -9999 -9999 -9999 -9999 -9999 -9999 -9999 -9999 -9999 -9999 -9999 -9999 -9999 -9999 -9999 -9999 -9999 -9999 -9999 -9999 -9999 -9999 -9999 -9999 -9999 -9999 -9999 -9999 -9999 -9999 -9999 -9999 -9999 -9999 -9999 -9999 -9999 -9999 -9999 -9999 -9999 -9999 -9999 -9999 -9999 -9999 -9999 -9999 -9999 -9999 -9999 -9999 -9999 -9999 -9999 -9999 -9999 -9999 -9999 -9999 -9999 -9999 -9999 -9999 -9999 -9999 -9999 -9999 -999 -9999 -9999 -9999 -9999 -9999 -9999 -9999 -9999 -9999 -9999 -9999 -9999 -9999 -9999 -9999 -9999 -9999 -9999 -9999 -9999 -9999 -9999 -9999 -9999 -9999 -9999 -9999 -9999 -9999 -

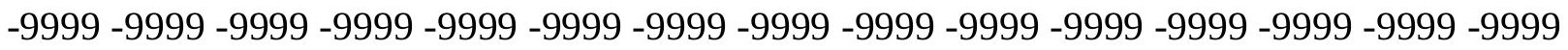

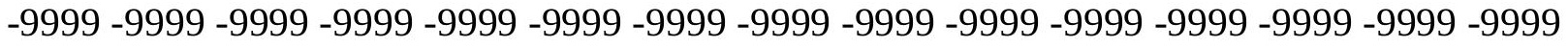

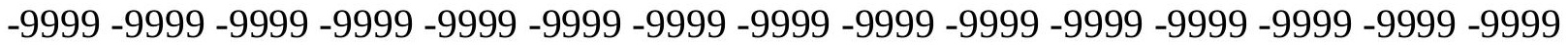
-9999 -9999 -9999 -9999 -9999 -9999 -9999 -9999 -9999 -9999 -9999 -9999 -9999 -9999 -9999 -

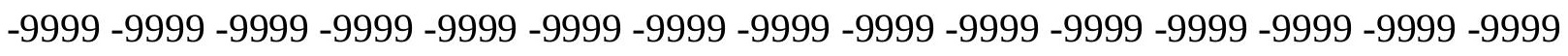

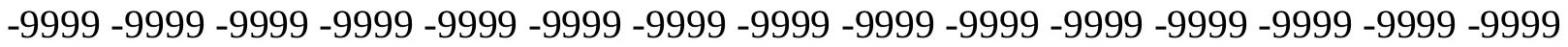

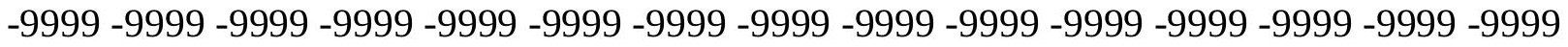
-9999 -9999 -9999 -9999 -9999 -9999 -9999 -9999 -9999 -9999 -9999 -9999 -9999 -9999 -9999 -

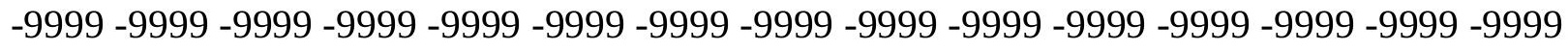

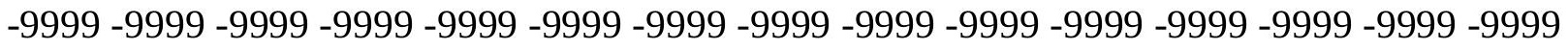
-9999 -9999 -9999 -9999 -9999 -9999 -9999 -9999 -9999 -9999 -9999 -9999 -9999 -9999 -9999 -9999 -9999 -9999 -9999 -9999 -9999 -9999 -9999 -9999-9999 -9999 -9999 -9999 -9999 -9999 -9999 -9999 -9999 -9999 -9999 -9999 -9999 -9999 -9999 -9999 -9999 -9999 -9999 -9999 -9999 -

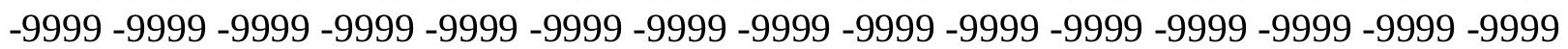


-9999 -9999 -9999 -9999 -9999 -9999 -9999 -9999 -9999 -9999 -9999 -9999 -9999 -9999 -9999 -9999 -9999 -9999 -9999 -9999 -9999 -9999 -9999 -9999 -9999 -9999 -9999 -9999 -9999 -9999 -

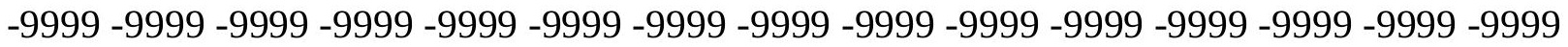
-9999 -9999 -9999 -9999 -9999 -9999 -9999 -9999 -9999 -9999 -9999 -9999 -9999 -9999 -9999 -9999 -9999 -9999 -9999 -9999 -9999 -9999 -9999 -9999-9999 -9999 -9999 -9999 -9999 -9999 -9999 -9999 -9999 -9999 -9999 -9999 -9999 -9999 -9999 -9999 -9999 -9999 -9999 -9999 -9999 -9999 -9999 -9999 -9999 -9999 -9999 -9999 -9999 -9999 -9999 -9999 -9999 -9999 -9999 -9999

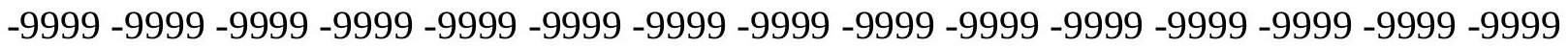

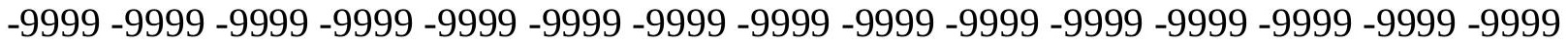
-9999 -9999 -9999 -9999 -9999 -9999 -9999 -9999 -9999 -9999 -9999 -9999 -9999 -9999 -9999 -9999 -9999 -9999 -9999 -9999 -9999 -9999 -9999 -9999 -9999 -9999 -9999 -9999 -9999 -9999 -9999 -9999 -9999 -9999 -9999 -9999 -9999 -9999 -9999 -9999 -9999 -9999 -9999 -9999 -9999 -9999 -9999 -9999 -9999 -9999 -9999 -9999 -9999 -9999 -9999 -9999 -9999 -9999 -9999 -9999 -9999 -9999 -9999 -9999 -9999 -9999 -9999 -9999 -9999 -9999 -9999 -9999 -9999 - 9999 -9999 -9999 -9999 -9999 -9999 -9999 -9999 -9999 -9999 -9999 -9999 -9999 -9999 -9999 -9999

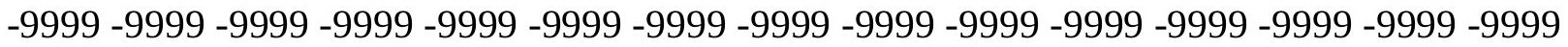
-9999 -9999 -9999 -9999 -9999 -9999 -9999 -9999 -9999 -9999 -9999 -9999 -9999 -9999 -9999 -9999 -9999 -9999 -9999 -9999 -9999 -9999 -9999 -9999 -9999 -9999 -9999 -9999 -9999 -9999 -9999 -9999 -9999 -9999 -9999 -9999 -9999 -9999 -9999 -9999 -9999 -9999 -9999 -9999 -9999 -

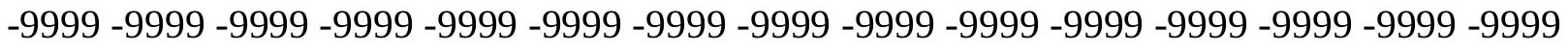

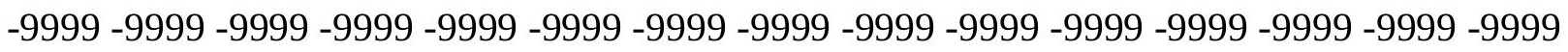
-9999 -9999 -9999 -9999 -9999 -9999 -9999 -9999 -9999 -9999 -9999 -9999 -9999 -9999 -9999 -9999 -9999 -9999 -9999 -9999 -9999 -9999 -9999 -9999 -9999 -9999 -9999 -9999 -9999 -9999 -9999 -9999 -9999 -9999 -9999 -9999 -9999 -9999 -9999 -9999 -9999 -9999 -9999 -9999 -9999 -

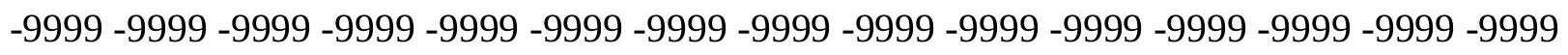
-9999 -9999 -9999 -9999 -9999 -9999 -9999 -9999 -9999 -9999 -9999 -9999 -9999 -9999 -9999 -9999 -9999 -9999 -9999 -9999 -9999 -9999 -9999 -9999 -9999 -9999 -9999 -9999 -9999 -9999 -

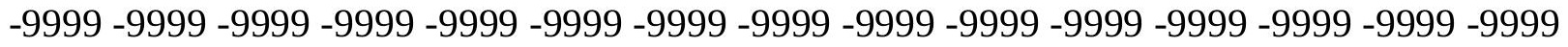
-9999 -9999 -9999 -9999 -9999 -9999 -9999 -9999 -9999 -9999 -9999 -9999 -9999 -9999 -9999 -9999 -9999 -9999 -9999 -9999 -9999 -9999 -9999 -9999 -9999 -9999 -9999 -9999 -9999 -999 -9999 -9999 -9999 -9999 -9999 -9999 -9999 -9999 -9999 -9999 -9999 -9999 -9999 -9999 -9999 -9999 -9999 -9999 -9999 -9999 -9999 -9999 -9999 -9999 -9999 -9999 -9999 -9999 -9999 -9999 -

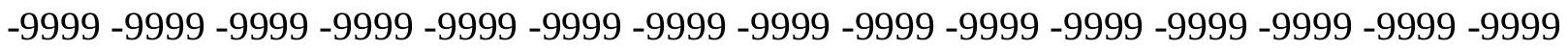

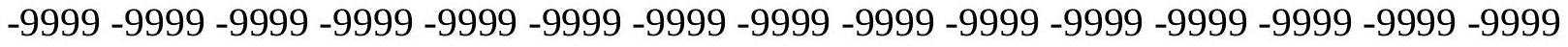

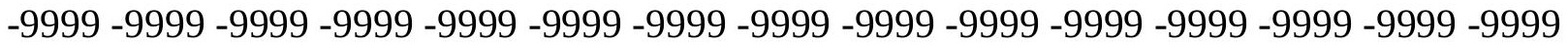

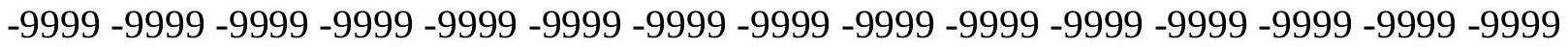

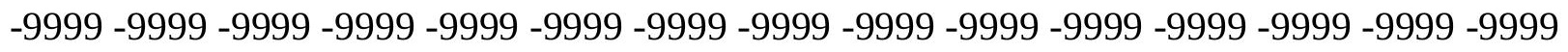

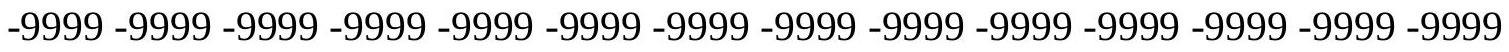
-9999 -9999 -9999 -9999 -9999 -9999 -9999 -9999 -9999 -9999 -9999 -9999 -9999 -9999 -9999 -9999 -9999 -9999 -9999 -9999 -9999 -9999 -9999 -9999 -9999 -9999 -9999 -9999 -9999 -9999 -

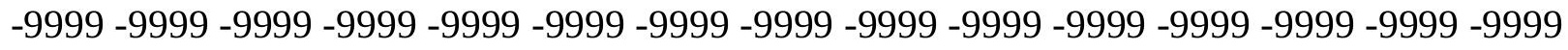

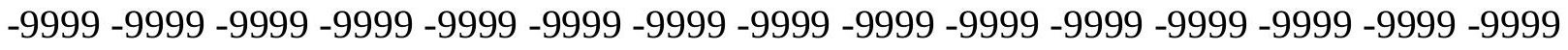
-9999 -9999 -9999 -9999 -9999 -9999 -9999 -9999 -9999 -9999 -9999 -9999 -9999 -9999 -9999 -9999 -9999 -9999 -9999 -9999 -9999 -9999 -9999 -9999-9999 -9999 -9999 -9999 -9999 -9999 -9999 -9999 -9999 -9999 -9999 -9999 -9999 -9999 -9999 -9999 -9999 -9999 -9999 -9999 -9999 -

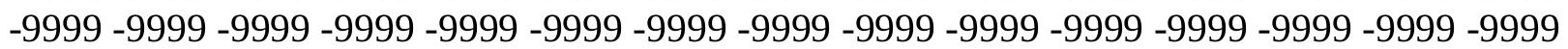


-9999 -9999 -9999 -9999 -9999 -9999 -9999 -9999 -9999 -9999 -9999 -9999 -9999 -9999 -9999 -9999 -9999 -9999 -9999 -9999 -9999 -9999 -9999 -9999 -9999 -9999 -9999 -9999 -9999 -9999 -9999 -9999 -9999 -9999 -9999 -9999 -9999 -9999 -9999 -9999 -9999 -9999 -9999 -9999 -9999 -9999 -9999 -9999 -9999 -9999 -9999 -9999 -9999 -9999 -9999 -9999 -9999 -9999 -9999 -9999 -9999 -9999 -9999 -9999 -9999 -9999 -9999 -9999 -9999 -9999 -9999 -9999 -9999 -9999 -9999 -9999 -9999 -9999 -9999 -9999 -9999 -9999 -9999 -9999 -9999 -9999 -9999 -9999 -9999 -9999 -9999 -9999 -9999 -9999 -9999 -9999 -9999 -9999 -9999 -9999 -9999 -9999 -9999 -9999 -9999 -9999 -9999 -9999 -9999 -9999 -9999 -9999 -9999 -9999 -9999 -9999 -9999 -9999 -9999 -9999 -9999 -9999 -9999 -9999 -9999 -9999 -9999 -9999 -9999 -9999 -9999 -9999 -9999 -9999 -9999 -9999 -9999 -9999 -9999 -9999 -9999 -9999 -9999 -9999 -9999 -9999 -9999 -9999 -9999 -9999 -

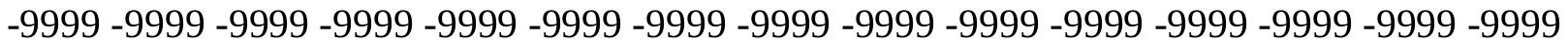
-9999 -9999 -9999 -9999 -9999 -9999 -9999 -9999 -9999 -9999 -9999 -9999 -9999 -9999 -9999

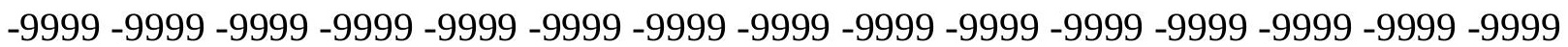
-9999 -9999 -9999 -9999 -9999 -9999 -9999 -9999 -9999 -9999 -9999 -9999 -9999 -9999 -9999 -9999 -9999 -9999 -9999 -9999 -9999 -9999 -9999 -9999 -9999 -9999 -9999 -9999 -9999 -9999 -9999 -9999 -9999 -9999 -9999 -9999 -9999 -9999 -9999 -9999 -9999 -9999 -9999 -9999 -9999 -

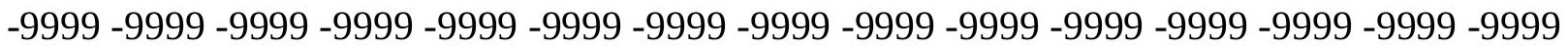
-9999 -9999 -9999 -9999 -9999 -9999 -9999 -9999 -9999 -9999 -9999 -9999 -9999 -9999 - -999 -9999 -9999 -9999 -9999 -9999 -9999 -9999 -9999 -9999 -9999 -9999 -9999 -9999 -9999 -9999 -9999 -9999 -9999 -9999 -9999 -9999 -9999 -9999 -9999 -9999 -9999 -9999 -9999 -9999 -9999

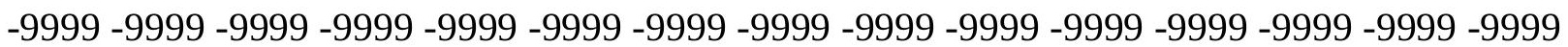
-9999 -9999 -9999 -9999 -9999 -9999 -9999 -9999 -9999 -9999 -9999 -9999 -9999 -9999 -9999 -9999 -9999 -9999 -9999 -9999 -9999 -9999 -9999 -9999 -9999 -9999 -9999 -9999 -9999 -9999 -9999 -9999 -9999 -9999 -9999 -9999 -9999 -9999 -9999 -9999 -9999 -9999 -9999 -9999 -9999

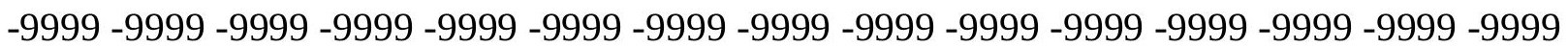
-9999 -9999 -9999 -9999 -9999 -9999 -9999 -9999 -9999 -9999 -9999 -9999 -9999 -9999 -9999 -9999 -9999 -9999 -9999 -9999 -9999 -9999 -9999 -9999 -9999 -9999 -9999 -9999 -9999 -9999 -9999 -9999 -9999 -9999 -9999 -9999 -9999 -9999 -9999 -9999 -9999 -9999 401.6620788574 401.6983947754401 .9889831543402 .4393615723403 .0233154297403 .6625061035 404.3156738281404 .9696960449405 .6425476074406 .3609313965407 .1292114258 407.924041748408 .6707763672409 .2937011719409 .8389892578410 .3905944824 410.647064209410 .4686584473410 .0519104004409 .8660583496410 .0528869629 410.4262390137410 .6883850098410 .9674377441411 .2944946289411 .6948242188 412.2819519043413 .1953430176414 .1817016602415 .1983947754416 .3114929199 417.2894592285 417.9281616211418.3983154297419.0264282227420.0320129395 421.2519836426422 .5872802734424 .0661315918425 .6713867188427 .3002929688 428.3324279785429 .0858459473429 .9742126465431 .107421875432 .3799743652 433.6593017578434 .8779907227435 .9048461914436 .6046142578436 .8964233398 436.87890625436 .810760498436 .9458312988437 .4243164062438 .2457885742 439.3035583496 440.5139770508 -9999 -9999 -9999 -9999 -9999 -9999 -9999 -9999 -9999 -9999 -9999 -9999 -9999 -9999 -9999 -9999 -9999 -9999 -9999 -9999 -9999 -9999 -9999 -9999

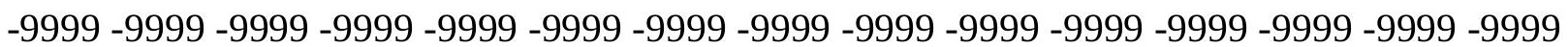
-9999 -9999 -9999 -9999 -9999 -9999 -9999 -9999 -9999 -9999 -9999 -9999 -9999 -9999 -9999 -9999 -9999 -9999 -9999 -9999 -9999 -9999 -9999 -9999 -9999 -9999 -9999 -9999 -9999 -9999 -9999 -9999 -9999 -9999 -9999 -9999 -9999 -9999 -9999 -9999 -9999 -9999 -9999 -9999 -9999

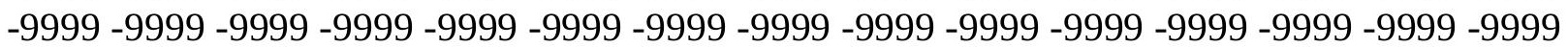


-9999 -9999 -9999 -9999 -9999 -9999 -9999 -9999 -9999 -9999 -9999 -9999 -9999 -9999 -9999 -9999 -9999 -9999 -9999 -9999 -9999 -9999 -9999 -9999 -9999 -9999 -9999 -9999 -9999 -9999 -9999 -9999 -9999 -9999 -9999 -9999 -9999 -9999 -9999 -9999 -9999 -9999 -9999 -9999 -9999 -9999 -9999 -9999 -9999 -9999 -9999 -9999 -9999 -9999 -9999 -9999 -9999 -9999 -9999 -9999

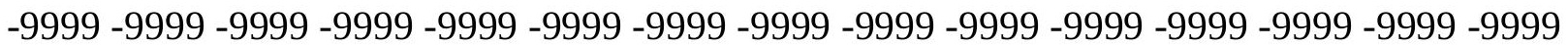
-9999 -9999 -9999 -9999 -9999 -9999 -9999 -9999 -9999 -9999

-9999 -9999 -9999 -9999 -9999 -9999 -9999 -9999 -9999 -9999 -9999 -9999 -9999 -9999 -9999

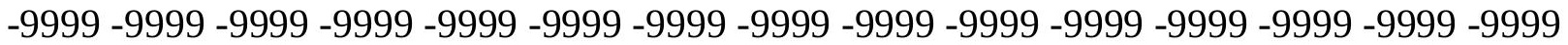

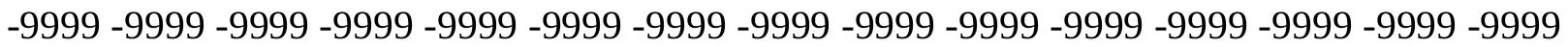
-9999 -9999 -9999 -9999 -9999 -9999 -9999 -9999 -9999 -9999 -9999 -9999 -9999 -9999 -9999 -

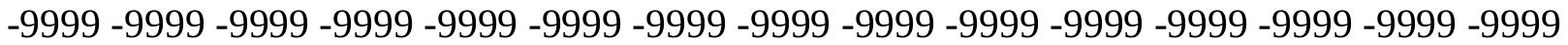
-9999 -9999 -9999 -9999 -9999 -9999 -9999 -9999 -9999 -9999 -9999 -9999 -9999 -9999 -9999

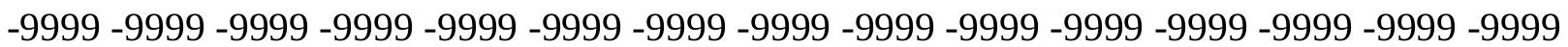
-9999 -9999 -9999 -9999 -9999 -9999 -9999 -9999 -9999 -9999 -9999 -9999 -9999 -9999 -9999 -9999 -9999 -9999 -9999 -9999 -9999 -9999 -9999 -9999 -9999 -9999 -9999 -9999 -9999 -9999 -9999 -9999 -9999 -9999 -9999 -9999 393.5291137695394 .140045166394 .6686401367 395.1468811035395 .5419311523395 .5808105469395 .0889892578394 .9375395 .1480102539 395.6206054688396 .2520751953396 .892364502397 .5396118164398 .1277160645 398.6748046875399 .3355712891400 .1237182617400 .9026184082401 .7067871094 402.31640625402 .6211853027403 .5354919434403 .8403015137403 .5354919434 402.6211853027402 .31640625402 .6211853027403 .2307128906403 .2307128906 403.5354919434403 .8403015137404 .145111084404 .4498901367405 .6690063477 406.5833129883407 .4977111816408 .7168884277409 .9360046387410 .240814209 410.5455932617410 .8503112793412 .0694885254413 .2886047363414 .5078125 416.0317077637417 .250793457419 .6890869141420 .0678710938420 .4194335938 421.1523742676422 .3084716797423 .6779174805424 .991027832426 .2192687988 427.409576416428 .1367492676428 .1291503906427 .6358337402427 .0626831055 426.8146362305427 .1558837891428 .0547180176429 .2230529785430 .4382019043 431.6004943848432 .8173828125434 .2616271973436 .2035522461438 .8008117676 442.104888916445 .9786682129449 .9897155762453 .3924255371455 .0869750977 454.8817749023453 .2586364746451 .5034179688450 .6997070312451 .2468566895 453.2475585938456 .0612792969458 .9535522461461 .1394042969462 .294921875 -9999 -9999 -9999 -9999 -9999 -9999 -9999 -9999 -9999 -9999 -9999 -9999 -9999 -9999 -9999 -9999 -9999 -9999 -9999 -9999 -9999 -9999 -9999 -9999 -9999 -9999 -9999 -9999 -9999 -9999 -9999 -

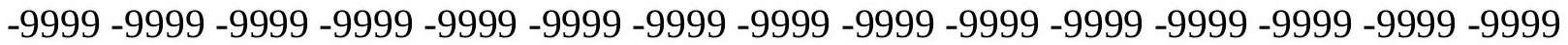
-9999 -9999 -9999 -9999 -9999 -9999 -9999 -9999 -9999 -9999 -9999 -9999 -9999 -9999 -9999 -9999 -9999 -9999 -9999 -9999 -9999 -9999 -9999 -9999 -9999 -9999 -9999 -9999 -9999 -9999

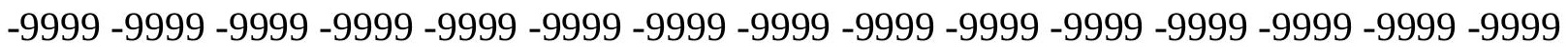
-9999 -9999 -9999 -9999 -9999 -9999 -9999 -9999 -9999 -9999 -9999 -9999 -9999 -9999 -9999 -9999 -9999 -9999 -9999 -9999 -9999 -9999 -9999 -9999 -9999 -9999 -9999 -9999 -9999 -9999 -9999 -9999 -9999 -9999 -9999 -9999 -9999 -9999 -9999 -9999 -9999 -9999 -9999 -9999 -9999 -9999 -9999 -9999 -9999 -9999 -9999 -9999 -9999 -9999 -9999 -9999 -9999 -9999 -9999 -9999 -9999 -9999 -9999 -9999 -9999 -9999 -9999 -9999 -9999 -9999 -9999 -9999 -9999 -9999 -9999 -9999 -9999 -9999 -9999 -9999 -9999 -9999 -9999 -9999 -9999 -9999 -9999 -9999 -9999 -9999 -9999 -9999 -9999 -9999 -9999 -9999 -9999 -9999 -9999 -9999 -9999 -9999 -9999

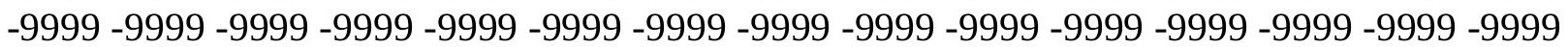


-9999 -9999 -9999 -9999 -9999 -9999 -9999 -9999 -9999 -9999 -9999 -9999 -9999 -9999 -9999 -9999 -9999 -9999 -9999 -9999 -9999 -9999 -9999 -9999 -9999 -9999 -9999 -9999 -9999 -9999 -9999 -9999 -9999 -9999 -9999 -9999 -9999 -9999 -9999 -9999 -9999 -9999 -9999 -9999 -9999 -9999 -9999 -9999 -9999 -9999 -9999 -9999 -9999 -9999 -9999 -9999 -9999 -9999 -9999 -9999 -9999 -9999 -9999 -9999 -9999 -9999 -9999 -9999 -9999 -9999 -9999 -9999 -9999 -9999 -9999 -9999 -9999 -9999 -9999 -9999 -9999 -9999 -9999 -9999 -9999 -9999 -9999 -9999 -9999 -9999 -9999 383.6713256836 384.7183837891385.6102294922 386.379119873387 .0427856445 387.6579589844388 .2210693359388 .640045166388 .9430236816389 .3304748535 389.8201904297387 .9914855957388 .296295166388 .296295166388 .9057922363 389.515411377390 .125390 .7344970703391 .3440856934391 .6488952637392 .2585144043 393.1727905273393 .782409668394 .391998291395 .0014953613395 .611114502 396.220703125396 .5255126953396 .220703125395 .611114502395 .3063049316 395.611114502395 .611114502395 .9158935547396 .220703125396 .5255126953 396.8302001953397 .4397888184398 .049407959398 .9637145996400 .1828918457 401.0971984863402 .0115966797402 .31640625402 .9259033203403 .5354919434 404.4498901367405 .6690063477406 .8882141113408 .1072998047409 .326385498 410.5455932617411 .4598999023411 .7647094727412 .3742980957413 .5934143066 415.1173095703416 .3364868164417 .250793457418 .7746887207419 .6890869141 419.3202819824 418.3599853516417.2401733398416.5799255371416.792175293 417.9566040039419 .4540100098420 .5885009766421 .590423584422 .5448608398 423.5842590332425 .1690368652427 .8139953613431 .295715332435 .5229492188 440.3889465332444 .819519043447 .0653381348445 .7898864746442 .6734924316 439.7142028809438 .0904541016438 .6620788574441 .0665893555444 .7637329102 448.4501342773450 .9532165527451 .7619934082451 .2801208496450 .7340393066 451.6156311035454 .5012512207458 .3363342285461 .3055725098462 .0715026855 460.6224060059458 .5936584473457 .6274414062458 .209564209459 .8896484375 462.0254821777463 .9770202637465 .3132629395465 .9994812012466 .0946960449 465.7037353516465 .1172180176464 .5679626465464 .1964111328464 .1948547363 464.8552246094466 .2284545898468 .3900756836471 .1820983887474 .1968994141 476.9066162109479 .0475158691480 .5606079102481 .3348083496481 .0532531738 479.7057800293478 .7876281738479 .190826416480 .0854187012480 .4782409668 479.9499206543478 .894317627478 .1830749512 -9999 -9999 -9999 -9999 -9999 -9999 -9999 -9999 -9999 -9999 -9999 -9999 -9999 -9999 -9999 -9999 -9999 -9999 -9999 -9999 -9999 -9999 -9999 -9999 -9999 -9999 -9999 -9999 -9999 -9999 -9999 -9999 -9999 -9999 -9999 -9999 -9999

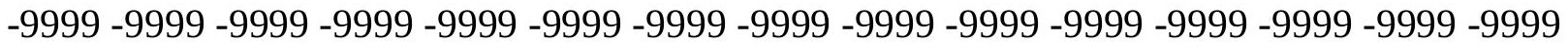
-9999 -9999 -9999 -9999 -9999 -9999 -9999 -9999 -9999 -9999 -9999 -9999 -9999 -9999 -9999

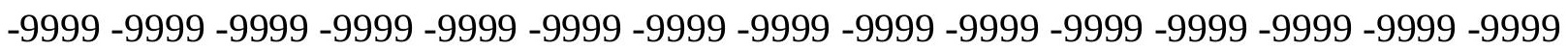

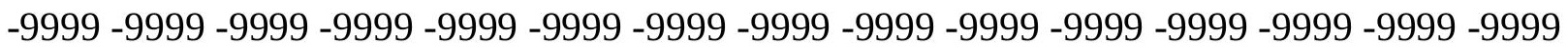
-9999 -9999 -9999 -9999 -9999 -9999 -9999 -9999 -9999 -9999 -9999 -9999 -9999 -9999 -9999 -9999 -9999 -9999 -9999 -9999 -9999 -9999 -9999 -9999 -9999 -9999 -9999 -9999 -9999 -9999 -9999 -9999 -9999 -9999 -9999 -9999 -9999 -9999 -9999 -9999 -9999 -9999

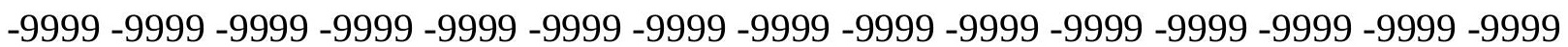
-9999 -9999 -9999 -9999 -9999 -9999 -9999 -9999 -9999 -9999 -9999 -9999 -9999 -9999 -9999 -9999 -9999 -9999 -9999 -9999 -9999 -9999 -9999 -9999 -9999 -9999 -9999 -9999 -9999 -9999 -9999 -9999 -9999 -9999 -9999 -9999 -9999 -9999 -9999 -9999 -9999 -9999 -9999 -9999 -9999

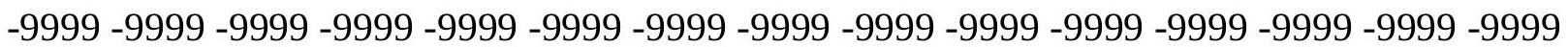


-9999 -9999 -9999 -9999 -9999 -9999 -9999 -9999 -9999 -9999 -9999 -9999 -9999 -9999 -9999 -9999 -9999 -9999 -9999 -9999 -9999 -9999 -9999 -9999 -9999 -9999 -9999 -9999 -9999 -9999 -9999 -9999 -9999 -9999 -9999 -9999 -9999 -9999 -9999 -9999 -9999 -9999 373.1936645508 374.6921691895376 .0201416016377 .2191772461378 .3138122559379 .2742614746 380.0172729492380 .6104125977381 .1524047852381 .591003418382 .200592041 382.5053100586382 .5053100586382 .5053100586382 .200592041381 .8958129883 381.8958129883381 .8958129883382 .5053100586382 .8100891113383 .419708252 383.7244873047384 .3340148926384 .9436035156385 .5531921387386 .1628112793 386.7723083496387 .3818969727387 .9914855957388 .296295166388 .6010131836 388.9057922363388 .9057922363388 .6010131836388 .296295166388 .296295166 388.6010131836388 .9057922363388 .9057922363389 .2106018066389 .8201904297390 .125 391.0393066406391 .6488952637392 .5632019043393 .4776000977394 .0871887207 394.696685791395 .3063049316395 .9158935547396 .8302001953397 .7445983887 398.9637145996400 .1828918457401 .0971984863402 .31640625402 .9259033203 403.8403015137404 .4498901367405 .3641967773406 .5833129883407 .4977111816 408.412109375409 .326385498410 .240814209410 .240814209409 .0216064453 407.4977111816406 .5833129883406 .5833129883408 .1072998047410 .240814209 410.8503112793411 .7647094727412 .6789855957413 .2886047363414 .2030029297 417.250793457420 .6034851074424 .5657043457430 .0517883301435 .2331848145 439.1954040527435 .8427124023431 .5757141113428 .2231140137425 .4800109863 426.6991882324428 .8327026367433 .4043884277437 .6713867188440 .4144897461 441.0241088867439 .804901123438 .2810058594438 .5857849121442 .2431945801 447.1198120117450 .7771911621451 .6915893555448 .9484863281445 .900604248 444.6814880371445 .5958862305447 .4245910645449 .8629150391451 .996307373 453.2155151367453 .825012207453 .825012207453 .2155151367452 .3010864258 451.6915893555451 .0820007324450 .7771911621451 .3868103027452 .6058959961 454.7394104004457 .7872924805461 .1398925781463 .8829956055466 .0163879395 467.5404052734468 .4547119141468 .7594909668466 .0163879395464 .4924926758 466.216217041467 .9638977051468 .589263916467 .749206543465 .7184753418 464.1862792969464 .729888916466 .431854248468 .2030639648469 .4545288086 470.0500793457469 .8731689453 -9999 -9999 -9999 -9999 -9999 -9999 -9999 -9999 -9999 -9999 -9999 -9999 -9999 -9999 -9999 -9999 -9999 -9999 -9999 -9999 -9999 -9999 -9999 -9999 -9999 -9999 -9999 -9999 -9999 -9999 -9999 -9999 -9999 -9999 -9999 -9999 -9999 -9999 -9999 -9999 -9999 -9999 -9999 -9999 -9999 -9999 -9999 -9999 -9999 -9999 -9999 -9999 -9999 -9999 -

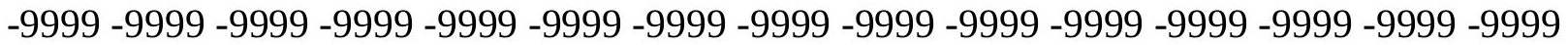
-9999 -9999 -9999 -9999 -9999 -9999 -9999 -9999 -9999 -9999 -9999 -9999 -9999 -9999 -9999 -9999 -9999 -9999 -9999 -9999 -9999 -9999 -9999 -9999 -9999 -9999 -9999 -9999 -9999 -9999

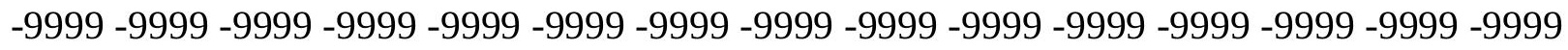
-9999 -9999-9999-9999

-9999 -9999 -9999 -9999 -9999 -9999 -9999 -9999 -9999 -9999 -9999 -9999 -9999 -9999 -9999

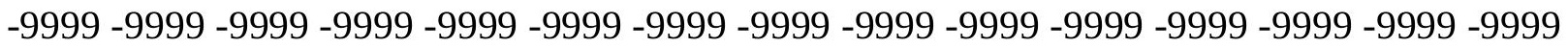
-9999 -9999 -9999 -9999 -9999 -9999 -9999 -9999 -9999 -9999 -9999 -9999 -9999 -9999 -9999 -9999 -9999 -9999 -9999 -9999 -9999 -9999 -9999 -9999 -9999 -9999 -9999 -9999 -9999 -9999 -9999 -9999 -9999 -9999 -9999 -9999 -9999 -9999 -9999 -9999 -9999 -9999 -9999 -9999 -9999 -9999 -9999 -9999 -9999 -9999 -9999 -9999 -9999 -9999 -9999 -9999 -9999 -9999 -9999 -9999

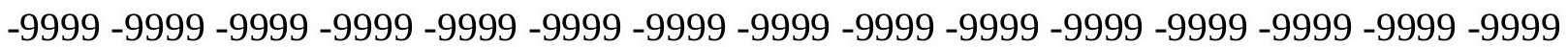


-9999 -9999 -9999 -9999 -9999 -9999 -9999 -9999 -9999 -9999 -9999 -9999 -9999 -9999 -9999 -9999 -9999 -9999 -9999 -9999 -9999 -9999 358.6018676758 360.86328125362 .9598388672 364.8689575195366 .6221618652368 .210357666369 .5615234375370 .7080688477 371.7520751953372 .7521972656373 .666595459374 .2760925293374 .5809020996 375.1904907227375 .495300293375 .799987793376 .104888916376 .104888916 376.104888916375 .799987793375 .495300293375 .495300293375 .495300293375 .799987793 376.104888916376 .7143859863377 .0191955566377 .6288146973377 .93359375 378.5430908203379 .1527099609379 .762298584380 .066986084380 .6766052246 380.9814147949381 .2861938477381 .591003418381 .591003418381 .591003418 381.2861938477381 .2861938477381 .591003418381 .591003418381 .8958129883 382.200592041382 .5053100586383 .1148986816383 .7244873047384 .3340148926 385.2484130859385 .858001709386 .4674987793387 .0770874023387 .9914855957 388.6010131836389 .2106018066390 .125391 .3440856934392 .2585144043393 .1727905273 394.0871887207395 .0014953613395 .611114502396 .5255126953397 .1350097656 398.049407959398 .6589050293399 .5733032227400 .1828918457400 .487701416 400.1828918457399 .2684936523398 .3541870117397 .7445983887398 .049407959 398.9637145996400 .1828918457401 .4020080566402 .0115966797402 .9259033203 403.5354919434405 .059387207407 .4977111816410 .5455932617414 .5078125 419.0795898438423 .346496582425 .4800109863423 .9560852051420 .9082946777 417.8604125977416 .0317077637416 .3364868164418 .4700012207421 .517791748 424.870513916427 .3086853027428 .2231140137427 .9183044434427 .613494873 428.5278930664431 .2709960938434 .6235961914437 .0618896484437 .6713867188 436.4523010254434 .9284057617434 .0140075684434 .3187866211435 .537902832 437.3666992188438 .8905944824440 .1097106934440 .7192993164440 .7192993164 440.4144897461439 .500213623438 .8905944824438 .2810058594438 .2810058594 438.5857849121439 .804901123441 .633605957444 .3767089844447 .1198120117 449.5581054688451 .6915893555453 .2155151367453 .825012207453 .5202941895 451.996307373451 .3868103027453 .2155151367455 .3489990234455 .9585876465 455.3489990234452 .3010864258449 .2532958984451 .3489074707453 .8579101562 456.0230102539457 .5995788574458 .3746643066458 .3802490234457 .4937438965 456.0797424316454 .5596923828453 .2434082031 -9999 -9999 -9999 -9999 -9999 -9999 -9999 -9999 -9999 -9999 -9999 -9999 -9999 -9999 -9999 -9999 -9999 -9999 -9999 -9999 -9999 -9999

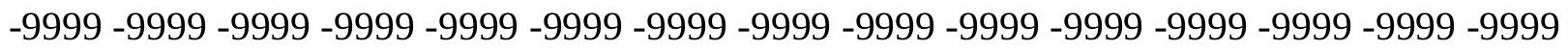
-9999 -9999 -9999 -9999 -9999 -9999 -9999 -9999 -9999 -9999 -9999 -9999 -9999 -9999 -9999 -9999 -9999 -9999 -9999 -9999 -9999 -9999 -9999 -9999 -9999 -9999 -9999 -9999 -9999 -9999 -

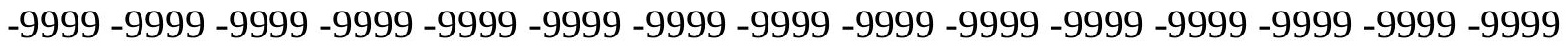

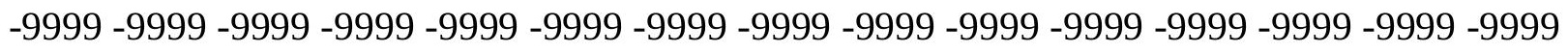

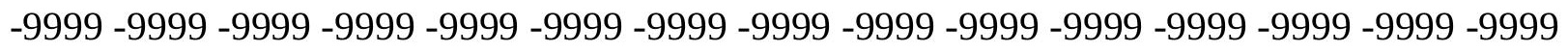
-9999-9999

-9999 -9999 -9999 -9999 -9999 -9999 -9999 -9999 -9999 -9999 -9999 -9999 -9999 -9999 -9999

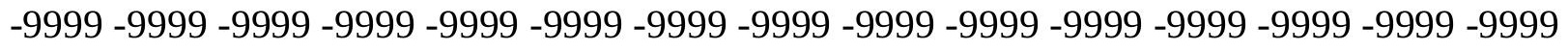

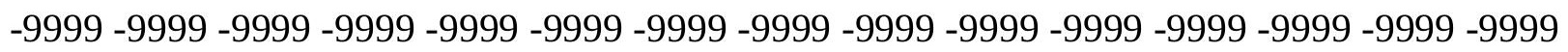
-9999 -9999 -9999 -9999 -9999 -9999 -9999 -9999 -9999 -9999 -9999 -9999 -9999 -9999 -9999 -9999 -9999 -9999 -9999 -9999 -9999 -9999 -9999 -9999-9999 -9999 -9999 -9999 -9999 -9999 -9999 -9999 -9999 -9999 -9999 -9999 -9999 -9999 -9999 -9999 -9999 -9999 -9999 -9999 -9999 -

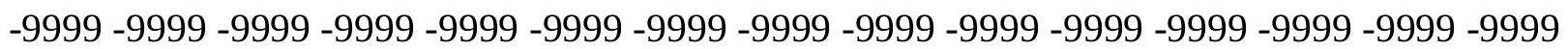


-9999 -9999 -9999 -9999 -9999 -9999 -9999 -9999 -9999 -9999 -9999 -9999 -9999 -9999 334.795135498337 .3912658691339 .9030761719342 .3250732422344 .678314209 347.0104980469349 .3580932617351 .7176208496354 .0275268555356 .2241821289 358.2030639648359 .9213867188361 .4685974121362 .9991149902364 .2182006836 365.132598877366 .0469055176366 .9613037109367 .570892334368 .1803894043 368.4851989746368 .7900085449369 .0947875977369 .399597168369 .399597168 369.399597168369 .399597168369 .0947875977369 .0947875977369 .0947875977 369.0947875977369 .399597168369 .399597168369 .7043151855370 .3139038086 370.6187133789371 .228302002371 .5331115723372 .1426086426372 .4473876953 373.0570068359373 .3617858887373 .666595459373 .9713134766374 .2760925293 374.2760925293374 .2760925293374 .2760925293374 .2760925293374 .5809020996 374.5809020996374 .8857116699375 .1904907227375 .495300293376 .104888916 376.4096069336377 .0191955566377 .6288146973378 .5430908203379 .1527099609 379.762298584380 .3717956543380 .9814147949381 .8958129883382 .5053100586 383.419708252384 .3340148926385 .2484130859386 .1628112793386 .7723083496 387.686706543388 .296295166388 .9057922363389 .515411377390 .125390 .4296875 390.7344970703390 .7344970703390 .4296875389 .8201904297389 .2106018066 388.9057922363389 .2106018066389 .8201904297390 .7344970703391 .6488952637 392.5632019043393 .1727905273394 .391998291395 .9158935547398 .049407959 400.792388916404 .145111084407 .8024902344410 .8503112793412 .0694885254 411.4598999023409 .6311950684407 .4977111816406 .5833129883406 .5833129883 408.1072998047410 .5455932617412 .9838867188414 .8125915527416 .0317077637 416.3364868164416 .6412963867417 .8604125977419 .6890869141422 .1274108887 423.9560852051424 .5657043457424 .2608947754423 .346496582422 .7369995117 423.0416870117423 .6513061523424 .870513916426 .0895996094427 .3086853027 427.613494873427 .613494873427 .3086853027426 .6991882324426 .0895996094 425.7847900391425 .4800109863426 .0895996094427 .0039978027428 .5278930664 430.6614074707433 .0997009277435 .2331848145437 .0618896484438 .2810058594 438.8905944824438 .5857849121438 .2810058594438 .2810058594439 .1954040527 440.1097106934440 .7192993164440 .1097106934438 .5857849121437 .6713867188 438.8905944824441 .3288879395443 .4624023438445 .2911071777445 .900604248 446.5101928711445 .2865905762443 .7341308594442 .1233520508440 .762298584 439.8735046387 439.4077758789439 .2682800293 -9999 -9999 -9999 -9999 -9999 -9999 -9999 -9999 -9999 -9999 -9999 -9999 -9999 -9999 -9999 -9999 -9999 -9999 -9999 -9999 -9999 -9999 -9999 -9999 -9999 -9999 -9999 -9999 -9999 -9999 -9999 -9999 -9999 -9999 -9999 -9999 -9999

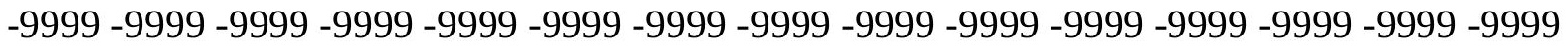

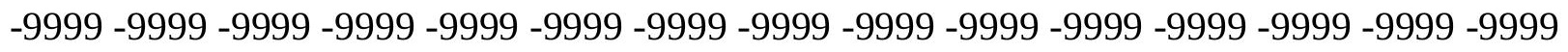

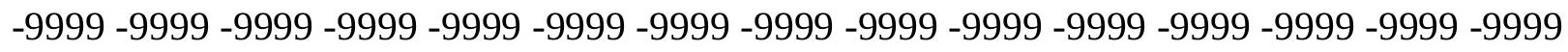
-9999 -9999 -9999 -9999 -9999 -9999 -9999 -9999 -9999 -9999 -9999 -9999 -9999 -9999 -9999 -9999 -9999 -9999 -9999 -9999 -9999 -9999 -9999 -9999 -9999 -9999 -9999 -9999 -9999 - -999 -

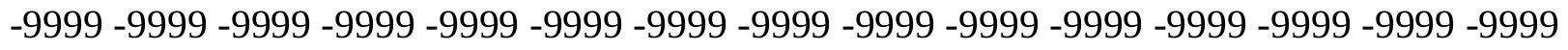

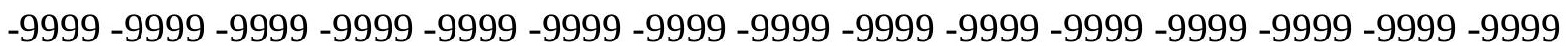
-9999 -9999 -9999 -9999 -9999 -9999 -9999 -9999 -9999 -9999 -9999 -9999 -9999 -9999 -9999 -9999 -9999 -9999 -9999 -9999 -9999 -9999 -9999 -9999-9999 -9999 -9999 -9999 -9999 -9999 -9999 -9999 -9999 -9999 -9999 -9999 -9999 -9999 -9999 -9999 -9999 -9999 -9999 -9999 -9999 -

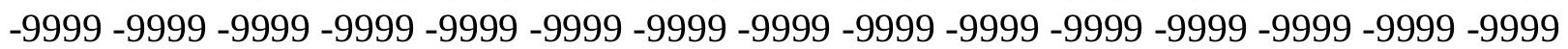


-9999 -9999 -9999 -9999 -9999 -9999 -9999 -9999 -9999 -9999 -9999 -9999 -9999 -9999 -9999 -9999 -9999 -9999 -9999-9999 306.6187744141309 .5541381836312 .4672851562 315.3404541016318 .1533508301320 .9158325195323 .6187133789326 .2733764648 328.8504333496331 .3522338867333 .7733459473336 .1052246094338 .3495788574 340.4588928223342 .5656738281344 .7875366211347 .0623779297349 .2838134766 351.4172058105353 .2460021973354 .7698974609355 .9890136719357 .208190918 358.4273071289359 .3417053223360 .2560119629360 .8656005859361 .475189209 361.7799072266362 .0846862793362 .3894958496362 .6943054199362 .6943054199 362.9991149902362 .6943054199362 .6943054199362 .6943054199362 .3894958496 362.3894958496362 .3894958496362 .6943054199362 .6943054199362 .9991149902 363.303894043363 .9135131836364 .2182006836364 .5230102539365 .132598877 365.4374084473365 .7421875366 .3517150879366 .6564941406366 .6564941406 366.9613037109366 .9613037109367 .2661132812367 .2661132812367 .2661132812 367.570892334367 .570892334367 .8756103516368 .1803894043368 .4851989746 368.7900085449369 .399597168370 .009185791370 .6187133789371 .228302002 371.5331115723372 .4473876953373 .0570068359373 .666595459374 .2760925293 375.1904907227375 .799987793376 .7143859863377 .324005127377 .93359375 378.8479003906379 .4574890137380 .066986084380 .6766052246380 .9814147949 381.591003418381 .591003418381 .591003418381 .591003418381 .2861938477 380.6766052246380 .3717956543380 .3717956543380 .3717956543380 .6766052246 381.591003418382 .200592041383 .1148986816384 .029296875384 .9436035156 386.4674987793388 .6010131836390 .7344970703393 .4776000977396 .220703125 398.3541870117399 .2684936523399 .2684936523398 .3541870117397 .1350097656 396.5255126953396 .8302001953397 .7445983887399 .5733032227401 .4020080566 402.9259033203403 .8403015137404 .7546081543405 .3641967773406 .5833129883 408.1072998047409 .6311950684411 .155090332411 .7647094727411 .7647094727 411.4598999023411 .155090332411 .4598999023411 .7647094727412 .6789855957 413.5934143066414 .2030029297414 .8125915527414 .8125915527414 .5078125 413.8981933594413 .5934143066412 .9838867188412 .9838867188413 .2886047363 414.2030029297415 .422088623417 .250793457419 .0795898438420 .6034851074 422.1274108887423 .0416870117423 .6513061523423 .9560852051423 .9560852051 423.9560852051424 .5657043457425 .1752929688425 .7847900391425 .4800109863 425.1752929688425 .1752929688426 .0895996094427 .9183044434430 .0517883301 431.5757141113432 .4901123047432 .7948913574432 .1853027344430 .9661865234 429.442199707427 .9183044434427 .584564209427 .2826538086427 .2749328613

427.7991638184428 .7786254883430 .0639038086 -9999 -9999 -9999 -9999 -9999 -9999 -9999

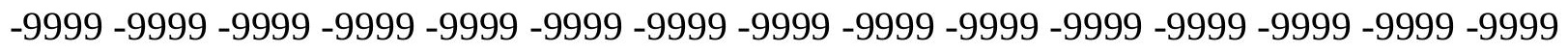

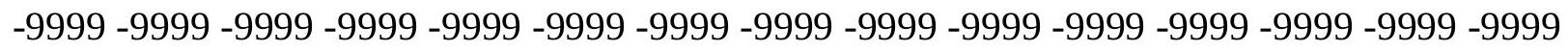
-9999 -9999 -9999 -9999 -9999 -9999 -9999 -9999 -9999 -9999 -9999 -9999 -9999 -9999 -9999 -9999 -9999 -9999 -9999 -9999 -9999 -9999 -9999 -9999 -9999 -9999 -9999 -9999 -9999 -9999

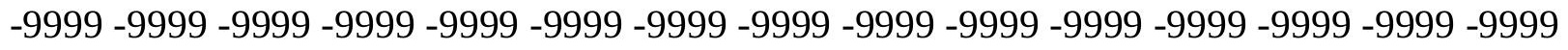

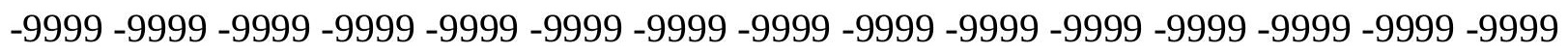
-9999 -9999 -9999 -9999 -9999 -9999 -9999 -9999 -9999 -9999 -9999 -9999 -9999 -9999 -9999 -9999 -9999 -9999 -9999 -9999 -9999 -9999 -9999 -9999 -9999 -9999 -9999 -9999 -9999 -9999 -9999 -9999 -9999 -9999 -9999 -9999 -9999 -9999 -9999 -9999 -9999 -

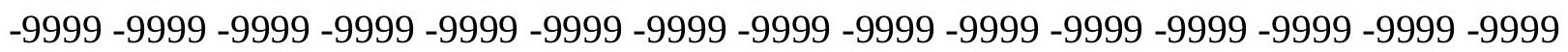


-9999 -9999 -9999 -9999 -9999 -9999 -9999 -9999 -9999 -9999 -9999 -9999 -9999 -9999 -9999 -9999 -9999 -9999 -9999 -9999 -9999 -9999 -9999 -9999 -9999 -9999 -9999 -9999 -9999 -9999

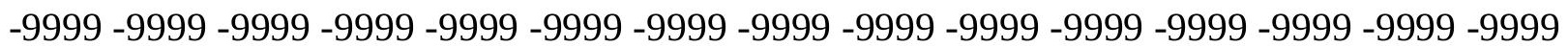
-9999 -9999 -9999 -9999 -9999 -9999 -9999 -9999 -9999 -9999 -9999 -9999 282.1948852539 285.1043395996287 .9761047363290 .8161010742293 .617767334296 .3704223633 299.0977172852301 .8020019531304 .5552368164307 .3529663086310 .164855957 312.8596801758315 .496887207318 .084197998320 .6298828125323 .0931396484 325.5378112793327 .8628845215330 .0493164062332 .2157897949334 .3493041992 336.1780090332338 .0067138672340 .1401977539342 .2737121582344 .4071960449 346.2359008789347 .7597961426349 .2838134766350 .5028991699351 .4172058105 352.6364135742353 .2460021973354 .1603088379354 .7698974609355 .0747070312 355.379486084355 .6842041016355 .9890136719355 .9890136719356 .2937927246 356.2937927246355 .9890136719355 .9890136719355 .9890136719355 .6842041016 355.6842041016355 .6842041016355 .9890136719355 .9890136719356 .2937927246 356.5986022949356 .9034118652357 .208190918357 .5129089355358 .1224975586 358.4273071289358 .7320861816359 .036895752359 .3417053223359 .6465148926 359.6465148926359 .9512023926359 .9512023926360 .2560119629360 .2560119629 360.5607910156360 .5607910156360 .8656005859361 .1704101562361 .475189209 361.7799072266362 .3894958496362 .6943054199363 .303894043363 .9135131836 364.5230102539364 .8277893066365 .4374084473366 .0469055176366 .9613037109 367.570892334368 .1803894043368 .7900085449369 .399597168370 .009185791 370.9234924316371 .228302002371 .837890625372 .4473876953372 .7521972656 373.0570068359373 .0570068359373 .0570068359372 .7521972656372 .4473876953 372.1426086426371 .837890625371 .5331115723371 .837890625372 .1426086426 372.4473876953373 .0570068359373 .9713134766374 .5809020996375 .799987793 377.0191955566378 .8479003906380 .6766052246382 .8100891113384 .6387939453 386.1628112793387 .0770874023387 .0770874023386 .7723083496386 .4674987793 386.1628112793386 .4674987793387 .3818969727388 .6010131836390 .125391 .3440856934 392.2585144043393 .1727905273394 .0871887207395 .0014953613396 .220703125 397.4397888184398 .6589050293399 .2684936523399 .5733032227399 .5733032227 399.5733032227399 .5733032227400 .1828918457400 .487701416401 .0971984863 401.7067871094402 .0115966797402 .0115966797401 .7067871094401 .4020080566 400.792388916400 .487701416400 .487701416400 .792388916401 .4020080566402 .31640625 403.5354919434405 .059387207406 .2785949707407 .1929016113408 .1072998047 408.7168884277409 .0216064453409 .326385498409 .326385498409 .9360046387 410.240814209410 .8503112793410 .8503112793411 .155090332411 .7647094727 412.9838867188414 .5078125416 .0317077637417 .5556030273418 .4700012207 418.7746887207418 .4700012207417 .8604125977416 .6412963867415 .422088623 415.7268981934415 .422088623415 .422088623416 .4035949707417 .6279907227 419.2547607422421 .1319580078423 .1086730957 -9999 -9999 -9999 -9999 -9999 -9999 -9999 -9999 -9999 -9999 -9999 -9999 -9999 -9999 -9999 -9999 -9999 -9999 -9999 -9999 -9999 -9999

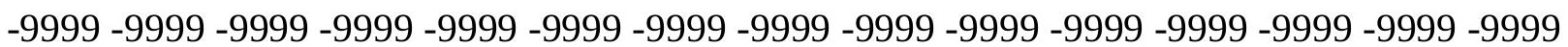
-9999 -9999 -9999 -9999 -9999 -9999 -9999 -9999 -9999 -9999 -9999 -9999 -9999 -9999 -9999 -9999 -9999 -9999 -9999 -9999 -9999 -9999 -9999 -9999 -9999 -9999 -9999 -9999 -9999 -9999 -999 -9999 -9999 -9999 -9999 -9999 -9999 -9999 -9999 -9999 -9999 -9999 -9999 -9999 -9999 -9999

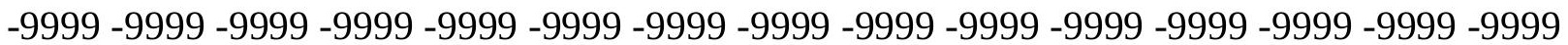


-9999 -9999 -9999 -9999 -9999 -9999 -9999 -9999 -9999

-9999 -9999 -9999 -9999 -9999 -9999 -9999 -9999 -9999 -9999 -9999 -9999 -9999 -9999 -9999

-9999 -9999 -9999 -9999 -9999 -9999 -9999 -9999 -9999 -9999 -9999 -9999 -9999 -9999 -9999

-9999 -9999 -9999 -9999 -9999 -9999 -9999 -9999 -9999 -9999 -9999 -9999 -9999 -9999 -9999

-9999 -9999 -9999 -9999 -9999 -9999 -9999 -9999 -9999 -9999 -9999 -9999 -9999 -9999 -9999 -

-9999 -9999 -9999 -9999 -9999 -9999 -9999 -9999 -9999 -9999 -9999 -9999 -9999 -9999 -9999 -

-9999 -9999 -9999 -9999 -9999 -9999 -9999 -9999 -9999 -9999 -9999 -9999 -9999 -9999 -9999 -999 -

-9999 -9999 -9999 -9999 -9999 259.8616638184263 .4389953613266 .9303283691

270.2436218262273 .3424377441276 .2225036621279 .0409545898281 .7803955078

284.442565918287 .09765625289 .7403564453292 .3469238281294 .9091186523

297.3945617676299 .8946228027302 .4206237793305 .0517883301307 .8330078125

310.2713012695312 .7095031738315 .1477966309317 .5860900879319 .7196044922

322.1578979492324 .2914123535326 .1200866699328 .2536010742330 .0823059082

331.9110107422333 .7396850586335 .5683898926337 .3970947266339 .2258911133

340.749786377342 .2737121582343 .4927978516344 .7120056152345 .6263122559

346.5407104492347 .1502990723347 .7597961426348 .3693847656348 .6741943359

348.9790039062349 .2838134766349 .2838134766349 .2838134766349 .2838134766

349.2838134766 349.2838134766 349.2838134766 349.2838134766 348.9790039062

348.9790039062348 .9790039062349 .2838134766349 .2838134766349 .5885009766 349.8933105469349 .8933105469350 .5028991699350 .8077087402351 .112487793 351.4172058105351 .7219848633352 .0267944336352 .3316040039352 .3316040039 352.6364135742352 .941192627352 .941192627353 .2460021973353 .2460021973 353.5508117676353 .5508117676353 .8554992676354 .1603088379354 .4650878906 354.7698974609355 .379486084355 .6842041016355 .9890136719356 .5986022949 357.208190918357 .5129089355358 .1224975586358 .7320861816359 .3417053223 359.9512023926360 .5607910156361 .1704101562361 .7799072266362 .3894958496 362.6943054199363 .303894043363 .6086120605364 .2182006836364 .2182006836 364.5230102539364 .5230102539364 .2182006836364 .2182006836363 .9135131836 363.6086120605363 .303894043362 .9991149902363 .303894043363 .303894043 363.6086120605364 .2182006836364 .8277893066365 .4374084473366 .3517150879 367.570892334369 .0947875977370 .3139038086371 .837890625373 .3617858887 374.5809020996375 .1904907227375 .495300293375 .495300293375 .495300293 375.799987793376 .104888916376 .7143859863377 .6288146973378 .8479003906 379.762298584380 .6766052246381 .591003418382 .5053100586383 .7244873047 384.6387939453385 .5531921387386 .4674987793387 .0770874023387 .3818969727 387.686706543387 .686706543387 .9914855957388 .296295166388 .6010131836 388.9057922363389 .2106018066389 .515411377389 .2106018066389 .2106018066 388.9057922363388 .296295166388 .296295166387 .9914855957388 .296295166 388.6010131836389 .2106018066390 .125391 .0393066406391 .953704834392 .5632019043 393.4776000977393 .782409668394 .0871887207394 .391998291394 .696685791 395.0014953613395 .611114502395 .9158935547396 .5255126953397 .1350097656 398.049407959399 .2684936523400 .792388916402 .0115966797403 .5354919434 404.145111084404 .7546081543404 .7546081543404 .4498901367403 .8403015137 403.5354919434402 .9259033203404 .145111084404 .7546081543405 .6690063477 406.8882141113408 .9022827148411 .0360412598413 .3068237305415 .5762329102 417.7712097168 -9999 -9999 -9999 -9999 -9999 -9999 -9999 -9999 -9999 -9999 -9999 -9999 
-9999 -9999 -9999 -9999 -9999 -9999 -9999 -9999 -9999 -9999 -9999 -9999 -9999 -9999 -9999 -9999 -9999 -9999 -9999 -9999 -9999 -9999 -9999 -9999 -9999 -9999 -9999 -9999 -9999 -9999

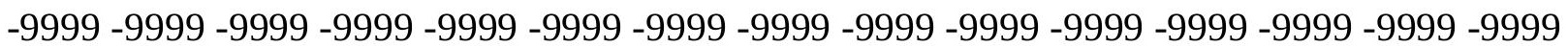
-9999 -9999 -9999 -9999 -9999 -9999 -9999 -9999 -9999 -9999 -9999 -9999 -9999 -9999 -9999 -9999 -9999 -9999 -9999 -9999 -9999 -9999 -9999 -9999 -9999 -9999 -9999 -9999 -9999 -9999

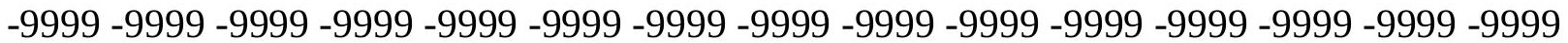
$-9999-9999$

-9999 -9999 -9999 -9999 -9999 -9999 -9999 -9999 -9999 -9999 -9999 -9999 -9999 -9999 -9999 -9999 -9999 -9999 -9999 -9999 -9999 -9999 -9999 -9999 -9999 -9999 -9999 -9999 -9999 -9999 -9999 -9999 -9999 -9999 -9999 -9999 -9999 -9999 -9999 -9999 -9999 -9999 -9999 -9999 -9999 -9999 -9999 -9999 -9999 -9999 -9999 -9999 -9999 -9999 -9999 -9999 -9999 -9999 -9999 -9999 -9999 -9999 -9999 -9999 -9999 -9999 -9999 -9999 -9999 -9999 -9999 -9999 -9999 -9999 -9999 -9999 -9999 -9999 -9999 -9999 -9999 -9999 -9999 -9999 -9999 -9999 -9999 -9999 235.7307281494239 .4440917969243 .1184539795246 .7462005615250 .3543548584 253.9258270264257 .4354858398260 .8637390137264 .2847900391267 .6147460938 270.7881469727273 .6971130371276 .1353149414278 .8783874512281 .3167114258 283.7549133301286 .1932067871288 .6315002441291 .0697937012293 .5080871582 295.6416015625298 .0798950195300 .2132873535302 .6516113281305 .0899047852 307.5281982422309 .6617126465312 .1000061035314 .2334899902316 .3670043945 318.5004882812320 .3291931152322 .1578979492323 .9866027832325 .8153076172 327.3392028809329 .1679077148330 .6918945312332 .5205993652334 .0444946289 335.2636108398336 .4827880859337 .7019042969338 .6163024902339 .5306091309 340.4450073242341 .0545959473341 .6640930176341 .9689025879342 .2737121582 342.5784912109342 .5784912109342 .5784912109342 .5784912109342 .5784912109 342.5784912109342 .5784912109342 .2737121582342 .2737121582342 .2737121582 342.2737121582342 .2737121582342 .2737121582342 .5784912109342 .5784912109 342.8833007812343 .1879882812343 .4927978516343 .7976074219344 .1023864746 344.4071960449344 .7120056152345 .0168151855345 .3215026855345 .3215026855 345.6263122559345 .9310913086345 .9310913086346 .2359008789346 .2359008789 346.5407104492346 .845489502346 .845489502347 .1502990723347 .4549865723 347.7597961426348 .0646057129348 .6741943359348 .9790039062349 .5885009766 349.8933105469350 .5028991699350 .8077087402351 .4172058105352 .0267944336 352.3316040039352 .941192627353 .5508117676354 .1603088379354 .4650878906 355.0747070312355 .379486084355 .6842041016355 .9890136719355 .9890136719 356.2937927246355 .9890136719355 .9890136719355 .6842041016355 .379486084 355.0747070312354 .7698974609354 .7698974609354 .7698974609354 .7698974609 355.0747070312355 .379486084355 .6842041016356 .2937927246357 .208190918 358.1224975586359 .036895752360 .2560119629361 .1704101562362 .3894958496 363.303894043363 .9135131836364 .2182006836364 .5230102539364 .8277893066 365.132598877365 .4374084473366 .0469055176366 .9613037109367 .8756103516 368.7900085449369 .7043151855370 .3139038086371 .228302002372 .1426086426 373.0570068359373 .9713134766374 .5809020996375 .1904907227375 .495300293 375.799987793376 .104888916376 .4096069336376 .7143859863376 .7143859863 377.0191955566377 .0191955566377 .324005127377 .0191955566376 .7143859863 376.4096069336376 .104888916375 .799987793375 .495300293375 .495300293 375.799987793376 .104888916376 .7143859863377 .324005127377 .6288146973 
378.2383117676378 .8479003906379 .1527099609379 .4574890137379 .762298584 380.066986084380 .3717956543380 .6766052246381 .2861938477381 .8958129883 382.8100891113384 .029296875385 .2484130859386 .7723083496387 .9914855957 389.2106018066390 .4296875391 .0393066406391 .6488952637391 .6488952637 391.6488952637391 .6488952637391 .6488952637391 .953704834394 .0871887207 395.611114502397 .4397888184399 .2684936523401 .4020080566403 .9848327637 406.3604736328408 .6885681152410 .9749145508413 .184173584 -9999 -9999 -9999 -9999 -9999 -9999 -9999 -9999 -9999 -9999 -9999 -9999 -9999 -9999 -9999 -9999 -9999 -9999 -9999

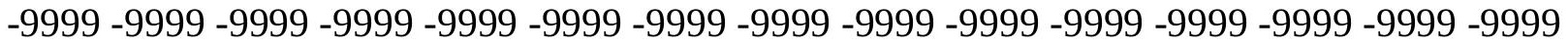
-9999 -9999 -9999 -9999 -9999 -9999 -9999 -9999 -9999 -9999 -9999 -9999 -9999 -9999 -9999 -9999 -9999 -9999 -9999 -9999 -9999 -9999 -9999 -9999 -9999 -9999 -9999 -9999 -9999 -9999 -9999 -9999 -9999 -9999 -9999 -9999 -9999 -9999 -9999 -9999 -9999 -9999 -9999 -9999 -9999 -

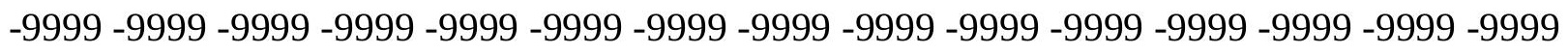
-9999 -9999 -9999 -9999 -9999 -9999 -9999 -9999

-9999 -9999 -9999 -9999 -9999 -9999 -9999 -9999 -9999 -9999 -9999 -9999 -9999 -9999 -9999

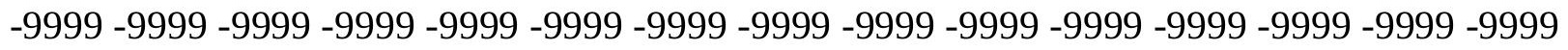
-9999 -9999 -9999 -9999 -9999 -9999 -9999 -9999 -9999 -9999 -9999 -9999 -9999 -9999 -9999 -9999 -9999 -9999 -9999 -9999 -9999 -9999 -9999 -9999 -9999 -9999 -9999 -9999 -9999 -9999 -

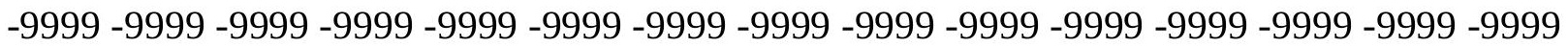
-9999 -9999-9999 -9999 -9999 -9999-9999 216.4643859863220.1958312988223.8404541016 227.4374542236231.0332183838234.7147369385238.3119049072 241.825088501 245.2470550537248 .6884002686252 .0519256592255 .4098968506258 .7626037598 261.8103942871265 .1630859375268 .2109069824271 .2587890625273 .6971130371 276.1353149414278 .5736083984280 .7070922852283 .1453857422285 .2789001465 287.4124145508289 .8505859375291 .9841918945294 .1176147461296 .2510986328 298.0798950195300 .5180969238302 .6516113281304 .7850952148306 .9186096191 309.0520935059310 .8807983398313 .0143127441314 .8429870605316 .6718139648 318.1957092285320 .0244140625321 .5483093262323 .0722045898324 .5961914062 325.8153076172327 .3392028809328 .5584106445329 .7774963379330 .9966125488 331.9110107422332 .8252868652333 .4349060059334 .0444946289334 .6541137695 335.2636108398335 .5683898926335 .5683898926335 .8731994629335 .8731994629 335.8731994629335 .8731994629335 .8731994629335 .8731994629335 .5683898926 335.5683898926335 .5683898926335 .5683898926335 .5683898926335 .5683898926 335.5683898926335 .5683898926335 .8731994629336 .1780090332336 .1780090332 336.4827880859336 .7875976562337 .0922851562337 .3970947266337 .7019042969 338.0067138672338 .3114929199338 .3114929199338 .6163024902338 .9211120605 338.9211120605339 .2258911133339 .5306091309339 .5306091309339 .8353881836 340.1401977539340 .4450073242340 .4450073242340 .749786377341 .3593139648 341.6640930176341 .9689025879342 .2737121582342 .8833007812343 .1879882812 343.7976074219344 .1023864746344 .7120056152345 .0168151855345 .6263122559 345.9310913086346 .2359008789346 .845489502347 .1502990723347 .4549865723 347.7597961426347 .7597961426348 .0646057129348 .0646057129347 .7597961426 347.7597961426347 .4549865723347 .1502990723346 .845489502346 .5407104492 346.5407104492346 .2359008789346 .2359008789346 .2359008789346 .5407104492 346.845489502347 .4549865723347 .7597961426348 .6741943359349 .2838134766 350.1980895996350 .8077087402351 .7219848633352 .3316040039352 .6364135742 
353.2460021973353 .5508117676353 .8554992676354 .4650878906354 .7698974609 355.379486084356 .2937927246356 .9034118652357 .8176879883358 .4273071289 359.3417053223360 .2560119629360 .8656005859361 .7799072266362 .3894958496 362.9991149902363 .303894043363 .9135131836364 .2182006836364 .5230102539 364.8277893066365 .132598877365 .132598877365 .4374084473365 .4374084473 365.132598877365 .132598877364 .8277893066364 .5230102539363 .9135131836 363.6086120605363 .303894043362 .9991149902362 .9991149902363 .303894043 363.303894043363 .6086120605363 .9135131836364 .2182006836364 .5230102539 364.5230102539364.8277893066 365.132598877 365.132598877 365.7421875 366.0469055176366 .6564941406367 .570892334368 .4851989746369 .7043151855 371.228302002372 .7521972656374 .2760925293375 .495300293376 .7143859863 377.93359375378 .5430908203379 .1527099609379 .4574890137380 .066986084 380.3717956543381 .2861938477382 .200592041385 .2484130859387 .686706543 390.4296875392 .8680114746395 .3063049316397 .4397888184399 .927154541 402.2671508789404 .6141967773406 .9305114746409 .1912536621 -9999 -9999 -9999 -9999 -9999 -9999 -9999 -9999 -9999 -9999 -9999 -9999 -9999 -9999 -9999 -9999 -9999 -9999 -9999 -9999 -9999 -9999 -9999 -9999 -9999 -9999 -9999 -9999 -9999 -9999 -9999 -9999 -9999 -9999 -9999 -9999 -9999 -9999 -9999 -9999 -9999 -9999 -9999 -9999 -9999 -9999 -9999 -9999 -9999 -999 -9999 -9999 -9999 -9999 -9999 -9999 -9999 -9999 -9999 -9999 -9999 -9999 -9999 -9999 -9999 -9999 -9999 -9999 -9999 -9999 -9999 -9999 -9999 -9999 -9999 -9999 -9999 -9999 -9999 -9999 -

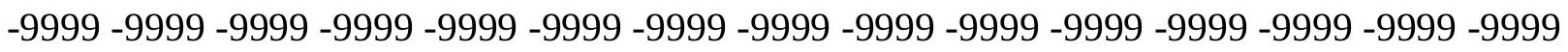
-9999 -9999 -9999-9999-9999-9999 -9999 -9999 -9999 -9999 -9999 -9999 -9999 -9999 -9999 -9999 -9999 -9999 -9999 -9999 -9999 -9999 -9999 -9999 -9999 -9999 -9999 -9999 -9999 -9999 -9999 -9999 -9999 -9999 -9999 -9999 -9999 -9999 -9999 -9999 -9999 -9999 -9999 -9999 -9999 -9999 -9999 -9999 -9999 -9999 -9999 -9999 -9999 -9999 -9999 -9999 -9999 -9999 -9999 -9999 -9999 -9999 -9999 -9999 -9999 -9999 -9999 -9999 -9999 -9999 -9999 -9999 -9999 -9999 -9999 -9999 -9999 -9999 -9999 -9999 -9999 190.9302825928196 .029510498200 .8489227295205 .2933959961209 .399230957 213.2165374756216 .8597259521220 .4399108887223 .9797821045227 .4224395752 230.7718658447234 .0749969482237 .7324066162241 .0850067139244 .4376983643 247.4855041504250 .8381958008253 .8860015869256 .9338989258259 .9816894531 263.0296020508266 .0773925781268 .8204956055271 .2587890625273 .6971130371 276.1353149414278 .2687988281280 .4023132324282 .5357971191284 .3645019531 286.4979858398288 .3266906738290 .4602050781292 .2889099121294 .1176147461 296.2510986328298 .0798950195299 .9085998535302 .0421142578303 .8707885742 305.6994934082307 .5281982422309 .3569030762311 .1856079102312 .7095031738 314.2334899902315 .7573852539316 .9765014648318 .5004882812319 .7196044922 320.9388122559322 .1578979492323 .3770141602324 .2914123535325 .2056884766 326.1200866699326 .7296142578327 .3392028809327 .9487915039328 .5584106445 328.8631896973328 .8631896973329 .1679077148329 .1679077148329 .1679077148 329.1679077148329 .1679077148329 .1679077148328 .8631896973328 .8631896973 328.8631896973328 .5584106445328 .5584106445328 .5584106445328 .5584106445 328.8631896973328 .8631896973329 .1679077148329 .1679077148329 .4726867676 329.7774963379330 .0823059082330 .3870849609330 .3870849609330 .6918945312 330.9966125488331 .3013916016331 .6062011719331 .6062011719331 .9110107422 332.2157897949332 .2157897949332 .5205993652332 .8252868652332 .8252868652 
333.1301879883333 .4349060059333 .7396850586334 .0444946289334 .3493041992 334.6541137695334 .9588928223335 .2636108398335 .5683898926336 .1780090332 336.4827880859336 .7875976562337 .3970947266337 .7019042969338 .0067138672 338.3114929199338 .9211120605339 .2258911133339 .2258911133339 .5306091309 339.8353881836339 .8353881836339 .8353881836339 .8353881836339 .8353881836 339.5306091309339 .2258911133338 .9211120605338 .6163024902338 .3114929199 338.3114929199338 .0067138672338 .0067138672338 .0067138672338 .0067138672 338.0067138672338 .3114929199338 .6163024902339 .2258911133339 .5306091309 340.1401977539340 .749786377341 .0545959473341 .6640930176341 .9689025879 342.5784912109342 .8833007812343 .4927978516343 .7976074219344 .4071960449 345.0168151855345 .6263122559346 .2359008789347 .1502990723347 .7597961426 348.6741943359349 .2838134766349 .8933105469350 .5028991699351 .112487793 351.7219848633352 .0267944336352 .6364135742352 .941192627353 .2460021973 353.5508117676353 .5508117676353 .8554992676353 .8554992676353 .8554992676 353.5508117676353 .2460021973352 .941192627352 .6364135742352 .0267944336 351.7219848633351 .112487793350 .8077087402350 .5028991699350 .5028991699 350.1980895996350 .1980895996350 .1980895996350 .1980895996350 .5028991699 350.5028991699350 .5028991699350 .8077087402350 .8077087402351 .112487793 351.7219848633352 .3316040039353 .2460021973354 .4650878906355 .6842041016 357.208190918359 .036895752360 .5607910156362 .0846862793363 .6086120605 364.8277893066366 .0469055176366 .9613037109367 .8756103516368 .7900085449 369.7043151855370 .9234924316372 .4473876953373 .9713134766377 .93359375 381.2861938477384 .3340148926386 .7723083496389 .2106018066391 .6488952637 393.782409668396 .3548583984398 .6999816895401 .0728149414403 .4842529297 405.8484191895 -9999 -9999 -9999 -9999 -9999 -9999 -9999 -9999 -9999 -9999 -9999 -9999 -9999 -9999 -9999 -9999 -9999 -9999 -9999 -9999 -9999 -9999 -9999 -9999 -9999 -9999 -9999 -9999 -9999 -9999 -9999 -9999 -9999 -9999 -9999 -9999 -9999 -9999 -9999 -9999 -9999 -9999

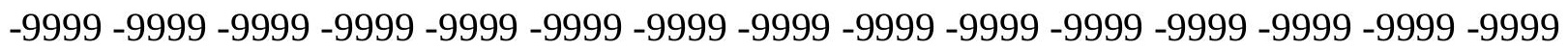
-9999 -9999 -9999 -9999 -9999 -9999 -9999 -9999 -9999 -9999 -9999 -9999 -9999 -9999 -9999 -9999 -9999 -9999 -9999 -9999 -9999 -9999 -9999 -9999 -9999 -9999 -9999 -9999 -9999 -9999 -9999 -9999 -9999 -9999 -9999 -9999 -9999 -9999 -9999 -9999 -9999

-9999 -9999 -9999 -9999 -9999 -9999 -9999 -9999 -9999 -9999 -9999 -9999 -9999 -9999 -9999

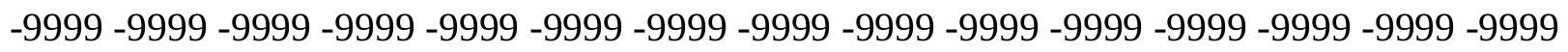
-9999 -9999 -9999 -9999 -9999 -9999 -9999 -9999 -9999 -9999 -9999 -9999 -9999 -9999 -9999 -9999 -9999 -9999 -9999 -9999 -9999 -9999 -9999 -9999 -9999 -9999 -9999 -9999 -9999 -9999 -9999 -9999 -9999 -9999 -9999 -9999 -9999 -9999 -9999 -9999 -9999 -9999 180.4891357422 185.9193878174191 .2444152832196 .4780273438201 .567565918206 .3008117676 210.5853271484214 .3899536133217 .9214019775221 .2740020752224 .6266021729 227.9792938232231 .3318939209234 .3798065186237 .7324066162240 .7801971436 244.1329040527247 .1806945801250 .2286071777252 .9716033936256 .0195007324 258.7626037598261 .5056152344264 .2486877441266 .9917907715269 .4301147461 271.5635070801274 .0018005371275 .8305053711277 .9641113281279 .7927856445 281.6214904785283 .4501953125285 .2789001465287 .1076049805288 .6315002441 290.4602050781292 .2889099121293 .8128967285295 .6416015625297 .4703063965 299.2990112305300 .8229064941302 .6516113281304 .1755981445306 .0043029785 307.5281982422308 .7473144531310 .2713012695311 .4903869629312 .7095031738 
313.9287109375315 .1477966309316 .0621948242316 .9765014648317 .8908996582 318.8052062988319 .7196044922320 .3291931152320 .9388122559321 .2434997559 321.8530883789322 .1578979492322 .4627075195322 .4627075195322 .4627075195 322.7674865723322 .4627075195322 .4627075195322 .4627075195322 .1578979492 322.1578979492322 .1578979492321 .8530883789321 .8530883789321 .8530883789 321.8530883789321 .8530883789321 .8530883789322 .1578979492322 .1578979492 322.4627075195322 .7674865723322 .7674865723323 .0722045898323 .3770141602 323.6817932129323 .9866027832324 .2914123535324 .2914123535324 .5961914062 324.9009094238325 .2056884766325 .2056884766325 .5104980469325 .8153076172 325.8153076172326 .1200866699326 .4248962402326 .4248962402326 .7296142578 327.0344848633327 .3392028809327 .6440124512327 .9487915039328 .2536010742 328.5584106445328 .8631896973329 .1679077148329 .7774963379330 .0823059082 330.3870849609330 .6918945312330 .9966125488331 .3013916016331 .6062011719 331.6062011719331 .9110107422331 .9110107422331 .9110107422331 .9110107422 331.9110107422331 .6062011719331 .6062011719331 .3013916016330 .9966125488 330.6918945312330 .3870849609330 .0823059082329 .7774963379329 .4726867676 329.4726867676 329.4726867676 329.4726867676 329.4726867676 329.7774963379 329.7774963379330 .0823059082330 .3870849609330 .6918945312330 .9966125488 331.3013916016331 .6062011719332 .2157897949332 .5205993652333 .1301879883 333.4349060059334 .0444946289334 .6541137695335 .5683898926336 .1780090332 336.7875976562337 .3970947266338 .0067138672338 .6163024902339 .2258911133 339.5306091309340 .1401977539340 .749786377341 .0545959473341 .6640930176 341.9689025879342 .2737121582342 .5784912109342 .5784912109342 .8833007812 342.5784912109342 .5784912109342 .2737121582341 .9689025879341 .6640930176 341.0545959473340 .4450073242339 .8353881836339 .2258911133338 .9211120605 338.3114929199338.0067138672 337.7019042969 337.3970947266337.0922851562 336.7875976562336 .7875976562336 .7875976562336 .4827880859336 .7875976562 336.7875976562337 .0922851562337 .7019042969338 .3114929199339 .2258911133 340.4450073242341 .9689025879343 .7976074219345 .6263122559347 .4549865723 349.2838134766 351.112487793 352.6364135742 354.1603088379 355.379486084 356.5986022949358 .1224975586359 .3417053223360 .8656005859362 .6943054199 364.5230102539368 .1803894043372 .4473876953375 .495300293378 .2383117676 380.9814147949383 .419708252386 .1628112793388 .6010131836390 .7344970703 393.1727905273395 .7759399414398 .2730712891400 .6326904297 -9999 -9999 -9999 -9999 -9999 -9999 -9999 -9999 -9999 -9999 -9999 -9999 -9999 -9999 -9999 -9999 -9999 -9999 -9999 -9999 -9999 -9999 -9999 -9999 -9999 -9999 -9999 -9999 -9999 -9999 -9999 -9999 -9999 -9999

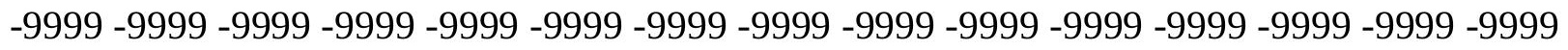

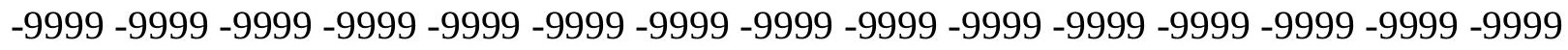
-9999 -9999 -9999 -9999 -9999 -9999 -9999 -9999 -9999 -9999 -9999 -9999 -9999 -9999 -9999 -

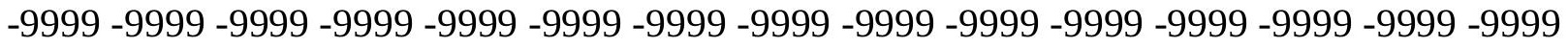
-9999-9999-9999

-9999 -9999 -9999 -9999 -9999 -9999 -9999 -9999 -9999 -9999 -9999 -9999 -9999 -9999 -9999 -9999 -9999 -9999 -9999 -9999 -9999 -9999 -9999 -9999 -9999 -9999 -9999 -9999 -9999 -9999 -9999 -9999 -9999 -9999 -9999 -9999 -9999 -9999 -9999 -9999 -9999 -9999 -9999 -9999 -9999 -9999 -9999 -9999 -9999 -9999 -9999 -9999 -9999 -9999 -9999 -9999 -9999 -9999 -9999 -9999 -9999 -9999 -9999 -9999 -9999 -9999 -9999 -9999 -9999 170.0105133057 175.6692199707 
181.1843566895186 .5870819092191 .8710021973197 .0028381348202 .0724945068 207.25390625211 .8256988525216 .0926971436219 .4452972412222 .7978973389 226.150604248229 .1983947754232 .246307373235 .5989074707238 .3419952393 241.3898010254244 .4376983643247 .1806945801250 .2286071777252 .9716033936 255.4098968506258 .1530151367260 .5913085938263 .0296020508265 .4678039551 267.9060974121270 .0396118164272 .1730957031274 .0018005371275 .8305053711 277.6592102051279 .4880065918281 .0119018555282 .5357971191284 .0596923828 285.5835876465287 .1076049805288 .6315002441290 .1553955078291 .6794128418 293.2033081055294 .7272033691296 .5559082031298 .0798950195299 .6037902832 300.8229064941302 .3468017578303 .5660095215305 .0899047852306 .3091125488 307.2233886719308 .4425048828309 .3569030762310 .2713012695311 .1856079102 311.7951965332312 .7095031738313 .3190917969313 .9287109375314 .5382080078 314.8429870605315 .1477966309315 .4526062012315 .7573852539316 .0621948242 316.0621948242316 .0621948242316 .0621948242316 .0621948242315 .7573852539 315.7573852539315 .4526062012315 .4526062012315 .1477966309315 .1477966309 315.1477966309315 .1477966309315 .1477966309315 .1477966309315 .1477966309 315.4526062012315 .4526062012315 .7573852539316 .0621948242316 .0621948242 316.3670043945316 .6718139648316 .9765014648317 .2813110352317 .2813110352 317.5860900879317 .8908996582318 .1957092285318 .1957092285318 .5004882812 318.8052062988318 .8052062988319 .1099853516319 .4147949219319 .4147949219 319.7196044922320 .0244140625320 .3291931152320 .6339111328320 .6339111328 320.9388122559321 .2434997559321 .5483093262321 .8530883789322 .1578979492 322.4627075195322 .7674865723323 .0722045898323 .3770141602323 .6817932129 323.6817932129323 .9866027832323 .9866027832324 .2914123535324 .2914123535 324.2914123535324 .2914123535323 .9866027832323 .6817932129323 .6817932129 323.3770141602322 .7674865723322 .4627075195322 .1578979492321 .8530883789 321.5483093262321 .2434997559321 .2434997559320 .9388122559320 .9388122559 320.6339111328320 .6339111328320 .9388122559320 .9388122559320 .9388122559 320.9388122559321 .2434997559321 .2434997559321 .5483093262321 .8530883789 322.4627075195322 .7674865723323 .3770141602324 .2914123535324 .9009094238 325.5104980469326 .1200866699326 .7296142578327 .3392028809327 .9487915039 328.2536010742328 .8631896973329 .1679077148329 .4726867676330 .0823059082 330.3870849609330 .6918945312331 .3013916016331 .6062011719331 .6062011719 331.9110107422331 .9110107422331 .9110107422331 .6062011719331 .3013916016 330.9966125488330 .3870849609329 .7774963379329 .1679077148328 .5584106445 327.6440124512327 .0344848633326 .4248962402325 .8153076172325 .2056884766 324.5961914062324 .2914123535323 .9866027832323 .6817932129323 .3770141602 323.3770141602323 .0722045898323 .3770141602323 .3770141602323 .9866027832 324.5961914062325 .5104980469327 .0344848633328 .5584106445330 .6918945312 332.5205993652334 .6541137695336 .7875976562338 .9211120605340 .749786377 342.5784912109344 .4071960449345 .9310913086347 .7597961426349 .5885009766 351.4172058105353 .2460021973355 .379486084357 .8176879883362 .6943054199 366.0469055176368 .7900085449371 .837890625374 .8857116699377 .93359375 380.9814147949383 .7244873047385 .858001709388 .296295166390 .888671875 393.2906799316395 .5884094238 -9999 -9999 -9999 -9999 -9999 -9999 -9999 -9999 -9999 -9999 -9999 -9999 -9999 -9999 -9999 -9999 -9999 -9999 -9999 -9999 -9999 -9999 -9999 -9999 
-9999 -9999 -9999 -9999 -9999 -9999 -9999 -9999 -9999 -9999 -9999 -9999 -9999 -9999 -9999 -9999 -9999 -9999 -9999 -9999 -9999 -9999 -9999 -9999 -9999 -9999 -9999 -9999 -9999 -9999

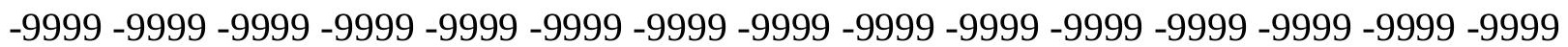
-9999 -9999 -9999 -9999 -9999 -9999 -9999 -9999 -9999 -9999 -9999 -9999 -9999 -9999 -9999 -9999 -9999 -9999 -9999 -9999 -9999 -9999 -9999 -9999 -9999 -9999 -9999 -9999 -9999 -9999 -9999 -9999 -9999 -9999 -9999 -9999 -9999 -9999 -9999 -9999 -9999 -9999 -9999 -9999 -9999 -9999 -9999 -9999 -9999 -9999 -9999 -9999 -9999 -9999 -9999 -9999 -9999 -9999 -9999 -9999 -9999 -9999 -9999 -9999 -9999 -9999 -9999 -9999 -9999 -9999 -9999 -9999 -999 -9999 -9999 -9999 -9999 -9999 -9999 -9999 -9999 -9999 -9999 -9999 -9999 -9999 -9999 -9999 -9999 -9999 -9999 -9999-9999-9999 159.0201263428 165.2570953369 171.2150878906 176.8771209717182 .3332519531187 .6627655029192 .9290008545198 .1103057861 202.9868927002207 .8634033203212 .7400054932217 .3117980957221 .2740020752 224.6266021729227 .9792938232231 .0270996094234 .0749969482236 .8179931641 239.8659057617242 .6089935303245 .3520050049248 .0950927734250 .8381958008 253.2763977051255 .7147064209258 .1530151367260 .2864990234262 .7247924805 264.8583068848266 .6870117188268 .8204956055270 .6492004395272 .4779052734 274.3066101074275 .8305053711277 .3544921875278 .8783874512280 .4023132324 281.6214904785283 .1453857422284 .3645019531285 .5835876465286 .8027954102 288.3266906738289.5458984375290.7650146484292.2889099121293.5080871582 295.0320129395296 .2510986328297 .4703063965298 .9942016602299 .9085998535 301.1276855469302 .3468017578303 .2611999512304 .1755981445304 .7850952148 305.6994934082306 .3091125488306 .9186096191307 .2233886719307 .8330078125 308.1377868652308 .7473144531309 .0520935059309 .3569030762309 .3569030762 309.6617126465309 .6617126465309 .6617126465309 .6617126465309 .3569030762 309.3569030762309 .0520935059309 .0520935059308 .7473144531308 .4425048828 308.4425048828308 .4425048828308 .1377868652308 .1377868652308 .4425048828 308.4425048828308 .4425048828308 .7473144531308 .7473144531309 .0520935059 309.3569030762309 .3569030762309 .6617126465309 .9664916992310 .2713012695 310.5759887695310 .5759887695310 .8807983398311 .1856079102311 .4903869629 311.4903869629311 .7951965332312 .1000061035312 .1000061035312 .4047851562 312.7095031738312 .7095031738313 .0143127441313 .3190917969313 .3190917969 313.6239013672313 .9287109375314 .2334899902314 .5382080078314 .8429870605 314.8429870605315 .1477966309315 .4526062012315 .7573852539315 .7573852539 316.0621948242316 .3670043945316 .3670043945316 .6718139648316 .6718139648 316.6718139648316 .6718139648316 .6718139648316 .3670043945316 .3670043945 316.0621948242315 .7573852539315 .4526062012315 .1477966309314 .5382080078 314.2334899902313 .9287109375313 .6239013672313 .3190917969313 .0143127441 312.7095031738312 .4047851562312 .4047851562312 .1000061035312 .1000061035 311.7951965332311 .7951965332311 .7951965332311 .7951965332311 .7951965332 311.7951965332312 .1000061035312 .4047851562313 .0143127441313 .9287109375 314.5382080078315 .4526062012316 .0621948242316 .6718139648317 .2813110352 317.5860900879318 .1957092285318 .5004882812318 .8052062988319 .1099853516 319.4147949219319 .7196044922320 .0244140625320 .3291931152320 .9388122559 321.2434997559321 .2434997559321 .5483093262321 .5483093262321 .5483093262 321.2434997559320 .9388122559320 .3291931152319 .7196044922319 .1099853516 318.1957092285317 .5860900879316 .6718139648315 .7573852539314 .8429870605 
314.2334899902313 .3190917969312 .7095031738312 .1000061035311 .4903869629 310.8807983398310 .5759887695310 .2713012695310 .2713012695310 .2713012695 310.5759887695310 .8807983398311 .4903869629312 .7095031738314 .2334899902 316.0621948242318 .1957092285320 .3291931152322 .7674865723325 .2056884766 327.3392028809329 .7774963379331 .9110107422334 .0444946289335 .8731994629 338.0067138672339 .8353881836341 .9689025879344 .4071960449346 .5407104492 349.2838134766352 .0267944336354 .7698974609357 .8176879883362 .3894958496 366.0469055176369 .7043151855373 .3617858887376 .104888916378 .5430908203 380.9814147949383 .7244873047386 .0777893066388 .2844543457390 .794921875 -9999 -9999 -9999 -9999 -9999 -9999 -9999 -9999 -9999 -9999 -9999 -9999 -9999 -9999 -9999 -9999 -9999 -9999 -9999 -9999 -9999 -9999 -9999 -9999 -9999 -9999 -9999 -9999 -9999 -9999 -9999 -9999 -9999 -9999 -9999 -9999 -9999 -9999 -9999 -9999 -9999 -9999 -9999 -9999 -9999 -9999 -9999 -9999 -9999 -9999 -9999 -9999 -9999 -9999 -9999 -9999 -9999 -9999 -9999 -9999 -9999 -9999 -9999 -9999 -9999 -9999 -9999 -9999 -9999 -9999 -9999 -9999 -9999 -9999 -9999 -9999 -9999 -9999 -9999 -9999 -9999 -9999 -9999 -9999 -9999 -9999 -9999 -9999 -9999 -9999 -9999 -9999 -9999 -9999-9999

-9999 -9999 -9999 -9999 -9999 -9999 -9999 -9999 -9999 -9999 -9999 -9999 -9999 -9999 -9999 -9999 -9999 -9999 -9999 -9999 -9999 -9999 -9999 -9999 -9999 -9999 -9999 -9999 -9999 -9999 -9999 -9999 -9999 -9999 -9999 -9999 -9999 -9999 -9999 -9999 -9999 -9999 -9999 -9999 -9999 -9999 -9999 -9999 -9999 -9999 -9999 -9999 -9999 -9999 -9999 -9999 -9999 -9999 -9999 -9999 -9999 -9999 -9999 146.8931121826153.6020507812 160.1589202881166 .5575256348 172.7152404785178 .5738677979184 .0901947021189 .2716064453194 .4528961182 199.6342926025204 .5108032227209 .3874053955214 .2639007568218 .5308990479 222.7978973389226 .4553985596230 .1127929688233 .1605987549236 .2084960938 238.9515075684241 .6945953369244 .1329040527246 .8759002686249 .3141937256 251.7525024414254 .1907958984256 .6290893555258 .7626037598260 .8960876465 262.7247924805264 .5534973145266 .3822021484268 .2109069824269 .7348022461 271.2587890625272 .7827148438274 .3066101074275 .8305053711277 .0497131348 278.2687988281279 .4880065918280 .7070922852281 .9262084961282 .8406066895 284.0596923828285 .2789001465286 .1932067871287 .4124145508288 .6315002441 289.5458984375290 .7650146484291 .9841918945293 .2033081055294 .4223937988 295.3367919922296 .2510986328297 .4703063965298 .3846130371298 .9942016602 299.6037902832300 .2132873535300 .8229064941301 .4324951172301 .7373046875 302.0421142578302 .3468017578302 .6516113281302 .9563903809302 .9563903809 303.2611999512303 .2611999512303 .5660095215303 .5660095215303 .2611999512 303.2611999512302 .9563903809302 .6516113281302 .6516113281302 .3468017578 302.0421142578301 .7373046875301 .7373046875301 .4324951172301 .4324951172 301.4324951172301 .7373046875301 .7373046875301 .7373046875302 .0421142578 302.0421142578302 .3468017578302 .6516113281302 .6516113281302 .9563903809 303.2611999512 303.5660095215303 .8707885742304 .1755981445304 .1755981445 304.4802856445304 .7850952148305 .0899047852305 .0899047852305 .3947143555 305.3947143555305 .6994934082306 .0043029785306 .0043029785306 .3091125488 306.6138000488306 .6138000488306 .9186096191307 .2233886719307 .5281982422 307.5281982422307 .8330078125308 .1377868652308 .1377868652308 .4425048828 308.7473144531308 .7473144531309 .0520935059309 .0520935059309 .0520935059 309.3569030762 309.3569030762 309.3569030762 309.0520935059 309.0520935059 
308.7473144531308 .7473144531308 .4425048828308 .1377868652307 .5281982422 307.2233886719306 .9186096191306 .3091125488306 .0043029785305 .6994934082 305.3947143555304 .7850952148304 .4802856445304 .1755981445303 .8707885742 303.5660095215303 .2611999512303 .2611999512302 .9563903809302 .6516113281 302.6516113281302 .3468017578302 .3468017578302 .6516113281302 .9563903809 303.5660095215304 .4802856445305 .3947143555306 .3091125488306 .9186096191 307.5281982422308 .1377868652308 .4425048828308 .7473144531308 .7473144531 309.0520935059 309.0520935059309.3569030762 309.6617126465 310.2713012695 310.5759887695310 .8807983398311 .1856079102311 .4903869629311 .4903869629 311.4903869629311 .4903869629311 .1856079102310 .5759887695310 .2713012695 309.3569030762308 .7473144531307 .8330078125306 .9186096191306 .0043029785 305.0899047852303 .8707885742302 .9563903809302 .0421142578301 .1276855469 300.2132873535299 .6037902832298 .9942016602298 .6893920898298 .3846130371 298.0798950195298 .0798950195298 .3846130371298 .6893920898299 .2990112305 300.2132873535301 .7373046875303 .8707885742306 .3091125488309 .0520935059 311.4903869629314 .2334899902316 .6718139648319 .4147949219321 .5483093262 323.9866027832326 .4248962402328 .5584106445330 .9966125488333 .1301879883 335.5683898926338 .3114929199341 .0545959473343 .7976074219346 .5407104492 349.5885009766352 .941192627355 .9890136719360 .8656005859365 .132598877 368.1803894043370 .9234924316373 .666595459376 .4096069336379 .1527099609 380.9814147949383 .9287719727386 .8137817383389 .4114685059 -9999-9999-9999 -9999 -9999 -9999 -9999 -9999 -9999 -9999 -9999 -9999 -9999 -9999 -9999 -9999 -9999 -9999 -9999 -

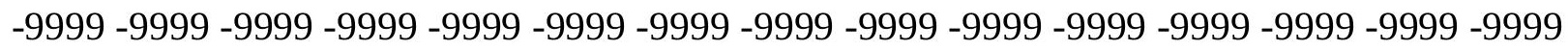
-9999 -9999 -9999 -9999 -9999 -9999 -9999 -9999 -9999 -9999 -9999 -9999 -9999 -9999 -9999 -9999 -9999 -9999 -9999 -9999 -9999 -9999 -9999 -9999 -9999 -9999 -9999 -9999 -9999 -9999 -9999 -9999 -9999 -9999 -9999 -9999 -9999 -9999 -9999 -9999 -9999 -9999 -9999 -9999 -9999 -9999 -9999 -9999 -9999 -9999 -9999 -9999 -9999 -9999 -9999 -9999 -9999 -9999 -9999 -

-9999 -9999 -9999 -9999 -9999 -9999 -9999 -9999 -9999 -9999 -9999 -9999 -9999 -9999 -9999 -9999 -9999 -9999 -9999 -9999 -9999 -9999 -9999 -9999 -9999 -9999 -9999 -9999 -9999 -9999 -9999 -9999 -9999 -9999 -9999 -9999 -9999 -9999 -9999 -9999 -9999 -9999 -9999 -9999 -9999 -9999 -9999 -9999 -9999 -9999 -9999 -9999 -9999 -9999 -9999 -9999 -9999 -9999 -9999 -9999 -9999 141.3858642578 148.2701568604 154.9886169434161.5602722168 168.0124664307 174.337097168180 .432800293186 .2236938477191 .7097930908196 .5863952637 201.7678070068206 .6443023682211 .520904541216 .0926971436220 .3596038818 224.6266021729228 .5888977051231 .9414978027235 .2940979004238 .3419952393 241.0850067139243 .8280944824246 .2664031982248 .7046966553251 .1428985596 253.5812072754255 .7147064209257 .8482055664259 .9816894531261 .8103942871 263.3344116211265.1630859375 266.6870117188 268.2109069824 269.4301147461 270.9540100098272 .1730957031273 .3923034668274 .6113891602275 .8305053711 276.7449035645277 .9641113281278 .8783874512279 .7927856445280 .7070922852 281.6214904785282 .5357971191283 .4501953125284 .3645019531284 .9740905762 286.1932067871 287.1076049805 288.0219116211288.9363098145 289.8505859375 291.0697937012291 .9841918945292 .8984985352293 .5080871582294 .4223937988 295.0320129395295 .3367919922295 .9464111328296 .2510986328296 .5559082031 296.5559082031296 .8606872559296 .8606872559297 .1654968262297 .1654968262 297.1654968262297 .4703063965297 .4703063965297 .4703063965297 .1654968262 
297.1654968262296 .8606872559296 .5559082031296 .2510986328295 .9464111328 295.6416015625295 .3367919922295 .0320129395295 .0320129395294 .7272033691 294.7272033691295 .0320129395295 .0320129395295 .0320129395295 .3367919922 295.3367919922295 .6416015625295 .6416015625295 .9464111328296 .2510986328 296.5559082031296 .8606872559296 .8606872559297 .1654968262297 .4703063965 297.7750854492298 .0798950195298 .0798950195298 .3846130371298 .6893920898 298.6893920898298 .9942016602299 .2990112305299 .2990112305299 .6037902832 299.6037902832299 .9085998535300 .2132873535300 .2132873535300 .5180969238 300.5180969238300 .8229064941301 .1276855469301 .1276855469301 .4324951172 301.4324951172301 .7373046875301 .7373046875301 .7373046875302 .0421142578 302.0421142578302 .0421142578302 .0421142578301 .7373046875301 .7373046875 301.7373046875301 .4324951172301 .1276855469300 .8229064941300 .5180969238 299.9085998535299 .6037902832299 .2990112305298 .6893920898298 .3846130371 297.7750854492297 .4703063965297 .1654968262296 .5559082031296 .2510986328 295.9464111328295 .3367919922295 .0320129395294 .7272033691294 .4223937988 294.1176147461293 .8128967285293 .5080871582293 .2033081055293 .2033081055 293.8128967285294 .4223937988295 .6416015625296 .5559082031297 .4703063965 298.3846130371298 .9942016602299 .6037902832299 .9085998535299 .9085998535 299.9085998535299 .6037902832299 .9085998535299 .9085998535300 .2132873535 300.5180969238300 .8229064941301 .4324951172301 .7373046875301 .7373046875 302.0421142578302 .0421142578301 .7373046875301 .4324951172301 .1276855469 300.5180969238299 .6037902832298 .6893920898297 .7750854492296 .8606872559 295.6416015625294 .7272033691293 .5080871582292 .5936889648291 .3746032715 290.4602050781289 .2410888672288 .3266906738287 .7171936035287 .1076049805 287.1076049805287 .1076049805286 .8027954102286 .8027954102287 .1076049805 287.7171936035288 .9363098145290 .4602050781292 .5936889648295 .3367919922 298.3846130371 301.1276855469304 .1755981445306 .9186096191309 .6617126465 312.1000061035314 .8429870605317 .2813110352319 .7196044922322 .1578979492 324.9009094238327 .3392028809330 .0823059082332 .8252868652335 .8731994629 338.9211120605341 .9689025879345 .0168151855348 .0646057129351 .4172058105 355.6842041016359 .3417053223362 .6943054199365 .7421875368 .7900085449 372.1426086426375 .1904907227377 .324005127380 .5407104492383 .2743835449 385.5083007812 -9999 -9999 -9999 -9999 -9999 -9999 -9999 -9999 -9999 -9999 -9999 -9999 -9999 -9999 -9999 -9999 -9999 -9999 -9999 -9999 -9999 -9999 -9999 -9999 -9999 -9999 -9999 -9999 -9999 -9999 -9999 -9999 -9999 -9999 -9999 -9999 -9999 -9999 -9999 -9999 -9999 -9999 -9999 -9999 -9999 -9999 -9999 -9999 -9999 -9999 -9999 -9999 -9999 -9999 -9999 -9999 -9999

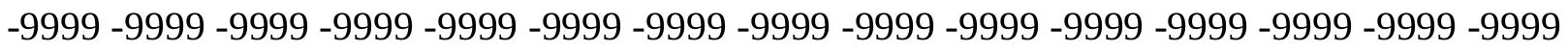

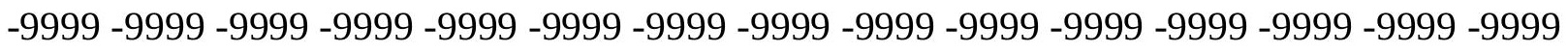
-9999 -9999-9999-9999-9999

-9999 -9999 -9999 -9999 -9999 -9999 -9999 -9999 -9999 -9999 -9999 -9999 -9999 -9999 -9999

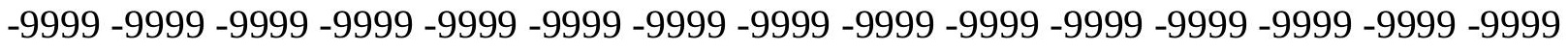

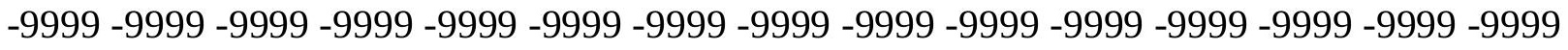
-9999 -9999 -9999 -9999 -9999 -9999 -9999 -9999 -9999 -9999 -9999 -9999 -9999 128.7151031494136 .0629730225143 .1792755127150 .0745391846156 .7627258301 163.3648071289169 .7653045654176 .165802002182 .261505127188 .3571929932 194.1481018066 199.329498291204.5108032227 209.3874053955 113.959197998 
218.5308990479222 .7978973389227 .0648956299230 .7223052979234 .3798065186 237.7324066162240 .7801971436243 .5233001709245 .9615936279248 .7046966553 250.8381958008253 .2763977051255 .4098968506257 .5433959961259 .6769104004 261.5056152344263 .3344116211264 .8583068848266 .0773925781267 .6012878418 268.8204956055269 .7348022461270 .9540100098271 .8682861328272 .7827148438 273.6971130371274 .6113891602275 .5257873535276 .4400939941277 .3544921875 278.2687988281278 .8783874512279 .4880065918280 .4023132324281 .0119018555 281.6214904785282 .2309875488282 .8406066895283 .4501953125284 .3645019531 285.2789001465285 .8884887695286 .8027954102287 .7171936035288 .6315002441 289.2410888672289 .8505859375290 .4602050781291 .0697937012291 .3746032715 291.6794128418291 .6794128418291 .6794128418291 .6794128418291 .6794128418 291.6794128418291 .6794128418291 .6794128418291 .6794128418291 .3746032715 291.3746032715291 .3746032715291 .3746032715291 .0697937012290 .7650146484 290.4602050781290 .1553955078289 .5458984375288 .9363098145288 .6315002441 288.3266906738 288.3266906738288.3266906738 288.3266906738 288.3266906738 288.3266906738 288.6315002441 288.6315002441 288.9363098145 288.9363098145 289.2410888672289 .5458984375289 .8505859375289 .8505859375290 .1553955078 290.4602050781290 .7650146484291 .0697937012291 .3746032715291 .3746032715 291.6794128418291 .9841918945291 .9841918945292 .2889099121292 .5936889648 292.5936889648292 .8984985352292 .8984985352293 .2033081055293 .2033081055 293.5080871582293 .8128967285293 .8128967285294 .1176147461294 .1176147461 294.4223937988294 .4223937988294 .4223937988294 .7272033691294 .7272033691 294.7272033691294 .7272033691294 .7272033691294 .7272033691294 .7272033691 294.7272033691294 .7272033691294 .4223937988294 .4223937988294 .1176147461 293.8128967285293 .5080871582292 .8984985352292 .5936889648291 .9841918945 291.6794128418291 .0697937012290 .7650146484290 .1553955078289 .8505859375 289.2410888672 288.9363098145288.3266906738 288.0219116211 287.4124145508 287.1076049805286 .8027954102286 .1932067871285 .8884887695285 .2789001465 284.6693115234284 .3645019531284 .3645019531284 .9740905762285 .8884887695 287.1076049805288 .3266906738289 .2410888672290 .4602050781291 .0697937012 291.6794128418291 .6794128418291 .3746032715291 .0697937012290 .7650146484 290.7650146484290 .7650146484291 .0697937012291 .3746032715291 .6794128418 292.2889099121292 .5936889648292 .5936889648292 .5936889648292 .5936889648 292.5936889648292 .2889099121291 .6794128418291 .0697937012290 .1553955078 289.2410888672 288.3266906738 287.1076049805 285.8884887695 284.9740905762 283.7549133301282 .5357971191281 .6214904785280 .4023132324279 .1831970215 278.2687988281277 .0497131348277 .0497131348276 .7449035645276 .7449035645 276.7449035645276 .7449035645277 .0497131348277 .3544921875278 .2687988281 280.0975036621282 .5357971191285 .5835876465288 .6315002441291 .6794128418 294.7272033691297 .7750854492300 .5180969238303 .5660095215306 .3091125488 308.7473144531311 .4903869629314 .2334899902316 .9765014648319 .4147949219 322.4627075195325 .2056884766328 .2536010742331 .3013916016334 .3493041992 337.3970947266340 .749786377344 .1023864746347 .1502990723350 .5028991699 353.8554992676357 .208190918360 .5607910156363 .9135131836367 .2661132812 371.5331115723374 .5809020996377 .1126098633379 .3272705078381 .3492736816 -9999 -9999 -9999 -9999 -9999 -9999 -9999 -9999 -9999 -9999 -9999 -9999 -9999 -9999 -9999 -9999 
-9999 -9999 -9999 -9999 -9999 -9999 -9999 -9999 -9999 -9999 -9999 -9999 -9999 -9999 -9999 -9999 -9999 -9999 -9999 -9999 -9999 -9999 -9999 -9999 -9999 -9999 -9999 -9999 -9999 -9999 -9999 -9999 -9999 -9999 -9999 -9999 -9999 -9999 -9999 -9999 -9999 -9999 -9999 -9999 -9999 -9999 -9999 -9999 -9999 -9999 -9999 -9999 -9999 -9999 -9999 -9999 -9999 -9999 -9999 -9999 -9999 -9999 -9999 -9999 -9999 -9999 -9999 -9999 -9999 -9999 -9999 -9999 -9999 -9999 -9999 -9999 -9999 -9999 -9999 -9999 -9999 -9999 -9999 -9999 -9999 -9999 -9999 -9999 -9999 -9999 -9999 -9999 -9999 -9999 -9999 -9999 -9999 -9999 -9999 -9999 -9999 -9999 -9999 -9999 -9999 -9999 -9999 -9999 -9999 -9999 -9999 -9999 -9999 -9999 -9999 -9999 -9999 -9999 -9999 -9999 -9999 -9999 -9999 -9999 -9999 -9999 -9999 -9999 -9999 -9999 114.8134841919 123.2087020874130 .8989562988138 .2636260986145 .4180603027152 .3537902832 159.0977935791165 .4983062744171 .8988037109178 .2993011475184 .699798584 190.795501709196 .5863952637202 .0724945068207 .25390625212 .4351959229 217.0070037842221 .5787963867225 .8457946777229 .8079986572233 .4653930664 237.1228027344240 .1707000732243 .2185058594245 .9615936279248 .7046966553 251.1428985596253 .2763977051255 .4098968506257 .5433959961259 .6769104004 261.5056152344263 .3344116211265 .1630859375266 .6870117188267 .9060974121 268.8204956055269 .7348022461270 .6492004395271 .5635070801272 .1730957031 272.7827148438273 .6971130371274 .3066101074274 .9161987305275 .5257873535 276.4400939941277 .0497131348277 .3544921875277 .9641113281278 .5736083984 278.8783874512279 .4880065918279 .7927856445280 .0975036621280 .7070922852 281.0119018555281 .6214904785282 .2309875488283 .1453857422283 .7549133301 284.3645019531285.2789001465 285.8884887695286.1932067871286.8027954102 287.1076049805287 .1076049805287 .4124145508287 .1076049805287 .1076049805 286.8027954102286 .8027954102286 .4979858398286 .1932067871285 .8884887695 285.8884887695285 .8884887695285 .5835876465285 .5835876465285 .2789001465 285.2789001465284 .9740905762284 .3645019531283 .7549133301283 .1453857422 282.5357971191282 .2309875488281 .9262084961281 .9262084961281 .9262084961 281.9262084961281 .9262084961281 .9262084961282 .2309875488282 .2309875488 282.5357971191282 .5357971191282 .8406066895283 .1453857422283 .4501953125 283.4501953125283 .7549133301284 .0596923828284 .3645019531284 .6693115234 284.9740905762284 .9740905762285 .2789001465285 .5835876465285 .5835876465 285.8884887695285 .8884887695286 .1932067871286 .4979858398286 .4979858398 286.8027954102286 .8027954102287 .1076049805287 .1076049805287 .4124145508 287.4124145508287 .7171936035287 .7171936035287 .7171936035287 .7171936035 288.0219116211288 .0219116211288 .0219116211288 .0219116211288 .0219116211 287.7171936035287 .7171936035287 .7171936035287 .4124145508287 .4124145508 287.1076049805286 .8027954102286 .4979858398286 .1932067871285 .5835876465 285.2789001465284 .6693115234284 .0596923828283 .7549133301283 .1453857422 282.8406066895282 .2309875488281 .9262084961281 .3167114258281 .0119018555 280.4023132324280 .0975036621279 .4880065918278 .8783874512278 .5736083984 277.9641113281277 .3544921875276 .7449035645276 .1353149414275 .8305053711 276.7449035645277 .9641113281279 .1831970215280 .4023132324281 .6214904785 282.8406066895283 .7549133301284 .0596923828284 .0596923828283 .4501953125 282.8406066895282 .5357971191281 .9262084961281 .9262084961282 .2309875488 282.8406066895283 .1453857422283 .4501953125283 .7549133301283 .7549133301 284.0596923828283 .7549133301283 .7549133301283 .4501953125282 .8406066895 
282.2309875488 281.3167114258280.0975036621279.1831970215277.9641113281 276.7449035645275 .5257873535274 .6113891602273 .3923034668272 .1730957031 271.2587890625270 .0396118164269 .1253051758268 .2109069824267 .9060974121 267.6012878418267 .6012878418267 .6012878418267 .6012878418267 .9060974121 268.5156860352269 .4301147461270 .6492004395273 .3923034668276 .7449035645 280.0975036621283 .1453857422286 .1932067871289 .5458984375294 .1176147461 295.3367919922298 .3846130371301 .1276855469303 .8707885742306 .6138000488 309.3569030762312 .1000061035314 .8429870605317 .8908996582320 .9388122559 323.9866027832327 .0344848633330 .0823059082333 .4349060059336 .7875976562 340.1401977539343 .4927978516346 .845489502350 .1980895996353 .8554992676 357.208190918360 .5607910156363 .9135131836367 .8756103516370 .6187133789 372.9875488281375 .1986999512377 .1012573242 -9999 -9999 -9999 -9999 -9999 -9999 -9999 -9999 -9999 -9999 -9999 -9999 -9999 -9999 -9999 -9999 -9999 -9999 -9999 -9999 -9999 -9999

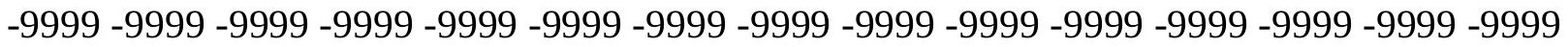
-9999 -9999 -9999 -9999 -9999 -9999 -9999 -9999 -9999 -9999 -9999 -9999 -9999 -9999 -9999

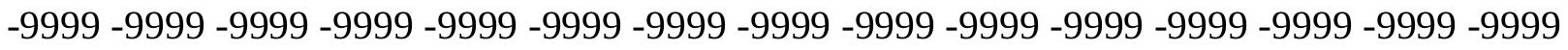

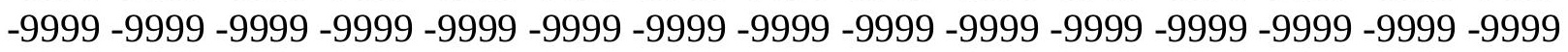
-9999 -9999 -9999 -9999 -9999 -9999-9999 -9999 -9999 -9999 -9999 -9999 -9999 -9999 -9999 -9999 -9999 -9999 -9999 -9999 -9999 -9999 -9999 -9999 -9999 -9999 -9999 -9999 -9999 -9999 -9999 -9999 -9999 -9999 -9999 -9999 -9999 -9999 -9999 -9999 -9999 -9999 -9999 -9999 -9999 -9999 -9999 -9999 -9999 -9999 -9999 -9999 -9999 -9999 -9999 -9999 -9999 -9999 -9999 -9999 -9999 105.8280487061116 .5823516846 125.9345855713133 .7872161865141 .0551605225148 .1255950928155 .1356048584 161.8408966064168 .241394043174 .6419067383181 .0424041748187 .4429016113 193.5386047363199 .6342926025205 .1204071045210 .6065063477215 .787902832 220.3596038818224 .9313964844229 .1983947754233 .1605987549236 .8179931641 240.1707000732243 .5233001709246 .2664031982249 .0093994141251 .4476928711 253.5812072754256 .0195007324258 .1530151367259 .9816894531262 .1152038574 263.9439086914265 .4678039551267 .2966003418268 .8204956055270 .0396118164 270.9540100098271 .5635070801272 .1730957031272 .4779052734273 .0874938965 273.3923034668274 .0018005371274 .3066101074274 .6113891602275 .2210083008 275.5257873535276 .1353149414276 .4400939941276 .7449035645277 .0497131348 277.3544921875277 .6592102051277 .9641113281277 .9641113281278 .2687988281 278.5736083984278 .5736083984279 .1831970215279 .4880065918280 .0975036621 280.7070922852281 .3167114258281 .9262084961282 .2309875488282 .8406066895 283.1453857422283 .1453857422283 .1453857422283 .1453857422282 .8406066895 282.5357971191282.2309875488281.6214904785 281.3167114258 280.7070922852 280.4023132324280 .4023132324280 .0975036621280 .0975036621279 .7927856445 279.7927856445279 .4880065918278 .8783874512278 .5736083984277 .9641113281 277.3544921875276 .4400939941275 .8305053711275 .8305053711275 .5257873535 275.5257873535275 .5257873535275 .5257873535275 .8305053711275 .8305053711 276.1353149414276 .1353149414276 .4400939941276 .4400939941276 .7449035645 277.0497131348277 .3544921875277 .6592102051277 .6592102051277 .9641113281 278.2687988281278 .5736083984278 .8783874512278 .8783874512279 .1831970215 279.1831970215279 .4880065918279 .7927856445279 .7927856445280 .0975036621 280.0975036621280 .4023132324280 .4023132324280 .7070922852280 .7070922852 
281.0119018555281 .0119018555281 .0119018555281 .0119018555281 .3167114258 281.3167114258281 .3167114258281 .3167114258281 .3167114258281 .0119018555 281.0119018555281 .0119018555280 .7070922852280 .7070922852280 .4023132324 280.0975036621280 .0975036621279 .7927856445279 .1831970215278 .8783874512 278.2687988281277 .9641113281277 .3544921875277 .0497131348276 .4400939941 275.8305053711275 .5257873535274 .9161987305274 .6113891602274 .0018005371 273.6971130371273 .0874938965272 .7827148438272 .1730957031271 .5635070801 271.2587890625270 .6492004395270 .0396118164269 .4301147461269 .1253051758 268.8204956055269 .4301147461270 .3443908691271 .5635070801273 .0874938965 274.3066101074275 .5257873535276 .4400939941277 .0497131348276 .4400939941 275.8305053711275 .2210083008274 .6113891602274 .0018005371273 .6971130371 274.0018005371274 .6113891602274 .9161987305275 .2210083008275 .5257873535 275.5257873535275 .5257873535275 .5257873535275 .2210083008274 .9161987305 274.3066101074273 .6971130371272 .7827148438271 .5635070801270 .3443908691 269.4301147461268 .2109069824266 .9917907715265 .7726135254264 .8583068848 263.6390991211262 .7247924805261 .8103942871260 .8960876465259 .9816894531 259.6769104004259 .3721008301259 .3721008301259 .3721008301259 .6769104004 259.9816894531260 .8960876465261 .8103942871263 .3344116211266 .0773925781 269.1253051758272 .4779052734275 .5257873535278 .8783874512283 .4501953125 286.8027954102288 .0219116211291 .0697937012293 .8128967285296 .5559082031 299.6037902832302 .3468017578305 .0899047852308 .1377868652310 .8807983398 313.9287109375316 .9765014648320 .0244140625323 .0722045898326 .4248962402 329.7774963379333 .1301879883336 .4827880859339 .8353881836343 .4927978516 346.845489502350 .1980895996353 .8554992676356 .9034118652360 .2560119629 363.303894043366 .6564941406368 .9636535645370 .9749755859372 .9047241211 374.6227111816 -9999 -9999 -9999 -9999 -9999 -9999 -9999 -9999 -9999 -9999 -9999 -9999

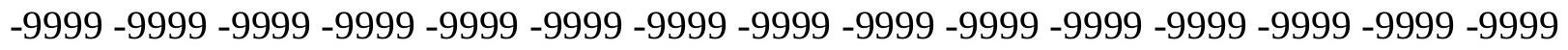

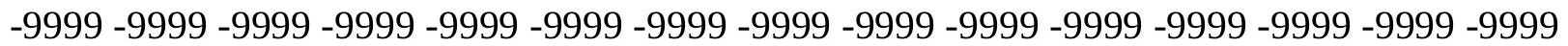
-9999 -9999 -9999 -9999 -9999 -9999 -9999 -9999 -9999 -9999 -9999 -9999 -9999 -9999 -9999 -9999 -9999 -9999 -9999 -9999 -9999 -9999 -9999 -9999 -9999 -9999 -9999 -9999 -9999 -9999

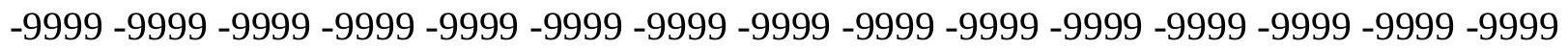
$-9999$

-9999 -9999 -9999 -9999 -9999 -9999 -9999 -9999 -9999 -9999 -9999 -9999 -9999 -9999 -9999 -9999 -9999 -9999 -9999 -9999 -9999 -9999 -9999 -9999 -9999 -9999 -9999 -9999 -9999 -9999 -9999 -9999 -9999 -9999 -9999 -9999 -9999 -9999 -9999 -9999 -9999 -9999 -9999 -9999 -9999 -9999 -9999 -9999 -9999 -9999 -9999-9999 104.8586120605117 .0872650146128 .1933441162 137.7628936768144 .4682006836151 .4781951904158 .4882965088165 .1934967041 171.5939941406177 .9945068359184 .3950042725190 .795501709196 .891204834 202.6820983887208 .4730072021213 .959197998219 .1405029297224 .0171051025 228.8936004639233 .1605987549236 .8179931641240 .4754943848243 .8280944824 246.8759002686249 .6190032959252 .3621063232254 .4956054688256 .6290893555 258.7626037598260 .5913085938262 .4200134277264 .2486877441266 .0773925781 267.9060974121269 .4301147461270 .9540100098272 .1730957031273 .3923034668 273.6971130371274 .0018005371274 .3066101074274 .3066101074274 .6113891602 274.9161987305274 .9161987305275 .2210083008275 .2210083008275 .5257873535 275.8305053711275 .8305053711276 .1353149414276 .1353149414276 .4400939941 
276.4400939941276 .4400939941276 .4400939941276 .4400939941276 .4400939941 276.4400939941276 .4400939941276 .4400939941276 .7449035645277 .3544921875 277.6592102051278 .2687988281278 .5736083984278 .8783874512279 .1831970215 279.4880065918279 .4880065918279 .4880065918279 .1831970215278 .5736083984 278.2687988281277 .6592102051277 .0497131348276 .4400939941275 .5257873535 274.9161987305274 .9161987305274 .9161987305274 .6113891602274 .3066101074 274.0018005371273 .6971130371273 .3923034668272 .7827148438272 .1730957031 271.2587890625270 .6492004395270 .0396118164269 .7348022461269 .7348022461 269.4301147461269 .4301147461269 .4301147461269 .7348022461269 .7348022461 269.7348022461270 .0396118164270 .0396118164270 .3443908691270 .6492004395 270.9540100098270 .9540100098271 .2587890625271 .5635070801271 .8682861328 272.1730957031272 .1730957031272 .4779052734272 .7827148438272 .7827148438 273.0874938965273 .3923034668273 .3923034668273 .6971130371273 .6971130371 274.0018005371274 .0018005371274 .3066101074274 .3066101074274 .3066101074 274.6113891602274 .6113891602274 .6113891602274 .6113891602274 .6113891602 274.6113891602274 .6113891602274 .6113891602274 .6113891602274 .3066101074 274.3066101074274 .0018005371273 .6971130371273 .6971130371273 .3923034668 273.0874938965272 .7827148438272 .4779052734272 .1730957031271 .5635070801 271.2587890625270 .6492004395270 .3443908691269 .7348022461269 .4301147461 268.8204956055268 .5156860352267 .9060974121267 .6012878418266 .9917907715 266.6870117188266 .0773925781265 .7726135254265 .1630859375264 .8583068848 264.2486877441263 .6390991211263 .3344116211262 .7247924805262 .4200134277 262.4200134277263 .0296020508263 .6390991211264 .8583068848266 .0773925781 267.2966003418268 .5156860352269 .1253051758269 .4301147461269 .4301147461 268.8204956055268 .2109069824267 .6012878418266 .9917907715266 .6870117188 266.6870117188267 .2966003418267 .6012878418267 .6012878418267 .6012878418 267.6012878418267 .6012878418267 .2966003418267 .2966003418266 .6870117188 266.0773925781265 .4678039551264 .5534973145263 .3344116211262 .4200134277 261.2008972168260 .2864990234259 .0674133301257 .8482055664256 .9338989258 256.0195007324255 .1051025391254 .1907958984253 .2763977051252 .6669006348 252.3621063232252 .3621063232252 .0572967529252 .3621063232252 .6669006348 253.2763977051255 .4098968506257 .2385864258259 .0674133301261 .2008972168 262.7247924805265 .7726135254270 .0396118164274 .0018005371277 .3544921875 280.4023132324282 .2309875488284 .3645019531287 .4124145508290 .1553955078 292.8984985352295 .6416015625298 .6893920898301 .4324951172304 .1755981445 307.2233886719310 .2713012695313 .3190917969316 .3670043945319 .7196044922 323.0722045898326 .4248962402329 .7774963379333 .1301879883336 .4827880859 340.1401977539343 .4927978516346 .845489502350 .5028991699353 .5508117676 356.5986022949360 .5607910156362 .3894958496364 .78973388667367 .0145874023 368.900604248370 .5129089355 -9999 -9999 -9999 -9999 -9999 -9999 -9999 -9999 -9999

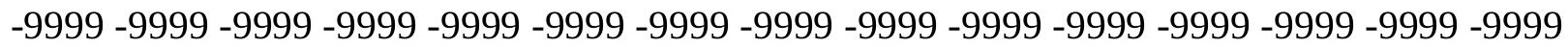
-9999 -

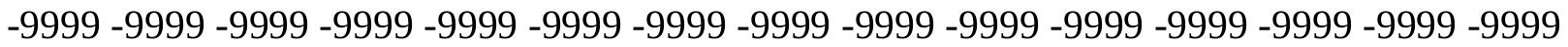
-9999 -

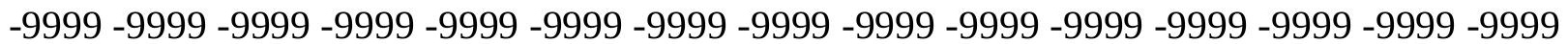
$-9999-9999-9999$ 
-9999 -9999 -9999 -9999 -9999 -9999 -9999 -9999 -9999 -9999 -9999 -9999 -9999 -9999 -9999 -9999 -9999 -9999 -9999 -9999 -9999 -9999 -9999 -9999 -9999 -9999 -9999 -9999 -9999 -9999 -9999 -9999 -9999 -9999 -9999 -9999 -9999 -9999 -9999 -9999 -9999 -9999 -9999 -9999 -9999 -9999 -9999 -9999 -9999 -9999 88.79692077637 102.9247360229116 .2337188721 128.6728668213139 .8963928223148 .4304046631155 .7451934814162 .4505004883 169.1557006836175 .5561981201181 .9566955566188 .3571929932194 .4528961182 200.5485992432206 .3394927979212 .1304016113217 .6165924072223 .1027069092 227.9792938232232 .5511016846237 .1228027344241 .0850067139244 .7424926758 248.0950927734250 .8381958008253 .5812072754256 .0195007324258 .1530151367 259.9816894531261 .8103942871263 .6390991211265 .1630859375266 .9917907715 268.5156860352270 .0396118164271 .5635070801272 .7827148438274 .0018005371 274.9161987305275 .8305053711276 .1353149414276 .1353149414276 .1353149414 276.1353149414276 .1353149414276 .1353149414275 .8305053711275 .8305053711 275.8305053711275 .8305053711275 .8305053711275 .8305053711275 .5257873535 275.5257873535275 .5257873535275 .2210083008275 .2210083008274 .9161987305 274.6113891602274 .6113891602274 .3066101074274 .0018005371274 .0018005371 274.3066101074274 .6113891602274 .9161987305275 .2210083008275 .5257873535 275.5257873535275 .8305053711275 .8305053711275 .8305053711275 .5257873535 274.9161987305274 .3066101074273 .6971130371273 .0874938965272 .4779052734 271.5635070801270 .9540100098270 .3443908691269 .7348022461269 .7348022461 269.4301147461269 .1253051758268 .8204956055268 .2109069824267 .9060974121 267.2966003418266.3822021484265.7726135254265.1630859375 264.5534973145 264.2486877441263 .9439086914263 .6390991211263 .6390991211263 .6390991211 263.6390991211263 .6390991211263 .9439086914263 .9439086914264 .2486877441 264.2486877441264 .5534973145264 .8583068848264 .8583068848265 .1630859375 265.4678039551265 .7726135254265 .7726135254266 .0773925781266 .3822021484 266.6870117188266 .6870117188266 .9917907715266 .9917907715267 .2966003418 267.2966003418267 .6012878418267 .6012878418267 .9060974121267 .9060974121 268.2109069824268 .2109069824268 .2109069824268 .2109069824268 .2109069824 268.2109069824268 .2109069824268 .2109069824268 .2109069824267 .9060974121 267.9060974121267 .6012878418267 .6012878418267 .2966003418266 .9917907715 266.6870117188266 .3822021484266 .0773925781265 .7726135254265 .4678039551 265.1630859375264 .5534973145263 .9439086914263 .6390991211263 .0296020508 262.7247924805262 .4200134277261 .8103942871261 .5056152344260 .8960876465 260.5913085938260 .2864990234259 .6769104004259 .3721008301259 .0674133301 258.4577941895258 .1530151367257 .8482055664257 .2385864258256 .9338989258 256.6290893555256 .3243103027256 .6290893555256 .9338989258257 .5433959961 258.4577941895259 .6769104004260 .8960876465261 .5056152344262 .4200134277 262.4200134277262 .4200134277261 .8103942871261 .5056152344260 .8960876465 260.2864990234260 .2864990234259 .9816894531260 .2864990234260 .2864990234 260.2864990234260 .2864990234260 .2864990234259 .9816894531259 .9816894531 259.3721008301259 .0674133301258 .4577941895257 .5433959961256 .6290893555 255.7147064209254 .8003997803253 .5812072754252 .6669006348251 .7525024414 250.5334014893249 .6190032959248 .7046966553248 .0950927734247 .1806945801 246.5711975098246 .2664031982245 .9615936279245 .6567993164245 .9615936279 246.2664031982246 .5711975098248 .7046966553250 .5334014893252 .6669006348 
254.8003997803256 .9338989258259 .3721008301262 .1152038574265 .1630859375 268.5156860352271 .8682861328274 .6113891602276 .4400939941278 .2687988281 281.3167114258284 .0596923828286 .8027954102289 .5458984375292 .2889099121 295.3367919922298 .0798950195301 .1276855469303 .8707885742306 .9186096191 310.2713012695313 .3190917969316 .3670043945319 .7196044922323 .0722045898 326.4248962402330 .0823059082333 .4349060059336 .7875976562340 .4450073242 343.7976074219347 .1502990723350 .1980895996354 .1603088379355 .9890136719 358.7320861816361 .1704101562363 .2021484375364 .9775390625366 .492401123 -9999 -9999 -9999 -9999 -9999 -9999 -9999 -9999 -9999 -9999 -9999 -9999 -9999 -9999 -9999 -9999 -9999 -9999 -9999 -9999 -9999 -9999 -9999 -9999 -9999 -9999 -9999 -9999 -9999 -9999 -9999

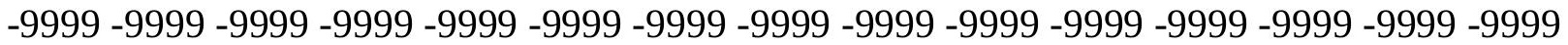
-9999 -9999 -9999 -9999 -9999 -9999 -9999 -9999 -9999 -9999 -9999 -9999 -9999 -9999 -9999

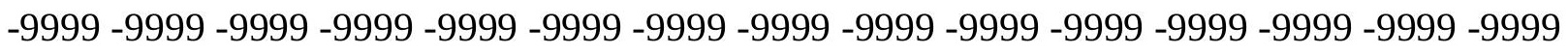
-9999 -9999 -9999 -9999 -9999 -9999 -9999 -9999 -9999 -9999

-9999 -9999 -9999 -9999 -9999 -9999 -9999 -9999 -9999 -9999 -9999 -9999 -9999 -9999 -9999

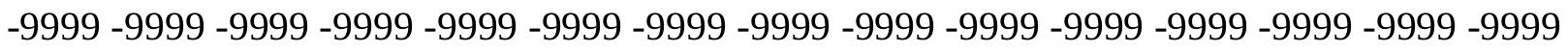
-9999 -9999 -9999 -9999 -9999 -9999 -9999 -9999 -9999 -9999 -9999 -9999 -9999 -9999 -9999 -9999 -9999 -9999-9999 85.40929412842 100.727973938 115.1215515137128.3144989014 140.5059967041150 .8686065674159 .7073974609167 .0222015381173 .7274932861 180.1280059814186 .2236938477192 .3193969727198 .4151000977204 .5108032227 210.3016967773216 .0926971436221 .5787963867227 .0648956299231 .9414978027 236.8179931641241 .0850067139245 .3520050049249 .0093994141252 .3621063232 255.4098968506257 .8482055664259 .9816894531262 .1152038574263 .6390991211 265.4678039551266 .9917907715268 .2109069824269 .7348022461270 .9540100098 272.4779052734273 .6971130371274 .9161987305276 .1353149414277 .0497131348 277.6592102051277 .9641113281278 .2687988281277 .9641113281277 .9641113281 277.6592102051277 .3544921875277 .0497131348276 .7449035645276 .4400939941 276.1353149414276 .1353149414275 .8305053711275 .5257873535275 .2210083008 274.9161987305274 .6113891602274 .3066101074274 .0018005371273 .6971130371 273.0874938965272 .7827148438272 .4779052734272 .1730957031271 .8682861328 271.8682861328271 .8682861328272 .1730957031272 .1730957031272 .4779052734 272.4779052734272 .4779052734272 .1730957031272 .1730957031271 .5635070801 270.9540100098270 .3443908691269 .7348022461268 .8204956055267 .9060974121 266.9917907715266 .3822021484265 .7726135254265 .1630859375264 .8583068848 264.2486877441263 .9439086914263 .3344116211263 .0296020508262 .4200134277 261.8103942871261 .2008972168260 .2864990234259 .6769104004259 .0674133301 258.7626037598258 .4577941895258 .1530151367257 .8482055664257 .8482055664 257.8482055664257 .8482055664257 .8482055664258 .1530151367258 .1530151367 258.4577941895258 .4577941895258 .7626037598259 .0674133301259 .0674133301 259.3721008301259 .6769104004259 .6769104004259 .9816894531260 .2864990234 260.5913085938260 .5913085938260 .8960876465260 .8960876465261 .2008972168 261.2008972168261 .5056152344261 .5056152344261 .8103942871261 .8103942871 262.1152038574262 .1152038574262 .1152038574262 .1152038574262 .1152038574 262.1152038574262 .1152038574261 .8103942871261 .8103942871261 .5056152344 261.5056152344261 .2008972168260 .8960876465260 .5913085938260 .2864990234 259.9816894531259 .6769104004259 .3721008301258 .7626037598258 .4577941895 
258.1530151367257 .5433959961257 .2385864258256 .6290893555256 .3243103027 255.7147064209255 .4098968506255 .1051025391254 .8003997803254 .1907958984 253.8860015869253 .5812072754253 .2763977051252 .9716033936252 .6669006348 252.3621063232252 .0572967529251 .7525024414251 .4476928711251 .1428985596 250.8381958008250 .8381958008250 .8381958008251 .4476928711252 .0572967529 252.6669006348253 .5812072754254 .4956054688255 .4098968506255 .7147064209 256.0195007324255 .7147064209255 .4098968506255 .1051025391254 .8003997803 254.1907958984253 .8860015869253 .8860015869253 .8860015869253 .5812072754 253.5812072754253 .5812072754253 .2763977051252 .9716033936252 .6669006348 252.3621063232251 .7525024414251 .1428985596250 .2286071777249 .6190032959 248.7046966553247 .4855041504246 .5711975098245 .6567993164244 .7424926758 243.8280944824242 .9136962891242 .3041992188241 .6945953369241 .0850067139 240.4754943848240 .1707000732240 .1707000732240 .1707000732240 .1707000732 240.7801971436241 .3898010254243 .5233001709245 .6567993164247 .7902984619 250.5334014893252 .9716033936255 .4098968506257 .8482055664260 .2864990234 263.3344116211266 .0773925781268 .5156860352269 .7348022461273 .0874938965 275.8305053711278 .5736083984281 .3167114258284 .0596923828286 .8027954102 289.5458984375292 .2889099121295 .0320129395298 .0798950195301 .1276855469 304.1755981445307 .2233886719310 .2713012695313 .6239013672316 .9765014648 320.3291931152323 .6817932129327 .0344848633330 .3870849609334 .0444946289 337.3970947266340 .749786377343 .7976074219346 .845489502349 .8933105469 352.6364135742355 .0747070312357 .5129089355359 .5209655762361 .1721496582 362.5004577637 -9999 -9999 -9999 -9999 -9999 -9999 -9999 -9999 -9999 -9999 -9999 -9999

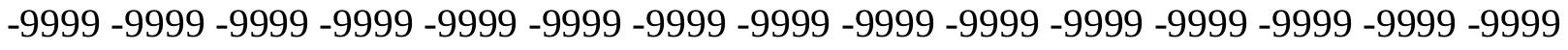

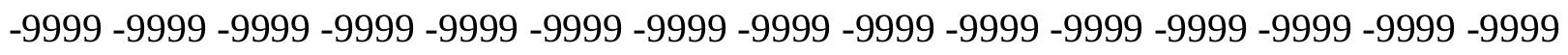
-9999 -9999 -9999 -9999 -9999 -9999 -9999 -9999 -9999 -9999 -9999 -9999 -9999 -9999 -9999 -9999 -9999 -9999 -9999 -9999 -9999 -9999 -9999 -9999 -9999 -9999 -9999 -9999 -9999 -9999 -9999 -9999 -9999 -9999 -9999 -9999 -9999 -9999 -9999 -9999 -9999 -9999 -999 - -999 -9999 -9999 -9999 -9999 -9999 -9999 -9999 -9999 -9999 -9999 -9999 -9999 -9999 -9999 -9999 -9999 -9999 -9999 -9999 -9999 -9999 -9999 -9999 -9999 -9999 -9999 -9999 -9999 -9999 -999 -9999 -9999 -9999 -9999 -9999 -9999 -9999 -9999 -9999 -9999 -9999 -9999 -9999 -9999 -9999 -9999 -9999 64.84825134277 81.9117584228598.70196533203 114.5837631226 128.9241027832141 .7250976562153 .0021057129162 .7552947998170 .9844970703 178.2993011475184 .699798584191 .1002960205196 .891204834202 .9868927002 208.7778015137214 .5686950684220 .3596038818225 .8457946777231 .0270996094 236.2084960938240 .7801971436245 .3520050049249 .6190032959253 .2763977051 256.9338989258259 .6769104004262 .4200134277264 .5534973145266 .3822021484 267.9060974121269 .1253051758270 .3443908691271 .5635070801272 .7827148438 274.0018005371274 .9161987305276 .1353149414277 .0497131348277 .9641113281 278.8783874512279 .4880065918279 .7927856445280 .0975036621280 .0975036621 279.7927856445279 .4880065918278 .8783874512278 .5736083984277 .9641113281 277.6592102051277 .0497131348276 .7449035645276 .1353149414275 .8305053711 275.2210083008274 .9161987305274 .3066101074273 .6971130371273 .3923034668 272.7827148438272 .1730957031271 .5635070801271 .2587890625270 .6492004395 270.0396118164269 .7348022461269 .7348022461269 .4301147461269 .4301147461 269.4301147461269 .4301147461269 .1253051758269 .1253051758268 .8204956055 
268.2109069824267 .9060974121266 .9917907715266 .3822021484265 .4678039551 264.5534973145263 .6390991211262 .7247924805262 .1152038574261 .2008972168 260.5913085938259 .9816894531259 .6769104004259 .0674133301258 .4577941895 257.8482055664257 .2385864258256 .6290893555255 .7147064209255 .1051025391 254.4956054688253 .8860015869253 .2763977051252 .9716033936252 .6669006348 252.3621063232252 .3621063232252 .3621063232252 .3621063232252 .3621063232 252.3621063232252 .3621063232252 .6669006348252 .6669006348252 .9716033936 252.9716033936253 .2763977051253 .5812072754253 .5812072754253 .8860015869 254.1907958984254 .1907958984254 .4956054688254 .8003997803254 .8003997803 255.1051025391255 .1051025391255 .4098968506255 .4098968506255 .7147064209 255.7147064209256 .0195007324256 .0195007324256 .0195007324256 .0195007324 256.0195007324256 .0195007324256 .0195007324255 .7147064209255 .7147064209 255.4098968506255 .1051025391255 .1051025391254 .8003997803254 .4956054688 253.8860015869253 .5812072754253 .2763977051252 .9716033936252 .3621063232 252.0572967529251 .7525024414251 .1428985596250 .8381958008250 .2286071777 249.9237976074249.6190032959249.0093994141248.7046966553248.3999023438 248.0950927734247 .7902984619247 .4855041504247 .1806945801246 .8759002686 246.8759002686246 .5711975098246 .2664031982245 .9615936279245 .9615936279 245.6567993164245 .6567993164245 .3520050049245 .6567993164245 .6567993164 246.2664031982246 .5711975098247 .4855041504248 .0950927734248 .7046966553 249.3141937256249 .6190032959249 .9237976074249 .9237976074249 .6190032959 249.3141937256248 .7046966553248 .3999023438248 .0950927734247 .7902984619 247.7902984619247 .4855041504247 .1806945801246 .8759002686246 .8759002686 246.2664031982245 .9615936279245 .3520050049244 .7424926758244 .1329040527 243.5233001709242 .6089935303241 .6945953369241 .0850067139240 .1707000732 239.2563018799 238.3419952393237.7324066162 236.8179931641 236.2084960938 235.9037017822235 .2940979004234 .9893035889234 .9893035889234 .9893035889 234.9893035889235 .2940979004235 .9037017822236 .8179931641237 .7324066162 240.4754943848242 .9136962891245 .6567993164248 .7046966553250 .8381958008 252.9716033936255 .4098968506257 .8482055664260 .2864990234262 .1152038574 264.8583068848267 .9060974121270 .6492004395273 .3923034668276 .1353149414 278.8783874512281 .3167114258284 .0596923828286 .8027954102289 .8505859375 292.5936889648295 .3367919922298 .3846130371301 .4324951172304 .4802856445 307.5281982422310 .8807983398313 .9287109375317 .2813110352320 .9388122559 324.2914123535327 .6440124512330 .9966125488334 .3493041992337 .7019042969 340.749786377343 .7976074219346 .845489502349 .2838134766351 .7219848633 354.1603088379355 .8817443848357 .3213806152358 .4749755859 -9999 -9999-9999-9999 -9999 -9999 -9999 -9999 -9999 -9999 -9999 -9999 -9999 -9999 -9999 -9999 -9999 -9999 -9999 -9999 -9999 -9999 -9999 -9999 -9999 -9999 -9999 -9999 -9999 -9999 -9999 -9999 -9999 -9999 -9999 -9999 -9999 -9999 -9999 -9999 -9999 -9999 -9999 -9999 -9999 -9999 -9999 -9999 -9999 -

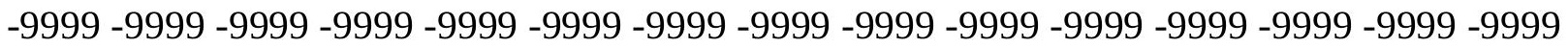
-9999 -9999 -9999 -9999 -9999 -9999 -9999 -9999 -9999 -9999 -9999 -9999 -9999 -9999 -9999 -9999 -9999-9999-9999-9999 -9999 -9999 -9999 -9999 -9999 -9999 -9999 -9999 -9999 -9999 -9999 -9999 -9999 -9999 -9999 -9999 -9999 -9999 -9999 -9999 -9999 -9999 -9999 -9999 -9999 -9999 -9999 -9999 -9999 -9999

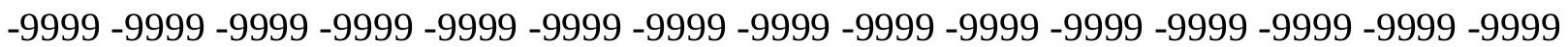


-9999 60.35862350464 78.8103561401497.38557434082114.9039993286131.0576019287 144.7729034424156 .6596069336166 .7174987793175 .5561981201182 .87109375 189.5764007568195 .9768066406201 .7678070068207 .25390625213 .0447998047 218.8356933594224 .3218994141230 .1127929688235 .2940979004240 .4754943848 245.0471954346249 .6190032959253 .5812072754257 .5433959961261 .2008972168 264.2486877441266.9917907715269.1253051758270.6492004395 272.1730957031 273.3923034668274 .3066101074275 .2210083008276 .1353149414277 .0497131348 277.9641113281278 .8783874512279 .4880065918280 .4023132324281 .0119018555 281.3167114258 281.9262084961281.9262084961 281.9262084961 281.6214904785 281.3167114258280.7070922852 280.0975036621279.4880065918278.8783874512 278.2687988281277 .6592102051277 .0497131348276 .4400939941275 .5257873535 274.9161987305274 .3066101074273 .6971130371273 .0874938965272 .1730957031 271.5635070801270 .9540100098270 .3443908691269 .4301147461268 .8204956055 268.5156860352267 .9060974121267 .6012878418267 .2966003418266 .9917907715 266.6870117188266 .3822021484266 .0773925781265 .7726135254265 .1630859375 264.8583068848263 .9439086914263 .3344116211262 .4200134277261 .5056152344 260.5913085938259 .6769104004258 .7626037598257 .8482055664256 .9338989258 256.3243103027255 .7147064209255 .1051025391254 .1907958984253 .5812072754 252.9716033936252 .3621063232251 .4476928711250 .8381958008250 .2286071777 249.3141937256248.7046966553248.0950927734247.7902984619247.4855041504 247.1806945801246 .8759002686246 .8759002686246 .5711975098246 .5711975098 246.8759002686246 .8759002686246 .8759002686246 .8759002686247 .1806945801 247.1806945801247 .4855041504247 .4855041504247 .7902984619248 .0950927734 248.0950927734248 .3999023438248 .7046966553248 .7046966553249 .0093994141 249.3141937256249 .3141937256249 .6190032959249 .6190032959249 .9237976074 249.9237976074250 .2286071777250 .2286071777250 .2286071777250 .2286071777 250.2286071777250 .2286071777249 .9237976074249 .9237976074249 .6190032959 249.3141937256249 .0093994141248 .7046966553248 .3999023438248 .0950927734 247.4855041504247 .1806945801246 .8759002686246 .2664031982245 .9615936279 245.3520050049245 .0471954346244 .4376983643244 .1329040527243 .8280944824 243.2185058594242 .9136962891242 .6089935303242 .3041992188241 .9994049072 241.6945953369241 .3898010254241 .3898010254241 .0850067139241 .0850067139 240.7801971436240 .7801971436240 .4754943848240 .4754943848240 .4754943848 240.1707000732240 .1707000732240 .4754943848240 .4754943848240 .7801971436 241.0850067139241 .6945953369242 .3041992188242 .9136962891243 .5233001709 243.8280944824244 .1329040527244 .4376983643244 .1329040527244 .1329040527 243.8280944824243 .2185058594242 .9136962891242 .6089935303242 .3041992188 241.9994049072241 .6945953369241 .3898010254241 .0850067139240 .4754943848 240.1707000732239 .5610961914238 .9515075684238 .3419952393237 .7324066162 237.1228027344236 .5133056641235 .5989074707234 .6844940186234 .0749969482 233.4653930664232 .5511016846231 .9414978027231 .3318939209231 .0270996094 230.4176025391230 .4176025391230 .1127929688230 .1127929688230 .1127929688 230.4176025391231 .0270996094231 .9414978027232 .8558044434234 .0749969482 235.2940979004237 .1228027344240 .4754943848242 .9136962891245 .3520050049 247.4855041504249 .0093994141252 .0572967529254 .8003997803257 .8482055664 260.5913085938263 .6390991211266 .3822021484268 .8204956055271 .5635070801 
274.0018005371276 .7449035645279 .1831970215281 .9262084961284 .6693115234 287.4124145508290 .1553955078293 .2033081055295 .9464111328298 .9942016602 302.0421142578305 .0899047852308 .1377868652311 .4903869629314 .8429870605 318.1957092285321 .5483093262324 .9009094238328 .2536010742331 .6062011719 334.6541137695338 .0067138672340 .749786377343 .7976074219346 .2359008789 348.6741943359350 .5028991699352 .2002258301353 .4396362305 -9999 -9999 -9999 -9999 -9999 -9999 -9999 -9999 -9999 -9999 -9999 -9999 -9999 -9999 -9999 -9999 -9999 -9999 -9999

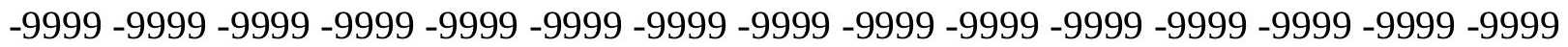
-9999 -9999 -9999 -9999 -9999 -9999 -9999 -9999 -9999 -9999 -9999 -9999 -9999 -9999 -9999 -9999 -9999 -9999 -9999 -9999 -9999 -9999 -9999 -9999 -9999 -9999 -9999 -9999 -9999 -9999

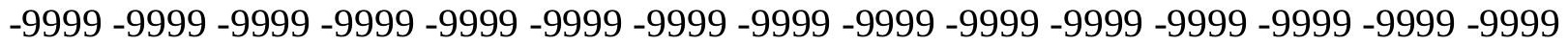
-9999 -9999-9999-9999-9999

-9999 -9999 -9999 -9999 -9999 -9999 -9999 -9999 -9999 -9999 -9999 -9999 -9999 -9999 -9999 -9999 -9999 -9999 -9999 -9999 -9999 -9999 -9999 -9999 -9999 -9999 -9999 -9999 -9999 -9999 -9999 -9999 -9999 -9999 -9999 -9999 -9999 -9999 -9999 -9999 -9999 -9999 -9999 -9999 -9999 57.4863891601676 .6705780029397 .8722076416117 .647102356135 .6293945312 150.2590942383162 .4505004883172 .5084075928181 .0424041748188 .6620025635195 .0625 201.158203125206 .6443023682212 .1304016113217 .6165924072222 .7978973389 228.2841033936234 .0749969482239 .2563018799244 .7424926758249 .6190032959 253.8860015869257 .8482055664261 .8103942871265 .1630859375268 .5156860352 271.5635070801273 .3923034668274 .9161987305276 .4400939941277 .6592102051 278.5736083984279 .1831970215279 .7927856445280 .4023132324281 .0119018555 281.6214904785282 .2309875488282 .8406066895283 .1453857422283 .4501953125 283.7549133301283 .7549133301283 .7549133301283 .4501953125283 .1453857422 282.5357971191281 .9262084961281 .3167114258280 .4023132324279 .7927856445 278.8783874512277 .9641113281277 .0497131348276 .4400939941275 .5257873535 274.6113891602273 .6971130371273 .0874938965272 .1730957031271 .2587890625 270.3443908691269 .7348022461268 .8204956055267 .9060974121267 .2966003418 266.6870117188266 .0773925781265 .4678039551264 .8583068848264 .5534973145 263.9439086914263 .6390991211263 .0296020508262 .4200134277261 .8103942871 261.2008972168260 .5913085938259 .6769104004258 .7626037598257 .8482055664 256.6290893555255 .7147064209254 .8003997803253 .8860015869252 .9716033936 252.0572967529251 .4476928711250 .5334014893249 .9237976074249 .0093994141 248.3999023438247 .4855041504246 .8759002686245 .9615936279245 .3520050049 244.4376983643243 .8280944824243 .2185058594242 .6089935303242 .3041992188 241.9994049072241 .6945953369241 .3898010254241 .3898010254241 .3898010254 241.3898010254241 .3898010254241 .3898010254241 .3898010254241 .3898010254 241.6945953369241 .6945953369241 .9994049072241 .9994049072242 .3041992188 242.6089935303242 .6089935303242 .9136962891242 .9136962891243 .2185058594 243.5233001709243 .5233001709243 .8280944824243 .8280944824244 .1329040527 244.1329040527244 .4376983643244 .4376983643244 .4376983643244 .4376983643 244.4376983643244 .1329040527244 .1329040527243 .8280944824243 .5233001709 243.2185058594242 .9136962891242 .6089935303242 .3041992188241 .6945953369 241.3898010254240.7801971436240.4754943848239.8659057617239.5610961914 238.9515075684238 .6468048096238 .0372009277237 .7324066162237 .4275970459 236.8179931641236 .5133056641236 .2084960938235 .9037017822235 .9037017822 
235.5989074707235 .2940979004235 .2940979004235 .2940979004235 .2940979004 234.9893035889234 .9893035889234 .9893035889234 .9893035889235 .2940979004 235.2940979004235 .2940979004235 .5989074707235 .9037017822236 .2084960938 236.5133056641237 .1228027344237 .4275970459238 .0372009277238 .3419952393 238.6468048096238 .9515075684238 .9515075684238 .9515075684238 .6468048096 238.3419952393238 .0372009277237 .7324066162237 .4275970459236 .8179931641 236.5133056641236 .2084960938235 .5989074707235 .2940979004234 .6844940186 234.3798065186 233.7702026367 233.1605987549232.5511016846 231.9414978027 231.3318939209230 .4176025391229 .8079986572229 .1983947754228 .5888977051 227.9792938232227 .3697052002226 .7601013184226 .4553985596226 .150604248 225.8457946777225 .8457946777225 .8457946777225 .8457946777226 .150604248 226.7601013184227 .3697052002228 .2841033936229 .1983947754230 .4176025391 232.246307373233 .7702026367235 .9037017822238 .0372009277240 .4754943848 242.9136962891245 .6567993164248 .3999023438251 .1428985596254 .1907958984 256.9338989258259 .6769104004262 .4200134277264 .8583068848267 .6012878418 270.0396118164272 .4779052734274 .9161987305277 .6592102051280 .0975036621 282.8406066895285 .5835876465288 .3266906738291 .0697937012293 .8128967285 296.5559082031299 .6037902832302 .6516113281306 .0043029785309 .0520935059 312.4047851562315 .7573852539319 .1099853516322 .4627075195325 .5104980469 328.8631896973 331.9110107422 334.9588928223 338.0067138672 340.749786377 $343.1879882812345 .3215026855347 .1502990723348 .3593139648349 .3154907227-9999$ -9999 -9999 -9999 -9999 -9999 -9999 -9999 -9999 -9999 -9999 -9999 -9999 -9999 -9999 -9999 -9999 -9999 -9999 -9999 -9999 -9999 -9999 -9999 -9999 -9999 -9999 -9999 -9999 -9999 -9999 -

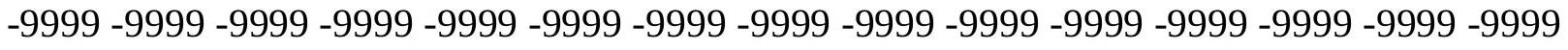
-9999 -9999 -9999 -9999 -9999 -9999 -9999 -9999 -9999 -9999 -9999 -9999 -9999 -9999 -9999 -9999 -9999 -9999 -9999 -9999 -9999 -9999 -9999 -9999 -9999 -9999 -9999 -9999 -9999 -9999 -9999 -9999 -9999 -9999-9999-9999-9999

-9999 -9999 -9999 -9999 -9999 -9999 -9999 -9999 -9999 -9999 -9999 -9999 -9999 -9999 -9999 -

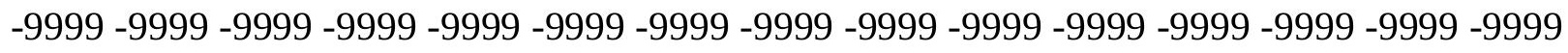
-9999 -9999 -9999 -9999 -9999 -9999 -9999 -9999 -9999 -9999 -9999 -9999 -9999 51.1933174133361 .2461929321376 .72499084473101 .4978942871124 .9618988037 145.0776977539160 .3170013428172 .2035980225181 .6519012451189 .5764007568 196.2816009521 202.0724945068 207.25390625 212.4351959229 217.3117980957 222.1884002686227 .0648956299232 .246307373237 .4275970459242 .9136962891 248.3999023438253 .5812072754258 .4577941895262 .4200134277265 .7726135254 269.1253051758271 .8682861328274 .9161987305277 .0497131348279 .1831970215 280.4023132324281 .6214904785282 .5357971191283 .1453857422283 .7549133301 284.0596923828284 .3645019531284 .9740905762285 .2789001465285 .5835876465 285.5835876465285 .8884887695285 .8884887695285 .8884887695285 .8884887695 285.5835876465284 .9740905762284 .3645019531283 .7549133301282 .8406066895 282.2309875488 281.3167114258 280.4023132324 279.1831970215 278.2687988281 277.3544921875276 .4400939941275 .2210083008274 .3066101074273 .3923034668 272.1730957031271 .2587890625270 .3443908691269 .4301147461268 .2109069824 267.2966003418266 .3822021484265 .4678039551264 .8583068848263 .9439086914 263.3344116211262 .7247924805262 .1152038574261 .5056152344260 .8960876465 259.9816894531259 .3721008301258 .7626037598257 .8482055664256 .9338989258 
256.0195007324255 .1051025391253 .8860015869252 .9716033936252 .0572967529 250.8381958008249 .9237976074249 .0093994141248 .0950927734247 .1806945801 246.2664031982245 .3520050049244 .7424926758243 .8280944824242 .9136962891 241.9994049072241 .3898010254240 .4754943848239 .8659057617238 .9515075684 238.3419952393237 .7324066162237 .4275970459236 .8179931641236 .5133056641 236.2084960938236 .2084960938235 .9037017822235 .9037017822235 .9037017822 235.9037017822235 .9037017822235 .9037017822236 .2084960938236 .2084960938 236.2084960938236 .5133056641236 .5133056641236 .8179931641237 .1228027344 237.1228027344237 .4275970459237 .7324066162237 .7324066162238 .0372009277 238.0372009277238 .3419952393238 .6468048096238 .6468048096238 .6468048096 238.6468048096238 .9515075684238 .6468048096238 .6468048096238 .6468048096 238.3419952393 238.0372009277237.7324066162 237.4275970459 237.1228027344 236.8179931641236 .2084960938235 .9037017822235 .2940979004234 .6844940186 234.3798065186233 .7702026367233 .4653930664232 .8558044434232 .5511016846 231.9414978027231 .6367034912231 .3318939209230 .7223052979230 .4176025391 230.4176025391230 .1127929688229 .8079986572229 .8079986572229 .8079986572 229.5032043457229 .5032043457229 .8079986572229 .8079986572229 .8079986572 230.1127929688230 .1127929688230 .4176025391230 .4176025391230 .7223052979 231.0270996094231 .3318939209231 .6367034912232 .246307373232 .5511016846 233.1605987549233 .4653930664233 .7702026367234 .0749969482234 .0749969482 234.0749969482234 .0749969482233 .7702026367233 .4653930664233 .1605987549 232.8558044434232 .246307373231 .9414978027231 .3318939209231 .0270996094 230.4176025391229 .8079986572229 .5032043457228 .8936004639228 .2841033936 227.6744995117227 .0648956299226 .4553985596225 .8457946777225 .2362060547 224.6266021729224 .0171051025223 .4075012207222 .7978973389222 .4931030273 222.1884002686221 .883605957221 .5787963867221 .5787963867221 .5787963867 221.883605957222 .1884002686222 .4931030273223 .1027069092224 .0171051025 224.9313964844226 .150604248227 .6744995117229 .1983947754231 .0270996094 233.1605987549235 .2940979004237 .7324066162240 .1707000732242 .9136962891 245.3520050049248 .0950927734250 .8381958008253 .5812072754256 .3243103027 259.0674133301261 .5056152344263 .9439086914266 .3822021484268 .8204956055 271.2587890625273 .6971130371276 .1353149414278 .8783874512281 .3167114258 283.7549133301286 .4979858398288 .9363098145291 .6794128418294 .4223937988 297.4703063965300 .5180969238303 .5660095215306 .9186096191309 .9664916992 313.3190917969316 .6718139648319 .7196044922323 .0722045898326 .1200866699 329.1679077148332 .2157897949334 .9588928223337 .7019042969339 .8353881836 341.6640930176343 .1928405762344 .2900390625 -9999 -9999 -9999 -9999 -9999 -9999 -9999

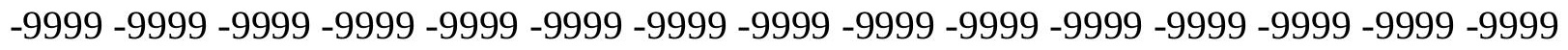
-9999 -9999 -9999 -9999 -9999 -9999 -9999 -9999 -9999 -9999 -9999 -9999 -9999 -9999 -9999 -9999 -9999 -9999 -9999 -9999 -9999 -9999 -9999 -9999 -9999 -9999 -9999 -9999 -9999 -9999 -

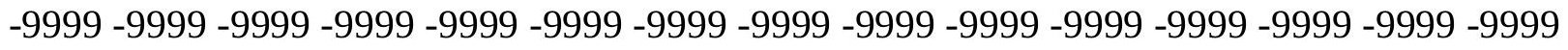
-9999 -9999 -9999 -9999 -9999 -9999 -9999 -9999 -9999 -9999 -9999 -9999 -9999 -9999 -9999 $-9999$

-9999 -9999 -9999 -9999 -9999 -9999 -9999 -9999 -9999 -9999 -9999 -9999 -9999 -9999 -9999 -9999 -9999 -9999 -9999 -9999 -9999 -9999 -9999 -9999 -9999 -9999 -9999 -9999 -9999 -9999 -9999 -9999 -9999 -9999 -9999 -9999 -9999 -9999 -9999 -9999 -9999 -9999 72.12590789795 
83.5826339721790 .44185638428107 .5891036987141 .7250976562163 .6696014404 178.2993011475188 .3571929932196 .2816009521202 .0724945068207 .25390625 211.520904541215 .4830932617219 .4452972412223 .4075012207227 .3697052002 231.3318939209235 .9037017822240 .7801971436245 .6567993164251 .1428985596 256.6290893555261 .8103942871266 .6870117188270 .0396118164273 .0874938965 275.5257873535277 .9641113281280 .4023132324282 .2309875488284 .0596923828 285.2789001465286 .1932067871286 .8027954102287 .4124145508287 .7171936035 288.0219116211288 .0219116211288 .3266906738288 .3266906738288 .3266906738 288.3266906738288 .3266906738288 .0219116211288 .0219116211287 .4124145508 287.1076049805286 .4979858398285 .5835876465284 .6693115234283 .7549133301 282.8406066895281 .9262084961280 .7070922852279 .4880065918278 .5736083984 277.3544921875276 .1353149414274 .9161987305273 .6971130371272 .7827148438 271.5635070801270 .3443908691269 .1253051758268 .2109069824266 .9917907715 266.0773925781264 .8583068848263 .9439086914263 .0296020508262 .1152038574 261.2008972168260 .2864990234259 .6769104004258 .7626037598258 .1530151367 257.2385864258256 .3243103027255 .4098968506254 .4956054688253 .5812072754 252.6669006348251 .4476928711250 .5334014893249 .3141937256248 .3999023438 247.1806945801245 .9615936279245 .0471954346244 .1329040527243 .2185058594 242.3041992188241 .3898010254240 .4754943848239 .5610961914238 .6468048096 237.7324066162236 .8179931641235 .9037017822234 .9893035889234 .3798065186 233.7702026367233 .1605987549232 .5511016846231 .9414978027231 .6367034912 231.3318939209231 .0270996094231 .0270996094230 .7223052979230 .7223052979 230.7223052979230 .7223052979230 .7223052979230 .7223052979230 .7223052979 231.0270996094231 .0270996094231 .0270996094231 .3318939209231 .6367034912 231.6367034912231 .9414978027231 .9414978027232 .246307373232 .5511016846 232.5511016846232 .8558044434233 .1605987549233 .1605987549233 .1605987549 233.1605987549233 .1605987549233 .1605987549233 .1605987549232 .8558044434 232.8558044434232 .5511016846232 .246307373231 .6367034912231 .3318939209 231.0270996094230 .4176025391230 .1127929688229 .5032043457228 .8936004639 228.5888977051227 .9792938232227 .3697052002227 .0648956299226 .4553985596 226.150604248225 .8457946777225 .5410003662225 .2362060547224 .9313964844 224.6266021729224 .3218994141224 .3218994141224 .3218994141224 .3218994141 224.3218994141224 .3218994141224 .3218994141224 .6266021729224 .9313964844 224.9313964844225 .2362060547225 .5410003662225 .8457946777226 .4553985596 226.7601013184227 .0648956299227 .6744995117227 .9792938232228 .2841033936 228.8936004639229 .1983947754229 .5032043457229 .5032043457229 .8079986572 229.8079986572229 .5032043457229 .1983947754228 .8936004639228 .5888977051 227.9792938232227 .6744995117227 .0648956299226 .4553985596226 .150604248 225.5410003662224 .9313964844224 .3218994141223 .7122955322223 .1027069092 222.4931030273221 .883605957221 .2740020752220 .6643981934220 .3596038818 219.7501068115219 .1405029297218 .8356933594218 .5308990479218 .2261962891 217.9214019775 217.6165924072 217.6165924072 217.9214019775 217.9214019775 218.2261962891218 .8356933594219 .4452972412220 .3596038818221 .2740020752 222.1884002686223 .7122955322225 .2362060547226 .7601013184228 .5888977051 230.7223052979232 .8558044434235 .2940979004237 .7324066162240 .4754943848 242.9136962891245 .6567993164248 .3999023438251 .1428985596253 .5812072754 
256.3243103027258 .7626037598261 .2008972168263 .3344116211265 .7726135254 267.9060974121270 .3443908691272 .7827148438275 .2210083008277 .3544921875 279.7927856445282 .2309875488284 .6693115234287 .1076049805289 .8505859375 292.5936889648295 .6416015625298 .6893920898301 .7373046875304 .7850952148 307.8330078125311 .1856079102314 .2334899902317 .2813110352320 .6339111328 323.6817932129326 .4248962402329 .4726867676331 .9110107422334 .3493041992 336.4827880859338 .0217285156339 .2424926758340 .1477966309 -9999 -9999 -9999 -9999 -9999 -9999 -9999 -9999 -9999 -9999 -9999 -9999 -9999 -9999 -9999 -9999 -9999 -9999 -9999

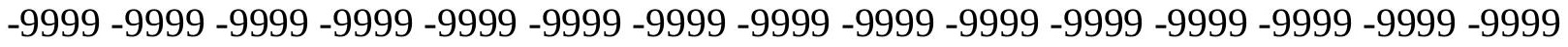
-9999 -9999 -9999 -9999 -9999 -9999 -9999 -9999 -9999 -9999 -9999 -9999 -9999 -9999 -9999

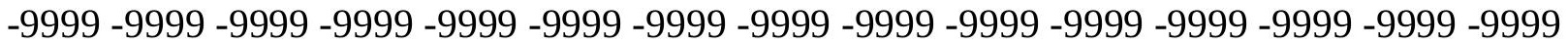

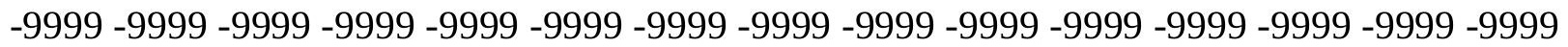
-9999 -9999-9999

-9999 -9999 -9999 -9999 -9999 -9999 -9999 -9999 -9999 -9999 -9999 -9999 -9999 -9999 -9999 -9999 -9999 -9999 -9999 -9999 -9999 -9999 -9999 -9999 -9999 -9999 -9999 -9999 -9999 -9999 -9999 -9999 -9999 -9999 -9999 -9999 -9999 -9999 -9999 -9999 40.64063644409 76.93597412109115 .4757232666141 .2157440186136 .2389984131180 .1280059814 198.4151000977208 .1681976318213 .959197998217 .9214019775220 .3596038818 222.4931030273224 .6266021729226 .4553985596228 .5888977051231 .0270996094 233.7702026367236 .8179931641240 .1707000732243 .8280944824248 .3999023438 253.2763977051258.1530151367263.6390991211268.8204956055 274.0018005371 276.7449035645279 .1831970215281 .3167114258283 .4501953125285 .2789001465 286.8027954102288 .3266906738289 .2410888672290 .1553955078290 .7650146484 291.0697937012291 .3746032715291 .3746032715291 .3746032715291 .3746032715 291.0697937012291 .0697937012290 .7650146484290 .4602050781290 .1553955078 289.5458984375 288.9363098145288.3266906738 287.4124145508 286.4979858398 285.5835876465284 .6693115234283 .4501953125282 .2309875488281 .0119018555 279.7927856445278 .5736083984277 .3544921875275 .8305053711274 .6113891602 273.3923034668271 .8682861328270 .6492004395269 .4301147461268 .2109069824 266.9917907715265 .7726135254264 .5534973145263 .3344116211262 .1152038574 261.2008972168260 .2864990234259 .0674133301258 .1530151367257 .2385864258 256.3243103027255 .4098968506254 .4956054688253 .5812072754252 .3621063232 251.4476928711250 .2286071777249 .3141937256248 .0950927734246 .8759002686 245.9615936279244 .7424926758243 .5233001709242 .3041992188241 .3898010254 240.1707000732239 .2563018799238 .0372009277237 .1228027344236 .2084960938 235.2940979004234 .3798065186233 .1605987549232 .246307373231 .6367034912 230.7223052979229 .8079986572229 .1983947754228 .5888977051227 .9792938232 227.3697052002226 .7601013184226 .4553985596226 .150604248225 .8457946777 225.8457946777225 .5410003662225 .5410003662225 .5410003662225 .5410003662 225.5410003662225 .5410003662225 .5410003662225 .5410003662225 .8457946777 225.8457946777226 .150604248226 .150604248226 .4553985596226 .7601013184 226.7601013184227 .0648956299227 .3697052002227 .3697052002227 .6744995117 227.6744995117227 .9792938232227 .9792938232227 .9792938232227 .9792938232 227.6744995117227 .6744995117227 .3697052002227 .0648956299226 .7601013184 226.4553985596225 .8457946777225 .5410003662224 .9313964844224 .6266021729 224.0171051025223 .4075012207223 .1027069092222 .4931030273221 .883605957 
221.5787963867220 .9691925049220 .6643981934220 .3596038818220 .054901123 219.7501068115219 .4452972412219 .1405029297219 .1405029297219 .1405029297 219.1405029297219 .1405029297219 .1405029297219 .4452972412219 .4452972412 219.7501068115220 .054901123220 .3596038818220 .9691925049221 .2740020752 221.5787963867222 .1884002686222 .7978973389223 .1027069092223 .7122955322 224.0171051025224 .3218994141224 .9313964844225 .2362060547225 .2362060547 225.5410003662225 .5410003662225 .5410003662225 .2362060547224 .9313964844 224.6266021729224 .3218994141223 .7122955322223 .1027069092222 .4931030273 221.883605957221 .5787963867220 .9691925049220 .3596038818219 .7501068115 219.1405029297 218.5308990479 217.9214019775 217.3117980957 216.7021942139 216.0926971436215 .787902832215 .1782989502214 .8735046387214 .5686950684 214.2639007568214 .2639007568213 .959197998213 .959197998214 .2639007568 214.5686950684214 .8735046387215 .1782989502215 .787902832216 .7021942139 217.6165924072218 .8356933594220 .054901123221 .5787963867223 .1027069092 224.9313964844226 .7601013184228 .8936004639231 .0270996094233 .4653930664 235.9037017822238 .3419952393241 .0850067139243 .5233001709246 .2664031982 248.7046966553251 .4476928711253 .8860015869256 .3243103027258 .7626037598 260.8960876465263 .3344116211265 .4678039551267 .6012878418269 .7348022461 271.8682861328274 .0018005371276 .1353149414278 .2687988281280 .7070922852 282.8406066895285 .5835876465288 .0219116211291 .0697937012293 .8128967285 296.8606872559299 .6037902832302 .6516113281305 .6994934082308 .7473144531 311.7951965332314 .8429870605317 .8908996582320 .9388122559323 .6817932129 326.4248962402328 .8631896973330 .9966125488332 .8252868652334 .2339172363 335.2511291504 -9999 -9999 -9999 -9999 -9999 -9999 -9999 -9999 -9999 -9999 -9999 -9999 -9999 -9999 -9999 -9999 -9999 -9999 -9999 -9999 -9999 -9999 -9999 -9999 -9999 -9999 -9999 -9999 -9999 -9999 -9999 -9999 -9999 -9999 -9999 -9999 -9999 -9999 -9999 -9999 -9999 -9999 -9999 -9999 -9999 -9999 -9999 -9999 -9999 -9999 -9999 -9999 -9999 -9999 -9999 -9999 -9999 -

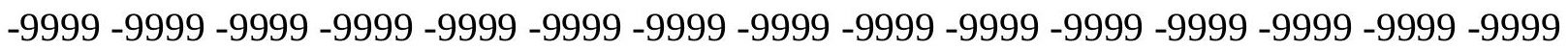
-9999 -9999 -9999 -9999 -9999 -9999 -9999 -9999 -9999 -9999

-9999 -9999 -9999 -9999 -9999 -9999 -9999 -9999 -9999 -9999 -9999 -9999 -9999 -9999 -999 -9999 -9999 -9999 -9999 -9999 -9999 -9999 -9999 -9999 -9999 -9999 -9999 -9999 -9999 -9999 -9999 -9999 -9999 -9999 -9999 -9999 -9999-9999 -9999 24.5777072906547 .4503364563 93.54960632324165 .6828308105225 .2362060547261 .2008972168254 .4956054688 252.3621063232250 .5334014893248 .0950927734245 .6567993164243 .5233001709 241.6945953369240 .7801971436240 .4754943848240 .7801971436241 .6945953369 243.5233001709245 .3520050049247 .7902984619251 .1428985596254 .8003997803 259.3721008301264 .2486877441269 .4301147461274 .3066101074278 .5736083984 281.6214904785284 .0596923828285 .8884887695287 .7171936035289 .5458984375 290.7650146484291 .9841918945292 .8984985352293 .8128967285294 .1176147461 294.4223937988294 .4223937988294 .4223937988294 .1176147461294 .1176147461 293.8128967285293 .5080871582292 .8984985352292 .5936889648291 .9841918945 291.0697937012290 .4602050781289 .5458984375288 .6315002441287 .4124145508 286.4979858398285 .2789001465283 .7549133301282 .5357971191281 .3167114258 279.7927856445278 .5736083984277 .0497131348275 .5257873535274 .0018005371 272.7827148438271 .2587890625269 .7348022461268 .5156860352266 .9917907715 265.7726135254264 .2486877441263 .0296020508261 .8103942871260 .5913085938 
259.3721008301258 .1530151367256 .9338989258256 .0195007324254 .8003997803 253.8860015869252 .6669006348251 .7525024414250 .5334014893249 .6190032959 248.3999023438247 .1806945801245 .9615936279244 .7424926758243 .5233001709 242.3041992188241 .0850067139239 .8659057617238 .9515075684237 .7324066162 236.5133056641235 .2940979004234 .3798065186233 .1605987549232 .246307373 231.0270996094230 .1127929688229 .1983947754228 .2841033936227 .3697052002 226.4553985596225 .5410003662224 .6266021729224 .0171051025223 .4075012207 222.7978973389222 .1884002686221 .883605957221 .2740020752220 .9691925049 220.9691925049220 .6643981934220 .3596038818220 .3596038818220 .3596038818 220.3596038818220 .3596038818220 .3596038818220 .3596038818220 .3596038818 220.6643981934220 .6643981934220 .9691925049221 .2740020752221 .2740020752 221.5787963867221 .883605957222 .1884002686222 .1884002686222 .4931030273 222.4931030273222 .7978973389222 .7978973389222 .7978973389222 .4931030273 222.4931030273222 .1884002686222 .1884002686221 .883605957221 .5787963867 220.9691925049220 .6643981934220 .3596038818219 .7501068115219 .1405029297 218.8356933594218 .2261962891217 .9214019775217 .3117980957216 .7021942139 216.3973999023216 .0926971436215 .4830932617215 .1782989502214 .8735046387 214.5686950684214 .2639007568214 .2639007568214 .2639007568213 .959197998 213.959197998214 .2639007568214 .2639007568214 .5686950684214 .8735046387 215.1782989502215 .787902832216 .0926971436216 .7021942139217 .0070037842 217.6165924072218 .2261962891218 .8356933594219 .4452972412219 .7501068115 220.3596038818220 .6643981934220 .9691925049221 .2740020752221 .5787963867 221.5787963867221 .5787963867221 .5787963867221 .2740020752220 .9691925049 220.6643981934220 .054901123219 .4452972412218 .8356933594218 .2261962891 217.6165924072217 .0070037842216 .3973999023215 .787902832215 .1782989502 214.5686950684213 .959197998213 .3495941162213 .0447998047212 .4351959229 212.1304016113211 .520904541211 .2160949707210 .9113006592210 .6065063477 210.6065063477210 .6065063477210 .6065063477210 .9113006592210 .9113006592 211.520904541211 .8256988525212 .7400054932213 .3495941162214 .2639007568 215.4830932617216 .7021942139217 .9214019775219 .7501068115221 .2740020752 223.1027069092225 .2362060547227 .3697052002229 .5032043457231 .9414978027 234.3798065186236 .8179931641239 .2563018799241 .9994049072244 .4376983643 247.1806945801249 .6190032959252 .0572967529254 .4956054688256 .6290893555 259.0674133301261 .2008972168263 .3344116211265 .4678039551267 .2966003418 269.4301147461271 .2587890625273 .0874938965275 .2210083008277 .0497131348 279.1831970215281 .6214904785284 .0596923828286 .8027954102289 .5458984375 292.2889099121295 .0320129395297 .7750854492300 .8229064941303 .5660095215 306.6138000488309 .3569030762312 .4047851562315 .4526062012318 .1957092285 320.9388122559323 .3770141602325 .5104980469327 .6440124512329 .2561340332 330.3973693848331 .1524353027 -9999 -9999 -9999 -9999 -9999 -9999 -9999 -9999 -9999

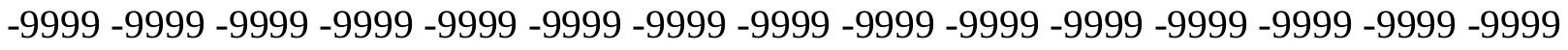

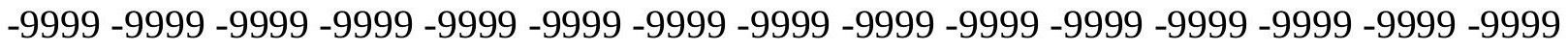
-9999 -9999 -9999 -9999 -9999 -9999 -9999 -9999 -9999 -9999 -9999 -9999 -9999 -9999 -9999 -9999 -9999 -9999 -9999 -9999 -9999 -9999 -9999 -9999-9999 -9999 -9999 -9999 -9999 -9999 -9999 -9999 -9999 -9999 -9999 -9999 -9999 -9999 -9999 -9999 -9999 -9999 -

-9999 -9999 -9999 -9999 -9999 -9999 -9999 -9999 -9999 -9999 -9999 -9999 -9999 -9999 -9999 
-9999 -9999 -9999 -9999 -9999 -9999 -9999 -9999 -9999 -9999 -9999 -9999 -9999 -9999 -9999 -9999 -9999 -9999 -9999-9999 -9999 -9999 -9999 24.493097305338 .4927406311 56.6044845581187 .77810668945218 .5308990479281 .0119018555300 .8229064941 302.0421142578293 .8128967285284 .6693115234276 .4400939941269 .4301147461 263.3344116211258 .7626037598255 .1051025391252 .9716033936252 .0572967529 251.7525024414252 .3621063232253 .2763977051254 .8003997803257 .2385864258 260.2864990234264 .2486877441268 .8204956055273 .6971130371278 .2687988281 282.2309875488285 .5835876465288 .0219116211289 .8505859375291 .6794128418 293.2033081055 294.4223937988295.3367919922 296.2510986328296.8606872559 297.1654968262297 .1654968262297 .1654968262297 .1654968262296 .8606872559 296.5559082031295 .9464111328295 .3367919922294 .7272033691294 .1176147461 293.5080871582292 .5936889648291 .6794128418290 .4602050781289 .5458984375 288.3266906738 286.8027954102 285.5835876465 284.3645019531282.8406066895 281.3167114258279 .7927856445278 .2687988281276 .7449035645275 .2210083008 273.6971130371272 .1730957031270 .3443908691268 .8204956055267 .2966003418 266.0773925781264 .5534973145263 .0296020508261 .5056152344260 .2864990234 258.7626037598257 .5433959961256 .3243103027255 .1051025391253 .8860015869 252.6669006348251 .4476928711250 .2286071777249 .0093994141247 .7902984619 246.5711975098245 .3520050049244 .1329040527242 .9136962891241 .6945953369 240.1707000732238 .9515075684237 .7324066162236 .5133056641235 .2940979004 234.0749969482232 .8558044434231 .6367034912230 .4176025391229 .5032043457 228.2841033936227 .0648956299226 .150604248224 .9313964844224 .0171051025 223.1027069092222 .1884002686221 .2740020752220 .3596038818219 .7501068115 218.8356933594218 .2261962891217 .6165924072217 .3117980957216 .7021942139 216.3973999023216 .0926971436215 .787902832215 .4830932617215 .4830932617 215.1782989502215 .1782989502215 .1782989502215 .1782989502215 .1782989502 215.4830932617215 .4830932617215 .787902832215 .787902832216 .0926971436 216.0926971436216 .3973999023216 .7021942139217 .0070037842217 .0070037842 217.3117980957 217.6165924072 217.6165924072 217.6165924072 217.6165924072 217.6165924072217 .3117980957217 .3117980957217 .0070037842216 .7021942139 216.3973999023216 .0926971436215 .787902832215 .4830932617214 .8735046387 214.5686950684213 .959197998213 .3495941162213 .0447998047212 .4351959229 212.1304016113211 .520904541211 .2160949707210 .9113006592210 .6065063477 210.3016967773209 .9969024658209 .692199707209 .692199707209 .3874053955 209.3874053955 209.692199707209.692199707209.9969024658 210.3016967773 210.6065063477210 .9113006592211 .520904541212 .1304016113212 .7400054932 213.3495941162 213.959197998214.5686950684215.1782989502 215.787902832 216.3973999023 216.7021942139217.3117980957 217.6165924072 217.9214019775 217.9214019775 217.9214019775 217.9214019775 217.9214019775 217.6165924072 217.3117980957 216.7021942139216.0926971436215.787902832 215.1782989502 214.2639007568213 .6544036865213 .0447998047212 .4351959229211 .8256988525 211.2160949707210 .6065063477209 .9969024658209 .3874053955209 .0825958252 208.4730072021 208.1681976318207.8634033203207.5587005615 207.25390625 207.25390625 207.25390625 207.25390625 207.5587005615 207.8634033203208.1681976318 208.7778015137209 .3874053955210 .3016967773211 .2160949707212 .4351959229 213.6544036865214 .8735046387216 .3973999023218 .2261962891220 .054901123 
221.883605957224 .0171051025226 .150604248228 .2841033936230 .7223052979 233.1605987549235 .5989074707238 .3419952393240 .7801971436243 .2185058594 245.6567993164248 .3999023438250 .5334014893252 .9716033936255 .4098968506 257.5433959961259 .6769104004261 .5056152344263 .6390991211265 .4678039551 267.2966003418268.8204956055270.6492004395272.1730957031274.0018005371 275.8305053711277 .9641113281280 .4023132324282 .8406066895285 .5835876465 288.0219116211290 .7650146484293 .2033081055295 .9464111328298 .6893920898 301.4324951172304 .1755981445306 .9186096191309 .6617126465312 .7095031738 315.1477966309317 .8908996582320 .3291931152322 .4627075195324 .2914123535 325.5325012207326 .3861999512 -9999 -9999 -9999 -9999 -9999 -9999 -9999 -9999 -9999 -9999 -9999 -9999 -9999 -9999 -9999 -9999 -9999 -9999 -9999 -9999 -9999 -9999 -9999 -9999 -9999 -9999 -9999 -9999 -9999 -9999 -9999 -9999 -9999 -9999 -9999 -9999 -9999 -9999 -9999 -9999 -9999 -9999 -9999 -9999 -9999 -9999 -9999 -9999 -9999 -9999 -9999 -9999 -9999 -9999 -

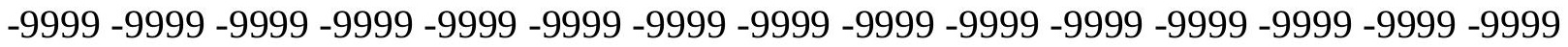
-9999 -9999 -9999 -9999 -9999 -9999 -9999 -9999 -9999 -9999 -9999 -9999 -

-9999 -9999 -9999 -9999 -9999 -9999 -9999 -9999 -9999 -9999 -9999 -9999 -9999 -9999 - -999 -9999 -9999 -9999 -9999 -9999 -9999 -9999 -9999 -9999 -9999 -9999 -9999 -9999 -9999 -9999 -9999 -9999 -9999 -9999 -9999 -9999 -9999 29.3358478546143 .4060478210460 .5424156189 85.94940185547130 .4479980469204 .2059936523273 .6971130371306 .6138000488 317.8908996582314 .8429870605306 .3091125488296 .8606872559287 .7171936035 279.4880065918272 .4779052734266 .9917907715263 .6390991211261 .8103942871 260.8960876465260 .5913085938260 .2864990234260 .8960876465262 .1152038574 264.8583068848268 .2109069824272 .7827148438277 .0497131348281 .6214904785 285.2789001465288 .6315002441291 .0697937012293 .2033081055294 .7272033691 296.2510986328297 .4703063965298 .3846130371298 .9942016602299 .6037902832 299.6037902832299 .9085998535299 .6037902832299 .2990112305298 .9942016602 298.3846130371297 .7750854492297 .1654968262296 .5559082031295 .6416015625 294.7272033691293 .8128967285292 .5936889648291 .3746032715290 .1553955078 288.9363098145287 .4124145508285 .8884887695284 .3645019531282 .8406066895 281.3167114258279 .4880065918277 .9641113281276 .4400939941274 .6113891602 273.0874938965271 .2587890625269 .7348022461267 .9060974121266 .3822021484 264.8583068848263 .0296020508261 .5056152344259 .9816894531258 .4577941895 257.2385864258255 .7147064209254 .1907958984252 .9716033936251 .4476928711 250.2286071777249 .0093994141247 .4855041504246 .2664031982245 .0471954346 243.8280944824242 .3041992188241 .0850067139239 .8659057617238 .3419952393 237.1228027344235 .9037017822234 .3798065186233 .1605987549231 .9414978027 230.7223052979229 .1983947754227 .9792938232226 .7601013184225 .8457946777 224.6266021729223 .4075012207222 .1884002686221 .2740020752220 .054901123 219.1405029297218 .2261962891217 .3117980957216 .3973999023215 .4830932617 214.5686950684213 .959197998213 .3495941162212 .7400054932212 .1304016113 211.8256988525211 .520904541211 .2160949707210 .9113006592210 .6065063477 210.3016967773210 .3016967773210 .3016967773210 .3016967773210 .3016967773 210.3016967773210 .6065063477210 .6065063477210 .9113006592210 .9113006592 211.2160949707211 .520904541211 .8256988525211 .8256988525212 .1304016113 212.4351959229212 .4351959229212 .7400054932212 .7400054932212 .7400054932 212.7400054932212 .7400054932212 .4351959229212 .4351959229212 .1304016113 
211.8256988525211 .520904541211 .2160949707210 .9113006592210 .3016967773 209.9969024658209 .3874053955209 .0825958252208 .4730072021208 .1681976318 207.8634033203207 .25390625206 .9490966797206 .6443023682206 .3394927979 206.0346984863205 .7299957275205 .425201416205 .425201416205 .425201416 205.425201416205 .425201416205 .425201416205 .7299957275206 .0346984863 206.6443023682206 .9490966797207 .5587005615208 .1681976318208 .7778015137 209.3874053955 210.3016967773210.9113006592 211.520904541212.4351959229 213.0447998047213 .3495941162213 .959197998214 .2639007568214 .5686950684 214.5686950684214 .5686950684214 .5686950684214 .2639007568213 .959197998 213.6544036865213 .0447998047212 .7400054932212 .1304016113211 .2160949707 210.6065063477209 .9969024658209 .3874053955208 .4730072021207 .8634033203 207.25390625206 .6443023682206 .3394927979205 .7299957275205 .1204071045 204.8155975342204 .5108032227204 .2059936523204 .2059936523204 .2059936523 204.2059936523204 .2059936523204 .5108032227204 .8155975342205 .425201416 205.7299957275206 .6443023682207 .25390625208 .4730072021209 .3874053955 210.6065063477212 .1304016113213 .6544036865215 .1782989502217 .0070037842 218.8356933594220 .9691925049223 .1027069092225 .2362060547227 .6744995117 230.1127929688232 .5511016846234 .9893035889237 .4275970459239 .8659057617 242.6089935303245 .0471954346247 .4855041504249 .6190032959252 .0572967529 254.1907958984256 .3243103027258 .4577941895260 .2864990234262 .1152038574 263.9439086914265 .4678039551267 .2966003418268 .8204956055270 .0396118164 271.5635070801272 .7827148438275 .2210083008277 .3544921875279 .7927856445 281.9262084961284 .3645019531286 .8027954102288 .9363098145291 .3746032715 293.8128967285296 .5559082031298 .9942016602301 .7373046875304 .4802856445 307.2233886719 309.6617126465 312.4047851562 314.8429870605 316.9765014648 319.1099853516 320.6521606445321 .6396484375322 .215423584 -9999 -9999 -9999 -9999 -9999 -9999 -9999 -9999 -9999 -9999 -9999 -9999 -9999 -9999 -9999 -9999 -9999 -9999 -9999

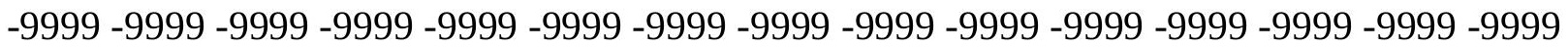

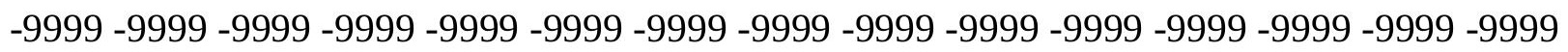

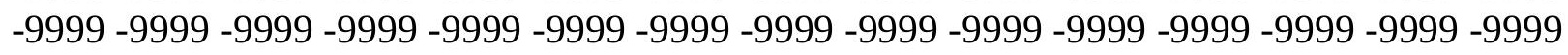

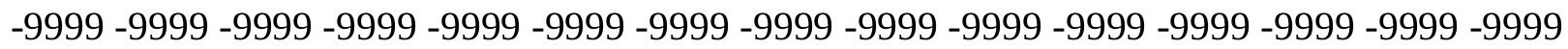
$-9999$

-9999 -9999 -9999 -9999 -9999 -9999 -9999 -9999 -9999 -9999 -9999 -9999 -9999 -9999 -9999

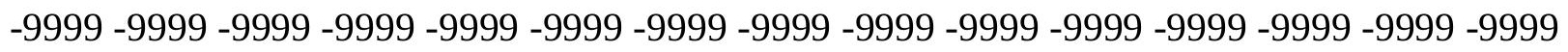
-9999 -9999 -9999 -9999-9999-9999 33.3601112365748 .4243125915566 .23707580566 88.69246673584116 .4279022217159 .4026031494211 .8256988525264 .8583068848 300.5180969238317 .2813110352320 .6339111328316 .3670043945308 .7473144531 300.2132873535291 .6794128418283 .4501953125276 .4400939941273 .0874938965 270.9540100098269 .1253051758267 .9060974121266 .3822021484265 .7726135254 266.0773925781268 .2109069824271 .5635070801275 .5257873535280 .0975036621 284.0596923828288 .0219116211291 .0697937012293 .8128967285295 .9464111328 297.4703063965298 .9942016602300 .2132873535300 .8229064941301 .4324951172 301.7373046875302 .0421142578302 .0421142578301 .7373046875301 .4324951172 300.8229064941300 .2132873535299 .6037902832298 .6893920898297 .7750854492 296.8606872559295 .6416015625294 .7272033691293 .5080871582291 .9841918945 290.7650146484289 .2410888672287 .7171936035286 .1932067871284 .3645019531 
282.8406066895281 .0119018555279 .1831970215277 .6592102051275 .8305053711 274.0018005371272 .1730957031270 .3443908691268 .8204956055266 .9917907715 265.1630859375263 .3344116211261 .8103942871259 .9816894531258 .4577941895 256.9338989258255 .4098968506253 .8860015869252 .3621063232250 .8381958008 249.3141937256247 .7902984619246 .5711975098245 .0471954346243 .8280944824 242.3041992188240 .7801971436239 .5610961914238 .0372009277236 .8179931641 235.2940979004234 .0749969482232 .5511016846231 .3318939209229 .8079986572 228.58889977051227 .0648956299225 .8457946777224 .6266021729223 .4075012207 222.1884002686220 .9691925049219 .7501068115218 .5308990479217 .3117980957 216.3973999023215 .1782989502214 .2639007568213 .0447998047212 .1304016113 211.520904541210 .6065063477209 .692199707209 .0825958252208 .4730072021 207.8634033203207 .25390625206 .9490966797206 .6443023682206 .0346984863 206.0346984863205 .7299957275205 .425201416205 .425201416205 .425201416 205.425201416205 .425201416205 .425201416205 .7299957275205 .7299957275 206.0346984863206 .3394927979206 .6443023682206 .9490966797207 .25390625 207.25390625207 .5587005615207 .8634033203207 .8634033203207 .8634033203 207.8634033203207 .8634033203207 .8634033203207 .8634033203207 .8634033203 207.5587005615207 .25390625207 .25390625206 .9490966797206 .6443023682 206.3394927979205 .7299957275205 .425201416205 .1204071045204 .5108032227 204.2059936523203 .9011993408203 .596496582202 .9868927002202 .6820983887 202.3773040771202 .3773040771202 .0724945068201 .7678070068201 .7678070068 201.4629974365201 .4629974365201 .4629974365201 .7678070068202 .0724945068 202.3773040771 202.6820983887 203.2917022705 203.9011993408 204.5108032227 205.425201416206 .0346984863206 .9490966797207 .5587005615208 .4730072021 209.0825958252209 .692199707210 .3016967773210 .9113006592211 .2160949707 211.520904541211 .520904541211 .520904541211 .2160949707211 .2160949707 210.9113006592210 .3016967773209 .692199707209 .0825958252208 .4730072021 207.8634033203207 .25390625206 .3394927979205 .7299957275205 .1204071045 204.5108032227203 .9011993408203 .2917022705202 .6820983887202 .3773040771 201.7678070068201 .4629974365202 .3773040771202 .9868927002203 .596496582 204.2059936523204 .8155975342205 .1204071045205 .7299957275206 .0346984863 206.0346984863206 .0346984863205 .7299957275205 .7299957275206 .6443023682 207.8634033203209 .3874053955210 .9113006592212 .4351959229214 .2639007568 216.0926971436218 .2261962891220 .3596038818222 .4931030273224 .6266021729 227.0648956299229 .5032043457231 .9414978027234 .3798065186237 .1228027344 239.5610961914241 .9994049072244 .4376983643246 .8759002686249 .3141937256 251.4476928711253 .5812072754255 .7147064209257 .5433959961259 .3721008301 261.2008972168263 .0296020508264 .5534973145265 .7726135254267 .2966003418 268.5156860352269 .7348022461271 .2587890625273 .0874938965274 .9161987305 277.0497131348279 .1831970215281 .0119018555283 .1453857422284 .9740905762 287.1076049805 289.5458984375 291.6794128418294.1176147461 296.5559082031 299.2990112305301 .7373046875304 .4802856445306 .9186096191309 .3569030762 311.7951965332313 .9287109375315 .7573852539316 .8735351562317 .5771789551 -9999

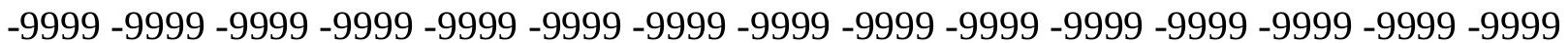

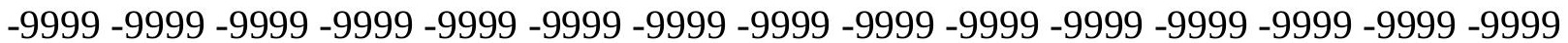
-9999- 
-9999 -9999 -9999 -9999 -9999 -9999 -9999 -9999 -9999 -9999 -9999 -9999 -9999 -9999 -9999 -9999 -9999 -9999 -9999 -9999 -9999 -9999 -9999 -9999 -9999 -9999 -9999 -9999 -9999 -9999 -9999 -9999-9999-9999

-9999 -9999 -9999 -9999 -9999 -9999 -9999 -9999 -9999 -9999 -9999 -9999 -9999 -9999 -9999 -9999 -9999 -9999 -9999 -9999 -9999 -9999 -9999 -9999 -9999 -9999 -9999 -9999 -9999 -9999 -9999 -9999 -9999 -9999 22.26164245605 35.5431442260750 .5990676879967 .94895935059 88.69246673584112 .4656982422142 .0299072266178 .9089050293220 .9691925049 261.2008972168292 .5936889648311 .1856079102318 .8052062988318 .8052062988 313.9287109375307 .2233886719299 .9085998535292 .2889099121286 .1932067871 281.6214904785278 .5736083984276 .4400939941274 .6113891602271 .8682861328 269.7348022461269 .4301147461270 .9540100098274 .3066101074278 .2687988281 282.5357971191286 .4979858398290 .1553955078293 .5080871582295 .9464111328 298.0798950195 299.9085998535 301.1276855469 302.3468017578 302.9563903809 303.5660095215303 .8707885742303 .8707885742303 .8707885742303 .5660095215 302.9563903809302 .3468017578301 .7373046875300 .8229064941299 .9085998535 298.9942016602297 .7750854492296 .5559082031295 .3367919922294 .1176147461 292.5936889648291 .0697937012289 .5458984375287 .7171936035286 .1932067871 284.3645019531282 .5357971191280 .7070922852278 .8783874512277 .0497131348 275.2210083008273 .3923034668271 .2587890625269 .4301147461267 .6012878418 265.7726135254263 .9439086914262 .1152038574260 .2864990234258 .7626037598 256.9338989258255 .1051025391253 .5812072754252 .0572967529250 .2286071777 248.7046966553247 .1806945801245 .6567993164244 .1329040527242 .6089935303 241.0850067139239 .5610961914238 .3419952393236 .8179931641235 .2940979004 233.7702026367232 .246307373231 .0270996094229 .5032043457227 .9792938232 226.7601013184225 .2362060547224 .0171051025222 .4931030273221 .2740020752 219.7501068115218 .5308990479217 .3117980957216 .0926971436214 .8735046387 213.6544036865212 .4351959229211 .520904541210 .3016967773209 .3874053955 208.4730072021207 .5587005615206 .6443023682205 .7299957275204 .8155975342 204.2059936523203 .596496582202 .9868927002202 .3773040771202 .0724945068 201.7678070068201 .4629974365201 .158203125200 .8533935547200 .8533935547 200.5485992432200 .5485992432200 .5485992432200 .8533935547200 .8533935547 201.158203125201 .4629974365201 .4629974365201 .7678070068202 .0724945068 202.3773040771202 .6820983887202 .9868927002202 .9868927002203 .2917022705 203.2917022705203 .596496582203 .596496582203 .596496582203 .596496582 203.596496582203 .2917022705203 .2917022705202 .9868927002202 .9868927002 202.6820983887202 .3773040771202 .0724945068201 .7678070068201 .4629974365 201.158203125200 .8533935547200 .5485992432199 .9389953613199 .6342926025 199.329498291 199.0247039795 199.0247039795 198.7198944092198 .4151000977 198.1103057861198 .1103057861198 .1103057861198 .1103057861198 .1103057861 198.4151000977198 .7198944092199 .329498291199 .9389953613200 .5485992432 201.158203125202 .0724945068202 .6820983887203 .596496582204 .5108032227 205.1204071045206 .0346984863206 .6443023682207 .25390625207 .8634033203 208.1681976318208 .4730072021208 .4730072021208 .4730072021208 .4730072021 208.1681976318207 .5587005615207 .25390625206 .6443023682206 .0346984863 205.425201416204.5108032227 203.9011993408 203.2917022705 202.3773040771 201.7678070068202 .6820983887202 .9868927002202 .9868927002203 .2917022705 
203.596496582204 .2059936523204 .5108032227205 .1204071045205 .7299957275 206.3394927979 206.6443023682 207.25390625 207.5587005615 207.8634033203 208.1681976318208 .1681976318208 .1681976318207 .8634033203207 .5587005615 206.9490966797206 .6443023682208 .4730072021209 .9969024658211 .8256988525 213.6544036865215 .787902832217 .6165924072220 .054901123222 .1884002686 224.6266021729227 .0648956299229 .5032043457231 .9414978027234 .3798065186 237.1228027344239 .5610961914241 .9994049072244 .4376983643246 .8759002686 249.0093994141251 .1428985596253 .2763977051255 .4098968506257 .2385864258 259.0674133301260 .5913085938262 .1152038574263 .6390991211265 .1630859375 266.3822021484267 .6012878418268 .8204956055270 .0396118164271 .5635070801 273.0874938965274 .9161987305276 .4400939941278 .2687988281279 .7927856445 281.6214904785283 .4501953125285 .2789001465287 .4124145508289 .5458984375 291.6794128418294 .1176147461296 .5559082031298 .9942016602301 .4324951172 303.8707885742306 .3091125488308 .4425048828310 .5759887695312 .0507202148 312.9509277344313 .4053649902 -9999 -9999 -9999 -9999 -9999 -9999 -9999 -9999 -9999

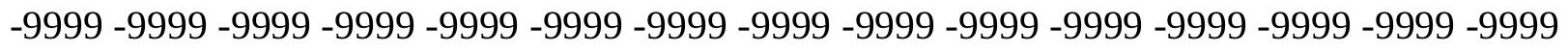
-9999 -9999 -9999 -9999 -9999 -9999 -9999 -9999 -9999 -9999 -9999 -9999 -9999 -9999 -9999 -9999 -9999 -9999 -9999 -9999 -9999 -9999 -9999 -9999 -9999 -9999 -9999 -9999 -9999 -9999 -9999 -9999 -9999 -9999 -9999 -9999 -9999 -9999 -9999 -9999 -9999 -9999 -9999 -9999 -9999 -9999 -9999 -9999-9999-9999-9999-9999 -9999 -9999-9999

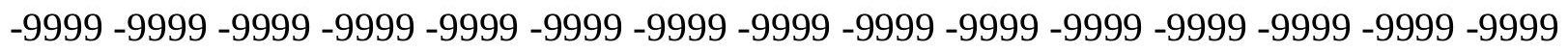
-9999 -9999 -9999 -9999 -9999 -9999 -9999 -9999 -9999 -9999 -9999 -9999 -9999 -9999 -9999 -9999 -9999 -9999 23.59705543518 36.244277954150.65900802612 67.35751342773 85.64462280273107 .5891036987132 .2767028809160 .9264984131192 .9290008545 227.3697052002 259.6769104004 286.1932067871303.8707885742 313.6239013672 316.3670043945314 .8429870605310 .5759887695304 .7850952148298 .9942016602 293.2033081055288 .6315002441284 .9740905762282 .2309875488279 .1831970215 276.4400939941274 .0018005371272 .1730957031273 .6971130371277 .0497131348 281.0119018555284 .9740905762288 .9363098145292 .2889099121295 .3367919922 298.0798950195300 .2132873535301 .7373046875303 .2611999512304 .1755981445 304.7850952148305 .3947143555305 .3947143555305 .3947143555305 .3947143555 304.7850952148304 .4802856445303 .8707885742302 .9563903809302 .0421142578 301.1276855469299 .9085998535298 .6893920898297 .1654968262295 .9464111328 294.4223937988292 .8984985352291 .0697937012289 .5458984375287 .7171936035 285.8884887695284 .0596923828282 .2309875488280 .4023132324278 .2687988281 276.4400939941274 .6113891602272 .4779052734270 .6492004395268 .5156860352 266.6870117188264 .5534973145262 .7247924805260 .8960876465259 .0674133301 256.9338989258255 .4098968506253 .5812072754251 .7525024414249 .9237976074 248.3999023438246 .5711975098245 .0471954346243 .2185058594241 .6945953369 240.1707000732238 .6468048096237 .1228027344235 .5989074707234 .0749969482 232.5511016846231 .0270996094229 .5032043457227 .9792938232226 .4553985596 224.9313964844223 .4075012207222 .1884002686220 .6643981934219 .1405029297 217.9214019775216 .3973999023215 .1782989502213 .959197998212 .7400054932 211.2160949707209 .9969024658209 .0825958252207 .8634033203206 .6443023682 205.7299957275204 .5108032227203 .596496582202 .6820983887201 .7678070068 200.8533935547200 .2438049316199 .329498291198 .7198944092198 .1103057861 
197.8054962158 197.1959991455 196.891204834196.5863952637 196.2816009521 196.2816009521195 .9768066406195 .9768066406195 .9768066406195 .9768066406 196.2816009521196 .5863952637196 .5863952637196 .891204834197 .1959991455 197.500793457197 .8054962158198 .1103057861198 .4151000977198 .7198944092 198.7198944092199 .0247039795199 .0247039795199 .329498291199 .329498291 199.329498291 199.329498291 199.329498291 199.329498291 199.329498291199.329498291 199.329498291199 .0247039795198 .7198944092198 .7198944092198 .4151000977 198.1103057861197 .8054962158197 .1959991455196 .891204834196 .5863952637 196.5863952637 196.2816009521 195.9768066406 195.6721038818 195.3672943115 195.0625 195.0625194 .7577056885194 .7577056885194 .7577056885195 .0625195 .3672943115 195.9768066406196 .5863952637197 .1959991455197 .8054962158198 .7198944092 199.6342926025200 .5485992432201 .4629974365202 .0724945068202 .9868927002 203.596496582204 .5108032227204 .8155975342205 .425201416205 .7299957275 205.7299957275205 .7299957275205 .425201416205 .1204071045204 .8155975342 204.2059936523203 .596496582202 .9868927002203 .596496582203 .9011993408 204.2059936523 204.5108032227 204.5108032227 204.8155975342 205.1204071045 205.425201416205 .7299957275206 .0346984863206 .3394927979206 .9490966797 207.25390625207 .8634033203208 .4730072021208 .7778015137209 .3874053955 209.692199707209 .692199707209 .692199707209 .692199707209 .692199707209 .692199707 209.692199707 209.692199707 209.0825958252 208.4730072021 207.5587005615 209.3874053955 211.2160949707 213.3495941162 215.4830932617217.6165924072 220.054901123222 .1884002686224 .6266021729227 .0648956299229 .8079986572 232.246307373234.6844940186237.1228027344239.8659057617242.3041992188 244.7424926758246 .8759002686249 .3141937256251 .4476928711253 .5812072754 255.4098968506257 .2385864258259 .0674133301260 .5913085938262 .1152038574 263.3344116211264 .5534973145265 .7726135254266 .9917907715268 .2109069824 269.1253051758270 .6492004395271 .8682861328273 .0874938965274 .6113891602 275.8305053711277 .0497131348278 .5736083984279 .7927856445281 .3167114258 283.1453857422284 .9740905762287 .1076049805289 .5458984375291 .6794128418 294.1176147461296 .2510986328298 .6893920898300 .8229064941303 .2611999512 305.3947143555307 .2233886719308 .3585510254308 .9576416016 -9999 -9999 -9999 -9999 -9999 -9999 -9999 -9999 -9999 -9999 -9999 -9999 -9999 -9999 -9999 -9999 -9999 -9999 -9999

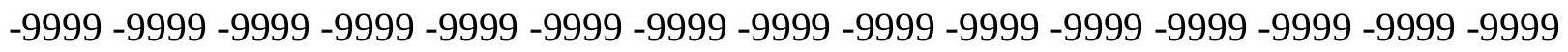
-9999 -9999 -9999 -9999 -9999 -9999 -9999 -9999 -9999 -9999 -9999 -9999 -9999 -9999 -9999 -9999 -9999 -9999 -9999 -9999 -9999 -9999 -9999 -9999 -9999 -9999 -9999 -9999 -9999 -9999 -

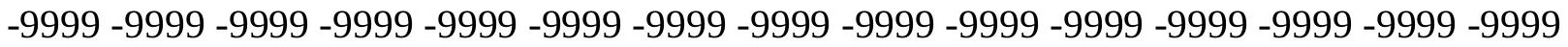

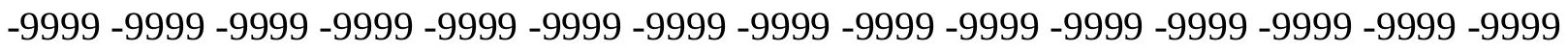

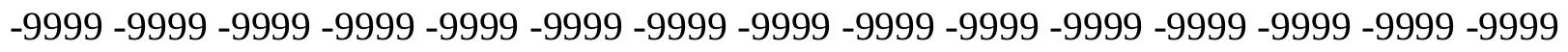
-9999 -9999 24.43616867065 36.55858612061 49.8968009948764 .61444854736 81.98719787598101 .7982025146123 .43800354147 .8208007812174 .0323028564 202.3773040771231.0270996094257.8482055664 280.4023132324296.8606872559 307.2233886719 312.1000061035 313.0143127441310.8807983398 307.2233886719 302.6516113281298 .0798950195293 .8128967285290 .1553955078286 .8027954102 283.4501953125280 .7070922852278 .2687988281277 .3544921875278 .2687988281 280.7070922852284 .0596923828287 .7171936035291 .3746032715294 .4223937988 297.1654968262299 .9085998535301 .7373046875303 .5660095215304 .7850952148 
305.6994934082306 .3091125488306 .6138000488306 .9186096191306 .9186096191 306.6138000488306 .0043029785305 .3947143555304 .7850952148303 .8707885742 302.9563903809301 .7373046875300 .5180969238299 .2990112305297 .7750854492 296.2510986328294 .7272033691292 .8984985352291 .3746032715289 .5458984375 287.7171936035285 .5835876465283 .7549133301281 .9262084961279 .7927856445 277.6592102051275 .8305053711273 .6971130371271 .5635070801269 .4301147461 267.6012878418265 .4678039551263 .3344116211261 .5056152344259 .3721008301 257.5433959961255 .4098968506253 .5812072754251 .7525024414249 .9237976074 248.0950927734246 .2664031982244 .4376983643242 .9136962891241 .0850067139 239.2563018799237 .7324066162236 .2084960938234 .3798065186232 .8558044434 231.3318939209 229.8079986572 227.9792938232 226.4553985596 224.9313964844 223.4075012207 221.883605957220.3596038818219.1405029297217.6165924072 216.0926971436214 .5686950684213 .3495941162211 .8256988525210 .6065063477 209.3874053955207 .8634033203206 .6443023682205 .425201416204 .2059936523 202.9868927002202 .0724945068200 .8533935547199 .9389953613199 .0247039795 197.8054962158197 .1959991455196 .2816009521195 .3672943115194 .7577056885 194.1481018066193 .5386047363192 .9290008545192 .624206543192 .3193969727 192.0146026611191 .7097930908191 .7097930908191 .4051055908191 .4051055908 191.7097930908191 .7097930908192 .0146026611192 .0146026611192 .3193969727 192.624206543193 .233795166193 .5386047363193 .8433074951194 .1481018066 194.1481018066194 .4528961182194 .7577056885194 .7577056885195 .0625195 .3672943115 195.3672943115195 .6721038818195 .6721038818195 .9768066406195 .9768066406 195.9768066406195 .9768066406195 .9768066406195 .9768066406195 .6721038818 195.3672943115195 .0625194 .7577056885194 .4528961182194 .4528961182194 .1481018066 193.8433074951193 .5386047363193 .5386047363192 .9290008545192 .624206543 192.3193969727192 .0146026611191 .7097930908191 .7097930908191 .7097930908 192.0146026611192 .3193969727192 .9290008545193 .233795166194 .1481018066 194.7577056885195 .6721038818196 .5863952637197 .500793457198 .4151000977 199.329498291200 .2438049316200 .8533935547201 .4629974365202 .0724945068 202.6820983887202 .9868927002202 .9868927002202 .9868927002202 .6820983887 202.3773040771 203.2917022705 203.9011993408204.5108032227 204.8155975342 205.425201416205 .7299957275206 .0346984863206 .6443023682206 .9490966797 207.25390625207 .5587005615207 .8634033203208 .4730072021208 .7778015137 209.3874053955 209.692199707 209.692199707 209.692199707 209.692199707 209.692199707 209.692199707 209.692199707 209.692199707 209.692199707 209.692199707 209.692199707 209.692199707 209.692199707 209.692199707 209.692199707209.692199707 209.692199707 209.0825958252 210.9113006592 213.3495941162 215.4830932617 217.6165924072220 .054901123222 .4931030273225 .2362060547227 .6744995117 230.1127929688232 .8558044434235 .2940979004237 .7324066162240 .4754943848 242.9136962891245 .0471954346247 .4855041504249 .6190032959251 .7525024414 253.8860015869255 .7147064209257 .5433959961259 .3721008301260 .8960876465 262.1152038574263 .6390991211264 .5534973145265 .7726135254266 .6870117188 267.9060974121268 .8204956055269 .7348022461270 .9540100098271 .8682861328 272.7827148438274 .0018005371274 .9161987305275 .8305053711277 .0497131348 277.9641113281279 .4880065918281 .0119018555282 .8406066895284 .9740905762 287.1076049805289 .2410888672291 .3746032715293 .5080871582295 .6416015625 
297.7750854492300 .2132873535302 .3468017578303 .7972412109304 .5723266602 304.7660827637 -9999 -9999 -9999 -9999 -9999 -9999 -9999 -9999 -9999 -9999 -9999 -9999 -9999 -9999 -9999 -9999 -9999 -9999 -9999 -9999 -9999 -9999 -9999 -9999 -9999 -9999 -9999 -9999 -9999 -9999 -9999 -9999 -9999 -9999 -9999 -9999 -9999 -9999 -9999 -9999 -9999 -9999 -9999 -9999 -9999 -9999 -9999 -9999 -9999 -9999 -9999-9999 -9999 -9999 -9999 -9999 -9999 -

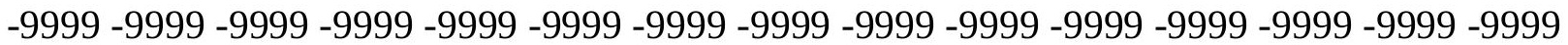
-9999 -9999 -9999-9999-9999-9999

-9999 -9999 -9999 -9999 -9999 -9999 -9999 -9999 -9999 -9999 -9999 -9999 -9999 -9999 -9999 -9999 -9999 -9999 -9999 -9999 -9999 -9999 -9999 -9999 -9999 -9999 -9999 -9999 -9999 -9999 -9999 24.6851062774736.23168182373 48.8483428955162 .7857398986878 .02498626709 95.3977432251114 .9039993286135 .9342041016158 .7929992676183 .1759033203 208.1681976318232 .8558044434255 .4098968506274 .9161987305290 .1553955078 300.5180969238306 .6138000488309 .3569030762309 .3569030762307 .5281982422 304.4802856445300 .8229064941297 .4703063965293 .8128967285290 .4602050781 287.4124145508284 .6693115234282 .8406066895282 .2309875488282 .8406066895 284.9740905762287 .7171936035290 .7650146484293 .8128967285296 .5559082031 299.2990112305 301.4324951172303 .2611999512304 .7850952148306 .0043029785 306.9186096191307 .5281982422307 .8330078125307 .8330078125307 .8330078125 307.5281982422306 .9186096191306 .3091125488305 .3947143555304 .4802856445 303.5660095215302 .3468017578300 .8229064941299 .6037902832298 .0798950195 296.5559082031294 .7272033691292 .8984985352291 .0697937012289 .2410888672 287.4124145508285 .2789001465283 .1453857422281 .3167114258279 .1831970215 277.0497131348274 .9161987305272 .7827148438270 .6492004395268 .5156860352 266.3822021484264 .2486877441262 .1152038574259 .9816894531257 .8482055664 255.7147064209253 .8860015869251 .7525024414249 .9237976074248 .0950927734 245.9615936279244 .1329040527242 .3041992188240 .4754943848238 .6468048096 237.1228027344235 .2940979004233 .4653930664231 .9414978027230 .1127929688 228.5888977051227 .0648956299225 .2362060547223 .7122955322222 .1884002686 220.6643981934219 .1405029297217 .6165924072216 .0926971436214 .5686950684 213.0447998047211 .520904541209 .9969024658208 .7778015137207 .25390625 206.0346984863204 .5108032227203 .2917022705202 .0724945068200 .8533935547 199.6342926025198 .4151000977197 .500793457196 .2816009521195 .3672943115 194.1481018066193 .233795166192 .3193969727191 .7097930908190 .795501709 190.1858978271189 .5764007568188 .966796875188 .3571929932188 .0523986816 187.7476043701187 .4429016113187 .1381072998187 .1381072998187 .1381072998 187.1381072998187 .4429016113187 .4429016113187 .7476043701188 .0523986816 188.3571929932188 .6620025635189 .2716064453189 .5764007568189 .8811035156 190.1858978271190 .4907073975190 .4907073975190 .795501709191 .1002960205 191.4051055908191 .7097930908192 .0146026611192 .3193969727192 .624206543 192.9290008545193 .233795166193 .233795166193 .5386047363193 .233795166 193.233795166192 .9290008545192 .624206543192 .3193969727192 .0146026611 192.0146026611191 .7097930908191 .4051055908191 .1002960205191 .1002960205 190.4907073975190 .1858978271189 .5764007568189 .2716064453188 .966796875 188.6620025635188 .6620025635188 .966796875189 .2716064453189 .8811035156 190.4907073975191 .1002960205191 .7097930908192 .624206543193 .5386047363 194.4528961182195 .3672943115196 .2816009521197 .1959991455198 .1103057861 
199.0247039795199 .6342926025199 .9389953613200 .2438049316200 .5485992432 201.7678070068202 .6820983887203 .596496582204 .5108032227205 .1204071045 205.7299957275206 .6443023682206 .9490966797207 .5587005615208 .1681976318 208.7778015137209 .0825958252209 .692199707209 .692199707209 .692199707 209.692199707 209.692199707 209.692199707 209.692199707 209.692199707 209.692199707 209.692199707209 .692199707209 .692199707209 .692199707209 .692199707209 .692199707 209.692199707209 .692199707209 .692199707209 .692199707209 .692199707209 .692199707 209.692199707 209.692199707 208.7778015137211.2160949707 213.3495941162 215.787902832218 .2261962891220 .6643981934223 .1027069092225 .8457946777 228.2841033936231 .0270996094233 .4653930664236 .2084960938238 .6468048096 241.0850067139243 .5233001709245 .9615936279248 .3999023438250 .5334014893 252.6669006348254 .8003997803256 .6290893555258 .1530151367259 .9816894531 261.5056152344262 .7247924805263 .9439086914265 .1630859375266 .0773925781 266.9917907715267 .9060974121268 .8204956055269 .4301147461270 .3443908691 270.9540100098271 .8682861328272 .4779052734273 .0874938965273 .6971130371 274.6113891602275 .2210083008276 .1353149414277 .3544921875279 .1831970215 281.3167114258283 .1453857422284 .9740905762286 .4979858398288 .3266906738 290.4602050781292 .5936889648295 .0320129395297 .1654968262299 .2990112305 300.1989135742300 .4803771973 -9999 -9999 -9999 -9999 -9999 -9999 -9999 -9999 -9999

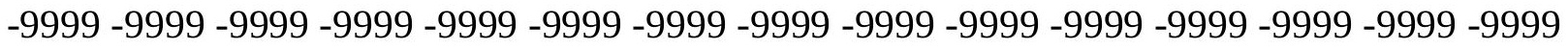

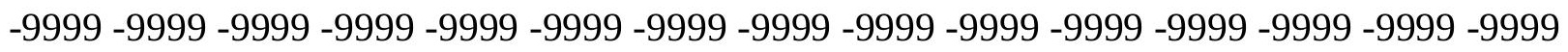
-9999 -9999 -9999 -9999 -9999 -9999 -9999 -9999 -9999 -9999 -9999 -9999 -9999 -9999 -9999 -

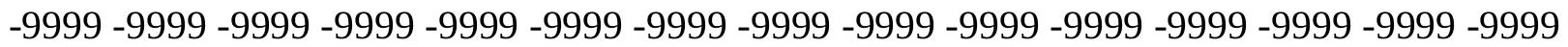
-9999 -9999 -9999 -9999 -9999 -9999 -9999 -9999 -9999

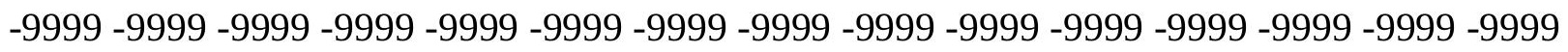
-9999 -9999 -9999 -9999 -9999 -9999 -9999 -9999 -9999 -9999 -9999 -9999 -9999 -9999 -9999 24.5302867889435 .4487838745147 .2157020568860 .0426712036173 .75800323486 89.3020401001106 .3700027466125 .2667007446145 .3825073242166 .7174987793 188.966796875211 .2160949707232 .5511016846252 .3621063232269 .7348022461 283.7549133301294 .1176147461300 .8229064941304 .7850952148306 .3091125488 306.0043029785304 .4802856445302 .0421142578299 .2990112305296 .2510986328 293.2033081055 290.7650146484288.3266906738 287.1076049805 286.4979858398 287.1076049805288 .9363098145291 .0697937012293 .5080871582296 .2510986328 298.6893920898300 .8229064941302 .9563903809304 .7850952148306 .3091125488 307.2233886719308 .1377868652308 .7473144531308 .7473144531308 .7473144531 308.7473144531308 .1377868652307 .8330078125306 .9186096191306 .0043029785 305.0899047852303 .8707885742302 .6516113281301 .1276855469299 .6037902832 298.0798950195296 .2510986328294 .7272033691292 .8984985352290 .7650146484 288.9363098145286 .8027954102284 .6693115234282 .5357971191280 .4023132324 278.2687988281276 .1353149414274 .0018005371271 .8682861328269 .4301147461 267.2966003418265 .1630859375262 .7247924805260 .5913085938258 .4577941895 256.3243103027 254.1907958984252.0572967529 250.2286071777248.0950927734 245.9615936279244 .1329040527241 .9994049072240 .1707000732238 .3419952393 236.5133056641234 .6844940186232 .8558044434231 .0270996094229 .5032043457 227.6744995117225 .8457946777224 .3218994141222 .4931030273220 .9691925049 219.4452972412217 .6165924072216 .0926971436214 .5686950684213 .0447998047 
211.520904541209 .9969024658208 .4730072021206 .9490966797205 .7299957275 204.2059936523202 .6820983887201 .4629974365200 .2438049316198 .7198944092 197.500793457 196.2816009521 195.0625193.8433074951 192.9290008545191.7097930908 190.795501709189 .5764007568188 .6620025635187 .7476043701187 .1381072998 186.2236938477 185.6141052246 185.0045928955 184.3950042725 183.7854003906 183.4806976318183 .1759033203182 .87109375182 .87109375182 .87109375182 .87109375 183.1759033203183 .1759033203183 .4806976318183 .7854003906184 .0901947021 184.699798584185.0045928955 185.3094024658 185.6141052246 185.9188995361 186.2236938477 186.528503418 187.1381072998 187.4429016113187.7476043701 188.0523986816188 .6620025635189 .2716064453189 .5764007568190 .1858978271 190.4907073975190 .795501709191 .1002960205191 .1002960205191 .1002960205 190.795501709190 .4907073975190 .1858978271189 .8811035156189 .5764007568 189.2716064453 188.966796875 188.6620025635 188.3571929932188.0523986816 187.4429016113186 .8332977295186 .2236938477185 .9188995361185 .6141052246 185.6141052246185 .9188995361186 .2236938477186 .8332977295187 .4429016113 188.0523986816188 .966796875189 .5764007568190 .4907073975191 .4051055908 192.624206543193 .5386047363194 .4528961182195 .3672943115196 .2816009521 196.891204834199 .329498291200 .5485992432201 .7678070068202 .6820983887 203.9011993408204 .8155975342205 .7299957275206 .6443023682207 .25390625 208.1681976318208 .7778015137209 .3874053955209 .692199707209 .692199707 209.692199707 209.692199707 209.692199707 209.692199707 209.692199707 209.692199707 209.692199707209 .692199707209 .692199707209 .692199707209 .692199707209 .692199707 209.692199707209 .692199707209 .692199707209 .692199707209 .692199707209 .692199707 209.692199707 209.692199707 209.692199707 209.692199707 209.692199707 209.692199707 209.0825958252211 .2160949707213 .6544036865216 .0926971436218 .8356933594 221.2740020752224 .0171051025226 .7601013184229 .1983947754231 .9414978027 234.6844940186237 .1228027344239 .8659057617242 .3041992188244 .7424926758 247.1806945801249 .3141937256251 .7525024414253 .5812072754255 .7147064209 257.5433959961259 .0674133301260 .8960876465262 .1152038574263 .3344116211 264.5534973145265 .7726135254266 .6870117188267 .2966003418268 .2109069824 268.8204956055269 .4301147461270 .0396118164270 .6492004395271 .2587890625 271.5635070801271 .8682861328272 .4779052734272 .7827148438273 .0874938965 273.6971130371274 .3066101074276 .4400939941278 .2687988281279 .7927856445 281.3167114258282 .5357971191283 .7549133301285 .2789001465287 .4124145508 289.8505859375291 .9841918945294 .4223937988295 .7558288574296 .2199401855 296.108001709 -9999 -9999 -9999 -9999 -9999 -9999 -9999 -9999 -9999 -9999 -9999 -9999

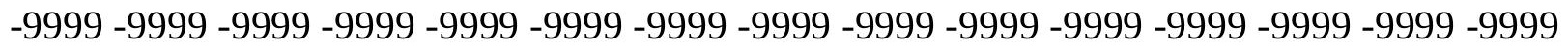

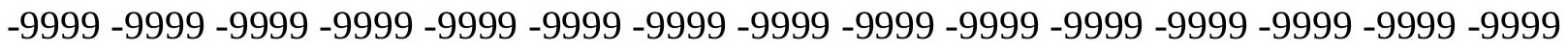

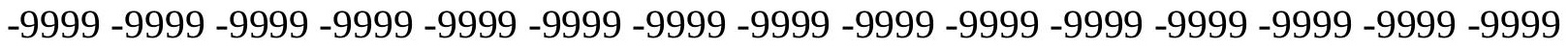

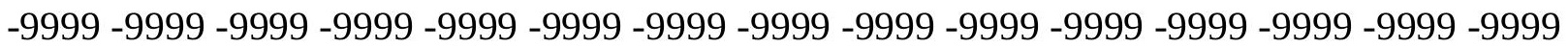
-9999 -9999 -9999 -9999-9999

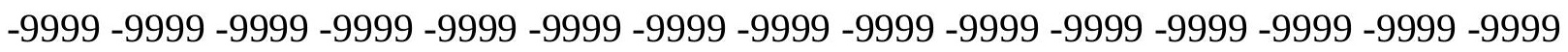
-9999 -9999 -9999 -9999 -9999 -9999 -9999 -9999 -9999 -9999 -9999 -9999 -9999 13.7514553070123 .9650821685834 .4084129333545 .2847862243756 .99481964111 69.4910125732483 .206336975198 .4455871582115 .2088012695132 .8863067627 152.0877990723171 .8988037109192 .0146026611211 .8256988525231 .0270996094 
248.7046966553264 .2486877441277 .3544921875287 .4124145508295 .0320129395 299.9085998535302 .3468017578303 .5660095215302 .9563903809301 .7373046875 299.9085998535297 .7750854492295 .3367919922293 .5080871582291 .6794128418 290.7650146484290 .4602050781291 .0697937012292 .2889099121294 .1176147461 296.2510986328298 .3846130371300 .5180969238302 .6516113281304 .4802856445 306.0043029785307 .2233886719308 .4425048828309 .0520935059309 .3569030762 309.6617126465309 .6617126465309 .3569030762308 .7473144531308 .1377868652 307.2233886719306 .3091125488305 .3947143555304 .1755981445302 .6516113281 301.1276855469299 .6037902832298 .0798950195296 .2510986328294 .4223937988 292.2889099121290 .4602050781288 .3266906738286 .1932067871284 .0596923828 281.9262084961279 .7927856445277 .3544921875275 .2210083008272 .7827148438 270.6492004395268 .2109069824266 .0773925781263 .6390991211261 .5056152344 259.3721008301256 .9338989258254 .8003997803252 .6669006348250 .5334014893 248.3999023438246 .2664031982244 .1329040527241 .9994049072240 .1707000732 238.0372009277236 .2084960938234 .0749969482232 .246307373230 .4176025391 228.5888977051226 .7601013184224 .9313964844223 .4075012207221 .5787963867 219.7501068115218 .2261962891216 .3973999023214 .8735046387213 .3495941162 211.520904541209 .9969024658208 .4730072021206 .9490966797205 .425201416 203.9011993408202 .6820983887201 .158203125199 .6342926025198 .4151000977 196.891204834195 .6721038818194 .4528961182193 .233795166192 .0146026611 190.795501709189 .5764007568188 .3571929932187 .1381072998186 .2236938477 185.3094024658184 .3950042725183 .4806976318182 .5662994385181 .6519012451 181.0424041748180 .432800293179 .8231964111179 .5184020996179 .2136993408 178.9089050293178 .604095459178 .604095459178 .604095459178 .9089050293 179.2136993408179 .5184020996179 .8231964111180 .1280059814180 .432800293 181.0424041748181 .3471984863181 .6519012451181 .9566955566182 .5662994385 182.87109375183 .1759033203183 .7854003906184 .0901947021184 .699798584 185.3094024658185 .9188995361186 .8332977295187 .4429016113188 .0523986816 188.6620025635188 .966796875189 .2716064453189 .2716064453188 .966796875 188.3571929932188 .0523986816187 .4429016113186 .8332977295186 .528503418 186.2236938477185 .9188995361185 .3094024658184 .699798584184 .0901947021 183.1759033203182 .5662994385182 .261505127182 .261505127182 .261505127 182.87109375183 .1759033203183 .7854003906184 .3950042725185 .0045928955 185.9188995361186 .528503418187 .4429016113188 .6620025635189 .5764007568 190.795501709193 .233795166195 .0625196 .891204834198 .4151000977199 .9389953613 201.158203125202 .3773040771203 .596496582204 .8155975342205 .7299957275 206.6443023682 207.5587005615 208.4730072021209.3874053955 209.692199707 209.692199707 209.692199707 209.692199707 209.692199707 209.692199707 209.692199707 209.692199707 209.692199707 209.692199707 209.692199707 209.692199707209.692199707 209.692199707209 .692199707209 .692199707209 .692199707209 .692199707209 .692199707 209.692199707 209.692199707 209.692199707 209.692199707 209.692199707209.692199707 209.692199707 209.692199707 209.692199707 209.3874053955 211.8256988525 214.2639007568217 .0070037842219 .4452972412222 .1884002686224 .9313964844 227.6744995117230 .4176025391233 .1605987549235 .9037017822238 .6468048096 241.0850067139243 .5233001709246 .2664031982248 .3999023438250 .8381958008 252.9716033936255 .1051025391256 .9338989258258 .7626037598260 .2864990234 
261.8103942871263 .3344116211264 .5534973145265 .4678039551266 .3822021484 267.2966003418268.2109069824 268.8204956055 269.1253051758269.7348022461 270.3443908691270 .6492004395270 .9540100098271 .2587890625271 .2587890625 271.5635070801271 .8682861328271 .8682861328272 .4779052734273 .3923034668 274.6113891602276 .1353149414277 .3544921875278 .2687988281278 .8783874512 279.4880065918280 .7070922852282 .2309875488284 .6693115234287 .1076049805 289.5458984375291 .3746032715291 .9605407715291 .9525756836 -9999 -9999 -9999 -9999 -9999 -9999 -9999 -9999 -9999 -9999 -9999 -9999 -9999 -9999 -9999 -9999 -9999 -9999 -9999

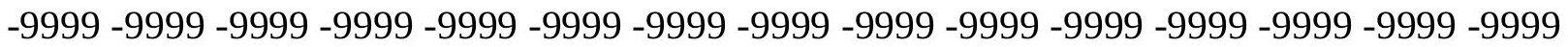
-9999 -9999 -9999 -9999 -9999 -9999 -9999 -9999 -9999 -9999 -9999 -9999 -9999 -9999 -9999 -

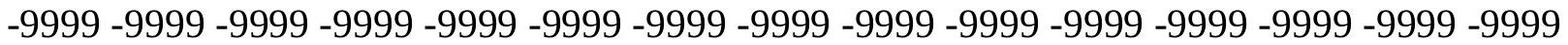
-9999 -9999 -9999 -9999 -9999 -9999 -9999 -9999 -9999 -9999 -9999 -9999 -9999 -9999 -9999 -9999 -9999 -9999 -9999 -9999 -9999 -9999 -9999 -9999 -9999 -9999 -9999 -9999 -9999 -9999 -9999 -9999 -9999 -9999 -9999 -9999 -9999 -9999 -9999 -9999 12.14500045776 22.6163654327433 .1231536865243 .3506317138753 .9469718933165 .22400665283 77.7202072143691 .13075256348106 .0652008057121 .9140014648138 .6772003174 156.6596069336174 .9467010498193 .233795166211 .520904541228 .8936004639 244.7424926758259 .0674133301271 .2587890625281 .3167114258288 .9363098145 294.4223937988298 .0798950195300 .2132873535300 .8229064941300 .5180969238 299.6037902832298 .3846130371296 .8606872559295 .3367919922294 .4223937988 293.8128967285293 .8128967285294 .4223937988295 .6416015625297 .1654968262 298.6893920898300 .5180969238302 .6516113281304 .1755981445305 .6994934082 307.2233886719308 .4425048828309 .0520935059309 .6617126465309 .9664916992 309.9664916992309 .9664916992309 .6617126465309 .0520935059308 .4425048828 307.5281982422306 .6138000488305 .3947143555304 .1755981445302 .6516113281 301.1276855469299 .2990112305297 .7750854492295 .9464111328293 .8128967285 291.9841918945289 .8505859375287 .7171936035285 .5835876465283 .4501953125 281.0119018555278 .8783874512276 .4400939941274 .0018005371271 .8682861328 269.4301147461266 .9917907715264 .8583068848262 .4200134277259 .9816894531 257.8482055664255 .4098968506252 .9716033936250 .8381958008248 .7046966553 246.5711975098244 .1329040527241 .9994049072240 .1707000732238 .0372009277 235.9037017822233 .7702026367231 .9414978027230 .1127929688227 .9792938232 226.150604248224 .3218994141222 .4931030273220 .6643981934218 .8356933594 217.3117980957 215.4830932617213.6544036865 212.1304016113210.6065063477 208.7778015137207 .25390625205 .7299957275204 .2059936523202 .6820983887 201.158203125199 .6342926025198 .1103057861196 .891204834195 .3672943115 194.1481018066192 .624206543191 .4051055908190 .1858978271188 .6620025635 187.4429016113186 .2236938477185 .0045928955184 .0901947021182 .87109375 181.9566955566180 .7375946045179 .8231964111178 .9089050293177 .9945068359 177.3849029541176 .7754058838176 .165802002175 .5561981201175 .2514038086 174.9467010498174 .6419067383174 .6419067383174 .6419067383174 .9467010498 174.9467010498175 .2514038086175 .8609924316176 .165802002176 .7754058838 177.0802001953177 .3849029541177 .9945068359178 .2993011475178 .604095459 179.2136993408179 .5184020996180 .1280059814180 .7375946045181 .3471984863 182.261505127183 .1759033203183 .7854003906184 .699798584185 .6141052246 186.528503418186 .8332977295187 .4429016113187 .4429016113187 .1381072998 
186.528503418185 .6141052246184 .699798584183 .7854003906183 .1759033203 182.5662994385182 .261505127181 .6519012451180 .7375946045179 .5184020996 178.604095459177 .9945068359177 .6896972656177 .9945068359178 .604095459 179.2136993408179 .8231964111180 .7375946045181 .3471984863181 .9566955566 182.5662994385183 .4806976318184 .3950042725185 .6141052246188 .6620025635 191.1002960205193 .233795166195 .0625196 .891204834198 .7198944092200 .2438049316 201.4629974365202 .9868927002204 .2059936523205 .425201416206 .3394927979 207.5587005615208 .4730072021209 .692199707209 .692199707209 .692199707 209.692199707 209.692199707 209.692199707 209.692199707 209.692199707 209.692199707 209.692199707 209.692199707 209.692199707 209.692199707 209.692199707 209.692199707 209.692199707 209.692199707 209.692199707 209.692199707 209.692199707 209.692199707 209.692199707 209.692199707 209.692199707 209.692199707 209.692199707 209.692199707 209.692199707 209.692199707209.692199707 209.9969024658 212.4351959229 215.1782989502217 .9214019775220 .6643981934223 .4075012207226 .150604248 228.8936004639231 .9414978027234 .6844940186237 .4275970459240 .1707000732 242.6089935303245 .3520050049247 .7902984619249 .9237976074252 .3621063232 254.4956054688256 .3243103027258 .4577941895260 .2864990234261 .8103942871 263.3344116211264 .5534973145265 .7726135254266 .6870117188267 .6012878418 268.2109069824 268.8204956055269.4301147461270.0396118164270.3443908691 270.6492004395270 .6492004395270 .9540100098270 .9540100098271 .2587890625 271.2587890625271 .2587890625271 .5635070801271 .8682861328272 .7827148438 274.0018005371274 .9161987305275 .5257873535275 .8305053711276 .1353149414 276.1353149414276 .4400939941277 .6592102051279 .7927856445282 .5357971191 284.9740905762286 .8027954102287 .7346191406287 .8835449219 -9999 -9999 -9999 -9999 -9999 -9999 -9999 -9999 -9999 -9999 -9999 -9999 -9999 -9999 -9999 -9999 -9999 -9999 -9999 -9999 -9999 -9999 -9999 -9999 -9999 -9999 -9999 -9999 -9999 -9999 -9999 -9999 -9999 -9999 -9999 -9999 -9999 -9999 -9999 -9999 -9999 -9999 -9999 -9999 -9999 -9999 -9999 -9999 -9999

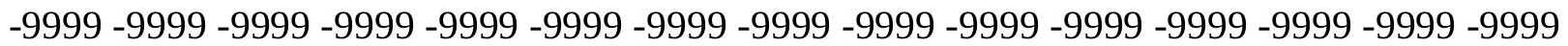
-9999 -9999 -9999 -9999 -9999 -9999 -9999 -9999 -9999 -9999 -9999 -9999 -9999 -9999 -9999 -9999 -9999 -9999 -9999 -9999 -9999 -9999 -9999 -9999 -9999 -9999 -9999 -9999 -9999 -9999 -9999 -9999 -9999 -9999 -9999 -9999 -9999 -9999 -9999 -9999 19.71306800842 30.4099979400641 .4507789611850 .8991203308161 .2618103027372 .53885650635 84.7302627563597 .83602905273112 .1608963013127 .0953979492143 .2489929199 159.7073974609176 .4705963135193 .5386047363209 .9969024658225 .8457946777 240.7801971436253 .8860015869265 .4678039551275 .2210083008283 .1453857422 289.2410888672 293.5080871582 296.2510986328298.0798950195298.6893920898 298.6893920898298 .3846130371297 .7750854492296 .8606872559296 .5559082031 296.5559082031296 .5559082031297 .1654968262298 .3846130371299 .6037902832 301.1276855469302 .6516113281304 .1755981445305 .6994934082306 .9186096191 308.1377868652309 .0520935059309 .9664916992310 .2713012695310 .5759887695 310.5759887695310 .2713012695309 .6617126465309 .0520935059308 .4425048828 307.5281982422306 .3091125488305 .0899047852303 .8707885742302 .3468017578 300.8229064941298 .9942016602297 .1654968262295 .3367919922293 .2033081055 291.3746032715289 .2410888672286 .8027954102284 .6693115234282 .5357971191 280.0975036621277 .6592102051275 .2210083008273 .0874938965270 .6492004395 268.2109069824265 .7726135254263 .3344116211260 .8960876465258 .4577941895 
256.0195007324253 .8860015869251 .4476928711249 .0093994141246 .8759002686 244.4376983643242 .3041992188240 .1707000732238 .0372009277235 .9037017822 233.7702026367231 .6367034912229 .5032043457227 .6744995117225 .5410003662 223.7122955322221 .883605957220 .054901123218 .2261962891216 .3973999023 214.5686950684212 .7400054932211 .2160949707209 .3874053955207 .8634033203 206.0346984863204 .5108032227202 .9868927002201 .4629974365199 .9389953613 198.4151000977196 .891204834195 .3672943115193 .8433074951192 .624206543 191.1002960205189 .8811035156188 .3571929932187 .1381072998185 .9188995361 184.699798584183 .1759033203181 .9566955566180 .7375946045179 .8231964111 178.604095459177 .3849029541176 .4705963135175 .5561981201174 .6419067383 173.7274932861173 .1179962158172 .5084075928171 .8988037109171 .5939941406 170.9844970703170 .9844970703170 .6797027588170 .6797027588170 .9844970703 171.2891998291171 .5939941406171 .8988037109172 .5084075928172 .8132019043 173.4226989746173 .7274932861174 .337097168174 .6419067383175 .2514038086 175.5561981201176 .165802002176 .7754058838177 .3849029541178 .2993011475 178.9089050293180 .1280059814181 .0424041748182 .261505127183 .4806976318 184.3950042725185 .0045928955185 .6141052246185 .6141052246185 .0045928955 184.3950042725183 .1759033203181 .6519012451180 .1280059814178 .9089050293 177.9945068359177 .3849029541176 .4705963135175 .2514038086173 .7274932861 172.5084075928171 .8988037109171 .8988037109172 .8132019043174 .337097168 175.5561981201176 .4705963135177 .0802001953177 .6896972656178 .2993011475 179.2136993408179 .8231964111182 .261505127185 .3094024658188 .0523986816 190.4907073975192 .9290008545195 .0625196 .891204834198 .7198944092200 .2438049316 201.7678070068202 .9868927002204 .5108032227205 .7299957275206 .9490966797 208.1681976318209 .3874053955209 .692199707209 .692199707209 .692199707 209.692199707 209.692199707 209.692199707 209.692199707 209.692199707 209.692199707 209.692199707209 .692199707209 .692199707209 .692199707209 .692199707209 .692199707 209.692199707209 .692199707209 .692199707209 .692199707209 .692199707209 .692199707 209.692199707 209.692199707 209.692199707 209.692199707 209.692199707 209.692199707 209.692199707209.692199707209.692199707210.6065063477213.3495941162 216.0926971436218 .8356933594221 .883605957224 .6266021729227 .6744995117 230.4176025391233 .4653930664236 .2084960938238 .9515075684241 .6945953369 244.4376983643246 .8759002686249 .3141937256251 .7525024414253 .8860015869 256.0195007324258 .1530151367259 .9816894531261 .8103942871263 .3344116211 264.8583068848266 .0773925781266 .9917907715268 .2109069824268 .8204956055 269.4301147461270 .0396118164270 .3443908691270 .6492004395270 .9540100098 271.2587890625271 .2587890625271 .2587890625271 .2587890625271 .2587890625 271.2587890625271 .2587890625271 .5635070801271 .8682861328272 .7827148438 273.6971130371274 .3066101074274 .6113891602274 .3066101074274 .0018005371 273.6971130371273 .3923034668273 .3923034668275 .8305053711278 .5736083984 $281.0119018555282 .8406066895283 .7549133301283 .9719543457283 .6492004395-9999$ -9999 -9999 -9999 -9999 -9999 -9999 -9999 -9999 -9999 -9999 -9999 -9999 -9999 -9999 -9999 -9999 -9999 -9999 -9999 -9999 -9999 -9999 -9999 -9999 -9999 -9999 -9999 -9999 -9999 -9999 -9999 -9999 -9999 -9999 -9999 -9999 -9999 -9999 -9999 -9999 -9999 -9999 -9999 -9999 -9999 -9999 -9999 -9999 -9999 -9999 -9999 -9999 -9999 -9999 -9999 -9999 -9999 -9999 -9999 -9999 -

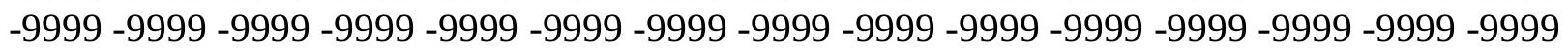


-9999 -9999 -9999 -9999 -9999 -9999 -9999 -9999 -9999 -9999 -9999 -9999 -9999 -9999 -9999 -9999 -9999 -9999 -9999 -9999 -9999 -9999 -9999 -9999 -9999 -9999 16.176404953 26.32966232336 .6988906860446 .9369087219256 .9948196411167 .35751342773 78.6345596313590 .52117919922103 .3221969604117 .0374984741131 .3623962402 146.2969055176161 .8408966064177 .3849029541193 .233795166208 .4730072021 223.1027069092236 .5133056641249 .0093994141260 .2864990234269 .7348022461 277.6592102051284 .0596923828288 .9363098145292 .5936889648295 .0320129395 296.5559082031297 .4703063965297 .7750854492298 .0798950195298 .0798950195 298.0798950195298 .3846130371298 .6893920898299 .6037902832300 .5180969238 301.7373046875302 .9563903809304 .1755981445305 .6994934082306 .9186096191 308.1377868652309 .0520935059309 .6617126465310 .2713012695310 .5759887695 310.5759887695310 .5759887695310 .2713012695309 .6617126465309 .0520935059 308.1377868652307 .2233886719306 .0043029785304 .7850952148303 .2611999512 301.7373046875300 .2132873535298 .3846130371296 .5559082031294 .7272033691 292.5936889648290 .4602050781288 .3266906738285 .8884887695283 .7549133301 281.3167114258278 .8783874512276 .7449035645274 .3066101074271 .5635070801 269.1253051758266 .6870117188264 .2486877441261 .8103942871259 .3721008301 256.9338989258254 .4956054688252 .0572967529249 .6190032959247 .1806945801 245.0471954346242 .6089935303240 .1707000732238 .0372009277235 .9037017822 233.7702026367231 .6367034912229 .5032043457227 .3697052002225 .2362060547 223.4075012207 221.2740020752 219.4452972412 217.3117980957 215.4830932617 213.6544036865211 .8256988525210 .3016967773208 .4730072021206 .6443023682 205.1204071045203 .2917022705201 .7678070068200 .2438049316198 .7198944092 197.1959991455195 .6721038818194 .1481018066192 .624206543191 .1002960205 189.8811035156188 .3571929932187 .1381072998185 .6141052246184 .3950042725 182.87109375181 .6519012451180 .432800293179 .2136993408177 .9945068359 176.7754058838175 .5561981201174 .337097168173 .4226989746172 .2035980225 171.2891998291170 .3748931885169 .7653045654168 .8509979248168 .241394043 167.9365997314167 .6318054199167 .3269958496167 .0222015381167 .0222015381 167.3269958496167 .3269958496167 .9365997314168 .241394043168 .8509979248 169.1557006836169 .7653045654170 .3748931885170 .6797027588171 .2891998291 171.5939941406172 .2035980225172 .5084075928173 .1179962158174 .0323028564 174.9467010498175 .8609924316177 .0802001953178 .2993011475179 .5184020996 181.0424041748181 .9566955566182 .87109375183 .1759033203183 .1759033203 182.87109375181 .6519012451180 .1280059814177 .6896972656175 .5561981201 173.4226989746171 .8988037109171 .2891998291170 .3748931885168 .8509979248 166.4127044678166 .7174987793165 .1934967041164 .8887023926166 .7174987793 169.1557006836171 .2891998291172 .8132019043173 .4226989746174 .0323028564 174.6419067383175 .2514038086177 .3849029541180 .7375946045184 .0901947021 187.1381072998189 .5764007568192 .0146026611194 .4528961182196 .2816009521 198.1103057861199 .9389953613201 .4629974365202 .6820983887204 .2059936523 205.7299957275206 .9490966797208 .4730072021209 .692199707209 .692199707 209.692199707209.692199707 209.692199707209.692199707 209.692199707209.692199707 209.692199707209 .692199707209 .692199707209 .692199707209 .692199707209 .692199707 209.692199707209 .692199707209 .692199707209 .692199707209 .692199707209 .692199707 209.692199707 209.692199707 209.692199707 209.692199707 209.692199707 209.692199707 
209.692199707 209.692199707 209.692199707 209.692199707 209.692199707 211.2160949707214 .2639007568217 .0070037842220 .054901123223 .1027069092 226.150604248229 .1983947754231 .9414978027234 .9893035889238 .0372009277 240.7801971436243 .5233001709246 .2664031982248 .7046966553251 .1428985596 253.5812072754255 .7147064209257 .8482055664259 .9816894531261 .8103942871 263.3344116211265 .1630859375266 .3822021484267 .6012878418268 .5156860352 269.4301147461270 .0396118164270 .6492004395270 .9540100098271 .2587890625 271.5635070801271 .8682861328271 .8682861328271 .8682861328271 .8682861328 271.8682861328271 .5635070801271 .5635070801271 .5635070801271 .5635070801 271.8682861328272 .4779052734273 .3923034668274 .3066101074273 .6971130371 273.0874938965272 .4779052734271 .8682861328271 .5635070801271 .8682861328 273.3923034668275 .5257873535277 .6592102051279 .1831970215280 .0975036621 280.2518310547279 .9180297852 -9999 -9999 -9999 -9999 -9999 -9999 -9999 -9999 -9999

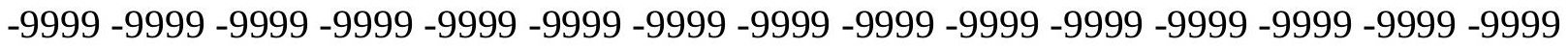

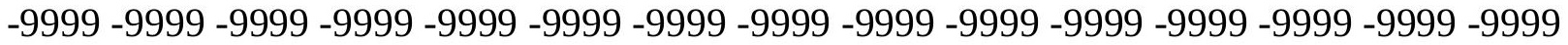

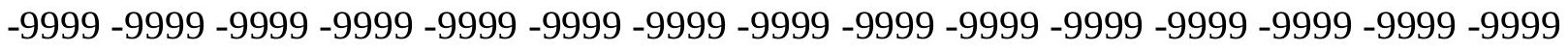

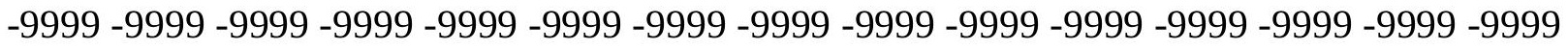
-9999 -9999 -9999 -9999 -9999 -9999 -9999

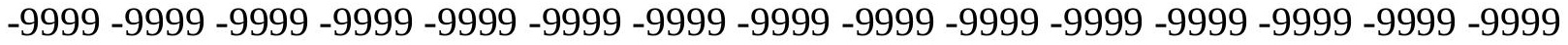
-9999 -9999 -9999 -9999 -9999-9999-9999 -9999 -9999-9999 12.53897666931 22.18815231323 32.06818389893 42.0603485107452.11825942993 62.17617034912 72.8436431884883 .8159103393695 .70252990723108 .1986999512121 .3044967651 134.7149963379149 .0399017334163 .3648071289177 .9945068359192 .3193969727 206.6443023682220 .054901123232 .8558044434244 .7424926758255 .4098968506 264.5534973145272 .4779052734279 .1831970215284 .6693115234288 .6315002441 291.9841918945294 .4223937988295 .9464111328297 .1654968262297 .7750854492 298.3846130371298 .9942016602299 .6037902832300 .5180969238301 .1276855469 302.3468017578303 .2611999512304 .4802856445305 .6994934082306 .9186096191 307.8330078125308 .7473144531309 .6617126465310 .2713012695310 .5759887695 310.8807983398310 .8807983398310 .5759887695310 .2713012695309 .6617126465 308.7473144531307 .8330078125306 .9186096191305 .6994934082304 .1755981445 302.9563903809301 .1276855469299 .6037902832297 .7750854492295 .6416015625 293.8128967285291 .6794128418289 .5458984375287 .1076049805284 .9740905762 282.5357971191280 .0975036621277 .6592102051275 .2210083008272 .7827148438 270.3443908691267 .9060974121265 .1630859375262 .7247924805260 .2864990234 257.8482055664255 .1051025391252 .6669006348250 .2286071777247 .7902984619 245.3520050049242 .9136962891240 .4754943848238 .3419952393235 .9037017822 233.7702026367231 .3318939209229 .1983947754227 .0648956299224 .9313964844 222.7978973389220 .9691925049218 .8356933594217 .0070037842214 .8735046387 213.0447998047211 .2160949707209 .3874053955207 .5587005615205 .7299957275 204.2059936523 202.3773040771 200.8533935547 199.0247039795 197.500793457 195.9768066406194 .4528961182192 .9290008545191 .4051055908189 .8811035156 188.6620025635187 .1381072998185 .6141052246184 .3950042725182 .87109375 181.6519012451180 .432800293178 .9089050293177 .6896972656176 .4705963135 175.2514038086173 .7274932861172 .5084075928171 .2891998291170 .3748931885 169.1557006836168 .241394043167 .3269958496166 .4127044678165 .4983062744 
164.8887023926164 .5839996338163 .974395752163 .6696014404163 .3648071289 163.3648071289163 .6696014404163 .974395752164 .2792053223164 .5839996338 165.1934967041165 .8031005859166 .4127044678166 .7174987793167 .3269958496 167.6318054199168 .241394043168 .5462036133169 .1557006836169 .7653045654 170.6797027588171 .2891998291172 .5084075928173 .7274932861174 .9467010498 176.4705963135177 .9945068359179 .2136993408180 .1280059814180 .432800293 180.432800293179 .5184020996178 .2993011475176 .165802002173 .1179962158 169.1557006836165 .8031005859163 .6696014404163 .3648071289163 .3648071289 160.9264984131161 .2312927246163 .0599975586160 .9264984131156 .3547973633 160.0122070312163 .974395752167 .0222015381168 .8509979248169 .7653045654 170.070098877170 .3748931885171 .2891998291174 .9467010498178 .604095459 182.261505127185 .3094024658188 .0523986816190 .795501709193 .233795166 195.3672943115 197.1959991455 199.0247039795 200.5485992432 202.0724945068 203.596496582205 .1204071045206 .6443023682208 .1681976318209 .692199707 209.692199707209 .692199707209 .692199707209 .692199707209 .692199707209 .692199707 209.692199707 209.692199707 209.692199707 209.692199707 209.692199707 209.692199707 209.692199707 209.692199707 209.692199707 209.692199707 209.692199707209.692199707 209.692199707 209.692199707 209.692199707 209.692199707 209.692199707209.692199707 209.692199707209.692199707209.692199707 209.692199707209.692199707 209.3874053955 212.1304016113215.1782989502 218.2261962891221.2740020752 224.3218994141227 .6744995117230 .7223052979233 .7702026367236 .8179931641 239.8659057617242 .6089935303245 .3520050049248 .0950927734250 .8381958008 253.2763977051255 .4098968506257 .8482055664259 .6769104004261 .8103942871 263.6390991211265 .1630859375266 .6870117188268 .2109069824269 .4301147461 270.3443908691270 .9540100098271 .5635070801271 .8682861328272 .1730957031 272.4779052734272 .4779052734272 .4779052734272 .4779052734272 .4779052734 272.4779052734272 .4779052734272 .4779052734272 .1730957031271 .8682861328 271.8682861328271 .8682861328272 .1730957031272 .7827148438273 .0874938965 272.7827148438272 .1730957031271 .2587890625270 .6492004395270 .3443908691 270.6492004395271 .8682861328273 .0874938965274 .6113891602275 .8305053711 276.4400939941276 .7449035645276 .3561096191275 .5592651367 -9999-9999 -9999 -9999 -9999 -9999 -9999 -9999 -9999 -9999 -9999 -9999 -9999 -9999 -9999 -9999 -9999 -9999 -9999

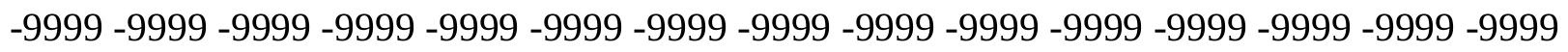

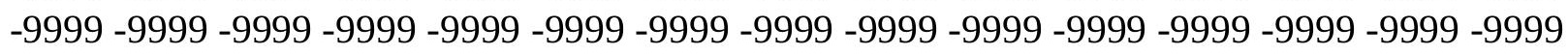

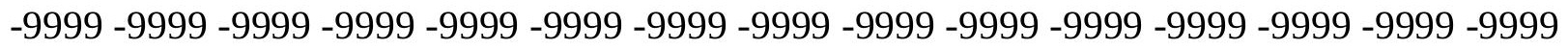
-9999 -9999 -9999 -9999-9999 -9999-9999-9999-9999-9999-9999 -

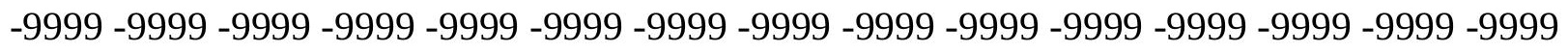
-9999 -9999-9999 -9999 -9999 -9999-9999 -9999 -9999 8.891442298889 18.19316482544 27.6282157897937 .1837806701746 .9369087219256 .6900291442967 .05272674561 77.4154205322388 .3876876831199 .96952056885112 .1608963013124 .6570968628 137.4580993652150 .8686065674164 .5839996338177 .9945068359191 .7097930908 204.8155975342217 .6165924072229 .5032043457240 .7801971436250 .8381958008 259.9816894531267 .9060974121274 .9161987305280 .7070922852285 .2789001465 288.9363098145291 .9841918945294 .1176147461295 .9464111328297 .4703063965 298.6893920898299 .6037902832300 .5180969238301 .4324951172302 .3468017578 303.5660095215304 .4802856445305 .6994934082306 .6138000488307 .5281982422 
308.4425048828309 .3569030762309 .9664916992310 .2713012695310 .5759887695 310.8807983398310 .5759887695310 .2713012695309 .9664916992309 .0520935059 308.4425048828307 .5281982422306 .3091125488305 .0899047852303 .5660095215 302.0421142578300 .5180969238298 .6893920898296 .8606872559294 .7272033691 292.8984985352290 .7650146484288 .3266906738286 .1932067871283 .7549133301 281.3167114258278 .8783874512276 .4400939941274 .0018005371271 .5635070801 268.8204956055266 .3822021484263 .6390991211261 .2008972168258 .4577941895 256.0195007324253 .5812072754250 .8381958008248 .3999023438245 .9615936279 243.5233001709241 .0850067139238 .6468048096236 .2084960938233 .7702026367 231.6367034912229 .1983947754227 .0648956299224 .9313964844222 .7978973389 220.6643981934218 .5308990479216 .3973999023214 .5686950684212 .4351959229 210.6065063477208 .7778015137206 .9490966797205 .1204071045203 .2917022705 201.4629974365199 .9389953613198 .1103057861196 .5863952637195 .0625193 .233795166 191.7097930908190 .1858978271188 .966796875187 .4429016113185 .9188995361 184.699798584183 .1759033203181 .9566955566180 .432800293179 .2136993408 177.6896972656176 .4705963135174 .9467010498173 .7274932861172 .5084075928 171.2891998291169 .7653045654168 .5462036133167 .3269958496166 .4127044678 165.1934967041164 .2792053223163 .3648071289162 .4505004883161 .8408966064 161.2312927246160 .6217956543160 .3170013428160 .0122070312160 .0122070312 160.0122070312160 .3170013428160 .9264984131161 .5361022949162 .1457061768 162.4505004883163 .0599975586163 .6696014404163 .974395752164 .5839996338 164.8887023926165 .4983062744165 .8031005859166 .4127044678167 .0222015381 167.9365997314168 .8509979248170 .070098877171 .5939941406172 .8132019043 174.337097168 175.5561981201 176.4705963135176.4705963135176.165802002 174.9467010498173 .4226989746171 .2891998291167 .0222015381161 .2312927246 155.1356048584152 .3925933838153 .0021057129155 .4403991699153 .6116943359 152.3925933838157 .5738983154153 .0021057129148 .4304046631152 .6972961426 158.4882965088163 .0599975586165 .1934967041165 .8031005859165 .8031005859 166.1078948975167 .0222015381171 .8988037109175 .8609924316179 .5184020996 182.87109375185 .9188995361188 .966796875191 .4051055908193 .5386047363 195.6721038818197 .500793457199 .329498291200 .8533935547202 .6820983887 204.2059936523 206.0346984863207.8634033203209.692199707209.692199707 209.692199707 209.692199707 209.692199707 209.692199707 209.692199707 209.692199707 209.692199707 209.692199707 209.692199707 209.692199707 209.692199707 209.692199707 209.692199707 209.692199707 209.692199707 209.692199707 209.692199707 209.692199707 209.692199707 209.692199707 209.692199707 209.692199707 209.692199707 209.692199707 209.692199707209 .692199707209 .692199707209 .692199707209 .9969024658 213.0447998047216 .3973999023219 .4452972412222 .7978973389225 .8457946777 229.1983947754232 .5511016846235 .5989074707238 .6468048096241 .6945953369 244.7424926758247 .4855041504250 .2286071777252 .6669006348255 .1051025391 257.5433959961259 .6769104004261 .8103942871263 .6390991211265 .4678039551 266.9917907715268 .5156860352270 .0396118164270 .9540100098271 .8682861328 272.4779052734272 .7827148438273 .0874938965273 .3923034668273 .3923034668 273.3923034668273 .3923034668273 .3923034668273 .3923034668273 .3923034668 273.3923034668273 .0874938965272 .7827148438272 .4779052734272 .1730957031 271.8682861328271 .8682861328271 .8682861328271 .8682861328271 .5635070801 
270.9540100098270 .3443908691269 .7348022461269 .4301147461269 .7348022461 270.3443908691271 .2587890625272 .1730957031273 .0874938965273 .3923034668 273.3923034668272 .9379882812272 .1036682129 -9999 -9999 -9999 -9999 -9999 -9999 -9999

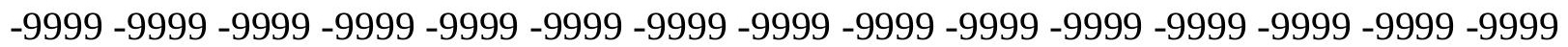

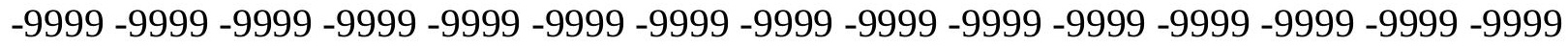

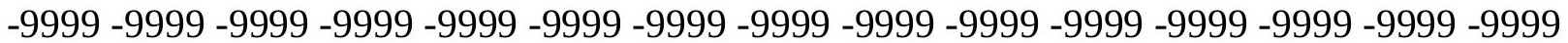

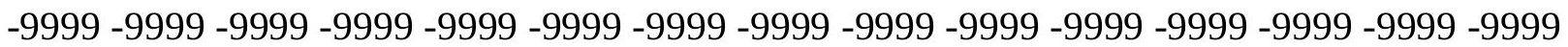
-9999 -9999 -9999 -9999 -9999 -9999 -9999 -9999

-9999 -9999 -9999 -9999 -9999 -9999 -9999 -9999 -9999 -9999 -9999 -9999 -9999 -9999 -9999 -9999 -9999 -9999 -9999 -9999 -9999 -9999 -9999 5.229504585266 14.2241230011 23.3648071289132 .6120109558141 .7555618286151 .2038993835460 .95701980591 71.3197174072381 .6824111938592 .65467834473103 .9317016602115 .5136032104 127.4001998901139 .8963928223152 .3925933838165 .1934967041177 .9945068359 190.795501709203 .2917022705215 .1782989502226 .7601013184237 .4275970459 247.1806945801256 .0195007324263 .9439086914270 .9540100098276 .7449035645 281.9262084961286 .1932067871289 .5458984375292 .2889099121294 .7272033691 296.5559082031298 .3846130371299 .6037902832300 .8229064941302 .0421142578 303.2611999512304 .1755981445305 .3947143555306 .3091125488307 .2233886719 308.1377868652309 .0520935059309 .6617126465309 .9664916992310 .2713012695 310.5759887695310 .5759887695310 .2713012695309 .9664916992309 .3569030762 308.7473144531307 .8330078125306 .6138000488305 .3947143555304 .1755981445 302.6516113281301 .1276855469299 .6037902832297 .7750854492295 .6416015625 293.8128967285291 .6794128418289 .5458984375287 .1076049805284 .9740905762 282.5357971191280 .0975036621277 .6592102051274 .9161987305272 .4779052734 270.0396118164267 .2966003418264 .8583068848262 .1152038574259 .3721008301 256.9338989258254 .1907958984251 .7525024414249 .0093994141246 .5711975098 243.8280944824241 .3898010254238 .9515075684236 .5133056641234 .0749969482 231.6367034912229 .1983947754227 .0648956299224 .6266021729222 .4931030273 220.3596038818218 .2261962891216 .0926971436213 .959197998212 .1304016113 209.9969024658208 .1681976318206 .0346984863204 .2059936523202 .3773040771 200.8533935547199 .0247039795197 .1959991455195 .6721038818193 .8433074951 192.3193969727 190.795501709 189.2716064453 187.7476043701 186.2236938477 185.0045928955183 .4806976318182 .261505127180 .7375946045179 .5184020996 177.9945068359176 .7754058838175 .2514038086174 .0323028564172 .8132019043 171.2891998291170 .070098877168 .5462036133167 .3269958496166 .1078948975 164.8887023926163 .6696014404162 .4505004883161 .2312927246160 .3170013428 159.7073974609158 .7929992676158 .1835021973157 .878692627157 .2691040039 156.9642944336156 .9642944336156 .9642944336157 .2691040039157 .5738983154 158.1835021973158 .7929992676159 .4026031494160 .0122070312160 .6217956543 160.9264984131161 .2312927246161 .8408966064162 .1457061768162 .4505004883 163.0599975586163 .6696014404164 .2792053223165 .1934967041166 .1078948975 167.3269958496168 .5462036133169 .7653045654170 .9844970703171 .8988037109 171.5939941406170 .070098877167 .9365997314165 .8031005859163 .6696014404 160.0122070312150 .8686065674143 .8585968018138 .9819946289139 .2868041992 145.0776977539149 .9542999268138 .3724975586141 .1154937744140 .8106994629 138.3724975586145 .0776977539153 .6116943359160 .0122070312161 .5361022949 
161.2312927246161 .2312927246161 .8408966064162 .7552947998167 .9365997314 171.8988037109175 .8609924316179 .5184020996183 .1759033203186 .528503418 189.2716064453191 .4051055908193 .5386047363195 .3672943115197 .1959991455 199.0247039795200 .8533935547202 .6820983887204 .8155975342206 .9490966797 209.0825958252 209.692199707209.692199707 209.692199707 209.692199707 209.692199707209 .692199707209 .692199707209 .692199707209 .692199707209 .692199707 209.692199707 209.692199707 209.692199707 209.692199707 209.692199707 209.692199707 209.692199707 209.692199707 209.692199707 209.692199707 209.692199707 209.692199707 209.692199707 209.692199707 209.692199707 209.692199707 209.692199707209.692199707 209.692199707210 .9113006592214 .2639007568217 .6165924072220 .6643981934 224.0171051025227 .6744995117231 .0270996094234 .0749969482237 .4275970459 240.7801971436243 .8280944824246 .8759002686249 .6190032959252 .3621063232 254.8003997803257 .2385864258259 .6769104004261 .8103942871263 .6390991211 265.4678039551267 .2966003418268 .8204956055270 .3443908691271 .5635070801 272.7827148438273 .6971130371274 .0018005371274 .3066101074274 .3066101074 274.3066101074274 .3066101074274 .3066101074274 .3066101074274 .0018005371 274.0018005371274 .0018005371274 .0018005371274 .0018005371273 .3923034668 272.7827148438272 .1730957031271 .8682861328271 .5635070801271 .2587890625 270.9540100098270 .6492004395270 .0396118164269 .4301147461268 .8204956055 268.8204956055268 .8204956055268 .8204956055269 .4301147461270 .0396118164 270.3443908691270 .6492004395270 .3443908691269 .7348022461268 .8453979492 267.5138244629 -9999 -9999 -9999 -9999 -9999 -9999 -9999 -9999 -9999 -9999 -9999 -9999 -9999 -9999 -9999 -9999 -9999 -9999 -9999 -9999 -9999 -9999 -9999 -9999 -9999 -9999 -9999 -9999 -9999 -9999 -9999 -9999 -9999 -9999 -9999 -9999 -9999 -9999 -9999 -9999 -9999 -9999 -9999 -9999 -9999 -9999 -9999 -9999 -9999 -9999 -9999 -9999 -9999 -9999 -9999 -9999 -9999 -9999 -9999 -9999 -9999 -9999 -9999 -9999 -9999 -9999 -9999 -9999 -9999 -9999 -9999 -9999 $-9999-9999$

-9999 -9999 -9999 -9999 -9999 -9999 -9999 -9999 -9999 -9999 -9999 -9999 -9999 -9999 -9999 -9999 -9999-9999 -9999-9999 -9999-9999 -9999 10.28270721436 19.0817565918 28.0402297973636 .8790016174346 .0225486755455 .4708900451765 .22400665283 75.2819290161185 .3398437596 .00731658936106 .979598999118 .2565994263 130.1432037354141 .7250976562153 .9165039062166 .1078948975178 .2993011475 190.1858978271201 .7678070068213 .3495941162224 .0171051025234 .3798065186 243.8280944824252 .3621063232260 .2864990234267 .2966003418273 .3923034668 278.8783874512283 .4501953125287 .4124145508290 .4602050781293 .2033081055 295.6416015625297 .7750854492299 .2990112305300 .8229064941302 .3468017578 303.5660095215304 .7850952148305 .6994934082306 .9186096191307 .5281982422 308.4425048828309 .0520935059309 .6617126465309 .9664916992310 .2713012695 310.2713012695309 .9664916992309 .6617126465309 .3569030762308 .7473144531 307.8330078125306 .9186096191306 .0043029785304 .7850952148303 .2611999512 301.7373046875300 .2132873535298 .3846130371296 .5559082031294 .7272033691 292.5936889648290 .4602050781288 .3266906738285 .8884887695283 .4501953125 281.0119018555278 .5736083984276 .1353149414273 .3923034668270 .9540100098 268.2109069824265 .7726135254263 .0296020508260 .2864990234257 .8482055664 255.1051025391252 .3621063232249 .6190032959247 .1806945801244 .4376983643 241.9994049072239 .2563018799236 .8179931641234 .3798065186231 .9414978027 
229.5032043457227 .0648956299224 .6266021729222 .4931030273220 .3596038818 217.9214019775215 .787902832213 .6544036865211 .520904541209 .692199707 207.5587005615205 .7299957275203 .596496582201 .7678070068199 .9389953613 198.1103057861196 .5863952637194 .7577056885193 .233795166191 .4051055908 189.8811035156188 .3571929932186 .8332977295185 .3094024658184 .0901947021 182.5662994385181 .0424041748179 .8231964111178 .2993011475177 .0802001953 175.8609924316174 .337097168173 .1179962158171 .8988037109170 .3748931885 169.1557006836167 .6318054199166 .4127044678164 .8887023926163 .6696014404 162.4505004883161 .2312927246160 .0122070312158 .7929992676157 .878692627 156.9642944336156 .0500030518155 .4403991699155 .1356048584154 .5260925293 154.2212982178153 .9165039062153 .9165039062154 .2212982178154 .8307952881 155.4403991699156 .0500030518156 .6596069336157 .2691040039157 .5738983154 157.878692627158 .1835021973158 .4882965088158 .7929992676159 .0977935791 159.4026031494160 .0122070312160 .6217956543161 .2312927246161 .8408966064 162.7552947998163 .6696014404164 .5839996338165 .8031005859166 .4127044678 165.8031005859163 .0599975586158 .7929992676157 .2691040039155 .4403991699 151.1734008789140 .8106994629133 .8007049561128 .6192932129124 .6570968628 130.1432037354130 .1432037354124 .0475006104124 .9618988037128 .0097961426 128.6192932129136 .2389984131151 .1734008789156 .9642944336156 .6596069336 155.7451934814156 .0500030518157 .5738983154159 .0977935791162 .7552947998 166.4127044678170 .9844970703175 .2514038086179 .5184020996183 .1759033203 186.2236938477188 .6620025635190 .795501709192 .624206543194 .7577056885 196.5863952637198 .7198944092200 .8533935547202 .9868927002205 .425201416 207.8634033203209 .692199707209 .692199707209 .692199707209 .692199707 209.692199707209 .692199707209 .692199707209 .692199707209 .692199707209 .692199707 209.692199707209 .692199707209 .692199707209 .692199707209 .692199707209 .692199707 209.692199707209 .692199707209 .692199707209 .692199707209 .692199707209 .692199707 209.692199707209 .692199707209 .692199707209 .692199707209 .692199707209 .692199707 209.692199707 211.8256988525 215.1782989502 218.8356933594222.1884002686 225.5410003662229 .1983947754232 .5511016846235 .9037017822239 .2563018799 242.6089935303245 .9615936279248 .7046966553251 .7525024414254 .4956054688 256.9338989258259 .3721008301261 .8103942871263 .9439086914265 .7726135254 267.6012878418269 .1253051758270 .6492004395271 .8682861328273 .0874938965 274.3066101074275 .2210083008275 .2210083008275 .2210083008275 .2210083008 275.2210083008274 .9161987305274 .9161987305274 .9161987305274 .6113891602 274.6113891602274 .6113891602274 .3066101074274 .0018005371273 .6971130371 272.7827148438272 .1730957031271 .5635070801271 .2587890625270 .6492004395 270.3443908691269 .7348022461269 .1253051758268 .5156860352268 .2109069824 267.9060974121267 .6012878418267 .6012878418267 .6012878418267 .9060974121 267.9060974121267 .9060974121267 .6012878418266 .9917907715265 .7625427246 264.2408752441 -9999 -9999 -9999 -9999 -9999 -9999 -9999 -9999 -9999 -9999 -9999 -9999

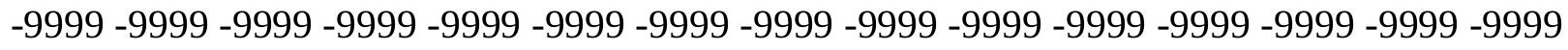
-9999 -9999 -9999 -9999 -9999 -9999 -9999 -9999 -9999 -9999 -9999 -9999 -9999 -9999 -9999 -9999 -9999 -9999 -9999 -9999 -9999 -9999 -9999 -9999 -9999 -9999 -9999 -9999 -9999 -9999 -

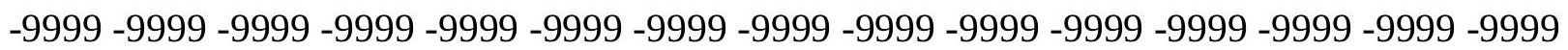
$-9999-9999$ 
-9999 -9999 -9999 -9999 -9999 -9999 -9999 -9999 -9999 -9999 -9999 -9999 -9999 -9999 -9999 -9999 -9999 -9999 -9999 -9999 -9999-9999 6.420082569122 14.9535493850723 .46845054626 32.0024414062540 .8412094116249 .9847602844259 .1283111572368 .88143920898 78.6345596313588 .9972534179799 .35994720459110 .0273971558120 .9997024536 132.2767028809143 .5538024902155 .1356048584166 .7174987793178 .2993011475 189.5764007568200 .8533935547211 .520904541221 .883605957231 .6367034912 240.7801971436249 .3141937256257 .2385864258264 .2486877441270 .3443908691 275.8305053711280 .7070922852284 .9740905762288 .6315002441291 .6794128418 294.4223937988296 .8606872559298 .6893920898300 .5180969238302 .0421142578 303.5660095215304 .7850952148305 .6994934082306 .9186096191307 .5281982422 308.4425048828308 .7473144531309 .3569030762309 .6617126465309 .6617126465 309.6617126465309 .3569030762309 .0520935059308 .4425048828307 .8330078125 306.9186096191306 .0043029785304 .7850952148303 .5660095215302 .0421142578 300.5180969238298 .9942016602297 .1654968262295 .3367919922293 .2033081055 291.0697937012288 .9363098145286 .8027954102284 .3645019531281 .9262084961 279.4880065918277 .0497131348274 .6113891602271 .8682861328269 .1253051758 266.6870117188263 .9439086914261 .2008972168258 .4577941895255 .7147064209 253.2763977051250 .5334014893247 .7902984619245 .0471954346242 .6089935303 239.8659057617237 .4275970459234 .6844940186232 .246307373229 .8079986572 227.3697052002 224.9313964844 222.4931030273220.054901123217.9214019775 215.4830932617 213.3495941162 211.2160949707 209.0825958252 207.25390625 205.1204071045203 .2917022705201 .158203125199 .329498291197 .500793457 195.6721038818194 .1481018066192 .3193969727190 .795501709188 .966796875 187.4429016113185 .9188995361184 .3950042725183 .1759033203181 .6519012451 180.1280059814178 .9089050293177 .6896972656176 .165802002174 .9467010498 173.7274932861172 .2035980225170 .9844970703169 .7653045654168 .241394043 167.0222015381165 .4983062744164 .2792053223163 .0599975586161 .5361022949 160.3170013428158 .7929992676157 .5738983154156 .3547973633155 .4403991699 154.5260925293153 .6116943359153 .3069000244152 .6972961426152 .0877990723 151.4781951904151 .1734008789151 .4781951904151 .7830047607152 .3925933838 152.6972961426153 .3069000244153 .9165039062154 .5260925293154 .8307952881 155.1356048584155 .4403991699155 .4403991699155 .7451934814156 .0500030518 156.0500030518156 .3547973633156 .6596069336156 .9642944336157 .5738983154 157.878692627158 .1835021973158 .7929992676159 .7073974609160 .9264984131 160.3170013428155 .1356048584149 .3446960449149 .0399017334149 .0399017334 137.7628936768128 .9241027832122 .8283996582120 .3900985718120 .0852966309 119.7806015015119 .4757995605119 .4757995605119 .4757995605119 .7806015015 120.6949005127121 .3044967651153 .9165039062150 .8686065674147 .8208007812 147.8208007812150 .8686065674154 .2212982178156 .6596069336158 .1835021973 158.7929992676164 .5839996338170 .070098877175 .2514038086179 .2136993408 182.5662994385185 .3094024658187 .4429016113189 .2716064453191 .1002960205 193.233795166195 .3672943115198 .1103057861200 .8533935547203 .596496582 206.6443023682209 .3874053955209 .692199707209 .692199707209 .692199707 209.692199707209 .692199707209 .692199707209 .692199707209 .692199707209 .692199707 209.692199707209 .692199707209 .692199707209 .692199707209 .692199707209 .692199707 209.692199707 209.692199707 209.692199707 209.692199707 209.692199707 209.692199707 
209.692199707 209.692199707 209.692199707 209.692199707209.692199707 209.692199707 209.3874053955213 .0447998047216 .3973999023220 .054901123223 .4075012207 227.0648956299230 .7223052979234 .3798065186237 .7324066162241 .3898010254 244.7424926758247 .7902984619251 .1428985596253 .8860015869256 .6290893555 259.3721008301261 .5056152344263 .9439086914265 .7726135254267 .6012878418 269.1253051758270 .6492004395272 .1730957031273 .0874938965274 .3066101074 275.2210083008275 .8305053711276 .1353149414276 .1353149414275 .8305053711 275.8305053711275 .5257873535275 .5257873535275 .2210083008275 .2210083008 274.9161987305274 .6113891602274 .6113891602274 .0018005371273 .6971130371 272.7827148438272 .1730957031271 .5635070801270 .9540100098270 .3443908691 269.7348022461269 .1253051758268 .2109069824267 .9060974121267 .2966003418 266.6870117188266 .3822021484266 .0773925781266 .0773925781265 .7726135254 265.7726135254265 .1630859375264 .5534973145263 .9439086914262 .7247924805 261.0583190918259 .1223144531 -9999 -9999 -9999 -9999 -9999 -9999 -9999 -9999 -9999

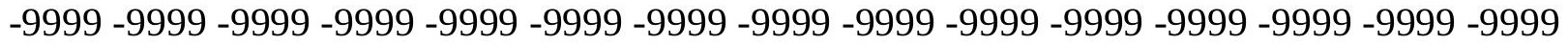

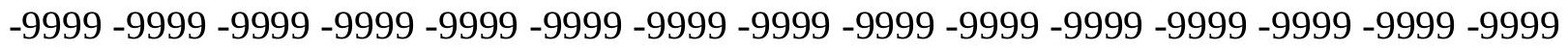

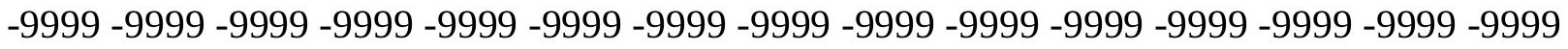

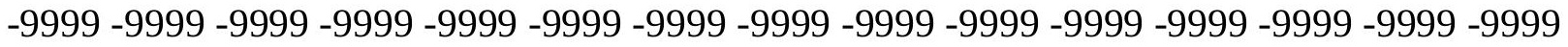
-9999 -9999 -9999 -9999

-9999 -9999 -9999 -9999 -9999 -9999 -9999 -9999 -9999 -9999 -9999 -9999 -9999 -9999 -9999 -9999 -9999 -9999 -9999 -9999 -9999 2.45528793335 10.9809436798119 .20145988464 27.430660247835 .6598587036144 .4986305236853 .3373985290562 .78573989868 72.2340774536181 .9871978759892 .04509735107102 .1029968262112 .4656982422 123.1332015991134 .1054992676145 .0776977539156 .0500030518167 .0222015381 178.2993011475188 .966796875199 .6342926025209 .9969024658220 .054901123 229.5032043457238 .3419952393246 .5711975098254 .1907958984261 .2008972168 267.6012878418273 .3923034668278 .2687988281282 .8406066895286 .8027954102 290.1553955078292 .8984985352295 .6416015625297 .7750854492299 .9085998535 301.4324951172302 .9563903809304 .1755981445305 .3947143555306 .3091125488 307.2233886719307 .8330078125308 .4425048828308 .7473144531309 .0520935059 309.0520935059308 .7473144531308 .4425048828308 .1377868652307 .5281982422 306.9186096191306 .0043029785304 .7850952148303 .5660095215302 .3468017578 300.8229064941299 .2990112305297 .7750854492295 .9464111328293 .8128967285 291.9841918945289 .8505859375287 .4124145508285 .2789001465282 .8406066895 280.4023132324277 .9641113281275 .5257873535272 .7827148438270 .0396118164 267.6012878418264 .8583068848262 .1152038574259 .3721008301256 .6290893555 253.8860015869251 .1428985596248 .3999023438245 .6567993164243 .2185058594 240.4754943848237 .7324066162235 .2940979004232 .5511016846230 .1127929688 227.3697052002 224.9313964844222.4931030273220.054901123217.9214019775 215.4830932617213 .3495941162210 .9113006592208 .7778015137206 .6443023682 204.8155975342202 .6820983887200 .5485992432198 .7198944092196 .891204834195 .0625 193.233795166191 .7097930908189 .8811035156188 .3571929932186 .8332977295 185.0045928955183 .7854003906182 .261505127180 .7375946045179 .5184020996 177.9945068359176 .7754058838175 .2514038086174 .0323028564172 .8132019043 171.5939941406170 .3748931885169 .1557006836167 .6318054199166 .4127044678 165.1934967041163 .6696014404162 .4505004883160 .9264984131159 .7073974609 
158.1835021973156 .9642944336155 .4403991699154 .2212982178153 .3069000244 152.3925933838151 .7830047607151 .1734008789150 .5639038086149 .9542999268 149.6495056152149 .3446960449149 .3446960449149 .6495056152149 .9542999268 150.2590942383150 .8686065674151 .4781951904152 .0877990723152 .0877990723 152.3925933838152 .6972961426152 .6972961426152 .6972961426153 .0021057129 153.0021057129153 .0021057129153 .0021057129153 .0021057129153 .0021057129 153.0021057129153 .0021057129153 .0021057129152 .6972961426155 .4403991699 155.7451934814149 .3446960449141 .7250976562135 .3246002197128 .0097961426 123.1332015991119 .7806015015119 .1709976196118 .5614013672118 .2565994263 117.9517974854117 .9517974854117 .9517974854117 .9517974854118 .2565994263 118.5614013672120 .9997024536132 .8863067627135 .6293945312134 .7149963379 138.9819946289146 .6015930176152 .3925933838155 .7451934814156 .0500030518 155.4403991699156 .9642944336164 .2792053223169 .7653045654174 .6419067383 177.9945068359180 .7375946045182 .87109375184 .699798584186 .528503418 188.6620025635191 .4051055908194 .4528961182197 .8054962158201 .158203125 204.5108032227207 .8634033203209 .692199707209 .692199707209 .692199707 209.692199707 209.692199707 209.692199707 209.692199707 209.692199707 209.692199707 209.692199707 209.692199707 209.692199707 209.692199707 209.692199707209.692199707 209.692199707209 .692199707209 .692199707209 .692199707209 .692199707209 .692199707 209.692199707 209.692199707 209.692199707209.692199707209.692199707209.692199707 210.3016967773213 .959197998217 .6165924072221 .2740020752224 .9313964844 228.5888977051232 .246307373235 .9037017822239 .5610961914243 .2185058594 246.5711975098249 .9237976074253 .2763977051256 .0195007324258 .7626037598 261.5056152344263 .6390991211265 .7726135254267 .9060974121269 .4301147461 270.9540100098272 .1730957031273 .3923034668274 .3066101074275 .2210083008 275.8305053711276 .4400939941276 .4400939941276 .4400939941276 .4400939941 276.1353149414276 .1353149414275 .8305053711275 .5257873535275 .2210083008 275.2210083008274 .9161987305274 .6113891602274 .0018005371273 .3923034668 272.7827148438272 .1730957031271 .2587890625270 .6492004395269 .7348022461 269.1253051758268 .5156860352267 .6012878418266 .9917907715266 .3822021484 265.7726135254265 .1630859375264 .8583068848264 .5534973145263 .9439086914 263.6390991211262 .7247924805262 .1152038574260 .8960876465259 .6769104004 257.9186706543 255.8953552246 -9999 -9999 -9999 -9999 -9999 -9999 -9999 -9999 -9999 -9999 -9999 -9999 -9999 -9999 -9999 -9999 -9999 -9999 -9999 -9999 -9999 -9999 -9999 -9999 -9999 -9999 -9999 -9999 -9999 -9999 -9999 -9999 -9999 -9999 -9999 -9999 -9999 -9999 -9999

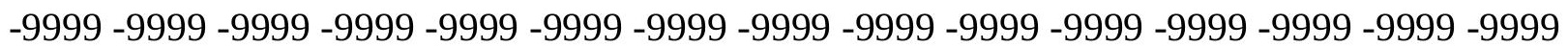

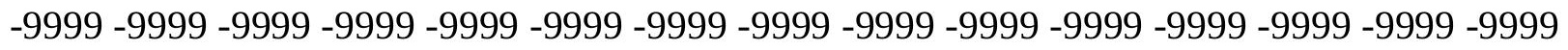
-9999 -9999-9999-9999

-9999 -9999 -9999 -9999 -9999 -9999 -9999 -9999 -9999 -9999 -9999 -9999 -9999 -9999 -9999 -9999 -9999 -9999 -9999-9999 -2.10811018944 6.617172241211 15.23925971985 22.8588790893631 .0880794525139 .3172798156747 .8512611389256 .69002914429 65.8335876464875 .2819290161184 .7302627563594 .78817749023104 .5412979126 114.9039993286125 .2667007446135 .6293945312146 .2969055176156 .9642944336 167.6318054199178 .2993011475188 .6620025635198 .7198944092208 .7778015137 218.2261962891227 .3697052002236 .2084960938244 .1329040527251 .7525024414 258.7626037598265 .1630859375270 .6492004395275 .8305053711280 .7070922852 
284.6693115234288 .3266906738291 .3746032715294 .1176147461296 .5559082031 298.6893920898300 .5180969238302 .3468017578303 .5660095215304 .7850952148 305.6994934082306 .6138000488307 .2233886719307 .5281982422307 .8330078125 308.1377868652308 .1377868652307 .8330078125307 .5281982422306 .9186096191 306.3091125488305 .6994934082304 .7850952148303 .5660095215302 .3468017578 301.1276855469299 .6037902832298 .0798950195296 .2510986328294 .4223937988 292.2889099121290 .4602050781288 .3266906738285 .8884887695283 .7549133301 281.3167114258278 .8783874512276 .1353149414273 .6971130371270 .9540100098 268.5156860352265 .7726135254263 .0296020508260 .2864990234257 .5433959961 254.8003997803252 .0572967529249 .3141937256246 .5711975098243 .8280944824 241.0850067139238 .3419952393235 .5989074707232 .8558044434230 .4176025391 227.6744995117225 .2362060547222 .7978973389220 .3596038818217 .9214019775 215.4830932617213 .0447998047210 .9113006592208 .7778015137206 .3394927979 204.2059936523 202.3773040771 200.2438049316198.4151000977 196.2816009521 194.4528961182192 .624206543190 .795501709189 .2716064453187 .4429016113 185.9188995361184 .3950042725182 .87109375181 .3471984863179 .8231964111 178.604095459177 .0802001953175 .8609924316174 .6419067383173 .4226989746 172.2035980225170 .9844970703169 .7653045654168 .5462036133167 .3269958496 166.1078948975164 .5839996338163 .3648071289162 .1457061768160 .6217956543 159.4026031494157 .878692627156 .6596069336155 .1356048584153 .9165039062 152.6972961426151 .1734008789150 .5639038086149 .9542999268149 .3446960449 148.7351074219148 .1255950928147 .8208007812147 .5160064697147 .5160064697 147.5160064697147 .8208007812148 .1255950928148 .4304046631149 .0399017334 149.3446960449149 .6495056152149 .6495056152149 .9542999268149 .9542999268 149.9542999268149 .9542999268149 .6495056152149 .6495056152149 .3446960449 149.3446960449149 .0399017334148 .4304046631148 .1255950928148 .1255950928 148.7351074219150 .2590942383151 .4781951904149 .0399017334133 .4958953857 120.3900985718119 .4757995605118 .8662033081117 .9517974854117 .342300415 116.7326965332116 .4279022217116 .1231002808116 .1231002808116 .1231002808 116.4279022217116 .7326965332117 .0374984741116 .7326965332120 .3900985718 121.6092987061120 .0852966309131 .9720001221145 .0776977539153 .3069000244 156.0500030518153 .9165039062151 .1734008789149 .3446960449157 .5738983154 163.3648071289168 .241394043172 .5084075928175 .2514038086176 .7754058838 178.604095459180 .7375946045183 .1759033203186 .528503418190 .1858978271 194.1481018066198 .1103057861202 .0724945068206 .0346984863209 .692199707 209.692199707209 .692199707209 .692199707209 .692199707209 .692199707209 .692199707 209.692199707 209.692199707 209.692199707 209.692199707 209.692199707 209.692199707 209.692199707209 .692199707209 .692199707209 .692199707209 .692199707209 .692199707 209.692199707209 .692199707209 .692199707209 .692199707209 .692199707209 .692199707 209.692199707 209.692199707 211.2160949707 214.8735046387218.5308990479 222.4931030273226 .150604248230 .1127929688234 .0749969482237 .7324066162 241.3898010254245 .0471954346248 .7046966553252 .0572967529255 .1051025391 258.1530151367260 .8960876465263 .6390991211265 .7726135254267 .9060974121 269.7348022461271 .2587890625272 .4779052734273 .6971130371274 .6113891602 275.2210083008276 .1353149414276 .4400939941276 .7449035645277 .0497131348 276.7449035645276 .7449035645276 .4400939941276 .4400939941276 .1353149414 
275.8305053711275 .5257873535275 .2210083008274 .9161987305274 .3066101074 274.0018005371273 .3923034668272 .4779052734271 .8682861328270 .9540100098 270.3443908691269 .4301147461268 .8204956055267 .9060974121266 .9917907715 266.3822021484265 .4678039551264 .8583068848264 .2486877441263 .6390991211 263.0296020508262 .4200134277261 .5056152344260 .5913085938259 .6769104004 258.1530151367256 .6290893555254 .8754272461252 .7878723145 -9999 -9999 -9999 -9999 -9999 -9999 -9999 -9999 -9999 -9999 -9999 -9999 -9999 -9999 -9999 -9999 -9999 -9999 -9999

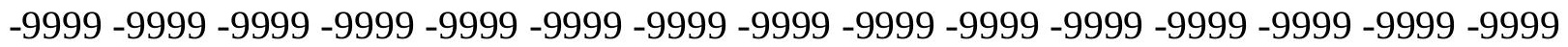

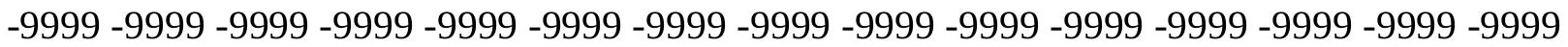
-9999 -9999 -9999 -9999 -9999 -9999 -9999 -9999 -9999 -9999 -9999 -9999 -9999 -9999 -9999 -9999 -9999 -9999 -9999 -9999 -9999 -9999 -9999 -9999

-9999 -9999 -9999 -9999 -9999 -9999 -9999 -9999 -9999 -9999 -9999 -9999 -9999 -9999 -9999 -9999 -9999 -9999 -9999 -7.1429772377 1.534408688545 10.125805854818 .287109375 26.2115192413334 .1359291076742 .3651313781750 .8991203308159 .73788070679 68.8814392089878 .0249862670987 .4733276367297 .22646331787106 .979598999 116.7326965332127 .0953979492137 .1533050537147 .5160064697157 .878692627 167.9365997314178 .2993011475188 .0523986816198 .1103057861207 .5587005615 216.7021942139225 .5410003662234 .0749969482241 .9994049072249 .3141937256 256.3243103027262 .7247924805268 .5156860352273 .6971130371278 .2687988281 282.5357971191286 .4979858398289 .8505859375292 .5936889648295 .3367919922 297.4703063965299 .2990112305301 .1276855469302 .6516113281303 .8707885742 304.7850952148305 .6994934082306 .3091125488306 .6138000488306 .9186096191 306.9186096191306 .9186096191306 .6138000488306 .3091125488305 .6994934082 305.0899047852304 .1755981445303 .2611999512302 .3468017578300 .8229064941 299.6037902832298 .0798950195296 .5559082031294 .7272033691292 .8984985352 290.7650146484288 .6315002441286 .4979858398284 .3645019531281 .9262084961 279.4880065918277 .0497131348274 .3066101074271 .8682861328269 .1253051758 266.3822021484263 .6390991211260 .8960876465258 .1530151367255 .4098968506 252.6669006348249 .9237976074247 .1806945801244 .4376983643241 .6945953369 238.9515075684236 .2084960938233 .4653930664230 .7223052979227 .9792938232 225.5410003662222 .7978973389220 .3596038818217 .9214019775215 .4830932617 213.0447998047210 .9113006592208 .4730072021206 .3394927979204 .2059936523 202.0724945068199 .9389953613197 .8054962158195 .9768066406193 .8433074951 192.0146026611190 .1858978271188 .6620025635186 .8332977295185 .3094024658 183.4806976318181 .9566955566180 .7375946045179 .2136993408177 .6896972656 176.4705963135175 .2514038086173 .7274932861172 .5084075928171 .2891998291 170.070098877169 .1557006836167 .9365997314166 .7174987793165 .4983062744 164.2792053223163 .0599975586161 .8408966064160 .6217956543159 .4026031494 157.878692627156 .6596069336155 .1356048584153 .9165039062152 .3925933838 151.1734008789149 .9542999268149 .0399017334148 .4304046631147 .8208007812 147.2111968994146 .6015930176146 .2969055176145 .9920959473145 .6873016357 145.6873016357145 .9920959473145 .9920959473146 .2969055176146 .6015930176 146.9064025879147 .2111968994147 .2111968994147 .2111968994147 .2111968994 147.2111968994146 .9064025879146 .9064025879146 .6015930176146 .2969055176 145.6873016357145 .0776977539144 .4682006836143 .8585968018143 .5538024902 144.1634063721144 .4682006836142 .9441986084135 .6293945312121 .6092987061 
118.8662033081117 .9517974854117 .0374984741116 .1231002808115 .5136032104 114.9039993286114 .5991973877114 .5991973877114 .2944030762114 .5991973877 114.9039993286115 .2088012695115 .5136032104116 .1231002808116 .7326965332 117.342300415119 .1709976196129 .533706665144 .4682006836156 .0500030518 155.1356048584149 .6495056152144 .7729034424143 .8585968018148 .7351074219 153.6116943359160 .0122070312165 .1934967041167 .6318054199169 .1557006836 170.6797027588173 .1179962158176 .4705963135180 .432800293185 .0045928955 189.8811035156194 .4528961182199 .329498291203 .596496582208 .1681976318 209.692199707 209.692199707 209.692199707 209.692199707 209.692199707 209.692199707 209.692199707 209.692199707209.692199707 209.692199707 209.692199707 209.692199707 209.692199707209 .692199707209 .692199707209 .692199707209 .692199707209 .692199707 209.692199707 209.692199707 209.692199707 209.692199707 209.692199707 209.692199707 209.692199707 209.692199707212.1304016113215.787902832 219.7501068115 223.4075012207227 .3697052002231 .3318939209235 .2940979004239 .2563018799 243.2185058594246 .8759002686250 .5334014893254 .1907958984257 .2385864258 260.2864990234263 .0296020508265 .4678039551267 .9060974121269 .7348022461 271.2587890625272 .7827148438274 .0018005371274 .9161987305275 .5257873535 276.1353149414276 .4400939941276 .7449035645277 .0497131348277 .0497131348 277.0497131348277 .0497131348276 .7449035645276 .4400939941276 .1353149414 275.8305053711275 .5257873535275 .2210083008274 .6113891602274 .3066101074 273.6971130371273 .0874938965272 .4779052734271 .5635070801270 .9540100098 270.0396118164269 .1253051758268 .2109069824267 .2966003418266 .6870117188 265.7726135254264 .8583068848264 .2486877441263 .3344116211262 .4200134277 261.5056152344260 .5913085938259 .6769104004258 .4577941895257 .2385864258 255.7147064209253 .8860015869252 .0572967529249 .8177185059247 .3705291748 -9999 -9999 -9999 -9999 -9999 -9999 -9999 -9999 -9999 -9999 -9999 -9999 -9999 -9999 -9999 -9999 -9999 -9999 -9999 -9999 -9999 -9999 -9999 -9999 -9999 -9999 -9999 -9999 -9999 -9999 -9999

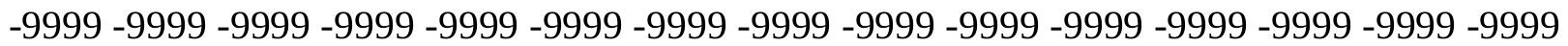
-9999 -9999 -9999 -9999 -9999 -9999 -9999 -9999 -9999 -9999 -9999 -9999 -9999 -9999 -9999 -9999 -9999 -9999 -9999 -9999 -9999 -9999 -9999 -9999 -9999 -9999

-9999 -9999 -9999 -9999 -9999 -9999 -9999 -9999 -9999 -9999 -9999 -9999 -9999 -9999 -9999 -9999 -9999-9999-9999-3.97982096672 4.566295623779 13.10575962067 21.03017044067 28.9545898437536 .8790016174345 .1082000732453 .6421813964862 .48094940186 71.3197174072380 .4632720947389 .9116134643699 .35994720459108 .8082962036 118.5614013672128 .6192932129138 .3724975586148 .4304046631158 .4882965088 168.241394043177 .9945068359187 .7476043701197 .1959991455206 .6443023682 215.4830932617224 .0171051025232 .246307373239 .8659057617247 .1806945801 253.8860015869260 .2864990234266 .0773925781271 .2587890625276 .1353149414 280.4023132324284 .3645019531287 .7171936035290 .7650146484293 .5080871582 295.9464111328298 .0798950195299 .6037902832301 .1276855469302 .3468017578 303.5660095215304 .1755981445304 .7850952148305 .3947143555305 .6994934082 305.6994934082305 .6994934082305 .3947143555304 .7850952148304 .4802856445 303.5660095215302 .9563903809301 .7373046875300 .8229064941299 .2990112305 298.0798950195296 .5559082031294 .7272033691292 .8984985352291 .0697937012 288.9363098145286 .8027954102284 .6693115234282 .5357971191280 .0975036621 277.6592102051275 .2210083008272 .4779052734269 .7348022461267 .2966003418 
264.5534973145261 .8103942871259 .0674133301256 .3243103027253 .2763977051 250.5334014893247 .7902984619245 .0471954346242 .3041992188239 .2563018799 236.5133056641233 .7702026367231 .0270996094228 .5888977051225 .8457946777 223.1027069092220 .6643981934217 .9214019775215 .4830932617213 .0447998047 210.6065063477208 .4730072021206 .0346984863203 .9011993408201 .7678070068 199.6342926025197 .500793457195 .3672943115193 .5386047363191 .7097930908 189.5764007568188 .0523986816186 .2236938477184 .3950042725182 .87109375 181.3471984863179.8231964111 178.2993011475 177.0802001953175 .5561981201 174.337097168173 .1179962158171 .8988037109170 .6797027588169 .4604949951 168.5462036133167 .3269958496166 .1078948975165 .1934967041163 .974395752 162.7552947998161 .8408966064160 .6217956543159 .4026031494158 .1835021973 156.6596069336155 .4403991699153 .9165039062152 .6972961426151 .4781951904 150.2590942383149 .0399017334148 .1255950928147 .2111968994146 .6015930176 145.6873016357145 .3825073242144 .7729034424144 .4682006836144 .1634063721 144.1634063721144 .1634063721144 .1634063721144 .1634063721144 .4682006836 144.4682006836144 .7729034424144 .7729034424144 .7729034424144 .7729034424 144.4682006836144 .1634063721144 .1634063721143 .5538024902143 .2489929199 142.3347015381141 .7250976562140 .8106994629139 .8963928223139 .2868041992 138.9819946289138 .0677032471135 .0198059082128 .6192932129120 .0852966309 117.342300415116 .4279022217115 .5136032104114 .5991973877113 .9896011353 113.3800964355112 .7705001831112 .7705001831112 .7705001831112 .7705001831 113.3800964355113 .6848983765114 .2944030762114 .9039993286115 .5136032104 115.5136032104119 .1709976196126 .1809997559138 .3724975586157 .5738983154 146.6015930176140 .8106994629136 .5437011719132 .8863067627134 .7149963379 140.8106994629148 .1255950928156 .3547973633157 .2691040039158 .4882965088 160.6217956543163 .974395752168 .241394043173 .4226989746179 .2136993408 184.699798584190 .4907073975195 .6721038818200 .8533935547205 .7299957275 209.692199707209 .692199707209 .692199707209 .692199707209 .692199707209 .692199707 209.692199707 209.692199707 209.692199707 209.692199707 209.692199707 209.692199707 209.692199707 209.692199707 209.692199707 209.692199707 209.692199707 209.692199707 209.692199707 209.692199707209.692199707 209.692199707 209.692199707 209.692199707 209.692199707209 .0825958252212 .7400054932216 .7021942139220 .6643981934 224.6266021729228 .5888977051232 .8558044434236 .8179931641240 .7801971436 244.7424926758248 .7046966553252 .3621063232256 .0195007324259 .3721008301 262.4200134277265 .1630859375267 .6012878418269 .7348022461271 .5635070801 272.7827148438274 .0018005371274 .9161987305275 .8305053711276 .1353149414 276.7449035645277 .0497131348277 .0497131348277 .3544921875277 .0497131348 277.0497131348277 .0497131348276 .7449035645276 .4400939941276 .1353149414 275.8305053711275 .5257873535274 .9161987305274 .6113891602274 .0018005371 273.3923034668272 .7827148438272 .1730957031271 .5635070801270 .6492004395 269.7348022461268 .8204956055267 .9060974121266 .9917907715266 .0773925781 265.1630859375264 .2486877441263 .3344116211262 .4200134277261 .5056152344 260.5913085938259 .3721008301258 .1530151367256 .6290893555255 .1051025391 253.5812072754251 .4476928711249 .3141937256247 .0106506348244 .4732971191 -9999 -9999 -9999 -9999 -9999 -9999 -9999 -9999 -9999 -9999 -9999 -9999 -9999 -9999 -9999 -9999

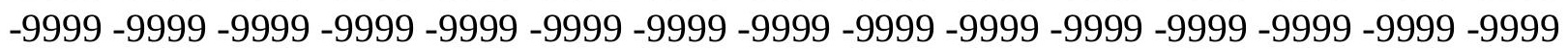


-9999 -9999 -9999 -9999 -9999 -9999 -9999 -9999 -9999 -9999 -9999 -9999 -9999 -9999 -9999 -9999 -9999 -9999 -9999 -9999 -9999 -9999 -9999 -9999 -9999 -9999 -9999 -9999 -9999 -9999 -9999 -9999 -9999 -9999 -9999 -9999 -9999 -9999 -9999 -9999 -9999

-9999 -9999 -9999 -9999 -9999 -9999 -9999 -9999 -9999 -9999 -9999 -9999 -9999 -9999 -9999 -9999 -9999 -9999 -9.55377292633 -1.29957580566 7.010057926178 14.9344701767 23.1636695861831 .0880794525139 .3172798156747 .5464782714856 .08045959473 64.9192428588973 .7580032348682 .5967712402391 .74033355713101 .1886978149 110.6370010376120 .0852966309129 .8385009766139 .5915985107149 .0399017334 158.7929992676168 .5462036133177 .9945068359187 .4429016113196 .5863952637 205.425201416214 .2639007568222 .4931030273230 .4176025391238 .0372009277 245.0471954346251 .7525024414258 .1530151367263 .9439086914269 .1253051758 274.0018005371278 .2687988281282 .2309875488285 .8884887695288 .9363098145 291.6794128418294 .1176147461296 .2510986328298 .0798950195299 .6037902832 300.8229064941302 .0421142578302 .6516113281303 .5660095215303 .8707885742 304.1755981445304 .1755981445304 .1755981445303 .8707885742303 .2611999512 302.6516113281302 .0421142578301 .1276855469300 .2132873535298 .9942016602 297.7750854492296 .2510986328294 .7272033691292 .8984985352291 .0697937012 289.2410888672 287.1076049805284.9740905762 282.8406066895 280.4023132324 277.9641113281275 .5257873535273 .0874938965270 .6492004395267 .9060974121 265.1630859375262 .4200134277259 .6769104004256 .9338989258254 .1907958984 251.1428985596248 .3999023438245 .6567993164242 .6089935303239 .8659057617 237.1228027344234 .3798065186231 .6367034912228 .8936004639226 .150604248 223.4075012207220 .9691925049218 .2261962891215 .787902832213 .0447998047 210.6065063477208 .4730072021206 .0346984863203 .596496582201 .4629974365 199.329498291197 .1959991455195 .0625192 .9290008545191 .1002960205189 .2716064453 187.4429016113185 .6141052246183 .7854003906182 .261505127180 .7375946045 179.2136993408177 .6896972656176 .165802002174 .9467010498173 .7274932861 172.2035980225170 .9844970703170 .070098877168 .8509979248167 .6318054199 166.7174987793165 .4983062744164 .5839996338163 .6696014404162 .4505004883 161.5361022949160 .3170013428159 .4026031494158 .1835021973156 .9642944336 155.7451934814154 .5260925293153 .0021057129151 .7830047607150 .5639038086 149.3446960449148 .1255950928147 .2111968994146 .2969055176145 .3825073242 144.7729034424144 .1634063721143 .5538024902142 .9441986084142 .6394042969 142.6394042969142 .3347015381142 .3347015381142 .3347015381142 .3347015381 142.3347015381142 .3347015381142 .3347015381142 .3347015381142 .3347015381 142.0299072266141 .7250976562141 .4203033447140 .8106994629140 .2012023926 139.5915985107138 .3724975586137 .4580993652136 .2389984131135 .3246002197 134.4102020264132 .5814971924129 .8385009766124 .9618988037119 .1709976196 115.818397522114 .9039993286113 .6848983765113 .075302124112 .1608963013 111.551399231111 .24659729112 .7705001831115 .2088012695116 .1231002808 115.818397522115 .818397522115 .818397522115 .818397522116 .1231002808 116.7326965332118 .8662033081121 .9140014648123 .7427978516117 .342300415 128.6192932129130 .4479980469128 .3144989014125 .2667007446122 .2188034058 125.5715026855147 .8208007812144 .1634063721143 .2489929199145 .6873016357 149.0399017334153 .3069000244162 .1457061768168 .5462036133172 .5084075928 179.2136993408185 .9188995361192 .0146026611197 .500793457203 .2917022705 
208.4730072021209.692199707209.692199707 209.692199707 209.692199707 209.692199707 209.692199707 209.692199707 209.692199707 209.692199707 209.692199707 209.692199707209 .692199707209 .692199707209 .692199707209 .692199707209 .692199707 209.692199707209 .692199707209 .692199707209 .692199707209 .692199707209 .692199707 209.692199707 209.692199707 209.3874053955 213.3495941162 217.3117980957 221.5787963867225 .5410003662229 .8079986572234 .0749969482238 .0372009277 242.3041992188246 .2664031982250 .2286071777254 .1907958984257 .8482055664 261.2008972168264 .2486877441266 .9917907715269 .4301147461271 .2587890625 273.0874938965274 .3066101074275 .2210083008275 .8305053711276 .4400939941 276.7449035645277 .0497131348277 .0497131348277 .3544921875277 .3544921875 277.0497131348277 .0497131348276 .7449035645276 .4400939941276 .1353149414 275.8305053711275 .5257873535275 .2210083008274 .9161987305274 .3066101074 274.0018005371273 .3923034668272 .7827148438271 .8682861328271 .2587890625 270.3443908691269 .7348022461268 .8204956055267 .9060974121266 .6870117188 265.7726135254264 .8583068848263 .9439086914262 .7247924805261 .8103942871 260.5913085938259 .3721008301258 .1530151367256 .6290893555255 .1051025391 253.2763977051251 .4476928711249 .3141937256246 .8759002686244 .479888916 241.8074645996 -9999 -9999 -9999 -9999 -9999 -9999 -9999 -9999 -9999 -9999 -9999 -9999

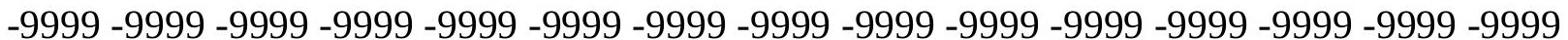

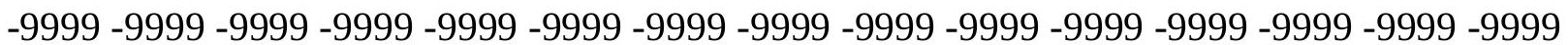

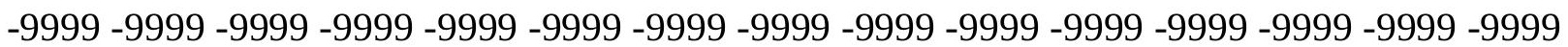
-9999 -

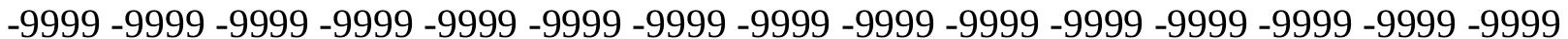
-9999 -9999-9999-6.99866676331 9616696834564 8.83876895904516 .76317977905 24.9923801422133 .2215805053741 .4507789611849 .6799812316958 .21395874023 66.7479400634875 .5867080688584 .4254837036193 .56903076172102 .712600708 112.1608963013121 .6092987061130 .7528076172140 .2012023926149 .6495056152 159.0977935791168 .5462036133177 .6896972656186 .8332977295195 .6721038818 204.5108032227212 .7400054932220 .9691925049228 .8936004639236 .2084960938 243.2185058594249 .6190032959255 .7147064209261 .5056152344266 .6870117188 271.5635070801276 .1353149414280 .0975036621283 .7549133301286 .8027954102 289.5458984375292 .2889099121294 .4223937988296 .2510986328297 .7750854492 298.9942016602300 .2132873535301 .1276855469301 .7373046875302 .0421142578 302.3468017578302 .3468017578302 .3468017578302 .0421142578301 .7373046875 301.1276855469300 .2132873535299 .2990112305298 .3846130371297 .1654968262 295.9464111328294 .4223937988292 .8984985352291 .0697937012289 .2410888672 287.4124145508285 .2789001465283 .1453857422280 .7070922852278 .5736083984 276.1353149414273 .6971130371270 .9540100098268 .5156860352265 .7726135254 263.0296020508260 .2864990234257 .5433959961254 .8003997803251 .7525024414 249.0093994141246 .2664031982243 .2185058594240 .4754943848237 .7324066162 234.6844940186231 .9414978027229 .1983947754226 .4553985596223 .7122955322 220.9691925049218 .5308990479215 .787902832213 .3495941162210 .9113006592 208.1681976318206 .0346984863203 .596496582201 .158203125199 .0247039795 196.891204834194 .7577056885192 .624206543190 .795501709188 .6620025635 186.8332977295185 .0045928955183 .4806976318181 .6519012451180 .1280059814 178.604095459177 .0802001953175 .5561981201174 .337097168172 .8132019043 
171.5939941406170 .3748931885169 .1557006836168 .241394043167 .0222015381 166.1078948975165 .1934967041163 .974395752163 .0599975586162 .1457061768 161.2312927246160 .3170013428159 .4026031494158 .1835021973157 .2691040039 156.0500030518154 .8307952881153 .6116943359152 .3925933838151 .1734008789 149.9542999268148 .7351074219147 .5160064697146 .6015930176145 .3825073242 144.4682006836143 .8585968018142 .9441986084142 .3347015381141 .7250976562 141.4203033447141 .1154937744140 .8106994629140 .5059967041140 .5059967041 140.5059967041140 .5059967041140 .2012023926140 .2012023926140 .2012023926 139.8963928223139 .5915985107139 .2868041992138 .9819946289138 .3724975586 137.7628936768136 .8484954834135 .6293945312134 .4102020264133 .1911010742 131.9720001221130 .7528076172128 .9241027832126 .4858016968123 .43800354 119.4757995605115 .2088012695113 .3800964355112 .4656982422111 .551399231 110.6370010376110 .6370010376113 .3800964355116 .7326965332120 .6949005127 120.0852966309119 .4757995605119 .1709976196118 .8662033081118 .8662033081 118.5614013672118 .5614013672118 .5614013672117 .647102356116 .7326965332 117.342300415117 .9517974854121 .3044967651121 .9140014648120 .0852966309 119.1709976196122 .8283996582131 .3623962402132 .8863067627128 .6192932129 132.5814971924136 .5437011719147 .8208007812158 .1835021973165 .4983062744 169.1557006836173 .4226989746180 .7375946045187 .4429016113193 .8433074951 199.9389953613205.7299957275 209.692199707 209.692199707 209.692199707 209.692199707 209.692199707 209.692199707 209.692199707 209.692199707 209.692199707 209.692199707209.692199707 209.692199707209.692199707 209.692199707209.692199707 209.692199707209 .692199707209 .692199707209 .692199707209 .692199707209 .692199707 209.692199707209.692199707209.692199707209.9969024658 213.959197998 218.2261962891222 .1884002686226 .4553985596230 .7223052979234 .9893035889 239.2563018799243.5233001709 247.7902984619251.7525024414255.7147064209 259.3721008301 262.7247924805266.0773925781268.8204956055 270.9540100098 272.7827148438274 .3066101074275 .2210083008276 .1353149414276 .4400939941 276.7449035645277 .0497131348277 .0497131348277 .3544921875277 .0497131348 277.0497131348277 .0497131348276 .7449035645276 .4400939941276 .4400939941 276.1353149414275 .8305053711275 .5257873535275 .2210083008274 .6113891602 274.3066101074273 .6971130371273 .0874938965272 .4779052734271 .8682861328 271.2587890625270 .3443908691269 .4301147461268 .5156860352267 .6012878418 266.6870117188265 .4678039551264 .5534973145263 .3344116211262 .4200134277 261.2008972168259 .9816894531258 .4577941895256 .9338989258255 .4098968506 253.5812072754251 .7525024414249 .6190032959247 .4855041504244 .7424926758 242.3041992188 239.3789672852 236.2184295654 -9999 -9999 -9999 -9999 -9999 -9999 -9999

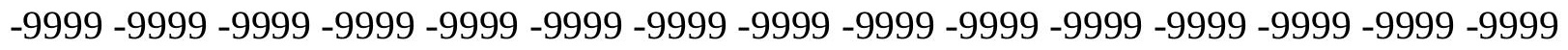
-9999 -9999 -9999 -9999 -9999 -9999 -9999 -9999 -9999 -9999 -9999 -9999 -9999 -9999 -9999 -9999 -9999 -9999 -9999 -9999 -9999 -9999 -9999 -9999 -9999 -9999 -9999 -9999 -9999 -9999 -

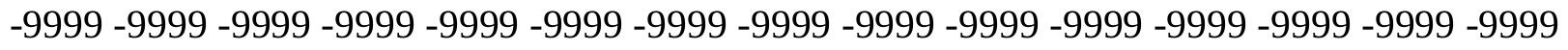
-9999 -9999-9999 -9999

-9999 -9999 -9999 -9999 -9999 -9999 -9999 -9999 -9999 -9999 -9999 -9999 -9999 -9999 -9999 -9999 -9999-12.4374227524-4.68150520325 3.04785108566310 .66748046875 18.8966808319126 .8210906982435 .0502891540543 .2794914245651 .50868988037 60.0426712036168 .5766525268677 .4154205322386 .254188537695 .09295654297 
104.2365036011 113.3800964355 122.5235977173131 .6672058105141 .1154937744 150.2590942383159 .4026031494168 .5462036133177 .3849029541186 .2236938477195 .0625 203.2917022705 211.520904541219.4452972412 227.0648956299 234.3798065186 241.0850067139247 .4855041504253 .5812072754259 .3721008301264 .5534973145 269.4301147461273 .6971130371277 .6592102051281 .3167114258284 .6693115234 287.4124145508289 .8505859375292 .2889099121294 .1176147461295 .6416015625 297.1654968262298 .0798950195298 .9942016602299 .9085998535300 .2132873535 300.5180969238300 .5180969238300 .5180969238300 .2132873535299 .9085998535 299.2990112305298 .3846130371297 .4703063965296 .5559082031295 .3367919922 293.8128967285292 .5936889648290 .7650146484289 .2410888672287 .1076049805 285.2789001465283 .1453857422281 .0119018555278 .8783874512276 .4400939941 274.0018005371271 .5635070801268 .8204956055266 .3822021484263 .6390991211 260.8960876465258 .1530151367255 .4098968506252 .3621063232249 .6190032959 246.8759002686243 .8280944824241 .0850067139238 .0372009277235 .2940979004 232.5511016846229 .8079986572226 .7601013184224 .0171051025221 .2740020752 218.8356933594216 .0926971436213 .3495941162210 .9113006592208 .4730072021 206.0346984863203 .596496582201 .158203125198 .7198944092196 .5863952637 194.4528961182192 .3193969727190 .1858978271188 .3571929932186 .528503418 184.699798584182 .87109375181 .0424041748179 .5184020996177 .9945068359 176.4705963135174 .9467010498173 .4226989746172 .2035980225170 .9844970703 169.7653045654168 .5462036133167 .3269958496166 .4127044678165 .4983062744 164.2792053223163 .3648071289162 .4505004883161 .8408966064160 .9264984131 160.0122070312159 .0977935791158 .1835021973157 .2691040039156 .3547973633 155.4403991699154 .2212982178153 .0021057129151 .7830047607150 .5639038086 149.3446960449148 .1255950928146 .9064025879145 .9920959473144 .7729034424 143.8585968018142 .9441986084142 .0299072266141 .4203033447140 .8106994629 140.2012023926139 .8963928223139 .2868041992138 .9819946289138 .9819946289 138.6772003174138 .6772003174138 .3724975586138 .3724975586138 .0677032471 137.7628936768137 .4580993652137 .1533050537136 .5437011719135 .9342041016 135.3246002197134 .4102020264133 .4958953857131 .9720001221130 .7528076172 129.533706665128 .0097961426126 .4858016968124 .6570968628122 .8283996582 120.6949005127117 .342300415114 .9039993286113 .3800964355112 .7705001831 113.075302124114 .2944030762116 .4279022217118 .8662033081121 .9140014648 122.2188034058122 .2188034058122 .2188034058121 .6092987061121 .6092987061 120.9997024536120 .3900985718119 .4757995605117 .647102356115 .2088012695 116.7326965332117 .342300415117 .9517974854118 .5614013672117 .9517974854 117.9517974854120 .0852966309121 .9140014648122 .5235977173120 .3900985718 121.3044967651129 .533706665142 .3347015381154 .8307952881160 .6217956543 163.6696014404167 .3269958496175 .2514038086182 .261505127189 .2716064453 195.9768066406202 .6820983887208 .7778015137209 .692199707209 .692199707 209.692199707 209.692199707 209.692199707 209.692199707 209.692199707 209.692199707 209.692199707 209.692199707 209.692199707 209.692199707 209.692199707 209.692199707 209.692199707209 .692199707209 .692199707209 .692199707209 .692199707209 .692199707 209.692199707 209.692199707 209.692199707210.6065063477214.5686950684 218.8356933594223 .1027069092227 .3697052002231 .6367034912235 .9037017822 240.1707000732244 .7424926758248 .7046966553252 .9716033936256 .9338989258 
260.8960876465264 .2486877441267 .6012878418270 .3443908691272 .4779052734 274.3066101074275 .2210083008276 .1353149414276 .7449035645277 .0497131348 277.0497131348277 .0497131348277 .0497131348277 .0497131348277 .0497131348 276.7449035645276 .7449035645276 .4400939941276 .1353149414276 .1353149414 275.8305053711275 .5257873535275 .2210083008274 .9161987305274 .6113891602 274.0018005371273 .6971130371273 .0874938965272 .4779052734271 .8682861328 270.9540100098270 .3443908691269 .4301147461268 .5156860352267 .6012878418 266.3822021484265 .4678039551264 .2486877441263 .3344116211262 .1152038574 260.5913085938259 .3721008301257 .8482055664256 .0195007324254 .4956054688 252.3621063232250 .2286071777248 .0950927734245 .6567993164242 .9136962891 240.1707000732237 .1238708496233 .7819519043 -9999 -9999 -9999 -9999 -9999 -9999 -9999 -9999 -9999 -9999 -9999 -9999 -9999 -9999 -9999 -9999 -9999 -9999 -9999 -9999 -9999 -9999 -9999 -9999 -9999 -9999 -9999 -9999 -9999 -9999 -9999 -9999 -9999 -9999 -9999 -9999 -9999 -9999 -9999 -9999 -9999 -9999 -9999 -9999 -9999 -9999 -9999 -9999 -9999 -9999 -9999 -9999 -9999 -9999 -9999 -9999 -9999 -9999 -9999 -9999 -9999 -9999 -9999 -9999 -9999 -999 - -9999 -9999-9999-9999-9999

-9999 -9999 -9999 -9999 -9999 -9999 -9999 -9999 -9999 -9999 -9999 -9999 -9999 -9999 -9999 -9999-17.7833175659-10.0763559341 -2.47894835472 4.8765621185312 .49619007111 20.4206008911128 .6497993469236 .5742111206144 .8034095764253 .33739852905 61.5666007995670 .1005783081178 .9393463134887 .4733276367296 .31210327148 105.4557037354114 .2944030762123 .43800354132 .2767028809141 .4203033447 150.5639038086159 .4026031494168 .241394043177 .0802001953185 .6141052246 194.1481018066202 .3773040771210 .3016967773217 .9214019775225 .2362060547 232.246307373238.9515075684245.3520050049251.4476928711256.9338989258 262.1152038574266 .9917907715271 .2587890625275 .2210083008278 .8783874512 282.2309875488284.9740905762 287.7171936035 289.8505859375 291.9841918945 293.5080871582295 .0320129395295 .9464111328296 .8606872559297 .7750854492 298.0798950195298 .3846130371298 .6893920898298 .3846130371298 .0798950195 297.7750854492297 .1654968262296 .5559082031295 .6416015625294 .4223937988 293.2033081055291 .9841918945290 .4602050781288 .6315002441287 .1076049805 285.2789001465283 .1453857422281 .0119018555278 .8783874512276 .7449035645 274.3066101074271 .8682861328269 .4301147461266 .6870117188263 .9439086914 261.5056152344258 .7626037598255 .7147064209252 .9716033936250 .2286071777 247.1806945801244 .4376983643241 .6945953369238 .6468048096235 .9037017822 232.8558044434230 .1127929688227 .3697052002224 .3218994141221 .5787963867 218.8356933594216 .3973999023213 .6544036865210 .9113006592208 .4730072021 206.0346984863203.596496582 201.158203125 198.7198944092 196.2816009521 194.1481018066192 .0146026611189 .8811035156188 .0523986816185 .9188995361 184.0901947021182 .261505127180 .432800293178 .9089050293177 .3849029541 175.8609924316174 .337097168172 .8132019043171 .5939941406170 .070098877 168.8509979248167 .9365997314166 .7174987793165 .8031005859164 .5839996338 163.6696014404162 .7552947998161 .8408966064161 .2312927246160 .3170013428 159.7073974609158 .7929992676158 .1835021973157 .2691040039156 .6596069336 155.7451934814154 .8307952881153 .9165039062152 .6972961426151 .7830047607 150.5639038086149 .0399017334147 .8208007812146 .6015930176145 .3825073242 144.1634063721143 .2489929199142 .0299072266141 .1154937744140 .5059967041 
139.5915985107138 .9819946289138 .6772003174138 .0677032471137 .7628936768 137.4580993652137 .1533050537136 .8484954834136 .5437011719136 .2389984131 136.2389984131135 .9342041016135 .3246002197135 .0198059082134 .4102020264 133.8007049561133 .1911010742132 .2767028809131 .3623962402130 .1432037354 128.9241027832127 .7050018311126 .4858016968125 .2667007446123 .7427978516 122.5235977173120 .9997024536119 .1709976196117 .647102356116 .7326965332 116.4279022217116 .7326965332117 .342300415118 .8662033081120 .3900985718 121.9140014648122 .8283996582123 .43800354123 .43800354123 .43800354123 .1332015991 122.8283996582122 .2188034058121 .6092987061119 .4757995605117 .342300415 116.7326965332117 .0374984741117 .647102356117 .9517974854117 .647102356 118.2565994263118 .2565994263118 .2565994263118 .2565994263118 .2565994263 117.9517974854122 .5235977173133 .4958953857149 .9542999268150 .2590942383 154.2212982178161 .2312927246169 .1557006836176 .4705963135183 .7854003906 191.4051055908198 .7198944092205 .7299957275209 .692199707209 .692199707 209.692199707209 .692199707209 .692199707209 .692199707209 .692199707209 .692199707 209.692199707 209.692199707 209.692199707 209.692199707 209.692199707 209.692199707 209.692199707 209.692199707 209.692199707 209.692199707 209.692199707 209.692199707 209.692199707209 .692199707209 .692199707210 .9113006592214 .8735046387 219.1405029297223 .4075012207227 .9792938232232 .246307373236 .8179931641 241.0850067139245 .3520050049249 .9237976074253 .8860015869258 .1530151367 261.8103942871265 .4678039551268 .8204956055271 .5635070801273 .6971130371 275.2210083008276 .1353149414276 .7449035645277 .0497131348277 .0497131348 277.0497131348277 .0497131348276 .7449035645276 .7449035645276 .7449035645 276.4400939941276 .1353149414276 .1353149414275 .8305053711275 .8305053711 275.5257873535275 .2210083008274 .9161987305274 .6113891602274 .3066101074 274.0018005371273 .3923034668273 .0874938965272 .4779052734271 .8682861328 270.9540100098270 .3443908691269 .4301147461268 .5156860352267 .6012878418 266.3822021484265 .4678039551264 .2486877441263 .0296020508261 .8103942871 260.2864990234258 .7626037598257 .2385864258255 .4098968506253 .5812072754 251.4476928711249 .0093994141246 .5711975098244 .1329040527241 .0850067139 238.3419952393235 .066986084231 .5376281738 -9999 -9999 -9999 -9999 -9999 -9999 -9999 -9999 -9999 -9999 -9999 -9999 -9999 -9999 -9999 -9999 -9999 -9999 -9999 -9999 -9999 -9999

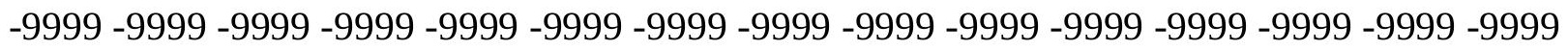
-9999 -9999 -9999 -9999 -9999 -9999 -9999 -9999 -9999 -9999 -9999 -9999 -9999 -9999 -9999

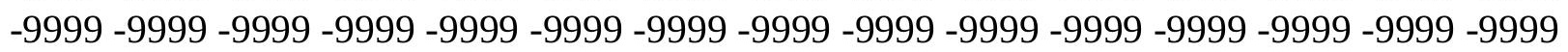
-9999 -9999 -9999 -9999

-9999 -9999 -9999 -9999 -9999 -9999 -9999 -9999 -9999 -9999 -9999 -9999 -9999 -9999 -9999 -9999-15.5281572342 -7.95930719376 -.304785102606 6.705273151398 14.32489967346 22.2493095397930 .1737308502238 .4029312133846 .6321296691954 .86132049561 63.0905189514271 .6244964599680 .1584930419988 .6924667358497 .53124237061 106.3700027466115.2088012695124.0475006104 132.8863067627141.7250976562 150.5639038086159 .4026031494167 .9365997314176 .4705963135185 .0045928955 193.233795166 201.158203125 208.7778015137216.3973999023223.7122955322 230.4176025391237 .1228027344243 .2185058594249 .0093994141254 .4956054688 259.6769104004264 .5534973145268 .8204956055272 .7827148438276 .4400939941 279.7927856445282 .5357971191285 .2789001465287 .4124145508289 .5458984375 
291.0697937012292 .5936889648293 .8128967285294 .7272033691295 .3367919922 295.9464111328296 .2510986328296 .2510986328296 .2510986328295 .9464111328 295.6416015625295 .0320129395294 .4223937988293 .5080871582292 .2889099121 291.0697937012289 .8505859375288 .3266906738286 .4979858398284 .9740905762 282.8406066895281 .0119018555278 .8783874512276 .7449035645274 .3066101074 271.8682861328269 .4301147461266 .9917907715264 .5534973145261 .8103942871 259.0674133301256 .3243103027253 .5812072754250 .8381958008247 .7902984619 245.0471954346241 .9994049072239 .2563018799236 .2084960938233 .4653930664 230.4176025391227 .6744995117224 .9313964844221 .883605957219 .1405029297 216.3973999023213 .6544036865211 .2160949707208 .4730072021206 .0346984863 203.596496582200 .8533935547198 .7198944092196 .2816009521194 .1481018066 191.7097930908189 .5764007568187 .7476043701185 .6141052246183 .7854003906 181.9566955566180 .1280059814178 .2993011475176 .7754058838175 .2514038086 173.7274932861172 .2035980225170 .6797027588169 .4604949951168 .241394043 167.0222015381166 .1078948975164 .8887023926163 .974395752163 .0599975586 162.1457061768161 .2312927246160 .6217956543159 .7073974609159 .0977935791 158.4882965088157 .878692627157 .2691040039156 .6596069336155 .7451934814 155.1356048584154 .5260925293153 .6116943359152 .6972961426151 .4781951904 150.2590942383149 .0399017334147 .5160064697146 .2969055176145 .0776977539 143.5538024902142 .6394042969141 .4203033447140 .5059967041139 .5915985107 138.6772003174138 .0677032471137 .4580993652136 .8484954834136 .2389984131 135.9342041016135 .6293945312135 .3246002197135 .0198059082134 .7149963379 134.4102020264134 .1054992676133 .4958953857133 .1911010742132 .5814971924 131.9720001221131 .3623962402130 .4479980469129 .533706665128 .3144989014 127.4001998901126 .1809997559125 .2667007446124 .3523025513123 .43800354 122.5235977173121 .3044967651120 .3900985718119 .7806015015119 .4757995605 119.4757995605119 .4757995605120 .0852966309120 .6949005127121 .3044967651 121.6092987061123 .1332015991123 .7427978516124 .0475006104124 .3523025513 124.0475006104123 .7427978516123 .43800354122 .5235977173121 .3044967651 120.0852966309119 .4757995605119 .1709976196119 .1709976196118 .5614013672 117.647102356117 .647102356117 .9517974854117 .9517974854117 .647102356 117.647102356117 .342300415116 .7326965332118 .5614013672126 .7906036377 136.2389984131145 .6873016357154 .8307952881162 .1457061768169 .4604949951 177.3849029541 185.9188995361 194.4528961182 202.3773040771 209.692199707 209.692199707 209.692199707 209.692199707 209.692199707 209.692199707 209.692199707 209.692199707 209.692199707 209.692199707 209.692199707 209.692199707 209.692199707 209.692199707 209.692199707 209.692199707 209.692199707 209.692199707 209.692199707 209.692199707209 .692199707209 .692199707209 .692199707211 .2160949707 215.1782989502219 .4452972412224 .0171051025228 .2841033936232 .8558044434 237.1228027344241 .6945953369245 .9615936279250 .5334014893254 .8003997803 258.7626037598262 .7247924805266 .3822021484269 .7348022461272 .4779052734 274.3066101074275 .5257873535276 .4400939941276 .7449035645276 .7449035645 276.7449035645276 .7449035645276 .7449035645276 .4400939941276 .4400939941 276.1353149414276 .1353149414275 .8305053711275 .5257873535275 .5257873535 275.2210083008275 .2210083008274 .9161987305274 .6113891602274 .6113891602 274.3066101074273 .6971130371273 .3923034668272 .7827148438272 .4779052734 
271.8682861328270 .9540100098270 .3443908691269 .4301147461268 .5156860352 267.6012878418266 .6870117188265 .4678039551264 .2486877441263 .0296020508 261.5056152344259 .9816894531258 .4577941895256 .6290893555254 .8003997803 252.6669006348250 .5334014893248 .0950927734245 .3520050049242 .6089935303 239.5610961914236 .5133056641233 .2062225342229 .5166778564 -9999 -9999 -9999-9999 -9999 -9999 -9999 -9999 -9999 -9999 -9999 -9999 -9999 -9999 -9999 -9999 -9999 -9999 -9999

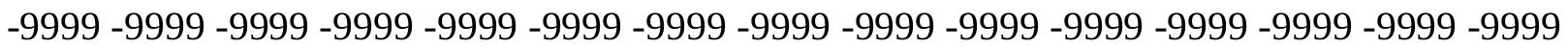

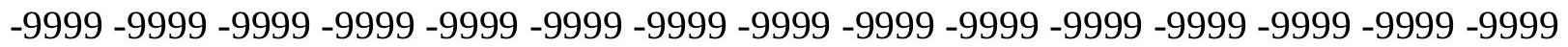

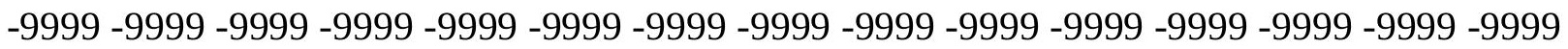
-9999 -9999 -9999 -9999-9999-9999-9999

-9999 -9999 -9999 -9999 -9999 -9999 -9999 -9999 -9999 -9999 -9999 -9999 -9999 -9999 -9999 -20.8926181793 -13.4321336746-6.12847280502 9143553972244 8.533983230591 16.1536102294923 .7732391357431 .6976509094239 .9268493652347 .85126113892 56.0804595947364 .3096618652372 .8436431884881 .3776321411189 .91161346436 98.4455871582106 .979598999115 .818397522124 .3523025513133 .1911010742 141.7250976562150 .5639038086159 .0977935791167 .3269958496175 .8609924316 184.0901947021192 .0146026611199 .9389953613207 .25390625214 .5686950684 221.883605957228 .5888977051234 .9893035889241 .0850067139246 .8759002686 252.0572967529257 .2385864258261 .8103942871266 .0773925781270 .0396118164 273.6971130371277 .0497131348280 .0975036621282 .5357971191284 .9740905762 287.1076049805 288.6315002441290.1553955078 291.3746032715 292.2889099121 293.2033081055293 .5080871582294 .1176147461294 .1176147461294 .1176147461 293.8128967285293 .5080871582292 .8984985352291 .9841918945291 .0697937012 290.1553955078288 .9363098145287 .4124145508285 .8884887695284 .3645019531 282.5357971191280 .7070922852278 .5736083984276 .4400939941274 .3066101074 272.1730957031269 .7348022461267 .2966003418264 .5534973145262 .1152038574 259.3721008301256 .6290893555253 .8860015869251 .1428985596248 .3999023438 245.3520050049242 .6089935303239 .5610961914236 .8179931641233 .7702026367 231.0270996094227 .9792938232225 .2362060547222 .4931030273219 .4452972412 216.7021942139213 .959197998211 .2160949707208 .7778015137206 .0346984863 203.596496582200 .8533935547198 .4151000977196 .2816009521193 .8433074951 191.7097930908189 .2716064453187 .4429016113185 .3094024658183 .1759033203 181.3471984863179 .5184020996177 .6896972656176 .165802002174 .6419067383 173.1179962158171 .5939941406170 .070098877168 .8509979248167 .6318054199 166.4127044678165 .1934967041164 .2792053223163 .3648071289162 .4505004883 161.5361022949160 .6217956543160 .0122070312159 .0977935791158 .4882965088 157.878692627157 .2691040039156 .6596069336156 .3547973633155 .7451934814 155.1356048584154 .5260925293153 .9165039062153 .3069000244152 .6972961426 151.4781951904150 .2590942383148 .7351074219147 .5160064697145 .9920959473 144.4682006836143 .2489929199142 .0299072266140 .8106994629139 .8963928223 138.6772003174138 .0677032471137 .1533050537136 .2389984131135 .6293945312 135.0198059082134 .4102020264134 .1054992676133 .8007049561133 .1911010742 132.8863067627132 .5814971924132 .2767028809131 .9720001221131 .3623962402 130.7528076172130 .1432037354129 .533706665128 .6192932129128 .0097961426 127.0953979492126 .1809997559125 .2667007446124 .3523025513123 .43800354 122.8283996582122 .2188034058121 .6092987061121 .3044967651120 .9997024536 
121.3044967651121 .9140014648121 .3044967651121 .6092987061121 .9140014648 122.2188034058122 .8283996582123 .43800354124 .3523025513124 .6570968628 124.6570968628124 .6570968628124 .3523025513124 .0475006104123 .43800354 122.5235977173121 .9140014648121 .6092987061121 .6092987061120 .6949005127 119.7806015015118 .5614013672116 .7326965332117 .342300415117 .342300415 117.0374984741117 .0374984741116 .4279022217116 .1231002808115 .818397522 120.0852966309129 .2288970947138 .6772003174147 .8208007812155 .1356048584 163.6696014404168 .8509979248179 .5184020996189 .5764007568198 .7198944092 206.9490966797209 .692199707209 .692199707209 .692199707209 .692199707 209.692199707209 .692199707209 .692199707209 .692199707209 .692199707209 .692199707 209.692199707209 .692199707209 .692199707209 .692199707209 .692199707209 .692199707 209.692199707 209.692199707 209.692199707 209.692199707 209.692199707209.692199707 211.2160949707215 .4830932617219 .7501068115224 .3218994141228 .5888977051 233.1605987549237 .4275970459241 .9994049072246 .5711975098250 .8381958008 255.1051025391259 .3721008301263 .3344116211266 .9917907715270 .3443908691 272.7827148438274 .6113891602275 .8305053711276 .4400939941276 .4400939941 276.4400939941276 .4400939941276 .4400939941276 .1353149414275 .8305053711 275.8305053711275 .5257873535275 .5257873535275 .2210083008275 .2210083008 274.9161987305274 .9161987305274 .9161987305274 .6113891602274 .6113891602 274.3066101074274 .0018005371273 .6971130371273 .3923034668272 .7827148438 272.4779052734271 .8682861328270 .9540100098270 .3443908691269 .4301147461 268.8204956055267 .6012878418266 .6870117188265 .4678039551264 .2486877441 263.0296020508261 .5056152344259 .9816894531258 .1530151367256 .3243103027 254.1907958984252 .0572967529249 .6190032959247 .1806945801244 .4376983643 241.3898010254238 .3419952393234 .9893035889231 .6367034912227 .7222442627 223.5156555176 -9999 -9999 -9999 -9999 -9999 -9999 -9999 -9999 -9999 -9999 -9999 -9999 -9999 -9999 -9999 -9999 -9999 -9999 -9999 -9999 -9999 -9999 -9999 -9999 -9999 -9999 - -9999 -

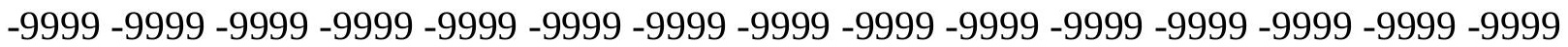
-9999 -9999 -9999 -9999 -9999 -9999 -9999 -9999 -9999 -9999 -9999 -9999 -9999 -9999 -9999 -9999 -9999 -9999 -9999 -9999 -9999 -9999 -9999 -9999 -9999 -9999 -9999 -9999 -9999 -9999 -9999 -9999 -9999 -9999 -9999 -9999 -9999 -9999 -9999 -9999 -9999 -9999 -9999 -18.8340167999-11.5249147415-4.26699209213 2.743066072464 10.05790996552 17.6775398254425 .2971591949533 .2215805053741 .1459884643649 .07040023804 57.2995986938565 .5288009643673 .7580032348682 .2919769287190 .52117919922 99.05516815186107 .5891036987116 .1231002808124 .6570968628133 .1911010742 141.7250976562150 .2590942383158 .4882965088166 .7174987793174 .9467010498 182.87109375190 .795501709198 .4151000977205 .7299957275213 .0447998047 219.7501068115226 .4553985596232 .8558044434238 .6468048096244 .4376983643 249.6190032959254.8003997803259.3721008301263.6390991211267.6012878418 271.2587890625274 .3066101074277 .3544921875280 .0975036621282 .2309875488 284.3645019531286 .1932067871287 .7171936035288 .9363098145289 .8505859375 290.7650146484291 .0697937012291 .6794128418291 .6794128418291 .6794128418 291.3746032715291 .0697937012290 .4602050781289 .8505859375288 .9363098145 287.7171936035286 .4979858398285 .2789001465283 .7549133301281 .9262084961 280.0975036621278 .2687988281276 .4400939941274 .3066101074272 .1730957031 269.7348022461 267.2966003418264.8583068848 262.4200134277 259.6769104004 
256.9338989258254 .4956054688251 .4476928711248 .7046966553245 .9615936279 242.9136962891240 .1707000732237 .1228027344234 .3798065186231 .3318939209 228.5888977051225 .5410003662222 .7978973389220 .054901123217 .0070037842 214.2639007568211 .520904541208 .7778015137206 .0346984863203 .596496582 201.158203125198 .4151000977195 .9768066406193 .8433074951191 .4051055908 189.2716064453187 .1381072998185 .0045928955182 .87109375181 .0424041748 179.2136993408177 .3849029541175 .5561981201174 .0323028564172 .5084075928 170.9844970703169 .4604949951168 .241394043167 .0222015381165 .8031005859 164.5839996338163 .6696014404162 .7552947998161 .5361022949160 .9264984131 160.0122070312159 .0977935791158 .4882965088157 .878692627157 .2691040039 156.6596069336156 .3547973633155 .7451934814155 .4403991699154 .8307952881 154.5260925293154 .2212982178153 .6116943359153 .0021057129152 .6972961426 151.4781951904149 .9542999268148 .7351074219147 .2111968994145 .6873016357 144.1634063721142 .9441986084141 .7250976562140 .2012023926139 .2868041992 138.0677032471137 .1533050537136 .2389984131135 .3246002197134 .7149963379 133.8007049561133 .1911010742132 .8863067627132 .2767028809131 .9720001221 131.3623962402131 .0576019287130 .7528076172130 .1432037354129 .8385009766 129.2288970947128 .6192932129128 .0097961426127 .4001998901126 .4858016968 125.8762969971124 .9618988037124 .0475006104123 .43800354122 .8283996582 122.5235977173121 .9140014648121 .9140014648121 .6092987061121 .6092987061 121.9140014648121 .9140014648121 .9140014648122 .2188034058122 .8283996582 123.1332015991123 .7427978516124 .3523025513124 .9618988037125 .2667007446 125.2667007446125 .2667007446124 .9618988037124 .6570968628124 .3523025513 123.7427978516123 .43800354123 .1332015991122 .5235977173121 .9140014648 120.9997024536119 .4757995605117 .342300415116 .7326965332116 .7326965332 116.4279022217116 .4279022217115 .818397522115 .5136032104114 .9039993286 114.5991973877122 .2188034058130 .4479980469138 .6772003174152 .6972961426 162.7552947998168 .5462036133172 .5084075928184 .699798584195 .0625203 .596496582 209.692199707 209.692199707 209.692199707 209.692199707 209.692199707 209.692199707 209.692199707 209.692199707 209.692199707 209.692199707 209.692199707 209.692199707 209.692199707 209.692199707 209.692199707 209.692199707 209.692199707209.692199707 209.692199707209 .692199707209 .692199707209 .692199707211 .2160949707 215.4830932617220 .054901123224 .3218994141228 .8936004639233 .1605987549 237.7324066162242 .3041992188246 .5711975098251 .1428985596255 .4098968506 259.3721008301263 .6390991211267 .2966003418270 .6492004395273 .0874938965 274.9161987305275 .8305053711276 .1353149414276 .1353149414276 .1353149414 275.8305053711275 .5257873535275 .5257873535275 .2210083008275 .2210083008 275.2210083008274 .9161987305274 .9161987305274 .9161987305274 .6113891602 274.6113891602274 .3066101074274 .3066101074274 .3066101074274 .0018005371 274.0018005371273 .6971130371273 .3923034668272 .7827148438272 .4779052734 271.8682861328271 .2587890625270 .6492004395269 .7348022461268 .8204956055 267.9060974121266 .6870117188265 .7726135254264 .2486877441263 .0296020508 261.5056152344259 .6769104004257 .8482055664256 .0195007324253 .8860015869 251.7525024414249 .0093994141246 .5711975098243 .5233001709240 .4754943848 237.4275970459233.7702026367230.1127929688226.1711425781 221.7509765625 -9999 -9999 -9999 -9999 -9999 -9999 -9999 -9999 -9999 -9999 -9999 -9999 -9999 -9999 -9999 -9999 
-9999 -9999 -9999 -9999 -9999 -9999 -9999 -9999 -9999 -9999 -9999 -9999 -9999 -9999 -9999 -9999 -9999 -9999 -9999 -9999 -9999 -9999 -9999 -9999 -9999 -9999 -9999 -9999 -9999 -9999 -

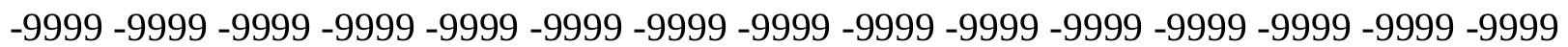
-9999 -9999 -9999 -9999 -9999 -9999 -9999 -9999 -9999

-9999 -9999 -9999 -9999 -9999 -9999 -9999 -9999 -9999 -9999 -9999 -9999 -9999 -9999 -24.2671642303 -16.8748474121 -9.75312423706 -2.74306607246 4.266992092133 11.5818300247219 .2014598846426 .8210906982434 .4407196044942 .36513137817 50.2895507812558 .2139587402366 .4431610107474 .6723632812582 .90155792236 91.1307525634899 .66472625732107 .8938980103116 .4279022217124 .6570968628 133.1911010742141 .4203033447149 .6495056152157 .878692627166 .1078948975 174.0323028564181 .6519012451189 .5764007568196 .891204834204 .2059936523 211.2160949707217 .9214019775224 .3218994141230 .4176025391236 .5133056641 241.9994049072247 .1806945801252 .0572967529256 .6290893555260 .8960876465 264.8583068848268 .5156860352271 .5635070801274 .6113891602277 .3544921875 279.4880065918281 .6214904785283 .4501953125284 .9740905762286 .1932067871 287.4124145508288 .0219116211288 .6315002441288 .9363098145289 .2410888672 289.2410888672 288.9363098145288.6315002441288.0219116211287.4124145508 286.4979858398285 .2789001465284 .0596923828282 .8406066895281 .3167114258 279.4880065918277 .6592102051275 .8305053711274 .0018005371271 .8682861328 269.7348022461267 .2966003418264 .8583068848262 .4200134277259 .9816894531 257.2385864258254 .8003997803252 .0572967529249 .0093994141246 .2664031982 243.5233001709240 .7801971436237 .7324066162234 .6844940186231 .9414978027 228.8936004639226 .150604248223 .1027069092220 .3596038818217 .3117980957 214.5686950684211 .8256988525209 .0825958252206 .3394927979203 .596496582 201.158203125198 .4151000977195 .9768066406193 .5386047363191 .4051055908 188.966796875186 .8332977295184 .699798584182 .5662994385180 .7375946045 178.9089050293177 .0802001953175 .2514038086173 .4226989746171 .8988037109 170.3748931885169 .1557006836167 .6318054199166 .4127044678165 .1934967041 163.974395752163 .0599975586161 .8408966064160 .9264984131160 .0122070312 159.4026031494158 .4882965088157 .878692627157 .2691040039156 .6596069336 156.0500030518155 .7451934814155 .1356048584154 .8307952881154 .5260925293 154.2212982178153 .9165039062153 .6116943359153 .0021057129152 .6972961426 152.0877990723150 .8686065674149 .6495056152148 .4304046631146 .9064025879 145.3825073242143 .8585968018142 .6394042969141 .1154937744139 .8963928223 138.6772003174137 .4580993652136 .5437011719135 .3246002197134 .4102020264 133.8007049561132 .8863067627132 .2767028809131 .6672058105131 .0576019287 130.4479980469130 .1432037354129 .533706665129 .2288970947128 .6192932129 128.3144989014127 .7050018311127 .0953979492126 .4858016968125 .8762969971 125.2667007446124 .6570968628124 .0475006104123 .1332015991122 .5235977173 122.2188034058121 .9140014648121 .6092987061121 .6092987061121 .9140014648 121.9140014648121 .9140014648121 .6092987061121 .6092987061122 .5235977173 123.43800354124 .0475006104124 .6570968628124 .9618988037125 .2667007446 125.5715026855125 .8762969971125 .8762969971125 .5715026855125 .5715026855 125.2667007446124 .6570968628124 .3523025513124 .0475006104123 .7427978516 123.1332015991122 .2188034058120 .9997024536118 .8662033081115 .818397522 116.1231002808116 .1231002808115 .818397522115 .2088012695114 .9039993286 
114.2944030762113 .9896011353116 .7326965332122 .8283996582135 .9342041016 152.6972961426162 .4505004883167 .6318054199170 .6797027588180 .1280059814 191.1002960205199 .9389953613207 .5587005615209 .692199707209 .692199707 209.692199707 209.692199707 209.692199707 209.692199707 209.692199707 209.692199707 209.692199707209 .692199707209 .692199707209 .692199707209 .692199707209 .692199707 209.692199707209 .692199707209 .692199707209 .692199707209 .692199707209 .692199707 209.692199707 211.2160949707 215.4830932617219.7501068115224.3218994141 228.5888977051233 .1605987549237 .7324066162241 .9994049072246 .5711975098 250.8381958008255 .1051025391259 .3721008301263 .3344116211266 .9917907715 270.3443908691273 .3923034668274 .6113891602275 .2210083008275 .5257873535 275.5257873535275 .2210083008274 .9161987305274 .9161987305274 .9161987305 274.9161987305274 .6113891602274 .6113891602274 .6113891602274 .6113891602 274.3066101074274 .3066101074274 .0018005371274 .3066101074274 .3066101074 274.0018005371274 .0018005371274 .0018005371273 .6971130371273 .3923034668 273.0874938965272 .4779052734271 .8682861328271 .2587890625270 .6492004395 270.0396118164269 .1253051758268 .2109069824266 .9917907715265 .7726135254 264.5534973145263 .0296020508261 .5056152344259 .6769104004257 .8482055664 256.0195007324253 .5812072754251 .4476928711248 .7046966553245 .9615936279 243.2185058594239 .8659057617236 .5133056641232 .8558044434229 .1983947754 224.9548797607220 .2241210938 -9999 -9999 -9999 -9999 -9999 -9999 -9999 -9999 -9999

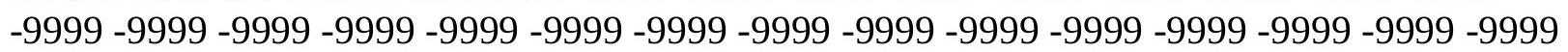
-9999 -9999 -9999 -9999 -9999 -9999 -9999 -9999 -9999 -9999 -9999 -9999 -9999 -9999 -9999 -9999 -9999 -9999 -9999 -9999 -9999 -9999 -9999 -9999 -9999 -9999 -9999-9999-9999-9999 -999 -9999 -9999 -9999 -9999 -9999 -9999 -9999 -9999 -9999 -9999 -9999 -9999 -9999 -9999 -9999 $-9999$

-9999 -9999 -9999 -9999 -9999 -9999 -9999 -9999 -9999 -9999 -9999 -9999 -9999 -9999 -22.4548892975 -15.0211353302 -7.92441320419-1.21914100647 5.790916919708 13.1057596206720 .4206008911128 .0402297973635 .6598587036143 .58427047729 51.2038993835459 .1283111572367 .3575134277375 .2819290161183 .51112365723 91.7403335571399 .96952056885108 .1986999512116 .4279022217124 .6570968628 132.8863067627141 .1154937744149 .0399017334157 .2691040039165 .1934967041 172.8132019043180 .432800293188 .0523986816195 .3672943115202 .3773040771 209.3874053955 215.787902832 222.1884002686228.2841033936234.0749969482 239.5610961914244 .7424926758249 .3141937256253 .8860015869258 .1530151367 262.1152038574265 .4678039551268 .8204956055271 .8682861328274 .3066101074 276.7449035645278 .8783874512280 .7070922852282 .2309875488283 .4501953125 284.6693115234285 .5835876465286 .1932067871286 .4979858398286 .8027954102 286.8027954102286 .4979858398286 .1932067871285 .5835876465284 .6693115234 283.7549133301282 .8406066895281 .6214904785280 .0975036621278 .8783874512 277.0497131348275 .2210083008273 .3923034668271 .5635070801269 .4301147461 267.2966003418264 .8583068848262 .4200134277259 .9816894531257 .5433959961 254.8003997803252 .0572967529249 .6190032959246 .5711975098243 .8280944824 241.0850067139238 .0372009277235 .2940979004232 .246307373229 .5032043457 226.4553985596223 .7122955322220 .6643981934217 .9214019775214 .8735046387 212.1304016113209 .3874053955206 .6443023682203 .9011993408201 .158203125 198.7198944092195 .9768066406193 .5386047363191 .1002960205188 .966796875 
186.528503418184 .3950042725182 .261505127180 .432800293178 .2993011475 176.4705963135174 .6419067383173 .1179962158171 .5939941406170 .070098877 168.5462036133167 .0222015381165 .8031005859164 .5839996338163 .3648071289 162.4505004883161 .2312927246160 .3170013428159 .4026031494158 .7929992676 157.878692627157 .2691040039156 .6596069336156 .0500030518155 .4403991699 155.1356048584154 .5260925293154 .2212982178153 .9165039062153 .9165039062 153.6116943359153 .3069000244153 .0021057129152 .6972961426152 .0877990723 151.4781951904150 .5639038086149 .3446960449148 .1255950928146 .6015930176 145.0776977539143 .5538024902142 .3347015381140 .8106994629139 .2868041992 138.0677032471136 .8484954834135 .6293945312134 .7149963379133 .8007049561 132.8863067627131 .9720001221131 .0576019287130 .4479980469129 .8385009766 129.2288970947128 .9241027832128 .3144989014128 .0097961426127 .4001998901 127.0953979492126 .4858016968125 .8762969971125 .5715026855124 .9618988037 124.3523025513123 .7427978516123 .1332015991122 .2188034058121 .9140014648 121.3044967651120 .9997024536120 .9997024536121 .3044967651121 .3044967651 121.6092987061121 .9140014648122 .2188034058122 .5235977173123 .1332015991 124.0475006104124 .6570968628125 .2667007446125 .5715026855125 .8762969971 126.1809997559126 .4858016968126 .4858016968126 .4858016968126 .1809997559 125.8762969971125 .5715026855125 .2667007446124 .9618988037124 .6570968628 124.0475006104123 .1332015991122 .2188034058120 .9997024536117 .342300415 115.818397522115 .5136032104115 .2088012695114 .5991973877114 .2944030762 113.6848983765113 .3800964355113 .075302124117 .647102356134 .4102020264 153.9165039062159 .4026031494163 .974395752168 .241394043176 .165802002 186.2236938477 195.0625 203.2917022705 209.692199707 209.692199707 209.692199707 209.692199707209 .692199707209 .692199707209 .692199707209 .692199707209 .692199707 209.692199707209 .692199707209 .692199707209 .692199707209 .692199707209 .692199707 209.692199707209 .692199707209 .692199707209 .692199707209 .692199707209 .692199707 210.9113006592215 .1782989502219 .7501068115224 .0171051025228 .5888977051 232.8558044434237 .4275970459241 .9994049072246 .2664031982250 .5334014893 254.8003997803258 .7626037598262 .4200134277266 .0773925781269 .4301147461 271.8682861328273 .3923034668274 .3066101074274 .6113891602274 .6113891602 274.6113891602274 .3066101074274 .3066101074274 .3066101074274 .3066101074 274.3066101074274 .0018005371274 .0018005371274 .3066101074274 .0018005371 274.0018005371274 .0018005371274 .0018005371274 .0018005371274 .0018005371 274.0018005371273 .6971130371273 .6971130371273 .3923034668273 .0874938965 272.4779052734272 .1730957031271 .5635070801270 .9540100098270 .0396118164 269.4301147461268 .2109069824267 .2966003418266 .0773925781264 .8583068848 263.3344116211261 .5056152344259 .9816894531257 .8482055664256 .0195007324 253.5812072754251 .1428985596248 .7046966553245 .9615936279242 .9136962891 239.5610961914235 .9037017822232 .246307373228 .2841033936224 .0171051025 218.8663482666 213.2967376709 -9999 -9999 -9999 -9999 -9999 -9999 -9999 -9999 -9999 -9999 -9999 -9999 -9999 -9999 -9999 -9999 -9999 -9999 -9999 -9999 -9999 -9999 -9999 -9999 -9999 -9999 -9999 -9999 -9999 -9999 -9999 -9999 -9999 -9999 -9999 -9999 -9999 -9999 -9999 -9999 -9999 -9999 -9999 -9999 -9999 -9999 -9999 -9999 -9999 -9999 -9999 -9999 -9999 -9999

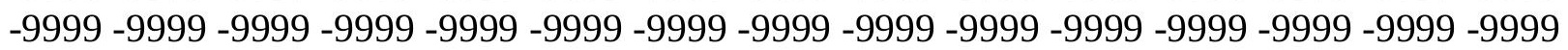
-9999 -9999 -9999 -9999 -9999 -9999 -9999 -9999 -9999 -9999 -9999 -9999 -9999 
-28.6334495544 -21.005689621 -13.4105501175 -6.7052731514-9999 7.010057926178 14.0201196670521 .6397399902328 .9545898437536 .5742111206144 .49863052368 52.1182594299360 .0426712036167 .9670867919975 .8914871215883 .81591033936 92.0450973510799 .96952056885108 .1986999512116 .4279022217124 .3523025513 132.5814971924140 .5059967041148 .4304046631156 .3547973633163 .974395752 171.5939941406179 .2136993408186 .528503418193 .5386047363200 .5485992432 207.25390625213 .6544036865220 .054901123225 .8457946777231 .6367034912 236.8179931641241 .9994049072246 .8759002686251 .1428985596255 .4098968506 259.3721008301 262.7247924805 266.0773925781268.8204956055 271.5635070801 274.0018005371276 .1353149414277 .9641113281279 .4880065918280 .7070922852 281.9262084961282 .8406066895283 .4501953125283 .7549133301284 .0596923828 284.0596923828283 .7549133301283 .4501953125282 .8406066895282 .2309875488 281.3167114258280 .4023132324279 .1831970215277 .6592102051276 .1353149414 274.6113891602272 .7827148438270 .9540100098268 .8204956055266 .9917907715 264.5534973145262 .4200134277259 .9816894531257 .5433959961255 .1051025391 252.3621063232249 .6190032959247 .1806945801244 .1329040527241 .3898010254 238.6468048096235 .5989074707232 .8558044434229 .8079986572227 .0648956299 224.0171051025221 .2740020752218 .2261962891215 .1782989502212 .4351959229 209.692199707206.9490966797204.2059936523201.4629974365198.7198944092 196.2816009521193 .5386047363191 .1002960205188 .6620025635186 .528503418 184.3950042725182 .261505127180 .1280059814177 .9945068359176 .165802002 174.337097168172 .5084075928170 .9844970703169 .4604949951167 .9365997314 166.7174987793165 .1934967041163 .974395752162 .7552947998161 .8408966064 160.9264984131159 .7073974609158 .7929992676158 .1835021973157 .2691040039 156.6596069336155 .7451934814155 .4403991699154 .8307952881154 .5260925293 154.2212982178153 .6116943359153 .6116943359153 .3069000244153 .0021057129 153.0021057129152 .6972961426152 .3925933838152 .0877990723151 .4781951904 150.8686065674149 .9542999268149 .0399017334147 .8208007812146 .2969055176 144.7729034424143 .2489929199141 .7250976562140 .5059967041138 .9819946289 137.7628936768136 .2389984131135 .0198059082134 .1054992676132 .8863067627 131.9720001221131 .0576019287130 .1432037354129 .533706665128 .6192932129 128.0097961426127 .7050018311127 .0953979492126 .7906036377126 .1809997559 125.8762969971125 .2667007446124 .9618988037124 .3523025513124 .0475006104 123.43800354122 .8283996582122 .2188034058121 .3044967651120 .9997024536 120.3900985718120 .3900985718120 .3900985718120 .6949005127120 .9997024536 121.6092987061122 .2188034058122 .8283996582123 .43800354124 .0475006104 124.6570968628125 .2667007446125 .8762969971126 .1809997559126 .4858016968 126.7906036377127 .0953979492127 .0953979492127 .0953979492127 .0953979492 126.7906036377126 .4858016968126 .1809997559125 .8762969971125 .5715026855 124.9618988037124 .3523025513123 .43800354121 .6092987061119 .1709976196 115.818397522114 .9039993286114 .5991973877113 .9896011353113 .6848983765 113.3800964355112 .7705001831112 .4656982422116 .7326965332128 .6192932129 140.8106994629149 .6495056152156 .9642944336163 .974395752169 .1557006836 178.604095459188 .966796875197 .8054962158206 .0346984863209 .692199707 209.692199707209 .692199707209 .692199707209 .692199707209 .692199707209 .692199707 209.692199707 209.692199707 209.692199707 209.692199707 209.692199707209.692199707 
209.692199707 209.692199707 209.692199707 209.692199707 209.692199707 209.692199707 209.692199707210 .6065063477214 .8735046387219 .4452972412223 .7122955322 228.2841033936232 .5511016846237 .1228027344241 .3898010254245 .6567993164 249.9237976074253 .8860015869257 .8482055664261 .5056152344265 .1630859375 267.9060974121270 .3443908691272 .1730957031273 .0874938965273 .6971130371 274.0018005371274 .0018005371274 .0018005371274 .0018005371274 .0018005371 274.0018005371274 .0018005371274 .0018005371274 .0018005371274 .0018005371 274.0018005371274 .0018005371274 .0018005371274 .0018005371274 .0018005371 274.0018005371274 .0018005371274 .0018005371273 .6971130371273 .3923034668 273.0874938965272 .7827148438272 .4779052734271 .8682861328271 .2587890625 270.3443908691269 .7348022461268 .5156860352267 .6012878418266 .3822021484 265.1630859375263 .6390991211261 .8103942871260 .2864990234258 .1530151367 256.3243103027253 .8860015869251 .4476928711248 .7046966553245 .9615936279 242.9136962891239 .2563018799235 .5989074707231 .6367034912227 .3697052002 223.1027069092217 .5182189941211 .5459594727 -9999 -9999 -9999 -9999 -9999 -9999 -9999

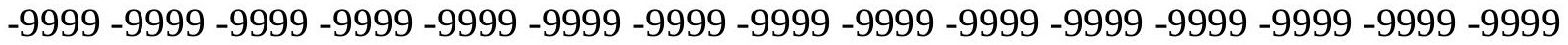

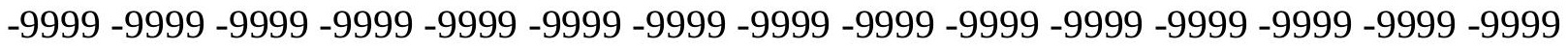

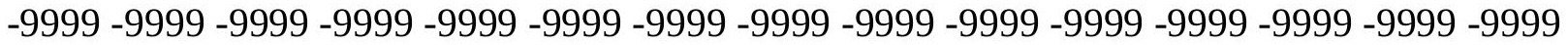

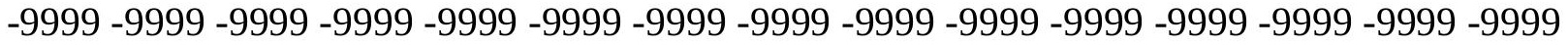
$-9999-9999$

-9999 -9999 -9999 -9999 -9999 -9999 -9999 -9999 -9999 -9999 -9999 -9999 -9999 -27.5684223175 -20.1266231537-12.8009700775 -5.79091691971.9143553972244 7.92441320419315 .2392597198522 .5541000366229 .8689403533937 .48857116699 45.1082000732452 .7278289794960 .6522407531768 .2718734741276 .19628143311 84.1206970214892 .04509735107100 .2742996216108 .1986999512116 .1231002808 124.0475006104131 .9720001221139 .8963928223147 .8208007812155 .4403991699 163.0599975586170 .3748931885177 .6896972656185 .0045928955192 .0146026611 198.7198944092205 .425201416211 .520904541217 .6165924072223 .7122955322 229.1983947754234 .3798065186239 .2563018799244 .1329040527248 .3999023438 252.6669006348256 .3243103027259 .9816894531263 .3344116211266 .0773925781 268.8204956055271 .2587890625273 .3923034668275 .2210083008276 .7449035645 277.9641113281279 .1831970215280 .0975036621280 .7070922852281 .0119018555 281.3167114258281 .3167114258281 .3167114258280 .7070922852280 .4023132324 279.4880065918278 .5736083984277 .6592102051276 .4400939941275 .2210083008 273.6971130371271 .8682861328270 .3443908691268 .5156860352266 .3822021484 264.2486877441262 .1152038574259 .9816894531257 .5433959961255 .1051025391 252.6669006348249 .9237976074247 .1806945801244 .4376983643241 .6945953369 238.9515075684236 .2084960938233 .1605987549230 .4176025391227 .3697052002 224.6266021729221 .5787963867218 .5308990479215 .787902832212 .7400054932 209.9969024658207 .25390625204 .5108032227201 .7678070068199 .0247039795 196.2816009521193 .8433074951191 .1002960205188 .6620025635186 .528503418 184.0901947021181 .9566955566179 .8231964111177 .6896972656175 .8609924316 174.0323028564172 .2035980225170 .6797027588168 .8509979248167 .6318054199 166.1078948975164 .8887023926163 .3648071289162 .4505004883161 .2312927246 160.3170013428159 .4026031494158 .4882965088157 .5738983154156 .6596069336 156.0500030518155 .4403991699154 .8307952881154 .2212982178153 .9165039062 
153.6116943359153 .3069000244153 .0021057129152 .6972961426152 .6972961426 152.6972961426152 .3925933838152 .3925933838152 .0877990723151 .7830047607 151.1734008789150 .5639038086149 .6495056152148 .7351074219147 .2111968994 145.9920959473144 .4682006836142 .9441986084141 .4203033447140 .2012023926 138.6772003174137 .1533050537135 .9342041016134 .4102020264133 .1911010742 132.2767028809131 .0576019287130 .1432037354129 .2288970947128 .3144989014 127.7050018311127 .0953979492126 .4858016968125 .8762969971125 .5715026855 124.9618988037124 .6570968628124 .3523025513124 .0475006104123 .43800354 123.43800354123 .1332015991122 .5235977173121 .6092987061120 .3900985718 119.7806015015119 .4757995605119 .7806015015120 .0852966309120 .3900985718 120.9997024536121 .9140014648122 .8283996582123 .7427978516124 .3523025513 124.9618988037125 .5715026855126 .1809997559126 .4858016968126 .7906036377 127.0953979492127 .4001998901127 .4001998901127 .7050018311127 .7050018311 127.7050018311127 .7050018311127 .4001998901127 .0953979492126 .7906036377 126.4858016968126 .1809997559125 .5715026855124 .6570968628122 .5235977173 120.9997024536118 .2565994263114 .5991973877113 .9896011353113 .3800964355 113.075302124112 .7705001831112 .1608963013111 .8561019897113 .075302124 120.3900985718127 .4001998901135 .9342041016146 .9064025879158 .7929992676 166.7174987793170 .070098877181 .6519012451192 .0146026611200 .8533935547 209.0825958252 209.692199707209.692199707 209.692199707 209.692199707 209.692199707 209.692199707 209.692199707 209.692199707 209.692199707 209.692199707 209.692199707 209.692199707 209.692199707 209.692199707 209.692199707 209.692199707 209.692199707209 .692199707209 .692199707210 .3016967773214 .5686950684 218.8356933594223 .4075012207227 .6744995117231 .9414978027236 .5133056641 240.7801971436245 .0471954346249 .0093994141252 .9716033936256 .9338989258 260.5913085938263 .6390991211266 .3822021484268 .8204956055270 .6492004395 271.8682861328272 .7827148438273 .3923034668273 .6971130371274 .0018005371 274.0018005371274 .0018005371274 .0018005371274 .0018005371274 .0018005371 274.0018005371274 .0018005371274 .0018005371274 .0018005371274 .0018005371 274.0018005371274 .0018005371274 .0018005371274 .0018005371274 .0018005371 273.6971130371273 .6971130371273 .3923034668273 .0874938965272 .4779052734 272.1730957031271 .5635070801270 .6492004395270 .0396118164269 .1253051758 267.9060974121266 .6870117188265 .4678039551263 .9439086914262 .4200134277 260.5913085938258 .7626037598256 .6290893555254 .4956054688252 .0572967529 249.3141937256246 .2664031982243 .2185058594239 .5610961914235 .5989074707 231.3318939209 226.7601013184221.883605957 216.1276550293209.8619232178 -9999 -9999 -9999 -9999 -9999 -9999 -9999 -9999 -9999 -9999 -9999 -9999 -9999 -9999 -9999 -9999

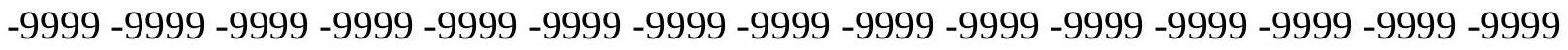

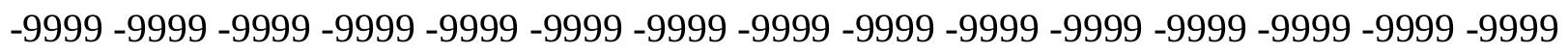
-9999 -9999 -9999 -9999 -9999 -9999 -9999 -9999 -9999 -9999 -9999 -9999 -9999 -9999 -9999 -9999 -9999 -9999-9999-9999 -9999-9999-9999

-9999 -9999 -9999 -9999 -9999 -9999 -9999 -9999 -9999 -9999 -9999 -9999 -9999 -26.825958252-19.6167793274-12.4961900711 -5.18134689331 1.523926019669 8.53398323059115 .8488302230823 .1636695861830 .7833003997838 .09814071655 45.717769622853 .3373985290560 .9570198059168 .8814392089876 .50106811523 84.4254837036192 .349891662699 .96952056885107 .8938980103115 .818397522 
123.7427978516131 .3623962402139 .2868041992146 .9064025879154 .2212982178 161.8408966064169 .1557006836176 .4705963135183 .4806976318190 .1858978271 196.891204834203 .2917022705209 .3874053955215 .4830932617221 .2740020752 226.7601013184231 .9414978027236 .8179931641241 .3898010254245 .6567993164 249.9237976074253 .5812072754257 .2385864258260 .2864990234263 .3344116211 265.7726135254268 .2109069824270 .3443908691272 .1730957031274 .0018005371 275.2210083008276 .4400939941277 .3544921875277 .9641113281278 .2687988281 278.5736083984278 .5736083984278 .5736083984278 .2687988281277 .6592102051 276.7449035645276 .1353149414274 .9161987305273 .6971130371272 .4779052734 270.9540100098269 .4301147461267 .6012878418265 .7726135254263 .9439086914 261.8103942871259 .6769104004257 .2385864258255 .1051025391252 .6669006348 249.9237976074 247.4855041504 244.7424926758 241.9994049072 239.2563018799 236.5133056641233 .7702026367230 .7223052979227 .9792938232224 .9313964844 222.1884002686219 .1405029297216 .0926971436213 .3495941162210 .3016967773 207.5587005615204 .8155975342201 .7678070068199 .0247039795196 .5863952637 193.8433074951191 .4051055908188 .6620025635186 .528503418184 .0901947021 181.9566955566179 .5184020996177 .6896972656175 .5561981201173 .7274932861 171.8988037109170 .070098877168 .5462036133167 .0222015381165 .4983062744 164.2792053223163 .0599975586161 .8408966064160 .6217956543159 .7073974609 158.7929992676157 .878692627156 .9642944336156 .3547973633155 .7451934814 154.8307952881154 .2212982178153 .6116943359153 .3069000244153 .0021057129 152.6972961426152 .6972961426152 .3925933838152 .0877990723152 .0877990723 152.0877990723152 .0877990723152 .0877990723151 .7830047607151 .4781951904 150.8686065674150 .2590942383149 .3446960449148 .4304046631147 .2111968994 145.6873016357144 .4682006836142 .9441986084141 .4203033447139 .5915985107 138.0677032471136 .8484954834135 .3246002197134 .1054992676132 .5814971924 131.3623962402130 .4479980469129 .2288970947128 .3144989014127 .4001998901 126.7906036377126 .1809997559125 .5715026855124 .9618988037124 .6570968628 124.0475006104123 .7427978516123 .43800354123 .1332015991122 .8283996582 122.5235977173122 .2188034058122 .2188034058120 .6949005127119 .4757995605 118.8662033081118 .8662033081119 .1709976196120 .0852966309120 .6949005127 121.3044967651122 .5235977173123 .7427978516124 .6570968628125 .5715026855 126.1809997559126 .4858016968126 .7906036377127 .0953979492127 .4001998901 127.7050018311127 .7050018311128 .0097961426128 .0097961426128 .3144989014 128.3144989014128 .3144989014128 .0097961426127 .7050018311127 .4001998901 127.4001998901127 .0953979492126 .7906036377126 .4858016968125 .5715026855 124.0475006104121 .3044967651117 .647102356113 .6848983765112 .7705001831 112.4656982422112 .1608963013111 .551399231111 .24659729110 .9418029785 113.075302124116 .7326965332120 .6949005127136 .5437011719152 .6972961426 164.2792053223166 .4127044678174 .337097168185 .3094024658195 .0625203 .9011993408 209.692199707 209.692199707 209.692199707 209.692199707 209.692199707 209.692199707 209.692199707209 .692199707209 .692199707209 .692199707209 .692199707209 .692199707 209.692199707 209.692199707 209.692199707 209.692199707 209.692199707209.692199707 209.692199707 209.692199707213.959197998 218.2261962891222.7978973389 227.0648956299231 .3318939209235 .5989074707239 .8659057617244 .1329040527 248.0950927734252 .0572967529255 .7147064209259 .0674133301262 .4200134277 
265.1630859375267 .6012878418269 .4301147461270 .9540100098271 .8682861328 272.7827148438273 .3923034668273 .6971130371274 .0018005371274 .0018005371 274.0018005371274 .0018005371274 .0018005371274 .0018005371274 .0018005371 274.0018005371274 .0018005371274 .0018005371274 .3066101074274 .3066101074 274.3066101074274 .3066101074274 .0018005371274 .0018005371273 .6971130371 273.3923034668273 .0874938965272 .7827148438272 .1730957031271 .8682861328 270.9540100098270 .3443908691269 .4301147461268 .2109069824266 .9917907715 265.7726135254264 .2486877441262 .7247924805261 .2008972168259 .3721008301 257.2385864258 255.1051025391252.6669006348 250.2286071777 247.1806945801 243.8280944824240 .1707000732236 .2084960938231 .6367034912226 .7601013184 220.9691925049214 .9502563477208 .3456573486201 .4403381348 -9999 -9999 -9999 -9999 -9999 -9999 -9999 -9999 -9999 -9999 -9999 -9999 -9999 -9999 -9999 -9999 -9999 -9999 -9999 -9999 -9999 -9999 -9999 -9999 -9999 -9999 -9999 -9999 -9999 -9999 -9999 -9999 -9999 -9999 -9999 -9999 -9999 -9999 -9999 -9999 -9999 -9999 -9999 -9999 -9999 -9999 -9999 -9999 - -9999 -

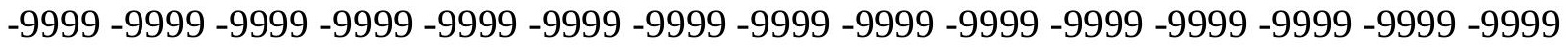
-9999-9999-9999-9999

-9999 -9999 -9999 -9999 -9999 -9999 -9999 -9999 -9999 -9999 -9999 -9999 -33.2903289795 $-26.2248821259-19.2014598846-11.8866195679-4.876562118532 .133496046066$ 9.4483394622816 .4584007263223 .7732391357431 .3928699493438 .70771026611 46.3273391723653 .6421813964861 .2618103027368 .8814392089876 .80584716797 84.4254837036192 .0450973510799 .96952056885107 .5891036987115 .5136032104 123.1332015991130 .7528076172138 .3724975586145 .9920959473153 .3069000244 160.6217956543167 .9365997314174 .9467010498181 .6519012451188 .3571929932195 .0625 201.158203125 207.25390625 213.3495941162 218.8356933594224.3218994141 229.5032043457234 .0749969482238 .6468048096243 .2185058594247 .1806945801 250.8381958008254 .1907958984257 .5433959961260 .2864990234263 .0296020508 265.4678039551267 .6012878418269 .4301147461270 .9540100098272 .4779052734 273.3923034668274 .3066101074275 .2210083008275 .5257873535275 .8305053711 275.8305053711275 .8305053711275 .2210083008274 .9161987305274 .3066101074 273.3923034668272 .1730957031271 .2587890625269 .7348022461268 .2109069824 266.6870117188265 .1630859375263 .3344116211261 .2008972168259 .3721008301 256.9338989258254 .8003997803252 .3621063232249 .9237976074247 .4855041504 245.0471954346242 .3041992188239 .5610961914236 .8179931641234 .0749969482 231.3318939209228 .2841033936225 .5410003662222 .4931030273219 .7501068115 216.7021942139213 .6544036865210 .9113006592207 .8634033203205 .1204071045 202.3773040771199 .6342926025196 .891204834194 .1481018066191 .4051055908 188.966796875186 .528503418184 .0901947021181 .6519012451179 .5184020996 177.3849029541 175.2514038086173.4226989746171.5939941406169.7653045654 168.241394043166 .7174987793165 .1934967041163 .6696014404162 .4505004883 161.2312927246160 .3170013428159 .0977935791158 .1835021973157 .2691040039 156.6596069336155 .7451934814155 .1356048584154 .5260925293153 .9165039062 153.3069000244152 .6972961426152 .3925933838152 .3925933838152 .0877990723 152.0877990723152 .0877990723151 .7830047607151 .7830047607151 .7830047607 151.7830047607151 .7830047607151 .4781951904151 .1734008789150 .8686065674 149.9542999268149 .3446960449148 .1255950928146 .9064025879145 .6873016357 144.1634063721142 .6394042969141 .1154937744139 .2868041992137 .7628936768 
136.2389984131134 .7149963379133 .4958953857131 .9720001221130 .7528076172 129.533706665128 .6192932129127 .4001998901126 .7906036377125 .8762969971 125.2667007446124 .6570968628124 .0475006104123 .7427978516123 .1332015991 122.8283996582122 .8283996582122 .5235977173122 .2188034058121 .9140014648 121.3044967651120 .3900985718119 .1709976196118 .2565994263117 .9517974854 118.2565994263119 .4757995605120 .9997024536122 .2188034058123 .43800354 124.3523025513125 .2667007446126 .1809997559127 .0953979492127 .4001998901 127.7050018311127 .7050018311128 .0097961426128 .0097961426128 .3144989014 128.3144989014128 .3144989014128 .3144989014128 .6192932129128 .6192932129 128.6192932129128 .3144989014128 .0097961426128 .0097961426128 .0097961426 128.0097961426128 .0097961426128 .0097961426127 .7050018311127 .0953979492 124.0475006104120 .3900985718116 .7326965332113 .075302124111 .8561019897 111.551399231110 .9418029785110 .6370010376110 .3321990967110 .0273971558 110.6370010376116 .4279022217127 .4001998901142 .3347015381160 .6217956543 156.9642944336166 .4127044678178 .2993011475188 .6620025635197 .8054962158 206.3394927979 209.692199707 209.692199707 209.692199707 209.692199707 209.692199707 209.692199707 209.692199707 209.692199707 209.692199707 209.692199707 209.692199707 209.692199707 209.692199707 209.692199707 209.692199707209.692199707 209.692199707 209.692199707209.0825958252 213.3495941162 217.6165924072 221.883605957226 .150604248230 .4176025391234 .6844940186238 .9515075684 242.9136962891246 .8759002686250 .8381958008254 .4956054688257 .8482055664 260.8960876465263 .6390991211266 .0773925781268 .2109069824269 .7348022461 271.2587890625272 .1730957031273 .0874938965273 .6971130371274 .0018005371 274.3066101074274 .3066101074274 .3066101074274 .3066101074274 .0018005371 274.0018005371274 .3066101074274 .3066101074274 .3066101074274 .3066101074 274.3066101074274 .3066101074274 .3066101074274 .3066101074274 .0018005371 274.0018005371273 .6971130371273 .3923034668273 .0874938965272 .4779052734 272.1730957031271 .2587890625270 .6492004395269 .7348022461268 .8204956055 267.6012878418266 .3822021484264 .8583068848263 .3344116211261 .8103942871 259.9816894531258 .1530151367256 .3243103027253 .8860015869251 .4476928711 248.3999023438245 .0471954346241 .3898010254237 .1228027344232 .246307373 226.7601013184220 .9691925049214 .2639007568207 .0736083984199 .6660766602 -9999 -9999 -9999 -9999 -9999 -9999 -9999 -9999 -9999 -9999 -9999 -9999 -9999 -9999 -9999 -9999 -9999 -9999 -9999 -9999 -9999 -9999 -9999 -9999 -9999 -9999 -9999 -9999 -9999 -9999 -9999

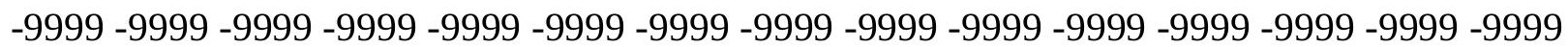

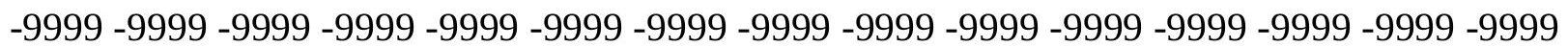
-9999 -9999 -9999 -9999 -9999 -9999 -9999

-9999 -9999 -9999 -9999 -9999 -9999 -9999 -9999 -9999 -9999 -9999 -9999 -32.5721511841 -25.6036739349-18.5918903351 -11.2770500183 -4.26699209213 2.743066072464 9.75312423706117 .0679702758824 .3828105926531 .6976509094239 .01250076294 46.6321296691953 .9469718933161 .5666007995669 .1862335205176 .80584716797 84.4254837036192 .0450973510799 .66472625732107 .2844009399114 .9039993286 122.5235977173129 .8385009766137 .4580993652144 .7729034424152 .0877990723 159.4026031494166 .4127044678173 .4226989746180 .1280059814186 .8332977295 192.9290008545199 .329498291205 .1204071045210 .9113006592216 .7021942139 221.883605957226 .7601013184231 .6367034912236 .2084960938240 .4754943848 
244.4376983643248 .0950927734251 .4476928711254 .8003997803257 .5433959961 260.2864990234262 .4200134277264 .5534973145266 .3822021484268 .2109069824 269.4301147461270 .6492004395271 .5635070801272 .1730957031272 .7827148438 273.0874938965273 .0874938965272 .7827148438272 .4779052734272 .1730957031 271.2587890625270 .6492004395269 .4301147461268 .5156860352266 .9917907715 265.7726135254264 .2486877441262 .4200134277260 .5913085938258 .7626037598 256.6290893555254 .4956054688252 .3621063232249 .9237976074247 .4855041504 245.0471954346242 .6089935303239 .8659057617237 .1228027344234 .3798065186 231.6367034912228 .8936004639225 .8457946777223 .1027069092220 .054901123 217.3117980957 214.2639007568 211.520904541 208.4730072021 205.7299957275 202.6820983887199 .9389953613197 .1959991455194 .4528961182191 .7097930908 188.966796875186 .528503418184 .0901947021181 .6519012451179 .5184020996 177.3849029541175 .2514038086173 .1179962158171 .2891998291169 .4604949951 167.9365997314166 .4127044678164 .8887023926163 .3648071289162 .1457061768 160.9264984131159 .7073974609158 .7929992676157 .878692627156 .9642944336 156.0500030518155 .4403991699154 .8307952881154 .2212982178153 .6116943359 153.3069000244152 .6972961426152 .0877990723152 .0877990723152 .0877990723 151.7830047607151 .7830047607151 .7830047607151 .7830047607151 .7830047607 151.7830047607151 .7830047607151 .7830047607151 .4781951904151 .1734008789 150.5639038086149 .9542999268149 .0399017334148 .1255950928146 .9064025879 145.3825073242143 .8585968018142 .3347015381140 .8106994629138 .9819946289 137.4580993652135 .9342041016134 .4102020264132 .8863067627131 .3623962402 130.1432037354128 .9241027832127 .7050018311126 .7906036377125 .8762969971 124.9618988037124 .3523025513123 .7427978516123 .1332015991122 .8283996582 122.5235977173122 .2188034058122 .2188034058121 .9140014648121 .6092987061 120.9997024536120 .0852966309119 .1709976196118 .2565994263117 .647102356 117.647102356118 .5614013672120 .9997024536123 .43800354124 .9618988037 125.8762969971126 .4858016968127 .0953979492127 .7050018311128 .3144989014 128.3144989014128 .6192932129128 .6192932129128 .6192932129128 .6192932129 128.6192932129128 .6192932129128 .6192932129128 .6192932129128 .6192932129 128.6192932129128 .3144989014128 .3144989014128 .3144989014128 .3144989014 128.6192932129128 .6192932129128 .9241027832129 .2288970947128 .9241027832 128.3144989014126 .1809997559122 .8283996582119 .4757995605115 .818397522 112.4656982422110 .9418029785110 .3321990967110 .0273971558109 .7226028442 109.4179000854109 .4179000854112 .1608963013119 .4757995605126 .7906036377 133.1911010742145 .0776977539157 .878692627170 .3748931885181 .3471984863 190.795501709199 .6342926025208 .1681976318209 .692199707209 .692199707 209.692199707 209.692199707 209.692199707 209.692199707 209.692199707 209.692199707 209.692199707209 .692199707209 .692199707209 .692199707209 .692199707209 .692199707 209.692199707209.692199707209.692199707 209.692199707 212.7400054932 216.7021942139220 .9691925049225 .2362060547229 .5032043457233 .7702026367 237.7324066162241 .6945953369245 .6567993164249 .6190032959252 .9716033936 256.3243103027259 .3721008301262 .4200134277264 .8583068848266 .9917907715 268.8204956055270 .3443908691271 .5635070801272 .7827148438273 .3923034668 274.0018005371274 .3066101074274 .6113891602274 .6113891602274 .3066101074 274.3066101074 274.3066101074 274.3066101074 274.3066101074 274.3066101074 
274.3066101074274 .3066101074274 .3066101074274 .3066101074274 .3066101074 274.3066101074274 .0018005371274 .0018005371273 .6971130371273 .3923034668 272.7827148438272 .4779052734271 .8682861328270 .9540100098270 .0396118164 269.1253051758268 .2109069824266 .9917907715265 .4678039551264 .2486877441 262.7247924805261 .2008972168259 .3721008301257 .5433959961255 .4098968506 252.9716033936250 .2286071777246 .8759002686243 .2185058594238 .6468048096 233.4653930664227 .6744995117220 .9691925049213 .959197998206 .0827026367 198.0446014404 -9999 -9999 -9999 -9999 -9999 -9999 -9999 -9999 -9999 -9999 -9999 -9999 -9999 -9999 -9999 -9999 -9999 -9999 -9999 -9999 -9999 -9999 -9999 -9999 -9999 -9999 -9999 -9999 -9999 -9999 -9999 -9999 -9999 -9999 -9999 -9999 -9999 -9999 -9999 -9999 -9999 -9999 -9999 -9999 -9999 -9999 -9999 -9999 -9999 -9999 -9999 -9999 -9999 -9999 -9999 -9999 -9999 -9999 -9999 -9999 -9999 -9999 -9999 -9999 -9999 -9999 -9999 -9999

-9999 -9999 -9999-9999 -9999-9999 -9999 -9999 -9999 -9999 -9999 -9999 -31.8977508545 -24.9596500397 -17.9823207855 -10.9722604752 -3.65742206573 3.047851085663 10.3626899719217 .3727493286124 .6875991821332 .0024414062539 .31727981567 46.6321296691954 .2517509460461 .5666007995669 .1862335205176 .50106811523 84.1206970214891 .7403335571399 .35994720459106 .6747970581114 .2944030762 121.6092987061129 .2288970947136 .5437011719143 .8585968018150 .8686065674 158.1835021973164 .8887023926171 .8988037109178 .2993011475185 .0045928955 191.1002960205197 .1959991455203 .2917022705208 .7778015137214 .2639007568 219.4452972412224 .3218994141229 .1983947754233 .4653930664237 .7324066162 241.6945953369245 .3520050049248 .7046966553251 .7525024414254 .8003997803 257.2385864258259 .6769104004261 .8103942871263 .6390991211265 .1630859375 266.6870117188267 .6012878418268 .5156860352269 .4301147461269 .7348022461 270.0396118164270 .0396118164270 .0396118164269 .7348022461269 .1253051758 268.5156860352267 .9060974121266 .6870117188265 .7726135254264 .5534973145 263.0296020508261 .5056152344259 .6769104004257 .8482055664256 .0195007324 254.1907958984252 .0572967529249 .6190032959247 .4855041504245 .0471954346 242.6089935303240 .1707000732237 .4275970459234 .6844940186231 .9414978027 229.1983947754226 .4553985596223 .7122955322220 .6643981934217 .9214019775 214.8735046387212 .1304016113209 .0825958252206 .0346984863203 .2917022705 200.5485992432197 .500793457194 .7577056885192 .0146026611189 .2716064453 186.8332977295184 .3950042725181 .9566955566179 .5184020996177 .3849029541 175.2514038086173 .1179962158171 .2891998291169 .4604949951167 .6318054199 166.1078948975164 .2792053223163 .0599975586161 .5361022949160 .3170013428 159.4026031494158 .1835021973157 .2691040039156 .3547973633155 .7451934814 155.1356048584154 .2212982178153 .9165039062153 .3069000244153 .0021057129 152.6972961426152 .3925933838152 .0877990723152 .0877990723152 .0877990723 151.7830047607151 .7830047607151 .4781951904151 .4781951904151 .7830047607 151.7830047607151 .7830047607151 .7830047607151 .4781951904151 .1734008789 150.5639038086149 .9542999268149 .0399017334148 .1255950928146 .9064025879 145.3825073242143 .8585968018142 .3347015381140 .5059967041138 .9819946289 137.1533050537135 .6293945312133 .8007049561132 .2767028809130 .7528076172 129.533706665128 .3144989014127 .0953979492125 .8762969971124 .9618988037 124.3523025513123 .43800354123 .1332015991122 .5235977173122 .2188034058 121.9140014648121 .9140014648121 .9140014648121 .6092987061121 .3044967651 
120.6949005127120 .9997024536120 .3900985718119 .4757995605118 .2565994263 118.8662033081120 .0852966309124 .6570968628127 .4001998901128 .6192932129 129.2288970947129 .2288970947129 .2288970947129 .533706665129 .533706665 129.533706665129 .533706665129 .2288970947129 .2288970947129 .2288970947 129.2288970947128 .9241027832128 .9241027832128 .9241027832128 .9241027832 128.6192932129128 .3144989014128 .3144989014128 .3144989014128 .6192932129 128.9241027832128 .9241027832129 .2288970947129 .2288970947129 .2288970947 128.9241027832127 .4001998901124 .9618988037121 .6092987061118 .2565994263 114.9039993286111 .8561019897109 .4179000854109 .4179000854109 .1130981445 108.8082962036109 .1130981445108 .5035018921111 .8561019897115 .5136032104 122.8283996582135 .3246002197148 .7351074219161 .8408966064172 .8132019043 182.5662994385192 .0146026611201 .158203125209 .692199707209 .692199707 209.692199707 209.692199707 209.692199707 209.692199707 209.692199707209.692199707 209.692199707209 .692199707209 .692199707209 .692199707209 .692199707209 .692199707 209.692199707209 .692199707209 .692199707209 .692199707211 .8256988525 215.787902832220 .054901123224 .3218994141228 .2841033936232 .5511016846 236.5133056641240 .4754943848244 .4376983643248 .0950927734251 .7525024414 254.8003997803258 .1530151367260 .8960876465263 .3344116211265 .7726135254 267.6012878418269 .4301147461270 .9540100098272 .4779052734273 .3923034668 274.0018005371274 .6113891602274 .9161987305274 .9161987305274 .6113891602 274.6113891602274 .6113891602274 .6113891602274 .6113891602274 .6113891602 274.6113891602274 .6113891602274 .6113891602274 .6113891602274 .6113891602 274.3066101074274 .3066101074274 .0018005371273 .6971130371273 .3923034668 273.0874938965272 .7827148438272 .1730957031271 .2587890625270 .6492004395 269.7348022461268 .5156860352267 .6012878418266 .3822021484265 .1630859375 263.6390991211262 .4200134277260 .8960876465259 .0674133301257 .2385864258 255.1051025391252 .6669006348249 .6190032959245 .6567993164241 .0850067139 235.9037017822229 .5032043457222 .1884002686213 .959197998205 .3549346924 196.586227417 -9999 -9999 -9999 -9999 -9999 -9999 -9999 -9999 -9999 -9999 -9999 -9999 -9999 -9999 -9999 -9999 -9999 -9999 -9999 -9999 -9999 -9999 -9999 -9999 -9999 -9999 -9999 -9999 -9999 -9999 -9999 -9999 -9999 -9999 -9999 -9999 -9999 -9999 -9999 -9999 -9999 -9999 -9999 -9999 -9999 -9999 -9999 -9999 -9999 -9999 -9999 -9999 -9999 -9999 -9999 -9999 -9999 -9999 -9999-9999-9999-9999-9999-9999-9999-9999-9999-9999 - -999-

-9999 -9999 -9999 -9999 -9999 -9999 -9999 -9999 -9999 -9999 -9999 -38.1902122498 -31.2408065796 -24.3828105927 -17.3727493286 -10.3626899719 -3.35263609886 3.35263609886210 .6674804687517 .6775398254424 .9923801422132 .00244140625 39.3172798156746 .6321296691953 .9469718933161 .5666007995668 .88143920898 76.5010681152383 .8159103393691 .4355392456198 .75038146973106 .0652008057 113.6848983765120 .9997024536128 .3144989014135 .6293945312142 .6394042969 149.6495056152156 .6596069336163 .6696014404170 .3748931885176 .7754058838 183.1759033203189 .2716064453195 .3672943115201 .158203125206 .6443023682 211.8256988525217 .0070037842221 .883605957226 .4553985596231 .0270996094 234.9893035889238 .9515075684242 .6089935303245 .9615936279249 .0093994141 251.7525024414254 .4956054688256 .6290893555258 .7626037598260 .5913085938 262.4200134277263 .6390991211264 .8583068848265 .7726135254266 .3822021484 266.9917907715267 .2966003418267 .2966003418267 .2966003418266 .9917907715 
266.3822021484265 .7726135254264 .8583068848263 .9439086914263 .0296020508 261.8103942871260 .2864990234258 .7626037598257 .2385864258255 .4098968506 253.5812072754251 .4476928711249 .3141937256247 .1806945801245 .0471954346 242.6089935303240 .1707000732237 .7324066162234 .9893035889232 .5511016846 229.8079986572227 .0648956299224 .0171051025221 .2740020752218 .5308990479 215.4830932617212 .7400054932209 .692199707206 .6443023682203 .9011993408 200.8533935547198 .1103057861195 .3672943115192 .624206543189 .8811035156 187.1381072998184 .3950042725181 .9566955566179 .5184020996177 .3849029541 175.2514038086173 .1179962158170 .9844970703169 .1557006836167 .3269958496 165.8031005859164 .2792053223162 .7552947998161 .2312927246160 .0122070312 158.7929992676157 .878692627156 .9642944336156 .0500030518155 .4403991699 154.5260925293153 .9165039062153 .3069000244153 .0021057129152 .6972961426 152.3925933838152 .0877990723152 .0877990723152 .0877990723152 .3925933838 152.0877990723151 .7830047607151 .4781951904151 .4781951904151 .4781951904 151.4781951904151 .7830047607151 .7830047607151 .7830047607151 .4781951904 151.1734008789150 .8686065674150 .2590942383149 .3446960449148 .1255950928 146.9064025879145 .3825073242143 .8585968018142 .0299072266140 .2012023926 138.6772003174136 .8484954834135 .0198059082133 .4958953857131 .6672058105 130.1432037354128 .9241027832127 .4001998901126 .4858016968125 .2667007446 124.3523025513123 .7427978516122 .8283996582122 .2188034058121 .9140014648 121.6092987061121 .3044967651121 .3044967651121 .6092987061121 .6092987061 120.9997024536121 .3044967651121 .6092987061121 .3044967651120 .6949005127 119.7806015015123 .43800354127 .4001998901130 .7528076172132 .8863067627 132.8863067627132 .5814971924131 .9720001221131 .3623962402131 .0576019287 130.7528076172130 .4479980469130 .4479980469130 .1432037354129 .8385009766 129.8385009766129 .533706665129 .533706665129 .2288970947129 .2288970947 128.9241027832128 .9241027832128 .6192932129128 .6192932129128 .6192932129 128.6192932129128 .9241027832128 .9241027832128 .9241027832128 .9241027832 128.9241027832129 .2288970947128 .3144989014126 .1809997559123 .43800354 120.6949005127117 .647102356114 .2944030762111 .24659729108 .8082962036 108.5035018921108 .5035018921108 .8082962036108 .8082962036109 .1130981445 109.7226028442113 .6848983765124 .6570968628138 .0677032471152 .6972961426 162.4505004883172 .2035980225182 .87109375193 .5386047363203 .9011993408 209.692199707 209.692199707 209.692199707 209.692199707 209.692199707 209.692199707 209.692199707209 .692199707209 .692199707209 .692199707209 .692199707209 .692199707 209.692199707209.692199707 209.692199707 209.692199707 209.692199707 210.6065063477214 .8735046387218 .8356933594223 .1027069092227 .0648956299 231.3318939209 235.2940979004 239.2563018799242.9136962891246.5711975098 250.2286071777253 .2763977051256 .6290893555259 .3721008301262 .1152038574 264.5534973145266 .6870117188268 .5156860352270 .3443908691271 .8682861328 273.0874938965274 .3066101074274 .9161987305275 .2210083008275 .2210083008 274.9161987305274 .9161987305274 .6113891602274 .6113891602274 .6113891602 274.6113891602274 .6113891602274 .6113891602274 .6113891602274 .6113891602 274.6113891602274 .6113891602274 .3066101074274 .3066101074274 .0018005371 273.6971130371273 .3923034668273 .0874938965272 .4779052734271 .8682861328 270.9540100098270 .0396118164269 .1253051758268 .2109069824267 .2966003418 
266.0773925781264 .8583068848263 .6390991211262 .4200134277261 .2008972168 259.6769104004257 .8482055664255 .7147064209252 .6669006348249 .3141937256 244.7424926758238 .9515075684232 .246307373224 .3218994141214 .8735046387 205.1111450195195 .3766784668186 .0913085938 -9999 -9999 -9999 -9999 -9999 -9999 -9999 -9999 -9999 -9999 -9999 -9999 -9999 -9999 -9999 -9999 -9999 -9999 -9999 -9999 -9999 -9999 -9999 -9999 -9999 -9999 -9999 -9999 -9999 -9999 -9999 -9999 -9999 -9999 -9999 -9999 -9999

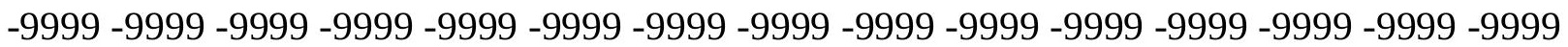

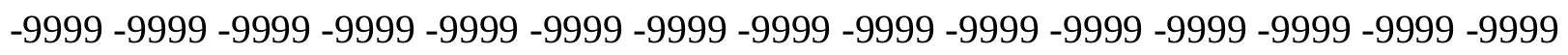
-9999 -9999 -9999 -9999 -9999 -9999 -9999 -9999 -9999 -9999 -9999 -37.5237846375 -30.5519695282 -23.7732391357-16.7631797791-10.0579099655 -3.04785108566 3.65742206573510 .6674804687517 .6775398254424 .9923801422132 .00244140625 39.3172798156746 .6321296691953 .9469718933161 .2618103027368 .57665252686 76.1962814331183 .5111236572390 .8259735107498 .14080810547105 .4557037354 112.7705001831120 .0852966309127 .4001998901134 .4102020264141 .7250976562 148.4304046631155 .4403991699162 .1457061768168 .5462036133174 .9467010498 181.3471984863187 .4429016113193 .233795166199 .0247039795204 .5108032227 209.692199707214 .5686950684219 .4452972412224 .0171051025228 .2841033936 232.5511016846236 .2084960938239 .8659057617243 .2185058594246 .2664031982 249.0093994141251 .4476928711253 .8860015869256 .0195007324257 .8482055664 259.3721008301260.8960876465261.8103942871262.7247924805 263.6390991211 263.9439086914264 .2486877441264 .2486877441264 .2486877441263 .9439086914 263.6390991211263 .0296020508262 .1152038574261 .2008972168260 .2864990234 259.0674133301257 .5433959961256 .0195007324254 .4956054688252 .6669006348 250.8381958008249 .0093994141246 .8759002686244 .7424926758242 .6089935303 240.1707000732237 .7324066162235 .2940979004232 .5511016846230 .1127929688 227.3697052002224 .6266021729221 .883605957219 .1405029297216 .0926971436 213.3495941162210 .3016967773207 .5587005615204 .5108032227201 .7678070068 198.7198944092195 .9768066406192 .9290008545190 .1858978271187 .4429016113 185.0045928955182 .261505127179 .8231964111177 .3849029541175 .2514038086 173.1179962158170 .9844970703169 .1557006836167 .3269958496165 .4983062744 163.974395752162 .4505004883160 .9264984131159 .7073974609158 .4882965088 157.5738983154156 .6596069336155 .7451934814154 .8307952881154 .2212982178 153.6116943359153 .3069000244152 .6972961426152 .3925933838152 .0877990723 152.0877990723151 .7830047607152 .0877990723152 .0877990723152 .0877990723 151.7830047607151 .7830047607151 .4781951904151 .4781951904151 .4781951904 151.7830047607151 .7830047607151 .7830047607151 .7830047607151 .7830047607 151.4781951904151 .1734008789150 .5639038086149 .6495056152148 .4304046631 146.9064025879145 .3825073242143 .8585968018142 .0299072266140 .2012023926 138.3724975586136 .5437011719134 .7149963379132 .8863067627131 .3623962402 129.533706665128 .3144989014126 .7906036377125 .5715026855124 .6570968628 123.7427978516122 .8283996582122 .2188034058121 .9140014648121 .3044967651 120.9997024536120 .9997024536120 .9997024536121 .3044967651121 .6092987061 120.9997024536120 .6949005127121 .9140014648122 .2188034058121 .9140014648 122.8283996582130 .1432037354136 .5437011719137 .7628936768137 .7628936768 136.8484954834135 .6293945312134 .4102020264133 .4958953857132 .5814971924 131.9720001221131 .6672058105131 .0576019287130 .7528076172130 .4479980469 
130.1432037354129 .8385009766129 .8385009766129 .533706665129 .2288970947 129.2288970947128 .9241027832128 .9241027832128 .6192932129128 .6192932129 128.9241027832128 .9241027832128 .6192932129128 .3144989014128 .0097961426 128.6192932129128 .6192932129128 .3144989014126 .7906036377124 .9618988037 122.5235977173120 .0852966309116 .7326965332113 .3800964355110 .3321990967 107.8938980103108 .1986999512108 .5035018921108 .5035018921108 .8082962036 108.8082962036110 .0273971558114 .2944030762125 .2667007446137 .7628936768 149.0399017334160 .3170013428172 .5084075928185 .0045928955197 .500793457 209.0825958252 209.692199707 209.692199707 209.692199707 209.692199707 209.692199707 209.692199707 209.692199707 209.692199707 209.692199707 209.692199707 209.692199707 209.692199707 209.692199707 209.692199707 209.692199707 209.692199707 209.692199707213 .6544036865217 .9214019775221 .883605957225 .8457946777 229.8079986572233 .7702026367237 .7324066162241 .3898010254245 .0471954346 248.7046966553251 .7525024414255 .1051025391257 .8482055664260 .5913085938 263.3344116211265 .4678039551267 .6012878418269 .7348022461271 .2587890625 273.0874938965274 .0018005371274 .9161987305275 .2210083008275 .2210083008 275.2210083008274 .9161987305274 .6113891602274 .6113891602274 .6113891602 274.6113891602274 .6113891602274 .6113891602274 .9161987305274 .9161987305 274.6113891602274 .6113891602274 .6113891602274 .3066101074274 .3066101074 274.0018005371273 .6971130371273 .0874938965272 .7827148438272 .1730957031 271.5635070801270 .6492004395269 .7348022461268 .8204956055267 .9060974121 266.9917907715266 .0773925781265 .1630859375264 .2486877441263 .3344116211 262.1152038574260 .8960876465259 .0674133301256 .9338989258253 .5812072754 249.3141937256243.5233001709 236.2084960938 227.3697052002 217.0070037842 205.425201416 194.5377655029 184.402130127 -9999 -9999 -9999 -9999 -9999 -9999 -9999

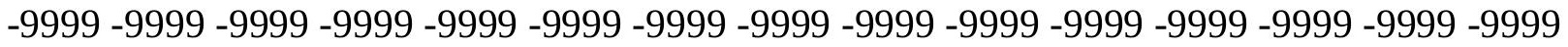

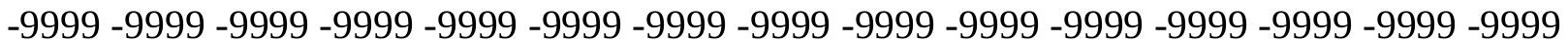

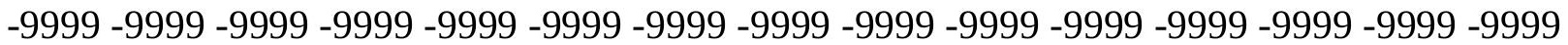

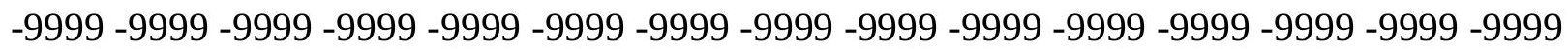
-9999 -9999 -9999 -9999 -9999 -9999 -9999 -9999 -9999 -9999 -9999 -36.9821777344 $-29.818983078-23.1636695862-16.4584007263-9.75312423706-3.04785108566$ 3.65742206573510 .6674804687517 .6775398254424 .9923801422132 .00244140625 39.31727981567 46.3273391723653.64218139648 60.9570198059168.27187347412 75.5867080688582 .9015579223690 .2164001464897 .53124237061104 .8460998535 112.1608963013119 .4757995605126 .4858016968133 .4958953857140 .5059967041 147.2111968994 153.9165039062 160.6217956543 167.0222015381 173.4226989746 179.5184020996185 .6141052246191 .4051055908196 .891204834202 .3773040771 207.5587005615212 .4351959229217 .0070037842221 .5787963867225 .8457946777 229.8079986572233 .4653930664237 .1228027344240 .4754943848243 .5233001709 246.2664031982248 .7046966553251 .1428985596252 .9716033936254 .8003997803 256.3243103027257 .8482055664259 .0674133301259 .9816894531260 .5913085938 261.2008972168261 .5056152344261 .5056152344261 .5056152344261 .2008972168 260.8960876465260 .2864990234259 .3721008301258 .4577941895257 .5433959961 256.3243103027254 .8003997803253 .5812072754251 .7525024414250 .2286071777 248.3999023438246 .2664031982244 .4376983643242 .3041992188240 .1707000732 237.7324066162235 .2940979004232 .8558044434230 .4176025391227 .6744995117 
225.2362060547222.4931030273219.7501068115216.7021942139213.959197998 211.2160949707 208.1681976318 205.425201416 202.3773040771 199.6342926025 196.5863952637193 .8433074951190 .795501709188 .0523986816185 .3094024658 182.87109375180 .1280059814177 .6896972656175 .2514038086173 .1179962158 170.9844970703169 .1557006836167 .0222015381165 .4983062744163 .6696014404 162.1457061768160 .6217956543159 .4026031494158 .1835021973157 .2691040039 156.3547973633155 .4403991699154 .5260925293153 .9165039062153 .3069000244 153.0021057129152 .3925933838152 .0877990723151 .7830047607151 .7830047607 151.7830047607151 .7830047607151 .7830047607151 .7830047607151 .7830047607 151.7830047607151 .7830047607151 .4781951904151 .4781951904151 .4781951904 151.7830047607151 .7830047607151 .7830047607152 .0877990723152 .0877990723 151.7830047607151 .4781951904150 .8686065674149 .9542999268148 .7351074219 147.2111968994145 .6873016357143 .8585968018141 .7250976562139 .8963928223 138.0677032471135 .9342041016134 .1054992676132 .2767028809130 .7528076172 128.9241027832127 .4001998901126 .1809997559124 .9618988037124 .0475006104 123.1332015991122 .5235977173121 .9140014648121 .3044967651120 .9997024536 120.6949005127120 .3900985718120 .3900985718120 .3900985718120 .6949005127 120.6949005127120 .9997024536122 .2188034058124 .6570968628127 .7050018311 132.8863067627138 .9819946289142 .6394042969142 .9441986084141 .7250976562 139.8963928223138 .0677032471136 .5437011719135 .0198059082134 .1054992676 133.1911010742132 .5814971924131 .9720001221131 .3623962402131 .0576019287 130.7528076172130 .4479980469130 .1432037354129 .8385009766129 .533706665 129.2288970947 129.2288970947 128.9241027832 128.9241027832128 .9241027832 128.9241027832128 .6192932129128 .6192932129128 .3144989014128 .3144989014 128.3144989014128 .3144989014128 .0097961426127 .0953979492125 .8762969971 124.0475006104122 .2188034058118 .5614013672115 .2088012695112 .1608963013 109.4179000854108 .1986999512108 .1986999512108 .5035018921108 .5035018921 108.5035018921108 .5035018921112 .1608963013117 .0374984741123 .43800354 135.6293945312147 .2111968994161 .5361022949176 .7754058838191 .1002960205 204.5108032227209 .692199707209 .692199707209 .692199707209 .692199707 209.692199707 209.692199707 209.692199707 209.692199707 209.692199707 209.692199707 209.692199707 209.692199707 209.692199707 209.692199707 209.692199707 209.692199707 209.692199707 212.4351959229 216.3973999023 220.6643981934224.6266021729 228.5888977051232 .246307373236 .2084960938239 .8659057617243 .5233001709 246.8759002686250 .2286071777253 .2763977051256 .3243103027259 .0674133301 261.8103942871264 .2486877441266 .6870117188268 .8204956055270 .6492004395 272.4779052734274 .0018005371274 .6113891602275 .2210083008275 .2210083008 274.9161987305274 .9161987305274 .6113891602274 .6113891602274 .6113891602 274.6113891602274 .6113891602274 .9161987305274 .9161987305274 .9161987305 274.9161987305274 .9161987305274 .6113891602274 .6113891602274 .3066101074 274.3066101074274 .0018005371273 .3923034668273 .0874938965272 .4779052734 271.8682861328271 .2587890625270 .3443908691269 .7348022461268 .8204956055 268.2109069824267 .6012878418266 .9917907715266 .3822021484265 .7726135254 265.1630859375264 .5534973145263 .3344116211261 .5056152344259 .0674133301 255.1051025391249 .3141937256241 .3898010254231 .6367034912219 .7501068115 206.6443023682 194.2257232666 183.0252685547 -9999 -9999 -9999 -9999 -9999 -9999 -9999 
-9999 -9999 -9999 -9999 -9999 -9999 -9999 -9999 -9999 -9999 -9999 -9999 -9999 -9999 -9999 -9999 -9999 -9999 -9999 -9999 -9999 -9999 -9999 -9999 -9999 -9999 -9999 -9999 -9999 -9999 -9999 -9999 -9999 -9999 -9999 -9999 -9999 -9999 -9999 -9999 -9999 -9999 -9999 -9999 -9999 -9999 -9999 -9999 -9999 -9999 -9999 -9999 -9999 -9999 -9999 -9999 -9999 -9999 -9999 -9999 -9999 -9999 -9999 -9999 -9999 -9999 -9999 -9999 -9999 -9999 -9999 -36.9030456543 -29.2593708038 -22.8588790894 -16.4584007263 -9.75312423706 -3.04785108566 3.65742206573510 .6674804687517 .6775398254424 .6875991821331 .69765090942 39.0125007629446 .0225486755453 .3373985290560 .6522407531767 .96708679199 75.2819290161182 .2919769287189 .6068267822396 .92166900635104 .2365036011 111.24659729118 .5614013672125 .5715026855132 .5814971924139 .2868041992 145.9920959473152 .6972961426159 .0977935791165 .4983062744171 .8988037109 177.6896972656183 .7854003906189 .2716064453194 .7577056885200 .2438049316 205.1204071045209 .9969024658214 .5686950684219 .1405029297223 .4075012207 227.3697052002231 .0270996094234 .3798065186237 .7324066162240 .7801971436 243.5233001709245 .9615936279248 .0950927734250 .2286071777252 .0572967529 253.5812072754254 .8003997803256 .0195007324256 .9338989258257 .5433959961 258.1530151367258 .4577941895258 .4577941895258 .4577941895258 .4577941895 257.8482055664257 .2385864258256 .6290893555255 .7147064209254 .8003997803 253.5812072754252 .3621063232250 .8381958008249 .3141937256247 .4855041504 245.6567993164243 .8280944824241 .9994049072239 .8659057617237 .7324066162 235.2940979004232 .8558044434230 .7223052979227 .9792938232225 .5410003662 222.7978973389220 .3596038818217 .6165924072214 .5686950684211 .8256988525 209.0825958252206 .0346984863203 .2917022705200 .2438049316197 .500793457 194.4528961182191 .7097930908188 .966796875186 .2236938477183 .4806976318 180.7375946045178 .2993011475175 .8609924316173 .4226989746171 .2891998291 169.1557006836167 .0222015381165 .1934967041163 .6696014404162 .1457061768 160.6217956543159 .0977935791158 .1835021973156 .9642944336156 .0500030518 155.1356048584154 .2212982178153 .6116943359153 .0021057129152 .6972961426 152.3925933838152 .0877990723151 .7830047607151 .7830047607151 .4781951904 151.4781951904151 .4781951904151 .4781951904151 .7830047607151 .7830047607 151.7830047607151 .4781951904151 .4781951904151 .4781951904151 .7830047607 151.7830047607151 .7830047607152 .0877990723152 .0877990723152 .0877990723 152.3925933838152 .0877990723151 .4781951904150 .5639038086149 .0399017334 147.5160064697145 .6873016357143 .8585968018141 .7250976562139 .5915985107 137.7628936768135 .6293945312133 .8007049561131 .6672058105130 .1432037354 128.3144989014126 .7906036377125 .5715026855124 .3523025513123 .1332015991 122.5235977173121 .9140014648121 .3044967651120 .9997024536120 .6949005127 120.3900985718120 .0852966309120 .0852966309119 .7806015015119 .7806015015 120.0852966309121 .3044967651124 .0475006104128 .3144989014133 .4958953857 140.5059967041147 .8208007812147 .8208007812146 .2969055176144 .4682006836 142.0299072266139 .8963928223138 .0677032471136 .5437011719135 .0198059082 134.1054992676133 .1911010742132 .5814971924131 .9720001221131 .3623962402 131.0576019287130 .7528076172130 .4479980469130 .1432037354129 .8385009766 129.533706665129 .2288970947128 .9241027832128 .9241027832128 .9241027832 128.6192932129128 .6192932129128 .6192932129128 .3144989014128 .3144989014 128.3144989014128 .3144989014127 .7050018311127 .0953979492126 .1809997559 
124.6570968628122 .5235977173119 .7806015015116 .7326965332113 .6848983765 110.9418029785108 .8082962036108 .1986999512108 .1986999512108 .1986999512 108.1986999512108 .5035018921111 .551399231116 .4279022217124 .6570968628 137.1533050537148 .7351074219154 .5260925293169 .1557006836185 .9188995361 200.5485992432209 .692199707209 .692199707209 .692199707209 .692199707 209.692199707209 .692199707209 .692199707209 .692199707209 .692199707209 .692199707 209.692199707 209.692199707 209.692199707 209.692199707 209.692199707209.692199707 209.692199707 211.2160949707 215.1782989502 219.1405029297223.1027069092 227.0648956299230 .7223052979234 .6844940186238 .3419952393241 .6945953369 245.3520050049248 .7046966553251 .7525024414254 .8003997803257 .5433959961 260.2864990234263 .0296020508265 .4678039551267 .6012878418269 .7348022461 271.8682861328273 .3923034668274 .3066101074274 .6113891602274 .9161987305 274.9161987305274 .6113891602274 .3066101074274 .3066101074274 .3066101074 274.6113891602274 .6113891602274 .9161987305274 .9161987305274 .9161987305 274.9161987305274 .9161987305274 .6113891602274 .6113891602274 .6113891602 274.3066101074274 .0018005371273 .6971130371273 .3923034668272 .7827148438 272.4779052734271 .8682861328270 .9540100098270 .3443908691269 .7348022461 269.1253051758268 .8204956055268 .5156860352268 .2109069824268 .2109069824 268.2109069824268 .2109069824267 .9060974121266 .9917907715265 .1630859375 261.8103942871256 .3243103027248 .0950927734237 .1228027344223 .7122955322 208.4730072021 194.4742736816 182.1212921143 171.660369873 -9999 -9999 -9999 -9999 -9999 -9999 -9999 -9999 -9999 -9999 -9999 -9999 -9999 -9999 -9999 -9999 -9999 -9999 -9999 -9999 -9999 -9999 -9999 -9999 -9999 -9999 -9999 -9999 -9999 -9999 -9999-9999-9999-9999 -999 -9999 -9999 -9999 -9999 -9999 -9999 -9999 -9999 -9999 -9999 -9999 -9999 -9999 -9999 -9999 -

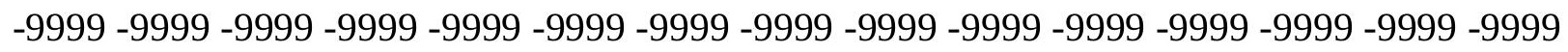
-9999-9999

-9999 -9999 -9999 -9999 -9999 -9999 -9999 -9999 -9999 -9999 -9999 -37.5821495056 -30.478509903 -23.4684505463 -16.7631797791 -10.0579099655 -3.35263609886 3.35263609886210 .3626899719217 .3727493286124 .3828105926531 .39286994934 38.7077102661145 .717769622853 .0326118469260 .0426712036167 .35751342773 74.6723632812581 .6824111938588 .9972534179796 .31210327148103 .3221969604 110.3321990967117 .647102356124 .3523025513131 .3623962402138 .0677032471 144.7729034424151 .4781951904157 .878692627163 .974395752170 .070098877 176.165802002181 .9566955566187 .4429016113192 .9290008545198 .1103057861 202.9868927002207 .8634033203212 .4351959229216 .7021942139220 .9691925049 224.6266021729228 .2841033936231 .6367034912234 .9893035889238 .0372009277 240.4754943848243 .2185058594245 .3520050049247 .4855041504249 .0093994141 250.5334014893252 .0572967529253 .2763977051254 .1907958984254 .8003997803 255.4098968506255 .7147064209255 .7147064209255 .7147064209255 .4098968506 255.1051025391254 .4956054688253 .8860015869252 .9716033936252 .0572967529 250.8381958008249 .6190032959248 .0950927734246 .5711975098245 .0471954346 243.2185058594241 .3898010254239 .5610961914237 .4275970459235 .2940979004 233.1605987549230 .7223052979228 .2841033936225 .8457946777223 .4075012207 220.6643981934218 .2261962891215 .4830932617212 .7400054932209 .9969024658 206.9490966797204 .2059936523201 .158203125198 .4151000977195 .3672943115 192.624206543189 .8811035156186 .8332977295184 .0901947021181 .3471984863 
178.9089050293176 .165802002173 .7274932861171 .5939941406169 .1557006836 167.3269958496165 .1934967041163 .6696014404161 .8408966064160 .3170013428 159.0977935791157 .878692627156 .6596069336155 .7451934814154 .8307952881 153.9165039062153 .3069000244152 .6972961426152 .3925933838152 .0877990723 151.7830047607151 .7830047607151 .4781951904151 .4781951904151 .4781951904 151.4781951904151 .4781951904151 .4781951904151 .4781951904151 .4781951904 151.4781951904151 .4781951904151 .4781951904151 .4781951904151 .7830047607 151.7830047607152 .0877990723152 .0877990723152 .0877990723152 .3925933838 152.6972961426152 .6972961426152 .0877990723150 .8686065674149 .3446960449 147.5160064697145 .6873016357143 .8585968018141 .7250976562139 .5915985107 137.4580993652135 .3246002197133 .1911010742131 .0576019287129 .2288970947 127.7050018311126 .1809997559124 .6570968628123 .43800354122 .5235977173 121.6092987061121 .3044967651120 .9997024536120 .9997024536120 .6949005127 120.3900985718120 .0852966309119 .7806015015119 .7806015015119 .7806015015 120.3900985718121 .6092987061126 .1809997559131 .6672058105137 .4580993652 143.5538024902148 .1255950928149 .0399017334147 .8208007812145 .3825073242 142.9441986084140 .8106994629138 .6772003174137 .1533050537135 .9342041016 134.7149963379133 .8007049561132 .8863067627132 .2767028809131 .6672058105 131.3623962402131 .0576019287130 .4479980469130 .1432037354129 .8385009766 129.533706665129 .2288970947128 .9241027832128 .9241027832128 .6192932129 128.6192932129128 .6192932129128 .3144989014128 .3144989014128 .3144989014 128.0097961426128 .0097961426127 .7050018311127 .0953979492126 .1809997559 124.6570968628122 .8283996582120 .3900985718117 .647102356114 .9039993286 112.4656982422110 .3321990967108 .8082962036108 .1986999512107 .8938980103 108.1986999512109 .4179000854111 .551399231115 .818397522123 .43800354 135.9342041016151 .7830047607153 .9165039062163 .0599975586182 .5662994385 197.8054962158209 .692199707209 .692199707209 .692199707209 .692199707 209.692199707 209.692199707 209.692199707 209.692199707 209.692199707 209.692199707 209.692199707209 .692199707209 .692199707209 .692199707209 .692199707209 .692199707 209.692199707209 .692199707213 .6544036865217 .6165924072221 .5787963867 225.2362060547229 .1983947754232 .8558044434236 .5133056641240 .1707000732 243.5233001709246 .8759002686250 .2286071777253 .2763977051256 .0195007324 258.7626037598261 .5056152344263 .9439086914266 .3822021484268 .5156860352 270.6492004395272 .1730957031273 .0874938965274 .0018005371274 .3066101074 274.3066101074274 .3066101074274 .3066101074274 .3066101074274 .3066101074 274.6113891602274 .6113891602274 .9161987305274 .9161987305274 .9161987305 274.9161987305274 .9161987305274 .9161987305274 .6113891602274 .6113891602 274.3066101074274 .3066101074274 .0018005371273 .6971130371273 .0874938965 272.7827148438272 .1730957031271 .5635070801270 .9540100098270 .6492004395 270.3443908691270 .0396118164269 .7348022461270 .0396118164270 .6492004395 271.2587890625272 .1730957031272 .7827148438273 .0874938965272 .1730957031 269.7348022461264 .5534973145256 .3243103027244 .4376983643229 .1983947754 211.520904541195 .490524292181 .8070678711171 .0229492188 -9999 -9999 -9999 -9999 -9999 -9999 -9999 -9999 -9999 -9999 -9999 -9999 -9999 -9999 -9999 -9999 -9999 -9999 -999 -999 -999 -999 -

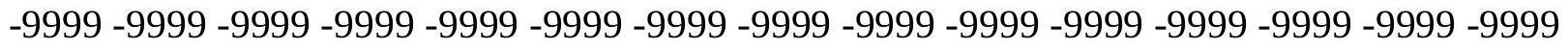

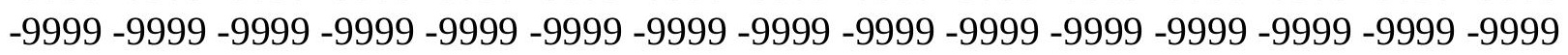


-9999 -9999 -9999 -9999 -9999 -9999 -9999 -9999 -9999 -9999 -9999 -9999 -9999 -9999 -9999 -9999-9999

-9999 -9999 -9999 -9999 -9999 -9999 -9999 -9999 -9999 -9999 -9999 -38.6015510559 -31.6976509094-24.3828105927-17.6775398254-10.6674804688 -3.65742206573 2.7430660724649 .75312423706116 .7631797790523 .7732391357431 .08807945251 38.0981407165545 .1082000732452 .4230384826759 .7378807067966 .74794006348 74.062782287681 .0728530883888 .3876876831195 .3977432251102 .4077987671 109.7226028442116 .4279022217123 .43800354130 .1432037354136 .8484954834 143.5538024902149 .9542999268156 .3547973633162 .4505004883168 .5462036133 174.337097168180 .1280059814185 .6141052246190 .795501709195 .9768066406 200.8533935547205 .7299957275209 .9969024658214 .2639007568218 .5308990479 222.1884002686225 .8457946777229 .1983947754232 .246307373235 .2940979004 237.7324066162240 .1707000732242 .6089935303244 .4376983643246 .2664031982 247.7902984619249 .0093994141250 .2286071777251 .1428985596251 .7525024414 252.3621063232252 .6669006348252 .9716033936252 .6669006348252 .6669006348 252.3621063232251 .7525024414251 .1428985596250 .2286071777249 .3141937256 248.0950927734246 .8759002686245 .6567993164244 .1329040527242 .3041992188 240.7801971436238 .9515075684237 .1228027344234 .9893035889232 .8558044434 230.7223052979228 .5888977051226 .150604248223 .7122955322221 .2740020752 218.5308990479216 .0926971436213 .3495941162210 .6065063477207 .8634033203 205.1204071045202 .3773040771199 .329498291196 .5863952637193 .5386047363 190.795501709188 .0523986816185 .0045928955182 .261505127179 .5184020996 177.0802001953174 .337097168171 .8988037109169 .7653045654167 .3269958496 165.4983062744163 .6696014404161 .8408966064160 .3170013428158 .7929992676 157.5738983154156 .6596069336155 .4403991699154 .5260925293153 .9165039062 153.3069000244152 .6972961426152 .0877990723151 .7830047607151 .7830047607 151.4781951904151 .4781951904151 .4781951904151 .4781951904151 .4781951904 151.4781951904151 .4781951904151 .4781951904151 .4781951904151 .4781951904 151.4781951904151 .4781951904151 .4781951904151 .7830047607151 .7830047607 151.7830047607152 .0877990723152 .3925933838152 .6972961426153 .0021057129 153.0021057129153 .0021057129152 .3925933838151 .1734008789149 .6495056152 147.8208007812145 .6873016357143 .5538024902141 .4203033447139 .2868041992 136.8484954834134 .7149963379132 .5814971924130 .4479980469128 .6192932129 126.7906036377125 .2667007446123 .7427978516122 .5235977173121 .6092987061 120.9997024536120 .6949005127120 .6949005127120 .9997024536120 .9997024536 120.6949005127120 .0852966309119 .7806015015119 .7806015015120 .3900985718 121.9140014648124 .6570968628128 .9241027832134 .1054992676139 .5915985107 144.4682006836147 .2111968994148 .1255950928147 .2111968994145 .0776977539 142.9441986084140 .8106994629138 .9819946289137 .7628936768136 .5437011719 135.3246002197134 .4102020264133 .4958953857132 .5814971924132 .2767028809 131.6672058105131 .0576019287130 .7528076172130 .4479980469129 .8385009766 129.533706665129 .2288970947128 .9241027832128 .6192932129128 .6192932129 128.3144989014128 .3144989014128 .3144989014128 .0097961426128 .0097961426 128.0097961426127 .7050018311127 .4001998901126 .7906036377125 .8762969971 124.6570968628123 .1332015991120 .9997024536118 .8662033081116 .4279022217 114.2944030762112 .4656982422110 .9418029785110 .3321990967110 .0273971558 
110.3321990967110 .9418029785112 .1608963013114 .9039993286119 .4757995605 128.0097961426139 .8963928223148 .1255950928158 .7929992676180 .432800293 194.7577056885207 .25390625209 .692199707209 .692199707209 .692199707209 .692199707 209.692199707209 .692199707209 .692199707209 .692199707209 .692199707209 .692199707 209.692199707 209.692199707 209.692199707 209.692199707 209.692199707 209.692199707 209.692199707212 .1304016113216 .0926971436219 .7501068115223 .7122955322 227.3697052002231 .0270996094234 .6844940186238 .3419952393241 .6945953369 245.0471954346248 .3999023438251 .4476928711254 .4956054688257 .2385864258 259.9816894531262 .4200134277264 .8583068848266 .9917907715269 .1253051758 270.6492004395271 .8682861328272 .7827148438273 .3923034668273 .6971130371 273.6971130371274 .0018005371274 .0018005371274 .3066101074274 .3066101074 274.6113891602274 .6113891602274 .9161987305274 .9161987305274 .9161987305 274.9161987305274 .6113891602274 .6113891602274 .6113891602274 .6113891602 274.3066101074274 .0018005371273 .6971130371273 .3923034668273 .0874938965 272.7827148438272 .1730957031271 .8682861328271 .2587890625270 .9540100098 270.9540100098270 .9540100098271 .5635070801272 .4779052734274 .0018005371 275.8305053711277 .6592102051279 .1831970215279 .7927856445278 .2687988281 274.0018005371265 .7726135254252 .9716033936235 .9037017822216 .0926971436 197.1959991455 182.4361877441 172.0661621094 -9999 -9999 -9999 -9999 -9999 -9999 -9999 -9999 -9999 -9999 -9999 -9999 -9999 -9999 -9999 -9999 -9999 -9999 -9999 -9999 -9999 -9999

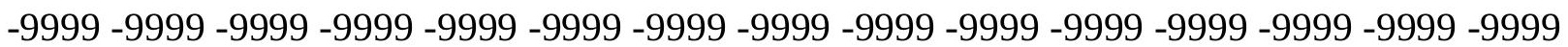
-9999 -9999 -9999 -9999 -9999 -9999 -9999 -9999 -9999 -9999 -9999 -9999 -9999 -9999 -9999 -9999 -9999 -9999 -9999 -9999 -9999 -9999 -9999 -9999 -9999 -9999 -9999 -9999 -9999 -9999 -9999 -9999 -9999 -9999 -9999 -9999 -9999 -9999 -9999 -9999 -39.5672264099 $-32.6120109558-25.6019496918-18.287109375-11.2770500183-4.57177686691$ 2.1334960460669 .14355373382616 .1536102294923 .4684505462630 .47850990295 37.4885711669944 .4986305236851 .8134689331158 .8235282897966 .13836669922 73.1484298706180 .4632720947387 .4733276367294 .78817749023101 .7982025146 108.8082962036115 .5136032104122 .5235977173129 .2288970947135 .9342041016 142.3347015381148 .7351074219154 .8307952881160 .9264984131167 .0222015381 172.8132019043178 .2993011475183 .7854003906188 .966796875194 .1481018066 198.7198944092203 .596496582207 .8634033203212 .1304016113216 .0926971436 219.7501068115223 .4075012207226 .4553985596229 .8079986572232 .5511016846 235.2940979004237 .4275970459239 .8659057617241 .6945953369243 .5233001709 245.0471954346246 .2664031982247 .4855041504248 .3999023438249 .0093994141 249.6190032959249 .9237976074249 .9237976074249 .9237976074249 .9237976074 249.3141937256249 .0093994141248 .3999023438247 .4855041504246 .5711975098 245.3520050049244 .1329040527242 .9136962891241 .3898010254239 .8659057617 238.3419952393236 .5133056641234 .6844940186232 .5511016846230 .7223052979 228.5888977051226 .150604248224 .0171051025221 .5787963867219 .1405029297 216.7021942139213 .959197998211 .520904541208 .7778015137206 .0346984863 203.2917022705200 .5485992432197 .500793457194 .7577056885192 .0146026611 188.966796875186 .2236938477183 .4806976318180 .432800293177 .9945068359 175.2514038086172 .5084075928170 .070098877167 .9365997314165 .8031005859 163.6696014404161 .8408966064160 .3170013428158 .7929992676157 .5738983154 156.3547973633155 .4403991699154 .5260925293153 .9165039062153 .0021057129 
152.6972961426152 .0877990723151 .7830047607151 .4781951904151 .4781951904 151.4781951904151 .4781951904151 .4781951904151 .4781951904151 .4781951904 151.7830047607151 .7830047607151 .7830047607151 .7830047607151 .7830047607 151.7830047607151 .7830047607151 .7830047607151 .7830047607151 .7830047607 152.0877990723152 .3925933838152 .6972961426153 .3069000244153 .3069000244 153.6116943359153 .3069000244152 .6972961426151 .4781951904149 .9542999268 148.1255950928145 .9920959473143 .5538024902141 .4203033447138 .9819946289 136.5437011719134 .4102020264131 .9720001221129 .8385009766128 .0097961426 126.1809997559124 .3523025513122 .8283996582121 .6092987061121 .9140014648 121.3044967651120 .0852966309120 .3900985718120 .9997024536121 .3044967651 120.9997024536120 .3900985718120 .0852966309120 .3900985718121 .6092987061 124.0475006104127 .4001998901131 .6672058105136 .2389984131140 .8106994629 144.1634063721145 .9920959473146 .2969055176145 .3825073242143 .8585968018 142.0299072266140 .5059967041138 .9819946289137 .7628936768136 .8484954834 135.6293945312134 .7149963379133 .8007049561133 .1911010742132 .5814971924 131.9720001221131 .3623962402130 .7528076172130 .4479980469129 .8385009766 129.533706665129 .2288970947128 .6192932129128 .3144989014128 .3144989014 128.0097961426128 .0097961426128 .0097961426127 .7050018311127 .7050018311 127.4001998901127 .4001998901127 .0953979492126 .4858016968125 .5715026855 124.6570968628123 .1332015991121 .6092987061119 .7806015015117 .647102356 115.818397522114 .2944030762113 .075302124112 .4656982422112 .1608963013 112.4656982422112 .7705001831113 .6848983765114 .9039993286116 .1231002808 117.647102356132 .2767028809142 .9441986084154 .5260925293174 .0323028564 190.1858978271203 .596496582209 .692199707209 .692199707209 .692199707 209.692199707 209.692199707 209.692199707 209.692199707 209.692199707 209.692199707 209.692199707 209.692199707 209.692199707 209.692199707 209.692199707 209.692199707 209.692199707 209.692199707 210.6065063477214.2639007568 218.2261962891 221.883605957225 .5410003662229 .5032043457232 .8558044434236 .5133056641 239.8659057617243 .2185058594246 .5711975098249 .6190032959252 .6669006348 255.4098968506258 .1530151367260 .8960876465263 .3344116211265 .4678039551 267.2966003418269 .1253051758270 .3443908691271 .5635070801272 .1730957031 272.7827148438273 .0874938965273 .6971130371273 .6971130371274 .0018005371 274.3066101074274 .6113891602274 .6113891602274 .6113891602274 .6113891602 274.6113891602274 .6113891602274 .6113891602274 .6113891602274 .6113891602 274.6113891602274 .3066101074274 .3066101074274 .0018005371273 .6971130371 273.3923034668273 .0874938965272 .7827148438272 .1730957031271 .8682861328 271.8682861328271 .5635070801271 .8682861328272 .7827148438274 .3066101074 276.4400939941279 .1831970215282 .2309875488285 .2789001465287 .1076049805 287.1076049805284 .0596923828276 .7449035645263 .6390991211245 .3520050049 222.1884002686198.7198944092185.7788238525176.5111541748 167.0545196533-9999 -9999 -9999-9999 -9999 -9999 -9999 -9999 -9999 -9999-9999 -9999 -9999 -9999 -9999 -9999 -

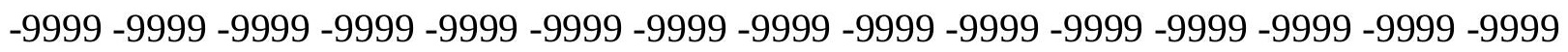

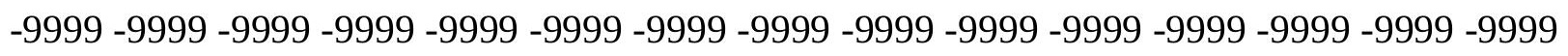

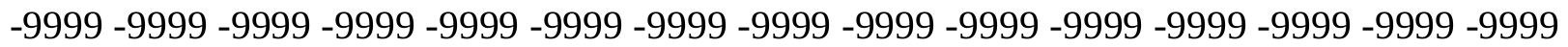
-9999 -9999 -9999 -9999

-9999 -9999 -9999 -9999 -9999 -9999 -9999 -9999 -9999 -9999 -9999 -40.4975967407 
-33.5263595581 -26.2115192413 -19.2014598846 -12.1914100647 -5.18134689331 1.5239260196698 .53398323059115 .5440397262622 .5541000366229 .86894035339 36.8790016174343 .8890609741251 .2038993835458 .2139587402365 .52880096436 72.5388565063579 .5489196777386 .8637619018693 .87381744385100 .8839035034 107.8938980103114 .5991973877121 .3044967651128 .0097961426134 .7149963379 141.1154937744147 .5160064697153 .6116943359159 .7073974609165 .4983062744 171.2891998291176 .7754058838181 .9566955566187 .1381072998192 .0146026611 196.891204834201 .4629974365205 .7299957275209 .692199707213 .6544036865 217.3117980957220 .6643981934224 .0171051025227 .0648956299229 .8079986572 232.5511016846234 .6844940186236 .8179931641238 .9515075684240 .4754943848 241.9994049072243 .5233001709244 .4376983643245 .3520050049245 .9615936279 246.5711975098246 .8759002686247 .1806945801247 .1806945801246 .8759002686 246.5711975098246 .2664031982245 .6567993164244 .7424926758243 .8280944824 242.9136962891241 .6945953369240 .4754943848238 .9515075684237 .4275970459 235.9037017822234 .0749969482232 .246307373230 .4176025391228 .2841033936 226.150604248224 .0171051025221 .883605957219 .4452972412217 .3117980957 214.5686950684212 .1304016113209 .692199707206 .9490966797204 .2059936523 201.4629974365198 .7198944092195 .9768066406193 .233795166190 .1858978271 187.4429016113184 .699798584181 .6519012451178 .9089050293176 .165802002 173.7274932861170 .9844970703168 .5462036133166 .4127044678164 .2792053223 162.1457061768160 .3170013428158 .7929992676157 .5738983154156 .3547973633 155.1356048584154 .5260925293153 .6116943359153 .0021057129152 .3925933838 152.0877990723151 .7830047607151 .4781951904151 .4781951904151 .4781951904 151.4781951904151 .7830047607151 .7830047607151 .7830047607151 .7830047607 151.7830047607152 .0877990723152 .0877990723152 .0877990723152 .0877990723 151.7830047607151 .7830047607151 .7830047607151 .7830047607152 .0877990723 152.3925933838152 .6972961426153 .3069000244153 .6116943359153 .9165039062 153.9165039062153 .6116943359153 .0021057129151 .7830047607149 .9542999268 148.1255950928145 .6873016357143 .5538024902141 .1154937744138 .6772003174 136.2389984131133 .8007049561131 .3623962402129 .2288970947127 .0953979492 125.2667007446123 .43800354122 .2188034058122 .2188034058121 .6092987061 121.3044967651120 .6949005127119 .7806015015120 .6949005127121 .6092987061 121.3044967651120 .9997024536120 .6949005127121 .3044967651123 .43800354 126.4858016968130 .1432037354134 .4102020264138 .3724975586141 .7250976562 143.8585968018144 .7729034424144 .4682006836143 .5538024902142 .0299072266 140.8106994629139 .8963928223138 .6772003174137 .7628936768136 .8484954834 135.9342041016135 .0198059082134 .1054992676133 .4958953857132 .5814971924 131.9720001221131 .3623962402131 .0576019287130 .4479980469129 .8385009766 129.533706665128 .9241027832128 .6192932129128 .3144989014128 .0097961426 127.7050018311127 .7050018311127 .4001998901127 .4001998901127 .0953979492 127.0953979492126 .7906036377126 .4858016968126 .1809997559125 .5715026855 124.6570968628123 .43800354122 .2188034058120 .6949005127119 .1709976196 117.647102356116 .1231002808115 .2088012695114 .9039993286114 .5991973877 114.9039993286115 .2088012695115 .818397522116 .7326965332118 .8662033081 123.7427978516133 .1911010742142 .3347015381150 .8686065674169 .1557006836 185.6141052246199 .6342926025209 .692199707209 .692199707209 .692199707 
209.692199707 209.692199707 209.692199707 209.692199707209.692199707209.692199707 209.692199707 209.692199707 209.692199707 209.692199707 209.692199707 209.692199707 209.692199707 209.692199707 209.692199707 212.7400054932 216.3973999023 220.054901123223 .7122955322227 .3697052002231 .0270996094234 .6844940186 238.0372009277241 .3898010254244 .7424926758247 .7902984619250 .8381958008 253.5812072754256 .6290893555259 .0674133301261 .5056152344263 .6390991211 265.7726135254267 .2966003418268 .8204956055270 .0396118164271 .2587890625 271.8682861328272 .4779052734273 .0874938965273 .3923034668273 .6971130371 274.3066101074274 .3066101074274 .6113891602274 .6113891602274 .6113891602 274.6113891602274 .6113891602274 .6113891602274 .6113891602274 .6113891602 274.6113891602274 .6113891602274 .3066101074274 .3066101074274 .0018005371 273.6971130371273 .3923034668273 .0874938965272 .7827148438272 .4779052734 272.4779052734272 .1730957031272 .4779052734273 .3923034668275 .5257873535 278.2687988281282 .2309875488286 .1932067871290 .4602050781293 .8128967285 295.6416015625294 .1176147461288 .0219116211276 .1353149414258 .1530151367 234.0749969482 204.8155975342 196.4752197266 186.3198852539 173.5366210938-9999 -9999 -9999 -9999 -9999 -9999 -9999 -9999 -9999 -9999 -9999 -9999 -9999 -9999 -9999 -999 - 9999 - 9999 -

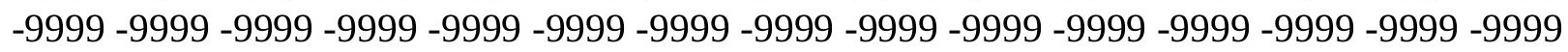

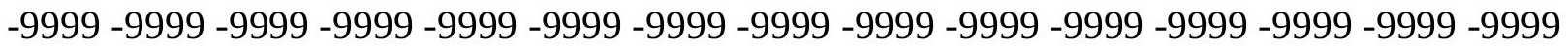

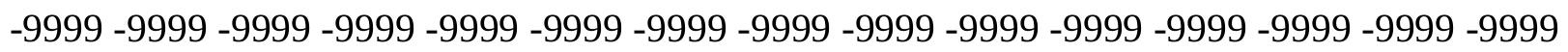
-9999 -9999 -9999-9999

-9999 -9999 -9999 -9999 -9999 -9999 -9999 -9999 -9999 -9999 -9999 -41.3483085632 -34.4407196045-27.1258792877-20.115819931-13.1057596207-6.095703125 .91435539722447 .92441320419314 .934470176721 .9445304870628 .95458984375 36.2694282531743 .2794914245650 .2895507812557 .6043891906764 .61444854736 71.9292907714878 .9393463134885 .9494018554792 .9594726562599 .96952056885 106.979598999113 .6848983765120 .3900985718127 .0953979492133 .4958953857 139.8963928223146 .2969055176152 .3925933838158 .1835021973163 .974395752 169.4604949951174 .9467010498180 .1280059814185 .3094024658190 .1858978271 194.7577056885199 .329498291203 .596496582207 .5587005615211 .520904541 214.8735046387218 .5308990479221 .5787963867224 .6266021729227 .3697052002 229.8079986572232 .246307373234 .3798065186236 .2084960938237 .7324066162 239.2563018799240 .4754943848241 .6945953369242 .6089935303243 .2185058594 243.8280944824244 .1329040527244 .4376983643244 .4376983643244 .1329040527 243.8280944824243 .5233001709242 .9136962891241 .9994049072241 .0850067139 240.1707000732238 .9515075684237 .7324066162236 .5133056641234 .9893035889 233.4653930664231 .6367034912230 .1127929688227 .9792938232226 .150604248 224.0171051025221 .883605957219 .7501068115217 .6165924072215 .1782989502 212.7400054932210 .3016967773207 .8634033203205 .425201416202 .6820983887 199.9389953613 197.1959991455 194.4528961182191.7097930908 188.966796875 185.9188995361 183.1759033203 180.432800293 177.3849029541 174.6419067383 172.2035980225169 .4604949951167 .0222015381164 .8887023926162 .7552947998 160.6217956543159 .0977935791157 .5738983154156 .3547973633155 .1356048584 154.2212982178153 .6116943359153 .0021057129152 .3925933838152 .0877990723 151.7830047607151 .4781951904151 .4781951904151 .4781951904151 .4781951904 151.7830047607151 .7830047607152 .0877990723152 .0877990723152 .0877990723 
152.0877990723152 .3925933838152 .3925933838152 .3925933838152 .3925933838 152.3925933838152 .0877990723152 .0877990723152 .0877990723152 .3925933838 153.0021057129153 .3069000244153 .6116943359153 .9165039062154 .2212982178 153.9165039062153 .6116943359153 .0021057129151 .7830047607149 .9542999268 147.8208007812145 .6873016357143 .2489929199140 .8106994629138 .0677032471 135.6293945312133 .1911010742130 .7528076172128 .6192932129126 .4858016968 124.3523025513122 .8283996582122 .5235977173122 .2188034058121 .6092987061 120.9997024536120 .3900985718120 .0852966309119 .7806015015120 .3900985718 120.9997024536121 .3044967651121 .9140014648123 .43800354125 .5715026855 128.9241027832132 .8863067627136 .8484954834140 .5059967041142 .6394042969 143.8585968018143 .8585968018142 .9441986084141 .7250976562140 .5059967041 139.8963928223139 .2868041992138 .3724975586137 .7628936768136 .8484954834 135.9342041016135 .0198059082134 .4102020264133 .4958953857132 .8863067627 132.2767028809131 .6672058105131 .0576019287130 .4479980469129 .8385009766 129.2288970947128 .9241027832128 .3144989014128 .0097961426127 .7050018311 127.4001998901127 .0953979492127 .0953979492126 .7906036377126 .7906036377 126.4858016968126 .4858016968126 .1809997559125 .8762969971125 .2667007446 124.6570968628123 .7427978516122 .8283996582121 .6092987061120 .3900985718 119.1709976196117 .9517974854117 .0374984741116 .7326965332116 .7326965332 116.7326965332117 .342300415118 .2565994263120 .0852966309124 .3523025513 131.6672058105139 .5915985107146 .2969055176150 .2590942383164 .8887023926 181.3471984863196 .2816009521209 .3874053955209 .692199707209 .692199707 209.692199707 209.692199707 209.692199707 209.692199707 209.692199707209.692199707 209.692199707 209.692199707 209.692199707209.692199707 209.692199707209.692199707 209.692199707 209.692199707 209.692199707 210.9113006592 214.5686950684 218.2261962891221 .883605957225 .5410003662229 .1983947754232 .8558044434 236.2084960938239 .5610961914242 .9136962891245 .9615936279249 .0093994141 251.7525024414254 .8003997803257 .2385864258259 .6769104004262 .1152038574 263.9439086914265 .7726135254267 .2966003418268 .8204956055269 .7348022461 270.9540100098271 .5635070801272 .1730957031272 .7827148438273 .3923034668 274.0018005371274 .3066101074274 .3066101074274 .3066101074274 .3066101074 274.3066101074274 .3066101074274 .6113891602274 .6113891602274 .6113891602 274.6113891602274 .6113891602274 .3066101074274 .3066101074274 .0018005371 274.0018005371273 .6971130371273 .3923034668273 .3923034668273 .0874938965 272.7827148438272 .7827148438272 .7827148438273 .6971130371276 .1353149414 279.7927856445284 .3645019531289 .2410888672294 .4223937988299 .2990112305 302.3468017578302 .6516113281298 .3846130371288 .6315002441273 .0874938965 253.2763977051 233.1605987549 217.3848571777 199.2863616943 180.6504058838 -9999 -9999 -9999 -9999 -9999 -9999 -9999 -9999 -9999 -9999 -9999 -9999 -9999 -9999 -9999 -9999 -9999 -9999 -9999 -9999 -9999 -9999 -9999 -9999 -9999 -9999 -9999 -9999 -9999 -9999 -9999 -

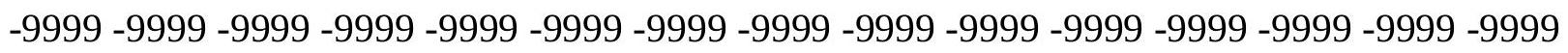

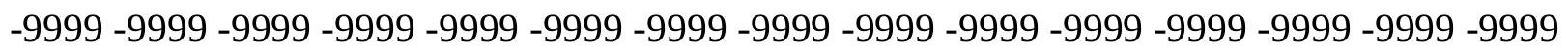
-9999 -9999 -9999-9999 -9999 -9999 -9999 -9999 -9999 -9999 -9999 -9999 -9999 -9999 -9999 -42.1293678284 -35.0502891541 -28.0402297974-21.0301704407-13.7153301239-6.7052731514-9999 7.01005792617814 .0201196670521 .0301704406728 .3450202941935 .35507965088 
42.3651313781749 .6799812316956 .6900291442964 .004882812571 .0149307251 78.0249862670985 .0350494384892 .0450973510799 .05516815186106 .0652008057 112.7705001831119 .4757995605125 .8762969971132 .5814971924138 .6772003174 145.0776977539150 .8686065674156 .9642944336162 .4505004883167 .9365997314 173.4226989746178 .604095459183 .4806976318188 .3571929932192 .9290008545 197.1959991455201 .4629974365205 .425201416209 .0825958252212 .7400054932 216.0926971436219 .1405029297221 .883605957224 .6266021729227 .0648956299 229.5032043457231 .6367034912233 .4653930664234 .9893035889236 .5133056641 237.7324066162238 .9515075684239 .5610961914240 .4754943848240 .7801971436 241.3898010254241 .3898010254241 .3898010254241 .3898010254241 .0850067139 240.7801971436240 .1707000732239 .5610961914238 .6468048096237 .7324066162 236.5133056641235 .2940979004234 .0749969482232 .5511016846231 .0270996094 229.5032043457227 .6744995117225 .8457946777224 .0171051025222 .1884002686 220.054901123217 .9214019775215 .787902832213 .3495941162211 .2160949707 208.7778015137206 .3394927979203 .596496582201 .158203125198 .4151000977 195.6721038818192 .9290008545190 .1858978271187 .4429016113184 .699798584 181.9566955566178 .9089050293176 .165802002173 .4226989746170 .6797027588 168.241394043165 .8031005859163 .3648071289161 .2312927246159 .4026031494 157.5738983154156 .3547973633155 .1356048584154 .2212982178153 .3069000244 152.6972961426152 .3925933838152 .0877990723151 .7830047607151 .4781951904 151.4781951904151 .4781951904151 .7830047607151 .7830047607152 .0877990723 152.0877990723152 .3925933838152 .3925933838152 .3925933838152 .6972961426 152.6972961426152 .6972961426152 .6972961426152 .6972961426152 .6972961426 152.6972961426152 .6972961426152 .6972961426153 .0021057129153 .3069000244 153.9165039062154 .2212982178154 .5260925293154 .5260925293154 .2212982178 153.6116943359152 .6972961426151 .4781951904149 .6495056152147 .5160064697 145.3825073242142 .9441986084140 .2012023926137 .7628936768135 .0198059082 132.5814971924130 .1432037354128 .0097961426125 .8762969971123 .7427978516 123.1332015991122 .5235977173121 .9140014648121 .3044967651120 .6949005127 120.3900985718119 .7806015015119 .4757995605119 .4757995605120 .3900985718 121.6092987061123 .43800354125 .5715026855128 .0097961426131 .3623962402 135.0198059082138 .6772003174142 .3347015381143 .2489929199143 .5538024902 142.9441986084141 .7250976562140 .2012023926139 .5915985107139 .2868041992 138.6772003174138 .0677032471137 .4580993652136 .8484954834135 .9342041016 135.3246002197134 .4102020264133 .8007049561132 .8863067627132 .2767028809 131.6672058105131 .0576019287130 .4479980469129 .8385009766129 .2288970947 128.6192932129128 .0097961426127 .7050018311127 .0953979492126 .7906036377 126.7906036377126 .4858016968126 .4858016968126 .1809997559126 .1809997559 125.8762969971125 .5715026855125 .2667007446124 .9618988037124 .6570968628 124.0475006104123 .1332015991122 .5235977173121 .6092987061120 .3900985718 119.1709976196118 .8662033081118 .5614013672118 .2565994263118 .5614013672 118.8662033081119 .7806015015122 .8283996582128 .6192932129138 .3724975586 147.8208007812152 .6972961426153 .9165039062161 .8408966064177 .9945068359 193.233795166207 .25390625209 .692199707209 .692199707209 .692199707209 .692199707 209.692199707209 .692199707209 .692199707209 .692199707209 .692199707209 .692199707 209.692199707 209.692199707 209.692199707 209.692199707 209.692199707 209.692199707 
209.692199707 208.7778015137212.7400054932 216.3973999023220.054901123 223.7122955322227 .0648956299230 .7223052979234 .0749969482237 .4275970459 240.7801971436244 .1329040527247 .1806945801249 .9237976074252 .6669006348 255.4098968506257 .8482055664260 .2864990234262 .4200134277264 .2486877441 265.7726135254267 .2966003418268 .5156860352269 .7348022461270 .6492004395 271.5635070801272 .1730957031272 .7827148438273 .3923034668273 .6971130371 274.0018005371274 .0018005371274 .0018005371274 .0018005371274 .3066101074 274.3066101074274 .3066101074274 .6113891602274 .6113891602274 .3066101074 274.3066101074274 .3066101074274 .3066101074274 .0018005371274 .0018005371 273.6971130371273 .6971130371273 .3923034668273 .3923034668273 .3923034668 273.6971130371274 .6113891602277 .0497131348280 .7070922852285 .2789001465 291.0697937012296 .8606872559302 .6516113281307 .2233886719308 .7473144531 306.6138000488298 .9942016602286 .4979858398270 .3443908691254 .1907958984 238.9515075684208 .4743347168184 .3420410156165 .6812286377 -9999 -9999 -9999 -9999 -9999 -9999 -9999 -9999 -9999 -9999 -9999 -9999 -9999 -9999 -9999 -9999 -9999 -9999 -9999

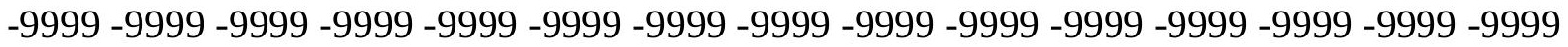
-9999 -9999 -9999 -9999 -9999 -9999 -9999 -9999 -9999 -9999 -9999 -9999 -9999 -9999 -9999 -9999 -9999 -9999 -9999 -9999 -9999 -9999 -9999 -9999 -9999 -9999 -9999 -9999 -9999 - 9999 -9999 -9999 -9999 -9999 -9999 -9999 -9999 -9999 -9999 -9999 -9999-42.9100990295 -35.9646492004 -28.9545898438 -21.6397399902 -14.6296901703 -7.61962795258 -.6095703244216.09570312513.1057596206720.1158199310327.4306602478 34.4407196044941 .7555618286148 .765621185356 .0804595947363 .09051895142 70.1005783081177 .4154205322384 .4254837036191 .4355392456198 .14080810547 105.1509017944111 .8561019897118 .5614013672124 .9618988037131 .3623962402 137.7628936768143 .8585968018149 .6495056152155 .4403991699161 .2312927246 166.7174987793171 .8988037109177 .0802001953181 .9566955566186 .528503418 191.1002960205195 .3672943115199 .329498291203 .2917022705206 .9490966797 210.3016967773213 .6544036865216 .7021942139219 .4452972412222 .1884002686 224.6266021729226 .7601013184228 .8936004639230 .7223052979232 .246307373 233.7702026367234 .9893035889235 .9037017822236 .8179931641237 .7324066162 238.0372009277238 .3419952393238 .6468048096238 .6468048096238 .6468048096 238.3419952393238 .0372009277237 .4275970459236 .8179931641235 .9037017822 234.9893035889234 .0749969482232 .8558044434231 .6367034912230 .1127929688 228.5888977051227 .0648956299225 .5410003662223 .7122955322221 .883605957 220.054901123217 .9214019775216 .0926971436213 .959197998211 .520904541 209.3874053955 206.9490966797204.5108032227 202.0724945068 199.6342926025 197.1959991455194 .4528961182191 .7097930908188 .966796875186 .2236938477 183.4806976318180 .7375946045177 .9945068359175 .2514038086172 .5084075928 169.7653045654167 .0222015381164 .5839996338162 .1457061768160 .0122070312 158.1835021973156 .3547973633155 .1356048584153 .9165039062153 .3069000244 152.6972961426152 .0877990723151 .7830047607151 .7830047607151 .4781951904 151.4781951904151 .4781951904151 .7830047607151 .7830047607152 .0877990723 152.3925933838152 .3925933838152 .6972961426152 .6972961426153 .0021057129 153.0021057129153 .0021057129153 .0021057129153 .3069000244153 .3069000244 153.3069000244153 .3069000244153 .3069000244153 .3069000244153 .6116943359 153.9165039062154 .5260925293154 .8307952881154 .8307952881154 .8307952881 
154.5260925293153 .9165039062152 .6972961426151 .4781951904149 .3446960449 147.2111968994144 .7729034424142 .3347015381139 .8963928223137 .1533050537 134.4102020264131 .9720001221129 .533706665127 .4001998901124 .9618988037 123.1332015991122 .8283996582122 .2188034058121 .6092987061121 .3044967651 120.6949005127120 .0852966309119 .7806015015119 .4757995605118 .5614013672 120.3900985718122 .5235977173124 .9618988037127 .7050018311130 .4479980469 133.1911010742136 .5437011719139 .5915985107142 .0299072266143 .2489929199 143.2489929199 142.6394042969 141.4203033447 140.2012023926139.5915985107 138.9819946289138 .6772003174138 .0677032471137 .4580993652136 .8484954834 135.9342041016135 .3246002197134 .4102020264133 .8007049561132 .8863067627 132.2767028809131 .6672058105130 .7528076172130 .1432037354129 .533706665 128.9241027832128 .3144989014127 .7050018311127 .0953979492126 .7906036377 126.4858016968126 .1809997559126 .1809997559125 .8762969971125 .8762969971 125.5715026855125 .5715026855125 .2667007446124 .9618988037124 .6570968628 124.3523025513123 .7427978516123 .43800354122 .8283996582121 .9140014648 120.9997024536120 .3900985718119 .7806015015119 .7806015015119 .4757995605 119.4757995605119 .4757995605120 .0852966309122 .5235977173128 .3144989014 139.8963928223155 .1356048584156 .9642944336156 .6596069336159 .0977935791 175.5561981201191 .4051055908205 .7299957275209 .692199707209 .692199707 209.692199707 209.692199707 209.692199707 209.692199707 209.692199707 209.692199707 209.692199707 209.692199707 209.692199707 209.692199707 209.692199707 209.692199707 209.692199707209 .692199707209 .692199707209 .692199707210 .6065063477 214.2639007568217 .9214019775221 .5787963867225 .2362060547228 .5888977051 232.246307373235.5989074707 238.9515075684241.9994049072 245.0471954346 248.0950927734250 .8381958008253 .5812072754256 .0195007324258 .4577941895 260.5913085938262 .4200134277264 .2486877441265 .7726135254267 .2966003418 268.5156860352269 .7348022461270 .6492004395271 .5635070801272 .1730957031 272.7827148438273 .3923034668273 .6971130371273 .6971130371274 .0018005371 274.0018005371274 .0018005371274 .3066101074274 .3066101074274 .3066101074 274.3066101074 274.3066101074274.3066101074274.3066101074 274.3066101074 274.3066101074274 .0018005371274 .0018005371274 .0018005371274 .0018005371 273.6971130371273 .6971130371274 .0018005371275 .2210083008277 .3544921875 281.0119018555285 .5835876465291 .0697937012297 .4703063965303 .8707885742 309.0520935059311 .7951965332310 .8807983398305 .3947143555295 .0320129395 279.7927856445259 .6769104004231 .6367034912206 .435546875183 .2592468262 164.7038574219 -9999 -9999 -9999 -9999 -9999 -9999 -9999 -9999 -9999 -9999 -9999 -9999

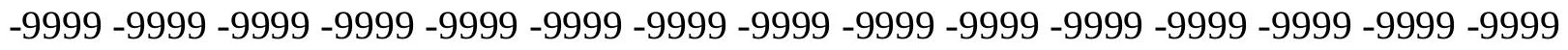

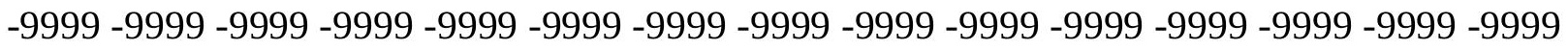
-9999 -9999 -9999 -9999 -9999 -9999 -9999 -9999 -9999 -9999 -9999 -9999 -9999 -9999 -9999 -9999 -9999 -9999 -9999-9999-9999-9999 -9999 -9999 -9999 -9999 -9999 -9999 -9999 -9999 -9999 -9999 -9999-43.631023407 -36.5742111206 -29.5641593933 -22.5541000366 -15.5440397263 -8.53398323059 -1.523926019675.181346893311 12.191410064719 .2014598846426 .51630973816 33.5263595581140 .8412094116247 .8512611389255 .1661109924362 .17617034912 69.4910125732476 .5010681152383 .5111236572390 .5211791992297 .53124237061 104.2365036011110 .9418029785117 .647102356124 .0475006104130 .4479980469 
136.5437011719142 .6394042969148 .7351074219154 .2212982178160 .0122070312 165.1934967041170 .3748931885175 .5561981201180 .1280059814184 .699798584 189.2716064453193 .5386047363197 .500793457201 .158203125204 .8155975342 208.1681976318211 .2160949707214 .2639007568217 .0070037842219 .7501068115 222.1884002686224 .3218994141226 .150604248227 .9792938232229 .5032043457 231.0270996094232 .246307373233 .1605987549234 .0749969482234 .6844940186 235.2940979004235 .5989074707235 .9037017822235 .9037017822235 .9037017822 235.5989074707235 .2940979004234 .6844940186234 .0749969482233 .4653930664 232.5511016846231 .6367034912230 .4176025391229 .1983947754227 .9792938232 226.4553985596224 .9313964844223 .4075012207221 .5787963867219 .7501068115 217.9214019775216 .0926971436214 .2639007568212 .1304016113209 .9969024658 207.8634033203 205.425201416203.2917022705 200.8533935547 198.4151000977 195.9768066406 193.233795166190.795501709 188.0523986816185.3094024658 182.5662994385179 .8231964111177 .0802001953174 .337097168171 .5939941406 168.8509979248166 .1078948975163 .6696014404161 .2312927246159 .0977935791 156.9642944336155 .4403991699154 .2212982178153 .0021057129152 .3925933838 152.0877990723151 .7830047607151 .7830047607151 .4781951904151 .4781951904 151.7830047607151 .7830047607152 .0877990723152 .0877990723152 .3925933838 152.6972961426152 .6972961426153 .0021057129153 .3069000244153 .3069000244 153.3069000244153 .6116943359153 .6116943359153 .6116943359153 .6116943359 153.9165039062153 .9165039062153 .9165039062154 .2212982178154 .2212982178 154.5260925293154 .8307952881155 .1356048584155 .1356048584154 .8307952881 154.5260925293153 .9165039062152 .6972961426151 .1734008789149 .0399017334 146.9064025879144 .4682006836141 .7250976562139 .2868041992136 .5437011719 133.8007049561131 .3623962402128 .9241027832126 .7906036377124 .6570968628 122.5235977173122 .5235977173122 .2188034058121 .6092987061120 .9997024536 120.6949005127120 .0852966309119 .7806015015119 .4757995605118 .8662033081 120.6949005127124 .3523025513127 .4001998901130 .1432037354132 .5814971924 135.0198059082137 .4580993652139 .8963928223141 .4203033447142 .3347015381 142.6394042969142 .0299072266141 .4203033447140 .5059967041139 .5915985107 138.9819946289138 .6772003174138 .0677032471137 .4580993652136 .8484954834 135.9342041016135 .3246002197134 .4102020264133 .8007049561132 .8863067627 132.2767028809131 .3623962402130 .7528076172130 .1432037354129 .2288970947 128.6192932129128 .0097961426127 .4001998901126 .7906036377126 .4858016968 126.1809997559125 .8762969971125 .5715026855125 .2667007446125 .2667007446 124.9618988037124 .9618988037124 .6570968628124 .6570968628124 .3523025513 124.0475006104123 .7427978516123 .1332015991122 .8283996582122 .2188034058 121.3044967651120 .9997024536120 .6949005127120 .3900985718120 .3900985718 120.0852966309119 .7806015015119 .4757995605120 .3900985718123 .7427978516 133.1911010742147 .8208007812156 .9642944336158 .4882965088156 .9642944336 174.337097168190 .4907073975205 .425201416209 .692199707209 .692199707 209.692199707 209.692199707 209.692199707 209.692199707 209.692199707 209.692199707 209.692199707209 .692199707209 .692199707209 .692199707209 .692199707209 .692199707 209.692199707 209.692199707209.692199707 209.692199707 209.692199707 212.1304016113215 .787902832219 .4452972412223 .1027069092226 .7601013184 230.1127929688233 .4653930664236 .8179931641240 .1707000732243 .2185058594 
246.2664031982249 .0093994141251 .7525024414254 .1907958984256 .6290893555 258.7626037598260 .8960876465262 .7247924805264 .5534973145266 .0773925781 267.2966003418268 .5156860352269 .7348022461270 .6492004395271 .5635070801 272.1730957031272 .7827148438273 .0874938965273 .3923034668273 .6971130371 274.0018005371274 .0018005371274 .3066101074274 .3066101074274 .3066101074 274.3066101074 274.3066101074 274.3066101074 274.3066101074 274.3066101074 274.3066101074274 .3066101074274 .0018005371274 .0018005371274 .0018005371 274.3066101074274 .0018005371274 .3066101074275 .2210083008277 .0497131348 280.0975036621284 .3645019531289 .8505859375295 .9464111328302 .3468017578 307.8330078125311 .1856079102311 .4903869629306 .9186096191297 .4703063965 281.3167114258257 .8482055664224 .6266021729199 .288482666178 .7376708984 162.237411499 -9999 -9999 -9999 -9999 -9999 -9999 -9999 -9999 -9999 -9999 -9999 -9999 -9999 -9999 -9999 -9999 -9999 -9999 -9999 -9999 -9999 -9999 -9999 -9999 -9999 -9999 -9999

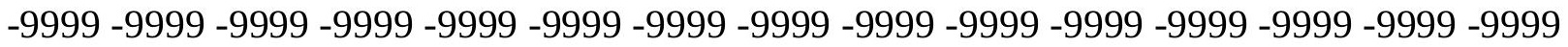
-9999 -9999 -9999 -9999 -9999 -9999 -9999 -9999 -9999 -9999 -9999 -9999 -9999 -9999 -9999 -9999 -9999 -9999 -9999-9999-9999-9999

-9999 -9999 -9999 -9999 -9999 -9999 -9999 -9999 -9999 -9999 -9999-44.3704376221 -37.1837806702 -30.1737308502 -23.4684505463 -16.7631797791 -9.75312423706 -2.743066072463.96220707893410.9722604751618.287109375 25.29715919495 32.6120109558139 .9268493652346 .9369087219254 .2517509460461 .56660079956 68.5766525268675 .5867080688582 .9015579223689 .9116134643696 .61688232422 103.6268997192110 .3321990967116 .7326965332123 .1332015991129 .533706665 135.6293945312141 .7250976562147 .5160064697153 .3069000244158 .7929992676 163.974395752169 .1557006836174 .0323028564178 .604095459183 .1759033203 187.4429016113191 .7097930908195 .3672943115199 .329498291202 .6820983887 206.0346984863209 .0825958252212 .1304016113214 .8735046387217 .3117980957 219.4452972412221 .5787963867223 .7122955322225 .2362060547226 .7601013184 228.2841033936229 .5032043457230 .4176025391231 .3318939209231 .9414978027 232.5511016846232 .8558044434233 .1605987549233 .1605987549233 .1605987549 233.1605987549232 .5511016846232 .246307373231 .6367034912230 .7223052979 230.1127929688229 .1983947754227 .9792938232226 .7601013184225 .5410003662 224.3218994141222 .7978973389221 .2740020752219 .4452972412217 .9214019775 216.0926971436214 .2639007568212 .4351959229210 .3016967773208 .1681976318 206.3394927979203 .9011993408201 .7678070068199 .329498291197 .1959991455 194.7577056885192 .3193969727189 .5764007568187 .1381072998184 .3950042725 181.6519012451178 .9089050293176 .165802002173 .4226989746170 .6797027588 168.241394043165 .4983062744162 .7552947998160 .3170013428158 .1835021973 156.0500030518154 .5260925293153 .3069000244152 .3925933838151 .7830047607 151.7830047607151 .4781951904151 .4781951904151 .7830047607151 .7830047607 151.7830047607152 .0877990723152 .3925933838152 .3925933838152 .6972961426 153.0021057129153 .3069000244153 .6116943359153 .6116943359153 .9165039062 153.9165039062153 .9165039062154 .2212982178154 .2212982178154 .2212982178 154.2212982178154 .5260925293154 .5260925293154 .8307952881154 .8307952881 155.1356048584155 .4403991699155 .4403991699155 .1356048584154 .8307952881 154.5260925293153 .6116943359152 .6972961426150 .8686065674148 .7351074219 146.2969055176143 .8585968018141 .1154937744138 .3724975586135 .9342041016 
133.1911010742130 .7528076172128 .3144989014126 .1809997559124 .0475006104 123.1332015991122 .5235977173121 .9140014648121 .6092987061120 .9997024536 120.6949005127120 .0852966309120 .0852966309119 .7806015015120 .3900985718 124.0475006104127 .4001998901130 .4479980469132 .8863067627134 .7149963379 136.5437011719138 .0677032471139 .8963928223141 .1154937744141 .7250976562 142.0299072266141 .7250976562141 .1154937744140 .5059967041139 .8963928223 139.2868041992 138.6772003174138.0677032471 137.4580993652 136.8484954834 135.9342041016135 .3246002197134 .4102020264133 .8007049561132 .8863067627 131.9720001221131 .3623962402130 .4479980469129 .8385009766128 .9241027832 128.3144989014127 .7050018311127 .0953979492126 .4858016968126 .1809997559 125.5715026855125 .2667007446125 .2667007446124 .9618988037124 .6570968628 124.6570968628124 .3523025513124 .3523025513124 .0475006104124 .0475006104 123.7427978516123 .43800354123 .1332015991122 .5235977173122 .2188034058 121.6092987061121 .3044967651120 .9997024536120 .9997024536120 .6949005127 120.0852966309119 .4757995605118 .8662033081118 .8662033081119 .7806015015 121.9140014648146 .6015930176157 .878692627158 .7929992676156 .6596069336 174.337097168191 .1002960205206 .0346984863209 .692199707209 .692199707 209.692199707 209.692199707 209.692199707 209.692199707 209.692199707 209.692199707 209.692199707209 .692199707209 .692199707209 .692199707209 .692199707209 .692199707 209.692199707 209.692199707 209.692199707 209.692199707209.692199707 209.9969024658 213.6544036865 217.3117980957 220.9691925049 224.6266021729 227.9792938232231 .6367034912234 .9893035889238 .0372009277241 .0850067139 244.1329040527247 .1806945801249 .9237976074252 .3621063232254 .8003997803 257.2385864258259 .3721008301261 .2008972168263 .0296020508264 .5534973145 266.0773925781267 .2966003418268 .5156860352269 .7348022461270 .6492004395 271.2587890625272 .1730957031272 .4779052734273 .0874938965273 .3923034668 273.6971130371274 .0018005371274 .3066101074274 .3066101074274 .3066101074 274.3066101074274 .3066101074274 .3066101074274 .3066101074274 .3066101074 274.3066101074274 .0018005371274 .0018005371274 .0018005371274 .0018005371 274.0018005371273 .6971130371274 .0018005371274 .6113891602276 .1353149414 278.5736083984282 .2309875488287 .1076049805292 .5936889648298 .6893920898 303.8707885742307 .2233886719307 .8330078125304 .4802856445295 .6416015625 279.7927856445256 .0195007324225 .2362060547193 .5386047363176 .2576904297 160.965057373 -9999 -9999 -9999 -9999 -9999 -9999 -9999 -9999 -9999 -9999 -9999 -9999

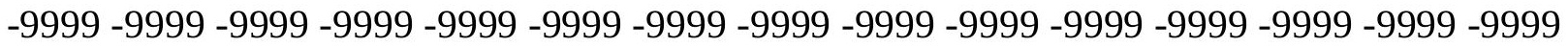

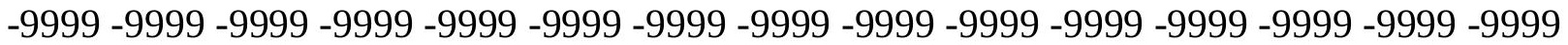

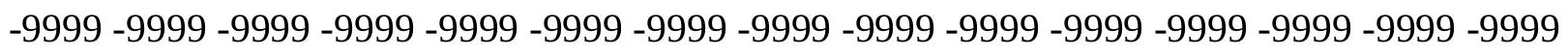
-9999 -9999 -9999 -9999 -9999 -9999 -9999

-9999 -9999 -9999 -9999 -9999 -9999 -9999 -9999 -9999 -9999 -9999 -45.3600654602 -37.7933502197 -31.3928699493 -24.6875991821 -17.6775398254-10.9722604752 -3.96220707893 3.04785108566310.05790996552 17.06797027588 24.38281059265 31.6976509094239 .0125007629446 .0225486755453 .3373985290560 .65224075317 67.9670867919974 .9771423339881 .9871978759888 .9972534179796 .00731658936 102.712600708109 .4179000854116 .1231002808122 .5235977173128 .6192932129 134.7149963379140 .8106994629146 .6015930176152 .0877990723157 .5738983154 162.7552947998167 .6318054199172 .5084075928177 .0802001953181 .6519012451 
185.9188995361189 .8811035156193 .5386047363197 .1959991455200 .5485992432 203.9011993408206 .9490966797209 .692199707212 .4351959229214 .8735046387 217.0070037842219 .1405029297220 .9691925049222 .7978973389224 .3218994141 225.5410003662226 .7601013184227 .6744995117228 .5888977051229 .1983947754 229.8079986572230 .1127929688230 .4176025391230 .7223052979230 .4176025391 230.4176025391230 .1127929688229 .5032043457228 .8936004639228 .2841033936 227.6744995117226 .7601013184225 .5410003662224 .6266021729223 .4075012207 221.883605957220 .6643981934219 .1405029297217 .6165924072215 .787902832 214.2639007568212 .4351959229210 .6065063477208 .7778015137206 .6443023682 204.8155975342202 .6820983887200 .5485992432198 .1103057861195 .9768066406 193.5386047363191 .4051055908188 .6620025635186 .2236938477183 .7854003906 181.0424041748178 .604095459175 .8609924316173 .1179962158170 .3748931885 167.6318054199165 .1934967041162 .4505004883160 .0122070312157 .5738983154 155.4403991699153 .6116943359152 .3925933838151 .7830047607151 .4781951904 151.4781951904151 .4781951904151 .7830047607151 .7830047607152 .0877990723 152.3925933838152 .3925933838152 .6972961426153 .0021057129153 .3069000244 153.6116943359153 .6116943359153 .9165039062154 .2212982178154 .2212982178 154.5260925293154 .5260925293154 .5260925293154 .8307952881154 .8307952881 154.8307952881155 .1356048584155 .1356048584155 .1356048584155 .4403991699 155.4403991699155 .4403991699155 .4403991699155 .1356048584154 .8307952881 154.2212982178153 .0021057129151 .7830047607149 .9542999268147 .8208007812 145.3825073242142 .9441986084140 .2012023926137 .7628936768135 .0198059082 132.5814971924130 .1432037354127 .7050018311125 .5715026855123 .7427978516 122.8283996582122 .5235977173121 .9140014648121 .3044967651120 .9997024536 120.3900985718120 .3900985718120 .0852966309120 .0852966309123 .43800354 128.3144989014131 .6672058105134 .1054992676135 .3246002197136 .5437011719 137.4580993652138 .6772003174139 .5915985107140 .5059967041141 .1154937744 141.4203033447141 .4203033447141 .1154937744140 .5059967041139 .8963928223 139.2868041992138 .6772003174138 .0677032471137 .4580993652136 .8484954834 135.9342041016135 .3246002197134 .4102020264133 .4958953857132 .8863067627 131.9720001221131 .0576019287130 .4479980469129 .533706665128 .6192932129 128.0097961426127 .4001998901126 .7906036377126 .1809997559125 .5715026855 125.2667007446124 .9618988037124 .6570968628124 .3523025513124 .3523025513 124.0475006104124 .0475006104123 .7427978516123 .7427978516123 .43800354 123.43800354123 .1332015991122 .8283996582122 .5235977173122 .2188034058 121.6092987061121 .3044967651121 .3044967651120 .9997024536120 .6949005127 120.3900985718119 .4757995605118 .8662033081118 .5614013672120 .9997024536 132.5814971924156 .6596069336157 .5738983154156 .6596069336158 .7929992676 176.7754058838193 .5386047363207 .8634033203209 .692199707209 .692199707 209.692199707 209.692199707 209.692199707 209.692199707 209.692199707 209.692199707 209.692199707209 .692199707209 .692199707209 .692199707209 .692199707209 .692199707 209.692199707 209.692199707 209.692199707 209.692199707 209.692199707 209.692199707 211.520904541215 .1782989502218 .8356933594222 .4931030273225 .8457946777 229.5032043457232 .8558044434236 .2084960938239 .2563018799242 .3041992188 245.3520050049248 .0950927734250 .8381958008253 .2763977051255 .4098968506 257.5433959961259 .6769104004261 .5056152344263 .3344116211264 .8583068848 
266.3822021484267 .6012878418268 .8204956055269 .7348022461270 .6492004395 271.2587890625271 .8682861328272 .4779052734273 .0874938965273 .3923034668 274.0018005371274 .3066101074274 .3066101074274 .3066101074274 .3066101074 274.3066101074274 .3066101074274 .3066101074274 .0018005371274 .0018005371 274.0018005371274 .0018005371273 .6971130371273 .6971130371273 .3923034668 273.3923034668273 .3923034668274 .0018005371274 .9161987305276 .7449035645 279.4880065918283 .1453857422288 .0219116211293 .2033081055297 .7750854492 300.8229064941301 .7373046875298 .6893920898291 .3746032715278 .2687988281 256.0195007324229 .5032043457202 .3773040771179 .434387207162 .0628509521 148.1993103027 -9999 -9999 -9999 -9999 -9999 -9999 -9999 -9999 -9999 -9999 -9999 -9999 -9999 -9999 -9999 -9999 -9999 -9999 -9999 -9999 -9999 -9999 -9999 -9999 -9999 -9999 -9999 -9999 -9999 -9999 -9999 -9999 -9999 -9999 -9999 -9999 -9999 -9999 -9999 -9999 -9999 -9999 -

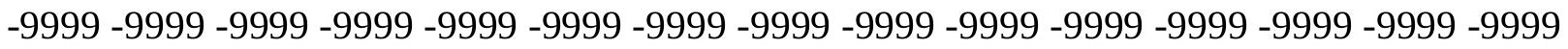
-9999 -9999 -9999-9999-9999-9999 -9999 -9999 -9999 -9999 -9999 -9999 -9999 -9999 -9999 -9999 -9999 -46.8878746033 -39.6684303284 -32.9167900085-25.9067401886 -19.2014598846 -12.1914100647 -5.18134689331 1.828711032867 8.838768959045 16.15361022949 23.46845054626 30.7833003997838 .0981407165545 .4129791259852 .7278289794959 .73788070679 67.0527267456174 .3675689697381 .3776321411188 .3876876831195 .3977432251 102.1029968262108 .8082962036115 .2088012695121 .6092987061128 .0097961426 134.1054992676139 .8963928223145 .6873016357151 .1734008789156 .3547973633 161.5361022949166 .4127044678171 .2891998291175 .8609924316180 .1280059814 184.0901947021188 .0523986816191 .7097930908195 .3672943115198 .7198944092 201.7678070068204 .8155975342207 .5587005615209 .9969024658212 .4351959229 214.5686950684216 .7021942139218 .5308990479220 .054901123221 .5787963867 222.7978973389224 .0171051025224 .9313964844225 .8457946777226 .4553985596 227.0648956299 227.6744995117 227.6744995117227.9792938232 227.9792938232 227.6744995117227 .3697052002227 .0648956299226 .4553985596225 .8457946777 225.2362060547224 .3218994141223 .4075012207222 .1884002686220 .9691925049 219.7501068115218 .5308990479217 .0070037842215 .4830932617213 .959197998 212.4351959229210 .6065063477208 .7778015137206 .9490966797205 .1204071045 203.2917022705 201.158203125 199.329498291 197.1959991455 195.0625192.624206543 190.4907073975188 .0523986816185 .6141052246183 .1759033203180 .7375946045 177.9945068359175 .5561981201172 .8132019043170 .3748931885167 .6318054199 164.8887023926162 .4505004883160 .0122070312157 .5738983154155 .1356048584 153.3069000244151 .7830047607151 .4781951904151 .4781951904151 .7830047607 151.7830047607152 .0877990723152 .3925933838152 .6972961426152 .6972961426 153.0021057129153 .3069000244153 .6116943359153 .9165039062153 .9165039062 154.2212982178154 .5260925293154 .5260925293154 .8307952881154 .8307952881 154.8307952881155 .1356048584155 .1356048584155 .1356048584155 .4403991699 155.4403991699155 .4403991699155 .7451934814155 .7451934814155 .7451934814 155.7451934814155 .4403991699155 .1356048584154 .5260925293153 .3069000244 152.3925933838150 .8686065674149 .0399017334146 .9064025879144 .4682006836 141.7250976562139 .2868041992136 .8484954834134 .1054992676131 .6672058105 129.533706665127 .4001998901125 .2667007446123 .43800354122 .8283996582 122.2188034058121 .9140014648121 .3044967651120 .9997024536120 .3900985718 
120.3900985718120 .3900985718119 .7806015015128 .6192932129133 .8007049561 135.9342041016137 .4580993652137 .4580993652137 .7628936768138 .3724975586 138.9819946289139 .5915985107140 .2012023926140 .8106994629141 .1154937744 141.1154937744140 .8106994629140 .5059967041140 .2012023926139 .5915985107 138.9819946289138 .3724975586137 .4580993652136 .8484954834136 .2389984131 135.3246002197134 .4102020264133 .4958953857132 .5814971924131 .6672058105 131.0576019287130 .1432037354129 .2288970947128 .3144989014127 .7050018311 127.0953979492126 .4858016968125 .8762969971125 .2667007446124 .9618988037 124.6570968628124 .3523025513124 .0475006104123 .7427978516123 .7427978516 123.43800354123 .43800354123 .43800354123 .1332015991123 .1332015991122 .8283996582 122.5235977173122 .2188034058121 .9140014648121 .6092987061121 .6092987061 121.3044967651121 .3044967651120 .9997024536120 .6949005127120 .0852966309 119.4757995605119 .7806015015122 .8283996582131 .9720001221144 .4682006836 151.1734008789152 .6972961426160 .9264984131179 .8231964111196 .2816009521 209.692199707 209.692199707 209.692199707 209.692199707 209.692199707 209.692199707 209.692199707 209.692199707 209.692199707 209.692199707 209.692199707 209.692199707 209.692199707 209.692199707 209.692199707 209.692199707 209.692199707 209.692199707 209.692199707 209.692199707 209.692199707 209.3874053955 213.0447998047 216.7021942139220 .3596038818224 .0171051025227 .3697052002230 .7223052979 234.0749969482237 .4275970459240 .4754943848243 .5233001709246 .2664031982 249.0093994141251 .4476928711253 .8860015869256 .0195007324258 .1530151367 260.2864990234262 .1152038574263 .6390991211265 .1630859375266 .3822021484 267.6012878418268 .8204956055269 .7348022461270 .6492004395271 .5635070801 272.1730957031272 .7827148438273 .0874938965273 .6971130371274 .3066101074 274.3066101074274 .3066101074274 .3066101074274 .3066101074274 .3066101074 274.0018005371274 .0018005371274 .0018005371274 .0018005371273 .6971130371 273.6971130371273 .3923034668273 .0874938965273 .0874938965272 .7827148438 273.0874938965273 .3923034668274 .6113891602276 .1353149414278 .8783874512 282.5357971191287 .1076049805290 .7650146484293 .2033081055293 .8128967285 291.6794128418285 .5835876465274 .3066101074256 .9338989258234 .6844940186 209.9969024658185 .0045928955165 .9061737061150 .4212799072 -9999 -9999 -9999 -9999

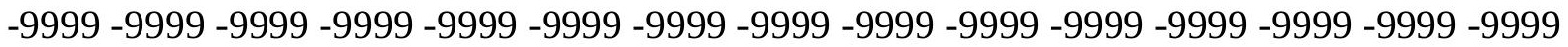

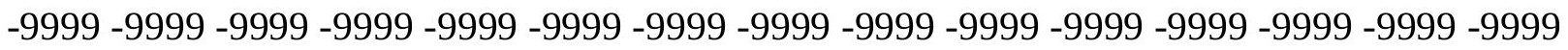

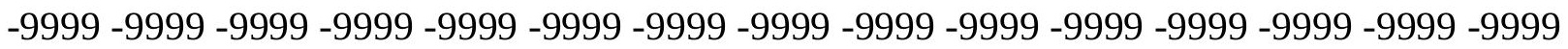

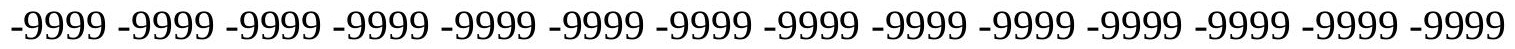
-9999 -9999 -9999 -9999 -9999 -9999 -9999 -9999 -9999 -9999 -9999 -48.6961326599 $-41.5308456421-34.4407196045-27.4306602478-20.4206008911-13.4105501175$ $-6.40048694611 .60957032442097 .61962795257614 .934470176722 .24930953979$ 29.5641593933137 .1837806701744 .4986305236851 .8134689331159 .12831115723 66.4431610107473 .4532165527380 .7680587768687 .7781066894594 .78817749023 101.4934005737108 .1986999512114 .5991973877120 .9997024536127 .0953979492 133.1911010742138 .9819946289144 .7729034424150 .2590942383155 .4403991699 160.6217956543165 .4983062744170 .070098877174 .337097168178 .604095459 182.5662994385186 .528503418190 .1858978271193 .5386047363196 .891204834 199.9389953613202 .6820983887205 .425201416207 .8634033203209 .9969024658 212.1304016113214 .2639007568215 .787902832217 .6165924072218 .8356933594 
220.3596038818221 .2740020752222 .4931030273223 .1027069092224 .0171051025 224.3218994141224 .9313964844225 .2362060547225 .2362060547225 .2362060547 225.2362060547224 .9313964844224 .6266021729224 .0171051025223 .4075012207 222.7978973389221 .883605957220 .9691925049219 .7501068115218 .8356933594 217.6165924072216 .3973999023214 .8735046387213 .3495941162211 .8256988525 210.3016967773208 .7778015137207 .25390625205 .425201416203 .596496582 201.7678070068199 .9389953613198 .1103057861195 .9768066406194 .1481018066 192.0146026611189 .5764007568187 .4429016113185 .3094024658182 .87109375 180.432800293177 .9945068359175 .5561981201172 .8132019043170 .3748931885 167.6318054199165 .1934967041162 .7552947998160 .3170013428157 .878692627 155.4403991699153 .3069000244151 .4781951904152 .0877990723152 .0877990723 152.3925933838152 .3925933838152 .6972961426153 .0021057129153 .3069000244 153.6116943359153 .6116943359153 .9165039062154 .2212982178154 .5260925293 154.5260925293154 .8307952881154 .8307952881155 .1356048584155 .1356048584 155.1356048584155 .4403991699155 .4403991699155 .4403991699155 .4403991699 155.7451934814155 .7451934814155 .7451934814155 .7451934814155 .7451934814 155.7451934814155 .4403991699155 .1356048584154 .5260925293153 .6116943359 152.6972961426151 .1734008789149 .6495056152147 .5160064697145 .3825073242 143.2489929199140 .5059967041138 .0677032471135 .6293945312133 .1911010742 131.0576019287128 .9241027832126 .7906036377124 .9618988037123 .43800354 122.2188034058122 .2188034058121 .9140014648121 .3044967651120 .9997024536 120.3900985718120 .3900985718119 .7806015015126 .4858016968137 .1533050537 138.3724975586138 .3724975586138 .6772003174138 .3724975586138 .3724975586 138.6772003174139 .2868041992139 .5915985107139 .8963928223140 .5059967041 140.8106994629140 .8106994629140 .8106994629140 .8106994629140 .2012023926 139.8963928223139 .2868041992138 .3724975586137 .7628936768136 .8484954834 136.2389984131135 .3246002197134 .4102020264133 .4958953857132 .5814971924 131.6672058105130 .7528076172129 .8385009766128 .9241027832128 .0097961426 127.4001998901126 .7906036377126 .1809997559125 .5715026855124 .9618988037 124.6570968628124 .0475006104123 .7427978516123 .7427978516123 .43800354 123.1332015991123 .1332015991123 .1332015991122 .8283996582122 .8283996582 122.8283996582122 .5235977173122 .5235977173122 .2188034058121 .9140014648 121.6092987061121 .6092987061121 .3044967651121 .3044967651120 .9997024536 120.6949005127120 .3900985718120 .6949005127121 .3044967651121 .6092987061 123.7427978516134 .4102020264142 .6394042969146 .9064025879160 .9264984131 181.9566955566197 .8054962158209 .692199707209 .692199707209 .692199707 209.692199707 209.692199707 209.692199707 209.692199707 209.692199707 209.692199707 209.692199707 209.692199707 209.692199707 209.692199707 209.692199707 209.692199707 209.692199707 209.692199707 209.692199707 209.692199707 209.692199707 209.692199707 209.692199707 210.9113006592 214.5686950684218.2261962891221.883605957 225.2362060547228 .8936004639232 .246307373235 .2940979004238 .6468048096 241.6945953369244 .4376983643247 .1806945801249 .9237976074252 .3621063232 254.4956054688256 .6290893555258 .7626037598260 .5913085938262 .4200134277 263.9439086914265 .4678039551266 .6870117188267 .9060974121269 .1253051758 270.0396118164270 .9540100098271 .5635070801272 .1730957031272 .7827148438 273.3923034668274 .0018005371274 .0018005371274 .3066101074274 .3066101074 
274.3066101074274 .3066101074274 .0018005371274 .0018005371274 .0018005371 274.0018005371273 .6971130371273 .3923034668273 .0874938965272 .7827148438 272.4779052734272 .4779052734272 .1730957031272 .4779052734272 .7827148438 273.3923034668274 .3066101074277 .6592102051281 .0119018555283 .7549133301 285.5835876465285 .8884887695284 .3645019531280 .4023132324272 .4779052734 259.3721008301241.0850067139218.5308990479 193.233795166171.5931243896 153.9085235596 -9999 -9999 -9999 -9999 -9999 -9999 -9999 -9999 -9999 -9999 -9999 -9999

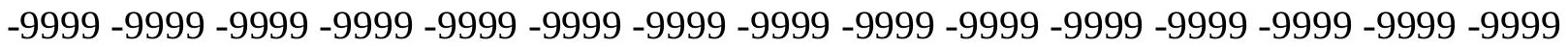

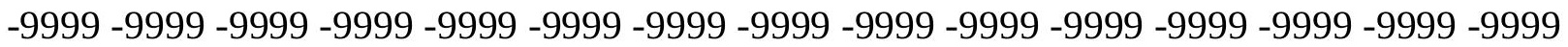

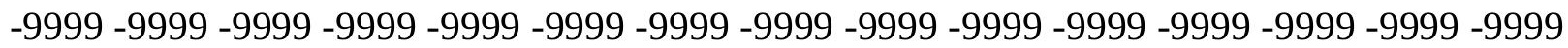
-9999 -9999-9999-9999-9999-9999 -9999 -9999 -9999 -9999 -9999 -9999 -9999 -9999 -9999 -9999 -9999 -50.5303840637 $-43.3763465881-36.2694282532-29.2593708038-21.9445304871-14.9344701767$ -7.61962795258 -.6095703244216.705273151398 14.02011966705 21.3349609375 28.6497993469236 .2694282531743 .5842704772950 .8991203308158 .51874923706 65.8335876464872 .8436431884880 .1584930419987 .1685485839894 .17859649658 100.8839035034107 .5891036987113 .9896011353120 .3900985718126 .7906036377 132.5814971924138 .3724975586144 .1634063721149 .3446960449154 .5260925293 159.4026031494164 .2792053223168 .8509979248173 .1179962158177 .3849029541 181.3471984863185 .0045928955188 .3571929932191 .7097930908195 .0625197 .8054962158 200.5485992432203 .2917022705205 .7299957275207 .8634033203209 .9969024658 211.8256988525213 .3495941162214 .8735046387216 .3973999023217 .6165924072 218.8356933594219 .7501068115220 .6643981934221 .2740020752221 .883605957 222.1884002686222 .4931030273222 .4931030273222 .7978973389222 .4931030273 222.1884002686221 .883605957221 .5787963867220 .9691925049220 .3596038818 219.4452972412218 .5308990479217 .6165924072216 .3973999023215 .4830932617 214.2639007568212 .7400054932211 .520904541209 .9969024658208 .4730072021 206.9490966797205.425201416203.9011993408202.3773040771200.5485992432 198.7198944092196 .891204834195 .0625193 .233795166191 .1002960205188 .966796875 186.8332977295184 .699798584182 .5662994385180 .1280059814177 .9945068359 175.5561981201173 .1179962158170 .6797027588168 .241394043165 .8031005859 163.3648071289160 .9264984131158 .4882965088156 .3547973633154 .5260925293 153.3069000244153 .0021057129153 .0021057129153 .3069000244153 .3069000244 153.6116943359153 .9165039062153 .9165039062154 .2212982178154 .5260925293 154.8307952881154 .8307952881155 .1356048584155 .1356048584155 .4403991699 155.4403991699155 .4403991699155 .7451934814155 .7451934814155 .7451934814 155.7451934814155 .7451934814155 .7451934814155 .7451934814155 .7451934814 155.7451934814155 .7451934814155 .7451934814155 .4403991699155 .1356048584 154.5260925293153 .6116943359152 .6972961426151 .4781951904149 .9542999268 148.1255950928145 .9920959473143 .8585968018141 .7250976562139 .2868041992 136.8484954834134 .4102020264132 .2767028809130 .1432037354128 .0097961426 126.1809997559124 .6570968628123 .43800354122 .2188034058122 .2188034058 121.9140014648120 .9997024536121 .6092987061120 .6949005127120 .6949005127 122.2188034058130 .7528076172137 .7628936768139 .8963928223139 .2868041992 138.3724975586138 .3724975586138 .6772003174138 .9819946289139 .2868041992 139.5915985107139 .8963928223140 .2012023926140 .8106994629140 .8106994629 
141.1154937744140 .8106994629140 .5059967041139 .8963928223139 .2868041992 138.6772003174138 .0677032471137 .1533050537136 .2389984131135 .3246002197 134.4102020264133 .1911010742132 .2767028809131 .3623962402130 .4479980469 129.533706665128 .6192932129127 .7050018311127 .0953979492126 .4858016968 125.5715026855125 .2667007446124 .6570968628124 .3523025513123 .7427978516 123.43800354123 .1332015991123 .1332015991122 .8283996582122 .8283996582 122.5235977173122 .5235977173122 .5235977173122 .5235977173122 .2188034058 122.2188034058121 .9140014648121 .9140014648121 .6092987061121 .6092987061 121.3044967651121 .3044967651120 .9997024536120 .9997024536120 .9997024536 120.9997024536120 .6949005127120 .9997024536123 .1332015991129 .2288970947 136.2389984131142 .0299072266155 .7451934814182 .261505127195 .3672943115 206.3394927979 209.692199707 209.692199707 209.692199707 209.692199707 209.692199707 209.692199707 209.692199707 209.692199707 209.692199707 209.692199707 209.692199707 209.692199707 209.692199707 209.692199707 209.692199707 209.692199707 209.692199707209 .692199707209 .692199707209 .692199707209 .692199707209 .692199707 212.4351959229216 .0926971436219 .7501068115223 .4075012207226 .7601013184 230.1127929688233 .4653930664236 .8179931641239 .8659057617242 .6089935303 245.6567993164248 .0950927734250 .8381958008253 .2763977051255 .4098968506 257.5433959961259 .3721008301261 .2008972168263 .0296020508264 .5534973145 265.7726135254266 .9917907715268 .2109069824269 .4301147461270 .3443908691 270.9540100098271 .8682861328272 .4779052734273 .0874938965273 .3923034668 274.0018005371274 .0018005371274 .0018005371274 .3066101074274 .0018005371 274.0018005371274 .0018005371274 .0018005371273 .6971130371273 .6971130371 273.3923034668273 .0874938965272 .7827148438272 .4779052734272 .1730957031 271.8682861328271 .5635070801271 .5635070801271 .8682861328272 .4779052734 274.3066101074276 .4400939941277 .9641113281279 .1831970215279 .1831970215 278.2687988281277 .0497131348273 .0874938965264 .5534973145249 .9237976074 228.8936004639203 .2917022705178 .1347045898158 .3528900146143 .4833221436 -9999 -9999 -9999 -9999 -9999 -9999 -9999 -9999 -9999 -9999 -9999 -9999 -9999 -9999 -9999 -9999 -9999 -9999 -9999 -9999 -9999 -9999 -9999 -9999 -9999 -9999 -9999 -9999 -9999 -9999 -9999

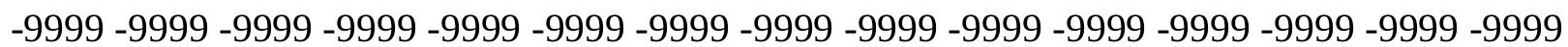
-9999 -9999 -9999 -9999 -9999 -9999 -9999 -9999 -9999 -9999 -9999 -9999 -9999 -9999 -9999 $-9999$

-9999 -9999 -9999 -9999 -9999 -9999 -9999 -9999 -9999 -9999-9999-52.3063735962 $-45.1730804443-38.0981407166-30.7833003998-23.4684505463-16.4584007263$ -9.14355373383 -1.828711032875.486132144928 12.8009700775120 .42060089111 27.7354507446335 .3550796508842 .9747009277350 .2895507812557 .9091796875 65.2240066528372 .5388565063579 .5489196777386 .8637619018693 .56903076172 100.5791015625107 .2844009399113 .6848983765120 .0852966309126 .1809997559 132.2767028809137 .7628936768143 .2489929199148 .7351074219153 .9165039062 158.7929992676163 .3648071289167 .9365997314171 .8988037109176 .165802002 179.8231964111183 .4806976318186 .8332977295190 .1858978271193 .233795166 195.9768066406198 .7198944092201 .158203125203 .2917022705205 .425201416 207.5587005615209 .3874053955210 .9113006592212 .4351959229213 .959197998 215.1782989502216 .0926971436217 .0070037842217 .9214019775218 .5308990479 219.1405029297219 .4452972412219 .7501068115220 .054901123220 .054901123 
220.054901123219 .7501068115219 .4452972412219 .1405029297218 .5308990479 217.9214019775217 .0070037842216 .3973999023215 .1782989502214 .2639007568 213.0447998047211 .8256988525210 .6065063477209 .3874053955208 .1681976318 206.6443023682205 .425201416203 .9011993408202 .3773040771200 .8533935547 199.329498291197 .500793457195 .9768066406194 .1481018066192 .3193969727 190.4907073975188 .6620025635186 .528503418184 .3950042725182 .5662994385 180.1280059814177 .9945068359175 .8609924316173 .4226989746171 .2891998291 168.8509979248166 .4127044678164 .2792053223161 .8408966064159 .7073974609 157.878692627156 .3547973633155 .1356048584154 .5260925293154 .5260925293 154.5260925293154 .5260925293154 .5260925293154 .8307952881155 .1356048584 155.1356048584155 .4403991699155 .4403991699155 .7451934814155 .7451934814 155.7451934814156 .0500030518156 .0500030518156 .0500030518156 .0500030518 156.0500030518156 .0500030518156 .0500030518155 .7451934814155 .7451934814 155.7451934814155 .7451934814155 .7451934814155 .7451934814155 .4403991699 155.1356048584154 .5260925293153 .6116943359152 .6972961426151 .4781951904 149.9542999268148 .1255950928146 .2969055176144 .4682006836142 .3347015381 140.2012023926137 .7628936768135 .6293945312133 .1911010742131 .0576019287 129.2288970947 127.4001998901 125.8762969971 124.3523025513123.43800354 122.5235977173121 .6092987061120 .9997024536120 .9997024536121 .9140014648 122.8283996582125 .2667007446129 .533706665135 .3246002197138 .9819946289 139.8963928223138 .9819946289137 .4580993652138 .0677032471138 .6772003174 139.2868041992139 .5915985107139 .8963928223139 .8963928223140 .5059967041 140.8106994629141 .1154937744141 .1154937744141 .1154937744140 .8106994629 140.2012023926139 .5915985107138 .9819946289138 .0677032471137 .1533050537 136.2389984131135 .3246002197134 .4102020264133 .1911010742132 .2767028809 131.0576019287130 .1432037354129 .2288970947128 .3144989014127 .4001998901 126.7906036377126 .1809997559125 .5715026855124 .9618988037124 .3523025513 124.0475006104123 .43800354123 .1332015991122 .8283996582122 .8283996582 122.5235977173122 .5235977173122 .2188034058122 .2188034058122 .2188034058 122.2188034058122 .2188034058121 .9140014648121 .9140014648121 .9140014648 121.6092987061121 .6092987061121 .3044967651121 .3044967651120 .9997024536 120.9997024536120 .9997024536120 .9997024536120 .9997024536120 .9997024536 122.8283996582126 .7906036377132 .5814971924138 .9819946289144 .4682006836 167.9365997314186 .2236938477199 .329498291209 .692199707209 .692199707 209.692199707 209.692199707 209.692199707 209.692199707 209.692199707 209.692199707 209.692199707 209.692199707 209.692199707 209.692199707 209.692199707 209.692199707 209.692199707 209.692199707 209.692199707 209.692199707 209.692199707 209.692199707 209.692199707 209.692199707210.3016967773213.959197998 217.6165924072 221.2740020752224 .9313964844228 .2841033936231 .6367034912234 .9893035889 238.0372009277241 .0850067139243 .8280944824246 .5711975098249 .3141937256 251.7525024414253 .8860015869256 .3243103027258 .1530151367259 .9816894531 261.8103942871263 .3344116211264 .8583068848266 .3822021484267 .6012878418 268.5156860352269 .7348022461270 .6492004395271 .2587890625272 .1730957031 272.7827148438273 .0874938965273 .6971130371273 .6971130371274 .0018005371 274.0018005371274 .0018005371274 .0018005371274 .0018005371274 .0018005371 273.6971130371273 .3923034668273 .3923034668273 .0874938965272 .4779052734 
272.1730957031271 .8682861328271 .5635070801271 .2587890625270 .9540100098 270.9540100098271 .5635070801272 .4779052734273 .3923034668274 .0018005371 275.2210083008275 .2210083008273 .6971130371276 .7449035645277 .0497131348 272.4779052734261 .8103942871242 .9136962891215 .787902832184 .699798584 164.3545227051148 .0549468994 -9999 -9999 -9999 -9999 -9999 -9999 -9999 -9999 -9999 -9999 -9999 -9999 -9999 -9999 -9999 -9999 -9999 -9999 -9999 -9999 -9999 -9999 -9999 -9999 -9999 -9999 -9999 -9999 -9999 -9999 -9999 -9999 -9999 -9999 -9999 -9999 -9999 -9999 -9999

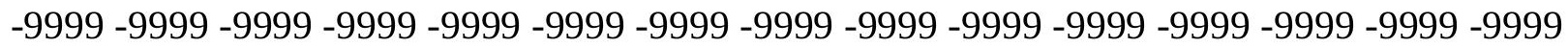
-9999 -9999 -9999 -9999 -9999 -9999 -9999 -9999

-9999 -9999 -9999 -9999 -9999 -9999 -9999 -9999 -9999 -9999 -9999 -9999 -46.805770874 -39.6136016846 -32.307220459-24.9923801422 -17.6775398254 -10.3626899719 -3.04785108566 4.26699209213311.88661956787 19.20145988464 26.82109069824 34.4407196044942 .0603485107449 .6799812316957 .2995986938564 .61444854736 71.9292907714879 .2441329956186 .254188537693 .26425170898100 .2742996216 106.979598999113 .3800964355119 .7806015015125 .8762969971131 .6672058105 137.4580993652142 .9441986084148 .1255950928153 .0021057129157 .878692627 162.4505004883166 .7174987793170 .9844970703174 .9467010498178 .604095459 181.9566955566185 .3094024658188 .3571929932191 .4051055908194 .1481018066 196.5863952637199 .0247039795201 .158203125203 .2917022705205 .1204071045 206.9490966797208 .4730072021209 .9969024658211 .2160949707212 .4351959229 213.6544036865214 .5686950684215 .1782989502215 .787902832216 .3973999023 217.0070037842217 .3117980957217 .3117980957217 .6165924072217 .3117980957 217.3117980957217 .0070037842216 .7021942139216 .0926971436215 .4830932617 214.8735046387213 .959197998213 .0447998047212 .1304016113210 .9113006592 209.692199707 208.7778015137207.5587005615 206.0346984863204.8155975342 203.596496582202 .0724945068200 .8533935547199 .329498291197 .8054962158 196.2816009521194 .7577056885193 .233795166191 .4051055908189 .8811035156 188.0523986816186 .2236938477184 .3950042725182 .261505127180 .432800293 178.2993011475176 .165802002174 .0323028564171 .8988037109169 .4604949951 167.3269958496165 .1934967041163 .3648071289161 .2312927246159 .7073974609 158.1835021973156 .9642944336156 .3547973633156 .0500030518155 .7451934814 155.7451934814156 .0500030518156 .0500030518156 .0500030518156 .3547973633 156.3547973633156 .3547973633156 .3547973633156 .3547973633156 .3547973633 156.3547973633156 .3547973633156 .3547973633156 .3547973633156 .3547973633 156.0500030518156 .0500030518155 .7451934814155 .7451934814155 .7451934814 155.4403991699155 .4403991699155 .1356048584154 .8307952881154 .5260925293 153.6116943359152 .6972961426151 .1734008789149 .9542999268148 .1255950928 146.6015930176144 .4682006836142 .6394042969140 .5059967041138 .3724975586 136.2389984131134 .1054992676131 .9720001221130 .1432037354128 .3144989014 126.4858016968125 .2667007446124 .0475006104123 .43800354122 .8283996582 121.9140014648122 .2188034058120 .9997024536122 .2188034058124 .9618988037 129.2288970947134 .7149963379140 .8106994629139 .5915985107138 .9819946289 138.6772003174138 .0677032471138 .3724975586138 .9819946289139 .5915985107 140.2012023926140 .2012023926140 .5059967041140 .8106994629141 .4203033447 141.4203033447141 .7250976562141 .4203033447141 .1154937744140 .8106994629 140.2012023926139 .2868041992138 .3724975586137 .4580993652136 .5437011719 
135.3246002197134 .4102020264133 .1911010742131 .9720001221131 .0576019287 129.8385009766128 .9241027832128 .0097961426127 .4001998901126 .4858016968 125.8762969971125 .2667007446124 .6570968628124 .0475006104123 .7427978516 123.1332015991122 .8283996582122 .5235977173122 .5235977173122 .2188034058 122.2188034058121 .9140014648121 .9140014648121 .9140014648121 .9140014648 121.9140014648121 .9140014648121 .9140014648121 .9140014648121 .9140014648 121.9140014648121 .6092987061121 .3044967651121 .3044967651120 .9997024536 120.9997024536121 .3044967651121 .6092987061121 .3044967651121 .9140014648 124.9618988037130 .1432037354137 .1533050537144 .4682006836155 .7451934814 174.0323028564188 .6620025635200 .8533935547209 .692199707209 .692199707 209.692199707 209.692199707 209.692199707 209.692199707 209.692199707209.692199707 209.692199707 209.692199707 209.692199707 209.692199707 209.692199707 209.692199707 209.692199707 209.692199707 209.692199707 209.692199707 209.692199707 209.692199707 209.692199707209 .692199707212 .1304016113215 .787902832219 .4452972412 222.7978973389226 .4553985596229 .8079986572233 .1605987549236 .5133056641 239.5610961914242 .3041992188245 .0471954346247 .7902984619250 .2286071777 252.6669006348255 .1051025391256 .9338989258259 .0674133301260 .8960876465 262.4200134277263 .9439086914265 .4678039551266 .6870117188267 .9060974121 269.1253051758270 .0396118164270 .9540100098271 .5635070801272 .1730957031 272.7827148438273 .0874938965273 .3923034668273 .6971130371274 .0018005371 274.0018005371274 .0018005371274 .0018005371274 .0018005371273 .6971130371 273.3923034668273 .3923034668273 .0874938965272 .4779052734272 .1730957031 271.8682861328271 .5635070801271 .2587890625270 .9540100098270 .9540100098 271.2587890625271 .5635070801272 .4779052734273 .0874938965274 .0018005371 275.2210083008276 .7449035645279 .7927856445282 .5357971191281 .9262084961 275.8305053711259 .9816894531231 .6367034912198 .4151000977172 .6294708252 153.4412994385 -9999 -9999 -9999 -9999 -9999 -9999 -9999 -9999 -9999 -9999 -9999 -9999 -9999 -9999 -9999 -9999 -9999 -9999 -9999 -9999 -9999 -9999 -9999 -9999 -9999 -9999 -9999 -9999 -9999 -9999 -9999 -9999 -9999 -9999 -9999 -9999 -9999 -9999 -9999 -9999 -9999 -9999

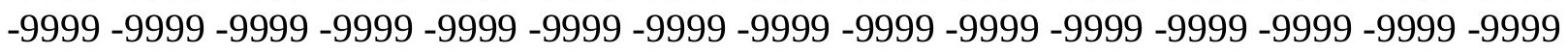
-9999 -9999-9999-9999-9999

-9999 -9999 -9999 -9999 -9999 -9999 -9999 -9999 -9999 -9999 -9999 -9999 -48.3010101318 $-41.0554084778-33.8311500549-26.5163097382-19.2014598846-11.5818300247$ $-4.266992092133 .04785108566310 .6674804687518 .28710937526 .21151924133$ 33.8311500549341 .4507789611849 .0704002380456 .6900291442964 .30966186523 71.6244964599678 .9393463134886 .254188537693 .2642517089899 .96952056885 106.6747970581113 .3800964355119 .4757995605125 .5715026855131 .3623962402 137.1533050537142 .3347015381147 .5160064697152 .6972961426157 .2691040039 161.8408966064166 .1078948975170 .070098877173 .7274932861177 .3849029541 180.7375946045183 .7854003906186 .8332977295189 .5764007568192 .3193969727 194.7577056885196 .891204834199 .0247039795201 .158203125202 .9868927002 204.5108032227206 .0346984863207 .5587005615208 .7778015137209 .9969024658 210.9113006592211 .8256988525212 .7400054932213 .3495941162213 .959197998 214.2639007568214 .5686950684214 .8735046387214 .8735046387214 .8735046387 214.8735046387214 .5686950684214 .2639007568213 .6544036865213 .0447998047 212.4351959229211 .520904541210 .9113006592209 .692199707208 .7778015137 
207.8634033203206 .6443023682205 .425201416204 .2059936523202 .9868927002 201.7678070068200 .5485992432199 .329498291198 .1103057861196 .5863952637 195.3672943115193 .8433074951192 .3193969727190 .795501709189 .2716064453 187.4429016113185 .9188995361184 .0901947021182 .261505127180 .432800293 178.2993011475176 .4705963135174 .6419067383172 .5084075928170 .3748931885 168.5462036133166 .7174987793164 .5839996338163 .0599975586161 .5361022949 160.0122070312159 .0977935791158 .1835021973157 .878692627157 .5738983154 157.2691040039 157.2691040039 157.2691040039 157.2691040039 157.2691040039 157.2691040039 157.2691040039 157.2691040039 157.2691040039 156.9642944336 156.9642944336156 .9642944336156 .6596069336156 .6596069336156 .3547973633 156.0500030518156 .0500030518155 .7451934814155 .4403991699155 .1356048584 154.8307952881154 .5260925293154 .2212982178153 .9165039062153 .3069000244 152.6972961426151 .1734008789149 .6495056152148 .1255950928146 .2969055176 144.4682006836142 .6394042969140 .8106994629138 .6772003174136 .5437011719 134.7149963379132 .5814971924130 .7528076172128 .9241027832127 .0953979492 125.5715026855124 .3523025513123 .43800354123 .1332015991123 .1332015991 121.9140014648122 .2188034058121 .9140014648121 .9140014648126 .4858016968 132.2767028809137 .4580993652138 .9819946289138 .0677032471138 .6772003174 138.6772003174138 .9819946289139 .2868041992139 .8963928223140 .5059967041 140.8106994629141 .1154937744141 .4203033447141 .7250976562142 .0299072266 142.3347015381142 .3347015381142 .0299072266141 .7250976562141 .1154937744 140.5059967041139 .8963928223138 .6772003174137 .7628936768136 .5437011719 135.6293945312134 .4102020264133 .1911010742131 .9720001221130 .7528076172 129.8385009766128 .9241027832128 .0097961426127 .0953979492126 .1809997559 125.5715026855124 .9618988037124 .3523025513123 .7427978516123 .43800354 123.1332015991122 .5235977173122 .5235977173122 .2188034058121 .9140014648 121.9140014648121 .6092987061121 .6092987061121 .6092987061121 .6092987061 121.6092987061121 .6092987061121 .9140014648121 .9140014648121 .9140014648 121.9140014648121 .6092987061121 .3044967651121 .3044967651121 .3044967651 121.3044967651121 .3044967651120 .9997024536120 .6949005127120 .9997024536 122.8283996582127 .4001998901135 .3246002197144 .7729034424152 .0877990723 161.5361022949176 .7754058838189 .5764007568200 .8533935547209 .692199707 209.692199707 209.692199707 209.692199707 209.692199707 209.692199707 209.692199707 209.692199707 209.692199707 209.692199707 209.692199707 209.692199707 209.692199707 209.692199707209 .692199707209 .692199707209 .692199707209 .692199707209 .692199707 209.692199707209 .692199707209 .9969024658213 .6544036865217 .3117980957 220.9691925049224 .6266021729227 .9792938232231 .6367034912234 .6844940186 238.0372009277240 .7801971436243 .8280944824246 .5711975098249 .0093994141 251.4476928711253 .8860015869256 .0195007324258 .1530151367259 .9816894531 261.5056152344263 .3344116211264 .8583068848266 .0773925781267 .2966003418 268.5156860352269 .4301147461270 .3443908691271 .2587890625271 .8682861328 272.4779052734272 .7827148438273 .3923034668273 .3923034668273 .6971130371 273.6971130371274 .0018005371274 .0018005371273 .6971130371273 .6971130371 273.6971130371273 .3923034668273 .0874938965272 .7827148438272 .4779052734 272.1730957031271 .8682861328271 .5635070801271 .2587890625271 .2587890625 271.5635070801271 .8682861328272 .4779052734273 .6971130371274 .9161987305 
277.0497131348280 .0975036621284 .0596923828287 .7171936035289 .2410888672 286.8027954102278 .5736083984245 .3520050049209 .3874053955180 .5306854248 159.1559753418143 .4895172119 -9999 -9999 -9999 -9999 -9999 -9999 -9999 -9999 -9999 -9999 -9999 -9999 -9999 -9999 -9999 -9999 -9999 -9999 -9999 -9999 -9999 -9999 -9999 -9999 -9999 -9999 -9999 -9999 -9999 -9999 -9999 -9999 -9999-9999 -9999 -9999 -9999 -9999 -9999 -

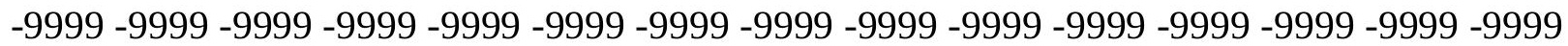
-9999 -9999 -9999 -9999 -9999 -9999 -9999

-9999 -9999-9999 -9999-9999 -9999 -9999-9999 -9999 -9999 -9999 -9999 -49.7080383301 $-42.3931655884-35.0502891541-27.7354507446-20.4206008911-12.8009700775$ -5.181346893312.133496046066 9.753124237061 17.67753982544 25.29715919495 33.2215805053740 .8412094116248 .765621185356 .3852500915564 .0048828125 71.3197174072378 .9393463134885 .9494018554792 .9594726562599 .96952056885 106.6747970581113 .075302124119 .4757995605125 .5715026855131 .3623962402 136.8484954834142 .3347015381147 .2111968994152 .0877990723156 .6596069336 161.2312927246165 .1934967041169 .1557006836172 .8132019043176 .165802002 179.5184020996182 .5662994385185 .3094024658188 .0523986816190 .4907073975 192.9290008545195 .0625196 .891204834199 .0247039795200 .5485992432202 .3773040771 203.596496582205 .1204071045206 .3394927979207 .25390625208 .4730072021 209.3874053955 209.9969024658210.6065063477211.2160949707 211.8256988525 212.1304016113212 .4351959229212 .4351959229212 .4351959229212 .4351959229 212.1304016113211 .8256988525211 .2160949707210 .6065063477209 .9969024658 209.3874053955 208.4730072021207.5587005615 206.6443023682 205.7299957275 204.5108032227203 .596496582202 .3773040771201 .158203125200 .2438049316 199.0247039795197 .8054962158196 .5863952637195 .3672943115194 .1481018066 192.9290008545191 .4051055908189 .8811035156188 .6620025635187 .1381072998 185.3094024658183 .7854003906181 .9566955566180 .432800293178 .604095459 176.7754058838174 .9467010498173 .1179962158171 .2891998291169 .7653045654 167.9365997314166 .1078948975164 .5839996338163 .3648071289162 .1457061768 161.2312927246160 .3170013428159 .7073974609159 .4026031494159 .0977935791 158.7929992676158 .4882965088158 .4882965088158 .4882965088158 .1835021973 158.1835021973157 .878692627157 .878692627157 .5738983154157 .5738983154 157.2691040039156 .9642944336156 .6596069336156 .3547973633156 .0500030518 155.7451934814155 .4403991699154 .8307952881154 .5260925293154 .2212982178 153.6116943359153 .0021057129152 .6972961426151 .7830047607150 .8686065674 149.3446960449147 .8208007812145 .9920959473144 .4682006836142 .6394042969 140.8106994629138 .6772003174136 .8484954834135 .0198059082132 .8863067627 131.0576019287129 .2288970947127 .7050018311126 .1809997559124 .6570968628 123.7427978516124 .0475006104123 .7427978516123 .43800354121 .9140014648 121.9140014648121 .6092987061121 .9140014648128 .6192932129135 .0198059082 140.5059967041139 .8963928223138 .9819946289138 .9819946289138 .9819946289 139.5915985107140 .2012023926140 .8106994629141 .4203033447141 .7250976562 142.0299072266142 .3347015381142 .6394042969142 .9441986084142 .9441986084 142.9441986084142 .6394042969142 .3347015381141 .7250976562141 .1154937744 140.2012023926139 .2868041992138 .0677032471136 .8484954834135 .6293945312 134.4102020264133 .1911010742131 .9720001221130 .7528076172129 .8385009766 128.6192932129127 .7050018311126 .7906036377126 .1809997559125 .5715026855 
124.6570968628124 .3523025513123 .7427978516123 .1332015991122 .8283996582 122.5235977173122 .2188034058121 .9140014648121 .6092987061121 .6092987061 121.6092987061121 .6092987061121 .6092987061121 .6092987061121 .6092987061 121.6092987061121 .6092987061121 .9140014648121 .9140014648121 .9140014648 121.6092987061121 .6092987061121 .3044967651121 .3044967651121 .3044967651 120.9997024536120 .6949005127120 .3900985718120 .3900985718121 .3044967651 124.0475006104132 .8863067627143 .2489929199153 .6116943359154 .2212982178 163.974395752177 .3849029541189 .2716064453200 .2438049316209 .692199707 209.692199707 209.692199707 209.692199707 209.692199707 209.692199707 209.692199707 209.692199707209 .692199707209 .692199707209 .692199707209 .692199707209 .692199707 209.692199707209 .692199707209 .692199707209 .692199707209 .692199707209 .692199707 209.692199707 209.692199707 211.8256988525 215.4830932617219.1405029297 222.7978973389226 .4553985596229 .8079986572233 .1605987549236 .5133056641 239.5610961914242 .6089935303245 .3520050049247 .7902984619250 .5334014893 252.6669006348255 .1051025391256 .9338989258259 .0674133301260 .8960876465 262.4200134277263 .9439086914265 .4678039551266 .6870117188267 .9060974121 268.8204956055269 .7348022461270 .6492004395271 .5635070801272 .1730957031 272.4779052734273 .0874938965273 .3923034668273 .3923034668273 .6971130371 273.6971130371273 .6971130371273 .6971130371273 .6971130371273 .6971130371 273.3923034668273 .0874938965273 .0874938965272 .7827148438272 .4779052734 272.1730957031271 .8682861328271 .5635070801271 .8682861328271 .8682861328 272.4779052734273 .3923034668274 .6113891602276 .4400939941278 .8783874512 282.5357971191286 .4979858398290 .4602050781292 .5936889648289 .5458984375 277.0497131348 251.1428985596 217.9214019775 186.2236938477 164.6770324707 148.1806945801 -9999 -9999 -9999 -9999 -9999 -9999 -9999 -9999 -9999 -9999 -9999 -9999

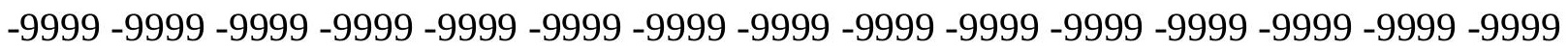

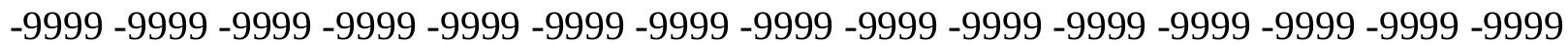
-9999 -9999-9999 -9999-9999 -9999

-9999 -9999 -9999 -9999 -9999 -9999 -9999 -9999 -9999 -9999 -9999 -9999 -51.0385322571 $-43.6642875671-36.2694282532-28.9545898438$-21.6397399902 -14.0201196671 $-6.400486946111 .219141006478 .83876895904516 .7631797790524 .68759918213$ 32.6120109558140 .5364189147948 .4608306884856 .0804595947363 .70008850098 71.3197174072378 .6345596313585 .9494018554793 .2642517089899 .96952056885 106.6747970581113 .3800964355119 .4757995605125 .5715026855131 .3623962402 136.8484954834142 .0299072266147 .2111968994151 .7830047607156 .3547973633 160.6217956543164 .5839996338168 .241394043171 .8988037109175 .2514038086 178.2993011475181 .0424041748183 .7854003906186 .528503418188 .966796875 191.1002960205192 .9290008545195 .0625196 .891204834198 .4151000977199 .9389953613 201.158203125202 .6820983887203 .596496582204 .8155975342205 .7299957275 206.6443023682207 .25390625208 .1681976318208 .7778015137209 .0825958252 209.3874053955 209.692199707 209.9969024658 209.9969024658 209.692199707 209.692199707 209.3874053955208.7778015137208.4730072021207.8634033203 206.9490966797206 .3394927979205 .425201416204 .5108032227203 .596496582 202.6820983887201 .4629974365200 .5485992432199 .6342926025198 .4151000977 197.500793457 196.2816009521 195.3672943115 194.1481018066192.9290008545 
191.7097930908190 .4907073975189 .2716064453187 .7476043701186 .528503418 185.0045928955183 .4806976318181 .9566955566180 .432800293178 .604095459 177.0802001953175 .5561981201174 .0323028564172 .2035980225170 .6797027588 169.1557006836167 .6318054199166 .4127044678165 .1934967041163 .974395752 163.0599975586162 .1457061768161 .5361022949160 .9264984131160 .6217956543 160.3170013428160 .0122070312159 .7073974609159 .4026031494159 .0977935791 159.0977935791158 .7929992676158 .4882965088158 .1835021973157 .878692627 157.5738983154157 .2691040039156 .6596069336156 .3547973633155 .7451934814 155.4403991699154 .8307952881154 .2212982178153 .6116943359153 .0021057129 152.3925933838151 .7830047607150 .8686065674149 .9542999268148 .7351074219 147.2111968994145 .6873016357143 .8585968018142 .3347015381140 .5059967041 138.6772003174136 .8484954834135 .0198059082133 .1911010742131 .3623962402 129.533706665128 .0097961426126 .4858016968125 .2667007446123 .7427978516 124.3523025513124 .0475006104123 .7427978516123 .43800354122 .2188034058 123.7427978516125 .5715026855128 .0097961426132 .5814971924137 .1533050537 140.2012023926140 .8106994629140 .2012023926139 .5915985107139 .5915985107 140.5059967041141 .1154937744141 .7250976562142 .3347015381142 .9441986084 143.2489929199143 .5538024902143 .8585968018143 .8585968018143 .8585968018 143.8585968018143 .5538024902143 .2489929199142 .6394042969141 .7250976562 140.8106994629139 .8963928223138 .6772003174137 .4580993652135 .9342041016 134.7149963379133 .1911010742131 .9720001221130 .7528076172129 .533706665 128.6192932129127 .7050018311126 .7906036377126 .1809997559125 .2667007446 124.6570968628124 .0475006104123 .43800354123 .1332015991122 .5235977173 122.2188034058121 .9140014648121 .6092987061121 .6092987061121 .6092987061 121.3044967651121 .3044967651121 .3044967651121 .3044967651121 .6092987061 121.6092987061121 .6092987061121 .9140014648121 .9140014648121 .9140014648 121.9140014648121 .6092987061121 .6092987061121 .3044967651121 .3044967651 120.9997024536120 .6949005127120 .0852966309120 .0852966309120 .9997024536 124.0475006104130 .1432037354137 .7628936768144 .4682006836147 .8208007812 150.5639038086163 .974395752176 .7754058838189 .2716064453200 .2438049316 209.0825958252 209.692199707209.692199707 209.692199707 209.692199707 209.692199707 209.692199707 209.692199707 209.692199707 209.692199707 209.692199707 209.692199707 209.692199707 209.692199707 209.692199707 209.692199707 209.692199707 209.692199707 209.692199707 209.692199707 209.9969024658 213.959197998 217.6165924072221 .2740020752224 .9313964844228 .2841033936231 .9414978027 234.9893035889238 .3419952393241 .0850067139244 .1329040527246 .8759002686 249.3141937256251 .7525024414254 .1907958984256 .3243103027258 .1530151367 259.9816894531261 .8103942871263 .3344116211264 .8583068848266 .0773925781 267.2966003418268.5156860352 269.4301147461270.3443908691270.9540100098 271.5635070801272 .1730957031272 .7827148438273 .0874938965273 .3923034668 273.6971130371273 .6971130371273 .6971130371273 .6971130371273 .6971130371 273.6971130371273 .6971130371273 .3923034668273 .3923034668273 .0874938965 272.7827148438272 .7827148438272 .4779052734272 .1730957031272 .4779052734 272.7827148438273 .0874938965274 .0018005371275 .2210083008277 .0497131348 279.4880065918282 .8406066895286 .8027954102290 .1553955078291 .3746032715 287.7171936035274 .6113891602252 .3621063232223 .7122955322193 .8433074951 
170.3638458252152 .958190918 -9999 -9999 -9999 -9999 -9999 -9999 -9999 -9999 -9999 -9999 -9999 -9999 -9999 -9999 -9999 -9999 -9999 -9999 -9999 -9999 -9999 -9999 -9999 -9999

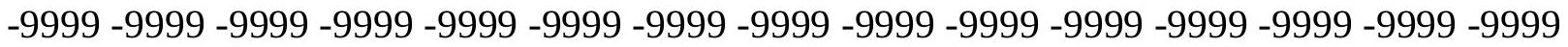
-9999 -9999 -9999 -9999 -9999 -9999 -9999 -9999 -9999 -9999 -9999 -9999 -9999 -9999 -9999 -9999 -9999 -9999 -9999-9999-9999-9999

-9999 -9999 -9999 -9999 -9999 -9999 -9999 -9999 -9999 -9999 -9999 -9999 -9999 $-44.8906898499-37.488571167-30.1737308502-22.5541000366-14.9344701767$ $-7.3148431778 .30478510260588 .22919845581116 .1536102294924 .07802963257$ 32.3072204589840 .2316398620648 .1560516357456 .0804595947363 .70008850098 71.3197174072378 .9393463134886 .254188537693 .26425170898100 .2742996216 106.979598999113 .3800964355119 .7806015015125 .8762969971131 .3623962402 136.8484954834142 .0299072266146 .9064025879151 .4781951904156 .0500030518 160.0122070312163 .974395752167 .6318054199170 .9844970703174 .0323028564 177.0802001953179 .8231964111182 .5662994385185 .0045928955187 .1381072998 189.2716064453 191.1002960205192.9290008545194.7577056885196.2816009521 197.500793457199 .0247039795200 .2438049316201 .158203125202 .3773040771 203.2917022705203 .9011993408204 .8155975342205 .425201416206 .0346984863 206.6443023682206 .9490966797207 .25390625207 .25390625207 .25390625207 .25390625 207.25390625206 .9490966797206 .6443023682206 .0346984863205 .425201416 204.8155975342203 .9011993408203 .2917022705202 .3773040771201 .4629974365 200.5485992432199 .6342926025198 .7198944092197 .8054962158196 .891204834 195.9768066406 195.0625 194.1481018066192.9290008545192.0146026611 190.795501709 189.5764007568188 .3571929932187 .1381072998185 .6141052246184 .3950042725 182.87109375181 .3471984863180 .1280059814178 .604095459177 .0802001953 175.8609924316174 .337097168173 .1179962158171 .5939941406170 .3748931885 169.1557006836167 .9365997314166 .7174987793165 .8031005859164 .8887023926 163.974395752163 .3648071289162 .7552947998162 .1457061768161 .8408966064 161.2312927246160 .9264984131160 .6217956543160 .0122070312159 .7073974609 159.4026031494159 .0977935791158 .4882965088158 .1835021973157 .5738983154 157.2691040039156 .6596069336156 .0500030518155 .4403991699154 .8307952881 154.2212982178153 .3069000244152 .6972961426151 .7830047607150 .8686065674 149.9542999268149 .0399017334147 .8208007812146 .6015930176145 .0776977539 143.5538024902141 .7250976562140 .2012023926138 .3724975586136 .5437011719 134.7149963379132 .8863067627131 .3623962402129 .533706665128 .0097961426 126.4858016968125 .2667007446124 .0475006104124 .6570968628124 .6570968628 124.3523025513124 .0475006104123 .7427978516123 .1332015991125 .8762969971 130.1432037354134 .4102020264137 .4580993652139 .5915985107141 .1154937744 141.4203033447140 .8106994629140 .2012023926140 .8106994629141 .4203033447 142.3347015381142 .9441986084143 .5538024902144 .1634063721144 .4682006836 144.7729034424144 .7729034424145 .0776977539144 .7729034424144 .7729034424 144.4682006836143 .8585968018143 .2489929199142 .6394042969141 .7250976562 140.5059967041139 .2868041992137 .7628936768136 .2389984131135 .0198059082 133.4958953857131 .9720001221130 .7528076172129 .8385009766128 .6192932129 127.7050018311127 .0953979492126 .1809997559125 .2667007446124 .6570968628 124.0475006104123 .43800354122 .8283996582122 .5235977173122 .2188034058 121.9140014648121 .6092987061121 .3044967651121 .3044967651121 .3044967651 
121.3044967651 121.3044967651 121.3044967651 121.3044967651 121.6092987061 121.6092987061121 .9140014648121 .9140014648121 .9140014648121 .9140014648 121.6092987061121 .6092987061121 .6092987061121 .3044967651120 .9997024536 120.6949005127120 .3900985718120 .3900985718120 .9997024536122 .8283996582 126.1809997559130 .1432037354134 .1054992676138 .3724975586143 .8585968018 150.2590942383162 .7552947998177 .3849029541191 .1002960205200 .2438049316 206.3394927979 209.692199707 209.692199707 209.692199707 209.692199707 209.692199707 209.692199707 209.692199707 209.692199707 209.692199707 209.692199707 209.692199707 209.692199707 209.692199707 209.692199707 209.692199707209.692199707 209.692199707 209.692199707 209.692199707 212.1304016113216.0926971436 219.7501068115223 .4075012207227 .0648956299230 .4176025391233 .7702026367 237.1228027344240 .1707000732242 .9136962891245 .6567993164248 .3999023438 250.8381958008253 .2763977051255 .4098968506257 .5433959961259 .3721008301 261.2008972168262 .7247924805264 .2486877441265 .7726135254266 .9917907715 267.9060974121269 .1253051758270 .0396118164270 .6492004395271 .2587890625 271.8682861328272 .4779052734272 .7827148438273 .0874938965273 .3923034668 273.6971130371273 .6971130371273 .6971130371273 .6971130371273 .6971130371 273.6971130371273 .6971130371273 .6971130371273 .6971130371273 .3923034668 273.0874938965273 .0874938965272 .7827148438273 .0874938965273 .3923034668 273.6971130371274 .6113891602275 .5257873535277 .0497131348278 .8783874512 281.3167114258 284.3645019531287.1076049805 287.7171936035 284.0596923828 272.4779052734252 .6669006348226 .7601013184199 .6342926025175 .2514038086 158.029876709 144.3883361816 -9999 -9999 -9999 -9999 -9999 -9999 -9999 -9999 -9999

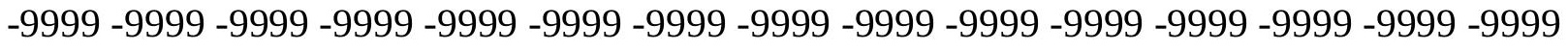
-9999 -9999 -9999 -9999 -9999 -9999 -9999 -9999 -9999 -9999 -9999 -9999 -9999 -9999 -9999 -9999 -9999 -9999 -9999 -9999 -9999 -9999 -9999 -9999 -9999 -9999 -9999 -9999 -9999 -9999 -9999 -9999 -9999-9999-9999-9999

-9999 -9999 -9999 -9999 -9999 -9999 -9999 -9999 -9999 -9999 -9999 -9999 -9999 $-46.0402984619-38.5702514648-31.0880794525-23.7732391357-15.8488302231$ -8.22919845581 -.304785102606 7.619627952576 15.5440397262623 .77323913574 31.6976509094239 .9268493652347 .8512611389256 .0804595947363 .70008850098 71.6244964599679 .2441329956186 .5589828491293 .56903076172100 .5791015625 107.2844009399 113.9896011353120 .0852966309126 .1809997559131 .6672058105 137.1533050537142 .3347015381146 .9064025879151 .4781951904155 .7451934814 159.7073974609163 .3648071289167 .0222015381170 .3748931885173 .1179962158 176.165802002178 .604095459181 .0424041748183 .4806976318185 .6141052246 187.4429016113189 .2716064453190 .795501709192 .624206543193 .8433074951 195.3672943115196 .5863952637197 .8054962158198 .7198944092199 .6342926025 200.5485992432201 .4629974365202 .0724945068202 .6820983887203 .2917022705 203.9011993408204 .2059936523204 .5108032227204 .8155975342204 .8155975342 204.8155975342204 .8155975342204 .5108032227204 .2059936523203 .596496582 202.9868927002202 .3773040771201 .7678070068201 .158203125200 .2438049316 199.329498291 198.7198944092197.8054962158 196.891204834195.9768066406 195.3672943115194 .4528961182193 .5386047363192 .624206543191 .7097930908 190.795501709189 .8811035156188 .6620025635187 .4429016113186 .2236938477 185.0045928955183 .4806976318182 .261505127181 .0424041748179 .5184020996 
178.2993011475 177.0802001953175.8609924316174.6419067383173.4226989746 172.5084075928171 .2891998291170 .3748931885169 .4604949951168 .241394043 167.3269958496166 .4127044678165 .8031005859164 .8887023926164 .2792053223 163.6696014404163 .0599975586162 .4505004883161 .8408966064161 .5361022949 160.9264984131160 .3170013428160 .0122070312159 .4026031494158 .7929992676 158.1835021973157 .5738983154156 .9642944336156 .3547973633155 .7451934814 154.8307952881154 .2212982178153 .3069000244152 .3925933838151 .4781951904 150.2590942383149 .3446960449148 .1255950928146 .9064025879145 .6873016357 144.1634063721142 .6394042969141 .1154937744139 .5915985107137 .7628936768 136.2389984131134 .4102020264132 .8863067627131 .0576019287129 .533706665 128.0097961426126 .4858016968125 .2667007446125 .2667007446124 .9618988037 124.6570968628124 .6570968628124 .3523025513124 .0475006104124 .0475006104 123.1332015991127 .4001998901133 .1911010742139 .8963928223140 .8106994629 141.7250976562142 .0299072266142 .3347015381142 .0299072266141 .7250976562 142.3347015381142 .9441986084143 .5538024902144 .4682006836144 .7729034424 145.3825073242145 .6873016357145 .9920959473145 .9920959473145 .9920959473 145.9920959473145 .6873016357145 .3825073242145 .0776977539144 .1634063721 143.5538024902142 .3347015381141 .1154937744139 .8963928223138 .3724975586 136.8484954834135 .3246002197133 .8007049561132 .2767028809131 .0576019287 129.8385009766128 .9241027832128 .0097961426127 .0953979492126 .1809997559 125.5715026855124 .6570968628124 .0475006104123 .43800354122 .8283996582 122.5235977173121 .9140014648121 .6092987061121 .3044967651121 .3044967651 120.9997024536120 .9997024536120 .9997024536120 .9997024536121 .3044967651 121.3044967651 121.3044967651 121.6092987061 121.6092987061 121.6092987061 121.9140014648121 .9140014648121 .9140014648121 .6092987061121 .6092987061 121.6092987061121 .3044967651120 .9997024536120 .6949005127120 .6949005127 120.6949005127121 .3044967651122 .2188034058122 .8283996582124 .0475006104 127.4001998901135 .9342041016146 .6015930176154 .8307952881164 .5839996338 181.9566955566189 .5764007568195 .3672943115201 .158203125206 .6443023682 209.692199707 209.692199707 209.692199707 209.692199707 209.692199707 209.692199707 209.692199707 209.692199707 209.692199707 209.692199707 209.692199707 209.692199707 209.692199707209.692199707209.692199707209.692199707209.692199707 210.6065063477214 .5686950684218 .2261962891221 .883605957225 .5410003662 229.1983947754232 .5511016846235 .9037017822238 .9515075684241 .9994049072 245.0471954346247 .4855041504250 .2286071777252 .6669006348254 .8003997803 256.9338989258258 .7626037598260 .5913085938262 .4200134277263 .9439086914 265.1630859375266 .3822021484267 .6012878418268 .8204956055269 .7348022461 270.3443908691271 .2587890625271 .8682861328272 .1730957031272 .7827148438 273.0874938965273 .3923034668273 .6971130371273 .6971130371273 .6971130371 274.0018005371274 .0018005371274 .0018005371274 .0018005371274 .0018005371 274.0018005371274 .0018005371273 .6971130371273 .6971130371273 .3923034668 273.3923034668273 .6971130371274 .0018005371274 .6113891602275 .5257873535 276.1353149414277 .3544921875278 .2687988281280 .0975036621281 .9262084961 282.2309875488279.1831970215270.6492004395 251.1428985596228.2841033936 203.9011993408181 .3471984863163 .4370117188149 .2263641357 -9999 -9999 -9999 -9999 -9999 -9999 -9999 -9999 -9999 -9999 -9999 -9999 -9999 -9999 -9999 -9999 -9999 -9999 -9999 
-9999 -9999 -9999 -9999 -9999 -9999 -9999 -9999 -9999 -9999 -9999 -9999 -9999 -9999 -9999

-9999 -9999 -9999 -9999 -9999 -9999 -9999 -9999 -9999 -9999 -9999 -9999 -9999 -9999 -9999 -

-9999 -9999 -9999 -9999 -9999 -9999 -9999 -9999 -9999 -9999 -9999

-9999 -9999 -9999 -9999 -9999 -9999 -9999 -9999 -9999 -9999 -9999 -9999 -9999

$-47.0765075684-39.5548858643-32.0024414062-24.6875991821-16.7631797791$

-8.83876895905 -.914355397224 7.010057926178 15.23925971985 23.46845054626

31.6976509094239 .9268493652348 .1560516357456 .0804595947364 .0048828125

71.9292907714879 .5489196777386 .8637619018694 .17859649658101 .1886978149

107.8938980103114 .5991973877120 .6949005127126 .4858016968132 .2767028809

137.4580993652142 .3347015381147 .2111968994151 .4781951904155 .7451934814 159.7073974609163 .0599975586166 .4127044678169 .4604949951172 .5084075928 174.9467010498177 .6896972656179 .8231964111181 .9566955566183 .7854003906 185.6141052246187 .4429016113188 .966796875190 .4907073975191 .7097930908 192.9290008545194 .1481018066195 .0625196 .2816009521197 .1959991455198 .1103057861 198.7198944092199 .6342926025200 .2438049316200 .8533935547201 .158203125 201.7678070068202 .0724945068202 .3773040771202 .3773040771202 .3773040771 202.3773040771202 .0724945068201 .7678070068201 .4629974365200 .8533935547 200.2438049316199 .6342926025199 .0247039795198 .1103057861197 .500793457 196.5863952637195 .9768066406195 .0625194 .4528961182193 .5386047363192 .9290008545 192.3193969727191 .4051055908190 .4907073975189 .5764007568188 .6620025635 187.7476043701186 .528503418185 .3094024658183 .7854003906182 .5662994385 181.3471984863180 .1280059814178 .9089050293177 .6896972656176 .4705963135 175.5561981201174 .6419067383173 .7274932861172 .8132019043172 .2035980225 171.2891998291170 .3748931885169 .7653045654168 .8509979248167 .9365997314 167.3269958496166 .4127044678165 .8031005859164 .8887023926164 .2792053223 163.6696014404162 .7552947998162 .1457061768161 .5361022949160 .9264984131 160.3170013428159 .7073974609159 .0977935791158 .1835021973157 .5738983154 156.6596069336156 .0500030518155 .1356048584154 .2212982178153 .3069000244 152.0877990723150 .8686065674149 .9542999268148 .7351074219147 .5160064697 145.9920959473144 .7729034424143 .5538024902142 .0299072266140 .5059967041 138.9819946289137 .4580993652135 .6293945312134 .1054992676132 .5814971924 130.7528076172129 .2288970947127 .7050018311126 .4858016968125 .2667007446 125.2667007446125 .2667007446124 .9618988037124 .9618988037124 .6570968628 124.3523025513124 .3523025513124 .0475006104124 .0475006104128 .0097961426 133.8007049561138 .6772003174141 .4203033447142 .3347015381142 .9441986084 143.2489929199143 .2489929199143 .5538024902143 .8585968018144 .4682006836 145.0776977539145 .6873016357146 .2969055176146 .6015930176146 .9064025879 147.2111968994 147.2111968994 147.2111968994 147.2111968994146.9064025879 146.6015930176145 .9920959473145 .3825073242144 .4682006836143 .2489929199 142.0299072266140 .8106994629139 .2868041992137 .7628936768135 .9342041016 134.4102020264132 .8863067627131 .3623962402130 .1432037354129 .2288970947 128.3144989014127 .4001998901126 .4858016968125 .5715026855124 .9618988037 124.0475006104123 .43800354122 .8283996582122 .2188034058121 .9140014648 121.6092987061121 .3044967651120 .9997024536120 .9997024536120 .9997024536 120.9997024536120 .9997024536120 .9997024536121 .3044967651121 .3044967651 121.3044967651121 .6092987061121 .6092987061121 .6092987061121 .6092987061 
121.6092987061121 .6092987061121 .6092987061121 .6092987061121 .6092987061 121.3044967651121 .3044967651120 .6949005127120 .3900985718119 .7806015015 119.1709976196117 .9517974854116 .7326965332116 .1231002808128 .6192932129 142.0299072266154 .2212982178153 .6116943359164 .8887023926175 .5561981201 182.87109375189 .5764007568195 .9768066406202 .6820983887209 .692199707 209.692199707 209.692199707 209.692199707 209.692199707 209.692199707 209.692199707 209.692199707 209.692199707 209.692199707 209.692199707 209.692199707209.692199707 209.692199707 209.692199707 209.692199707 209.3874053955 213.0447998047 217.0070037842220 .6643981934224 .3218994141227 .9792938232231 .6367034912 234.9893035889238 .0372009277241 .0850067139244 .1329040527246 .8759002686 249.6190032959252 .0572967529254 .1907958984256 .3243103027258 .4577941895 260.2864990234261 .8103942871263 .3344116211264 .8583068848266 .0773925781 267.2966003418268 .5156860352269 .4301147461270 .0396118164270 .9540100098 271.5635070801272 .1730957031272 .4779052734273 .0874938965273 .3923034668 273.3923034668273 .6971130371274 .0018005371274 .0018005371274 .0018005371 274.0018005371274 .0018005371274 .0018005371274 .3066101074274 .3066101074 274.3066101074274 .0018005371274 .0018005371274 .0018005371274 .0018005371 274.3066101074274 .6113891602274 .9161987305274 .9161987305275 .2210083008 274.9161987305274 .3066101074276 .1353149414276 .1353149414272 .4779052734 263.3344116211247.4855041504 227.6744995117206.3394927979 185.9188995361 168.4276428223 154.0229797363 142.04737854 -9999 -9999 -9999 -9999 -9999 -9999 -9999 -9999 -9999 -9999 -9999 -9999 -9999 -9999 -9999 -9999 -9999 -9999 -9999 -9999 -9999 -9999 -9999 -9999 -9999 -9999 -9999 -9999 -9999 -9999 -9999 -9999 -9999 -9999-9999-9999-9999 -999 -

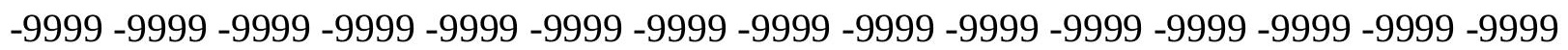
-9999 -9999 -9999 -9999 -9999 -9999 -9999

-9999 -9999 -9999 -9999 -9999 -9999 -9999 -9999 -9999 -9999 -9999 -9999 -9999 -47.9858169556 -40.4478302002 -32.9167900085 -25.2971591949 -17.3727493286 -9.44833946228 -1.52392601967 6.705273151398 14.934470176723 .16366958618 31.6976509094239 .9268493652348 .1560516357456 .3852500915564 .61444854736 72.5388565063580 .1584930419987 .7781066894595 .09295654297102 .1029968262 108.8082962036115 .2088012695121 .3044967651127 .0953979492132 .5814971924 138.0677032471142 .9441986084147 .5160064697151 .7830047607155 .7451934814 159.4026031494162 .7552947998166 .1078948975168 .8509979248171 .5939941406 174.0323028564176 .4705963135178 .604095459180 .432800293182 .261505127 184.0901947021185 .6141052246186 .8332977295188 .3571929932189 .5764007568 190.795501709191 .7097930908192 .624206543193 .5386047363194 .4528961182 195.3672943115 196.2816009521 196.891204834197.500793457 198.1103057861 198.7198944092199 .0247039795199 .329498291199 .6342926025199 .9389953613 199.9389953613199 .9389953613199 .6342926025199 .329498291199 .0247039795 198.4151000977 198.1103057861 197.500793457196.891204834195.9768066406 195.3672943115194 .7577056885194 .1481018066193 .233795166192 .624206543 192.0146026611191 .4051055908190 .795501709190 .1858978271189 .2716064453 188.6620025635187 .4429016113186 .528503418185 .3094024658184 .0901947021 182.5662994385181 .3471984863180 .1280059814178 .9089050293177 .6896972656 176.7754058838175 .8609924316174 .9467010498174 .337097168173 .7274932861 173.1179962158172 .5084075928171 .8988037109171 .2891998291170 .6797027588 
170.070098877169 .1557006836168 .5462036133167 .6318054199166 .7174987793 166.1078948975165 .1934967041164 .2792053223163 .6696014404162 .7552947998 162.1457061768161 .2312927246160 .6217956543159 .7073974609158 .7929992676 158.1835021973157 .2691040039156 .3547973633155 .4403991699154 .2212982178 153.3069000244152 .0877990723150 .8686065674149 .3446960449148 .1255950928 146.9064025879145 .3825073242144 .1634063721142 .6394042969141 .1154937744 139.5915985107138 .0677032471136 .5437011719135 .0198059082133 .4958953857 131.9720001221130 .4479980469128 .9241027832127 .7050018311126 .1809997559 124.9618988037125 .5715026855125 .2667007446125 .2667007446124 .9618988037 124.9618988037124 .6570968628124 .6570968628124 .3523025513124 .3523025513 123.7427978516128 .0097961426132 .8863067627137 .1533050537140 .2012023926 142.0299072266142 .9441986084143 .5538024902144 .1634063721144 .7729034424 145.3825073242145 .9920959473146 .6015930176146 .9064025879147 .5160064697 147.8208007812148 .1255950928148 .1255950928148 .4304046631148 .4304046631 148.1255950928147 .8208007812147 .5160064697146 .9064025879146 .2969055176 145.3825073242144 .4682006836143 .2489929199141 .7250976562140 .5059967041 138.6772003174137 .1533050537135 .3246002197133 .4958953857131 .9720001221 131.0576019287130 .1432037354128 .9241027832128 .0097961426126 .7906036377 125.8762969971124 .9618988037124 .0475006104123 .43800354122 .8283996582 122.2188034058121 .9140014648121 .3044967651121 .3044967651120 .9997024536 120.9997024536120 .9997024536120 .9997024536120 .9997024536120 .9997024536 121.3044967651121 .3044967651121 .3044967651121 .3044967651121 .6092987061 121.6092987061121 .6092987061121 .6092987061121 .6092987061121 .6092987061 121.6092987061121 .6092987061121 .9140014648121 .6092987061120 .9997024536 120.3900985718119 .1709976196117 .647102356115 .5136032104114 .5991973877 116.7326965332124 .6570968628134 .7149963379142 .3347015381144 .4682006836 149.3446960449160 .0122070312168 .8509979248176 .4705963135184 .0901947021 192.3193969727200 .2438049316208 .1681976318209 .692199707209 .692199707 209.692199707 209.692199707 209.692199707 209.692199707 209.692199707 209.692199707 209.692199707 209.692199707 209.692199707 209.692199707 209.692199707 209.692199707 209.692199707211 .8256988525215 .787902832219 .7501068115223 .4075012207 227.0648956299230 .7223052979234 .0749969482237 .4275970459240 .4754943848 243.5233001709246 .2664031982249 .0093994141251 .4476928711253 .8860015869 256.0195007324257 .8482055664259 .6769104004261 .5056152344263 .0296020508 264.5534973145265 .7726135254266 .9917907715268 .2109069824269 .1253051758 270.0396118164270 .6492004395271 .5635070801271 .8682861328272 .4779052734 272.7827148438273 .0874938965273 .3923034668273 .6971130371274 .0018005371 274.0018005371274 .3066101074274 .3066101074274 .3066101074274 .3066101074 274.6113891602274 .6113891602274 .6113891602274 .3066101074274 .3066101074 274.0018005371274 .0018005371274 .0018005371274 .0018005371274 .0018005371 273.6971130371273 .0874938965272 .1730957031271 .5635070801271 .2587890625 269.7348022461265 .1630859375256 .3243103027242 .9136962891226 .150604248 207.5587005615189 .2716064453172 .5084075928158 .5051269531146 .509552002 -9999

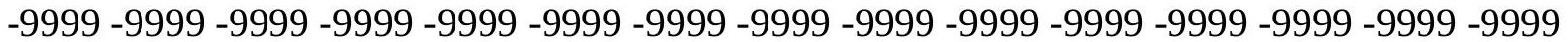

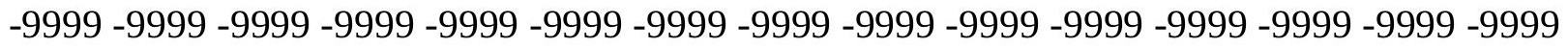

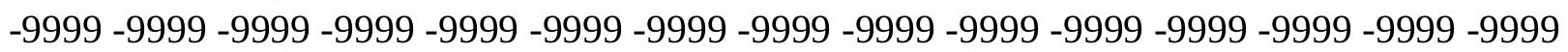


-9999 -9999 -9999 -9999 -9999 -9999 -9999 -9999 -9999 -9999 -9999 -9999 -9999 -9999 -9999 -9999 -9999 -9999 -9999 -9999 -9999 -9999 -9999 -9999 -9999 -9999 -48.7473716736 -41.1615219116 -33.5263595581 -25.9067401886 -17.9823207855 -10.0579099655 -1.82871103287 6.400486946106 14.9344701767 23.16366958618 31.6976509094240 .2316398620648 .765621185356 .9948196411165 .22400665283 73.1484298706181 .0728530883888 .6924667358496 .00731658936103 .0174026489 109.7226028442116 .1231002808122 .2188034058128 .0097961426133 .4958953857 138.6772003174143 .2489929199147 .8208007812152 .0877990723155 .7451934814 159.4026031494162 .7552947998165 .8031005859168 .5462036133170 .9844970703 173.1179962158175 .2514038086177 .3849029541179 .2136993408180 .7375946045 182.261505127183 .7854003906185 .0045928955186 .2236938477187 .1381072998 188.3571929932189 .2716064453190 .1858978271191 .1002960205192 .0146026611 192.624206543193 .5386047363194 .1481018066194 .7577056885195 .3672943115 195.9768066406196 .2816009521196 .891204834197 .1959991455197 .1959991455 197.1959991455 197.1959991455 197.1959991455 196.891204834196.5863952637 196.2816009521195 .6721038818195 .3672943115194 .7577056885194 .1481018066 193.233795166192 .624206543192 .3193969727191 .7097930908191 .1002960205 190.4907073975189 .8811035156189 .5764007568188 .966796875188 .0523986816 187.4429016113186 .528503418185 .3094024658184 .0901947021182 .5662994385 181.3471984863179 .8231964111178 .2993011475177 .0802001953175 .8609924316 174.9467010498174 .337097168173 .7274932861173 .4226989746173 .1179962158 172.8132019043172 .5084075928172 .2035980225171 .8988037109171 .2891998291 170.9844970703170 .070098877169 .4604949951168 .5462036133167 .6318054199 166.7174987793165 .8031005859164 .8887023926163 .974395752163 .0599975586 162.1457061768161 .5361022949160 .6217956543159 .7073974609158 .7929992676 157.878692627156 .6596069336155 .7451934814154 .5260925293153 .3069000244 152.0877990723150 .5639038086149 .0399017334147 .8208007812146 .2969055176 144.7729034424143 .2489929199141 .7250976562140 .5059967041138 .9819946289 137.4580993652135 .9342041016134 .4102020264132 .8863067627131 .3623962402 129.8385009766128 .6192932129127 .4001998901126 .1809997559124 .9618988037 125.5715026855125 .5715026855125 .2667007446125 .2667007446124 .9618988037 124.9618988037124 .6570968628124 .6570968628124 .6570968628124 .3523025513 124.3523025513128 .0097961426131 .9720001221135 .6293945312138 .6772003174 141.1154937744142 .6394042969143 .8585968018145 .0776977539145 .6873016357 146.6015930176147 .2111968994147 .8208007812148 .1255950928148 .7351074219 149.0399017334149 .3446960449149 .3446960449149 .3446960449149 .3446960449 149.3446960449149 .0399017334148 .4304046631148 .1255950928147 .2111968994 146.6015930176145 .3825073242144 .4682006836142 .9441986084141 .7250976562 140.2012023926138 .3724975586136 .8484954834135 .0198059082133 .4958953857 132.2767028809131 .0576019287129 .8385009766128 .6192932129127 .4001998901 126.1809997559125 .2667007446124 .3523025513123 .43800354122 .8283996582 122.2188034058121 .6092987061121 .3044967651120 .9997024536120 .9997024536 120.9997024536120 .9997024536120 .9997024536120 .9997024536120 .9997024536 121.3044967651121 .3044967651121 .3044967651121 .3044967651121 .3044967651 121.3044967651121 .3044967651121 .3044967651121 .3044967651121 .6092987061 121.6092987061121 .6092987061121 .9140014648121 .6092987061121 .3044967651 
120.6949005127119 .1709976196117 .342300415115 .818397522115 .2088012695 117.0374984741121 .9140014648127 .7050018311131 .9720001221133 .4958953857 135.3246002197145 .3825073242154 .5260925293162 .7552947998171 .2891998291 180.7375946045190 .1858978271198 .7198944092206 .6443023682209 .692199707 209.692199707209 .692199707209 .692199707209 .692199707209 .692199707209 .692199707 209.692199707 209.692199707 209.692199707 209.692199707 209.692199707 209.692199707 209.692199707210 .9113006592214 .8735046387218 .5308990479222 .4931030273 226.150604248229 .8079986572233 .4653930664236 .8179931641239 .8659057617 242.9136962891245 .9615936279248 .3999023438251 .1428985596253 .2763977051 255.7147064209257 .5433959961259 .6769104004261 .2008972168263 .0296020508 264.2486877441265 .7726135254266 .9917907715267 .9060974121269 .1253051758 269.7348022461270 .6492004395271 .2587890625271 .8682861328272 .4779052734 272.7827148438273 .0874938965273 .3923034668273 .6971130371274 .0018005371 274.3066101074274 .3066101074274 .3066101074274 .6113891602274 .6113891602 274.6113891602274 .9161987305274 .6113891602274 .6113891602274 .6113891602 274.3066101074274 .0018005371274 .0018005371273 .6971130371273 .0874938965 272.4779052734271 .2587890625270 .0396118164268 .8204956055266 .9917907715 263.9439086914258 .7626037598250 .2286071777238 .3419952393224 .0171051025 207.8634033203191 .7097930908176 .165802002162 .7572784424150 .9295196533 140.3232879639 -9999 -9999 -9999 -9999 -9999 -9999 -9999 -9999 -9999 -9999 -9999 -9999 -9999 -9999 -9999 -9999 -9999 -9999 -9999 -9999 -9999 -9999 -9999 -9999 -9999 -9999 -9999 -9999 -9999 -9999 -9999 -9999 -9999 -9999 -9999 -9999 -9999 -9999 -9999 -9999 -9999 -9999 -9999 -9999 -9999 -9999 -9999 -9999 -9999 -9999 -9999 -9999 -9999 -9999 -9999 -9999 -9999 $-9999$

-9999 -9999 -9999 -9999 -9999 -9999 -9999 -9999 -9999 -9999 -9999 -9999 -9999 -9999 -41.6992797852 -34.0196342468 -26.2115192413 -18.287109375 -10.0579099655 -1.82871103287 6.400486946106 14.9344701767 23.46845054626 32.00244140625 40.8412094116249 .3751907348657 .909179687566 .1383666992274 .36756896973 82.2919769287189 .9116134643697 .22646331787104 .2365036011110 .9418029785 117.342300415123 .43800354128 .9241027832134 .4102020264139 .2868041992 144.1634063721148 .4304046631152 .3925933838156 .0500030518159 .4026031494 162.4505004883165 .4983062744167 .9365997314170 .3748931885172 .5084075928 174.337097168176 .165802002177 .6896972656179 .2136993408180 .432800293 181.9566955566182 .87109375184 .0901947021185 .0045928955185 .9188995361 186.8332977295187 .7476043701188 .6620025635189 .2716064453190 .1858978271 190.795501709191 .4051055908192 .0146026611192 .624206543193 .233795166 193.8433074951194 .1481018066194 .4528961182194 .7577056885194 .7577056885 194.7577056885194 .7577056885194 .4528961182194 .4528961182193 .8433074951 193.5386047363192 .9290008545192 .624206543192 .0146026611191 .4051055908 190.795501709190 .1858978271189 .8811035156189 .2716064453188 .966796875 188.3571929932188 .0523986816187 .4429016113186 .8332977295186 .2236938477 185.0045928955184 .0901947021182 .5662994385181 .0424041748179 .5184020996 177.6896972656176 .165802002174 .9467010498173 .7274932861172 .8132019043 172.2035980225171 .8988037109171 .8988037109172 .2035980225172 .2035980225 172.2035980225172 .2035980225172 .2035980225171 .8988037109171 .2891998291 170.6797027588170 .070098877169 .1557006836168 .241394043167 .3269958496 
166.4127044678165 .1934967041164 .2792053223163 .3648071289162 .1457061768 161.2312927246160 .3170013428159 .4026031494158 .1835021973157 .2691040039 156.0500030518154 .8307952881153 .6116943359152 .0877990723150 .5639038086 149.0399017334147 .5160064697145 .6873016357144 .1634063721142 .6394042969 141.1154937744139 .5915985107138 .0677032471136 .5437011719135 .0198059082 133.8007049561132 .2767028809130 .7528076172129 .533706665128 .0097961426 126.7906036377125 .5715026855125 .8762969971125 .8762969971125 .5715026855 125.5715026855125 .2667007446124 .9618988037124 .9618988037124 .9618988037 124.6570968628124 .6570968628124 .6570968628124 .3523025513125 .2667007446 128.0097961426131 .3623962402134 .4102020264137 .4580993652140 .2012023926 142.3347015381144 .1634063721145 .3825073242146 .6015930176147 .5160064697 148.1255950928148 .7351074219149 .3446960449149 .6495056152149 .9542999268 150.2590942383150 .2590942383150 .2590942383150 .2590942383150 .2590942383 149.9542999268149 .6495056152149 .0399017334148 .4304046631147 .5160064697 146.6015930176145 .6873016357144 .4682006836142 .9441986084141 .7250976562 139.8963928223138 .3724975586136 .8484954834135 .0198059082133 .4958953857 132.2767028809130 .7528076172129 .2288970947128 .0097961426126 .7906036377 125.5715026855124 .3523025513123 .43800354122 .8283996582122 .2188034058 121.6092987061121 .3044967651120 .9997024536120 .9997024536120 .9997024536 120.9997024536120 .9997024536120 .9997024536120 .9997024536121 .3044967651 121.3044967651121 .3044967651121 .3044967651121 .3044967651121 .3044967651 121.3044967651121 .3044967651121 .3044967651121 .3044967651121 .3044967651 121.6092987061121 .6092987061121 .9140014648121 .6092987061120 .9997024536 119.7806015015118 .2565994263116 .7326965332116 .1231002808117 .342300415 119.4757995605122 .5235977173124 .0475006104124 .3523025513123 .1332015991 131.9720001221140 .5059967041149 .0399017334157 .5738983154167 .3269958496 179.2136993408187 .7476043701196 .891204834206 .0346984863209 .692199707 209.692199707 209.692199707 209.692199707 209.692199707 209.692199707 209.692199707 209.692199707 209.692199707 209.692199707 209.692199707 209.692199707 209.692199707 209.9969024658213 .959197998217 .6165924072221 .5787963867225 .5410003662 229.1983947754232 .8558044434236 .2084960938239 .5610961914242 .6089935303 245.3520050049248 .0950927734250 .8381958008253 .2763977051255 .4098968506 257.5433959961259 .3721008301261 .2008972168262 .7247924805264 .2486877441 265.4678039551266 .6870117188267 .9060974121268 .8204956055269 .7348022461 270.6492004395271 .2587890625271 .8682861328272 .4779052734272 .7827148438 273.0874938965273 .3923034668273 .6971130371274 .0018005371274 .3066101074 274.6113891602274 .6113891602274 .9161987305274 .9161987305274 .9161987305 274.9161987305274 .9161987305274 .9161987305274 .6113891602274 .3066101074 274.0018005371273 .6971130371273 .0874938965272 .1730957031271 .2587890625 269.7348022461 268.2109069824266.0773925781263.3344116211259.3721008301 253.5812072754245 .3520050049234 .6844940186221 .883605957207 .8634033203 $193.5386047363179 .5184020996166 .8857727051155 .3201446533144 .6806335449-9999$ -9999 -9999 -9999 -9999 -9999 -9999 -9999 -9999 -9999 -9999 -9999 -9999 -9999 -9999 -9999 -9999 -9999 -9999 -9999 -9999 -9999 -9999 -9999 -9999 -9999 -9999 -9999 -9999 -9999 -9999 -

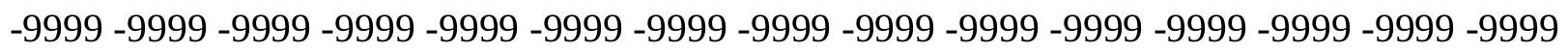
-9999 -9999 -9999 -9999 -9999 -9999 -9999 -9999 -9999 -9999 -9999 -9999 
-9999 -9999 -9999 -9999 -9999 -9999 -9999 -9999 -9999 -9999 -9999 -9999 -9999 -9999 -42.0026741028 -34.2715110779 -26.5163097382 -18.287109375 -10.0579099655 -1.82871103287 6.400486946106 15.2392597198524.0780296325732.61201095581 41.4507789611850 .2895507812558 .8235282897967 .3575134277375 .58670806885 83.5111236572391 .1307525634898 .75038146973105 .7603988647112 .4656982422 118.8662033081124 .6570968628130 .1432037354135 .6293945312140 .5059967041 144.7729034424149 .0399017334153 .0021057129156 .3547973633159 .7073974609 162.4505004883165 .1934967041167 .6318054199169 .7653045654171 .5939941406 173.4226989746174 .9467010498176 .4705963135177 .6896972656178 .9089050293 179.8231964111181 .0424041748181 .9566955566182 .87109375183 .4806976318 184.3950042725185 .0045928955185 .9188995361186 .528503418187 .4429016113 188.0523986816188 .6620025635189 .2716064453189 .8811035156190 .4907073975 191.1002960205191 .4051055908191 .7097930908192 .0146026611192 .3193969727 192.3193969727192 .3193969727192 .0146026611192 .0146026611191 .7097930908 191.4051055908190 .795501709190 .4907073975189 .8811035156189 .2716064453 188.966796875188 .3571929932188 .0523986816187 .4429016113187 .1381072998 186.8332977295186 .528503418186 .2236938477185 .6141052246184 .699798584 183.7854003906182 .5662994385181 .0424041748179 .2136993408177 .3849029541 175.2514038086173 .4226989746171 .8988037109170 .6797027588170 .070098877 169.4604949951169 .7653045654170 .070098877170 .3748931885170 .9844970703 171.2891998291171 .5939941406171 .8988037109171 .8988037109171 .5939941406 170.9844970703170 .3748931885169 .4604949951168 .5462036133167 .6318054199 166.4127044678165 .1934967041164 .2792053223163 .0599975586161 .8408966064 160.9264984131159 .7073974609158 .4882965088157 .5738983154156 .3547973633 154.8307952881153 .6116943359152 .0877990723150 .5639038086149 .0399017334 147.2111968994145 .3825073242143 .8585968018142 .0299072266140 .5059967041 138.9819946289137 .4580993652135 .9342041016134 .4102020264132 .8863067627 131.6672058105130 .1432037354128 .9241027832127 .4001998901126 .1809997559 126.4858016968126 .1809997559126 .1809997559125 .8762969971125 .5715026855 125.2667007446125 .2667007446124 .9618988037124 .9618988037124 .9618988037 124.6570968628124 .6570968628124 .6570968628124 .0475006104126 .1809997559 128.3144989014131 .0576019287133 .8007049561136 .8484954834139 .8963928223 142.3347015381144 .4682006836145 .9920959473147 .5160064697148 .4304046631 149.0399017334149 .6495056152150 .2590942383150 .8686065674151 .1734008789 151.1734008789151 .1734008789151 .1734008789151 .1734008789151 .1734008789 150.8686065674150 .5639038086150 .2590942383149 .6495056152148 .7351074219 147.8208007812146 .9064025879145 .6873016357144 .7729034424143 .2489929199 141.7250976562140 .2012023926138 .6772003174136 .8484954834135 .3246002197 133.4958953857131 .9720001221130 .1432037354128 .6192932129127 .0953979492 125.8762969971124 .6570968628123 .7427978516122 .8283996582122 .2188034058 121.6092987061121 .3044967651120 .9997024536120 .9997024536120 .9997024536 120.9997024536120 .9997024536121 .3044967651121 .3044967651121 .3044967651 121.3044967651121 .3044967651121 .3044967651121 .3044967651120 .9997024536 120.9997024536120 .9997024536120 .9997024536120 .9997024536120 .9997024536 121.3044967651121 .6092987061121 .9140014648121 .9140014648121 .9140014648 120.3900985718119 .1709976196117 .9517974854117 .0374984741117 .342300415 
117.9517974854118 .8662033081119 .1709976196118 .5614013672118 .5614013672 120.6949005127127 .4001998901135 .6293945312143 .8585968018152 .3925933838 164.2792053223175 .2514038086185 .6141052246195 .9768066406206 .3394927979 209.692199707209 .692199707209 .692199707209 .692199707209 .692199707209 .692199707 209.692199707209 .692199707209 .692199707209 .692199707209 .692199707209 .692199707 209.0825958252213 .0447998047217 .0070037842220 .9691925049224 .9313964844 228.5888977051232 .246307373235 .9037017822239 .2563018799242 .3041992188 245.3520050049248 .0950927734250 .5334014893252 .9716033936255 .4098968506 257.5433959961259 .3721008301261 .2008972168262 .7247924805264 .2486877441 265.4678039551266 .6870117188267 .9060974121268 .8204956055269 .7348022461 270.6492004395271 .2587890625271 .8682861328272 .4779052734272 .7827148438 273.0874938965273 .6971130371274 .0018005371274 .3066101074274 .3066101074 274.6113891602274 .9161987305274 .9161987305275 .2210083008275 .2210083008 275.2210083008275 .2210083008274 .9161987305274 .9161987305274 .3066101074 274.0018005371273 .3923034668272 .4779052734271 .2587890625270 .0396118164 268.2109069824266 .0773925781263 .6390991211259 .9816894531255 .4098968506 249.3141937256241 .6945953369231 .9414978027220 .6643981934209 .692199707 195.3672943115182 .87109375170 .9844970703159 .671585083149 .1675262451 139.2720947266 -9999 -9999 -9999 -9999 -9999 -9999 -9999 -9999 -9999 -9999 -9999 -9999

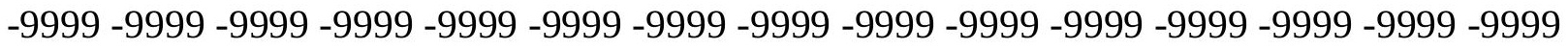

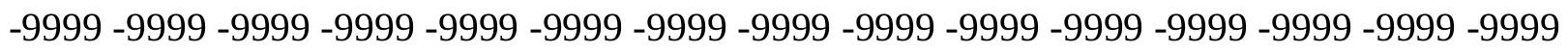
-9999 -9999 -9999 -9999 -9999 -9999 -9999 -9999 -9999 -9999 -9999 -9999 -9999 -9999 -9999 -9999 -9999 -9999 -9999 -9999 -9999 -9999 -9999 -9999 -9999 -9999 -9999 -9999 -9999 -42.0863037109-34.2080917358 -26.2115192413-18.287109375 -10.0579099655 -1.52392601967 7.010057926178 15.5440397262624.68759918213 33.52635955811 42.3651313781751 .5086898803760 .3474502563568 .8814392089877 .1106262207 85.3398437592.95947265625 100.5791015625 107.5891036987 114.2944030762 120.3900985718126 .1809997559131 .6672058105136 .8484954834141 .4203033447 145.6873016357149 .9542999268153 .6116943359156 .6596069336159 .7073974609 162.4505004883164 .8887023926167 .0222015381169 .1557006836170 .6797027588 172.5084075928173 .7274932861174 .9467010498176 .165802002177 .0802001953 177.9945068359178 .9089050293179 .8231964111180 .432800293181 .0424041748 181.9566955566182 .5662994385183 .1759033203183 .7854003906184 .699798584 185.3094024658185 .9188995361186 .528503418187 .1381072998187 .7476043701 188.0523986816188 .6620025635188 .966796875189 .2716064453189 .5764007568 189.5764007568189 .8811035156189 .5764007568189 .5764007568189 .2716064453 188.966796875188 .6620025635188 .3571929932187 .7476043701187 .1381072998 186.8332977295186 .2236938477185 .9188995361185 .6141052246185 .3094024658 185.0045928955185 .0045928955184 .699798584184 .0901947021183 .4806976318 182.261505127181 .0424041748179 .2136993408177 .0802001953174 .9467010498 172.8132019043170 .6797027588168 .5462036133167 .3269958496166 .4127044678 166.4127044678166 .7174987793167 .6318054199168 .5462036133169 .4604949951 170.3748931885170 .9844970703171 .2891998291171 .5939941406171 .2891998291 170.9844970703170 .3748931885169 .4604949951168 .5462036133167 .3269958496 166.1078948975164 .8887023926163 .6696014404162 .4505004883161 .2312927246 160.0122070312158 .7929992676157 .5738983154156 .3547973633155 .1356048584 
153.6116943359152 .0877990723150 .2590942383148 .7351074219146 .9064025879 145.0776977539143 .2489929199141 .7250976562139 .8963928223138 .3724975586 136.8484954834135 .3246002197133 .8007049561132 .2767028809130 .7528076172 129.533706665128 .3144989014126 .7906036377126 .7906036377126 .7906036377 126.4858016968126 .4858016968126 .1809997559125 .8762969971125 .5715026855 125.2667007446125 .2667007446124 .9618988037124 .9618988037124 .6570968628 124.6570968628124 .6570968628123 .7427978516125 .5715026855127 .4001998901 129.2288970947131 .3623962402133 .4958953857136 .8484954834139 .8963928223 142.6394042969145 .0776977539146 .9064025879148 .1255950928149 .3446960449 149.9542999268150 .5639038086151 .1734008789151 .4781951904151 .7830047607 151.7830047607151 .7830047607151 .7830047607151 .7830047607151 .7830047607 151.7830047607151 .4781951904151 .1734008789150 .5639038086149 .9542999268 149.0399017334148 .1255950928147 .2111968994146 .2969055176145 .0776977539 143.8585968018142 .3347015381140 .5059967041138 .6772003174136 .8484954834 135.0198059082133 .1911010742131 .0576019287129 .2288970947127 .7050018311 126.1809997559124 .9618988037123 .7427978516122 .8283996582122 .2188034058 121.9140014648121 .3044967651121 .3044967651120 .9997024536120 .9997024536 121.3044967651121 .3044967651121 .3044967651121 .6092987061121 .6092987061 121.6092987061121 .3044967651121 .3044967651121 .3044967651120 .9997024536 120.9997024536120 .6949005127120 .6949005127120 .6949005127120 .9997024536 120.9997024536121 .3044967651121 .6092987061121 .9140014648121 .6092987061 120.9997024536119 .7806015015118 .8662033081117 .9517974854117 .342300415 117.0374984741116 .7326965332116 .4279022217115 .818397522115 .818397522 116.4279022217118 .8662033081122 .8283996582130 .4479980469143 .2489929199 155.4403991699161 .5361022949173 .1179962158185 .3094024658197 .500793457 208.7778015137209 .692199707209 .692199707209 .692199707209 .692199707 209.692199707209 .692199707209 .692199707209 .692199707209 .692199707209 .692199707 209.692199707 209.692199707 212.4351959229 216.3973999023220.6643981934 224.3218994141228 .2841033936231 .9414978027235 .5989074707238 .9515075684 242.3041992188245 .3520050049248 .0950927734250 .8381958008253 .2763977051 255.4098968506257 .5433959961259 .3721008301261 .2008972168262 .7247924805 264.2486877441265 .4678039551266 .6870117188267 .9060974121268 .8204956055 269.7348022461270 .6492004395271 .2587890625271 .8682861328272 .4779052734 272.7827148438273 .3923034668273 .6971130371274 .0018005371274 .3066101074 274.6113891602274 .9161987305275 .2210083008275 .2210083008275 .5257873535 275.5257873535275 .5257873535275 .5257873535275 .2210083008274 .9161987305 274.3066101074273 .6971130371272 .7827148438271 .8682861328270 .3443908691 268.8204956055266 .9917907715264 .2486877441261 .2008972168257 .5433959961 252.6669006348246 .2664031982238 .6468048096229 .8079986572219 .7501068115 209.692199707 197.1959991455 185.6141052246174.9467010498163.9589080811 153.7835693359143 .8400268555 -9999 -9999 -9999 -9999 -9999 -9999 -9999 -9999 -9999 -9999 -9999 -9999 -9999 -9999 -9999 -9999 -9999 -9999 -9999 -9999 -9999 -9999 -9999 -9999 -9999 -9999 -9999 -9999 -9999 -9999 -9999 -9999 -9999 -9999 -9999 -9999 -9999 -9999 -9999 -

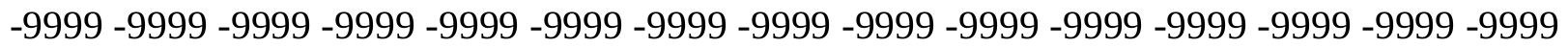
-9999 -9999-9999

-9999 -9999 -9999 -9999 -9999 -9999 -9999 -9999 -9999 -9999 -9999 -9999 -9999 -9999 
-41.9713783264 -33.9445266724 -25.9067401886-17.9823207855 -9.44833946228 -.914355397224 7.314843177795 16.45840072632 25.29715919495 34.74551010132 43.8890609741253 .0326118469261 .8713798522970 .7101516723679 .24413299561 87.4733276367295 .09295654297102 .712600708109 .7226028442116 .1231002808 122.2188034058128 .0097961426133 .4958953857138 .3724975586142 .6394042969 146.9064025879150 .5639038086154 .2212982178157 .2691040039160 .0122070312 162.4505004883164 .8887023926166 .7174987793168 .5462036133170 .070098877 171.2891998291172 .5084075928173 .7274932861174 .6419067383175 .2514038086 176.165802002176 .7754058838177 .3849029541177 .9945068359178 .604095459 179.2136993408179 .8231964111180 .432800293181 .0424041748181 .6519012451 182.261505127182 .87109375183 .4806976318184 .0901947021184 .699798584 185.3094024658185 .9188995361186 .2236938477186 .528503418186 .8332977295 187.1381072998187 .1381072998187 .1381072998187 .1381072998187 .1381072998 186.8332977295186 .528503418185 .9188995361185 .6141052246185 .0045928955 184.3950042725184 .0901947021183 .7854003906183 .4806976318183 .1759033203 183.1759033203183 .1759033203182 .87109375182 .5662994385181 .9566955566 180.7375946045179 .2136993408177 .3849029541175 .2514038086172 .8132019043 170.070098877167 .3269958496165 .1934967041163 .3648071289162 .4505004883 162.4505004883163 .3648071289164 .5839996338166 .1078948975167 .6318054199 168.8509979248169 .7653045654170 .3748931885170 .6797027588170 .6797027588 170.3748931885169 .7653045654168 .8509979248167 .9365997314166 .7174987793 165.4983062744164 .2792053223162 .7552947998161 .5361022949160 .0122070312 158.7929992676157 .5738983154156 .3547973633155 .1356048584153 .6116943359 152.0877990723150 .2590942383148 .4304046631146 .6015930176144 .7729034424 142.9441986084141 .1154937744139 .5915985107137 .7628936768136 .2389984131 134.7149963379133 .1911010742131 .6672058105130 .1432037354128 .9241027832 127.7050018311126 .4858016968127 .0953979492127 .0953979492126 .7906036377 126.7906036377126 .4858016968126 .1809997559125 .8762969971125 .5715026855 125.2667007446125 .2667007446124 .9618988037124 .9618988037124 .6570968628 124.6570968628124 .3523025513125 .5715026855127 .4001998901129 .2288970947 131.0576019287132 .8863067627135 .0198059082137 .7628936768140 .8106994629 143.5538024902145 .6873016357147 .5160064697149 .0399017334150 .2590942383 150.8686065674151 .1734008789151 .7830047607152 .0877990723152 .3925933838 152.3925933838152 .3925933838152 .0877990723152 .0877990723152 .0877990723 152.3925933838152 .3925933838152 .3925933838151 .4781951904150 .8686065674 149.9542999268149 .3446960449148 .7351074219147 .8208007812146 .9064025879 145.9920959473144 .4682006836142 .6394042969140 .8106994629138 .6772003174 136.5437011719134 .4102020264132 .2767028809130 .1432037354128 .3144989014 126.4858016968124 .9618988037124 .0475006104123 .1332015991122 .5235977173 121.9140014648121 .6092987061121 .3044967651121 .3044967651121 .3044967651 121.3044967651121 .6092987061121 .6092987061121 .9140014648121 .9140014648 121.6092987061121 .6092987061121 .3044967651121 .3044967651120 .9997024536 120.6949005127120 .6949005127120 .6949005127120 .6949005127120 .6949005127 120.6949005127120 .9997024536121 .3044967651121 .6092987061121 .6092987061 120.9997024536120 .3900985718119 .7806015015118 .8662033081117 .9517974854 117.0374984741116 .1231002808115 .2088012695114 .2944030762113 .9896011353 
113.9896011353114 .9039993286117 .0374984741121 .6092987061138 .9819946289 156.9642944336159 .4026031494161 .2312927246173 .1179962158187 .7476043701 201.4629974365209 .692199707209 .692199707209 .692199707209 .692199707 209.692199707209 .692199707209 .692199707209 .692199707209 .692199707209 .692199707 209.692199707 209.692199707212.1304016113216.0926971436220.3596038818 224.3218994141228 .2841033936231 .9414978027235 .5989074707238 .9515075684 242.3041992188245 .3520050049248 .0950927734250 .8381958008253 .2763977051 255.4098968506257 .5433959961259 .6769104004261 .2008972168263 .0296020508 264.2486877441265 .7726135254266 .9917907715267 .9060974121268 .8204956055 269.7348022461270 .6492004395271 .2587890625271 .8682861328272 .4779052734 272.7827148438273 .3923034668273 .6971130371274 .0018005371274 .3066101074 274.6113891602274 .9161987305275 .2210083008275 .5257873535275 .5257873535 275.8305053711275 .5257873535275 .5257873535275 .2210083008274 .9161987305 274.3066101074273 .3923034668272 .4779052734271 .2587890625269 .7348022461 267.9060974121265 .4678039551262 .7247924805259 .3721008301255 .4098968506 250.2286071777244 .1329040527236 .8179931641228 .2841033936219 .1405029297 209.0825958252 209.692199707 188.3571929932 178.2993011475 168.8509979248 158.3682861328 148.4439697266 138.8758544922 -9999 -9999 -9999-9999 -9999 -9999 -9999 -9999 -9999 -9999 -9999 -9999 -9999 -9999 -9999 -9999 -9999 -9999 -9999 -9999 -9999 -9999 -9999 -9999 -9999 -9999 -9999 -9999 -9999 -9999 -9999 -9999 -9999 -9999 -9999 -9999 -9999 -

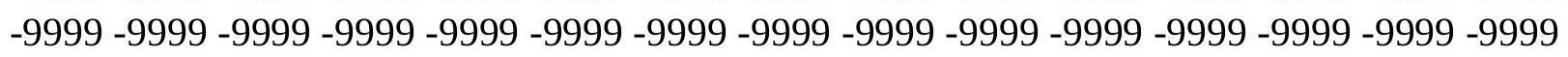
-9999 -9999 -9999 -9999

-9999 -9999 -9999 -9999 -9999 -9999 -9999 -9999 -9999 -9999 -9999 -9999 -9999 -9999 -9999 -33.5548286438 -25.3068084717-17.0679702759-8.83876895905-.304785102606 8.22919845581117 .0679702758826 .5163097381635 .9646492004445 .41297912598 54.5565414428764 .004882812572 .8436431884881 .6824111938589 .91161346436 97.83602905273105 .1509017944112 .1608963013118 .5614013672124 .6570968628 130.1432037354135 .3246002197139 .8963928223144 .1634063721148 .1255950928 151.7830047607154 .8307952881157 .878692627160 .3170013428162 .7552947998 164.5839996338166 .4127044678167 .9365997314169 .1557006836170 .3748931885 171.2891998291172 .2035980225172 .8132019043173 .4226989746174 .0323028564 174.6419067383175 .2514038086175 .5561981201176 .165802002176 .7754058838 177.0802001953177 .6896972656178 .2993011475178 .9089050293179 .5184020996 180.1280059814180 .7375946045181 .3471984863181 .9566955566182 .261505127 182.87109375183 .4806976318183 .7854003906184 .0901947021184 .3950042725 184.699798584184 .699798584184 .699798584184 .699798584184 .3950042725 184.0901947021183 .7854003906183 .1759033203182 .87109375182 .261505127 181.6519012451181 .3471984863181 .0424041748180 .7375946045180 .7375946045 181.0424041748181 .0424041748180 .7375946045180 .1280059814179 .2136993408 177.9945068359175 .8609924316173 .7274932861170 .6797027588167 .6318054199 164.2792053223161 .5361022949159 .4026031494158 .1835021973158 .4882965088 159.7073974609161 .5361022949163 .6696014404165 .4983062744167 .0222015381 168.241394043169 .1557006836169 .4604949951169 .4604949951169 .1557006836 168.8509979248167 .9365997314166 .7174987793165 .8031005859164 .2792053223 163.0599975586161 .5361022949160 .0122070312158 .4882965088157 .2691040039 156.0500030518154 .8307952881153 .6116943359151 .7830047607149 .9542999268 
148.1255950928146 .2969055176144 .4682006836142 .3347015381140 .5059967041 138.9819946289137 .1533050537135 .6293945312134 .1054992676132 .5814971924 131.0576019287129 .533706665128 .3144989014127 .0953979492127 .0953979492 127.0953979492127 .4001998901127 .4001998901127 .0953979492127 .0953979492 126.7906036377126 .4858016968125 .8762969971125 .5715026855125 .2667007446 124.9618988037124 .9618988037124 .6570968628124 .0475006104125 .2667007446 126.4858016968128 .0097961426129 .533706665131 .3623962402133 .1911010742 135.0198059082137 .1533050537139 .5915985107142 .0299072266144 .4682006836 146.9064025879148 .7351074219150 .2590942383151 .1734008789151 .4781951904 151.7830047607152 .0877990723152 .3925933838152 .3925933838152 .3925933838 152.3925933838152 .3925933838152 .3925933838152 .6972961426152 .6972961426 152.6972961426152 .3925933838152 .0877990723151 .4781951904150 .8686065674 150.2590942383149 .9542999268149 .6495056152149 .0399017334147 .8208007812 146.6015930176144 .4682006836142 .6394042969140 .2012023926137 .7628936768 135.6293945312133 .1911010742131 .0576019287128 .9241027832127 .0953979492 125.2667007446124 .3523025513123 .43800354122 .5235977173122 .2188034058 121.6092987061121 .6092987061121 .6092987061121 .6092987061121 .6092987061 121.9140014648122 .2188034058122 .2188034058122 .2188034058121 .9140014648 121.9140014648121 .6092987061121 .3044967651120 .9997024536120 .6949005127 120.3900985718120 .3900985718120 .3900985718120 .3900985718120 .6949005127 120.9997024536121 .3044967651121 .3044967651121 .6092987061121 .3044967651 120.9997024536120 .6949005127119 .4757995605118 .2565994263117 .0374984741 116.1231002808114 .9039993286113 .6848983765112 .7705001831112 .4656982422 112.7705001831114 .5991973877120 .6949005127132 .2767028809144 .1634063721 151.1734008789155 .4403991699159 .4026031494177 .0802001953194 .1481018066 206.3394927979 209.692199707 209.692199707 209.692199707 209.692199707 209.692199707209 .692199707209 .692199707209 .692199707209 .692199707209 .692199707 209.692199707211 .8256988525216 .0926971436220 .054901123224 .3218994141 228.2841033936231 .9414978027235 .5989074707239 .2563018799242 .6089935303 245.6567993164248 .3999023438251 .1428985596253 .5812072754256 .0195007324 257.8482055664259 .9816894531261 .5056152344263 .0296020508264 .5534973145 265.7726135254266 .9917907715268 .2109069824269 .1253051758270 .0396118164 270.6492004395271 .2587890625271 .8682861328272 .4779052734273 .0874938965 273.3923034668273 .6971130371274 .0018005371274 .6113891602274 .9161987305 275.2210083008275 .5257873535275 .8305053711275 .8305053711275 .8305053711 275.8305053711275 .5257873535275 .2210083008274 .6113891602274 .0018005371 273.0874938965272 .1730957031270 .6492004395269 .1253051758266 .9917907715 264.5534973145261 .5056152344257 .8482055664253 .5812072754248 .3999023438 242.3041992188235 .2940979004227 .6744995117218 .8356933594209 .692199707 209.692199707 209.692199707 181.3471984863172.2035980225 162.4560241699 153.1401824951143 .6434936523 -9999 -9999 -9999 -9999 -9999 -9999 -9999 -9999 -9999 -9999 -9999 -9999 -9999 -9999 -9999 -9999 -9999 -9999 -9999 -9999 -9999 -9999 -9999 -9999 -9999 -9999 -9999 -9999 -9999 -9999 -9999 -9999 -9999 -9999 -9999 -9999 -9999 -9999 -9999 -9999 -9999 -9999 -9999 -9999 -9999 -9999 -9999 -9999 -9999 -9999 -9999 -9999 -9999 -9999 -9999-9999

-9999 -9999 -9999 -9999 -9999 -9999 -9999 -9999 -9999 -9999 -9999 -9999 -9999 -9999 -9999 
-33.1222305298 -24.6105194092 -16.1536102295 -7.92441320419-9999 8.838768959045 18.28710937527 .7354507446337 .4885711669947 .2416992187556 .69002914429 66.4431610107475 .5867080688584 .4254837036192 .95947265625100 .5791015625 108.1986999512114 .9039993286121 .3044967651127 .0953979492132 .5814971924 137.4580993652141 .7250976562145 .6873016357149 .3446960449152 .6972961426 155.7451934814158 .4882965088160 .6217956543162 .7552947998164 .5839996338 166.1078948975167 .3269958496168 .5462036133169 .4604949951170 .070098877 170.6797027588171 .2891998291171 .5939941406172 .2035980225172 .5084075928 172.8132019043173 .1179962158173 .7274932861174 .0323028564174 .337097168 174.9467010498175 .2514038086175 .8609924316176 .4705963135177 .0802001953 177.6896972656178 .2993011475178 .9089050293179 .2136993408179 .8231964111 180.432800293181 .0424041748181 .3471984863181 .6519012451181 .9566955566 181.9566955566 182.261505127 182.261505127 181.9566955566181.9566955566 181.3471984863181 .0424041748180 .1280059814179 .5184020996178 .9089050293 178.2993011475177 .9945068359177 .9945068359177 .9945068359178 .604095459 178.9089050293178 .9089050293178 .604095459177 .6896972656176 .4705963135 174.6419067383172 .2035980225169 .1557006836165 .8031005859161 .8408966064 157.878692627155 .1356048584153 .9165039062154 .2212982178156 .0500030518 158.4882965088161 .2312927246163 .6696014404165 .4983062744166 .7174987793 167.3269958496 167.6318054199167.9365997314167.6318054199167.0222015381 166.4127044678165 .1934967041163 .974395752162 .7552947998161 .2312927246 159.7073974609158 .1835021973156 .6596069336155 .1356048584153 .6116943359 152.3925933838150 .8686065674149 .3446960449147 .5160064697145 .6873016357 143.8585968018141 .7250976562139 .8963928223138 .3724975586136 .5437011719 135.0198059082133 .1911010742131 .9720001221130 .4479980469128 .9241027832 127.7050018311126 .4858016968127 .0953979492127 .4001998901127 .4001998901 127.7050018311127 .7050018311127 .4001998901127 .4001998901126 .7906036377 126.4858016968125 .8762969971125 .5715026855124 .9618988037124 .9618988037 124.3523025513125 .5715026855126 .4858016968127 .7050018311129 .2288970947 130.7528076172132 .2767028809133 .8007049561135 .6293945312137 .4580993652 139.2868041992141 .4203033447143 .5538024902145 .9920959473148 .1255950928 149.9542999268151 .1734008789152 .0877990723152 .0877990723152 .3925933838 152.3925933838152 .3925933838152 .6972961426152 .6972961426152 .6972961426 152.6972961426152 .6972961426152 .6972961426152 .6972961426152 .6972961426 152.3925933838152 .0877990723151 .7830047607151 .4781951904151 .1734008789 151.1734008789150 .8686065674150 .8686065674149 .9542999268148 .4304046631 146.6015930176144 .1634063721141 .7250976562139 .2868041992136 .8484954834 134.4102020264131 .9720001221129 .533706665127 .7050018311125 .8762969971 124.6570968628123 .7427978516122 .8283996582122 .2188034058121 .9140014648 121.6092987061121 .6092987061121 .9140014648121 .9140014648122 .2188034058 122.5235977173122 .5235977173122 .5235977173122 .5235977173122 .2188034058 121.6092987061121 .3044967651120 .6949005127120 .3900985718120 .0852966309 120.0852966309120 .0852966309120 .0852966309120 .3900985718120 .6949005127 120.9997024536121 .3044967651121 .6092987061121 .6092987061121 .9140014648 121.6092987061120 .3900985718119 .1709976196117 .647102356116 .4279022217 114.9039993286113 .6848983765112 .4656982422111 .551399231111 .551399231 
113.075302124117 .342300415124 .0475006104131 .9720001221139 .8963928223 147.2111968994 154.8307952881 165.1934967041 187.4429016113198.1103057861 206.6443023682209 .692199707209 .692199707209 .692199707209 .692199707 209.692199707209 .692199707209 .692199707209 .692199707209 .692199707209 .692199707 211.8256988525216 .0926971436220 .054901123224 .3218994141228 .2841033936 232.246307373236 .2084960938239 .5610961914242 .9136962891245 .9615936279 249.0093994141251 .7525024414254 .1907958984256 .3243103027258 .4577941895 260.2864990234261 .8103942871263 .6390991211264 .8583068848266 .0773925781 267.2966003418268 .2109069824269 .4301147461270 .0396118164270 .9540100098 271.5635070801272 .1730957031272 .7827148438273 .0874938965273 .3923034668 274.0018005371274 .3066101074274 .6113891602274 .9161987305275 .2210083008 275.5257873535275 .8305053711275 .8305053711275 .8305053711275 .8305053711 275.5257873535275 .2210083008274 .6113891602273 .6971130371272 .7827148438 271.5635070801270 .0396118164268 .2109069824266 .0773925781263 .3344116211 260.2864990234256 .6290893555252 .0572967529247 .1806945801241 .0850067139 234.3798065186227 .0648956299219 .1405029297210 .6065063477209 .692199707 209.692199707184 .0901947021175 .5561981201167 .0222015381157 .8965606689 148.4353637695 138.7275085449 -9999 -9999 -9999 -9999 -9999 -9999 -9999 -9999 -9999 -9999 -9999 -9999 -9999 -9999 -9999 -9999 -9999 -9999 -9999 -9999 -9999 -9999 -9999 -9999 -9999 -9999 -9999 -9999 -9999 -9999 -9999 -9999 -9999 -9999 -9999 -9999 -9999 -9999 -9999 -

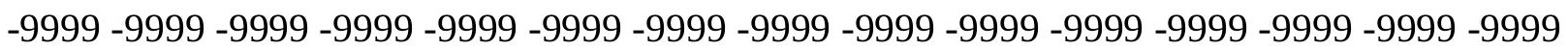
$-9999$

-9999 -9999 -9999 -9999 -9999 -9999 -9999 -9999 -9999 -9999 -9999 -9999 -9999 -9999 -9999 -32.893787384-24.1620578766 -15.2392597198 -7.3148431778 .6095703244209 9.75312423706119 .2014598846428 .9545898437539 .0125007629449 .07040023804 59.1283111572369 .1862335205178 .6345596313587 .7781066894596 .31210327148 104.2365036011111 .551399231118 .2565994263124 .3523025513129 .8385009766 135.0198059082139 .5915985107143 .8585968018147 .5160064697150 .8686065674 153.9165039062156 .6596069336159 .0977935791161 .2312927246163 .0599975586 164.5839996338165 .8031005859166 .7174987793167 .6318054199168 .241394043 168.8509979248169 .1557006836169 .4604949951169 .7653045654170 .070098877 170.3748931885170 .3748931885170 .6797027588170 .9844970703171 .2891998291 171.5939941406171 .8988037109172 .5084075928172 .8132019043173 .4226989746 174.0323028564174 .337097168174 .9467010498175 .5561981201176 .165802002 176.7754058838177 .3849029541177 .9945068359178 .2993011475178 .9089050293 179.2136993408179 .5184020996179 .5184020996179 .5184020996179 .5184020996 179.2136993408178 .9089050293178 .2993011475177 .6896972656176 .7754058838 175.8609924316174 .9467010498174 .6419067383174 .337097168174 .6419067383 175.2514038086176 .165802002176 .4705963135176 .165802002175 .5561981201 174.337097168172 .8132019043170 .9844970703168 .241394043164 .2792053223 159.4026031494154 .5260925293150 .8686065674149 .0399017334149 .6495056152 152.0877990723155 .7451934814159 .4026031494161 .8408966064163 .6696014404 164.5839996338165 .1934967041165 .4983062744165 .4983062744165 .4983062744 165.1934967041164 .2792053223163 .0599975586161 .8408966064160 .3170013428 159.0977935791157 .5738983154155 .7451934814154 .2212982178152 .6972961426 151.1734008789149 .6495056152148 .1255950928146 .6015930176144 .7729034424 
142.9441986084141 .1154937744139 .2868041992137 .4580993652135 .9342041016 134.1054992676132 .5814971924131 .0576019287129 .8385009766128 .6192932129 127.4001998901126 .1809997559126 .7906036377127 .0953979492127 .4001998901 127.7050018311128 .0097961426128 .0097961426128 .0097961426127 .7050018311 127.0953979492126 .4858016968125 .8762969971125 .2667007446124 .9618988037 125.5715026855127 .0953979492128 .3144989014129 .533706665130 .7528076172 132.2767028809133 .8007049561135 .3246002197136 .8484954834138 .3724975586 139.8963928223141 .7250976562143 .5538024902145 .3825073242147 .2111968994 149.0399017334150 .8686065674152 .3925933838152 .3925933838152 .3925933838 152.6972961426152 .6972961426152 .6972961426152 .6972961426153 .0021057129 152.6972961426152 .6972961426152 .3925933838152 .6972961426153 .0021057129 152.6972961426152 .3925933838152 .3925933838152 .0877990723151 .7830047607 151.7830047607151 .7830047607152 .0877990723152 .3925933838152 .0877990723 150.2590942383148 .1255950928145 .6873016357143 .2489929199140 .5059967041 137.7628936768135 .3246002197132 .8863067627130 .4479980469128 .3144989014 126.7906036377125 .2667007446124 .0475006104123 .1332015991122 .5235977173 122.2188034058121 .9140014648121 .9140014648122 .2188034058122 .2188034058 122.8283996582123 .1332015991123 .1332015991123 .1332015991123 .1332015991 122.5235977173121 .9140014648121 .3044967651120 .6949005127120 .0852966309 119.7806015015119 .7806015015119 .7806015015120 .0852966309120 .3900985718 120.6949005127120 .9997024536121 .3044967651121 .9140014648122 .2188034058 122.2188034058121 .9140014648120 .9997024536119 .7806015015118 .5614013672 117.0374984741115 .2088012695113 .6848983765112 .1608963013110 .9418029785 110.3321990967110 .9418029785112 .7705001831116 .1231002808120 .9997024536 128.3144989014139 .2868041992150 .5639038086160 .0122070312172 .8132019043 186.8332977295197 .1959991455205 .7299957275209 .692199707209 .692199707 209.692199707209 .692199707209 .692199707209 .692199707209 .692199707209 .692199707 209.692199707211 .8256988525216 .0926971436220 .3596038818224 .6266021729 228.8936004639232 .8558044434236 .5133056641240 .1707000732243 .5233001709 246.5711975098249 .6190032959252 .3621063232254 .8003997803256 .9338989258 259.0674133301260 .8960876465262 .4200134277263 .9439086914265 .1630859375 266.3822021484267 .6012878418268 .5156860352269 .4301147461270 .3443908691 270.9540100098271 .5635070801272 .1730957031272 .7827148438273 .0874938965 273.6971130371274 .0018005371274 .3066101074274 .6113891602275 .2210083008 275.5257873535275 .5257873535275 .8305053711276 .1353149414275 .8305053711 275.8305053711275 .5257873535275 .2210083008274 .3066101074273 .6971130371 272.4779052734271 .2587890625269 .4301147461267 .6012878418265 .1630859375 262.4200134277259 .3721008301255 .4098968506251 .1428985596245 .9615936279 240.1707000732233 .7702026367226 .7601013184219 .1405029297211 .2160949707 209.692199707 209.692199707209.692199707 178.2993011475 170.070098877 162.4505004883 153.0244293213143 .286605835 -9999-9999 -9999 -9999-9999-9999 -9999 -9999 -9999 -9999 -9999 -9999 -9999 -9999 -9999 -9999 -9999 -9999 -9999 -9999 -9999 -9999 -9999 -9999 -9999 -9999 -9999 -9999 -9999 -9999 -9999 -9999 -9999 -9999 -9999 -9999 -9999 -

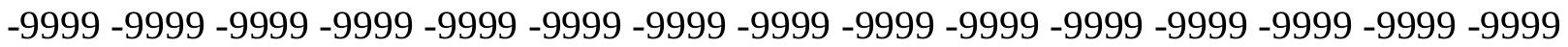
-9999-9999-9999

-9999 -9999 -9999 -9999 -9999 -9999 -9999 -9999 -9999 -9999 -9999 -9999 -9999 -9999 -9999 
-9999 -24.3170223236-15.6705236435 -7.3148431778.9143553972244 10.36268997192 20.1158199310330 .4785099029540 .8412094116251 .5086898803762 .17617034912 72.2340774536181 .9871978759891 .4355392456199 .96952056885107 .8938980103 115.2088012695121 .6092987061127 .7050018311132 .8863067627137 .7628936768 142.0299072266145 .6873016357149 .3446960449152 .3925933838155 .1356048584 157.5738983154159 .7073974609161 .5361022949163 .0599975586164 .2792053223 165.1934967041166 .1078948975166 .7174987793167 .3269958496167 .6318054199 167.6318054199167 .9365997314167 .9365997314167 .9365997314167 .9365997314 167.9365997314168 .241394043168 .241394043168 .5462036133168 .8509979248 169.1557006836169 .4604949951169 .7653045654170 .3748931885170 .6797027588 171.2891998291171 .8988037109172 .5084075928173 .1179962158173 .7274932861 174.337097168174 .9467010498175 .2514038086175 .8609924316176 .165802002 176.4705963135176 .7754058838176 .7754058838176 .7754058838176 .7754058838 176.165802002175 .5561981201174 .9467010498173 .7274932861172 .5084075928 171.2891998291170 .3748931885170 .070098877170 .3748931885171 .2891998291 172.5084075928173 .1179962158173 .4226989746172 .5084075928171 .5939941406 170.3748931885168 .8509979248167 .0222015381163 .0599975586157 .2691040039 150.8686065674145 .6873016357143 .5538024902144 .4682006836148 .1255950928 153.0021057129157 .5738983154160 .3170013428161 .2312927246161 .5361022949 161.8408966064162 .1457061768162 .7552947998162 .7552947998162 .4505004883 161.5361022949160 .3170013428158 .7929992676157 .5738983154156 .0500030518 154.8307952881153 .0021057129151 .4781951904149 .6495056152148 .1255950928 146.6015930176145 .0776977539143 .5538024902141 .7250976562140 .2012023926 138.3724975586136 .5437011719135 .0198059082133 .1911010742131 .6672058105 130.4479980469129 .2288970947128 .0097961426126 .7906036377125 .5715026855 126.4858016968126 .7906036377127 .4001998901127 .7050018311128 .0097961426 128.3144989014128 .3144989014128 .3144989014128 .0097961426127 .4001998901 126.7906036377125 .8762969971125 .2667007446126 .4858016968128 .6192932129 130.1432037354131 .6672058105132 .8863067627134 .4102020264135 .6293945312 136.8484954834138 .3724975586139 .8963928223141 .1154937744142 .6394042969 144.1634063721145 .3825073242146 .9064025879148 .4304046631149 .9542999268 151.1734008789152 .0877990723152 .0877990723152 .6972961426152 .6972961426 153.0021057129153 .0021057129153 .0021057129153 .0021057129152 .6972961426 152.0877990723151 .7830047607151 .7830047607152 .6972961426152 .3925933838 152.3925933838152 .3925933838152 .3925933838152 .3925933838152 .0877990723 152.6972961426153 .0021057129153 .0021057129152 .6972961426151 .1734008789 149.3446960449146 .9064025879144 .4682006836141 .7250976562138 .9819946289 136.2389984131 133.8007049561 131.3623962402 129.2288970947127.4001998901 125.8762969971124 .3523025513123 .43800354122 .8283996582122 .2188034058 122.2188034058122 .2188034058122 .2188034058122 .5235977173123 .1332015991 123.43800354123 .7427978516123 .7427978516123 .7427978516123 .1332015991 122.5235977173121 .3044967651120 .3900985718119 .7806015015119 .4757995605 119.4757995605119 .4757995605119 .7806015015120 .0852966309120 .6949005127 120.9997024536121 .6092987061121 .9140014648122 .2188034058122 .5235977173 122.2188034058121 .6092987061120 .6949005127119 .1709976196117 .647102356 115.818397522113 .9896011353112 .1608963013110 .6370010376109 .1130981445 
108.5035018921108 .8082962036110 .0273971558112 .4656982422117 .342300415 134.1054992676149 .0399017334159 .7073974609166 .1078948975174 .6419067383 187.1381072998197 .500793457206 .6443023682209 .692199707209 .692199707 209.692199707209 .692199707209 .692199707209 .692199707209 .692199707209 .692199707 212.1304016113216 .7021942139220 .9691925049225 .2362060547229 .5032043457 233.4653930664237 .4275970459241 .0850067139244 .4376983643247 .4855041504 250.5334014893252 .9716033936255 .4098968506257 .5433959961259 .6769104004 261.5056152344263 .0296020508264 .5534973145265 .7726135254266 .9917907715 267.9060974121268 .8204956055269 .7348022461270 .6492004395271 .2587890625 271.8682861328272 .4779052734272 .7827148438273 .3923034668273 .6971130371 274.0018005371274 .6113891602274 .9161987305275 .2210083008275 .5257873535 275.8305053711275 .8305053711275 .8305053711275 .8305053711275 .8305053711 275.5257873535274 .9161987305274 .3066101074273 .3923034668272 .1730957031 270.6492004395269 .1253051758266 .9917907715264 .5534973145261 .8103942871 258.4577941895254 .4956054688250 .2286071777245 .0471954346239 .5610961914 233.4653930664226 .7601013184219 .7501068115212 .1304016113209 .692199707 209.692199707 209.692199707 180.7375946045173.1179962158 165.4983062744 157.0705718994 147.6674194336 137.7749633789 -9999 -9999-9999 -9999 -9999 -9999-9999 -9999 -9999 -9999 -9999 -9999 -9999 -9999 -9999 -9999 -9999 -9999 -9999 -9999 -9999 -9999

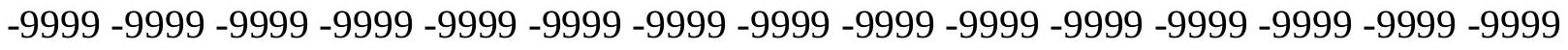

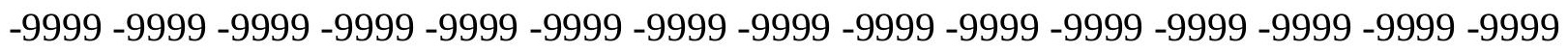
-9999-9999

-9999 -9999 -9999 -9999 -9999 -9999 -9999 -9999 -9999 -9999 -9999 -9999 -9999 -9999 -9999 -9999-24.8242721558 -16.2697048187 -7.61962795258 9143553972244 10.97226047516 21.3349609375 32.0024414062542 .9747009277354 .2517509460465 .22400665283 75.8914871215885 .9494018554795 .3977432251104 .2365036011112 .1608963013 119.1709976196125 .5715026855131 .3623962402136 .2389984131140 .5059967041 144.4682006836147 .8208007812150 .8686065674153 .6116943359156 .0500030518 158.1835021973160 .0122070312161 .8408966064163 .0599975586163 .974395752 164.8887023926165 .4983062744165 .8031005859166 .1078948975166 .1078948975 166.1078948975166 .1078948975165 .8031005859165 .8031005859165 .4983062744 165.4983062744165 .4983062744165 .4983062744165 .8031005859165 .8031005859 166.1078948975166 .4127044678166 .7174987793167 .0222015381167 .6318054199 167.9365997314168 .5462036133169 .1557006836169 .7653045654170 .3748931885 170.9844970703171 .5939941406172 .2035980225172 .8132019043173 .1179962158 173.7274932861173 .7274932861174 .0323028564174 .0323028564173 .7274932861 173.4226989746172 .8132019043171 .8988037109170 .3748931885168 .8509979248 167.0222015381165 .4983062744164 .5839996338164 .8887023926166 .1078948975 167.9365997314168 .8509979248169 .1557006836167 .9365997314166 .7174987793 165.4983062744164 .5839996338163 .974395752161 .5361022949153 .9165039062 145.3825073242139 .5915985107137 .1533050537138 .6772003174143 .2489929199 149.9542999268155 .7451934814158 .1835021973157 .878692627157 .5738983154 157.2691040039157 .878692627158 .7929992676159 .4026031494159 .0977935791 157.878692627156 .6596069336155 .1356048584153 .9165039062152 .6972961426 151.4781951904149 .6495056152148 .1255950928146 .2969055176144 .7729034424 143.5538024902142 .0299072266140 .2012023926138 .6772003174137 .1533050537 
135.6293945312133 .8007049561132 .2767028809131 .0576019287129 .533706665 128.3144989014127 .0953979492126 .1809997559124 .9618988037125 .8762969971 126.4858016968127 .0953979492127 .4001998901128 .0097961426128 .3144989014 128.6192932129128 .9241027832128 .9241027832128 .6192932129128 .0097961426 127.0953979492125 .8762969971127 .7050018311130 .4479980469132 .2767028809 134.1054992676135 .3246002197136 .5437011719137 .7628936768138 .9819946289 140.2012023926141 .7250976562142 .9441986084144 .1634063721145 .3825073242 146.2969055176147 .5160064697148 .4304046631149 .6495056152150 .5639038086 151.4781951904152 .0877990723152 .3925933838152 .6972961426153 .0021057129 153.0021057129153 .0021057129153 .0021057129153 .0021057129153 .0021057129 151.4781951904150 .2590942383150 .2590942383150 .8686065674151 .4781951904 152.0877990723152 .3925933838152 .6972961426152 .6972961426153 .0021057129 153.3069000244153 .6116943359153 .6116943359153 .0021057129152 .0877990723 150.2590942383147 .8208007812145 .3825073242142 .6394042969139 .8963928223 137.1533050537134 .4102020264131 .9720001221129 .8385009766127 .7050018311 126.1809997559124 .9618988037123 .7427978516123 .1332015991122 .5235977173 122.2188034058122 .2188034058122 .2188034058122 .8283996582123 .1332015991 123.43800354124 .0475006104124 .3523025513124 .3523025513123 .7427978516 122.8283996582121 .6092987061120 .3900985718119 .4757995605118 .8662033081 119.1709976196119 .4757995605119 .7806015015120 .0852966309120 .6949005127 120.9997024536121 .6092987061121 .9140014648122 .5235977173122 .5235977173 122.5235977173122 .2188034058121 .6092987061120 .0852966309118 .2565994263 116.4279022217114 .2944030762112 .1608963013110 .0273971558108 .1986999512 106.6747970581105 .4557037354105 .7603988647108 .1986999512116 .4279022217 132.8863067627150 .2590942383160 .3170013428165 .4983062744168 .5462036133 177.9945068359189 .8811035156200 .5485992432209 .692199707209 .692199707 209.692199707209 .692199707209 .692199707209 .692199707209 .692199707209 .692199707 212.7400054932217 .3117980957221 .5787963867226 .150604248230 .4176025391 234.3798065186238 .3419952393241 .9994049072245 .3520050049248 .3999023438 251.4476928711253 .8860015869256 .3243103027258 .4577941895260 .2864990234 262.1152038574263 .6390991211265 .1630859375266 .3822021484267 .2966003418 268.5156860352269 .4301147461270 .0396118164270 .9540100098271 .5635070801 272.1730957031272 .4779052734273 .0874938965273 .3923034668273 .6971130371 274.3066101074274 .6113891602274 .9161987305275 .2210083008275 .5257873535 275.8305053711275 .8305053711275 .8305053711275 .8305053711275 .5257873535 275.2210083008274 .6113891602274 .0018005371273 .0874938965271 .8682861328 270.3443908691268 .5156860352266 .3822021484263 .9439086914260 .8960876465 257.5433959961253 .8860015869249 .3141937256244 .7424926758239 .2563018799 233.4653930664227 .0648956299220 .054901123213 .0447998047209 .692199707 209.692199707 209.692199707209.692199707 175.8609924316 168.241394043 160.9264984131151 .7396240234141 .9858551025 -9999 -9999 -9999 -9999 -9999 -9999 -9999

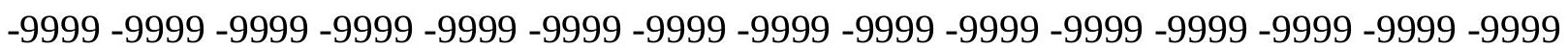

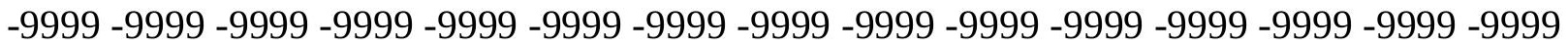

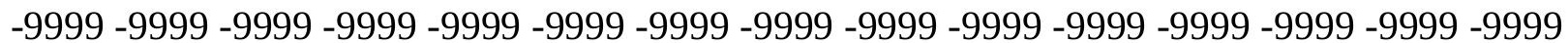
$-9999-9999$

-9999 -9999 -9999 -9999 -9999 -9999 -9999 -9999 -9999 -9999 -9999 -9999 -9999 -9999 -9999 
-9999 -9999-16.8828296661 -8.09255027771 1.21914100647 11.27705001831 22.2493095397933 .5263595581145 .4129791259856 .9948196411168 .57665252686 79.8537063598690 .52117919922100 .2742996216109 .1130981445116 .7326965332 123.7427978516129 .8385009766135 .0198059082139 .5915985107143 .5538024902 146.9064025879149 .9542999268152 .6972961426155 .1356048584157 .2691040039 159.0977935791160 .6217956543161 .8408966064163 .0599975586163 .6696014404 164.2792053223164 .5839996338164 .8887023926164 .8887023926164 .5839996338 164.2792053223163 .974395752163 .6696014404163 .3648071289163 .0599975586 163.0599975586162 .7552947998162 .7552947998162 .7552947998163 .0599975586 163.0599975586163 .3648071289163 .6696014404163 .974395752164 .2792053223 164.5839996338165 .1934967041165 .8031005859166 .4127044678167 .0222015381 167.6318054199168 .241394043168 .8509979248169 .4604949951170 .070098877 170.3748931885170 .6797027588170 .9844970703170 .9844970703170 .6797027588 170.3748931885169 .7653045654168 .5462036133167 .0222015381164 .8887023926 162.4505004883159 .7073974609157 .878692627157 .2691040039158 .4882965088 160.9264984131163 .0599975586162 .7552947998160 .9264984131159 .4026031494 157.878692627156 .6596069336156 .3547973633157 .878692627145 .9920959473 137.1533050537131 .9720001221130 .1432037354131 .3623962402136 .5437011719 144.4682006836153 .6116943359153 .6116943359152 .6972961426151 .4781951904 150.8686065674151 .4781951904153 .3069000244154 .8307952881154 .8307952881 153.6116943359152 .0877990723150 .5639038086149 .3446960449148 .1255950928 147.2111968994145 .6873016357144 .1634063721142 .9441986084141 .4203033447 140.2012023926138 .6772003174137 .1533050537135 .6293945312134 .1054992676 132.5814971924131 .3623962402129 .8385009766128 .6192932129127 .4001998901 126.1809997559125 .2667007446124 .3523025513125 .2667007446125 .8762969971 126.4858016968127 .0953979492127 .4001998901128 .0097961426128 .3144989014 128.9241027832129 .2288970947129 .2288970947129 .2288970947128 .6192932129 127.0953979492129 .8385009766133 .1911010742134 .7149963379136 .5437011719 137.7628936768139 .2868041992140 .2012023926141 .4203033447142 .6394042969 143.5538024902144 .7729034424145 .9920959473147 .2111968994147 .8208007812 148.7351074219149 .3446960449150 .2590942383150 .8686065674151 .4781951904 151.7830047607152 .0877990723152 .3925933838153 .0021057129153 .0021057129 153.3069000244153 .3069000244153 .3069000244153 .0021057129152 .0877990723 150.5639038086149 .0399017334147 .8208007812149 .0399017334150 .5639038086 151.7830047607152 .6972961426153 .0021057129153 .3069000244153 .6116943359 153.9165039062153 .9165039062153 .9165039062153 .6116943359152 .3925933838 150.8686065674148 .7351074219145 .9920959473143 .2489929199140 .5059967041 137.7628936768135 .0198059082132 .5814971924130 .4479980469128 .3144989014 126.7906036377125 .2667007446124 .0475006104123 .1332015991122 .5235977173 122.2188034058122 .2188034058122 .2188034058122 .5235977173123 .1332015991 123.43800354124 .0475006104124 .6570968628125 .2667007446124 .3523025513 123.1332015991121 .6092987061120 .3900985718119 .1709976196118 .5614013672 118.8662033081119 .1709976196119 .7806015015120 .0852966309120 .6949005127 120.9997024536121 .6092987061121 .9140014648122 .5235977173122 .8283996582 122.8283996582122 .8283996582122 .2188034058120 .9997024536119 .1709976196 117.0374984741114 .9039993286112 .4656982422110 .0273971558107 .5891036987 
105.4557037354103 .6268997192103 .3221969604105 .4557037354112 .7705001831 128.3144989014153 .0021057129158 .1835021973162 .1457061768165 .4983062744 170.6797027588184 .0901947021195 .6721038818206 .0346984863209 .692199707 209.692199707 209.692199707 209.692199707 209.692199707 209.692199707 208.7778015137213 .6544036865218 .2261962891222 .7978973389227 .0648956299 231.6367034912235 .5989074707239 .5610961914243 .2185058594246 .5711975098 249.6190032959252 .6669006348255 .1051025391257 .5433959961259 .3721008301 261.5056152344263 .0296020508264 .5534973145265 .7726135254266 .9917907715 267.9060974121268 .8204956055269 .7348022461270 .3443908691271 .2587890625 271.5635070801272 .1730957031272 .7827148438273 .0874938965273 .6971130371 274.0018005371274 .3066101074274 .6113891602274 .9161987305275 .2210083008 275.5257873535275 .5257873535275 .8305053711275 .8305053711275 .8305053711 275.5257873535274 .9161987305274 .3066101074273 .6971130371272 .4779052734 271.2587890625269 .7348022461267 .9060974121265 .7726135254263 .3344116211 260.2864990234256 .9338989258253 .2763977051249 .0093994141244 .1329040527 238.9515075684 233.1605987549227.0648956299220.6643981934213.959197998 209.692199707209.692199707209.692199707 209.692199707 178.2993011475 $170.9844970703163 .6696014404155 .5068969727146 .0796356201136 .0157470703-9999$

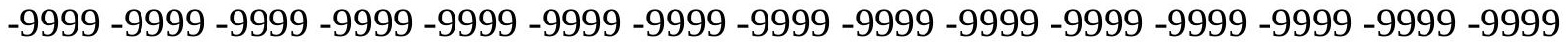

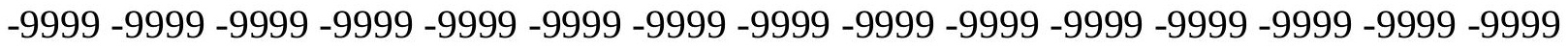

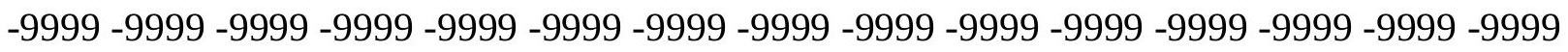
-9999 -9999 -9999 -9999 -9999 -9999 -9999 -9999 -9999 -9999 -9999 -9999 -9999 -9999 -9999 -9999 -9999 -9999 -9999 -9999 -9999 -999 -999 -9999 -9999 -17.3176193237-8.39223384857 1.21914100647 11.88661956787

23.1636695861835.05028915405 47.54647827148 60.04267120361 72.53885650635 84.1206970214895.3977432251 105.4557037354 114.2944030762 121.9140014648 128.6192932129134 .1054992676138 .9819946289142 .9441986084146 .2969055176 149.3446960449152 .0877990723154 .2212982178156 .3547973633158 .1835021973 159.7073974609160 .9264984131161 .8408966064162 .7552947998163 .3648071289 163.6696014404163 .6696014404163 .6696014404163 .3648071289163 .0599975586 162.7552947998162 .1457061768161 .5361022949161 .2312927246160 .6217956543 160.3170013428160 .0122070312160 .0122070312160 .0122070312160 .0122070312 160.0122070312160 .3170013428160 .6217956543160 .6217956543160 .9264984131 161.2312927246161 .5361022949162 .1457061768162 .7552947998163 .3648071289 164.2792053223164 .8887023926165 .4983062744166 .1078948975166 .7174987793 167.0222015381167 .3269958496167 .3269958496167 .3269958496167 .0222015381 166.7174987793166 .1078948975165 .1934967041163 .3648071289160 .6217956543 156.9642944336153 .3069000244149 .9542999268148 .1255950928148 .1255950928 150.5639038086155 .4403991699152 .3925933838150 .8686065674149 .9542999268 148.4304046631145 .3825073242141 .4203033447136 .5437011719131 .6672058105 127.4001998901124 .3523025513123 .1332015991124 .0475006104128 .3144989014 136.2389984131143 .2489929199145 .9920959473145 .3825073242143 .5538024902 142.3347015381142 .9441986084145 .6873016357149 .6495056152149 .0399017334 147.8208007812146 .6015930176145 .3825073242144 .4682006836143 .5538024902 142.3347015381141 .4203033447140 .2012023926139 .2868041992138 .0677032471 136.8484954834135 .3246002197134 .1054992676132 .8863067627131 .3623962402 
130.1432037354128 .9241027832127 .7050018311126 .4858016968125 .2667007446 124.3523025513123 .7427978516124 .6570968628125 .2667007446125 .8762969971 126.4858016968126 .7906036377127 .4001998901128 .0097961426128 .6192932129 128.9241027832129 .533706665129 .533706665129 .8385009766128 .6192932129 131.0576019287133 .8007049561136 .8484954834138 .6772003174140 .5059967041 141.7250976562142 .9441986084143 .8585968018144 .7729034424145 .9920959473 146.9064025879147 .8208007812149 .0399017334149 .9542999268150 .5639038086 150.8686065674151 .1734008789151 .4781951904152 .0877990723152 .3925933838 152.3925933838152 .3925933838153 .0021057129153 .3069000244153 .3069000244 153.6116943359153 .3069000244153 .3069000244153 .0021057129152 .3925933838 150.8686065674148 .4304046631145 .6873016357148 .7351074219150 .8686065674 152.0877990723153 .0021057129153 .3069000244153 .6116943359153 .9165039062 154.2212982178154 .2212982178154 .2212982178153 .6116943359153 .0021057129 151.4781951904149 .3446960449146 .6015930176143 .8585968018140 .8106994629 138.0677032471135 .3246002197132 .8863067627130 .7528076172128 .6192932129 127.0953979492125 .5715026855124 .3523025513123 .43800354122 .5235977173 122.2188034058122 .2188034058122 .2188034058122 .5235977173122 .5235977173 122.8283996582123 .1332015991124 .0475006104125 .5715026855124 .3523025513 123.1332015991121 .6092987061120 .3900985718119 .4757995605118 .8662033081 118.8662033081119 .4757995605119 .7806015015120 .0852966309120 .6949005127 120.9997024536121 .6092987061121 .9140014648122 .2188034058122 .5235977173 122.8283996582122 .8283996582122 .5235977173121 .3044967651119 .7806015015 117.9517974854115 .5136032104112 .7705001831110 .0273971558107 .2844009399 104.8460998535103 .0174026489103 .3221969604103 .6268997192107 .8938980103 114.9039993286136 .5437011719149 .3446960449156 .0500030518160 .9264984131 166.1078948975180 .1280059814192 .624206543203 .596496582209 .692199707 209.692199707209 .692199707209 .692199707209 .692199707209 .692199707209 .692199707 214.5686950684219 .4452972412224 .0171051025228 .5888977051232 .8558044434 237.1228027344241 .0850067139244 .7424926758248 .0950927734251 .1428985596 253.8860015869256 .3243103027258 .7626037598260 .5913085938262 .4200134277 263.9439086914265 .4678039551266 .6870117188267 .6012878418268 .5156860352 269.4301147461270 .0396118164270 .9540100098271 .5635070801271 .8682861328 272.4779052734272 .7827148438273 .3923034668273 .6971130371274 .0018005371 274.3066101074274 .6113891602274 .9161987305275 .2210083008275 .5257873535 275.5257873535275 .5257873535275 .5257873535275 .5257873535275 .2210083008 274.9161987305274 .0018005371273 .3923034668272 .1730957031270 .9540100098 269.4301147461 267.2966003418265.1630859375 262.7247924805 259.6769104004 256.3243103027252 .6669006348248 .3999023438243 .8280944824238 .9515075684 233.4653930664227 .6744995117221 .2740020752214 .8735046387209 .692199707 209.692199707 209.692199707209.692199707209.692199707 173.4226989746 166.4127044678159 .4026031494149 .8742523193140 .0127258301 -9999 -9999 -9999-9999 -9999 -9999 -9999 -9999 -9999 -9999 -9999 -9999 -9999 -9999 -9999 -9999 -9999 -9999 -9999 -9999 -9999 -9999 -9999 -9999 -9999 -9999 -9999 -9999 -9999 -9999 -9999 -9999 -9999 -9999 -

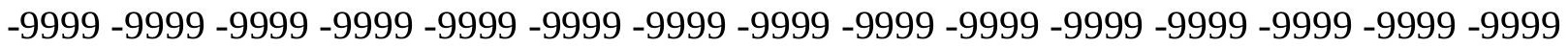
-9999 -9999-9999-9999

-9999 -9999 -9999 -9999 -9999 -9999 -9999 -9999 -9999 -9999 -9999 -9999 -9999 -9999 -9999 
-9999 -9999 -9999-8.47218418121 1.414189934731 12.1914100647 24.07802963257 36.5742111206149 .9847602844263 .3953094482476 .5010681152388 .99725341797 100.5791015625110 .9418029785119 .7806015015127 .4001998901133 .4958953857 138.6772003174142 .9441986084146 .2969055176149 .0399017334151 .4781951904 153.6116943359155 .7451934814157 .2691040039158 .7929992676160 .0122070312 160.9264984131161 .8408966064162 .4505004883162 .7552947998163 .0599975586 162.7552947998162 .4505004883162 .1457061768161 .5361022949160 .9264984131 160.0122070312159 .4026031494158 .7929992676158 .1835021973157 .5738983154 157.2691040039156 .9642944336156 .9642944336156 .9642944336156 .9642944336 157.2691040039157 .2691040039157 .5738983154157 .5738983154157 .878692627 158.1835021973158 .4882965088159 .0977935791159 .7073974609160 .6217956543 161.2312927246162 .1457061768162 .7552947998163 .0599975586163 .6696014404 163.6696014404163 .6696014404163 .3648071289163 .0599975586162 .4505004883 161.8408966064160 .9264984131159 .4026031494156 .3547973633151 .4781951904 145.6873016357141 .1154937744138 .0677032471136 .2389984131135 .6293945312 135.9342041016137 .7628936768139 .2868041992139 .8963928223138 .6772003174 135.0198059082127 .4001998901115 .818397522118 .8662033081119 .1709976196 118.2565994263117 .9517974854118 .2565994263119 .7806015015128 .3144989014 134.7149963379137 .7628936768137 .4580993652135 .3246002197132 .8863067627 132.5814971924135 .6293945312139 .2868041992141 .1154937744141 .1154937744 140.5059967041139 .5915985107138 .9819946289138 .3724975586137 .7628936768 137.1533050537136 .2389984131135 .6293945312134 .4102020264133 .4958953857 132.2767028809131 .0576019287129 .8385009766128 .6192932129127 .7050018311 126.4858016968125 .5715026855124 .6570968628123 .7427978516122 .8283996582 124.0475006104124 .3523025513124 .9618988037125 .5715026855126 .1809997559 126.7906036377127 .4001998901128 .0097961426128 .6192932129128 .9241027832 129.533706665129 .8385009766129 .533706665131 .9720001221134 .7149963379 137.4580993652140 .2012023926142 .3347015381144 .1634063721145 .3825073242 146.2969055176147 .2111968994148 .1255950928149 .0399017334149 .9542999268 150.8686065674151 .4781951904152 .3925933838152 .6972961426153 .0021057129 153.0021057129153 .3069000244153 .3069000244153 .6116943359153 .6116943359 153.6116943359153 .6116943359153 .9165039062153 .9165039062153 .9165039062 153.9165039062153 .6116943359153 .3069000244153 .0021057129152 .3925933838 149.9542999268149 .0399017334150 .5639038086151 .4781951904152 .6972961426 153.3069000244153 .9165039062154 .2212982178154 .5260925293154 .5260925293 154.5260925293154 .2212982178153 .6116943359152 .6972961426151 .4781951904 149.3446960449146 .9064025879144 .1634063721141 .4203033447138 .3724975586 135.6293945312133 .1911010742131 .0576019287129 .2288970947127 .4001998901 125.8762969971124 .6570968628123 .43800354122 .8283996582122 .2188034058 121.9140014648121 .9140014648122 .2188034058122 .2188034058122 .2188034058 122.2188034058121 .9140014648123 .1332015991123 .43800354122 .5235977173 121.6092987061120 .6949005127119 .7806015015119 .4757995605119 .4757995605 119.4757995605119 .7806015015120 .3900985718120 .6949005127120 .9997024536 121.6092987061121 .9140014648122 .2188034058122 .5235977173122 .5235977173 122.5235977173122 .2188034058121 .6092987061120 .6949005127118 .8662033081 116.4279022217113 .6848983765110 .9418029785107 .8938980103105 .1509017944 
104.2365036011 103.6268997192102.712600708 105.7603988647113.6848983765 126.4858016968138 .9819946289148 .1255950928155 .1356048584164 .2792053223 178.9089050293191 .7097930908202 .6820983887209 .692199707209 .692199707 209.692199707 209.692199707 209.692199707 209.692199707 211.2160949707 216.0926971436220 .9691925049225 .5410003662230 .1127929688234 .6844940186 238.6468048096242 .6089935303246 .2664031982249 .6190032959252 .6669006348 255.4098968506257 .8482055664259 .9816894531261 .8103942871263 .6390991211 265.1630859375266 .3822021484267 .6012878418268 .5156860352269 .1253051758 270.0396118164270 .6492004395271 .2587890625271 .8682861328272 .1730957031 272.7827148438273 .0874938965273 .3923034668273 .6971130371274 .0018005371 274.3066101074274 .6113891602274 .9161987305275 .2210083008275 .2210083008 275.5257873535275 .5257873535275 .5257873535275 .2210083008274 .9161987305 274.6113891602273 .6971130371273 .0874938965271 .8682861328270 .6492004395 268.8204956055266 .9917907715264 .8583068848262 .1152038574259 .3721008301 256.0195007324252 .3621063232248 .0950927734243 .5233001709238 .6468048096 233.4653930664227 .9792938232221 .883605957215 .787902832209 .3874053955 209.692199707 209.692199707209.692199707209.692199707 175.8609924316 $169.1557006836162 .1457061768153 .282699585144 .1411590576134 .1022186279-9999$ -9999 -9999 -9999 -9999 -9999 -9999 -9999 -9999 -9999 -9999 -9999 -9999 -9999 -9999 -9999

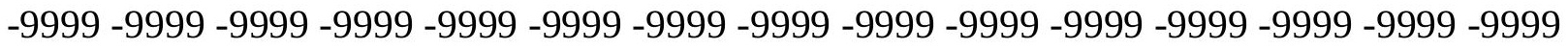

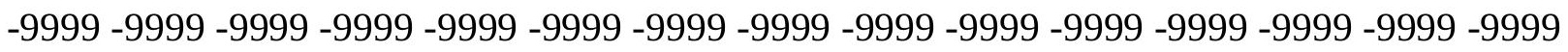
-9999 -9999 -9999-9999-9999-9999

-9999 -9999 -9999 -9999 -9999 -9999 -9999 -9999 -9999 -9999 -9999 -9999 -9999 -9999 -9999 -9999-9999-9999-8.41370582581 1.626861572266 12.80097007751 24.68759918213 38.0981407165552 .1182594299366 .7479400634881 .0728530883894 .48339080811 106.6747970581117 .342300415126 .1809997559133 .1911010742138 .6772003174 143.2489929199146 .6015930176149 .3446960449151 .4781951904153 .6116943359 155.1356048584156 .6596069336157 .878692627159 .0977935791160 .0122070312 160.9264984131161 .5361022949161 .8408966064162 .1457061768162 .1457061768 161.8408966064161 .2312927246160 .6217956543159 .7073974609158 .7929992676 157.878692627156 .9642944336156 .0500030518155 .4403991699154 .8307952881 154.2212982178154 .2212982178153 .9165039062153 .9165039062153 .9165039062 153.9165039062154 .2212982178154 .2212982178154 .2212982178154 .2212982178 154.5260925293154 .8307952881155 .4403991699156 .0500030518156 .9642944336 157.5738983154158 .1835021973159 .0977935791159 .4026031494159 .7073974609 159.7073974609159 .4026031494158 .7929992676158 .1835021973157 .5738983154 156.6596069336155 .7451934814154 .2212982178152 .0877990723145 .0776977539 138.0677032471131 .9720001221128 .6192932129126 .1809997559122 .8283996582 117.647102356124 .6570968628129 .2288970947131 .0576019287130 .7528076172 127.4001998901122 .2188034058117 .342300415115 .5136032104115 .2088012695 115.2088012695115 .5136032104117 .0374984741119 .7806015015124 .6570968628 128.9241027832131 .0576019287130 .7528076172128 .6192932129125 .2667007446 121.9140014648126 .4858016968130 .4479980469133 .1911010742134 .1054992676 134.4102020264134 .1054992676133 .8007049561133 .4958953857133 .4958953857 133.1911010742132 .5814971924131 .9720001221131 .3623962402130 .4479980469 129.533706665128 .3144989014127 .4001998901126 .1809997559125 .2667007446 
124.3523025513123 .7427978516122 .8283996582122 .2188034058123 .1332015991 123.7427978516124 .3523025513124 .6570968628125 .2667007446125 .8762969971 126.4858016968127 .0953979492127 .7050018311128 .3144989014128 .9241027832 129.533706665129 .8385009766132 .5814971924135 .3246002197138 .0677032471 140.8106994629143 .5538024902145 .6873016357147 .2111968994148 .4304046631 149.6495056152150 .2590942383151 .1734008789151 .7830047607152 .3925933838 153.3069000244153 .9165039062154 .5260925293154 .8307952881154 .8307952881 154.8307952881154 .8307952881154 .8307952881154 .8307952881154 .8307952881 154.8307952881154 .5260925293154 .5260925293154 .5260925293154 .5260925293 154.2212982178153 .9165039062153 .9165039062153 .6116943359153 .0021057129 152.0877990723151 .4781951904152 .0877990723152 .6972961426153 .3069000244 153.9165039062154 .2212982178154 .5260925293154 .8307952881154 .8307952881 154.8307952881154 .5260925293153 .6116943359152 .6972961426151 .1734008789 149.3446960449146 .9064025879144 .4682006836141 .4203033447138 .6772003174 135.9342041016133 .1911010742131 .0576019287129 .533706665127 .7050018311 126.4858016968124 .9618988037123 .7427978516122 .8283996582121 .9140014648 121.6092987061121 .9140014648121 .9140014648121 .9140014648121 .9140014648 121.6092987061121 .6092987061121 .9140014648122 .2188034058122 .2188034058 121.3044967651120 .6949005127120 .0852966309119 .7806015015119 .7806015015 120.0852966309120 .0852966309120 .3900985718120 .6949005127120 .9997024536 121.3044967651121 .6092987061121 .9140014648122 .2188034058122 .2188034058 122.2188034058122 .2188034058121 .9140014648121 .3044967651119 .7806015015 117.647102356114 .9039993286111 .8561019897108 .8082962036106 .0652008057 103.9317016602103 .9317016602103 .0174026489105 .7603988647111 .8561019897 120.9997024536131 .0576019287140 .8106994629149 .3446960449164 .2792053223 179.5184020996192 .3193969727202 .9868927002209 .692199707209 .692199707 209.692199707209 .692199707209 .692199707209 .692199707212 .7400054932 217.6165924072222 .7978973389227 .3697052002232 .246307373236 .5133056641 240.7801971436244 .7424926758248 .3999023438251 .4476928711254 .4956054688 257.2385864258259 .6769104004261 .5056152344263 .3344116211264 .8583068848 266.3822021484267 .2966003418268 .5156860352269 .1253051758270 .0396118164 270.6492004395271 .2587890625271 .5635070801272 .1730957031272 .4779052734 272.7827148438273 .3923034668273 .6971130371273 .6971130371274 .0018005371 274.3066101074274 .6113891602274 .9161987305275 .2210083008275 .2210083008 275.2210083008275 .2210083008275 .2210083008274 .9161987305274 .6113891602 274.3066101074273 .3923034668272 .4779052734271 .5635070801270 .0396118164 268.5156860352266 .3822021484264 .2486877441261 .8103942871258 .7626037598 255.4098968506251 .7525024414247 .7902984619243 .5233001709238 .9515075684 233.7702026367228 .2841033936222 .7978973389216 .7021942139210 .6065063477 209.692199707 209.692199707209.692199707 209.692199707209.692199707 $171.5939941406164 .8887023926158 .1835021973148 .3236694336138 .2886657715-9999$

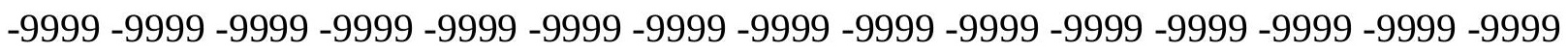

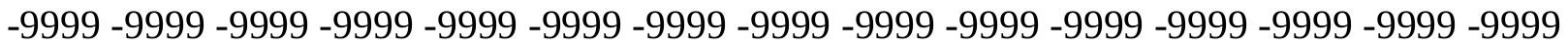

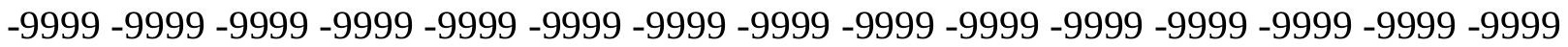
-9999 -9999 -9999 -9999-9999-9999

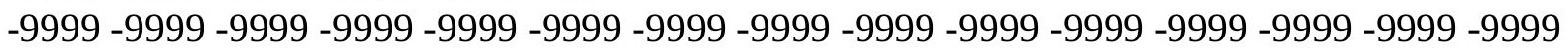


-9999 -9999 -9999 -9999 1.774270534515 12.93762207031 25.29715919495 39.31727981567 54.5565414428770 .1005783081185 .64462280273100 .2742996216113 .3800964355 124.0475006104132 .5814971924138 .9819946289143 .8585968018147 .2111968994 149.9542999268152 .0877990723153 .6116943359154 .8307952881156 .0500030518 157.2691040039158 .1835021973159 .0977935791160 .0122070312160 .6217956543 160.9264984131161 .2312927246161 .2312927246160 .9264984131160 .6217956543 159.7073974609158 .7929992676157 .878692627156 .6596069336155 .7451934814 154.5260925293153 .6116943359152 .6972961426151 .7830047607151 .4781951904 151.1734008789150 .8686065674150 .5639038086150 .5639038086150 .5639038086 150.8686065674150 .5639038086150 .5639038086150 .8686065674150 .8686065674 151.1734008789151 .7830047607152 .3925933838153 .0021057129153 .6116943359 154.5260925293155 .1356048584155 .7451934814156 .0500030518155 .4403991699 154.8307952881153 .9165039062153 .0021057129151 .7830047607150 .5639038086 149.3446960449147 .5160064697144 .1634063721138 .3724975586131 .0576019287 124.0475006104122 .2188034058120 .3900985718117 .647102356116 .4279022217 118.8662033081122 .5235977173124 .9618988037125 .2667007446123 .7427978516 121.9140014648121 .3044967651116 .7326965332114 .9039993286114 .9039993286 115.818397522117 .9517974854121 .6092987061124 .0475006104126 .1809997559 127.0953979492126 .4858016968124 .3523025513121 .6092987061120 .0852966309 121.6092987061124 .6570968628127 .0953979492128 .3144989014128 .6192932129 128.6192932129128 .9241027832129 .2288970947129 .2288970947129 .2288970947 129.2288970947 128.9241027832128.3144989014127.7050018311 126.7906036377 125.8762969971124 .9618988037124 .0475006104123 .43800354122 .8283996582 122.2188034058121 .9140014648122 .2188034058122 .8283996582123 .43800354 124.0475006104124 .3523025513124 .9618988037125 .5715026855126 .1809997559 126.7906036377127 .4001998901128 .0097961426128 .6192932129129 .8385009766 132.8863067627135 .9342041016138 .9819946289141 .7250976562144 .1634063721 146.6015930176148 .7351074219150 .2590942383151 .4781951904152 .0877990723 153.0021057129153 .6116943359154 .2212982178154 .8307952881155 .4403991699 156.0500030518156 .3547973633156 .3547973633156 .6596069336156 .6596069336 156.3547973633156 .3547973633156 .3547973633156 .0500030518155 .7451934814 155.7451934814155 .4403991699155 .1356048584155 .1356048584154 .8307952881 154.5260925293154 .5260925293154 .2212982178153 .6116943359153 .3069000244 153.3069000244153 .3069000244153 .9165039062154 .2212982178154 .5260925293 154.8307952881155 .1356048584155 .1356048584155 .1356048584155 .1356048584 154.5260925293153 .6116943359152 .3925933838151 .1734008789149 .6495056152 147.5160064697144 .7729034424142 .0299072266138 .6772003174135 .9342041016 133.1911010742131 .3623962402129 .8385009766128 .3144989014127 .0953979492 125.5715026855124 .3523025513123 .1332015991121 .9140014648121 .6092987061 121.6092987061121 .6092987061121 .6092987061121 .6092987061121 .6092987061 121.6092987061121 .6092987061121 .9140014648121 .9140014648121 .3044967651 120.9997024536120 .6949005127120 .3900985718120 .3900985718120 .3900985718 120.3900985718120 .6949005127120 .9997024536121 .3044967651121 .3044967651 121.6092987061121 .9140014648121 .9140014648121 .9140014648121 .9140014648 121.6092987061122 .2188034058122 .2188034058120 .9997024536118 .8662033081 116.1231002808113 .075302124110 .0273971558107 .2844009399105 .1509017944 
103.9317016602103 .6268997192105 .7603988647109 .7226028442116 .4279022217 124.9618988037134 .4102020264148 .4304046631166 .4127044678181 .9566955566 194.7577056885204 .5108032227209 .692199707209 .692199707209 .692199707 209.692199707 209.692199707 209.3874053955 214.5686950684219.7501068115 224.9313964844229 .8079986572234 .3798065186238 .9515075684242 .9136962891 246.8759002686250 .5334014893253 .5812072754256 .6290893555259 .0674133301 261.2008972168263 .3344116211264 .8583068848266 .3822021484267 .6012878418 268.5156860352269 .4301147461270 .0396118164270 .6492004395271 .2587890625 271.5635070801272 .1730957031272 .4779052734272 .7827148438273 .0874938965 273.3923034668273 .6971130371274 .0018005371274 .3066101074274 .3066101074 274.6113891602274 .9161987305274 .9161987305275 .2210083008275 .2210083008 275.2210083008274 .9161987305274 .9161987305274 .3066101074274 .0018005371 273.0874938965272 .1730957031270 .9540100098269 .7348022461267 .9060974121 266.0773925781263 .9439086914261 .2008972168258 .4577941895255 .1051025391 251.7525024414247 .7902984619243 .5233001709238 .9515075684234 .0749969482 228.8936004639223 .4075012207217 .6165924072211 .8256988525209 .692199707 209.692199707 209.692199707 209.692199707 209.692199707 209.692199707 $167.3269958496160 .9264984131151 .9778289795142 .641494751132 .3867797852-9999$ -9999 -9999 -9999 -9999 -9999 -9999 -9999 -9999 -9999 -9999 -9999 -9999 -9999 -9999 -9999

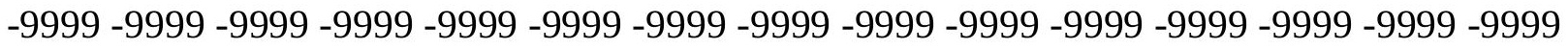

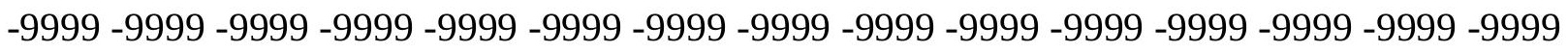
-9999 -9999-9999-9999-9999

-9999 -9999 -9999 -9999 -9999 -9999 -9999 -9999 -9999 -9999 -9999 -9999 -9999 -9999 -9999 -9999 -9999 -9999-9999 1.980565190315 13.1523504257225 .906740188640 .53641891479 56.3852500915573 .7580032348690 .82597351074106 .979598999120 .6949005127 131.3623962402139 .2868041992144 .7729034424148 .4304046631150 .8686065674 152.6972961426153 .9165039062154 .8307952881155 .7451934814156 .6596069336 157.2691040039158 .1835021973158 .7929992676159 .4026031494160 .0122070312 160.3170013428160 .3170013428160 .3170013428159 .7073974609159 .0977935791 158.1835021973156 .9642944336155 .7451934814154 .5260925293153 .3069000244 152.0877990723150 .8686065674149 .9542999268149 .0399017334148 .4304046631 147.8208007812147 .5160064697147 .2111968994147 .2111968994147 .2111968994 147.2111968994147 .2111968994147 .2111968994147 .2111968994147 .5160064697 147.5160064697148 .1255950928148 .4304046631149 .0399017334149 .6495056152 150.2590942383150 .8686065674151 .4781951904151 .7830047607150 .8686065674 149.6495056152148 .4304046631146 .9064025879145 .3825073242143 .8585968018 142.3347015381140 .2012023926136 .8484954834131 .9720001221126 .4858016968 121.9140014648119 .7806015015119 .1709976196118 .5614013672117 .9517974854 117.9517974854119 .7806015015121 .3044967651121 .9140014648121 .6092987061 120.9997024536120 .0852966309117 .9517974854116 .4279022217116 .1231002808 117.342300415119 .4757995605122 .2188034058124 .0475006104125 .2667007446 125.5715026855124 .6570968628122 .8283996582121 .3044967651119 .7806015015 120.0852966309121 .6092987061123 .1332015991124 .0475006104124 .3523025513 124.3523025513124 .6570968628125 .2667007446125 .8762969971126 .1809997559 126.1809997559126 .1809997559125 .8762969971125 .2667007446124 .6570968628 124.0475006104123 .1332015991122 .2188034058121 .6092987061121 .6092987061 
121.3044967651 120.9997024536121 .9140014648122 .5235977173123 .1332015991 123.43800354124 .0475006104124 .6570968628124 .9618988037125 .5715026855 126.1809997559126 .7906036377127 .4001998901129 .533706665133 .1911010742 136.5437011719139 .5915985107142 .6394042969144 .7729034424146 .9064025879 149.0399017334151 .4781951904152 .6972961426153 .9165039062154 .5260925293 155.4403991699156 .0500030518156 .6596069336156 .9642944336157 .2691040039 157.5738983154157 .878692627158 .1835021973158 .1835021973158 .1835021973 157.878692627157 .878692627157 .5738983154157 .2691040039156 .9642944336 156.6596069336156 .3547973633156 .0500030518155 .7451934814155 .4403991699 155.1356048584155 .1356048584154 .8307952881154 .5260925293154 .5260925293 154.5260925293154 .5260925293154 .8307952881154 .8307952881155 .1356048584 155.4403991699155 .7451934814155 .7451934814155 .7451934814155 .4403991699 154.8307952881153 .9165039062152 .3925933838151 .4781951904150 .2590942383 148.1255950928145 .3825073242142 .3347015381139 .2868041992135 .9342041016 133.4958953857131 .6672058105130 .4479980469129 .2288970947128 .0097961426 126.4858016968124 .9618988037123 .43800354122 .5235977173121 .6092987061 121.3044967651121 .3044967651121 .6092987061121 .6092987061121 .6092987061 121.6092987061121 .6092987061121 .6092987061121 .9140014648121 .6092987061 121.3044967651120 .9997024536120 .6949005127120 .6949005127120 .6949005127 120.6949005127120 .9997024536120 .9997024536121 .3044967651121 .6092987061 121.6092987061121 .6092987061121 .6092987061121 .6092987061121 .6092987061 121.9140014648122 .2188034058122 .2188034058121 .6092987061120 .0852966309 117.342300415114 .2944030762111 .24659729108 .5035018921106 .3700027466 104.8460998535104 .5412979126105 .4557037354107 .5891036987112 .1608963013 119.4757995605130 .1432037354149 .9542999268169 .1557006836185 .6141052246 197.500793457206 .0346984863209 .692199707209 .692199707209 .692199707 209.692199707209 .692199707211 .2160949707216 .7021942139222 .1884002686 227.3697052002232 .246307373237 .1228027344241 .3898010254245 .6567993164 249.3141937256252 .9716033936256 .0195007324258 .7626037598261 .2008972168 263.3344116211265 .1630859375266 .6870117188267 .9060974121268 .8204956055 269.7348022461270 .3443908691270 .9540100098271 .5635070801271 .8682861328 272.1730957031272 .4779052734272 .7827148438273 .0874938965273 .3923034668 273.6971130371273 .6971130371274 .0018005371274 .3066101074274 .3066101074 274.6113891602274 .9161987305274 .9161987305274 .9161987305274 .9161987305 274.9161987305274 .9161987305274 .6113891602274 .3066101074273 .6971130371 272.7827148438271 .8682861328270 .6492004395269 .4301147461267 .6012878418 265.7726135254263 .6390991211260 .8960876465258 .1530151367254 .8003997803 251.4476928711247 .4855041504243 .5233001709238 .9515075684234 .3798065186 229.5032043457224 .0171051025218 .5308990479213 .0447998047209 .692199707 209.692199707 209.692199707209.692199707209.692199707 209.692199707 $169.7653045654163 .3648071289156 .9642944336146 .9251861572136 .7094116211-9999$ -9999 -9999 -9999 -9999 -9999 -9999 -9999 -9999 -9999 -9999 -9999 -9999 -9999 -9999 -9999 -9999 -9999 -9999 -9999 -9999 -9999 -9999 -9999 -9999 -9999 -9999 -9999 -9999 -9999 -9999 -

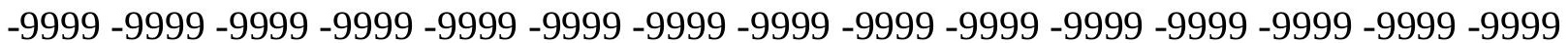
-9999 -9999-9999-9999-9999

-9999 -9999 -9999 -9999 -9999 -9999 -9999 -9999 -9999 -9999 -9999 -9999 -9999 -9999 -9999 
-9999 -9999 -9999 -9999 -9999 13.40898132324 26.25428009033 41.14598846436 58.2139587402376 .8058471679796 .00731658936113 .6848983765128 .3144989014 138.9819946289145 .6873016357149 .6495056152152 .0877990723153 .6116943359 154.5260925293155 .1356048584155 .4403991699156 .0500030518156 .3547973633 156.9642944336157 .2691040039157 .878692627158 .4882965088158 .7929992676 159.0977935791159 .0977935791158 .7929992676158 .1835021973157 .5738983154 156.3547973633155 .1356048584153 .6116943359152 .0877990723150 .5639038086 149.3446960449148.1255950928 146.9064025879 145.9920959473145.3825073242 144.7729034424144 .1634063721143 .8585968018143 .8585968018143 .5538024902 143.5538024902143 .5538024902143 .5538024902143 .5538024902143 .8585968018 143.8585968018144 .4682006836144 .7729034424145 .0776977539145 .3825073242 145.9920959473146 .2969055176146 .6015930176146 .2969055176145 .6873016357 144.4682006836142 .6394042969140 .8106994629138 .9819946289136 .8484954834 135.0198059082133 .1911010742130 .7528076172127 .7050018311124 .0475006104 120.9997024536119 .7806015015120 .0852966309121 .9140014648119 .4757995605 118.2565994263118 .5614013672119 .1709976196119 .7806015015119 .7806015015 119.7806015015118 .8662033081118 .2565994263117 .647102356117 .9517974854 119.4757995605121 .6092987061123 .43800354125 .2667007446125 .8762969971 125.5715026855124 .6570968628123 .1332015991121 .3044967651120 .3900985718 120.0852966309120 .6949005127121 .3044967651121 .6092987061121 .6092987061 120.9997024536121 .9140014648122 .8283996582123 .43800354123 .7427978516 124.0475006104124 .0475006104123 .7427978516123 .7427978516123 .1332015991 122.2188034058121 .6092987061120 .6949005127120 .3900985718120 .3900985718 120.3900985718120 .3900985718121 .6092987061122 .2188034058122 .5235977173 123.1332015991123 .7427978516124 .0475006104124 .6570968628124 .9618988037 125.2667007446127 .0953979492130 .1432037354133 .1911010742136 .8484954834 140.2012023926143 .5538024902146 .2969055176148 .4304046631149 .6495056152 151.1734008789153 .3069000244154 .8307952881155 .7451934814156 .6596069336 157.2691040039157 .878692627158 .4882965088158 .7929992676159 .0977935791 159.4026031494159 .4026031494159 .4026031494159 .4026031494159 .4026031494 159.4026031494159 .0977935791158 .7929992676158 .4882965088158 .1835021973 157.5738983154157 .2691040039156 .6596069336156 .3547973633156 .0500030518 155.7451934814155 .7451934814155 .4403991699155 .4403991699155 .4403991699 155.4403991699155 .4403991699155 .4403991699155 .7451934814155 .7451934814 156.0500030518156 .0500030518156 .3547973633156 .0500030518155 .7451934814 155.4403991699154 .5260925293153 .6116943359152 .6972961426151 .1734008789 149.0399017334146 .2969055176143 .5538024902140 .2012023926137 .1533050537 133.8007049561132 .8863067627131 .6672058105130 .4479980469129 .2288970947 127.7050018311126 .1809997559124 .3523025513123 .1332015991121 .9140014648 121.6092987061121 .3044967651121 .6092987061121 .6092987061121 .6092987061 121.6092987061121 .9140014648121 .9140014648121 .9140014648121 .6092987061 121.6092987061121 .3044967651120 .9997024536120 .9997024536120 .9997024536 120.9997024536120 .9997024536121 .3044967651121 .3044967651121 .6092987061 121.6092987061121 .6092987061121 .6092987061121 .6092987061121 .6092987061 121.6092987061121 .9140014648121 .9140014648121 .9140014648121 .3044967651 118.2565994263115 .2088012695112 .1608963013109 .4179000854107 .2844009399 
106.0652008057105 .4557037354105 .4557037354106 .3700027466108 .5035018921 114.9039993286129 .8385009766149 .9542999268170 .3748931885188 .966796875 198.4151000977206 .0346984863209 .692199707209 .692199707209 .692199707 209.692199707209 .692199707213 .6544036865219 .4452972412224 .9313964844 230.1127929688234 .9893035889239 .8659057617244 .4376983643248 .3999023438 252.0572967529255 .4098968506258 .4577941895261 .2008972168263 .3344116211 265.4678039551266 .9917907715268 .5156860352269 .4301147461270 .3443908691 270.9540100098271 .5635070801271 .8682861328272 .1730957031272 .4779052734 272.7827148438272 .7827148438273 .0874938965273 .3923034668273 .3923034668 273.6971130371274 .0018005371274 .0018005371274 .3066101074274 .6113891602 274.6113891602274 .6113891602274 .9161987305274 .9161987305274 .9161987305 274.9161987305274 .6113891602274 .3066101074274 .0018005371273 .3923034668 272.4779052734271 .5635070801270 .3443908691269 .1253051758267 .2966003418 265.4678039551263 .3344116211260 .5913085938257 .8482055664254 .8003997803 251.4476928711247 .4855041504243 .5233001709239 .2563018799234 .6844940186 229.8079986572224 .9313964844219 .7501068115214 .2639007568209 .692199707 209.692199707 209.692199707 209.692199707 209.692199707 209.692199707 209.692199707 $165.8031005859159 .4026031494150 .5820770264141 .2128601074130 .8012084961-9999$ -9999 -9999 -9999 -9999 -9999 -9999 -9999 -9999 -9999 -9999 -9999 -9999 -9999 -9999 -9999

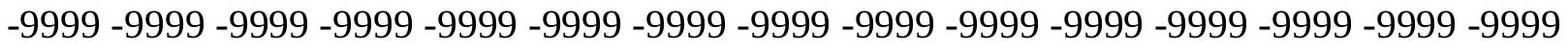

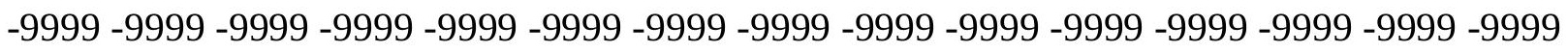
-9999 -9999-9999-9999

-9999 -9999 -9999 -9999 -9999 -9999 -9999 -9999 -9999 -9999 -9999 -9999 -9999 -9999 -9999 -9999 -9999 -9999 -9999-9999 13.6908445358326 .2640323638941 .14598846436 58.8235282897978 .93934631348100 .2742996216120 .6949005127136 .2389984131 146.6015930176151 .4781951904153 .3069000244154 .2212982178154 .8307952881 155.1356048584155 .1356048584155 .1356048584155 .4403991699155 .4403991699 155.7451934814156 .0500030518156 .6596069336156 .9642944336157 .5738983154 157.878692627157 .5738983154157 .2691040039156 .6596069336155 .4403991699 154.2212982178152 .6972961426151 .1734008789149 .3446960449147 .8208007812 146.6015930176145 .0776977539143 .8585968018142 .9441986084142 .0299072266 141.4203033447140 .8106994629140 .5059967041140 .2012023926140 .2012023926 139.8963928223139 .8963928223139 .8963928223140 .2012023926140 .2012023926 140.5059967041140 .5059967041140 .8106994629141 .1154937744141 .4203033447 141.4203033447141 .7250976562141 .4203033447141 .1154937744140 .2012023926 138.9819946289137 .1533050537135 .0198059082132 .8863067627130 .4479980469 128.3144989014127 .4001998901126 .4858016968124 .6570968628122 .2188034058 120.3900985718119 .4757995605119 .7806015015120 .0852966309119 .1709976196 118.2565994263117 .647102356117 .647102356117 .9517974854118 .2565994263 118.2565994263118 .2565994263118 .2565994263118 .8662033081119 .7806015015 121.6092987061123 .7427978516125 .5715026855127 .0953979492127 .4001998901 126.7906036377125 .5715026855124 .0475006104122 .5235977173121 .3044967651 120.6949005127120 .6949005127120 .9997024536120 .9997024536120 .6949005127 120.3900985718120 .3900985718120 .9997024536121 .6092987061122 .2188034058 122.2188034058122 .2188034058122 .2188034058122 .2188034058122 .2188034058 121.3044967651120 .3900985718119 .7806015015119 .4757995605119 .7806015015 
120.0852966309120 .6949005127121 .3044967651121 .3044967651121 .6092987061 122.5235977173122 .5235977173124 .0475006104125 .5715026855127 .0953979492 128.9241027832131 .3623962402134 .4102020264137 .7628936768140 .8106994629 144.1634063721147 .2111968994149 .6495056152151 .7830047607152 .6972961426 153.9165039062155 .1356048584156 .6596069336157 .5738983154158 .4882965088 159.0977935791159 .7073974609160 .0122070312160 .3170013428160 .6217956543 160.9264984131160 .9264984131160 .9264984131160 .9264984131160 .6217956543 160.6217956543160 .3170013428160 .0122070312159 .4026031494159 .0977935791 158.4882965088157 .878692627157 .5738983154156 .9642944336156 .6596069336 156.3547973633156 .3547973633156 .0500030518156 .0500030518156 .0500030518 156.0500030518156 .0500030518156 .3547973633156 .3547973633156 .6596069336 156.6596069336156 .9642944336156 .9642944336156 .6596069336156 .3547973633 156.0500030518155 .1356048584154 .5260925293153 .6116943359152 .6972961426 150.2590942383147 .5160064697144 .7729034424142 .0299072266138 .9819946289 136.5437011719135 .0198059082133 .8007049561132 .2767028809131 .0576019287 129.2288970947 127.4001998901 125.5715026855123 .7427978516122 .5235977173 121.6092987061121 .6092987061121 .9140014648121 .6092987061121 .6092987061 121.6092987061121 .9140014648121 .9140014648121 .9140014648121 .9140014648 121.6092987061121 .6092987061121 .3044967651121 .3044967651121 .3044967651 121.3044967651121 .3044967651121 .3044967651121 .6092987061121 .6092987061 121.6092987061121 .6092987061121 .6092987061121 .6092987061121 .6092987061 121.9140014648121 .9140014648121 .9140014648121 .9140014648120 .6949005127 118.2565994263115 .5136032104112 .7705001831110 .0273971558108 .1986999512 106.979598999106 .3700027466106 .3700027466106 .979598999107 .5891036987 111.24659729128 .9241027832148 .7351074219167 .9365997314184 .0901947021 195.3672943115204 .2059936523209 .692199707209 .692199707209 .692199707 209.692199707 210.6065063477216.3973999023222.1884002686227.6744995117 233.1605987549238 .3419952393242 .9136962891247 .4855041504251 .4476928711 255.1051025391258 .1530151367261 .2008972168263 .6390991211265 .7726135254 267.6012878418269 .1253051758270 .3443908691270 .9540100098271 .5635070801 272.1730957031272 .4779052734272 .7827148438272 .7827148438273 .0874938965 273.0874938965273 .3923034668273 .3923034668273 .3923034668273 .6971130371 274.0018005371274 .0018005371274 .3066101074274 .3066101074274 .3066101074 274.6113891602274 .6113891602274 .9161987305274 .9161987305274 .9161987305 274.6113891602274 .6113891602274 .3066101074273 .6971130371273 .0874938965 272.4779052734271 .2587890625270 .3443908691268 .8204956055266 .9917907715 265.1630859375263 .0296020508260 .5913085938257 .5433959961254 .4956054688 251.1428985596247 .7902984619243 .8280944824239 .5610961914235 .2940979004 230.4176025391225 .5410003662220 .6643981934215 .1782989502209 .9969024658 209.692199707209 .692199707209 .692199707209 .692199707209 .692199707209 .692199707 $168.241394043162 .1457061768155 .7451934814145 .6778259277135 .3226165771-9999$ -9999 -9999 -9999 -9999 -9999 -9999 -9999 -9999 -9999 -9999 -9999 -9999 -9999 -9999 -9999 -9999 -9999 -9999 -9999 -9999 -9999 -9999 -9999 -9999 -9999 -9999 -9999 -9999 -9999 -9999 -

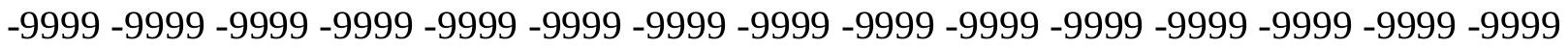
-9999 -9999-9999-9999

-9999 -9999 -9999 -9999 -9999 -9999 -9999 -9999 -9999 -9999 -9999 -9999 -9999 -9999 -9999 
-9999 -9999 -9999 -9999 -9999 -9999 26.11790657043 40.40752792358 57.9091796875 79.24413299561103 .0174026489126 .1809997559144 .1634063721152 .6972961426 154.8307952881154 .8307952881154 .8307952881154 .8307952881154 .5260925293 154.2212982178153 .9165039062153 .9165039062153 .9165039062153 .9165039062 154.2212982178154 .5260925293155 .1356048584155 .7451934814156 .0500030518 155.7451934814155 .1356048584154 .2212982178153 .3069000244151 .7830047607 149.9542999268148 .4304046631146 .6015930176145 .0776977539143 .5538024902 142.0299072266140 .8106994629139 .8963928223138 .9819946289138 .3724975586 137.7628936768137 .1533050537136 .8484954834136 .5437011719136 .5437011719 136.5437011719136 .5437011719136 .5437011719136 .5437011719136 .8484954834 136.8484954834136 .8484954834137 .1533050537137 .1533050537137 .1533050537 137.1533050537136 .5437011719135 .9342041016135 .0198059082133 .8007049561 132.2767028809130 .1432037354127 .7050018311124 .9618988037122 .5235977173 123.43800354123 .7427978516122 .5235977173120 .6949005127119 .1709976196 118.5614013672118 .2565994263117 .9517974854117 .647102356116 .7326965332 116.4279022217116 .1231002808116 .1231002808116 .4279022217116 .7326965332 117.342300415118 .2565994263119 .4757995605121 .3044967651123 .7427978516 126.1809997559128 .3144989014129 .533706665129 .8385009766128 .9241027832 127.4001998901125 .8762969971124 .0475006104122 .8283996582121 .9140014648 121.6092987061121 .6092987061121 .6092987061120 .9997024536120 .3900985718 120.3900985718120 .3900985718120 .6949005127120 .9997024536121 .3044967651 121.3044967651121 .3044967651121 .3044967651120 .9997024536120 .3900985718 119.7806015015119 .4757995605119 .4757995605120 .0852966309120 .6949005127 121.9140014648 123.1332015991 123.7427978516124.0475006104124.6570968628 125.8762969971127 .0953979492128 .9241027832130 .7528076172133 .1911010742 135.9342041016138 .9819946289142 .0299072266145 .0776977539148 .1255950928 150.5639038086152 .6972961426154 .2212982178155 .4403991699156 .3547973633 157.2691040039158 .4882965088159 .4026031494160 .0122070312160 .6217956543 161.2312927246161 .5361022949161 .8408966064161 .8408966064161 .8408966064 161.8408966064161 .8408966064161 .8408966064161 .8408966064161 .5361022949 161.5361022949160 .9264984131160 .3170013428159 .7073974609159 .0977935791 158.4882965088157 .878692627157 .5738983154157 .2691040039156 .9642944336 156.6596069336156 .6596069336156 .6596069336156 .6596069336156 .6596069336 156.6596069336156 .9642944336156 .9642944336157 .2691040039157 .2691040039 157.5738983154157 .5738983154157 .5738983154157 .2691040039156 .6596069336 156.0500030518155 .4403991699154 .5260925293153 .0021057129151 .1734008789 149.0399017334146 .6015930176144 .1634063721142 .0299072266139 .8963928223 138.0677032471136 .2389984131134 .7149963379132 .8863067627131 .0576019287 128.9241027832126 .7906036377124 .9618988037123 .1332015991121 .6092987061 121.6092987061121 .6092987061121 .6092987061121 .6092987061121 .6092987061 121.6092987061121 .9140014648121 .9140014648121 .9140014648121 .6092987061 121.6092987061121 .6092987061121 .6092987061121 .6092987061121 .6092987061 121.6092987061121 .6092987061121 .6092987061121 .6092987061121 .9140014648 121.9140014648121 .9140014648121 .9140014648121 .9140014648121 .6092987061 121.9140014648121 .9140014648121 .3044967651120 .0852966309117 .9517974854 115.5136032104112 .7705001831110 .6370010376108 .8082962036107 .5891036987 
107.2844009399 108.5035018921 111.551399231114 .5991973877111 .24659729 133.1911010742146 .9064025879163 .0599975586177 .9945068359190 .4907073975 200.5485992432209 .0825958252209 .692199707209 .692199707209 .692199707 213.3495941162219 .4452972412225 .2362060547231 .0270996094236 .5133056641 241.6945953369246 .5711975098250 .8381958008254 .8003997803258 .1530151367 261.2008972168 263.9439086914266.0773925781 268.2109069824 269.7348022461 270.9540100098271 .8682861328272 .7827148438273 .0874938965273 .0874938965 273.3923034668273 .3923034668273 .3923034668273 .3923034668273 .3923034668 273.3923034668273 .6971130371273 .6971130371273 .6971130371274 .0018005371 274.0018005371274 .3066101074274 .3066101074274 .3066101074274 .6113891602 274.6113891602274 .6113891602274 .9161987305274 .9161987305274 .6113891602 274.6113891602274 .3066101074273 .6971130371273 .0874938965272 .1730957031 271.2587890625270 .0396118164268 .5156860352266 .9917907715264 .8583068848 262.7247924805260 .2864990234257 .5433959961254 .4956054688251 .4476928711 247.7902984619244 .1329040527239 .8659057617235 .5989074707231 .0270996094 226.4553985596221 .5787963867216 .3973999023211 .2160949707209 .692199707 209.692199707209.692199707 209.692199707209.692199707 209.692199707209.692199707 $164.5839996338158 .4882965088149 .5357818604140 .0031890869129 .3899688721-9999$ -9999 -9999 -9999 -9999 -9999 -9999 -9999 -9999 -9999 -9999 -9999 -9999 -9999 -9999 -9999

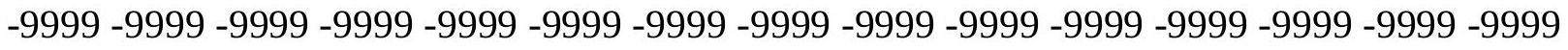
-9999 -9999 -9999 -9999 -9999 -9999 -9999 -9999 -9999 -9999 -9999 -9999 -9999 -9999 -9999 -9999-9999-9999

-9999 -9999 -9999 -9999 -9999 -9999 -9999 -9999 -9999 -9999 -9999 -9999 -9999 -9999 -9999 -9999 -9999 -9999 -9999 -9999 -9999 26.31484985352 39.4914627075255 .47089004517 77.41542053223102 .1029968262127 .7050018311150 .8686065674154 .8307952881 154.8307952881153 .3069000244153 .6116943359153 .3069000244152 .6972961426 152.0877990723151 .7830047607151 .7830047607151 .4781951904151 .4781951904 151.7830047607152 .0877990723152 .3925933838153 .0021057129153 .6116943359 153.0021057129152 .0877990723151 .1734008789150 .2590942383148 .7351074219 146.9064025879145 .0776977539143 .5538024902141 .7250976562140 .2012023926 138.9819946289137 .7628936768136 .5437011719135 .9342041016135 .0198059082 134.4102020264133 .8007049561133 .4958953857133 .4958953857133 .1911010742 133.1911010742133 .4958953857133 .4958953857133 .1911010742133 .1911010742 132.8863067627132 .8863067627132 .8863067627133 .1911010742133 .1911010742 132.8863067627132 .2767028809131 .3623962402130 .4479980469129 .533706665 128.0097961426126 .1809997559124 .0475006104121 .9140014648120 .6949005127 121.3044967651122 .2188034058120 .6949005127119 .1709976196117 .647102356 116.7326965332116 .1231002808115 .818397522115 .5136032104114 .9039993286 114.5991973877114 .2944030762114 .2944030762114 .5991973877115 .5136032104 116.4279022217117 .9517974854120 .0852966309122 .5235977173125 .5715026855 128.3144989014131 .0576019287132 .5814971924132 .5814971924131 .3623962402 129.8385009766127 .7050018311125 .8762969971124 .3523025513123 .43800354 122.8283996582122 .2188034058121 .9140014648121 .3044967651120 .9997024536 120.6949005127120 .6949005127120 .6949005127120 .6949005127120 .6949005127 120.6949005127120 .6949005127120 .9997024536120 .6949005127120 .3900985718 120.0852966309120 .0852966309120 .6949005127121 .9140014648122 .5235977173 
124.6570968628126 .1809997559127 .0953979492127 .7050018311128 .6192932129 129.533706665131 .0576019287132 .8863067627135 .0198059082137 .4580993652 140.2012023926143 .2489929199146 .6015930176149 .3446960449151 .7830047607 153.3069000244155 .1356048584156 .6596069336157 .5738983154158 .4882965088 159.4026031494160 .3170013428160 .9264984131161 .5361022949162 .1457061768 162.4505004883162 .7552947998163 .0599975586163 .0599975586163 .0599975586 162.7552947998162 .7552947998162 .4505004883162 .4505004883162 .4505004883 162.1457061768161 .5361022949160 .9264984131160 .3170013428159 .7073974609 159.0977935791158 .4882965088158 .1835021973157 .878692627157 .5738983154 157.2691040039157 .2691040039157 .2691040039157 .2691040039157 .2691040039 157.2691040039157 .5738983154157 .5738983154157 .878692627157 .878692627 158.1835021973158 .1835021973158 .1835021973157 .878692627157 .5738983154 156.9642944336156 .0500030518155 .1356048584153 .9165039062152 .0877990723 150.5639038086148 .7351074219146 .9064025879145 .0776977539143 .2489929199 141.1154937744139 .2868041992137 .1533050537135 .0198059082132 .8863067627 130.4479980469128 .3144989014126 .1809997559124 .3523025513122 .8283996582 122.2188034058121 .9140014648121 .6092987061121 .6092987061121 .6092987061 121.6092987061121 .6092987061121 .9140014648121 .9140014648121 .9140014648 121.9140014648121 .6092987061121 .6092987061121 .6092987061121 .6092987061 121.6092987061121 .6092987061121 .6092987061121 .9140014648121 .9140014648 121.9140014648121 .9140014648121 .9140014648121 .9140014648121 .9140014648 121.9140014648121 .6092987061120 .9997024536119 .4757995605117 .342300415 115.2088012695112 .7705001831110 .6370010376109 .1130981445107 .8938980103 108.1986999512110 .0273971558115 .2088012695128 .3144989014153 .9165039062 149.6495056152154 .5260925293162 .1457061768171 .5939941406184 .699798584 195.9768066406206 .0346984863209 .692199707209 .692199707209 .692199707 216.0926971436222 .4931030273228 .5888977051234 .6844940186240 .1707000732 245.6567993164250 .5334014893254 .8003997803258 .4577941895261 .8103942871 264.5534973145266 .9917907715268 .8204956055270 .6492004395271 .8682861328 272.7827148438273 .6971130371274 .3066101074274 .3066101074274 .0018005371 274.0018005371274 .0018005371274 .0018005371273 .6971130371273 .6971130371 273.6971130371273 .6971130371273 .6971130371273 .6971130371274 .0018005371 274.0018005371274 .3066101074274 .3066101074274 .3066101074274 .6113891602 274.6113891602274 .6113891602274 .9161987305274 .9161987305274 .6113891602 274.6113891602274 .3066101074273 .6971130371273 .0874938965272 .1730957031 271.2587890625270 .0396118164268 .5156860352266 .9917907715264 .8583068848 262.7247924805260 .2864990234257 .5433959961254 .8003997803251 .4476928711 248.0950927734244 .4376983643240 .4754943848236 .2084960938231 .9414978027 227.3697052002222 .4931030273217 .6165924072212 .4351959229209 .692199707 209.692199707 209.692199707209.692199707209.692199707209.692199707209.692199707 $167.0222015381160 .9264984131154 .8307952881144 .5646209717134 .055267334-9999$ -9999 -9999 -9999 -9999 -9999 -9999 -9999 -9999 -9999 -9999 -9999 -9999 -9999 -9999 -9999 -9999 -9999 -9999 -9999 -9999 -9999 -9999 -9999 -9999 -9999 -9999 -9999 -9999 -9999 -9999 -

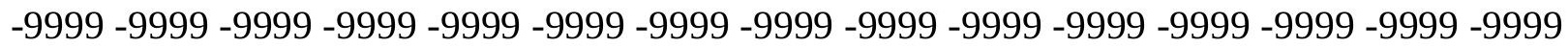
-9999 -9999 -9999

-9999 -9999 -9999 -9999 -9999 -9999 -9999 -9999 -9999 -9999 -9999 -9999 -9999 -9999 -9999 
-9999 -9999 -9999 -9999 -9999 -9999 -9999 39.44833755493 54.528316497874 .0627822876 97.83602905273121 .9140014648140 .8106994629149 .6495056152151 .7830047607 151.4781951904151 .1734008789150 .8686065674150 .2590942383149 .6495056152 149.0399017334148 .7351074219148 .4304046631148 .4304046631148 .7351074219 149.0399017334149 .3446960449149 .6495056152149 .9542999268149 .3446960449 148.7351074219147 .8208007812146 .6015930176145 .0776977539143 .5538024902 141.7250976562140 .2012023926138 .3724975586137 .1533050537135 .6293945312 134.7149963379133 .4958953857132 .5814971924131 .9720001221131 .3623962402 130.7528076172130 .4479980469130 .1432037354130 .1432037354130 .1432037354 130.4479980469130 .4479980469130 .1432037354129 .8385009766129 .533706665 129.2288970947129 .2288970947129 .2288970947129 .2288970947128 .9241027832 128.3144989014127 .7050018311126 .7906036377126 .1809997559124 .9618988037 123.43800354121 .6092987061120 .0852966309119 .1709976196119 .1709976196 119.1709976196118 .2565994263117 .0374984741115 .818397522114 .5991973877 113.9896011353113 .3800964355112 .7705001831112 .4656982422112 .1608963013 112.1608963013112 .1608963013112 .7705001831113 .9896011353115 .5136032104 117.647102356120 .0852966309123 .1332015991126 .7906036377130 .4479980469 133.8007049561135 .6293945312135 .3246002197133 .8007049561131 .9720001221 129.8385009766127 .7050018311126 .1809997559124 .9618988037124 .0475006104 123.43800354122 .8283996582122 .2188034058121 .6092987061121 .3044967651 121.3044967651120 .9997024536120 .9997024536120 .9997024536120 .9997024536 120.9997024536121 .3044967651121 .6092987061121 .9140014648121 .9140014648 121.9140014648124 .0475006104126 .4858016968128 .0097961426129 .2288970947 130.4479980469131 .3623962402131 .9720001221132 .5814971924133 .8007049561 135.0198059082136 .8484954834138 .9819946289141 .4203033447144 .4682006836 147.2111968994 150.2590942383153.3069000244154.8307952881 156.3547973633 157.5738983154158 .7929992676159 .7073974609160 .6217956543161 .2312927246 161.8408966064162 .4505004883163 .0599975586163 .3648071289163 .6696014404 163.974395752163 .974395752163 .974395752163 .6696014404163 .6696014404 163.3648071289163 .0599975586163 .0599975586162 .7552947998162 .4505004883 161.8408966064161 .2312927246160 .6217956543160 .0122070312159 .4026031494 158.7929992676158 .4882965088158 .1835021973157 .878692627157 .878692627 157.5738983154157 .5738983154157 .5738983154157 .878692627157 .878692627 157.878692627158 .1835021973158 .4882965088158 .7929992676158 .7929992676 158.7929992676158 .7929992676158 .7929992676158 .1835021973157 .878692627 156.9642944336156 .0500030518154 .8307952881153 .6116943359152 .3925933838 151.1734008789149 .9542999268148 .1255950928146 .2969055176144 .4682006836 142.0299072266139 .8963928223137 .1533050537134 .7149963379132 .2767028809 129.8385009766127 .4001998901125 .5715026855124 .0475006104122 .8283996582 122.2188034058121 .9140014648121 .6092987061121 .6092987061121 .6092987061 121.6092987061121 .6092987061121 .6092987061121 .9140014648121 .9140014648 121.6092987061121 .6092987061121 .6092987061121 .6092987061121 .6092987061 121.6092987061121 .9140014648121 .9140014648121 .9140014648121 .9140014648 121.9140014648121 .9140014648121 .9140014648121 .9140014648121 .9140014648 121.6092987061120 .3900985718118 .8662033081117 .0374984741114 .9039993286 112.7705001831110 .6370010376109 .1130981445108 .1986999512108 .5035018921 
110.3321990967116 .1231002808128 .6192932129145 .9920959473154 .5260925293 160.3170013428166 .4127044678173 .1179962158179 .8231964111191 .4051055908 202.6820983887209 .692199707209 .692199707212 .7400054932219 .4452972412 225.8457946777232 .246307373238 .3419952393244 .4376983643249 .6190032959 254.4956054688258 .7626037598262 .4200134277265 .1630859375267 .9060974121 269.7348022461271 .5635070801273 .0874938965274 .0018005371274 .6113891602 274.9161987305275 .2210083008274 .9161987305274 .6113891602274 .6113891602 274.3066101074274 .3066101074274 .0018005371274 .0018005371273 .6971130371 273.6971130371273 .6971130371273 .6971130371274 .0018005371274 .0018005371 274.0018005371274 .3066101074274 .3066101074274 .3066101074274 .6113891602 274.6113891602274 .9161987305274 .9161987305274 .9161987305274 .6113891602 274.3066101074274 .0018005371273 .0874938965272 .4779052734271 .2587890625 270.0396118164268 .5156860352266 .9917907715264 .8583068848262 .7247924805 260.2864990234257 .8482055664254 .8003997803251 .7525024414248 .3999023438 244.7424926758240 .7801971436236 .8179931641232 .5511016846228 .2841033936 223.4075012207218 .8356933594213 .6544036865209 .692199707209 .692199707 209.692199707 209.692199707209.692199707 209.692199707 209.692199707 209.692199707 163.3648071289157 .2691040039148 .3425445557138 .8739318848128 .286895752 -9999

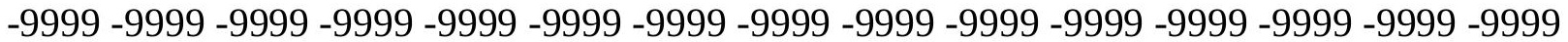

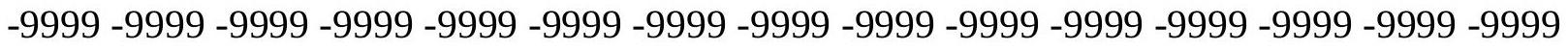

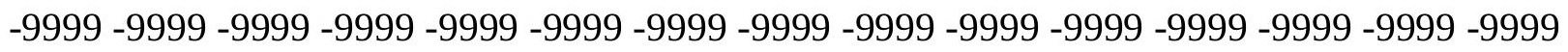
$-9999-9999$ -9999 -9999 -9999 -9999 -9999 -9999 -9999 -9999 -9999 -9999 -9999 -9999 -9999 -9999 -9999 -9999 -9999 -9999 -9999-9999-9999-9999 40.71154022217 53.9800071716369 .49101257324 91.74033355713113 .6848983765130 .4479980469141 .1154937744145 .6873016357 147.2111968994147 .5160064697147 .2111968994146 .6015930176145 .9920959473 145.3825073242145 .0776977539144 .7729034424144 .7729034424145 .0776977539 145.0776977539145 .3825073242145 .6873016357145 .6873016357145 .3825073242 144.7729034424143 .8585968018142 .6394042969141 .1154937744139 .8963928223 138.0677032471136 .5437011719135 .0198059082133 .8007049561132 .5814971924 131.6672058105130 .7528076172129 .8385009766129 .2288970947128 .6192932129 128.0097961426127 .4001998901127 .0953979492127 .4001998901127 .7050018311 127.7050018311127 .7050018311127 .4001998901126 .7906036377126 .1809997559 125.5715026855125 .8762969971126 .1809997559126 .1809997559125 .8762969971 125.2667007446124 .3523025513124 .0475006104123 .7427978516123 .1332015991 121.6092987061120 .0852966309118 .5614013672117 .647102356117 .0374984741 116.4279022217115 .5136032104114 .5991973877113 .3800964355112 .4656982422 111.551399231110 .9418029785110 .3321990967110 .0273971558109 .7226028442 109.7226028442110 .0273971558110 .9418029785112 .4656982422114 .2944030762 116.7326965332119 .7806015015123 .43800354127 .4001998901131 .3623962402 135.3246002197 138.3724975586137.4580993652 135.6293945312 133.4958953857 131.3623962402129 .533706665128 .0097961426126 .4858016968125 .5715026855 124.6570968628123 .7427978516123 .1332015991122 .8283996582122 .5235977173 122.2188034058122 .2188034058121 .9140014648121 .9140014648121 .9140014648 121.9140014648122 .5235977173123 .43800354124 .3523025513124 .9618988037 126.4858016968128 .9241027832131 .9720001221133 .8007049561134 .4102020264 
135.0198059082135 .6293945312136 .2389984131136 .8484954834137 .7628936768 138.6772003174140 .5059967041142 .6394042969145 .0776977539148 .1255950928 150.5639038086153 .0021057129155 .4403991699156 .9642944336158 .4882965088 159.7073974609160 .6217956543161 .5361022949162 .4505004883163 .0599975586 163.3648071289163 .974395752164 .2792053223164 .5839996338164 .8887023926 164.8887023926164 .5839996338164 .5839996338164 .2792053223163 .974395752 163.6696014404163 .3648071289163 .0599975586162 .7552947998162 .4505004883 161.8408966064161 .2312927246160 .9264984131160 .3170013428159 .7073974609 159.0977935791158 .7929992676158 .4882965088158 .1835021973158 .1835021973 157.878692627158 .1835021973158 .1835021973158 .1835021973158 .4882965088 158.4882965088158 .7929992676159 .0977935791159 .4026031494159 .4026031494 159.7073974609159 .7073974609159 .4026031494159 .0977935791158 .4882965088 157.878692627156 .9642944336155 .7451934814154 .8307952881153 .9165039062 153.3069000244152 .3925933838150 .8686065674149 .0399017334147 .2111968994 144.7729034424142 .0299072266139 .2868041992136 .2389984131133 .4958953857 131.0576019287128 .6192932129126 .7906036377124 .9618988037123 .7427978516 122.8283996582121 .9140014648121 .6092987061121 .6092987061121 .6092987061 121.6092987061121 .6092987061121 .6092987061121 .6092987061121 .9140014648 121.9140014648121 .9140014648121 .6092987061121 .6092987061121 .6092987061 121.6092987061121 .9140014648121 .9140014648121 .9140014648121 .9140014648 121.9140014648121 .9140014648121 .9140014648121 .9140014648121 .9140014648 121.3044967651120 .3900985718118 .5614013672116 .7326965332114 .5991973877 112.7705001831110 .9418029785109 .4179000854108 .8082962036108 .8082962036 110.3321990967113 .6848983765118 .5614013672137 .1533050537151 .7830047607 160.9264984131168 .241394043174 .9467010498181 .6519012451188 .3571929932 199.9389953613209 .692199707209 .692199707215 .4830932617222 .4931030273 229.1983947754235 .9037017822242 .3041992188248 .7046966553254 .1907958984 259.0674133301263 .0296020508266 .3822021484269 .1253051758271 .2587890625 272.7827148438274 .3066101074275 .5257873535276 .1353149414276 .4400939941 276.1353149414275 .8305053711275 .5257873535274 .9161987305274 .6113891602 274.6113891602274 .3066101074274 .0018005371274 .0018005371273 .6971130371 273.6971130371273 .6971130371273 .6971130371273 .6971130371273 .6971130371 274.0018005371274 .0018005371274 .3066101074274 .3066101074274 .6113891602 274.9161987305274 .9161987305275 .2210083008274 .9161987305274 .9161987305 274.6113891602274 .0018005371273 .3923034668272 .4779052734271 .5635070801 270.3443908691268 .8204956055266 .9917907715265 .1630859375263 .0296020508 260.5913085938258 .1530151367255 .1051025391252 .0572967529248 .7046966553 245.3520050049241 .3898010254237 .4275970459233 .4653930664229 .1983947754 224.6266021729219 .7501068115215 .1782989502209 .9969024658209 .692199707 209.692199707209 .692199707209 .692199707209 .692199707209 .692199707209 .692199707 $165.8031005859159 .7073974609153 .6116943359143 .6271209717133 .2929382324-9999$ -9999 -9999 -9999 -9999 -9999 -9999 -9999 -9999 -9999 -9999 -9999 -9999 -9999 -9999 -9999 -9999 -9999 -9999 -9999 -9999 -9999 -9999 -9999 -9999 -9999 -9999 -9999 -9999 -9999 -9999

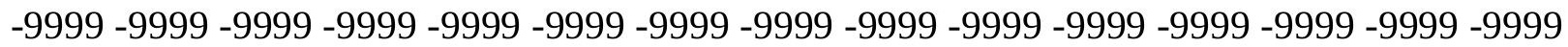
$-9999-9999$

-9999 -9999 -9999 -9999 -9999 -9999 -9999 -9999 -9999 -9999 -9999 -9999 -9999 -9999 -9999 
-9999 -9999 -9999 -9999 -9999 -9999 -9999 -9999 55.54498291016 70.31627655029 87.77810668945106 .3700027466121 .9140014648132 .5814971924138 .3724975586 141.1154937744142 .0299072266142 .3347015381142 .0299072266141 .7250976562 141.4203033447141 .1154937744140 .8106994629140 .8106994629140 .8106994629 141.1154937744141 .4203033447141 .4203033447141 .4203033447141 .1154937744 140.5059967041139 .5915985107138 .3724975586137 .1533050537135 .9342041016 134.7149963379133 .1911010742131 .9720001221130 .4479980469129 .533706665 128.6192932129128 .0097961426127 .4001998901126 .7906036377126 .1809997559 125.2667007446124 .6570968628124 .3523025513124 .6570968628125 .2667007446 125.5715026855125 .8762969971125 .2667007446124 .3523025513123 .43800354 122.5235977173123 .1332015991123 .7427978516124 .0475006104123 .7427978516 122.8283996582121 .9140014648122 .2188034058122 .5235977173122 .2188034058 120.6949005127118 .8662033081117 .342300415116 .1231002808114 .9039993286 113.9896011353113 .075302124112 .1608963013110 .9418029785110 .0273971558 109.1130981445108 .5035018921107 .5891036987107 .2844009399106 .979598999 107.2844009399 107.5891036987 108.8082962036110.6370010376112.7705001831 115.818397522119 .1709976196123 .1332015991127 .0953979492131 .3623962402 135.0198059082 137.1533050537 137.4580993652 136.2389984131 134.4102020264 132.5814971924131 .0576019287129 .533706665128 .3144989014127 .0953979492 126.1809997559125 .2667007446124 .6570968628124 .0475006104123 .7427978516 123.43800354123 .43800354123 .43800354123 .43800354123 .7427978516124 .0475006104 124.9618988037126 .1809997559127 .7050018311129 .2288970947131 .0576019287 133.1911010742135 .9342041016137 .4580993652138 .6772003174139 .2868041992 139.8963928223140 .2012023926140 .5059967041141 .1154937744142 .3347015381 143.8585968018145 .6873016357147 .8208007812150 .2590942383152 .6972961426 154.8307952881156 .9642944336158 .7929992676160 .0122070312161 .2312927246 162.1457061768163 .0599975586163 .974395752164 .5839996338164 .8887023926 165.1934967041165 .4983062744165 .4983062744165 .4983062744165 .4983062744 165.1934967041164 .8887023926164 .5839996338164 .2792053223163 .974395752 163.6696014404163 .0599975586162 .7552947998162 .1457061768161 .8408966064 161.2312927246160 .6217956543160 .0122070312159 .7073974609159 .0977935791 158.7929992676158 .4882965088158 .4882965088158 .4882965088158 .1835021973 158.4882965088158 .4882965088158 .4882965088158 .7929992676159 .0977935791 159.0977935791159 .4026031494160 .0122070312160 .3170013428160 .3170013428 160.3170013428160 .0122070312159 .7073974609159 .0977935791158 .4882965088 157.5738983154156 .6596069336155 .7451934814155 .1356048584154 .5260925293 153.6116943359152 .6972961426151 .1734008789149 .3446960449146 .9064025879 143.8585968018140 .8106994629137 .7628936768134 .7149963379132 .2767028809 129.8385009766128 .0097961426126 .1809997559124 .6570968628123 .43800354 122.5235977173121 .6092987061121 .3044967651121 .3044967651121 .6092987061 121.6092987061121 .6092987061121 .6092987061121 .9140014648121 .9140014648 121.9140014648121 .9140014648121 .9140014648121 .9140014648121 .9140014648 121.9140014648121 .9140014648121 .9140014648121 .9140014648121 .9140014648 121.6092987061121 .9140014648121 .9140014648121 .9140014648121 .3044967651 120.0852966309118 .2565994263116 .4279022217114 .2944030762112 .7705001831 110.9418029785109 .7226028442109 .4179000854109 .7226028442111 .24659729 
114.5991973877122 .2188034058135 .3246002197149 .3446960449160 .3170013428 168.8509979248176 .165802002182 .87109375189 .5764007568197 .500793457 209.0825958252210 .9113006592218 .2261962891225 .5410003662232 .8558044434 239.8659057617246 .5711975098252 .9716033936258 .7626037598263 .9439086914 267.9060974121270 .9540100098273 .0874938965274 .9161987305276 .4400939941 277.3544921875277 .9641113281277 .9641113281277 .9641113281277 .3544921875 276.7449035645275 .8305053711275 .2210083008274 .6113891602274 .3066101074 274.3066101074274 .0018005371273 .6971130371273 .6971130371273 .6971130371 273.6971130371273 .6971130371273 .6971130371273 .6971130371273 .6971130371 274.0018005371274 .3066101074274 .6113891602274 .9161987305275 .2210083008 275.2210083008275 .5257873535275 .5257873535275 .2210083008274 .9161987305 274.6113891602274 .0018005371273 .0874938965271 .8682861328270 .6492004395 269.1253051758267 .6012878418265 .4678039551263 .3344116211260 .8960876465 258.4577941895255 .7147064209252 .6669006348249 .3141937256245 .9615936279 242.3041992188238 .3419952393234 .3798065186230 .1127929688225 .5410003662 220.9691925049216 .3973999023211 .520904541209 .692199707209 .692199707 209.692199707209.692199707209.692199707209.692199707 209.692199707209.692199707 $162.1457061768156 .3547973633147 .6118011475138 .5184326172128 .1808776855-9999$ -9999 -9999 -9999 -9999 -9999 -9999 -9999 -9999 -9999 -9999 -9999 -9999 -9999 -9999 -9999

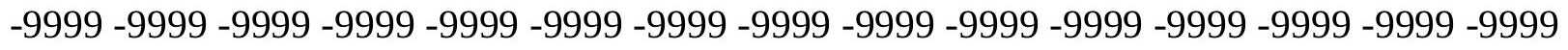
-9999 -9999-9999 -9999 -9999 -9999 -9999 -9999 -9999 -9999 -9999 -9999 -9999 -9999 -999 -999 $-9999$

-9999 -9999 -9999 -9999 -9999 -9999 -9999 -9999 -9999 -9999 -9999 -9999 -9999 -9999 -9999 -9999 -9999-9999 -9999-9999-9999-9999-9999 58.6610336303772 .1978225708 87.15026092529102 .1029968262115 .818397522125 .2667007446131 .0576019287 134.4102020264136 .2389984131136 .8484954834137 .1533050537137 .1533050537 137.1533050537136 .8484954834136 .8484954834136 .8484954834136 .8484954834 137.1533050537 137.4580993652 137.4580993652 137.1533050537 136.8484954834 135.9342041016135 .3246002197134 .4102020264133 .4958953857132 .2767028809 131.0576019287129 .8385009766128 .6192932129127 .7050018311126 .7906036377 125.8762969971125 .5715026855124 .9618988037124 .6570968628124 .0475006104 123.43800354122 .8283996582122 .2188034058123 .1332015991123 .7427978516 124.3523025513124 .0475006104123 .7427978516122 .5235977173121 .6092987061 120.9997024536121 .3044967651122 .2188034058122 .5235977173122 .5235977173 122.2188034058121 .6092987061121 .6092987061121 .6092987061121 .6092987061 119.7806015015117 .9517974854116 .1231002808114 .5991973877113 .075302124 111.8561019897110 .6370010376109 .7226028442108 .5035018921107 .5891036987 106.6747970581105 .7603988647105 .1509017944104 .5412979126104 .5412979126 104.5412979126105 .1509017944106 .6747970581108 .5035018921111 .24659729 114.5991973877118 .2565994263122 .2188034058126 .1809997559130 .1432037354 133.4958953857135 .6293945312136 .2389984131135 .9342041016134 .7149963379 133.4958953857132 .2767028809131 .0576019287129 .8385009766128 .9241027832 128.0097961426127 .0953979492126 .4858016968125 .8762969971125 .5715026855 125.2667007446124 .9618988037125 .2667007446125 .2667007446125 .8762969971 126.7906036377128 .0097961426129 .533706665131 .3623962402133 .1911010742 135.0198059082 137.1533050537138.9819946289140.8106994629141.7250976562 
142.9441986084143 .5538024902143 .5538024902143 .8585968018144 .1634063721 145.0776977539146 .6015930176148 .1255950928149 .9542999268151 .7830047607 154.2212982178156 .3547973633158 .4882965088160 .0122070312161 .5361022949 162.7552947998163 .6696014404164 .5839996338165 .1934967041165 .8031005859 166.1078948975166 .1078948975166 .4127044678166 .4127044678166 .1078948975 166.1078948975165 .8031005859165 .1934967041164 .8887023926164 .5839996338 163.974395752163 .3648071289163 .0599975586162 .4505004883162 .1457061768 161.5361022949160 .9264984131160 .6217956543160 .0122070312159 .7073974609 159.0977935791158 .7929992676158 .7929992676158 .4882965088158 .4882965088 158.4882965088158 .7929992676158 .7929992676159 .0977935791159 .0977935791 159.4026031494159 .7073974609160 .0122070312160 .6217956543160 .6217956543 160.9264984131160 .9264984131160 .6217956543160 .0122070312159 .4026031494 158.7929992676157 .878692627157 .2691040039156 .3547973633155 .7451934814 155.1356048584154 .2212982178153 .6116943359152 .6972961426150 .8686065674 148.1255950928144 .7729034424141 .7250976562138 .3724975586135 .6293945312 133.1911010742130 .7528076172128 .9241027832127 .0953979492125 .5715026855 124.3523025513123 .1332015991121 .9140014648121 .6092987061121 .6092987061 121.6092987061121 .6092987061121 .6092987061121 .6092987061121 .6092987061 121.9140014648121 .9140014648121 .9140014648121 .9140014648121 .9140014648 121.9140014648121 .6092987061121 .9140014648121 .9140014648121 .9140014648 121.9140014648121 .9140014648121 .9140014648121 .9140014648121 .6092987061 120.6949005127119 .4757995605117 .9517974854116 .1231002808114 .2944030762 112.7705001831111 .24659729110 .3321990967110 .0273971558110 .9418029785 113.075302124117 .9517974854126 .4858016968137 .4580993652149 .6495056152 160.3170013428168 .8509979248176 .165802002183 .4806976318190 .4907073975 198.1103057861208 .1681976318213 .3495941162220 .9691925049228 .5888977051 236.2084960938243 .5233001709250 .5334014893257 .2385864258263 .6390991211 268.8204956055272 .4779052734275 .2210083008277 .3544921875278 .8783874512 279.7927856445280 .4023132324280 .4023132324280 .0975036621279 .4880065918 278.5736083984277 .3544921875276 .1353149414275 .2210083008274 .3066101074 274.0018005371273 .6971130371273 .6971130371273 .3923034668273 .6971130371 273.6971130371273 .6971130371273 .6971130371273 .3923034668273 .6971130371 273.6971130371274 .0018005371274 .3066101074274 .6113891602274 .9161987305 275.5257873535275 .8305053711275 .8305053711275 .8305053711275 .8305053711 275.5257873535275 .2210083008274 .3066101074273 .6971130371272 .4779052734 271.2587890625269 .7348022461267 .9060974121266 .0773925781263 .9439086914 261.5056152344258 .7626037598256 .0195007324252 .9716033936249 .9237976074 246.5711975098242 .9136962891239 .2563018799235 .2940979004231 .0270996094 226.7601013184222 .1884002686217 .6165924072213 .0447998047209 .692199707 209.692199707209 .692199707209 .692199707209 .692199707209 .692199707209 .692199707 209.692199707 164.5839996338158.7929992676 152.6972961426143.9485626221 133.8188934326 -9999 -9999 -9999 -9999 -9999 -9999 -9999 -9999 -9999 -9999 -9999 -9999 -9999 -9999 -9999 -9999 -9999 -9999 -9999 -9999 -9999 -9999 -9999 -9999 -9999 -9999 -9999 -9999 -9999 -9999 -9999 -9999 -9999 -9999 -9999 -9999 -9999 -9999 -9999 -9999 -9999 -9999 -9999 -9999-9999-9999-9999

-9999 -9999 -9999 -9999 -9999 -9999 -9999 -9999 -9999 -9999 -9999 -9999 -9999 -9999 -9999 
-9999 -9999 -9999 -9999 -9999 -9999 -9999 -9999 -9999 74.58930969238 87.81101226807 101.1886978149112 .1608963013119 .4757995605124 .3523025513127 .7050018311 129.8385009766131 .3623962402132 .2767028809132 .8863067627133 .1911010742 133.1911010742133 .1911010742132 .8863067627133 .1911010742133 .1911010742 133.4958953857133 .4958953857133 .1911010742132 .5814971924131 .9720001221 131.0576019287130 .4479980469129 .8385009766128 .9241027832128 .0097961426 127.0953979492126 .1809997559125 .2667007446124 .3523025513123 .7427978516 123.43800354123 .1332015991123 .1332015991122 .8283996582122 .2188034058 121.9140014648121 .6092987061122 .2188034058122 .8283996582123 .1332015991 122.8283996582122 .5235977173120 .9997024536120 .0852966309119 .7806015015 120.0852966309120 .9997024536121 .3044967651121 .9140014648121 .9140014648 121.3044967651120 .9997024536120 .6949005127119 .7806015015118 .2565994263 116.4279022217114 .5991973877112 .7705001831111 .24659729110 .0273971558 108.5035018921107 .5891036987106 .3700027466105 .1509017944104 .2365036011 103.3221969604102 .712600708102 .1029968262101 .7982025146102 .1029968262 102.712600708104 .2365036011106 .3700027466109 .4179000854113 .075302124 116.7326965332120 .9997024536124 .9618988037128 .6192932129131 .6672058105 133.8007049561135 .0198059082135 .3246002197134 .7149963379134 .1054992676 133.1911010742132 .2767028809131 .3623962402130 .7528076172129 .8385009766 128.9241027832128 .3144989014127 .7050018311127 .4001998901127 .0953979492 126.7906036377127 .0953979492127 .4001998901128 .3144989014129 .533706665 131.0576019287132 .8863067627135 .0198059082137 .1533050537138 .9819946289 140.5059967041142 .0299072266143 .2489929199144 .4682006836145 .0776977539 145.6873016357145 .9920959473146 .2969055176146 .9064025879147 .5160064697 148.7351074219150 .2590942383151 .7830047607153 .6116943359155 .7451934814 157.878692627159 .7073974609161 .2312927246162 .7552947998163 .974395752 164.8887023926165 .8031005859166 .4127044678166 .7174987793167 .0222015381 167.0222015381167 .0222015381167 .0222015381166 .7174987793166 .4127044678 165.8031005859165 .4983062744164 .8887023926164 .2792053223163 .6696014404 163.3648071289162 .7552947998162 .1457061768161 .5361022949161 .2312927246 160.6217956543160 .0122070312159 .7073974609159 .4026031494159 .0977935791 158.7929992676158 .4882965088158 .4882965088158 .4882965088158 .7929992676 158.7929992676159 .0977935791159 .4026031494159 .7073974609160 .0122070312 160.3170013428160 .6217956543160 .9264984131161 .2312927246161 .2312927246 161.2312927246160 .9264984131160 .3170013428159 .7073974609158 .7929992676 157.878692627156 .9642944336156 .3547973633155 .4403991699154 .8307952881 153.9165039062153 .3069000244152 .3925933838151 .4781951904148 .1255950928 144.7729034424141 .7250976562138 .6772003174135 .9342041016133 .4958953857 131.3623962402129 .533706665128 .0097961426126 .4858016968125 .2667007446 124.0475006104123 .1332015991122 .5235977173122 .2188034058121 .9140014648 121.9140014648121 .6092987061121 .6092987061121 .6092987061121 .6092987061 121.9140014648121 .9140014648121 .9140014648121 .9140014648121 .9140014648 121.6092987061121 .6092987061121 .6092987061121 .9140014648121 .9140014648 121.9140014648121 .9140014648121 .6092987061121 .3044967651120 .3900985718 119.1709976196117 .647102356115 .818397522114 .2944030762112 .7705001831 111.551399231110 .9418029785110 .9418029785112 .1608963013115 .2088012695 
120.6949005127129 .2288970947140 .2012023926151 .1734008789160 .6217956543 168.241394043175 .5561981201183 .1759033203191 .1002960205199 .0247039795 207.25390625215 .4830932617223 .7122955322231 .6367034912239 .5610961914 247.1806945801254 .4956054688261 .2008972168267 .9060974121273 .6971130371 276.7449035645279 .4880065918281 .3167114258282 .5357971191283 .1453857422 283.4501953125283 .1453857422282 .2309875488281 .3167114258279 .7927856445 277.9641113281276 .4400939941274 .9161987305274 .0018005371273 .3923034668 273.0874938965273 .0874938965273 .0874938965273 .3923034668273 .6971130371 273.6971130371273 .3923034668273 .3923034668273 .3923034668273 .6971130371 274.0018005371274 .3066101074274 .9161987305275 .5257873535275 .8305053711 276.4400939941276 .7449035645276 .7449035645276 .7449035645276 .4400939941 275.8305053711275 .2210083008274 .3066101074273 .0874938965271 .8682861328 270.3443908691268 .5156860352266 .6870117188264 .5534973145262 .1152038574 259.3721008301256 .6290893555253 .8860015869250 .5334014893247 .1806945801 243.8280944824239 .8659057617236 .2084960938231 .9414978027227 .9792938232 223.4075012207218 .8356933594214 .2639007568209 .692199707209 .692199707 209.692199707 209.692199707 209.692199707209.692199707 209.692199707209.692199707 209.692199707161 .2312927246155 .1356048584149 .0399017334139 .1900482178 128.1714324951 -9999 -9999 -9999 -9999 -9999 -9999 -9999 -9999 -9999 -9999 -9999 -9999 -9999 -9999 -9999 -9999 -9999 -9999 -9999 -9999 -9999 -9999 -9999 -9999 -9999 -9999 -9999

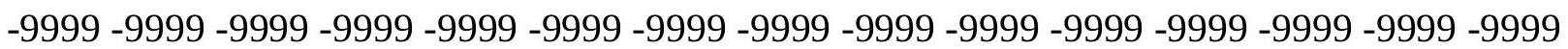
-9999 -9999-9999-9999

-9999 -9999 -9999 -9999 -9999 -9999 -9999 -9999 -9999 -9999 -9999 -9999 -9999 -9999 -9999 -9999 -9999 -9999 -9999 -9999 -9999 -9999 -9999 -9999 -9999 88.51052856445 99.71430969238109 .4179000854114 .2944030762118 .5614013672121 .6092987061 124.0475006104125 .8762969971127 .7050018311128 .9241027832129 .8385009766 130.1432037354129 .8385009766129 .533706665129 .533706665130 .1432037354 130.1432037354130 .1432037354129 .533706665128 .6192932129128 .0097961426 127.4001998901126 .7906036377126 .4858016968125 .8762969971125 .5715026855 124.9618988037124 .0475006104123 .43800354122 .5235977173121 .9140014648 121.9140014648121 .9140014648122 .2188034058121 .9140014648121 .9140014648 121.6092987061121 .6092987061121 .9140014648122 .5235977173121 .9140014648 121.3044967651120 .3900985718119 .4757995605118 .5614013672118 .2565994263 118.5614013672119 .1709976196119 .7806015015120 .6949005127121 .6092987061 120.6949005127119 .7806015015119 .1709976196117 .9517974854116 .7326965332 114.9039993286113 .075302124111 .24659729109 .7226028442108 .1986999512 106.6747970581105 .4557037354104 .2365036011103 .0174026489102 .1029968262 101.1886978149100 .579101562599 .9695205688599 .6647262573299 .66472625732 100.5791015625102 .1029968262104 .5412979126107 .8938980103111 .551399231 115.5136032104119 .7806015015123 .7427978516127 .4001998901130 .1432037354 132.2767028809 133.8007049561 134.4102020264134.7149963379 134.4102020264 134.1054992676133 .4958953857132 .8863067627132 .2767028809131 .6672058105 131.0576019287130 .4479980469129 .8385009766129 .2288970947128 .9241027832 128.9241027832128 .9241027832129 .533706665130 .4479980469131 .9720001221 133.8007049561135 .9342041016138 .0677032471140 .5059967041142 .0299072266 143.5538024902144 .4682006836145 .3825073242146 .2969055176146 .9064025879 
147.2111968994 147.8208007812 148.1255950928 148.7351074219149 .6495056152 150.8686065674152 .0877990723153 .6116943359155 .4403991699157 .2691040039 159.0977935791160 .9264984131162 .4505004883163 .974395752165 .1934967041 166.1078948975166 .7174987793167 .3269958496167 .6318054199167 .6318054199 167.6318054199167 .6318054199167 .3269958496167 .0222015381166 .4127044678 165.8031005859165 .4983062744164 .8887023926163 .974395752163 .3648071289 162.7552947998162 .1457061768161 .5361022949161 .2312927246160 .6217956543 160.0122070312159 .7073974609159 .4026031494159 .0977935791158 .7929992676 158.4882965088158 .4882965088158 .4882965088158 .4882965088158 .7929992676 158.7929992676159 .0977935791159 .7073974609160 .0122070312160 .3170013428 160.9264984131161 .2312927246161 .5361022949161 .5361022949161 .5361022949 161.5361022949160 .9264984131160 .3170013428159 .4026031494158 .4882965088 157.5738983154156 .3547973633155 .4403991699154 .5260925293153 .6116943359 152.6972961426151 .7830047607150 .5639038086149 .0399017334146 .6015930176 143.5538024902140 .5059967041138 .0677032471135 .6293945312133 .4958953857 131.6672058105130 .1432037354128 .9241027832127 .4001998901126 .4858016968 125.2667007446124 .3523025513123 .43800354122 .8283996582122 .2188034058 121.9140014648121 .6092987061121 .6092987061121 .6092987061121 .9140014648 121.9140014648121 .9140014648121 .9140014648121 .9140014648121 .9140014648 121.9140014648121 .9140014648121 .6092987061121 .9140014648121 .9140014648 121.9140014648121 .6092987061121 .3044967651120 .6949005127120 .0852966309 118.8662033081117 .342300415115 .818397522114 .2944030762113 .075302124 111.8561019897111 .551399231111 .551399231113 .075302124116 .1231002808 121.6092987061129 .8385009766140 .8106994629152 .0877990723159 .7073974609 166.4127044678173 .7274932861182 .261505127190 .795501709199 .9389953613 208.7778015137217 .6165924072226 .4553985596234 .6844940186242 .6089935303 250.5334014893257 .8482055664264 .8583068848271 .2587890625276 .4400939941 280.4023132324283 .1453857422284 .9740905762285 .8884887695286 .4979858398 286.4979858398285 .8884887695284 .6693115234283 .1453857422281 .0119018555 278.8783874512276 .4400939941274 .6113891602273 .0874938965272 .4779052734 272.1730957031272 .4779052734272 .7827148438273 .3923034668273 .6971130371 273.6971130371273 .3923034668273 .3923034668273 .3923034668273 .6971130371 274.0018005371274 .9161987305275 .5257873535276 .1353149414276 .7449035645 277.0497131348277 .6592102051277 .6592102051277 .6592102051277 .3544921875 276.7449035645276 .1353149414275 .2210083008274 .0018005371272 .7827148438 271.2587890625269 .4301147461267 .2966003418265 .1630859375262 .7247924805 260.2864990234257 .5433959961254 .4956054688251 .4476928711248 .0950927734 244.4376983643240 .7801971436237 .1228027344233 .1605987549228 .8936004639 224.6266021729220 .3596038818215 .787902832211 .2160949707209 .692199707 209.692199707209 .692199707209 .692199707209 .692199707209 .692199707209 .692199707 209.692199707163 .6696014404157 .5738983154151 .7830047607143 .766784668 133.4546661377 -9999 -9999 -9999 -9999 -9999 -9999 -9999 -9999 -9999 -9999 -9999 -9999

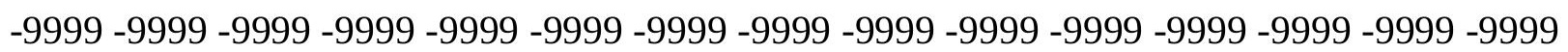

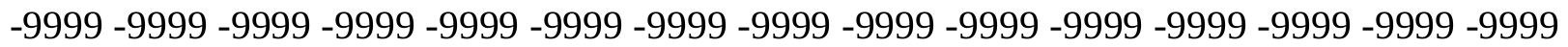
-9999 -9999 -9999 -9999

-9999 -9999 -9999 -9999 -9999 -9999 -9999 -9999 -9999 -9999 -9999 -9999 -9999 -9999 -9999 
-9999 -9999 -9999 -9999 -9999 -9999 -9999 -9999 -9999 -9999 89.04930877686 97.93086242676105 .0816497803109 .7226028442113 .3800964355116 .1231002808 118.2565994263120 .3900985718123 .1332015991125 .5715026855127 .4001998901 127.7050018311127 .0953979492126 .4858016968126 .4858016968127 .0953979492 127.7050018311127 .7050018311126 .7906036377125 .5715026855124 .6570968628 124.0475006104124 .0475006104123 .7427978516123 .7427978516123 .7427978516 123.43800354122 .8283996582122 .2188034058121 .6092987061121 .3044967651 121.3044967651121 .3044967651121 .6092987061121 .6092987061121 .6092987061 121.3044967651120 .9997024536120 .6949005127120 .6949005127120 .0852966309 119.1709976196118 .2565994263117 .647102356116 .7326965332116 .4279022217 116.7326965332117 .0374984741117 .9517974854118 .5614013672119 .1709976196 118.8662033081118 .2565994263117 .342300415116 .1231002808114 .9039993286 113.3800964355111 .551399231109 .7226028442107 .8938980103106 .3700027466 104.8460998535103 .6268997192102 .4077987671101 .1886978149100 .2742996216 99.3599472045998.7503814697398.1408081054797.8360290527398.14080810547 98.75038146973100 .2742996216103 .0174026489106 .3700027466110 .6370010376 114.9039993286119 .1709976196122 .8283996582126 .1809997559128 .9241027832 131.3623962402132 .8863067627134 .1054992676134 .7149963379135 .0198059082 135.0198059082134 .7149963379134 .4102020264134 .1054992676133 .4958953857 133.1911010742132 .5814971924131 .9720001221131 .3623962402130 .7528076172 130.7528076172130 .7528076172131 .3623962402132 .2767028809133 .8007049561 135.9342041016138 .0677032471140 .5059967041142 .9441986084144 .4682006836 145.6873016357146 .6015930176147 .2111968994147 .8208007812148 .1255950928 148.4304046631148 .7351074219149 .3446960449149 .9542999268150 .8686065674 152.3925933838153 .6116943359155 .1356048584156 .6596069336158 .4882965088 160.3170013428162 .1457061768163 .6696014404164 .8887023926166 .1078948975 167.0222015381167 .6318054199167 .9365997314168 .241394043168 .241394043 168.241394043167 .9365997314167 .6318054199167 .0222015381166 .4127044678 165.8031005859165 .1934967041164 .2792053223163 .6696014404163 .0599975586 162.4505004883161 .5361022949161 .2312927246160 .6217956543160 .0122070312 159.7073974609159 .0977935791158 .7929992676158 .4882965088158 .4882965088 158.1835021973158 .1835021973158 .1835021973158 .4882965088158 .4882965088 158.7929992676159 .0977935791159 .7073974609160 .3170013428160 .6217956543 161.2312927246161 .5361022949161 .8408966064161 .8408966064161 .8408966064 161.5361022949160 .9264984131160 .0122070312158 .7929992676157 .5738983154 156.3547973633154 .8307952881153 .9165039062152 .6972961426151 .4781951904 150.2590942383149 .0399017334147 .5160064697145 .6873016357143 .5538024902 141.1154937744138 .6772003174136 .5437011719134 .7149963379133 .1911010742 131.6672058105130 .4479980469129 .2288970947128 .3144989014127 .4001998901 126.4858016968125 .5715026855124 .6570968628123 .7427978516122 .8283996582 122.2188034058121 .6092987061121 .6092987061121 .6092987061121 .6092987061 121.9140014648121 .9140014648121 .9140014648121 .9140014648121 .9140014648 121.9140014648121 .9140014648121 .6092987061121 .9140014648121 .9140014648 121.6092987061121 .6092987061121 .3044967651120 .6949005127119 .7806015015 118.5614013672117 .342300415116 .1231002808114 .5991973877113 .3800964355 112.4656982422111 .8561019897111 .8561019897113 .075302124115 .5136032104 
120.0852966309126 .4858016968136 .2389984131150 .8686065674153 .9165039062 161.2312927246170 .6797027588180 .432800293190 .4907073975200 .5485992432 210.3016967773219 .7501068115228 .8936004639237 .7324066162245 .9615936279 253.5812072754260 .8960876465267 .9060974121274 .0018005371279 .1831970215 283.4501953125286 .1932067871288 .3266906738289 .2410888672289 .8505859375 289.5458984375288 .6315002441287 .1076049805284 .9740905762282 .5357971191 279.7927856445276 .7449035645274 .3066101074272 .7827148438271 .8682861328 271.5635070801271 .8682861328272 .4779052734273 .3923034668274 .0018005371 274.0018005371273 .3923034668273 .3923034668273 .3923034668273 .6971130371 274.6113891602275 .2210083008276 .1353149414277 .0497131348277 .6592102051 278.2687988281278 .5736083984278 .8783874512278 .8783874512278 .5736083984 277.9641113281277 .3544921875276 .4400939941275 .2210083008273 .6971130371 272.1730957031270 .3443908691268 .2109069824266 .0773925781263 .6390991211 261.2008972168 258.1530151367 255.4098968506 252.3621063232 249.0093994141 245.3520050049241 .9994049072238 .0372009277234 .0749969482230 .1127929688 225.8457946777221 .5787963867217 .3117980957212 .7400054932209 .692199707 209.692199707 209.692199707 209.692199707 209.692199707 209.692199707 209.692199707 209.692199707 209.692199707 160.0122070312 154.2212982178 148.1255950928 138.2702026367 127.0364761353 -9999 -9999 -9999 -9999 -9999 -9999 -9999 -9999 -9999

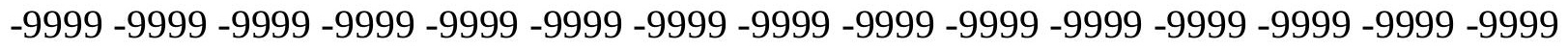

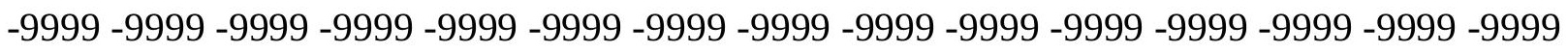
-9999 -9999 -9999-9999-9999-9999 -9999 -9999 -9999 -9999 -9999 -9999 -9999 -9999 -9999 -9999 -9999 -9999 -9999 -9999 -9999 -9999 -9999 -9999 -9999 -9999 -9999 -9999 -9999 -9999 -9999 89.70762634277 96.61632537842102 .1575775146106 .3034667969109 .2724151611111 .551399231 113.075302124114 .9039993286117 .9517974854122 .5235977173125 .2667007446 125.5715026855123 .43800354122 .5235977173123 .43800354124 .9618988037 125.8762969971125 .8762969971124 .9618988037123 .43800354121 .9140014648 121.9140014648121 .9140014648122 .2188034058122 .5235977173122 .8283996582 122.8283996582122 .5235977173122 .2188034058121 .9140014648121 .3044967651 121.3044967651121 .3044967651121 .3044967651121 .6092987061121 .6092987061 120.9997024536120 .0852966309119 .4757995605118 .8662033081118 .2565994263 117.342300415116 .4279022217115 .5136032104114 .9039993286114 .5991973877 114.5991973877114 .9039993286115 .5136032104116 .1231002808116 .4279022217 116.4279022217116 .1231002808115 .2088012695114 .2944030762113 .075302124 111.551399231110 .0273971558108 .1986999512106 .3700027466104 .8460998535 103.3221969604101 .7982025146100 .579101562599 .6647262573298 .75038146973 98.14080810547 97.53124237061 97.2264633178797.2264633178797.22646331787 97.8360290527399 .35994720459102 .1029968262105 .7603988647110 .6370010376 114.9039993286118 .8662033081122 .5235977173125 .5715026855128 .3144989014 130.4479980469132 .2767028809133 .8007049561134 .7149963379135 .3246002197 135.6293945312135 .9342041016135 .9342041016135 .9342041016135 .6293945312 135.0198059082134 .7149963379134 .1054992676133 .1911010742132 .8863067627 132.2767028809132 .2767028809132 .8863067627133 .8007049561135 .3246002197 137.4580993652139 .8963928223142 .3347015381144 .7729034424146 .6015930176 147.8208007812148 .4304046631148 .7351074219148 .7351074219149 .0399017334 
149.3446960449149 .3446960449149 .9542999268150 .5639038086151 .7830047607 153.0021057129154 .5260925293156 .0500030518157 .878692627159 .7073974609 161.5361022949163 .0599975586164 .5839996338165 .8031005859167 .0222015381 167.6318054199168 .241394043168 .5462036133168 .8509979248168 .5462036133 168.5462036133167 .9365997314167 .6318054199167 .0222015381166 .1078948975 165.4983062744164 .5839996338163 .974395752163 .0599975586162 .4505004883 161.5361022949160 .9264984131160 .3170013428159 .7073974609159 .4026031494 159.0977935791158 .4882965088158 .4882965088158 .1835021973157 .878692627 157.878692627157 .878692627157 .878692627158 .1835021973158 .1835021973 158.4882965088159 .0977935791159 .4026031494160 .0122070312160 .6217956543 161.2312927246161 .5361022949161 .8408966064161 .8408966064161 .5361022949 160.9264984131160 .3170013428159 .0977935791157 .878692627156 .0500030518 154.5260925293152 .6972961426151 .1734008789149 .6495056152148 .1255950928 146.6015930176145 .0776977539143 .5538024902142 .0299072266140 .2012023926 138.0677032471136 .2389984131134 .7149963379133 .1911010742131 .9720001221 131.0576019287130 .4479980469129 .8385009766129 .2288970947128 .6192932129 127.7050018311126 .7906036377125 .8762969971124 .6570968628123 .7427978516 122.5235977173121 .6092987061121 .6092987061121 .6092987061121 .9140014648 121.9140014648121 .9140014648121 .9140014648121 .9140014648121 .9140014648 121.9140014648121 .9140014648121 .9140014648121 .9140014648121 .6092987061 121.6092987061121 .3044967651120 .9997024536120 .3900985718119 .7806015015 118.8662033081117 .647102356116 .4279022217114 .9039993286113 .6848983765 112.7705001831111 .8561019897111 .8561019897112 .4656982422113 .9896011353 117.0374984741121 .3044967651125 .8762969971128 .3144989014143 .2489929199 155.4403991699166 .7174987793178 .2993011475189 .8811035156201 .158203125 212.1304016113222 .1884002686231 .9414978027240 .7801971436249 .0093994141 256.6290893555263 .9439086914270 .3443908691276 .4400939941281 .9262084961 286.1932067871289 .5458984375291 .3746032715292 .5936889648293 .2033081055 292.5936889648291 .6794128418289 .8505859375287 .4124145508284 .6693115234 281.3167114258277 .6592102051274 .3066101074272 .7827148438271 .5635070801 271.2587890625271 .2587890625271 .8682861328273 .0874938965274 .3066101074 274.0018005371273 .3923034668273 .3923034668273 .3923034668274 .0018005371 275.2210083008276 .1353149414277 .3544921875278 .2687988281279 .1831970215 279.7927856445280 .0975036621280 .4023132324280 .0975036621279 .7927856445 279.4880065918278 .5736083984277 .6592102051276 .4400939941274 .9161987305 273.0874938965271 .2587890625269 .4301147461266 .9917907715264 .5534973145 262.1152038574259 .0674133301256 .3243103027253 .2763977051249 .9237976074 246.5711975098242 .9136962891239 .2563018799235 .2940979004231 .3318939209 227.3697052002 223.1027069092 218.8356933594214.2639007568209.692199707 209.692199707209 .692199707209 .692199707209 .692199707209 .692199707209 .692199707 209.692199707209 .692199707162 .4505004883156 .6596069336150 .5639038086 142.5588378906132 .109954834 -9999 -9999 -9999 -9999 -9999 -9999 -9999 -9999 -9999 -9999 -9999 -9999 -9999 -9999 -9999 -9999 -9999 -9999 -9999 -9999 -9999 -9999 -9999 -9999 -

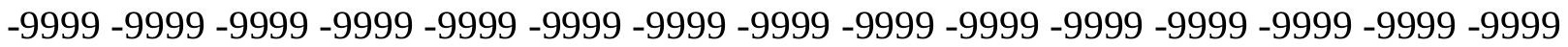
-9999 -9999 -9999-9999-9999-9999

-9999 -9999 -9999 -9999 -9999 -9999 -9999 -9999 -9999 -9999 -9999 -9999 -9999 -9999 -9999 
-9999 -9999 -9999 -9999 -9999 -9999 -9999 -9999 -9999 -9999 90.97328948975 96.3295211792100 .6603088379103 .9235153198106 .0881347656107 .3947601318 108.0676269531108 .8082962036111 .24659729117 .342300415124 .3523025513 121.9140014648117 .342300415116 .4279022217119 .1709976196122 .8283996582 124.6570968628124 .6570968628123 .7427978516122 .5235977173121 .6092987061 121.3044967651121 .3044967651121 .6092987061122 .2188034058122 .8283996582 123.1332015991123 .1332015991122 .8283996582122 .5235977173122 .2188034058 121.6092987061121 .6092987061121 .3044967651121 .3044967651120 .9997024536 120.0852966309119 .1709976196118 .2565994263117 .342300415116 .4279022217 115.5136032104114 .5991973877113 .6848983765113 .075302124112 .7705001831 112.7705001831112 .7705001831113 .3800964355113 .9896011353114 .2944030762 114.2944030762113 .9896011353113 .6848983765112 .7705001831111 .551399231 110.3321990967108 .8082962036106 .979598999105 .1509017944103 .6268997192 102.1029968262100 .579101562599 .3599472045998 .445587158297 .83602905273 97.2264633178796 .9216690063597 .2264633178797 .5312423706197 .83602905273 98.1408081054798 .75038146973101 .4934005737106 .0652008057111 .551399231 116.1231002808119 .4757995605122 .2188034058124 .9618988037127 .7050018311 130.1432037354132 .2767028809133 .8007049561135 .3246002197136 .2389984131 136.8484954834137 .1533050537137 .4580993652137 .7628936768137 .4580993652 137.4580993652136 .8484954834136 .2389984131135 .3246002197134 .7149963379 133.8007049561133 .4958953857133 .8007049561134 .7149963379136 .2389984131 138.3724975586140 .8106994629143 .5538024902146 .2969055176148 .1255950928 149.3446960449149 .6495056152149 .6495056152149 .6495056152149 .6495056152 149.6495056152149 .9542999268150 .2590942383150 .8686065674152 .0877990723 153.6116943359155 .4403991699157 .2691040039159 .0977935791160 .9264984131 162.4505004883164 .2792053223165 .4983062744166 .7174987793167 .6318054199 168.5462036133168 .8509979248169 .1557006836169 .1557006836168 .8509979248 168.5462036133167 .9365997314167 .3269958496166 .7174987793165 .8031005859 164.8887023926164 .2792053223163 .3648071289162 .4505004883161 .5361022949 160.9264984131160 .3170013428159 .7073974609159 .0977935791158 .4882965088 158.1835021973157 .878692627157 .878692627157 .5738983154157 .5738983154 157.2691040039 157.2691040039 157.5738983154 157.5738983154157.878692627 158.1835021973158 .4882965088159 .0977935791159 .7073974609160 .3170013428 160.9264984131161 .5361022949161 .5361022949161 .5361022949160 .9264984131 160.3170013428159 .0977935791157 .878692627156 .0500030518153 .9165039062 151.7830047607149 .6495056152147 .5160064697145 .6873016357144 .1634063721 142.3347015381140 .8106994629139 .2868041992137 .7628936768135 .9342041016 134.7149963379133 .1911010742132 .2767028809131 .3623962402130 .7528076172 130.4479980469130 .1432037354129 .8385009766129 .8385009766129 .533706665 128.9241027832128 .0097961426127 .0953979492125 .8762969971124 .3523025513 123.1332015991122 .2188034058121 .9140014648121 .9140014648121 .9140014648 121.6092987061121 .9140014648121 .9140014648121 .9140014648121 .9140014648 121.9140014648121 .9140014648121 .9140014648121 .9140014648121 .6092987061 121.6092987061121 .3044967651120 .9997024536120 .3900985718119 .7806015015 118.8662033081117 .9517974854116 .7326965332115 .5136032104114 .2944030762 113.075302124112 .1608963013111 .551399231111 .551399231112 .1608963013 
113.6848983765115 .818397522119 .1709976196124 .6570968628136 .2389984131 149.9542999268163 .3648071289176 .7754058838189 .8811035156202 .3773040771 213.959197998224 .9313964844234 .9893035889244 .1329040527252 .3621063232 259.9816894531266 .6870117188273 .0874938965279 .1831970215284 .6693115234 288.9363098145292 .2889099121294 .7272033691295 .9464111328296 .2510986328 295.9464111328294 .7272033691292 .8984985352290 .1553955078287 .1076049805 283.4501953125279 .7927856445276 .4400939941274 .0018005371272 .1730957031 270.9540100098270 .6492004395271 .2587890625272 .1730957031273 .0874938965 273.0874938965273 .0874938965273 .3923034668274 .0018005371274 .9161987305 276.4400939941277 .6592102051278 .8783874512279 .7927856445280 .7070922852 281.3167114258 281.9262084961281.9262084961 281.9262084961 281.6214904785 281.0119018555280 .0975036621279 .1831970215277 .6592102051276 .1353149414 274.6113891602272 .4779052734270 .3443908691268 .2109069824265 .7726135254 263.0296020508260 .2864990234257 .2385864258254 .1907958984250 .8381958008 247.4855041504243 .8280944824240 .1707000732236 .5133056641232 .5511016846 228.5888977051224 .3218994141220 .054901123215 .787902832211 .2160949707 209.692199707 209.692199707 209.692199707 209.692199707 209.692199707209.692199707 209.692199707 209.692199707 209.692199707 159.0977935791 153.0021057129 146.9064025879136 .8479003906125 .3110275269 -9999 -9999 -9999 -9999 -9999 -9999 -9999

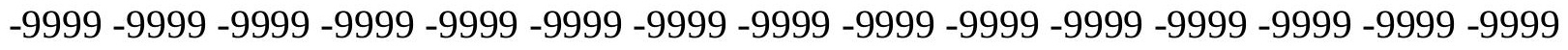

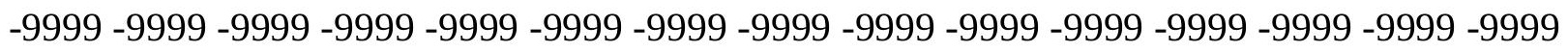
-9999 -9999 -9999 -9999-9999-9999-9999 -9999 -9999 -9999 -9999 -9999 -9999 -9999 -9999 -9999 -9999 -9999 -9999 -9999 -9999 -9999 -9999 -9999 -9999 -9999 -9999 -9999 -9999 -9999 -9999 -9999 93.09544372559 97.21999359131100 .5116271973102 .8020401001104 .0704269409104 .4325027466 104.1836242676103 .7488708496103 .3486099243104 .2365036011124 .9618988037 111.551399231105 .4557037354107 .5891036987113 .6848983765121 .3044967651 122.8283996582123 .1332015991123 .1332015991122 .5235977173122 .2188034058 121.9140014648121 .9140014648122 .2188034058123 .43800354124 .6570968628 124.9618988037124 .9618988037124 .6570968628124 .0475006104123 .43800354 122.8283996582122 .5235977173121 .9140014648121 .3044967651120 .6949005127 119.7806015015118 .5614013672117 .647102356116 .4279022217115 .2088012695 114.2944030762113 .3800964355112 .4656982422111 .551399231111 .24659729 110.9418029785111 .24659729111 .8561019897112 .1608963013112 .7705001831 112.7705001831112 .7705001831112 .4656982422111 .551399231110 .6370010376 109.4179000854107 .8938980103106 .0652008057104 .2365036011102 .712600708 100.883903503499 .6647262573298 .445587158297 .5312423706196 .92166900635 96.9216690063597 .2264633178797 .8360290527398 .7503814697399 .96952056885 100.2742996216100 .2742996216101 .7982025146107 .8938980103116 .4279022217 118.8662033081119 .7806015015121 .6092987061124 .6570968628126 .7906036377 129.8385009766132 .5814971924134 .4102020264135 .9342041016137 .1533050537 138.0677032471138 .6772003174139 .2868041992139 .5915985107139 .5915985107 139.5915985107139 .2868041992138 .6772003174137 .4580993652136 .2389984131 135.3246002197134 .7149963379134 .7149963379135 .3246002197136 .5437011719 138.6772003174141 .4203033447144 .4682006836147 .5160064697149 .6495056152 150.5639038086150 .5639038086150 .2590942383149 .9542999268149 .9542999268 
150.2590942383150 .2590942383150 .5639038086151 .1734008789152 .6972961426 154.5260925293156 .3547973633158 .1835021973160 .0122070312161 .8408966064 163.6696014404165 .1934967041166 .7174987793167 .6318054199168 .5462036133 169.1557006836169 .4604949951169 .4604949951169 .4604949951169 .1557006836 168.5462036133167 .9365997314167 .0222015381166 .1078948975165 .1934967041 164.2792053223163 .3648071289162 .4505004883161 .5361022949160 .6217956543 160.0122070312159 .4026031494158 .7929992676158 .1835021973157 .878692627 157.5738983154157 .2691040039157 .2691040039156 .9642944336156 .9642944336 156.9642944336156 .9642944336156 .9642944336156 .9642944336156 .9642944336 157.2691040039157 .878692627158 .4882965088159 .0977935791159 .7073974609 160.6217956543160 .9264984131161 .2312927246160 .9264984131160 .0122070312 159.0977935791157 .5738983154155 .7451934814153 .6116943359151 .1734008789 148.4304046631145 .6873016357143 .2489929199141 .1154937744139 .2868041992 137.4580993652135 .9342041016134 .4102020264132 .8863067627131 .6672058105 130.7528076172129 .8385009766129 .2288970947128 .9241027832128 .9241027832 129.2288970947129 .533706665130 .1432037354130 .4479980469130 .4479980469 130.1432037354129 .2288970947128 .0097961426126 .7906036377125 .2667007446 123.7427978516122 .8283996582121 .9140014648121 .6092987061121 .6092987061 121.3044967651121 .3044967651121 .6092987061121 .9140014648121 .9140014648 121.9140014648121 .9140014648121 .9140014648121 .9140014648121 .6092987061 121.6092987061121 .3044967651120 .9997024536120 .3900985718119 .7806015015 119.1709976196118 .2565994263117 .342300415116 .1231002808114 .9039993286 113.6848983765112 .4656982422111 .551399231110 .9418029785110 .6370010376 111.24659729112 .7705001831116 .1231002808123 .1332015991133 .4958953857 147.2111968994161 .5361022949176 .165802002190 .4907073975203 .9011993408 216.3973999023227 .9792938232238 .3419952393247 .7902984619256 .0195007324 263.3344116211270 .0396118164276 .4400939941282 .2309875488287 .4124145508 291.9841918945295 .3367919922297 .7750854492299 .2990112305299 .6037902832 299.2990112305298 .0798950195295 .9464111328293 .2033081055290 .1553955078 286.4979858398282 .5357971191278 .8783874512275 .8305053711273 .3923034668 271.5635070801270 .6492004395270 .6492004395271 .2587890625272 .1730957031 272.7827148438273 .0874938965273 .6971130371274 .9161987305276 .4400939941 277.9641113281279 .4880065918281 .0119018555281 .9262084961282 .8406066895 283.4501953125284 .0596923828284 .0596923828284 .0596923828283 .4501953125 282.8406066895281 .9262084961280 .7070922852279 .4880065918277 .6592102051 275.8305053711274 .0018005371271 .8682861328269 .4301147461266 .6870117188 264.2486877441261 .2008972168258 .4577941895255 .1051025391252 .0572967529 248.7046966553245 .0471954346241 .3898010254237 .7324066162233 .7702026367 229.8079986572225 .8457946777221 .5787963867217 .3117980957212 .7400054932 209.692199707209 .692199707209 .692199707209 .692199707209 .692199707209 .692199707 209.692199707 209.692199707 209.692199707 161.5361022949155 .4403991699

149.3446960449 141.102722168 130.3527679443 -9999 -9999 -9999 -9999 -9999 -9999 -9999 -9999 -9999 -9999 -9999 -9999 -9999 -9999 -9999 -9999 -9999 -9999 -9999 -9999 -9999 -9999 -9999 -9999 -9999 -9999 -9999 -9999 -9999 -9999 -9999 -9999 -9999 -9999 -9999 -9999 -9999 -9999 -9999 -9999 -9999 -9999 -9999 -9999

-9999 -9999 -9999 -9999 -9999 -9999 -9999 -9999 -9999 -9999 -9999 -9999 -9999 -9999 -9999 
-9999 -9999 -9999 -9999 -9999 -9999 -9999 -9999 -9999 -9999 -9999 99.31730651855 101.6875991821103 .1159133911103 .5679626465103 .1283035278101 .9702453613 100.511863708599 .73168945312101 .4050369263102 .826683044493 .56903076172 91.4355392456199 .05516815186107 .8938980103115 .2088012695119 .1709976196 121.6092987061122 .2188034058122 .8283996582123 .1332015991123 .43800354 124.0475006104124 .9618988037126 .4858016968127 .7050018311128 .0097961426 128.0097961426127 .0953979492126 .4858016968125 .5715026855124 .9618988037 124.0475006104123 .1332015991122 .2188034058121 .3044967651120 .0852966309 118.5614013672117 .342300415116 .1231002808114 .9039993286113 .6848983765 112.4656982422111 .551399231110 .9418029785110 .3321990967110 .3321990967 110.6370010376111 .24659729111 .8561019897112 .4656982422112 .7705001831 112.4656982422112 .1608963013111 .24659729110 .3321990967109 .1130981445 107.2844009399 105.7603988647103.6268997192101.7982025146100.2742996216 98.7503814697397 .5312423706196 .9216690063596 .6168823242296 .92166900635 97.8360290527399 .35994720459101 .1886978149103 .6268997192105 .4557037354 105.4557037354102 .1029968262109 .9349746704116 .3429260254119 .4373550415 120.6708602905121 .9857025146124 .0531158447126 .7232894897130 .1432037354 132.8863067627135 .3246002197137 .1533050537138 .3724975586139 .2868041992 140.2012023926140 .8106994629141 .1154937744141 .4203033447141 .7250976562 141.4203033447140 .8106994629139 .5915985107137 .7628936768136 .5437011719 135.3246002197135 .0198059082135 .6293945312136 .8484954834138 .6772003174 141.4203033447144 .7729034424148 .1255950928151 .1734008789151 .4781951904 151.1734008789150 .5639038086150 .2590942383150 .5639038086150 .8686065674 151.1734008789151 .4781951904151 .7830047607153 .6116943359155 .4403991699 157.5738983154159 .4026031494161 .5361022949163 .3648071289164 .8887023926 166.4127044678167 .6318054199168 .5462036133169 .1557006836169 .7653045654 169.7653045654169 .7653045654169 .4604949951169 .1557006836168 .241394043 167.6318054199166 .7174987793165 .8031005859164 .5839996338163 .6696014404 162.4505004883161 .5361022949160 .6217956543159 .7073974609159 .0977935791 158.1835021973157 .5738983154157 .2691040039156 .9642944336156 .6596069336 156.6596069336156 .3547973633156 .3547973633156 .3547973633156 .3547973633 156.0500030518156 .0500030518156 .0500030518156 .3547973633156 .3547973633 156.9642944336157 .5738983154158 .1835021973158 .7929992676159 .7073974609 160.3170013428160 .3170013428160 .0122070312158 .7929992676157 .2691040039 155.4403991699153 .3069000244150 .8686065674147 .5160064697144 .1634063721 141.1154937744138 .3724975586136 .2389984131134 .1054992676132 .2767028809 130.7528076172129 .2288970947128 .0097961426127 .0953979492126 .4858016968 126.1809997559125 .8762969971126 .1809997559126 .7906036377127 .7050018311 128.6192932129129 .8385009766131 .0576019287131 .3623962402131 .0576019287 130.1432037354128 .9241027832127 .4001998901125 .5715026855124 .0475006104 122.8283996582121 .9140014648121 .3044967651120 .9997024536120 .6949005127 120.6949005127120 .9997024536121 .3044967651121 .6092987061121 .6092987061 121.9140014648121 .9140014648121 .9140014648121 .6092987061121 .6092987061 121.3044967651120 .9997024536120 .6949005127120 .0852966309119 .4757995605 118.8662033081117 .9517974854117 .0374984741115 .818397522114 .5991973877 113.075302124111 .8561019897110 .6370010376110 .0273971558110 .0273971558 
111.24659729114 .9039993286122 .2188034058132 .8863067627146 .2969055176 161.2312927246176 .4705963135191 .4051055908206 .0346984863219 .4452972412 231.6367034912242 .6089935303251 .7525024414259 .9816894531266 .9917907715 273.3923034668279 .4880065918285 .2789001465290 .7650146484295 .0320129395 298.6893920898301 .1276855469302 .6516113281302 .9563903809302 .6516113281 301.4324951172299 .2990112305296 .5559082031293 .5080871582289 .8505859375 285.8884887695282 .2309875488278 .5736083984275 .2210083008272 .4779052734 270.9540100098270 .9540100098271 .5635070801272 .4779052734273 .3923034668 274.0018005371274 .6113891602276 .7449035645278 .5736083984280 .4023132324 281.9262084961283 .4501953125284 .3645019531285 .2789001465286 .1932067871 286.4979858398286 .4979858398286 .1932067871285 .8884887695284 .9740905762 284.0596923828282 .5357971191281 .0119018555279 .4880065918277 .6592102051 275.5257873535273 .0874938965270 .6492004395268 .2109069824265 .4678039551 262.4200134277259 .3721008301256 .3243103027252 .9716033936249 .6190032959 246.2664031982242 .6089935303238 .9515075684235 .2940979004231 .3318939209 227.3697052002 223.1027069092 218.8356933594214.5686950684209.9969024658 209.692199707 209.692199707 209.692199707 209.692199707 209.692199707209.692199707 209.692199707 209.692199707 209.692199707 157.878692627 151.7830047607 145.3825073242135 .0899810791123 .2766723633 -9999 -9999 -9999 -9999 -9999 -9999-9999

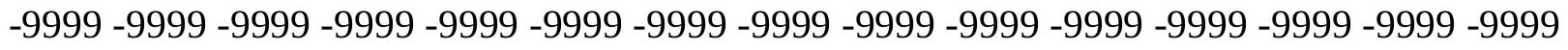

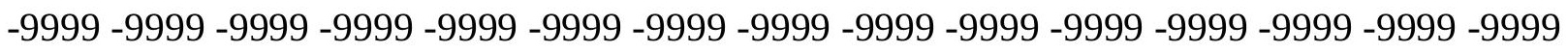
-9999 -9999 -9999-9999-9999-9999 -9999 -9999 -9999 -9999 -9999 -9999 -9999 -9999 -9999 -9999 -9999 -9999 -9999 -9999 -9999 -9999 -9999 -9999 -9999 -9999 -9999 -9999 -9999 -9999 -9999 -9999 102.6226425171 104.249130249104 .9785690308104 .773475647103 .7066955566101 .9866409302 99.9733200073298.1679458618296.9041137695393.40831756592 89.91033935547 89.8066253662195 .80139923096104 .8460998535111 .8561019897115 .2088012695 118.2565994263120 .9997024536123 .43800354124 .9618988037125 .8762969971 126.7906036377128 .6192932129130 .7528076172132 .2767028809132 .5814971924 131.9720001221130 .7528076172129 .8385009766128 .9241027832128 .0097961426 126.7906036377125 .5715026855124 .3523025513122 .8283996582121 .3044967651 119.4757995605117 .9517974854116 .4279022217115 .2088012695113 .9896011353 112.7705001831111 .8561019897110 .9418029785110 .6370010376110 .6370010376 111.24659729112 .1608963013113 .075302124113 .9896011353114 .2944030762 113.9896011353113 .3800964355112 .1608963013110 .9418029785109 .4179000854 107.5891036987105 .7603988647103 .6268997192101 .798202514699 .66472625732 98.445587158297 .2264633178796 .6168823242296 .6168823242297 .53124237061 98.75038146973101 .1886978149103 .9317016602107 .5891036987111 .8561019897 116.4279022217114 .0772857666115 .2918395996118 .1436386108120 .2922439575 121.4054412842122 .4145507812123 .9658966064126 .4789581299129 .8385009766 133.4958953857136 .2389984131138 .3724975586139 .8963928223141 .1154937744 141.7250976562142 .3347015381142 .9441986084143 .2489929199143 .5538024902 143.5538024902143 .2489929199141 .1154937744138 .9819946289137 .1533050537 135.9342041016135 .3246002197135 .6293945312136 .5437011719138 .6772003174 141.1154937744144 .4682006836147 .8208007812150 .2590942383151 .4781951904 151.4781951904151 .1734008789150 .8686065674151 .1734008789152 .0877990723 
152.6972961426153 .3069000244154 .2212982178155 .7451934814157 .2691040039 159.0977935791161 .2312927246163 .0599975586164 .5839996338166 .1078948975 167.6318054199168 .5462036133169 .4604949951170 .070098877170 .3748931885 170.3748931885170 .070098877169 .4604949951168 .8509979248167 .9365997314 167.0222015381166 .1078948975164 .8887023926163 .974395752162 .7552947998 161.5361022949160 .6217956543159 .7073974609158 .7929992676157 .878692627 157.2691040039156 .6596069336156 .3547973633156 .0500030518156 .0500030518 155.7451934814155 .7451934814155 .7451934814155 .7451934814155 .7451934814 155.4403991699155 .4403991699155 .4403991699155 .4403991699155 .4403991699 155.7451934814156 .3547973633156 .9642944336157 .5738983154158 .4882965088 158.7929992676159 .0977935791158 .4882965088156 .9642944336155 .1356048584 152.6972961426149 .9542999268146 .6015930176143 .2489929199139 .5915985107 136.2389984131133 .1911010742130 .7528076172128 .6192932129127 .0953979492 125.5715026855124 .3523025513123 .43800354124 .3523025513124 .6570968628 124.9618988037125 .2667007446125 .2667007446125 .2667007446125 .8762969971 127.7050018311129 .533706665131 .3623962402132 .2767028809131 .9720001221 131.0576019287129 .2288970947127 .4001998901125 .2667007446123 .7427978516 122.2188034058120 .9997024536120 .0852966309119 .7806015015119 .4757995605 119.4757995605119 .7806015015120 .0852966309120 .6949005127121 .3044967651 121.6092987061121 .9140014648121 .9140014648121 .6092987061121 .6092987061 121.3044967651120 .9997024536120 .6949005127120 .3900985718120 .0852966309 119.4757995605118 .5614013672117 .9517974854116 .7326965332115 .5136032104 113.9896011353112 .4656982422110 .9418029785109 .7226028442109 .7226028442 110.9418029785114 .5991973877121 .6092987061132 .8863067627147 .2111968994 162.1457061768177 .6896972656192 .9290008545208 .1681976318222 .7978973389 235.9037017822247 .1806945801256 .3243103027263 .9439086914270 .6492004395 276.7449035645282 .5357971191288 .3266906738293 .5080871582298 .0798950195 301.7373046875304 .4802856445306 .0043029785306 .6138000488306 .0043029785 304.7850952148302 .9563903809300 .2132873535297 .1654968262293 .5080871582 289.8505859375285 .8884887695281 .9262084961278 .2687988281275 .2210083008 272.4779052734272 .7827148438273 .3923034668274 .3066101074275 .5257873535 276.4400939941277 .6592102051279 .4880065918281 .6214904785283 .4501953125 284.9740905762286 .4979858398287 .4124145508288 .3266906738288 .9363098145 289.2410888672 289.2410888672 288.9363098145 288.3266906738 287.4124145508 286.1932067871284 .6693115234283 .1453857422281 .3167114258279 .1831970215 277.0497131348274 .6113891602272 .1730957031269 .4301147461266 .6870117188 263.6390991211260 .5913085938257 .5433959961254 .1907958984250 .8381958008 247.4855041504243 .8280944824240 .1707000732236 .5133056641232 .5511016846 228.5888977051224 .6266021729220 .3596038818216 .0926971436211 .8256988525 209.692199707 209.692199707 209.692199707 209.692199707 209.692199707209.692199707 209.692199707 209.692199707 209.692199707 160.3170013428 154.2212982178 147.8208007812 139.4159545898128 .4112091064 -9999 -9999 -9999 -9999 -9999 -9999 -9999 -9999 -9999 -9999 -9999 -9999 -9999 -9999 -9999 -9999 -9999 -9999 -9999 -9999 -9999 -9999

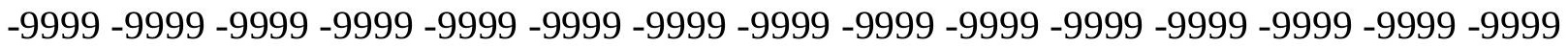
-9999 -9999 -9999-9999-9999-9999

-9999 -9999 -9999 -9999 -9999 -9999 -9999 -9999 -9999 -9999 -9999 -9999 -9999 -9999 -9999 
-9999 -9999 -9999 -9999 -9999 -9999 -9999 -9999 -9999 -9999 -9999 107.1471099854 108.1911697388108 .3896179199107 .7281723022106 .2782287598104 .1955795288 101.724388122699 .1266555786196 .339431762793 .1576232910291 .4077835083 92.3557586669996 .78665924072103 .1517715454108 .3885879517111 .24659729 116.1231002808121 .6092987061125 .5715026855127 .7050018311128 .3144989014 129.533706665132 .5814971924135 .6293945312138 .0677032471137 .7628936768 136.5437011719135 .3246002197134 .1054992676133 .1911010742132 .2767028809 130.7528076172129 .2288970947127 .4001998901125 .5715026855123 .43800354 121.6092987061119 .7806015015118 .2565994263117 .0374984741115 .818397522 114.5991973877113 .3800964355112 .4656982422112 .1608963013112 .4656982422 113.3800964355115 .2088012695116 .7326965332117 .647102356117 .9517974854 117.342300415116 .1231002808114 .2944030762112 .7705001831110 .9418029785 108.8082962036106 .6747970581104 .2365036011101 .798202514699 .96952056885 98.445587158297 .2264633178796 .9216690063597 .2264633178798 .14080810547 99.96952056885102 .712600708106 .3700027466111 .24659729116 .4279022217 123.1332015991122 .6392974854121 .8396224976121 .9825668335122 .4372634888 122.951423645123 .4971237183124 .5249252319126 .669090271129 .8385009766 134.4102020264137 .7628936768140 .2012023926141 .7250976562142 .6394042969 143.5538024902144 .1634063721144 .7729034424145 .0776977539145 .0776977539 144.7729034424143 .8585968018142 .0299072266139 .5915985107137 .7628936768 136.2389984131135 .6293945312135 .9342041016136 .8484954834138 .6772003174 141.1154937744144 .1634063721147 .2111968994149 .9542999268151 .7830047607 152.3925933838152 .3925933838151 .7830047607153 .3069000244154 .5260925293 155.4403991699156 .3547973633157 .2691040039158 .4882965088159 .7073974609 161.5361022949163 .0599975586164 .8887023926166 .4127044678167 .6318054199 168.8509979248169 .7653045654170 .3748931885170 .6797027588170 .6797027588 170.6797027588170 .070098877169 .4604949951168 .5462036133167 .6318054199 166.4127044678165 .4983062744164 .2792053223162 .7552947998161 .8408966064 160.6217956543159 .4026031494158 .4882965088157 .5738983154156 .9642944336 156.0500030518155 .7451934814155 .4403991699155 .1356048584155 .1356048584 155.1356048584155 .1356048584155 .4403991699155 .1356048584155 .1356048584 155.1356048584154 .8307952881154 .5260925293154 .2212982178154 .2212982178 154.8307952881155 .1356048584155 .7451934814156 .3547973633156 .6596069336 156.9642944336156 .9642944336156 .3547973633154 .8307952881152 .3925933838 149.3446960449145 .9920959473142 .3347015381138 .3724975586134 .7149963379 131.0576019287128 .0097961426125 .5715026855123 .43800354122 .8283996582 123.1332015991123 .43800354123 .7427978516124 .3523025513124 .6570968628 124.9618988037125 .2667007446125 .5715026855125 .5715026855125 .8762969971 125.8762969971128 .6192932129131 .3623962402132 .5814971924132 .2767028809 130.7528076172128 .9241027832126 .7906036377124 .6570968628122 .5235977173 122.2188034058121 .3044967651120 .3900985718119 .1709976196117 .9517974854 117.9517974854118 .5614013672118 .8662033081119 .7806015015120 .3900985718 120.9997024536121 .6092987061121 .6092987061121 .6092987061121 .6092987061 121.3044967651121 .3044967651120 .9997024536120 .6949005127120 .3900985718 120.0852966309119 .4757995605118 .8662033081117 .9517974854116 .7326965332 115.2088012695113 .075302124111 .24659729110 .3321990967110 .3321990967 
111.551399231115 .2088012695120 .9997024536134 .7149963379149 .0399017334 163.6696014404178 .2993011475193 .8433074951209 .9969024658226 .150604248 240.4754943848252 .0572967529261 .2008972168267 .9060974121273 .6971130371 279.4880065918285 .2789001465291 .0697937012296 .2510986328301 .1276855469 304.7850952148307 .5281982422309 .3569030762309 .9664916992309 .6617126465 308.4425048828306 .6138000488304 .1755981445301 .1276855469297 .4703063965 293.8128967285290 .1553955078286 .1932067871282 .5357971191279 .4880065918 277.3544921875 276.4400939941277.0497131348277.9641113281278.8783874512 280.0975036621281 .6214904785283 .4501953125285 .2789001465287 .1076049805 288.6315002441289 .8505859375291 .0697937012291 .6794128418292 .2889099121 292.2889099121292 .2889099121291 .6794128418291 .0697937012289 .8505859375 288.6315002441287 .1076049805285 .2789001465283 .1453857422281 .0119018555 278.8783874512276 .1353149414273 .6971130371270 .9540100098267 .9060974121 264.8583068848261 .8103942871258 .7626037598255 .4098968506252 .0572967529 248.7046966553245 .0471954346241 .3898010254237 .7324066162234 .0749969482 230.1127929688226 .150604248221 .883605957217 .9214019775213 .6544036865 209.0825958252 209.692199707 209.692199707 209.692199707 209.692199707 209.692199707 209.692199707 209.692199707 209.692199707 209.692199707 $156.6596069336150 .2590942383143 .8585968018133 .2545318604121 .0096359253-9999$ -9999 -9999 -9999 -9999 -9999 -9999 -9999 -9999 -9999 -9999 -9999 -9999 -9999 -9999 -9999 -9999 -9999 -9999 -9999 -9999 -9999 -9999 -9999 -9999 -9999 -9999 -9999 -9999 -9999 -9999 -9999 -9999 -9999 -9999 -9999 -9999 -9999 -9999 -9999 -9999 -9999 -9999 -9999 -9999 -9999 -9999 -9999 -9999 -9999 -9999 -9999 -9999 -9999 -9999 -9999 -9999 -9999 -9999 -9999 -9999 -9999 -9999 -9999 -9999 -9999 -9999 -9999 112.8602294922 113.4907531738113 .3528442383112 .4316329956110 .779296875108 .5388031006 105.8778915405102 .9985046387100 .037620544497 .5641555786196 .46720123291 97.48844909668100 .6892547607105 .1179199219109 .5104141235113 .7003173828 118.6081237793123 .9579849243128 .6192932129131 .3623962402131 .0576019287 131.3623962402135 .0198059082142 .6394042969144 .7729034424143 .2489929199 141.7250976562140 .5059967041139 .5915985107138 .6772003174137 .7628936768 136.5437011719134 .4102020264132 .2767028809129 .8385009766127 .4001998901 124.9618988037123 .1332015991121 .3044967651120 .0852966309118 .8662033081 117.647102356116 .4279022217115 .5136032104114 .9039993286115 .5136032104 117.342300415119 .7806015015122 .5235977173124 .0475006104124 .0475006104 122.5235977173120 .3900985718117 .9517974854115 .818397522113 .3800964355 110.9418029785108 .1986999512105 .4557037354103 .0174026489100 .8839035034 99.0551681518698.1408081054797.8360290527398.445587158299.35994720459 101.4934005737104 .2365036011108 .1986999512113 .075302124122 .5235977173 125.2667007446126 .7906036377127 .4001998901126 .4858016968125 .8762969971 126.1809997559126 .1809997559126 .4858016968128 .3144989014132 .2767028809 136.5437011719140 .2012023926142 .3347015381143 .5538024902144 .4682006836 145.0776977539145 .6873016357146 .2969055176146 .6015930176146 .2969055176 145.6873016357144 .1634063721142 .3347015381140 .2012023926138 .3724975586 137.1533050537136 .5437011719136 .8484954834137 .7628936768139 .2868041992 141.7250976562144 .4682006836147 .8208007812150 .8686065674153 .0021057129 154.2212982178154 .8307952881155 .4403991699156 .3547973633157 .5738983154 
158.7929992676159 .7073974609160 .6217956543161 .5361022949162 .7552947998 164.2792053223165 .4983062744167 .0222015381168 .241394043169 .4604949951 170.3748931885170 .9844970703171 .2891998291171 .5939941406171 .2891998291 170.9844970703170 .3748931885169 .4604949951168 .241394043167 .3269958496 165.8031005859164 .5839996338163 .0599975586161 .8408966064160 .6217956543 159.4026031494158 .4882965088157 .2691040039156 .3547973633155 .7451934814 155.1356048584154 .5260925293154 .2212982178154 .2212982178154 .2212982178 154.5260925293154 .8307952881154 .8307952881154 .8307952881154 .5260925293 154.5260925293154 .2212982178153 .6116943359153 .0021057129153 .0021057129 153.3069000244154 .2212982178154 .8307952881155 .1356048584155 .1356048584 154.5260925293154 .2212982178153 .3069000244152 .0877990723149 .3446960449 145.9920959473142 .0299072266137 .7628936768133 .4958953857129 .8385009766 126.1809997559123 .1332015991120 .6949005127120 .6949005127121 .6092987061 122.2188034058122 .8283996582123 .1332015991123 .7427978516124 .0475006104 124.6570968628124 .9618988037125 .2667007446125 .5715026855125 .8762969971 125.8762969971127 .0953979492130 .1432037354132 .5814971924131 .6672058105 129.8385009766127 .7050018311125 .2667007446124 .0475006104123 .43800354 122.5235977173121 .6092987061120 .3900985718119 .1709976196117 .9517974854 116.4279022217116 .7326965332117 .647102356118 .5614013672119 .4757995605 120.3900985718120 .9997024536121 .6092987061121 .6092987061121 .6092987061 121.6092987061121 .6092987061121 .3044967651120 .9997024536120 .6949005127 120.3900985718120 .0852966309119 .4757995605118 .8662033081118 .2565994263 116.1231002808113 .6848983765112 .1608963013110 .9418029785110 .9418029785 112.7705001831117 .0374984741125 .2667007446137 .7628936768151 .1734008789 163.974395752177 .0802001953192 .624206543210 .6065063477229 .1983947754 245.6567993164257 .8482055664266 .0773925781271 .5635070801276 .1353149414 281.0119018555286 .8027954102292 .8984985352298 .9942016602303 .8707885742 307.8330078125310 .8807983398312 .4047851562313 .3190917969313 .0143127441 312.1000061035310 .2713012695307 .8330078125305 .0899047852301 .7373046875 298.3846130371294 .7272033691291 .0697937012287 .7171936035284 .9740905762 282.8406066895281 .9262084961281 .9262084961282 .5357971191283 .7549133301 284.9740905762286 .4979858398288 .0219116211289 .8505859375291 .3746032715 292.8984985352293 .8128967285294 .7272033691295 .3367919922295 .6416015625 295.6416015625295 .3367919922294 .7272033691293 .8128967285292 .5936889648 291.3746032715289 .5458984375287 .4124145508285 .2789001465283 .1453857422 280.7070922852277 .9641113281275 .2210083008272 .4779052734269 .4301147461 266.3822021484263 .0296020508259 .9816894531256 .6290893555253 .2763977051 249.9237976074246 .2664031982242 .6089935303238 .9515075684235 .2940979004 231.6367034912227 .6744995117223 .7122955322219 .4452972412215 .1782989502 210.9113006592209 .692199707209 .692199707209 .692199707209 .692199707 209.692199707 209.692199707 209.692199707 209.692199707 209.692199707 159.0977935791 152.6972961426 146.2969055176 137.6251678467 126.135307312 -9999 -9999 -9999 -9999 -9999 -9999 -9999 -9999 -9999 -9999 -9999 -9999 -9999 -9999 -9999 -9999 -9999 -9999 -9999 -9999 -9999 -9999 -9999 -9999 -9999-9999 -9999 -9999 -9999 -9999 -9999 -9999 -9999 -9999 -9999 -9999 -9999 -9999 -9999 -9999 -9999 -9999

-9999 -9999 -9999 -9999 -9999 -9999 -9999 -9999 -9999 -9999 -9999 -9999 -9999 -9999 -9999 
-9999 -9999 -9999 -9999 -9999 -9999 -9999 -9999 -9999 -9999 -9999 119.7186965942 120.0991668701119 .7815628052118 .7750167847117 .1298522949114 .9276199341 112.3581542969109 .5972900391106 .9841308594105 .0079574585104 .2456054688 105.0934829712107 .4695053101110 .9040222168114 .8717803955119 .2496871948 123.9530410767128 .7187347412132 .7199249268134 .9663238525135 .2544403076 134.4586181641134 .7149963379154 .2212982178149 .3446960449147 .5160064697 146.6015930176146 .2969055176145 .9920959473145 .9920959473145 .3825073242 143.8585968018141 .1154937744138 .3724975586135 .3246002197132 .5814971924 129.8385009766127 .7050018311125 .8762969971124 .6570968628123 .7427978516 122.8283996582121 .3044967651120 .0852966309119 .1709976196119 .7806015015 122.2188034058126 .1809997559130 .4479980469132 .5814971924131 .9720001221 128.9241027832125 .5715026855122 .5235977173119 .7806015015117 .0374984741 113.9896011353110 .9418029785107 .5891036987104 .8460998535102 .4077987671 100.8839035034100 .274299621699 .96952056885100 .5791015625101 .4934005737 103.0174026489105 .4557037354109 .1130981445113 .6848983765120 .9997024536 124.3523025513128 .9241027832131 .3623962402131 .9720001221131 .6672058105 131.3623962402131 .0576019287131 .6672058105133 .1911010742135 .9342041016 139.5915985107143 .2489929199144 .4682006836145 .6873016357146 .2969055176 146.9064025879147 .5160064697147 .8208007812148 .1255950928147 .8208007812 146.6015930176145 .0776977539142 .6394042969140 .8106994629139 .2868041992 138.9819946289138 .9819946289139 .2868041992140 .2012023926141 .4203033447 143.5538024902146 .2969055176149 .9542999268153 .0021057129155 .7451934814 157.5738983154158 .7929992676159 .7073974609160 .6217956543161 .5361022949 162.4505004883163 .3648071289164 .2792053223165 .1934967041166 .1078948975 167.0222015381168 .241394043169 .4604949951170 .3748931885171 .2891998291 171.8988037109172 .2035980225172 .5084075928172 .5084075928171 .8988037109 171.2891998291170 .3748931885169 .4604949951167 .9365997314166 .7174987793 165.1934967041163 .6696014404162 .1457061768160 .9264984131159 .4026031494 158.4882965088157 .2691040039156 .3547973633155 .4403991699154 .8307952881 154.2212982178153 .6116943359153 .3069000244153 .3069000244153 .6116943359 153.9165039062154 .2212982178154 .2212982178154 .2212982178154 .2212982178 153.9165039062153 .6116943359152 .3925933838151 .4781951904151 .1734008789 151.7830047607153 .0021057129153 .9165039062153 .9165039062153 .3069000244 152.0877990723151 .1734008789149 .9542999268148 .4304046631145 .9920959473 142.3347015381137 .7628936768133 .4958953857128 .9241027832125 .2667007446 121.6092987061118 .8662033081118 .5614013672119 .4757995605120 .0852966309 120.9997024536121 .6092987061122 .2188034058122 .5235977173123 .1332015991 123.7427978516124 .0475006104124 .3523025513124 .6570968628125 .5715026855 125.8762969971125 .8762969971127 .4001998901129 .2288970947128 .9241027832 127.7050018311125 .5715026855124 .9618988037124 .3523025513123 .7427978516 122.5235977173121 .3044967651120 .0852966309118 .5614013672117 .342300415 116.1231002808115 .2088012695116 .1231002808117 .0374984741118 .2565994263 119.4757995605120 .6949005127121 .6092987061122 .2188034058122 .2188034058 122.2188034058121 .9140014648121 .6092987061121 .3044967651121 .3044967651 120.9997024536120 .6949005127120 .0852966309119 .1709976196118 .2565994263 116.4279022217114 .2944030762112 .7705001831111 .551399231111 .551399231 
113.3800964355117 .9517974854126 .7906036377139 .2868041992153 .0021057129 161.5361022949171 .5939941406187 .7476043701209 .0825958252231 .9414978027 251.4476928711264 .8583068848271 .5635070801274 .6113891602277 .3544921875 281.6214904785288 .0219116211294 .7272033691301 .1276855469306 .3091125488 310.5759887695313 .6239013672315 .4526062012316 .3670043945316 .0621948242 315.4526062012313 .6239013672311 .4903869629309 .0520935059306 .0043029785 302.9563903809299 .6037902832296 .5559082031293 .5080871582291 .0697937012 289.2410888672 288.3266906738288.0219116211 288.3266906738 289.2410888672 290.4602050781291 .9841918945293 .2033081055294 .7272033691296 .2510986328 297.4703063965298 .3846130371298 .9942016602299 .6037902832299 .6037902832 299.6037902832298 .9942016602298 .3846130371297 .1654968262295 .6416015625 294.1176147461291 .9841918945289 .8505859375287 .7171936035285 .2789001465 282.5357971191279 .7927856445276 .7449035645274 .0018005371270 .9540100098 267.6012878418264 .5534973145261 .2008972168257 .8482055664254 .4956054688 251.1428985596247 .4855041504244 .1329040527240 .4754943848236 .8179931641 232.8558044434229 .1983947754225 .2362060547221 .2740020752217 .0070037842 212.7400054932209 .692199707209 .692199707209 .692199707209 .692199707 209.692199707 209.692199707 209.692199707209.692199707 209.692199707209.692199707 $155.1356048584148 .7351074219142 .0299072266130 .8614349365117 .9984588623-9999$ -9999 -9999 -9999 -9999 -9999 -9999 -9999 -9999 -9999-9999 -9999 -9999 -9999 -9999 -9999 -9999 -9999 -9999 -9999 -9999 -9999 -9999 -9999 -9999 -9999 -9999 -9999 -9999 -9999 -9999 -9999 -9999-9999 -9999-9999-9999-9999-9999-9999-9999 -9999 -9999 -9999 -9999 -9999 -9999 -9999 -9999 -9999 -9999 -9999 -9999 -9999 -9999 -9999 -9999 -9999 -9999-9999-9999 -9999 -9999 -9999 -9999-9999-9999-9999 127.9364547729 127.5983886719126 .6539154053125 .1585006714123 .1828765869120 .9021987915 118.5121688843116 .3562545776114 .8200531006114 .3057785034115 .0076522827 116.9161529541119 .7960891724123 .3748626709127 .4301071167131 .7278289795 135.8780059814139 .3009490967141 .3986206055142 .3224029541143 .3392486572 147.3716430664154 .2066497803155 .4443206787153 .3069000244153 .0021057129 153.0021057129153 .6116943359154 .5260925293154 .5260925293152 .6972961426 149.6495056152145 .9920959473142 .3347015381139 .2868041992136 .2389984131 133.4958953857131 .6672058105130 .4479980469130 .1432037354129 .533706665 128.3144989014126 .1809997559124 .9618988037124 .9618988037127 .7050018311 132.5814971924138 .6772003174142 .6394042969140 .2012023926135 .3246002197 131.0576019287128 .0097961426125 .2667007446122 .2188034058118 .2565994263 114.5991973877110 .6370010376107 .5891036987105 .4557037354104 .2365036011 103.6268997192103 .9317016602104 .2365036011104 .8460998535105 .7603988647 106.979598999 109.4179000854 113.075302124118.2565994263 124.3523025513 130.7528076172135 .6293945312137 .1533050537137 .1533050537136 .8484954834 136.5437011719136 .8484954834138 .0677032471140 .2012023926142 .6394042969 145.0776977539146 .6015930176147 .2111968994147 .8208007812148 .4304046631 149.0399017334149 .6495056152149 .6495056152149 .3446960449148 .1255950928 146.2969055176143 .8585968018141 .7250976562141 .4203033447142 .3347015381 143.8585968018144 .4682006836145 .9920959473146 .2969055176147 .2111968994 149.9542999268153 .6116943359156 .9642944336159 .4026031494161 .5361022949 163.0599975586163 .974395752164 .8887023926165 .4983062744166 .4127044678 
167.0222015381167 .9365997314168 .5462036133169 .4604949951170 .070098877 170.9844970703171 .8988037109172 .5084075928173 .1179962158173 .4226989746 173.7274932861173 .4226989746173 .1179962158172 .5084075928171 .8988037109 170.6797027588169 .1557006836167 .6318054199166 .1078948975164 .2792053223 162.7552947998161 .2312927246159 .7073974609158 .4882965088157 .2691040039 156.3547973633155 .4403991699154 .5260925293153 .9165039062153 .3069000244 153.0021057129152 .6972961426152 .6972961426153 .0021057129153 .3069000244 153.6116943359153 .6116943359153 .6116943359153 .3069000244153 .6116943359 153.0021057129150 .8686065674149 .0399017334148 .4304046631149 .3446960449 151.7830047607153 .3069000244153 .0021057129151 .4781951904149 .6495056152 148.1255950928146 .6015930176145 .0776977539142 .6394042969138 .6772003174 133.8007049561129 .2288970947124 .9618988037121 .3044967651117 .9517974854 116.4279022217117 .0374984741117 .647102356118 .5614013672119 .4757995605 120.0852966309120 .6949005127120 .9997024536121 .6092987061122 .2188034058 122.2188034058122 .5235977173123 .1332015991124 .0475006104125 .2667007446 125.8762969971125 .2667007446125 .5715026855125 .8762969971124 .9618988037 125.2667007446124 .9618988037124 .3523025513123 .43800354122 .2188034058 120.6949005127119 .1709976196117 .647102356116 .4279022217115 .5136032104 114.2944030762114 .2944030762115 .5136032104117 .0374984741118 .8662033081 120.3900985718121 .9140014648123 .1332015991123 .43800354123 .1332015991 122.5235977173121 .9140014648121 .6092987061121 .3044967651121 .3044967651 120.9997024536120 .3900985718119 .4757995605117 .9517974854116 .4279022217 114.5991973877113 .075302124111 .8561019897111 .551399231113 .075302124 116.4279022217122 .8283996582133 .4958953857151 .4781951904151 .4781951904 160.0122070312177 .6896972656205 .1204071045234 .9893035889258 .7626037598 272.7827148438277 .0497131348276 .7449035645276 .7449035645281 .3167114258 288.6315002441296 .2510986328302 .9563903809308 .7473144531313 .0143127441 316.0621948242317 .8908996582318 .8052062988319 .1099853516318 .1957092285 316.9765014648315 .1477966309312 .7095031738310 .2713012695307 .5281982422 304.7850952148302 .0421142578299 .6037902832297 .4703063965295 .9464111328 295.0320129395294 .7272033691295 .0320129395295 .6416015625296 .5559082031 297.7750854492298 .9942016602300 .2132873535301 .4324951172302 .3468017578 303.2611999512303 .8707885742304 .1755981445303 .8707885742303 .5660095215 302.9563903809301 .7373046875300 .5180969238298 .9942016602297 .1654968262 295.0320129395292 .5936889648290 .1553955078287 .4124145508284 .6693115234 281.6214904785278 .5736083984275 .5257873535272 .1730957031269 .1253051758 265.7726135254262 .4200134277259 .0674133301255 .7147064209252 .3621063232 248.7046966553245 .3520050049241 .6945953369238 .0372009277234 .3798065186 230.7223052979226 .7601013184222 .7978973389218 .8356933594214 .5686950684 210.3016967773209 .692199707209 .692199707209 .692199707209 .692199707 209.692199707209.692199707 209.692199707 209.692199707 209.692199707 $157.5738983154150 .8686065674144 .1634063721135 .0915222168122 .9084091187-9999$ -9999 -9999 -9999 -9999 -9999 -9999 -9999 -9999 -9999 -9999 -9999 -9999 -9999 -9999 -9999 -9999 -9999 -9999 -9999 -9999 -9999 -9999 -9999 -9999-9999 -9999 -9999 -9999 -9999 -9999 -9999 -9999 -9999 -9999 -9999 -9999 -9999 -9999 -9999-9999

-9999 -9999 -9999 -9999 -9999 -9999 -9999 -9999 -9999 -9999 -9999 -9999 -9999 -9999 -9999 
-9999 -9999 -9999 -9999 -9999 -9999 -9999 -9999 -9999 -9999 -9999 -9999 136.9129638672 136.6683349609135 .9078826904134 .6752471924133 .0558013916131 .1971435547 129.3115844727127 .6612319946126 .5705566406126 .2932357788126 .9865570068 128.6430358887131 .169342041134 .3697662354138 .0438079834141 .889541626 145.5624847412148 .6956787109151 .0270690918152 .8223114014154 .9307250977 158.4736480713161 .4124450684163 .3528137207163 .1566314697163 .0725708008 163.4368286133164 .1311950684164 .8887023926166 .4127044678163 .0599975586 159.0977935791154 .8307952881151 .1734008789147 .5160064697144 .4682006836 141.1154937744138 .3724975586137 .4580993652138 .0677032471138 .3724975586 136.2389984131133 .4958953857131 .6672058105131 .0576019287132 .5814971924 136.8484954834144 .1634063721153 .0021057129145 .0776977539139 .2868041992 136.2389984131134 .4102020264132 .2767028809128 .6192932129124 .0475006104 119.1709976196114 .9039993286111 .551399231109 .7226028442108 .8082962036 109.1130981445109 .7226028442110 .0273971558109 .7226028442109 .4179000854 109.4179000854110 .3321990967112 .4656982422116 .7326965332122 .8283996582 131.0576019287139 .2868041992141 .4203033447142 .0299072266142 .0299072266 141.7250976562142 .0299072266142 .9441986084144 .1634063721145 .9920959473 147.2111968994 148.4304046631 149.0399017334149.3446960449149.9542999268 150.5639038086151 .1734008789151 .4781951904151 .4781951904150 .5639038086 148.7351074219146 .2969055176147 .8208007812146 .2969055176148 .7351074219 153.0021057129155 .1356048584155 .7451934814154 .5260925293153 .0021057129 156.3547973633160 .0122070312162 .1457061768164 .2792053223166 .1078948975 167.6318054199168 .241394043168 .8509979248169 .4604949951170 .070098877 170.6797027588171 .2891998291171 .8988037109172 .5084075928173 .1179962158 173.7274932861174 .337097168174 .6419067383174 .9467010498174 .9467010498 174.9467010498174 .6419067383174 .337097168173 .4226989746172 .2035980225 170.9844970703169 .1557006836167 .3269958496165 .4983062744163 .6696014404 161.8408966064160 .3170013428158 .7929992676157 .5738983154156 .6596069336 155.7451934814154 .8307952881153 .9165039062153 .3069000244152 .6972961426 152.3925933838152 .0877990723151 .7830047607152 .3925933838153 .0021057129 153.3069000244153 .3069000244153 .0021057129152 .0877990723152 .3925933838 152.3925933838148 .4304046631145 .3825073242144 .1634063721145 .6873016357 149.0399017334153.3069000244 151.7830047607 149.3446960449 147.2111968994 145.0776977539143 .5538024902142 .0299072266140 .2012023926135 .0198059082 130.1432037354125 .5715026855121 .6092987061117 .9517974854115 .2088012695 114.9039993286115 .5136032104116 .1231002808116 .7326965332117 .647102356 118.2565994263118 .5614013672118 .8662033081119 .1709976196119 .1709976196 119.1709976196119 .4757995605120 .0852966309120 .9997024536122 .5235977173 124.6570968628123 .1332015991122 .2188034058122 .8283996582124 .0475006104 124.6570968628124 .6570968628123 .43800354122 .2188034058120 .6949005127 119.1709976196117 .647102356116 .4279022217115 .5136032104114 .5991973877 113.6848983765112 .4656982422113 .9896011353115 .818397522117 .9517974854 120.0852966309122 .2188034058124 .0475006104124 .9618988037124 .6570968628 123.1332015991121 .6092987061121 .6092987061121 .6092987061121 .6092987061 121.3044967651120 .3900985718119 .4757995605118 .2565994263116 .4279022217 114.9039993286113 .075302124111 .8561019897110 .9418029785111 .24659729 
112.7705001831115 .818397522119 .1709976196118 .8662033081133 .4958953857 146.2969055176162 .7552947998199 .6342926025237 .7324066162266 .9917907715 280.0975036621281 .6214904785278 .2687988281274 .0018005371281 .6214904785 289.8505859375297 .7750854492304 .7850952148310 .2713012695314 .8429870605 317.8908996582320 .0244140625320 .9388122559321 .2434997559320 .9388122559 319.7196044922318 .1957092285316 .3670043945314 .2334899902311 .7951965332 309.6617126465307 .5281982422305 .3947143555303 .8707885742302 .6516113281 301.7373046875301 .4324951172301 .7373046875302 .3468017578303 .2611999512 304.1755981445305 .0899047852306 .3091125488307 .2233886719307 .8330078125 308.4425048828308 .7473144531308 .7473144531308 .4425048828307 .8330078125 306.9186096191305 .6994934082304 .1755981445302 .3468017578300 .2132873535 297.7750854492295 .3367919922292 .5936889648289 .5458984375286 .4979858398 283.4501953125280 .4023132324277 .0497131348273 .6971130371270 .3443908691 266.9917907715263 .6390991211260 .2864990234256 .9338989258253 .5812072754 250.2286071777246 .5711975098243 .2185058594239 .5610961914235 .9037017822 232.246307373228 .5888977051224 .6266021729220 .6643981934216 .3973999023 212.1304016113209 .692199707209 .692199707209 .692199707209 .692199707 209.692199707 209.692199707 209.692199707 209.692199707 209.692199707 209.692199707 $153.3069000244146 .6015930176139 .5915985107127 .3162765503113 .3935928345-9999$ -9999 -9999 -9999 -9999 -9999 -9999 -9999 -9999 -9999 -9999 -9999 -9999 -9999 -9999 -9999 -

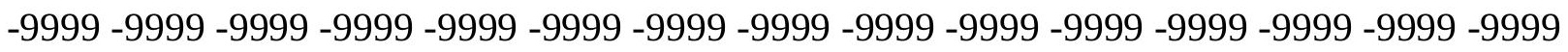
-9999 -9999 -9999 -9999 -9999 -9999 -9999 -9999 -9999

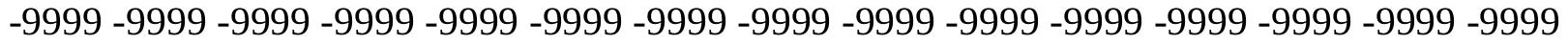
-9999 -9999 -9999 -9999 -9999 -9999 -9999 -9999 -9999 -9999 -9999 -9999 146.9130096436 146.8591461182146 .3640289307145 .4801940918144 .2989196777142 .9576416016 141.6409301758140 .5456542969139 .9070739746139 .9114990234140 .676940918 142.2485961914144 .5408630371147 .4535369873150 .7644958496154 .2422943115 157.6223602295160 .6605529785163 .2443389893165 .5555877686167 .9977874756 170.6570739746172 .8990631104174 .4990997314175 .2984619141175 .7412414551 176.3192901611176 .9816741943177 .51512146177 .155960083174 .6268463135 170.5515289307165 .8031005859161 .5361022949156 .6596069336154 .2212982178 149.6495056152146 .9064025879145 .0776977539145 .0776977539149 .0399017334 144.1634063721142 .0299072266140 .5059967041138 .6772003174138 .0677032471 140.2012023926144 .1634063721146 .2969055176144 .1634063721141 .4203033447 142.0299072266142 .6394042969141 .1154937744136 .5437011719131 .0576019287 125.2667007446120 .3900985718117 .0374984741115 .2088012695115 .2088012695 116.4279022217117 .647102356117 .9517974854116 .7326965332114 .5991973877 112.7705001831112 .1608963013114 .2944030762117 .0374984741120 .6949005127 128.9241027832137 .7628936768143 .5538024902145 .9920959473146 .2969055176 146.2969055176146 .6015930176147 .2111968994148 .1255950928148 .7351074219 149.6495056152150 .2590942383150 .5639038086150 .8686065674151 .4781951904 152.0877990723153 .0021057129153 .6116943359153 .9165039062153 .6116943359 156.3547973633160 .9264984131164 .2792053223164 .5839996338164 .8887023926 168.241394043170 .9844970703168 .241394043166 .4127044678165 .1934967041 167.3269958496167 .3269958496167 .9365997314169 .4604949951171 .2891998291 172.5084075928172 .2035980225171 .8988037109172 .5084075928173 .4226989746 
174.0323028564174 .337097168174 .9467010498175 .5561981201176 .165802002 176.4705963135176 .4705963135176 .7754058838176 .7754058838176 .7754058838 176.4705963135176 .165802002175 .2514038086174 .337097168173 .1179962158 171.2891998291169 .4604949951167 .3269958496165 .1934967041163 .0599975586 161.2312927246159 .4026031494158 .1835021973156 .9642944336156 .0500030518 155.1356048584154 .5260925293153 .6116943359153 .0021057129152 .3925933838 152.0877990723151 .7830047607151 .7830047607152 .0877990723152 .6972961426 153.0021057129153 .0021057129152 .6972961426152 .0877990723150 .8686065674 148.4304046631144 .4682006836140 .5059967041138 .9819946289140 .8106994629 145.3825073242149 .0399017334149 .9542999268148 .1255950928145 .3825073242 143.2489929199141 .4203033447138 .9819946289135 .9342041016131 .6672058105 126.7906036377122 .8283996582119 .1709976196116 .4279022217114 .2944030762 113.3800964355113 .6848983765114 .2944030762114 .9039993286115 .818397522 116.4279022217116 .4279022217116 .1231002808115 .818397522115 .5136032104 115.5136032104115 .818397522115 .818397522116 .4279022217117 .342300415 118.2565994263118 .8662033081120 .0852966309120 .3900985718121 .6092987061 123.43800354122 .8283996582121 .6092987061120 .3900985718118 .5614013672 117.0374984741115 .818397522114 .5991973877113 .9896011353113 .3800964355 112.7705001831112 .1608963013112 .7705001831114 .5991973877116 .7326965332 119.1709976196121 .9140014648124 .3523025513126 .4858016968125 .2667007446 123.7427978516122 .5235977173121 .9140014648121 .6092987061121 .9140014648 121.3044967651120 .3900985718119 .4757995605118 .2565994263116 .7326965332 115.2088012695113 .3800964355111 .551399231110 .0273971558109 .1130981445 108.5035018921108 .1986999512108 .1986999512110 .3321990967120 .0852966309 135.3246002197158 .4882965088192 .9290008545234 .0749969482273 .6971130371 280.0975036621281 .3167114258280 .0975036621280 .0975036621284 .6693115234 291.6794128418298 .9942016602305 .6994934082311 .4903869629315 .7573852539 319.1099853516321 .2434997559322 .4627075195322 .7674865723322 .7674865723 321.8530883789320 .9388122559319 .4147949219317 .8908996582316 .0621948242 314.2334899902312 .7095031738311 .1856079102309 .9664916992309 .3569030762 308.7473144531308 .7473144531308 .7473144531309 .3569030762309 .9664916992 310.8807983398311 .7951965332312 .4047851562313 .3190917969313 .6239013672 314.2334899902314 .2334899902313 .9287109375313 .3190917969312 .4047851562 311.1856079102309 .6617126465307 .8330078125305 .6994934082303 .5660095215 300.8229064941298 .0798950195295 .0320129395291 .9841918945288 .6315002441 285.5835876465282 .2309875488278 .5736083984275 .2210083008271 .8682861328 268.5156860352264 .8583068848261 .5056152344258 .1530151367254 .8003997803 251.4476928711247 .7902984619244 .4376983643241 .0850067139237 .4275970459 233.7702026367230 .1127929688226 .4553985596222 .4931030273218 .5308990479 214.2639007568209 .9969024658209 .692199707209 .692199707209 .692199707 209.692199707 209.692199707209.692199707 209.692199707 209.692199707 209.692199707 $155.7451934814149 .0399017334142 .0299072266130 .7500152588117 .6362380981-9999$ -9999 -9999 -9999 -9999 -9999 -9999 -9999 -9999 -9999 -9999 -9999 -9999 -9999 -9999 -9999

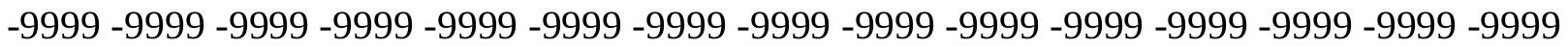
-9999 -9999 -9999 -9999 -9999 -9999 -9999 -9999 -9999

-9999 -9999 -9999 -9999 -9999 -9999 -9999 -9999 -9999 -9999 -9999 -9999 -9999 -9999 -9999 
-9999 -9999 -9999 -9999 -9999 -9999 -9999 -9999 -9999 -9999 -9999 -9999 157.8000335693 158.0213928223157 .8735656738157 .4124145508156 .7262115479155 .9380645752 155.2001953125154 .6632385254154 .4902801514154 .8180236816155 .7568206787 157.3391571045159 .5233001709162 .2158660889165 .2679901123168 .4880218506 171.6895751953174 .6857910156177 .4243621826179 .9720001221182 .4521789551 184.757232666186 .7845001221188 .338760376189 .4926757812190 .3209228516 190.9934387207191 .4406433105191 .4190368652190 .2923126221187 .8413085938 184.033203125179 .4922943115174 .7275085449170 .0707702637165 .7182006836 161.2312927246159 .0977935791156 .9642944336151 .7830047607150 .5639038086 150.8686065674153 .0021057129151 .5727386475150 .0631408691149 .4247589111 150.198638916151 .7910308838152 .4410095215152 .2897491455151 .8187713623 152.3048706055152 .6972961426152 .0877990723145 .6873016357139 .2868041992 132.5814971924127 .4001998901123 .7427978516122 .5235977173122 .8283996582 124.6570968628127 .7050018311128 .0097961426125 .5715026855120 .9997024536 117.647102356116 .1231002808117 .342300415119 .7806015015121 .3044967651 126.7906036377137 .4580993652146 .2969055176149 .6495056152149 .9542999268 149.6495056152150 .2590942383151 .1734008789151 .4781951904151 .7830047607 152.0877990723152 .0877990723152 .3925933838152 .3925933838153 .0021057129 153.6116943359154 .8307952881156 .0500030518156 .9642944336160 .6217956543 166.7174987793170 .3748931885172 .8132019043174 .9467010498176 .7754058838 178.4231262207 179.9008636475 179.2663879395 177.5393371582 176.0453643799 175.0903778076174 .3372802734174 .2240447998174 .9619140625176 .165802002 177.6896972656174 .337097168174 .0323028564175 .5561981201177 .0802001953 176.7754058838177 .0802001953177 .9945068359178 .9089050293178 .9089050293 178.9089050293178 .604095459178 .604095459178 .2993011475178 .2993011475 178.2993011475177 .6896972656176 .7754058838175 .5561981201174 .0323028564 172.2035980225170 .070098877167 .6318054199165 .1934967041162 .7552947998 160.6217956543158 .7929992676157 .5738983154156 .6596069336155 .7451934814 155.1356048584154 .2212982178153 .3069000244152 .6972961426152 .0877990723 151.7830047607151 .4781951904151 .7830047607152 .0877990723152 .3925933838 152.6972961426152 .6972961426152 .3925933838151 .7830047607149 .0399017334 145.3825073242140 .8106994629135 .6293945312133 .4958953857135 .3246002197 142.3347015381148 .1255950928150 .5639038086148 .4304046631145 .3825073242 143.5538024902141 .4203033447138 .3724975586134 .1054992676129 .533706665 125.2667007446121 .9140014648119 .1709976196117 .342300415115 .818397522 114.2944030762113 .075302124112 .4656982422112 .4656982422113 .3800964355 114.5991973877114 .2944030762113 .3800964355112 .4656982422111 .8561019897 111.551399231110 .9418029785112 .1608963013113 .3800964355114 .9039993286 116.1231002808117 .342300415118 .5614013672118 .5614013672118 .2565994263 119.4757995605119 .7806015015118 .8662033081117 .647102356115 .818397522 114.5991973877113 .3800964355112 .4656982422112 .1608963013111 .8561019897 111.8561019897111 .551399231111 .551399231113 .3800964355115 .818397522 118.2565994263120 .6949005127123 .1332015991124 .6570968628124 .6570968628 123.7427978516122 .5235977173121 .9140014648121 .6092987061120 .9997024536 120.9997024536120 .6949005127120 .0852966309118 .8662033081117 .342300415 115.5136032104113 .6848983765111 .551399231109 .4179000854107 .2844009399 
106.3700027466106.979598999 107.5891036987111.24659729 112.1608963013 126.7906036377149 .9542999268181 .3471984863217 .3117980957248 .3999023438 265.4678039551274 .0018005371278 .5736083984281 .9262084961286 .4979858398 292.5936889648299 .6037902832306 .0043029785311 .4903869629315 .7573852539 319.1099853516321 .2434997559322 .7674865723323 .3770141602323 .6817932129 323.3770141602322 .7674865723321 .8530883789320 .9388122559319 .7196044922 318.5004882812317 .5860900879316 .6718139648316 .0621948242315 .7573852539 315.7573852539315 .7573852539316 .0621948242316 .3670043945316 .9765014648 317.8908996582318 .5004882812319 .1099853516319 .4147949219319 .7196044922 320.0244140625319 .7196044922319 .1099853516318 .1957092285317 .2813110352 315.7573852539313 .9287109375311 .7951965332309 .3569030762306 .9186096191 303.8707885742300 .8229064941297 .7750854492294 .4223937988291 .0697937012 287.4124145508283 .7549133301280 .4023132324276 .7449035645273 .0874938965 269.7348022461266 .0773925781262 .7247924805259 .3721008301256 .0195007324 252.6669006348249 .0093994141245 .6567993164242 .3041992188238 .9515075684 235.2940979004231 .6367034912227 .9792938232224 .3218994141220 .3596038818 216.3973999023212 .1304016113209 .692199707209 .692199707209 .692199707 209.692199707 209.692199707 209.692199707209.692199707 209.692199707209.692199707 209.692199707 151.4781951904 144.4682006836133.8615570068122.0181045532 108.157699585 -9999 -9999 -9999 -9999 -9999 -9999 -9999 -9999 -9999 -9999 -9999 -9999 -9999 -9999 -9999 -9999 -9999 -9999 -9999 -9999 -9999 -9999 -9999 -9999 -9999 -9999 -9999 -9999 -9999 -9999 -9999 -9999 -9999 -9999 -9999 -9999 -9999 -9999 -9999 -9999 -9999 -9999 -9999 -9999 -9999 -9999 -9999 -9999 -9999 -9999 -9999 -9999 -9999 -9999 -9999 -9999 -9999 -9999 -9999 -9999 -9999 -9999 -9999 -9999 -9999 -9999 169.4339599609 169.9878692627170 .2392272949170 .2407684326170 .0731964111169 .8415679932 169.66796875169 .6782531738169 .9798278809170 .6856689453171 .8687591553 173.5668029785175 .7261199951178 .3014221191181 .1873168945184 .2395782471 187.3172912598 190.2992095947 193.1077270508 195.7573547363198.2217254639 200.4703674316202 .4460144043204 .0782470703205 .3992156982206 .4007110596 207.0729064941207 .3168029785206 .9010772705205 .5319519043203 .100692749 199.5940856934195 .307723999190 .5813140869185 .8231658936181 .0875396729 176.9007873535173 .3484954834169 .7109985352165 .9013366699163 .6679229736 163.9370422363164 .9497070312165 .1100769043164 .6798248291164 .4841156006 164.8810119629165 .5886688232166 .0856628418166 .308303833166 .3883666992 166.34425354165 .6237030029162 .8928833008157 .1633453369149 .6495056152 140.8106994629135 .6293945312133 .1911010742132 .2767028809130 .7528076172 132.2767028809137 .1533050537140 .2012023926132 .8863067627127 .0953979492 124.3523025513122 .5235977173124 .2972717285125 .5527572632125 .3481826782 124.6570968628141 .1154937744151 .4781951904152 .0877990723151 .7830047607 152.0877990723152 .6972961426153 .6116943359153 .9165039062154 .2212982178 154.2212982178154 .2212982178154 .2212982178154 .2212982178154 .5260925293 155.1356048584156 .6596069336158 .1835021973160 .0122070312161 .5361022949 167.6318054199171 .5939941406173 .7274932861178 .2993011475182 .261505127 184.3950042725186 .8332977295187 .683807373186 .6352233887184 .1651611328 181.4266204834179 .7476043701179 .2873840332179 .9156341553180 .9138793945 181.0815124512179 .8238830566179 .2949523926180 .7601165771183 .4806976318 
177.9945068359180 .432800293181 .6519012451181 .9566955566181 .3471984863 180.7375946045180 .432800293180 .1280059814180 .1280059814180 .1280059814 180.1280059814179 .5184020996178 .604095459177 .0802001953175 .5561981201 173.4226989746170 .9844970703168 .5462036133165 .4983062744162 .7552947998 160.3170013428158 .4882965088157 .2691040039156 .6596069336156 .0500030518 155.1356048584154 .2212982178153 .0021057129152 .0877990723151 .4781951904 151.1734008789151 .1734008789151 .7830047607152 .0877990723152 .3925933838 152.3925933838151 .7830047607151 .1734008789149 .9542999268147 .5160064697 144.1634063721139 .5915985107133 .4958953857129 .8385009766132 .2767028809 142.0299072266155 .4403991699156 .6596069336150 .8686065674148 .4304046631 148.4304046631146 .2969055176141 .7250976562136 .2389984131131 .3623962402 127.7050018311124 .6570968628122 .8283996582122 .2188034058121 .9140014648 120.9997024536118 .8662033081118 .2565994263119 .1709976196121 .3044967651 121.9140014648120 .0852966309117 .342300415114 .9039993286113 .9896011353 114.2944030762114 .9039993286115 .5136032104115 .818397522116 .1231002808 116.4279022217117 .342300415117 .9517974854117 .9517974854117 .342300415 116.1231002808116 .1231002808115 .5136032104114 .2944030762112 .7705001831 111.551399231110 .6370010376110 .3321990967110 .3321990967110 .6370010376 110.9418029785110 .9418029785110 .9418029785112 .7705001831114 .5991973877 117.0374984741119 .4757995605121 .6092987061122 .8283996582123 .1332015991 122.8283996582122 .2188034058121 .6092987061121 .3044967651121 .3044967651 121.3044967651120 .9997024536120 .3900985718119 .4757995605117 .9517974854 116.1231002808113 .9896011353111 .551399231108 .8082962036106 .0652008057 105.4557037354106 .3700027466106 .979598999107 .8938980103110 .0273971558 119.4757995605136 .8484954834163 .0599975586192 .624206543219 .7501068115 241.3898010254257 .8482055664270 .9540100098277 .3544921875283 .7549133301 291.0697937012298 .0798950195304 .4802856445309 .9664916992314 .2334899902 317.5860900879320 .0244140625321 .8530883789323 .0722045898323 .6817932129 323.9866027832323 .6817932129323 .3770141602323 .0722045898322 .7674865723 322.4627075195322 .1578979492322 .1578979492322 .1578979492322 .1578979492 322.4627075195322 .7674865723323 .0722045898323 .6817932129324 .2914123535 324.9009094238325 .5104980469325 .8153076172326 .1200866699326 .1200866699 325.8153076172325 .5104980469324 .5961914062323 .3770141602322 .1578979492 320.3291931152318 .1957092285315 .7573852539313 .0143127441310 .2713012695 307.2233886719303 .8707885742300 .2132873535296 .8606872559293 .2033081055 289.2410888672 285.5835876465281.9262084961 278.2687988281274.6113891602 270.9540100098267 .2966003418263 .9439086914260 .5913085938256 .9338989258 253.5812072754250 .5334014893247 .1806945801243 .8280944824240 .4754943848 236.8179931641233 .4653930664229 .8079986572226 .150604248222 .4931030273 218.5308990479214 .2639007568209 .9969024658209 .692199707209 .692199707 209.692199707 209.692199707 209.692199707 209.692199707 209.692199707 209.692199707 209.692199707 154.2212982178 146.9064025879 139.5915985107 126.7194976807 112.9774093628 -9999 -9999 -9999 -9999 -9999 -9999 -9999 -9999 -9999 -9999 -9999 -9999 -9999 -9999 -9999 -9999 -9999 -9999 -9999 -9999 -9999 -9999 -9999 -9999 -9999 -9999 -9999 -9999 -9999 -9999 -9999 -9999 -9999 -9999 -9999 -9999 -9999 -9999 -9999 -9999 -9999 -9999 -9999 -9999 -9999 -9999 -9999 -9999 -9999 -9999 -9999 -9999 -9999 -9999 
-9999 -9999 -9999 -9999 -9999 -9999 -9999 -9999 -9999 -9999 -9999 -9999 181.6714630127 182.591583252183 .2702026367183 .7486572266184 .1020050049184 .4157409668 184.7860870361185 .3106384277186 .0850219727187 .172088623188 .6432189941 190.5005645752192 .7397155762195 .3067626953198 .1229400635201 .0873718262 204.0976715088207 .0689697266209 .9228668213212 .6265106201215 .1298522949 217.4107208252219 .4247131348221 .162612915222 .5891265869223 .6631317139 224.3134155273224 .4352111816223 .8735961914222 .4904632568220 .1777496338 216.958114624212 .9899291992208 .5195465088203 .8475494385199 .1815185547 194.8106536865190 .6784820557186 .7448730469183 .4496154785181 .2905731201 180.7776184082181 .0858306885181 .5824737549181 .8920135498182 .2638092041 182.8170166016183 .4191436768183 .8695220947184 .0045166016183 .7636566162 182.9063568115180 .9223632812176 .9080200195170 .6052093506162 .2194671631 152.9555206299144 .4682006836149 .6495056152144 .7729034424139 .8963928223 136.5437011719139 .2868041992154 .5260925293132 .2767028809131 .0744171143 132.0633544922133 .642074585135 .2139587402135 .5433959961135 .6225280762 139.5915985107144 .1634063721150 .8686065674153 .0021057129152 .3925933838 153.9165039062154 .8307952881155 .7451934814156 .0500030518156 .0500030518 156.0500030518156 .0500030518155 .7451934814155 .7451934814156 .0500030518 156.3547973633158 .4882965088160 .6217956543162 .7552947998165 .1934967041 167.9365997314170 .9844970703175 .2514038086180 .432800293185 .3094024658 189.5764007568192 .0146026611193 .8433074951193 .8433074951189 .2716064453 185.2160339355182 .8509216309182 .5106811523183 .7183837891185 .2244873047 185.6566009521184 .9527435303183 .8976898193183 .5593566895183 .2016448975 182.2906341553 183.6477966309 186.2236938477 184.3950042725 183.4806976318 182.5662994385181 .6519012451181 .0424041748181 .0424041748181 .6519012451 181.9566955566181 .6519012451180 .432800293179 .2136993408177 .3849029541 175.2514038086172 .8132019043169 .7653045654166 .7174987793163 .3648071289 160.6217956543158 .4882965088157 .2691040039156 .9642944336156 .6596069336 156.0500030518154 .5260925293153 .0021057129151 .4781951904150 .5639038086 150.2590942383150 .5639038086151 .4781951904152 .3925933838152 .3925933838 152.0877990723151 .1734008789149 .6495056152148 .4304046631146 .6015930176 144.7729034424142 .6394042969138 .6772003174130 .7528076172139 .2868041992 142.0299072266177 .9945068359168 .241394043153 .9165039062157 .5738983154 160.0122070312158 .7929992676151 .4781951904143 .2489929199138 .6772003174 136.2389984131133 .8007049561131 .6672058105132 .8863067627134 .4102020264 134.1054992676130 .7528076172128 .0097961426131 .0576019287135 .6293945312 136.5437011719132 .5814971924126 .4858016968123 .1332015991121 .9140014648 121.9140014648122 .2188034058121 .9140014648120 .6949005127119 .1709976196 118.5614013672118 .5614013672118 .8662033081118 .5614013672117 .647102356 115.818397522113 .9896011353112 .4656982422110 .9418029785110 .0273971558 109.4179000854108 .8082962036108 .8082962036108 .8082962036109 .1130981445 110.3321990967110 .0273971558110 .9418029785112 .4656982422113 .9896011353 116.1231002808118 .2565994263120 .0852966309121 .3044967651121 .6092987061 121.9140014648121 .6092987061121 .3044967651121 .3044967651121 .3044967651 121.9140014648121 .6092987061120 .9997024536120 .0852966309118 .8662033081 117.0374984741114 .9039993286112 .1608963013109 .1130981445105 .7603988647 
104.5412979126105 .4557037354106 .3700027466107 .2844009399107 .8938980103 115.2088012695128 .3144989014143 .5538024902167 .0222015381190 .795501709 214.5686950684235 .5989074707252 .6669006348265 .4678039551276 .1353149414 285.5835876465293 .5080871582300 .5180969238306 .3091125488310 .8807983398 314.5382080078317 .5860900879319 .7196044922321 .2434997559322 .4627075195 323.0722045898323 .6817932129324 .2914123535324 .5961914062325 .2056884766 325.8153076172326 .4248962402327 .0344848633327 .6440124512328 .2536010742 329.1679077148329 .7774963379330 .3870849609330 .9966125488331 .6062011719 331.9110107422332 .2157897949332 .5205993652332 .5205993652332 .2157897949 331.9110107422330 .9966125488330 .0823059082328 .5584106445327 .0344848633 324.9009094238322 .4627075195319 .7196044922316 .9765014648313 .6239013672 310.2713012695306 .6138000488302 .9563903809299 .2990112305295 .3367919922 291.3746032715287 .4124145508283 .4501953125279 .4880065918275 .8305053711 272.1730957031268 .5156860352264 .8583068848261 .5056152344258 .1530151367 254.8003997803251 .4476928711248 .3999023438245 .0471954346241 .6945953369 238.6468048096235 .2940979004231 .6367034912228 .2841033936224 .3218994141 220.6643981934216 .7021942139212 .4351959229209 .692199707209 .692199707 209.692199707209 .692199707209 .692199707209 .692199707209 .692199707209 .692199707 209.692199707 209.692199707 149.6495056152142.3347015381 130.8364868164 118.198387146103 .7221984863 -9999 -9999 -9999 -9999 -9999 -9999 -9999 -9999 -9999 -9999 -9999 -9999 -9999 -9999 -9999 -9999 -9999 -9999 -9999 -9999 -9999 -9999 -9999 -9999 -9999 -9999 -9999 -9999 -9999 -9999 -9999 -9999 -9999 -9999 -9999 -9999 -9999 -9999 -9999 -9999 -9999 -9999 -9999 -9999 -9999 -9999 -9999 -9999 -9999 -9999 -9999 -9999 -9999 -9999 -9999 -9999 -9999 -9999 -9999 -9999 -9999 -9999 -9999 -9999 -9999 -9999 195.6792144775196 .7882385254197 .7456665039198 .6086273193199 .447052002 200.3372497559201.355178833202.5715179443204.0425872803205.8087463379 207.8832855225210 .2555389404212 .8851623535215 .7128601074218 .6642303467 221.6628570557224 .6398773193227 .532623291230 .290725708232 .8690490723 235.2291870117237 .3358154297239 .163772583240 .6661224365241 .7890472412 242.4489898682242 .5545501709242 .0194854736240 .7318572998238 .6320800781 235.7337799072232 .1271057129228 .0353393555223 .6594543457219 .2061309814 214.832321167210 .631729126206 .7730102539203 .5858154297201 .3914489746 200.3287963867 200.1716918945200.5502166748 201.1751403809 201.94921875 202.789932251203 .5180664062203 .9042663574203 .7405548096202 .8821105957 201.1678161621198 .2580566406193 .5377655029186 .6667938232177 .7878112793 169.314666748167 .7778625488178 .9089050293161 .8408966064151 .4781951904 142.3347015381131 .6672058105140 .9210510254139 .4909667969138 .084197998 140.73878479145 .486541748149 .0388031006148 .46875146 .2969055176146 .9064025879 149.3446960449152 .6972961426154 .5260925293155 .4403991699156 .0500030518 156.9642944336157 .5738983154157 .878692627157 .878692627157 .878692627 157.5738983154157 .5738983154157 .2691040039157 .5738983154158 .4882965088 160.3170013428162 .4505004883165 .1934967041168 .241394043171 .2891998291 174.9467010498179 .2136993408183 .7854003906188 .3571929932192 .3193969727 195.3672943115198 .4151000977197 .1959991455190 .795501709185 .9848632812 183.0658874512183 .389251709186 .2048950195189 .2135925293190 .4521636963 189.324432373 186.7410888672 184.3386077881 182.8189544678 183.2783355713 
184.9481658936186 .9838409424186 .9262390137184 .699798584184 .0901947021 182.5662994385181 .3471984863181 .3471984863182 .87109375183 .7854003906 183.4806976318182 .5662994385181 .3471984863179 .5184020996177 .3849029541 174.9467010498172 .2035980225168 .5462036133164 .5839996338160 .9264984131 158.4882965088157 .5738983154157 .5738983154158 .1835021973157 .5738983154 155.7451934814153 .0021057129150 .5639038086149 .0399017334149 .0399017334 149.9542999268151 .1734008789152 .3925933838152 .3925933838151 .7830047607 150.8686065674149 .3446960449147 .5160064697145 .9920959473145 .0776977539 146.2969055176151 .1734008789150 .2590942383166 .1078948975170 .6797027588 180.1280059814181 .0424041748176 .165802002175 .2514038086177 .3849029541 179.5184020996169 .1557006836162 .4505004883158 .4882965088154 .8307952881 152.3925933838148 .1255950928152 .0877990723154 .8307952881156 .3547973633 153.3069000244142 .0299072266150 .5639038086157 .5738983154158 .7929992676 151.1734008789138 .9819946289136 .5437011719134 .4102020264134 .1054992676 135.0198059082134 .1054992676129 .533706665125 .2667007446122 .8283996582 122.5235977173122 .8283996582121 .6092987061119 .7806015015117 .342300415 115.2088012695113 .6848983765112 .7705001831111 .8561019897111 .551399231 111.551399231111 .8561019897111 .8561019897111 .8561019897111 .551399231 111.24659729111 .551399231112 .7705001831113 .9896011353115 .818397522 117.647102356119 .1709976196120 .0852966309120 .6949005127120 .6949005127 120.6949005127120 .6949005127120 .9997024536121 .3044967651121 .6092987061 121.6092987061121 .6092987061120 .9997024536119 .7806015015118 .2565994263 116.1231002808113 .3800964355110 .0273971558106 .3700027466103 .6268997192 104.5412979126105 .4557037354106 .3700027466107 .2844009399108 .1986999512 123.1332015991135 .3246002197149 .0399017334170 .070098877194 .1481018066 212.1304016113232 .246307373249 .3141937256263 .6390991211276 .4400939941 285.5835876465293 .5080871582300 .2132873535305 .6994934082309 .9664916992 313.3190917969315 .7573852539317 .8908996582319 .4147949219320 .9388122559 322.1578979492323 .6817932129325 .2056884766326 .7296142578328 .2536010742 330.0823059082331 .6062011719332 .8252868652334 .3493041992335 .2636108398 336.4827880859337 .3970947266338 .0067138672338 .6163024902338 .9211120605 339.2258911133339 .2258911133339 .2258911133338 .6163024902338 .0067138672 336.7875976562335 .5683898926334 .0444946289331 .9110107422329 .4726867676 326.7296142578323 .9866027832320 .6339111328317 .2813110352313 .3190917969 309.6617126465305 .6994934082301 .4324951172297 .4703063965293 .2033081055 288.9363098145284 .9740905762281 .0119018555277 .0497131348273 .0874938965 269.4301147461266.0773925781262.4200134277259.3721008301256.0195007324 252.6669006348249 .6190032959246 .5711975098243 .2185058594240 .1707000732 236.8179931641233 .4653930664230 .1127929688226 .4553985596222 .7978973389 219.1405029297214 .8735046387210 .6065063477209 .692199707209 .692199707 209.692199707 209.692199707 209.692199707 209.692199707 209.692199707 209.692199707 209.692199707 152.3925933838 145.0776977539 137.1533050537123.4921340942 109.0144195557 -9999 -9999 -9999 -9999 -9999 -9999 -9999 -9999 -9999 -9999 -9999 -9999 -9999 -9999 -9999 -9999 -9999 -9999 -9999 -9999 -9999 -9999 -9999 -9999 -9999 -9999 -9999 -9999 -9999 -9999 -9999 -9999 -9999 -9999 -9999 -9999 -9999 -9999

-9999 -9999 -9999 -9999 -9999 -9999 -9999 -9999 -9999 -9999 -9999 -9999 -9999 -9999 -9999 
-9999 -9999 -9999 -9999 -9999 -9999 -9999 -9999 -9999 -9999 -9999 -9999 -9999 209.1066131592210 .6415252686212 .0604858398213 .4100036621214 .7455749512 216.1266021729217 .611618042219 .2548217773221 .0987091064223 .173324585 225.4873504639228 .0317230225230 .7752838135233 .6737823486236 .671081543 239.7082366943242 .7268371582245 .6720428467248 .4938201904251 .1496124268 253.5940246582255 .7899780273257 .6951293945259 .2659301758260 .4457702637 261.1669921875261 .3443603516260 .9129333496259 .8005065918257 .9642333984 255.4065551758252 .2519683838248 .6364440918244 .7077026367240 .6156311035 236.4857635498232 .4559631348228 .7199859619225 .5261535645223 .1210784912 221.6176757812220 .9945068359221 .0864257812221 .7075958252222 .6659088135 223.73878479224 .6194915771224 .9363098145224 .3783874512222 .7793273926 220.1722259521216 .6421661377211 .7416534424204 .8119659424196 .2415161133 187.5888519287180 .1280059814178 .9089050293166 .7174987793160 .2949981689 151.1233062744143 .7138366699142 .0633850098143 .5090026855144 .7706604004 148.8851470947155 .8235931396163 .3648071289160 .0122070312154 .5260925293 153.3069000244154 .2212982178156 .0500030518157 .2691040039158 .1835021973 158.7929992676159 .4026031494159 .7073974609159 .7073974609159 .7073974609 159.4026031494159 .0977935791158 .7929992676158 .7929992676159 .4026031494 160.3170013428162 .1457061768164 .2792053223167 .0222015381170 .070098877 173.4226989746176 .7754058838180 .7375946045184 .3950042725188 .3571929932 192.0146026611195 .3672943115199 .9389953613198 .7198944092190 .795501709 183.3142700195179 .7868499756181 .5550231934187 .3186340332192 .8213043213 194.6811523438192 .8590698242188 .2579040527183 .3053741455181 .3587188721 182.2878875732184 .4394836426186 .8833618164189 .2716064453186 .8332977295 185.3094024658183 .1759033203179 .5184020996180 .1280059814183 .7854003906 185.3094024658185 .0045928955184 .699798584183 .4806976318181 .9566955566 179.8231964111177 .9945068359175 .5561981201171 .8988037109167 .0222015381 161.8408966064158 .4882965088157 .878692627159 .4026031494160 .9264984131 160.6217956543158 .1835021973153 .6116943359149 .9542999268147 .8208007812 148.1255950928149 .0399017334150 .5639038086151 .7830047607152 .3925933838 151.7830047607150 .8686065674149 .0399017334147 .2111968994145 .3825073242 144.4682006836145 .9920959473158 .7929992676169 .1557006836179 .2136993408 191.1002960205190 .1858978271196 .2816009521196 .891204834196 .891204834 199.0247039795196 .891204834196 .5863952637197 .1959991455193 .8433074951 186.2236938477181 .6519012451187 .7476043701178 .9089050293179 .2136993408 183.1759033203189 .8811035156179 .8231964111178 .604095459182 .87109375 186.8332977295174 .337097168163 .0599975586156 .6596069336153 .6116943359 150.5639038086156 .3547973633153 .0021057129143 .5538024902134 .4102020264 131.0576019287131 .3623962402131 .0576019287129 .2288970947124 .9618988037 121.3044967651118 .5614013672117 .647102356116 .7326965332116 .1231002808 115.818397522116 .1231002808116 .7326965332116 .7326965332116 .1231002808 114.9039993286113 .3800964355113 .075302124113 .6848983765114 .9039993286 116.1231002808117 .647102356118 .8662033081119 .4757995605120 .0852966309 120.0852966309120 .0852966309120 .0852966309120 .3900985718120 .6949005127 120.9997024536121 .6092987061121 .9140014648121 .3044967651120 .6949005127 119.4757995605117 .342300415114 .9039993286111 .551399231107 .8938980103 
103.6268997192103 .3221969604104 .5412979126105 .4557037354106 .3700027466 107.2844009399120 .6949005127124 .6570968628130 .4479980469152 .6972961426 173.4226989746190 .4907073975211 .520904541230 .7223052979247 .7902984619 262.1152038574274 .3066101074283 .7549133301291 .6794128418298 .0798950195 302.9563903809306 .9186096191309 .9664916992312 .7095031738314 .8429870605 316.9765014648319 .4147949219321 .8530883789324 .5961914062327 .3392028809 330.0823059082332 .8252868652335 .5683898926337 .7019042969339 .8353881836 341.3593139648342 .8833007812344 .1023864746345 .0168151855345 .3215026855 345.9310913086345 .9310913086345 .9310913086345 .6263122559344 .7120056152 343.7976074219342 .5784912109341 .0545959473338 .9211120605336 .7875976562 334.0444946289330 .9966125488327 .9487915039324 .2914123535320 .6339111328 316.6718139648312 .4047851562308 .1377868652303 .8707885742299 .2990112305 295.0320129395290 .7650146484286 .4979858398282 .2309875488278 .2687988281 274.3066101074270 .6492004395266 .9917907715263 .6390991211260 .2864990234 256.9338989258253 .8860015869250 .8381958008247 .7902984619244 .7424926758 241.6945953369238 .6468048096235 .5989074707232 .246307373228 .8936004639 225.2362060547221 .2740020752217 .6165924072213 .3495941162208 .7778015137 209.692199707209 .692199707209 .692199707209 .692199707209 .692199707209 .692199707 209.692199707 209.692199707209.692199707 147.8208007812140 .2012023926 128.0280609131 114.5829467773 99.23876190186 -9999 -9999 -9999 -9999 -9999 -9999 -9999

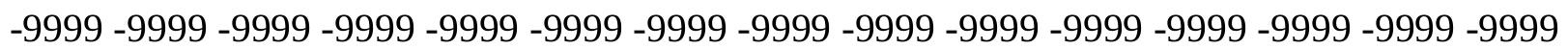
-9999 -9999 -9999 -9999 -9999 -9999 -9999 -9999 -9999 -9999 -9999 -9999 -9999 -9999 -9999 -9999 -9999 -9999 -9999 -9999 -9999 -9999 -9999 -9999 -9999 -9999 -9999 -9999 -9999 -9999 -9999 -9999 -9999 -9999 -9999 -9999 -9999 -9999 -9999 -9999 -9999 -9999 -9999 222.7477111816224 .6914367676226 .5482788086228 .3553466797230 .1558532715 231.9954986572233 .9188842773235 .9668426514238 .1708831787240 .5524749756 243.1170654297245 .8566131592248 .7469940186251 .7539978027254 .8339385986 257.939453125261 .0213623047264 .0309448242266 .9220581055269 .6495056152 272.1712646484274 .4432678223276 .4228515625278 .0623474121279 .306427002 280.1024475098280 .3780822754280 .0854797363279 .1863708496277 .6211547852 275.4754943848272 .8258361816269 .7663879395266 .3982543945262 .8134155273 259.0972595215255 .3559570312251 .7418365479248 .4593658447245 .724899292 243.7124786377242 .5210571289242 .15184021242 .5230102539243 .4565124512 244.6605987549245 .7051544189246 .0234375245 .0802612305242 .6636352539 238.920791626234 .5380706787230 .1127929688223 .1027069092214 .2639007568 205.425201416198 .7198944092190 .5426483154182 .766418457174 .200378418 164.9932861328156 .5791931152151 .2680053711150 .4624023438152 .1026916504 156.0500030518162 .7552947998166 .4127044678164 .8887023926161 .8408966064 159.7073974609159 .4026031494160 .0122070312160 .6217956543161 .2312927246 161.5361022949161 .5361022949161 .5361022949161 .5361022949160 .9264984131 160.6217956543160 .3170013428160 .0122070312160 .3170013428160 .9264984131 161.8408966064163 .3648071289165 .4983062744167 .9365997314170 .9844970703 174.0323028564177 .0802001953180 .1280059814183 .1759033203185 .6141052246 187.4429016113189 .8811035156187 .8593597412186 .2921142578182 .8503112793 178.0955200195174 .337097168177 .6896972656187 .1381072998195 .3672943115 196.5863952637194 .7577056885188 .966796875180 .432800293179 .5184020996 
181.3305206299 183.5298156738185.3094024658 187.4429016113187.1381072998 185.2751159668183 .0246582031181 .1454620361181 .4180755615183 .365524292 184.783203125184 .699798584185 .9188995361186 .528503418184 .0901947021 181.9566955566181 .0424041748179 .8231964111176 .4705963135170 .6797027588 163.6696014404158 .4882965088158 .7929992676162 .1457061768165 .4983062744 166.4127044678163 .0599975586156 .0500030518149 .6495056152147 .5160064697 148.1255950928149 .3446960449150 .2590942383151 .1734008789151 .7830047607 151.7830047607151 .1734008789149 .6495056152147 .2111968994144 .7729034424 142.6394042969142 .3347015381156 .9642944336174 .0323028564193 .5386047363 202.1905517578207 .8440093994212 .1938934326215 .0875549316216 .7846679688 218.0867462158218 .4226074219219 .2080078125219 .3147888184217 .7226104736 216.7524719238220 .6643981934213 .3495941162212 .4351959229210 .6065063477 209.692199707 213.0447998047210.9113006592 206.9490966797 205.1204071045 202.0724945068194 .1481018066185 .6141052246179 .8231964111177 .9945068359 181.0424041748188 .0523986816177 .6896972656163 .974395752153 .6116943359 150.5639038086147 .2111968994146 .9064025879143 .8585968018136 .5437011719 130.4479980469127 .0953979492126 .4858016968124 .6570968628123 .1332015991 123.1332015991123 .7427978516124 .0475006104123 .7427978516122 .2188034058 118.8662033081116 .1231002808114 .9039993286115 .2088012695116 .1231002808 117.342300415118 .5614013672119 .4757995605119 .7806015015120 .0852966309 119.7806015015119 .7806015015119 .7806015015119 .7806015015120 .0852966309 120.6949005127120 .9997024536121 .6092987061121 .6092987061121 .3044967651 120.6949005127119 .1709976196116 .7326965332113 .6848983765110 .0273971558 105.7603988647101 .1886978149103 .0174026489104 .2365036011105 .4557037354 106.3700027466106 .979598999113 .3800964355122 .8283996582137 .7628936768 154.5260925293171 .2891998291191 .7097930908211 .520904541229 .8079986572 245.9615936279259 .6769104004271 .5635070801280 .7070922852288 .0219116211 294.1176147461298 .6893920898302 .3468017578305 .0899047852308 .1377868652 311.4903869629314 .8429870605318 .5004882812322 .4627075195326 .7296142578 330.9966125488334 .9588928223338 .9211120605341 .9689025879345 .0168151855 347.1502990723348 .9790039062350 .5028991699351 .4172058105352 .0267944336 352.3316040039352 .3316040039352 .3316040039351 .7219848633350 .8077087402 349.5885009766348 .0646057129346 .2359008789344 .1023864746341 .3593139648 338.6163024902335 .2636108398331 .6062011719327 .9487915039323 .6817932129 319.4147949219315 .1477966309310 .5759887695306 .0043029785301 .1276855469 296.5559082031291 .9841918945287 .7171936035283 .4501953125279 .1831970215 275.2210083008271 .2587890625267 .9060974121264 .5534973145261 .2008972168 258.1530151367255 .1051025391252 .0572967529249 .3141937256246 .2664031982 243.5233001709240 .4754943848237 .4275970459234 .3798065186231 .0270996094 227.6744995117224 .0171051025220 .054901123216 .0926971436211 .8256988525 209.692199707 209.692199707 209.692199707 209.692199707 209.692199707 209.692199707 209.692199707 209.692199707 209.692199707 151.1734008789 142.9441986084 134.7149963379120 .1280517578104 .6118469238 -9999 -9999 -9999 -9999 -9999 -9999 -9999 -9999 -9999 -9999 -9999 -9999 -9999 -9999 -9999 -9999 -9999 -9999 -9999 -9999 -9999 -9999 -9999 -9999 -9999 -9999 -9999 -9999 -9999 -9999 -9999 -9999 -9999 -9999 -9999 -9999 -9999 -

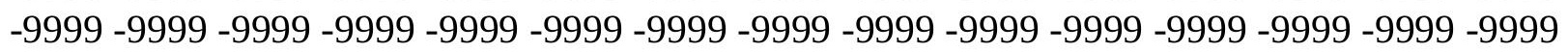


-9999 -9999 -9999 -9999 -9999 -9999 -9999 -9999 -9999 -9999 -9999 -9999 -9999 236.4907989502238 .8184509277241 .0830230713243 .3132781982245 .5422821045 247.8045043945250 .1331634521252 .5583190918255 .1024627686257 .7803649902 260.5944213867263 .5372619629266 .589263916269 .7229003906272 .902923584 276.0900268555279 .2422790527282 .3162231445285 .2691955566288 .057434082 290.6397705078292 .9700317383295 .0055236816296 .6986694336297 .9873962402 298.8463134766299 .1999511719299 .0403747559298 .3414611816297 .1028137207 295.3799438477 293.2480773926 290.7819213867 288.0414123535 285.0629272461 281.8602294922278 .4633789062274 .9481811523271 .4826660156268 .2901000977 265.6182556152263 .6842651367262 .6461181641262 .539855957263 .2543945312 264.4912719727265 .7402954102266 .2751464844265 .1108398438261 .9836425781 256.9940490723250 .8381958008245 .6567993164238 .3419952393229 .5032043457 220.9691925049213 .6544036865207 .510055542200 .9143829346192 .453414917 181.6228027344170 .3245697021161 .8132781982160 .1166687012161 .8408966064 166.4127044678169 .1557006836169 .7653045654168 .8509979248166 .7174987793 164.8887023926164 .2792053223163 .974395752164 .2792053223164 .2792053223 164.2792053223163 .974395752163 .6696014404163 .0599975586162 .4505004883 161.8408966064161 .5361022949161 .2312927246161 .2312927246161 .8408966064 162.7552947998164 .2792053223166 .1078948975168 .241394043170 .9844970703 173.7274932861176 .165802002178 .604095459180 .1280059814181 .0424041748 180.7375946045177 .9945068359170 .9844970703173 .0204467773173 .2962188721 172.8132019043173 .7274932861177 .9945068359184 .699798584190 .4907073975 193.233795166191 .4051055908186 .8332977295182 .261505127180 .432800293 181.3471984863183 .1759033203185 .0045928955185 .6141052246185 .8547058105 184.6758422852183 .0500793457182 .0286712646182 .1780548096183 .3536376953 184.8745422363186 .5875396729189 .336517334192 .3193969727183 .4806976318 183.4806976318184 .0901947021184 .3950042725181 .9566955566177 .0802001953 167.9365997314158 .4882965088162 .1457061768167 .0222015381171 .8988037109 174.337097168171 .5939941406162 .4505004883150 .2590942383150 .5639038086 151.1734008789151 .4781951904151 .1734008789150 .8686065674151 .1734008789 151.7830047607152 .0877990723150 .5639038086147 .8208007812144 .4682006836 141.4203033447138 .6772003174144 .1634063721164 .2792053223187 .0599365234 206.6523132324218 .2574615479223 .8106079102227 .9377288818230 .6491851807 232.7964172363234 .2561340332234 .6376647949233 .8759918213232 .8010253906 232.7528533936233 .2040100098231 .3393249512231 .1575622559232 .3032073975 236.4033203125242 .6089935303237 .1228027344228 .8936004639222 .1884002686 216.0926971436209 .692199707204 .2059936523202 .3773040771201 .4629974365 205.425201416207 .5587005615202 .3773040771192 .3193969727183 .1759033203 177.6896972656174 .6419067383172 .5084075928169 .1557006836163 .6696014404 158.4882965088146 .6015930176143 .2489929199137 .1533050537133 .8007049561 134.7149963379135 .9342041016134 .4102020264131 .9720001221129 .8385009766 122.5235977173118 .5614013672117 .342300415117 .647102356118 .5614013672 119.4757995605120 .3900985718120 .6949005127120 .6949005127120 .3900985718 120.0852966309119 .4757995605119 .1709976196119 .1709976196119 .1709976196 119.7806015015120 .3900985718120 .9997024536121 .6092987061121 .9140014648 121.6092987061120 .6949005127119 .1709976196116 .4279022217112 .7705001831 
108.1986999512103 .6268997192101 .7982025146103 .0174026489103 .9317016602 104.8460998535105 .7603988647106 .3700027466113 .075302124124 .6570968628 138.0677032471153 .9165039062173 .1179962158193 .233795166211 .8256988525 228.8936004639243 .5233001709256 .0195007324266 .6870117188275 .8305053711 282.8406066895288 .0219116211291 .9841918945295 .3367919922299 .2990112305 303.5660095215308 .1377868652313 .6239013672319 .1099853516325 .2056884766 330.9966125488336 .4827880859341 .6640930176345 .9310913086349 .5885009766 352.3316040039354 .7698974609356 .2937927246357 .5129089355358 .1224975586 358.4273071289358 .4273071289358 .1224975586357 .5129089355356 .5986022949 355.0747070312353 .2460021973351 .4172058105348 .6741943359345 .9310913086 342.5784912109339 .2258911133335 .2636108398331 .3013916016326 .7296142578 322.1578979492317 .5860900879312 .7095031738307 .8330078125302 .9563903809 298.0798950195293 .2033081055288 .6315002441284 .3645019531280 .0975036621 276.1353149414272 .1730957031268 .5156860352265 .1630859375262 .1152038574 259.0674133301256 .0195007324253 .2763977051250 .5334014893247 .7902984619 245.0471954346242 .3041992188239 .2563018799236 .2084960938233 .1605987549 230.1127929688226 .4553985596222 .7978973389218 .8356933594214 .8735046387 210.3016967773209 .692199707209 .692199707209 .692199707209 .692199707 209.692199707209.692199707209.692199707209.692199707 209.692199707 $146.2969055176137 .7628936768124 .9025878906110 .213714599693 .40871429443-9999$ -9999 -9999 -9999 -9999 -9999 -9999 -9999 -9999 -9999 -9999 -9999 -9999 -9999 -9999 -9999 -9999 -9999 -9999 -9999 -9999 -9999 -9999 -9999 -9999 -9999 -9999 -9999 -9999 -9999 -9999 -9999 -9999-9999-9999-9999

-9999 -9999 -9999 -9999 -9999 -9999 -9999 -9999 -9999 -9999 -9999 -9999 -9999 -9999 -9999 -9999 -9999 -9999 -9999 -9999 -9999 -9999 -9999 -9999 -9999 -9999 -9999 -9999 250.2367553711252 .9184112549255 .5561676025258 .1717529297260 .7896728516 263.4350891113266 .1319274902268 .9013061523271 .7584228516274 .7122802734 277.7628173828280 .9022521973284 .1137084961287 .3739013672290 .6531982422 293.9179992676297 .1319580078300 .2562255859303 .2504272461306 .0762329102 308.6888427734311 .0405578613313 .0906066895314 .7896728516316 .104095459 316.9962463379317 .4277954102317 .3806762695316 .8549194336315 .8804626465 314.5168457031312 .8432922363310 .9276123047308 .7988891602306 .4413452148 303.7797851562300 .7199401855297 .2450561523293 .4526062012289 .6410217285 286.128326416283 .2399902344281 .3243713379280 .5310058594280 .8572387695 282.0234375283 .4635314941284 .4868164062283 .6986083984279 .7927856445 274.0018005371267 .9060974121261 .5056152344253 .2763977051243 .8280944824 236.5133056641229 .5032043457224 .3218994141217 .4452972412210 .9113006592 197.1959991455184 .699798584170 .070098877170 .9844970703179 .8231964111 177.0802001953175 .5561981201174 .0323028564172 .5084075928170 .6797027588 169.4604949951168 .5462036133168 .241394043167 .9365997314167 .6318054199 167.0222015381166 .4127044678165 .4983062744164 .5839996338163 .974395752 163.0599975586162 .7552947998162 .4505004883162 .4505004883162 .7552947998 163.6696014404164 .8887023926166 .4127044678168 .241394043170 .3748931885 172.8132019043174 .6419067383176 .165802002176 .7754058838176 .4705963135 174.0323028564170 .070098877166 .1078948975165 .1934967041166 .1078948975 168.8509979248172 .2035980225176 .7754058838182 .261505127186 .8332977295 
189.2716064453 188.6620025635186.2236938477183.1759033203181.6519012451 181.9566955566183 .4806976318186 .2236938477185 .3761901855184 .6229858398 183.6619720459182 .5514373779181 .8992767334182 .110244751183 .2024230957 184.986328125187 .3059082031189 .532043457189 .784942627186 .8332977295 185.3094024658185 .9188995361186 .528503418186 .2236938477185 .0045928955 175.2514038086168 .5462036133168 .5462036133172 .8132019043177 .9945068359 182.87109375182 .87109375173 .1179962158163 .974395752159 .4026031494 157.2691040039155 .4403991699153 .6116943359151 .7830047607151 .7830047607 152.0877990723152 .3925933838151 .4781951904148 .7351074219145 .0776977539 141.4203033447138 .9819946289138 .3724975586146 .9064025879170 .9844970703 205.425201416216 .6435699463225 .863571167231 .0330657959234 .6927337646 239.0909881592241 .6674041748241 .747467041239 .377746582236 .8714904785 235.5147094727235 .1091461182236 .1711730957238 .6433258057243 .4101257324 250.0617828369256 .3924255371259 .3721008301246 .5711975098233 .1605987549 226.150604248220 .9691925049219 .7501068115226 .4553985596227 .6744995117 227.6744995117227 .6744995117225 .8457946777220 .054901123216 .0926971436 215.4830932617209 .0825958252206 .9490966797202 .0724945068195 .6721038818 187.7476043701181 .0424041748165 .8031005859154 .5260925293148 .4304046631 154.5260925293156 .0500030518151 .4781951904141 .7250976562131 .9720001221 125.2667007446122 .2188034058121 .3044967651121 .6092987061122 .2188034058 122.8283996582123 .1332015991122 .8283996582122 .2188034058121 .6092987061 120.6949005127119 .7806015015118 .8662033081118 .5614013672118 .5614013672 118.8662033081119 .4757995605120 .3900985718121 .3044967651121 .9140014648 122.2188034058122 .2188034058121 .3044967651119 .4757995605115 .818397522 110.9418029785106 .3700027466101 .7982025146101 .4934005737102 .712600708 103.3221969604104 .2365036011104 .8460998535105 .1509017944113 .075302124 123.7427978516138 .0677032471156 .6596069336176 .4705963135195 .0625211 .520904541 226.150604248238 .9515075684250 .5334014893260 .5913085938269 .4301147461 274.3066101074278 .5736083984282 .8406066895287 .7171936035293 .2033081055 299.6037902832306 .6138000488314 .5382080078322 .1578979492330 .0823059082 337.3970947266343 .7976074219349 .2838134766353 .5508117676357 .208190918 359.6465148926361 .7799072266362 .9991149902363 .6086120605363 .9135131836 363.9135131836363 .6086120605362 .6943054199361 .7799072266360 .2560119629 358.1224975586355 .9890136719353 .2460021973350 .1980895996346 .5407104492 342.8833007812338 .6163024902334 .3493041992329 .4726867676324 .5961914062 319.7196044922314 .5382080078309 .6617126465304 .4802856445299 .2990112305 294.4223937988289 .5458984375284 .9740905762280 .7070922852276 .7449035645 272.7827148438269 .1253051758265 .7726135254262 .7247924805259 .9816894531 257.2385864258254 .4956054688251 .7525024414249 .3141937256246 .5711975098 244.1329040527241 .3898010254238 .6468048096235 .5989074707232 .5511016846 229.1983947754225 .8457946777221 .883605957217 .9214019775213 .6544036865 209.0825958252 209.692199707 209.692199707 209.692199707 209.692199707 209.692199707209 .692199707209 .692199707209 .692199707149 .6495056152 141.1154937744 132.2767028809 115.553993225198 .10623931885 -9999 -9999 -9999 -9999 -9999 -9999 -9999 -9999 -9999 -9999 -9999 -9999 -9999 -9999 -9999 -9999 -9999 -9999 -9999

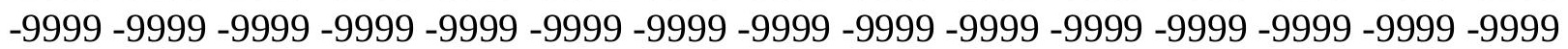


$-9999-9999$

-9999 -9999 -9999 -9999 -9999 -9999 -9999 -9999 -9999 -9999 -9999 -9999 -9999 -9999 -9999 -

-9999 -9999 -9999 -9999 -9999 -9999 -9999 -9999 -9999 -9999 -9999 -9999 -9999

263.8981933594266 .8999633789269 .873046875272 .8330078125275 .7971801758

278.782989502281 .8065490723284 .8815917969288 .0170898438291 .2172546387

294.479309082297 .7946166992301 .1475219727304 .5171203613307 .8774719238

311.1988525391314 .44921875317 .5940246582320 .5962524414323 .418182373

326.0071105957328 .329864502330 .3510437012332 .0350036621333 .3414916992

334.2364807129334 .6923217773334 .6928405762334 .2481079102333 .4024963379

332.2364501953330 .8469543457329 .3152770996327 .6532592773325 .7893676758

323.5955810547320 .7734680176317 .2222900391312 .8695983887308 .2268066406

303.6986694336299 .7094421387296 .7098083496295 .1077270508295 .0149841309

296.0074157715297 .3569641113298 .6174926758299 .6037902832294 .4223937988

288.9363098145283 .4501953125276 .7449035645268 .8204956055259 .6769104004

251.1428985596243 .5233001709236 .5133056641229 .5032043457219 .7501068115

207.25390625194 .4528961182185 .0045928955183 .7854003906185 .6141052246

184.699798584181 .9566955566178 .9089050293176 .165802002174 .6419067383

173.7274932861173 .1179962158172 .5084075928171 .8988037109170 .9844970703

169.7653045654168 .8509979248167 .6318054199166 .4127044678165 .4983062744 164.5839996338163 .974395752163 .3648071289163 .3648071289163 .6696014404 164.2792053223165 .1934967041166 .4127044678167 .9365997314169 .7653045654 171.5939941406173 .1179962158174 .0323028564174 .0323028564172 .8132019043 170.3748931885167 .0222015381164 .2792053223163 .0599975586163 .974395752 167.0222015381170 .6797027588175 .5561981201180 .1280059814184 .0901947021 186.2236938477186 .528503418185 .3094024658183 .4806976318182 .261505127 181.6519012451182 .261505127183 .7048187256184 .0415344238183 .3150024414 182.3023834229181 .3266906738180 .8382415771181 .1377868652182 .2701263428 184.0979309082186 .2341003418187 .8722381592188 .0988769531187 .7476043701 185.6141052246186 .2236938477187 .1381072998187 .4429016113185 .3094024658 180.432800293176 .165802002175 .5561981201177 .9945068359182 .261505127 185.6141052246185 .9188995361181 .9566955566176 .4705963135170 .3748931885 165.1934967041161 .2312927246157 .878692627155 .1356048584153 .6116943359 153.0021057129152 .3925933838153 .3069000244149 .3446960449145 .3825073242 142.3347015381140 .2012023926135 .6293945312136 .5437011719151 .7830047607 181.6519012451199 .6342926025218 .2261962891219 .1666870117224 .5216064453 233.1324157715239 .1832122803238 .7028503418234 .59815979230 .451965332 227.821975708227 .6111450195230 .2847442627235 .5139160156242 .9502716064 251.3177185059257 .8250732422258 .8688354492251 .4476928711241 .3898010254 231.0270996094227 .0648956299225 .5410003662226 .7601013184229 .8079986572 237.1228027344241 .0850067139240 .3484344482238 .266494751236 .5402526855 235.0534057617232 .4335632324230 .0411682129228 .1428985596227 .6744995117 220.9691925049209 .692199707195 .9768066406176 .4705963135172 .8132019043 186.2236938477 187.7476043701 180.432800293156.0500030518138.0677032471 131.6672058105129 .8385009766128 .3144989014127 .4001998901127 .0953979492 127.0953979492126 .4858016968125 .5715026855124 .3523025513122 .8283996582 121.3044967651120 .0852966309118 .8662033081118 .2565994263117 .9517974854 
117.9517974854118 .5614013672119 .4757995605120 .6949005127121 .6092987061 122.5235977173123 .1332015991123 .1332015991122 .2188034058118 .2565994263 113.9896011353109 .4179000854105 .1509017944101 .1886978149100 .8839035034 102.1029968262102 .712600708103 .3221969604103 .6268997192106 .6747970581 113.9896011353124 .0475006104142 .9441986084162 .4505004883179 .2136993408 194.4528961182208 .1681976318220 .9691925049232 .246307373242 .3041992188 250.8381958008257 .2385864258262 .4200134277267 .9060974121273 .6971130371 280.7070922852288 .9363098145297 .7750854492307 .8330078125317 .8908996582 327.9487915039337 .0922851562345 .0168151855351 .7219848633356 .9034118652 361.1704101562363 .9135131836366 .0469055176367 .570892334368 .4851989746 368.7900085449368 .7900085449368 .1803894043367 .570892334366 .3517150879 364.5230102539362 .6943054199359 .9512023926357 .208190918353 .8554992676 349.8933105469345 .9310913086341 .6640930176336 .7875976562331 .9110107422 326.7296142578321 .5483093262316 .3670043945310 .8807983398305 .6994934082 300.5180969238295 .3367919922290 .4602050781285 .5835876465281 .3167114258 277.0497131348 273.3923034668 269.7348022461 266.3822021484263.3344116211 260.5913085938258 .1530151367255 .4098968506252 .9716033936250 .8381958008 248.3999023438245 .9615936279243 .2185058594240 .7801971436238 .0372009277 234.9893035889231 .9414978027228 .5888977051224 .9313964844221 .2740020752 217.0070037842212 .4351959229209 .692199707209 .692199707209 .692199707 209.692199707 209.692199707 209.692199707 209.692199707 209.692199707 209.692199707 144.7729034424135 .6293945312119 .2611846924102 .880432128985 .58026123047 -9999 -9999 -9999 -9999 -9999 -9999 -9999 -9999 -9999 -9999 -9999 -9999 -9999 -9999 -9999 -9999

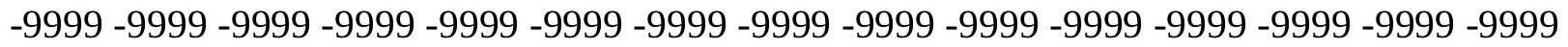
-9999 -9999 -9999 -9999

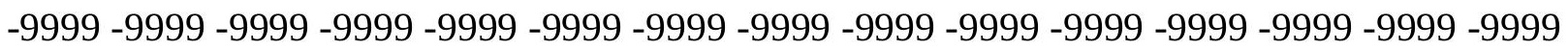
-9999 -9999 -9999 -9999 -9999 -9999 -9999 -9999 -9999 -9999 -9999 -9999 -9999 -9999 280.6849975586283 .9534912109287 .2150268555290 .4807128906293 .7613830566 297.0665283203300 .4034729004303 .775970459307 .1837463379310 .6214294434 314.0788879395317 .5406799316320 .9868164062324 .3920593262327 .7333984375 330.9771728516334 .0946350098337 .0514526367339 .8112487793342 .3154907227 344.5791320801346 .5343017578348 .1478271484349 .3875427246350 .2209472656 350.615020752350 .5466918945350 .0195617676349 .0805053711347 .8321533203 346.4092407227344 .9284973145343 .4199829102341 .7117004395339 .689666748 336.9503479004332 .9932250977327 .9045410156321 .9737548828316 .3235473633 311.4660949707307 .0106201172304 .7542724609304 .6512451172305 .425567627 306.6138000488306 .6138000488306 .3091125488304 .1755981445300 .5180969238 296.5559082031291 .0697937012282 .8406066895273 .3923034668264 .2486877441 255.4098968506247 .1806945801238 .6468048096228 .2841033936217 .0070037842 206.3394927979198 .7198944092194 .7577056885193 .233795166191 .4051055908 188.0523986816184 .0901947021180 .1280059814179 .5184020996178 .9089050293 178.2993011475177 .3849029541176 .165802002174 .6419067383173 .1179962158 171.5939941406170 .070098877168 .5462036133167 .3269958496166 .1078948975 165.4983062744164 .8887023926164 .5839996338164 .5839996338164 .8887023926 165.4983062744166 .4127044678167 .6318054199169 .1557006836170 .3748931885 171.5939941406172 .2035980225172 .2035980225170 .9844970703169 .1557006836 
166.7174987793164 .5839996338163 .6696014404164 .5839996338166 .7174987793 170.3748931885174 .337097168178 .2993011475181 .6519012451183 .7854003906 184.699798584184 .3950042725183 .1759033203181 .9566955566180 .7375946045 180.1280059814181 .6607666016182 .2627105713181 .59765625180 .4562530518 179.4223022461178 .9741668701179 .3218536377180 .4380645752182 .1897125244 184.2702789307 185.7313232422 186.0323944092185.1998291016184.0901947021 185.3094024658186 .528503418186 .528503418185 .3094024658182 .87109375 180.7375946045180 .1280059814181 .3471984863184 .0901947021186 .2236938477 186.8332977295186 .8332977295185 .9188995361178 .9089050293172 .2035980225 167.0222015381162 .4505004883159 .0977935791156 .6596069336154 .8307952881 153.3069000244151 .7830047607149 .0399017334145 .6873016357142 .3347015381 138.9819946289136 .8484954834139 .5915985107151 .1734008789165 .8031005859 180.7375946045187 .7476043701187 .4429016113198 .4151000977209 .0825958252 224.9313964844222 .5292510986219 .0988464355214 .6624908447211 .6977233887 211.8366394043215 .8134918213223 .26171875232 .8081512451242 .357635498 249.6407470703252 .3036804199248 .0950927734243 .5233001709234 .0749969482 227.6744995117227 .6744995117230 .4176025391234 .6844940186240 .3753204346 244.7408905029246 .3596496582246 .3141174316245 .6967773438244 .7357635498 243.8082733154242 .7782897949242 .1155090332240 .4380645752235 .1907653809 225.9987487793216 .0957489014211 .8256988525215 .4830932617220 .054901123 239.2563018799227 .0648956299180 .432800293153 .6116943359150 .5639038086 144.7729034424138 .9819946289135 .6293945312133 .8007049561132 .2767028809 130.4479980469128 .6192932129126 .4858016968124 .3523025513122 .2188034058 120.3900985718118 .8662033081117 .647102356117 .0374984741117 .0374984741 117.647102356118 .5614013672120 .0852966309121 .3044967651122 .5235977173 123.43800354123 .7427978516122 .8283996582120 .0852966309116 .7326965332 112.7705001831108 .8082962036104 .8460998535101 .798202514699 .35994720459 100.8839035034101 .4934005737101 .7982025146103 .3221969604108 .8082962036 118.5614013672133 .1911010742150 .8686065674164 .5839996338177 .6896972656 190.4907073975202 .3773040771213 .0447998047222 .7978973389230 .7223052979 237.7324066162243 .8280944824250 .2286071777257 .2385864258265 .7726135254 275.5257873535286 .8027954102299 .2990112305311 .7951965332324 .2914123535 335.5683898926345 .3215026855353 .2460021973359 .3417053223363 .9135131836 367.2661132812369 .399597168371 .228302002372 .1426086426372 .4473876953 372.7521972656372 .1426086426371 .5331115723370 .3139038086368 .4851989746 366.3517150879363 .6086120605360 .5607910156356 .9034118652352 .941192627 348.6741943359343 .7976074219338 .9211120605333 .7396850586328 .5584106445 323.0722045898317 .5860900879312 .1000061035306 .6138000488301 .1276855469 295.9464111328290 .7650146484285 .8884887695281 .6214904785277 .3544921875 273.6971130371270 .0396118164266 .9917907715263 .9439086914261 .5056152344 259.0674133301256 .6290893555254 .4956054688252 .0572967529249 .9237976074 247.7902984619245 .3520050049242 .9136962891240 .4754943848237 .7324066162 234.6844940186231 .6367034912228 .2841033936224 .6266021729220 .6643981934 216.3973999023211 .520904541209 .692199707209 .692199707209 .692199707 209.692199707209 .692199707209 .692199707209 .692199707209 .692199707 148.4304046631139 .2868041992124 .6708374023108 .323448181290 .75949859619 -9999 
-9999 -9999 -9999 -9999 -9999 -9999 -9999 -9999 -9999 -9999 -9999 -9999 -9999 -9999 -9999 -9999 -9999 -9999 -9999 -9999 -9999 -9999 -9999 -9999 -9999 -9999 -9999 -9999 -9999 -9999 -9999 -9999 -9999-9999

-9999 -9999 -9999 -9999 -9999 -9999 -9999 -9999 -9999 -9999 -9999 -9999 -9999 -9999 -9999 -9999 -9999 -9999 -9999 -9999 -9999 -9999 -9999 -9999 -9999 -9999 -9999 -9999 -9999 294.2022399902297 .7245788574301 .2430114746304 .7632751465308 .2903137207 311.8278808594315 .3776855469318 .9386901855322 .5065612793326 .0733032227 329.6272888184333 .1509094238336 .6260986328340 .027923584343 .332824707 346.5118408203349 .5362548828352 .3769226074355 .0239562988357 .4273986816 359.5579833984361 .3721923828362 .8316955566363 .9101867676364 .5758972168 364.7836303711364 .4800109863363 .6406555176362 .298828125360 .5576782227 358.6294250488356 .6787719727354 .8099365234352 .7445678711350 .0299682617 347.1502990723341 .9689025879336 .4827880859328 .2536010742321 .5483093262 316.3670043945310 .2713012695308 .1377868652309 .3569030762309 .6617126465 309.6617126465309 .9664916992309 .9664916992309 .3569030762307 .8330078125 305.6994934082302 .6516113281293 .8128967285284 .0596923828274 .3066101074 264.8583068848256 .0195007324246 .5711975098236 .8179931641226 .7601013184 217.3117980957210 .3016967773205 .1204071045201 .7678070068198 .7198944092195 .0625 191.4051055908188 .0523986816186 .2236938477185 .0045928955184 .0901947021 182.5662994385180 .7375946045178 .604095459176 .4705963135174 .337097168 172.5084075928170 .9844970703169 .4604949951168 .241394043167 .0222015381 166.4127044678165 .8031005859165 .4983062744165 .4983062744166 .1078948975 166.7174987793167 .6318054199168 .8509979248169 .7653045654170 .6797027588 171.2891998291171 .2891998291170 .6797027588169 .1557006836167 .6318054199 166.1078948975165 .4983062744166 .1078948975167 .6318054199170 .3748931885 173.7274932861177 .0802001953179 .8231964111181 .9566955566182 .87109375 183.1759033203182 .261505127181 .0424041748179 .8231964111178 .2993011475 180.7375946045180 .7629699707179 .6565246582178 .099899292176 .940322876 176.5934143066177 .0168609619178 .0392150879179 .6416320801181 .8385772705 183.8697967529183 .9934692383182 .7252044678181 .9566955566184 .0901947021 185.3094024658185 .3094024658184 .699798584183 .4806976318182 .5662994385 182.261505127182 .87109375184 .0901947021184 .699798584185 .6141052246 186.528503418186 .2236938477182 .5662994385176 .7754058838171 .5939941406 166.7174987793162 .7552947998159 .4026031494156 .6596069336154 .2212982178 151.1734008789149 .0399017334145 .9920959473142 .3347015381139 .2868041992 138.0677032471140 .5059967041146 .2969055176153 .0021057129158 .1835021973 156.6596069336151 .7830047607153 .3069000244157 .2691040039181 .3471984863 194.4528961182196 .2816009521191 .6982421875189 .8625946045190 .5347290039 194.7382354736204 .1251220703215 .9647827148226 .0212860107234 .1609802246 241.0649414062244 .4376983643237 .7324066162229 .1983947754222 .1884002686 223.7122955322227 .6744995117234 .3798065186239 .0229492188243 .0153198242 245.3050231934246 .0458831787245 .9974212646245 .6590881348245 .3685302734 245.0673828125244 .5042572021242 .596572876238 .5715026855232 .6320800781 226.704574585222 .557144165216 .276184082212 .7400054932315 .7573852539 270.6492004395244 .1329040527209 .3874053955181 .9566955566165 .1934967041 151.4781951904145 .6873016357141 .7250976562138 .3724975586135 .0198059082 
131.6672058105128 .6192932129125 .8762969971123 .43800354120 .9997024536 119.1709976196117 .342300415116 .4279022217116 .4279022217116 .7326965332 117.647102356119 .1709976196120 .6949005127121 .9140014648123 .1332015991 123.43800354123 .1332015991121 .6092987061119 .1709976196116 .1231002808 112.7705001831109 .1130981445105 .7603988647103 .0174026489101 .1886978149 100.2742996216100 .5791015625102 .4077987671106 .6747970581113 .9896011353 124.6570968628137 .1533050537149 .6495056152161 .5361022949173 .1179962158 184.0901947021195 .9768066406208 .4730072021210 .6065063477217 .3117980957 224.0171051025230 .7223052979238 .6468048096248 .0950927734259 .6769104004 273.3923034668288 .3266906738303 .8707885742319 .1099853516332 .8252868652 344.4071960449353 .5508117676360 .5607910156365 .4374084473369 .0947875977 371.5331115723373 .3617858887374 .5809020996375 .1904907227375 .495300293 375.1904907227374 .5809020996373 .3617858887371 .5331115723369 .0947875977 366.3517150879362 .9991149902359 .3417053223355 .0747070312350 .5028991699 345.6263122559340 .4450073242335 .2636108398329 .7774963379323 .9866027832 318.5004882812312 .7095031738307 .2233886719301 .4324951172296 .2510986328 291.0697937012286 .1932067871281 .6214904785277 .3544921875273 .6971130371 270.3443908691267 .2966003418264 .5534973145262 .1152038574259 .6769104004 257.5433959961255 .7147064209253 .5812072754251 .7525024414249 .6190032959 247.4855041504245 .3520050049242 .9136962891240 .4754943848237 .7324066162 234.6844940186231 .6367034912228 .2841033936224 .3218994141220 .3596038818 215.787902832210 .6065063477209 .692199707209 .692199707209 .692199707 209.692199707209.692199707209.692199707 209.692199707209.692199707 $142.9441986084133 .1911010742114 .082946777396 .5916137695378 .80461883545-9999$ -9999 -9999 -9999 -9999 -9999 -9999 -9999 -9999 -9999 -9999 -9999 -9999 -9999 -9999 -9999 -9999 -9999 -9999 -9999 -9999 -9999 -9999 -9999 -9999 -9999 -9999 -9999 -9999 -9999 -9999 -9999 -9999-9999

-9999 -9999 -9999 -9999 -9999 -9999 -9999 -9999 -9999 -9999 -9999 -9999 -9999 -9999 -9999 -9999 -9999 -9999 -9999 -9999 -9999 -9999 -9999 -9999 -9999 -9999 -9999 -9999 -9999 307.3911132812311 .1250610352314 .8549194336318 .5813903809322 .3041381836 326.021697998329 .7306518555333 .4255981445337 .0982666016340 .7379150391 344.330078125347 .8571777344351 .2992553711354 .6323547363357 .8307800293 360.8670654297363 .7340698242366 .4140319824368 .8826904297371 .1011657715 373.0203552246374 .5913391113375 .765045166376 .5299072266376 .8687438965 376.7279052734375 .9831237793374 .5469360352372 .4225158691369 .684753418 366.6322631836363 .4961853027360 .4812927246357 .8176879883352 .941192627 347.4549865723341 .3593139648334 .6541137695326 .4248962402317 .2813110352 306.9186096191306 .6138000488306 .9186096191307 .5281982422308 .7473144531 309.6617126465310 .2713012695310 .8807983398310 .8807983398310 .5759887695 309.3569030762306 .9186096191299 .2990112305290 .4602050781281 .0119018555 271.8682861328262 .7247924805253 .5812072754244 .4376983643235 .2940979004 227.0648956299220 .3596038818214 .8735046387210 .6065063477206 .6443023682 203.2917022705 199.6342926025 196.5863952637194.1481018066192.3193969727 190.4907073975188 .3571929932185 .9188995361183 .1759033203180 .432800293 177.6896972656175 .5561981201173 .7274932861172 .2035980225170 .6797027588 169.1557006836168 .241394043167 .3269958496166 .7174987793166 .4127044678 
166.7174987793167 .0222015381167 .6318054199168 .5462036133169 .4604949951 170.3748931885170 .9844970703171 .2891998291170 .9844970703170 .6797027588 169.7653045654168 .5462036133167 .9365997314167 .9365997314169 .1557006836 170.9844970703173 .4226989746176 .165802002178 .604095459180 .432800293 181.3471984863181 .6519012451181 .3471984863180 .432800293179 .2136993408 177.9945068359178 .2993011475179 .5184020996177 .6896972656175 .4340362549 174.2028045654174 .2603759766174 .8999786377175 .7115783691177 .0000305176 178.9089050293183 .1759033203182 .5662994385180 .7375946045181 .6519012451 183.4806976318184 .0901947021184 .0901947021183 .7854003906183 .1759033203 182.87109375182 .5662994385183 .1759033203183 .4806976318183 .1759033203 182.261505127184 .699798584185 .0045928955182 .87109375178 .9089050293 174.337097168169 .7653045654165 .8031005859162 .1457061768159 .0977935791 155.7451934814152 .6972961426149 .9542999268146 .9064025879143 .8585968018 140.5059967041139 .8963928223140 .2012023926141 .4203033447142 .6394042969 141.7250976562137 .1533050537131 .6672058105131 .3623962402137 .7628936768 151.1734008789161 .5361022949165 .8031005859167 .0222015381167 .9365997314 168.5462036133169 .4604949951180 .432800293195 .3672943115204 .3700561523 212.3734283447219 .9864044189232 .8558044434227 .3697052002222 .7978973389 217.3117980957 214.2639007568219.7501068115226.7601013184232.7057189941 236.8124542236238 .8698272705239 .4851379395239 .4098510742239 .2009735107 239.0913696289239 .0089569092238 .5368804932237 .1081237793234 .4138946533 230.6852416992226 .6877593994223 .3960266113224 .4597015381240 .7352600098 263.305267334247 .1806945801308 .4425048828241 .9994049072202 .0724945068 185.0045928955167 .6318054199157 .2691040039150 .5639038086144 .7729034424 139.5915985107134 .7149963379130 .7528076172127 .4001998901124 .3523025513 121.6092987061119 .1709976196117 .342300415116 .1231002808115 .5136032104 116.1231002808117 .0374984741118 .5614013672120 .0852966309121 .6092987061 122.8283996582123 .43800354123 .43800354122 .8283996582121 .3044967651 119.1709976196116 .7326965332113 .6848983765110 .3321990967107 .2844009399 104.8460998535103 .3221969604102 .712600708103 .3221969604105 .7603988647 110.6370010376117 .0374984741125 .5715026855135 .9342041016146 .9064025879 157.2691040039169 .7653045654186 .2236938477198 .1103057861207 .8634033203 209.692199707 209.692199707 210.3016967773 218.2261962891228.5888977051 241.3898010254256 .9338989258274 .9161987305293 .8128967285312 .1000061035 328.5584106445342 .2737121582352 .6364135742360 .2560119629365 .4374084473 369.0947875977371 .837890625373 .666595459375 .1904907227376 .4096069336 377.0191955566377 .0191955566376 .4096069336375 .495300293373 .666595459 371.228302002368 .4851989746364 .8277893066360 .8656005859356 .5986022949 351.7219848633346 .845489502341 .6640930176335 .8731994629330 .3870849609 324.5961914062318 .8052062988313 .0143127441307 .2233886719301 .7373046875 296.2510986328291 .0697937012285 .8884887695281 .6214904785277 .3544921875 273.6971130371270 .3443908691267 .2966003418264 .8583068848262 .7247924805 260.5913085938258 .7626037598256 .9338989258255 .1051025391253 .2763977051 251.4476928711249 .6190032959247 .4855041504245 .3520050049243 .2185058594 240.7801971436238 .0372009277234 .9893035889231 .9414978027228 .2841033936 224.3218994141220 .054901123215 .1782989502209 .692199707209 .692199707 
209.692199707 209.692199707 209.692199707209.692199707209.692199707209.692199707 147.2111968994 137.1533050537 121.1629943848 103.4970932007 85.00550079346-9999

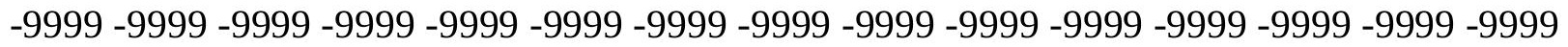

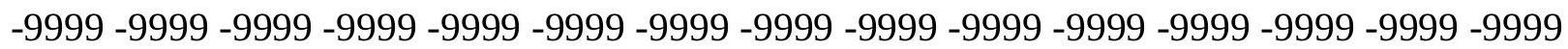
$-9999-9999-9999$

-9999 -9999 -9999 -9999 -9999 -9999 -9999 -9999 -9999 -9999 -9999 -9999 -9999 -9999 -9999 -9999 -9999 -9999 -9999 -9999 -9999 -9999 -9999 -9999 -9999 -9999 -9999 -9999 320.1928710938324 .0954284668327 .9900817871331 .8728027344335 .7381286621 339.5797729492 343.3893432617347.1573486328 350.8728637695 354.5185241699 358.082824707361 .5432739258364 .8786621094368 .0641479492371 .0723571777 373.8948364258376 .5390930176378 .9788208008381 .1874389648383 .1188964844 384.7069091797385 .8887939453386 .5921936035386 .7958068848386 .5750732422 385.8824462891384 .4953613281382 .1463317871378 .7623291016374 .5612792969 369.6033935547364 .8277893066359 .6465148926353 .8554992676348 .0646057129 342.2737121582335 .8731994629328 .8631896973321 .2434997559313 .3190917969 306.6138000488304 .1755981445304 .1755981445305 .0899047852306 .3091125488 307.2233886719 308.4425048828 309.3569030762 309.6617126465 309.3569030762 308.1377868652305 .3947143555300 .5180969238293 .2033081055284 .9740905762 276.4400939941267 .6012878418259 .0674133301250 .8381958008242 .9136962891 235.5989074707 229.1983947754223.7122955322 219.1405029297 215.4830932617 211.8256988525208 .4730072021205 .425201416202 .6820983887200 .2438049316 197.8054962158195 .0625191 .7097930908188 .3571929932184 .699798584181 .3471984863 178.9089050293177 .0802001953175 .2514038086173 .4226989746171 .8988037109 170.3748931885169 .1557006836168 .241394043167 .9365997314167 .6318054199 167.9365997314168 .241394043168 .8509979248169 .7653045654170 .3748931885 171.2891998291171 .8988037109172 .2035980225172 .5084075928172 .2035980225 171.2891998291170 .3748931885170 .070098877170 .6797027588171 .8988037109 173.7274932861175 .5561981201177 .6896972656179 .2136993408180 .1280059814 180.7375946045180 .432800293179 .8231964111178 .9089050293177 .9945068359 177.9945068359177 .0802001953175 .5561981201173 .1179962158171 .8988037109 172.8132019043173 .7274932861174 .0323028564175 .2514038086177 .6896972656 180.432800293181 .0424041748181 .0424041748181 .6519012451182 .5662994385 182.87109375182 .87109375182 .5662994385182 .5662994385182 .5662994385 182.5662994385182 .87109375182 .87109375182 .5662994385182 .5662994385 183.4806976318183 .4806976318182 .261505127179 .5184020996175 .8609924316 171.8988037109168 .241394043164 .5839996338161 .2312927246158 .1835021973 155.1356048584152 .3925933838149 .3446960449146 .9064025879144 .4682006836 142.9441986084141 .1154937744138 .9819946289136 .5437011719132 .5814971924 128.0097961426124 .0475006104123 .43800354127 .7050018311135 .3246002197 143.5538024902149 .9542999268155 .1356048584151 .4781951904149 .3446960449 149.6495056152154 .5260925293165 .1934967041181 .6519012451190 .795501709 187.4429016113196 .2816009521207 .25390625211 .2160949707209 .0825958252 207.5587005615209 .692199707215 .4830932617223 .1027069092227 .0438079834 228.2979278564228 .2628173828227 .7423248291227 .2602386475227 .0681610107 227.0436859131226 .8288116455226 .1105499268224 .7716369629222 .9903869629 221.4024505615221 .3243865967225 .3483886719236 .6998748779243 .7626953125 
253.9837646484256 .0942687988219 .1405029297203 .2917022705188 .966796875 177.0802001953167 .3269958496159 .7073974609152 .3925933838144 .7729034424 138.0677032471132 .8863067627129 .2288970947125 .8762969971122 .8283996582 119.7806015015117 .342300415115 .818397522115 .2088012695115 .5136032104 116.7326965332117 .9517974854119 .7806015015121 .3044967651122 .5235977173 123.43800354124 .0475006104123 .7427978516123 .1332015991121 .9140014648 120.6949005127117 .647102356114 .5991973877111 .8561019897109 .4179000854 107.5891036987106 .0652008057105 .7603988647106 .3700027466108 .5035018921 111.8561019897116 .1231002808124 .9618988037134 .4102020264143 .2489929199 156.6596069336173 .1179962158185 .3094024658195 .0625203 .9011993408209 .692199707 209.692199707 209.692199707 209.692199707220.3596038818237.7324066162 258.4577941895281 .0119018555303 .2611999512323 .0722045898338 .6163024902 349.8933105469357 .8176879883362 .9991149902366 .6564941406369 .7043151855 372.1426086426374 .2760925293376 .104888916377 .324005127377 .6288146973 377.6288146973376 .7143859863374 .8857116699372 .4473876953369 .399597168 366.0469055176361 .7799072266357 .208190918352 .3316040039347 .1502990723 341.6640930176336 .1780090332330 .3870849609324 .5961914062318 .8052062988 312.7095031738306 .9186096191301 .4324951172295 .9464111328290 .4602050781 285.5835876465281 .0119018555277 .0497131348273 .3923034668270 .3443908691 267.6012878418265 .1630859375263 .0296020508261 .2008972168259 .6769104004 258.1530151367256 .6290893555254 .8003997803253 .2763977051251 .7525024414 249.9237976074248 .0950927734245 .9615936279243 .8280944824241 .3898010254 238.6468048096235 .5989074707232 .246307373228 .5888977051224 .3218994141 219.7501068115214 .5686950684208 .7778015137209 .692199707209 .692199707 209.692199707 209.692199707 209.692199707 209.692199707 209.692199707 141.4203033447130 .7528076172110 .264083862391 .70195770264 -9999 -9999 -9999 -9999 -9999 -9999 -9999 -9999 -9999 -9999 -9999 -9999 -9999 -9999 -9999 -9999 -9999 -9999 -9999 -

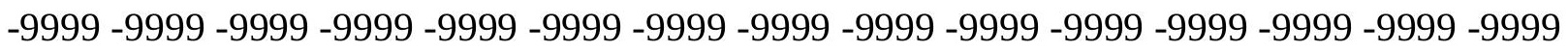
-9999 -9999 -9999 -9999 -9999 -9999 -9999 -9999 -9999 -9999 -9999 -9999 -9999 -9999 -9999 -9999 -9999 -9999-9999 -9999 -9999 -9999 -9999 -9999-9999 -9999 -9999 -9999 -9999 332.5577392578336 .5858459473340 .5983276367344 .5863952637348 .5396118164 352.4467163086356 .2945861816360 .0694885254363 .7554931641367 .3364868164 370.7929077148374 .1040344238377 .246887207380 .1941223145382 .9190979004 385.4656066895387 .7997436523389 .8987731934391 .7300720215393 .2375488281 394.3284301758394 .9110412598394 .929473877394 .2030029297393 .0445251465 391.520690918389 .4429626465385 .8315734863380 .5215454102374 .5809020996 366.9613037109359 .6465148926352 .6364135742346 .2359008789340 .1401977539 333.7396850586327 .6440124512321 .5483093262315 .4526062012309 .6617126465 305.3947143555302 .6516113281303 .2611999512305 .0899047852306 .9186096191 307.8330078125306 .6138000488306 .6138000488306 .9186096191306 .3091125488 304.1755981445302 .3468017578298 .6893920898293 .2033081055286 .1932067871 278.5736083984270 .9540100098263 .3344116211255 .7147064209248 .7046966553 242.6089935303236 .8179931641231 .9414978027227 .6744995117223 .7122955322 220.3596038818217 .0070037842214 .2639007568211 .2160949707208 .4730072021 205.425201416202 .0724945068198 .4151000977194 .4528961182190 .1858978271 185.9188995361183 .4806976318181 .3471984863179 .2136993408177 .0802001953 
175.2514038086173 .1179962158171 .5939941406170 .3748931885169 .7653045654 169.1557006836169 .1557006836169 .4604949951169 .7653045654170 .3748931885 170.9844970703171 .8988037109172 .8132019043173 .7274932861174 .337097168 175.2514038086173 .7274932861172 .8132019043172 .2035980225172 .2035980225 172.8132019043174 .0323028564175 .5561981201176 .7754058838178 .2993011475 179.2136993408179 .5184020996179 .5184020996179 .2136993408178 .604095459 177.9945068359177 .3849029541176 .165802002174 .9467010498173 .4226989746 172.5084075928172 .5084075928173 .1179962158174 .0323028564175 .2514038086 177.0802001953178 .9089050293180 .1280059814180 .7375946045181 .3471984863 181.6519012451181 .9566955566182 .261505127182 .261505127182 .261505127 182.261505127182 .261505127182 .5662994385182 .5662994385182 .5662994385 182.5662994385182 .87109375182 .87109375181 .6519012451179 .8231964111 176.7754058838173 .4226989746170 .070098877166 .7174987793163 .6696014404 160.6217956543157 .5738983154155 .1356048584152 .6972961426150 .5639038086 148.7351074219147 .5160064697143 .2489929199138 .9819946289134 .7149963379 130.1432037354125 .8762969971122 .5235977173121 .6092987061124 .0475006104 129.2288970947135 .9342041016141 .7250976562145 .0776977539145 .0776977539 143.8585968018144 .4682006836147 .2111968994153 .9165039062161 .2312927246 167.3269958496170 .070098877175 .5561981201179 .5184020996190 .1858978271 192.624206543192 .3193969727197 .1959991455203 .9011993408210 .9113006592 214.2639007568214 .7960357666214 .1593780518212 .9534301758211 .9741668701 211.5799255371211 .5740509033211 .6491241455211 .6903076172211 .7456207275 211.9585723877212 .5663909912214 .4893951416219 .0895996094225 .8022918701 231.4492950439236 .5899047852227 .4971618652211 .2921142578193 .5386047363 188.3571929932181 .3471984863174 .6419067383168 .5462036133161 .5361022949 151.4781951904141 .7250976562136 .2389984131132 .5814971924128 .9241027832 124.6570968628120 .6949005127117 .647102356115 .818397522115 .5136032104 115.818397522116 .7326965332118 .2565994263119 .7806015015121 .3044967651 122.8283996582123 .7427978516124 .3523025513124 .6570968628124 .3523025513 123.7427978516122 .5235977173120 .6949005127118 .5614013672116 .4279022217 114.2944030762112 .1608963013110 .3321990967108 .8082962036108 .1986999512 108.5035018921110 .0273971558112 .7705001831117 .9517974854124 .6570968628 132.2767028809141 .1154937744159 .0977935791169 .7653045654179 .5184020996 188.966796875199 .0247039795209 .0825958252209 .692199707209 .692199707 209.692199707 215.4830932617238.9515075684265.7726135254292.2889099121 315.4526062012333 .1301879883345 .0168151855352 .6364135742357 .5129089355 361.475189209365 .132598877368 .4851989746371 .5331115723373 .9713134766 376.104888916377 .0191955566377 .324005127376 .7143859863375 .1904907227 372.7521972656369 .7043151855365 .7421875361 .475189209356 .9034118652 351.7219848633346 .5407104492341 .0545959473335 .2636108398329 .7774963379 323.6817932129317 .8908996582312 .1000061035306 .3091125488300 .8229064941 295.0320129395289 .8505859375284 .9740905762280 .4023132324276 .4400939941 273.0874938965270 .0396118164267 .6012878418265 .4678039551263 .6390991211 262.1152038574260 .5913085938259 .3721008301257 .8482055664256 .6290893555 255.1051025391253 .8860015869252 .3621063232250 .5334014893248 .7046966553 246.8759002686244 .7424926758242 .3041992188239 .5610961914236 .5133056641 
232.8558044434 229.1983947754224.6266021729 219.7501068115 214.2639007568 209.692199707 209.692199707209.692199707209.692199707209.692199707209.692199707 209.692199707145 .9920959473135 .0198059082117 .964378356999 .20024871826 79.80883789062 -9999 -9999 -9999 -9999 -9999 -9999 -9999 -9999 -9999 -9999 -9999 -9999 -9999 -9999 -9999 -9999 -9999 -9999 -9999 -9999 -9999 -9999 -9999 -9999 -9999 -9999 -9999 -9999 -9999 -9999-9999-9999-9999

-9999 -9999 -9999 -9999 -9999 -9999 -9999 -9999 -9999 -9999 -9999 -9999 -9999 -9999 -9999

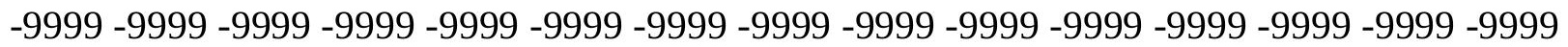
348.544342041352 .6268920898356 .668182373360 .6524963379364 .5635986328 368.3851623535372 .0936889648375 .6772460938379 .1104431152382 .3732910156 385.4437255859388 .2972412109390 .9040527344393 .2745056152395 .4378662109 397.3667907715398 .9935913086400 .2832946777401 .1761169434401 .5587463379 401.2380371094400 .2987976074398 .3964538574395 .450592041392 .6854553223390 .125 385.2484130859377 .324005127366 .9613037109358 .7320861816350 .8077087402 343.4927978516336 .4827880859330 .0823059082323 .6817932129317 .8908996582 313.0143127441308 .7473144531305 .0899047852302 .0421142578302 .9563903809 305.0899047852306 .9186096191308 .4425048828308 .7473144531307 .5281982422 304.1755981445303 .2611999512302 .6516113281301 .1276855469298 .9942016602 295.9464111328291 .3746032715285 .5835876465279 .1831970215272 .4779052734 265.7726135254259 .3721008301253 .2763977051247 .7902984619243 .2185058594 238.9515075684234 .9893035889231 .6367034912228 .2841033936225 .5410003662 222.4931030273219 .7501068115216 .7021942139213 .3495941162209 .692199707 205.7299957275201 .158203125196 .5863952637192 .624206543189 .2716064453 186.528503418184 .0901947021181 .3471984863178 .9089050293176 .7754058838 174.6419067383173 .1179962158172 .2035980225171 .2891998291170 .9844970703 170.9844970703171 .2891998291171 .8988037109172 .5084075928173 .1179962158 174.0323028564175 .2514038086175 .8609924316176 .165802002175 .5561981201 174.6419067383174 .0323028564173 .7274932861174 .0323028564174 .6419067383 175.5561981201176 .7754058838177 .6896972656178 .2993011475178 .604095459 178.604095459178 .604095459177 .9945068359177 .6896972656177 .0802001953 176.165802002174 .9467010498174 .0323028564173 .4226989746173 .4226989746 173.7274932861174 .6419067383175 .5561981201177 .0802001953178 .2993011475 179.5184020996180 .1280059814180 .7375946045181 .0424041748181 .3471984863 181.3471984863181 .6519012451181 .6519012451181 .9566955566181 .9566955566 182.261505127182 .261505127182 .261505127182 .5662994385182 .5662994385 182.261505127181 .3471984863179 .5184020996177 .0802001953174 .337097168 171.2891998291168 .5462036133165 .4983062744163 .0599975586160 .3170013428 158.1835021973156 .0500030518154 .2212982178152 .3925933838149 .9542999268 145.9920959473141 .1154937744136 .2389984131132 .2767028809128 .9241027832 125.2667007446123 .7427978516124 .6570968628128 .3144989014133 .8007049561 138.9819946289141 .7250976562143 .5538024902145 .0776977539146 .9064025879 147.8208007812149 .6495056152152 .6972961426156 .3547973633160 .3170013428 163.6696014404167 .3269958496169 .7653045654172 .2035980225176 .165802002 180.7375946045185 .3094024658194 .7577056885198 .4151000977200 .5485992432 199.6279602051197 .2974090576195 .7683410645195 .18359375195 .0416717529 195.2348022461195 .8950042725197 .197052002199 .3864898682201 .797164917 
204.6002197266208 .4740753174212 .9805755615217 .8829345703219 .2421569824 213.5088500977203 .9621429443193 .233795166187 .7476043701184 .0901947021 180.7375946045177 .3849029541173 .1179962158163 .6696014404146 .6015930176 143.5538024902139 .2868041992134 .1054992676128 .0097961426122 .5235977173 118.5614013672116 .7326965332116 .1231002808116 .4279022217117 .647102356 118.8662033081120 .3900985718121 .9140014648123 .1332015991124 .3523025513 124.9618988037125 .2667007446125 .2667007446124 .6570968628124 .0475006104 122.8283996582121 .6092987061120 .3900985718119 .1709976196116 .7326965332 114.2944030762112 .4656982422110 .9418029785110 .3321990967110 .3321990967 111.8561019897114 .5991973877118 .2565994263124 .3523025513130 .1432037354 138.3724975586150 .8686065674161 .5361022949172 .2035980225183 .4806976318 195.3672943115 207.25390625 209.692199707 209.692199707 209.692199707 216.3973999023246 .8759002686278 .8783874512306 .3091125488325 .8153076172 337.0922851562343 .7976074219348 .6741943359352 .941192627357 .8176879883 362.3894958496366 .6564941406370 .3139038086373 .3617858887375 .1904907227 376.104888916375 .495300293374 .2760925293371 .837890625368 .7900085449 364.8277893066360 .2560119629355 .379486084350 .1980895996345 .0168151855 339.5306091309333 .7396850586328 .2536010742322 .4627075195316 .6718139648 311.1856079102305 .3947143555299 .9085998535294 .4223937988288 .9363098145 283.7549133301279 .1831970215275 .2210083008272 .1730957031269 .7348022461 267.6012878418265 .7726135254264 .2486877441263 .0296020508261 .8103942871 260.5913085938259 .3721008301258 .1530151367256 .9338989258255 .7147064209 254.4956054688253 .2763977051251 .7525024414249 .9237976074248 .0950927734 245.9615936279243 .5233001709240 .7801971436237 .4275970459233 .7702026367 229.8079986572224 .9313964844219 .7501068115213 .6544036865209 .692199707 209.692199707 209.692199707209.692199707 209.692199707209.692199707 209.692199707 139.8963928223128 .0097961426106 .318038940486 .65369415283 -9999 -9999 -9999 -9999 -9999 -9999 -9999 -9999 -9999 -9999 -9999 -9999 -9999 -9999 -9999 -9999 -9999 -9999 -9999 -9999 -9999 -9999 -9999 -9999 -9999 -9999 -9999 -9999 -9999 -9999 -9999 -9999 -9999 -

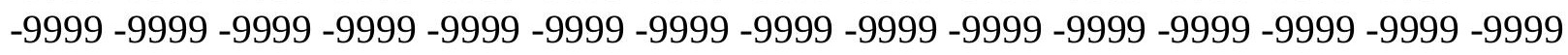
-9999 -9999 -9999 -9999 -9999 -9999 -9999 -9999 -9999 -9999 -9999 -9999 -9999 -9999 -9999 359.9274597168364 .0321960449368 .074005127372 .0315856934375 .8832702637 379.6054992676383 .1770629883386 .5724487305389 .7686767578392 .7430114746 395.4710998535397 .9273681641400 .086151123402 .0072021484403 .710144043 405.0916442871406 .0774230957406 .6047058105406 .622467041406 .0332641602 404.4613647461401 .8415222168399 .2684936523393 .1727905273388 .9057922363 384.6387939453378 .8479003906369 .399597168357 .208190918348 .0646057129 340.1401977539332 .5205993652325 .5104980469319 .1099853516313 .3190917969 307.8330078125305 .0899047852302 .3468017578300 .2132873535301 .4324951172 303.8707885742306 .3091125488308 .1377868652309 .0520935059308 .7473144531 306.9186096191302 .9563903809299 .2990112305298 .3846130371297 .1654968262 295.0320129395292 .2889099121288 .3266906738283 .7549133301278 .5736083984 272.7827148438266 .9917907715261 .5056152344256 .6290893555252 .0572967529 247.7902984619244 .4376983643241 .6945953369238 .3419952393235 .5989074707 233.1605987549230 .4176025391227 .6744995117224 .6266021729220 .9691925049 217.3117980957 213.0447998047208.4730072021 203.9011993408 199.6342926025 
195.9768066406192 .624206543189 .5764007568186 .528503418183 .7854003906 181.0424041748178 .604095459176 .4705963135175 .2514038086174 .337097168 173.7274932861173 .4226989746173 .4226989746173 .7274932861174 .337097168 174.9467010498175 .8609924316176 .7754058838177 .3849029541177 .3849029541 177.0802001953176 .4705963135175 .8609924316175 .5561981201175 .5561981201 175.5561981201176 .165802002176 .7754058838177 .3849029541177 .9945068359 177.9945068359177 .9945068359177 .9945068359177 .6896972656177 .3849029541 177.0802001953176 .4705963135175 .8609924316174 .9467010498174 .6419067383 174.6419067383174 .6419067383175 .2514038086176 .165802002177 .0802001953 177.9945068359178 .9089050293179 .5184020996180 .1280059814180 .432800293 180.7375946045180 .7375946045181 .0424041748181 .0424041748181 .3471984863 181.6519012451181 .6519012451181 .9566955566181 .9566955566182 .261505127 181.9566955566181 .6519012451180 .7375946045179 .2136993408177 .0802001953 174.9467010498172 .2035980225169 .7653045654167 .3269958496165 .1934967041 163.0599975586160 .9264984131159 .4026031494157 .5738983154155 .7451934814 153.3069000244149 .9542999268145 .3825073242140 .2012023926138 .0677032471 135.3246002197130 .7528076172127 .7050018311127 .4001998901129 .533706665 134.1054992676139 .5915985107141 .1154937744143 .2489929199146 .9064025879 152.3925933838149 .0399017334148 .1255950928149 .6495056152152 .3925933838 155.1356048584157 .5738983154160 .0122070312162 .4505004883164 .8887023926 167.9365997314171 .5939941406176 .165802002181 .6519012451185 .9188995361 188.3571929932187 .4429016113183 .7854003906181 .6519012451180 .773223877 179.9248199463179 .805557251180 .8011779785183 .0797576904186 .8520812988 191.4867248535194 .2539672852195 .5939941406199 .6523132324204 .2458190918 206.5487213135204 .6685028076199 .2105407715193 .5386047363189 .8811035156 186.2236938477 185.0045928955 184.3950042725 184.0901947021 183.1759033203 167.0222015381156 .6596069336149 .6495056152141 .4203033447132 .5814971924 124.9618988037120 .3900985718118 .2565994263117 .9517974854118 .2565994263 119.1709976196120 .3900985718121 .6092987061122 .8283996582124 .0475006104 124.9618988037125 .5715026855125 .8762969971125 .8762969971125 .2667007446 124.6570968628124 .0475006104123 .43800354123 .43800354123 .1332015991 120.3900985718117 .9517974854115 .818397522114 .2944030762113 .075302124 112.4656982422112 .7705001831113 .9896011353116 .1231002808119 .7806015015 123.7427978516127 .7050018311130 .7528076172142 .3347015381154 .2212982178 167.3269958496181 .0424041748194 .7577056885207 .5587005615209 .692199707 209.692199707 209.692199707223.7122955322 261.5056152344295.6416015625 314.5382080078323 .6817932129329 .4726867676334 .9588928223340 .749786377 347.1502990723353 .5508117676359 .9512023926365 .132598877369 .399597168 372.1426086426373 .3617858887373 .3617858887372 .1426086426369 .7043151855 366.6564941406362 .3894958496357 .8176879883352 .941192627347 .7597961426 342.2737121582336 .7875976562331 .3013916016325 .8153076172320 .3291931152 315.1477966309309 .6617126465304 .1755981445298 .6893920898293 .2033081055 288.0219116211282 .8406066895277 .9641113281274 .0018005371271 .2587890625 269.4301147461267 .9060974121266 .3822021484265 .1630859375263 .9439086914 262.7247924805261 .8103942871260 .8960876465259 .9816894531259 .0674133301 257.8482055664256 .9338989258255 .7147064209254 .4956054688252 .9716033936 
251.4476928711249 .6190032959247 .4855041504245 .0471954346241 .9994049072 238.6468048096234 .9893035889230 .4176025391225 .2362060547219 .4452972412 213.0447998047209.692199707209.692199707 209.692199707 209.692199707 209.692199707 209.692199707 145.0776977539132.8863067627 114.3311309814 93.9935073852573 .35293579102 -9999 -9999 -9999 -9999 -9999 -9999 -9999 -9999 -9999 -9999 -9999 -9999 -9999 -9999 -9999 -9999 -9999 -9999 -9999 -9999 -9999 -9999 -9999 -9999 -9999 -9999 -9999 -9999 -9999 -9999 -9999 -9999 -9999 -9999 -9999 -9999 -9999 -9999 -9999 -9999 -9999 -9999 -9999 -9999 -9999 -9999 -9999 -9999 -9999 -9999 -9999 -9999 -9999 -9999 -9999 -9999 -9999 -9999 -9999 -9999 -9999 -9999 370.686920166374 .7651672363378 .7538757324382 .627532959386 .3522338867 389.9077148438393 .2593688965396 .3810119629399 .2461547852401 .8291931152 404.1040039062406 .0313415527407 .6575927734409 .0463867188410 .1255187988 410.8201293945410 .9838256836410 .4807128906409 .1967468262407 .292388916 404.7546081543398 .6589050293393 .4776000977387 .9914855957382 .200592041 375.495300293366 .6564941406355 .0747070312344 .4071960449336 .4827880859 328.5584106445321 .2434997559314 .2334899902308 .7473144531304 .1755981445 300.5180969238298 .0798950195296 .5559082031297 .7750854492300 .8229064941 303.2611999512306 .0043029785307 .5281982422307 .8330078125306 .6138000488 303.8707885742299 .6037902832294 .7272033691293 .8128967285292 .5936889648 290.7650146484288 .0219116211284 .9740905762281 .0119018555276 .4400939941 271.8682861328266 .9917907715262 .7247924805258 .4577941895254 .8003997803 251.4476928711248 .7046966553246 .2664031982243 .8280944824241 .6945953369 239.5610961914237 .7324066162234 .9893035889231 .6367034912228 .2841033936 224.6266021729220 .3596038818215 .787902832211 .2160949707206 .9490966797 202.9868927002199 .329498291195 .6721038818192 .3193969727188 .966796875 185.9188995361183 .1759033203180 .7375946045178 .9089050293177 .9945068359 177.3849029541 176.7754058838176.4705963135176.4705963135176.7754058838 177.3849029541178 .2993011475178 .9089050293179 .2136993408179 .2136993408 178.604095459177 .9945068359177 .3849029541177 .0802001953176 .7754058838 176.7754058838177 .0802001953177 .3849029541177 .6896972656177 .9945068359 177.9945068359177 .9945068359177 .3849029541177 .0802001953177 .0802001953 177.0802001953176 .7754058838176 .4705963135176 .165802002175 .8609924316 175.8609924316175 .8609924316176 .165802002176 .7754058838177 .3849029541 177.9945068359178 .604095459179 .2136993408179 .5184020996179 .8231964111 180.1280059814180 .1280059814180 .432800293180 .432800293180 .7375946045 181.0424041748181 .3471984863181 .3471984863181 .6519012451181 .6519012451 181.3471984863180 .7375946045179 .8231964111178 .604095459177 .0802001953 174.9467010498173 .1179962158170 .9844970703168 .8509979248167 .0222015381 165.4983062744163 .974395752162 .4505004883161 .2312927246159 .7073974609 157.5738983154154 .8307952881152 .0877990723149 .3446960449146 .6015930176 142.0299072266136 .5437011719132 .2767028809130 .4479980469131 .3623962402 134.1054992676137 .1533050537139 .2868041992141 .7250976562144 .7729034424 146.9064025879146 .6015930176146 .9064025879148 .7351074219151 .1734008789 153.0021057129154 .2212982178155 .7451934814157 .5738983154159 .7073974609 162.4505004883165 .4983062744169 .1557006836172 .8132019043176 .4705963135 178.604095459179 .5184020996179 .8231964111174 .337097168170 .070098877 
168.241394043167 .6318054199168 .8509979248171 .8988037109175 .2514038086 185.0045928955186 .2236938477180 .7375946045187 .7476043701191 .4051055908 196.891204834197 .8054962158195 .0625191 .7097930908191 .1002960205192 .0146026611 187.4429016113188 .6620025635189 .5764007568187 .4429016113180 .432800293 171.2891998291162 .1457061768151 .7830047607139 .8963928223133 .4958953857 124.0475006104121 .6092987061120 .6949005127120 .6949005127121 .3044967651 122.2188034058123 .1332015991124 .0475006104124 .9618988037125 .5715026855 126.1809997559126 .1809997559125 .8762969971125 .5715026855124 .9618988037 124.3523025513124 .3523025513124 .3523025513124 .0475006104122 .5235977173 120.6949005127119 .1709976196117 .647102356116 .4279022217115 .2088012695 114.5991973877114 .5991973877115 .818397522117 .9517974854120 .3900985718 122.5235977173124 .6570968628126 .4858016968135 .9342041016150 .5639038086 166.1078948975181 .9566955566196 .891204834209 .692199707209 .692199707 209.692199707 209.692199707235.9037017822 282.8406066895294.4223937988 302.0421142578308 .7473144531316 .0621948242324 .2914123535333 .4349060059 342.8833007812351 .4172058105358 .7320861816364 .2182006836367 .8756103516 369.7043151855370 .009185791369 .0947875977366 .6564941406363 .303894043 359.036895752354 .1603088379349 .2838134766344 .1023864746338 .6163024902 333.4349060059328 .2536010742323 .0722045898317 .8908996582312 .7095031738 307.5281982422302 .3468017578297 .4703063965292 .2889099121287 .1076049805 281.9262084961 277.3544921875 272.7827148438270.9540100098 269.4301147461 268.2109069824266 .9917907715265 .7726135254264 .8583068848263 .9439086914 263.0296020508262 .4200134277261 .5056152344260 .8960876465259 .9816894531 259.0674133301258 .1530151367257 .2385864258256 .0195007324254 .8003997803 253.2763977051251 .4476928711249 .3141937256246 .8759002686243 .8280944824 240.1707000732236 .2084960938231 .3318939209225 .8457946777219 .4452972412 212.1304016113209 .692199707209 .692199707209 .692199707209 .692199707 209.692199707 209.692199707 138.0677032471 124.9618988037100 .3746948242 78.91652679443 -9999 -9999 -9999 -9999 -9999 -9999 -9999 -9999 -9999 -9999 -9999 -9999 -9999 -9999 -9999 -9999 -9999 -9999 -9999 -9999 -9999 -9999 -9999 -9999 -9999 -9999 -9999 -9999 -9999-9999-9999-9999

-9999 -9999 -9999 -9999 -9999 -9999 -9999 -9999 -9999 -9999 -9999 -9999 -9999 -9999 -9999

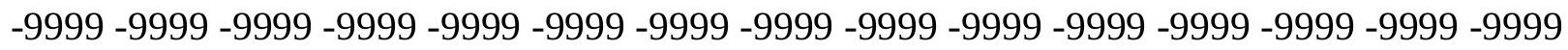
380.7828369141384 .7858886719388 .6673583984392 .3930358887395 .9300231934 399.2401123047402 .2892456055405 .046081543407 .4798583984409 .5556335449 411.2702026367412 .5901794434413 .5970458984414 .2603149414414 .556854248 414.3705749512413 .5492858887411 .8084411621408 .9296569824404 .7546081543 399.5733032227393 .4776000977387 .3818969727381 .2861938477373 .9713134766 363.9135131836352 .0267944336341 .0545959473333 .1301879883325 .2056884766 317.5860900879310 .5759887695303 .8707885742299 .9085998535296 .8606872559 294.4223937988292 .5936889648292 .5936889648294 .4223937988297 .1654968262 300.5180969238302 .9563903809304 .4802856445303 .8707885742301 .1276855469 296.8606872559291 .6794128418289 .8505859375288 .9363098145287 .7171936035 285.8884887695283 .4501953125280 .7070922852277 .3544921875273 .6971130371 270.0396118164266 .0773925781262 .4200134277259 .0674133301256 .3243103027 253.5812072754251 .4476928711249 .6190032959247 .7902984619246 .2664031982 
245.0471954346243 .5233001709240 .7801971436238 .0372009277234 .9893035889 231.6367034912227 .3697052002222 .7978973389218 .2261962891213 .959197998 209.9969024658206 .0346984863202 .3773040771198 .7198944092195 .3672943115 192.0146026611188 .6620025635185 .9188995361183 .7854003906182 .5662994385 181.9566955566181 .3471984863180 .432800293180 .1280059814180 .1280059814 180.7375946045181 .0424041748181 .3471984863181 .6519012451181 .3471984863 180.7375946045179 .8231964111179 .2136993408178 .604095459178 .2993011475 178.2993011475178 .2993011475178 .2993011475178 .604095459178 .604095459 178.2993011475177 .9945068359177 .6896972656177 .0802001953177 .3849029541 177.6896972656177 .6896972656177 .6896972656177 .3849029541177 .3849029541 177.3849029541 177.3849029541 177.3849029541 177.6896972656177.9945068359 178.2993011475178 .604095459178 .9089050293179 .2136993408179 .2136993408 179.5184020996179 .5184020996179 .8231964111179 .8231964111180 .1280059814 180.432800293180 .432800293180 .7375946045180 .7375946045180 .7375946045 180.432800293180 .1280059814179 .2136993408177 .9945068359176 .7754058838 175.2514038086173 .4226989746171 .8988037109170 .3748931885168 .8509979248 167.6318054199166 .4127044678165 .4983062744164 .5839996338163 .6696014404 162.1457061768160 .6217956543158 .7929992676157 .5738983154156 .0500030518 148.7351074219141 .4203033447136 .2389984131133 .8007049561133 .4958953857 134.1054992676135 .3246002197136 .8484954834138 .6772003174140 .8106994629 141.7250976562141 .7250976562144 .1634063721147 .5160064697151 .1734008789 151.1734008789151 .7830047607153 .0021057129154 .8307952881156 .3547973633 158.4882965088160 .9264984131163 .6696014404166 .4127044678168 .8509979248 170.9844970703171 .8988037109171 .2891998291167 .9365997314164 .5839996338 162.1457061768161 .5361022949162 .7552947998165 .4983062744171 .5939941406 181.0424041748176 .4705963135173 .7274932861175 .8609924316181 .0424041748 186.528503418189 .5764007568189 .5764007568188 .6620025635187 .4429016113 188.3571929932188 .0523986816189 .5764007568190 .795501709190 .1858978271 187.4429016113182 .5662994385174 .9467010498163 .0599975586149 .3446960449 140.8106994629135 .3246002197126 .7906036377124 .9618988037124 .3523025513 124.3523025513124 .9618988037125 .5715026855125 .8762969971126 .4858016968 126.7906036377126 .7906036377126 .7906036377126 .1809997559125 .2667007446 124.6570968628124 .3523025513124 .0475006104124 .0475006104124 .0475006104 123.43800354122 .5235977173121 .3044967651120 .3900985718119 .4757995605 118.2565994263117 .0374984741116 .4279022217116 .4279022217117 .342300415 118.5614013672120 .0852966309121 .3044967651122 .5235977173122 .8283996582 134.4102020264151 .4781951904169 .1557006836185 .9188995361200 .2438049316 209.692199707 209.692199707 209.692199707 209.692199707 239.2563018799 260.5913085938272 .4779052734281 .9262084961292 .5936889648304 .4802856445 317.5860900879330 .0823059082341 .6640930176351 .112487793358 .1224975586 362.9991149902365 .4374084473365 .7421875364 .8277893066362 .0846862793 358.7320861816354 .1603088379349 .2838134766344 .1023864746338 .9211120605 333.7396850586328 .8631896973323 .9866027832319 .1099853516314 .5382080078 309.9664916992305 .3947143555300 .5180969238295 .9464111328291 .0697937012 286.4979858398281 .6214904785277 .3544921875274 .0018005371271 .8682861328 270.3443908691269 .1253051758267 .9060974121266 .9917907715266 .0773925781 
265.1630859375264 .2486877441263 .6390991211263 .0296020508262 .4200134277 261.8103942871261 .2008972168260 .5913085938259 .9816894531259 .0674133301 258.1530151367256 .9338989258255 .4098968506253 .5812072754251 .4476928711 248.7046966553245 .6567993164241 .6945953369237 .4275970459231 .9414978027 226.150604248219 .1405029297211 .2160949707209 .692199707209 .692199707 209.692199707 209.692199707 209.692199707 144.1634063721 130.4479980469 105.77484893884 .7707061767666 .5648651123 -9999 -9999 -9999 -9999 -9999 -9999 -9999 -9999 -9999 -9999 -9999 -9999 -9999 -9999 -9999 -9999 -9999 -9999 -9999 -9999 -9999 -9999 -9999 -9999-9999 -9999 -9999 -9999 -9999 -9999 -9999

-9999 -9999 -9999 -9999 -9999 -9999 -9999 -9999 -9999 -9999 -9999 -9999 -9999 -9999 -9999 -9999 -9999 -9999 -9999 -9999 -9999 -9999 -9999 -9999 -9999 -9999 -9999 -9999 -9999 -9999 390.169128418394 .0493164062397 .7664794922401 .2884521484404 .5659179688 407.556640625410 .2190551758412 .5182800293414 .4419555664415 .9371032715 417.0070495605417 .6105651855417 .7973022461417 .5572509766416 .8254089355 415.5264282227413 .5195007324410 .4706420898405 .9737854004398 .9637145996 392.5632019043386 .7723083496380 .066986084372 .4473876953362 .9991149902 350.8077087402340 .4450073242331 .9110107422323 .3770141602315 .1477966309 308.4425048828302 .3468017578297 .1654968262293 .5080871582291 .0697937012 289.2410888672 288.0219116211287.1076049805 286.8027954102 289.8505859375 293.8128967285297 .1654968262298 .6893920898296 .8606872559292 .2889099121 286.1932067871285.5835876465 284.9740905762 284.0596923828 282.5357971191 281.0119018555278 .8783874512276 .1353149414273 .3923034668270 .3443908691 267.2966003418264 .2486877441261 .5056152344259 .0674133301256 .6290893555 254.8003997803252 .9716033936251 .7525024414250 .5334014893249 .3141937256 248.3999023438247 .1806945801245 .0471954346242 .9136962891240 .1707000732 237.7324066162233 .4653930664228 .8936004639224 .6266021729220 .6643981934 216.7021942139212 .7400054932209 .0825958252205 .425201416202 .0724945068 198.7198944092195 .3672943115192 .0146026611189 .2716064453188 .6620025635 188.0523986816 187.1381072998 185.6141052246184.3950042725 184.3950042725 184.699798584184 .699798584184 .699798584184 .3950042725183 .7854003906 182.87109375181 .9566955566181 .0424041748180 .432800293180 .1280059814 179.8231964111179 .8231964111179 .8231964111179 .5184020996179 .5184020996 179.2136993408178 .9089050293178 .604095459178 .2993011475178 .2993011475 178.604095459178 .9089050293178 .9089050293178 .9089050293178 .9089050293 178.9089050293178 .604095459178 .9089050293178 .9089050293178 .9089050293 178.604095459178 .604095459178 .9089050293178 .9089050293178 .9089050293 179.2136993408179 .2136993408179 .2136993408179 .5184020996179 .5184020996 179.8231964111179 .8231964111180 .1280059814180 .1280059814179 .8231964111 179.5184020996179 .2136993408178 .2993011475177 .3849029541176 .4705963135 175.2514038086173 .7274932861172 .5084075928171 .2891998291170 .3748931885 169.4604949951168 .8509979248168 .241394043167 .9365997314167 .3269958496 166.7174987793165 .8031005859164 .2792053223162 .7552947998159 .4026031494 153.3069000244146 .2969055176139 .8963928223137 .7628936768136 .5437011719 135.0198059082134 .4102020264134 .4102020264135 .6293945312137 .1533050537 138.0677032471139 .2868041992141 .7250976562144 .4682006836147 .2111968994 148.4304046631149 .3446960449150 .5639038086152 .6972961426153 .9165039062 
155.7451934814157 .5738983154159 .7073974609161 .5361022949163 .3648071289 164.5839996338165 .1934967041164 .2792053223162 .4505004883160 .3170013428 158.7929992676158 .4882965088159 .7073974609162 .7552947998167 .6318054199 171.2891998291170 .9844970703170 .070098877171 .2891998291175 .5561981201 180.7375946045183 .4806976318184 .699798584185 .0045928955185 .3094024658 185.9188995361186 .8332977295188 .3571929932189 .8811035156190 .795501709 190.4907073975189 .5764007568186 .8332977295173 .1179962158158 .7929992676 146.6015930176141 .7250976562135 .9342041016129 .8385009766128 .3144989014 128.0097961426128 .0097961426128 .0097961426128 .3144989014128 .3144989014 128.0097961426127 .7050018311127 .0953979492126 .4858016968125 .2667007446 124.0475006104123 .43800354123 .43800354123 .43800354123 .7427978516123 .43800354 123.1332015991122 .8283996582122 .5235977173122 .2188034058120 .3900985718 118.8662033081117 .9517974854117 .647102356117 .9517974854118 .5614013672 119.1709976196120 .0852966309120 .9997024536121 .3044967651120 .0852966309 136.5437011719155 .1356048584174 .337097168190 .795501709201 .158203125 207.8634033203 209.692199707 209.692199707 209.692199707 221.883605957 237.4275970459250 .8381958008265 .4678039551282 .2309875488299 .9085998535 316.6718139648331 .3013916016343 .1879882812351 .7219848633357 .5129089355 360.2560119629360 .8656005859359 .6465148926356 .5986022949352 .941192627 348.0646057129343 .1879882812338 .0067138672332 .8252868652327 .9487915039 323.3770141602319 .1099853516314 .8429870605310 .5759887695306 .6138000488 302.6516113281298 .6893920898294 .4223937988290 .1553955078285 .8884887695 281.9262084961278 .2687988281275 .2210083008273 .0874938965271 .5635070801 270.6492004395269 .4301147461268 .2109069824267 .2966003418266 .3822021484 265.7726135254265 .1630859375264 .5534973145264 .2486877441263 .9439086914 263.3344116211263 .0296020508262 .4200134277261 .8103942871261 .2008972168 260.2864990234259 .0674133301257 .5433959961255 .7147064209253 .5812072754 250.8381958008247 .4855041504243 .5233001709238 .6468048096232 .8558044434 226.150604248218 .5308990479209 .9969024658209 .692199707209 .692199707 209.692199707 209.692199707 209.692199707 136.5437011719 111.3729629517 92.5101318359475 .22673034668 -9999 -9999 -9999 -9999 -9999 -9999 -9999 -9999 -9999 -9999 -9999 -9999 -9999 -9999 -9999 -9999 -9999 -9999 -9999 -9999 -9999 -9999 -9999 -9999 -9999-9999-9999-9999-9999-9999-9999

-9999 -9999 -9999 -9999 -9999 -9999 -9999 -9999 -9999 -9999 -9999 -9999 -9999 -9999 -9999 -9999 -9999 -9999 -9999 -9999 -9999 -9999 -9999 -9999 -9999 -9999 -9999 -9999 -9999 -9999 398.8090820312402 .5117492676406 .0145874023409 .2666931152412 .2164611816 414.8117980957417 .0035095215418 .7903442383420 .125420 .959197998421 .2737121582 421.0229492188420 .2122192383418 .8199768066416 .8101196289414 .1029968262 410.6571960449406 .2785949707398 .9637145996391 .6488952637384 .6387939453 378.8479003906372 .4473876953363 .303894043351 .7219848633340 .749786377 332.5205993652324 .2914123535315 .4526062012306 .9186096191301 .4324951172 296.2510986328292 .2889099121288 .9363098145286 .4979858398284 .9740905762 284.0596923828283 .4501953125283 .1453857422282 .8406066895282 .8406066895 285.2789001465286 .1932067871282 .2309875488282 .2309875488281 .6214904785 281.0119018555280 .0975036621278 .8783874512277 .3544921875275 .8305053711 274.0018005371271 .5635070801269 .1253051758266 .6870117188264 .2486877441 
261.8103942871259 .6769104004257 .8482055664256 .3243103027255 .1051025391 253.8860015869252 .9716033936252 .0572967529251 .1428985596250 .5334014893 249.3141937256248 .0950927734246 .2664031982244 .1329040527241 .3898010254 238.0372009277234 .3798065186230 .4176025391226 .7601013184223 .1027069092 219.7501068115216 .0926971436212 .7400054932209 .3874053955206 .0346984863 202.6820983887199 .9389953613197 .8054962158196 .5863952637195 .3672943115 194.1481018066192 .3193969727190 .795501709189 .8811035156189 .2716064453 188.966796875188 .6620025635187 .7476043701186 .8332977295185 .9188995361 184.699798584183 .1759033203182 .87109375182 .5662994385181 .9566955566 181.6519012451181 .6519012451181 .3471984863181 .0424041748180 .7375946045 180.432800293180 .1280059814179 .8231964111179 .8231964111180 .1280059814 180.432800293180 .7375946045180 .7375946045180 .432800293180 .432800293 180.432800293180 .432800293180 .1280059814179 .8231964111179 .5184020996 179.2136993408178 .9089050293178 .9089050293178 .9089050293178 .9089050293 178.9089050293178 .9089050293178 .9089050293178 .9089050293179 .2136993408 179.2136993408179 .2136993408179 .2136993408179 .2136993408178 .9089050293 178.2993011475177 .6896972656177 .0802001953176 .165802002174 .9467010498 174.0323028564172 .8132019043172 .2035980225171 .2891998291170 .9844970703 170.6797027588170 .6797027588170 .6797027588170 .6797027588170 .6797027588 169.7653045654168 .5462036133165 .8031005859161 .8408966064156 .6596069336 151.1734008789146 .6015930176143 .8585968018141 .7250976562138 .0677032471 134.1054992676133 .1911010742133 .8007049561135 .0198059082139 .5915985107 137.4580993652139 .2868041992141 .4203033447143 .2489929199144 .7729034424 146.2969055176147 .8208007812149 .9542999268151 .7830047607153 .6116943359 155.4403991699156 .9642944336158 .1835021973159 .0977935791159 .7073974609 160.0122070312159 .4026031494158 .4882965088157 .5738983154156 .9642944336 156.9642944336158 .1835021973160 .9264984131163 .974395752165 .8031005859 166.7174987793167 .0222015381168 .8509979248171 .8988037109175 .5561981201 178.604095459180 .432800293181 .6519012451182 .5662994385183 .4806976318 185.0045928955186 .2236938477187 .7476043701189 .2716064453190 .4907073975 190.795501709187 .4429016113178 .604095459166 .7174987793153 .9165039062 145.6873016357139 .5915985107135 .3246002197132 .8863067627131 .6672058105 131.3623962402131 .0576019287131 .0576019287130 .4479980469129 .8385009766 128.9241027832128 .0097961426126 .7906036377125 .2667007446123 .7427978516 122.5235977173122 .5235977173122 .8283996582123 .1332015991123 .1332015991 123.1332015991123 .1332015991123 .1332015991122 .5235977173121 .6092987061 120.3900985718119 .4757995605118 .8662033081118 .8662033081118 .8662033081 119.4757995605120 .0852966309120 .9997024536121 .6092987061119 .7806015015 120.6949005127138 .9819946289159 .7073974609180 .432800293187 .7476043701 193.8433074951200 .2438049316206 .9490966797209 .692199707209 .692199707 209.692199707218 .2261962891237 .1228027344259 .0674133301281 .6214904785 302.9563903809320 .9388122559334 .9588928223345 .0168151855351 .4172058105 354.4650878906355 .0747070312353 .5508117676350 .1980895996345 .9310913086 340.749786377335 .5683898926330 .3870849609325 .5104980469320 .9388122559 316.9765014648313 .3190917969309 .6617126465306 .3091125488303 .2611999512 299.9085998535296 .5559082031292 .8984985352289 .2410888672285 .5835876465 
282.2309875488279 .1831970215276 .4400939941274 .6113891602273 .3923034668 272.1730957031270 .9540100098269 .4301147461268 .5156860352267 .6012878418 266.9917907715266 .3822021484266 .0773925781265 .7726135254265 .4678039551 265.4678039551265 .1630859375264 .8583068848264 .5534973145264 .2486877441 263.6390991211262 .7247924805261 .8103942871260 .2864990234258 .4577941895 256.0195007324252 .9716033936249 .6190032959245 .0471954346239 .8659057617 233.7702026367226 .4553985596217 .9214019775209 .692199707209 .692199707 209.692199707 209.692199707 209.692199707 143.8585968018 128.6192932129 105.9052276611 86.0137405395567 .34675598145 -9999 -9999 -9999 -9999 -9999 -9999 -9999 -9999 -9999 -9999 -9999 -9999 -9999 -9999 -9999 -9999 -9999 -9999 -9999 -9999 -9999 -9999 -9999 -9999 -9999 -9999 -9999 -9999-9999 -9999 -9999 -9999 -9999 -9999 -9999 -9999 -9999 -9999 -9999 -9999 -9999 -9999 -9999 -9999 -9999 -9999 -9999 -9999 -9999 -9999 -9999 -9999 -9999 -9999 -9999 -9999 -9999 -9999 -9999 -9999 -9999 410.1375427246413.3647155762 416.285736084418.8395080566420.9579772949 422.6319274902423 .8240356445424 .4859313965424 .5749816895424 .0160217285 422.758026123420 .7402648926417 .9930419922414 .478515625410 .1428222656 404.7546081543397 .4397888184390 .125382 .8100891113376 .104888916370 .3139038086 363.9135131836355 .6842041016344 .1023864746333 .4349060059326 .1200866699 318.5004882812310 .5759887695303 .2611999512297 .4703063965292 .5936889648 288.6315002441285 .5835876465283 .4501953125281 .9262084961281 .0119018555 280.4023132324280 .0975036621279 .7927856445279 .4880065918279 .1831970215 278.8783874512278 .5736083984278 .2687988281277 .3544921875276 .4400939941 275.2210083008273 .6971130371272 .1730957031270 .6492004395268 .8204956055 266.9917907715264 .8583068848262 .7247924805260 .5913085938258 .7626037598 257.5433959961256 .3243103027255 .4098968506254 .4956054688253 .8860015869 253.2763977051252 .6669006348252 .0572967529251 .4476928711250 .8381958008 249.6190032959248 .3999023438246 .5711975098244 .1329040527241 .6945953369 238.6468048096235 .5989074707232 .246307373229 .5032043457226 .150604248 223.1027069092220 .054901123216 .7021942139213 .6544036865210 .6065063477 208.1681976318206 .3394927979205 .1204071045203 .596496582201 .7678070068 199.329498291 197.500793457195.9768066406 194.7577056885 193.8433074951 192.624206543191 .7097930908190 .4907073975189 .2716064453187 .7476043701 186.528503418185 .9188995361185 .3094024658184 .699798584184 .0901947021 183.7854003906183 .1759033203182 .87109375182 .5662994385182 .261505127 181.9566955566181 .6519012451181 .6519012451181 .9566955566182 .261505127 182.5662994385182 .5662994385182 .261505127182 .261505127182 .261505127 181.9566955566181 .6519012451181 .0424041748180 .1280059814179 .5184020996 179.2136993408178 .9089050293178 .9089050293178 .604095459178 .604095459 178.604095459178 .604095459178 .604095459178 .604095459178 .604095459178 .604095459 178.604095459178 .604095459178 .2993011475177 .6896972656177 .0802001953 176.4705963135175 .8609924316174 .9467010498174 .0323028564173 .4226989746 172.5084075928172 .2035980225171 .8988037109171 .8988037109172 .2035980225 172.5084075928173 .1179962158173 .4226989746173 .1179962158171 .2891998291 168.241394043164 .2792053223160 .0122070312156 .0500030518152 .6972961426 151.1734008789149 .6495056152145 .0776977539135 .0198059082134 .7149963379 134.4102020264134 .7149963379138 .9819946289136 .2389984131137 .4580993652 
138.9819946289140 .2012023926141 .4203033447142 .9441986084145 .0776977539 147.5160064697149 .6495056152152 .0877990723153 .9165039062154 .8307952881 155.4403991699155 .7451934814156 .0500030518156 .3547973633156 .3547973633 156.0500030518156 .0500030518156 .0500030518156 .6596069336157 .878692627 159.4026031494160 .9264984131162 .4505004883163 .6696014404164 .5839996338 166.4127044678169 .1557006836171 .8988037109174 .6419067383176 .7754058838 178.604095459180 .1280059814181 .3471984863182 .5662994385183 .7854003906 184.699798584186 .2236938477188 .0523986816189 .2716064453187 .4429016113 182.261505127173 .7274932861163 .6696014404153 .9165039062145 .6873016357 140.2012023926137 .1533050537135 .6293945312135 .0198059082134 .7149963379 134.1054992676133 .1911010742131 .9720001221130 .7528076172129 .2288970947 127.4001998901125 .5715026855124 .0475006104122 .8283996582122 .5235977173 122.5235977173122 .5235977173122 .8283996582123 .1332015991123 .1332015991 122.8283996582122 .5235977173121 .9140014648120 .9997024536120 .3900985718 120.0852966309119 .7806015015119 .7806015015120 .0852966309120 .3900985718 120.9997024536120 .9997024536120 .3900985718118 .8662033081120 .9997024536 140.2012023926157 .2691040039168 .8509979248177 .3849029541185 .0045928955 193.233795166201 .7678070068209 .692199707209 .692199707209 .692199707 209.692199707236 .8179931641264 .2486877441289 .5458984375310 .8807983398 327.0344848633338 .0067138672344 .7120056152348 .0646057129348 .6741943359 346.845489502342 .8833007812338 .0067138672332 .5205993652326 .7296142578 321.5483093262316 .9765014648313 .3190917969309 .9664916992306 .9186096191 304.4802856445302 .0421142578299 .6037902832296 .8606872559294 .4223937988 291.3746032715288 .3266906738285 .5835876465282 .5357971191279 .7927856445 277.6592102051276 .1353149414274 .9161987305274 .0018005371272 .1730957031 270.6492004395269 .4301147461268 .8204956055268 .2109069824267 .6012878418 267.6012878418267 .2966003418267 .2966003418267 .2966003418267 .2966003418 267.2966003418267 .2966003418266 .9917907715266 .6870117188266 .0773925781 265.4678039551264 .5534973145263 .0296020508261 .2008972168258 .4577941895 255.4098968506251 .4476928711246 .8759002686241 .0850067139234 .3798065186 226.4553985596217 .3117980957209 .692199707209 .692199707209 .692199707 209.692199707 209.692199707 136.5437011719120.999702453697.42169189453 77.57913970947 -9999 -9999 -9999 -9999 -9999 -9999 -9999 -9999 -9999 -9999 -9999 -9999

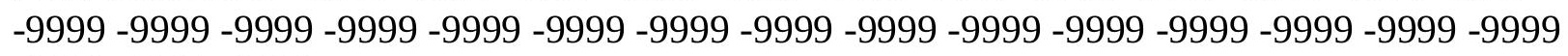
$-9999-9999-9999$

-9999 -9999 -9999 -9999 -9999 -9999 -9999 -9999 -9999 -9999 -9999 -9999 -9999 -9999 -9999

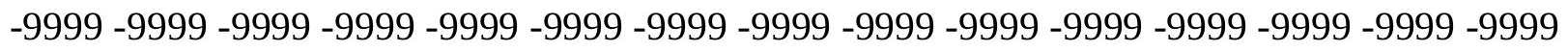
-9999 416.8852233887 419.7774353027422.3026733398424.390411377425.9774475098 427.0526733398427 .5909118652427 .4950561523426 .6987915039425 .1495361328 422.759185791419 .3593139648415 .0287780762409 .8288269043403 .8403015137 395.3063049316387 .686706543380 .6766052246373 .9713134766367 .8756103516 362.3894958496355 .9890136719348 .3693847656336 .7875976562327 .3392028809 320.9388122559314 .2334899902307 .5281982422300 .8229064941295 .3367919922 290.4602050781286 .4979858398283 .7549133301281 .3167114258279 .7927856445 278.5736083984277 .6592102051277 .3544921875276 .7449035645276 .4400939941 276.1353149414275 .8305053711275 .2210083008274 .3066101074273 .3923034668 
272.1730957031270 .3443908691268 .8204956055266 .9917907715265 .1630859375 263.6390991211262 .4200134277260 .2864990234258 .4577941895256 .9338989258 255.7147064209254 .8003997803254 .1907958984253 .8860015869253 .2763977051 252.9716033936252 .6669006348252 .6669006348252 .3621063232251 .7525024414 251.4476928711250 .5334014893249 .6190032959248 .3999023438246 .5711975098 244.4376983643242 .3041992188239 .5610961914237 .4275970459234 .9893035889 232.5511016846229 .8079986572227 .0648956299224 .0171051025220 .9691925049 218.2261962891216 .0926971436214 .2639007568213 .0447998047212 .1304016113 209.0825958252 206.3394927979 203.9011993408 201.7678070068200.2438049316 198.7198944092197 .1959991455195 .6721038818194 .4528961182192 .9290008545 191.4051055908190 .1858978271189 .2716064453188 .3571929932187 .4429016113 186.8332977295186 .2236938477185 .6141052246185 .0045928955184 .699798584 184.0901947021183 .7854003906183 .7854003906183 .7854003906183 .7854003906 184.0901947021184 .3950042725184 .3950042725184 .3950042725184 .0901947021 184.0901947021183 .7854003906183 .4806976318181 .9566955566180 .7375946045 180.1280059814179 .5184020996179 .2136993408179 .2136993408178 .9089050293 178.9089050293178 .604095459178 .604095459178 .604095459178 .604095459 178.604095459178 .2993011475178 .2993011475177 .9945068359177 .6896972656 177.3849029541176 .7754058838176 .165802002175 .5561981201174 .6419067383 174.0323028564173 .4226989746173 .1179962158172 .5084075928172 .5084075928 172.5084075928172 .8132019043173 .4226989746174 .337097168174 .9467010498 175.5561981201173 .1179962158170 .070098877166 .4127044678163 .0599975586 160.0122070312157 .878692627156 .9642944336156 .9642944336157 .2691040039 145.9920959473139 .5915985107137 .1533050537136 .2389984131135 .9342041016 136.2389984131136 .5437011719137 .1533050537138 .0677032471139 .2868041992 140.5059967041142 .9441986084145 .3825073242148 .1255950928150 .5639038086 152.6972961426153 .3069000244153 .3069000244153 .6116943359153 .6116943359 153.9165039062154 .2212982178154 .8307952881155 .4403991699156 .0500030518 156.9642944336157 .878692627158 .4882965088159 .4026031494160 .3170013428 161.2312927246162 .4505004883164 .2792053223166 .7174987793169 .1557006836 171.5939941406174 .0323028564175 .8609924316177 .6896972656179 .2136993408 180.432800293181 .3471984863181 .9566955566182 .261505127185 .3094024658 187.4429016113187 .4429016113185 .3094024658180 .432800293172 .5084075928 161.2312927246150 .5639038086144 .1634063721141 .4203033447139 .8963928223 138.9819946289138 .3724975586137 .4580993652136 .5437011719134 .7149963379 132.8863067627130 .7528076172128 .3144989014126 .1809997559124 .3523025513 123.1332015991122 .2188034058121 .9140014648122 .2188034058122 .2188034058 122.5235977173122 .5235977173122 .5235977173122 .2188034058121 .9140014648 121.6092987061121 .3044967651120 .9997024536120 .9997024536120 .6949005127 120.6949005127120 .9997024536120 .9997024536120 .9997024536120 .6949005127 120.3900985718119 .7806015015120 .6949005127135 .3246002197148 .1255950928 159.0977935791169 .1557006836178 .9089050293189 .2716064453199 .329498291 209.0825958252209 .692199707209 .692199707217 .6165924072248 .0950927734 276.7449035645300 .5180969238318 .1957092285329 .7774963379336 .7875976562 340.749786377341 .3593139648339 .2258911133334 .9588928223329 .4726867676 323.0722045898316 .9765014648311 .7951965332307 .8330078125304 .7850952148 
302.3468017578300 .5180969238298 .9942016602297 .4703063965295 .9464111328 294.1176147461292 .2889099121290 .1553955078287 .7171936035285 .2789001465 282.8406066895280 .7070922852278 .5736083984277 .0497131348275 .5257873535 274.3066101074273 .0874938965271 .5635070801270 .6492004395269 .7348022461 269.1253051758268 .8204956055268 .8204956055268 .8204956055268 .8204956055 269.1253051758269 .1253051758269 .4301147461269 .4301147461269 .4301147461 269.4301147461269 .4301147461269 .1253051758268 .2109069824267 .2966003418 265.7726135254263 .9439086914261 .2008972168257 .8482055664253 .8860015869 248.7046966553242 .6089935303235 .2940979004226 .4553985596216 .3973999023 209.692199707 209.692199707 209.692199707 209.692199707 145.6873016357 128.9241027832108 .557075500588 .4962081909268 .8278427124 -9999 -9999 -9999 -9999 -9999 -9999 -9999 -9999 -9999 -9999 -9999 -9999 -9999 -9999 -9999 -9999 -9999 -9999 -9999 -9999 -9999 -9999 -9999 -9999 -9999 -9999 -9999 -9999-9999

-9999 -9999 -9999 -9999 -9999 -9999 -9999 -9999 -9999 -9999 -9999 -9999 -9999 -9999 - -999 -9999 -9999 -9999 -9999 -9999 -9999 -9999 -9999 -9999 -9999 -9999 -9999 -9999 -9999 -9999 -9999 422.7217407227 425.2171020508 427.2781677246428.827545166429.8134460449 430.243560791430 .0176696777429 .0245361328427 .1995544434424 .514465332 420.8700866699416 .0626831055409 .8243713379402 .9259033203394 .0871887207 385.858001709378 .2383117676371 .5331115723366 .6564941406362 .0846862793 356.9034118652349 .8933105469339 .8353881836327 .6440124512322 .4627075195 317.2813110352311 .4903869629305 .3947143555299 .6037902832294 .4223937988 289.5458984375285 .5835876465282 .2309875488279 .7927856445277 .9641113281 276.7449035645275 .8305053711274 .9161987305274 .3066101074273 .6971130371 273.3923034668272 .4779052734271 .8682861328270 .9540100098269 .4301147461 267.9060974121266 .0773925781263 .9439086914261 .8103942871259 .6769104004 257.8482055664257 .2385864258254 .8003997803253 .5812072754252 .9716033936 252.3621063232252 .3621063232252 .0572967529252 .0572967529252 .0572967529 252.0572967529252 .0572967529251 .7525024414251 .7525024414251 .7525024414 251.4476928711250 .8381958008250 .5334014893249 .6190032959248 .3999023438 246.8759002686245 .0471954346243 .2185058594241 .6945953369240 .1707000732 238.3419952393236 .2084960938233 .7702026367230 .7223052979227 .9792938232 225.2362060547223 .1027069092221 .5787963867220 .054901123218 .2261962891 215.4830932617212 .7400054932209 .9969024658207 .5587005615205 .425201416 203.596496582201 .7678070068199 .9389953613198 .4151000977196 .891204834 195.3672943115194 .1481018066192 .9290008545191 .7097930908190 .795501709 189.8811035156188 .966796875188 .3571929932187 .4429016113186 .8332977295 186.528503418185 .9188995361185 .6141052246185 .6141052246185 .9188995361 185.9188995361 186.2236938477 186.528503418 186.2236938477 186.2236938477 185.9188995361185 .3094024658184 .3950042725182 .87109375181 .3471984863 180.7375946045180 .432800293180 .1280059814179 .8231964111179 .5184020996 179.2136993408178 .9089050293178 .604095459178 .604095459178 .604095459 178.604095459178 .2993011475178 .2993011475177 .9945068359177 .6896972656 177.0802001953176 .4705963135175 .8609924316175 .2514038086174 .6419067383 174.337097168173 .7274932861173 .1179962158172 .8132019043172 .8132019043 172.8132019043173 .1179962158173 .4226989746174 .337097168174 .9467010498 174.9467010498173 .4226989746170 .9844970703167 .9365997314165 .1934967041 
163.0599975586161 .5361022949160 .9264984131160 .6217956543158 .1835021973 152.0877990723145 .3825073242141 .1154937744138 .9819946289138 .3724975586 137.7628936768136 .8484954834136 .2389984131137 .1533050537138 .3724975586 139.8963928223142 .0299072266144 .1634063721146 .6015930176148 .7351074219 150.5639038086151 .1734008789151 .4781951904151 .7830047607151 .7830047607 152.3925933838153 .0021057129154 .2212982178155 .4403991699156 .9642944336 157.878692627158 .4882965088158 .1835021973158 .1835021973158 .4882965088 159.4026031494160 .9264984131162 .4505004883164 .5839996338167 .0222015381 169.1557006836171 .5939941406173 .7274932861175 .5561981201177 .0802001953 178.2993011475179 .2136993408180 .1280059814181 .3471984863183 .4806976318 185.6141052246186 .8332977295186 .528503418185 .0045928955181 .0424041748 167.0222015381153 .0021057129148 .4304046631145 .6873016357144 .1634063721 143.2489929199142 .3347015381141 .4203033447139 .8963928223137 .7628936768 135.3246002197132 .2767028809129 .533706665126 .7906036377124 .9618988037 123.1332015991122 .2188034058121 .6092987061121 .6092987061121 .6092987061 121.6092987061121 .9140014648121 .9140014648121 .9140014648121 .6092987061 121.6092987061121 .6092987061121 .6092987061121 .9140014648121 .6092987061 121.3044967651121 .3044967651121 .3044967651121 .3044967651121 .3044967651 121.6092987061121 .9140014648122 .8283996582119 .4757995605129 .2288970947 141.4203033447153 .3069000244165 .1934967041176 .7754058838188 .0523986816 198.7198944092208 .4730072021209 .692199707209 .692199707231 .6367034912 262.4200134277288 .9363098145306 .3091125488318 .1957092285326 .4248962402 331.3013916016332 .8252868652330 .9966125488326 .7296142578320 .3291931152 313.0143127441306 .3091125488301 .4324951172298 .0798950195295 .9464111328 295.0320129395294 .1176147461293 .5080871582292 .8984985352292 .2889099121 291.3746032715290 .4602050781288 .9363098145287 .1076049805284 .9740905762 283.1453857422281 .0119018555279 .1831970215277 .3544921875275 .8305053711 274.6113891602273 .3923034668272 .1730957031271 .2587890625270 .6492004395 270.3443908691270 .0396118164270 .0396118164270 .0396118164270 .3443908691 270.6492004395270 .9540100098271 .2587890625271 .5635070801271 .8682861328 272.1730957031272 .1730957031272 .1730957031271 .8682861328271 .2587890625 270.3443908691268 .8204956055266 .6870117188263 .9439086914260 .5913085938 256.0195007324250 .5334014893243 .8280944824235 .9037017822226 .4553985596 215.4830932617209 .692199707209 .692199707209 .692199707209 .692199707 138.0677032471 120.694900512799 .1296234130978 .6024017334 -9999 -9999 -9999 -9999 -9999 -9999 -9999 -9999 -9999 -9999 -9999 -9999 -9999 -9999 -9999 -9999 -9999 -9999 -9999 -9999 -9999 -9999-9999-9999-9999-9999-9999-9999-9999

-9999 -9999 -9999 -9999 -9999 -9999 -9999 -9999 -9999 -9999 -9999 -9999 -9999 -9999 -9999 - -999 -9999 -9999 -9999 -9999 -9999 -9999 -9999 -9999 -9999 -9999 -9999 -9999 -9999 -9999 -9999 -9999 427.6198120117429.6529541016 431.176940918432.108795166432.4336547852 432.0972290039431 .0164489746429 .0118103027425 .8991394043421 .7813415527 416.7054443359410 .8503112793402 .0115966797393 .4776000977384 .9436035156 376.7143859863369 .399597168363 .303894043360 .2560119629357 .5129089355 352.941192627345 .0168151855332 .5205993652322 .7674865723318 .5004882812 314.2334899902309 .3569030762304 .4802856445299 .2990112305293 .8128967285 289.2410888672 284.9740905762 281.6214904785 278.8783874512276.7449035645 
275.2210083008274 .0018005371273 .0874938965272 .1730957031271 .2587890625 270.6492004395269 .7348022461268 .8204956055267 .6012878418266 .0773925781 264.2486877441262 .1152038574259 .6769104004256 .9338989258253 .8860015869 251.4476928711249 .3141937256249 .0093994141249 .0093994141249 .3141937256 249.6190032959249 .9237976074249 .9237976074250 .2286071777250 .5334014893 250.5334014893250 .5334014893250 .5334014893250 .8381958008250 .8381958008 250.8381958008250 .8381958008250 .5334014893250 .2286071777249 .6190032959 248.7046966553247 .4855041504246 .2664031982245 .3520050049244 .4376983643 243.2185058594241 .9994049072239 .2563018799236 .5133056641234 .0749969482 231.6367034912229 .5032043457227 .6744995117225 .8457946777223 .4075012207 220.9691925049218 .2261962891215 .4830932617212 .7400054932210 .6065063477 208.1681976318206 .3394927979204 .2059936523202 .3773040771200 .5485992432 199.329498291198 .1103057861196 .891204834195 .3672943115194 .1481018066 192.9290008545192 .0146026611190 .795501709190 .1858978271189 .2716064453 188.6620025635188 .3571929932187 .7476043701187 .7476043701187 .7476043701 188.0523986816188 .3571929932188 .6620025635188 .6620025635188 .3571929932 187.7476043701187 .1381072998185 .9188995361184 .0901947021182 .261505127 181.9566955566181 .9566955566181 .6519012451181 .0424041748180 .432800293 180.1280059814179 .5184020996179 .2136993408179 .2136993408178 .9089050293 178.9089050293178 .604095459178 .604095459177 .9945068359177 .6896972656 177.0802001953176 .4705963135175 .8609924316175 .5561981201174 .9467010498 174.337097168174 .0323028564173 .4226989746173 .1179962158172 .8132019043 172.5084075928172 .5084075928172 .8132019043173 .4226989746174 .0323028564 174.0323028564173 .1179962158171 .2891998291169 .1557006836167 .0222015381 165.1934967041163 .974395752163 .0599975586161 .8408966064158 .7929992676 154.8307952881149 .9542999268145 .9920959473142 .6394042969143 .8585968018 141.1154937744137 .4580993652136 .2389984131137 .1533050537138 .9819946289 140.2012023926141 .7250976562143 .5538024902145 .3825073242147 .2111968994 148.7351074219149 .6495056152149 .9542999268150 .2590942383150 .8686065674 151.4781951904152 .3925933838153 .6116943359155 .4403991699157 .5738983154 159.0977935791159 .0977935791157 .5738983154156 .9642944336156 .9642944336 157.878692627159 .4026031494160 .9264984131162 .7552947998164 .8887023926 167.0222015381169 .4604949951171 .5939941406173 .4226989746175 .2514038086 176.7754058838177 .6896972656178 .9089050293180 .432800293181 .9566955566 183.7854003906185 .3094024658186 .528503418185 .6141052246180 .432800293 170.6797027588160 .3170013428153 .6116943359150 .2590942383148 .1255950928 146.9064025879146 .2969055176145 .3825073242143 .8585968018141 .4203033447 138.0677032471134 .4102020264130 .7528076172127 .7050018311125 .2667007446 123.43800354121 .9140014648121 .3044967651120 .9997024536120 .9997024536 120.9997024536121 .3044967651121 .3044967651121 .6092987061121 .6092987061 121.6092987061121 .6092987061121 .9140014648121 .9140014648121 .9140014648 121.6092987061121 .6092987061121 .3044967651121 .6092987061121 .6092987061 122.2188034058122 .5235977173122 .5235977173120 .9997024536119 .1709976196 126.4858016968139 .2868041992152 .3925933838165 .1934967041177 .6896972656 188.966796875199 .0247039795207 .5587005615209 .692199707212 .1304016113 241.9994049072273 .0874938965286 .4979858398299 .6037902832311 .4903869629 
318.8052062988322 .4627075195322 .1578979492318 .5004882812311 .4903869629 302.9563903809295 .6416015625290 .4602050781288 .3266906738287 .7171936035 287.7171936035288 .0219116211288 .6315002441288 .9363098145289 .2410888672 289.2410888672288 .6315002441288 .0219116211286 .4979858398284 .9740905762 283.1453857422281 .3167114258279 .1831970215277 .6592102051275 .8305053711 274.6113891602273 .3923034668272 .4779052734271 .8682861328271 .5635070801 271.2587890625270 .9540100098270 .9540100098271 .2587890625271 .5635070801 271.8682861328272 .1730957031272 .7827148438273 .3923034668273 .6971130371 274.3066101074274 .6113891602274 .9161987305274 .9161987305274 .6113891602 274.3066101074273 .3923034668271 .8682861328269 .7348022461266 .9917907715 263.3344116211258 .4577941895252 .6669006348245 .6567993164237 .1228027344 226.7601013184214 .5686950684209 .692199707209 .692199707209 .692199707 $148.4304046631129 .8385009766108 .854179382388 .4990997314568 .55072784424-9999$ -9999 -9999 -9999 -9999 -9999 -9999 -9999 -9999 -9999 -9999 -9999 -9999 -9999 -9999 -9999 -9999 -9999 -9999 -9999 -9999 -9999 -9999 -9999 -9999 -9999 -9999 -9999 -

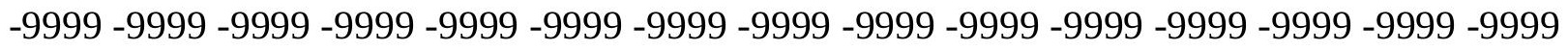
-9999 -9999 -9999 -9999 -9999 -9999 -9999 -9999 -9999 -9999 -9999 -9999 -9999 -9999 -9999 -9999 431.5646057129433.0705871582433.9825134277434.2135925293433.7546081543 432.5352478027430 .4315490723427 .2635803223422 .7786865234416 .7299804688 409.9360046387401 .0971984863392 .5632019043384 .029296875376 .104888916 368.7900085449362 .3894958496357 .8176879883355 .379486084353 .8554992676 351.112487793344 .4071960449330 .6918945312318 .5004882812315 .1477966309 311.7951965332308 .1377868652303 .8707885742298 .9942016602293 .8128967285 288.9363098145 284.9740905762 281.3167114258 278.2687988281 276.1353149414 274.3066101074272 .7827148438271 .2587890625270 .3443908691269 .1253051758 268.2109069824267 .2966003418266 .0773925781264 .5534973145263 .0296020508 260.8960876465258 .4577941895256 .0195007324252 .9716033936249 .6190032959 245.9615936279242 .3041992188243 .8280944824245 .6567993164246 .5711975098 247.1806945801247 .7902984619248 .0950927734248 .7046966553248 .7046966553 249.0093994141249 .0093994141249 .0093994141249 .3141937256249 .3141937256 249.6190032959249 .9237976074250 .2286071777250 .2286071777250 .2286071777 249.9237976074249 .6190032959249 .0093994141248 .3999023438247 .7902984619 246.8759002686245 .6567993164243 .8280944824241 .3898010254239 .2563018799 237.1228027344234 .9893035889232 .8558044434231 .0270996094228 .5888977051 225.8457946777223 .1027069092220 .3596038818217 .6165924072214 .8735046387 212.7400054932210 .6065063477208 .1681976318206 .0346984863204 .5108032227 203.2917022705 202.0724945068200.8533935547 199.329498291 197.8054962158 196.2816009521195 .0625193 .5386047363192 .624206543191 .7097930908191 .1002960205 190.4907073975190 .1858978271189 .8811035156189 .8811035156190 .1858978271 190.4907073975190 .795501709191 .1002960205190 .795501709190 .1858978271 189.2716064453188.0523986816186.528503418185.3094024658 184.3950042725 183.7854003906183 .4806976318182 .87109375181 .9566955566181 .3471984863 180.432800293180 .1280059814180 .1280059814179 .8231964111179 .8231964111 179.5184020996179 .2136993408178 .604095459177 .9945068359177 .3849029541 176.7754058838176 .165802002175 .8609924316175 .2514038086174 .6419067383 174.337097168174 .0323028564173 .7274932861173 .1179962158172 .5084075928 
171.8988037109171 .8988037109172 .5084075928173 .1179962158173 .4226989746 172.8132019043171 .5939941406170 .070098877168 .241394043166 .7174987793 165.4983062744164 .2792053223162 .4505004883160 .0122070312156 .9642944336 153.9165039062151 .4781951904151 .1734008789153 .3069000244145 .3825073242 138.0677032471137 .7628936768138 .3724975586139 .8963928223141 .1154937744 142.3347015381143 .5538024902145 .0776977539146 .2969055176147 .2111968994 148.1255950928148 .7351074219149 .3446960449149 .6495056152150 .5639038086 151.4781951904153 .0021057129154 .8307952881156 .9642944336160 .0122070312 158.7929992676156 .6596069336155 .4403991699156 .0500030518156 .9642944336 158.1835021973159 .7073974609161 .5361022949163 .3648071289165 .1934967041 167.3269958496169 .7653045654171 .5939941406173 .4226989746174 .9467010498 176.4705963135177 .6896972656178 .9089050293180 .432800293181 .6519012451 182.5662994385184 .3950042725184 .3950042725179 .5184020996172 .2035980225 164.2792053223158 .1835021973154 .2212982178152 .0877990723150 .2590942383 149.3446960449149 .0399017334147 .8208007812144 .7729034424140 .8106994629 136.5437011719132 .2767028809128 .6192932129125 .5715026855123 .43800354 121.9140014648120 .9997024536120 .3900985718120 .3900985718120 .3900985718 120.6949005127120 .9997024536120 .9997024536121 .3044967651121 .6092987061 121.6092987061121 .9140014648121 .9140014648121 .9140014648121 .9140014648 121.6092987061121 .6092987061121 .6092987061121 .6092987061121 .9140014648 122.2188034058121 .9140014648121 .3044967651120 .3900985718120 .0852966309 127.4001998901141 .1154937744154 .8307952881167 .3269958496179 .2136993408 189.5764007568197 .8054962158204 .8155975342209 .692199707211 .2160949707 234.0749969482253 .5812072754272 .4779052734291 .3746032715301 .7373046875 309.0520935059312 .4047851562310 .8807983398303 .8707885742293 .8128967285 284.6693115234281 .0119018555280 .4023132324281 .0119018555281 .6214904785 282.8406066895284 .0596923828285 .5835876465286 .4979858398287 .1076049805 287.4124145508287 .1076049805286 .1932067871284 .6693115234283 .1453857422 281.3167114258279 .4880065918277 .6592102051275 .8305053711274 .3066101074 273.3923034668272 .7827148438272 .4779052734272 .1730957031271 .8682861328 271.8682861328272 .1730957031272 .1730957031272 .4779052734273 .0874938965 273.3923034668274 .0018005371274 .6113891602275 .2210083008276 .1353149414 276.7449035645277 .0497131348277 .6592102051277 .6592102051277 .6592102051 277.3544921875276 .4400939941274 .9161987305272 .7827148438269 .7348022461 266.0773925781261 .2008972168255 .1051025391247 .7902984619238 .6468048096 227.3697052002213 .6544036865209 .692199707209 .692199707160 .3170013428 139.8963928223 120.085296630998 .5876464843878 .04404449463 -9999 -9999 -9999 -9999 -9999 -9999 -9999 -9999 -9999 -9999 -9999 -9999 -9999 -9999 -9999 -9999 -9999 -9999 -9999 -9999 -9999 -9999 -9999 -9999 -9999 -9999 -9999 -9999 -9999 -9999 -9999 -9999 -9999 -9999 -9999 -9999 -9999 -9999 -9999 -9999 -9999 -9999 -9999

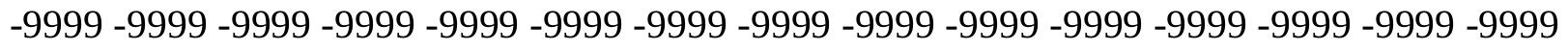
-9999 -9999 435.472442627435.6988830566435.1394958496433.7650146484 431.4454345703428 .0346374512423 .5245361328417 .8604125977409 .0216064453 400.1828918457391 .3440856934382 .8100891113374 .8857116699367 .570892334 361.1704101562355 .9890136719352 .6364135742350 .8077087402348 .9790039062 347.7597961426342 .8833007812329 .4726867676315 .1477966309312 .4047851562 
309.6617126465306 .6138000488303 .5660095215298 .3846130371293 .5080871582 288.9363098145284 .6693115234281 .0119018555277 .9641113281275 .5257873535 273.3923034668271 .5635070801270 .0396118164268 .5156860352267 .2966003418 266.0773925781264 .8583068848263 .3344116211261 .8103942871260 .2864990234 258.1530151367255 .7147064209252 .9716033936249 .9237976074246 .5711975098 243.5233001709241 .3898010254241 .9994049072243 .8280944824244 .7424926758 245.6567993164246 .2664031982246 .8759002686247 .1806945801247 .1806945801 247.4855041504247 .4855041504247 .4855041504247 .4855041504247 .4855041504 247.7902984619248 .3999023438249 .3141937256249 .9237976074250 .5334014893 250.8381958008250 .8381958008250 .8381958008250 .5334014893249 .9237976074 249.6190032959248 .3999023438247 .1806945801245 .3520050049243 .5233001709 241.6945953369239 .5610961914237 .7324066162235 .5989074707233 .1605987549 230.4176025391227 .6744995117224 .6266021729221 .5787963867218 .8356933594 216.3973999023214 .5686950684211 .2160949707209 .3874053955208 .1681976318 207.25390625 206.3394927979 204.8155975342 202.9868927002 201.158203125 199.329498291 197.8054962158 196.2816009521 195.0625 194.1481018066193.5386047363 192.9290008545192 .3193969727192 .0146026611192 .0146026611192 .3193969727 192.9290008545193 .5386047363193 .8433074951193 .5386047363192 .9290008545 192.3193969727191 .1002960205189 .5764007568188 .3571929932187 .4429016113 186.528503418185 .9188995361185 .0045928955184 .0901947021183 .1759033203 182.261505127 181.9566955566181.6519012451 181.6519012451 181.3471984863 180.7375946045180 .432800293179 .8231964111178 .9089050293178 .2993011475 177.3849029541176 .7754058838176 .4705963135175 .8609924316175 .5561981201 174.9467010498174 .6419067383174 .337097168173 .7274932861173 .1179962158 172.2035980225170 .9844970703172 .2035980225173 .1179962158173 .4226989746 173.1179962158172 .2035980225171 .2891998291169 .7653045654168 .241394043 167.0222015381165 .4983062744163 .6696014404161 .8408966064159 .4026031494 157.5738983154156 .0500030518155 .7451934814154 .2212982178149 .3446960449 144.4682006836142 .0299072266141 .7250976562142 .3347015381143 .2489929199 143.8585968018144 .1634063721145 .0776977539145 .6873016357146 .2969055176 147.2111968994147 .8208007812148 .4304046631149 .0399017334149 .6495056152 150.8686065674152 .0877990723153 .6116943359154 .5260925293156 .6690216064 157.0116119385156 .3696594238155 .9188232422156 .0500030518156 .6596069336 157.5738983154158 .7929992676160 .0122070312161 .8408966064163 .6696014404 165.8031005859167 .6318054199169 .7653045654171 .5939941406173 .1179962158 174.6419067383175 .8609924316177 .3849029541178 .604095459179 .5184020996 180.7375946045181 .6519012451181 .0424041748177 .3849029541172 .2035980225 166.1078948975160 .9264984131156 .9642944336154 .2212982178152 .3925933838 151.4781951904151 .4781951904151 .4781951904147 .5160064697143 .2489929199 138.3724975586133 .8007049561129 .533706665126 .1809997559123 .7427978516 121.9140014648120 .6949005127120 .0852966309119 .7806015015119 .7806015015 120.0852966309120 .3900985718120 .9997024536121 .3044967651121 .3044967651 121.6092987061121 .9140014648121 .9140014648122 .2188034058122 .2188034058 121.9140014648121 .9140014648121 .6092987061121 .6092987061121 .6092987061 121.9140014648121 .6092987061121 .6092987061121 .3044967651121 .3044967651 122.2188034058131 .6672058105144 .7729034424157 .2691040039169 .1557006836 
179.8231964111186 .8332977295193 .233795166199 .329498291205 .425201416 209.692199707213 .3495941162237 .4275970459259 .6769104004277 .9641113281 292.5936889648301 .7373046875304 .1755981445298 .9942016602288 .3266906738 275.2210083008275 .5257873535275 .8305053711276 .1353149414277 .0497131348 278.5736083984280 .4023132324282 .5357971191284 .3645019531285 .5835876465 286.4979858398286 .4979858398285 .8884887695284 .6693115234283 .1453857422 281.3167114258279 .4880065918277 .6592102051275 .8305053711274 .0018005371 273.3923034668273 .0874938965273 .0874938965272 .7827148438272 .7827148438 272.7827148438272 .7827148438273 .0874938965273 .3923034668274 .0018005371 274.6113891602275 .2210083008275 .8305053711276 .4400939941277 .3544921875 278.2687988281278 .8783874512279 .4880065918280 .0975036621280 .4023132324 280.4023132324280 .0975036621279 .4880065918277 .9641113281275 .8305053711 272.7827148438269 .1253051758264 .2486877441258 .4577941895250 .5334014893 240.4754943848227 .6744995117211 .8256988525209 .692199707209 .692199707 151.4781951904130 .4479980469108 .673156738387 .9977569580167 .81122589111 -9999 -9999 -9999 -9999 -9999 -9999 -9999 -9999 -9999 -9999 -9999 -9999 -9999 -9999 -9999 -9999 -9999 -9999 -9999 -9999 -9999 -9999 -9999 -9999 -9999 -9999 -9999 - -

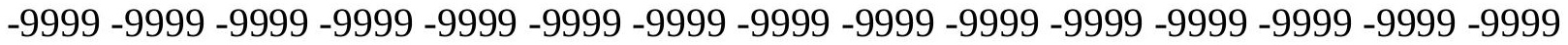

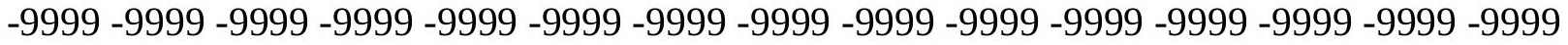
-9999 -9999 436.8824157715 436.3639831543434 .9115905762432 .4544372559 428.8173828125423 .9070739746417 .5556030273408 .71688844277399 .5733032227 390.7344970703381 .8958129883373 .666595459365 .7421875358 .7320861816 352.6364135742348 .0646057129345 .0168151855344 .4071960449343 .4927978516 340.4450073242334 .6541137695324 .2914123535311 .7951965332309 .6617126465 307.5281982422304 .7850952148301 .7373046875297 .4703063965292 .8984985352 288.6315002441284 .3645019531280 .7070922852277 .6592102051274 .9161987305 272.4779052734270 .6492004395268 .8204956055266 .9917907715265 .7726135254 264.2486877441262 .7247924805261 .2008972168259 .6769104004257 .8482055664 255.7147064209253 .5812072754250 .8381958008248 .0950927734245 .3520050049 242.9136962891241 .6945953369241 .9994049072242 .9136962891243 .8280944824 244.7424926758245 .3520050049245 .6567993164245 .9615936279245 .9615936279 245.6567993164245 .6567993164245 .6567993164245 .6567993164245 .6567993164 246.2664031982246 .8759002686248 .0950927734249 .3141937256250 .2286071777 251.1428985596251 .7525024414251 .7525024414251 .7525024414251 .7525024414 251.4476928711250 .8381958008249 .6190032959248 .7046966553247 .1806945801 245.6567993164243 .8280944824241 .9994049072240 .1707000732237 .7324066162 234.9893035889231 .6367034912228 .5888977051225 .2362060547222 .1884002686 219.4452972412216 .7021942139213 .3495941162212 .7400054932212 .1304016113 211.520904541210 .6065063477208 .7778015137206 .6443023682204 .5108032227 202.3773040771 200.5485992432199.0247039795 197.500793457 196.5863952637 195.9768066406195 .6721038818195 .3672943115194 .7577056885194 .4528961182 195.3672943115195 .9768066406196 .5863952637196 .891204834196 .891204834 196.2816009521195 .3672943115194 .1481018066192 .9290008545192 .0146026611 190.795501709189 .8811035156188 .966796875188 .0523986816187 .1381072998 185.9188995361185 .0045928955184 .3950042725184 .0901947021183 .7854003906 183.4806976318182 .87109375181 .9566955566181 .0424041748180 .1280059814 
179.2136993408178 .604095459177 .9945068359177 .3849029541176 .7754058838 176.4705963135176 .165802002175 .8609924316175 .5561981201175 .2514038086 174.6419067383173 .7274932861173 .1179962158173 .4226989746174 .0323028564 174.337097168174 .0323028564173 .4226989746172 .5084075928171 .2891998291 170.070098877168 .5462036133167 .0222015381165 .4983062744163 .6696014404 162.1457061768160 .6217956543159 .7073974609158 .4882965088156 .3547973633 153.0021057129149 .6495056152147 .2111968994146 .6015930176146 .2969055176 145.9920959473145 .6873016357145 .3825073242145 .3825073242145 .6873016357 145.9920959473146 .6015930176146 .9064025879147 .5160064697148 .1255950928 149.0399017334149 .9542999268151 .1734008789152 .0877990723153 .0021057129 153.9165039062154 .7311248779155 .5379180908156 .2446746826156 .6596069336 156.3547973633156 .6596069336157 .5738983154158 .7929992676160 .3170013428 162.1457061768163 .974395752165 .8031005859167 .6318054199169 .4604949951 170.9844970703172 .5084075928173 .7274932861174 .9467010498176 .165802002 177.0802001953177 .9945068359178 .2993011475177 .3849029541174 .9467010498 170.9844970703166 .4127044678162 .1457061768158 .4882965088155 .4403991699 153.6116943359152 .3925933838152 .3925933838151 .7830047607149 .3446960449 145.6873016357140 .8106994629135 .9342041016130 .7528076172127 .7050018311 124.9618988037122 .5235977173120 .9997024536120 .0852966309119 .4757995605 119.7806015015120 .0852966309120 .3900985718120 .9997024536121 .3044967651 121.6092987061121 .9140014648121 .9140014648122 .2188034058122 .2188034058 122.5235977173122 .2188034058122 .2188034058121 .9140014648121 .6092987061 121.6092987061121 .6092987061121 .6092987061121 .6092987061121 .6092987061 121.6092987061121 .6092987061124 .3523025513135 .9342041016147 .5160064697 157.878692627167 .0222015381174 .337097168180 .432800293186 .2236938477 192.3193969727198 .7198944092206 .0346984863209 .692199707225 .5410003662 248.7046966553271 .5635070801289 .5458984375296 .8606872559295 .3367919922 288.6315002441281 .3167114258277 .0497131348274 .9161987305273 .0874938965 274.0018005371275 .5257873535277 .6592102051280 .0975036621282 .5357971191 284.6693115234285 .5835876465285 .8884887695285 .5835876465284 .6693115234 283.1453857422281 .6214904785279 .7927856445277 .9641113281276 .1353149414 274.9161987305274 .0018005371273 .6971130371273 .3923034668273 .3923034668 273.3923034668273 .3923034668273 .6971130371274 .0018005371274 .3066101074 274.6113891602275 .2210083008275 .8305053711276 .4400939941277 .3544921875 278.2687988281279 .1831970215280 .0975036621281 .0119018555281 .9262084961 282.5357971191283 .1453857422283 .1453857422283 .1453857422282 .2309875488 280.7070922852278 .8783874512276 .1353149414272 .7827148438268 .5156860352 262.7247924805254 .1907958984242 .3041992188226 .4553985596209 .692199707 209.692199707 163.6696014404 141.4203033447120.390098571898.27326202393 77.42032623291 -9999 -9999 -9999 -9999 -9999 -9999 -9999 -9999 -9999 -9999 -9999 -9999

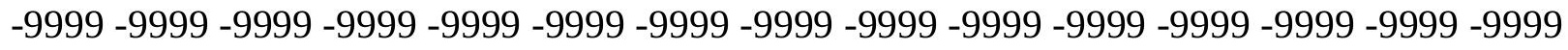

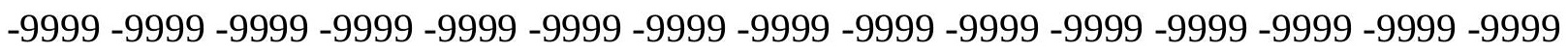
-9999 -9999 -9999 -9999 -9999 -9999 -9999 -9999 -9999 -9999 -9999 -9999 -9999 -9999 -9999 -9999 -9999 437.3734130859436.059967041433.6303405762 429.8866271973 424.7521057129418 .1651916504409 .0216064453399 .878112793390 .4296875 381.2861938477372 .7521972656364 .2182006836356 .5986022949349 .2838134766 
343.4927978516338 .9211120605336 .1780090332335 .5683898926334 .6541137695 330.0823059082323 .6817932129316 .6718139648309 .0520935059307 .5281982422 305.3947143555302 .9563903809299 .9085998535296 .2510986328291 .9841918945 288.0219116211284 .0596923828280 .4023132324277 .3544921875274 .3066101074 271.8682861328269 .7348022461267 .6012878418265 .7726135254263 .9439086914 262.4200134277260 .8960876465259 .0674133301257 .5433959961255 .7147064209 253.8860015869251 .7525024414249 .3141937256247 .1806945801245 .0471954346 243.2185058594242 .3041992188242 .3041992188242 .9136962891243 .5233001709 244.1329040527244 .7424926758245 .0471954346245 .0471954346244 .7424926758 244.1329040527243 .8280944824244 .1329040527244 .1329040527243 .8280944824 244.4376983643245 .3520050049246 .8759002686248 .7046966553250 .2286071777 251.1428985596252 .0572967529252 .6669006348252 .6669006348252 .6669006348 252.6669006348252 .3621063232251 .7525024414251 .1428985596250 .2286071777 249.0093994141247 .4855041504245 .9615936279244 .1329040527241 .6945953369 238.9515075684235 .5989074707232 .246307373228 .5888977051225 .2362060547 222.1884002686219 .4452972412217 .6165924072216 .3973999023216 .0926971436 215.4830932617214 .8735046387212 .4351959229209 .9969024658207 .5587005615 205.1204071045202 .9868927002201 .158203125199 .9389953613199 .0247039795 198.7198944092198 .7198944092199 .0247039795199 .0247039795198 .7198944092 199.329498291199 .6342926025200 .2438049316200 .2438049316200 .2438049316 199.6342926025198 .7198944092197 .8054962158196 .5863952637195 .3672943115 194.4528961182193 .233795166192 .3193969727191 .4051055908190 .1858978271 189.2716064453188 .3571929932187 .7476043701187 .1381072998186 .8332977295 186.2236938477 185.3094024658 184.3950042725183.1759033203181.9566955566 180.7375946045180 .1280059814179 .5184020996178 .9089050293178 .2993011475 177.9945068359177 .6896972656177 .6896972656177 .6896972656177 .3849029541 177.0802001953176 .165802002175 .8609924316175 .5561981201175 .5561981201 175.5561981201175 .5561981201174 .9467010498174 .0323028564173 .1179962158 171.8988037109170 .6797027588169 .1557006836167 .6318054199166 .1078948975 164.8887023926163 .6696014404162 .4505004883161 .2312927246159 .4026031494 156.9642944336154 .2212982178152 .3925933838151 .4781951904150 .8686065674 149.3446960449148 .1255950928147 .2111968994146 .6015930176146 .2969055176 146.2969055176146 .2969055176146 .6015930176147 .2111968994147 .5160064697 148.1255950928149 .0399017334149 .9542999268150 .8686065674151 .7830047607 151.7830047607152 .0877990723153 .9165039062155 .7451934814155 .7451934814 155.4403991699155 .7451934814156 .3547973633157 .5738983154158 .7929992676 160.3170013428162 .1457061768163 .6696014404165 .4983062744167 .3269958496 168.8509979248170 .070098877171 .2891998291172 .2035980225173 .1179962158 173.7274932861174 .337097168174 .337097168173 .7274932861171 .8988037109 169.1557006836165 .8031005859162 .4505004883159 .0977935791156 .3547973633 154.2212982178152 .0877990723152 .6972961426152 .3925933838150 .8686065674 147.5160064697143 .8585968018139 .2868041992134 .7149963379130 .7528076172 126.7906036377123 .7427978516121 .3044967651120 .0852966309119 .7806015015 119.7806015015120 .3900985718120 .6949005127121 .3044967651121 .6092987061 121.9140014648122 .2188034058122 .5235977173122 .8283996582122 .8283996582 123.1332015991122 .8283996582122 .8283996582122 .2188034058121 .9140014648 
121.6092987061121 .6092987061121 .6092987061121 .3044967651121 .3044967651 121.3044967651120 .6949005127120 .3900985718128 .3144989014138 .0677032471 146.9064025879154 .5260925293160 .9264984131166 .4127044678171 .5939941406 177.0802001953184 .0901947021192 .3193969727200 .2438049316205 .7299957275 214.2639007568241 .9994049072273 .6971130371283 .4501953125289 .2410888672 289.8505859375286 .1932067871280 .7070922852275 .8305053711272 .4779052734 271.8682861328273 .0874938965275 .5257873535278 .5736083984281 .9262084961 284.0596923828285 .2789001465285 .5835876465285 .2789001465284 .3645019531 283.1453857422281 .6214904785280 .0975036621278 .5736083984276 .7449035645 275.5257873535274 .9161987305274 .3066101074274 .0018005371274 .0018005371 274.0018005371274 .0018005371274 .3066101074274 .3066101074274 .9161987305 275.2210083008275 .8305053711276 .1353149414277 .0497131348277 .6592102051 278.5736083984279 .4880065918280 .7070922852281 .9262084961283 .1453857422 284.0596923828284 .9740905762285 .5835876465285 .8884887695285 .5835876465 284.6693115234283 .4501953125281 .9262084961280 .0975036621277 .3544921875 273.3923034668 267.2966003418256.6290893555 241.0850067139221.2740020752 209.692199707 209.692199707 152.3925933838130.4479980469 108.3111953735 87.4569854736366 .93838500977 -9999 -9999 -9999 -9999 -9999 -9999 -9999 -9999 -9999 -9999 -9999 -9999 -9999 -9999 -9999 -9999 -9999 -9999 -9999 -9999 -9999 -9999 -9999 -9999 $-9999-9999$

-9999 -9999 -9999 -9999 -9999 -9999 -9999 -9999 -9999 -9999 -9999 -9999 -9999 -9999 -9999 -9999 -9999 -9999 -9999 -9999 -9999 -9999 -9999 -9999 -9999 -9999 -9999 -9999 -9999 -9999 -9999 -9999 437.0090637207434.8949279785 431.338684082426.2205200195 419.3843078613410 .240814209400 .792388916391 .0393066406381 .591003418 372.1426086426363 .303894043354 .4650878906348 .3693847656343 .1879882812 338.3114929199333 .7396850586328 .8631896973323 .6817932129321 .8530883789 318.8052062988314 .2334899902307 .5281982422306 .3091125488305 .3947143555 303.8707885742301 .1276855469298 .0798950195294 .7272033691291 .0697937012 287.1076049805283 .4501953125280 .0975036621276 .7449035645274 .0018005371 271.2587890625268 .8204956055266 .6870117188264 .5534973145262 .7247924805 260.8960876465259 .0674133301257 .5433959961255 .7147064209253 .8860015869 252.0572967529250 .2286071777248 .3999023438246 .5711975098245 .0471954346 243.8280944824242 .9136962891242 .9136962891243 .2185058594243 .8280944824 244.1329040527244 .4376983643244 .1329040527244 .1329040527243 .2185058594 242.6089935303242 .3041992188242 .9136962891243 .2185058594243 .2185058594 243.5233001709244 .1329040527246 .2664031982248 .0950927734249 .9237976074 251.1428985596252 .0572967529252 .6669006348252 .9716033936252 .9716033936 253.2763977051253 .2763977051253 .2763977051252 .9716033936252 .3621063232 251.7525024414250 .8381958008249 .3141937256247 .4855041504245 .3520050049 242.9136962891239 .2563018799235 .5989074707231 .9414978027228 .5888977051 225.2362060547223 .4075012207221 .883605957220 .9691925049220 .054901123 219.1405029297217.9214019775 215.4830932617212.7400054932 210.3016967773 207.5587005615205 .1204071045203 .2917022705201 .7678070068201 .158203125 201.158203125202 .0724945068202 .9868927002203 .596496582203 .596496582 203.596496582203 .596496582203 .596496582203 .9011993408203 .596496582 203.2917022705 202.3773040771201.4629974365 200.2438049316199.0247039795 
197.8054962158196 .891204834195 .9768066406194 .7577056885193 .8433074951 192.9290008545192 .3193969727191 .4051055908190 .795501709190 .1858978271 189.2716064453188 .6620025635187 .4429016113186 .2236938477184 .699798584 182.87109375182 .261505127181 .6519012451181 .0424041748180 .432800293 179.8231964111179 .5184020996179 .8231964111180 .1280059814180 .432800293 180.1280059814179 .5184020996178 .604095459178 .2993011475177 .9945068359 177.6896972656177 .3849029541176 .7754058838176 .165802002175 .2514038086 174.0323028564172 .8132019043171 .5939941406170 .070098877168 .8509979248 167.6318054199166 .4127044678165 .4983062744164 .2792053223162 .4505004883 160.6217956543158 .7929992676156 .9642944336155 .4403991699154 .2212982178 152.3925933838150 .5639038086148 .7351074219147 .8208007812146 .9064025879 146.6015930176146 .6015930176146 .6015930176146 .9064025879147 .2111968994 147.5160064697148 .1255950928148 .7351074219149 .6495056152149 .9542999268 150.2590942383150 .2590942383150 .5639038086152 .3925933838153 .3069000244 153.6116943359154 .2212982178155 .1356048584156 .0500030518157 .2691040039 158.4882965088160 .0122070312161 .8408966064163 .3648071289164 .8887023926 166.1078948975167 .3269958496168 .5462036133169 .1557006836169 .7653045654 170.3748931885170 .3748931885170 .3748931885169 .7653045654168 .8509979248 167.0222015381164 .5839996338162 .1457061768159 .4026031494156 .9642944336 155.1356048584153 .9165039062153 .6116943359153 .3069000244152 .3925933838 149.6495056152146 .9064025879143 .8585968018139 .5915985107134 .4102020264 129.2288970947124 .9618988037122 .2188034058120 .6949005127120 .3900985718 120.3900985718120 .9997024536121 .3044967651121 .9140014648122 .2188034058 122.8283996582123 .1332015991123 .43800354123 .43800354123 .7427978516 124.0475006104123 .7427978516123 .7427978516123 .1332015991122 .5235977173 122.2188034058121 .9140014648121 .6092987061121 .3044967651120 .9997024536 120.6949005127120 .0852966309119 .7806015015121 .6092987061129 .2288970947 136.2389984131142 .3347015381147 .5160064697151 .7830047607156 .3547973633 159.7073974609166 .1078948975175 .5561981201186 .8332977295191 .4051055908 195.6721038818199 .329498291231 .0270996094259 .0674133301277 .9641113281 286.4979858398286 .1932067871280 .7070922852273 .6971130371269 .7348022461 269.4301147461271 .5635070801273 .6971130371278 .8783874512282 .2309875488 284.0596923828284 .9740905762284 .9740905762284 .6693115234284 .0596923828 283.1453857422281 .9262084961280 .4023132324278 .8783874512277 .3544921875 276.1353149414275 .5257873535274 .9161987305274 .6113891602274 .3066101074 274.3066101074 274.3066101074274.6113891602 274.9161987305 275.2210083008 275.5257873535275 .8305053711276 .4400939941277 .0497131348277 .6592102051 278.5736083984279 .4880065918280 .7070922852281 .9262084961283 .4501953125 284.6693115234285 .8884887695286 .8027954102287 .4124145508287 .7171936035 287.4124145508287 .1076049805286 .1932067871285 .2789001465284 .0596923828 282.2309875488 278.2687988281269.7348022461253.8860015869 233.1605987549 210.3016967773209 .692199707162 .7552947998140 .2012023926119 .7806015015 97.6326751709 76.59285736084 -9999 -9999 -9999 -9999 -9999 -9999 -9999 -9999 -9999 -9999 -9999 -9999 -9999 -9999 -9999 -9999 -9999 -9999 -9999 -9999 -9999 -9999 -9999 -9999 $-9999-9999$

-9999 -9999 -9999 -9999 -9999 -9999 -9999 -9999 -9999 -9999 -9999 -9999 -9999 -9999 -9999 
-9999 -9999 -9999 -9999 -9999 -9999 -9999 -9999 -9999 -9999 -9999 -9999 -9999 -9999 -9999 -9999 -9999 435.7995300293432 .8794555664428 .2257995605421 .517791748 412.3742980957402 .6211853027392 .8680114746382 .8100891113373 .0570068359 364.8277893066359 .3417053223353 .2460021973347 .4549865723341 .6640930176 336.4827880859330 .9966125488325 .5104980469320 .0244140625314 .8429870605 310.2713012695306 .6138000488303 .8707885742303 .8707885742304 .1755981445 302.0421142578299 .2990112305296 .5559082031293 .5080871582289 .8505859375 286.4979858398282 .8406066895279 .4880065918276 .4400939941273 .3923034668 270.6492004395267 .9060974121265 .4678039551263 .3344116211261 .5056152344 259.3721008301257 .5433959961255 .7147064209254 .1907958984252 .3621063232 250.8381958008249 .0093994141247 .4855041504246 .2664031982245 .0471954346 244.1329040527243 .5233001709243 .5233001709243 .5233001709244 .1329040527 244.4376983643244 .1329040527242 .9136962891241 .3898010254241 .3898010254 241.3898010254241 .3898010254241 .9994049072242 .6089935303242 .9136962891 243.5233001709244 .1329040527246 .2664031982248 .0950927734249 .9237976074 251.1428985596252 .0572967529252 .3621063232252 .6669006348252 .6669006348 252.9716033936253 .2763977051253 .8860015869254 .1907958984254 .1907958984 253.8860015869253 .2763977051252 .0572967529250 .2286071777248 .0950927734 245.6567993164242 .3041992188238 .6468048096235 .2940979004232 .246307373 229.8079986572227 .9792938232226 .4553985596225 .2362060547224 .0171051025 222.4931030273220 .6643981934218 .5308990479215 .787902832212 .7400054932 209.692199707 207.25390625 204.8155975342 203.2917022705 202.9868927002 203.2917022705 204.8155975342 206.9490966797208.4730072021 208.4730072021 207.8634033203 207.25390625 207.25390625 207.25390625 207.25390625 206.9490966797 206.0346984863204 .8155975342203 .596496582202 .6820983887201 .4629974365 200.5485992432199 .6342926025198 .7198944092197 .8054962158196 .891204834 195.9768066406195 .3672943115194 .7577056885193 .8433074951193 .233795166 192.3193969727191 .1002960205189 .5764007568188 .0523986816186 .8332977295 185.6141052246185 .0045928955184 .0901947021183 .1759033203182 .5662994385 181.9566955566182 .5662994385183 .4806976318184 .0901947021183 .4806976318 182.5662994385181 .6519012451181 .0424041748180 .432800293179 .8231964111 179.2136993408178 .604095459177 .9945068359177 .3849029541176 .4705963135 175.2514038086174 .0323028564172 .8132019043171 .2891998291170 .3748931885 169.4604949951168 .5462036133167 .3269958496166 .1078948975164 .5839996338 162.7552947998161 .2312927246159 .4026031494157 .5738983154155 .4403991699 153.0021057129150 .8686065674149 .0399017334148 .1255950928147 .2111968994 146.9064025879146 .9064025879146 .9064025879146 .9064025879147 .2111968994 147.5160064697147 .8208007812148 .4304046631148 .7351074219148 .7351074219 148.7351074219149 .0399017334149 .9542999268150 .5639038086151 .4781951904 152.3925933838153 .6116943359154 .2212982178155 .1356048584156 .6596069336 158.1835021973159 .4026031494160 .9264984131162 .4505004883163 .6696014404 164.5839996338165 .4983062744166 .1078948975166 .4127044678166 .4127044678 166.4127044678166 .1078948975166 .1078948975165 .8031005859164 .8887023926 163.3648071289161 .5361022949159 .4026031494157 .5738983154156 .3547973633 155.4403991699154 .8307952881154 .2212982178153 .3069000244151 .1734008789 150.2590942383148 .4304046631144 .7729034424138 .3724975586131 .3623962402 
126.1809997559123 .43800354121 .9140014648121 .3044967651121 .6092987061 122.2188034058122 .5235977173123 .1332015991123 .7427978516124 .0475006104 124.3523025513124 .6570968628124 .9618988037125 .2667007446125 .2667007446 124.9618988037124 .6570968628124 .0475006104123 .43800354122 .8283996582 122.2188034058121 .6092987061121 .6092987061120 .9997024536120 .3900985718 119.7806015015118 .8662033081118 .5614013672121 .9140014648127 .0953979492 131.3623962402134 .7149963379137 .1533050537138 .9819946289141 .1154937744 145.6873016357155 .4403991699166 .1078948975174 .0323028564179 .5184020996 184.3950042725190 .1858978271227 .6744995117259 .9816894531273 .6971130371 278.5736083984271 .5635070801262 .7247924805260 .2864990234264 .2486877441 270.6492004395276 .4400939941280 .7070922852283 .1453857422284 .0596923828 284.3645019531284 .0596923828284 .0596923828283 .4501953125282 .8406066895 281.6214904785280 .4023132324279 .1831970215277 .6592102051276 .7449035645 275.8305053711275 .2210083008274 .9161987305274 .6113891602274 .6113891602 274.6113891602274 .9161987305275 .2210083008275 .5257873535275 .5257873535 275.8305053711276 .1353149414276 .7449035645277 .3544921875277 .9641113281 278.8783874512280 .0975036621281 .6214904785283 .1453857422284 .6693115234 286.1932067871287 .4124145508288 .3266906738288 .9363098145288 .9363098145 288.9363098145288 .3266906738288 .0219116211287 .4124145508286 .4979858398 284.6693115234280 .4023132324262 .4200134277241 .3898010254218 .5308990479 209.692199707 209.692199707 149.6495056152 128.6192932129 107.2575302124 86.6181564331165 .60276794434 -9999 -9999 -9999 -9999 -9999 -9999 -9999 -9999 -9999 -9999 -9999 -9999 -9999 -9999 -9999 -9999 -9999 -9999 -9999 -9999 -9999 -9999 -9999 -9999 $-9999$

-9999 -9999 -9999 -9999 -9999 -9999 -9999 -9999 -9999 -9999 -9999 -9999 -9999 -9999 -9999 -9999 -9999 -9999 -9999 -9999 -9999 -9999 -9999 -9999 -9999 -9999 -9999 -9999 -9999 -9999 -9999 -9999 433.7543945312429.9862670898 424.5657043457415.1173095703 405.6690063477395 .611114502385 .5531921387375 .1904907227364 .5230102539 361.1704101562356 .2937927246351 .112487793345 .3215026855339 .5306091309 334.0444946289328 .2536010742322 .4627075195316 .9765014648311 .7951965332 307.2233886719303 .8707885742302 .0421142578301 .4324951172301 .1276855469 299.6037902832297 .4703063965295 .0320129395291 .9841918945288 .9363098145 285.5835876465282 .2309875488279 .1831970215275 .8305053711272 .7827148438 270.0396118164267 .2966003418264 .8583068848262 .4200134277260 .2864990234 258.1530151367256 .3243103027254 .4956054688252 .6669006348251 .1428985596 249.6190032959248 .0950927734246 .8759002686245 .6567993164244 .7424926758 244.1329040527243 .5233001709243 .5233001709243 .8280944824244 .1329040527 244.1329040527243 .5233001709241 .9994049072240 .7801971436240 .1707000732 240.4754943848240 .7801971436241 .3898010254242 .3041992188243 .2185058594 244.1329040527245 .3520050049246 .8759002686248 .7046966553250 .2286071777 251.1428985596251 .7525024414252 .0572967529251 .7525024414251 .7525024414 252.0572967529252 .6669006348253 .5812072754254 .4956054688255 .1051025391 255.1051025391254 .8003997803253 .8860015869252 .3621063232250 .5334014893 247.7902984619244 .7424926758241 .3898010254238 .9515075684236 .5133056641 234.3798065186232.5511016846231.0270996094229.5032043457227.9792938232 226.150604248223 .7122955322221 .2740020752218 .2261962891215 .1782989502 
211.8256988525208 .7778015137206 .3394927979204 .8155975342203 .9011993408 204.8155975342206 .9490966797209 .9969024658212 .7400054932212 .1304016113 210.9113006592210 .3016967773210 .3016967773210 .3016967773210 .6065063477 210.3016967773209 .3874053955208 .1681976318206 .9490966797205 .7299957275 204.8155975342204 .2059936523203 .2917022705202 .6820983887201 .7678070068 200.8533935547199 .9389953613199 .329498291198 .7198944092198 .1103057861 197.1959991455 196.2816009521 195.3672943115 194.1481018066192.624206543 191.4051055908189 .8811035156188 .966796875187 .7476043701186 .8332977295 186.2236938477185 .9188995361186 .2236938477186 .8332977295187 .1381072998 186.528503418185 .9188995361184 .699798584183 .7854003906183 .1759033203 182.261505127181 .6519012451181 .0424041748180 .1280059814179 .5184020996 178.604095459177 .6896972656176 .165802002174 .9467010498173 .7274932861 172.8132019043172 .2035980225171 .5939941406170 .6797027588169 .7653045654 168.241394043166 .7174987793165 .1934967041163 .0599975586160 .9264984131 158.4882965088155 .7451934814153 .0021057129150 .8686065674149 .3446960449 148.4304046631147 .8208007812147 .2111968994146 .9064025879146 .9064025879 146.9064025879147 .2111968994147 .2111968994147 .5160064697147 .8208007812 147.8208007812147 .8208007812147 .8208007812148 .1255950928148 .4304046631 149.0399017334149 .6495056152150 .8686065674152 .3925933838153 .0021057129 154.8307952881156 .0500030518157 .2691040039158 .4882965088160 .0122070312 160.9264984131161 .5361022949162 .4505004883162 .7552947998163 .0599975586 162.7552947998162 .4505004883162 .1457061768162 .7552947998163 .0599975586 163.0599975586162 .1457061768160 .9264984131159 .4026031494158 .1835021973 156.9642944336156 .3547973633155 .7451934814155 .4403991699154 .8307952881 153.9165039062153 .3069000244152 .3925933838150 .5639038086140 .8106994629 132.5814971924127 .4001998901124 .9618988037123 .7427978516123 .43800354 123.43800354123 .7427978516124 .3523025513124 .9618988037125 .2667007446 125.5715026855126 .1809997559126 .4858016968126 .7906036377127 .0953979492 126.7906036377126 .7906036377126 .1809997559125 .2667007446124 .6570968628 123.7427978516122 .8283996582122 .2188034058121 .6092987061121 .3044967651 120.3900985718119 .1709976196118 .2565994263117 .9517974854117 .9517974854 118.5614013672121 .6092987061123 .1332015991124 .0475006104124 .0475006104 124.0475006104124 .6570968628135 .9342041016146 .9064025879155 .7451934814 162.7552947998168 .241394043172 .8132019043191 .4051055908221 .5787963867 244.4376983643261 .5056152344245 .3520050049237 .7324066162241 .9994049072 255.7147064209269 .7348022461279 .1831970215283 .4501953125284 .0596923828 283.4501953125282 .8406066895282 .5357971191282 .5357971191282 .5357971191 282.2309875488 281.3167114258 280.4023132324 279.1831970215 277.9641113281 276.7449035645275 .8305053711275 .2210083008274 .9161987305274 .6113891602 274.6113891602274 .9161987305275 .2210083008275 .2210083008275 .5257873535 275.5257873535275 .8305053711275 .8305053711276 .1353149414276 .4400939941 277.0497131348277 .9641113281279 .1831970215280 .7070922852282 .2309875488 284.0596923828285 .5835876465287 .1076049805288 .3266906738288 .9363098145 289.2410888672288 .9363098145288 .6315002441288 .0219116211287 .1076049805 286.1932067871284 .0596923828277 .6592102051263 .9439086914245 .0471954346 223.7122955322209 .692199707209 .692199707157 .2691040039136 .8484954834 
118.561401367296 .5387420654375 .07856750488 -9999 -9999 -9999 -9999 -9999 -9999 -9999 -9999 -9999 -9999 -9999 -9999 -9999 -9999 -9999 -9999 -9999 -9999 -9999 -9999 -9999 -9999 -9999 -9999-9999

-9999 -9999 -9999 -9999 -9999 -9999 -9999 -9999 -9999 -9999 -9999 -9999 -9999 -9999 -9999 -9999 -9999 -9999 -9999 -9999 -9999 -9999 -9999 -9999 -9999 -9999 -9999 -9999 -9999 -9999 -9999 -9999 431.0638427734 426.1034851074419.0795898438409.326385498 399.2684936523389 .2106018066378 .8479003906368 .1803894043361 .475189209 358.1224975586353 .5508117676348 .3693847656342 .8833007812337 .0922851562 331.3013916016325 .8153076172320 .0244140625314 .5382080078309 .3569030762 305.0899047852302 .3468017578300 .5180969238299 .6037902832298 .6893920898 297.4703063965295 .6416015625293 .5080871582290 .7650146484288 .0219116211 284.9740905762281 .9262084961278 .5736083984275 .5257873535272 .4779052734 269.4301147461266.6870117188263.9439086914261.5056152344 259.0674133301 256.9338989258254 .8003997803252 .9716033936251 .4476928711249 .9237976074 248.3999023438247 .1806945801245 .9615936279245 .3520050049244 .4376983643 244.1329040527243 .5233001709243 .2185058594243 .2185058594243 .5233001709 243.8280944824242 .3041992188240 .7801971436239 .8659057617239 .2563018799 239.2563018799239.8659057617241.0850067139242.3041992188243.8280944824 245.3520050049246 .8759002686248 .3999023438249 .6190032959250 .8381958008 251.4476928711251 .7525024414251 .4476928711250 .8381958008250 .2286071777 250.5334014893251 .4476928711252 .9716033936254 .4956054688255 .4098968506 255.7147064209255 .4098968506254 .8003997803253 .5812072754252 .0572967529 249.6190032959246 .8759002686243 .8280944824242 .3041992188240 .4754943848 238.6468048096236 .8179931641235 .2940979004233 .4653930664231 .6367034912 229.5032043457226 .7601013184223 .7122955322220 .6643981934217 .3117980957 213.6544036865210 .3016967773208 .1681976318206 .0346984863204 .8155975342 205.1204071045207 .8634033203211 .2160949707213 .959197998214 .5686950684 212.4351959229212 .4351959229212 .7400054932213 .0447998047213 .3495941162 213.6544036865212 .4351959229210 .9113006592209 .692199707208 .7778015137 208.1681976318 207.5587005615 207.25390625 206.3394927979 205.7299957275 204.8155975342203 .9011993408203 .2917022705202 .6820983887202 .0724945068 201.7678070068200 .8533935547199 .9389953613199 .0247039795197 .8054962158 196.2816009521195 .0625193 .5386047363192 .0146026611191 .1002960205190 .4907073975 190.4907073975190 .795501709190 .795501709190 .4907073975189 .8811035156 188.966796875187 .7476043701186 .8332977295185 .6141052246184 .699798584 184.0901947021183 .1759033203182 .5662994385181 .6519012451181 .0424041748 179.8231964111178 .2993011475177 .0802001953175 .8609924316174 .9467010498 174.6419067383174 .6419067383174 .0323028564173 .4226989746172 .2035980225 170.6797027588168 .8509979248167 .0222015381164 .5839996338161 .8408966064 159.0977935791156 .0500030518153 .0021057129151 .1734008789149 .9542999268 148.7351074219147 .8208007812147 .5160064697147 .2111968994146 .9064025879 146.9064025879146 .9064025879147 .2111968994147 .2111968994147 .2111968994 147.2111968994146 .9064025879146 .9064025879146 .9064025879146 .9064025879 146.9064025879148 .7351074219150 .5639038086153 .0021057129153 .3069000244 154.2212982178155 .1356048584156 .3547973633157 .2691040039157 .878692627 158.7929992676159 .4026031494159 .7073974609160 .0122070312160 .0122070312 
159.4026031494158 .4882965088160 .3170013428161 .5361022949161 .8408966064 161.5361022949160 .6217956543159 .4026031494158 .1835021973157 .5738983154 156.9642944336156 .6596069336156 .6596069336156 .3547973633156 .3547973633 156.0500030518154 .5260925293150 .2590942383141 .7250976562132 .8863067627 129.2288970947 127.7050018311 126.7906036377126 .1809997559125 .8762969971 125.8762969971126 .1809997559126 .7906036377127 .4001998901128 .0097961426 128.6192932129128 .9241027832129 .2288970947129 .2288970947129 .2288970947 128.6192932129127 .7050018311126 .7906036377125 .5715026855124 .6570968628 123.43800354122 .5235977173121 .9140014648121 .6092987061120 .3900985718 118.8662033081117 .647102356117 .0374984741117 .0374984741117 .647102356 118.5614013672119 .7806015015120 .0852966309118 .8662033081117 .342300415 117.647102356121 .9140014648130 .7528076172139 .2868041992146 .2969055176 152.0877990723155 .7451934814160 .0122070312183 .1759033203201 .158203125 206.6443023682200 .2438049316198 .7198944092216 .0926971436244 .1329040527 268.8204956055280 .7070922852283 .7549133301283 .1453857422281 .0119018555 279.4880065918279 .7927856445280 .7070922852281 .3167114258281 .3167114258 280.7070922852279 .7927856445278 .8783874512277 .6592102051276 .7449035645 275.8305053711275 .2210083008274 .9161987305274 .6113891602274 .6113891602 274.9161987305274 .9161987305275 .2210083008275 .2210083008275 .2210083008 275.2210083008275 .2210083008275 .2210083008275 .2210083008275 .8305053711 276.7449035645277 .6592102051279 .1831970215281 .0119018555282 .8406066895 284.6693115234286 .1932067871287 .4124145508288 .0219116211288 .0219116211 287.7171936035287 .1076049805285 .8884887695284 .0596923828281 .9262084961 278.8783874512272 .1730957031260 .8960876465244 .7424926758225 .8457946777 209.692199707 209.692199707 209.692199707 143.8585968018125 .8762969971

105.3635635376 84.685546875 -9999 -9999 -9999 -9999 -9999 -9999 -9999 -9999 -9999 -9999 -9999 -9999 -9999 -9999 -9999 -9999 -9999 -9999 -9999 -9999 -9999 -9999 -9999 -9999 -9999

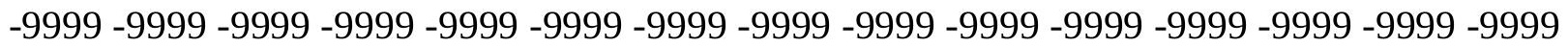
-9999 -9999 -9999 -9999 -9999 -9999 -9999 -9999 -9999 -9999 -9999 -9999 -9999 -9999 -9999 -9999-9999 428.0603637695 422.0132141113413.8981933594 404.145111084 393.782409668 383.419708252372 .7521972656362 .3894958496359 .9512023926355 .9890136719 351.112487793345 .9310913086340 .4450073242334 .9588928223329 .1679077148 323.6817932129318 .1957092285313 .0143127441308 .1377868652304 .1755981445 301.4324951172299 .2990112305298 .0798950195296 .8606872559295 .6416015625 294.1176147461292 .2889099121289 .8505859375287 .4124145508284 .3645019531 281.3167114258278 .2687988281275 .2210083008272 .1730957031269 .1253051758 266.0773925781263 .3344116211260 .5913085938258 .1530151367255 .7147064209 253.5812072754251 .7525024414250 .2286071777248 .7046966553247 .4855041504 246.2664031982245 .3520050049244 .7424926758244 .1329040527243 .8280944824 243.2185058594242 .6089935303242 .3041992188241 .9994049072241 .6945953369 240.4754943848239 .2563018799238 .0372009277237 .7324066162237 .7324066162 238.6468048096240 .1707000732241 .9994049072244 .7424926758246 .2664031982 247.7902984619249 .6190032959250 .8381958008251 .7525024414252 .0572967529 251.7525024414250 .8381958008249 .6190032959248 .3999023438248 .0950927734 249.6190032959251 .7525024414253 .8860015869255 .1051025391255 .4098968506 255.4098968506254 .8003997803253 .5812072754252 .6669006348250 .8381958008 
249.0093994141247 .1806945801245 .6567993164244 .1329040527242 .3041992188 240.7801971436238 .9515075684237 .1228027344234 .9893035889232 .5511016846 229.5032043457226 .150604248222 .4931030273218 .8356933594215 .4830932617 212.7400054932210 .3016967773207 .5587005615205 .1204071045204 .2059936523 208.1681976318212 .1304016113214 .2639007568214 .8735046387214 .5686950684 214.2639007568214 .2639007568214 .8735046387215 .1782989502215 .1782989502 214.5686950684 213.3495941162 212.1304016113211.520904541 211.2160949707 210.9113006592210 .9113006592210 .3016967773209 .3874053955208 .4730072021 207.8634033203207 .25390625206 .6443023682206 .3394927979206 .0346984863 205.425201416205 .1204071045204 .2059936523203 .2917022705201 .7678070068 200.2438049316198 .4151000977196 .891204834195 .6721038818195 .0625195 .3672943115 195.3672943115195 .0625194 .4528961182193 .5386047363192 .0146026611190 .795501709 189.5764007568188 .3571929932187 .4429016113186 .528503418185 .6141052246 184.699798584183 .7854003906183 .1759033203181 .9566955566180 .432800293 178.9089050293177 .6896972656176 .7754058838176 .7754058838177 .3849029541 177.3849029541176 .7754058838175 .5561981201174 .0323028564172 .5084075928 170.6797027588168 .5462036133165 .8031005859162 .7552947998159 .4026031494 156.3547973633153 .9165039062151 .7830047607149 .9542999268148 .7351074219 148.1255950928147 .5160064697147 .2111968994147 .2111968994146 .9064025879 146.9064025879146 .9064025879146 .9064025879146 .6015930176146 .6015930176 146.2969055176145 .9920959473145 .6873016357145 .9920959473146 .9064025879 148.4304046631149 .9542999268150 .8686065674151 .7830047607153 .0021057129 154.2212982178154 .5260925293155 .1356048584155 .7451934814156 .3547973633 156.9642944336157 .2691040039157 .5738983154157 .5738983154158 .1835021973 159.4026031494160 .9264984131161 .5361022949161 .2312927246160 .3170013428 159.0977935791158 .1835021973157 .5738983154157 .2691040039157 .2691040039 157.5738983154157 .5738983154157 .878692627157 .5738983154156 .0500030518 152.3925933838145 .3825073242133 .4958953857134 .7149963379133 .4958953857 131.3623962402129 .8385009766128 .6192932129128 .3144989014128 .6192932129 128.9241027832129 .8385009766130 .7528076172131 .3623962402131 .9720001221 132.2767028809132 .2767028809131 .6672058105131 .0576019287129 .8385009766 128.6192932129127 .0953979492125 .5715026855124 .0475006104122 .8283996582 121.6092987061120 .9997024536120 .0852966309118 .5614013672117 .342300415 116.4279022217116 .4279022217116 .7326965332117 .342300415117 .9517974854 117.9517974854117 .342300415116 .4279022217116 .1231002808116 .7326965332 118.8662033081125 .2667007446131 .0576019287135 .3246002197138 .3724975586 141.1154937744152 .3925933838160 .3170013428160 .3170013428167 .3269958496 171.5939941406189 .2716064453229 .8079986572268 .2109069824275 .8305053711 278.2687988281278 .2687988281276 .4400939941274 .0018005371276 .4400939941 278.2687988281279 .1831970215279 .4880065918279 .4880065918279 .1831970215 277.9641113281277 .0497131348276 .1353149414275 .5257873535274 .9161987305 274.6113891602274 .3066101074274 .3066101074274 .6113891602274 .9161987305 274.9161987305274 .9161987305274 .6113891602274 .3066101074274 .3066101074 274.0018005371274 .0018005371274 .3066101074274 .9161987305275 .8305053711 277.0497131348278 .8783874512281 .0119018555282 .8406066895284 .3645019531 285.5835876465286 .1932067871286 .1932067871285 .5835876465284 .3645019531 
282.5357971191279 .4880065918275 .2210083008272 .4779052734266 .3822021484 256.0195007324242 .3041992188225 .5410003662209 .692199707209 .692199707 209.692199707 149.6495056152131.9720001221 115.81839752293.84102630615 72.02894592285 -9999 -9999 -9999 -9999 -9999 -9999 -9999 -9999 -9999 -9999 -9999 -9999 -9999 -9999 -9999 -9999 -9999 -9999 -9999 -9999 -9999 -9999 -9999 -9999 -9999 -9999 -9999 -9999 -9999 -9999 -9999 -9999 -9999 -9999 -9999 -9999 -9999 -9999 -9999 -9999 -9999 -9999 -9999 -9999 -9999 -9999 -9999 -9999 -9999 -9999 -9999 -9999 -9999 -9999 -9999 -9999 425.1139221191418.4092407227409.6311950684399.2684936523 388.9057922363378 .5430908203367 .570892334364 .2182006836359 .3417053223 354.4650878906349 .2838134766344 .1023864746338 .6163024902333 .1301879883 327.9487915039322 .4627075195317 .2813110352312 .1000061035307 .8330078125 303.8707885742301 .1276855469298 .9942016602297 .4703063965296 .2510986328 294.7272033691293 .5080871582291 .6794128418289 .5458984375287 .1076049805 284.3645019531281 .3167114258278 .2687988281275 .2210083008271 .8682861328 268.8204956055265 .7726135254262 .7247924805259 .9816894531257 .2385864258 254.8003997803252 .6669006348250 .8381958008249 .0093994141247 .4855041504 246.5711975098245 .6567993164244 .7424926758244 .1329040527243 .5233001709 242.9136962891242 .3041992188241 .3898010254240 .7801971436240 .1707000732 239.2563018799238 .0372009277236 .8179931641235 .9037017822235 .2940979004 235.5989074707236 .5133056641238 .3419952393240 .4754943848243 .2185058594 245.9615936279248 .3999023438250 .2286071777251 .4476928711252 .0572967529 252.0572967529251 .4476928711250 .2286071777248 .7046966553246 .8759002686 245.3520050049247 .7902984619250 .5334014893252 .3621063232253 .8860015869 254.1907958984253 .8860015869252 .9716033936252 .3621063232251 .7525024414 251.1428985596250 .2286071777249 .3141937256248 .3999023438246 .8759002686 245.3520050049243 .5233001709241 .6945953369240 .1707000732238 .0372009277 234.9893035889231 .6367034912227 .9792938232224 .0171051025220 .3596038818 216.7021942139214 .2639007568212 .4351959229208 .4730072021206 .0346984863 205.425201416208 .1681976318212 .4351959229213 .959197998214 .8735046387 215.1782989502215 .1782989502215 .4830932617216 .0926971436216 .3973999023 216.3973999023216 .0926971436215 .1782989502214 .2639007568213 .6544036865 213.6544036865213 .959197998214 .2639007568213 .6544036865212 .7400054932 212.1304016113211 .2160949707210 .9113006592210 .3016967773210 .3016967773 210.3016967773209 .9969024658209 .692199707209 .3874053955208 .7778015137 207.5587005615206 .0346984863203 .9011993408202 .0724945068200 .2438049316 200.2438049316200 .5485992432200 .2438049316199 .6342926025198 .7198944092 197.1959991455195 .3672943115193 .8433074951192 .624206543191 .4051055908 190.1858978271189 .2716064453188 .0523986816187 .1381072998185 .9188995361 184.699798584183 .7854003906182 .261505127180 .7375946045179 .2136993408 177.9945068359178 .2993011475180 .432800293180 .7375946045179 .8231964111 178.604095459177 .3849029541175 .8609924316174 .337097168172 .2035980225 169.7653045654166 .7174987793163 .3648071289160 .3170013428156 .9642944336 154.2212982178151 .7830047607149 .9542999268148 .7351074219148 .4304046631 148.1255950928147 .5160064697147 .5160064697147 .2111968994147 .2111968994 146.9064025879146 .6015930176146 .2969055176145 .9920959473145 .6873016357 145.3825073242145 .3825073242145 .6873016357146 .6015930176147 .2111968994 
148.1255950928148 .7351074219150 .2590942383151 .7830047607151 .7830047607 151.7830047607152 .6972961426153 .6116943359154 .5260925293155 .1356048584 155.7451934814156 .6596069336157 .878692627159 .7073974609161 .2312927246 162.1457061768161 .5361022949160 .0122070312158 .4882965088157 .878692627 157.5738983154157 .5738983154157 .5738983154157 .878692627158 .1835021973 158.7929992676158 .7929992676157 .878692627156 .0500030518153 .6116943359 153.9165039062145 .0776977539139 .8963928223136 .5437011719133 .4958953857 131.6672058105130 .7528076172130 .7528076172131 .3623962402132 .2767028809 133.4958953857134 .7149963379135 .3246002197135 .6293945312135 .3246002197 134.7149963379133 .8007049561132 .2767028809130 .4479980469128 .6192932129 126.7906036377124 .9618988037123 .43800354122 .2188034058121 .3044967651 120.0852966309118 .5614013672117 .0374984741116 .1231002808115 .818397522 115.818397522116 .4279022217116 .7326965332116 .7326965332116 .1231002808 115.5136032104114 .9039993286114 .5991973877113 .9896011353113 .9896011353 118.2565994263121 .3044967651123 .1332015991127 .0953979492131 .9720001221 133.1911010742136 .5437011719145 .6873016357152 .0877990723172 .5084075928 210.6065063477242 .6089935303259 .6769104004266 .6870117188269 .1253051758 269.4301147461270.3443908691273.0874938965 274.3066101074275.5257873535 277.0497131348277 .9641113281277 .9641113281277 .0497131348275 .8305053711 275.2210083008274 .9161987305274 .6113891602274 .0018005371274 .3066101074 274.0018005371274 .0018005371274 .3066101074274 .6113891602274 .0018005371 273.6971130371273 .3923034668273 .0874938965272 .7827148438272 .7827148438 273.0874938965273 .3923034668274 .0018005371274 .9161987305277 .0497131348 279.1831970215281 .0119018555282 .2309875488283 .1453857422283 .4501953125 283.1453857422282 .5357971191281 .0119018555278 .5736083984275 .5257873535 271.5635070801266 .9917907715260 .5913085938251 .1428985596238 .9515075684 224.0171051025209 .692199707209 .692199707209 .692199707209 .692199707 137.1533050537120 .9997024536101 .539466857981 .16857147217 -9999 -9999 -9999 -9999 -9999 -9999 -9999 -9999 -9999 -9999 -9999 -9999 -9999 -9999 -9999 -9999 -9999 -9999 -9999 -9999 -9999-9999-9999-9999

-9999 -9999 -9999 -9999 -9999 -9999 -9999 -9999 -9999 -9999 -9999 -9999 -9999 -9999 -9999 -9999 -9999 -9999 -9999 -9999 -9999 -9999 -9999 -9999 -9999 -9999 -9999 -9999 -9999 -9999 -9999 -9999 422.2537841797415.422088623 405.6690063477395 .3063049316 384.9436035156374 .2760925293367 .2661132812362 .6943054199358 .1224975586 353.2460021973348 .3693847656343 .1879882812337 .7019042969332 .5205993652 327.3392028809322 .1578979492317 .2813110352312 .4047851562308 .1377868652 304.4802856445301 .4324951172299 .2990112305297 .7750854492296 .2510986328 294.7272033691293 .5080871582291 .6794128418289 .5458984375287 .1076049805 284.6693115234281 .6214904785278 .5736083984275 .5257873535272 .1730957031 268.8204956055265 .7726135254262 .4200134277259 .3721008301256 .6290893555 253.8860015869251 .7525024414249 .6190032959247 .7902984619246 .5711975098 245.6567993164244 .7424926758244 .1329040527243 .2185058594242 .6089935303 241.6945953369241 .0850067139239 .8659057617238 .9515075684237 .7324066162 236.5133056641235 .2940979004234 .0749969482232 .8558044434232 .5511016846 232.5511016846233 .4653930664235 .2940979004237 .7324066162240 .7801971436 244.4376983643247 .4855041504249 .9237976074251 .4476928711251 .7525024414 
251.7525024414250 .8381958008249 .6190032959247 .7902984619246 .2664031982 245.9615936279247 .1806945801248 .7046966553250 .2286071777251 .1428985596 251.4476928711250 .2286071777249 .0093994141248 .3999023438248 .7046966553 249.3141937256249 .3141937256249 .3141937256249 .3141937256248 .3999023438 246.8759002686244 .7424926758243 .8280944824242 .6089935303240 .4754943848 237.1228027344233 .4653930664229 .1983947754225 .2362060547220 .9691925049 217.3117980957 213.959197998 211.2160949707 208.4730072021 206.3394927979 205.7299957275206 .9490966797209 .692199707212 .4351959229214 .2639007568 214.8735046387215 .4830932617216 .0926971436216 .7021942139217 .0070037842 217.3117980957 217.3117980957217.0070037842 216.3973999023 216.0926971436 216.0926971436216 .3973999023216 .7021942139216 .3973999023215 .787902832 215.1782989502214 .5686950684214 .2639007568213 .6544036865213 .959197998 213.959197998214 .2639007568214 .2639007568213 .959197998213 .6544036865 213.0447998047211 .2160949707209 .3874053955207 .8634033203206 .6443023682 206.0346984863205 .7299957275205 .425201416204 .5108032227202 .9868927002 200.8533935547198 .7198944092196 .891204834195 .6721038818194 .7577056885 193.5386047363192 .3193969727191 .1002960205189 .5764007568187 .7476043701 186.8332977295185 .6141052246184 .3950042725182 .87109375181 .6519012451 179.5184020996177 .9945068359184 .3950042725183 .4806976318182 .261505127 181.0424041748180 .1280059814178 .9089050293177 .6896972656176 .165802002 174.0323028564170 .9844970703167 .9365997314164 .2792053223160 .6217956543 157.2691040039154 .2212982178151 .4781951904150 .2590942383149 .6495056152 149.0399017334148 .4304046631148 .1255950928147 .8208007812147 .5160064697 147.2111968994146 .9064025879146 .6015930176146 .2969055176145 .6873016357 145.0776977539144 .7729034424144 .7729034424145 .0776977539145 .0776977539 145.0776977539145 .6873016357146 .6015930176147 .5160064697148 .1255950928 148.7351074219149 .6495056152150 .8686065674152 .0877990723153 .3069000244 154.2212982178155 .7451934814157 .5738983154159 .4026031494161 .5361022949 163.0599975586161 .5361022949159 .4026031494157 .5738983154157 .2691040039 157.2691040039157 .5738983154157 .878692627158 .1835021973158 .4882965088 159.0977935791159 .7073974609160 .0122070312159 .7073974609159 .4026031494 157.5738983154152 .3925933838146 .2969055176141 .1154937744136 .8484954834 134.1054992676132 .5814971924132 .5814971924133 .4958953857135 .0198059082 136.5437011719138 .0677032471138 .9819946289139 .2868041992138 .9819946289 138.0677032471136 .5437011719134 .7149963379132 .8863067627130 .4479980469 128.3144989014126 .4858016968124 .6570968628123 .43800354122 .2188034058 120.9997024536119 .1709976196117 .342300415115 .818397522115 .5136032104 115.5136032104115 .818397522116 .1231002808115 .818397522115 .5136032104 114.5991973877113 .6848983765112 .7705001831111 .8561019897111 .551399231 112.1608963013 113.3800964355 114.9039993286 117.647102356120.3900985718 117.9517974854120 .3900985718128 .0097961426136 .5437011719161 .5361022949 192.0146026611218 .8356933594238 .3419952393249 .6190032959255 .7147064209 259.3721008301262 .4200134277265 .4678039551267 .9060974121270 .3443908691 272.7827148438274 .9161987305276 .4400939941276 .1353149414274 .0018005371 274.0018005371274 .3066101074274 .3066101074274 .6113891602273 .6971130371 273.3923034668273 .0874938965273 .0874938965273 .0874938965272 .7827148438 
272.4779052734272 .1730957031271 .8682861328271 .5635070801271 .5635070801 271.5635070801271 .8682861328272 .4779052734273 .6971130371275 .2210083008 277.0497131348278 .5736083984279 .7927856445280 .4023132324280 .4023132324 279.7927856445278 .8783874512277 .0497131348274 .6113891602271 .5635070801 267.2966003418262 .4200134277255 .4098968506246 .5711975098234 .9893035889 221.5787963867209 .692199707209 .692199707209 .692199707209 .692199707 141.1154937744125 .8762969971111 .55139923190 .0068664550867 .84785461426 -9999 -9999 -9999 -9999 -9999 -9999 -9999 -9999 -9999 -9999 -9999 -9999 -9999 -9999 -9999 -999 -999 -999 - 9999 - 9999 -9999 -9999 -9999 -9999 -9999 -9999 -9999

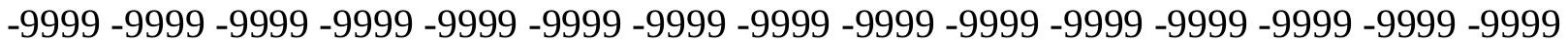

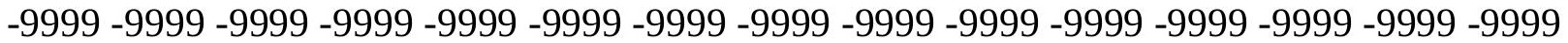
-9999 -9999 419.393737793 411.7647094727 402.31640625 391.953704834382.200592041 373.3617858887366 .3517150879361 .475189209357 .208190918352 .941192627 348.0646057129343 .1879882812338 .0067138672332 .8252868652327 .9487915039 323.0722045898318 .1957092285313 .6239013672309 .3569030762305 .3947143555 302.6516113281300 .5180969238298 .6893920898297 .1654968262295 .6416015625 294.1176147461292 .2889099121290 .4602050781288 .0219116211285 .2789001465 282.2309875488 279.1831970215 275.8305053711 272.4779052734 269.1253051758 265.7726135254262 .4200134277259 .3721008301256 .3243103027253 .2763977051 250.8381958008248 .7046966553246 .8759002686245 .6567993164244 .7424926758 244.1329040527243 .5233001709242 .6089935303241 .6945953369240 .7801971436 239.5610961914238 .3419952393236 .8179931641235 .2940979004234 .0749969482 232.246307373231 .0270996094229 .5032043457228 .8936004639228 .5888977051 229.5032043457231 .0270996094233 .7702026367237 .1228027344241 .0850067139 245.3520050049248 .7046966553249 .6190032959249 .9237976074249 .9237976074 249.3141937256247 .7902984619245 .9615936279245 .0471954346245 .0471954346 245.6567993164246 .2664031982246 .2664031982246 .5711975098246 .8759002686 244.4376983643242 .3041992188241 .6945953369242 .6089935303244 .7424926758 244.4376983643245 .3520050049247 .7902984619248 .0950927734247 .1806945801 244.4376983643245 .3520050049244 .4376983643241 .6945953369238 .0372009277 234.0749969482229 .8079986572225 .5410003662221 .2740020752217 .3117980957 213.0447998047209 .9969024658207 .8634033203206 .0346984863204 .8155975342 205.1204071045206 .9490966797210 .6065063477213 .0447998047214 .2639007568 215.1782989502216 .0926971436217 .0070037842217 .6165924072218 .2261962891 218.5308990479218 .5308990479218 .2261962891218 .2261962891218 .5308990479 218.5308990479218 .8356933594218 .5308990479218 .2261962891217 .9214019775 217.6165924072 217.3117980957 217.3117980957 217.3117980957 217.6165924072 217.9214019775 217.9214019775 217.9214019775 217.6165924072 217.0070037842 215.787902832214 .2639007568213 .0447998047212 .4351959229211 .2160949707 210.6065063477210 .3016967773209 .3874053955207 .5587005615204 .8155975342 201.7678070068200 .2438049316199 .0247039795198 .4151000977197 .1959991455 195.9768066406194 .4528961182192 .3193969727190 .4907073975189 .5764007568 188.0523986816186 .8332977295185 .6141052246184 .0901947021182 .5662994385 182.5662994385184 .0901947021184 .3950042725183 .1759033203182 .5662994385 181.9566955566181 .6519012451181 .0424041748179 .8231964111177 .9945068359 175.2514038086172 .2035980225168 .5462036133164 .5839996338160 .9264984131 
157.5738983154154 .8307952881152 .6972961426151 .4781951904150 .5639038086 149.6495056152149 .0399017334148 .7351074219148 .4304046631147 .8208007812 147.5160064697147 .2111968994146 .6015930176146 .2969055176145 .6873016357 145.0776977539144 .7729034424144 .1634063721143 .8585968018142 .9441986084 143.2489929199143 .2489929199144 .1634063721144 .7729034424145 .9920959473 147.2111968994148 .4304046631149 .6495056152151 .1734008789152 .6972961426 154.5260925293156 .3547973633158 .7929992676160 .6217956543161 .5361022949 160.6217956543158 .7929992676157 .5738983154156 .9642944336156 .9642944336 157.2691040039157 .878692627158 .1835021973158 .4882965088159 .0977935791 160.3170013428161 .2312927246161 .5361022949161 .2312927246159 .4026031494 155.7451934814150 .2590942383144 .4682006836139 .2868041992135 .6293945312 133.8007049561133 .8007049561135 .3246002197137 .4580993652139 .5915985107 141.4203033447142 .6394042969142 .9441986084142 .3347015381141 .1154937744 139.5915985107137 .4580993652135 .3246002197132 .8863067627130 .4479980469 128.0097961426126 .1809997559124 .6570968628123 .7427978516122 .8283996582 120.6949005127117 .342300415115 .818397522115 .818397522115 .818397522 116.1231002808116 .1231002808115 .818397522115 .2088012695114 .2944030762 113.075302124111 .8561019897110 .6370010376109 .7226028442109 .4179000854 109.1130981445109 .4179000854109 .7226028442109 .4179000854108 .1986999512 110.6370010376114 .9039993286129 .8385009766151 .7830047607175 .2514038086 197.8054962158216 .3973999023230 .1127929688239 .2563018799245 .9615936279 250.8381958008255 .4098968506259 .3721008301263 .0296020508266 .6870117188 270.0396118164273 .3923034668275 .5257873535273 .3923034668272 .7827148438 272.7827148438272 .7827148438272 .7827148438272 .4779052734271 .8682861328 271.5635070801271 .2587890625271 .2587890625270 .9540100098270 .6492004395 270.3443908691270 .0396118164270 .0396118164269 .7348022461270 .0396118164 270.3443908691270 .9540100098272 .1730957031273 .3923034668274 .9161987305 276.1353149414277 .0497131348277 .3544921875277 .0497131348276 .1353149414 274.9161987305273 .0874938965270 .6492004395267 .6012878418263 .3344116211 257.8482055664250 .8381958008241 .9994049072231 .3318939209219 .1405029297 209.692199707 209.692199707 209.692199707 209.692199707 209.692199707 130.1432037354116 .427902221797 .6231231689576 .76637268066 -9999 -9999 -9999 -9999 -9999 -9999 -9999 -9999 -9999 -9999 -9999 -9999 -9999 -9999 -9999 -9999 -9999 -9999 -9999 -9999 -9999 -9999-9999

-9999 -9999 -9999 -9999 -9999 -9999 -9999 -9999 -9999 -9999 -9999 -9999 -9999 -9999 -9999 -9999 -9999 -9999 -9999 -9999 -9999 -9999 -9999 -9999 -9999 -9999 -9999 -9999 -9999 -9999 -9999-9999 416.8152770996 409.6311950684 400.792388916 391.6488952637 382.200592041 373.666595459365 .4374084473361 .475189209357 .5129089355353 .5508117676 348.9790039062344 .1023864746339 .2258911133334 .3493041992329 .4726867676 324.5961914062320 .0244140625315 .4526062012311 .4903869629307 .8330078125 304.7850952148302 .6516113281300 .5180969238298 .9942016602297 .4703063965 295.6416015625293 .8128967285291 .6794128418289 .5458984375286 .4979858398 283.7549133301280 .4023132324277 .0497131348273 .3923034668270 .0396118164 266.3822021484262 .7247924805259 .3721008301256 .0195007324252 .9716033936 250.2286071777247 .7902984619245 .6567993164244 .7424926758244 .1329040527 243.8280944824243 .2185058594241 .9994049072240 .7801971436239 .2563018799 
238.0372009277236 .5133056641234 .6844940186233 .1605987549231 .3318939209 229.5032043457227 .6744995117225 .8457946777224 .6266021729224 .3218994141 224.6266021729226 .150604248228 .58889977051231 .6367034912235 .9037017822 240.4754943848245 .3520050049244 .7424926758244 .4376983643245 .0471954346 246.2664031982243 .8280944824242 .3041992188241 .3898010254241 .6945953369 242.9136962891241 .0850067139239 .8659057617238 .6468048096237 .4275970459 235.2940979004233 .1605987549232 .246307373232 .5511016846233 .7702026367 234.6844940186236 .8179931641240 .1707000732244 .4376983643244 .7424926758 246.2664031982245 .3520050049244 .4376983643241 .6945953369237 .4275970459 233.1605987549229 .1983947754225 .2362060547221 .2740020752217 .6165924072 214.5686950684211 .2160949707208 .4730072021206 .0346984863204 .5108032227 204.8155975342206 .6443023682209 .692199707212 .7400054932213 .3495941162 214.8735046387216 .3973999023217 .3117980957218 .2261962891218 .8356933594 219.4452972412219 .7501068115220 .054901123220 .054901123220 .3596038818 220.3596038818220 .6643981934220 .6643981934220 .6643981934220 .3596038818 220.3596038818220 .054901123220 .054901123220 .3596038818220 .6643981934 220.6643981934220 .9691925049220 .9691925049220 .6643981934220 .054901123 219.1405029297218 .2261962891217 .0070037842216 .3973999023215 .4830932617 214.5686950684213 .959197998213 .6544036865211 .520904541209 .0825958252 206.3394927979 203.9011993408203.2917022705 202.3773040771 201.158203125 199.6342926025198 .1103057861197 .1959991455196 .5863952637192 .624206543 191.4051055908190 .1858978271188 .6620025635187 .4429016113186 .2236938477 185.9188995361185 .6141052246185 .0045928955184 .0901947021183 .4806976318 183.1759033203183 .1759033203183 .4806976318182 .261505127181 .0424041748 179.2136993408176 .165802002172 .2035980225168 .5462036133164 .8887023926 161.2312927246158 .1835021973155 .7451934814153 .9165039062152 .3925933838 151.1734008789150 .2590942383149 .6495056152149 .3446960449149 .0399017334 148.4304046631148 .1255950928147 .5160064697146 .9064025879146 .6015930176 145.9920959473145 .0776977539144 .4682006836143 .5538024902142 .9441986084 142.3347015381142 .3347015381142 .6394042969143 .2489929199143 .8585968018 145.0776977539146 .2969055176147 .5160064697149 .0399017334150 .5639038086 152.6972961426154 .8307952881157 .2691040039159 .0977935791160 .0122070312 159.4026031494157 .878692627156 .9642944336156 .3547973633156 .9642944336 157.5738983154158 .1835021973158 .4882965088159 .0977935791160 .0122070312 160.9264984131161 .8408966064162 .1457061768161 .5361022949159 .7073974609 156.3547973633152 .3925933838145 .3825073242139 .5915985107136 .2389984131 134.7149963379134 .7149963379137 .1533050537139 .8963928223142 .6394042969 145.0776977539146 .2969055176146 .6015930176145 .6873016357144 .4682006836 142.6394042969140 .5059967041138 .0677032471135 .3246002197132 .5814971924 129.8385009766127 .7050018311126 .1809997559125 .2667007446124 .6570968628 124.0475006104117 .0374984741116 .7326965332117 .0374984741117 .342300415 117.342300415117 .0374984741116 .4279022217115 .5136032104114 .5991973877 113.3800964355112 .1608963013110 .6370010376109 .1130981445107 .5891036987 106.3700027466105 .1509017944103 .9317016602102 .712600708102 .1029968262 103.6268997192109 .1130981445121 .3044967651142 .0299072266158 .1835021973 177.9945068359195 .9768066406210 .6065063477221 .5787963867230 .1127929688 
237.1228027344243 .2185058594248 .3999023438253 .5812072754258 .4577941895 263.0296020508266 .6870117188269 .1253051758269 .7348022461269 .7348022461 270.0396118164270 .0396118164270 .3443908691270 .0396118164269 .7348022461 269.4301147461269 .1253051758268 .8204956055268 .8204956055268 .5156860352 268.2109069824 268.2109069824 267.9060974121 267.9060974121 268.2109069824 268.5156860352269 .4301147461270 .0396118164271 .2587890625272 .1730957031 273.3923034668274 .0018005371274 .0018005371273 .6971130371272 .4779052734 271.2587890625269 .1253051758266 .6870117188263 .3344116211258 .7626037598 253.2763977051246 .2664031982238 .0372009277227 .9792938232216 .3973999023 209.692199707 209.692199707 209.692199707 209.692199707 209.692199707 134.1054992676120 .6949005127108 .198699951284 .9803543090861 .08938598633 -9999 -9999 -9999 -9999 -9999 -9999 -9999 -9999 -9999 -9999 -9999 -9999 -9999 -9999 -9999 -9999 -9999 -9999 -9999-9999-9999-9999

-9999 -9999 -9999 -9999 -9999 -9999 -9999 -9999 -9999 -9999 -9999 -9999 -9999 -9999 -9999 -9999 -9999 -9999 -9999 -9999 -9999 -9999 -9999 -9999 -9999 -9999 -9999 -9999 -9999 -9999 -9999 -9999 414.4878845215 407.4977111816 399.5733032227391 .3440856934 382.8100891113374 .8857116699368 .4851989746363 .6086120605359 .6465148926 355.6842041016351 .112487793346 .5407104492341 .3593139648336 .4827880859 331.6062011719327 .0344848633322 .4627075195318 .1957092285314 .2334899902 310.8807983398307 .8330078125305 .3947143555303 .2611999512301 .4324951172 299.9085998535298.0798950195 296.2510986328 294.1176147461 291.3746032715 288.6315002441285.2789001465 281.9262084961278.2687988281274.6113891602 270.9540100098267 .2966003418263 .6390991211259 .9816894531256 .3243103027 252.9716033936249 .6190032959246 .8759002686244 .7424926758243 .5233001709 243.8280944824243 .8280944824242 .9136962891241 .3898010254239 .5610961914 238.0372009277236.2084960938234.6844940186232.8558044434231.0270996094 228.8936004639226 .7601013184224 .6266021729222 .4931030273220 .6643981934 219.7501068115220 .054901123220 .9691925049222 .7978973389225 .2362060547 228.5888977051232 .246307373234 .6844940186235 .5989074707236 .2084960938 237.1228027344237 .7324066162237 .1228027344235 .9037017822235 .2940979004 235.2940979004234 .9893035889233 .4653930664231 .0270996094229 .1983947754 226.7601013184224 .6266021729222 .1884002686220 .6643981934220 .9691925049 221.5787963867222 .4931030273224 .6266021729228 .5888977051233 .1605987549 236.2084960938238 .3419952393240 .1707000732241 .9994049072238 .3419952393 234.3798065186230 .7223052979227 .3697052002224 .0171051025220 .9691925049 217.9214019775215 .1782989502212 .7400054932209 .9969024658207 .25390625 204.8155975342205 .425201416207 .25390625209 .692199707211 .8256988525 213.6544036865215 .1782989502216 .3973999023217 .6165924072218 .8356933594 219.7501068115220 .3596038818220 .9691925049221 .2740020752221 .5787963867 221.883605957222 .1884002686222 .1884002686222 .4931030273222 .4931030273 222.4931030273222 .4931030273222 .4931030273222 .7978973389222 .7978973389 223.1027069092 223.1027069092 223.4075012207223.4075012207223.1027069092 222.7978973389221 .883605957220 .9691925049220 .054901123219 .1405029297 218.2261962891 217.3117980957216.7021942139215.4830932617214.2639007568 213.0447998047209 .692199707209 .0825958252208 .7778015137206 .6443023682 204.5108032227203 .2917022705201 .7678070068201 .158203125200 .5485992432 
197.1959991455 195.0625193.8433074951 192.3193969727191.1002960205189.8811035156 188.6620025635187 .7476043701186 .528503418184 .699798584184 .3950042725 183.7854003906183 .7854003906183 .7854003906183 .4806976318183 .1759033203 182.5662994385179 .2136993408175 .5561981201171 .8988037109168 .5462036133 165.4983062744162 .1457061768159 .0977935791156 .3547973633154 .2212982178 152.6972961426151 .7830047607151 .1734008789150 .5639038086149 .9542999268 149.6495056152149 .3446960449148 .7351074219148 .1255950928147 .5160064697 146.9064025879146 .2969055176145 .3825073242144 .4682006836143 .8585968018 142.9441986084142 .6394042969142 .3347015381142 .3347015381142 .9441986084 143.5538024902144 .4682006836145 .6873016357146 .9064025879148 .7351074219 150.5639038086152 .6972961426155 .1356048584156 .9642944336158 .4882965088 157.5738983154156 .3547973633155 .7451934814156 .0500030518156 .6596069336 157.5738983154158 .4882965088159 .0977935791159 .7073974609160 .6217956543 161.2312927246161 .8408966064162 .1457061768161 .2312927246159 .0977935791 155.1356048584149 .6495056152143 .5538024902138 .6772003174135 .9342041016 135.3246002197136 .5437011719138 .9819946289142 .3347015381145 .6873016357 148.4304046631149 .9542999268149 .6495056152148 .7351074219147 .2111968994 145.3825073242143 .5538024902141 .1154937744138 .3724975586135 .3246002197 131.9720001221129 .2288970947127 .4001998901126 .7906036377126 .1809997559 124.6570968628121 .6092987061120 .0852966309119 .7806015015119 .4757995605 118.8662033081118 .2565994263117 .342300415116 .4279022217115 .5136032104 114.5991973877113 .075302124111 .24659729109 .4179000854107 .2844009399 105.1509017944103 .0174026489101 .188697814999 .3599472045999 .05516815186 100.2742996216104 .8460998535111 .8561019897119 .7806015015141 .7250976562 160.9264984131177 .6896972656192 .0146026611203 .9011993408213 .3495941162 221.883605957229 .1983947754235 .9037017822242 .3041992188248 .0950927734 253.5812072754258 .1530151367261 .5056152344263 .6390991211264 .8583068848 265.7726135254266 .3822021484266 .6870117188266 .6870117188266 .6870117188 266.6870117188266 .3822021484266 .3822021484266 .0773925781266 .0773925781 265.7726135254265 .7726135254265 .7726135254266 .0773925781266 .0773925781 266.6870117188267 .2966003418267 .9060974121268 .8204956055269 .7348022461 270.3443908691270 .6492004395270 .6492004395270 .0396118164268 .8204956055 267.2966003418265 .1630859375262 .4200134277259 .0674133301254 .4956054688 248.7046966553241 .9994049072233 .7702026367224 .3218994141213 .6544036865 209.692199707209 .692199707209 .692199707209 .692199707209 .692199707209 .692199707 124.6570968628112 .465698242290 .4316024780368 .54158782959 -9999 -9999 -9999 -9999 -9999 -9999 -9999 -9999 -9999 -9999 -9999 -9999 -9999 -9999 -9999 -9999 -9999 -9999 -9999 -9999-9999-9999

-9999 -9999 -9999 -9999 -9999 -9999 -9999 -9999 -9999 -9999 -9999 -9999 -9999 -9999 -9999

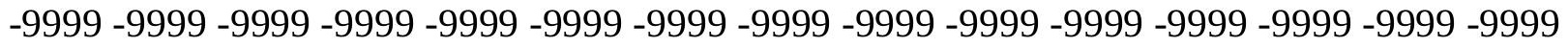
-9999 -9999 412.4561157227405.6690063477398.6589050293 391.3440856934 384.029296875377 .324005127371 .5331115723366 .9613037109362 .9991149902 358.7320861816354 .1603088379349 .5885009766344 .4071960449339 .5306091309 334.6541137695329 .7774963379325 .5104980469321 .5483093262317 .8908996582 314.5382080078311 .4903869629309 .0520935059306 .6138000488304 .7850952148 303.2611999512301 .1276855469299 .2990112305296 .8606872559294 .4223937988 
291.0697937012287 .7171936035284 .0596923828280 .0975036621276 .1353149414 272.4779052734268 .5156860352264 .5534973145260 .8960876465256 .9338989258 253.2763977051249 .6190032959246 .5711975098244 .1329040527243 .2185058594 243.5233001709244 .1329040527242 .3041992188240 .1707000732238 .3419952393 236.2084960938234 .3798065186232 .8558044434231 .0270996094228 .8936004639 226.7601013184224 .6266021729221 .883605957219 .4452972412217 .0070037842 215.4830932617215 .787902832216 .3973999023217 .3117980957218 .5308990479 220.6643981934222 .7978973389223 .7122955322224 .3218994141225 .5410003662 227.3697052002 228.2841033936 228.2841033936 227.9792938232 227.3697052002 227.0648956299226 .150604248224 .0171051025221 .5787963867218 .8356933594 216.7021942139214 .5686950684211 .8256988525209 .0825958252209 .9969024658 210.6065063477210 .6065063477210 .6065063477216 .0926971436220 .6643981934 224.3218994141226 .7601013184228 .8936004639231 .0270996094230 .7223052979 229.1983947754 227.0648956299 224.6266021729 222.4931030273220.054901123 217.9214019775215 .787902832213 .6544036865211 .8256988525208 .7778015137 206.9490966797206 .6443023682208 .1681976318210 .3016967773213 .3495941162 214.2639007568215 .4830932617216 .7021942139218 .2261962891219 .1405029297 220.3596038818221 .2740020752221 .883605957222 .4931030273222 .7978973389 223.1027069092223 .4075012207223 .7122955322224 .0171051025224 .3218994141 224.3218994141224 .3218994141224 .6266021729224 .6266021729224 .9313964844 225.2362060547 225.2362060547 225.2362060547 225.2362060547 225.2362060547 224.6266021729224 .0171051025223 .1027069092222 .1884002686221 .2740020752 220.054901123219 .1405029297218 .2261962891216 .7021942139215 .1782989502 212.4351959229209 .0825958252213 .959197998213 .959197998209 .0825958252 206.6443023682205 .7299957275204 .8155975342203 .596496582202 .3773040771 200.2438049316198 .4151000977197 .1959991455195 .9768066406194 .7577056885 193.5386047363191 .7097930908189 .8811035156188 .6620025635187 .7476043701 185.6141052246184 .0901947021183 .4806976318183 .1759033203183 .4806976318 183.4806976318182 .87109375180 .432800293177 .6896972656174 .9467010498 172.5084075928169 .4604949951166 .1078948975162 .1457061768158 .7929992676 156.3547973633154 .5260925293153 .3069000244152 .3925933838151 .7830047607 151.4781951904151 .1734008789150 .8686065674150 .2590942383149 .6495056152 149.0399017334148 .4304046631147 .8208007812146 .9064025879146 .2969055176 145.3825073242144 .1634063721143 .5538024902142 .9441986084142 .3347015381 142.3347015381142 .3347015381142 .9441986084143 .5538024902145 .0776977539 146.6015930176148 .7351074219150 .5639038086152 .6972961426154 .5260925293 155.4403991699155 .1356048584154 .8307952881154 .8307952881155 .4403991699 156.9642944336158 .1835021973159 .0977935791159 .7073974609160 .3170013428 160.6217956543161 .2312927246161 .5361022949161 .5361022949160 .6217956543 158.1835021973153 .9165039062147 .2111968994140 .5059967041136 .5437011719 135.6293945312135 .9342041016138 .0677032471140 .8106994629144 .4682006836 148.1255950928151 .1734008789153 .3069000244151 .7830047607150 .8686065674 149.3446960449147 .8208007812146 .2969055176144 .4682006836141 .7250976562 138.6772003174135 .0198059082131 .3623962402128 .9241027832128 .6192932129 128.3144989014127 .4001998901125 .8762969971124 .0475006104123 .1332015991 122.5235977173120 .9997024536119 .7806015015118 .5614013672117 .9517974854 
117.0374984741116 .1231002808114 .9039993286113 .3800964355110 .9418029785 108.5035018921105 .7603988647103 .0174026489100 .579101562598 .75038146973 98.1408081054799 .05516815186102 .4077987671107 .8938980103117 .0374984741 131.6672058105147 .5160064697162 .1457061768174 .9467010498186 .2236938477 196.5863952637205 .7299957275214 .2639007568222 .4931030273230 .1127929688 236.8179931641243 .2185058594248 .7046966553252 .9716033936256 .3243103027 258.4577941895260 .2864990234261 .5056152344262 .1152038574262 .7247924805 263.0296020508263 .0296020508263 .0296020508263 .0296020508263 .0296020508 263.0296020508263 .0296020508263 .0296020508263 .3344116211263 .6390991211 263.9439086914264 .2486877441264 .8583068848265 .4678039551266 .0773925781 266.6870117188266 .9917907715267 .2966003418266 .9917907715266 .0773925781 265.1630859375263 .3344116211261 .2008972168258 .1530151367254 .4956054688 249.9237976074244 .4376983643237 .7324066162229 .8079986572220 .9691925049 210.9113006592209 .692199707209 .692199707209 .692199707209 .692199707 209.692199707 209.692199707 128.0097961426116.427902221797.75897979736 76.5501174926853 .46409606934 -9999 -9999 -9999 -9999 -9999 -9999 -9999 -9999 -9999 -9999 -9999 -9999 -9999 -9999 -9999 -9999 -9999 -9999 -9999 -9999 -9999 -9999 -9999 -9999 -9999 -9999 -9999 -9999 -9999 -9999 -9999 -9999 -9999 -9999 -9999 -9999 -9999 -9999 -9999 -9999 -9999 -9999 -9999 -9999 -9999 -9999 -9999 -9999 -9999 -9999 -9999 -9999 -9999 410.940826416 404.4498901367 398.049407959 391.6488952637385 .5531921387 379.762298584374 .5809020996370 .3139038086366 .6564941406362 .3894958496 357.8176879883353 .2460021973348 .0646057129343 .1879882812338 .0067138672 333.1301879883328 .8631896973325 .2056884766321 .5483093262318 .5004882812 315.7573852539313 .3190917969311 .1856079102309 .0520935059307 .2233886719 305.0899047852302 .9563903809300 .5180969238297 .7750854492294 .1176147461 290.4602050781286 .1932067871282 .2309875488278 .2687988281274 .3066101074 270.3443908691266 .0773925781262 .4200134277258 .4577941895254 .4956054688 250.5334014893246 .8759002686243 .8280944824243 .2185058594243 .2185058594 242.6089935303241 .0850067139238 .9515075684236 .8179931641234 .6844940186 232.8558044434231 .0270996094229 .1983947754227 .3697052002225 .2362060547 222.7978973389220 .054901123217 .3117980957214 .5686950684212 .1304016113 213.0447998047213 .959197998213 .959197998212 .7400054932214 .2639007568 214.8735046387214 .2639007568213 .0447998047215 .787902832217 .9214019775 219.1405029297219 .1405029297219 .1405029297218 .8356933594218 .5308990479 217.3117980957 215.4830932617212.4351959229 209.0825958252 208.1681976318 206.3394927979 204.5108032227 202.6820983887 202.3773040771202.3773040771 202.0724945068202 .9868927002205 .7299957275209 .0825958252212 .1304016113 214.2639007568215 .787902832219 .7501068115221 .883605957222 .4931030273 222.1884002686221 .5787963867220 .3596038818219 .1405029297217 .3117980957 215.787902832213 .959197998212 .1304016113209 .9969024658208 .4730072021 208.1681976318209 .0825958252210 .6065063477212 .7400054932214 .2639007568 215.787902832217 .0070037842218 .5308990479219 .7501068115220 .9691925049 221.883605957222 .4931030273223 .4075012207223 .7122955322224 .3218994141 224.6266021729224 .9313964844225 .2362060547225 .5410003662225 .8457946777 225.8457946777226 .150604248226 .4553985596226 .4553985596226 .7601013184 226.7601013184226 .7601013184226 .7601013184226 .4553985596226 .150604248 
225.5410003662224 .6266021729223 .7122955322222 .7978973389221 .5787963867 220.3596038818219 .1405029297217 .6165924072215 .787902832213 .3495941162 212.1304016113213 .6544036865213 .0447998047208 .7778015137208 .7778015137 208.1681976318207 .5587005615206 .0346984863203 .9011993408202 .9868927002 201.4629974365200 .2438049316199 .329498291198 .1103057861196 .5863952637 194.4528961182191 .7097930908190 .795501709188 .966796875186 .528503418 184.3950042725182 .87109375182 .5662994385183 .1759033203183 .4806976318 182.87109375181 .0424041748178 .9089050293177 .0802001953175 .5561981201 173.4226989746169 .4604949951164 .8887023926161 .2312927246158 .1835021973 156.0500030518154 .8307952881153 .9165039062153 .3069000244152 .6972961426 152.3925933838152 .3925933838151 .4781951904150 .8686065674150 .2590942383 149.9542999268149 .3446960449149 .0399017334148 .1255950928147 .2111968994 145.9920959473144 .7729034424143 .8585968018142 .9441986084142 .0299072266 141.4203033447141 .4203033447142 .0299072266143 .2489929199144 .7729034424 146.9064025879148 .7351074219150 .5639038086152 .0877990723152 .6972961426 152.6972961426153 .3069000244153 .9165039062154 .8307952881156 .6596069336 158.4882965088159 .7073974609160 .0122070312160 .0122070312160 .3170013428 160.6217956543160 .9264984131160 .9264984131160 .0122070312157 .878692627 153.9165039062147 .2111968994137 .4580993652136 .2389984131136 .2389984131 137.1533050537139 .5915985107142 .6394042969146 .2969055176149 .9542999268 152.6972961426153 .9165039062153 .6116943359152 .3925933838151 .1734008789 149.9542999268149 .0399017334147 .8208007812145 .6873016357142 .6394042969 139.2868041992135 .0198059082131 .3623962402132 .2767028809132 .2767028809 131.3623962402 129.8385009766128 .0097961426126 .4858016968124 .9618988037 123.1332015991121 .6092987061120 .0852966309119 .4757995605118 .8662033081 118.5614013672117 .647102356115 .818397522113 .6848983765110 .6370010376 107.5891036987104 .5412979126101 .798202514699 .9695205688599 .35994720459 99.96952056885103 .0174026489108 .8082962036117 .0374984741127 .0953979492 138.0677032471149 .0399017334159 .7073974609169 .7653045654179 .8231964111 189.8811035156199 .329498291208 .4730072021217 .3117980957225 .2362060547 232.246307373238 .6468048096243 .8280944824248 .0950927734251 .4476928711 253.8860015869255 .7147064209256 .9338989258258 .1530151367258 .7626037598 259.0674133301259 .3721008301259 .3721008301259 .6769104004259 .6769104004 259.9816894531260 .2864990234260 .2864990234260 .8960876465261 .2008972168 261.5056152344262 .1152038574262 .7247924805263 .0296020508263 .6390991211 263.6390991211263 .6390991211263 .3344116211262 .4200134277261 .2008972168 259.3721008301 256.9338989258253.8860015869250.2286071777245.6567993164 240.1707000732233 .4653930664226 .150604248217 .6165924072209 .692199707 209.692199707209 .692199707209 .692199707209 .692199707209 .692199707209 .692199707 209.692199707119 .7806015015109 .113098144584 .4328689575262 .0253868103 -9999-9999 -9999 -9999 -9999 -9999 -9999 -9999 -9999 -9999 -9999 -9999 -9999 -9999 -9999 -9999 -9999 -9999 -9999-9999 -9999 -9999 -9999 -9999 -9999 -9999 -9999 -9999 -9999 -9999 -9999 -9999 -9999 -9999 -9999 -9999 -9999 -9999-9999 -9999 -9999 -9999 -9999 -9999 -9999 -9999 -9999 -9999 -9999 -9999 -9999 -9999 -9999 410.0475463867404.0165405273 398.049407959392 .2585144043 387.0770874023381 .8958129883377 .324005127373 .3617858887369 .399597168 
365.7421875361 .475189209357 .208190918352 .0267944336346 .845489502341 .6640930176 336.7875976562332 .8252868652329 .1679077148326 .1200866699323 .0722045898 320.6339111328318 .1957092285316 .0621948242313 .9287109375311 .7951965332 309.3569030762307 .2233886719304 .4802856445301 .7373046875297 .4703063965 293.2033081055288 .9363098145284 .6693115234280 .4023132324276 .4400939941 272.4779052734268 .2109069824264 .2486877441260 .2864990234256 .3243103027 252.3621063232248 .7046966553245 .9615936279244 .1329040527243 .2185058594 241.9994049072240 .4754943848238 .0372009277235 .5989074707233 .1605987549 231.0270996094229 .5032043457227 .9792938232226 .150604248224 .3218994141 221.883605957219 .1405029297216 .3973999023213 .959197998212 .4351959229 212.4351959229213 .3495941162213 .0447998047211 .8256988525210 .6065063477 209.692199707 208.4730072021 207.8634033203 208.7778015137210.3016967773 211.2160949707211 .520904541210 .9113006592211 .2160949707210 .9113006592 209.9969024658208 .1681976318205 .7299957275203 .596496582202 .0724945068 200.8533935547199 .6342926025198 .4151000977197 .500793457196 .891204834 196.5863952637196 .891204834197 .8054962158199 .6342926025201 .4629974365 204.2059936523207 .25390625210 .9113006592213 .959197998215 .787902832 217.3117980957218 .2261962891218 .2261962891217 .6165924072216 .7021942139 215.4830932617213 .959197998212 .4351959229210 .6065063477209 .3874053955 209.0825958252209 .3874053955210 .6065063477212 .1304016113213 .6544036865 215.4830932617217 .3117980957218 .8356933594220 .054901123221 .2740020752 222.1884002686223 .1027069092224 .0171051025224 .6266021729225 .2362060547 225.5410003662226 .150604248226 .4553985596226 .7601013184227 .0648956299 227.3697052002 227.3697052002 227.6744995117227.9792938232 227.9792938232 227.9792938232227 .9792938232227 .9792938232227 .6744995117227 .0648956299 226.4553985596225 .5410003662224 .6266021729223 .7122955322222 .4931030273 221.2740020752220 .054901123218 .5308990479216 .7021942139215 .1782989502 214.5686950684214 .2639007568213 .6544036865212 .7400054932211 .520904541 211.2160949707210 .9113006592209 .3874053955207 .25390625206 .6443023682 204.8155975342203 .9011993408202 .6820983887201 .4629974365199 .6342926025 197.500793457195 .0625192 .9290008545190 .4907073975188 .0523986816185 .6141052246 183.4806976318182 .5662994385183 .1759033203183 .7854003906183 .4806976318 181.9566955566179 .5184020996177 .3849029541176 .7754058838177 .3849029541 171.5939941406166 .7174987793163 .0599975586160 .0122070312157 .878692627 156.3547973633155 .1356048584154 .5260925293153 .9165039062153 .6116943359 153.3069000244152 .6972961426152 .0877990723151 .7830047607151 .4781951904 151.1734008789150 .8686065674150 .2590942383149 .3446960449148 .1255950928 146.6015930176145 .0776977539143 .5538024902142 .0299072266140 .8106994629 140.2012023926140 .5059967041141 .4203033447143 .2489929199145 .3825073242 147.2111968994149 .0399017334150 .2590942383150 .8686065674151 .4781951904 151.7830047607152 .3925933838153 .6116943359156 .0500030518158 .7929992676 159.7073974609159 .4026031494159 .0977935791159 .0977935791159 .4026031494 160.0122070312160 .3170013428159 .7073974609157 .878692627154 .8307952881 151.1734008789142 .9441986084138 .9819946289138 .0677032471138 .9819946289 141.1154937744144 .1634063721147 .8208007812151 .4781951904153 .6116943359 154.5260925293154 .5260925293153 .6116943359152 .0877990723151 .4781951904 
150.8686065674150 .5639038086149 .9542999268147 .2111968994143 .2489929199 141.4203033447139 .8963928223138 .6772003174137 .7628936768136 .2389984131 134.1054992676131 .9720001221129 .533706665127 .4001998901125 .2667007446 123.43800354121 .6092987061121 .3044967651120 .9997024536120 .9997024536 120.6949005127118 .8662033081116 .7326965332113 .6848983765110 .6370010376 107.5891036987104 .5412979126102 .4077987671101 .4934005737102 .1029968262 105.1509017944110 .3321990967118 .2565994263123 .7427978516130 .7528076172 138.0677032471 145.9920959473154.2212982178 163.974395752 174.337097168 184.699798584195 .0625204 .5108032227213 .3495941162221 .2740020752228 .2841033936 234.3798065186239 .5610961914243 .8280944824246 .8759002686249 .6190032959 251.4476928711252 .6669006348253 .8860015869254 .4956054688255 .1051025391 255.4098968506256 .0195007324256 .3243103027256 .6290893555256 .9338989258 257.2385864258257 .5433959961258 .1530151367258 .7626037598259 .0674133301 259.6769104004259 .9816894531260 .2864990234260 .2864990234259 .9816894531 259.3721008301258 .4577941895256 .9338989258255 .1051025391252 .6669006348 249.6190032959245 .6567993164241 .3898010254235 .9037017822229 .5032043457 222.4931030273214 .5686950684209 .692199707209 .692199707209 .692199707 209.692199707 209.692199707209.692199707 209.692199707 209.692199707 122.8283996582112 .465698242293 .5762786865271 .6870727539147 .90670013428 -9999 -9999 -9999 -9999 -9999 -9999 -9999 -9999 -9999 -9999 -9999 -9999 -9999 -9999 -9999 -9999 -9999-9999-9999-9999

-9999 -9999 -9999 -9999 -9999 -9999 -9999 -9999 -9999 -9999 -9999 -9999 -9999 -9999 -9999 -9999 -9999 -9999 -9999 -9999 -9999 -9999 -9999 -9999 -9999 -9999 -9999 -9999 -9999 -9999 -9999 -9999 409.6744384766 403.9750976562 398.3541870117393.1727905273 388.296295166383 .7244873047379 .4574890137375 .495300293371 .837890625 368.4851989746365 .132598877360 .8656005859355 .9890136719350 .1980895996 345.0168151855340 .4450073242336 .7875976562333 .4349060059330 .6918945312 327.9487915039325 .8153076172323 .6817932129321 .2434997559319 .1099853516 316.6718139648314 .2334899902311 .7951965332308 .7473144531305 .0899047852 301.1276855469296 .5559082031291 .9841918945287 .4124145508283 .1453857422 278.8783874512274 .9161987305270 .9540100098266 .9917907715263 .0296020508 259.0674133301255 .1051025391251 .4476928711248 .3999023438245 .9615936279 244.1329040527242 .3041992188240 .4754943848238 .0372009277234 .9893035889 232.246307373230 .1127929688228 .8936004639227 .3697052002225 .8457946777 223.7122955322221 .5787963867218 .8356933594216 .3973999023214 .2639007568 212.7400054932212 .7400054932213 .0447998047213 .959197998211 .2160949707 208.7778015137206 .6443023682205 .1204071045204 .5108032227204 .5108032227 205.1204071045205 .425201416205 .425201416205 .425201416205 .1204071045 204.8155975342203 .9011993408202 .3773040771200 .8533935547199 .329498291 198.1103057861197 .500793457196 .5863952637195 .3672943115194 .1481018066 193.233795166192 .624206543192 .624206543192 .624206543192 .9290008545 193.5386047363197 .1959991455200 .8533935547204 .5108032227208 .1681976318 210.9113006592213 .3495941162215 .1782989502216 .0926971436216 .3973999023 216.0926971436214 .8735046387213 .6544036865212 .4351959229211 .2160949707 209.9969024658209 .3874053955209 .3874053955210 .3016967773211 .520904541 213.3495941162 215.4830932617 217.3117980957218.8356933594220.3596038818 
221.5787963867222 .7978973389223 .7122955322224 .6266021729225 .2362060547 225.8457946777226 .4553985596226 .7601013184227 .3697052002227 .6744995117 227.9792938232228 .2841033936228 .5888977051228 .5888977051228 .8936004639 228.8936004639228 .8936004639228 .8936004639228 .5888977051228 .2841033936 227.9792938232227 .0648956299226 .4553985596225 .5410003662224 .3218994141 223.4075012207222 .1884002686220 .9691925049219 .4452972412218 .2261962891 217.0070037842216 .0926971436215 .4830932617214 .8735046387214 .2639007568 213.959197998213 .959197998214 .5686950684213 .0447998047212 .1304016113 211.520904541209 .0825958252207 .5587005615206 .3394927979204 .8155975342 202.9868927002200 .8533935547198 .4151000977195 .6721038818192 .9290008545 190.1858978271187 .7476043701185 .3094024658183 .4806976318184 .699798584 185.9188995361185 .9188995361184 .0901947021180 .7375946045177 .0802001953 175.8609924316175 .2514038086171 .2891998291168 .5462036133164 .8887023926 161.8408966064159 .4026031494157 .878692627156 .6596069336155 .7451934814 155.1356048584154 .5260925293154 .2212982178153 .6116943359153 .3069000244 153.0021057129152 .6972961426152 .6972961426152 .6972961426152 .3925933838 150.8686065674149 .9542999268148 .7351074219146 .9064025879144 .7729034424 142.6394042969140 .8106994629139 .2868041992139 .2868041992140 .2012023926 142.0299072266144 .1634063721146 .2969055176147 .8208007812149 .0399017334 149.6495056152150 .2590942383150 .5639038086151 .1734008789151 .7830047607 153.3069000244159 .4026031494158 .1835021973156 .9642944336156 .6596069336 156.9642944336157 .878692627158 .4882965088159 .0977935791158 .7929992676 157.5738983154155 .1356048584151 .1734008789146 .2969055176142 .3347015381 140.8106994629141 .4203033447142 .9441986084145 .6873016357148 .7351074219 151.7830047607153 .9165039062155 .1356048584155 .1356048584154 .5260925293 153.3069000244152 .6972961426152 .0877990723151 .4781951904152 .6972961426 153.0021057129143 .8585968018149 .6495056152148 .4304046631145 .9920959473 143.2489929199140 .8106994629138 .3724975586135 .3246002197132 .5814971924 129.8385009766127 .4001998901125 .2667007446123 .7427978516123 .1332015991 122.8283996582122 .8283996582122 .5235977173121 .6092987061119 .7806015015 117.342300415113 .9896011353110 .9418029785107 .8938980103105 .7603988647 104.5412979126104 .8460998535106 .6747970581110 .3321990967115 .2088012695 119.7806015015124 .3523025513128 .6192932129133 .8007049561140 .5059967041 149.6495056152160 .3170013428171 .2891998291182 .261505127192 .3193969727 202.0724945068210 .6065063477218 .5308990479225 .2362060547231 .3318939209 236.2084960938239 .8659057617242 .9136962891245 .3520050049247 .1806945801 248.7046966553249 .6190032959250 .5334014893251 .14289855596251 .7525024414 252.3621063232252 .9716033936253 .2763977051253 .8860015869254 .4956054688 254.8003997803255 .4098968506255 .7147064209256 .3243103027256 .6290893555 256.6290893555256 .6290893555256 .3243103027255 .7147064209254 .4956054688 252.9716033936251 .1428985596248 .3999023438245 .3520050049241 .6945953369 237.1228027344231 .9414978027225 .8457946777219 .1405029297211 .520904541 209.692199707 209.692199707 209.692199707 209.692199707 209.692199707 209.692199707 209.692199707209.692199707209.692199707 115.818397522 106.0652008057 80.51864624023 57.27783966064 -9999 -9999 -9999 -9999 -9999 -9999 -9999 -9999 -9999 -9999 -9999 -9999 -9999 -9999 -9999 -9999 -9999 -9999 -9999 -9999 
-9999 -9999 -9999 -9999 -9999 -9999 -9999 -9999 -9999 -9999 -9999 -9999 -9999 -9999 -9999 -9999 -9999 -9999 -9999 -9999 -9999 -9999 -9999 -9999 -9999 -9999 -9999 -9999 -9999 -9999 -9999 -9999 409.7696228027404.3472900391398.9637145996 394.391998291389.515411377 385.2484130859380 .9814147949377 .324005127373 .666595459370 .3139038086 367.570892334364 .5230102539358 .7320861816353 .2460021973348 .3693847656 344.1023864746340 .749786377337 .7019042969335 .5683898926333 .4349060059 331.3013916016329 .1679077148327 .0344848633324 .9009094238322 .4627075195 319.4147949219316 .3670043945313 .0143127441309 .0520935059304 .4802856445 299.6037902832294 .7272033691290 .1553955078285 .8884887695281 .9262084961 277.9641113281274 .0018005371270 .0396118164266 .0773925781262 .1152038574 258.4577941895254 .8003997803251 .7525024414249 .0093994141246 .2664031982 243.8280944824241 .9994049072239 .8659057617236 .8179931641231 .9414978027 230.7223052979229 .1983947754227 .9792938232226 .150604248224 .3218994141 221.883605957219 .4452972412217 .0070037842214 .8735046387213 .3495941162 212.7400054932212 .4351959229211 .520904541209 .692199707207 .25390625 204.8155975342202 .9868927002202 .0724945068201 .4629974365201 .158203125 201.158203125201 .158203125201 .158203125200 .8533935547200 .2438049316 199.329498291 198.4151000977 197.1959991455195.9768066406195.0625194.7577056885 194.7577056885193 .233795166191 .7097930908190 .795501709190 .1858978271 189.5764007568189 .5764007568189 .8811035156190 .795501709193 .5386047363 196.891204834200 .5485992432204 .2059936523207 .5587005615210 .3016967773 212.7400054932214 .5686950684215 .4830932617215 .4830932617214 .5686950684 213.3495941162 212.4351959229 211.2160949707 210.3016967773 209.3874053955 209.3874053955 209.692199707210.6065063477213.0447998047214.8735046387 217.0070037842218 .8356933594220 .6643981934221 .883605957223 .1027069092 224.0171051025224 .9313964844225 .5410003662226 .150604248226 .7601013184 227.3697052002 227.6744995117228.2841033936228.5888977051228.8936004639 229.1983947754229 .5032043457229 .5032043457229 .8079986572229 .8079986572 229.5032043457229 .1983947754228 .8936004639228 .2841033936227 .6744995117 227.0648956299226 .150604248224 .9313964844224 .0171051025222 .7978973389 221.5787963867220 .3596038818219 .4452972412218 .5308990479217 .6165924072 217.0070037842216 .0926971436215 .1782989502214 .2639007568215 .1782989502 215.787902832215 .1782989502214 .5686950684213 .3495941162212 .1304016113 210.9113006592209 .692199707208 .1681976318206 .3394927979204 .8155975342 202.3773040771 199.329498291 195.9768066406193 .5386047363191 .1002960205 188.966796875187 .7476043701188 .3571929932189 .5764007568189 .5764007568 188.3571929932185 .0045928955176 .4705963135176 .4705963135175 .8609924316 175.2514038086172 .2035980225167 .6318054199163 .974395752161 .2312927246 159.4026031494158 .1835021973157 .2691040039156 .3547973633155 .7451934814 155.1356048584154 .8307952881154 .5260925293154 .2212982178153 .9165039062 153.9165039062153 .3069000244152 .3925933838151 .7830047607152 .0877990723 150.5639038086148 .4304046631145 .9920959473143 .5538024902141 .1154937744 138.9819946289138 .3724975586139 .5915985107142 .0299072266144 .1634063721 145.9920959473147 .5160064697148 .4304046631149 .0399017334149 .3446960449 149.6495056152149 .6495056152150 .2590942383151 .7830047607153 .6116943359 153.6116943359153 .0021057129152 .6972961426153 .9165039062155 .4403991699 
156.6596069336157 .5738983154157 .5738983154156 .9642944336153 .9165039062 150.8686065674147 .5160064697144 .7729034424143 .5538024902143 .5538024902 144.7729034424146 .9064025879149 .3446960449151 .7830047607153 .9165039062 155.4403991699156 .0500030518155 .1356048584153 .9165039062153 .0021057129 152.3925933838151 .1734008789149 .0399017334150 .8686065674150 .8686065674 152.6972961426154 .5260925293151 .1734008789148 .1255950928145 .0776977539 142.0299072266138 .6772003174135 .0198059082131 .9720001221129 .533706665 127.4001998901125 .8762969971124 .9618988037124 .3523025513124 .3523025513 124.0475006104123 .7427978516122 .8283996582120 .0852966309117 .342300415 114.2944030762111 .551399231109 .1130981445107 .5891036987106 .979598999 107.8938980103109 .7226028442112 .1608963013114 .9039993286117 .647102356 120.0852966309123 .1332015991128 .3144989014137 .1533050537148 .1255950928 159.4026031494170 .3748931885181 .3471984863191 .4051055908200 .8533935547 209.3874053955 216.7021942139223.1027069092228.5888977051233.1605987549 236.5133056641239 .2563018799241 .6945953369243 .2185058594244 .7424926758 245.9615936279246 .8759002686247 .4855041504248 .3999023438249 .0093994141 249.6190032959250 .2286071777250 .8381958008251 .4476928711251 .7525024414 252.3621063232252 .6669006348252 .9716033936252 .9716033936252 .9716033936 252.3621063232251 .7525024414250 .5334014893249 .0093994141246 .8759002686 244.4376983643241 .3898010254237 .4275970459233 .1605987549227 .9792938232 222.4931030273215 .787902832208 .7778015137209 .692199707209 .692199707 209.692199707 209.692199707 209.692199707 209.692199707 209.692199707 209.692199707 209.692199707 118.5614013672109 .113098144590 .0931015014667 .43895721436 -9999 -9999 -9999 -9999 -9999 -9999 -9999 -9999 -9999 -9999 -9999 -9999 -9999 -9999 -9999 -9999 -9999 -9999 -9999-9999

-9999 -9999 -9999 -9999 -9999 -9999 -9999 -9999 -9999 -9999 -9999 -9999 -9999 -9999 -9999 -9999 -9999 -9999 -9999 -9999 -9999 -9999 -9999 -9999 -9999 -9999 -9999 -9999 -9999 -9999 -9999 -9999 410.2862243652 405.2168884277400.1828918457 395.611114502 391.0393066406386 .4674987793382 .5053100586378 .5430908203374 .8857116699 371.5331115723368 .1803894043364 .5230102539359 .9512023926355 .379486084 351.112487793347 .4549865723344 .7120056152342 .5784912109340 .749786377 339.2258911133 337.3970947266335.5683898926333.4349060059330.9966125488 328.2536010742325 .2056884766321 .8530883789317 .8908996582313 .3190917969 308.1377868652302 .9563903809297 .7750854492293 .2033081055289 .2410888672 285.2789001465281 .3167114258277 .6592102051273 .6971130371269 .7348022461 266.0773925781262 .4200134277258 .7626037598255 .7147064209252 .6669006348 249.9237976074247 .4855041504245 .3520050049243 .2185058594241 .0850067139 236.2084960938233.1605987549231.0270996094229.1983947754227.3697052002 225.2362060547222 .7978973389220 .3596038818217 .9214019775215 .4830932617 213.6544036865212 .1304016113211 .2160949707209 .692199707207 .8634033203 205.425201416 203.2917022705 201.4629974365 200.2438049316 199.329498291 198.7198944092198 .4151000977198 .1103057861197 .8054962158197 .1959991455 196.891204834195 .9768066406195 .0625194 .1481018066193 .233795166192 .624206543 192.3193969727192 .0146026611191 .1002960205189 .8811035156188 .966796875 188.3571929932188 .0523986816188 .0523986816188 .6620025635189 .8811035156 192.0146026611 195.0625 198.1103057861201.4629974365 204.8155975342 207.8634033203 
210.9113006592213 .3495941162214 .5686950684214 .8735046387214 .5686950684 213.3495941162212 .4351959229211 .520904541210 .3016967773209 .3874053955 209.0825958252 209.3874053955 210.3016967773 211.2160949707 214.2639007568 217.0070037842218 .8356933594220 .6643981934221 .883605957223 .1027069092 224.0171051025224 .9313964844225 .5410003662226 .4553985596227 .0648956299 227.6744995117227 .9792938232228 .5888977051228 .8936004639229 .5032043457 229.8079986572230 .1127929688230 .1127929688230 .1127929688230 .1127929688 230.1127929688229 .8079986572229 .1983947754228 .5888977051227 .9792938232 227.3697052002226 .4553985596225 .5410003662224 .6266021729223 .4075012207 222.4931030273221 .5787963867220 .6643981934219 .7501068115218 .8356933594 218.2261962891 217.3117980957216.7021942139216.0926971436216.3973999023 216.3973999023216 .0926971436215 .4830932617214 .2639007568213 .3495941162 213.3495941162213 .0447998047210 .3016967773209 .692199707209 .0825958252 207.25390625204 .8155975342200 .5485992432198 .7198944092195 .9768066406 193.233795166192 .624206543193 .233795166194 .1481018066194 .4528961182 193.233795166 190.4907073975 187.1381072998 181.3471984863179.8231964111 182.261505127178 .2993011475172 .2035980225166 .4127044678163 .6696014404 161.5361022949160 .0122070312158 .4882965088157 .5738983154156 .6596069336 156.0500030518155 .7451934814155 .4403991699155 .1356048584155 .1356048584 154.8307952881154 .2212982178153 .6116943359153 .3069000244153 .3069000244 152.3925933838150 .2590942383147 .8208007812145 .0776977539142 .6394042969 140.5059967041138 .3724975586141 .1154937744143 .5538024902145 .3825073242 146.6015930176147 .5160064697148 .4304046631148 .7351074219148 .7351074219 148.7351074219148 .4304046631148 .4304046631148 .7351074219148 .1255950928 147.5160064697146 .9064025879148 .1255950928150 .5639038086152 .6972961426 154.5260925293155 .4403991699156 .0500030518155 .1356048584152 .3925933838 150.5639038086148 .4304046631146 .6015930176145 .3825073242145 .3825073242 146.2969055176147 .8208007812149 .9542999268152 .0877990723154 .2212982178 155.7451934814156 .6596069336155 .4403991699153 .9165039062152 .6972961426 152.0877990723151 .1734008789150 .5639038086151 .4781951904153 .3069000244 154.5260925293155 .1356048584153 .3069000244151 .4781951904148 .4304046631 145.0776977539141 .1154937744137 .4580993652134 .4102020264131 .6672058105 129.2288970947127 .7050018311126 .4858016968125 .5715026855125 .2667007446 124.9618988037124 .6570968628123 .7427978516122 .2188034058119 .7806015015 117.342300415114 .9039993286112 .4656982422110 .6370010376109 .1130981445 108.5035018921108 .8082962036109 .7226028442110 .6370010376112 .1608963013 113.6848983765115 .5136032104117 .647102356128 .0097961426138 .3724975586 149.0399017334160 .3170013428171 .2891998291181 .9566955566191 .7097930908 200.8533935547208 .7778015137215 .787902832221 .5787963867226 .4553985596 230.4176025391233 .4653930664235 .9037017822238 .0372009277239 .5610961914 241.0850067139241 .9994049072243 .2185058594244 .1329040527244 .7424926758 245.6567993164246 .2664031982246 .8759002686247 .4855041504248 .0950927734 248.7046966553249 .0093994141249 .3141937256249 .3141937256249 .0093994141 248.7046966553247 .7902984619246 .5711975098245 .0471954346242 .9136962891 240.4754943848237 .1228027344233 .4653930664229 .1983947754224 .3218994141 218.8356933594212 .7400054932209 .692199707209 .692199707209 .692199707 
209.692199707 209.692199707 209.692199707209.692199707209.692199707209.692199707 209.692199707209 .692199707111 .8561019897103 .017402648976 .49540710449 51.61903381348 -9999 -9999 -9999 -9999 -9999 -9999 -9999 -9999 -9999 -9999 -9999 -9999 -9999 -9999 -9999 -9999 -9999 -9999 -9999

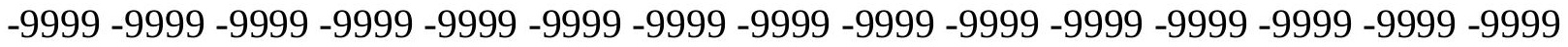

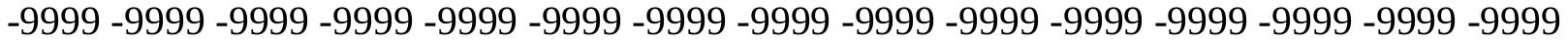
-9999 -9999 411.1407165527 406.4521789551401.7067871094 397.1350097656 392.2585144043387 .9914855957383 .7244873047379 .762298584375 .799987793 372.1426086426368 .1803894043364 .5230102539360 .5607910156356 .9034118652 353.5508117676350 .8077087402348 .9790039062347 .4549865723346 .5407104492 345.3215026855344 .1023864746342 .5784912109340 .1401977539337 .7019042969 334.6541137695331 .3013916016327 .3392028809322 .7674865723317 .8908996582 312.4047851562306 .6138000488301 .1276855469296 .5559082031292 .5936889648 288.9363098145285 .2789001465281 .3167114258277 .6592102051274 .0018005371 270.3443908691266 .6870117188263 .3344116211259 .9816894531257 .2385864258 254.1907958984251 .7525024414249 .6190032959247 .1806945801244 .4376983643 240.7801971436236 .8179931641234 .0749969482231 .6367034912229 .5032043457 227.3697052002224 .6266021729221 .5787963867218 .8356933594216 .0926971436 213.6544036865211 .520904541209 .9969024658208 .1681976318206 .0346984863 203.9011993408202 .0724945068200 .2438049316198 .7198944092197 .500793457 196.5863952637196 .2816009521195 .6721038818195 .3672943115194 .7577056885 194.1481018066193 .5386047363192 .624206543192 .0146026611191 .1002960205 190.795501709190 .1858978271189 .8811035156189 .2716064453188 .3571929932 187.7476043701187 .4429016113187 .4429016113187 .7476043701188 .6620025635 189.8811035156192 .0146026611194 .4528961182196 .891204834199 .9389953613 202.9868927002206 .0346984863209 .0825958252212 .1304016113213 .959197998 214.8735046387214 .5686950684213 .3495941162212 .7400054932211 .520904541 210.3016967773209 .0825958252208 .7778015137209 .0825958252210 .3016967773 212.1304016113214 .5686950684217 .0070037842218 .8356933594220 .6643981934 221.883605957223 .1027069092224 .0171051025224 .9313964844225 .5410003662 226.150604248226 .7601013184227 .3697052002227 .9792938232228 .5888977051 229.1983947754229 .8079986572230 .1127929688230 .4176025391230 .4176025391 230.7223052979230 .4176025391230 .4176025391230 .1127929688229 .5032043457 228.8936004639228 .2841033936227 .3697052002226 .7601013184225 .8457946777 224.9313964844224 .0171051025223 .1027069092222 .1884002686221 .5787963867 220.6643981934220 .054901123219 .4452972412218 .5308990479217 .9214019775 217.6165924072217 .3117980957217 .3117980957217 .0070037842216 .0926971436 214.8735046387213 .6544036865214 .5686950684214 .5686950684209 .9969024658 213.6544036865213 .3495941162212 .1304016113211 .2160949707210 .9113006592 206.0346984863200 .2438049316197 .500793457197 .1959991455197 .8054962158 198.7198944092199 .0247039795198 .7198944092196 .2816009521193 .233795166 190.4907073975191 .1002960205187 .4429016113183 .7854003906176 .4705963135 170.6797027588166 .7174987793163 .974395752161 .8408966064160 .3170013428 158.7929992676157 .5738983154156 .9642944336156 .6596069336156 .3547973633 156.0500030518156 .0500030518155 .7451934814155 .4403991699154 .8307952881 154.5260925293154 .2212982178153 .3069000244151 .4781951904149 .3446960449 
147.2111968994145 .3825073242144 .1634063721144 .1634063721145 .3825073242 146.6015930176147 .2111968994147 .8208007812148 .1255950928148 .7351074219 148.7351074219148 .4304046631148 .1255950928147 .2111968994146 .6015930176 145.6873016357144 .1634063721142 .6394042969140 .8106994629143 .8585968018 147.2111968994150 .2590942383151 .4781951904153 .0021057129154 .2212982178 153.9165039062152 .6972961426150 .8686065674149 .0399017334147 .5160064697 146.6015930176146 .6015930176147 .2111968994148 .7351074219150 .2590942383 152.0877990723153 .9165039062155 .4403991699156 .0500030518155 .4403991699 153.9165039062152 .0877990723149 .9542999268151 .7830047607152 .0877990723 152.6972961426153 .9165039062155 .1356048584155 .7451934814155 .1356048584 153.9165039062151 .1734008789147 .2111968994143 .2489929199139 .8963928223 136.5437011719134 .1054992676131 .3623962402129 .2288970947127 .7050018311 126.7906036377126 .1809997559125 .5715026855125 .2667007446124 .3523025513 123.43800354121 .9140014648120 .0852966309118 .2565994263115 .5136032104 113.075302124110 .9418029785109 .1130981445108 .1986999512107 .5891036987 107.5891036987108 .1986999512109 .1130981445111 .8561019897117 .342300415 122.5235977173130 .7528076172140 .5059967041151 .4781951904162 .4505004883 173.4226989746183 .7854003906193 .5386047363201 .7678070068209 .0825958252 215.1782989502220 .054901123224 .3218994141227 .6744995117230 .4176025391 232.5511016846234 .3798065186235 .9037017822237 .4275970459238 .6468048096 239.5610961914240 .4754943848241 .3898010254242 .3041992188242 .9136962891 243.8280944824244 .4376983643244 .7424926758245 .3520050049245 .3520050049 245.3520050049245 .0471954346244 .7424926758243 .8280944824242 .6089935303 241.0850067139238 .9515075684236 .5133056641233 .4653930664229 .8079986572 225.5410003662220 .9691925049215 .787902832209 .9969024658209 .692199707 209.692199707 209.692199707 209.692199707 209.692199707 209.692199707 209.692199707 209.692199707 209.692199707209.692199707 209.692199707 114.5991973877 106.0652008057 86.33309936523 61.26748275757 -9999 -9999 -9999 -9999 -9999 -9999 -9999 -9999 -9999 -9999 -9999 -9999 -9999 -9999 -9999 -9999 -9999 -9999 -9999

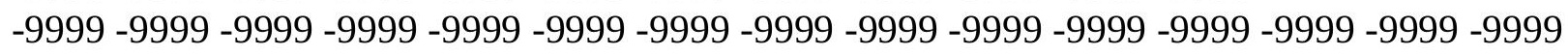

-9999 -9999 -9999 -9999 -9999 -9999 -9999 -9999 -9999 -9999 -9999 -9999 -9999 -9999 -9999 -9999 -9999 412.1608276367407.8296508789403.5354919434 398.6589050293 393.782409668389 .515411377384 .9436035156380 .9814147949376 .7143859863 372.7521972656368 .4851989746364 .5230102539361 .475189209358 .7320861816 356.2937927246354 .4650878906353 .2460021973352 .941192627352 .6364135742 352.3316040039351 .4172058105349 .8933105469347 .4549865723344 .7120056152 341.3593139648337 .3970947266333 .4349060059328 .5584106445323 .0722045898 316.9765014648310 .5759887695304 .4802856445300 .2132873535296 .5559082031 292.8984985352289 .2410888672285 .5835876465281 .9262084961278 .2687988281 274.6113891602271 .2587890625268 .2109069824265 .1630859375262 .1152038574 259.3721008301 256.9338989258254.4956054688 252.0572967529 249.0093994141 245.3520050049241 .3898010254237 .7324066162235 .2940979004232 .8558044434 230.1127929688227 .0648956299223 .4075012207220 .054901123216 .7021942139 213.6544036865211 .2160949707208 .7778015137206 .9490966797204 .8155975342 202.6820983887 200.8533935547 199.0247039795 197.500793457 196.2816009521 195.3672943115194 .7577056885194 .1481018066193 .5386047363192 .9290008545 
192.3193969727 191.7097930908191.1002960205 190.1858978271189 .5764007568 188.966796875188 .6620025635188 .0523986816187 .7476043701187 .1381072998 187.1381072998187 .1381072998187 .4429016113188 .0523986816189 .2716064453 190.795501709192 .624206543194 .4528961182196 .5863952637199 .0247039795 201.4629974365204 .2059936523207 .25390625210 .3016967773213 .3495941162 214.5686950684214 .8735046387214 .5686950684213 .3495941162211 .520904541 209.692199707 208.4730072021208.1681976318208.7778015137210.6065063477 213.0447998047215 .1782989502217 .0070037842218 .8356933594220 .3596038818 221.883605957222 .7978973389223 .7122955322224 .3218994141224 .9313964844 225.8457946777226 .4553985596227 .0648956299227 .9792938232228 .5888977051 229.1983947754229 .8079986572230 .1127929688230 .4176025391230 .7223052979 230.7223052979230 .7223052979230 .4176025391230 .1127929688229 .5032043457 228.8936004639228 .2841033936227 .6744995117226 .7601013184226 .150604248 225.2362060547224 .6266021729223 .7122955322223 .1027069092222 .1884002686 221.5787963867220 .9691925049220 .3596038818219 .7501068115219 .1405029297 218.8356933594218 .5308990479218 .2261962891217 .6165924072216 .7021942139 215.787902832215 .1782989502215 .1782989502214 .5686950684213 .959197998 215.1782989502216 .0926971436216 .3973999023216 .3973999023216 .0926971436 213.6544036865202 .9868927002201 .158203125200 .8533935547201 .7678070068 201.4629974365202 .0724945068203 .2917022705200 .5485992432197 .8054962158 195.6721038818193 .5386047363189 .8811035156184 .699798584178 .9089050293 173.7274932861169 .4604949951166 .4127044678163 .974395752161 .8408966064 160.3170013428158 .7929992676157 .878692627157 .5738983154157 .2691040039 157.2691040039156 .9642944336156 .6596069336156 .3547973633156 .0500030518 155.4403991699155 .1356048584153 .9165039062152 .3925933838150 .8686065674 149.3446960449148 .7351074219148 .7351074219149 .6495056152151 .1734008789 150.2590942383149 .3446960449149 .3446960449149 .3446960449149 .3446960449 149.0399017334148 .4304046631147 .5160064697146 .2969055176145 .0776977539 143.5538024902141 .7250976562140 .2012023926139 .8963928223141 .7250976562 144.4682006836146 .6015930176147 .8208007812150 .8686065674153 .3069000244 153.3069000244152 .3925933838150 .8686065674149 .3446960449147 .8208007812 147.2111968994 147.2111968994147.8208007812149.0399017334150.5639038086 152.0877990723153 .9165039062155 .4403991699156 .0500030518155 .7451934814 154.2212982178151 .7830047607152 .0877990723152 .0877990723152 .6972961426 153.3069000244154 .2212982178155 .1356048584155 .7451934814155 .7451934814 155.1356048584153 .6116943359147 .8208007812144 .7729034424143 .2489929199 140.5059967041137 .1533050537133 .8007049561131 .0576019287129 .2288970947 127.7050018311126 .7906036377126 .1809997559125 .5715026855124 .9618988037 124.0475006104123 .1332015991122 .2188034058120 .9997024536118 .2565994263 115.2088012695112 .4656982422110 .0273971558107 .8938980103106 .6747970581 105.7603988647105 .4557037354106 .3700027466108 .8082962036112 .7705001831 117.647102356124 .3523025513133 .1911010742143 .5538024902154 .8307952881 166.4127044678177 .0802001953187 .1381072998195 .6721038818202 .9868927002 209.0825958252214 .2639007568218 .5308990479221 .883605957224 .9313964844 227.3697052002 229.5032043457231.0270996094232.5511016846233.7702026367 234.9893035889 236.2084960938237.1228027344 238.0372009277238.9515075684 
239.5610961914240 .1707000732240 .7801971436241 .0850067139241 .3898010254 241.3898010254241 .0850067139240 .7801971436239 .8659057617238 .6468048096 237.1228027344 234.9893035889232.5511016846 229.5032043457 226.150604248 222.1884002686217 .6165924072212 .7400054932209 .692199707209 .692199707 209.692199707209 .692199707209 .692199707209 .692199707209 .692199707209 .692199707 209.692199707 209.692199707209.692199707 209.692199707209.692199707 108.8082962036100 .274299621668 .5289459228539 .15798568726 -9999 -9999 -9999 -9999 -9999 -9999 -9999 -9999 -9999 -9999 -9999 -9999 -9999 -9999 -9999 -9999 -9999 -9999

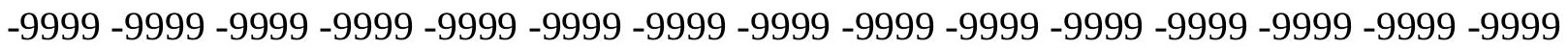

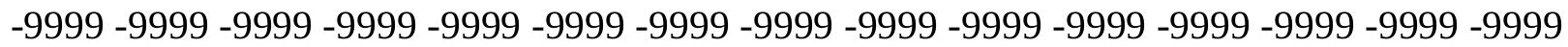
-9999 -9999-9999 409.0672607422 404.7546081543400.1828918457 395.611114502 391.0393066406386 .7723083496382 .5053100586378 .2383117676374 .2760925293 370.009185791365 .7421875363 .6086120605361 .7799072266359 .9512023926 358.4273071289358 .4273071289359 .036895752359 .6465148926359 .9512023926 359.3417053223357 .5129089355355 .0747070312351 .7219848633348 .0646057129 344.1023864746339 .5306091309334 .3493041992328 .5584106445321 .8530883789 315.1477966309309 .0520935059304 .4802856445300 .8229064941297 .1654968262 293.5080871582289 .8505859375286 .1932067871282 .5357971191279 .1831970215 276.1353149414273 .0874938965270 .3443908691267 .6012878418264 .8583068848 262.4200134277260 .2864990234257 .8482055664254 .8003997803251 .4476928711 247.4855041504242 .6089935303240 .4754943848237 .4275970459233 .7702026367 229.8079986572225 .5410003662221 .5787963867217 .6165924072213 .6544036865 210.9113006592208 .4730072021206 .0346984863203 .9011993408201 .7678070068 199.6342926025198 .1103057861196 .5863952637195 .3672943115194 .4528961182 193.5386047363192 .9290008545192 .3193969727191 .7097930908191 .4051055908 190.795501709189 .8811035156189 .2716064453188 .6620025635188 .0523986816 187.4429016113187 .1381072998186 .8332977295186 .528503418186 .528503418 186.8332977295187 .4429016113188 .3571929932189 .8811035156191 .7097930908 193.5386047363195 .0625196 .5863952637198 .1103057861200 .2438049316202 .6820983887 205.1204071045207 .8634033203210 .6065063477213 .0447998047214 .5686950684 214.8735046387213 .959197998211 .2160949707209 .0825958252207 .5587005615 207.25390625 207.8634033203 210.3016967773213.6544036865 215.1782989502 217.0070037842218 .8356933594220 .054901123221 .2740020752222 .4931030273 223.1027069092223 .7122955322224 .3218994141224 .9313964844225 .8457946777 226.7601013184227 .3697052002228 .2841033936228 .8936004639229 .8079986572 230.1127929688230 .4176025391230 .7223052979231 .0270996094230 .7223052979 230.7223052979230 .4176025391229 .8079986572229 .1983947754228 .2841033936 227.6744995117227 .0648956299226 .4553985596225 .8457946777224 .9313964844 224.3218994141223 .7122955322223 .1027069092222 .4931030273221 .883605957 221.2740020752220 .6643981934220 .3596038818219 .7501068115219 .4452972412 218.8356933594218 .2261962891217 .6165924072217 .0070037842216 .3973999023 216.0926971436215 .787902832216 .3973999023217 .0070037842218 .2261962891 219.1405029297219 .4452972412218 .8356933594215 .787902832209 .9969024658 205.7299957275203 .2917022705201 .7678070068201 .4629974365202 .3773040771 202.9868927002202 .0724945068199 .9389953613197 .8054962158194 .4528961182 190.1858978271184 .3950042725180 .1280059814175 .8609924316171 .8988037109 
168.5462036133165 .8031005859163 .6696014404161 .8408966064160 .3170013428 159.0977935791158 .4882965088158 .1835021973158 .1835021973157 .878692627 157.5738983154157 .2691040039156 .9642944336156 .6596069336156 .0500030518 155.1356048584153 .9165039062152 .3925933838151 .4781951904151 .7830047607 152.6972961426153 .0021057129153 .3069000244152 .3925933838151 .4781951904 150.5639038086150 .2590942383149 .9542999268149 .6495056152148 .7351074219 147.5160064697145 .9920959473144 .1634063721142 .3347015381140 .5059967041 139.5915985107139 .8963928223141 .1154937744142 .9441986084145 .0776977539 146.9064025879149 .0399017334150 .8686065674151 .7830047607151 .7830047607 150.2590942383148 .7351074219147 .5160064697147 .2111968994147 .2111968994 148.1255950928149 .3446960449150 .5639038086152 .0877990723153 .9165039062 155.4403991699156 .0500030518156 .0500030518155 .7451934814153 .0021057129 152.6972961426152 .6972961426153 .0021057129153 .6116943359154 .2212982178 154.8307952881154 .8307952881154 .8307952881154 .8307952881153 .9165039062 145.0776977539147 .2111968994147 .5160064697145 .6873016357141 .1154937744 136.2389984131132 .8863067627130 .7528076172129 .2288970947127 .7050018311 126.7906036377125 .8762969971125 .2667007446124 .6570968628123 .7427978516 123.1332015991121 .9140014648119 .7806015015117 .0374984741113 .9896011353 110.9418029785108 .1986999512106 .0652008057104 .5412979126103 .6268997192 103.9317016602105 .7603988647108 .5035018921112 .7705001831118 .5614013672 126.4858016968136 .5437011719148 .1255950928160 .3170013428171 .5939941406 181.6519012451190 .4907073975197 .500793457203 .596496582208 .7778015137 213.0447998047216 .7021942139219 .4452972412222 .1884002686224 .3218994141 226.150604248227 .9792938232229 .1983947754230 .7223052979231 .6367034912 232.8558044434233 .7702026367234 .6844940186235 .5989074707236 .2084960938 236.8179931641237 .1228027344237 .4275970459237 .4275970459237 .1228027344 236.5133056641235 .9037017822234 .6844940186233 .1605987549231 .0270996094 228.5888977051225 .8457946777222 .4931030273218 .5308990479214 .2639007568 209.692199707 209.692199707 209.692199707 209.692199707 209.692199707 209.692199707 209.692199707 209.692199707 209.692199707 209.692199707 209.692199707209.692199707 209.692199707 209.692199707 110.9418029785103.0174026489 72.5168762207 44.9310836792 -9999 -9999 -9999 -9999 -9999 -9999 -9999 -9999 -9999 -9999 -9999 -9999 -9999-9999 -9999-9999-9999-9999

-9999 -9999 -9999 -9999 -9999 -9999 -9999 -9999 -9999 -9999 -9999 -9999 -9999 -9999 -9999 -9999 -9999 -9999 -9999 -9999 -9999 -9999 -9999 -9999 -9999 -9999 -9999 -9999 -9999 -9999 -9999 -9999 -9999 410.306427002405.9790344238401.4020080566 397.1350097656 392.8680114746388 .6010131836384 .6387939453380 .6766052246376 .7143859863 373.3617858887 370.3139038086 368.1803894043 366.6564941406 365.132598877 363.6086120605365 .132598877366 .3517150879367 .570892334368 .1803894043 367.8756103516365 .4374084473362 .3894958496359 .036895752355 .0747070312 351.112487793346 .5407104492341 .0545959473334 .3493041992327 .0344848633 319.7196044922313 .0143127441308 .1377868652304 .1755981445301 .1276855469 297.4703063965293 .5080871582290 .1553955078286 .8027954102284 .0596923828 281.0119018555278 .2687988281275 .8305053711273 .0874938965270 .6492004395 268.5156860352266 .3822021484263 .9439086914261 .5056152344258 .7626037598 255.4098968506251 .4476928711247 .4855041504243 .2185058594238 .3419952393 
233.1605987549228 .2841033936223 .4075012207218 .8356933594214 .8735046387 211.520904541208 .4730072021205 .7299957275203 .2917022705201 .158203125 199.0247039795197 .500793457195 .9768066406194 .7577056885193 .8433074951 192.9290008545192 .3193969727191 .7097930908191 .4051055908190 .795501709 190.1858978271189 .5764007568188 .966796875188 .3571929932187 .7476043701 187.1381072998186 .8332977295186 .528503418186 .528503418186 .528503418 187.1381072998187 .7476043701188 .966796875190 .4907073975192 .624206543 194.7577056885195 .6721038818196 .2816009521197 .500793457199 .0247039795 200.5485992432202 .3773040771204 .5108032227207 .25390625210 .3016967773 213.6544036865213 .959197998212 .7400054932209 .692199707208 .1681976318 206.6443023682205 .7299957275206 .3394927979208 .1681976318211 .520904541 214.5686950684216 .7021942139218 .2261962891219 .7501068115220 .9691925049 221.5787963867222 .1884002686222 .7978973389223 .4075012207224 .0171051025 224.9313964844225 .8457946777227 .0648956299227 .9792938232228 .5888977051 229.5032043457230 .1127929688230 .4176025391230 .7223052979231 .0270996094 231.0270996094230 .7223052979230 .4176025391229 .8079986572229 .1983947754 228.5888977051227 .6744995117227 .0648956299226 .7601013184226 .150604248 225.5410003662224 .9313964844224 .3218994141223 .7122955322223 .1027069092 222.4931030273222 .1884002686221 .5787963867221 .2740020752220 .6643981934 220.054901123219 .7501068115219 .1405029297218 .5308990479217 .9214019775 217.3117980957217 .0070037842217 .0070037842217 .6165924072218 .5308990479 219.4452972412220 .3596038818220 .9691925049220 .3596038818218 .2261962891 215.1782989502210 .3016967773205 .1204071045200 .5485992432199 .9389953613 201.158203125202 .0724945068202 .0724945068200 .5485992432198 .1103057861 194.7577056885190 .4907073975185 .6141052246181 .0424041748177 .0802001953 173.7274932861170 .3748931885167 .6318054199165 .1934967041163 .0599975586 161.5361022949160 .3170013428159 .4026031494159 .0977935791159 .0977935791 158.7929992676158 .4882965088158 .1835021973157 .5738983154157 .5738983154 156.9642944336156 .3547973633155 .4403991699154 .2212982178153 .9165039062 154.2212982178154 .8307952881154 .8307952881154 .8307952881153 .9165039062 153.0021057129151 .7830047607151 .4781951904151 .1734008789150 .5639038086 149.3446960449147 .8208007812145 .9920959473143 .8585968018142 .0299072266 140.5059967041139 .8963928223140 .2012023926141 .1154937744142 .9441986084 144.7729034424146 .2969055176147 .5160064697148 .7351074219149 .3446960449 149.3446960449148 .4304046631147 .5160064697146 .6015930176146 .2969055176 146.9064025879147 .8208007812149 .3446960449150 .8686065674152 .0877990723 154.2212982178155 .7451934814156 .3547973633156 .6596069336155 .7451934814 154.5260925293153 .6116943359153 .3069000244153 .3069000244153 .6116943359 153.9165039062154 .2212982178153 .9165039062152 .3925933838151 .7830047607 151.4781951904150 .5639038086152 .0877990723151 .7830047607151 .4781951904 145.3825073242138 .0677032471135 .3246002197133 .1911010742131 .3623962402 129.8385009766128 .0097961426127 .0953979492125 .8762969971124 .6570968628 123.7427978516123 .1332015991122 .5235977173120 .9997024536118 .5614013672 115.2088012695111 .8561019897108 .8082962036106 .3700027466104 .2365036011 103.0174026489102 .4077987671103 .3221969604105 .1509017944108 .1986999512 112.7705001831119 .7806015015129 .8385009766142 .3347015381155 .4403991699 
167.6318054199177 .6896972656185 .9188995361192 .9290008545198 .4151000977 203.596496582 207.5587005615 211.2160949707 214.2639007568 217.0070037842 219.4452972412221 .2740020752223 .1027069092224 .6266021729226 .150604248 227.3697052002228 .5888977051229 .5032043457230 .4176025391231 .3318939209 231.9414978027232 .5511016846233 .1605987549233 .1605987549233 .1605987549 233.1605987549232 .5511016846231 .6367034912230 .7223052979229 .1983947754 227.0648956299224 .9313964844222 .1884002686218 .8356933594215 .1782989502 211.2160949707209 .692199707209 .692199707209 .692199707209 .692199707 209.692199707 209.692199707 209.692199707 209.692199707 209.692199707 209.692199707 209.692199707 209.692199707 209.692199707 209.692199707 209.692199707 104.541297912675 .4695587158252 .52362442017 -9999 -9999 -9999 -9999 -9999 -9999 -9999 -9999 -9999 -9999 -9999 -9999 -9999 -9999 -9999 -9999 -9999 -9999

-9999 -9999 -9999 -9999 -9999 -9999 -9999 -9999 -9999 -9999 -9999 -9999 -9999 -9999 -9999 -9999 -9999 -9999 -9999 -9999 -9999 -9999 -9999 -9999 -9999 -9999 -9999 -9999 -9999 -9999 -9999 -9999 -9999 411.6953125 407.5400085449403.341583252 399.2684936523 395.0014953613390 .7344970703387 .0770874023383 .7244873047380 .6766052246 377.93359375375 .799987793374 .2760925293373 .0570068359372 .4473876953 372.4473876953373 .3617858887374 .8857116699375 .799987793376 .104888916 375.495300293373 .3617858887370 .3139038086366 .3517150879362 .3894958496 358.4273071289353 .8554992676348 .0646057129340 .749786377332 .2157897949 323.6817932129315 .7573852539309 .6617126465306 .0043029785304 .1755981445 299.9085998535296 .5559082031293 .5080871582291 .0697937012288 .6315002441 286.1932067871283 .7549133301281 .3167114258278 .8783874512276 .7449035645 274.6113891602272 .7827148438270 .9540100098268 .8204956055266 .6870117188 264.2486877441260 .8960876465255 .4098968506249 .3141937256242 .9136962891 236.8179931641230 .7223052979225 .2362060547220 .3596038818216 .0926971436 212.4351959229209 .0825958252206 .0346984863203 .2917022705200 .8533935547 198.7198944092196 .891204834195 .6721038818194 .4528961182193 .5386047363 192.624206543192 .3193969727191 .7097930908191 .1002960205190 .795501709 190.1858978271189 .5764007568188 .966796875188 .3571929932187 .7476043701 187.1381072998186 .8332977295186 .528503418186 .528503418186 .8332977295 187.4429016113188 .3571929932189 .5764007568191 .1002960205192 .9290008545 194.4528961182195 .3672943115195 .9768066406196 .891204834197 .8054962158 198.7198944092199 .6342926025200 .8533935547202 .9868927002206 .3394927979 209.692199707212 .1304016113212 .4351959229210 .3016967773207 .8634033203 206.0346984863204 .8155975342204 .8155975342205 .7299957275209 .9969024658 213.6544036865216 .0926971436217 .6165924072218 .8356933594219 .7501068115 220.6643981934220 .9691925049221 .2740020752221 .883605957222 .7978973389 224.0171051025224 .9313964844226 .150604248227 .3697052002228 .2841033936 228.8936004639229 .8079986572230 .1127929688230 .7223052979230 .7223052979 230.7223052979230 .7223052979230 .4176025391229 .8079986572229 .5032043457 228.5888977051227 .9792938232227 .3697052002227 .0648956299226 .4553985596 225.8457946777225 .2362060547224 .6266021729224 .0171051025223 .7122955322 223.1027069092222 .4931030273222 .1884002686221 .883605957221 .2740020752 220.9691925049220 .3596038818220 .054901123219 .4452972412218 .8356933594 218.2261962891 217.9214019775 217.6165924072 218.2261962891 219.1405029297 
220.3596038818221 .2740020752221 .5787963867221 .2740020752220 .054901123 218.2261962891215 .787902832206 .6443023682198 .1103057861199 .0247039795 200.5485992432201 .7678070068202 .0724945068200 .8533935547198 .7198944092 195.3672943115191 .1002960205186 .528503418182 .261505127178 .604095459 175.2514038086172 .2035980225169 .4604949951166 .7174987793164 .5839996338 162.7552947998161 .2312927246160 .3170013428160 .0122070312159 .7073974609 159.7073974609159 .4026031494159 .0977935791158 .7929992676158 .4882965088 158.4882965088157 .5738983154156 .9642944336156 .0500030518156 .0500030518 156.0500030518156 .0500030518156 .3547973633155 .7451934814155 .1356048584 154.2212982178153 .3069000244152 .6972961426152 .3925933838151 .1734008789 149.9542999268148 .4304046631146 .2969055176144 .1634063721142 .0299072266 140.8106994629140 .5059967041140 .8106994629141 .7250976562143 .2489929199 145.0776977539145 .3825073242145 .9920959473146 .6015930176146 .9064025879 146.6015930176145 .9920959473145 .3825073242145 .0776977539145 .0776977539 145.6873016357147 .2111968994149 .0399017334151 .1734008789154 .2212982178 155.1356048584156 .0500030518156 .9642944336156 .9642944336156 .3547973633 155.4403991699154 .5260925293153 .9165039062153 .6116943359153 .3069000244 153.3069000244153 .0021057129153 .0021057129150 .2590942383147 .5160064697 151.7830047607152 .6972961426153 .3069000244153 .6116943359153 .0021057129 150.5639038086144 .1634063721139 .2868041992136 .2389984131134 .7149963379 132.8863067627131 .3623962402129 .2288970947127 .0953979492124 .9618988037 123.43800354122 .8283996582122 .5235977173122 .2188034058119 .4757995605 116.4279022217113 .075302124110 .0273971558106 .979598999104 .5412979126 102.712600708101 .7982025146101 .7982025146102 .712600708104 .8460998535 108.1986999512113 .6848983765123 .1332015991137 .1533050537152 .0877990723 164.5839996338174 .337097168181 .9566955566188 .3571929932193 .5386047363 198.4151000977205 .1204071045209 .692199707209 .3874053955212 .1304016113 214.5686950684216 .7021942139218 .5308990479220 .3596038818221 .883605957 223.1027069092224 .3218994141225 .2362060547226 .150604248227 .0648956299 227.9792938232 228.2841033936228.8936004639 229.19839477754229.1983947754 228.8936004639228 .5888977051227 .6744995117226 .7601013184225 .2362060547 223.4075012207221 .2740020752218 .5308990479215 .4830932617212 .1304016113 209.692199707 209.692199707 209.692199707 209.692199707 209.692199707 209.692199707 209.692199707 209.692199707 209.692199707 209.692199707 209.692199707 209.692199707 209.692199707209 .692199707209 .692199707209 .692199707106 .0652008057

98.14080810547 61.9592628479 31.20285797119 -9999 -9999 -9999 -9999 -9999 -9999 -9999 -9999 -9999 -9999 -9999 -9999 -9999 -9999-9999 -9999 -9999

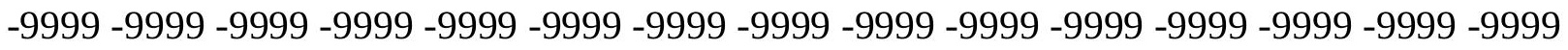

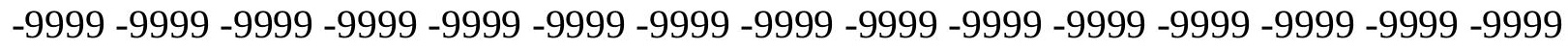
-9999 -9999 -9999 -9999 409.3912963867 405.4463500977 401.4872436523397 .5147705078 393.659942627390 .125387 .3818969727384 .9436035156383 .1148986816381 .8958129883 380.9814147949380 .6766052246380 .9814147949381 .8958129883382 .8100891113 383.7244873047384 .3340148926384 .3340148926383 .419708252381 .2861938477 378.2383117676374 .5809020996370 .3139038086366 .6564941406362 .3894958496 356.2937927246347 .4549865723337 .0922851562326 .4248962402316 .6718139648 309.3569030762305 .0899047852302 .6516113281300 .2132873535298 .0798950195 
296.5559082031294 .7272033691292 .8984985352291 .0697937012288 .9363098145 286.8027954102284 .9740905762282 .8406066895281 .0119018555279 .4880065918 277.6592102051276 .1353149414274 .3066101074272 .1730957031269 .7348022461 262.4200134277254 .8003997803247 .1806945801239 .8659057617233 .1605987549 227.3697052002 222.1884002686217.6165924072 213.6544036865 209.9969024658 206.6443023682 203.596496582 200.8533935547 198.7198944092196 .891204834 195.3672943115194 .1481018066193 .5386047363192 .9290008545192 .3193969727 192.0146026611191 .4051055908191 .1002960205190 .4907073975189 .8811035156 189.2716064453 188.6620025635188.0523986816 187.7476043701 187.1381072998 187.1381072998 187.1381072998 187.4429016113188.0523986816188.966796875 189.8811035156191 .4051055908192 .624206543193 .8433074951194 .7577056885 195.3672943115195 .9768066406196 .5863952637196 .891204834197 .1959991455 197.8054962158198 .4151000977202 .3773040771206 .0346984863209 .692199707 211.8256988525210 .3016967773207 .8634033203205 .7299957275203 .9011993408 204.5108032227206 .3394927979209 .692199707213 .3495941162215 .1782989502 216.3973999023217 .6165924072218 .5308990479218 .8356933594218 .8356933594 219.1405029297220 .3596038818221 .5787963867222 .7978973389224 .0171051025 225.2362060547226 .4553985596227 .6744995117228 .5888977051229 .1983947754 229.8079986572230 .4176025391230 .7223052979230 .7223052979230 .7223052979 230.4176025391230 .1127929688229 .5032043457228 .8936004639228 .5888977051 227.9792938232227 .3697052002226 .7601013184226 .4553985596225 .8457946777 225.2362060547224 .6266021729224 .0171051025223 .4075012207223 .1027069092 222.7978973389222 .4931030273222 .1884002686221 .5787963867221 .2740020752 220.9691925049220 .3596038818219 .7501068115219 .1405029297218 .5308990479 218.2261962891219 .1405029297219 .7501068115220 .6643981934221 .2740020752 221.5787963867221 .2740020752220 .3596038818218 .8356933594215 .787902832 208.4730072021202 .6820983887200 .8533935547201 .4629974365202 .3773040771 202.6820983887201 .7678070068199 .6342926025196 .2816009521192 .3193969727 188.0523986816183 .4806976318179 .8231964111176 .7754058838173 .7274932861 170.6797027588167 .9365997314165 .8031005859163 .974395752162 .4505004883 161.5361022949160 .9264984131160 .6217956543160 .3170013428160 .3170013428 160.0122070312159 .7073974609159 .4026031494159 .0977935791158 .7929992676 158.1835021973157 .5738983154157 .5738983154157 .2691040039157 .2691040039 157.2691040039156 .9642944336156 .3547973633155 .4403991699154 .5260925293 153.9165039062153 .0021057129151 .7830047607151 .1734008789149 .6495056152 147.2111968994144 .7729034424142 .6394042969141 .7250976562141 .4203033447 141.7250976562142 .6394042969143 .2489929199144 .1634063721144 .4682006836 144.4682006836144 .4682006836144 .1634063721143 .8585968018143 .5538024902 143.2489929199142 .9441986084143 .2489929199144 .1634063721145 .6873016357 148.1255950928150 .8686065674153 .3069000244155 .1356048584156 .3547973633 157.2691040039157 .2691040039156 .9642944336156 .0500030518155 .1356048584 154.2212982178153 .6116943359153 .0021057129152 .6972961426151 .7830047607 149.0399017334149 .9542999268149 .9542999268151 .1734008789152 .6972961426 153.0021057129153 .0021057129152 .6972961426154 .5260925293148 .4304046631 142.6394042969139 .5915985107138 .6772003174137 .7628936768135 .6293945312 132.5814971924129 .2288970947125 .5715026855122 .8283996582122 .2188034058 
121.9140014648121 .3044967651119 .7806015015117 .342300415114 .5991973877 111.551399231108 .5035018921105 .7603988647103 .3221969604102 .1029968262 101.1886978149101 .4934005737102 .712600708105 .4557037354109 .4179000854 116.1231002808133 .1911010742150 .8686065674161 .8408966064170 .9844970703 177.6896972656183 .4806976318188 .6620025635193 .233795166202 .6820983887 209.692199707209 .692199707209 .692199707209 .9969024658212 .1304016113 214.2639007568215 .787902832217 .6165924072218 .8356933594220 .054901123 221.2740020752222 .1884002686223 .1027069092223 .7122955322224 .3218994141 224.6266021729224 .9313964844224 .9313964844224 .9313964844224 .3218994141 223.7122955322222 .7978973389221 .2740020752219 .4452972412217 .6165924072 214.8735046387212 .1304016113209 .692199707209 .692199707209 .692199707 209.692199707 209.692199707 209.692199707 209.692199707 209.692199707 209.692199707 209.692199707 209.692199707 209.692199707 209.692199707 209.692199707 209.692199707 209.692199707 209.692199707 107.2844009399 99.66472625732 67.49005126953 38.43560028076 -9999 -9999 -9999 -9999 -9999 -9999 -9999 -9999 -9999 -9999 -9999 -9999 -9999 -9999-9999-9999-9999

-9999 -9999 -9999 -9999 -9999 -9999 -9999 -9999 -9999 -9999 -9999 -9999 -9999 -9999 -9999 -9999 -9999 -9999 -9999 -9999 -9999 -9999 -9999 -9999 -9999 -9999 -9999 -9999 -9999 -9999 -9999 -9999-9999 -9999 411.4151306152407.7216491699404.0327148438400.4258422852 397.0370178223394 .049621582391 .6535949707389 .8397521973388 .6657104492 388.1695861816388 .296295166387 .9914855957389 .2106018066390 .7344970703 391.6488952637392 .2585144043392 .5632019043392 .5632019043391 .6488952637 389.515411377387 .3818969727384 .029296875379 .1527099609377 .324005127 372.7521972656365 .132598877354 .7698974609341 .9689025879328 .5584106445 316.0621948242307 .2233886719302 .3468017578300 .5180969238299 .9085998535 299.2990112305298 .9942016602298 .3846130371297 .1654968262295 .6416015625 293.8128967285291 .9841918945290 .4602050781288 .9363098145287 .4124145508 285.8884887695284 .3645019531282 .8406066895280 .7070922852277 .9641113281 273.6971130371266 .9917907715258 .7626037598250 .5334014893242 .6089935303 235.5989074707229 .5032043457224 .0171051025219 .1405029297214 .8735046387 211.2160949707207 .25390625203 .9011993408200 .8533935547198 .7198944092 196.891204834195 .3672943115194 .4528961182193 .5386047363193 .233795166 192.624206543192 .3193969727192 .0146026611191 .7097930908191 .1002960205 190.4907073975189 .8811035156189 .2716064453188 .6620025635188 .3571929932 188.0523986816187 .7476043701187 .7476043701188 .0523986816188 .6620025635 189.5764007568190 .4907073975191 .4051055908192 .624206543193 .5386047363 194.4528961182194 .7577056885195 .3672943115195 .6721038818195 .6721038818 195.9768066406196 .2816009521197 .500793457199 .9389953613202 .9868927002 206.0346984863212 .7400054932210 .6065063477207 .8634033203206 .0346984863 204.8155975342205 .425201416206 .9490966797209 .692199707212 .1304016113 213.6544036865214 .8735046387215 .787902832217 .0070037842216 .3973999023 216.3973999023217 .0070037842218 .5308990479220 .054901123221 .5787963867 223.1027069092224 .3218994141225 .8457946777226 .7601013184227 .9792938232 228.8936004639229 .5032043457230 .1127929688230 .4176025391230 .4176025391 230.4176025391230 .1127929688230 .1127929688229 .5032043457229 .1983947754 228.8936004639228 .2841033936227 .6744995117227 .3697052002226 .7601013184 
226.150604248225 .5410003662224 .9313964844224 .3218994141224 .0171051025 223.4075012207223 .1027069092223 .1027069092222 .7978973389222 .4931030273 222.1884002686221 .883605957221 .2740020752220 .9691925049220 .3596038818 219.7501068115219 .7501068115220 .054901123220 .6643981934220 .9691925049 221.5787963867221 .5787963867220 .9691925049219 .7501068115217 .3117980957 213.959197998209 .9969024658206 .3394927979204 .2059936523203 .9011993408 204.5108032227204 .2059936523203 .2917022705201 .158203125197 .8054962158 193.8433074951189 .5764007568185 .3094024658181 .3471984863177 .9945068359 174.6419067383171 .8988037109169 .1557006836167 .0222015381165 .1934967041 163.6696014404162 .7552947998162 .1457061768161 .5361022949161 .2312927246 160.9264984131160 .9264984131160 .6217956543160 .3170013428160 .0122070312 159.7073974609159 .0977935791158 .7929992676158 .7929992676158 .4882965088 158.4882965088158 .1835021973157 .878692627157 .2691040039156 .6596069336 155.7451934814154 .8307952881153 .9165039062153 .0021057129152 .6972961426 150.8686065674148 .7351074219145 .9920959473143 .5538024902143 .2489929199 143.2489929199143 .2489929199143 .2489929199143 .5538024902143 .5538024902 143.2489929199142 .9441986084142 .3347015381142 .0299072266141 .4203033447 141.1154937744140 .8106994629140 .5059967041140 .8106994629142 .0299072266 143.8585968018146 .2969055176149 .3446960449152 .3925933838154 .8307952881 156.6596069336157 .5738983154157 .878692627157 .5738983154156 .6596069336 155.7451934814154 .8307952881153 .6116943359152 .6972961426151 .4781951904 152.3925933838151 .1734008789152 .3925933838151 .7830047607151 .7830047607 152.3925933838152 .3925933838152 .3925933838152 .3925933838153 .3069000244 151.1734008789144 .4682006836144 .4682006836143 .2489929199144 .1634063721 141.1154937744136 .2389984131131 .3623962402127 .4001998901124 .3523025513 122.5235977173121 .6092987061120 .9997024536120 .0852966309118 .5614013672 116.1231002808113 .075302124110 .0273971558107 .2844009399104 .8460998535 103.0174026489101 .7982025146101 .4934005737102 .1029968262104 .2365036011 108.5035018921117 .0374984741130 .4479980469145 .6873016357158 .1835021973 166.7174987793172 .5084075928177 .9945068359183 .1759033203190 .4907073975 200.2438049316208 .7778015137209 .692199707209 .692199707209 .692199707 209.692199707 209.9969024658 211.8256988525 213.3495941162 214.8735046387 216.0926971436217 .0070037842217 .9214019775218 .8356933594219 .4452972412 220.054901123220 .6643981934220 .6643981934220 .9691925049220 .6643981934 220.3596038818219 .7501068115218 .8356933594217 .3117980957215 .787902832 213.959197998211 .520904541209 .692199707209 .692199707209 .692199707209 .692199707 209.692199707 209.692199707 209.692199707 209.692199707 209.692199707 209.692199707 209.692199707 209.692199707 209.692199707 209.692199707 209.692199707 209.692199707 209.692199707 209.692199707209.692199707 100.8839035034 71.06176757812 47.14702987671 -9999 -9999 -9999 -9999 -9999 -9999 -9999 -9999 -9999 -9999 -9999 -9999 -9999 -9999-9999-9999-9999

-9999 -9999 -9999 -9999 -9999 -9999 -9999 -9999 -9999 -9999 -9999 -9999 -9999 -9999 -9999 -9999 -9999 -9999 -9999 -9999 -9999 -9999 -9999 -9999 -9999 -9999 -9999 -9999 -9999 -9999 -9999 -9999 -9999 -9999 -9999 410.1624450684 406.8106079102403 .5977783203 400.6487426758398 .1135864258396 .1044921875394 .720123291393 .9750366211 393.8371887207394 .1504211426394 .783203125396 .0081787109397 .4413146973 
398.5851135254399 .3328552246399 .753326416399 .8128051758399 .308013916 398.1973876953396 .601348877394 .3694152832391 .9703063965389 .8201904297 383.7244873047374 .2760925293362 .3894958496347 .1502990723330 .6918945312 315.1477966309304 .1755981445299 .9085998535299 .6037902832300 .2132873535 300.8229064941301 .4324951172301 .7373046875301 .4324951172299 .9085998535 298.0798950195296 .8606872559295 .6416015625294 .7272033691293 .5080871582 292.2889099121290 .7650146484288 .6315002441285 .8884887695281 .9262084961 276.7449035645270 .0396118164262 .1152038574253 .5812072754244 .7424926758 238.0372009277231 .9414978027226 .150604248220 .6643981934216 .0926971436 211.8256988525207 .5587005615204 .2059936523201 .158203125198 .7198944092 196.891204834195 .3672943115194 .4528961182193 .8433074951193 .5386047363 193.233795166192 .9290008545192 .9290008545192 .624206543192 .0146026611 191.4051055908190 .795501709190 .1858978271189 .5764007568189 .2716064453 188.6620025635188 .6620025635188 .6620025635188 .966796875189 .2716064453 189.8811035156190 .795501709191 .7097930908192 .624206543193 .233795166 193.8433074951194 .4528961182194 .7577056885194 .7577056885195 .0625195 .0625 195.6721038818196 .891204834199 .0247039795201 .4629974365204 .8155975342 207.8634033203208 .4730072021207 .5587005615206 .3394927979205 .7299957275 206.0346984863207 .5587005615209 .3874053955211 .2160949707212 .7400054932 213.3495941162 214.2639007568213.959197998 213.959197998 213.6544036865 215.1782989502217 .0070037842218 .8356933594220 .3596038818222 .1884002686 223.4075012207224 .9313964844226 .150604248227 .3697052002228 .2841033936 228.8936004639229 .5032043457230 .1127929688230 .1127929688230 .1127929688 230.1127929688229 .8079986572229 .5032043457229 .1983947754228 .8936004639 228.5888977051227 .9792938232227 .3697052002227 .0648956299226 .150604248 225.5410003662225 .2362060547224 .6266021729224 .3218994141223 .7122955322 223.7122955322223 .4075012207223 .4075012207223 .1027069092223 .1027069092 222.7978973389222 .4931030273222 .1884002686221 .5787963867221 .2740020752 220.9691925049220 .9691925049221 .2740020752221 .5787963867221 .5787963867 221.2740020752220 .3596038818218 .8356933594216 .3973999023212 .7400054932 211.2160949707209 .0825958252207 .5587005615206 .9490966797206 .9490966797 206.6443023682205 .425201416203 .2917022705199 .6342926025195 .3672943115 190.795501709186 .528503418182 .5662994385178 .9089050293175 .5561981201 172.5084075928170 .070098877167 .9365997314166 .1078948975164 .5839996338 163.6696014404163 .0599975586162 .4505004883162 .1457061768161 .8408966064 161.5361022949161 .2312927246160 .9264984131160 .6217956543160 .3170013428 160.0122070312159 .7073974609159 .7073974609159 .7073974609159 .4026031494 159.4026031494158 .7929992676158 .4882965088157 .878692627156 .9642944336 155.7451934814154 .8307952881153 .6116943359152 .6972961426152 .0877990723 149.9542999268148 .1255950928146 .6015930176145 .6873016357145 .3825073242 144.7729034424144 .4682006836144 .1634063721143 .5538024902142 .6394042969 141.7250976562140 .8106994629139 .8963928223139 .2868041992138 .9819946289 138.3724975586138 .0677032471138 .3724975586139 .2868041992141 .4203033447 144.4682006836148 .1255950928151 .4781951904154 .5260925293156 .6596069336 157.878692627158 .1835021973158 .1835021973157 .5738983154156 .3547973633 154.8307952881153 .6116943359152 .6972961426148 .4304046631150 .5639038086 
151.7830047607152 .3925933838152 .3925933838152 .3925933838152 .0877990723 152.0877990723152 .0877990723152 .3925933838152 .0877990723152 .3925933838 153.0021057129150 .2590942383150 .5639038086152 .3925933838145 .0776977539 138.9819946289134 .1054992676129 .8385009766125 .8762969971123 .1332015991 121.3044967651120 .6949005127120 .3900985718120 .0852966309117 .9517974854 115.2088012695112 .1608963013109 .1130981445106 .3700027466104 .5412979126 103.0174026489102 .4077987671103 .0174026489104 .8460998535109 .1130981445 116.4279022217127 .0953979492140 .2012023926153 .6116943359160 .0122070312 165.8031005859171 .8988037109177 .6896972656187 .4429016113197 .500793457 206.0346984863209 .692199707209 .692199707209 .692199707209 .692199707 209.692199707 209.692199707 209.3874053955 210.9113006592 212.1304016113 213.0447998047213 .959197998214 .8735046387215 .4830932617216 .0926971436 216.3973999023216 .7021942139216 .7021942139216 .7021942139216 .3973999023 215.787902832214 .8735046387213 .6544036865212 .1304016113210 .3016967773 209.692199707 209.692199707 209.692199707 209.692199707 209.692199707 209.692199707 209.692199707 209.692199707 209.692199707 209.692199707 209.692199707 209.692199707 209.692199707 209.692199707 209.692199707209.692199707 209.692199707 209.692199707 209.692199707 209.692199707 102.1029968262 95.09295654297 57.46415328979 25.3595867157 -9999 -9999 -9999 -9999 -9999 -9999 -9999 -9999 -9999 -9999 -9999 -9999 -9999 -9999-9999-9999 -9999 -9999 -9999 -9999 -9999 -9999 -9999 -9999 -9999 -9999 -9999 -9999 -9999 -9999 -9999

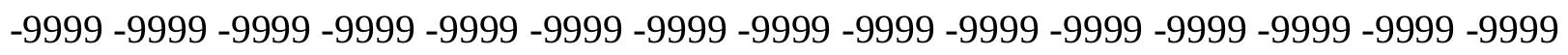
-9999 -9999 -9999 -9999 -9999 412.6783752441409 .6669921875406 .8175354004 404.2339172363402 .0304260254400 .3106384277399 .1654663086398 .610168457 398.6096801758399 .0825805664400 .0578613281401 .3602905273402 .7666015625 403.9759216309404 .8428649902405 .424621582405 .7691040039405 .8557128906 405.6220397949404 .9254455566403 .7186279297401 .9875793457398 .8846740723 393.1727905273381 .8958129883369 .7043151855352 .0267944336334 .0444946289 316.9765014648306 .0043029785301 .4324951172302 .3468017578303 .2611999512 303.8707885742304 .4802856445304 .7850952148305 .3947143555302 .9563903809 301.1276855469300 .5180969238300 .2132873535299 .6037902832298 .6893920898 297.7750854492296 .2510986328293 .8128967285290 .1553955078285 .2789001465 279.4880065918272 .7827148438264 .8583068848256 .6290893555248 .3999023438 241.0850067139234 .3798065186228 .2841033936222 .4931030273217 .3117980957 212.4351959229208 .1681976318204 .2059936523201 .158203125198 .7198944092 196.891204834195 .6721038818194 .7577056885194 .1481018066194 .1481018066 193.8433074951193 .8433074951193 .8433074951193 .5386047363193 .233795166 192.624206543191 .7097930908191 .1002960205190 .4907073975189 .8811035156 189.5764007568189 .5764007568189 .5764007568189 .5764007568189 .8811035156 190.4907073975191 .1002960205192 .0146026611192 .624206543193 .233795166 193.5386047363193 .8433074951194 .1481018066194 .4528961182194 .4528961182195 .0625 195.6721038818196 .891204834198 .4151000977200 .5485992432202 .9868927002 204.5108032227206 .0346984863206 .3394927979206 .0346984863206 .0346984863 206.6443023682207 .8634033203209 .3874053955210 .9113006592212 .4351959229 213.6544036865213 .6544036865213 .0447998047213 .0447998047213 .3495941162 214.2639007568216 .0926971436217 .9214019775219 .4452972412220 .9691925049 
222.4931030273224 .0171051025225 .2362060547226 .4553985596227 .3697052002 228.2841033936228 .8936004639229 .5032043457229 .8079986572229 .8079986572 229.8079986572229 .5032043457229 .5032043457229 .1983947754228 .8936004639 228.5888977051228 .2841033936227 .6744995117227 .0648956299226 .4553985596 225.8457946777225 .2362060547224 .6266021729224 .3218994141224 .0171051025 224.0171051025224 .0171051025224 .0171051025223 .7122955322223 .7122955322 223.7122955322223 .4075012207223 .1027069092222 .7978973389222 .4931030273 222.1884002686222 .1884002686222 .1884002686222 .1884002686221 .883605957 221.5787963867220 .3596038818218 .8356933594216 .7021942139214 .2639007568 212.4351959229211 .520904541210 .3016967773209 .9969024658209 .692199707 209.3874053955 208.1681976318205.425201416201.4629974365 196.5863952637 191.7097930908187 .1381072998183 .1759033203179 .2136993408175 .8609924316 172.8132019043170 .3748931885168 .5462036133166 .7174987793165 .4983062744 164.5839996338163 .974395752163 .3648071289162 .7552947998162 .4505004883 161.8408966064161 .5361022949161 .2312927246161 .2312927246160 .9264984131 160.6217956543160 .6217956543160 .3170013428160 .3170013428160 .3170013428 160.0122070312160 .0122070312159 .4026031494158 .7929992676157 .878692627 156.9642944336155 .4403991699153 .9165039062152 .0877990723151 .7830047607 151.1734008789150 .2590942383149 .6495056152148 .7351074219147 .5160064697 146.6015930176145 .6873016357144 .7729034424143 .5538024902142 .3347015381 141.1154937744139 .5915985107138 .6772003174137 .7628936768136 .8484954834 136.2389984131136 .2389984131136 .2389984131136 .8484954834138 .9819946289 142.6394042969147 .2111968994151 .1734008789154 .5260925293156 .6596069336 158.1835021973158 .7929992676158 .7929992676158 .1835021973156 .9642944336 155.1356048584153 .0021057129151 .7830047607150 .2590942383150 .2590942383 151.4781951904152 .0877990723152 .3925933838152 .3925933838151 .7830047607 151.7830047607151 .7830047607152 .3925933838151 .7830047607152 .6972961426 153.6116943359153 .3069000244153 .6116943359153 .0021057129145 .3825073242 141.4203033447137 .1533050537132 .5814971924128 .0097961426124 .0475006104 120.9997024536119 .7806015015120 .3900985718121 .9140014648119 .4757995605 117.0374984741113 .9896011353111 .24659729108 .8082962036106 .6747970581 105.1509017944104 .2365036011104 .5412979126106 .0652008057109 .4179000854 114.9039993286122 .5235977173131 .6672058105141 .4203033447149 .6495056152 157.5738983154165 .1934967041171 .8988037109184 .0901947021193 .8433074951 202.0724945068209 .3874053955209 .692199707209 .692199707209 .692199707 209.692199707 209.692199707 209.692199707 209.692199707 209.692199707 209.3874053955209.9969024658210.9113006592 211.520904541212.1304016113 212.4351959229212 .4351959229212 .7400054932212 .4351959229212 .1304016113 211.8256988525210 .9113006592209 .692199707209 .692199707209 .692199707 209.692199707 209.692199707 209.692199707 209.692199707 209.692199707 209.692199707 209.692199707 209.692199707 209.692199707 209.692199707 209.692199707 209.692199707 209.692199707 209.692199707 209.692199707 209.692199707 209.692199707 209.692199707 209.692199707 209.692199707 103.3221969604 96.3121032714863.33002471924 33.18174743652 -9999 -9999 -9999 -9999 -9999 -9999 -9999 -9999 -9999 -9999 -9999 -9999 -9999 -9999 -9999 -9999 -9999 -9999 -9999 -9999 -9999 -9999 -9999 -9999 -9999 -9999 -9999 -9999 -9999 -9999 -9999 
-9999 -9999 -9999 -9999 -9999 -9999 -9999 -9999 -9999 -9999 -9999 -9999 -9999 -9999 -9999 -9999 -9999 -9999 -9999 -9999 -9999 412.4641418457 409.9208984375407 .611907959 405.625579834404 .0489196777402 .9660644531402 .3910827637402 .3179931641 402.8247070312403 .8688964844405 .2380065918406 .6493225098407 .8161315918 408.6206970215409 .1949768066409 .7416381836410 .341003418410 .7803344727 410.7208557129409 .8548583984407 .8817138672403 .8270874023397 .2836914062 388.296295166371 .837890625355 .0747070312338 .6163024902323 .9866027832 313.6239013672309 .9664916992309 .3569030762309 .6617126465309 .3569030762 308.7473144531307 .5281982422306 .0043029785304 .1755981445302 .9563903809 303.2611999512304 .1755981445302 .9563903809302 .3468017578302 .3468017578 301.4324951172298 .0798950195293 .5080871582288 .0219116211281 .9262084961 274.9161987305267 .6012878418259 .6769104004252 .0572967529244 .4376983643 237.4275970459230 .7223052979224 .6266021729218 .5308990479213 .0447998047 208.4730072021204 .8155975342201 .4629974365199 .0247039795197 .1959991455 195.6721038818195 .0625194 .7577056885194 .4528961182194 .7577056885194 .7577056885 194.7577056885194 .7577056885194 .1481018066193 .5386047363192 .624206543 192.0146026611191 .4051055908190 .795501709190 .4907073975190 .1858978271 190.1858978271190 .1858978271190 .4907073975191 .1002960205191 .4051055908 192.0146026611192 .624206543193 .233795166193 .5386047363193 .5386047363 193.8433074951193 .8433074951194 .4528961182194 .7577056885195 .6721038818 196.891204834198 .1103057861199 .9389953613201 .7678070068202 .9868927002 204.2059936523205 .1204071045205 .425201416206 .0346984863206 .6443023682 207.5587005615209 .0825958252210 .6065063477212 .1304016113213 .3495941162 213.3495941162213 .3495941162213 .0447998047213 .3495941162214 .2639007568 215.4830932617217 .0070037842218 .5308990479220 .054901123221 .5787963867 223.1027069092 224.3218994141225.5410003662 226.4553985596 227.3697052002 228.2841033936228 .5888977051228 .8936004639229 .1983947754229 .1983947754 229.1983947754229 .1983947754228 .8936004639228 .8936004639228 .5888977051 228.2841033936227 .6744995117227 .0648956299226 .4553985596225 .8457946777 225.2362060547224 .6266021729224 .3218994141224 .3218994141224 .0171051025 224.3218994141224 .3218994141224 .3218994141224 .6266021729224 .6266021729 224.3218994141224 .3218994141224 .0171051025223 .7122955322223 .4075012207 223.4075012207 223.1027069092 222.7978973389 222.4931030273 221.883605957 220.9691925049219 .4452972412217 .9214019775216 .3973999023215 .1782989502 214.5686950684213 .0447998047212 .1304016113212 .4351959229212 .4351959229 211.2160949707 207.25390625 202.0724945068 196.5863952637191.4051055908 186.8332977295182 .5662994385178 .9089050293175 .5561981201172 .8132019043 170.3748931885168 .5462036133167 .3269958496166 .1078948975165 .4983062744 164.5839996338163 .974395752163 .3648071289162 .7552947998162 .4505004883 161.8408966064161 .5361022949161 .5361022949161 .2312927246161 .2312927246 160.9264984131160 .9264984131160 .9264984131160 .9264984131160 .9264984131 160.6217956543160 .3170013428159 .7073974609159 .0977935791157 .878692627 156.3547973633154 .8307952881153 .3069000244152 .3925933838152 .0877990723 151.7830047607152 .0877990723151 .1734008789149 .6495056152148 .4304046631 146.9064025879145 .6873016357144 .1634063721142 .3347015381140 .8106994629 138.9819946289137 .7628936768136 .2389984131135 .3246002197134 .7149963379 
134.7149963379134 .7149963379135 .3246002197136 .5437011719141 .4203033447 146.9064025879151 .4781951904154 .5260925293156 .9642944336158 .4882965088 159.4026031494159 .7073974609159 .0977935791157 .5738983154155 .4403991699 153.6116943359152 .0877990723151 .4781951904151 .1734008789151 .7830047607 152.0877990723152 .3925933838152 .3925933838151 .7830047607150 .8686065674 151.1734008789152 .0877990723152 .6972961426153 .0021057129153 .3069000244 153.0021057129152 .0877990723151 .1734008789148 .1255950928144 .4682006836 140.5059967041136 .2389984131131 .0576019287125 .8762969971121 .3044967651 118.8662033081119 .4757995605120 .9997024536120 .3900985718118 .8662033081 116.4279022217113 .6848983765111 .24659729109 .1130981445107 .5891036987 106.6747970581106 .3700027466107 .2844009399109 .4179000854112 .7705001831 117.0374984741122 .2188034058128 .9241027832138 .6772003174149 .0399017334 158.7929992676166 .7174987793179 .5184020996188 .3571929932196 .891204834 204.5108032227209 .692199707209 .692199707209 .692199707209 .692199707 209.692199707 209.692199707 209.692199707 209.692199707 209.692199707 209.692199707 209.692199707 209.692199707 209.692199707 209.692199707 209.692199707 209.692199707 209.692199707 209.692199707 209.692199707 209.692199707 209.692199707209.692199707 209.692199707 209.692199707 209.692199707 209.692199707 209.692199707 209.692199707 209.692199707209 .692199707209 .692199707209 .692199707209 .692199707209 .692199707 209.692199707 209.692199707 209.692199707 209.692199707 209.692199707 209.692199707 209.692199707 209.692199707 209.692199707 209.692199707 97.53124237061 67.05999755859 42.39894485474 -9999 -9999 -9999 -9999 -9999 -9999 -9999 -9999 -9999 -9999 -9999 -9999 -9999 -9999 -9999-9999 -9999 -9999 -9999 -9999 -9999 -9999 -9999 -9999 -9999 -9999 -9999 -9999 -9999 -9999 -9999 -

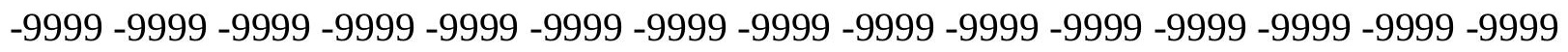
-9999 -9999 -9999 -9999-9999-9999 415.0860290527412 .7906494141410 .6743774414 408.7981567383407 .2326049805406 .0378723145405 .2343444824404 .8997497559 405.2212524414406 .1429443359407 .4894104004408 .8902587891409 .8718261719 410.2940979004410 .431640625410 .8326721191411 .7139587402412 .610748291 412.6733093262411 .3701171875408 .5245666504403 .7637634277395 .0422058105 383.7244873047369 .399597168356 .5986022949344 .4071960449334 .3493041992 327.0344848633322 .7674865723320 .6339111328319 .1099853516316 .9765014648 314.2334899902310 .8807983398307 .2233886719304 .4802856445303 .8707885742 304.4802856445304 .7850952148304 .4802856445304 .1755981445304 .7850952148 305.0899047852300 .5180969238295 .3367919922289 .8505859375283 .7549133301 277.0497131348270 .0396118164262 .7247924805255 .4098968506247 .7902984619 240.7801971436233 .7702026367226 .7601013184220 .3596038818214 .2639007568 209.3874053955 205.1204071045 201.7678070068 199.329498291 197.1959991455 195.9768066406 195.0625194.7577056885 195.0625195.3672943115195.6721038818 195.9768066406195 .6721038818195 .0625194 .1481018066193 .5386047363192 .624206543 192.0146026611191 .4051055908191 .1002960205190 .795501709190 .795501709 190.795501709191 .1002960205191 .4051055908191 .7097930908192 .3193969727 192.624206543193 .233795166193 .233795166193 .233795166193 .5386047363 193.8433074951194 .1481018066194 .7577056885195 .6721038818196 .891204834 198.1103057861199 .6342926025200 .8533935547202 .3773040771203 .2917022705 204.2059936523 205.1204071045 205.7299957275 206.3394927979 207.25390625 
208.4730072021 209.692199707 211.2160949707 212.1304016113212.7400054932 213.0447998047213 .0447998047213 .3495941162214 .2639007568215 .1782989502 216.7021942139217 .9214019775219 .4452972412220 .6643981934221 .883605957 223.4075012207224 .3218994141225 .5410003662226 .4553985596227 .0648956299 227.6744995117227 .9792938232228 .2841033936228 .2841033936228 .5888977051 228.5888977051228 .5888977051228 .5888977051228 .5888977051228 .2841033936 227.6744995117226 .7601013184226 .150604248225 .5410003662224 .9313964844 224.3218994141224 .3218994141224 .0171051025224 .3218994141224 .3218994141 224.6266021729224 .9313964844224 .9313964844225 .2362060547225 .2362060547 224.9313964844224 .9313964844224 .6266021729224 .3218994141224 .0171051025 224.0171051025223 .7122955322223 .1027069092222 .7978973389221 .883605957 220.9691925049219 .7501068115218 .8356933594217 .9214019775216 .7021942139 215.1782989502213 .6544036865214 .5686950684215 .1782989502213 .959197998 207.8634033203201 .4629974365195 .3672943115189 .8811035156185 .3094024658 181.3471984863177 .6896972656174 .6419067383172 .2035980225170 .070098877 168.5462036133167 .3269958496166 .4127044678165 .8031005859165 .1934967041 164.2792053223163 .6696014404163 .0599975586162 .4505004883162 .1457061768 161.8408966064161 .5361022949161 .5361022949161 .5361022949161 .5361022949 161.5361022949161 .5361022949161 .5361022949161 .5361022949161 .5361022949 161.2312927246160 .9264984131160 .3170013428159 .0977935791157 .5738983154 156.0500030518154 .5260925293153 .3069000244152 .6972961426152 .3925933838 152.6972961426152 .3925933838151 .1734008789149 .6495056152148 .1255950928 146.6015930176144 .7729034424142 .6394042969140 .8106994629138 .6772003174 137.1533050537135 .6293945312134 .4102020264133 .8007049561133 .8007049561 134.4102020264135 .3246002197137 .7628936768141 .7250976562146 .9064025879 152.0877990723154 .8307952881156 .6596069336158 .4882965088159 .4026031494 160.0122070312159 .7073974609158 .1835021973155 .7451934814153 .9165039062 152.6972961426152 .0877990723152 .0877990723152 .0877990723152 .0877990723 152.3925933838152 .3925933838152 .3925933838149 .6495056152150 .8686065674 151.7830047607152 .6972961426152 .3925933838152 .3925933838151 .1734008789 151.4781951904151 .4781951904150 .2590942383147 .8208007812144 .7729034424 140.5059967041135 .0198059082129 .2288970947123 .43800354118 .2565994263 120.0852966309121 .6092987061121 .9140014648120 .9997024536118 .8662033081 116.4279022217113 .9896011353112 .1608963013110 .3321990967109 .1130981445 108.5035018921108 .8082962036109 .7226028442110 .9418029785112 .7705001831 114.9039993286117 .647102356129 .8385009766142 .0299072266153 .3069000244 162.4505004883169 .4604949951180 .1280059814189 .8811035156198 .7198944092 206.9490966797209.692199707 209.692199707 209.692199707 209.692199707 209.692199707 209.692199707 209.692199707 209.692199707 209.692199707 209.692199707 209.692199707 209.692199707 209.692199707 209.692199707 209.692199707 209.692199707 209.692199707209 .692199707209 .692199707209 .692199707209 .692199707209 .692199707 209.692199707209 .692199707209 .692199707209 .692199707209 .692199707209 .692199707 209.692199707209 .692199707209 .692199707209 .692199707209 .692199707209 .692199707 209.692199707 209.692199707 209.692199707 209.692199707 209.692199707 209.692199707 209.692199707 209.692199707 209.69219970798.7503814697392.04509735107 53.2429847717319 .98337745667 -9999 -9999 -9999 -9999 -9999 -9999 -9999 -9999 -9999 
-9999 -9999 -9999 -9999-9999 -9999

-9999 -9999 -9999 -9999 -9999 -9999 -9999 -9999 -9999 -9999 -9999 -9999 -9999 -9999 -9999

-9999 -9999 -9999 -9999 -9999 -9999 -9999 -9999 -9999 -9999 -9999 -9999 -9999 -9999 -9999

-9999 -9999 -9999 -9999 -9999 -9999 -9999 415.3542480469413 .3690490723411 .5205078125 409.8479919434408 .3839111328407 .157989502406 .335357666406 .1563415527 406.6812133789407 .7970275879409 .1235961914409 .76171875409 .3154907227 408.225402832407 .9105529785408 .7971496582410 .146484375409 .7265014648 406.8729858398401 .9141540527397 .4397888184386 .7723083496372 .7521972656 364.2182006836357 .5129089355350 .8077087402345 .3215026855341 .0545959473 337.7019042969334 .6541137695330 .6918945312326 .4248962402321 .5483093262 316.3670043945311 .1856079102305 .6994934082306 .6138000488306 .9186096191 306.6138000488305 .0899047852304 .7850952148304 .1755981445303 .2611999512 300.2132873535295 .9464111328290 .7650146484285 .2789001465279 .1831970215 272.7827148438265 .7726135254258 .7626037598251 .4476928711244 .1329040527 237.1228027344229 .8079986572222 .7978973389216 .3973999023210 .6065063477 206.0346984863202 .3773040771199 .329498291197 .500793457195 .9768066406195 .0625 195.0625195 .0625195 .6721038818196 .2816009521196 .5863952637196 .5863952637 195.6721038818194 .7577056885193 .8433074951193 .233795166192 .624206543 192.0146026611191 .7097930908191 .4051055908191 .4051055908191 .4051055908 191.4051055908191 .7097930908192 .0146026611192 .3193969727192 .624206543 192.9290008545192 .9290008545193 .233795166193 .233795166193 .5386047363 194.1481018066194 .7577056885195 .6721038818196 .891204834197 .8054962158 199.329498291200 .5485992432201 .7678070068202 .6820983887203 .596496582 204.5108032227 205.1204071045 206.0346984863206.6443023682 207.5587005615 208.7778015137209 .9969024658211 .2160949707212 .1304016113212 .7400054932 213.0447998047213 .3495941162214 .2639007568214 .8735046387216 .0926971436 217.3117980957 218.5308990479219.7501068115220.9691925049 222.1884002686 223.4075012207224 .3218994141225 .2362060547225 .8457946777226 .4553985596 227.0648956299227 .3697052002227 .3697052002227 .6744995117227 .6744995117 227.9792938232227 .9792938232228 .2841033936227 .6744995117227 .0648956299 226.4553985596225 .8457946777224 .9313964844224 .3218994141224 .0171051025 224.0171051025224 .0171051025224 .0171051025224 .3218994141224 .6266021729 225.2362060547225 .5410003662225 .8457946777225 .8457946777225 .5410003662 225.5410003662225 .2362060547224 .9313964844224 .9313964844224 .6266021729 224.3218994141224 .0171051025223 .4075012207222 .7978973389222 .1884002686 221.5787963867220 .9691925049220 .054901123218 .8356933594217 .6165924072 216.3973999023216 .0926971436215 .4830932617213 .6544036865206 .3394927979 198.7198944092192 .0146026611186 .8332977295182 .5662994385178 .9089050293 175.8609924316173 .1179962158170 .9844970703169 .4604949951167 .9365997314 167.0222015381166 .1078948975165 .4983062744164 .8887023926164 .2792053223 163.6696014404163 .0599975586162 .4505004883162 .1457061768161 .8408966064 161.5361022949161 .5361022949161 .5361022949161 .5361022949161 .8408966064 161.8408966064161 .8408966064162 .1457061768162 .1457061768162 .1457061768 161.8408966064161 .2312927246160 .3170013428158 .7929992676157 .2691040039 155.7451934814154 .5260925293153 .6116943359153 .0021057129153 .0021057129 152.3925933838151 .7830047607150 .5639038086149 .0399017334147 .5160064697 
145.3825073242143 .2489929199141 .1154937744138 .9819946289137 .1533050537 135.3246002197134 .1054992676133 .8007049561134 .1054992676135 .0198059082 136.2389984131138 .9819946289142 .6394042969147 .2111968994151 .1734008789 154.2212982178156 .3547973633157 .878692627158 .7929992676159 .7073974609 160.0122070312157 .5738983154155 .4403991699153 .9165039062153 .0021057129 152.3925933838152 .0877990723152 .0877990723152 .3925933838152 .3925933838 152.3925933838152 .0877990723151 .4781951904151 .4781951904150 .8686065674 149.9542999268149 .9542999268150 .2590942383148 .1255950928152 .0877990723 152.3925933838151 .7830047607151 .1734008789149 .0399017334144 .7729034424 139.5915985107133 .8007049561128 .6192932129124 .9618988037124 .0475006104 124.3523025513124 .3523025513123 .7427978516121 .9140014648119 .4757995605 117.342300415115 .2088012695113 .3800964355111 .8561019897110 .9418029785 110.6370010376110 .3321990967110 .6370010376110 .9418029785112 .4656982422 116.4279022217124 .9618988037136 .5437011719148 .7351074219158 .7929992676 165.1934967041170 .6797027588181 .9566955566191 .7097930908201 .158203125 209.692199707 209.692199707 209.692199707 209.692199707 209.692199707 209.692199707 209.692199707 209.692199707 209.692199707 209.692199707 209.692199707209.692199707 209.692199707 209.692199707 209.692199707 209.692199707 209.692199707209.692199707 209.692199707 209.692199707 209.692199707 209.692199707 209.692199707 209.692199707 209.692199707 209.692199707 209.692199707 209.692199707 209.692199707 209.692199707 209.692199707 209.692199707 209.692199707 209.692199707 209.692199707 209.692199707 209.692199707 209.692199707 209.692199707 209.692199707 209.692199707 209.692199707 209.692199707 99.6647262573293.26425170898 59.4192237854 28.3626499176-9999-9999 -9999 -9999 -9999 -9999 -9999 -9999 -9999 -9999 -9999 -9999 -9999 -9999 -9999 -9999 -9999 -9999 -9999 -9999 -9999 -9999 -9999 -9999 -9999 -9999 -9999 -9999 -9999 -9999 -9999 -9999 -9999 -9999 -9999 -9999 -9999 -9999 -9999 -9999 -9999 -9999 -9999 -9999 -9999 -9999 -9999 -9999 -9999 -9999 -9999-9999 417.5590820312415.6699523926413.8018798828 411.9474182129410 .0983276367408 .2986755371406 .7009887695405 .6687011719 405.3288269043405 .7224121094406 .5852661133406 .9829711914404 .9023132324 401.5046081543399 .7125244141400 .6317443848402 .31640625400 .792388916 395.3063049316387 .3818969727376 .104888916371 .5331115723365 .4374084473 361.7799072266359 .036895752356 .9034118652355 .379486084354 .4650878906 352.941192627348 .9790039062342 .8833007812336 .7875976562330 .3870849609 324.2914123535318 .5004882812314 .5382080078312 .7095031738312 .1000061035 310.2713012695308 .1377868652305 .3947143555303 .2611999512301 .1276855469 298.9942016602295 .6416015625291 .3746032715286 .8027954102281 .3167114258 275.2210083008268 .8204956055262 .1152038574255 .1051025391247 .7902984619 240.7801971436233 .4653930664225 .8457946777218 .8356933594212 .4351959229 207.25390625202 .9868927002199 .9389953613197 .500793457195 .9768066406195 .0625 194.7577056885195 .0625195 .6721038818196 .2816009521196 .2816009521195 .9768066406 195.3672943115194 .7577056885193 .8433074951193 .233795166192 .9290008545 192.3193969727192 .3193969727192 .0146026611192 .0146026611191 .7097930908 191.7097930908191 .7097930908192 .0146026611192 .0146026611192 .3193969727 192.624206543192 .624206543192 .9290008545193 .233795166193 .5386047363 194.1481018066194 .7577056885195 .6721038818196 .5863952637197 .8054962158 199.0247039795 200.2438049316201.4629974365 202.3773040771 203.2917022705 
203.9011993408204 .8155975342205 .425201416206 .0346984863206 .9490966797 208.1681976318209 .0825958252209 .9969024658211 .2160949707212 .1304016113 213.0447998047213 .3495941162213 .959197998214 .5686950684215 .4830932617 216.3973999023217 .6165924072218 .5308990479219 .7501068115220 .9691925049 222.1884002686223 .1027069092224 .0171051025224 .6266021729225 .2362060547 225.8457946777226 .150604248226 .4553985596226 .7601013184226 .7601013184 227.0648956299227 .0648956299227 .0648956299226 .7601013184226 .4553985596 225.8457946777225 .2362060547224 .6266021729224 .0171051025223 .7122955322 223.4075012207223 .4075012207223 .7122955322224 .0171051025224 .6266021729 225.2362060547225 .8457946777226 .150604248226 .150604248226 .150604248 225.8457946777225 .5410003662225 .5410003662225 .2362060547225 .2362060547 224.9313964844224 .6266021729224 .3218994141224 .0171051025223 .4075012207 223.1027069092222 .4931030273221 .883605957220 .9691925049219 .4452972412 217.9214019775215 .787902832213 .0447998047208 .1681976318201 .158203125 193.5386047363187 .1381072998182 .5662994385178 .9089050293176 .165802002 173.4226989746171 .2891998291169 .7653045654168 .241394043167 .0222015381 166.1078948975165 .4983062744164 .8887023926164 .5839996338163 .974395752 163.3648071289162 .7552947998162 .4505004883161 .8408966064161 .8408966064 161.5361022949161 .5361022949161 .5361022949161 .5361022949161 .8408966064 162.1457061768162 .1457061768162 .4505004883162 .4505004883162 .4505004883 162.4505004883162 .1457061768161 .8408966064160 .0122070312158 .1835021973 156.6596069336155 .1356048584154 .2212982178153 .6116943359153 .0021057129 152.3925933838151 .7830047607151 .1734008789149 .9542999268148 .4304046631 146.2969055176143 .8585968018141 .4203033447139 .2868041992137 .4580993652 135.9342041016135 .0198059082134 .7149963379135 .0198059082135 .9342041016 137.7628936768140 .2012023926143 .5538024902147 .2111968994150 .5639038086 153.6116943359155 .4403991699156 .9642944336157 .5738983154157 .878692627 156.9642944336155 .4403991699154 .2212982178153 .3069000244152 .6972961426 152.3925933838152 .3925933838152 .3925933838152 .6972961426152 .6972961426 152.3925933838152 .3925933838152 .6972961426152 .6972961426150 .2590942383 147.5160064697146 .2969055176152 .3925933838152 .6972961426152 .6972961426 153.3069000244153 .6116943359153 .6116943359153 .0021057129148 .7351074219 144.1634063721139 .5915985107135 .3246002197131 .6672058105129 .533706665 128.6192932129128 .0097961426126 .7906036377124 .9618988037122 .8283996582 120.6949005127118 .5614013672116 .4279022217114 .9039993286113 .6848983765 112.7705001831111 .8561019897111 .551399231111 .551399231112 .4656982422 116.1231002808122 .2188034058131 .3623962402142 .3347015381154 .8307952881 158.1835021973162 .4505004883173 .7274932861185 .0045928955195 .0625204 .5108032227 209.692199707209 .692199707209 .692199707209 .692199707209 .692199707209 .692199707 209.692199707209 .692199707209 .692199707209 .692199707209 .692199707209 .692199707 209.692199707209 .692199707209 .692199707209 .692199707209 .692199707209 .692199707 209.692199707209 .692199707209 .692199707209 .692199707209 .692199707209 .692199707 209.692199707209.692199707 209.692199707 209.692199707 209.692199707209.692199707 209.692199707209 .692199707209 .692199707209 .692199707209 .692199707209 .692199707 209.692199707209 .692199707209 .692199707209 .692199707209 .692199707209 .692199707 209.692199707 94.17859649658 63.3358268737838 .25073623657 -9999 -9999 -9999 -9999 
-9999 -9999 -9999 -9999 -9999 -9999 -9999 -9999 -9999 -9999 -9999

-9999 -9999 -9999 -9999 -9999 -9999 -9999 -9999 -9999 -9999 -9999 -9999 -9999 -9999 -9999

-9999 -9999 -9999 -9999 -9999 -9999 -9999 -9999 -9999 -9999 -9999 -9999 -9999 -9999 -9999

-9999 -9999 -9999 -9999 -9999 -9999 -9999 -9999 417.5726318359415 .6856079102

413.6409912109411 .3695678711408 .8784790039406 .3204956055404 .0556640625

402.3939208984401 .0567016602399 .9847106934400 .1828918457395 .3063049316

389.2106018066385 .858001709388 .6010131836387 .3818969727382 .8100891113

371.837890625366 .3517150879358 .7320861816360 .8656005859361 .7799072266

361.7799072266362 .0846862793362 .3894958496363 .6086120605365 .132598877

366.9613037109360 .8656005859353 .8554992676346 .5407104492339 .5306091309 333.4349060059328 .2536010742324 .5961914062322 .1578979492319 .7196044922 316.9765014648313 .3190917969308 .4425048828302 .9563903809301 .1276855469 298.9942016602295 .9464111328292 .2889099121288 .3266906738283 .4501953125 277.9641113281271 .8682861328265 .4678039551259 .0674133301252 .0572967529 244.7424926758237 .4275970459229 .1983947754221 .5787963867214 .5686950684 208.4730072021203.9011993408200.2438049316197.8054962158 195.9768066406 194.7577056885194 .4528961182194 .4528961182195 .0625195 .3672943115195 .3672943115 195.0625194 .7577056885194 .1481018066193 .5386047363193 .233795166192 .9290008545 192.624206543192 .624206543192 .3193969727192 .3193969727192 .0146026611 192.0146026611192 .0146026611192 .0146026611192 .0146026611192 .0146026611 192.3193969727192 .3193969727192 .624206543192 .9290008545193 .5386047363 193.8433074951194 .7577056885195 .6721038818196 .5863952637197 .8054962158 199.0247039795200 .2438049316201 .4629974365202 .0724945068202 .9868927002 203.596496582204 .2059936523204 .8155975342205 .7299957275206 .3394927979 207.25390625208 .1681976318209 .0825958252210 .3016967773211 .2160949707 212.1304016113212 .7400054932213 .3495941162213 .959197998214 .5686950684 215.4830932617216 .3973999023217 .6165924072218 .5308990479219 .7501068115 220.6643981934221 .883605957222 .4931030273223 .4075012207224 .0171051025 224.6266021729224 .9313964844225 .2362060547225 .5410003662225 .5410003662 225.8457946777225 .8457946777225 .8457946777225 .8457946777225 .2362060547 224.9313964844224 .3218994141223 .7122955322223 .4075012207223 .1027069092 222.7978973389222 .7978973389223 .1027069092223 .4075012207224 .0171051025 224.6266021729225 .5410003662226 .150604248226 .150604248226 .150604248 225.8457946777225 .8457946777225 .5410003662225 .5410003662225 .2362060547 225.2362060547224 .9313964844224 .6266021729224 .3218994141224 .3218994141 224.0171051025223 .4075012207222 .7978973389221 .5787963867220 .054901123 217.6165924072213 .959197998208 .4730072021201 .7678070068194 .1481018066 187.1381072998181 .0424041748177 .6896972656175 .2514038086172 .8132019043 170.9844970703169 .4604949951167 .9365997314166 .7174987793165 .8031005859 165.1934967041164 .5839996338164 .2792053223163 .6696014404163 .3648071289 162.7552947998162 .4505004883161 .8408966064161 .5361022949161 .5361022949 161.2312927246161 .2312927246161 .5361022949161 .5361022949161 .8408966064 162.1457061768162 .1457061768162 .4505004883162 .7552947998162 .7552947998 162.7552947998162 .4505004883161 .8408966064160 .3170013428158 .7929992676 157.2691040039155 .7451934814154 .8307952881153 .9165039062153 .0021057129 152.0877990723152 .0877990723152 .0877990723151 .1734008789149 .6495056152 
147.2111968994144 .7729034424142 .3347015381140 .2012023926138 .6772003174 137.4580993652136 .5437011719136 .2389984131136 .5437011719137 .1533050537 138.9819946289141 .1154937744143 .8585968018147 .2111968994150 .2590942383 153.0021057129154 .8307952881155 .7451934814156 .0500030518155 .7451934814 154.5260925293152 .6972961426152 .6972961426152 .6972961426152 .3925933838 152.3925933838152 .0877990723152 .6972961426153 .3069000244153 .0021057129 152.6972961426152 .6972961426152 .6972961426151 .7830047607149 .6495056152 147.2111968994149 .3446960449152 .0877990723153 .6116943359153 .9165039062 154.2212982178154 .5260925293154 .2212982178153 .3069000244150 .8686065674 147.5160064697144 .4682006836141 .7250976562137 .7628936768135 .3246002197 133.4958953857131 .9720001221130 .4479980469128 .6192932129126 .1809997559 124.0475006104121 .9140014648119 .7806015015117 .9517974854116 .4279022217 115.2088012695113 .9896011353113 .075302124112 .7705001831113 .6848983765 115.818397522119 .7806015015125 .5715026855132 .2767028809139 .5915985107 146.6015930176153 .6116943359166 .4127044678177 .9945068359189 .2716064453 199.329498291209.0825958252 209.692199707 209.692199707 209.692199707 209.692199707 209.692199707 209.692199707 209.692199707 209.692199707 209.692199707 209.692199707 209.692199707 209.692199707 209.692199707 209.692199707209.692199707 209.692199707209 .692199707209 .692199707209 .692199707209 .692199707209 .692199707 209.692199707 209.692199707 209.692199707209.692199707 209.692199707 209.692199707 209.692199707 209.692199707 209.692199707 209.692199707 209.692199707 209.692199707 209.692199707 209.692199707 209.692199707 209.692199707 209.692199707 209.692199707 209.692199707209.692199707209.692199707 95.3977432251 89.3020401001 49.8844451904316 .06331253052 -9999 -9999 -9999 -9999 -9999 -9999 -9999 -9999 -9999 -9999 -9999 -9999 -9999-9999

-9999 -9999 -9999 -9999 -9999 -9999 -9999 -9999 -9999 -9999 -9999 -9999 -9999 -9999 -9999 -9999 -9999 -9999 -9999 -9999-9999 -9999 -9999 -9999 -9999 -9999 -9999 -9999 -9999 - 9999 -9999 -9999 -9999 -9999-9999 -9999 -9999 -9999 419.0545349121 417.1986694336 415.0474243164412 .440032959409 .3045043945405 .7669067383402 .0115966797 398.9637145996395 .611114502390 .7344970703381 .2861938477373 .9713134766 371.5331115723372 .1426086426374 .5809020996373 .0570068359368 .7900085449 361.1704101562353 .8554992676353 .5508117676356 .9034118652360 .5607910156 363.9135131836365 .4374084473367 .2661132812369 .0947875977370 .9234924316 371.228302002367 .8756103516362 .0846862793354 .7698974609347 .7597961426 342.2737121582338 .3114929199335 .5683898926332 .8252868652330 .0823059082 326.1200866699320 .9388122559314 .8429870605309 .0520935059304 .1755981445 300.5180969238297 .4703063965294 .4223937988290 .4602050781286 .1932067871 282.2309875488 277.3544921875270.9540100098263.0296020508 256.3243103027 249.0093994141241 .6945953369232 .8558044434224 .3218994141216 .3973999023 209.9969024658204 .8155975342200 .8533935547197 .8054962158195 .9768066406 194.4528961182193 .8433074951193 .5386047363193 .8433074951193 .8433074951 194.1481018066193 .8433074951193 .5386047363193 .233795166192 .9290008545 192.624206543192 .624206543192 .624206543192 .624206543192 .624206543 192.3193969727192 .3193969727192 .0146026611192 .0146026611192 .0146026611 192.0146026611192 .0146026611192 .0146026611192 .3193969727192 .624206543 192.9290008545193 .233795166193 .8433074951194 .7577056885195 .3672943115 
196.5863952637197 .500793457198 .7198944092199 .9389953613200 .8533935547 201.7678070068202 .3773040771202 .9868927002203 .596496582204 .5108032227 205.1204071045205 .7299957275206 .6443023682207 .5587005615208 .4730072021 209.3874053955210 .3016967773210 .9113006592211 .8256988525212 .4351959229 213.0447998047213 .6544036865214 .5686950684215 .4830932617216 .3973999023 217.3117980957218 .5308990479219 .4452972412220 .3596038818221 .2740020752 221.883605957222 .4931030273223 .1027069092223 .7122955322224 .0171051025 224.3218994141224 .3218994141224 .6266021729224 .6266021729224 .6266021729 224.3218994141224 .0171051025223 .7122955322223 .4075012207222 .7978973389 222.4931030273222 .1884002686222 .1884002686222 .1884002686222 .1884002686 222.7978973389223 .1027069092224 .0171051025224 .6266021729225 .2362060547 225.5410003662225 .5410003662225 .5410003662225 .5410003662225 .5410003662 225.2362060547225 .2362060547225 .2362060547224 .9313964844224 .9313964844 224.6266021729224 .3218994141224 .0171051025223 .4075012207222 .4931030273 220.9691925049218 .8356933594215 .1782989502210 .3016967773202 .9868927002 194.7577056885186 .528503418181 .3471984863176 .7754058838173 .7274932861 171.5939941406169 .7653045654168 .241394043167 .0222015381166 .1078948975 165.1934967041164 .5839996338163 .974395752163 .6696014404163 .3648071289 162.7552947998162 .4505004883162 .1457061768161 .8408966064161 .5361022949 161.2312927246161 .2312927246160 .9264984131161 .2312927246161 .2312927246 161.2312927246161 .5361022949161 .8408966064162 .1457061768162 .4505004883 162.4505004883162 .7552947998162 .7552947998162 .1457061768161 .5361022949 160.3170013428159 .0977935791157 .5738983154156 .3547973633155 .1356048584 154.2212982178153 .3069000244152 .6972961426152 .3925933838152 .3925933838 152.0877990723150 .5639038086148 .7351074219146 .2969055176143 .2489929199 141.7250976562140 .5059967041139 .2868041992138 .3724975586137 .7628936768 137.7628936768138 .6772003174139 .8963928223141 .7250976562144 .4682006836 147.2111968994149 .9542999268152 .3925933838153 .9165039062154 .8307952881 154.8307952881154 .2212982178153 .0021057129152 .0877990723152 .3925933838 152.6972961426152 .3925933838152 .0877990723152 .0877990723152 .6972961426 153.0021057129153 .0021057129153 .0021057129152 .6972961426152 .3925933838 151.7830047607150 .8686065674150 .5639038086152 .3925933838152 .6972961426 153.6116943359153 .9165039062154 .2212982178154 .5260925293154 .2212982178 153.3069000244151 .7830047607149 .9542999268147 .8208007812145 .3825073242 142.6394042969139 .8963928223137 .7628936768135 .9342041016134 .1054992676 132.2767028809 129.8385009766 127.7050018311 125.2667007446123.1332015991 120.9997024536119 .1709976196117 .647102356116 .4279022217115 .5136032104 114.5991973877114 .5991973877115 .5136032104117 .342300415119 .7806015015 122.5235977173124 .6570968628135 .0198059082147 .2111968994159 .4026031494 171.5939941406183 .4806976318194 .4528961182204 .8155975342209 .692199707 209.692199707 209.692199707 209.692199707 209.692199707 209.692199707 209.692199707 209.692199707209 .692199707209 .692199707209 .692199707209 .692199707209 .692199707 209.692199707209.692199707 209.692199707 209.692199707 209.692199707209.692199707 209.692199707209 .692199707209 .692199707209 .692199707209 .692199707209 .692199707 209.692199707209 .692199707209 .692199707209 .692199707209 .692199707209 .692199707 209.692199707 209.692199707 209.692199707 209.692199707 209.692199707 209.692199707 
209.692199707 209.692199707 209.692199707 209.692199707 209.692199707 96.3121032714890 .2164001464856 .7256622314525 .65716552734 -9999 -9999 -9999 -9999 -9999 -9999 -9999 -9999 -9999 -9999 -9999 -9999 -9999 -9999

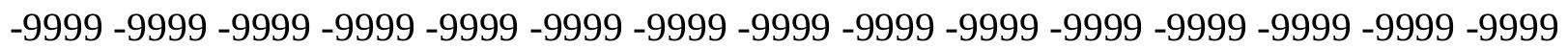
-9999-9999 -9999 -9999 -9999 -9999 -9999 -9999 -9999 -9999 418.3073730469 416.205657959 413.5227966309409 .9360046387405 .6690063477401 .4020080566396 .5255126953 391.0393066406383 .7244873047372 .7521972656361 .475189209364 .5230102539 368.4851989746369 .399597168365 .7421875365 .7421875362 .6943054199359 .6465148926 358.1224975586359 .6465148926362 .9991149902366 .3517150879369 .0947875977 370.9234924316372 .7521972656373 .666595459372 .7521972656370 .6187133789 367.570892334359 .6465148926354 .1603088379350 .5028991699348 .3693847656 347.1502990723345 .0168151855341 .6640930176337 .0922851562331 .3013916016 323.9866027832316 .6718139648309 .9664916992304 .1755981445300 .8229064941 297.4703063965293 .8128967285289 .5458984375284 .9740905762281 .3167114258 275.8305053711267 .9060974121260 .8960876465253 .5812072754245 .0471954346 236.2084960938227 .0648956299218 .5308990479211 .2160949707205 .7299957275 201.4629974365198 .4151000977195 .6721038818194 .1481018066193 .233795166 192.624206543192 .624206543192 .624206543192 .3193969727192 .3193969727 192.3193969727192 .0146026611192 .0146026611192 .0146026611192 .0146026611 192.3193969727192 .624206543192 .624206543192 .3193969727192 .3193969727 192.0146026611192 .0146026611191 .7097930908191 .7097930908191 .7097930908 192.0146026611192 .0146026611192 .3193969727192 .624206543193 .233795166 193.8433074951194 .4528961182195 .3672943115196 .2816009521197 .500793457 198.4151000977199 .329498291200 .5485992432201 .158203125201 .7678070068 202.6820983887203 .2917022705203 .9011993408204 .5108032227205 .1204071045 205.7299957275206 .6443023682207 .25390625208 .1681976318209 .0825958252 209.692199707210 .6065063477211 .2160949707211 .8256988525212 .4351959229 213.3495941162214 .2639007568215 .1782989502216 .0926971436217 .0070037842 217.9214019775218 .8356933594219 .7501068115220 .6643981934221 .2740020752 221.5787963867222 .1884002686222 .4931030273222 .7978973389223 .1027069092 223.1027069092223 .1027069092223 .1027069092223 .1027069092222 .7978973389 222.4931030273222 .1884002686221 .883605957221 .5787963867221 .2740020752 221.2740020752221 .2740020752221 .2740020752221 .5787963867222 .1884002686 222.7978973389223 .7122955322224 .3218994141224 .6266021729224 .9313964844 224.9313964844224 .9313964844224 .9313964844224 .9313964844224 .9313964844 224.9313964844224 .6266021729224 .3218994141224 .0171051025223 .7122955322 223.1027069092222 .1884002686220 .6643981934218 .5308990479215 .787902832 210.3016967773203 .9011993408196 .2816009521188 .6620025635181 .6519012451 176.4705963135172 .8132019043170 .070098877168 .241394043167 .0222015381 165.8031005859164 .8887023926164 .2792053223163 .6696014404163 .0599975586 162.7552947998162 .4505004883162 .1457061768161 .8408966064161 .5361022949 161.2312927246161 .2312927246160 .9264984131160 .6217956543160 .6217956543 160.6217956543160 .6217956543160 .9264984131161 .2312927246161 .2312927246 161.5361022949161 .8408966064162 .1457061768162 .1457061768162 .4505004883 162.1457061768161 .8408966064161 .2312927246160 .3170013428159 .0977935791 
157.878692627156 .6596069336155 .4403991699154 .5260925293153 .6116943359 153.0021057129152 .6972961426152 .3925933838152 .3925933838151 .7830047607 150.5639038086148 .4304046631145 .9920959473144 .1634063721142 .6394042969 141.4203033447140 .2012023926139 .5915985107139 .2868041992139 .5915985107 140.8106994629142 .3347015381144 .4682006836147 .2111968994149 .9542999268 152.3925933838153 .3069000244153 .9165039062153 .9165039062153 .3069000244 152.6972961426152 .0877990723152 .0877990723152 .3925933838153 .0021057129 151.1734008789151 .7830047607152 .6972961426153 .0021057129153 .0021057129 153.0021057129152 .6972961426152 .3925933838152 .0877990723152 .0877990723 152.3925933838152 .6972961426152 .6972961426153 .3069000244153 .6116943359 153.9165039062153 .9165039062153 .6116943359152 .6972961426152 .3925933838 151.4781951904149 .9542999268147 .8208007812145 .6873016357143 .8585968018 141.7250976562139 .8963928223138 .0677032471135 .9342041016133 .4958953857 131.0576019287128 .6192932129126 .1809997559124 .0475006104122 .2188034058 120.3900985718118 .8662033081117 .647102356116 .7326965332115 .818397522 115.5136032104115 .5136032104115 .818397522116 .7326965332120 .0852966309 129.533706665140 .8106994629153 .0021057129165 .4983062744177 .6896972656 189.5764007568200 .8533935547209 .692199707209 .692199707209 .692199707 209.692199707 209.692199707 209.692199707 209.692199707 209.692199707 209.692199707 209.692199707 209.692199707 209.692199707 209.692199707 209.692199707 209.692199707 209.692199707209 .692199707209 .692199707209 .692199707209 .692199707209 .692199707 209.692199707209.692199707 209.692199707209.692199707 209.692199707209.692199707 209.692199707 209.692199707 209.692199707 209.692199707 209.692199707 209.692199707 209.692199707209 .692199707209 .692199707209 .692199707209 .692199707209 .692199707 209.692199707 209.692199707 209.692199707 209.69219970791.43553924561 60.9917221069336 .99085235596 -9999 -9999 -9999 -9999 -9999 -9999 -9999 -9999 -9999 -9999 -9999 -9999 -9999-9999

-9999 -9999 -9999 -9999 -9999 -9999 -9999 -9999 -9999 -9999 -9999 -9999 -9999 -9999 -9999 -

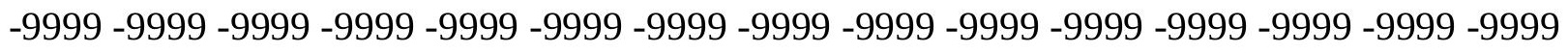
-9999 -9999 -9999 -9999 -9999 -9999 -9999 -9999 -9999 418.8403625488416 .902923584 414.5078125411 .155090332406 .5833129883401 .4020080566395 .3063049316 388.9057922363381 .591003418374 .5809020996370 .3139038086371 .5331115723 373.9713134766 374.5809020996373.666595459373.0570068359 371.837890625 370.3139038086368 .1803894043366 .6564941406369 .0947875977371 .5331115723 373.3617858887374 .5809020996375 .1904907227375 .1904907227373 .666595459 370.009185791365 .7421875361 .1704101562358 .4273071289357 .5129089355 358.4273071289359 .3417053223358 .1224975586354 .7698974609349 .8933105469 343.1879882812334 .9588928223326 .1200866699317 .5860900879310 .8807983398 305.6994934082301 .7373046875298 .0798950195293 .8128967285289 .2410888672 285.5835876465281 .3167114258273 .3923034668266 .3822021484258 .4577941895 249.3141937256239.5610961914229.8079986572 220.9691925049 213.3495941162 207.25390625202 .6820983887198 .7198944092195 .9768066406193 .8433074951 192.3193969727191 .4051055908191 .1002960205190 .795501709190 .795501709 190.795501709190 .795501709190 .795501709191 .1002960205191 .1002960205 191.4051055908191 .7097930908192 .0146026611192 .0146026611192 .0146026611 192.0146026611191 .7097930908191 .7097930908191 .7097930908191 .7097930908 
191.7097930908191 .7097930908192 .0146026611192 .0146026611192 .624206543 192.9290008545193 .5386047363194 .4528961182195 .3672943115196 .2816009521 197.1959991455198 .1103057861199 .0247039795199 .9389953613200 .8533935547 201.4629974365202 .0724945068202 .6820983887203 .2917022705203 .9011993408 204.5108032227 205.1204071045 205.7299957275 206.3394927979 206.9490966797 207.8634033203208 .4730072021209 .0825958252209 .692199707210 .6065063477 211.2160949707211 .8256988525212 .7400054932213 .6544036865214 .5686950684 215.4830932617216 .7021942139217 .6165924072218 .5308990479219 .1405029297 219.7501068115220 .3596038818220 .6643981934220 .9691925049221 .2740020752 221.5787963867221 .5787963867221 .883605957221 .883605957221 .883605957 221.5787963867221 .5787963867221 .2740020752220 .9691925049220 .6643981934 220.3596038818220 .054901123220 .054901123220 .054901123220 .3596038818 220.9691925049221 .5787963867222 .4931030273223 .1027069092223 .4075012207 223.7122955322224 .0171051025224 .0171051025224 .3218994141224 .3218994141 224.3218994141224 .0171051025224 .0171051025223 .7122955322223 .1027069092 222.4931030273221 .2740020752219 .7501068115217 .3117980957213 .959197998 209.0825958252202 .9868927002196 .2816009521189 .2716064453182 .87109375 177.0802001953172 .5084075928169 .4604949951167 .0222015381165 .4983062744 164.2792053223163 .6696014404162 .7552947998162 .4505004883162 .1457061768 161.8408966064161 .5361022949161 .2312927246161 .2312927246160 .9264984131 160.9264984131160 .6217956543160 .3170013428160 .3170013428160 .3170013428 160.0122070312160 .3170013428160 .3170013428160 .6217956543160 .9264984131 161.2312927246161 .5361022949161 .5361022949161 .8408966064161 .8408966064 161.8408966064161 .8408966064161 .2312927246160 .6217956543160 .0122070312 159.0977935791157 .878692627156 .9642944336156 .0500030518155 .1356048584 154.2212982178153 .3069000244152 .6972961426152 .0877990723152 .0877990723 152.3925933838152 .0877990723150 .5639038086148 .4304046631146 .6015930176 145.0776977539143 .2489929199142 .0299072266141 .1154937744140 .5059967041 140.5059967041141 .1154937744142 .6394042969144 .4682006836146 .9064025879 149.3446960449151 .4781951904153 .0021057129153 .3069000244153 .3069000244 153.0021057129152 .3925933838152 .0877990723152 .3925933838152 .3925933838 150.8686065674147 .8208007812152 .6972961426153 .0021057129153 .3069000244 153.3069000244153 .0021057129152 .6972961426152 .6972961426152 .3925933838 152.6972961426152 .6972961426152 .3925933838152 .0877990723152 .6972961426 153.3069000244153 .6116943359153 .6116943359153 .3069000244153 .0021057129 152.6972961426152 .3925933838151 .1734008789149 .6495056152148 .4304046631 146.9064025879145 .3825073242143 .5538024902141 .7250976562139 .2868041992 137.1533050537 134.4102020264131.9720001221 129.533706665 127.0953979492 124.9618988037123 .1332015991121 .6092987061119 .7806015015118 .5614013672 117.342300415116 .1231002808114 .9039993286113 .9896011353114 .2944030762 116.7326965332124 .3523025513135 .0198059082146 .6015930176159 .0977935791 172.2035980225185 .0045928955196 .891204834207 .5587005615209 .692199707 209.692199707 209.692199707 209.692199707 209.692199707 209.692199707 209.692199707 209.692199707209 .692199707209 .692199707209 .692199707209 .692199707209 .692199707 209.692199707209 .692199707209 .692199707209 .692199707209 .692199707209 .692199707 209.692199707 209.692199707209.692199707 209.692199707209.692199707209.692199707 
209.692199707 209.692199707 209.692199707 209.692199707209.692199707209.692199707 209.692199707209 .692199707209 .692199707209 .692199707209 .692199707209 .692199707 209.692199707 209.692199707 209.692199707 209.692199707 209.692199707 92.0450973510786 .5589828491250 .6162147522 -9999 -9999 -9999 -9999 -9999 -9999 -9999 -9999 -9999 -9999 -9999 -9999 -9999-9999

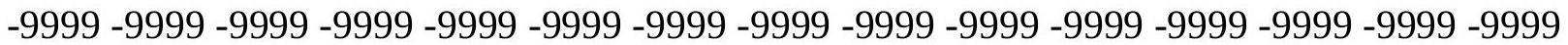

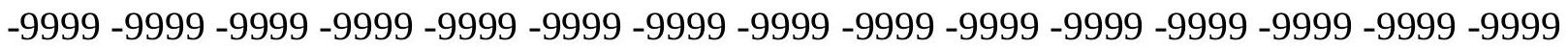
-9999 -9999 -9999 -9999 -9999 -9999 -9999 -9999 -9999 -9999 416.7891845703 414.5566711426411 .7647094727407 .4977111816402 .31640625395 .611114502 389.2106018066384 .029296875381 .2861938477381 .8958129883384 .3340148926 386.1628112793386 .7723083496386 .1628112793385 .5531921387385 .858001709 384.3340148926381 .591003418378 .8479003906378 .5430908203378 .8479003906 378.5430908203378 .2383117676377 .93359375377 .324005127375 .1904907227 370.3139038086364 .2182006836362 .6943054199362 .0846862793364 .8277893066 368.7900085449372 .4473876953373 .3617858887368 .7900085449364 .2182006836 356.5986022949346 .5407104492335 .8731994629326 .12008666699318 .5004882812 311.7951965332306 .6138000488303 .2611999512297 .7750854492293 .8128967285 289.8505859375286 .4979858398279 .7927856445272 .7827148438264 .5534973145 254.8003997803243 .8280944824233 .4653930664223 .7122955322215 .787902832 209.3874053955 203.9011993408 199.6342926025 196.2816009521 193.5386047363 191.7097930908190 .4907073975189 .8811035156189 .2716064453189 .2716064453 189.2716064453 189.2716064453189.5764007568 189.8811035156190.1858978271 190.4907073975190 .795501709191 .1002960205191 .4051055908191 .4051055908 191.4051055908191 .4051055908191 .4051055908191 .4051055908191 .4051055908 191.4051055908191 .4051055908191 .7097930908192 .0146026611192 .3193969727 192.9290008545193 .5386047363194 .1481018066195 .0625195 .9768066406196 .891204834 197.8054962158198 .7198944092199 .6342926025200 .2438049316200 .8533935547 201.4629974365202 .0724945068202 .3773040771202 .9868927002203 .596496582 204.2059936523 204.5108032227205.1204071045 205.72999557275206.3394927979 206.9490966797207 .8634033203208 .4730072021209 .0825958252209 .692199707 210.6065063477211 .520904541212 .4351959229213 .3495941162214 .2639007568 215.1782989502216 .0926971436217 .0070037842217 .6165924072218 .2261962891 218.8356933594219 .1405029297219 .4452972412219 .7501068115220 .054901123 220.3596038818220 .3596038818220 .3596038818220 .3596038818220 .3596038818 220.3596038818220 .054901123219 .7501068115219 .4452972412219 .4452972412 219.1405029297218 .8356933594218 .8356933594219 .1405029297219 .7501068115 220.3596038818220 .9691925049221 .5787963867222 .1884002686222 .4931030273 222.7978973389223 .1027069092223 .1027069092223 .4075012207223 .1027069092 223.1027069092222 .7978973389222 .4931030273221 .883605957220 .6643981934 219.1405029297 216.7021942139212.7400054932 207.8634033203201.7678070068 195.3672943115188 .3571929932182 .5662994385177 .3849029541172 .8132019043 169.1557006836166 .4127044678164 .5839996338163 .0599975586162 .1457061768 161.5361022949161 .2312927246160 .9264984131160 .6217956543160 .6217956543 160.3170013428160 .3170013428160 .3170013428160 .0122070312160 .0122070312 160.0122070312159 .7073974609159 .7073974609159 .7073974609159 .7073974609 159.7073974609159 .7073974609160 .0122070312160 .3170013428160 .9264984131 
161.2312927246161 .5361022949161 .5361022949161 .5361022949161 .5361022949 161.2312927246160 .6217956543160 .3170013428159 .4026031494158 .7929992676 158.1835021973157 .2691040039156 .6596069336155 .7451934814154 .8307952881 153.9165039062152 .6972961426152 .0877990723152 .0877990723152 .3925933838 152.3925933838152 .0877990723150 .5639038086148 .7351074219147 .2111968994 145.3825073242143 .5538024902142 .0299072266141 .1154937744140 .8106994629 141.4203033447142 .3347015381144 .1634063721146 .6015930176149 .0399017334 150.8686065674152 .3925933838153 .0021057129153 .0021057129152 .6972961426 152.3925933838152 .0877990723152 .3925933838152 .0877990723151 .7830047607 150.8686065674151 .7830047607153 .0021057129153 .3069000244153 .3069000244 153.0021057129153 .0021057129152 .6972961426152 .6972961426152 .6972961426 152.6972961426152 .3925933838152 .3925933838152 .6972961426153 .0021057129 153.3069000244153 .3069000244153 .3069000244153 .0021057129152 .6972961426 152.3925933838151 .7830047607150 .8686065674150 .2590942383149 .3446960449 148.1255950928146 .9064025879145 .0776977539142 .9441986084140 .2012023926 137.7628936768135 .0198059082132 .2767028809129 .8385009766127 .7050018311 125.5715026855123 .7427978516121 .9140014648120 .3900985718119 .1709976196 117.342300415 115.2088012695 113.3800964355 113.075302124114.2944030762 119.1709976196128 .6192932129139 .5915985107152 .3925933838166 .1078948975 180.432800293193 .233795166204 .5108032227209 .692199707209 .692199707 209.692199707 209.692199707 209.692199707 209.692199707 209.692199707 209.692199707 209.692199707209 .692199707209 .692199707209 .692199707209 .692199707209 .692199707 209.692199707209 .692199707209 .692199707209 .692199707209 .692199707209 .692199707 209.692199707209 .692199707209 .692199707209 .692199707209 .692199707209 .692199707 209.692199707 209.692199707 209.692199707 209.692199707 209.692199707 209.692199707 209.692199707 209.692199707 209.692199707 209.692199707 209.692199707 209.692199707 209.692199707209.692199707 209.692199707 209.69219970792.95947265625

87.4733276367255 .6622924804721 .44422531128 -9999 -9999 -9999 -9999 -9999 -9999 -9999 -9999 -9999 -9999 -9999-9999-9999

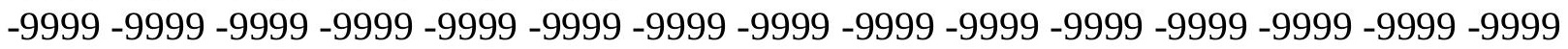

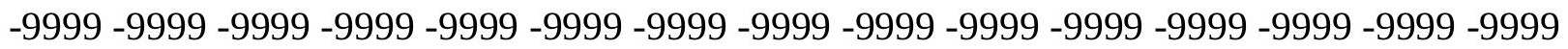
-9999 -9999 -9999 -9999 -9999 -9999 -9999 -9999 -9999 417.5392150879 415.7026367188 413.4329223633410 .4995727539406 .5973510742401 .7521057129396 .3629455566 391.4540710449388 .1618652344387 .214050293388 .5363464355390 .852935791 392.8588256836393 .965057373394 .3354492188394 .4692382812394 .4420166016 393.4355773926391 .4916992188389 .5909118652388 .6010131836387 .686706543 384.3340148926381 .591003418381 .591003418381 .591003418379 .1527099609 374.8857116699370 .009185791369 .0947875977368 .4851989746373 .9713134766 379.2398071289382 .9487915039383 .7101135254381 .0039672852376 .1180419922 369.399597168358 .7320861816345 .3215026855335 .2636108398326 .7296142578 318.8052062988311 .7951965332304 .4802856445302 .3468017578299 .2990112305 295.9464111328291 .9841918945287 .1076049805280 .4023132324271 .8682861328 261.5056152344249 .3141937256237 .4275970459227 .0648956299218 .5308990479 211.520904541205 .7299957275200 .8533935547196 .891204834193 .5386047363 191.4051055908189 .5764007568188 .6620025635188 .0523986816187 .7476043701 187.7476043701188 .0523986816188 .3571929932188 .6620025635189 .2716064453 
189.5764007568190 .1858978271190 .4907073975190 .795501709191 .1002960205 191.1002960205191 .1002960205191 .1002960205191 .1002960205191 .1002960205 191.1002960205191 .1002960205191 .4051055908191 .7097930908192 .0146026611 192.624206543193 .233795166194 .1481018066194 .7577056885195 .6721038818 196.5863952637197 .500793457198 .4151000977199 .0247039795199 .9389953613 200.5485992432200 .8533935547201 .4629974365201 .7678070068202 .3773040771 202.6820983887202 .9868927002203 .596496582203 .9011993408204 .5108032227 205.1204071045205 .7299957275206 .3394927979206 .9490966797207 .5587005615 208.1681976318209 .0825958252209 .9969024658210 .9113006592211 .8256988525 212.7400054932213 .6544036865214 .8735046387215 .4830932617216 .3973999023 217.0070037842217 .3117980957217 .9214019775217 .9214019775218 .2261962891 218.5308990479218 .8356933594218 .8356933594219 .1405029297219 .1405029297 219.1405029297219 .1405029297218 .8356933594218 .8356933594218 .5308990479 218.2261962891 217.9214019775 217.9214019775 217.9214019775 218.2261962891 218.5308990479219 .1405029297219 .7501068115220 .3596038818220 .9691925049 221.2740020752221 .5787963867221 .883605957221 .883605957222 .1884002686 221.883605957221 .883605957221 .2740020752220 .6643981934220 .054901123 218.5308990479216 .0926971436212 .7400054932207 .5587005615201 .4629974365 194.7577056885188 .0523986816181 .0424041748176 .7754058838172 .8132019043 169.1557006836166 .4127044678163 .974395752162 .4505004883161 .2312927246 160.3170013428160 .0122070312159 .7073974609159 .4026031494159 .4026031494 159.4026031494159 .4026031494159 .4026031494159 .4026031494159 .4026031494 159.4026031494159 .4026031494159 .0977935791159 .0977935791159 .0977935791 159.0977935791159 .0977935791159 .4026031494159 .7073974609160 .0122070312 160.6217956543160 .9264984131161 .2312927246161 .2312927246161 .2312927246 160.9264984131160 .6217956543160 .0122070312159 .7073974609159 .0977935791 158.7929992676158 .1835021973157 .5738983154157 .2691040039156 .3547973633 155.7451934814154 .5260925293153 .3069000244151 .7830047607151 .7830047607 152.0877990723152 .3925933838152 .3925933838151 .7830047607150 .8686065674 149.3446960449147 .2111968994144 .7729034424142 .6394042969141 .1154937744 140.5059967041141 .1154937744142 .3347015381143 .8585968018146 .2969055176 148.7351074219150 .5639038086152 .0877990723152 .6972961426152 .6972961426 152.6972961426152 .3925933838152 .3925933838152 .0877990723152 .3925933838 152.3925933838152 .0877990723152 .3925933838153 .0021057129153 .3069000244 153.0021057129153 .0021057129153 .0021057129152 .6972961426152 .6972961426 152.6972961426152 .6972961426152 .3925933838152 .3925933838152 .6972961426 152.6972961426153 .0021057129153 .0021057129153 .0021057129153 .0021057129 152.6972961426152 .3925933838152 .0877990723151 .7830047607151 .4781951904 151.1734008789150 .5639038086149 .9542999268148 .1255950928145 .9920959473 143.2489929199140 .5059967041137 .7628936768135 .0198059082132 .2767028809 130.1432037354127 .7050018311125 .8762969971123 .7427978516121 .9140014648 121.3044967651118 .5614013672115 .818397522113 .6848983765112 .4656982422 112.4656982422114 .5991973877121 .9140014648132 .2767028809144 .7729034424 159.7073974609175 .2514038086189 .8811035156201 .158203125209 .692199707 209.692199707209 .692199707209 .692199707209 .692199707209 .692199707209 .692199707 209.692199707 209.692199707 209.692199707 209.692199707 209.692199707209.692199707 
209.692199707 209.692199707 209.692199707 209.692199707209.692199707209.692199707 209.692199707 209.692199707 209.692199707 209.692199707 209.692199707 209.692199707 209.692199707 209.692199707 209.692199707 209.692199707 209.692199707 209.692199707 209.692199707209 .692199707209 .692199707209 .692199707209 .692199707209 .692199707 209.692199707 209.692199707209.692199707 209.692199707 209.692199707 93.5690307617288 .3876876831156 .577560424826 .01452255249 -9999 -9999 -9999 -9999 -9999 -9999 -9999 -9999 -9999 -9999 -9999 -9999 -9999

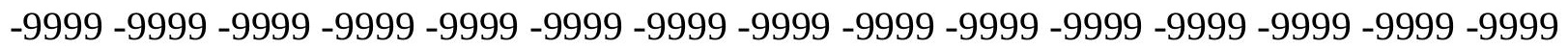

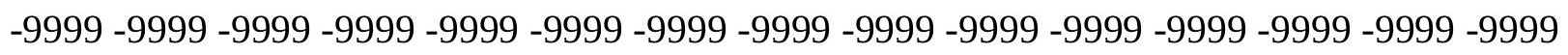
-9999 -9999 -9999 -9999 -9999 -9999 -9999 -9999 -9999 415.5496520996 413.5935974121 411.2351074219408 .312713623404 .7910461426400 .7550964355396 .6944580078 393.2812805176391 .2569885254390 .9756469727392 .1723632812394 .0998535156 396.0055847168397 .4784545898398 .5445861816399 .3085327148399 .6045837402 399.2296447754 398.1752624512 396.9036254883 395.5404968262 393.5970458984 390.6630859375388 .0867919922386 .8523864746386 .1955566406384 .7399902344 382.3913574219380 .2847595215379 .7968444824381 .4979858398385 .5312805176 389.9803771973392 .8600463867393 .0994262695390 .6045227051385 .4927062988 377.9477539062367 .7041625977356 .0492553711345 .3215026855335 .5683898926 326.7296142578319 .1099853516313 .0143127441308 .7473144531305 .6994934082 302.6516113281299 .2990112305294 .7272033691288 .9363098145281 .0119018555 270.0396118164255 .7147064209241 .6945953369230 .7223052979222 .1884002686 214.8735046387208 .4730072021202 .6820983887197 .8054962158193 .8433074951 191.1002960205190 .4907073975190 .1858978271189 .5764007568188 .966796875 188.0523986816186 .8332977295187 .1381072998187 .7476043701188 .3571929932 188.6620025635189 .2716064453189 .8811035156190 .1858978271190 .4907073975 190.795501709190 .795501709190 .795501709190 .795501709190 .795501709190 .795501709 191.1002960205191 .1002960205191 .4051055908191 .7097930908192 .3193969727 192.9290008545193 .8433074951194 .7577056885195 .6721038818196 .5863952637 197.1959991455 198.1103057861 198.7198944092199.329498291 199.9389953613 200.2438049316200 .8533935547201 .158203125201 .4629974365201 .7678070068 202.0724945068202 .3773040771202 .6820983887203 .2917022705203 .596496582 204.2059936523 204.8155975342 205.425201416206.0346984863206.6443023682 207.5587005615 208.4730072021 209.3874053955 210.3016967773211.2160949707 212.4351959229213 .3495941162214 .2639007568214 .8735046387215 .4830932617 216.0926971436216 .3973999023216 .7021942139216 .7021942139217 .0070037842 217.0070037842 217.6165924072 217.9214019775 217.9214019775 218.2261962891 217.9214019775 217.9214019775 217.6165924072 217.3117980957 217.3117980957 217.0070037842 217.0070037842 217.0070037842 217.3117980957 217.6165924072 218.2261962891218 .5308990479219 .1405029297219 .4452972412219 .7501068115 220.054901123220 .3596038818220 .6643981934220 .6643981934220 .6643981934 220.3596038818219 .7501068115218 .8356933594217 .9214019775215 .787902832 212.4351959229207 .8634033203201 .7678070068195 .0625188 .3571929932182 .261505127 176.7754058838172 .5084075928169 .1557006836166 .4127044678163 .974395752 162.1457061768160 .6217956543159 .7073974609159 .0977935791158 .4882965088 158.4882965088158 .1835021973158 .1835021973158 .4882965088158 .4882965088 158.4882965088158 .4882965088158 .7929992676158 .7929992676158 .7929992676 
158.7929992676158 .7929992676158 .7929992676158 .7929992676158 .7929992676 158.7929992676159 .0977935791159 .7073974609160 .3170013428160 .6217956543 160.9264984131161 .2312927246160 .9264984131160 .6217956543160 .3170013428 159.7073974609159 .0977935791158 .7929992676158 .7929992676158 .4882965088 158.1835021973157 .878692627157 .5738983154156 .9642944336156 .0500030518 154.5260925293152 .3925933838152 .0877990723152 .0877990723152 .0877990723 152.3925933838152 .6972961426152 .0877990723151 .1734008789148 .7351074219 145.3825073242142 .0299072266139 .8963928223139 .5915985107140 .5059967041 142.0299072266143 .8585968018146 .2969055176148 .4304046631150 .2590942383 151.4781951904152 .0877990723152 .3925933838152 .3925933838152 .3925933838 152.0877990723152 .0877990723152 .0877990723152 .3925933838152 .3925933838 153.0021057129153 .0021057129153 .3069000244153 .0021057129153 .0021057129 153.0021057129152 .6972961426152 .6972961426152 .6972961426152 .3925933838 152.3925933838152 .3925933838152 .6972961426152 .6972961426152 .6972961426 152.6972961426152 .6972961426152 .6972961426152 .3925933838152 .3925933838 152.3925933838152 .0877990723152 .0877990723152 .0877990723152 .3925933838 152.3925933838150 .5639038086148 .1255950928145 .3825073242142 .6394042969 139.8963928223137 .1533050537134 .7149963379132 .2767028809130 .1432037354 127.7050018311125 .8762969971124 .0475006104122 .2188034058119 .7806015015 116.7326965332114 .2944030762112 .1608963013111 .551399231112 .4656982422 115.2088012695124 .6570968628136 .5437011719152 .0877990723169 .1557006836 186.2236938477196 .5863952637205 .7299957275209 .692199707209 .692199707 209.692199707 209.692199707 209.692199707 209.692199707 209.692199707209.692199707 209.692199707 209.692199707 209.692199707209.692199707 209.692199707 209.692199707 209.692199707 209.692199707 209.692199707 209.692199707 209.692199707 209.692199707 209.692199707 209.692199707 209.692199707 209.692199707 209.692199707 209.692199707 209.692199707209 .692199707209 .692199707209 .692199707209 .692199707209 .692199707 209.692199707209 .692199707209 .692199707209 .692199707209 .692199707209 .692199707 209.692199707 209.692199707 209.692199707 209.692199707 88.99725341797

57.9695777893132 .83076095581 -9999 -9999 -9999 -9999 -9999 -9999 -9999 -9999 -9999 -9999 -9999-9999-9999

-9999 -9999 -9999 -9999 -9999 -9999 -9999 -9999 -9999 -9999 -9999 -9999 -9999 -9999 -9999

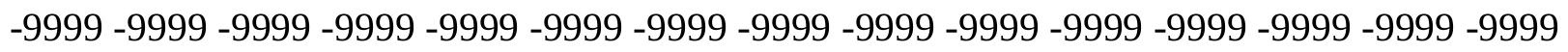
-9999 -9999 -9999 -9999 -9999 -9999 -9999 -9999 -9999 412.7271118164410 .6214904785 408.2091369629405 .4443664551402 .3782348633399 .1882629395396 .2310791016 393.9476623535392 .71875392 .6616210938393 .5458984375394 .9514160156 396.4908752441397 .9942016602399 .4528808594400 .789642334401 .6981506348 401.895324707401 .3321533203400 .2857971191398 .9350891113397 .1131896973 394.4618835449391 .8753967285390 .133605957389 .9009399414390 .022857666 390.0561523438390 .3777160645391 .6828613281394 .4280090332397 .8392028809 400.966583252402 .4413757324401 .5877990723398 .2976989746392 .6991577148 384.9901733398375 .5247192383365 .0719909668354 .4813842773344 .7120056152 335.8731994629328 .5584106445322 .1578979492317 .2813110352313 .0143127441 309.3569030762306 .0043029785300 .5180969238296 .8606872559291 .9841918945 280.4023132324264 .2486877441246 .8759002686236 .5133056641227 .0648956299 218.8356933594211 .520904541204 .8155975342199 .0247039795194 .4528961182 
192.0146026611191 .4051055908191 .1002960205190 .4907073975189 .8811035156 188.6620025635187 .7476043701186 .2236938477186 .8332977295187 .4429016113 188.0523986816188 .6620025635189 .2716064453189 .5764007568190 .1858978271 190.4907073975190 .4907073975190 .4907073975190 .795501709190 .4907073975 190.4907073975190 .795501709190 .795501709191 .1002960205191 .4051055908 192.0146026611192 .624206543193 .5386047363194 .4528961182195 .3672943115 196.2816009521197 .1959991455197 .8054962158198 .4151000977199 .0247039795 199.329498291199 .9389953613199 .9389953613200 .2438049316200 .5485992432 200.8533935547200 .8533935547201 .158203125201 .4629974365201 .7678070068 202.0724945068202 .6820983887202 .9868927002203 .596496582204 .2059936523 205.1204071045206 .0346984863206 .9490966797207 .8634033203208 .7778015137 209.9969024658210 .9113006592211 .8256988525213 .0447998047213 .6544036865 213.959197998214 .5686950684214 .8735046387215 .1782989502215 .4830932617 215.4830932617215 .787902832216 .0926971436216 .7021942139217 .0070037842 217.0070037842217 .0070037842217 .0070037842216 .7021942139216 .3973999023 216.0926971436216 .0926971436216 .0926971436216 .0926971436216 .3973999023 216.7021942139217 .0070037842217 .3117980957217 .6165924072217 .9214019775 218.2261962891218 .5308990479218 .8356933594218 .8356933594218 .8356933594 218.8356933594218 .5308990479217 .9214019775217 .0070037842215 .1782989502 213.6544036865209 .0825958252202 .9868927002195 .9768066406189 .2716064453 183.1759033203178 .2993011475173 .7274932861170 .070098877167 .0222015381 164.5839996338162 .4505004883160 .9264984131159 .4026031494158 .4882965088 157.878692627157 .5738983154157 .5738983154157 .5738983154157 .5738983154 157.5738983154157 .878692627157 .878692627158 .1835021973158 .1835021973 158.1835021973158 .1835021973158 .4882965088158 .4882965088158 .4882965088 158.4882965088158 .4882965088158 .4882965088158 .7929992676159 .7073974609 160.3170013428160 .6217956543160 .9264984131161 .2312927246160 .9264984131 160.6217956543160 .0122070312159 .0977935791158 .4882965088158 .7929992676 159.0977935791159 .0977935791159 .0977935791159 .0977935791158 .4882965088 158.1835021973157 .5738983154156 .6596069336154 .2212982178152 .3925933838 152.0877990723152 .0877990723152 .6972961426153 .6116943359153 .9165039062 153.3069000244150 .5639038086145 .0776977539140 .2012023926137 .7628936768 137.7628936768139 .5915985107141 .7250976562144 .1634063721146 .2969055176 148.1255950928149 .9542999268150 .8686065674151 .7830047607150 .5639038086 152.3925933838152 .3925933838152 .0877990723152 .0877990723151 .7830047607 152.0877990723152 .6972961426153 .0021057129153 .0021057129153 .0021057129 153.0021057129153 .0021057129152 .6972961426152 .6972961426152 .6972961426 152.3925933838152 .3925933838152 .3925933838152 .3925933838152 .3925933838 152.3925933838152 .3925933838152 .3925933838152 .3925933838152 .3925933838 152.3925933838152 .3925933838152 .3925933838152 .3925933838152 .3925933838 152.3925933838153 .0021057129153 .0021057129152 .0877990723149 .6495056152 147.2111968994 144.4682006836142.0299072266139.2868041992 136.8484954834 134.4102020264131 .9720001221129 .8385009766127 .7050018311125 .5715026855 123.43800354120 .6949005127117 .9517974854115 .2088012695112 .7705001831 111.551399231111 .24659729113 .075302124117 .342300415127 .7050018311 144.4682006836161 .5361022949177 .3849029541189 .8811035156199 .9389953613 
208.7778015137209 .692199707209 .692199707209 .692199707209 .692199707 209.692199707 209.692199707 209.692199707 209.692199707 209.692199707 209.692199707 209.692199707209 .692199707209 .692199707209 .692199707209 .692199707209 .692199707 209.692199707209 .692199707209 .692199707209 .692199707209 .692199707209 .692199707 209.692199707 209.692199707 209.692199707 209.692199707 209.692199707 209.692199707 209.692199707209 .692199707209 .692199707209 .692199707209 .692199707209 .692199707 209.692199707209 .692199707209 .692199707209 .692199707209 .692199707209 .692199707 209.69219970788 .9972534179783 .8159103393641 .22255325317 -9999 -9999 -9999 -9999 -9999 -9999 -9999 -9999 -9999 -9999 -9999 -9999 -9999

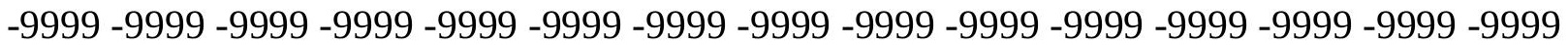

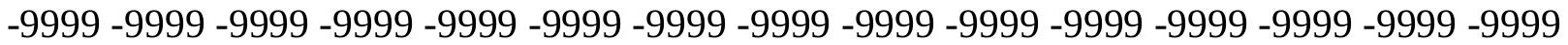
-9999 -9999 -9999 -9999 -9999 -9999 -9999-9999 -9999 409.127532959 406.9076538086 404.4983215332401 .9412536621399 .339050293396 .8748474121394 .7796020508 393.2825317383392 .5289916992392 .4840393066392 .9397888184393 .6602478027 394.5365905762395 .6737060547397 .2200317383399 .0819702148400 .6838684082 401.2356262207400 .5743408203399 .0876159668397 .5411071777396 .0060424805 393.7938537598389 .7532348633387 .9241943359389 .2710266113392 .101348877 394.5328674316397 .5030212402401 .1549682617405 .1182556152408 .6936340332 410.8183898926410 .8520812988408 .5748901367404 .1344909668397 .9415283203 390.4290466309381 .9639282227372 .8423156738363 .2036437988353 .2460021973 346.2359008789338 .6163024902331 .9110107422326 .4248962402321 .5483093262 315.7573852539308 .1377868652304 .7850952148302 .6516113281304 .7850952148 290.7650146484274 .3066101074258 .4577941895245 .0471954346233 .4653930664 223.4075012207214 .5686950684206 .9490966797200 .5485992432195 .3672943115 192.9290008545192 .624206543192 .0146026611191 .4051055908190 .795501709 189.8811035156188 .6620025635187 .1381072998186 .2236938477186 .8332977295 187.7476043701188 .3571929932188 .966796875189 .2716064453189 .8811035156 190.1858978271190 .4907073975190 .4907073975190 .4907073975190 .4907073975 190.4907073975190 .4907073975190 .4907073975190 .795501709191 .1002960205 191.7097930908192 .3193969727193 .233795166194 .1481018066195 .0625195 .9768066406 196.891204834197 .8054962158198 .4151000977198 .7198944092199 .0247039795 199.329498291 199.329498291 199.6342926025 199.6342926025 199.6342926025 199.6342926025199 .9389953613199 .9389953613200 .2438049316200 .5485992432 200.8533935547201 .4629974365202 .0724945068202 .6820983887203 .2917022705 204.2059936523 205.425201416 206.3394927979 207.25390625 208.4730072021 209.3874053955210 .6065063477211 .520904541212 .1304016113212 .7400054932 213.0447998047213 .6544036865213 .959197998214 .2639007568214 .5686950684 214.8735046387215 .1782989502215 .787902832216 .0926971436216 .0926971436 216.0926971436216 .0926971436215 .787902832215 .4830932617215 .1782989502 215.1782989502215 .1782989502215 .1782989502215 .4830932617215 .787902832 216.0926971436216 .3973999023216 .3973999023216 .7021942139216 .7021942139 216.7021942139217 .0070037842217 .3117980957217 .3117980957217 .3117980957 217.0070037842216 .3973999023215 .1782989502212 .4351959229210 .3016967773 205.7299957275199 .329498291192 .0146026611184 .0901947021179 .8231964111 175.5561981201171 .8988037109168 .5462036133165 .8031005859163 .3648071289 161.5361022949160 .0122070312158 .7929992676157 .878692627157 .2691040039 
156.9642944336156 .9642944336156 .9642944336156 .9642944336157 .2691040039 157.2691040039157 .5738983154157 .5738983154157 .878692627157 .878692627 157.878692627158 .1835021973158 .1835021973158 .1835021973158 .1835021973 158.4882965088158 .7929992676159 .0977935791159 .7073974609160 .6217956543 160.9264984131161 .2312927246161 .2312927246160 .9264984131160 .6217956543 160.0122070312159 .0977935791158 .4882965088159 .0977935791159 .7073974609 160.3170013428160 .3170013428160 .3170013428159 .7073974609159 .0977935791 158.1835021973156 .9642944336155 .1356048584153 .3069000244152 .3925933838 152.3925933838153 .0021057129153 .9165039062154 .8307952881154 .5260925293 152.6972961426143 .5538024902136 .5437011719134 .7149963379136 .2389984131 138.6772003174141 .7250976562144 .1634063721146 .6015930176148 .4304046631 149.6495056152150 .5639038086149 .9542999268147 .2111968994153 .6116943359 153.6116943359153 .0021057129152 .6972961426151 .7830047607150 .2590942383 152.0877990723152 .0877990723152 .3925933838152 .6972961426152 .6972961426 152.6972961426152 .6972961426152 .3925933838152 .3925933838152 .3925933838 152.3925933838152 .3925933838152 .0877990723152 .3925933838152 .3925933838 152.0877990723152 .3925933838152 .3925933838152 .3925933838152 .3925933838 152.3925933838152 .3925933838152 .3925933838152 .6972961426152 .6972961426 152.6972961426152 .6972961426151 .7830047607150 .2590942383148 .1255950928 145.6873016357143 .2489929199140 .8106994629138 .3724975586135 .9342041016 133.8007049561131 .3623962402129 .2288970947127 .0953979492124 .6570968628 122.2188034058119 .4757995605116 .4279022217113 .6848983765111 .8561019897 111.24659729111 .8561019897114 .5991973877124 .3523025513138 .3724975586 153.9165039062168 .8509979248181 .9566955566193 .233795166203 .2917022705 209.692199707 209.692199707 209.692199707 209.692199707 209.692199707 209.692199707 209.692199707 209.692199707 209.692199707 209.692199707 209.692199707 209.692199707 209.692199707209 .692199707209 .692199707209 .692199707209 .692199707209 .692199707 209.692199707209 .692199707209 .692199707209 .692199707209 .692199707209 .692199707 209.692199707 209.692199707 209.692199707 209.692199707 209.692199707 209.692199707 209.692199707 209.692199707 209.692199707 209.692199707 209.692199707 209.692199707 209.692199707209.692199707209.692199707209.692199707209.692199707 89.3020401001 84.1206970214842 .35149002075 5.203633308411 -9999 -9999 -9999 -9999 -9999 -9999 -9999 -9999 -9999-9999 -9999-9999

-9999 -9999 -9999 -9999 -9999 -9999 -9999 -9999 -9999 -9999 -9999 -9999 -9999 -9999 -9999 -9999 -9999 -9999 -9999 -9999 -9999 -9999 -9999 -9999 -9999 -9999 -9999 -9999 -9999 -9999 -999 -9999 -9999 -9999-9999 -9999 -9999 -9999-9999 -9999 404.866973877402 .5335693359 400.1370544434397 .7648925781395 .5468139648393 .6387939453392 .1676330566 391.1692810059390 .6201782227390 .4059753418390 .296875390 .0763549805 389.8892822266 390.106262207 391.2998657227 393.5808410645 396.1041870117 396.8709411621395 .3179931641392 .128112793389 .3175354004387 .5235900879 386.7723083496377 .93359375376 .7143859863380 .3717956543387 .686706543 392.2933349609398 .8365783691405 .4526367188411 .4670715332416 .0094604492 417.6192321777416 .5585021973412 .8936157227407 .1891479492400 .4679260254 393.4631958008386 .3810424805379 .1191101074371 .6073303223364 .3310852051 357.8176879883347 .7597961426341 .0545959473336 .4827880859331 .9110107422 324.5961914062317 .5860900879314 .8429870605309 .6617126465306 .9186096191 
298.6893920898285 .2789001465270 .3443908691255 .1051025391241 .0850067139 228.5888977051217 .9214019775209 .3874053955202 .0724945068196 .5863952637 194.1481018066193 .5386047363193 .233795166192 .624206543192 .0146026611 190.795501709189 .5764007568188 .0523986816185 .9188995361186 .528503418 187.4429016113188 .0523986816188 .6620025635189 .2716064453189 .8811035156 190.1858978271190 .4907073975190 .4907073975190 .4907073975190 .4907073975 190.1858978271190 .1858978271190 .1858978271190 .4907073975190 .795501709 191.4051055908192 .0146026611192 .9290008545193 .8433074951195 .0625195 .9768066406 196.891204834197 .500793457198 .1103057861198 .4151000977198 .7198944092 198.7198944092198 .7198944092198 .7198944092198 .7198944092198 .7198944092 198.7198944092198 .7198944092198 .7198944092198 .7198944092199 .0247039795 199.329498291 199.6342926025 200.2438049316200.8533935547 201.7678070068 202.6820983887203 .596496582204 .8155975342206 .0346984863206 .9490966797 208.1681976318209 .0825958252209 .9969024658210 .6065063477211 .2160949707 211.8256988525212 .4351959229212 .7400054932213 .0447998047213 .6544036865 213.959197998214 .5686950684214 .8735046387215 .1782989502215 .4830932617 215.4830932617215 .1782989502214 .5686950684214 .2639007568214 .2639007568 214.2639007568214 .2639007568214 .5686950684214 .5686950684214 .8735046387 215.1782989502215 .1782989502215 .4830932617215 .4830932617215 .1782989502 215.1782989502215 .1782989502215 .4830932617215 .4830932617215 .4830932617 215.4830932617214 .8735046387213 .959197998212 .7400054932208 .1681976318 202.9868927002196 .5863952637189 .8811035156183 .4806976318178 .2993011475 174.337097168170 .6797027588167 .6318054199164 .8887023926162 .7552947998 160.9264984131159 .7073974609158 .4882965088157 .5738983154156 .9642944336 156.6596069336156 .6596069336156 .6596069336156 .6596069336156 .9642944336 156.9642944336157 .2691040039157 .2691040039157 .5738983154157 .5738983154 157.878692627157 .878692627158 .1835021973158 .1835021973158 .4882965088 158.7929992676159 .0977935791159 .7073974609160 .3170013428160 .9264984131 161.2312927246161 .2312927246161 .2312927246161 .2312927246160 .9264984131 160.3170013428160 .0122070312160 .0122070312160 .3170013428161 .2312927246 161.8408966064161 .8408966064161 .5361022949160 .9264984131160 .0122070312 158.7929992676157 .2691040039155 .7451934814153 .9165039062152 .6972961426 152.0877990723152 .6972961426153 .9165039062155 .1356048584154 .5260925293 149.9542999268141 .1154937744131 .3623962402132 .8863067627135 .6293945312 138.6772003174141 .7250976562144 .4682006836146 .6015930176148 .4304046631 149.6495056152150 .2590942383150 .8686065674153 .3069000244153 .3069000244 153.6116943359153 .3069000244153 .3069000244153 .0021057129145 .0776977539 148.4304046631150 .5639038086151 .7830047607152 .3925933838152 .6972961426 152.3925933838152 .3925933838152 .3925933838152 .3925933838152 .3925933838 152.3925933838152 .3925933838152 .0877990723152 .0877990723152 .0877990723 152.0877990723152 .0877990723152 .3925933838152 .3925933838152 .3925933838 152.3925933838152 .3925933838152 .3925933838152 .3925933838152 .3925933838 152.3925933838152 .0877990723151 .4781951904150 .5639038086148 .7351074219 146.9064025879144 .4682006836142 .3347015381139 .8963928223137 .4580993652 135.3246002197132 .8863067627130 .7528076172128 .3144989014126 .1809997559 123.7427978516121 .3044967651117 .9517974854115 .2088012695112 .7705001831 
111.551399231111 .551399231112 .7705001831121 .3044967651133 .4958953857 147.5160064697161 .5361022949174 .6419067383186 .8332977295197 .8054962158 207.8634033203209 .692199707209 .692199707209 .692199707209 .692199707 209.692199707209 .692199707209 .692199707209 .692199707209 .692199707209 .692199707 209.692199707209 .692199707209 .692199707209 .692199707209 .692199707209 .692199707 209.692199707 209.692199707 209.692199707 209.692199707 209.692199707 209.692199707 209.692199707209 .692199707209 .692199707209 .692199707209 .692199707209 .692199707 209.692199707 209.692199707 209.692199707 209.692199707 209.692199707 209.692199707 209.692199707 209.692199707 209.692199707 209.692199707 209.692199707209.692199707 209.692199707 84.42548370361 34.67044067383 5.230223655701 -9999-9999-9999-9999 -9999 -9999 -9999 -9999 -9999 -9999-9999 -9999

-9999 -9999 -9999 -9999 -9999 -9999 -9999 -9999 -9999 -9999 -9999 -9999 -9999 -9999 -9999 -9999 -9999 -9999 -9999 -9999 -9999 -9999 -9999 -9999 -9999 -9999 -9999 -9999 -9999 -9999 -999 -9999 -9999-9999-9999-9999-9999-9999-9999-9999 400.0010681152 397.5303649902 395.0979309082392 .8076171875390 .800201416389 .2057800293388 .0833435059 387.3023376465386 .5928955078385 .9427490234385 .1240234375383 .6972045898 381.9426269531380 .4247131348380 .5186157227382 .8804931641386 .6056213379 388.5183105469384 .6185302734378 .0853271484373 .3617858887370 .6187133789 361.475189209357 .208190918355 .6842041016358 .7320861816368 .1803894043 382.200592041392 .2585144043401 .5079345703411 .3120727539416 .8941345215 418.8297119141417 .5582275391412 .7651977539405 .759979248398 .8324584961 392.8746948242387 .800994873383 .1233825684378 .2647399902372 .7525939941 365.8899536133357 .4508972168349 .2838134766347 .4549865723344 .1023864746 337.3970947266330 .6918945312325 .5104980469319 .4147949219314 .2334899902 307.2233886719297 .4703063965282 .8406066895265 .7726135254248 .3999023438 233.4653930664220 .9691925049211 .8256988525204 .2059936523197 .8054962158 195.3672943115195 .0625194 .7577056885194 .1481018066193 .233795166192 .0146026611 190.795501709188 .966796875187 .1381072998186 .528503418187 .4429016113 188.0523986816188 .6620025635189 .2716064453189 .8811035156190 .1858978271 190.4907073975190 .4907073975190 .4907073975190 .4907073975190 .1858978271 190.1858978271189 .8811035156190 .1858978271190 .4907073975191 .1002960205 191.7097930908192 .624206543193 .5386047363194 .7577056885195 .6721038818 196.5863952637 197.1959991455 197.8054962158 198.1103057861 198.1103057861 198.1103057861198 .1103057861197 .8054962158197 .8054962158197 .500793457 197.500793457197 .1959991455197 .1959991455197 .1959991455197 .500793457 197.500793457197 .8054962158198 .4151000977199 .0247039795199 .9389953613 200.8533935547202 .0724945068203 .2917022705204 .5108032227205 .7299957275 206.6443023682207 .5587005615208 .4730072021209 .3874053955209 .9969024658 210.6065063477211 .2160949707211 .8256988525212 .1304016113212 .7400054932 213.3495941162213 .6544036865214 .2639007568214 .5686950684214 .5686950684 214.5686950684214 .5686950684213 .959197998213 .3495941162213 .3495941162 213.3495941162213 .3495941162213 .6544036865213 .959197998214 .2639007568 214.2639007568214 .2639007568214 .2639007568214 .2639007568213 .959197998 213.3495941162213 .959197998214 .2639007568214 .2639007568213 .6544036865 213.959197998213 .3495941162212 .4351959229209 .9969024658206 .0346984863 200.5485992432194 .7577056885188 .966796875183 .4806976318178 .2993011475 
174.0323028564170 .3748931885167 .3269958496164 .8887023926162 .7552947998 160.9264984131159 .4026031494158 .4882965088157 .5738983154156 .9642944336 156.6596069336156 .6596069336156 .6596069336156 .6596069336156 .6596069336 156.9642944336156 .9642944336157 .2691040039157 .5738983154157 .5738983154 157.878692627157 .878692627158 .1835021973158 .4882965088158 .4882965088 159.0977935791159 .4026031494160 .0122070312160 .9264984131161 .2312927246 161.5361022949161 .5361022949161 .5361022949161 .5361022949161 .2312927246 161.2312927246161 .2312927246161 .2312927246162 .1457061768163 .0599975586 163.6696014404163 .3648071289162 .7552947998161 .5361022949160 .6217956543 159.0977935791157 .5738983154155 .7451934814153 .9165039062152 .6972961426 151.7830047607151 .7830047607153 .3069000244154 .5260925293154 .2212982178 148.4304046631141 .4203033447135 .6293945312134 .4102020264136 .5437011719 139.2868041992142 .3347015381144 .7729034424146 .9064025879148 .4304046631 149.9542999268150 .8686065674151 .7830047607152 .6972961426153 .3069000244 153.3069000244153 .0021057129152 .0877990723150 .5639038086147 .8208007812 148.1255950928149 .6495056152151 .1734008789152 .3925933838152 .3925933838 152.3925933838152 .3925933838152 .3925933838152 .3925933838152 .3925933838 152.3925933838152 .3925933838152 .3925933838152 .0877990723152 .0877990723 152.0877990723152 .0877990723152 .0877990723152 .3925933838152 .3925933838 152.3925933838152 .3925933838152 .3925933838152 .3925933838152 .0877990723 152.0877990723152 .0877990723151 .4781951904150 .5639038086149 .0399017334 147.5160064697145 .3825073242143 .2489929199141 .1154937744138 .6772003174 136.5437011719134 .1054992676131 .9720001221129 .533706665127 .4001998901 124.9618988037122 .5235977173119 .7806015015116 .7326965332114 .2944030762 112.4656982422111 .551399231112 .1608963013118 .2565994263129 .533706665 141.7250976562155 .1356048584168 .241394043180 .7375946045192 .624206543 203.596496582209 .692199707209 .692199707209 .692199707209 .692199707209 .692199707 209.692199707209 .692199707209 .692199707209 .692199707209 .692199707209 .692199707 209.692199707 209.692199707 209.692199707 209.692199707 209.692199707 209.692199707 209.692199707 209.692199707 209.692199707 209.692199707 209.692199707 209.692199707 209.692199707209 .692199707209 .692199707209 .692199707209 .692199707209 .692199707 209.692199707 209.692199707 209.692199707 209.692199707 209.692199707 209.692199707 209.692199707 209.692199707209.692199707 209.692199707 209.692199707 209.692199707 84.7302627563544 .3954238891611 .80404949188 -9999 -9999 -9999 -9999 -9999 -9999 -9999 -9999 -9999-9999-9999-9999

-9999 -9999 -9999 -9999 -9999 -9999 -9999 -9999 -9999 -9999 -9999 -9999 -9999 -9999 -9999

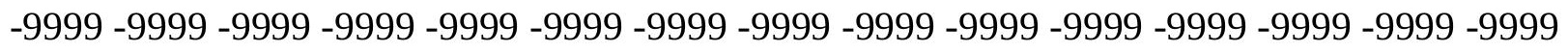
-9999 -9999 -9999 -9999-9999-9999 -9999 -9999-9999 394.5600891113391 .8915100098 389.3122558594386 .9060668945384 .8099365234383 .1413879395381 .9505615234 381.0621032715379 .6778564453377 .9452514648376 .1475830078373 .8731689453 369.7670898438365 .7283935547363 .7566223145365 .0330810547369 .1960449219 375.1904907227366 .9613037109356 .5986022949348 .9790039062345 .0168151855 341.6640930176338 .9211120605338 .9211120605342 .8833007812353 .2460021973 365.132598877372 .1426086426386 .1628112793402 .6211853027405 .9815063477 411.291595459411 .8391418457405 .6564025879397 .6037597656391 .387512207 387.3576965332384 .9883117676383 .4095153809381 .5311889648377 .9970703125 
372.3760681152365 .7139892578360 .213470459357 .7572937012356 .5986022949 352.3316040039341 .9689025879332 .8252868652329 .7774963379327 .9487915039 322.7674865723312 .1000061035296 .2510986328276 .4400939941255 .7147064209 237.1228027344223 .7122955322214 .2639007568206 .0346984863199 .6342926025 197.1959991455196 .891204834196 .2816009521195 .6721038818194 .7577056885 193.5386047363192 .0146026611190 .1858978271188 .0523986816186 .8332977295 187.7476043701 188.3571929932 189.2716064453 189.8811035156190.1858978271 190.4907073975190 .795501709190 .795501709190 .795501709190 .4907073975 190.1858978271189 .8811035156189 .8811035156189 .8811035156190 .1858978271 190.795501709191 .7097930908192 .3193969727193 .233795166194 .1481018066 195.3672943115196 .2816009521196 .891204834197 .500793457197 .8054962158 197.8054962158197 .500793457197 .1959991455196 .891204834196 .5863952637 196.2816009521196 .2816009521195 .9768066406195 .9768066406195 .9768066406 195.9768066406195 .9768066406196 .2816009521196 .5863952637197 .1959991455 198.1103057861199 .329498291200 .5485992432201 .7678070068202 .9868927002 204.2059936523 205.425201416 206.3394927979 207.25390625 208.1681976318 208.7778015137209 .3874053955209 .9969024658210 .6065063477211 .2160949707 211.8256988525212 .4351959229212 .7400054932213 .3495941162213 .6544036865 213.959197998213 .959197998213 .959197998213 .6544036865213 .0447998047 212.7400054932212 .7400054932212 .7400054932213 .0447998047213 .0447998047 213.3495941162213 .6544036865213 .6544036865213 .3495941162213 .3495941162 213.0447998047213 .0447998047213 .3495941162213 .6544036865213 .6544036865 213.0447998047212 .4351959229211 .520904541209 .9969024658207 .25390625 203.596496582198.7198944092 193.5386047363 188.3571929932183.7854003906 178.604095459174 .337097168170 .6797027588167 .6318054199165 .1934967041 163.0599975586161 .2312927246159 .7073974609158 .7929992676157 .878692627 157.2691040039156 .9642944336156 .6596069336156 .6596069336156 .6596069336 156.6596069336156 .9642944336157 .2691040039157 .2691040039157 .5738983154 157.5738983154157 .878692627158 .1835021973158 .1835021973158 .4882965088 158.7929992676159 .0977935791159 .7073974609160 .3170013428160 .9264984131 161.5361022949161 .8408966064161 .8408966064161 .8408966064161 .8408966064 161.8408966064161 .8408966064162 .1457061768162 .4505004883163 .3648071289 164.2792053223165 .1934967041164 .5839996338163 .3648071289162 .1457061768 160.9264984131159 .4026031494157 .5738983154155 .7451934814153 .9165039062 152.6972961426151 .7830047607151 .7830047607152 .6972961426153 .0021057129 151.4781951904147 .8208007812142 .9441986084139 .2868041992137 .7628936768 138.6772003174140 .5059967041142 .9441986084145 .0776977539146 .9064025879 148.4304046631149 .9542999268151 .1734008789152 .0877990723152 .0877990723 153.0021057129153 .0021057129152 .6972961426151 .7830047607150 .5639038086 149.6495056152149 .3446960449149 .9542999268151 .1734008789152 .0877990723 152.3925933838152 .3925933838152 .3925933838152 .3925933838152 .3925933838 152.3925933838152 .3925933838152 .3925933838152 .3925933838152 .3925933838 152.0877990723152 .0877990723152 .0877990723152 .0877990723152 .0877990723 152.0877990723152 .3925933838152 .3925933838152 .3925933838152 .3925933838 152.0877990723152 .0877990723152 .0877990723151 .4781951904150 .8686065674 149.6495056152148 .1255950928146 .2969055176144 .1634063721142 .0299072266 
139.5915985107137 .4580993652135 .0198059082132 .8863067627130 .7528076172 128.3144989014126 .1809997559123 .7427978516121 .3044967651118 .5614013672 115.818397522113 .6848983765112 .4656982422112 .1608963013115 .818397522 125.5715026855136 .8484954834149 .3446960449162 .4505004883175 .5561981201 188.3571929932200 .2438049316209 .692199707209 .692199707209 .692199707 209.692199707 209.692199707 209.692199707 209.692199707 209.692199707 209.692199707 209.692199707 209.692199707 209.692199707 209.692199707 209.692199707 209.692199707 209.692199707 209.692199707 209.692199707 209.692199707 209.692199707 209.692199707 209.692199707 209.692199707 209.692199707 209.692199707 209.692199707 209.692199707 209.692199707 209.692199707 209.692199707 209.692199707 209.692199707 209.692199707 209.692199707 209.692199707 209.692199707 209.692199707 209.692199707 209.692199707 209.692199707 209.692199707 84.73026275635 80.15849304199 23.1477355957 -9999 -9999 -9999 -9999 -9999 -9999 -9999 -9999 -9999 -9999 -9999 -9999

-9999 -9999 -9999 -9999 -9999 -9999 -9999 -9999 -9999 -9999 -9999 -9999 -9999 -9999 -9999 -9999 -9999 -9999 -9999 -9999 -9999 -9999 -9999 -9999 -9999 -9999 -9999 -9999 -9999 -9999 -9999 -9999-9999 -9999 -9999 -9999-9999 -9999 -9999 388.5602111816385 .5844116211 382.6903686523379 .8898925781377 .2383422852374 .904083252372 .9039306641 371.2808532715369 .1583862305364 .3357543945360 .7096252441359 .6465148926 352.0267944336345 .6263122559341 .3593139648340 .1401977539342 .5784912109 343.1879882812339 .2258911133330 .9966125488327 .6440124512326 .7296142578 323.6817932129321 .5483093262323 .0722045898327 .9487915039337 .3970947266 346.5407104492349 .5885009766361 .1704101562369 .7043151855377 .324005127 393.1727905273397 .1350097656387 .4602966309380 .7587890625377 .3598937988 376.1097106934376 .8202209473378 .6015930176379 .903137207379 .1367492676 374.9567871094369 .6993103027366 .091003418364 .104095459362 .6696777344 358.9815368652352 .5351867676346 .4735717773343 .7976074219345 .6263122559 340.1401977539327 .6440124512310 .2713012695287 .4124145508262 .7247924805 239.5610961914226 .150604248216 .0926971436207 .8634033203201 .4629974365 199.6342926025199 .0247039795198 .4151000977197 .1959991455196 .2816009521 194.7577056885193 .233795166191 .4051055908189 .2716064453187 .7476043701 188.3571929932188 .966796875189 .5764007568190 .1858978271190 .795501709 191.1002960205191 .4051055908191 .4051055908191 .1002960205190 .795501709 190.4907073975190 .1858978271189 .8811035156189 .8811035156190 .1858978271 190.795501709191 .4051055908192 .0146026611192 .9290008545193 .8433074951 194.7577056885195 .6721038818196 .2816009521196 .891204834197 .1959991455 197.1959991455196 .891204834196 .2816009521195 .9768066406195 .6721038818 195.3672943115195 .0625194 .7577056885194 .7577056885194 .4528961182194 .4528961182 194.4528961182194 .7577056885195 .0625195 .6721038818196 .5863952637197 .8054962158 199.0247039795200 .5485992432201 .7678070068202 .9868927002204 .2059936523 205.1204071045206 .0346984863206 .9490966797207 .5587005615208 .4730072021 209.0825958252 209.692199707 210.3016967773210.6065063477 211.2160949707 211.8256988525212 .1304016113212 .7400054932213 .0447998047213 .3495941162 213.6544036865213 .0447998047212 .4351959229212 .1304016113211 .8256988525 211.8256988525212 .1304016113212 .4351959229212 .7400054932213 .0447998047 212.7400054932212 .7400054932212 .7400054932212 .4351959229212 .7400054932 212.7400054932213 .0447998047213 .0447998047212 .4351959229211 .2160949707 
209.9969024658 207.8634033203205.1204071045201.4629974365 196.891204834 192.0146026611187 .4429016113182 .87109375178 .2993011475174 .337097168 170.9844970703167 .9365997314165 .4983062744163 .3648071289161 .8408966064 160.3170013428159 .0977935791158 .1835021973157 .5738983154157 .2691040039 156.9642944336156 .9642944336156 .9642944336156 .9642944336157 .2691040039 157.2691040039157 .5738983154157 .5738983154157 .878692627158 .1835021973 158.1835021973158 .4882965088158 .7929992676159 .0977935791159 .4026031494 160.0122070312160 .6217956543161 .2312927246161 .5361022949161 .8408966064 162.1457061768162 .1457061768162 .1457061768162 .1457061768162 .1457061768 162.7552947998163 .3648071289163 .974395752164 .8887023926165 .1934967041 164.8887023926163 .6696014404162 .4505004883161 .2312927246159 .4026031494 157.878692627156 .0500030518154 .2212982178152 .6972961426152 .0877990723 151.7830047607151 .7830047607151 .4781951904150 .2590942383147 .5160064697 144.4682006836142 .0299072266140 .8106994629140 .8106994629142 .0299072266 143.2489929199145 .0776977539146 .6015930176148 .1255950928149 .6495056152 151.1734008789152 .6972961426152 .6972961426152 .6972961426152 .6972961426 152.3925933838151 .7830047607151 .1734008789150 .8686065674150 .5639038086 150.8686065674151 .4781951904152 .0877990723152 .3925933838152 .3925933838 152.0877990723152 .0877990723152 .3925933838152 .3925933838152 .3925933838 152.3925933838152 .3925933838152 .3925933838152 .0877990723152 .0877990723 152.0877990723152 .0877990723152 .0877990723152 .0877990723152 .3925933838 152.3925933838152 .3925933838152 .3925933838152 .3925933838152 .3925933838 152.0877990723151 .7830047607150 .8686065674149 .9542999268148 .4304046631 146.6015930176144 .7729034424142 .6394042969140 .5059967041138 .3724975586 135.9342041016133 .8007049561131 .3623962402129 .2288970947127 .0953979492 124.9618988037122 .8283996582120 .3900985718117 .647102356115 .5136032104 113.6848983765113 .3800964355113 .9896011353122 .2188034058132 .5814971924 143.8585968018156 .9642944336171 .2891998291185 .3094024658197 .8054962158 208.7778015137209.692199707 209.692199707 209.692199707 209.692199707 209.692199707 209.692199707 209.692199707 209.692199707 209.692199707 209.692199707 209.692199707209 .692199707209 .692199707209 .692199707209 .692199707209 .692199707 209.692199707 209.692199707 209.692199707 209.692199707 209.692199707 209.692199707 209.692199707 209.692199707 209.692199707 209.692199707 209.692199707 209.692199707 209.692199707 209.692199707 209.692199707 209.692199707 209.692199707 209.692199707 209.692199707209 .692199707209 .692199707209 .692199707209 .692199707209 .692199707 209.692199707 80.1584930419919 .38539123535 -16.9951629639 -9999 -9999 -9999 -9999 -9999 -9999-9999-9999-9999-9999-9999

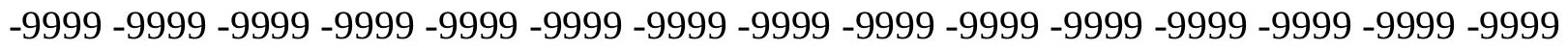
-9999 -9999 -9999 -9999 -9999 -9999 -9999 -9999 -9999 -9999 -9999 -9999 -9999 -9999 -9999 -9999 -9999 -9999 -9999 -9999 -9999 -9999 -9999 385.4921875382 .0100402832 378.5606079102375 .1335754395371 .6440124512367 .8754882812364 .1256713867 360.0209655762355 .9536132812353 .8554992676343 .4927978516336 .1780090332 333.1301879883328 .8631896973322 .7674865723315 .7573852539308 .4425048828 313.6239013672315 .7573852539313 .0143127441306 .0043029785305 .6994934082 306.0043029785304 .4802856445303 .8707885742306 .6138000488311 .1856079102 317.5860900879323 .6817932129326 .1200866699333 .7396850586339 .2258911133 
342.8833007812352 .6364135742359 .9512023926356 .9034118652357 .5129089355 358.1224975586359 .3417053223362 .6943054199367 .2661132812370 .6187133789 373.666595459370 .009185791366 .0469055176364 .8277893066364 .4149475098 364.2915344238362 .7833862305359 .9861450195357 .2242736816356 .297454834 356.6715698242354 .4650878906340 .749786377320 .9388122559296 .8606872559 270.3443908691246 .8759002686230 .1127929688218 .5308990479210 .3016967773 203.9011993408202 .0724945068201 .158203125200 .2438049316199 .0247039795 197.8054962158196 .2816009521194 .4528961182192 .624206543190 .4907073975 188.3571929932189 .2716064453189 .8811035156190 .4907073975191 .1002960205 191.4051055908191 .7097930908191 .7097930908191 .7097930908191 .7097930908 191.4051055908191 .1002960205190 .4907073975189 .8811035156189 .8811035156 190.1858978271190 .4907073975191 .1002960205191 .7097930908192 .3193969727 193.233795166193 .8433074951194 .7577056885195 .3672943115196 .2816009521 196.5863952637196 .2816009521195 .6721038818195 .3672943115194 .7577056885 194.4528961182194 .1481018066193 .8433074951193 .5386047363193 .5386047363 193.233795166193.233795166193.233795166193.233795166193.5386047363 193.8433074951195 .0625196 .5863952637197 .8054962158199 .329498291200 .5485992432 201.7678070068202 .9868927002204 .2059936523205 .1204071045205 .7299957275 206.6443023682207 .25390625207 .8634033203208 .4730072021209 .0825958252 209.692199707 209.9969024658210.6065063477210.9113006592 211.520904541 211.8256988525212 .1304016113212 .1304016113211 .8256988525211 .520904541 211.2160949707211 .2160949707211 .2160949707211 .2160949707211 .520904541 211.8256988525212 .1304016113212 .1304016113212 .1304016113212 .1304016113 212.1304016113212 .1304016113212 .4351959229212 .4351959229212 .1304016113 211.2160949707209 .9969024658208 .1681976318206 .0346984863202 .9868927002 199.6342926025195 .3672943115190 .795501709186 .528503418182 .261505127 178.2993011475174 .6419067383171 .5939941406168 .5462036133166 .1078948975 164.2792053223162 .4505004883160 .9264984131160 .0122070312159 .0977935791 158.4882965088157 .878692627157 .5738983154157 .5738983154157 .5738983154 157.5738983154157 .5738983154157 .5738983154157 .878692627157 .878692627 158.1835021973158 .4882965088158 .4882965088158 .7929992676158 .7929992676 159.0977935791159 .4026031494160 .0122070312160 .6217956543161 .2312927246 161.8408966064162 .1457061768162 .1457061768162 .1457061768162 .1457061768 162.1457061768162 .4505004883162 .7552947998163 .3648071289163 .974395752 164.5839996338164 .8887023926164 .5839996338163 .6696014404162 .4505004883 161.2312927246159 .7073974609157 .878692627156 .0500030518154 .5260925293 153.0021057129152 .3925933838151 .7830047607151 .1734008789150 .5639038086 149.6495056152147 .8208007812145 .6873016357143 .8585968018142 .6394042969 142.3347015381142 .6394042969143 .5538024902144 .4682006836145 .9920959473 147.2111968994 148.7351074219 150.2590942383151.4781951904 152.3925933838 152.3925933838152 .3925933838152 .0877990723152 .0877990723152 .0877990723 152.0877990723151 .7830047607151 .7830047607152 .0877990723152 .0877990723 152.3925933838152 .0877990723151 .4781951904151 .1734008789152 .0877990723 152.0877990723152 .3925933838152 .3925933838152 .3925933838152 .3925933838 152.0877990723152 .0877990723152 .0877990723152 .0877990723152 .0877990723 152.0877990723152 .0877990723152 .3925933838152 .3925933838152 .3925933838 
152.3925933838152 .3925933838152 .3925933838152 .0877990723151 .1734008789 150.2590942383149 .0399017334147 .2111968994145 .3825073242143 .2489929199 141.1154937744138 .9819946289136 .5437011719134 .4102020264131 .9720001221 129.8385009766127 .7050018311125 .8762969971124 .0475006104122 .2188034058 119.4757995605117 .0374984741115 .5136032104114 .5991973877114 .9039993286 119.4757995605128 .6192932129139 .2868041992152 .0877990723167 .6318054199 183.1759033203196 .5863952637207 .5587005615209 .692199707209 .692199707 209.692199707 209.692199707 209.692199707 209.692199707 209.692199707 209.692199707 209.692199707 209.692199707 209.692199707 209.692199707 209.692199707 209.692199707 209.692199707209 .692199707209 .692199707209 .692199707209 .692199707209 .692199707 209.692199707209 .692199707209 .692199707209 .692199707209 .692199707209 .692199707 209.692199707 209.692199707 209.692199707 209.692199707 209.692199707 209.692199707 209.692199707 209.692199707 209.692199707 209.692199707 209.692199707 209.692199707 209.692199707209 .692199707209 .69219970780 .4632720947322 .53054237366 -14.3625354767 -9999 -9999 -9999 -9999 -9999 -9999 -9999 -9999 -9999 -9999 -9999

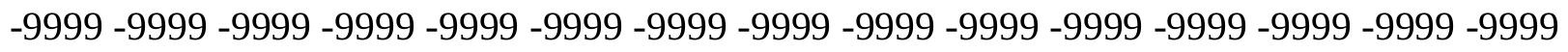
-9999 -9999 -9999 -9999 -9999 -9999 -9999 -9999 -9999 -9999 -9999 -9999 -9999 -9999 -9999 -9999 -9999 -9999 -9999 -9999 -9999 -9999 -9999 379.0386047363374 .9382629395 370.7838134766366 .5509033203362 .0680847168356 .7782287598350 .5233154297 344.7120056152335 .5683898926320 .9388122559315 .1477966309307 .5281982422 309.0520935059306 .9186096191302 .3468017578296 .5559082031292 .5936889648 292.8984985352293 .8128967285291 .6794128418287 .1076049805285 .5835876465 286.8027954102287 .1076049805287 .7171936035290 .7650146484294 .7272033691 298.0798950195 301.1276855469303 .8707885742309 .6617126465312 .7095031738 313.3190917969320 .3291931152326 .4248962402324 .9009094238332 .2157897949 336.4827880859339 .5306091309343 .4927978516347 .7597961426350 .5028991699 351.7219848633353 .8554992676354 .7698974609354 .7698974609358 .7320861816 361.0700683594362 .9371032715362 .925201416362 .3256225586362 .3136901855 361.598815918356 .9584350586344 .7535095215325 .8153076172302 .9563903809 274.9161987305251 .7525024414234 .0749969482221 .5787963867213 .0447998047 206.9490966797204 .8155975342203 .2917022705202 .0724945068200 .8533935547 199.329498291 197.8054962158195.9768066406193.8433074951 191.7097930908 189.5764007568190 .1858978271190 .795501709191 .4051055908192 .0146026611 192.3193969727192 .624206543192 .624206543192 .624206543192 .3193969727 192.0146026611191 .7097930908191 .1002960205190 .795501709190 .4907073975 190.4907073975190 .795501709190 .795501709191 .1002960205191 .7097930908 192.3193969727192 .9290008545193 .5386047363194 .1481018066194 .7577056885195 .0625 195.0625194 .4528961182194 .1481018066193 .8433074951193 .233795166192 .9290008545 192.624206543192 .624206543192 .3193969727192 .3193969727192 .3193969727 192.3193969727192 .3193969727192 .3193969727192 .624206543193 .8433074951 195.3672943115196 .891204834198 .4151000977199 .6342926025200 .8533935547 202.0724945068202.9868927002 203.9011993408 204.8155975342 205.425201416 206.0346984863 206.6443023682 207.25390625 207.8634033203 208.4730072021 208.7778015137209 .3874053955209 .692199707209 .9969024658210 .3016967773 210.6065063477210 .6065063477210 .6065063477210 .3016967773210 .3016967773 209.9969024658209.9969024658210.3016967773210.3016967773210.6065063477 
210.9113006592211 .2160949707211 .2160949707211 .520904541211 .520904541 211.8256988525211 .8256988525211 .520904541210 .9113006592209 .9969024658 208.7778015137206 .6443023682204 .5108032227201 .4629974365198 .1103057861 194.1481018066189 .8811035156185 .6141052246181 .3471984863177 .9945068359 174.9467010498172 .2035980225169 .4604949951167 .0222015381165 .1934967041 163.3648071289161 .8408966064160 .6217956543159 .7073974609159 .0977935791 158.4882965088158 .1835021973158 .1835021973158 .1835021973158 .1835021973 158.1835021973158 .1835021973158 .1835021973158 .4882965088158 .4882965088 158.7929992676158 .7929992676158 .7929992676159 .0977935791159 .0977935791 159.4026031494160 .0122070312160 .3170013428161 .2312927246161 .8408966064 162.4505004883162 .4505004883162 .1457061768161 .8408966064161 .8408966064 162.1457061768162 .4505004883163 .0599975586163 .6696014404163 .974395752 164.2792053223163 .974395752163 .0599975586162 .1457061768160 .9264984131 159.4026031494157 .878692627156 .3547973633154 .8307952881153 .3069000244 152.3925933838151 .4781951904150 .8686065674150 .2590942383149 .3446960449 147.8208007812146 .2969055176144 .7729034424143 .5538024902142 .9441986084 142.6394042969142 .9441986084143 .5538024902144 .7729034424145 .9920959473 147.2111968994 148.7351074219150.2590942383151.1734008789152.0877990723 152.0877990723152 .0877990723152 .3925933838152 .3925933838152 .3925933838 152.3925933838152 .0877990723152 .0877990723152 .3925933838151 .7830047607 151.1734008789150 .5639038086149 .3446960449148 .1255950928151 .7830047607 152.3925933838152 .3925933838152 .3925933838152 .3925933838152 .0877990723 152.0877990723152 .0877990723152 .0877990723152 .0877990723152 .0877990723 152.0877990723152 .3925933838152 .3925933838152 .3925933838152 .3925933838 152.6972961426152 .6972961426152 .3925933838151 .7830047607150 .5639038086 149.3446960449 147.5160064697 145.6873016357 143.8585968018141 .7250976562 139.2868041992137 .1533050537134 .7149963379132 .5814971924130 .4479980469 128.3144989014126 .4858016968124 .6570968628122 .5235977173120 .3900985718 118.5614013672117 .0374984741116 .1231002808116 .1231002808116 .4279022217 125.5715026855135 .3246002197146 .9064025879165 .4983062744182 .87109375 195.9768066406206 .0346984863209 .692199707209 .692199707209 .692199707 209.692199707 209.692199707 209.692199707 209.692199707 209.692199707 209.692199707 209.692199707 209.692199707 209.692199707 209.692199707 209.692199707 209.692199707 209.692199707 209.692199707 209.692199707 209.692199707 209.692199707 209.692199707 209.692199707209 .692199707209 .692199707209 .692199707209 .692199707209 .692199707 209.692199707209 .692199707209 .692199707209 .692199707209 .692199707209 .692199707 209.692199707 209.692199707 209.692199707 209.692199707 209.692199707 209.692199707 209.692199707 209.692199707 80.76805877686 45.22420883179 -2.38248109818-9999-9999 -9999 -9999 -9999 -9999 -9999 -9999 -9999 -9999 -9999

-9999 -9999 -9999 -9999 -9999 -9999 -9999 -9999 -9999 -9999 -9999 -9999 -9999 -9999 -9999

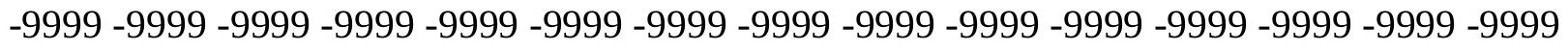
-9999 -9999 -9999 -9999 -9999 -9999 -9999 -9999 372.348236084 367.4682617188 362.3342895508356 .8175964355350 .9360351562344 .7120056152333 .4349060059 325.8153076172315 .7573852539303 .2611999512292 .5936889648290 .4602050781 291.0697937012290 .4602050781287 .4124145508283 .7549133301281 .0119018555 279.7927856445278 .8783874512277 .3544921875274 .3066101074271 .2587890625 
272.7827148438273 .6971130371275 .2210083008277 .9641113281280 .4023132324 282.5357971191284 .3645019531286 .1932067871290 .1553955078291 .6794128418 291.6794128418296 .8606872559302 .0421142578305 .6994934082311 .4903869629 315.7573852539319 .1099853516323 .0722045898327 .0344848633329 .1679077148 331.3013916016336 .7875976562339 .8353881836340 .4450073242345 .3215026855 352.0267944336359 .036895752360 .1849975586361 .1868286133362 .1542053223 361.4489746094356 .3612976074345 .0114746094326 .8406677246302 .9332275391 276.1353149414255 .1051025391237 .1228027344224 .0171051025215 .787902832 210.6065063477206 .3394927979204 .8155975342203 .596496582202 .0724945068 200.5485992432199 .0247039795197 .1959991455195 .0625192 .9290008545191 .1002960205 191.7097930908192 .0146026611192 .624206543192 .9290008545193 .233795166 193.233795166193 .5386047363193 .233795166193 .233795166192 .9290008545 192.3193969727192 .0146026611191 .4051055908191 .1002960205190 .795501709 190.4907073975190 .4907073975190 .4907073975190 .795501709191 .4051055908 191.7097930908192 .3193969727192 .9290008545193 .233795166193 .5386047363 193.233795166193.233795166 192.9290008545 192.624206543192.3193969727 192.0146026611191 .7097930908191 .4051055908191 .4051055908191 .4051055908 191.4051055908191 .4051055908191 .7097930908191 .7097930908192 .3193969727 193.5386047363194 .7577056885196 .2816009521197 .500793457198 .7198944092 199.9389953613200 .8533935547201 .7678070068202 .6820983887203 .596496582 204.2059936523 205.1204071045 205.7299957275206.03469848863206.6443023682 207.25390625 207.5587005615 207.8634033203208.1681976318208.4730072021 208.7778015137209 .0825958252209 .0825958252209 .0825958252208 .7778015137 208.7778015137208 .7778015137208 .7778015137209 .0825958252209 .3874053955 209.692199707209 .9969024658209 .9969024658210 .3016967773210 .6065063477 210.9113006592210 .9113006592210 .9113006592210 .6065063477209 .9969024658 209.0825958252207 .5587005615205 .425201416202 .9868927002200 .2438049316 196.891204834193 .233795166189 .2716064453185 .3094024658181 .0424041748 178.2993011475175 .5561981201172 .8132019043170 .3748931885167 .9365997314 166.1078948975164 .2792053223162 .7552947998161 .5361022949160 .6217956543 160.0122070312159 .4026031494159 .0977935791158 .7929992676158 .7929992676 158.7929992676158 .7929992676158 .7929992676158 .7929992676159 .0977935791 159.0977935791159 .0977935791159 .0977935791159 .0977935791159 .0977935791 159.0977935791159 .4026031494159 .7073974609160 .0122070312160 .6217956543 161.5361022949162 .4505004883161 .8408966064161 .5361022949161 .2312927246 161.2312927246161 .5361022949162 .1457061768162 .4505004883163 .0599975586 163.3648071289163 .3648071289163 .0599975586162 .4505004883161 .5361022949 160.6217956543159 .4026031494157 .878692627156 .3547973633154 .8307952881 153.3069000244152 .0877990723151 .4781951904150 .8686065674149 .9542999268 149.0399017334147 .8208007812146 .6015930176145 .0776977539143 .8585968018 142.6394042969142 .0299072266142 .0299072266142 .3347015381142 .9441986084 144.1634063721145 .6873016357147 .2111968994148 .4304046631149 .9542999268 150.8686065674151 .4781951904151 .7830047607152 .0877990723152 .3925933838 152.3925933838152 .3925933838152 .0877990723152 .0877990723151 .7830047607 151.1734008789150 .5639038086149 .6495056152148 .7351074219149 .0399017334 150.5639038086151 .7830047607152 .3925933838152 .3925933838152 .0877990723 
152.0877990723152 .0877990723152 .0877990723152 .0877990723152 .0877990723 152.0877990723152 .0877990723152 .0877990723152 .3925933838152 .3925933838 152.6972961426152 .6972961426152 .6972961426152 .6972961426152 .0877990723 150.8686065674149 .6495056152148 .1255950928146 .2969055176144 .1634063721 142.0299072266139 .8963928223137 .4580993652135 .3246002197132 .8863067627 130.7528076172128 .6192932129126 .7906036377124 .6570968628122 .8283996582 121.3044967651119 .7806015015118 .5614013672117 .9517974854117 .342300415 117.0374984741123 .1332015991133 .1911010742146 .2969055176163 .974395752 183.1759033203193 .8433074951203 .2917022705209 .692199707209 .692199707 209.692199707209 .692199707209 .692199707209 .692199707209 .692199707209 .692199707 209.692199707 209.692199707 209.692199707 209.692199707 209.692199707209.692199707 209.692199707 209.692199707 209.692199707 209.692199707 209.692199707 209.692199707 209.692199707 209.692199707 209.692199707 209.692199707 209.692199707 209.692199707 209.692199707209 .692199707209 .692199707209 .692199707209 .692199707209 .692199707 209.692199707209 .692199707209 .692199707209 .692199707209 .692199707209 .692199707 209.692199707209 .692199707209 .692199707209 .69219970785 .53720855713 3.519374370575 -9999 -9999 -9999 -9999 -9999 -9999 -9999 -9999 -9999 -9999 -9999 -9999 -9999 -9999 -9999 -9999 -9999 -9999 -9999 -9999 -9999 -9999 -9999 -9999 -9999 -9999 - -999 -9999 -9999 -9999 -9999 -9999 -9999 -9999 -9999 -9999 -9999 -9999 -9999 -9999 -9999 -9999 -9999 -9999 -9999 -9999-9999 -9999 -9999 -9999 365.5854797363359 .8183288574 353.5618896484346 .5725097656338 .3114929199327 .6440124512316 .0621948242 309.6617126465302 .9563903809294 .4223937988287 .4124145508283 .4501953125 281.9262084961280 .7070922852278 .2687988281275 .5257873535273 .0874938965 271.5635070801270 .0396118164268 .2109069824266 .0773925781263 .9439086914 262.4200134277263 .6390991211264 .8583068848266 .9917907715268 .5156860352 270.0396118164271 .2587890625273 .6971130371276 .1353149414277 .0497131348 276.7449035645280 .4023132324284 .9740905762291 .0697937012295 .9464111328 298.9942016602300 .5180969238306 .0043029785309 .6617126465311 .1856079102 313.0143127441319 .4147949219324 .2914123535324 .9009094238329 .7774963379 338.3114929199346 .845489502351 .5729675293354 .9573669434358 .0863037109 358.8866882324355 .0253295898344 .9542236328328 .1654968262305 .4769287109 280.0975036621259 .0674133301241 .6945953369227 .0648956299218 .5308990479 212.1304016113207 .25390625205 .425201416204 .5108032227203 .2917022705 201.7678070068199 .9389953613198 .1103057861196 .2816009521194 .1481018066 192.624206543192 .9290008545193 .5386047363193 .8433074951194 .1481018066 194.4528961182194 .4528961182194 .1481018066194 .1481018066193 .8433074951 193.5386047363193 .233795166192 .9290008545192 .3193969727191 .7097930908 191.1002960205190 .4907073975190 .1858978271189 .8811035156189 .8811035156 190.1858978271190 .795501709191 .1002960205191 .7097930908191 .7097930908 192.0146026611192 .0146026611191 .7097930908191 .7097930908191 .4051055908 191.1002960205190 .795501709190 .4907073975190 .4907073975190 .4907073975 190.4907073975190 .4907073975190 .795501709191 .1002960205191 .7097930908 192.3193969727193 .233795166194 .4528961182195 .6721038818196 .891204834 197.8054962158199 .0247039795199 .9389953613200 .8533935547201 .7678070068 202.6820983887203 .2917022705203 .9011993408204 .5108032227204 .8155975342 205.425201416205 .7299957275206 .0346984863206 .6443023682206 .6443023682 
206.9490966797 207.25390625 207.25390625 207.25390625 207.25390625 207.25390625 207.25390625 207.25390625 207.5587005615 207.5587005615 207.8634033203 208.1681976318208 .7778015137209 .0825958252209 .3874053955209 .692199707 209.9969024658210 .3016967773210 .3016967773209 .692199707209 .0825958252 207.8634033203206 .3394927979204 .2059936523201 .7678070068199 .0247039795 195.6721038818192 .624206543188 .966796875185 .6141052246182 .261505127 179.2136993408176 .7754058838174 .0323028564171 .2891998291169 .1557006836 167.0222015381165 .1934967041163 .974395752162 .7552947998161 .5361022949 160.9264984131160 .3170013428160 .0122070312159 .7073974609159 .4026031494 159.4026031494159 .4026031494159 .4026031494159 .4026031494159 .7073974609 159.7073974609159 .7073974609159 .4026031494159 .4026031494159 .0977935791 159.0977935791159 .0977935791159 .0977935791159 .4026031494160 .0122070312 160.6217956543160 .9264984131160 .6217956543160 .6217956543160 .3170013428 160.6217956543160 .9264984131161 .2312927246161 .5361022949162 .1457061768 162.1457061768162 .4505004883162 .1457061768161 .8408966064160 .9264984131 160.3170013428159 .0977935791157 .878692627156 .6596069336155 .1356048584 153.9165039062152 .3925933838151 .7830047607151 .1734008789150 .2590942383 149.3446960449148 .1255950928146 .6015930176145 .0776977539143 .5538024902 142.0299072266141 .1154937744140 .5059967041140 .8106994629141 .1154937744 142.3347015381143 .5538024902145 .3825073242146 .9064025879148 .1255950928 149.3446960449150 .5639038086151 .1734008789151 .7830047607152 .0877990723 152.0877990723152 .0877990723151 .7830047607151 .4781951904151 .1734008789 150.5639038086149 .6495056152149 .0399017334148 .7351074219149 .3446960449 150.2590942383151 .1734008789152 .0877990723152 .0877990723151 .7830047607 151.7830047607151 .7830047607151 .7830047607151 .7830047607151 .7830047607 152.0877990723152 .0877990723152 .0877990723152 .3925933838152 .3925933838 152.6972961426153 .0021057129153 .0021057129152 .6972961426152 .3925933838 151.1734008789149 .9542999268148 .4304046631146 .6015930176144 .4682006836 142.3347015381140 .2012023926137 .7628936768135 .6293945312133 .1911010742 131.0576019287128 .9241027832126 .7906036377124 .9618988037123 .1332015991 121.9140014648120 .6949005127120 .0852966309119 .4757995605118 .8662033081 118.2565994263120 .9997024536130 .7528076172143 .8585968018159 .7073974609 175.5561981201188 .6620025635199 .329498291208 .4730072021209 .692199707 209.692199707 209.692199707 209.692199707 209.692199707 209.692199707 209.692199707 209.692199707209 .692199707209 .692199707209 .692199707209 .692199707209 .692199707 209.692199707209 .692199707209 .692199707209 .692199707209 .692199707209 .692199707 209.692199707 209.692199707 209.692199707 209.692199707 209.692199707 209.692199707 209.692199707209 .692199707209 .692199707209 .692199707209 .692199707209 .692199707 209.692199707209 .692199707209 .692199707209 .692199707209 .692199707209 .692199707 209.692199707209 .692199707209 .692199707209 .69219970776 .80584716797

2.251605272293 -9999 -9999 -9999 -9999 -9999 -9999 -9999 -9999 -9999 -9999 -9999 -9999 -9999 -9999 -9999 -9999 -9999 -9999 -9999 -9999 -9999 -9999 -9999 -9999 -9999 -9999 -9999 -9999 -9999 -9999 -9999 -9999 -9999 -9999 -9999 -9999 -9999 -9999 -9999 -9999 -9999 -9999 -9999 -9999 -9999 -9999 -9999 -9999 -9999 358.9678039551352 .2964172363 344.9308776855336 .4827880859326 .1200866699314 .5382080078302 .6516113281 298.9942016602295 .6416015625290 .4602050781285 .5835876465281 .3167114258 
278.5736083984276 .4400939941274 .0018005371271 .5635070801269 .1253051758 266.9917907715265 .1630859375263 .3344116211261 .2008972168259 .3721008301 257.8482055664256 .9338989258256 .6290893555258 .7626037598259 .9816894531 260.8960876465262 .4200134277264 .5534973145266 .0773925781267 .2966003418 268.2109069824270 .3443908691274 .6113891602279 .7927856445284 .6693115234 287.7171936035290 .7650146484294 .4223937988297 .4703063965298 .9942016602 298.9942016602304 .1755981445309 .3569030762312 .7095031738316 .3670043945 323.6817932129332 .2157897949339 .8353881836346 .1227111816352 .8615112305 356.4236450195354 .736328125346 .8298950195332 .5349121094312 .6995239258 289.8505859375269 .4301147461249 .0093994141232 .5511016846222 .4931030273 214.5686950684210 .6065063477206 .9490966797205 .1204071045203 .9011993408 202.6820983887200 .8533935547199 .0247039795196 .891204834194 .7577056885 194.1481018066194 .7577056885195 .0625195 .3672943115195 .3672943115195 .3672943115 195.3672943115195 .0625194 .7577056885194 .7577056885194 .4528961182194 .1481018066 193.8433074951193 .233795166192 .3193969727191 .4051055908190 .1858978271 189.2716064453 188.966796875 188.966796875 189.2716064453189.8811035156 190.1858978271190 .4907073975190 .4907073975190 .4907073975190 .4907073975 190.4907073975190 .4907073975190 .1858978271190 .1858978271189 .8811035156 189.5764007568189 .5764007568189 .5764007568189 .5764007568189 .8811035156 190.4907073975191 .1002960205191 .7097930908192 .3193969727193 .233795166 194.1481018066195 .0625 196.2816009521 197.1959991455 198.1103057861 199.0247039795 199.9389953613200 .5485992432201 .4629974365202 .0724945068202 .6820983887 203.2917022705 203.596496582 204.2059936523 204.5108032227 204.8155975342 204.8155975342205 .1204071045205 .425201416205 .425201416205 .425201416 205.425201416205 .425201416205 .425201416205 .7299957275205 .7299957275 206.0346984863206 .3394927979206 .6443023682206 .9490966797207 .25390625 207.8634033203208 .1681976318208 .7778015137209 .0825958252209 .3874053955 209.3874053955 209.0825958252 208.1681976318206.9490966797205.1204071045 202.9868927002200 .5485992432197 .8054962158194 .7577056885191 .7097930908 188.966796875185 .9188995361183 .1759033203180 .7375946045177 .9945068359 174.9467010498172 .5084075928170 .070098877167 .9365997314166 .4127044678 164.8887023926163 .6696014404162 .7552947998161 .8408966064161 .2312927246 160.9264984131160 .6217956543160 .3170013428160 .3170013428160 .3170013428 160.3170013428160 .3170013428160 .3170013428160 .3170013428160 .0122070312 160.0122070312159 .7073974609159 .4026031494159 .0977935791158 .7929992676 158.4882965088158 .4882965088158 .7929992676159 .0977935791159 .4026031494 159.4026031494159 .0977935791159 .4026031494159 .7073974609160 .0122070312 160.3170013428160 .6217956543160 .9264984131161 .2312927246161 .2312927246 161.2312927246160 .9264984131160 .3170013428159 .7073974609159 .0977935791 157.878692627156 .9642944336155 .7451934814154 .5260925293153 .3069000244 152.3925933838151 .7830047607150 .8686065674149 .6495056152148 .4304046631 146.9064025879145 .0776977539143 .2489929199141 .4203033447139 .8963928223 138.9819946289138 .9819946289139 .2868041992140 .5059967041142 .0299072266 143.5538024902145 .0776977539146 .6015930176148 .1255950928149 .3446960449 150.2590942383150 .8686065674151 .1734008789151 .4781951904151 .4781951904 151.1734008789150 .8686065674150 .2590942383149 .6495056152149 .3446960449 
148.7351074219148 .7351074219149 .0399017334149 .9542999268150 .5639038086 151.1734008789151 .4781951904151 .4781951904151 .4781951904151 .4781951904 151.4781951904151 .4781951904151 .7830047607151 .7830047607152 .0877990723 152.0877990723152 .0877990723152 .0877990723152 .6972961426153 .0021057129 153.0021057129153 .0021057129152 .3925933838151 .4781951904150 .2590942383 148.4304046631146 .6015930176144 .7729034424142 .6394042969140 .2012023926 138.0677032471135 .6293945312133 .4958953857131 .0576019287128 .9241027832 126.7906036377124 .9618988037123 .43800354122 .2188034058121 .6092987061 121.3044967651120 .9997024536120 .6949005127119 .7806015015118 .2565994263 127.0953979492138 .9819946289153 .0021057129167 .9365997314181 .6519012451 193.8433074951204 .2059936523209 .692199707209 .692199707209 .692199707 209.692199707 209.692199707 209.692199707 209.692199707 209.692199707 209.692199707 209.692199707 209.692199707 209.692199707 209.692199707 209.692199707 209.692199707 209.692199707209 .692199707209 .692199707209 .692199707209 .692199707209 .692199707 209.692199707209 .692199707209 .692199707209 .692199707209 .692199707209 .692199707 209.692199707 209.692199707 209.692199707 209.692199707 209.692199707 209.692199707 209.692199707 209.692199707 209.692199707209.692199707 209.692199707209.692199707 209.692199707 209.69219970776 .80584716797 -3.233076334 -50.2483634949 -9999 -9999 -9999 -9999 -9999 -9999 -9999 -9999-9999 -9999 -9999 -9999 -9999 -9999 -9999 -9999 -9999 -9999 -9999 -9999 -9999 -9999 -9999 -9999 -9999 -

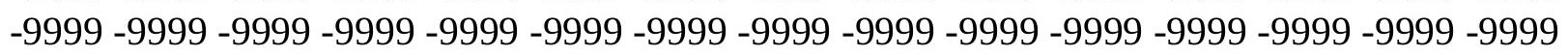
-9999 -9999-9999-9999-9999 -9999-9999 -9999 352.7160644531345 .2591552734 337.0922851562327 .0344848633316 .0621948242304 .4802856445295 .6416015625 295.0320129395293 .2033081055289 .8505859375286 .1932067871282 .5357971191 279.4880065918276 .4400939941273 .6971130371270 .9540100098268 .5156860352 266.0773925781263 .6390991211261 .5056152344259 .3721008301257 .2385864258 255.7147064209254 .4956054688253 .8860015869253 .5812072754254 .1907958984 255.1051025391256 .3243103027257 .8482055664259 .3721008301260 .5913085938 262.4200134277265 .1630859375269 .1253051758273 .3923034668277 .6592102051 281.3167114258284 .9740905762288 .0219116211291 .3746032715293 .5080871582 295.0320129395296 .8606872559299 .2990112305305 .0899047852310 .8807983398 317.2813110352323 .0722045898325 .2056884766339 .7921447754350 .3662719727 356.1220092773356 .5779724121351 .2329101562340 .1328125324 .0687255859 304.6667480469283 .4501953125260 .8960876465242 .3041992188228 .2841033936 219.1405029297214 .2639007568210 .9113006592206 .6443023682204 .5108032227 202.9868927002201 .158203125199 .329498291197 .1959991455195 .0625195 .6721038818 196.2816009521 196.891204834196.891204834196.5863952637196.2816009521 195.9768066406195 .6721038818195 .3672943115195 .3672943115195 .0625194 .7577056885 194.4528961182193 .8433074951192 .9290008545191 .4051055908189 .5764007568 188.3571929932187 .7476043701188 .0523986816188 .3571929932188 .966796875 189.2716064453 189.2716064453 189.2716064453 188.966796875 189.2716064453 189.2716064453189 .2716064453189 .2716064453188 .966796875188 .966796875 188.6620025635188 .6620025635188 .6620025635188 .966796875189 .2716064453 189.8811035156190 .795501709191 .7097930908192 .3193969727193 .233795166 193.8433074951194 .7577056885195 .3672943115196 .2816009521197 .1959991455 197.8054962158198 .7198944092199 .6342926025200 .2438049316200 .8533935547 
201.4629974365202 .0724945068202 .3773040771202 .6820983887202 .9868927002 202.9868927002203 .2917022705203 .2917022705203 .596496582203 .596496582 203.596496582203 .596496582203 .596496582203 .596496582203 .9011993408 203.9011993408204 .2059936523204 .5108032227204 .8155975342205 .425201416 206.0346984863206 .3394927979206 .9490966797207 .5587005615207 .8634033203 208.4730072021 208.4730072021208.1681976318207.25390625 205.7299957275 203.9011993408201 .7678070068199 .0247039795196 .2816009521193 .8433074951 191.1002960205188 .3571929932186 .2236938477183 .7854003906181 .9566955566 178.604095459175 .8609924316173 .1179962158170 .9844970703168 .8509979248 167.3269958496165 .8031005859164 .5839996338163 .6696014404162 .7552947998 162.1457061768161 .8408966064161 .5361022949161 .2312927246161 .2312927246 160.9264984131160 .9264984131160 .9264984131160 .9264984131160 .9264984131 160.9264984131160 .6217956543160 .0122070312159 .7073974609159 .0977935791 158.4882965088157 .878692627157 .5738983154157 .5738983154157 .5738983154 157.878692627157 .878692627157 .878692627158 .1835021973158 .4882965088 159.0977935791159 .4026031494159 .7073974609160 .0122070312160 .0122070312 160.3170013428160 .3170013428160 .0122070312159 .7073974609159 .4026031494 158.7929992676158 .1835021973157 .2691040039156 .3547973633155 .4403991699 154.5260925293153 .6116943359152 .6972961426151 .7830047607150 .5639038086 149.0399017334147.2111968994145.0776977539142.9441986084140.5059967041 138.6772003174137 .4580993652137 .1533050537137 .7628936768138 .6772003174 140.2012023926142 .0299072266143 .5538024902145 .3825073242146 .6015930176 148.1255950928149 .0399017334149 .6495056152150 .2590942383150 .2590942383 150.2590942383150 .2590942383149 .9542999268149 .6495056152149 .0399017334 148.7351074219148 .4304046631148 .4304046631148 .7351074219149 .3446960449 149.9542999268150 .2590942383150 .5639038086150 .5639038086150 .8686065674 150.8686065674150 .8686065674151 .1734008789151 .4781951904151 .7830047607 152.0877990723152 .3925933838152 .3925933838152 .3925933838152 .6972961426 153.0021057129153 .0021057129153 .0021057129152 .3925933838151 .4781951904 150.2590942383148 .7351074219146 .9064025879144 .7729034424142 .6394042969 140.5059967041138 .0677032471135 .9342041016133 .4958953857131 .3623962402 128.9241027832127 .0953979492125 .2667007446123 .7427978516122 .5235977173 122.2188034058122 .2188034058122 .5235977173122 .2188034058121 .3044967651 120.0852966309122 .2188034058132 .5814971924145 .6873016357160 .3170013428 174.9467010498188 .0523986816199 .6342926025209 .692199707209 .692199707 209.692199707 209.692199707 209.692199707 209.692199707 209.692199707 209.692199707 209.692199707 209.692199707 209.692199707 209.692199707 209.692199707 209.692199707 209.692199707209 .692199707209 .692199707209 .692199707209 .692199707209 .692199707 209.692199707209 .692199707209 .692199707209 .692199707209 .692199707209 .692199707 209.692199707209 .692199707209 .692199707209 .692199707209 .692199707209 .692199707 209.692199707 209.692199707 209.692199707 209.692199707 209.692199707 209.692199707 209.692199707 209.692199707 209.692199707 77.1106262207-4.83478975296 -51.3172569275 -9999 -9999 -9999 -9999 -9999 -9999 -9999 -9999 -9999 -9999 -9999 -9999 -9999 -9999 -9999 -9999 -9999 -9999 -9999 -9999 -9999 -9999 -9999 -9999 -9999 -9999 -9999 -9999 -9999 -9999 -9999 -9999 -9999 -9999 -9999 -9999 -9999 -9999 -9999 -9999 -9999 -9999 -9999 -9999 -9999 -9999 -9999 -9999 347.1036682129 338.9578552246 
330.0823059082319 .4147949219308 .7473144531300 .5180969238297 .1654968262 295.6416015625294 .1176147461291 .6794128418288 .9363098145285 .5835876465 282.5357971191279 .4880065918276 .4400939941273 .3923034668270 .3443908691 267.6012878418264 .5534973145262 .1152038574259 .3721008301257 .2385864258 255.1051025391253 .5812072754252 .3621063232251 .7525024414251 .4476928711 251.7525024414252 .3621063232253 .2763977051254 .4956054688256 .0195007324 258.4577941895261 .5056152344265 .1630859375269 .7348022461274 .0018005371 278.2687988281282 .2309875488285 .8884887695289 .8505859375293 .8128967285 297.4703063965300 .8229064941303 .5660095215307 .2233886719312 .1000061035 317.5860900879326 .1200866699332 .3469238281342 .1305847168352 .024810791 358.6089782715360 .4978942871357 .3538208008349 .3421630859336 .9057312012 320.3301391602299 .4070739746276 .1353149414252 .0572967529233 .7702026367 222.4931030273216 .7021942139214 .2639007568208 .1681976318203 .596496582 202.6820983887200 .8533935547199 .0247039795196 .2816009521196 .5863952637 197.1959991455 197.8054962158 198.4151000977 198.1103057861 197.500793457 197.1959991455 196.891204834196.2816009521 195.9768066406195.6721038818 195.3672943115195 .0625194 .7577056885194 .4528961182193 .233795166190 .4907073975 188.0523986816186 .528503418186 .2236938477186 .8332977295187 .7476043701 188.3571929932188 .6620025635188 .3571929932188 .0523986816187 .7476043701 187.7476043701188 .0523986816188 .0523986816188 .3571929932188 .0523986816 188.0523986816187 .7476043701187 .7476043701187 .7476043701188 .0523986816 188.3571929932189 .2716064453190 .1858978271191 .4051055908192 .3193969727 192.9290008545 193.5386047363193.8433074951 194.4528961182195.3672943115 195.9768066406196 .891204834197 .8054962158198 .4151000977199 .0247039795 199.6342926025200 .2438049316200 .5485992432200 .8533935547201 .158203125 201.4629974365201 .4629974365201 .4629974365201 .7678070068201 .7678070068 201.7678070068201 .4629974365201 .7678070068201 .7678070068201 .7678070068 201.7678070068202 .0724945068202 .3773040771202 .6820983887203 .2917022705 203.9011993408204 .2059936523204 .8155975342205 .425201416206 .0346984863 206.6443023682207 .25390625207 .5587005615207 .25390625206 .3394927979 204.5108032227202 .6820983887200 .2438049316197 .500793457195 .0625192 .3193969727 189.8811035156187 .7476043701185 .6141052246183 .7854003906181 .3471984863 178.9089050293176 .165802002173 .7274932861171 .5939941406169 .7653045654 168.241394043166 .7174987793165 .4983062744164 .5839996338163 .6696014404 163.0599975586162 .7552947998162 .1457061768162 .1457061768161 .8408966064 161.8408966064161 .8408966064161 .8408966064161 .8408966064161 .8408966064 161.5361022949161 .2312927246160 .6217956543160 .0122070312159 .4026031494 158.4882965088157 .5738983154156 .9642944336156 .6596069336156 .3547973633 156.6596069336156 .9642944336157 .2691040039157 .5738983154157 .878692627 158.1835021973158 .4882965088158 .7929992676158 .7929992676159 .0977935791 159.0977935791159 .4026031494159 .0977935791159 .0977935791158 .7929992676 158.4882965088158 .1835021973157 .5738983154157 .2691040039156 .6596069336 156.0500030518155 .1356048584154 .2212982178153 .0021057129151 .7830047607 149.9542999268147 .8208007812145 .6873016357142 .9441986084140 .2012023926 137.7628936768135 .9342041016135 .6293945312136 .2389984131137 .4580993652 138.9819946289140 .8106994629142 .3347015381144 .1634063721145 .6873016357 
146.9064025879147 .8208007812148 .4304046631149 .0399017334149 .3446960449 149.3446960449149 .3446960449149 .0399017334148 .7351074219148 .4304046631 148.1255950928148 .1255950928148 .1255950928148 .1255950928148 .7351074219 149.0399017334149 .3446960449149 .6495056152149 .6495056152149 .9542999268 150.2590942383150 .5639038086150 .5639038086151 .1734008789151 .4781951904 151.7830047607152 .0877990723152 .3925933838152 .3925933838152 .3925933838 152.6972961426153 .0021057129152 .6972961426152 .3925933838151 .4781951904 150.2590942383148 .7351074219146 .9064025879144 .7729034424142 .6394042969 140.5059967041138 .0677032471135 .9342041016133 .4958953857131 .3623962402 129.2288970947127 .0953979492125 .2667007446123 .7427978516122 .8283996582 122.5235977173122 .8283996582123 .1332015991123 .43800354122 .8283996582 121.6092987061120 .3900985718125 .8762969971138 .9819946289153 .9165039062 169.1557006836183 .1759033203195 .6721038818206 .6443023682209 .692199707 209.692199707209 .692199707209 .692199707209 .692199707209 .692199707209 .692199707 209.692199707 209.692199707 209.692199707 209.692199707 209.692199707 209.692199707 209.692199707 209.692199707 209.692199707 209.692199707 209.692199707 209.692199707 209.692199707 209.692199707 209.692199707 209.692199707 209.692199707209.692199707 209.692199707 209.692199707 209.692199707 209.692199707 209.692199707 209.692199707 209.692199707209 .692199707209 .692199707209 .692199707209 .692199707209 .692199707 $209.692199707209 .692199707209 .69219970777 .41542053223-2.19673657417$ -45.5406150818 -9999 -9999 -9999 -9999 -9999 -9999 -9999 -9999 -9999 -9999 -9999 -9999 -9999 -9999 -9999 -9999 -9999 -9999 -9999 -9999 -9999 -9999 -9999 -9999 -9999 -9999 -9999 -9999 -9999 -9999 -9999 -9999 -9999 -9999 -9999 -9999 -9999 -9999 -9999 -9999 -9999 -9999 -9999 -9999 -9999 -9999 -9999 350.6196899414342 .3792724609333 .7396850586 324.9009094238316 .0621948242308 .4425048828303 .2611999512299 .9085998535 298.0798950195296 .5559082031294 .7272033691292 .5936889648290 .1553955078 287.4124145508284 .3645019531281 .3167114258277 .9641113281274 .6113891602 270.9540100098267 .6012878418264 .5534973145261 .5056152344258 .7626037598 256.0195007324253 .8860015869252 .0572967529250 .8381958008249 .9237976074 249.6190032959249 .6190032959250 .2286071777252 .3621063232254 .1907958984 256.6290893555258 .7626037598262 .7247924805267 .2966003418272 .4779052734 277.3544921875282 .2309875488287 .1076049805292 .5936889648299 .2990112305 305.6994934082311 .1856079102315 .7573852539319 .7196044922325 .2056884766 332.2157897949336 .6170043945342 .7145385742349 .9534301758357 .545501709 363.095489502365 .1390075684363 .175201416357 .3479919434347 .9923400879 334.4893493652314 .4717712402287 .1076049805257 .2385864258235 .5989074707 222.4931030273 215.1782989502 210.9113006592 206.9490966797 203.2917022705 202.0724945068 200.2438049316197.8054962158 197.500793457 197.8054962158 198.1103057861198 .7198944092199 .0247039795198 .7198944092198 .4151000977 197.8054962158197 .1959991455196 .891204834196 .2816009521195 .9768066406 195.3672943115195 .0625194 .4528961182193 .8433074951192 .9290008545188 .3571929932 185.6141052246184 .0901947021184 .0901947021185 .0045928955186 .8332977295 188.3571929932188 .0523986816187 .4429016113186 .528503418186 .2236938477 186.528503418186 .8332977295187 .1381072998187 .4429016113187 .4429016113 187.1381072998186 .8332977295186 .528503418186 .528503418186 .8332977295 187.4429016113188 .3571929932189 .5764007568190 .795501709192 .0146026611 
192.3193969727192 .624206543192 .9290008545193 .5386047363194 .1481018066 194.7577056885195 .6721038818196 .5863952637197 .1959991455197 .8054962158 198.4151000977199 .0247039795199 .329498291199 .6342926025199 .6342926025 199.9389953613199 .9389953613199 .9389953613199 .6342926025199 .6342926025 199.6342926025199 .6342926025199 .6342926025199 .6342926025199 .6342926025 199.9389953613199 .9389953613200 .5485992432200 .8533935547201 .4629974365 202.0724945068202 .6820983887203 .2917022705203 .9011993408204 .5108032227 205.1204071045205 .7299957275206 .0346984863206 .0346984863204 .8155975342 202.9868927002200 .8533935547198 .4151000977195 .9768066406193 .233795166 190.795501709188 .6620025635186 .528503418184 .699798584182 .87109375 180.7375946045178 .604095459176 .165802002174 .0323028564172 .2035980225 170.3748931885168 .8509979248167 .6318054199166 .4127044678165 .4983062744 164.5839996338163 .974395752163 .3648071289163 .0599975586162 .7552947998 162.7552947998162 .4505004883162 .4505004883162 .4505004883162 .4505004883 162.4505004883162 .1457061768161 .8408966064161 .2312927246160 .6217956543 160.0122070312159 .0977935791157 .878692627156 .6596069336155 .7451934814 155.7451934814156 .0500030518156 .3547973633156 .6596069336156 .9642944336 157.2691040039 157.5738983154 157.878692627 157.878692627 157.878692627 158.1835021973158 .1835021973158 .4882965088158 .4882965088158 .4882965088 158.4882965088158 .1835021973158 .1835021973157 .878692627157 .878692627 157.5738983154157 .2691040039156 .6596069336155 .7451934814154 .5260925293 153.0021057129151 .1734008789149 .0399017334146 .2969055176143 .2489929199 140.5059967041137 .4580993652135 .0198059082135 .0198059082135 .9342041016 136.8484954834138 .3724975586139 .8963928223141 .7250976562143 .2489929199 144.4682006836145 .6873016357146 .6015930176147 .5160064697147 .8208007812 148.1255950928148 .4304046631148 .1255950928148 .1255950928147 .8208007812 147.5160064697147 .5160064697147 .2111968994147 .5160064697147 .5160064697 147.8208007812148 .1255950928148 .4304046631148 .4304046631148 .7351074219 149.0399017334149 .3446960449149 .6495056152149 .9542999268150 .5639038086 150.8686065674151 .4781951904152 .0877990723152 .3925933838152 .0877990723 152.3925933838152 .6972961426152 .6972961426152 .3925933838152 .0877990723 151.1734008789149 .9542999268148 .4304046631146 .6015930176144 .7729034424 142.6394042969140 .5059967041138 .3724975586135 .9342041016133 .8007049561 131.3623962402129 .2288970947127 .4001998901125 .2667007446123 .7427978516 122.5235977173122 .2188034058122 .8283996582123 .43800354124 .0475006104 123.7427978516122 .5235977173121 .3044967651120 .9997024536134 .4102020264 149.9542999268165 .1934967041179 .8231964111192 .624206543204 .2059936523 209.692199707 209.692199707 209.692199707 209.692199707 209.692199707 209.692199707 209.692199707209 .692199707209 .692199707209 .692199707209 .692199707209 .692199707 209.692199707209 .692199707209 .692199707209 .692199707209 .692199707209 .692199707 209.692199707209 .692199707209 .692199707209 .692199707209 .692199707209 .692199707 209.692199707209 .692199707209 .692199707209 .692199707209 .692199707209 .692199707 209.692199707 209.692199707 209.692199707 209.692199707 209.692199707209.692199707 209.692199707209 .692199707209 .692199707209 .69219970777 .41542053223 6.610837459564 -29.7413444519 -9999 -9999 -9999 -9999 -9999 -9999 -9999 -9999 -9999 -9999 
-9999 -9999 -9999 -9999 -9999 -9999 -9999 -9999 -9999 -9999 -9999 -9999 -9999 -9999 -9999 -9999 -9999 -9999 -9999 -9999 -9999 -9999 -9999 -9999 -9999 -9999 -9999 -9999 -9999 -9999 -9999 -9999 -9999 -9999 -9999 -9999-9999 347.4492492676 338.8145141602330 .0823059082 322.1578979492314 .8429870605309 .0520935059304 .7850952148302 .3468017578 300.5180969238299 .6037902832298 .3846130371296 .8606872559295 .3367919922 292.8984985352290 .1553955078287 .1076049805283 .7549133301280 .0975036621 276.1353149414272 .1730957031268 .2109069824264 .5534973145261 .2008972168 258.1530151367255 .4098968506253 .2763977051251 .1428985596249 .6190032959 248.7046966553248 .0950927734250 .5334014893252 .6669006348254 .8003997803 257.5433959961260 .8960876465264 .2486877441266 .9917907715271 .8682861328 279.1831970215288 .0219116211295 .3367919922300 .5180969238309 .3569030762 319.4147949219326 .4248962402332 .8252868652337 .0922851562341 .0545959473 345.1794128418348 .7497558594353 .0807495117358 .1458129883363 .285736084 367.0387268066368 .1560668945365 .9739990234360 .8199462891353 .0792236328 342.7159423828326 .7296142578292 .5936889648255 .4098968506234 .6844940186 220.3596038818211 .2160949707206 .6443023682203 .9011993408202 .0724945068 200.5485992432199 .329498291198 .7198944092198 .7198944092198 .7198944092 199.0247039795199 .329498291199 .329498291199 .329498291198 .7198944092 198.1103057861197 .500793457196 .891204834196 .2816009521195 .9768066406 195.3672943115194 .7577056885193 .8433074951192 .0146026611188 .3571929932 184.0901947021182 .261505127181 .9566955566181 .9566955566182 .87109375 185.6141052246188 .3571929932187 .1381072998185 .9188995361185 .0045928955 185.0045928955185 .0045928955185 .6141052246186 .528503418186 .8332977295 186.8332977295186 .528503418186 .2236938477185 .6141052246185 .3094024658 185.6141052246186 .2236938477187 .4429016113188 .6620025635189 .8811035156 191.1002960205191 .4051055908191 .4051055908191 .7097930908192 .0146026611 192.9290008545193 .5386047363194 .4528961182195 .3672943115195 .9768066406 196.5863952637197 .1959991455197 .8054962158198 .1103057861198 .1103057861 198.4151000977198 .1103057861198 .1103057861198 .1103057861197 .8054962158 197.8054962158197 .500793457197 .500793457197 .500793457197 .500793457 197.500793457197 .8054962158198 .1103057861198 .4151000977199 .0247039795 199.329498291199 .9389953613200 .8533935547201 .4629974365202 .0724945068 202.6820983887203 .2917022705203 .596496582203 .9011993408203 .596496582 202.6820983887200 .8533935547198 .7198944092196 .5863952637194 .1481018066 191.7097930908189 .2716064453186 .8332977295185 .0045928955183 .1759033203 181.6519012451179 .8231964111177 .9945068359176 .165802002174 .337097168 172.5084075928170 .9844970703169 .4604949951168 .241394043167 .3269958496 166.1078948975165 .4983062744164 .8887023926164 .2792053223163 .974395752 163.6696014404163 .3648071289163 .3648071289163 .3648071289163 .3648071289 163.3648071289163 .0599975586162 .7552947998162 .1457061768161 .5361022949 161.2312927246160 .6217956543160 .0122070312158 .7929992676156 .9642944336 155.4403991699155 .7451934814156 .0500030518156 .3547973633156 .6596069336 156.9642944336157 .2691040039157 .2691040039157 .2691040039157 .2691040039 157.2691040039157 .2691040039157 .5738983154157 .5738983154157 .878692627 157.878692627157 .878692627157 .878692627158 .1835021973158 .1835021973 158.1835021973158 .1835021973158 .1835021973157 .878692627156 .9642944336 
155.7451934814154 .2212982178152 .3925933838149 .9542999268147 .2111968994 144.4682006836141 .4203033447138 .6772003174136 .5437011719135 .9342041016 136.2389984131137 .1533050537138 .3724975586139 .5915985107141 .1154937744 142.6394042969143 .8585968018144 .7729034424145 .6873016357146 .6015930176 146.9064025879147 .2111968994147 .2111968994147 .2111968994147 .2111968994 146.9064025879146 .6015930176146 .6015930176146 .6015930176146 .6015930176 146.6015930176146 .9064025879146 .9064025879147 .2111968994147 .5160064697 147.8208007812148 .1255950928148 .4304046631149 .0399017334149 .3446960449 149.9542999268150 .5639038086151 .1734008789151 .7830047607152 .3925933838 152.3925933838152 .3925933838152 .3925933838152 .3925933838152 .3925933838 152.0877990723151 .1734008789149 .9542999268148 .4304046631146 .6015930176 144.7729034424142 .6394042969140 .5059967041138 .3724975586136 .2389984131 133.8007049561131 .6672058105129 .533706665127 .4001998901125 .5715026855 123.7427978516122 .5235977173121 .6092987061122 .5235977173123 .43800354 124.0475006104123 .7427978516122 .8283996582120 .9997024536122 .2188034058 134.1054992676148 .4304046631163 .6696014404177 .9945068359191 .1002960205 202.3773040771209.692199707 209.692199707 209.692199707 209.692199707 209.692199707 209.692199707 209.692199707 209.692199707 209.692199707209.692199707 209.692199707 209.692199707 209.692199707 209.692199707 209.692199707 209.692199707 209.692199707 209.692199707 209.692199707 209.692199707 209.692199707 209.692199707 209.692199707 209.692199707 209.692199707 209.692199707 209.692199707 209.692199707 209.692199707 209.692199707 209.692199707209.692199707 209.692199707209.692199707 209.692199707 209.692199707209.692199707209.692199707209.692199707209.692199707 77.110626220728 .73767471313 -2.34269165993 -9999 -9999-9999 -9999 -9999 -9999 -9999 -9999 -9999-9999

-9999 -9999 -9999 -9999 -9999 -9999 -9999 -9999 -9999 -9999 -9999 -9999 -9999 -9999 -9999 -9999 -9999 -9999 -9999 -9999 -9999 -9999 -9999 -9999 -9999 -9999 -9999 -9999 -9999 -9999 -9999 -9999-9999 -9999-9999-9999-9999 345.4754943848 336.6112365723327 .3392028809 319.4147949219313 .0143127441308 .4425048828305 .3947143555303 .8707885742 302.6516113281302 .0421142578301 .7373046875301 .4324951172300 .5180969238 298.6893920898296 .5559082031293 .8128967285290 .7650146484286 .8027954102 282.2309875488277 .6592102051273 .0874938965268 .8204956055264 .8583068848 261.5056152344258 .1530151367255 .1051025391252 .6669006348250 .2286071777 248.7046966553247 .7902984619250 .8381958008253 .8860015869256 .9338989258 259.9816894531263 .3344116211267 .2966003418270 .3443908691275 .5257873535 284.6693115234295 .3367919922305 .0899047852314 .5382080078323 .9866027832 340.1401977539347 .5965881348352 .4574890137354 .8230285645355 .5875244141 356.123260498357 .4842834473359 .7777709961362 .6651611328365 .4011535645 366.9700317383366 .5163574219362 .7850646973356 .5471801758348 .3958740234 339.0828552246323 .3770141602292 .2889099121259 .3721008301233 .7702026367 215.4830932617206 .0346984863203 .9011993408201 .4629974365200 .8533935547 200.2438049316199 .9389953613199 .6342926025199 .6342926025199 .6342926025 199.6342926025199 .9389953613199 .6342926025199 .329498291198 .7198944092 198.1103057861197 .500793457196 .891204834196 .2816009521195 .6721038818195 .0625 194.4528961182193 .233795166190 .795501709185 .9188995361178 .9089050293 180.1280059814181 .3471984863180 .432800293179 .8231964111184 .0901947021 
185.6141052246185 .0045928955184 .3950042725183 .7854003906183 .4806976318 184.0901947021185 .0045928955185 .9188995361186 .528503418186 .528503418 185.9188995361185 .3094024658184 .699798584184 .0901947021184 .0901947021 185.0045928955185 .9188995361187 .1381072998188 .3571929932189 .2716064453 189.5764007568189 .8811035156189 .8811035156190 .4907073975191 .1002960205 192.0146026611192 .9290008545193 .8433074951194 .7577056885195 .6721038818 195.9768066406196 .5863952637196 .5863952637196 .891204834196 .5863952637 196.5863952637 196.2816009521 196.2816009521 195.9768066406195.6721038818 195.3672943115195 .3672943115195 .0625195 .0625195 .3672943115195 .3672943115 195.6721038818196 .2816009521196 .891204834197 .500793457198 .1103057861 198.7198944092199 .329498291199 .9389953613200 .5485992432201 .158203125 201.4629974365201 .4629974365200 .8533935547199 .9389953613198 .4151000977 196.5863952637194 .4528961182192 .0146026611189 .8811035156187 .4429016113 185.3094024658183 .1759033203181 .6519012451180 .432800293178 .9089050293 177.3849029541175 .8609924316174 .337097168172 .8132019043171 .5939941406 170.3748931885169 .1557006836167 .9365997314167 .0222015381166 .1078948975 165.4983062744164 .8887023926164 .5839996338164 .2792053223163 .974395752 163.974395752163 .974395752163 .974395752163 .974395752163 .6696014404 163.3648071289162 .4505004883161 .8408966064161 .8408966064161 .8408966064 161.8408966064160 .3170013428158 .7929992676157 .2691040039156 .6596069336 156.6596069336156 .9642944336157 .2691040039157 .2691040039157 .2691040039 157.2691040039156 .9642944336156 .9642944336156 .6596069336156 .9642944336 156.9642944336157 .2691040039157 .2691040039157 .2691040039157 .5738983154 157.5738983154157 .878692627158 .1835021973158 .1835021973158 .4882965088 158.7929992676158 .7929992676157 .5738983154156 .3547973633155 .1356048584 153.3069000244151 .1734008789148 .4304046631145 .6873016357142 .6394042969 140.2012023926138 .3724975586137 .4580993652137 .4580993652138 .0677032471 138.6772003174139 .8963928223141 .1154937744142 .3347015381143 .2489929199 144.1634063721145 .0776977539145 .6873016357145 .9920959473146 .2969055176 146.2969055176146 .2969055176145 .9920959473145 .9920959473145 .9920959473 145.6873016357145 .6873016357145 .6873016357145 .6873016357145 .9920959473 145.9920959473146 .2969055176146 .6015930176146 .9064025879147 .2111968994 147.5160064697148 .1255950928148 .7351074219149 .0399017334149 .6495056152 150.5639038086151 .1734008789151 .7830047607151 .7830047607152 .0877990723 152.0877990723152 .0877990723152 .3925933838152 .0877990723150 .8686065674 149.6495056152148 .1255950928146 .2969055176144 .4682006836142 .6394042969 140.5059967041138 .3724975586136 .2389984131134 .1054992676131 .9720001221 129.8385009766127 .7050018311125 .8762969971124 .0475006104122 .8283996582 122.2188034058122 .2188034058123 .1332015991123 .43800354123 .1332015991 121.9140014648120 .3900985718124 .9618988037136 .2389984131149 .3446960449 163.6696014404177 .6896972656190 .4907073975201 .7678070068209 .692199707 209.692199707 209.692199707 209.692199707 209.692199707 209.692199707 209.692199707 209.692199707209.692199707 209.692199707 209.692199707 209.692199707209.692199707 209.692199707209 .692199707209 .692199707209 .692199707209 .692199707209 .692199707 209.692199707209 .692199707209 .692199707209 .692199707209 .692199707209 .692199707 209.692199707 209.692199707 209.692199707 209.692199707 209.692199707 209.692199707 
209.692199707 209.692199707 209.692199707 209.692199707209.692199707209.692199707 209.692199707209 .692199707209 .69219970776 .5010681152372 .23407745361 28.15198326111 -9999 -9999 -9999 -9999 -9999 -9999 -9999 -9999 -9999 -9999

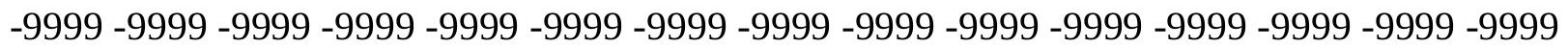

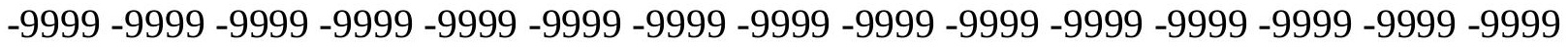
-9999 -9999 -9999 -9999 -9999 -9999 352.8651733398344 .5400695801335 .8731994629 326.4248962402316 .3670043945310 .2713012695306 .6138000488305 .0899047852 304.7850952148304 .1755981445303 .8707885742304 .4802856445304 .7850952148 305.3947143555303 .8707885742302 .3468017578300 .5180969238297 .7750854492 293.5080871582288 .6315002441283 .7549133301278 .5736083984274 .0018005371 269.4301147461265 .1630859375261 .5056152344257 .8482055664254 .8003997803 252.0572967529249 .6190032959248 .0950927734251 .4476928711255 .7147064209 259.9816894531263 .9439086914266 .6870117188270 .0396118164276 .1353149414 284.0596923828 293.2033081055 303.2611999512 313.0143127441325.2056884766 339.204864502 354.112121582 364.5197143555 368.6401062012367.6437072754 363.8443908691360 .2213439941358 .8012084961359 .2420349121359 .9547424316 359.8150939941358 .9490661621356 .4514160156351 .4040527344341 .6509399414 330.700958252320 .9388122559313 .3190917969281 .6214904785252 .9716033936 233.1605987549207 .8634033203202 .3773040771200 .8533935547200 .5485992432 200.5485992432200 .8533935547200 .8533935547200 .8533935547200 .5485992432 200.5485992432200 .5485992432200 .2438049316199 .9389953613199 .329498291 198.7198944092198 .1103057861197 .1959991455196 .5863952637195 .6721038818195 .0625 194.7577056885194 .1481018066193 .233795166191 .4051055908188 .3571929932 183.0886535645180 .6467590332180 .0932006836179 .899230957180 .584854126 182.606338501184 .0656280518184 .4017944336184 .047958374183 .4806976318 182.5662994385183 .4806976318184 .699798584186 .2236938477186 .8332977295 186.528503418185 .6141052246184 .699798584183 .7854003906183 .1759033203 182.87109375183 .7854003906184 .699798584185 .6141052246186 .8332977295 187.4429016113187 .4429016113187 .7476043701188 .0523986816188 .6620025635 189.5764007568 190.4907073975191.7097930908 192.624206543193.5386047363 194.4528961182194 .7577056885195 .0625195 .3672943115195 .3672943115195 .0625 195.0625194 .7577056885194 .4528961182194 .1481018066193 .5386047363193 .233795166 193.233795166192 .9290008545192 .9290008545192 .9290008545193 .233795166 193.5386047363194 .1481018066194 .7577056885195 .3672943115195 .9768066406 196.891204834197 .500793457198 .1103057861198 .4151000977198 .7198944092 199.0247039795198 .7198944092198 .4151000977197 .1959991455195 .9768066406 194.1481018066192 .0146026611190 .1858978271188 .0523986816186 .2236938477 184.0901947021181 .6519012451180 .432800293179 .5184020996178 .2993011475 177.0802001953175 .8609924316174 .6419067383173 .4226989746171 .8988037109 170.6797027588169 .7653045654168 .5462036133167 .6318054199167 .0222015381 166.1078948975165 .4983062744165 .1934967041164 .8887023926164 .5839996338 164.2792053223164 .2792053223164 .2792053223164 .2792053223164 .2792053223 163.6696014404162 .4505004883161 .5361022949161 .8408966064163 .6696014404 163.974395752162 .4505004883160 .6217956543159 .0977935791158 .1835021973 157.878692627157 .878692627157 .878692627157 .878692627157 .5738983154 157.2691040039156 .9642944336156 .6596069336156 .6596069336156 .6596069336 
156.6596069336156 .9642944336156 .9642944336156 .9642944336156 .9642944336 157.2691040039157 .5738983154157 .878692627158 .1835021973158 .4882965088 158.4882965088158 .4882965088157 .878692627156 .9642944336155 .7451934814 154.2212982178152 .0877990723149 .6495056152146 .9064025879144 .4682006836 142.3347015381140 .5059967041139 .5915985107138 .9819946289139 .2868041992 139.5915985107140 .5059967041141 .4203033447142 .3347015381142 .9441986084 143.8585968018144 .4682006836144 .7729034424145 .0776977539145 .3825073242 145.3825073242145 .3825073242145 .0776977539145 .0776977539144 .7729034424 144.7729034424144 .7729034424144 .7729034424144 .7729034424144 .7729034424 145.0776977539145 .0776977539145 .3825073242145 .6873016357145 .9920959473 146.6015930176147 .2111968994147 .8208007812148 .4304046631149 .0399017334 149.6495056152150 .2590942383150 .8686065674151 .1734008789151 .4781951904 151.7830047607151 .7830047607151 .7830047607151 .4781951904150 .2590942383 149.0399017334147 .5160064697145 .9920959473144 .1634063721142 .3347015381 140.5059967041138 .3724975586136 .5437011719134 .4102020264132 .2767028809 130.1432037354128 .0097961426126 .1809997559124 .6570968628123 .1332015991 122.5235977173122 .2188034058122 .2188034058122 .5235977173121 .9140014648 120.9997024536119 .4757995605128 .0097961426138 .9819946289151 .4781951904 165.1934967041178 .604095459190 .795501709201 .7678070068209 .692199707 209.692199707 209.692199707 209.692199707 209.692199707 209.692199707 209.692199707 209.692199707 209.692199707 209.692199707209.692199707 209.692199707209.692199707 209.692199707 209.692199707 209.692199707209.692199707 209.692199707209.692199707 209.692199707209 .692199707209 .692199707209 .692199707209 .692199707209 .692199707 209.692199707 209.692199707 209.692199707209.692199707 209.692199707 209.692199707 209.692199707 209.692199707 209.692199707 209.692199707 209.692199707 209.692199707 209.692199707 209.692199707 209.692199707 75.89148712158 71.92929077148 44.13599777222 -9999 -9999 -9999 -9999 -9999 -9999 -9999 -9999 -9999 -9999 -9999 -9999 -9999 -9999 -9999 -9999 -9999 -9999 -9999 -9999 -9999 -9999 -9999 -9999 -

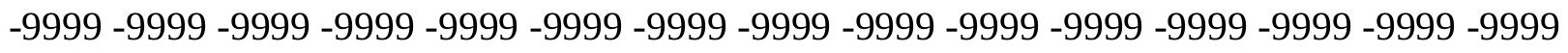
-9999 -9999 -9999 -9999 -9999 -9999 352.7752075195344 .3695373535335 .5683898926 326.1200866699316 .6718139648307 .2233886719304 .4802856445303 .8707885742 304.1755981445304 .4802856445305 .3947143555306 .3091125488307 .2233886719 307.8330078125307 .8330078125306 .9186096191306 .0043029785304 .4802856445 299.6037902832294 .7272033691289 .5458984375284 .0596923828279 .1831970215 274.3066101074 269.7348022461 265.1630859375261.2008972168 257.5433959961 254.1907958984251 .4476928711249 .3141937256250 .8381958008256 .3243103027 262.7247924805268 .5156860352270 .6492004395273 .6971130371282 .5357971191 292.8984985352300 .5180969238308 .1377868652316 .3670043945328 .116394043 344.3754577637360 .490234375371 .8416137695374 .8683776855369 .7311706543 360.5344238281352 .3708190918348 .2327880859347 .8534240723346 .9513549805 342.3637084961338 .0067138672332 .8252868652330 .3870849609313 .3190917969 301.7373046875291 .3746032715278 .8783874512260 .2864990234236 .5133056641 223.4075012207210 .9113006592204 .2059936523202 .0724945068201 .4629974365 201.7678070068202 .0724945068202 .0724945068202 .0724945068201 .7678070068 201.4629974365201 .158203125200 .8533935547200 .2438049316199 .329498291 198.7198944092197 .8054962158196 .891204834195 .9768066406195 .0625194 .4528961182 
194.1481018066193 .5386047363196 .891204834195 .3672943115191 .4051055908 186.2401885986182 .3323364258180 .4418640137180 .3492431641181 .2995605469 182.6550445557183 .905456543184 .578414917184 .4742431641183 .9827880859 183.6138153076184 .3203887939185 .989074707187 .4429016113187 .4429016113 186.528503418185 .3094024658184 .0901947021183 .1759033203182 .87109375 182.5662994385182 .87109375183 .4806976318184 .3950042725185 .0045928955 185.6141052246185 .6141052246185 .6141052246185 .9188995361186 .528503418 187.4429016113188 .966796875190 .1858978271191 .7097930908192 .624206543 193.233795166193 .8433074951193 .8433074951193 .8433074951193 .8433074951 193.5386047363193 .233795166192 .9290008545192 .624206543192 .0146026611 191.7097930908191 .4051055908191 .1002960205190 .795501709190 .795501709 190.795501709191 .1002960205191 .4051055908192 .0146026611192 .624206543 193.233795166 194.1481018066194.7577056885195.3672943115195.9768066406 196.2816009521196 .5863952637196 .5863952637196 .2816009521195 .6721038818 194.7577056885193 .233795166191 .7097930908189 .8811035156188 .0523986816 186.2236938477184 .699798584183 .4806976318181 .3471984863180 .1280059814 178.9089050293177 .9945068359176 .7754058838175 .8609924316174 .6419067383 173.4226989746172 .5084075928171 .2891998291170 .070098877169 .1557006836 168.241394043167 .3269958496166 .7174987793166 .1078948975165 .8031005859 165.1934967041164 .8887023926164 .8887023926164 .5839996338164 .5839996338 164.5839996338164 .2792053223163 .974395752163 .0599975586161 .2312927246 160.0122070312167 .3269958496166 .1078948975164 .2792053223162 .4505004883 160.9264984131160 .0122070312159 .4026031494159 .0977935791158 .7929992676 158.4882965088157 .878692627157 .5738983154157 .2691040039156 .9642944336 156.6596069336156 .6596069336156 .6596069336156 .6596069336156 .6596069336 156.6596069336156 .6596069336156 .9642944336156 .9642944336157 .2691040039 157.5738983154157 .878692627157 .878692627157 .878692627157 .5738983154 156.9642944336156 .0500030518154 .8307952881153 .3069000244150 .8686065674 148.4304046631146 .2969055176144 .1634063721142 .6394042969141 .7250976562 141.1154937744140 .8106994629140 .8106994629141 .4203033447141 .7250976562 142.3347015381142 .9441986084143 .5538024902144 .1634063721144 .4682006836 144.4682006836144 .7729034424144 .4682006836144 .4682006836144 .1634063721 144.1634063721143 .8585968018143 .8585968018143 .8585968018143 .8585968018 143.8585968018143 .8585968018143 .8585968018144 .1634063721144 .1634063721 144.4682006836145 .0776977539145 .6873016357145 .9920959473146 .6015930176 147.2111968994 148.1255950928 148.7351074219149.3446960449149.9542999268 150.2590942383150 .5639038086150 .8686065674150 .8686065674150 .8686065674 150.2590942383149 .6495056152148 .4304046631147 .2111968994145 .6873016357 144.1634063721142 .3347015381140 .5059967041138 .6772003174136 .5437011719 134.7149963379132 .5814971924130 .4479980469128 .6192932129126 .7906036377 124.9618988037123 .43800354122 .5235977173121 .9140014648121 .6092987061 121.3044967651120 .3900985718119 .4757995605122 .2188034058130 .4479980469 141.4203033447153 .9165039062167 .0222015381179 .8231964111191 .7097930908 201.7678070068209 .692199707209 .692199707209 .692199707209 .692199707 209.692199707209 .692199707209 .692199707209 .692199707209 .692199707209 .692199707 209.692199707 209.692199707 209.692199707 209.692199707 209.692199707 209.692199707 
209.692199707 209.692199707 209.692199707 209.692199707209.692199707209.692199707 209.692199707 209.692199707 209.692199707 209.692199707 209.692199707 209.692199707 209.692199707 209.692199707 209.692199707 209.692199707 209.692199707 209.692199707 209.692199707209 .692199707209 .692199707209 .692199707209 .692199707209 .692199707 75.2819290161171 .3197174072349 .15486526489 -9999 -9999 -9999 -9999 -9999 -9999 -9999 -9999 -9999 -9999

-9999 -9999 -9999 -9999 -9999 -9999 -9999 -9999 -9999 -9999 -9999 -9999 -9999 -9999 - 9999 - 9999 - 9999 -

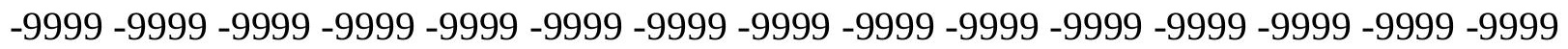
-9999 -9999 -9999 -9999 -9999 -9999 353.3707885742344 .8807373047335 .8731994629 326.7296142578317 .8908996582309 .0520935059302 .6516113281302 .9563903809 303.8707885742305 .0899047852306 .3091125488307 .5281982422309 .0520935059 309.9664916992310 .2713012695310 .2713012695309 .3569030762307 .8330078125 304.1755981445299 .9085998535294 .7272033691289 .5458984375284 .3645019531 279.1831970215274 .0018005371269 .1253051758264 .8583068848260 .5913085938 256.9338989258253 .5812072754250 .8381958008249 .0093994141253 .8860015869 264.8583068848274 .6113891602277 .0497131348279 .7927856445289 .2410888672 298.9942016602303 .8707885742306 .6138000488310 .5759887695318 .5004882812 335.5683898926351 .4172058105361 .475189209363 .303894043354 .4650878906 341.0545959473329 .1679077148321 .5483093262321 .5483093262320 .9388122559 310.5759887695296 .2510986328293 .5080871582286 .8027954102272 .7827148438 266.3822021484256 .9338989258246 .2664031982240 .4754943848229 .5032043457 219.7501068115213 .0447998047208 .1681976318205 .7299957275204 .5108032227 204.2059936523 204.2059936523 204.2059936523203.9011993408203.596496582 202.9868927002202 .0724945068201 .4629974365200 .5485992432199 .6342926025 198.4151000977197 .500793457196 .2816009521195 .3672943115194 .4528961182 193.8433074951193 .233795166192 .624206543192 .3193969727191 .7097930908 190.4907073975187 .7476043701183 .7854003906181 .3471984863181 .3471984863 182.261505127183 .3091430664184 .3534698486185 .1817474365185 .5175323486 184.8619384766184 .3782653809184 .8803405762186 .6644592285189 .2716064453 187.7476043701185 .9188995361184 .699798584183 .4806976318182 .87109375 182.5662994385182 .5662994385182 .5662994385182 .87109375183 .4806976318 184.0901947021184 .0901947021183 .4806976318183 .1759033203183 .4806976318 184.3950042725185 .6141052246187 .4429016113189 .2716064453190 .795501709 191.7097930908192 .3193969727192 .624206543192 .624206543192 .624206543 192.3193969727192 .0146026611191 .4051055908191 .1002960205190 .795501709 190.1858978271189 .8811035156189 .2716064453188 .966796875188 .6620025635 188.3571929932188 .3571929932188 .6620025635189 .2716064453189 .8811035156 190.4907073975191 .4051055908192 .0146026611192 .624206543193 .233795166 193.8433074951194 .1481018066194 .1481018066194 .1481018066193 .8433074951 193.233795166 192.3193969727 191.1002960205 189.5764007568 187.7476043701 185.9188995361184 .3950042725183 .4806976318182 .261505127181 .0424041748 179.8231964111178 .9089050293177 .9945068359176 .7754058838175 .8609924316 174.9467010498173 .7274932861172 .8132019043171 .5939941406170 .6797027588 169.7653045654168 .8509979248167 .9365997314167 .3269958496166 .7174987793 166.1078948975165 .8031005859165 .1934967041165 .1934967041164 .8887023926 164.8887023926164 .5839996338164 .2792053223163 .974395752163 .3648071289 
162.4505004883163 .0599975586165 .4983062744166 .1078948975165 .1934967041 163.6696014404162 .4505004883161 .5361022949160 .6217956543160 .0122070312 159.7073974609159 .0977935791158 .4882965088158 .1835021973157 .878692627 157.2691040039156 .9642944336156 .9642944336156 .6596069336156 .6596069336 156.6596069336156 .3547973633156 .3547973633156 .3547973633156 .6596069336 156.6596069336156 .9642944336156 .9642944336157 .2691040039157 .2691040039 156.9642944336156 .6596069336156 .0500030518155 .1356048584153 .6116943359 151.7830047607149 .6495056152147 .8208007812146 .2969055176144 .7729034424 143.5538024902142 .9441986084142 .3347015381142 .3347015381142 .3347015381 142.6394042969142 .9441986084143 .2489929199143 .5538024902143 .8585968018 143.8585968018144 .1634063721143 .8585968018143 .8585968018143 .5538024902 143.5538024902143 .2489929199142 .9441986084142 .9441986084142 .6394042969 142.6394042969142 .6394042969142 .6394042969142 .9441986084142 .9441986084 143.2489929199143 .5538024902143 .8585968018144 .4682006836145 .0776977539 145.6873016357146 .2969055176146 .9064025879147 .5160064697148 .4304046631 148.7351074219149 .3446960449149 .6495056152149 .9542999268149 .9542999268 149.9542999268149 .3446960449148 .7351074219147 .8208007812146 .6015930176 145.0776977539143 .8585968018142 .0299072266140 .5059967041138 .6772003174 136.8484954834135 .0198059082132 .8863067627131 .0576019287129 .2288970947 127.0953979492125 .5715026855123 .7427978516122 .5235977173121 .3044967651 120.6949005127120 .0852966309119 .1709976196117 .9517974854123 .1332015991 131.6672058105142 .6394042969155 .1356048584168 .5462036133181 .0424041748 192.3193969727201 .7678070068209 .692199707209 .692199707209 .692199707 209.692199707209 .692199707209 .692199707209 .692199707209 .692199707209 .692199707 209.692199707 209.692199707 209.692199707 209.692199707 209.692199707 209.692199707 209.692199707 209.692199707 209.692199707 209.692199707 209.692199707 209.692199707 209.692199707209 .692199707209 .692199707209 .692199707209 .692199707209 .692199707 209.692199707209 .692199707209 .692199707209 .692199707209 .692199707209 .692199707 209.692199707 209.692199707 209.692199707 209.692199707 209.692199707 209.692199707 209.692199707 74.6723632812571 .014930725148 .67092132568 -9999 -9999 -9999 -9999 -9999 -9999 -9999 -9999-9999-9999

-9999 -9999 -9999 -9999 -9999 -9999 -9999 -9999 -9999 -9999 -9999 -9999 -9999 -9999 -9999

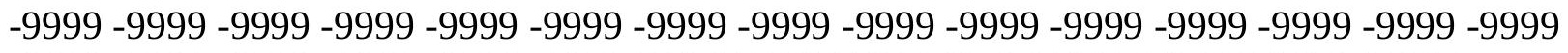
-9999 -9999 -9999 -9999-9999 -9999 354.6203308105346 .2359008789337 .0922851562 328.2536010742319 .7196044922311 .4903869629302 .9563903809303 .5660095215 304.7850952148306 .0043029785307 .5281982422309 .0520935059310 .5759887695 311.4903869629312 .1000061035312 .4047851562311 .7951965332310 .2713012695 307.8330078125304 .1755981445299 .6037902832294 .7272033691289 .2410888672 283.7549133301278 .5736083984273 .3923034668268 .5156860352263 .9439086914 259.9816894531256 .0195007324252 .9716033936250 .5334014893249 .6190032959 262.7247924805275 .5257873535278 .8783874512281 .0119018555289 .2410888672 296.2510986328296 .5559082031295 .6416015625295 .9464111328299 .2990112305 308.1377868652316 .6718139648318 .5004882812316 .0621948242313 .0143127441 306.0043029785293 .2033081055281 .0119018555273 .6971130371267 .2966003418 261.2008972168254 .4956054688258 .4577941895252 .6669006348238 .6468048096 234.0749969482224 .6266021729228 .2841033936228 .2841033936224 .6266021729 
219.7501068115215 .787902832213 .3495941162209 .9969024658208 .1681976318 207.25390625206 .9490966797206 .6443023682206 .0346984863205 .425201416 204.5108032227203 .2917022705202 .0724945068200 .8533935547199 .6342926025 198.4151000977196 .891204834195 .9768066406194 .7577056885193 .8433074951 192.9290008545192 .0146026611191 .4051055908190 .795501709190 .1858978271 188.6620025635186 .528503418185 .6141052246184 .699798584182 .261505127 182.87109375183 .7854003906184 .699798584185 .3094024658186 .8332977295 185.0045928955184 .0901947021184 .3950042725185 .3094024658186 .8332977295 186.528503418185 .0045928955183 .4806976318182 .87109375182 .5662994385 182.5662994385182 .5662994385182 .5662994385182 .87109375183 .1759033203 183.1759033203182 .87109375181 .6519012451181 .0424041748181 .0424041748 181.9566955566184 .0901947021186 .2236938477188 .3571929932190 .1858978271 191.1002960205191 .7097930908191 .7097930908191 .4051055908191 .1002960205 190.795501709190 .1858978271189 .8811035156189 .2716064453188 .966796875 188.3571929932188 .0523986816187 .4429016113187 .1381072998186 .8332977295 186.2236938477 186.2236938477 186.528503418 187.1381072998 187.7476043701 188.6620025635189 .2716064453190 .1858978271190 .795501709191 .4051055908 191.7097930908192 .0146026611192 .0146026611192 .0146026611191 .7097930908 191.1002960205190 .1858978271188 .966796875187 .4429016113185 .9188995361 184.3950042725182 .87109375182 .261505127181 .6519012451180 .7375946045 179.8231964111178 .9089050293177 .9945068359177 .0802001953176 .165802002 175.2514038086174 .0323028564173 .1179962158172 .2035980225170 .9844970703 170.070098877169 .1557006836168 .241394043167 .6318054199167 .0222015381 166.4127044678165 .8031005859165 .4983062744165 .1934967041164 .8887023926 164.8887023926164 .5839996338164 .5839996338164 .2792053223163 .6696014404 163.6696014404164 .2792053223165 .1934967041165 .8031005859165 .4983062744 164.5839996338163 .3648071289162 .4505004883161 .8408966064161 .2312927246 160.6217956543160 .0122070312159 .4026031494158 .7929992676158 .1835021973 157.878692627157 .5738983154157 .2691040039156 .9642944336156 .9642944336 156.6596069336156 .6596069336156 .3547973633156 .0500030518156 .0500030518 156.3547973633156 .0500030518156 .3547973633156 .3547973633156 .6596069336 156.6596069336156 .6596069336156 .3547973633155 .7451934814154 .2212982178 152.3925933838151 .1734008789149 .9542999268148 .4304046631146 .9064025879 145.6873016357144 .7729034424144 .1634063721143 .5538024902143 .5538024902 143.5538024902143 .5538024902143 .5538024902143 .5538024902143 .5538024902 143.5538024902143 .5538024902143 .5538024902143 .2489929199142 .9441986084 142.6394042969142 .3347015381142 .0299072266142 .0299072266141 .7250976562 141.7250976562141 .7250976562141 .7250976562141 .7250976562142 .0299072266 142.0299072266142 .6394042969142 .9441986084143 .5538024902144 .1634063721 144.7729034424145 .3825073242145 .9920959473146 .6015930176147 .2111968994 147.8208007812148 .1255950928148 .7351074219149 .0399017334149 .0399017334 148.7351074219148 .4304046631147 .8208007812146 .9064025879145 .9920959473 144.7729034424143 .5538024902142 .0299072266140 .5059967041138 .6772003174 137.1533050537135 .3246002197133 .4958953857131 .6672058105129 .533706665 127.7050018311125 .8762969971124 .3523025513122 .5235977173121 .3044967651 120.0852966309118 .8662033081117 .647102356116 .4279022217123 .1332015991 
131.3623962402 142.3347015381 154.8307952881 168.5462036133181.6519012451 192.0146026611200 .2438049316207 .8634033203209 .692199707209 .692199707 209.692199707 209.692199707 209.692199707 209.692199707 209.692199707 209.692199707 209.692199707209 .692199707209 .692199707209 .692199707209 .692199707209 .692199707 209.692199707209 .692199707209 .692199707209 .692199707209 .692199707209 .692199707 209.692199707 209.692199707 209.692199707 209.692199707 209.692199707 209.692199707 209.692199707 209.692199707 209.692199707 209.692199707 209.692199707209.692199707 209.692199707 209.692199707 209.692199707 209.692199707 209.692199707209.692199707 209.692199707 74.3675689697370 .4053573608442 .89408493042 -9999 -9999 -9999 -9999 -9999 -9999 -9999 -9999 -9999 -9999 -9999 -9999 -9999 -9999 -9999 -9999 -9999 -9999 -9999 -9999 -9999 -9999 -9999 -9999 -9999 -9999 -9999 -9999 -9999 -9999 -9999 -9999 -9999 -9999 -9999 -9999 -9999 -9999 -9999 -9999 -9999 -9999 -9999 -9999 -9999 364.386505127356 .4543151855348 .0646057129 339.5306091309330 .6918945312322 .4627075195314 .5382080078306 .9186096191 306.0043029785306 .9186096191308 .1377868652309 .6617126465310 .8807983398 312.1000061035313 .3190917969313 .9287109375313 .9287109375313 .6239013672 312.4047851562310 .2713012695307 .5281982422303 .8707885742299 .2990112305 293.8128967285288 .3266906738282 .8406066895277 .3544921875272 .1730957031 267.2966003418263.0296020508259.0674133301255.4098968506252.3621063232 249.9237976074251.1428985596259.0674133301264.5534973145 267.9060974121 270.0396118164269 .7348022461266 .6870117188263 .6390991211265 .1630859375 268.5156860352267 .6012878418266 .3822021484270 .0396118164271 .2587890625 264.2486877441256 .3243103027250 .8381958008246 .2664031982240 .7801971436 235.2940979004228 .2841033936231 .9414978027235 .5989074707234 .0749969482 227.9792938232222 .7978973389220 .9691925049222 .7978973389224 .0171051025 223.4075012207220 .9691925049218 .5308990479216 .3973999023213 .959197998 211.8256988525210 .6065063477209 .9969024658209 .3874053955208 .7778015137 207.5587005615206 .0346984863204 .5108032227202 .9868927002201 .158203125 199.6342926025198 .1103057861196 .5863952637195 .0625193 .8433074951192 .9290008545 192.0146026611191 .1002960205190 .1858978271189 .2716064453188 .0523986816 189.2716064453188 .3571929932187 .1381072998186 .2236938477182 .5662994385 182.87109375183 .1759033203184 .3950042725185 .3094024658185 .3094024658 184.0901947021182 .5662994385182 .5662994385183 .7854003906184 .699798584 184.699798584183 .7854003906182 .261505127182 .5662994385182 .5662994385 182.5662994385182 .87109375182 .87109375182 .87109375182 .87109375182 .5662994385 181.6519012451180 .1280059814178 .2993011475177 .9945068359179 .5184020996 182.261505127185 .6141052246188 .0523986816189 .8811035156190 .795501709 190.795501709190 .795501709190 .1858978271189 .5764007568188 .966796875 188.6620025635188 .0523986816187 .4429016113187 .1381072998186 .8332977295 186.528503418185 .9188995361185 .6141052246185 .0045928955184 .3950042725 184.0901947021184 .3950042725185 .0045928955185 .9188995361186 .8332977295 187.7476043701188 .3571929932188 .966796875189 .2716064453189 .8811035156 189.8811035156190 .1858978271189 .8811035156189 .5764007568188 .966796875 188.3571929932187 .1381072998185 .6141052246184 .0901947021183 .1759033203 182.261505127181 .6519012451181 .3471984863180 .7375946045179 .8231964111 179.2136993408 178.2993011475 177.3849029541 176.4705963135175.5561981201 
174.337097168 173.4226989746172.5084075928 171.2891998291170.3748931885 169.4604949951168 .5462036133167 .9365997314167 .0222015381166 .4127044678 166.1078948975165 .8031005859165 .1934967041165 .1934967041164 .8887023926 164.5839996338164 .5839996338164 .5839996338164 .2792053223164 .5839996338 164.8887023926165 .1934967041165 .4983062744165 .4983062744164 .8887023926 164.2792053223163 .6696014404162 .7552947998162 .1457061768161 .5361022949 160.6217956543160 .0122070312159 .4026031494158 .7929992676158 .1835021973 157.878692627157 .5738983154157 .2691040039157 .2691040039156 .9642944336 156.9642944336156 .6596069336156 .3547973633156 .0500030518155 .7451934814 155.7451934814155 .4403991699155 .7451934814156 .0500030518156 .3547973633 156.6596069336156 .9642944336156 .6596069336155 .7451934814154 .5260925293 153.3069000244151 .7830047607150 .5639038086149 .0399017334147 .8208007812 146.6015930176145 .6873016357145 .0776977539144 .7729034424144 .4682006836 144.1634063721143 .8585968018143 .8585968018143 .8585968018143 .5538024902 143.2489929199142 .9441986084142 .6394042969142 .3347015381141 .7250976562 141.4203033447141 .1154937744140 .8106994629140 .8106994629140 .5059967041 140.5059967041140 .5059967041140 .5059967041140 .8106994629141 .1154937744 141.4203033447142 .0299072266142 .3347015381142 .9441986084143 .5538024902 144.1634063721144 .7729034424145 .3825073242145 .9920959473146 .6015930176 147.2111968994147 .5160064697147 .8208007812147 .8208007812147 .8208007812 147.5160064697146 .9064025879146 .2969055176145 .3825073242144 .1634063721 142.9441986084141 .7250976562140 .2012023926138 .6772003174137 .1533050537 135.6293945312133 .8007049561131 .9720001221130 .1432037354128 .3144989014 126.4858016968124 .6570968628122 .8283996582121 .3044967651119 .4757995605 117.9517974854116 .4279022217114 .9039993286121 .3044967651129 .533706665 139.5915985107151 .7830047607165 .8031005859180 .432800293188 .966796875 196.891204834204 .5108032227209 .692199707209 .692199707209 .692199707 209.692199707 209.692199707 209.692199707 209.692199707 209.692199707 209.692199707 209.692199707 209.692199707 209.692199707 209.692199707 209.692199707 209.692199707 209.692199707 209.692199707 209.692199707 209.692199707 209.692199707 209.692199707 209.692199707209 .692199707209 .692199707209 .692199707209 .692199707209 .692199707 209.692199707 209.692199707 209.692199707 209.692199707 209.692199707 209.692199707 209.692199707 209.692199707 209.692199707 209.692199707 209.692199707 209.692199707 73.7580032348670 .1005783081134 .02592468262 -9999 -9999 -9999 -9999 -9999 -9999 -9999 -9999 -9999 -9999

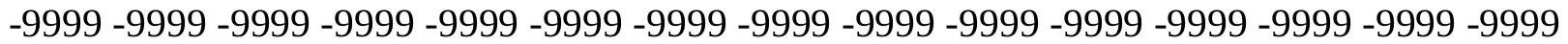

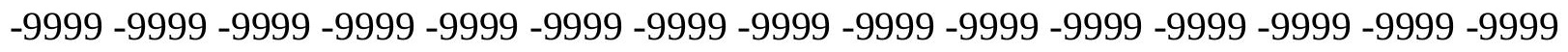
-9999 -9999 -9999 -9999 -9999 366.7768554688358 .9801330566350 .8077087402 342.2737121582334 .0444946289325 .8153076172318 .1957092285310 .8807983398 310.2713012695310 .5759887695311 .1856079102312 .4047851562313 .3190917969 314.2334899902315 .1477966309315 .4526062012315 .4526062012314 .8429870605 313.9287109375312 .4047851562310 .2713012695307 .5281982422302 .9563903809 298.0798950195292 .5936889648286 .8027954102281 .0119018555275 .8305053711 270.6492004395266 .0773925781262 .1152038574258 .1530151367254 .8003997803 252.0572967529249 .3141937256247 .4855041504246 .8759002686251 .1428985596 246.8759002686245 .6567993164246 .8759002686247 .1806945801245 .6567993164 
247.4855041504245 .6567993164240 .4754943848241 .0850067139240 .4754943848 238.6468048096234 .9893035889230 .4176025391226 .7601013184224 .0171051025 221.5787963867221 .883605957224 .0171051025226 .7601013184227 .3697052002 225.5410003662224 .0171051025223 .4075012207224 .0171051025224 .9313964844 224.6266021729223 .4075012207221 .2740020752219 .1405029297217 .0070037842 215.1782989502213 .959197998213 .0447998047212 .4351959229211 .2160949707 209.692199707207 .5587005615205 .7299957275203 .596496582201 .4629974365 199.329498291197 .500793457195 .9768066406194 .4528961182193 .233795166 192.0146026611191 .1002960205189 .8811035156188 .966796875187 .7476043701 188.3571929932188 .966796875188 .3571929932187 .7476043701182 .5662994385 182.5662994385182 .87109375184 .3950042725185 .3094024658185 .6141052246 185.6141052246184 .699798584183 .4806976318181 .9566955566182 .5662994385 183.1759033203183 .1759033203182 .87109375182 .261505127182 .261505127182 .87109375 182.87109375182 .87109375182 .87109375182 .87109375182 .87109375182 .261505127 181.0424041748178 .9089050293175 .5561981201174 .6419067383177 .0802001953 181.0424041748185 .0045928955188 .0523986816189 .8811035156190 .4907073975 190.1858978271189 .5764007568188 .966796875188 .0523986816187 .4429016113 186.8332977295186 .2236938477185 .9188995361185 .6141052246185 .3094024658 185.0045928955184 .699798584184 .3950042725184 .0901947021183 .1759033203 182.261505127182 .87109375183 .4806976318184 .3950042725185 .6141052246 186.2236938477 186.8332977295 187.1381072998 187.7476043701 187.7476043701 188.0523986816188 .0523986816188 .0523986816187 .7476043701187 .4429016113 186.528503418185 .6141052246184 .3950042725182 .87109375182 .5662994385 182.261505127181 .6519012451181 .3471984863181 .0424041748180 .432800293 179.5184020996178 .604095459177 .6896972656176 .7754058838175 .8609924316 174.6419067383173 .7274932861172 .5084075928171 .5939941406170 .6797027588 169.4604949951168 .8509979248167 .9365997314167 .3269958496166 .7174987793 166.1078948975165 .8031005859165 .1934967041165 .1934967041164 .8887023926 164.5839996338164 .5839996338164 .5839996338164 .5839996338164 .8887023926 164.8887023926165 .1934967041165 .4983062744165 .4983062744165 .1934967041 164.5839996338164 .2792053223163 .6696014404163 .0599975586162 .1457061768 161.2312927246160 .6217956543159 .7073974609159 .0977935791158 .4882965088 158.1835021973157 .878692627157 .878692627157 .5738983154157 .5738983154 157.5738983154157 .2691040039156 .9642944336156 .3547973633155 .7451934814 155.1356048584154 .8307952881155 .1356048584155 .4403991699156 .3547973633 157.2691040039157 .5738983154157 .878692627157 .5738983154156 .6596069336 155.4403991699154 .2212982178152 .6972961426151 .1734008789149 .6495056152 148.4304046631147 .5160064697146 .6015930176145 .9920959473145 .3825073242 144.7729034424144 .4682006836144 .1634063721143 .8585968018143 .5538024902 142.9441986084142 .6394042969142 .0299072266141 .7250976562141 .1154937744 140.8106994629140 .2012023926139 .8963928223139 .5915985107139 .5915985107 139.2868041992139 .2868041992139 .5915985107139 .5915985107139 .8963928223 140.5059967041140 .8106994629141 .4203033447142 .0299072266142 .3347015381 142.9441986084143 .5538024902144 .1634063721144 .7729034424145 .3825073242 145.9920959473146 .2969055176146 .6015930176146 .9064025879146 .9064025879 146.6015930176146 .2969055176145 .3825073242144 .7729034424143 .8585968018 
142.6394042969141 .4203033447140 .2012023926138 .6772003174137 .1533050537 135.6293945312134 .1054992676132 .5814971924130 .7528076172128 .9241027832 127.0953979492124 .9618988037123 .1332015991121 .3044967651119 .4757995605 117.647102356115 .818397522114 .2944030762118 .5614013672125 .5715026855 134.7149963379145 .9920959473158 .7929992676171 .5939941406181 .9566955566 191.4051055908199 .6342926025207 .5587005615209 .692199707209 .692199707 209.692199707 209.692199707 209.692199707 209.692199707 209.692199707 209.692199707 209.692199707 209.692199707 209.692199707 209.692199707 209.692199707 209.692199707 209.692199707 209.692199707 209.692199707 209.692199707 209.692199707 209.692199707 209.692199707209 .692199707209 .692199707209 .692199707209 .692199707209 .692199707 209.692199707 209.692199707 209.692199707 209.692199707 209.692199707209.692199707 209.692199707 209.692199707 209.692199707 209.692199707 209.692199707 209.692199707 209.692199707 69.49101257324 16.76901626587 -9999 -9999 -9999 -9999 -9999 -9999 -9999 -9999 -9999-9999

-9999 -9999 -9999 -9999 -9999 -9999 -9999 -9999 -9999 -9999 -9999 -9999 -9999 -9999 -9999

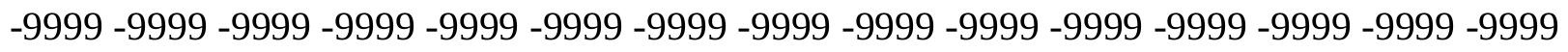
-9999 -9999 -9999 -9999 -9999 369.7742614746 362.1543579102354 .1603088379 345.9310913086337 .7019042969330 .0823059082322 .7674865723317 .5860900879 315.7573852539315 .4526062012315 .4526062012315 .7573852539316 .3670043945 316.6718139648316 .9765014648316 .9765014648316 .6718139648316 .0621948242 315.1477966309313 .6239013672311 .7951965332309 .3569030762305 .6994934082 301.1276855469295 .9464111328290 .1553955078284 .3645019531279 .1831970215 274.0018005371269 .4301147461265 .1630859375261 .2008972168257 .8482055664 254.8003997803251 .7525024414249 .3141937256247 .1806945801245 .0471954346 242.9136962891242 .3041992188241 .3898010254239 .5610961914237 .7324066162 236.5133056641234 .6844940186232 .5511016846231 .3318939209230 .1127929688 227.9792938232224 .9313964844222 .1884002686220 .6643981934220 .054901123 220.9691925049222 .4931030273224 .6266021729226 .7601013184227 .6744995117 227.9792938232227 .6744995117227 .6744995117227 .9792938232228 .2841033936 227.6744995117226 .4553985596224 .3218994141222 .1884002686220 .3596038818 218.5308990479216 .7021942139215 .4830932617214 .5686950684213 .6544036865 211.2160949707208 .7778015137206 .6443023682204 .2059936523201 .7678070068 199.329498291196 .891204834195 .0625193 .8433074951192 .624206543191 .4051055908 190.1858978271188 .966796875187 .7476043701186 .528503418188 .0523986816 188.3571929932188 .0523986816182 .5662994385183 .4806976318183 .7854003906 184.3950042725185 .0045928955185 .6141052246185 .9188995361185 .6141052246 185.0045928955183 .7854003906182 .261505127181 .6519012451182 .261505127 182.261505127 182.261505127 182.261505127 182.261505127 182.261505127 182.5662994385182 .5662994385182 .87109375182 .87109375182 .5662994385 181.9566955566180 .7375946045178 .9510345459175 .4936065674173 .6918792725 175.2514038086179 .5184020996184 .3950042725188 .6620025635189 .8811035156 189.5764007568188 .966796875188 .3571929932187 .4429016113186 .528503418 185.6141052246185 .0045928955184 .699798584184 .3950042725184 .0901947021 183.7854003906183 .7854003906183 .7854003906183 .7854003906183 .4806976318 182.87109375182 .261505127182 .261505127182 .5662994385183 .4806976318 184.3950042725185 .0045928955185 .6141052246185 .9188995361185 .9188995361 
186.2236938477 186.2236938477 186.528503418186.528503418 186.2236938477 185.9188995361185 .6141052246184 .699798584183 .7854003906182 .87109375 182.5662994385182 .261505127182 .261505127181 .9566955566181 .3471984863 180.7375946045180 .1280059814179 .2136993408178 .2993011475177 .0802001953 176.165802002174 .9467010498173 .7274932861172 .8132019043171 .5939941406 170.6797027588169 .7653045654168 .8509979248167 .9365997314167 .3269958496 166.4127044678166 .1078948975165 .4983062744165 .1934967041164 .8887023926 164.8887023926164 .5839996338164 .5839996338164 .5839996338164 .5839996338 164.8887023926164 .8887023926165 .1934967041165 .1934967041165 .1934967041 165.1934967041164 .8887023926164 .5839996338164 .2792053223163 .3648071289 162.4505004883161 .8408966064160 .9264984131160 .3170013428159 .4026031494 159.0977935791158 .4882965088158 .1835021973158 .1835021973158 .1835021973 158.4882965088158 .4882965088158 .1835021973157 .5738983154156 .6596069336 155.7451934814154 .8307952881154 .5260925293154 .5260925293155 .4403991699 156.6596069336157 .878692627158 .7929992676159 .0977935791159 .4026031494 158.7929992676157 .5738983154156 .0500030518154 .5260925293153 .0021057129 151.4781951904149 .9542999268148 .7351074219147 .8208007812146 .9064025879 146.2969055176145 .6873016357145 .0776977539144 .4682006836144 .1634063721 143.5538024902142 .9441986084142 .3347015381141 .7250976562141 .1154937744 140.5059967041139 .8963928223139 .2868041992138 .9819946289138 .6772003174 138.3724975586138.3724975586138.3724975586138.3724975586138.6772003174 138.9819946289139 .2868041992139 .8963928223140 .2012023926140 .8106994629 141.4203033447142 .0299072266142 .6394042969142 .9441986084143 .5538024902 144.1634063721144 .7729034424145 .3825073242145 .6873016357145 .9920959473 145.9920959473145 .6873016357145 .3825073242144 .7729034424144 .1634063721 143.2489929199142 .3347015381141 .1154937744139 .8963928223138 .6772003174 137.1533050537135 .9342041016134 .4102020264132 .8863067627131 .0576019287 129.2288970947 127.4001998901 125.5715026855123 .7427978516121 .6092987061 119.4757995605117 .342300415115 .2088012695113 .6848983765114 .9039993286 120.6949005127128 .3144989014138 .0677032471149 .3446960449161 .2312927246 173.1179962158184 .0901947021194 .1481018066203 .2917022705209 .692199707 209.692199707 209.692199707 209.692199707 209.692199707 209.692199707 209.692199707 209.692199707 209.692199707 209.692199707 209.692199707 209.692199707 209.692199707 209.692199707 209.692199707 209.692199707 209.692199707 209.692199707 209.692199707 209.692199707209 .692199707209 .692199707209 .692199707209 .692199707209 .692199707 209.692199707209 .692199707209 .692199707209 .692199707209 .692199707209 .692199707 209.692199707 209.692199707 209.692199707 209.692199707209.692199707 209.692199707 209.692199707 209.692199707 69.18623352051 7.821116924286 -9999 -9999 -9999 -9999 -9999 -9999 -9999 -9999-9999-9999 -9999 -9999 -9999 -9999 -9999 -9999 -9999 -9999 -9999 -9999 -9999 -9999 -9999 -9999 -9999

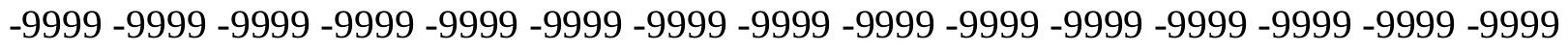
-9999 -9999 -9999-9999-9999 373.3774719238365 .9332885742358 .4273071289 350.1980895996342 .2737121582333 .7396850586328 .5584106445324 .5961914062 322.4627075195320 .9388122559320 .3291931152320 .0244140625319 .7196044922 319.7196044922319 .4147949219319 .1099853516318 .1957092285317 .2813110352 315.7573852539314 .2334899902312 .4047851562310 .2713012695307 .5281982422 
303.8707885742298 .6893920898292 .8984985352287 .4124145508281 .9262084961 277.0497131348272 .4779052734268 .5156860352264 .8583068848261 .5056152344 258.1530151367255 .4098968506252 .9716033936250 .2286071777247 .7902984619 245.3520050049243 .2185058594240 .7801971436238 .0372009277235 .5989074707 233.7702026367232 .8558044434231 .9414978027230 .4176025391228 .2841033936 225.2362060547222 .4931030273220 .9691925049221 .2740020752222 .7978973389 225.5410003662228 .2841033936230 .1127929688231 .3318939209231 .6367034912 232.246307373232 .246307373232 .5511016846232 .5511016846232 .246307373 231.0270996094229 .5032043457227 .6744995117225 .5410003662223 .4075012207 221.2740020752219 .4452972412217 .9214019775216 .0926971436214 .2639007568 212.1304016113209 .692199707207 .5587005615204 .8155975342201 .7678070068 199.0247039795196 .2816009521194 .4528961182192 .9290008545192 .0146026611 190.795501709189 .8811035156188 .6620025635187 .1381072998186 .8332977295 187.1381072998 187.4429016113 182.261505127 183.4806976318183.7854003906 184.0901947021184 .3950042725185 .0045928955185 .3094024658185 .6141052246 185.3094024658184 .699798584183 .7854003906182 .261505127181 .3471984863 181.6519012451181 .6519012451181 .6519012451181 .6519012451181 .9566955566 181.9566955566181 .9566955566182 .261505127182 .261505127182 .261505127 182.261505127181 .6519012451181 .3471984863180 .432800293174 .7991485596 171.8218078613173 .2562408447177 .4906616211182 .4366607666186 .6149291992 188.6620025635188 .0523986816187 .4429016113186 .528503418185 .3094024658 184.3950042725183 .7854003906183 .4806976318183 .1759033203182 .87109375 182.5662994385182 .5662994385182 .5662994385183 .1759033203183 .4806976318 183.1759033203182 .87109375181 .9566955566181 .9566955566182 .261505127 183.1759033203184 .0901947021184 .3950042725184 .3950042725184 .699798584 184.699798584184 .699798584184 .699798584184 .699798584185 .0045928955 185.0045928955185 .0045928955184 .699798584184 .0901947021183 .4806976318 183.1759033203182 .87109375182 .87109375182 .87109375182 .261505127181 .9566955566 181.3471984863180 .7375946045179 .5184020996178 .604095459177 .3849029541 176.165802002175 .2514038086174 .0323028564172 .8132019043171 .8988037109 170.6797027588169 .7653045654168 .8509979248167 .9365997314167 .0222015381 166.4127044678165 .8031005859165 .4983062744164 .8887023926164 .5839996338 164.5839996338164 .2792053223164 .2792053223164 .5839996338164 .5839996338 164.5839996338164 .8887023926165 .1934967041165 .1934967041165 .1934967041 165.1934967041165 .1934967041164 .8887023926164 .2792053223163 .6696014404 162.7552947998162 .1457061768161 .2312927246160 .6217956543160 .0122070312 159.4026031494158 .7929992676158 .4882965088158 .4882965088158 .7929992676 159.0977935791159 .4026031494159 .0977935791158 .4882965088157 .5738983154 156.0500030518154 .8307952881153 .9165039062154 .5260925293155 .7451934814 157.2691040039158 .7929992676159 .7073974609160 .6217956543160 .9264984131 160.9264984131159 .4026031494157 .5738983154156 .0500030518154 .5260925293 153.0021057129151 .4781951904150 .2590942383149 .0399017334148 .1255950928 147.2111968994146 .2969055176145 .6873016357145 .0776977539144 .4682006836 143.5538024902142 .9441986084142 .0299072266141 .4203033447140 .5059967041 139.8963928223139 .2868041992138 .3724975586138 .0677032471137 .4580993652 137.1533050537 137.1533050537 137.1533050537 137.1533050537 137.4580993652 
137.7628936768138 .3724975586138 .6772003174139 .2868041992139 .8963928223 140.5059967041141 .1154937744141 .4203033447142 .0299072266142 .6394042969 143.2489929199143 .8585968018144 .4682006836144 .7729034424145 .0776977539 145.0776977539144 .7729034424144 .4682006836144 .1634063721143 .5538024902 142.6394042969141 .7250976562140 .5059967041139 .5915985107138 .3724975586 137.1533050537 135.9342041016134.4102020264133.1911010742131.3623962402 129.533706665127 .7050018311125 .8762969971124 .0475006104122 .2188034058 119.7806015015117 .342300415115 .2088012695113 .3800964355112 .1608963013 115.2088012695120 .9997024536128 .9241027832138 .9819946289151 .1734008789 164.2792053223176 .7754058838188 .6620025635199 .0247039795208 .1681976318 209.692199707 209.692199707 209.692199707 209.692199707 209.692199707209.692199707 209.692199707 209.692199707 209.692199707 209.692199707 209.692199707 209.692199707 209.692199707 209.692199707 209.692199707 209.692199707 209.692199707209.692199707 209.692199707209 .692199707209 .692199707209 .692199707209 .692199707209 .692199707 209.692199707209 .692199707209 .692199707209 .692199707209 .692199707209 .692199707 209.692199707 209.692199707 209.692199707 209.692199707 209.692199707 209.692199707 209.692199707 209.69219970768 .881439208981 .684824824333 -9999 -9999 -9999-9999 -9999 -9999 -9999 -9999-9999-9999 -9999 -9999 -9999 -9999 -9999 -9999 -9999 -9999 -9999 -9999 -9999 -9999 -9999 -9999 -9999

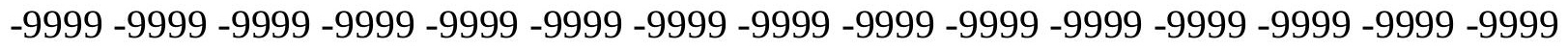
-9999-9999-9999-9999-9999 377.706237793 370.3139038086 362.9991149902 355.0747070312348 .0646057129341 .6640930176336 .4827880859332 .2157897949 329.1679077148327 .3392028809325 .8153076172324 .5961914062323 .9866027832 323.0722045898322 .4627075195321 .2434997559320 .0244140625318 .5004882812 316.6718139648314 .5382080078312 .4047851562310 .2713012695308 .1377868652 305.6994934082300 .2132873535294 .7272033691289 .5458984375284 .6693115234 279.7927856445275 .5257873535271 .8682861328268 .5156860352265 .4678039551 262.7247924805259 .9816894531257 .8482055664255 .7147064209253 .2763977051 250.8381958008248 .0950927734244 .7424926758241 .0850067139238 .3419952393 237.1228027344236 .8179931641236 .8179931641235 .5989074707232 .246307373 228.2841033936225 .5410003662224 .6266021729225 .8457946777228 .8936004639 233.4653930664 237.1228027344 237.7324066162 237.1228027344 236.5133056641 236.8179931641237 .1228027344237 .1228027344236 .8179931641235 .9037017822 234.6844940186232 .8558044434230 .7223052979228 .5888977051226 .4553985596 224.3218994141222 .1884002686220 .054901123217 .6165924072214 .8735046387 212.4351959229210 .6065063477208 .7778015137206 .0346984863202 .3773040771 198.7198944092195 .6721038818193 .5386047363192 .624206543191 .7097930908 190.795501709189 .8811035156188 .3571929932187 .1381072998185 .6141052246 186.2236938477182 .87109375182 .261505127183 .1759033203183 .4806976318 184.0901947021184 .3950042725184 .699798584185 .0045928955185 .0045928955 184.699798584184 .0901947021183 .1759033203181 .0424041748181 .0424041748 181.3471984863181 .3471984863181 .3471984863181 .3471984863181 .3471984863 181.3471984863181 .6519012451181 .6519012451181 .6519012451181 .6519012451 181.3471984863181 .0424041748180 .7375946045177 .3849029541172 .8132019043 168.8509979248171 .5939941406175 .5569152832180 .1410522461184 .1376800537 187.4510040283190 .1858978271186 .528503418184 .699798584183 .1759033203 
182.5662994385181 .9566955566181 .9566955566181 .6519012451181 .3471984863 181.3471984863181 .6519012451181 .9566955566182 .5662994385183 .1759033203 182.261505127181 .3471984863180 .7375946045181 .3471984863182 .261505127 183.1759033203183 .7854003906183 .7854003906183 .4806976318183 .4806976318 183.4806976318183 .1759033203183 .1759033203183 .4806976318183 .7854003906 184.0901947021184 .0901947021184 .0901947021183 .7854003906183 .4806976318 183.1759033203183 .1759033203183 .1759033203182 .87109375182 .87109375 182.5662994385181 .9566955566181 .0424041748179 .8231964111178 .604095459 177.3849029541176 .4705963135175 .2514038086174 .0323028564172 .8132019043 171.5939941406170 .6797027588169 .4604949951168 .5462036133167 .6318054199 166.7174987793166 .1078948975165 .4983062744165 .1934967041164 .5839996338 164.2792053223164 .2792053223163 .974395752163 .974395752164 .2792053223 164.2792053223164 .5839996338164 .5839996338164 .8887023926165 .1934967041 165.1934967041165 .1934967041164 .8887023926164 .8887023926164 .2792053223 163.6696014404163 .0599975586162 .1457061768161 .5361022949160 .9264984131 160.0122070312159 .4026031494159 .0977935791158 .7929992676158 .7929992676 159.4026031494160 .0122070312160 .6217956543160 .6217956543159 .7073974609 158.4882965088156 .9642944336155 .4403991699153 .9165039062155 .1356048584 156.6596069336158 .4882965088160 .0122070312160 .9264984131161 .8408966064 161.8408966064161 .5361022949160 .6217956543159 .0977935791157 .2691040039 155.7451934814154 .2212982178152 .6972961426151 .4781951904150 .2590942383 149.0399017334148 .1255950928147 .2111968994146 .2969055176145 .6873016357 144.7729034424143 .8585968018142 .9441986084142 .0299072266141 .1154937744 140.2012023926139 .2868041992138 .3724975586137 .7628936768137 .1533050537 136.5437011719136 .2389984131135 .9342041016135 .9342041016136 .2389984131 136.5437011719136 .8484954834137 .4580993652137 .7628936768138 .3724975586 138.9819946289139 .5915985107140 .2012023926140 .8106994629141 .1154937744 141.7250976562142 .3347015381142 .9441986084143 .5538024902143 .8585968018 144.1634063721144 .1634063721144 .1634063721143 .8585968018143 .2489929199 142.6394042969142 .0299072266141 .1154937744140 .2012023926138 .9819946289 138.0677032471136 .8484954834135 .6293945312134 .4102020264133 .1911010742 131.6672058105129 .8385009766128 .0097961426126 .1809997559124 .3523025513 122.2188034058119 .7806015015117 .342300415114 .9039993286113 .075302124 111.8561019897111 .551399231113 .6848983765120 .3900985718129 .2288970947 142.0299072266156 .6596069336170 .9844970703184 .0901947021195 .6721038818 205.7299957275209 .692199707209 .692199707209 .692199707209 .692199707 209.692199707 209.692199707 209.692199707 209.692199707 209.692199707 209.692199707 209.692199707 209.692199707 209.692199707 209.692199707 209.692199707 209.692199707 209.692199707 209.692199707 209.692199707 209.692199707 209.692199707209.692199707 209.692199707209 .692199707209 .692199707209 .692199707209 .692199707209 .692199707 209.692199707 209.692199707 209.692199707 209.692199707 209.692199707 209.692199707 209.692199707 209.692199707 209.692199707 209.692199707 68.27187347412 -326263010502 -9999 -9999 -9999 -9999 -9999 -9999 -9999 -9999 -9999 -9999 -9999 -9999 -9999 -9999 -9999 -9999 -9999 -9999 -9999 -9999 -9999 -9999 -9999 -9999 -9999

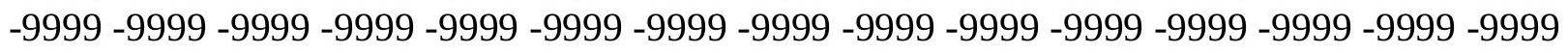
-9999 -9999 -9999 -9999 -9999 382.8088684082 376.104888916369 .0947875977 
362.0846862793355 .379486084349 .2838134766344 .1023864746339 .8353881836 336.4827880859333 .7396850586331 .6062011719330 .0823059082328 .5584106445 327.0344848633325 .5104980469323 .9866027832322 .1578979492319 .7196044922 317.2813110352314 .8429870605312 .1000061035309 .6617126465306 .9186096191 304.1755981445300 .2132873535295 .9464111328291 .0697937012286 .8027954102 282.5357971191278 .5736083984275 .2210083008272 .4779052734269 .7348022461 267.6012878418265 .7726135254264 .2486877441262 .7247924805260 .8960876465 259.0674133301256 .3243103027252 .6669006348248 .7046966553244 .7424926758 244.1329040527244 .1329040527244 .4376983643244 .7424926758238 .6468048096 234.0749969482231 .3318939209230 .7223052979232 .246307373235 .5989074707 240.7801971436246 .5711975098243 .8280944824241 .6945953369240 .7801971436 240.7801971436241 .0850067139241 .0850067139240 .4754943848239 .2563018799 237.7324066162235 .9037017822234 .0749969482231 .9414978027229 .8079986572 227.6744995117225 .2362060547222 .7978973389219 .7501068115216 .3973999023 212.7400054932212 .4351959229211 .2160949707207 .8634033203203 .596496582 199.0247039795195 .3672943115193 .5386047363192 .9290008545192 .3193969727 191.7097930908190 .4907073975188 .966796875187 .4429016113185 .9188995361 184.3950042725183 .1759033203182 .261505127182 .261505127182 .261505127 183.7854003906184 .0901947021184 .0901947021184 .3950042725184 .3950042725 184.0901947021183 .4806976318182 .5662994385181 .0424041748181 .0424041748 181.0424041748181 .0424041748181 .0424041748181 .0424041748181 .0424041748 181.0424041748180 .7375946045180 .7375946045180 .7375946045180 .432800293 180.1280059814179 .2136993408177 .6896972656175 .2514038086172 .2035980225 170.3748931885171 .2891998291174 .0323028564178 .4418792725181 .7109069824 184.0342559814186 .160446167186 .2236938477181 .6519012451181 .3471984863 181.0424041748180 .7375946045180 .432800293180 .1280059814180 .1280059814 180.1280059814180 .432800293180 .7375946045181 .6519012451182 .5662994385 180.432800293178 .604095459178 .604095459179 .8231964111181 .3471984863 183.1759033203183 .1759033203182 .87109375182 .5662994385182 .5662994385 182.261505127182 .261505127182 .261505127182 .5662994385183 .1759033203 183.4806976318183 .7854003906183 .7854003906183 .7854003906183 .4806976318 183.4806976318183 .4806976318183 .4806976318183 .1759033203182 .5662994385 182.87109375182 .5662994385181 .3471984863180 .1280059814178 .604095459 177.3849029541176 .165802002175 .2514038086174 .0323028564172 .8132019043 171.5939941406170 .3748931885169 .4604949951168 .241394043167 .3269958496 166.4127044678165 .8031005859165 .1934967041164 .5839996338164 .2792053223 163.974395752163 .6696014404163 .6696014404163 .6696014404163 .6696014404 163.974395752163 .974395752164 .2792053223164 .5839996338164 .8887023926 164.8887023926164 .8887023926164 .8887023926164 .5839996338164 .2792053223 163.6696014404163 .0599975586162 .4505004883161 .5361022949160 .9264984131 160.3170013428159 .7073974609159 .0977935791159 .0977935791159 .0977935791 159.7073974609160 .6217956543161 .5361022949161 .8408966064161 .2312927246 160.0122070312158 .1835021973156 .9642944336156 .0500030518156 .6596069336 158.1835021973159 .7073974609161 .2312927246162 .1457061768162 .4505004883 162.7552947998162 .1457061768161 .2312927246160 .0122070312158 .4882965088 156.9642944336155 .4403991699153 .9165039062152 .6972961426151 .1734008789 
149.9542999268149 .0399017334148 .1255950928147 .2111968994145 .9920959473 145.0776977539144 .1634063721143 .2489929199142 .0299072266141 .1154937744 139.8963928223138 .9819946289137 .7628936768136 .8484954834136 .2389984131 135.6293945312135 .0198059082135 .0198059082135 .0198059082135 .0198059082 135.3246002197135 .9342041016136 .5437011719136 .8484954834137 .4580993652 138.0677032471138 .6772003174139 .2868041992139 .8963928223140 .5059967041 141.1154937744141 .7250976562142 .3347015381142 .9441986084143 .2489929199 143.5538024902143 .5538024902143 .2489929199143 .2489929199142 .6394042969 142.0299072266141 .4203033447140 .5059967041139 .5915985107138 .6772003174 137.4580993652136 .2389984131135 .3246002197134 .1054992676132 .8863067627 131.3623962402129 .533706665128 .0097961426126 .1809997559124 .3523025513 122.2188034058120 .0852966309117 .342300415114 .9039993286112 .7705001831 111.24659729110 .9418029785112 .7705001831117 .647102356126 .4858016968 138.3724975586152.3925933838167.6318054199181.6519012451 193.8433074951 204.5108032227209 .692199707209 .692199707209 .692199707209 .692199707 209.692199707 209.692199707 209.692199707 209.692199707 209.692199707 209.692199707 209.692199707 209.692199707 209.692199707 209.692199707 209.692199707209.692199707 209.692199707 209.692199707 209.692199707 209.692199707 209.692199707 209.692199707 209.692199707209 .692199707209 .692199707209 .692199707209 .692199707209 .692199707 209.692199707 209.692199707 209.692199707209.692199707 209.692199707 209.692199707 209.692199707 209.692199707209.692199707209.692199707 67.96708679199 -0.4126072824 -9999 -9999 -9999 -9999 -9999 -9999 -9999 -9999 -9999 -9999 -9999 -9999 -9999 -9999 -9999 -9999 -9999 -9999 -9999 -9999 -9999 -9999 -9999 -9999 -9999

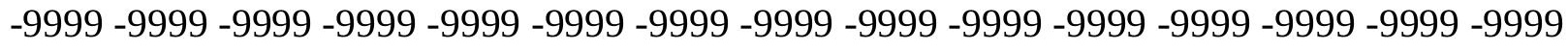
-9999 -9999-9999-9999-9999 388.4240112305 382.200592041375 .495300293 369.0947875977 362.9991149902357 .208190918352 .3316040039347 .7597961426 344.1023864746341 .0545959473338 .3114929199335 .8731994629333 .7396850586 331.6062011719329 .4726867676327 .0344848633324 .5961914062321 .8530883789 318.5004882812315 .4526062012312 .1000061035308 .4425048828305 .3947143555 302.6516113281299 .6037902832296 .2510986328292 .2889099121288 .6315002441 284.9740905762281 .6214904785278 .8783874512276 .4400939941274 .3066101074 273.0874938965271 .8682861328271 .2587890625270 .9540100098270 .3443908691 269.4301147461266 .9917907715263 .6390991211259 .6769104004256 .0195007324 253.8860015869253 .2763977051252 .3621063232249 .9237976074245 .0471954346 241.3898010254238.9515075684238.0372009277238.9515075684241.9994049072 245.6567993164248 .0950927734247 .1806945801244 .4376983643244 .1329040527 244.4376983643244 .4376983643244 .7424926758243 .5233001709242 .3041992188 240.7801971436239 .2563018799237 .1228027344235 .2940979004233 .4653930664 231.3318939209228 .8936004639226 .150604248222 .7978973389219 .4452972412 216.7021942139215 .4830932617214 .8735046387210 .3016967773205 .7299957275 200.5485992432195 .6721038818195 .3672943115195 .0625194 .1481018066192 .9290008545 191.7097930908 189.8811035156188.3571929932186.528503418185.0045928955 183.7854003906182 .87109375182 .87109375182 .87109375182 .87109375182 .87109375 182.87109375183 .4806976318183 .4806976318183 .1759033203182 .5662994385 181.3471984863181 .0424041748181 .0424041748180 .7375946045180 .7375946045 180.7375946045180 .7375946045180 .7375946045180 .432800293180 .1280059814 
179.8231964111179 .5184020996179 .2136993408178 .604095459177 .6896972656 176.165802002174 .0323028564172 .2035980225171 .2891998291171 .8988037109 174.337097168177 .6896972656179 .5184020996178 .9089050293181 .9566955566 182.5662994385181 .0424041748179 .8231964111179 .5184020996179 .2136993408 178.9089050293178 .9089050293178 .604095459178 .604095459178 .9089050293 179.2136993408179 .5184020996179 .2136993408177 .3849029541175 .2514038086 176.4705963135177 .9945068359179 .8231964111181 .0424041748181 .6519012451 181.6519012451181 .6519012451181 .3471984863181 .3471984863181 .6519012451 181.9566955566182 .261505127182 .5662994385183 .1759033203183 .4806976318 183.4806976318183 .4806976318183 .4806976318183 .4806976318183 .4806976318 183.4806976318183 .1759033203182 .87109375182 .261505127181 .9566955566 181.0424041748179 .8231964111178 .604095459177 .3849029541176 .165802002 174.9467010498173 .7274932861172 .5084075928171 .2891998291170 .3748931885 169.1557006836167 .9365997314167 .0222015381166 .1078948975165 .4983062744 164.8887023926164 .2792053223163 .6696014404163 .3648071289163 .3648071289 163.3648071289163 .3648071289163 .3648071289163 .3648071289163 .6696014404 163.974395752164 .2792053223164 .5839996338164 .8887023926164 .8887023926 164.8887023926164 .5839996338163 .974395752163 .6696014404163 .0599975586 162.1457061768161 .5361022949160 .9264984131160 .6217956543159 .7073974609 159.0977935791158 .7929992676159 .0977935791160 .0122070312161 .2312927246 162.4505004883163 .3648071289162 .4505004883161 .2312927246160 .0122070312 158.7929992676158 .1835021973158 .4882965088159 .7073974609160 .9264984131 162.1457061768162 .7552947998163 .0599975586163 .0599975586162 .7552947998 161.8408966064160 .6217956543159 .4026031494157 .878692627156 .3547973633 155.1356048584153 .6116943359152 .3925933838151 .1734008789149 .9542999268 148.7351074219147 .8208007812146 .9064025879145 .6873016357144 .4682006836 143.5538024902142 .3347015381141 .1154937744139 .8963928223138 .6772003174 137.4580993652136 .2389984131135 .3246002197134 .7149963379134 .1054992676 133.8007049561133 .8007049561134 .1054992676134 .4102020264135 .0198059082 135.6293945312136 .2389984131136 .8484954834137 .4580993652138 .0677032471 138.6772003174139 .2868041992139 .8963928223140 .5059967041141 .1154937744 141.7250976562142 .3347015381142 .6394042969142 .6394042969142 .9441986084 142.6394042969142 .3347015381142 .0299072266141 .4203033447140 .8106994629 139.8963928223138 .9819946289138 .0677032471136 .8484954834135 .9342041016 134.7149963379133 .4958953857132 .2767028809130 .7528076172129 .533706665 127.7050018311126 .1809997559124 .6570968628122 .5235977173120 .3900985718 117.647102356114 .9039993286112 .1608963013110 .6370010376110 .0273971558 111.24659729114 .9039993286122 .5235977173135 .6293945312151 .1734008789 166.7174987793181 .0424041748193 .5386047363204 .2059936523209 .692199707 209.692199707209 .692199707209 .692199707209 .692199707209 .692199707209 .692199707 209.692199707209 .692199707209 .692199707209 .692199707209 .692199707209 .692199707 209.692199707209 .692199707209 .692199707209 .692199707209 .692199707209 .692199707 209.692199707209.692199707 209.692199707 209.692199707 209.692199707209.692199707 209.692199707209 .692199707209 .692199707209 .692199707209 .692199707209 .692199707 209.692199707209 .692199707209 .692199707209 .692199707209 .692199707209 .692199707 209.692199707 67.66230010986. 1162604689598 -9999 -9999 -9999 -9999 -9999 -9999 -9999 
-9999 -9999 -9999

-9999 -9999 -9999 -9999 -9999 -9999 -9999 -9999 -9999 -9999 -9999 -9999 -9999 -9999 -9999

-9999 -9999 -9999 -9999 -9999 -9999 -9999 -9999 -9999 -9999 -9999 -9999 -9999 -9999 -9999

-9999 -9999 -9999-9999 -9999 394.3477783203 388.296295166 382.200592041

376.4096069336370 .6187133789365 .132598877360 .2560119629355 .6842041016

351.7219848633348 .3693847656345 .0168151855342 .2737121582339 .5306091309

336.7875976562334 .0444946289330 .9966125488327 .6440124512324 .2914123535

320.6339111328316 .6718139648312 .7095031738308 .4425048828304 .1755981445

302.0421142578299 .6037902832296 .8606872559293 .5080871582290 .1553955078

287.1076049805284 .3645019531282 .2309875488280 .4023132324279 .1831970215 278.5736083984278 .2687988281278 .8783874512279 .4880065918280 .4023132324 280.7070922852279 .4880065918276 .4400939941272 .1730957031268 .2109069824 265.1630859375263 .0296020508260 .8960876465257 .5433959961253 .8860015869 249.9237976074247 .1806945801245 .9615936279245 .9615936279247 .4855041504 249.3141937256250.2286071777249.6190032959248.3999023438247.4855041504 247.4855041504247 .1806945801246 .8759002686246 .2664031982245 .0471954346 243.5233001709241 .9994049072240 .4754943848238 .6468048096236 .8179931641 234.9893035889232 .5511016846229 .8079986572226 .4553985596223 .1027069092 220.3596038818218 .2261962891215 .787902832212 .1304016113208 .4730072021 204.8155975342201 .7678070068199 .9389953613198 .4151000977196 .891204834195 .0625 193.233795166191 .4051055908189 .5764007568188 .0523986816186 .528503418 185.3094024658184 .3950042725183 .7854003906183 .7854003906183 .7854003906 183.4806976318183 .4806976318183 .1759033203182 .5662994385182 .261505127 181.9566955566181 .3471984863181 .0424041748181 .0424041748181 .0424041748 180.7375946045180 .7375946045180 .7375946045180 .432800293180 .1280059814 179.5184020996178 .9089050293178 .2993011475177 .6896972656177 .0802001953 176.165802002174 .6419067383173 .1179962158172 .2035980225171 .5939941406 172.2035980225173 .7274932861175 .5561981201176 .7754058838177 .6896972656 178.9089050293179 .5184020996179 .5184020996178 .9089050293178 .2993011475 177.9945068359177 .6896972656177 .3849029541177 .0802001953177 .0802001953 177.0802001953177 .0802001953176 .7754058838176 .165802002174 .9467010498 174.0323028564174 .6419067383176 .165802002177 .6896972656178 .9089050293 179.8231964111180 .1280059814180 .1280059814180 .432800293180 .432800293 180.7375946045181 .3471984863181 .9566955566182 .87109375182 .87109375 183.1759033203183 .4806976318183 .4806976318183 .4806976318183 .4806976318 183.7854003906183 .7854003906183 .1759033203182 .261505127181 .3471984863 180.7375946045179 .8231964111179 .2136993408177 .9945068359177 .0802001953 175.8609924316174 .6419067383173 .7274932861172 .5084075928171 .2891998291 170.070098877168 .8509979248167 .6318054199166 .7174987793165 .8031005859 164.8887023926164 .2792053223163 .6696014404163 .3648071289163 .0599975586 162.7552947998162 .7552947998162 .7552947998162 .7552947998163 .0599975586 163.0599975586163 .6696014404163 .974395752164 .2792053223164 .5839996338 164.5839996338164 .5839996338164 .2792053223163 .974395752163 .3648071289 162.7552947998162 .1457061768161 .5361022949160 .9264984131160 .0122070312 159.4026031494158 .7929992676158 .4882965088159 .0977935791160 .0122070312 161.2312927246162 .4505004883163 .3648071289163 .0599975586162 .4505004883 
161.2312927246160 .6217956543160 .3170013428160 .6217956543161 .2312927246 162.1457061768163 .0599975586163 .3648071289163 .6696014404163 .6696014404 163.0599975586162 .4505004883161 .2312927246160 .0122070312158 .7929992676 157.5738983154156 .0500030518154 .8307952881153 .3069000244152 .0877990723 150.8686065674149 .6495056152148 .7351074219147 .5160064697146 .2969055176 145.0776977539143 .8585968018142 .3347015381141 .1154937744139 .5915985107 138.3724975586137 .1533050537135 .6293945312134 .7149963379133 .8007049561 133.1911010742132 .8863067627132 .8863067627133 .1911010742133 .8007049561 134.1054992676134 .7149963379135 .6293945312136 .2389984131136 .8484954834 137.4580993652138 .0677032471138 .9819946289139 .5915985107140 .2012023926 140.8106994629141 .1154937744141 .7250976562142 .0299072266142 .3347015381 142.3347015381142 .0299072266141 .7250976562141 .4203033447140 .8106994629 140.2012023926139 .2868041992138 .3724975586137 .4580993652136 .5437011719 135.3246002197134 .1054992676132 .8863067627131 .6672058105130 .4479980469 128.9241027832127 .7050018311126 .1809997559124 .6570968628122 .8283996582 120.6949005127117 .647102356114 .5991973877111 .8561019897109 .7226028442 108.8082962036109 .4179000854114 .9039993286124 .9618988037138 .3724975586 153.3069000244168 .5462036133182 .5662994385194 .7577056885204 .8155975342 209.692199707209 .692199707209 .692199707209 .692199707209 .692199707209 .692199707 209.692199707 209.692199707 209.692199707209.692199707 209.692199707 209.692199707 209.692199707 209.692199707 209.692199707 209.692199707 209.692199707 209.692199707 209.692199707 209.692199707 209.692199707 209.692199707 209.692199707 209.692199707 209.692199707209 .692199707209 .692199707209 .692199707209 .692199707209 .692199707 209.692199707209 .692199707209 .692199707209 .692199707209 .692199707209 .692199707 209.692199707 209.692199707 67.35751342773 6939925551414 -9999-9999 -9999 -9999 -9999 -9999 -9999 -9999-9999 -9999 -9999 -9999 -9999 -9999 -9999 -9999 -9999 -9999 -9999 -9999 -9999 -9999 -9999 -9999 -9999

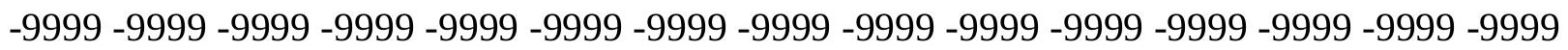
-9999 -9999 -9999 -9999 -9999 400.6536254883395 .0014953613389 .515411377 384.029296875378 .5430908203373 .3617858887368 .4851989746363 .9135131836 359.6465148926355 .9890136719352 .3316040039348 .9790039062345 .9310913086 342.5784912109338 .9211120605335 .5683898926331 .6062011719327 .6440124512 323.3770141602318 .8052062988314 .2334899902309 .9664916992306 .0043029785 302.9563903809300 .5180969238297 .4703063965294 .7272033691291 .9841918945 289.2410888672 287.1076049805 285.5835876465284.3645019531284.0596923828 284.0596923828284 .6693115234285 .8884887695287 .7171936035289 .8505859375 292.2889099121292 .5936889648289 .2410888672284 .0596923828279 .4880065918 275.8305053711272 .7827148438270 .0396118164266 .6870117188263 .0296020508 259.3721008301256 .3243103027253 .8860015869252 .9716033936252 .9716033936 252.9716033936252 .9716033936252 .3621063232251 .4476928711250 .5334014893 250.2286071777249 .6190032959249 .3141937256248 .3999023438247 .4855041504 246.2664031982244 .7424926758243 .2185058594241 .9994049072240 .4754943848 238.6468048096236 .5133056641233 .7702026367230 .4176025391226 .7601013184 223.4075012207220 .054901123217 .0070037842214 .2639007568211 .8256988525 209.9969024658208 .4730072021205 .7299957275202 .9868927002200 .2438049316 197.8054962158195 .3672943115193 .233795166191 .4051055908189 .5764007568 
188.3571929932187 .1381072998186 .2236938477185 .6141052246185 .3094024658 185.0045928955184 .699798584184 .3950042725183 .7854003906183 .4806976318 182.87109375182 .261505127181 .6519012451181 .3471984863181 .0424041748 181.0424041748181 .0424041748181 .0424041748180 .7375946045180 .432800293 179.8231964111178 .9089050293178 .2993011475177 .3849029541176 .4705963135 175.5561981201174 .6419067383173 .7274932861172 .5084075928171 .8988037109 171.5939941406172 .2035980225173 .1179962158174 .337097168175 .2514038086 176.4705963135177 .0802001953177 .6896972656177 .6896972656177 .3849029541 177.0802001953176 .4705963135176 .165802002175 .8609924316175 .5561981201 175.2514038086174 .9467010498174 .6419067383174 .337097168173 .7274932861 173.1179962158172 .8132019043173 .1179962158174 .337097168175 .5561981201 176.7754058838177 .6896972656178 .2993011475178 .9089050293179 .2136993408 179.5184020996180 .1280059814180 .7375946045181 .3471984863182 .261505127 182.5662994385183 .1759033203183 .1759033203183 .1759033203183 .1759033203 183.4806976318183 .4806976318183 .1759033203182 .87109375181 .0424041748 179.5184020996179 .2136993408178 .604095459178 .2993011475177 .3849029541 176.7754058838175 .5561981201174 .337097168173 .4226989746172 .2035980225 170.6797027588169 .4604949951168 .241394043167 .3269958496166 .1078948975 165.1934967041164 .2792053223163 .6696014404163 .0599975586162 .7552947998 162.4505004883162 .1457061768162 .1457061768162 .1457061768162 .4505004883 162.4505004883162 .7552947998163 .3648071289163 .6696014404163 .974395752 164.2792053223164 .5839996338164 .5839996338164 .2792053223163 .974395752 163.3648071289162 .7552947998162 .1457061768161 .2312927246160 .6217956543 159.7073974609158 .7929992676158 .1835021973158 .1835021973158 .4882965088 159.7073974609161 .2312927246162 .4505004883163 .3648071289163 .6696014404 163.3648071289162 .4505004883162 .1457061768161 .8408966064162 .1457061768 162.4505004883163 .0599975586163 .6696014404163 .974395752164 .2792053223 163.974395752163 .6696014404162 .7552947998161 .8408966064160 .9264984131 159.7073974609158 .4882965088156 .9642944336155 .7451934814154 .2212982178 153.0021057129151 .7830047607150 .8686065674149 .6495056152148 .4304046631 147.2111968994145 .6873016357144 .1634063721142 .9441986084141 .4203033447 139.8963928223138 .3724975586136 .8484954834135 .3246002197134 .1054992676 132.8863067627132 .2767028809131 .9720001221132 .2767028809132 .5814971924 133.1911010742133 .4958953857134 .1054992676135 .0198059082135 .6293945312 136.2389984131137 .1533050537137 .7628936768138 .3724975586138 .9819946289 139.5915985107140 .2012023926140 .8106994629141 .1154937744141 .4203033447 141.7250976562141 .7250976562141 .7250976562141 .4203033447140 .8106994629 140.5059967041139 .5915985107138 .9819946289138 .0677032471136 .8484954834 135.9342041016134 .7149963379133 .4958953857132 .2767028809131 .0576019287 129.8385009766128 .6192932129127 .4001998901125 .8762969971124 .3523025513 122.8283996582120 .3900985718117 .342300415113 .9896011353111 .24659729 109.1130981445108 .1986999512108 .8082962036117 .0374984741128 .0097961426 142.0299072266157 .2691040039171 .8988037109185 .3094024658196 .5863952637 206.0346984863209 .692199707209 .692199707209 .692199707209 .692199707 209.692199707209 .692199707209 .692199707209 .692199707209 .692199707209 .692199707 209.692199707209 .692199707209 .692199707209 .692199707209 .692199707209 .692199707 
209.692199707 209.692199707 209.692199707 209.692199707209.692199707209.692199707 209.692199707 209.692199707 209.692199707 209.692199707 209.692199707 209.692199707 209.692199707209 .692199707209 .692199707209 .692199707209 .692199707209 .692199707 209.692199707209 .692199707209 .692199707209 .69219970767 .05272674561 $1.150218725204-9999-9999-9999-9999-9999-9999-9999-9999-9999-9999$ -9999 -9999 -9999 -9999 -9999 -9999 -9999 -9999 -9999 -9999 -9999 -9999 -9999 -9999 - 9999 - 9999 - 9999 -

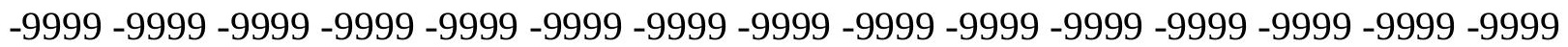
-9999 -9999 -9999 -9999-9999 407.3614807129 402.0115966797396.8302001953 391.6488952637386 .4674987793381 .591003418376 .7143859863372 .1426086426 367.8756103516363 .9135131836359 .9512023926356 .2937927246352 .6364135742 348.6741943359344 .7120056152340 .749786377336 .1780090332331 .6062011719 327.0344848633322 .1578979492317 .2813110352312 .7095031738308 .7473144531 305.0899047852302 .0421142578298 .9942016602295 .9464111328293 .5080871582 291.3746032715289 .8505859375288 .9363098145288 .6315002441288 .6315002441 289.2410888672290 .4602050781291 .9841918945294 .4223937988297 .1654968262 300.8229064941304 .1755981445298 .9942016602293 .8128967285289 .2410888672 285.5835876465282 .5357971191279 .7927856445276 .4400939941272 .7827148438 268.8204956055265 .1630859375262 .1152038574259 .9816894531258 .4577941895 257.5433959961256 .6290893555255 .7147064209254 .4956054688253 .5812072754 252.9716033936252 .0572967529251 .4476928711250 .5334014893249 .6190032959 248.3999023438247 .1806945801245 .9615936279244 .7424926758243 .5233001709 241.9994049072240 .1707000732237 .7324066162234 .3798065186230 .4176025391 226.150604248221 .883605957218 .2261962891215 .4830932617213 .959197998 213.6544036865214 .5686950684210 .3016967773206 .6443023682203 .2917022705 200.2438049316197 .8054962158195 .3672943115193 .233795166191 .7097930908 190.1858978271189 .2716064453188 .3571929932187 .7476043701187 .1381072998 186.528503418186 .2236938477185 .6141052246185 .0045928955184 .3950042725 183.7854003906183 .1759033203182 .261505127181 .3471984863181 .3471984863 181.3471984863181 .3471984863181 .3471984863181 .3471984863180 .432800293 179.5184020996178 .604095459177 .3849029541176 .4705963135175 .5561981201 174.6419067383173 .7274932861172 .8132019043171 .8988037109171 .5939941406 171.5939941406171 .8988037109172 .8132019043173 .7274932861174 .337097168 174.9467010498175 .5561981201175 .8609924316176 .165802002175 .8609924316 175.5561981201175 .2514038086174 .6419067383174 .337097168173 .7274932861 173.4226989746173 .1179962158172 .8132019043172 .2035980225171 .8988037109 171.2891998291171 .2891998291171 .8988037109172 .8132019043174 .0323028564 174.9467010498176 .165802002176 .7754058838177 .3849029541177 .9945068359 178.604095459179 .2136993408179 .8231964111180 .7375946045181 .3471984863 182.261505127182 .5662994385182 .87109375182 .87109375182 .5662994385 183.1759033203183 .4806976318182 .261505127180 .432800293178 .2993011475 177.3849029541177 .3849029541177 .3849029541177 .3849029541176 .7754058838 176.165802002175 .2514038086174 .0323028564172 .8132019043171 .5939941406 170.3748931885169 .1557006836167 .9365997314166 .7174987793165 .4983062744 164.5839996338163 .6696014404163 .0599975586162 .4505004883162 .1457061768 161.8408966064161 .5361022949161 .5361022949161 .8408966064161 .8408966064 162.1457061768162 .7552947998163 .0599975586163 .6696014404163 .974395752 
164.2792053223 164.2792053223 164.2792053223164.2792053223163.6696014404 163.0599975586162 .4505004883161 .8408966064160 .9264984131160 .3170013428 159.4026031494158 .4882965088157 .878692627157 .878692627158 .1835021973 159.7073974609161 .5361022949163 .0599975586163 .974395752164 .2792053223 164.2792053223163 .6696014404163 .3648071289163 .3648071289163 .6696014404 163.974395752164 .2792053223164 .5839996338164 .8887023926164 .8887023926 164.5839996338163 .974395752163 .3648071289162 .4505004883161 .5361022949 160.3170013428159 .4026031494158 .1835021973156 .9642944336155 .4403991699 154.2212982178153 .0021057129151 .7830047607150 .5639038086149 .3446960449 147.8208007812146 .2969055176144 .7729034424143 .2489929199141 .7250976562 139.8963928223138 .3724975586136 .8484954834135 .3246002197133 .8007049561 132.5814971924131 .3623962402131 .3623962402131 .6672058105132 .2767028809 132.5814971924133 .1911010742133 .8007049561134 .4102020264135 .0198059082 135.9342041016136 .5437011719137 .4580993652138 .0677032471138 .6772003174 139.2868041992139 .8963928223140 .5059967041140 .8106994629141 .1154937744 141.4203033447141 .1154937744141 .1154937744140 .8106994629140 .5059967041 139.8963928223139 .2868041992138 .3724975586137 .4580993652136 .2389984131 135.3246002197134 .1054992676132 .8863067627131 .6672058105130 .4479980469 129.2288970947 128.0097961426126.7906036377 125.5715026855124 .0475006104 122.2188034058119 .7806015015116 .7326965332113 .6848983765110 .9418029785 108.8082962036107 .8938980103109 .7226028442118 .5614013672130 .4479980469 145.0776977539161 .2312927246175 .8609924316188 .6620025635198 .4151000977 206.6443023682209 .692199707209 .692199707209 .692199707209 .692199707 209.692199707209 .692199707209 .692199707209 .692199707209 .692199707209 .692199707 209.692199707209 .692199707209 .692199707209 .692199707209 .692199707209 .692199707 209.692199707 209.692199707 209.692199707 209.692199707 209.692199707 209.692199707 209.692199707209 .692199707209 .692199707209 .692199707209 .692199707209 .692199707 209.692199707209 .692199707209 .692199707209 .692199707209 .692199707209 .692199707 209.692199707 209.692199707 209.692199707 209.692199707 66.74794006348 1.561469554901 -9999 -9999 -9999 -9999 -9999 -9999 -9999 -9999 -9999 -9999 -9999 -9999 -9999 -9999 -9999 -9999 -9999 -9999 -9999 -9999 -9999 -9999 -9999 -9999 -9999 -9999 -9999 -9999 -9999 -9999 -9999 -9999 -9999 -9999 -9999 -9999 -9999 -9999 -9999 -9999 -9999 -9999 -9999-9999-9999 414.4055786133409.4097290039404.4498901367 399.5733032227394 .696685791389 .8201904297385 .2484130859380 .6766052246 376.4096069336372 .1426086426368 .1803894043363 .9135131836359 .6465148926 355.379486084351 .112487793346 .5407104492341 .6640930176336 .7875976562 331.6062011719326 .4248962402321 .2434997559316 .3670043945311 .7951965332 307.8330078125304 .4802856445300 .8229064941297 .4703063965295 .0320129395 293.2033081055 292.2889099121291.9841918945292.5936889648293.2033081055 294.4223937988295 .6416015625297 .1654968262298 .9942016602301 .4324951172 304.4802856445305 .6994934082304 .1755981445300 .5180969238296 .8606872559 293.8128967285291 .3746032715288 .9363098145286 .1932067871282 .2309875488 277.9641113281273 .6971130371270 .0396118164266 .9917907715264 .5534973145 262.4200134277260 .5913085938259 .0674133301259 .9816894531261 .2008972168 259.9816894531257 .5433959961253 .5812072754252 .6669006348251 .4476928711 250.5334014893249 .6190032959248 .3999023438247 .4855041504246 .2664031982 
245.3520050049243 .5233001709241 .3898010254238 .0372009277233 .7702026367 228.2841033936223 .1027069092218 .5308990479215 .4830932617214 .2639007568 214.2639007568214 .2639007568212 .1304016113209 .0825958252205 .7299957275 202.6820983887199 .9389953613197 .500793457195 .6721038818194 .1481018066 192.624206543191 .4051055908190 .795501709189 .8811035156189 .2716064453 188.966796875188 .3571929932187 .4429016113186 .8332977295185 .6141052246 184.699798584183 .4806976318182 .5662994385181 .6519012451181 .3471984863 181.3471984863181 .6519012451181 .9566955566181 .9566955566181 .0424041748 179.5184020996178 .2993011475177 .0802001953175 .8609924316174 .9467010498 173.7274932861172 .8132019043172 .2035980225171 .5939941406171 .2891998291 171.5939941406171 .8988037109172 .5084075928173 .1179962158173 .4226989746 174.0323028564174 .337097168174 .6419067383174 .6419067383174 .337097168 174.0323028564173 .7274932861173 .1179962158172 .8132019043172 .2035980225 171.8988037109171 .2891998291170 .9844970703170 .6797027588170 .3748931885 170.070098877170 .070098877170 .6797027588171 .2891998291172 .5084075928 173.4226989746174 .337097168175 .2514038086176 .165802002176 .7754058838 177.3849029541178 .2993011475178 .9089050293179 .8231964111180 .432800293 181.3471984863181 .9566955566182 .5662994385182 .5662994385182 .87109375 183.1759033203183 .1759033203181 .0424041748178 .2993011475175 .2514038086 175.5561981201176 .165802002176 .4705963135176 .7754058838176 .4705963135 175.8609924316174 .9467010498173 .7274932861172 .5084075928171 .2891998291 170.070098877168 .8509979248167 .3269958496166 .1078948975164 .8887023926 163.974395752163 .0599975586162 .4505004883161 .8408966064161 .2312927246 160.9264984131160 .9264984131160 .9264984131161 .2312927246161 .5361022949 161.8408966064162 .4505004883162 .7552947998163 .3648071289163 .6696014404 164.2792053223164 .2792053223164 .2792053223164 .2792053223163 .6696014404 163.0599975586162 .4505004883161 .5361022949160 .9264984131160 .0122070312 159.0977935791158 .4882965088157 .878692627158 .1835021973159 .0977935791 160.6217956543162 .1457061768163 .6696014404164 .8887023926165 .1934967041 165.4983062744165 .1934967041164 .8887023926164 .8887023926164 .8887023926 165.1934967041165 .1934967041165 .4983062744165 .4983062744165 .4983062744 165.1934967041164 .5839996338163 .974395752163 .0599975586162 .1457061768 161.2312927246160 .3170013428159 .0977935791157 .878692627156 .6596069336 155.4403991699154 .2212982178153 .0021057129151 .7830047607150 .2590942383 148.7351074219147 .2111968994145 .3825073242143 .8585968018142 .0299072266 140.5059967041138 .6772003174137 .1533050537135 .6293945312134 .1054992676 132.8863067627131 .9720001221131 .6672058105131 .6672058105131 .9720001221 132.2767028809132 .8863067627133 .4958953857134 .1054992676134 .7149963379 135.6293945312136 .2389984131136 .8484954834137 .7628936768138 .3724975586 138.9819946289139 .5915985107140 .2012023926140 .5059967041140 .8106994629 140.8106994629140 .8106994629140 .8106994629140 .5059967041139 .8963928223 139.2868041992138 .6772003174137 .7628936768136 .8484954834135 .9342041016 134.7149963379133 .4958953857132 .2767028809131 .0576019287129 .8385009766 128.6192932129127 .4001998901126 .4858016968125 .2667007446123 .7427978516 121.6092987061119 .1709976196116 .4279022217113 .3800964355110 .6370010376 108.8082962036108 .1986999512109 .7226028442119 .1709976196131 .0576019287 
146.2969055176163 .3648071289179 .5184020996190 .1858978271198 .4151000977 206.0346984863209 .692199707209 .692199707209 .692199707209 .692199707 209.692199707209 .692199707209 .692199707209 .692199707209 .692199707209 .692199707 209.692199707209 .692199707209 .692199707209 .692199707209 .692199707209 .692199707 209.692199707209 .692199707209 .692199707209 .692199707209 .692199707209 .692199707 209.692199707 209.692199707 209.692199707 209.692199707 209.692199707 209.692199707 209.692199707209 .692199707209 .692199707209 .692199707209 .692199707209 .692199707 209.692199707 209.692199707 209.692199707 209.692199707 66.74794006348 2.178817749023 -9999 -9999 -9999 -9999 -9999 -9999 -9999 -9999 -9999 -9999 -9999 -9999 -9999 -9999 -9999 -9999 -9999 -9999 -9999 -9999 -9999 -9999 -9999 -9999 -9999 -9999 -9999 -9999 -9999 -9999 -9999 -9999 -9999 -9999 -9999 -9999 -9999 -9999 -9999 -9999 -9999 -9999 -9999 -9999-9999 421.6907043457417 .0050964355412 .3742980957 407.8024902344402 .9259033203398 .3541870117393 .782409668389 .2106018066 384.9436035156380 .6766052246376 .4096069336371 .837890625367 .570892334 362.9991149902358 .1224975586352 .941192627347 .7597961426342 .2737121582 336.7875976562331 .3013916016325 .8153076172320 .6339111328315 .7573852539 311.1856079102306 .6138000488302 .6516113281299 .2990112305296 .5559082031 295.3367919922294 .7272033691295 .3367919922296 .2510986328297 .7750854492 299.2990112305300 .5180969238301 .4324951172302 .3468017578303 .5660095215 304.7850952148306 .0043029785306 .3091125488304 .4802856445302 .3468017578 300.2132873535298 .6893920898297 .4703063965295 .0320129395291 .0697937012 286.1932067871281 .3167114258277 .0497131348273 .3923034668270 .0396118164 267.2966003418265 .1630859375264 .2486877441264 .8583068848264 .8583068848 264.2486877441262 .1152038574259 .6769104004256 .6290893555253 .5812072754 252.6669006348251 .4476928711250 .5334014893249 .6190032959248 .7046966553 247.7902984619246 .5711975098244 .7424926758241 .6945953369236 .8179931641 230.4176025391224 .0171051025218 .2261962891214 .2639007568212 .7400054932 213.0447998047213 .3495941162212 .4351959229210 .3016967773207 .5587005615 204.8155975342202 .0724945068199 .9389953613198 .1103057861196 .5863952637 195.3672943115194 .1481018066193 .5386047363192 .624206543192 .0146026611 191.4051055908190 .795501709189 .8811035156188 .966796875187 .7476043701 186.2236938477184 .699798584183 .1759033203181 .9566955566181 .3471984863 181.3471984863181 .9566955566182 .261505127182 .87109375181 .3471984863 179.5184020996177 .9945068359176 .7754058838175 .5561981201174 .6419067383 173.7274932861172 .8132019043171 .8988037109171 .2891998291171 .2891998291 171.5939941406171 .8988037109172 .2035980225172 .5084075928172 .8132019043 173.1179962158173 .4226989746173 .4226989746173 .1179962158172 .8132019043 172.5084075928172 .2035980225171 .5939941406170 .9844970703170 .6797027588 170.070098877169 .7653045654169 .4604949951169 .1557006836168 .8509979248 168.8509979248169 .1557006836169 .4604949951170 .070098877170 .9844970703 171.8988037109172 .8132019043173 .7274932861174 .6419067383175 .5561981201 176.165802002177 .0802001953177 .9945068359178 .604095459179 .5184020996 180.432800293181 .0424041748181 .6519012451181 .9566955566182 .261505127 182.5662994385181 .9566955566180 .1280059814177 .6896972656175 .8609924316 175.2514038086175 .8609924316176 .165802002176 .165802002175 .8609924316 175.5561981201174 .6419067383173 .4226989746172 .2035980225170 .9844970703 
169.7653045654168 .241394043167 .0222015381165 .4983062744164 .2792053223 163.3648071289162 .4505004883161 .5361022949160 .9264984131160 .6217956543 160.3170013428160 .3170013428160 .6217956543160 .6217956543161 .2312927246 161.5361022949162 .1457061768162 .7552947998163 .0599975586163 .6696014404 163.974395752164 .2792053223164 .2792053223164 .2792053223163 .6696014404 163.0599975586162 .1457061768161 .2312927246160 .6217956543160 .0122070312 159.4026031494158 .7929992676158 .7929992676159 .0977935791160 .0122070312 161.5361022949163 .3648071289164 .8887023926166 .1078948975166 .7174987793 166.7174987793166 .4127044678166 .1078948975166 .1078948975166 .1078948975 166.1078948975166 .1078948975166 .1078948975166 .1078948975166 .1078948975 165.8031005859165 .4983062744164 .5839996338163 .974395752162 .7552947998 162.1457061768161 .2312927246160 .3170013428159 .0977935791157 .878692627 156.6596069336155 .1356048584153 .9165039062152 .6972961426151 .1734008789 149.6495056152147 .8208007812146 .2969055176144 .4682006836142 .6394042969 140.8106994629139 .2868041992137 .4580993652135 .9342041016134 .4102020264 133.1911010742132 .5814971924131 .9720001221131 .9720001221131 .9720001221 132.2767028809132 .8863067627133 .1911010742133 .8007049561134 .4102020264 135.3246002197135 .9342041016136 .5437011719137 .4580993652138 .0677032471 138.9819946289139 .5915985107139 .8963928223140 .5059967041140 .5059967041 140.5059967041140 .5059967041140 .2012023926139 .8963928223139 .5915985107 138.9819946289138 .3724975586137 .4580993652136 .5437011719135 .3246002197 134.1054992676132 .8863067627131 .6672058105130 .1432037354128 .9241027832 128.0097961426126 .7906036377125 .8762969971124 .9618988037123 .43800354 121.3044967651118 .8662033081116 .1231002808113 .075302124110 .6370010376 109.1130981445108 .8082962036110 .3321990967118 .2565994263129 .533706665 143.5538024902160 .3170013428180 .1280059814186 .528503418194 .7577056885 203.2917022705 209.692199707 209.692199707 209.692199707 209.692199707 209.692199707209 .692199707209 .692199707209 .692199707209 .692199707209 .692199707 209.692199707 209.692199707 209.692199707 209.692199707 209.692199707 209.692199707 209.692199707 209.692199707 209.692199707 209.692199707 209.692199707 209.692199707 209.692199707209 .692199707209 .692199707209 .692199707209 .692199707209 .692199707 209.692199707209 .692199707209 .692199707209 .692199707209 .692199707209 .692199707 209.692199707 209.692199707 209.692199707 209.692199707 66.44316101074 3.493041753769 -9999 -9999 -9999 -9999 -9999 -9999 -9999 -9999 -9999 -9999 -9999 -9999 -9999 -9999 -9999 -9999 -9999 -9999 -9999 -9999 -9999 -9999 -9999 -9999 -9999 -9999 -9999 -9999 -9999 -9999 -9999 -9999 -9999 -9999 -9999 -9999 -9999 -9999 -9999 -9999 -9999 -9999 -9999 -9999-9999 429.136505127424.7006835938 420.2987060547 415.7268981934411 .155090332406 .5833129883402 .31640625398 .049407959 393.782409668389 .515411377384 .9436035156380 .3717956543375 .495300293 370.6187133789365 .4374084473360 .2560119629354 .4650878906348 .6741943359 342.8833007812337 .0922851562332 .2157897949325 .5104980469320 .0244140625 314.8429870605309 .6617126465305 .0899047852301 .1276855469298 .3846130371 297.1654968262297 .4703063965298 .3846130371299 .9085998535302 .0421142578 303.8707885742304 .7850952148305 .0899047852305 .3947143555305 .3947143555 304.4802856445306 .9186096191307 .8330078125307 .5281982422306 .6138000488 305.0899047852304 .7850952148304 .1755981445303 .2611999512298 .0798950195 
292.8984985352287 .7171936035283 .1453857422279 .1831970215275 .5257873535 272.1730957031269 .4301147461268 .2109069824268 .2109069824267 .9060974121 266.9917907715265 .4678039551263 .3344116211260 .8960876465257 .8482055664 254.4956054688253 .5812072754252 .3621063232251 .4476928711250 .5334014893 249.6190032959248 .7046966553247 .4855041504245 .3520050049239 .5610961914 232.5511016846225 .2362060547217 .9214019775212 .4351959229210 .9113006592 211.520904541212 .4351959229212 .7400054932211 .2160949707209 .0825958252 206.3394927979 204.2059936523 202.0724945068 200.5485992432 199.329498291 198.1103057861197 .1959991455196 .5863952637195 .9768066406195 .3672943115 194.7577056885194 .1481018066193 .233795166192 .0146026611190 .4907073975 188.6620025635186 .528503418184 .699798584183 .1759033203181 .9566955566 181.9566955566182 .261505127182 .5662994385182 .261505127181 .0424041748 179.5184020996177 .9945068359176 .7754058838175 .8609924316174 .9467010498 174.0323028564173 .1179962158172 .2035980225171 .5939941406171 .5939941406 171.5939941406171 .8988037109171 .8988037109172 .2035980225172 .2035980225 172.5084075928172 .2035980225172 .2035980225171 .8988037109171 .5939941406 170.9844970703170 .6797027588170 .070098877169 .4604949951169 .1557006836 168.5462036133168 .241394043167 .9365997314167 .6318054199167 .6318054199 167.6318054199167 .9365997314168 .241394043168 .8509979248169 .7653045654 170.6797027588171 .5939941406172 .5084075928173 .1179962158174 .0323028564 174.9467010498175 .8609924316176 .7754058838177 .3849029541178 .2993011475 179.2136993408179 .8231964111180 .432800293181 .0424041748181 .3471984863 181.3471984863180 .7375946045179 .5184020996177 .6896972656176 .4705963135 175.8609924316175 .8609924316176 .165802002176 .165802002175 .8609924316 175.2514038086174 .337097168173 .1179962158171 .8988037109170 .6797027588 169.1557006836167 .9365997314166 .4127044678165 .1934967041163 .6696014404 162.7552947998161 .5361022949160 .9264984131160 .3170013428159 .7073974609 159.7073974609159 .7073974609160 .0122070312160 .3170013428160 .6217956543 161.2312927246161 .8408966064162 .4505004883163 .0599975586163 .6696014404 163.974395752164 .2792053223164 .5839996338164 .2792053223163 .6696014404 162.7552947998161 .8408966064161 .2312927246160 .3170013428159 .7073974609 159.4026031494159 .0977935791159 .4026031494160 .0122070312161 .2312927246 162.7552947998164 .5839996338166 .1078948975167 .6318054199167 .9365997314 167.9365997314167 .6318054199167 .3269958496167 .3269958496167 .0222015381 167.0222015381167 .0222015381167 .0222015381166 .7174987793166 .7174987793 166.4127044678166 .1078948975165 .4983062744164 .8887023926163 .974395752 163.0599975586162 .1457061768161 .2312927246160 .0122070312158 .7929992676 157.5738983154156 .3547973633154 .8307952881153 .6116943359152 .0877990723 150.5639038086148 .7351074219146 .9064025879145 .0776977539143 .2489929199 141.4203033447139 .8963928223138 .0677032471136 .5437011719135 .0198059082 134.1054992676133 .1911010742132 .5814971924132 .2767028809132 .2767028809 132.5814971924132 .8863067627133 .1911010742133 .8007049561134 .4102020264 135.0198059082135 .6293945312136 .5437011719137 .1533050537137 .7628936768 138.6772003174139 .2868041992139 .8963928223140 .2012023926140 .2012023926 140.2012023926140 .2012023926139 .8963928223139 .5915985107139 .2868041992 138.6772003174137 .7628936768137 .1533050537135 .9342041016135 .0198059082 
133.8007049561132 .5814971924131 .0576019287129 .8385009766128 .3144989014 127.4001998901126 .1809997559125 .2667007446124 .6570968628123 .43800354 121.6092987061118 .8662033081116 .1231002808113 .075302124110 .9418029785 109.4179000854109 .1130981445110 .6370010376115 .5136032104125 .8762969971 138.0677032471150 .8686065674160 .6217956543177 .0802001953188 .966796875 199.0247039795207 .5587005615209 .692199707209 .692199707209 .692199707 209.692199707 209.692199707 209.692199707 209.692199707 209.692199707209.692199707 209.692199707 209.692199707 209.692199707 209.692199707 209.692199707 209.692199707 209.692199707 209.692199707 209.692199707 209.692199707 209.692199707 209.692199707 209.692199707 209.692199707 209.692199707 209.692199707 209.692199707 209.692199707 209.692199707 209.692199707 209.692199707 209.692199707 209.692199707 209.692199707 209.692199707209.692199707 209.692199707 209.69219970766 .44316101074 7.296219348907 -9999 -9999 -9999 -9999 -9999 -9999 -9999 -9999 -9999 -9999 -9999 -9999 -9999 -9999 -9999 -9999 -9999 -9999 -9999 -9999 -9999 -9999 -9999 -9999 -9999 -9999 -9999 -9999 -9999 -9999 -9999 -9999 -9999 -9999 -9999 -9999 -9999 -9999 -9999 -9999 -9999 -9999 -9999 -9999 -9999 -9999 432.4315795898428 .0927124023423 .6513061523 419.3843078613415 .1173095703411 .155090332406 .8882141113402 .6211853027 398.3541870117393 .782409668389 .2106018066384 .029296875378 .8479003906 373.666595459367 .8756103516362 .0846862793355 .9890136719349 .5885009766 344.7120056152338 .6163024902331 .9110107422324 .9009094238319 .1099853516 313.6239013672308 .1377868652303 .5660095215300 .5180969238299 .6037902832 300.5180969238302 .0421142578303 .8707885742306 .0043029785307 .5281982422 308.4425048828311 .7951965332315 .7573852539316 .9765014648310 .8807983398 309.3569030762 310.2713012695 310.5759887695310 .2713012695309 .6617126465 309.3569030762 308.4425048828 306.3091125488302.3468017578 297.4703063965 292.8984985352288 .3266906738284 .3645019531280 .4023132324276 .7449035645 273.3923034668271 .2587890625270 .6492004395270 .0396118164269 .1253051758 267.6012878418266 .0773925781263 .9439086914261 .5056152344259 .0674133301 256.3243103027254 .1907958984253 .2763977051252 .0572967529251 .1428985596 249.9237976074248 .3999023438245 .9615936279241 .3898010254235 .2940979004 227.6744995117219 .4452972412211 .2160949707210 .3016967773210 .9113006592 212.1304016113213 .3495941162211 .8256988525209 .9969024658207 .8634033203 206.0346984863204 .5108032227203 .2917022705202 .3773040771201 .4629974365 200.8533935547200 .2438049316199 .6342926025199 .0247039795198 .7198944092 197.8054962158196 .891204834195 .6721038818193 .8433074951192 .0146026611 189.5764007568187 .4429016113185 .0045928955183 .1759033203183 .1759033203 183.1759033203182 .87109375182 .261505127181 .0424041748179 .5184020996 178.2993011475177 .3849029541176 .4705963135175 .8609924316174 .9467010498 174.0323028564173 .1179962158172 .5084075928172 .2035980225172 .2035980225 172.2035980225172 .2035980225172 .2035980225172 .2035980225171 .8988037109 171.5939941406171 .2891998291170 .6797027588170 .3748931885169 .7653045654 169.1557006836168 .5462036133168 .241394043167 .6318054199167 .3269958496 167.0222015381166 .7174987793166 .4127044678166 .4127044678166 .7174987793 166.7174987793167 .3269958496167 .9365997314168 .5462036133169 .1557006836 170.070098877170 .9844970703171 .8988037109172 .8132019043173 .4226989746 174.337097168 175.2514038086176.165802002 176.7754058838177.6896972656 
178.604095459179 .2136993408179 .8231964111180 .1280059814180 .1280059814 179.8231964111178 .9089050293177 .9945068359177 .0802001953176 .4705963135 176.4705963135176 .4705963135176 .165802002175 .8609924316174 .9467010498 174.0323028564172 .8132019043171 .5939941406170 .3748931885168 .8509979248 167.3269958496166 .1078948975164 .5839996338163 .0599975586161 .8408966064 160.9264984131160 .0122070312159 .4026031494159 .0977935791159 .0977935791 159.0977935791159 .4026031494160 .0122070312160 .3170013428160 .9264984131 161.8408966064162 .4505004883163 .0599975586163 .6696014404163 .974395752 164.2792053223164 .2792053223164 .2792053223163 .6696014404162 .7552947998 161.8408966064160 .9264984131160 .0122070312159 .7073974609159 .4026031494 159.4026031494159 .7073974609160 .6217956543161 .8408966064163 .3648071289 165.1934967041167 .0222015381168 .8509979248169 .1557006836168 .8509979248 168.5462036133168 .241394043168 .241394043167 .9365997314167 .9365997314 167.6318054199167 .6318054199167 .3269958496167 .3269958496167 .0222015381 166.7174987793166 .4127044678165 .8031005859165 .1934967041164 .2792053223 163.3648071289162 .1457061768160 .9264984131159 .7073974609158 .4882965088 157.2691040039 155.7451934814 154.2212982178 152.6972961426151 .1734008789 149.3446960449147 .5160064697145 .9920959473144 .1634063721142 .3347015381 140.5059967041138 .6772003174137 .1533050537135 .9342041016134 .7149963379 133.8007049561133 .1911010742132 .8863067627132 .5814971924132 .5814971924 132.8863067627133 .1911010742133 .8007049561134 .1054992676134 .7149963379 135.3246002197136 .2389984131136 .8484954834137 .7628936768138 .3724975586 138.9819946289139 .5915985107139 .8963928223139 .8963928223139 .8963928223 139.8963928223139 .5915985107139 .2868041992138 .6772003174138 .3724975586 137.4580993652136 .8484954834135 .6293945312134 .7149963379133 .4958953857 131.9720001221130 .7528076172129 .2288970947128 .0097961426126 .7906036377 125.5715026855124 .9618988037124 .0475006104123 .1332015991121 .6092987061 118.8662033081116 .1231002808113 .3800964355110 .9418029785109 .4179000854 109.1130981445110 .3321990967113 .6848983765121 .3044967651131 .3623962402 142.3347015381153 .9165039062168 .241394043181 .6519012451193 .5386047363 203.596496582209 .692199707209 .692199707209 .692199707209 .692199707209 .692199707 209.692199707 209.692199707 209.692199707 209.692199707 209.692199707 209.692199707 209.692199707 209.692199707 209.692199707 209.692199707 209.692199707 209.692199707 209.692199707 209.692199707 209.692199707 209.692199707 209.692199707 209.692199707 209.692199707209 .692199707209 .692199707209 .692199707209 .692199707209 .692199707 209.692199707 209.692199707 209.692199707 209.692199707 209.692199707 209.692199707 209.692199707 209.692199707 67.66230010986 18.84828186035 -9999 -9999 -9999 -9999 -9999 -9999 -9999 -9999-9999 -9999 -9999 -9999 -9999 -9999 -9999 -9999 -9999 -9999 -9999 -9999 -9999 -9999 -9999 -9999 -9999 -9999 -9999 -9999 -9999 -9999 -9999 -9999 -9999 -9999 -9999 -9999 -9999 -9999 -9999 -9999 -9999 -9999-9999 -9999 -9999-9999 440.268737793 436.0916748047 431.8804931641 427.9183044434423 .9560852051419 .9938964844416 .0317077637411 .7647094727 407.4977111816402 .9259033203398 .049407959392 .8680114746387 .686706543 381.8958129883376 .104888916370 .009185791363 .6086120605357 .208190918 352.0267944336345 .0168151855337 .3970947266330 .9966125488324 .5961914062 318.5004882812312 .7095031738307 .5281982422303 .5660095215303 .5660095215 
304.4802856445306 .0043029785308 .1377868652309 .9664916992311 .4903869629 316.0621948242320 .3291931152324 .2914123535326 .1200866699322 .4627075195 317.5860900879315 .1477966309313 .9287109375313 .9287109375313 .6239013672 312.7095031738311 .1856079102308 .4425048828304 .7850952148300 .5180969238 296.2510986328292 .5936889648288 .9363098145284 .9740905762281 .0119018555 277.0497131348273 .6971130371272 .4779052734271 .5635070801270 .3443908691 269.1253051758267 .6012878418266 .0773925781264 .2486877441262 .4200134277 259.9816894531257 .5433959961254 .8003997803253 .2763977051252 .0572967529 250.5334014893248 .7046966553246 .2664031982242 .9136962891238 .3419952393 231.9414978027224 .3218994141217 .6165924072213 .6544036865212 .1304016113 212.7400054932213 .3495941162212 .4351959229210 .9113006592209 .0825958252 207.8634033203206 .9490966797206 .3394927979205 .7299957275205 .1204071045 204.8155975342204 .2059936523203 .9011993408203 .596496582202 .9868927002 202.3773040771201 .4629974365200 .2438049316198 .4151000977196 .2816009521 193.8433074951191 .1002960205188 .6620025635186 .8332977295185 .9188995361 185.3094024658184 .3950042725182 .87109375181 .3471984863180 .1280059814 178.9089050293178 .2993011475177 .6896972656177 .3849029541176 .4705963135 175.2514038086174 .337097168173 .7274932861173 .4226989746173 .1179962158 172.8132019043172 .8132019043172 .5084075928172 .2035980225171 .5939941406 171.2891998291170 .6797027588170 .070098877169 .4604949951168 .5462036133 167.9365997314167 .3269958496167 .0222015381166 .4127044678166 .1078948975 165.8031005859165 .4983062744165 .4983062744165 .4983062744165 .4983062744 165.8031005859166 .1078948975166 .7174987793167 .3269958496167 .9365997314 168.8509979248169 .4604949951170 .3748931885171 .2891998291171 .8988037109 172.8132019043173 .7274932861174 .6419067383175 .2514038086176 .165802002 177.0802001953177 .6896972656178 .2993011475178 .9089050293178 .9089050293 178.9089050293178 .2993011475177 .9945068359177 .3849029541177 .0802001953 176.7754058838176 .4705963135176 .165802002175 .8609924316174 .9467010498 174.0323028564172 .8132019043171 .5939941406170 .070098877168 .5462036133 167.0222015381165 .4983062744163 .974395752162 .4505004883161 .2312927246 160.0122070312159 .0977935791158 .4882965088158 .1835021973158 .1835021973 158.4882965088159 .0977935791159 .4026031494160 .0122070312160 .9264984131 161.5361022949162 .1457061768163 .0599975586163 .6696014404163 .974395752 164.2792053223164 .2792053223163 .974395752163 .3648071289162 .4505004883 161.5361022949160 .6217956543160 .0122070312159 .4026031494159 .0977935791 159.4026031494159 .7073974609160 .6217956543162 .1457061768163 .6696014404 165.4983062744167 .3269958496168 .8509979248169 .4604949951169 .4604949951 169.1557006836168 .8509979248168 .8509979248168 .5462036133168 .241394043 168.241394043167 .9365997314167 .9365997314167 .6318054199167 .6318054199 167.3269958496167 .0222015381166 .7174987793166 .1078948975165 .1934967041 164.2792053223163 .0599975586161 .8408966064160 .6217956543159 .0977935791 157.878692627156 .3547973633155 .1356048584153 .6116943359151 .7830047607 150.2590942383148 .4304046631146 .6015930176144 .7729034424142 .9441986084 141.1154937744139 .5915985107138 .0677032471136 .8484954834135 .6293945312 134.7149963379133 .8007049561133 .4958953857133 .1911010742133 .1911010742 133.1911010742133 .4958953857133 .8007049561134 .1054992676134 .7149963379 
135.3246002197135 .9342041016136 .5437011719137 .1533050537138 .0677032471 138.6772003174139 .2868041992139 .5915985107139 .5915985107139 .5915985107 139.5915985107139 .2868041992138 .9819946289138 .6772003174138 .0677032471 137.4580993652136 .5437011719135 .6293945312134 .4102020264133 .1911010742 131.9720001221130 .4479980469128 .9241027832127 .7050018311126 .1809997559 124.9618988037124 .3523025513123 .7427978516122 .5235977173120 .9997024536 118.5614013672115 .818397522113 .3800964355111 .24659729109 .4179000854 108.8082962036109 .1130981445111 .24659729116 .4279022217125 .5715026855 136.2389984131148 .7351074219162 .1457061768175 .8609924316188 .3571929932 199.329498291208 .7778015137209 .692199707209 .692199707209 .692199707 209.692199707 209.692199707 209.692199707 209.692199707 209.692199707 209.692199707 209.692199707 209.692199707 209.692199707 209.692199707 209.692199707 209.692199707 209.692199707 209.692199707 209.692199707 209.692199707 209.692199707 209.692199707 209.692199707209 .692199707209 .692199707209 .692199707209 .692199707209 .692199707 209.692199707 209.692199707 209.692199707 209.692199707 209.692199707 209.692199707 209.692199707 209.692199707 209.692199707 69.79579162598 47.84257125854 -9999 -9999 -9999 -9999 -9999 -9999 -9999 -9999-9999 -9999

-9999 -9999 -9999 -9999 -9999 -9999 -9999 -9999 -9999 -9999 -9999 -9999 -9999 -9999 -9999 -9999 -9999 -9999 -9999 -9999 -9999 -9999 -9999 -9999 -9999 -9999 -9999 -9999 -9999 -9999 -999 -9999 -9999 -9999-9999 -9999 -9999 -9999 444.3459777832440.3995666504 436.4523010254 432.7948913574429 .137512207425 .1752929688421 .2130126953416 .9460144043 412.0694885254407 .1929016113402 .0115966797396 .5255126953390 .7344970703 384.6387939453378 .2383117676371 .837890625365 .132598877359 .3417053223 351.4172058105344 .4071960449337 .7019042969330 .9966125488324 .5961914062 318.8052062988313 .9287109375310 .2713012695309 .3569030762309 .9664916992 311.1856079102313 .0143127441314 .5382080078318 .5004882812322 .4627075195 326.4248962402329 .1679077148330 .0823059082329 .4726867676327 .0344848633 324.5961914062321 .5483093262317 .5860900879316 .9765014648315 .7573852539 313.6239013672310 .5759887695306 .6138000488302 .3468017578299 .2990112305 296.2510986328292 .8984985352288 .9363098145284 .9740905762280 .7070922852 276.7449035645273 .6971130371272 .7827148438271 .2587890625270 .3443908691 269.1253051758267 .9060974121266 .6870117188264 .8583068848263 .0296020508 260.8960876465258 .4577941895254 .8003997803252 .6669006348250 .8381958008 248.7046966553246 .5711975098244 .4376983643241 .9994049072238 .0372009277 231.3318939209224 .6266021729219 .4452972412216 .3973999023215 .1782989502 214.2639007568213 .0447998047211 .8256988525210 .3016967773209 .692199707 209.692199707 209.692199707 209.3874053955 209.3874053955 209.3874053955 209.0825958252 208.7778015137208.4730072021208.1681976318207.8634033203 206.9490966797205 .425201416203 .596496582201 .4629974365198 .7198944092 196.2816009521193 .5386047363191 .4051055908189 .8811035156188 .3571929932 186.8332977295185 .0045928955182 .87109375181 .0424041748179 .8231964111 179.5184020996179 .5184020996179 .5184020996178 .2993011475177 .0802001953 175.8609924316175 .2514038086174 .6419067383174 .337097168173 .7274932861 173.4226989746172 .8132019043172 .5084075928171 .8988037109170 .9844970703 170.3748931885169 .4604949951168 .5462036133167 .9365997314167 .0222015381 166.4127044678165 .8031005859165 .4983062744165 .1934967041164 .8887023926 
164.5839996338164 .5839996338164 .5839996338164 .5839996338164 .8887023926 165.1934967041165 .4983062744166 .1078948975166 .7174987793167 .3269958496 168.241394043168 .8509979248169 .7653045654170 .3748931885171 .2891998291 172.2035980225172 .8132019043173 .7274932861174 .337097168175 .2514038086 175.8609924316176 .7754058838177 .0802001953177 .6896972656177 .6896972656 177.6896972656177 .6896972656177 .3849029541177 .0802001953177 .0802001953 176.7754058838176 .4705963135175 .8609924316174 .9467010498174 .0323028564 172.8132019043171 .2891998291170 .070098877168 .241394043166 .7174987793 165.1934967041163 .6696014404162 .1457061768160 .6217956543159 .4026031494 158.1835021973157 .5738983154157 .2691040039157 .5738983154158 .1835021973 158.4882965088159 .0977935791160 .0122070312160 .6217956543161 .5361022949 162.1457061768163 .0599975586163 .6696014404163 .974395752164 .2792053223 164.2792053223163 .974395752163 .3648071289162 .4505004883161 .5361022949 160.3170013428159 .4026031494158 .7929992676158 .4882965088158 .7929992676 159.4026031494160 .6217956543162 .1457061768163 .6696014404165 .4983062744 167.0222015381168 .241394043169 .1557006836169 .4604949951169 .4604949951 169.4604949951169 .1557006836168 .8509979248168 .8509979248168 .5462036133 168.5462036133168 .241394043167 .9365997314167 .9365997314167 .6318054199 167.6318054199167 .3269958496167 .0222015381166 .1078948975164 .8887023926 163.6696014404162 .4505004883161 .2312927246159 .7073974609158 .4882965088 156.9642944336155 .7451934814154 .2212982178152 .3925933838150 .8686065674 149.0399017334147 .2111968994145 .6873016357143 .8585968018142 .0299072266 140.5059967041138 .9819946289137 .7628936768136 .5437011719135 .3246002197 134.7149963379134 .1054992676133 .8007049561133 .4958953857133 .4958953857 133.4958953857133 .8007049561134 .1054992676134 .4102020264135 .0198059082 135.6293945312136 .2389984131136 .8484954834137 .4580993652138 .0677032471 138.6772003174138 .9819946289139 .2868041992139 .2868041992139 .2868041992 138.9819946289138 .6772003174138 .3724975586137 .7628936768137 .1533050537 136.2389984131 135.3246002197 134.4102020264133.1911010742 131.6672058105 130.4479980469128 .9241027832127 .7050018311126 .1809997559124 .9618988037 124.0475006104123 .1332015991121 .9140014648120 .3900985718118 .2565994263 115.818397522113 .3800964355111 .24659729109 .7226028442108 .5035018921 108.5035018921109 .4179000854112 .4656982422120 .6949005127131 .6672058105 144.4682006836157 .878692627171 .5939941406184 .0901947021195 .6721038818 205.425201416209 .692199707209 .692199707209 .692199707209 .692199707209 .692199707 209.692199707209 .692199707209 .692199707209 .692199707209 .692199707209 .692199707 209.692199707 209.692199707 209.692199707 209.692199707 209.692199707 209.692199707 209.692199707209 .692199707209 .692199707209 .692199707209 .692199707209 .692199707 209.692199707209 .692199707209 .692199707209 .692199707209 .692199707209 .692199707 209.692199707209 .692199707209 .692199707209 .692199707209 .692199707209 .692199707 209.692199707 209.69219970778 .75400543213 -9999 -9999 -9999 -9999 -9999 -9999 -9999 $-9999-9999-9999$ -9999 -9999 -9999 -9999 -9999 -9999 -9999 -9999 -9999 -9999 -9999 -9999 -9999 -9999 -9999 -9999 -9999-9999 -9999 -9999 -9999 -9999 -9999 -9999 -9999 -9999 -9999 -9999 -9999 -9999 -9999 -9999 -9999 -9999 -9999 -9999 -9999 452.7646789551 449.1134643555 445.4930419922 441.9383850098438 .2810058594434 .6235961914430 .6614074707426 .3944091797 
421.8226013184416 .6412963867411 .4598999023405 .9737854004399 .878112793 393.782409668387 .3818969727380 .3717956543373 .666595459366 .3517150879 359.3417053223352 .3316040039345 .3215026855338 .6163024902332 .2157897949 326.4248962402321 .5483093262318 .1957092285316 .6718139648316 .6718139648 317.2813110352318 .5004882812320 .0244140625323 .3770141602327 .6440124512 330.9966125488333 .1301879883334 .6541137695334 .9588928223334 .0444946289 332.2157897949329 .4726867676326 .7296142578322 .4627075195319 .1099853516 316.3670043945313 .0143127441308 .7473144531304 .1755981445302 .3468017578 300.2132873535297 .1654968262293 .2033081055288 .3266906738283 .7549133301 280.0975036621276 .7449035645274 .3066101074272 .4779052734270 .9540100098 270.6492004395270 .0396118164268 .8204956055267 .6012878418265 .7726135254 263.6390991211261 .2008972168258 .4577941895255 .4098968506251 .1428985596 248.7046966553246 .2664031982245 .0471954346244 .7424926758244 .7424926758 237.7324066162231 .0270996094225 .5410003662221 .5787963867218 .5308990479 216.3973999023214 .5686950684213 .0447998047211 .520904541211 .520904541 212.7400054932213 .3495941162213 .959197998214 .2639007568214 .5686950684 214.2639007568213 .959197998214 .2639007568214 .2639007568213 .6544036865 212.7400054932211 .520904541209 .692199707207 .25390625204 .5108032227 201.7678070068199 .329498291196 .891204834194 .7577056885192 .624206543 190.4907073975188 .0523986816185 .3094024658182 .87109375181 .3471984863 181.0424041748181 .3471984863181 .9566955566180 .1280059814178 .604095459 177.6896972656176 .7754058838176 .165802002175 .8609924316175 .2514038086 174.6419067383173 .7274932861173 .1179962158172 .2035980225171 .2891998291 170.3748931885169 .1557006836168 .241394043167 .3269958496166 .4127044678 165.8031005859165 .1934967041164 .5839996338164 .2792053223163 .974395752 163.6696014404163 .6696014404163 .6696014404163 .6696014404163 .974395752 164.2792053223164 .5839996338165 .1934967041165 .4983062744166 .1078948975 166.7174987793167 .3269958496168 .241394043168 .8509979248169 .4604949951 170.3748931885170 .9844970703171 .8988037109172 .5084075928173 .4226989746 174.0323028564174 .9467010498175 .5561981201176 .165802002176 .4705963135 176.7754058838177 .0802001953177 .0802001953177 .0802001953177 .0802001953 176.7754058838176 .4705963135175 .8609924316174 .9467010498174 .0323028564 172.8132019043171 .2891998291169 .7653045654168 .241394043166 .4127044678 164.8887023926163 .0599975586161 .5361022949160 .0122070312158 .7929992676 157.5738983154156 .6596069336156 .6596069336156 .9642944336157 .5738983154 158.1835021973159 .0977935791159 .7073974609160 .6217956543161 .5361022949 162.1457061768163 .0599975586163 .6696014404163 .974395752164 .2792053223 164.2792053223163 .974395752163 .3648071289162 .4505004883161 .2312927246 160.3170013428159 .0977935791158 .4882965088157 .878692627157 .878692627 158.7929992676160 .0122070312161 .8408966064163 .6696014404165 .1934967041 166.7174987793167 .9365997314168 .8509979248169 .4604949951169 .4604949951 169.4604949951169 .4604949951169 .1557006836168 .8509979248168 .8509979248 168.5462036133168 .241394043168 .241394043167 .9365997314167 .9365997314 167.6318054199167 .6318054199167 .0222015381166 .1078948975165 .1934967041 163.974395752162 .7552947998161 .5361022949160 .3170013428158 .7929992676 157.5738983154156 .0500030518154 .5260925293153 .0021057129151 .4781951904 
149.9542999268148 .1255950928146 .2969055176144 .4682006836142 .9441986084 141.4203033447139 .8963928223138 .6772003174137 .4580993652136 .2389984131 135.6293945312134 .7149963379134 .4102020264134 .1054992676133 .8007049561 133.8007049561133 .8007049561134 .1054992676134 .4102020264134 .7149963379 135.3246002197135 .9342041016136 .5437011719137 .1533050537137 .7628936768 138.0677032471138 .3724975586138 .6772003174138 .9819946289138 .9819946289 138.6772003174138 .3724975586138 .0677032471137 .4580993652136 .8484954834 136.2389984131135 .3246002197134 .4102020264133 .1911010742131 .6672058105 130.4479980469128 .9241027832127 .7050018311126 .4858016968125 .2667007446 124.0475006104123 .1332015991121 .6092987061119 .7806015015117 .9517974854 115.818397522113 .6848983765111 .551399231109 .7226028442108 .5035018921 108.1986999512108 .8082962036111 .8561019897118 .2565994263128 .6192932129 141.4203033447154 .8307952881168 .241394043181 .0424041748192 .624206543 202.9868927002209 .692199707209 .692199707209 .692199707209 .692199707 209.692199707 209.692199707 209.692199707 209.692199707 209.692199707 209.692199707 209.692199707 209.692199707 209.692199707 209.692199707 209.692199707 209.692199707 209.692199707 209.692199707 209.692199707 209.692199707 209.692199707209.692199707 209.692199707 209.692199707 209.692199707 209.692199707 209.692199707 209.692199707 209.692199707 209.692199707 209.692199707 209.692199707209.692199707 209.692199707 209.692199707 209.692199707 70.10057830811 47.88320922852 -9999 -9999 -9999 -9999 -9999 -9999 -9999 -9999-9999-9999 -9999 -9999 -9999 -9999 -9999 -9999 -9999 -9999 -9999 -9999 -9999 -9999 -9999 -9999 -9999 -9999 -9999 -9999 -9999 -9999 -9999 -9999 -9999 -9999 -9999 -9999 -9999 -9999 -9999 -9999 -9999 -9999 -9999 -9999 -9999 -9999 -9999 -9999 457.9118347168454 .5757141113 451.2093811035447 .729309082444 .0718994141440 .1097106934435 .8427124023 431.2709960938426 .3944091797420 .9082946777415 .422088623409 .326385498 403.2307128906396 .5255126953389 .515411377382 .5053100586375 .1904907227 367.8756103516360 .8656005859353 .8554992676346 .845489502340 .749786377 334.9588928223330 .3870849609327 .0344848633325 .2056884766324 .2914123535 324.5961914062325 .2056884766326 .1200866699328 .2536010742332 .2157897949 335.5683898926337 .3970947266338 .6163024902339 .2258911133338 .9211120605 338.0067138672336 .1780090332334 .3493041992331 .3013916016324 .5961914062 319.7196044922316 .3670043945312 .4047851562308 .7473144531306 .3091125488 304.4802856445301 .4324951172296 .8606872559291 .6794128418286 .8027954102 283.1453857422280 .0975036621278 .2687988281276 .7449035645275 .2210083008 274.3066101074272 .7827148438271 .5635070801269 .7348022461267 .6012878418 266.3822021484263 .9439086914261 .2008972168258 .1530151367254 .8003997803 251.4476928711247 .4855041504244 .4376983643244 .7424926758244 .1329040527 240.7801971436235 .9037017822231 .0270996094226 .7601013184222 .7978973389 219.4452972412 216.7021942139214.5686950684212.4351959229 213.959197998 215.787902832217 .3117980957218 .8356933594219 .7501068115220 .3596038818 220.6643981934220 .6643981934220 .6643981934220 .6643981934220 .054901123 219.4452972412218 .2261962891216 .0926971436213 .6544036865210 .9113006592 207.8634033203205 .1204071045202 .3773040771199 .9389953613197 .8054962158195 .0625 192.3193969727189 .2716064453186 .2236938477183 .1759033203183 .1759033203 183.1759033203182 .5662994385181 .3471984863180 .432800293179 .5184020996 
178.9089050293178 .2993011475177 .6896972656176 .7754058838175 .8609924316 174.9467010498174 .0323028564173 .1179962158171 .8988037109170 .6797027588 169.1557006836167 .9365997314167 .0222015381166 .1078948975165 .1934967041 164.5839996338163 .974395752163 .6696014404163 .3648071289163 .0599975586 163.0599975586162 .7552947998163 .0599975586163 .0599975586163 .3648071289 163.6696014404163 .974395752164 .5839996338164 .8887023926165 .4983062744 166.1078948975166 .7174987793167 .3269958496167 .9365997314168 .5462036133 169.1557006836170 .070098877170 .6797027588171 .5939941406172 .2035980225 173.1179962158173 .7274932861174 .337097168174 .9467010498175 .5561981201 176.165802002176 .4705963135176 .7754058838176 .7754058838176 .7754058838 176.4705963135175 .8609924316175 .2514038086174 .0323028564172 .8132019043 171.2891998291169 .7653045654167 .9365997314166 .1078948975164 .2792053223 162.7552947998161 .2312927246159 .7073974609158 .1835021973157 .2691040039 156.3547973633156 .3547973633156 .6596069336157 .2691040039158 .1835021973 158.7929992676159 .7073974609160 .6217956543161 .5361022949162 .4505004883 163.0599975586163 .6696014404164 .2792053223164 .5839996338164 .2792053223 163.974395752163 .3648071289162 .4505004883161 .5361022949160 .3170013428 159.0977935791157 .878692627156 .9642944336156 .9642944336157 .878692627 159.7073974609161 .5361022949163 .3648071289164 .8887023926166 .4127044678 167.6318054199168 .5462036133169 .1557006836169 .4604949951169 .4604949951 169.4604949951169 .1557006836168 .8509979248168 .8509979248168 .5462036133 168.241394043168 .241394043167 .9365997314167 .9365997314167 .6318054199 167.3269958496 166.7174987793166.1078948975 165.1934967041 163.974395752 163.0599975586161 .8408966064160 .6217956543159 .0977935791157 .878692627 156.6596069336155 .1356048584153 .6116943359152 .0877990723150 .5639038086 148.7351074219146 .9064025879145 .3825073242143 .8585968018142 .3347015381 140.8106994629139 .5915985107138 .3724975586137 .4580993652136 .5437011719 135.6293945312135 .0198059082134 .4102020264134 .1054992676134 .1054992676 133.8007049561134 .1054992676134 .1054992676134 .4102020264135 .0198059082 135.3246002197135 .9342041016136 .5437011719137 .1533050537137 .4580993652 138.0677032471138 .3724975586138 .3724975586138 .6772003174138 .3724975586 138.3724975586138 .0677032471137 .4580993652136 .8484954834136 .2389984131 135.3246002197134 .4102020264133 .1911010742131 .9720001221130 .7528076172 129.2288970947128 .0097961426126 .4858016968125 .2667007446124 .0475006104 122.8283996582121 .3044967651119 .7806015015117 .9517974854115 .818397522 113.9896011353111 .8561019897110 .0273971558108 .8082962036108 .5035018921 109.7226028442113 .3800964355119 .4757995605133 .8007049561144 .7729034424 153.3069000244166 .4127044678178 .9089050293190 .4907073975200 .8533935547 209.692199707 209.692199707 209.692199707 209.692199707 209.692199707 209.692199707 209.692199707 209.692199707 209.692199707 209.692199707 209.692199707 209.692199707 209.692199707209 .692199707209 .692199707209 .692199707209 .692199707209 .692199707 209.692199707209 .692199707209 .692199707209 .692199707209 .692199707209 .692199707 209.692199707209 .692199707209 .692199707209 .692199707209 .692199707209 .692199707 209.692199707209 .692199707209 .692199707209 .692199707209 .692199707209 .692199707 67.6623001098618 .55198097229 -9999 -9999 -9999 -9999 -9999 -9999 -9999 -9999 -9999 $-9999$ 
-9999 -9999 -9999 -9999 -9999 -9999 -9999 -9999 -9999 -9999 -9999 -9999 -9999 -9999 -9999

-9999 -9999 -9999 -9999 -9999 -9999 -9999 -9999 -9999 -9999 -9999 -9999 -9999 -9999 -9999 -

-9999 -9999 -9999 -9999 -9999 -9999 -9999 -9999 -9999 463.5516662598460 .4074707031

457.1777038574453 .5202941895449 .5581054688445 .2911071777440 .7192993164 435.8427124023430 .6614074707425 .1752929688419 .0795898438412 .6789855957 405.9737854004398 .9637145996391 .6488952637384 .3340148926377 .0191955566 369.7043151855362 .6943054199355 .9890136719349 .8933105469344 .4071960449 339.8353881836336 .4827880859334 .0444946289332 .8252868652332 .5205993652 332.5205993652332 .8252868652333 .1301879883337 .3970947266340 .4450073242 341.9689025879342 .8833007812343 .4927978516343 .1879882812342 .2737121582 341.0545959473339 .8353881836337 .3970947266333 .4349060059329 .1679077148 326.1200866699322 .7674865723318 .5004882812313 .3190917969308 .4425048828 306.3091125488299 .9085998535294 .1176147461289 .5458984375286 .4979858398 284.0596923828282 .5357971191281 .6214904785280 .7070922852279 .7927856445 278.8783874512277 .3544921875275 .2210083008273 .0874938965270 .0396118164 266.6870117188263 .9439086914260 .8960876465257 .5433959961254 .1907958984 250.8381958008247 .4855041504244 .4376983643244 .4376983643242 .9136962891 240.1707000732236 .2084960938231 .6367034912227 .3697052002223 .1027069092 219.7501068115217 .3117980957216 .3973999023217 .3117980957219 .4452972412 222.1884002686224 .3218994141225 .8457946777226 .7601013184227 .3697052002 227.3697052002 227.3697052002 227.3697052002 227.0648956299226.150604248 224.9313964844223 .1027069092220 .6643981934217 .6165924072214 .5686950684 211.2160949707208 .4730072021206 .0346984863203 .2917022705200 .5485992432 197.500793457194 .1481018066190 .795501709188 .3571929932186 .8332977295 185.9188995361184 .3950042725182 .5662994385182 .261505127181 .6519012451 181.3471984863180 .7375946045179 .5184020996178 .604095459177 .3849029541 176.4705963135175 .5561981201174 .337097168173 .1179962158171 .5939941406 169.7653045654168 .241394043167 .0222015381165 .8031005859165 .1934967041 164.5839996338163 .974395752163 .3648071289163 .0599975586162 .4505004883 162.4505004883162 .4505004883162 .4505004883162 .4505004883162 .4505004883 162.7552947998163 .0599975586163 .3648071289163 .6696014404164 .2792053223 164.5839996338165 .1934967041165 .4983062744166 .1078948975166 .7174987793 167.3269958496167 .9365997314168 .8509979248169 .4604949951170 .3748931885 170.9844970703171 .8988037109172 .8132019043173 .7274932861174 .337097168 174.9467010498175 .5561981201176 .165802002176 .4705963135176 .7754058838 176.4705963135176 .165802002175 .2514038086174 .337097168172 .8132019043 171.2891998291169 .4604949951167 .6318054199165 .8031005859163 .974395752 162.4505004883160 .6217956543159 .4026031494157 .878692627156 .9642944336 156.3547973633156 .3547973633156 .6596069336157 .2691040039157 .878692627 158.7929992676159 .7073974609160 .6217956543161 .5361022949162 .4505004883 163.3648071289163 .974395752164 .5839996338164 .5839996338164 .8887023926 164.5839996338163 .974395752163 .0599975586161 .8408966064160 .6217956543 159.0977935791157 .878692627156 .6596069336156 .0500030518157 .5738983154 159.4026031494161 .2312927246163 .0599975586164 .8887023926166 .1078948975 167.3269958496168 .241394043168 .8509979248169 .1557006836169 .1557006836 169.1557006836168 .8509979248168 .8509979248168 .5462036133168 .241394043 
167.9365997314 167.9365997314167.6318054199 167.6318054199167.3269958496 167.0222015381166 .4127044678165 .8031005859164 .8887023926163 .974395752 163.0599975586161 .8408966064160 .6217956543159 .4026031494158 .1835021973 156.9642944336155 .4403991699154 .2212982178152 .6972961426151 .1734008789 149.3446960449147 .8208007812146 .2969055176144 .7729034424143 .2489929199 142.0299072266140 .5059967041139 .2868041992138 .3724975586137 .4580993652 136.5437011719135 .6293945312135 .0198059082134 .7149963379134 .1054992676 134.1054992676133 .8007049561134 .1054992676134 .1054992676134 .4102020264 135.0198059082135 .3246002197135 .9342041016136 .5437011719137 .1533050537 137.4580993652138 .0677032471138 .0677032471138 .3724975586138 .3724975586 138.0677032471137 .7628936768137 .4580993652136 .8484954834136 .2389984131 135.3246002197134 .4102020264133 .1911010742131 .9720001221130 .7528076172 129.533706665128 .0097961426126 .7906036377125 .5715026855124 .0475006104 122.8283996582121 .3044967651119 .7806015015117 .9517974854116 .4279022217 114.2944030762112 .4656982422110 .6370010376109 .1130981445108 .8082962036 110.9418029785117 .0374984741129 .8385009766145 .0776977539153 .6116943359 155.7451934814165 .8031005859177 .9945068359189 .5764007568199 .9389953613 209.0825958252209 .692199707209 .692199707209 .692199707209 .692199707 209.692199707209 .692199707209 .692199707209 .692199707209 .692199707209 .692199707 209.692199707 209.692199707 209.692199707209.692199707 209.692199707 209.692199707 209.692199707 209.692199707 209.692199707 209.692199707 209.692199707 209.692199707 209.692199707 209.692199707 209.692199707209.692199707 209.692199707209.692199707 209.692199707209 .692199707209 .692199707209 .692199707209 .692199707209 .692199707 209.69219970765 .528800964366 .297807216644 -9999 -9999 -9999 -9999 -9999 -9999-9999 -9999 -9999-9999

-9999 -9999 -9999 -9999 -9999 -9999 -9999 -9999 -9999 -9999 -9999 -9999 -9999 -9999 -9999 -9999 -9999 -9999 -9999 -9999-9999 -9999 -9999 -9999 -9999 -9999 -9999 -9999 -9999 - 9999 -9999 -9999 -9999 -9999 -9999 -9999 -9999 -9999 -9999 -9999 469.3210144043 466.1434631348462 .6637878418458 .7015991211454 .4346008301450 .1676025391 445.2911071777440 .4144897461434 .9284057617428 .8327026367422 .4321899414 415.7268981934408 .412109375401 .0971984863393 .782409668386 .4674987793 379.1527099609372 .1426086426365 .7421875359 .6465148926354 .1603088379 349.5885009766346 .2359008789343 .4927978516341 .9689025879341 .0545959473 340.4450073242340 .4450073242340 .1401977539343 .1879882812345 .9310913086 347.1502990723347 .7597961426347 .4549865723346 .845489502345 .9310913086 344.7120056152343 .4927978516341 .9689025879340 .749786377339 .2258911133 336.1780090332332 .2157897949327 .3392028809321 .8530883789315 .7573852539 309.3569030762 303.2611999512 298.0798950195292.8984985352 290.7650146484 289.2410888672 288.3266906738288.0219116211287.4124145508 287.1076049805 286.1932067871284 .3645019531282 .2309875488279 .4880065918276 .4400939941 272.4779052734268 .2109069824263 .6390991211260 .2864990234256 .9338989258 253.5812072754250 .8381958008248 .0950927734246 .2664031982245 .6567993164 244.1329040527241 .3898010254236 .8179931641231 .9414978027227 .3697052002 223.4075012207220 .9691925049220 .3596038818221 .5787963867224 .0171051025 227.3697052002 230.4176025391232.5511016846233.4653930664 234.0749969482 234.3798065186234.3798065186234.3798065186234.0749969482 233.4653930664 
232.246307373230.4176025391227.6744995117224.6266021729 221.2740020752 217.9214019775214 .8735046387212 .1304016113209 .3874053955206 .6443023682 203.596496582200 .2438049316196 .5863952637193 .8433074951191 .4051055908 189.5764007568187 .7476043701186 .2236938477185 .0045928955184 .3950042725 183.7854003906183 .4806976318181 .6519012451180 .432800293179 .2136993408 178.2993011475177 .3849029541176 .165802002174 .6419067383172 .8132019043 170.9844970703169 .1557006836167 .3269958496166 .1078948975165 .1934967041 164.5839996338163 .974395752163 .3648071289162 .7552947998162 .4505004883 162.1457061768161 .8408966064161 .8408966064161 .8408966064161 .8408966064 162.1457061768162 .1457061768162 .4505004883162 .7552947998163 .0599975586 163.3648071289163 .6696014404163 .974395752164 .5839996338164 .8887023926 165.4983062744166 .1078948975166 .7174987793167 .3269958496168 .241394043 169.1557006836170 .070098877170 .9844970703171 .8988037109172 .8132019043 174.0323028564174 .6419067383175 .5561981201176 .165802002176 .4705963135 176.4705963135176 .165802002175 .5561981201174 .337097168172 .8132019043 171.2891998291169 .4604949951167 .6318054199165 .4983062744163 .6696014404 162.1457061768160 .3170013428159 .0977935791157 .878692627156 .9642944336 156.3547973633156 .3547973633156 .6596069336157 .2691040039157 .878692627 158.7929992676159 .7073974609160 .9264984131161 .8408966064162 .7552947998 163.6696014404164 .2792053223164 .8887023926165 .1934967041165 .1934967041 164.8887023926164 .5839996338163 .6696014404162 .4505004883161 .2312927246 159.7073974609158 .1835021973157 .2691040039156 .9642944336157 .5738983154 159.4026031494160 .9264984131162 .7552947998164 .5839996338166 .1078948975 167.3269958496167 .9365997314168 .5462036133168 .8509979248168 .8509979248 168.8509979248168 .5462036133168 .241394043168 .241394043167 .9365997314 167.6318054199167 .3269958496167 .3269958496167 .0222015381166 .7174987793 166.4127044678165 .8031005859165 .1934967041164 .5839996338163 .6696014404 162.7552947998161 .8408966064160 .6217956543159 .4026031494158 .1835021973 156.9642944336155 .7451934814154 .5260925293153 .0021057129151 .4781951904 149.9542999268148 .4304046631146 .9064025879145 .6873016357144 .1634063721 142.9441986084141 .7250976562140 .5059967041139 .2868041992138 .3724975586 137.1533050537136 .5437011719135 .6293945312135 .0198059082134 .4102020264 134.1054992676133 .8007049561133 .8007049561133 .8007049561134 .1054992676 134.4102020264135 .0198059082135 .3246002197135 .9342041016136 .5437011719 137.1533050537137 .4580993652137 .7628936768138 .0677032471138 .0677032471 138.0677032471137 .7628936768137 .4580993652136 .8484954834136 .2389984131 135.3246002197134 .4102020264133 .4958953857132 .2767028809131 .0576019287 129.8385009766128 .3144989014127 .0953979492125 .5715026855124 .0475006104 122.8283996582121 .3044967651120 .0852966309118 .5614013672117 .0374984741 115.2088012695113 .075302124111 .24659729109 .7226028442109 .4179000854 111.24659729117 .342300415132 .5814971924158 .1835021973159 .0977935791 158.7929992676166 .1078948975178 .2993011475189 .5764007568199 .6342926025 208.7778015137209 .692199707209 .692199707209 .692199707209 .692199707 209.692199707 209.692199707 209.692199707 209.692199707 209.692199707 209.692199707 209.692199707209 .692199707209 .692199707209 .692199707209 .692199707209 .692199707 209.692199707 209.692199707 209.692199707 209.692199707 209.692199707 209.692199707 
209.692199707 209.692199707 209.692199707 209.692199707209.692199707209.692199707 209.692199707 209.692199707 209.692199707 209.692199707 209.692199707 209.692199707 209.692199707 64.61444854736 1.817760705948 -9999 -9999 -9999 -9999 -9999 -9999 -9999 $-9999-9999-9999$

-9999 -9999 -9999 -9999 -9999 -9999 -9999 -9999 -9999 -9999 -9999 -9999 -9999 -9999 -

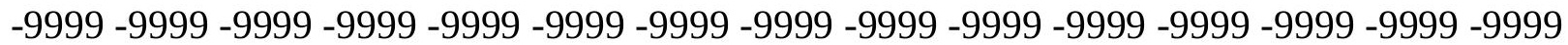
-9999 -9999 -9999 -9999 -9999 -9999 -9999 -9999 -9999 -9999 477.9060058594 474.8001403809471 .4022521973467 .6403198242463 .5781860352459 .3111877441 454.7394104004449 .8629150391444 .6814880371438 .5857849121432 .1853027344 425.4800109863418 .1651916504410 .5455932617403 .2307128906395 .9158935547 388.9057922363381 .8958129883375 .495300293369 .7043151855364 .5230102539 359.9512023926 356.2937927246353.2460021973 351.4172058105349 .8933105469 348.9790039062348 .3693847656347 .7597961426351 .112487793352 .6364135742 352.941192627352 .6364135742351 .7219848633350 .1980895996348 .9790039062 347.7597961426346 .5407104492345 .3215026855344 .7120056152343 .7976074219 341.3593139648338 .3114929199334 .6541137695330 .0823059082323 .3770141602 316.0621948242308 .1377868652301 .4324951172297 .4703063965296 .5559082031 295.6416015625295 .3367919922295 .6416015625295 .9464111328295 .9464111328 295.0320129395293 .5080871582291 .0697937012288 .0219116211284 .0596923828 279.7927856445274 .9161987305269 .7348022461264 .5534973145259 .3721008301 256.3243103027253 .5812072754250 .2286071777249 .3141937256248 .7046966553 247.7902984619246 .5711975098241 .6945953369236 .2084960938231 .6367034912 227.6744995117225 .2362060547224 .3218994141225 .5410003662228 .5888977051 232.8558044434236 .8179931641239 .2563018799240 .1707000732240 .4754943848 241.0850067139241 .0850067139241 .0850067139240 .7801971436240 .4754943848 239.5610961914237 .4275970459234 .6844940186231 .3318939209227 .9792938232 224.6266021729221 .2740020752218 .5308990479215 .4830932617212 .7400054932 210.3016967773206 .3394927979202 .6820983887199 .329498291196 .5863952637 194.1481018066192 .0146026611190 .1858978271188 .6620025635187 .7476043701 186.8332977295185 .3094024658183 .7854003906182 .261505127181 .0424041748 180.432800293179 .5184020996178 .2993011475176 .7754058838174 .6419067383 172.5084075928170 .3748931885168 .241394043167 .0222015381166 .1078948975 165.1934967041164 .2792053223163 .3648071289162 .7552947998162 .4505004883 161.8408966064161 .8408966064161 .5361022949161 .5361022949161 .5361022949 161.5361022949161 .5361022949161 .5361022949161 .8408966064161 .8408966064 162.1457061768162 .4505004883162 .4505004883162 .7552947998163 .0599975586 163.6696014404163 .974395752164 .5839996338165 .1934967041166 .1078948975 167.0222015381167 .9365997314169 .1557006836170 .3748931885171 .2891998291 172.5084075928173 .7274932861174 .6419067383175 .5561981201176 .165802002 176.4705963135176 .165802002175 .5561981201174 .337097168172 .8132019043 170.9844970703169 .1557006836167 .3269958496165 .1934967041163 .3648071289 161.8408966064160 .0122070312158 .7929992676157 .5738983154156 .9642944336 156.6596069336156 .3547973633156 .6596069336157 .2691040039158 .1835021973 159.0977935791160 .0122070312160 .9264984131162 .1457061768163 .0599975586 163.974395752164 .5839996338165 .1934967041165 .4983062744165 .8031005859 165.8031005859165 .4983062744164 .8887023926163 .6696014404162 .1457061768 
160.6217956543159 .0977935791157 .878692627157 .878692627158 .1835021973 159.4026031494161 .2312927246162 .7552947998164 .2792053223165 .8031005859 167.0222015381167 .9365997314168 .241394043168 .5462036133168 .5462036133 168.241394043168 .241394043167 .9365997314167 .6318054199167 .3269958496 167.0222015381166 .7174987793166 .7174987793166 .4127044678166 .1078948975 165.8031005859165 .1934967041164 .8887023926164 .2792053223163 .3648071289 162.4505004883161 .5361022949160 .6217956543159 .4026031494158 .1835021973 156.9642944336155 .7451934814154 .5260925293153 .0021057129151 .7830047607 150.2590942383149 .0399017334147 .5160064697146 .6015930176145 .3825073242 144.1634063721142 .9441986084141 .7250976562140 .5059967041139 .2868041992 138.0677032471137 .1533050537136 .2389984131135 .3246002197134 .7149963379 134.1054992676 133.8007049561 133.4958953857 133.4958953857 133.4958953857 133.8007049561134 .1054992676134 .7149963379135 .6293945312136 .2389984131 136.8484954834137 .1533050537137 .7628936768137 .7628936768138 .0677032471 137.7628936768137 .7628936768137 .1533050537136 .8484954834136 .2389984131 135.3246002197134 .7149963379133 .8007049561132 .5814971924131 .3623962402 130.1432037354128 .9241027832127 .4001998901125 .8762969971124 .3523025513 122.8283996582121 .6092987061120 .6949005127119 .4757995605117 .9517974854 116.1231002808113 .9896011353111 .8561019897110 .3321990967110 .0273971558 111.8561019897116 .1231002808122 .8283996582145 .3825073242156 .3547973633 159.0977935791 167.6318054199179.5184020996190.1858978271 200.2438049316 209.0825958252209 .692199707209 .692199707209 .692199707209 .692199707 209.692199707 209.692199707 209.692199707 209.692199707 209.692199707 209.692199707 209.692199707209 .692199707209 .692199707209 .692199707209 .692199707209 .692199707 209.692199707 209.692199707 209.692199707 209.692199707 209.692199707 209.692199707 209.692199707 209.692199707 209.692199707 209.692199707 209.692199707 209.692199707 209.692199707209 .692199707209 .692199707209 .692199707209 .692199707209 .692199707 209.692199707 64.61444854736 1956929564476 -9999 -9999 -9999 -9999 -9999 -9999 -9999 -9999 -9999-9999

-9999 -9999 -9999 -9999 -9999 -9999 -9999 -9999 -9999 -9999 -9999 -9999 -9999 -9999 -9999 -9999 -9999 -9999 -9999 -9999 -9999 -9999 -9999 -9999 -9999 -9999 -9999 -9999 -9999 -9999 -9999 -9999 -9999 -9999 -9999 -9999 -9999 -9999 -9999 -9999 -9999 -9999 479.9104614258 476.3596191406 472.518157959468.3721313477463.8829956055 459.3111877441 454.1299133301448 .3388977051441 .9383850098434 .9284057617427 .613494873 419.9938964844412 .6789855957405 .3641967773398 .3541870117391 .953704834 385.858001709380 .066986084374 .8857116699370 .3139038086366 .3517150879 363.303894043361 .1704101562359 .3417053223358 .1224975586356 .9034118652 359.036895752360 .2560119629360 .5607910156359 .6465148926358 .1224975586 355.6842041016353 .5508117676351 .7219848633350 .5028991699349 .2838134766 348.0646057129347 .1502990723345 .6263122559344 .1023864746341 .6640930176 339.8353881836336 .4827880859330 .3870849609322 .7674865723313 .9287109375 306.6138000488305 .0899047852304 .7850952148304 .7850952148304 .4802856445 305.6994934082306 .3091125488306 .6138000488305 .6994934082304 .1755981445 301.4324951172298 .0798950195293 .8128967285288 .6315002441283 .1453857422 277.3544921875271 .8682861328266 .6870117188261 .8103942871258 .1530151367 255.4098968506253 .8860015869252 .6669006348251 .4476928711249 .3141937256 
245.6567993164241 .0850067139236 .5133056641232 .5511016846229 .8079986572 228.5888977051229 .1983947754232 .246307373237 .4275970459243 .8280944824 245.0471954346245 .6567993164246 .5711975098246 .8759002686247 .1806945801 247.1806945801247 .1806945801247 .1806945801246 .8759002686244 .1329040527 241.0850067139237 .7324066162234 .3798065186230 .7223052979227 .6744995117 224.3218994141221 .5787963867218 .5308990479215 .4830932617211 .8256988525 208.4730072021205 .1204071045202 .0724945068199 .0247039795196 .5863952637 194.4528961182192 .624206543191 .4051055908189 .8811035156188 .0523986816 186.2236938477184 .0901947021183 .4806976318183 .1759033203182 .261505127 181.0424041748179 .2136993408177 .0802001953174 .6419067383172 .2035980225 170.070098877168 .5462036133167 .0222015381165 .8031005859164 .8887023926 163.974395752163 .0599975586162 .4505004883162 .1457061768161 .8408966064 161.5361022949161 .2312927246161 .2312927246161 .2312927246160 .9264984131 160.9264984131160 .9264984131160 .9264984131160 .9264984131160 .9264984131 161.2312927246161 .2312927246161 .5361022949161 .5361022949162 .1457061768 162.4505004883163 .0599975586163 .974395752164 .8887023926165 .8031005859 167.0222015381168 .5462036133169 .7653045654170 .9844970703172 .5084075928 173.7274932861174 .9467010498175 .8609924316176 .4705963135176 .4705963135 175.5561981201174 .337097168172 .5084075928170 .6797027588168 .8509979248 166.7174987793164 .8887023926163 .0599975586161 .2312927246159 .7073974609 158.4882965088157 .5738983154156 .9642944336156 .3547973633156 .3547973633 156.6596069336157 .2691040039158 .1835021973159 .0977935791160 .0122070312 161.2312927246162 .1457061768163 .3648071289164 .2792053223165 .1934967041 165.8031005859166 .1078948975166 .4127044678166 .4127044678166 .4127044678 165.8031005859164 .8887023926163 .3648071289161 .5361022949160 .0122070312 159.0977935791158 .4882965088158 .7929992676159 .7073974609161 .2312927246 162.7552947998164 .2792053223165 .8031005859166 .7174987793167 .6318054199 167.9365997314167 .9365997314167 .9365997314167 .6318054199167 .3269958496 167.0222015381166 .7174987793166 .4127044678166 .4127044678166 .1078948975 165.8031005859165 .4983062744165 .4983062744165 .1934967041164 .5839996338 164.2792053223163 .6696014404163 .0599975586162 .1457061768161 .5361022949 160.6217956543159 .4026031494158 .4882965088157 .2691040039155 .7451934814 154.5260925293153 .0021057129151 .7830047607150 .5639038086149 .3446960449 148.4304046631147 .5160064697146 .2969055176145 .0776977539144 .1634063721 142.9441986084141 .4203033447140 .2012023926138 .9819946289137 .7628936768 136.8484954834135 .6293945312135 .0198059082134 .1054992676133 .4958953857 133.1911010742132 .8863067627132 .8863067627133 .1911010742133 .4958953857 134.1054992676135 .0198059082135 .6293945312136 .5437011719137 .1533050537 137.4580993652137 .7628936768137 .7628936768137 .7628936768137 .4580993652 137.1533050537136 .8484954834136 .2389984131135 .6293945312134 .7149963379 133.8007049561132 .8863067627131 .9720001221130 .7528076172129 .2288970947 127.7050018311126 .1809997559124 .6570968628123 .1332015991121 .9140014648 121.3044967651120 .6949005127119 .4757995605117 .647102356115 .5136032104 113.075302124111 .551399231111 .24659729113 .075302124117 .342300415126 .4858016968 139.5915985107151 .1734008789156 .6596069336169 .7653045654181 .3471984863 192.0146026611201 .4629974365209 .692199707209 .692199707209 .692199707 
209.692199707 209.692199707 209.692199707 209.692199707209.692199707209.692199707 209.692199707 209.692199707 209.692199707 209.692199707 209.692199707 209.692199707 209.692199707 209.692199707 209.692199707 209.692199707 209.692199707 209.692199707 209.692199707209 .692199707209 .692199707209 .692199707209 .692199707209 .692199707 209.692199707 209.692199707 209.692199707 209.692199707 209.692199707 209.692199707 209.692199707209 .692199707209 .69219970764 .61444854736 -.434548676014 -9999 -9999 -9999 -9999 -9999 -9999 -9999 -9999 -9999 -9999

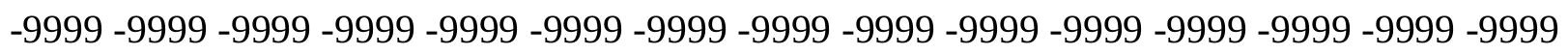

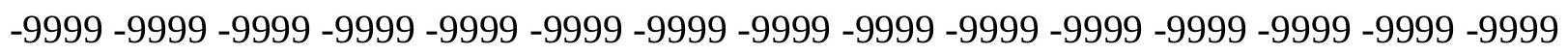
-9999 -9999 -9999 -9999 -9999 -9999 -9999 -9999 -9999 -9999 -9999 -9999 -9999 484.8115234375481 .1752624512477 .2460327148473 .0919189453468 .7594909668 463.5781860352457 .7872924805451 .3868103027444 .3767089844436 .7571105957 429.137512207421 .517791748414 .5078125408 .1072998047402 .0115966797 395.9158935547390 .4296875385 .2484130859380 .6766052246376 .7143859863 373.666595459371 .228302002369 .0947875977367 .2661132812367 .570892334 370.3139038086371 .228302002370 .3139038086367 .8756103516364 .2182006836 360.2560119629357 .5129089355356 .2937927246355 .0747070312353 .8554992676 352.3316040039350 .5028991699348 .3693847656345 .6263122559343 .7976074219 341.9689025879339 .5306091309335 .8731994629330 .3870849609322 .4627075195 316.0621948242316 .0621948242316 .3670043945316 .6718139648317 .2813110352 318.1957092285318 .8052062988319 .1099853516318 .5004882812316 .6718139648 313.9287109375310 .2713012695305 .3947143555299 .6037902832293 .2033081055 287.1076049805281 .0119018555275 .5257873535270 .3443908691266 .0773925781 262.4200134277259 .3721008301257 .5433959961255 .7147064209253 .5812072754 250.5334014893246 .8759002686242 .6089935303238 .9515075684235 .5989074707 233.7702026367233 .4653930664235 .5989074707240 .7801971436246 .2664031982 249.3141937256250 .8381958008252 .0572967529252 .3621063232252 .9716033936 252.9716033936253 .2763977051252 .9716033936252 .0572967529249 .9237976074 246.8759002686243 .5233001709240 .1707000732236 .8179931641233 .4653930664 230.1127929688227 .0648956299223 .7122955322220 .3596038818217 .0070037842 213.6544036865210 .6065063477207 .25390625204 .2059936523201 .4629974365 199.0247039795197 .1959991455195 .3672943115193 .5386047363191 .7097930908 189.5764007568188 .0523986816186 .8332977295185 .91889953361185 .3094024658 184.3950042725181 .9566955566179 .5184020996177 .0802001953174 .6419067383 172.2035980225170 .070098877168 .5462036133167 .0222015381165 .8031005859 164.5839996338163 .6696014404163 .0599975586162 .4505004883162 .1457061768 161.8408966064161 .5361022949161 .2312927246160 .9264984131160 .6217956543 160.6217956543160 .3170013428160 .3170013428160 .0122070312160 .0122070312 159.7073974609159 .7073974609159 .7073974609160 .0122070312160 .0122070312 160.6217956543160 .9264984131161 .8408966064162 .7552947998163 .974395752 165.1934967041166 .4127044678167 .9365997314169 .4604949951170 .9844970703 172.5084075928173 .7274932861174 .9467010498176 .165802002176 .4705963135 175.5561981201174 .0323028564171 .8988037109170 .070098877168 .241394043 166.1078948975164 .2792053223162 .4505004883160 .9264984131159 .4026031494 158.1835021973157 .2691040039156 .6596069336156 .3547973633156 .3547973633 156.6596069336157 .2691040039158 .1835021973159 .0977935791160 .3170013428 
161.5361022949162 .4505004883163 .6696014404164 .5839996338165 .4983062744 166.1078948975166 .7174987793167 .0222015381167 .3269958496167 .3269958496 167.0222015381166 .4127044678164 .5839996338162 .7552947998160 .9264984131 159.7073974609159 .4026031494159 .4026031494160 .0122070312161 .2312927246 162.4505004883163 .974395752165 .4983062744166 .4127044678167 .3269958496 167.3269958496167 .3269958496167 .3269958496167 .0222015381166 .7174987793 166.4127044678166 .1078948975165 .8031005859165 .4983062744165 .1934967041 164.8887023926164 .8887023926164 .5839996338164 .2792053223163 .974395752 163.6696014404163 .0599975586162 .7552947998161 .8408966064161 .2312927246 160.3170013428159 .4026031494158 .1835021973157 .2691040039156 .0500030518 154.5260925293153 .3069000244151 .7830047607150 .8686065674149 .9542999268 149.3446960449 148.4304046631 147.5160064697 146.2969055176145.3825073242 144.1634063721142 .6394042969141 .4203033447139 .8963928223138 .6772003174 137.1533050537135 .9342041016135 .0198059082134 .1054992676133 .1911010742 132.5814971924132 .2767028809132 .2767028809132 .2767028809132 .5814971924 133.4958953857134 .4102020264135 .3246002197136 .2389984131136 .8484954834 137.4580993652137 .7628936768138 .0677032471137 .7628936768137 .4580993652 137.1533050537136 .5437011719136 .2389984131135 .6293945312135 .0198059082 134.1054992676133 .1911010742132 .2767028809131 .3623962402130 .1432037354 128.3144989014126 .7906036377124 .9618988037123 .1332015991121 .9140014648 121.6092987061 121.9140014648120.9997024536119.4757995605 117.0374984741 114.2944030762112 .7705001831112 .7705001831115 .5136032104120 .9997024536 129.533706665139 .2868041992148 .7351074219160 .3170013428172 .5084075928 183.7854003906193 .8433074951203 .2917022705209 .692199707209 .692199707 209.692199707 209.692199707 209.692199707 209.692199707 209.692199707 209.692199707 209.692199707209 .692199707209 .692199707209 .692199707209 .692199707209 .692199707 209.692199707209 .692199707209 .692199707209 .692199707209 .692199707209 .692199707 209.692199707209 .692199707209 .692199707209 .692199707209 .692199707209 .692199707 209.692199707 209.692199707 209.692199707 209.692199707 209.692199707 209.692199707 209.692199707209.692199707 209.692199707 209.692199707 64.30966186523 -.785923063755 -9999 -9999 -9999 -9999 -9999 -9999 -9999 -9999 -9999 -9999 -9999 -9999 -9999 -9999 -9999 -9999 -9999 -9999 -9999 -9999 -9999 -9999 -9999 -9999 -9999

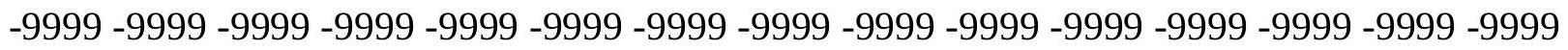

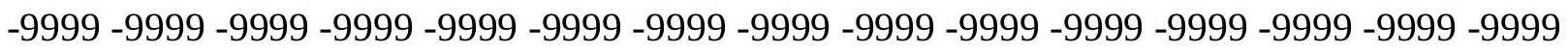
485.742401123481 .6980895996477 .223449707472 .139465332466 .4443664551 460.2255859375453 .2155151367445 .5958862305437 .6713867188430 .3565979004 423.9560852051417 .8604125977412 .0694885254406 .2785949707400 .792388916 395.611114502391 .3440856934387 .3818969727384 .029296875381 .2861938477 378.8479003906377 .0191955566379 .762298584381 .591003418382 .5053100586 381.2861938477377 .6288146973372 .1426086426365 .4374084473364 .2182006836 363.303894043362 .0846862793360 .8656005859359 .6465148926358 .4273071289 356.5986022949354 .1603088379351 .4172058105348 .0646057129344 .1023864746 339.5306091309336 .7875976562332 .2157897949330 .3870849609330 .0823059082 330.3870849609330 .9966125488331 .9110107422332 .8252868652333 .4349060059 333.4349060059332 .8252868652330 .9966125488328 .2536010742324 .2914123535 318.8052062988312 .7095031738305 .6994934082298 .6893920898292 .2889099121 
286.4979858398280 .7070922852275 .5257873535270 .6492004395266 .6870117188 263.9439086914261 .8103942871259 .9816894531257 .5433959961254 .8003997803 251.1428985596246 .8759002686243 .5233001709241 .0850067139239 .5610961914 239.5610961914245 .0471954346250 .2286071777253 .8860015869256 .0195007324 257.2385864258258 .1530151367258 .4577941895258 .7626037598258 .7626037598 258.4577941895257 .2385864258255 .1051025391252 .3621063232249 .0093994141 245.6567993164242 .3041992188238 .6468048096235 .2940979004231 .9414978027 228.5888977051225 .2362060547221 .883605957218 .5308990479215 .4830932617 212.1304016113209 .0825958252206 .3394927979203 .9011993408201 .4629974365 199.6342926025197 .500793457195 .6721038818193 .5386047363192 .0146026611 190.4907073975189 .2716064453188 .3571929932186 .8332977295184 .699798584 182.261505127179 .5184020996177 .0802001953174 .337097168172 .2035980225 170.070098877168 .241394043166 .7174987793165 .8031005859164 .5839996338 163.974395752163 .0599975586162 .7552947998162 .1457061768161 .8408966064 161.2312927246160 .9264984131160 .6217956543160 .3170013428160 .0122070312 159.7073974609159 .4026031494159 .0977935791158 .7929992676158 .4882965088 158.1835021973158 .1835021973158 .1835021973158 .4882965088158 .7929992676 159.7073974609160 .6217956543161 .5361022949163 .0599975586164 .2792053223 165.8031005859167 .6318054199169 .1557006836170 .6797027588172 .5084075928 173.7274932861175 .2514038086175 .8609924316174 .6419067383173 .1179962158 171.2891998291169 .1557006836167 .3269958496165 .1934967041163 .3648071289 161.8408966064160 .3170013428158 .7929992676157 .5738983154156 .9642944336 156.3547973633156 .0500030518156 .3547973633156 .6596069336157 .2691040039 158.1835021973159 .4026031494160 .6217956543161 .5361022949162 .7552947998 163.974395752164 .8887023926165 .8031005859166 .7174987793167 .3269958496 167.6318054199167 .9365997314167 .9365997314167 .3269958496166 .7174987793 165.1934967041163 .3648071289161 .5361022949160 .3170013428159 .7073974609 159.7073974609160 .0122070312160 .9264984131162 .1457061768163 .3648071289 164.8887023926166 .1078948975166 .7174987793166 .7174987793166 .7174987793 166.4127044678166 .1078948975165 .8031005859165 .4983062744165 .1934967041 164.8887023926164 .5839996338164 .2792053223163 .974395752163 .974395752 163.6696014404163 .3648071289163 .3648071289163 .0599975586162 .7552947998 162.1457061768161 .5361022949160 .9264984131160 .3170013428159 .4026031494 158.4882965088157 .2691040039156 .0500030518154 .8307952881153 .3069000244 152.3925933838151 .4781951904150 .8686065674150 .2590942383149 .6495056152 148.7351074219147 .8208007812146 .6015930176145 .3825073242143 .8585968018 142.3347015381140 .8106994629139 .2868041992137 .7628936768136 .2389984131 135.0198059082134 .1054992676132 .8863067627132 .2767028809131 .6672058105 131.3623962402131 .3623962402131 .6672058105132 .5814971924133 .4958953857 134.7149963379135 .6293945312136 .5437011719137 .4580993652138 .0677032471 138.0677032471138 .0677032471137 .7628936768137 .1533050537136 .5437011719 136.2389984131135 .6293945312135 .0198059082134 .1054992676133 .4958953857 132.5814971924131 .9720001221130 .7528076172129 .2288970947127 .0953979492 125.2667007446123 .43800354121 .6092987061122 .2188034058122 .5235977173 122.2188034058121 .3044967651118 .2565994263115 .5136032104113 .6848983765 114.2944030762117 .647102356124 .0475006104132 .5814971924140 .8106994629 
149.9542999268 163.3648071289 175.2514038086186.2236938477 196.2816009521 205.1204071045209 .692199707209 .692199707209 .692199707209 .692199707 209.692199707209 .692199707209 .692199707209 .692199707209 .692199707209 .692199707 209.692199707209 .692199707209 .692199707209 .692199707209 .692199707209 .692199707 209.692199707209 .692199707209 .692199707209 .692199707209 .692199707209 .692199707 209.692199707209 .692199707209 .692199707209 .692199707209 .692199707209 .692199707 209.692199707209 .692199707209 .692199707209 .692199707209 .692199707209 .692199707 209.692199707 209.69219970764 .30966186523 -1.04838466644 -9999 -9999 -9999 -9999 -9999 -9999 -9999-9999-9999-9999

-9999 -9999 -9999 -9999 -9999 -9999 -9999 -9999 -9999 -9999 -9999 -9999 -9999 -9999 -9999

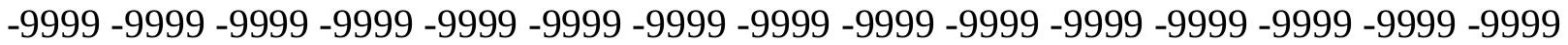
-9999 -9999 -9999 -9999 -9999 -9999 -9999 -9999 -9999 -9999 -9999 -9999 -9999 -9999 -9999 -9999 -9999 485.158203125 480.0784301758474.3888549805 468.091003418461.130279541 453.5459594727445 .5958862305438 .8905944824433 .0997009277427 .613494873 422.4321899414416 .9460144043411 .4598999023406 .2785949707401 .7067871094 397.7445983887394 .696685791391 .6488952637391 .0393066406391 .6488952637 392.2585144043393 .1727905273394 .391998291394 .0871887207389 .515411377 382.8100891113375 .799987793371 .228302002370 .3139038086369 .399597168 368.4851989746367 .8756103516366 .6564941406365 .4374084473363 .9135131836 361.475189209359 .036895752355 .9890136719352 .941192627350 .1980895996 348.0646057129346 .845489502346 .2359008789346 .5407104492347 .1502990723 348.0646057129348 .6741943359349 .5885009766349 .5885009766348 .9790039062 347.1502990723344 .4071960449340 .1401977539334 .6541137695327 .9487915039 320.6339111328312 .4047851562306 .3091125488300 .2132873535293 .8128967285 287.4124145508281 .6214904785276 .1353149414272 .4779052734270 .3443908691 269.1253051758267 .9060974121265 .7726135254262 .7247924805258 .7626037598 254.4956054688250 .8381958008249 .0093994141249 .6190032959253 .2763977051 257.2385864258260 .5913085938262 .4200134277263 .3344116211263 .9439086914 264.2486877441264 .5534973145264 .5534973145263 .9439086914262 .7247924805 260.5913085938257 .8482055664254 .4956054688250 .8381958008247 .1806945801 243.8280944824240 .1707000732236 .5133056641233 .1605987549229 .8079986572 226.4553985596223 .1027069092220 .054901123216 .7021942139213 .959197998 211.2160949707208 .4730072021206 .3394927979204 .2059936523202 .0724945068 199.9389953613198 .1103057861196 .2816009521194 .4528961182192 .9290008545 191.4051055908189 .5764007568187 .4429016113184 .699798584182 .261505127 179.5184020996176 .7754058838174 .0323028564171 .5939941406169 .7653045654 168.241394043167 .0222015381165 .8031005859164 .8887023926164 .2792053223 163.3648071289162 .7552947998162 .4505004883161 .8408966064161 .2312927246 160.9264984131160 .3170013428159 .7073974609159 .4026031494158 .7929992676 158.1835021973157 .878692627157 .5738983154156 .9642944336156 .6596069336 156.3547973633156 .3547973633156 .9642944336157 .5738983154158 .4882965088 159.4026031494160 .9264984131162 .1457061768163 .6696014404165 .4983062744 167.3269958496168 .8509979248170 .3748931885171 .8988037109173 .1179962158 173.7274932861172 .8132019043171 .5939941406169 .7653045654167 .9365997314 166.1078948975164 .2792053223162 .4505004883160 .9264984131159 .4026031494 158.1835021973156 .9642944336156 .3547973633156 .0500030518155 .7451934814 
156.0500030518156 .3547973633157 .2691040039158 .1835021973159 .4026031494 160.6217956543161 .8408966064163 .0599975586164 .2792053223165 .4983062744 166.4127044678167 .0222015381167 .6318054199168 .241394043168 .241394043 167.9365997314167 .6318054199166 .7174987793165 .1934967041163 .6696014404 162.1457061768160 .6217956543160 .0122070312159 .4026031494159 .7073974609 160.3170013428161 .2312927246162 .7552947998164 .2792053223165 .4983062744 165.8031005859165 .8031005859165 .4983062744165 .4983062744165 .1934967041 164.8887023926164 .5839996338163 .974395752163 .6696014404163 .3648071289 163.0599975586163 .0599975586162 .7552947998162 .7552947998162 .7552947998 162.7552947998162 .4505004883162 .1457061768161 .8408966064161 .2312927246 160.9264984131160 .0122070312159 .4026031494158 .4882965088157 .5738983154 156.3547973633155 .1356048584153 .9165039062152 .6972961426152 .0877990723 151.7830047607151 .4781951904150 .8686065674149 .9542999268149 .0399017334 147.8208007812146 .6015930176145 .0776977539143 .2489929199141 .7250976562 139.8963928223138 .3724975586136 .5437011719135 .3246002197133 .8007049561 132.5814971924131 .6672058105131 .0576019287130 .7528076172130 .4479980469 130.7528076172131 .3623962402132 .5814971924133 .8007049561135 .3246002197 136.5437011719137 .4580993652138 .0677032471138 .3724975586138 .0677032471 137.7628936768137 .1533050537136 .8484954834136 .2389984131135 .6293945312 135.0198059082134 .1054992676133 .4958953857132 .8863067627132 .2767028809 131.3623962402129 .533706665127 .7050018311125 .5715026855124 .0475006104 122.8283996582122 .8283996582122 .8283996582122 .8283996582121 .3044967651 118.8662033081116 .1231002808114 .5991973877115 .2088012695118 .8662033081 125.5715026855134 .7149963379141 .4203033447152 .6972961426165 .8031005859 177.6896972656188 .6620025635198 .4151000977206 .9490966797209 .692199707 209.692199707 209.692199707 209.692199707 209.692199707 209.692199707 209.692199707 209.692199707 209.692199707 209.692199707 209.692199707 209.692199707 209.692199707 209.692199707 209.692199707 209.692199707 209.692199707 209.692199707 209.692199707 209.692199707 209.692199707 209.692199707 209.692199707 209.692199707 209.692199707 209.692199707 209.692199707 209.692199707 209.692199707 209.692199707 209.692199707 209.692199707209 .692199707209 .692199707209 .692199707209 .69219970764 .0048828125 -1.38067662716 -9999 -9999 -9999 -9999 -9999 -9999 -9999 -9999 -9999 -9999 -9999 -

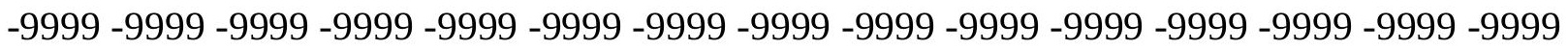

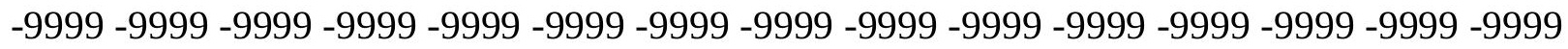
-9999 -9999 -9999 -9999 481.9019775391 475.6694335938468.9013366699461.7623901367 454.6993103027448 .2764282227442 .5480041504437 .9761962891432 .7948913574 427.3086853027421 .8226013184416 .6412963867412 .3742980957408 .412109375 405.059387207404 .145111084404 .4498901367404 .4498901367403 .5354919434 403.2307128906404 .7546081543404 .7546081543399 .878112793392 .8680114746 385.858001709378 .2383117676377 .324005127376 .7143859863376 .4096069336 376.104888916375 .799987793375 .1904907227373 .9713134766372 .4473876953 370.6187133789369 .0947875977367 .2661132812365 .7421875364 .5230102539 363.9135131836363 .6086120605363 .9135131836364 .2182006836365 .132598877 365.7421875366 .6564941406366 .9613037109366 .3517150879364 .8277893066 362.0846862793357 .8176879883352 .3316040039345 .6263122559338 .3114929199 
330.6918945312323 .6817932129316 .6718139648309 .6617126465302 .3468017578 295.3367919922288 .6315002441283 .7549133301282 .2309875488281 .9262084961 281.6214904785280 .4023132324277 .9641113281273 .6971130371268 .5156860352 263.9439086914261 .8103942871262 .4200134277264 .8583068848267 .9060974121 269.7348022461270 .0396118164270 .0396118164270 .3443908691270 .6492004395 270.9540100098270 .9540100098270 .3443908691268 .5156860352266 .3822021484 263.3344116211259 .6769104004256 .0195007324252 .0572967529248 .3999023438 244.7424926758240 .7801971436237 .4275970459233 .7702026367230 .7223052979 227.3697052002224 .3218994141221 .5787963867218 .5308990479215 .787902832 213.3495941162210 .9113006592208 .7778015137206 .6443023682204 .5108032227 202.3773040771200 .5485992432198 .7198944092196 .5863952637194 .7577056885 192.624206543190 .1858978271187 .4429016113184 .699798584181 .9566955566 178.604095459175 .8609924316173 .4226989746171 .5939941406169 .7653045654 168.5462036133167 .3269958496166 .4127044678165 .4983062744164 .5839996338 163.974395752163 .0599975586162 .4505004883161 .8408966064161 .2312927246 160.6217956543160 .0122070312159 .0977935791158 .4882965088157 .878692627 157.2691040039156 .6596069336155 .7451934814155 .1356048584154 .8307952881 154.5260925293154 .8307952881155 .4403991699156 .3547973633157 .2691040039 158.4882965088160 .0122070312161 .5361022949163 .3648071289165 .1934967041 166.7174987793168 .241394043169 .7653045654170 .6797027588170 .9844970703 170.6797027588169 .4604949951168 .241394043166 .4127044678164 .8887023926 163.0599975586161 .5361022949160 .0122070312158 .4882965088157 .2691040039 156.3547973633155 .7451934814155 .4403991699155 .4403991699155 .7451934814 156.3547973633156 .9642944336158 .1835021973159 .4026031494160 .6217956543 162.1457061768163 .3648071289164 .5839996338165 .8031005859166 .7174987793 167.6318054199168 .241394043168 .5462036133168 .5462036133168 .241394043 167.6318054199166 .4127044678165 .1934967041163 .6696014404162 .1457061768 160.9264984131159 .7073974609159 .0977935791159 .0977935791159 .4026031494 160.3170013428161 .5361022949162 .7552947998163 .974395752164 .2792053223 164.5839996338164 .2792053223164 .2792053223163 .974395752163 .6696014404 163.3648071289163 .0599975586162 .7552947998162 .4505004883162 .1457061768 162.1457061768161 .8408966064161 .8408966064161 .8408966064161 .8408966064 161.8408966064161 .8408966064161 .5361022949161 .2312927246160 .6217956543 160.0122070312159 .4026031494158 .4882965088157 .5738983154156 .6596069336 155.7451934814154 .5260925293153 .6116943359153 .0021057129152 .6972961426 152.3925933838152 .0877990723151 .4781951904150 .5639038086149 .3446960449 147.8208007812146 .2969055176144 .4682006836142 .3347015381140 .5059967041 138.6772003174136 .8484954834135 .3246002197133 .8007049561132 .5814971924 131.3623962402130 .4479980469129 .8385009766129 .533706665129 .533706665 130.1432037354131 .3623962402132 .8863067627134 .7149963379136 .5437011719 137.7628936768138 .3724975586138 .6772003174138 .3724975586138 .0677032471 137.4580993652136 .8484954834136 .2389984131135 .6293945312134 .7149963379 134.1054992676133 .4958953857132 .8863067627131 .9720001221131 .0576019287 129.533706665127 .7050018311125 .8762969971124 .3523025513123 .43800354 123.1332015991123 .1332015991122 .5235977173121 .3044967651118 .8662033081 116.1231002808114 .5991973877115 .2088012695118 .5614013672124 .3523025513 
131.9720001221139 .5915985107152 .0877990723167 .0222015381179 .5184020996 190.4907073975199 .9389953613208 .4730072021209 .692199707209 .692199707 209.692199707209 .692199707209 .692199707209 .692199707209 .692199707209 .692199707 209.692199707209 .692199707209 .692199707209 .692199707209 .692199707209 .692199707 209.692199707209 .692199707209 .692199707209 .692199707209 .692199707209 .692199707 209.692199707 209.692199707 209.692199707 209.692199707 209.692199707 209.692199707 209.692199707209 .692199707209 .692199707209 .692199707209 .692199707209 .692199707 209.692199707209 .692199707209 .692199707209 .69219970763 .70008850098 -1.74379181862 -9999 -9999 -9999 -9999 -9999 -9999 -9999 -9999 -9999 -9999 -9999 -9999 -9999 -9999 -9999 -9999 -9999 -9999 -9999 -9999 -9999 -9999 -9999 -9999 -9999 -9999 -9999 -9999 -9999 -9999 -9999 -9999 -9999 -9999 -9999 -9999 -9999 -9999 -9999 -9999 -999 -9999 -9999 -9999 -9999 -9999 -9999 -9999 -9999 -9999 -9999 -9999 -9999 -9999 -9999 -9999 -9999 -9999 -9999 -9999 -9999 -9999 476.8674316406470 .3087463379463 .9282531738 458.0198059082452 .8170776367448 .2295837402443 .4624023438437 .6713867188 432.1853027344426 .6991882324422 .4321899414419 .0795898438416 .0317077637 414.8125915527414 .2030029297413 .2886047363411 .7647094727410 .5455932617 409.9360046387408 .412109375403 .8403015137398 .049407959393 .1727905273 387.3818969727384 .6387939453384 .6387939453384 .9436035156385 .2484130859 385.2484130859384 .9436035156384 .3340148926383 .7244873047382 .8100891113 382.200592041381 .8958129883381 .591003418381 .591003418381 .591003418 381.591003418381 .591003418381 .8958129883382 .200592041383 .1148986816 384.029296875384 .6387939453384 .6387939453383 .419708252380 .9814147949 377.0191955566371 .5331115723365 .132598877358 .1224975586350 .8077087402 343.1879882812335 .8731994629328 .2536010742320 .6339111328312 .7095031738 305.0899047852298 .3846130371298 .3846130371298 .6893920898298 .9942016602 298.6893920898297 .1654968262291 .9841918945285 .8884887695280 .0975036621 276.7449035645277 .6592102051280 .4023132324282 .2309875488281 .6214904785 279.4880065918277 .9641113281277 .3544921875277 .6592102051278 .2687988281 278.2687988281277 .3544921875275 .5257873535272 .4779052734269 .1253051758 265.1630859375260 .8960876465256 .6290893555252 .6669006348248 .7046966553 244.7424926758241 .0850067139237 .7324066162234 .6844940186231 .6367034912 228.5888977051225 .8457946777223 .1027069092220 .6643981934218 .2261962891 215.787902832213 .3495941162211 .2160949707209 .0825958252206 .9490966797 204.8155975342202 .6820983887200 .5485992432198 .4151000977195 .6721038818 192.9290008545189 .8811035156186 .528503418183 .1759033203180 .1280059814 177.3849029541175 .2514038086173 .4226989746171 .8988037109170 .6797027588 169.4604949951168 .241394043167 .0222015381166 .1078948975165 .1934967041 164.2792053223163 .6696014404162 .7552947998162 .1457061768161 .2312927246 160.3170013428159 .4026031494158 .4882965088157 .5738983154156 .6596069336 155.7451934814154 .8307952881153 .9165039062153 .3069000244153 .0021057129 153.3069000244153 .9165039062154 .5260925293155 .4403991699156 .3547973633 157.878692627159 .4026031494161 .2312927246162 .7552947998164 .5839996338 165.8031005859167 .0222015381167 .9365997314168 .241394043167 .9365997314 167.3269958496166 .1078948975164 .8887023926163 .3648071289161 .8408966064 160.3170013428159 .0977935791157 .5738983154156 .6596069336155 .7451934814 155.1356048584154 .8307952881154 .8307952881155 .1356048584155 .7451934814 
156.9642944336157 .878692627159 .4026031494160 .6217956543162 .1457061768 163.6696014404164 .8887023926166 .1078948975167 .0222015381167 .9365997314 168.5462036133168 .5462036133168 .5462036133167 .9365997314167 .3269958496 166.4127044678164 .8887023926163 .3648071289162 .1457061768160 .6217956543 159.4026031494158 .7929992676158 .1835021973158 .4882965088159 .0977935791 160.0122070312161 .2312927246162 .1457061768162 .7552947998163 .0599975586 163.0599975586163 .0599975586163 .0599975586162 .7552947998162 .4505004883 162.1457061768161 .8408966064161 .5361022949161 .2312927246160 .9264984131 160.9264984131161 .2312927246161 .2312927246161 .5361022949161 .5361022949 161.2312927246161 .2312927246160 .9264984131160 .6217956543160 .0122070312 159.4026031494158 .7929992676157 .878692627156 .9642944336156 .0500030518 155.4403991699154 .5260925293154 .2212982178153 .6116943359153 .3069000244 153.0021057129152 .3925933838151 .7830047607150 .5639038086149 .0399017334 147.2111968994145 .0776977539143 .2489929199141 .1154937744138 .9819946289 137.1533050537135 .3246002197133 .8007049561132 .2767028809131 .0576019287 130.1432037354129 .2288970947128 .6192932129128 .3144989014128 .6192932129 130.1432037354131 .9720001221134 .1054992676136 .2389984131138 .0677032471 138.6772003174138 .6772003174138 .3724975586138 .0677032471137 .4580993652 136.8484954834135 .9342041016135 .3246002197134 .7149963379133 .8007049561 133.1911010742132 .2767028809131 .3623962402130 .4479980469128 .9241027832 127.4001998901125 .8762969971124 .3523025513123 .43800354122 .8283996582 122.5235977173122 .2188034058121 .6092987061118 .5614013672116 .1231002808 114.2944030762114 .5991973877117 .0374984741121 .9140014648128 .6192932129 136.8484954834152 .3925933838167 .3269958496180 .432800293191 .4051055908 201.158203125209 .692199707209 .692199707209 .692199707209 .692199707209 .692199707 209.692199707 209.692199707 209.692199707 209.692199707 209.692199707 209.692199707 209.692199707209 .692199707209 .692199707209 .692199707209 .692199707209 .692199707 209.692199707209 .692199707209 .692199707209 .692199707209 .692199707209 .692199707 209.692199707 209.692199707 209.692199707 209.692199707 209.692199707 209.692199707 209.692199707 209.692199707 209.692199707 209.692199707 209.692199707209.692199707 209.692199707 209.69219970763 .70008850098 -2.07210469246 -9999 -9999 -9999 -9999 -9999 -9999 -9999 -9999-9999-9999 -9999 -9999 -9999 -9999 -9999 -9999 -9999 -9999 -9999-9999 -9999 -9999 -9999 -9999 -9999 -9999 -9999 -9999 -9999 -9999 -9999 -9999 -9999 -9999 -9999 -9999 -9999 -9999 -9999 -9999

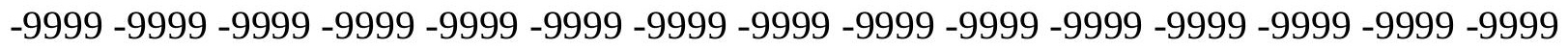
-9999 -9999 -9999 -9999 -9999 -9999 -9999 -9999 473.1217956543467 .6724243164 462.7551269531458 .2729492188454 .1448669434450 .1676025391441 .9383850098 435.8427124023432 .1853027344429 .7470092773426 .6991882324423 .6513061523 422.7369995117420 .9082946777419 .0795898438416 .6412963867413 .5934143066 409.9360046387405 .059387207400 .487701416397 .4397888184394 .0871887207 391.6488952637392 .2585144043393 .4776000977394 .391998291395 .3063049316 395.611114502395 .3063049316395 .0014953613394 .696685791395 .3063049316 396.5255126953397 .7445983887398 .6589050293399 .2684936523399 .2684936523 398.9637145996398 .9637145996398 .9637145996399 .878112793401 .0971984863 402.31640625403 .2307128906402 .6211853027400 .487701416396 .8302001953 391.953704834385 .858001709379 .1527099609372 .1426086426364 .8277893066 
357.5129089355349 .8933105469341 .9689025879334 .3493041992327 .3392028809 322.1578979492320 .3291931152320 .0244140625320 .3291931152319 .7196044922 317.5860900879313 .0143127441307 .2233886719300 .5180969238295 .0320129395 296.8606872559299 .2990112305300 .5180969238295 .9464111328290 .7650146484 287.1076049805285 .5835876465286 .1932067871286 .8027954102286 .8027954102 285.5835876465283 .1453857422279 .7927856445275 .5257873535270 .9540100098 266.0773925781261 .2008972168256 .6290893555252 .3621063232248 .7046966553 245.0471954346241 .6945953369238 .6468048096235 .5989074707232 .8558044434 230.4176025391227 .6744995117225 .5410003662223 .1027069092220 .6643981934 218.2261962891215 .787902832213 .6544036865211 .520904541209 .0825958252 206.9490966797204 .5108032227202 .0724945068199 .329498291195 .9768066406 192.3193969727188 .3571929932184 .3950042725181 .3471984863178 .9089050293 177.0802001953175 .8609924316174 .337097168173 .1179962158171 .8988037109 170.3748931885169 .1557006836167 .9365997314167 .0222015381166 .1078948975 165.1934967041164 .2792053223163 .0599975586162 .1457061768160 .9264984131 160.0122070312158 .7929992676157 .5738983154156 .6596069336155 .4403991699 154.2212982178153 .0021057129152 .0877990723151 .7830047607151 .7830047607 152.6972961426153 .0021057129153 .6116943359154 .5260925293155 .7451934814 157.2691040039159 .0977935791160 .6217956543162 .1457061768163 .6696014404 164.5839996338165 .4983062744165 .8031005859165 .4983062744165 .1934967041 164.2792053223163 .0599975586161 .8408966064160 .6217956543159 .0977935791 157.878692627156 .6596069336155 .7451934814154 .8307952881154 .2212982178 153.9165039062154 .2212982178154 .5260925293155 .4403991699156 .6596069336 157.878692627159 .4026031494160 .6217956543162 .1457061768163 .6696014404 165.1934967041166 .4127044678167 .3269958496168 .241394043168 .5462036133 168.5462036133168 .5462036133167 .9365997314167 .0222015381166 .1078948975 164.5839996338163 .3648071289161 .8408966064160 .3170013428159 .0977935791 157.878692627157 .2691040039157 .2691040039157 .5738983154158 .4882965088 159.7073974609160 .6217956543161 .2312927246161 .8408966064162 .1457061768 162.1457061768162 .1457061768161 .8408966064161 .5361022949161 .2312927246 160.9264984131160 .6217956543160 .0122070312160 .0122070312160 .0122070312 160.3170013428160 .6217956543160 .9264984131160 .9264984131161 .2312927246 160.9264984131160 .9264984131160 .6217956543160 .0122070312159 .7073974609 158.7929992676158 .1835021973157 .5738983154156 .6596069336156 .0500030518 155.4403991699154 .8307952881154 .5260925293154 .2212982178153 .9165039062 153.3069000244152 .6972961426151 .7830047607150 .2590942383148 .1255950928 145.9920959473143 .5538024902141 .4203033447139 .2868041992137 .1533050537 135.3246002197133 .4958953857132 .2767028809130 .7528076172129 .8385009766 128.9241027832128 .0097961426127 .7050018311127 .4001998901129 .2288970947 131.3623962402133 .4958953857135 .6293945312137 .1533050537138 .0677032471 138.3724975586138 .0677032471137 .7628936768137 .1533050537136 .5437011719 135.6293945312135 .0198059082134 .1054992676133 .4958953857132 .5814971924 131.6672058105130 .7528076172129 .8385009766128 .3144989014126 .7906036377 125.5715026855124 .0475006104123 .1332015991122 .5235977173121 .9140014648 121.6092987061120 .3900985718118 .2565994263115 .818397522113 .9896011353 113.9896011353115 .5136032104119 .4757995605124 .6570968628136 .8484954834 
153.0021057129167 .6318054199180 .7375946045192 .0146026611201 .7678070068 209.692199707 209.692199707209.692199707209.692199707 209.692199707209.692199707 209.692199707209 .692199707209 .692199707209 .692199707209 .692199707209 .692199707 209.692199707209 .692199707209 .692199707209 .692199707209 .692199707209 .692199707 209.692199707209 .692199707209 .692199707209 .692199707209 .692199707209 .692199707 209.692199707209 .692199707209 .692199707209 .692199707209 .692199707209 .692199707 209.692199707209 .692199707209 .692199707209 .692199707209 .692199707209 .692199707 $209.69219970763 .39530944824-2.42971467972$-9999 -9999 -9999 -9999 -9999 -9999 -9999 -9999 -9999-9999

-9999 -9999 -9999 -9999 -9999 -9999 -9999 -9999 -9999 -9999 -9999 -9999 -9999 -9999 -9999

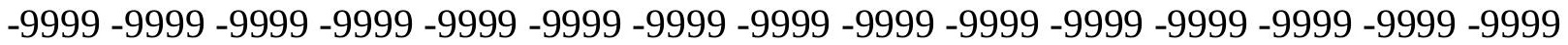

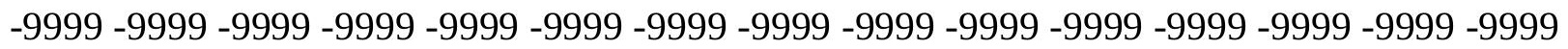
-9999 -9999 -9999 -9999 -9999 -9999 -9999 -9999 -9999 -9999 472.2272644043 467.801361084463 .4200134277458 .363861084452 .0215454102446 .1019592285 441.633605957440 .7192993164437 .3666992188434 .0140075684430 .6614074707 428.8327026367425 .7847900391422 .4321899414417 .5556030273412 .0694885254 407.8024902344403 .8403015137400 .792388916398 .9637145996398 .9637145996 400.1828918457402 .31640625404 .4498901367405 .6690063477406 .2785949707 406.2785949707405 .9737854004406 .5833129883408 .1072998047410 .8503112793 413.8981933594416 .0317077637416 .9460144043416 .6412963867415 .7268981934 414.8125915527414 .5078125415 .1173095703417 .250793457419 .3843078613 421.2130126953421 .8226013184420 .2987060547417 .250793457412 .3742980957 406.8882141113400 .792388916394 .391998291387 .686706543380 .6766052246 373.666595459366 .3517150879359 .3417053223353 .2460021973348 .6741943359 346.2359008789345 .3215026855345 .0168151855344 .1023864746341 .6640930176 337.7019042969332 .2157897949326 .7296142578323 .0722045898322 .1578979492 321.5483093262319 .1099853516312 .4047851562303 .8707885742297 .4703063965 295.6416015625296 .5559082031297 .4703063965296 .8606872559294 .7272033691 291.6794128418287 .4124145508282 .5357971191277 .0497131348271 .2587890625 265.7726135254260 .8960876465256 .3243103027252 .0572967529248 .7046966553 245.3520050049242 .6089935303239 .8659057617237 .1228027344234 .6844940186 232.5511016846230 .1127929688227 .9792938232225 .5410003662222 .7978973389 220.3596038818218 .2261962891215 .787902832213 .3495941162211 .2160949707 208.7778015137206 .0346984863202 .9868927002199 .329498291195 .0625190 .4907073975 186.2236938477182 .5662994385180 .7375946045179 .5184020996178 .9089050293 177.6896972656176 .165802002174 .6419067383173 .1179962158171 .5939941406 170.070098877169 .1557006836168 .241394043167 .0222015381166 .1078948975 164.5839996338163 .3648071289162 .1457061768160 .6217956543159 .4026031494 157.878692627156 .6596069336155 .4403991699153 .9165039062153 .0021057129 152.0877990723151 .7830047607151 .7830047607152 .3925933838152 .3925933838 152.3925933838152 .6972961426153 .9165039062155 .4403991699156 .9642944336 158.4882965088160 .0122070312161 .2312927246162 .1457061768163 .0599975586 163.3648071289163 .3648071289162 .7552947998162 .1457061768161 .2312927246 160.3170013428159 .0977935791157 .878692627156 .6596069336155 .7451934814 154.8307952881153 .9165039062153 .6116943359153 .3069000244153 .6116943359 154.2212982178155 .1356048584156 .3547973633157 .5738983154159 .0977935791 
160.6217956543162 .1457061768163 .6696014404165 .1934967041166 .4127044678 167.6318054199168 .5462036133168 .8509979248168 .5462036133168 .241394043 167.6318054199166 .7174987793165 .8031005859164 .2792053223163 .0599975586 161.5361022949160 .0122070312158 .4882965088157 .2691040039156 .3547973633 156.0500030518156 .3547973633157 .2691040039158 .4882965088159 .4026031494 160.0122070312160 .6217956543160 .9264984131161 .2312927246161 .2312927246 161.2312927246160 .9264984131160 .6217956543160 .3170013428159 .7073974609 159.4026031494159 .0977935791159 .4026031494160 .0122070312160 .3170013428 160.6217956543160 .9264984131160 .9264984131160 .9264984131160 .9264984131 160.6217956543160 .3170013428159 .7073974609159 .0977935791158 .4882965088 157.878692627157 .2691040039156 .6596069336156 .0500030518155 .4403991699 155.1356048584154 .5260925293154 .2212982178153 .9165039062153 .3069000244 152.3925933838150 .8686065674148 .7351074219146 .6015930176144 .1634063721 141.7250976562139 .5915985107137 .1533050537135 .3246002197133 .4958953857 131.9720001221130 .7528076172129 .533706665128 .6192932129128 .0097961426 127.7050018311128 .0097961426129 .2288970947131 .0576019287133 .1911010742 135.0198059082136 .5437011719137 .4580993652137 .7628936768137 .7628936768 137.4580993652136 .8484954834135 .9342041016135 .3246002197134 .4102020264 133.8007049561132 .8863067627131 .9720001221131 .0576019287130 .1432037354 128.9241027832127 .7050018311126 .1809997559124 .6570968628123 .43800354 122.5235977173121 .9140014648121 .6092987061120 .9997024536119 .4757995605 117.647102356115 .818397522114 .2944030762113 .9896011353114 .9039993286 118.2565994263124 .3523025513138 .3724975586153 .3069000244167 .6318054199 180.432800293192 .0146026611202 .0724945068209 .692199707209 .692199707 209.692199707 209.692199707 209.692199707 209.692199707 209.692199707 209.692199707 209.692199707209 .692199707209 .692199707209 .692199707209 .692199707209 .692199707 209.692199707209 .692199707209 .692199707209 .692199707209 .692199707209 .692199707 209.692199707209 .692199707209 .692199707209 .692199707209 .692199707209 .692199707 209.692199707 209.692199707 209.692199707 209.692199707 209.692199707 209.692199707 209.692199707209 .692199707209 .692199707209 .692199707209 .692199707 63.39530944824 -2.77280807495 -9999 -9999 -9999 -9999 -9999 -9999 -9999 -9999 -9999 $-9999$

-9999 -9999 -9999 -9999 -9999 -9999 -9999 -9999 -9999 -9999 -9999 -9999 -9999 -9999 -9999 -9999 -9999 -9999 -9999 -9999 -9999 -9999 -9999 -9999 -9999 -9999 -9999 -9999 -9999 -9999 -9999 -9999 -9999 -9999 -9999 -9999 -9999 -9999 -9999 -9999 -9999 -9999 -9999 -9999 -9999 -9999 -9999 -9999 -9999 -9999 -9999 -9999 -9999 -9999 -9999 -9999 -9999 -9999 466.8092956543461 .4221496582456 .3276062012452 .468536377449 .8447570801 447.080657959444 .0718994141440 .4144897461437 .6713867188434 .0140075684 430.0517883301426 .0895996094421 .517791748416 .6412963867411 .7647094727 407.8024902344405 .6690063477405 .6690063477408 .1072998047411 .4598999023 414.8125915527416 .9460144043417 .5556030273417 .5556030273417 .5556030273 418.1651916504420 .9082946777426 .0895996094430 .9661865234433 .709197998 434.3187866211433 .4043884277431 .2709960938428 .8327026367427 .613494873 428.2231140137431 .2709960938435 .2331848145438 .8905944824440 .7192993164 439.804901123437 .0618896484432 .4901123047427 .613494873422 .4321899414 416.9460144043410 .8503112793404 .7546081543398 .6589050293392 .5632019043 
386.4674987793381 .2861938477377 .0191955566374 .2760925293373 .0570068359 372.1426086426371 .228302002368 .7900085449365 .4374084473361 .1704101562 356.9034118652353 .8554992676351 .4172058105348 .6741943359342 .8833007812 333.7396850586322 .1578979492309 .9664916992309 .0520935059309 .9664916992 310.5759887695308 .1377868652304 .7850952148300 .8229064941295 .9464111328 289.8505859375283 .1453857422276 .7449035645270 .3443908691264 .8583068848 259.9816894531255 .7147064209252 .0572967529249 .0093994141246 .5711975098 243.8280944824241 .3898010254239 .5610961914237 .4275970459235 .2940979004 232.8558044434230 .4176025391227 .6744995117225 .2362060547222 .4931030273 220.054901123217 .6165924072215 .1782989502213 .0447998047210 .3016967773 206.9490966797202 .9868927002198 .4151000977193 .8433074951188 .966796875 184.699798584183 .7854003906183 .1759033203182 .5662994385181 .3471984863 179.8231964111177 .9945068359175 .8609924316174 .0323028564172 .5084075928 171.5939941406170 .6797027588169 .7653045654168 .241394043166 .7174987793 165.1934967041163 .3648071289161 .8408966064160 .3170013428158 .4882965088 156.9642944336155 .7451934814154 .2212982178153 .3069000244152 .3925933838 152.0877990723152 .0877990723152 .3925933838152 .0877990723151 .7830047607 152.0877990723152 .6972961426153 .9165039062155 .4403991699156 .6596069336 157.878692627159 .0977935791160 .0122070312160 .6217956543160 .9264984131 160.9264984131160 .9264984131160 .3170013428159 .7073974609158 .7929992676 157.878692627156 .6596069336155 .7451934814154 .8307952881153 .9165039062 153.3069000244152 .6972961426152 .6972961426153 .0021057129153 .6116943359 154.8307952881156 .0500030518157 .5738983154159 .0977935791160 .6217956543 162.1457061768163 .6696014404165 .1934967041166 .4127044678167 .6318054199 168.5462036133168 .8509979248168 .5462036133167 .9365997314167 .3269958496 166.4127044678165 .4983062744164 .2792053223162 .7552947998161 .2312927246 159.7073974609158 .4882965088156 .9642944336155 .7451934814154 .8307952881 155.7451934814156 .6596069336157 .5738983154158 .4882965088159 .0977935791 159.7073974609160 .3170013428160 .6217956543160 .6217956543160 .6217956543 160.3170013428160 .0122070312159 .7073974609159 .4026031494159 .0977935791 159.0977935791159 .0977935791159 .7073974609160 .0122070312160 .3170013428 160.6217956543160 .9264984131160 .9264984131160 .9264984131160 .6217956543 160.3170013428160 .0122070312159 .4026031494158 .7929992676158 .1835021973 157.5738983154156 .9642944336156 .3547973633155 .7451934814155 .4403991699 154.8307952881154 .5260925293154 .2212982178153 .6116943359152 .6972961426 151.1734008789149 .3446960449146 .9064025879144 .4682006836142 .0299072266 139.5915985107137 .1533050537135 .3246002197133 .4958953857131 .9720001221 130.7528076172129 .8385009766128 .9241027832128 .3144989014128 .3144989014 128.6192932129129 .533706665131 .0576019287132 .5814971924134 .4102020264 135.6293945312136 .5437011719136 .8484954834136 .8484954834136 .8484954834 136.2389984131135 .6293945312134 .7149963379134 .1054992676133 .1911010742 132.2767028809131 .3623962402130 .4479980469129 .2288970947128 .0097961426 126.7906036377125 .5715026855124 .3523025513122 .8283996582121 .6092987061 121.6092987061121 .6092987061120 .6949005127119 .4757995605117 .9517974854 116.7326965332115 .818397522115 .5136032104116 .1231002808118 .8662033081 125.2667007446137 .1533050537152 .6972961426167 .0222015381180 .1280059814 
191.7097930908202 .0724945068209 .692199707209 .692199707209 .692199707 209.692199707 209.692199707 209.692199707 209.692199707 209.692199707 209.692199707 209.692199707209 .692199707209 .692199707209 .692199707209 .692199707209 .692199707 209.692199707209 .692199707209 .692199707209 .692199707209 .692199707209 .692199707 209.692199707 209.692199707 209.692199707 209.692199707 209.692199707 209.692199707 209.692199707209 .692199707209 .692199707209 .692199707209 .692199707209 .692199707 209.692199707209 .692199707209 .692199707209 .69219970763 .09051895142 -3.13803291321 -9999 -9999 -9999 -9999 -9999 -9999 -9999 -9999 -9999 -9999

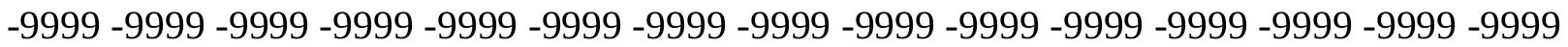

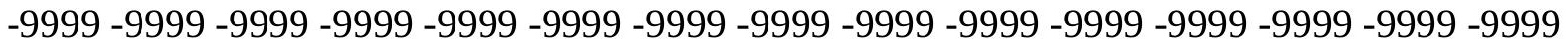

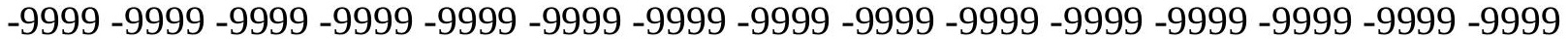

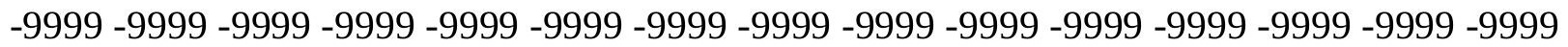
-9999 462.3960571289459.2112731934 456.3203735352 453.208984375 449.9490661621 446.7197265625443 .4624023438439 .500213623435 .2331848145430 .9661865234 425.4800109863419 .6890869141414 .8125915527411 .7647094727412 .0694885254 415.422088623421 .2130126953426 .3944091797428 .8327026367429 .137512207 429.137512207430 .0517883301431 .5757141113433 .709197998443 .1575927734 449.8629150391451 .996307373451 .6915893555449 .5581054688445 .5958862305 441.0241088867437 .9761962891438 .2810058594442 .2431945801449 .2532958984 455.6538085938459 .0064086914458 .7015991211455 .9585876465451 .3868103027 447.1198120117443 .7672119141439 .500213623434 .3187866211429 .137512207 424.5657043457419 .9938964844415 .1173095703410 .240814209405 .9737854004 403.5354919434402 .0115966797401 .4020080566400 .487701416398 .3541870117 395.3063049316391 .953704834388 .6010131836386 .1628112793384 .029296875 380.066986084372 .4473876953360 .8656005859347 .1502990723334 .9588928223 328.2536010742325 .2056884766322 .7674865723319 .4147949219315 .1477966309 310.2713012695304 .7850952148297 .1654968262289 .5458984375281 .9262084961 274.9161987305268 .8204956055263 .6390991211259 .06741333301255 .7147064209 252.6669006348250 .2286071777248 .0950927734246 .2664031982244 .4376983643 242.6089935303240 .4754943848238 .0372009277235 .5989074707232 .5511016846 229.8079986572226 .7601013184224 .3218994141221 .5787963867219 .4452972412 217.0070037842214 .8735046387210 .9113006592206 .9490966797202 .6820983887 198.1103057861193 .8433074951190 .4907073975188 .966796875188 .0523986816 186.8332977295185 .3094024658183 .4806976318181 .6519012451178 .604095459 176.165802002174 .9467010498174 .337097168173 .7274932861172 .8132019043 170.9844970703169 .1557006836167 .0222015381165 .1934967041163 .3648071289 161.2312927246159 .7073974609157 .878692627156 .3547973633154 .8307952881 153.6116943359153 .0021057129152 .3925933838152 .0877990723152 .0877990723 151.7830047607151 .7830047607151 .7830047607152 .0877990723153 .0021057129 153.9165039062155 .1356048584156 .0500030518157 .2691040039157 .878692627 158.4882965088159 .0977935791159 .0977935791158 .7929992676158 .4882965088 157.878692627157 .2691040039156 .6596069336155 .7451934814154 .8307952881 153.9165039062153 .3069000244152 .6972961426152 .0877990723152 .0877990723 152.6972961426153 .6116943359154 .8307952881156 .0500030518157 .5738983154 159.0977935791160 .6217956543162 .1457061768163 .6696014404164 .8887023926 166.4127044678167 .3269958496168 .241394043168 .241394043168 .241394043 
167.6318054199167 .0222015381166 .1078948975165 .1934967041163 .974395752 162.7552947998161 .2312927246159 .7073974609158 .4882965088156 .9642944336 156.0500030518155 .4403991699155 .7451934814156 .3547973633157 .2691040039 157.878692627158 .7929992676159 .4026031494159 .7073974609160 .0122070312 160.0122070312160 .0122070312160 .0122070312159 .7073974609159 .4026031494 159.4026031494159 .0977935791159 .0977935791159 .4026031494159 .7073974609 160.0122070312160 .3170013428160 .6217956543160 .9264984131160 .9264984131 160.9264984131160 .9264984131160 .6217956543160 .3170013428159 .7073974609 159.0977935791158 .4882965088157 .878692627157 .2691040039156 .6596069336 156.0500030518155 .4403991699154 .8307952881154 .5260925293153 .9165039062 153.6116943359153 .0021057129151 .7830047607149 .6495056152147 .2111968994 144.7729034424142 .0299072266139 .5915985107137 .1533050537135 .3246002197 133.4958953857132 .2767028809131 .0576019287129 .8385009766129 .2288970947 128.9241027832128 .9241027832129 .2288970947130 .1432037354131 .0576019287 132.5814971924133 .8007049561135 .0198059082135 .6293945312136 .2389984131 136.2389984131135 .9342041016135 .6293945312135 .0198059082134 .1054992676 133.4958953857132 .5814971924131 .6672058105130 .7528076172129 .533706665 128.6192932129127 .4001998901126 .1809997559124 .9618988037123 .7427978516 122.5235977173121 .6092987061121 .3044967651120 .9997024536120 .3900985718 119.4757995605118 .8662033081118 .2565994263118 .2565994263119 .1709976196 119.7806015015120 .3900985718128 .6192932129135 .9342041016151 .4781951904 166.1078948975179 .5184020996191 .1002960205201 .7678070068209 .692199707 209.692199707 209.692199707 209.692199707 209.692199707 209.692199707 209.692199707 209.692199707209 .692199707209 .692199707209 .692199707209 .692199707209 .692199707 209.692199707 209.692199707 209.692199707 209.692199707 209.692199707 209.692199707 209.692199707209 .692199707209 .692199707209 .692199707209 .692199707209 .692199707 209.692199707209 .692199707209 .692199707209 .692199707209 .692199707209 .692199707 209.692199707209 .692199707209 .692199707209 .692199707209 .692199707209 .692199707 63.09051895142 -3.45783853531 -9999 -9999 -9999 -9999 -9999 -9999 -9999 -9999 -9999 $-9999$

-9999 -9999 -9999 -9999 -9999 -9999 -9999 -9999 -9999 -9999 -9999 -9999 -9999 -9999 -9999 -9999 -9999 -9999 -9999 -9999 -9999 -9999 -9999 -9999 -9999 -9999 -9999 -9999 -9999 -9999 -

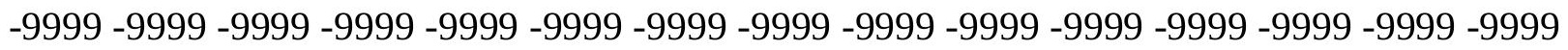
-9999 -9999 -9999 -9999 -9999 -9999 -9999 -9999 -9999 -9999 -9999 -9999 -9999 -9999 -9999 -9999 -9999 -9999-9999 462.2249755859459.0423278809 455.7628479004 452.363494873 448.6733703613444 .8785400391441 .0241088867434 .3187866211427 .613494873 422.4321899414418 .4700012207417 .5556030273422 .4321899414431 .8804931641 439.804901123441 .633605957440 .7192993164440 .7192993164444 .9862976074 447.2171630859452 .202331543461 .0412597656470 .5881958008469 .9786987305 469.0643005371464 .7973022461458 .7015991211451 .996307373445 .5958862305 444.0718994141449 .2532958984461 .1398925781471 .8074035645475 .4648132324 475.7695922852473 .9408874512468 .7594909668463 .5781860352465 .4068908691 460.5303039551456 .2633056641452 .9107055664450 .4724121094447 .729309082 443.4624023438438 .8905944824435 .2331848145432 .4901123047431 .5757141113 431.2709960938430 .6614074707428 .8327026367426 .0895996094423 .0416870117 420.2987060547419 .0795898438418 .4700012207415 .1173095703406 .2785949707 
392.5632019043376 .104888916361 .475189209350 .1980895996342 .2737121582 336.4827880859331 .3013916016325 .8153076172319 .7196044922312 .7095031738 304.4802856445295 .9464111328287 .4124145508279 .7927856445273 .0874938965 267.2966003418262 .7247924805259 .3721008301256 .6290893555254 .4956054688 252.9716033936251 .4476928711249 .9237976074248 .0950927734246 .2664031982 243.5233001709240 .4754943848237 .4275970459234 .3798065186231 .3318939209 228.2841033936225.8457946777223.4075012207220.9691925049 218.5308990479 215.1782989502211 .2160949707207 .25390625203 .2917022705199 .9389953613 197.1959991455195 .0625193 .5386047363192 .0146026611189 .5764007568187 .1381072998 184.0901947021180 .7375946045178 .2993011475177 .3849029541177 .6896972656 177.6896972656176 .4705963135174 .337097168171 .8988037109169 .4604949951 167.0222015381164 .8887023926163 .0599975586160 .9264984131159 .0977935791 157.2691040039155 .7451934814154 .5260925293153 .6116943359152 .6972961426 152.3925933838152 .0877990723152 .0877990723152 .0877990723151 .7830047607 152.0877990723152 .3925933838153 .0021057129153 .6116943359154 .5260925293 155.4403991699156 .3547973633156 .6596069336157 .2691040039157 .2691040039 157.2691040039156 .9642944336156 .6596069336156 .0500030518155 .4403991699 154.8307952881153 .9165039062153 .3069000244152 .6972961426152 .3925933838 152.0877990723152 .0877990723152 .6972961426153 .6116943359154 .5260925293 156.0500030518157 .2691040039158 .7929992676160 .3170013428161 .8408966064 163.3648071289164 .8887023926166 .1078948975167 .0222015381167 .6318054199 167.9365997314167 .6318054199167 .3269958496166 .7174987793166 .1078948975 164.8887023926163 .974395752162 .4505004883161 .2312927246160 .0122070312 158.7929992676157 .5738983154156 .6596069336156 .0500030518156 .0500030518 156.6596069336157 .2691040039157 .878692627158 .4882965088159 .0977935791 159.4026031494159 .7073974609159 .7073974609160 .0122070312159 .7073974609 159.7073974609159 .4026031494159 .4026031494159 .4026031494159 .4026031494 159.4026031494160 .0122070312160 .3170013428160 .6217956543160 .9264984131 161.2312927246161 .2312927246161 .2312927246161 .2312927246160 .9264984131 160.6217956543160 .0122070312159 .4026031494158 .7929992676158 .1835021973 157.5738983154156 .6596069336156 .0500030518155 .1356048584154 .5260925293 153.9165039062153 .6116943359153 .3069000244153 .0021057129152 .0877990723 150.2590942383147 .5160064697144 .7729034424142 .0299072266139 .5915985107 137.1533050537135 .3246002197133 .4958953857132 .2767028809131 .0576019287 130.4479980469129 .8385009766129 .533706665129 .2288970947129 .8385009766 130.4479980469131 .3623962402132 .2767028809133 .1911010742134 .1054992676 135.0198059082135 .3246002197135 .3246002197135 .3246002197134 .7149963379 134.1054992676133 .4958953857132 .8863067627131 .9720001221131 .0576019287 129.8385009766128 .9241027832127 .7050018311126 .7906036377125 .5715026855 124.3523025513123 .43800354122 .5235977173121 .9140014648121 .3044967651 120.9997024536120 .3900985718120 .0852966309119 .7806015015120 .0852966309 121.3044967651123 .7427978516127 .4001998901131 .0576019287135 .9342041016 140.2012023926150 .5639038086165 .4983062744178 .9089050293190 .795501709 201.4629974365209 .692199707209 .692199707209 .692199707209 .692199707 209.692199707209 .692199707209 .692199707209 .692199707209 .692199707209 .692199707 209.692199707209 .692199707209 .692199707209 .692199707209 .692199707209 .692199707 
209.692199707 209.692199707 209.692199707 209.692199707209.692199707209.692199707 209.692199707 209.692199707 209.692199707 209.692199707 209.692199707 209.692199707 209.692199707209 .692199707209 .692199707209 .692199707209 .692199707209 .692199707 209.692199707 209.692199707 209.692199707 63.09051895142 -3.80737996101 -9999 -9999 -9999 -9999 -9999 -9999-9999 -9999 -9999-9999

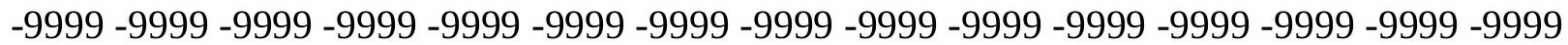

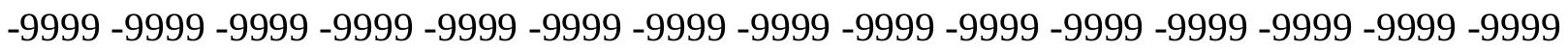

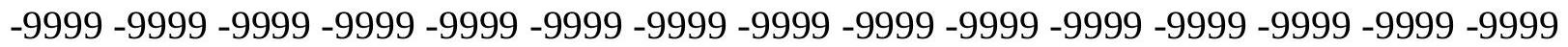

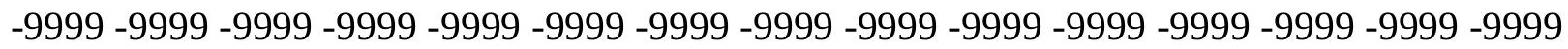
-9999 -9999 -9999 -9999 -9999 -9999 -9999 461.1518249512457 .537902832453 .6575012207 449.0479125977443 .2732849121437 .2633361816432 .2510070801429 .1579589844 429.3531494141433 .8048706055441 .0607910156447 .5528564453450 .9098815918 452.1864318848453 .8802490234457 .2606506348461 .6592102051467 .9432983398 475.7567749023482 .6838684082485 .4071655273484 .6083068848477 .9031066895 471.1978149414462 .6637878418451 .996307373445 .2911071777452 .3010864258 466.9531860352478 .8410949707485 .6712646484488 .2766723633487 .8422851562 485.5069274902483 .4659118652482 .7732849121480 .9811401367478 .6293640137 476.7249145508475 .4648132324474 .8551940918472 .1122131348466 .9307861328 463.2734069824460 .8351135254460 .5303039551460 .5303039551460 .8351135254 459.0064086914456 .5681152344454 .1299133301450 .1676025391450 .1676025391 452.9107055664452 .3010864258442 .2431945801425 .1752929688405 .6690063477 387.0770874023371 .5331115723359 .9512023926351 .112487793343 .7976074219 336.7875976562329 .1679077148321 .2434997559312 .1000061035302 .6516113281 293.2033081055284 .6693115234277 .3544921875271 .2587890625266 .6870117188 263.3344116211260 .8960876465259 .3721008301258 .1530151367256 .9338989258 255.7147064209253 .8860015869251 .7525024414249 .0093994141245 .9615936279 242.6089935303238 .9515075684235 .5989074707232 .5511016846229 .8079986572 227.3697052002 224.9313964844222.4931030273 219.4452972412 216.0926971436 212.4351959229209 .3874053955206 .3394927979203 .9011993408202 .0724945068 199.9389953613197 .500793457194 .4528961182190 .795501709186 .8332977295 182.87109375179 .8231964111179 .5184020996180 .7375946045181 .9566955566 179.8231964111177 .3849029541174 .6419067383172 .2035980225169 .4604949951 167.0222015381164 .8887023926162 .4505004883160 .6217956543158 .7929992676 156.9642944336155 .4403991699154 .5260925293153 .3069000244152 .6972961426 152.3925933838152 .0877990723152 .3925933838152 .0877990723152 .0877990723 152.0877990723152 .3925933838152 .3925933838153 .3069000244154 .2212982178 154.8307952881155 .1356048584155 .4403991699155 .7451934814155 .7451934814 155.7451934814155 .4403991699154 .8307952881154 .5260925293153 .9165039062 153.3069000244153 .0021057129152 .3925933838152 .0877990723152 .0877990723 152.3925933838152 .6972961426153 .6116943359154 .8307952881156 .0500030518 157.2691040039158 .7929992676160 .3170013428161 .8408966064163 .0599975586 164.5839996338165 .4983062744166 .4127044678167 .0222015381167 .3269958496 167.3269958496167 .0222015381166 .4127044678165 .8031005859164 .8887023926 163.6696014404162 .7552947998161 .5361022949160 .3170013428159 .0977935791 158.1835021973157 .2691040039156 .9642944336156 .6596069336156 .9642944336 157.2691040039157 .878692627158 .4882965088158 .7929992676159 .0977935791 
159.4026031494159 .7073974609159 .7073974609159 .7073974609159 .7073974609 159.7073974609159 .7073974609159 .7073974609159 .7073974609160 .0122070312 160.3170013428160 .6217956543160 .9264984131161 .2312927246161 .5361022949 161.5361022949161 .5361022949161 .5361022949161 .2312927246160 .9264984131 160.3170013428159 .7073974609159 .0977935791158 .4882965088157 .5738983154 156.6596069336156 .0500030518154 .8307952881153 .9165039062153 .3069000244 153.0021057129152 .6972961426152 .6972961426152 .0877990723150 .5639038086 147.8208007812145 .0776977539142 .0299072266139 .2868041992137 .1533050537 135.0198059082133 .8007049561132 .5814971924131 .6672058105130 .7528076172 130.1432037354129 .8385009766129 .8385009766130 .1432037354130 .7528076172 131.3623962402132 .2767028809132 .8863067627133 .8007049561134 .1054992676 134.4102020264134 .4102020264134 .4102020264134 .1054992676133 .4958953857 132.8863067627131 .9720001221131 .3623962402130 .1432037354129 .2288970947 128.3144989014127 .0953979492126 .1809997559124 .9618988037124 .0475006104 123.1332015991122 .5235977173121 .9140014648121 .3044967651120 .9997024536 120.6949005127120 .3900985718120 .6949005127121 .3044967651123 .43800354 127.4001998901134 .4102020264141 .7250976562142 .9441986084143 .8585968018 150.2590942383165 .1934967041178 .604095459190 .4907073975201 .158203125 209.692199707209 .692199707209 .692199707209 .692199707209 .692199707209 .692199707 209.692199707 209.692199707 209.692199707209.692199707 209.692199707 209.692199707 209.692199707 209.692199707 209.692199707 209.692199707 209.692199707 209.692199707 209.692199707 209.692199707 209.692199707 209.692199707 209.692199707 209.692199707 209.692199707209.692199707 209.692199707209.692199707 209.692199707209.692199707 209.692199707209 .692199707209 .692199707209 .692199707209 .692199707209 .692199707 209.69219970762 .78573989868 -4.26762104034 -9999 -9999 -9999 -9999 -9999 -9999 -9999 -9999 -9999-9999 -9999 -9999 -9999 -9999 -9999 -9999 -9999 -9999 -9999 -9999 -9999 -9999 -9999 -9999 -9999

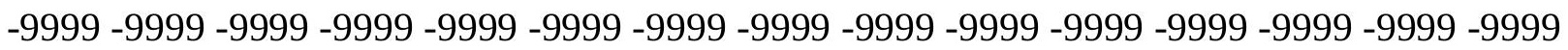
-9999 -9999 -9999 -9999 -9999 -9999 -9999 -9999 -9999 -9999 -9999 -9999 -9999 -9999 -9999

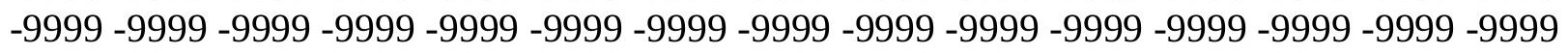
-9999 -9999 -9999 -9999 -9999 -9999 -9999 -9999 -9999 462.1622924805 457.6308898926 452.6331787109447 .6678161621443 .6119384766441 .4618835449442 .0291137695 445.4578857422450 .6340026855455 .7074890137459 .5552978516462 .305267334 465.1045532227468 .6867370605473 .5997619629479 .7407836914486 .6318054199 492.7454528809496 .3479614258494 .3615112305488 .5705871582482 .4749145508 475.1600036621464 .187713623459 .9056396484464 .2897338867474 .6921081543 485.6139526367493 .7789306641498 .4828186035500 .3869628906500 .7196655273 500.7301635742500 .549407959500 .3240966797499 .6944274902499 .1857299805 498.8878173828498 .3143615723496 .4367370605493 .3481445312490 .4840393066 488.7187194824488 .1724853516488 .2294616699488 .1140136719487 .0855712891 485.3721008301483 .438873291482 .1175231934483 .2016906738486 .6856994629 489.4848937988474 .5504150391454 .7394104004431 .8804931641409 .6311950684 391.0393066406377 .0191955566366 .0469055176356 .9034118652348 .3693847656 339.8353881836330 .6918945312320 .6339111328310 .2713012695299 .9085998535 290.1553955078282 .2309875488279 .7927856445275 .8305053711271 .5635070801 267.9060974121264 .5534973145263 .9439086914263 .3344116211262 .1152038574 
260.2864990234257 .8482055664254 .8003997803251 .1428985596247 .4855041504 243.8280944824240 .1707000732236 .8179931641234 .0749969482231 .9414978027 229.5032043457227 .0648956299224 .6266021729221 .5787963867218 .5308990479 215.787902832213 .0447998047210 .9113006592208 .7778015137206 .6443023682 203.2917022705 199.6342926025 195.3672943115190.795501709 186.2236938477 183.1759033203182 .87109375184 .0901947021184 .3950042725183 .1759033203 180.7375946045177 .6896972656174 .9467010498172 .2035980225169 .4604949951 167.0222015381164 .5839996338162 .4505004883160 .3170013428158 .4882965088 156.9642944336155 .4403991699154 .2212982178153 .3069000244152 .6972961426 152.3925933838152 .0877990723152 .0877990723152 .0877990723152 .0877990723 152.0877990723152 .3925933838152 .6972961426153 .0021057129153 .6116943359 153.9165039062154 .2212982178154 .5260925293154 .5260925293154 .5260925293 154.5260925293154 .2212982178153 .6116943359153 .3069000244153 .0021057129 152.3925933838152 .0877990723152 .0877990723152 .0877990723152 .3925933838 153.0021057129153 .9165039062154 .8307952881156 .0500030518157 .2691040039 158.7929992676160 .3170013428161 .5361022949163 .0599975586164 .2792053223 165.1934967041166 .1078948975166 .7174987793167 .0222015381167 .0222015381 166.7174987793166 .1078948975165 .4983062744164 .8887023926163 .974395752 162.7552947998161 .8408966064160 .6217956543159 .7073974609158 .7929992676 158.1835021973157 .5738983154157 .5738983154157 .5738983154157 .878692627 158.1835021973158 .4882965088159 .0977935791159 .4026031494159 .7073974609 159.7073974609160 .0122070312160 .0122070312160 .0122070312160 .0122070312 160.0122070312160 .0122070312160 .3170013428160 .3170013428160 .6217956543 160.9264984131161 .2312927246161 .5361022949161 .8408966064161 .8408966064 161.8408966064161 .8408966064161 .5361022949161 .2312927246160 .9264984131 160.3170013428159 .4026031494158 .7929992676157 .878692627156 .9642944336 155.7451934814154 .8307952881153 .6116943359152 .3925933838152 .3925933838 152.0877990723152 .6972961426152 .3925933838150 .5639038086148 .1255950928 145.3825073242142 .3347015381139 .2868041992136 .8484954834135 .0198059082 133.8007049561132 .8863067627131 .9720001221131 .3623962402130 .7528076172 130.4479980469130 .4479980469130 .7528076172131 .0576019287131 .3623962402 131.9720001221132 .5814971924133 .1911010742133 .4958953857133 .8007049561 133.8007049561133 .8007049561133 .4958953857132 .8863067627132 .2767028809 131.3623962402130 .7528076172129 .533706665128 .6192932129127 .7050018311 126.4858016968125 .5715026855124 .6570968628123 .7427978516122 .8283996582 122.5235977173121 .9140014648121 .6092987061121 .3044967651120 .9997024536 120.9997024536120 .9997024536121 .6092987061123 .1332015991126 .4858016968 133.8007049561148 .7351074219143 .5538024902144 .4682006836150 .5639038086 165.4983062744178 .604095459190 .4907073975200 .8533935547209 .692199707 209.692199707209 .692199707209 .692199707209 .692199707209 .692199707209 .692199707 209.692199707209 .692199707209 .692199707209 .692199707209 .692199707209 .692199707 209.692199707209 .692199707209 .692199707209 .692199707209 .692199707209 .692199707 209.692199707209.692199707 209.692199707 209.692199707 209.692199707209.692199707 209.692199707209 .692199707209 .692199707209 .692199707209 .692199707209 .692199707 209.692199707209 .692199707209 .692199707209 .692199707209 .692199707209 .692199707 62.78573989868 -4.78898572922 -9999 -9999 -9999 -9999 -9999 -9999 -9999 -9999 -9999 
$-9999$

-9999 -9999 -9999 -9999 -9999 -9999 -9999 -9999 -9999 -9999 -9999 -9999 -9999 -9999 -9999

-9999 -9999 -9999 -9999 -9999 -9999 -9999 -9999 -9999 -9999 -9999 -9999 -9999 -9999 - 9999 -

-9999 -9999 -9999 -9999 -9999 -9999 -9999 -9999 -9999 -9999 -9999 -9999 -9999 -9999 -9999

-9999 -9999 -9999 -9999 -9999 -9999 -9999 -9999 -9999 -9999 -9999 -9999 -9999 - -9999 - -9999 -

-9999 -9999 -9999 -9999 -9999 -9999 -9999 -9999 -9999 -9999 -9999 -9999 458.5118103027

455.4309082031453 .9335327148454 .4580688477456 .9273681641460 .6515197754

464.6362609863468 .3090820312471 .5862731934474 .8482055664478 .5874633789

483.1633300781488 .494934082494 .1780395508499 .5329589844503 .7658691406

505.0289916992495 .8854064941490 .0945129395486 .4371032715478 .6834106445

475.4264831543478 .1887512207485 .5276184082494 .4887390137502 .4886169434

508.3843078613512 .2182006836514 .6322631836516 .3035888672517 .5420532227

518.506652832519 .2005615234519 .7340087891520 .1038208008519 .9647827148

518.9810180664517 .3561401367515 .6442871094514 .508972168514 .0174560547

513.9317626953513 .7053833008513 .0877685547512 .0498657227511 .0068054199

510.7645874023511 .6444702148512 .4897460938509 .0717773438497 .1046142578

479.7318115234451 .996307373427 .613494873407 .8024902344392 .5632019043

380.3717956543370 .3139038086361 .1704101562351 .7219848633341 .6640930176

330.6918945312319 .1099853516307 .5281982422296 .8606872559290 .4602050781

287.1076049805283 .1453857422278 .8783874512275 .2210083008271 .8682861328

270.6492004395270 .3443908691269 .1253051758267 .2966003418264 .2486877441

260.8960876465256 .9338989258252 .9716033936249 .0093994141246 .2664031982

243.5233001709240 .7801971436237 .7324066162234 .6844940186232 .5511016846

230.1127929688227 .3697052002224 .9313964844222 .1884002686219 .4452972412

217.3117980957215 .1782989502213 .0447998047209 .0825958252205 .1204071045

200.5485992432196 .2816009521192 .9290008545190 .1858978271188 .3571929932

188.3571929932188 .0523986816186 .528503418184 .0901947021181 .0424041748

177.9945068359175 .2514038086172 .2035980225169 .4604949951167 .0222015381

164.5839996338162 .4505004883160 .3170013428158 .4882965088156 .9642944336

155.4403991699154 .5260925293153 .3069000244152 .6972961426152 .0877990723

151.7830047607151 .7830047607152 .0877990723152 .0877990723152 .0877990723

152.0877990723152 .0877990723152 .6972961426153 .0021057129153 .3069000244

153.6116943359153 .6116943359153 .6116943359153 .6116943359153 .3069000244

153.0021057129152 .6972961426152 .3925933838152 .3925933838152 .0877990723

152.0877990723152 .3925933838152 .6972961426153 .3069000244153 .9165039062

155.1356048584156 .0500030518157 .5738983154158 .7929992676160 .0122070312 161.5361022949162 .7552947998163 .974395752164 .8887023926165 .4983062744

166.1078948975166 .4127044678166 .4127044678166 .4127044678166 .1078948975 165.4983062744164 .8887023926163 .974395752163 .0599975586162 .1457061768

161.2312927246160 .3170013428159 .4026031494158 .7929992676158 .4882965088 158.1835021973158 .1835021973158 .1835021973158 .4882965088158 .7929992676 159.0977935791159 .4026031494159 .7073974609160 .0122070312160 .0122070312 160.3170013428160 .3170013428160 .3170013428160 .3170013428160 .6217956543 160.6217956543160 .9264984131161 .2312927246161 .5361022949161 .8408966064 162.1457061768162 .1457061768162 .4505004883162 .4505004883162 .1457061768 162.1457061768161 .5361022949161 .2312927246160 .6217956543159 .7073974609 
159.0977935791158 .1835021973156 .9642944336156 .0500030518154 .8307952881 153.6116943359152 .6972961426152 .0877990723152 .3925933838152 .6972961426 152.6972961426150 .8686065674148 .4304046631145 .6873016357142 .6394042969 139.5915985107136 .8484954834135 .3246002197134 .4102020264133 .4958953857 132.5814971924131 .9720001221131 .3623962402131 .0576019287131 .0576019287 131.0576019287131 .3623962402131 .6672058105131 .9720001221132 .5814971924 132.8863067627133 .1911010742133 .1911010742133 .1911010742133 .1911010742 132.8863067627132 .2767028809131 .6672058105131 .0576019287130 .1432037354 129.2288970947128 .0097961426127 .0953979492125 .8762969971124 .9618988037 124.0475006104123 .43800354122 .8283996582122 .2188034058121 .9140014648 121.6092987061121 .6092987061121 .3044967651120 .9997024536120 .6949005127 120.9997024536121 .9140014648123 .43800354124 .3523025513121 .9140014648 136.2389984131144 .4682006836151 .4781951904166 .1078948975178 .9089050293 190.1858978271200 .5485992432209 .3874053955209 .692199707209 .692199707 209.692199707 209.692199707 209.692199707 209.692199707 209.692199707209.692199707 209.692199707 209.692199707 209.692199707 209.692199707 209.692199707 209.692199707 209.692199707 209.692199707 209.692199707 209.692199707 209.692199707209.692199707 209.692199707209 .692199707209 .692199707209 .692199707209 .692199707209 .692199707 209.692199707 209.692199707 209.692199707 209.692199707 209.692199707 209.692199707 209.692199707209 .692199707209 .692199707209 .69219970762 .48094940186 -5.43762159348 -9999 -9999 -9999 -9999 -9999 -9999 -9999 -9999 -9999 -9999 -9999 -9999 -9999 -9999 -9999 -9999 -9999 -9999 -9999 -9999 -9999 -9999 -9999 -9999 -9999 -9999 -9999 -9999 -9999 -9999 -9999 -9999 -9999 -9999 -9999 -9999 -9999 -9999 -9999 -9999 -9999 -9999 -9999 -9999 -9999 -9999 -9999 -9999 -9999 -9999 -9999 -9999 -9999 -9999 -9999 -9999 -9999 -9999 -9999 -9999 -9999 -9999 -9999 -9999 -9999 -9999 -9999 -9999 -9999 -9999 -9999 -9999 -9999 -9999 -9999 -9999 -9999 -9999 -9999 -9999 -9999 -9999 -9999 -9999 -9999 466.4275512695468 .1797180176470 .8875732422474 .0108337402477 .2563781738 480.4592590332483 .6844787598487 .1556091309490 .9981079102495 .1183166504 499.1805114746502.8016052246505.9250183105 508.0768127441497.4093017578 495.0981750488493 .1034851074490 .4196166992489 .4011230469491 .9310302734 497.652557373505 .0523071289512 .4672851562518 .8435668945523 .8717651367 527.7643432617530 .8517456055533 .375535 .4309692383537 .1281738281538 .4971313477 539.475769043539 .9431762695539 .8070678711539 .2272338867538 .4989624023 537.9339599609537 .6528930664537 .5322265625537 .3319091797536 .8768920898 536.186340332535 .4357299805534 .850769043534 .1040649414531 .6892700195 524.8418579102511 .9961242676491 .7742919922465 .1021118164441 .9383850098 422.7369995117407 .4977111816395 .0014953613384 .6387939453375 .1904907227 365.132598877354 .4650878906342 .8833007812330 .3870849609317 .2813110352 304.7850952148298 .3846130371294 .4223937988290 .4602050781286 .4979858398 282.8406066895279 .1831970215278 .2687988281278 .2687988281277 .3544921875 274.9161987305271 .5635070801267 .6012878418263 .0296020508260 .2864990234 257.2385864258254 .1907958984251 .1428985596247 .7902984619244 .7424926758 241.6945953369238 .3419952393236 .2084960938234 .0749969482231 .3318939209 228.2841033936225.5410003662 223.1027069092 220.6643981934217.9214019775 214.5686950684210 .6065063477206 .6443023682202 .6820983887200 .2438049316 196.5863952637195 .0625193 .8433074951192 .624206543190 .4907073975188 .0523986816 
184.699798584181 .6519012451178 .604095459175 .5561981201172 .5084075928 169.7653045654167 .3269958496164 .8887023926162 .7552947998160 .6217956543 158.7929992676157 .2691040039155 .7451934814154 .5260925293153 .3069000244 152.3925933838151 .7830047607151 .7830047607152 .3925933838152 .0877990723 152.0877990723152 .0877990723152 .0877990723152 .0877990723152 .3925933838 152.6972961426152 .6972961426153 .0021057129153 .0021057129153 .0021057129 153.0021057129152 .6972961426152 .3925933838152 .0877990723152 .0877990723 152.0877990723152 .3925933838152 .3925933838152 .6972961426153 .3069000244 154.2212982178155 .1356048584156 .3547973633157 .5738983154158 .7929992676 160.0122070312161 .2312927246162 .4505004883163 .6696014404164 .5839996338 165.1934967041165 .8031005859166 .1078948975166 .1078948975166 .1078948975 165.8031005859165 .4983062744164 .8887023926163 .974395752163 .3648071289 162.4505004883161 .5361022949160 .6217956543160 .0122070312159 .4026031494 159.0977935791158 .7929992676158 .7929992676158 .7929992676159 .0977935791 159.4026031494159 .4026031494159 .7073974609160 .0122070312160 .3170013428 160.3170013428160 .6217956543160 .6217956543160 .9264984131160 .9264984131 160.9264984131161 .2312927246161 .5361022949161 .8408966064162 .1457061768 162.1457061768162 .4505004883162 .7552947998162 .7552947998162 .7552947998 162.7552947998162 .4505004883162 .1457061768161 .5361022949160 .9264984131 160.3170013428159 .4026031494158 .4882965088157 .2691040039156 .0500030518 154.8307952881153 .6116943359152 .6972961426152 .0877990723152 .3925933838 152.6972961426152 .3925933838150 .8686065674148 .4304046631145 .6873016357 142.9441986084140 .2012023926137 .7628936768136 .2389984131135 .0198059082 133.8007049561133 .1911010742132 .2767028809131 .9720001221131 .6672058105 131.3623962402131 .3623962402131 .3623962402131 .6672058105131 .9720001221 132.2767028809132 .5814971924132 .5814971924132 .8863067627132 .5814971924 132.5814971924132 .2767028809131 .6672058105131 .0576019287130 .4479980469 129.533706665128 .6192932129127 .7050018311126 .4858016968125 .5715026855 124.6570968628123 .7427978516122 .8283996582122 .5235977173122 .2188034058 122.2188034058121 .9140014648121 .6092987061121 .3044967651120 .6949005127 120.0852966309119 .7806015015119 .7806015015119 .7806015015120 .0852966309 121.3044967651135 .6293945312146 .9064025879152 .3925933838166 .4127044678 178.604095459189 .8811035156199 .9389953613208 .7778015137209 .692199707 209.692199707 209.692199707 209.692199707 209.692199707 209.692199707 209.692199707 209.692199707 209.692199707 209.692199707 209.692199707 209.692199707 209.692199707 209.692199707 209.692199707 209.692199707 209.692199707 209.692199707 209.692199707 209.692199707 209.692199707 209.692199707 209.692199707 209.692199707 209.692199707 209.692199707 209.692199707 209.692199707 209.692199707 209.692199707 209.692199707 209.692199707209 .692199707209 .692199707209 .692199707209 .692199707 $62.48094940186-6.20213508606$-9999 -9999 -9999 -9999 -9999 -9999 -9999 -9999 -9999 $-9999$

-9999 -9999 -9999 -9999 -9999 -9999 -9999 -9999 -9999 -9999 -9999 -9999 -9999 -9999 -9999 -9999 -9999 -9999 -9999 -9999 -9999 -9999 -9999 -9999 -9999 -9999 -9999 -9999 -9999 -9999 -9999 -9999 -9999 -9999 -9999 -9999 -9999 -9999 -9999 -9999 -9999 -9999 -9999 -9999 -9999 -9999 -9999 -9999 -9999 -9999 -9999 -9999 -9999 -9999 -9999 -9999 -9999 -9999 -9999 -9999

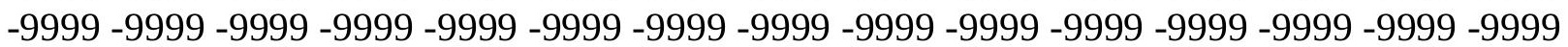


-9999 -9999 -9999 483.6312866211486.3552246094 489.1882324219492.0553283691 494.9713745117497 .9026794434500 .6803588867502 .9822692871504 .3703308105 503.9747314453500 .1524047852500 .6944885254500 .4641113281500 .3608398438 500.5986022949501 .7639465332504 .8901672363510 .068145752516 .580871582 523.4747314453529 .9668579102535 .6798095703540 .540222168544 .6733398438 548.1929321289551 .1376953125553 .6270141602555 .6603393555557 .2426147461 558.3311767578558 .922668457559 .1168823242559 .1014404297559 .0455932617 558.9978637695558 .9321899414558 .716003418558 .2646484375557 .5076293945 556.4359741211554 .8680419922552 .2225341797547 .1563720703538 .0430908203 523.7476806641503 .8124694824480 .6430664062457 .7721252441437 .3666992188 422.4321899414410 .240814209400 .1828918457390 .7344970703380 .6766052246 369.399597168357 .208190918343 .7976074219330 .0823059082316 .9765014648 307.8330078125302 .6516113281298 .6893920898295 .0320129395290 .7650146484 285.8884887695286 .8027954102287 .4124145508286 .4979858398283 .7549133301 279.1831970215274 .3066101074269 .4301147461268 .2109069824265 .1630859375 261.8103942871258 .1530151367254 .8003997803251 .4476928711248 .3999023438 244.7424926758242 .9136962891240 .7801971436237 .7324066162234 .6844940186 231.6367034912228 .8936004639226 .150604248223 .1027069092219 .7501068115 216.0926971436212 .7400054932209 .3874053955206 .6443023682204 .5108032227 202.0724945068199 .9389953613197 .8054962158195 .3672943115192 .624206543 189.2716064453186 .2236938477182 .87109375179 .2136993408176 .165802002 173.1179962158170 .3748931885167 .9365997314165 .4983062744163 .3648071289 161.2312927246159 .4026031494157 .5738983154156 .0500030518154 .5260925293 153.3069000244152 .0877990723152 .0877990723152 .0877990723151 .7830047607 151.7830047607151 .7830047607151 .7830047607152 .0877990723152 .3925933838 152.3925933838152 .3925933838152 .6972961426152 .6972961426152 .6972961426 152.6972961426152 .3925933838152 .3925933838152 .0877990723152 .0877990723 152.0877990723152 .3925933838152 .3925933838153 .0021057129153 .6116943359 154.2212982178155 .1356048584156 .3547973633157 .5738983154158 .7929992676 160.0122070312161 .2312927246162 .1457061768163 .3648071289164 .2792053223 164.8887023926165 .4983062744165 .8031005859165 .8031005859165 .8031005859 165.8031005859165 .1934967041164 .8887023926164 .2792053223163 .3648071289 162.7552947998162 .1457061768161 .2312927246160 .6217956543160 .3170013428 159.7073974609159 .7073974609159 .4026031494159 .4026031494159 .4026031494 159.7073974609160 .0122070312160 .0122070312160 .3170013428160 .6217956543 160.6217956543160 .9264984131160 .9264984131161 .2312927246161 .2312927246 161.5361022949161 .8408966064162 .1457061768162 .1457061768162 .4505004883 162.7552947998163 .0599975586163 .3648071289163 .3648071289163 .3648071289 163.3648071289163 .0599975586162 .7552947998162 .1457061768161 .5361022949 160.6217956543159 .7073974609158 .7929992676157 .5738983154156 .3547973633 155.1356048584153 .9165039062153 .0021057129152 .0877990723152 .3925933838 152.3925933838152 .0877990723150 .5639038086148 .4304046631145 .9920959473 143.5538024902140 .8106994629138 .6772003174137 .1533050537135 .6293945312 134.7149963379133 .8007049561132 .8863067627132 .2767028809131 .9720001221 131.6672058105131 .6672058105131 .6672058105131 .9720001221131 .9720001221 132.2767028809132 .2767028809132 .2767028809132 .2767028809132 .2767028809 
131.9720001221131 .6672058105131 .3623962402130 .7528076172129 .8385009766 129.2288970947128 .3144989014127 .0953979492126 .1809997559124 .9618988037 124.0475006104123 .1332015991122 .5235977173122 .2188034058122 .2188034058 122.2188034058122 .2188034058121 .6092987061120 .9997024536120 .0852966309 118.8662033081117 .9517974854117 .647102356118 .8662033081122 .8283996582 132.5814971924145 .6873016357153 .9165039062157 .2691040039165 .8031005859 177.6896972656188 .6620025635198 .7198944092207 .5587005615209 .692199707 209.692199707 209.692199707 209.692199707 209.692199707 209.692199707 209.692199707 209.692199707 209.692199707 209.692199707 209.692199707 209.692199707 209.692199707 209.692199707209 .692199707209 .692199707209 .692199707209 .692199707209 .692199707 209.692199707209 .692199707209 .692199707209 .692199707209 .692199707209 .692199707 209.692199707 209.692199707 209.692199707 209.692199707 209.692199707 209.692199707 209.692199707209 .692199707209 .692199707209 .692199707209 .692199707 62.17617034912 -7.16397619247 -9999 -9999 -9999 -9999 -9999 -9999 -9999 -9999 -9999 $-9999$

-9999 -9999 -9999 -9999 -9999 -9999 -9999 -9999 -9999 -9999 -9999 -9999 -9999 -9999 -9999

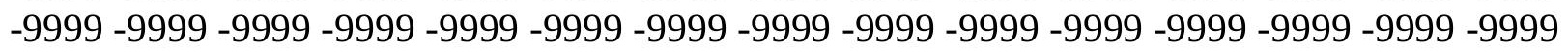

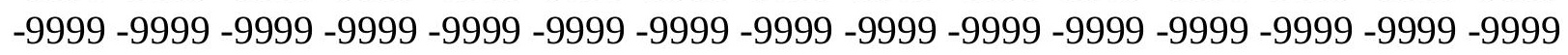

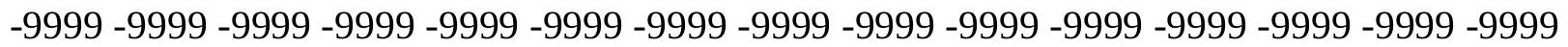

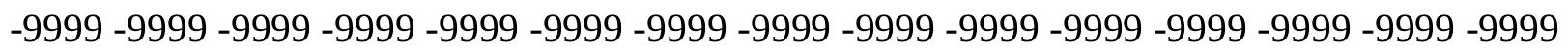
-9999 -9999-9999-9999-9999-9999 500.3230285645 502.602722168504.660369873 506.2834777832507 .125579834506 .6823425293504 .7242126465504 .2832641602 505.5327148438506 .9975280762508 .7300415039510 .7322998047513 .4372558594 517.3000488281522 .4359130859528 .5681762695535 .1220092773541 .6168212891 547.6585693359553 .1079101562557 .9420166016562 .1591186523565 .7736206055 568.8719482422571 .4686279297573 .5801391602575 .2066040039576 .3790893555 577.1736450195577 .6888427734578 .0041503906578 .1588134766578 .1320800781 577.8552246094577 .235534668576 .1582641602574 .4405517578571 .7499389648 567.4769287109560 .6057739258550 .1567993164535 .5141601562516 .916809082 496.028137207474 .8182067871455 .3991699219438 .8905944824426 .6991882324 417.250793457408 .1072998047397 .7445983887386 .1628112793373 .3617858887 359.6465148926345 .3215026855331 .3013916016319 .4147949219312 .7095031738 307.8330078125303 .5660095215298 .6893920898295 .3367919922296 .5559082031 297.4703063965296 .5559082031292 .5936889648286 .8027954102281 .0119018555 277.3544921875275 .5257873535272 .4779052734268 .8204956055265 .1630859375 261.5056152344258 .1530151367254 .8003997803251 .4476928711249 .3141937256 246.8759002686243 .8280944824240 .7801971436237 .7324066162234 .3798065186 231.3318939209228 .2841033936224 .9313964844221 .883605957218 .8356933594 216.0926971436213 .959197998212 .1304016113209 .0825958252206 .3394927979 203.596496582200 .8533935547197 .8054962158194 .4528961182191 .1002960205 187.4429016113183 .7854003906180 .1280059814177 .0802001953174 .0323028564 171.2891998291168 .8509979248166 .4127044678164 .2792053223162 .1457061768 160.3170013428158 .1835021973156 .3547973633154 .8307952881153 .6116943359 152.3925933838152 .0877990723151 .7830047607151 .7830047607151 .7830047607 152.0877990723152 .3925933838152 .3925933838152 .3925933838152 .3925933838 152.3925933838152 .3925933838152 .3925933838152 .3925933838152 .3925933838 
152.3925933838152 .0877990723152 .0877990723152 .0877990723152 .3925933838 152.6972961426153 .0021057129153 .6116943359154 .5260925293155 .4403991699 156.3547973633157 .5738983154158 .4882965088159 .7073974609160 .9264984131 162.1457061768163 .0599975586163 .974395752164 .5839996338165 .1934967041 165.4983062744165 .8031005859165 .8031005859165 .4983062744165 .1934967041 164.8887023926164 .2792053223163 .6696014404163 .0599975586162 .4505004883 161.8408966064161 .2312927246160 .9264984131160 .3170013428160 .3170013428 160.0122070312160 .0122070312160 .0122070312160 .0122070312160 .3170013428 160.3170013428160 .6217956543160 .9264984131160 .9264984131161 .2312927246 161.5361022949161 .5361022949161 .8408966064162 .1457061768162 .1457061768 162.4505004883162 .7552947998163 .0599975586163 .3648071289163 .6696014404 163.6696014404163 .974395752163 .974395752163 .6696014404163 .6696014404 163.3648071289162 .7552947998162 .1457061768161 .2312927246160 .3170013428 159.4026031494158 .1835021973156 .9642944336155 .7451934814154 .5260925293 153.3069000244152 .6972961426152 .3925933838152 .0877990723151 .4781951904 150.2590942383148 .1255950928145 .9920959473143 .8585968018141 .4203033447 139.5915985107137 .7628936768136 .5437011719135 .3246002197134 .4102020264 133.4958953857132 .8863067627132 .5814971924132 .2767028809131 .9720001221 131.9720001221131 .9720001221131 .9720001221131 .9720001221132 .2767028809 132.2767028809 131.9720001221 131.9720001221 131.6672058105131.3623962402 130.7528076172130 .4479980469129 .533706665128 .9241027832127 .7050018311 126.7906036377125 .8762969971124 .6570968628123 .7427978516122 .8283996582 122.2188034058121 .6092987061122 .2188034058122 .5235977173122 .2188034058 121.3044967651120 .0852966309118 .8662033081117 .342300415116 .1231002808 115.818397522117 .647102356124 .0475006104138 .3724975586158 .4882965088 160.0122070312161 .2312927246163 .0599975586175 .5561981201186 .528503418 196.891204834206 .0346984863209 .692199707209 .692199707209 .692199707 209.692199707 209.692199707 209.692199707 209.692199707 209.692199707 209.692199707 209.692199707 209.692199707 209.692199707 209.692199707 209.692199707 209.692199707 209.692199707 209.692199707 209.692199707 209.692199707 209.692199707 209.692199707 209.692199707209 .692199707209 .692199707209 .692199707209 .692199707209 .692199707 209.692199707 209.692199707 209.692199707 209.692199707 209.692199707 209.692199707 209.692199707 209.692199707 209.692199707 62.17617034912 -8.28934192657-9999-9999 -9999 -9999 -9999 -9999 -9999 -9999 -9999 -9999 -9999 -9999 -9999 -9999 -9999 -9999 -9999 -9999 -9999 -9999 -9999 -9999 -9999 -9999 -9999 -

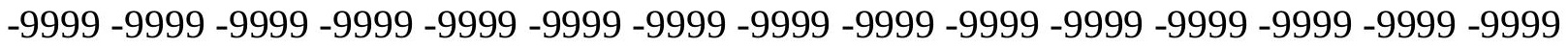

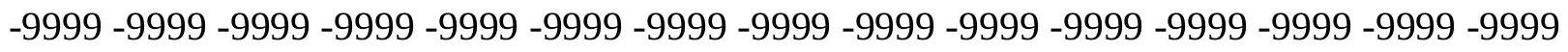

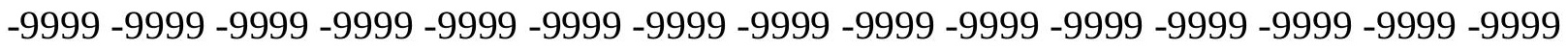
-9999 -9999 -9999 -9999 -9999 -9999 -9999 -9999 -9999 -9999 -9999 -9999 -9999 -9999 -9999 -9999 -9999 -9999 -9999 -9999 -9999 -9999 -9999 -9999 512.7124633789 512.8441772461 512.2210693359511 .411529541511 .7467956543513 .1983642578515 .4959716797 518.2221069336521 .337890625525 .0315551758529 .4893798828534 .772277832 540.7629394531547 .1350097656553 .5696411133559 .7529296875565 .5173950195 570.7496337891575 .4037475586579 .4995117188583 .0616455078586 .1083374023 588.6532592773590 .7207641602592 .3482055664593 .5837402344594 .4736938477 595.0531005859595 .3334350586595 .3016967773594 .8897094727594 .000793457 
592.4762573242590 .0521240234586 .3739013672580 .911315918572 .9749755859 561.9837646484547 .7232666016530 .6202392578511 .7472229004492 .5504150391 474.5836486816458 .9184265137446 .2054138184436 .7571105957427 .613494873 416.9460144043404 .4498901367391 .3440856934377 .0191955566362 .3894958496 348.0646057129335 .5683898926326 .7296142578318 .1957092285310 .8807983398 305.6994934082305 .6994934082306 .6138000488307 .2233886719307 .2233886719 300.8229064941293 .8128967285287 .4124145508283 .1453857422281 .3167114258 278.2687988281274 .9161987305271 .5635070801267 .9060974121264 .5534973145 261.5056152344258 .1530151367256 .0195007324253 .2763977051250 .2286071777 247.1806945801243 .8280944824240 .4754943848237 .1228027344233 .7702026367 231.6367034912228 .8936004639226 .4553985596224 .0171051025221 .5787963867 218.2261962891215 .4830932617212 .4351959229209 .3874053955206 .6443023682 203.2917022705 199.9389953613196.5863952637192.9290008545189.2716064453 185.6141052246181 .9566955566178 .604095459175 .5561981201172 .8132019043 170.070098877167 .6318054199165 .4983062744163 .3648071289161 .2312927246 159.0977935791157 .2691040039155 .4403991699153 .9165039062152 .3925933838 152.3925933838152 .3925933838152 .0877990723152 .0877990723152 .6972961426 153.0021057129152 .6972961426152 .6972961426152 .3925933838152 .3925933838 152.3925933838152 .3925933838152 .3925933838152 .0877990723152 .0877990723 152.0877990723152 .0877990723152 .3925933838152 .6972961426153 .0021057129 153.6116943359154 .5260925293155 .4403991699156 .3547973633157 .2691040039 158.4882965088159 .7073974609160 .6217956543161 .8408966064162 .7552947998 163.6696014404164 .2792053223164 .8887023926165 .1934967041165 .4983062744 165.4983062744165 .4983062744165 .1934967041164 .8887023926164 .2792053223 163.974395752163 .3648071289162 .7552947998162 .1457061768161 .8408966064 161.2312927246160 .9264984131160 .6217956543160 .6217956543160 .6217956543 160.6217956543160 .6217956543160 .6217956543160 .9264984131160 .9264984131 161.2312927246161 .2312927246161 .5361022949161 .8408966064162 .1457061768 162.1457061768162 .4505004883162 .7552947998163 .0599975586163 .3648071289 163.6696014404163 .974395752163 .974395752164 .2792053223164 .2792053223 164.5839996338164 .2792053223164 .2792053223163 .974395752163 .3648071289 162.7552947998161 .8408966064160 .9264984131160 .0122070312158 .7929992676 157.5738983154156 .0500030518155 .1356048584153 .9165039062153 .3069000244 152.6972961426151 .7830047607150 .8686065674149 .6495056152147 .8208007812 145.9920959473143 .8585968018142 .0299072266140 .2012023926138 .3724975586 136.8484954834135 .9342041016134 .7149963379134 .1054992676133 .4958953857 132.8863067627132 .5814971924132 .2767028809132 .2767028809132 .2767028809 131.9720001221131 .9720001221131 .9720001221131 .9720001221131 .9720001221 131.6672058105131 .3623962402131 .0576019287130 .4479980469130 .1432037354 129.2288970947 128.6192932129 127.7050018311 126.4858016968 125.5715026855 124.3523025513123 .43800354122 .5235977173121 .6092987061121 .9140014648 122.2188034058122 .5235977173122 .2188034058120 .6949005127118 .8662033081 117.0374984741114 .9039993286113 .3800964355112 .7705001831114 .2944030762 120.3900985718132 .5814971924148 .4304046631158 .7929992676163 .6696014404 165.1934967041172 .2035980225184 .0901947021194 .7577056885204 .5108032227 209.692199707 209.692199707 209.692199707 209.692199707 209.692199707 209.692199707 
209.692199707 209.692199707209.692199707209.692199707209.692199707209.692199707 209.692199707 209.692199707 209.692199707 209.692199707 209.692199707 209.692199707 209.692199707 209.692199707 209.692199707 209.692199707 209.692199707 209.692199707 209.692199707 209.692199707 209.692199707 209.692199707 209.692199707 209.692199707 209.692199707209 .692199707209 .692199707209 .692199707209 .692199707209 .692199707 61.87137985229 -9.57949733734 -9999 -9999 -9999 -9999 -9999 -9999 -9999 -9999 -9999 $-9999$

-9999 -9999 -9999 -9999 -9999 -9999 -9999 -9999 -9999 -9999 -9999 -9999 -9999 -9999 -9999 -9999 -9999 -9999 -9999 -9999 -9999 -9999 -9999 -9999 -9999 -9999 -9999 -9999 -9999 - -9999 -

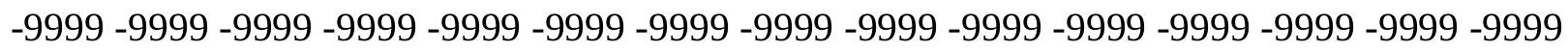

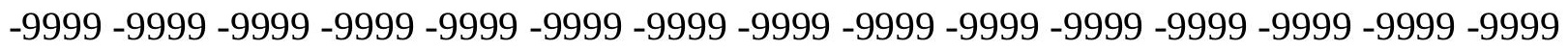

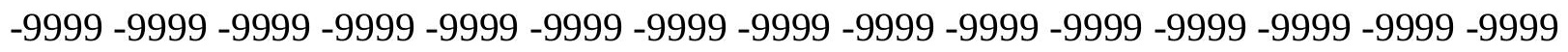
-9999 -9999 -9999 -9999 -9999 -9999 -9999 -9999 -9999 -9999 -9999 -9999 -9999 521.049987793522 .8054199219525 .4589233398528 .7199707031532 .5022583008 536.7892456055541 .6603393555547 .1053466797553 .0451049805559 .3070678711 565.6498413086571 .8534545898577 .7323608398583 .1654052734588 .0954589844 592.5062255859596 .3968505859599 .7766723633602 .6579589844605 .0618286133 607.0153198242608 .5474243164609 .6794433594610 .4209594727610 .7629394531 610.6705322266610 .080871582608 .8696289062606 .8685302734603 .8216552734 599.3850097656593 .1599731445584 .7162475586573 .7358398438560 .2320556641 544.5943603516527 .6354980469510 .4436950684494 .1468505859479 .6809692383 467.5426635742457 .6412658691448 .6437072754436 .7571105957423 .9560852051 410.240814209395 .9158935547381 .2861938477366 .3517150879352 .941192627 342.5784912109330 .6918945312321 .8530883789318 .8052062988317 .5860900879 316.6718139648315 .4526062012312 .7095031738307 .2233886719300 .2132873535 293.5080871582288 .3266906738286 .4979858398283 .7549133301280 .7070922852 277.3544921875274 .3066101074270 .3443908691267 .9060974121265 .4678039551 262.7247924805259 .9816894531256 .9338989258253 .5812072754250 .2286071777 247.7902984619244 .7424926758241 .3898010254238 .3419952393235 .9037017822 233.4653930664231 .0270996094228 .2841033936226 .150604248223 .4075012207 219.7501068115215 .4830932617212 .4351959229209 .0825958252206 .0346984863 202.6820983887199 .329498291195 .6721038818191 .7097930908187 .7476043701 183.7854003906180 .1280059814177 .3849029541174 .6419067383171 .8988037109 169.4604949951167 .0222015381164 .5839996338162 .4505004883160 .0122070312 158.1835021973156 .0500030518154 .5260925293153 .6116943359152 .6972961426 152.3925933838152 .0877990723152 .6972961426153 .3069000244153 .0021057129 152.3925933838152 .3925933838152 .0877990723152 .0877990723152 .0877990723 152.0877990723152 .0877990723152 .0877990723152 .0877990723152 .0877990723 152.3925933838152 .6972961426153 .3069000244153 .9165039062154 .5260925293 155.4403991699156 .3547973633157 .2691040039158 .4882965088159 .4026031494 160.6217956543161 .5361022949162 .7552947998163 .3648071289164 .2792053223 164.8887023926165 .1934967041165 .4983062744165 .4983062744165 .4983062744 165.1934967041164 .8887023926164 .5839996338163 .974395752163 .6696014404 163.0599975586162 .4505004883162 .1457061768161 .8408966064161 .5361022949 161.2312927246160 .9264984131160 .9264984131160 .9264984131160 .9264984131 160.9264984131161 .2312927246161 .2312927246161 .5361022949161 .5361022949 
161.8408966064162 .1457061768162 .4505004883162 .7552947998162 .7552947998 163.0599975586163 .3648071289163 .6696014404163 .974395752164 .2792053223 164.5839996338164 .8887023926164 .8887023926164 .8887023926164 .8887023926 164.8887023926164 .5839996338163 .974395752163 .3648071289162 .7552947998 161.8408966064160 .6217956543159 .4026031494158 .1835021973156 .6596069336 155.4403991699154 .5260925293153 .6116943359152 .6972961426151 .7830047607 150.5639038086149 .0399017334147 .5160064697145 .6873016357143 .8585968018 142.0299072266140 .5059967041138 .9819946289137 .4580993652136 .2389984131 135.3246002197134 .4102020264133 .8007049561133 .1911010742132 .8863067627 132.5814971924132 .5814971924132 .2767028809132 .2767028809131 .9720001221 131.9720001221131 .9720001221131 .6672058105131 .3623962402131 .0576019287 130.7528076172130 .4479980469129 .8385009766128 .9241027832128 .3144989014 127.4001998901126 .4858016968125 .2667007446124 .3523025513123 .43800354 122.2188034058121 .6092987061121 .6092987061121 .9140014648121 .9140014648 120.9997024536119 .4757995605117 .0374984741114 .5991973877112 .1608963013 110.3321990967109 .1130981445109 .7226028442113 .3800964355120 .0852966309 139.8963928223155 .7451934814164 .2792053223167 .6318054199167 .9365997314 181.3471984863192 .624206543202 .6820983887209 .692199707209 .692199707 209.692199707209 .692199707209 .692199707209 .692199707209 .692199707209 .692199707 209.692199707 209.692199707 209.692199707209.692199707 209.692199707 209.692199707 209.692199707 209.692199707 209.692199707209.692199707 209.692199707209.692199707 209.692199707 209.692199707 209.692199707209.692199707 209.692199707209.692199707 209.692199707209 .692199707209 .692199707209 .692199707209 .692199707209 .692199707 209.692199707209 .692199707209 .692199707209 .69219970761 .87137985229 -10.8310146332 -9999 -9999 -9999 -9999 -9999 -9999 -9999 -9999 -9999 -9999 -9999 -9999 -9999 -9999 -9999 -9999 -9999 -9999 -9999 -9999 -9999 -9999 -9999 -9999 -9999 -

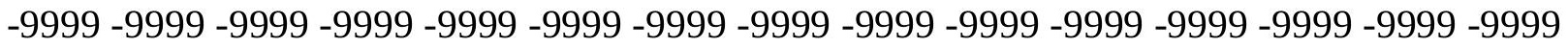

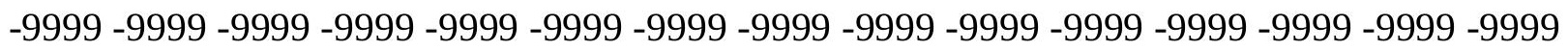
-9999 -9999 -9999 -9999 -9999 -9999 -9999 -9999 -9999 -9999 -9999 -9999 -9999 -9999 -9999 -9999 -9999 -9999 -9999 -9999 -9999 -9999 -9999 -9999 -9999 -9999 -9999 -9999 -9999 -9999 -9999 -9999 -9999 -9999 -9999 -9999 -9999 -9999 -9999 -9999 -9999 -9999 -9999 -9999 -9999 -9999 -9999 -9999 -9999 553.8512573242 559.4313964844 565.3455200195 571.4967041016 577.7218017578583 .8466796875589 .7200317383595 .2261962891600 .2959594727 604.8889160156608 .9887084961612 .5941772461615 .7096557617618 .3471679688 620.5206298828622 .2430419922623 .5179443359624 .3373413086624 .6751708984 624.4839477539623 .6837158203622 .1547241211619 .7263793945616 .1729125977 611.22265625604 .5895996094596 .021484375585 .3756713867572 .7561035156 558.5396728516543 .3265380859527 .9536743164513 .2363891602499 .8778991699 488.170135498477 .7527770996467 .5523681641456 .2633056641442 .8528137207 429.442199707415 .7268981934401 .0971984863386 .1628112793371 .5331115723 359.6465148926347 .1502990723338 .9211120605333 .7396850586330 .0823059082 327.0344848633323 .9866027832319 .4147949219313 .3190917969306 .3091125488 299.6037902832295 .0320129395291 .6794128418288 .9363098145286 .1932067871 283.7549133301281 .0119018555278 .5736083984275 .8305053711273 .0874938965 270.0396118164266 .9917907715263 .6390991211260 .2864990234257 .8482055664 255.1051025391252 .0572967529248 .7046966553245 .6567993164242 .9136962891 
240.4754943848237 .7324066162234 .9893035889232 .5511016846229 .8079986572 226.150604248222 .7978973389218 .2261962891215 .1782989502212 .1304016113 209.3874053955 206.0346984863203.2917022705 199.329498291 195.0625190.795501709 186.528503418182 .5662994385179 .8231964111177 .0802001953174 .0323028564 171.2891998291168 .5462036133166 .1078948975163 .6696014404161 .5361022949 159.0977935791 157.2691040039155.4403991699153.9165039062 152.6972961426 151.7830047607152 .0877990723152 .3925933838152 .3925933838152 .0877990723 151.7830047607151 .7830047607151 .7830047607152 .0877990723152 .0877990723 152.3925933838152 .0877990723152 .3925933838152 .3925933838152 .3925933838 152.6972961426153 .3069000244153 .9165039062154 .5260925293155 .4403991699 156.3547973633157 .2691040039158 .1835021973159 .4026031494160 .3170013428 161.5361022949162 .4505004883163 .3648071289163 .974395752164 .5839996338 164.8887023926165 .1934967041165 .1934967041165 .1934967041165 .1934967041 164.8887023926164 .5839996338164 .2792053223163 .6696014404163 .3648071289 162.7552947998162 .4505004883162 .1457061768161 .8408966064161 .5361022949 161.2312927246161 .2312927246161 .2312927246161 .2312927246161 .2312927246 161.2312927246161 .5361022949161 .5361022949161 .8408966064162 .1457061768 162.4505004883162 .7552947998163 .0599975586163 .3648071289163 .6696014404 163.974395752164 .2792053223164 .5839996338164 .8887023926164 .8887023926 165.1934967041165 .4983062744165 .4983062744165 .4983062744165 .4983062744 165.1934967041164 .8887023926164 .2792053223163 .3648071289162 .4505004883 161.5361022949160 .3170013428158 .7929992676157 .5738983154156 .0500030518 154.8307952881153 .6116943359152 .6972961426151 .4781951904149 .9542999268 148.7351074219147 .2111968994145 .3825073242143 .8585968018142 .3347015381 140.5059967041139 .2868041992137 .7628936768136 .8484954834135 .6293945312 135.0198059082134 .4102020264133 .8007049561133 .1911010742132 .8863067627 132.5814971924132 .2767028809132 .2767028809131 .9720001221131 .9720001221 131.6672058105131 .6672058105131 .3623962402131 .0576019287130 .7528076172 130.1432037354129 .533706665128 .9241027832128 .0097961426127 .0953979492 126.1809997559125 .2667007446124 .3523025513123 .1332015991122 .2188034058 121.3044967651120 .6949005127120 .9997024536121 .3044967651119 .4757995605 117.342300415114 .5991973877111 .8561019897109 .4179000854106 .979598999 105.1509017944105 .4557037354109 .1130981445119 .4757995605137 .4580993652 155.4403991699165 .8031005859170 .070098877170 .6797027588178 .9089050293 190.4907073975200 .8533935547209 .692199707209 .692199707209 .692199707 209.692199707209 .692199707209 .692199707209 .692199707209 .692199707209 .692199707 209.692199707 209.692199707 209.692199707 209.692199707 209.692199707 209.692199707 209.692199707 209.692199707 209.692199707 209.692199707 209.692199707 209.692199707 209.692199707209.692199707 209.692199707 209.692199707 209.692199707209.692199707 209.692199707209 .692199707209 .692199707209 .692199707209 .692199707209 .692199707 209.692199707 209.692199707209 .69219970761 .56660079956 -11.6894788742 -9999-9999 -9999 -9999 -9999 -9999 -9999 -9999 -9999 -9999 -9999 -9999 -9999 -9999 -9999 -9999 -9999 -9999 -9999 -9999 -9999 -9999 -9999 -9999 -9999 -9999 -9999 -9999 -9999 -9999 -9999 -9999 -9999 -9999-9999 -9999 -9999 -9999 -9999 -9999 -9999 -9999 -9999 -9999 -9999 -9999 -9999 -9999 -9999 -9999 -9999 -9999 -9999 -9999 -9999 -

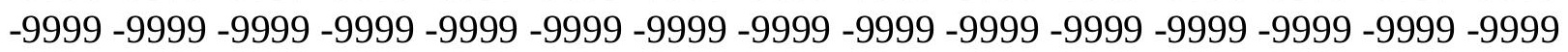


-9999 -9999 -9999 -9999 -9999 -9999 -9999 -9999 -9999 -9999 -9999 -9999 -9999 -9999 -9999 -9999 -9999 -9999 -9999 -9999 -9999 -9999 -9999 -9999 -9999 -9999 -9999 -9999 -9999 -9999 -9999 -9999 -9999 -9999 -9999 -9999 -9999 -9999 -9999 -9999 601.4439697266 606.9343261719612 .0397338867616 .709777832620 .9183349609624 .6525268555 627.9084472656630 .686706543632 .9888916016634 .8143310547636 .1530151367 636.9841918945637 .2694091797636 .9512939453635 .9440307617634 .1323852539 631.3632202148627 .4544677734622 .2005615234615 .4097900391606 .9561767578 596.8038330078585 .1034545898572 .1694946289558 .4874267578544 .6611938477 531.2916259766518 .8365478516507 .4129638672496 .7019348145485 .9273071289 474.3320617676461 .4447021484448 .9484863281435 .8427124023421 .517791748 406.5833129883391 .6488952637377 .93359375366 .0469055176356 .2937927246 348.9790039062343 .4927978516338 .3114929199333 .4349060059327 .6440124512 320.9388122559313 .6239013672306 .6138000488303 .2611999512300 .2132873535 297.7750854492295 .3367919922292 .8984985352289 .8505859375287 .1076049805 284.0596923828281 .0119018555277 .6592102051274 .3066101074270 .9540100098 267.2966003418264 .8583068848262 .1152038574259 .3721008301256 .3243103027 253.2763977051250 .2286071777247 .4855041504244 .4376983643241 .6945953369 238.6468048096235 .5989074707232 .5511016846229 .5032043457226 .150604248 222.7978973389219 .7501068115215 .787902832213 .0447998047210 .9113006592 206.9490966797202 .3773040771198 .1103057861193 .8433074951188 .966796875 185.9188995361182 .5662994385179 .2136993408176 .165802002173 .4226989746 170.6797027588167 .9365997314165 .4983062744162 .7552947998160 .3170013428 157.878692627155 .4403991699153 .6116943359152 .3925933838151 .7830047607 151.4781951904151 .4781951904151 .4781951904151 .4781951904151 .4781951904 151.7830047607151 .7830047607152 .0877990723152 .0877990723152 .3925933838 152.3925933838152 .3925933838152 .3925933838152 .6972961426153 .3069000244 153.9165039062154 .5260925293155 .1356048584156 .0500030518157 .2691040039 158.1835021973159 .0977935791160 .3170013428161 .2312927246162 .1457061768 163.0599975586163 .974395752164 .2792053223164 .8887023926165 .1934967041 165.1934967041165 .1934967041165 .1934967041164 .8887023926164 .5839996338 164.2792053223163 .974395752163 .3648071289163 .0599975586162 .7552947998 162.4505004883162 .1457061768161 .8408966064161 .5361022949161 .5361022949 161.5361022949161 .5361022949161 .5361022949161 .5361022949161 .5361022949 161.8408966064162 .1457061768162 .4505004883162 .7552947998163 .0599975586 163.3648071289163 .6696014404163 .974395752164 .2792053223164 .5839996338 164.8887023926165 .1934967041165 .4983062744165 .8031005859165 .8031005859 166.1078948975166 .1078948975166 .1078948975165 .8031005859165 .4983062744 164.8887023926164 .2792053223163 .6696014404162 .4505004883161 .2312927246 160.0122070312158 .4882965088156 .9642944336155 .4403991699153 .9165039062 152.6972961426151 .1734008789149 .6495056152148 .4304046631146 .9064025879 145.3825073242143 .8585968018142 .3347015381140 .8106994629139 .5915985107 138.3724975586137 .1533050537136 .2389984131135 .3246002197134 .7149963379 134.1054992676133 .4958953857133 .1911010742132 .8863067627132 .5814971924 132.2767028809132 .2767028809131 .9720001221131 .6672058105131 .3623962402 131.0576019287130 .7528076172130 .4479980469130 .1432037354129 .533706665 128.6192932129128 .0097961426127 .0953979492126 .1809997559125 .2667007446 
124.3523025513 123.1332015991 122.2188034058120.6949005127119.4757995605 119.1709976196118 .5614013672117 .0374984741114 .5991973877111 .8561019897 109.1130981445106 .3700027466103 .9317016602102 .4077987671102 .712600708 106.3700027466117 .0374984741136 .5437011719159 .0977935791167 .6318054199 171.5939941406172 .8132019043177 .0802001953188 .966796875199 .329498291 208.1681976318209 .692199707209 .692199707209 .692199707209 .692199707 209.692199707209 .692199707209 .692199707209 .692199707209 .692199707209 .692199707 209.692199707 209.692199707 209.692199707 209.692199707 209.692199707 209.692199707 209.692199707 209.692199707 209.692199707 209.692199707 209.692199707 209.692199707 209.692199707209 .692199707209 .692199707209 .692199707209 .692199707209 .692199707 209.692199707 209.692199707209.692199707 209.692199707 209.692199707209.692199707 209.692199707 60.95701980591 -10.9951114655 -9999 -9999 -9999 -9999 -9999 -9999 -9999 -9999 -9999-9999

-9999 -9999 -9999 -9999 -9999 -9999 -9999 -9999 -9999 -9999 -9999 -9999 -9999 -9999 -9999 -9999 -9999 -9999 -9999 -9999 -9999 -9999 -9999 -9999 -9999 -9999 -9999 -9999 -9999 -9999

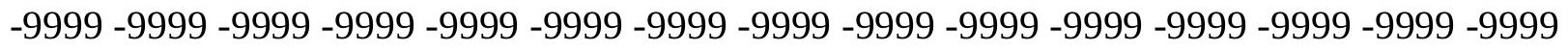
-9999 -9999 -9999 -9999 -9999 -9999 -9999 -9999 -9999 -9999 -9999 -9999 -9999 -9999 -9999 -9999 -9999 -9999 -9999 -9999 -9999 -9999 -9999 -9999 -9999 -9999 -9999 -9999 -9999 -9999 -

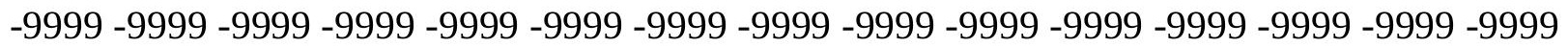
-9999 -9999 -9999 -9999 -9999 -9999 -9999 -9999 -9999 -9999 -9999 -9999 -9999 -9999 -9999 -9999 639.3452148438 642.1848144531644.5397338867 646.3981933594 647.7396850586 648.5339355469648 .7346191406648 .2794189453647 .0835571289645 .0421142578 642.0267944336637 .8975830078632 .5097045898625 .7442016602617 .5369873047 607.9275512695597 .09765625585 .2959594727572 .8889770508560 .3489379883 548.0582275391536 .3385620117525 .2336425781514 .4680175781503 .6735229492 492.4501342773480 .7063293457468 .4547119141456 .2633056641442 .2431945801 426.6991882324411 .4598999023397 .1350097656384 .3340148926373 .3617858887 364.5230102539357 .208190918350 .5028991699344 .1023864746337 .7019042969 330.6918945312323 .9866027832317 .8908996582313 .6239013672310 .5759887695 307.8330078125305 .3947143555302 .6516113281299 .2990112305295 .9464111328 292.5936889648289 .2410888672285 .5835876465281 .9262084961278 .2687988281 274.6113891602271 .2587890625269 .4301147461266 .9917907715263 .9439086914 260.5913085938257 .5433959961254 .4956054688251 .4476928711248 .0950927734 245.0471954346241 .6945953369238 .9515075684236 .2084960938233 .1605987549 230.1127929688227 .0648956299224 .0171051025220 .9691925049217 .6165924072 213.959197998209 .692199707205 .425201416200 .8533935547196 .2816009521 192.624206543188 .966796875185 .3094024658181 .3471984863178 .604095459 175.8609924316172 .8132019043170 .070098877167 .0222015381163 .974395752 160.9264984131157 .878692627155 .1356048584153 .0021057129151 .7830047607 150.8686065674150 .5639038086150 .8686065674150 .8686065674151 .1734008789 151.4781951904151 .7830047607152 .0877990723152 .0877990723152 .3925933838 152.3925933838152 .3925933838152 .6972961426153 .0021057129153 .3069000244 153.9165039062154 .5260925293155 .1356048584156 .0500030518156 .9642944336 157.878692627159 .0977935791160 .0122070312161 .2312927246162 .1457061768 163.0599975586163 .6696014404164 .2792053223164 .5839996338164 .8887023926 165.1934967041165 .1934967041165 .1934967041164 .8887023926164 .5839996338 
164.2792053223163 .974395752163 .6696014404163 .0599975586162 .7552947998 162.4505004883162 .1457061768161 .8408966064161 .8408966064161 .5361022949 161.5361022949161 .5361022949161 .5361022949161 .5361022949161 .8408966064 161.8408966064162 .1457061768162 .4505004883162 .7552947998163 .0599975586 163.3648071289163 .974395752164 .2792053223164 .5839996338164 .8887023926 165.1934967041165 .4983062744165 .8031005859166 .1078948975166 .4127044678 166.4127044678166 .7174987793166 .7174987793166 .4127044678166 .1078948975 165.8031005859165 .1934967041164 .5839996338163 .6696014404162 .4505004883 161.2312927246159 .7073974609157 .878692627156 .0500030518154 .5260925293 152.6972961426151 .1734008789149 .6495056152148 .1255950928146 .6015930176 145.3825073242143 .8585968018142 .3347015381141 .1154937744139 .5915985107 138.6772003174137 .4580993652136 .5437011719135 .6293945312135 .0198059082 134.4102020264133 .8007049561133 .4958953857133 .1911010742132 .8863067627 132.5814971924132 .2767028809131 .9720001221131 .6672058105131 .3623962402 131.0576019287130 .7528076172130 .4479980469129 .8385009766129 .2288970947 128.6192932129128 .0097961426127 .0953979492126 .1809997559125 .2667007446 124.0475006104123 .1332015991121 .9140014648120 .3900985718118 .8662033081 117.647102356116 .1231002808114 .2944030762111 .8561019897109 .1130981445 106.3700027466103 .9317016602101 .7982025146100 .8839035034102 .1029968262 105.7603988647113 .075302124135 .6293945312155 .4403991699167 .0222015381 172.2035980225174 .0323028564176 .165802002187 .7476043701198 .1103057861 206.9490966797209 .692199707209 .692199707209 .692199707209 .692199707 209.692199707 209.692199707 209.692199707 209.692199707 209.692199707 209.692199707 209.692199707209 .692199707209 .692199707209 .692199707209 .692199707209 .692199707 209.692199707 209.692199707 209.692199707 209.692199707 209.692199707 209.692199707 209.692199707209 .692199707209 .692199707209 .692199707209 .692199707209 .692199707 209.692199707209 .692199707209 .692199707209 .692199707209 .692199707209 .692199707 209.692199707 60.34745025635 -6.72870635986 -9999 -9999-9999 -9999 -9999 -9999 -9999 -9999 -9999-9999

-9999 -9999 -9999 -9999 -9999 -9999 -9999 -9999 -9999 -9999 -9999 -9999 -9999 -9999 -9999 -9999 -9999 -9999 -9999 -9999 -9999 -9999 -9999 -9999 -9999 -9999 -9999 -9999 -9999 -9999 -9999 -9999 -9999 -9999 -9999 -9999 -9999 -9999 -9999 -9999 -9999 -9999 -9999 -9999 -9999 -

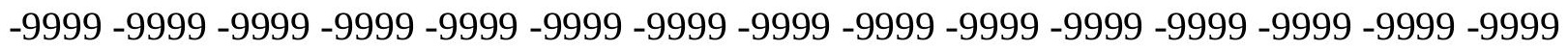
-9999 -9999 -9999 -9999 -9999 -9999 -9999 -9999 -9999 -9999 -9999 -9999 -9999 -9999 -9999 -9999 -9999 -9999 -9999 -9999 -9999 -9999 -9999 -9999 -9999 -9999 -9999 -9999 -9999 -9999 -9999 -9999 -9999 -9999 -9999 -9999 -9999 -9999 -9999 -9999 -9999 -9999 -9999 -9999 -9999 -9999 -9999-9999 -9999 -9999-9999-9999 659.2362670898 658.6467285156 657.2899169922 655.075378418651 .9002075195647 .6616821289642 .2626342773635 .6357421875 627.7626953125618 .70703125608 .623840332597 .7562866211586 .4050292969 574.8903198242563 .4938354492552 .3931884766541 .6279907227531 .0780029297 520.5728759766509 .9761962891499 .2820739746488 .2802734375476 .0744018555 461.7495117188445 .900604248429 .7470092773414 .8125915527401 .4020080566 389.8201904297379 .762298584371 .228302002363 .303894043356 .2937927246 349.2838134766342 .5784912109335 .8731994629330 .3870849609325 .8153076172 322.1578979492318 .8052062988315 .7573852539312 .7095031738309 .0520935059 305.3947143555301 .7373046875297 .7750854492293 .8128967285289 .8505859375 
285.8884887695281 .9262084961278 .5736083984276 .4400939941274 .0018005371 270.9540100098267 .6012878418264 .5534973145261 .2008972168258 .1530151367 254.8003997803251 .4476928711248 .0950927734245 .3520050049242 .9136962891 240.1707000732237 .1228027344234 .3798065186231 .0270996094227 .9792938232 224.3218994141220 .6643981934216 .7021942139212 .4351959229207 .25390625 203.596496582199 .6342926025195 .6721038818192 .0146026611188 .3571929932 184.699798584181 .6519012451178 .2993011475175 .2514038086171 .8988037109 168.241394043164 .5839996338160 .6217956543156 .9642944336153 .9165039062 151.7830047607150 .5639038086150 .2590942383150 .5639038086150 .8686065674 151.1734008789151 .4781951904151 .7830047607152 .0877990723152 .0877990723 152.3925933838152 .3925933838152 .3925933838152 .6972961426153 .0021057129 153.3069000244153 .6116943359154 .2212982178155 .1356048584156 .0500030518 156.9642944336157 .878692627158 .7929992676160 .0122070312160 .9264984131 161.8408966064162 .7552947998163 .6696014404164 .2792053223164 .5839996338 164.8887023926165 .1934967041165 .1934967041165 .1934967041164 .8887023926 164.5839996338164 .2792053223163 .974395752163 .6696014404163 .0599975586 162.7552947998162 .4505004883162 .1457061768162 .1457061768161 .8408966064 161.8408966064161 .5361022949161 .5361022949161 .5361022949161 .8408966064 161.8408966064162 .1457061768162 .1457061768162 .4505004883162 .7552947998 163.3648071289163 .6696014404163 .974395752164 .2792053223164 .5839996338 164.8887023926165 .4983062744165 .8031005859166 .1078948975166 .4127044678 166.7174987793167 .0222015381167 .0222015381167 .3269958496167 .0222015381 167.0222015381166 .7174987793166 .1078948975165 .4983062744164 .5839996338 163.6696014404162 .4505004883161 .2312927246159 .4026031494157 .5738983154 155.7451934814153 .6116943359151 .1734008789149 .6495056152148 .1255950928 146.6015930176145 .0776977539143 .8585968018142 .3347015381141 .1154937744 139.8963928223138 .9819946289137 .7628936768136 .8484954834135 .9342041016 135.3246002197134 .7149963379134 .1054992676133 .8007049561133 .1911010742 132.8863067627132 .5814971924132 .2767028809131 .9720001221131 .6672058105 131.3623962402131 .0576019287130 .7528076172130 .1432037354129 .8385009766 129.2288970947 128.6192932129 127.7050018311 126.7906036377126 .1809997559 124.9618988037124 .0475006104122 .8283996582121 .6092987061119 .7806015015 117.9517974854116 .1231002808114 .2944030762112 .1608963013109 .4179000854 106.6747970581104 .2365036011101 .7982025146100 .5791015625100 .5791015625 103.3221969604109 .4179000854121 .3044967651138 .6772003174155 .1356048584 166.1078948975171 .8988037109174 .337097168175 .8609924316187 .1381072998 196.891204834205 .425201416209 .692199707209 .692199707209 .692199707209 .692199707 209.692199707 209.692199707 209.692199707 209.692199707 209.692199707 209.692199707 209.692199707209 .692199707209 .692199707209 .692199707209 .692199707209 .692199707 209.692199707 209.692199707 209.692199707 209.692199707 209.692199707 209.692199707 209.692199707209 .692199707209 .692199707209 .692199707209 .692199707209 .692199707 209.692199707 209.692199707 209.692199707 209.692199707 209.692199707 209.692199707 209.69219970760 .04267120361 -2.31013894081 -9999-9999 -9999 -9999-9999 -9999 -9999 -9999 -9999 -9999 -9999 -9999 -9999 -9999 -9999 -9999 -9999 -9999 -9999 -9999 -9999 -9999 -9999 -9999 -9999

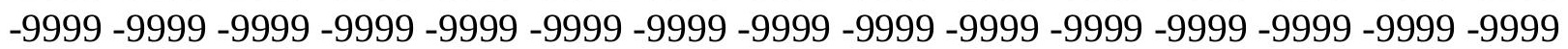


-9999 -9999 -9999 -9999 -9999 -9999 -9999 -9999 -9999 -9999 -9999 -9999 -9999 -9999 -9999 -9999 -9999 -9999 -9999 -9999 -9999 -9999 -9999 -9999 -9999 -9999 -9999 -9999 -9999 -9999

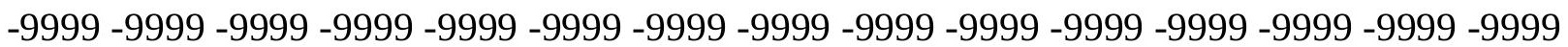
-9999 -9999 -9999 -9999 -9999 -9999 -9999 -9999 -9999 -9999 -9999 -9999 -9999 -9999 -9999 -9999 -9999 -9999 -9999 -9999 -9999 -9999 -9999 -9999 -9999 -9999 -9999-9999 -9999 -9999 -9999 -9999 -9999 -9999 -9999 -9999 -9999 -9999 -9999 -9999 -9999 -9999 -9999 651.5177612305645 .0908203125637 .5768432617629 .0491333008619 .6474609375 609.5734863281599 .0632324219588 .3559570312577 .655090332567 .0830688477 556.6837768555546 .4141845703536 .2386474609526 .1040649414515 .9807128906 505.8586425781495 .2757873535479 .1221923828462 .3590087891445 .900604248 430.6614074707416 .9460144043405 .059387207394 .391998291385 .2484130859 377.0191955566369 .399597168362 .0846862793355 .379486084349 .2838134766 343.4927978516338 .6163024902334 .6541137695330 .6918945312327 .0344848633 323.3770141602319 .4147949219315 .4526062012311 .1856079102306 .9186096191 302.6516113281298 .0798950195293 .5080871582289 .5458984375285 .8884887695 282.8406066895280 .4023132324277 .6592102051274 .6113891602271 .2587890625 267.9060974121264 .5534973145261 .2008972168257 .5433959961254 .1907958984 252.3621063232249 .6190032959246 .8759002686244 .1329040527241 .3898010254 238.3419952393234 .6844940186231 .3318939209227 .3697052002223 .4075012207 219.4452972412214 .2639007568210 .9113006592206 .9490966797202 .9868927002 199.0247039795195 .3672943115191 .7097930908188 .0523986816184 .3950042725 180.7375946045177 .3849029541173 .4226989746169 .1557006836164 .2792053223 159.7073974609155 .4403991699152 .0877990723150 .8686065674150 .8686065674 150.8686065674151 .1734008789151 .4781951904151 .4781951904151 .7830047607 152.0877990723152 .3925933838152 .3925933838152 .3925933838152 .3925933838 152.6972961426152 .6972961426153 .3069000244153 .6116943359154 .2212982178 154.8307952881155 .7451934814156 .6596069336157 .5738983154158 .4882965088 159.7073974609160 .6217956543161 .5361022949162 .4505004883163 .3648071289 163.974395752164 .5839996338164 .8887023926165 .1934967041165 .1934967041 164.8887023926164 .8887023926164 .5839996338164 .2792053223163 .6696014404 163.3648071289163 .0599975586162 .7552947998162 .4505004883162 .1457061768 161.8408966064161 .8408966064161 .5361022949161 .5361022949161 .5361022949 161.5361022949161 .5361022949161 .8408966064162 .1457061768162 .1457061768 162.4505004883162 .7552947998163 .3648071289163 .6696014404163 .974395752 164.2792053223164 .5839996338165 .1934967041165 .4983062744165 .8031005859 166.4127044678166 .7174987793167 .0222015381167 .3269958496167 .6318054199 167.6318054199167 .6318054199167 .6318054199167 .3269958496167 .0222015381 166.4127044678165 .8031005859164 .8887023926163 .974395752162 .7552947998 161.2312927246159 .4026031494157 .2691040039154 .8307952881152 .3925933838 150.2590942383148 .4304046631146 .9064025879145 .3825073242143 .8585968018 142.6394042969141 .4203033447140 .2012023926138 .9819946289138 .0677032471 137.1533050537136 .2389984131135 .6293945312135 .0198059082134 .4102020264 133.8007049561133 .4958953857132 .8863067627132 .5814971924132 .2767028809 131.9720001221131 .6672058105131 .3623962402131 .0576019287130 .7528076172 130.1432037354129 .8385009766129 .2288970947128 .3144989014127 .7050018311 126.7906036377125 .8762969971124 .9618988037124 .0475006104122 .8283996582 
121.3044967651 119.4757995605 117.342300415 115.2088012695112.7705001831 110.0273971558107 .5891036987104 .8460998535102 .4077987671100 .5791015625 99.66472625732100 .5791015625104 .8460998535113 .6848983765128 .0097961426 144.1634063721156 .9642944336165 .4983062744170 .9844970703173 .7274932861 174.9467010498186 .528503418195 .6721038818204 .2059936523209 .692199707 209.692199707 209.692199707 209.692199707 209.692199707 209.692199707 209.692199707 209.692199707 209.692199707 209.692199707 209.692199707 209.692199707209.692199707 209.692199707 209.692199707 209.692199707 209.692199707 209.692199707 209.692199707 209.692199707 209.692199707 209.692199707 209.692199707 209.692199707 209.692199707 209.692199707 209.692199707 209.692199707 209.692199707 209.692199707 209.692199707 209.692199707 209.692199707 209.692199707 63.70008850098 59.43310165405 2.903992652893 -9999 -9999 -9999 -9999 -9999 -9999 -9999 -9999 -9999-9999 -9999 -9999 -9999 -9999 -9999 -9999 -9999 -9999 -9999 -9999 -9999 -9999 -9999 -9999 -9999 -9999 -9999 -9999 -9999 -9999 -9999 -9999 -9999 -9999 -9999 -9999 -9999 -9999 -9999 -9999 -9999 -9999 -9999 -9999 -9999 -9999 -9999 -9999 -9999 -9999 -9999 -9999 -9999 -9999 -9999 -

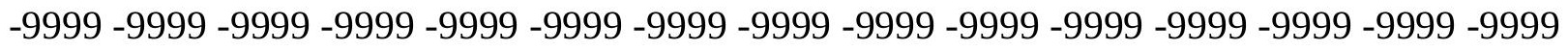

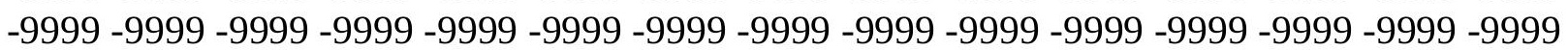
-9999 -9999 -9999 -9999 -9999 -9999 -9999 -9999 -9999 -9999 -9999 -9999 -9999 -9999 -9999 -999 -9999 -9999 -9999 -9999 -9999 -9999 -9999 -9999 -9999 -9999 -9999 -9999 -9999 -9999 -9999 -9999 -9999 -9999 -9999 -9999 -9999 -9999 -9999 -9999 -9999 -9999 -9999 -9999 -9999 -9999 -9999 -9999-9999-9999 610.8463134766 600.7853393555 590.6403198242580.5045776367 570.4194946289560 .3888549805550 .3955078125540 .4154663086530 .3334350586 519.7484741211507 .5936279297492 .8375854492476 .0744018555459 .9206848145 444.9862976074431 .2709960938419 .3843078613408 .7168884277399 .2684936523 390.7344970703383 .1148986816375 .799987793369 .399597168362 .9991149902 357.5129089355352 .3316040039347 .4549865723343 .1879882812338 .9211120605 334.3493041992330 .0823059082325 .5104980469320 .9388122559316 .0621948242 311.4903869629306 .6138000488301 .1276855469296 .5559082031292 .8984985352 290.7650146484288 .6315002441285 .8884887695282 .8406066895279 .1831970215 275.5257873535272 .1730957031268 .5156860352265 .1630859375261 .5056152344 259.3721008301256 .6290893555253 .5812072754250 .8381958008248 .0950927734 245.0471954346241 .3898010254237 .7324066162234 .0749969482230 .1127929688 226.150604248220 .9691925049217 .6165924072213 .959197998209 .9969024658 206.3394927979 202.6820983887 198.7198944092 194.4528961182190.4907073975 186.528503418182 .87109375179 .2136993408174 .337097168169 .1557006836 163.974395752158 .4882965088153 .6116943359153 .0021057129152 .6972961426 152.3925933838152 .0877990723152 .0877990723152 .0877990723151 .7830047607 151.7830047607152 .0877990723152 .3925933838152 .3925933838152 .3925933838 152.3925933838152 .6972961426153 .0021057129153 .6116943359154 .2212982178 154.8307952881155 .4403991699156 .3547973633157 .2691040039158 .4882965088 159.4026031494160 .3170013428161 .5361022949162 .4505004883163 .3648071289 163.974395752164 .5839996338164 .8887023926165 .1934967041165 .1934967041 164.8887023926164 .5839996338164 .2792053223163 .974395752163 .6696014404 163.3648071289163 .0599975586162 .7552947998162 .4505004883162 .1457061768 161.8408966064161 .5361022949161 .5361022949161 .5361022949161 .5361022949 161.5361022949161 .5361022949161 .8408966064161 .8408966064162 .1457061768 
162.4505004883162 .7552947998163 .0599975586163 .6696014404163 .974395752 164.2792053223164 .8887023926165 .1934967041165 .4983062744166 .1078948975 166.4127044678167 .0222015381167 .3269958496167 .6318054199167 .9365997314 167.9365997314168 .241394043167 .9365997314167 .9365997314167 .6318054199 167.3269958496 166.7174987793166.1078948975 165.1934967041 164.2792053223 163.3648071289161 .5361022949159 .0977935791156 .0500030518153 .3069000244 150.8686065674148 .7351074219146 .9064025879145 .3825073242143 .8585968018 142.6394042969141 .4203033447140 .5059967041139 .2868041992138 .3724975586 137.4580993652136 .5437011719135 .9342041016135 .3246002197134 .7149963379 134.1054992676133 .4958953857133 .1911010742132 .8863067627132 .2767028809 131.9720001221131 .6672058105131 .3623962402131 .0576019287130 .7528076172 130.1432037354129 .533706665128 .9241027832128 .3144989014127 .4001998901 126.7906036377125 .8762969971124 .9618988037123 .7427978516122 .5235977173 121.3044967651119 .1709976196116 .7326965332114 .2944030762111 .551399231 108.8082962036106 .0652008057103 .3221969604101 .188697814999 .35994720459 99.05516815186100 .5791015625105 .1509017944114 .2944030762129 .533706665 149.0399017334156 .6596069336163 .6696014404168 .8509979248172 .5084075928 174.0323028564185 .3094024658194 .4528961182202 .3773040771209 .3874053955 209.692199707 209.692199707 209.692199707 209.692199707 209.692199707209.692199707 209.692199707 209.692199707 209.692199707209.692199707 209.692199707 209.692199707 209.692199707 209.692199707 209.692199707 209.692199707 209.692199707 209.692199707 209.692199707 209.692199707 209.692199707209.692199707 209.692199707209.692199707 209.692199707209 .692199707209 .692199707209 .692199707209 .692199707209 .692199707 209.692199707 209.692199707 209.692199707 63.09051895142 19.53934860229

-9.98252010345 -9999 -9999 -9999 -9999 -9999 -9999 -9999 -9999 -9999 -9999

-9999 -9999 -9999 -9999 -9999 -9999 -9999 -9999 -9999 -9999 -9999 -9999 -9999 -9999 -9999 -9999 -9999 -9999 -9999 -9999 -9999 -9999 -9999 -9999 -9999 -9999 -9999 -9999 -9999 -9999

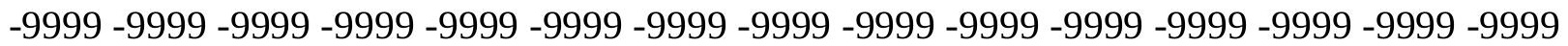
-9999 -9999 -9999 -9999 -9999 -9999 -9999 -9999 -9999 -9999 -9999 -9999 -9999 -9999 -9999

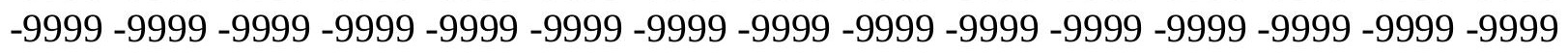
-9999 -9999 -9999 -9999 -9999 -9999 -9999 -9999 -9999 -9999 -9999 -9999 -9999 -9999 -9999 -9999 -9999 -9999 -9999 -9999 -9999 -9999 -9999 -9999 -9999 -9999 -9999 -9999 -9999-999 -999 -

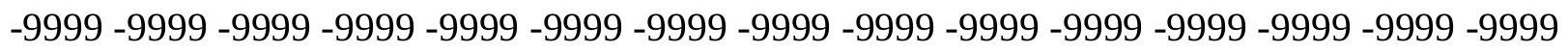
-9999 -9999 -9999 -9999-9999 -9999 -9999 -9999-9999 -9999 563.0388183594 552.9052734375542 .4069213867531 .0701293945518 .1692504883503 .4038696289 487.0466003418471 .8074035645457 .7872924805444 .6814880371432 .7948913574 422.4321899414412 .9838867188404 .7546081543397 .1350097656390 .125383 .7244873047 377.324005127 371.5331115723366 .0469055176360 .8656005859355 .9890136719 351.112487793346 .2359008789341 .0545959473336 .1780090332330 .9966125488 325.8153076172320 .3291931152314 .5382080078308 .7473144531303 .5660095215 299.9085998535298 .3846130371297 .4703063965294 .7272033691291 .0697937012 287.1076049805283 .1453857422279 .4880065918276 .1353149414272 .4779052734 269.1253051758265 .7726135254263 .0296020508259 .9816894531257 .2385864258 254.1907958984251 .1428985596247 .7902984619244 .4376983643240 .4754943848 236.5133056641232 .5511016846228 .8936004639224 .0171051025220 .6643981934 217.0070037842213 .3495941162209 .9969024658205 .425201416200 .8533935547 
196.5863952637192 .624206543188 .3571929932184 .3950042725179 .5184020996 174.6419067383169 .4604949951164 .5839996338160 .0122070312157 .5738983154 156.0500030518154 .8307952881153 .6116943359152 .6972961426152 .3925933838 151.4781951904151 .4781951904151 .7830047607152 .0877990723152 .3925933838 152.3925933838152 .3925933838152 .6972961426153 .0021057129153 .3069000244 153.9165039062154 .5260925293155 .4403991699156 .0500030518156 .9642944336 158.1835021973159 .0977935791160 .0122070312161 .2312927246162 .1457061768 163.0599975586163 .974395752164 .5839996338164 .8887023926164 .8887023926 164.8887023926164 .8887023926164 .5839996338164 .2792053223163 .6696014404 163.3648071289163 .0599975586162 .7552947998162 .4505004883162 .1457061768 161.8408966064161 .5361022949161 .5361022949161 .2312927246161 .2312927246 161.2312927246161 .2312927246161 .2312927246161 .5361022949161 .8408966064 161.8408966064162 .1457061768162 .7552947998163 .0599975586163 .3648071289 163.6696014404164 .2792053223164 .5839996338165 .1934967041165 .4983062744 166.1078948975166 .4127044678167 .0222015381167 .3269958496167 .9365997314 168.241394043168 .241394043168 .5462036133168 .5462036133168 .5462036133 168.241394043167 .9365997314167 .6318054199167 .3269958496166 .7174987793 165.8031005859165 .8031005859163 .6696014404160 .6217956543157 .2691040039 154.2212982178151 .1734008789149 .0399017334147 .2111968994145 .6873016357 144.1634063721142 .9441986084141 .7250976562140 .5059967041139 .5915985107 138.6772003174137 .7628936768136 .8484954834136 .2389984131135 .3246002197 134.7149963379134 .1054992676133 .8007049561133 .1911010742132 .8863067627 132.5814971924131 .9720001221131 .6672058105131 .3623962402131 .0576019287 130.4479980469130 .1432037354129 .533706665128 .9241027832128 .0097961426 127.4001998901126 .4858016968125 .5715026855124 .6570968628123 .7427978516 122.2188034058120 .6949005127118 .8662033081116 .4279022217113 .6848983765 110.9418029785107 .8938980103105 .1509017944102 .4077987671100 .2742996216 98.7503814697398 .445587158299 .66472625732103 .6268997192110 .9418029785 123.1332015991138 .6772003174150 .8686065674159 .4026031494165 .8031005859 170.070098877172 .5084075928183 .7854003906192 .624206543200 .2438049316 207.25390625209 .692199707209 .692199707209 .692199707209 .692199707209 .692199707 209.692199707 209.692199707 209.692199707 209.692199707 209.692199707 209.692199707 209.692199707 209.692199707 209.692199707 209.692199707 209.692199707 209.692199707 209.692199707 209.692199707 209.692199707 209.692199707 209.692199707 209.692199707 209.692199707 209.692199707 209.692199707 209.692199707 209.692199707 209.692199707 209.692199707209 .692199707209 .692199707209 .69219970762 .48094940186 9.384657859802 -16.275844574 -9999 -9999 -9999 -9999 -9999 -9999 -9999 -9999 -9999 -9999 -9999 -9999 -9999 -9999 -9999 -9999 -9999 -9999 -9999 -9999 -9999 -9999 -9999 -9999 -9999 -

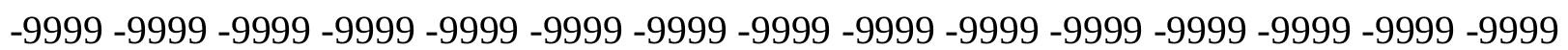
-9999 -9999 -9999 -9999 -9999 -9999 -9999 -9999 -9999 -9999 -9999 -9999 -9999 -9999 -9999 -

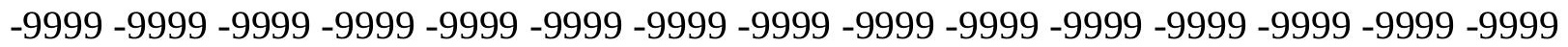
-9999 -9999 -9999 -9999 -9999 -9999 -9999 -9999 -9999 -9999 -9999 -9999 -9999 -9999 -9999 -9999 -9999 -9999 -9999 -9999 -9999 -9999 -9999 -9999 -9999 -9999 -9999 -9999 -9999 -9999 -9999 -9999 -9999 -9999 -9999 -9999 -9999 -9999 -9999 -9999 -9999 -9999 -9999 -9999 -9999

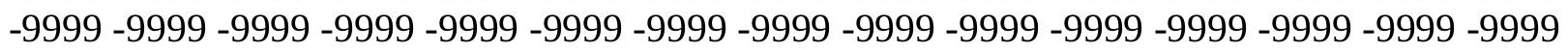
-9999 -9999 -9999 -9999 -9999 -9999 -9999 -9999 -9999 -9999 -9999 -9999 -9999 -9999 
527.9929199219513 .5083007812498 .2077026367483 .0844116211469 .6738891602 457.1777038574445 .900604248435 .8427124023426 .6991882324418 .7746887207 411.4598999023404 .4498901367398 .049407959391 .953704834385 .858001709 380.066986084374 .5809020996369 .0947875977363 .6086120605358 .1224975586 352.6364135742347 .1502990723341 .3593139648335 .5683898926329 .4726867676 323.3770141602317 .2813110352311 .1856079102306 .0043029785306 .3091125488 306.9186096191302 .9563903809298 .6893920898294 .7272033691290 .4602050781 286.8027954102283 .4501953125280 .0975036621276 .7449035645273 .0874938965 269.7348022461266 .0773925781262 .7247924805259 .9816894531256 .9338989258 253.8860015869250 .5334014893246 .5711975098242 .9136962891239 .2563018799 235.5989074707231 .6367034912227 .9792938232223 .4075012207219 .7501068115 216.0926971436211 .520904541206 .9490966797203 .596496582199 .329498291195 .0625 189.8811035156185 .3094024658181 .0424041748176 .4705963135171 .8988037109 167.6318054199163 .6696014404160 .6217956543158 .1835021973155 .4403991699 153.0021057129151 .4781951904150 .8686065674151 .1734008789152 .0877990723 152.3925933838152 .3925933838152 .3925933838152 .3925933838152 .6972961426 152.6972961426153 .3069000244153 .6116943359154 .2212982178155 .1356048584 155.7451934814156 .6596069336157 .878692627158 .7929992676159 .7073974609 160.9264984131161 .8408966064162 .7552947998163 .6696014404164 .2792053223 164.8887023926164 .8887023926164 .8887023926164 .5839996338164 .2792053223 163.974395752163 .3648071289163 .0599975586162 .7552947998162 .4505004883 162.1457061768161 .8408966064161 .5361022949161 .2312927246161 .2312927246 161.2312927246160 .9264984131160 .9264984131160 .9264984131161 .2312927246 161.2312927246161 .5361022949161 .8408966064162 .1457061768162 .4505004883 162.7552947998163 .0599975586163 .6696014404163 .974395752164 .5839996338 164.8887023926165 .4983062744166 .1078948975166 .4127044678167 .0222015381 167.6318054199167 .9365997314168 .241394043168 .5462036133168 .8509979248 168.8509979248168 .8509979248168 .8509979248168 .5462036133168 .241394043 167.9365997314167 .9365997314167 .9365997314168 .5462036133165 .4983062744 161.8408966064158 .1835021973154 .8307952881151 .7830047607149 .3446960449 147.5160064697145 .6873016357144 .1634063721142 .9441986084141 .7250976562 140.8106994629139 .8963928223138 .9819946289138 .0677032471137 .1533050537 136.2389984131135 .6293945312135 .0198059082134 .4102020264133 .8007049561 133.4958953857132 .8863067627132 .5814971924132 .2767028809131 .6672058105 131.3623962402131 .0576019287130 .4479980469129 .8385009766129 .2288970947 128.6192932129128 .0097961426127 .0953979492126 .4858016968125 .5715026855 124.3523025513123 .43800354122 .2188034058120 .3900985718118 .5614013672 116.1231002808113 .3800964355110 .6370010376107 .5891036987104 .8460998535 102.407798767199 .9695205688598 .445587158298 .1408081054799 .05516815186 101.7982025146106 .6747970581113 .075302124129 .2288970947143 .5538024902 154.2212982178161 .8408966064167 .3269958496170 .6797027588181 .6519012451 190.1858978271197 .8054962158204 .8155975342209 .692199707209 .692199707 209.692199707 209.692199707 209.692199707 209.692199707 209.692199707 209.692199707 209.692199707 209.692199707 209.692199707 209.692199707 209.692199707209.692199707 209.692199707209 .692199707209 .692199707209 .692199707209 .692199707209 .692199707 209.692199707209 .692199707209 .692199707209 .692199707209 .692199707209 .692199707 
209.692199707 209.692199707209.692199707209.692199707209.692199707209.692199707 66.1383666992261 .8713798522921 .43017196655 -12.5539245605 -9999 -9999 -9999 -9999 -9999 -9999 -9999 -9999-9999-9999

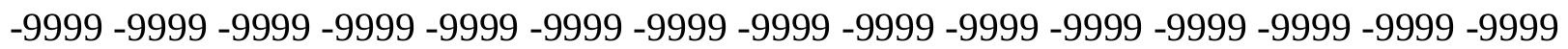

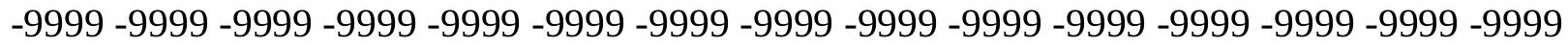

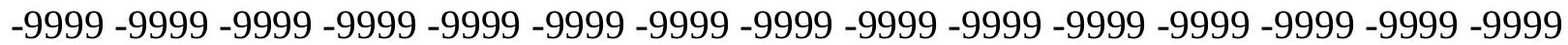

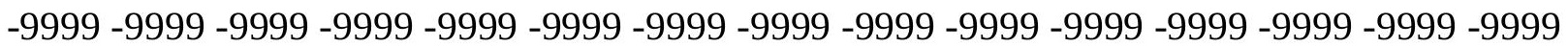

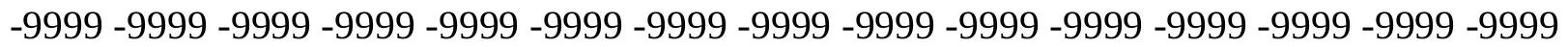

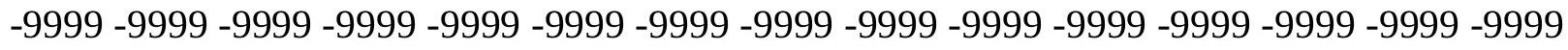

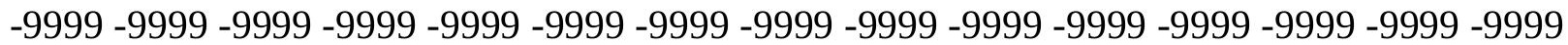
-9999 -

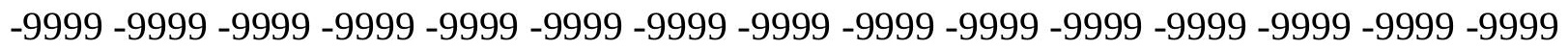
523.6611938477509 .2381896973495 .0570678711481 .8652954102469 .6738891602 458.7015991211448 .6437072754440 .1097106934432 .4901123047425 .4800109863 419.0795898438412 .6789855957406 .5833129883400 .487701416394 .391998291 388.296295166382 .5053100586376 .7143859863370 .6187133789364 .5230102539 358.4273071289352 .0267944336345 .6263122559339 .2258911133332 .8252868652 326.4248962402320 .3291931152316 .3670043945314 .5382080078313 .0143127441 309.9664916992306 .0043029785301 .7373046875297 .7750854492293 .8128967285 290.4602050781287 .4124145508284 .0596923828280 .7070922852277 .3544921875 273.6971130371269 .7348022461266 .0773925781262 .4200134277259 .6769104004 256.6290893555252 .9716033936249 .3141937256245 .6567993164241 .9994049072 238.3419952393234 .6844940186231 .0270996094226 .7601013184222 .7978973389 218.8356933594214 .8735046387211 .2160949707207 .25390625203 .2917022705 198.7198944092193 .8433074951188 .6620025635183 .4806976318180 .1280059814 174.9467010498170 .3748931885166 .4127044678162 .4505004883158 .7929992676 154.8307952881150 .8686065674150 .5639038086151 .1734008789152 .3925933838 152.3925933838152 .3925933838152 .0877990723152 .3925933838152 .3925933838 152.6972961426153 .0021057129153 .6116943359153 .9165039062154 .8307952881 155.4403991699156 .3547973633157 .2691040039158 .4882965088159 .4026031494 160.6217956543161 .5361022949162 .4505004883163 .3648071289164 .2792053223 164.8887023926164 .8887023926164 .5839996338164 .2792053223163 .974395752 163.3648071289163 .0599975586162 .7552947998162 .4505004883161 .8408966064 161.5361022949161 .5361022949161 .2312927246160 .9264984131160 .9264984131 160.6217956543160 .6217956543160 .6217956543160 .6217956543160 .9264984131 160.9264984131161 .2312927246161 .5361022949161 .8408966064162 .1457061768 162.4505004883162 .7552947998163 .3648071289163 .6696014404164 .2792053223 164.8887023926165 .1934967041165 .8031005859166 .4127044678167 .0222015381 167.3269958496167 .9365997314168 .241394043168 .5462036133168 .8509979248 168.8509979248169 .1557006836168 .8509979248168 .8509979248168 .8509979248 168.5462036133168 .5462036133168 .5462036133167 .9365997314165 .4983062744 162.1457061768158 .7929992676155 .1356048584152 .3925933838149 .6495056152 147.8208007812145 .9920959473144 .4682006836143 .2489929199142 .0299072266 141.1154937744139 .8963928223138 .9819946289138 .0677032471137 .4580993652 136.5437011719135 .9342041016135 .0198059082134 .4102020264133 .8007049561 133.4958953857132 .8863067627132 .5814971924132 .2767028809131 .6672058105 
131.3623962402130 .7528076172130 .4479980469129 .8385009766129 .2288970947 128.6192932129127 .7050018311127 .0953979492126 .1809997559125 .2667007446 124.3523025513123 .1332015991121 .9140014648120 .0852966309118 .2565994263 115.818397522113 .3800964355110 .6370010376107 .5891036987104 .8460998535 102.4077987671100 .579101562599 .0551681518698 .445587158298 .75038146973 100.8839035034105 .1509017944113 .075302124124 .9618988037138 .3724975586 149.6495056152158 .4882965088164 .8887023926169 .7653045654179 .5184020996 187.7476043701195 .3672943115202 .0724945068208 .1681976318209 .692199707 209.692199707 209.692199707 209.692199707 209.692199707 209.692199707 209.692199707 209.692199707209 .692199707209 .692199707209 .692199707209 .692199707209 .692199707 209.692199707 209.692199707 209.692199707 209.692199707 209.692199707 209.692199707 209.692199707 209.692199707 209.692199707 209.692199707 209.692199707 209.692199707 209.692199707 209.692199707 209.692199707 209.692199707209.692199707 209.692199707 65.8335876464861 .5666007995628 .90551185608 -6.00256919861 -9999-9999 -9999 -9999 -9999 -9999 -9999 -9999-9999-9999

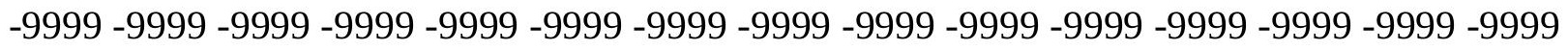

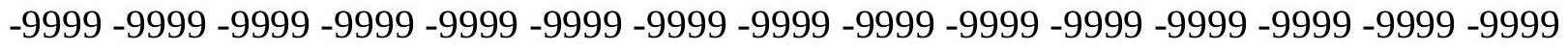

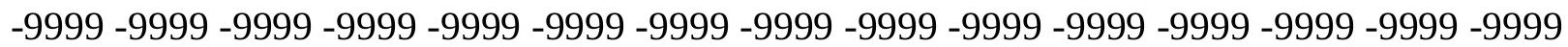

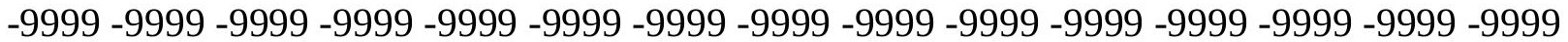

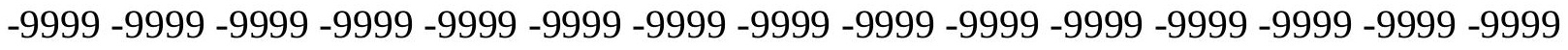

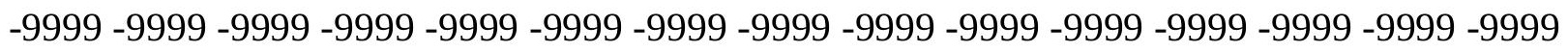

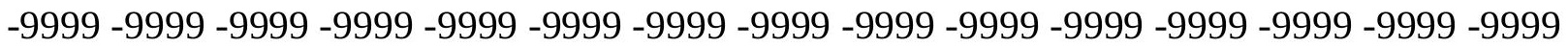

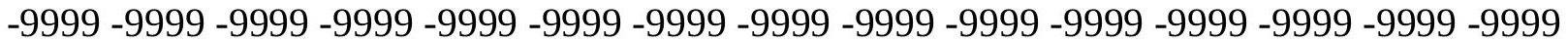
-9999 -9999 -9999 -9999 -9999 -9999 -9999 -9999 -9999 -9999 -9999 -9999 -9999 -9999 -9999 -999 -9999520.1937255859506.7653503418493.9776306152482.0892944336 471.1978149414 461.4447021484453 .2155151367446 .2054138184439 .804901123433 .709197998 427.3086853027 420.9082946777414 .8125915527408 .412109375402 .31640625 396.220703125389 .8201904297383 .419708252376 .7143859863370 .009185791 363.303894043356 .2937927246349 .2838134766342 .5784912109336 .1780090332 330.3870849609326 .1200866699322 .7674865723319 .7196044922316 .6718139648 312.7095031738308 .4425048828304 .4802856445300 .8229064941297 .7750854492 294.7272033691291 .6794128418288 .3266906738284 .6693115234280 .7070922852 276.7449035645273 .0874938965269 .1253051758265 .1630859375262 .1152038574 258.7626037598255 .4098968506251 .7525024414248 .3999023438245 .0471954346 241.3898010254237 .7324066162233 .7702026367229 .8079986572226 .150604248 222.1884002686218 .5308990479214 .8735046387211 .2160949707206 .3394927979 201.158203125195 .9768066406191 .1002960205186 .2236938477181 .9566955566 177.3849029541172 .8132019043167 .9365997314163 .0599975586158 .1835021973 154.2212982178151 .7830047607151 .7830047607152 .0877990723152 .0877990723 152.0877990723152 .0877990723152 .0877990723152 .3925933838152 .6972961426 152.6972961426153 .3069000244153 .6116943359154 .5260925293155 .1356048584 156.0500030518156 .9642944336157 .878692627159 .0977935791160 .0122070312 161.2312927246162 .1457061768163 .0599975586163 .974395752164 .5839996338 164.5839996338164 .2792053223163 .6696014404163 .3648071289163 .0599975586 162.4505004883162 .1457061768161 .8408966064161 .5361022949161 .2312927246 160.9264984131160 .6217956543160 .6217956543160 .3170013428160 .3170013428 
160.3170013428160 .3170013428160 .3170013428160 .3170013428160 .6217956543 160.9264984131160 .9264984131161 .2312927246161 .5361022949162 .1457061768 162.4505004883163 .0599975586163 .3648071289163 .974395752164 .5839996338 165.1934967041165 .4983062744166 .1078948975166 .7174987793167 .3269958496 167.9365997314168 .241394043168 .5462036133168 .8509979248169 .1557006836 169.1557006836169 .1557006836168 .8509979248168 .8509979248168 .8509979248 168.5462036133167 .9365997314167 .0222015381164 .8887023926161 .8408966064 158.7929992676155 .4403991699152 .3925933838149 .9542999268147 .8208007812 146.2969055176144 .7729034424143 .5538024902142 .3347015381141 .1154937744 140.2012023926139 .2868041992138 .3724975586137 .4580993652136 .5437011719 135.9342041016135 .3246002197134 .7149963379134 .1054992676133 .4958953857 132.8863067627132 .5814971924131 .9720001221131 .6672058105131 .3623962402 130.7528076172130 .1432037354129 .8385009766128 .9241027832128 .3144989014 127.7050018311126 .7906036377125 .8762969971124 .9618988037124 .0475006104 122.8283996582121 .6092987061120 .0852966309118 .2565994263115 .818397522 113.3800964355110 .9418029785108 .1986999512105 .4557037354103 .0174026489 101.188697814999 .6647262573299 .0551681518699 .66472625732101 .7982025146 106.3700027466113 .9896011353124 .3523025513135 .9342041016147 .2111968994 156.3547973633163 .0599975586167 .6318054199177 .0802001953185 .0045928955 192.3193969727199 .0247039795205 .1204071045209 .692199707209 .692199707 209.692199707 209.692199707 209.692199707 209.692199707 209.692199707 209.692199707 209.692199707 209.692199707 209.692199707209.692199707 209.692199707209.692199707 209.692199707209 .692199707209 .692199707209 .692199707209 .692199707209 .692199707 209.692199707 209.692199707 209.692199707209.692199707 209.692199707209.692199707 209.692199707 209.692199707 209.692199707 209.692199707 209.692199707 65.2240066528360 .9570198059134 .38436126709 -1.60244596004 -9999 -9999 -9999 -9999 -9999 -9999 -9999 -9999-9999 -9999

-9999 -9999 -9999 -9999 -9999 -9999 -9999 -9999 -9999 -9999 -9999 -9999 -9999 -9999 -9999

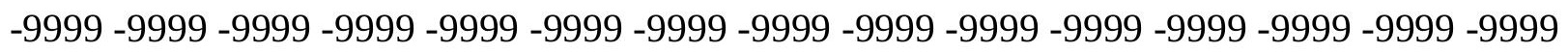

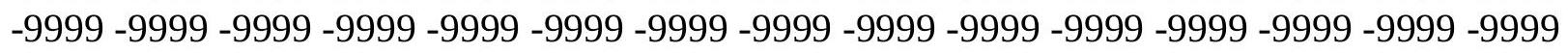
-9999 -9999 -9999 -9999 -9999 -9999 -9999 -9999 -9999 -9999 -9999 -9999 -9999 -9999 -9999 -9999 -9999 -9999 -9999 -9999 -9999 -9999 -9999 -9999 -9999 -9999 -9999 -9999 -9999 -9999

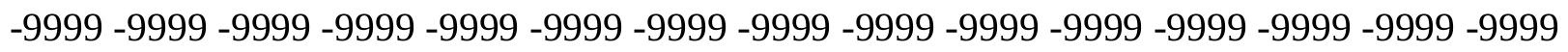

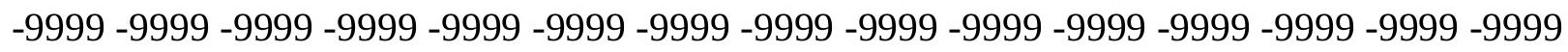
-9999 -9999 -9999 -9999 -9999 -9999 -9999 -9999 -9999 -9999 -9999 -9999 -9999 -9999 -9999

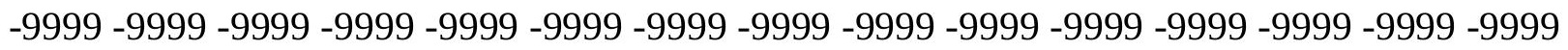
-9999 -9999-9999 506.0129394531494.5308227539483.9077453613474.2456970215 466.3212890625460 .2255859375454 .4346008301448 .3388977051441 .9383850098 435.2331848145428 .8327026367422 .4321899414416 .3364868164409 .6311950684 402.9259033203396 .220703125388 .9057922363381 .8958129883374 .5809020996 367.2661132812359 .9512023926352 .941192627346 .2359008789340 .4450073242 335.2636108398330 .9966125488327 .0344848633323 .3770141602319 .4147949219 315.1477966309311 .4903869629307 .8330078125304 .7850952148301 .7373046875 298.9942016602295 .6416015625291 .9841918945287 .7171936035283 .7549133301 279.4880065918275 .5257873535271 .5635070801267 .6012878418264 .5534973145 261.2008972168257 .8482055664254 .1907958984251 .1428985596247 .4855041504 
244.1329040527240 .1707000732236 .5133056641232 .8558044434229 .1983947754 225.5410003662221 .883605957217 .9214019775213 .3495941162208 .1681976318 203.2917022705 198.1103057861 193.233795166188.0523986816183.7854003906 179.5184020996174 .337097168168 .5462036133163 .3648071289159 .0977935791 155.7451934814153 .9165039062152 .6972961426152 .3925933838152 .0877990723 152.0877990723152 .0877990723152 .0877990723152 .3925933838152 .6972961426 153.0021057129153 .3069000244153 .9165039062154 .8307952881155 .4403991699 156.3547973633157 .5738983154158 .4882965088159 .7073974609160 .6217956543 161.5361022949162 .4505004883163 .3648071289163 .6696014404163 .6696014404 163.3648071289163 .0599975586162 .7552947998162 .4505004883161 .8408966064 161.5361022949161 .2312927246160 .9264984131160 .6217956543160 .3170013428 160.3170013428160 .0122070312160 .0122070312160 .0122070312159 .7073974609 159.7073974609160 .0122070312160 .0122070312160 .0122070312160 .3170013428 160.6217956543160 .9264984131161 .2312927246161 .5361022949162 .1457061768 162.4505004883163 .0599975586163 .6696014404164 .2792053223164 .5839996338 165.1934967041165 .8031005859166 .4127044678167 .0222015381167 .6318054199 167.9365997314168 .241394043168 .5462036133168 .8509979248168 .8509979248 168.8509979248168 .8509979248168 .5462036133168 .5462036133167 .9365997314 167.3269958496165 .8031005859163 .974395752161 .2312927246158 .4882965088 155.4403991699152 .3925933838150 .2590942383148 .4304046631146 .6015930176 145.0776977539143 .8585968018142 .6394042969141 .4203033447140 .5059967041 139.2868041992138 .3724975586137 .4580993652136 .8484954834135 .9342041016 135.3246002197134 .7149963379134 .1054992676133 .4958953857132 .8863067627 132.5814971924131 .9720001221131 .6672058105131 .0576019287130 .7528076172 130.1432037354129 .533706665128 .9241027832128 .0097961426127 .4001998901 126.4858016968125 .5715026855124 .6570968628123 .43800354122 .5235977173 121.3044967651120 .0852966309118 .2565994263116 .1231002808113 .6848983765 111.24659729108 .8082962036106 .3700027466104 .2365036011102 .4077987671 101.1886978149100 .5791015625101 .1886978149103 .6268997192108 .1986999512 115.5136032104125 .2667007446136 .2389984131146 .9064025879155 .7451934814 162.4505004883167 .0222015381174 .9467010498182 .5662994385189 .5764007568 195.9768066406202 .0724945068207 .25390625209 .692199707209 .692199707 209.692199707 209.692199707 209.692199707 209.692199707 209.692199707 209.692199707 209.692199707 209.692199707 209.692199707 209.692199707 209.692199707 209.692199707 209.692199707209 .692199707209 .692199707209 .692199707209 .692199707209 .692199707 209.692199707 209.692199707 209.692199707 209.692199707 209.692199707 209.692199707 209.692199707 209.692199707 209.692199707 209.692199707 64.61444854736 60.3474502563534 .78240966797 -9999 -9999 -9999 -9999 -9999 -9999 -9999 -9999 -9999 -9999-9999

-9999 -9999 -9999 -9999 -9999 -9999 -9999 -9999 -9999 -9999 -9999 -9999 -9999 -9999 -9999

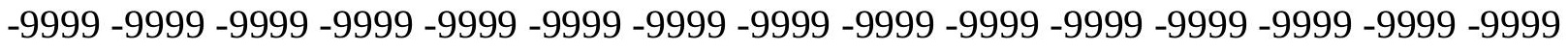

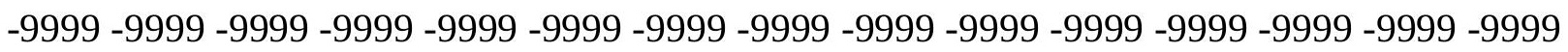
-9999 -9999 -9999 -9999 -9999 -9999 -9999 -9999 -9999 -9999 -9999 -9999 -9999 -9999 -9999 -9999 -9999 -9999 -9999 -9999 -9999 -9999 -9999 -9999 -9999 -9999 -9999 -9999 -9999 -9999 -

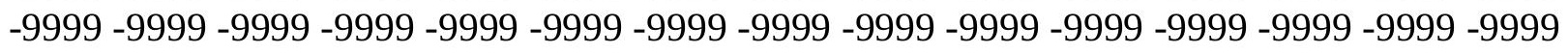

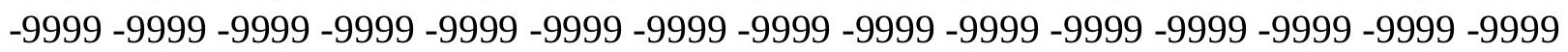


-9999 -9999 -9999 -9999 -9999 -9999 -9999 -9999 -9999 -9999 -9999 -9999 -9999 -9999 -9999 -9999 -9999 -9999 -9999 -9999 -9999 -9999 -9999 -9999 -9999 -9999 -9999 -9999 -9999 -9999 -9999 -9999 -9999 -9999 507.0630187988496.9866943359488.0452575684480.5023193359 474.2456970215469 .0643005371462 .9685974121455 .9585876465449 .2532958984 442.5480041504436 .4523010254430 .0517883301423 .346496582416 .3364868164 409.0216064453401 .4020080566393 .782409668385 .858001709378 .2383117676 370.6187133789363 .303894043356 .5986022949350 .1980895996344 .4071960449 339.2258911133 334.6541137695330.3870849609 326.1200866699321.8530883789 318.1957092285314 .5382080078311 .4903869629308 .4425048828305 .6994934082 302.9563903809298 .6893920898294 .4223937988290 .1553955078286 .1932067871 281.9262084961277 .9641113281274 .0018005371270 .0396118164265 .7726135254 263.0296020508259 .9816894531256 .6290893555253 .5812072754249 .9237976074 246.5711975098242 .9136962891239 .2563018799235 .5989074707231 .9414978027 228.2841033936224 .0171051025219 .7501068115214 .8735046387210 .3016967773 205.1204071045200 .2438049316195 .0625190 .1858978271186 .2236938477180 .432800293 174.9467010498169 .4604949951164 .5839996338160 .6217956543157 .2691040039 155.1356048584153 .3069000244152 .3925933838152 .0877990723152 .0877990723 152.0877990723152 .3925933838152 .3925933838152 .6972961426153 .0021057129 153.6116943359154 .2212982178155 .1356048584156 .0500030518156 .9642944336 157.878692627159 .0977935791160 .0122070312160 .9264984131161 .5361022949 162.1457061768162 .7552947998162 .7552947998162 .7552947998162 .4505004883 162.1457061768161 .5361022949161 .2312927246160 .9264984131160 .6217956543 160.3170013428160 .0122070312160 .0122070312159 .7073974609159 .7073974609 159.4026031494159 .4026031494159 .4026031494159 .4026031494159 .4026031494 159.4026031494159 .7073974609159 .7073974609160 .0122070312160 .3170013428 160.6217956543161 .2312927246161 .5361022949162 .1457061768162 .4505004883 163.0599975586163 .6696014404164 .2792053223164 .8887023926165 .4983062744 166.1078948975166 .7174987793167 .3269958496167 .6318054199167 .9365997314 168.5462036133168 .5462036133168 .8509979248168 .8509979248168 .5462036133 168.241394043167 .9365997314167 .3269958496166 .4127044678164 .8887023926 163.0599975586160 .9264984131158 .1835021973155 .4403991699153 .0021057129 150.5639038086148 .7351074219146 .9064025879145 .3825073242144 .1634063721 142.9441986084141 .7250976562140 .5059967041139 .5915985107138 .6772003174 137.7628936768136 .8484954834135 .9342041016135 .3246002197134 .7149963379 134.1054992676133 .4958953857132 .8863067627132 .5814971924131 .9720001221 131.3623962402131 .0576019287130 .4479980469129 .8385009766129 .2288970947 128.6192932129128 .0097961426127 .0953979492126 .1809997559125 .2667007446 124.0475006104123 .1332015991121 .9140014648120 .9997024536120 .0852966309 118.5614013672116 .7326965332114 .2944030762111 .8561019897109 .4179000854 107.2844009399 105.1509017944 103.9317016602 102.712600708 102.1029968262 102.712600708105 .4557037354110 .3321990967117 .9517974854127 .0953979492 138.3724975586148 .7351074219156 .9642944336163 .0599975586167 .0222015381 172.5084075928179 .8231964111186 .528503418192 .9290008545198 .7198944092 203.9011993408208 .4730072021209 .692199707209 .692199707209 .692199707 209.692199707209 .692199707209 .692199707209 .692199707209 .692199707209 .692199707 209.692199707209.692199707209.692199707209.692199707209.692199707209.692199707 
209.692199707 209.692199707 209.692199707 209.692199707209.692199707209.692199707 209.692199707209 .692199707209 .692199707209 .692199707209 .692199707209 .692199707 209.69219970767 .9670867919963 .7000885009859 .4331016540530 .41048431396 -9999 -9999 -9999 -9999 -9999 -9999 -9999 -9999 -9999 -9999 -9999

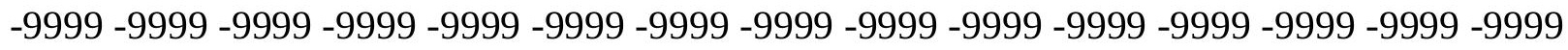

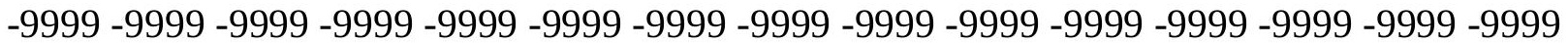

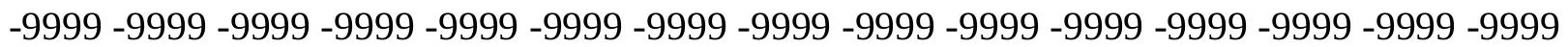

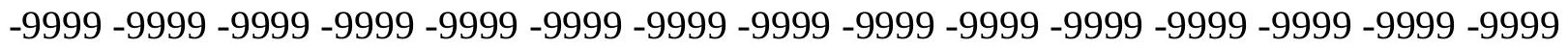

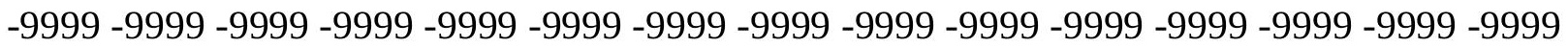

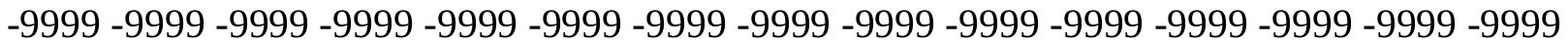

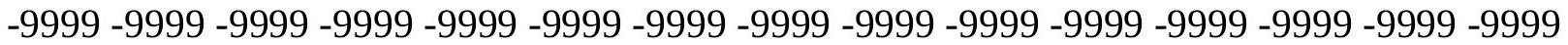

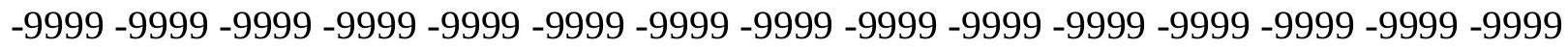

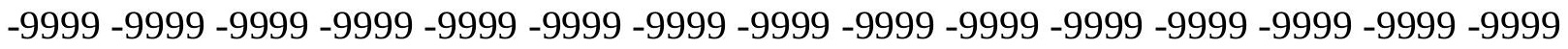
-9999 -9999 -9999 -9999 -9999 -9999 501.8164978027 494.5802612305 488.3588867188 482.7529907227476 .9887084961469 .3691101074462 .3590087891455 .9585876465 449.8629150391443 .7672119141437 .0618896484429 .7470092773421 .8226013184 413.8981933594405 .6690063477397 .4397888184389 .2106018066381 .2861938477 373.666595459366 .3517150879359 .6465148926353 .2460021973347 .4549865723 342.2737121582337 .3970947266332 .8252868652328 .5584106445324 .5961914062 320.9388122559317 .8908996582314 .8429870605311 .7951965332308 .4425048828 304.7850952148300 .8229064941296 .5559082031292 .5936889648288 .3266906738 284.3645019531280 .0975036621276 .1353149414271 .8682861328267 .9060974121 265.1630859375262 .1152038574259 .0674133301255 .7147064209252 .3621063232 249.0093994141245 .3520050049241 .6945953369238 .0372009277234 .3798065186 230.1127929688225 .8457946777221 .5787963867216 .7021942139211 .8256988525 206.9490966797202 .0724945068196 .891204834191 .1002960205186 .2236938477 180.7375946045175 .5561981201170 .3748931885165 .4983062744161 .5361022949 158.1835021973155 .1356048584153 .0021057129151 .7830047607152 .0877990723 152.0877990723152 .0877990723152 .3925933838152 .6972961426152 .6972961426 153.3069000244153 .9165039062154 .5260925293155 .7451934814156 .6596069336 157.5738983154158 .4882965088159 .4026031494160 .0122070312160 .6217956543 161.2312927246161 .5361022949161 .5361022949161 .5361022949161 .5361022949 161.2312927246160 .9264984131160 .6217956543160 .3170013428160 .0122070312 159.7073974609159 .4026031494159 .0977935791159 .0977935791159 .0977935791 158.7929992676158 .7929992676158 .7929992676158 .7929992676158 .7929992676 158.7929992676159 .0977935791159 .4026031494159 .4026031494159 .7073974609 160.3170013428160 .6217956543160 .9264984131161 .5361022949162 .1457061768 162.7552947998163 .0599975586163 .6696014404164 .2792053223165 .1934967041 165.8031005859166 .1078948975166 .7174987793167 .3269958496167 .6318054199 167.9365997314168 .241394043168 .241394043168 .241394043168 .241394043 167.6318054199167 .3269958496166 .4127044678165 .4983062744163 .974395752 162.4505004883160 .3170013428157 .878692627155 .7451934814153 .3069000244 151.1734008789149 .3446960449147 .5160064697145 .6873016357144 .4682006836 142.9441986084141 .7250976562140 .8106994629139 .5915985107138 .6772003174 137.7628936768136 .8484954834135 .9342041016135 .3246002197134 .7149963379 133.8007049561133 .4958953857132 .8863067627132 .2767028809131 .9720001221 
131.3623962402 130.7528076172130.4479980469 129.8385009766129 .2288970947 128.3144989014127 .7050018311126 .7906036377125 .8762969971124 .9618988037 124.0475006104122 .8283996582121 .6092987061121 .3044967651120 .6949005127 119.1709976196117 .0374984741114 .9039993286112 .4656982422110 .3321990967 108.1986999512106 .3700027466104 .8460998535104 .2365036011103 .3221969604 103.9317016602106 .6747970581112 .1608963013120 .3900985718131 .3623962402 142.6394042969152 .3925933838159 .4026031494164 .2792053223167 .6318054199 170.070098877177 .3849029541183 .7854003906189 .8811035156195 .6721038818 200.5485992432205 .1204071045209 .0825958252209 .692199707209 .692199707 209.692199707209 .692199707209 .692199707209 .692199707209 .692199707209 .692199707 209.692199707 209.692199707 209.692199707 209.692199707 209.692199707209.692199707 209.692199707 209.692199707 209.692199707 209.692199707 209.692199707 209.692199707 209.692199707209.692199707209.692199707 209.692199707 209.692199707209.692199707 209.692199707 67.3575134277362.78573989868 46.6913299560521 .70446586609 -9999 -9999 -9999 -9999 -9999 -9999 -9999 -9999 -9999 -9999 -9999

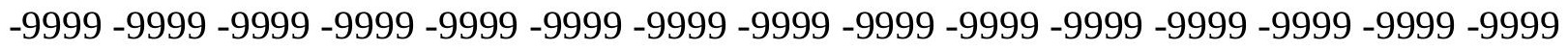
-9999 -9999 -9999 -9999 -9999 -9999 -9999 -9999 -9999 -9999 -9999 -9999 -9999 -9999 -9999 -9999 -9999 -9999 -9999 -9999 -9999 -9999 -9999 -9999 -9999 -9999 -9999 -9999 -9999 -9999 -9999 -9999 -9999 -9999 -9999 -9999 -9999 -9999 -9999 -9999 -9999 -9999 -9999 -9999 -9999

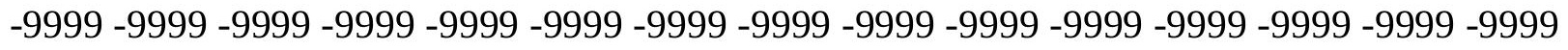

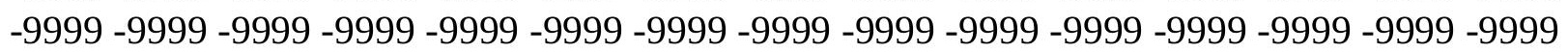

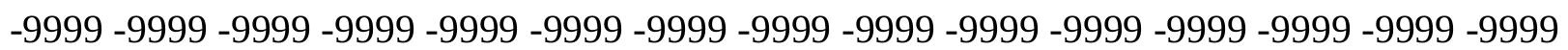

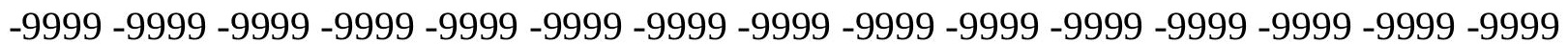
-9999 -9999 -9999 -9999 -9999 -9999 -9999 -9999 -9999 -9999 -9999 -9999 -9999 -9999 -9999 -9999 -9999 -9999 -9999-9999-9999-9999 508.1357421875 501.7789306641495 .6920471191 489.2580566406482 .0248718262474 .5504150391468 .4547119141463 .2734069824 457.4825134277450 .7771911621443 .1575927734434 .6235961914426 .0895996094 417.5556030273408 .7168884277400 .1828918457391 .953704834384 .029296875 376.104888916369 .0947875977362 .0846862793355 .6842041016349 .8933105469 344.4071960449339 .5306091309334 .9588928223330 .9966125488327 .3392028809 323.6817932129320 .6339111328317 .2813110352313 .9287109375310 .5759887695 306.6138000488302 .6516113281298 .6893920898294 .4223937988290 .4602050781 286.1932067871282 .2309875488277 .9641113281274 .0018005371270 .0396118164 267.6012878418264 .5534973145261 .5056152344258 .1530151367254 .8003997803 251.1428985596247 .7902984619244 .1329040527240 .1707000732236 .2084960938 231.9414978027227 .6744995117223 .1027069092218 .5308990479213 .6544036865 208.7778015137203 .9011993408199 .0247039795194 .4528961182189 .5764007568 183.4806976318177 .0802001953170 .6797027588166 .1078948975161 .8408966064 157.878692627154 .2212982178150 .8686065674151 .4781951904151 .7830047607 152.0877990723152 .3925933838152 .3925933838152 .6972961426153 .0021057129 153.6116943359154 .5260925293155 .4403991699156 .3547973633157 .2691040039 158.1835021973158 .7929992676159 .4026031494159 .7073974609160 .0122070312 160.3170013428160 .6217956543160 .6217956543160 .3170013428160 .3170013428 160.0122070312159 .7073974609159 .4026031494159 .0977935791158 .7929992676 158.7929992676158 .4882965088158 .4882965088158 .1835021973158 .1835021973 158.1835021973158 .1835021973158 .1835021973158 .1835021973158 .4882965088 
158.4882965088158 .7929992676158 .7929992676159 .0977935791159 .7073974609 160.0122070312160 .3170013428160 .9264984131161 .5361022949162 .1457061768 162.7552947998163 .3648071289163 .974395752164 .5839996338165 .1934967041 165.8031005859166 .4127044678166 .7174987793167 .0222015381167 .6318054199 167.6318054199167 .6318054199167 .6318054199167 .6318054199167 .0222015381 166.4127044678165 .8031005859164 .5839996338163 .3648071289161 .5361022949 159.7073974609157 .878692627155 .7451934814153 .6116943359151 .4781951904 149.6495056152147 .8208007812145 .9920959473144 .4682006836143 .2489929199 142.0299072266140 .8106994629139 .5915985107138 .6772003174137 .7628936768 136.8484954834135 .9342041016135 .3246002197134 .4102020264133 .8007049561 133.1911010742132 .5814971924132 .2767028809131 .6672058105131 .0576019287 130.7528076172130 .1432037354129 .533706665128 .9241027832128 .3144989014 127.4001998901126 .7906036377125 .8762969971124 .9618988037123 .7427978516 122.8283996582122 .2188034058121 .9140014648121 .6092987061119 .7806015015 117.647102356115 .5136032104113 .075302124110 .9418029785108 .8082962036 106.979598999 105.7603988647 104.5412979126 104.2365036011 104.8460998535 107.5891036987 113.075302124121.9140014648 134.4102020264147.5160064697 156.3547973633161 .5361022949165 .4983062744168 .241394043170 .3748931885 174.9467010498181 .3471984863187 .1381072998192 .3193969727197 .1959991455 201.7678070068205 .7299957275209 .3874053955209 .692199707209 .692199707 209.692199707 209.692199707 209.692199707 209.692199707 209.692199707 209.692199707 209.692199707209 .692199707209 .692199707209 .692199707209 .692199707209 .692199707 209.692199707209 .692199707209 .692199707209 .692199707209 .692199707209 .692199707 209.692199707209 .692199707209 .692199707209 .692199707209 .692199707209 .692199707 66.4431610107461 .8713798522942 .5948524475113 .934009552 -9999 -9999 -9999 -9999 -9999 -9999 -9999 -9999 -9999 -9999 -9999

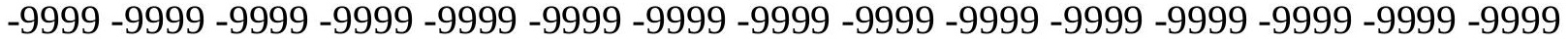

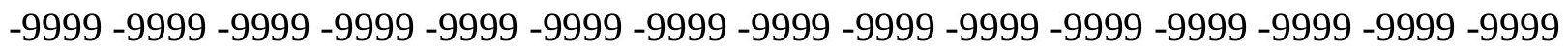

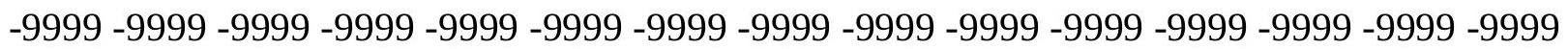

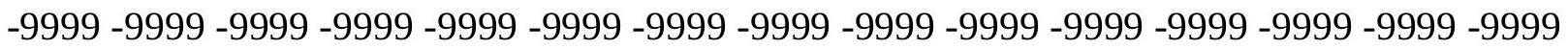

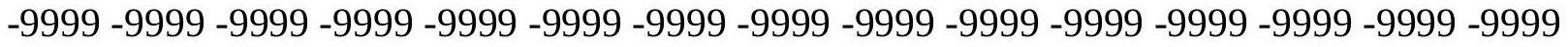

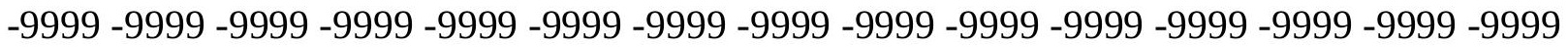

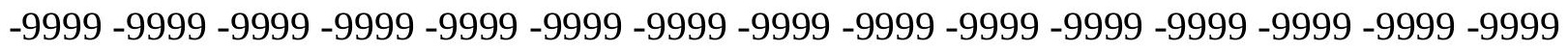

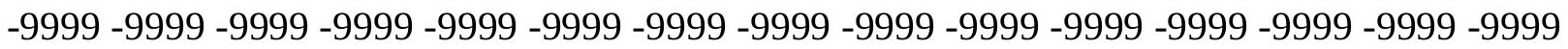

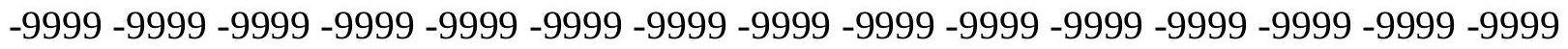
-9999 -9999 -9999 -9999 -9999 -9999 -9999 -9999 -9999 508.0743713379 501.4251098633 494.4773864746487 .4670715332480 .9508972168476 .3792114258471 .1978149414 464.187713623455 .9585876465447 .1198120117437 .9761962891428 .8327026367 419.9938964844411 .155090332402 .6211853027394 .0871887207385 .858001709 378.2383117676370 .9234924316363 .9135131836357 .5129089355351 .4172058105 346.2359008789341 .3593139648337 .0922851562333 .1301879883329 .4726867676 326.1200866699322 .7674865723319 .4147949219316 .0621948242312 .4047851562 308.4425048828304 .4802856445300 .5180969238296 .5559082031292 .2889099121 288.3266906738284 .0596923828279 .7927856445275 .8305053711271 .5635070801 269.7348022461266 .6870117188263 .3344116211260 .2864990234256 .9338989258 253.2763977051249 .6190032959245 .9615936279241 .9994049072238 .0372009277 
233.7702026367229 .5032043457224 .9313964844220 .3596038818215 .4830932617 210.6065063477205 .7299957275201 .158203125196 .2816009521191 .1002960205 185.0045928955178 .9089050293172 .8132019043167 .0222015381161 .2312927246 156.9642944336153 .6116943359151 .7830047607151 .7830047607152 .0877990723 152.0877990723152 .3925933838152 .0877990723152 .3925933838153 .0021057129 154.2212982178155 .4403991699156 .6596069336157 .5738983154158 .1835021973 158.4882965088158 .7929992676158 .7929992676159 .0977935791159 .4026031494 159.4026031494159 .4026031494159 .4026031494159 .0977935791159 .0977935791 158.7929992676158 .4882965088158 .1835021973158 .1835021973157 .878692627 157.878692627157 .5738983154157 .5738983154157 .5738983154157 .5738983154 157.5738983154157 .5738983154157 .5738983154157 .5738983154157 .878692627 158.1835021973158 .1835021973158 .4882965088158 .7929992676159 .4026031494 159.7073974609160 .3170013428160 .9264984131161 .5361022949162 .1457061768 162.7552947998163 .3648071289163 .974395752164 .5839996338165 .1934967041 165.8031005859166 .1078948975166 .7174987793167 .0222015381167 .0222015381 167.0222015381167 .0222015381166 .7174987793166 .4127044678165 .8031005859 164.8887023926163 .974395752162 .4505004883160 .9264984131159 .4026031494 157.5738983154155 .4403991699153 .6116943359151 .4781951904149 .6495056152 147.8208007812146 .2969055176144 .7729034424143 .2489929199142 .0299072266 140.8106994629139 .5915985107138 .6772003174137 .4580993652136 .5437011719 135.9342041016135 .0198059082134 .4102020264133 .8007049561133 .1911010742 132.5814971924131 .9720001221131 .3623962402131 .0576019287130 .4479980469 129.8385009766129 .2288970947128 .6192932129128 .0097961426127 .4001998901 126.4858016968125 .5715026855124 .6570968628123 .7427978516123 .1332015991 122.5235977173122 .2188034058121 .3044967651119 .7806015015117 .9517974854 115.818397522113 .6848983765111 .551399231109 .4179000854107 .5891036987 106.0652008057104 .8460998535104 .5412979126105 .1509017944107 .8938980103 112.4656982422120 .6949005127133 .4958953857152 .0877990723157 .878692627 162.4505004883166 .1078948975168 .5462036133170 .3748931885173 .1179962158 178.9089050293184 .3950042725189 .2716064453193 .8433074951198 .1103057861 202.0724945068205 .7299957275209 .0825958252209 .692199707209 .692199707 209.692199707 209.692199707 209.692199707 209.692199707 209.692199707 209.692199707 209.692199707 209.692199707 209.692199707 209.692199707 209.692199707 209.692199707 209.692199707 209.692199707 209.692199707 209.692199707 209.692199707 209.692199707 209.692199707 209.692199707 209.692199707 209.692199707209.692199707 65.5288009643660 .9570198059139 .839588165287 .972745418549 -9999 -9999 -9999 -9999 -9999 -9999 -9999 -9999 -9999 -9999 -9999

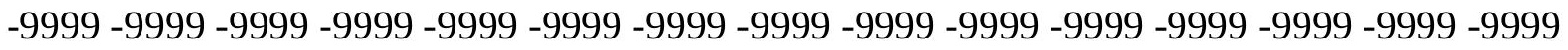

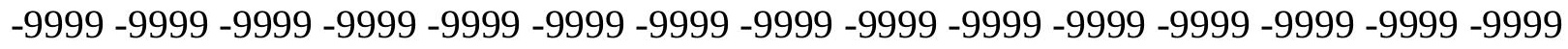

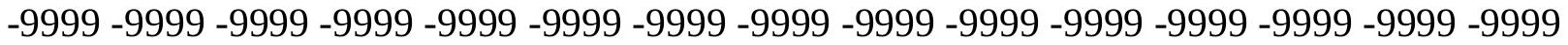

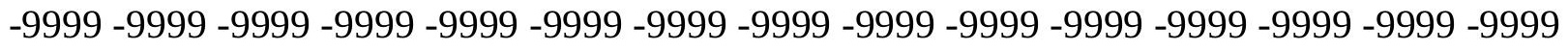

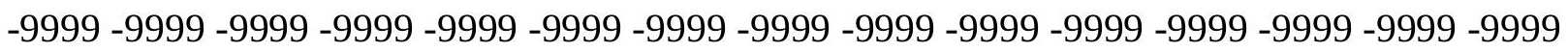

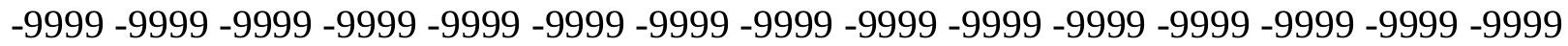

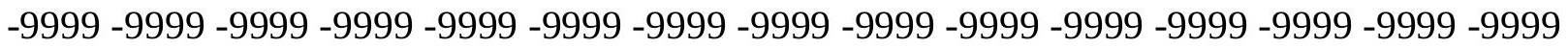

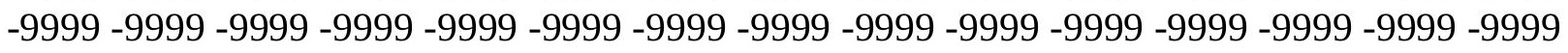

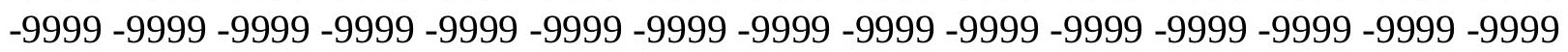


-9999 -9999 -9999 -9999 -9999 -9999 -9999 -9999 -9999 -9999 513.4899902344 506.8474121094500 .3977355957494 .5813903809489 .6878356934484 .9130859375 476.9887084961468 .1499938965459 .0064086914449 .5581054688440 .1097106934 430.9661865234421 .8226013184412 .9838867188404 .145111084395 .611114502 387.3818969727379 .4574890137371 .837890625365 .132598877358 .7320861816 352.941192627347 .7597961426343 .1879882812338 .9211120605335 .2636108398 331.9110107422328 .2536010742324 .9009094238321 .5483093262317 .8908996582 314.2334899902310 .2713012695306 .3091125488302 .3468017578298 .3846130371 294.1176147461290 .1553955078285 .8884887695281 .6214904785277 .3544921875 274.9161987305271 .8682861328268 .5156860352265 .1630859375262 .1152038574 258.7626037598255 .1051025391251 .4476928711247 .4855041504243 .8280944824 239.5610961914235 .2940979004231 .0270996094226 .4553985596221 .883605957 217.0070037842212 .4351959229207 .25390625202 .3773040771197 .500793457 192.3193969727186 .528503418180 .432800293174 .6419067383169 .1557006836 163.6696014404158 .4882965088153 .9165039062152 .0877990723151 .7830047607 151.4781951904151 .4781951904151 .4781951904151 .7830047607152 .6972961426 154.2212982178155 .7451934814157 .5738983154158 .4882965088158 .7929992676 158.4882965088158 .1835021973158 .1835021973158 .1835021973158 .1835021973 158.4882965088158 .4882965088158 .1835021973158 .1835021973157 .878692627 157.878692627157 .5738983154157 .5738983154157 .2691040039157 .2691040039 156.9642944336156 .9642944336156 .9642944336156 .9642944336156 .9642944336 156.9642944336156 .9642944336156 .9642944336156 .9642944336157 .2691040039 157.2691040039157 .5738983154157 .878692627158 .1835021973158 .4882965088 159.0977935791159 .7073974609160 .0122070312160 .6217956543161 .2312927246 162.1457061768162 .7552947998163 .3648071289163 .974395752164 .5839996338 165.1934967041165 .4983062744165 .8031005859166 .1078948975166 .4127044678 166.4127044678166 .4127044678166 .1078948975165 .8031005859165 .1934967041 164.2792053223163 .3648071289161 .8408966064160 .6217956543158 .7929992676 157.2691040039155 .4403991699153 .3069000244151 .4781951904149 .6495056152 148.1255950928146 .2969055176144 .7729034424143 .2489929199142 .0299072266 140.8106994629139 .5915985107138 .3724975586137 .4580993652136 .5437011719 135.6293945312134 .7149963379134 .1054992676133 .4958953857132 .8863067627 132.2767028809131 .6672058105131 .0576019287130 .7528076172130 .1432037354 129.533706665128 .9241027832128 .3144989014127 .7050018311127 .0953979492 126.4858016968125 .5715026855124 .6570968628124 .0475006104123 .1332015991 122.8283996582122 .2188034058121 .3044967651119 .7806015015117 .9517974854 116.1231002808113 .9896011353111 .8561019897109 .7226028442107 .8938980103 106.3700027466105 .1509017944104 .8460998535105 .4557037354107 .8938980103 112.1608963013118 .5614013672126 .4858016968143 .8585968018155 .1356048584 161.5361022949165 .4983062744168 .5462036133170 .3748931885171 .5939941406 176.7754058838181 .6519012451186 .2236938477190 .4907073975194 .7577056885 198.4151000977202 .0724945068205 .1204071045208 .4730072021209 .692199707 209.692199707209.692199707 209.692199707 209.692199707 209.692199707209.692199707 209.692199707209 .692199707209 .692199707209 .692199707209 .692199707209 .692199707 209.692199707209 .692199707209 .692199707209 .692199707209 .692199707209 .692199707 209.692199707209.692199707209.692199707209.692199707 68.88143920898 
64.6144485473660 .0426712036136 .727005004882 .381851434708 -9999 -9999 -9999 -9999 -9999 -9999 -9999 -9999 -9999 -9999 -9999

-9999 -9999 -9999 -9999 -9999 -9999 -9999 -9999 -9999 -9999 -9999 -9999 -9999 -9999 -9999 -9999 -9999 -9999 -9999 -9999 -9999 -9999 -9999 -9999 -9999 -9999 -9999 -9999 -9999 -9999 -9999 -9999 -9999 -9999 -9999 -9999 -9999 -9999 -9999 -9999 -9999 -9999 -9999 -9999 -9999 -9999 -9999 -9999 -9999 -9999 -9999 -9999 -9999 -9999 -9999 -9999 -9999 -9999 -9999 -9999 -9999 -9999 -9999 -9999 -9999 -9999 -9999 -9999 -9999 -9999 -9999 -9999 -9999 -9999 -9999 -9999 -9999 -9999 -9999 -9999 -9999 -9999 -9999 -9999 -9999 -9999 -9999 -9999 -9999 -9999

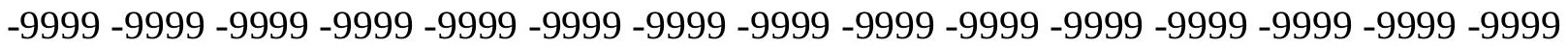
-9999 -9999 -9999 -9999 -9999 -9999 -9999 -9999 -9999 -9999 -9999 -9999 -9999 -9999 -9999 -

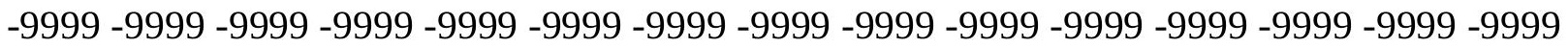
-9999 -9999 -9999 -9999 -9999 -9999 -9999 -9999 -9999 -9999 -9999 -9999 512.8190307617 507.1767578125501 .7494812012495 .7677612305488 .2658081055479 .4270019531 469.9786987305460 .2255859375450 .7771911621441 .633605957432 .4901123047 423.346496582414 .5078125405 .3641967773396 .8302001953388 .296295166380 .066986084 372.4473876953365 .4374084473359 .3417053223353 .8554992676348 .9790039062 344.7120056152341 .0545959473337 .3970947266334 .0444946289330 .6918945312 327.3392028809323 .6817932129320 .0244140625316 .0621948242312 .4047851562 308.4425048828304 .1755981445300 .2132873535295 .9464111328291 .6794128418 287.1076049805282 .8406066895278 .5736083984276 .1353149414273 .0874938965 270.0396118164266 .9917907715263 .6390991211260 .2864990234256 .6290893555 252.9716033936249 .0093994141245 .0471954346241 .0850067139236 .8179931641 232.5511016846227 .9792938232223 .4075012207218 .5308990479213 .0447998047 207.8634033203203 .2917022705198 .4151000977193 .233795166187 .7476043701 181.9566955566175 .8609924316170 .3748931885165 .1934967041160 .0122070312 154.8307952881152 .3925933838151 .7830047607151 .1734008789150 .8686065674 150.8686065674151 .7830047607153 .6116943359156 .3547973633158 .4882965088 159.7073974609159 .4026031494158 .4882965088157 .878692627157 .2691040039 156.9642944336157 .2691040039157 .2691040039157 .2691040039157 .2691040039 157.2691040039156 .9642944336156 .9642944336156 .6596069336156 .6596069336 156.3547973633156 .3547973633156 .3547973633156 .3547973633156 .3547973633 156.0500030518156 .0500030518156 .3547973633156 .3547973633156 .3547973633 156.3547973633156 .3547973633156 .6596069336156 .9642944336156 .9642944336 157.5738983154157 .878692627158 .1835021973158 .7929992676159 .4026031494 160.0122070312160 .6217956543161 .2312927246161 .8408966064162 .7552947998 163.3648071289163 .974395752164 .2792053223164 .8887023926165 .1934967041 165.4983062744165 .8031005859165 .8031005859165 .4983062744165 .4983062744 164.8887023926164 .2792053223163 .6696014404162 .4505004883161 .5361022949 160.0122070312158 .4882965088156 .9642944336155 .1356048584153 .3069000244 151.4781951904149 .6495056152147 .8208007812146 .2969055176144 .7729034424 143.2489929199141 .7250976562140 .5059967041139 .2868041992138 .0677032471 137.1533050537136 .2389984131135 .3246002197134 .4102020264133 .8007049561 133.1911010742132 .5814971924131 .9720001221131 .3623962402130 .7528076172 130.4479980469129 .8385009766129 .2288970947128 .9241027832128 .3144989014 127.7050018311127 .0953979492126 .4858016968125 .5715026855124 .6570968628 124.0475006104123 .1332015991122 .5235977173121 .6092987061120 .6949005127 
119.4757995605117 .647102356116 .1231002808113 .9896011353112 .1608963013 110.3321990967108 .5035018921106 .979598999105 .7603988647105 .4557037354 106.3700027466108 .5035018921112 .7705001831119 .1709976196128 .3144989014 140.5059967041151 .7830047607159 .7073974609164 .5839996338167 .9365997314 170.070098877171 .2891998291174 .6419067383178 .9089050293183 .1759033203 187.1381072998191 .1002960205194 .7577056885198 .1103057861201 .4629974365 204.5108032227207 .5587005615209 .692199707209 .692199707209 .692199707 209.692199707 209.692199707 209.692199707 209.692199707 209.692199707 209.692199707 209.692199707 209.692199707 209.692199707 209.692199707 209.692199707 209.692199707 209.692199707 209.692199707 209.692199707 209.692199707 209.692199707 209.692199707 209.692199707 67.9670867919963.7000885009859.12831115723 31.7792930603 -9999-9999 -9999 -9999 -9999 -9999 -9999 -9999 -9999 -9999 -9999 -9999

-9999 -9999 -9999 -9999 -9999 -9999 -9999 -9999 -9999 -9999 -9999 -9999 -9999 -9999 -9999 -9999 -9999 -9999 -9999 -9999 -9999 -9999 -9999 -9999 -9999 -9999 -9999 -9999 -9999 -9999 -9999 -9999 -9999 -9999 -9999 -9999 -9999 -9999 -9999 -9999 -9999 -9999 -9999 -9999 -9999

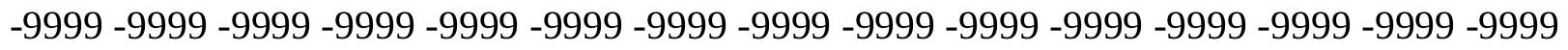

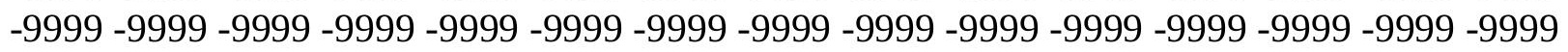

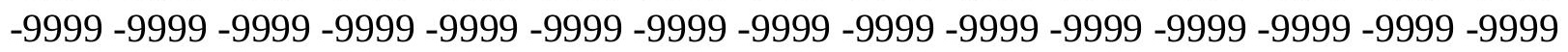

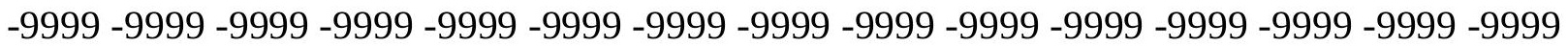

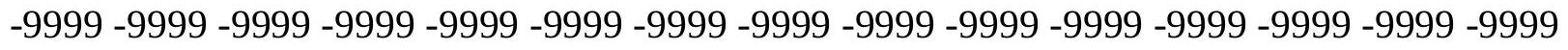

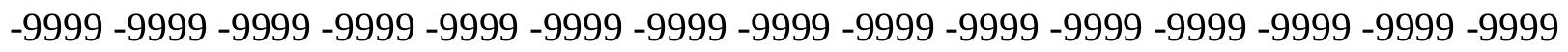
-9999 -9999 -9999 -9999 -9999 -9999 -9999 -9999 -9999 -9999-9999 -9999 -9999 518.5400390625512 .5971679688505 .9906005859498 .3606262207489 .5768127441 480.0365905762470 .5881958008461 .1398925781451 .996307373442 .8528137207 434.0140075684424 .870513916415 .422088623406 .2785949707397 .1350097656 388.296295166 380.066986084372.4473876953 365.7421875359 .9512023926 355.0747070312350 .8077087402347 .1502990723343 .4927978516340 .1401977539 336.4827880859333 .1301879883329 .4726867676325 .8153076172322 .1578979492 318.1957092285314 .2334899902310 .2713012695306 .0043029785301 .7373046875 297.1654968262292 .5936889648288 .3266906738283 .7549133301279 .4880065918 277.3544921875274 .6113891602271 .5635070801268 .5156860352265 .1630859375 261.8103942871258 .1530151367254 .1907958984250 .5334014893246 .5711975098 242.6089935303238 .3419952393234 .0749969482229 .5032043457224 .6266021729 218.8356933594213 .3495941162208 .1681976318203 .596496582199 .0247039795 194.4528961182188 .6620025635182 .5662994385177 .0802001953171 .8988037109 166.4127044678161 .2312927246155 .7451934814153 .0021057129151 .4781951904 150.8686065674150 .5639038086150 .8686065674152 .6972961426156 .6596069336 160.0122070312160 .9264984131159 .7073974609158 .1835021973157 .2691040039 156.3547973633156 .0500030518156 .0500030518156 .0500030518156 .3547973633 156.3547973633156 .0500030518156 .0500030518156 .0500030518155 .7451934814 155.7451934814155 .7451934814155 .7451934814155 .4403991699155 .4403991699 155.4403991699155 .4403991699155 .4403991699155 .4403991699155 .4403991699 155.7451934814155 .7451934814155 .7451934814156 .0500030518156 .0500030518 156.3547973633156 .6596069336156 .9642944336157 .5738983154158 .1835021973 158.7929992676159 .4026031494160 .0122070312160 .6217956543161 .2312927246 161.8408966064162 .4505004883163 .0599975586163 .6696014404164 .2792053223 
164.5839996338164 .8887023926164 .8887023926164 .8887023926164 .8887023926 164.5839996338164 .2792053223163 .6696014404163 .0599975586162 .1457061768 160.9264984131159 .7073974609158 .1835021973156 .6596069336154 .8307952881 153.3069000244151 .4781951904149 .6495056152147 .8208007812145 .9920959473 144.4682006836142 .9441986084141 .4203033447140 .2012023926138 .6772003174 137.7628936768136 .5437011719135 .6293945312134 .7149963379134 .1054992676 133.4958953857132 .8863067627132 .2767028809131 .6672058105131 .0576019287 130.4479980469130 .1432037354129 .533706665129 .2288970947128 .6192932129 128.0097961426127 .7050018311127 .0953979492126 .4858016968125 .5715026855 124.9618988037124 .0475006104123 .1332015991121 .9140014648121 .3044967651 120.3900985718118 .8662033081117 .342300415115 .818397522113 .9896011353 112.1608963013110 .6370010376108 .8082962036107 .5891036987106 .6747970581 106.3700027466 107.2844009399 109.7226028442 114.5991973877 121.6092987061 131.0576019287141 .4203033447151 .1734008789158 .4882965088163 .6696014404 167.3269958496169 .4604949951170 .6797027588172 .5084075928176 .165802002 180.1280059814183 .7854003906187 .4429016113191 .1002960205194 .4528961182 197.8054962158200 .8533935547203 .9011993408206 .3394927979209 .0825958252 209.692199707 209.692199707 209.692199707 209.692199707 209.692199707 209.692199707 209.692199707 209.692199707 209.692199707 209.692199707 209.692199707 209.692199707 209.692199707 209.692199707 209.692199707 209.692199707 209.692199707 209.692199707 209.692199707 209.692199707 67.0527267456162.48094940186 49.93032073975 23.89297485352 -9999 -9999 -9999 -9999 -9999 -9999 -9999 -9999 -9999 -9999 -9999 -9999

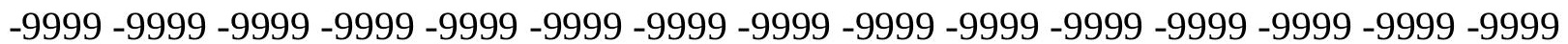

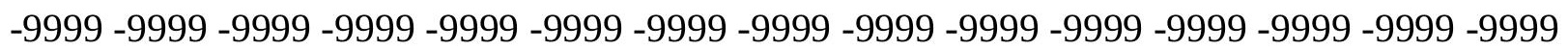

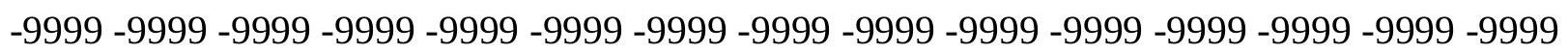

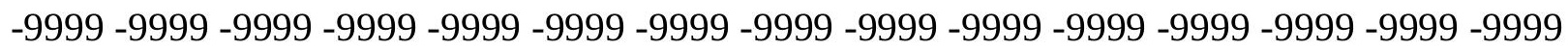

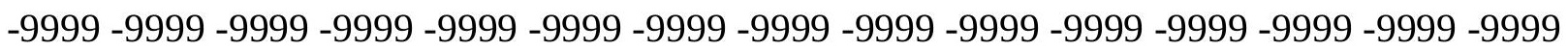

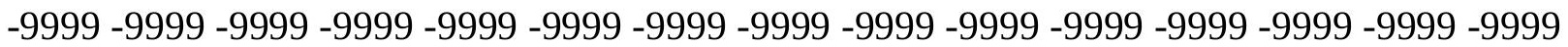

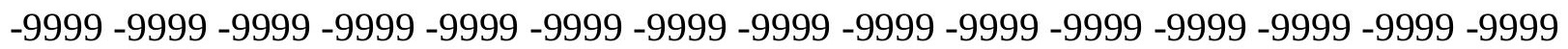

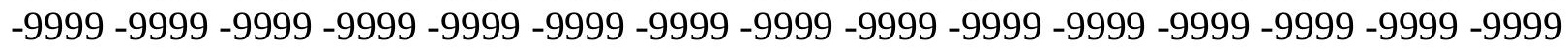

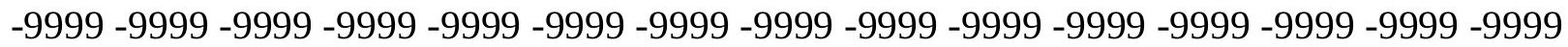

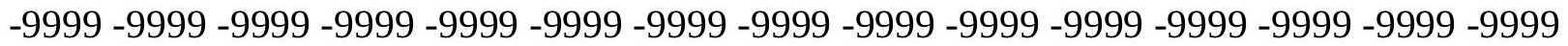
515.7327880859507 .9872131348499 .3544921875490 .0270080566480 .3414001465 471.1978149414462 .3590087891453 .5202941895444 .6814880371435 .537902832 425.7847900391416 .0317077637406 .5833129883396 .8302001953387 .9914855957 379.762298584372 .4473876953366 .3517150879361 .1704101562356 .9034118652 353.2460021973349 .8933105469346 .2359008789342 .8833007812339 .5306091309 335.8731994629331 .9110107422328 .2536010742324 .2914123535320 .0244140625 316.0621948242311 .7951965332307 .2233886719302 .6516113281298 .0798950195 293.5080871582288 .9363098145284 .6693115234281 .3167114258278 .5736083984 275.8305053711273 .0874938965270 .0396118164266 .6870117188262 .7247924805 259.0674133301255 .4098968506251 .7525024414248 .0950927734244 .1329040527 239.8659057617235 .5989074707230 .7223052979225 .2362060547219 .1405029297 213.3495941162208 .1681976318203 .9011993408199 .6342926025194 .4528961182 188.966796875183 .7854003906178 .2993011475173 .1179962158167 .6318054199 162.1457061768155 .7451934814153 .3069000244151 .7830047607150 .5639038086 
150.2590942383151 .1734008789155 .1356048584161 .8408966064160 .6217956543 158.7929992676157 .2691040039156 .3547973633155 .4403991699155 .1356048584 155.1356048584155 .1356048584155 .1356048584155 .1356048584155 .1356048584 155.1356048584155 .1356048584155 .1356048584154 .8307952881154 .8307952881 154.8307952881154 .8307952881154 .8307952881154 .8307952881154 .8307952881 154.8307952881154 .8307952881154 .8307952881155 .1356048584155 .1356048584 155.1356048584155 .1356048584155 .4403991699155 .4403991699155 .7451934814 156.3547973633156 .6596069336157 .2691040039157 .878692627158 .4882965088 159.0977935791160 .0122070312160 .6217956543161 .2312927246161 .8408966064 162.4505004883163 .0599975586163 .3648071289163 .6696014404163 .974395752 164.2792053223164 .2792053223164 .2792053223163 .974395752163 .6696014404 163.0599975586162 .4505004883161 .5361022949160 .3170013428159 .0977935791 157.878692627156 .3547973633154 .8307952881153 .0021057129151 .1734008789 149.3446960449147 .5160064697145 .9920959473144 .1634063721142 .6394042969 141.1154937744139 .5915985107138 .3724975586137 .1533050537135 .9342041016 135.0198059082134 .4102020264133 .4958953857132 .8863067627132 .2767028809 131.6672058105131 .0576019287130 .7528076172130 .1432037354129 .8385009766 129.2288970947128 .9241027832128 .3144989014128 .0097961426127 .4001998901 127.0953979492126 .4858016968125 .8762969971124 .9618988037124 .0475006104 123.1332015991122 .2188034058120 .9997024536119 .7806015015118 .5614013672 117.0374984741115 .5136032104113 .9896011353112 .4656982422110 .9418029785 109.4179000854108 .1986999512107 .5891036987107 .5891036987108 .8082962036 111.551399231117 .0374984741128 .6192932129138 .6772003174145 .6873016357 152.3925933838158 .7929992676163 .3648071289166 .7174987793168 .8509979248 170.070098877170 .9844970703173 .1179962158176 .7754058838180 .432800293 183.7854003906187 .4429016113190 .795501709194 .1481018066197 .1959991455 199.9389953613202 .6820983887205 .425201416207 .8634033203209 .692199707 209.692199707 209.692199707 209.692199707 209.692199707 209.692199707 209.692199707 209.692199707209 .692199707209 .692199707209 .692199707209 .692199707209 .692199707 209.692199707209 .692199707209 .692199707209 .692199707209 .692199707 $70.7101516723666 .1383666992261 .5666007995644 .0883941650415 .74940395355-9999$ -9999 -9999 -9999 -9999 -9999 -9999 -9999 -9999 -9999 -9999 -9999 -9999 -9999 -9999 -9999 -9999 -9999 -9999 -9999 -9999 -9999 -9999 -9999 -9999 -9999 -9999 -9999 -9999 -9999 -9999 -9999 -9999 -9999 -9999 -9999 -9999 -9999 -9999 -9999 -9999 -9999 -

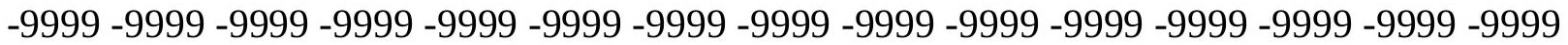
-9999 -9999 -9999 -9999 -9999 -9999 -9999 -9999 -9999 -9999 -9999 -9999 -9999 -9999 -9999 -9999 -9999 -9999 -9999 -9999 -9999 -9999 -9999 -9999 -9999 -9999 -9999 -9999 -9999 -9999

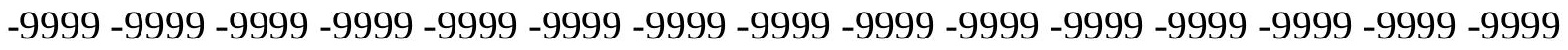
-9999 -9999 -9999 -9999 -9999 -9999 -9999 -9999 -9999 -9999 -9999 -9999 -9999 -9999 -9999 -9999 -9999 -9999 -9999 -9999 -9999 -9999 -9999 -9999 -9999 -9999 -9999 -9999 -9999 -9999 -

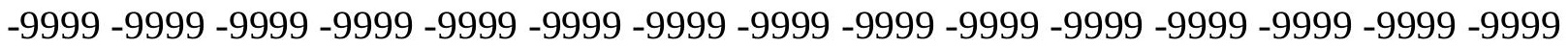

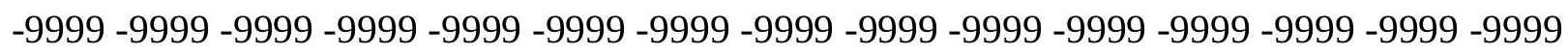
-9999 517.3964233398509.0077209473500.0889587402490.9289550781481.8358459473 472.7217102051464 .7973022461456 .2633056641446 .8150024414436 .7571105957 426.3944091797416 .0317077637405 .9737854004396 .220703125387 .0770874023 379.1527099609372 .7521972656367 .8756103516363 .9135131836360 .2560119629 
356.5986022949353 .2460021973349 .5885009766345 .9310913086342 .2737121582 338.3114929199334 .3493041992330 .3870849609326 .1200866699321 .8530883789 317.2813110352312 .7095031738308 .1377868652303 .2611999512298 .6893920898 294.1176147461289 .5458984375285 .2789001465282 .5357971191279 .7927856445 277.3544921875274 .6113891602270 .9540100098267 .2966003418263 .6390991211 260.2864990234256 .6290893555253 .2763977051249 .3141937256245 .6567993164 241.3898010254236 .8179931641231 .3318939209225 .5410003662219 .1405029297 213.3495941162208 .7778015137204 .8155975342199 .9389953613194 .7577056885 189.8811035156184 .699798584179 .5184020996174 .0323028564168 .241394043 162.4505004883156 .3547973633153 .6116943359151 .1734008789149 .9542999268 149.6495056152150 .5639038086156 .0500030518157 .5738983154156 .9642944336 156.0500030518155 .1356048584154 .5260925293154 .2212982178154 .2212982178 154.2212982178154 .2212982178154 .2212982178154 .2212982178154 .2212982178 154.2212982178154 .2212982178154 .2212982178154 .2212982178154 .2212982178 154.2212982178154 .2212982178154 .2212982178154 .2212982178154 .2212982178 154.2212982178154 .2212982178154 .2212982178154 .5260925293154 .5260925293 154.5260925293154 .5260925293154 .8307952881155 .1356048584155 .4403991699 156.0500030518156 .6596069336157 .2691040039157 .878692627158 .4882965088 159.0977935791159 .7073974609160 .6217956543161 .2312927246161 .8408966064 162.1457061768162 .7552947998163 .0599975586163 .3648071289163 .3648071289 163.6696014404163 .3648071289163 .3648071289163 .0599975586162 .4505004883 161.8408966064160 .9264984131160 .0122070312159 .0977935791157 .5738983154 156.3547973633154 .5260925293153 .0021057129151 .1734008789149 .3446960449 147.2111968994145 .3825073242143 .5538024902142 .0299072266140 .2012023926 138.9819946289137 .4580993652136 .2389984131135 .3246002197134 .4102020264 133.4958953857132 .8863067627132 .2767028809131 .6672058105131 .0576019287 130.7528076172130 .1432037354129 .8385009766129 .2288970947128 .9241027832 128.6192932129128 .3144989014128 .0097961426127 .4001998901127 .0953979492 126.4858016968125 .8762969971125 .2667007446124 .3523025513123 .43800354 122.2188034058120 .9997024536119 .4757995605117 .9517974854116 .4279022217 114.9039993286113 .6848983765112 .1608963013110 .9418029785110 .0273971558 109.1130981445108 .8082962036109 .1130981445110 .3321990967113 .6848983765 119.7806015015129 .533706665139 .8963928223148 .7351074219155 .4403991699 160.0122070312163 .6696014404166 .4127044678168 .241394043169 .4604949951 170.070098877170 .070098877173 .4226989746176 .7754058838180 .1280059814 183.7854003906187 .1381072998190 .1858978271193 .5386047363196 .2816009521 199.0247039795201 .7678070068204 .2059936523206 .6443023682208 .7778015137 209.692199707 209.692199707 209.692199707 209.692199707 209.692199707 209.692199707 209.692199707 209.692199707 209.692199707 209.692199707 209.692199707209.692199707 209.692199707 209.692199707 209.692199707 209.692199707 69.49101257324 65.2240066528360 .6522407531739 .761783599858 .26421546936 -9999 -9999 -9999 -9999 -9999 -9999 -9999 -9999 -9999 -9999-9999 -9999

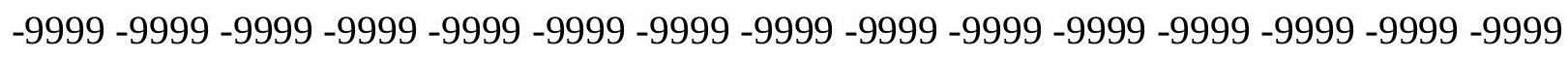
-9999 -9999 -9999 -9999 -9999 -9999 -9999 -9999 -9999 -9999 -9999 -9999 -9999 -9999 -9999 -9999 -9999 -9999 -9999 -9999 -9999 -9999 -9999 -9999 -9999 -9999 -9999 -9999 -9999 -9999 -

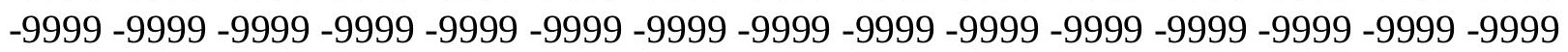


-9999 -9999 -9999 -9999 -9999 -9999 -9999 -9999 -9999 -9999 -9999 -9999 -9999 -9999 -9999 -9999 -9999 -9999 -9999 -9999 -9999 -9999 -9999 -9999 -9999 -9999 -9999 -9999 -9999 -9999

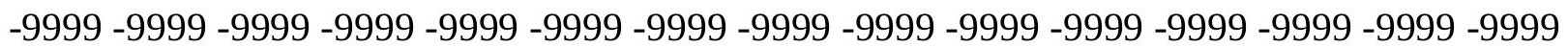
-9999 -9999 -9999 -9999 -9999 -9999 -9999 -9999 -9999 -9999 -9999 -9999 -9999 -9999 -9999

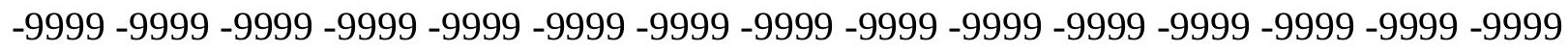

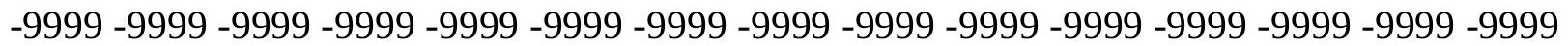
-9999 -9999-9999510.1932678223501.5901184082492.9902038574 484.7245788574 476.9887084961468 .1499938965458 .3967895508448 .0340881348437 .3666992188 426.3944091797415 .422088623405 .059387207395 .611114502387 .0770874023 380.066986084375 .495300293371 .5331115723367 .8756103516364 .2182006836 360.5607910156356 .5986022949352 .941192627348 .9790039062345 .0168151855 340.749786377336 .7875976562332 .2157897949327 .6440124512323 .0722045898 318.1957092285313 .3190917969308 .4425048828303 .5660095215298 .9942016602 294.4223937988290 .1553955078285 .8884887695283 .7549133301281 .0119018555 278.2687988281274 .9161987305271 .2587890625267 .9060974121264 .8583068848 261.5056152344258 .1530151367254 .4956054688250 .8381958008246 .8759002686 242.6089935303237 .4275970459231 .6367034912225 .5410003662219 .7501068115 214.8735046387210 .3016967773205 .425201416200 .5485992432195 .6721038818 190.4907073975185 .6141052246180 .432800293174 .6419067383168 .5462036133 162.4505004883156 .3547973633153 .0021057129150 .5639038086149 .6495056152 150.5639038086152 .6972961426154 .5260925293154 .5260925293154 .2212982178 153.6116943359153 .6116943359153 .3069000244153 .3069000244153 .3069000244 153.3069000244153 .3069000244153 .3069000244153 .3069000244153 .3069000244 153.3069000244153 .3069000244153 .3069000244153 .3069000244153 .6116943359 153.6116943359153 .6116943359153 .6116943359153 .6116943359153 .6116943359 153.6116943359153 .9165039062153 .9165039062153 .9165039062153 .9165039062 153.9165039062154 .2212982178154 .2212982178154 .8307952881155 .1356048584 155.7451934814156 .3547973633157 .2691040039157 .878692627158 .4882965088 159.0977935791159 .7073974609160 .3170013428160 .9264984131161 .5361022949 161.8408966064162 .4505004883162 .7552947998162 .7552947998162 .7552947998 162.7552947998162 .7552947998162 .4505004883161 .8408966064161 .2312927246 160.6217956543159 .7073974609158 .7929992676157 .5738983154156 .0500030518 154.5260925293152 .6972961426150 .8686065674149 .0399017334146 .9064025879 145.0776977539142 .9441986084141 .1154937744139 .5915985107138 .0677032471 136.8484954834135 .6293945312134 .4102020264133 .4958953857132 .8863067627 132.2767028809131 .6672058105131 .0576019287130 .4479980469130 .1432037354 129.8385009766129 .2288970947128 .9241027832128 .6192932129128 .3144989014 128.0097961426127 .7050018311127 .4001998901127 .0953979492126 .4858016968 125.8762969971125 .2667007446124 .3523025513123 .43800354122 .2188034058 120.6949005127118 .8662033081117 .342300415115 .5136032104114 .2944030762 113.075302124112 .1608963013111 .24659729110 .6370010376110 .3321990967 110.0273971558110 .9418029785112 .7705001831116 .4279022217121 .9140014648 135.6293945312147 .2111968994154 .2212982178158 .4882965088161 .5361022949 163.974395752165 .8031005859167 .3269958496168 .241394043168 .8509979248 169.1557006836169 .7653045654173 .1179962158176 .7754058838180 .1280059814 183.4806976318186 .528503418189 .8811035156192 .624206543195 .6721038818 
198.1103057861200 .5485992432202 .9868927002205 .425201416207 .25390625 209.3874053955209.692199707209.692199707 209.692199707 209.692199707 209.692199707 209.692199707 209.692199707 209.692199707 209.692199707 209.692199707 209.692199707209 .692199707209 .692199707209 .69219970768 .57665252686 $64.3096618652360 .0426712036134 .11761093146 .64624572 e-02$-9999 -9999 -9999 -9999 -9999 -9999 -9999 -9999 -9999 -9999 -9999 -9999

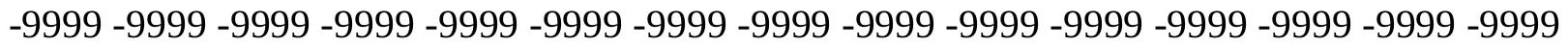

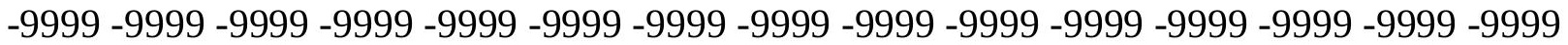

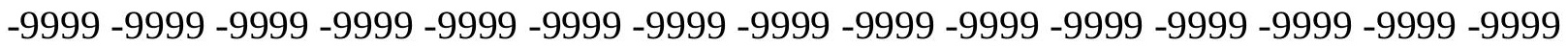

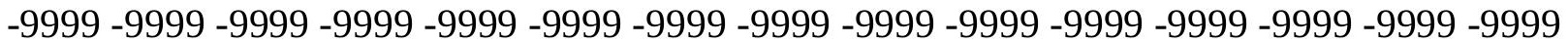

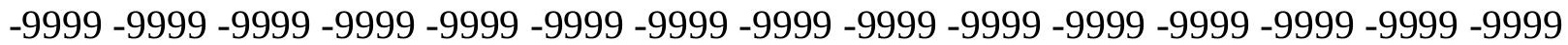

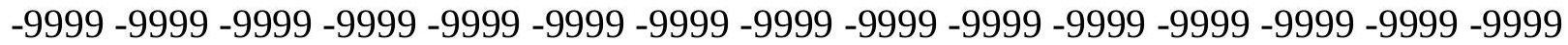

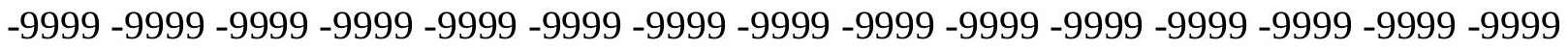

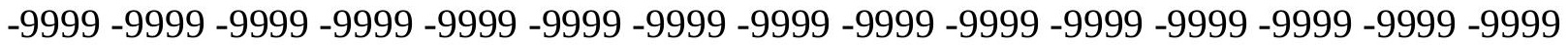

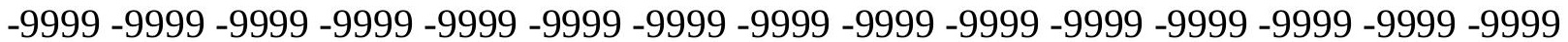
-9999 -9999 -9999 -9999 -9999 -9999 -9999 -9999 -9999 -9999 -9999 -9999 -9999 -9999 -999 -999 -999 -999 -999 -999 -999-9999 -9999 -9999 -9999 512.1243896484 504.0910339355 496.1794128418 488.1137390137 479.4241027832469.9786987305 459.6159973145 448.9484863281 437.6713867188 425.7847900391414 .5078125404 .7546081543396 .5255126953389 .8201904297 384.6387939453380 .3717956543376 .4096069336372 .4473876953368 .4851989746 364.2182006836360 .2560119629356 .2937927246352 .0267944336347 .4549865723 343.1879882812338 .6163024902333 .7396850586328 .8631896973323 .9866027832 318.8052062988313 .6239013672308 .7473144531303 .8707885742298 .9942016602 294.7272033691290 .7650146484286 .8027954102284 .6693115234281 .9262084961 278.5736083984275 .2210083008272 .1730957031269 .1253051758266 .0773925781 262.7247924805259 .3721008301255 .7147064209252 .0572967529247 .7902984619 242.9136962891238 .0372009277232 .5511016846226 .7601013184221 .5787963867 216.3973999023211 .2160949707206 .0346984863200 .8533935547195 .9768066406 191.4051055908186 .528503418180 .7375946045174 .337097168168 .241394043 161.8408966064156 .3547973633153 .0021057129151 .1734008789150 .8686065674 151.7830047607152 .3925933838152 .3925933838152 .6972961426152 .6972961426 152.6972961426152 .6972961426152 .6972961426152 .6972961426152 .6972961426 152.6972961426152 .6972961426152 .6972961426152 .6972961426152 .6972961426 152.6972961426152 .6972961426152 .6972961426153 .0021057129153 .0021057129 153.0021057129153 .0021057129153 .0021057129153 .3069000244153 .3069000244 153.3069000244153 .3069000244153 .3069000244153 .3069000244153 .6116943359 153.6116943359153 .6116943359153 .9165039062154 .5260925293155 .1356048584 155.7451934814156 .6596069336157 .2691040039157 .878692627158 .4882965088 159.0977935791159 .7073974609160 .3170013428160 .9264984131161 .2312927246 161.5361022949161 .8408966064162 .1457061768162 .1457061768162 .1457061768 162.1457061768161 .8408966064161 .5361022949160 .9264984131160 .3170013428 159.4026031494158 .4882965088157 .2691040039156 .0500030518154 .5260925293 152.6972961426150 .8686065674148 .7351074219146 .6015930176144 .4682006836 142.3347015381140 .5059967041138 .6772003174137 .1533050537135 .6293945312 134.4102020264133 .4958953857132 .5814971924131 .9720001221131 .3623962402 130.7528076172130 .4479980469129 .8385009766129 .533706665129 .2288970947 
128.9241027832128 .6192932129128 .3144989014128 .3144989014128 .0097961426 127.7050018311127 .4001998901127 .0953979492126 .4858016968125 .8762969971 125.2667007446124 .3523025513123 .1332015991121 .9140014648120 .0852966309 118.2565994263116 .4279022217114 .9039993286113 .3800964355112 .4656982422 111.8561019897111 .551399231111 .24659729111 .24659729111 .551399231112 .7705001831 115.2088012695120 .6949005127130 .4479980469143 .5538024902154 .8307952881 158.4882965088160 .6217956543162 .4505004883163 .6696014404165 .1934967041 166.4127044678167 .3269958496167 .9365997314167 .9365997314167 .6318054199 169.7653045654173 .1179962158176 .4705963135179 .8231964111183 .1759033203 186.2236938477189 .2716064453192 .0146026611194 .7577056885197 .1959991455 199.6342926025201 .7678070068203 .9011993408206 .0346984863207 .8634033203 209.692199707 209.692199707 209.692199707 209.692199707 209.692199707 209.692199707 209.692199707209 .692199707209 .692199707209 .692199707209 .692199707209 .692199707 209.69219970767 .3575134277363 .0905189514250 .6015701293925 .07670974731 -9999 -9999 -9999 -9999 -9999 -9999 -9999 -9999 -9999 -9999 -9999 -9999 -9999 -9999 -9999 -9999 -9999 -9999 -9999 -9999 -9999 -9999 -9999 -9999 -9999 -9999 -9999 -9999 - -999 -

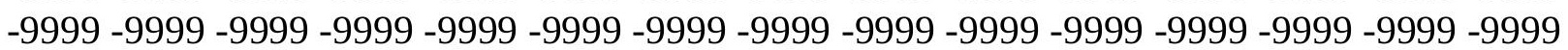
-9999 -9999 -9999 -9999 -9999 -9999 -9999 -9999 -9999 -9999 -9999 -9999 -9999 -9999 -9999 -999 -9999 -9999 -9999 -9999 -9999 -9999 -9999 -9999 -9999 -9999 -9999 -9999 -9999 -9999 -9999 -9999 -9999 -9999 -9999 -9999 -9999 -9999 -9999 -9999 -9999 -9999 -9999 -9999 -9999 -9999 -9999 -9999 -9999 -9999 -9999 -9999 -9999 -9999 -9999 -9999 -9999 -9999 -9999 -9999 -9999 -9999 -9999 -9999 -9999 -9999 -9999 -9999 -9999 -9999 -9999 -9999 -9999 -9999 -9999 -9999 -9999 -9999 -9999 -9999 -9999 -9999 -9999 -9999 -9999 -9999 -9999 -9999 -9999 -9999 -9999 -9999 -9999 -9999 -9999 -9999 -9999 -9999 -9999 -9999 -9999 -9999 -9999 -9999 -9999 -9999 -9999 -9999 -9999 -9999 -9999 -9999 -9999 -9999 -9999 -9999 -9999 -9999 -9999 -9999 -9999 -9999 -9999 -9999 -9999 -9999 -9999 506.9510498047 498.9532165527490 .4541320801 481.1940612793471 .1978149414462 .0542907715450 .4724121094437 .3666992188 424.870513916415 .422088623407 .8024902344401 .0971984863395 .3063049316 390.4296875385 .5531921387381 .2861938477376 .7143859863372 .4473876953 367.8756103516363 .6086120605359 .036895752354 .4650878906349 .8933105469 345.0168151855340 .1401977539334 .9588928223329 .7774963379324 .2914123535 319.1099853516313 .9287109375308 .7473144531303 .8707885742299 .6037902832 295.6416015625291 .6794128418287 .7171936035285 .5835876465282 .5357971191 279.1831970215276 .1353149414273 .3923034668270 .3443908691267 .2966003418 263.9439086914260 .5913085938256 .9338989258252 .9716033936248 .7046966553 244.1329040527238 .9515075684233 .1605987549227 .6744995117222 .1884002686 216.7021942139211 .520904541206 .0346984863200 .8533935547196 .2816009521 191.7097930908186 .2236938477180 .432800293174 .337097168167 .9365997314 161.8408966064156 .3547973633153 .0021057129151 .4781951904151 .1734008789 151.4781951904151 .7830047607151 .7830047607151 .7830047607152 .0877990723 152.3925933838152 .3925933838152 .3925933838152 .3925933838152 .0877990723 152.0877990723151 .7830047607151 .7830047607152 .0877990723152 .0877990723 152.0877990723152 .3925933838152 .3925933838152 .3925933838152 .3925933838 152.3925933838152 .6972961426152 .6972961426153 .0021057129153 .0021057129 153.0021057129153 .0021057129153 .0021057129153 .0021057129153 .0021057129 153.3069000244153 .6116943359154 .2212982178154 .8307952881155 .4403991699 
156.0500030518156 .6596069336157 .2691040039157 .878692627158 .4882965088 159.0977935791159 .7073974609160 .0122070312160 .6217956543160 .9264984131 161.2312927246161 .5361022949161 .5361022949161 .5361022949161 .5361022949 161.2312927246160 .9264984131160 .6217956543160 .0122070312159 .4026031494 158.4882965088157 .2691040039156 .0500030518154 .5260925293152 .6972961426 150.5639038086148 .4304046631145 .9920959473143 .5538024902141 .4203033447 139.2868041992137 .4580993652135 .9342041016134 .7149963379133 .4958953857 132.5814971924131 .6672058105131 .0576019287130 .4479980469130 .1432037354 129.533706665129 .2288970947128 .9241027832128 .6192932129128 .3144989014 128.3144989014128 .0097961426128 .0097961426127 .7050018311127 .7050018311 127.4001998901127 .0953979492126 .4858016968125 .8762969971124 .9618988037 124.0475006104122 .5235977173120 .9997024536119 .1709976196117 .0374984741 115.2088012695113 .6848983765112 .7705001831111 .8561019897111 .551399231 111.551399231111 .8561019897112 .1608963013112 .7705001831114 .2944030762 117.0374984741122 .5235977173134 .1054992676149 .6495056152155 .4403991699 158.7929992676160 .9264984131162 .1457061768163 .0599975586163 .974395752 165.1934967041165 .8031005859166 .4127044678166 .7174987793166 .4127044678 165.8031005859170 .070098877173 .4226989746176 .4705963135179 .5184020996 182.5662994385185 .6141052246188 .3571929932191 .1002960205193 .5386047363 195.9768066406198 .4151000977200 .5485992432202 .6820983887204 .5108032227 206.3394927979 208.1681976318209.692199707 209.692199707 209.692199707 209.692199707209.692199707209.692199707209.692199707209.692199707209.692199707 209.692199707 209.69219970765.8335876464861.5666007995643.15386199951 14.60032653809 -9999 -9999 -9999 -9999 -9999 -9999 -9999 -9999 -9999 -9999 -9999 -9999 $-9999$

-9999 -9999 -9999 -9999 -9999 -9999 -9999 -9999 -9999 -9999 -9999 -9999 -9999 -9999 -9999 -9999 -9999 -9999 -9999 -9999 -9999 -9999 -9999 -9999 -9999 -9999 -9999 -9999 -9999 -9999 -

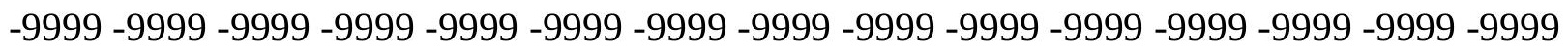
-9999 -9999 -9999 -9999 -9999 -9999 -9999 -9999 -9999 -9999 -9999 -9999 -9999 -9999 -9999 -9999 -9999 -9999 -9999 -9999 -9999 -9999 -9999 -9999 -9999 -9999 -9999 -9999 -9999 -9999 -9999 -9999 -9999 -9999 -9999 -9999 -9999 -9999 -9999 -9999 -9999 -9999 -9999 -9999 -9999 -9999 -9999 -9999 -9999 -9999 -9999 -9999 -9999 -9999 -9999 -9999 -9999 -9999 -9999 -9999 -

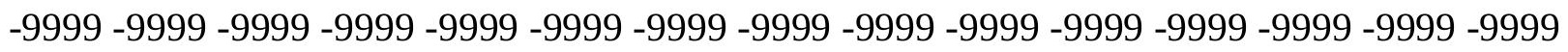
-9999 -9999 -9999 -9999 -9999 -9999 -9999 -9999 -9999 -9999 -9999 -9999 -9999 -9999 -9999 -9999 -9999 -9999 -9999 -9999 -9999 -9999 -9999 -9999 -9999 -9999 -9999 -9999 -9999 -9999 -9999 -9999 -9999 -9999 -9999 -9999 -9999 509.4294128418 501.2798156738 492.688293457 483.8343811035474 .746307373464 .4924926758451 .0820007324436 .1474914551 428.2231140137420 .9082946777413 .5934143066407 .1929016113401 .0971984863 395.611114502390 .4296875385 .5531921387380 .6766052246376 .104888916 371.5331115723366 .6564941406361 .7799072266356 .9034118652351 .7219848633 346.5407104492341 .0545959473335 .5683898926330 .0823059082324 .5961914062 319.1099853516 313.9287109375 309.3569030762 304.7850952148300 .8229064941 296.5559082031292 .8984985352288 .9363098145286 .4979858398283 .4501953125 280.4023132324277 .3544921875274 .3066101074271 .2587890625268 .2109069824 264.8583068848261 .5056152344257 .8482055664254 .1907958984249 .9237976074 244.7424926758239 .2563018799233 .4653930664227 .9792938232222 .1884002686 
216.7021942139211 .2160949707205 .7299957275201 .158203125196 .5863952637 191.4051055908185 .9188995361180 .1280059814174 .337097168167 .9365997314 161.8408966064156 .0500030518152 .3925933838151 .4781951904151 .1734008789 150.8686065674150 .8686065674151 .1734008789151 .7830047607152 .3925933838 152.3925933838152 .3925933838152 .0877990723151 .7830047607151 .4781951904 151.1734008789151 .1734008789151 .4781951904151 .4781951904151 .7830047607 151.7830047607152 .0877990723152 .0877990723152 .0877990723152 .0877990723 152.3925933838152 .3925933838152 .6972961426152 .6972961426152 .6972961426 152.6972961426152 .6972961426152 .6972961426153 .0021057129153 .0021057129 153.3069000244153 .9165039062154 .2212982178154 .8307952881155 .4403991699 156.0500030518156 .6596069336157 .2691040039157 .878692627158 .4882965088 159.0977935791159 .4026031494160 .0122070312160 .3170013428160 .6217956543 160.9264984131160 .9264984131160 .9264984131160 .9264984131160 .9264984131 160.6217956543160 .3170013428159 .7073974609159 .0977935791158 .1835021973 157.2691040039156 .0500030518154 .5260925293152 .6972961426150 .2590942383 147.8208007812145 .3825073242142 .6394042969140 .2012023926138 .0677032471 136.2389984131134 .7149963379133 .4958953857132 .2767028809131 .3623962402 130.7528076172130 .1432037354129 .8385009766129 .2288970947128 .9241027832 128.6192932129128 .3144989014128 .0097961426128 .0097961426127 .7050018311 127.7050018311127 .7050018311127 .7050018311127 .4001998901127 .4001998901 127.0953979492126 .4858016968125 .8762969971124 .9618988037123 .43800354 121.9140014648119 .7806015015117 .647102356115 .818397522113 .9896011353 112.7705001831111 .8561019897111 .551399231111 .551399231111 .8561019897 112.4656982422113 .3800964355114 .2944030762115 .818397522117 .9517974854 121.9140014648129 .8385009766142 .3347015381151 .7830047607156 .9642944336 159.4026031494160 .6217956543161 .8408966064162 .7552947998163 .6696014404 164.2792053223164 .8887023926165 .1934967041164 .8887023926164 .2792053223 167.0222015381170 .070098877173 .4226989746176 .4705963135179 .2136993408 182.261505127185 .0045928955187 .7476043701190 .1858978271192 .624206543195 .0625 197.1959991455199 .329498291201 .158203125203 .2917022705205 .1204071045 206.9490966797208 .4730072021209 .692199707209 .692199707209 .692199707 209.692199707 209.692199707 209.692199707 209.692199707 209.692199707 68.8814392089864 .3096618652360 .0426712036134 .659233093262 .935678482056 -9999 -9999 -9999 -9999 -9999 -9999 -9999 -9999 -9999 -9999 -9999 -9999 -9999

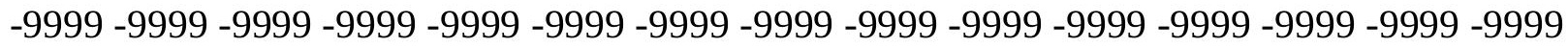
-9999 -9999 -9999 -9999 -9999 -9999 -9999 -9999 -9999 -9999 - -9999 -9999 -999 -9999 -999 -

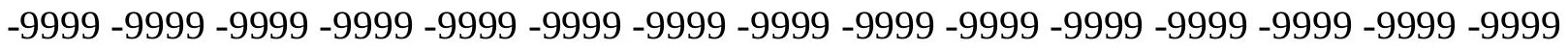

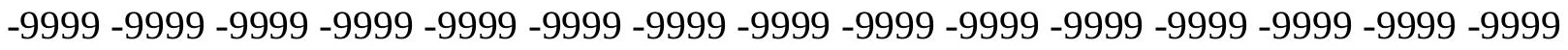

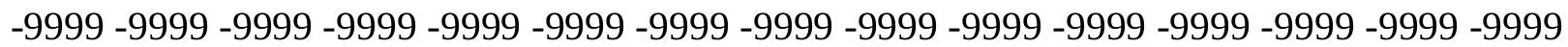

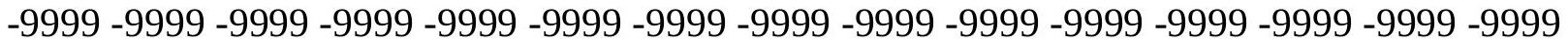

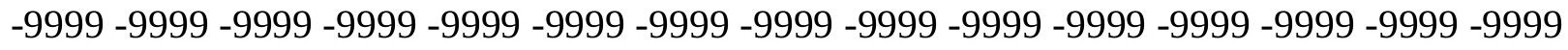

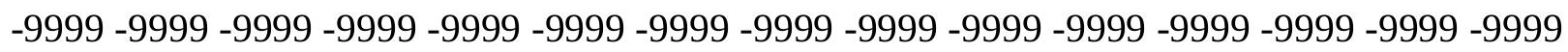

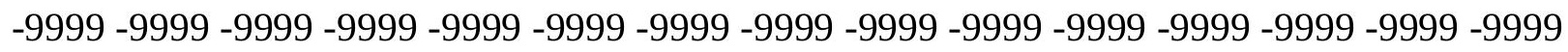

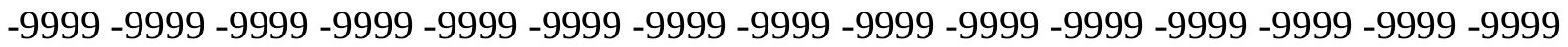
-9999 -9999 -9999 -9999 -9999 -9999 -9999 -9999 -9999 503.8910217285 495.7697753906 487.1813049316477 .8424682617467 .5404052734454 .7394104004444 .0718994141 
435.2331848145427 .0039978027419 .3843078613412 .3742980957405 .9737854004 400.1828918457394 .696685791389 .515411377384 .3340148926379 .4574890137 374.2760925293369 .399597168363 .9135131836358 .4273071289352 .941192627 347.4549865723341 .6640930176335 .8731994629330 .3870849609324 .9009094238 319.7196044922314 .5382080078309 .9664916992305 .6994934082301 .7373046875 297.7750854492293 .8128967285289 .8505859375287 .4124145508284 .3645019531 281.3167114258 278.2687988281275.2210083008 272.1730957031269.1253051758 265.7726135254262 .1152038574258 .7626037598254 .4956054688249 .9237976074 244.4376983643238 .9515075684233 .1605987549227 .6744995117222 .1884002686 216.7021942139211 .2160949707206 .6443023682201 .7678070068196 .891204834 191.4051055908185 .9188995361180 .1280059814174 .337097168168 .241394043 162.1457061768156 .3547973633153 .6116943359151 .7830047607150 .5639038086 150.5639038086150 .8686065674151 .4781951904152 .3925933838152 .3925933838 152.3925933838151 .7830047607151 .4781951904150 .8686065674150 .5639038086 150.5639038086150 .8686065674150 .8686065674151 .1734008789151 .4781951904 151.7830047607152 .0877990723152 .0877990723152 .0877990723152 .0877990723 152.3925933838152 .3925933838152 .3925933838152 .3925933838152 .6972961426 152.6972961426152 .6972961426152 .6972961426153 .0021057129153 .3069000244 153.6116943359153 .9165039062154 .5260925293155 .1356048584155 .7451934814 156.3547973633156 .6596069336157 .2691040039157 .878692627158 .4882965088 158.7929992676159 .4026031494159 .7073974609160 .0122070312160 .3170013428 160.3170013428160 .6217956543160 .6217956543160 .3170013428160 .3170013428 160.0122070312159 .4026031494159 .0977935791158 .1835021973157 .2691040039 156.0500030518154 .5260925293152 .6972961426150 .2590942383147 .2111968994 144.4682006836141 .7250976562138 .9819946289136 .8484954834134 .7149963379 133.1911010742131 .9720001221131 .0576019287130 .4479980469129 .8385009766 129.2288970947128 .9241027832128 .6192932129128 .3144989014128 .0097961426 127.7050018311127 .7050018311127 .4001998901127 .4001998901127 .4001998901 127.4001998901127 .4001998901127 .4001998901127 .0953979492127 .0953979492 126.4858016968125 .8762969971124 .9618988037123 .43800354121 .3044967651 118.8662033081116 .4279022217114 .2944030762112 .4656982422111 .551399231 111.24659729111 .24659729111 .551399231112 .4656982422113 .3800964355 114.5991973877116 .1231002808117 .9517974854120 .0852966309122 .2188034058 123.43800354137 .7628936768148 .4304046631154 .2212982178157 .2691040039 158.7929992676160 .0122070312160 .9264984131162 .1457061768162 .7552947998 163.3648071289163 .6696014404163 .3648071289162 .7552947998164 .2792053223 167.3269958496170 .3748931885173 .1179962158176 .165802002178 .9089050293 181.6519012451184 .3950042725186 .8332977295189 .2716064453191 .7097930908 193.8433074951195 .9768066406198 .1103057861199 .9389953613201 .7678070068 203.596496582205 .425201416207 .25390625209 .0825958252209 .692199707209 .692199707 209.692199707209 .692199707209 .692199707209 .69219970767 .35751342773 62.7857398986846 .4317092895522 .08864402771 -9999 -9999-9999-9999-9999 -9999-9999 -9999 -9999 -9999 -9999 -9999 -9999-9999 -9999 -9999 -9999 -9999 -9999 -9999 -9999 -9999 -9999 -9999 -9999 -9999 -9999 -9999 -9999 -9999 -9999 -9999 -9999 -9999 -9999 -9999 -9999 -9999 -9999 -9999 -9999 -9999 -9999 -9999

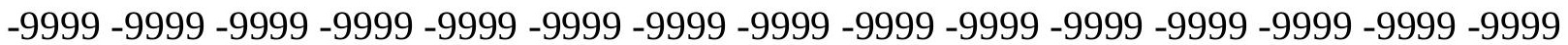


-9999 -9999 -9999 -9999 -9999 -9999 -9999 -9999 -9999 -9999 -9999 -9999 -9999 -9999 -9999 -9999 -9999 -9999 -9999 -9999 -9999 -9999 -9999 -9999 -9999 -9999 -9999 -9999 -9999 -9999

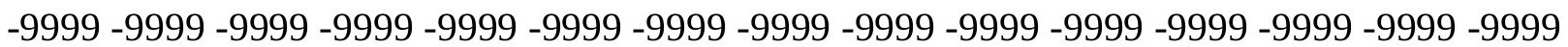
-9999 -9999 -9999 -9999 -9999 -9999 -9999 -9999 -9999 -9999 -9999 -9999 -9999 -9999 -9999

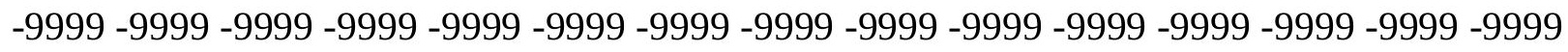
-9999 -9999 -9999 -9999 -9999 -9999 -9999 -9999 -9999 -9999 -9999 -9999 -9999 -9999 -9999 -9999 -9999 -9999 -9999 -9999 -9999 -9999 -9999 -9999 -9999 -9999 -9999 -9999 -9999 -9999 -9999 -9999 -9999 -9999 -9999 -9999 -9999 -9999 -9999 -9999 506.7768554688 498.8210754395490 .3008728027481 .1070861816471 .5025939941459 .9206848145 449.8629150391440 .4144897461431 .5757141113423 .6513061523416 .3364868164 409.9360046387403.8403015137398.3541870117393.1727905273 387.686706543 382.5053100586377 .0191955566371 .228302002365 .7421875359 .6465148926 353.8554992676347 .7597961426341 .9689025879336 .1780090332330 .6918945312 325.2056884766320 .0244140625315 .4526062012310 .8807983398306 .6138000488 302.6516113281298 .6893920898294 .7272033691290 .7650146484288 .6315002441 285.2789001465282 .2309875488279 .1831970215276 .1353149414273 .0874938965 269.7348022461266 .3822021484262 .7247924805258 .4577941895254 .1907958984 249.3141937256243 .8280944824238 .3419952393232 .5511016846227 .3697052002 221.883605957217 .0070037842211 .8256988525207 .25390625202 .0724945068 196.891204834191 .7097930908186 .2236938477180 .432800293174 .6419067383 168.5462036133162 .4505004883157 .2691040039154 .2212982178151 .4781951904 150.8686065674150 .8686065674151 .4781951904151 .7830047607152 .3925933838 152.3925933838151 .7830047607150 .8686065674150 .2590942383149 .9542999268 149.9542999268150 .2590942383150 .5639038086150 .8686065674151 .1734008789 151.4781951904151 .7830047607152 .0877990723152 .0877990723152 .0877990723 152.0877990723152 .3925933838152 .3925933838152 .3925933838152 .3925933838 152.3925933838152 .6972961426152 .6972961426153 .0021057129153 .0021057129 153.3069000244153 .9165039062154 .2212982178154 .8307952881155 .1356048584 155.7451934814156 .3547973633156 .9642944336157 .2691040039157 .878692627 158.4882965088158 .7929992676159 .0977935791159 .4026031494159 .7073974609 159.7073974609160 .0122070312160 .0122070312160 .0122070312160 .0122070312 159.7073974609159 .4026031494158 .7929992676158 .1835021973156 .9642944336 156.0500030518154 .5260925293152 .6972961426149 .6495056152146 .6015930176 143.2489929199140 .2012023926137 .4580993652135 .3246002197133 .1911010742 131.9720001221130 .7528076172130 .1432037354129 .2288970947128 .9241027832 128.3144989014128 .0097961426127 .7050018311127 .7050018311127 .4001998901 127.0953979492127 .0953979492127 .0953979492127 .0953979492127 .0953979492 127.0953979492127 .0953979492127 .0953979492127 .0953979492126 .7906036377 126.4858016968125 .8762969971124 .6570968628123 .1332015991120 .9997024536 117.647102356114 .5991973877112 .4656982422111 .24659729110 .6370010376 110.6370010376110 .9418029785111 .8561019897112 .7705001831113 .9896011353 115.5136032104117 .647102356120 .3900985718124 .0475006104128 .3144989014 133.1911010742141 .4203033447148 .1255950928152 .6972961426155 .1356048584 156.9642944336158 .1835021973159 .4026031494160 .3170013428161 .2312927246 161.8408966064162 .1457061768161 .8408966064161 .2312927246162 .1457061768 164.5839996338167 .3269958496170 .3748931885173 .1179962158175 .8609924316 
178.604095459181 .0424041748183 .4806976318185 .9188995361188 .3571929932 190.4907073975192 .624206543194 .7577056885196 .5863952637198 .4151000977 200.2438049316202 .0724945068203 .9011993408205 .7299957275207 .5587005615 209.3874053955 209.692199707 209.692199707 209.692199707 209.692199707 65.8335876464861 .2618103027337 .7211151123 7.373924732208 -9999 -9999 -9999 -9999 -9999 -9999 -9999 -9999 -9999 -9999 -9999 -9999 -9999 -9999 -9999 -9999 -9999 -9999 -9999 -9999 -9999 -9999 -9999 -9999 -9999 -9999 -9999 -9999 -9999

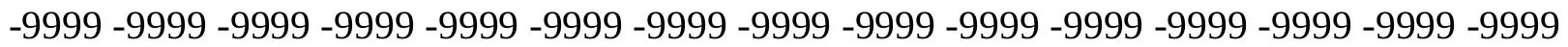
-9999 -9999 -9999 -9999 -9999 -9999 -9999 -9999 -9999 -9999 -9999 -9999 -9999 -9999 -9999 -9999 -9999 -9999 -9999 -9999 -9999 -9999 -9999 -9999 -9999 -9999 -9999 -9999 -9999 -9999 -

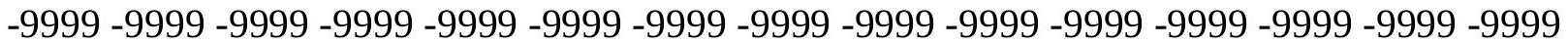
-9999 -9999 -9999 -9999 -9999 -9999 -9999 -9999 -9999 -9999 -9999 -9999 -9999 -9999 -9999 -9999 -9999 -9999 -9999 -9999 -9999 -9999 -9999 -9999 -9999 -9999 -9999 -9999 -9999 -9999 -9999 -9999 -9999 -9999 -9999 -9999 -9999 -9999 -9999 -9999 -9999 -9999 -9999 -9999 -9999 -9999 -9999 -9999 -9999 -9999 -9999 -9999 -9999 -9999 -9999 -9999 -9999 -9999 -9999 -9999

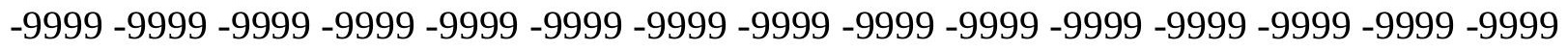
-9999 -9999 -9999 -9999 -9999 -9999 -9999 -9999 -9999 -9999-9999 -9999 501.2190246582 492.615814209483 .3161621094473 .2119445801463 .2734069824452 .9107055664 443.4624023438434 .3187866211426 .3944091797419 .3843078613413 .2886047363 407.4977111816401.7067871094 396.220703125 390.7344970703384 .9436035156 378.8479003906372 .7521972656366 .6564941406360 .5607910156354 .1603088379 348.0646057129341 .9689025879336 .1780090332330 .6918945312325 .5104980469 320.6339111328316 .0621948242311 .7951965332307 .5281982422303 .2611999512 299.2990112305295 .6416015625291 .6794128418289 .5458984375286 .1932067871 282.8406066895279 .7927856445276 .4400939941273 .3923034668270 .0396118164 266.3822021484262 .4200134277258 .1530151367253 .5812072754248 .0950927734 242.6089935303237 .4275970459231 .9414978027227 .0648956299221 .883605957 217.3117980957 212.4351959229 207.25390625 202.3773040771 197.1959991455 191.7097930908186 .528503418180 .7375946045174 .6419067383168 .5462036133 162.1457061768157 .878692627154 .8307952881152 .6972961426151 .4781951904 151.1734008789151 .4781951904151 .7830047607152 .3925933838151 .4781951904 150.2590942383149 .6495056152149 .3446960449149 .3446960449149 .6495056152 150.2590942383150 .5639038086150 .8686065674151 .4781951904151 .7830047607 152.0877990723152 .0877990723152 .0877990723152 .0877990723152 .3925933838 152.3925933838152 .3925933838152 .3925933838152 .3925933838152 .6972961426 152.6972961426152 .6972961426153 .0021057129153 .3069000244153 .6116943359 153.9165039062154 .5260925293154 .8307952881155 .4403991699156 .0500030518 156.3547973633156 .9642944336157 .2691040039157 .878692627158 .1835021973 158.4882965088158 .7929992676159 .0977935791159 .4026031494159 .4026031494 159.4026031494159 .7073974609159 .4026031494159 .4026031494159 .0977935791 158.4882965088157 .878692627156 .9642944336155 .7451934814154 .2212982178 152.0877990723149 .0399017334145 .6873016357142 .0299072266138 .6772003174 135.9342041016133 .4958953857131 .9720001221130 .4479980469129 .533706665 128.9241027832128 .3144989014128 .0097961426127 .7050018311127 .4001998901 127.0953979492127 .0953979492126 .7906036377126 .7906036377126 .7906036377 126.7906036377126 .7906036377126 .7906036377126 .7906036377126 .7906036377 
127.0953979492126 .7906036377126 .7906036377126 .4858016968125 .8762969971 124.6570968628122 .8283996582120 .3900985718116 .4279022217113 .075302124 111.24659729110 .3321990967110 .3321990967110 .6370010376111 .24659729 112.1608963013113 .3800964355114 .5991973877116 .4279022217118 .8662033081 122.2188034058128 .0097961426136 .2389984131144 .4682006836148 .4304046631 150.5639038086152 .3925933838153 .9165039062155 .1356048584156 .3547973633 157.5738983154158 .7929992676159 .7073974609160 .3170013428160 .3170013428 160.3170013428159 .7073974609159 .0977935791162 .4505004883164 .8887023926 167.3269958496170 .070098877172 .8132019043175 .2514038086177 .9945068359 180.432800293182 .87109375185 .0045928955187 .1381072998189 .2716064453 191.4051055908193 .233795166195 .3672943115197 .1959991455199 .0247039795 200.8533935547202 .6820983887204 .2059936523206 .0346984863207 .8634033203 209.692199707 209.692199707 209.692199707 64.30966186523 59.73788070679 21.01029396057 -11.98442173 -9999 -9999 -9999 -9999 -9999 -9999 -9999 -9999 -9999 -9999 -9999 -9999 -9999-9999

-9999 -9999 -9999 -9999 -9999 -9999 -9999 -9999 -9999-9999 -9999 -9999 -9999 -9999 -9999 -

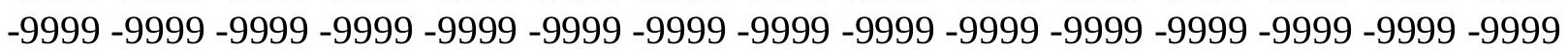
-9999 -9999 -9999 -9999 -9999 -9999 -9999 -9999 -9999 -9999 -9999 -9999 -9999 -9999 -9999 -9999 -9999 -9999 -9999 -9999 -9999 -9999 -9999 -9999 -9999 -9999 -9999 -9999 -9999 -9999 -9999 -9999 -9999 -9999 -9999 -9999 -9999 -9999 -9999 -9999 -9999 -9999 -9999 -9999 -9999 -

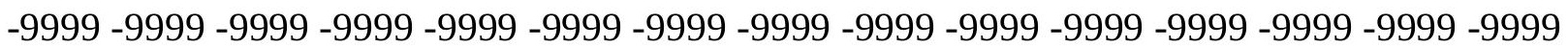
-9999 -9999 -9999 -9999 -9999 -9999 -9999 -9999 -9999 -9999 -9999 -9999 -9999 -9999 -9999 -9999 -9999 -9999 -9999 -9999 -9999 -9999 -9999 -9999 -9999 -9999 -9999 -9999 -9999 -9999 -9999 -9999 -9999 -9999 -9999 -9999 -9999 -9999 -9999 -9999 -9999 -9999 -9999 -9999 -9999

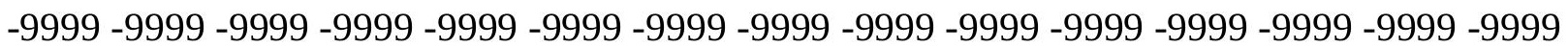
-9999 -9999 -9999 -9999 -9999 -9999 -9999 -9999 -9999 -9999 -9999 -9999 -9999 502.2781066895493 .3101501465483 .8645324707474 .0702209473464 .187713623 454.1299133301444 .3767089844435 .8427124023428 .5278930664422 .1274108887 416.3364868164410 .5455932617405 .059387207398 .9637145996392 .8680114746 386.4674987793380 .066986084373 .666595459366 .9613037109360 .5607910156 354.1603088379348 .0646057129341 .9689025879336 .4827880859330 .9966125488 325.8153076172321 .2434997559316 .6718139648312 .1000061035308 .1377868652 303.8707885742299 .9085998535296 .2510986328292 .5936889648290 .1553955078 286.8027954102283 .1453857422279 .7927856445276 .7449035645273 .3923034668 270.0396118164266 .0773925781261 .8103942871257 .2385864258252 .0572967529 246.8759002686241 .6945953369236 .5133056641231 .6367034912226 .7601013184 222.1884002686217 .6165924072212 .4351959229207 .25390625202 .0724945068 196.891204834192 .0146026611186 .528503418180 .432800293174 .0323028564 167.6318054199163 .0599975586158 .7929992676155 .4403991699152 .6972961426 151.1734008789150 .8686065674151 .1734008789151 .1734008789150 .5639038086 149.6495056152149 .0399017334148 .7351074219149 .0399017334149 .3446960449 149.9542999268150 .2590942383150 .8686065674151 .1734008789151 .7830047607 152.0877990723152 .0877990723152 .0877990723152 .0877990723152 .3925933838 152.3925933838152 .3925933838152 .3925933838152 .3925933838152 .6972961426 152.6972961426152 .6972961426153 .0021057129153 .0021057129153 .3069000244 153.9165039062154 .2212982178154 .5260925293155 .1356048584155 .4403991699 
156.0500030518156 .3547973633156 .9642944336157 .2691040039157 .5738983154 157.878692627158 .1835021973158 .4882965088158 .7929992676158 .7929992676 159.0977935791159 .0977935791159 .0977935791159 .0977935791158 .7929992676 158.4882965088157 .878692627156 .9642944336155 .7451934814153 .9165039062 151.4781951904148 .4304046631144 .4682006836140 .8106994629137 .1533050537 134.4102020264132 .2767028809130 .4479980469129 .533706665128 .6192932129 128.0097961426127 .7050018311127 .4001998901127 .0953979492126 .7906036377 126.7906036377126 .4858016968126 .4858016968126 .1809997559126 .1809997559 126.1809997559126 .4858016968126 .4858016968126 .4858016968126 .4858016968 126.7906036377126 .7906036377126 .4858016968126 .1809997559125 .5715026855 124.6570968628123 .1332015991120 .3900985718116 .1231002808111 .551399231 110.6370010376110 .3321990967110 .3321990967110 .6370010376111 .551399231 112.7705001831113 .9896011353115 .2088012695117 .0374984741119 .1709976196 122.5235977173128 .3144989014138 .9819946289153 .6116943359151 .7830047607 151.1734008789151 .4781951904152 .3925933838153 .3069000244154 .5260925293 156.0500030518156 .9642944336158 .1835021973158 .7929992676158 .7929992676 158.7929992676158 .4882965088157 .5738983154160 .0122070312162 .4505004883 164.5839996338167 .3269958496169 .7653045654172 .5084075928174 .9467010498 177.3849029541179 .5184020996181 .9566955566184 .0901947021186 .2236938477 188.0523986816190 .1858978271192 .0146026611193 .8433074951195 .6721038818 197.500793457199 .329498291201 .158203125202 .9868927002204 .8155975342 206.6443023682208 .4730072021209 .69219970762 .7857398986816 .57991409302 -8.2531080246 -33.9186859131 -9999 -9999 -9999 -9999 -9999 -9999 -9999 -9999 -9999 -9999 -9999-9999-9999-9999

-9999 -9999 -9999 -9999 -9999 -9999 -9999 -9999 -9999 -9999 -9999 -9999 -9999 -9999 -9999 -9999 -9999 -9999 -9999 -9999 -9999 -9999 -9999 -9999 -9999 -9999 -9999 -9999 -9999 -9999 -9999 -9999 -9999 -9999 -9999 -9999 -9999 -9999 -9999 -9999 -9999 -9999 -9999 -9999 -9999 -

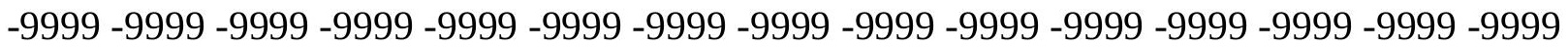

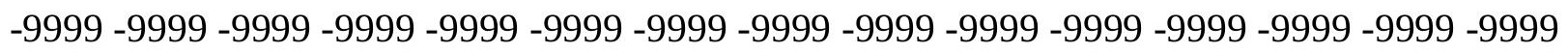

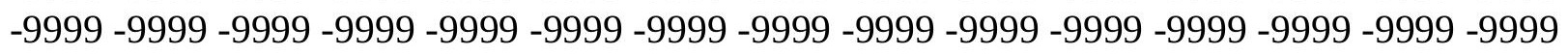
-9999 -9999 -9999 -9999 -9999 -9999 -9999 -9999 -9999 -9999 -9999 -9999 -9999 -9999 -9999 -9999 -9999 -9999 -9999 -9999 -9999 -9999 -9999 -9999 -9999 -9999 -9999 -9999 -9999 -9999 -

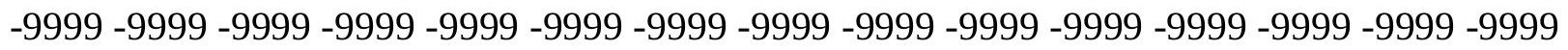

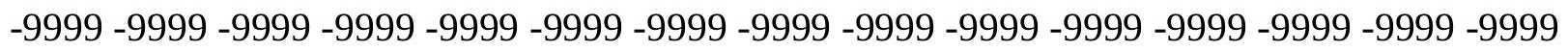
-9999 -9999 -9999 -9999 -9999 -9999 -9999 -9999 -9999-9999 -9999 -9999 -9999 -9999 501.932800293492 .8049926758483 .2703857422473 .4971923828463 .5781860352 453.5202941895444 .3767089844437 .3666992188430 .9661865234425 .1752929688 419.3843078613413 .5934143066407 .4977111816400 .792388916394 .0871887207 387.3818969727380 .3717956543373 .666595459366 .6564941406359 .9512023926 353.5508117676347 .4549865723341 .6640930176336 .1780090332330 .9966125488 327.9487915039323 .6817932129318 .1957092285312 .7095031738308 .4425048828 304.4802856445300 .8229064941296 .8606872559293 .2033081055290 .4602050781 286.8027954102283 .4501953125280 .0975036621277 .0497131348273 .3923034668 269.7348022461265 .4678039551260 .8960876465256 .0195007324250 .8381958008 245.6567993164240 .7801971436235 .9037017822231 .3318939209226 .7601013184 222.1884002686217 .3117980957212 .1304016113206 .9490966797201 .7678070068 
196.891204834191 .4051055908185 .6141052246178 .9089050293173 .7274932861 168.5462036133163 .3648071289158 .7929992676154 .8307952881151 .4781951904 150.8686065674150 .8686065674150 .5639038086149 .9542999268148 .7351074219 148.4304046631148 .4304046631148 .7351074219149 .3446960449149 .6495056152 150.2590942383150 .8686065674151 .4781951904151 .7830047607152 .0877990723 152.3925933838152 .3925933838152 .0877990723152 .3925933838152 .3925933838 152.3925933838152 .3925933838152 .6972961426152 .6972961426152 .6972961426 152.6972961426152 .6972961426153 .0021057129153 .3069000244153 .6116943359 153.9165039062154 .2212982178154 .8307952881155 .1356048584155 .7451934814 156.0500030518156 .3547973633156 .9642944336157 .2691040039157 .5738983154 157.878692627157 .878692627158 .1835021973158 .4882965088158 .4882965088 158.7929992676158 .7929992676158 .7929992676158 .4882965088158 .1835021973 157.5738983154156 .6596069336155 .4403991699153 .6116943359151 .1734008789 147.8208007812143 .5538024902139 .5915985107135 .9342041016132 .8863067627 131.0576019287129 .533706665128 .6192932129128 .0097961426127 .4001998901 127.0953979492 126.7906036377126 .7906036377126 .4858016968126 .1809997559 126.1809997559126 .1809997559125 .8762969971125 .8762969971125 .8762969971 125.8762969971126 .1809997559126 .1809997559126 .1809997559126 .4858016968 126.4858016968126 .1809997559125 .8762969971125 .5715026855124 .6570968628 123.1332015991120 .9997024536117 .0374984741113 .3800964355111 .551399231 110.9418029785110 .9418029785111 .551399231112 .4656982422113 .6848983765 114.5991973877115 .818397522117 .342300415118 .8662033081120 .9997024536 124.9618988037132 .2767028809142 .3347015381147 .8208007812149 .3446960449 149.9542999268150 .8686065674151 .7830047607153 .3069000244154 .5260925293 155.7451934814156 .6596069336157 .2691040039157 .5738983154157 .2691040039 156.9642944336156 .3547973633157 .878692627160 .0122070312162 .1457061768 164.5839996338167 .0222015381169 .4604949951171 .8988037109174 .337097168 176.4705963135178 .9089050293181 .0424041748182 .87109375185 .0045928955 186.8332977295188 .966796875190 .795501709192 .624206543194 .4528961182 196.2816009521198 .1103057861199 .9389953613201 .7678070068203 .596496582 205.425201416 207.25390625 61.56660079956 -3.43610429764 -33.8920631409 -9999 -9999 -9999 -9999 -9999 -9999 -9999 -9999 -9999 -9999 -9999 -9999 -9999 -9999 -9999 -9999 -9999 -9999 -9999 -9999 -9999 -9999 -9999 -9999 -9999 -9999 -9999 -9999 -9999 -999 -9999 -9999 -9999 -9999 -9999 -9999 -9999 -9999 -9999 -9999 -9999 -9999 -9999 -9999 -9999 -9999 -9999 -9999 -9999 -9999 -9999 -9999 -9999 -9999 -9999 -9999 -9999 -9999 -9999 -9999 -9999 -9999 -9999 -9999 -9999 -9999 -9999 -9999 -9999 -9999 -9999 -9999 -9999 -9999 -9999

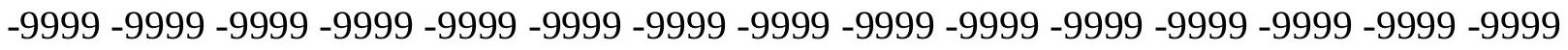

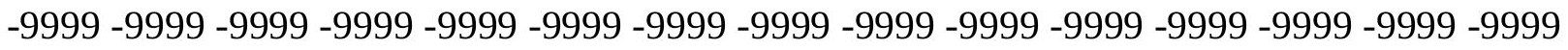
-9999 -9999 -9999 -9999 -9999 -9999 -9999 -9999 -9999 -9999 -9999 -9999 -9999 -9999 -9999 -9999 -9999 -9999 -9999 -9999 -9999 -9999 -9999 -9999 -9999 -9999 -9999 -9999 -9999 -9999 -

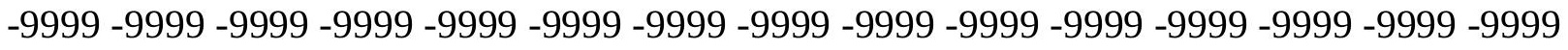

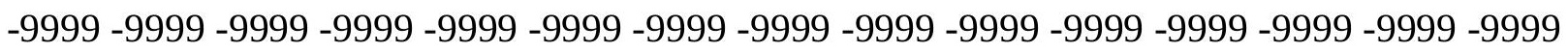
-9999 -9999 -9999 -9999 -9999 -9999 -9999 -9999 -9999 -9999 -9999 -9999 -9999 -9999 -9999 -9999 491.3341064453481.7132568359471.8305053711461.8374633789452.3010864258 445.900604248439 .804901123434 .0140075684428 .2231140137422 .1274108887 415.7268981934408 .7168884277401 .7067871094394 .391998291387 .0770874023 
379.762298584372 .7521972656365 .7421875359 .3417053223352 .941192627346 .845489502 341.3593139648335 .8731994629333 .1301879883329 .4726867676323 .9866027832 318.5004882812313 .0143127441308 .7473144531305 .0899047852301 .1276855469 297.4703063965293 .5080871582290 .4602050781287 .1076049805283 .7549133301 280.4023132324276 .7449035645273 .0874938965268 .8204956055264 .2486877441 259.3721008301254 .4956054688249 .6190032959244 .4376983643240 .1707000732 235.5989074707231 .0270996094226 .4553985596221 .5787963867216 .7021942139 211.520904541206 .3394927979201 .158203125195 .6721038818189 .5764007568 185.3094024658179 .5184020996173 .7274932861168 .241394043162 .7552947998 157.5738983154153 .6116943359151 .4781951904150 .8686065674150 .8686065674 150.5639038086148 .4304046631148 .7351074219148 .7351074219149 .0399017334 149.3446960449149 .9542999268150 .2590942383150 .8686065674151 .4781951904 152.0877990723152 .0877990723152 .3925933838152 .3925933838152 .3925933838 152.3925933838152 .3925933838152 .3925933838152 .3925933838152 .3925933838 152.6972961426152 .6972961426152 .6972961426152 .6972961426153 .0021057129 153.3069000244153 .6116943359153 .9165039062154 .2212982178154 .5260925293 154.8307952881155 .4403991699155 .7451934814156 .0500030518156 .3547973633 156.6596069336156 .9642944336157 .2691040039157 .5738983154157 .5738983154 157.878692627158 .1835021973158 .1835021973158 .4882965088158 .4882965088 158.1835021973157 .878692627157 .2691040039156 .6596069336155 .1356048584 153.6116943359151 .1734008789147 .5160064697142 .9441986084138 .6772003174 134.7149963379131 .9720001221130 .1432037354129 .2288970947128 .3144989014 127.7050018311127 .0953979492126 .7906036377126 .7906036377126 .4858016968 126.1809997559126 .1809997559125 .8762969971125 .8762969971125 .5715026855 125.5715026855125 .5715026855125 .8762969971125 .8762969971125 .8762969971 125.8762969971125 .8762969971125 .8762969971125 .8762969971125 .5715026855 125.2667007446124 .3523025513122 .8283996582120 .9997024536117 .9517974854 115.2088012695113 .3800964355112 .4656982422112 .4656982422112 .7705001831 113.6848983765114 .5991973877115 .818397522116 .7326965332117 .9517974854 118.8662033081120 .0852966309120 .9997024536121 .3044967651133 .4958953857 142.3347015381146 .2969055176148 .1255950928149 .3446960449150 .5639038086 152.0877990723153 .3069000244154 .5260925293155 .7451934814156 .0500030518 156.3547973633156 .0500030518155 .7451934814154 .8307952881155 .7451934814 157.878692627160 .0122070312162 .1457061768164 .5839996338166 .7174987793 169.1557006836171 .2891998291173 .4226989746175 .8609924316177 .6896972656 179.8231964111181 .9566955566183 .7854003906185 .6141052246187 .4429016113 189.2716064453191.1002960205 192.9290008545194 .7577056885196 .5863952637 198.4151000977 200.2438049316202.0724945068203.9011993408 60.65224075317 -16.404378891 -51.2480697632 -9999 -9999 -9999 -9999 -9999 -9999-9999 -9999 -9999 -9999 -9999 -9999-9999-9999-9999

-9999 -9999 -9999 -9999 -9999 -9999 -9999 -9999 -9999 -9999 -9999 -9999 -9999 -9999 - 9999 -

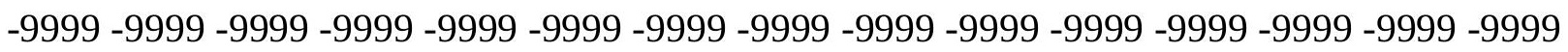
-9999 -9999 -9999 -9999 -9999 -9999 -9999 -9999 -9999 -9999 -9999 -9999 -9999 -9999 -9999 -9999 -9999 -9999 -9999 -9999 -9999 -9999 -9999 -9999 -9999 -9999 -9999 -9999 -9999 -9999 -

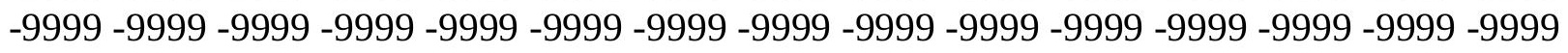

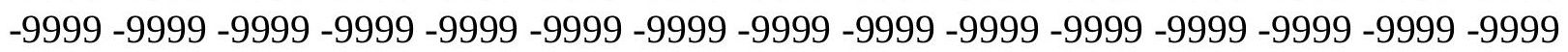


-9999 -9999 -9999 -9999 -9999 -9999 -9999 -9999 -9999 -9999 -9999 -9999 -9999 -9999 -9999 -9999 -9999 -9999 -9999 -9999 -9999 -9999 -9999 -9999 -9999 -9999 -9999 -9999 -9999 -9999 -9999 -9999 -9999 -9999 -9999 -9999 -9999 -9999 -9999 -9999 -9999 -9999 -9999 -9999 -9999 -9999 -9999 -9999 -9999 -9999 -9999 -9999 -9999 -9999 -9999 -9999 -9999 -9999 -9999 -9999 -9999 -9999 -9999 -9999 -9999 -9999 -9999 -9999 -9999 -9999 -9999 -9999 -9999 -9999 -9999 -9999 -9999 489.282409668 479.7489013672470.3511657715 461.8004760742 454.7394104004448 .6437072754442 .8528137207436 .7571105957430 .3565979004 423.6513061523416 .3364868164408 .7168884277401 .0971984863393 .4776000977 385.858001709378 .5430908203371 .228302002364 .5230102539357 .8176879883 351.7219848633345 .9310913086340 .4450073242337 .0922851562333 .4349060059 328.5584106445323 .3770141602318 .5004882812313 .0143127441309 .0520935059 305.3947143555301 .4324951172297 .4703063965293 .5080871582290 .7650146484 287.1076049805283 .4501953125279 .7927856445276 .1353149414271 .8682861328 267.6012878418263 .0296020508258 .1530151367253 .2763977051248 .7046966553 244.1329040527239 .8659057617235 .2940979004230 .7223052979225 .8457946777 220.9691925049215 .787902832210 .6065063477205 .425201416199 .9389953613 194.1481018066189 .8811035156184 .699798584179 .2136993408173 .1179962158 167.0222015381160 .9264984131155 .7451934814152 .3925933838150 .8686065674 151.4781951904152 .6972961426150 .8686065674149 .9542999268149 .6495056152 149.6495056152149 .9542999268150 .2590942383150 .5639038086151 .1734008789 151.4781951904152 .0877990723152 .3925933838152 .3925933838152 .3925933838 152.3925933838152 .3925933838152 .3925933838152 .3925933838152 .3925933838 152.3925933838152 .3925933838152 .6972961426152 .6972961426152 .6972961426 153.0021057129153 .0021057129153 .3069000244153 .6116943359153 .9165039062 154.2212982178154 .8307952881155 .1356048584155 .4403991699155 .7451934814 156.0500030518156 .3547973633156 .3547973633156 .6596069336156 .9642944336 157.2691040039157 .2691040039157 .5738983154157 .878692627157 .878692627 157.878692627157 .878692627157 .5738983154156 .9642944336156 .3547973633 155.1356048584153 .3069000244150 .8686065674147 .2111968994142 .9441986084 138.3724975586133 .8007049561131 .9720001221130 .4479980469129 .2288970947 128.3144989014127 .7050018311127 .4001998901127 .0953979492126 .7906036377 126.4858016968126 .1809997559125 .8762969971125 .8762969971125 .5715026855 125.5715026855125 .5715026855125 .5715026855125 .5715026855125 .5715026855 125.5715026855125 .5715026855125 .5715026855125 .5715026855125 .5715026855 125.2667007446124 .6570968628123 .7427978516122 .5235977173120 .6949005127 118.8662033081116 .7326965332115 .2088012695114 .2944030762114 .2944030762 114.5991973877115 .2088012695116 .1231002808116 .7326965332117 .647102356 118.8662033081120 .0852966309121 .3044967651123 .1332015991126 .4858016968 133.4958953857140 .2012023926144 .7729034424147 .2111968994148 .7351074219 149.9542999268151 .4781951904152 .6972961426153 .9165039062154 .8307952881 155.1356048584155 .4403991699155 .1356048584154 .5260925293153 .9165039062 153.9165039062155 .7451934814157 .5738983154159 .7073974609161 .8408966064 164.2792053223166 .4127044678168 .5462036133170 .6797027588172 .8132019043 174.6419067383176 .7754058838178 .604095459180 .7375946045182 .5662994385 184.3950042725186 .2236938477188 .0523986816189 .8811035156191 .7097930908 193.5386047363195 .3672943115197 .1959991455199 .024703979564 .30966186523 
20.60671424866 -28.93567276 -61.88697052 -9999 -9999 -9999 -9999 -9999 -9999 -9999 -9999 -9999 -9999 -9999 -9999 -9999 -9999 -9999

-9999 -9999 -9999 -9999 -9999 -9999 -9999 -9999 -9999 -9999 -9999 -9999 -9999 -9999 -9999 -9999 -9999 -9999 -9999 -9999 -9999 -9999 -9999 -9999 -9999 -9999 -9999 -9999 -9999 -9999 -9999 -9999 -9999 -9999 -9999 -9999 -9999 -9999 -9999 -9999 -9999 -9999 -9999 -9999 -9999 -9999 -9999 -9999 -9999 -9999 -9999 -9999 -9999 -9999 -9999 -9999 -9999 -9999 -9999 -9999 -9999 -9999 -9999 -9999 -9999 -9999 -9999 -9999 -9999 -9999 -9999 -9999 -9999 -9999 -9999

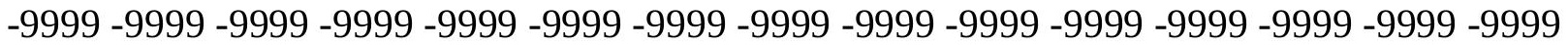
-9999 -9999 -9999 -9999 -9999 -9999 -9999 -9999 -9999 -9999 -9999 -9999 -9999 -9999 -9999 -9999 -9999 -9999 -9999 -9999 -9999 -9999 -9999 -9999 -9999 -9999 -9999 -9999 -9999 -9999 -9999 -9999 -9999 -9999 -9999 -9999 -9999 -9999 -9999 -9999 -9999 -9999 -9999 -9999 -9999 -9999 -9999 -9999 -9999 -9999 -9999 -9999 -9999 -9999 -9999 -9999 -9999 -9999 -9999 -9999 -9999 -9999 -9999 -9999 -9999 -9999 -9999 -9999 -9999 -9999 -9999 -9999 -9999 -9999 -9999 -9999 -9999 -9999 487.473236084 478.7813110352470 .779296875463 .5781860352 457.4825134277451 .6915893555445 .2911071777438 .2810058594430 .9661865234 423.346496582415 .422088623407 .4977111816399 .5733032227391 .6488952637 383.7244873047376 .4096069336369 .399597168362 .6943054199356 .2937927246 350.5028991699345 .0168151855339 .5306091309336 .4827880859331 .9110107422 327.3392028809322 .7674865723318 .1957092285313 .0143127441309 .3569030762 305.3947143555301 .4324951172297 .4703063965293 .5080871582290 .4602050781 286.8027954102282 .8406066895278 .8783874512274 .9161987305270 .6492004395 266.3822021484261 .8103942871257 .2385864258252 .6669006348248 .0950927734 243.8280944824239 .2563018799234 .3798065186229 .8079986572224 .6266021729 219.7501068115214 .5686950684209 .3874053955203 .9011993408198 .4151000977 193.8433074951189 .2716064453184 .0901947021178 .2993011475171 .8988037109 164.8887023926157 .878692627152 .6972961426151 .1734008789151 .4781951904 152.3925933838152 .0877990723151 .1734008789150 .5639038086150 .2590942383 150.5639038086150 .5639038086150 .8686065674151 .1734008789151 .4781951904 151.7830047607152 .0877990723152 .0877990723152 .3925933838152 .3925933838 152.3925933838152 .0877990723152 .0877990723152 .0877990723152 .3925933838 152.3925933838152 .3925933838152 .6972961426152 .6972961426152 .6972961426 153.0021057129153 .3069000244153 .6116943359153 .9165039062154 .2212982178 154.5260925293154 .8307952881155 .1356048584155 .4403991699155 .4403991699 155.7451934814156 .0500030518156 .3547973633156 .3547973633156 .6596069336 156.9642944336156 .9642944336157 .2691040039157 .5738983154157 .5738983154 157.5738983154157 .2691040039156 .6596069336156 .0500030518154 .8307952881 153.0021057129150 .5639038086147 .5160064697143 .5538024902139 .2868041992 135.6293945312133 .1911010742131 .3623962402130 .1432037354128 .9241027832 128.3144989014127 .7050018311127 .4001998901126 .7906036377126 .4858016968 126.1809997559125 .8762969971125 .8762969971125 .5715026855125 .5715026855 125.2667007446125 .2667007446125 .2667007446125 .2667007446125 .2667007446 125.2667007446125 .2667007446125 .2667007446124 .9618988037124 .6570968628 124.0475006104123 .43800354122 .2188034058120 .9997024536119 .4757995605 117.9517974854117 .0374984741116 .4279022217116 .1231002808116 .4279022217 117.0374984741117 .647102356118 .2565994263118 .8662033081120 .0852966309 122.2188034058125 .2667007446129 .2288970947134 .1054992676138 .9819946289 
143.2489929199145 .9920959473147 .5160064697148 .7351074219149 .9542999268 151.1734008789152 .3925933838153 .6116943359154 .2212982178154 .5260925293 154.5260925293154 .2212982178153 .6116943359153 .0021057129151 .7830047607 153.9165039062155 .7451934814157 .5738983154159 .7073974609161 .5361022949 163.6696014404165 .8031005859167 .9365997314169 .7653045654171 .8988037109 173.7274932861175 .5561981201177 .3849029541179 .2136993408181 .0424041748 182.87109375184 .699798584186 .528503418188 .3571929932190 .1858978271 $192.0146026611193 .8433074951195 .672103881863 .09051895142-5.1317987442$ -45.075428009 -9999 -9999 -9999 -9999 -9999 -9999 -9999 -9999 -9999 -9999 -9999 -9999 -9999 -9999 -9999 -9999

-9999 -9999 -9999 -9999 -9999 -9999 -9999 -9999 -9999 -9999 -9999 -9999 -9999 -9999 -9999 -9999 -9999 -9999 -9999 -9999 -9999 -9999 -9999 -9999 -9999 -9999 -9999 -9999 -9999 -9999 -9999 -9999 -9999 -9999 -9999 -9999 -9999 -9999 -9999 -9999 -9999 -9999 -9999 -9999 -9999 -9999 -9999 -9999 -9999 -9999 -9999 -9999 -9999 -9999 -9999 -9999 -9999 -9999 -9999 -9999 -9999 -9999 -9999 -9999 -9999 -9999 -9999 -9999 -9999 -9999 -9999 -9999 -9999 -9999 -9999

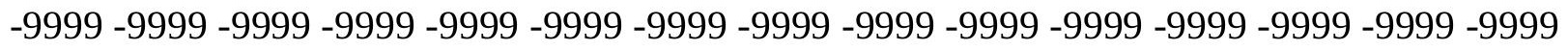

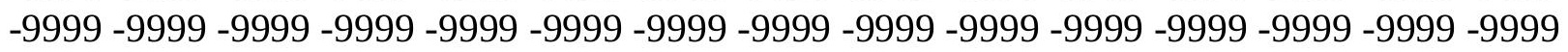

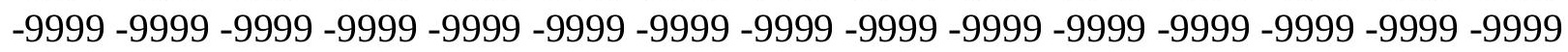

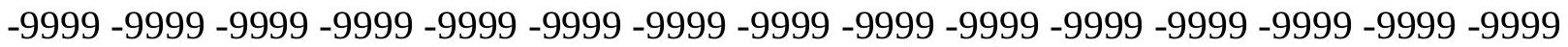

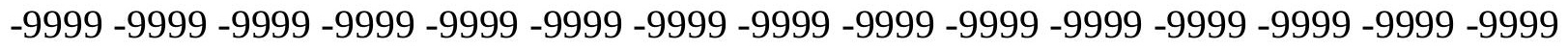

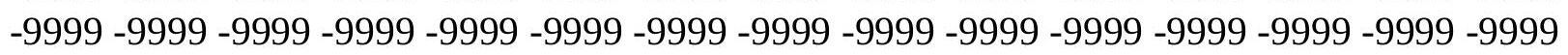
-9999 -9999-9999 -9999 486.6905212402479.1687011719472.3923339844 466.3212890625 460.2255859375453 .2155151367445 .900604248437 .9761962891429 .7470092773 421.517791748413 .2886047363405 .059387207396 .8302001953388 .9057922363 381.2861938477373 .9713134766367 .2661132812360 .8656005859354 .7698974609 348.9790039062343 .7976074219338 .6163024902335 .5683898926331 .3013916016 326.7296142578321 .8530883789316 .9765014648313 .0143127441309 .0520935059 305.0899047852301 .1276855469297 .1654968262292 .8984985352289 .8505859375 285.8884887695281 .9262084961277 .9641113281274 .0018005371269 .4301147461 265.1630859375260 .5913085938256 .3243103027251 .7525024414247 .4855041504 242.9136962891238 .0372009277233 .4653930664228 .5888977051223 .4075012207 218.2261962891213 .0447998047207 .5587005615202 .0724945068197 .8054962158 193.5386047363188 .966796875183 .7854003906177 .3849029541169 .4604949951 160.9264984131153 .0021057129151 .7830047607151 .7830047607152 .0877990723 152.3925933838151 .7830047607151 .4781951904151 .1734008789151 .1734008789 151.1734008789151 .1734008789151 .1734008789150 .5639038086150 .2590942383 150.8686065674149 .6495056152151 .1734008789153 .3069000244152 .3925933838 152.3925933838152 .0877990723152 .0877990723152 .3925933838152 .3925933838 152.3925933838152 .3925933838152 .6972961426152 .6972961426153 .0021057129 153.3069000244153 .6116943359153 .9165039062153 .9165039062154 .2212982178 154.5260925293154 .8307952881154 .8307952881155 .1356048584155 .4403991699 155.4403991699155 .7451934814155 .7451934814156 .0500030518156 .3547973633 156.6596069336156 .6596069336156 .9642944336156 .9642944336156 .9642944336 156.9642944336156 .3547973633155 .7451934814154 .8307952881153 .3069000244 151.1734008789148 .1255950928144 .4682006836140 .8106994629137 .4580993652 135.0198059082132 .8863067627131 .3623962402130 .1432037354129 .2288970947 
128.3144989014127 .7050018311127 .4001998901126 .7906036377126 .4858016968 126.1809997559125 .8762969971125 .5715026855125 .5715026855125 .2667007446 125.2667007446125 .2667007446124 .9618988037124 .9618988037124 .9618988037 124.9618988037124 .6570968628124 .6570968628124 .3523025513123 .7427978516 122.8283996582121 .9140014648120 .9997024536120 .0852966309119 .1709976196 118.5614013672117 .9517974854118 .2565994263118 .2565994263118 .8662033081 119.1709976196119 .1709976196119 .7806015015121 .3044967651124 .0475006104 129.2288970947136 .5437011719142 .9441986084147 .5160064697149 .0399017334 149.3446960449149 .6495056152149 .9542999268150 .8686065674151 .7830047607 152.6972961426153 .6116943359154 .2212982178154 .2212982178154 .2212982178 153.6116943359153 .0021057129152 .0877990723151 .1734008789152 .0877990723 153.6116943359155 .4403991699157 .2691040039159 .0977935791161 .2312927246 163.0599975586164 .8887023926167 .0222015381168 .8509979248170 .6797027588 172.5084075928174 .337097168176 .165802002177 .9945068359179 .8231964111 181.6519012451183 .4806976318185 .3094024658187 .1381072998188 .966796875 190.795501709192 .62420654362 .17617034912 -10.2752904892 -50.9216308594 -9999 -9999 -9999 -9999 -9999 -9999 -9999 -9999 -9999 -9999 -9999 -9999 -9999 -9999 -9999 -9999 -9999 -9999 -9999 -9999 -9999 -9999 -9999 -9999 -9999 -9999 -9999 -9999 -9999 -9999 - -999 -9999 -9999 -9999 -9999 -9999 -9999 -9999 -9999 -9999 -9999 -9999 -9999 -9999 -9999 -9999 -

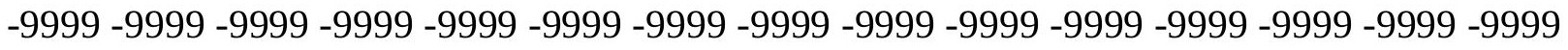

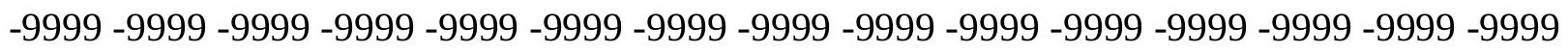
-9999 -9999 -9999 -9999 -9999 -9999 -9999 -9999 -9999 -9999 -9999 -9999 -9999 -9999 -9999 -9999 -9999 -9999 -9999 -9999 -9999 -9999 -9999 -9999 -9999 -9999 -9999 -9999 -9999 -9999 -

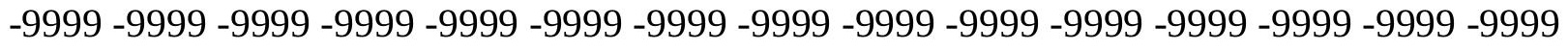

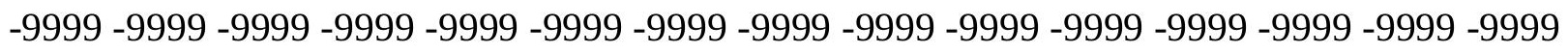
-9999 -9999 -9999 -9999 -9999 -9999 -9999 -9999 -9999 -9999 -9999 -9999 -9999 -9999 -9999 -9999 -9999 -9999 -9999 -9999 -9999 -9999 -9999 -9999 -9999 -9999 -9999 -9999 -9999 -9999 -

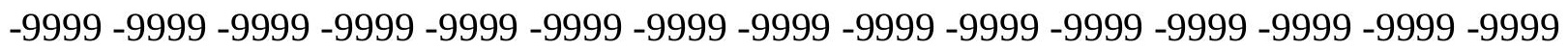
-9999 -9999 -9999 -9999-9999 486.7378234863480 .1573181152474 .0946044922 468.1499938965460 .5303039551452 .3010864258443 .7672119141435 .537902832 427.0039978027418 .4700012207409 .9360046387401 .4020080566393 .1727905273 385.5531921387378 .2383117676371 .228302002364 .8277893066358 .4273071289 352.941192627347 .4549865723342 .2737121582338 .6163024902334 .3493041992 330.0823059082325 .5104980469320 .3291931152316 .3670043945312 .7095031738 308.7473144531304 .7850952148300 .5180969238296 .2510986328292 .8984985352 288.9363098145284 .9740905762281 .0119018555277 .0497131348272 .7827148438 268.5156860352263 .9439086914259 .6769104004255 .1051025391250 .8381958008 246.2664031982241 .6945953369236 .8179931641231 .9414978027226 .7601013184 221.5787963867216 .3973999023211 .2160949707205 .1204071045201 .158203125 197.1959991455192 .9290008545188 .6620025635183 .4806976318174 .337097168 165.1934967041158 .1835021973154 .2212982178152 .6972961426152 .0877990723 152.3925933838152 .0877990723151 .7830047607151 .7830047607152 .0877990723 152.0877990723151 .7830047607150 .8686065674149 .3446960449147 .2111968994 144.1634063721142 .9441986084146 .9064025879154 .8307952881153 .3069000244 152.3925933838152 .6972961426152 .6972961426152 .3925933838152 .3925933838 152.3925933838152 .3925933838152 .3925933838152 .6972961426153 .0021057129 
153.3069000244153 .6116943359153 .6116943359153 .9165039062154 .2212982178 154.2212982178154 .5260925293154 .5260925293154 .8307952881154 .8307952881 155.1356048584155 .1356048584155 .4403991699155 .4403991699155 .7451934814 156.0500030518156 .0500030518156 .3547973633156 .6596069336156 .6596069336 156.3547973633156 .0500030518155 .7451934814154 .8307952881153 .6116943359 151.7830047607149 .0399017334145 .9920959473142 .6394042969139 .5915985107 136.8484954834134 .7149963379132 .8863067627131 .3623962402130 .1432037354 129.2288970947128 .6192932129128 .0097961426127 .4001998901127 .0953979492 126.4858016968126 .1809997559125 .8762969971125 .5715026855125 .2667007446 125.2667007446124 .9618988037124 .9618988037124 .6570968628124 .6570968628 124.6570968628124 .3523025513124 .0475006104123 .7427978516123 .1332015991 122.5235977173121 .9140014648121 .3044967651120 .6949005127120 .0852966309 119.7806015015119 .7806015015120 .0852966309120 .3900985718120 .3900985718 120.3900985718120 .0852966309120 .0852966309120 .9997024536124 .0475006104 130.4479980469141 .7250976562152 .0877990723155 .7451934814154 .8307952881 153.3069000244152 .3925933838152 .0877990723152 .0877990723153 .0021057129 153.6116943359154 .2212982178154 .5260925293154 .5260925293153 .9165039062 153.3069000244152 .6972961426151 .7830047607150 .5639038086150 .2590942383 151.7830047607153 .3069000244155 .1356048584156 .9642944336158 .4882965088 160.3170013428162 .1457061768163 .974395752165 .8031005859167 .6318054199 169.4604949951171 .2891998291173 .1179962158174 .9467010498176 .7754058838 178.604095459180 .432800293181 .9566955566183 .7854003906185 .6141052246 $187.4429016113189 .271606445361 .26181030273-14.0435781479-53.3033409119-9999$ -9999 -9999 -9999 -9999 -9999 -9999 -9999 -9999 -9999 -9999 -9999 -9999 -9999 -9999 -9999 -9999 -9999 -9999 -9999 -9999 -9999 -9999 -9999 -9999 -9999 -9999 -9999 -9999 -9999 -9999 -9999 -9999 -9999 -9999 -9999 -9999 -9999 -9999 -9999 -9999 -9999 -9999 -9999 -9999 -9999 -9999 -9999 -9999 -9999 -9999 -9999 -9999 -9999 -9999 -9999 -9999 -9999 -9999 -9999 -9999

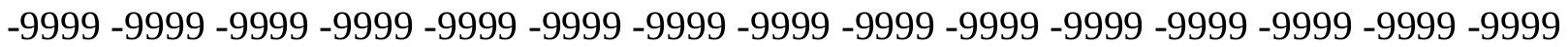

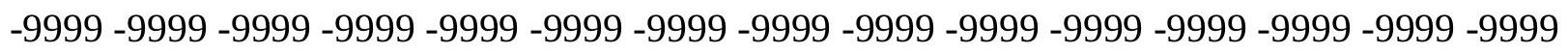

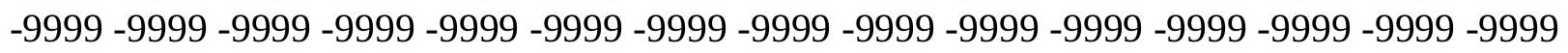
-9999 -9999 -9999 -9999 -9999 -9999 -9999 -9999 -9999 -9999 -9999 -9999 -9999 -9999 -9999 -9999 -9999 -9999 -9999 -9999 -9999 -9999 -9999 -9999 -9999 -9999 -9999 -9999 -9999-999 -999 -

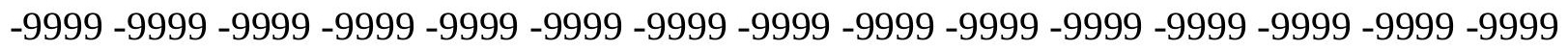

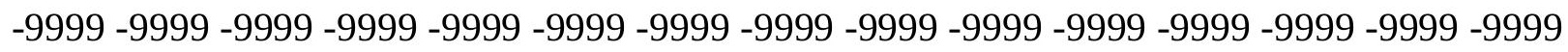
-9999 -9999 -9999 -9999 -9999 -9999 -9999 -9999 -9999 -9999 -9999 -9999 -9999 -9999 -9999 -999 -9999 -9999-9999 -9999-9999-9999 486.682434082 480.2867431641 473.6567993164 466.3212890625457 .1777038574448 .6437072754440 .4144897461431 .8804931641 423.0416870117414 .2030029297405 .3641967773397 .1350097656389 .2106018066 381.8958129883374 .8857116699368 .1803894043362 .0846862793356 .2937927246 350.8077087402345 .6263122559340 .749786377337 .0922851562333 .1301879883 328.8631896973324 .9009094238320 .6339111328315 .7573852539311 .7951965332 307.8330078125303 .8707885742299 .6037902832295 .0320129395291 .9841918945 288.0219116211284 .0596923828279 .7927856445275 .5257873535271 .2587890625 266.9917907715262 .7247924805258 .4577941895253 .8860015869249 .3141937256 244.7424926758239 .8659057617234 .9893035889229 .8079986572224 .9313964844 219.7501068115214 .5686950684208 .1681976318204 .2059936523200 .5485992432 
196.5863952637192 .0146026611186 .2236938477178 .604095459170 .3748931885 163.0599975586157 .5738983154153 .9165039062152 .0877990723151 .4781951904 151.7830047607152 .0877990723152 .3925933838152 .3925933838152 .6972961426 152.3925933838151 .4781951904149 .0399017334145 .0776977539139 .2868041992 133.8007049561140 .2012023926146 .9064025879151 .4781951904153 .0021057129 153.3069000244153 .0021057129152 .3925933838152 .3925933838152 .3925933838 152.3925933838152 .3925933838152 .6972961426153 .0021057129153 .3069000244 153.6116943359153 .6116943359153 .9165039062154 .2212982178154 .2212982178 154.2212982178154 .2212982178154 .5260925293154 .5260925293154 .5260925293 154.5260925293154 .8307952881154 .8307952881155 .1356048584155 .4403991699 155.7451934814155 .7451934814156 .0500030518156 .0500030518156 .0500030518 155.7451934814155 .4403991699154 .8307952881153 .9165039062152 .3925933838 149.9542999268147 .2111968994144 .1634063721141 .1154937744138 .6772003174 136.2389984131134 .4102020264132 .8863067627131 .3623962402130 .4479980469 129.533706665128 .6192932129128 .0097961426127 .4001998901126 .7906036377 126.4858016968126 .1809997559125 .8762969971125 .5715026855125 .2667007446 124.9618988037124 .6570968628124 .6570968628124 .3523025513124 .3523025513 124.0475006104123 .7427978516123 .43800354122 .8283996582122 .5235977173 121.9140014648121 .3044967651120 .9997024536120 .6949005127120 .6949005127 120.9997024536121 .3044967651121 .9140014648121 .9140014648121 .3044967651 120.3900985718119 .4757995605119 .7806015015121 .3044967651126 .4858016968 138.9819946289160 .3170013428159 .0977935791157 .2691040039155 .7451934814 154.8307952881154 .2212982178154 .2212982178154 .5260925293154 .8307952881 155.1356048584155 .1356048584154 .8307952881154 .2212982178153 .3069000244 152.3925933838151 .4781951904149 .9542999268148 .4304046631149 .6495056152 151.1734008789152 .6972961426154 .5260925293156 .0500030518157 .878692627 159.7073974609161 .2312927246163 .0599975586164 .8887023926166 .4127044678 168.241394043170 .070098877171 .8988037109173 .7274932861175 .5561981201 177.0802001953178 .9089050293180 .7375946045182 .5662994385184 .3950042725 64.9192428588926 .54286575317 -20.3928527832 -9999 -9999 -9999 -9999 -9999 -9999 -9999 -9999 -9999 -9999 -9999 -9999 -9999 -9999 -9999 -9999 -9999

-9999 -9999 -9999 -9999 -9999 -9999 -9999 -9999 -9999 -9999 -9999 -9999 -9999 -9999 -9999

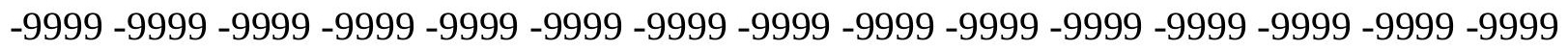

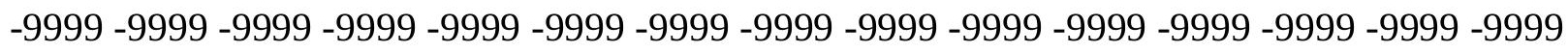
-9999 -9999 -9999 -9999 -9999 -9999 -9999 -9999 -9999 -9999 -9999 -9999 -9999 -9999 -9999

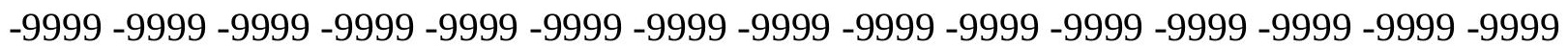

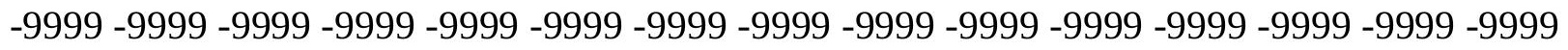

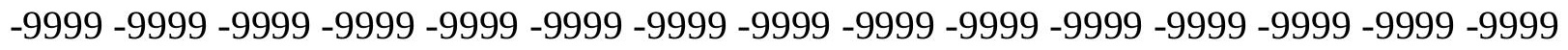

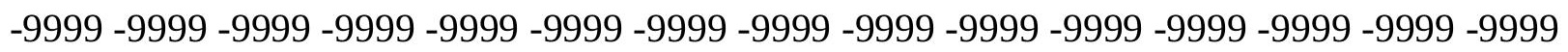

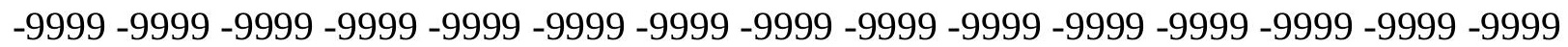

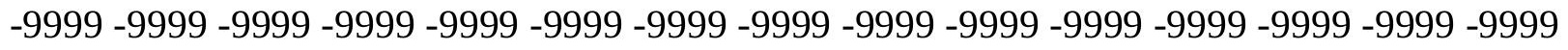

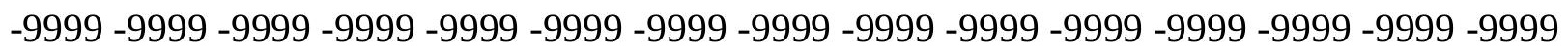
-9999 -9999 -9999-9999-9999-9999-9999 485.2089233398 477.9582214355 469.7834777832 460.5303039551453 .2155151367444 .9862976074436 .1474914551427 .0039978027 417.8604125977409 .0216064453400 .487701416392 .5632019043385 .2484130859 378.2383117676 371.5331115723 365.4374084473 359.6465148926354.1603088379 
348.9790039062344 .1023864746339 .5306091309334 .9588928223331 .9110107422 327.9487915039323 .9866027832319 .7196044922314 .8429870605310 .8807983398 306.6138000488302 .3468017578298 .0798950195294 .7272033691290 .7650146484 286.8027954102282 .5357971191278 .5736083984274 .3066101074270 .0396118164 265.7726135254261 .2008972168256 .9338989258252 .3621063232247 .7902984619 242.9136962891237 .7324066162232 .8558044434227 .6744995117222 .7978973389 217.6165924072212 .1304016113207 .25390625203 .2917022705199 .329498291 194.7577056885188 .966796875182 .261505127174 .9467010498167 .6318054199 160.9264984131155 .4403991699151 .7830047607150 .5639038086150 .8686065674 152.0877990723152 .3925933838152 .6972961426153 .0021057129153 .0021057129 152.0877990723149 .9542999268145 .0776977539139 .2868041992136 .4708709717 139.0690612793144 .3253326416149 .6495056152153 .6116943359153 .3069000244 152.6972961426152 .0877990723152 .0877990723152 .0877990723152 .0877990723 152.3925933838152 .6972961426153 .0021057129153 .3069000244153 .6116943359 153.9165039062153 .9165039062153 .9165039062154 .2212982178154 .2212982178 154.2212982178153 .9165039062153 .9165039062153 .9165039062153 .9165039062 154.2212982178154 .2212982178154 .5260925293154 .8307952881155 .1356048584 155.4403991699155 .4403991699155 .7451934814155 .7451934814155 .4403991699 155.1356048584154 .5260925293153 .9165039062152 .3925933838150 .5639038086 148.1255950928145 .3825073242142 .6394042969140 .2012023926137 .7628936768 135.9342041016134 .1054992676132 .5814971924131 .3623962402130 .4479980469 129.533706665128 .6192932129128 .0097961426127 .4001998901126 .7906036377 126.4858016968125 .8762969971125 .5715026855125 .2667007446124 .9618988037 124.6570968628124 .3523025513124 .3523025513124 .0475006104123 .7427978516 123.43800354123 .1332015991122 .8283996582122 .2188034058121 .9140014648 121.6092987061121 .3044967651120 .9997024536121 .3044967651121 .6092987061 122.2188034058123 .1332015991123 .1332015991121 .9140014648119 .7806015015 118.2565994263117 .647102356118 .2565994263120 .3900985718124 .0475006104 144.4682006836154 .2212982178156 .6596069336156 .9642944336156 .6596069336 156.6596069336156 .6596069336156 .6596069336156 .6596069336156 .6596069336 156.3547973633155 .7451934814154 .8307952881153 .6116943359152 .6972961426 151.1734008789149 .9542999268148 .1255950928147 .8208007812149 .0399017334 150.5639038086152 .0877990723153 .6116943359155 .4403991699156 .9642944336 158.4882965088160 .3170013428161 .8408966064163 .6696014404165 .1934967041 167.0222015381168 .8509979248170 .6797027588172 .2035980225174 .0323028564 175.8609924316177 .6896972656179 .5184020996181 .042404174863 .70008850098 5.196622848511 -32.0477752686 -9999 -9999 -9999 -9999 -9999 -9999 -9999 -9999 -9999 -9999 -9999-9999-9999-9999 -9999-9999-9999 -9999 -9999 -9999 -9999 -9999 -9999 -9999 -9999 -9999 -9999 -9999 -9999 -9999 -9999 -9999 -9999 -9999 -9999 -9999 -9999 -9999 -9999 -9999 -9999 -9999 -9999 -9999 -9999 -9999 -9999 -

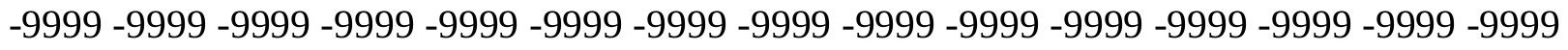

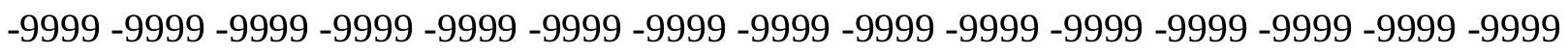
-9999 -9999 -9999 -9999 -9999 -9999 -9999 -9999 -9999 -9999 -9999 -9999 -9999 -9999 -9999 -9999 -9999 -9999 -9999 -9999 -9999 -9999 -9999 -9999 -9999 -9999 -9999 -9999 -9999 -9999 -9999 -9999 -9999 -9999 -9999 -9999 -9999 -9999 -9999 -9999 -9999 -9999 -9999 -9999 -9999 -

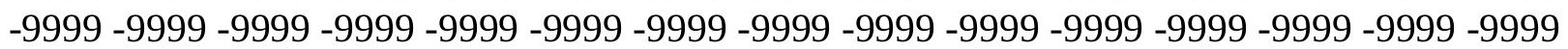


-9999 -9999 -9999 -9999 -9999 -9999 -9999 -9999 -9999 -9999 -9999 -9999 -9999 -9999 -9999 -9999 -9999 -9999 -9999 -9999 -9999 -9999 -9999 -9999 -9999 -9999 -9999 -9999 -9999 -9999 -9999 -9999 -9999 -9999 -9999 -9999 -9999 -9999 -9999 -9999 -9999 -9999 -9999 -9999 -9999 -9999 -9999 -9999 -9999 -9999 -9999 -9999 -9999 481.6195068359473 .3871765137 464.9727478027456 .8852539062448 .6437072754439 .500213623430 .0517883301 420.9082946777411 .7647094727403 .5354919434395 .611114502388 .296295166 381.2861938477374 .5809020996368 .4851989746362 .3894958496356 .9034118652 351.7219848633346 .845489502342 .2737121582338 .0067138672334 .9588928223 331.3013916016327 .3392028809323 .0722045898318 .8052062988313 .6239013672 309.3569030762305 .3947143555301 .1276855469297 .7750854492293 .5080871582 289.5458984375285 .2789001465281 .0119018555277 .0497131348272 .7827148438 268.2109069824263 .9439086914259 .3721008301254 .8003997803250 .2286071777 245.3520050049240 .1707000732235 .2940979004230 .4176025391225 .5410003662 220.3596038818215 .1782989502209 .9969024658206 .0346984863202 .0724945068 197.500793457192 .3193969727186 .2236938477179 .5184020996172 .2035980225 164.5839996338157 .5738983154151 .4781951904150 .2590942383150 .2590942383 151.1734008789152 .0877990723152 .6972961426153 .0021057129153 .0021057129 152.6972961426152 .0877990723145 .9920959473142 .0299072266139 .9368896484 140.9653778076144 .6100616455149 .1109924316153 .0021057129152 .0877990723 151.7830047607151 .7830047607151 .7830047607152 .0877990723152 .0877990723 152.3925933838152 .6972961426153 .0021057129153 .3069000244153 .6116943359 153.9165039062153 .9165039062153 .9165039062153 .9165039062153 .9165039062 153.9165039062153 .6116943359153 .6116943359153 .6116943359153 .6116943359 153.6116943359153 .6116943359153 .9165039062154 .2212982178154 .5260925293 154.8307952881155 .1356048584155 .1356048584155 .1356048584155 .1356048584 154.8307952881154 .5260925293153 .6116943359152 .3925933838150 .5639038086 148.7351074219146 .2969055176143 .8585968018141 .4203033447138 .9819946289 137.1533050537135 .3246002197133 .8007049561132 .5814971924131 .3623962402 130.4479980469129 .533706665128 .6192932129128 .0097961426127 .4001998901 126.7906036377126 .1809997559125 .8762969971125 .2667007446124 .9618988037 124.6570968628124 .3523025513124 .0475006104124 .0475006104123 .7427978516 123.43800354122 .8283996582122 .5235977173122 .2188034058121 .6092987061 121.6092987061121 .3044967651121 .3044967651121 .3044967651121 .6092987061 122.2188034058122 .8283996582123 .43800354120 .9997024536118 .2565994263 116.4279022217115 .2088012695115 .2088012695117 .647102356124 .3523025513 136.2389984131147 .5160064697153 .9165039062156 .9642944336158 .1835021973 158.7929992676159 .0977935791159 .0977935791158 .7929992676158 .4882965088 157.5738983154156 .6596069336155 .4403991699154 .2212982178153 .0021057129 151.4781951904149 .9542999268148 .1255950928146 .2969055176146 .9064025879 148.4304046631149 .9542999268151 .1734008789152 .6972961426154 .2212982178 155.7451934814157 .5738983154159 .0977935791160 .6217956543162 .4505004883 163.974395752165 .8031005859167 .6318054199169 .1557006836170 .9844970703 172.8132019043174 .6419067383176 .165802002177 .994506835962 .48094940186 -3.4462082386 -37.3892555237 -9999 -9999 -9999 -9999 -9999 -9999 -9999 -9999 -9999 -9999 -9999 -9999 -9999 -9999 -9999 -9999 -9999 -9999 -9999 -9999 -9999 -9999 -9999 -9999 -9999 -9999 -9999 -9999 -9999 -9999 -9999 -9999 
-9999 -9999 -9999 -9999 -9999 -9999 -9999 -9999 -9999 -9999 -9999 -9999 -9999 -9999 -9999 -9999 -9999 -9999 -9999 -9999 -9999 -9999 -9999 -9999 -9999 -9999 -9999 -9999 -9999 -9999

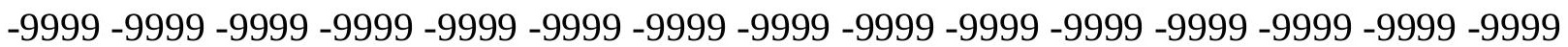
-9999 -9999 -9999 -9999 -9999 -9999 -9999 -9999 -9999 -9999 -9999 -9999 -9999 -9999 -9999 -9999 -9999 -9999 -9999 -9999 -9999 -9999 -9999 -9999 -9999 -9999 -9999 -9999 -9999 -9999 -9999 -9999 -9999 -9999 -9999 -9999 -9999 -9999 -9999 -9999 -9999 -9999 -9999 -9999 -9999 -9999 -9999 -9999 -9999 -9999 -9999 -9999 -9999 -9999 -9999 -9999 -9999 -9999 -9999 -9999

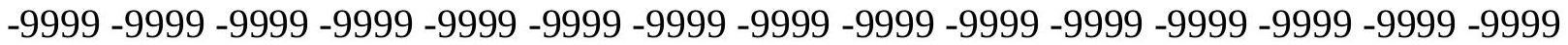

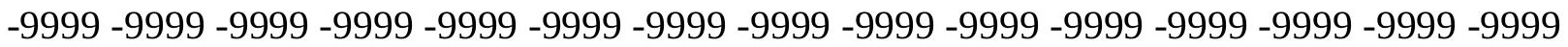
-9999 -9999 -9999 -9999 -9999 -9999 -9999 -9999 -9999 -9999 -9999 -9999 -9999 -9999 -9999 -999 -9999 -9999 -9999 -9999 -9999 -9999 -9999 -9999 -9999 -9999 468.5473632812 460.0913391113451 .4091186523442 .2431945801432 .4901123047423 .0416870117 414.5078125405 .9737854004398 .3541870117391 .0393066406384 .029296875 377.324005127370 .9234924316365 .132598877359 .6465148926354 .4650878906 349.5885009766345 .0168151855340 .4450073242337 .3970947266334 .0444946289 330.3870849609326 .4248962402322 .1578979492317 .5860900879313 .3190917969 309.0520935059304 .7850952148300 .5180969238296 .2510986328291 .9841918945 287.7171936035283 .4501953125279 .4880065918275 .2210083008270 .9540100098 266.3822021484261 .8103942871257 .2385864258252 .3621063232247 .4855041504 242.6089935303237 .7324066162232 .8558044434227 .9792938232223 .1027069092 217.6165924072212 .7400054932208 .7778015137204 .5108032227200 .2438049316 195.3672943115190 .1858978271184 .0901947021177 .0802001953168 .8509979248 160.6217956543154 .2212982178150 .8686065674149 .9542999268150 .2590942383 151.4781951904152 .3925933838153 .0021057129153 .0021057129152 .3925933838 150.2590942383145 .6873016357144 .094039917143 .0786590576143 .5841369629 145.7425842285148 .5255584717150 .1675415039149 .6495056152150 .8686065674 151.1734008789151 .4781951904151 .7830047607152 .0877990723152 .3925933838 152.6972961426153 .3069000244153 .6116943359153 .9165039062153 .9165039062 154.2212982178154 .2212982178153 .9165039062153 .9165039062153 .6116943359 153.3069000244153 .3069000244153 .0021057129153 .0021057129153 .0021057129 153.0021057129153 .3069000244153 .6116943359153 .9165039062154 .2212982178 154.5260925293154 .8307952881154 .8307952881154 .8307952881154 .5260925293 154.2212982178153 .3069000244152 .3925933838150 .8686065674149 .0399017334 146.9064025879144 .4682006836142 .3347015381140 .2012023926138 .0677032471 136.5437011719134 .7149963379133 .4958953857132 .2767028809131 .0576019287 130.1432037354129 .2288970947128 .6192932129127 .7050018311127 .0953979492 126.4858016968126 .1809997559125 .5715026855125 .2667007446124 .9618988037 124.3523025513124 .0475006104123 .7427978516123 .43800354123 .1332015991 122.8283996582122 .5235977173122 .2188034058121 .6092987061121 .3044967651 121.3044967651120 .9997024536120 .9997024536120 .9997024536120 .9997024536 120.9997024536120 .3900985718118 .2565994263115 .818397522113 .9896011353 112.7705001831113 .6848983765117 .0374984741124 .3523025513134 .1054992676 144.1634063721152 .0877990723157 .2691040039160 .0122070312161 .5361022949 162.1457061768161 .8408966064161 .5361022949160 .6217956543159 .4026031494 158.1835021973156 .6596069336155 .1356048584153 .3069000244151 .7830047607 149.9542999268148 .1255950928145 .9920959473144 .7729034424146 .2969055176 
147.5160064697149 .0399017334150 .2590942383151 .7830047607153 .3069000244 154.8307952881156 .0500030518157 .878692627159 .4026031494160 .9264984131 162.7552947998164 .5839996338166 .4127044678167 .9365997314169 .7653045654 $171.2891998291173 .117996215866 .4431610107432 .38507461548-8.88073253632$ -38.8891601562 -9999 -9999 -9999 -9999 -9999 -9999 -9999 -9999 -9999 -9999 -9999 -9999 -9999 -9999 -9999-9999-9999

-9999 -9999 -9999 -9999 -9999 -9999 -9999 -9999 -9999 -9999 -9999 -9999 -9999 -9999 -9999

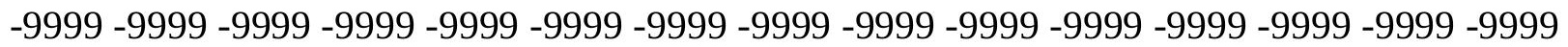
-9999 -9999 -9999 -9999 -9999 -9999 -9999 -9999 -9999 -9999 -9999 -9999 -9999 -9999 -9999 -9999 -9999 -9999 -9999 -9999 -9999 -9999 -9999 -9999 -9999 -9999 -9999 -9999 -9999 -9999 -9999 -9999 -9999 -9999 -9999 -9999 -9999 -9999 -9999 -9999 -9999 -9999 -9999 -9999 -9999 -9999 -9999 -9999 -9999 -9999 -9999 -9999 -9999 -9999 -9999 -9999 -9999 -9999 -9999 -9999 -9999 -9999 -9999 -9999 -9999 -9999 -9999 -9999 -9999 -9999 -9999 -9999 -9999 -9999 -9999 -9999 -9999 -9999 -9999 -9999 -9999 -9999 -9999 -9999 -9999 -9999 -9999 -9999 -9999 -9999 -9999 -9999 -9999 -9999 -9999 -9999 -9999 -9999 -9999 -9999 -9999 -9999 -9999 -9999 -9999

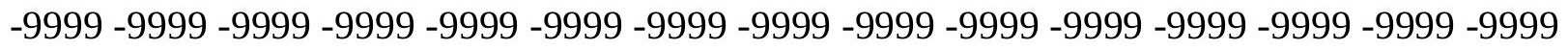

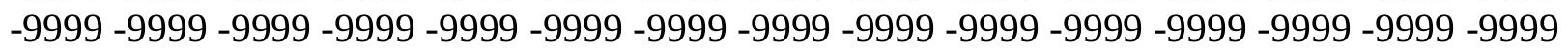
-9999 -9999 -9999 -9999 -9999 -9999 -9999 -9999 -9999-9999 -9999 462.7528381348 453.778717041444 .4324035645434 .7695007324425 .1752929688416 .6412963867 408.412109375400 .792388916393 .4776000977386 .4674987793379 .762298584 373.3617858887 367.570892334362.0846862793 356.9034118652 352.0267944336 347.4549865723342 .8833007812338 .9211120605336 .4827880859333 .1301879883 329.4726867676324 .9009094238320 .6339111328316 .3670043945311 .7951965332 307.5281982422302 .9563903809298 .6893920898294 .4223937988290 .1553955078 285.8884887695281 .6214904785277 .3544921875273 .0874938965268 .8204956055 263.9439086914259 .3721008301254 .8003997803249 .9237976074245 .0471954346 240.1707000732235 .5989074707230 .4176025391225 .5410003662220 .3596038818 215.1782989502210 .9113006592207 .25390625202 .9868927002198 .7198944092 193.5386047363188 .0523986816181 .9566955566172 .8132019043163 .974395752 156.3547973633151 .7830047607149 .6495056152149 .6495056152150 .8686065674 152.0877990723152 .6972961426152 .6972961426151 .7830047607150 .2590942383 148.7351074219146 .7741088867145 .8546447754145 .9221801758146 .9208374023 148.313293457149 .2961273193150 .0095367432150 .8686065674151 .1734008789 151.4781951904151 .7830047607152 .0877990723152 .6972961426153 .0021057129 153.3069000244153 .9165039062153 .9165039062154 .2212982178154 .2212982178 154.2212982178153 .9165039062153 .6116943359153 .6116943359153 .3069000244 153.0021057129152 .6972961426152 .3925933838152 .3925933838152 .6972961426 153.0021057129153 .3069000244153 .6116943359153 .9165039062154 .2212982178 154.5260925293154 .5260925293154 .5260925293154 .2212982178153 .9165039062 153.0021057129152 .0877990723150 .8686065674149 .0399017334147 .2111968994 145.3825073242143 .2489929199141 .1154937744139 .2868041992137 .4580993652 135.9342041016134 .4102020264133 .1911010742131 .9720001221130 .7528076172 129.8385009766128 .9241027832128 .3144989014127 .7050018311126 .7906036377 126.4858016968125 .8762969971125 .2667007446124 .9618988037124 .6570968628 124.3523025513123 .7427978516123 .43800354123 .1332015991122 .8283996582 122.5235977173121 .9140014648121 .6092987061121 .3044967651120 .9997024536 
120.3900985718120 .0852966309119 .7806015015119 .1709976196118 .2565994263 116.7326965332114 .5991973877112 .4656982422110 .9418029785110 .6370010376 112.4656982422117 .0374984741124 .3523025513133 .8007049561143 .5538024902 152.0877990723158 .4882965088162 .4505004883164 .5839996338165 .1934967041 165.1934967041164 .2792053223162 .7552947998161 .2312927246159 .7073974609 157.878692627156 .0500030518154 .2212982178152 .3925933838150 .2590942383 148.1255950928145 .9920959473143 .8585968018143 .8585968018145 .0776977539 146.6015930176147 .8208007812149 .3446960449150 .5639038086152 .0877990723 153.3069000244154 .8307952881156 .3547973633158 .1835021973160 .0122070312 161.5361022949163 .3648071289164 .8887023926166 .7174987793168 .241394043 170.07009887765 .5288009643615 .66964149475 -16.5821628571 -9999 -9999 -9999 -9999 -9999 -9999 -9999 -9999 -9999 -9999 -9999 -9999 -9999 -9999 -9999 -9999 -9999 -9999 -9999 -9999 -9999 -9999 -9999 -9999 -9999 -9999 -9999 -9999 -9999 -9999 -9999 -9999 -9999 -9999 -9999 -9999 -9999 -9999 -9999 -9999 -9999 -9999 -9999 -9999 -9999 -9999 -9999 -9999 -9999 -9999 -9999 -9999 -9999 -9999 -9999 -9999 -9999 -9999 -9999 -9999 -9999 -9999 -9999

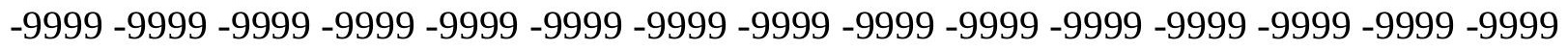

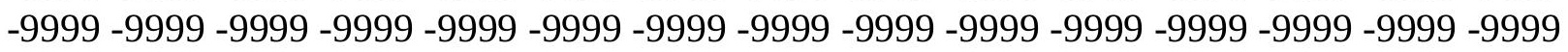

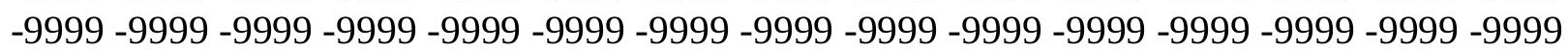
-9999 -9999 -9999 -9999 -9999 -9999 -9999 -9999 -9999 -9999 -9999 -9999 -9999 -9999 -9999

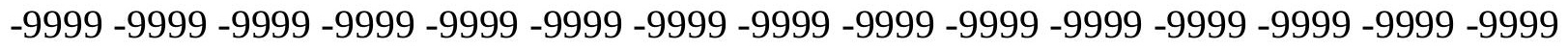

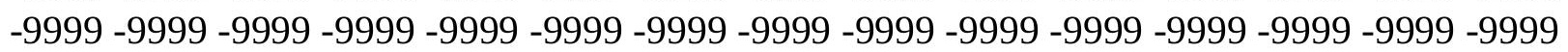

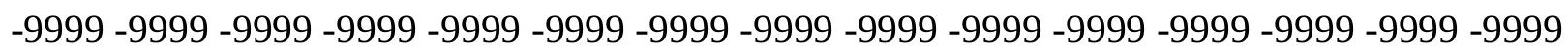
-9999 -9999 -9999 -9999 -9999 -9999 -9999 -9999 -9999 -9999 -9999 -9999 -9999 -9999 -9999 -9999 -9999 -9999 -9999 -9999 -9999 -9999 -9999 -9999 -9999 -9999 -9999 455.8748474121 446.5137634277437 .0406494141427 .7763671875419 .0474243164410 .8503112793 403.2307128906396 .220703125389 .2106018066382 .200592041375 .495300293 369.7043151855363 .9135131836359 .036895752354 .1603088379349 .5885009766 345.3215026855341 .3593139648338 .3114929199335 .8731994629332 .2157897949 327.6440124512323 .3770141602319 .1099853516314 .5382080078309 .9664916992 305.3947143555301 .1276855469296 .5559082031292 .2889099121288 .0219116211 283.7549133301279 .4880065918275 .2210083008270 .6492004395266 .0773925781 261.5056152344256 .9338989258252 .0572967529247 .4855041504242 .6089935303 237.7324066162232 .8558044434227 .6744995117222 .4931030273217 .3117980957 213.3495941162209 .692199707205 .7299957275201 .7678070068196 .891204834 191.4051055908184 .699798584176 .165802002167 .0222015381158 .4882965088 152.0877990723149 .3446960449149 .3446960449150 .5639038086151 .7830047607 152.3925933838152 .3925933838151 .7830047607150 .8686065674150 .5639038086 149.3132171631 148.3347015381 147.8989715576148.099609375148.7287750244 149.4891815186150 .3817138672151 .1734008789150 .8686065674151 .1734008789 151.7830047607152 .3925933838152 .6972961426153 .3069000244153 .6116943359 153.9165039062154 .2212982178154 .2212982178154 .2212982178154 .2212982178 153.9165039062153 .6116943359153 .3069000244153 .0021057129152 .6972961426 152.3925933838152 .0877990723152 .0877990723152 .0877990723152 .3925933838 152.6972961426153 .3069000244153 .6116943359153 .9165039062154 .2212982178 154.2212982178154 .2212982178153 .9165039062153 .6116943359153 .0021057129 151.7830047607150 .8686065674149 .3446960449147 .5160064697145 .6873016357 
143.8585968018142 .0299072266140 .2012023926138 .3724975586136 .8484954834 135.3246002197133 .8007049561132 .5814971924131 .6672058105130 .4479980469 129.533706665128 .6192932129128 .0097961426127 .4001998901126 .7906036377 126.1809997559125 .5715026855125 .2667007446124 .6570968628124 .3523025513 124.0475006104123 .43800354123 .1332015991122 .8283996582122 .2188034058 121.9140014648121 .6092987061120 .9997024536120 .3900985718119 .7806015015 119.1709976196117 .9517974854116 .7326965332114 .9039993286112 .7705001831 110.6370010376108 .8082962036107 .8938980103108 .5035018921111 .24659729 116.4279022217124 .3523025513134 .1054992676144 .4682006836153 .9165039062 160.9264984131165 .8031005859168 .241394043168 .8509979248168 .241394043 167.0222015381165 .1934967041163 .3648071289161 .2312927246159 .0977935791 157.2691040039155.1356048584153.0021057129150.5639038086148.4304046631 145.9920959473143 .5538024902141 .1154937744142 .9441986084144 .1634063721 145.3825073242146 .6015930176148 .1255950928149 .3446960449150 .5639038086 152.0877990723153 .6116943359155 .1356048584156 .9642944336158 .7929992676 160.3170013428162 .1457061768163 .6696014404165 .4983062744167 .0222015381 64.6144485473614 .20066070557 -16.4247741699 -9999 -9999 -9999 -9999 -9999 -9999 -9999 -9999 -9999 -9999 -9999 -9999 -9999 -9999 -9999 -9999 -9999 -9999 -9999 -9999 -9999 -9999 -9999 -9999 -9999 -9999 -9999 -9999 -9999 -9999 -9999 -9999 -9999

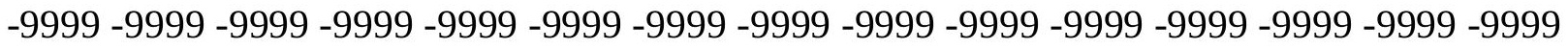

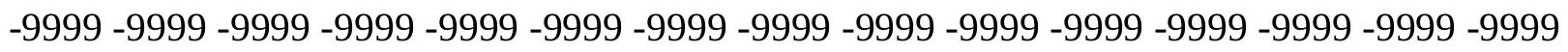
-9999 -9999 -9999 -9999 -9999 -9999 -9999 -9999 -9999 -9999 -9999 -9999 -9999 -9999 -9999 -9999 -9999 -9999 -9999 -9999 -9999 -9999 -9999 -9999 -9999 -9999 -9999 -9999 -9999 -9999 -

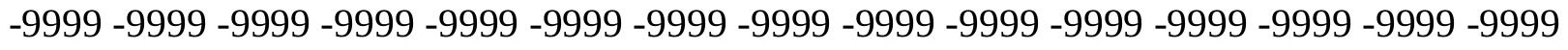

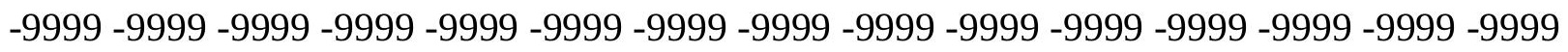
-9999 -9999 -9999 -9999 -9999 -9999 -9999 -9999 -9999 -9999 -9999 -9999 -9999 -9999 -9999

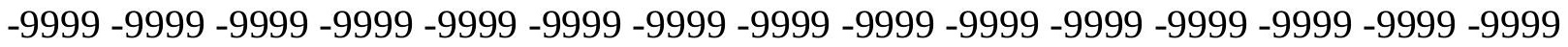

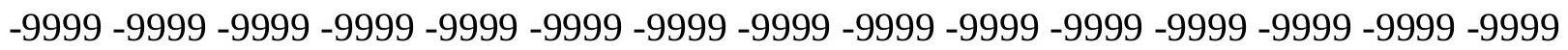

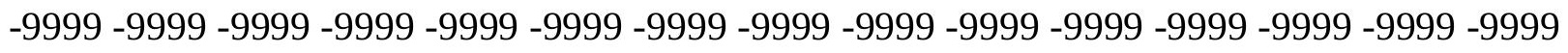
-9999 -9999 -9999 -9999 -9999 -9999 -9999 -9999 -9999 -9999 -9999 -9999 -9999 448.5229187012439 .259979248430 .2020263672421 .5302124023413 .3862609863 405.7990112305398 .6589050293391 .3440856934384 .029296875377 .324005127 371.228302002366 .0469055176360 .8656005859356 .2937927246351 .7219848633 347.4549865723343 .4927978516339 .5306091309337 .7019042969334 .0444946289 330.0823059082325 .8153076172321 .5483093262316 .9765014648312 .4047851562 307.8330078125303 .2611999512298 .6893920898294 .4223937988289 .8505859375 285.2789001465281 .0119018555276 .4400939941272 .1730957031267 .9060974121 263.3344116211258 .7626037598254 .1907958984249 .6190032959245 .0471954346 240.1707000732234 .9893035889229 .8079986572224 .6266021729219 .4452972412 215.4830932617212 .1304016113208 .4730072021204 .5108032227199 .6342926025 194.1481018066187 .4429016113179 .5184020996170 .3748931885160 .9264984131 152.3925933838149 .9542999268149 .3446960449150 .5639038086152 .0877990723 152.3925933838152 .3925933838152 .0877990723151 .4781951904151 .1734008789 151.1734008789150 .1524353027149 .3753967285149 .08984375149 .3068847656 149.8697662354150 .4932403564150 .8686065674150 .5639038086151 .1734008789 151.7830047607152 .3925933838153 .0021057129153 .3069000244153 .9165039062 
153.9165039062154 .2212982178154 .5260925293154 .5260925293154 .2212982178 153.9165039062153 .6116943359153 .3069000244153 .0021057129152 .3925933838 152.0877990723151 .7830047607151 .7830047607151 .7830047607152 .0877990723 152.6972961426153 .0021057129153 .3069000244153 .6116943359153 .6116943359 153.9165039062153 .9165039062153 .6116943359153 .3069000244152 .6972961426 151.7830047607150 .5639038086149 .3446960449147 .8208007812146 .2969055176 144.4682006836142 .6394042969140 .8106994629139 .2868041992137 .4580993652 135.9342041016134 .7149963379133 .4958953857132 .2767028809131 .0576019287 130.1432037354129 .2288970947128 .3144989014127 .7050018311127 .0953979492 126.4858016968125 .8762969971125 .2667007446124 .9618988037124 .3523025513 124.0475006104123 .7427978516123 .1332015991122 .8283996582122 .2188034058 121.9140014648121 .3044967651120 .6949005127120 .0852966309119 .1709976196 117.9517974854116 .4279022217114 .2944030762112 .1608963013109 .4179000854 107.2844009399 105.4557037354105.1509017944 106.6747970581 110.0273971558 115.818397522124 .3523025513135 .3246002197146 .6015930176156 .6596069336 164.2792053223 169.1557006836171.8988037109 172.2035980225171.5939941406 169.7653045654167 .6318054199165 .4983062744163 .0599975586160 .6217956543 158.1835021973156 .0500030518153 .6116943359151 .1734008789148 .7351074219 146.2969055176143 .8585968018141 .1154937744140 .5059967041141 .7250976562 142.9441986084144 .1634063721145 .3825073242146 .6015930176148 .1255950928 149.3446960449150 .8686065674152 .3925933838154 .2212982178155 .7451934814 157.5738983154159 .0977935791160 .6217956543162 .450500488368 .57665252686 63.3953094482417 .9058971405 -14.6264514923 -9999 -9999 -9999 -9999 -9999 -9999 -9999 -9999 -9999 -9999 -9999 -9999 -9999 -9999 -9999 -9999 -9999 -9999

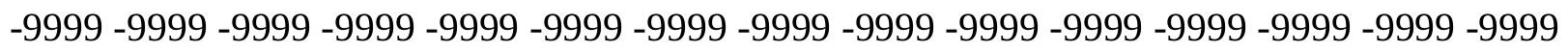
-9999 -9999 -9999 -9999 -9999 -9999 -9999 -9999 -9999 -9999 -9999 -9999 -9999 -9999 -9999 -9999 -9999 -9999 -9999 -9999 -9999 -9999 -9999 -9999 -9999 -9999 -9999 -9999 -9999 - -9999 -

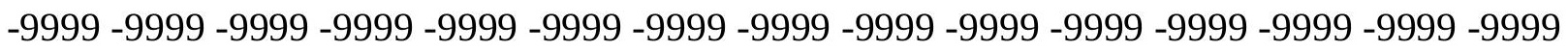
-9999 -9999 -9999 -9999 -9999 -9999 -9999 -9999 -9999 -9999 -9999 -9999 -9999 -9999 -9999

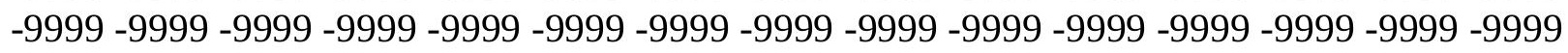
-9999 -9999 -9999 -9999 -9999 -9999 -9999 -9999 -9999 -9999 -9999 -9999 -9999 -9999 -9999 -9999 -9999 -9999 -9999 -9999 -9999 -9999 -9999 -9999 -9999 -9999 -9999 -9999 -9999 -9999 -

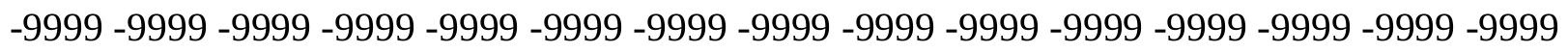

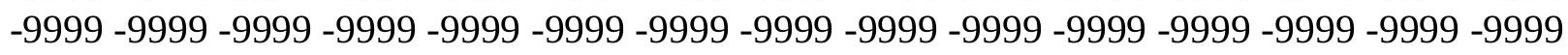
-9999 -9999 -9999 -9999 -9999 -9999 -9999 -9999 -9999 -9999 -9999 -9999 -9999 -9999 -9999 -9999 -9999 -9999 -9999 -9999 -9999 -9999 -9999 -9999 -9999 -9999 -9999 -9999 450.3781433105441 .3144836426432 .4289550781423 .8597106934415 .7070922852 407.9849243164400 .6087646484393 .4776000977385 .5531921387378 .8479003906 373.0570068359367 .570892334362 .6943054199358 .1224975586353 .8554992676 349.5885009766345 .6263122559341 .6640930176339 .2258911133335 .8731994629 332.2157897949328 .2536010742323 .6817932129319 .1099853516314 .5382080078 309.6617126465305 .0899047852300 .8229064941296 .2510986328291 .6794128418 287.1076049805282 .5357971191277 .6592102051273 .6971130371269 .4301147461 265.1630859375260 .8960876465256 .3243103027251 .4476928711246 .8759002686 242.3041992188237 .1228027344231 .9414978027226 .4553985596220 .9691925049 217.3117980957 214.2639007568210.9113006592 206.9490966797 202.3773040771 
196.891204834190 .795501709183 .1759033203174 .337097168164 .8887023926 156.6596069336151 .4781951904149 .6495056152149 .9542999268151 .1734008789 152.3925933838152 .3925933838152 .0877990723151 .7830047607151 .4781951904 151.7830047607151 .0914306641150 .1933746338149 .6549530029149 .7147674561 150.1387329102150 .5201721191150 .3727874756149 .9542999268150 .5639038086 151.4781951904152 .3925933838153 .0021057129153 .3069000244153 .9165039062 153.9165039062154 .2212982178154 .5260925293154 .5260925293154 .5260925293 154.2212982178153 .6116943359153 .3069000244152 .6972961426152 .3925933838 152.0877990723151 .7830047607151 .7830047607151 .7830047607152 .0877990723 152.3925933838152 .6972961426153 .0021057129153 .3069000244153 .6116943359 153.6116943359153 .6116943359153 .3069000244153 .0021057129152 .3925933838 151.7830047607150 .5639038086149 .3446960449148 .1255950928146 .6015930176 144.7729034424143 .2489929199141 .4203033447139 .8963928223138 .3724975586 136.8484954834135 .3246002197134 .1054992676132 .8863067627131 .6672058105 130.7528076172129 .533706665128 .9241027832128 .0097961426127 .4001998901 126.7906036377126 .1809997559125 .5715026855125 .2667007446124 .6570968628 124.3523025513123 .7427978516123 .1332015991122 .8283996582122 .2188034058 121.6092987061120 .9997024536120 .3900985718119 .4757995605118 .5614013672 117.0374984741115 .2088012695112 .7705001831109 .7226028442106 .6747970581 104.2365036011102 .712600708103 .0174026489105 .4557037354110 .0273971558 116.4279022217124 .6570968628137 .4580993652149 .9542999268160 .3170013428 168.241394043173 .1179962158175 .2514038086175 .5561981201174 .6419067383 172.5084075928170 .070098877167 .3269958496164 .5839996338162 .1457061768 159.4026031494156 .9642944336154 .2212982178151 .7830047607149 .0399017334 146.6015930176143 .8585968018141 .1154937744138 .0677032471139 .2868041992 140.5059967041141 .7250976562142 .9441986084144 .1634063721145 .3825073242 146.9064025879148 .1255950928149 .6495056152151 .4781951904153 .0021057129 154.5260925293156 .3547973633157 .878692627159 .402603149467 .66230010986 36.148361206059 .694295883179 -9999 -9999 -9999 -9999 -9999 -9999 -9999 -9999 -9999 -9999 -9999 -9999 -9999 -9999 -9999 -9999 -9999 -9999 -9999 -9999 -9999 -9999 -9999 -9999 -9999 -9999 -9999 -9999 -9999 -9999 -9999 -9999 -9999 -9999

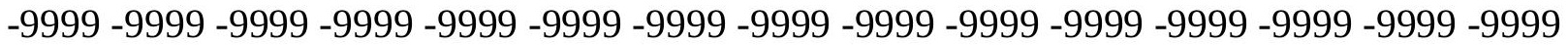

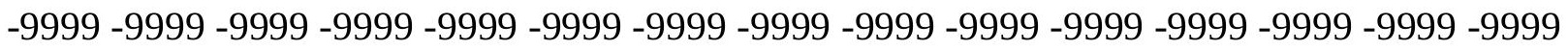
-9999 -9999 -9999 -9999 -9999 -9999 -9999 -9999 -9999 -9999 -9999 -9999 -9999 -9999 -9999 -9999 -9999 -9999 -9999 -9999 -9999 -9999 -9999 -9999 -9999 -9999 -9999 -9999 -9999 -9999 -9999 -9999 -9999 -9999 -9999 -9999 -9999 -9999 -9999 -9999 -9999 -9999 -9999 -9999 -9999

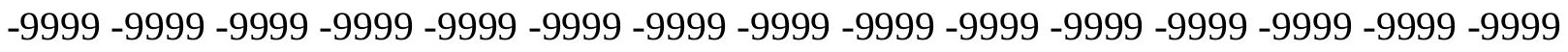

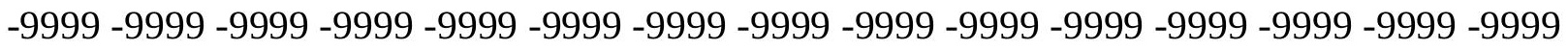
-9999 -9999 -9999 -9999 -9999 -9999 -9999 -9999 -9999 -9999 -9999 -9999 -9999 -9999 -9999 -9999 -9999 -9999 -9999 -9999 -9999 -9999 -9999 -9999 -9999 -9999 -9999 -9999 -9999 -9999 -

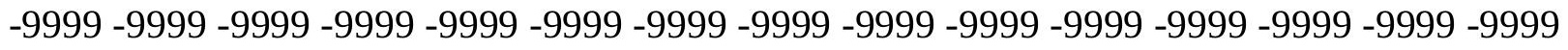

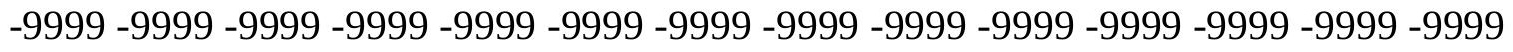
443.1757507324434 .435546875425 .9402770996417 .7498474121409 .8674316406 402.1752929688394 .417388916386 .4674987793380 .066986084374 .5809020996 369.399597168364 .5230102539360 .2560119629355 .9890136719351 .7219848633 347.7597961426343 .7976074219340 .749786377338 .0067138672334 .3493041992 
330.3870849609325 .8153076172320 .9388122559316 .3670043945311 .7951965332 306.9186096191302 .3468017578297 .7750854492293 .5080871582288 .9363098145 283.4501953125278 .8783874512275 .5257873535271 .2587890625266 .9917907715 262.4200134277257 .8482055664253 .2763977051248 .7046966553243 .8280944824 238.6468048096233 .4653930664228 .2841033936223 .1027069092218 .2261962891 215.1782989502212 .7400054932208 .7778015137204 .5108032227199 .6342926025 194.1481018066187 .7476043701179 .5184020996169 .7653045654160 .3170013428 153.0021057129149 .9542999268149 .3446960449150 .2590942383152 .0877990723 151.7830047607151 .7830047607151 .7830047607151 .4781951904151 .4781951904 151.4781951904150 .2208862305149 .7176513672149 .8282775879150 .2505493164 150.6436157227150 .516998291149 .6495056152150 .2590942383151 .1734008789 152.0877990723152 .6972961426153 .3069000244153 .6116943359153 .9165039062 154.2212982178154 .5260925293154 .5260925293154 .5260925293154 .2212982178 153.6116943359153 .3069000244152 .6972961426152 .3925933838152 .0877990723 151.7830047607151 .7830047607151 .7830047607152 .0877990723152 .3925933838 152.6972961426152 .6972961426153 .0021057129153 .3069000244153 .3069000244 153.3069000244153 .3069000244153 .0021057129152 .3925933838151 .4781951904 150.5639038086149 .6495056152148 .1255950928146 .9064025879145 .3825073242 143.5538024902142 .0299072266140 .5059967041138 .9819946289137 .4580993652 135.9342041016134 .7149963379133 .4958953857132 .2767028809131 .0576019287 130.1432037354129 .2288970947128 .3144989014127 .4001998901126 .7906036377 126.1809997559125 .8762969971125 .2667007446124 .9618988037124 .3523025513 124.0475006104123 .43800354122 .8283996582122 .2188034058121 .6092987061 120.9997024536120 .0852966309119 .4757995605118 .2565994263116 .7326965332 114.2944030762111 .551399231108 .1986999512104 .8460998535102 .1029968262 100.8839035034101 .4934005737104 .8460998535110 .9418029785119 .1709976196 128.0097961426142 .0299072266154 .2212982178164 .2792053223171 .8988037109 176.4705963135178 .604095459178 .604095459177 .0802001953174 .9467010498 172.2035980225169 .1557006836166 .1078948975163 .3648071289160 .6217956543 157.878692627155 .1356048584152 .3925933838149 .6495056152146 .9064025879 143.8585968018141 .1154937744137 .7628936768137 .1533050537138 .0677032471 139.2868041992 140.5059967041 141.7250976562142.9441986084144.1634063721 145.6873016357147 .2111968994148 .7351074219150 .2590942383151 .7830047607 153.3069000244154 .8307952881156 .354797363366 .7479400634827 .36231994629 3.949595928192 -9999 -9999 -9999 -9999 -9999 -9999 -9999 -9999 -9999 -9999 -9999 -9999 -9999 -9999 -9999 -9999 -9999 -9999 -9999

-9999 -9999 -9999 -9999 -9999 -9999 -9999 -9999 -9999 -9999 -9999 -9999 -9999 -9999 -9999 -

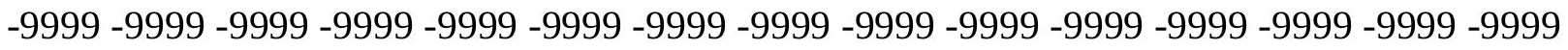
-9999 -9999 -9999 -9999 -9999 -9999 -9999 -9999 -9999 -9999 -9999 -9999 -9999 -9999 -9999 -9999 -9999 -9999 -9999 -9999 -9999 -9999 -9999 -9999 -9999 -9999 -9999 -9999 -9999 -9999 -

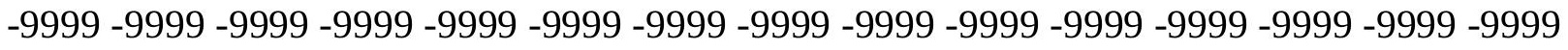

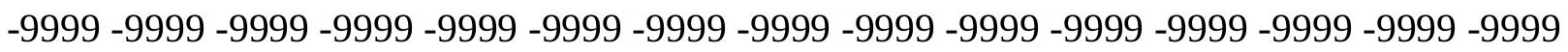
-9999 -9999 -9999 -9999 -9999 -9999 -9999 -9999 -9999 -9999 -9999 -9999 -9999 -9999 -9999 -9999 -9999 -9999 -9999 -9999 -9999 -9999 -9999 -9999 -9999 -9999 -9999 -9999 -9999 -9999 -

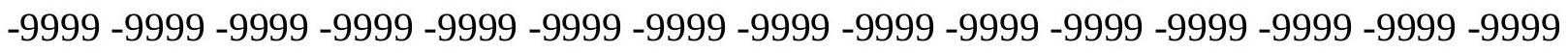

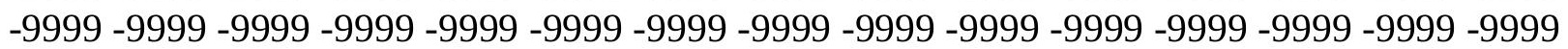


-9999 -9999 -9999 -9999 -9999 -9999 -9999 -9999 -9999 -9999 -9999 -9999 -9999 -9999 -9999 -9999 -9999 -9999 -9999 -9999 -9999 -9999 -9999 -9999 -9999 -9999 -9999 -9999 -9999 444.8412475586436 .2230224609427 .7883300781419 .5709228516411 .5604248047 403.6924438477395 .9168395996388 .5203857422381 .8958129883376 .104888916 371.228302002366 .6564941406362 .0846862793357 .8176879883353 .5508117676 349.8933105469345 .9310913086341 .9689025879339 .8353881836336 .4827880859 332.2157897949327 .3392028809322 .7674865723317 .8908996582313 .3190917969 308.7473144531304 .1755981445299 .6037902832295 .0320129395289 .5458984375 285.2789001465281 .0119018555276 .4400939941273 .0874938965268 .8204956055 264.2486877441259 .6769104004254 .8003997803250 .2286071777245 .3520050049 240.1707000732234 .9893035889229 .8079986572224 .6266021729219 .4452972412 215.1782989502212 .4351959229209 .3874053955206 .0346984863202 .0724945068 197.1959991455191 .7097930908185 .0045928955174 .0323028564163 .3648071289 155.1356048584150 .2590942383148 .4304046631148 .7351074219149 .9542999268 150.8686065674151 .1734008789151 .4781951904151 .4781951904151 .4781951904 150.8686065674149 .6495056152149 .7137145996149 .8587493896150 .0248413086 150.4409484863151 .1734008789149 .3446960449149 .6495056152150 .2590942383 150.8686065674151 .7830047607152 .3925933838152 .6972961426153 .3069000244 153.9165039062154 .5260925293154 .5260925293154 .5260925293154 .2212982178 153.9165039062153 .0021057129152 .6972961426152 .0877990723152 .0877990723 151.7830047607151 .7830047607152 .0877990723152 .0877990723152 .3925933838 152.3925933838152 .6972961426153 .0021057129153 .0021057129153 .0021057129 153.0021057129153 .0021057129152 .6972961426152 .0877990723151 .4781951904 150.5639038086149 .6495056152148 .4304046631147 .2111968994145 .6873016357 144.1634063721142 .6394042969141 .1154937744139 .5915985107138 .0677032471 136.5437011719135 .0198059082133 .8007049561132 .5814971924131 .3623962402 130.4479980469129 .2288970947128 .6192932129127 .7050018311127 .0953979492 126.4858016968125 .8762969971125 .5715026855125 .2667007446124 .6570968628 124.0475006104123 .43800354122 .8283996582122 .2188034058121 .3044967651 120.6949005127120 .0852966309119 .4757995605118 .2565994263116 .7326965332 114.2944030762111 .24659729107 .5891036987103 .9317016602100 .8839035034 99.66472625732100 .5791015625104 .5412979126111 .8561019897122 .8283996582 137.7628936768147 .2111968994158 .1835021973167 .6318054199174 .9467010498 179.2136993408181 .0424041748180 .7375946045179 .2136993408176 .4705963135 173.7274932861170 .6797027588167 .6318054199164 .5839996338161 .5361022949 158.4882965088155 .7451934814153 .0021057129149 .9542999268147 .2111968994 144.1634063721141 .1154937744137 .7628936768134 .4102020264135 .6293945312 136.8484954834138 .0677032471138 .9819946289140 .2012023926141 .7250976562 142.9441986084144 .1634063721145 .6873016357147 .2111968994148 .7351074219 150.2590942383151 .783004760770 .7101516723665 .8335876464827 .92432403564 1.298405528069 -9999 -9999 -9999 -9999 -9999 -9999 -9999 -9999 -9999 -9999 -9999 -9999 -9999 -9999 -9999-9999-9999-9999-9999

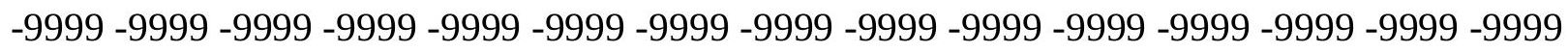
-9999 -9999 -9999 -9999 -9999 -9999 -9999 -9999 -9999-9999 -9999 -9999 -9999 -9999 -9999 -

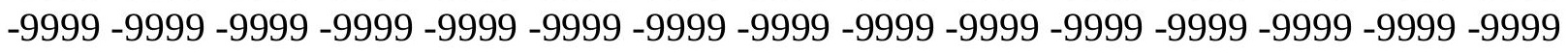

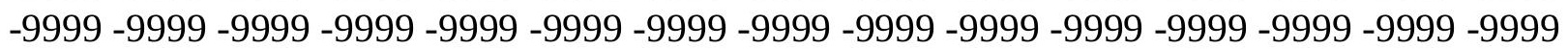


-9999 -9999 -9999 -9999 -9999 -9999 -9999 -9999 -9999 -9999 -9999 -9999 -9999 -9999 -9999 -9999 -9999 -9999 -9999 -9999 -9999 -9999 -9999 -9999 -9999 -9999 -9999 -9999 -9999 -9999

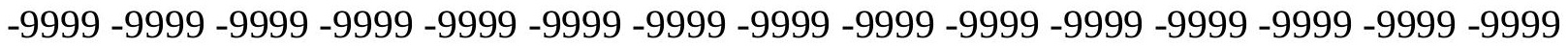
-9999 -9999 -9999 -9999 -9999 -9999 -9999 -9999 -9999 -9999 -9999 -9999 -9999 -9999 -9999 -9999 -9999 -9999 -9999 -9999 -9999 -9999 -9999 -9999 -9999 -9999 -9999-9999 -9999 -9999 -9999 -9999 -9999 -9999 -9999 -9999 -9999 -9999 -9999 -9999 -9999 -9999 -9999 -9999 -9999

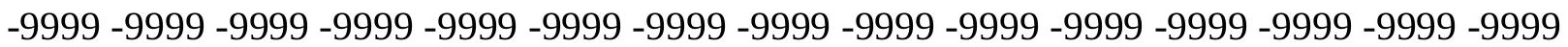
-9999 -9999 -9999 -9999 -9999 -9999 -9999 -9999 -9999 -9999 -9999 -9999 -9999 -9999 -9999 437.8092041016429 .4452514648421 .2512817383413 .2382202148405 .4125366211 397.8366394043390 .7216491699384 .2312316895378 .5512695312373 .666595459 368.7900085449363 .9135131836359 .6465148926355 .379486084351 .7219848633 348.0646057129344 .1023864746341 .3593139648337 .7019042969333 .4349060059 328.8631896973324 .2914123535319 .4147949219314 .8429870605310 .2713012695 305.3947143555301 .1276855469296 .5559082031291 .6794128418287 .4124145508 283.1453857422278 .5736083984274 .9161987305270 .3443908691265 .7726135254 261.2008972168256 .3243103027251 .4476928711246 .5711975098241 .3898010254 236.5133056641231 .3318939209226 .150604248220 .9691925049215 .787902832 212.1304016113209 .9969024658207 .5587005615203 .9011993408199 .6342926025 194.1481018066186 .528503418176 .4705963135165 .8031005859156 .3547973633 149.6495056152147 .2111968994147 .2111968994148 .4304046631149 .6495056152 150.5639038086151 .1734008789151 .4781951904151 .4781951904151 .1734008789 150.8686065674150 .2590942383149 .9276885986149 .4494171143149 .1565704346 148.7351074219148 .4304046631148 .4304046631148 .7351074219149 .3446960449 150.2590942383150 .8686065674151 .7830047607152 .6972961426153 .3069000244 154.2212982178154 .5260925293154 .5260925293154 .5260925293153 .9165039062 153.0021057129152 .3925933838152 .0877990723152 .0877990723151 .7830047607 152.0877990723152 .0877990723152 .0877990723152 .3925933838152 .3925933838 152.6972961426152 .6972961426153 .0021057129153 .0021057129153 .0021057129 152.6972961426152 .6972961426152 .0877990723151 .4781951904150 .8686065674 149.6495056152148 .7351074219147 .5160064697145 .9920959473144 .4682006836 142.9441986084141 .4203033447139 .8963928223138 .3724975586136 .8484954834 135.6293945312134 .1054992676132 .8863067627131 .6672058105130 .4479980469 129.533706665128 .6192932129127 .7050018311127 .0953979492126 .4858016968 126.1809997559125 .5715026855125 .2667007446124 .6570968628124 .3523025513 123.7427978516122 .8283996582121 .9140014648121 .3044967651120 .6949005127 120.0852966309119 .4757995605118 .8662033081117 .647102356115 .2088012695 111.8561019897107 .8938980103103 .9317016602100 .579101562599 .05516815186 99.96952056885103 .9317016602111 .8561019897123 .1332015991136 .5437011719 149.0399017334160 .3170013428170 .070098877176 .7754058838180 .7375946045 182.261505127181 .9566955566180 .1280059814177 .6896972656174 .9467010498 171.5939941406168 .5462036133165 .4983062744162 .4505004883159 .4026031494 156.3547973633153 .3069000244150 .2590942383147 .2111968994144 .1634063721 141.1154937744137 .7628936768134 .4102020264133 .4958953857134 .4102020264 135.3246002197136 .5437011719137 .7628936768138 .9819946289140 .2012023926 141.4203033447142 .9441986084144 .4682006836145 .6873016357147 .2111968994 148.735107421969 .7957916259842 .7397613525420 .53318405151 -9999 -9999 -9999 -9999 
-9999 -9999 -9999 -9999 -9999 -9999 -9999 -9999 -9999 -9999 -9999 -9999 -9999 -9999 -9999 $-9999$

-9999 -9999 -9999 -9999 -9999 -9999 -9999 -9999 -9999 -9999 -9999 -9999 -9999 -9999 -9999 -9999 -9999 -9999 -9999 -9999 -9999 -9999 -9999 -9999 -9999 -9999 -9999 -9999 -9999 -9999

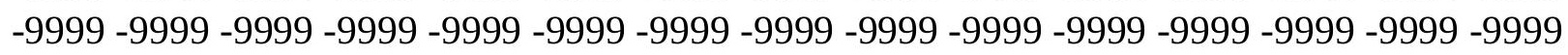
-9999 -9999 -9999 -9999 -9999 -9999 -9999 -9999 -9999 -9999 -9999 -9999 -999 - -9999 - -9999 -

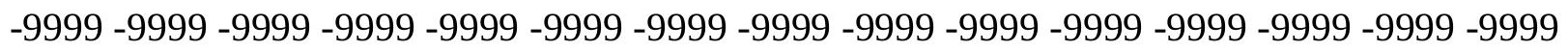
-9999 -9999 -9999 -9999 -9999 -9999 -9999 -9999 -9999 -9999 -9999 -9999 -9999 -9999 -9999 -9999 -9999 -9999 -9999 -9999 -9999 -9999 -9999 -9999 -9999 -9999 -9999 -9999 -9999 -9999

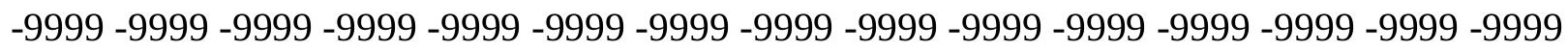
-9999 -9999 -9999 -9999 -9999 -9999 -9999 -9999 -9999 -9999 -9999 -9999 -9999 -9999-999 -9999 -9999 -9999 -9999 -9999 -9999 -9999 -9999 -9999 -9999 -9999 -9999 -9999 -9999 -9999 -9999 -9999 -9999 -9999 -9999 -9999 -9999 -9999 -9999 -9999 -9999 -9999 -9999 -9999 -9999

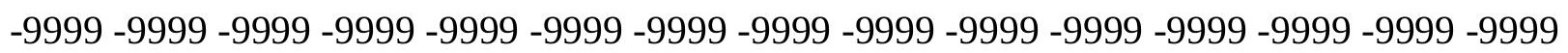
439.2232666016430 .9533996582422 .8394775391414 .9153442383407 .2284851074 399.867980957392 .9571228027386 .6103515625380 .8892822266375 .6595458984 370.6510925293365 .7962036133361 .1704101562357 .208190918353 .5508117676 349.8933105469345 .9310913086341 .9689025879338 .9211120605334 .6541137695 330.0823059082325 .5104980469320 .6339111328316 .0621948242311 .4903869629 306.9186096191302 .3468017578297 .4703063965293 .2033081055289 .2410888672 284.9740905762280 .4023132324275 .8305053711271 .8682861328267 .2966003418 262.4200134277257 .5433959961252 .6669006348247 .7902984619242 .6089935303 237.7324066162232 .5511016846227 .3697052002222 .1884002686217 .0070037842 212.4351959229210 .9113006592208 .7778015137205 .7299957275201 .4629974365 195.6721038818188 .0523986816178 .604095459167 .9365997314157 .5738983154 148.7351074219146 .6015930176146 .2969055176147 .2111968994148 .4304046631 149.6495056152150 .8686065674151 .7830047607152 .0877990723152 .0877990723 152.0877990723152 .0877990723149 .9542999268148 .4304046631147 .5160064697 146.9064025879146 .9064025879146 .6015930176146 .9064025879147 .5160064697 148.4304046631149 .3446960449150 .2590942383151 .4781951904152 .6972961426 153.9165039062154 .5260925293154 .8307952881154 .5260925293153 .9165039062 153.0021057129152 .3925933838152 .0877990723152 .0877990723152 .0877990723 152.0877990723152 .0877990723152 .0877990723152 .3925933838152 .3925933838 152.3925933838152 .6972961426152 .6972961426152 .6972961426152 .6972961426 152.6972961426152 .3925933838152 .0877990723151 .4781951904150 .8686065674 149.9542999268148 .7351074219147 .5160064697146 .2969055176144 .7729034424 143.2489929199141 .7250976562140 .2012023926138 .6772003174137 .1533050537 135.6293945312134 .4102020264132 .8863067627131 .6672058105130 .7528076172 129.533706665128 .6192932129127 .7050018311127 .0953979492126 .4858016968 126.1809997559125 .5715026855125 .2667007446124 .6570968628124 .3523025513 123.7427978516122 .8283996582121 .9140014648120 .9997024536120 .3900985718 120.0852966309119 .7806015015119 .4757995605118 .5614013672116 .7326965332 113.075302124108 .8082962036104 .5412979126100 .883903503499 .05516815186 99.66472625732103 .0174026489110 .0273971558120 .0852966309133 .1911010742 147.5160064697160 .6217956543170 .9844970703177 .6896972656181 .3471984863 182.5662994385182 .261505127180 .7375946045178 .2993011475175 .2514038086 
172.2035980225169 .1557006836166 .1078948975163 .0599975586160 .0122070312 156.6596069336153 .6116943359150 .5639038086147 .5160064697144 .4682006836 141.1154937744137 .7628936768134 .1054992676130 .4479980469131 .9720001221 132.8863067627134 .1054992676135 .0198059082136 .2389984131137 .4580993652 138.6772003174139 .8963928223141 .4203033447142 .6394042969144 .1634063721 145.687301635768 .8814392089836 .5918617248517 .12621688843 -9999 -9999 -9999-9999 -9999 -9999 -9999 -9999 -9999 -9999 -9999 -9999 -9999 -9999 -9999 -9999 -9999 -9999 -9999 $-9999$

-9999 -9999 -9999 -9999 -9999 -9999 -9999 -9999 -9999 -9999 -9999 -9999 -9999 -9999 -9999 -9999 -9999 -9999 -9999 -9999 -9999 -9999 -9999 -9999 -9999 -9999 -9999 -9999 -9999 -9999 -9999 -9999 -9999 -9999 -9999 -9999 -9999 -9999 -9999 -9999 -9999 -9999 -9999 -9999 -9999 -999 -9999 -9999 -9999 -9999 -9999 -9999 -9999 -9999 -9999 -9999 -9999 -9999 -9999 -9999 -9999 -9999 -9999 -9999 -9999 -9999 -9999 -9999 -9999 -9999 -9999 -9999 -9999 -9999 -9999 -9999 -9999 -9999 -9999 -9999 -9999 -9999 -9999 -9999 -9999 -9999 -9999 -9999 -9999 -9999 -9999 -9999 -9999 -9999 -9999 -9999 -9999 -9999 -9999 -9999 -9999 -9999 -9999 -9999 -9999 -9999

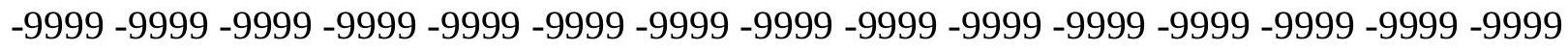

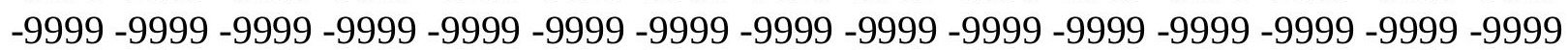

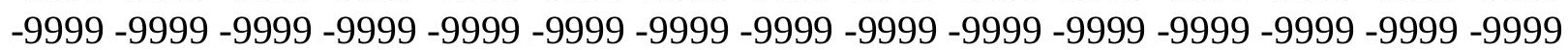
-9999 -9999 -9999 -9999 -9999 -9999 -9999 -9999 -9999 -9999 -9999 -9999 -9999 -9999 -9999 -9999 -9999 -9999 -9999 -9999 -9999 -9999 -9999 -9999 -9999 -9999 -9999 -9999 -9999 -9999 -9999 432.3328552246 424.3371582031416.5451049805 409.0161132812401 .829284668 395.0614624023388 .7742614746382 .9718933105377 .565612793372 .4633178711 367.6315612793363 .128692627359 .086730957355 .379486084351 .7219848633 347.7597961426343 .7976074219339 .5306091309334 .9588928223330 .3870849609 325.8153076172320 .9388122559317 .2813110352311 .7951965332307 .2233886719 303.2611999512298 .9942016602295 .0320129395290 .7650146484286 .4979858398 281.9262084961277 .3544921875272 .4779052734267 .6012878418263 .6390991211 258.7626037598253 .8860015869249 .0093994141243 .8280944824238 .9515075684 233.7702026367228 .5888977051223 .4075012207218 .2261962891213 .959197998 212.4351959229210 .6065063477207 .5587005615202 .9868927002197 .1959991455 189.8811035156180 .7375946045170 .070098877159 .7073974609151 .4781951904 147.2111968994145 .9920959473146 .2969055176147 .8208007812149 .3446960449 150.8686065674151 .7830047607152 .3925933838152 .6972961426152 .6972961426 151.4781951904149 .6495056152147 .8208007812146 .2969055176145 .3825073242 144.7729034424144 .4682006836144 .7729034424145 .0776977539145 .9920959473 147.2111968994148 .4304046631149 .9542999268151 .7830047607153 .3069000244 154.2212982178154 .5260925293154 .5260925293153 .9165039062153 .0021057129 152.3925933838152 .0877990723152 .0877990723152 .0877990723152 .0877990723 152.0877990723152 .0877990723152 .3925933838152 .3925933838152 .3925933838 152.3925933838152 .6972961426152 .6972961426152 .6972961426152 .3925933838 152.3925933838152 .0877990723151 .4781951904150 .8686065674149 .9542999268 149.0399017334147 .8208007812146 .6015930176145 .0776977539143 .5538024902 142.0299072266140 .5059967041138 .9819946289137 .4580993652135 .9342041016 134.4102020264133 .1911010742131 .9720001221130 .7528076172129 .533706665 128.6192932129127 .7050018311126 .7906036377126 .1809997559125 .8762969971 125.2667007446124 .9618988037124 .3523025513124 .0475006104123 .43800354 
122.8283996582121 .6092987061120 .6949005127120 .0852966309119 .7806015015 119.7806015015119 .7806015015119 .4757995605118 .5614013672114 .2944030762 109.7226028442105 .4557037354101 .798202514699 .6647262573299 .66472625732 102.1029968262107 .2844009399115 .818397522128 .0097961426144 .1634063721 159.7073974609170 .3748931885176 .7754058838180 .1280059814181 .6519012451 181.3471984863180 .1280059814177 .9945068359175 .2514038086172 .5084075928 169.4604949951166 .4127044678163 .3648071289160 .3170013428157 .2691040039 153.9165039062150 .8686065674147 .8208007812144 .4682006836141 .1154937744 137.4580993652133 .8007049561130 .1432037354129 .533706665130 .4479980469 131.3623962402132 .5814971924133 .4958953857134 .7149963379135 .9342041016 137.1533050537138 .3724975586139 .5915985107141 .115493774472 .84364318848 67.6623001098641 .7288322448718 .66919517517 -9999 -9999 -9999 -9999 -9999 -9999 -9999 -9999 -9999 -9999 -9999 -9999 -9999 -9999 -9999 -9999 -9999 -9999 -9999 -9999 -9999 -9999 -9999 -9999 -9999 -9999 -9999 -9999 -9999 -9999 -9999 -9999 -9999 -9999 - 9999 -9999 -9999 -9999 -9999 -9999 -9999 -9999 -9999 -9999 -9999 -9999 -9999 -9999 -9999 -9999 -

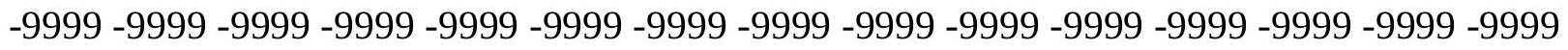
-9999 -9999 -9999 -9999 -9999 -9999 -9999 -9999 -9999 -9999 -9999 -9999 -9999 -9999 -9999 -9999 -9999 -9999 -9999 -9999 -9999 -9999 -9999 -9999 -9999 -9999 -9999 -9999 -9999 -9999 -9999 -9999 -9999 -9999 -9999 -9999 -9999 -9999 -9999 -9999 -9999 -9999 -9999 -9999 -9999 -

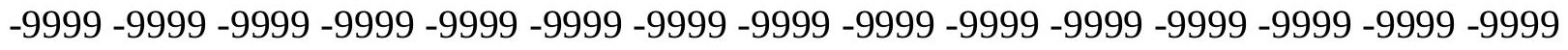

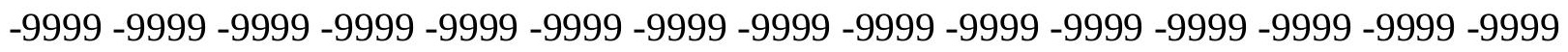
-9999 -9999 -9999 -9999 -9999 -9999 -9999 -9999 -9999 -9999 -9999 -9999 -9999 -9999 -9999 -9999 -9999 -9999 -9999 -9999 -9999 -9999 -9999 -9999 -9999 -9999 -9999 -9999 -9999 -9999 -

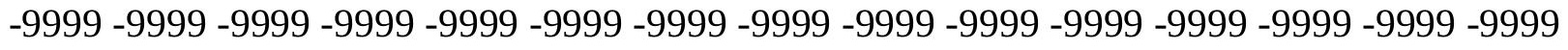

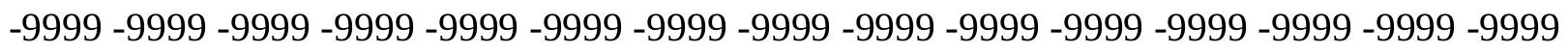
-9999 -9999 425.7208862305 418.0705566406410.6867370605 403.6303710938 396.9544372559390 .687713623384 .8284301758379 .3391723633374 .1859741211 369.3587036133 364.8758544922360 .7323303223356 .8360900879353 .0115356445 349.1678466797345 .3215026855340 .749786377336 .4827880859331 .6062011719 327.0344848633322 .4627075195317 .8908996582313 .3190917969308 .7473144531 304.4802856445300 .5180969238296 .2510986328291 .9841918945287 .7171936035 283.4501953125278 .8783874512274 .0018005371269 .1253051758264 .2486877441 259.9816894531255 .1051025391249 .9237976074245 .0471954346239 .8659057617 234.9893035889229 .8079986572224 .6266021729218 .8356933594216 .0926971436 213.959197998212 .1304016113208 .4730072021204 .2059936523198 .7198944092 192.0146026611183 .1759033203172 .5084075928161 .8408966064153 .3069000244 147.8208007812145 .6873016357145 .6873016357146 .9064025879148 .7351074219 150.5639038086152 .0877990723152 .6972961426152 .6972961426152 .3925933838 150.5639038086148 .7351074219146 .6015930176144 .7729034424143 .5538024902 142.6394042969142 .0299072266142 .0299072266142 .3347015381143 .2489929199 144.4682006836146 .2969055176148 .1255950928150 .5639038086152 .6972961426 153.6116943359154 .2212982178154 .2212982178153 .6116943359153 .0021057129 152.3925933838152 .0877990723151 .7830047607152 .0877990723152 .0877990723 152.0877990723152 .0877990723152 .3925933838152 .3925933838152 .3925933838 152.3925933838152 .3925933838152 .6972961426152 .6972961426152 .3925933838 152.3925933838152 .0877990723151 .7830047607150 .8686065674150 .2590942383 
149.0399017334148 .1255950928146 .6015930176145 .3825073242143 .8585968018 142.3347015381140 .8106994629139 .2868041992137 .7628936768135 .9342041016 134.7149963379133 .1911010742131 .6672058105130 .4479980469129 .2288970947 128.3144989014127 .4001998901126 .4858016968125 .8762969971125 .5715026855 124.9618988037124 .3523025513123 .7427978516123 .1332015991122 .5235977173 122.2188034058120 .6949005127119 .7806015015119 .4757995605119 .4757995605 119.7806015015119 .7806015015119 .4757995605117 .9517974854114 .5991973877 110.6370010376106 .3700027466103 .0174026489100 .579101562599 .96952056885 101.4934005737105 .4557037354111 .8561019897120 .9997024536140 .2012023926 159.0977935791167 .9365997314173 .7274932861177 .6896972656179 .5184020996 179.8231964111178 .9089050293177 .0802001953174 .9467010498172 .2035980225 169.4604949951166 .4127044678163 .3648071289160 .3170013428157 .2691040039 154.2212982178150 .8686065674147 .8208007812144 .4682006836141 .1154937744 137.4580993652133 .8007049561129 .8385009766127 .0953979492128 .0097961426 128.9241027832129 .8385009766130 .7528076172131 .9720001221132 .8863067627 134.1054992676135 .3246002197136 .5437011719137 .762893676871 .92929077148 66.7479400634843 .1221771240220 .71552276611 -9999 -9999 -9999 -9999 -9999 -9999 -9999 -9999 -9999 -9999 -9999 -9999 -9999 -9999 -9999 -9999 -9999 -9999 -9999 -9999 -9999 -9999 -9999 -9999 -9999 -9999 -9999 -9999 -9999 -9999 -9999 -9999 -9999 -9999 -9999 -

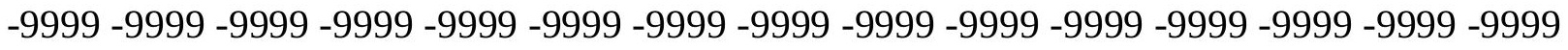

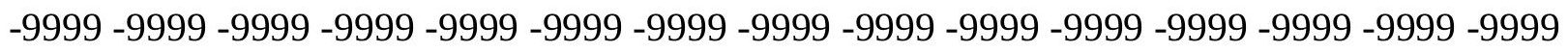
-9999 -9999 -9999 -9999 -9999 -9999 -9999 -9999 -9999 -9999 -9999 -9999 -9999 -9999 -9999 -9999 -9999 -9999 -9999 -9999 -9999 -9999 -9999 -9999 -9999 -9999 -9999 -9999 -9999 -9999 -

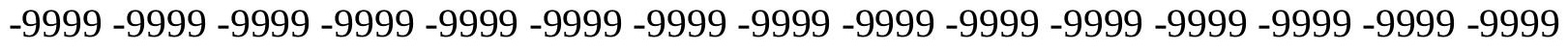

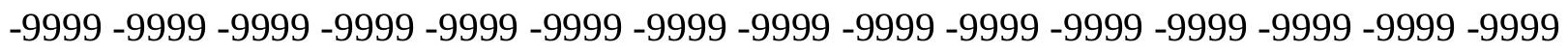
-9999 -9999 -9999 -9999 -9999 -9999 -9999 -9999 -9999 -9999 -9999 -9999 -9999 -9999 -9999 -

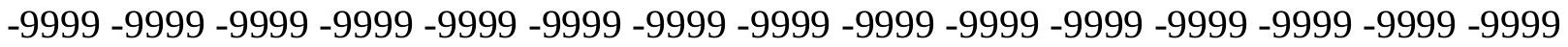

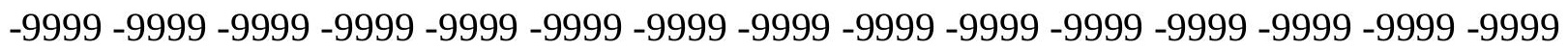
-9999 -9999 -9999 -9999 -9999 -9999 -9999 -9999 -9999 -9999 -9999 -9999 -9999 -9999 -9999 -9999 -9999 -9999 -9999 -9999 -9999 -9999 -9999 -9999 -9999 -9999 -9999 -9999 -9999 -9999 -9999 -9999 426.9617919922 419.4447631836412.1847229004 405.2291870117 398.6125183105392 .3564758301386 .4606628418380 .9179382324375 .714630127 370.8431091309366 .2889709473362 .0070800781357 .921875353 .9324951172 349.9665527344345 .8807983398341 .5608215332337 .118927002332 .5205993652 327.9487915039323 .3770141602318 .8052062988314 .2334899902309 .9664916992 305.6994934082301 .4324951172297 .1654968262292 .8984985352288 .6315002441 284.3645019531280 .0975036621275 .5257873535270 .6492004395265 .7726135254 260.5913085938255 .4098968506250 .8381958008245 .9615936279241 .0850067139 235.9037017822230 .7223052979224 .9313964844220 .9691925049217 .3117980957 214.5686950684212 .1304016113208 .7778015137204 .5108032227199 .329498291 193.233795166185 .6141052246173 .7274932861162 .7552947998153 .6116943359 147.8208007812145 .3825073242145 .0776977539146 .2969055176148 .1255950928 149.9542999268152 .0877990723152 .6972961426152 .0877990723150 .8686065674 149.0399017334147 .2111968994145 .0776977539143 .2489929199141 .7250976562 140.2012023926139 .5915985107139 .2868041992139 .2868041992140 .2012023926 141.4203033447143 .2489929199145 .6873016357148 .1255950928150 .5639038086 
152.3925933838153 .3069000244153 .6116943359153 .0021057129152 .3925933838 151.7830047607151 .7830047607151 .4781951904151 .7830047607151 .7830047607 152.0877990723152 .3925933838152 .3925933838152 .3925933838152 .0877990723 152.3925933838152 .3925933838152 .6972961426152 .6972961426152 .6972961426 152.3925933838152 .0877990723151 .7830047607151 .1734008789150 .2590942383 149.3446960449148 .1255950928146 .9064025879145 .3825073242144 .1634063721 142.6394042969140 .8106994629139 .2868041992137 .7628936768136 .2389984131 134.7149963379133 .1911010742131 .6672058105130 .4479980469129 .2288970947 128.0097961426127 .0953979492126 .1809997559125 .2667007446124 .9618988037 124.3523025513123 .7427978516122 .8283996582121 .6092987061120 .0852966309 119.1709976196118 .5614013672118 .2565994263118 .8662033081119 .1709976196 119.7806015015119 .7806015015119 .1709976196117 .342300415114 .9039993286 111.24659729107 .8938980103104 .5412979126102 .1029968262101 .1886978149 101.7982025146104 .8460998535110 .6370010376120 .6949005127135 .6293945312 150.8686065674162 .1457061768169 .4604949951174 .0323028564176 .4705963135 177.3849029541177 .0802001953175 .5561981201173 .7274932861171 .5939941406 168.8509979248166 .1078948975163 .3648071289160 .3170013428157 .2691040039 154.2212982178150 .8686065674147 .8208007812144 .4682006836140 .8106994629 137.1533050537133 .4958953857129 .533706665125 .2667007446125 .2667007446 126.1809997559127 .0953979492128 .0097961426128 .9241027832130 .1432037354 131.0576019287132 .2767028809133 .495895385776 .1962814331170 .71015167236 58.5040550231941 .51906204224 -9999 -9999 -9999 -9999 -9999 -9999 -9999 -9999 -9999 -9999 -9999 -9999 -9999 -9999 -9999 -9999 -9999 -9999 -9999 -9999 -9999

-9999 -9999 -9999 -9999 -9999 -9999 -9999 -9999 -9999 -9999 -9999 -9999 -9999 -9999 -9999 -

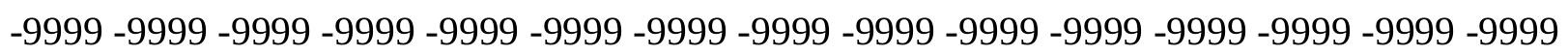

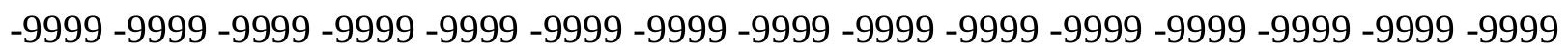

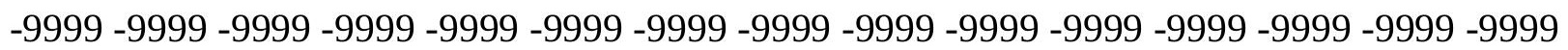

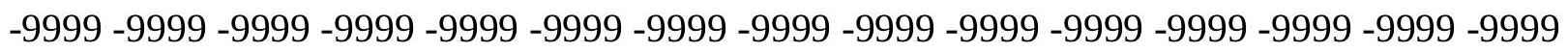

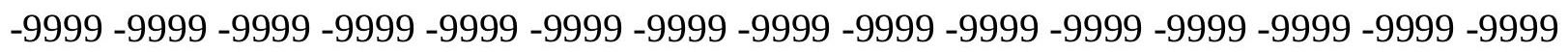

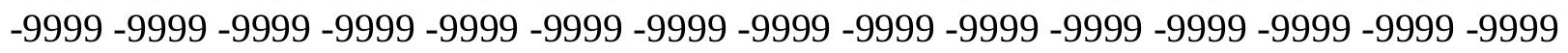

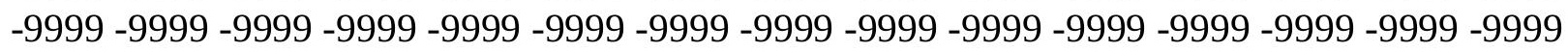

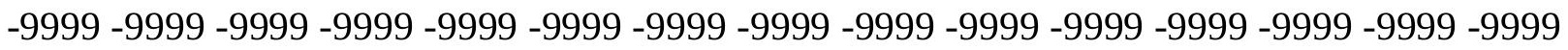

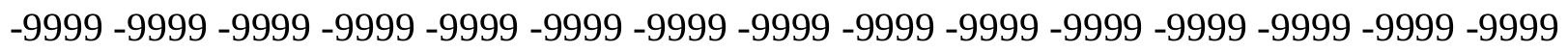

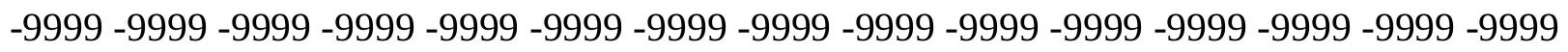

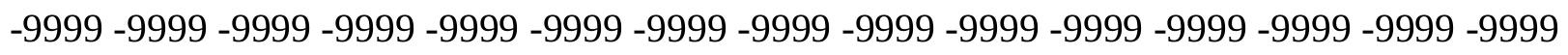
-9999 -9999-9999 420.6390075684 413.4819030762406.6035461426400.029510498 393.777923584387 .8540039062382 .2600708008376 .9892883301372 .0306091309 367.3525085449 362.9108886719 358.6343383789 354.4571838379 350.309967041 346.0924682617341 .7972717285337 .3779907227332 .9044189453328 .3663330078 323.7947998047319 .1735839844314 .5382080078310 .2713012695306 .0043029785 301.7373046875297 .7750854492293 .5080871582289 .2410888672284 .9740905762 280.7070922852276 .4400939941271 .8682861328266 .9917907715261 .8103942871 256.9338989258251 .7525024414246 .5711975098241 .6945953369236 .5133056641 231.3318939209226 .4553985596221 .883605957217 .9214019775214 .2639007568 211.2160949707207 .8634033203203 .9011993408199 .0247039795192 .624206543 184.3950042725173 .4226989746162 .1457061768152 .3925933838146 .9064025879 
144.4682006836144 .1634063721145 .0776977539146 .9064025879148 .4304046631 149.9542999268150 .5639038086149 .9542999268148 .7351074219147 .2111968994 145.0776977539143 .2489929199141 .4203033447139 .5915985107137 .7628936768 136.8484954834135 .9342041016136 .2389984131136 .8484954834138 .3724975586 140.2012023926142 .3347015381145 .0776977539147 .8208007812150 .2590942383 152.0877990723152 .6972961426152 .0877990723151 .4781951904151 .1734008789 150.8686065674150 .8686065674151 .1734008789151 .4781951904152 .0877990723 152.3925933838152 .3925933838152 .3925933838152 .3925933838152 .3925933838 152.3925933838152 .6972961426152 .6972961426152 .6972961426152 .6972961426 152.3925933838151 .7830047607151 .1734008789150 .5639038086149 .3446960449 148.4304046631146 .9064025879145 .6873016357144 .1634063721142 .6394042969 141.1154937744139 .2868041992137 .7628936768136 .2389984131134 .4102020264 132.8863067627131 .6672058105130 .1432037354128 .9241027832127 .7050018311 126.4858016968125 .5715026855124 .6570968628124 .0475006104123 .43800354 123.1332015991121 .9140014648120 .0852966309117 .647102356115 .818397522 115.818397522117 .0374984741117 .9517974854119 .1709976196119 .7806015015 119.7806015015118 .8662033081117 .342300415114 .9039993286112 .1608963013 109.1130981445106 .3700027466103 .9317016602102 .712600708103 .0174026489 105.1509017944110 .3321990967118 .8662033081130 .7528076172143 .5538024902 155.1356048584163 .6696014404169 .4604949951172 .8132019043174 .337097168 174.6419067383173 .7274932861172 .2035980225170 .3748931885167 .9365997314 165.4983062744162 .7552947998160 .0122070312156 .9642944336153 .9165039062 150.8686065674147 .5160064697144 .1634063721140 .8106994629137 .1533050537 133.1911010742129 .2288970947124 .9618988037122 .8283996582123 .7427978516 124.3523025513125 .2667007446126 .1809997559127 .0953979492128 .3144989014 129.2288970947130 .447998046974 .9771423339869 .7957916259854 .90813446045 38.63371276855 -9999 -9999 -9999 -9999 -9999 -9999 -9999 -9999 -9999 -9999 -9999 -9999 -9999 -9999 -9999 -9999 -9999 -9999 -9999 -9999 -9999

-9999 -9999 -9999 -9999 -9999 -9999 -9999 -9999 -9999 -9999 -9999 -9999 -9999 -9999 -9999 -

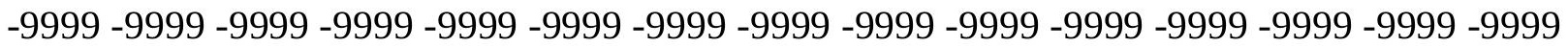
-9999 -9999 -9999 -9999 -9999 -9999 -9999 -9999 -9999 -9999 -9999 -9999 -9999 -9999 -9999 -9999 -9999 -9999 -9999 -9999 -9999 -9999 -9999 -9999 -9999 -9999 -9999 -9999 -9999 -9999 -9999 -9999 -9999 -9999 -9999 -9999 -9999 -9999 -9999 -9999 -9999 -9999 -9999 -9999 -9999 -9999 -9999 -9999 -9999 -9999 -9999 -9999 -9999 -9999 -9999 -9999 -9999 -9999 -9999 -9999 -

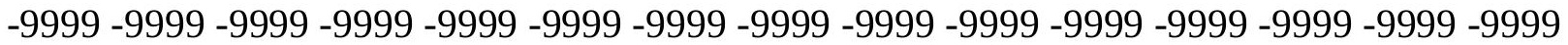
-9999 -9999 -9999 -9999 -9999 -9999 -9999 -9999 -9999 -9999 -9999 -9999 -9999 -9999 -9999 -9999 -9999 -9999 -9999 -9999 -9999 -9999 -9999 -9999 -9999 -9999 -9999 -9999 -9999 -9999

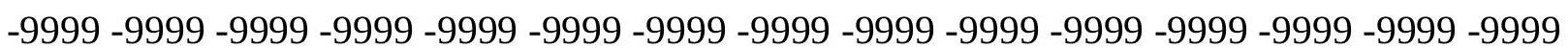
-9999 -9999 -9999 -9999 -9999 -9999 -9999 -9999 -9999 -9999 -9999 -9999 -9999 -9999 -9999 -9999 -9999 -9999 -9999 -9999 -9999 -9999 -9999 -9999 -9999 -9999 -9999 -9999 -9999 -9999 -9999 -9999-9999 421.6343994141414.5614624023407.7427368164 401.1986083984 394.9453735352388 .9900512695383 .3375244141377 .9822692871372 .9108886719 368.0911560059363 .4787902832359 .0175476074354 .6607055664350 .3431396484 346.0192871094341 .6678161621337 .2672119141332 .8210754395328 .3163757324 323.7547912598319 .162109375314 .6347045898310 .2429504395305 .9516906738 301.7373046875297 .7750854492293 .5080871582289 .2410888672284 .9740905762 
281.0119018555276 .7449035645272 .1730957031267 .6012878418262 .7247924805 257.8482055664252 .9716033936247 .7902984619242 .6089935303237 .4275970459 232.5511016846227 .3697052002222 .1884002686217 .6165924072213 .0447998047 209.9969024658206 .6443023682202 .3773040771197 .500793457191 .4051055908 182.87109375172 .5084075928160 .9264984131150 .2590942383145 .6873016357 143.8585968018143 .2489929199143 .8585968018145 .3825073242146 .6015930176 147.5160064697147 .8208007812147 .5160064697146 .6015930176145 .0776977539 143.2489929199142 .6394042969140 .0264129639137 .4969482422135 .3246002197 133.8007049561132 .5814971924132 .5814971924133 .4958953857134 .7149963379 136.5437011719138 .9819946289141 .4203033447144 .4682006836147 .2111968994 149.6495056152151 .7830047607150 .8686065674150 .2590942383149 .9542999268 149.6495056152149 .9542999268150 .5639038086150 .8686065674151 .4781951904 152.0877990723152 .0877990723152 .0877990723152 .0877990723152 .0877990723 152.3925933838152 .6972961426152 .6972961426152 .6972961426152 .6972961426 152.3925933838152 .0877990723151 .4781951904150 .5639038086149 .6495056152 148.4304046631147 .2111968994145 .6873016357144 .1634063721142 .6394042969 141.1154937744139 .2868041992137 .7628936768135 .9342041016134 .4102020264 132.8863067627131 .3623962402129 .8385009766128 .6192932129127 .4001998901 126.1809997559124 .9618988037124 .0475006104123 .1332015991122 .5235977173 122.2188034058121 .3044967651118 .8662033081115 .818397522112 .7705001831 114.2944030762116 .1231002808117 .9517974854119 .4757995605120 .3900985718 120.0852966309118 .8662033081117 .342300415115 .2088012695113 .075302124 110.9418029785108 .5035018921106 .3700027466104 .8460998535104 .5412979126 106.0652008057110 .0273971558116 .7326965332125 .8762969971137 .7628936768 149.3446960449158 .4882965088165 .1934967041168 .8509979248170 .9844970703 171.5939941406171 .2891998291170 .3748931885168 .8509979248166 .7174987793 164.5839996338162 .1457061768159 .4026031494156 .6596069336153 .9165039062 150.5639038086147 .5160064697144 .1634063721140 .5059967041136 .8484954834 132.8863067627128 .6192932129124 .3523025513119 .7806015015120 .9997024536 121.9140014648122 .5235977173123 .43800354124 .3523025513125 .2667007446 126.1809997559127 .400199890174 .062782287668 .5766525268653 .13481903076 36.02107620239 -9999 -9999 -9999 -9999 -9999 -9999 -9999 -9999 -9999 -9999 -9999 -9999 -9999 -9999 -9999 -9999 -9999 -9999 -9999 -9999 -9999

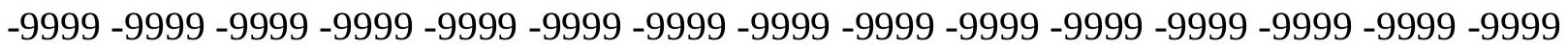

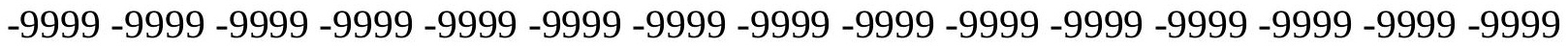

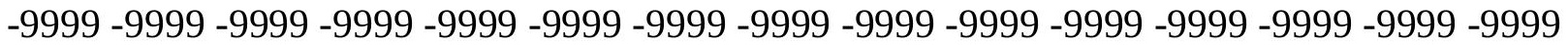

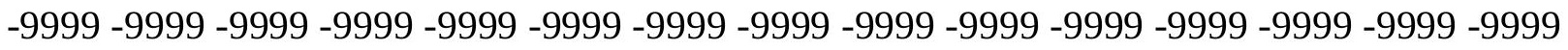

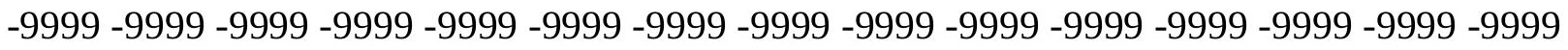

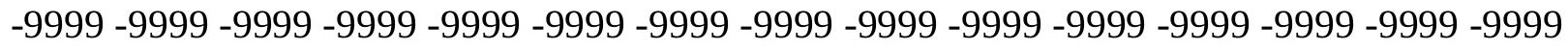

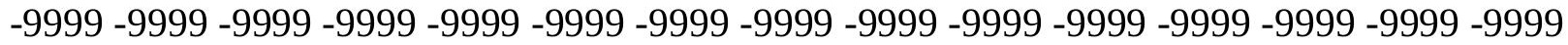

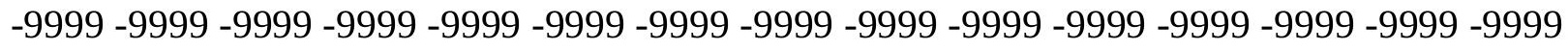

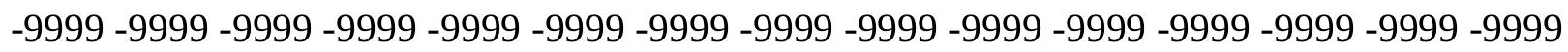

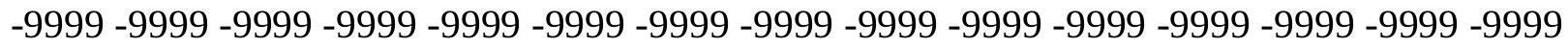

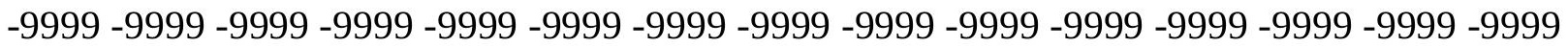

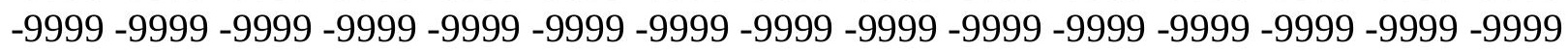
-9999 -9999 -9999 -9999 415.4179077148 408.6441650391402 .1187744141395 .8560791016 
389.8628234863384 .1436462402378 .6929626465373 .4975280762368 .528503418 363.7486572266359 .1131591797354 .5825500488350 .1117553711345 .6713562012 341.2378845215336 .7959899902332 .3245849609327 .820098877323 .2675170898 318.7171020508314 .2128295898309 .8059997559305 .488861084301 .2813415527 297.1259460449292 .9131469727288 .641784668284 .3645324707280 .0975036621 276.1353149414271 .8682861328267 .2966003418262 .4200134277257 .8482055664 252.6669006348247 .7902984619242 .6089935303237 .7324066162232 .5511016846 227.0648956299221 .883605957217 .0070037842212 .4351959229208 .7778015137 204.8155975342200 .2438049316195 .0625189 .5764007568181 .9566955566171 .5939941406 160.3170013428151 .1734008789145 .6873016357143 .2489929199142 .3347015381 142.9441986084143 .5538024902144 .4682006836145 .3825073242145 .6873016357 145.3825073242144 .7729034424143 .5538024902142 .4306488037141 .0360565186 138.7799835205135 .9834442139133 .1487579346130 .63331604129 .2288970947 129.533706665130 .4479980469131 .3623962402132 .8863067627135 .0198059082 137.4580993652140 .5059967041143 .2489929199145 .9920959473147 .8208007812 148.1255950928147 .8208007812147 .8208007812148 .1255950928148 .7351074219 149.3446960449149 .9542999268150 .8686065674151 .4781951904151 .7830047607 152.0877990723152 .0877990723152 .0877990723152 .3925933838152 .6972961426 153.0021057129153 .0021057129152 .6972961426152 .3925933838152 .0877990723 151.4781951904150 .5639038086149 .6495056152148 .4304046631147 .2111968994 145.6873016357144 .1634063721142 .6394042969141 .1154937744139 .2868041992 137.7628936768135 .9342041016134 .4102020264132 .5814971924131 .0576019287 129.533706665128 .3144989014126 .7906036377125 .5715026855124 .3523025513 123.1332015991121 .9140014648121 .6092987061120 .9997024536119 .7806015015 117.9517974854115 .5136032104113 .9896011353114 .5991973877116 .1231002808 118.2565994263120 .0852966309120 .9997024536120 .6949005127119 .1709976196 117.647102356115 .818397522113 .9896011353112 .7705001831111 .24659729 108.8082962036106 .979598999106 .3700027466107 .2844009399110 .0273971558 114.9039993286121 .6092987061133 .1911010742144 .7729034424154 .5260925293 160.9264984131165 .1934967041167 .3269958496168 .5462036133168 .8509979248 168.241394043167 .0222015381165 .1934967041163 .3648071289161 .2312927246 158.7929992676156 .3547973633153 .3069000244150 .2590942383147 .2111968994 143.8585968018140 .2012023926136 .5437011719132 .5814971924128 .3144989014 123.7427978516119 .1709976196118 .2565994263119 .1709976196120 .0852966309 120.6949005127121 .6092987061122 .5235977173123 .4380035478 .32978057861

72.8436431884862 .5162277221749 .44232940674 -9999 -9999 -9999 -9999 -9999 -9999-9999

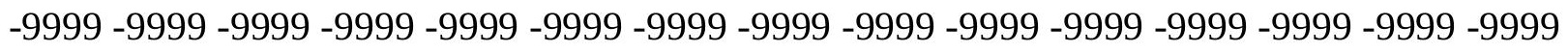

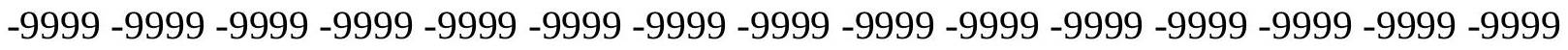

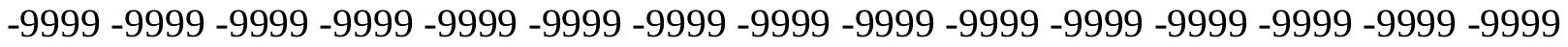
-9999 -9999 -9999 -9999 -9999 -9999 -9999 -9999 -9999 -9999 -9999 -9999 -9999 -9999 -9999 -

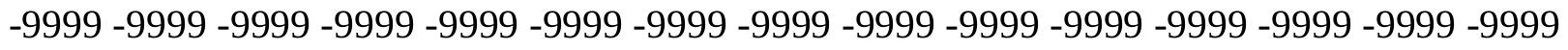

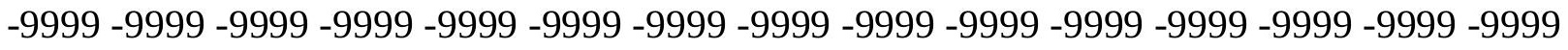
-9999 -9999 -9999 -9999 -9999 -9999 -9999 -9999 -9999 -9999 -9999 -9999 -9999 -9999 -9999 -9999 -9999 -9999 -9999 -9999 -9999 -9999 -9999 -9999-9999 -9999 -9999 -9999 -9999 -9999 -9999 -9999 -9999 -9999 -9999 -9999 -9999 -9999 -9999 -9999 -9999 -9999 -9999 -9999 -9999 -

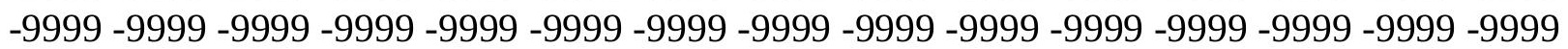


-9999 -9999 -9999 -9999 -9999 -9999 -9999 -9999 -9999 -9999 -9999 -9999 -9999 -9999 -9999 -9999 -9999 -9999 -9999 -9999 -9999 -9999 -9999 -9999 -9999 -9999 -9999 -9999 -9999 -9999 -9999 -9999 -9999 -9999 -9999 -9999 -9999 -9999 -9999 -9999 -9999 -9999 -9999 -9999 -9999 -9999 -9999-9999 -9999 416.0485839844 409.3068237305402 .7897033691396 .5093688965 390.4713134766384 .6791992188379 .1276550293373 .8051147461368 .6874389648 363.7448730469358 .9420471191354 .2457275391349 .6252746582345 .0560302734 340.5163574219335 .9858093262331 .4491271973326 .8967895508322 .3323059082 317.7795410156313 .2729492188308 .8372497559304 .4860534668300 .2162780762 295.9601135254291 .6985778809287 .3954467773283 .0899047852278 .8324890137 274.642364502270 .3458862305265 .8246765137261 .1419677734256 .3715209961 251.4302368164246 .4466400146241 .3975982666236 .3229217529231 .0814971924 225.7302703857220 .5084381104215 .5249938965210 .9159240723206 .5798492432 202.1414794922197 .1959991455191 .4051055908186 .2236938477181 .0424041748 169.7653045654159 .0977935791150 .8686065674145 .6873016357142 .9441986084 141.7250976562141 .7250976562142 .3347015381142 .9441986084143 .5538024902 143.8585968018143 .8585968018143 .5538024902143 .066116333142 .1876068115 140.6402587891138 .3740997314135 .4071044922132 .1125488281128 .7804870605 125.8762969971127 .0953979492127 .7050018311128 .3144989014129 .2288970947 131.0576019287133 .4958953857136 .2389984131138 .9819946289141 .4203033447 143.2489929199144 .4682006836144 .7729034424145 .3825073242145 .9920959473 146.9064025879147 .8208007812148 .7351074219149 .6495056152150 .5639038086 151.1734008789151 .4781951904151 .7830047607152 .0877990723152 .3925933838 152.6972961426153 .0021057129153 .0021057129152 .6972961426152 .3925933838 152.0877990723151 .4781951904150 .8686065674149 .6495056152148 .7351074219 147.2111968994145 .9920959473144 .1634063721142 .6394042969141 .1154937744 139.2868041992137 .4580993652135 .9342041016134 .1054992676132 .5814971924 131.0576019287129 .2288970947128 .0097961426126 .4858016968125 .2667007446 123.7427978516122 .5235977173121 .6092987061120 .6949005127120 .0852966309 118.8662033081117 .647102356116 .1231002808115 .5136032104115 .818397522 117.0374984741118 .8662033081120 .3900985718121 .3044967651120 .9997024536 119.7806015015118 .2565994263116 .4279022217116 .4279022217115 .818397522 113.6848983765111 .24659729109 .1130981445108 .1986999512108 .5035018921 110.6370010376114 .5991973877120 .9997024536130 .4479980469141 .4203033447 151.4781951904156 .9642944336160 .9264984131163 .6696014404165 .1934967041 165.8031005859165 .4983062744164 .8887023926163 .6696014404162 .1457061768 160.3170013428158 .1835021973155 .7451934814153 .0021057129149 .9542999268 146.9064025879143 .5538024902139 .8963928223135 .9342041016131 .9720001221 127.7050018311123 .43800354118 .5614013672115 .818397522116 .4279022217 117.342300415117 .9517974854118 .8662033081119 .7806015015120 .6949005127 77.110626220771 .6244964599659 .2958641052245 .90906524658 -9999 -9999 -9999 -9999 -9999 -9999 -9999 -9999 -9999 -9999 -9999 -9999 -9999 -9999 -9999 -9999 -9999 -9999 -9999 $-9999-9999-9999$ -9999 -9999 -9999 -9999 -9999 -9999 -9999 -9999 -9999 -9999 -9999 -9999 -9999 -9999 -9999 -9999 -9999 -9999 -9999 -9999 -9999 -9999 -9999 -9999 -9999 -9999 -9999 -9999 -9999 -9999 -9999 -9999 -9999 -9999 -9999 -9999 -9999 -9999 -9999 -9999 -9999 -9999 -9999 -9999 -9999

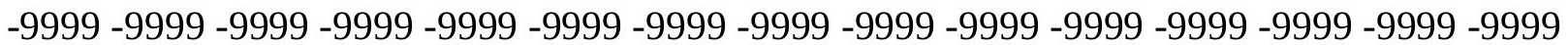


-9999 -9999 -9999 -9999 -9999 -9999 -9999 -9999 -9999 -9999 -9999 -9999 -9999 -9999 -9999 -9999 -9999 -9999 -9999 -9999 -9999 -9999 -9999 -9999 -9999 -9999 -9999 -9999 -9999 -9999

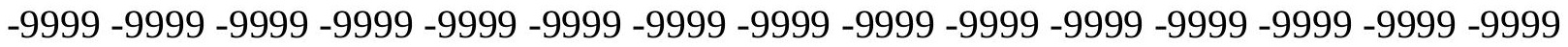
-9999 -9999 -9999 -9999 -9999 -9999 -9999 -9999 -9999 -9999 -9999 -9999 -9999 -9999 -9999 -9999 -9999 -9999 -9999 -9999 -9999 -9999 -9999 -9999 -9999 -9999 -9999-9999 -9999 -9999 -9999 -9999 -9999 -9999 -9999 -9999 -9999 -9999 -9999 -9999 -9999 -9999 -9999 -9999 -9999

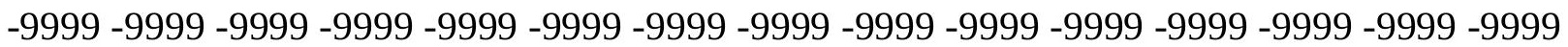
-9999 -9999 -9999 -9999 -9999 -9999 -9999 -9999 -9999 -9999 -9999 -9999 -9999 -9999 -9999 -9999 -9999 -9999 -9999-9999 409.7360534668403 .2177429199396 .912322998 390.8238220215384 .9548034668379 .3004150391373 .8513793945368 .5883483887 363.4879760742358 .5221252441353 .6647338867348 .890838623344 .1788024902 339.5085144043334 .8628845215330 .2289123535325 .6004638672320 .9818725586 316.3885498047311 .8391418457307 .3502197266302 .924407959298 .5537414551 294.209564209289 .8650512695285 .5049438477281 .139831543276 .795501709 272.4430847168268 .0301513672263 .4909057617258 .8322753906254 .0316314697 249.1418609619244 .1358795166239 .074005127233 .920425415228 .6862945557 223.4202880859218 .2215881348213 .2058105469208 .4150390625203 .7180023193 198.894241333193 .6959991455188 .111618042182 .0343475342174 .337097168 165.8031005859157 .2691040039149 .9542999268145 .3825073242142 .6394042969 141.4203033447141 .1154937744141 .4203033447142 .0299072266142 .3347015381 142.9441986084143 .2489929199143 .6507873535143 .6828460693143 .1098022461 141.733795166139 .4600830078136 .3437957764132 .7153930664129 .2724761963 127.0206832886126 .1809997559126 .1809997559125 .2667007446125 .5715026855 127.4001998901129 .533706665132 .2767028809134 .7149963379137 .1533050537 138.9819946289140 .2012023926141 .4203033447142 .3347015381143 .5538024902 144.7729034424145 .9920959473147 .2111968994148 .4304046631149 .3446960449 150.2590942383150 .8686065674151 .4781951904152 .0877990723152 .3925933838 152.6972961426153 .0021057129153 .0021057129153 .0021057129152 .6972961426 152.0877990723151 .7830047607150 .8686065674149 .9542999268148 .7351074219 147.2111968994145 .6873016357144 .1634063721142 .6394042969140 .8106994629 139.2868041992 137.4580993652 135.6293945312 134.1054992676132.2767028809 130.7528076172129 .2288970947127 .7050018311126 .1809997559124 .6570968628 123.43800354122 .2188034058121 .3044967651120 .3900985718119 .4757995605 118.5614013672117 .647102356116 .7326965332116 .4279022217117 .0374984741 117.9517974854119 .4757995605120 .9997024536121 .3044967651120 .9997024536 120.3900985718119 .1709976196117 .9517974854117 .342300415117 .342300415 115.2088012695112 .7705001831110 .6370010376109 .4179000854109 .7226028442 111.24659729114 .9039993286120 .6949005127128 .6192932129137 .7628936768 145.9920959473152 .0877990723156 .3547973633159 .4026031494161 .2312927246 162.4505004883162 .7552947998162 .4505004883161 .8408966064160 .6217956543 159.0977935791157 .2691040039154 .8307952881152 .3925933838149 .6495056152 146.6015930176143 .2489929199139 .5915985107135 .6293945312131 .6672058105 127.0953979492122 .8283996582117 .9517974854113 .075302124113 .9896011353 114.5991973877115 .5136032104116 .1231002808117 .0374984741117 .9517974854 76.1962814331170 .7101516723657 .5682563781743 .20398330688 -9999 -9999 -9999 -9999 -9999 -9999 -9999 -9999 -9999 -9999 -9999 -9999 -9999 -9999 -9999 -9999 -9999 -9999 -9999 
-9999 -9999 -9999

-9999 -9999 -9999 -9999 -9999 -9999 -9999 -9999 -9999 -9999 -9999 -9999 -9999 -9999 -9999

-9999 -9999 -9999 -9999 -9999 -9999 -9999 -9999 -9999 -9999 -9999 -9999 -9999 -9999 - 9999 -

-9999 -9999 -9999 -9999 -9999 -9999 -9999 -9999 -9999 -9999 -9999 -9999 -9999 -9999 -9999

-9999 -9999 -9999 -9999 -9999 -9999 -9999 -9999 -9999 -9999 -9999 -9999-9999 -9999 -9999 -

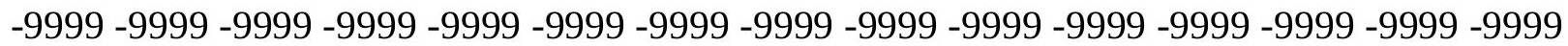

-9999 -9999 -9999 -9999 -9999 -9999 -9999 -9999 -9999 -9999 -9999 -9999 -9999 -9999 -9999 -999 -

-9999 -9999 -9999 -9999 -9999 -9999 -9999 -9999 -9999 -9999 -9999 -9999 -9999 -9999 -9999

-9999 -9999 -9999 -9999 -9999 -9999 -9999 -9999 -9999 -9999 -9999 -9999 -9999 -9999 -9999 -

-9999 -9999 -9999 -9999 -9999 -9999 -9999 -9999 -9999 -9999 -9999 -9999 -9999 -9999 -9999 -

-9999 -9999 -9999 -9999 -9999 -9999 -9999 -9999 -9999 -9999 -9999 -9999 -9999 -9999 -9999

-9999 -9999 -9999 -9999 -9999 -9999 -9999 -9999 -9999 -9999 -9999 -9999 -9999 -9999 -9999

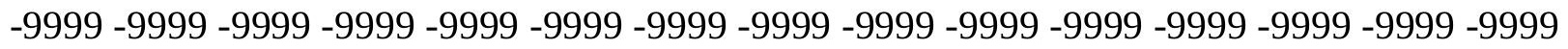

-9999 -9999-9999-9999-9999 409.9373779297403.4094238281 397.0725402832

390.9292907715384 .9813537598379 .2243041992373 .6510925293368 .2466430664

362.9928588867357 .8671569824352 .8483886719347 .9156494141343 .0505065918

338.2354431152333 .4562988281328 .703338623323 .9727783203319 .2669372559

314.5937194824309 .9630126953305 .3844909668300 .8545532227296 .3663024902 291.9042358398287 .4502868652282 .9948730469278 .536315918274 .0750427246 269.5923461914265 .0623474121260 .4564819336255 .7544403076250 .9436645508 246.032699585241 .0268249512235 .9405822754230 .7801208496225 .5702667236 220.3522949219215 .2014770508210 .1537475586205 .2230377197200 .3204345703 195.2813262939189 .9586486816184 .2452697754177 .9109802246170 .7334136963 163.2030181885155 .4403991699149 .3446960449145 .0776977539142 .6394042969 141.4203033447140 .8106994629141 .1154937744141 .4203033447142 .0299072266 142.9441986084144 .0048980713144 .9560089111145 .5424957275145 .4772491455 144.4826202393142 .3852386475139 .214630127135 .258682251131 .1653289795 128.3697814941128 .6192932129124 .3523025513124 .0475006104126 .1809997559 128.0097961426129 .533706665130 .4479980469130 .7528076172132 .8863067627 134.7149963379136 .5437011719138 .0677032471139 .2868041992140 .8106994629 142.6394042969144 .1634063721145 .3825073242146 .9064025879148 .1255950928 149.0399017334149 .9542999268150 .8686065674151 .7830047607152 .3925933838 152.6972961426153 .0021057129153 .0021057129153 .0021057129152 .6972961426 152.3925933838151 .7830047607150 .8686065674149 .9542999268148 .7351074219 147.2111968994 145.6873016357 144.1634063721 142.3347015381 140.8106994629 138.9819946289137 .1533050537135 .6293945312133 .8007049561132 .2767028809 130.4479980469128 .9241027832127 .4001998901125 .8762969971124 .3523025513 123.1332015991121 .9140014648120 .9997024536120 .0852966309119 .1709976196 118.5614013672117 .9517974854117 .342300415117 .342300415117 .9517974854 118.8662033081119 .7806015015120 .6949005127120 .9997024536120 .9997024536 120.6949005127120 .0852966309119 .1709976196118 .5614013672117 .647102356 116.1231002808113 .6848983765111 .8561019897110 .6370010376110 .6370010376 112.1608963013114 .9039993286120 .0852966309126 .7906036377134 .4102020264 141.4203033447147 .5160064697152 .0877990723155 .1356048584157 .5738983154 159.0977935791160 .0122070312160 .3170013428160 .0122070312159 .4026031494 157.878692627156 .3547973633154 .2212982178151 .7830047607149 .0399017334 
145.9920959473142 .6394042969138 .9819946289135 .3246002197131 .0576019287 126.7906036377122 .2188034058117 .342300415112 .4656982422111 .24659729 112.1608963013112 .7705001831113 .6848983765114 .599197387780 .46327209473 74.9771423339865 .8003997802754 .49714279175 -9999 -9999 -9999 -9999 -9999 -9999 -9999 -9999 -9999 -9999 -9999 -9999 -9999 -9999 -9999 -9999 -9999 -9999 -9999 -9999 -9999 -9999 $-9999$

-9999 -9999 -9999 -9999 -9999 -9999 -9999 -9999 -9999 -9999 -9999 -9999 -9999 -9999 -9999

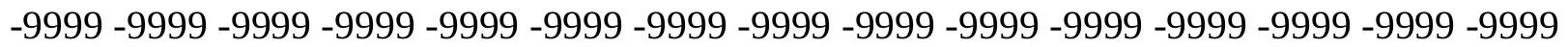

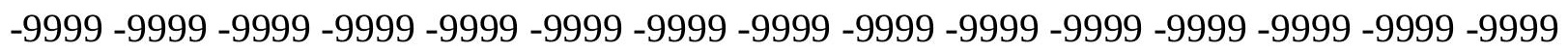
-9999 -9999 -9999 -9999 -9999 -9999 -9999 -9999 -9999 -9999 -9999 -9999 -9999 -9999 -9999 -9999 -9999 -9999 -9999 -9999 -9999 -9999 -9999 -9999 -9999 -9999 -9999 -9999 -9999 -9999 -999 -9999 -9999 -9999 -9999 -9999 -9999 -9999 -9999 -9999 -9999 -9999 -9999 -9999 -9999 -9999 -9999 -9999 -9999 -9999 -9999 -9999 -9999 -9999 -9999 -9999 -9999 -9999 -9999 -9999 -9999 -9999 -9999 -9999 -9999 -9999 -9999 -9999 -9999 -9999 -9999 -9999 -9999 -9999 -9999 -9999 -9999 -9999 -9999 -9999 -9999 -9999 -9999 -9999 -9999 -9999 -9999 -9999 -9999 -9999 -9999

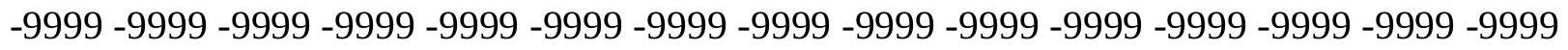

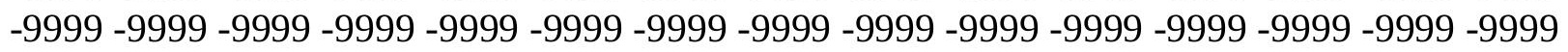

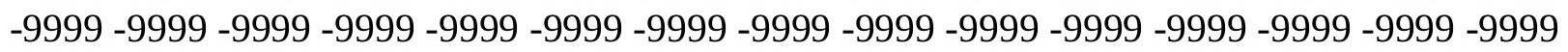
-9999 -9999 -9999 -9999 -9999 -9999 403.3764953613397 .0029296875390 .8020019531 384.7744445801378 .9164123535373 .2222900391367 .6804504395362 .277130127 356.9942932129351 .8144836426346 .7199401855341 .6954040527336 .7264709473 331.8019104004326 .9138183594322 .0589904785317 .2373046875312 .4518432617 307.7066650391303 .0044250488298 .3428039551293 .7150268555289 .1116943359 284.5229797363279 .9412841797275 .3606262207270 .7723388672266 .1644897461 261.5216369629256 .8274536133252 .0635070801247 .218536377242 .2850036621 237.272277832 232.1862182617227.0445404053 221.8728637695 216.7072753906 211.5855102539206 .5275878906201 .5231323242196 .5109558105191 .3872680664 186.0352172852180 .3849334717174 .3433380127168 .0130462646161 .6396026611 155.4403991699148 .7351074219145 .0776977539142 .6394042969141 .4203033447 141.1154937744141 .1154937744141 .7250976562142 .6394042969144 .0592956543 145.6851654053147 .2659912109148 .586227417149 .2821807861148 .9422149658 147.2514801025144 .1289520264139 .8433380127134 .8937683105129 .4280548096 122.8283996582122 .8283996582125 .5715026855128 .0097961426129 .8385009766 131.0576019287131 .6672058105131 .9720001221132 .2767028809131 .9720001221 132.8863067627134 .7149963379136 .5437011719138 .3724975586140 .2012023926 142.0299072266143 .5538024902145 .0776977539146 .6015930176147 .8208007812 149.0399017334150 .2590942383151 .1734008789152 .0877990723152 .3925933838 152.6972961426152 .6972961426152 .6972961426152 .6972961426152 .3925933838 151.7830047607150 .8686065674149 .9542999268148 .4304046631147 .2111968994 145.6873016357143 .8585968018142 .3347015381140 .5059967041138 .6772003174 137.1533050537135 .3246002197133 .4958953857131 .9720001221130 .1432037354 128.6192932129127 .0953979492125 .5715026855124 .3523025513122 .8283996582 121.9140014648120 .6949005127119 .7806015015119 .1709976196118 .5614013672 118.2565994263117 .9517974854117 .9517974854118 .2565994263119 .1709976196 119.7806015015120 .6949005127120 .9997024536121 .3044967651120 .9997024536 120.6949005127120 .3900985718119 .4757995605118 .2565994263116 .4279022217 
114.2944030762112 .4656982422111 .551399231111 .551399231112 .7705001831 115.2088012695118 .8662033081124 .9618988037131 .3623962402137 .7628936768 143.5538024902147 .8208007812151 .4781951904154 .2212982178156 .0500030518 157.5738983154158 .1835021973158 .4882965088157 .878692627156 .9642944336 155.4403991699153 .6116943359151 .1734008789148 .7351074219145 .6873016357 142.3347015381138 .6772003174134 .7149963379130 .4479980469126 .1809997559 121.3044967651116 .4279022217111 .551399231108 .8082962036109 .4179000854 110.3321990967 111.24659729 111.8561019897 79.54891967773 73.75800323486 63.0447616577151 .62986373901 -9999 -9999 -9999 -9999 -9999 -9999 -9999 -9999 -9999 -9999 -9999 -9999 -9999 -9999 -9999 -9999 -9999 -9999 -9999 -9999 -9999 -9999 -9999 -9999 -9999 -9999 -9999 -9999 -9999 -9999 -9999 -9999 -9999 -9999 -9999 -9999 -9999 -9999 -9999 -9999 -9999 -9999 -9999 -9999 -9999 -9999 -9999 -9999 -9999 -9999 -9999 -9999 -9999 -9999 -9999 -9999 -9999 -9999 -9999 -9999 -9999 -9999 -9999 -9999 -9999 -9999 -9999 -9999 -

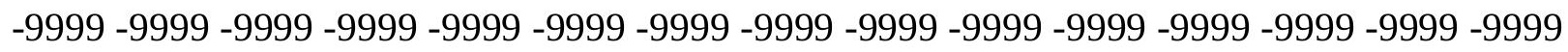
-9999 -9999 -9999 -9999 -9999 -9999 -9999 -9999 -9999 -9999 -9999 -9999 -9999 -9999 -9999

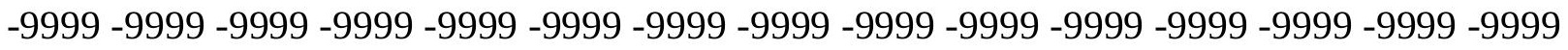
-9999 -9999 -9999 -9999 -9999 -9999 -9999 -9999 -9999 -9999 -9999 -9999 -9999 -9999 -9999 -9999 -9999 -9999 -9999 -9999 -9999 -9999 -9999 -9999 -9999 -9999 -9999 -9999 -9999 -9999 -9999 -9999 -9999 -9999 -9999 -9999 -9999 -9999 -9999 -9999 -9999 -9999 -9999 -9999 -9999 -

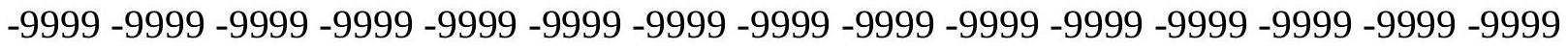

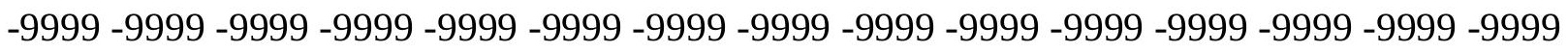
-9999 -9999 -9999 -9999 -9999 -9999 -9999 -9999 -9999 -9999 -9999 -9999 -9999 -9999 -9999 -9999 -9999 -9999 -9999 -9999 -9999 403.1298522949396 .7155456543390 .4549560547 384.3481750488 378.3915100098 372.5804748535 366.9057312012361 .3567199707 355.9193725586350 .5795288086345 .3221435547340 .1345214844335 .005279541 329.9254760742324 .8881835938319 .8897094727314 .9283447266310 .0042419434 305.1180419922300 .2695922852295 .4555664062290 .6708679199285 .9096069336 281.1667175293276 .436920166271 .7139282227266 .988861084262 .2522583008 257.4942932129252 .704208374247 .8695983887242 .9789886475238 .0252685547 233.0089416504227 .9378051758222 .8281555176217 .7031860352212 .5889587402 207.5065155029202 .4633178711197 .4454193115192 .4072723389187 .2909698486 182.0413818359176 .6077423096171 .0473937988165 .4936828613160 .0885162354 154.8307952881149 .3446960449145 .0776977539142 .9441986084141 .7250976562 141.4203033447141 .7250976562142 .6394042969144 .0175323486145 .8764343262 148.0360717773150 .2934875488152 .5213775635154 .2904052734154 .9615936279 153.9405212402151 .0167236328146 .3996124268140 .5004730225133 .9974822998 128.3144989014125 .8762969971128 .0097961426130 .1432037354131 .6672058105 132.8863067627133 .1911010742133 .1911010742133 .1911010742132 .8863067627 132.5814971924131 .6672058105133 .4958953857135 .6293945312137 .7628936768 139.5915985107141 .7250976562143 .2489929199145 .0776977539146 .6015930176 148.1255950928149 .3446960449150 .5639038086151 .4781951904152 .0877990723 152.3925933838152 .3925933838152 .6972961426152 .6972961426152 .3925933838 151.7830047607150 .8686065674149 .6495056152148 .4304046631146 .9064025879 145.3825073242143 .5538024902142 .0299072266140 .2012023926138 .6772003174 136.8484954834135 .0198059082133 .4958953857131 .6672058105130 .1432037354 128.3144989014126 .7906036377125 .2667007446124 .0475006104122 .8283996582 
121.6092987061120 .6949005127119 .7806015015119 .1709976196118 .8662033081 118.2565994263118 .2565994263118 .2565994263118 .5614013672119 .1709976196 119.7806015015120 .3900985718120 .9997024536121 .3044967651121 .3044967651 121.3044967651120 .9997024536120 .6949005127118 .8662033081116 .7326965332 114.2944030762112 .7705001831111 .8561019897112 .1608963013113 .3800964355 115.5136032104119 .1709976196123 .7427978516129 .533706665135 .0198059082 140.2012023926144 .7729034424148 .4304046631151 .1734008789153 .9165039062 155.4403991699156 .6596069336156 .9642944336156 .6596069336156 .0500030518 154.8307952881153 .0021057129150 .8686065674148 .1255950928145 .0776977539 141.7250976562138 .0677032471134 .1054992676129 .8385009766125 .2667007446 120.6949005127115 .818397522110 .6370010376105 .4557037354106 .979598999 107.8938980103108 .5035018921109 .417900085478 .3297805786172 .53885650635 61.5253219604549 .51675033569 -9999 -9999 -9999 -9999 -9999 -9999 -9999 -9999 -9999 -9999 -9999 -9999 -9999 -9999 -9999 -9999 -9999 -9999 -9999 -9999 -9999 -9999 -9999 -9999 -9999 -9999 -9999 -9999 -9999 -9999 -9999 -9999 -9999 -9999 -9999 -9999 -9999 -9999

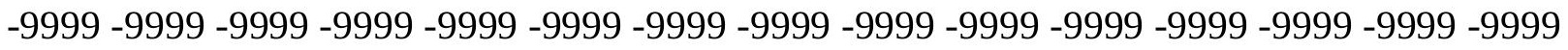
-9999 -9999 -9999 -9999 -9999 -9999 -9999 -9999 -9999 -9999 -9999 -9999 -9999 -9999 -9999 -9999 -9999 -9999 -9999 -9999 -9999 -9999 -9999 -9999 -9999 -9999 -9999 -9999 -9999 -9999 -

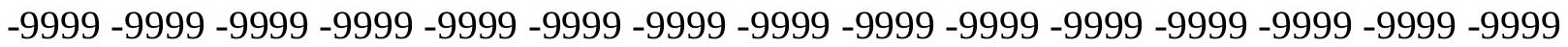

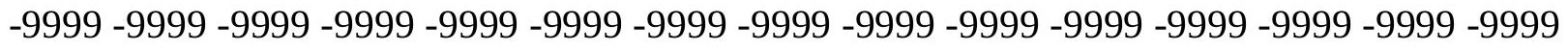

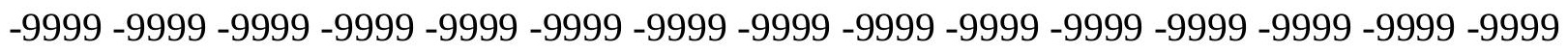
-9999 -9999 -9999 -9999 -9999 -9999 -9999 -9999 -9999 -9999 -9999 -9999 -9999 -9999 -9999 -9999 -9999 -9999 -9999 -9999 -9999 -9999 -9999 -9999 -9999 -9999 -9999 -9999 -9999 -9999 -

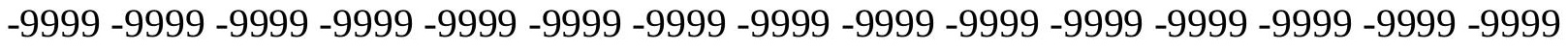

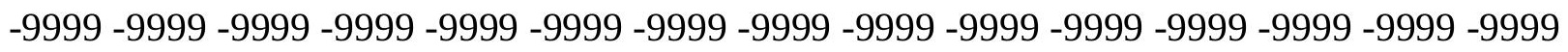

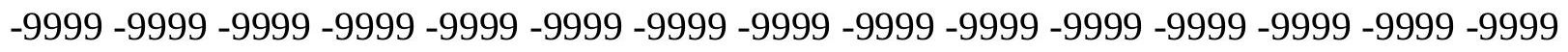
-9999 -9999 -9999 -9999 -9999-9999-9999 396.2261962891 389.9048156738383 .7196655273 377.6671447754371 .7432861328365 .9404296875360 .250213623354 .6614685059 349.1632385254343 .7431030273338 .3904418945333 .0958557129327 .8524169922 322.6538696289317 .4960327148312 .3760070801307 .2926635742302 .244934082 297.2314758301292 .2489929199287 .2938232422282 .3626708984277 .4531555176 272.5621948242267 .6851806641262 .8154296875257 .9460449219253 .0710449219 248.1839904785243 .2767028809238 .3395080566233 .3651733398228 .3516845703 223.3051147461 218.237991333213.1678009033208.1126556396203.0854492188 198.0884094238193 .1101531982188 .1251373291183 .1052856445178 .0283050537 172.9020690918167 .7864074707162 .7928771973158 .1229400635153 .9165039062 147.8208007812145 .0776977539143 .5538024902142 .6394042969142 .3347015381 142.6394042969143 .8585968018145 .8071136475148 .1519012451150 .8058624268 153.6951904297156 .8427886963160 .0321044922162 .1686859131162 .0084838867 159.4851837158154 .8260498047148 .5646057129141 .5767974854135 .6293945312 131.0576019287131 .3623962402132 .8863067627134 .1054992676134 .7149963379 134.7149963379134 .4102020264134 .1054992676133 .4958953857133 .1911010742 132.5814971924131 .0576019287133 .1911010742135 .3246002197137 .4580993652 139.5915985107141 .4203033447143 .2489929199145 .0776977539146 .6015930176 148.1255950928149 .6495056152150 .5639038086151 .4781951904152 .3925933838 152.3925933838152 .3925933838152 .6972961426152 .3925933838151 .7830047607 
150.5639038086149 .3446960449148 .1255950928146 .6015930176145 .0776977539 143.2489929199141 .7250976562139 .8963928223138 .3724975586136 .5437011719 135.0198059082133 .1911010742131 .6672058105129 .8385009766128 .3144989014 126.7906036377125 .2667007446124 .0475006104122 .5235977173121 .6092987061 120.6949005127120 .0852966309119 .4757995605118 .8662033081118 .5614013672 118.2565994263118 .2565994263118 .5614013672119 .1709976196119 .7806015015 120.3900985718120 .9997024536121 .6092987061121 .6092987061121 .9140014648 121.9140014648121 .9140014648119 .7806015015117 .0374984741114 .2944030762 112.7705001831112 .4656982422112 .7705001831113 .9896011353116 .1231002808 119.1709976196123 .1332015991128 .0097961426133 .1911010742138 .0677032471 142.3347015381146 .2969055176149 .3446960449152 .0877990723153 .9165039062 155.4403991699156 .0500030518155 .7451934814155 .1356048584154 .2212982178 152.3925933838150 .2590942383147 .8208007812144 .7729034424141 .4203033447 137.4580993652133 .4958953857129 .2288970947124 .6570968628119 .7806015015 114.9039993286109 .7226028442104 .5412979126104 .5412979126105 .1509017944 106.065200805782 .5967712402377 .110626220768 .8349838256859 .15795135498 47.77234268188 -9999 -9999 -9999 -9999 -9999 -9999 -9999 -9999 -9999 -9999 -9999 -9999 -9999 -9999 -9999 -9999 -9999 -9999 -9999 -9999 -9999 -9999 -9999

-9999 -9999 -9999 -9999 -9999 -9999 -9999 -9999 -9999 -9999 -9999 -9999 -9999 -9999 -9999

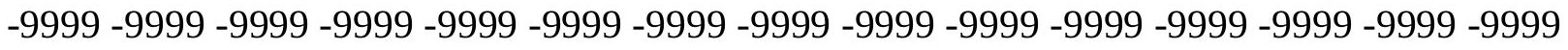

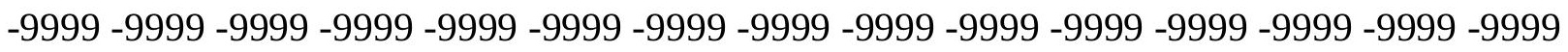
-9999 -9999 -9999 -9999 -9999 -9999 -9999 -9999 -9999 -9999 -9999 -9999 -9999 -9999 -9999 -9999 -9999 -9999 -9999 -9999 -9999 -9999 -9999 -9999 -9999 -9999 -9999 -9999 -9999 -9999 -

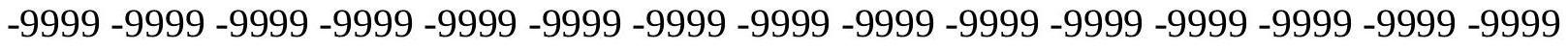

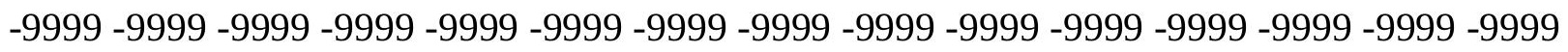
-9999 -9999 -9999 -9999 -9999 -9999 -9999 -9999 -9999 -9999 -9999 -9999 -9999 -9999 -9999 -

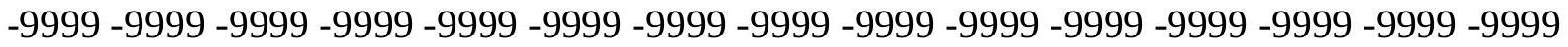

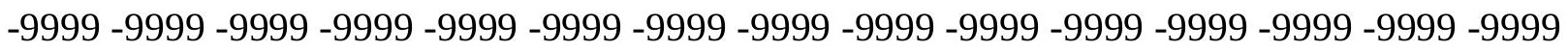
-9999 -9999 -9999 -9999 -9999 -9999 -9999 -9999 -9999 -9999 -9999 -9999 -9999 -9999 -9999 -9999 -9999 -9999 -9999 -9999 -9999 -9999 -9999 -9999 -9999 -9999 -9999 -9999 -9999 -9999 -9999 -9999 -9999 -9999 -9999 -9999 -9999 -9999 389.1666259766382 .9043884277 376.7588500977370 .7263183594364 .8002624512358 .973815918353 .2378540039 347.5837097168342 .0016784668336 .4829711914331 .0194396973325 .6052856445 320.2352905273314 .9054260254309 .6122131348304 .3538513184299 .1288452148 293.935760498288 .772064209283 .6356201172278 .5251159668273 .4404602051 268.3807678223263 .3439941406258 .3262939453253 .3239440918248 .3338012695 243.3529052734238.3761138916233.3961791992 228.4061889648 223.402923584 218.389541626 213.3749389648 208.3712463379 203.3908233643 198.4420623779 193.5272979736188 .6410827637183 .7738647461178 .9164886475174 .0733337402 169.2870025635164 .6136779785160 .1155090332155 .6602325439150 .8686065674 147.8208007812145 .3825073242144 .1634063721143 .2489929199143 .2489929199 143.8585968018145 .7233428955148 .0012664795150 .708984375153 .8257141113 157.2416229248160 .9264984131165 .8031005859169 .7653045654170 .5629425049 168.6672058105164 .3749847412158 .2124328613150 .7565917969142 .3347015381 135.0198059082135 .6293945312135 .6293945312136 .2389984131136 .2389984131 135.9342041016135 .3246002197134 .7149963379134 .1054992676133 .4958953857 
132.8863067627131 .9720001221131 .0576019287133 .4958953857135 .6293945312 137.7628936768139 .8963928223141 .7250976562143 .5538024902145 .3825073242 146.9064025879148 .4304046631149 .6495056152150 .5639038086151 .4781951904 151.7830047607152 .0877990723152 .3925933838151 .7830047607151 .1734008789 149.9542999268148 .7351074219147 .5160064697145 .9920959473144 .4682006836 142.9441986084141 .4203033447139 .5915985107138 .0677032471136 .2389984131 134.7149963379132 .8863067627131 .3623962402129 .8385009766128 .0097961426 126.4858016968125 .2667007446123 .7427978516122 .5235977173121 .6092987061 120.6949005127120 .0852966309119 .4757995605119 .1709976196118 .5614013672 118.2565994263118 .2565994263118 .8662033081119 .4757995605120 .0852966309 120.6949005127120 .9997024536121 .6092987061121 .9140014648122 .2188034058 122.2188034058122 .2188034058120 .6949005127117 .9517974854113 .9896011353 113.6848983765113 .6848983765113 .9896011353114 .9039993286116 .4279022217 119.1709976196122 .8283996582127 .0953979492131 .6672058105136 .5437011719 140.8106994629144 .7729034424148 .1255950928150 .8686065674153 .0021057129 154.2212982178155 .1356048584155 .1356048584154 .5260925293153 .6116943359 152.0877990723149 .9542999268147 .2111968994144 .1634063721140 .8106994629 137.1533050537132 .8863067627128 .6192932129124 .0475006104119 .1709976196 113.9896011353108 .8082962036103 .6268997192102 .1029968262102 .712600708 86.8637619018681 .3776321411175 .5867080688566 .6172485351657 .01955795288 -9999 -9999 -9999 -9999 -9999 -9999 -9999 -9999 -9999 -9999 -9999 -9999 -9999 -9999 -9999 -9999 -9999 -9999 -9999 -9999 -9999 -9999 -9999 -9999

-9999 -9999 -9999 -9999 -9999 -9999 -9999 -9999 -9999 -9999 -9999 -9999 -9999 -9999 -9999

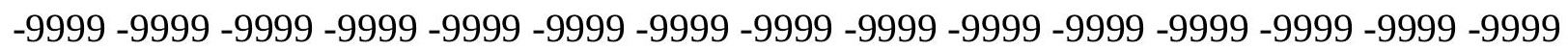

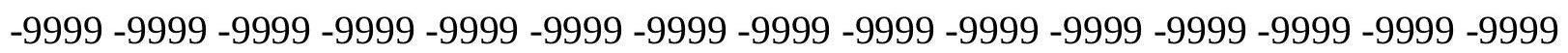

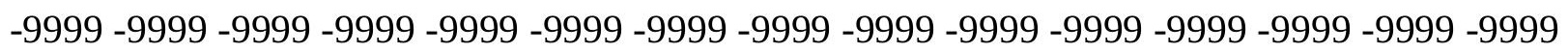

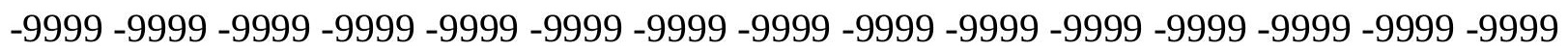

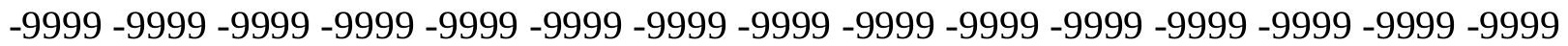

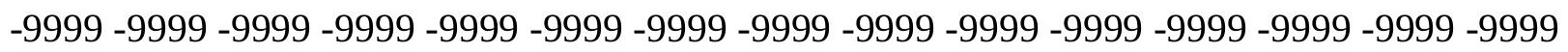

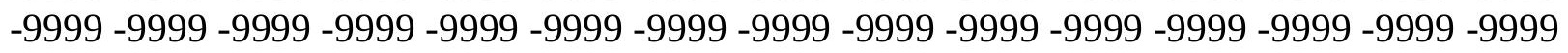
-9999 -9999 -9999 -9999 -9999 -9999 -9999 -9999 -9999 -9999 -9999 -9999 -9999 -9999 -9999

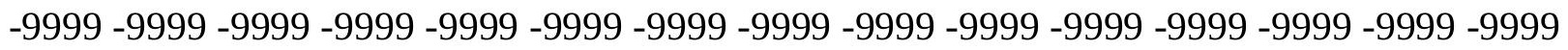

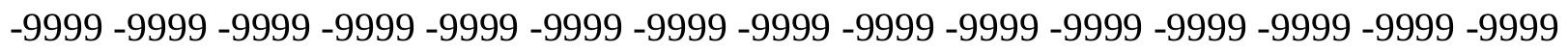

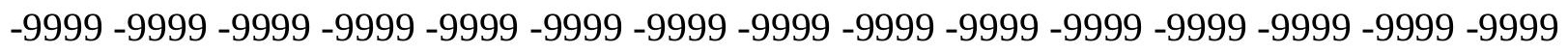
-9999 -9999 -9999 -9999-9999 -9999 -9999 -9999 388.2581787109381 .9203796387 375.684753418369 .5476379395363 .5032043457357 .5456237793351 .667175293 345.8607177734340 .1184997559334 .43359375328 .7989196777323 .2092895508 317.6602783203312 .1486816406306 .671295166301 .2262268066295 .8121948242 290.4284667969285 .0738830566279 .7480773926274 .4517211914269 .1868591309 263.9548950195258 .7565917969253 .5911254883248 .4580383301243 .3570709229 238.2880859375 233.248550415 228.2334747314 223.2364959717 218.253692627 213.2855529785208 .3372344971203 .4163513184198 .5312957764193 .6885681152 188.8925018311184 .1445922852179 .4474945068174 .8083648682170 .2492218018 165.8196105957161 .569229126157 .5514678955153 .828414917150 .5639038086 147.8208007812145 .9920959473144 .7729034424144 .1634063721144 .4682006836 146.2969055176147 .9576263428150 .3768310547153 .4159698486156 .9400024414 
160.9264984131165 .4983062744170 .6797027588174 .9467010498178 .2993011475 177.2947692871173 .6630096436168 .1234283447161 .0673675537152 .6972961426 143.8585968018140 .2012023926138 .3724975586137 .7628936768137 .4580993652 136.8484954834136 .2389984131135 .3246002197134 .4102020264133 .8007049561 132.8863067627132 .2767028809131 .6672058105131 .3623962402133 .8007049561 135.9342041016138 .0677032471140 .2012023926142 .0299072266143 .8585968018 145.6873016357147 .2111968994148 .4304046631149 .6495056152150 .2590942383 150.8686065674151 .1734008789151 .1734008789150 .8686065674150 .2590942383 149.3446960449148 .1255950928146 .9064025879145 .3825073242143 .8585968018 142.3347015381140 .8106994629139 .2868041992137 .7628936768135 .9342041016 134.4102020264132 .8863067627131 .0576019287129 .533706665128 .0097961426 126.4858016968124 .9618988037123 .7427978516122 .5235977173121 .6092987061 120.9997024536120 .3900985718119 .7806015015119 .4757995605118 .8662033081 118.2565994263118 .2565994263119 .1709976196119 .7806015015120 .3900985718 120.9997024536121 .3044967651121 .6092987061121 .9140014648121 .9140014648 121.9140014648121 .9140014648122 .5235977173119 .7806015015117 .342300415 115.818397522115 .2088012695114 .9039993286115 .5136032104117 .0374984741 119.1709976196122 .5235977173126 .4858016968130 .7528076172135 .6293945312 139.8963928223144 .1634063721147 .5160064697150 .2590942383152 .0877990723 153.6116943359154 .5260925293154 .8307952881154 .2212982178153 .3069000244 151.4781951904149 .3446960449146 .9064025879143 .8585968018140 .5059967041 136.5437011719132 .2767028809128 .0097961426123 .1332015991118 .2565994263 113.075302124107 .8938980103102 .407798767199 .66472625732100 .2742996216 $85.6446228027379 .8537063598674 .3675689697365 .396202087455 .43812179565-9999$ -9999 -9999 -9999 -9999 -9999 -9999 -9999 -9999 -9999 -9999 -9999 -9999 -9999 -9999 -9999 -9999 -9999 -9999 -9999 -9999 -9999 -9999 -9999

-9999 -9999 -9999 -9999 -9999 -9999 -9999 -9999 -9999 -9999 -9999 -9999 -9999 -9999 -9999 -

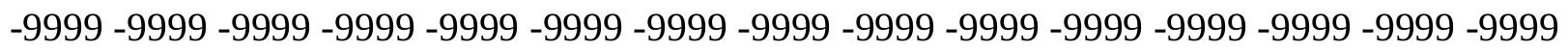

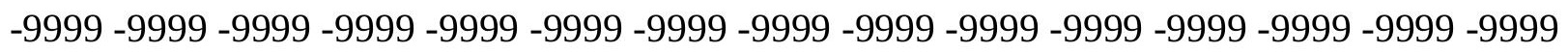

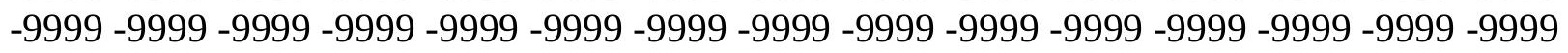

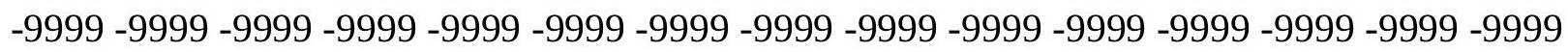

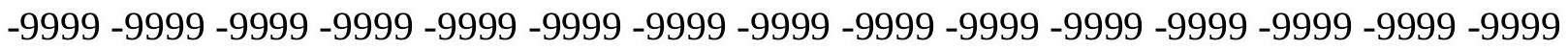

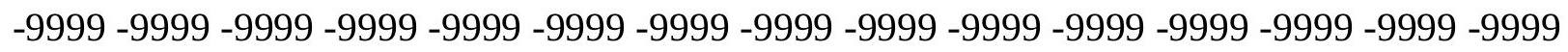

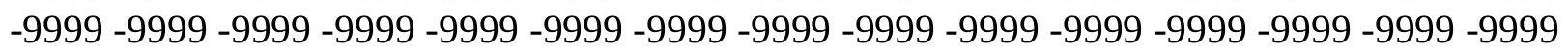

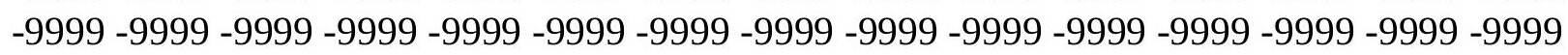

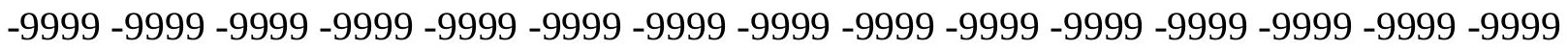

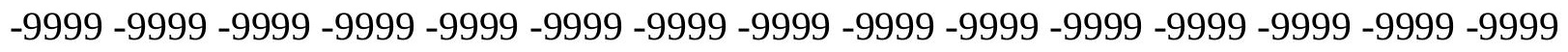

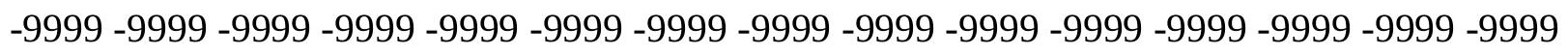
-9999 -9999-9999 -9999 -9999-9999-9999-9999-9999 380.7841796875 374.4614868164 368.2239074707 362.0659484863355 .9822998047349 .9663391113344 .0118713379 338.1123657227332 .2621765137326 .4554748535320 .6876831055314 .9550170898 309.2550048828303 .5854797363297 .9451599121292 .3334960938286 .7510681152 281.1985473633275 .6777648926270 .1914367676264 .7438964844259 .3389587402 253.9801483154248 .6694641113243 .4096221924238 .2033233643233 .0535125732 227.9602050781222 .9207305908217 .9292144775212 .981048584208 .07421875 203.2105865479 198.3936920166193.6290283203188.9222259521 184.2803649902 
179.7110595703175 .226776123170 .846206665166 .6020812988162 .5432739258 158.7372283936155 .293762207152 .3208007812149 .9542999268147 .8208007812 146.2969055176145 .3825073242145 .3825073242145 .9920959473147 .8491516113 150.1328125152 .8563842773156 .1271362305160 .0122070312164 .5839996338 169.4604949951174 .337097168178 .604095459182 .261505127183 .7854003906 181.0633239746176 .9860076904171 .3931884766163 .3648071289153 .0021057129 144.1634063721141 .1154937744138 .6772003174138 .0677032471137 .1533050537 136.2389984131135 .3246002197134 .4102020264133 .8007049561132 .8863067627 132.2767028809131 .6672058105130 .7528076172132 .2767028809134 .4102020264 136.5437011719138 .6772003174140 .8106994629142 .6394042969144 .4682006836 145.9920959473147 .2111968994148 .4304046631149 .3446960449149 .6495056152 150.2590942383150 .2590942383149 .6495056152149 .0399017334148 .1255950928 147.2111968994 145.9920959473144.7729034424 143.2489929199142.0299072266 140.5059967041138 .9819946289137 .4580993652135 .9342041016134 .1054992676 132.5814971924131 .0576019287129 .533706665128 .0097961426126 .4858016968 124.9618988037123 .7427978516122 .5235977173121 .6092987061120 .9997024536 120.6949005127120 .3900985718120 .0852966309119 .7806015015119 .1709976196 118.2565994263120 .0852966309120 .6949005127120 .9997024536121 .3044967651 121.6092987061121 .6092987061121 .9140014648121 .9140014648121 .6092987061 121.9140014648122 .2188034058121 .6092987061119 .7806015015117 .9517974854 116.7326965332116 .1231002808116 .1231002808117 .0374984741119 .1709976196 121.9140014648125 .8762969971130 .1432037354135 .0198059082139 .5915985107 143.8585968018147 .5160064697149 .9542999268151 .7830047607153 .3069000244 154.2212982178154 .5260925293153 .9165039062153 .0021057129151 .1734008789 149.0399017334146 .6015930176143 .5538024902139 .8963928223135 .9342041016 131.9720001221127 .4001998901122 .5235977173117 .342300415112 .1608963013 106.6747970581101 .188697814997 .2264633178789 .9116134643684 .42548370361 78.6345596313571 .9705963134863 .6581382751554 .03985214233 -9999 -9999 -9999 -9999 -9999 -9999 -9999 -9999 -9999 -9999 -9999 -9999 -9999 -9999 -9999 -9999 -9999 -9999 -9999 -9999 -9999-9999-9999-9999

-9999 -9999 -9999 -9999 -9999 -9999 -9999 -9999 -9999 -9999 -9999 -9999 -9999 -9999 -9999

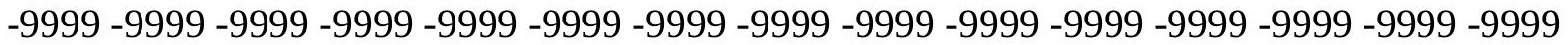

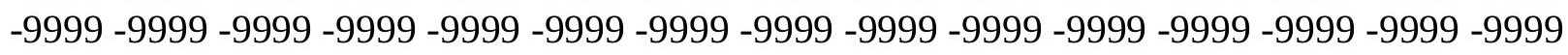
-9999 -9999 -9999 -9999 -9999 -9999 -9999 -9999 -9999 -9999 -9999 -9999 -9999 -9999 -9999 -9999 -9999 -9999 -9999 -9999 -9999 -9999 -9999 -9999 -9999 -9999 -9999 -9999 -9999 -9999 -9999 -9999 -9999 -9999 -9999 -9999 -9999 -9999 -9999 -9999 -9999 -9999 -9999 -9999 -9999

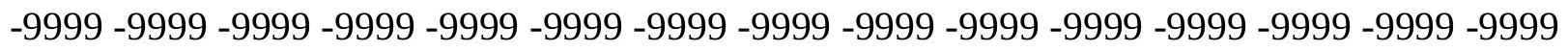

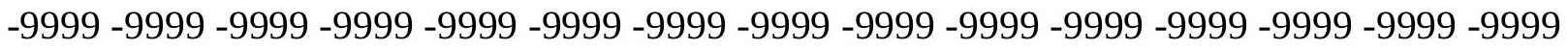
-9999 -9999 -9999 -9999 -9999 -9999 -9999 -9999 -9999 -9999 -9999 -9999 -9999 -9999 -9999 -

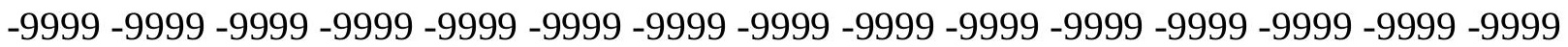

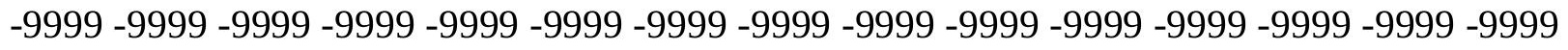

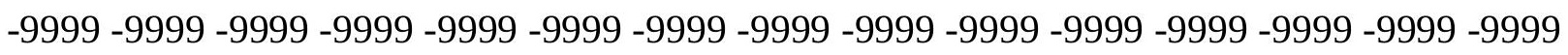
-9999 -9999 -9999 -9999 -9999 -9999 -9999 -9999 -9999 379.5145263672373 .1080627441 366.7741088867360 .5073852539354 .3027954102348 .1543273926342 .0564880371 336.0033874512329 .990234375324 .0121459961318 .0653991699312 .1468811035 306.2548522949300 .3882446289294 .5470581055288 .7320861816282 .9455566406 
277.1903686523271 .4707946777265 .7920227051260 .1607666016254 .5834655762 249.0664520264243 .6145477295238 .2333526611232 .9283905029227 .705947876 222.5691375732217 .5179290771212 .54737854207 .6519470215202 .8268280029 198.0704650879193 .3826141357188 .7658538818184 .2250823975179 .7702484131 175.4147338867171 .1785736084167 .088394165163 .1826934814159 .5117340088 156.1500549316153 .2022247314150 .8152008057149 .0399017334147 .5160064697 146.6015930176146 .2969055176146 .6015930176147 .5160064697149 .7945709229 152.3856201172155 .3460235596158 .7929992676163 .0599975586167 .6318054199 172.2035980225176 .7754058838180 .432800293183 .1759033203185 .3276367188 185.2543334961183 .2838287354179 .6912689209173 .7274932861160 .6217956543 147.8208007812142 .0299072266138 .6772003174137 .7628936768136 .8484954834 135.9342041016135 .0198059082134 .4102020264133 .4958953857132 .8863067627 132.2767028809 131.3623962402 130.7528076172 130.7528076172133 .1911010742 135.3246002197137 .4580993652139 .2868041992141 .1154937744142 .9441986084 144.4682006836145 .9920959473147 .2111968994147 .8208007812148 .4304046631 148.7351074219148 .7351074219148 .4304046631147 .8208007812146 .9064025879 145.9920959473145 .0776977539143 .8585968018142 .6394042969141 .4203033447 140.2012023926138 .6772003174137 .1533050537135 .6293945312134 .1054992676 132.5814971924131 .0576019287129 .533706665128 .0097961426126 .4858016968 124.9618988037123 .7427978516122 .8283996582121 .9140014648121 .3044967651 120.9997024536120 .6949005127120 .6949005127120 .6949005127120 .6949005127 120.9997024536122 .2188034058121 .6092987061121 .6092987061121 .6092987061 121.6092987061121 .6092987061121 .6092987061121 .6092987061121 .9140014648 122.2188034058 122.2188034058 122.2188034058120.9997024536119.7806015015 117.9517974854116 .7326965332116 .4279022217117 .342300415118 .8662033081 121.6092987061124 .9618988037129 .533706665134 .7149963379139 .8963928223 144.4682006836148 .1255950928150 .5639038086152 .0877990723153 .6116943359 154.2212982178154 .2212982178153 .9165039062152 .6972961426151 .1734008789 149.0399017334146 .2969055176142 .9441986084139 .5915985107135 .6293945312 131.3623962402126 .4858016968121 .6092987061116 .4279022217111 .24659729 105.760398864799 .9695205688594 .4833908081188 .6924667358482 .90155792236 77.110626220770 .0267105102561 .7912139892652 .56214904785 -9999 -9999 -9999 -9999 -9999 -9999 -9999 -9999 -9999 -9999 -9999 -9999 -9999 -9999 -9999 -9999 -9999 -9999 -9999 -9999 -9999-9999-9999-9999

-9999 -9999 -9999 -9999 -9999 -9999 -9999 -9999 -9999 -9999 -9999 -9999 -9999 -9999 -9999

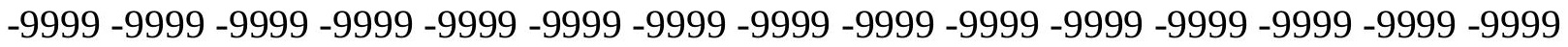

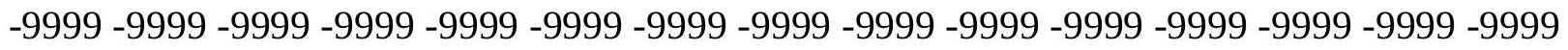

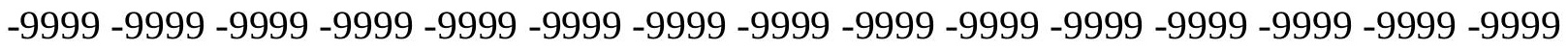
-9999 -9999 -9999 -9999 -9999 -9999 -9999 -9999 -9999 -9999 -9999 -9999 -9999 -9999 -9999 -9999 -9999 -9999 -9999 -9999 -9999 -9999 -9999 -9999 -9999 -9999 -9999 -9999 -9999 -9999

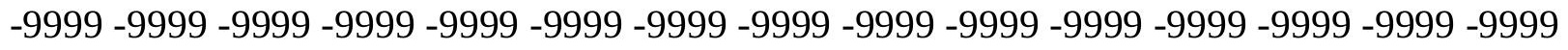

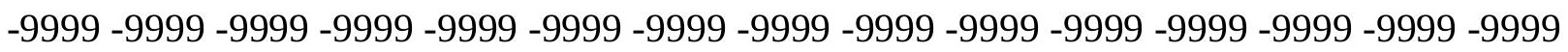
-9999 -9999 -9999 -9999 -9999 -9999 -9999 -9999 -9999 -9999 -9999 -9999 -9999 -9999 -9999 -9999 -9999 -9999 -9999 -9999 -9999 -9999 -9999 -9999 -9999 -9999 -9999 -9999 -9999 -9999 -9999 -9999 -9999 -9999 -9999 -9999 -9999 -9999 -9999 -9999 -9999 -9999 -9999 -9999 -9999 -

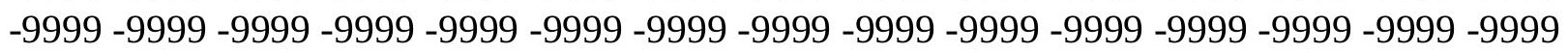


-9999 -9999 -9999 -9999 -9999 -9999 -9999 -9999 -9999 -9999 371.6421508789 365.2162475586358 .8456726074352 .5254211426346 .2497558594340 .0134887695 333.8112792969327 .638671875321 .4915771484315 .3669128418309 .2624511719 303.1772766113297 .1114501953291 .0664978027285 .0450439453279 .0513305664 273.0906677246267 .1700439453261 .2972412109255 .4817047119249 .732635498 244.0595397949238 .4702301025232 .9734039307227 .5771942139222 .2913208008 217.1223297119212 .0736999512207 .1419677734202 .3211517334197 .602935791 192.9814453125188 .4517059326184 .0127563477179 .6681213379175 .4302825928 171.3184814453167 .3600616455163 .5878143311160 .0435333252156 .7705688477 153.8333740234151 .3290863037149 .3446960449148 .1255950928147 .5160064697 146.9064025879147 .2111968994147 .8208007812150 .2590942383152 .0918121338 154.6912078857157 .878692627161 .8408966064165 .8031005859170 .070098877 174.337097168177 .9945068359181 .0424041748182 .87109375185 .3980255127 186.7971191406186 .3572998047183 .842010498177 .9945068359164 .5839996338 152.0877990723140 .8106994629137 .7628936768136 .5437011719135 .9342041016 135.3246002197134 .4102020264133 .8007049561133 .1911010742132 .5814971924 131.9720001221131 .3623962402130 .7528076172129 .8385009766131 .9720001221 134.1054992676135 .9342041016138 .0677032471139 .8963928223141 .7250976562 143.2489929199144 .7729034424145 .6873016357146 .6015930176147 .2111968994 147.5160064697147 .5160064697147 .2111968994146 .6015930176145 .6873016357 144.7729034424143 .8585968018142 .9441986084142 .0299072266140 .8106994629 139.5915985107138 .3724975586136 .8484954834135 .6293945312134 .1054992676 132.5814971924131 .0576019287129 .533706665128 .0097961426126 .4858016968 125.2667007446123 .7427978516122 .8283996582121 .9140014648121 .6092987061 121.3044967651120 .9997024536121 .3044967651121 .6092987061121 .9140014648 121.9140014648122 .2188034058121 .9140014648121 .6092987061121 .9140014648 121.9140014648121 .9140014648121 .6092987061121 .9140014648121 .9140014648 121.9140014648122 .2188034058121 .6092987061120 .6949005127120 .6949005127 117.647102356116 .4279022217116 .4279022217117 .0374984741118 .5614013672 120.6949005127124 .3523025513128 .9241027832134 .7149963379140 .5059967041 145.6873016357149 .6495056152152 .0877990723153 .6116943359154 .2212982178 154.5260925293154 .5260925293153 .9165039062152 .6972961426150 .8686065674 148.7351074219145 .9920959473142 .6394042969138 .9819946289135 .0198059082 130.7528076172125 .8762969971120 .6949005127115 .5136032104110 .0273971558 104.541297912698 .7503814697392 .9594726562587 .1685485839881 .37763214111 75.5867080688568 .1851425170959 .95595550537 -9999 -9999 -9999 -9999 -9999 -9999 -9999 -9999 -9999 -9999 -9999 -9999 -9999 -9999 -9999 -9999 -9999 -9999 -9999 -9999 -9999 -9999 -9999-9999-9999 -9999 -9999 -9999 -9999 -9999 -9999 -9999 -9999 -9999 -9999 -9999 -9999 -9999 -9999 -9999 -9999 -9999 -9999 -9999 -9999 -9999 -9999 -9999 -9999 -9999 -9999 -9999 -9999 -9999 -9999 -

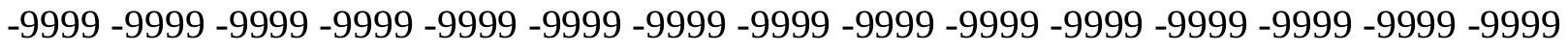

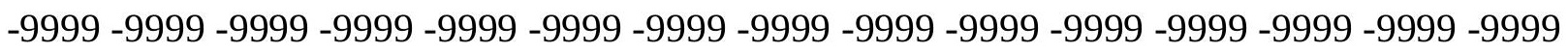
-9999 -9999 -9999 -9999 -9999 -9999 -9999 -9999 -9999 -9999 -9999 -9999 -9999 -9999 -9999 -9999 -9999 -9999 -9999 -9999 -9999 -9999 -9999 -9999 -9999 -9999 -9999 -9999 -9999 -9999 -9999 -9999 -9999 -9999 -9999 -9999 -9999 -9999 -9999 -9999 -9999 -9999 -9999 -9999 -9999 -

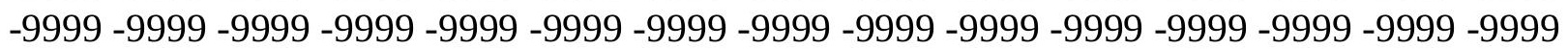


-9999 -9999 -9999 -9999 -9999 -9999 -9999 -9999 -9999 -9999 -9999 -9999 -9999 -9999 -9999 -9999 -9999 -9999 -9999 -9999 -9999 -9999 -9999 -9999 -9999 -9999 -9999 -9999 -9999 -9999

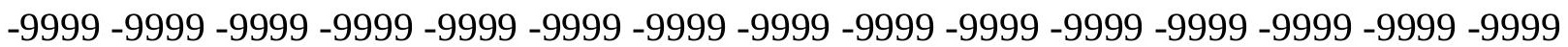
-9999 -9999 -9999 -9999 -9999 -9999 -9999 -9999 -9999 -9999 -9999 -9999 -9999 -9999 -9999 -9999 -9999 -9999 -9999 -9999 -9999 -9999 -9999 -9999 -9999 370.0824279785 363.5696105957357 .1006469727350 .6704101562344 .2733154297337 .9042358398 331.5581359863325 .2307739258318 .918548584312 .618927002306 .3304443359 300.0531921387293 .7884521484287 .5393371582281 .3103942871275 .1082458496 268.9407958984262 .8179016113256 .7500305176250 .7494506836244 .8282775879 238.9995574951233 .2747344971227 .6661376953222 .1851501465216 .8449554443 211.6558227539206 .6252288818201 .7521209717197 .0306549072192 .4490356445 187.9953613281183 .6575927734179 .4292297363175 .3107757568171 .316619873 167.4731750488163 .8118896484160 .3800201416157 .2265167236154 .3941040039 151.8799133301149 .8006896973148 .4304046631147 .8208007812147 .5160064697 147.5160064697148 .1255950928149 .3446960449151 .6930999756154 .1510162354 156.9642944336160 .6217956543164 .2792053223168 .241394043172 .2035980225 175.8609924316178 .9089050293181 .0424041748182 .261505127184 .9261474609 186.6551361084186 .4920806885183 .839630127177 .6896972656165 .8031005859 153.6116943359141 .4203033447136 .2389984131134 .7149963379134 .4102020264 134.1054992676133 .8007049561133 .1911010742132 .5814971924132 .2767028809 131.6672058105131 .0576019287130 .4479980469129 .8385009766130 .7528076172 132.8863067627135 .0198059082136 .8484954834138 .6772003174140 .5059967041 142.0299072266143 .5538024902144 .4682006836145 .3825073242145 .9920959473 146.2969055176146 .2969055176145 .6873016357145 .0776977539144 .1634063721 143.5538024902142 .6394042969142 .0299072266141 .1154937744140 .5059967041 139.2868041992 138.3724975586137.1533050537135.6293945312 134.1054992676 132.5814971924131 .0576019287129 .533706665128 .0097961426126 .4858016968 125.2667007446124 .0475006104122 .8283996582122 .2188034058121 .6092987061 121.3044967651121 .3044967651121 .6092987061121 .9140014648121 .9140014648 121.9140014648121 .9140014648121 .9140014648121 .9140014648121 .9140014648 121.9140014648121 .9140014648121 .9140014648121 .9140014648121 .9140014648 121.9140014648121 .9140014648121 .6092987061119 .7806015015115 .2088012695 116.1231002808116 .1231002808116 .1231002808116 .7326965332117 .9517974854 120.0852966309123 .1332015991128 .6192932129134 .7149963379140 .8106994629 146.9064025879151 .4781951904153 .9165039062154 .8307952881155 .1356048584 155.1356048584154 .8307952881153 .9165039062152 .6972961426150 .8686065674 148.4304046631145 .6873016357142 .3347015381138 .6772003174134 .4102020264 130.1432037354125 .2667007446120 .0852966309114 .5991973877109 .1130981445 103.322196960497 .5312423706191 .7403335571385 .6446228027379 .85370635986 73.4496612548866 .195457458558 .14554595947 -9999 -9999 -9999 -9999 -9999 -9999 -9999 -9999 -9999 -9999 -9999 -9999 -9999 -9999 -9999 -9999 -9999 -9999 -9999 -9999 -9999 -9999 -9999-9999-9999 -9999 -9999 -9999 -9999 -9999 -9999 -9999 -9999 -9999 -9999 -9999 -9999 -9999 -9999 -9999 -9999 -9999 -9999 -9999 -9999 -9999 -9999 -9999 -9999 -9999 -9999 -9999 -9999 -9999 -9999

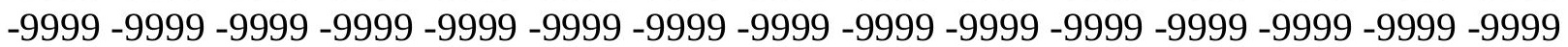

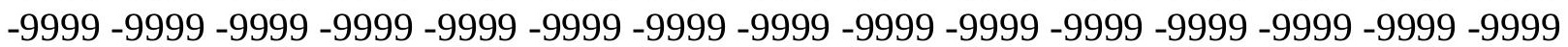


-9999 -9999 -9999 -9999 -9999 -9999 -9999 -9999 -9999 -9999 -9999 -9999 -9999 -9999 -9999 -9999 -9999 -9999 -9999 -9999 -9999 -9999 -9999 -9999 -9999 -9999 -9999 -9999 -9999 -9999

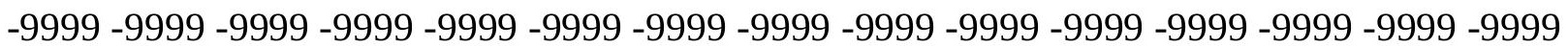
-9999 -9999 -9999 -9999 -9999 -9999 -9999 -9999 -9999 -9999 -9999 -9999 -9999 -9999 -9999 -9999 -9999 -9999 -9999 -9999 -9999 -9999 -9999 -9999 -9999 -9999 -9999 -9999 -9999 -9999 -9999 -9999 -9999 -9999 -9999 -9999 -9999 -9999 -9999 -9999 -9999 -9999 -9999 -9999 -9999 -9999 -9999 -9999 -9999 -9999 -9999 -9999 -9999 -9999 -9999 -9999 -9999 -9999 -9999 -9999 -9999 -9999 -9999 -9999 -9999 -9999 -9999 -9999 -9999 -9999 -9999 -9999 -9999 -9999 -9999 -9999 -9999 -9999 -9999 -9999 -9999 -9999 -9999 -9999 -9999 -9999 361.8521118164 355.291015625348 .7573547363342 .2454528809335 .7501525879329 .2665100098 322.7903442383316 .318359375309 .8484802246303 .3799743652296 .9137573242 290.4525146484284 .0008239746277 .5653381348271 .1550598145264 .780670166 258.4548339844252 .1908111572246 .0037536621239 .9088592529233 .9231262207 228.0622558594222 .3431854248216 .7814178467211 .3945159912206 .1967010498 201.2000274658196 .4065246582191 .8117523193187 .4004821777183 .1535339355 179.0482025146175 .0683746338171 .2085723877167 .4842224121163 .9147644043 160.5551605225157 .4649810791154 .7542114258152 .4513397217150 .4657592773 148.7351074219147 .8208007812147 .8208007812147 .8208007812148 .4304046631 149.6495056152151 .1895446777153 .4303894043156 .1494140625159 .0977935791 162.7552947998166 .4127044678170 .070098877173 .7274932861177 .0802001953 179.5184020996181 .3471984863182 .5662994385184 .4447174072185 .6130828857 184.816192627181 .2582397461174 .337097168164 .5839996338153 .0021057129 141.4203033447134 .7149963379133 .4958953857133 .1911010742132 .8863067627 132.8863067627132 .5814971924132 .2767028809131 .6672058105131 .3623962402 130.7528076172130 .4479980469129 .8385009766130 .1432037354131 .9720001221 133.8007049561135 .9342041016137 .7628936768139 .2868041992140 .8106994629 142.3347015381143 .5538024902144 .4682006836145 .0776977539145 .0776977539 145.0776977539144 .4682006836143 .8585968018142 .9441986084142 .0299072266 141.4203033447140 .8106994629140 .5059967041139 .8963928223139 .2868041992 138.3724975586137 .1533050537135 .9342041016134 .4102020264132 .8863067627 131.0576019287129 .533706665128 .0097961426126 .4858016968125 .2667007446 124.0475006104123 .1332015991122 .2188034058121 .6092987061121 .6092987061 121.6092987061121 .6092987061121 .6092987061121 .6092987061121 .6092987061 121.9140014648121 .9140014648121 .6092987061121 .9140014648121 .9140014648 121.9140014648121 .9140014648121 .9140014648121 .9140014648121 .9140014648 121.6092987061121 .6092987061120 .9997024536117 .342300415116 .1231002808 115.818397522116 .1231002808116 .4279022217117 .647102356119 .4757995605 122.8283996582128 .0097961426134 .4102020264141 .1154937744147 .5160064697 153.3069000244154 .8307952881155 .7451934814155 .7451934814155 .4403991699 154.8307952881153 .9165039062152 .3925933838150 .5639038086148 .1255950928 145.3825073242142 .0299072266138 .3724975586134 .1054992676129 .533706665 124.3523025513119 .1709976196113 .6848983765107 .8938980103102 .1029968262 96.0073165893690 .2164001464884 .1206970214878 .0249862670971 .47727203369 64.2355422973656 .35974121094 -9999 -9999 -9999 -9999 -9999 -9999 -9999 -9999 -9999 -9999 -9999 -9999 -9999 -9999 -9999 -9999 -9999 -9999 -9999 -9999 -9999 -9999 -9999 -9999 $-9999$ 
-9999 -9999 -9999 -9999 -9999 -9999 -9999 -9999 -9999 -9999 -9999 -9999 -9999 -9999 -9999 -9999 -9999 -9999 -9999 -9999 -9999 -9999 -9999 -9999 -9999 -9999 -9999 -9999 -9999 -9999

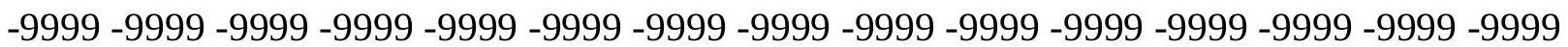
-9999 -9999 -9999 -9999 -9999 -9999 -9999 -9999 -9999 -9999 -9999 -9999 -9999 -9999 -9999 -9999 -9999 -9999 -9999 -9999 -9999 -9999 -9999 -9999 -9999 -9999 -9999 -9999 -9999 -9999 -9999 -9999 -9999 -9999 -9999 -9999 -9999 -9999 -9999 -9999 -9999 -9999 -9999 -9999 -9999 -9999 -9999 -9999 -9999 -9999 -9999 -9999 -9999 -9999 -9999 -9999 -9999 -9999 -9999 -9999

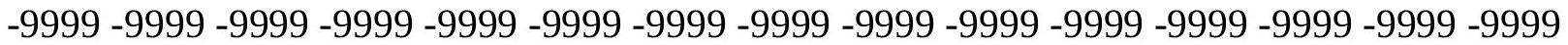
-9999 -9999 -9999 -9999 -9999 -9999 -9999 -9999 -9999 -9999 -9999 -9999 -9999 -9999 -9999 -9999 -9999 -9999 -9999 -9999 -9999 -9999 -9999 -9999 -9999 -9999 -9999 -9999 -9999 -9999 -9999 -9999 -9999 -9999 -9999 -9999 -9999 -9999 -9999 -9999 -9999 -9999 -9999 -9999 -9999 -9999 -9999 -9999 -9999 -9999 -9999 -9999 -9999 -9999 -9999 -9999 -9999 -9999 -9999 -9999 -9999 -9999 -9999 -9999 -9999 -9999 -9999 -9999 -9999 -9999 -9999 360.0816955566 353.4356994629346 .8061218262340 .1871948242333 .5734558105326 .9598999023 320.3422851562313 .7174377441307 .0835876465300 .4406738281293 .7904663086 287.1369628906280 .4862365723273 .8467102051267 .2298278809260 .6490783691 254.1197814941247 .657913208241 .28175354235 .0101013184228 .864364624 222.8651275635217 .0346984863211 .3934631348205 .96434021200 .7666168213 195.8176727295191 .1239471436186 .6836853027182 .4795379639178 .4836425781 174.6562805176170 .9774017334167 .4202423096163 .9889068604160 .6897888184 157.5828857422154 .8155059814152 .5298919678150 .8309631348149 .606262207 148.7351074219147 .8208007812147 .8208007812148 .4304046631149 .3446960449 150.8686065674152 .864730835155 .2614440918158 .1835021973161 .2312927246 164.5839996338167 .9365997314171 .5939941406174 .9467010498177 .9945068359 180.432800293181 .9566955566182 .5662994385184 .1062011719184 .3717803955 182.4405670166177 .8769836426170 .6797027588161 .8408966064151 .4781951904 140.5059967041134 .1054992676132 .5814971924132 .2767028809131 .9720001221 131.9720001221131 .9720001221131 .6672058105131 .3623962402131 .0576019287 130.4479980469130 .1432037354129 .533706665129 .2288970947131 .0576019287 132.8863067627134 .7149963379136 .5437011719138 .3724975586139 .8963928223 141.4203033447142 .6394042969143 .5538024902144 .1634063721144 .1634063721 144.1634063721143 .5538024902142 .6394042969141 .7250976562140 .8106994629 140.2012023926139 .8963928223139 .8963928223139 .5915985107139 .2868041992 138.6772003174137 .4580993652135 .9342041016134 .4102020264132 .8863067627 131.3623962402129 .533706665128 .0097961426126 .7906036377125 .2667007446 124.0475006104123 .1332015991122 .2188034058121 .9140014648121 .6092987061 121.6092987061121 .6092987061121 .6092987061121 .6092987061121 .6092987061 121.9140014648121 .9140014648121 .9140014648121 .9140014648121 .9140014648 121.9140014648121 .9140014648121 .9140014648121 .9140014648121 .9140014648 121.9140014648121 .6092987061120 .6949005127118 .8662033081117 .0374984741 116.4279022217116 .1231002808116 .1231002808117 .0374984741118 .8662033081 122.2188034058127 .0953979492133 .4958953857140 .2012023926146 .6015930176 151.7830047607154 .5260925293155 .7451934814155 .7451934814155 .4403991699 154.5260925293153 .6116943359152 .0877990723150 .2590942383148 .1255950928 145.0776977539141 .7250976562137 .7628936768133 .4958953857128 .9241027832 123.7427978516118 .2565994263112 .4656982422106 .6747970581100 .5791015625 
94.4833908081188 .3876876831182 .5967712402376 .5010681152369 .62730407715 62.3623886108454 .69752120972 -9999 -9999 -9999 -9999 -9999 -9999 -9999 -9999 -9999 -9999 -9999 -9999 -9999 -9999 -9999 -9999 -9999 -9999 -9999 -9999 -9999 -9999 -9999 -9999 $-9999$

-9999 -9999 -9999 -9999 -9999 -9999 -9999 -9999 -9999 -9999 -9999 -9999 -9999 -9999 -9999 -9999 -9999 -9999 -9999 -9999 -9999 -9999 -9999 -9999 -9999 -9999 -9999 -9999 -9999 -9999

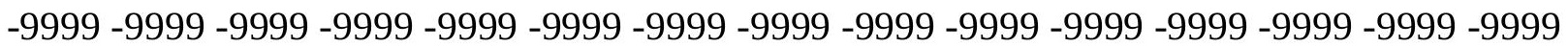

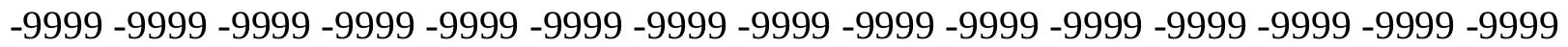
-9999 -9999 -9999 -9999 -9999 -9999 -9999 -9999 -9999 -9999 -9999 -9999 -9999 -9999 -9999 -9999 -9999 -9999 -9999 -9999 -9999 -9999 -9999 -9999 -9999 -9999 -9999 -9999 -9999 -9999 -

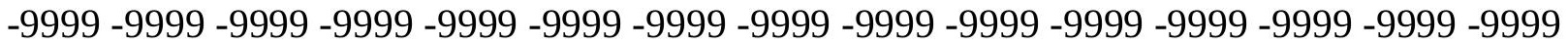
-9999 -9999 -9999 -9999 -9999 -9999 -9999 -9999 -9999 -9999 -9999 -9999 -9999 -9999 -9999 -9999 -9999 -9999 -9999 -9999 -9999 -9999 -9999 -9999 -9999 -9999 -9999 -9999 -9999 -9999 -9999 -9999 -9999 -9999 -9999 -9999 -9999 -9999 -9999 -9999 -9999 -9999 -9999 -9999 -9999 -9999 -9999 -9999 -9999 -9999 -9999 -9999 -9999 -9999 -9999 -9999 -9999 -9999 -9999 -9999

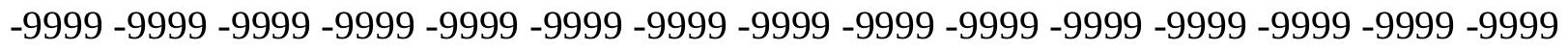
-9999 -9999-9999-9999 -9999-9999 -9999 -9999 -9999-9999 -9999-9999 351.5521850586 344.8354492188338 .1184997559331 .3954772949324 .6611328125317 .9108276367 311.1415100098304 .3515319824297 .5414123535290 .7138061523283 .8739624023 277.0293579102270 .1900024414263 .3692321777256 .5830993652249 .8497314453 243.1877441406236 .6188659668230 .1662597656223 .8563537598217 .7151031494 211.7706756592206 .0489044189200 .5787506104195 .385635376190 .4939880371 185.9163208008181 .6563873291177 .696685791174 .0017242432170 .5191192627 167.2172241211164 .0365600586160 .9267730713157 .880355835154 .9767913818 152.4137268066150 .4669799805149 .3390808105149 .0399017334148 .4304046631 148.1255950928148 .4304046631149 .3446960449150 .5639038086152 .3568878174 154.532989502156 .9642944336159 .7073974609162 .7552947998166 .1078948975 169.4604949951172 .8132019043175 .8609924316178 .604095459180 .7375946045 182.5662994385183 .4806976318184 .055480957183 .2853088379180 .1341247559 174.5826873779167 .0222015381158 .7929992676149 .0399017334139 .2868041992 134.7149963379132 .8863067627131 .3623962402131 .3623962402131 .3623962402 131.3623962402131 .0576019287131 .0576019287130 .7528076172130 .1432037354 129.8385009766129 .533706665128 .6192932129130 .4479980469132 .2767028809 133.8007049561135 .6293945312137 .4580993652138 .9819946289140 .5059967041 141.7250976562142 .6394042969143 .2489929199143 .5538024902143 .5538024902 142.9441986084142 .0299072266141 .1154937744139 .8963928223138 .9819946289 138.9819946289139 .2868041992139 .5915985107139 .5915985107138 .9819946289 137.7628936768136 .2389984131134 .7149963379132 .8863067627131 .3623962402 129.8385009766128 .0097961426126 .7906036377125 .2667007446124 .0475006104 123.1332015991122 .5235977173121 .9140014648121 .6092987061121 .6092987061 121.6092987061121 .6092987061121 .6092987061121 .6092987061121 .9140014648 121.9140014648121 .6092987061121 .9140014648121 .9140014648121 .9140014648 121.9140014648121 .6092987061121 .9140014648121 .9140014648121 .9140014648 121.6092987061120 .9997024536119 .4757995605117 .9517974854116 .7326965332 115.818397522115 .818397522116 .4279022217117 .9517974854120 .9997024536 125.8762969971132 .2767028809138 .6772003174144 .7729034424149 .6495056152 
153.0021057129154 .8307952881155 .1356048584154 .8307952881154 .2212982178 153.3069000244152 .0877990723150 .2590942383147 .8208007812144 .7729034424 141.4203033447137 .4580993652133 .1911010742128 .3144989014123 .1332015991 117.342300415111 .551399231105 .455703735499 .3599472045992 .95947265625 86.8637619018680 .7680587768674 .4774627685567 .7411651611360 .59182357788 -9999 -9999 -9999 -9999 -9999 -9999 -9999 -9999 -9999 -9999 -9999 -9999 -9999 -9999 -9999 -9999 -9999 -9999 -9999 -9999 -9999 -9999 -9999 -9999 -9999 -9999

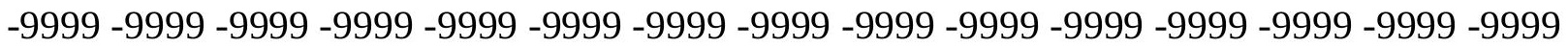

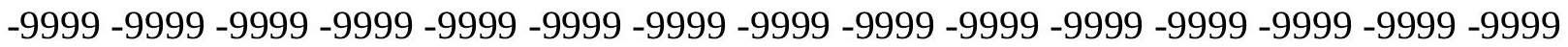
-9999 -9999 -9999 -9999 -9999 -9999 -9999 -9999 -9999 -9999 -9999 -9999 -9999 -9999 -9999 -9999 -9999 -9999 -9999 -9999 -9999 -9999 -9999 -9999 -9999 -9999 -9999 -9999 -9999 -9999 -999 -9999 -9999 -9999 -9999 -9999 -9999 -9999 -9999 -9999 -9999 -9999 -9999 -9999 -9999 -9999 -9999 -9999 -9999 -9999 -9999 -9999 -9999 -9999 -9999 -9999 -9999 -9999 -9999 -9999 -9999 -9999 -9999 -9999 -9999 -9999 -9999 -9999 -9999 -9999 -9999 -9999 -9999 -9999 -9999 -9999 -9999 -9999 -9999 -9999 -9999 -9999 -9999 -9999 -9999 -9999 -9999 -9999 -9999 -9999 -9999

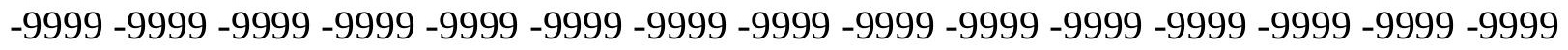
-9999 -9999 -9999 -9999 -9999 -9999 -9999 -9999 -9999 -9999 -9999 -9999 -9999 -9999 -9999 -

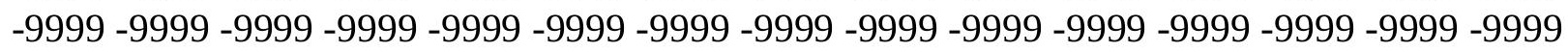

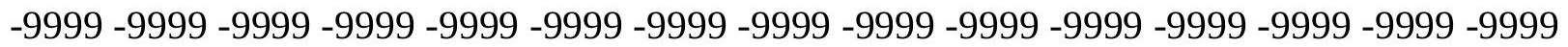
-9999 -9999-9999-9999 -9999-9999 -9999 -9999 -9999-9999 -9999-9999 349.6571350098 342.8630981445336 .0582275391329 .2362060547322 .3913574219315 .5185241699 308.6143188477301 .6772460938294 .7085266113287 .7115783691280 .692779541 273.6608886719266 .6272888184259 .6065673828252 .6165924072245 .6782226562 238.8134155273232 .0479736328225 .4100341797218 .9315032959212 .6437072754 206.5810241699200 .7754669189195 .2623596191190 .0736846924185 .2422637939 180.7893829346176 .7277984619173 .0452270508169 .693069458166 .6454925537 163.8178405762161 .1143493652158 .3939971924155 .6229248047152 .8709259033 150.4144287109148 .6105651855147 .8208007812148 .1255950928148 .4304046631 148.7351074219149 .3446960449150 .4948577881152 .0460968018153 .9760894775 156.2319030762158 .7929992676161 .2312927246164 .2792053223167 .3269958496 170.3748931885173 .4226989746176 .165802002178 .604095459181 .0424041748 182.5662994385183 .7854003906183 .7854003906182 .3411102295178 .2351531982 171.360534668163 .6696014404155 .7451934814146 .6015930176139 .8963928223 135.6293945312133 .4958953857131 .6672058105131 .0576019287131 .0576019287 131.0576019287130 .7528076172130 .7528076172130 .4479980469130 .1432037354 129.8385009766129 .533706665128 .3144989014129 .8385009766131 .3623962402 133.1911010742134 .7149963379136 .5437011719138 .0677032471139 .5915985107 140.8106994629142 .0299072266142 .9441986084143 .2489929199143 .2489929199 142.9441986084142 .0299072266140 .8106994629139 .5915985107138 .3724975586 138.9819946289139 .2868041992139 .5915985107139 .5915985107139 .2868041992 137.7628936768136 .2389984131134 .7149963379132 .8863067627131 .3623962402 129.8385009766128 .0097961426126 .7906036377125 .2667007446124 .0475006104 123.1332015991122 .2188034058121 .9140014648121 .6092987061121 .3044967651 121.3044967651121 .3044967651121 .6092987061121 .6092987061121 .6092987061 121.6092987061121 .6092987061121 .6092987061121 .9140014648121 .9140014648 121.6092987061121 .9140014648121 .9140014648122 .2188034058122 .2188034058 
122.2188034058121 .6092987061120 .0852966309118 .2565994263116 .7326965332 115.5136032104115 .2088012695115 .818397522117 .0374984741119 .4757995605 124.6570968628130 .7528076172136 .8484954834142 .6394042969147 .5160064697 151.1734008789153 .6116943359153 .9165039062153 .6116943359153 .3069000244 152.6972961426151 .7830047607149 .9542999268147 .5160064697144 .7729034424 141.1154937744137 .1533050537132 .5814971924127 .7050018311122 .5235977173 116.7326965332110 .6370010376104 .541297912698 .1408081054791 .43553924561 85.0350494384878 .9393463134872 .5524215698265 .9028701782258 .93035125732 -9999 -9999 -9999 -9999 -9999 -9999 -9999 -9999 -9999 -9999 -9999 -9999 -9999 -9999 -9999 -9999 -9999 -9999 -9999 -9999 -9999 -9999 -9999 -9999 -9999 -9999

-9999 -9999 -9999 -9999 -9999 -9999 -9999 -9999 -9999 -9999 -9999 -9999 -9999 -9999 -9999

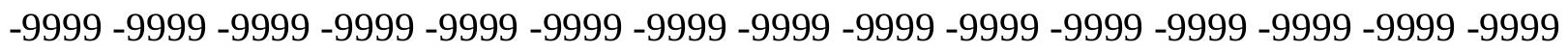
-9999 -9999 -9999 -9999 -9999 -9999 -9999 -9999 -9999 -9999 -9999 -9999 -9999 -9999 -9999 -9999 -9999 -9999 -9999 -9999 -9999 -9999 -9999 -9999 -9999 -9999 -9999 -9999 -9999 -9999 -9999 -9999 -9999 -9999 -9999 -9999 -9999 -9999 -9999 -9999 -9999 -9999 -9999 -9999 -9999

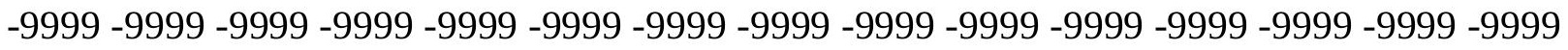
-9999 -9999 -9999 -9999 -9999 -9999 -9999 -9999 -9999 -9999 -9999 -9999 -9999 -9999 -9999 -9999 -9999 -9999 -9999 -9999 -9999 -9999 -9999 -9999 -9999 -9999 -9999 -9999 -9999 -9999 -

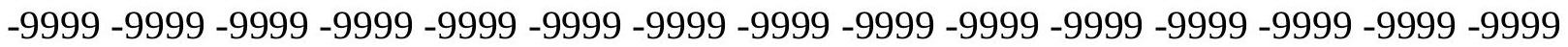

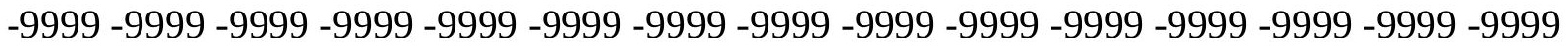

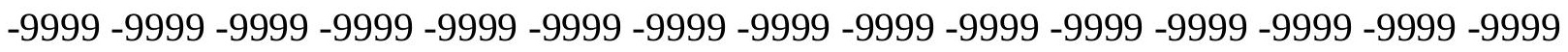

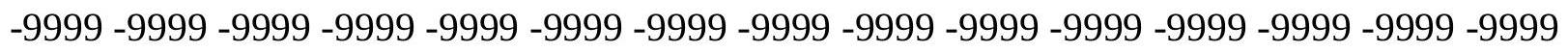
-9999 -9999 -9999 -9999 -9999 -9999 -9999 -9999 -9999 -9999 -9999 -9999 -9999 340.9052734375 334.023651123 327.1138305664 320.1697387695 313.1855773926 306.1574707031299 .0839233398291 .9668884277284 .8105163574277 .6219787598 270.4108886719263 .1898498535255 .9742584229248 .7830200195241 .6392211914 234.5689849854227 .6031036377220 .7753753662214 .1237030029207 .684753418 201.4989318848195 .6048278809190 .044631958184 .8565216064180 .081451416 175.751159668171 .8918914795168 .5041046143165 .5431060791163 .0103912354 160.7921447754158 .686706543156 .4812164307154 .0313873291151 .4510192871 149.0193023682147 .2111968994147 .2111968994147 .8208007812148 .4304046631 149.3446960449150 .4865112305151 .8984985352153 .6256103516155 .6523284912 157.878692627160 .0122070312162 .7552947998165 .4983062744168 .241394043 170.9844970703173 .4226989746176 .165802002178 .2993011475180 .1280059814 181.6519012451182 .87109375182 .5662994385180 .7375946045176 .7754058838 167.6318054199160 .6217956543153 .0021057129146 .2969055176141 .4203033447 136.8484954834134 .4102020264132 .5814971924131 .0576019287130 .7528076172 130.7528076172130 .4479980469130 .4479980469130 .1432037354129 .8385009766 129.533706665129 .2288970947128 .9241027832129 .2288970947130 .7528076172 132.2767028809134 .1054992676135 .6293945312137 .1533050537138 .6772003174 140.2012023926141 .4203033447142 .6394042969143 .2489929199143 .5538024902 143.2489929199142 .3347015381141 .4203033447140 .5059967041139 .5915985107 139.5915985107139 .8963928223139 .8963928223139 .5915985107138 .9819946289 137.7628936768136 .2389984131134 .7149963379132 .8863067627131 .3623962402 129.533706665128 .0097961426126 .4858016968125 .2667007446124 .0475006104 122.8283996582122 .2188034058121 .6092987061121 .3044967651121 .3044967651 
121.3044967651 121.3044967651 121.3044967651 121.6092987061 121.6092987061 121.6092987061121 .6092987061121 .6092987061121 .6092987061121 .6092987061 121.6092987061121 .9140014648121 .9140014648122 .5235977173122 .8283996582 122.8283996582122 .2188034058120 .6949005127118 .2565994263115 .818397522 114.5991973877114 .5991973877115 .2088012695116 .7326965332119 .4757995605 123.7427978516129 .2288970947135 .0198059082140 .5059967041145 .3825073242 149.0399017334151 .4781951904152 .3925933838152 .3925933838152 .6972961426 152.3925933838151 .4781951904149 .6495056152147 .5160064697144 .4682006836 141.1154937744136 .8484954834132 .2767028809127 .4001998901121 .9140014648 115.818397522109 .7226028442103 .322196960496 .9216690063590 .21640014648 83.5111236572377 .110626220770 .8252639770564 .2740402221757 .42087554932 -9999 -9999 -9999 -9999 -9999 -9999 -9999 -9999 -9999 -9999 -9999 -9999 -9999 -9999 -9999 -9999 -9999 -9999 -9999 -9999 -9999 -9999 -9999 -9999 -9999-9999

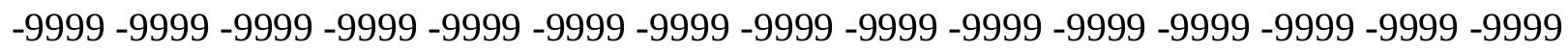
-9999 -9999 -9999 -9999 -9999 -9999 -9999 -9999 -9999 -9999 -9999 -9999 -9999 -9999 -9999

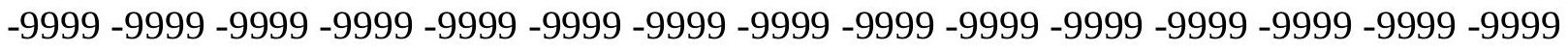
-9999 -9999 -9999 -9999 -9999 -9999 -9999 -9999 -9999 -9999 -9999 -9999 -9999 -9999 -9999 -9999 -9999 -9999 -9999 -9999 -9999 -9999 -9999 -9999 -9999 -9999 -9999 -9999 -9999 -9999 -

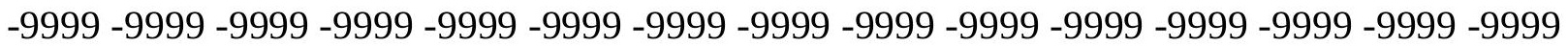

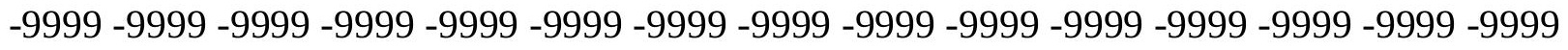

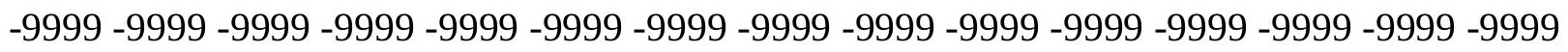
-9999 -9999 -9999 -9999 -9999 -9999 -9999 -9999 -9999 -9999 -9999 -9999 -9999 -9999 -9999 -9999 -9999 -9999 -9999 -9999 -9999 -9999 -9999 -9999 -9999 -9999 -9999 -9999 -9999 -9999 -

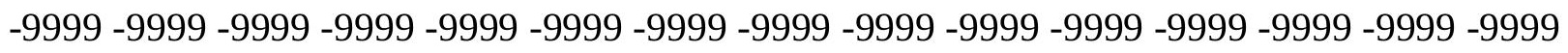

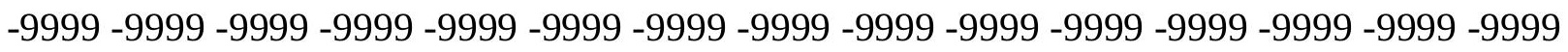
-9999 -9999 -9999 -9999 -9999 -9999 -9999 -9999 -9999 -9999 -9999 -9999 -9999 338.9758300781332 .0293273926325 .0436706543318 .0123291016310 .9289855957 303.7895507812296 .592376709289 .3398742676282 .0365905762274 .6899414062 267.3098449707 259.9096374512 252.505355835245.1165618896237.7683868408 230.4912109375223 .3215026855216 .2991027832209 .4687194824202 .873550415 196.5601043701190 .5730743408184 .961227417179 .768081665175 .0408782959 170.8203277588167 .1472473145164 .0438232422161 .5137481689159 .5610198975 158.0397949219156 .684387207155 .1343994141153 .1490936279150 .6810455322 148.4304046631147 .5160064697147 .5160064697148 .1255950928149 .0399017334 150.371963501151 .8639526367153 .475692749155 .2643737793157 .2691040039 159.4026031494161 .5361022949163 .974395752166 .4127044678168 .8509979248 171.2891998291173 .4226989746175 .5561981201177 .3849029541178 .9089050293 179.8231964111180 .1280059814178 .9089050293176 .4705963135172 .2035980225 165.8031005859159 .0977935791152 .6972961426147 .2111968994142 .3347015381 138.3724975586135 .3246002197133 .4958953857131 .3623962402130 .7528076172 130.7528076172130 .4479980469130 .1432037354130 .1432037354129 .8385009766 129.533706665129 .2288970947128 .9241027832128 .6192932129130 .1432037354 131.6672058105133 .1911010742134 .7149963379136 .5437011719138 .0677032471 139.5915985107141 .1154937744142 .3347015381143 .5538024902143 .8585968018 143.8585968018143 .2489929199142 .6394042969141 .7250976562141 .1154937744 140.8106994629140 .5059967041140 .2012023926139 .5915985107138 .6772003174 
137.4580993652135 .9342041016134 .4102020264132 .8863067627131 .0576019287 129.533706665128 .0097961426126 .4858016968125 .2667007446124 .0475006104 122.8283996582121 .9140014648121 .6092987061121 .3044967651121 .3044967651 121.3044967651121 .3044967651121 .3044967651121 .3044967651121 .6092987061 121.6092987061121 .6092987061121 .6092987061121 .6092987061121 .6092987061 121.6092987061121 .9140014648122 .2188034058122 .5235977173123 .43800354 123.7427978516123 .43800354121 .9140014648116 .7326965332113 .9896011353 113.075302124113 .3800964355114 .5991973877116 .4279022217119 .1709976196 123.1332015991128 .0097961426133 .1911010742138 .3724975586142 .9441986084 146.9064025879149 .6495056152151 .1734008789152 .0877990723152 .3925933838 152.0877990723151 .1734008789149 .6495056152147 .2111968994144 .4682006836 140.8106994629136 .5437011719131 .9720001221126 .7906036377121 .3044967651 115.2088012695109 .1130981445102 .407798767195 .7025299072388 .99725341797 82.2919769287175 .8393936157269 .4418869018662 .8813896179256 .07665252686 -9999 -9999 -9999 -9999 -9999 -9999 -9999 -9999 -9999 -9999 -9999 -9999 -9999 -9999 -9999 -9999 -9999 -9999 -9999-9999-9999-9999-9999 -9999 -9999-9999

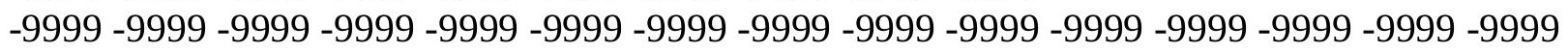
-9999 -9999 -9999 -9999 -9999 -9999 -9999 -9999 -9999 -9999 -9999 -9999 -9999 -9999 -9999 -

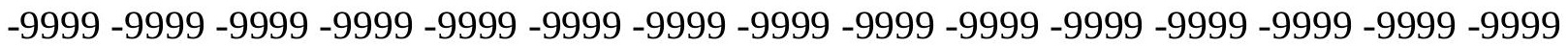

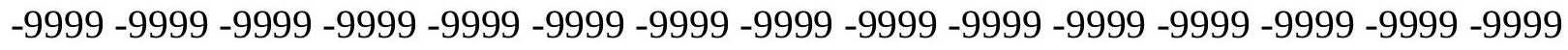

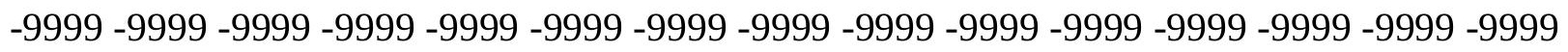

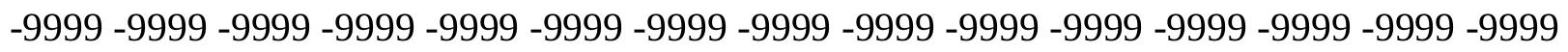
-9999 -9999 -9999 -9999 -9999 -9999 -9999 -9999 -9999 -9999 -9999 -9999 -9999 -9999 -9999 -

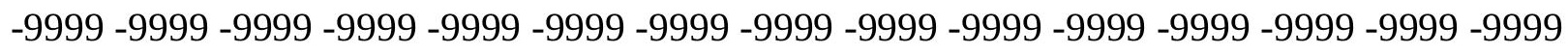

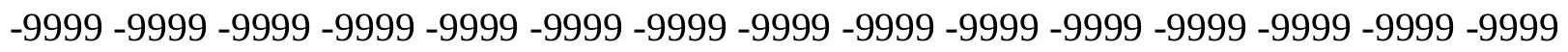
-9999 -9999 -9999 -9999 -9999 -9999 -9999 -9999 -9999 -9999 -9999 -9999 -9999 -9999 -9999

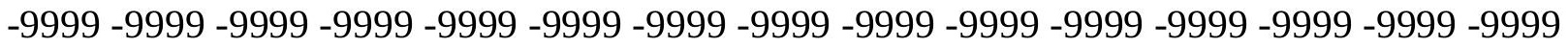

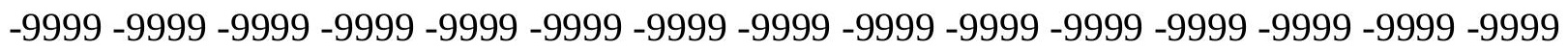

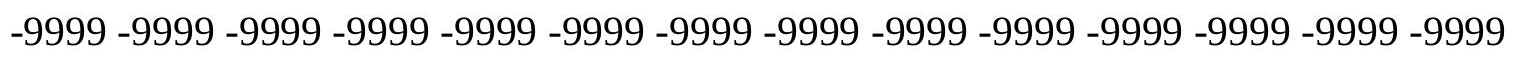
330.0880737305323 .0396728516315 .9346008301308 .766418457301 .531036377 294.2266235352 286.8555603027 279.4221191406 271.9331054688 264.3977355957 256.8295593262249 .2448425293241 .6639556885234 .1138153076226 .6291656494 219.252243042212 .0293121338205 .0125427246198 .253616333191 .8071594238 185.7238006592180 .0577392578174 .8561248779170 .1692047119166 .0413513184 162.5294036865159 .6759643555157 .5382385254156 .1440887451155 .384475708 154.8545379639154 .1045532227152 .6972961426150 .2590942383148 .7351074219 147.8208007812148 .1255950928149 .0399017334150 .3417510986151 .8730621338 153.552947998155 .2661743164156 .9642944336158 .7929992676160 .9264984131 162.7552947998164 .8887023926167 .0222015381169 .1557006836171 .2891998291 173.1179962158174 .6419067383176 .165802002177 .0802001953177 .3849029541 177.6896972656176 .165802002173 .1179962158169 .1557006836163 .974395752 158.4882965088153 .3069000244148 .1255950928143 .5538024902139 .5915985107 136.5437011719134 .4102020264132 .2767028809130 .7528076172130 .4479980469 130.4479980469130 .1432037354129 .8385009766129 .8385009766129 .533706665 129.2288970947128 .9241027832128 .0097961426129 .533706665130 .7528076172 132.2767028809134 .1054992676135 .6293945312137 .1533050537138 .9819946289 
140.5059967041142 .0299072266143 .5538024902144 .1634063721144 .7729034424 144.4682006836144 .1634063721143 .5538024902142 .6394042969142 .0299072266 141.4203033447140 .5059967041139 .5915985107138 .6772003174137 .1533050537 135.9342041016134 .1054992676132 .5814971924131 .0576019287129 .533706665 128.0097961426126 .4858016968124 .9618988037123 .7427978516122 .8283996582 121.9140014648121 .3044967651121 .3044967651120 .9997024536120 .9997024536 121.3044967651121 .3044967651121 .3044967651121 .6092987061121 .6092987061 121.6092987061121 .6092987061121 .9140014648121 .6092987061121 .6092987061 121.6092987061122 .2188034058122 .8283996582123 .7427978516124 .6570968628 124.3523025513121 .3044967651113 .6848983765112 .4656982422112 .1608963013 112.4656982422113 .6848983765115 .818397522118 .8662033081122 .5235977173 126.7906036377131 .6672058105136 .5437011719141 .1154937744145 .0776977539 148.1255950928150 .2590942383151 .7830047607152 .3925933838152 .3925933838 151.1734008789149 .6495056152147 .2111968994144 .4682006836140 .8106994629 136.5437011719131 .6672058105126 .4858016968120 .9997024536114 .9039993286 108.5035018921101 .798202514695 .0929565429788 .3876876831181 .37763214111 74.9019470214868 .3762741088961 .7203216552754 .88942337036 -9999 -9999 -9999-9999 -9999 -9999 -9999 -9999 -9999 -9999 -9999 -9999 -9999 -9999 -9999 -9999 -9999 -9999 -9999 -9999 -9999 -9999 -9999 -9999 -9999 -9999

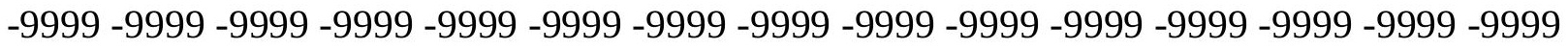

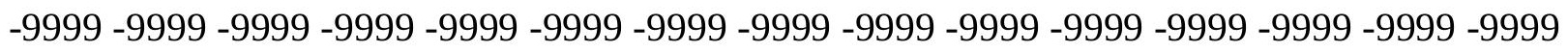

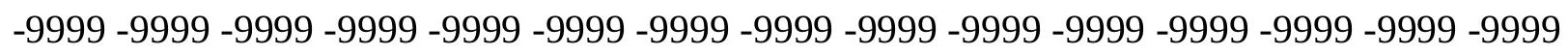
-9999 -9999 -9999 -9999 -9999 -9999 -9999 -9999 -9999 -9999 -9999 -9999 -9999 -9999 -9999 -

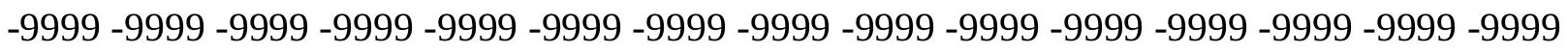

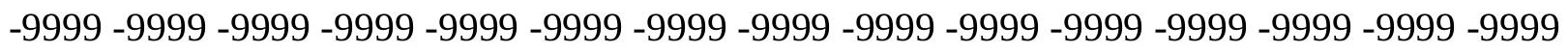
-9999 -9999 -9999 -9999 -9999 -9999 -9999 -9999 -9999 -9999 -9999 -9999 -9999 -9999 -9999

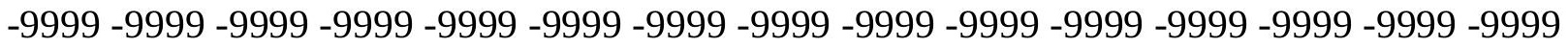

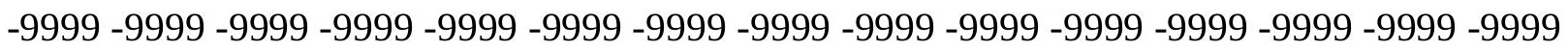
-9999 -9999 -9999 -9999 -9999 -9999 -9999 -9999 -9999 -9999 -9999 -9999 -9999 -9999 -9999

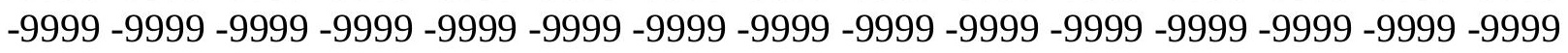
-9999 -9999 -9999 -9999 -9999 -9999 -9999 -9999 -9999 -9999 -9999 -9999 -9999 -9999 -9999 -9999 -9999 -9999 -9999 -9999 -9999 -9999 -9999 -9999 -9999 -9999 -9999 -9999 -9999 -9999 321.1133117676313 .9506530762306 .7155761719299 .404083252292 .0137939453 284.5463256836277 .0047302246269 .3944091797261 .7228088379254 .0024108887 246.2493591309238 .4846343994230 .7367858887223 .0442657471215 .4553985596 208.023727417200.8101196289 193.8765258789 187.2885742188 181.1052093506 175.3857116699170 .1790008545165 .5343170166161 .4955596924158 .1262969971 155.4931182861153 .6527099609152 .6551361084152 .5336761475152 .8835296631 153.0021057129151 .1734008789149 .6495056152148 .7351074219148 .7351074219 149.3446960449150 .5789794922152 .1026153564153 .7743835449155 .4870452881 157.2691040039158 .7929992676160 .6217956543162 .4505004883164 .2792053223 166.1078948975167 .9365997314169 .4604949951171 .2891998291172 .5084075928 173.7274932861175 .5561981201176 .165802002176 .165802002175 .2514038086 173.7274932861170 .6797027588167 .0222015381162 .7552947998158 .1835021973 153.3069000244148 .7351074219144 .4682006836140 .8106994629137 .4580993652 135.3246002197133 .4958953857131 .3623962402130 .4479980469130 .4479980469 
130.1432037354129 .8385009766129 .8385009766129 .533706665129 .2288970947 129.2288970947 128.6192932129 128.9241027832 130.1432037354131.6672058105 133.1911010742134 .7149963379136 .5437011719138 .0677032471139 .8963928223 141.7250976562143 .2489929199144 .7729034424145 .3825073242145 .6873016357 145.3825073242144 .7729034424143 .8585968018142 .9441986084142 .0299072266 140.8106994629139 .5915985107138 .3724975586136 .8484954834135 .3246002197 133.8007049561132 .2767028809130 .7528076172129 .2288970947127 .7050018311 126.1809997559124 .9618988037123 .7427978516122 .8283996582121 .9140014648 121.3044967651121 .3044967651120 .9997024536120 .9997024536120 .9997024536 121.3044967651121 .3044967651121 .3044967651121 .6092987061121 .6092987061 121.9140014648121 .9140014648121 .6092987061121 .6092987061121 .6092987061 122.2188034058122 .8283996582124 .0475006104124 .9618988037125 .2667007446 124.0475006104117 .0374984741112 .7705001831110 .9418029785111 .24659729 113.075302124115 .2088012695118 .2565994263121 .9140014648125 .8762969971 130.4479980469135 .0198059082139 .2868041992143 .5538024902146 .9064025879 149.6495056152151 .4781951904152 .6972961426152 .3925933838151 .4781951904 149.6495056152147 .5160064697144 .4682006836140 .8106994629136 .2389984131 131.6672058105126 .1809997559120 .3900985718114 .2944030762107 .8938980103 101.188697814994 .4833908081187 .7781066894581 .0728530883874 .24781036377 67.5012893676860 .72090911865 -9999 -9999 -9999 -9999 -9999 -9999 -9999 -9999 -9999 -9999 -9999 -9999 -9999 -9999 -9999 -9999 -9999 -9999 -9999 -9999 -9999 -9999 -9999 -9999 $-9999-9999-9999$

-9999 -9999 -9999 -9999 -9999 -9999 -9999 -9999 -9999 -9999 -9999 -9999 -9999 -9999 -9999 -9999 -9999 -9999 -9999 -9999 -9999 -9999 -9999 -9999 -9999 -9999 -9999 -9999 -9999 -9999

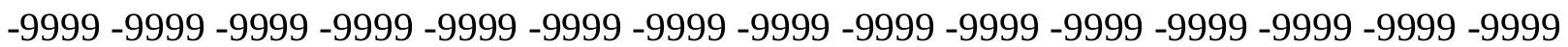
-9999 -9999 -9999 -9999 -9999 -9999 -9999 -9999 -9999 -9999 -9999 -9999 -9999 -9999 -9999 -9999 -9999 -9999 -9999 -9999 -9999 -9999 -9999 -9999 -9999 -9999 -9999 -9999 -9999 -9999 -9999 -9999 -9999 -9999 -9999 -9999 -9999 -9999 -9999 -9999 -9999 -9999 -9999 -9999 -9999 -9999 -9999 -9999 -9999 -9999 -9999 -9999 -9999 -9999 -9999 -9999 -9999 -9999 -9999 -9999

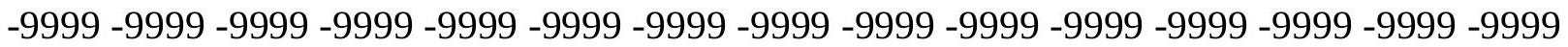
-9999 -9999 -9999 -9999 -9999 -9999 -9999 -9999 -9999 -9999 -9999 -9999 -9999 -9999 -9999 -9999 -9999 -9999 -9999 -9999 -9999 -9999 -9999 -9999 -9999 -9999 -9999 -9999 -9999 -9999 -9999 -9999 -9999 -9999 -9999 -9999 -9999 -9999 -9999 -9999 -9999 -9999 -9999 -9999 -9999 -9999 -9999 -9999 -9999 -9999 -9999 -9999 -9999 -9999 -9999 -9999 -9999 -9999 -9999 -9999 -9999 -9999 -9999 -9999 -9999 -9999 -9999 -9999 -9999 -9999 -9999 -9999 -9999 -9999 -9999 319.2757873535312 .0745849609304 .7944335938297 .4312438965289 .9815368652 282.4450073242 274.822479248267.1172180176259.3340148926251.4829864502 243.578704834235 .6424407959227 .7037506104219 .80418396211 .9976959229 204.3467254639196.922958374189.8009643555183.0603027344176.771697998 171.0002441406165 .802154541161 .2130737305157 .2886199951154 .0862884521 151.6434173584149 .9830780029149 .1025238037149 .2974853516150 .5639038086 150.2590942383149 .6495056152149 .0399017334149 .0399017334150 .5639038086 151.3664245605152 .6271209717154 .2376708984156 .0500030518157 .5738983154 159.0977935791160 .6217956543162 .1457061768163 .974395752165 .4983062744 167.0222015381168 .5462036133169 .7653045654170 .9844970703171 .8988037109 173.7274932861174 .337097168174 .6419067383174 .337097168173 .4226989746 
171.5939941406168 .8509979248165 .4983062744161 .8408966064157 .5738983154 153.6116943359149 .3446960449145 .3825073242142 .0299072266138 .9819946289 136.2389984131134 .4102020264132 .2767028809130 .4479980469130 .4479980469 130.1432037354130 .1432037354129 .8385009766129 .533706665129 .533706665 129.2288970947128 .9241027832128 .0097961426129 .2288970947130 .7528076172 131.9720001221133 .4958953857135 .3246002197137 .1533050537138 .9819946289 141.1154937744142 .9441986084144 .7729034424145 .9920959473146 .6015930176 146.6015930176145 .9920959473144 .7729034424143 .5538024902142 .3347015381 140.8106994629139 .5915985107138 .0677032471136 .5437011719135 .0198059082 133.4958953857131 .9720001221130 .4479980469128 .9241027832127 .4001998901 126.1809997559124 .9618988037123 .7427978516122 .5235977173121 .9140014648 121.3044967651121 .3044967651120 .9997024536120 .9997024536120 .9997024536 121.3044967651121 .3044967651121 .3044967651121 .6092987061121 .6092987061 121.9140014648121 .9140014648121 .9140014648121 .6092987061121 .9140014648 122.2188034058123 .1332015991124 .0475006104125 .2667007446125 .2667007446 123.1332015991117 .9517974854112 .7705001831110 .0273971558110 .0273971558 111.8561019897114 .5991973877117 .647102356120 .9997024536124 .9618988037 128.9241027832133 .4958953857138 .0677032471142 .3347015381145 .9920959473 149.0399017334151 .1734008789152 .3925933838152 .3925933838151 .4781951904 149.9542999268 147.5160064697 144.4682006836140.5059967041 136.2389984131 131.3623962402125 .8762969971120 .0852966309113 .9896011353107 .5891036987 100.883903503493 .8738174438587 .1685485839880 .4632720947373 .60580444336 66.7177658081159 .81380462646 -9999 -9999 -9999 -9999 -9999 -9999 -9999 -9999 -9999 -9999 -9999 -9999 -9999 -9999 -9999 -9999 -9999 -9999 -9999 -9999 -9999 -9999 -9999 -9999 -9999 -9999-9999

-9999 -9999 -9999 -9999 -9999 -9999 -9999 -9999 -9999 -9999 -9999 -9999 -9999 -9999 -9999 -9999 -9999 -9999 -9999 -9999 -9999 -9999 -9999 -9999 -9999 -9999 -9999 -9999 -9999 -9999 -

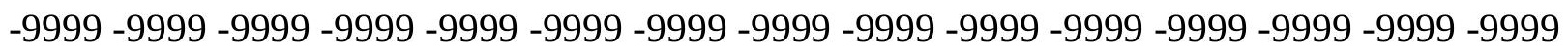
-9999 -9999 -9999 -9999 -9999 -9999 -9999 -9999 -9999 -9999 -9999 -9999 -9999 -9999 -9999 -9999 -9999 -9999 -9999 -9999 -9999 -9999 -9999 -9999 -9999 -9999 -9999 -9999 -9999 -9999 -9999 -9999 -9999 -9999 -9999 -9999 -9999 -9999 -9999 -9999 -9999 -9999 -9999 -9999 -9999

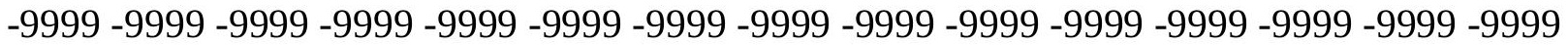

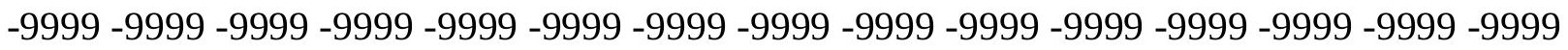
-9999 -9999 -9999 -9999 -9999 -9999 -9999 -9999 -9999 -9999 -9999 -9999 -9999 -9999 -9999 -9999 -9999 -9999 -9999 -9999 -9999 -9999 -9999 -9999 -9999 -9999 -9999 -9999 -9999 -9999 -9999 -9999 -9999 -9999 -9999 -9999 -9999 -9999 -9999 -9999 -9999 -9999 -9999 -9999 -9999

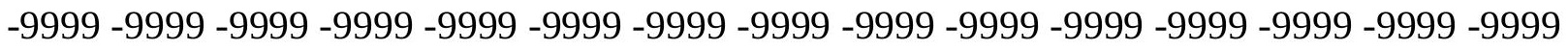

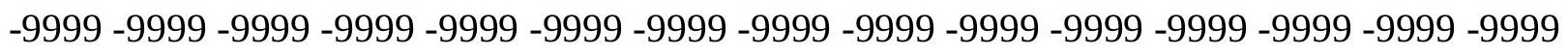
-9999 310.3180541992303.017364502 295.6294555664288.149230957280.5738525391 272.9009094238265 .1306762695257 .2645874023249 .3093261719241 .2763366699 233.1854553223225 .0664367676216 .9629058838208 .9343109131201 .0529327393 193.4041595459186 .0784606934179 .1727905273172 .7744445801166 .9608612061 161.7869873047157 .2959136963153 .5336914062150 .5383605957148 .3462677002 146.9151916504146 .0991973877145 .6873016357147 .2111968994148 .4304046631 148.7351074219148 .7351074219150 .4194488525152 .1430053711153 .6275787354 155.0784606934156 .6596069336158 .4882965088160 .0122070312161 .2312927246 
162.7552947998163 .974395752165 .4983062744166 .7174987793167 .9365997314 168.8509979248170 .070098877170 .6797027588172 .2035980225173 .1179962158 173.4226989746173 .1179962158172 .5084075928171 .2891998291169 .7653045654 167.0222015381164 .2792053223160 .9264984131157 .2691040039153 .6116943359 149.9542999268146 .2969055176142 .9441986084139 .8963928223137 .4580993652 135.3246002197133 .4958953857131 .3623962402130 .4479980469130 .1432037354 130.1432037354129 .8385009766129 .8385009766129 .533706665129 .533706665 129.2288970947128 .9241027832128 .6192932129129 .8385009766131 .0576019287 132.5814971924134 .1054992676135 .9342041016137 .7628936768139 .8963928223 142.3347015381144 .4682006836146 .2969055176147 .2111968994147 .2111968994 146.6015930176145 .3825073242143 .8585968018142 .0299072266140 .5059967041 138.9819946289137 .4580993652136 .2389984131134 .7149963379133 .1911010742 131.6672058105130 .1432037354128 .6192932129127 .4001998901126 .1809997559 124.9618988037123 .7427978516122 .8283996582121 .9140014648121 .6092987061 121.3044967651120 .9997024536120 .9997024536120 .9997024536121 .3044967651 121.3044967651121 .6092987061121 .6092987061121 .9140014648121 .9140014648 121.9140014648121 .9140014648121 .9140014648121 .9140014648122 .2188034058 123.1332015991124 .0475006104124 .9618988037125 .2667007446123 .43800354 118.5614013672111 .24659729108 .1986999512109 .1130981445111 .24659729 113.9896011353117 .0374984741120 .0852966309123 .7427978516128 .0097961426 132.2767028809137 .1533050537141 .7250976562145 .6873016357148 .7351074219 151.1734008789152 .3925933838152 .3925933838151 .4781951904149 .9542999268 147.5160064697144 .4682006836140 .5059967041136 .2389984131131 .0576019287 125.5715026855119 .7806015015113 .6848983765106 .979598999100 .2742996216 93.5690307617286 .5589828491279 .8537063598672 .8827362060565 .91474914551 58.94094085693 -9999 -9999 -9999 -9999 -9999 -9999 -9999 -9999 -9999 -9999 -9999 -9999 -9999 -9999 -9999 -9999 -9999 -9999 -9999 -9999 -9999 -9999 -9999 -9999 -9999 -9999 -9999 -

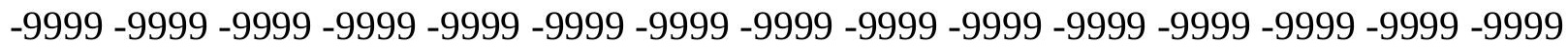

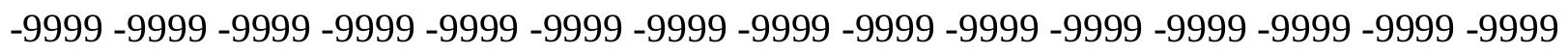

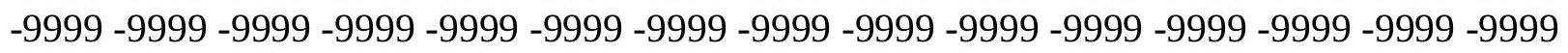
-9999 -9999 -9999 -9999 -9999 -9999 -9999 -9999 -9999 -9999 -9999 -9999 -9999 -9999 -9999 -9999 -9999 -9999 -9999 -9999 -9999 -9999 -9999 -9999 -9999 -9999 -9999 -9999 -9999 -9999

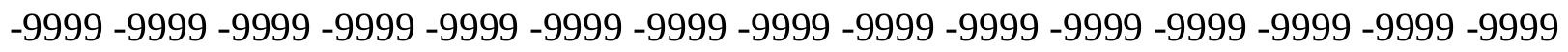

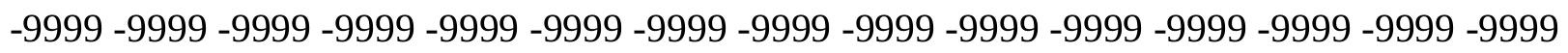
-9999 -9999 -9999 -9999 -9999 -9999 -9999 -9999 -9999 -9999 -9999 -9999 -9999 -9999 -9999

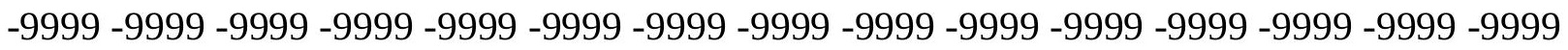

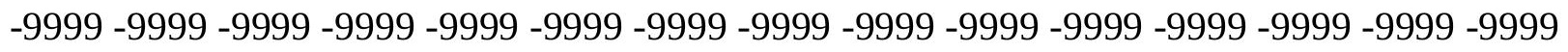

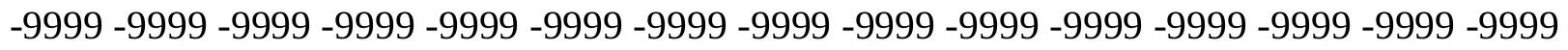

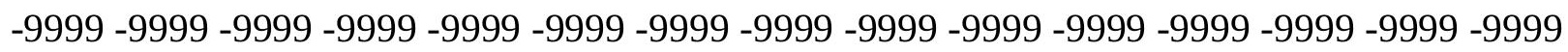

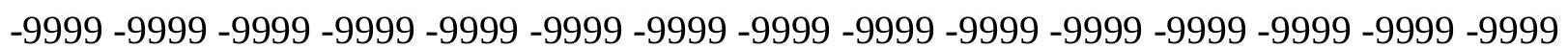
-9999 308.6910705566 301.3966369629 294.0127563477286.5325317383 278.9501647949 271.2597045898263 .4576416016255 .541229248247 .5127563477239 .3789825439 231.1564331055222 .8725891113214 .572052002206 .3187255859198 .1960144043 190.3057403564182 .7587127686175 .6729888916169 .1602630615163 .3123168945 158.1969909668153 .85546875150 .3273925781147 .6372528076145 .7563934326 144.6827392578144 .4682006836144 .1634063721145 .9920959473147 .8208007812 
149.9542999268151 .2427062988152 .9838562012154 .7483673096156 .3625030518 157.878692627159 .7073974609160 .9264984131162 .4505004883163 .6696014404 164.8887023926165 .8031005859167 .0222015381167 .9365997314168 .8509979248 169.4604949951170 .070098877170 .3748931885171 .8988037109172 .2035980225 172.2035980225171 .8988037109171 .2891998291169 .7653045654167 .9365997314 165.8031005859163 .0599975586160 .0122070312156 .9642944336153 .6116943359 150.2590942383147 .2111968994144 .1634063721141 .1154937744138 .3724975586 136.2389984131134 .4102020264132 .5814971924130 .7528076172130 .4479980469 130.1432037354130 .1432037354129 .8385009766129 .8385009766129 .533706665 129.533706665129 .2288970947128 .9241027832128 .6192932129129 .8385009766 131.0576019287132 .5814971924134 .1054992676135 .9342041016138 .3724975586 140.8106994629143 .5538024902145 .9920959473147 .2111968994147 .5160064697 146.6015930176145 .0776977539143 .2489929199141 .7250976562139 .8963928223 138.3724975586136 .8484954834135 .6293945312134 .1054992676132 .5814971924 131.0576019287129 .8385009766128 .3144989014127 .0953979492125 .8762969971 124.6570968628123 .7427978516122 .8283996582122 .2188034058121 .6092987061 121.3044967651121 .3044967651120 .9997024536120 .9997024536121 .3044967651 121.3044967651121 .6092987061121 .6092987061121 .9140014648121 .9140014648 122.2188034058121 .9140014648121 .9140014648122 .2188034058122 .5235977173 123.1332015991124 .0475006104124 .9618988037125 .2667007446124 .3523025513 121.9140014648106 .979598999107 .2844009399109 .1130981445111 .24659729 113.9896011353116 .7326965332119 .4757995605122 .8283996582126 .7906036377 131.3623962402136 .2389984131141 .1154937744145 .3825073242149 .0399017334 151.4781951904152 .6972961426152 .6972961426151 .7830047607149 .9542999268 147.5160064697144 .4682006836140 .5059967041135 .9342041016131 .0576019287 125.2667007446119 .4757995605113 .075302124106 .370002746699 .66472625732 92.9594726562585 .9494018554778 .9393463134872 .0714950561565 .08654785156 58.06203460693 -9999 -9999 -9999 -9999 -9999 -9999 -9999 -9999 -9999 -9999 -9999 -9999 -9999 -9999 -9999 -9999 -9999 -9999 -9999 -9999 -9999 -9999 -9999 -9999 -9999 -9999 -9999 -9999 -9999 -9999 -9999 -9999 -9999 -9999 -9999 -9999 -9999 -9999 -9999 -9999 -9999 -9999 -9999 -9999 -9999 -9999 -9999 -9999 -9999 -9999 -9999 -9999 -9999 -9999 -9999 -9999 -9999 -9999 -9999 -9999 -9999 -9999 -9999 -9999 -9999 -9999 -9999 -9999 -9999 -9999 -9999 -9999 -

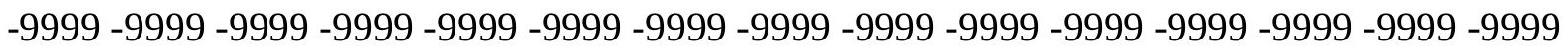
-9999 -9999 -9999 -9999 -9999 -9999 -9999 -9999 -9999 -9999 -9999 -9999 -9999 -9999 -9999 -9999 -9999 -9999 -9999 -9999 -9999 -9999 -9999 -9999 -9999 -9999 -9999 -9999 -9999 -9999

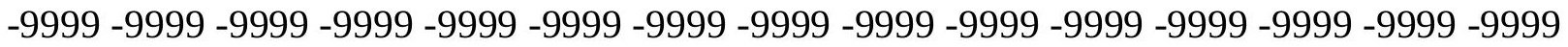

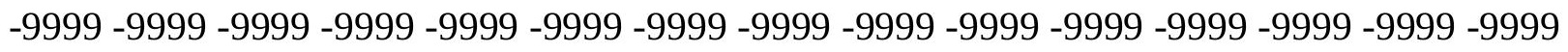

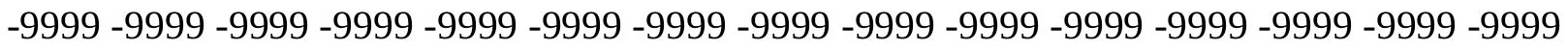
-9999 -9999 -9999 -9999 -9999 -9999 -9999 -9999 -9999 -9999 -9999 -9999 -9999 -9999 -9999 -9999 -9999 -9999 -9999 -9999 -9999 -9999 -9999 -9999 -9999 -9999 -9999 -9999 -9999 -9999 -

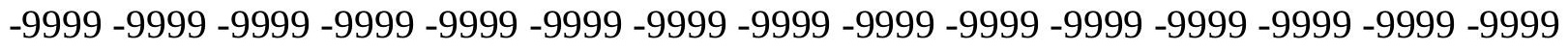

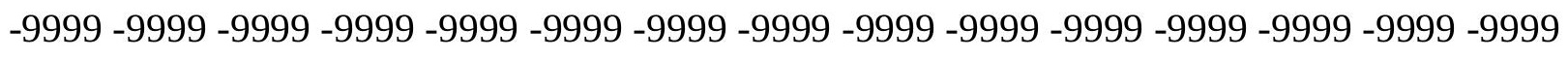
-9999 -9999 299.9374389648292.5874328613285.1386108398277.5824584961 269.9091491699262 .1110534668254 .1805267334246 .1144714355237 .9136352539 229.5888671875221 .1627349854212 .6774749756204 .1998748779195 .8254089355 187.6727600098179 .8840026855172 .6009674072165 .9682617188160 .0989685059 
155.074432373150 .9413146973147 .7204589844145 .4478149414144 .0854949951 143.4400024414143 .2489929199144 .7729034424146 .6015930176149 .4674835205 152.2537231445154 .6412963867156 .7082824707158 .475982666159 .7073974609 161.2312927246162 .7552947998163 .974395752165 .1934967041166 .1078948975 167.0222015381167 .9365997314168 .5462036133169 .1557006836169 .7653045654 170.070098877170 .3748931885170 .3748931885171 .2891998291171 .5939941406 171.2891998291170 .6797027588169 .7653045654168 .5462036133166 .7174987793 164.5839996338162 .1457061768159 .4026031494156 .6596069336153 .6116943359 150.5639038086147 .8208007812144 .7729034424142 .3347015381139 .5915985107 137.4580993652135 .6293945312133 .8007049561131 .6672058105130 .7528076172 130.4479980469130 .4479980469130 .1432037354130 .1432037354129 .8385009766 129.8385009766129 .533706665129 .2288970947128 .6192932129128 .6192932129 129.533706665130 .7528076172131 .9720001221133 .8007049561135 .9342041016 138.3724975586141 .4203033447144 .4682006836146 .6015930176146 .6015930176 145.3825073242143 .8585968018142 .3347015381140 .5059967041138 .9819946289 137.4580993652136 .2389984131134 .7149963379133 .4958953857131 .9720001221 130.7528076172129 .533706665128 .0097961426126 .7906036377125 .8762969971 124.6570968628123 .7427978516122 .8283996582122 .2188034058121 .9140014648 121.6092987061121 .3044967651121 .3044967651121 .3044967651121 .3044967651 121.3044967651121 .6092987061121 .6092987061121 .9140014648122 .2188034058 122.2188034058122 .2188034058122 .2188034058122 .2188034058122 .5235977173 123.1332015991123 .7427978516124 .6570968628124 .9618988037123 .7427978516 119.7806015015113 .075302124110 .3321990967110 .6370010376112 .1608963013 114.2944030762116 .4279022217118 .8662033081121 .9140014648125 .8762969971 130.7528076172135 .9342041016140 .8106994629145 .3825073242149 .3446960449 152.0877990723153 .3069000244153 .0021057129152 .0877990723150 .2590942383 147.8208007812144 .4682006836140 .5059967041135 .9342041016130 .7528076172 124.9618988037118 .8662033081112 .4656982422106 .065200805799 .05516815186 92.349891662685 .3398437578 .3297805786171 .2518844604564 .19731140137 -9999-9999 -9999 -9999 -9999 -9999 -9999 -9999 -9999 -9999 -9999 -9999 -9999 -9999 -9999 -9999 -9999 -9999 -9999 -9999 -9999 -9999 -9999 -9999 -9999 -9999 -9999 -9999

-9999 -9999 -9999 -9999 -9999 -9999 -9999 -9999 -9999 -9999 -9999 -9999 -9999 -9999 -9999

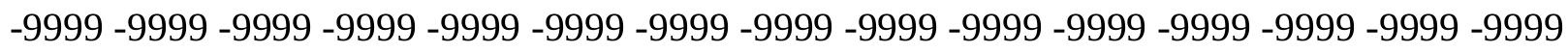

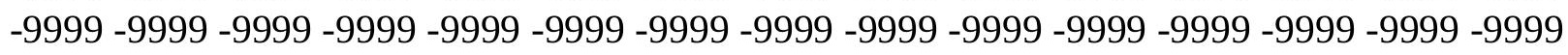
-9999 -9999 -9999 -9999 -9999 -9999 -9999 -9999 -9999 -9999 -9999 -9999 -9999 -9999 -9999

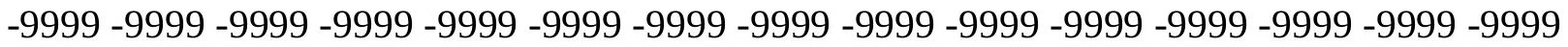

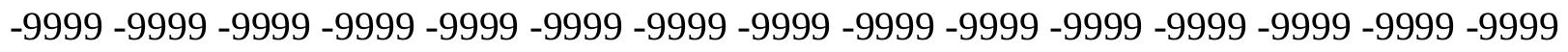

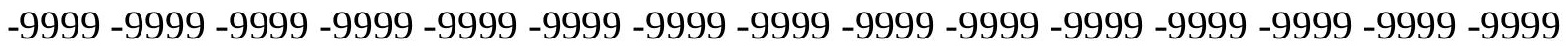
-9999 -9999 -9999 -9999 -9999 -9999 -9999 -9999 -9999 -9999 -9999 -9999 -9999 -9999 -9999 -

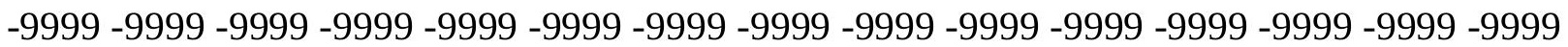

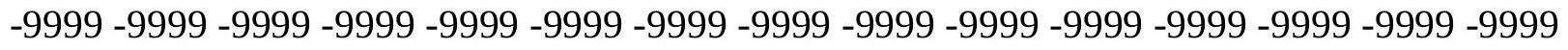

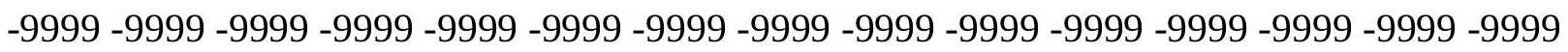
-9999 -9999 -9999 -9999 -9999 -9999 -9999 -9999 -9999 -9999 -9999 -9999 -9999 -9999 -9999 -9999 -9999 -9999 -9999 -9999 -9999 -9999 -9999 -9999 -9999 -9999 -9999 -9999 -9999 -9999 -9999 -9999 298.6416625977291.3561096191283.9713745117276.4760131836 268.856628418261 .1010437012253 .1963806152245 .1334838867236 .9058532715 
228.5165100098219 .9795379639211 .3306884766202 .6352996826193 .9967651367 185.5880432129177 .5266265869170 .010269165163 .2400665283157 .3596496582 152.4613342285148 .579284668145 .7391967773143 .9595184326143 .2460784912 143.5538024902144 .4682006836146 .6015930176149 .4665222168152 .8332824707 156.0925750732158 .9248504639161 .159576416163 .0599975586163 .6696014404 164.8887023926166 .1078948975167 .0222015381167 .9365997314168 .5462036133 169.1557006836169 .7653045654170 .070098877170 .3748931885170 .6797027588 170.6797027588170 .3748931885170 .070098877170 .9844970703170 .9844970703 170.3748931885169 .7653045654168 .5462036133167 .3269958496165 .4983062744 163.6696014404161 .2312927246158 .7929992676156 .3547973633153 .6116943359 150.8686065674148 .4304046631145 .6873016357143 .2489929199140 .8106994629 138.6772003174136 .5437011719134 .7149963379132 .8863067627131 .0576019287 130.7528076172130 .7528076172130 .4479980469130 .4479980469130 .4479980469 130.1432037354129 .8385009766129 .533706665129 .2288970947128 .6192932129 128.0097961426128 .9241027832129 .8385009766131 .0576019287132 .8863067627 135.0198059082138 .0677032471141 .7250976562145 .3825073242144 .4682006836 143.2489929199141 .7250976562140 .5059967041138 .9819946289137 .4580993652 136.2389984131135 .0198059082133 .8007049561132 .5814971924131 .3623962402 130.1432037354128 .9241027832127 .7050018311126 .7906036377125 .5715026855 124.6570968628123 .7427978516123 .1332015991122 .5235977173121 .9140014648 121.6092987061121 .3044967651121 .3044967651121 .3044967651121 .3044967651 121.3044967651121 .6092987061121 .9140014648121 .9140014648122 .2188034058 122.5235977173122 .5235977173122 .5235977173122 .5235977173122 .8283996582 123.1332015991123 .7427978516124 .3523025513124 .3523025513123 .43800354 120.6949005127117 .0374984741113 .9896011353113 .3800964355113 .9896011353 114.9039993286116 .4279022217118 .2565994263121 .3044967651125 .2667007446 130.1432037354135 .3246002197140 .8106994629145 .3825073242149 .6495056152 153.0021057129153 .6116943359153 .3069000244152 .0877990723150 .2590942383 147.8208007812144 .4682006836140 .2012023926135 .6293945312130 .4479980469 124.6570968628118 .5614013672111 .8561019897105 .150901794498 .4455871582 $91.4355392456184 .4254837036177 .4154205322370 .3561248779363 .25224304199-9999$ -9999 -9999 -9999 -9999 -9999 -9999 -9999 -9999 -9999 -9999 -9999 -9999 -9999 -9999 -9999 -9999 -9999 -9999 -9999 -9999 -9999 -9999 -9999 -9999 -9999 -9999 -9999 -

-9999 -9999 -9999 -9999 -9999 -9999 -9999 -9999 -9999 -9999 -9999 -9999 -9999 -9999 -9999 -9999 -9999 -9999 -9999 -9999 -9999 -9999 -9999 -9999 -9999 -9999 -9999 -9999 -9999 -9999 -9999 -9999 -9999 -9999 -9999 -9999 -9999 -9999 -9999 -9999 -9999 -9999 -9999 -9999 - -9999 -

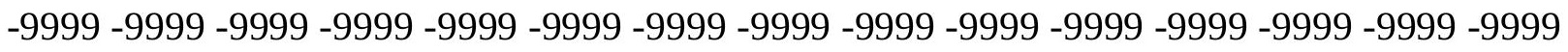

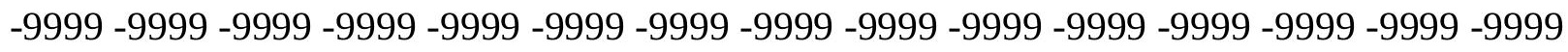
-9999 -9999 -9999 -9999 -9999 -9999 -9999 -9999 -9999 -9999 -9999 -9999 -9999 -9999 -9999 -9999 -9999 -9999 -9999 -9999 -9999 -9999 -9999 -9999 -9999 -9999 -9999 -9999 -9999 -9999 -

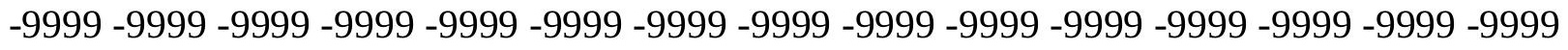

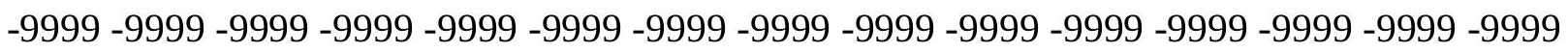
-9999 -9999 -9999 -9999 -9999 -9999 -9999 -9999 -9999 -9999 -9999 -9999 -9999 -9999 -9999 -9999 -9999 -9999 -9999 -9999 -9999 -9999 -9999 -9999 -9999 -9999 -9999 -9999 -9999 -9999 -

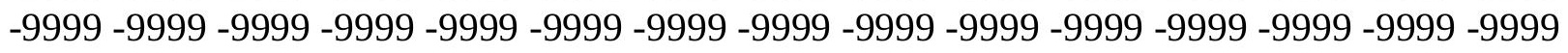

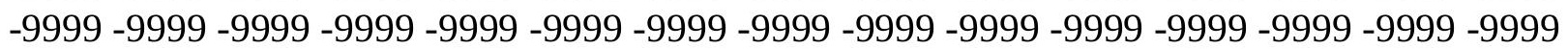


-9999 -9999 -9999 290.3132019043283.0252380371275.625793457 268.0977783203 260.4247131348252 .5883178711244 .5733032227236 .3651733398227 .9575653076 219.3525543213210 .5734710693201 .694732666192 .7822113037184 .0066375732 175.5769042969167 .7591552734160 .8309631348155 .0005493164150 .3421783447 146.8189239502144 .4196929932143 .2176513672143 .2489929199144 .1634063721 145.9920959473149 .6836700439153 .6606750488157 .5769348145161 .1549224854 164.1180877686166 .1078948975166 .7174987793167 .9365997314168 .8509979248 169.7653045654170 .3748931885170 .6797027588171 .2891998291171 .5939941406 171.5939941406171 .8988037109171 .8988037109171 .5939941406171 .2891998291 170.6797027588170 .070098877170 .6797027588170 .3748931885169 .7653045654 168.8509979248167 .6318054199166 .4127044678164 .5839996338162 .7552947998 160.6217956543158 .4882965088156 .0500030518153 .6116943359151 .1734008789 148.7351074219146 .2969055176144 .1634063721141 .7250976562139 .5915985107 137.7628936768135 .9342041016134 .1054992676132 .2767028809131 .0576019287 131.0576019287131 .0576019287130 .7528076172130 .7528076172130 .4479980469 130.4479980469129 .8385009766129 .533706665128 .9241027832128 .3144989014 127.0953979492127 .7050018311128 .3144989014129 .2288970947130 .7528076172 133.4958953857136 .5437011719139 .2868041992140 .2012023926139 .8963928223 138.9819946289138 .0677032471136 .8484954834135 .9342041016135 .0198059082 133.8007049561132 .8863067627131 .6672058105130 .4479980469129 .533706665 128.6192932129127 .4001998901126 .4858016968125 .5715026855124 .6570968628 123.7427978516123 .1332015991122 .5235977173121 .9140014648121 .6092987061 121.3044967651121 .3044967651121 .3044967651121 .3044967651121 .3044967651 121.6092987061121 .9140014648121 .9140014648122 .2188034058122 .5235977173 122.8283996582122 .8283996582122 .8283996582123 .1332015991123 .43800354 123.7427978516124 .0475006104124 .0475006104123 .7427978516122 .5235977173 119.4757995605117 .0374984741115 .818397522115 .5136032104115 .818397522 116.7326965332117 .9517974854120 .3900985718124 .6570968628129 .533706665 135.0198059082140 .5059967041145 .3825073242149 .3446960449152 .3925933838 153.3069000244153 .3069000244152 .0877990723150 .2590942383147 .8208007812 144.1634063721140 .2012023926135 .3246002197129 .8385009766124 .0475006104 117.9517974854111 .24659729104 .541297912697 .5312423706190 .52117919922 83.5111236572376 .5010681152369 .321563720762 .19261550903 -9999 -9999 -9999 -9999 -9999 -9999 -9999 -9999 -9999 -9999 -9999 -9999 -9999 -9999 -9999 -9999 -9999 -9999 -9999 -9999 -9999 -9999 -9999 -9999 -9999 -9999 -9999 -9999

-9999 -9999 -9999 -9999 -9999 -9999 -9999 -9999 -9999 -9999 -9999 -9999 -9999 -9999 -9999

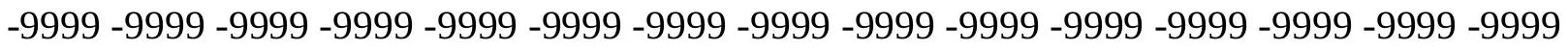

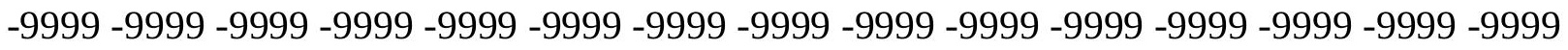
-9999 -9999 -9999 -9999 -9999 -9999 -9999 -9999 -9999 -9999 -9999 -9999 -9999 -9999 -9999 -9999 -9999 -9999 -9999 -9999 -9999 -9999 -9999 -9999 -9999 -9999 -9999 -9999 -9999 -9999 -

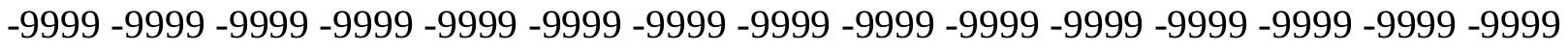

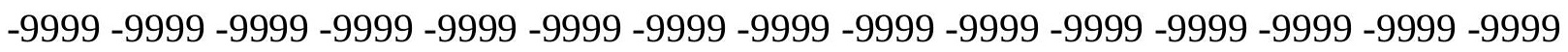
-9999 -9999 -9999 -9999 -9999 -9999 -9999 -9999 -9999 -9999 -9999 -9999 -9999 -9999 -9999 -9999 -9999 -9999 -9999 -9999 -9999 -9999 -9999 -9999 -9999 -9999 -9999 -9999 -9999 -9999 -9999 -9999 -9999 -9999 -9999 -9999 -9999 -9999 -9999 -9999 -9999 -9999 -9999 -9999 -9999 -9999 -9999 -9999 -9999 -9999 -9999 -9999 -9999 -9999 -9999 -9999 -9999 -9999 -9999 -9999 - 
-9999 -9999 -9999 -9999 -9999 -9999 -9999 -9999 -9999 -9999 -9999 -9999 -9999 -9999 -9999 -9999 -9999 -9999 -9999 -9999 -9999 -9999 -9999 -9999 -9999 -9999 -9999 -9999 -9999 -9999 -9999 -9999 -9999 289.4492492676 282.2903442383275.0215148926267.622253418 260.0718078613252 .3470001221244 .4267883301236 .2893829346227 .9183502197 219.3014678955210 .4432220459201 .3781585693192 .155456543182 .9584197998 174.0445098877165 .8299102783158 .6861572266152 .9524078369148 .6972961426 145.6969299316143 .8816375732143 .2489929199143 .8585968018146 .6015930176 149.9074401855154 .1817474365158 .8712768555163 .3061676025167 .0149688721 169.7949523926171 .5939941406171 .5939941406172 .2035980225172 .8132019043 173.4226989746173 .7274932861173 .7274932861173 .7274932861173 .7274932861 173.7274932861173 .4226989746173 .1179962158172 .5084075928171 .8988037109 170.9844970703170 .070098877170 .3748931885169 .7653045654169 .1557006836 167.9365997314166 .7174987793165 .4983062744163 .6696014404162 .1457061768 160.0122070312157 .878692627155 .7451934814153 .6116943359151 .4781951904 149.3446960449146 .9064025879145 .0776977539142 .9441986084140 .8106994629 138.9819946289137 .1533050537135 .3246002197133 .4958953857131 .9720001221 131.3623962402131 .3623962402131 .3623962402131 .3623962402131 .0576019287 130.7528076172130 .4479980469129 .8385009766129 .2288970947128 .6192932129 127.7050018311126 .7906036377125 .8762969971125 .8762969971126 .4858016968 127.7050018311130 .4479980469133 .1911010742135 .0198059082135 .6293945312 135.6293945312135 .3246002197134 .7149963379134 .1054992676133 .1911010742 132.5814971924131 .6672058105130 .7528076172129 .8385009766128 .9241027832 128.0097961426127 .0953979492126 .1809997559125 .2667007446124 .6570968628 123.7427978516123 .1332015991122 .5235977173122 .2188034058121 .6092987061 121.6092987061121 .3044967651121 .3044967651121 .3044967651121 .3044967651 121.6092987061121 .9140014648122 .2188034058122 .5235977173122 .8283996582 122.8283996582123 .1332015991123 .1332015991123 .43800354123 .43800354 123.7427978516124 .0475006104123 .7427978516123 .43800354122 .2188034058 120.6949005127118 .8662033081117 .647102356117 .0374984741117 .0374984741 117.342300415118 .2565994263119 .7806015015124 .3523025513129 .8385009766 135.0198059082140 .5059967041145 .0776977539149 .0399017334151 .7830047607 153.0021057129153 .0021057129152 .0877990723150 .2590942383147 .5160064697 144.1634063721139 .8963928223135 .0198059082129 .533706665123 .43800354 117.0374984741110 .6370010376103 .626899719296 .6168823242289 .3020401001 82.2919769287175 .1835403442468 .0858840942461 .01317596436 -9999 -9999 -9999 -9999 -9999 -9999 -9999 -9999 -9999 -9999 -9999 -9999 -9999 -9999 -9999 -9999 -9999 -9999 -9999 -9999 -9999 -9999 -9999 -9999 -9999 -9999 -9999 -9999

-9999 -9999 -9999 -9999 -9999 -9999 -9999 -9999 -9999 -9999 -9999 -9999 -9999 -9999 -9999 -9999 -9999 -9999 -9999 -9999 -9999 -9999 -9999 -9999 -9999 -9999 -9999 -9999 -9999 -9999 -9999 -9999 -9999 -9999 -9999 -9999 -9999 -9999 -9999 -9999 -9999 -9999 -9999 -9999 -9999 -9999 -9999 -9999 -9999 -9999 -9999 -9999 -9999 -9999 -9999 -9999 -9999 -9999 -9999 -9999 -9999 -9999 -9999 -9999 -9999 -9999 -9999 -9999 -9999 -9999 -9999 -9999 -9999 -9999 -9999 -9999 -9999 -9999 -9999 -9999 -9999 -9999 -9999 -9999 -9999 -9999 -9999 -9999 -9999 -9999 -9999 -9999 -9999 -9999 -9999 -9999 -9999 -9999 -9999 -9999 -9999 -9999 -9999 -9999 -9999 -999 -9999 -9999 -9999 -9999 -9999 -9999 -9999 -9999 -9999 -9999 -9999 -9999 -9999 -9999 -9999

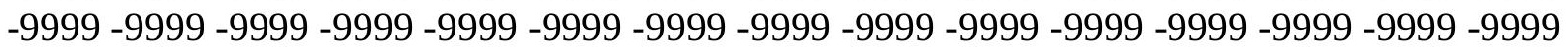


-9999 -9999 -9999 -9999 -9999 -9999 -9999 -9999 -9999 -9999 -9999 -9999 -9999 -9999 -9999 -9999 -9999 -9999 -9999 -9999 -9999 -9999 -9999 -9999 -9999 -9999 -9999 -9999 -9999 -9999

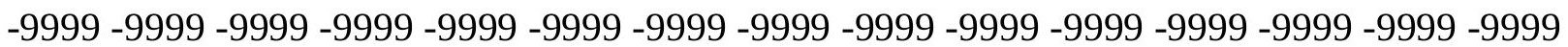
-9999 -9999 -9999 -9999 -9999 -9999 -9999 -9999 -9999 -9999 -9999 -9999 -9999 -9999 -9999 -9999 -9999 -9999 -9999 281.7461547852 274.6406555176 267.4050292969 260.0146179199 252.4418945312244 .661529541236 .6461486816228 .3715820312219 .8111877441 210.9521942139201 .7267608643192 .1885528564182 .4880065918172 .9889984131 164.1982269287156 .7335968018151 .0820617676147 .4203948975145 .2891693115 144.1634063721144 .1634063721146 .6015930176150 .0516204834154 .4913635254 159.5281677246164 .7816467285169 .6288909912173 .3960418701175 .5561981201 176.7754058838176 .165802002176 .4705963135176 .7754058838176 .7754058838 176.7754058838176 .7754058838176 .4705963135176 .165802002175 .5561981201 174.9467010498174 .337097168173 .7274932861172 .5084075928171 .5939941406 170.070098877170 .070098877169 .4604949951168 .5462036133167 .3269958496 166.1078948975164 .5839996338163 .0599975586161 .2312927246159 .4026031494 157.5738983154155 .4403991699153 .6116943359151 .4781951904149 .6495056152 147.5160064697145 .6873016357143 .8585968018142 .0299072266140 .2012023926 138.3724975586136 .8484954834135 .0198059082133 .1911010742131 .6672058105 131.6672058105131 .6672058105131 .6672058105131 .6672058105131 .3623962402 131.0576019287130 .4479980469129 .8385009766128 .9241027832127 .7050018311 126.7906036377125 .5715026855124 .3523025513122 .8283996582122 .2188034058 125.2667007446128 .0097961426130 .1432037354131 .3623962402132 .2767028809 132.2767028809132 .2767028809131 .9720001221131 .6672058105131 .0576019287 130.4479980469129 .8385009766128 .9241027832128 .3144989014127 .4001998901 126.7906036377125 .8762969971125 .2667007446124 .6570968628123 .7427978516 123.1332015991122 .5235977173122 .2188034058121 .6092987061121 .3044967651 121.3044967651121 .3044967651121 .3044967651121 .3044967651121 .6092987061 121.9140014648122 .2188034058122 .5235977173122 .8283996582123 .1332015991 123.43800354123 .43800354123 .7427978516123 .7427978516123 .7427978516 123.7427978516123 .43800354122 .8283996582121 .9140014648120 .6949005127 119.7806015015118 .5614013672118 .2565994263117 .9517974854118 .2565994263 119.4757995605121 .6092987061125 .2667007446130 .1432037354135 .3246002197 140.5059967041144 .7729034424148 .4304046631151 .1734008789152 .6972961426 152.6972961426151 .7830047607149 .9542999268147 .5160064697143 .8585968018 139.5915985107134 .7149963379128 .9241027832122 .8283996582116 .4279022217 109.4179000854 102.407798767195.3977432251 88.08290100098 80.76805877686 73.693771362366 .69956207275 -9999 -9999 -9999 -9999 -9999 -9999 -9999 -9999 -9999 -9999 -9999 -9999 -9999 -9999 -9999 -9999 -9999 -9999 -9999 -9999 -9999 -9999 -9999 -9999 -9999 -9999-9999-9999-9999

-9999 -9999 -9999 -9999 -9999 -9999 -9999 -9999 -9999 -9999 -9999 -9999 -9999 -9999 -9999 -9999 -9999 -9999 -9999 -9999 -9999 -9999 -9999 -9999 -9999 -9999 -9999 -9999 -9999 -9999

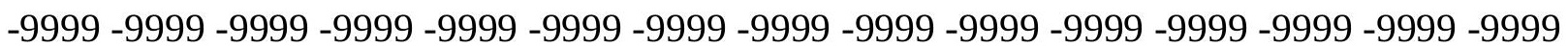
-9999 -9999 -9999 -9999 -9999 -9999 -9999 -9999 -9999 -9999 -9999 -9999 -9999 -9999 -9999 -9999 -9999 -9999 -9999 -9999 -9999 -9999 -9999 -9999 -9999 -9999 -9999 -9999 -9999 -9999 -999 -9999 -9999 -9999 -9999 -9999 -9999 -9999 -9999 -9999 -9999 -9999 -9999 -9999 -9999 -9999

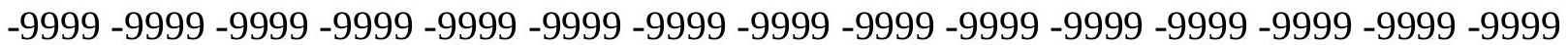


-9999 -9999 -9999 -9999 -9999 -9999 -9999 -9999 -9999 -9999 -9999 -9999 -9999 -9999 -9999 -9999 -9999 -9999 -9999 -9999 -9999 -9999 -9999 -9999 -9999 -9999 -9999 -9999 -9999 -9999

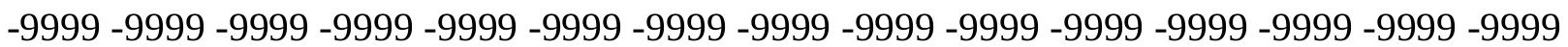
-9999 -9999 -9999 -9999 -9999 -9999 -9999 -9999 -9999 -9999 -9999 -9999 -9999 -9999 -9999 -9999 -9999 -9999 -9999 -9999 -9999 -9999 -9999 -9999 -9999 -9999 -9999 -9999 -9999 -9999 -9999 -9999 -9999 -9999 -9999 -9999 -9999 -9999 -9999 -9999 -9999 -9999 -9999 -9999 -9999 -9999 -9999 -9999 -9999 281.3670349121 274.4545898438 267.4139404297 260.2162780762 252.8301544189245 .2274932861237 .3790740967229 .2569122314220 .8246917725 212.0535736084202 .7608032227192 .9535827637182 .7463226318172 .5439453125 162.9953765869154 .9553833008149 .2399749756146 .2597045898145 .6873016357 145.0776977539146 .2969055176149 .6723632812154 .1584777832159 .4242858887 165.0798187256170 .7097320557175 .861114502179 .8231964111181 .6519012451 181.9566955566180 .7375946045180 .7375946045180 .432800293180 .432800293 180.1280059814179 .5184020996178 .9089050293178 .2993011475177 .3849029541 176.4705963135175 .5561981201174 .6419067383173 .4226989746171 .8988037109 170.3748931885169 .7653045654168 .8509979248167 .9365997314166 .7174987793 165.4983062744163 .974395752162 .4505004883160 .6217956543159 .0977935791 157.2691040039155.4403991699153.6116943359151.7830047607 149.9542999268 148.1255950928146 .6015930176144 .7729034424143 .2489929199141 .4203033447 139.5915985107138 .0677032471136 .5437011719134 .7149963379133 .1911010742 132.2767028809132 .2767028809132 .2767028809132 .2767028809131 .9720001221 131.6672058105130 .7528076172130 .1432037354128 .9241027832128 .0097961426 126.4858016968125 .2667007446124 .0475006104122 .5235977173121 .3044967651 122.5235977173124 .6570968628126 .4858016968128 .0097961426129 .2288970947 129.8385009766130 .1432037354130 .1432037354129 .8385009766129 .533706665 129.2288970947128 .9241027832128 .3144989014127 .7050018311127 .0953979492 126.4858016968125 .8762969971124 .9618988037124 .3523025513123 .7427978516 123.1332015991122 .5235977173122 .2188034058121 .6092987061121 .3044967651 121.3044967651120 .9997024536120 .9997024536121 .3044967651121 .6092987061 121.9140014648122 .2188034058122 .5235977173122 .8283996582123 .1332015991 123.43800354123 .7427978516123 .7427978516123 .7427978516123 .7427978516 123.7427978516123 .1332015991122 .5235977173121 .6092987061120 .6949005127 119.7806015015119 .1709976196118 .8662033081118 .8662033081119 .4757995605 120.6949005127123 .1332015991126 .7906036377131 .0576019287135 .6293945312 140.5059967041144 .4682006836148 .1255950928150 .8686065674152 .3925933838 152.3925933838151 .7830047607149 .9542999268147 .2111968994143 .5538024902 139.2868041992134 .1054992676128 .3144989014122 .2188034058115 .5136032104 108.5035018921101 .493400573794 .1785964965886 .8637619018679 .24413299561 72.149139404365 .23365783691 -9999 -9999 -9999 -9999 -9999 -9999 -9999 -9999 -9999 -9999 -9999 -9999 -9999 -9999 -9999 -9999 -9999 -9999 -9999 -9999 -9999 -9999 -9999 -9999 $-9999-9999-9999-9999-9999$

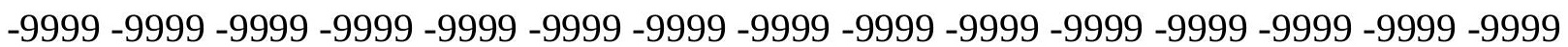
-9999 -9999 -9999 -9999 -9999 -9999 -9999 -9999 -9999 -9999 -9999 -9999 -9999 -9999 -9999 -9999 -9999 -9999 -9999 -9999 -9999 -9999 -9999 -9999 -9999 -9999 -9999 -9999 -9999 -9999 -9999 -9999 -9999 -9999 -9999 -9999 -9999 -9999 -9999 -9999 -9999 -9999 -9999 -9999 -9999

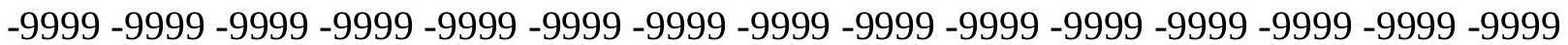


-9999 -9999 -9999 -9999 -9999 -9999 -9999 -9999 -9999 -9999 -9999 -9999 -9999 -9999 -9999 -9999 -9999 -9999 -9999 -9999 -9999 -9999 -9999 -9999 -9999 -9999 -9999 -9999 -9999 -9999

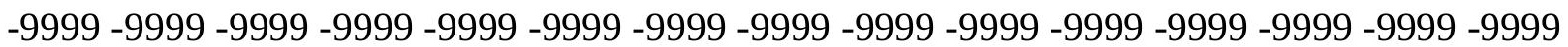
-9999 -9999 -9999 -9999 -9999 -9999 -9999 -9999 -9999 -9999 -9999 -9999 -9999 -9999 -9999 -9999 -9999 -9999 -9999 -9999 -9999 -9999 -9999 -9999 -9999 -9999 -9999 -9999 -9999 -9999 -9999 -9999 -9999 -9999 -9999 -9999 -9999 -9999 -9999 -9999 -9999 -9999 -9999 -9999 -9999 -9999 -9999 -9999 -9999 -9999 -9999 -9999 -9999 -9999 -9999 -9999 -9999 -9999 -9999 -9999 -9999 -9999 -9999 -9999 -9999 -9999 -9999 -9999 -9999 -9999 -9999 -9999 -9999 -9999 -9999 -9999 -9999 -9999-9999-9999 274.4234619141267.6039733887 260.6247253418 253.4498596191246 .0489044189238 .3942108154230 .4632873535222 .2289733887 213.6432800293204 .4777526855194 .5983428955183 .9480438232172 .9460601807 162.4882965088153 .6765594482147 .6266021729145 .0776977539145 .6873016357 146.6015930176149 .2665863037153 .3223266602158 .5156707764164 .3675079346 170.3910980225176 .0596160889181 .0424041748184 .699798584185 .9188995361 185.6141052246184 .699798584184 .3950042725184 .0901947021183 .4806976318 182.87109375182 .261505127181 .3471984863180 .432800293179 .2136993408 177.9945068359176 .7754058838175 .5561981201174 .0323028564172 .5084075928 170.6797027588169 .7653045654168 .8509979248167 .6318054199166 .4127044678 164.8887023926163 .3648071289161 .8408966064160 .3170013428158 .4882965088 156.6596069336155 .1356048584153 .3069000244151 .7830047607150 .2590942383 148.7351074219147 .2111968994145 .6873016357144 .4682006836142 .6394042969 141.1154937744139 .5915985107138 .0677032471136 .5437011719135 .0198059082 133.1911010742133 .1911010742133 .1911010742132 .8863067627132 .5814971924 131.9720001221131 .3623962402130 .4479980469129 .2288970947127 .7050018311 126.4858016968124 .9618988037123 .1332015991121 .3044967651120 .9997024536 121.3044967651122 .5235977173124 .0475006104125 .5715026855126 .7906036377 127.4001998901128 .0097961426128 .3144989014128 .3144989014128 .3144989014 128.0097961426127 .7050018311127 .4001998901127 .0953979492126 .4858016968 126.1809997559125 .5715026855124 .9618988037124 .3523025513123 .7427978516 123.1332015991122 .5235977173122 .2188034058121 .6092987061121 .3044967651 120.9997024536120 .9997024536120 .9997024536120 .9997024536121 .3044967651 121.9140014648122 .2188034058122 .8283996582123 .1332015991123 .1332015991 123.43800354123 .7427978516123 .7427978516124 .0475006104123 .7427978516 123.43800354122 .8283996582122 .2188034058121 .3044967651120 .3900985718 119.7806015015119 .4757995605119 .4757995605119 .7806015015120 .3900985718 122.2188034058124 .6570968628128 .0097961426131 .9720001221136 .2389984131 140.5059967041144 .4682006836147 .8208007812150 .2590942383152 .0877990723 152.3925933838151 .4781951904149 .6495056152146 .9064025879143 .2489929199 138.6772003174133 .4958953857127 .7050018311121 .3044967651114 .5991973877 107.284400939999 .9695205688592 .6546783447385 .3398437577 .72020721436 70.6242141723663 .75828552246 -9999 -9999 -9999 -9999 -9999 -9999 -9999 -9999 -9999 -9999 -9999 -9999 -9999 -9999 -9999 -9999 -9999 -9999 -9999 -9999 -9999 -9999 -9999 -9999 -9999 -9999 -9999 -9999-9999 -9999 -9999 -9999 -9999 -9999 -9999 -9999 -9999 -9999 -9999 -9999 -9999 -9999 -9999 -9999 -9999 -9999 -9999 -9999 -9999 -9999 -9999 -9999 -9999 -9999 -9999 -9999 -9999 -9999 -9999

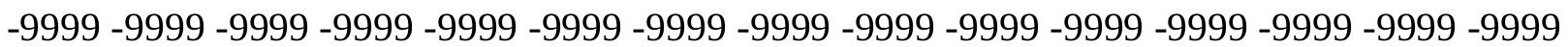


-9999 -9999 -9999 -9999 -9999 -9999 -9999 -9999 -9999 -9999 -9999 -9999 -9999 -9999 -9999 -9999 -9999 -9999 -9999 -9999 -9999 -9999 -9999 -9999 -9999 -9999 -9999 -9999 -9999 -9999

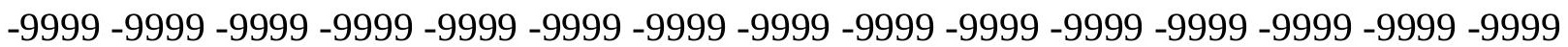
-9999 -9999 -9999 -9999 -9999 -9999 -9999 -9999 -9999 -9999 -9999 -9999 -9999 -9999 -9999 -9999 -9999 -9999 -9999 -9999 -9999 -9999 -9999 -9999 -9999 -9999 -9999 -9999 -9999 -9999 -9999 -9999 -9999 -9999 -9999 -9999 -9999 -9999 -9999 -9999 -9999 -9999 -9999 -9999 -9999 -9999 -9999 -9999 -9999 -9999 -9999 -9999 -9999 -9999 -9999 -9999 -9999 -9999 -9999 -9999

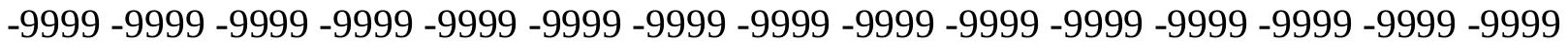

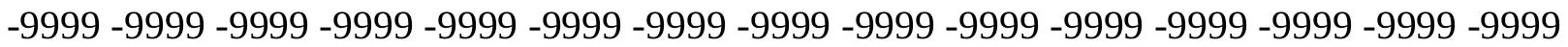
-9999 -9999 -9999 -9999 -9999 -9999 -9999 -9999 -9999 -9999 -9999 -9999 -9999 -9999 -9999 -9999 -9999 -9999 -9999 -9999 -9999 267.9248657227 261.1835327148 254.234588623 247.0483856201239 .6201324463231 .9195556641223 .9486236572215 .6164550781 206.7812652588197 .1569061279186 .395904541174 .5226745605163 .1743774414 153.4318847656146 .9064025879145 .6873016357147 .5160064697149 .1253509521 152.4100036621157 .1220397949162 .8257904053169 .0291290283175 .238861084 180.7375946045184 .0901947021186 .528503418187 .4429016113188 .0523986816 188.0523986816187 .7476043701187 .1381072998186 .528503418185 .6141052246 184.3950042725183 .4806976318182 .261505127180 .7375946045179 .5184020996 177.9945068359176 .4705963135174 .6419067383172 .8132019043170 .9844970703 168.8509979248168 .5462036133167 .3269958496165 .8031005859164 .5839996338 163.0599975586161 .2312927246159 .7073974609158 .1835021973156 .3547973633 154.8307952881153 .3069000244151 .7830047607150 .5639038086149 .0399017334 147.8208007812146 .6015930176145 .3825073242144 .1634063721142 .6394042969 141.1154937744139 .5915985107138 .3724975586136 .8484954834135 .3246002197 134.1054992676133 .8007049561133 .4958953857133 .1911010742132 .5814971924 131.6672058105130 .4479980469129 .2288970947127 .7050018311125 .8762969971 124.3523025513121 .6092987061121 .6092987061120 .9997024536120 .9997024536 121.6092987061122 .8283996582123 .7427978516124 .9618988037125 .5715026855 126.1809997559126 .7906036377127 .0953979492127 .0953979492127 .0953979492 127.0953979492126 .7906036377126 .4858016968126 .1809997559125 .5715026855 125.2667007446124 .6570968628124 .3523025513123 .7427978516123 .1332015991 122.8283996582122 .2188034058121 .6092987061121 .3044967651120 .6949005127 120.6949005127120 .6949005127120 .9997024536121 .3044967651121 .9140014648 122.2188034058122 .8283996582123 .1332015991123 .43800354123 .43800354 123.7427978516123 .7427978516124 .0475006104123 .7427978516123 .43800354 122.8283996582121 .6092987061120 .9997024536120 .0852966309119 .7806015015 119.4757995605119 .4757995605120 .0852966309121 .3044967651123 .1332015991 125.5715026855128 .6192932129132 .5814971924136 .5437011719140 .5059967041 144.1634063721147 .2111968994149 .9542999268151 .4781951904152 .0877990723 151.1734008789149 .3446960449146 .6015930176142 .9441986084138 .3724975586 132.8863067627127 .0953979492120 .3900985718113 .3800964355106 .0652008057 98.7503814697391 .1307525634883 .8159103393676 .1962814331169 .11406707764 62.29406738281 -9999 -9999 -9999 -9999 -9999 -9999 -9999 -9999 -9999 -9999 -9999 -9999 -9999 -9999 -9999 -9999 -9999 -9999 -9999 -9999 -9999 -9999 -9999 -9999 -9999 -9999 -9999 $-9999-9999$

-9999 -9999 -9999 -9999 -9999 -9999 -9999 -9999 -9999 -9999 -9999 -9999 -9999 -9999 -9999 
-9999 -9999 -9999 -9999 -9999 -9999 -9999 -9999 -9999 -9999 -9999 -9999 -9999 -9999 -9999 -9999 -9999 -9999 -9999 -9999 -9999 -9999 -9999 -9999 -9999 -9999 -9999 -9999 -9999 -9999 -9999 -9999 -9999 -9999 -9999 -9999 -9999 -9999 -9999 -9999 -9999 -9999 -9999 -9999 -9999 -9999 -9999 -9999 -9999 -9999 -9999 -9999 -9999 -9999 -9999 -9999 -9999 -9999 -9999 -9999 -9999 -9999 -9999 -9999 -9999 -9999 -9999 -9999 -9999 -9999 -9999 -9999 -9999 -9999 -9999 -9999 -9999 -9999 -9999 -9999 -9999 -9999 -9999 -9999 -9999 -9999 -9999 -9999 -9999 -9999 -9999 -9999 -9999 -9999 -9999 -9999 -9999 -9999 -9999 -9999 -9999 -9999 -9999 -9999 -9999

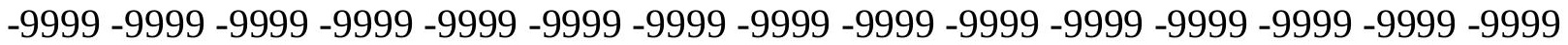

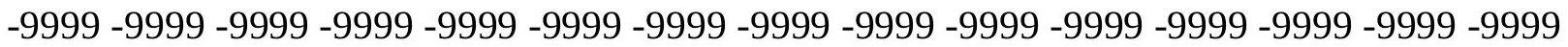
-9999 -9999 -9999 -9999 -9999 -9999 -9999 -9999 -9999 -9999 -9999 -9999 -9999 -9999 -9999 -9999 -9999 -9999 -9999 -9999 -9999 -9999 -9999 -9999 -9999 -9999 -9999 -9999 -9999 -9999 -9999 -9999 -9999 -9999 -9999 -9999 -9999 -9999 -9999 -9999 -9999 -9999 -9999 -9999 -9999 -9999 -9999 -9999 -9999 -9999 -9999 268.3176269531 261.8288574219 255.1132659912 248.1669921875240 .958114624233 .4783782959225 .725479126217 .684463501 209.3148040771200.4065551758 190.3179931641 177.8991394043164.9939575195 155.1356048584150 .5639038086147 .5160064697148 .6033172607151 .3987426758 155.4517822266160 .708770752166 .7776489258173 .1837158203179 .3038787842 184.3950042725187 .4429016113189 .5764007568190 .4907073975191 .1002960205 191.1002960205190 .4907073975189 .8811035156188 .966796875187 .7476043701 186.528503418185 .3094024658183 .7854003906182 .261505127180 .7375946045 179.2136993408177 .3849029541175 .5561981201173 .4226989746171 .2891998291 169.1557006836168 .241394043167 .0222015381165 .4983062744163 .974395752 162.4505004883160 .9264984131159 .4026031494157 .5738983154156 .0500030518 154.5260925293153 .3069000244151 .7830047607150 .5639038086149 .6495056152 148.4304046631147 .5160064697146 .6015930176145 .6873016357144 .1634063721 142.9441986084141 .4203033447140 .2012023926138 .9819946289137 .4580993652 135.9342041016134 .4102020264134 .1054992676133 .8007049561133 .1911010742 131.9720001221130 .7528076172129 .2288970947127 .4001998901125 .5715026855 123.43800354121 .6092987061121 .3044967651120 .9997024536120 .9997024536 121.3044967651121 .9140014648122 .8283996582123 .43800354124 .0475006104 124.6570968628125 .2667007446125 .8762969971126 .1809997559126 .1809997559 126.1809997559126 .1809997559125 .8762969971125 .5715026855125 .2667007446 124.9618988037124 .6570968628124 .0475006104123 .7427978516123 .1332015991 122.8283996582122 .2188034058121 .6092987061120 .9997024536120 .3900985718 120.0852966309120 .0852966309120 .6949005127120 .9997024536121 .6092987061 122.5235977173122 .8283996582123 .1332015991123 .43800354123 .43800354123 .43800354 123.7427978516123 .7427978516123 .43800354122 .8283996582122 .2188034058 120.9997024536120 .0852966309119 .7806015015119 .4757995605119 .1709976196 119.4757995605120 .3900985718121 .6092987061123 .43800354126 .1809997559 129.2288970947132 .5814971924136 .5437011719140 .2012023926143 .8585968018 146.9064025879149 .6495056152151 .1734008789151 .7830047607151 .1734008789 149.3446960449146 .6015930176142 .6394042969138 .0677032471132 .5814971924 126.1809997559119 .4757995605112 .4656982422104 .846099853597 .22646331787 89.6068267822381 .9871978759874 .6723632812567 .62799072266 -9999 -9999 -9999 -9999 -9999 -9999 -9999 -9999 -9999 -9999 -9999 -9999 -9999 -9999 -9999 -9999 -9999 -9999 -9999 -9999 -9999 -9999 -9999 -9999 -9999 -9999 -9999 -9999 -9999 -9999 
-9999 -9999 -9999 -9999 -9999 -9999 -9999 -9999 -9999 -9999 -9999 -9999 -9999 -9999 -9999 -9999 -9999 -9999 -9999 -9999 -9999 -9999 -9999 -9999 -9999 -9999 -9999 -9999 -9999 -9999

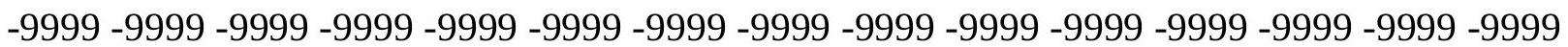
-9999 -9999 -9999 -9999 -9999 -9999 -9999 -9999 -9999 -9999 -9999 -9999 -9999 -9999 -9999 -9999 -9999 -9999 -9999 -9999 -9999 -9999 -9999 -9999 -9999 -9999 -9999 -9999 -9999 -9999 -9999 -9999 -9999 -9999 -9999 -9999 -9999 -9999 -9999 -9999 -9999 -9999 -9999 -9999 -9999 -9999 -9999 -9999 -9999 -9999 -9999 -9999 -9999 -9999 -9999 -9999 -9999 -9999 -9999 -9999

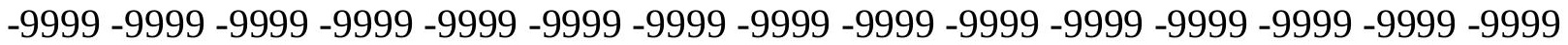
-9999 -9999 -9999 -9999 -9999 -9999 -9999 -9999 -9999 -9999 -9999 -9999 -9999 -9999 -9999 -9999 -9999 -9999 -9999 -9999 -9999 -9999 -9999 -9999 -9999 -9999 -9999 -9999 -9999 -9999 -9999 -9999 -9999 -9999 -9999 -9999 -9999 -9999 -9999 -9999 -9999 -9999 -9999 -9999 -9999 -9999 -9999 -9999 -9999 -9999 -9999 -9999 -9999 -9999 -9999 -9999 -9999 -9999 -9999 -9999

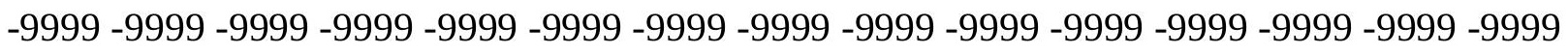
-9999 -9999 -9999 -9999 -9999 -9999 -9999 262.4925231934 256.0363769531249.3185272217 242.3088378906 234.9857635498227.3378143311219.3917694092 211.2687835693 203.2301635742195 .1101226807184 .4056243896167 .3269958496161 .2312927246 154.2212982178150 .2590942383150 .5041046143153 .5263824463158 .1293029785 163.836730957170 .1492614746176 .6030578613182 .5920410156187 .4429016113 190.1858978271192 .0146026611192 .9290008545193 .5386047363193 .5386047363 192.9290008545192 .3193969727191 .1002960205189 .8811035156188 .3571929932 186.8332977295185 .3094024658183 .7854003906181 .9566955566180 .1280059814 177.9945068359176 .165802002174 .0323028564171 .5939941406169 .4604949951 167.9365997314166 .7174987793165 .1934967041163 .6696014404162 .1457061768 160.6217956543158 .7929992676157 .2691040039155 .7451934814154 .2212982178 153.0021057129151 .7830047607150 .8686065674149 .9542999268149 .0399017334 148.4304046631147 .5160064697146 .9064025879145 .9920959473144 .7729034424 143.5538024902142 .3347015381141 .4203033447139 .8963928223138 .3724975586 136.5437011719134 .7149963379134 .1054992676133 .4958953857132 .2767028809 130.7528076172128 .9241027832126 .7906036377124 .6570968628121 .6092987061 121.6092987061121 .3044967651120 .9997024536120 .9997024536120 .9997024536 121.6092987061121 .9140014648122 .5235977173122 .8283996582123 .7427978516 124.3523025513124 .6570968628125 .2667007446125 .2667007446125 .5715026855 125.5715026855125 .5715026855125 .2667007446124 .9618988037124 .6570968628 124.3523025513124 .0475006104123 .7427978516123 .1332015991122 .8283996582 122.2188034058121 .6092987061120 .6949005127120 .0852966309119 .4757995605 119.4757995605120 .0852966309120 .9997024536121 .9140014648122 .8283996582 123.1332015991123 .1332015991123 .1332015991123 .1332015991123 .1332015991 123.1332015991123 .1332015991122 .8283996582120 .9997024536119 .7806015015 119.4757995605119 .1709976196118 .8662033081118 .8662033081118 .8662033081 119.4757995605120 .3900985718121 .6092987061123 .7427978516126 .1809997559 129.2288970947132 .5814971924136 .2389984131140 .2012023926143 .5538024902 146.9064025879149 .3446960449150 .8686065674151 .4781951904151 .1734008789 149.3446960449146 .6015930176142 .6394042969137 .7628936768131 .9720001221 125.5715026855118 .5614013672111 .24659729103 .626899719296 .00731658936 88.0829010009880 .4632720947373 .0704879760766 .10792541504 -9999 -9999 -9999 -9999 -9999 -9999 -9999 -9999 -9999 -9999 -9999 -9999 -9999 -9999 -9999 -9999 -9999 -9999 -9999 
-9999 -9999 -9999 -9999 -9999 -9999 -9999 -9999 -9999 -9999 -9999

-9999 -9999 -9999 -9999 -9999 -9999 -9999 -9999 -9999 -9999 -9999 -9999 -9999 -9999 -9999

-9999 -9999 -9999 -9999 -9999 -9999 -9999 -9999 -9999 -9999 -9999 -9999 -9999 -9999 -9999

-9999 -9999 -9999 -9999 -9999 -9999 -9999 -9999 -9999 -9999 -9999 -9999 -9999 -9999 -9999

-9999 -9999 -9999 -9999 -9999 -9999 -9999 -9999 -9999 -9999 -9999 -9999 -9999 -9999 -9999 -

-9999 -9999 -9999 -9999 -9999 -9999 -9999 -9999 -9999 -9999 -9999 -9999 -9999 -9999 -9999 -

-9999 -9999 -9999 -9999 -9999 -9999 -9999 -9999 -9999 -9999 -9999 -9999 -9999 -9999 -9999

-9999 -9999 -9999 -9999 -9999 -9999 -9999 -9999 -9999 -9999 -9999 -9999 -9999 -9999 -9999

-9999 -9999 -9999 -9999 -9999 -9999 -9999 -9999 -9999 -9999 -9999 -9999 -9999 -9999 -9999

-9999 -9999 -9999 -9999 -9999 -9999 -9999 -9999 -9999 -9999 -9999 -9999 -9999 -9999 -9999 -

-9999 -9999 -9999 -9999 -9999 -9999 -9999 -9999 -9999 -9999 -9999 -9999 -9999 -9999 -9999

-9999 -9999 -9999 -9999 -9999 -9999 -9999 -9999 -9999 -9999 -9999 -9999 -9999 -9999 -9999

-9999 -9999 -9999 -9999 -9999 -9999 -9999 -9999 -9999 -9999 -9999 -9999 -9999 -9999 -9999 -

-9999 -9999 -9999 -9999 -9999 -9999 -9999 -9999 -9999 -9999 -9999 -9999 -9999 -9999 -9999

-9999 -9999 -9999 -9999 -9999 -9999 -9999 263.0989990234256 .9124450684250 .4293670654

243.5982513428236 .3587188721228 .6575469971220 .4875183105211 .9331665039

203.3467559814196 .1870422363192 .9290008545178 .604095459164 .8887023926

155.7451934814151 .9868164062152 .3008117676155 .5021057129160 .4590911865

166.4153442383172 .8355865479179 .2091217041185 .0045928955189 .2716064453 192.0146026611193 .8433074951194 .7577056885195 .3672943115195 .3672943115 194.7577056885193 .8433074951192 .9290008545191 .4051055908189 .8811035156 188.3571929932186 .528503418184 .699798584182 .87109375180 .7375946045 178.604095459176 .4705963135174 .337097168171 .8988037109169 .7653045654 167.0222015381166 .4127044678164 .8887023926163 .3648071289161 .8408966064 160.3170013428158 .4882965088156 .9642944336155 .4403991699153 .9165039062 153.0021057129151 .7830047607151 .1734008789150 .2590942383149 .6495056152 149.0399017334148 .7351074219148 .1255950928147 .5160064697146 .6015930176 145.6873016357144 .7729034424143 .8585968018142 .6394042969141 .1154937744 139.2868041992136 .8484954834134 .4102020264133 .8007049561132 .2767028809 130.7528076172128 .6192932129126 .1809997559123 .7427978516121 .6092987061 121.6092987061121 .3044967651120 .9997024536120 .9997024536120 .9997024536 120.9997024536121 .3044967651121 .6092987061121 .9140014648122 .8283996582 123.43800354124 .0475006104124 .3523025513124 .6570968628124 .9618988037 124.9618988037124 .9618988037124 .9618988037124 .6570968628124 .6570968628 124.3523025513124 .0475006104123 .7427978516123 .1332015991122 .8283996582 122.2188034058121 .3044967651120 .3900985718119 .4757995605118 .5614013672 118.2565994263118 .8662033081120 .3900985718121 .9140014648122 .8283996582 123.1332015991123 .1332015991123 .1332015991122 .8283996582122 .5235977173 121.9140014648121 .6092987061121 .9140014648117 .342300415117 .342300415 117.647102356117 .9517974854118 .2565994263118 .2565994263118 .5614013672 119.1709976196120 .0852966309121 .3044967651123 .43800354125 .8762969971 128.9241027832132 .2767028809135 .9342041016139 .5915985107143 .2489929199 146.6015930176149 .0399017334150 .8686065674151 .7830047607151 .1734008789 149.3446960449146 .2969055176142 .3347015381137 .4580993652131 .3623962402 124.9618988037117 .9517974854110 .3321990967102 .407798767194 .48339080811 86.5589828491278 .6345596313571 .4043731689564 .64756774902 -9999 -9999 -9999 -9999 
-9999 -9999 -9999 -9999 -9999 -9999 -9999 -9999 -9999 -9999 -9999 -9999 -9999 -9999 -9999 -9999 -9999 -9999 -9999 -9999 -9999 -9999 -9999 -9999 -9999 -9999

-9999 -9999 -9999 -9999 -9999 -9999 -9999 -9999 -9999 -9999 -9999 -9999 -9999 -9999 -9999 -9999 -9999 -9999 -9999 -9999 -9999 -9999 -9999 -9999 -9999 -9999 -9999 -9999 -9999 -9999 -9999 -9999 -9999 -9999 -9999 -9999 -9999 -9999 -9999 -9999 -9999 -9999 -9999 -9999 -9999 -9999 -9999 -9999 -9999 -9999 -9999 -9999 -9999 -9999 -9999 -9999 -9999 -9999 -9999 -9999 -9999 -9999 -9999 -9999 -9999 -9999 -9999 -9999 -9999 -9999 -9999 -9999 -9999 -9999 -9999 -9999 -9999 -9999 -9999 -9999 -9999 -9999 -9999 -9999 -9999 -9999 -9999 -9999 -9999 -9999 -9999 -9999 -9999 -9999 -9999 -9999 -9999 -9999 -9999 -9999 -9999 -9999 -9999 -9999 -9999 -9999 -9999 -9999 -9999 -9999 -9999 -9999 -9999 -9999 -9999 -9999 -9999 -9999 -9999 -9999

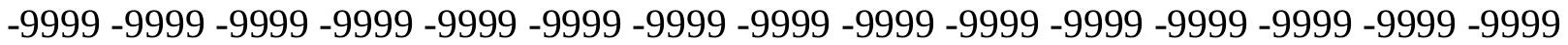
-9999 -9999 -9999 -9999 -9999 -9999 -9999 -9999 -9999 -9999 -9999 -9999 -9999 -9999 -9999 -

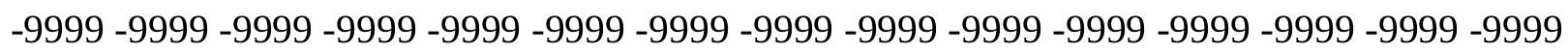
-9999 -9999 -9999 -9999 -9999 -9999 -9999 -9999 -9999 -9999 -9999 -9999 -9999 -9999 -9999 -9999 -9999 -9999 -9999 -9999 -9999 -9999 -9999 -9999 -9999 -9999 -9999 -9999 -9999 -9999 -9999 -9999 -9999 -9999 -9999 -9999 -9999 -9999 257.6567993164251 .4214630127 244.7676544189237 .5667877197229 .6637878418220 .9395294189211 .4442749023 201.2747344971190 .4907073975179 .2136993408174 .6419067383164 .2792053223 155.1356048584152 .2852172852153 .5054931641157 .216003418162 .4404907227 168.5022888184174 .8649139404180 .9819488525186 .2236938477190 .1858978271 192.9290008545195 .0625195 .9768066406196 .5863952637196 .5863952637196 .2816009521 195.3672943115194 .1481018066192 .624206543191 .1002960205189 .2716064453 187.4429016113185 .6141052246183 .4806976318181 .3471984863179 .2136993408 177.0802001953174 .6419067383172 .2035980225169 .7653045654167 .3269958496 166.1078948975164 .5839996338163 .0599975586161 .5361022949160 .0122070312 158.1835021973156 .6596069336155 .1356048584153 .9165039062152 .6972961426 152.0877990723151 .1734008789150 .5639038086150 .2590942383149 .6495056152 149.3446960449149 .0399017334149 .0399017334148 .7351074219147 .8208007812 147.2111968994146 .2969055176145 .3825073242144 .1634063721142 .3347015381 139.8963928223136 .5437011719133 .4958953857132 .2767028809130 .4479980469 128.0097961426125 .2667007446121 .9140014648121 .9140014648121 .6092987061 121.3044967651120 .9997024536120 .6949005127120 .6949005127120 .9997024536 120.9997024536121 .3044967651121 .6092987061122 .2188034058122 .8283996582 123.43800354124 .0475006104124 .3523025513124 .3523025513124 .6570968628 124.6570968628124 .6570968628124 .3523025513124 .3523025513124 .0475006104 124.0475006104123 .7427978516123 .43800354122 .8283996582122 .2188034058 121.3044967651120 .0852966309118 .5614013672117 .342300415116 .4279022217 116.4279022217118 .2565994263121 .6092987061121 .9140014648122 .5235977173 122.8283996582122 .8283996582122 .5235977173121 .9140014648120 .6949005127 118.8662033081116 .4279022217115 .5136032104116 .1231002808116 .7326965332 117.342300415117 .647102356117 .647102356117 .9517974854118 .5614013672 119.4757995605120 .9997024536122 .8283996582125 .2667007446128 .3144989014 131.6672058105135 .3246002197139 .2868041992142 .9441986084146 .2969055176 149.0399017334151 .1734008789152 .0877990723151 .4781951904149 .6495056152 146.6015930176142 .3347015381137 .1533050537131 .0576019287124 .3523025513 117.0374984741109 .4179000854101 .493400573793 .2642517089885 .03504943848 
76.8058471679769 .9732971191463 .3957824707 -9999 -9999 -9999 -9999 -9999 -9999 -9999 -9999 -9999 -9999 -9999 -9999 -9999 -9999 -9999 -9999 -9999 -9999 -9999 -9999 -9999 -9999 -9999 -9999 -9999 -9999-9999-9999-9999-9999

-9999 -9999 -9999 -9999 -9999 -9999 -9999 -9999 -9999 -9999 -9999 -9999 -9999 -9999 -9999 -9999 -9999 -9999 -9999 -9999 -9999 -9999 -9999 -9999 -9999 -9999 -9999-9999 -9999 -9999 -9999 -9999 -9999 -9999 -9999 -9999 -9999 -9999 -9999 -9999 -9999 -9999 -9999 -9999 -9999

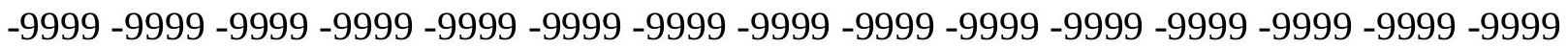
-9999 -9999 -9999 -9999 -9999 -9999 -9999 -9999 -9999 -9999 -9999 -9999 -9999 -9999 -9999 -9999 -9999 -9999 -9999 -9999 -9999 -9999 -9999 -9999 -9999 -9999 -9999 -9999 -9999 -9999 -9999 -9999 -9999 -9999 -9999 -9999 -9999 -9999 -9999 -9999 -9999 -9999 -9999 -9999 -9999 -9999 -9999 -9999 -9999 -9999 -9999 -9999 -9999 -9999 -9999 -9999 -9999 -9999 -9999 -9999 -

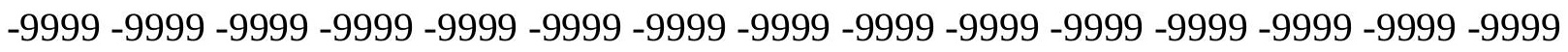
-9999 -9999 -9999 -9999 -9999 -9999 -9999 -9999 -9999 -9999 -9999 -9999 -9999 -9999 -9999 -9999 -9999 -9999 -9999 -9999 -9999 -9999 -9999 -9999 -9999 -9999 -9999 -9999 -9999 -9999 -9999 -9999 -9999 -9999 -9999 -9999 -9999 -9999 -9999 -9999 -9999 -9999 -9999 -9999 -9999

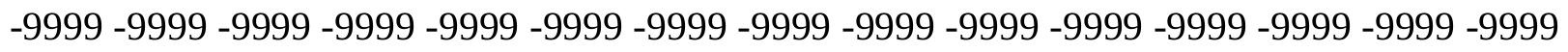
-9999 -9999 -9999 -9999 -9999 -9999 -9999 -9999 258.1607055664252 .1918029785 245.7391815186238 .5913696289230 .4505767822220 .9921112061210 .0380096436 197.7021789551184 .3950042725171 .5939941406165 .4983062744158 .4882965088 152.0877990723152 .0811767578154 .5388031006158 .7068786621164 .0713653564 170.1048278809176 .3180236816182 .1862182617187 .1381072998190 .795501709 193.8433074951195 .6721038818196 .891204834197 .500793457197 .500793457 197.1959991455196 .2816009521195 .0625193 .5386047363192 .0146026611190 .1858978271 188.3571929932 186.2236938477184.0901947021 181.9566955566179.5184020996 177.3849029541174 .9467010498172 .5084075928170 .070098877167 .6318054199 166.1078948975164 .5839996338163 .0599975586161 .2312927246159 .7073974609 158.1835021973156 .3547973633155 .1356048584153 .6116943359152 .6972961426 152.0877990723151 .4781951904150 .8686065674150 .5639038086150 .2590942383 150.2590942383149 .9542999268149 .9542999268149 .9542999268149 .9542999268 149.6495056152149 .0399017334148 .4304046631147 .2111968994145 .3825073242 142.6394042969139 .5915985107135 .6293945312131 .9720001221129 .533706665 127.0953979492124 .0475006104121 .9140014648121 .9140014648121 .9140014648 121.3044967651120 .9997024536120 .6949005127120 .6949005127120 .6949005127 120.9997024536121 .3044967651121 .6092987061122 .2188034058122 .5235977173 123.1332015991123 .43800354123 .7427978516124 .0475006104124 .0475006104 124.3523025513124 .3523025513124 .3523025513124 .0475006104124 .0475006104 123.7427978516123 .7427978516123 .43800354122 .8283996582122 .2188034058 120.9997024536119 .7806015015117 .9517974854115 .818397522114 .2944030762 113.3800964355114 .2944030762117 .0374984741119 .7806015015121 .3044967651 122.5235977173122 .8283996582122 .5235977173121 .9140014648120 .6949005127 118.2565994263112 .7705001831115 .818397522116 .4279022217116 .7326965332 116.7326965332117 .0374984741117 .0374984741117 .342300415117 .9517974854 118.8662033081120 .0852966309121 .9140014648124 .3523025513127 .4001998901 130.7528076172134 .4102020264138 .3724975586142 .3347015381145 .9920959473 149.0399017334151 .1734008789152 .3925933838151 .7830047607149 .6495056152 146.6015930176142 .0299072266136 .8484954834130 .4479980469123 .7427978516 
116.4279022217108 .5035018921100 .579101562592 .349891662684 .12069702148 76.1962814331169 .0867080688562 .42923355103 -9999 -9999 -9999 -9999 -9999 -9999 -9999 -9999 -9999 -9999 -9999 -9999 -9999 -9999 -9999 -9999 -9999 -9999 -9999 -9999 -9999 -9999 -9999 -9999 -9999 -9999 -9999 -9999 -9999 -9999

-9999 -9999 -9999 -9999 -9999 -9999 -9999 -9999 -9999 -9999 -9999 -9999 -9999 -9999 -9999 -9999 -9999 -9999 -9999 -9999 -9999 -9999 -9999 -9999 -9999 -9999 -9999 -9999 -9999 -9999 -9999 -9999 -9999 -9999 -9999 -9999 -9999 -9999 -9999 -9999 -9999 -9999 -9999 -9999 -9999

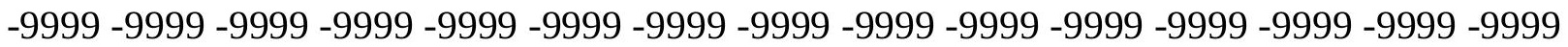
-9999 -9999 -9999 -9999 -9999 -9999 -9999 -9999 -9999 -9999 -9999 -9999 -9999 -9999 -9999 -9999 -9999 -9999 -9999 -9999 -9999 -9999 -9999 -9999 -9999 -9999 -9999 -9999 -9999 -9999 -

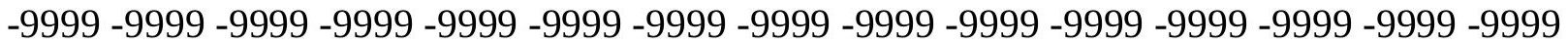
-9999 -9999 -9999 -9999 -9999 -9999 -9999 -9999 -9999 -9999 -9999 -9999 -9999 -9999 -9999 -9999 -9999 -9999 -9999 -9999 -9999 -9999 -9999 -9999 -9999 -9999 -9999 -9999 -9999 -9999 -9999 -9999 -9999 -9999 -9999 -9999 -9999 -9999 -9999 -9999 -9999 -9999 -9999 -9999 -9999 -9999 -9999 -9999 -9999 -9999 -9999 -9999 -9999 -9999 -9999 -9999 -9999 -9999 -9999 -9999

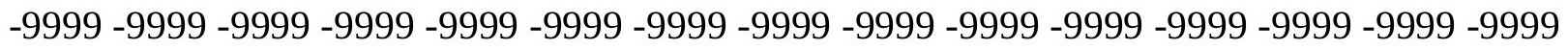
-9999 -9999 -9999 -9999 -9999 -9999 -9999 -9999 -9999 -9999 -9999 -9999 -9999 -9999 -9999 -9999 -9999 -9999 -9999-9999-9999 -9999 -9999 -9999 252.5894012451 246.3699035645 239.358581543231.0953216553220.9153289795208.3309783936194.4528961182 177.3849029541 165.1934967041 157.2691040039153.0021057129151.7830047607 152.7205047607155 .6512145996160 .0358734131165 .3686523438171 .2504272461 177.2327575684182 .8959655762187 .7476043701191 .1002960205194 .1481018066 195.9768066406197 .500793457198 .1103057861198 .1103057861197 .8054962158 196.891204834195 .6721038818194 .1481018066192 .624206543190 .4907073975 188.6620025635186 .528503418184 .3950042725182 .261505127179 .8231964111 177.3849029541175 .2514038086172 .8132019043170 .3748931885167 .9365997314 165.4983062744164 .2792053223162 .7552947998161 .2312927246159 .4026031494 157.878692627156 .3547973633154 .8307952881153 .6116943359152 .6972961426 152.0877990723151 .4781951904151 .1734008789150 .8686065674150 .8686065674 150.8686065674150 .8686065674150 .8686065674151 .1734008789151 .4781951904 151.4781951904151 .7830047607151 .1734008789150 .2590942383148 .4304046631 145.6873016357142 .3347015381138 .3724975586133 .8007049561128 .6192932129 125.5715026855121 .9140014648121 .9140014648121 .6092987061121 .6092987061 120.9997024536120 .6949005127120 .3900985718120 .3900985718120 .6949005127 120.6949005127121 .3044967651121 .6092987061121 .9140014648122 .5235977173 122.8283996582123 .1332015991123 .43800354123 .7427978516123 .7427978516 123.7427978516124 .0475006104124 .0475006104124 .0475006104123 .7427978516 123.7427978516123 .43800354123 .43800354122 .8283996582122 .2188034058 121.3044967651119 .4757995605117 .342300415115 .2088012695112 .7705001831 110.9418029785109 .4179000854113 .9896011353117 .9517974854120 .3900985718 121.9140014648122 .8283996582122 .5235977173122 .2188034058121 .6092987061 121.3044967651123 .1332015991119 .1709976196117 .647102356117 .0374984741 116.7326965332116 .7326965332116 .7326965332116 .7326965332117 .342300415 117.9517974854119 .1709976196120 .9997024536123 .1332015991126 .1809997559 129.533706665133 .1911010742137 .4580993652141 .7250976562145 .6873016357 149.0399017334151.1734008789 152.3925933838151.7830047607 149.6495056152 
146.2969055176 141.7250976562136.2389984131 130.1432037354123.1332015991 115.818397522107 .893898010399 .9695205688591 .7403335571383 .51112365723 75.8914871215868 .5519561767661 .73013305664 -9999 -9999 -9999 -9999 -9999 -9999 -9999 -9999 -9999 -9999 -9999 -9999 -9999 -9999 -9999 -9999 -9999 -9999 -9999 -9999 -9999 -9999 -9999 -9999 -9999 -9999-9999-9999-9999-9999

-9999 -9999 -9999 -9999 -9999 -9999 -9999 -9999 -9999 -9999 -9999 -9999 -9999 -9999 -9999

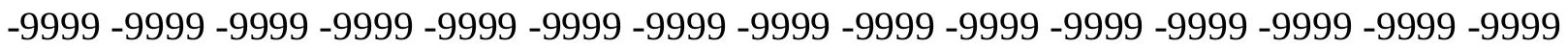

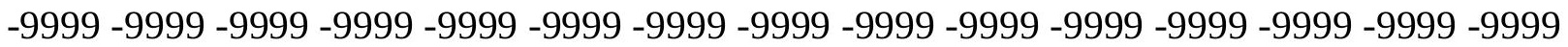

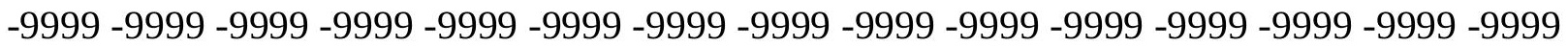
-9999 -9999 -9999 -9999 -9999 -9999 -9999 -9999 -9999 -9999 -9999 -9999 -9999 -9999 -9999 -

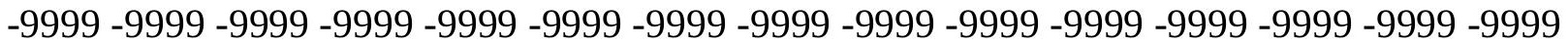
-9999 -9999 -9999 -9999 -9999 -9999 -9999 -9999 -9999 -9999 -9999 -9999 -9999 -9999 -9999 -9999 -9999 -9999 -9999 -9999 -9999 -9999 -9999 -9999 -9999 -9999 -9999 -9999 -9999 -9999 -9999 -9999 -9999 -9999 -9999 -9999 -9999 -9999 -9999 -9999 -9999 -9999 -9999 -9999 -9999 -9999 -9999 -9999 -9999 -9999 -9999 -9999 -9999 -9999 -9999 -9999 -9999 -9999 -9999 -9999

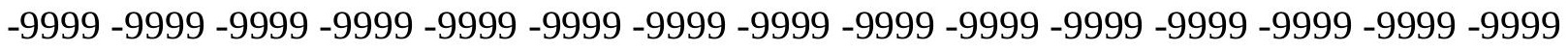

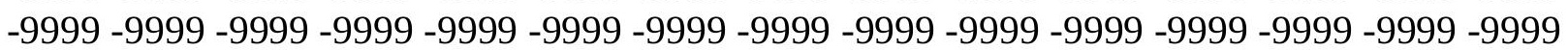
-9999 -9999 -9999 -9999 -9999 -9999 -9999 -9999 -9999 -9999 -9999 -9999 -9999 -9999 -9999 -999 -9999 -9999 -9999 -9999 -9999 -9999 -9999 -9999 -9999 252.4183654785 246.4102478027 239.5932006836231 .5061035156221 .2391204834207 .0277862549188 .0523986816 171.5939941406160 .3170013428154 .2212982178151 .7830047607152 .3925933838 153.8675994873156 .9167175293161 .1912536621166 .3181915283171 .9286499023 177.6429443359183 .0605926514187 .7476043701191 .1002960205193 .8433074951 195.9768066406197 .500793457198 .1103057861198 .1103057861197 .8054962158 196.891204834195 .6721038818194 .4528961182192 .624206543190 .795501709 188.6620025635186 .528503418184 .3950042725182 .261505127179 .8231964111 177.6896972656175 .2514038086172 .8132019043170 .3748931885167 .9365997314 165.4983062744164 .2792053223162 .4505004883160 .9264984131159 .4026031494 157.878692627156 .3547973633154 .8307952881153 .6116943359152 .6972961426 152.0877990723151 .7830047607151 .4781951904151 .1734008789151 .1734008789 151.1734008789151 .4781951904151 .7830047607152 .0877990723152 .3925933838 153.0500793457153 .4937438965153 .4062194824152 .7888641357151 .4781951904 148.4304046631144 .7729034424140 .5059967041135 .9342041016130 .7528076172 125.2667007446121 .9140014648121 .9140014648121 .3044967651120 .9997024536 120.6949005127120 .3900985718120 .3900985718120 .0852966309120 .3900985718 120.6949005127120 .9997024536121 .6092987061121 .9140014648122 .2188034058 122.5235977173122 .8283996582123 .1332015991123 .1332015991123 .43800354 123.43800354123 .43800354123 .7427978516123 .7427978516123 .7427978516 123.7427978516123 .43800354123 .43800354123 .1332015991122 .5235977173 121.6092987061119 .7806015015117 .342300415114 .9039993286112 .7705001831 110.9418029785110 .9418029785113 .6848983765117 .342300415120 .3900985718 122.2188034058122 .8283996582123 .1332015991122 .8283996582122 .8283996582 122.8283996582122 .8283996582120 .9997024536118 .8662033081117 .647102356 116.7326965332116 .4279022217116 .1231002808116 .1231002808116 .4279022217 117.0374984741118 .2565994263119 .7806015015121 .6092987061124 .3523025513 127.7050018311131 .6672058105136 .2389984131140 .8106994629145 .3825073242 
149.0399017334151 .4781951904152 .3925933838151 .7830047607149 .6495056152 146.2969055176141 .4203033447135 .9342041016129 .533706665122 .5235977173 114.9039993286107 .284400939999 .3599472045991 .1307525634883 .2063369751 75.2819290161168 .0676269531261 .18534469604 -9999 -9999 -9999 -9999 -9999 -9999 -9999 -9999 -9999 -9999 -9999 -9999 -9999 -9999 -9999 -9999 -9999 -9999 -9999 -9999 -9999 -9999 -9999 -9999 -9999 -9999 -9999 -9999 -9999 -9999

-9999 -9999 -9999 -9999 -9999 -9999 -9999 -9999 -9999 -9999 -9999 -9999 -9999 -9999 -9999 -9999 -9999 -9999 -9999 -9999 -9999 -9999 -9999 -9999 -9999 -9999 -9999 -9999 -9999 -9999 -9999 -9999 -9999 -9999 -9999 -9999 -9999 -9999 -9999 -9999 -9999 -9999 -9999 -9999 -9999 -9999 -9999 -9999 -9999 -9999 -9999 -9999 -9999 -9999 -9999 -9999 -9999 -9999 -9999 -9999 -

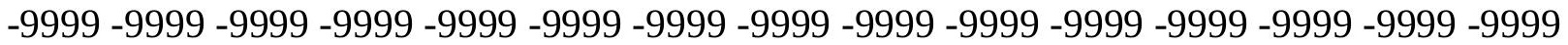
-9999 -9999 -9999 -9999 -9999 -9999 -9999 -9999 -9999 -9999 -9999 -9999 -9999 -9999 -9999 -999 -9999 -9999 -9999 -9999 -9999 -9999 -9999 -9999 -9999 -9999 -9999 -9999 -9999 -9999 -9999 -9999 -9999 -9999 -9999 -9999 -9999 -9999 -9999 -9999 -9999 -9999 -9999 -9999 -9999 -9999 -9999 -9999 -9999 -9999 -9999 -9999 -9999 -9999 -9999 -9999 -9999 -9999 -9999 -9999 -9999

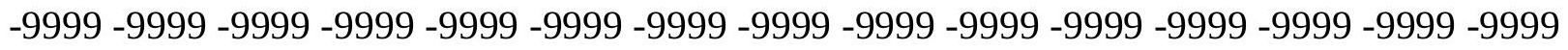
-9999 -9999 -9999 -9999 -9999 -9999 -9999 -9999 -9999 -9999 -9999 -9999 -9999 -9999 -9999 -

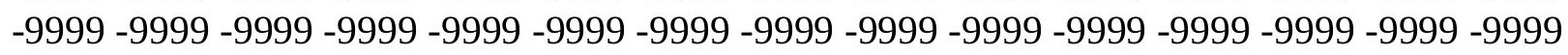
-9999 -9999 -9999 -9999 -9999 -9999 -9999 -9999 -9999 -9999 -9999 -9999 -9999 -999 -999 -9999 -9999 -9999-9999 -9999-9999-9999-9999-9999-9999 245.5810699463 238.8532562256 230.8808746338221.0587005615208.1681976318 186.2236938477 167.3269958496154 .2212982178150 .2590942383150 .8686065674152 .6972961426 154.8930511475157 .9785003662162 .0358123779166 .8603515625172 .1552734375 177.5720062256182 .7206420898187 .1381072998190 .4907073975193 .5386047363 195.6721038818197 .1959991455197 .8054962158198 .1103057861197 .500793457 196.891204834195 .6721038818194 .1481018066192 .3193969727190 .4907073975 188.6620025635186 .528503418184 .3950042725181 .9566955566179 .8231964111 177.3849029541175 .2514038086172 .8132019043170 .3748931885168 .241394043 165.8031005859163 .3648071289162 .4505004883160 .9264984131159 .4026031494 157.5738983154156 .3547973633154 .8307952881153 .6116943359153 .0021057129 152.0877990723151 .7830047607151 .4781951904151 .4781951904151 .4781951904 151.4781951904151 .7830047607152 .0877990723152 .6972961426153 .3707122803 154.1708068848154 .7768096924154 .9660644531154 .4996795654153 .110244751 150.5639038086146 .9064025879142 .6394042969138 .0677032471132 .8863067627 127.4001998901121 .3044967651120 .9997024536120 .6949005127120 .3900985718 120.0852966309120 .0852966309119 .7806015015119 .7806015015120 .0852966309 120.3900985718120 .6949005127121 .3044967651121 .6092987061121 .9140014648 122.2188034058122 .5235977173122 .5235977173122 .8283996582123 .1332015991 123.1332015991123 .1332015991123 .43800354123 .43800354123 .43800354123 .43800354 123.43800354123 .1332015991122 .8283996582122 .5235977173121 .6092987061 119.7806015015117 .647102356115 .5136032104113 .6848983765112 .4656982422 113.075302124115 .2088012695118 .5614013672121 .3044967651122 .5235977173 123.1332015991123 .43800354123 .1332015991123 .1332015991122 .8283996582 121.6092987061120 .6949005127119 .1709976196117 .9517974854116 .7326965332 116.1231002808115 .5136032104115 .5136032104115 .5136032104116 .1231002808 117.0374984741118 .2565994263119 .7806015015122 .2188034058125 .2667007446 
129.533706665134 .4102020264139 .8963928223145 .0776977539149 .3446960449 151.7830047607152 .3925933838151 .4781951904149 .3446960449145 .6873016357 141.1154937744135 .3246002197128 .9241027832121 .6092987061114 .2944030762 106.370002746698 .445587158290 .5211791992282 .5967712402374 .97714233398 67.6305313110460 .67811965942 -9999 -9999 -9999 -9999 -9999 -9999 -9999 -9999 -9999 -9999 -9999 -9999 -9999 -9999 -9999 -9999 -9999 -9999 -9999 -9999 -9999 -9999 -9999 -999 -9999 -9999 -9999-9999-9999-9999

-9999 -9999 -9999 -9999 -9999 -9999 -9999 -9999 -9999 -9999 -9999 -9999 -9999 -9999 -9999

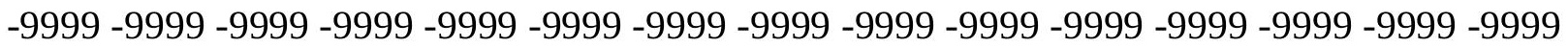
-9999 -9999 -9999 -9999 -9999 -9999 -9999 -9999 -9999 -9999 -9999 -9999 -9999 -9999 -9999 -9999 -9999 -9999 -9999 -9999 -9999 -9999 -9999 -9999 -9999 -9999 -9999 -9999 -9999 -9999 -999 -9999 -9999 -9999 -9999 -9999 -9999 -9999 -9999 -9999 -9999 -9999 -9999 -9999 -9999 -9999 -999 -9999 -9999 -9999 -9999 -9999 -9999 -9999 -9999 -9999 -9999 -9999 -9999 -9999 -9999 -9999 -9999 -9999 -9999 -9999 -9999 -9999 -9999 -9999 -9999 -9999 -9999 -9999 -9999 -9999 -9999 -9999 -9999 -9999 -9999 -9999 -9999 -9999 -9999 -9999 -9999 -9999 -9999 -9999 -9999 -9999

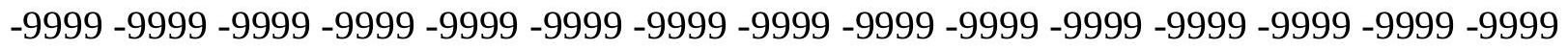
-9999 -9999 -9999 -9999 -9999 -9999 -9999 -9999 -9999 -9999 -9999 -9999 -9999 -9999 -9999 -

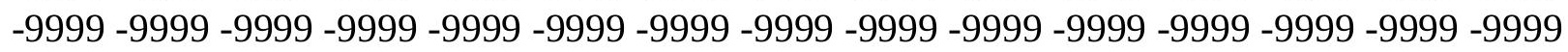

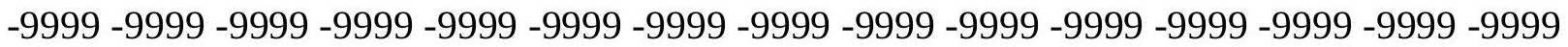

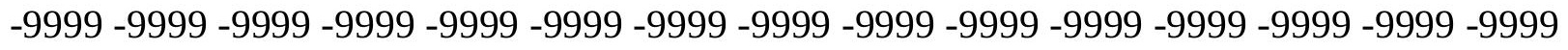
-9999 -9999 -9999-9999 -9999-9999-9999-9999-9999 -9999 243.6632232666 236.8091888428228 .6779785156218 .5959777832205 .1204071045185 .3094024658 164.8887023926149 .3446960449146 .9064025879149 .9542999268152 .6972961426 155.3513641357 158.5130615234162.3757171631 166.9078674316171.9227294922 177.0980072021182 .0232696533186 .2971496582189 .8811035156192 .9290008545195 .0625 196.5863952637 197.1959991455 197.500793457 197.1959991455 196.2816009521 195.0625 193.5386047363192 .0146026611190 .1858978271188 .0523986816185 .9188995361 183.7854003906181 .6519012451179 .5184020996177 .0802001953174 .9467010498 172.5084075928170 .3748931885168 .241394043165 .8031005859163 .6696014404 161.5361022949160 .6217956543159 .0977935791157 .5738983154156 .3547973633 154.8307952881153 .9165039062153 .0021057129152 .3925933838151 .7830047607 151.4781951904151 .4781951904151 .4781951904151 .7830047607152 .0877990723 152.3925933838153 .0021057129153 .9436798096154 .8782958984155 .6181488037 155.9156494141155 .5494384766154 .2625274658151 .9153137207148 .4304046631 144.1634063721139 .5915985107134 .4102020264128 .9241027832123 .43800354 120.0852966309120 .0852966309119 .7806015015119 .4757995605119 .4757995605 119.4757995605119 .4757995605119 .7806015015120 .0852966309120 .3900985718 120.6949005127120 .9997024536121 .6092987061121 .9140014648122 .2188034058 122.2188034058122 .5235977173122 .5235977173122 .8283996582122 .8283996582 123.1332015991123 .1332015991123 .1332015991123 .1332015991123 .1332015991 123.1332015991122 .8283996582122 .5235977173121 .6092987061120 .0852966309 118.2565994263116 .4279022217114 .9039993286114 .5991973877115 .2088012695 117.0374984741119 .7806015015122 .5235977173123 .1332015991123 .43800354 123.43800354123 .43800354123 .1332015991122 .5235977173121 .6092987061 120.3900985718119 .1709976196117 .647102356116 .4279022217115 .5136032104 114.9039993286114 .5991973877114 .9039993286115 .2088012695115 .818397522 
116.7326965332117 .9517974854119 .7806015015122 .5235977173126 .7906036377 132.2767028809138 .9819946289145 .0776977539149 .9542999268152 .3925933838 152.3925933838151 .4781951904149 .0399017334145 .0776977539140 .2012023926 134.4102020264128 .0097961426120 .6949005127113 .3800964355105 .7603988647 97.8360290527389 .9116134643681 .9871978759874 .3675689697367 .11742401123 60.16595077515 -9999 -9999 -9999 -9999 -9999 -9999 -9999 -9999 -9999 -9999 -9999 -9999 -9999 -9999-9999 -9999 -9999 -9999 -9999 -9999 -9999 -9999 -9999 -9999 -9999 -9999 - -9999 -9999 -9999-9999

-9999 -9999 -9999 -9999 -9999 -9999 -9999 -9999 -9999 -9999 -9999 -9999 -9999 -9999 -9999 -9999 -9999 -9999 -9999 -9999 -9999 -9999 -9999 -9999 -9999 -9999 -9999 -9999 -9999 -9999

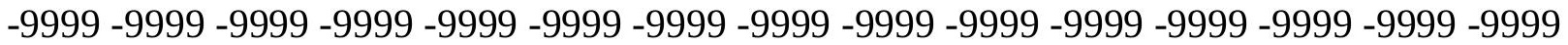

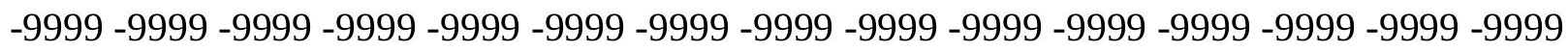
-9999 -9999 -9999 -9999 -9999 -9999 -9999 -9999 -9999 -9999 -9999 -9999 -9999 -9999 -9999 -9999 -9999 -9999 -9999 -9999 -9999 -9999 -9999 -9999 -9999 -9999 -9999 -9999 -9999 -9999 -9999 -9999 -9999 -9999 -9999 -9999 -9999 -9999 -9999 -9999 -9999 -9999 -9999 -9999 -9999

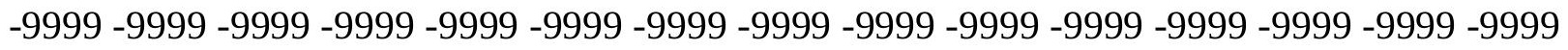
-9999 -9999 -9999 -9999 -9999 -9999 -9999 -9999 -9999 -9999 -9999 -9999 -9999 -9999 -9999 -9999 -9999 -9999 -9999 -9999 -9999 -9999 -9999 -9999 -9999 -9999 -9999 -9999 -9999 -9999 -

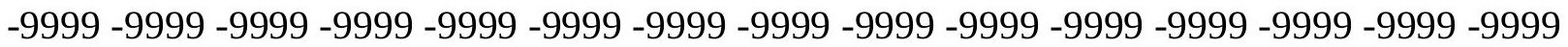

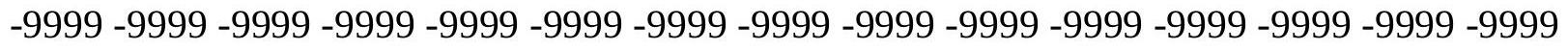

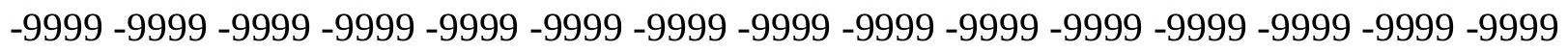
-9999 -9999 -9999 -9999 -9999 -9999 -9999 -9999 -9999 -9999 -9999 233.4066619873 224.7025299072213 .9016571045199 .9389953613181 .0424041748163 .0599975586 149.6495056152146 .2969055176148 .4304046631152 .0877990723155 .1947784424 158.486114502162 .1776580811166 .4651794434171 .2924346924176 .3640899658 181.2593078613185 .5385742188188 .966796875192 .0146026611194 .1481018066 195.6721038818196 .5863952637196 .5863952637196 .2816009521195 .3672943115 194.1481018066192 .9290008545191 .1002960205189 .2716064453187 .4429016113 185.3094024658183 .1759033203181 .0424041748178 .9089050293176 .7754058838 174.6419067383172 .5084075928170 .070098877167 .9365997314165 .8031005859 163.974395752161 .8408966064159 .7073974609159 .0977935791157 .5738983154 156.3547973633154 .8307952881153 .9165039062153 .0021057129152 .3925933838 152.0877990723151 .7830047607151 .7830047607151 .7830047607151 .7830047607 152.0877990723152 .3925933838153 .1869354248154 .2071838379155 .2229614258 156.0290985107156 .3959350586156 .1245880127155 .0137481689152 .9420166016 149.9072723389145 .9920959473141 .1154937744135 .9342041016130 .7528076172 124.9618988037119 .4757995605119 .4757995605119 .4757995605119 .1709976196 119.1709976196118 .8662033081119 .1709976196119 .1709976196119 .4757995605 120.0852966309120 .3900985718120 .6949005127120 .9997024536121 .6092987061 121.9140014648121 .9140014648122 .2188034058122 .2188034058122 .5235977173 122.5235977173122 .8283996582122 .8283996582123 .1332015991123 .1332015991 123.1332015991122 .8283996582122 .8283996582122 .2188034058121 .6092987061 120.3900985718118 .8662033081117 .342300415116 .4279022217116 .1231002808 117.0374984741118 .2565994263120 .3900985718121 .9140014648122 .8283996582 123.1332015991123 .1332015991123 .1332015991122 .8283996582122 .2188034058 121.3044967651120 .0852966309118 .5614013672117 .342300415116 .1231002808 
114.9039993286114 .2944030762113 .9896011353113 .9896011353114 .2944030762 114.5991973877115 .5136032104116 .4279022217117 .647102356119 .7806015015 123.7427978516130 .1432037354137 .7628936768145 .3825073242150 .8686065674 153.0021057129152 .6972961426151 .1734008789148 .1255950928144 .1634063721 138.9819946289133 .1911010742126 .7906036377119 .7806015015112 .4656982422 104.846099853596 .9216690063589 .302040100181 .3776321411173 .75800323486 66.5541763305759 .60696411133 -9999 -9999 -9999 -9999 -9999 -9999 -9999 -9999 -9999 -9999 -9999 -9999 -9999 -9999 -9999 -9999 -9999 -9999 -9999 -9999 -9999 -9999 -9999 -9999 -9999 -9999 -9999-9999-9999-9999

-9999 -9999 -9999 -9999 -9999 -9999 -9999 -9999 -9999 -9999 -9999 -9999 -9999 -9999 -9999 -9999 -9999 -9999 -9999 -9999 -9999 -9999 -9999 -9999 -9999 -9999 -9999 -9999 -9999 -9999 -999 -9999 -9999 -9999 -9999 -9999 -9999 -9999 -9999 -9999 -9999 -9999 -9999 -9999 -9999 -9999 -999 -9999 -9999 -9999 -9999 -9999 -9999 -9999 -9999 -9999 -9999 -9999 -9999 -9999 -9999 -9999 -9999 -9999 -9999 -9999 -9999 -9999 -9999 -9999 -9999 -9999 -9999 -9999 -9999 -9999 -9999 -9999 -9999 -9999 -9999 -9999 -9999 -9999 -9999 -9999 -9999 -9999 -9999 -9999 -9999 -9999

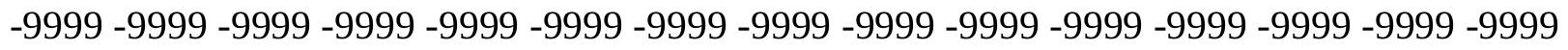

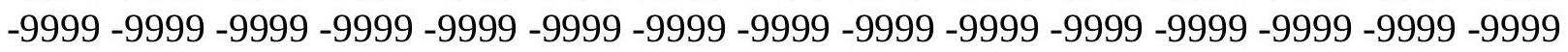

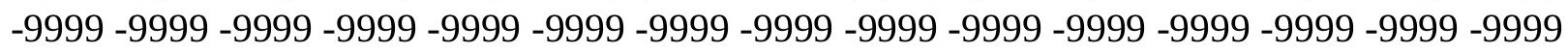

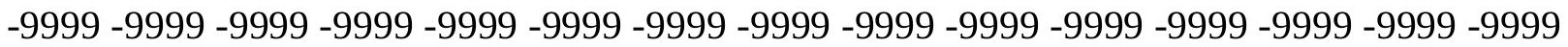

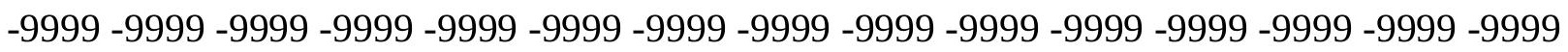

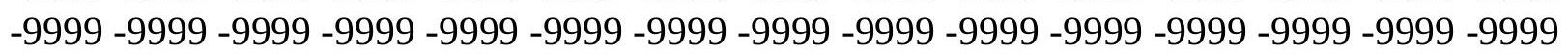

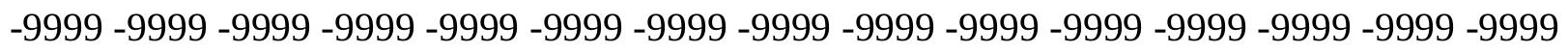
-9999 -9999 -9999 -9999-9999 -9999 -9999 -9999 -9999 -9999 -9999 228.9533691406 219.6192016602208 .0690460205193 .6081390381176 .7754058838161 .5361022949 150.8686065674146 .2969055176146 .9064025879150 .8686065674154 .5762176514 157.9286499023161 .3979949951165 .4980621338170 .3099822998175 .4682006836 180.4808959961184 .9452056885188 .6620025635191 .4051055908193 .5386047363 194.7577056885195 .3672943115195 .3672943115195 .0625194 .1481018066192 .9290008545 191.7097930908190 .1858978271188 .3571929932186 .528503418184 .3950042725 182.5662994385180 .432800293178 .2993011475176 .165802002174 .0323028564 171.8988037109170 .070098877167 .9365997314165 .8031005859163 .974395752 161.8408966064160 .0122070312158 .4882965088157 .5738983154156 .3547973633 155.1356048584153 .9165039062153 .0021057129152 .3925933838152 .0877990723 151.7830047607151 .7830047607151 .7830047607151 .7830047607152 .0877990723 152.3925933838153 .205581665154 .2388763428155 .2773590088156 .1015167236 156.5116424561156 .3321075439155 .4061431885153 .6362915039151 .0194702148 147.5160064697142 .3347015381137 .1533050537131 .9720001221126 .4858016968 121.3044967651119 .4757995605119 .1709976196118 .8662033081118 .5614013672 118.5614013672118 .5614013672118 .8662033081119 .1709976196119 .4757995605 120.0852966309120 .3900985718120 .6949005127121 .3044967651121 .6092987061 121.6092987061121 .9140014648121 .9140014648122 .2188034058122 .2188034058 122.5235977173122 .5235977173122 .8283996582122 .8283996582122 .8283996582 122.8283996582122 .5235977173122 .2188034058121 .6092987061120 .3900985718 119.4757995605118 .2565994263117 .9517974854117 .647102356118 .2565994263 119.4757995605120 .6949005127121 .6092987061121 .9140014648122 .5235977173 122.8283996582123 .1332015991122 .8283996582122 .2188034058120 .9997024536 
119.7806015015118 .2565994263116 .7326965332115 .5136032104114 .5991973877 113.6848983765113 .3800964355113 .3800964355113 .3800964355113 .9896011353 114.2944030762115 .2088012695116 .1231002808117 .9517974854120 .3900985718 128.0097961426136 .5437011719144 .7729034424151 .7830047607152 .6972961426 151.7830047607149 .9542999268146 .9064025879142 .6394042969137 .4580993652 131.6672058105125 .2667007446118 .2565994263110 .9418029785103 .6268997192 96.0073165893688 .3876876831180 .7680587768673 .1484298706165 .94834899902 58.98036193848 -9999 -9999 -9999 -9999 -9999 -9999 -9999 -9999 -9999 -9999 -9999 -9999 -9999 -9999 -9999 -9999 -9999 -9999 -9999 -9999 -9999 -9999 -9999 -9999 -9999 -9999 -9999 -9999-9999-9999

-9999 -9999 -9999 -9999 -9999 -9999 -9999 -9999 -9999 -9999 -9999 -9999 -9999 -9999 -9999 -9999 -9999 -9999 -9999 -9999 -9999 -9999 -9999 -9999 -9999 -9999 -9999 -9999 -9999 -9999 -9999 -9999 -9999 -9999 -9999 -9999 -9999 -9999 -9999 -9999 -9999 -9999 -9999 -9999 -9999 -9999 -9999 -9999 -9999 -9999 -9999 -9999 -9999 -9999 -9999 -9999 -9999 -9999 -9999 - 9999 -9999 -9999 -9999 -9999 -9999 -9999 -9999 -9999 -9999 -9999 -9999 -9999 -9999 -9999 -9999

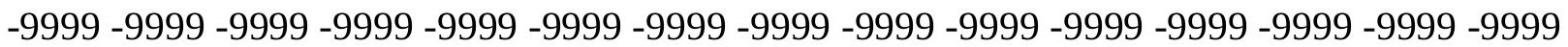

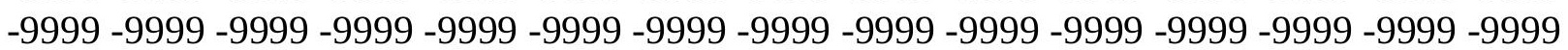
-9999 -9999 -9999 -9999 -9999 -9999 -9999 -9999 -9999 -9999 -9999 -9999 -9999 -9999 -9999 -999 -9999 -9999 -9999 -9999 -9999 -9999 -9999 -9999 -9999 -9999 -9999 -9999 -9999 -9999 -9999 -9999 -9999 -9999 -9999 -9999 -9999 -9999 -9999 -9999 -9999 -9999 -9999 -9999 -9999 -9999 -9999 -9999 -9999 -9999 -9999 -9999 -9999 -9999 -9999 -9999 -9999 -9999 -9999 -9999 -9999 -9999 -9999 -9999 -9999 -9999 -9999 -9999 -9999 -9999 -9999 -9999 -9999 -9999 -9999 -9999 -9999 -9999 -9999 -9999 -9999 -9999 -9999 -9999 -9999 -9999 -9999 -9999 -9999 -9999 -9999 -9999 -9999 -9999 -9999 -9999 -9999 -9999 -9999 -9999 -9999 -9999 -9999 214.2148590088 202.5697784424188 .8402557373173 .7274932861159 .0977935791148 .1255950928 144.7729034424145 .6873016357149 .3446960449153 .9165039062156 .7840881348 159.8826446533163 .9449157715169 .0241546631174 .4973144531179 .7760925293 184.4103393555188 .0523986816190 .4907073975192 .3193969727193 .5386047363 194.1481018066193 .8433074951193 .5386047363192 .624206543191 .7097930908 190.1858978271188 .6620025635187 .1381072998185 .3094024658183 .4806976318 181.3471984863179 .5184020996177 .3849029541175 .5561981201173 .4226989746 171.5939941406169 .4604949951167 .6318054199165 .8031005859163 .974395752 162.1457061768160 .3170013428158 .4882965088156 .9642944336155 .4403991699 155.1356048584153 .9165039062153 .3069000244152 .6972961426152 .0877990723 152.0877990723151 .7830047607151 .7830047607152 .0877990723152 .0877990723 152.3925933838153 .1417236328154 .1131286621155 .1231689453155 .9332122803 156.3562011719156 .240020752155 .4590454102153 .9207305908151 .5494995117 148.2191009521143 .8585968018138 .3724975586132 .8863067627128 .0097961426 122.8283996582120 .0852966309119 .1709976196118 .5614013672118 .2565994263 118.2565994263118 .2565994263118 .5614013672118 .8662033081119 .1709976196 119.4757995605120 .0852966309120 .3900985718120 .9997024536121 .3044967651 121.6092987061121 .6092987061121 .6092987061121 .6092987061121 .9140014648 122.2188034058122 .5235977173122 .5235977173122 .5235977173122 .5235977173 122.5235977173122 .2188034058121 .9140014648121 .3044967651120 .6949005127 120.0852966309119 .1709976196118 .8662033081118 .8662033081119 .4757995605 120.0852966309120 .6949005127121 .3044967651121 .9140014648122 .2188034058 
122.5235977173122 .8283996582122 .5235977173121 .9140014648120 .6949005127 119.1709976196117 .647102356116 .1231002808114 .9039993286113 .9896011353 113.075302124112 .7705001831112 .7705001831113 .075302124113 .3800964355 113.9896011353114 .5991973877115 .818397522117 .647102356121 .3044967651 127.4001998901134 .7149963379142 .0299072266147 .5160064697149 .9542999268 149.6495056152147 .8208007812144 .7729034424140 .5059967041135 .6293945312 129.8385009766123 .43800354116 .7326965332109 .4179000854102 .1029968262 94.7881774902387 .1685485839879 .8537063598672 .5388565063565 .21466827393 58.22188186646 -9999 -9999 -9999 -9999 -9999 -9999 -9999 -9999 -9999 -9999 -9999 -9999

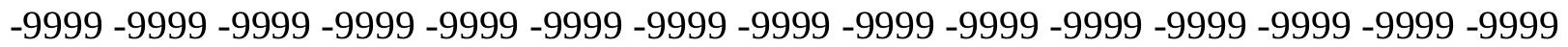
-9999 -9999-9999

-9999 -9999 -9999 -9999 -9999 -9999 -9999 -9999 -9999 -9999 -9999 -9999 -9999 -9999 -9999 -9999 -9999 -9999 -9999 -9999 -9999 -9999 -9999 -9999 -9999 -9999 -9999 -9999 -9999 -9999 -9999 -9999 -9999 -9999 -9999 -9999 -9999 -9999 -9999 -9999 -9999 -9999 -9999 -9999 -9999 -9999 -9999 -9999 -9999 -9999 -9999 -9999 -9999 -9999 -9999 -9999 -9999 -9999 -9999 -9999

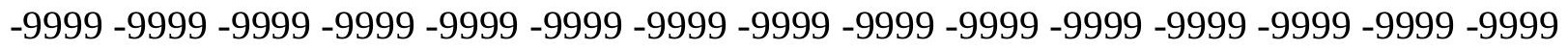

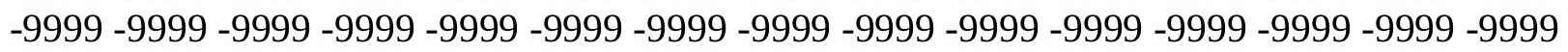

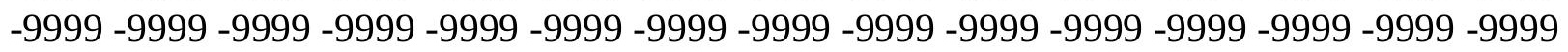
-9999 -9999 -9999 -9999 -9999 -9999 -9999 -9999 -9999 -9999 -9999 -9999 -9999 -9999 -9999 -999 -

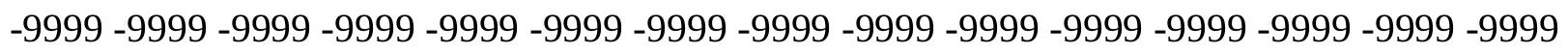

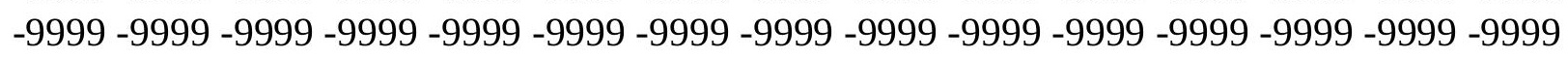

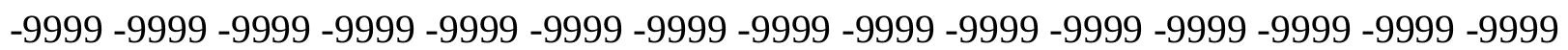
-9999 -9999 -9999 -9999 -9999 -9999 -9999 -9999 -9999 -9999 -9999 -9999 -9999 -9999 -9999 -

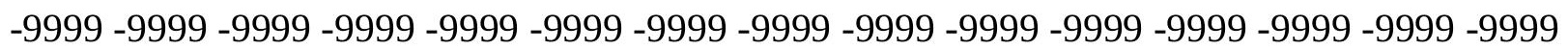
-9999 -9999 -9999 -9999 -9999 -9999 -9999 -9999 -9999 -9999 -9999 -9999 -9999 197.938079834185 .444519043172 .2035980225157 .2691040039146 .2969055176 143.5538024902144 .7729034424148 .1255950928152 .3925933838154 .8307952881 157.4393920898161 .9315795898167 .6279296875173 .5861816406179 .1181945801 183.8253173828187 .4429016113189 .5764007568191 .1002960205192 .0146026611 192.3193969727192 .3193969727191 .7097930908190 .795501709189 .8811035156 188.6620025635187 .1381072998185 .6141052246183 .7854003906181 .9566955566 180.1280059814178 .2993011475176 .4705963135174 .6419067383172 .8132019043 170.9844970703169 .1557006836167 .3269958496165 .4983062744163 .6696014404 162.1457061768160 .3170013428158 .7929992676157 .2691040039156 .0500030518 154.5260925293153 .3069000244153 .3069000244152 .6972961426152 .3925933838 152.0877990723152 .0877990723152 .0877990723152 .0877990723152 .3925933838 152.6972961426153 .0021057129153 .9023590088154 .8604125977155 .6163635254 156.0097351074155 .912902832155 .2156219482153 .8251800537151 .6576538086 148.638671875144 .7729034424139 .5915985107134 .1054992676128 .9241027832 124.0475006104120 .6949005127119 .4757995605118 .5614013672117 .9517974854 117.9517974854117 .9517974854118 .2565994263118 .5614013672118 .8662033081 119.4757995605119 .7806015015120 .0852966309120 .6949005127120 .9997024536 121.3044967651121 .3044967651121 .6092987061121 .6092987061121 .9140014648 122.2188034058122 .2188034058122 .2188034058122 .5235977173122 .5235977173 122.2188034058122 .2188034058121 .9140014648121 .6092987061120 .9997024536 120.3900985718120 .0852966309119 .7806015015119 .7806015015120 .0852966309 
120.3900985718120 .9997024536121 .3044967651121 .3044967651121 .9140014648 122.2188034058122 .5235977173122 .5235977173121 .6092987061120 .3900985718 118.8662033081117 .0374984741115 .5136032104114 .2944030762113 .3800964355 112.4656982422112 .1608963013112 .1608963013112 .4656982422113 .075302124 113.6848983765114 .5991973877115 .818397522118 .2565994263121 .9140014648 126.7906036377132 .8863067627138 .9819946289143 .2489929199145 .6873016357 145.9920959473144 .4682006836141 .7250976562137 .7628936768132 .8863067627 127.4001998901121 .3044967651114 .5991973877107 .5891036987100 .5791015625 93.2642517089885 .9494018554778 .6345596313571 .3197174072364 .18098449707 57.29767990112 -9999 -9999 -9999 -9999 -9999 -9999 -9999 -9999 -9999 -9999 -9999 -9999

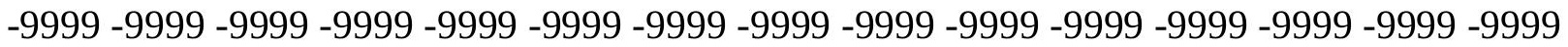
-9999 -9999-9999

-9999 -9999 -9999 -9999 -9999 -9999 -9999 -9999 -9999 -9999 -9999 -9999 -9999 -9999 -9999 -9999 -9999 -9999 -9999 -9999 -9999 -9999 -9999 -9999 -9999 -9999 -9999 -9999 -9999 -9999 -9999 -9999 -9999 -9999 -9999 -9999 -9999 -9999 -9999 -9999 -9999 -9999 -9999 -9999 -9999

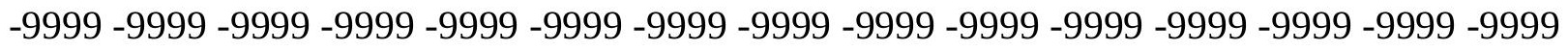
-9999 -9999 -9999 -9999 -9999 -9999 -9999 -9999 -9999 -9999 -9999 -9999 -9999 -9999 -9999 -9999 -9999 -9999 -9999 -9999 -9999 -9999 -9999 -9999 -9999 -9999 -9999 -9999 -9999 -9999 -

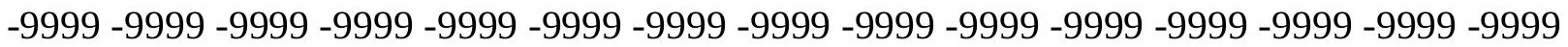

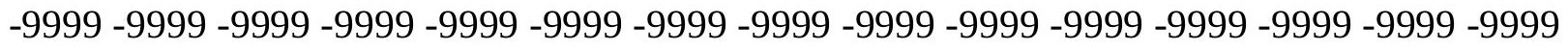

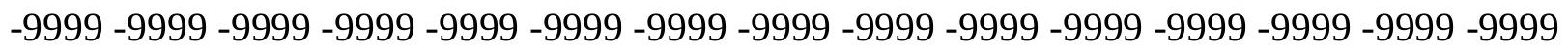

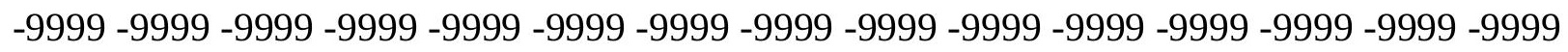
-9999 -9999 -9999 -9999 -9999 -9999 -9999 -9999 -9999 -9999 -9999 -9999 -9999 -9999 -9999 -

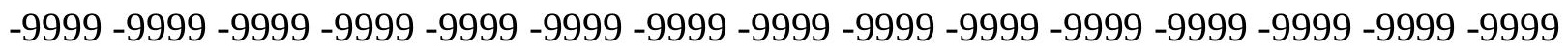

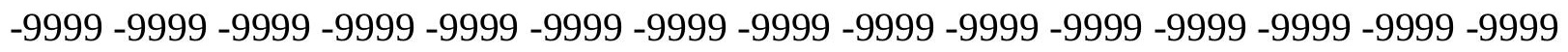
-9999 -9999 -9999 -9999 -9999 -9999 -9999 -9999 -9999 -9999 -9999 -9999 -9999 194.1893920898182 .8438262939170 .8118133545158 .7929992676149 .0399017334 145.6873016357145 .3825073242146 .9064025879149 .0399017334152 .0877990723 154.5260925293160 .1865386963166 .5135040283172 .9057312012178 .5525360107 183.1013336182186 .2236938477188 .0523986816189 .5764007568190 .1858978271 190.4907073975190 .1858978271189 .5764007568188 .966796875187 .7476043701 186.528503418185 .3094024658183 .7854003906182 .261505127180 .7375946045 178.9089050293177 .0802001953175 .5561981201173 .7274932861171 .8988037109 170.070098877168 .5462036133166 .7174987793165 .1934967041163 .3648071289 161.8408966064160 .3170013428158 .7929992676157 .5738983154156 .0500030518 154.8307952881153 .9165039062152 .6972961426151 .7830047607152 .3925933838 152.0877990723152 .0877990723152 .0877990723152 .3925933838152 .3925933838 152.6972961426153 .0021057129153 .7482452393154 .5702209473155 .2153778076 155.5312347412155 .4101715088154 .7488250732153 .4680938721151 .472366333 148.7002716064145 .0776977539140 .8106994629135 .6293945312130 .1432037354 125.2667007446120 .3900985718119 .1709976196118 .2565994263117 .9517974854 117.647102356117 .9517974854117 .9517974854118 .2565994263118 .8662033081 119.1709976196119 .4757995605120 .0852966309120 .3900985718120 .6949005127 120.9997024536121 .3044967651121 .6092987061121 .6092987061121 .9140014648 121.9140014648122 .2188034058122 .2188034058122 .2188034058122 .2188034058 122.2188034058122 .2188034058121 .9140014648121 .6092987061121 .3044967651 
120.9997024536120 .6949005127120 .3900985718120 .3900985718120 .6949005127 120.6949005127120 .9997024536120 .9997024536120 .9997024536121 .3044967651 121.9140014648122 .2188034058122 .2188034058121 .3044967651119 .7806015015 118.2565994263116 .4279022217114 .9039993286113 .3800964355112 .4656982422 112.1608963013111 .8561019897111 .8561019897112 .4656982422113 .075302124 113.6848983765114 .9039993286116 .4279022217118 .5614013672121 .9140014648 126.1809997559131 .0576019287135 .6293945312139 .2868041992141 .4203033447 141.7250976562140 .8106994629138 .0677032471134 .7149963379130 .1432037354 124.6570968628118 .8662033081112 .4656982422105 .760398864798 .75038146973 91.4355392456184 .4254837036177 .110626220769 .7957916259862 .89806747437 -9999 -9999 -9999 -9999 -9999 -9999 -9999 -9999 -9999 -9999 -9999 -9999 -9999 -9999 -9999 -9999 -9999 -9999 -9999 -9999 -9999 -9999 -9999 -9999 -9999 -9999 -9999 -9999 -9999 -9999 -9999 -9999 -9999 -9999 -9999 -9999 -9999 -9999 -9999 -9999 -9999 -9999 -9999 -9999 -9999 -9999 -9999 -9999 -9999 -9999 -9999 -9999 -9999 -9999 -9999 -9999 -9999 -9999 -9999 -9999 -9999 -9999 -9999 -9999 -9999 -9999 -9999 -9999 -9999 -9999 -9999 -9999 -9999 -9999 -9999 -9999

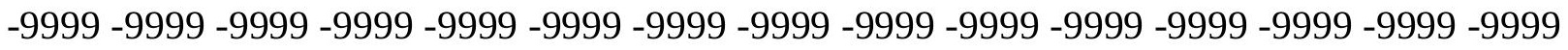
-9999 -9999 -9999 -9999 -9999 -9999 -9999 -9999 -9999 -9999 -9999 -9999 -9999 -9999 -9999 -9999 -9999 -9999 -9999 -9999 -9999 -9999 -9999 -9999 -9999 -9999 -9999 -9999 -9999 -9999 -

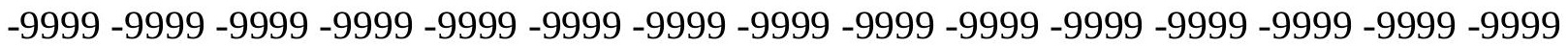

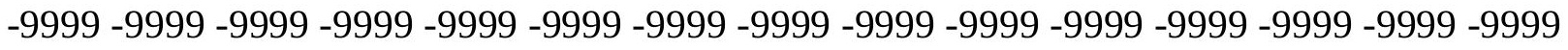

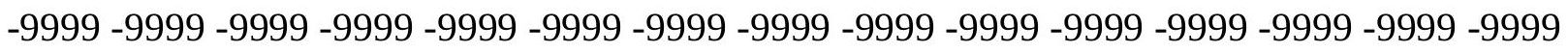
-9999 -9999 -9999 -9999 -9999 -9999 -9999 -9999 -9999 -9999 -9999 -9999 -9999 -9999 -9999 -9999 -9999 -9999 -9999 -9999 -9999 -9999 -9999 -9999 -9999 -9999 -9999 -9999 -9999 -9999

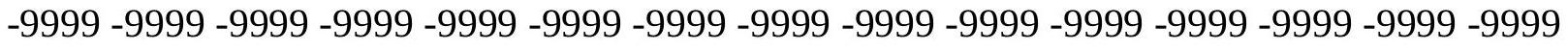

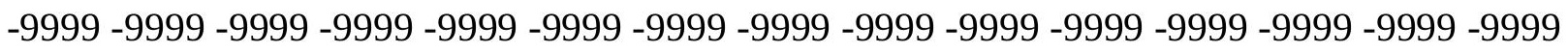
-9999 -9999 -9999 -9999 -9999 -9999 -9999 -9999 -9999 -9999 -9999 -9999 -9999 -9999 181.126083374170 .9894104004161 .5361022949153 .3069000244148 .7351074219 146.6015930176145 .6873016357148 .7351074219151 .4781951904154 .8307952881 159.4026031494165 .7699737549172 .3694458008178 .1067810059182 .0056152344 184.699798584186 .2236938477187 .4429016113188 .0523986816188 .0523986816 188.0523986816187 .4429016113186 .528503418185 .6141052246184 .699798584 183.1759033203181 .9566955566180 .432800293178 .9089050293177 .3849029541 175.8609924316174 .337097168172 .5084075928170 .9844970703169 .4604949951 167.6318054199166 .1078948975164 .5839996338163 .0599975586161 .5361022949 160.3170013428158 .7929992676157 .5738983154156 .3547973633155 .1356048584 153.9165039062153 .0021057129152 .3925933838151 .7830047607152 .3925933838 152.0877990723152 .3925933838152 .3925933838152 .6972961426152 .6972961426 153.0021057129153 .673034668154 .299697876154 .7643585205154 .9519500732 154.7653198242154 .1177368164152 .9215087891151 .0926513672148 .5650024414 145.3117828369141 .4203033447136 .8484954834131 .9720001221126 .4858016968 122.5235977173118 .8662033081118 .2565994263117 .9517974854117 .647102356 117.9517974854117 .9517974854118 .2565994263118 .5614013672119 .1709976196 119.4757995605119 .7806015015120 .3900985718120 .6949005127120 .9997024536 121.3044967651121 .3044967651121 .6092987061121 .9140014648121 .9140014648 121.9140014648121 .9140014648122 .2188034058122 .2188034058122 .2188034058 121.9140014648121 .9140014648121 .6092987061121 .6092987061121 .3044967651 
120.9997024536120 .9997024536120 .9997024536120 .9997024536120 .9997024536 120.9997024536120 .9997024536120 .6949005127120 .3900985718121 .9140014648 121.9140014648121 .6092987061120 .6949005127119 .1709976196117 .342300415 115.818397522113 .9896011353112 .7705001831111 .8561019897111 .551399231 111.551399231111 .8561019897112 .4656982422113 .3800964355114 .2944030762 115.5136032104117 .0374984741119 .1709976196121 .9140014648125 .2667007446 129.2288970947132 .5814971924135 .6293945312137 .1533050537137 .7628936768 136.5437011719134 .4102020264131 .0576019287126 .7906036377121 .6092987061 116.1231002808110 .0273971558103 .322196960496 .6168823242289 .60682678223 82.5967712402375 .2819290161168 .2718734741261 .53458786011 -9999 -9999 -9999 -9999

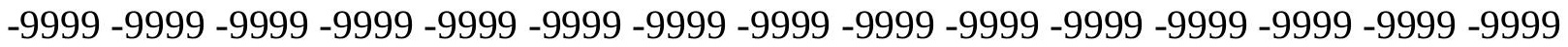

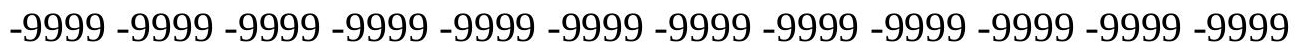

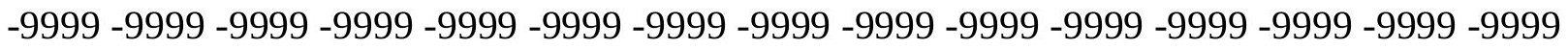

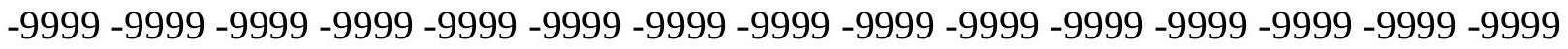

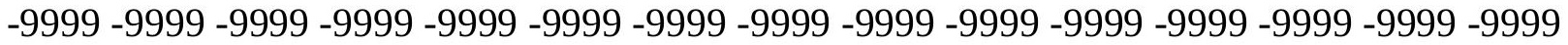

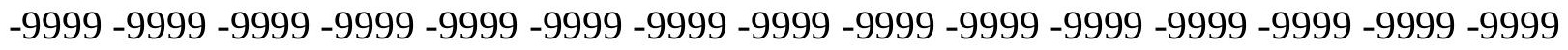

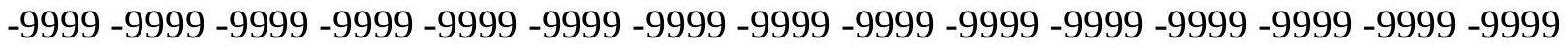

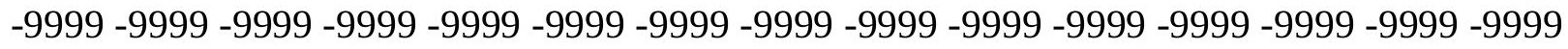

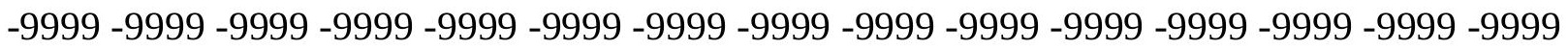

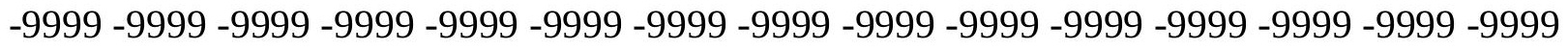

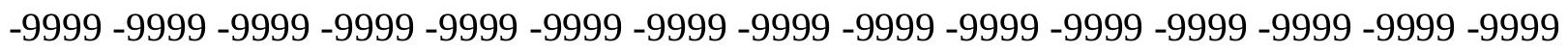

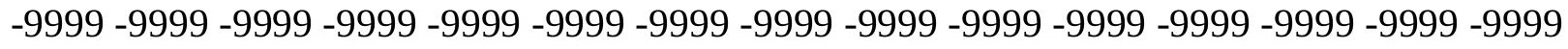

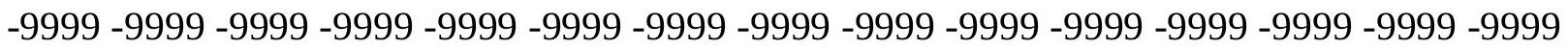

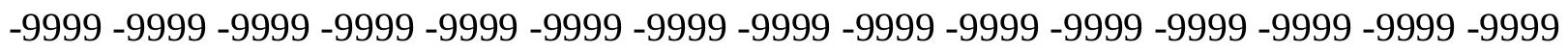

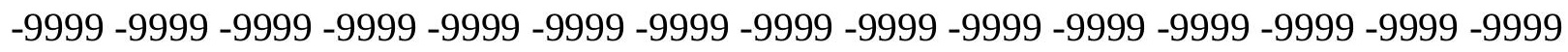
-9999 -9999 -9999 -9999 -9999 -9999 -9999 -9999 -9999 -9999 -9999 -9999 -9999 -9999 179.9976806641171 .5689086914163 .974395752156 .3547973633151 .4781951904 148.4304046631147 .8208007812149 .6495056152152 .0877990723155 .4403991699 159.7073974609165 .1934967041171 .2891998291177 .6896972656179 .8231964111 182.261505127183 .7854003906185 .0045928955185 .3094024658185 .6141052246 185.3094024658185 .0045928955184 .0901947021183 .1759033203182 .261505127 181.0424041748179 .8231964111178 .604095459177 .3849029541175 .8609924316 174.337097168172 .8132019043171 .5939941406170 .070098877168 .5462036133 167.0222015381165 .4983062744163 .974395752162 .7552947998161 .2312927246 160.0122070312158 .4882965088157 .2691040039156 .3547973633155 .1356048584 154.2212982178153 .3069000244152 .6972961426152 .0877990723152 .3925933838 152.3925933838152 .3925933838152 .3925933838152 .6972961426153 .0021057129 153.3069000244153 .6116943359153 .9851379395154 .2428588867154 .2647247314 153.9821624756153 .322555542152 .2147064209150 .5584106445148 .2776184082 145.3299560547141 .7250976562137 .7628936768133 .4958953857128 .6192932129 123.7427978516120 .0852966309118 .5614013672117 .9517974854117 .9517974854 117.9517974854118 .2565994263118 .5614013672118 .8662033081119 .1709976196 119.4757995605119 .7806015015120 .0852966309120 .3900985718120 .6949005127 120.9997024536121 .3044967651121 .6092987061121 .6092987061121 .6092987061 121.9140014648121 .9140014648121 .9140014648121 .9140014648121 .9140014648 121.9140014648121 .9140014648121 .6092987061121 .6092987061121 .3044967651 
121.3044967651 121.3044967651 121.3044967651 121.3044967651 121.3044967651 120.9997024536120 .9997024536120 .6949005127120 .6949005127121 .3044967651 121.6092987061120 .9997024536119 .7806015015118 .5614013672116 .7326965332 115.2088012695113 .3800964355112 .1608963013111 .24659729111 .24659729 111.551399231111 .8561019897112 .7705001831113 .6848983765114 .5991973877 115.818397522117 .342300415119 .4757995605121 .6092987061124 .3523025513 127.4001998901130 .1432037354132 .2767028809133 .4958953857133 .8007049561 132.5814971924130 .7528076172127 .4001998901123 .43800354118 .5614013672 113.3800964355107 .2844009399101 .188697814994 .4833908081187 .77810668945 80.7680587768673 .7580032348666 .7479400634860 .14137268066 -9999 -9999 -9999 -9999 -9999 -9999 -9999 -9999 -9999 -9999 -9999 -9999 -9999 -9999 -9999 -9999 -9999 -9999 -9999 -9999 -9999 -9999 -9999 -9999 -9999 -9999 -9999 -9999 -9999 -9999 -9999

-9999 -9999 -9999 -9999 -9999 -9999 -9999 -9999 -9999 -9999 -9999 -9999 -9999 -9999 -9999 -9999 -9999 -9999 -9999 -9999 -9999 -9999 -9999 -9999 -9999 -9999 -9999 -9999 -9999 -9999 -9999 -9999 -9999 -9999 -9999 -9999 -9999 -9999 -9999 -9999 -9999 -9999 -9999 -9999 -9999

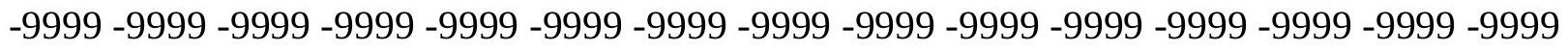
-9999 -9999 -9999 -9999 -9999 -9999 -9999 -9999 -9999 -9999 -9999 -9999 -9999 -9999 -9999 -9999 -9999 -9999 -9999 -9999 -9999 -9999 -9999 -9999 -9999 -9999 -9999 -9999 -9999 -9999 -

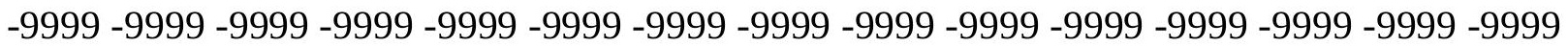

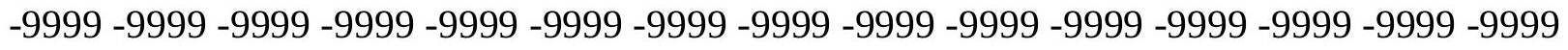
-9999 -9999 -9999 -9999 -9999 -9999 -9999 -9999 -9999 -9999 -9999 -9999 -9999 -9999 -9999

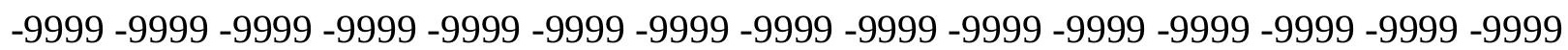
-9999 -9999 -9999 -9999 -9999 -9999 -9999 -9999 -9999 -9999 -9999 -9999 -9999 -9999 -9999 -

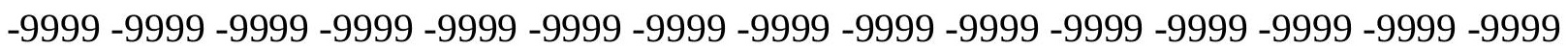
-9999 -9999 -9999 -9999 -9999 -9999 -9999 -9999 -9999 -9999 -9999 -9999 -9999 -9999 -9999

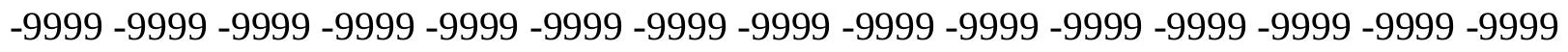
171.6799926758164 .8406677246158 .7929992676153 .9165039062149 .9542999268 149.9542999268151 .1734008789153 .0021057129156 .0500030518159 .7073974609 164.2792053223169 .1557006836173 .7274932861176 .7754058838179 .2136993408 181.0424041748182 .261505127182 .5662994385182 .87109375182 .5662994385 182.261505127181 .6519012451180 .7375946045179 .8231964111178 .9089050293 177.9945068359176 .7754058838175 .5561981201174 .337097168172 .8132019043 171.5939941406170 .3748931885168 .8509979248167 .6318054199166 .1078948975 164.8887023926163 .3648071289162 .1457061768160 .9264984131159 .4026031494 158.1835021973157 .2691040039156 .0500030518155 .1356048584154 .2212982178 153.3069000244152 .6972961426152 .0877990723151 .7830047607152 .3925933838 152.3925933838152 .3925933838152 .6972961426153 .0021057129153 .0021057129 153.3069000244153 .6116943359153 .6508331299153 .4493408203153 .0455322266 152.3535308838151 .3564910889149 .8732757568147 .8114929199145 .1802825928 142.0299072266138 .3724975586134 .4102020264130 .4479980469125 .8762969971 121.6092987061118 .8662033081118 .5614013672118 .2565994263118 .2565994263 118.5614013672118 .8662033081119 .1709976196119 .4757995605119 .7806015015 120.0852966309120 .3900985718120 .6949005127120 .6949005127120 .9997024536 121.3044967651121 .6092987061121 .6092987061121 .6092987061121 .9140014648 121.9140014648121 .9140014648121 .9140014648121 .9140014648121 .9140014648 121.9140014648121 .9140014648121 .6092987061121 .6092987061121 .3044967651 
121.3044967651 121.3044967651 121.3044967651 121.3044967651 120.9997024536 120.9997024536120 .6949005127120 .6949005127120 .9997024536120 .6949005127 120.0852966309119 .1709976196117 .647102356116 .1231002808114 .5991973877 113.075302124111 .8561019897110 .9418029785111 .24659729111 .551399231 112.4656982422113 .075302124113 .9896011353115 .2088012695116 .4279022217 117.9517974854119 .4757995605121 .6092987061123 .7427978516125 .8762969971 128.0097961426129 .533706665130 .1432037354130 .1432037354128 .9241027832 127.0953979492124 .0475006104120 .0852966309115 .5136032104110 .3321990967 104.846099853598 .7503814697392 .349891662685 .6446228027378 .93934631348 71.9292907714865 .2240066528358 .78152084351 -9999 -9999 -9999-9999 -9999 -9999 -9999 -9999 -9999 -9999 -9999 -9999 -9999 -9999 -9999 -9999 -9999 -9999 -9999 -9999 -9999 -9999 -9999 -9999 -9999 -9999 -9999 -9999 -9999 -9999 -9999

-9999 -9999 -9999 -9999 -9999 -9999 -9999 -9999 -9999 -9999 -9999 -9999 -9999 -9999 -9999 -9999 -9999 -9999 -9999 -9999 -9999 -9999 -9999 -9999 -9999 -9999 -9999 -9999 -9999 -9999 -9999 -9999 -9999 -9999 -9999 -9999 -9999 -9999 -9999 -9999 -9999 -9999 -9999 -9999 -9999

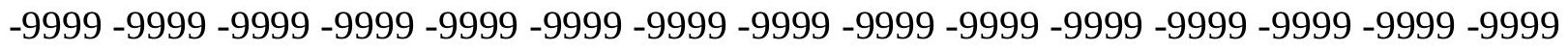
-9999 -9999 -9999 -9999 -9999 -9999 -9999 -9999 -9999 -9999 -9999 -9999 -9999 -9999 -9999 -9999 -9999 -9999 -9999 -9999 -9999 -9999 -9999 -9999 -9999 -9999 -9999 -9999 -9999 -9999 -

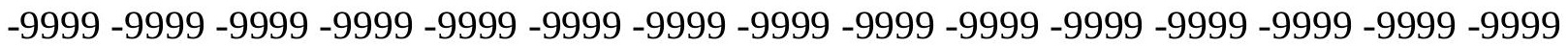

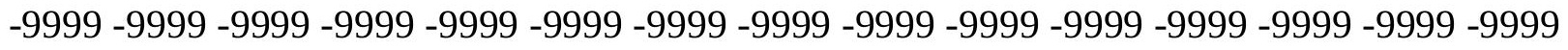

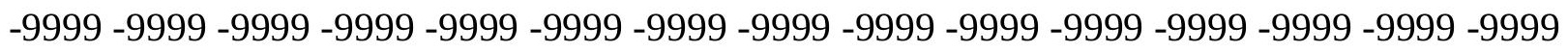
-9999 -9999 -9999 -9999 -9999 -9999 -9999 -9999 -9999 -9999 -9999 -9999 -9999 -9999 -9999 -9999 -9999 -9999 -9999 -9999 -9999 -9999 -9999 -9999 -9999 -9999 -9999 -9999 -9999 -9999 -

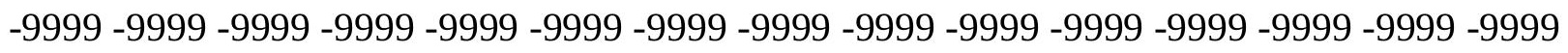

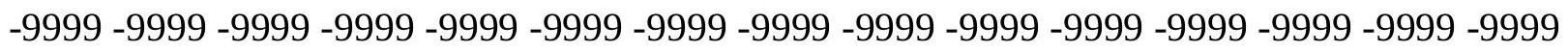

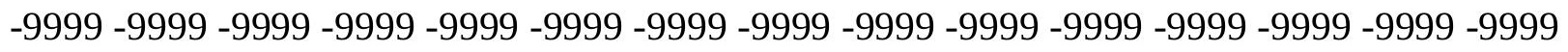
171.5048675537165 .4101257324160 .0970611572155 .7451934814153 .0021057129 152.0877990723152 .3925933838153 .9165039062156 .0500030518159 .4026031494 163.3648071289167 .3269958496170 .9844970703174 .0323028564176 .4705963135 178.2993011475179 .2136993408179 .8231964111180 .1280059814179 .8231964111 179.5184020996178 .9089050293178 .2993011475177 .6896972656176 .7754058838 175.8609924316174 .9467010498173 .7274932861172 .5084075928171 .2891998291 170.070098877168 .8509979248167 .6318054199166 .4127044678165 .1934967041 163.974395752162 .7552947998161 .5361022949160 .3170013428159 .0977935791 157.878692627156 .9642944336155 .7451934814154 .8307952881153 .9165039062 153.3069000244152 .6972961426152 .0877990723151 .7830047607152 .3925933838 152.3925933838152 .3925933838152 .6972961426152 .6972961426153 .0021057129 153.0021057129153 .0021057129153 .0021057129152 .6415100098151 .9176483154 151.259475708150 .3883972168149 .0396575928147 .1718902588144 .7729034424 141.7250976562138 .6772003174135 .3246002197131 .6672058105128 .0097961426 123.7427978516119 .4757995605118 .8662033081118 .8662033081118 .8662033081 118.8662033081119 .1709976196119 .4757995605119 .7806015015119 .7806015015 120.0852966309120 .3900985718120 .6949005127120 .9997024536120 .9997024536 121.3044967651121 .6092987061121 .6092987061121 .9140014648121 .9140014648 121.9140014648121 .9140014648121 .9140014648121 .9140014648121 .9140014648 121.9140014648121 .9140014648121 .6092987061121 .6092987061121 .6092987061 
121.3044967651 121.3044967651 121.3044967651 121.3044967651 120.9997024536 120.9997024536120 .6949005127120 .6949005127120 .3900985718120 .0852966309 119.4757995605118 .5614013672117 .342300415116 .1231002808114 .5991973877 113.3800964355112 .1608963013111 .551399231111 .551399231112 .1608963013 113.075302124113 .6848983765114 .5991973877115 .818397522117 .0374984741 118.2565994263119 .7806015015121 .3044967651122 .8283996582124 .6570968628 125.8762969971127 .0953979492127 .4001998901126 .7906036377125 .5715026855 123.7427978516120 .6949005127117 .0374984741112 .4656982422107 .5891036987 102.102996826296 .3121032714890 .2164001464883 .8159103393677 .1106262207 70.4053573608463 .7777214050357 .41694259644 -9999 -9999 -9999 -9999 -9999 -9999 -9999 -9999 -9999 -9999 -9999 -9999 -9999 -9999 -9999 -9999 -9999 -9999 -9999 -9999 -9999 -9999 -9999 -9999 -9999 -9999 -9999 -9999 -9999 -9999 -9999

-9999 -9999 -9999 -9999 -9999 -9999 -9999 -9999 -9999 -9999 -9999 -9999 -9999 -9999 -9999 -9999 -9999 -9999 -9999 -9999 -9999 -9999 -9999 -9999 -9999 -9999 -9999 -9999 -9999 -9999 -9999 -9999 -9999 -9999 -9999 -9999 -9999 -9999 -9999 -9999 -9999 -9999 -9999 -9999 -9999

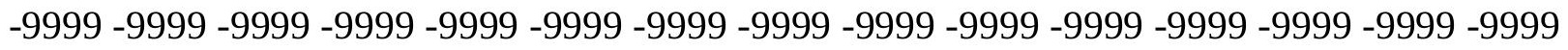
-9999 -9999 -9999 -9999 -9999 -9999 -9999 -9999 -9999 -9999 -9999 -9999 -9999 -9999 -9999 -9999 -9999 -9999 -9999 -9999 -9999 -9999 -9999 -9999 -9999 -9999 -9999 -9999 -9999 -9999 -

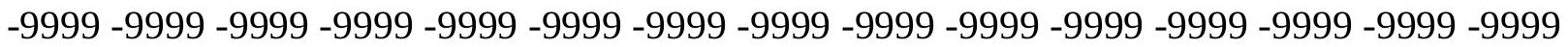

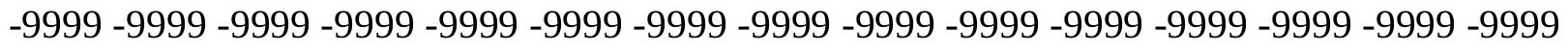

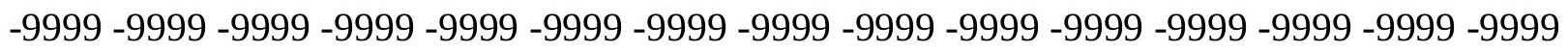
-9999 -9999 -9999 -9999 -9999 -9999 -9999 -9999 -9999 -9999 -9999 -9999 -9999 -9999 -9999 -9999 -9999 -9999 -9999 -9999 -9999 -9999 -9999 -9999 -9999 -9999 -9999 -9999 -9999 -9999 -

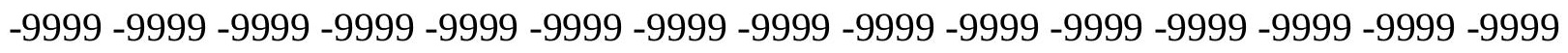

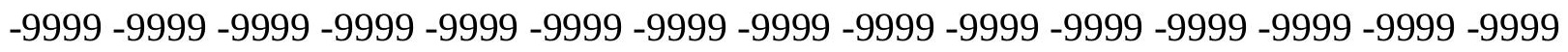

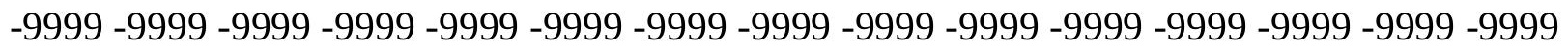
-9999 165.7485351562 161.0381011963 157.2913513184154.8307952881 153.6116943359 153.3069000244154 .2212982178156 .0500030518158 .7929992676162 .1457061768 165.4983062744168 .5462036133171 .5939941406173 .7274932861175 .2514038086 176.4705963135177 .0802001953177 .0802001953177 .0802001953176 .7754058838 176.4705963135175 .970993042175 .381652832174 .6597290039173 .8463592529 172.9533538818171 .9196166992170 .8139343262169 .7051391602168 .5811157227 167.4600067139166 .3584899902165 .2449645996164 .1516418457163 .0352478027 161.9277038574160 .7973937988159 .665435791158 .5557250977157 .4789733887 156.4584350586155 .4514465332154 .5260925293153 .9165039062153 .3069000244 152.6972961426152 .0877990723151 .7830047607151 .4781951904152 .3925933838 152.3925933838152 .3925933838152 .3925933838152 .3925933838152 .6972961426 152.6972961426152 .3925933838152 .0877990723150 .5639038086150 .2771453857 149.4336395264148 .0541992188146 .2969055176143 .8585968018141 .4203033447 138.3724975586 135.3246002197 132.2767028809 128.9241027832 125.2667007446 120.3900985718119 .7806015015119 .4757995605119 .4757995605119 .4757995605 119.4757995605119 .7806015015120 .0852966309120 .0852966309120 .3900985718 120.6949005127120 .9997024536120 .9997024536121 .3044967651121 .3044967651 121.6092987061121 .6092987061121 .6092987061121 .9140014648121 .9140014648 121.9140014648121 .9140014648121 .9140014648121 .9140014648121 .9140014648 121.9140014648121 .6092987061121 .6092987061121 .6092987061121 .3044967651 
121.3044967651 121.3044967651 121.3044967651 120.9997024536120.9997024536 120.6949005127120 .3900985718120 .0852966309119 .7806015015118 .8662033081 118.2565994263117 .0374984741115 .818397522114 .9039993286113 .6848983765 113.075302124112 .4656982422112 .7705001831113 .075302124113 .6848983765 114.5991973877115 .5136032104116 .4279022217117 .647102356118 .8662033081 120.0852966309121 .3044967651122 .5235977173123 .43800354124 .3523025513 124.9618988037124 .9618988037124 .0475006104122 .8283996582120 .3900985718 117.647102356113 .9896011353109 .7226028442104 .846099853599 .66472625732 93.8738174438587 .7781066894581 .6824111938575 .2819290161168 .57665252686 62.2624015808156 .05856704712 -9999 -9999 -9999 -9999 -9999 -9999 -9999 -9999 -9999 -9999 -9999 -9999 -9999 -9999 -9999 -9999 -9999 -9999 -9999 -9999 -9999 -9999 -9999 -9999 -9999 -9999 -9999 -9999 -9999 -9999 -9999

-9999 -9999 -9999 -9999 -9999 -9999 -9999 -9999 -9999 -9999 -9999 -9999 -9999 -9999 -9999 -9999 -9999 -9999 -9999 -9999 -9999 -9999 -9999 -9999 -9999 -9999 -9999 -9999 -9999 - 9999 -9999 -9999 -9999 -9999 -9999 -9999 -9999 -9999 -9999 -9999 -9999 -9999 -9999 -9999 -9999

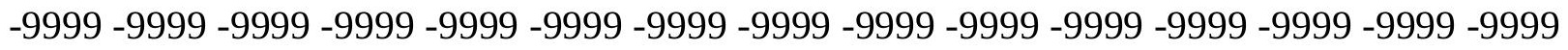
-9999 -9999 -9999 -9999 -9999 -9999 -9999 -9999 -9999 -9999 -9999 -9999 -9999 -9999 -9999 -9999 -9999 -9999 -9999 -9999 -9999 -9999 -9999 -9999 -9999 -9999 -9999 -9999 -9999 -9999 -9999 -9999 -9999 -9999 -9999 -9999 -9999 -9999 -9999 -9999 -9999 -9999 -9999 -9999 -9999 -

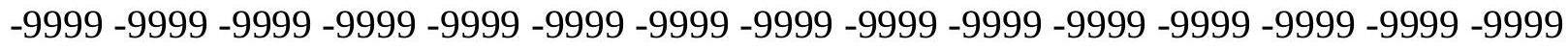

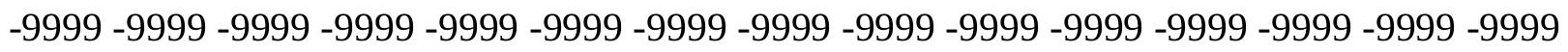
-9999 -9999 -9999 -9999 -9999 -9999 -9999 -9999 -9999 -9999 -9999 -9999 -9999 -9999 -9999 -9999 -9999 -9999 -9999 -9999 -9999 -9999 -9999 -9999 -9999 -9999 -9999 -9999 -9999 -9999 -

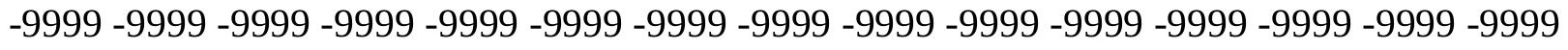

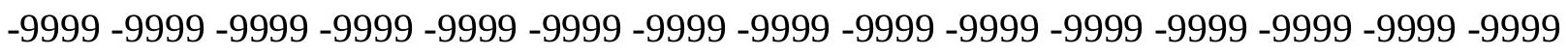

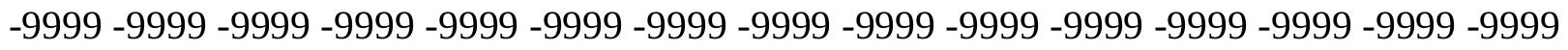
-9999 -9999 161.7012176514158.3742523193156.0461120605 154.6869812012 154.2632751465 154.7845001221 156.2108459473158.3680267334161.0020904541 163.7736968994166 .4596099854168 .9353790283170 .94140625172 .4535369873 173.5569763184174 .1878967285174 .414932251174 .4398040771174 .2897491455 174.0357818604173 .6515808105173 .1433868408172 .5317993164171 .816696167 171.001953125170 .0957946777169 .1160125732168 .1069030762167 .0847320557 -9999 -9999 164.0283050537 163.0146179199161.9940338135160.9652709961 159.9265899658 158.8896179199157 .8724365234156 .8941192627155 .9503326416155 .0970001221 154.364151001153 .8128814697153 .3522644043153 .0575866699153 .0021057129 151.7830047607151 .4781951904152 .0877990723152 .0877990723152 .0877990723 152.0877990723152 .0877990723152 .0877990723151 .7830047607151 .4781951904 151.1734008789150 .5639038086149 .6495056152148 .4304046631146 .9064025879 145.0776977539142 .9441986084140 .5059967041138 .0677032471135 .0198059082 131.6672058105128 .3144989014124 .3523025513121 .3044967651120 .6949005127 120.0852966309120 .0852966309120 .0852966309120 .0852966309120 .0852966309 120.3900985718120 .3900985718120 .6949005127120 .9997024536120 .9997024536 121.3044967651121 .3044967651121 .6092987061121 .6092987061121 .6092987061 121.6092987061121 .6092987061121 .9140014648121 .9140014648121 .9140014648 121.9140014648121 .9140014648121 .9140014648121 .6092987061121 .6092987061 121.6092987061121 .6092987061121 .3044967651121 .3044967651121 .3044967651 
120.9997024536120 .9997024536120 .6949005127120 .6949005127120 .3900985718 119.7806015015119 .4757995605118 .8662033081117 .9517974854117 .0374984741 116.1231002808115 .2088012695114 .2944030762113 .9896011353113 .6848983765 113.6848983765113 .9896011353114 .5991973877115 .5136032104116 .1231002808 117.342300415118 .2565994263119 .1709976196120 .3900985718121 .3044967651 122.2188034058122 .8283996582123 .1332015991123 .1332015991122 .8283996582 121.6092987061120 .0852966309117 .647102356114 .9039993286111 .24659729 106.979598999 102.4077987671 97.2264633178791.74033355713 85.94940185547 $79.8537063598673 .4532165527367 .0527267456160 .7486228942954 .6573677063-9999$ -9999 -9999 -9999 -9999 -9999 -9999 -9999 -9999 -9999 -9999 -9999 -9999 -9999 -9999 -9999

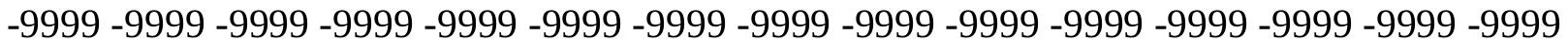
-9999 -9999 -9999 -9999 -9999 -9999 -9999 -9999 -9999 -9999 -9999 -9999 -9999 -9999 -9999 -9999 -9999 -9999 -9999 -9999 -9999 -9999 -9999 -9999 -9999 -9999 -9999 -9999 -9999 -9999 -9999 -9999 -9999 -9999 -9999 -9999 -9999 -9999 -9999 -9999 -9999 -9999 -9999 -9999 - 9999 -9999 -9999 -9999 -9999 -9999 -9999 -9999 -9999 -9999 -9999 -9999 -9999 -9999 -9999 -9999

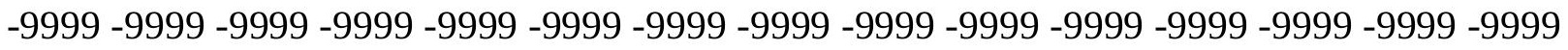
-9999 -9999 -9999 -9999 -9999 -9999 -9999 -9999 -9999 -9999 -9999 -9999 -9999 -9999 -9999 -9999 -9999 -9999 -9999 -9999 -9999 -9999 -9999 -9999 -9999 -9999 -9999 -9999 -9999 -9999 -9999 -9999 -9999 -9999 -9999 -9999 -9999 -9999 -9999 -9999 -9999 -9999 -9999 -9999 -9999 -

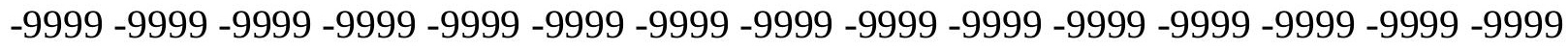

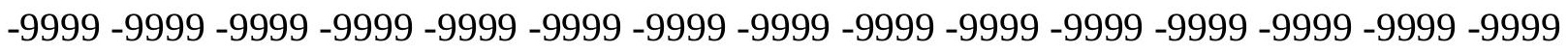
-9999 -9999 -9999 -9999 -9999 -9999 -9999 -9999 -9999 -9999 -9999 -9999 -9999 -9999 -9999 -9999 -9999 -9999 -9999 -9999 -9999 -9999 -9999 -9999 -9999 -9999 -9999 -9999 -9999 -9999 -

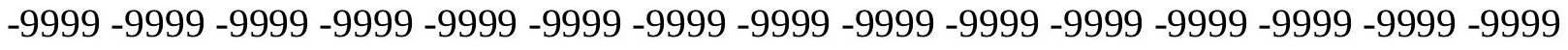

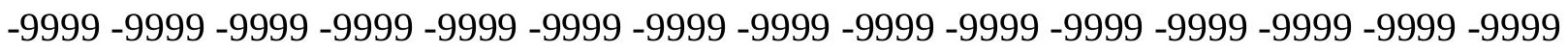
-9999 -9999 -9999 -9999 -9999 -9999 -9999 -9999 -9999 -9999 -9999 -9999 -9999 -9999 -9999 -

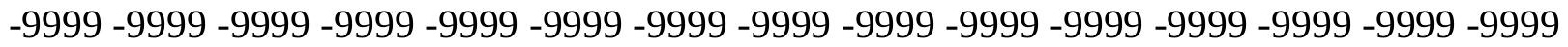
-9999 -9999 -9999 -9999 -9999 -9999 -9999 -9999 -9999 -9999 156.179473877 155.3569946289154 .6326141357154 .0394134521153 .5745697021153 .2263946533 152.9339599609152 .5222930908151 .8408813477151 .4093017578151 .1818695068 150.8686065674151 .7830047607151 .7830047607151 .4781951904151 .4781951904 151.1734008789150 .5639038086150 .2590942383149 .3446960449148 .4304046631 147.2111968994145.9920959473144.1634063721 142.0299072266 139.5915985107 137.1533050537134 .1054992676130 .7528076172126 .7906036377123 .43800354 121.9140014648121 .3044967651120 .9997024536120 .6949005127120 .6949005127 120.3900985718120 .3900985718120 .3900985718120 .3900985718120 .6949005127 120.9997024536121 .3044967651121 .3044967651121 .6092987061121 .6092987061 121.6092987061121 .6092987061121 .6092987061121 .6092987061121 .6092987061 121.6092987061121 .6092987061121 .6092987061121 .6092987061121 .6092987061 121.6092987061121 .6092987061121 .6092987061121 .6092987061121 .3044967651 121.3044967651121 .3044967651120 .9997024536120 .9997024536120 .6949005127 120.3900985718120 .0852966309119 .7806015015119 .1709976196118 .5614013672 117.9517974854117 .342300415116 .4279022217115 .818397522115 .2088012695 114.5991973877114 .5991973877114 .5991973877114 .9039993286115 .5136032104 116.4279022217117 .0374984741117 .9517974854118 .8662033081119 .7806015015 120.6949005127121 .3044967651121 .9140014648122 .2188034058122 .2188034058 
121.6092987061120 .9997024536119 .7806015015117 .647102356115 .2088012695 112.1608963013108 .8082962036104 .541297912699 .9695205688594 .78817749023 89.6068267822383 .8159103393677 .7202072143671 .6244964599665 .22400665283 59.2024765014653 .25179672241 -9999 -9999 -9999 -9999 -9999 -9999 -9999 -9999 -9999 -9999 -9999 -9999 -9999 -9999 -9999 -9999 -9999 -9999 -9999 -9999 -9999 -9999 -9999 -9999 -9999 -9999 -9999 -9999 -9999 -9999 -9999

-9999 -9999 -9999 -9999 -9999 -9999 -9999 -9999 -9999 -9999 -9999 -9999 -9999 -9999 -9999

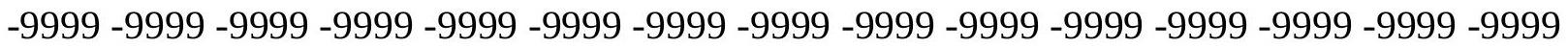

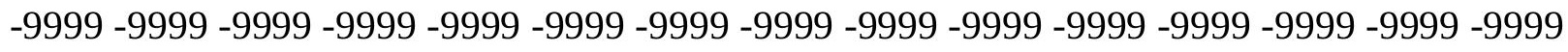
-9999 -9999 -9999 -9999 -9999 -9999 -9999 -9999 -9999 -9999 -9999 -9999 -9999 -9999 -9999 -

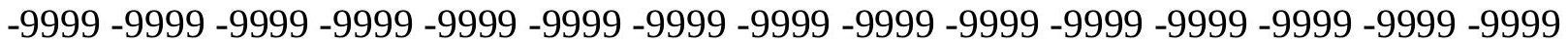
-9999 -9999 -9999 -9999 -9999 -9999 -9999 -9999 -9999 -9999 -9999 -9999 -9999 -9999 -9999 -9999 -9999 -9999 -9999 -9999 -9999 -9999 -9999 -9999 -9999 -9999 -9999 -9999 -9999 -9999 -9999 -9999 -9999 -9999 -9999 -9999 -9999 -9999 -9999 -9999 -9999 -9999 -9999 -9999 -9999 -9999 -9999 -9999 -9999 -9999 -9999 -9999 -9999 -9999 -9999 -9999 -9999 -9999 -9999 -9999

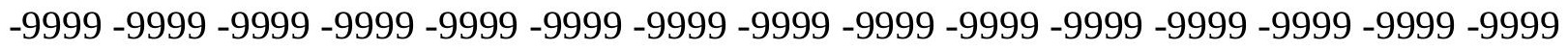
-9999 -9999 -9999 -9999 -9999 -9999 -9999 -9999 -9999 -9999 -9999 -9999 -9999 -9999 -9999 -9999 -9999 -9999 -9999 -9999 -9999 -9999 -9999 -9999 -9999 -9999 -9999 -9999 -9999 -9999 -9999 -9999 -9999 -9999 -9999 -9999 -9999 -9999 -9999 -9999 -9999 -9999 -9999 -9999 -9999

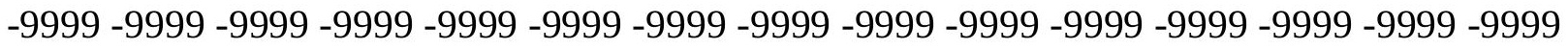

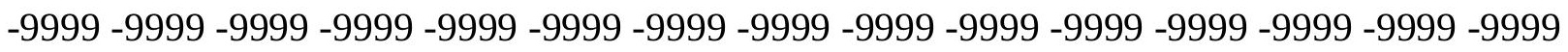
-9999 -9999 -9999 -9999 -9999 -9999 -9999 -9999 -9999 -9999 -9999 -9999 -9999 -9999 -9999 -9999 -9999 -9999 -9999 -9999 -9999 -9999 -9999 -9999 -9999 -9999 -9999 -9999 -9999 -9999 -9999-9999 151.9129180908 151.4000549316 150.9123535156150.5486450195 150.4504089355150 .6379241943150 .6099090576150 .2294769287149 .6495056152 150.2590942383148 .7351074219148 .1255950928147 .5160064697147 .2111968994 145.9920959473144 .4682006836142 .9441986084140 .8106994629138 .3724975586 135.6293945312132 .5814971924128 .9241027832125 .5715026855123 .7427978516 122.5235977173121 .6092987061121 .3044967651121 .3044967651120 .9997024536 120.6949005127120 .3900985718120 .3900985718120 .3900985718120 .6949005127 120.9997024536121 .3044967651121 .6092987061121 .9140014648121 .9140014648 121.9140014648121 .9140014648121 .9140014648121 .9140014648121 .9140014648 121.9140014648121 .6092987061121 .6092987061121 .6092987061121 .6092987061 121.6092987061121 .6092987061121 .6092987061121 .6092987061121 .3044967651 121.3044967651121 .3044967651120 .9997024536120 .6949005127120 .6949005127 120.3900985718120 .0852966309119 .7806015015119 .1709976196118 .5614013672 117.9517974854117 .342300415116 .7326965332116 .4279022217115 .818397522 115.5136032104115 .5136032104115 .818397522116 .1231002808116 .4279022217 117.0374984741117 .9517974854118 .8662033081119 .7806015015120 .3900985718 120.9997024536121 .6092987061121 .6092987061121 .6092987061121 .3044967651 120.3900985718119 .4757995605117 .9517974854115 .818397522113 .075302124 110.0273971558106 .3700027466102 .407798767197 .8360290527392 .65467834473 87.4733276367281 .6824111938575 .8914871215869 .7957916259863 .70008850098 57.704097747851 .82458877563 -9999 -9999 -9999 -9999 -9999 -9999 -9999 -9999 -9999 -9999 -9999 -9999 -9999 -9999 -9999 -9999 -9999 -9999 -9999 -9999 -9999 -9999 -9999 -9999 -9999 -9999 -9999 -9999 -9999 -9999 -9999 
-9999 -9999 -9999 -9999 -9999 -9999 -9999 -9999 -9999 -9999 -9999 -9999 -9999 -9999 -9999 -9999 -9999 -9999 -9999 -9999 -9999 -9999 -9999 -9999 -9999 -9999 -9999 -9999 -9999 -9999 -9999 -9999 -9999 -9999 -9999 -9999 -9999 -9999 -9999 -9999 -9999 -9999 -9999 -9999 -9999 -9999 -9999 -9999 -9999 -9999 -9999 -9999 -9999 -9999 -9999 -9999 -9999 -9999 -9999 -9999 -9999 -9999 -9999 -9999 -9999 -9999 -9999 -9999 -9999 -9999 -9999 -9999 -9999 -9999 -9999 -9999 -9999 -9999 -9999 -9999 -9999 -9999 -9999 -9999 -9999 -9999 -9999 -9999 -9999 -9999 -9999 -9999 -9999 -9999 -9999 -9999 -9999 -9999 -9999 -9999 -9999 -9999 -9999 -9999 -9999

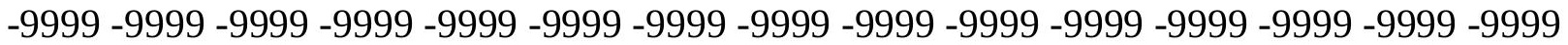
-9999 -9999 -9999 -9999 -9999 -9999 -9999 -9999 -9999 -9999 -9999 -9999 -9999 -9999 -9999 -9999 -9999 -9999 -9999 -9999 -9999 -9999 -9999 -9999 -9999 -9999 -9999 -9999 -9999 -9999 -9999 -9999 -9999 -9999 -9999 -9999 -9999 -9999 -9999 -9999 -9999 -9999 -9999 -9999 -9999 -9999 -9999 -9999 -9999 -9999 -9999 -9999 -9999 -9999 -9999 -9999 -9999 -9999 -9999 -9999

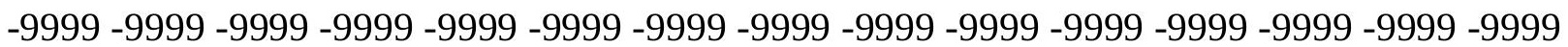
-9999 -9999 -9999 -9999 -9999 -9999 -9999 -9999 -9999 -9999 -9999 -9999 -9999 -9999 -9999 -9999 -9999 -9999 -9999 -9999 -9999 -9999 -9999 -9999 -9999 -9999 -9999 -9999 -9999 -9999 -9999 -9999 -9999 -9999 -9999 -9999 -9999 -9999 -9999 -9999 -9999 -9999 -9999 -9999 -9999 -9999 -9999 -9999 -9999 -9999 -9999 -9999 -9999 -9999 -9999 -9999 -9999 -9999 -9999 -9999 -9999 -9999 -9999 -9999-9999 149.8196563721 149.6261138916149.466506958 149.2473602295148 .8989868164148 .5565490723148 .2585296631147 .5353393555 146.8375549316146 .2969055176145 .0776977539143 .8585968018143 .2489929199 141.4203033447139 .2868041992136 .8484954834134 .1054992676130 .1432037354 127.7050018311125 .5715026855123 .7427978516122 .5235977173121 .9140014648 121.6092987061121 .6092987061121 .3044967651120 .9997024536120 .3900985718 119.7806015015119 .7806015015120 .3900985718120 .9997024536121 .3044967651 121.9140014648121 .9140014648121 .9140014648122 .2188034058121 .9140014648 121.9140014648121 .9140014648121 .9140014648121 .9140014648121 .6092987061 121.6092987061121 .6092987061121 .6092987061121 .6092987061121 .6092987061 121.6092987061121 .6092987061121 .3044967651121 .3044967651121 .3044967651 120.9997024536120 .6949005127120 .6949005127120 .3900985718120 .0852966309 119.7806015015119 .1709976196118 .8662033081118 .2565994263117 .647102356 117.342300415117 .0374984741116 .7326965332116 .4279022217116 .4279022217 116.7326965332117 .0374984741117 .342300415117 .9517974854118 .8662033081 119.4757995605120 .3900985718120 .9997024536121 .3044967651121 .6092987061 121.6092987061120 .9997024536120 .3900985718119 .4757995605117 .9517974854 116.4279022217113 .9896011353111 .24659729107 .8938980103104 .2365036011 100.274299621695 .7025299072390 .8259735107485 .6446228027379 .85370635986 74.062782287668 .2718734741262 .1761703491256 .1687774658250 .36485290527 -9999 -9999 -9999 -9999 -9999 -9999 -9999 -9999 -9999 -9999 -9999 -9999 -9999 -9999 -9999 -9999 -9999 -9999 -9999 -9999 -9999 -9999 -9999 -9999 -9999 -9999 -9999 -9999 -9999 -9999 -9999 -9999 -9999 -9999 -9999 -9999 -9999 -9999 -9999 -9999 -9999 -9999 -9999 -9999 - -9999 -9999 -9999 -9999 -9999 -9999 -9999 -9999 -9999 -9999 -9999 -9999 -9999 -9999 -9999 -9999 -9999

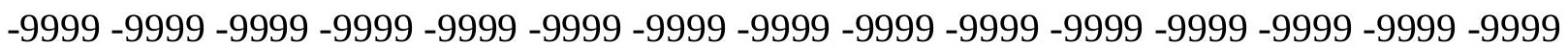
-9999 -9999 -9999 -9999 -9999 -9999 -9999 -9999 -9999 -9999 -9999 -9999 -9999 -9999 -9999 -9999 -9999 -9999 -9999 -9999 -9999 -9999 -9999 -9999 -9999 -9999 -9999 -9999 -9999 -9999 -9999 -9999 -9999 -9999 -9999 -9999 -9999 -9999 -9999 -9999 -9999 -9999 -9999 -9999 -9999

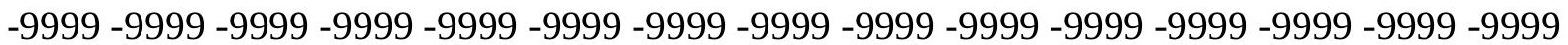


-9999 -9999 -9999 -9999 -9999 -9999 -9999 -9999 -9999 -9999 -9999 -9999 -9999 -9999 -9999 -9999 -9999 -9999 -9999 -9999 -9999 -9999 -9999 -9999 -9999 -9999 -9999 -9999 -9999 -9999 -9999 -9999 -9999 -9999 -9999 -9999 -9999 -9999 -9999 -9999 -9999 -9999 -9999 -9999 -9999 -9999 -9999 -9999 -9999 -9999 -9999 -9999 -9999 -9999 -9999 -9999 -9999 -9999 -9999 -9999 -9999 -9999 -9999 -9999 -9999 -9999 -9999 -9999 -9999 -9999 -9999 -9999 -9999 -9999 -9999 -9999 -9999 -9999 -9999 -9999 -9999 -9999 -9999 -9999 -9999 -9999 -9999 -9999 -9999 -9999 -9999 -9999 -9999 -9999 -9999 -9999 -9999 -9999 -9999 -9999 -9999 -9999 -9999 -9999 -9999

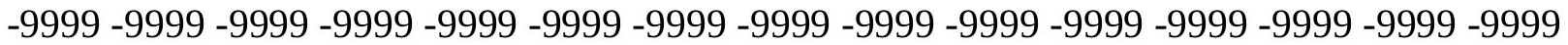

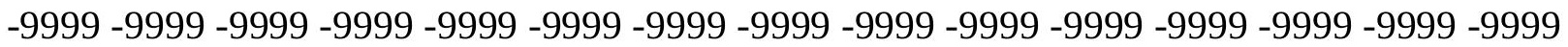
-9999 -9999 -9999 -9999 -9999 -9999 -9999 -9999 -9999 -9999 -9999 -9999 -9999 -9999 -9999 -999 -9999 -9999 -9999 -9999 -9999 -9999 -9999 -9999 147.8750762939147 .5081481934 147.1387786865146 .643661499146 .0941162109145 .4125518799144 .7044219971 143.8585968018142 .6394042969140 .8106994629138 .9819946289137 .7628936768 134.4102020264131 .6672058105129 .2288970947126 .7906036377124 .9618988037 123.1332015991122 .2188034058121 .6092987061121 .6092987061121 .9140014648 121.6092987061120 .9997024536119 .7806015015119 .1709976196119 .1709976196 119.7806015015120 .6949005127121 .6092987061121 .9140014648122 .2188034058 122.2188034058122 .2188034058122 .2188034058122 .2188034058122 .2188034058 121.9140014648121 .9140014648121 .6092987061121 .6092987061121 .6092987061 121.6092987061121 .6092987061121 .6092987061121 .6092987061121 .6092987061 121.6092987061121 .3044967651121 .3044967651120 .9997024536120 .6949005127 120.6949005127120 .3900985718120 .0852966309119 .7806015015119 .1709976196 118.8662033081118 .5614013672117 .9517974854117 .647102356117 .342300415 117.342300415117 .0374984741117 .342300415117 .342300415117 .9517974854 118.2565994263118 .8662033081119 .4757995605120 .0852966309120 .6949005127 121.3044967651121 .6092987061121 .9140014648121 .3044967651120 .6949005127 119.7806015015118 .5614013672117 .0374984741114 .9039993286112 .4656982422 109.7226028442106 .3700027466102 .407798767198 .445587158293 .87381744385 88.9972534179783 .8159103393678 .3297805786172 .5388565063566 .44316101074 60.3474502563554 .5841102600148 .90977859497 -9999 -9999 -9999 -9999 -9999 -9999 -9999 -9999 -9999 -9999 -9999 -9999 -9999 -9999 -9999 -9999 -9999 -9999 -9999 -9999 -9999 -9999 -9999 -9999 -9999-9999 -9999 -9999 -9999-9999-9999 -9999 -9999 -9999 -9999 -9999 -9999 -9999 -9999 -9999 -9999 -9999 -9999 -9999 -9999 -9999 -9999 -9999 -9999 -9999 -9999 -9999 -9999 -9999 -9999 -9999 -9999 -9999 -9999 -9999 -9999 -

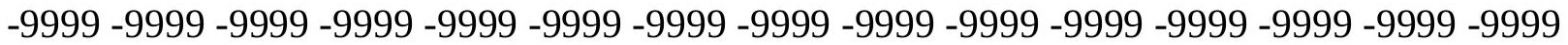
-9999 -9999 -9999 -9999 -9999 -9999 -9999 -9999 -9999 -9999 -9999 -9999 -9999 -9999 -9999 -9999 -9999 -9999 -9999 -9999 -9999 -9999 -9999 -9999 -9999 -9999 -9999 -9999 -9999 -9999

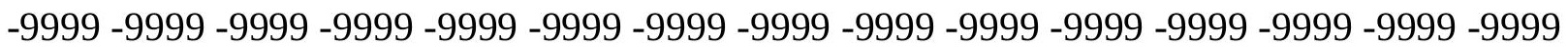
-9999 -9999 -9999 -9999 -9999 -9999 -9999 -9999 -9999 -9999 -9999 -9999 -9999 -9999 -9999 -9999 -9999 -9999 -9999 -9999 -9999 -9999 -9999 -9999 -9999 -9999 -9999 -9999 -9999 -9999 -9999 -9999 -9999 -9999 -9999 -9999 -9999 -9999 -9999 -9999 -9999 -9999 -9999 -9999 -9999

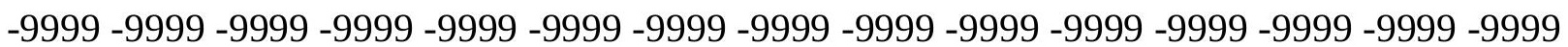
-9999 -9999 -9999 -9999 -9999 -9999 -9999 -9999 -9999 -9999 -9999 -9999 -9999 -9999 -9999 -9999 -9999 -9999 -9999 -9999 -9999 -9999 -9999 -9999 -9999 -9999 -9999 -9999 -9999 -9999 -9999 -9999 -9999 -9999 -9999 -9999 -9999 -9999 -9999 -9999 -9999 -9999 -9999 -9999 -9999

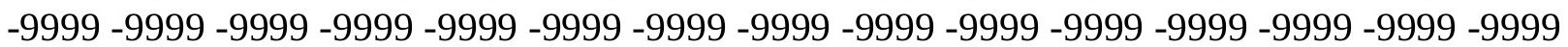


-9999 -9999 -9999 -9999 -9999 -9999 -9999 -9999 -9999 -9999 -9999 -9999 -9999 -9999 -9999 -9999 -9999 -9999 -9999 -9999 -9999 -9999 -9999 -9999 -9999 -9999 -9999 -9999 -9999 -9999 -9999 -9999 -9999 -9999 -9999 -9999 -9999 -9999 -9999 -9999 -9999 -9999 -9999 -9999 -9999 -9999 -9999 -9999 -9999 -9999 -9999 -9999 -9999 -9999 -9999 -9999 -9999 144.4342651367 143.7536010742142 .9543457031142 .0033721924140 .7769775391139 .2868041992 137.4580993652135 .3246002197132 .8863067627130 .4479980469128 .0097961426 125.5715026855123 .7427978516122 .2188034058121 .3044967651120 .9997024536 120.9997024536121 .6092987061121 .9140014648121 .3044967651119 .4757995605 117.9517974854118 .5614013672119 .7806015015120 .6949005127121 .6092987061 122.2188034058122 .5235977173122 .5235977173122 .5235977173122 .5235977173 122.5235977173122 .2188034058122 .2188034058121 .9140014648121 .9140014648 121.9140014648121 .9140014648121 .6092987061121 .9140014648121 .9140014648 121.9140014648121 .6092987061121 .6092987061121 .6092987061121 .3044967651 120.9997024536120 .9997024536120 .6949005127120 .3900985718120 .0852966309 119.7806015015119 .4757995605119 .1709976196118 .8662033081118 .5614013672 118.2565994263117 .9517974854117 .9517974854117 .9517974854117 .9517974854 118.2565994263118 .5614013672119 .1709976196119 .4757995605120 .0852966309 120.6949005127121 .3044967651121 .6092987061121 .9140014648121 .6092987061 121.3044967651120 .3900985718119 .1709976196117 .9517974854116 .1231002808 113.9896011353111 .24659729108 .1986999512104 .8460998535100 .8839035034 96.6168823242292 .0450973510787 .1685485839881 .9871978759876 .50106811523 71.014930725164 .9192428588958 .8235282897953 .0522537231447 .46571731567 -9999 -9999 -9999 -9999 -9999 -9999 -9999 -9999 -9999 -9999 -9999 -9999 -9999 -9999 -9999 -9999 -9999 -9999 -9999 -9999 -9999 -9999 -9999 -9999 -9999 -9999 -9999 -9999 -9999 -9999 -9999 -9999 -9999 -9999 -9999 -9999 -9999 -9999 -9999 -9999 -9999 -9999 -9999 -9999 -9999 -9999 -9999 -9999 -9999 -9999 -9999 -9999 -9999 -9999 -9999 -9999 -9999 -9999 -9999 -9999 -9999 -9999 -9999 -9999 -9999 -9999 -9999 -9999 -9999 -9999 -9999 -9999 -9999 -9999 -9999 -9999 -9999 -9999 -9999 -9999 -9999 -9999 -9999 -9999 -9999 -9999 -9999 -9999 -9999 -9999 -9999

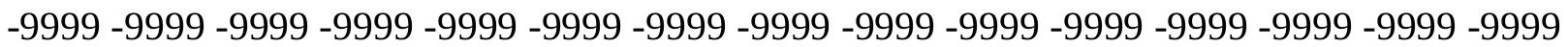
-9999 -9999 -9999 -9999 -9999 -9999 -9999 -9999 -9999 -9999 -9999 -9999 -9999 -9999 -9999 -9999 -9999 -9999 -9999 -9999 -9999 -9999 -9999 -9999 -9999 -9999 -9999 -9999 -9999 -9999 -9999 -9999 -9999 -9999 -9999 -9999 -9999 -9999 -9999 -9999 -9999 -9999 -9999 -9999 -9999 -9999 -9999 -9999 -9999 -9999 -9999 -9999 -9999 -9999 -9999 -9999 -9999 -9999 -9999 -9999 -9999 -9999 -9999 -9999 -9999 -9999 -9999 -9999 -9999 -9999 -9999 -9999 -9999 -9999 -9999 -9999 -9999 -9999 -9999 -9999 -9999 -9999 -9999 -9999 -9999 -9999 -9999 -9999 -9999 -9999 -9999 -9999 -9999 -9999 -9999 -9999 -9999 -9999 -9999 -9999 -9999 -9999 -9999 -9999 -9999 -

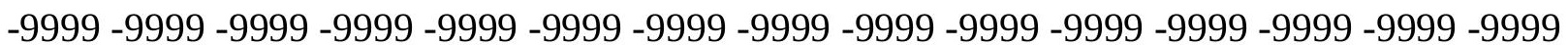
-9999 -9999 -9999 -9999 -9999 -9999 -9999 -9999 -9999 -9999 -9999 -9999 -9999 -9999 -9999 -9999 -9999 -9999 -9999 -9999 -9999 -9999 -9999 -9999 -9999 -9999 -9999 -9999 -9999 -9999 -9999 -9999 -9999 -9999 -9999 -9999 -9999 -9999 -9999 -9999 -9999 -9999 -9999 - -9999 -9999 -9999 -9999 -9999 -9999 -9999 -9999 -9999 -9999 -9999 -9999 -9999 -9999 -9999 -9999 -9999 -9999 -9999 -9999 -9999 -9999 -9999 -9999 -9999 -9999 -9999 -9999 -9999 -9999 -9999 140.9605560303139 .926651001138 .7014160156137 .2594909668135 .6268768311 133.8007049561131 .3623962402128 .6192932129126 .1809997559123 .7427978516 121.9140014648120 .6949005127119 .7806015015119 .7806015015120 .0852966309 120.6949005127121 .6092987061122 .2188034058120 .0852966309116 .7326965332 
118.8662033081120 .3900985718121 .3044967651121 .9140014648122 .5235977173 122.8283996582122 .8283996582122 .8283996582122 .8283996582122 .8283996582 122.5235977173122 .5235977173122 .2188034058122 .2188034058121 .9140014648 121.9140014648121 .9140014648121 .9140014648121 .9140014648121 .9140014648 121.9140014648121 .9140014648121 .6092987061121 .3044967651121 .3044967651 120.9997024536120 .6949005127120 .3900985718120 .0852966309119 .7806015015 119.4757995605119 .1709976196118 .8662033081118 .8662033081118 .5614013672 118.5614013672118 .2565994263118 .5614013672118 .5614013672118 .8662033081 119.1709976196119 .7806015015120 .0852966309120 .6949005127121 .3044967651 121.6092987061121 .9140014648121 .9140014648121 .6092987061120 .9997024536 120.0852966309118 .8662033081117 .342300415115 .2088012695113 .075302124 110.3321990967106 .979598999103 .626899719299 .6647262573295 .3977432251 90.5211791992285 .6446228027380 .4632720947374 .9771423339869 .49101257324 63.3953094482457 .2995986938551 .6249465942446 .0855140686 -9999 -9999 -9999 -9999 -9999 -9999 -9999 -9999 -9999 -9999 -9999 -9999 -9999 -9999 -9999 -9999 -9999 -9999 -9999 -9999 -9999 -9999 -9999 -9999 -9999 -9999 -9999 -9999 -9999 -9999 -9999 -

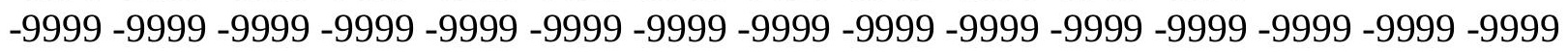
-9999 -9999 -9999 -9999 -9999 -9999 -9999 -9999 -9999 -9999 -9999 -9999 -9999 -9999 -9999 -

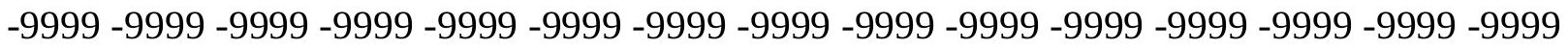

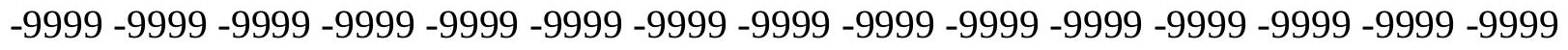

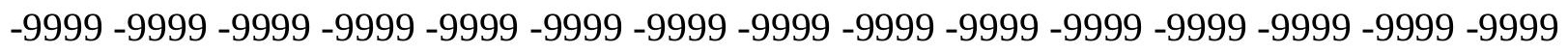

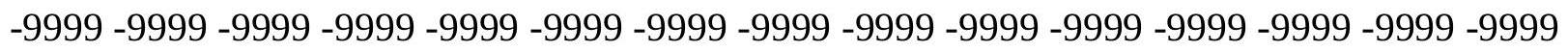
-9999 -9999 -9999 -9999 -9999 -9999 -9999 -9999 -9999 -9999 -9999 -9999 -9999 -9999 -9999 -

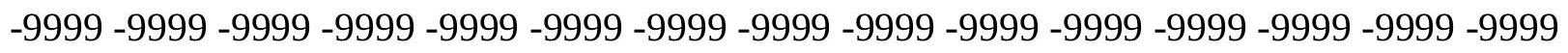

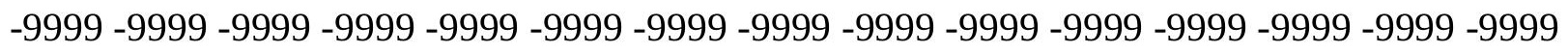
-9999 -9999 -9999 -9999 -9999 -9999 -9999 -9999 -9999 -9999 -9999 -9999 -9999 -9999 -9999 -9999 -9999 -9999 -9999 -9999 -9999 -9999 -9999 -9999 -9999 -9999 -9999 -9999 -9999 - -9999 -

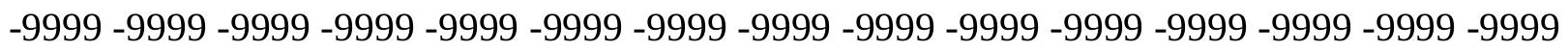

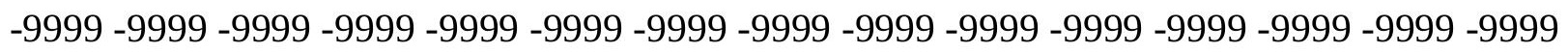

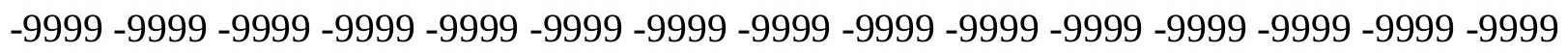
-9999 -9999 -9999 -9999 -9999 -9999 -9999 -9999 -9999 -9999 -9999 -9999 -9999 -9999 -9999 -9999 -9999 -9999 -9999 -9999 -9999 -9999 -9999 -9999 -9999 -9999 -9999 -9999 -9999 -9999 -

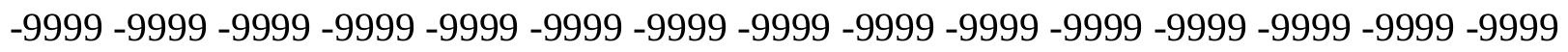

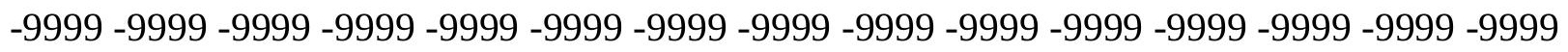
-9999 136.4337005615 135.0081176758 133.3964996338131.4856872559 129.1523742676 126.4858016968124 .0475006104121 .6092987061119 .7806015015118 .5614013672 117.9517974854117 .9517974854118 .5614013672119 .4757995605120 .6949005127 121.3044967651121 .3044967651122 .2188034058120 .9997024536121 .3044967651 121.9140014648122 .5235977173122 .8283996582123 .1332015991123 .1332015991 123.1332015991123 .1332015991123 .1332015991122 .8283996582122 .8283996582 122.5235977173122 .5235977173122 .5235977173122 .2188034058122 .2188034058 122.2188034058122 .2188034058122 .2188034058122 .2188034058121 .9140014648 121.9140014648121 .6092987061121 .3044967651120 .9997024536120 .6949005127 120.6949005127120 .3900985718120 .0852966309119 .7806015015119 .4757995605 119.1709976196118 .8662033081118 .8662033081118 .8662033081118 .8662033081 118.8662033081119 .1709976196119 .4757995605119 .7806015015120 .3900985718 
120.6949005127121 .3044967651121 .6092987061121 .9140014648122 .2188034058 121.9140014648121 .6092987061120 .9997024536120 .0852966309118 .5614013672 116.7326965332114 .9039993286112 .1608963013109 .4179000854106 .0652008057 102.407798767198 .445587158293 .8738174438589 .302040100184 .42548370361 79.2441329956173 .7580032348667 .9670867919962 .1761703491256 .08045959473 50.30391693115 -9999 -9999 -9999 -9999 -9999 -9999 -9999 -9999 -9999 -9999 -9999 -9999 -9999 -9999 -9999 -9999 -9999 -9999 -9999 -9999 -9999 -9999 -9999 -9999 -9999 -9999 -9999 -9999 -9999-9999-9999-9999

-9999 -9999 -9999 -9999 -9999-9999 -9999 -9999 -9999 -9999 -9999 -9999 -9999 -9999 -9999 -9999 -9999 -9999 -9999 -9999 -9999 -9999 -9999 -9999 -9999 -9999 -9999 -9999 -9999 -9999 -9999 -9999 -9999 -9999 -9999 -9999 -9999 -9999 -9999 -9999 -9999 -9999 -9999 -9999 -9999 -999 -9999 -9999 -9999 -9999 -9999 -9999 -9999 -9999 -9999 -9999 -9999 -9999 -9999 -9999 -9999 -999 -9999 -9999 -9999 -9999 -9999 -9999 -9999 -9999 -9999 -9999 -9999 -9999 -9999 -9999 -9999 -9999 -9999 -9999 -9999 -9999 -9999 -9999 -9999 -9999 -9999 -9999 -9999 -9999 -9999 -9999 -9999 -9999 -9999 -9999 -9999 -9999 -9999 -9999 -9999 -9999 -9999 -9999 -9999 -9999 -9999

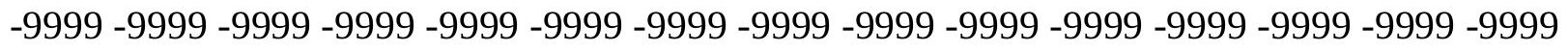

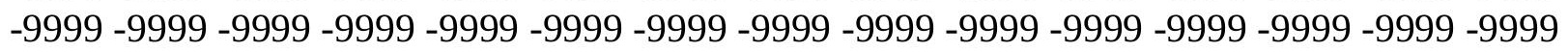

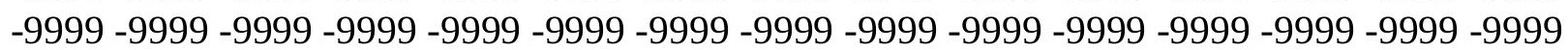

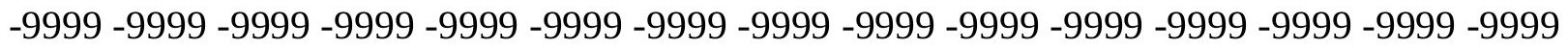

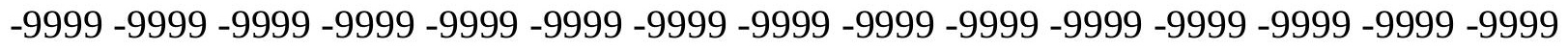

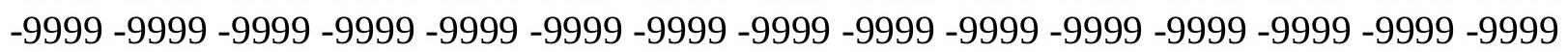

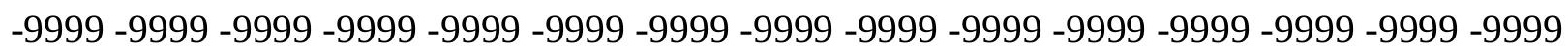
-9999 -9999 -9999 -9999 -9999 -9999 -9999 -9999 -9999 -9999 -9999 -9999 -9999 -9999 -9999 -

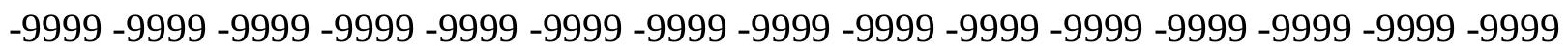

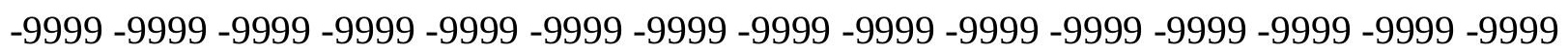

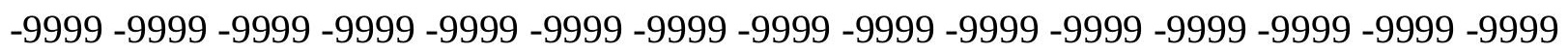
-9999 -9999 132.5419311523130.8750610352128.9271240234126.7005081177 124.3891448975122 .2188034058118 .8662033081117 .0374984741116 .1231002808 115.818397522115 .818397522116 .7326965332117 .647102356118 .8662033081 120.0852966309121 .3044967651121 .9140014648121 .9140014648121 .9140014648 122.2188034058122 .8283996582123 .1332015991123 .43800354123 .43800354123 .43800354 123.43800354123 .1332015991123 .1332015991123 .1332015991122 .8283996582 122.8283996582122 .8283996582122 .8283996582122 .5235977173122 .5235977173 122.5235977173122 .5235977173122 .2188034058122 .2188034058121 .9140014648 121.9140014648121 .6092987061121 .3044967651120 .9997024536120 .6949005127 120.3900985718120 .0852966309119 .7806015015119 .4757995605119 .1709976196 119.1709976196119 .1709976196119 .1709976196119 .1709976196119 .1709976196 119.4757995605119 .7806015015120 .3900985718120 .6949005127121 .3044967651 121.6092987061121 .9140014648122 .2188034058122 .2188034058122 .2188034058 121.9140014648120 .9997024536120 .0852966309118 .5614013672116 .7326965332 114.2944030762111 .551399231108 .5035018921105 .1509017944101 .4934005737 97.2264633178792 .9594726562588 .0829010009883 .206336975177 .72020721436 72.2340774536166 .7479400634860 .6522407531754 .5565414428749 .12191772461 -9999 -9999 -9999 -9999 -9999 -9999 -9999 -9999 -9999 -9999 -9999 -9999 -9999 -9999 -9999 -9999

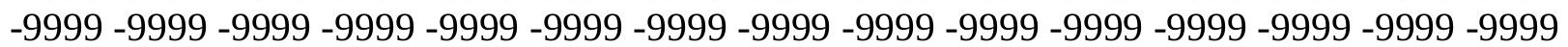
$-9999$ 
-9999 -9999 -9999 -9999 -9999 -9999 -9999 -9999 -9999 -9999 -9999 -9999 -9999 -9999 -9999 -9999 -9999 -9999 -9999 -9999 -9999 -9999 -9999 -9999 -9999 -9999 -9999 -9999 -9999 -9999 -9999 -9999 -9999 -9999 -9999 -9999 -9999 -9999 -9999 -9999 -9999 -9999 -9999 -9999 -9999 -9999 -9999 -9999 -9999 -9999 -9999 -9999 -9999 -9999 -9999 -9999 -9999 -9999 -9999 -9999 -9999 -9999 -9999 -9999 -9999 -9999 -9999 -9999 -9999 -9999 -9999 -9999 -9999 -9999 -9999 -9999 -9999 -9999 -9999 -9999 -9999 -9999 -9999 -9999 -9999 -9999 -9999 -9999 -9999 -9999 -9999 -9999 -9999 -9999 -9999 -9999 -9999 -9999 -9999 -9999 -9999 -9999 -9999 -9999 -9999

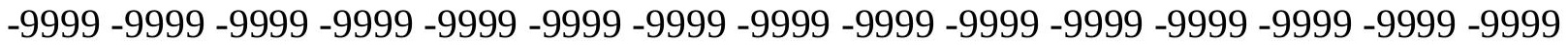
-9999 -9999 -9999 -9999 -9999 -9999 -9999 -9999 -9999 -9999 -9999 -9999 -9999 -9999 -9999 -9999 -9999 -9999 -9999 -9999 -9999 -9999 -9999 -9999 -9999 -9999 -9999 -9999 -9999 -9999 -

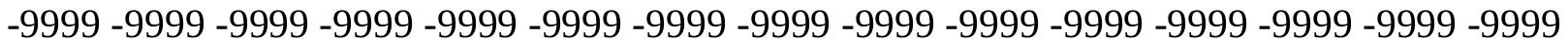
-9999 -9999 -9999 -9999 -9999 -9999 -9999 -9999 -9999 -9999 -9999 -9999 -9999 -9999 -9999

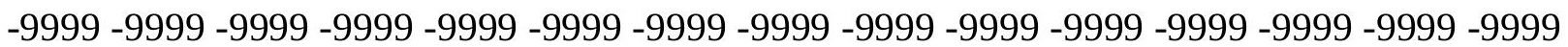
-9999 -9999 -9999 -9999 -9999 -9999 -9999 -9999 -9999 -9999 -9999 -9999 -9999 -9999 -9999 -9999 -9999 -9999 -9999 -9999 -9999 -9999 -9999 -9999 -9999 -9999 -9999 -9999 -9999 -9999 -9999 -9999 -9999 -9999 -9999 -9999 -9999 -9999 -9999 -9999 -9999 -9999 -9999 -9999 -9999 -9999 -9999 -9999 -9999 -9999 -9999 -9999 -9999 -9999 -9999 -9999 -9999 -9999 -9999 -9999 -9999 -9999 -9999 -9999 -9999 -9999 -9999 -9999 -9999 -9999 -9999 -9999 -9999 -9999 -9999 -9999 -9999 -9999 128.212097168 126.2482528687 124.061050415 121.6994781494 119.1083145142116 .3764038086114 .2944030762113 .6848983765113 .3800964355 113.6848983765114 .2944030762115 .5136032104117 .0374984741118 .5614013672 119.7806015015120 .9997024536121 .6092987061121 .9140014648122 .5235977173 123.1332015991123 .43800354123 .43800354123 .7427978516123 .7427978516123 .43800354 123.43800354123 .43800354123 .43800354123 .1332015991123 .1332015991123 .1332015991 123.1332015991123 .1332015991122 .8283996582122 .8283996582122 .8283996582 122.5235977173122 .5235977173122 .2188034058121 .9140014648121 .6092987061 121.3044967651120 .9997024536120 .6949005127120 .3900985718120 .0852966309 119.7806015015119 .4757995605119 .4757995605119 .1709976196119 .1709976196 119.1709976196119 .4757995605119 .4757995605119 .7806015015120 .0852966309 120.6949005127120 .9997024536121 .6092987061121 .9140014648122 .2188034058 122.5235977173122 .5235977173122 .5235977173121 .9140014648120 .9997024536 120.0852966309118 .2565994263116 .4279022217113 .9896011353111 .24659729 108.1986999512104 .5412979126100 .579101562596 .3121032714892 .04509735107 87.1685485839881 .9871978759876 .5010681152371 .014930725165 .22400665283 59.43310165405 54.25175094604 48.04661941528 -9999 -9999 -9999 -9999 -9999 -9999 -9999 -9999 -9999 -9999 -9999 -9999 -9999 -9999 -9999 -9999 -9999 -9999 -9999 -9999 -9999 -9999 -9999 -9999 -9999 -9999 -9999 -9999 -9999 -9999 -9999 -9999

-9999 -9999 -9999 -9999 -9999 -9999 -9999 -9999 -9999 -9999 -9999 -9999 -9999 -9999 -9999 -9999 -9999 -9999 -9999 -9999 -9999 -9999 -9999 -9999 -9999 -9999 -9999 -9999 -9999 -9999 -9999 -9999 -9999 -9999 -9999 -9999 -9999 -9999 -9999 -9999 -9999 -9999 -9999 -9999 -9999 -9999 -9999 -9999 -9999 -9999 -9999 -9999 -9999 -9999 -9999 -9999 -9999 -9999 -9999 -9999

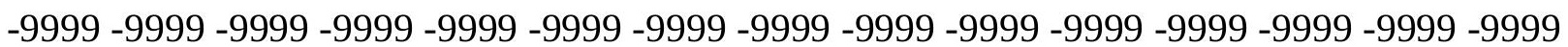
-9999 -9999 -9999 -9999 -9999 -9999 -9999 -9999 -9999 -9999 -9999 -9999 -9999 -9999 -9999 -9999 -9999 -9999 -9999 -9999 -9999 -9999 -9999 -9999 -9999 -9999 -9999 -9999 -9999 -9999 -9999 -9999 -9999 -9999 -9999 -9999 -9999 -9999 -9999 -9999 -9999 -9999 -9999 -9999 -9999

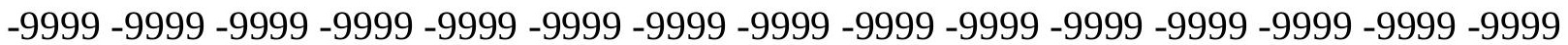


-9999 -9999 -9999 -9999 -9999 -9999 -9999 -9999 -9999 -9999 -9999 -9999 -9999 -9999 -9999 -9999 -9999 -9999 -9999 -9999 -9999 -9999 -9999 -9999 -9999 -9999 -9999 -9999 -9999 -9999 -9999 -9999 -9999 -9999 -9999 -9999 -9999 -9999 -9999 -9999 -9999 -9999 -9999 -9999 -9999 -9999 -9999 -9999 -9999 -9999 -9999 -9999 -9999 -9999 -9999 -9999 -9999 -9999 -9999 -9999 -9999 -9999 -9999 -9999 -9999 -9999 -9999 -9999 -9999 -9999 -9999 -9999 -9999 -9999 -9999 -9999 -9999 -9999 -9999 -9999 -9999 -9999 -9999 -9999 -9999 -9999 -9999 -9999 -9999 -9999 -9999 -9999 -9999 -9999 -9999 -9999 -9999 -9999 -9999 -9999 -9999 -9999 -9999 -9999 -9999

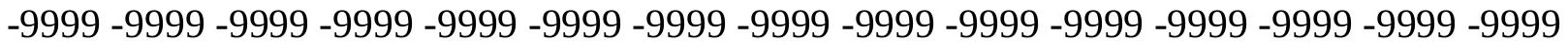
-9999 -9999 -9999 -9999 -9999 -9999 -9999 -9999 -9999 -9999 -9999 -9999 -9999 -9999 -9999 -9999 -9999 -9999 -9999 123.487487793 121.2625808716 118.8369369507 116.2483139038 113.801574707111 .8561019897111 .24659729110 .9418029785111 .24659729 112.1608963013113 .3800964355114 .9039993286116 .7326965332118 .2565994263 119.4757995605120 .6949005127121 .6092987061122 .2188034058123 .1332015991 123.43800354123 .7427978516123 .7427978516123 .7427978516123 .7427978516 123.7427978516123 .7427978516123 .7427978516123 .43800354123 .43800354123 .43800354 123.43800354123 .43800354123 .43800354123 .1332015991123 .1332015991122 .8283996582 122.8283996582122 .5235977173122 .2188034058121 .9140014648121 .6092987061 121.3044967651120 .9997024536120 .3900985718120 .0852966309119 .7806015015 119.7806015015119 .4757995605119 .4757995605119 .1709976196119 .4757995605 119.4757995605119 .7806015015120 .0852966309120 .3900985718120 .6949005127 121.3044967651121 .9140014648122 .2188034058122 .5235977173122 .8283996582 122.8283996582122 .5235977173122 .2188034058121 .3044967651120 .0852966309 118.5614013672116 .4279022217113 .9896011353110 .9418029785107 .8938980103 104.236503601199 .9695205688595 .7025299072391 .1307525634886 .2541885376 80.7680587768675 .5867080688569 .7957916259864 .004882812557 .9091796875 52.4281387329146 .62529754639 -9999 -9999 -9999 -9999 -9999 -9999 -9999 -9999 -9999 -9999 -9999 -9999 -9999 -9999 -9999 -9999 -9999 -9999 -9999 -9999 -9999 -9999 -9999 -9999 -9999 -9999 -9999 -9999 -9999 -9999-9999 -9999

-9999 -9999 -9999 -9999 -9999 -9999 -9999 -9999 -9999 -9999 -9999 -9999 -9999 -9999 -9999 -9999 -9999 -9999 -9999 -9999 -9999 -9999 -9999 -9999 -9999 -9999 -9999 -9999 -9999 -9999 -9999 -9999 -9999 -9999 -9999 -9999 -9999 -9999 -9999 -9999 -9999 -9999 -9999 -9999 -9999 -9999 -9999 -9999 -9999 -9999 -9999 -9999 -9999 -9999 -9999 -9999 -9999 -9999 -9999 -9999 -9999 -9999 -9999 -9999 -9999 -9999 -9999 -9999 -9999 -9999 -9999 -9999 -9999 -9999 -9999 -9999 -9999 -9999 -9999 -9999 -9999 -9999 -9999 -9999 -9999 -9999 -9999 -9999 -9999 -9999

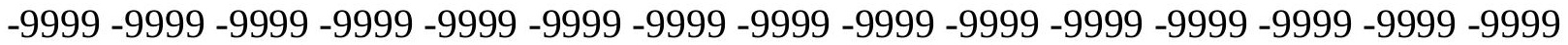
-9999 -9999 -9999 -9999 -9999 -9999 -9999 -9999 -9999 -9999 -9999 -9999 -9999 -9999 -9999 -9999 -9999 -9999 -9999 -9999 -9999 -9999 -9999 -9999 -9999 -9999 -9999 -9999 -9999 -9999

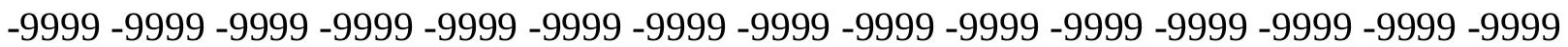
-9999 -9999 -9999 -9999 -9999 -9999 -9999 -9999 -9999 -9999 -9999 -9999 -9999 -9999 -9999 -9999 -9999 -9999 -9999 -9999 -9999 -9999 -9999 -9999 -9999 -9999 -9999 -9999 -9999 -9999 -9999 -9999 -9999 -9999 -9999 -9999 -9999 -9999 -9999 -9999 -9999 -9999 -9999 -9999 -9999

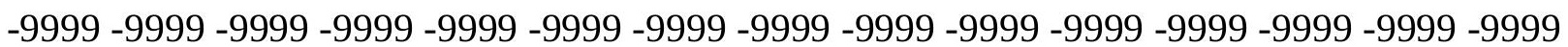
-9999 -9999 -9999 -9999 -9999 -9999 -9999 -9999 -9999 -9999 -9999 -9999 -9999 -9999 -9999 -9999 -9999 -9999 -9999 -9999 -9999 -9999 -9999 -9999 -9999 -9999 -9999 -9999 -9999 -9999 -9999 -9999 -9999 -9999 -9999 -9999 -9999 -9999 -9999 -9999 -9999 -9999 -9999 -9999 -9999

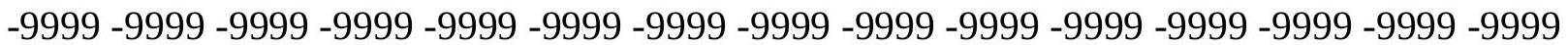


-9999 -9999 -9999 -9999 -9999 118.5283584595116 .1371612549113 .7120666504 111.5048751831109 .8139801025108 .8082962036108 .8082962036109 .1130981445 110.0273971558111 .551399231113 .075302124114 .9039993286116 .4279022217 118.2565994263119 .4757995605120 .6949005127121 .9140014648122 .8283996582 123.1332015991123 .43800354123 .7427978516123 .7427978516123 .7427978516 123.7427978516123 .7427978516123 .7427978516123 .7427978516123 .7427978516 123.7427978516123 .7427978516123 .7427978516123 .7427978516123 .43800354 123.43800354123 .1332015991123 .1332015991122 .8283996582122 .5235977173 122.2188034058121 .6092987061121 .3044967651120 .9997024536120 .6949005127 120.0852966309119 .7806015015119 .4757995605119 .4757995605119 .1709976196 119.1709976196119 .1709976196119 .4757995605119 .7806015015120 .0852966309 120.3900985718120 .9997024536121 .3044967651121 .9140014648122 .2188034058 122.8283996582122 .8283996582123 .1332015991122 .8283996582122 .5235977173 121.6092987061120 .3900985718118 .5614013672116 .4279022217113 .9896011353 110.9418029785107 .5891036987103 .931701660299 .6647262573295 .09295654297 90.5211791992285 .3398437579 .8537063598674 .3675689697368 .57665252686 62.7857398986856 .6900291442950 .8079261779845 .01663208008 -9999 -9999 -9999 -9999 -9999 -9999 -9999 -9999 -9999 -9999 -9999 -9999 -9999 -9999 -9999 -9999 -9999 -9999 -9999 -9999 -9999 -9999 -9999 -9999 -9999 -9999 -9999 -9999 -9999 -9999 -9999 -9999 -

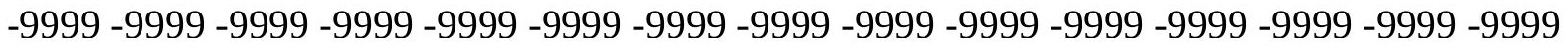

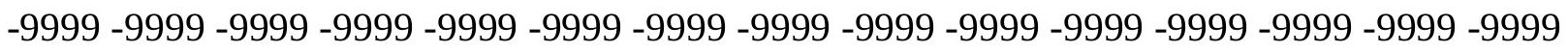
-9999 -9999 -9999 -9999 -9999 -9999 -9999 -9999 -9999 -9999 -9999 -9999 -9999 -9999 -9999 -9999 -9999 -9999 -9999 -9999 -9999 -9999 -9999 -9999 -9999 -9999 -9999 -9999 -9999 -9999 -

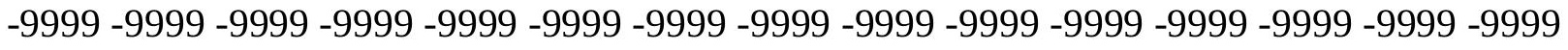

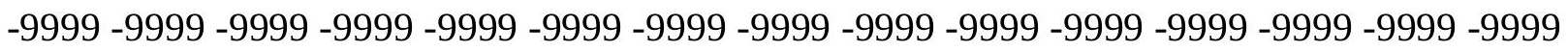
-9999 -9999 -9999 -9999 -9999 -9999 -9999 -9999 -9999 -9999 -9999 -9999 -9999 -9999 -9999 -9999 -9999 -9999 -9999 -9999 -9999 -9999 -9999 -9999 -9999 -9999 -9999 -9999 -9999 -9999 -

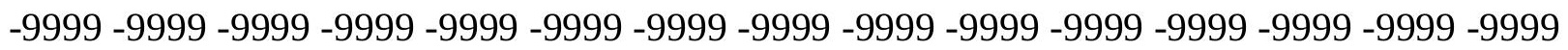
-9999 -9999 -9999 -9999 -9999 -9999 -9999 -9999 -9999 -9999 -9999 -9999 -9999 -9999 -9999 -9999 -9999 -9999 -9999 -9999 -9999 -9999 -9999 -9999 -9999 -9999 -9999 -9999 -9999 -9999 -9999 -9999 -9999 -9999 -9999 -9999 -9999 -9999 -9999-9999 -9999 -9999 -9999 -9999 -9999 -9999 -9999 -9999 -9999 -9999 -9999 -9999 -9999 -9999 -9999 -9999 -9999 -9999 -9999 -9999 -

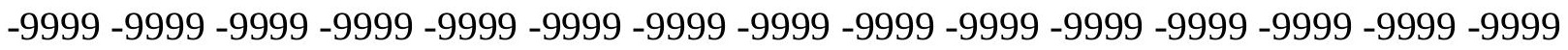
-9999 -9999 -9999 -9999 -9999 -9999 -9999 -9999 -9999 -9999 -9999 -9999 -9999 -9999 -9999 -9999 -9999 -9999 -9999 -9999 -9999 -9999 -9999 -9999 -9999 -9999 -9999 -9999 -9999 -9999 -

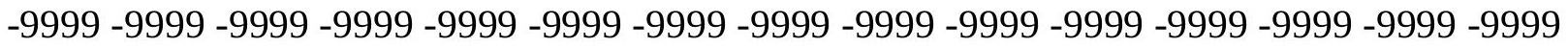

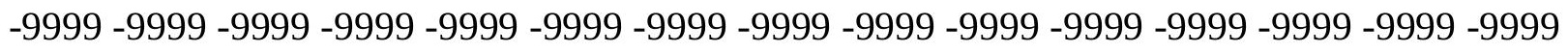
-9999 -9999-9999-9999-9999 -9999-9999 111.5163803101109 .53540802108 .0241851807 107.1312179565106 .979598999107 .2844009399108 .1986999512109 .7226028442 111.24659729113 .075302124114 .9039993286116 .7326965332118 .5614013672 120.0852966309121 .3044967651122 .5235977173123 .1332015991123 .43800354 123.43800354123 .7427978516123 .7427978516123 .7427978516123 .7427978516 124.0475006104124 .0475006104124 .0475006104124 .0475006104124 .0475006104 124.0475006104124 .0475006104123 .7427978516123 .7427978516123 .43800354 123.1332015991123 .1332015991122 .5235977173122 .2188034058121 .9140014648 121.6092987061120 .9997024536120 .6949005127120 .0852966309119 .7806015015 
119.4757995605119 .1709976196119 .1709976196119 .1709976196119 .1709976196 119.1709976196119 .4757995605119 .7806015015120 .3900985718120 .9997024536 121.3044967651121 .9140014648122 .5235977173122 .8283996582123 .1332015991 123.1332015991123 .1332015991122 .8283996582121 .9140014648120 .6949005127 118.8662033081116 .4279022217113 .9896011353110 .9418029785107 .5891036987 103.626899719299 .3599472045994 .7881774902389 .9116134643684 .73026275635 79.2441329956173 .4532165527367 .6623001098661 .5666007995655 .47089004517 49.3385810852143 .44110107422 -9999 -9999 -9999 -9999 -9999 -9999 -9999 -9999 -9999 -9999 -9999 -9999 -9999 -9999 -9999 -9999 -9999 -9999 -9999 -9999 -9999 -9999 -9999 -9999 -9999 -9999 -9999 -9999 -9999 -9999-9999 -9999

-9999 -9999 -9999 -9999 -9999 -9999 -9999 -9999 -9999 -9999 -9999 -9999 -9999 -9999 -9999 -9999 -9999 -9999 -9999 -9999 -9999 -9999 -9999 -9999 -9999 -9999 -9999 -9999 -9999 -9999 -9999 -9999 -9999 -9999 -9999 -9999 -9999 -9999 -9999 -9999 -9999 -9999 -9999 -9999 -9999 -9999 -9999 -9999 -9999 -9999 -9999 -9999 -9999 -9999 -9999 -9999 -9999 -9999 -9999 -9999 -9999 -9999 -9999 -9999 -9999 -9999 -9999 -9999 -9999 -9999 -9999 -9999 -9999 -9999 -9999

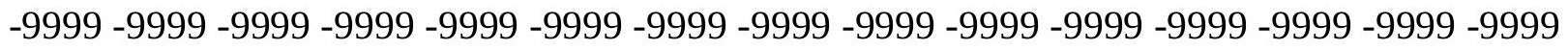
-9999 -9999 -9999 -9999 -9999 -9999 -9999 -9999 -9999 -9999 -9999 -9999 -9999 -9999 -9999 -9999 -9999 -9999 -9999 -9999 -9999 -9999 -9999 -9999 -9999 -9999 -9999 -9999 -9999 -9999 -

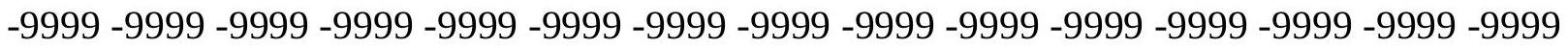

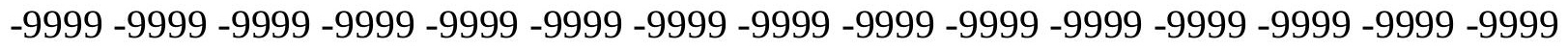

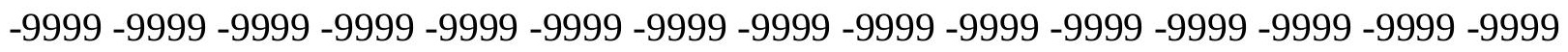
-9999 -9999 -9999 -9999 -9999 -9999 -9999 -9999 -9999 -9999 -9999 -9999 -9999 -9999 -9999 -9999 -9999 -9999 -9999 -9999 -9999 -9999 -9999 -9999 -9999 -9999 -9999 -9999 -9999 -9999 -

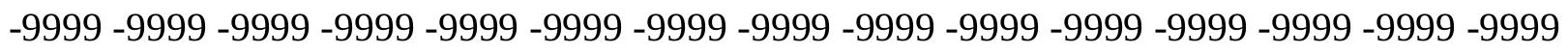

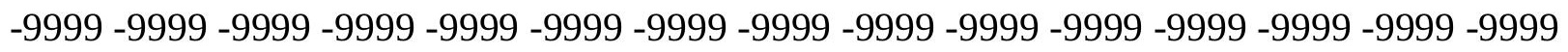
-9999 -9999 -9999 -9999 -9999 -9999 -9999 -9999 -9999 -9999 -9999 -9999 -9999 -9999 -9999

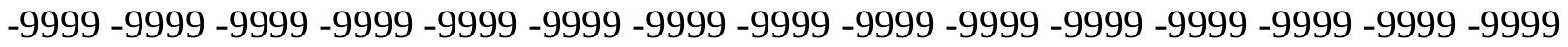

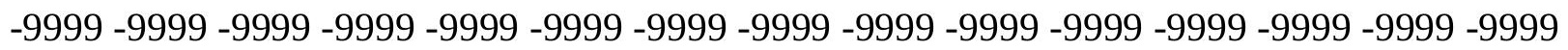
-9999 -9999 -9999-9999-9999 -9999-9999 -9999 107.9080429077106 .5508728027 105.7315979004105 .4557037354105 .7603988647106 .6747970581108 .1986999512 109.7226028442111 .8561019897113 .6848983765115 .5136032104117 .342300415 119.1709976196120 .6949005127121 .9140014648122 .5235977173122 .8283996582 123.1332015991123 .43800354123 .7427978516123 .7427978516123 .7427978516 124.0475006104124 .0475006104124 .3523025513124 .3523025513124 .3523025513 124.3523025513124 .3523025513124 .0475006104124 .0475006104123 .7427978516 123.43800354123 .1332015991122 .8283996582122 .5235977173122 .2188034058 121.6092987061120 .9997024536120 .6949005127120 .0852966309119 .7806015015 119.1709976196118 .8662033081118 .8662033081118 .8662033081118 .8662033081 118.8662033081119 .1709976196119 .7806015015120 .0852966309120 .6949005127 121.3044967651121 .9140014648122 .5235977173122 .8283996582123 .1332015991 123.43800354123 .1332015991122 .8283996582121 .9140014648120 .6949005127 118.8662033081116 .7326965332113 .9896011353110 .9418029785107 .5891036987 103.626899719299.3599472045994.4833908081189.60682678223 84.12069702148 78.6345596313572 .5388565063566 .4431610107460 .3474502563553 .94697189331 47.8613128662141 .92105484009 -9999 -9999 -9999 -9999 -9999 -9999 -9999 -9999 -9999 -9999 -9999 -9999 -9999 -9999 -9999 -9999 -9999 -9999 -9999 -9999 -9999 -9999 -9999 -9999 
-9999 -9999 -9999 -9999 -9999 -9999 -9999 -9999

-9999 -9999 -9999 -9999 -9999 -9999 -9999 -9999 -9999 -9999 -9999 -9999 -9999 -9999 -9999

-9999 -9999 -9999 -9999 -9999 -9999 -9999 -9999 -9999 -9999 -9999 -9999 -9999 -9999 -9999

-9999 -9999 -9999 -9999 -9999 -9999 -9999 -9999 -9999 -9999 -9999 -9999 -9999 -9999 -9999

-9999 -9999 -9999 -9999 -9999 -9999 -9999 -9999 -9999 -9999 -9999 -9999 -9999 -9999 -9999 -

-9999 -9999 -9999 -9999 -9999 -9999 -9999 -9999 -9999 -9999 -9999 -9999 -9999 -9999 -9999 -

-9999 -9999 -9999 -9999 -9999 -9999 -9999 -9999 -9999 -9999 -9999 -9999 -9999 -9999 -9999 -

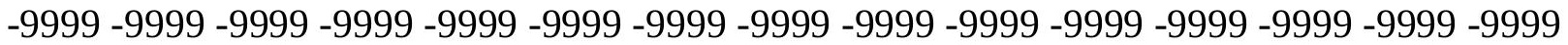

-9999 -9999 -9999 -9999 -9999 -9999 -9999 -9999 -9999 -9999 -9999 -9999 -9999 -9999 -9999

-9999 -9999 -9999 -9999 -9999 -9999 -9999 -9999 -9999 -9999 -9999 -9999 -9999 -9999 -9999 -

-9999 -9999 -9999 -9999 -9999 -9999 -9999 -9999 -9999 -9999 -9999 -9999 -9999 -9999 -9999 -

-9999 -9999 -9999 -9999 -9999 -9999 -9999 -9999 -9999 -9999 -9999 -9999 -9999 -9999 -9999

-9999 -9999 -9999 -9999 -9999 -9999 -9999 -9999 -9999 -9999 -9999 -9999 -9999 -9999 -9999 -

-9999 -9999 -9999 -9999 -9999 -9999 -9999 -9999 -9999 -9999 -9999 -9999 -9999 -9999 -9999 -

-9999 -9999 -9999 -9999 -9999 -9999 -9999 -9999 -9999 -9999 -9999 -9999 -9999 -9999 -9999

-9999 -9999 -9999 -9999 -9999 -9999 -9999 -9999 -9999 -9999 -9999 -9999 -9999 -9999 -9999

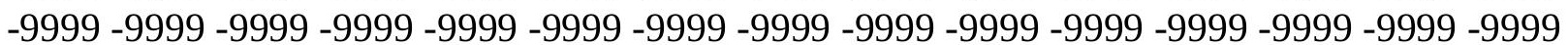

-9999 -9999 -9999 -9999 -9999 -9999 -9999 -9999 -9999 -9999 -9999 -9999 -9999 -9999 -9999 -

-9999 -9999 -9999 -9999 -9999 -9999 -9999 -9999 -9999 -9999 -9999 -9999 -9999 -9999 -9999 -999 -

-9999 -9999 -9999 -9999 -9999 -9999 -9999 -9999 -9999 105.3841934204104 .6273117065

104.3403244019104 .5412979126105 .4557037354106 .979598999108 .8082962036

110.6370010376112 .4656982422114 .5991973877116 .4279022217118 .2565994263

119.7806015015120 .9997024536121 .9140014648122 .5235977173122 .8283996582

123.1332015991123 .43800354123 .7427978516123 .7427978516124 .0475006104

124.0475006104124 .3523025513124 .3523025513124 .6570968628124 .6570968628

124.6570968628124 .3523025513124 .3523025513124 .0475006104123 .7427978516

123.43800354123 .1332015991122 .8283996582122 .2188034058121 .6092987061

120.9997024536120 .6949005127120 .0852966309119 .4757995605118 .8662033081

118.5614013672118 .2565994263118 .2565994263118 .2565994263118 .5614013672

118.8662033081119 .1709976196119 .7806015015120 .3900985718120 .9997024536

121.6092987061122 .2188034058122 .8283996582123 .1332015991123 .43800354

123.43800354122 .8283996582122 .2188034058120 .9997024536119 .1709976196

117.0374984741114 .2944030762111 .24659729107 .5891036987103 .6268997192

99.35994720459 94.48339080811 89.3020401001 83.8159103393678.02498626709

71.9292907714865 .5288009643659 .1283111572352 .7278289794946 .44356536865

40.42297363281 -9999 -9999 -9999 -9999 -9999 -9999 -9999 -9999 -9999 -9999 -9999 -9999

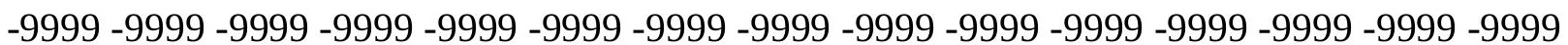

-9999 -9999-9999-9999-9999

-9999 -9999 -9999 -9999 -9999 -9999 -9999 -9999 -9999 -9999 -9999 -9999 -9999 -9999 -9999

-9999 -9999 -9999 -9999 -9999 -9999 -9999 -9999 -9999 -9999 -9999 -9999 -9999 -9999 -9999 -

-9999 -9999 -9999 -9999 -9999 -9999 -9999 -9999 -9999 -9999 -9999 -9999 -9999 -9999 -9999

-9999 -9999 -9999 -9999 -9999 -9999 -9999 -9999 -9999 -9999 -9999 -9999-9999-9999-9999 -

-9999 -9999 -9999 -9999 -9999 -9999 -9999 -9999 -9999 -9999 -9999 -9999 -9999 -9999 -9999 -

-9999 -9999 -9999 -9999 -9999 -9999 -9999 -9999 -9999 -9999 -9999 -9999 -9999 -9999 -9999 -

-9999 -9999 -9999 -9999 -9999 -9999 -9999 -9999 -9999 -9999 -9999 -9999 -9999 -9999 -9999

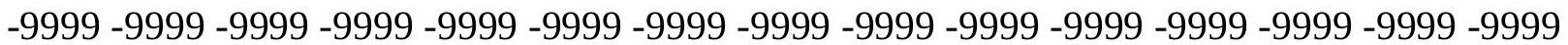


-9999 -9999 -9999 -9999 -9999 -9999 -9999 -9999 -9999 -9999 -9999 -9999 -9999 -9999 -9999 -9999 -9999 -9999 -9999 -9999 -9999 -9999 -9999 -9999 -9999 -9999 -9999 -9999 -9999 -9999 -9999 -9999 -9999 -9999 -9999 -9999 -9999 -9999 -9999 -9999 -9999 -9999 -9999 -9999 -9999 -9999 -9999 -9999 -9999 -9999 -9999 -9999 -9999 -9999 -9999 -9999 -9999 -9999 -9999 -9999 -9999 -9999 -9999 -9999 -9999 -9999 -9999 -9999 -9999 -9999 -9999 -9999 -9999 -9999 -9999 -9999 -9999 -9999 -9999 -9999 -9999 -9999 -9999 -9999 -9999 -9999 -9999 -9999 -9999 -9999 -9999 -9999 -9999 -9999 -9999 -9999 -9999 -9999 -9999 -9999 -9999 -9999 -9999 -9999 -9999

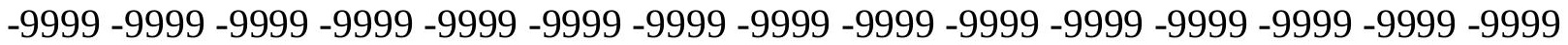

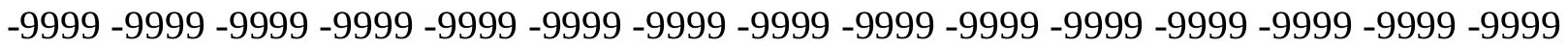
-9999 -9999 -9999 -9999 -9999 -9999 -9999 -9999 -9999 -9999 -9999 -9999 -9999 -9999 -9999 -999 -9999 -9999 -9999 -9999 -9999 -9999 -9999 -9999 -9999 -9999 103.8185882568 103.6056976318103 .9239120483104 .8460998535106 .0652008057107 .8938980103 109.7226028442111 .551399231113 .3800964355115 .5136032104117 .0374984741 118.5614013672119 .7806015015120 .9997024536121 .6092987061122 .2188034058 122.5235977173123 .1332015991123 .43800354123 .7427978516124 .0475006104 124.0475006104124 .3523025513124 .6570968628124 .6570968628124 .6570968628 124.6570968628124 .6570968628124 .6570968628124 .3523025513124 .0475006104 123.7427978516123 .43800354122 .8283996582122 .5235977173121 .9140014648 120.9997024536120 .3900985718119 .7806015015119 .1709976196118 .5614013672 118.2565994263117 .9517974854117 .647102356117 .647102356117 .9517974854 118.2565994263118 .5614013672119 .1709976196120 .0852966309120 .6949005127 121.3044967651122 .2188034058122 .5235977173123 .1332015991123 .43800354 123.43800354123 .1332015991122 .2188034058121 .3044967651119 .4757995605 117.342300415114 .5991973877111 .551399231107 .8938980103103 .9317016602 99.6647262573294 .7881774902389 .302040100183 .8159103393677 .72020721436 71.3197174072364 .9192428588958 .2139587402351 .5086898803745 .06336212158 38.95663833618 -9999 -9999 -9999 -9999 -9999 -9999 -9999 -9999 -9999 -9999 -9999 -9999 -9999 -9999 -9999 -9999 -9999 -9999 -9999 -9999 -9999 -9999 -9999 -9999 -9999 -9999 -9999 -9999 -9999 -9999 -9999 -9999

-9999 -9999 -9999 -9999 -9999 -9999 -9999 -9999 -9999 -9999 -9999 -9999 -9999 -9999 -9999 -9999 -9999 -9999 -9999 -9999 -9999 -9999 -9999 -9999 -9999 -9999 -9999 -9999 -9999 -9999 -

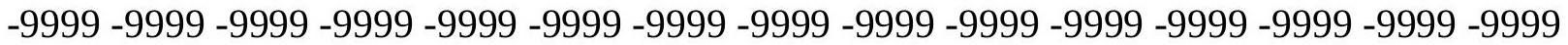
-9999 -9999 -9999 -9999 -9999 -9999 -9999 -9999 -9999 -9999 -9999 -9999 -9999 -9999 -9999 -9999 -9999 -9999 -9999 -9999 -9999 -9999 -9999 -9999 -9999 -9999 -9999 -9999 -9999 -9999 -

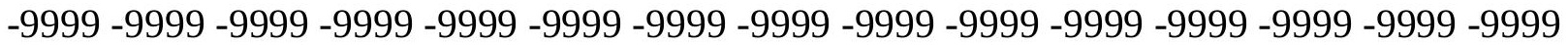
-9999 -9999 -9999 -9999 -9999 -9999 -9999 -9999 -9999 -9999 -9999 -9999 -9999 -9999 -9999 -9999 -9999 -9999 -9999 -9999 -9999 -9999 -9999 -9999 -9999 -9999 -9999 -9999 -9999 -9999

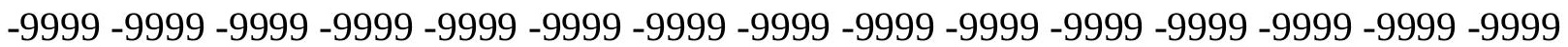
-9999 -9999 -9999 -9999 -9999 -9999 -9999 -9999 -9999 -9999 -9999 -9999 -9999 -9999 -9999 -9999 -9999 -9999 -9999 -9999 -9999 -9999 -9999 -9999 -9999 -9999 -9999 -9999 -9999 -9999 -

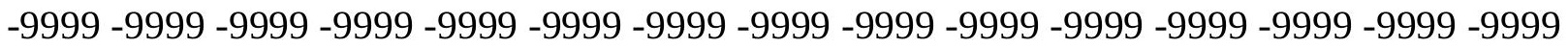
-9999 -9999 -9999 -9999 -9999 -9999 -9999 -9999 -9999 -9999 -9999 -9999 -9999 -9999 -9999 -9999 -9999 -9999 -9999 -9999 -9999 -9999 -9999 -9999 -9999 -9999 -9999 -9999 -9999 -9999 -9999 -9999 -9999 -9999 -9999 -9999 -9999 -9999 -9999 -9999 -9999 -9999 -9999 -9999 -9999 -999 -9999 -9999 -9999 -9999 -9999 -9999 -9999 -9999 -9999 -9999 -9999 -9999 -9999 -9999 -9999

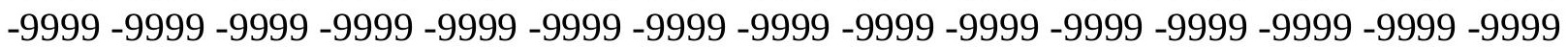


-9999 -9999 -9999 -9999 -9999 -9999 -9999 -9999 -9999 -9999 -9999 -9999 -9999 -9999 -9999 -9999 -9999 -9999 -9999 -9999 -9999 -9999 -9999 -9999 -9999 -9999 103.1477584839 103.4983215332104 .2844238281105 .4557037354107 .2844009399108 .8082962036 110.9418029785112 .7705001831114 .5991973877116 .1231002808117 .647102356 118.8662033081120 .0852966309120 .6949005127121 .6092987061122 .2188034058 122.5235977173123 .1332015991123 .43800354123 .7427978516124 .0475006104 124.3523025513124 .6570968628124 .9618988037124 .9618988037124 .9618988037 124.9618988037124 .9618988037124 .6570968628124 .3523025513124 .0475006104 123.7427978516123 .1332015991122 .5235977173121 .9140014648120 .9997024536 120.3900985718119 .4757995605118 .8662033081117 .9517974854117 .647102356 117.0374984741117 .0374984741117 .0374984741117 .0374984741117 .342300415 117.9517974854118 .5614013672119 .4757995605120 .0852966309120 .9997024536 121.9140014648122 .5235977173122 .8283996582123 .43800354123 .43800354 123.1332015991122 .5235977173121 .6092987061119 .7806015015117 .9517974854 115.2088012695112 .1608963013108 .5035018921104 .541297912699 .96952056885 95.0929565429789 .6068267822383 .8159103393677 .7202072143671 .31971740723 64.3096618652357 .6043891906750 .2895507812543 .78998184204 -9999 -9999 -9999 -9999 -9999 -9999 -9999 -9999 -9999 -9999 -9999 -9999 -9999 -9999 -9999 -9999 -9999 -9999 -9999 -9999 -9999 -9999 -9999 -9999 -9999 -9999 -9999 -9999 -9999 -9999 -9999 -9999 -9999 -

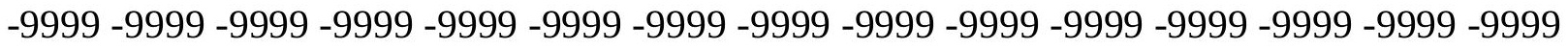
-9999 -9999 -9999 -9999 -9999 -9999 -9999 -9999 -9999 -9999 -9999 -9999 -9999 -9999 -9999 -9999 -9999 -9999 -9999 -9999 -9999 -9999 -9999 -9999 -9999 -9999 -9999 -9999 -9999 -9999 -9999 -9999 -9999 -9999 -9999 -9999 -9999 -9999 -9999 -9999 -9999 -9999 -9999 -9999 -9999 -9999 -9999 -9999 -9999 -9999 -9999 -9999 -9999 -9999 -9999 -9999 -9999 -9999 -9999 -9999 -9999 -9999 -9999 -9999 -9999 -9999 -9999 -9999 -9999 -9999 -9999 -9999 -9999 -9999 -9999 -9999 -9999 -9999 -9999 -9999 -9999 -9999 -9999 -9999 -9999 -9999 -9999 -9999 -9999 -9999 -9999 -9999 -9999 -9999 -9999 -9999 -9999 -9999 -9999 -9999 -9999 -9999 -9999 -9999 -9999 -9999 -9999 -9999 -9999 -9999 -9999 -9999 -9999 -9999 -9999 -9999 -9999 -9999 -9999 -9999 -9999 -9999 -9999 -9999 -9999 -9999 -9999 -9999 -9999 -9999 -9999 -9999 -9999 -9999 -9999 -9999 -9999 -9999 -9999 -9999 -9999 -9999 -9999 -9999 -9999 -9999 -9999 -9999 -9999 -999 -9999 -9999 -9999 -9999 -9999 -9999 -9999 -9999 -9999 -9999 -9999 -9999 -9999 -9999 -9999

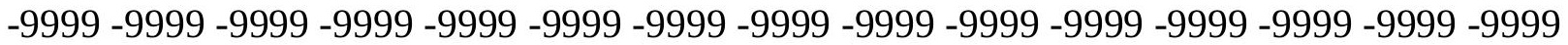

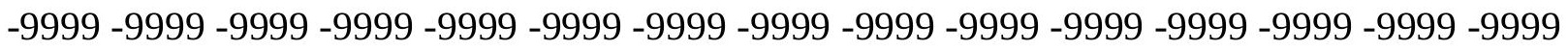

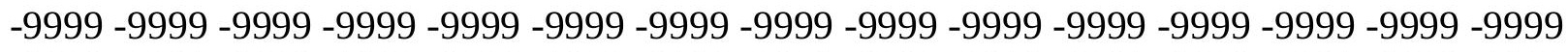
-9999 -9999 -9999 -9999 -9999 -9999 -9999 -9999 -9999 -9999 -9999 -9999 -9999 -9999 -9999 -9999 -9999 -9999 -9999 -9999 -9999 -9999 -9999 -9999 -9999 -9999 -9999 -9999 -9999 -9999

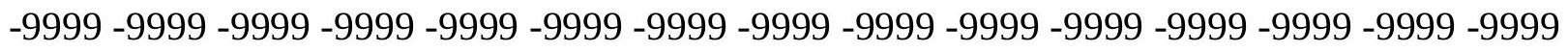
-9999 -9999-9999-9999 -9999-9999 -9999 -9999-9999-9999 -9999-9999 103.2129745483 103.983039856105 .1509017944106 .6747970581108 .5035018921110 .0273971558 111.8561019897113 .6848983765115 .2088012695116 .7326965332117 .9517974854 119.1709976196120 .0852966309120 .6949005127121 .6092987061122 .2188034058 122.5235977173123 .1332015991123 .7427978516124 .0475006104124 .3523025513 124.6570968628124 .9618988037124 .9618988037125 .2667007446125 .2667007446 124.9618988037124 .9618988037124 .6570968628124 .3523025513124 .0475006104 123.43800354122 .8283996582121 .9140014648120 .9997024536120 .0852966309 119.1709976196118 .2565994263117 .342300415116 .7326965332116 .1231002808 
116.1231002808115 .818397522116 .1231002808116 .4279022217117 .0374984741 117.9517974854118 .8662033081119 .7806015015120 .6949005127121 .3044967651 122.2188034058122 .8283996582123 .1332015991123 .43800354123 .1332015991 122.8283996582121 .9140014648120 .3900985718118 .2565994263115 .818397522 112.7705001831109 .1130981445105 .1509017944100 .579101562595 .70252990723 90.2164001464884 .4254837036178 .0249862670971 .3197174072364 .30966186523 56.9948196411149 .6799812316942 .76527023315 -9999 -9999 -9999 -9999 -9999 -9999 -9999 -9999 -9999 -9999 -9999 -9999 -9999 -9999 -9999 -9999 -9999 -9999 -9999 -9999 -9999 -9999 -9999 -9999 -9999 -9999 -9999 -9999 -9999 -9999 -9999 -9999 -9999 -9999 -9999 -9999 -9999 -9999 -9999 -9999 -9999 -9999 -9999 -9999 -9999 -9999 -9999 -9999 -9999 -9999 -9999 -9999 -9999 -9999 -9999 -9999 -9999 -9999 -9999 -9999 -9999 -9999 -9999 -999 -9999 -9999 -9999 -9999 -9999 -9999 -9999 -9999 -9999 -9999 -9999 -9999 -9999 -9999 -9999 -9999 -9999 -9999 -9999 -9999 -9999 -9999 -9999 -9999 -9999 -9999 -9999 -9999 -9999 -9999 -9999 -9999 -9999 -9999 -9999 -9999 -9999 -9999 -9999 -9999 -9999 -9999 -9999 -9999 -9999 -9999 -9999 -9999 -9999 -9999 -9999 -9999 -9999 -9999 -9999 -9999 -9999 -9999 -9999 -9999

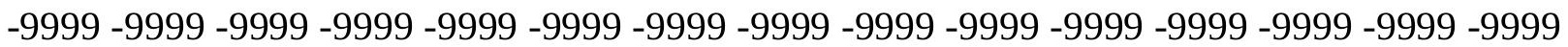

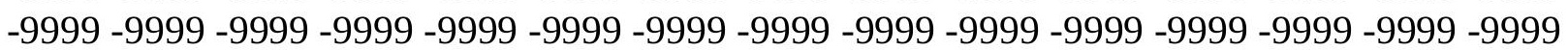
-9999 -9999 -9999 -9999 -9999 -9999 -9999 -9999 -9999 -9999 -9999 -9999 -9999 -9999 -9999 -999 -9999 -9999 -9999 -9999 -9999 -9999 -9999 -9999 -9999 -9999 -9999 -9999 -9999 -9999 -9999 -9999 -9999 -9999 -9999 -9999 -9999 -9999 -9999 -9999 -9999 -9999 -9999 -9999 -9999 -9999 -9999 -9999 -9999 -9999 -9999 -9999 -9999 -9999 -9999 -9999 -9999 -9999 -9999 -9999 -9999 -9999 -9999 -9999 -9999 -9999 -9999 -9999 -9999 -9999 -9999 -9999 -9999 -9999 -9999 -9999 -9999 -9999 -9999 -9999 -9999 -9999 -9999 -9999 -9999 -9999 -9999 -9999 -9999 -9999 -9999 -9999 -9999 -9999 -9999 -9999 -9999 -9999 -9999 -9999 -9999 -9999 -9999 -9999 -9999 -9999 -9999 -9999 -9999 -9999 -9999 -9999 -9999 -9999 -9999 -9999 -9999 -9999 -9999 -9999 -9999 -9999 -9999 -9999 -9999 -9999 -9999 -9999 -9999 -9999 -9999 -9999 -9999 -9999 -9999 -9999 -9999 -9999 -9999 -9999 -9999 -9999 -9999 -9999 -9999 -9999 -9999 -9999 -9999 -9999 -9999 -9999 -9999 -9999 -9999 -9999 -9999 -9999 -9999 -9999 -9999 -9999 -9999 -9999 103.8163146973104 .9642028809106 .3700027466107 .8938980103109 .7226028442 111.24659729112 .7705001831114 .2944030762115 .818397522117 .0374984741 118.2565994263119 .1709976196120 .0852966309120 .9997024536121 .6092987061 122.2188034058122 .8283996582123 .43800354123 .7427978516124 .3523025513 124.6570968628124 .9618988037125 .2667007446125 .2667007446125 .2667007446 125.2667007446125 .2667007446124 .9618988037124 .6570968628124 .0475006104 123.43800354122 .8283996582121 .9140014648120 .9997024536119 .7806015015 118.5614013672117 .647102356116 .7326965332115 .818397522115 .2088012695 114.9039993286114 .9039993286114 .9039993286115 .5136032104116 .1231002808 117.0374984741117 .9517974854118 .8662033081120 .0852966309120 .9997024536 121.9140014648122 .5235977173123 .1332015991123 .43800354123 .43800354 123.1332015991122 .5235977173120 .9997024536118 .8662033081116 .4279022217 113.3800964355110 .0273971558106 .0652008057101 .798202514696 .61688232422 91.1307525634885 .0350494384878 .6345596313571 .6244964599664 .30966186523 56.6900291442949 .0704002380441 .8927574157735 .22597885132 -9999 -9999 -9999-9999 -9999 -9999 -9999 -9999 -9999 -9999 -9999 -9999 -9999 -9999 -9999 -9999 -9999 -9999 -9999 -9999 -9999 -9999 -9999 -9999 -9999 -9999 -9999 -9999 -9999 -9999 -9999 -9999 -

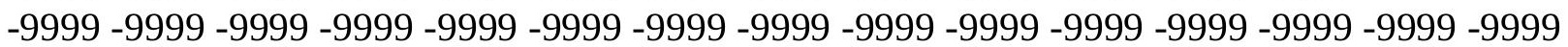


-9999 -9999 -9999 -9999 -9999 -9999 -9999 -9999 -9999 -9999 -9999 -9999 -9999 -9999 -9999 -9999 -9999 -9999 -9999 -9999 -9999 -9999 -9999 -9999 -9999 -9999 -9999 -9999 -9999 -9999 -9999 -9999 -9999 -9999 -9999 -9999 -9999 -9999 -9999 -9999 -9999 -9999 -9999 -9999 -9999 -9999 -9999 -9999 -9999 -9999 -9999 -9999 -9999 -9999 -9999 -9999 -9999 -9999 -9999 -9999 -9999 -9999 -9999 -9999 -9999 -9999 -9999 -9999 -9999 -9999 -9999 -9999 -9999 -9999 -9999 -9999 -9999 -9999 -9999 -9999 -9999 -9999 -9999 -9999 -9999 -9999 -9999 -9999 -9999 -9999 -9999 -9999 -9999 -9999 -9999 -9999 -9999 -9999 -9999 -9999 -9999 -9999 -9999 -9999 -9999

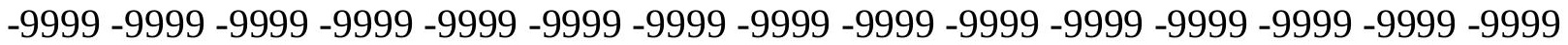
-9999 -9999 -9999 -9999 -9999 -9999 -9999 -9999 -9999 -9999 -9999 -9999 -9999 -9999 -9999 -9999 -9999 -9999 -9999 -9999 -9999 -9999 -9999 -9999 -9999 -9999 -9999 -9999 -9999 -9999 -9999 -9999 -9999 -9999 -9999 -9999 -9999 -9999 -9999 -9999 -9999 -9999 -9999 -9999 -9999 -9999 -9999 -9999 -9999 -9999 -9999 -9999 -9999 -9999 -9999 -9999 -9999 -9999 -9999 -9999

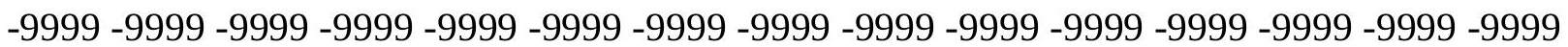
-9999 -9999 -9999 -9999 -9999 -9999 -9999 -9999 -9999 -9999 -9999 -9999 -9999 -9999 -9999 -9999 -9999 -9999 -9999 -9999 -9999 -9999 -9999 -9999 -9999 -9999 -9999 -9999 -9999 -9999

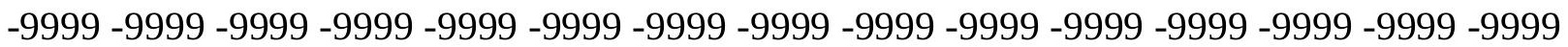

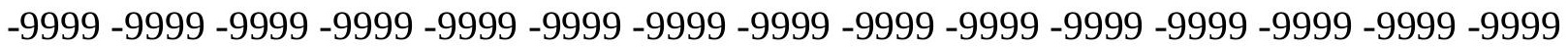
-9999 -9999 -9999 -9999 -9999 -9999 -9999 -9999 -9999 -9999 -9999 -9999 -9999 103.6895446777104 .8162689209106 .1787109375107 .5891036987109 .1130981445 110.6370010376112 .1608963013113 .6848983765114 .9039993286116 .1231002808 117.342300415118 .5614013672119 .4757995605120 .3900985718120 .9997024536 121.9140014648122 .5235977173123 .1332015991123 .7427978516124 .3523025513 124.6570968628124 .9618988037125 .2667007446125 .5715026855125 .5715026855 125.5715026855125 .2667007446124 .9618988037124 .6570968628124 .3523025513 123.7427978516122 .8283996582121 .9140014648120 .6949005127119 .1709976196 117.9517974854116 .7326965332115 .818397522114 .9039993286114 .2944030762 113.6848983765113 .6848983765113 .9896011353114 .2944030762115 .2088012695 116.1231002808117 .0374984741118 .2565994263119 .4757995605120 .3900985718 121.6092987061122 .2188034058122 .8283996582123 .1332015991123 .43800354 123.1332015991122 .5235977173121 .3044967651119 .4757995605117 .0374984741 114.2944030762110 .9418029785107 .2844009399103 .017402648997 .83602905273 92.6546783447386 .5589828491279 .8537063598672 .5388565063564 .91924285889 56.6900291442948 .765621185341 .2192802429234 .32999420166 -9999 -9999 -9999 -9999 -9999 -9999 -9999 -9999 -9999 -9999 -9999 -9999 -9999 -9999 -9999 -9999 -9999 -9999 -9999 -9999 -9999 -9999 -9999 -9999 -9999 -9999 -9999 -9999 -9999 -9999 -9999 -9999 -9999 -9999 -9999 -9999 -9999 -9999 -9999 -9999 -9999 -9999 -9999 -9999 -9999 -9999 -9999

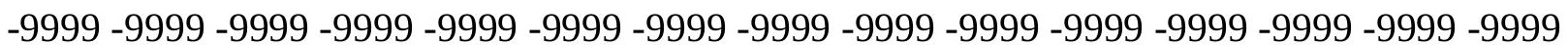

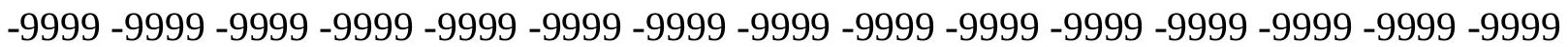
-9999 -9999 -9999 -9999 -9999 -9999 -9999 -9999 -9999 -9999 -9999 -9999 -9999 -9999 -9999 -9999 -9999 -9999 -9999 -9999 -9999 -9999 -9999 -9999 -9999 -9999 -9999 -9999 -9999 -9999 -9999 -9999 -9999 -9999 -9999 -9999 -9999 -9999 -9999 -9999 -9999 -9999 -9999 -9999 -9999

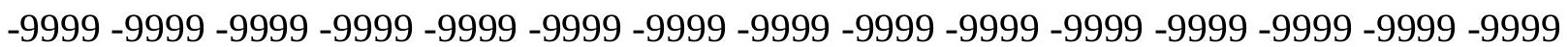
-9999 -9999 -9999 -9999 -9999 -9999 -9999 -9999 -9999 -9999 -9999 -9999 -9999 -9999 -9999 -999 -9999 -9999 -9999 -9999 -9999 -9999 -9999 -9999 -9999 -9999 -9999 -9999 -9999 -9999 -9999 -9999 -9999 -9999 -9999 -9999 -9999 -9999 -9999 -9999 -9999 -9999 -9999 -9999 -9999 -9999

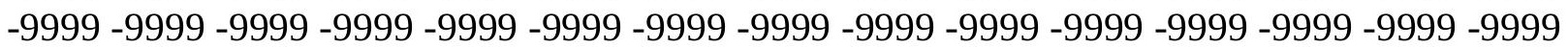


-9999 -9999 -9999 -9999 -9999 -9999 -9999 -9999 -9999 -9999 -9999 -9999 -9999 -9999 -9999 -9999 -9999 -9999 -9999 -9999 -9999 -9999 -9999 -9999 -9999 -9999 -9999 -9999 -9999 -9999 -9999 -9999 -9999 -9999 -9999 -9999 -9999 -9999 -9999 -9999 -9999 -9999 -9999 -9999 -9999 -9999 -9999 -9999 -9999 -9999 -9999 -9999 -9999 -9999 -9999 -9999 -9999 -9999 -9999 -9999 -9999 -9999 -9999 -9999 -9999 -9999 -9999 -9999 -9999 -9999 -9999 -9999 -9999 -9999 -9999 -9999 -9999 -9999 -9999 -9999 -9999 -9999 -9999 -9999 -9999 -9999 -9999 -9999 -9999 -9999 -

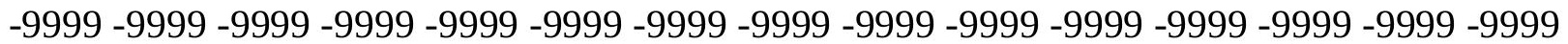
-9999 -9999 -9999 -9999 -9999 -9999 -9999 -9999 -9999 -9999 -9999 -9999 -9999 -9999 104.6487960815106 .0136795044107 .5891036987108 .8082962036110 .0273971558 111.551399231112 .7705001831113 .9896011353115 .5136032104116 .7326965332 117.647102356118 .8662033081119 .7806015015120 .6949005127121 .3044967651 122.2188034058122 .8283996582123 .43800354124 .0475006104124 .6570968628 124.9618988037125 .2667007446125 .5715026855125 .5715026855125 .5715026855 125.2667007446124 .9618988037124 .6570968628124 .0475006104123 .43800354 122.8283996582121 .6092987061120 .0852966309118 .5614013672117 .342300415 116.1231002808114 .9039993286113 .6848983765113 .075302124112 .4656982422 112.4656982422112 .4656982422113 .075302124113 .9896011353115 .2088012695 116.4279022217117 .647102356118 .8662033081120 .0852966309120 .9997024536 121.9140014648122 .5235977173123 .1332015991123 .43800354123 .1332015991 122.5235977173121 .6092987061120 .0852966309117 .9517974854115 .2088012695 112.1608963013108 .5035018921104 .236503601199 .6647262573294 .17859649658 88.0829010009881 .3776321411174 .062782287666 .1383666992257 .60438919067 48.4608306884840 .8599777221733 .70515441895 -9999 -9999 -9999 -9999 -9999 -9999 -9999 -9999 -9999 -9999 -9999 -9999 -9999 -9999 -9999 -9999 -9999 -9999 -9999 -9999 -9999 -9999 -9999 -9999 -9999 -9999 -9999 -9999 -9999 -9999 -9999 -9999 -9999 -9999 -9999 -9999 -9999 -9999 -9999 -9999 -9999 -9999 -9999 -9999 -9999 -9999 -9999 -9999 -9999 -9999 -9999 -9999 -9999 -9999 -9999 -9999 -9999 -9999 -9999 -9999 -9999 -9999 -9999 -9999 -9999 -9999 -9999 -9999 -9999 -9999 -9999 -9999 -9999 -9999 -9999 -9999 -9999 -9999 -9999 -9999 -9999 -9999 -9999 -9999 -9999 -9999 -9999 -9999 -9999 -9999 -9999 -9999 -9999 -9999 -9999 -9999 -9999 -9999 -9999 -9999 -9999 -9999 -9999 -9999 -9999 -9999 -9999 -9999 -9999 -9999 -9999 -9999 -9999 -9999 -9999 -9999 -9999 -9999 -9999 -9999 -9999 -9999 -9999 -9999 -9999 -9999 -9999 -9999 -9999 -9999 -9999 -9999 -9999 -9999 -9999 -9999 -9999 -9999 -9999 -9999 -9999 -9999 -9999 -9999 -9999 -9999 -9999 -9999 -9999 -9999 -9999 -9999 -9999 -9999 -9999 -9999 -9999 -9999 -9999 -9999 -9999 -9999 -9999 -9999 -9999 -9999 -9999

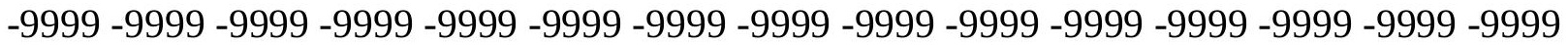
-9999 -9999 -9999 -9999 -9999 -9999 -9999 -9999 -9999 -9999 -9999 -9999 -9999 -9999 -9999 -9999 -9999 -9999 -9999 -9999 -9999 -9999 -9999 -9999 -9999 -9999 -9999 -9999 -9999 -9999

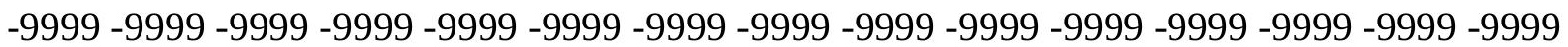
-9999 -9999 -9999 -9999 -9999 -9999 -9999 -9999 -9999 -9999 -9999 -9999 -9999 -9999 -9999 -9999 -9999 -9999 -9999 -9999 -9999 -9999 -9999 -9999 -9999 -9999 -9999 -9999 -9999 -9999 -9999 -9999 -9999 -9999 -9999 -9999 -9999 -9999 -9999 -9999 -9999 -9999 -9999 -9999 -9999

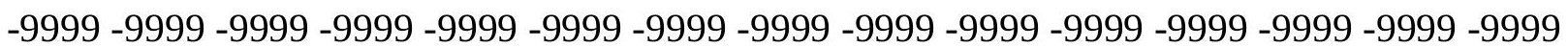
-9999 -9999 -9999 -9999 -9999 -9999 -9999 -9999 -9999 -9999 -9999 -9999 -9999 -9999 -9999 -9999 -9999 -9999 -9999 -9999 -9999 -9999 -9999 -9999 -9999 -9999 -9999 -9999 -9999 -9999 105.7006530762107 .0301742554108 .1986999512109 .4179000854110 .9418029785 112.1608963013113 .3800964355114 .5991973877115 .818397522117 .0374984741 
118.2565994263119 .1709976196120 .0852966309120 .9997024536121 .9140014648 122.5235977173123 .1332015991124 .0475006104124 .3523025513124 .9618988037 125.2667007446125 .5715026855125 .5715026855125 .5715026855125 .2667007446 124.9618988037124 .6570968628124 .0475006104123 .1332015991122 .2188034058 120.9997024536119 .4757995605117 .9517974854116 .4279022217115 .2088012695 113.6848983765112 .7705001831111 .8561019897111 .24659729110 .9418029785 111.24659729111 .8561019897113 .075302124114 .2944030762115 .5136032104 116.7326965332118 .2565994263119 .4757995605120 .6949005127121 .6092987061 122.5235977173122 .8283996582123 .1332015991123 .1332015991122 .8283996582 121.9140014648120 .3900985718118 .5614013672116 .1231002808113 .3800964355 110.0273971558106 .0652008057101 .493400573796 .3121032714890 .52117919922 83.81591033936 76.1962814331167.9670867919958.82352828979 49.67998123169 41.1476516723633 .36315536499 -9999 -9999 -9999 -9999 -9999 -9999 -9999 -9999 -9999 -9999 -9999 -9999 -9999 -9999 -9999 -9999 -9999 -9999 -9999 -9999 -9999 -9999 -9999 -9999 -9999 -9999 -9999 -9999 -9999 -9999 -9999 -9999

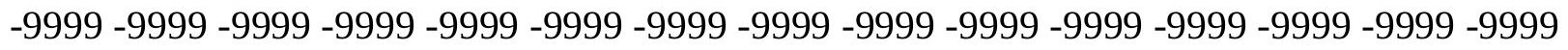

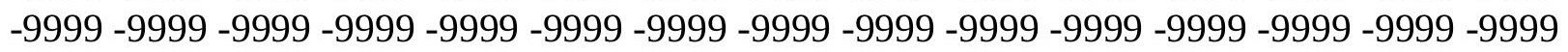

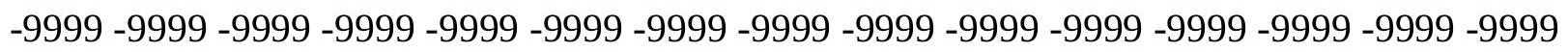

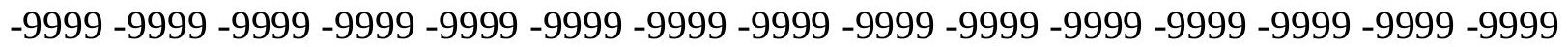

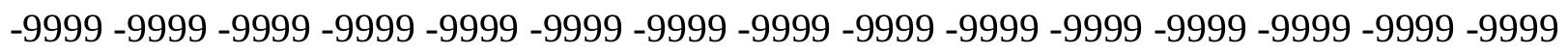

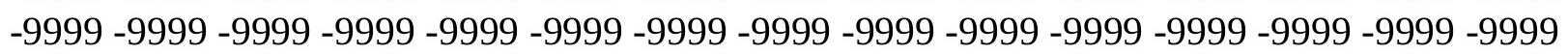

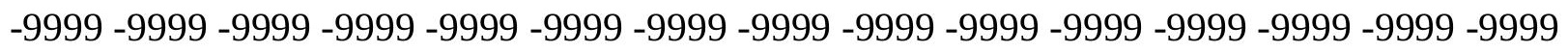

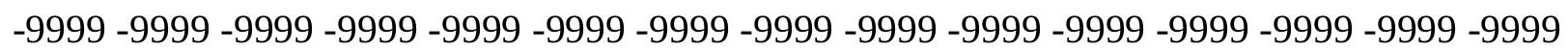

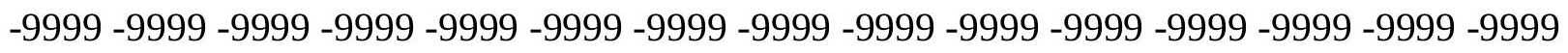

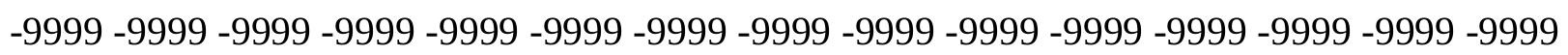

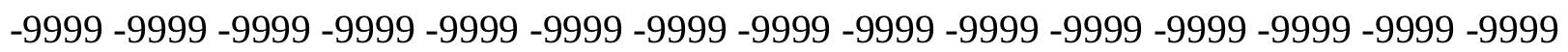

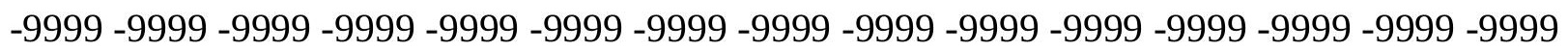

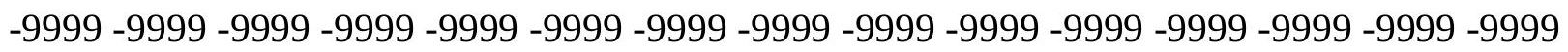

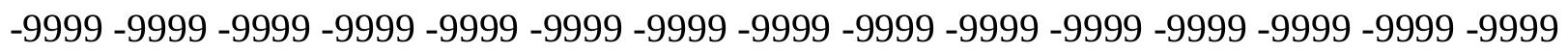

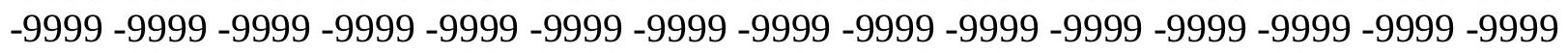
-9999 -9999 -9999 -9999 -9999 -9999 -9999 -9999 -9999 -9999 -9999 -9999 -9999 -9999 -9999

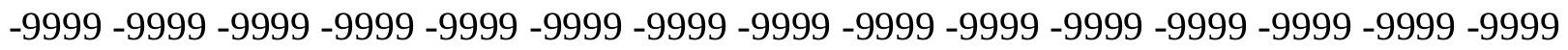

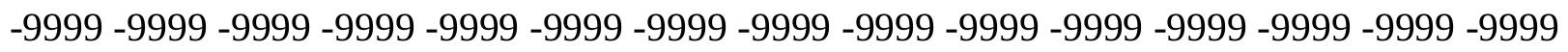

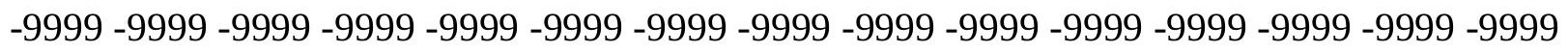
105.2601013184 106.4897384644 107.7530822754 109.1130981445110.3321990967 111.551399231112 .7705001831113 .9896011353115 .2088012695116 .4279022217 117.342300415118 .5614013672119 .4757995605120 .3900985718121 .3044967651 122.2188034058123 .1332015991123 .7427978516124 .3523025513124 .9618988037 125.2667007446125 .5715026855125 .5715026855125 .5715026855125 .2667007446 124.9618988037124 .3523025513123 .7427978516122 .8283996582121 .6092987061 120.3900985718118 .8662033081117 .342300415115 .818397522114 .2944030762 112.7705001831111 .551399231110 .6370010376110 .0273971558109 .7226028442 110.0273971558110 .9418029785111 .8561019897113 .3800964355114 .5991973877 116.1231002808117 .647102356118 .8662033081120 .0852966309121 .3044967651 122.2188034058122 .8283996582123 .1332015991123 .1332015991122 .8283996582 122.2188034058120 .9997024536119 .4757995605117 .342300415114 .5991973877 
111.8561019897108 .1986999512103 .931701660299 .0551681518693 .26425170898 86.5589828491278 .9393463134870 .4053573608460 .9570198059151 .20389938354 41.8278694152833 .27592849731 -9999 -9999 -9999 -9999 -9999 -9999 -9999 -9999 -9999 -9999 -9999 -9999 -9999 -9999 -9999 -9999 -9999 -9999 -9999 -9999 -9999 -9999 -9999 -9999 -9999 -9999 -9999 -9999-9999-9999-9999-9999

-9999 -9999 -9999 -9999 -9999 -9999 -9999 -9999 -9999 -9999 -9999 -9999 -9999 -9999 -9999 -9999 -9999 -9999 -9999 -9999 -9999 -9999 -9999 -9999 -9999 -9999 -9999 -9999 -9999 -9999 -9999 -9999 -9999 -9999 -9999 -9999 -9999 -9999 -9999 -9999 -9999 -9999 -9999 -9999 -9999 -9999 -9999 -9999 -9999 -9999 -9999 -9999 -9999 -9999 -9999 -9999 -9999 -9999 -9999 -9999 -9999 -9999 -9999 -9999 -9999 -9999 -9999 -9999 -9999 -9999 -9999 -9999 -9999 -9999 -9999 -

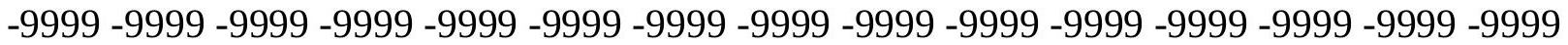
-9999 -9999 -9999 -9999 -9999 -9999 -9999 -9999 -9999 -9999 -9999 -9999 -9999 -9999 -9999 -9999 -9999 -9999 -9999 -9999 -9999 -9999 -9999 -9999 -9999 -9999 -9999 -9999 -9999 -9999 -9999 -9999 -9999 -9999 -9999 -9999 -9999 -9999 -9999 -9999 -9999 -9999 -9999 -9999 -9999 -9999 -9999 -9999 -9999 -9999 -9999 -9999 -9999 -9999 -9999 -9999 -9999 -9999 -9999 -9999

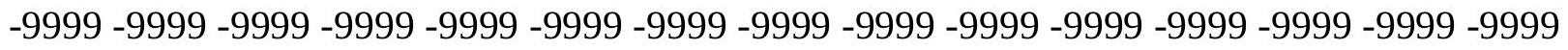
-9999 -9999 -9999 -9999 -9999 -9999 -9999 -9999 -9999 -9999 -9999 -9999 -9999 -9999 -9999 -9999 -9999 -9999 -9999 -9999 -9999 -9999 -9999 -9999 -9999 -9999 -9999 -9999 -9999 -9999 -

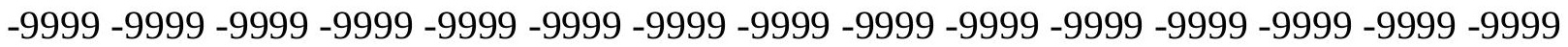

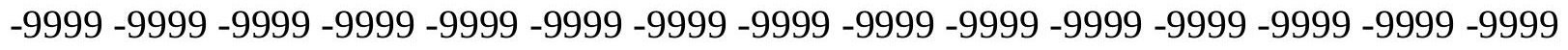

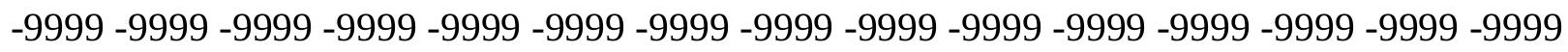
-9999 -9999 -9999 -9999 -9999 -9999 -9999 -9999 -9999 -9999 -9999 -9999 -9999 -9999 -9999 -9999 -9999 -9999 -9999 -9999 -9999 -9999 -9999 -9999 -9999 -9999 -9999-9999-9999-9999 -999 -9999 -9999 -9999 -9999 -9999 -9999 -9999 -9999 -9999 -9999 -9999 -9999 -9999 -9999 -9999 -9999 105.9604415894 107.2118377686108.4839096069 109.7226028442110.9418029785 112.1608963013113 .3800964355114 .5991973877115 .818397522116 .7326965332 117.9517974854118 .8662033081120 .0852966309120 .9997024536121 .9140014648 122.5235977173123 .43800354124 .0475006104124 .6570968628125 .2667007446 125.5715026855125 .5715026855125 .5715026855125 .2667007446124 .9618988037 124.0475006104123 .43800354122 .2188034058120 .9997024536119 .4757995605 117.9517974854116 .4279022217114 .9039993286113 .3800964355111 .8561019897 110.6370010376109 .7226028442108 .8082962036108 .5035018921108 .8082962036 109.7226028442111 .24659729112 .4656982422113 .9896011353115 .5136032104 117.0374984741118 .5614013672119 .7806015015120 .6949005127121 .9140014648 122.5235977173122 .8283996582123 .1332015991122 .8283996582122 .2188034058 121.3044967651120 .0852966309118 .2565994263116 .1231002808113 .3800964355 110.3321990967106 .6747970581102 .102996826296 .6168823242290 .21640014648 82.5967712402373 .4532165527363 .7000885009853 .0326118469242 .67330551147 33.26417922974 -9999 -9999 -9999 -9999 -9999 -9999 -9999 -9999 -9999 -9999 -9999 -9999 -9999 -9999 -9999 -9999 -9999-9999 -9999 -9999 -9999 -9999 -9999 -9999 -9999 -9999 - 9999 -9999 -9999-9999-9999-9999

-9999 -9999 -9999 -9999 -9999 -9999 -9999 -9999 -9999 -9999 -9999 -9999 -9999 -9999 -9999 -9999 -9999 -9999 -9999 -9999 -9999 -9999 -9999 -9999 -9999 -9999 -9999 -9999 -9999 -9999 -9999 -9999 -9999 -9999 -9999 -9999 -9999 -9999 -9999 -9999 -9999 -9999 -9999 -9999 -9999 -9999 -9999 -9999 -9999 -9999 -9999 -9999 -9999 -9999 -9999 -9999 -9999 -9999 -9999 -9999 -

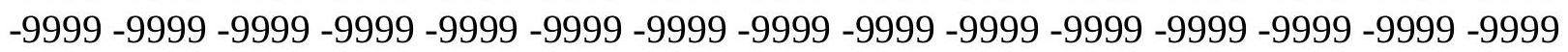


-9999 -9999 -9999 -9999 -9999 -9999 -9999 -9999 -9999 -9999 -9999 -9999 -9999 -9999 -9999 -9999 -9999 -9999 -9999 -9999 -9999 -9999 -9999 -9999 -9999 -9999 -9999 -9999 -9999 -9999 -9999 -9999 -9999 -9999 -9999 -9999 -9999 -9999 -9999 -9999 -9999 -9999 -9999 -9999 -9999 -9999 -9999 -9999 -9999 -9999 -9999 -9999 -9999 -9999 -9999 -9999 -9999 -9999 -9999 -9999 -9999 -9999 -9999 -9999 -9999 -9999 -9999 -9999 -9999 -9999 -9999 -9999 -9999 -9999 -9999 -9999 -9999 -9999 -9999 -9999 -9999 -9999 -9999 -9999 -9999 -9999 -9999 -9999 -9999 -9999 -9999 -9999 -9999 -9999 -9999 -9999 -9999 -9999 -9999 -9999 -9999 -9999 -9999 -9999 -9999

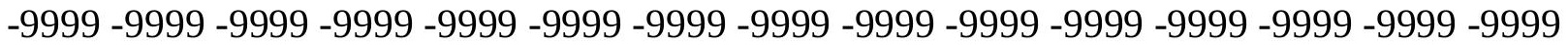
-9999 -9999 -9999 -9999 -9999 -9999 -9999 -9999 -9999 -9999 -9999 -9999 -9999 -9999 -9999 -9999 -9999 -9999 -9999 -9999 -9999 -9999 -9999 -9999 -9999 -9999 -9999 -9999 -9999 -9999 -

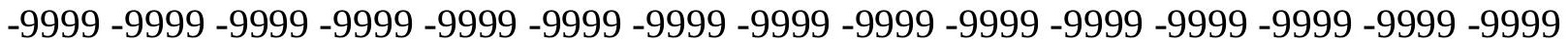
-9999 -9999 -9999 -9999 -9999 -9999 -9999 -9999 -9999 -9999 -9999 -9999 -9999 -9999 -9999

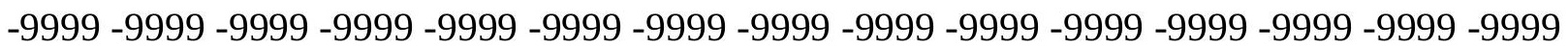
-9999 -9999 -9999 -9999 -9999 -9999 -9999 -9999 -9999 -9999 -9999 -9999 -9999 -9999 -9999 -9999 -9999 106.5676345825 107.7759170532108.9457397461 110.0273971558 111.24659729 112.4656982422113 .6848983765114 .9039993286116 .1231002808117 .342300415 118.2565994263119 .4757995605120 .3900985718121 .3044967651122 .2188034058 123.1332015991124 .0475006104124 .6570968628124 .9618988037125 .2667007446 125.5715026855125 .5715026855125 .2667007446124 .6570968628124 .0475006104 122.8283996582121 .9140014648120 .3900985718118 .8662033081117 .342300415 115.5136032104113 .9896011353112 .4656982422110 .9418029785109 .7226028442 108.8082962036108 .1986999512107 .8938980103107 .8938980103109 .1130981445 110.3321990967111 .8561019897113 .3800964355114 .9039993286116 .4279022217 117.9517974854119 .1709976196120 .3900985718121 .3044967651122 .2188034058 122.8283996582122 .8283996582122 .8283996582122 .5235977173121 .6092987061 120.6949005127119 .1709976196117 .647102356115 .5136032104112 .7705001831 109.4179000854105 .4557037354100 .579101562594 .4833908081186 .86376190186 77.4154205322366 .7479400634855 .1661109924343 .6708679199233 .2760925293 24.55838775635 -9999 -9999 -9999 -9999 -9999 -9999 -9999 -9999 -9999 -9999 -9999 -9999 -9999 -9999 -9999 -9999 -9999 -9999 -9999 -9999 -9999 -9999 -9999 -9999 -9999 -9999 -9999 -9999 -9999-9999-9999

-9999 -9999 -9999 -9999 -9999 -9999 -9999 -9999 -9999 -9999 -9999 -9999 -9999 -9999 -9999 -9999 -9999 -9999 -9999 -9999 -9999 -9999 -9999 -9999 -9999 -9999 -9999 -9999 -9999 -9999 -9999 -9999 -9999 -9999 -9999 -9999 -9999 -9999 -9999 -9999 -9999 -9999 -9999 -9999 -9999 -

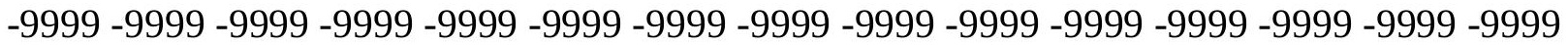
-9999 -9999 -9999 -9999 -9999 -9999 -9999 -9999 -9999 -9999 -9999 -9999 -9999 -9999 -9999 -9999 -9999 -9999 -9999 -9999 -9999 -9999 -9999 -9999 -9999 -9999 -9999 -9999 -9999 -9999

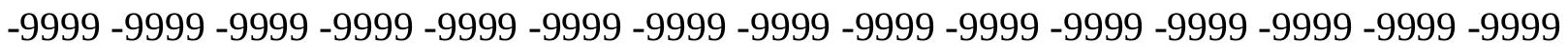
-9999 -9999 -9999 -9999 -9999 -9999 -9999 -9999 -9999 -9999 -9999 -9999 -9999 -9999 -9999 -9999 -9999 -9999 -9999 -9999 -9999 -9999 -9999 -9999 -9999 -9999 -9999 -9999 -9999 -9999 -9999 -9999 -9999 -9999 -9999 -9999 -9999 -9999 -9999 -9999 -9999 -9999 -9999 -9999 -9999 -9999 -9999 -9999 -9999 -9999 -9999 -9999 -9999 -9999 -9999 -9999 -9999 -9999 -9999 -9999 -9999 -9999 -9999 -9999 -9999 -9999 -9999 -9999 -9999 -9999 -9999 -9999 -9999 -9999 -9999 -9999 -9999 -9999 -9999 -9999 -9999 -9999 -9999 -9999 -9999 -9999 -9999 -9999 -9999 -9999 -9999 -9999 -9999 -9999 -9999 -9999 -9999 -9999 -9999 -9999 -9999 -9999 -9999 -9999 -9999

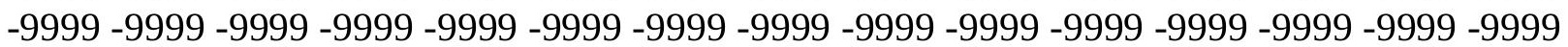


-9999 -9999 -9999 -9999 -9999 -9999 -9999 -9999 -9999 -9999 -9999 -9999 -9999 -9999 -9999 -9999 -9999 -9999 -9999 -9999 -9999 -9999 -9999 -9999 -9999 -9999 -9999 -9999 -9999 -9999 -9999 -9999 -9999 -9999 -9999 -9999 -9999 -9999 -9999 -9999 -9999 -9999 -9999 -9999 -9999 -9999 -9999 -9999 -9999 -9999 -9999 -9999 -9999 -9999 -9999 -9999 -9999 -9999 -9999 -9999 -9999 -9999-9999 107.0232315063108.1810455322 109.3637008667 110.6370010376 111.8561019897113 .075302124114 .2944030762115 .5136032104116 .7326965332 117.647102356118 .8662033081119 .7806015015120 .9997024536121 .9140014648 122.8283996582123 .7427978516124 .3523025513124 .9618988037125 .2667007446 125.2667007446125 .2667007446124 .9618988037124 .3523025513123 .7427978516 122.5235977173121 .3044967651119 .7806015015118 .2565994263116 .7326965332 114.9039993286113 .075302124111 .551399231110 .3321990967109 .1130981445 108.1986999512107 .5891036987107 .2844009399107 .8938980103108 .8082962036 110.0273971558111 .551399231113 .075302124114 .5991973877116 .1231002808 117.647102356118 .8662033081120 .0852966309120 .9997024536121 .9140014648 122.5235977173122 .8283996582122 .8283996582122 .5235977173121 .9140014648 121.3044967651120 .0852966309118 .8662033081117 .0374984741115 .2088012695 112.4656982422109 .1130981445104 .846099853599 .3599472045992 .04509735107 82.5967712402371 .3197174072358 .2139587402344 .9314422607433 .51829147339 24.21787452698 -9999 -9999 -9999 -9999 -9999 -9999 -9999 -9999 -9999 -9999 -9999 -9999

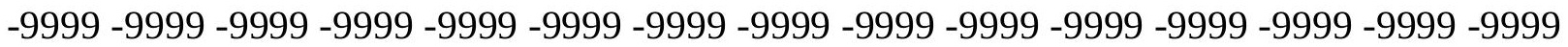
-9999 -9999 -9999-9999

-9999 -9999 -9999 -9999 -9999 -9999 -9999 -9999 -9999 -9999 -9999 -9999 -9999 -9999 -9999 -9999 -9999 -9999 -9999 -9999 -9999 -9999 -9999 -9999 -9999 -9999 -9999 -9999 -9999 -9999 -9999 -9999 -9999 -9999 -9999 -9999 -9999 -9999 -9999 -9999 -9999 -9999 -9999 -9999 -9999

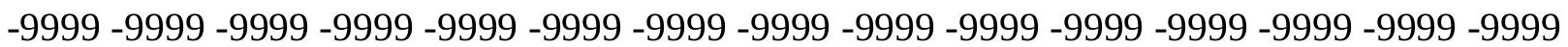
-9999 -9999 -9999 -9999 -9999 -9999 -9999 -9999 -9999 -9999 -9999 -9999 -9999 -9999 -9999 -9999 -9999 -9999 -9999 -9999 -9999 -9999 -9999 -9999 -9999 -9999 -9999 -9999 -9999 -9999 -9999 -9999 -9999 -9999 -9999 -9999 -9999 -9999 -9999 -9999 -9999 -9999 -9999 -9999 -9999 -9999 -9999 -9999 -9999 -9999 -9999 -9999 -9999 -9999 -9999 -9999 -9999 -9999 -9999 -9999 -9999 -9999 -9999 -9999 -9999 -9999 -9999 -9999 -9999 -9999 -9999 -9999 -9999 -9999 -9999 -9999 -9999 -9999 -9999 -9999 -9999 -9999 -9999 -9999 -9999 -9999 -9999 -9999 -9999 -9999 -

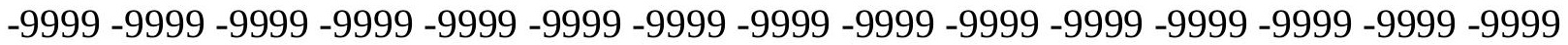
-9999 -9999 -9999 -9999 -9999 -9999 -9999 -9999 -9999 -9999 -9999 -9999 -9999 -9999 -9999 -9999 -9999 -9999 -9999 -9999 -9999 -9999 -9999 -9999 -9999 -9999 -9999 -9999 -9999 -9999 -

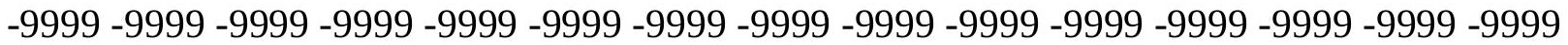
-9999 -9999 -9999 -9999 -9999 -9999 -9999 -9999 -9999 -9999 -9999 -9999 -9999 -9999 -9999 -9999 -9999 -9999 -9999 -9999 -9999 -9999 -9999 -9999 -9999 -9999 -9999 -9999 -9999 -9999

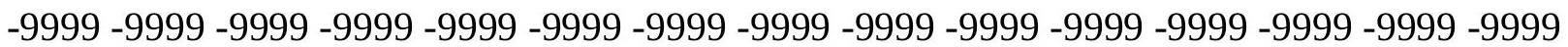
-9999 -9999 -9999 -9999 -9999 -9999 -9999 -9999 -9999 -9999 -9999 -9999 -9999 -9999 -9999 -9999 -9999 -9999 -9999 -9999 -9999 -9999 -9999 -9999 -9999 -9999 -9999 -9999 -9999 -9999 -9999 -9999 -9999 -9999 107.4351730347 108.6598052979 109.945602417 111.24659729 112.1608963013113 .3800964355114 .5991973877115 .818397522117 .0374984741 118.2565994263119 .4757995605120 .3900985718121 .6092987061122 .5235977173 123.43800354124 .0475006104124 .6570968628124 .9618988037125 .2667007446 125.2667007446124 .9618988037124 .3523025513123 .43800354122 .2188034058 120.9997024536119 .4757995605117 .647102356115 .818397522114 .2944030762 
112.4656982422110 .9418029785109 .4179000854108 .5035018921107 .5891036987 107.2844009399 107.2844009399 107.5891036987108.5035018921 109.7226028442 111.24659729112 .7705001831114 .2944030762115 .5136032104117 .0374984741 118.2565994263119 .4757995605120 .6949005127121 .3044967651121 .9140014648 122.5235977173122 .5235977173122 .5235977173122 .2188034058121 .6092987061 120.9997024536120 .0852966309118 .8662033081117 .342300415115 .5136032104 113.075302124109 .4179000854104 .846099853598 .1408081054789 .3020401001 77.4154205322363 .0905189514246 .9369087219234 .7768821716324 .50637435913 -9999 -9999 -9999 -9999 -9999 -9999 -9999 -9999 -9999 -9999 -9999 -9999 -9999 -9999 -9999 -9999 -9999 -9999 -9999 -9999 -9999 -9999 -9999 -9999 -9999 -9999 -9999 -9999 -9999 -9999 -9999 -

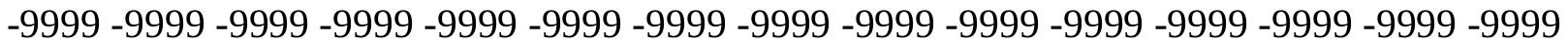
-9999 -9999 -9999 -9999 -9999 -9999 -9999 -9999 -9999 -9999 -9999 -9999 -9999 -9999 -9999 -9999 -9999 -9999 -9999 -9999 -9999 -9999 -9999 -9999 -9999 -9999 -9999 -9999 -9999 -9999 -9999 -9999 -9999 -9999 -9999 -9999 -9999 -9999 -9999 -9999 -9999 -9999 -9999 -9999 -9999 -9999 -9999 -9999 -9999 -9999 -9999 -9999 -9999 -9999 -9999 -9999 -9999 -9999 -9999 -9999

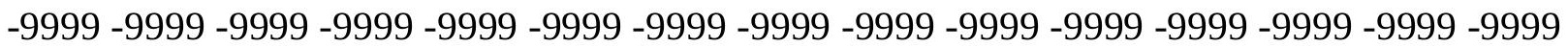

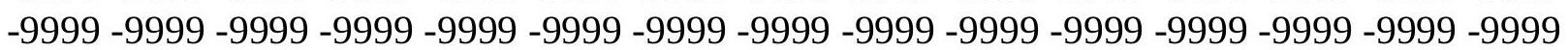
-9999 -9999 -9999 -9999 -9999 -9999 -9999 -9999 -9999 -9999 -9999 -9999 -9999 -9999 -9999 -999 -9999 -9999 -9999 -9999 -9999 -9999 -9999 -9999 -9999 -9999 -9999 -9999 -9999 -9999 -9999 -9999 -9999 -9999 -9999 -9999 -9999 -9999 -9999 -9999 -9999 -9999 -9999 -9999 -9999 -9999 -9999 -9999 -9999 -9999 -9999 -9999 -9999 -9999 -9999 -9999 -9999 -9999 -9999 -9999 -9999 -9999 -9999 -9999 -9999 -9999 -9999 -9999 -9999 -9999 -9999 -9999 -9999 -9999 -9999 -9999 -9999 -9999 -9999 -9999 -9999 -9999 -9999 -9999 -9999 -9999 -9999 -9999 -9999 -9999 -9999 -9999 -9999 -9999 -9999 -9999 -9999 -9999 -9999 -9999 -9999 -9999 -9999 -9999 -9999 -9999 -9999 -9999 -9999 -9999 -9999 -9999 -9999 -9999 -9999 -9999 -9999 -9999 -9999 -9999 -9999 -9999 -9999 -9999 -9999 -9999 -9999 -9999 -9999 -9999 -9999 -9999 -9999 -9999 -9999 -9999 -9999 -9999 -9999 -9999 -9999 -9999 -9999 -9999 -9999 -9999 -9999 -9999 -9999 -9999 -9999

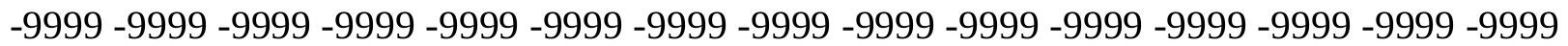
-9999 -9999 -9999 -9999 -9999 -9999 -9999 -9999 -9999 -9999 -9999 -9999 -9999 -9999 -9999 -999 -9999 -9999 -9999 -9999 -9999 107.8768692017 109.1210861206 110.3321990967 111.551399231112 .7705001831113 .9896011353115 .2088012695116 .4279022217 117.647102356118 .5614013672119 .7806015015120 .9997024536121 .9140014648 123.1332015991123 .7427978516124 .3523025513124 .9618988037124 .9618988037 124.9618988037124 .6570968628124 .0475006104123 .1332015991121 .9140014648 120.6949005127118 .8662033081117 .342300415115 .2088012695113 .3800964355 111.8561019897110 .3321990967108 .8082962036107 .8938980103107 .2844009399 106.979598999 106.979598999 107.5891036987108.5035018921 109.7226028442 110.9418029785112 .4656982422113 .9896011353115 .2088012695116 .7326965332 117.9517974854119 .1709976196120 .0852966309120 .9997024536121 .6092987061 121.9140014648122 .2188034058122 .2188034058121 .9140014648121 .6092987061 121.3044967651120 .9997024536120 .0852966309119 .1709976196117 .9517974854 116.4279022217114 .2944030762110 .6370010376105 .455703735497 .53124237061 86.254188537671 .014930725153 .3373985290538 .0267715454125 .59847068787 -9999 -9999 -9999 -9999 -9999 -9999 -9999 -9999 -9999 -9999 -9999 -9999 -9999 -9999 -9999 -9999 -9999 -9999 -9999 -9999 -9999 -9999 -9999 -9999 -9999 -9999 -9999 -9999 -9999 -9999 -9999 -9999 -9999 -9999 -9999 -9999 -9999 -9999 -9999 -9999 -9999 -9999 -9999 -9999 -9999 -9999 
-9999 -9999 -9999 -9999 -9999 -9999 -9999 -9999 -9999 -9999 -9999 -9999 -9999 -9999 -9999 -9999 -9999 -9999 -9999 -9999 -9999 -9999 -9999 -9999 -9999 -9999 -9999 -9999 -9999 -9999 -9999 -9999 -9999 -9999 -9999 -9999 -9999 -9999 -9999 -9999 -9999 -9999 -9999 -9999 -9999 -9999 -9999 -9999 -9999 -9999 -9999 -9999 -9999 -9999 -9999 -9999 -9999 -9999 -9999 -9999 -9999 -9999 -9999 -9999 -9999 -9999 -9999 -9999 -9999 -9999 -9999 -9999 -9999 -9999 -9999 -9999 -9999 -9999 -9999 -9999 -9999 -9999 -9999 -9999 -9999 -9999 -9999 -9999 -9999 -9999 -9999 -9999 -9999 -9999 -9999 -9999 -9999 -9999 -9999 -9999 -9999 -9999 -9999 -9999 -9999

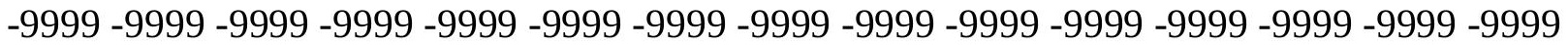
-9999 -9999 -9999 -9999 -9999 -9999 -9999 -9999 -9999 -9999 -9999 -9999 -9999 -9999 -9999 -9999 -9999 -9999 -9999 -9999 -9999 -9999 -9999 -9999 -9999 -9999 -9999 -9999 -9999 -9999 -

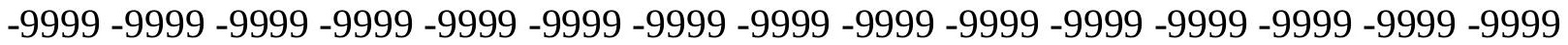
-9999 -9999 -9999 -9999 -9999 -9999 -9999 -9999 -9999 -9999 -9999 -9999 -9999 -9999 -9999

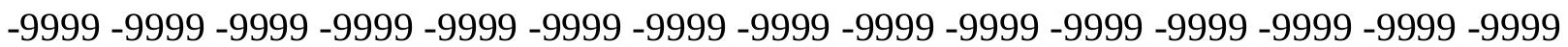
-9999 -9999 -9999 -9999 -9999 -9999 -9999 -9999 -9999 -9999 -9999 -9999 -9999 -9999 -9999 -9999 -9999 -9999 -9999 -9999 -9999 -9999 -9999 -9999 -9999 -9999 -9999 -9999 -9999 -9999 -9999 -9999 -9999 -9999 -9999 -9999 -9999 -9999 -9999 -9999 -9999 -9999 -9999 -9999 -9999 -

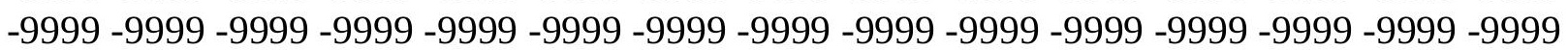
-9999 -9999 -9999 -9999 -9999 -9999 -9999 -9999 -9999 -9999 -9999 -9999 -9999 -9999 -9999 -9999 -9999 -9999 -9999 -9999-9999 108.2425765991 109.4493865967 110.6370010376 111.8561019897113 .075302124114 .2944030762115 .5136032104116 .7326965332 117.9517974854119 .1709976196120 .3900985718121 .3044967651122 .5235977173 123.43800354124 .0475006104124 .6570968628124 .9618988037124 .6570968628 124.3523025513123 .7427978516122 .8283996582121 .6092987061120 .3900985718 118.5614013672116 .7326965332114 .9039993286112 .7705001831111 .24659729 109.4179000854 108.1986999512 107.2844009399106.6747970581 106.6747970581 106.979598999107 .5891036987108 .5035018921109 .7226028442110 .9418029785 112.1608963013113 .6848983765114 .9039993286116 .1231002808117 .342300415 118.5614013672119 .4757995605120 .3900985718120 .9997024536121 .6092987061 121.9140014648121 .9140014648121 .9140014648121 .9140014648121 .9140014648 121.6092987061121 .3044967651120 .6949005127120 .3900985718119 .4757995605 118.2565994263116 .4279022217112 .7705001831106 .97959899997 .53124237061 82.2919769287162 .4809494018642 .758647918727 .60985565186 -9999 -9999 -9999 -9999 -9999 -9999 -9999 -9999 -9999 -9999 -9999 -9999 -9999 -9999 -9999 -9999 -9999 -9999 -9999 -9999 -9999 -9999 -9999 -9999 -9999 -9999 -9999 -9999 -9999 -9999 -9999 -9999 -9999 -9999 -9999 -9999 -9999 -9999 -9999 -9999 -9999 -9999 -9999 -9999 -9999 -9999 -9999 -9999 -9999 -9999 -9999 -9999 -9999 -9999 -9999 -9999 -9999 -9999 -9999 -9999 -9999 -9999 -9999 -9999 -9999 -9999 -9999 -9999 -9999 -9999 -9999 -9999 -9999 -9999 -9999 -9999

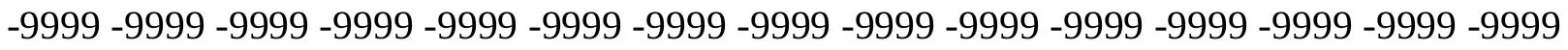
-9999 -9999 -9999 -9999 -9999 -9999 -9999 -9999 -9999 -9999 -9999 -9999 -9999 -9999 -9999 -9999 -9999 -9999 -9999 -9999 -9999 -9999 -9999 -9999 -9999 -9999 -9999 -9999 -9999 -9999 -9999 -9999 -9999 -9999 -9999 -9999 -9999 -9999 -9999 -9999 -9999 -9999 -9999 -9999 -9999 -999 -9999 -9999 -9999 -9999 -9999 -9999 -9999 -9999 -9999 -9999 -9999 -9999 -9999 -9999 -9999 -9999 -9999 -9999 -9999 -9999 -9999 -9999 -9999 -9999 -9999 -9999 -9999 -9999 -9999 -9999 -9999 -9999 -9999 -9999 -9999 -9999 -9999 -9999 -9999 -9999 -9999 -9999 -9999 -9999 -9999 -9999 -9999 -9999 -9999 -9999 -9999 -9999 -9999 -9999 -9999 -9999 -9999 -9999 -9999 -9999

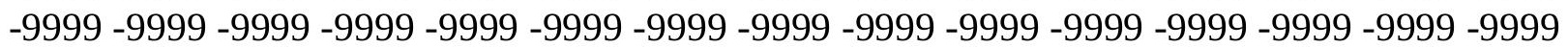


-9999 -9999 -9999 -9999 -9999 -9999 -9999 -9999 -9999 -9999 -9999 -9999 -9999 -9999 -9999 -9999 -9999 -9999 -9999 -9999 -9999 -9999 -9999 -9999 -9999 -9999 -9999 -9999 -9999 -9999 -9999 -9999 -9999 -9999 -9999 -9999 -9999 -9999 -9999 -9999 -9999 -9999 -9999 -9999 -9999 -9999 -9999 -9999 -9999 -9999 -9999 -9999 -9999 -9999 -9999 -9999 -9999 -9999 -9999 -9999 -9999 -9999 -9999 -9999 -9999 -9999 -9999 -9999 -9999 -9999 -9999 -9999 -9999 -9999 -9999 -9999 -9999 -9999 -9999 -9999 -9999 -9999 -9999 -9999 -9999 -9999 -9999 -9999 -9999 -9999 -9999 -9999 -9999 -9999 -9999 -9999 -9999 -9999 -9999 -9999 -9999 -9999 -9999 -9999 -9999 -9999 -9999 -9999 -9999 -9999 -9999 107.307762146 108.5228271484 109.7351226807 110.9418029785112 .1608963013113 .3800964355114 .5991973877115 .818397522 117.0374984741118 .2565994263119 .4757995605120 .6949005127121 .9140014648 122.8283996582123 .7427978516124 .3523025513124 .3523025513124 .3523025513 124.0475006104123 .7427978516122 .8283996582121 .6092987061120 .0852966309 118.2565994263116 .4279022217114 .2944030762112 .4656982422110 .6370010376 108.8082962036107 .5891036987106 .979598999106 .3700027466106 .3700027466 106.979598999107 .5891036987108 .5035018921109 .7226028442110 .9418029785 112.1608963013113 .3800964355114 .5991973877115 .818397522117 .0374984741 117.9517974854118 .8662033081119 .7806015015120 .3900985718120 .6949005127 121.3044967651121 .6092987061121 .6092987061121 .6092987061121 .9140014648 121.9140014648121 .9140014648121 .9140014648121 .6092987061121 .6092987061 121.3044967651120 .6949005127119 .4757995605116 .7326965332110 .3321990967 97.8360290527375 .2819290161148 .1560516357430 .9107208252 -9999 -9999 -9999 -9999 -9999 -9999 -9999 -9999 -9999 -9999 -9999 -9999 -9999 -9999 -9999 -9999 -9999 -9999 -9999 -9999 -9999 -9999 -9999 -9999 -9999 -9999 -9999 -9999 -9999 -9999 -9999

-9999 -9999 -9999 -9999 -9999 -9999 -9999 -9999 -9999 -9999 -9999 -9999 -9999 -9999 -9999

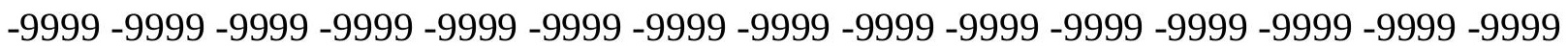
-9999 -9999 -9999 -9999 -9999 -9999 -9999 -9999 -9999 -9999 -9999 -9999 -9999 -9999 -9999 -9999 -9999 -9999 -9999 -9999 -9999 -9999 -9999 -9999 -9999 -9999 -9999 -9999 -9999 -9999 -9999 -9999 -9999 -9999 -9999 -9999 -9999 -9999 -9999 -9999 -9999 -9999 -9999 -9999 -9999 -9999 -9999 -9999 -9999 -9999 -9999 -9999 -9999 -9999 -9999 -9999 -9999 -9999 -9999 -9999 -9999 -9999 -9999 -9999 -9999 -9999 -9999 -9999 -9999 -9999 -9999 -9999 -9999 -9999 -9999 -9999 -9999 -9999 -9999 -9999 -9999 -9999 -9999 -9999 -9999 -9999 -9999 -9999 -9999 -9999 -9999 -9999 -9999 -9999 -9999 -9999 -9999 -9999 -9999 -9999 -9999 -9999 -9999 -9999 -9999 -9999 -9999 -9999 -9999 -9999 -9999 -9999 -9999 -9999 -9999 -9999 -9999 -9999 -9999 -9999 -9999 -9999 -9999 -9999 -9999 -9999 -9999 -9999 -9999 -9999 -9999 -9999 -9999 -9999 -9999 -

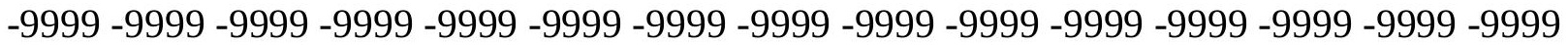
-9999 -9999 -9999 -9999 -9999 -9999 -9999 -9999 -9999 -9999 -9999 -9999 -9999 -9999 -9999 -9999 -9999 -9999 -9999 -9999 -9999 -9999 -9999 -9999 -9999 -9999 -9999 -9999 -9999 -9999

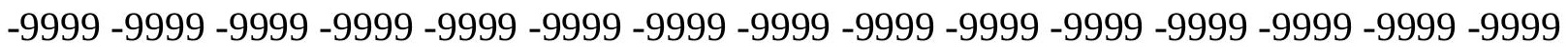
-9999 -9999 -9999 -9999 -9999 -9999 -9999 -9999 -9999 -9999 -9999 -9999 -9999 -9999 -9999 -9999 -9999 -9999 -9999 -9999 -9999 -9999 -9999 -9999 -9999 -9999 -9999 -9999 -9999 -9999 -9999 -9999 -9999 -9999 -9999 -9999 -9999 -9999 -9999 -9999 -9999 -9999 -9999 -9999 -9999 -9999 -9999 -9999 -9999 -9999 -9999 -9999 -9999 -9999 -9999 -9999 -9999 -9999 -9999 -9999 -9999 -9999 -9999 -9999 -9999 -9999 -9999 107.522857666108 .7433319092109 .9852905273 111.24659729112 .1608963013113 .3800964355114 .5991973877115 .818397522 117.0374984741118 .2565994263119 .7806015015120 .9997024536122 .2188034058 123.1332015991123 .7427978516124 .0475006104124 .0475006104123 .7427978516 
123.43800354122 .5235977173121 .3044967651120 .0852966309118 .2565994263 116.1231002808113 .9896011353111 .8561019897109 .7226028442108 .1986999512 106.979598999 106.3700027466106.0652008057 106.3700027466 106.979598999 107.8938980103108 .8082962036110 .0273971558111 .24659729112 .4656982422 113.3800964355114 .5991973877115 .5136032104116 .4279022217117 .342300415 118.2565994263118 .8662033081119 .4757995605120 .0852966309120 .3900985718 120.6949005127120 .9997024536121 .3044967651121 .3044967651121 .6092987061 121.6092987061121 .9140014648122 .2188034058122 .5235977173122 .8283996582 123.43800354123 .7427978516123 .7427978516122 .2188034058114 .5991973877 94.4833908081160 .6522407531735 .58413696289 -9999 -9999 -9999 -9999 -9999 -9999 -9999 -9999 -9999 -9999 -9999 -9999 -9999 -9999 -9999 -9999 -9999 -9999 -9999 -9999 -9999 -9999 -9999 -9999 -9999 -9999 -9999 -9999 -9999 -9999 -9999

-9999 -9999 -9999 -9999 -9999 -9999 -9999 -9999 -9999 -9999 -9999 -9999 -9999 -9999 -9999 -9999 -9999 -9999 -9999 -9999 -9999 -9999 -9999 -9999 -9999 -9999 -9999 -9999 -9999 -9999 -9999 -9999 -9999 -9999 -9999 -9999 -9999 -9999 -9999 -9999 -9999 -9999 -9999 -9999 -9999

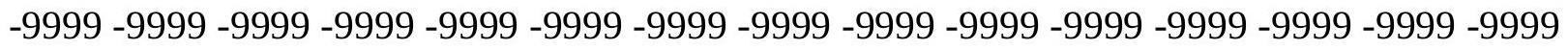
-9999 -9999 -9999 -9999 -9999 -9999 -9999 -9999 -9999 -9999 -9999 -9999 -9999 -9999 -9999 -9999 -9999 -9999 -9999 -9999 -9999 -9999 -9999 -9999 -9999 -9999 -9999 -9999 -9999 -9999 -

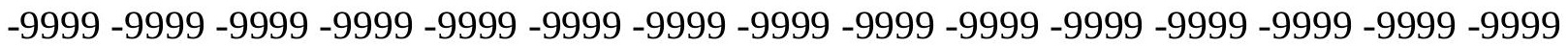

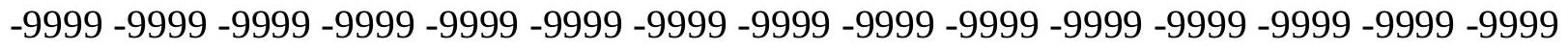
-9999 -9999 -9999 -9999 -9999 -9999 -9999 -9999 -9999 -9999 -9999 -9999 -9999 -9999 -9999 -9999 -9999 -9999 -9999 -9999 -9999 -9999 -9999 -9999 -9999 -9999 -9999 -9999 -9999 -9999 -9999 -9999 -9999 -9999 -9999 -9999 -9999 -9999 -9999 -9999 -9999 -9999 -9999 -9999 -9999 -9999 -9999 -9999 -9999 -9999 -9999 -9999 -9999 -9999 -9999 -9999 -9999 -9999 -9999 -9999 -9999 -9999 -9999 -9999 -9999 -9999 -9999 -9999 -9999 -9999 -9999 -9999 -9999 -9999 -9999 -9999 -9999 -9999 -9999 -9999 -9999 -9999 -9999 -9999 -9999 -9999 -9999 -9999 -9999 -9999 -9999 -9999 -9999 -9999 -9999 -9999 -9999 -9999 -9999 -9999 -9999 -9999 -9999 -9999 -9999

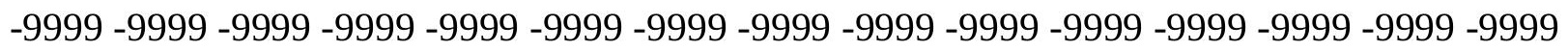
-9999 -9999 -9999 -9999 -9999 -9999 -9999 -9999 -9999 -9999 -9999 -9999 -9999 -9999 -9999 -9999 -9999 -9999 -9999 -9999 -9999 -9999 -9999 -9999 -9999 -9999 -9999 -9999 -9999 -9999 -9999 -9999 -9999 -9999 -9999 -9999 -9999 -9999 -9999 -9999 -9999 -9999 -9999 -9999 -9999 -9999 -9999 -9999 -9999 -9999 -9999 -9999 -9999 107.6100997925108 .7951660156 109.9171829224 110.9418029785111.8561019897 113.075302124114.2944030762 115.5136032104117 .0374984741118 .5614013672119 .7806015015121 .3044967651 122.2188034058122 .8283996582123 .1332015991123 .43800354123 .43800354 123.1332015991122 .5235977173121 .3044967651120 .0852966309118 .2565994263 116.1231002808113 .6848983765111 .24659729109 .1130981445107 .5891036987 106.3700027466 106.0652008057 106.0652008057 106.3700027466 107.2844009399 108.1986999512109 .4179000854110 .3321990967111 .551399231112 .4656982422 113.3800964355114 .2944030762115 .2088012695116 .1231002808116 .7326965332 117.342300415117 .9517974854118 .2565994263118 .8662033081119 .1709976196 119.4757995605119 .7806015015120 .0852966309120 .3900985718120 .6949005127 120.9997024536121 .6092987061121 .9140014648122 .5235977173122 .8283996582 123.43800354124 .6570968628126 .4858016968127 .7050018311125 .8762969971 118.561401367261 .8713798522938 .78553771973 -9999 -9999 -9999 -9999 -9999 -9999 -9999 -9999 -9999 -9999 -9999 -9999 -9999 -9999 -9999 -9999 -9999 -9999 -9999 -9999 -9999 -9999 
-9999 -9999 -9999 -9999 -9999 -9999 -9999 -9999 -9999

-9999 -9999 -9999 -9999 -9999 -9999 -9999 -9999 -9999 -9999 -9999 -9999 -9999 -9999 -9999

-9999 -9999 -9999 -9999 -9999 -9999 -9999 -9999 -9999 -9999 -9999 -9999 -9999 -9999 -9999

-9999 -9999 -9999 -9999 -9999 -9999 -9999 -9999 -9999 -9999 -9999 -9999 -9999 -9999 -9999

-9999 -9999 -9999 -9999 -9999 -9999 -9999 -9999 -9999 -9999 -9999 -9999 -9999 -9999 -9999 -

-9999 -9999 -9999 -9999 -9999 -9999 -9999 -9999 -9999 -9999 -9999 -9999 -9999 -9999 -9999 -

-9999 -9999 -9999 -9999 -9999 -9999 -9999 -9999 -9999 -9999 -9999 -9999 -9999 -9999 -9999 -

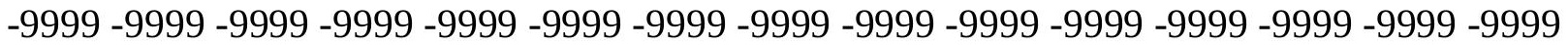

-9999 -9999 -9999 -9999 -9999 -9999 -9999 -9999 -9999 -9999 -9999 -9999 -9999 -9999 -9999

-9999 -9999 -9999 -9999 -9999 -9999 -9999 -9999 -9999 -9999 -9999 -9999 -9999 -9999 -9999

-9999 -9999 -9999 -9999 -9999 -9999 -9999 -9999 -9999 -9999 -9999 -9999 -9999 -9999 -9999 -

-9999 -9999 -9999 -9999 -9999 -9999 -9999 -9999 -9999 -9999 -9999 -9999 -9999 -9999 -9999

-9999 -9999 -9999 -9999 -9999 -9999 -9999 -9999 -9999 -9999 -9999 -9999 -9999 -9999 -9999 -

-9999 -9999 -9999 -9999 -9999 -9999 -9999 -9999 -9999 -9999 -9999 -9999 -9999 -9999 -9999 -

-9999 -9999 -9999 -9999 -9999 -9999 -9999 -9999 -9999 -9999 -9999 -9999 -9999 -9999 -9999

-9999 -9999 -9999 -9999 -9999 -9999 -9999 -9999 -9999 -9999 -9999 -9999 -9999 -9999 -9999

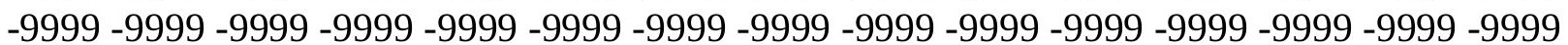

-9999 -9999 -9999 -9999 -9999 -9999 -9999 -9999 -9999 -9999 -9999 -9999 -9999 -9999 -9999 -

-9999 -9999 -9999 -9999 -9999 -9999 -9999 -9999 -9999 -9999 -9999 -9999 -9999 -9999 -9999

-9999 -9999 -9999 -9999 -9999 -9999 -9999 -9999 -9999 -9999 -9999 -9999 -9999 -9999 -9999

-9999 -9999 -9999 -9999 -9999 -9999 -9999 -9999 -9999 107.4219589233 108.4640731812

109.4532852173110 .4325714111111 .551399231112 .7705001831113 .9896011353

115.5136032104116 .7326965332118 .2565994263119 .7806015015121 .3044967651 121.9140014648122 .2188034058122 .5235977173122 .8283996582122 .8283996582 122.2188034058121 .6092987061120 .3900985718118 .5614013672116 .4279022217 113.6848983765110 .9418029785108 .5035018921106 .979598999105 .7603988647 105.7603988647106 .0652008057106 .979598999107 .8938980103109 .1130981445 110.0273971558111 .24659729112 .1608963013112 .7705001831113 .6848983765 114.2944030762114 .9039993286115 .5136032104115 .818397522116 .4279022217 116.7326965332117 .0374984741117 .342300415117 .647102356118 .2565994263 118.5614013672118 .8662033081118 .8662033081119 .1709976196119 .7806015015 120.0852966309120 .6949005127120 .9997024536121 .3044967651121 .6092987061 121.3044967651124 .6570968628125 .8762969971120 .9997024536103 .0174026489 68.8814392089843 .59565734863 -9999 -9999 -9999 -9999 -9999 -9999 -9999 -9999 -9999 -9999 -9999 -9999 -9999 -9999 -9999 -9999 -9999 -9999 -9999 -9999 -9999 -9999 -9999 -9999 -9999 -9999 -9999 -9999 -9999 -9999 -9999

-9999 -9999 -9999 -9999 -9999 -9999 -9999 -9999 -9999 -9999 -9999 -9999 -9999-9999-9999 -9999 -9999 -9999 -9999 -9999 -9999 -9999 -9999 -9999 -9999 -9999 -9999 -9999 -9999 -9999 -9999 -9999 -9999 -9999 -9999 -9999 -9999 -9999 -9999 -9999 -9999 -9999 -9999 -9999 -9999 -9999 -9999 -9999 -9999 -9999 -9999 -9999 -9999 -9999 -9999 -9999 -9999 -9999 - -9999 -9999 -9999 -9999 -9999 -9999 -9999 -9999 -9999 -9999 -9999 -9999 -9999 -9999 -9999 -9999 -9999

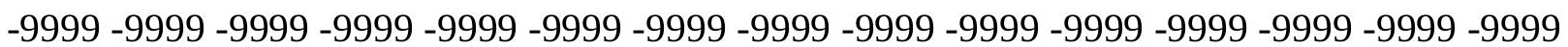
-9999 -9999 -9999 -9999 -9999 -9999 -9999 -9999 -9999 -9999 -9999 -9999 -9999 -9999 -9999 -9999 -9999 -9999 -9999 -9999 -9999 -9999 -9999 -9999 -9999 -9999 -9999 -9999 -9999 -9999 -9999 -9999 -9999 -9999 -9999 -9999 -9999 -9999 -9999 -9999 -9999 -9999 -9999 -9999 -9999

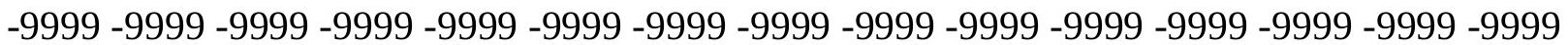


-9999 -9999 -9999 -9999 -9999 -9999 -9999 -9999 -9999 -9999 -9999 -9999 -9999 -9999 -9999 -9999 -9999 -9999 -9999 -9999 -9999 -9999 -9999 -9999 -9999 -9999 -9999 -9999 -9999 -9999 -9999 -9999 -9999 -9999 -9999 -9999 -9999 -9999 -9999 -9999 -9999 -9999 -9999 -9999 -9999 -9999 -9999 -9999 -9999 -9999 -9999 -9999 -9999 -9999 -9999 -9999 -9999 -9999 -9999 -9999 -9999 -9999 -9999 -9999 -9999 -9999 -9999 -9999 -9999 -9999 -9999 -9999 -9999 -9999 -9999 -9999 -9999 -9999 -9999 -9999 -9999 -9999 -9999 -9999 -9999 -9999 -9999 -9999 -9999 -9999 -9999 -9999 -9999 -9999 -9999 -9999 -9999 -9999 -9999 -9999 -9999 -9999 -9999 -9999 -9999

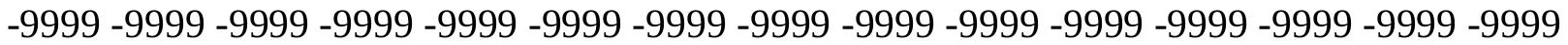
-9999 -9999 -9999 -9999 -9999 -9999 -9999 -9999 -9999 -9999 -9999 -9999 -9999 -9999 -9999 -9999 -9999 -9999 -9999 -9999 -9999 -9999 -9999 -9999 -9999 106.9161758423 107.875213623108 .8477478027109 .862739563110 .9418029785112 .1608963013 113.3800964355114 .9039993286116 .4279022217117 .9517974854119 .1709976196 120.0852966309120 .9997024536121 .6092987061122 .2188034058122 .2188034058 122.2188034058121 .6092987061120 .6949005127118 .8662033081116 .7326965332 113.9896011353110 .9418029785108 .1986999512106 .3700027466105 .4557037354 106.0652008057106 .979598999107 .8938980103109 .1130981445110 .3321990967 111.24659729112 .1608963013112 .7705001831113 .3800964355113 .9896011353 114.2944030762114 .5991973877114 .9039993286115 .2088012695115 .2088012695 115.5136032104115 .5136032104115 .818397522116 .1231002808116 .1231002808 116.4279022217116 .7326965332117 .0374984741117 .342300415117 .647102356 117.9517974854118 .5614013672118 .8662033081118 .8662033081118 .8662033081 119.1709976196119 .4757995605117 .647102356109 .722602844291 .13075256348 65.8335876464845 .96251678467 -9999 -9999 -9999 -9999 -9999 -9999 -9999 -9999 -9999 -9999 -9999 -9999 -9999 -9999 -9999 -9999 -9999 -9999 -9999 -9999 -9999 -9999 -9999 -9999 -9999 -9999 -9999 -9999 -9999 -9999 -9999

-9999 -9999 -9999 -9999 -9999 -9999 -9999 -9999 -9999 -9999 -9999 -9999 -9999 -9999 -9999 -9999 -9999 -9999 -9999 -9999 -9999 -9999 -9999 -9999 -9999 -9999 -9999 -9999 -9999 -9999 -9999 -9999 -9999 -9999 -9999 -9999 -9999 -9999 -9999 -9999 -9999 -9999 -9999 -9999 -9999 -9999 -9999 -9999 -9999 -9999 -9999 -9999 -9999 -9999 -9999 -9999 -9999 -9999 -9999 -9999 -9999 -9999 -9999 -9999 -9999 -9999 -9999 -9999 -9999 -9999 -9999 -9999 -9999 -9999 -9999 -9999 -9999 -9999 -9999 -9999 -9999 -9999 -9999 -9999 -9999 -9999 -9999 -9999 -9999 -9999 -9999 -9999 -9999 -9999 -9999 -9999 -9999 -9999 -9999 -9999 -9999 -9999 -9999 -9999 -9999 -9999 -9999 -9999 -9999 -9999 -9999 -9999 -9999 -9999 -9999 -9999 -9999 -9999 -9999 -9999 -9999 -9999 -9999 -9999 -9999 -9999 -9999 -9999 -9999 -9999 -9999 -9999 -9999 -9999 -9999 -

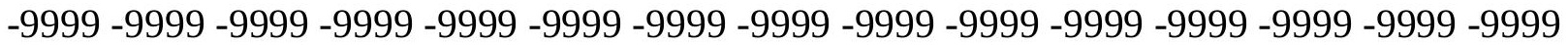
-9999 -9999 -9999 -9999 -9999 -9999 -9999 -9999 -9999 -9999 -9999 -9999 -9999 -9999 -9999 -9999 -9999 -9999 -9999 -9999 -9999 -9999 -9999 -9999 -9999 -9999 -9999 -9999 -9999 -9999

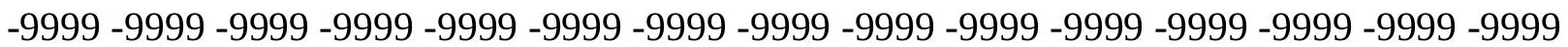
-9999 -9999 -9999 -9999 -9999 -9999 -9999 -9999 -9999 -9999 -9999 -9999 -9999 -9999 -9999 -9999 -9999 -9999 -9999 -9999 -9999 -9999 -9999 -9999 -9999 -9999 -9999 -9999 -9999 -9999 -9999 -9999 -9999 -9999 -9999 -9999 -9999 -9999 -9999 -9999 -9999 -9999 -9999 -9999 -9999

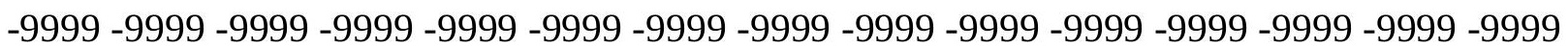
-9999 -9999 -9999 -9999 -9999 -9999 -9999 -9999 -9999 -9999 -9999 -9999 -9999 -9999 -9999 -999 -9999 -9999 -9999 -9999 -9999 -9999 -9999 -9999 -9999 -9999 -9999 -9999 -9999 -9999 -9999 -9999 -9999 -9999 -9999 -9999 -9999 -9999 -9999 -9999 -9999 -9999 -9999 107.1332015991 108.0696487427109 .0305938721110 .0273971558111 .24659729112 .7705001831 
114.2944030762115 .818397522117 .0374984741118 .2565994263119 .4757995605 120.3900985718121 .3044967651121 .9140014648122 .2188034058121 .9140014648 121.3044967651119 .7806015015117 .647102356114 .9039993286111 .551399231 108.1986999512106 .0652008057106 .0652008057106 .979598999108 .1986999512 109.7226028442110 .9418029785111 .8561019897112 .4656982422113 .075302124 113.6848983765113 .9896011353113 .9896011353114 .2944030762114 .2944030762 114.2944030762113 .9896011353113 .9896011353113 .9896011353113 .6848983765 113.6848983765113 .9896011353113 .9896011353113 .9896011353114 .2944030762 114.2944030762114 .5991973877114 .9039993286115 .2088012695115 .2088012695 115.5136032104115 .2088012695114 .9039993286114 .2944030762112 .7705001831 108.198699951298 .7503814697382 .9015579223663 .0905189514247 .19668197632 -9999 -9999 -9999 -9999 -9999 -9999 -9999 -9999 -9999 -9999 -9999 -9999 -9999 -9999 -9999 -9999 -9999 -9999 -9999 -9999 -9999 -9999 -9999 -9999 -9999 -9999 -9999 -9999 -9999 -9999 -9999 -9999 -9999 -9999 -9999 -9999 -9999 -9999 -9999 -9999 -9999 -9999 -9999 -9999 -9999 - 9999 -9999 -9999 -9999 -9999 -9999 -9999 -9999 -9999 -9999 -9999 -9999 -9999 -9999 -9999 -9999 -9999 -9999 -9999 -9999 -9999 -9999 -9999 -9999 -9999 -9999 -9999 -9999 -9999 -9999 -9999

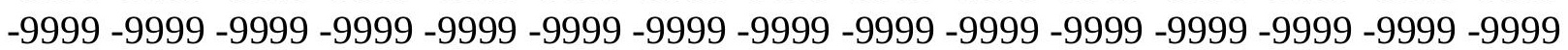
-9999 -9999 -9999 -9999 -9999 -9999 -9999 -9999 -9999 -9999 -9999 -9999 -9999 -9999 -9999 -999 -9999 -9999 -9999 -9999 -9999 -9999 -9999 -9999 -9999 -9999 -9999 -9999 -9999 -9999 -9999 -9999 -9999 -9999 -9999 -9999 -9999 -9999 -9999 -9999 -9999 -9999 -9999 -9999 -9999 -9999 -9999 -9999 -9999 -9999 -9999 -9999 -9999 -9999 -9999 -9999 -9999 -9999 -9999 -9999 -9999 -9999 -9999 -9999 -9999 -9999 -9999 -9999 -9999 -9999 -9999 -9999 -9999 -9999 -9999 -9999 -9999 -9999 -9999 -9999 -9999 -9999 -9999 -9999 -9999 -9999 -9999 -9999 -9999 -9999 -9999 -9999 -9999 -9999 -9999 -9999 -9999 -9999 -9999 -9999 -9999 -9999 -9999 -9999 -9999 -9999 -9999 -9999 -9999 -9999 -9999 -9999 -9999 -9999 -9999 -9999 -9999 -9999 -9999 -9999 -9999 -9999 -9999 -9999 -9999 -9999 -9999 -9999 -9999 -9999 -9999 -9999 -9999 -9999 -9999 -9999 -9999 -9999 -9999 -9999 -9999 -9999 -9999 -9999 -9999 -9999 -9999 -9999 -9999 -9999 -9999

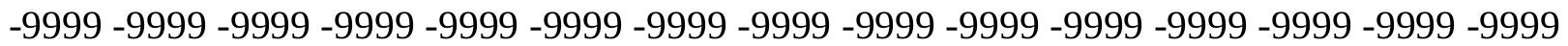

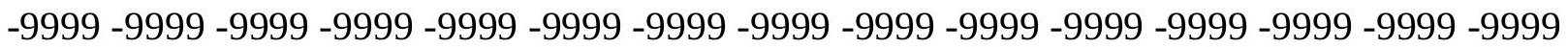
-9999 -9999 -9999 -9999 -9999 -9999 -9999 -9999 -9999 -9999 -9999 -9999 -9999 -9999 -9999 -9999 -9999 -9999 -9999 -9999 -9999 -9999 -9999 -9999 -9999 -9999 -9999 -9999 -9999 -9999 -9999 -9999 -9999 -9999 -9999 -9999 -9999 -9999 -9999 -9999 -9999 -9999 -9999 -9999 -9999 -9999 -9999 -9999 -9999 -9999 -9999 -9999 -9999 -9999 -9999-9999 -9999 -9999 106.2209777832 107.1218566895 108.1100845337 109.29271698110.6370010376 111.8561019897113 .3800964355114 .9039993286116 .1231002808117 .647102356 118.8662033081120 .0852966309120 .9997024536121 .9140014648122 .2188034058 121.9140014648120 .6949005127118 .8662033081116 .4279022217113 .075302124 109.7226028442106 .6747970581107 .8938980103109 .4179000854110 .9418029785 112.1608963013113 .075302124113 .9896011353114 .2944030762114 .5991973877 114.5991973877114 .5991973877114 .2944030762113 .9896011353113 .6848983765 113.3800964355112 .7705001831112 .4656982422112 .1608963013111 .8561019897 111.551399231111 .24659729111 .24659729111 .24659729111 .24659729111 .24659729 111.24659729111 .24659729111 .551399231111 .551399231111 .24659729110 .6370010376 109.7226028442107 .8938980103104 .846099853599 .0551681518689 .60682678223 76.8058471679761 .5666007995648 .15972518921 -9999 -9999 -9999 -9999 -9999 -9999 -9999 -9999 -9999 -9999 -9999 -9999 -9999 -9999 -9999 -9999 -9999 -9999 -9999 -9999 -9999 -9999 
-9999 -9999 -9999 -9999 -9999 -9999 -9999 -9999 -9999

-9999 -9999 -9999 -9999 -9999 -9999 -9999 -9999 -9999 -9999 -9999 -9999 -9999 -9999 -9999

-9999 -9999 -9999 -9999 -9999 -9999 -9999 -9999 -9999 -9999 -9999 -9999 -9999 -9999 -9999

-9999 -9999 -9999 -9999 -9999 -9999 -9999 -9999 -9999 -9999 -9999 -9999 -9999 -9999 -9999

-9999 -9999 -9999 -9999 -9999 -9999 -9999 -9999 -9999 -9999 -9999 -9999 -9999 -9999 -9999 -

-9999 -9999 -9999 -9999 -9999 -9999 -9999 -9999 -9999 -9999 -9999 -9999 -9999 -9999 -9999 -

-9999 -9999 -9999 -9999 -9999 -9999 -9999 -9999 -9999 -9999 -9999 -9999 -9999 -9999 -9999 -

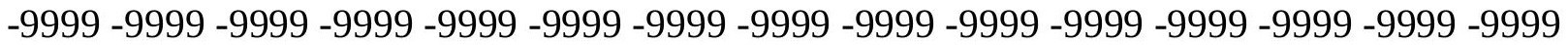

-9999 -9999 -9999 -9999 -9999 -9999 -9999 -9999 -9999 -9999 -9999 -9999 -9999 -9999 -9999

-9999 -9999 -9999 -9999 -9999 -9999 -9999 -9999 -9999 -9999 -9999 -9999 -9999 -9999 -9999 -

-9999 -9999 -9999 -9999 -9999 -9999 -9999 -9999 -9999 -9999 -9999 -9999 -9999 -9999 -9999 -

-9999 -9999 -9999 -9999 -9999 -9999 -9999 -9999 -9999 -9999 -9999 -9999 -9999 -9999 -9999

-9999 -9999 -9999 -9999 -9999 -9999 -9999 -9999 -9999 -9999 -9999 -9999 -9999 -9999 -9999 -

-9999 -9999 -9999 -9999 -9999 -9999 -9999 -9999 -9999 -9999 -9999 -9999 -9999 -9999 -9999 -

-9999 -9999 -9999 -9999 -9999 -9999 -9999 -9999 -9999 -9999 -9999 -9999 -9999 -9999 -9999

-9999 -9999 -9999 -9999 -9999 -9999 -9999 -9999 -9999 -9999 -9999 -9999 -9999 -9999 -9999

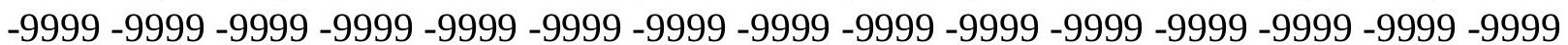

-9999 -9999 -9999 -9999 -9999 -9999 -9999 -9999 -9999 -9999 -9999 -9999 -9999 -9999 -9999 -

-9999 -9999 -9999 -9999 -9999 -9999 -9999 -9999 -9999 -9999 -9999 -9999 -9999 -9999 -9999 -

-9999 -9999 -9999 -9999 -9999 -9999 -9999 -9999 -9999 -9999 -9999 -9999 -9999 -9999 -9999

-9999 -9999 -9999 -9999 -9999 -9999 -9999 -9999 -9999 -9999 -9999 -9999 -9999 -9999 -9999

106.1865234375107 .2703704834108 .458946228109 .7226028442110 .9418029785

112.4656982422113 .9896011353115 .5136032104117 .0374984741118 .5614013672 120.0852966309121 .3044967651122 .2188034058122 .2188034058121 .6092987061 120.3900985718118 .5614013672116 .1231002808113 .3800964355111 .8561019897 111.8561019897113 .075302124114 .2944030762115 .2088012695116 .1231002808 116.1231002808116 .1231002808115 .818397522115 .5136032104114 .9039993286 114.2944030762113 .6848983765113 .075302124112 .1608963013111 .551399231 110.9418029785110 .0273971558109 .4179000854108 .8082962036108 .5035018921 108.1986999512107 .8938980103107 .5891036987107 .2844009399107 .2844009399 107.2844009399 106.979598999 106.6747970581 106.0652008057 105.1509017944 103.6268997192100 .883903503496 .9216690063590 .8259735107482 .29197692871 71.9292907714860 .3474502563548 .57996368408 -9999 -9999 -9999 -9999 -9999 -9999 -9999 -9999 -9999 -9999 -9999 -9999 -9999 -9999 -9999 -9999 -9999 -9999 -9999 -9999 -9999 -9999 -9999 -9999 -9999 -9999 -9999 -9999 -9999 -9999 -9999

-9999 -9999 -9999 -9999 -9999 -9999 -9999 -9999 -9999 -9999 -9999 -9999 -9999 -9999 -9999

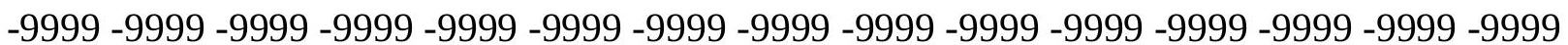
-9999 -9999 -9999 -9999 -9999 -9999 -9999 -9999 -9999 -9999 -9999 -9999 -9999 -9999 -9999 -9999 -9999 -9999 -9999 -9999 -9999 -9999 -9999 -9999 -9999 -9999 -9999 -9999 -9999 -9999 -9999 -9999 -9999 -9999 -9999 -9999 -9999 -9999 -9999 -9999 -9999 -9999 -9999 -9999 -9999 -9999 -9999 -9999 -9999 -9999 -9999 -9999 -9999 -9999 -9999 -9999 -9999 -9999 -9999 -9999

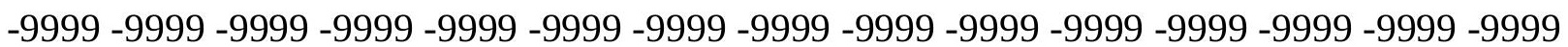
-9999 -9999 -9999 -9999 -9999 -9999 -9999 -9999 -9999 -9999 -9999 -9999 -9999 -9999 -9999 -9999 -9999 -9999 -9999 -9999 -9999 -9999 -9999 -9999 -9999 -9999 -9999 -9999 -9999 -9999 -9999 -9999 -9999 -9999 -9999 -9999 -9999 -9999 -9999 -9999 -9999 -9999 -9999 -9999 -9999 -9999 -9999 -9999 -9999 -9999 -9999 -9999 -9999 -9999 -9999 -9999 -9999 -9999 -9999 -9999 
-9999 -9999 -9999 -9999 -9999 -9999 -9999 -9999 -9999 -9999 -9999 -9999 -9999 -9999 -9999 -9999 -9999 -9999 -9999 -9999 -9999 -9999 -9999 -9999 -9999 -9999 -9999 -9999 -9999 -9999 -9999 -9999 -9999 -9999 -9999 -9999 -9999 -9999 -9999 -9999 -9999 -9999 -9999 -9999 - 9999 -9999 -9999 -9999 -9999 -9999 -9999 -9999 -9999 -9999 -9999 -9999 -9999 -9999 -9999 -9999 -9999 -9999 -9999 -9999 -9999 -9999 -9999 -9999 -9999-9999 -9999 -9999 -9999 -9999 -9999 -9999 -9999 -9999 -9999 -9999 -9999 -9999 -9999 -9999 -9999 -9999 -9999 -9999 -9999 -9999 -

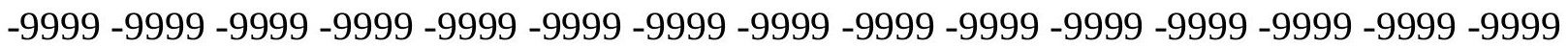

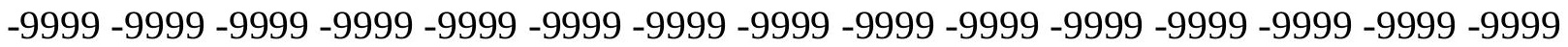
-9999 -9999 -9999 -9999 -9999 -9999 -9999 -9999 -9999 -9999 -9999 -9999 -9999 -9999 -9999 -9999 105.2154846191 106.2952423096 107.4555664062108.6812286377110.0273971558 111.551399231113 .075302124114 .5991973877116 .4279022217118 .2565994263 120.3900985718121 .9140014648122 .2188034058122 .2188034058121 .9140014648 120.6949005127119 .4757995605117 .9517974854117 .0374984741117 .0374984741 117.647102356118 .2565994263118 .8662033081118 .8662033081118 .5614013672 117.9517974854117 .0374984741116 .1231002808115 .2088012695114 .2944030762 113.075302124112 .1608963013110 .9418029785110 .0273971558108 .8082962036 107.8938980103106 .979598999106 .0652008057105 .1509017944104 .5412979126 104.2365036011103 .6268997192103 .3221969604102 .712600708102 .4077987671 102.1029968262101 .1886978149100 .274299621698 .7503814697396 .61688232422 93.5690307617289 .302040100183 .5111236572375 .8914871215867 .05272674561 57.909179687547 .89230728149 -9999 -9999 -9999 -9999 -9999 -9999 -9999 -9999 -9999 -9999 -9999 -9999 -9999 -9999 -9999 -9999 -9999 -9999 -9999 -9999 -9999 -9999 -9999 -9999 -9999 -9999 -9999 -9999 -9999 -9999 -9999

-9999 -9999 -9999 -9999 -9999 -9999 -9999 -9999 -9999 -9999 -9999 -9999 -9999 -9999 -9999 -9999 -9999 -9999 -9999 -9999 -9999 -9999 -9999 -9999 -9999 -9999 -9999 -9999 -9999 -9999 -9999 -9999 -9999 -9999 -9999 -9999 -9999 -9999 -9999 -9999 -9999 -9999 -9999 -9999 -9999 -9999 -9999 -9999 -9999 -9999 -9999 -9999 -9999 -9999 -9999 -9999 -9999 -9999 -9999 -9999 -

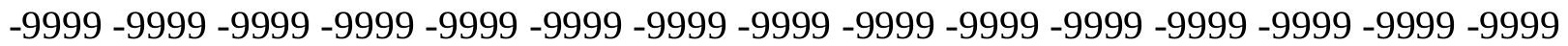

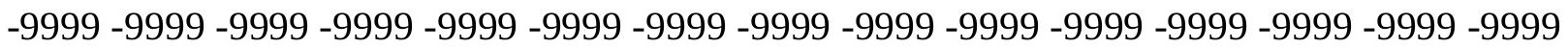
-9999 -9999 -9999 -9999 -9999 -9999 -9999 -9999 -9999 -9999 -9999 -9999 -9999 -9999 -9999 -9999 -9999 -9999 -9999 -9999 -9999 -9999 -9999 -9999 -9999 -9999 -9999 -9999 -9999 -9999

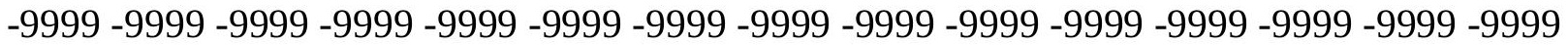

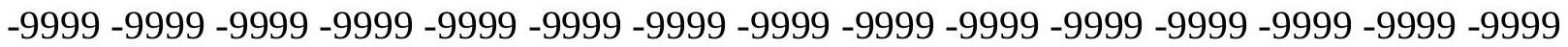
-9999 -9999 -9999 -9999 -9999 -9999 -9999 -9999 -9999 -9999 -9999 -9999 -9999 -9999 -9999 -9999 -9999 -9999 -9999 -9999 -9999 -9999 -9999 -9999 -9999 -9999 -9999 -9999 -9999 -9999 -9999 -9999 -9999 -9999 -9999 -9999 -9999 -9999 -9999 -9999 -9999 -9999 -9999 -9999 -9999

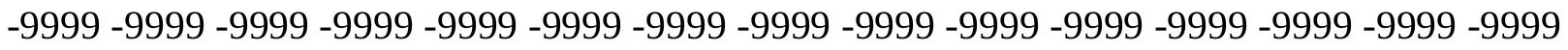

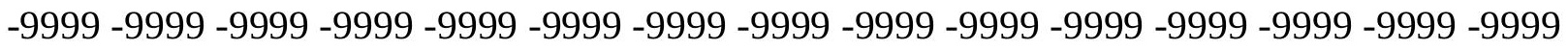
-9999 -9999 -9999 -9999 -9999 -9999 -9999 -9999 -9999 -9999 -9999 -9999 -9999 -9999 -9999 -9999 -9999 -9999 -9999 -9999 -9999 -9999 -9999 -9999 -9999 -9999 -9999 -9999 -9999 -9999 -

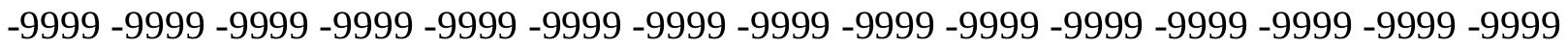
-9999 -9999 -9999 -9999 -9999 -9999 -9999 -9999 -9999 -9999 -9999 -9999 -9999 -9999 -9999 -9999 -9999 -9999 -9999 -9999 -9999 -9999 -9999 -9999 -9999 -9999 -9999 -9999 -9999 -9999 -9999 -9999 -9999 105.1856460571 106.3595123291107 .6655273438109 .1130981445 110.3321990967112 .1608963013113 .9896011353116 .1231002808117 .9517974854 119.7806015015120 .9997024536121 .9140014648122 .5235977173122 .8283996582 
122.5235977173121 .9140014648121 .9140014648121 .9140014648121 .9140014648 122.2188034058121 .9140014648121 .3044967651120 .3900985718119 .1709976196 117.9517974854116 .4279022217115 .2088012695113 .6848983765112 .4656982422 110.9418029785109 .7226028442108 .1986999512106 .6747970581105 .4557037354 103.9317016602102 .712600708101 .7982025146100 .883903503499 .96952056885 99.3599472045998.75038146973 98.14080810547 97.2264633178796.31210327148 95.397743225193 .8738174438592 .0450973510789 .6068267822386 .2541885376 81.9871978759876 .8058471679770 .1005783081162 .4809494018653 .94697189331 46.29574203491 -9999 -9999 -9999 -9999 -9999 -9999 -9999 -9999 -9999 -9999 -9999 -9999 -9999 -9999 -9999 -9999 -9999 -9999 -9999 -9999 -9999 -9999 -9999 -9999 -9999 -9999 -999 -9999 -9999-9999-9999

-9999 -9999 -9999 -9999 -9999 -9999 -9999 -9999 -9999 -9999 -9999 -9999 -9999 -9999 -9999 -9999 -9999 -9999 -9999 -9999 -9999 -9999 -9999 -9999 -9999 -9999 -9999 -9999 -9999 -9999 -9999 -9999 -9999 -9999 -9999 -9999 -9999 -9999 -9999 -9999 -9999 -9999 -9999 -9999 -9999 -9999 -9999 -9999 -9999 -9999 -9999 -9999 -9999 -9999 -9999 -9999 -9999 -9999 -9999 -9999

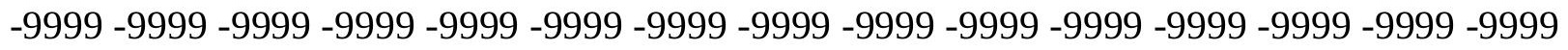

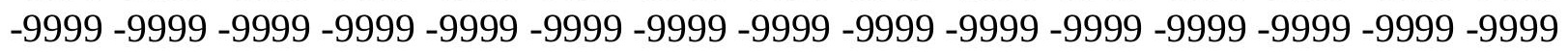

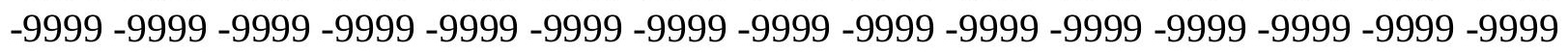

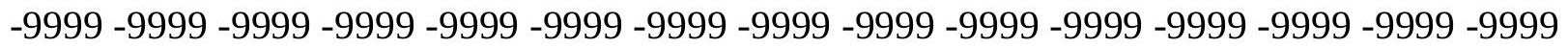

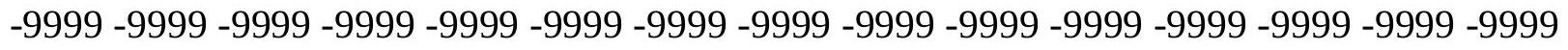

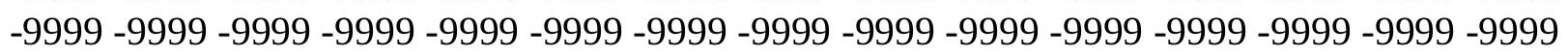

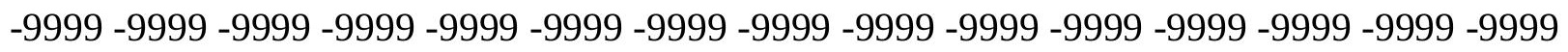
-9999 -9999 -9999 -9999 -9999 -9999 -9999 -9999 -9999 -9999 -9999 -9999 -9999 -9999 -9999 -

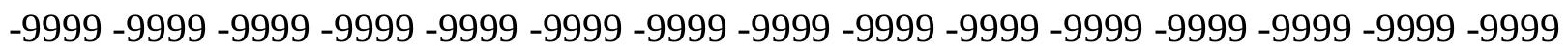

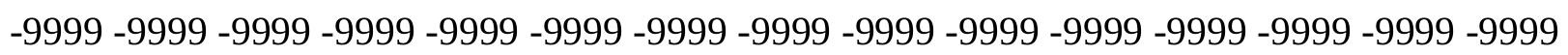

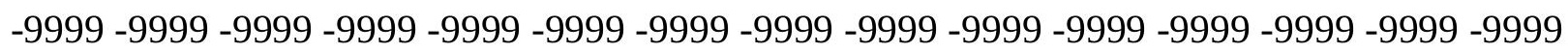
-9999 -9999 -9999 -9999 -9999 -9999 -9999 -9999 -9999 -9999 -9999 -9999 -9999 -9999 - -9999 -

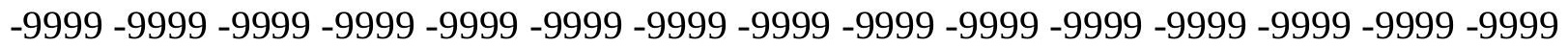

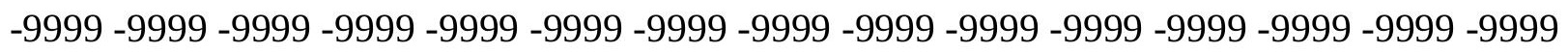

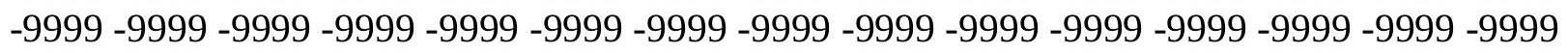
-9999 -9999 -9999 -9999 -9999 -9999 -9999 -9999 -9999 -9999 -9999 -9999 -9999 -9999 -9999 -9999 -9999 -9999 -9999 103.9537963867 105.1276626587 106.3589553833 107.6395111084 109.1130981445110 .9418029785113 .075302124115 .2088012695117 .0374984741 118.8662033081120 .3900985718122 .2188034058123 .7427978516124 .3523025513 124.6570968628124 .9618988037125 .2667007446125 .2667007446124 .9618988037 124.0475006104122 .8283996582121 .3044967651119 .7806015015117 .9517974854 116.1231002808114 .2944030762112 .7705001831111 .24659729109 .7226028442 107.8938980103 106.0652008057 104.2365036011 102.4077987671 100.8839035034 99.3599472045997 .8360290527396 .9216690063595 .7025299072394 .78817749023 93.87381744385 92.95947265625 92.0450973510790.82597351074 89.3020401001 87.1685485839885 .0350494384882 .2919769287179 .2441329956175 .28192901611 $70.7101516723665 .5288009643658 .8235282897951 .7740058898944 .7290687561-9999$ -9999 -9999 -9999 -9999 -9999 -9999 -9999 -9999 -9999 -9999 -9999 -9999 -9999 -9999 -9999 -9999 -9999 -9999 -9999 -9999 -9999 -9999 -9999 -9999 -9999 -9999 -9999 -9999 -9999 -9999 -9999 -9999 -9999 -9999 -9999 -9999 -9999 -9999 -9999 -9999 -9999 -9999 -9999 -9999 -9999 -

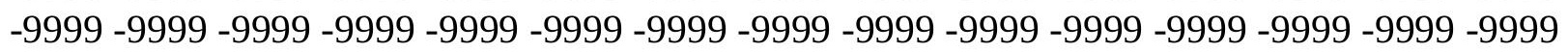


-9999 -9999 -9999 -9999 -9999 -9999 -9999 -9999 -9999 -9999 -9999 -9999 -9999 -9999 -9999 -9999 -9999 -9999 -9999 -9999 -9999 -9999 -9999 -9999 -9999 -9999 -9999 -9999 -9999 -9999 -9999 -9999 -9999 -9999 -9999 -9999 -9999 -9999 -9999 -9999 -9999 -9999 -9999 -9999 -9999 -9999 -9999 -9999 -9999 -9999 -9999 -9999 -9999 -9999 -9999 -9999 -9999 -9999 -9999 -9999 -9999 -9999 -9999 -9999 -9999 -9999 -9999 -9999 -9999 -9999 -9999 -9999 -9999 -9999 -9999 -9999 -9999 -9999 -9999 -9999 -9999 -9999 -9999 -9999 -9999 -9999 -9999 -9999 -9999 -9999 -9999 -9999 -9999 -9999 -9999 -9999 -9999 -9999 -9999 -9999 -9999 -9999 -9999 -9999 -9999

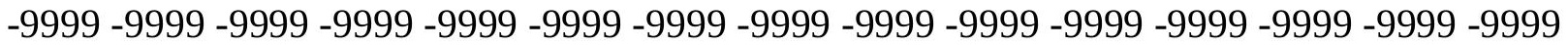
-9999 -9999 -9999 -9999 -9999 -9999 -9999 -9999 -9999 -9999 -9999 -9999 -9999 -9999 -9999 -9999 -9999 -9999 -9999 -9999 -9999 -9999 -9999 -9999 -9999 -9999 -9999 -9999 -9999 -9999 -9999 -9999 -9999 -9999 -9999 -9999 -9999 -9999 -9999 -9999 -9999 -9999 -9999 -9999 -9999 -9999 -9999 -9999 -9999 -9999 -9999 -9999 -9999 -9999 -9999 -9999 -9999 -9999 -9999 -9999

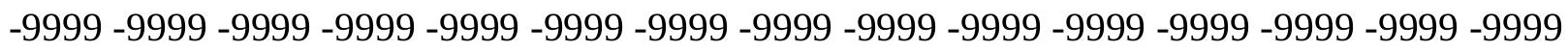
-9999 -9999 -9999 -9999 -9999 -9999 -9999 -9999 -9999 -9999 -9999 -9999 -9999 -9999 -9999 -9999 -9999 -9999 -9999 -9999 -9999 -9999 -9999 -9999 -9999 -9999 -9999 -9999 -9999 -9999

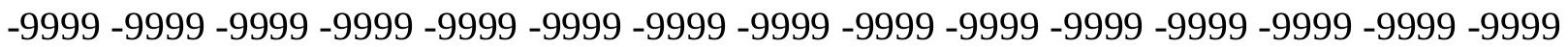

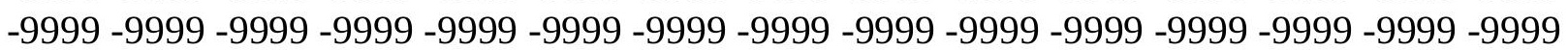
-9999 -9999 -9999 -9999 -9999 -9999 -9999 -9999 -9999 -9999 -9999 -9999 -9999 -9999 -9999 -9999 -9999 -9999 -9999 -9999-9999 103.5414047241104 .7263412476106 .0507202148 107.5891036987109 .4179000854111 .551399231113 .6848983765115 .5136032104 117.342300415119 .7806015015122 .8283996582123 .7427978516124 .9618988037 125.8762969971126 .4858016968126 .4858016968125 .8762969971124 .6570968628 123.1332015991120 .9997024536118 .8662033081116 .7326965332114 .9039993286 113.075302124111 .24659729109 .7226028442107 .8938980103105 .7603988647 103.9317016602101 .798202514699 .6647262573297 .5312423706195 .70252990723 93.87381744385 92.6546783447391.13075256348 89.91161346436 88.99725341797 87.7781066894586 .5589828491284 .7302627563582 .9015579223680 .76805877686 78.0249862670975 .2819290161172 .2340774536168 .5766525268665 .22400665283 61.2618103027356 .3852500915549 .7375564575243 .11631393433 -9999 -9999 -9999 -9999 -9999 -9999 -9999 -9999 -9999 -9999 -9999 -9999 -9999 -9999 -9999 -9999 -9999 -9999 -9999 -9999 -9999 -9999 -9999 -9999 -9999 -9999 -9999 -9999 -9999 -9999 -9999 -

-9999 -9999 -9999 -9999 -9999 -9999 -9999 -9999 -9999 -9999 -9999 -9999 -9999 -9999 -9999 -9999 -9999 -9999 -9999 -9999 -9999 -9999 -9999 -9999 -9999 -9999 -9999 -9999 -9999 -9999 -9999 -9999 -9999 -9999 -9999 -9999 -9999 -9999 -9999 -9999 -9999 -9999 -9999 -9999 -9999 -

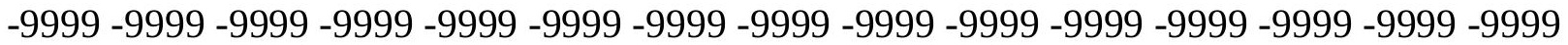
-9999 -9999 -9999 -9999 -9999 -9999 -9999 -9999 -9999 -9999 -9999 -9999 -9999 -9999 -9999 -9999 -9999 -9999 -9999 -9999 -9999 -9999 -9999 -9999 -9999 -9999 -9999 -9999 -9999 -9999

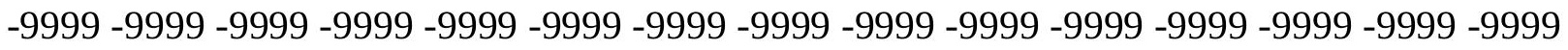
-9999 -9999 -9999 -9999 -9999 -9999 -9999 -9999 -9999 -9999 -9999 -9999 -9999 -9999 -9999 -9999 -9999 -9999 -9999 -9999 -9999 -9999 -9999 -9999 -9999 -9999 -9999 -9999 -9999 -9999 -9999 -9999 -9999 -9999 -9999 -9999 -9999 -9999 -9999 -9999 -9999 -9999 -9999 -9999 -9999 -999 -9999 -9999 -9999 -9999 -9999 -9999 -9999 -9999 -9999 -9999 -9999 -9999 -9999 -9999 -9999 -9999 -9999 -9999 -9999 -9999 -9999 -9999 -9999 -9999 -9999 -9999 -9999 -9999 -9999 -9999 -9999 -9999 -9999 -9999 -9999 -9999 -9999 -9999 -9999 -9999 -9999 -9999 -9999 -9999 -9999 -9999 -9999 -9999 -9999 -9999 -9999 -9999 -9999 -9999 -9999 -9999 -9999 -9999 -9999 -9999

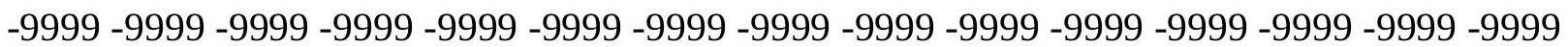


-9999 -9999 -9999 -9999 -9999 -9999 -9999 -9999 -9999 -9999 -9999 -9999 -9999 -9999 -9999 -9999 -9999 -9999 -9999 -9999 -9999 -9999 -9999 -9999 -9999 -9999 -9999 -9999 -9999 -9999

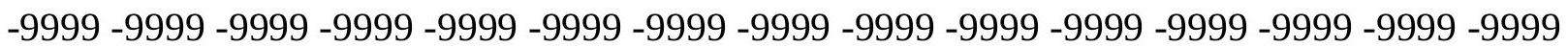
-9999 -9999 -9999 -9999 -9999 -9999 -9999 -9999 -9999 -9999 -9999 -9999 -9999 -9999 -9999 -9999 -9999 -9999 -9999 -9999 -9999 -9999 -9999 -9999 -9999 -9999 -9999 -9999 -9999 -9999 -9999 -9999 -9999 -9999 -9999 -9999 -9999 101.6835632324 102.85572052104 .2400054932 105.9241485596107 .8938980103109 .4179000854110 .9418029785112 .7705001831 114.9039993286117 .342300415119 .7806015015122 .5235977173124 .6570968628 125.5715026855125 .2667007446124 .6570968628123 .43800354121 .3044967651 119.1709976196116 .7326965332114 .5991973877112 .7705001831110 .9418029785 109.4179000854107 .5891036987105 .7603988647103 .6268997192101 .1886978149 98.7503814697396 .3121032714894 .1785964965891 .7403335571389 .91161346436 88.0829010009886 .5589828491285 .3398437583 .8159103393682 .59677124023 81.0728530883879 .2441329956176 .8058471679774 .062782287671 .31971740723 68.5766525268665 .5288009643662 .7857398986859 .4331016540557 .60438919067 52.7777099609447 .08769226074 -9999 -9999 -9999 -9999 -9999 -9999 -9999 -9999 -9999 -9999 -9999 -9999 -9999 -9999 -9999 -9999 -9999 -9999 -9999 -9999 -9999 -9999 -9999 -9999 -9999 -9999 -9999 -9999 -9999 -9999 -9999 -9999 -9999 -9999 -9999 -9999 -9999 -9999 -9999 -9999 -9999 -9999 -9999 -9999 -9999 -9999 -9999 -9999 -9999 -9999 -9999 -9999 -9999 -9999 -9999 -9999 -9999 -9999 -9999 -9999 -9999 -9999

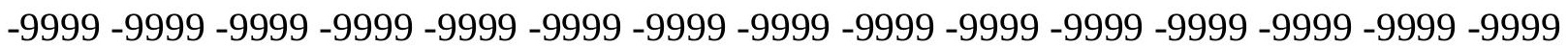
-9999 -9999 -9999 -9999 -9999 -9999 -9999 -9999 -9999 -9999 -9999 -9999 -9999 -9999 -9999 -9999 -9999 -9999 -9999 -9999 -9999 -9999 -9999 -9999 -9999 -9999 -9999 -9999 -9999 -9999 -9999 -9999 -9999 -9999 -9999 -9999 -9999 -9999 -9999 -9999 -9999 -9999 -9999 -9999 -9999

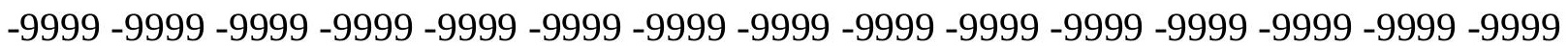
-9999 -9999 -9999 -9999 -9999 -9999 -9999 -9999 -9999 -9999 -9999 -9999 -9999 -9999 -9999 -9999 -9999 -9999 -9999 -9999 -9999 -9999 -9999 -9999 -9999 -9999 -9999 -9999 -9999 -9999 -9999 -9999 -9999 -9999 -9999 -9999 -9999 -9999 -9999 -9999 -9999 -9999 -9999 -9999 -9999 -9999 -9999 -9999 -9999 -9999 -9999 -9999 -9999 -9999 -9999 -9999 -9999 -9999 -9999 -9999 -9999 -9999 -9999 -9999 -9999 -9999 -9999 -9999 -9999 -9999 -9999 -9999 -9999 -9999 -9999 -9999 -9999 -9999 -9999 -9999 -9999 -9999 -9999 -9999 -9999 -9999 -9999 -9999 -9999 -9999 -9999 -9999 -9999 -9999 -9999 -9999 -9999 -9999 -9999 -9999 -9999 -9999 -9999 -9999 -9999 -9999 -9999 -9999 -9999 -9999 -9999 -9999 -9999 -9999 -9999 -9999 -9999 -9999 -9999 -9999 -9999 -9999 -9999 -9999 -9999 -9999 -9999 -9999 -9999 -9999 -9999 -9999 -9999 -9999 -9999

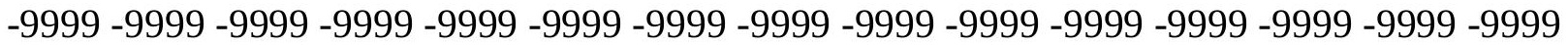
-9999 -9999 -9999 -9999 -9999 -9999 -9999 -9999 -9999 -9999 -9999 -9999 -9999 -9999 -9999 -9999 -9999 -9999 -9999 -9999 -9999 -9999 -9999 -9999 -9999 -9999 -9999 -9999 -9999 -9999 -9999 -9999 -9999 -9999 -9999 -9999 -9999 -9999 -9999 -9999 -9999 -9999 -9999 -9999 -9999 -9999 -9999 -9999 -9999 -9999 -9999 -9999 -9999 -9999 100.7036590576102 .0232009888 103.3686141968104 .5064544678105 .4557037354106 .6747970581108 .1986999512 110.0273971558112 .7705001831116 .4279022217120 .9997024536120 .9997024536 120.9997024536120 .9997024536120 .0852966309117 .9517974854115 .2088012695 112.7705001831110 .9418029785109 .4179000854108 .1986999512106 .6747970581 105.1509017944103 .3221969604100 .883903503498 .445587158295 .70252990723 92.9594726562590 .5211791992288 .0829010009885 .9494018554783 .81591033936 81.9871978759880 .4632720947378 .9393463134877 .7202072143676 .19628143311 
73.7580032348671 .014930725168 .2718734741265 .2240066528362 .48094940186 60.0088043212957 .5544738769555 .0513191223152 .4231986999548 .65454101562 43.95903015137 -9999 -9999 -9999 -9999 -9999 -9999 -9999 -9999 -9999 -9999 -9999 -9999 -9999 -9999 -9999 -9999 -9999 -9999 -9999 -9999 -9999 -9999 -9999 -9999 -9999 -9999 -9999 -9999 -9999-9999-9999-9999

-9999 -9999 -9999 -9999 -9999 -9999 -9999 -9999 -9999 -9999 -9999 -9999 -9999 -9999 -9999 -9999 -9999 -9999 -9999 -9999 -9999 -9999 -9999 -9999 -9999 -9999 -9999 -9999 -9999 -9999

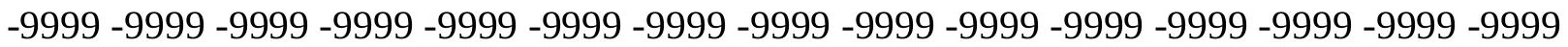

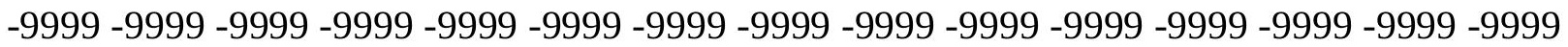
-9999 -9999 -9999 -9999 -9999 -9999 -9999 -9999 -9999 -9999 -9999 -9999 -9999 -9999 -9999

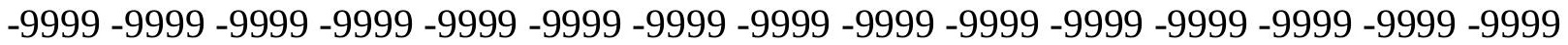
-9999 -9999 -9999 -9999 -9999 -9999 -9999 -9999 -9999 -9999 -9999 -9999 -9999 -9999 -9999 -9999 -9999 -9999 -9999 -9999 -9999 -9999 -9999 -9999 -9999 -9999 -9999 -9999 -9999 -9999 -9999 -9999 -9999 -9999 -9999 -9999 -9999 -9999 -9999 -9999 -9999 -9999 -9999 -9999 -9999 -9999 -9999 -9999 -9999 -9999 -9999 -9999 -9999 -9999 -9999 -9999 -9999 -9999 -9999 -9999

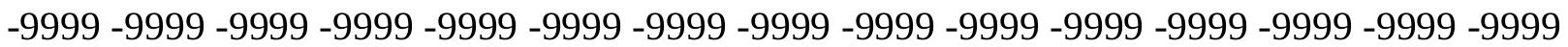

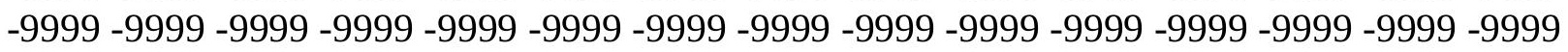
-9999 -9999 -9999 -9999 -9999 -9999 -9999 -9999 -9999 -9999 -9999 -9999 -9999 -9999 -9999 -999 -9999 -9999 -9999 -9999 -9999 -9999 -9999 -9999 -9999 -9999 -9999 -9999 -9999 -9999 -9999 -9999 -9999 -9999 -9999 -9999 -9999 -9999 -9999 -9999 -9999 -9999 -9999 -9999 -9999 -9999 -9999 -9999 -9999 -9999 -9999 -9999 -9999 -9999 -9999 -9999 -9999 -9999 -9999 -9999 -9999 -9999 -9999 -9999 -9999 -9999 -9999 -9999 -9999 -9999 -9999 -9999 -9999 -9999 -9999 -9999 -9999 -9999 -9999 -9999 -9999 -9999 -9999 -9999 -9999 -9999 -9999 -9999 -9999 -9999 -9999 -9999 -9999 -9999 -9999 -9999 -9999 -9999 -9999 -9999 -9999 -9999 -9999 -9999 -9999 -9999 -9999 -9999 -9999 -9999 -9999 -9999 -9999 -9999 -9999 -9999 -9999 -9999 -9999 -9999 -9999 -9999 -9999 -9999 -9999 -9999 -9999 -9999 -9999 -9999 -9999 -9999 98.72440338135 99.47550201416100 .1380615234100 .8413238525101 .6216506958102 .4077987671 103.9317016602107 .5891036987110 .6370010376112 .4656982422114 .2944030762 115.5136032104115 .5136032104112 .7705001831109 .4179000854107 .2844009399 106.0652008057105 .4557037354104 .5412979126103 .3221969604102 .1029968262 100.274299621698 .1408081054795 .397743225192 .6546783447389 .60682678223 86.8637619018684 .1206970214881 .6824111938579 .5489196777377 .72020721436 75.8914871215874 .062782287672 .8436431884871 .6244964599668 .88143920898 65.9544296264663 .0460128784260 .1909217834557 .5575256347755 .18775177002 52.9000053405850 .5729751586947 .83341217041 -9999 -9999 -9999 -9999 -9999 -9999 -9999 -9999 -9999 -9999 -9999 -9999 -9999 -9999 -9999 -9999 -9999 -9999 -9999 -9999 -9999 -9999 -9999 -9999 -9999 -9999 -9999 -9999 -9999 -9999 -9999 -9999 -9999 -9999

-9999 -9999 -9999 -9999 -9999 -9999 -9999 -9999 -9999 -9999 -9999 -9999 -9999 -9999 -9999 -9999 -9999 -9999 -9999 -9999 -9999 -9999 -9999 -9999 -9999 -9999 -9999 -9999 -9999 -9999 -9999 -9999 -9999 -9999 -9999 -9999 -9999 -9999 -9999 -9999 -9999 -9999 -9999 -9999 -9999 -9999 -9999 -9999 -9999 -9999 -9999 -9999 -9999 -9999 -9999 -9999 -9999 -9999 -9999 -9999 -999 -9999 -9999 -9999 -9999 -9999 -9999 -9999 -9999 -9999 -9999 -9999 -9999 -9999 -9999 -9999 -9999 -9999 -9999 -9999 -9999 -9999 -9999 -9999 -9999 -9999 -9999 -9999 -9999 -9999 -9999 -9999 -9999 -9999 -9999 -9999 -9999 -9999 -9999 -9999 -9999 -9999 -9999 -9999 -9999 -9999 -9999 -9999 -9999 -9999 -9999 -9999 -9999 -9999 -9999 -9999 -9999 -9999 -9999 -9999 -9999

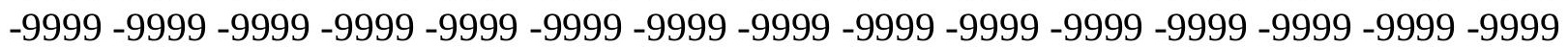


-9999 -9999 -9999 -9999 -9999 -9999 -9999 -9999 -9999 -9999 -9999 -9999 -9999 -9999 -9999 -9999 -9999 -9999 -9999 -9999 -9999 -9999 -9999 -9999 -9999 -9999 -9999 -9999 -9999 -9999 -9999 -9999 -9999 -9999 -9999 -9999 -9999 -9999 -9999 -9999 -9999 -9999 -9999 -9999 -9999 -9999 -9999 -9999 -9999 -9999 -9999 -9999 -9999 -9999 -9999 -9999 -9999 -9999 -9999 -9999 -9999 -9999 -9999 -9999 -9999 -9999 -9999 -9999 -9999 -9999 -9999 -9999 -9999 -9999 -9999 -9999 -9999 -9999 -9999 -9999 -9999 -9999 -9999 -9999 -9999 -9999 -9999 -9999 -9999 -9999 -9999 -9999 -9999 -9999 -9999 -9999 -9999 -9999 -9999 -9999 -9999 -9999 -9999 -9999 -9999

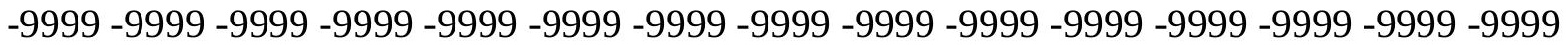
-9999 -9999 -9999 -9999 -9999 -9999 -9999 -9999 -9999 -9999 -9999 -9999 -9999 -9999 -9999 -9999 -9999 -9999 -9999 -9999 -9999 -9999 -9999 -9999 -9999 -9999 -9999 -9999 -9999 -9999 -

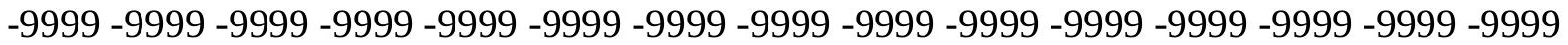
-9999 -9999 -9999 -9999 -9999 -9999 -9999 -9999 -9999 -9999 -9999 -9999 -9999 95.0138473510795 .3613128662195 .7429809570396 .3576354980597 .67502593994 99.84647369385101 .8009872437103 .0174026489105 .1509017944108 .5035018921 110.6370010376106 .3700027466101 .7982025146101 .1886978149100 .8839035034 100.5791015625100 .063247680799 .2128753662198 .0284729003996 .3938369751 94.3122024536191 .792129516689 .0257110595786 .1210479736383 .25213623047 80.5080718994177 .9726104736375 .7067413330173 .6464538574271 .69413757324 69.8905487060568 .2599411010766 .4444351196364 .0220947265661 .24396896362 58.4084930419955 .7014007568453 .19036102295 -9999 -9999 -9999 -9999 -9999 -9999 -9999

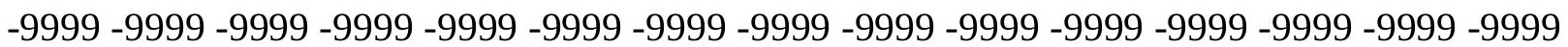

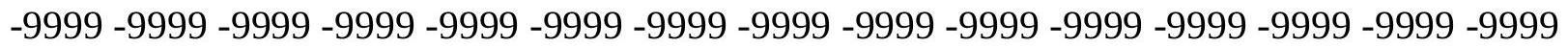
$-9999$

-9999 -9999 -9999 -9999 -9999 -9999 -9999 -9999 -9999 -9999 -9999 -9999 -9999 -9999 -9999

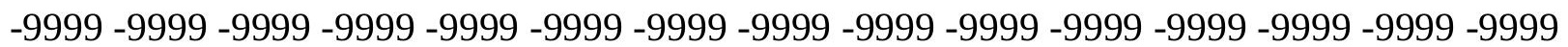
-9999 -9999 -9999 -9999 -9999 -9999 -9999 -9999 -9999 -9999 -9999 -9999 -9999 -9999 -9999 -9999 -9999 -9999 -9999 -9999 -9999 -9999 -9999 -9999 -9999 -9999 -9999 -9999 -9999 -9999

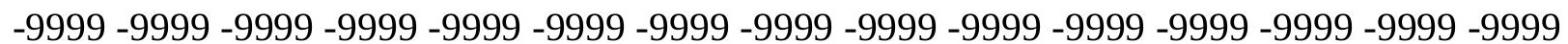

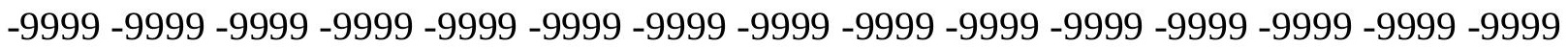
-9999 -9999 -9999 -9999 -9999 -9999 -9999 -9999 -9999 -9999 -9999 -9999 -9999 -9999 -9999 -9999 -9999 -9999 -9999 -9999 -9999 -9999 -9999 -9999 -9999 -9999 -9999 -9999 -9999 -9999

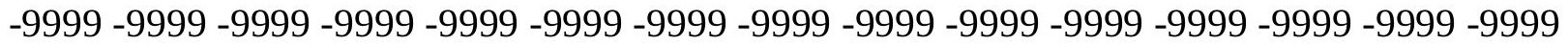

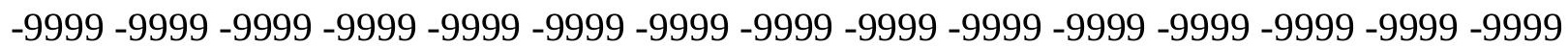
-9999 -9999 -9999 -9999 -9999 -9999 -9999 -9999 -9999 -9999 -9999 -9999 -9999 -9999 -9999

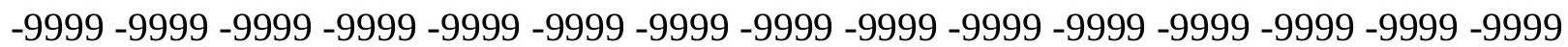
-9999 -9999 -9999 -9999 -9999 -9999 -9999 -9999 -9999 -9999 -9999 -9999 -9999 -9999 -9999 -9999 -9999 -9999 -9999 -9999 -9999 -9999 -9999 -9999 -9999 -9999 -9999 -9999 -9999 -9999

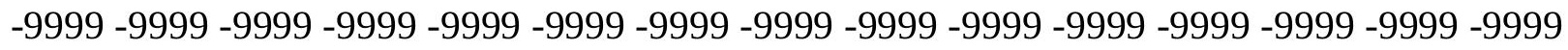
-9999 -9999 -9999 -9999 -9999 -9999 -9999 -9999 -9999 -9999 -9999 -9999 -9999 -9999 -9999 -9999 -9999 -9999 -9999 -9999 -9999 -9999 -9999 -9999 -9999 -9999 -9999 -9999 -9999 -9999 -9999 -9999 -9999 -9999 -9999 -9999 -9999 -9999 -9999 -9999 -9999 -9999 -9999 -9999 -9999 -999 -9999 -9999 -9999 -9999 -9999 -9999 -9999 -9999 -9999 -9999 -9999 -9999 -9999 -9999 -9999 -9999 -9999 -9999 -9999 -9999 -9999 -9999 -9999 -9999 -9999 -9999 -9999 -9999 -9999 -9999 -9999 -9999 -9999 -9999 -9999 -9999 -9999 -9999 -9999 -9999 -9999 -9999 -9999 -9999 -9999 -9999 91.1422882080192.1159515380993.4308929443494.8614578247196.43830108643 98.58612823486100 .9645690918101 .802078247199 .9400329589897 .37884521484 
96.1384429931695 .827705383395 .6631393432695 .3101730346794 .6266784668 93.5431823730592 .0437545776490 .1005020141687 .7843627929785 .17765808105 82.4324340820379 .649002075276 .9527587890674 .3994216918972 .02948760986 69.8199081420967 .7493591308665 .7864608764663 .84267044067 -9999 -9999 -9999 -9999 -9999 -9999 -9999 -9999 -9999 -9999 -9999 -9999 -9999 -9999 -9999 -9999 -9999 -9999 -9999 -9999 -9999 -9999 -9999 -9999 -9999 -9999 -9999 -9999 -9999 -9999 -9999 -9999 -9999 -9999 -9999 -9999 -9999 -9999 -9999 -9999 -9999 -9999 -9999 -9999

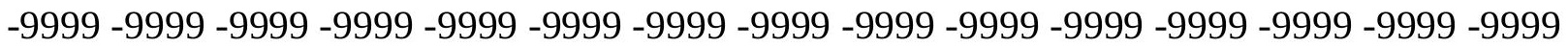

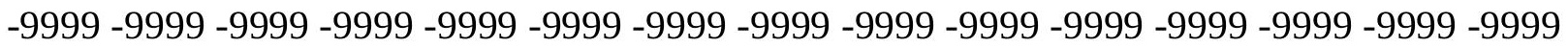
-9999 -9999 -9999 -9999 -9999 -9999 -9999 -9999 -9999 -9999 -9999 -9999 -9999 -9999 -9999

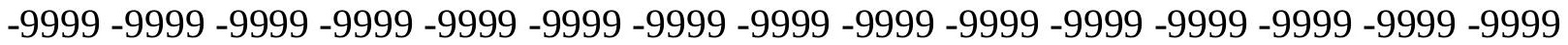
-9999 -9999 -9999 -9999 -9999 -9999 -9999 -9999 -9999 -9999 -9999 -9999 -9999 -9999 -9999 -9999 -9999 -9999 -9999 -9999 -9999 -9999 -9999 -9999 -9999 -9999 -9999 -9999 -9999 -9999 -9999 -9999 -9999 -9999 -9999 -9999 -9999 -9999 -9999 -9999 -9999 -9999 -9999 -9999 -9999 -9999 -9999 -9999 -9999 -9999 -9999 -9999 -9999 -9999 -9999 -9999 -9999 -9999 -9999 -9999

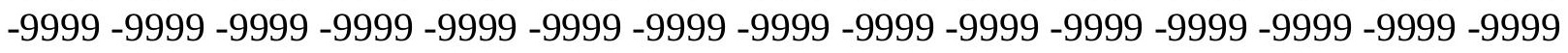
-9999 -9999 -9999 -9999 -9999 -9999 -9999 -9999 -9999 -9999 -9999 -9999 -9999 -9999 -9999 -9999 -9999 -9999 -9999 -9999 -9999 -9999 -9999 -9999 -9999 -9999 -9999 -9999 -9999 -9999 -9999 -9999 -9999 -9999 -9999 -9999 -9999 -9999 -9999 -9999 -9999 -9999 -9999 -9999 -9999 -9999 -9999 -9999 -9999 -9999 -9999 -9999 -9999 -9999 -9999 -9999 -9999 -9999 -9999 -9999 -9999 -9999 -9999 -9999 -9999 -9999 -9999 -9999 -9999 -9999 -9999 -9999 -9999 -9999 -9999 -9999 -9999 -9999 -9999 -9999 -9999 -9999 -9999 -9999 -9999 -9999 -9999 -9999 -9999 -9999 -9999 -9999 -9999 -9999 -9999 -9999 -9999 -9999 -9999 -9999 -9999 -9999 -9999 -9999 -9999 -9999 -9999 -9999 -9999 -9999 -9999 -9999 -9999 -9999 -9999 -9999 -9999 -9999 -9999 -9999 -9999 -9999 -9999 -9999 -9999 -9999 -9999 -9999 -9999 -9999 -9999 -9999 -9999 -9999 -9999 -9999 -9999 -9999 -9999 -9999 -9999 -9999 -9999 -9999 -9999 -9999 -9999 -9999 -9999 -9999 -9999 -9999 -9999 -9999 -9999 -9999 -9999 -9999 -9999 -9999 -9999 -9999 -9999 -9999 -9999 -

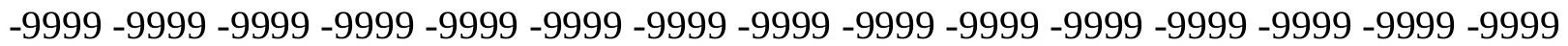

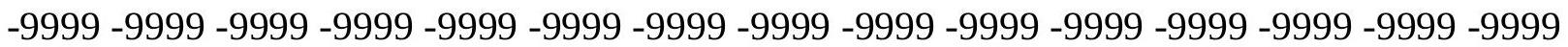
-9999 -9999 -9999 -9999 -9999 -9999 -9999 -9999 -9999 -9999 -9999 -9999 -9999 -9999 -9999 -9999 -9999 -9999 -9999 -9999 -9999 -9999 -9999 -9999 -9999 -9999 -9999 -9999 -9999 -9999

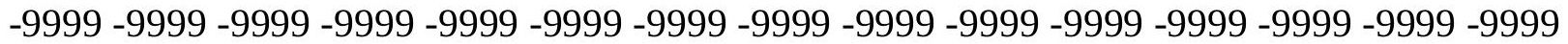
-9999 -9999 -9999 -9999 -9999 -9999 -9999 -9999 -9999 -9999 -9999 -9999 -9999 -9999 -9999 -9999 -9999 -9999 -9999 -9999 -9999 -9999 -9999 -9999 -9999 -9999 -9999 -9999 -9999 -9999 -9999 -9999 -9999 -9999 -9999 -9999 -9999 -9999 -9999 -9999 -9999 -9999 -9999 -9999 -9999 -9999 -9999 -9999 -9999 -9999 -9999 -9999 -9999 -9999 -9999 -9999 -9999 -9999 -9999

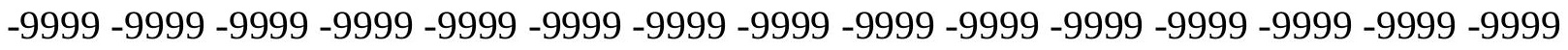

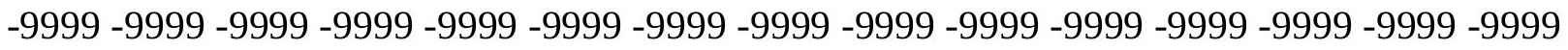
-9999 -9999 -9999 -9999 -9999 -9999 -9999 -9999 -9999 -9999 -9999 -9999 -9999 -9999 -9999 -9999 -9999 -9999 -9999 -9999 -9999 -9999 -9999 -9999 -9999 -9999 -9999 -9999 -9999 -9999 -9999 -9999 -9999 -9999 -9999 -9999 -9999 -9999 -9999 -9999 -9999 -9999 -9999 -9999 -9999 -999 -9999 -9999 -9999 -9999 -9999 -9999 -9999 -9999 -9999 -9999 -9999 -9999 -9999 -9999 -9999 -9999 -9999 -9999 -9999 -9999 -9999 -9999 -9999 -9999 -9999 -9999 -9999 -9999 -9999 -9999 -9999 -9999 -9999 -9999 -9999 -9999 -9999 -9999 -9999 -9999 -9999 -9999 -9999 -9999 -9999 -9999 -9999 -9999 -9999 -9999 -9999 -9999 -9999 -9999 -9999 -9999 -9999 -9999 -9999 -9999

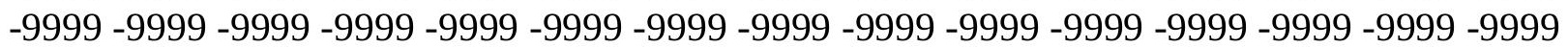


-9999 -9999 -9999 -9999 -9999 -9999 -9999 -9999 -9999 -9999 -9999 -9999 -9999 -9999 -9999 -9999 -9999 -9999 -9999 -9999 -9999 -9999 -9999 -9999 -9999 -9999 -9999 -9999 -9999 -9999 -

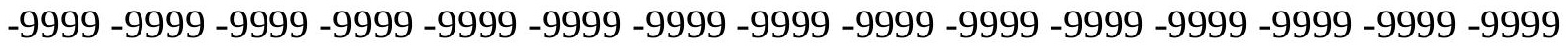
-9999 -9999 -9999 -9999 -9999 -9999 -9999 -9999 -9999 -9999 -9999 -9999 -9999 -9999 -9999 -9999 -9999 -9999 -9999 -9999 -9999 -9999 -9999 -9999-9999 -9999 -9999 -9999 -9999 -9999 -9999 -9999 -9999 -9999 -9999 -9999 -9999 -9999 -9999 -9999 -9999 -9999 -9999 -9999 -9999 -9999 -9999 -9999 -9999 -9999 -9999 -9999 -9999 -9999 -9999 -9999 -9999 -9999 -9999 -9999

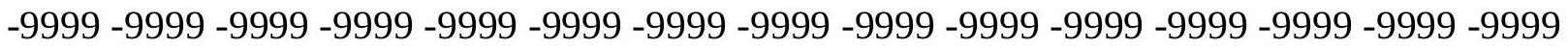

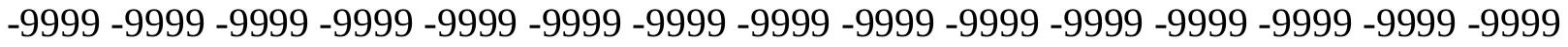
-9999 -9999 -9999 -9999 -9999 -9999 -9999 -9999 -9999 -9999 -9999 -9999 -9999 -9999 -9999 -9999 -9999 -9999 -9999 -9999 -9999 -9999 -9999 -9999 -9999 -9999 -9999 -9999 -9999 -9999 -9999 -9999 -9999 -9999 -9999 -9999 -9999 -9999 -9999 -9999 -9999 -9999 -9999 -9999 -9999 -9999 -9999 -9999 -9999 -9999 -9999 -9999 -9999 -9999 -9999 -9999 -9999 -9999 -9999 -9999 -9999 -9999 -9999 -9999 -9999 -9999 -9999 -9999 -9999 -9999 -9999 -9999 -9999 -9999 -9999 -9999 -9999 -9999 -9999 -9999 -9999 -9999 -9999 -9999 -9999 -9999 -9999 -9999 -9999 -

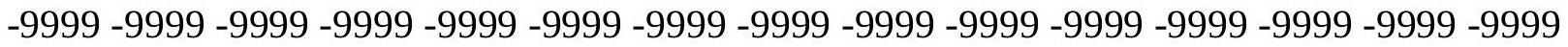
-9999 -9999 -9999 -9999 -9999 -9999 -9999 -9999 -9999 -9999 -9999 -9999 -9999 -9999 -9999 -9999 -9999 -9999 -9999 -9999 -9999 -9999 -9999 -9999 -9999 -9999 -9999 -9999 -9999 -9999 -9999 -9999 -9999 -9999 -9999 -9999 -9999 -9999 -9999 -9999 -9999 -9999 -9999 -9999 -9999 -

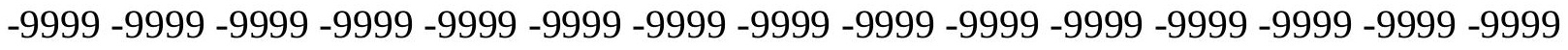
-9999 -9999 -9999 -9999 -9999 -9999 -9999 -9999 -9999 -9999 -9999 -9999 -9999 -9999 -9999

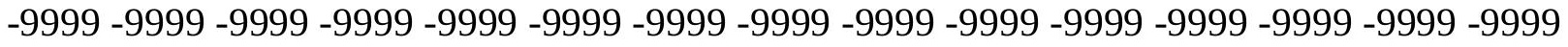
-9999 -9999 -9999 -9999 -9999 -9999 -9999 -9999 -9999 -9999 -9999 -9999 -9999 -9999 -9999 -9999 -9999 -9999 -9999 -9999 -9999 -9999 -9999 -9999 -9999 -9999 -9999 -9999 -9999 -9999 -

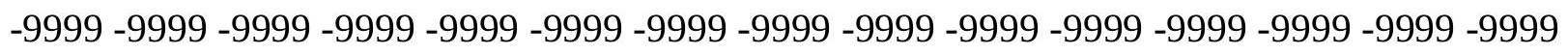
-9999 -9999 -9999 -9999 -9999 -9999 -9999 -9999 -9999 -9999 -9999 -9999 -9999 -9999 -9999 -9999 -9999 -9999 -9999 -9999 -9999 -9999 -9999 -9999 -9999 -9999 -9999 -9999 -9999 -9999 -

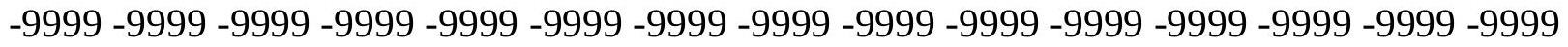
-9999 -9999 -9999 -9999 -9999 -9999 -9999 -9999 -9999 -9999 -9999 -9999 -9999 -9999 -9999 -9999 -9999 -9999 -9999 -9999 -9999 -9999 -9999 -9999 -9999 -9999 -9999 -9999 -9999 -999 -9999 -9999 -9999 -9999 -9999 -9999 -9999 -9999 -9999 -9999 -9999 -9999 -9999 -9999 -9999 -9999 -9999 -9999 -9999 -9999 -9999 -9999 -9999 -9999 -9999 -9999 -9999 -9999 -9999 -9999 -

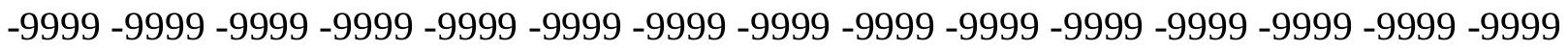

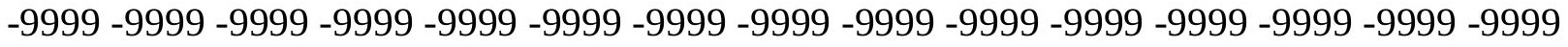

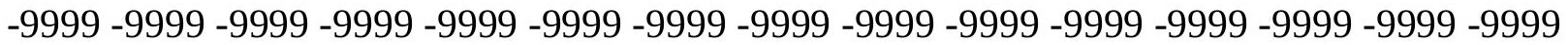
-9999 -9999 -9999 -9999 -9999 -9999 -9999 -9999 -9999 -9999 -9999 -9999 -9999 -9999 -9999 -

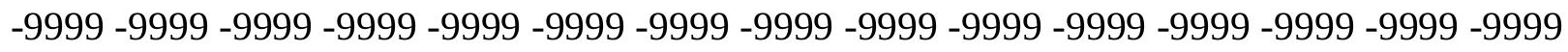

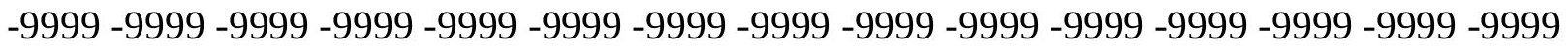
-9999 -9999 -9999 -9999 -9999 -9999 -9999 -9999 -9999 -9999 -9999 -9999 -9999 -9999 - -999 -9999 -9999 -9999 -9999 -9999 -9999 -9999 -9999 -9999 -9999 -9999 -9999 -9999 -9999 -9999 -

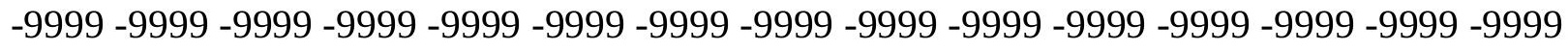

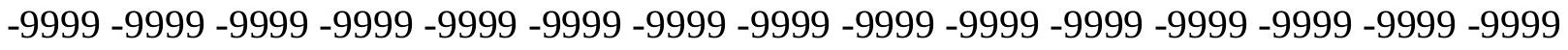
-9999 -9999 -9999 -9999 -9999 -9999 -9999 -9999 -9999 -9999 -9999 -9999 -9999 -9999 -9999 -9999 -9999 -9999 -9999 -9999 -9999 -9999 -9999 -9999-9999 -9999 -9999 -9999 -9999 -9999 -9999 -9999 -9999 -9999 -9999 -9999 -9999 -9999 -9999 -9999 -9999 -9999 -9999 -9999 -9999 -

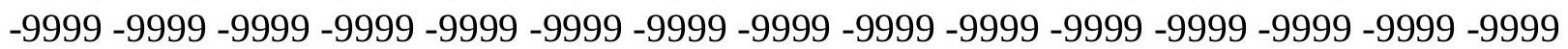


-9999 -9999 -9999 -9999 -9999 -9999 -9999 -9999 -9999 -9999 -9999 -9999 -9999 -9999 -9999 -9999 -9999 -9999 -9999 -9999 -9999 -9999 -9999 -9999 -9999 -9999 -9999 -9999 -9999 -9999 -

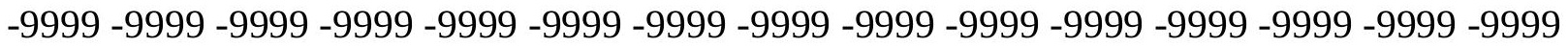
-9999 -9999 -9999 -9999 -9999 -9999 -9999 -9999 -9999 -9999 -9999 -9999 -9999 -9999 -9999 -9999 -9999 -9999 -9999 -9999 -9999 -9999 -9999 -9999-9999 -9999 -9999 -9999 -9999 -9999 -9999 -9999 -9999 -9999 -9999 -9999 -9999 -9999 -9999 -9999 -9999 -9999 -9999 -9999 -9999 -9999 -9999 -9999 -9999 -9999 -9999 -9999 -9999 -9999 -9999 -9999 -9999 -9999 -9999 -9999

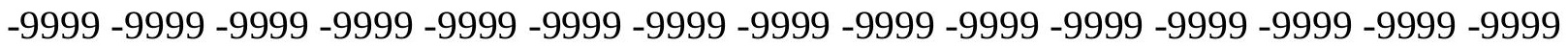

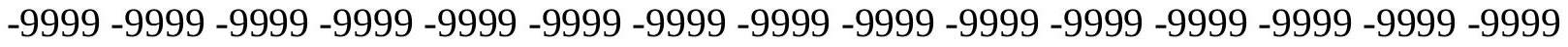
-9999 -9999 -9999 -9999 -9999 -9999 -9999 -9999 -9999 -9999 -9999 -9999 -9999 -9999 -9999 -9999 -9999 -9999 -9999 -9999 -9999 -9999 -9999 -9999 -9999 -9999 -9999 -9999 -9999 -9999 -9999 -9999 -9999 -9999 -9999 -9999 -9999 -9999 -9999 -9999 -9999 -9999 -9999 -9999 -9999 -9999 -9999 -9999 -9999 -9999 -9999 -9999 -9999 -9999 -9999 -9999 -9999 -9999 -9999 -9999 -

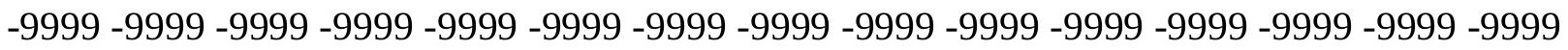
-9999 -9999 -9999 -9999 -9999 -9999 -9999 -9999 -9999 -9999 -9999 -9999 -9999 -9999 -9999 -

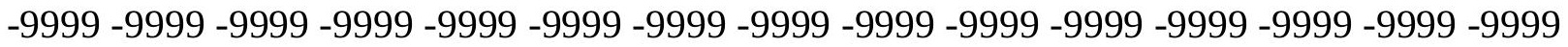
-9999 -9999 -9999 -9999 -9999 -9999 -9999 -9999 -9999 -9999 -9999 -9999 -9999 -9999 -9999 -9999 -9999 -9999 -9999 -9999 -9999 -9999 -9999 -9999 -9999 -9999 -9999 -9999 -9999 -9999 -9999 -9999 -9999 -9999 -9999 -9999 -9999 -9999 -9999 -9999 -9999 -9999 -9999 -9999 - -999 -

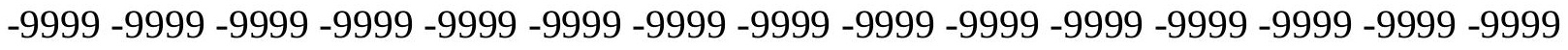

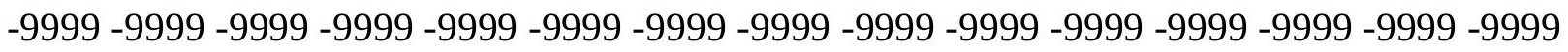
-9999 -9999 -9999 -9999 -9999 -9999 -9999 -9999 -9999 -9999 -9999 -9999 -9999 -9999 -9999 -9999 -9999 -9999 -9999 -9999 -9999 -9999 -9999 -9999 -9999 -9999 -9999 -9999 -9999 -9999 -9999 -9999 -9999 -9999 -9999 -9999 -9999 -9999 -9999 -9999 -9999 -9999 -9999 -9999 -9999 -

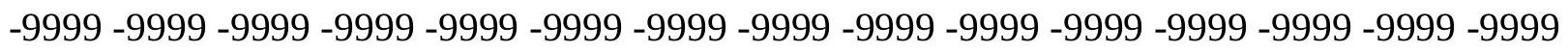
-9999 -9999 -9999 -9999 -9999 -9999 -9999 -9999 -9999 -9999 -9999 -9999 -9999 -9999 -9999 -9999 -9999 -9999 -9999 -9999 -9999 -9999 -9999 -9999 -9999 -9999 -9999 -9999 -9999 -9999 -

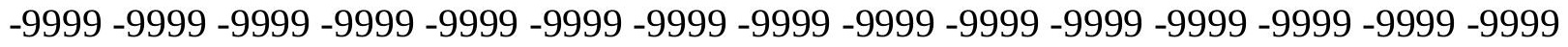
-9999 -9999 -9999 -9999 -9999 -9999 -9999 -9999 -9999 -9999 -9999 -9999 -9999 -9999 -9999 -9999 -9999 -9999 -9999 -9999 -9999 -9999 -9999 -9999 -9999 -9999 -9999 -9999 -9999 -999 -

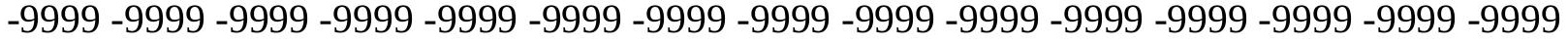
-9999 -9999 -9999 -9999 -9999 -9999 -9999 -9999 -9999 -9999 -9999 -9999 -9999 -9999 -9999 -

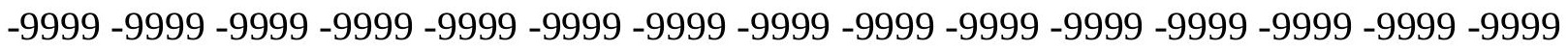

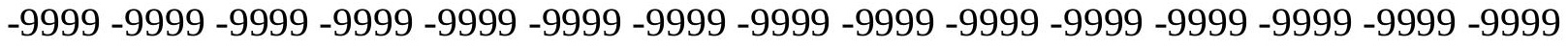

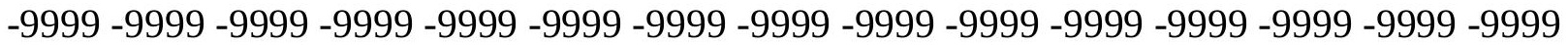

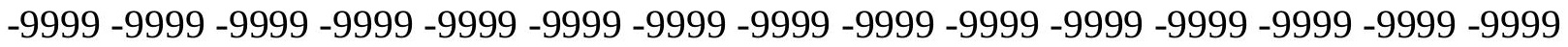

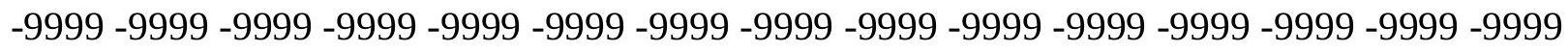

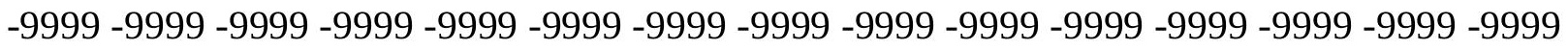

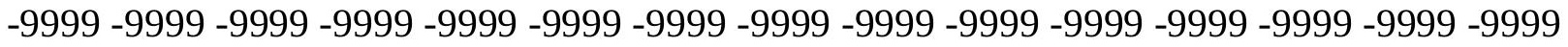
-9999 -9999 -9999 -9999 -9999 -9999 -9999 -9999 -9999 -9999 -9999 -9999 -9999 -9999 -9999 -

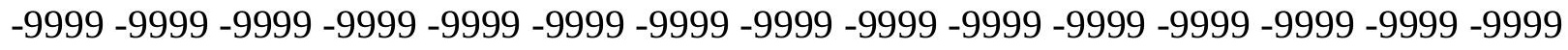

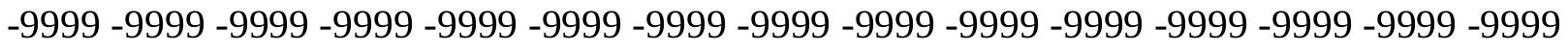
-9999 -9999 -9999 -9999 -9999 -9999 -9999 -9999 -9999 -9999 -9999 -9999 -9999 -9999 -9999 -9999 -9999 -9999 -9999 -9999 -9999 -9999 -9999 -9999 -9999 -9999 -9999 -9999 -9999 -9999 -9999 -9999 -9999 -9999 -9999 -9999 -9999 -9999 -9999 -9999 -9999 -9999 -9999 -9999 -

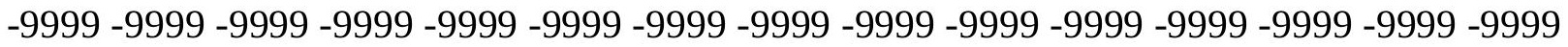


-9999 -9999 -9999 -9999 -9999 -9999 -9999 -9999 -9999 -9999 -9999 -9999 -9999 -9999 -9999 -9999 -9999 -9999 -9999 -9999 -9999 -9999 -9999 -9999 -9999 -9999 -9999 -9999 -9999 -9999 -

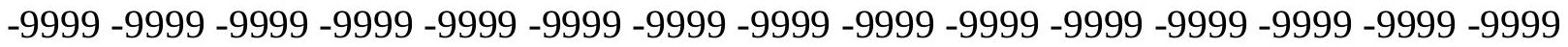
-9999 -9999 -9999 -9999 -9999 -9999 -9999 -9999 -9999 -9999 -9999 -9999 -9999 -9999 -9999 -9999 -9999 -9999 -9999 -9999 -9999 -9999 -9999 -9999-9999 -9999 -9999 -9999 -9999 -9999 -9999 -9999 -9999 -9999 -9999 -9999 -9999 -9999 -9999 -9999 -9999 -9999 -9999 -9999 -9999 -9999 -9999 -9999 -9999 -9999 -9999 -9999 -9999 -9999 -9999 -9999 -9999 -9999 -9999 -9999

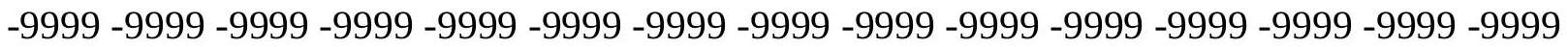

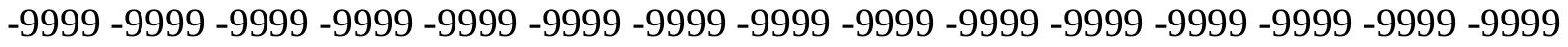
-9999 -9999 -9999 -9999 -9999 -9999 -9999 -9999 -9999 -9999 -9999 -9999 -9999 -9999 -9999 -9999 -9999 -9999 -9999 -9999 -9999 -9999 -9999 -9999 -9999 -9999 -9999 -9999 -9999 -9999 -9999 -9999 -9999 -9999 -9999 -9999 -9999 -9999 -9999 -9999 -9999 -9999 -9999 -9999 -9999 -9999 -9999 -9999 -9999 -9999 -9999 -9999 -9999 -9999 -9999 -9999 -9999 -9999 -9999 -9999 -

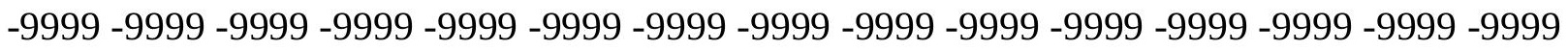
-9999 -9999 -9999 -9999 -9999 -9999 -9999 -9999 -9999 -9999 -9999 -9999 -9999 -9999 -9999 -

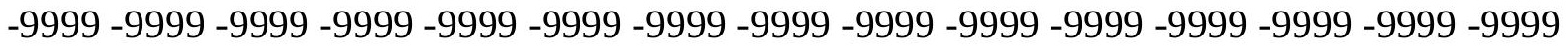
-9999 -9999 -9999 -9999 -9999 -9999 -9999 -9999 -9999 -9999 -9999 -9999 -9999 -9999 -9999 -9999 -9999 -9999 -9999 -9999 -9999 -9999 -9999 -9999 -9999 -9999 -9999 -9999 -9999 - 9999 -9999 -9999 -9999 -9999 -9999 -9999 -9999 -9999 -9999 -9999 -9999 -9999 -9999 -9999 -9999 -

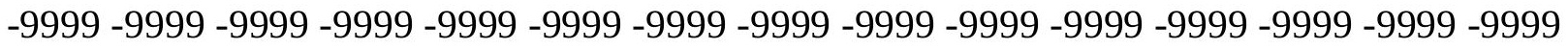

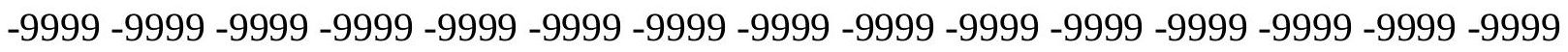
-9999 -9999 -9999 -9999 -9999 -9999 -9999 -9999 -9999 -9999 -9999 -9999 -9999 -9999 - 9999 -9999 -9999 -9999 -9999 -9999 -9999 -9999 -9999 -9999 -9999 -9999 -9999 -9999 -9999 -9999 -9999 -9999 -9999 -9999 -9999 -9999 -9999 -9999 -9999 -9999 -9999 -9999 -9999 -9999 -9999 -9999 -9999 -9999 -9999 -9999 -9999 -9999 -9999 -9999 -9999 -9999 -9999 -9999 -9999 -9999 -9999 -9999 -9999 -9999 -9999 -9999 -9999 -9999 -9999 -9999 -9999 -9999 -9999 -9999 -9999 -9999 -9999 -9999 -9999 -9999 -9999 -9999 -9999 -9999 -9999 -9999 -9999 -9999 -9999 -

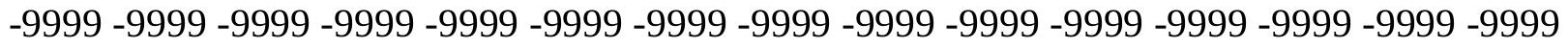
-9999 -9999 -9999 -9999 -9999 -9999 -9999 -9999 -9999 -9999 -9999 -9999 -9999 -9999 -9999 -9999 -9999 -9999 -9999 -9999 -9999 -9999 -9999 -9999 -9999 -9999 -9999 -9999 -9999 -999 -9999 -9999 -9999 -9999 -9999 -9999 -9999 -9999 -9999 -9999 -9999 -9999 -9999 -9999 -9999 -9999 -9999 -9999 -9999 -9999 -9999 -9999 -9999 -9999 -9999 -9999 -9999 -9999 -9999 -9999 -

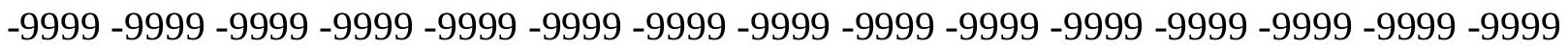

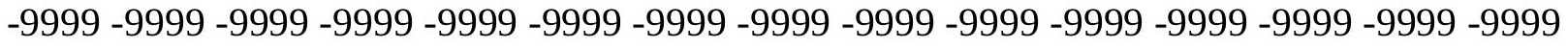

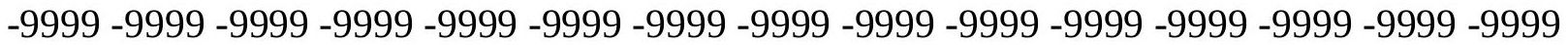

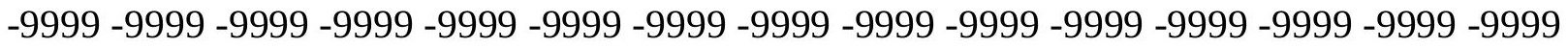

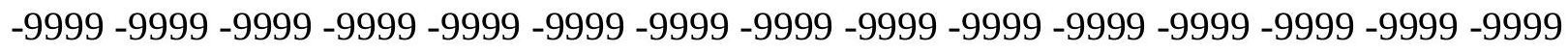

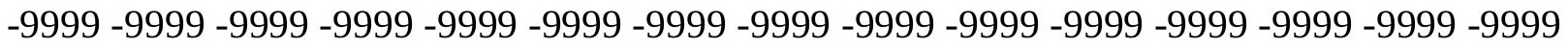

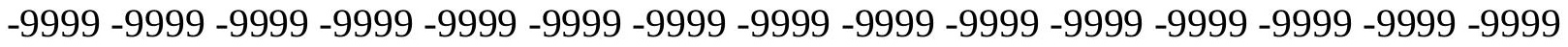
-9999 -9999 -9999 -9999 -9999 -9999 -9999 -9999 -9999 -9999 -9999 -9999 -9999 -9999 -9999 -

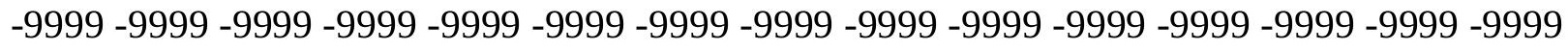

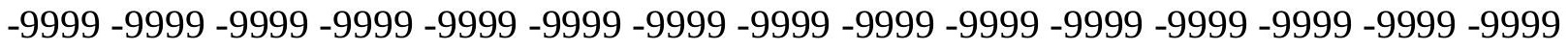
-9999 -9999 -9999 -9999 -9999 -9999 -9999 -9999 -9999 -9999 -9999 -9999 -9999 -9999 -9999 -9999 -9999 -9999 -9999 -9999 -9999 -9999 -9999 -9999-9999 -9999 -9999 -9999 -9999 -9999 -9999 -9999 -9999 -9999 -9999 -9999 -9999 -9999 -9999 -9999 -9999 -9999 -9999 -9999 -9999 -

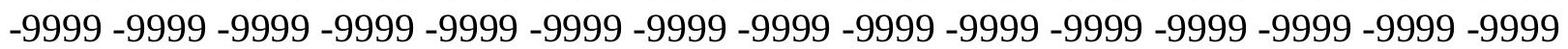


-9999 -9999 -9999 -9999 -9999 -9999 -9999 -9999 -9999 -9999 -9999 -9999 -9999 -9999 -9999 -9999 -9999 -9999 -9999 -9999 -9999 -9999 -9999 -9999 -9999 -9999 -9999 -9999 -9999 -9999 -9999 -9999 -9999 -9999 -9999 -9999 -9999 -9999 -9999 -9999 -9999 -9999 -9999 -9999 -9999 -9999 -9999 -9999 -9999 -9999 -9999 -9999 -9999 -9999 -9999 -9999 -9999 -9999 -9999 -9999 -9999 -9999 -9999 -9999 -9999 -9999 -9999 -9999 -9999 -9999 -9999 -9999 -9999 -9999 - -999 -9999 -9999 -9999 -9999 -9999 -9999 -9999 -9999 -9999 -9999 -9999 -9999 -9999 -9999 -9999 -9999 -9999 -9999 -9999 -9999 -9999 -9999 -9999 -9999 -9999 -9999 -9999 -9999 -9999 -9999

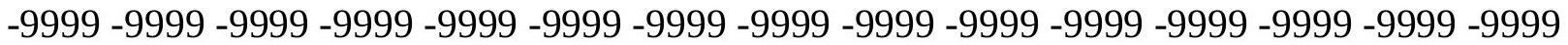
-9999 -9999 -9999 -9999 -9999 -9999 -9999 -9999 -9999 -9999 -9999 -9999 -9999 -9999 -9999 -9999 -9999 -9999 -9999 -9999 -9999 -9999 -9999 -9999 -9999 -9999 -9999 -9999 -9999 -9999 -9999 -9999 -9999 -9999 -9999 -9999 -9999 -9999 -9999 -9999 -9999 -9999 -9999 -9999 -9999 -9999 -9999 -9999 -9999 -9999 -9999 -9999 -9999 -9999 -9999 -9999 -9999 -9999 -9999 -9999 -9999 -9999 -9999 -9999 -9999 -9999 -9999 -9999 -9999 -9999 -9999 -9999 -9999 -9999 -9999 -9999 -9999 -9999 -9999 -9999 -9999 -9999 -9999 -9999 -9999 -9999 -9999 -9999 -9999 -9999 -9999 -9999 -9999 -9999 -9999 -9999 -9999 -9999 -9999 -9999 -9999 -9999 -9999 -9999 -9999 -

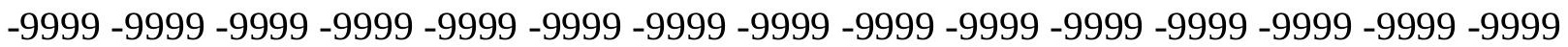
-9999 -9999 -9999 -9999 -9999 -9999 -9999 -9999 -9999 -9999 -9999 -9999 -9999 -9999 -9999 -9999 -9999 -9999 -9999 -9999 -9999 -9999 -9999 -9999 -9999 -9999 -9999 -9999 -9999 -9999 -9999 -9999 -9999 -9999 -9999 -9999 -9999 -9999 -9999 -9999 -9999 -9999 -9999 -9999 -9999 -9999 -9999 -9999 -9999 -9999 -9999 -9999 -9999 -9999 -9999 -9999 -9999 -9999 -9999 -9999 -

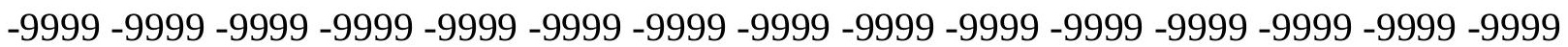
-9999 -9999 -9999 -9999 -9999 -9999 -9999 -9999 -9999 -9999 -9999 -9999 -9999 -9999 -9999 -9999 -9999 -9999 -9999 -9999 -9999 -9999 -9999 -9999 -9999 -9999 -9999 -9999 -9999 -9999 -9999 -9999 -9999 -9999 -9999 -9999 -9999 -9999 -9999 -9999 -9999 -9999 -9999 -9999 -9999

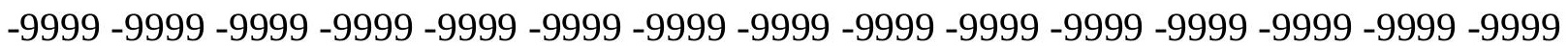
-9999 -9999 -9999 -9999 -9999 -9999 -9999 -9999 -9999 -9999 -9999 -9999 -9999 -9999 -9999 -9999 -9999 -9999 -9999 -9999 -9999 -9999 -9999 -9999 -9999 -9999 -9999 -9999 -9999 -9999 -9999 -9999 -9999 -9999 -9999 -9999 -9999 -9999 -9999 -9999 -9999 -9999 -9999 -9999 -9999

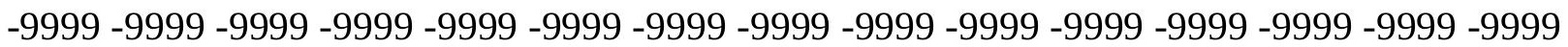
-9999 -9999 -9999 -9999 -9999 -9999 -9999 -9999 -9999 -9999 -9999 -9999 -9999 -9999 -9999 -9999 -9999 -9999 -9999 -9999 -9999 -9999 -9999 -9999 -9999 -9999 -9999 -9999 -9999 -999 -999 -999 -999 -999 -999 -999 
u2top_elev 


$\begin{array}{ll}\text { ncols } & 389 \\ \text { nrows } & 437 \\ \text { xllcorner } & 545925 \\ \text { yllcorner } & 100925 \\ \text { cellsize } & 150\end{array}$

NODATA_value -9999

-9999 -9999 -9999 -9999 -9999 -9999 -9999 -9999 -9999 -9999 -9999 -9999 -9999 -9999 -9999 -9999 -9999 -9999 -9999 -9999 -9999 -9999 -9999 -9999 -9999 -9999 -9999 -9999 -9999 -9999 -999 -9999 -9999 -9999 -9999 -9999 -9999 -9999 -9999 -9999 -9999 -9999 -9999 -9999 -9999 -9999 -9999 -9999 -9999 -9999 -9999 -9999 -9999 -9999 -9999 -9999 -9999 -9999 -9999 -9999 -9999

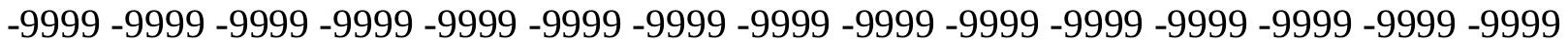
-9999 -9999 -9999 -9999 -9999 -9999 -9999 -9999 -9999 -9999 -9999 -9999 -9999 -9999 -9999 -9999 -9999 -9999 -9999 -9999 -9999 -9999 -9999 -9999 -9999 -9999 -9999 -9999 -9999 -9999 -9999 -9999 -9999 -9999 -9999 -9999 -9999 -9999 -9999 -9999 -9999 -9999 -9999 -9999 - 9999 -9999 -9999 -9999 -9999 -9999 -9999 -9999 -9999 -9999 -9999 -9999 -9999 -9999 -9999 -9999

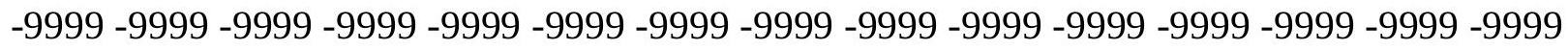
-9999 -9999 -9999 -9999 -9999 -9999 -9999 -9999 -9999 -9999 -9999 -9999 -9999 -9999 -9999 -9999 -9999 -9999 -9999 -9999 -9999 -9999 -9999 -9999 -9999 -9999 -9999 -9999 -9999 -9999 -999 -9999 -9999 -9999 -9999 -9999 -9999 -9999 -9999 -9999 -9999 -9999 -9999 -9999 -9999 -9999 -9999 -9999 -9999 -9999 -9999 -9999 -9999 -9999 -9999 -9999 -9999 -9999 -9999 -9999 -9999 -9999 -9999 -9999 -9999 -9999 -9999 -9999 -9999 -9999 -9999 -9999 -9999 -9999 -9999 -9999 -9999 -9999 -9999 -9999 -9999 -9999 -9999 -9999 -9999 -9999 -9999 -9999 -9999 -9999 -9999 -9999 -9999 -9999 -9999 -9999 -9999 -9999 -9999 -9999 -9999 -9999 -9999 -9999 -9999 -9999 -9999 -9999 -9999 -9999 -9999 -9999 -9999 -9999 -9999 -9999 -9999 -9999 -9999 -9999 -9999 -9999 -9999 -9999 -9999 -9999 -9999 -9999 -9999 -9999 -9999 -9999 -9999 -9999 -9999 -9999 -9999 -9999 -9999 -9999 -9999 -9999 -9999 -9999 -9999 -9999 -9999 -9999 -9999 -9999 -9999 -9999 -9999 -9999 -9999 -9999 -9999 -9999 -9999 -9999 -9999 -9999 -9999 -9999 -9999 -9999 -9999 -9999 -9999 -9999 -9999 -9999 -9999 -9999 -9999 -9999 -9999 -9999 -9999 -9999 -9999 -9999 -9999 -9999 -9999 -9999 -9999 -9999 -9999 -9999 -9999 -9999 -9999 -9999 -9999 -9999 -9999 -9999 -9999 -9999 -9999 -9999 -9999 -9999 -9999 -9999 -9999 -9999 -9999 -9999 -999 -9999 -9999 -9999 -9999 -9999 -9999 -9999 -9999 -9999 -9999 -9999 -9999 -9999 -9999 -9999 -9999 -9999 -9999 -9999 -9999 -9999 -9999 -9999 -9999 -9999 -9999 -9999 -9999 -9999 -

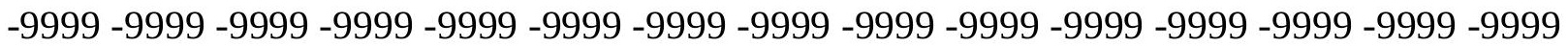
-9999 -9999 -9999 -9999 -9999 -9999 -9999 -9999 -9999 -9999 -9999 -9999 -9999 -9999 -9999 -9999 -9999 -9999 -9999 -9999 -9999 -9999 -9999 -9999 -9999 -9999 -9999 -9999 -9999 -9999 -

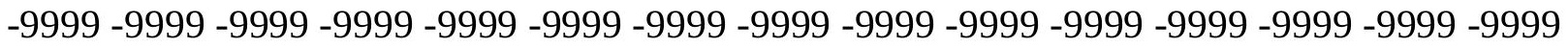

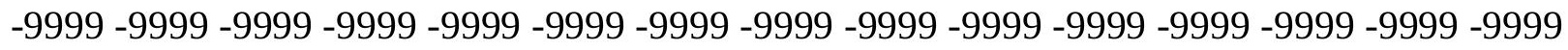
-9999 -9999 -9999 -9999 -9999 -9999 -9999 -9999 -9999 -9999 -9999 -9999 -9999 - 9999 - -9999 -9999 -9999 -9999 -9999 -9999 -9999 -9999 -9999 -9999 -9999 -9999 -9999 -9999 - 9999 - -999 -9999 -9999 -9999 -9999 -9999 -9999 -9999 -9999 -9999 -9999 -9999 -9999 -9999 -9999 -9999 -

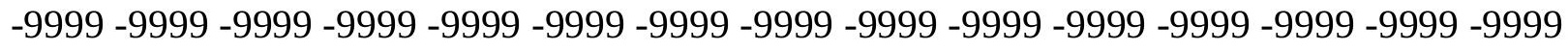

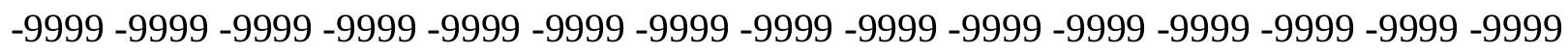
-9999 -9999 -9999 -9999 -9999 -9999 -9999 -9999 -9999 -9999 -9999 -9999 -9999 -9999 -9999 -9999 -9999 -9999 -9999 -9999 -9999 -9999 -9999 -9999-9999 -9999 -9999 -9999 -9999 -9999 -9999 -9999 -9999 -9999 -9999 -9999 -9999 -9999 -9999 -9999 -9999 -9999 -9999 -9999 -9999 -

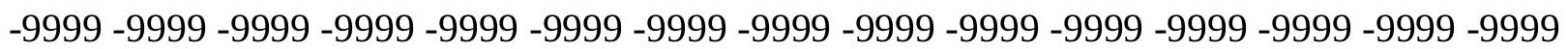


-9999 -9999 -9999 -9999 -9999 -9999 -9999 -9999 -9999 -9999 -9999 -9999 -9999 -9999 -9999 -9999 -9999 -9999 -9999 -9999 -9999 -9999 -9999 -9999 -9999 -9999 -9999 -9999 -9999 -9999 -

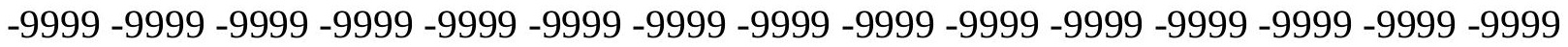
-9999 -9999 -9999 -9999 -9999 -9999 -9999 -9999 -9999 -9999 -9999 -9999 -9999 -9999 -9999 -9999 -9999 -9999 -9999 -9999 -9999 -9999 -9999 -9999-9999 -9999 -9999 -9999 -9999 -9999 -9999 -9999 -9999 -9999 -9999 -9999 -9999 -9999 -9999 -9999 -9999 -9999 -9999 -9999 -9999 -9999 -9999 -9999 -9999 -9999 -9999 -9999 -9999 -9999 -9999 -9999 -9999 -9999 -9999 -9999

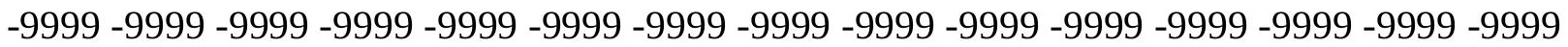

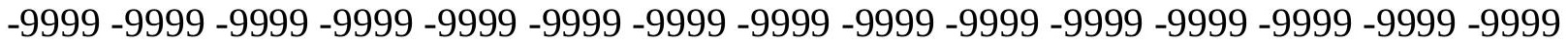
-9999 -9999 -9999 -9999 -9999 -9999 -9999 -9999 -9999 -9999 -9999 -9999 -9999 -9999 -9999 -9999 -9999 -9999 -9999 -9999 -9999 -9999 -9999 -9999 -9999 -9999 -9999 -9999 -9999 -9999 -9999 -9999 -9999 -9999 -9999 -9999 -9999 -9999 -9999 -9999 -9999 -9999 -9999 -9999 -9999 -9999 -9999 -9999 -9999 -9999 -9999 -9999 -9999 -9999 -9999 -9999 -9999 -9999 -9999 -9999 -9999 -9999 -9999 -9999 -9999 -9999 -9999 -9999 -9999 -9999 -9999 -9999 -9999 - 9999 -9999 -9999 -9999 -9999 -9999 -9999 -9999 -9999 -9999 -9999 -9999 -9999 -9999 -9999 -9999

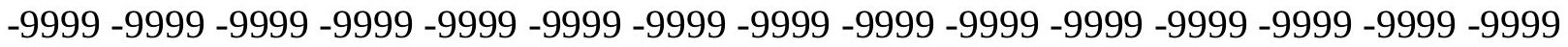
-9999 -9999 -9999 -9999 -9999 -9999 -9999 -9999 -9999 -9999 -9999 -9999 -9999 -9999 -9999 -9999 -9999 -9999 -9999 -9999 -9999 -9999 -9999 -9999 -9999 -9999 -9999 -9999 -9999 -9999 -9999 -9999 -9999 -9999 -9999 -9999 -9999 -9999 -9999 -9999 -9999 -9999 -9999 -9999 -9999 -

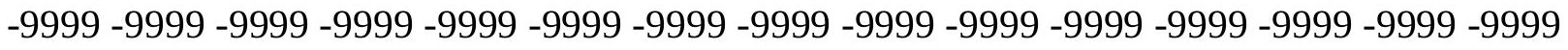

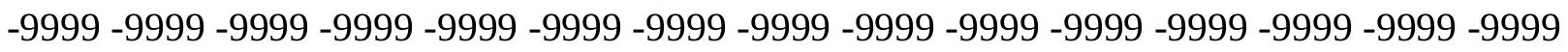
-9999 -9999 -9999 -9999 -9999 -9999 -9999 -9999 -9999 -9999 -9999 -9999 -9999 -9999 -9999 -9999 -9999 -9999 -9999 -9999 -9999 -9999 -9999 -9999 -9999 -9999 -9999 -9999 -9999 -9999 -9999 -9999 -9999 -9999 -9999 -9999 -9999 -9999 -9999 -9999 -9999 -9999 -9999 -9999 -9999 -

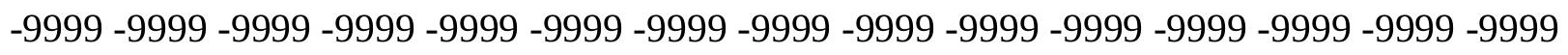
-9999 -9999 -9999 -9999 -9999 -9999 -9999 -9999 -9999 -9999 -9999 -9999 -9999 -9999 -9999 -9999 -9999 -9999 -9999 -9999 -9999 -9999 -9999 -9999 -9999 -9999 -9999 -9999 -9999 -9999 -

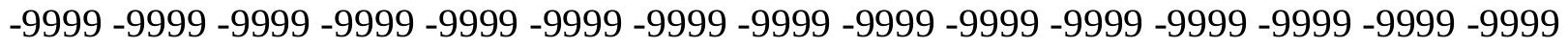
-9999 -9999 -9999 -9999 -9999 -9999 -9999 -9999 -9999 -9999 -9999 -9999 -9999 -9999 -9999 -9999 -9999 -9999 -9999 -9999 -9999 -9999 -9999 -9999 -9999 -9999 -9999 -9999 -9999 -999 -9999 -9999 -9999 -9999 -9999 -9999 -9999 -9999 -9999 -9999 -9999 -9999 -9999 -9999 -9999 -9999 -9999 -9999 -9999 -9999 -9999 -9999 -9999 -9999 -9999 -9999 -9999 -9999 -9999 -9999 -

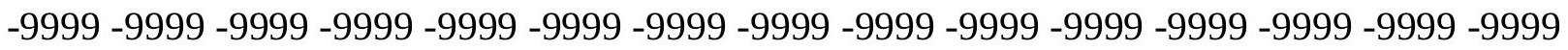

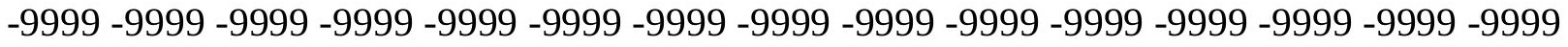

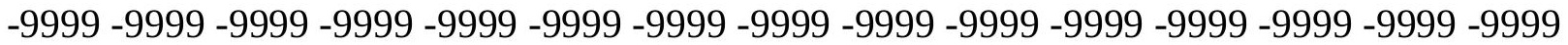

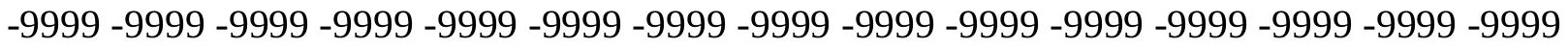

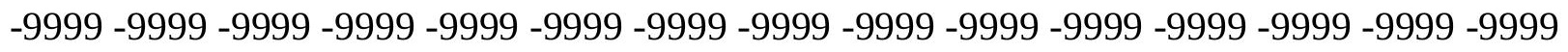

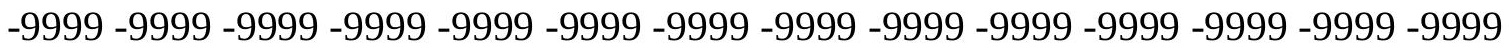
-9999 -9999 -9999 -9999 -9999 -9999 -9999 -9999 -9999 -9999 -9999 -9999 -9999 -9999 -9999 -9999 -9999 -9999 -9999 -9999 -9999 -9999 -9999 -9999 -9999 -9999 -9999 -9999 -9999 -9999 -

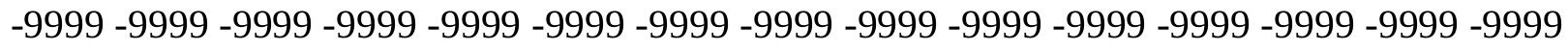

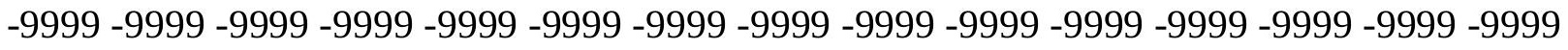
-9999 -9999 -9999 -9999 -9999 -9999 -9999 -9999 -9999 -9999 -9999 -9999 -9999 -9999 -9999 -9999 -9999 -9999 -9999 -9999 -9999 -9999 -9999 -9999-9999 -9999 -9999 -9999 -9999 -9999 -9999 -9999 -9999 -9999 -9999 -9999 -9999 -9999 -9999 -9999 -9999 -9999 -9999 -9999 -9999 -

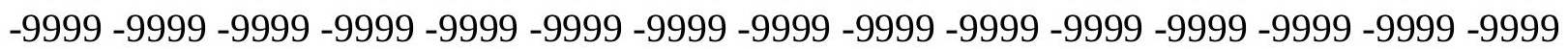


-9999 -9999 -9999 -9999 -9999 -9999 -9999 -9999 -9999 -9999 -9999 -9999 -9999 -9999 -9999 -9999 -9999 -9999 -9999 -9999 -9999 -9999 -9999 -9999 -9999 -9999 -9999 -9999 -9999 -9999 -9999 -9999 -9999 -9999 -9999 -9999 -9999 -9999 -9999 -9999 -9999 -9999 -9999 -9999 - 9999 -9999 -9999 -9999 -9999 -9999 -9999 -9999 -9999 -9999 -9999 -9999 -9999 -9999 -9999 -9999 -9999 -9999 -9999 -9999 -9999 -9999 -9999 -9999 -9999 -9999 -9999 -9999 -9999 -9999 -9999 -9999 -9999 -9999 -9999 -9999 -9999 -9999 -9999 -9999 -9999 -9999 -9999 -9999 -9999 -9999 -9999 -9999 -9999 -9999 -9999 -9999 -9999 -9999 -9999 -9999 -9999 -9999 -9999 -9999 -9999

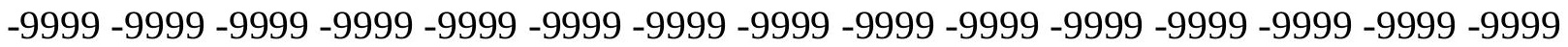
-9999 -9999 -9999 -9999 -9999 -9999 -9999 -9999 -9999 -9999 -9999 -9999 -9999 -9999 -9999 -9999 -9999 -9999 -9999 -9999 -9999 -9999 -9999 -9999 -9999 -9999 -9999 -9999 -9999 -9999

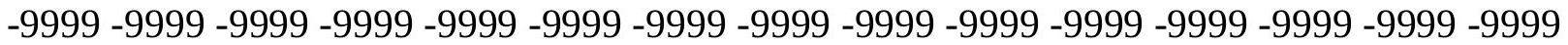
-9999 -9999 -9999 -9999 -9999 -9999 -9999 -9999 -9999 -9999 -9999 -9999 -9999 -9999 -9999 -9999 -9999 -9999 -9999 -9999 -9999 -9999 -9999 -9999 -9999 -9999 -9999 -9999 -9999 -9999 -

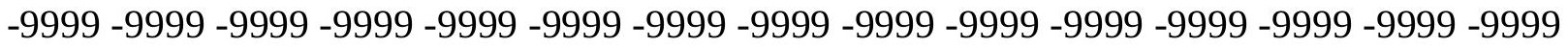
-9999 -9999 -9999 -9999 -9999 -9999 -9999 -9999 -9999 -9999 -9999 -9999 -9999 -9999 -9999

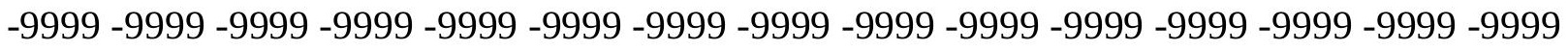
-9999 -9999 -9999 -9999 -9999 -9999 -9999 -9999 -9999 -9999 -9999 -9999 -9999 -9999 -9999 -9999 -9999 -9999 -9999 -9999 -9999 -9999 -9999 -9999 -9999 -9999 -9999 -9999 -9999 - -999 -9999 -9999 -9999 -9999 -9999 -9999 -9999 -9999 -9999 -9999 -9999 -9999 -9999 -9999 -9999 -9999 -9999 -9999 -9999 -9999 -9999 -9999 -9999 -9999 -9999 -9999 -9999 -9999 -9999 -9999 -9999 -9999 -9999 -9999 -9999 -9999 -9999 -9999 -9999 -9999 -9999 -9999 -9999 -9999 -9999 -999 -9999 -9999 -9999 -9999 -9999 -9999 -9999 -9999 -9999 -9999 -9999 -9999 -9999 -9999 -9999 -9999 -9999 -9999 -9999 -9999 -9999 -9999 -9999 -9999 -9999 -9999 -9999 -9999 -9999 -9999 -9999 -9999 -9999 -9999 -9999 -9999 -9999 -9999 -9999 -9999 -9999 -9999 -9999 -9999 -9999 -9999 -9999 -9999 -9999 -9999 -9999 -9999 -9999 -9999 -9999 -9999 -9999 -9999 -9999 -9999 -9999 -9999 -9999 -9999 -9999 -9999 -9999 -9999 -9999 -9999 -9999 -9999 -9999 -9999 -9999 -9999 -9999 -9999 -9999 -9999 -9999 -9999 -9999 -9999 -9999 -9999 -9999 -9999 -9999 -9999 -9999 -9999 -9999 -9999 -9999 -9999 -9999 -9999 -9999 -9999 -9999 -9999 -9999 -9999 -9999 -9999 -9999 -9999 -9999 -9999 -9999 -9999 -9999 -9999 -9999 -9999 -9999 -9999 -9999 -9999 -9999 -9999 -9999 -9999 -9999 -9999 -9999 -9999 -9999 -9999 -9999 -9999 -9999 -9999 -999 -9999 -9999 -9999 -9999 -9999 -9999 -9999 -9999 -9999 -9999 -9999 -9999 -9999 -9999 -9999 -9999 -9999 -9999 -9999 -9999 -9999 -9999 -9999 -9999 -9999 -9999 -9999 -9999 -9999 -9999 -

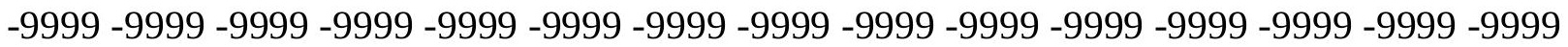

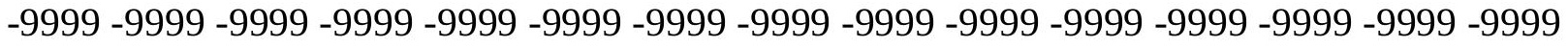

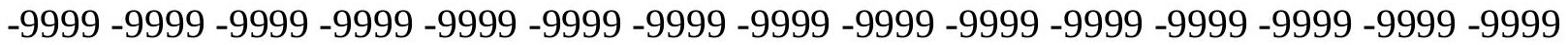
-9999 -9999 -9999 -9999 -9999 -9999 -9999 -9999 -9999 -9999 -9999 -9999 -9999 -9999 -9999

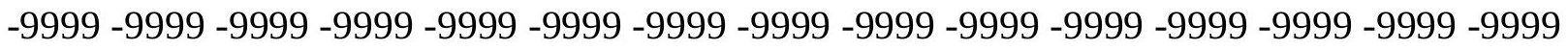

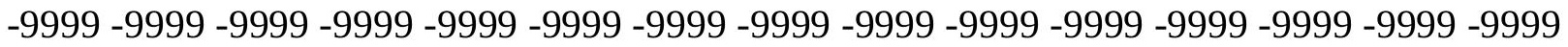

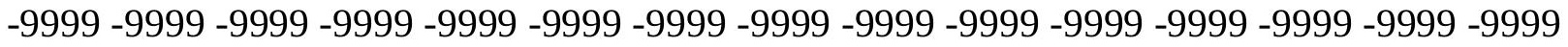
-9999 -9999 -9999 -9999 -9999 -9999 -9999 -9999 -9999 -9999 -9999 -9999 -9999 -9999 -9999 -

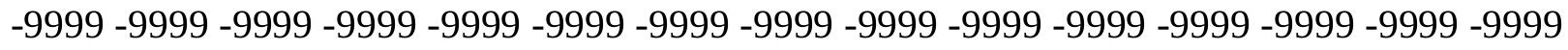

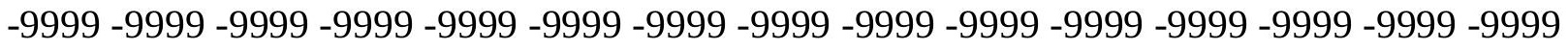
-9999 -9999 -9999 -9999 -9999 -9999 -9999 -9999 -9999 -9999 -9999 -9999 -9999 -9999 -9999 -9999 -9999 -9999 -9999 -9999 -9999 -9999 -9999 -9999 -9999 -9999 -9999 -9999 - -9999 -9999 -9999 -9999 -9999 -9999 -9999 -9999 -9999 -9999 -9999 -9999 -9999 -9999 -9999 -9999 -

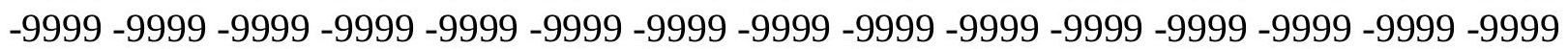


-9999 -9999 -9999 -9999 -9999 -9999 -9999 -9999 -9999 -9999 -9999 -9999 -9999 -9999 -9999 -9999 -9999 -9999 -9999 -9999 -9999 -9999 -9999 -9999 -9999 -9999 -9999 -9999 -9999 -9999 -9999 -9999 -9999 -9999 -9999 -9999 -9999 -9999 -9999 -9999 -9999 -9999 -9999 -9999 - 9999 -9999 -9999 -9999 -9999 -9999 -9999 -9999 -9999 -9999 -9999 -9999 -9999 -9999 -9999 -9999 -9999 -9999 -9999 -9999 -9999 -9999 -9999 -9999 -9999-9999 -9999 -9999 -9999 -9999 -9999 -9999 -9999 -9999 -9999 -9999 -9999 -9999 -9999 -9999 -9999 -9999 -9999 -9999 -9999 -9999 -9999 -9999 -9999 -9999 -9999 -9999 -9999 -9999 -9999 -9999 -9999 -9999 -9999 -9999 -9999

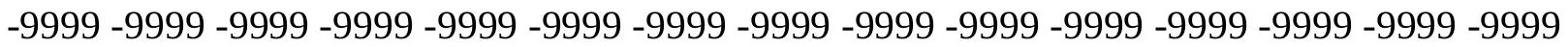

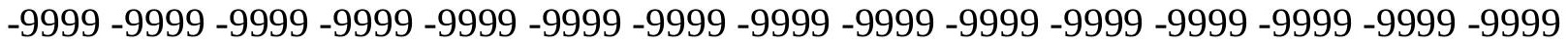
-9999 -9999 -9999 -9999 -9999 -9999 -9999 -9999 -9999 -9999 -9999 -9999 -9999 -9999 -9999

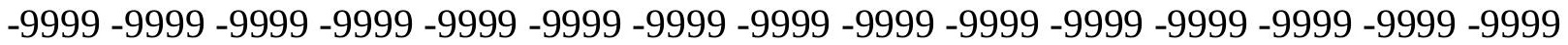
-9999 -9999 -9999 -9999 -9999 -9999 -9999 -9999 -9999 -9999 -9999 -9999 -9999 -9999 -9999 -9999 -9999 -9999 -9999 -9999 -9999 -9999 -9999 -9999 -9999 -9999 -9999 -9999 -9999 -9999 -

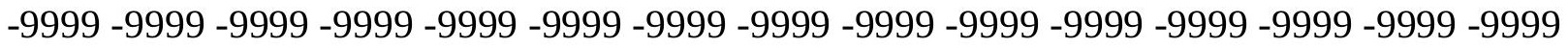
-9999 -9999 -9999 -9999 -9999 -9999 -9999 -9999 -9999 -9999 -9999 -9999 -9999 -9999 -9999

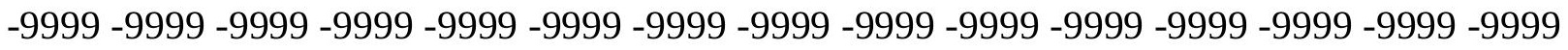
-9999 -9999 -9999 -9999 -9999 -9999 -9999 -9999 -9999 -9999 -9999 -9999 -9999 -9999 -9999 -9999 -9999 -9999 -9999 -9999 -9999 -9999 -9999 -9999 -9999 -9999 -9999 -9999 -9999 -9999 -9999 -9999 -9999 -9999 -9999 -9999 -9999 -9999 -9999 -9999 -9999 -9999 -9999 -9999 -9999 -9999 -9999 -9999 -9999 -9999 -9999 -9999 -9999 -9999 -9999 -9999 -9999 -9999 -9999 -9999 -9999 -9999 -9999 -9999 -9999 -9999 -9999 -9999 -9999 -9999 -9999 -9999 -9999 -9999 -9999 -999 -9999 -9999 -9999 -9999 -9999 -9999 -9999 -9999 -9999 -9999 -9999 -9999 -9999 -9999 -9999 -9999 -9999 -9999 -9999 -9999 -9999 -9999 -9999 -9999 -9999 -9999 -9999 -9999 -9999 -9999 -9999 -9999 -9999 -9999 -9999 -9999 -9999 -9999 -9999 -9999 -9999 -9999 -9999 -9999 -9999 -9999 -9999 -9999 -9999 -9999 -9999 -9999 -9999 -9999 -9999 -9999 -9999 -9999 -9999 -9999 -9999 -9999 -9999 -9999 -9999 -9999 -9999 -9999 -9999 -9999 -9999 -9999 -9999 -9999 -9999 -9999 -9999 -9999 -9999 -9999 -9999 -9999 -9999 -9999 -9999 -9999 -9999 -9999 -9999 -9999 -9999 -9999 -9999 -9999 -9999 -9999 -9999 -9999 -9999 -9999 -9999 -9999 -9999 -9999 -9999 -9999 -9999 -9999 -9999 -9999 -9999 -9999 -9999 -9999 -9999 -9999 -9999 -9999 -9999 -9999 -9999 -9999 -9999 -9999 -9999 -9999 -9999 -9999 -9999 -9999 -9999 -9999 -9999 -999 -9999 -9999 -9999 -9999 -9999 -9999 -9999 -9999 -9999 -9999 -9999 -9999 -9999 -9999 -9999 -9999 -9999 -9999 -9999 -9999 -9999 -9999 -9999 -9999 -9999 -9999 -9999 -9999 -9999 -9999 -

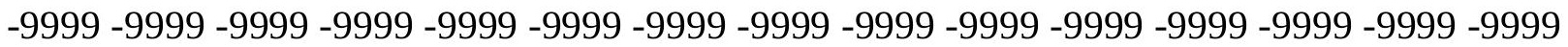

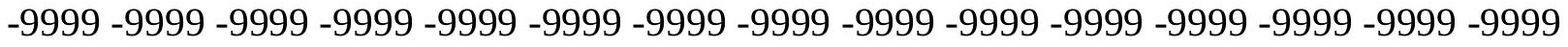

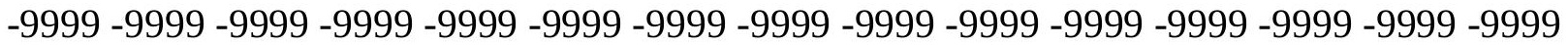
-9999 -9999 -9999 -9999 -9999 -9999 -9999 -9999 -9999 -9999 -9999 -9999 -9999 -9999 -9999

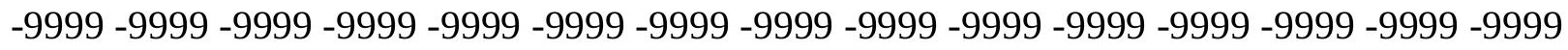

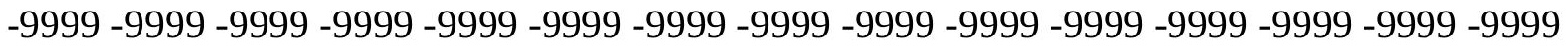
-9999 -9999 -9999 -9999 -9999 -9999 -9999 -9999 -9999 -9999 -9999 -9999 -9999 -9999 -9999 -9999 -9999 -9999 -9999 -9999 -9999 -9999 -9999 -9999 -9999 -9999 -9999 -9999 -9999 -9999 -

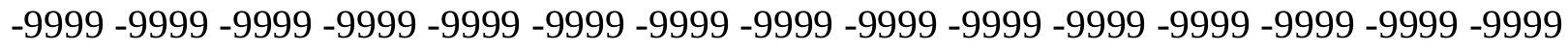

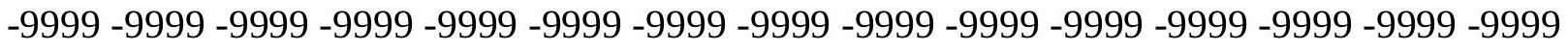
-9999 -9999 -9999 -9999 -9999 -9999 -9999 -9999 -9999 -9999 -9999 -9999 -9999 -9999 -9999 -9999 -9999 -9999 -9999 -9999 -9999 -9999 -9999 -9999-9999 -9999 -9999 -9999 -9999 -9999 -9999 -9999 -9999 -9999 -9999 -9999 -9999 -9999 -9999 -9999 -9999 -9999 -9999 -9999 -9999 -

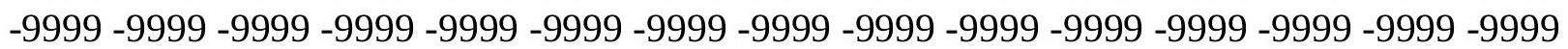


-9999 -9999 -9999 -9999 -9999 -9999 -9999 -9999 -9999 -9999 -9999 -9999 -9999 -9999 -9999 -9999 -9999 -9999 -9999 -9999 -9999 -9999 -9999 -9999 -9999 -9999 -9999 -9999 -9999 -9999 -9999 -9999 -9999 -9999 -9999 -9999 -9999 -9999 -9999 -9999 -9999 -9999 -9999 -9999 - 9999 -9999 -9999 -9999 -9999 -9999 -9999 -9999 -9999 -9999 -9999 -9999 -9999 -9999 -9999

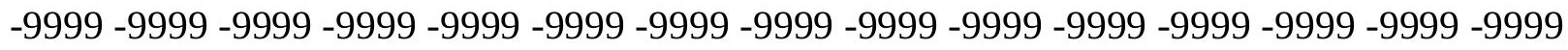
-9999 -9999 -9999 -9999 -9999 -9999 -9999 -9999 -9999 -9999 -9999 -9999 -9999 -9999 -9999 -9999 -9999 -9999 -9999 -9999 -9999 -9999 -9999 -9999 -9999 -9999 -9999 -9999 -9999 -9999

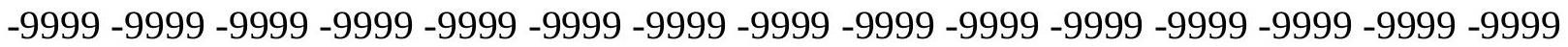

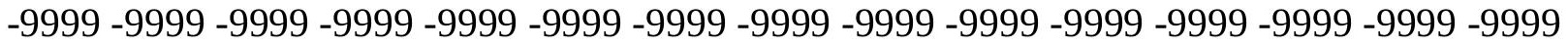
-9999 -9999 -9999 -9999 -9999 -9999 -9999 -9999 -9999 -9999 -9999 -9999 -9999 -9999 -9999 -9999 -9999 -9999 -9999 -9999 -9999 -9999 -9999 -9999 -9999 -9999 -9999 -9999 -9999 -9999 -9999 -9999 -9999 -9999 -9999 -9999 -9999 -9999 -9999 -9999 -9999 -9999 -9999 -9999 -9999 -9999 -9999 -9999 -9999 -9999 -9999 -9999 -9999 -9999 -9999 -9999 -9999 -9999 -9999 -9999 -

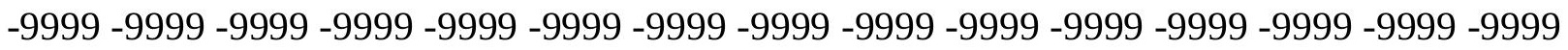
-9999 -9999 -9999 -9999 -9999 -9999 -9999 -9999 -9999 -9999 -9999 -9999 -9999 -9999 -9999 -

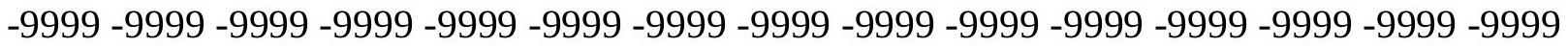
-9999 -9999 -9999 -9999 -9999 -9999 -9999 -9999 -9999 -9999 -9999 -9999 -9999 -9999 -9999 -9999 -9999 -9999 -9999 -9999 -9999 -9999 -9999 -9999 -9999 -9999 -9999 -9999 -9999 -9999 -9999 -9999 -9999 -9999 -9999 -9999 -9999 -9999 -9999 -9999 -9999 -9999 -9999 -9999 -9999 -

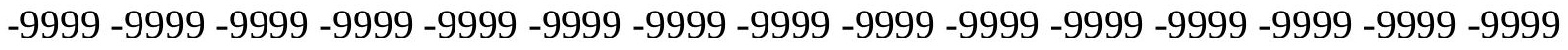
-9999 -9999 -9999 -9999 -9999 -9999 -9999 -9999 -9999 -9999 -9999 -9999 -9999 -9999 -9999

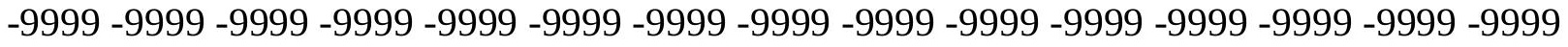
-9999 -9999 -9999 -9999 -9999 -9999 -9999 -9999 -9999 -9999 -9999 -9999 -9999 -9999 -9999 -9999 -9999 -9999 -9999 -9999 -9999 -9999 -9999 -9999 -9999 -9999 -9999 -9999 -9999 -9999 -9999 -9999 -9999 -9999 -9999 -9999 -9999 -9999 -9999 -9999 -9999 -9999 -9999 -9999 -9999 -9999 -9999 -9999 -9999 -9999 -9999 -9999 -9999 -9999 -9999 -9999 -9999 -9999 -9999 -9999 -9999 -9999 -9999 -9999 -9999 -9999 -9999 -9999 -9999 -9999 -9999 -9999 -9999 -9999 -9999 -9999 -9999 -9999 -9999 -9999 -9999 -9999 -9999 -9999 -9999 -9999 -9999 -9999 -9999 -9999 -9999 -9999 -9999 -9999 -9999 -9999 -9999 -9999 -9999 -9999 -9999 -9999 -9999 -9999 -9999 -9999 -9999 -9999 -9999 -9999 -9999 -9999 -9999 -9999 -9999 -9999 -9999 -9999 -9999 -9999 -9999 -9999 -9999 -9999 -9999 -9999 -9999 -9999 -9999 -9999 -9999 -9999 -9999 -9999 -9999 -9999 -9999 -9999 -9999 -9999 -9999 -9999 -9999 -9999 -9999 -9999 -9999 -9999 -9999 -

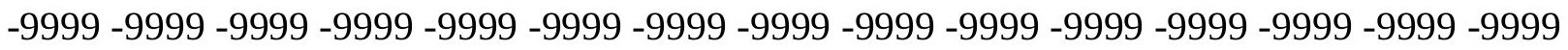

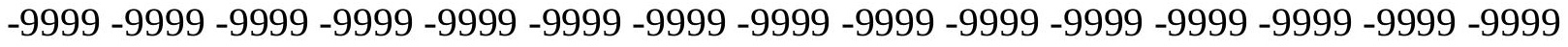
-9999 -9999 -9999 -9999 -9999 -9999 -9999 -9999 -9999 -9999 -9999 -9999 -9999 -9999 -9999 -

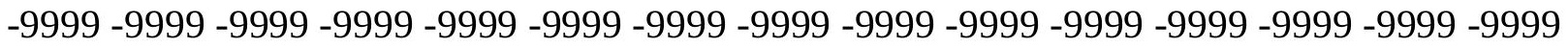

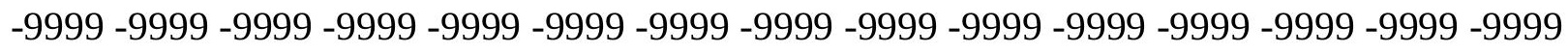

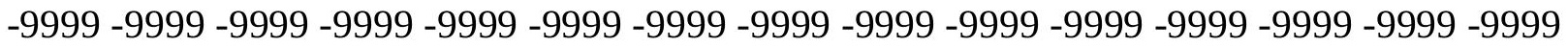

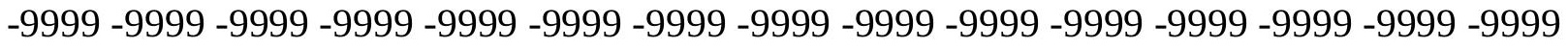
-9999 -9999 -9999 -9999 -9999 -9999 -9999 -9999 -9999 -9999 -9999 -9999 -9999 -9999 -9999 -

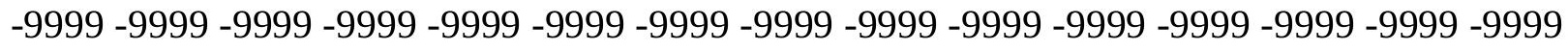

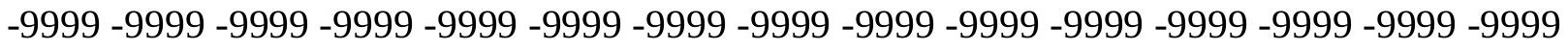
-9999 -9999 -9999 -9999 -9999 -9999 -9999 -9999 -9999 -9999 -9999 -9999 -9999 -9999 -9999 -9999 -9999 -9999 -9999 -9999 -9999 -9999 -9999 -9999-9999 -9999 -9999 -9999 -9999 -9999 -9999 -9999 -9999 -9999 -9999 -9999 -9999 -9999 -9999 -9999 -9999 -9999 -9999 -9999 -9999 -

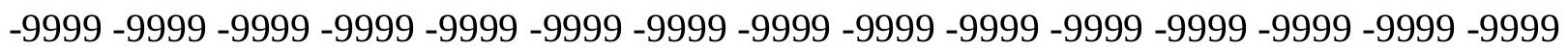


-9999 -9999 -9999 -9999 -9999 -9999 -9999 -9999 -9999 -9999 -9999 -9999 -9999 -9999 -9999 -9999 -9999 -9999 -9999 -9999 -9999 -9999 -9999 -9999 -9999 -9999 -9999 -9999 -9999 -9999 -9999 -9999 -9999 -9999 -9999 -9999 -9999 -9999 -9999 -9999 -9999 -9999 -9999 -9999 - 9999 -9999 -9999 -9999 -9999 -9999 -9999 -9999 -9999 -9999 -9999 -9999 -9999 -9999 -9999 -9999 -9999 -9999 -9999 -9999 -9999 -9999 -9999 -9999 -9999 -9999 -9999 -9999 -9999 -9999 -9999 -9999 -9999 -9999 -9999 -9999 -9999 -9999 -9999 -9999 -9999 -9999 -9999 -9999 -9999 -9999 -9999 -9999 -9999 -9999 -9999 -9999 -9999 -9999 -9999 -9999 -9999 -9999 -9999 -9999 -9999

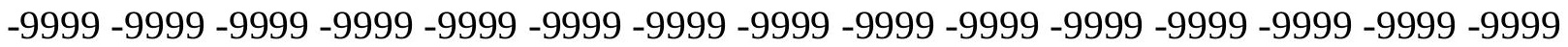

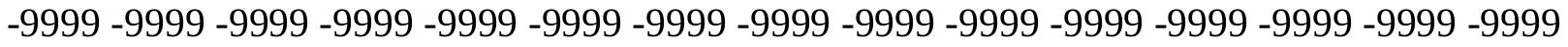
-9999 -9999 -9999 -9999 -9999 -9999 -9999 -9999 -9999 -9999 -9999 -9999 -9999 -9999 -9999 -9999 -9999 -9999 -9999 -9999 -9999 -9999 -9999 -9999 -9999 -9999 -9999 -9999 -9999 -9999 -9999 -9999 -9999 -9999 -9999 -9999 -9999 -9999 -9999 -9999 -9999 -9999 -9999 -9999 -9999 -9999 -9999 -9999 -9999 -9999 -9999 -9999 -9999 -9999 -9999 -9999 -9999 -9999 -9999 -9999 -9999 -9999 -9999 -9999 -9999 -9999 -9999 -9999 -9999 -9999 -9999 -9999 -9999 -9999 -9999 -9999 -9999 -9999 -9999 -9999 -9999 -9999 -9999 -9999 -9999 -9999 -9999 -9999 -9999 -

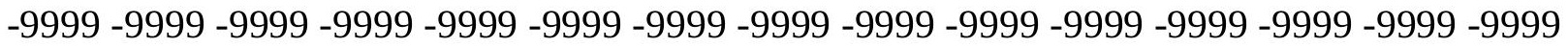
-9999 -9999 -9999 -9999 -9999 -9999 -9999 -9999 -9999 -9999 -9999 -9999 -9999 -9999 -9999 -9999 -9999 -9999 -9999 -9999 -9999 -9999 -9999 -9999 -9999 -9999 -9999 -9999 -9999 -9999 -9999 -9999 -9999 -9999 -9999 -9999 -9999 -9999 -9999 -9999 -9999 -9999 -9999 -9999 -9999 -9999 -9999 -9999 -9999 -9999 -9999 -9999 -9999 -9999 -9999 -9999 -9999 -9999 -9999 -9999 -9999 -9999 -9999 -9999 -9999 -9999 -9999 -9999 -9999 -9999 -9999 -9999 -9999 -9999 -9999 -999 -9999 -9999 -9999 -9999 -9999 -9999 -9999 -9999 -9999 -9999 -9999 -9999 -9999 -9999 -9999 -9999 -9999 -9999 -9999 -9999 -9999 -9999 -9999 -9999 -9999 -9999 -9999 -9999 -9999 -9999 -9999 -9999 -9999 -9999 -9999 -9999 -9999 -9999 -9999 -9999 -9999 -9999 -9999 -9999 -9999 -9999 -9999 -9999 -9999 -9999 -9999 -9999 -9999 -9999 -9999 -9999 -9999 -9999 -9999 -9999 -9999 -9999 -9999 -9999 -9999 -9999 -9999 -9999 -9999 -9999 -9999 -9999 -9999 -9999 -9999 -9999 -9999 -9999 -9999 -9999 -9999 -9999 -9999 -9999 -9999 -9999 -9999 -9999 -9999 -9999 -9999 -9999 -9999 -9999 -9999 -9999 -9999 -9999 -9999 -9999 -9999 -9999 -9999 -9999 -9999 -9999 -9999 -9999 -9999 -9999 -9999 -9999 -9999 -9999 -9999 -9999 -9999 -9999 -9999 -9999 -9999 -9999 -9999 -9999 -9999 -9999 -9999 -9999 -9999 -9999 -9999 -9999 -9999 -9999 -999 -9999 -9999 -9999 -9999 -9999 -9999 -9999 -9999 -9999 -9999 -9999 -9999 -9999 -9999 -9999 -9999 -9999 -9999 -9999 -9999 -9999 -9999 -9999 -9999 -9999 -9999 -9999 -9999 -9999 -9999 -

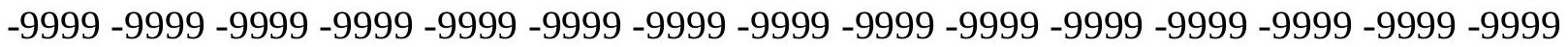

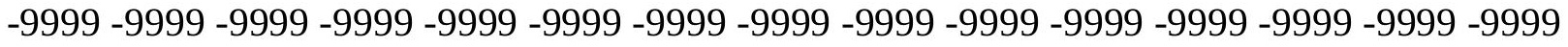

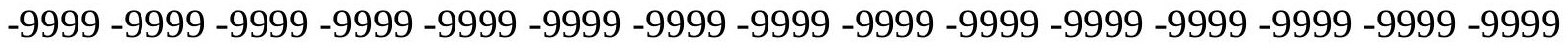
-9999 -9999 -9999 -9999 -9999 -9999 -9999 -9999 -9999 -9999 -9999 -9999 -9999 -9999 -9999 -9999 -9999 -9999 -9999 -9999 -9999 -9999 -9999 -9999 -9999 -9999 -9999 -9999 -9999 -

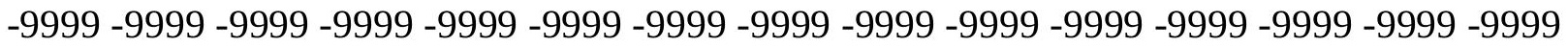
-9999 -9999 -9999 -9999 -9999 -9999 -9999 -9999 -9999 -9999 -9999 -9999 -9999 -9999 -9999 -9999 -9999 -9999 -9999 -9999 -9999 -9999 -9999 -9999 -9999 -9999 -9999 -9999 -9999 -9999 -

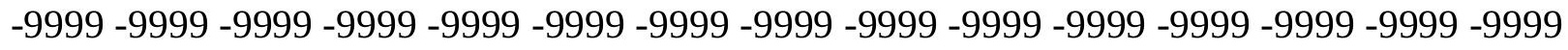

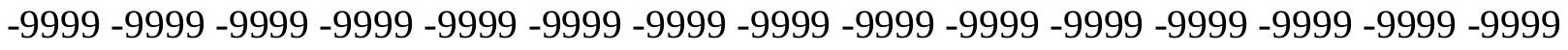
-9999 -9999 -9999 -9999 -9999 -9999 -9999 -9999 -9999 -9999 -9999 -9999 -9999 -9999 -9999 -9999 -9999 -9999 -9999 -9999 -9999 -9999 -9999 -9999-9999 -9999 -9999 -9999 -9999 -9999 -9999 -9999 -9999 -9999 -9999 -9999 -9999 -9999 -9999 -9999 -9999 -9999 -9999 -9999 -9999 -

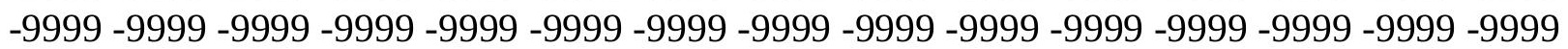


-9999 -9999 -9999 -9999 -9999 -9999 -9999 -9999 -9999 -9999 -9999 -9999 -9999 -9999 -9999 -9999 -9999 -9999 -9999 -9999 -9999 -9999 -9999 -9999 -9999 -9999 -9999 -9999 -9999 -9999 -

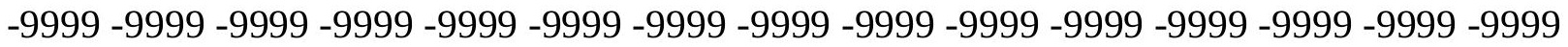
-9999 -9999 -9999 -9999 -9999 -9999 -9999 -9999 -9999 -9999 -9999 -9999 -9999 -9999 -9999 -9999 -9999 -9999 -9999 -9999 -9999 -9999 -9999 -9999-9999 -9999 -9999 -9999 -9999 -9999 -9999 -9999 -9999 -9999 -9999 -9999 -9999 -9999 -9999 -9999 -9999 -9999 -9999 -9999 -9999 -9999 -9999 -9999 -9999 -9999 -9999 -9999 -9999 -9999 -9999 -9999 -9999 -9999 -9999 -9999

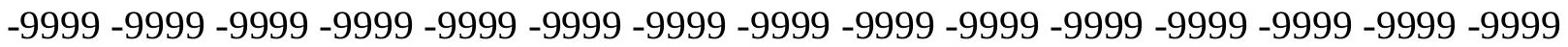

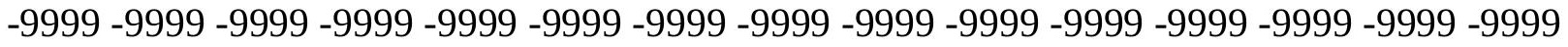
-9999 -9999 -9999 -9999 -9999 -9999 -9999 -9999 -9999 -9999 -9999 -9999 -9999 -9999 -9999 -9999 -9999 -9999 -9999 -9999 -9999 -9999 -9999 -9999 -9999 -9999 -9999 -9999 -9999 -9999 -9999 -9999 -9999 -9999 -9999 -9999 -9999 -9999 -9999 -9999 -9999 -9999 -9999 -9999 -9999 -9999 -9999 -9999 -9999 -9999 -9999 -9999 -9999 -9999 -9999 -9999 -9999 -9999 -9999 -9999 -9999 -9999 -9999 -9999 -9999 -9999 -9999 -9999 -9999 -9999 -9999 -9999 -9999 -9999 -9999 -9999 -9999 -9999 -9999 -9999 -9999 -9999 -9999 -9999 -9999 -9999 -9999 -9999 -9999 -9999 -

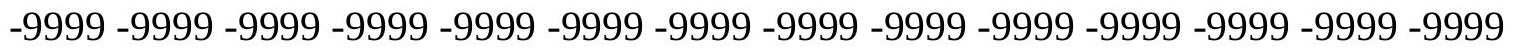
-9999 -9999 -9999 -9999 -9999 -9999 -9999 -9999 -9999 -9999 -9999 -9999 -9999 -9999 -9999 -9999 -9999 -9999 -9999 -9999 -9999 -9999 -9999 -9999 -9999 -9999 -9999 -9999 -9999 -9999 -9999 -9999 -9999 -9999 -9999 -9999 -9999 -9999 -9999 -9999 -9999 -9999 -9999 -9999 -9999 -

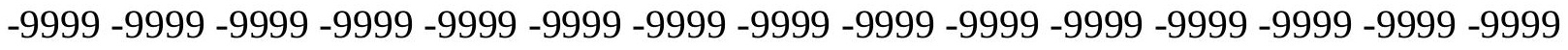

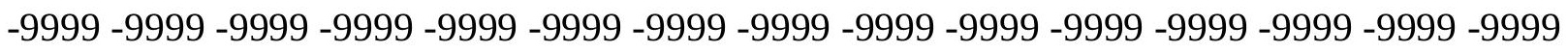
-9999 -9999 -9999 -9999 -9999 -9999 -9999 -9999 -9999 -9999 -9999 -9999 -9999 -9999 - 9999 -9999 -9999 -9999 -9999 -9999 -9999 -9999 -9999 -9999 -9999 -9999 -9999 -9999 -9999 -9999 -9999 -9999 -9999 -9999 -9999 -9999 -9999 -9999 -9999 -9999 -9999 -9999 -9999 -9999 -9999 -

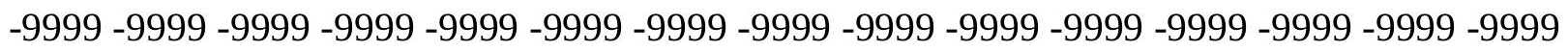
-9999 -9999 -9999 -9999 -9999 -9999 -9999 -9999 -9999 -9999 -9999 -9999 -9999 -9999 -9999 -9999 -9999 -9999 -9999 -9999 -9999 -9999 -9999 -9999 -9999 -9999 -9999 -9999 -9999 -9999 -

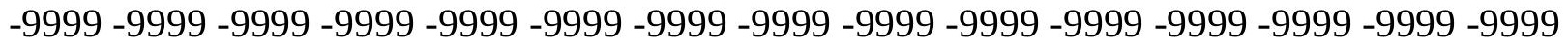
-9999 -9999 -9999 -9999 -9999 -9999 -9999 -9999 -9999 -9999 -9999 -9999 -9999 -9999 -9999 -9999 -9999 -9999 -9999 -9999 -9999 -9999 -9999 -9999 -9999 -9999 -9999 -9999 -9999 -999 -

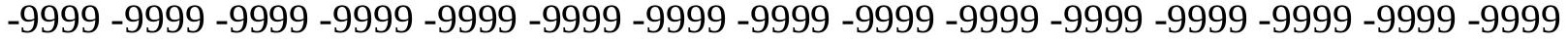
-9999 -9999 -9999 -9999 -9999 -9999 -9999 -9999 -9999 -9999 -9999 -9999 -9999 -9999 -9999 -

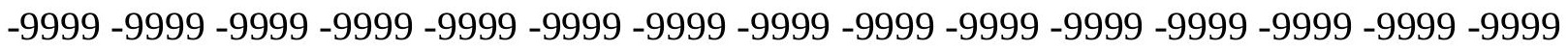

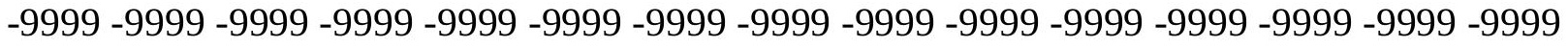

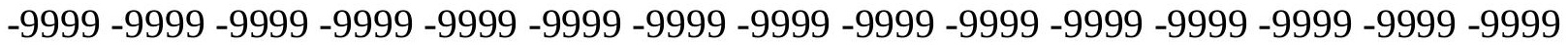
-9999 -9999 -9999 -9999 -9999 -9999 -9999 -9999 -9999 -9999 -9999 -9999 -9999 -9999 -9999 -

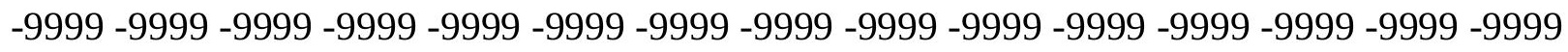

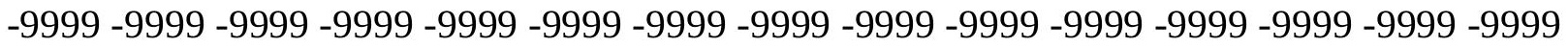
-9999 -9999 -9999 -9999 -9999 -9999 -9999 -9999 -9999 -9999 -9999 -9999 -9999 - 9999 - -999 -9999 -9999 -9999 -9999 -9999 -9999 -9999 -9999 -9999 -9999 -9999 -9999 -9999 -9999 -9999 -

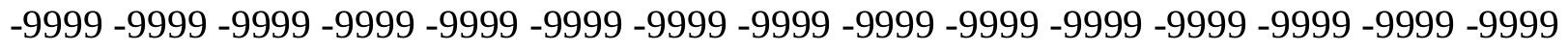

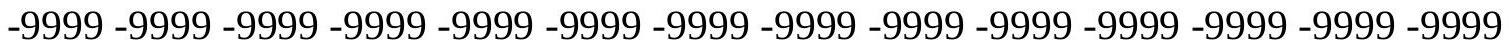
-9999 -9999 -9999 -9999 -9999 -9999 -9999 -9999 -9999 -9999 -9999 -9999 -9999 -9999 -9999 -9999 -9999 -9999 -9999 -9999 -9999 -9999 -9999 -9999-9999 -9999 -9999 -9999 -9999 -9999 -9999 -9999 -9999 -9999 -9999 -9999 -9999 -9999 -9999 -9999 -9999 -9999 -9999 -9999 -9999 -

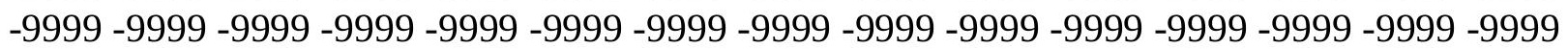


-9999 -9999 -9999 -9999 -9999 -9999 -9999 -9999 -9999 -9999 -9999 -9999 -9999 -9999 -9999 -9999 -9999 -9999 -9999 -9999 -9999 -9999 -9999 -9999 -9999 -9999 -9999 -9999 -9999 -9999 -

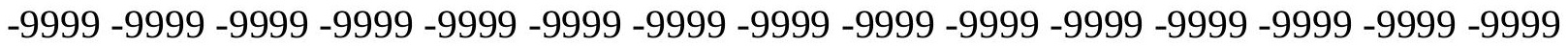
-9999 -9999 -9999 -9999 -9999 -9999 -9999 -9999 -9999 -9999 -9999 -9999 -9999 -9999 -9999 -9999 -9999 -9999 -9999 -9999 -9999 -9999 -9999 -9999-9999 -9999 -9999 -9999 -9999 -9999 -9999 -9999 -9999 -9999 -9999 -9999 -9999 -9999 -9999 -9999 -9999 -9999 -9999 -9999 -9999 -9999 -9999 -9999 -9999 -9999 -9999 -9999 -9999 -9999 -9999 -9999 -9999 -9999 -9999 -9999

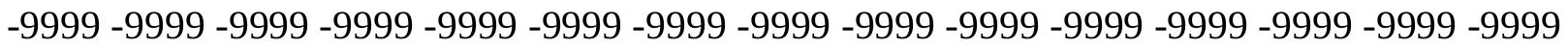

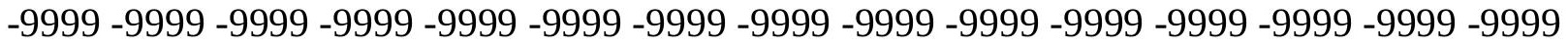
-9999 -9999 -9999 -9999 -9999 -9999 -9999 -9999 -9999 -9999 -9999 -9999 -9999 -9999 -9999 -9999 -9999 -9999 -9999 -9999 -9999 -9999 -9999 -9999 -9999 -9999 -9999 -9999 -9999 -9999 -9999 -9999 -9999 -9999 -9999 -9999 -9999 -9999 -9999 -9999 -9999 -9999 -9999 -9999 -9999 -9999 -9999 -9999 -9999 -9999 -9999 -9999 -9999 -9999 -9999 -9999 -9999 -9999 -9999 -9999 -

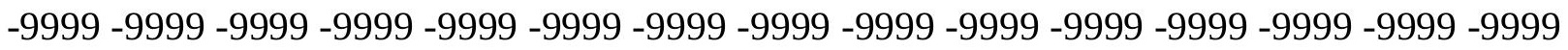
-9999 -9999 -9999 -9999 -9999 -9999 -9999 -9999 -9999 -9999 -9999 -9999 -9999 -9999 -9999 -

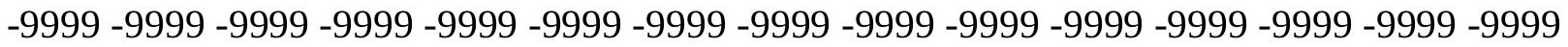
-9999 -9999 -9999 -9999 -9999 -9999 -9999 -9999 -9999 -9999 -9999 -9999 -9999 -9999 -9999 -9999 -9999 -9999 -9999 -9999 -9999 -9999 -9999 -9999 -9999 -9999 -9999 -9999 -9999 -9999 -9999 -9999 -9999 -9999 -9999 -9999 -9999 -9999 -9999 -9999 -9999 -9999 -9999 -9999 -9999 -

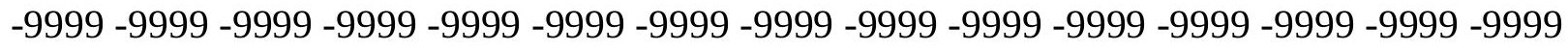

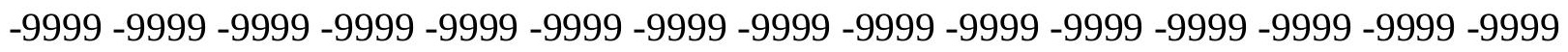
-9999 -9999 -9999 -9999 -9999 -9999 -9999 -9999 -9999 -9999 -9999 -9999 -9999 -9999 -9999 -9999 -9999 -9999 -9999 -9999 -9999 -9999 -9999 -9999 -9999 -9999 -9999 -9999 -9999 -9999 -9999 -9999 -9999 -9999 -9999 -9999 -9999 -9999 -9999 -9999 -9999 -9999 -9999 -9999 -

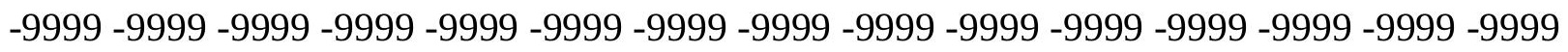
-9999 -9999 -9999 -9999 -9999 -9999 -9999 -9999 -9999 -9999 -9999 -9999 -9999 -9999 -9999 -9999 -9999 -9999 -9999 -9999 -9999 -9999 -9999 -9999 -9999 -9999 -9999 -9999 -9999 -9999 -

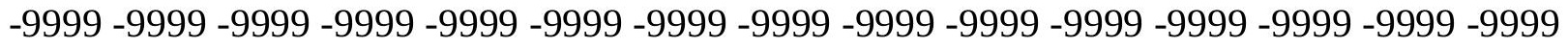
-9999 -9999 -9999 -9999 -9999 -9999 -9999 -9999 -9999 -9999 -9999 -9999 -9999 -9999 -9999 -9999 -9999 -9999 -9999 -9999 -9999 -9999 -9999 -9999 -9999 -9999 -9999 -9999 -9999 -999 -

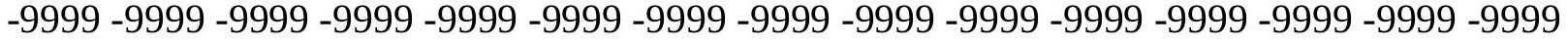
-9999 -9999 -9999 -9999 -9999 -9999 -9999 -9999 -9999 -9999 -9999 -9999 -9999 -9999 -9999 -

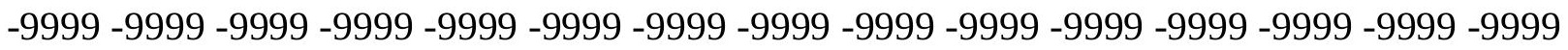

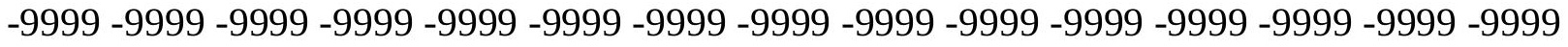

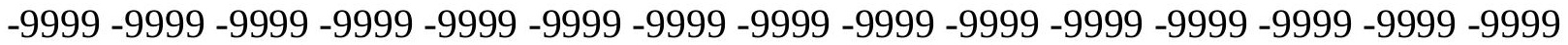

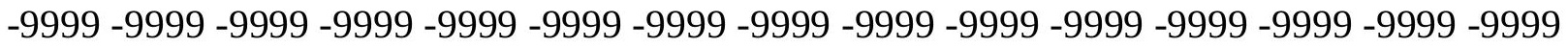

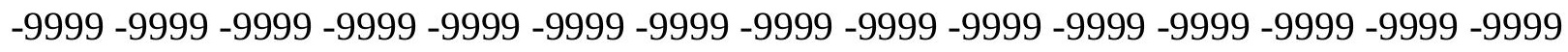

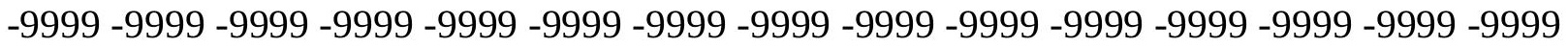

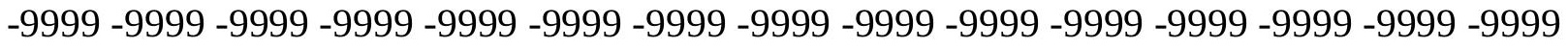
-9999 -9999 -9999 -9999 -9999 -9999 -9999 -9999 -9999 -9999 -9999 -9999 -9999 -9999 -9999 -

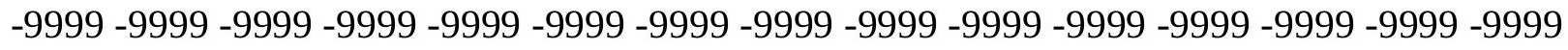

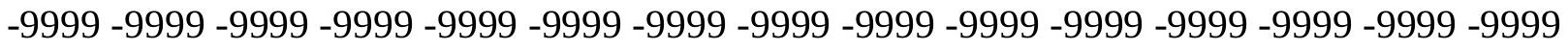
-9999 -9999 -9999 -9999 -9999 -9999 -9999 -9999 -9999 -9999 -9999 -9999 -9999 -9999 -9999 -9999 -9999 -9999 -9999 -9999 -9999 -9999 -9999 -9999-9999 -9999 -9999 -9999 -9999 -9999 -9999 -9999 -9999 -9999 -9999 -9999 -9999 -9999 -9999 -9999 -9999 -9999 -9999 -9999 -9999 -

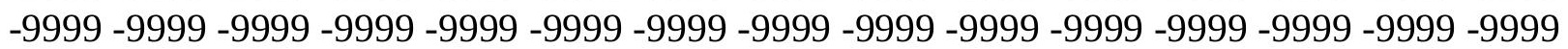


-9999 -9999 -9999 -9999 -9999 -9999 -9999 -9999 -9999 -9999 -9999 -9999 -9999 -9999 -9999 -9999 -9999 -9999 -9999 -9999 -9999 -9999 -9999 -9999 -9999 -9999 -9999 -9999 -9999 -

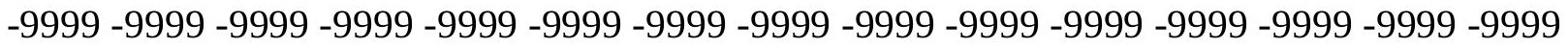
-9999 -9999 -9999 -9999 -9999 -9999 -9999 -9999 -9999 -9999 -9999 -9999 -9999 -9999 -9999 -9999 -9999 -9999 -9999 -9999 -9999 -9999 -9999 -9999 -9999 -9999 -9999 -9999 -9999 -9999 -9999 -9999 -9999 -9999 -9999 -9999 -9999 -9999 -9999 -9999 -9999 -9999 -9999 -9999 -9999 -9999 -9999 -9999 -9999 -9999 -9999 -9999 -9999 -9999 -9999 -9999 -9999 -9999 -9999 -9999

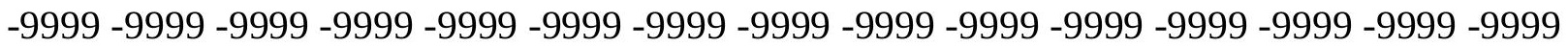

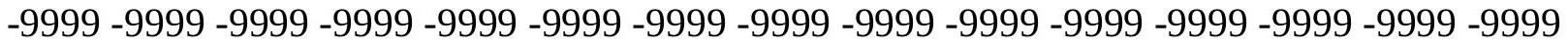
-9999 -9999 -9999 -9999 -9999 -9999 -9999 -9999 -9999 -9999 -9999 -9999 -9999 -9999 -9999 -9999 -9999 -9999 -9999 -9999 -9999 -9999 -9999 -9999 -9999 -9999 -9999 -9999 -9999 -9999 -9999 -9999 -9999 -9999 -9999 -9999 -9999 -9999 -9999 -9999 -9999 -9999 -9999 -9999 -9999 -9999 -9999 -9999 -9999 -9999 -9999 -9999 -9999 -9999 -9999 -9999 -9999 -9999 -9999 -9999 -9999 -9999 -9999 -9999 -9999 -9999 -9999 -9999 -9999 -9999 -9999 -9999 -9999 -9999 -9999 -9999 -9999 -9999 -9999 -9999 -9999 -9999 -9999 -9999 -9999 -9999 -9999 -9999 -9999 -9999 -

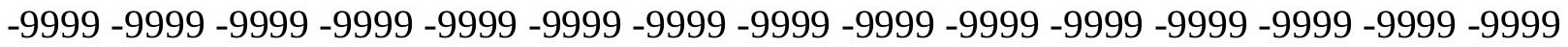
-9999 -9999 -9999 -9999 -9999 -9999 -9999 -9999 -9999 -9999 -9999 -9999 -9999 -9999 -9999 -9999 -9999 -9999 -9999 -9999 -9999 -9999 -9999 -9999 -9999 -9999 -9999 -9999 -9999 - 9999 -9999 -9999 -9999 -9999 -9999 -9999 -9999 -9999 -9999 -9999 -9999 -9999 -9999 -9999 -9999 -

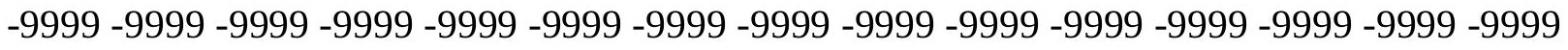

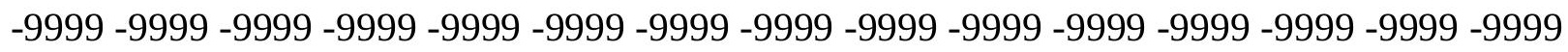

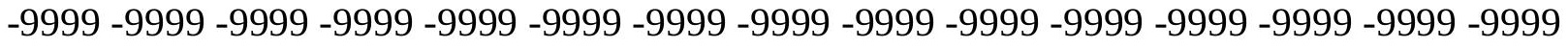
-9999 -9999 -9999 -9999 -9999 -9999 -9999 -9999 -9999 -9999 -9999 -9999 -9999 -9999 -9999 -9999 -9999 -9999 -9999 -9999 -9999 -9999 -9999 -9999 -9999 -9999 -9999 -9999 -9999 -9999 -

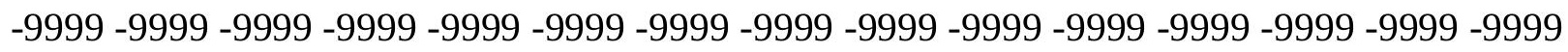
-9999 -9999 -9999 -9999 -9999 -9999 -9999 -9999 -9999 -9999 -9999 -9999 -9999 -9999 -9999 -9999 -9999 -9999 -9999 -9999 -9999 -9999 -9999 -9999 -9999 -9999 -9999 -9999 -9999 -9999 -9999 -9999 -9999 -9999 -9999 -9999 -9999 -9999 -9999 -9999 -9999 -9999 -9999 -9999 -9999 -9999 -9999 -9999 -9999 -9999 -9999 -9999 -9999 -9999 -9999 -9999 -9999 -9999 -9999 -9999 -9999 -9999 -9999 -9999 -9999 -9999 -9999 -9999 -9999 -9999 -9999 -9999 -9999 -999 -

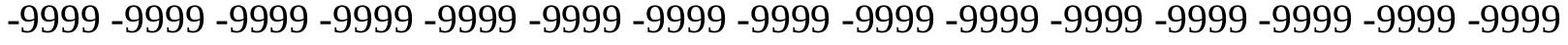
-9999 -9999 -9999 -9999 -9999 -9999 -9999 -9999 -9999 -9999 -9999 -9999 -9999 -9999 -9999 -

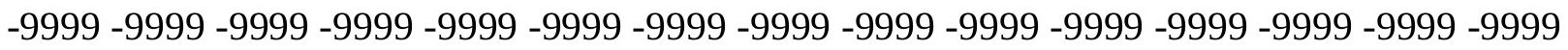

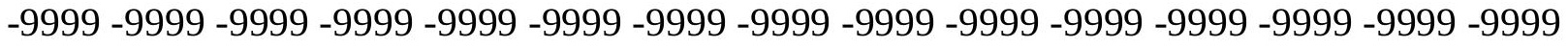

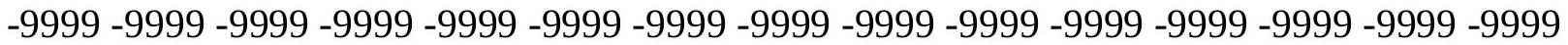

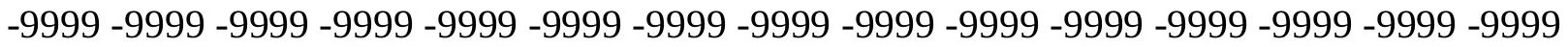

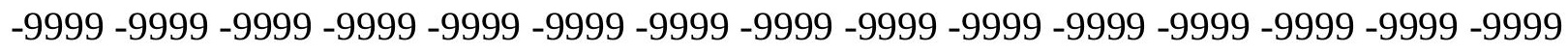

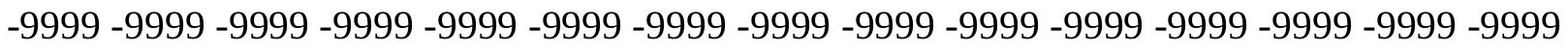

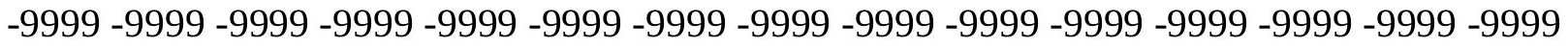
-9999 -9999 -9999 -9999 -9999 -9999 -9999 -9999 -9999 -9999 -9999 -9999 -9999 -9999 -9999 -

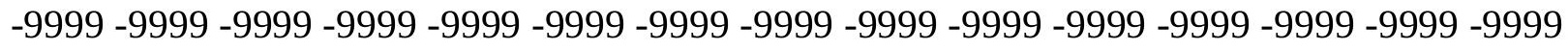

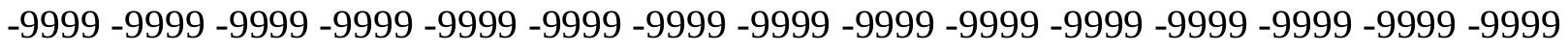
-9999 -9999 -9999 -9999 -9999 -9999 -9999 -9999 -9999 -9999 -9999 -9999 -9999 -9999 -9999 -9999 -9999 -9999 -9999 -9999 -9999 -9999 -9999 -9999-9999 -9999 -9999 -9999 -9999 -9999 -9999 -9999 -9999 -9999 -9999 -9999 -9999 -9999 -9999 -9999 -9999 -9999 -9999 -9999 -9999 -

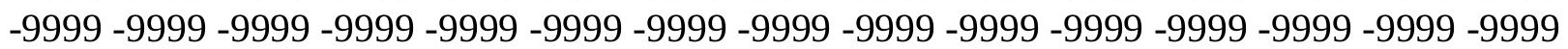


-9999 -9999 -9999 -9999 -9999 -9999 -9999 -9999 -9999 -9999 -9999 -9999 -9999 -9999 -9999 -9999 -9999 -9999 -9999 -9999 -9999 -9999 -9999 -9999 -9999 -9999 -9999 -9999 -9999 -9999 -

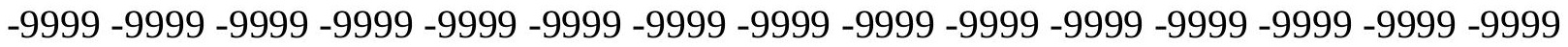
-9999 -9999 -9999 -9999 -9999 -9999 -9999 -9999 -9999 -9999 -9999 -9999 -9999 -9999 -9999 -9999 -9999 -9999 -9999 -9999 -9999 -9999 -9999 -9999-9999 -9999 -9999 -9999 -9999 -9999 -9999 -9999 -9999 -9999 -9999 -9999 -9999 -9999 -9999 -9999 -9999 -9999 -9999 -9999 -9999 -

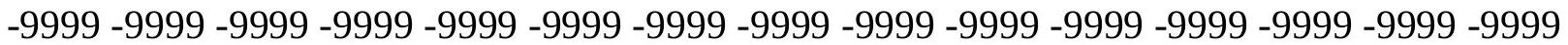
-9999 -9999 -9999 -9999 -9999 -9999 -9999 -9999 -9999 -9999 -9999 -9999 -9999 -9999 -9999 -9999 -9999 -9999 -9999 -9999 -9999 -9999 -9999 -9999 -9999 -9999 -9999 -9999 -9999 -9999 -9999 -9999 -9999 -9999 -9999 -9999 -9999 -9999 -9999 -9999 -9999 -9999 -9999 -9999 -9999 -9999 -9999 -9999 -9999 -9999 -9999 -9999 -9999 -9999 -9999 -9999 -9999 -9999 -9999 -9999 -9999 -9999 -9999 -9999 -9999 -9999 -9999 -9999 -9999 -9999 -9999 -9999 -9999 -9999 -9999 -9999 -9999 -9999 -9999 -9999 -9999 -9999 -9999 -9999 -9999 -9999 -9999 -9999 -9999 -9999 -9999 -9999 -9999 -9999 -9999 -9999 -9999 -9999 -9999 -9999 -9999 -9999 -9999 -9999 -9999 -9999 -9999 -9999 -9999 -9999 -9999 -9999 -9999 -9999 -9999 -9999 -9999 -9999 -9999 -

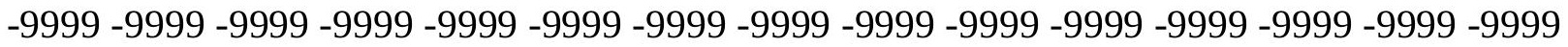
-9999 -9999 -9999 -9999 -9999 -9999 -9999 -9999 -9999 -9999 -9999 -9999 -9999 -9999 -9999 -9999 -9999 -9999 -9999 -9999 -9999 -9999 -9999 -9999 -9999 -9999 -9999 -9999 -9999 -9999 -9999 -9999 -9999 -9999 -9999 -9999 -9999 -9999 -9999 -9999 -9999 -9999 -9999 -9999 -9999 -

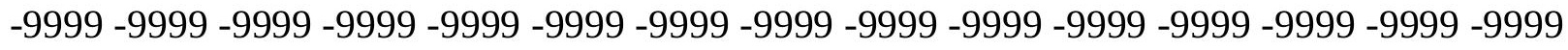

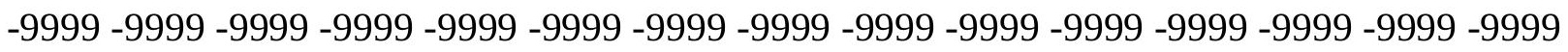
-9999 -9999 -9999 -9999 -9999 -9999 -9999 -9999 -9999 -9999 -9999 -9999 -9999 -9999 - 9999 -9999 -9999 -9999 -9999 -9999 -9999 -9999 -9999 -9999 -9999 -9999 -9999 -9999 -9999 -9999 -9999 -9999 -9999 -9999 -9999 -9999 -9999 -9999 -9999 -9999 -9999 -9999 -9999 -9999 -9999 -

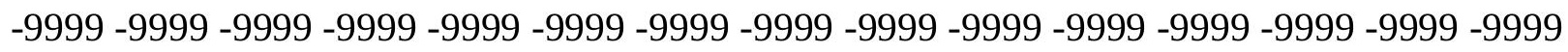
-9999 -9999 -9999 -9999 -9999 -9999 -9999 -9999 -9999 -9999 -9999 -9999 -9999 -9999 -9999 -9999 -9999 -9999 -9999 -9999 -9999 -9999 -9999 -9999 -9999 -9999 -9999 -9999 -9999 -9999 -

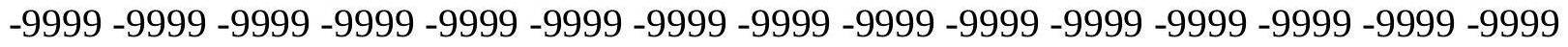
-9999 -9999 -9999 -9999 -9999 -9999 -9999 -9999 -9999 -9999 -9999 -9999 -9999 -9999 -9999 -9999 -9999 -9999 -9999 -9999 -9999 -9999 -9999 -9999 -9999 -9999 -9999 -9999 -9999 -999 -9999 -9999 -9999 -9999 -9999 -9999 -9999 -9999 -9999 -9999 -9999 -9999 -9999 -9999 -9999 -9999 -9999 -9999 -9999 -9999 -9999 -9999 -9999 -9999 -9999 -9999 -9999 -9999 -9999 -9999 -

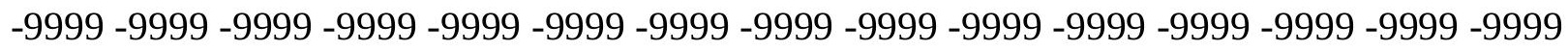

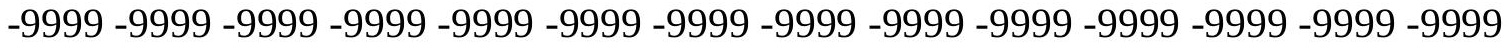
-9999 -9999 -9999 -9999 -9999 -9999 -9999 -9999 -9999 -9999 -9999 -9999 -9999 -9999 -9999

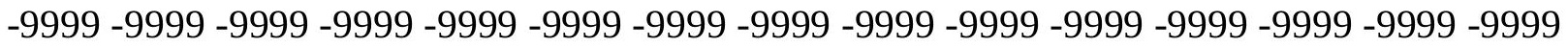

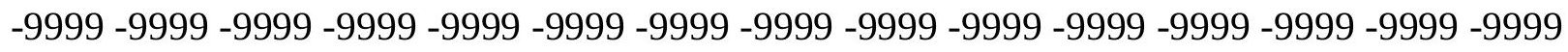

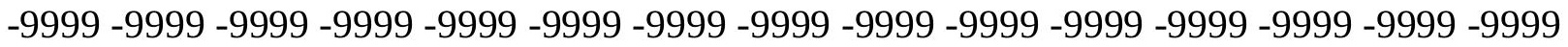

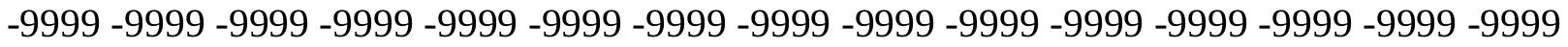
-9999 -9999 -9999 -9999 -9999 -9999 -9999 -9999 -9999 -9999 -9999 -9999 -9999 -9999 -9999 -

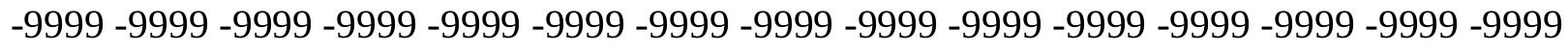

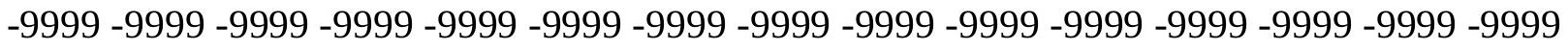
-9999 -9999 -9999 -9999 -9999 -9999 -9999 -9999 -9999 -9999 -9999 -9999 -9999 -9999 -9999 -9999 -9999 -9999 -9999 -9999 -9999 -9999 -9999 -9999-9999 -9999 -9999 -9999 -9999 -9999 -9999 -9999 -9999 -9999 -9999 -9999 -9999 -9999 -9999 -9999 -9999 -9999 -9999 -9999 -9999 -

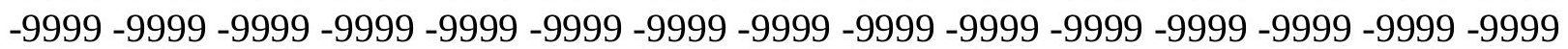


-9999 -9999 -9999 -9999 -9999 -9999 -9999 -9999 -9999 -9999 -9999 -9999 -9999 -9999 -9999 -9999 -9999 -9999 -9999 -9999 -9999 -9999 -9999 -9999 -9999 -9999 -9999 -9999 -9999 -9999 -

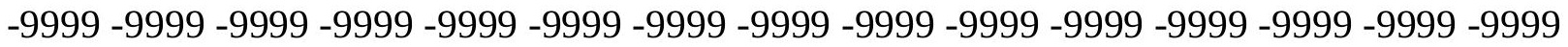
-9999 -9999 -9999 -9999 -9999 -9999 -9999 -9999 -9999 -9999 -9999 -9999 -9999 -9999 -9999 -9999 -9999 -9999 -9999 -9999 -9999 -9999 -9999 -9999-9999 -9999 -9999 -9999 -9999 -9999 -9999 -9999 -9999 -9999 -9999 -9999 -9999 -9999 -9999 -9999 -9999 -9999 -9999 -9999 -9999 -9999 -9999 -9999 -9999 -9999 -9999 -9999 -9999 -9999 -9999 -9999 -9999 -9999 -9999 -9999

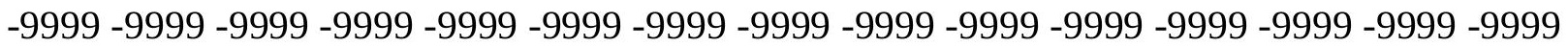

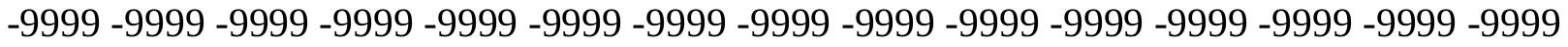
-9999 -9999 -9999 -9999 -9999 -9999 -9999 -9999 -9999 -9999 -9999 -9999 -9999 -9999 -9999 -9999 -9999 -9999 -9999 -9999 -9999 -9999 -9999 -9999 -9999 -9999 -9999 -9999 -9999 -9999 -9999 -9999 -9999 -9999 -9999 -9999 -9999 -9999 -9999 -9999 -9999 -9999 -9999 -9999 -9999 -9999 -9999 -9999 -9999 -9999 -9999 -9999 -9999 -9999 -9999 -9999 -9999 -9999 -9999 -9999 -9999 -9999 -9999 -9999 -9999 -9999 -9999 -9999 -9999 -9999 -9999 -9999 -9999 -9999 -9999 -9999 -9999 -9999 -9999 -9999 -9999 -9999 -9999 -9999 -9999 -9999 -9999 -9999 -9999

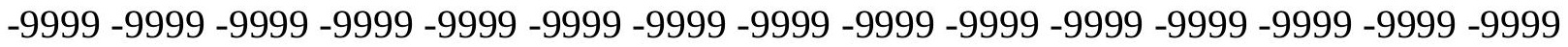
-9999 -9999 -9999 -9999 -9999 -9999 -9999 -9999 -9999 -9999 -9999 -9999 -9999 -9999 -9999 -9999 -9999 -9999 -9999 -9999 -9999 -9999 -9999 -9999 -9999 -9999 -9999 -9999 -9999 -9999 -9999 -9999 -9999 -9999 -9999 -9999 -9999 -9999 -9999 -9999 -9999 -9999 -9999 -9999 -9999 -

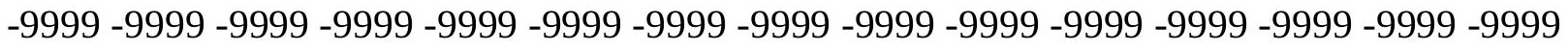

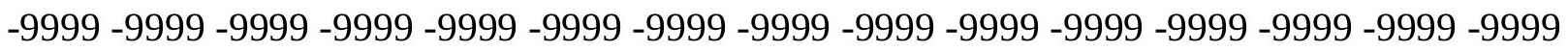
-9999 -9999 -9999 -9999 -9999 -9999 -9999 -9999 -9999 -9999 -9999 -9999 -9999 -9999 -9999 -9999 -9999 -9999 -9999 -9999 -9999 -9999 -9999 -9999 -9999 -9999 -9999 -9999 -9999 -9999 -9999 -9999 -9999 -9999 -9999 -9999 -9999 -9999 -9999 -9999 -9999 -9999 -9999 -9999 -9999 -

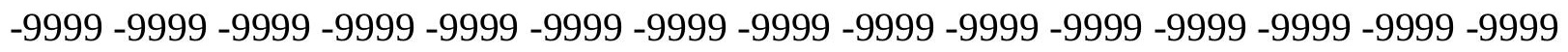
-9999 -9999 -9999 -9999 -9999 -9999 -9999 -9999 -9999 -9999 -9999 -9999 -9999 -9999 -9999 -9999 -9999 -9999 -9999 -9999 -9999 -9999 -9999 -9999 -9999 -9999 -9999 -9999 -9999 -9999 -

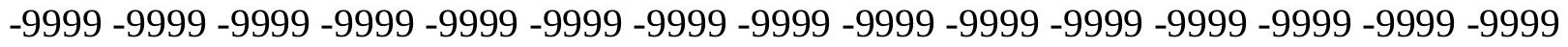
-9999 -9999 -9999 -9999 -9999 -9999 -9999 -9999 -9999 -9999 -9999 -9999 -9999 -9999 -9999 -9999 -9999 -9999 -9999 -9999 -9999 -9999 -9999 -9999 -9999 -9999 -9999 -9999 -9999 -999 -9999 -9999 -9999 -9999 -9999 -9999 -9999 -9999 -9999 -9999 -9999 -9999 -9999 -9999 -9999 -9999 -9999 -9999 -9999 -9999 -9999 -9999 -9999 -9999 -9999 -9999 -9999 -9999 -9999 -9999 -

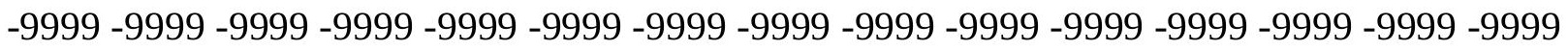

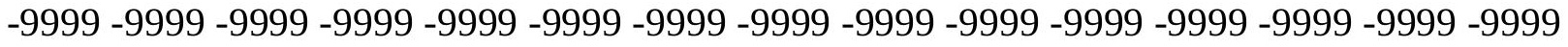

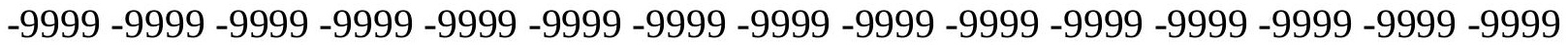

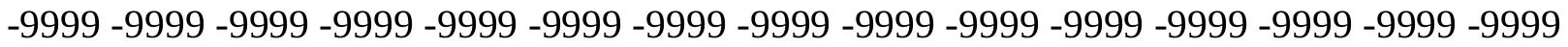

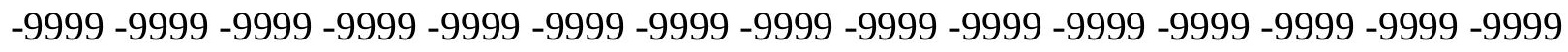

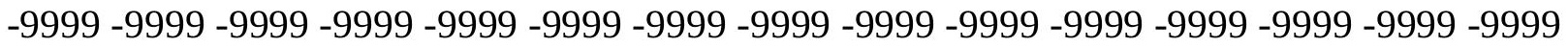
-9999 -9999 -9999 -9999 -9999 -9999 -9999 -9999 -9999 -9999 -9999 -9999 -9999 - 9999 - -999 -9999 -9999 -9999 -9999 -9999 -9999 -9999 -9999 -9999 -9999 -9999 -9999 -9999 -9999 - -999 -

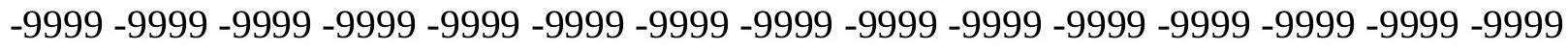

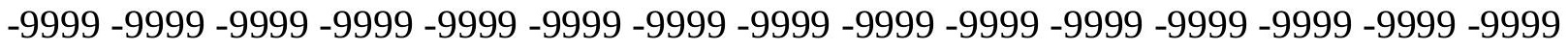
-9999 -9999 -9999 -9999 -9999 -9999 -9999 -9999 -9999 -9999 -9999 -9999 -9999 -9999 -9999 -9999 -9999 -9999 -9999 -9999 -9999 -9999 -9999 -9999-9999 -9999 -9999 -9999 -9999 -9999 -9999 -9999 -9999 -9999 -9999 -9999 -9999 -9999 -9999 -9999 -9999 -9999 -9999 -9999 -9999 -

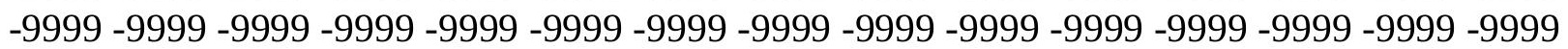


-9999 -9999 -9999 -9999 -9999 -9999 -9999 -9999 -9999 -9999 -9999 -9999 -9999 -9999 -9999 -9999 -9999 -9999 -9999 -9999 -9999 -9999 -9999 -9999 -9999 -9999 -9999 -9999 -9999 -9999 -9999 -9999 -9999 -9999 -9999 -9999 -9999 -9999 -9999 -9999 -9999 -9999 -9999 -9999 -9999 -9999 -9999 -9999 -9999 -9999 -9999 -9999 -9999 -9999 -9999 -9999 -9999 -9999 -9999 -9999 -9999 -9999 -9999 -9999 -9999 -9999 -9999 -9999 -9999 -9999 -9999 -9999 -9999 -9999 -9999 -9999 -9999 -9999 -9999 -9999 -9999 -9999 -9999 -9999 -9999 -9999 -9999 -9999 -9999 -9999 -9999 -9999 -9999 -9999 -9999 -9999 -9999 -9999 -9999 -9999 -9999 -9999 -9999 -9999 -9999 -

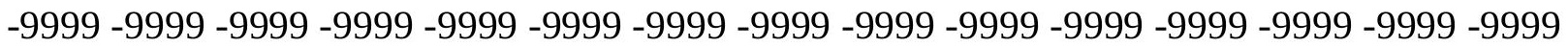
-9999 -9999 -9999 -9999 -9999 -9999 -9999 -9999 -9999 -9999 -9999 -9999 -9999 -9999 -9999 -9999 -9999 -9999 -9999 -9999 -9999 -9999 -9999 -9999 -9999 -9999 -9999 -9999 -9999 -9999 -

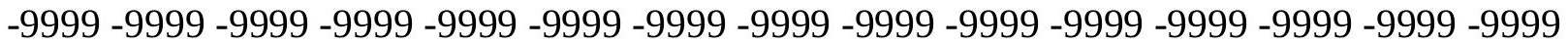
-9999 -9999 -9999 -9999 -9999 -9999 -9999 -9999 -9999 -9999 -9999 -9999 -9999 -9999 -9999 -9999 -9999 -9999 -9999 -9999 -9999 -9999 -9999 -9999 -9999 -9999 -9999 -9999 -9999 -9999 -9999 -9999 -9999 -9999 -9999 -9999 -9999 -9999 -9999 -9999 -9999 -9999 -9999 -9999 -9999 -9999 -9999 -9999 -9999 -9999 -9999 -9999 -9999 -9999 -9999 -9999 -9999 -9999 -9999 -9999

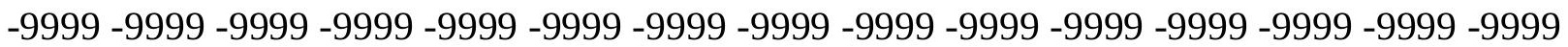
-9999 -9999 -9999 -9999 -9999 -9999 -9999 -9999 -9999 -9999 -9999 -9999 -9999 -9999 -9999 -9999 -9999 -9999 -9999 -9999 -9999 -9999 -9999 -9999 -9999 -9999 -9999 -9999 -9999 -9999 -9999 -9999 -9999 -9999 -9999 -9999 -9999 -9999 -9999 -9999 -9999 -9999 -9999 -9999 -9999 -9999 -9999 -9999 -9999 -9999 -9999 -9999 -9999 -9999 -9999 -9999 -9999 -9999 -9999 -9999 -9999 -9999 -9999 -9999 -9999 -9999 -9999 -9999 -9999 -9999 -9999 -9999 -9999 -9999 -9999 -9999 -9999 -9999 -9999 -9999 -9999 -9999 -9999 -9999 -9999 -9999 -9999 -9999 -9999 -9999 -9999 -9999 -9999 -9999 -9999 -9999 -9999 -9999 -9999 -9999 -9999 -9999 -9999 -9999 -9999 -9999 -9999 -9999 -9999 -9999 -9999 -9999 -9999 -9999 -9999 -9999 -9999 -9999 -9999 -9999 -9999 -9999 -9999 -9999 -9999 -9999 -9999 -9999 -9999 -9999 -9999 -9999 -9999 -9999 -9999 -9999 -9999 -9999 -9999 -9999 -9999 -9999 -9999 -9999 -9999 -9999 -9999 -9999 -9999 -9999 -9999 -9999 -9999 -9999 -9999 -9999 -9999 -9999 -9999 -9999 -9999 -9999 -9999 -9999 -9999 -9999 -9999 -9999 -9999 -9999 -9999 -9999 -9999 -9999 -9999 -9999 -9999 -9999 -9999

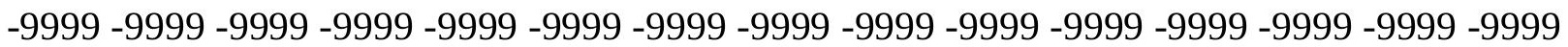
-9999 -9999 -9999 -9999 -9999 -9999 -9999 -9999 -9999 -9999 -9999 -9999 -9999 -9999 -9999 -9999 -9999 -9999 -9999 -9999 -9999 -9999 -9999 -9999 -9999 -9999 -9999 -9999 -9999 -9999 -

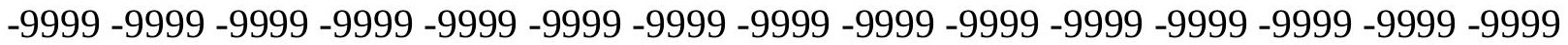
-9999 -9999 -9999 -9999 -9999 -9999 -9999 -9999 -9999 -9999 -9999 -9999 -9999 -9999 -9999 -9999 -9999 -9999 -9999 -9999 -9999 -9999 -9999 -9999 -9999 -9999 -9999 -9999 -9999 -9999 -9999 -9999 -9999 -9999 -9999 -9999 -9999 -9999 -9999 -9999 -9999 -9999 -9999 -9999 -9999 -9999 -9999 -9999 -9999 -9999 -9999 -9999 -9999 -9999 -9999 -9999 -9999 -9999 -9999 -9999 -9999 -9999 -9999 -9999 -9999 -9999 -9999 -9999 -9999 -9999 -9999 -9999 -9999 -9999 -9999

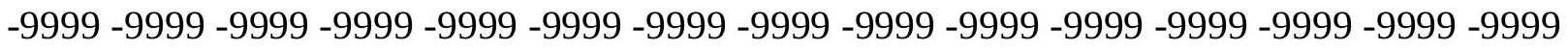
-9999 -9999 -9999 -9999 -9999 -9999 -9999 -9999 -9999 -9999 -9999 -9999 -9999 -9999 -9999 -9999 -9999 -9999 -9999 -9999 -9999 -9999 -9999 -9999 -9999 -9999 -9999 -9999 -9999 -9999 -9999 -9999 -9999 -9999 -9999 -9999 -9999 -9999 -9999 -9999 -9999 -9999 -9999 -9999 -9999 -999 -9999 -9999 -9999 -9999 -9999 -9999 -9999 -9999 -9999 -9999 -9999 -9999 -9999 -9999 -9999 -9999 -9999 -9999 -9999 -9999 -9999 -9999 -9999 -9999 -9999 -9999 -9999 -9999 -9999 -9999 -9999 -9999 -9999 -9999 -9999 -9999 -9999 -9999 -9999 -9999 -9999 -9999 -9999 -9999 -9999 -9999 -9999 -9999 -9999 -9999 -9999 -9999 -9999 -9999 -9999 -9999 -9999 -9999 -9999 -9999 -9999 -9999 -9999 -9999 -9999 -9999 -9999 -9999 -9999 -9999 -9999 -9999 -9999 -9999 
-9999 -9999 -9999 -9999 -9999 -9999 -9999 -9999 -9999 -9999 -9999 -9999 -9999 -9999 -9999 -9999 -9999 -9999 -9999 -9999 -9999 -9999 -9999 -9999 -9999 -9999 -9999 -9999 -9999 -9999 -

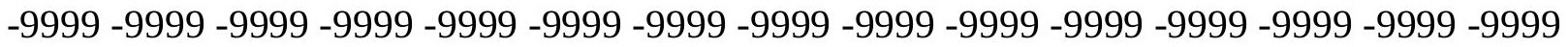
-9999 -9999 -9999 -9999 -9999 -9999 -9999 -9999 -9999 -9999 -9999 -9999 -9999 -9999 -9999 -9999 -9999 -9999 -9999 -9999 -9999 -9999 -9999 -9999-9999 -9999 -9999 -9999 -9999 -9999 -9999 -9999 -9999 -9999 -9999 -9999 -9999 -9999 -9999 -9999 -9999 -9999 -9999 -9999 -9999 -9999 -9999 -9999 -9999 -9999 -9999 -9999 -9999 -9999 -9999 -9999 -9999 -9999 -9999 -9999

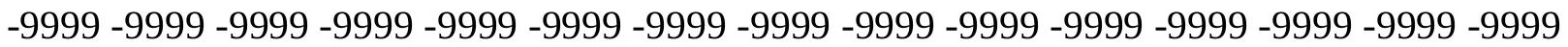

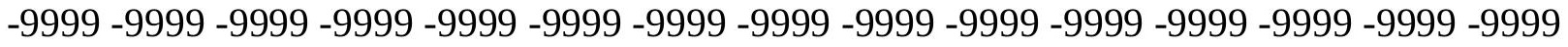
-9999 -9999 -9999 -9999 -9999 -9999 -9999 -9999 -9999 -9999 -9999 -9999 -9999 -9999 -9999 -9999 -9999 -9999 -9999 -9999 -9999 -9999 -9999 -9999 -9999 -9999 -9999 -9999 -9999 -9999 -9999 -9999 -9999 -9999 -9999 -9999 -9999 -9999 -9999 -9999 -9999 -9999 -9999 -9999 -9999 -9999 -9999 -9999 -9999 -9999 -9999 -9999 -9999 -9999 -9999 -9999 -9999 -9999 -9999 -9999 -

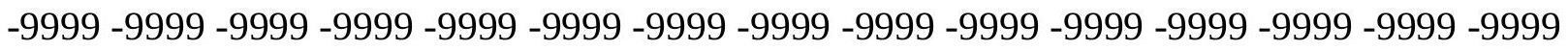
-9999 -9999 -9999 -9999 -9999 -9999 -9999 -9999 -9999 -9999 -9999 -9999 -9999 -9999 -9999 -

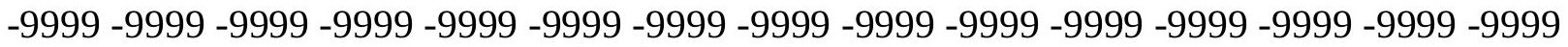
-9999 -9999 -9999 -9999 -9999 -9999 -9999 -9999 -9999 -9999 -9999 -9999 -9999 -9999 -9999 -9999 -9999 -9999 -9999 -9999 -9999 -9999 -9999 -9999 -9999 -9999 -9999 -9999 -9999 -9999 -9999 -9999 -9999 -9999 -9999 -9999 -9999 -9999 -9999 -9999 -9999 -9999 -9999 -9999 -9999 -

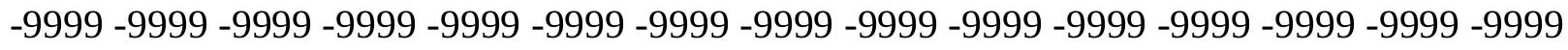

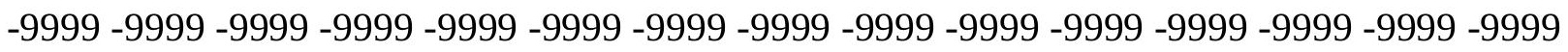

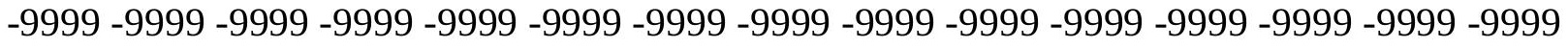
-9999 -9999 -9999 -9999 -9999 -9999 -9999 -9999 -9999 -9999 -9999 -9999 -9999 -9999 -9999 -9999 -9999 -9999 -9999 -9999 -9999 -9999 -9999 -9999 -9999 -9999 -9999 -9999 -9999 -9999 -

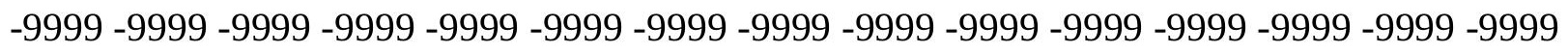
-9999 -9999 -9999 -9999 -9999 -9999 -9999 -9999 -9999 -9999 -9999 -9999 -9999 -9999 -9999 -9999 -9999 -9999 -9999 -9999 -9999 -9999 -9999 -9999 -9999 -9999 -9999 -9999 -9999 -

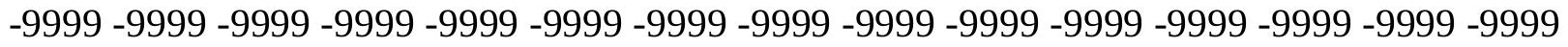
-9999 -9999 -9999 -9999 -9999 -9999 -9999 -9999 -9999 -9999 -9999 -9999 -9999 -9999 -9999 -9999 -9999 -9999 -9999 -9999 -9999 -9999 -9999 -9999 -9999 -9999 -9999 -9999 -9999 -999 -

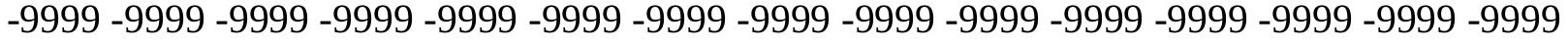
-9999 -9999 -9999 -9999 -9999 -9999 -9999 -9999 -9999 -9999 -9999 -9999 -9999 -9999 -9999 -

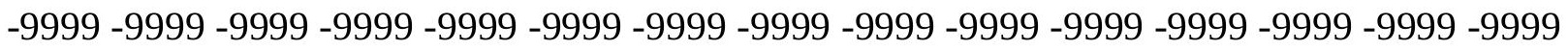

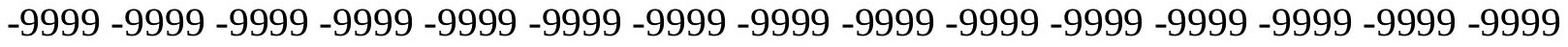

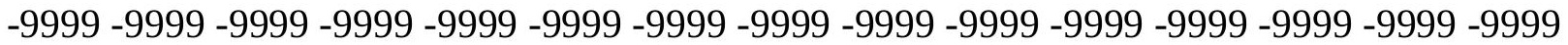
-9999 -9999 -9999 -9999 -9999 -9999 -9999 -9999 -9999 -9999 -9999 -9999 -9999 -9999 -9999

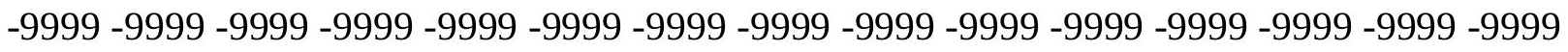

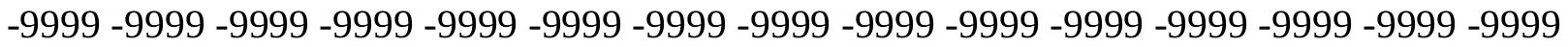
-9999 -9999 -9999 -9999 -9999 -9999 -9999 -9999 -9999 -9999 -9999 -9999 -9999 - 9999 - -999 -9999 -9999 -9999 -9999 -9999 -9999 -9999 -9999 -9999 -9999 -9999 -9999 -9999 -9999 -9999 -

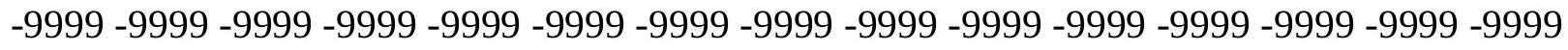

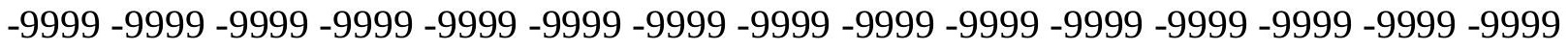
-9999 -9999 -9999 -9999 -9999 -9999 -9999 -9999 -9999 -9999 -9999 -9999 -9999 -9999 -9999 -9999 -9999 -9999 -9999 -9999 -9999 -9999 -9999 -9999-9999 -9999 -9999 -9999 -9999 -9999 -9999 -9999 -9999 -9999 -9999 -9999 -9999 -9999 -9999 -9999 -9999 -9999 -9999 -9999 -9999 -

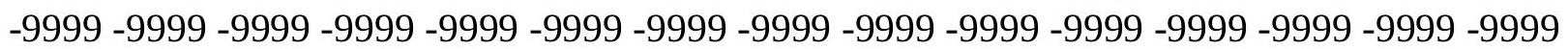


-9999 -9999 -9999 -9999 -9999 -9999 -9999 -9999 -9999 -9999 -9999 -9999 -9999 -9999 -9999 -9999 -9999 -9999 -9999 -9999 -9999 -9999 -9999 -9999 -9999 -9999 -9999 -9999 -9999 -9999 -9999 -9999 -9999 -9999 -9999 -9999 -9999 -9999 -9999 -9999 -9999 -9999 -9999 -9999 - 9999 -9999 -9999 -9999 -9999 -9999 -9999 -9999 -9999 -9999 -9999 -9999 -9999 -9999 -9999 -9999 -9999 -9999 -9999 -9999 -9999 -9999 -9999 -9999 -9999 -9999 -9999 -9999 -9999 -9999 - -9999 -9999 -9999 -9999 -9999 -9999 -9999 -9999 -9999 -9999 -9999 -9999 -9999 -9999 -9999 -9999 -9999 -9999 -9999 -9999 -9999 -9999 -9999 -9999 -9999 -9999 -9999 -9999 -9999 -9999

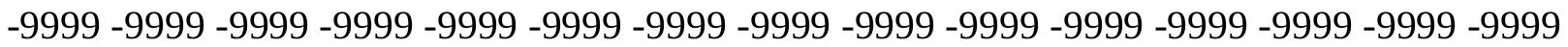

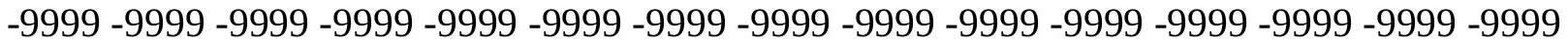
-9999 -9999 -9999 -9999 -9999 -9999 -9999 -9999 -9999 -9999 -9999 -9999 -9999 -9999 -9999

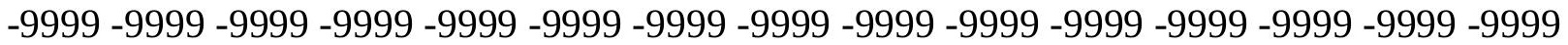
-9999 -9999 -9999 -9999 -9999 -9999 -9999 -9999 -9999 -9999 -9999 -9999 -9999 -9999 -9999 -9999 -9999 -9999 -9999 -9999 -9999 -9999 -9999 -9999 -9999 -9999 -9999 -9999 -9999 -9999 -9999 -9999 -9999 -9999 -9999 -9999 -9999 -9999 -9999 -9999 -9999 -9999 -9999 -9999 - -9999 -9999 -9999 -9999 -9999 -9999 -9999 -9999 -9999 -9999 -9999 -9999 -9999 -9999 -9999 -9999

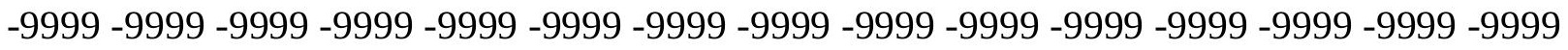
-9999 -9999 -9999 -9999 -9999 -9999 -9999 -9999 -9999 -9999 -9999 -9999 -9999 -9999 -9999 -9999 -9999 -9999 -9999 -9999 -9999 -9999 -9999 -9999 -9999 -9999 -9999 -9999 -9999 -9999 -9999 -9999 -9999 -9999 -9999 -9999 -9999 -9999 -9999 -9999 -9999 -9999 -9999 -9999 -9999 -

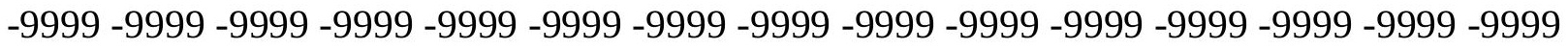
-9999 -9999 -9999 -9999 -9999 -9999 -9999 -9999 -9999 -9999 -9999 -9999 -9999 -9999 -9999 -999 -9999 -9999 -9999 -9999 -9999 -9999 -9999 -9999 -9999 -9999 -9999 -9999 -9999 -9999 -9999 -9999 -9999 -9999 -9999 -9999 -9999 -9999 -9999 -9999 -9999 -9999 -9999 -9999 -9999 -9999 -9999 -9999 -9999 -9999 -9999 -9999 -9999 -9999 -9999 -9999 -9999 -9999 -9999 -9999 -9999 -9999 -9999 -9999 -9999 -9999 -9999 -9999 -9999 -9999 -9999 -9999 -9999 -9999 -9999 -9999 -9999 -9999 -9999 -9999 -9999 -9999 -9999 -9999 -9999 -9999 -9999 -9999 -9999 -9999 -9999 -9999 -9999 -9999 -9999 -9999 -9999 -9999 -9999 -9999 -9999 -9999 -9999 -9999 -9999 -9999 -9999 -9999 -9999 -9999 -9999 -9999 -9999 -9999 -9999 -9999 -9999 -9999 -9999 -9999 -9999 -9999 -9999 -9999 -9999 -9999 -9999 -9999 -9999 -9999 -9999 -9999 -9999 -9999 -9999 -9999 -9999 -9999 -9999 -9999 -9999 -9999 -9999 -9999 -9999 -9999 -9999 -9999 -9999 -9999 -999 -9999 -9999 -9999 -9999 -9999 -9999 -9999 -9999 -9999 -9999 -9999 -9999 -9999 -9999 -9999 -9999 -9999 -9999 -9999 -9999 -9999 -9999 -9999 -9999 -9999 -9999 -9999 -9999 -9999 -

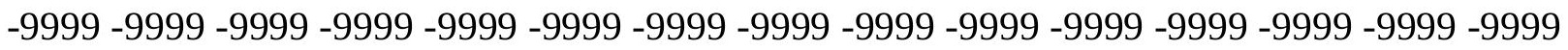

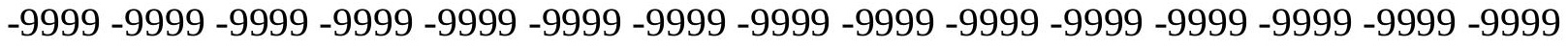

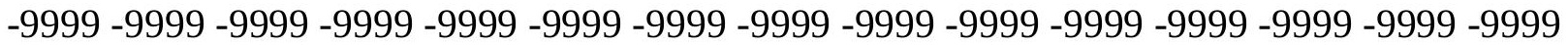
-9999 -9999 -9999 -9999 -9999 -9999 -9999 -9999 -9999 -9999 -9999 -9999 -9999 -9999 -9999 -

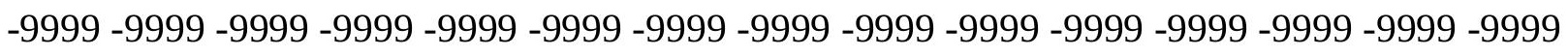

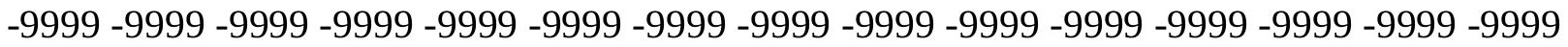

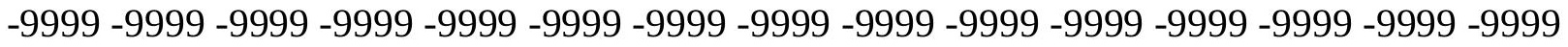
-9999 -9999 -9999 -9999 -9999 -9999 -9999 -9999 -9999 -9999 -9999 -9999 -9999 -9999 -9999 -

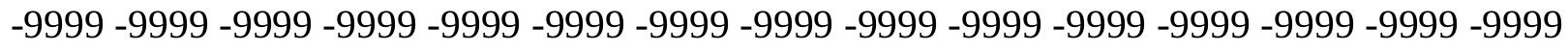

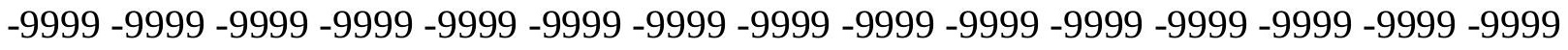
-9999 -9999 -9999 -9999 -9999 -9999 -9999 -9999 -9999 -9999 -9999 -9999 -9999 -9999 -9999 -9999 -9999 -9999 -9999 -9999 -9999 -9999 -9999 -9999-9999 -9999 -9999 -9999 -9999 -9999 -9999 -9999 -9999 -9999 -9999 -9999 -9999 -9999 -9999 -9999 -9999 -9999 -9999 -9999 -9999 -

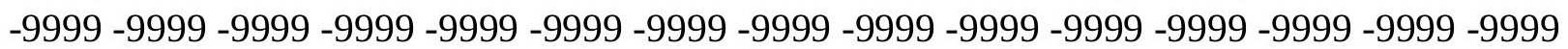


-9999 -9999 -9999 -9999 -9999 -9999 -9999 -9999 -9999 -9999 -9999 -9999 -9999 -9999 -9999 -9999 -9999 -9999 -9999 -9999 -9999 -9999 -9999 -9999 -9999 -9999 -9999 -9999 -9999 -9999 -

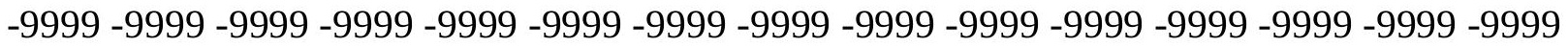
-9999 -9999 -9999 -9999 -9999 -9999 -9999 -9999 -9999 -9999 -9999 -9999 -9999 -9999 -9999 -9999 -9999 -9999 -9999 -9999 -9999 -9999 -9999 -9999-9999 -9999 -9999 -9999 -9999 -9999 -9999 -9999 -9999 -9999 -9999 -9999 -9999 -9999 -9999 -9999 -9999 -9999 -9999 -9999 -9999 -9999 -9999 -9999 -9999 -9999 -9999 -9999 -9999 -9999 -9999 -9999 -9999 -9999 -9999 -9999

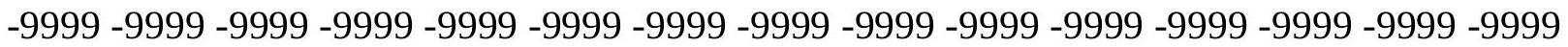

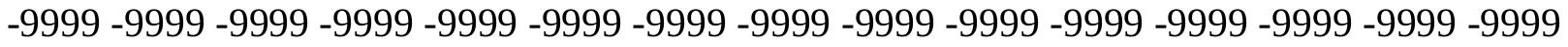
-9999 -9999 -9999 -9999 -9999 -9999 -9999 -9999 -9999 -9999 -9999 -9999 -9999 -9999 -9999 -9999 -9999 -9999 -9999 -9999 -9999 -9999 -9999 -9999 -9999 -9999 -9999 -9999 -9999 -9999 -9999 -9999 -9999 -9999 -9999 -9999 -9999 -9999 -9999 -9999 -9999 -9999 -9999 -9999 -9999 -9999 -9999 -9999 -9999 -9999 -9999 -9999 -9999 -9999 -9999 -9999 -9999 -9999 -9999 -9999 -9999 -9999 -9999 -9999 -9999 -9999 -9999 -9999 -9999 -9999 -9999 -9999 -9999 - 9999 -9999 -9999 -9999 -9999 -9999 -9999 -9999 -9999 -9999 -9999 -9999 -9999 -9999 -9999 -9999

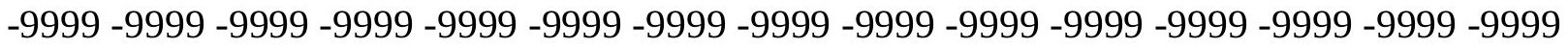
-9999 -9999 -9999 -9999 -9999 -9999 -9999 -9999 -9999 -9999 -9999 -9999 -9999 -9999 -9999 -9999 -9999 -9999 -9999 -9999 -9999 -9999 -9999 -9999 -9999 -9999 -9999 -9999 -9999 -9999 -9999 -9999 -9999 -9999 -9999 -9999 -9999 -9999 -9999 -9999 -9999 -9999 -9999 -9999 -9999 -

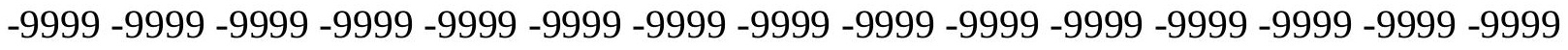

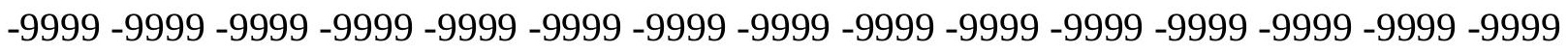
-9999 -9999 -9999 -9999 -9999 -9999 -9999 -9999 -9999 -9999 -9999 -9999 -9999 -9999 -9999 -9999 -9999 -9999 -9999 -9999 -9999 -9999 -9999 -9999 -9999 -9999 -9999 -9999 -9999 -9999 -9999 -9999 -9999 -9999 -9999 -9999 -9999 -9999 -9999 -9999 -9999 -9999 -9999 -9999 -9999 -

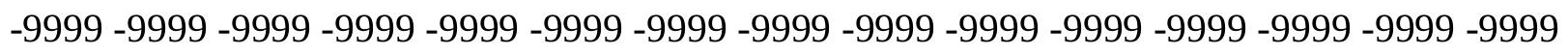
-9999 -9999 -9999 -9999 -9999 -9999 -9999 -9999 -9999 -9999 -9999 -9999 -9999 -9999 -9999 -9999 -9999 -9999 -9999 -9999 -9999 -9999 -9999 -9999 -9999 -9999 -9999 -9999 -9999 -9999 -

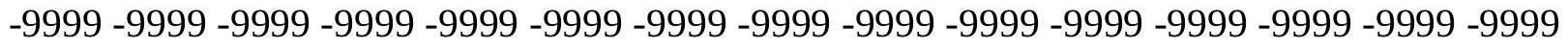
-9999 -9999 -9999 -9999 -9999 -9999 -9999 -9999 -9999 -9999 -9999 -9999 -9999 -9999 -9999 -9999 -9999 -9999 -9999 -9999 -9999 -9999 -9999 -9999 -9999 -9999 -9999 -9999 -9999 -999 -9999 -9999 -9999 -9999 -9999 -9999 -9999 -9999 -9999 -9999 -9999 -9999 -9999 -9999 -9999 -9999 -9999 -9999 -9999 -9999 -9999 -9999 -9999 -9999 -9999 -9999 -9999 -9999 -9999 -9999 -

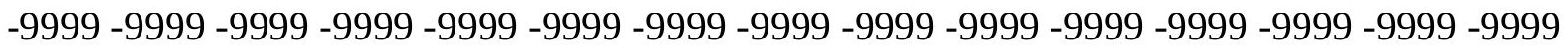

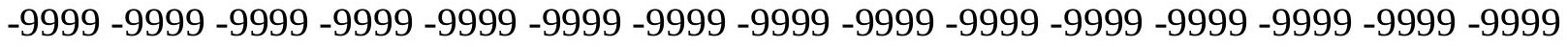

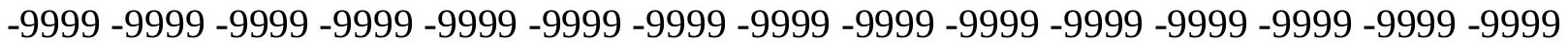

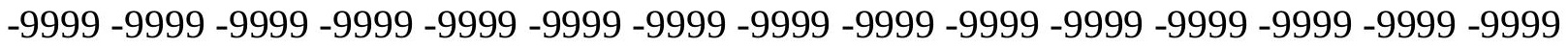

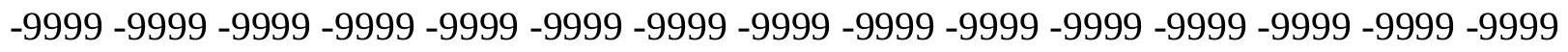

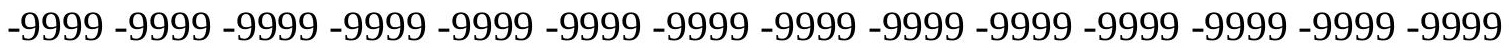
-9999 -9999 -9999 -9999 -9999 -9999 -9999 -9999 -9999 -9999 -9999 -9999 -9999 -9999 -9999 -9999 -9999 -9999 -9999 -9999 -9999 -9999 -9999 -9999 -9999 -9999 -9999 -9999 -9999 -9999 -

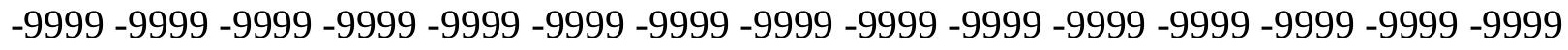

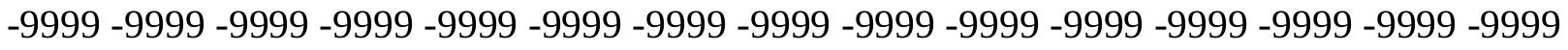
-9999 -9999 -9999 -9999 -9999 -9999 -9999 -9999 -9999 -9999 -9999 -9999 -9999 -9999 -9999 -9999 -9999 -9999 -9999 -9999 -9999 -9999 -9999 -9999-9999 -9999 -9999 -9999 -9999 -9999 -9999 -9999 -9999 -9999 -9999 -9999 -9999 -9999 -9999 -9999 -9999 -9999 -9999 -9999 -9999 -

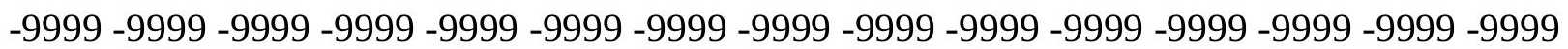


-9999 -9999 -9999 -9999 -9999 -9999 -9999 -9999 -9999 -9999 -9999 -9999 -9999 -9999 -9999 -9999 -9999 -9999 -9999 -9999 -9999 -9999 -9999 -9999 -9999 -9999 -9999 -9999 -9999 -9999 -9999 -9999 -9999 -9999 -9999 -9999 -9999 -9999 -9999 -9999 -9999 -9999 -9999 -9999 - 9999 -9999 -9999 -9999 -9999 -9999 -9999 -9999 -9999 -9999 -9999 -9999 -9999 -9999 -9999 -9999 -9999 -9999 -9999 -9999 -9999 -9999 -9999 -9999 -9999 -9999 -9999 -9999 -9999 -9999 -9999 -9999 -9999 -9999 -9999 -9999 -9999 -9999 -9999 -9999 -9999 -9999 -9999 -9999 -9999 -9999 -9999 -9999 -9999 -9999 -9999 -9999 -9999 -9999 -9999 -9999 -9999 -9999 -9999 -9999 -9999

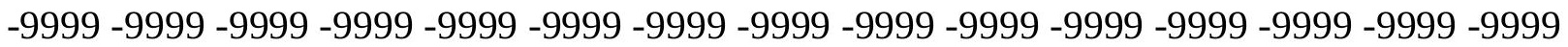
-9999 -9999 -9999 -9999 -9999 -9999 -9999 -9999 -9999 -9999 -9999 -9999 -9999 -9999 -9999 -9999 -9999 -9999 -9999 -9999 -9999 -9999 -9999 -9999 -9999 -9999 -9999 -9999 -9999 -9999

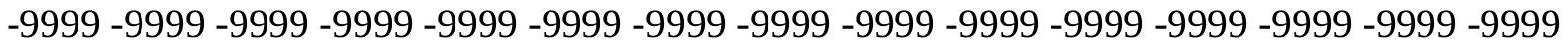
-9999 -9999 -9999 -9999 -9999 -9999 -9999 -9999 -9999 -9999 -9999 -9999 -9999 -9999 -9999 -9999 -9999 -9999 -9999 -9999 -9999 -9999 -9999 -9999 -9999 -9999 -9999 -9999 -9999 -9999 -

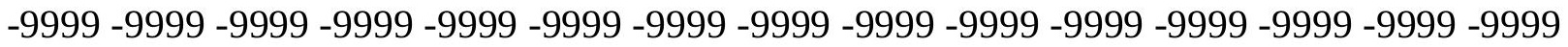
-9999 -9999 -9999 -9999 -9999 -9999 -9999 -9999 -9999 -9999 -9999 -9999 -9999 -9999 -9999

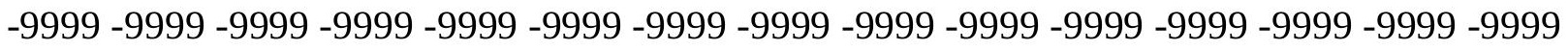
-9999 -9999 -9999 -9999 -9999 -9999 -9999 -9999 -9999 -9999 -9999 -9999 -9999 -9999 -9999 -9999 -9999 -9999 -9999 -9999 -9999 -9999 -9999 -9999 -9999 -9999 -9999 -9999 -9999 - -999 -9999 -9999 -9999 -9999 -9999 -9999 -9999 -9999 -9999 -9999 -9999 -9999 -9999 -9999 -9999 -9999 -9999 -9999 -9999 -9999 -9999 -9999 -9999 -9999 -9999 -9999 -9999 -9999 -9999 -9999 -9999 -9999 -9999 -9999 -9999 -9999 -9999 -9999 -9999 -9999 -9999 -9999 -9999 -9999 -9999 -999 -9999 -9999 -9999 -9999 -9999 -9999 -9999 -9999 -9999 -9999 -9999 -9999 -9999 -9999 -9999 -9999 -9999 -9999 -9999 -9999 -9999 -9999 -9999 -9999 -9999 -9999 -9999 -9999 -9999 -9999 -9999 -9999 -9999 -9999 -9999 -9999 -9999 -9999 -9999 -9999 -9999 -9999 -9999 -9999 -9999 -9999 -9999 -9999 -9999 -9999 -9999 -9999 -9999 -9999 -9999 -9999 -9999 -9999 -9999 -9999 -9999 -9999 -9999 -9999 -9999 -9999 -9999 -9999 -9999 -9999 -9999 -9999 -9999 -9999 -9999 -9999 -9999 -9999 -9999 -9999 -9999 -9999 -9999 -9999 -9999 -9999 -9999 -9999 -9999 -9999 -9999 -9999 -9999 -9999 -9999 -9999 -9999 -9999 -9999 -9999 -9999 -9999 -9999 -9999 -9999 -9999 -9999 -9999 -9999 -9999 -9999 -9999 -9999 -9999 -9999 -9999 -9999 -9999 -9999 -9999 -9999 -9999 -9999 -9999 -9999 -9999 -9999 -9999 -9999 -9999 -9999 -9999 -9999 -9999 -999 -9999 -9999 -9999 -9999 -9999 -9999 -9999 -9999 -9999 -9999 -9999 -9999 -9999 -9999 -9999 -9999 -9999 -9999 -9999 -9999 -9999 -9999 -9999 -9999 -9999 -9999 -9999 -9999 -9999 -9999 -

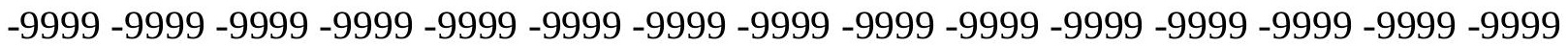

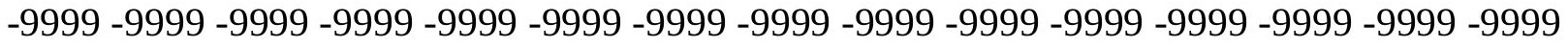

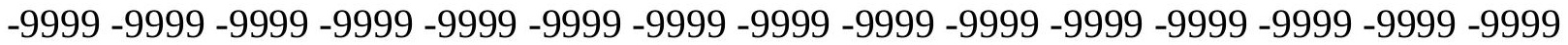
-9999 -9999 -9999 -9999 -9999 -9999 -9999 -9999 -9999 -9999 -9999 -9999 -9999 -9999 -9999

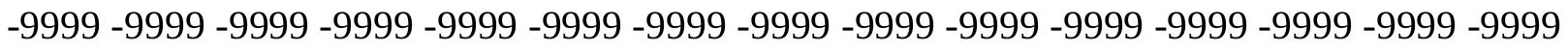

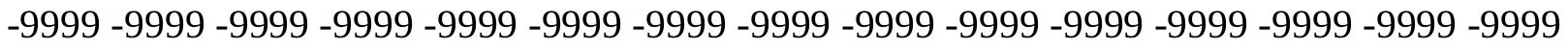

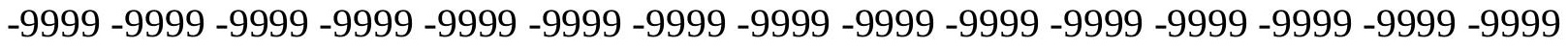
-9999 -9999 -9999 -9999 -9999 -9999 -9999 -9999 -9999 -9999 -9999 -9999 -9999 -9999 -9999 -

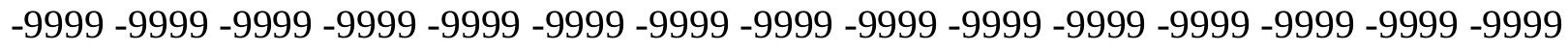

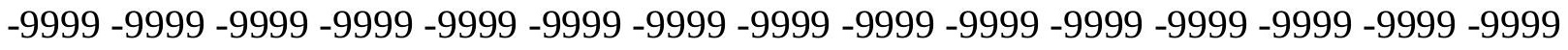
-9999 -9999 -9999 -9999 -9999 -9999 -9999 -9999 -9999 -9999 -9999 -9999 -9999 -9999 -9999 -9999 -9999 -9999 -9999 -9999 -9999 -9999 -9999 -9999 -9999 -9999 -9999 -9999 - -9999 -9999 -9999 -9999 -9999 -9999 -9999 -9999 -9999 -9999 -9999 -9999 -9999 -9999 -9999 -9999 -

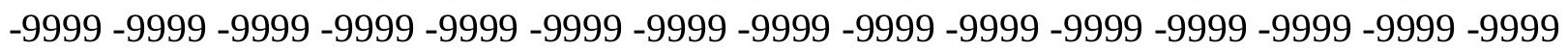


-9999 -9999 -9999 -9999 -9999 -9999 -9999 -9999 -9999 -9999 -9999 -9999 -9999 -9999 -9999 -9999 -9999 -9999 -9999 -9999 -9999 -9999 -9999 -9999 -9999 -9999 -9999 -9999 -9999 -9999 -9999 -9999 -9999 -9999 -9999 -9999 -9999 -9999 -9999 -9999 -9999 -9999 -9999 -9999 - 9999 -9999 -9999 -9999 -9999 -9999 -9999 -9999 -9999 -9999 -9999 -9999 -9999 -9999 -9999 -9999 -9999 -9999 -9999 -9999 -9999 -9999 -9999 -9999 -9999-9999 -9999 -9999 -9999 -9999 -9999 -9999 -9999 -9999 -9999 -9999 -9999 -9999 -9999 -9999 -9999 -9999 -9999 -9999 -9999 -9999 -9999 -9999 -9999 -9999 -9999 -9999 -9999 -9999 -9999 -9999 -9999 -9999 -9999 -9999 -9999

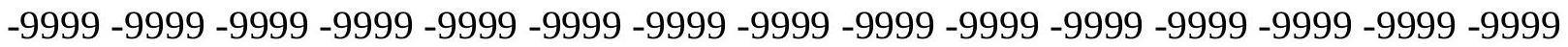

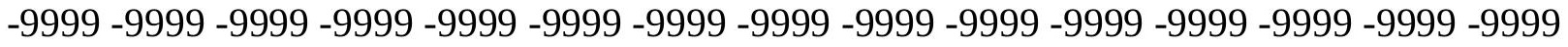
-9999 -9999 -9999 -9999 -9999 -9999 -9999 -9999 -9999 -9999 -9999 -9999 -9999 -9999 -9999

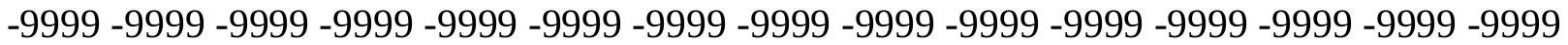
-9999 -9999 -9999 -9999 -9999 -9999 -9999 -9999 -9999 -9999 -9999 -9999 -9999 -9999 -9999 -9999 -9999 -9999 -9999 -9999 -9999 -9999 -9999 -9999 -9999 -9999 -9999 -9999 -9999 -9999 -

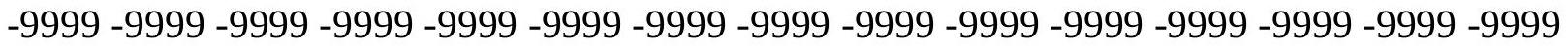
-9999 -9999 -9999 -9999 -9999 -9999 -9999 -9999 -9999 -9999 -9999 -9999 -9999 -9999 -9999

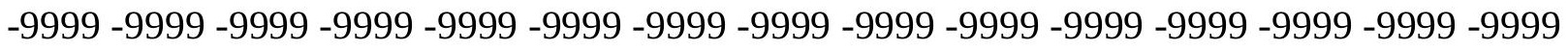
-9999 -9999 -9999 -9999 -9999 -9999 -9999 -9999 -9999 -9999 -9999 -9999 -9999 -9999 -9999 -9999 -9999 -9999 -9999 -9999 -9999 -9999 -9999 -9999 -9999 -9999 -9999 -9999 -9999 -9999 -9999 -9999 -9999 -9999 -9999 -9999 -9999 -9999 -9999 -9999 -9999 -9999 -9999 -9999 -9999 -9999 -9999 -9999 -9999 -9999 -9999 -9999 -9999 -9999 -9999 -9999 -9999 -9999 -9999 -9999 -9999 -9999 -9999 -9999 -9999 -9999 -9999 -9999 -9999 -9999 -9999 -9999 -9999 -9999 -9999 -999 -9999 -9999 -9999 -9999 -9999 -9999 -9999 -9999 -9999 -9999 -9999 -9999 -9999 -9999 -9999 -9999 -9999 -9999 -9999 -9999 -9999 -9999 -9999 -9999 -9999 -9999 -9999 -9999 -9999 -9999 -9999 -9999 -9999 -9999 -9999 -9999 -9999 -9999 -9999 -9999 -9999 -9999 -9999 -9999 -9999 -9999 -9999 -9999 -9999 -9999 -9999 -9999 -9999 -9999 -9999 -9999 -9999 -9999 -9999 -9999 -9999 -9999 -9999 -9999 -9999 -9999 -9999 -9999 -9999 -9999 -9999 -9999 -9999 -9999 -9999 -9999 -9999 -9999 -9999 -9999 -9999 -9999 -9999 -9999 -9999 -9999 -9999 -9999 -9999 -9999 -9999 -9999 -9999 -9999 -9999 -9999 -9999 -9999 -9999 -9999 -9999 -9999 -9999 -9999 -9999 -9999 -9999 -9999 -9999 -9999 -9999 -9999 -9999 -9999 -9999 -9999 -9999 -9999 -9999 -9999 -9999 -9999 -9999 -9999 -9999 -9999 -9999 -9999 -9999 -9999 -9999 -9999 -9999 -999 -9999 -9999 -9999 -9999 -9999 -9999 -9999 -9999 -9999 -9999 -9999 -9999 -9999 -9999 -9999 -9999 -9999 -9999 -9999 -9999 -9999 -9999 -9999 -9999 -9999 -9999 -9999 -9999 -9999 -9999 -

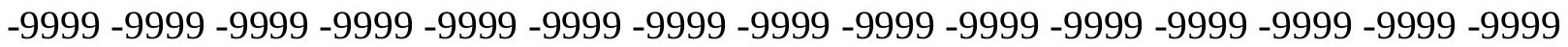

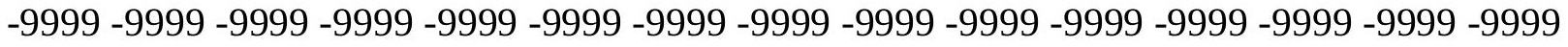

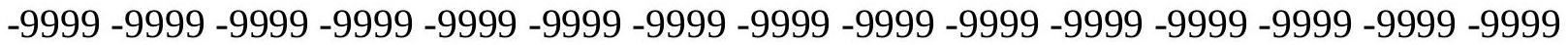
-9999 -9999 -9999 -9999 -9999 -9999 -9999 -9999 -9999 -9999 -9999 -9999 -9999 -9999 -9999

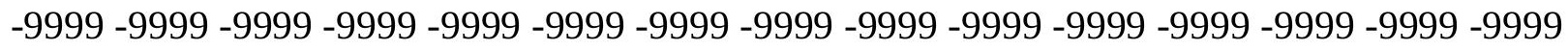

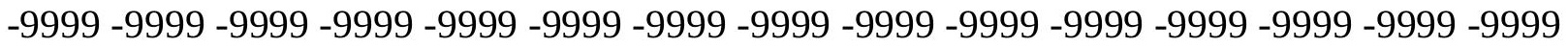
-9999 -9999 -9999 -9999 -9999 -9999 -9999 -9999 -9999 -9999 -9999 -9999 -9999 -9999 -9999 -9999 -9999 -9999 -9999 -9999 -9999 -9999 -9999 -9999 -9999 -9999 -9999 -9999 -9999 -9999 -

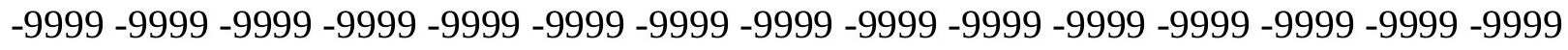

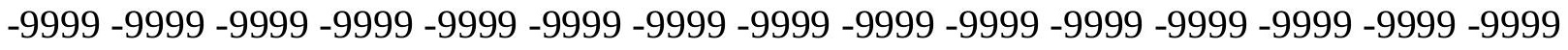
-9999 -9999 -9999 -9999 -9999 -9999 -9999 -9999 -9999 -9999 -9999 -9999 -9999 -9999 -9999 -9999 -9999 -9999 -9999 -9999 -9999 -9999 -9999 -9999-9999 -9999 -9999 -9999 -9999 -9999 -9999 -9999 -9999 -9999 -9999 -9999 -9999 -9999 -9999 -9999 -9999 -9999 -9999 -9999 -9999 -

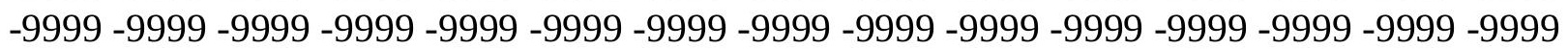


-9999 -9999 -9999 -9999 -9999 -9999 -9999 -9999 -9999 -9999 -9999 -9999 -9999 -9999 -9999 -9999 -9999 -9999 -9999 -9999 -9999 -9999 -9999 -9999 -9999 -9999 -9999 -9999 -9999 -9999 -9999 -9999 -9999 -9999 -9999 -9999 -9999 -9999 -9999 -9999 -9999 -9999 -9999 -9999 - 9999 -9999 -9999 -9999 -9999 -9999 -9999 -9999 -9999 -9999 -9999 -9999 -9999 -9999 -9999

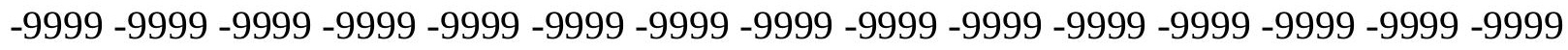
-9999 -9999 -9999 -9999 -9999 -9999 -9999 -9999 -9999 -9999 -9999 -9999 -9999 -9999 -9999 -9999 -9999 -9999 -9999 -9999 -9999 -9999 -9999 -9999 -9999 -9999 -9999 -9999 -9999 -9999

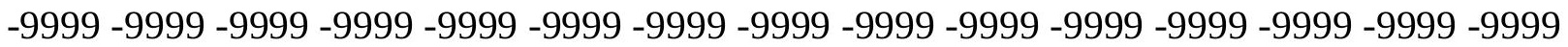

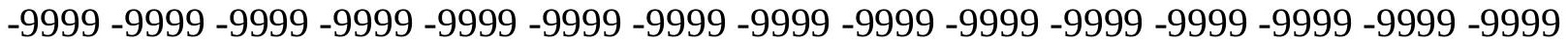
-9999 -9999 -9999 -9999 -9999 -9999 -9999 -9999 -9999 -9999 -9999 -9999 -9999 -9999 -9999 -9999 -9999 -9999 -9999 -9999 -9999 -9999 -9999 -9999 -9999 -9999 -9999 -9999 -9999 -9999 -9999 -9999 -9999 -9999 -9999 -9999 -9999 -9999 -9999 -9999 -9999 -9999 -9999 -9999 -9999 -9999 -9999 -9999 -9999 -9999 -9999 -9999 -9999 -9999 -9999 -9999 -9999 -9999 -9999 -9999 -

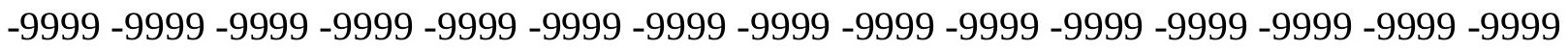
-9999 -9999 -9999 -9999 -9999 -9999 -9999 -9999 -9999 -9999 -9999 -9999 -9999 -9999 -9999 -

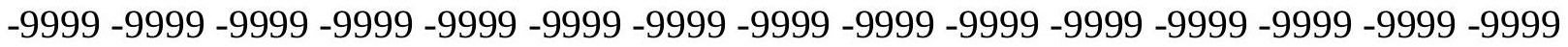
-9999 -9999 -9999 -9999 -9999 -9999 -9999 -9999 -9999 -9999 -9999 -9999 -9999 -9999 -9999 -9999 -9999 -9999 -9999 -9999 -9999 -9999 -9999 -9999 -9999 -9999 -9999 -9999 -9999 -9999 -9999 -9999 -9999 -9999 -9999 -9999 -9999 -9999 -9999 -9999 -9999 -9999 -9999 -9999 -9999 -

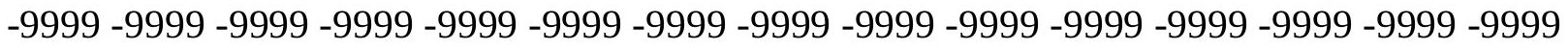
-9999 -9999 -9999 -9999 -9999 -9999 -9999 -9999 -9999 -9999 -9999 -9999 -9999 -9999 -9999

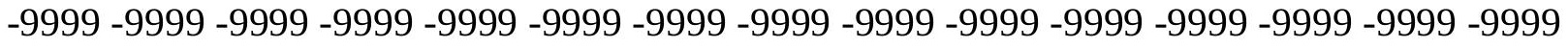
-9999 -9999 -9999 -9999 -9999 -9999 -9999 -9999 -9999 -9999 -9999 -9999 -9999 -9999 -9999 -9999 -9999 -9999 -9999 -9999 -9999 -9999 -9999 -9999 -9999 -9999 -9999 -9999 -9999 -9999 -9999 -9999 -9999 -9999 -9999 -9999 -9999 -9999 -9999 -9999 -9999 -9999 -9999 -9999 -9999 -9999 -9999 -9999 -9999 -9999 -9999 -9999 -9999 -9999 -9999 -9999 -9999 -9999 -9999 -9999 -9999 -9999 -9999 -9999 -9999 -9999 -9999 -9999 -9999 -9999 -9999 -9999 -9999 -9999 -9999 -9999 -9999 -9999 -9999 -9999 -9999 -9999 -9999 -9999 -9999 -9999 -9999 -9999 -9999 -9999 -9999 -9999 -9999 -9999 -9999 -9999 -9999 -9999 -9999 -9999 -9999 -9999 -9999 -9999 -9999 -9999 -9999 -9999 -9999 -9999 -9999 -9999 -9999 -9999 -9999 -9999 -9999 -9999 -9999 -9999 -9999 -9999 -9999 -9999 -9999 -9999 -9999 -9999 -9999 -9999 -9999 -9999 -9999 -9999 -9999 -9999 -9999 -9999 -9999 -9999 -9999 -9999 -9999 -9999 -9999 -9999 -9999 -9999 -9999 -

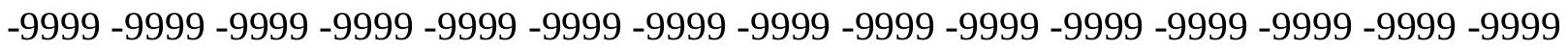

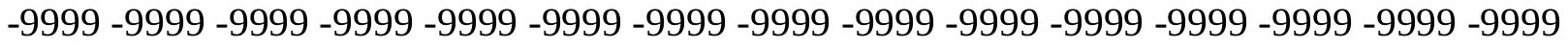
-9999 -9999 -9999 -9999 -9999 -9999 -9999 -9999 -9999 -9999 -9999 -9999 -9999 -9999 -9999 -

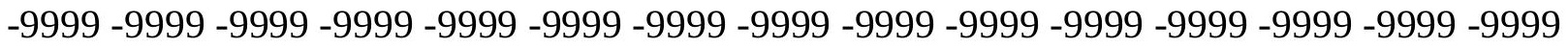

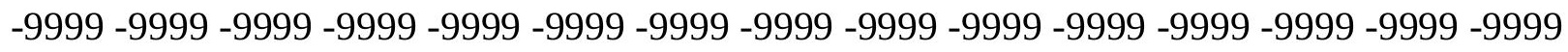

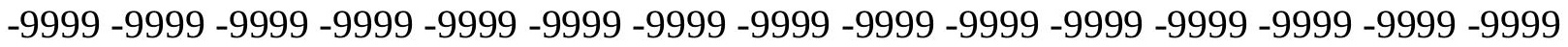

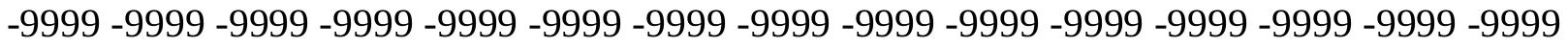
-9999 -9999 -9999 -9999 -9999 -9999 -9999 -9999 -9999 -9999 -9999 -9999 -9999 -9999 -9999 -

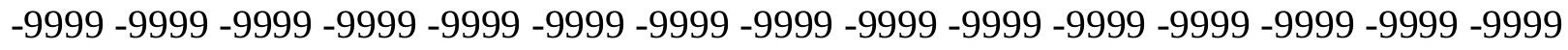

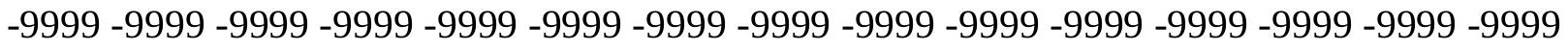
-9999 -9999 -9999 -9999 -9999 -9999 -9999 -9999 -9999 -9999 -9999 -9999 -9999 -9999 -9999 -9999 -9999 -9999 -9999 -9999 -9999 -9999 -9999 -9999-9999 -9999 -9999 -9999 -9999 -9999 -9999 -9999 -9999 -9999 -9999 -9999 -9999 -9999 -9999 -9999 -9999 -9999 -9999 -9999 -9999 -

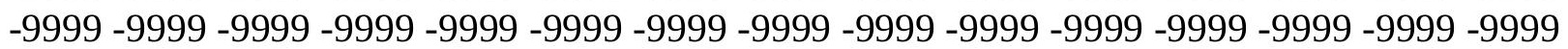


-9999 -9999 -9999 -9999 -9999 -9999 -9999 -9999 -9999 -9999 -9999 -9999 -9999 -9999 -9999 -9999 -9999 -9999 -9999 -9999 -9999 -9999 -9999 -9999 -9999 -9999 -9999 -9999 -9999 -9999 -9999 -9999 -9999 -9999 -9999 -9999 -9999 -9999 -9999 -9999 -9999 -9999 -9999 -9999 - 9999 -9999 -9999 -9999 -9999 -9999 -9999 -9999 -9999 -9999 -9999 -9999 -9999 -9999 -9999 -9999 -9999 -9999 -9999 -9999 -9999 -9999 -9999 -9999 -9999 -9999 -9999 -9999 -9999 -9999 -9999 -9999 -9999 -9999 -9999 -9999 -9999 -9999 -9999 -9999 -9999 -9999 -9999 -9999 -9999 -9999 -9999 -9999 -9999 -9999 -9999 -9999 -9999 -9999 -9999 -9999 -9999 -9999 -9999 -9999 -9999

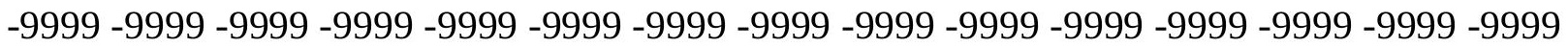

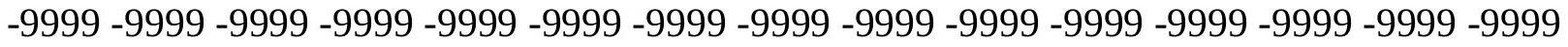
-9999 -9999 -9999 -9999 -9999 -9999 -9999 -9999 -9999 -9999 -9999 -9999 -9999 -9999 -9999 -9999 -9999 -9999 -9999 -9999 -9999 -9999 -9999 -9999 -9999 -9999 -9999 -9999 -9999 -9999 -9999 -9999 -9999 -9999 -9999 -9999 -9999 -9999 -9999 -9999 -9999 -9999 -9999 -9999 -9999 -9999 -9999 -9999 -9999 -9999 -9999 -9999 -9999 -9999 -9999 -9999 -9999 -9999 -9999 -9999 -9999 -9999 -9999 -9999 -9999 -9999 -9999 -9999 -9999 -9999 -9999 -9999 -9999 -9999 -9999 -9999 -9999 -9999 -9999 -9999 -9999 -9999 -9999 -9999 -9999 -9999 -9999 -9999 -9999 -

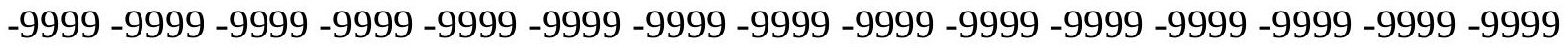
-9999 -9999 -9999 -9999 -9999 -9999 -9999 -9999 -9999 -9999 -9999 -9999 -9999 -9999 -9999 -9999 -9999 -9999 -9999 -9999 -9999 -9999 -9999 -9999 -9999 -9999 -9999 -9999 -9999 -9999 -9999 -9999 -9999 -9999 -9999 -9999 -9999 -9999 -9999 -9999 -9999 -9999 -9999 -9999 -9999 -9999 -9999 -9999 -9999 -9999 -9999 -9999 -9999 -9999 -9999 -9999 -9999 -9999 -9999 -9999 -9999 -9999 -9999 -9999 -9999 -9999 -9999 -9999 -9999 -9999 -9999 -9999 -9999 -9999 -9999 -999 -9999 -9999 -9999 -9999 -9999 -9999 -9999 -9999 -9999 -9999 -9999 -9999 -9999 -9999 -9999 -9999 -9999 -9999 -9999 -9999 -9999 -9999 -9999 -9999 -9999 -9999 -9999 -9999 -9999 -9999 -9999 -9999 -9999 -9999 -9999 -9999 -9999 -9999 -9999 -9999 -9999 -9999 -9999 -9999 -9999 -9999 -9999 -9999 -9999 -9999 -9999 -9999 -9999 -9999 -9999 -9999 -9999 -9999 -9999 -9999 -9999 -9999 -9999 -9999 -9999 -9999 -9999 -9999 -9999 -9999 -9999 -9999 -9999 -9999 -9999 -9999 -9999 -9999 -9999 -9999 -9999 -9999 -9999 -9999 -9999 -9999 -9999 -9999 -9999 -9999 -9999 -9999 -9999 -9999 -9999 -9999 -9999 -9999 -9999 -9999 -9999 -9999 -9999 -9999 -9999 -9999 -9999 -9999 -9999 -9999 -9999 -9999 -9999 -9999 -9999 -9999 -9999 -9999 -9999 -9999 -9999 -9999 -9999 -9999 -9999 -9999 -9999 -9999 -9999 -9999 -9999 -9999 -9999 -9999 -999 -9999 -9999 -9999 -9999 -9999 -9999 -9999 -9999 -9999 -9999 -9999 -9999 -9999 -9999 -9999 -9999 -9999 -9999 -9999 -9999 -9999 -9999 -9999 -9999 -9999 -9999 -9999 -9999 -9999 -9999 -

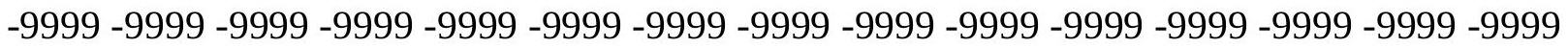

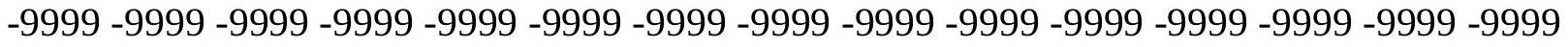

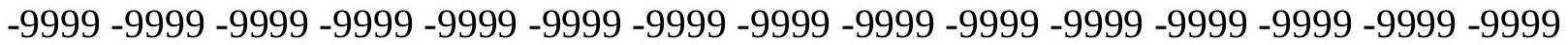
-9999 -9999 -9999 -9999 -9999 -9999 -9999 -9999 -9999 -9999 -9999 -9999 -9999 -9999 -9999 -9999 -9999 -9999 -9999 -9999 -9999 -9999 -9999 -9999 -9999 -9999 -9999 -9999 -9999 -

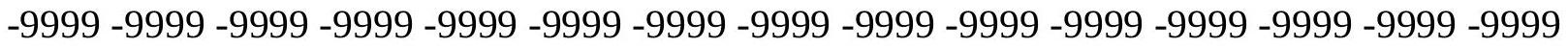
-9999 -9999 -9999 -9999 -9999 -9999 -9999 -9999 -9999 -9999 -9999 -9999 -9999 -9999 -9999 -9999 -9999 -9999 -9999 -9999 -9999 -9999 -9999 -9999 -9999 -9999 -9999 -9999 -9999 -9999 -

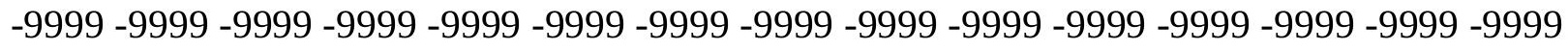

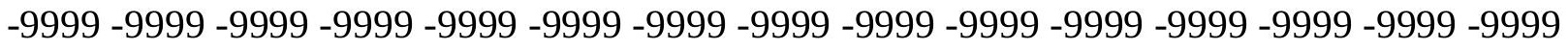
-9999 -9999 -9999 -9999 -9999 -9999 -9999 -9999 -9999 -9999 -9999 -9999 -9999 -9999 -9999 -9999 -9999 -9999 -9999 -9999 -9999 -9999 -9999 -9999-9999 -9999 -9999 -9999 -9999 -9999 -9999 -9999 -9999 -9999 -9999 -9999 -9999 -9999 -9999 -9999 -9999 -9999 -9999 -9999 -9999 -

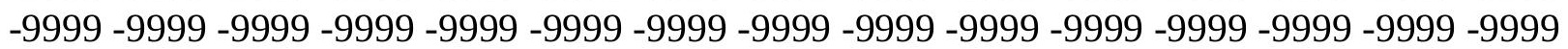


-9999 -9999 -9999 -9999 -9999 -9999 -9999 -9999 -9999 -9999 -9999 -9999 -9999 -9999 -9999 -9999 -9999 -9999 -9999 -9999 -9999 -9999 -9999 -9999 -9999 -9999 -9999 -9999 -9999 -9999 -

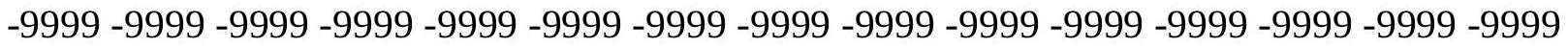
-9999 -9999 -9999 -9999 -9999 -9999 -9999 -9999 -9999 -9999 -9999 -9999 -9999 -9999 -9999 -9999 -9999 -9999 -9999 -9999 -9999 -9999 -9999 -9999-9999 -9999 -9999 -9999 -9999 -9999 -9999 -9999 -9999 -9999 -9999 -9999 -9999 -9999 -9999 -9999 -9999 -9999 -9999 -9999 -9999 -9999 -9999 -9999 -9999 -9999 -9999 -9999 -9999 -9999 -9999 -9999 -9999 -9999 -9999 -9999

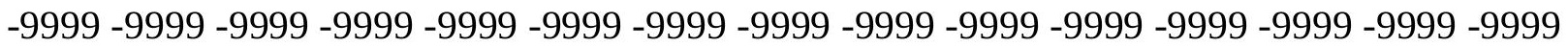

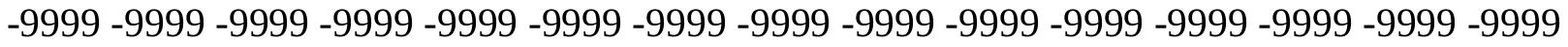
-9999 -9999 -9999 -9999 -9999 -9999 -9999 -9999 -9999 -9999 -9999 -9999 -9999 -9999 -9999 -9999 -9999 -9999 -9999 -9999 -9999 -9999 -9999 -9999 -9999 -9999 -9999 -9999 -9999 -9999 -9999 -9999 -9999 -9999 -9999 -9999 -9999 -9999 -9999 -9999 -9999 -9999 -9999 -9999 -9999 -9999 -9999 -9999 -9999 -9999 -9999 -9999 -9999 -9999 -9999 -9999 -9999 -9999 -9999 -9999 -9999 -9999 -9999 -9999 -9999 -9999 -9999 -9999 -9999 -9999 -9999 -9999 -9999 -9999 -9999 -9999 -9999 -9999 -9999 -9999 -9999 -9999 -9999 -9999 -9999 -9999 -9999 -9999 -9999 -9999 -

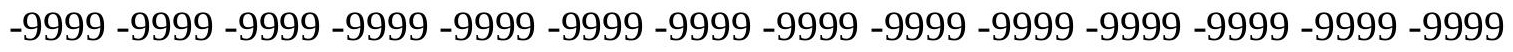
-9999 -9999 -9999 -9999 -9999 -9999 -9999 -9999 -9999 -9999 -9999 -9999 -9999 -9999 -9999 -9999 -9999 -9999 -9999 -9999 -9999 -9999 -9999 -9999 -9999 -9999 -9999 -9999 -9999 -9999 -9999 -9999 -9999 -9999 -9999 -9999 -9999 -9999 -9999 -9999 -9999 -9999 -9999 -9999 -9999 -

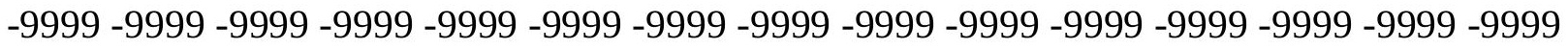

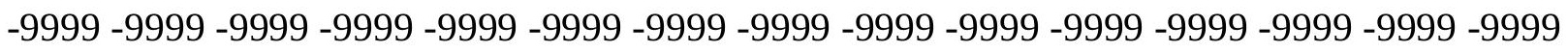
-9999 -9999 -9999 -9999 -9999 -9999 -9999 -9999 -9999 -9999 -9999 -9999 -9999 -9999 - 9999 -9999 -9999 -9999 -9999 -9999 -9999 -9999 -9999 -9999 -9999 -9999 -9999 -9999 -9999 -9999 -9999 -9999 -9999 -9999 -9999 -9999 -9999 -9999 -9999 -9999 -9999 -9999 -9999 -9999 -9999 -

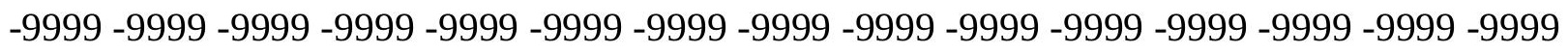
-9999 -9999 -9999 -9999 -9999 -9999 -9999 -9999 -9999 -9999 -9999 -9999 -9999 -9999 -9999 -9999 -9999 -9999 -9999 -9999 -9999 -9999 -9999 -9999 -9999 -9999 -9999 -9999 -9999 -9999 -

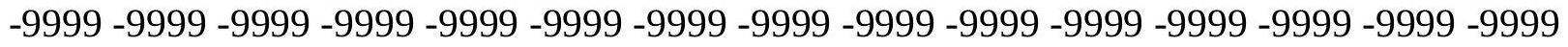
-9999 -9999 -9999 -9999 -9999 -9999 -9999 -9999 -9999 -9999 -9999 -9999 -9999 -9999 -9999 -9999 -9999 -9999 -9999 -9999 -9999 -9999 -9999 -9999 -9999 -9999 -9999 -9999 -9999 -999 -

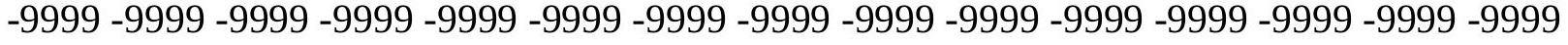
-9999 -9999 -9999 -9999 -9999 -9999 -9999 -9999 -9999 -9999 -9999 -9999 -9999 -9999 -9999 -

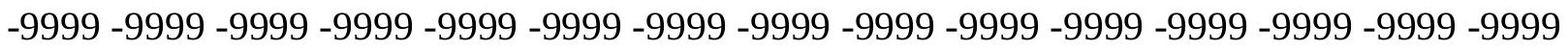

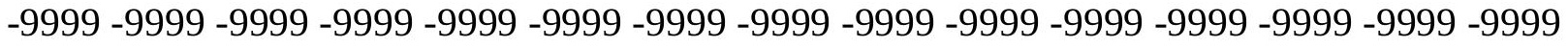

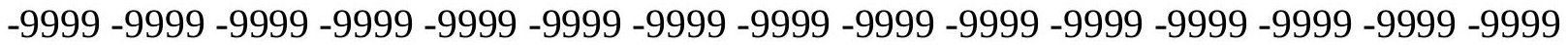
-9999 -9999 -9999 -9999 -9999 -9999 -9999 -9999 -9999 -9999 -9999 -9999 -9999 -9999 -9999 -

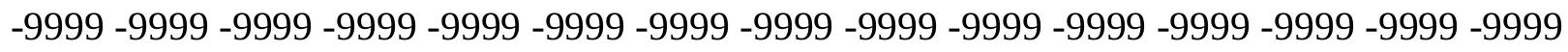

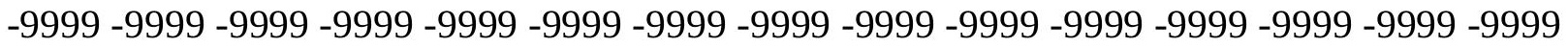
-9999 -9999 -9999 -9999 -9999 -9999 -9999 -9999 -9999 -9999 -9999 -9999 -9999 - 9999 - -999 -9999 -9999 -9999 -9999 -9999 -9999 -9999 -9999 -9999 -9999 -9999 -9999 -9999 -9999 -9999 -

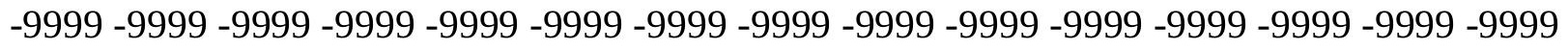

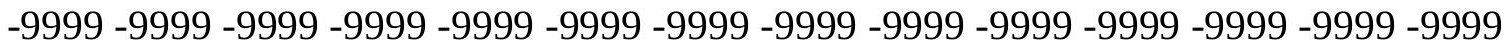
-9999 -9999 -9999 -9999 -9999 -9999 -9999 -9999 -9999 -9999 -9999 -9999 -9999 -9999 -9999 -9999 -9999 -9999 -9999 -9999 -9999 -9999 -9999 -9999-9999 -9999 -9999 -9999 -9999 -9999 -9999 -9999 -9999 -9999 -9999 -9999 -9999 -9999 -9999 -9999 -9999 -9999 -9999 -9999 -9999 -

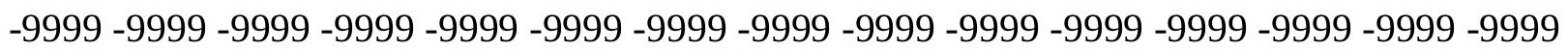


-9999 -9999 -9999 -9999 -9999 -9999 -9999 -9999 -9999 -9999 -9999 -9999 -9999 -9999 -9999 -9999 -9999 -9999 -9999 -9999 -9999 -9999 -9999 -9999 -9999 -9999 -9999 -9999 -9999 -9999 -

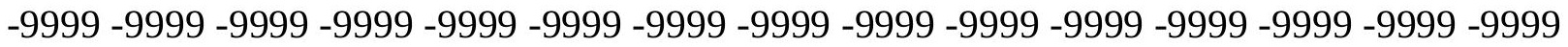
-9999 -9999 -9999 -9999 -9999 -9999 -9999 -9999 -9999 -9999 -9999 -9999 -9999 -9999 -9999 -9999 -9999 -9999 -9999 -9999 -9999 -9999 -9999 -9999-9999 -9999 -9999 -9999 -9999 -9999 -9999 -9999 -9999 -9999 -9999 -9999 -9999 -9999 -9999 -9999 -9999 -9999 -9999 -9999 -9999 -9999 -9999 -9999 -9999 -9999 -9999 -9999 -9999 -9999 -9999 -9999 -9999 -9999 -9999 -9999

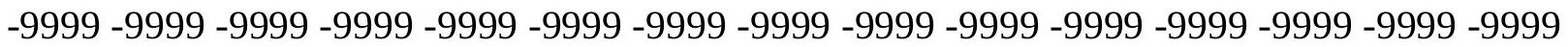

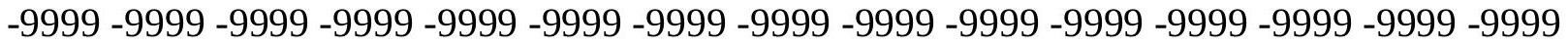
-9999 -9999 -9999 -9999 -9999 -9999 -9999 -9999 -9999 -9999 -9999 -9999 -9999 -9999 -9999 -9999 -9999 -9999 -9999 -9999 -9999 -9999 -9999 -9999 -9999 -9999 -9999 -9999 -9999 -9999 -9999 -9999 -9999 -9999 -9999 -9999 -9999 -9999 -9999 -9999 -9999 -9999 -9999 -9999 -9999 -9999 -9999 -9999 -9999 -9999 -9999 -9999 -9999 -9999 -9999 -9999 -9999 -9999 -9999 -9999 -

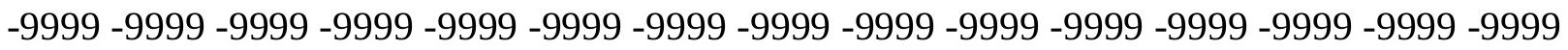
-9999 -9999 -9999 -9999 -9999 -9999 -9999 -9999 -9999 -9999 -9999 -9999 -9999 -9999 -9999 -

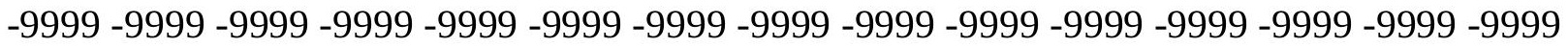
-9999 -9999 -9999 -9999 -9999 -9999 -9999 -9999 -9999 -9999 -9999 -9999 -9999 -9999 -9999 -9999 -9999 -9999 -9999 -9999 -9999 -9999 -9999 -9999 -9999 -9999 -9999 -9999 -9999 -9999 -9999 -9999 -9999 -9999 -9999 -9999 -9999 -9999 -9999 -9999 -9999 -9999 -9999 -9999 -9999 -

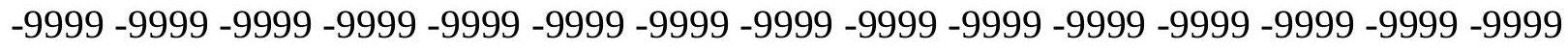

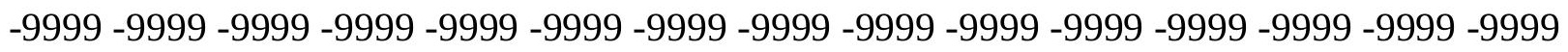
-9999 -9999 -9999 -9999 -9999 -9999 -9999 -9999 -9999 -9999 -9999 -9999 -9999 -9999 -9999 -9999 -9999 -9999 -9999 -9999 -9999 -9999 -9999 -9999 -9999 -9999 -9999 -9999 -9999 -9999 -9999 -9999 -9999 -9999 -9999 -9999 -9999 -9999 -9999 -9999 -9999 -9999 -9999 -9999 -

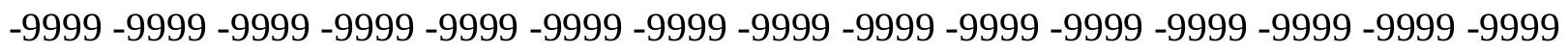
-9999 -9999 -9999 -9999 -9999 -9999 -9999 -9999 -9999 -9999 -9999 -9999 -9999 -9999 -9999 -9999 -9999 -9999 -9999 -9999 -9999 -9999 -9999 -9999 -9999 -9999 -9999 -9999 -9999 -9999 -

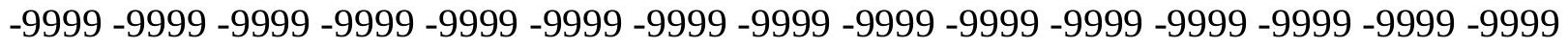
-9999 -9999 -9999 -9999 -9999 -9999 -9999 -9999 -9999 -9999 -9999 -9999 -9999 -9999 -9999 -9999 -9999 -9999 -9999 -9999 -9999 -9999 -9999 -9999 -9999 -9999 -9999 -9999 -9999 -999 -

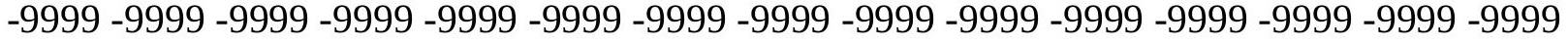
-9999 -9999 -9999 -9999 -9999 -9999 -9999 -9999 -9999 -9999 -9999 -9999 -9999 -9999 -9999 -

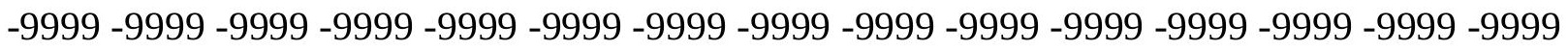

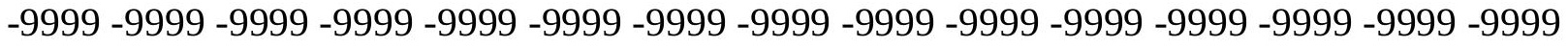

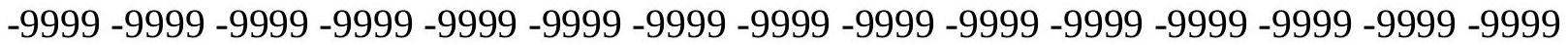

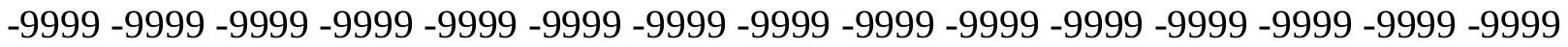

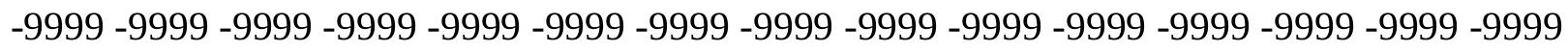

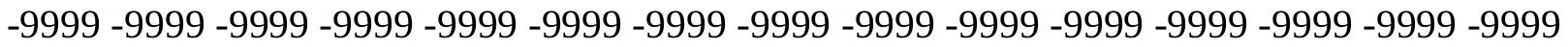

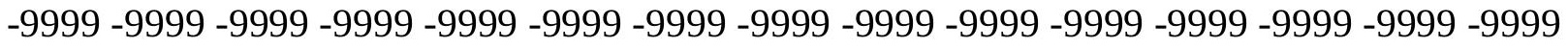
-9999 -9999 -9999 -9999 -9999 -9999 -9999 -9999 -9999 -9999 -9999 -9999 -9999 -9999 -9999 -

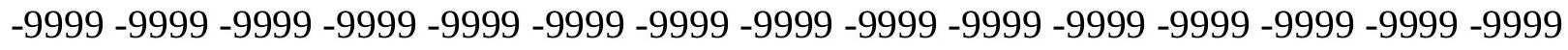

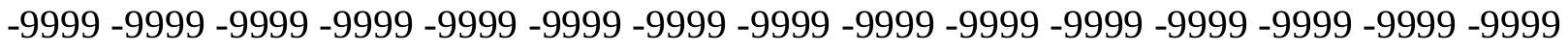
-9999 -9999 -9999 -9999 -9999 -9999 -9999 -9999 -9999 -9999 -9999 -9999 -9999 -9999 -9999 -9999 -9999 -9999 -9999 -9999 -9999 -9999 -9999 -9999-9999 -9999 -9999 -9999 -9999 -9999 -9999 -9999 -9999 -9999 -9999 -9999 -9999 -9999 -9999 -9999 -9999 -9999 -9999 -9999 -9999 -

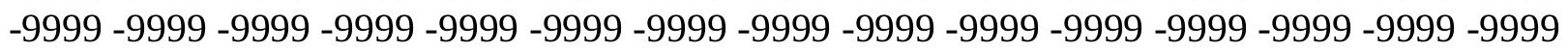


-9999 -9999 -9999 -9999 -9999 -9999 -9999 -9999 -9999 -9999 -9999 -9999 -9999 -9999 -9999 -9999 -9999 -9999 -9999 -9999 -9999 -9999 -9999 -9999 -9999 -9999 -9999 -9999 -9999 -

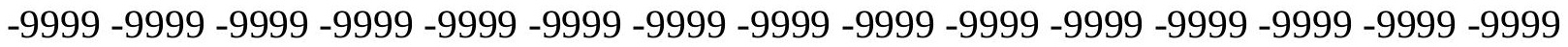
-9999 -9999 -9999 -9999 -9999 -9999 -9999 -9999 -9999 -9999 -9999 -9999 -9999 -9999 -9999 -9999 -9999 -9999 -9999 -9999 -9999 -9999 -9999 -9999 -9999 -9999 -9999 -9999 -9999 -9999 -9999 -9999 -9999 -9999 -9999 -9999 -9999 -9999 -9999 -9999 -9999 -9999 -9999 -9999 -9999 -9999 -9999 -9999 -9999 -9999 -9999 -9999 -9999 -9999 -9999 -9999 -9999 -9999 -9999 -9999

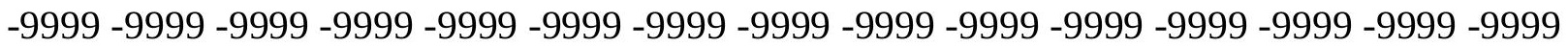

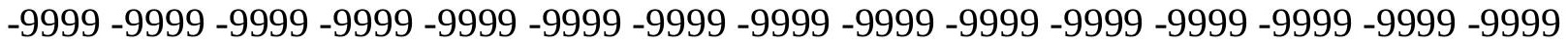
-9999 -9999 -9999 -9999 -9999 -9999 -9999 -9999 -9999 -9999 -9999 -9999 -9999 -9999 -9999 -9999 -9999 -9999 -9999 -9999 -9999 -9999 -9999 -9999 -9999 -9999 -9999 -9999 -9999 -9999 -9999 -9999 -9999 -9999 -9999 -9999 -9999 -9999 -9999 -9999 -9999 -9999 -9999 -9999 -9999 -9999 -9999 -9999 -9999 -9999 -9999 -9999 -9999 -9999 -9999 -9999 -9999 -9999 -9999 -9999 -9999 -9999 -9999 -9999 -9999 -9999 -9999 -9999 -9999 -9999 -9999 -9999 -9999 -9999 -9999 -9999 -9999 -9999 -9999 -9999 -9999 -9999 -9999 -9999 -9999 -9999 -9999 -9999 -9999 -9999 -

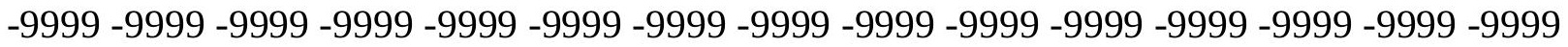
-9999 -9999 -9999 -9999 -9999 -9999 -9999 -9999 -9999 -9999 -9999 -9999 -9999 -9999 -9999 -9999 -9999 -9999 -9999 -9999 -9999 -9999 -9999 -9999 -9999 -9999 -9999 -9999 -9999 - 9999 -9999 -9999 -9999 -9999 -9999 -9999 -9999 -9999 -9999 -9999 -9999 -9999 -9999 -9999 -9999 -

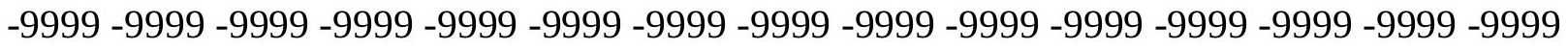

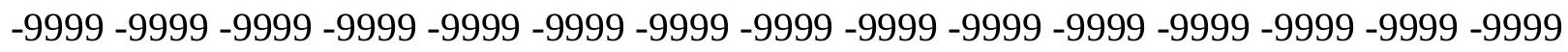

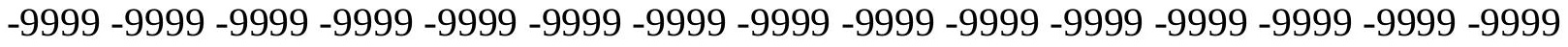
-9999 -9999 -9999 -9999 -9999 -9999 -9999 -9999 -9999 -9999 -9999 -9999 -9999 -9999 -9999 -9999 -9999 -9999 -9999 -9999 -9999 -9999 -9999 -9999 -9999 -9999 -9999 -9999 -9999 -9999 -

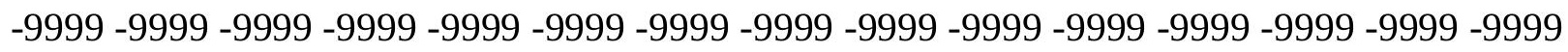
-9999 -9999 -9999 -9999 -9999 -9999 -9999 -9999 -9999 -9999 -9999 -9999 -9999 -9999 -9999 -9999 -9999 -9999 -9999 -9999 -9999 -9999 -9999 -9999 -9999 -9999 -9999 -9999 -9999 -9999 -9999 -9999 -9999 -9999 -9999 -9999 -9999 -9999 -9999 -9999 -9999 -9999 -9999 -9999 -9999 -9999 -9999 -9999 -9999 -9999 -9999 -9999 -9999 -9999 -9999 -9999 -9999 -9999 -9999 -9999 -9999 -9999 -9999 -9999 -9999 -9999 -9999 -9999 -9999 -9999 -9999 -9999 -9999 -999 -

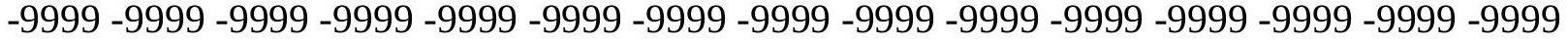
-9999 -9999 -9999 -9999 -9999 -9999 -9999 -9999 -9999 -9999 -9999 -9999 -9999 -9999 -9999 -

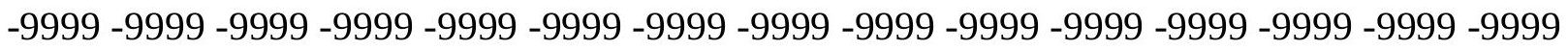

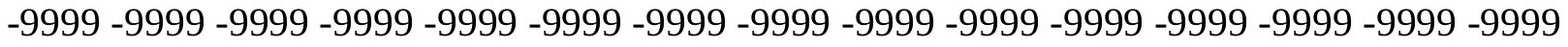

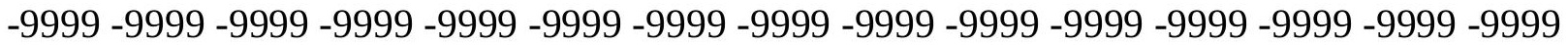

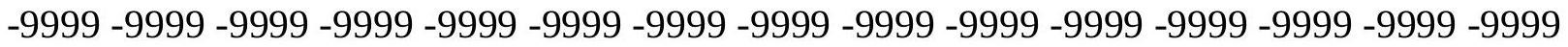

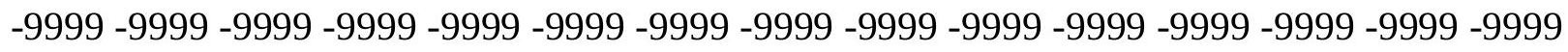

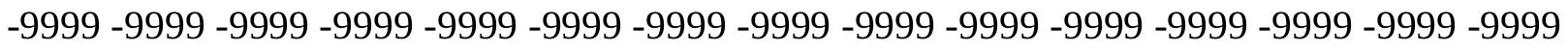

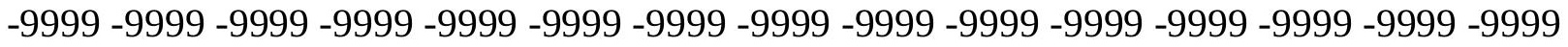
-9999 -9999 -9999 -9999 -9999 -9999 -9999 -9999 -9999 -9999 -9999 -9999 -9999 -9999 -9999 -

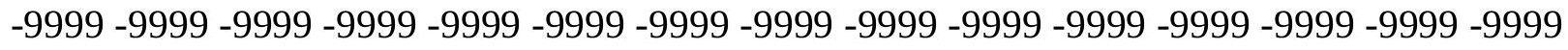

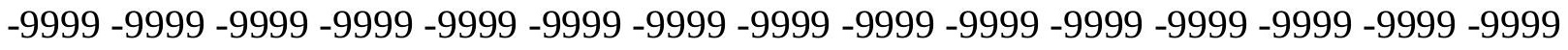
-9999 -9999 -9999 -9999 -9999 -9999 -9999 -9999 -9999 -9999 -9999 -9999 -9999 -9999 -9999 -9999 -9999 -9999 -9999 -9999 -9999 -9999 -9999 -9999-9999 -9999 -9999 -9999 -9999 -9999 -9999 -9999 -9999 -9999 -9999 -9999 -9999 -9999 -9999 -9999 -9999 -9999 -9999 -9999 -9999 -

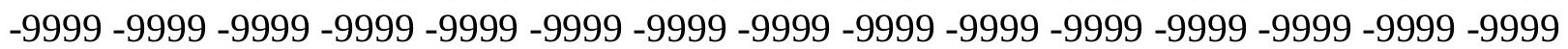


-9999 -9999 -9999 -9999 -9999 -9999 -9999 -9999 -9999 -9999 -9999 -9999 -9999 -9999 -9999 -9999 -9999 -9999 -9999 -9999 -9999 -9999 -9999 -9999 -9999 -9999 -9999 -9999 -9999 -9999 -

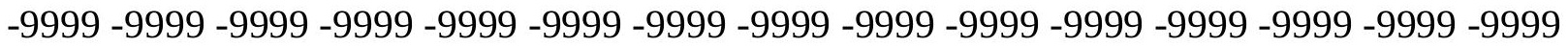
-9999 -9999 -9999 -9999 -9999 -9999 -9999 -9999 -9999 -9999 -9999 -9999 -9999 -9999 -9999 -9999 -9999 -9999 -9999 -9999 -9999 -9999 -9999 -9999-9999 -9999 -9999 -9999 -9999 -9999 -9999 -9999 -9999 -9999 -9999 -9999 -9999 -9999 -9999 -9999 -9999 -9999 -9999 -9999 -9999 -

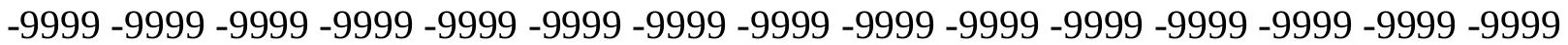
-9999 -9999 -9999 -9999 -9999 -9999 -9999 -9999 -9999 -9999 -9999 -9999 -9999 -9999 -9999 -9999 -9999 -9999 -9999 -9999 -9999 -9999 -9999 -9999 -9999 -9999 -9999 -9999 -9999 -9999 -9999 -9999 -9999 -9999 -9999 -9999 -9999 -9999 -9999 -9999 -9999 -9999 -9999 -9999 -9999 -9999 -9999 -9999 -9999 -9999 -9999 -9999 -9999 -9999 -9999 -9999 -9999 -9999 -9999 -9999 -9999 -9999 -9999 -9999 -9999 -9999 -9999 -9999 -9999 -9999 -9999 -9999 -9999 -9999 -9999 -9999 -9999 -9999 -9999 -9999 -9999 -9999 -9999 -9999 -9999 -9999 -9999 -9999 -9999 -9999 -9999 -9999 -9999 -9999 -9999 -9999 -9999 -9999 -9999 -9999 -9999 -9999 -9999 -9999 -9999 -9999 -9999 -9999 -9999 -9999 -9999 -9999 -9999 -9999 -9999 -9999 -9999 -9999 -9999 -

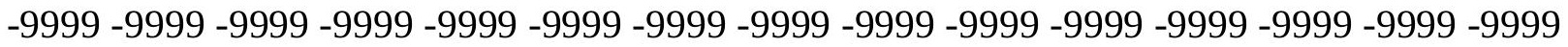
-9999 -9999 -9999 -9999 -9999 -9999 -9999 -9999 -9999 -9999 -9999 -9999 -9999 -9999 -9999 -9999 -9999 -9999 -9999 -9999 -9999 -9999 -9999 -9999 -9999 -9999 -9999 -9999 -9999 -9999 -9999 -9999 -9999 -9999 -9999 -9999 -9999 -9999 -9999 -9999 -9999 -9999 -9999 -9999 -9999 -

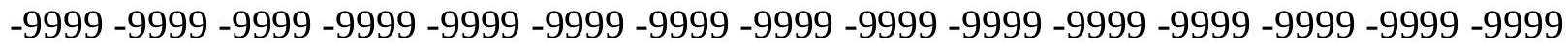

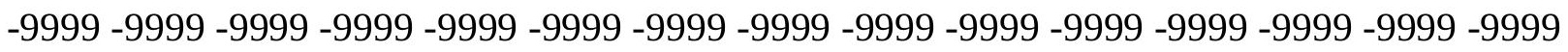
-9999 -9999 -9999 -9999 -9999 -9999 -9999 -9999 -9999 -9999 -9999 -9999 -9999 -9999 - 9999 -9999 -9999 -9999 -9999 -9999 -9999 -9999 -9999 -9999 -9999 -9999 -9999 -9999 -9999 -9999 -9999 -9999 -9999 -9999 -9999 -9999 -9999 -9999 -9999 -9999 -9999 -9999 -9999 -9999 -9999 -

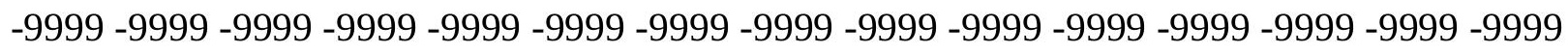
-9999 -9999 -9999 -9999 -9999 -9999 -9999 -9999 -9999 -9999 -9999 -9999 -9999 -9999 -9999 -9999 -9999 -9999 -9999 -9999 -9999 -9999 -9999 -9999 -9999 -9999 -9999 -9999 -9999 -9999 -

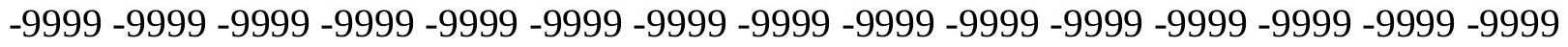
-9999 -9999 -9999 -9999 -9999 -9999 -9999 -9999 -9999 -9999 -9999 -9999 -9999 -9999 -9999 -9999 -9999 -9999 -9999 -9999 -9999 -9999 -9999 -9999 -9999 -9999 -9999 -9999 -9999 -999 -9999 -9999 -9999 -9999 -9999 -9999 -9999 -9999 -9999 -9999 -9999 -9999 -9999 -9999 -9999 -9999 -9999 -9999 -9999 -9999 -9999 -9999 -9999 -9999 -9999 -9999 -9999 -9999 -9999 -9999 -

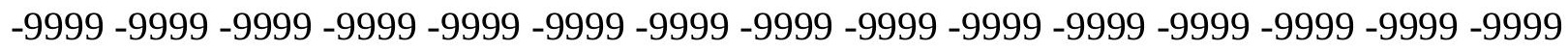

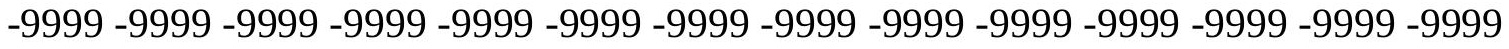
-9999 -9999 -9999 -9999 -9999 -9999 -9999 -9999 -9999 -9999 -9999 -9999 -9999 -9999 -9999

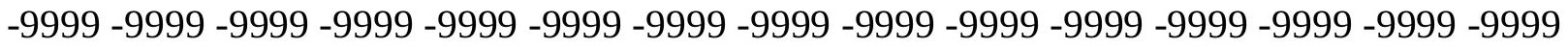

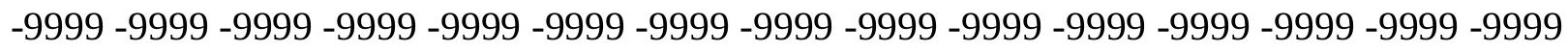

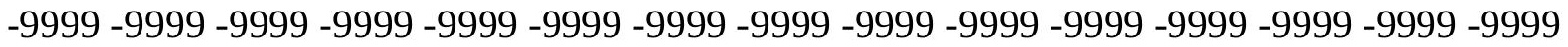

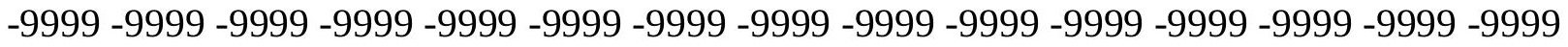
-9999 -9999 -9999 -9999 -9999 -9999 -9999 -9999 -9999 -9999 -9999 -9999 -9999 -9999 -9999 -

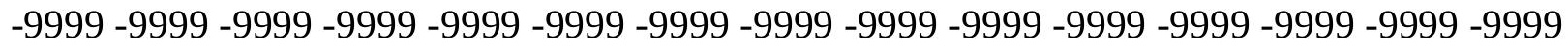

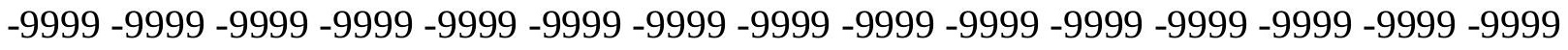
-9999 -9999 -9999 -9999 -9999 -9999 -9999 -9999 -9999 -9999 -9999 -9999 -9999 -9999 -9999 -9999 -9999 -9999 -9999 -9999 -9999 -9999 -9999 -9999-9999 -9999 -9999 -9999 -9999 -9999 -9999 -9999 -9999 -9999 -9999 -9999 -9999 -9999 -9999 -9999 -9999 -9999 -9999 -9999 -9999 -

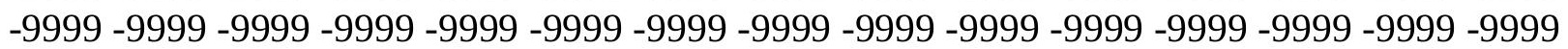


-9999 -9999 -9999 -9999 -9999 -9999 -9999 -9999 -9999 -9999 -9999 -9999 -9999 -9999 -9999 -9999 -9999 -9999 -9999 -9999 -9999 -9999 -9999 -9999 -9999 -9999 -9999 -9999 -9999 -9999 -

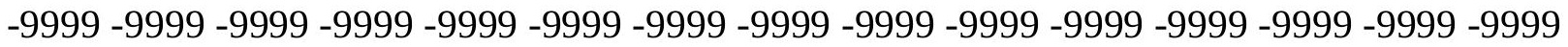
-9999 -9999 -9999 -9999 -9999 -9999 -9999 -9999 -9999 -9999 -9999 -9999 -9999 -9999 -9999 -9999 -9999 -9999 -9999 -9999 -9999 -9999 -9999 -9999-9999 -9999 -9999 -9999 -9999 -9999 -9999 -9999 -9999 -9999 -9999 -9999 -9999 -9999 -9999 -9999 -9999 -9999 -9999 -9999 -9999 -9999 -9999 -9999 -9999 -9999 -9999 -9999 -9999 -9999 -9999 -9999 -9999 -9999 -9999 -9999

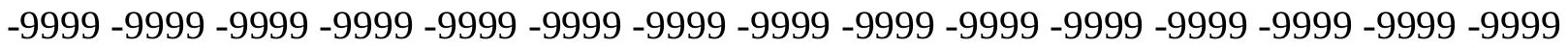

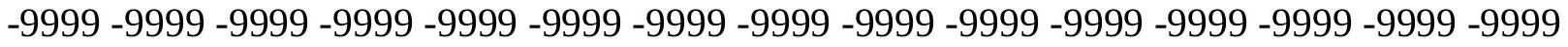
-9999 -9999 -9999 -9999 -9999 -9999 -9999 -9999 -9999 -9999 -9999 -9999 -9999 -9999 -9999 -9999 -9999 -9999 -9999 -9999 -9999 -9999 -9999 -9999 -9999 -9999 -9999 -9999 -9999 -9999 -9999 -9999 -9999 -9999 -9999 -9999 -9999 -9999 -9999 -9999 -9999 -9999 -9999 -9999 -9999 -9999 -9999 -9999 -9999 -9999 -9999 -9999 -9999 -9999 -9999 -9999 -9999 -9999 -9999 -9999 -9999 -9999 -9999 -9999 -9999 -9999 -9999 -9999 -9999 -9999 -9999 -9999 -9999 -9999 -9999 -9999 -9999 -9999 -9999 -9999 -9999 -9999 -9999 -9999 -9999 -9999 -9999 -9999 -9999

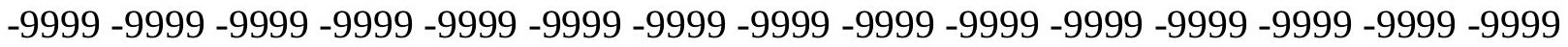
-9999 -9999 -9999 -9999 -9999 -9999 -9999 -9999 -9999 -9999 -9999 -9999 -9999 -9999 -9999 -9999 -9999 -9999 -9999 -9999 -9999 -9999 -9999 -9999 -9999 -9999 -9999 -9999 -9999 -9999 -9999 -9999 -9999 -9999 -9999 -9999 -9999 -9999 -9999 -9999 -9999 -9999 -9999 -9999 -9999 -

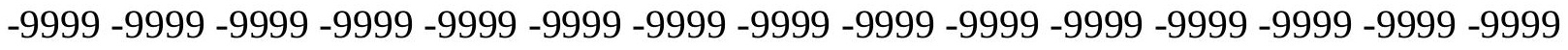

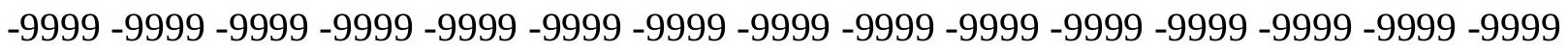
-9999 -9999 -9999 -9999 -9999 -9999 -9999 -9999 -9999 -9999 -9999 -9999 -9999 -9999 -9999 -9999 -9999 -9999 -9999 -9999 -9999 -9999 -9999 -9999 -9999 -9999 -9999 -9999 -9999 -9999 -9999 -9999 -9999 -9999 -9999 -9999 -9999 -9999 -9999 -9999 -9999 -9999 -9999 -9999 -9999 -

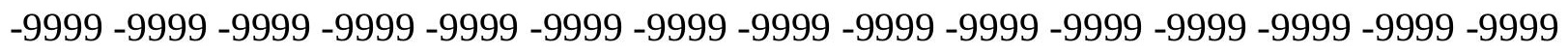
-9999 -9999 -9999 -9999 -9999 -9999 -9999 -9999 -9999 -9999 -9999 -9999 -9999 -9999 -9999 -9999 -9999 -9999 -9999 -9999 -9999 -9999 -9999 -9999 -9999 -9999 -9999 -9999 -9999 -9999 -

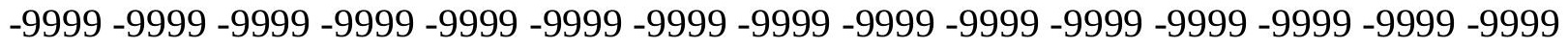
-9999 -9999 -9999 -9999 -9999 -9999 -9999 -9999 -9999 -9999 -9999 -9999 -9999 -9999 -9999 -9999 -9999 -9999 -9999 -9999 -9999 -9999 -9999 -9999 -9999 -9999 -9999 -9999 -9999 -999 -9999 -9999 -9999 -9999 -9999 -9999 -9999 -9999 -9999 -9999 -9999 -9999 -9999 -9999 -9999 -9999 -9999 -9999 -9999 -9999 -9999 -9999 -9999 -9999 -9999 -9999 -9999 -9999 -9999 -9999 -

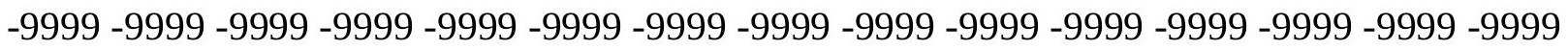

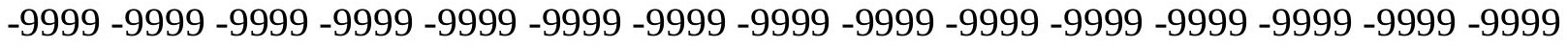

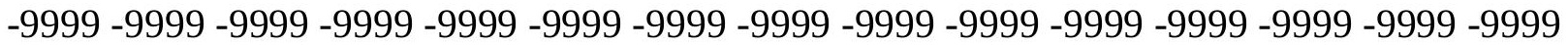

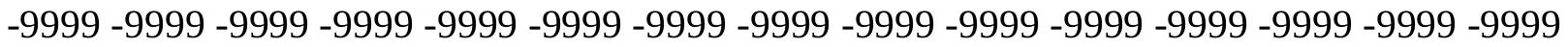

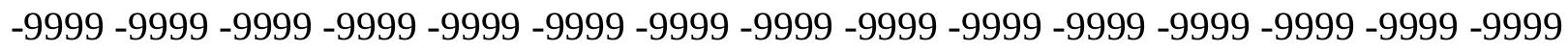

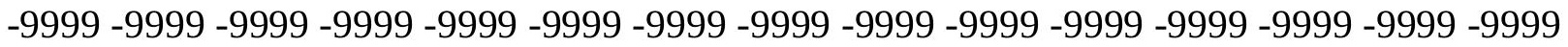
-9999 -9999 -9999 -9999 -9999 -9999 -9999 -9999 -9999 -9999 -9999 -9999 -9999 - 9999 - -999 -9999 -9999 -9999 -9999 -9999 -9999 -9999 -9999 -9999 -9999 -9999 -9999 -9999 -9999 - -999 -

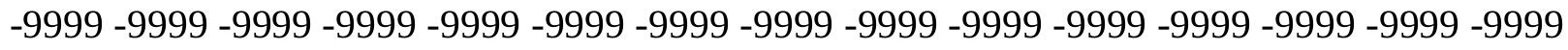

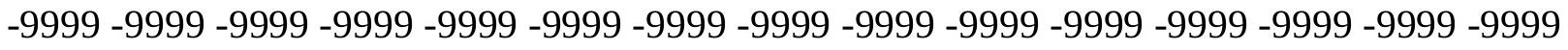
-9999 -9999 -9999 -9999 -9999 -9999 -9999 -9999 -9999 -9999 -9999 -9999 -9999 -9999 -9999 -9999 -9999 -9999 -9999 -9999 -9999 -9999 -9999 -9999-9999 -9999 -9999 -9999 -9999 -9999 -9999 -9999 -9999 -9999 -9999 -9999 -9999 -9999 -9999 -9999 -9999 -9999 -9999 -9999 -9999 -

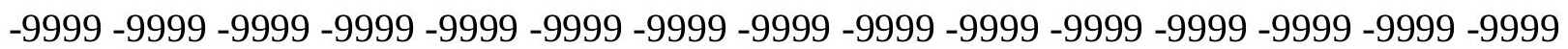


-9999 -9999 -9999 -9999 -9999 -9999 -9999 -9999 -9999 -9999 -9999 -9999 -9999 -9999 -9999 -9999 -9999 -9999 -9999 -9999 -9999 -9999 -9999 -9999 -9999 -9999 -9999 -9999 -9999 -9999 -9999 -9999 -9999 -9999 -9999 -9999 -9999 -9999 -9999 -9999 -9999 -9999 -9999 -9999 -9999 -9999 -9999 -9999 -9999 -9999 -9999 -9999 -9999 -9999 -9999 -9999 -9999 -9999 -9999 -9999 -9999 -9999 -9999 -9999 -9999 -9999 -9999 -9999 -9999 -9999 -9999 -9999 -9999 -9999 -9999 -9999 -9999 -9999 -9999 -9999 -9999 -9999 -9999 -9999 -9999 -9999 -9999 -9999 -9999 -9999 -9999 -9999 -9999 -9999 -9999 -9999 -9999 -9999 -9999 -9999 -9999 -9999 -9999 -9999 -9999 -

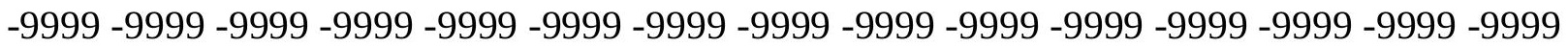
-9999 -9999 -9999 -9999 -9999 -9999 -9999 -9999 -9999 -9999 -9999 -9999 -9999 -9999 -9999 -9999 -9999 -9999 -9999 -9999 -9999 -9999 -9999 -9999 -9999 -9999 -9999 -9999 -9999 -9999 -

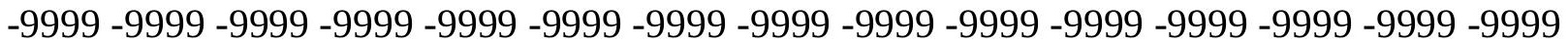
-9999 -9999 -9999 -9999 -9999 -9999 -9999 -9999 -9999 -9999 -9999 -9999 -9999 -9999 -9999 -9999 -9999 -9999 -9999 -9999 -9999 -9999 -9999 -9999 -9999 -9999 -9999 -9999 -9999 -9999 -9999 -9999 -9999 -9999 -9999 -9999 -9999 -9999 -9999 -9999 -9999 -9999 -9999 -9999 -9999 -9999 -9999 -9999 -9999 -9999 -9999 -9999 -9999 -9999 -9999 -9999 -9999 -9999 -9999 -9999

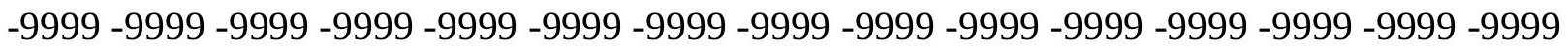
-9999 -9999 -9999 -9999 -9999 -9999 -9999 -9999 -9999 -9999 -9999 -9999 -9999 -9999 -9999 -9999 -9999 -9999 -9999 -9999 -9999 -9999 -9999 -9999 -9999 -9999 -9999 -9999 -9999 -9999 -9999 -9999 -9999 -9999 -9999 -9999 -9999 -9999 -9999 -9999 -9999 -9999 -9999 -9999 -9999 -9999 -9999 -9999 -9999 -9999 -9999 -9999 -9999 -9999 -9999 -9999 -9999 -9999 -9999 -9999 -9999 -9999 -9999 -9999 -9999 -9999 -9999 -9999 -9999 -9999 -9999 -9999 -9999 -9999 -9999 -9999 -9999 -9999 -9999 -9999 -9999 -9999 -9999 -9999 -9999 -9999 -9999 -9999 -9999 -9999 -9999 -9999 -9999 -9999 -9999 -9999 -9999 -9999 -9999 -9999 -9999 -9999 -9999 -9999 -9999 -9999 -9999 -9999 -9999 -9999 -9999 -9999 -9999 -9999 -9999 -9999 -9999 -9999 -9999 -9999 -9999 -9999 -9999 -9999 -9999 -9999 -9999 -9999 -9999 -9999 -9999 -9999 -9999 -9999 -9999 -9999 -9999 -9999 -9999 -9999 -9999 -9999 -9999 -9999 -9999 -9999 -9999 -9999 -9999 -9999 -9999 -9999 -9999 -9999 -9999 -9999 -9999 -9999 -9999 -9999 -9999 -9999 -9999 -9999 -9999 -9999 -9999 -9999 -9999 -9999 -9999 -9999 -9999 -9999 -9999 -9999 -9999 -9999 -9999

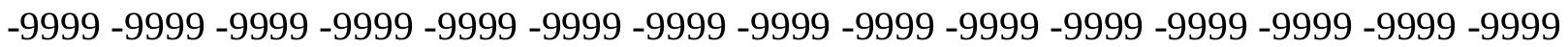
-9999 -9999 -9999 -9999 -9999 -9999 -9999 -9999 -9999 -9999 -9999 -9999 -9999 -9999 -9999 -9999 -9999 -9999 -9999 -9999 -9999 -9999 -9999 -9999 -9999 -9999 -9999 -9999 -9999 -9999 -

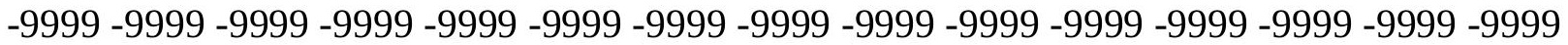
-9999 -9999 -9999 -9999 -9999 -9999 -9999 -9999 -9999 -9999 -9999 -9999 -9999 -9999 -9999 -9999 -9999 -9999 -9999 -9999 -9999 -9999 -9999 -9999 -9999 -9999 -9999 -9999 -9999 -9999 -9999 -9999 -9999 -9999 -9999 -9999 -9999 -9999 -9999 -9999 -9999 -9999 -9999 -9999 -9999 -9999 -9999 -9999 -9999 -9999 -9999 -9999 -9999 -9999 -9999 -9999 -9999 -9999 -9999 -9999 -9999 -9999 -9999 -9999 -9999 -9999 -9999 -9999 -9999 -9999 -9999 -9999 -9999 -9999 -9999

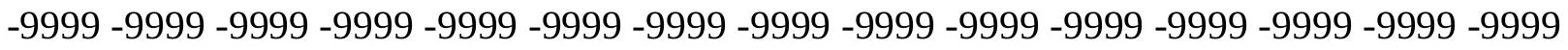
-9999 -9999 -9999 -9999 -9999 -9999 -9999 -9999 -9999 -9999 -9999 -9999 -9999 -9999 -9999 -9999 -9999 -9999 -9999 -9999 -9999 -9999 -9999 -9999 -9999 -9999 -9999 -9999 -9999 -9999 -9999 -9999 -9999 -9999 -9999 -9999 -9999 -9999 -9999 -9999 -9999 -9999 -9999 -9999 -9999 -999 -9999 -9999 -9999 -9999 -9999 -9999 -9999 -9999 -9999 -9999 -9999 -9999 -9999 -9999 -9999 -9999 -9999 -9999 -9999 -9999 -9999 -9999 -9999 -9999 -9999 -9999 -9999 -9999 -9999 -9999 -9999 -9999 -9999 -9999 -9999 -9999 -9999 -9999 -9999 -9999 -9999 -9999 -9999 -9999 -9999 -9999 -9999 -9999 -9999 -9999 -9999 -9999 -9999 -9999 -9999 -9999 -9999 -9999 -9999 -9999 -9999 -9999 -9999 -9999 -9999 -9999 -9999 -9999 -9999 -9999 -9999 -9999 -9999 -9999 
-9999 -9999 -9999 -9999 -9999 -9999 -9999 -9999 -9999 -9999 -9999 -9999 -9999 -9999 -9999 -9999 -9999 -9999 -9999 -9999 -9999 -9999 -9999 -9999 -9999 -9999 -9999 -9999 -9999 -9999 -

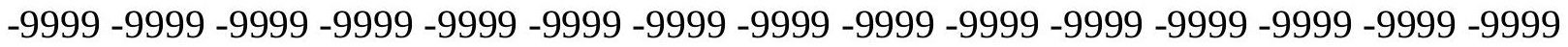
-9999 -9999 -9999 -9999 -9999 -9999 -9999 -9999 -9999 -9999 -9999 -9999 -9999 -9999 -9999 -9999 -9999 -9999 -9999 -9999 -9999 -9999 -9999 -9999-9999 -9999 -9999 -9999 -9999 -9999 -9999 -9999 -9999 -9999 -9999 -9999 -9999 -9999 -9999 -9999 -9999 -9999 -9999 -9999 -9999 -9999 -9999 -9999 -9999 -9999 -9999 -9999 -9999 -9999 -9999 -9999 -9999 -9999 -9999 -9999

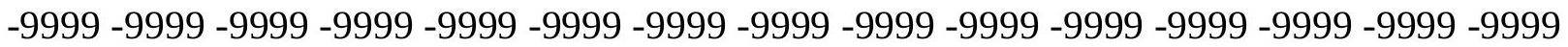

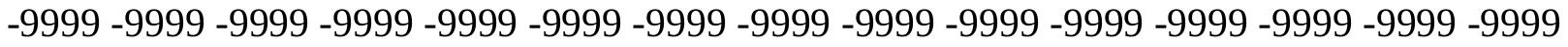
-9999 -9999 -9999 -9999 -9999 -9999 -9999 -9999 -9999 -9999 -9999 -9999 -9999 -9999 -9999 -9999 -9999 -9999 -9999 -9999 -9999 -9999 -9999 -9999 -9999 -9999 -9999 -9999 -9999 -9999 -9999 -9999 -9999 -9999 -9999 -9999 -9999 -9999 -9999 -9999 -9999 -9999 -9999 -9999 -9999 -9999 -9999 -9999 -9999 -9999 -9999 -9999 -9999 -9999 -9999 -9999 -9999 -9999 -9999 -9999 -

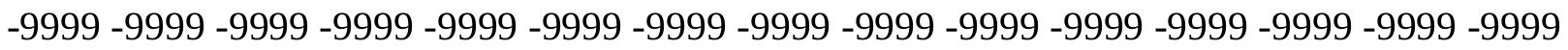
-9999 -9999 -9999 -9999 -9999 -9999 -9999 -9999 -9999 -9999 -9999 -9999 -9999 -9999 -9999 -

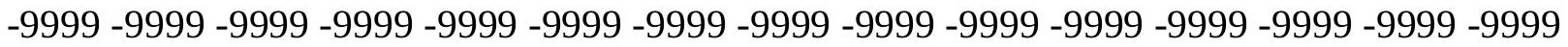
-9999 -9999 -9999 -9999 -9999 -9999 -9999 -9999 -9999 -9999 -9999 -9999 -9999 -9999 -9999 -9999 -9999 -9999 -9999 -9999 -9999 -9999 -9999 -9999 -9999 -9999 -9999 -9999 -9999 -9999 -9999 -9999 -9999 -9999 -9999 -9999 -9999 -9999 -9999 -9999 -9999 -9999 -9999 -9999 -9999 -

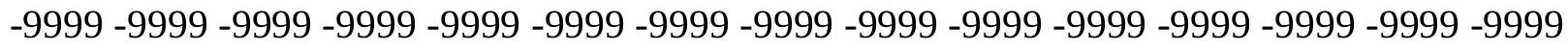

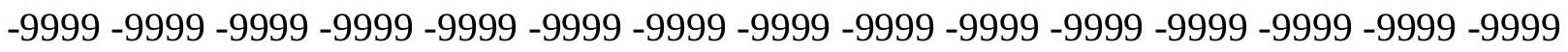

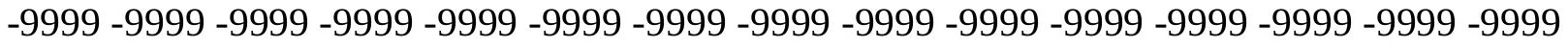
-9999 -9999 -9999 -9999 -9999 -9999 -9999 -9999 -9999 -9999 -9999 -9999 -9999 -9999 -9999 -9999 -9999 -9999 -9999 -9999 -9999 -9999 -9999 -9999 -9999 -9999 -9999 -9999 -9999 -9999 -

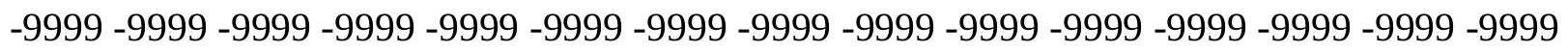
-9999 -9999 -9999 -9999 -9999 -9999 -9999 -9999 -9999 -9999 -9999 -9999 -9999 -9999 -9999 -9999 -9999 -9999 -9999 -9999 -9999 -9999 -9999 -9999 -9999 -9999 -9999 -9999 -9999 -

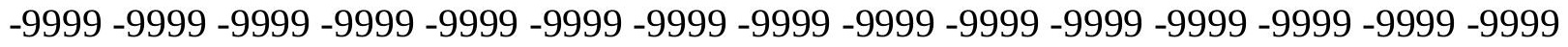
-9999 -9999 -9999 -9999 -9999 -9999 -9999 -9999 -9999 -9999 -9999 -9999 -9999 -9999 -9999 -9999 -9999 -9999 -9999 -9999 -9999 -9999 -9999 -9999 -9999 -9999 -9999 -9999 -9999 -999 -

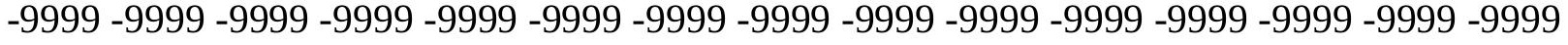
-9999 -9999 -9999 -9999 -9999 -9999 -9999 -9999 -9999 -9999 -9999 -9999 -9999 -9999 -9999 -

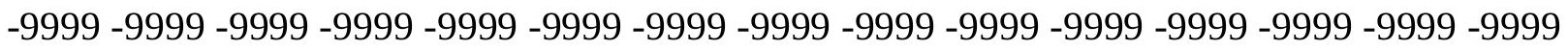

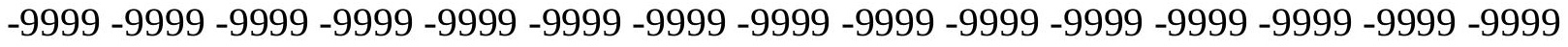

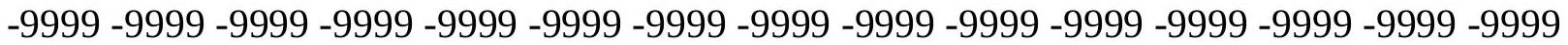
-9999 -9999 -9999 -9999 -9999 -9999 -9999 -9999 -9999 -9999 -9999 -9999 -9999 -9999 -9999

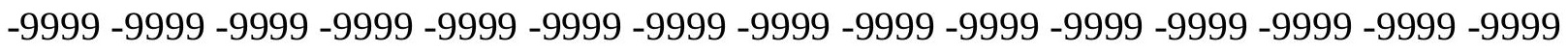

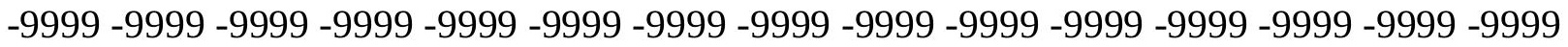
-9999 -9999 -9999 -9999 -9999 -9999 -9999 -9999 -9999 -9999 -9999 -9999 -9999 - 9999 - -999 -9999 -9999 -9999 -9999 -9999 -9999 -9999 -9999 -9999 -9999 -9999 -9999 -9999 -9999 -9999 -

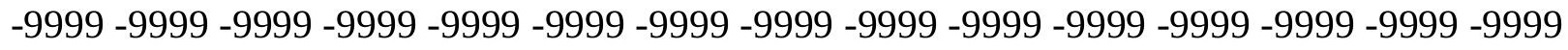

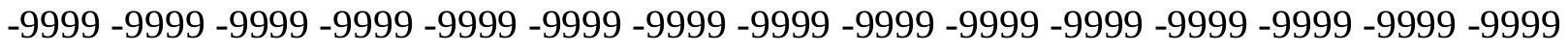
-9999 -9999 -9999 -9999 -9999 -9999 -9999 -9999 -9999 -9999 -9999 -9999 -9999 -9999 -9999 -9999 -9999 -9999 -9999 -9999 -9999 -9999 -9999 -9999-9999 -9999 -9999 -9999 -9999 -9999 -9999 -9999 -9999 -9999 -9999 -9999 -9999 -9999 -9999 -9999 -9999 -9999 -9999 -9999 -9999 -

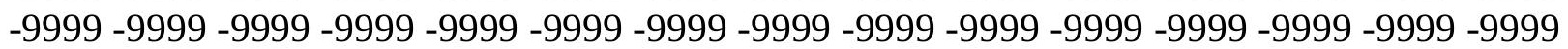


-9999 -9999 -9999 -9999 -9999 -9999 -9999 -9999 -9999 -9999 -9999 -9999 -9999 -9999 -9999 -9999 -9999 -9999 -9999 -9999 -9999 -9999 -9999 -9999 -9999 -9999 -9999 -9999 -9999 -9999 -9999 -9999 -9999 -9999 -9999 -9999 -9999 -9999 -9999 -9999 -9999 -9999 -9999 -9999 - 9999 -9999 -9999 -9999 -9999 -9999 -9999 -9999 -9999 -9999 -9999 -9999 -9999 -9999 -9999 -9999 -9999 -9999 -9999 -9999 -9999 -9999 -9999 -9999 -9999 -9999 -9999 -9999 -9999 -9999 - -9999 -9999 -9999 -9999 -9999 -9999 -9999 -9999 -9999 -9999 -9999 -9999 -9999 -9999 -9999 -9999 -9999 -9999 -9999 -9999 -9999 -9999 -9999 -9999 -9999 -9999 -9999 -9999 -9999 -9999

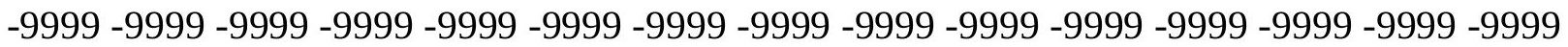

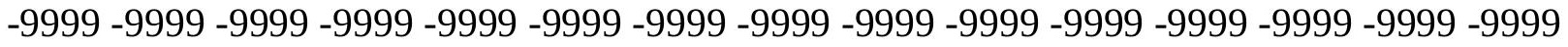
-9999 -9999 -9999 -9999 -9999 -9999 -9999 -9999 -9999 -9999 -9999 -9999 -9999 -9999 -9999

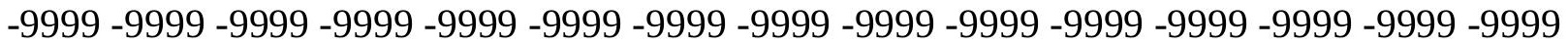
-9999 -9999 -9999 -9999 -9999 -9999 -9999 -9999 -9999 -9999 -9999 -9999 -9999 -9999 -9999 -9999 -9999 -9999 -9999 -9999 -9999 -9999 -9999 -9999 -9999 -9999 -9999 -9999 -9999 -9999 -9999 -9999 -9999 -9999 -9999 -9999 -9999 -9999 -9999 -9999 -9999 -9999 -9999 -9999 - -9999 -9999 -9999 -9999 -9999 -9999 -9999 -9999 -9999 -9999 -9999 -9999 -9999 -9999 -9999 -9999

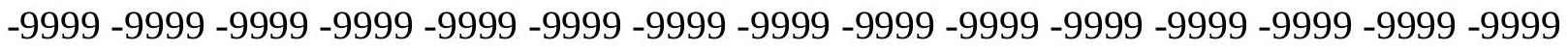
-9999 -9999 -9999 -9999 -9999 -9999 -9999 -9999 -9999 -9999 -9999 -9999 -9999 -9999 -9999 -9999 -9999 -9999 -9999 -9999 -9999 -9999 -9999 -9999 -9999 -9999 -9999 -9999 -9999 -9999 -9999 -9999 -9999 -9999 -9999 -9999 -9999 -9999 -9999 -9999 -9999 -9999 -9999 -9999 -9999 -

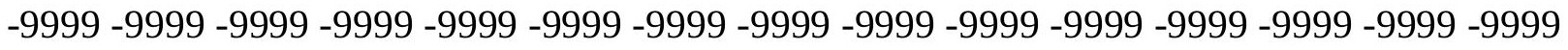
-9999 -9999 -9999 -9999 -9999 -9999 -9999 -9999 -9999 -9999 -9999 -9999 -9999 -9999 -9999 -999 -9999 -9999 -9999 -9999 -9999 -9999 -9999 -9999 -9999 -9999 -9999 -9999 -9999 -9999 -9999 -9999 -9999 -9999 -9999 -9999 -9999 -9999 -9999 -9999 -9999 -9999 -9999 -9999 -9999 -9999 -9999 -9999 -9999 -9999 -9999 -9999 -9999 -9999 -9999 -9999 -9999 -9999 -9999 -9999 -9999 -9999 -9999 -9999 -9999 -9999 -9999 -9999 -9999 -9999 -9999 -9999 -9999 -9999 -9999 -9999 -9999 -9999 -9999 -9999 -9999 -9999 -9999 -9999 -9999 -9999 -9999 -9999 -9999 -9999 -9999 -9999 -9999 -9999 -9999 -9999 -9999 -9999 -9999 -9999 -9999 -9999 -9999 -9999 -9999 -9999 -9999 -9999 -9999 -9999 -9999 -9999 -9999 -9999 -9999 -9999 -9999 -9999 -9999 -9999 -9999 -9999 -9999 -9999 -9999 -9999 -9999 -9999 -9999 -9999 -9999 -9999 -9999 -9999 -9999 -9999 -9999 -9999 -9999 -9999 -9999 -9999 -9999 -9999 -9999 -9999 -9999 -9999 -9999 -9999 -999 -9999 -9999 -9999 -9999 -9999 -9999 -9999 -9999 -9999 -9999 -9999 -9999 -9999 -9999 -9999 -9999 -9999 -9999 -9999 -9999 -9999 -9999 -9999 -9999 -9999 -9999 -9999 -9999 -9999 -

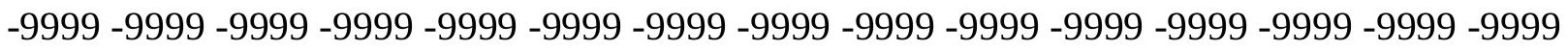

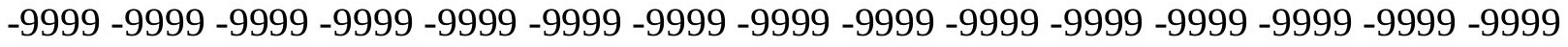

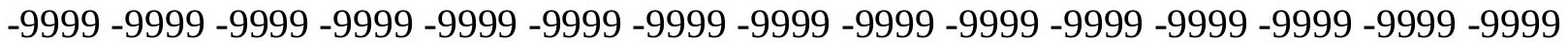
-9999 -9999 -9999 -9999 -9999 -9999 -9999 -9999 -9999 -9999 -9999 -9999 -9999 -9999 -9999 -

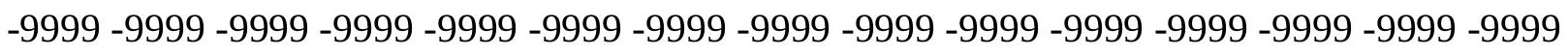

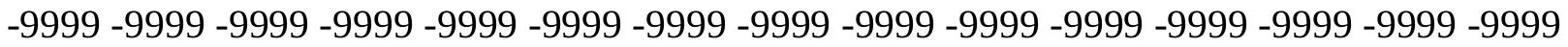

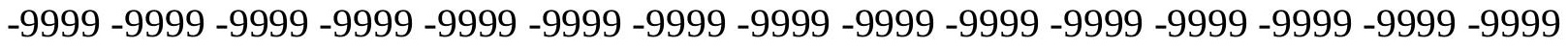
-9999 -9999 -9999 -9999 -9999 -9999 -9999 -9999 -9999 -9999 -9999 -9999 -9999 -9999 -9999 -

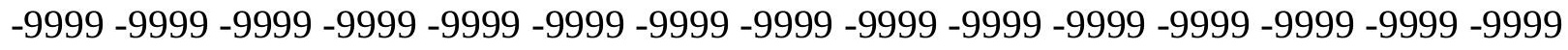

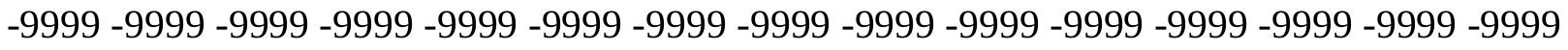
-9999 -9999 -9999 -9999 -9999 -9999 -9999 -9999 -9999 -9999 -9999 -9999 -9999 -9999 -9999 -9999 -9999 -9999 -9999 -9999 -9999 -9999 -9999 -9999-9999 -9999 -9999 -9999 -9999 -9999 -9999 -9999 -9999 -9999 -9999 -9999 -9999 -9999 -9999 -9999 -9999 -9999 -9999 -9999 -9999 -

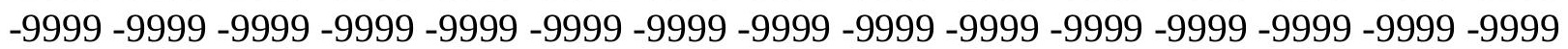


-9999 -9999 -9999 -9999 -9999 -9999 -9999 -9999 -9999 -9999 -9999 -9999 -9999 -9999 -9999 -9999 -9999 -9999 -9999 -9999 -9999 -9999 -9999 -9999 -9999 -9999 -9999 -9999 -9999 -9999 -

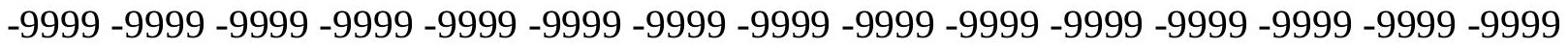
-9999 -9999 -9999 -9999 -9999 -9999 -9999 -9999 -9999 -9999 -9999 -9999 -9999 -9999 -9999 -9999 -9999 -9999 -9999 -9999 -9999 -9999 -9999 -9999-9999 -9999 -9999 -9999 -9999 -9999 -9999 -9999 -9999 -9999 -9999 -9999 -9999 -9999 -9999 -9999 -9999 -9999 -9999 -9999 -9999 -9999 -9999 -9999 -9999 -9999 -9999 -9999 -9999 -9999 -9999 -9999 -9999 -9999 -9999 -9999

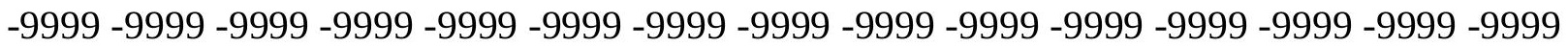

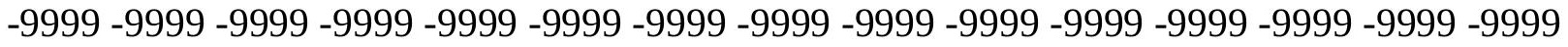
-9999 -9999 -9999 -9999 -9999 -9999 -9999 -9999 -9999 -9999 -9999 -9999 -9999 -9999 -9999 -9999 -9999 -9999 -9999 -9999 -9999 -9999 -9999 -9999 -9999 -9999 -9999 -9999 -9999 -9999 -9999 -9999 -9999 -9999 -9999 -9999 -9999 -9999 -9999 -9999 -9999 -9999 -9999 -9999 -9999 -9999 -9999 -9999 -9999 -9999 -9999 -9999 -9999 -9999 -9999 -9999 -9999 -9999 -9999 -9999 -9999 -9999 -9999 -9999 -9999 -9999 -9999 -9999 -9999 -9999 -9999 -9999 -9999 - 9999 -9999 -9999 -9999 -9999 -9999 -9999 -9999 -9999 -9999 -9999 -9999 -9999 -9999 -9999 -9999

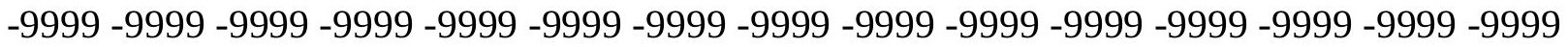
-9999 -9999 -9999 -9999 -9999 -9999 -9999 -9999 -9999 -9999 -9999 -9999 -9999 -9999 -9999 -9999 -9999 -9999 -9999 -9999 -9999 -9999 -9999 -9999 -9999 -9999 -9999 -9999 -9999 -9999 -9999 -9999 -9999 -9999 -9999 -9999 -9999 -9999 -9999 -9999 -9999 -9999 -9999 -9999 -9999 -

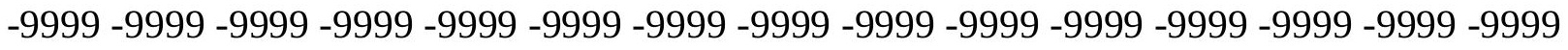

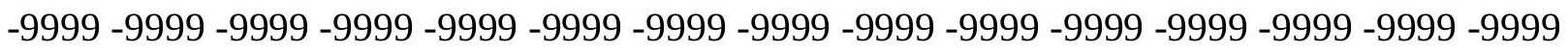
-9999 -9999 -9999 -9999 -9999 -9999 -9999 -9999 -9999 -9999 -9999 -9999 -9999 -9999 -9999 -9999 -9999 -9999 -9999 -9999 -9999 -9999 -9999 -9999 -9999 -9999 -9999 -9999 -9999 -9999 -9999 -9999 -9999 -9999 -9999 -9999 -9999 -9999 -9999 -9999 -9999 -9999 -9999 -9999 -9999 -

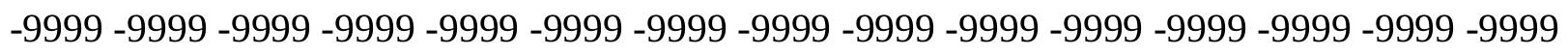
-9999 -9999 -9999 -9999 -9999 -9999 -9999 -9999 -9999 -9999 -9999 -9999 -9999 -9999 -9999 -9999 -9999 -9999 -9999 -9999 -9999 -9999 -9999 -9999 -9999 -9999 -9999 -9999 -9999 -9999 -

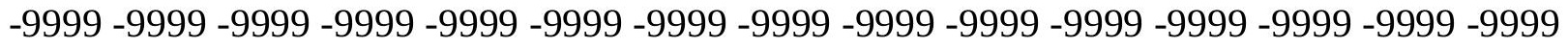
-9999 -9999 -9999 -9999 -9999 -9999 -9999 -9999 -9999 -9999 -9999 -9999 -9999 -9999 -9999 -9999 -9999 -9999 -9999 -9999 -9999 -9999 -9999 -9999 -9999 -9999 -9999 -9999 -9999 -999 -9999 -9999 -9999 -9999 -9999 -9999 -9999 -9999 -9999 -9999 -9999 -9999 -9999 -9999 -9999 -9999 -9999 -9999 -9999 -9999 -9999 -9999 -9999 -9999 -9999 -9999 -9999 -9999 -9999 -9999 -

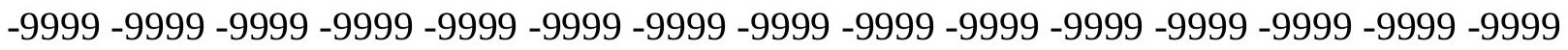

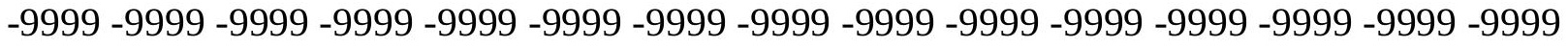

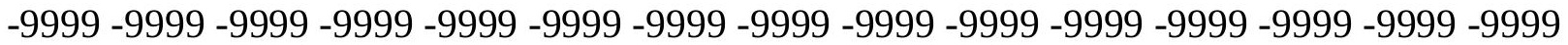

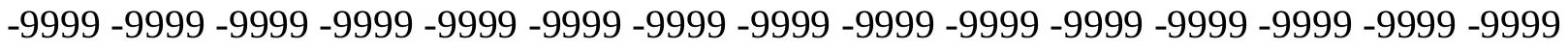

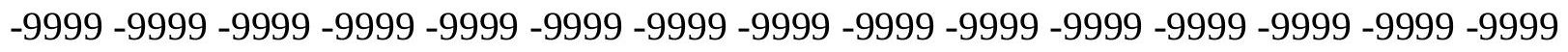

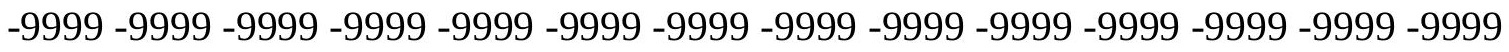
-9999 -9999 -9999 -9999 -9999 -9999 -9999 -9999 -9999 -9999 -9999 -9999 -9999 -9999 -9999 -9999 -9999 -9999 -9999 -9999 -9999 -9999 -9999 -9999 -9999 -9999 -9999 -9999 -9999 -9999 -

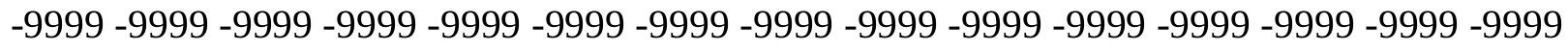

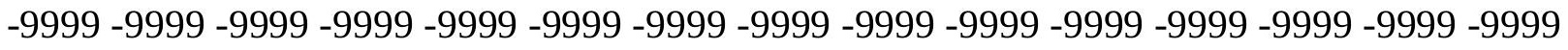
-9999 -9999 -9999 -9999 -9999 -9999 -9999 -9999 -9999 -9999 -9999 -9999 -9999 -9999 -9999 -9999 -9999 -9999 -9999 -9999 -9999 -9999 -9999 -9999-9999 -9999 -9999 -9999 -9999 -9999 -9999 -9999 -9999 -9999 -9999 -9999 -9999 -9999 -9999 -9999 -9999 -9999 -9999 -9999 -9999 -

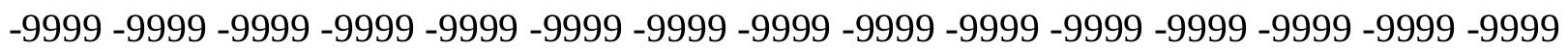


-9999 -9999 -9999 -9999 -9999 -9999 -9999 -9999 -9999 -9999 -9999 -9999 -9999 -9999 -9999 -9999 -9999 -9999 -9999 -9999 -9999 -9999 -9999 -9999 -9999 -9999 -9999 -9999 -9999 -9999 -9999 -9999 -9999 -9999 -9999 -9999 -9999 -9999 -9999 -9999 -9999 -9999 -9999 -9999 - 9999 -9999 -9999 -9999 -9999 -9999 -9999 -9999 -9999 -9999 -9999 -9999 -9999 -9999 -9999 -9999 -9999 -9999 -9999 -9999 -9999 -9999 -9999 -9999 -9999 -9999 -9999 -9999 -9999 -9999 -9999 -9999 -9999 -9999 -9999 -9999 -9999 -9999 -9999 -9999 -9999 -9999 -9999 -9999 -9999 -9999 -9999 -9999 -9999 -9999 -9999 -9999 -9999 -9999 -9999 -9999 -9999 -9999 -9999 -9999 -9999

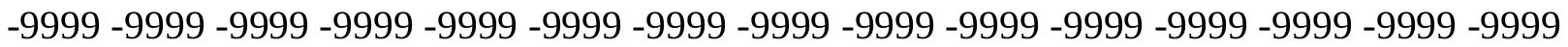
-9999 -9999 -9999 -9999 -9999 -9999 -9999 -9999 -9999 -9999 -9999 -9999 -9999 -9999 -9999 -9999 -9999 -9999 -9999 -9999 -9999 -9999 -9999 -9999 -9999 -9999 -9999 -9999 -9999 -9999

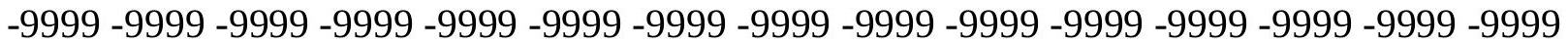
-9999 -9999 -9999 -9999 -9999 -9999 -9999 -9999 -9999 -9999 -9999 -9999 -9999 -9999 -9999 -9999 -9999 -9999 -9999 -9999 -9999 -9999 -9999 -9999 -9999 -9999 -9999 -9999 -9999 -9999 -

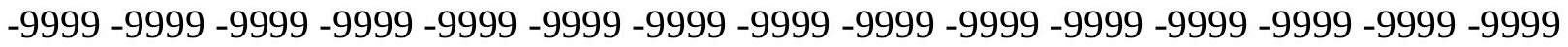
-9999 -9999 -9999 -9999 -9999 -9999 -9999 -9999 -9999 -9999 -9999 -9999 -9999 -9999 -9999

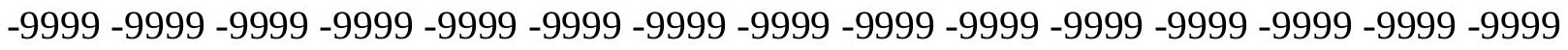
-9999 -9999 -9999 -9999 -9999 -9999 -9999 -9999 -9999 -9999 -9999 -9999 -9999 -9999 -9999 -9999 -9999 -9999 -9999 -9999 -9999 -9999 -9999 -9999 -9999 -9999 -9999 -9999 -9999 - -999 -9999 -9999 -9999 -9999 -9999 -9999 -9999 -9999 -9999 -9999 -9999 -9999 -9999 -9999 -9999 -9999 -9999 -9999 -9999 -9999 -9999 -9999 -9999 -9999 -9999 -9999 -9999 -9999 -9999 -9999 -9999 -9999 -9999 -9999 -9999 -9999 -9999 -9999 -9999 -9999 -9999 -9999 -9999 -9999 -9999 -999 -9999 -9999 -9999 -9999 -9999 -9999 -9999 -9999 -9999 -9999 -9999 -9999 -9999 -9999 -9999 -9999 -9999 -9999 -9999 -9999 -9999 -9999 -9999 -9999 -9999 -9999 -9999 -9999 -9999 -9999 -9999 -9999 -9999 -9999 -9999 -9999 -9999 -9999 -9999 -9999 -9999 -9999 -9999 -9999 -9999 -9999 -9999 -9999 -9999 -9999 -9999 -9999 -9999 -9999 -9999 -9999 -9999 -9999 -9999 -9999 -9999 -9999 -9999 -9999 -9999 -9999 -9999 -9999 -9999 -9999 -9999 -9999 -9999 -9999 -9999 -9999 -9999 -9999 -9999 -9999 -9999 -9999 -9999 -9999 -9999 -9999 -9999 -9999 -9999 -9999 -9999 -9999 -9999 -9999 -9999 -9999 -9999 -9999 -9999 -9999 -9999 -9999 -9999 -9999 -9999 -9999 -9999 -9999 -9999 -9999 -9999 -9999 -9999 -9999 -9999 -9999 -9999 -9999 -9999 -9999 -9999 -9999 -9999 -9999 -9999 -9999 -9999 -9999 -9999 -9999 -9999 -9999 -9999 -9999 -999 -9999 -9999 -9999 -9999 -9999 -9999 -9999 -9999 -9999 -9999 -9999 -9999 -9999 -9999 -9999 -9999 -9999 -9999 -9999 -9999 -9999 -9999 -9999 -9999 -9999 -9999 -9999 -9999 -9999 -9999 -

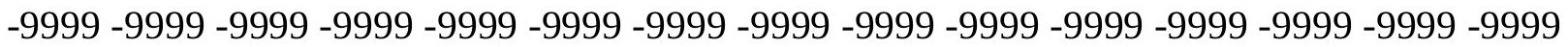

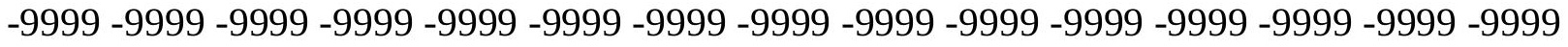

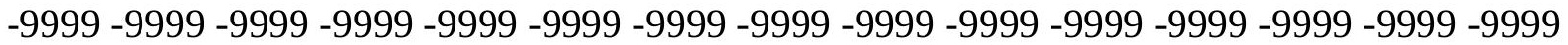
-9999 -9999 -9999 -9999 -9999 -9999 -9999 -9999 -9999 -9999 -9999 -9999 -9999 -9999 -9999

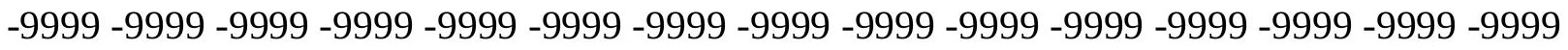

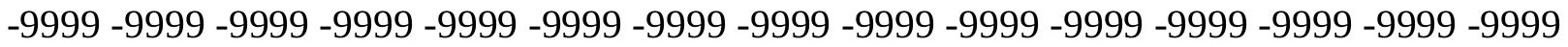

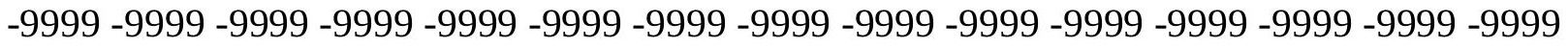
-9999 -9999 -9999 -9999 -9999 -9999 -9999 -9999 -9999 -9999 -9999 -9999 -9999 -9999 -9999 -

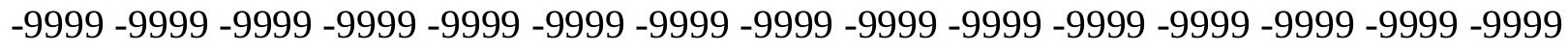

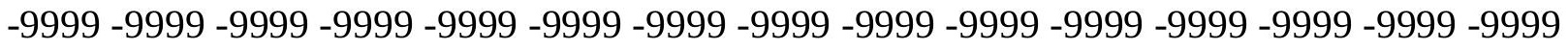
-9999 -9999 -9999 -9999 -9999 -9999 -9999 -9999 -9999 -9999 -9999 -9999 -9999 -9999 -9999 -9999 -9999 -9999 -9999 -9999 -9999 -9999 -9999 -9999 -9999 -9999 -9999 -9999 - -9999 -9999 -9999 -9999 -9999 -9999 -9999 -9999 -9999 -9999 -9999 -9999 -9999 -9999 -9999 -9999 -

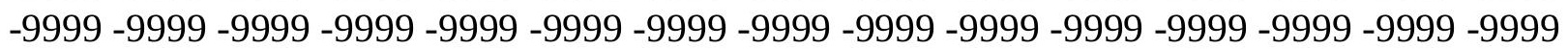


-9999 -9999 -9999 -9999 -9999 -9999 -9999 -9999 -9999 -9999 -9999 -9999 -9999 -9999 -9999 -9999 -9999 -9999 -9999 -9999 -9999 -9999 -9999 -9999 -9999 -9999 -9999 -9999 -9999 -9999 -9999 -9999 -9999 -9999 -9999 -9999 -9999 -9999 -9999 -9999 -9999 -9999 -9999 -9999 - 9999 -9999 -9999 -9999 -9999 -9999 -9999 -9999 -9999 -9999 -9999 -9999 -9999 -9999 -9999 -9999 -9999 -9999 -9999 -9999 -9999 -9999 -9999 -9999 -9999-9999 -9999 -9999 -9999 -9999 -9999 -9999 -9999 -9999 -9999 -9999 -9999 -9999 -9999 -9999 -9999 -9999 -9999 -9999 -9999 -9999 -9999 -9999 -9999 -9999 -9999 -9999 -9999 -9999 -9999 -9999 -9999 -9999 -9999 -9999 -9999

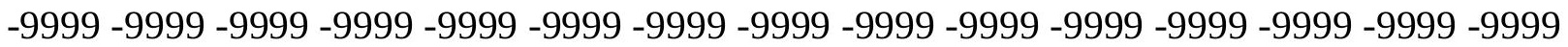

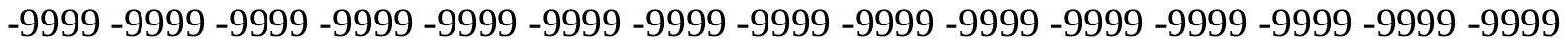
-9999 -9999 -9999 -9999 -9999 -9999 -9999 -9999 -9999 -9999 -9999 -9999 -9999 -9999 -9999

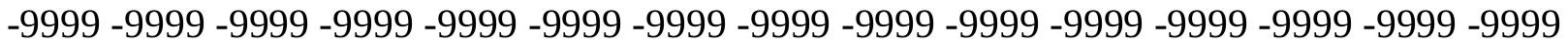
-9999 -9999 -9999 -9999 -9999 -9999 -9999 -9999 -9999 -9999 -9999 -9999 -9999 -9999 -9999 -9999 -9999 -9999 -9999 -9999 -9999 -9999 -9999 -9999 -9999 -9999 -9999 -9999 -9999 -9999 -

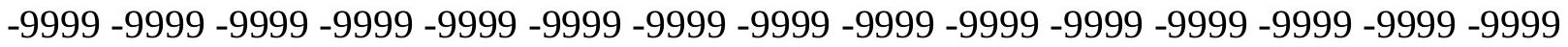
-9999 -9999 -9999 -9999 -9999 -9999 -9999 -9999 -9999 -9999 -9999 -9999 -9999 -9999 -9999

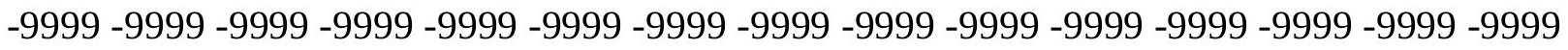
-9999 -9999 -9999 -9999 -9999 -9999 -9999 -9999 -9999 -9999 -9999 -9999 -9999 -9999 -9999 -9999 -9999 -9999 -9999 -9999 -9999 -9999 -9999 -9999 -9999 -9999 -9999 -9999 -9999 -9999 -9999 -9999 -9999 -9999 -9999 -9999 -9999 -9999 -9999 -9999 -9999 -9999 -9999 -9999 -9999 -9999 -9999 -9999 -9999 -9999 -9999 -9999 -9999 -9999 -9999 -9999 -9999 -9999 -9999 -9999 -9999 -9999 -9999 -9999 -9999 -9999 -9999 -9999 -9999 -9999 -9999 -9999 -9999 -9999 -9999 -999 -9999 -9999 -9999 -9999 -9999 -9999 -9999 -9999 -9999 -9999 -9999 -9999 -9999 -9999 -9999 -9999 -9999 -9999 -9999 -9999 -9999 -9999 -9999 -9999 -9999 -9999 -9999 -9999 -9999 -9999 -9999 -9999 -9999 -9999 -9999 -9999 -9999 -9999 -9999 -9999 -9999 -9999 -9999 -9999 -9999 -9999 -9999 -9999 -9999 -9999 -9999 -9999 -9999 -9999 -9999 -9999 -9999 -9999 -9999 -9999 -9999 -9999 -9999 -9999 -9999 -9999 -9999 -9999 -9999 -9999 -9999 -9999 -9999 -9999 -9999 -9999 -9999 -9999 -9999 -9999 -9999 -9999 -9999 -9999 -9999 -9999 -9999 -9999 -9999 -9999 -9999 -9999 -9999 -9999 -9999 -9999 -9999 -9999 -9999 -9999 -9999 -9999 -9999 -9999 -9999 -9999 -9999 -9999 -9999 -9999 -9999 -9999 -9999 -9999 -9999 -9999 -9999 -9999 -9999 -9999 -9999 -9999 -9999 -9999 -9999 -9999 -9999 -9999 -9999 -9999 -9999 -9999 -9999 -999 -9999 -9999 -9999 -9999 -9999 -9999 -9999 -9999 -9999 -9999 -9999 -9999 -9999 -9999 -9999 -9999 -9999 -9999 -9999 -9999 -9999 -9999 -9999 -9999 -9999 -9999 -9999 -9999 -9999 -9999 -

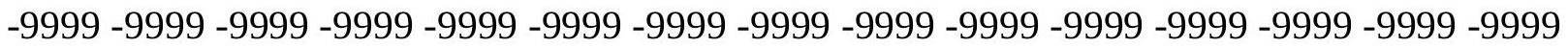

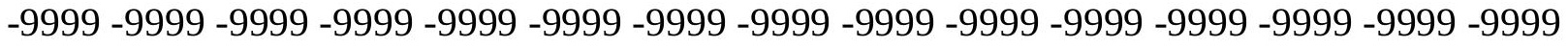

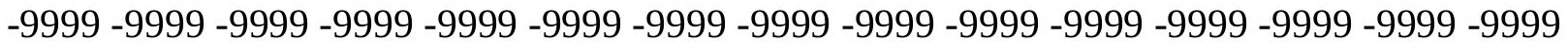
-9999 -9999 -9999 -9999 -9999 -9999 -9999 -9999 -9999 -9999 -9999 -9999 -9999 -9999 -9999

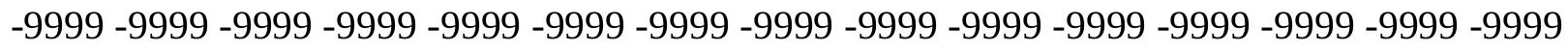

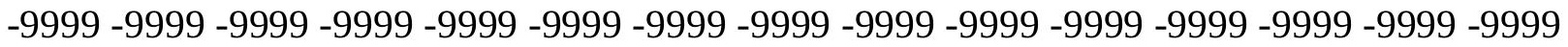
-9999 -9999 -9999 -9999 -9999 -9999 -9999 -9999 -9999 -9999 -9999 -9999 -9999 -9999 -9999 -9999 -9999 -9999 -9999 -9999 -9999 -9999 -9999 -9999 -9999 -9999 -9999 -9999 -9999 -9999 -

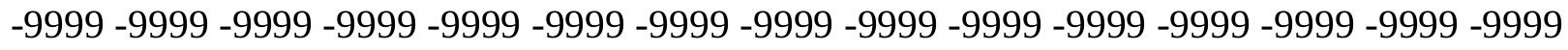

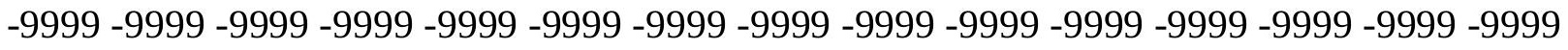
-9999 -9999 -9999 -9999 -9999 -9999 -9999 -9999 -9999 -9999 -9999 -9999 -9999 -9999 -9999 -9999 -9999 -9999 -9999 -9999 -9999 -9999 -9999 -9999-9999 -9999 -9999 -9999 -9999 -9999 -9999 -9999 -9999 -9999 -9999 -9999 -9999 -9999 -9999 -9999 -9999 -9999 -9999 -9999 -9999 -

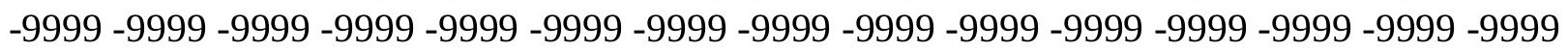


-9999 -9999 -9999 -9999 -9999 -9999 -9999 -9999 -9999 -9999 -9999 -9999 -9999 -9999 -9999 -9999 -9999 -9999 -9999 -9999 -9999 -9999 -9999 -9999 -9999 -9999 -9999 -9999 -9999 -9999 -9999 -9999 -9999 -9999 -9999 -9999 -9999 -9999 -9999 -9999 -9999 -9999 -9999 -9999 - 9999 -9999 -9999 -9999 -9999 -9999 -9999 -9999 -9999 -9999 -9999 -9999 -9999 -9999 -9999

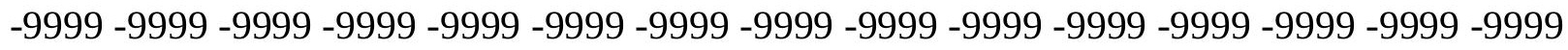
-9999 -9999 -9999 -9999 -9999 -9999 -9999 -9999 -9999 -9999 -9999 -9999 -9999 -9999 -9999 -9999 -9999 -9999 -9999 -9999 -9999 -9999 -9999 -9999 -9999 -9999 -9999 -9999 -9999 -9999

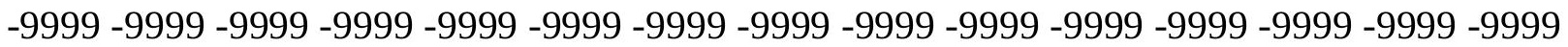

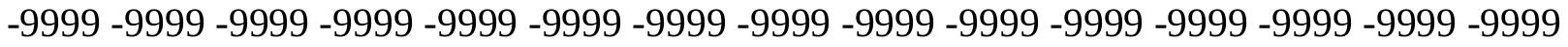
-9999 -9999 -9999 -9999 -9999 -9999 -9999 -9999 -9999 -9999 -9999 -9999 -9999 -9999 -9999 -9999 -9999 -9999 -9999 -9999 -9999 -9999 -9999 -9999 -9999 -9999 -9999 -9999 -9999 -9999 -9999 -9999 -9999 -9999 -9999 -9999 -9999 -9999 -9999 -9999 -9999 -9999 -9999 -9999 -9999 -9999 -9999 -9999 -9999 -9999 -9999 -9999 -9999 -9999 -9999 -9999 -9999 -9999 -9999 -9999 -

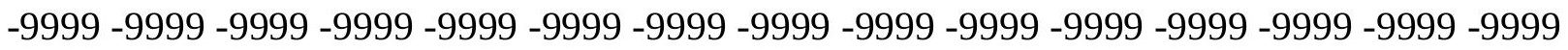
-9999 -9999 -9999 -9999 -9999 -9999 -9999 -9999 -9999 -9999 -9999 -9999 -9999 -9999 -9999 -

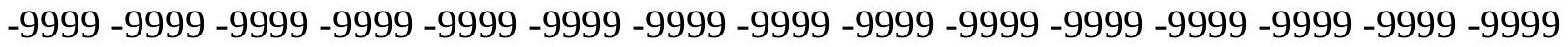
-9999 -9999 -9999 -9999 -9999 -9999 -9999 -9999 -9999 -9999 -9999 -9999 -9999 -9999 -9999 -9999 -9999 -9999 -9999 -9999 -9999 -9999 -9999 -9999 -9999 -9999 -9999 -9999 -9999 -9999 -9999 -9999 -9999 -9999 -9999 -9999 -9999 -9999 -9999 -9999 -9999 -9999 -9999 -9999 -9999 -

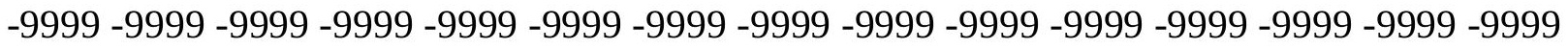
-9999 -9999 -9999 -9999 -9999 -9999 -9999 -9999 -9999 -9999 -9999 -9999 -9999 -9999 -9999

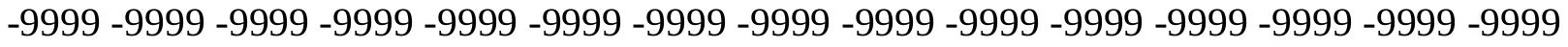
-9999 -9999 -9999 -9999 -9999 -9999 -9999 -9999 -9999 -9999 -9999 -9999 -9999 -9999 -9999 -9999 -9999 -9999 -9999 -9999 -9999 -9999 -9999 -9999 -9999 -9999 -9999 -9999 -9999 -9999 -9999 -9999 -9999 -9999 -9999 -9999 -9999 -9999 -9999 -9999 -9999 -9999 -9999 -9999 -9999 -9999 -9999 -9999 -9999 -9999 -9999 -9999 -9999 -9999 -9999 -9999 -9999 -9999 -9999 -9999 -9999 -9999 -9999 -9999 -9999 -9999 -9999 -9999 -9999 -9999 -9999 -9999 -9999 -9999 -9999 -9999 -9999 -9999 -9999 -9999 -9999 -9999 -9999 -9999 -9999 -9999 -9999 -9999 -9999 -9999 -9999 -9999 -9999 -9999 -9999 -9999 -9999 -9999 -9999 -9999 -9999 -9999 -9999 -9999 -9999 -9999 -9999 -9999 -9999 -9999 -9999 -9999 -9999 -9999 -9999 -9999 -9999 -9999 -9999 -9999 -9999 -9999 -9999 -9999 -9999 -9999 -9999 -9999 -9999 -9999 -9999 -9999 -9999 -9999 -9999 -9999 -9999 -9999 -9999 -9999 -9999 -9999 -9999 -9999 -9999 -9999 -9999 -9999 -9999 -

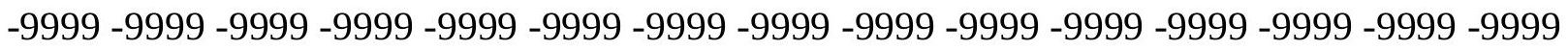

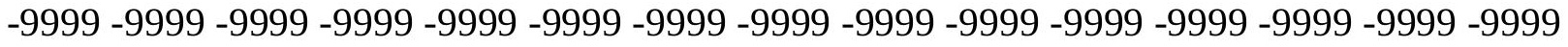
-9999 -9999 -9999 -9999 -9999 -9999 -9999 -9999 -9999 -9999 -9999 -9999 -9999 -9999 -9999 -

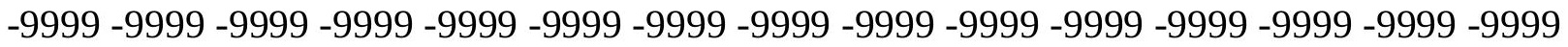

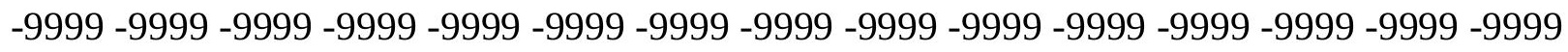

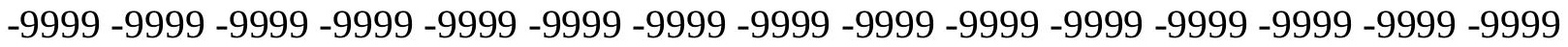

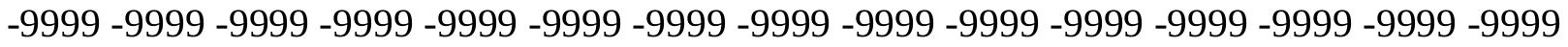
-9999 -9999 -9999 -9999 -9999 -9999 -9999 -9999 -9999 -9999 -9999 -9999 -9999 -9999 -9999 -

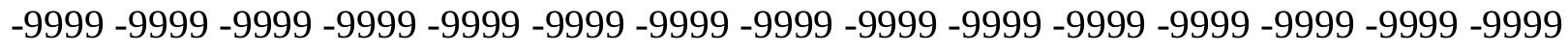

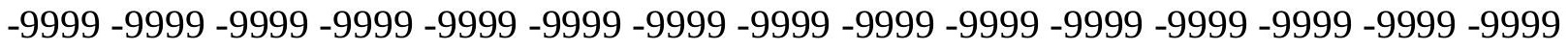
-9999 -9999 -9999 -9999 -9999 -9999 -9999 -9999 -9999 -9999 -9999 -9999 -9999 -9999 -9999 -9999 -9999 -9999 -9999 -9999 -9999 -9999 -9999 -9999-9999 -9999 -9999 -9999 -9999 -9999 -9999 -9999 -9999 -9999 -9999 -9999 -9999 -9999 -9999 -9999 -9999 -9999 -9999 -9999 -9999 -

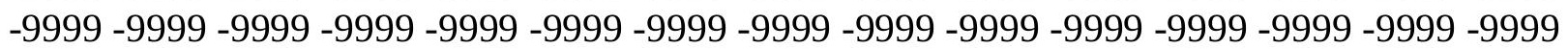


-9999 -9999 -9999 -9999 -9999 -9999 -9999 -9999 -9999 -9999 -9999 -9999 -9999 -9999 -9999 -9999 -9999 -9999 -9999 -9999 -9999 -9999 -9999 -9999 -9999 -9999 -9999 -9999 -9999 -9999 -9999 -9999 -9999 -9999 -9999 -9999 -9999 -9999 -9999 -9999 -9999 -9999 -9999 -9999 - 9999 -9999 -9999 -9999 -9999 -9999 -9999 -9999 -9999 -9999 -9999 -9999 -9999 -9999 -9999 -9999 -9999 -9999 -9999 -9999 -9999 -9999 -9999 -9999 -9999 -9999 -9999 -9999 -9999 -9999 -9999 -9999 -9999 -9999 -9999 -9999 -9999 -9999 -9999 -9999 -9999 -9999 -9999 -9999 -9999 -9999 -9999 -9999 -9999 -9999 -9999 -9999 -9999 -9999 -9999 -9999 -9999 -9999 -9999 -9999 -9999

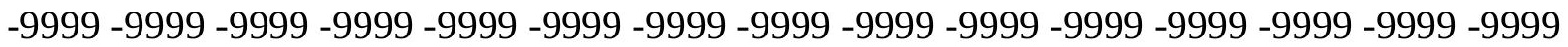

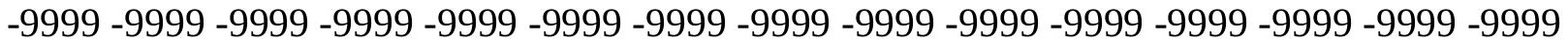
-9999 -9999 -9999 -9999 -9999 -9999 -9999 -9999 -9999 -9999 -9999 -9999 -9999 -9999 -9999 -9999 -9999 -9999 -9999 -9999 -9999 -9999 -9999 -9999 -9999 -9999 -9999 -9999 -9999 -9999 -9999 -9999 -9999 -9999 -9999 -9999 -9999 -9999 -9999 -9999 -9999 -9999 -9999 -9999 -9999 -9999 -9999 -9999 -9999 -9999 -9999 -9999 -9999 -9999 -9999 -9999 -9999 -9999 -9999 -9999 -9999 -9999 -9999 -9999 -9999 -9999 -9999 -9999 -9999 -9999 -9999 -9999 -9999 -9999 -9999 -9999 -9999 -9999 -9999 -9999 -9999 -9999 -9999 -9999 -9999 -9999 -9999 -9999 -9999 -

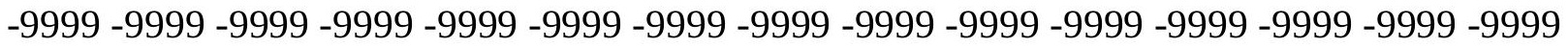
-9999 -9999 -9999 -9999 -9999 -9999 -9999 -9999 -9999 -9999 -9999 -9999 -9999 -9999 -9999 -9999 -9999 -9999 -9999 -9999 -9999 -9999 -9999 -9999 -9999 -9999 -9999 -9999 -9999 -9999 -9999 -9999 -9999 -9999 -9999 -9999 -9999 -9999 -9999 -9999 -9999 -9999 -9999 -9999 -9999 -9999 -9999 -9999 -9999 -9999 -9999 -9999 -9999 -9999 -9999 -9999 -9999 -9999 -9999 -9999 -9999 -9999 -9999 -9999 -9999 -9999 -9999 -9999 -9999 -9999 -9999 -9999 -9999 -9999 -9999 -999 -9999 -9999 -9999 -9999 -9999 -9999 -9999 -9999 -9999 -9999 -9999 -9999 -9999 -9999 -9999 -9999 -9999 -9999 -9999 -9999 -9999 -9999 -9999 -9999 -9999 -9999 -9999 -9999 -9999 -9999 -9999 -9999 -9999 -9999 -9999 -9999 -9999 -9999 -9999 -9999 -9999 -9999 -9999 -9999 -9999 -9999 -9999 -9999 -9999 -9999 -9999 -9999 -9999 -9999 -9999 -9999 -9999 -9999 -9999 -9999 -9999 -9999 -9999 -9999 -9999 -9999 -9999 -9999 -9999 -9999 -9999 -9999 -9999 -9999 -9999 -9999 -9999 -9999 -9999 -9999 -9999 -9999 -9999 -9999 -9999 -9999 -9999 -9999 -9999 -9999 -9999 -9999 -9999 -9999 -9999 -9999 -9999 -9999 -9999 -9999 -9999 -9999 -9999 -9999 -9999 -9999 -9999 -9999 -9999 -9999 -9999 -9999 -9999 -9999 -9999 -9999 -9999 -9999 -9999 -9999 -9999 -9999 -9999 -9999 -9999 -9999 -9999 -9999 -9999 -9999 -9999 -9999 -9999 -9999 -999 -9999 -9999 -9999 -9999 -9999 -9999 -9999 -9999 -9999 -9999 -9999 -9999 -9999 -9999 -9999 -9999 -9999 -9999 -9999 -9999 -9999 -9999 -9999 -9999 -9999 -9999 -9999 -9999 -9999 -9999 -

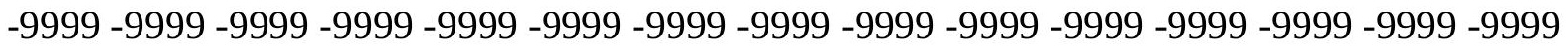

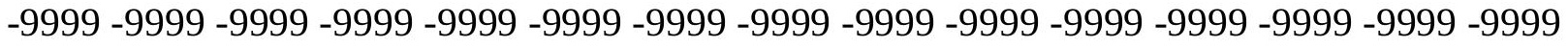

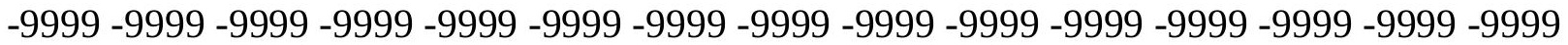
-9999 -9999 -9999 -9999 -9999 -9999 -9999 -9999 -9999 -9999 -9999 -9999 -9999 -9999 -9999 -9999 -9999 -9999 -9999 -9999 -9999 -9999 -9999 -9999 -9999 -9999 -9999 -9999 -9999 -

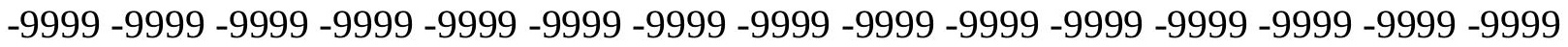
-9999 -9999 -9999 -9999 -9999 -9999 -9999 -9999 -9999 -9999 -9999 -9999 -9999 -9999 -9999 -9999 -9999 -9999 -9999 -9999 -9999 -9999 -9999 -9999 -9999 -9999 -9999 -9999 -9999 -9999 -

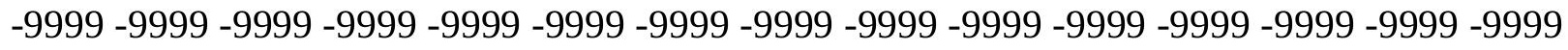

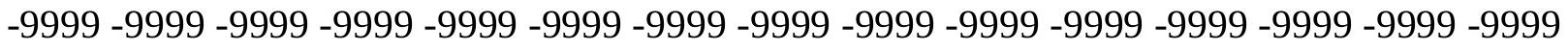
-9999 -9999 -9999 -9999 -9999 -9999 -9999 -9999 -9999 -9999 -9999 -9999 -9999 -9999 -9999 -9999 -9999 -9999 -9999 -9999 -9999 -9999 -9999 -9999-9999 -9999 -9999 -9999 -9999 -9999 -9999 -9999 -9999 -9999 -9999 -9999 -9999 -9999 -9999 -9999 -9999 -9999 -9999 -9999 -9999 -

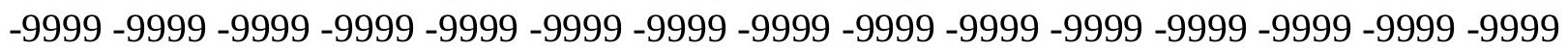


-9999 -9999 -9999 -9999 -9999 -9999 -9999 -9999 -9999 -9999 -9999 -9999 -9999 -9999 -9999 -9999 -9999 -9999 -9999 -9999 -9999 -9999 -9999 -9999 -9999 -9999 -9999 -9999 -9999 -9999 -

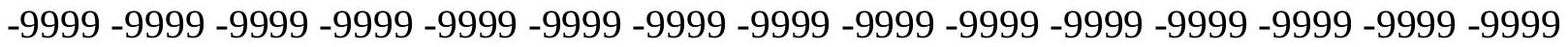
-9999 -9999 -9999 -9999 -9999 -9999 -9999 -9999 -9999 -9999 -9999 -9999 -9999 -9999 -9999 -9999 -9999 -9999 -9999 -9999 -9999 -9999 -9999 -9999-9999 -9999 -9999 -9999 -9999 -9999 -9999 -9999 -9999 -9999 -9999 -9999 -9999 -9999 -9999 -9999 -9999 -9999 -9999 -9999 -9999 -9999 -9999 -9999 -9999 -9999 -9999 -9999 -9999 -9999 -9999 -9999 -9999 -9999 -9999 -9999

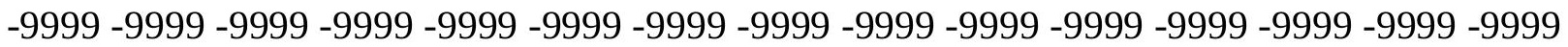

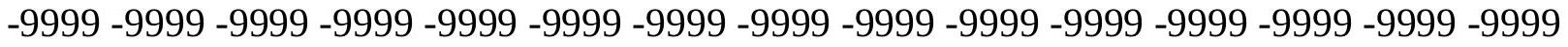
-9999 -9999 -9999 -9999 -9999 -9999 -9999 -9999 -9999 -9999 -9999 -9999 -9999 -9999 -9999 -9999 -9999 -9999 -9999 -9999 -9999 -9999 -9999 -9999 -9999 -9999 -9999 -9999 -9999 -9999 -9999 -9999 -9999 -9999 -9999 -9999 -9999 -9999 -9999 -9999 -9999 -9999 -9999 -9999 -9999 -9999 -9999 -9999 -9999 -9999 -9999 -9999 -9999 -9999 -9999 -9999 -9999 -9999 -9999 -9999 -9999 -9999 -9999 -9999 -9999 -9999 -9999 -9999 -9999 -9999 -9999 -9999 -9999 -9999 -9999 -9999 -9999 -9999 -9999 -9999 -9999 -9999 -9999 -9999 -9999 -9999 -9999 -9999 -9999 -9999 -

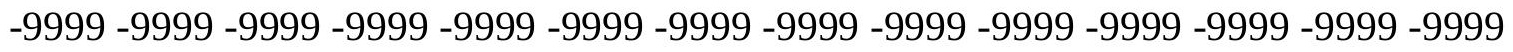
-9999 -9999 -9999 -9999 -9999 -9999 -9999 -9999 -9999 -9999 -9999 -9999 -9999 -9999 -9999 -9999 -9999 -9999 -9999 -9999 -9999 -9999 -9999 -9999 -9999 -9999 -9999 -9999 -9999 -9999 -9999 -9999 -9999 -9999 -9999 -9999 -9999 -9999 -9999 -9999 -9999 -9999 -9999 -9999 -9999 -

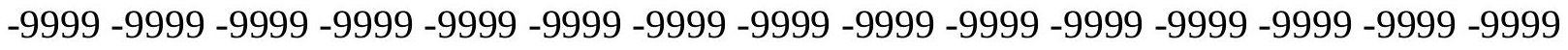

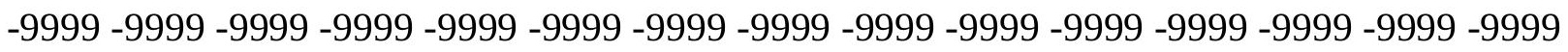
-9999 -9999 -9999 -9999 -9999 -9999 -9999 -9999 -9999 -9999 -9999 -9999 -9999 -9999 - 9999 -9999 -9999 -9999 -9999 -9999 -9999 -9999 -9999 -9999 -9999 -9999 -9999 -9999 -9999 -9999 -9999 -9999 -9999 -9999 -9999 -9999 -9999 -9999 -9999 -9999 -9999 -9999 -9999 -9999 -9999 -

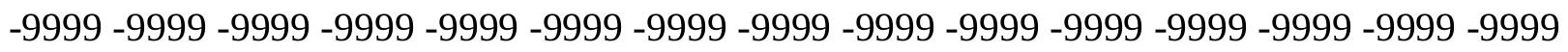
-9999 -9999 -9999 -9999 -9999 -9999 -9999 -9999 -9999 -9999 -9999 -9999 -9999 -9999 -9999 -9999 -9999 -9999 -9999 -9999 -9999 -9999 -9999 -9999 -9999 -9999 -9999 -9999 -9999 -9999 -

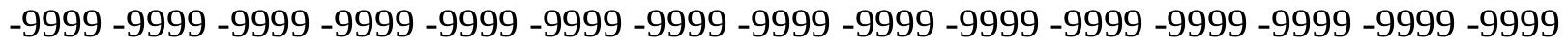
-9999 -9999 -9999 -9999 -9999 -9999 -9999 -9999 -9999 -9999 -9999 -9999 -9999 -9999 -9999 -9999 -9999 -9999 -9999 -9999 -9999 -9999 -9999 -9999 -9999 -9999 -9999 -9999 -9999 -999 -

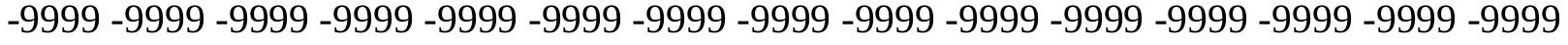
-9999 -9999 -9999 -9999 -9999 -9999 -9999 -9999 -9999 -9999 -9999 -9999 -9999 -9999 -9999 -

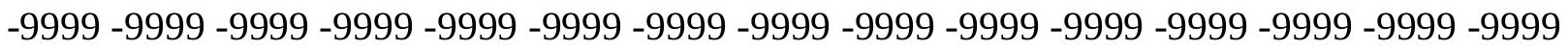

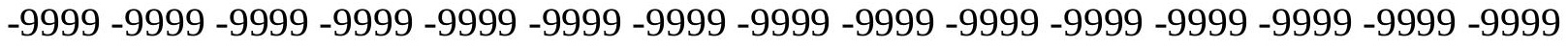

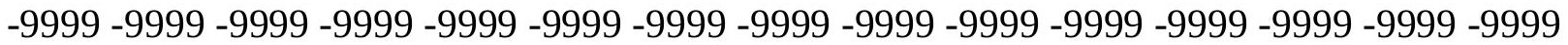
-9999 -9999 -9999 -9999 -9999 -9999 -9999 -9999 -9999 -9999 -9999 -9999 -9999 -9999 -9999 -

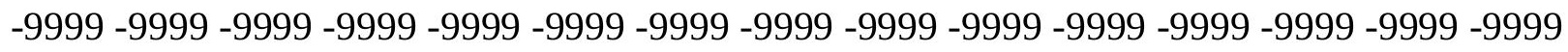

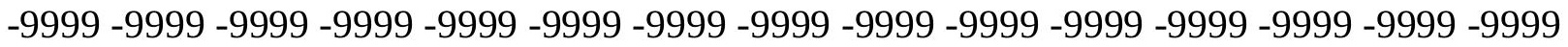
-9999 -9999 -9999 -9999 -9999 -9999 -9999 -9999 -9999 -9999 -9999 -9999 -9999 - 9999 - -999 -9999 -9999 -9999 -9999 -9999 -9999 -9999 -9999 -9999 -9999 -9999 -9999 -9999 -9999 -9999 -

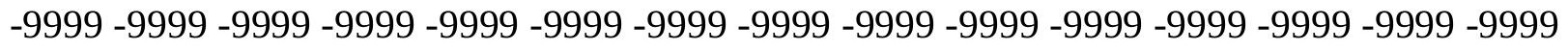

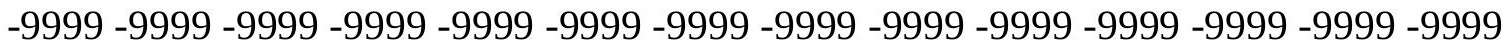
-9999 -9999 -9999 -9999 -9999 -9999 -9999 -9999 -9999 -9999 -9999 -9999 -9999 -9999 -9999 -9999 -9999 -9999 -9999 -9999 -9999 -9999 -9999 -9999-9999 -9999 -9999 -9999 -9999 -9999 -9999 -9999 -9999 -9999 -9999 -9999 -9999 -9999 -9999 -9999 -9999 -9999 -9999 -9999 -9999 -

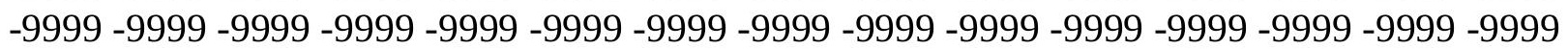


-9999 -9999 -9999 -9999 -9999 -9999 -9999 -9999 -9999 -9999 -9999 -9999 -9999 -9999 -9999 -9999 -9999 -9999 -9999 -9999 -9999 -9999 -9999 -9999 -9999 -9999 -9999 -9999 -9999 -9999 -

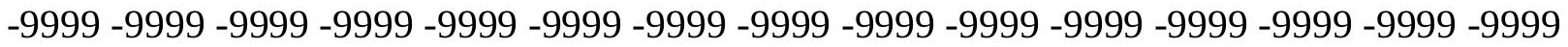
-9999 -9999 -9999 -9999 -9999 -9999 -9999 -9999 -9999 -9999 -9999 -9999 -9999 -9999 -9999 -9999 -9999 -9999 -9999 -9999 -9999 -9999 -9999 -9999-9999 -9999 -9999 -9999 -9999 -9999 -9999 -9999 -9999 -9999 -9999 -9999 -9999 -9999 -9999 -9999 -9999 -9999 -9999 -9999 -9999 -9999 -9999 -9999 -9999 -9999 -9999 -9999 -9999 -9999 -9999 -9999 -9999 -9999 -9999 -9999

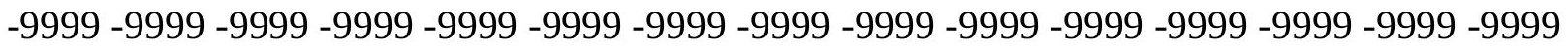

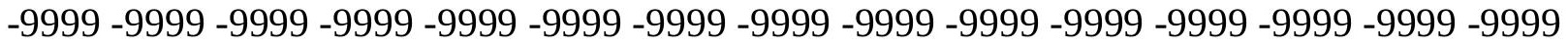
-9999 -9999 -9999 -9999 -9999 -9999 -9999 -9999 -9999 -9999 -9999 -9999 -9999 -9999 -9999 -9999 -9999 -9999 -9999 -9999 -9999 -9999 -9999 -9999 -9999 -9999 -9999 -9999 -9999 -9999 -9999 -9999 -9999 -9999 -9999 -9999 -9999 -9999 -9999 -9999 -9999 -9999 -9999 -9999 -9999 -9999 -9999 -9999 -9999 -9999 -9999 -9999 -9999 -9999 -9999 -9999 -9999 -9999 -9999 -9999 -

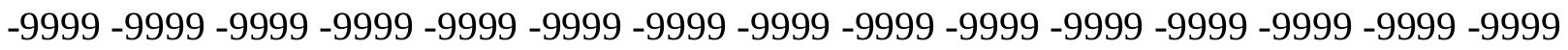
-9999 -9999 -9999 -9999 -9999 -9999 -9999 -9999 -9999 -9999 -9999 -9999 -9999 -9999 -9999 -

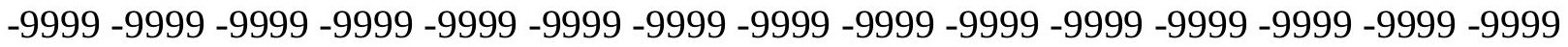
-9999 -9999 -9999 -9999 -9999 -9999 -9999 -9999 -9999 -9999 -9999 -9999 -9999 -9999 -9999 -9999 -9999 -9999 -9999 -9999 -9999 -9999 -9999 -9999 -9999 -9999 -9999 -9999 -9999 -9999 -9999 -9999 -9999 -9999 -9999 -9999 -9999 -9999 -9999 -9999 -9999 -9999 -9999 -9999 -9999 -

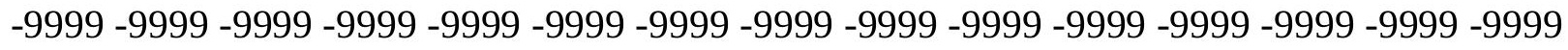

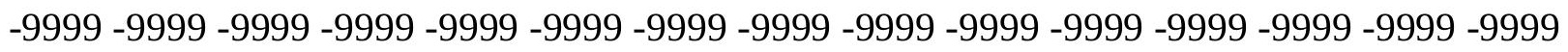
-9999 -9999 -9999 -9999 -9999 -9999 -9999 -9999 -9999 -9999 -9999 -9999 -9999 -9999 -9999 -9999 -9999 -9999 -9999 -9999 -9999 -9999 -9999 -9999 -9999 -9999 -9999 -9999 -9999 -9999 -9999 -9999 -9999 -9999 -9999 -9999 -9999 -9999 -9999 -9999 -9999 -9999 -9999 -9999 -

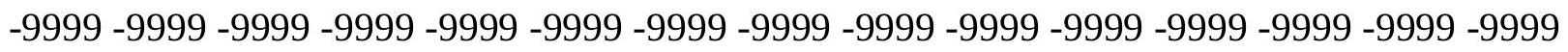
-9999 -9999 -9999 -9999 -9999 -9999 -9999 -9999 -9999 -9999 -9999 -9999 -9999 -9999 -9999 -9999 -9999 -9999 -9999 -9999 -9999 -9999 -9999 -9999 -9999 -9999 -9999 -9999 -9999 -9999 -

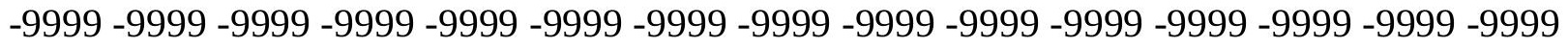
-9999 -9999 -9999 -9999 -9999 -9999 -9999 -9999 -9999 -9999 -9999 -9999 -9999 -9999 -9999 -9999 -9999 -9999 -9999 -9999 -9999 -9999 -9999 -9999 -9999 -9999 -9999 -9999 -9999 -999 -

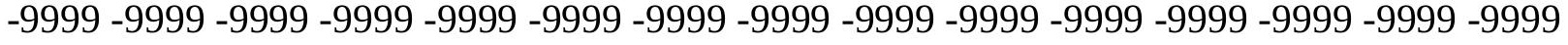
-9999 -9999 -9999 -9999 -9999 -9999 -9999 -9999 -9999 -9999 -9999 -9999 -9999 -9999 -9999 -

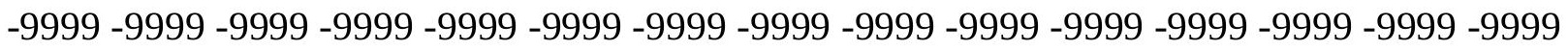

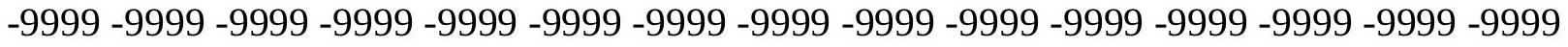

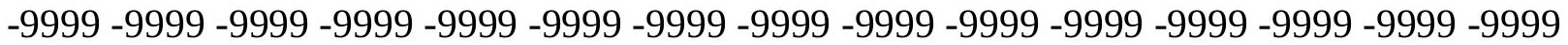

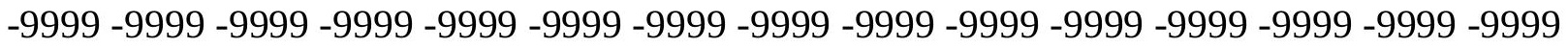

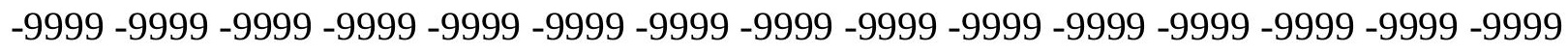

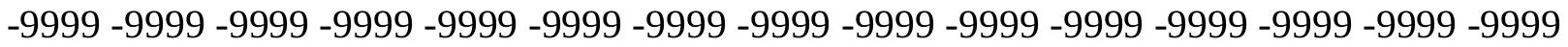

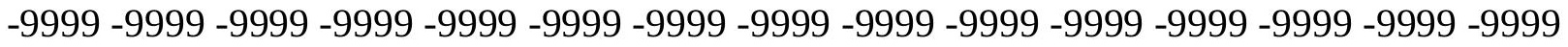
-9999 -9999 -9999 -9999 -9999 -9999 -9999 -9999 -9999 -9999 -9999 -9999 -9999 -9999 -9999 -

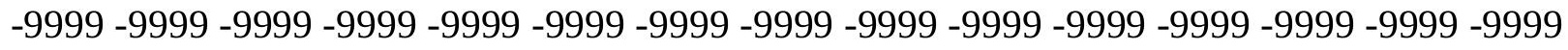

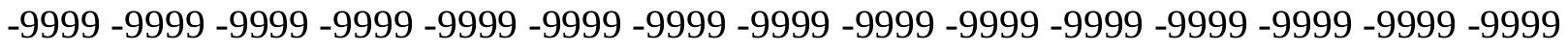
-9999 -9999 -9999 -9999 -9999 -9999 -9999 -9999 -9999 -9999 -9999 -9999 -9999 -9999 -9999 -9999 -9999 -9999 -9999 -9999 -9999 -9999 -9999 -9999-9999 -9999 -9999 -9999 -9999 -9999 -9999 -9999 -9999 -9999 -9999 -9999 -9999 -9999 -9999 -9999 -9999 -9999 -9999 -9999 -9999 -

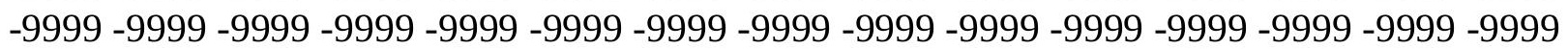


-9999 -9999 -9999 -9999 -9999 -9999 -9999 -9999 -9999 -9999 -9999 -9999 -9999 -9999 -9999 -9999 -9999 -9999 -9999 -9999 -9999 -9999 -9999 -9999 -9999 -9999 -9999 -9999 -9999 -

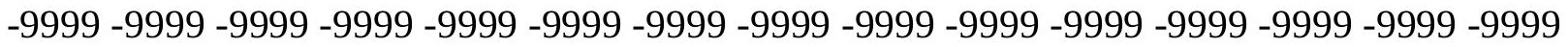
-9999 -9999 -9999 -9999 -9999 -9999 -9999 -9999 -9999 -9999 -9999 -9999 -9999 -9999 -9999 -9999 -9999 -9999 -9999 -9999 -9999 -9999 -9999 -9999 -9999 -9999 -9999 -9999 -9999 -9999 -9999 -9999 -9999 -9999 -9999 -9999 -9999 -9999 -9999 -9999 -9999 -9999 -9999 -9999 -9999 -9999 -9999 -9999 -9999 -9999 -9999 -9999 -9999 -9999 -9999 -9999 -9999 -9999 -9999 -9999

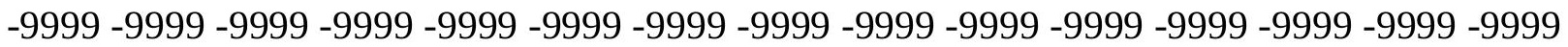

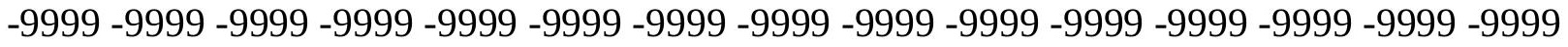
-9999 -9999 -9999 -9999 -9999 -9999 -9999 -9999 -9999 -9999 -9999 -9999 -9999 -9999 -9999 -9999 -9999 -9999 -9999 -9999 -9999 -9999 -9999 -9999 -9999 -9999 -9999 -9999 -9999 -9999 -9999 -9999 -9999 -9999 -9999 -9999 -9999 -9999 -9999 -9999 -9999 -9999 -9999 -9999 -9999 -9999 -9999 -9999 -9999 -9999 -9999 -9999 -9999 -9999 -9999 -9999 -9999 -9999 -9999 -9999 -9999 -9999 -9999 -9999 -9999 -9999 -9999 -9999 -9999 -9999 -9999 -9999 -9999 -9999 -9999 -9999 -9999 -9999 -9999 -9999 -9999 -9999 -9999 -9999 -9999 -9999 -9999 -9999 -9999 -9999 -

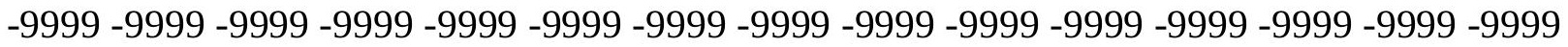
-9999 -9999 -9999 -9999 -9999 -9999 -9999 -9999 -9999 -9999 -9999 -9999 -9999 -9999 -9999 -9999 -9999 -9999 -9999 -9999 -9999 -9999 -9999 -9999 -9999 -9999 -9999 -9999 -9999 - 9999 -9999 -9999 -9999 -9999 -9999 -9999 -9999 -9999 -9999 -9999 -9999 -9999 -9999 -9999 -9999 -

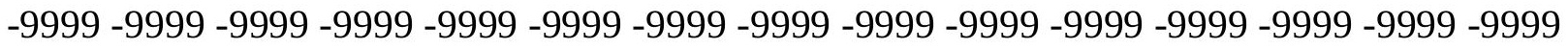

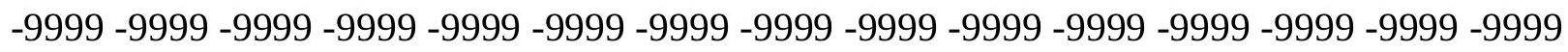

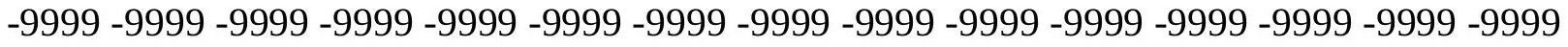
-9999 -9999 -9999 -9999 -9999 -9999 -9999 -9999 -9999 -9999 -9999 -9999 -9999 -9999 -9999 -9999 -9999 -9999 -9999 -9999 -9999 -9999 -9999 -9999 -9999 -9999 -9999 -9999 -9999 -9999 -

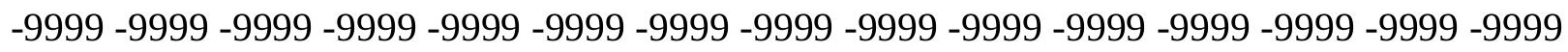
-9999 -9999 -9999 -9999 -9999 -9999 -9999 -9999 -9999 -9999 -9999 -9999 -9999 -9999 -9999 -9999 -9999 -9999 -9999 -9999 -9999 -9999 -9999 -9999 -9999 -9999 -9999 -9999 -9999 -9999 -9999 -9999 -9999 -9999 -9999 -9999 -9999 -9999 -9999 -9999 -9999 -9999 -9999 -9999 -9999 -9999 -9999 -9999 -9999 -9999 -9999 -9999 -9999 -9999 -9999 -9999 -9999 -9999 -9999 -9999 -9999 -9999 -9999 -9999 -9999 -9999 -9999 -9999 -9999 -9999 -9999 -9999 -9999 -999 -

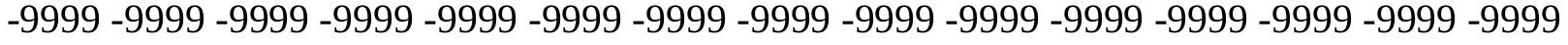
-9999 -9999 -9999 -9999 -9999 -9999 -9999 -9999 -9999 -9999 -9999 -9999 -9999 -9999 -9999 -

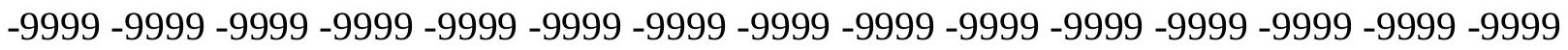

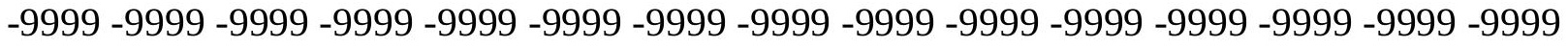

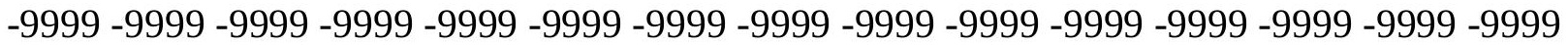

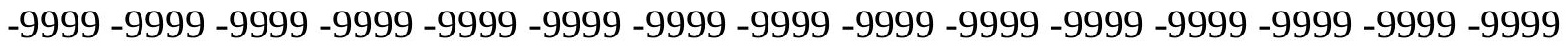

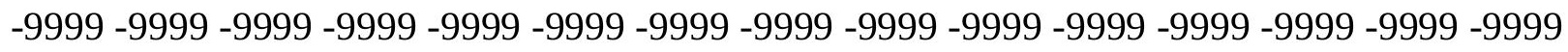

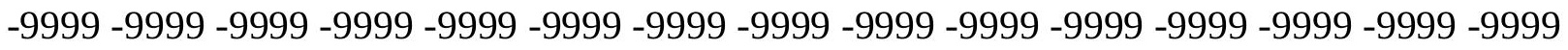

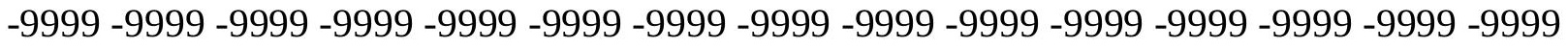
-9999 -9999 -9999 -9999 -9999 -9999 -9999 -9999 -9999 -9999 -9999 -9999 -9999 -9999 -9999 -

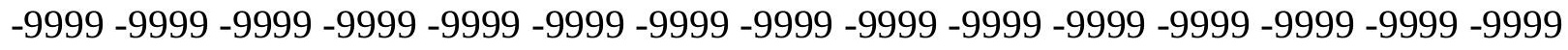

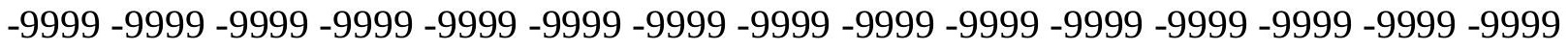
-9999 -9999 -9999 -9999 -9999 -9999 -9999 -9999 -9999 -9999 -9999 -9999 -9999 -9999 -9999 -9999 -9999 -9999 -9999 -9999 -9999 -9999 -9999 -9999-9999 -9999 -9999 -9999 -9999 -9999 -9999 -9999 -9999 -9999 -9999 -9999 -9999 -9999 -9999 -9999 -9999 -9999 -9999 -9999 -9999 -

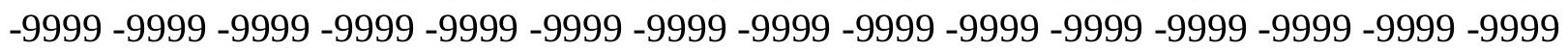


-9999 -9999 -9999 -9999 -9999 -9999 -9999 -9999 -9999 -9999 -9999 -9999 -9999 -9999 -9999 -9999 -9999 -9999 -9999 -9999 -9999 -9999 -9999 -9999 -9999 -9999 -9999 -9999 -9999 -9999 -

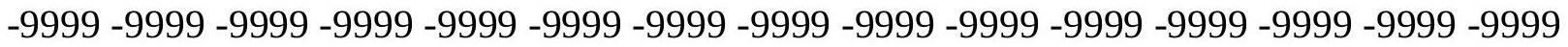
-9999 -9999 -9999 -9999 -9999 -9999 -9999 -9999 -9999 -9999 -9999 -9999 -9999 -9999 -9999 -9999 -9999 -9999 -9999 -9999 -9999 -9999 -9999 -9999-9999 -9999 -9999 -9999 -9999 -9999 -9999 -9999 -9999 -9999 -9999 -9999 -9999 -9999 -9999 -9999 -9999 -9999 -9999 -9999 -9999 -

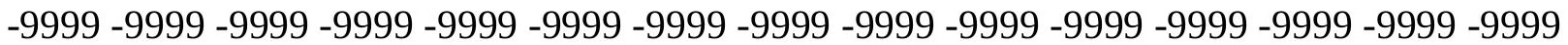
-9999 -9999 -9999 -9999 -9999 -9999 -9999 -9999 -9999 -9999 -9999 -9999 -9999 -9999 -9999 -9999 -9999 -9999 -9999 -9999 -9999 -9999 -9999 -9999 -9999 -9999 -9999 -9999 -9999 -9999 -9999 -9999 -9999 -9999 -9999 -9999 -9999 -9999 -9999 -9999 -9999 -9999 -9999 -9999 -9999 -9999 -9999 -9999 -9999 -9999 -9999 -9999 -9999 -9999 -9999 -9999 -9999 -9999 -9999 -9999 -9999 -9999 -9999 -9999 -9999 -9999 -9999 -9999 -9999 -9999 -9999 -9999 -9999 -9999 -9999 -9999 -9999 -9999 -9999 -9999 -9999 -9999 -9999 -9999 -9999 -9999 -9999 -9999 -9999 -9999 -9999 -9999 -9999 -9999 -9999 -9999 -9999 -9999 -9999 -9999 -9999 -9999 -9999 -9999 -9999 -9999 -9999 -9999 -9999 -9999 -9999 -9999 -9999 -9999 -9999 -9999 -9999 -9999 -9999 -

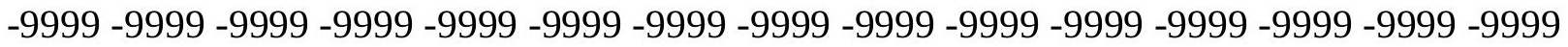
-9999 -9999 -9999 -9999 -9999 -9999 -9999 -9999 -9999 -9999 -9999 -9999 -9999 -9999 -9999 -9999 -9999 -9999 -9999 -9999 -9999 -9999 -9999 -9999 -9999 -9999 -9999 -9999 -9999 -9999 -9999 -9999 -9999 -9999 -9999 -9999 -9999 -9999 -9999 -9999 -9999 -9999 -9999 -9999 -9999 -

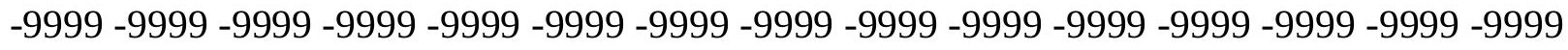

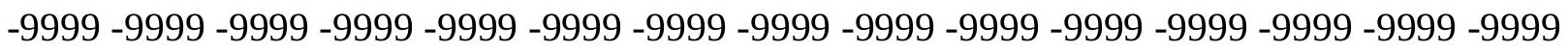
-9999 -9999 -9999 -9999 -9999 -9999 -9999 -9999 -9999 -9999 -9999 -9999 -9999 -9999 - 9999 -9999 -9999 -9999 -9999 -9999 -9999 -9999 -9999 -9999 -9999 -9999 -9999 -9999 -9999 -9999 -9999 -9999 -9999 -9999 -9999 -9999 -9999 -9999 -9999 -9999 -9999 -9999 -9999 -9999 -9999 -

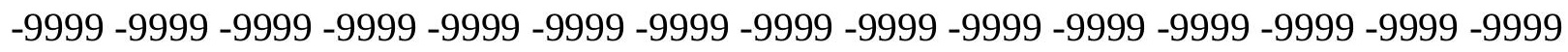
-9999 -9999 -9999 -9999 -9999 -9999 -9999 -9999 -9999 -9999 -9999 -9999 -9999 -9999 -9999 -9999 -9999 -9999 -9999 -9999 -9999 -9999 -9999 -9999 -9999 -9999 -9999 -9999 -9999 -9999 -

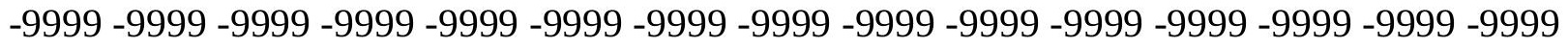
-9999 -9999 -9999 -9999 -9999 -9999 -9999 -9999 -9999 -9999 -9999 -9999 -9999 -9999 -9999 -9999 -9999 -9999 -9999 -9999 -9999 -9999 -9999 -9999 -9999 -9999 -9999 -9999 -9999 -999 -9999 -9999 -9999 -9999 -9999 -9999 -9999 -9999 -9999 -9999 -9999 -9999 -9999 -9999 -9999 -9999 -9999 -9999 -9999 -9999 -9999 -9999 -9999 -9999 -9999 -9999 -9999 -9999 -9999 -9999 -

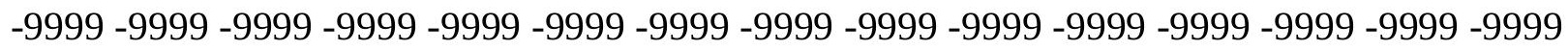

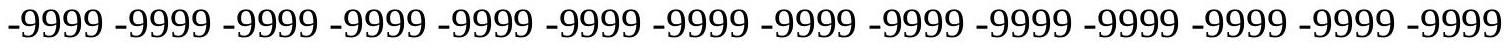
-9999 -9999 -9999 -9999 -9999 -9999 -9999 -9999 -9999 -9999 -9999 -9999 -9999 -9999 -9999

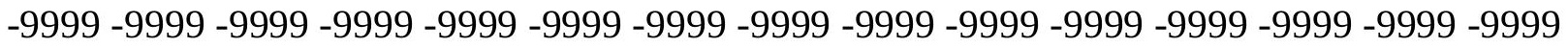

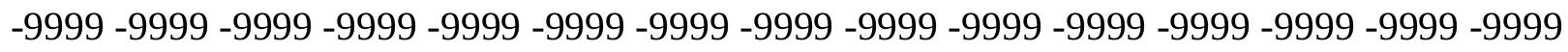

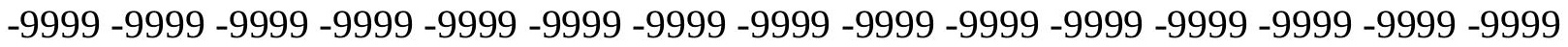

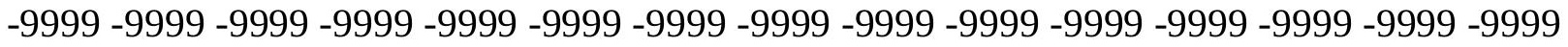
-9999 -9999 -9999 -9999 -9999 -9999 -9999 -9999 -9999 -9999 -9999 -9999 -9999 -9999 -9999 -

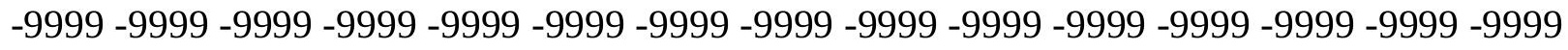

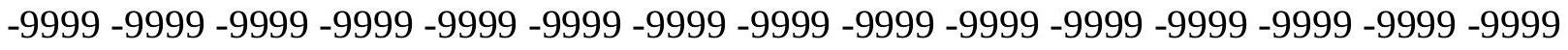
-9999 -9999 -9999 -9999 -9999 -9999 -9999 -9999 -9999 -9999 -9999 -9999 -9999 -9999 -9999 -9999 -9999 -9999 -9999 -9999 -9999 -9999 -9999 -9999-9999 -9999 -9999 -9999 -9999 -9999 -9999 -9999 -9999 -9999 -9999 -9999 -9999 -9999 -9999 -9999 -9999 -9999 -9999 -9999 -9999 -

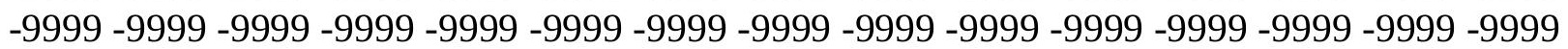


-9999 -9999 -9999 -9999 -9999 -9999 -9999 -9999 -9999 -9999 -9999 -9999 -9999 -9999 -9999 -9999 -9999 -9999 -9999 -9999 -9999 -9999 -9999 -9999 -9999 -9999 -9999 -9999 -9999 -9999 -

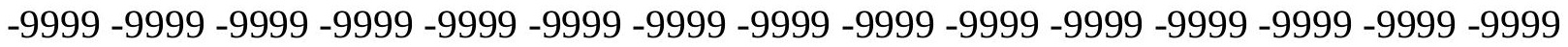
-9999 -9999 -9999 -9999 -9999 -9999 -9999 -9999 -9999 -9999 -9999 -9999 -9999 -9999 -9999 -9999 -9999 -9999 -9999 -9999 -9999 -9999 -9999 -9999-9999 -9999 -9999 -9999 -9999 -9999 -9999 -9999 -9999 -9999 -9999 -9999 -9999 -9999 -9999 -9999 -9999 -9999 -9999 -9999 -9999 -9999 -9999 -9999 -9999 -9999 -9999 -9999 -9999 -9999 -9999 -9999 -9999 -9999 -9999 -9999

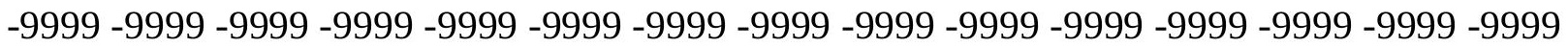

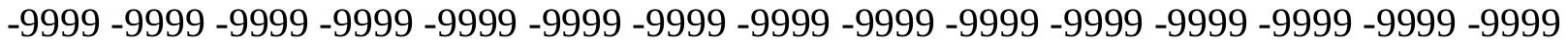
-9999 -9999 -9999 -9999 -9999 -9999 -9999 -9999 -9999 -9999 -9999 -9999 -9999 -9999 -9999 -9999 -9999 -9999 -9999 -9999 -9999 -9999 -9999 -9999 -9999 -9999 -9999 -9999 -9999 -9999 -9999 -9999 -9999 -9999 -9999 -9999 -9999 -9999 -9999 -9999 -9999 -9999 -9999 -9999 -9999 -9999 -9999 -9999 -9999 -9999 -9999 -9999 -9999 -9999 -9999 -9999 -9999 -9999 -9999 -9999 -9999 -9999 -9999 -9999 -9999 -9999 -9999 -9999 -9999 -9999 -9999 -9999 -9999 -9999 -9999 -9999 -9999 -9999 -9999 -9999 -9999 -9999 -9999 -9999 -9999 -9999 -9999 -9999 -9999

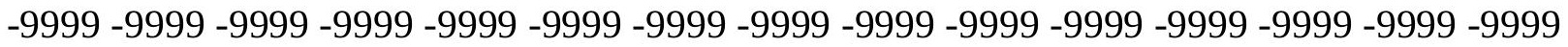
-9999 -9999 -9999 -9999 -9999 -9999 -9999 -9999 -9999 -9999 -9999 -9999 -9999 -9999 -9999 -9999 -9999 -9999 -9999 -9999 -9999 -9999 -9999 -9999 -9999 -9999 -9999 -9999 -9999 -9999 -9999 -9999 -9999 -9999 -9999 -9999 -9999 -9999 -9999 -9999 -9999 -9999 -9999 -9999 -9999 -

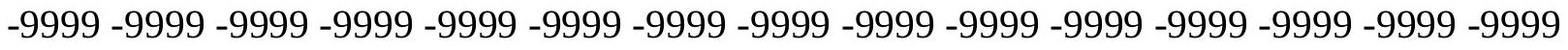

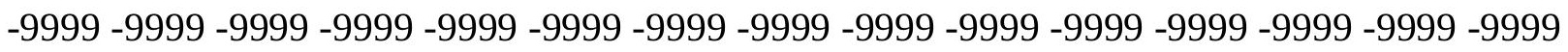
-9999 -9999 -9999 -9999 -9999 -9999 -9999 -9999 -9999 -9999 -9999 -9999 -9999 -9999 -9999 -9999 -9999 -9999 -9999 -9999 -9999 -9999 -9999 -9999 -9999 -9999 -9999 -9999 -9999 -9999 -9999 -9999 -9999 -9999 -9999 -9999 -9999 -9999 -9999 -9999 -9999 -9999 -9999 -9999 -9999 -

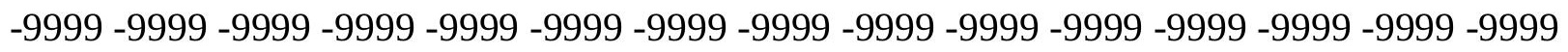
-9999 -9999 -9999 -9999 -9999 -9999 -9999 -9999 -9999 -9999 -9999 -9999 -9999 -9999 -9999 -9999 -9999 -9999 -9999 -9999 -9999 -9999 -9999 -9999 -9999 -9999 -9999 -9999 -9999 -9999 -

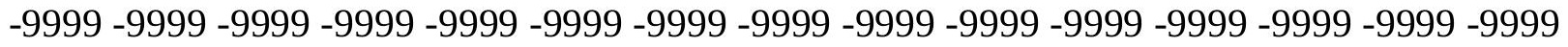
-9999 -9999 -9999 -9999 -9999 -9999 -9999 -9999 -9999 -9999 -9999 -9999 -9999 -9999 -9999 -9999 -9999 -9999 -9999 -9999 -9999 -9999 -9999 -9999 -9999 -9999 -9999 -9999 -9999 -999 -9999 -9999 -9999 -9999 -9999 -9999 -9999 -9999 -9999 -9999 -9999 -9999 -9999 -9999 -9999 -9999 -9999 -9999 -9999 -9999 -9999 -9999 -9999 -9999 -9999 -9999 -9999 -9999 -9999 -9999 -

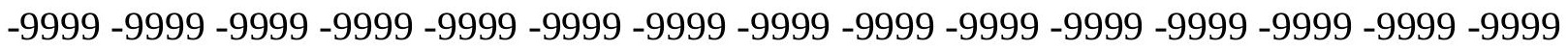

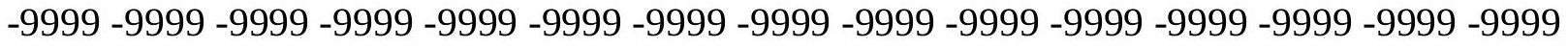

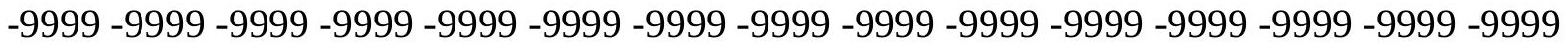

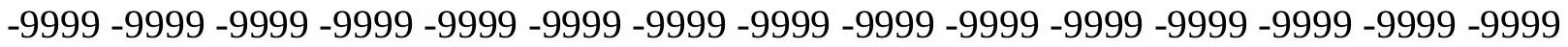

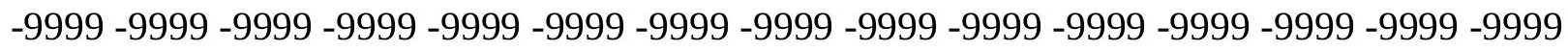

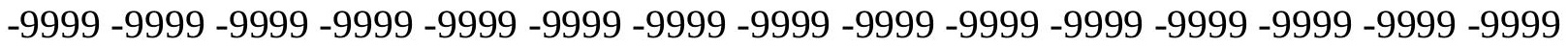
-9999 -9999 -9999 -9999 -9999 -9999 -9999 -9999 -9999 -9999 -9999 -9999 -9999 - 9999 - -999 -9999 -9999 -9999 -9999 -9999 -9999 -9999 -9999 -9999 -9999 -9999 -9999 -9999 -9999 - -999 -

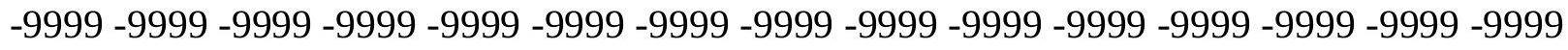

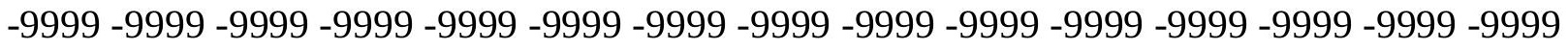
-9999 -9999 -9999 -9999 -9999 -9999 -9999 -9999 -9999 -9999 -9999 -9999 -9999 -9999 -9999 -9999 -9999 -9999 -9999 -9999 -9999 -9999 -9999 -9999-9999 -9999 -9999 -9999 -9999 -9999 -9999 -9999 -9999 -9999 -9999 -9999 -9999 -9999 -9999 -9999 -9999 -9999 -9999 -9999 -9999 -

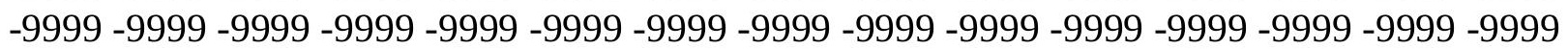


-9999 -9999 -9999 -9999 -9999 -9999 -9999 -9999 -9999 -9999 -9999 -9999 -9999 -9999 -9999 -9999 -9999 -9999 -9999 -9999 -9999 -9999 -9999 -9999 -9999 -9999 -9999 -9999 -9999 -9999 -9999 -9999 -9999 -9999 -9999 -9999 -9999 -9999 -9999 -9999 -9999 -9999 -9999 -9999 -9999 -9999 -9999 -9999 -9999 -9999 -9999 -9999 -9999 -9999 -9999 -9999 -9999 -9999 -9999 -9999 -9999 -9999 -9999 -9999 -9999 -9999 -9999 -9999 -9999 -9999 -9999 -9999 -9999 -9999 -9999 -9999 -9999 -9999 -9999 -9999 -9999 -9999 -9999 -9999 -9999 -9999 -9999 -9999 -9999 -9999 -9999 -9999 -9999 -9999 -9999 -9999 -9999 -9999 -9999 -9999 -9999 -9999 -9999 -9999 -9999 -

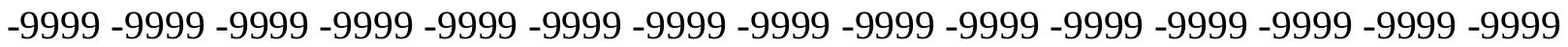
-9999 -9999 -9999 -9999 -9999 -9999 -9999 -9999 -9999 -9999 -9999 -9999 -9999 -9999 -9999 -9999 -9999 -9999 -9999 -9999 -9999 -9999 -9999 -9999 -9999 -9999 -9999 -9999 -9999 -9999 -

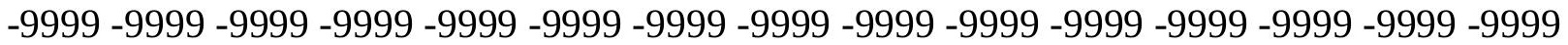
-9999 -9999 -9999 -9999 -9999 -9999 -9999 -9999 -9999 -9999 -9999 -9999 -9999 -9999 -9999 -9999 -9999 -9999 -9999 -9999 -9999 -9999 -9999 -9999 -9999 -9999 -9999 -9999 -9999 -9999 -9999 -9999 -9999 -9999 -9999 -9999 -9999 -9999 -9999 -9999 -9999 -9999 -9999 -9999 -9999 -9999 -9999 -9999 -9999 -9999 -9999 -9999 -9999 -9999 -9999 -9999 -9999 -9999 -9999 -9999

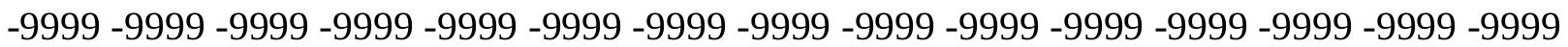
-9999 -9999 -9999 -9999 -9999 -9999 -9999 -9999 -9999 -9999 -9999 -9999 -9999 -9999 -9999 -9999 -9999 -9999 -9999 -9999 -9999 -9999 -9999 -9999 -9999 -9999 -9999 -9999 -9999 -9999 -9999 -9999 -9999 -9999 -9999 -9999 -9999 -9999 -9999 -9999 -9999 -9999 -9999 -9999 -9999 -9999 -9999 -9999 -9999 -9999 -9999 -9999 -9999 -9999 -9999 -9999 -9999 -9999 -9999 -9999 -9999 -9999 -9999 -9999 -9999 -9999 -9999 -9999 -9999 -9999 -9999 -9999 -9999 -9999 -9999 -9999 -9999 -9999 -9999 -9999 -9999 -9999 -9999 -9999 -9999 -9999 -9999 -9999 -9999 -9999 -9999 -9999 -9999 -9999 -9999 -9999 -9999 -9999 -9999 -9999 -9999 -9999 -9999 -9999 -9999 -9999 -9999 -9999 -9999 -9999 -9999 -9999 -9999 -9999 -9999 -9999 -9999 -9999 -9999 -9999 -9999 -9999 -9999 -9999 -9999 -9999 -9999 -9999 -9999 -9999 -9999 -9999 -9999 -9999 -9999 -9999 -9999 -9999 -9999 -9999 -9999 -9999 -9999 -9999 -9999 -9999 -9999 -9999 -9999 -9999 -9999 -9999 -9999 -9999 -9999 -9999 -9999 -9999 -9999 -9999 -9999 -9999 -9999 -9999 -9999 -9999 -9999 -9999 -9999 -9999 -9999 -9999 -9999 -9999 -9999 -9999 -9999 -9999 -9999

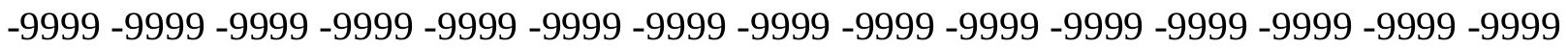
-9999 -9999 -9999 -9999 -9999 -9999 -9999 -9999 -9999 -9999 -9999 -9999 -9999 -9999 -9999 -9999 -9999 -9999 -9999 -9999 -9999 -9999 -9999 -9999 -9999 -9999 -9999 -9999 -9999 -9999 -

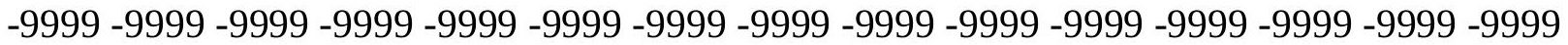
-9999 -9999 -9999 -9999 -9999 -9999 -9999 -9999 -9999 -9999 -9999 -9999 -9999 -9999 -9999 -9999 -9999 -9999 -9999 -9999 -9999 -9999 -9999 -9999 -9999 -9999 -9999 -9999 -9999 -9999 -9999 -9999 -9999 -9999 -9999 -9999 -9999 -9999 -9999 -9999 -9999 -9999 -9999 -9999 -9999 -9999 -9999 -9999 -9999 -9999 -9999 -9999 -9999 -9999 -9999 -9999 -9999 -9999 -9999 -9999 -9999 -9999 -9999 -9999 -9999 -9999 -9999 -9999 -9999 -9999 -9999 -9999 -9999 -9999 -9999

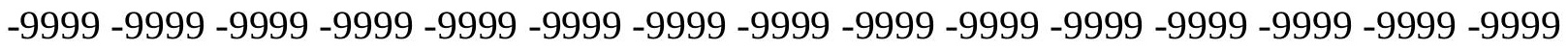
-9999 -9999 -9999 -9999 -9999 -9999 -9999 -9999 -9999 -9999 -9999 -9999 -9999 -9999 -9999 -9999 -9999 -9999 -9999 -9999 -9999 -9999 -9999 -9999 -9999 -9999 -9999 -9999 -9999 -9999 -9999 -9999 -9999 -9999 -9999 -9999 -9999 -9999 -9999 -9999 -9999 -9999 -9999 -9999 -9999 -999 -9999 -9999 -9999 -9999 -9999 -9999 -9999 -9999 -9999 -9999 -9999 -9999 -9999 -9999 -9999 -9999 -9999 -9999 -9999 -9999 -9999 -9999 -9999 -9999 -9999 -9999 -9999 -9999 -9999 -9999 -9999 -9999 -9999 -9999 -9999 -9999 -9999 -9999 -9999 -9999 -9999 -9999 -9999 -9999 -9999 -9999 -9999 -9999 -9999 -9999 -9999 -9999 -9999 -9999 -9999 -9999 -9999 -9999 -9999 -9999 -9999 -9999 -9999 -9999 -9999 -9999 -9999 -9999 -9999 -9999 -9999 -9999 -9999 -9999 
-9999 -9999 -9999 -9999 -9999 -9999 -9999 -9999 -9999 -9999 -9999 -9999 -9999 -9999 -9999 -9999 -9999 -9999 -9999 -9999 -9999 -9999 -9999 -9999 -9999 -9999 -9999 -9999 -9999 -9999 -

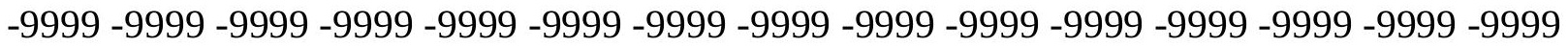
-9999 -9999 -9999 -9999 -9999 -9999 -9999 -9999 -9999 -9999 -9999 -9999 -9999 -9999 -9999 -9999 -9999 -9999 -9999 -9999 -9999 -9999 -9999 -9999-9999 -9999 -9999 -9999 -9999 -9999 -9999 -9999 -9999 -9999 -9999 -9999 -9999 -9999 -9999 -9999 -9999 -9999 -9999 -9999 -9999 -9999 -9999 -9999 -9999 -9999 -9999 -9999 -9999 -9999 -9999 -9999 -9999 -9999 -9999 -9999

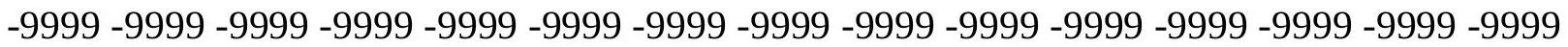

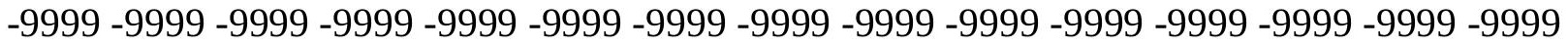
-9999 -9999 -9999 -9999 -9999 -9999 -9999 -9999 -9999 -9999 -9999 -9999 -9999 -9999 -9999 -9999 -9999 -9999 -9999 -9999 -9999 -9999 -9999 -9999 -9999 -9999 -9999 -9999 -9999 -9999 -9999 -9999 -9999 -9999 -9999 -9999 -9999 -9999 -9999 -9999 -9999 -9999 -9999 -9999 -9999 -9999 -9999 -9999 -9999 -9999 -9999 -9999 -9999 -9999 -9999 -9999 -9999 -9999 -9999 -9999 -

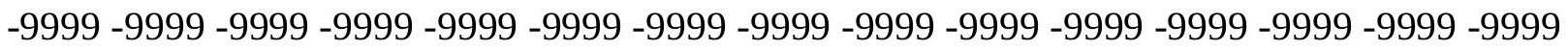
-9999 -9999 -9999 -9999 -9999 -9999 -9999 -9999 -9999 -9999 -9999 -9999 -9999 -9999 -9999 -

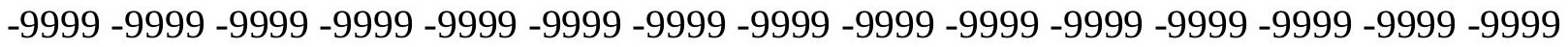
-9999 -9999 -9999 -9999 -9999 -9999 -9999 -9999 -9999 -9999 -9999 -9999 -9999 -9999 -9999 -9999 -9999 -9999 -9999 -9999 -9999 -9999 -9999 -9999 -9999 -9999 -9999 -9999 -9999 -9999 -9999 -9999 -9999 -9999 -9999 -9999 -9999 -9999 -9999 -9999 -9999 -9999 -9999 -9999 -9999 -

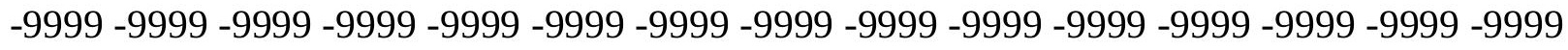

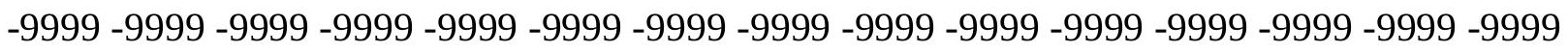

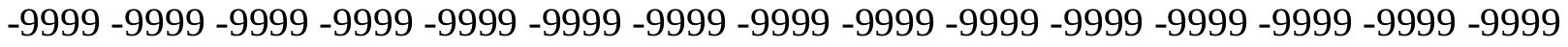
-9999 -9999 -9999 -9999 -9999 -9999 -9999 -9999 -9999 -9999 -9999 -9999 -9999 -9999 -9999 -9999 -9999 -9999 -9999 -9999 -9999 -9999 -9999 -9999 -9999 -9999 -9999 -9999 -9999 -9999 -

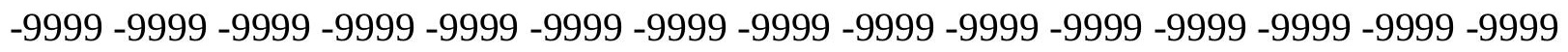
-9999 -9999 -9999 -9999 -9999 -9999 -9999 -9999 -9999 -9999 -9999 -9999 -9999 -9999 -9999 -9999 -9999 -9999 -9999 -9999 -9999 -9999 -9999 -9999 -9999 -9999 -9999 -9999 -9999 -

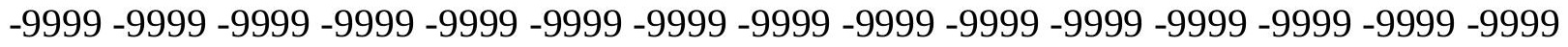
-9999 -9999 -9999 -9999 -9999 -9999 -9999 -9999 -9999 -9999 -9999 -9999 -9999 -9999 -9999 -9999 -9999 -9999 -9999 -9999 -9999 -9999 -9999 -9999 -9999 -9999 -9999 -9999 -9999 -999 -

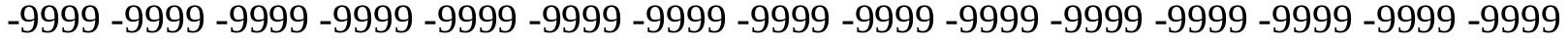
-9999 -9999 -9999 -9999 -9999 -9999 -9999 -9999 -9999 -9999 -9999 -9999 -9999 -9999 -9999 -

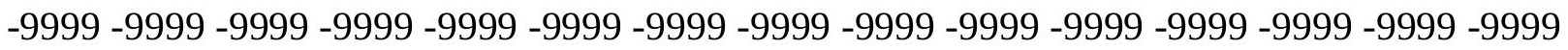

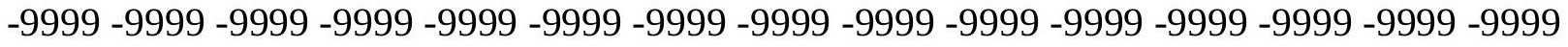

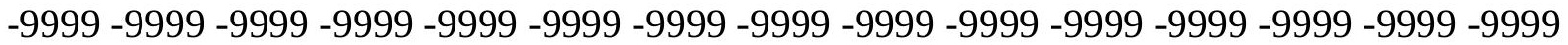
-9999 -9999 -9999 -9999 -9999 -9999 -9999 -9999 -9999 -9999 -9999 -9999 -9999 -9999 -9999

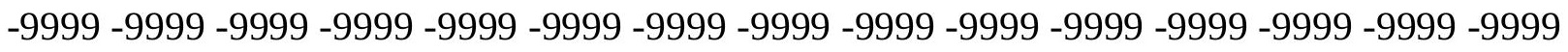

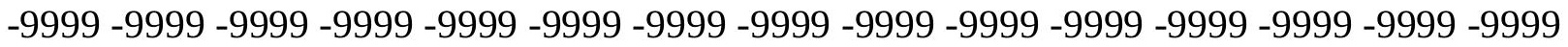
-9999 -9999 -9999 -9999 -9999 -9999 -9999 -9999 -9999 -9999 -9999 -9999 -9999 - 9999 - -999 -9999 -9999 -9999 -9999 -9999 -9999 -9999 -9999 -9999 -9999 -9999 -9999 -9999 -9999 -9999 -

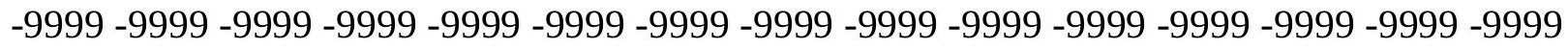

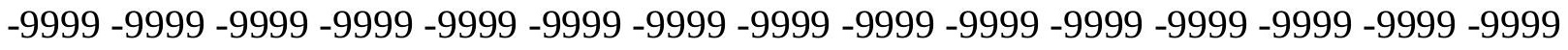
-9999 -9999 -9999 -9999 -9999 -9999 -9999 -9999 -9999 -9999 -9999 -9999 -9999 -9999 -9999 -9999 -9999 -9999 -9999 -9999 -9999 -9999 -9999 -9999-9999 -9999 -9999 -9999 -9999 -9999 -9999 -9999 -9999 -9999 -9999 -9999 -9999 -9999 -9999 -9999 -9999 -9999 -9999 -9999 -9999 -

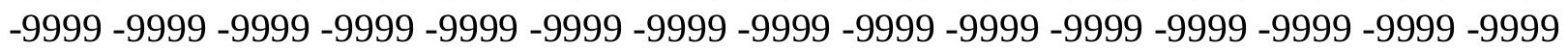


-9999 -9999 -9999 -9999 -9999 -9999 -9999 -9999 -9999 -9999 -9999 -9999 -9999 -9999 -9999 -9999 -9999 -9999 -9999 -9999 -9999 -9999 -9999 -9999 -9999 -9999 -9999 -9999 -9999 -9999 -9999 -9999 -9999 -9999 -9999 -9999 -9999 -9999 -9999 -9999 -9999 -9999 -9999 -9999 - 9999 -9999 -9999 -9999 -9999 -9999 -9999 -9999 -9999 -9999 -9999 -9999 -9999 -9999 -9999 -9999 -9999 -9999 -9999 -9999 -9999 -9999 -9999 -9999 -9999 -9999 -9999 -9999 -9999 -9999 - -9999 -9999 -9999 -9999 -9999 -9999 -9999 -9999 -9999 -9999 -9999 -9999 -9999 -9999 -9999 -9999 -9999 -9999 -9999 -9999 -9999 -9999 -9999 -9999 -9999 -9999 -9999 -9999 -9999 -9999

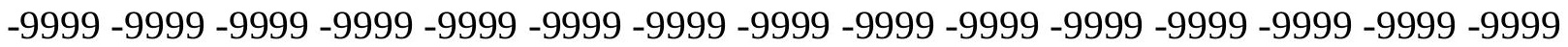

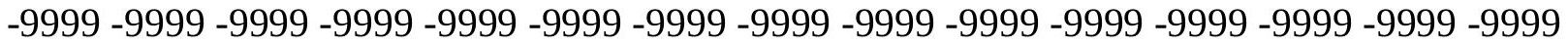
-9999 -9999 -9999 -9999 -9999 -9999 -9999 -9999 -9999 -9999 -9999 -9999 -9999 -9999 -9999

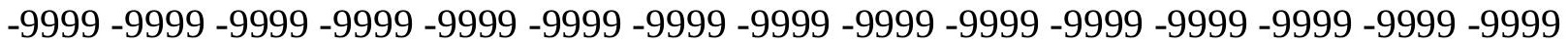
-9999 -9999 -9999 -9999 -9999 -9999 -9999 -9999 -9999 -9999 -9999 -9999 -9999 -9999 -9999 -9999 -9999 -9999 -9999 -9999 -9999 -9999 -9999 -9999 -9999 -9999 -9999 -9999 -9999 -9999 -9999 -9999 -9999 -9999 -9999 -9999 -9999 -9999 -9999 -9999 -9999 -9999 -9999 -9999 - -9999 -9999 -9999 -9999 -9999 -9999 -9999 -9999 -9999 -9999 -9999 -9999 -9999 -9999 -9999 -9999

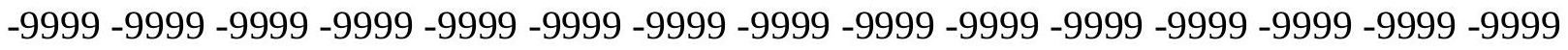
-9999 -9999 -9999 -9999 -9999 -9999 -9999 -9999 -9999 -9999 -9999 -9999 -9999 -9999 -9999 -9999 -9999 -9999 -9999 -9999 -9999 -9999 -9999 -9999 -9999 -9999 -9999 -9999 -9999 -9999 -9999 -9999 -9999 -9999 -9999 -9999 -9999 -9999 -9999 -9999 -9999 -9999 -9999 -9999 -9999 -

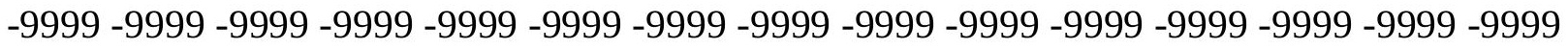
-9999 -9999 -9999 -9999 -9999 -9999 -9999 -9999 -9999 -9999 -9999 -9999 -9999 -9999 -9999 -999 -9999 -9999 -9999 -9999 -9999 -9999 -9999 -9999 -9999 -9999 -9999 -9999 -9999 -9999 -9999 -9999 -9999 -9999 -9999 -9999 -9999 -9999 -9999 -9999 -9999 -9999 -9999 -9999 -9999 -9999 -9999 -9999 -9999 -9999 -9999 -9999 -9999 -9999 -9999 -9999 -9999 -9999 -9999 -9999 -9999 -9999 -9999 -9999 -9999 -9999 -9999 -9999 -9999 -9999 -9999 -9999 -9999 -9999 -9999 -9999 -9999 -9999 -9999 -9999 -9999 -9999 -9999 -9999 -9999 -9999 -9999 -9999 -9999 -9999 -9999 -9999 -9999 -9999 -9999 -9999 -9999 -9999 -9999 -9999 -9999 -9999 -9999 -9999 -9999 -9999 -9999 -9999 -9999 -9999 -9999 -9999 -9999 -9999 -9999 -9999 -9999 -9999 -9999 -9999 -9999 -9999 -9999 -9999 -9999 -9999 -9999 -9999 -9999 -9999 -9999 -9999 -9999 -9999 -9999 -9999 -9999 -9999 -9999 -9999 -9999 -9999 -9999 -9999 -9999 -9999 -9999 -9999 -9999 -9999 -999 -9999 -9999 -9999 -9999 -9999 -9999 -9999 -9999 -9999 -9999 -9999 -9999 -9999 -9999 -9999 -9999 -9999 -9999 -9999 -9999 -9999 -9999 -9999 -9999 -9999 -9999 -9999 -9999 -9999 -

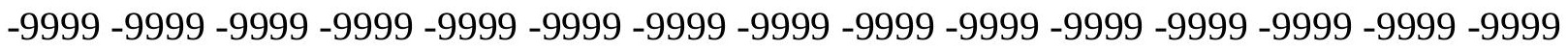

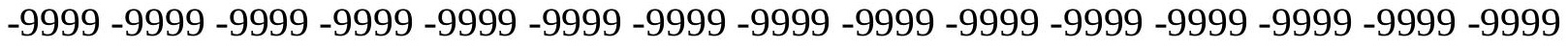

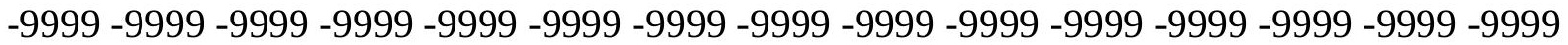
-9999 -9999 -9999 -9999 -9999 -9999 -9999 -9999 -9999 -9999 -9999 -9999 -9999 -9999 -9999 -

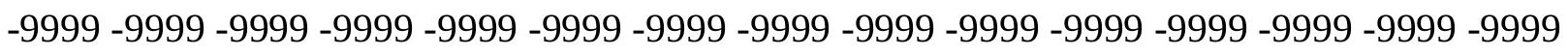

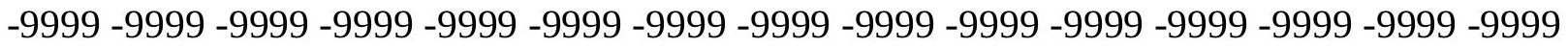

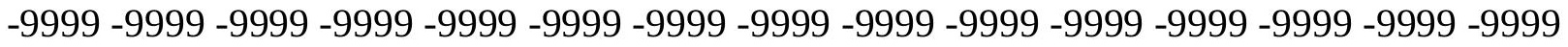
-9999 -9999 -9999 -9999 -9999 -9999 -9999 -9999 -9999 -9999 -9999 -9999 -9999 -9999 -9999 -

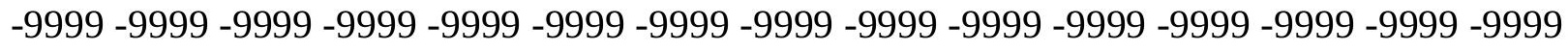

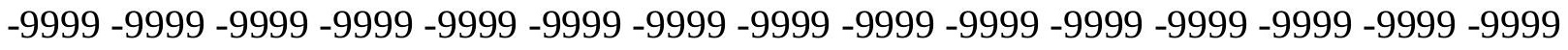
-9999 -9999 -9999 -9999 -9999 -9999 -9999 -9999 -9999 -9999 -9999 -9999 -9999 -9999 -9999 -9999 -9999 -9999 -9999 -9999 -9999 -9999 -9999 -9999-9999 -9999 -9999 -9999 -9999 -9999 -9999 -9999 -9999 -9999 -9999 -9999 -9999 -9999 -9999 -9999 -9999 -9999 -9999 -9999 -9999 -

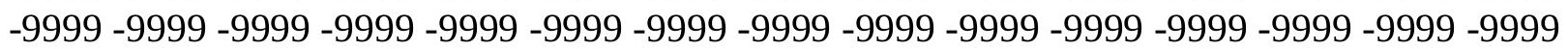


-9999 -9999 -9999 -9999 -9999 -9999 -9999 -9999 -9999 -9999 -9999 -9999 -9999 -9999 -9999 -9999 -9999 -9999 -9999 -9999 -9999 -9999 -9999 -9999 -9999 -9999 -9999 -9999 -9999 -9999 -

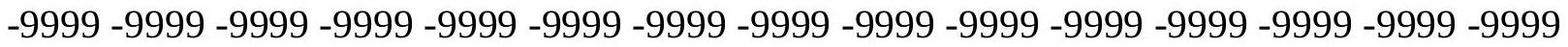
-9999 -9999 -9999 -9999 -9999 -9999 -9999 -9999 -9999 -9999 -9999 -9999 -9999 -9999 -9999 -9999 -9999 -9999 -9999 -9999 -9999 -9999 -9999 -9999-9999 -9999 -9999 -9999 -9999 -9999 -9999 -9999 -9999 -9999 -9999 -9999 -9999 -9999 -9999 -9999 -9999 -9999 -9999 -9999 -9999 -9999 -9999 -9999 -9999 -9999 -9999 -9999 -9999 -9999 -9999 -9999 -9999 -9999 -9999 -9999

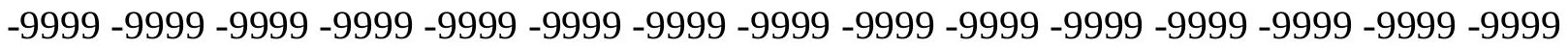

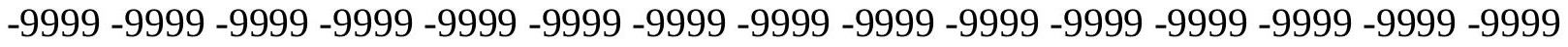
-9999 -9999 -9999 -9999 -9999 -9999 -9999 -9999 -9999 -9999 -9999 -9999 -9999 -9999 -9999 -9999 -9999 -9999 -9999 -9999 -9999 -9999 -9999 -9999 -9999 -9999 -9999 -9999 -9999 -9999 -9999 -9999 -9999 -9999 -9999 -9999 -9999 -9999 -9999 -9999 -9999 -9999 -9999 -9999 -9999 -9999 -9999 -9999 -9999 -9999 -9999 -9999 -9999 -9999 -9999 -9999 -9999 -9999 -9999 -9999 -9999 -9999 -9999 -9999 -9999 -9999 -9999 -9999 -9999 -9999 -9999 -9999 -9999 - 9999 -9999 -9999 -9999 -9999 -9999 -9999 -9999 -9999 -9999 -9999 -9999 -9999 -9999 -9999 -9999

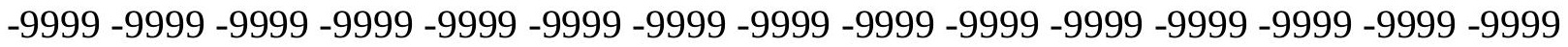
-9999 -9999 -9999 -9999 -9999 -9999 -9999 -9999 -9999 -9999 -9999 -9999 -9999 -9999 -9999 -9999 -9999 -9999 -9999 -9999 -9999 -9999 -9999 -9999 -9999 -9999 -9999 -9999 -9999 -9999 -9999 -9999 -9999 -9999 -9999 -9999 -9999 -9999 -9999 -9999 -9999 -9999 -9999 -9999 -9999 -

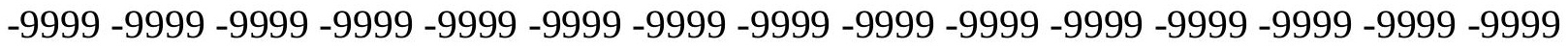

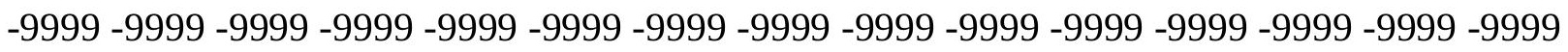
-9999 -9999 -9999 -9999 -9999 -9999 -9999 -9999 -9999 -9999 -9999 -9999 -9999 -9999 -9999 -9999 -9999 -9999 -9999 -9999 -9999 -9999 -9999 -9999 -9999 -9999 -9999 -9999 -9999 -9999 -9999 -9999 -9999 -9999 -9999 -9999 -9999 -9999 -9999 -9999 -9999 -9999 -9999 -9999 -9999 -

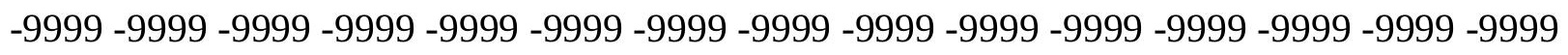
-9999 -9999 -9999 -9999 -9999 -9999 -9999 -9999 -9999 -9999 -9999 -9999 -9999 -9999 -9999 -9999 -9999 -9999 -9999 -9999 -9999 -9999 -9999 -9999 -9999 -9999 -9999 -9999 -9999 -9999 -

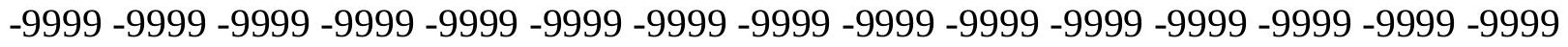
-9999 -9999 -9999 -9999 -9999 -9999 -9999 -9999 -9999 -9999 -9999 -9999 -9999 -9999 -9999 -9999 -9999 -9999 -9999 -9999 -9999 -9999 -9999 -9999 -9999 -9999 -9999 -9999 -9999 -999 -9999 -9999 -9999 -9999 -9999 -9999 -9999 -9999 -9999 -9999 -9999 -9999 -9999 -9999 -9999 -9999 -9999 -9999 -9999 -9999 -9999 -9999 -9999 -9999 -9999 -9999 -9999 -9999 -9999 -9999 -

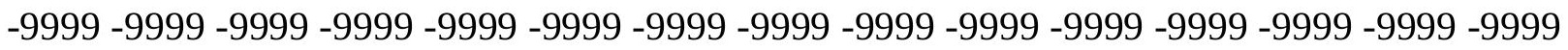

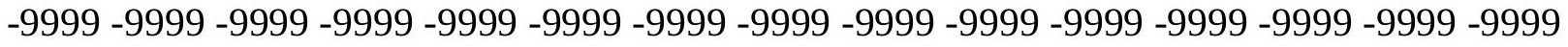

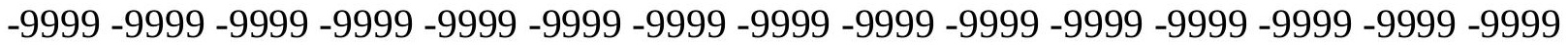

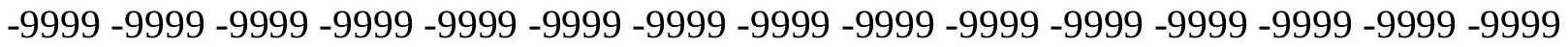

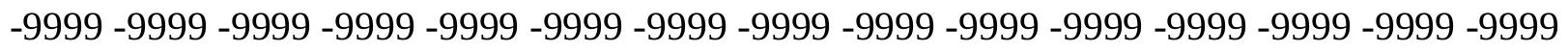

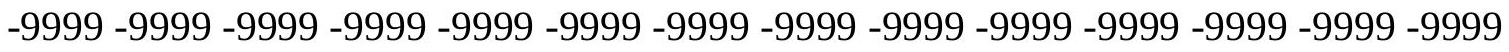
-9999 -9999 -9999 -9999 -9999 -9999 -9999 -9999 -9999 -9999 -9999 -9999 -9999 -9999 -9999 -9999 -9999 -9999 -9999 -9999 -9999 -9999 -9999 -9999 -9999 -9999 -9999 -9999 -9999 -9999 -

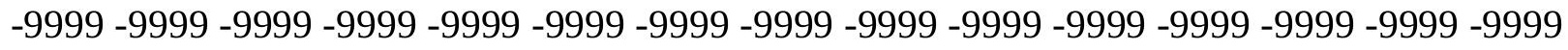

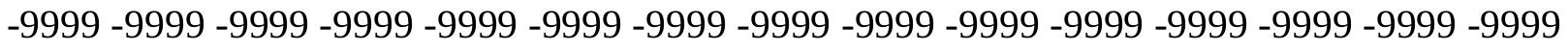
-9999 -9999 -9999 -9999 -9999 -9999 -9999 -9999 -9999 -9999 -9999 -9999 -9999 -9999 -9999 -9999 -9999 -9999 -9999 -9999 -9999 -9999 -9999 -9999-9999 -9999 -9999 -9999 -9999 -9999 -9999 -9999 -9999 -9999 -9999 -9999 -9999 -9999 -9999 -9999 -9999 -9999 -9999 -9999 -9999 -

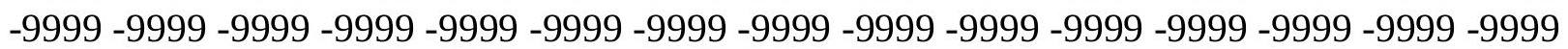


-9999 -9999 -9999 -9999 -9999 -9999 -9999 -9999 -9999 -9999 -9999 -9999 -9999 -9999 -9999 -9999 -9999 -9999 -9999 -9999 -9999 -9999 -9999 -9999 -9999 -9999 -9999 -9999 -9999 -9999 -9999 -9999 -9999 -9999 -9999 -9999 -9999 -9999 -9999 -9999 -9999 -9999 -9999 -9999 - 9999 -9999 -9999 -9999 -9999 -9999 -9999 -9999 -9999 -9999 -9999 -9999 -9999 -9999 -9999 -9999 -9999 -9999 -9999 -9999 -9999 -9999 -9999 -9999 -9999 -9999 -9999 -9999 -9999 -9999 -9999 -9999 -9999 -9999 -9999 -9999 -9999 -9999 -9999 -9999 -9999 -9999 -9999 -9999 -9999 -9999 -9999 -9999 -9999 -9999 -9999 -9999 -9999 -9999 -9999 -9999 -9999 -9999 -9999 -9999 -9999

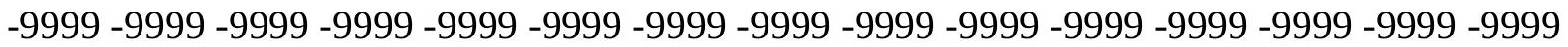
-9999 -9999 -9999 -9999 -9999 -9999 -9999 -9999 -9999 -9999 -9999 -9999 -9999 -9999 -9999 -9999 -9999 -9999 -9999 -9999 -9999 -9999 -9999 -9999 -9999 -9999 -9999 -9999 -9999 -9999

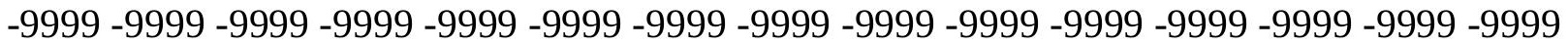
-9999 -9999 -9999 -9999 -9999 -9999 -9999 -9999 -9999 -9999 -9999 -9999 -9999 -9999 -9999 -9999 -9999 -9999 -9999 -9999 -9999 -9999 -9999 -9999 -9999 -9999 -9999 -9999 -9999 -9999 -

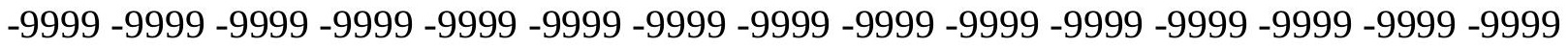
-9999 -9999 -9999 -9999 -9999 -9999 -9999 -9999 -9999 -9999 -9999 -9999 -9999 -9999 -9999

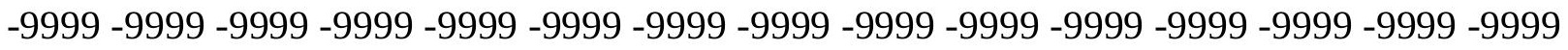
-9999 -9999 -9999 -9999 -9999 -9999 -9999 -9999 -9999 -9999 -9999 -9999 -9999 -9999 -9999 -9999 -9999 -9999 -9999 -9999 -9999 -9999 -9999 -9999 -9999 -9999 -9999 -9999 -9999 - -999 -9999 -9999 -9999 -9999 -9999 -9999 -9999 -9999 -9999 -9999 -9999 -9999 -9999 -9999 -9999 -9999 -9999 -9999 -9999 -9999 -9999 -9999 -9999 -9999 -9999 -9999 -9999 -9999 -9999 -9999 -9999 -9999 -9999 -9999 -9999 -9999 -9999 -9999 -9999 -9999 -9999 -9999 -9999 -9999 -9999 -999 -9999 -9999 -9999 -9999 -9999 -9999 -9999 -9999 -9999 -9999 -9999 -9999 -9999 -9999 -9999 -9999 -9999 -9999 -9999 -9999 -9999 -9999 -9999 -9999 -9999 -9999 -9999 -9999 -9999 -9999 -9999 -9999 -9999 -9999 -9999 -9999 -9999 -9999 -9999 -9999 -9999 -9999 -9999 -9999 -9999 -9999 -9999 -9999 -9999 -9999 -9999 -9999 -9999 -9999 -9999 -9999 -9999 -9999 -9999 -9999 -9999 -9999 -9999 -9999 -9999 -9999 -9999 -9999 -9999 -9999 -9999 -9999 -9999 -9999 -9999 -9999 -9999 -9999 -9999 -9999 -9999 -9999 -9999 -9999 -9999 -9999 -9999 -9999 -9999 -9999 -9999 -9999 -9999 -9999 -9999 -9999 -9999 -9999 -9999 -9999 -9999 -9999 -9999 -9999 -9999 -9999 -9999 -9999 -9999 -9999 -9999 -9999 -9999 -9999 -9999 -9999 -9999 -9999 -9999 -9999 -9999 -9999 -9999 -9999 -9999 -9999 -9999 -9999 -9999 -9999 -9999 -9999 -9999 -9999 -999 -9999 -9999 -9999 -9999 -9999 -9999 -9999 -9999 -9999 -9999 -9999 -9999 -9999 -9999 -9999 -9999 -9999 -9999 -9999 -9999 -9999 -9999 -9999 -9999 -9999 -9999 -9999 -9999 -9999 -9999 -

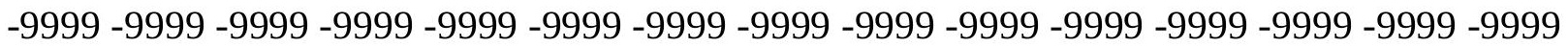

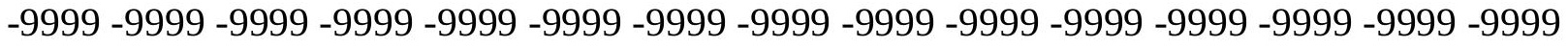

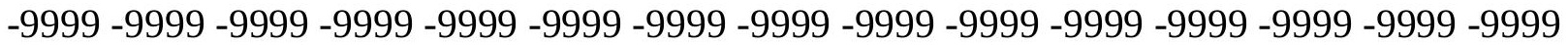
-9999 -9999 -9999 -9999 -9999 -9999 -9999 -9999 -9999 -9999 -9999 -9999 -9999 -9999 -9999

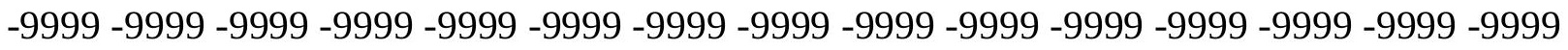

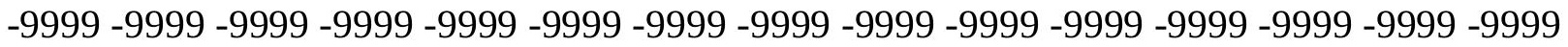

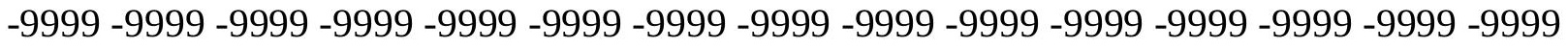
-9999 -9999 -9999 -9999 -9999 -9999 -9999 -9999 -9999 -9999 -9999 -9999 -9999 -9999 -9999 -

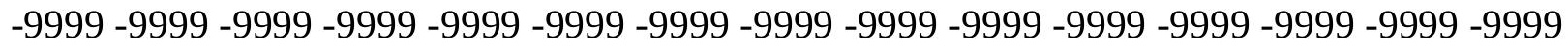

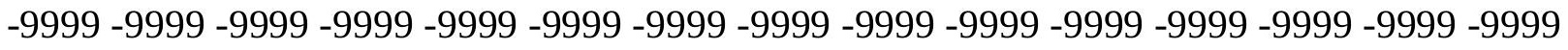
-9999 -9999 -9999 -9999 -9999 -9999 -9999 -9999 -9999 -9999 -9999 -9999 -9999 -9999 -9999 -9999 -9999 -9999 -9999 -9999 -9999 -9999 -9999 -9999 -9999 -9999 -9999 -9999 - -9999 -9999 -9999 -9999 -9999 -9999 -9999 -9999 -9999 -9999 -9999 -9999 -9999 -9999 -9999 -9999 -

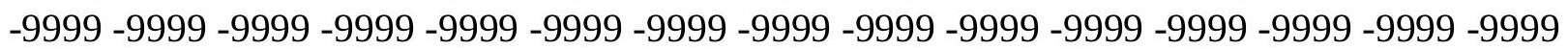


-9999 -9999 -9999 -9999 -9999 -9999 -9999 -9999 -9999 -9999 -9999 -9999 -9999 -9999 -9999 -9999 -9999 -9999 -9999 -9999 -9999 -9999 -9999 -9999 -9999 -9999 -9999 -9999 -9999 -9999 -9999 -9999 -9999 -9999 -9999 -9999 -9999 -9999 -9999 -9999 -9999 -9999 -9999 -9999 - 9999 -9999 -9999 -9999 -9999 -9999 -9999 -9999 -9999 -9999 -9999 -9999 -9999 -9999 -9999 -9999 -9999 -9999 -9999 -9999 -9999 -9999 -9999 -9999 -9999-9999 -9999 -9999 -9999 -9999 -9999 -9999 -9999 -9999 -9999 -9999 -9999 -9999 -9999 -9999 -9999 -9999 -9999 -9999 -9999 -9999 -9999 -9999 -9999 -9999 -9999 -9999 -9999 -9999 -9999 -9999 -9999 -9999 -9999 -9999 -9999

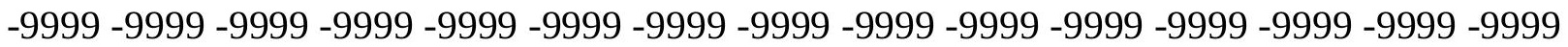

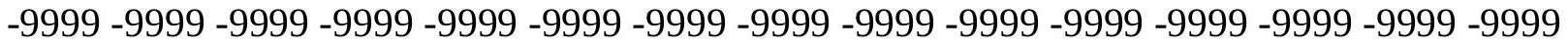
-9999 -9999 -9999 -9999 -9999 -9999 -9999 -9999 -9999 -9999 -9999 -9999 -9999 -9999 -9999

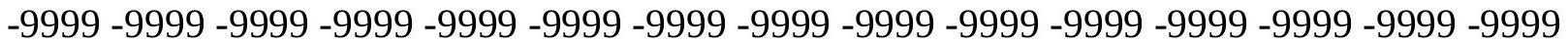
-9999 -9999 -9999 -9999 -9999 -9999 -9999 -9999 -9999 -9999 -9999 -9999 -9999 -9999 -9999 -9999 -9999 -9999 -9999 -9999 -9999 -9999 -9999 -9999 -9999 -9999 -9999 -9999 -9999 -9999 -

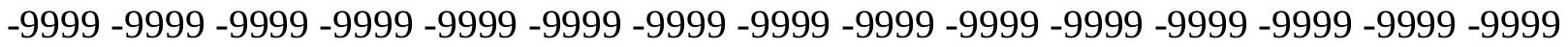
-9999 -9999 -9999 -9999 -9999 -9999 -9999 -9999 -9999 -9999 -9999 -9999 -9999 -9999 -9999

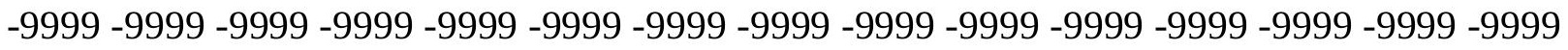
-9999 -9999 -9999 -9999 -9999 -9999 -9999 -9999 -9999 -9999 -9999 -9999 -9999 -9999 -9999 -9999 -9999 -9999 -9999 -9999 -9999 -9999 -9999 -9999 -9999 -9999 -9999 -9999 -9999 -9999 -9999 -9999 -9999 -9999 -9999 -9999 -9999 -9999 -9999 -9999 -9999 -9999 -9999 -9999 -9999 -9999 -9999 -9999 -9999 -9999 -9999 -9999 -9999 -9999 -9999 -9999 -9999 -9999 -9999 -9999 -9999 -9999 -9999 -9999 -9999 -9999 -9999 -9999 -9999 -9999 -9999 -9999 -9999 -9999 -9999 -999 -9999 -9999 -9999 -9999 -9999 -9999 -9999 -9999 -9999 -9999 -9999 -9999 -9999 -9999 -9999 -9999 -9999 -9999 -9999 -9999 -9999 -9999 -9999 -9999 -9999 -9999 -9999 -9999 -9999 -9999 -9999 -9999 -9999 -9999 -9999 -9999 -9999 -9999 -9999 -9999 -9999 -9999 -9999 -9999 -9999 -9999 -9999 -9999 -9999 -9999 -9999 -9999 -9999 -9999 -9999 -9999 -9999 -9999 -9999 -9999 -9999 -9999 -9999 -9999 -9999 -9999 -9999 -9999 -9999 -9999 -9999 -9999 -9999 -9999 -9999 -9999 -9999 -9999 -9999 -9999 -9999 -9999 -9999 -9999 -9999 -9999 -9999 -9999 -9999 -9999 -9999 -9999 -9999 -9999 -9999 -9999 -9999 -9999 -9999 -9999 -9999 -9999 -9999 -9999 -9999 -9999 -9999 -9999 -9999 -9999 -9999 -9999 -9999 -9999 -9999 -9999 -9999 -9999 -9999 -9999 -9999 -9999 -9999 -9999 -9999 -9999 -9999 -9999 -9999 -9999 -9999 -9999 -9999 -999 -9999 -9999 -9999 -9999 -9999 -9999 -9999 -9999 -9999 -9999 -9999 -9999 -9999 -9999 -9999 -9999 -9999 -9999 -9999 -9999 -9999 -9999 -9999 -9999 -9999 -9999 -9999 -9999 -9999 -9999 -

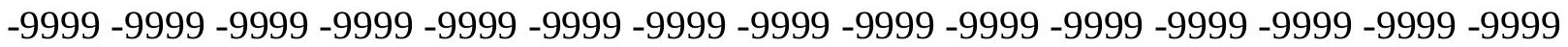

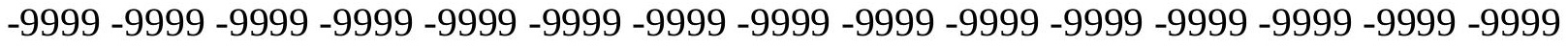

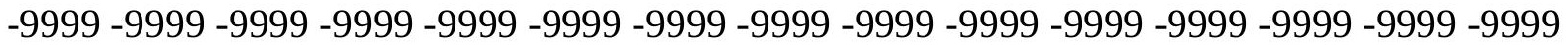
-9999 -9999 -9999 -9999 -9999 -9999 -9999 -9999 -9999 -9999 -9999 -9999 -9999 -9999 -9999

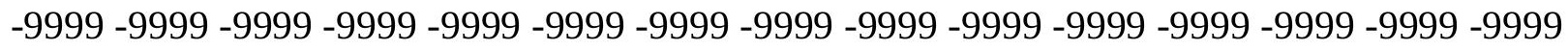

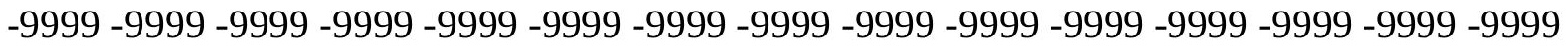
-9999 -9999 -9999 -9999 -9999 -9999 -9999 -9999 -9999 -9999 -9999 -9999 -9999 -9999 -9999 -9999 -9999 -9999 -9999 -9999 -9999 -9999 -9999 -9999 -9999 -9999 -9999 -9999 -9999 -9999 -

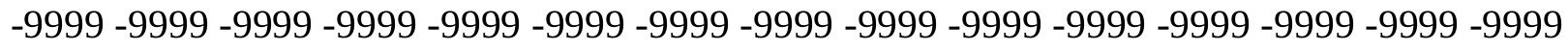

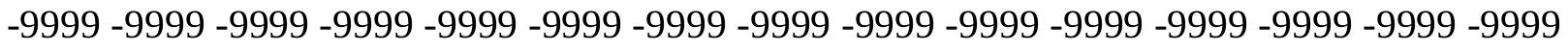
-9999 -9999 -9999 -9999 -9999 -9999 -9999 -9999 -9999 -9999 -9999 -9999 -9999 -9999 -9999 -9999 -9999 -9999 -9999 -9999 -9999 -9999 -9999 -9999-9999 -9999 -9999 -9999 -9999 -9999 -9999 -9999 -9999 -9999 -9999 -9999 -9999 -9999 -9999 -9999 -9999 -9999 -9999 -9999 -9999 -

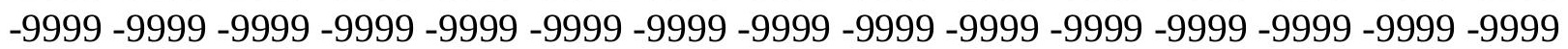


-9999 -9999 -9999 -9999 -9999 -9999 -9999 -9999 -9999 -9999 -9999 -9999 -9999 -9999 -9999 -9999 -9999 -9999 -9999 -9999 -9999 -9999 -9999 -9999 -9999 -9999 -9999 -9999 -9999 -9999 -9999 -9999 -9999 -9999 -9999 -9999 -9999 -9999 -9999 -9999 -9999 -9999 -9999 -9999 - 9999 -9999 -9999 -9999 -9999 -9999 -9999 -9999 -9999 -9999 -9999 -9999 -9999 -9999 -9999

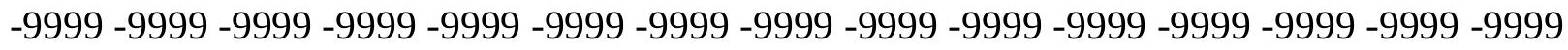
-9999 -9999 -9999 -9999 -9999 -9999 -9999 -9999 -9999 -9999 -9999 -9999 -9999 -9999 -9999 -9999 -9999 -9999 -9999 -9999 -9999 -9999 -9999 -9999 -9999 -9999 -9999 -9999 -9999 -9999

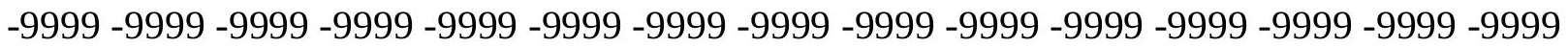

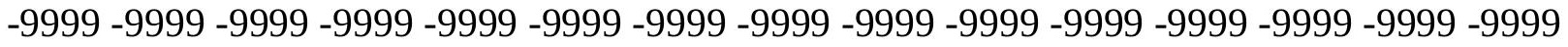
-9999 -9999 -9999 -9999 -9999 -9999 -9999 -9999 -9999 -9999 -9999 -9999 -9999 -9999 -9999 -9999 -9999 -9999 -9999 -9999 -9999 -9999 -9999 -9999 -9999 -9999 -9999 -9999 -9999 -9999 -9999 -9999 -9999 -9999 -9999 -9999 -9999 -9999 -9999 -9999 -9999 -9999 -9999 -9999 -9999 -9999 -9999 -9999 -9999 -9999 -9999 -9999 -9999 -9999 -9999 -9999 -9999 -9999 -9999 -9999 -

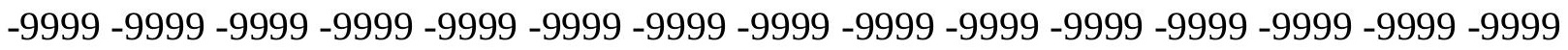
-9999 -9999 -9999 -9999 -9999 -9999 -9999 -9999 -9999 -9999 -9999 -9999 -9999 -9999 -9999 -

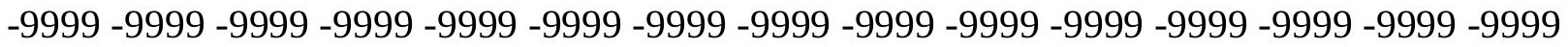
-9999 -9999 -9999 -9999 -9999 -9999 -9999 -9999 -9999 -9999 -9999 -9999 -9999 -9999 -9999 -9999 -9999 -9999 -9999 -9999 -9999 -9999 -9999 -9999 -9999 -9999 -9999 -9999 -9999 -9999 -9999 -9999 -9999 -9999 -9999 -9999 -9999 -9999 -9999 -9999 -9999 -9999 -9999 -9999 -9999 -

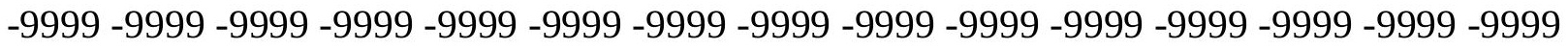
-9999 -9999 -9999 -9999 -9999 -9999 -9999 -9999 -9999 -9999 -9999 -9999 -9999 -9999 -9999

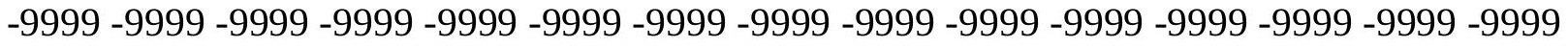
-9999 -9999 -9999 -9999 -9999 -9999 -9999 -9999 -9999 -9999 -9999 -9999 -9999 -9999 -9999 -9999 -9999 -9999 -9999 -9999 -9999 -9999 -9999 -9999 -9999 -9999 -9999 -9999 -9999 -9999 -9999 -9999 -9999 -9999 -9999 -9999 -9999 -9999 -9999 -9999 -9999 -9999 -9999 -9999 -9999 -9999 -9999 -9999 -9999 -9999 -9999 -9999 -9999 -9999 -9999 -9999 -9999 -9999 -9999 -9999 -9999 -9999 -9999 -9999 -9999 -9999 -9999 -9999 -9999 -9999 -9999 -9999 -9999 -9999 -9999 -9999 -9999 -9999 -9999 -9999 -9999 -9999 -9999 -9999 -9999 -9999 -9999 -9999 -9999 -9999 -9999 -9999 -9999 -9999 -9999 -9999 -9999 -9999 -9999 -9999 -9999 -9999 -9999 -9999 -9999 -9999 -9999 -9999 -9999 -9999 -9999 -9999 -9999 -9999 -9999 -9999 -9999 -9999 -9999 -9999 -9999 -9999 -9999 -9999 -9999 -9999 -9999 -9999 -9999 -9999 -9999 -9999 -9999 -9999 -9999 -9999 -9999 -9999 -9999 -9999 -9999 -9999 -9999 -9999 -9999 -9999 -9999 -9999 -9999 -

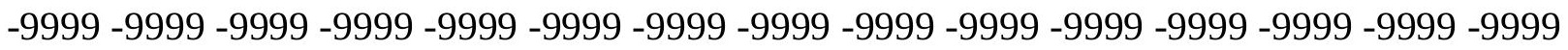

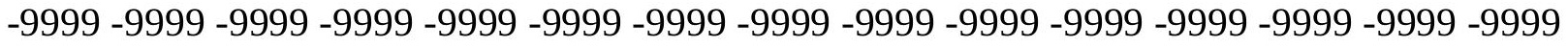
-9999 -9999 -9999 -9999 -9999 -9999 -9999 -9999 -9999 -9999 -9999 -9999 -9999 -9999 -9999 -

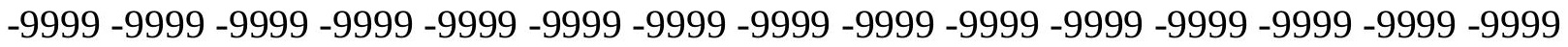

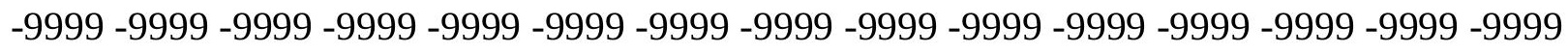

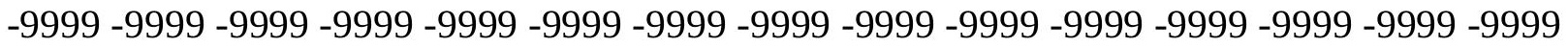

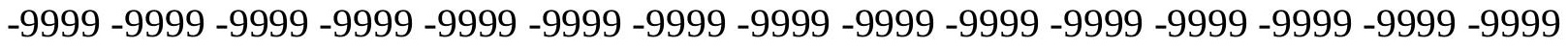
-9999 -9999 -9999 -9999 -9999 -9999 -9999 -9999 -9999 -9999 -9999 -9999 -9999 -9999 -9999 -

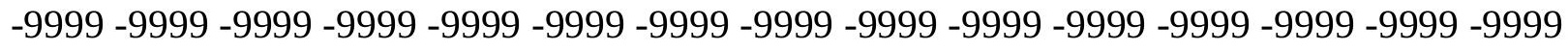

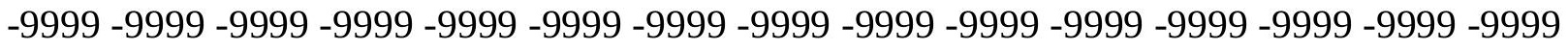
-9999 -9999 -9999 -9999 -9999 -9999 -9999 -9999 -9999 -9999 -9999 -9999 -9999 -9999 -9999 -9999 -9999 -9999 -9999 -9999 -9999 -9999 -9999 -9999-9999 -9999 -9999 -9999 -9999 -9999 -9999 -9999 -9999 -9999 -9999 -9999 -9999 -9999 -9999 -9999 -9999 -9999 -9999 -9999 -9999 -

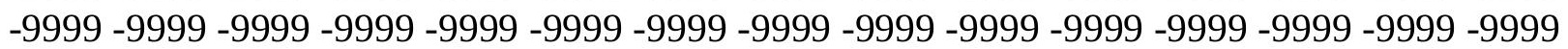


-9999 -9999 -9999 -9999 -9999 -9999 -9999 -9999 -9999 -9999 -9999 -9999 -9999 -9999 -9999 -9999 -9999 -9999 -9999 -9999 -9999 -9999 -9999 -9999 -9999 -9999 -9999 -9999 -9999 -9999 -9999 -9999 -9999 -9999 -9999 -9999 -9999 -9999 -9999 -9999 -9999 -9999 -9999 -9999 - 9999 -9999 -9999 -9999 -9999 -9999 -9999 -9999 -9999 -9999 -9999 -9999 -9999 -9999 -9999 -9999 -9999 -9999 -9999 -9999 -9999 -9999 -9999 -9999 -9999 -9999 -9999 -9999 -9999 -9999 -9999 -9999 -9999 -9999 -9999 -9999 -9999 -9999 -9999 -9999 -9999 -9999 -9999 -9999 -9999 -9999 -9999 -9999 -9999 -9999 -9999 -9999 -9999 -9999 -9999 -9999 -9999 -9999 -9999 -9999 -9999

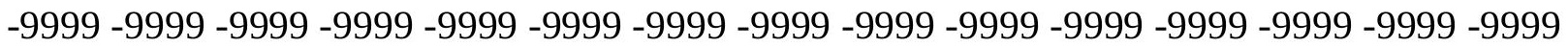

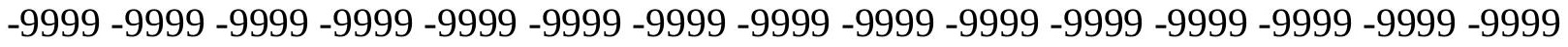
-9999 -9999 -9999 -9999 -9999 -9999 -9999 -9999 -9999 -9999 -9999 -9999 -9999 -9999 -9999 -9999 -9999 -9999 -9999 -9999 -9999 -9999 -9999 -9999 -9999 -9999 -9999 -9999 -9999 -9999 -9999 -9999 -9999 -9999 -9999 -9999 -9999 -9999 -9999 -9999 -9999 -9999 -9999 -9999 -9999 -9999 -9999 -9999 -9999 -9999 -9999 -9999 -9999 -9999 -9999 -9999 -9999 -9999 -9999 -9999 -9999 -9999 -9999 -9999 -9999 -9999 -9999 -9999 -9999 -9999 -9999 -9999 -9999 -9999 -9999 -9999 -9999 -9999 -9999 -9999 -9999 -9999 -9999 -9999 -9999 -9999 -9999 -9999 -9999 -

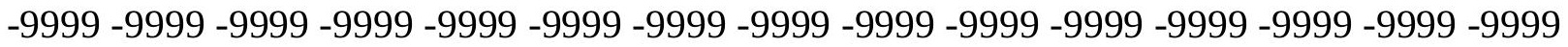
-9999 -9999 -9999 -9999 -9999 -9999 -9999 -9999 -9999 -9999 -9999 -9999 -9999 -9999 -9999 -9999 -9999 -9999 -9999 -9999 -9999 -9999 -9999 -9999 -9999 -9999 -9999 -9999 -9999 -9999 -9999 -9999 -9999 -9999 -9999 -9999 -9999 -9999 -9999 -9999 -9999 -9999 -9999 -9999 -9999 -9999 -9999 -9999 -9999 -9999 -9999 -9999 -9999 -9999 -9999 -9999 -9999 -9999 -9999 -9999 -9999 -9999 -9999 -9999 -9999 -9999 -9999 -9999 -9999 -9999 -9999 -9999 -9999 -9999 -9999 -999 -9999 -9999 -9999 -9999 -9999 -9999 -9999 -9999 -9999 -9999 -9999 -9999 -9999 -9999 -9999 -9999 -9999 -9999 -9999 -9999 -9999 -9999 -9999 -9999 -9999 -9999 -9999 -9999 -9999 -9999 -9999 -9999 -9999 -9999 -9999 -9999 -9999 -9999 -9999 -9999 -9999 -9999 -9999 -9999 -9999 -9999 -9999 -9999 -9999 -9999 -9999 -9999 -9999 -9999 -9999 -9999 -9999 -9999 -9999 -9999 -9999 -9999 -9999 -9999 -9999 -9999 -9999 -9999 -9999 -9999 -9999 -9999 -9999 -9999 -9999 -9999 -9999 -9999 -9999 -9999 -9999 -9999 -9999 -9999 -9999 -9999 -9999 -9999 -9999 -9999 -9999 -9999 -9999 -9999 -9999 -9999 -9999 -9999 -9999 -9999 -9999 -9999 -9999 -9999 -9999 -9999 -9999 -9999 -9999 -9999 -9999 -9999 -9999 -9999 -9999 -9999 -9999 -9999 -9999 -9999 -9999 -9999 -9999 -9999 -9999 -9999 -9999 -9999 -9999 -9999 -9999 -9999 -9999 -9999 -999 -9999 -9999 -9999 -9999 -9999 -9999 -9999 -9999 -9999 -9999 -9999 -9999 -9999 -9999 -9999 -9999 -9999 -9999 -9999 -9999 -9999 -9999 -9999 -9999 -9999 -9999 -9999 -9999 -9999 -9999 -

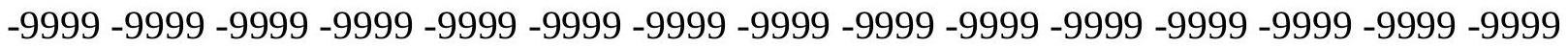

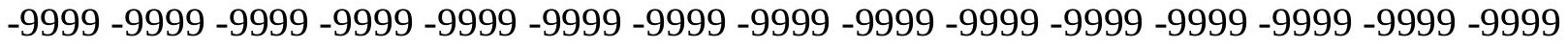

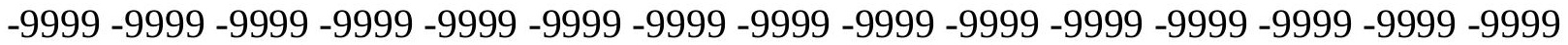
-9999 -9999 -9999 -9999 -9999 -9999 -9999 -9999 -9999 -9999 -9999 -9999 -9999 -9999 -9999 -9999 -9999 -9999 -9999 -9999 -9999 -9999 -9999 -9999 -9999 -9999 -9999 -9999 -9999 -

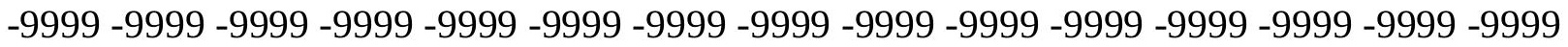
-9999 -9999 -9999 -9999 -9999 -9999 -9999 -9999 -9999 -9999 -9999 -9999 -9999 -9999 -9999 -9999 -9999 -9999 -9999 -9999 -9999 -9999 -9999 -9999 -9999 -9999 -9999 -9999 -9999 -9999 -

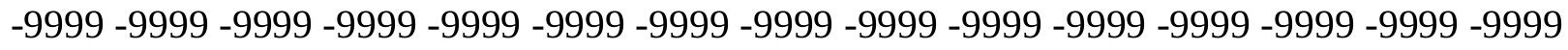

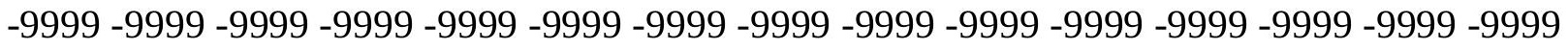
-9999 -9999 -9999 -9999 -9999 -9999 -9999 -9999 -9999 -9999 -9999 -9999 -9999 -9999 -9999 -9999 -9999 -9999 -9999 -9999 -9999 -9999 -9999 -9999-9999 -9999 -9999 -9999 -9999 -9999 -9999 -9999 -9999 -9999 -9999 -9999 -9999 -9999 -9999 -9999 -9999 -9999 -9999 -9999 -9999 -

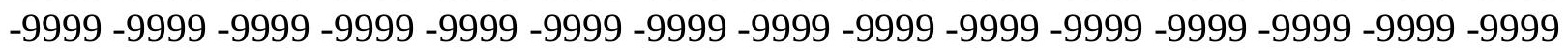


-9999 -9999 -9999 -9999 -9999 -9999 -9999 -9999 -9999 -9999 -9999 -9999 -9999 -9999 -9999 -9999 -9999 -9999 -9999 -9999 -9999 -9999 -9999 -9999 -9999 -9999 -9999 -9999 -9999 -9999 -

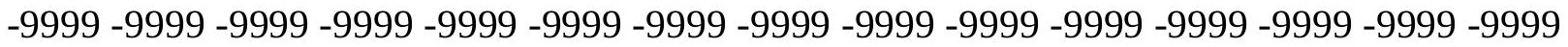
-9999 -9999 -9999 -9999 -9999 -9999 -9999 -9999 -9999 -9999 -9999 -9999 -9999 -9999 -9999 -9999 -9999 -9999 -9999 -9999 -9999 -9999 -9999 -9999-9999 -9999 -9999 -9999 -9999 -9999 -9999 -9999 -9999 -9999 -9999 -9999 -9999 -9999 -9999 -9999 -9999 -9999 -9999 -9999 -9999 -9999 -9999 -9999 -9999 -9999 -9999 -9999 -9999 -9999 -9999 -9999 -9999 -9999 -9999 -9999

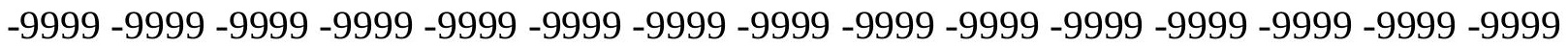

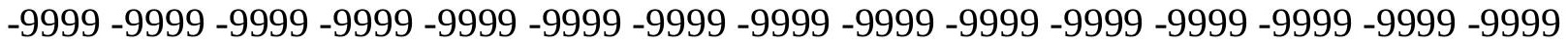
-9999 -9999 -9999 -9999 -9999 -9999 -9999 -9999 -9999 -9999 -9999 -9999 -9999 -9999 -9999 -9999 -9999 -9999 -9999 -9999 -9999 -9999 -9999 -9999 -9999 -9999 -9999 -9999 -9999 -9999 -9999 -9999 -9999 -9999 -9999 -9999 -9999 -9999 -9999 -9999 -9999 -9999 -9999 -9999 -9999 -9999 -9999 -9999 -9999 -9999 -9999 -9999 -9999 -9999 -9999 -9999 -9999 -9999 -9999 -9999 -9999 -9999 -9999 -9999 -9999 -9999 -9999 -9999 -9999 -9999 -9999 -9999 -9999 -9999 -9999 -9999 -9999 -9999 -9999 -9999 -9999 -9999 -9999 -9999 -9999 -9999 -9999 -9999 -9999 -9999 -

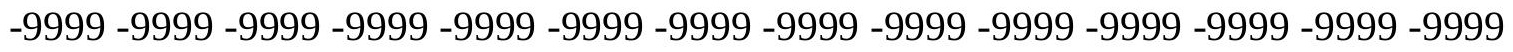
-9999 -9999 -9999 -9999 -9999 -9999 -9999 -9999 -9999 -9999 -9999 -9999 -9999 -9999 -9999 -9999 -9999 -9999 -9999 -9999 -9999 -9999 -9999 -9999 -9999 -9999 -9999 -9999 -9999 -9999 -9999 -9999 -9999 -9999 -9999 -9999 -9999 -9999 -9999 -9999 -9999 -9999 -9999 -9999 -9999 -

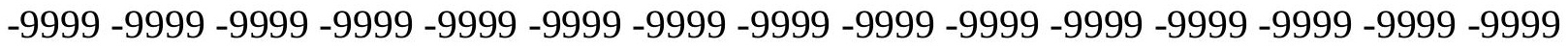

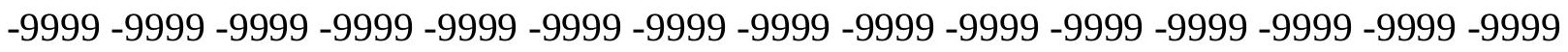
-9999 -9999 -9999 -9999 -9999 -9999 -9999 -9999 -9999 -9999 -9999 -9999 -9999 -9999 - 9999 -9999 -9999 -9999 -9999 -9999 -9999 -9999 -9999 -9999 -9999 -9999 -9999 -9999 -9999 -9999 -9999 -9999 -9999 -9999 -9999 -9999 -9999 -9999 -9999 -9999 -9999 -9999 -9999 -9999 -9999 -

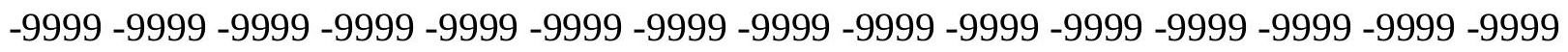
-9999 -9999 -9999 -9999 -9999 -9999 -9999 -9999 -9999 -9999 -9999 -9999 -9999 -9999 -9999 -9999 -9999 -9999 -9999 -9999 -9999 -9999 -9999 -9999 -9999 -9999 -9999 -9999 -9999 -9999 -

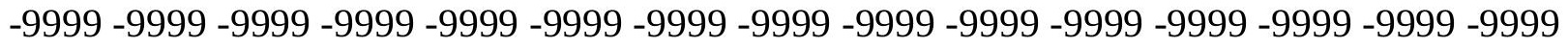
-9999 -9999 -9999 -9999 -9999 -9999 -9999 -9999 -9999 -9999 -9999 -9999 -9999 -9999 -9999 -9999 -9999 -9999 -9999 -9999 -9999 -9999 -9999 -9999 -9999 -9999 -9999 -9999 -9999 -999 -

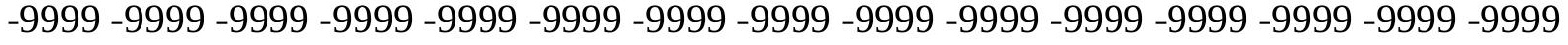
-9999 -9999 -9999 -9999 -9999 -9999 -9999 -9999 -9999 -9999 -9999 -9999 -9999 -9999 -9999 -

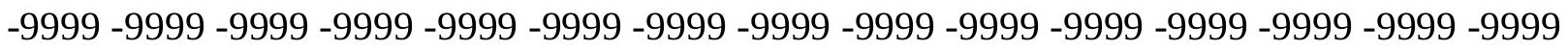

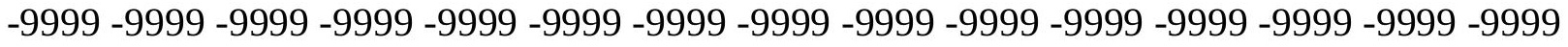

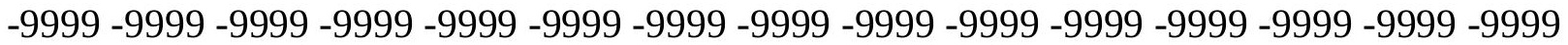
-9999 -9999 -9999 -9999 -9999 -9999 -9999 -9999 -9999 -9999 -9999 -9999 -9999 -9999 -9999 -

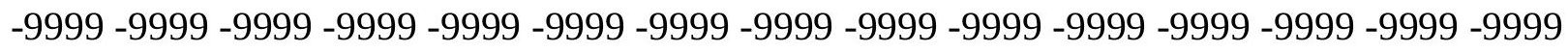

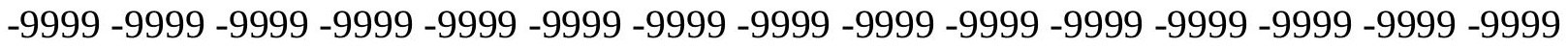
-9999 -9999 -9999 -9999 -9999 -9999 -9999 -9999 -9999 -9999 -9999 -9999 -9999 - 9999 - -999 -9999 -9999 -9999 -9999 -9999 -9999 -9999 -9999 -9999 -9999 -9999 -9999 -9999 -9999 -9999 -

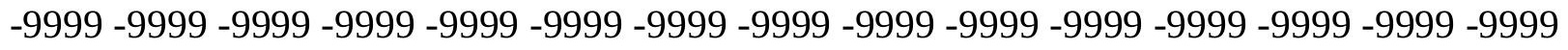

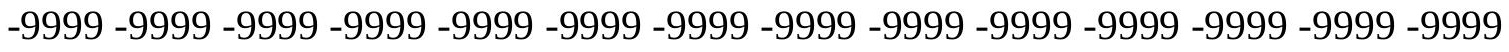
-9999 -9999 -9999 -9999 -9999 -9999 -9999 -9999 -9999 -9999 -9999 -9999 -9999 -9999 -9999 -9999 -9999 -9999 -9999 -9999 -9999 -9999 -9999 -9999-9999 -9999 -9999 -9999 -9999 -9999 -9999 -9999 -9999 -9999 -9999 -9999 -9999 -9999 -9999 -9999 -9999 -9999 -9999 -9999 -9999 -

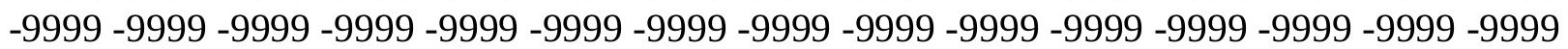


-9999 -9999 -9999 -9999 -9999 -9999 -9999 -9999 -9999 -9999 -9999 -9999 -9999 -9999 -9999 -9999 -9999 -9999 -9999 -9999 -9999 -9999 -9999 -9999 -9999 -9999 -9999 -9999 -9999 -9999 -

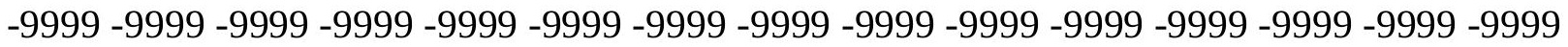
-9999 -9999 -9999 -9999 -9999 -9999 -9999 -9999 -9999 -9999 -9999 -9999 -9999 -9999 -9999 -9999 -9999 -9999 -9999 -9999 -9999 -9999 -9999 -9999-9999 -9999 -9999 -9999 -9999 -9999 -9999 -9999 -9999 -9999 -9999 -9999 -9999 -9999 -9999 -9999 -9999 -9999 -9999 -9999 -9999 -9999 -9999 -9999 -9999 -9999 -9999 -9999 -9999 -9999 -9999 -9999 -9999 -9999 -9999 -9999

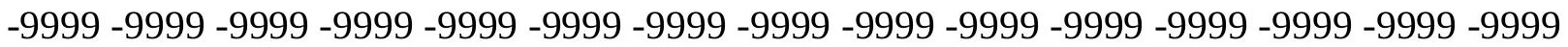

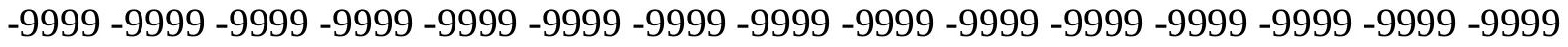
-9999 -9999 -9999 -9999 -9999 -9999 -9999 -9999 -9999 -9999 -9999 -9999 -9999 -9999 -9999 -9999 -9999 -9999 -9999 -9999 -9999 -9999 -9999 -9999 -9999 -9999 -9999 -9999 -9999 -9999 -9999 -9999 -9999 -9999 -9999 -9999 -9999 -9999 -9999 -9999 -9999 -9999 -9999 -9999 -9999 -9999 -9999 -9999 -9999 -9999 -9999 -9999 -9999 -9999 -9999 -9999 -9999 -9999 -9999 -9999 -

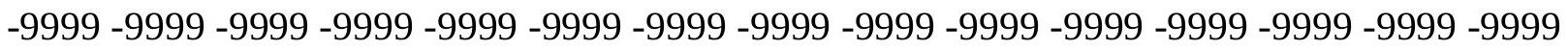
-9999 -9999 -9999 -9999 -9999 -9999 -9999 -9999 -9999 -9999 -9999 -9999 -9999 -9999 -9999 -

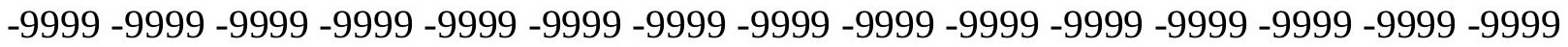
-9999 -9999 -9999 -9999 -9999 -9999 -9999 -9999 -9999 -9999 -9999 -9999 -9999 -9999 -9999 -9999 -9999 -9999 -9999 -9999 -9999 -9999 -9999 -9999 -9999 -9999 -9999 -9999 -9999 -9999 -9999 -9999 -9999 -9999 -9999 -9999 -9999 -9999 -9999 -9999 -9999 -9999 -9999 -9999 -9999 -

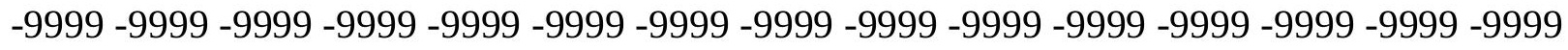

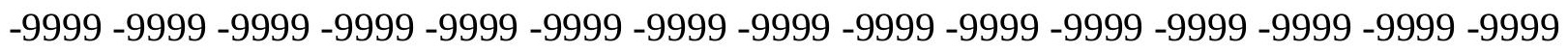
-9999 -9999 -9999 -9999 -9999 -9999 -9999 -9999 -9999 -9999 -9999 -9999 -9999 -9999 -9999 -9999 -9999 -9999 -9999 -9999 -9999 -9999 -9999 -9999 -9999 -9999 -9999 -9999 -9999 -9999 -9999 -9999 -9999 -9999 -9999 -9999 -9999 -9999 -9999 -9999 -9999 -9999 -9999 -9999 -

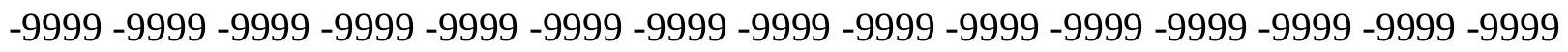
-9999 -9999 -9999 -9999 -9999 -9999 -9999 -9999 -9999 -9999 -9999 -9999 -9999 -9999 -9999 -9999 -9999 -9999 -9999 -9999 -9999 -9999 -9999 -9999 -9999 -9999 -9999 -9999 -9999 -9999 -

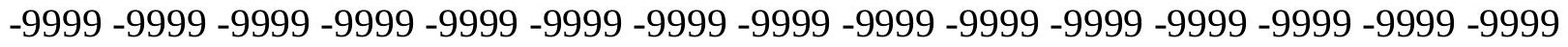
-9999 -9999 -9999 -9999 -9999 -9999 -9999 -9999 -9999 -9999 -9999 -9999 -9999 -9999 -9999 -9999 -9999 -9999 -9999 -9999 -9999 -9999 -9999 -9999 -9999 -9999 -9999 -9999 -9999 -999 -

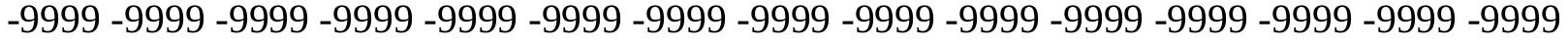
-9999 -9999 -9999 -9999 -9999 -9999 -9999 -9999 -9999 -9999 -9999 -9999 -9999 -9999 -9999 -

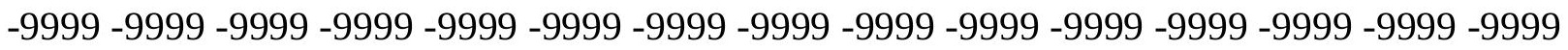

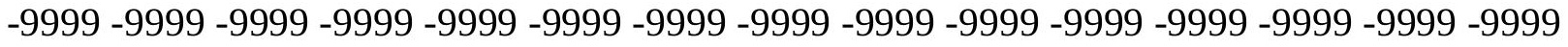

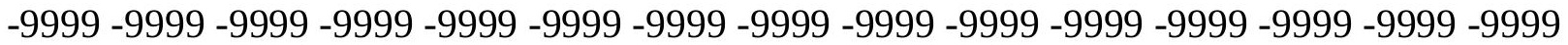

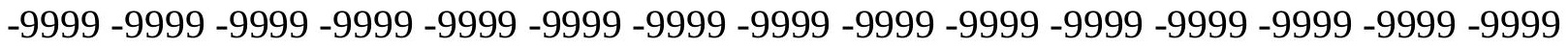

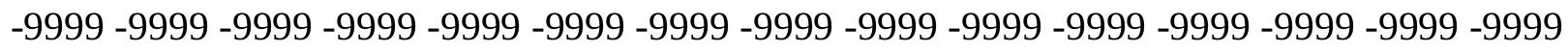

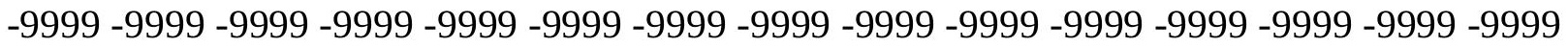

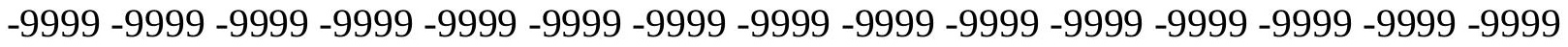
-9999 -9999 -9999 -9999 -9999 -9999 -9999 -9999 -9999 -9999 -9999 -9999 -9999 -9999 -9999 -

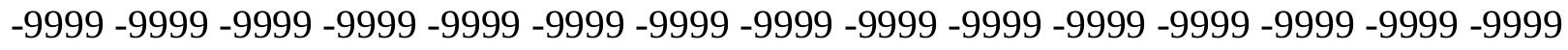

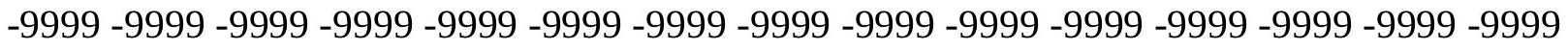
-9999 -9999 -9999 -9999 -9999 -9999 -9999 -9999 -9999 -9999 -9999 -9999 -9999 -9999 -9999 -9999 -9999 -9999 -9999 -9999 -9999 -9999 -9999 -9999-9999 -9999 -9999 -9999 -9999 -9999 -9999 -9999 -9999 -9999 -9999 -9999 -9999 -9999 -9999 -9999 -9999 -9999 -9999 -9999 -9999 -

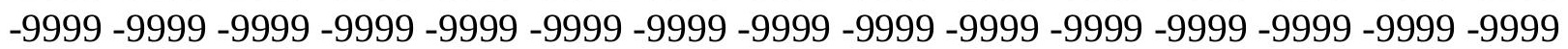


-9999 -9999 -9999 -9999 -9999 -9999 -9999 -9999 -9999 -9999 -9999 -9999 -9999 -9999 -9999 -9999 -9999 -9999 -9999 -9999 -9999 -9999 -9999 -9999 -9999 -9999 -9999 -9999 -9999 -

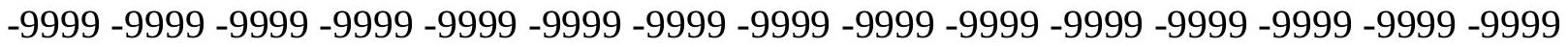
-9999 -9999 -9999 -9999 -9999 -9999 -9999 -9999 -9999 -9999 -9999 -9999 -9999 -9999 -9999 -9999 -9999 -9999 -9999 -9999 -9999 -9999 -9999 -9999 -9999 -9999 -9999 -9999 -9999 -9999 -9999 -9999 -9999 -9999 -9999 -9999 -9999 -9999 -9999 -9999 -9999 -9999 -9999 -9999 -9999 -9999 -9999 -9999 -9999 -9999 -9999 -9999 -9999 -9999 -9999 -9999 -9999 -9999 -9999 -9999

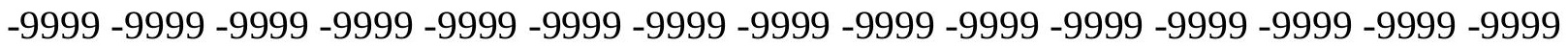

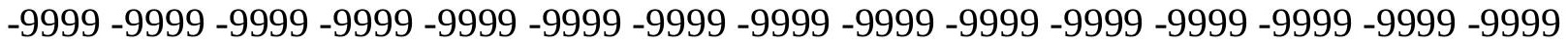
-9999 -9999 -9999 -9999 -9999 -9999 -9999 -9999 -9999 -9999 -9999 -9999 -9999 -9999 -9999 -9999 -9999 -9999 -9999 -9999 -9999 -9999 -9999 -9999 -9999 -9999 -9999 -9999 -9999 -9999 -9999 -9999 -9999 -9999 -9999 -9999 -9999 -9999 -9999 -9999 -9999 -9999 -9999 -9999 -9999 -9999 -9999 -9999 -9999 -9999 -9999 -9999 -9999 -9999 -9999 -9999 -9999 -9999 -9999 -9999 -9999 -9999 -9999 -9999 -9999 -9999 -9999 -9999 -9999 -9999 -9999 -9999 -9999 -9999 -9999 -9999 -9999 -9999 -9999 -9999 -9999 -9999 -9999 -9999 -9999 -9999 -9999 -9999 -9999 -9999 -

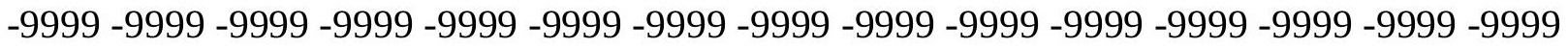
-9999 -9999 -9999 -9999 -9999 -9999 -9999 -9999 -9999 -9999 -9999 -9999 -9999 -9999 -9999 -9999 -9999 -9999 -9999 -9999 -9999 -9999 -9999 -9999 -9999 -9999 -9999 -9999 -9999 - 9999 -9999 -9999 -9999 -9999 -9999 -9999 -9999 -9999 -9999 -9999 -9999 -9999 -9999 -9999 -9999 -

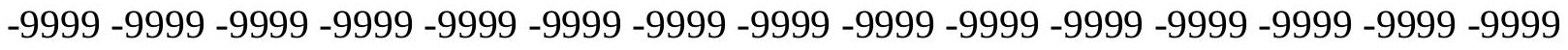

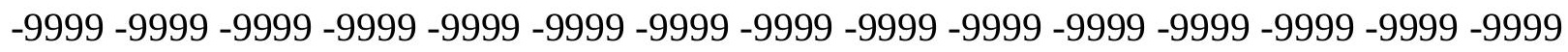

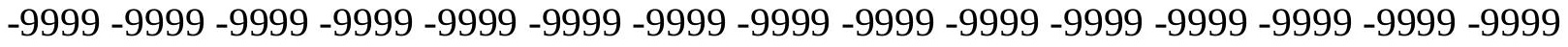
-9999 -9999 -9999 -9999 -9999 -9999 -9999 -9999 -9999 -9999 -9999 -9999 -9999 -9999 -9999 -9999 -9999 -9999 -9999 -9999 -9999 -9999 -9999 -9999 -9999 -9999 -9999 -9999 -9999 -9999 -

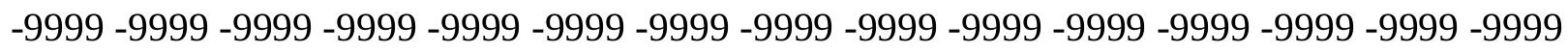
-9999 -9999 -9999 -9999 -9999 -9999 -9999 -9999 -9999 -9999 -9999 -9999 -9999 -9999 -9999 -9999 -9999 -9999 -9999 -9999 -9999 -9999 -9999 -9999 -9999 -9999 -9999 -9999 -9999 -9999 -9999 -9999 -9999 -9999 -9999 -9999 -9999 -9999 -9999 -9999 -9999 -9999 -9999 -9999 -9999 -9999 -9999 -9999 -9999 -9999 -9999 -9999 -9999 -9999 -9999 -9999 -9999 -9999 -9999 -9999 -9999 -9999 -9999 -9999 -9999 -9999 -9999 -9999 -9999 -9999 -9999 -9999 -9999 -999 -

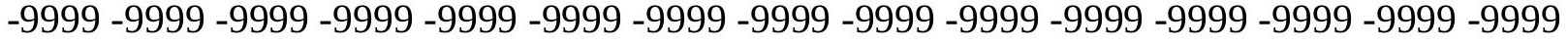
-9999 -9999 -9999 -9999 -9999 -9999 -9999 -9999 -9999 -9999 -9999 -9999 -9999 -9999 -9999 -

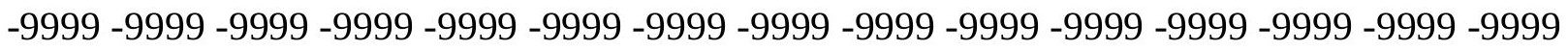

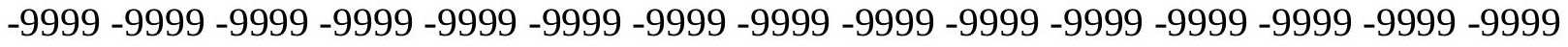

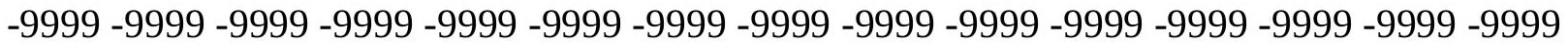

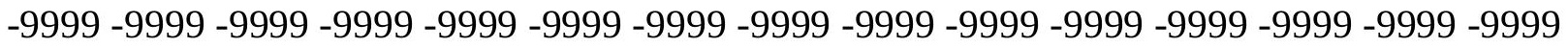

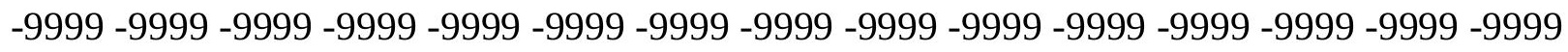

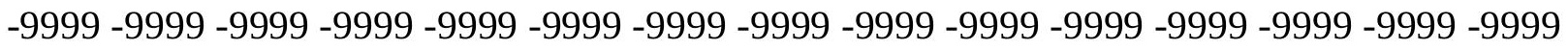

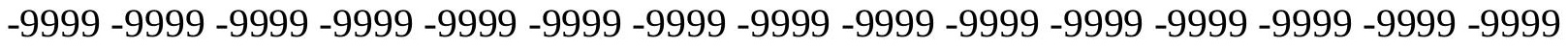
-9999 -9999 -9999 -9999 -9999 -9999 -9999 -9999 -9999 -9999 -9999 -9999 -9999 -9999 -9999 -

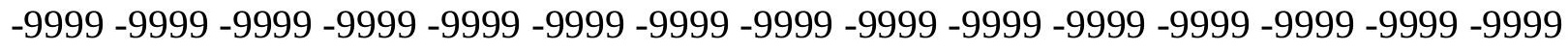

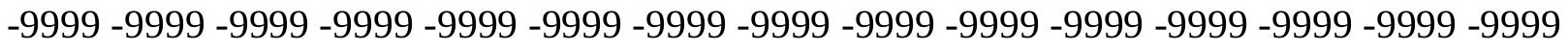
-9999 -9999 -9999 -9999 -9999 -9999 -9999 -9999 -9999 -9999 -9999 -9999 -9999 -9999 -9999 -9999 -9999 -9999 -9999 -9999 -9999 -9999 -9999 -9999-9999 -9999 -9999 -9999 -9999 -9999 -9999 -9999 -9999 -9999 -9999 -9999 -9999 -9999 -9999 -9999 -9999 -9999 -9999 -9999 -9999 -

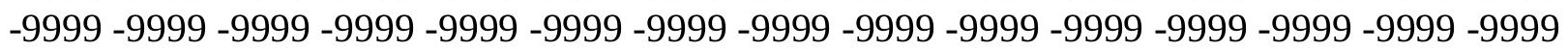


-9999 -9999 -9999 -9999 -9999 -9999 -9999 -9999 -9999 -9999 -9999 -9999 -9999 -9999 -9999 -9999 -9999 -9999 -9999 -9999 -9999 -9999 -9999 -9999 -9999 -9999 -9999 -9999 -9999 -9999 -

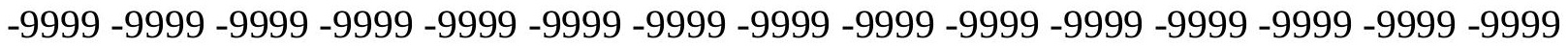
-9999 -9999 -9999 -9999 -9999 -9999 -9999 -9999 -9999 -9999 -9999 -9999 -9999 -9999 -9999 -9999 -9999 -9999 -9999 -9999 -9999 -9999 -9999 -9999-9999 -9999 -9999 -9999 -9999 -9999 -9999 -9999 -9999 -9999 -9999 -9999 -9999 -9999 -9999 -9999 -9999 -9999 -9999 -9999 -9999 -

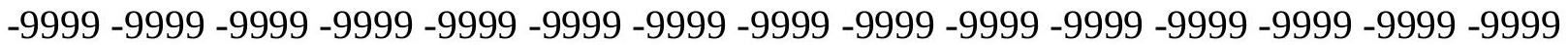
-9999 -9999 -9999 -9999 -9999 -9999 -9999 -9999 -9999 -9999 -9999 -9999 -9999 -9999 -9999 -9999 -9999 -9999 -9999 -9999 -9999 -9999 -9999 -9999 -9999 -9999 -9999 -9999 -9999 -9999 -9999 -9999 -9999 -9999 -9999 -9999 -9999 -9999 -9999 -9999 -9999 -9999 -9999 -9999 -9999 -9999 -9999 -9999 -9999 -9999 -9999 -9999 -9999 -9999 -9999 -9999 -9999 -9999 -9999 -9999 -9999 -9999 -9999 -9999 -9999 -9999 -9999 -9999 -9999 -9999 -9999 -9999 -9999 -9999 -9999 -9999 -9999 -9999 -9999 -9999 -9999 -9999 -9999 -9999 -9999 -9999 -9999 -9999 -9999 -9999 -9999 -9999 -9999 -9999 -9999 -9999 -9999 -9999 -9999 -9999 -9999 -9999 -9999 -9999 -9999 -9999 -9999 -9999 -9999 -9999 -9999 -9999 -9999 -9999 -9999 -9999 -9999 -9999 -9999 -

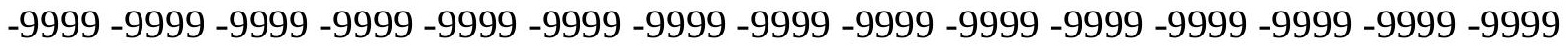
-9999 -9999 -9999 -9999 -9999 -9999 -9999 -9999 -9999 -9999 -9999 -9999 -9999 -9999 -9999 -9999 -9999 -9999 -9999 -9999 -9999 -9999 -9999 -9999 -9999 -9999 -9999 -9999 -9999 -9999 -9999 -9999 -9999 -9999 -9999 -9999 -9999 -9999 -9999 -9999 -9999 -9999 -9999 -9999 -9999 -

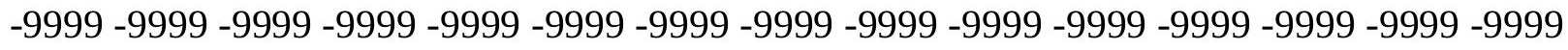

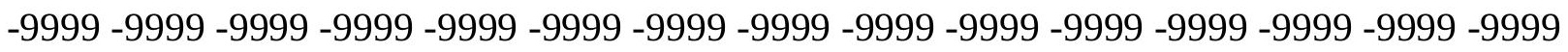
-9999 -9999 -9999 -9999 -9999 -9999 -9999 -9999 -9999 -9999 -9999 -9999 -9999 -9999 - 9999 -9999 -9999 -9999 -9999 -9999 -9999 -9999 -9999 -9999 -9999 -9999 -9999 -9999 -9999 -9999 -9999 -9999 -9999 -9999 -9999 -9999 -9999 -9999 -9999 -9999 -9999 -9999 -9999 -9999 -9999 -

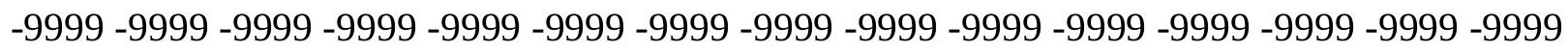
-9999 -9999 -9999 -9999 -9999 -9999 -9999 -9999 -9999 -9999 -9999 -9999 -9999 -9999 -9999 -9999 -9999 -9999 -9999 -9999 -9999 -9999 -9999 -9999 -9999 -9999 -9999 -9999 -9999 -9999 -

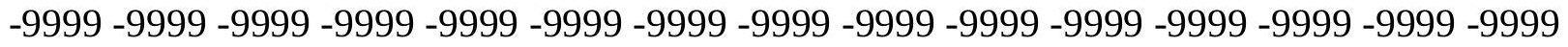
-9999 -9999 -9999 -9999 -9999 -9999 -9999 -9999 -9999 -9999 -9999 -9999 -9999 -9999 -9999 -9999 -9999 -9999 -9999 -9999 -9999 -9999 -9999 -9999 -9999 -9999 -9999 -9999 -9999 -999 -9999 -9999 -9999 -9999 -9999 -9999 -9999 -9999 -9999 -9999 -9999 -9999 -9999 -9999 -9999 -9999 -9999 -9999 -9999 -9999 -9999 -9999 -9999 -9999 -9999 -9999 -9999 -9999 -9999 -9999 -

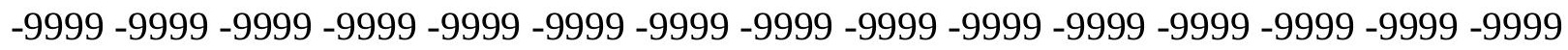

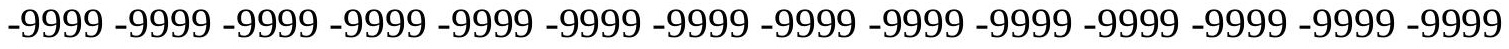
-9999 -9999 -9999 -9999 -9999 -9999 -9999 -9999 -9999 -9999 -9999 -9999 -9999 -9999 -9999

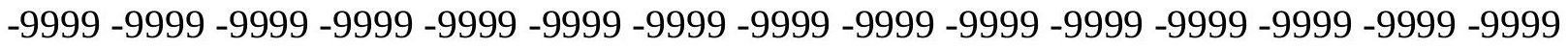

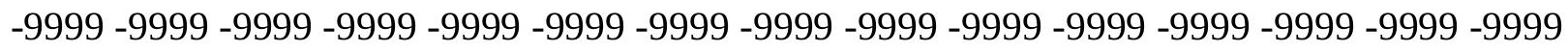

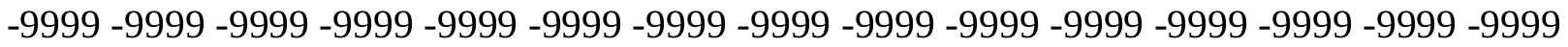

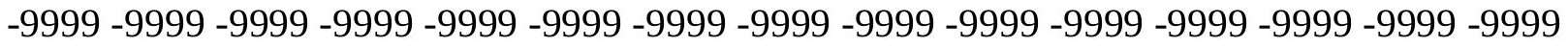
-9999 -9999 -9999 -9999 -9999 -9999 -9999 -9999 -9999 -9999 -9999 -9999 -9999 -9999 -9999 -

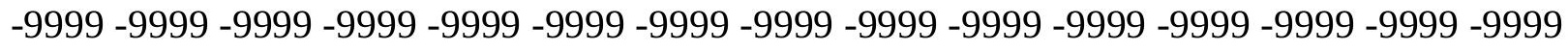

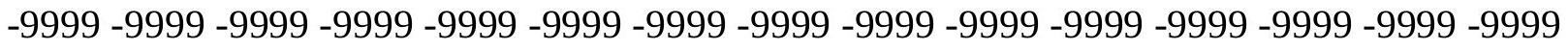
-9999 -9999 -9999 -9999 -9999 -9999 -9999 -9999 -9999 -9999 -9999 -9999 -9999 -9999 -9999 -9999 -9999 -9999 -9999 -9999 -9999 -9999 -9999 -9999-9999 -9999 -9999 -9999 -9999 -9999 -9999 -9999 -9999 -9999 -9999 -9999 -9999 -9999 -9999 -9999 -9999 -9999 -9999 -9999 -9999 -

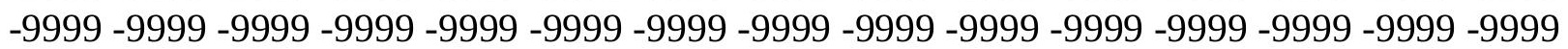


-9999 -9999 -9999 -9999 -9999 -9999 -9999 -9999 -9999 -9999 -9999 -9999 -9999 -9999 -9999 -9999 -9999 -9999 -9999 -9999 -9999 -9999 -9999 -9999 -9999 -9999 -9999 -9999 -9999 -9999 -

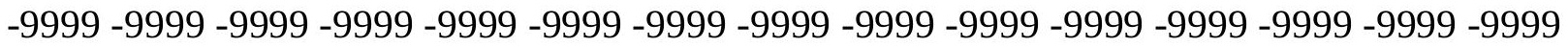
-9999 -9999 -9999 -9999 -9999 -9999 -9999 -9999 -9999 -9999 -9999 -9999 -9999 -9999 -9999 -9999 -9999 -9999 -9999 -9999 -9999 -9999 -9999 -9999-9999 -9999 -9999 -9999 -9999 -9999 -9999 -9999 -9999 -9999 -9999 -9999 -9999 -9999 -9999 -9999 -9999 -9999 -9999 -9999 -9999 -9999 -9999 -9999 -9999 -9999 -9999 -9999 -9999 -9999 -9999 -9999 -9999 -9999 -9999 -9999

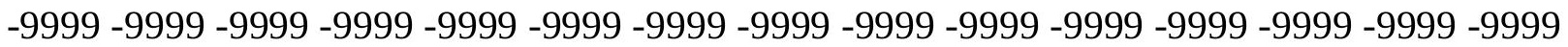

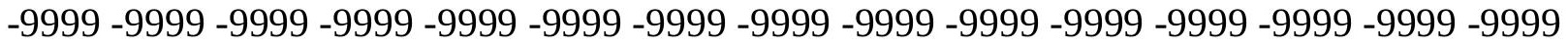
-9999 -9999 -9999 -9999 -9999 -9999 -9999 -9999 -9999 -9999 -9999 -9999 -9999 -9999 -9999 -9999 -9999 -9999 -9999 -9999 -9999 -9999 -9999 -9999 -9999 -9999 -9999 -9999 -9999 -9999 -9999 -9999 -9999 -9999 -9999 -9999 -9999 -9999 -9999 -9999 -9999 -9999 -9999 -9999 -9999 -9999 -9999 -9999 -9999 -9999 -9999 -9999 -9999 -9999 -9999 -9999 -9999 -9999 -9999 -9999 -9999 -9999 -9999 -9999 -9999 -9999 -9999 -9999 -9999 -9999 -9999 -9999 -9999 -9999 -9999 -9999 -9999 -9999 -9999 -9999 -9999 -9999 -9999 -9999 -9999 -9999 -9999 -9999 -9999

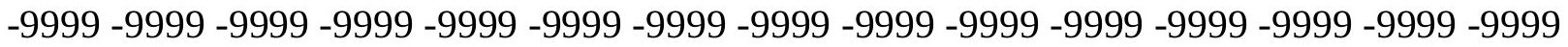
-9999 -9999 -9999 -9999 -9999 -9999 -9999 -9999 -9999 -9999 -9999 -9999 -9999 -9999 -9999 -9999 -9999 -9999 -9999 -9999 -9999 -9999 -9999 -9999 -9999 -9999 -9999 -9999 -9999 -9999 -9999 -9999 -9999 -9999 -9999 -9999 -9999 -9999 -9999 -9999 -9999 -9999 -9999 -9999 -9999 -

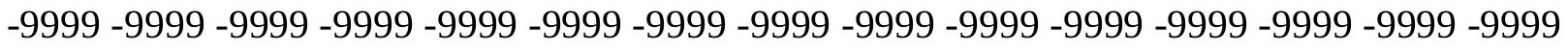

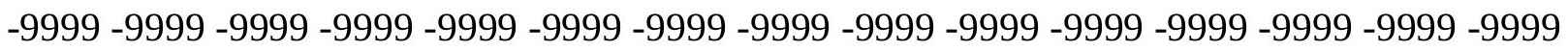
-9999 -9999 -9999 -9999 -9999 -9999 -9999 -9999 -9999 -9999 -9999 -9999 -9999 -9999 -9999 -9999 -9999 -9999 -9999 -9999 -9999 -9999 -9999 -9999 -9999 -9999 -9999 -9999 -9999 -9999 -9999 -9999 -9999 -9999 -9999 -9999 -9999 -9999 -9999 -9999 -9999 -9999 -9999 -9999 -9999 -

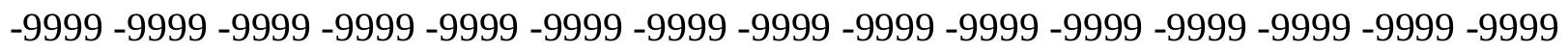
-9999 -9999 -9999 -9999 -9999 -9999 -9999 -9999 -9999 -9999 -9999 -9999 -9999 -9999 -9999 -9999 -9999 -9999 -9999 -9999 -9999 -9999 -9999 -9999 -9999 -9999 -9999 -9999 -9999 -9999 -

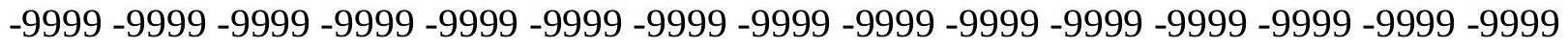
-9999 -9999 -9999 -9999 -9999 -9999 -9999 -9999 -9999 -9999 -9999 -9999 -9999 -9999 -9999 -9999 -9999 -9999 -9999 -9999 -9999 -9999 -9999 -9999 -9999 -9999 -9999 -9999 -9999 -999 -9999 -9999 -9999 -9999 -9999 -9999 -9999 -9999 -9999 -9999 -9999 -9999 -9999 -9999 -9999 -9999 -9999 -9999 -9999 -9999 -9999 -9999 -9999 -9999 -9999 -9999 -9999 -9999 -9999 -9999 -

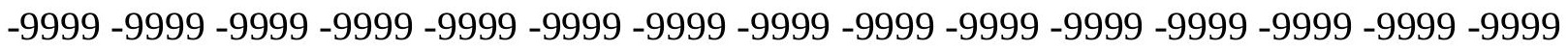

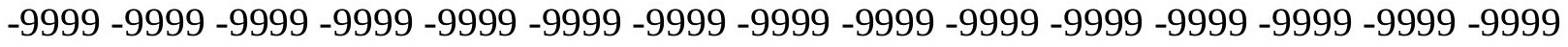

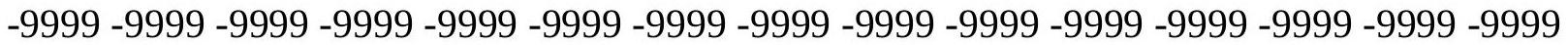

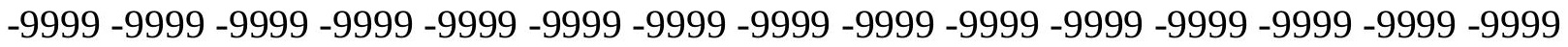

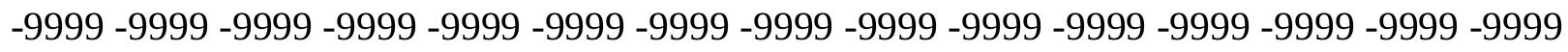

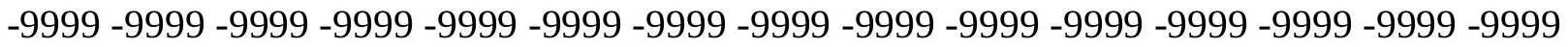
-9999 -9999 -9999 -9999 -9999 -9999 -9999 -9999 -9999 -9999 -9999 -9999 -9999 - 9999 - -999 -9999 -9999 -9999 -9999 -9999 -9999 -9999 -9999 -9999 -9999 -9999 -9999 -9999 -9999 - -999 -

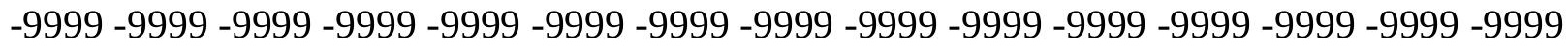

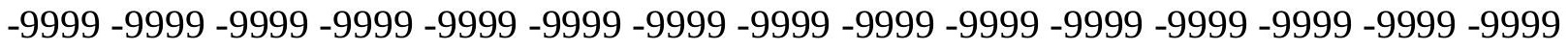
-9999 -9999 -9999 -9999 -9999 -9999 -9999 -9999 -9999 -9999 -9999 -9999 -9999 -9999 -9999 -9999 -9999 -9999 -9999 -9999 -9999 -9999 -9999 -9999-9999 -9999 -9999 -9999 -9999 -9999 -9999 -9999 -9999 -9999 -9999 -9999 -9999 -9999 -9999 -9999 -9999 -9999 -9999 -9999 -9999 -

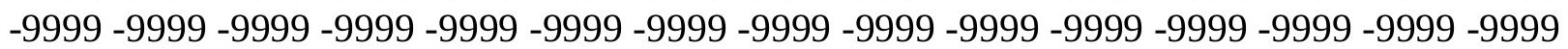


-9999 -9999 -9999 -9999 -9999 -9999 -9999 -9999 -9999 -9999 -9999 -9999 -9999 -9999 -9999 -9999 -9999 -9999 -9999 -9999 -9999 -9999 -9999 -9999 -9999 -9999 -9999 -9999 -9999 -9999 -9999 -9999 -9999 -9999 -9999 -9999 -9999 -9999 -9999 -9999 -9999 -9999 -9999 -9999 -9999 -9999 -9999 -9999 -9999 -9999 -9999 -9999 -9999 -9999 -9999 -9999 -9999 -9999 -9999 -9999 -9999 -9999 -9999 -9999 -9999 -9999 -9999 -9999 -9999 -9999 -9999 -9999 -9999 -9999 -9999 -9999 -9999 -9999 -9999 -9999 -9999 -9999 -9999 -9999 -9999 -9999 -9999 -9999 -9999 -9999 -9999 -9999 -9999 -9999 -9999 -9999 -9999 -9999 -9999 -9999 -9999 -9999 -9999 -9999 -9999 -

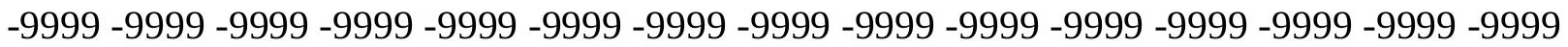
-9999 -9999 -9999 -9999 -9999 -9999 -9999 -9999 -9999 -9999 -9999 -9999 -9999 -9999 -9999 -9999 -9999 -9999 -9999 -9999 -9999 -9999 -9999 -9999 -9999 -9999 -9999 -9999 -9999 -9999 -

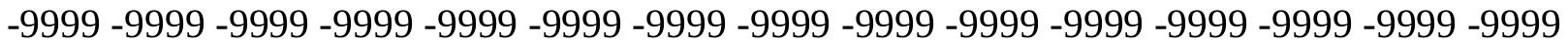
-9999 -9999 -9999 -9999 -9999 -9999 -9999 -9999 -9999 -9999 -9999 -9999 -9999 -9999 -9999 -9999 -9999 -9999 -9999 -9999 -9999 -9999 -9999 -9999 -9999 -9999 -9999 -9999 -9999 -9999 -9999 -9999 -9999 -9999 -9999 -9999 -9999 -9999 -9999 -9999 -9999 -9999 -9999 -9999 -9999 -9999 -9999 -9999 -9999 -9999 -9999 -9999 -9999 -9999 -9999 -9999 -9999 -9999 -9999 -9999

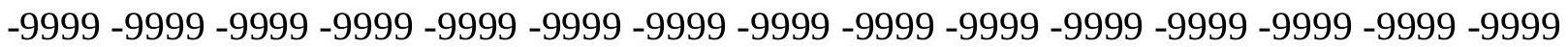
-9999 -9999 -9999 -9999 -9999 -9999 -9999 -9999 -9999 -9999 -9999 -9999 -9999 -9999 -9999 -9999 -9999 -9999 -9999 -9999 -9999 -9999 -9999 -9999 -9999 -9999 -9999 -9999 -9999 -9999 -9999 -9999 -9999 -9999 -9999 -9999 -9999 -9999 -9999 -9999 -9999 -9999 -9999 -9999 -9999 -9999 -9999 -9999 -9999 -9999 -9999 -9999 -9999 -9999 -9999 -9999 -9999 -9999 -9999 -9999 -9999 -9999 -9999 -9999 -9999 -9999 -9999 -9999 -9999 -9999 -9999 -9999 -9999 -9999 -9999 -9999 -9999 -9999 -9999 -9999 -9999 -9999 -9999 -9999 -9999 -9999 -9999 -9999 -9999 -9999 -9999 -9999 -9999 -9999 -9999 -9999 -9999 -9999 -9999 -9999 -9999 -9999 -9999 -9999 -9999 -9999 -9999 -9999 -9999 -9999 -9999 -9999 -9999 -9999 -9999 -9999 -9999 -9999 -9999 -9999 -9999 -9999 -9999 -9999 -9999 -9999 -9999 -9999 -9999 -9999 -9999 -9999 -9999 -9999 -9999 -9999 -9999 -9999 -9999 -9999 -9999 -9999 -9999 -9999 -9999 -9999 -9999 -9999 -9999 -9999 -9999 -9999 -9999 -9999 -9999 -9999 -9999 -9999 -9999 -9999 -9999 -9999 -9999 -9999 -9999 -9999 -9999 -9999 -9999 -9999 -9999 -9999 -9999 -9999 -9999 -9999 -9999 -9999 -9999

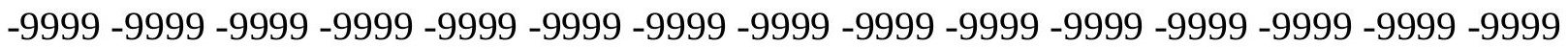
-9999 -9999 -9999 -9999 -9999 -9999 -9999 -9999 -9999 -9999 -9999 -9999 -9999 -9999 -9999 -9999 -9999 -9999 -9999 -9999 -9999 -9999 -9999 -9999 -9999 -9999 -9999 -9999 -9999 -9999 -

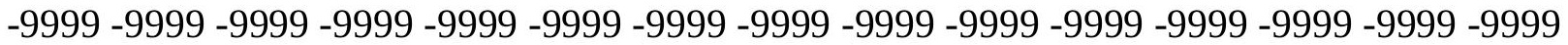
-9999 -9999 -9999 -9999 -9999 -9999 -9999 -9999 -9999 -9999 -9999 -9999 -9999 -9999 -9999 -9999 -9999 -9999 -9999 -9999 -9999 -9999 -9999 -9999 -9999 -9999 -9999 -9999 -9999 -9999 -9999 -9999 -9999 -9999 -9999 -9999 -9999 -9999 -9999 -9999 -9999 -9999 -9999 -9999 -9999 -9999 -9999 -9999 -9999 -9999 -9999 -9999 -9999 -9999 -9999 -9999 -9999 -9999 -9999 -9999 -9999 -9999 -9999 -9999 -9999 -9999 -9999 -9999 -9999 -9999 -9999 -9999 -9999 -9999 -9999

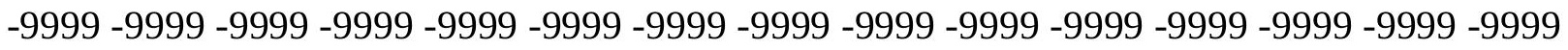
-9999 -9999 -9999 -9999 -9999 -9999 -9999 -9999 -9999 -9999 -9999 -9999 -9999 -9999 -9999 -9999 -9999 -9999 -9999 -9999 -9999 -9999 -9999 -9999 -9999 -9999 -9999 -9999 -9999 -9999 -9999 -9999 -9999 -9999 -9999 -9999 -9999 -9999 -9999 -9999 -9999 -9999 -9999 -9999 -9999 -999 -9999 -9999 -9999 -9999 -9999 -9999 -9999 -9999 -9999 -9999 -9999 -9999 -9999 -9999 -9999 -9999 -9999 -9999 -9999 -9999 -9999 -9999 -9999 -9999 -9999 -9999 -9999 -9999 -9999 -9999 -9999 -9999 -9999 -9999 -9999 -9999 -9999 -9999 -9999 -9999 -9999 -9999 -9999 -9999 -9999 -9999 -9999 -9999 -9999 -9999 -9999 -9999 -9999 -9999 -9999 -9999 -9999 -9999 -9999 -9999 -9999 -9999 -9999 -9999 -9999 -9999 -9999 -9999 -9999 -9999 -9999 -9999 -9999 -9999 
-9999 -9999 -9999 -9999 -9999 -9999 -9999 -9999 -9999 -9999 -9999 -9999 -9999 -9999 -9999 -9999 -9999 -9999 -9999 -9999 -9999 -9999 -9999 -9999 -9999 -9999 -9999 -9999 -9999 -9999 -

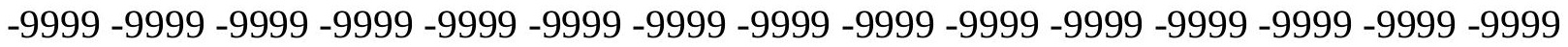
-9999 -9999 -9999 -9999 -9999 -9999 -9999 -9999 -9999 -9999 -9999 -9999 -9999 -9999 -9999 -9999 -9999 -9999 -9999 -9999 -9999 -9999 -9999 -9999-9999 -9999 -9999 -9999 -9999 -9999 -9999 -9999 -9999 -9999 -9999 -9999 -9999 -9999 -9999 -9999 -9999 -9999 -9999 -9999 -9999 -9999 -9999 -9999 -9999 -9999 -9999 -9999 -9999 -9999 -9999 -9999 -9999 -9999 -9999 -9999

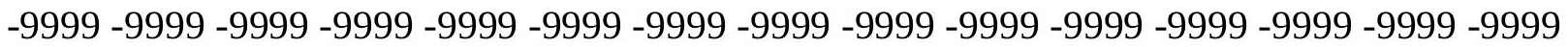

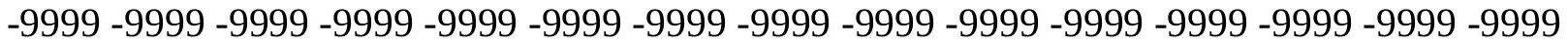
-9999 -9999 -9999 -9999 -9999 -9999 -9999 -9999 -9999 -9999 -9999 -9999 -9999 -9999 -9999 -9999 -9999 -9999 -9999 -9999 -9999 -9999 -9999 -9999 -9999 -9999 -9999 -9999 -9999 -9999 -9999 -9999 -9999 -9999 -9999 -9999 -9999 -9999 -9999 -9999 -9999 -9999 -9999 -9999 -9999 -9999 -9999 -9999 -9999 -9999 -9999 -9999 -9999 -9999 -9999 -9999 -9999 -9999 -9999 -9999 -

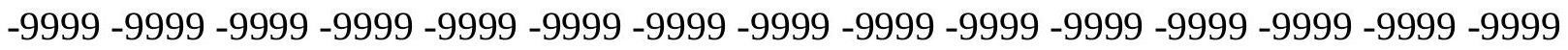
-9999 -9999 -9999 -9999 -9999 -9999 -9999 -9999 -9999 -9999 -9999 -9999 -9999 -9999 -9999 -

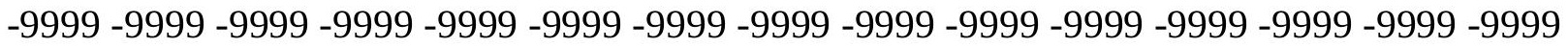
-9999 -9999 -9999 -9999 -9999 -9999 -9999 -9999 -9999 -9999 -9999 -9999 -9999 -9999 -9999 -9999 -9999 -9999 -9999 -9999 -9999 -9999 -9999 -9999 -9999 -9999 -9999 -9999 -9999 -9999 -9999 -9999 -9999 -9999 -9999 -9999 -9999 -9999 -9999 -9999 -9999 -9999 -9999 -9999 -9999 -

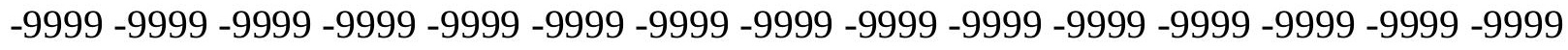

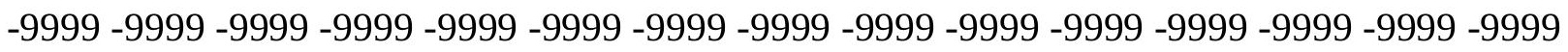

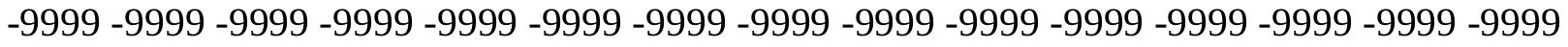
-9999 -9999 -9999 -9999 -9999 -9999 -9999 -9999 -9999 -9999 -9999 -9999 -9999 -9999 -9999 -9999 -9999 -9999 -9999 -9999 -9999 -9999 -9999 -9999 -9999 -9999 -9999 -9999 -9999 -9999 -

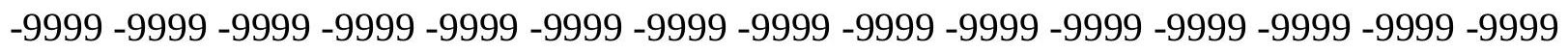
-9999 -9999 -9999 -9999 -9999 -9999 -9999 -9999 -9999 -9999 -9999 -9999 -9999 -9999 -9999 -9999 -9999 -9999 -9999 -9999 -9999 -9999 -9999 -9999 -9999 -9999 -9999 -9999 -9999 -

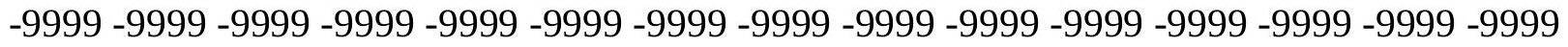
-9999 -9999 -9999 -9999 -9999 -9999 -9999 -9999 -9999 -9999 -9999 -9999 -9999 -9999 -9999 -9999 -9999 -9999 -9999 -9999 -9999 -9999 -9999 -9999 -9999 -9999 -9999 -9999 -9999 -999 -

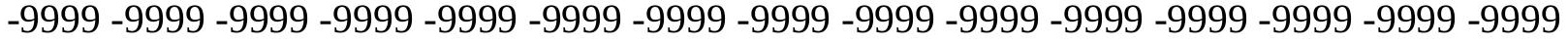
-9999 -9999 -9999 -9999 -9999 -9999 -9999 -9999 -9999 -9999 -9999 -9999 -9999 -9999 -9999 -

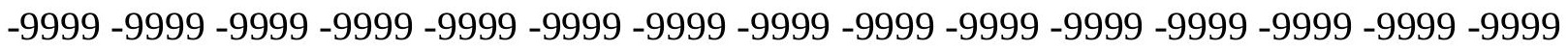

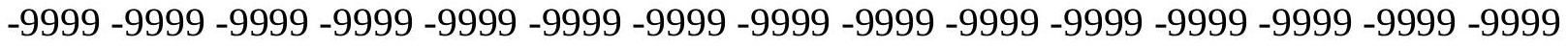

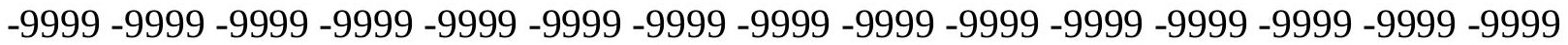
-9999 -9999 -9999 -9999 -9999 -9999 -9999 -9999 -9999 -9999 -9999 -9999 -9999 -9999 -9999

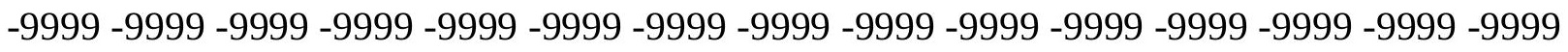

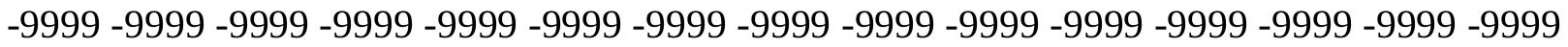
-9999 -9999 -9999 -9999 -9999 -9999 -9999 -9999 -9999 -9999 -9999 -9999 -9999 - 9999 - -999 -9999 -9999 -9999 -9999 -9999 -9999 -9999 -9999 -9999 -9999 -9999 -9999 -9999 -9999 -9999 -

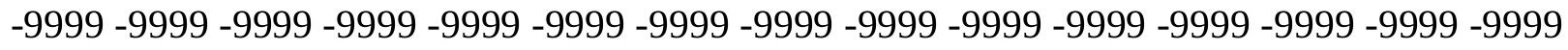

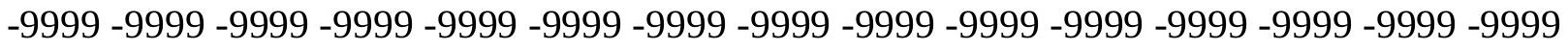
-9999 -9999 -9999 -9999 -9999 -9999 -9999 -9999 -9999 -9999 -9999 -9999 -9999 -9999 -9999 -9999 -9999 -9999 -9999 -9999 -9999 -9999 -9999 -9999-9999 -9999 -9999 -9999 -9999 -9999 -9999 -9999 -9999 -9999 -9999 -9999 -9999 -9999 -9999 -9999 -9999 -9999 -9999 -9999 -9999 -

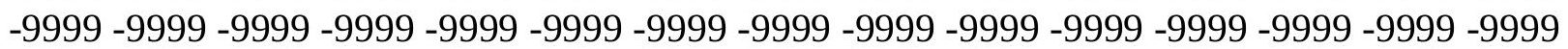


-9999 -9999 -9999 -9999 -9999 -9999 -9999 -9999 -9999 -9999 -9999 -9999 -9999 -9999 -9999 -9999 -9999 -9999 -9999 -9999 -9999 -9999 -9999 -9999 -9999 -9999 -9999 -9999 -9999 -9999 -9999 -9999 -9999 -9999 -9999 -9999 -9999 -9999 -9999 -9999 -9999 -9999 -9999 -9999 - 9999 -9999 -9999 -9999 -9999 -9999 -9999 -9999 -9999 -9999 -9999 -9999 -9999 -9999 -9999 -9999 -9999 -9999 -9999 -9999 -9999 -9999 -9999 -9999 -9999 -9999 -9999 -9999 -9999 -9999 - -9999 -9999 -9999 -9999 -9999 -9999 -9999 -9999 -9999 -9999 -9999 -9999 -9999 -9999 -9999 -9999 -9999 -9999 -9999 -9999 -9999 -9999 -9999 -9999 -9999 -9999 -9999 -9999 -9999 -9999

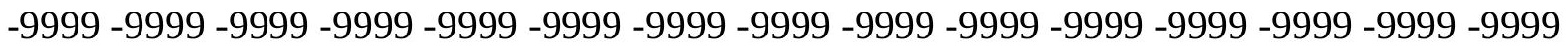

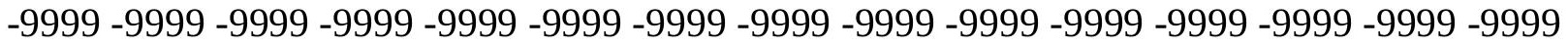
-9999 -9999 -9999 -9999 -9999 -9999 -9999 -9999 -9999 -9999 -9999 -9999 -9999 -9999 -9999

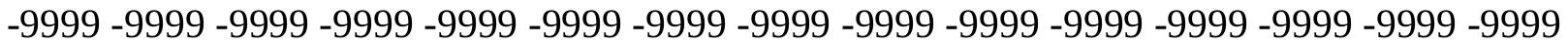
-9999 -9999 -9999 -9999 -9999 -9999 -9999 -9999 -9999 -9999 -9999 -9999 -9999 -9999 -9999 -9999 -9999 -9999 -9999 -9999 -9999 -9999 -9999 -9999 -9999 -9999 -9999 -9999 -9999 -9999 -9999 -9999 -9999 -9999 -9999 -9999 -9999 -9999 -9999 -9999 -9999 -9999 -9999 -9999 - -9999 -9999 -9999 -9999 -9999 -9999 -9999 -9999 -9999 -9999 -9999 -9999 -9999 -9999 -9999 -9999

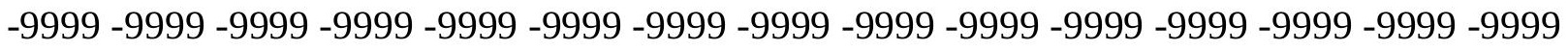
-9999 -9999 -9999 -9999 -9999 -9999 -9999 -9999 -9999 -9999 -9999 -9999 -9999 -9999 -9999 -9999 -9999 -9999 -9999 -9999 -9999 -9999 -9999 -9999 -9999 -9999 -9999 -9999 -9999 -9999 -9999 -9999 -9999 -9999 -9999 -9999 -9999 -9999 -9999 -9999 -9999 -9999 -9999 -9999 -9999 -

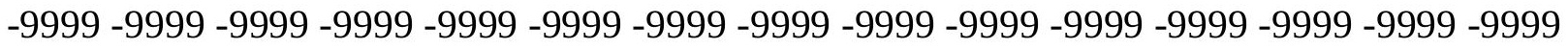
-9999 -9999 -9999 -9999 -9999 -9999 -9999 -9999 -9999 -9999 -9999 -9999 -9999 -9999 -9999 -999 -9999 -9999 -9999 -9999 -9999 -9999 -9999 -9999 -9999 -9999 -9999 -9999 -9999 -9999 -9999 -9999 -9999 -9999 -9999 -9999 -9999 -9999 -9999 -9999 -9999 -9999 -9999 -9999 -9999 -9999 -9999 -9999 -9999 -9999 -9999 -9999 -9999 -9999 -9999 -9999 -9999 -9999 -9999 -9999 -9999 -9999 -9999 -9999 -9999 -9999 -9999 -9999 -9999 -9999 -9999 -9999 -9999 -9999 -9999 -9999 -9999 -9999 -9999 -9999 -9999 -9999 -9999 -9999 -9999 -9999 -9999 -9999 -9999 -9999 -9999 -9999 -9999 -9999 -9999 -9999 -9999 -9999 -9999 -9999 -9999 -9999 -9999 -9999 -9999 -9999 -9999 -9999 -9999 -9999 -9999 -9999 -9999 -9999 -9999 -9999 -9999 -9999 -9999 -9999 -9999 -9999 -9999 -9999 -9999 -9999 -9999 -9999 -9999 -9999 -9999 -9999 -9999 -9999 -9999 -9999 -9999 -9999 -9999 -9999 -9999 -9999 -9999 -9999 -9999 -9999 -9999 -9999 -9999 -9999 -999 -9999 -9999 -9999 -9999 -9999 -9999 -9999 -9999 -9999 -9999 -9999 -9999 -9999 -9999 -9999 -9999 -9999 -9999 -9999 -9999 -9999 -9999 -9999 -9999 -9999 -9999 -9999 -9999 -9999 -

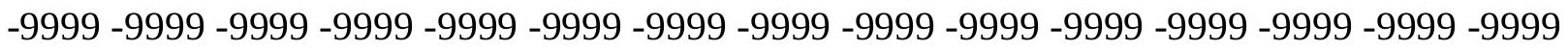

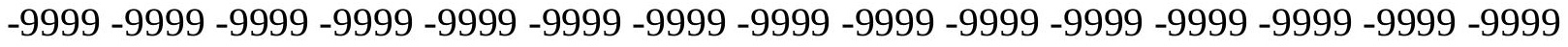

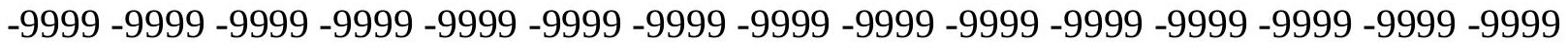
-9999 -9999 -9999 -9999 -9999 -9999 -9999 -9999 -9999 -9999 -9999 -9999 -9999 -9999 -9999 -

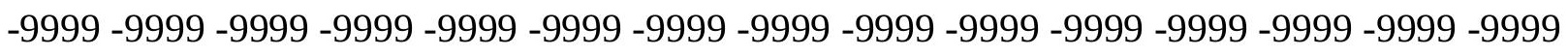

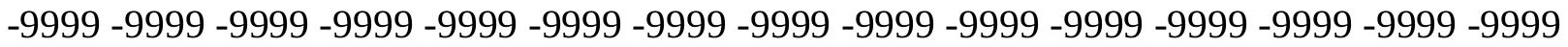

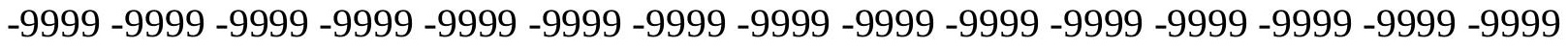
-9999 -9999 -9999 -9999 -9999 -9999 -9999 -9999 -9999 -9999 -9999 -9999 -9999 -9999 -9999 -

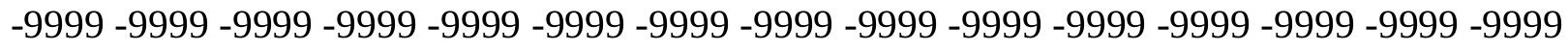

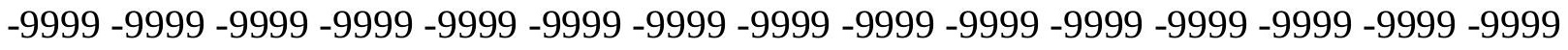
-9999 -9999 -9999 -9999 -9999 -9999 -9999 -9999 -9999 -9999 -9999 -9999 -9999 -9999 -9999 -9999 -9999 -9999 -9999 -9999 -9999 -9999 -9999 -9999-9999 -9999 -9999 -9999 -9999 -9999 -9999 -9999 -9999 -9999 -9999 -9999 -9999 -9999 -9999 -9999 -9999 -9999 -9999 -9999 -9999 -

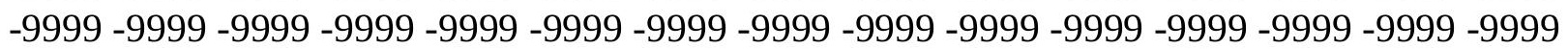


-9999 -9999 -9999 -9999 -9999 -9999 -9999 -9999 -9999 -9999 -9999 -9999 -9999 -9999 -9999 -9999 -9999 -9999 -9999 -9999 -9999 -9999 -9999 -9999 -9999 -9999 -9999 -9999 -9999 -9999 -

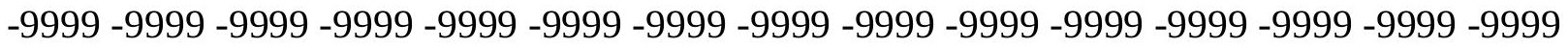
-9999 -9999 -9999 -9999 -9999 -9999 -9999 -9999 -9999 -9999 -9999 -9999 -9999 -9999 -9999 -9999 -9999 -9999 -9999 -9999 -9999 -9999 -9999 -9999-9999 -9999 -9999 -9999 -9999 -9999 -9999 -9999 -9999 -9999 -9999 -9999 -9999 -9999 -9999 -9999 -9999 -9999 -9999 -9999 -9999 -9999 -9999 -9999 -9999 -9999 -9999 -9999 -9999 -9999 -9999 -9999 -9999 -9999 -9999 -9999

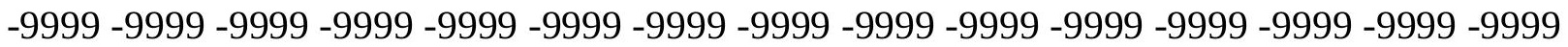

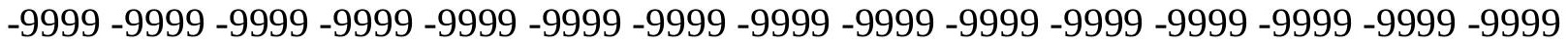
-9999 -9999 -9999 -9999 -9999 -9999 -9999 -9999 -9999 -9999 -9999 -9999 -9999 -9999 -9999 -9999 -9999 -9999 -9999 -9999 -9999 -9999 -9999 -9999 -9999 -9999 -9999 -9999 -9999 -9999 -9999 -9999 -9999 -9999 -9999 -9999 -9999 -9999 -9999 -9999 -9999 -9999 -9999 -9999 -9999 -9999 -9999 -9999 -9999 -9999 -9999 -9999 -9999 -9999 -9999 -9999 -9999 -9999 -9999 -9999 -9999 -9999 -9999 -9999 -9999 -9999 -9999 -9999 -9999 -9999 -9999 -9999 -9999 - 9999 -9999 -9999 -9999 -9999 -9999 -9999 -9999 -9999 -9999 -9999 -9999 -9999 -9999 -9999 -9999

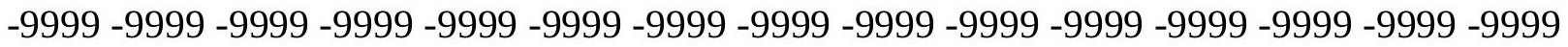
-9999 -9999 -9999 -9999 -9999 -9999 -9999 -9999 -9999 -9999 -9999 -9999 -9999 -9999 -9999 -9999 -9999 -9999 -9999 -9999 -9999 -9999 -9999 -9999 -9999 -9999 -9999 -9999 -9999 -9999 -9999 -9999 -9999 -9999 -9999 -9999 -9999 -9999 -9999 -9999 -9999 -9999 -9999 -9999 -9999 -

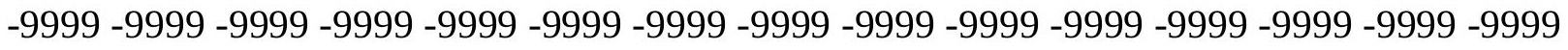

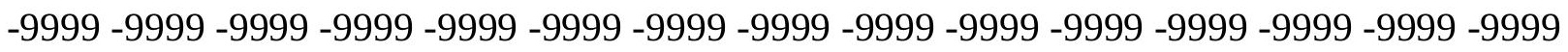
-9999 -9999 -9999 -9999 -9999 -9999 -9999 -9999 -9999 -9999 -9999 -9999 -9999 -9999 -9999 -9999 -9999 -9999 -9999 -9999 -9999 -9999 -9999 -9999 -9999 -9999 -9999 -9999 -9999 -9999 -9999 -9999 -9999 -9999 -9999 -9999 -9999 -9999 -9999 -9999 -9999 -9999 -9999 -9999 -9999 -

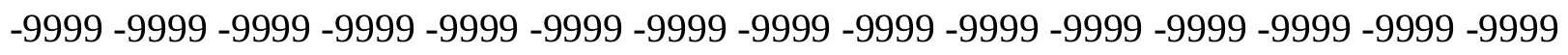
-9999 -9999 -9999 -9999 -9999 -9999 -9999 -9999 -9999 -9999 -9999 -9999 -9999 -9999 -9999 -9999 -9999 -9999 -9999 -9999 -9999 -9999 -9999 -9999 -9999 -9999 -9999 -9999 -9999 -9999 -

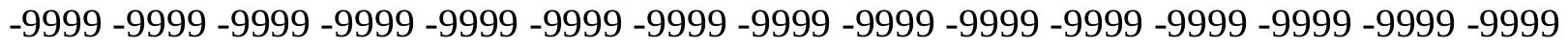
-9999 -9999 -9999 -9999 -9999 -9999 -9999 -9999 -9999 -9999 -9999 -9999 -9999 -9999 -9999 -9999 -9999 -9999 -9999 -9999 -9999 -9999 -9999 -9999 -9999 -9999 -9999 -9999 -9999 -999 -9999 -9999 -9999 -9999 -9999 -9999 -9999 -9999 -9999 -9999 -9999 -9999 -9999 -9999 -9999 -9999 -9999 -9999 -9999 -9999 -9999 -9999 -9999 -9999 -9999 -9999 -9999 -9999 -9999 -9999 -

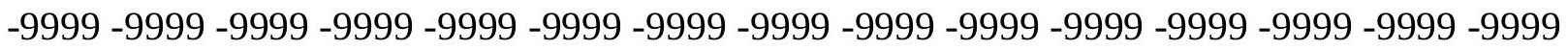

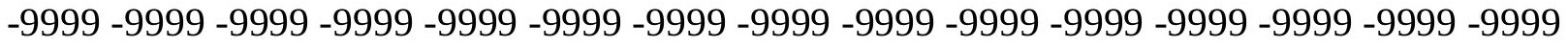

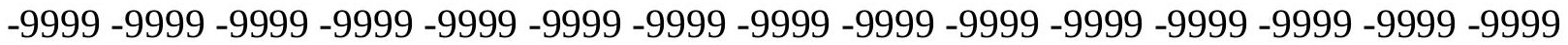

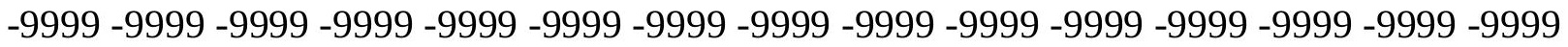

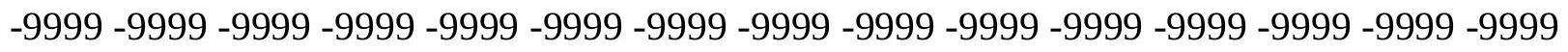

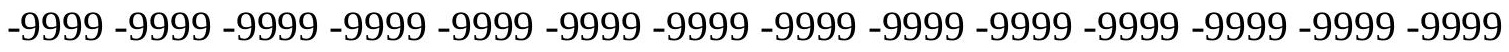
-9999 -9999 -9999 -9999 -9999 -9999 -9999 -9999 -9999 -9999 -9999 -9999 -9999 -9999 -9999 -9999 -9999 -9999 -9999 -9999 -9999 -9999 -9999 -9999 -9999 -9999 -9999 -9999 -9999 -9999 -

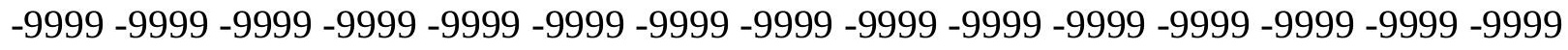

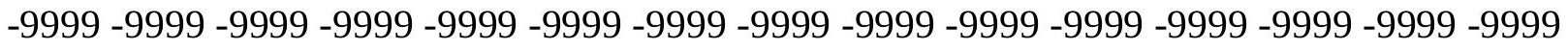
-9999 -9999 -9999 -9999 -9999 -9999 -9999 -9999 -9999 -9999 -9999 -9999 -9999 -9999 -9999 -9999 -9999 -9999 -9999 -9999 -9999 -9999 -9999 -9999-9999 -9999 -9999 -9999 -9999 -9999 -9999 -9999 -9999 -9999 -9999 -9999 -9999 -9999 -9999 -9999 -9999 -9999 -9999 -9999 -9999 -

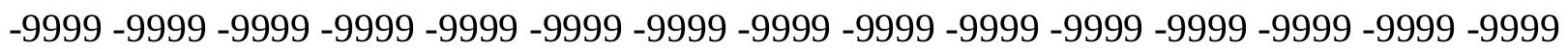


-9999 -9999 -9999 -9999 -9999 -9999 -9999 -9999 -9999 -9999 -9999 -9999 -9999 -9999 -9999 -9999 -9999 -9999 -9999 -9999 -9999 -9999 -9999 -9999 -9999 -9999 -9999 -9999 -9999 -9999 -9999 -9999 -9999 -9999 -9999 -9999 -9999 -9999 -9999 -9999 -9999 -9999 -9999 -9999 - 9999 -9999 -9999 -9999 -9999 -9999 -9999 -9999 -9999 -9999 -9999 -9999 -9999 -9999 -9999 -9999 -9999 -9999 -9999 -9999 -9999 -9999 -9999 -9999 -9999 -9999 -9999 -9999 -9999 -9999 -9999 -9999 -9999 -9999 -9999 -9999 -9999 -9999 -9999 -9999 -9999 -9999 -9999 -9999 -9999 -9999 -9999 -9999 -9999 -9999 -9999 -9999 -9999 -9999 -9999 -9999 -9999 -9999 -9999 -9999 -9999

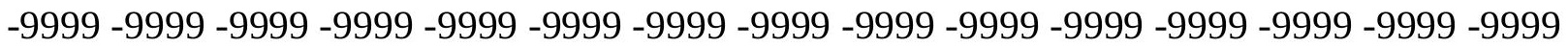
-9999 -9999 -9999 -9999 -9999 -9999 -9999 -9999 -9999 -9999 -9999 -9999 -9999 -9999 -9999 -9999 -9999 -9999 -9999 -9999 -9999 -9999 -9999 -9999 -9999 -9999 -9999 -9999 -9999 -9999

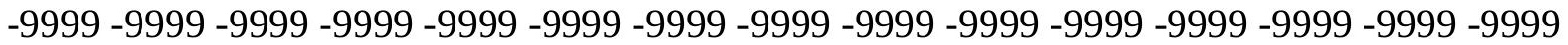
-9999 -9999 -9999 -9999 -9999 -9999 -9999 -9999 -9999 -9999 -9999 -9999 -9999 -9999 -9999 -9999 -9999 -9999 -9999 -9999 -9999 -9999 -9999 -9999 -9999 -9999 -9999 -9999 -9999 -9999 -

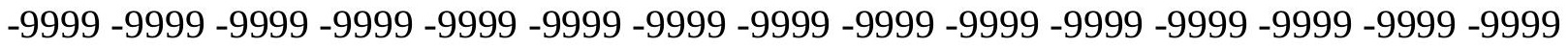
-9999 -9999 -9999 -9999 -9999 -9999 -9999 -9999 -9999 -9999 -9999 -9999 -9999 -9999 -9999

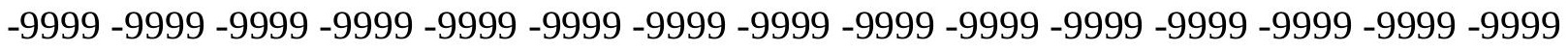
-9999 -9999 -9999 -9999 -9999 -9999 -9999 -9999 -9999 -9999 -9999 -9999 -9999 -9999 -9999 -9999 -9999 -9999 -9999 -9999 -9999 -9999 -9999 -9999 -9999 -9999 -9999 -9999 -9999 - -999 -9999 -9999 -9999 -9999 -9999 -9999 -9999 -9999 -9999 -9999 -9999 -9999 -9999 -9999 -9999 -9999 -9999 -9999 -9999 -9999 -9999 -9999 -9999 -9999 -9999 -9999 -9999 -9999 -9999 -9999 -9999 -9999 -9999 -9999 -9999 -9999 -9999 -9999 -9999 -9999 -9999 -9999 -9999 -9999 -9999 -999 -9999 -9999 -9999 -9999 -9999 -9999 -9999 -9999 -9999 -9999 -9999 -9999 -9999 -9999 -9999 -9999 -9999 -9999 -9999 -9999 -9999 -9999 -9999 -9999 -9999 -9999 -9999 -9999 -9999 -9999 -9999 -9999 -9999 -9999 -9999 -9999 -9999 -9999 -9999 -9999 -9999 -9999 -9999 -9999 -9999 -9999 -9999 -9999 -9999 -9999 -9999 -9999 -9999 -9999 -9999 -9999 -9999 -9999 -9999 -9999 -9999 -9999 -9999 -9999 -9999 -9999 -9999 -9999 -9999 -9999 -9999 -9999 -9999 -9999 -9999 -9999 -9999 -9999 -9999 -9999 -9999 -9999 -9999 -9999 -9999 -9999 -9999 -9999 -9999 -9999 -9999 -9999 -9999 -9999 -9999 -9999 -9999 -9999 -9999 -9999 -9999 -9999 -9999 -9999 -9999 -9999 -9999 -9999 -9999 -9999 -9999 -9999 -9999 -9999 -9999 -9999 -9999 -9999 -9999 -9999 -9999 -9999 -9999 -9999 -9999 -9999 -9999 -9999 -9999 -9999 -9999 -9999 -9999 -9999 -999 -9999 -9999 -9999 -9999 -9999 -9999 -9999 -9999 -9999 -9999 -9999 -9999 -9999 -9999 -9999 -9999 -9999 -9999 -9999 -9999 -9999 -9999 -9999 -9999 -9999 -9999 -9999 -9999 -9999 -9999 -

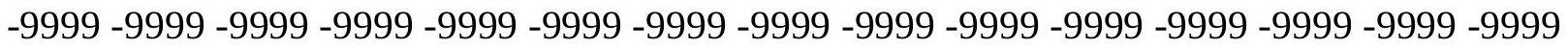

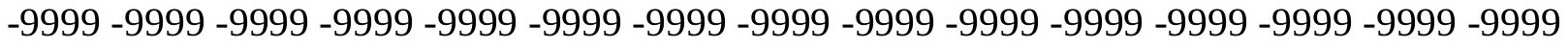

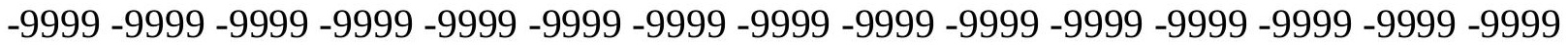
-9999 -9999 -9999 -9999 -9999 -9999 -9999 -9999 -9999 -9999 -9999 -9999 -9999 -9999 -9999

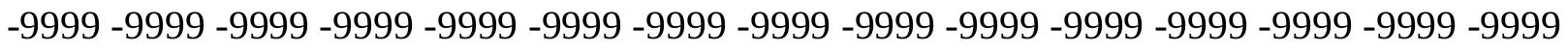

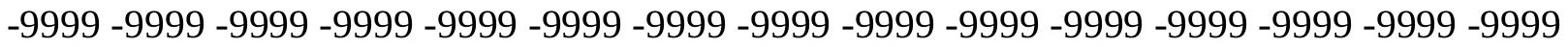

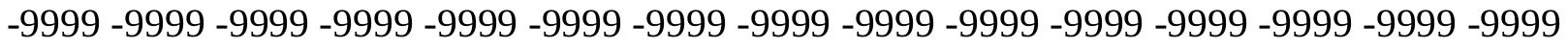
-9999 -9999 -9999 -9999 -9999 -9999 -9999 -9999 -9999 -9999 -9999 -9999 -9999 -9999 -9999 -

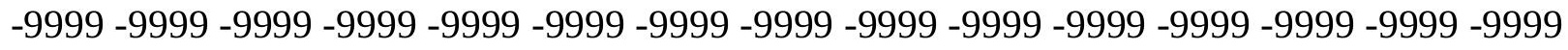

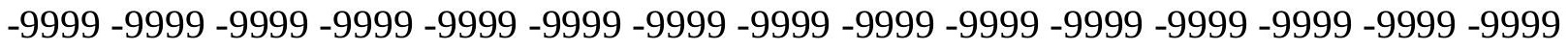
-9999 -9999 -9999 -9999 -9999 -9999 -9999 -9999 -9999 -9999 -9999 -9999 -9999 -9999 -9999 -9999 -9999 -9999 -9999 -9999 -9999 -9999 -9999 -9999 -9999 -9999 -9999 -9999 - -9999 -9999 -9999 -9999 -9999 -9999 -9999 -9999 -9999 -9999 -9999 -9999 -9999 -9999 -9999 -9999 -

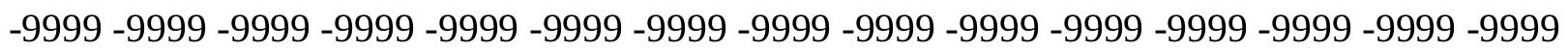


-9999 -9999 -9999 -9999 -9999 -9999 -9999 -9999 -9999 -9999 -9999 -9999 -9999 -9999 -9999 -9999 -9999 -9999 -9999 -9999 -9999 -9999 -9999 -9999 -9999 -9999 -9999 -9999 -9999 -9999 -9999 -9999 -9999 -9999 -9999 -9999 -9999 -9999 -9999 -9999 -9999 -9999 -9999 -9999 - 9999 -9999 -9999 -9999 -9999 -9999 -9999 -9999 -9999 -9999 -9999 -9999 -9999 -9999 -9999 -9999 -9999 -9999 -9999 -9999 -9999 -9999 -9999 -9999 -9999-9999 -9999 -9999 -9999 -9999 -9999 -9999 -9999 -9999 -9999 -9999 -9999 -9999 -9999 -9999 -9999 -9999 -9999 -9999 -9999 -9999 -9999 -9999 -9999 -9999 -9999 -9999 -9999 -9999 -9999 -9999 -9999 -9999 -9999 -9999 -9999

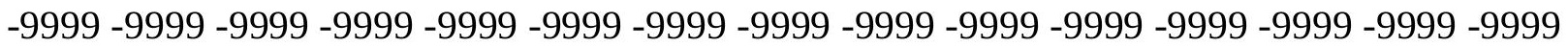

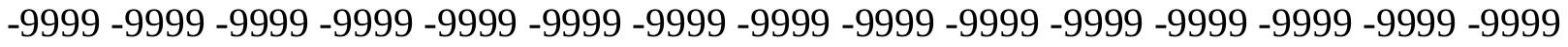
-9999 -9999 -9999 -9999 -9999 -9999 -9999 -9999 -9999 -9999 -9999 -9999 -9999 -9999 -9999

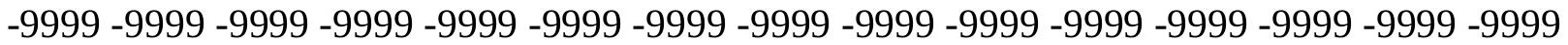
-9999 -9999 -9999 -9999 -9999 -9999 -9999 -9999 -9999 -9999 -9999 -9999 -9999 -9999 -9999 -9999 -9999 -9999 -9999 -9999 -9999 -9999 -9999 -9999 -9999 -9999 -9999 -9999 -9999 -9999 -

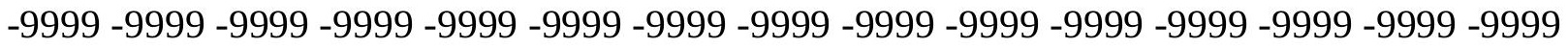
-9999 -9999 -9999 -9999 -9999 -9999 -9999 -9999 -9999 -9999 -9999 -9999 -9999 -9999 -9999

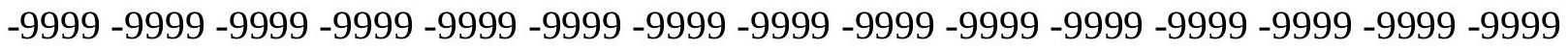
-9999 -9999 -9999 -9999 -9999 -9999 -9999 -9999 -9999 -9999 -9999 -9999 -9999 -9999 -9999 -9999 -9999 -9999 -9999 -9999 -9999 -9999 -9999 -9999 -9999 -9999 -9999 -9999 -9999 -9999 -9999 -9999 -9999 -9999 -9999 -9999 -9999 -9999 -9999 -9999 -9999 -9999 -9999 -9999 -9999 -9999 -9999 -9999 -9999 -9999 -9999 -9999 -9999 -9999 -9999 -9999 -9999 -9999 -9999 -9999 -9999 -9999 -9999 -9999 -9999 -9999 -9999 -9999 -9999 -9999 -9999 -9999 -9999 -9999 -9999 -999 -9999 -9999 -9999 -9999 -9999 -9999 -9999 -9999 -9999 -9999 -9999 -9999 -9999 -9999 -9999 -9999 -9999 -9999 -9999 -9999 -9999 -9999 -9999 -9999 -9999 -9999 -9999 -9999 -9999 -9999 -9999 -9999 -9999 -9999 -9999 -9999 -9999 -9999 -9999 -9999 -9999 -9999 -9999 -9999 -9999 -9999 -9999 -9999 -9999 -9999 -9999 -9999 -9999 -9999 -9999 -9999 -9999 -9999 -9999 -9999 -9999 -9999 -9999 -9999 -9999 -9999 -9999 -9999 -9999 -9999 -9999 -9999 -9999 -9999 -9999 -9999 -9999 -9999 -9999 -9999 -9999 -9999 -9999 -9999 -9999 -9999 -9999 -9999 -9999 -9999 -9999 -9999 -9999 -9999 -9999 -9999 -9999 -9999 -9999 -9999 -9999 -9999 -9999 -9999 -9999 -9999 -9999 -9999 -9999 -9999 -9999 -9999 -9999 -9999 -9999 -9999 -9999 -9999 -9999 -9999 -9999 -9999 -9999 -9999 -9999 -9999 -9999 -9999 -9999 -9999 -9999 -9999 -9999 -999 -9999 -9999 -9999 -9999 -9999 -9999 -9999 -9999 -9999 -9999 -9999 -9999 -9999 -9999 -9999 -9999 -9999 -9999 -9999 -9999 -9999 -9999 -9999 -9999 -9999 -9999 -9999 -9999 -9999 -9999 -

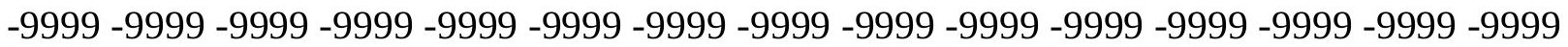

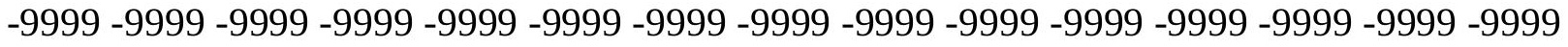

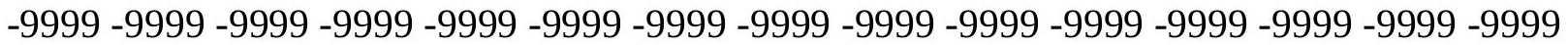
-9999 -9999 -9999 -9999 -9999 -9999 -9999 -9999 -9999 -9999 -9999 -9999 -9999 -9999 -9999

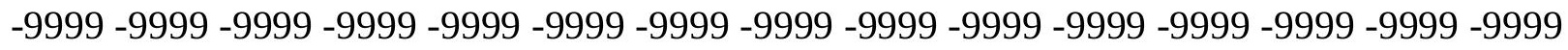

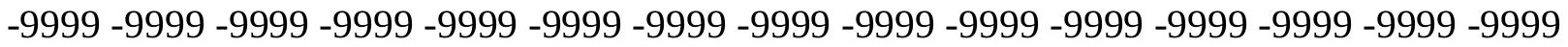
-9999 -9999 -9999 -9999 -9999 -9999 -9999 -9999 -9999 -9999 -9999 -9999 -9999 -9999 -9999 -9999 -9999 -9999 -9999 -9999 -9999 -9999 -9999 -9999 -9999 -9999 -9999 -9999 -9999 -9999 -

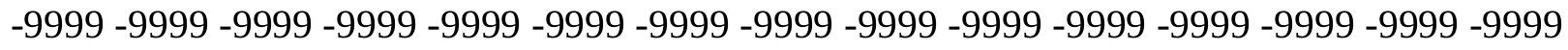

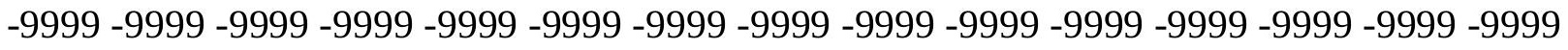
-9999 -9999 -9999 -9999 -9999 -9999 -9999 -9999 -9999 -9999 -9999 -9999 -9999 -9999 -9999 -9999 -9999 -9999 -9999 -9999 -9999 -9999 -9999 -9999-9999 -9999 -9999 -9999 -9999 -9999 -9999 -9999 -9999 -9999 -9999 -9999 -9999 -9999 -9999 -9999 -9999 -9999 -9999 -9999 -9999 -

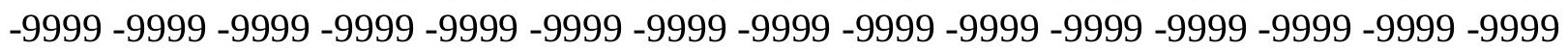


-9999 -9999 -9999 -9999 -9999 -9999 -9999 -9999 -9999 -9999 -9999 -9999 -9999 -9999 -9999 -9999 -9999 -9999 -9999 -9999 -9999 -9999 -9999 -9999 -9999 -9999 -9999 -9999 -9999 -9999 -9999 -9999 -9999 -9999 -9999 -9999 -9999 -9999 -9999 -9999 -9999 -9999 -9999 -9999 - 9999 -9999 -9999 -9999 -9999 -9999 -9999 -9999 -9999 -9999 -9999 -9999 -9999 -9999 -9999

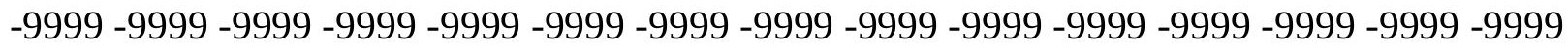
-9999 -9999 -9999 -9999 -9999 -9999 -9999 -9999 -9999 -9999 -9999 -9999 -9999 -9999 -9999 -9999 -9999 -9999 -9999 -9999 -9999 -9999 -9999 -9999 -9999 -9999 -9999 -9999 -9999 -9999

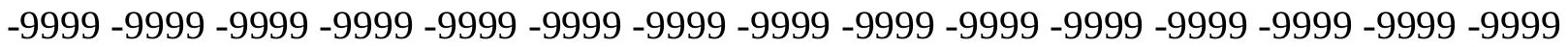

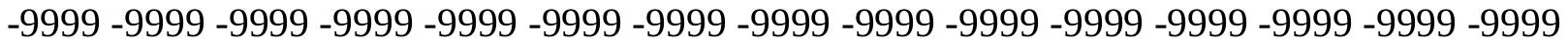
-9999 -9999 -9999 -9999 -9999 -9999 -9999 -9999 -9999 -9999 -9999 -9999 -9999 -9999 -9999 -9999 -9999 -9999 -9999 -9999 -9999 -9999 -9999 -9999 -9999 -9999 -9999 -9999 -9999 -9999 -9999 -9999 -9999 -9999 -9999 -9999 -9999 -9999 -9999 -9999 -9999 -9999 -9999 -9999 -9999 -9999 -9999 -9999 -9999 -9999 -9999 -9999 -9999 -9999 -9999 -9999 -9999 -9999 -9999 -9999 -

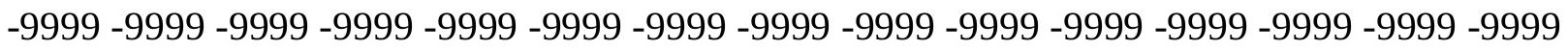
-9999 -9999 -9999 -9999 -9999 -9999 -9999 -9999 -9999 -9999 -9999 -9999 -9999 -9999 -9999 -

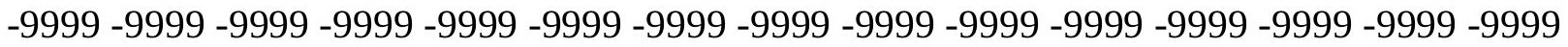
-9999 -9999 -9999 -9999 -9999 -9999 -9999 -9999 -9999 -9999 -9999 -9999 -9999 -9999 -9999 -9999 -9999 -9999 -9999 -9999 -9999 -9999 -9999 -9999 -9999 -9999 -9999 -9999 -9999 -9999 -9999 -9999 -9999 -9999 -9999 -9999 -9999 -9999 -9999 -9999 -9999 -9999 -9999 -9999 -9999 -

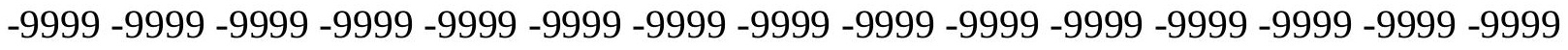
-9999 -9999 -9999 -9999 -9999 -9999 -9999 -9999 -9999 -9999 -9999 -9999 -9999 -9999 -9999

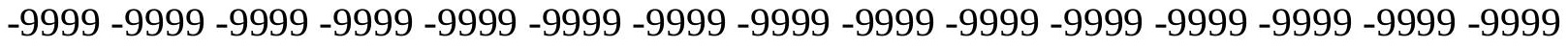
-9999 -9999 -9999 -9999 -9999 -9999 -9999 -9999 -9999 -9999 -9999 -9999 -9999 -9999 -9999 -9999 -9999 -9999 -9999 -9999 -9999 -9999 -9999 -9999 -9999 -9999 -9999 -9999 -9999 -9999 -9999 -9999 -9999 -9999 -9999 -9999 -9999 -9999 -9999 -9999 -9999 -9999 -9999 -9999 -9999 -9999 -9999 -9999 -9999 -9999 -9999 -9999 -9999 -9999 -9999 -9999 -9999 -9999 -9999 -9999 -9999 -9999 -9999 -9999 -9999 -9999 -9999 -9999 -9999 -9999 -9999 -9999 -9999 -9999 -9999 -9999 -9999 -9999 -9999 -9999 -9999 -9999 -9999 -9999 -9999 -9999 -9999 -9999 -9999 -9999 -9999 -9999 -9999 -9999 -9999 -9999 -9999 -9999 -9999 -9999 -9999 -9999 -9999 -9999 -9999 -9999 -9999 -9999 -9999 -9999 -9999 -9999 -9999 -9999 -9999 -9999 -9999 -9999 -9999 -9999 -9999 -9999 -9999 -9999 -9999 -9999 -9999 -9999 -9999 -9999 -9999 -9999 -9999 -9999 -9999 -9999 -9999 -9999 -9999 -9999 -9999 -9999 -9999 -9999 -9999 -9999 -9999 -9999 -9999 -

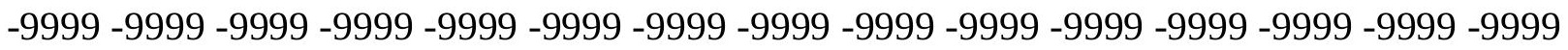

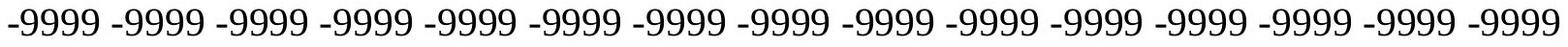
-9999 -9999 -9999 -9999 -9999 -9999 -9999 -9999 -9999 -9999 -9999 -9999 -9999 -9999 -9999 -

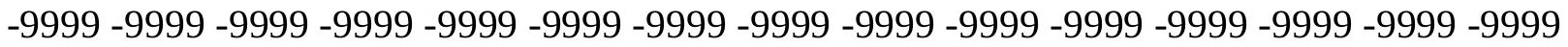

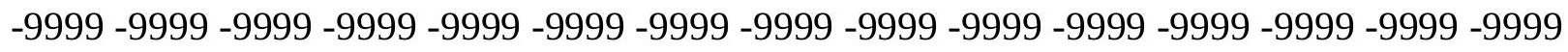

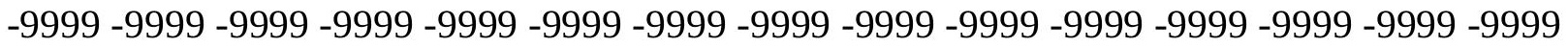

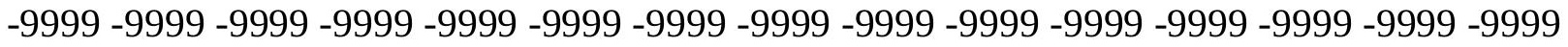
-9999 -9999 -9999 -9999 -9999 -9999 -9999 -9999 -9999 -9999 -9999 -9999 -9999 -9999 -9999 -

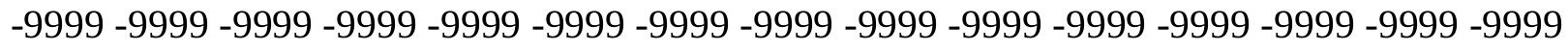

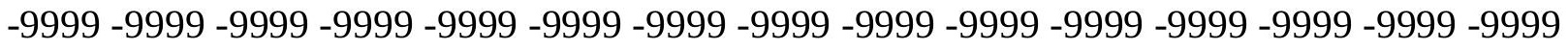
-9999 -9999 -9999 -9999 -9999 -9999 -9999 -9999 -9999 -9999 -9999 -9999 -9999 -9999 -9999 -9999 -9999 -9999 -9999 -9999 -9999 -9999 -9999 -9999-9999 -9999 -9999 -9999 -9999 -9999 -9999 -9999 -9999 -9999 -9999 -9999 -9999 -9999 -9999 -9999 -9999 -9999 -9999 -9999 -9999 -

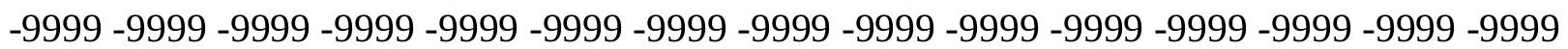


-9999 -9999 -9999 -9999 -9999 -9999 -9999 -9999 -9999 -9999 -9999 -9999 -9999 -9999 -9999 -9999 -9999 -9999 -9999 -9999 -9999 -9999 -9999 -9999 -9999 -9999 -9999 -9999 -9999 -9999 -9999 -9999 -9999 -9999 -9999 -9999 -9999 -9999 -9999 -9999 -9999 -9999 -9999 -9999 - 9999 -9999 -9999 -9999 -9999 -9999 -9999 -9999 -9999 -9999 -9999 -9999 -9999 -9999 -9999 -9999 -9999 -9999 -9999 -9999 -9999 -9999 -9999 -9999 -9999 -9999 -9999 -9999 -9999 -9999 -9999 -9999 -9999 -9999 -9999 -9999 -9999 -9999 -9999 -9999 -9999 -9999 -9999 -9999 -9999 -9999 -9999 -9999 -9999 -9999 -9999 -9999 -9999 -9999 -9999 -9999 -9999 -9999 -9999 -9999 -9999

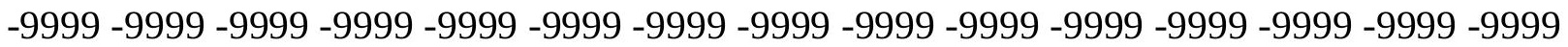

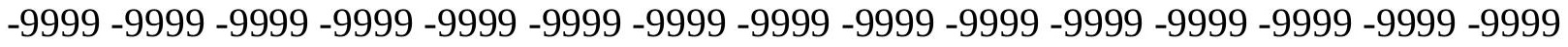
-9999 -9999 -9999 -9999 -9999 -9999 -9999 -9999 -9999 -9999 -9999 -9999 -9999 -9999 -9999 -9999 -9999 -9999 -9999 -9999 -9999 -9999 -9999 -9999 -9999 -9999 -9999 -9999 -9999 -9999 -9999 -9999 -9999 -9999 -9999 -9999 -9999 -9999 -9999 -9999 -9999 -9999 -9999 -9999 -9999 -9999 -9999 -9999 -9999 -9999 -9999 -9999 -9999 -9999 -9999 -9999 -9999 -9999 -9999 -9999 -9999 -9999 -9999 -9999 -9999 -9999 -9999 -9999 -9999 -9999 -9999 -9999 -9999 -9999 -9999 -9999 -9999 -9999 -9999 -9999 -9999 -9999 -9999 -9999 -9999 -9999 -9999 -9999 -9999 -

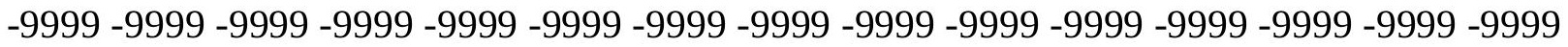
-9999 -9999 -9999 -9999 -9999 -9999 -9999 -9999 -9999 -9999 -9999 -9999 -9999 -9999 -9999 -9999 -9999 -9999 -9999 -9999 -9999 -9999 -9999 -9999 -9999 -9999 -9999 -9999 -9999 -9999 -9999 -9999 -9999 -9999 -9999 -9999 -9999 -9999 -9999 -9999 -9999 -9999 -9999 -9999 -9999 -9999 -9999 -9999 -9999 -9999 -9999 -9999 -9999 -9999 -9999 -9999 -9999 -9999 -9999 -9999 -9999 -9999 -9999 -9999 -9999 -9999 -9999 -9999 -9999 -9999 -9999 -9999 -9999 -9999 -9999 -999 -9999 -9999 -9999 -9999 -9999 -9999 -9999 -9999 -9999 -9999 -9999 -9999 -9999 -9999 -9999 -9999 -9999 -9999 -9999 -9999 -9999 -9999 -9999 -9999 -9999 -9999 -9999 -9999 -9999 -9999 -9999 -9999 -9999 -9999 -9999 -9999 -9999 -9999 -9999 -9999 -9999 -9999 -9999 -9999 -9999 -9999 -9999 -9999 -9999 -9999 -9999 -9999 -9999 -9999 -9999 -9999 -9999 -9999 -9999 -9999 -9999 -9999 -9999 -9999 -9999 -9999 -9999 -9999 -9999 -9999 -9999 -9999 -9999 -9999 -9999 -9999 -9999 -9999 -9999 -9999 -9999 -9999 -9999 -9999 -9999 -9999 -9999 -9999 -9999 -9999 -9999 -9999 -9999 -9999 -9999 -9999 -9999 -9999 -9999 -9999 -9999 -9999 -9999 -9999 -9999 -9999 -9999 -9999 -9999 -9999 -9999 -9999 -9999 -9999 -9999 -9999 -9999 -9999 -9999 -9999 -9999 -9999 -9999 -9999 -9999 -9999 -9999 -9999 -9999 -9999 -9999 -9999 -9999 -9999 -999 -9999 -9999 -9999 -9999 -9999 -9999 -9999 -9999 -9999 -9999 -9999 -9999 -9999 -9999 -9999 -9999 -9999 -9999 -9999 -9999 -9999 -9999 -9999 -9999 -9999 -9999 -9999 -9999 -9999 -9999 -

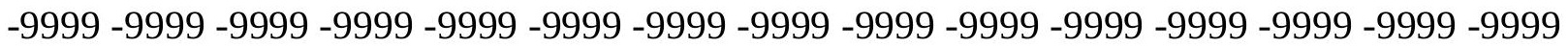

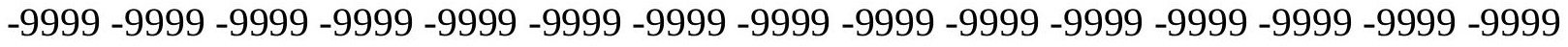

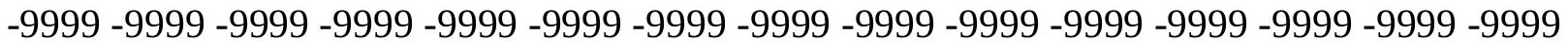
-9999 -9999 -9999 -9999 -9999 -9999 -9999 -9999 -9999 -9999 -9999 -9999 -9999 -9999 -9999 -9999 -9999 -9999 -9999 -9999 -9999 -9999 -9999 -9999 -9999 -9999 -9999 -9999 -9999 -

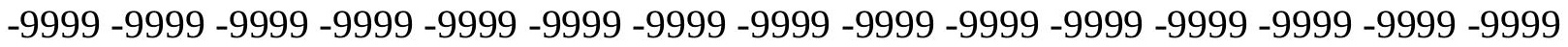
-9999 -9999 -9999 -9999 -9999 -9999 -9999 -9999 -9999 -9999 -9999 -9999 -9999 -9999 -9999 -9999 -9999 -9999 -9999 -9999 -9999 -9999 -9999 -9999 -9999 -9999 -9999 -9999 -9999 -9999 -

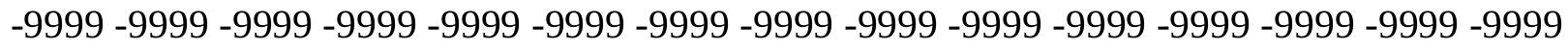

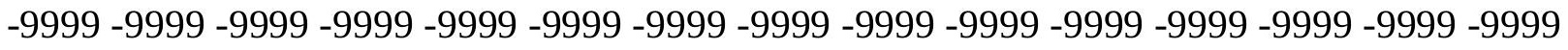
-9999 -9999 -9999 -9999 -9999 -9999 -9999 -9999 -9999 -9999 -9999 -9999 -9999 -9999 -9999 -9999 -9999 -9999 -9999 -9999 -9999 -9999 -9999 -9999-9999 -9999 -9999 -9999 -9999 -9999 -9999 -9999 -9999 -9999 -9999 -9999 -9999 -9999 -9999 -9999 -9999 -9999 -9999 -9999 -9999 -

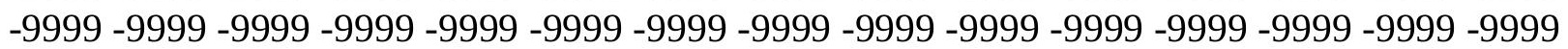


-9999 -9999 -9999 -9999 -9999 -9999 -9999 -9999 -9999 -9999 -9999 -9999 -9999 -9999 -9999 -9999 -9999 -9999 -9999 -9999 -9999 -9999 -9999 -9999 -9999 -9999 -9999 -9999 -9999 -9999 -

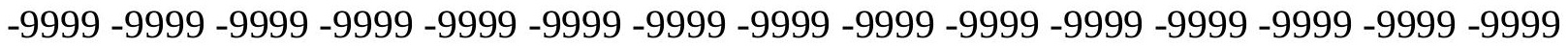
-9999 -9999 -9999 -9999 -9999 -9999 -9999 -9999 -9999 -9999 -9999 -9999 -9999 -9999 -9999 -9999 -9999 -9999 -9999 -9999 -9999 -9999 -9999 -9999-9999 -9999 -9999 -9999 -9999 -9999 -9999 -9999 -9999 -9999 -9999 -9999 -9999 -9999 -9999 -9999 -9999 -9999 -9999 -9999 -9999 -9999 -9999 -9999 -9999 -9999 -9999 -9999 -9999 -9999 -9999 -9999 -9999 -9999 -9999 -9999

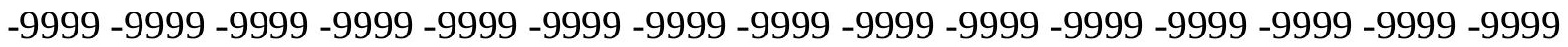

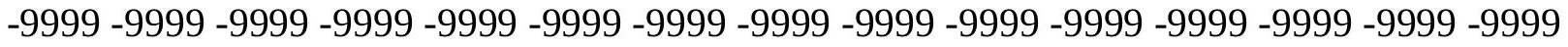
-9999 -9999 -9999 -9999 -9999 -9999 -9999 -9999 -9999 -9999 -9999 -9999 -9999 -9999 -9999 -9999 -9999 -9999 -9999 -9999 -9999 -9999 -9999 -9999 -9999 -9999 -9999 -9999 -9999 -9999 -9999 -9999 -9999 -9999 -9999 -9999 -9999 -9999 -9999 -9999 -9999 -9999 -9999 -9999 -9999 -9999 -9999 -9999 -9999 -9999 -9999 -9999 -9999 -9999 -9999 -9999 -9999 -9999 -9999 -9999 -9999 -9999 -9999 -9999 -9999 -9999 -9999 -9999 -9999 -9999 -9999 -9999 -9999 -9999 -9999 -9999 -9999 -9999 -9999 -9999 -9999 -9999 -9999 -9999 -9999 -9999 -9999 -9999 -9999 -9999 -

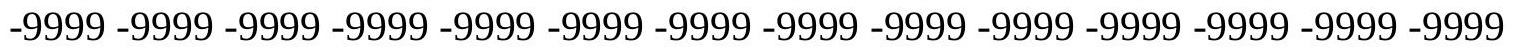
-9999 -9999 -9999 -9999 -9999 -9999 -9999 -9999 -9999 -9999 -9999 -9999 -9999 -9999 -9999 -9999 -9999 -9999 -9999 -9999 -9999 -9999 -9999 -9999 -9999 -9999 -9999 -9999 -9999 -9999 -9999 -9999 -9999 -9999 -9999 -9999 -9999 -9999 -9999 -9999 -9999 -9999 -9999 -9999 -9999 -

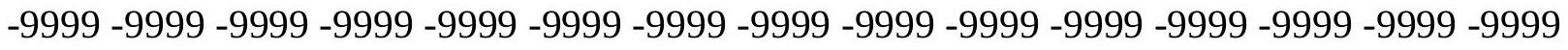

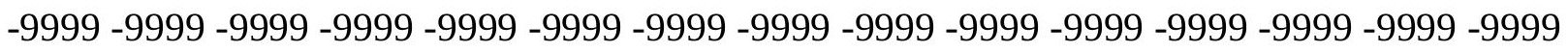
-9999 -9999 -9999 -9999 -9999 -9999 -9999 -9999 -9999 -9999 -9999 -9999 -9999 -9999 - 9999 -9999 -9999 -9999 -9999 -9999 -9999 -9999 -9999 -9999 -9999 -9999 -9999 -9999 -9999 -9999 -9999 -9999 -9999 -9999 -9999 -9999 -9999 -9999 -9999 -9999 -9999 -9999 -9999 -9999 -9999 -

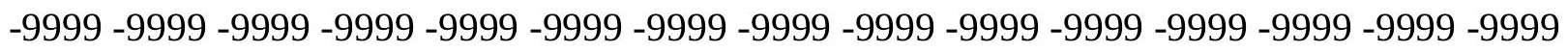
-9999 -9999 -9999 -9999 -9999 -9999 -9999 -9999 -9999 -9999 -9999 -9999 -9999 -9999 -9999 -9999 -9999 -9999 -9999 -9999 -9999 -9999 -9999 -9999 -9999 -9999 -9999 -9999 -9999 -9999 -

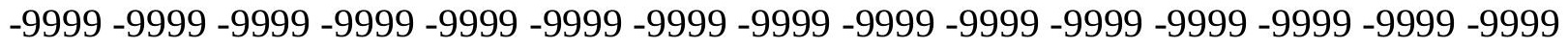
-9999 -9999 -9999 -9999 -9999 -9999 -9999 -9999 -9999 -9999 -9999 -9999 -9999 -9999 -9999 -9999 -9999 -9999 -9999 -9999 -9999 -9999 -9999 -9999 -9999 -9999 -9999 -9999 -9999 -999 -

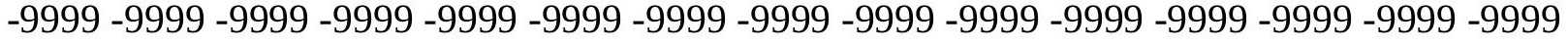
-9999 -9999 -9999 -9999 -9999 -9999 -9999 -9999 -9999 -9999 -9999 -9999 -9999 -9999 -9999 -

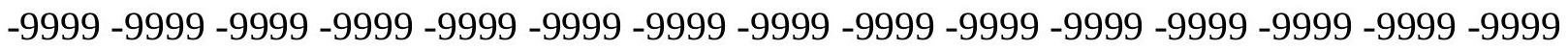

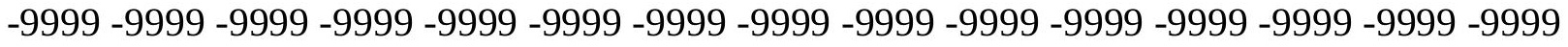

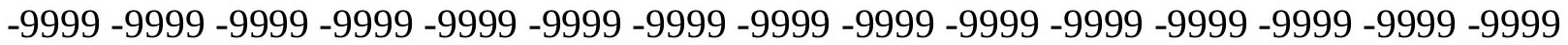
-9999 -9999 -9999 -9999 -9999 -9999 -9999 -9999 -9999 -9999 -9999 -9999 -9999 -9999 -9999 -

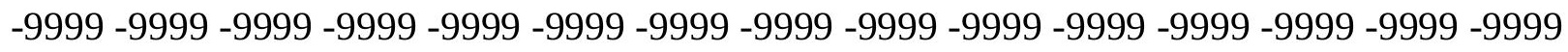

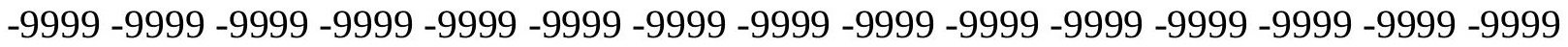
-9999 -9999 -9999 -9999 -9999 -9999 -9999 -9999 -9999 -9999 -9999 -9999 -9999 - 9999 - -999 -9999 -9999 -9999 -9999 -9999 -9999 -9999 -9999 -9999 -9999 -9999 -9999 -9999 -9999 -9999 -

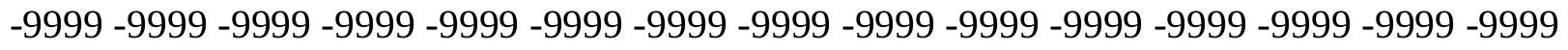

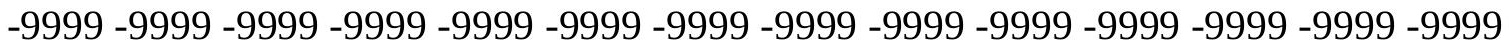
-9999 -9999 -9999 -9999 -9999 -9999 -9999 -9999 -9999 -9999 -9999 -9999 -9999 -9999 -9999 -9999 -9999 -9999 -9999 -9999 -9999 -9999 -9999 -9999-9999 -9999 -9999 -9999 -9999 -9999 -9999 -9999 -9999 -9999 -9999 -9999 -9999 -9999 -9999 -9999 -9999 -9999 -9999 -9999 -9999 -

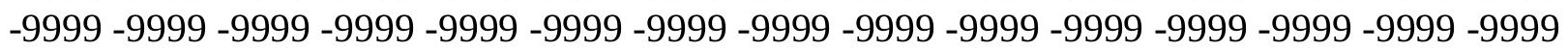


-9999 -9999 -9999 -9999 -9999 -9999 -9999 -9999 -9999 -9999 -9999 -9999 -9999 -9999 -9999 -9999 -9999 -9999 -9999 -9999 -9999 -9999 -9999 -9999 -9999 -9999 -9999 -9999 -9999 -9999 -

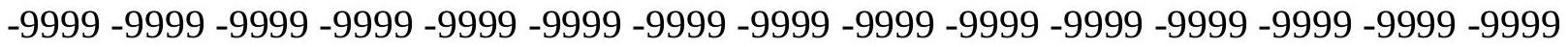
-9999 -9999 -9999 -9999 -9999 -9999 -9999 -9999 -9999 -9999 -9999 -9999 -9999 -9999 -9999 -9999 -9999 -9999 -9999 -9999 -9999 -9999 -9999 -9999-9999 -9999 -9999 -9999 -9999 -9999 -9999 -9999 -9999 -9999 -9999 -9999 -9999 -9999 -9999 -9999 -9999 -9999 -9999 -9999 -9999 -9999 -9999 -9999 -9999 -9999 -9999 -9999 -9999 -9999 -9999 -9999 -9999 -9999 -9999 -9999

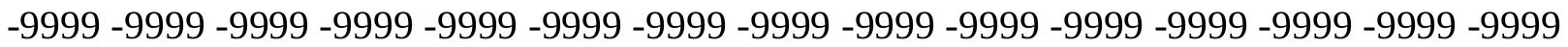

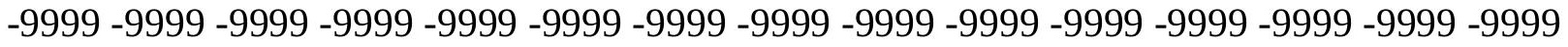
-9999 -9999 -9999 -9999 -9999 -9999 -9999 -9999 -9999 -9999 -9999 -9999 -9999 -9999 -9999 -9999 -9999 -9999 -9999 -9999 -9999 -9999 -9999 -9999 -9999 -9999 -9999 -9999 -9999 -9999 -9999 -9999 -9999 -9999 -9999 -9999 -9999 -9999 -9999 -9999 -9999 -9999 -9999 -9999 -9999 -9999 -9999 -9999 -9999 -9999 -9999 -9999 -9999 -9999 -9999 -9999 -9999 -9999 -9999 -9999 -

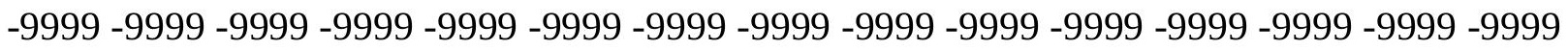
-9999 -9999 -9999 -9999 -9999 -9999 -9999 -9999 -9999 -9999 -9999 -9999 -9999 -9999 -9999 -

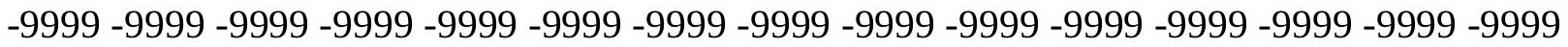
-9999 -9999 -9999 -9999 -9999 -9999 -9999 -9999 -9999 -9999 -9999 -9999 -9999 -9999 -9999 -9999 -9999 -9999 -9999 -9999 -9999 -9999 -9999 -9999 -9999 -9999 -9999 -9999 -9999 -9999 -9999 -9999 -9999 -9999 -9999 -9999 -9999 -9999 -9999 -9999 -9999 -9999 -9999 -9999 -9999 -

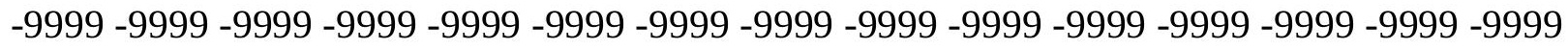

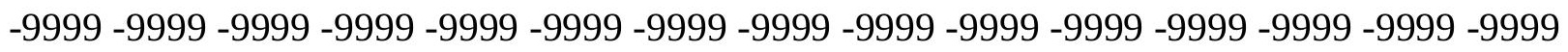
-9999 -9999 -9999 -9999 -9999 -9999 -9999 -9999 -9999 -9999 -9999 -9999 -9999 -9999 -9999 -9999 -9999 -9999 -9999 -9999 -9999 -9999 -9999 -9999 -9999 -9999 -9999 -9999 -9999 -9999 -9999 -9999 -9999 -9999 -9999 -9999 -9999 -9999 -9999 -9999 -9999 -9999 -9999 -9999 -

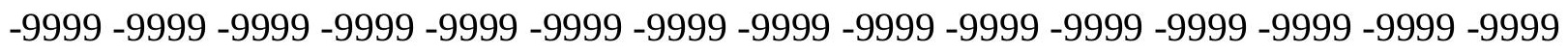
-9999 -9999 -9999 -9999 -9999 -9999 -9999 -9999 -9999 -9999 -9999 -9999 -9999 -9999 -9999 -9999 -9999 -9999 -9999 -9999 -9999 -9999 -9999 -9999 -9999 -9999 -9999 -9999 -9999 -9999 -

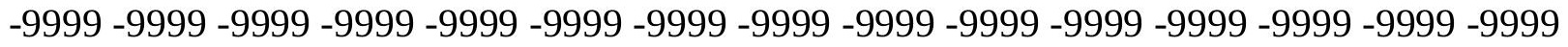
-9999 -9999 -9999 -9999 -9999 -9999 -9999 -9999 -9999 -9999 -9999 -9999 -9999 -9999 -9999 -9999 -9999 -9999 -9999 -9999 -9999 -9999 -9999 -9999 -9999 -9999 -9999 -9999 -9999 -999 -

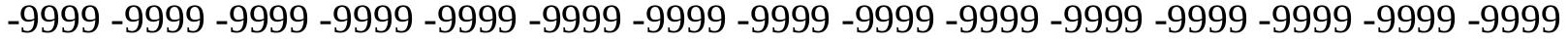
-9999 -9999 -9999 -9999 -9999 -9999 -9999 -9999 -9999 -9999 -9999 -9999 -9999 -9999 -9999 -

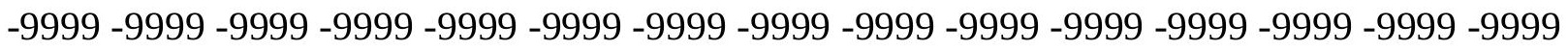

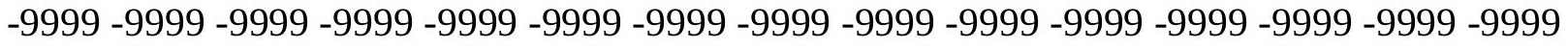

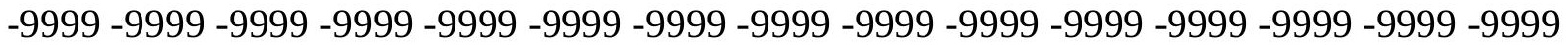

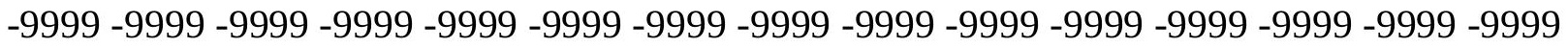

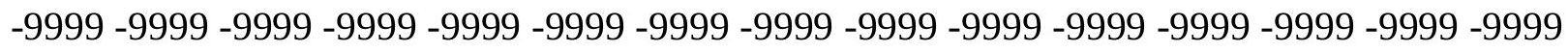

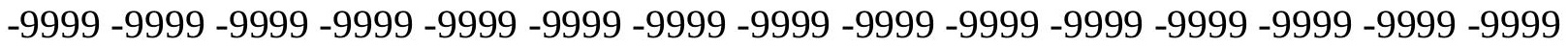

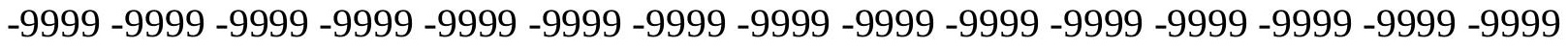
-9999 -9999 -9999 -9999 -9999 -9999 -9999 -9999 -9999 -9999 -9999 -9999 -9999 -9999 -9999 -

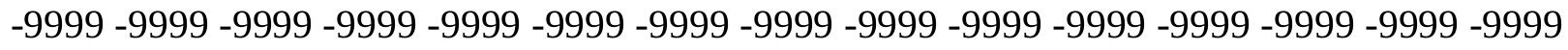

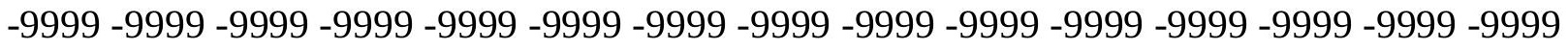
-9999 -9999 -9999 -9999 -9999 -9999 -9999 -9999 -9999 -9999 -9999 -9999 -9999 -9999 -9999 -9999 -9999 -9999 -9999 -9999 -9999 -9999 -9999 -9999-9999 -9999 -9999 -9999 -9999 -9999 -9999 -9999 -9999 -9999 -9999 -9999 -9999 -9999 -9999 -9999 -9999 -9999 -9999 -9999 -9999 -

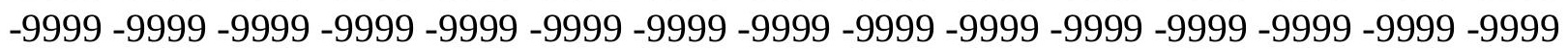


-9999 -9999 -9999 -9999 -9999 -9999 -9999 -9999 -9999 -9999 -9999 -9999 -9999 -9999 -9999 -9999 -9999 -9999 -9999 -9999 -9999 -9999 -9999 -9999 -9999 -9999 -9999 -9999 -9999 -

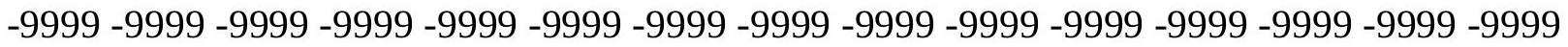
-9999 -9999 -9999 -9999 -9999 -9999 -9999 -9999 -9999 -9999 -9999 -9999 -9999 -9999 -9999 -9999 -9999 -9999 -9999 -9999 -9999 -9999 -9999 -9999 -9999 -9999 -9999 -9999 -9999 -9999 -9999 -9999 -9999 -9999 -9999 -9999 -9999 -9999 -9999 -9999 -9999 -9999 -9999 -9999 -9999 -9999 -9999 -9999 -9999 -9999 -9999 -9999 -9999 -9999 -9999 -9999 -9999 -9999 -9999 -9999

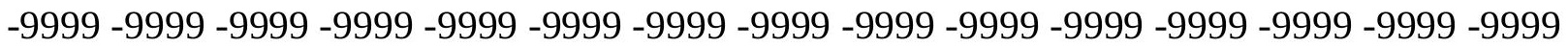

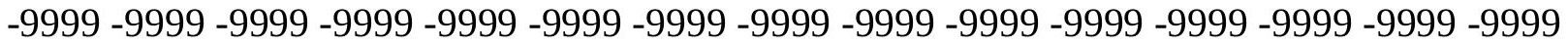
-9999 -9999 -9999 -9999 -9999 -9999 -9999 -9999 -9999 -9999 -9999 -9999 -9999 -9999 -9999 -9999 -9999 -9999 -9999 -9999 -9999 -9999 -9999 -9999 -9999 -9999 -9999 -9999 -9999 -9999 -9999 -9999 -9999 -9999 -9999 -9999 -9999 -9999 -9999 -9999 -9999 -9999 -9999 -9999 -9999 -9999 -9999 -9999 -9999 -9999 -9999 -9999 -9999 -9999 -9999 -9999 -9999 -9999 -9999 -9999 -9999 -9999 -9999 -9999 -9999 -9999 -9999 -9999 -9999 -9999 -9999 -9999 -9999 -9999 -9999 -9999 -9999 -9999 -9999 -9999 -9999 -9999 -9999 -9999 -9999 -9999 -9999 -9999 -9999 -9999 -

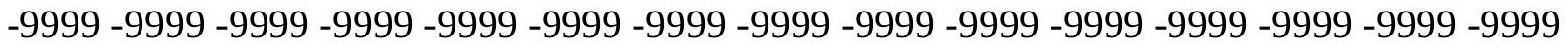
-9999 -9999 -9999 -9999 -9999 -9999 -9999 -9999 -9999 -9999 -9999 -9999 -9999 -9999 -9999 -9999 -9999 -9999 -9999 -9999 -9999 -9999 -9999 -9999 -9999 -9999 -9999 -9999 -9999 - 9999 -9999 -9999 -9999 -9999 -9999 -9999 -9999 -9999 -9999 -9999 -9999 -9999 -9999 -9999 -9999 -

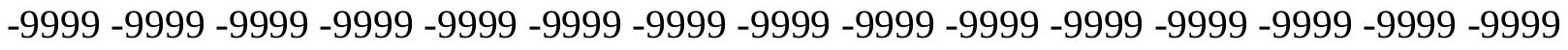

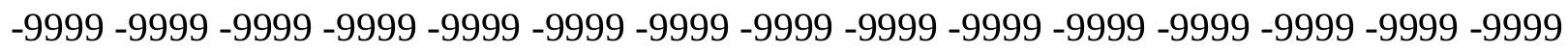

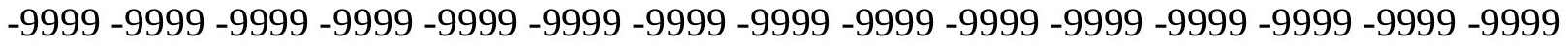
-9999 -9999 -9999 -9999 -9999 -9999 -9999 -9999 -9999 -9999 -9999 -9999 -9999 -9999 -9999 -9999 -9999 -9999 -9999 -9999 -9999 -9999 -9999 -9999 -9999 -9999 -9999 -9999 -9999 -9999 -

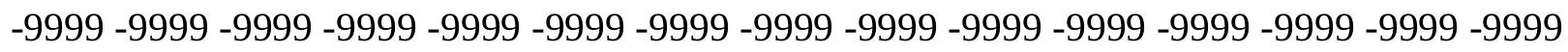
-9999 -9999 -9999 -9999 -9999 -9999 -9999 -9999 -9999 -9999 -9999 -9999 -9999 -9999 -9999 -9999 -9999 -9999 -9999 -9999 -9999 -9999 -9999 -9999 -9999 -9999 -9999 -9999 -9999 -9999 -9999 -9999 -9999 -9999 -9999 -9999 -9999 -9999 -9999 -9999 -9999 -9999 -9999 -9999 -9999 -9999 -9999 -9999 -9999 -9999 -9999 -9999 -9999 -9999 -9999 -9999 -9999 -9999 -9999 -9999 -9999 -9999 -9999 -9999 -9999 -9999 -9999 -9999 -9999 -9999 -9999 -9999 -9999 -999 -

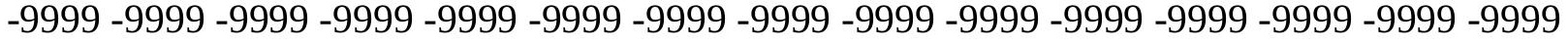
-9999 -9999 -9999 -9999 -9999 -9999 -9999 -9999 -9999 -9999 -9999 -9999 -9999 -9999 -9999 -

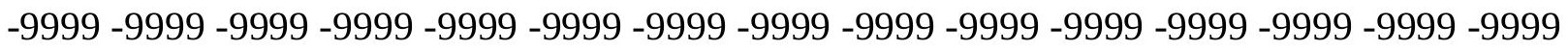

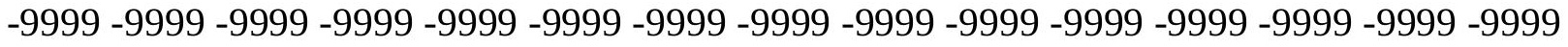

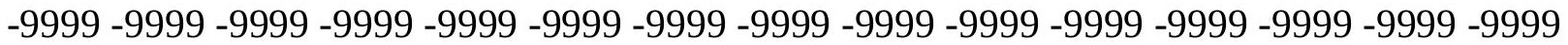

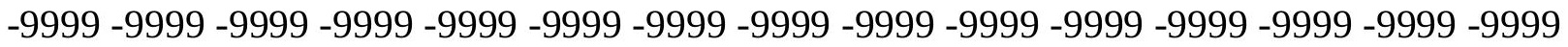

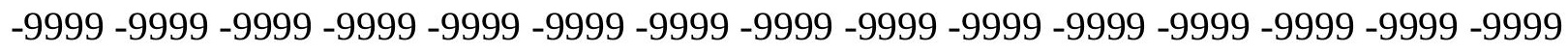

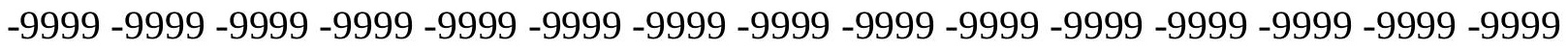

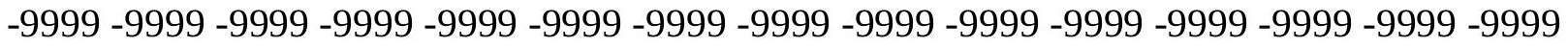
-9999 -9999 -9999 -9999 -9999 -9999 -9999 -9999 -9999 -9999 -9999 -9999 -9999 -9999 -9999 -

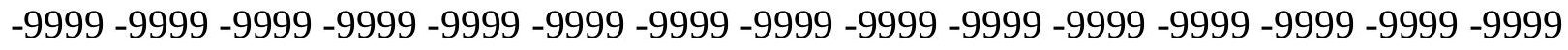

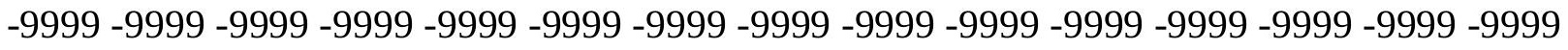
-9999 -9999 -9999 -9999 -9999 -9999 -9999 -9999 -9999 -9999 -9999 -9999 -9999 -9999 -9999 -9999 -9999 -9999 -9999 -9999 -9999 -9999 -9999 -9999-9999 -9999 -9999 -9999 -9999 -9999 -9999 -9999 -9999 -9999 -9999 -9999 -9999 -9999 -9999 -9999 -9999 -9999 -9999 -9999 -9999 -

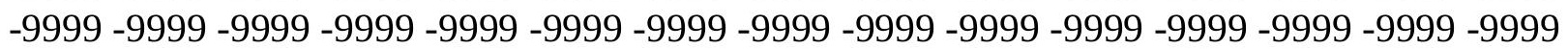


-9999 -9999 -9999 -9999 -9999 -9999 -9999 -9999 -9999 -9999 -9999 -9999 -9999 -9999 -9999 -9999 -9999 -9999 -9999 -9999 -9999 -9999 -9999 -9999 -9999 -9999 -9999 -9999 -9999 -9999 -

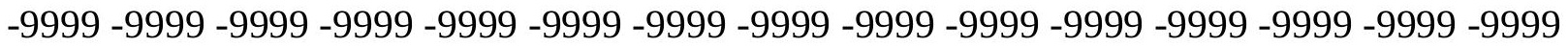
-9999 -9999 -9999 -9999 -9999 -9999 -9999 -9999 -9999 -9999 -9999 -9999 -9999 -9999 -9999 -9999 -9999 -9999 -9999 -9999 -9999 -9999 -9999 -9999-9999 -9999 -9999 -9999 -9999 -9999 -9999 -9999 -9999 -9999 -9999 -9999 -9999 -9999 -9999 -9999 -9999 -9999 -9999 -9999 -9999 -

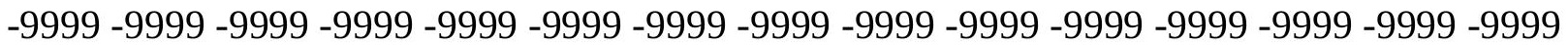
-9999 -9999 -9999 -9999 -9999 -9999 -9999 -9999 -9999 -9999 -9999 -9999 -9999 -9999 -9999 -9999 -9999 -9999 -9999 -9999 -9999 -9999 -9999 -9999 -9999 -9999 -9999 -9999 -9999 -9999 -9999 -9999 -9999 -9999 -9999 -9999 -9999 -9999 -9999 -9999 -9999 -9999 -9999 -9999 -9999 -9999 -9999 -9999 -9999 -9999 -9999 -9999 -9999 -9999 -9999 -9999 -9999 -9999 -9999 -9999 -9999 -9999 -9999 -9999 -9999 -9999 -9999 -9999 -9999 -9999 -9999 -9999 -9999 -9999 -9999 -9999 -9999 -9999 -9999 -9999 -9999 -9999 -9999 -9999 -9999 -9999 -9999 -9999 -9999 -9999 -9999 -9999 -9999 -9999 -9999 -9999 -9999 -9999 -9999 -9999 -9999 -9999 -9999 -9999 -9999 -9999 -9999 -9999 -9999 -9999 -9999 -9999 -9999 -9999 -9999 -9999 -9999 -9999 -9999 -

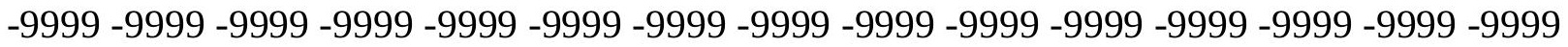
-9999 -9999 -9999 -9999 -9999 -9999 -9999 -9999 -9999 -9999 -9999 -9999 -9999 -9999 -9999 -9999 -9999 -9999 -9999 -9999 -9999 -9999 -9999 -9999 -9999 -9999 -9999 -9999 -9999 -9999 -9999 -9999 -9999 -9999 -9999 -9999 -9999 -9999 -9999 -9999 -9999 -9999 -9999 -9999 -9999 -

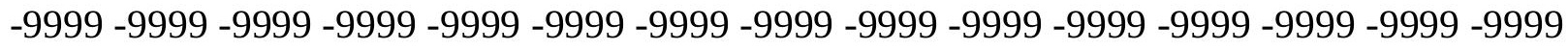

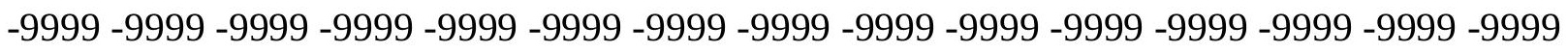
-9999 -9999 -9999 -9999 -9999 -9999 -9999 -9999 -9999 -9999 -9999 -9999 -9999 -9999 - 9999 -9999 -9999 -9999 -9999 -9999 -9999 -9999 -9999 -9999 -9999 -9999 -9999 -9999 -9999 -9999 -9999 -9999 -9999 -9999 -9999 -9999 -9999 -9999 -9999 -9999 -9999 -9999 -9999 -9999 -9999 -

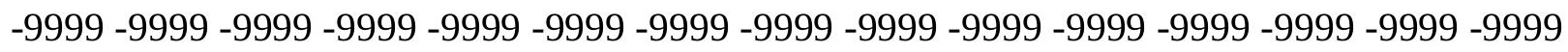
-9999 -9999 -9999 -9999 -9999 -9999 -9999 -9999 -9999 -9999 -9999 -9999 -9999 -9999 -9999 -9999 -9999 -9999 -9999 -9999 -9999 -9999 -9999 -9999 -9999 -9999 -9999 -9999 -9999 -9999 -

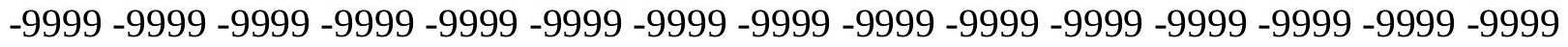
-9999 -9999 -9999 -9999 -9999 -9999 -9999 -9999 -9999 -9999 -9999 -9999 -9999 -9999 -9999 -9999 -9999 -9999 -9999 -9999 -9999 -9999 -9999 -9999 -9999 -9999 -9999 -9999 -9999 -999 -9999 -9999 -9999 -9999 -9999 -9999 -9999 -9999 -9999 -9999 -9999 -9999 -9999 -9999 -9999 -9999 -9999 -9999 -9999 -9999 -9999 -9999 -9999 -9999 -9999 -9999 -9999 -9999 -9999 -9999 -

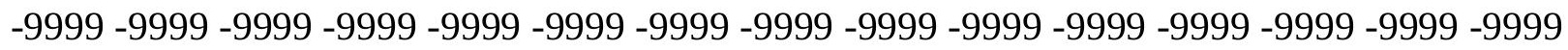

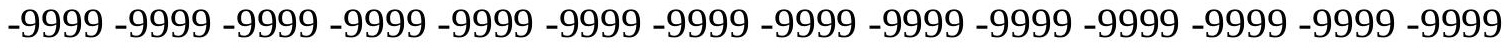
-9999 -9999 -9999 -9999 -9999 -9999 -9999 -9999 -9999 -9999 -9999 -9999 -9999 -9999 -9999

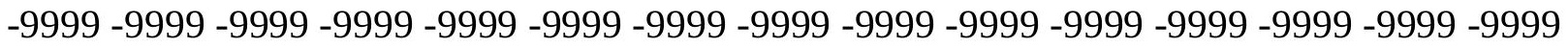

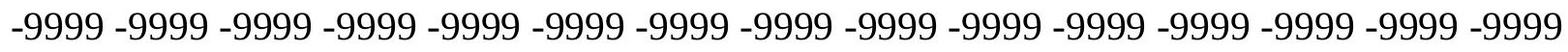

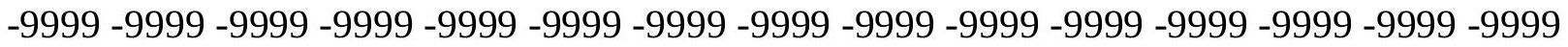

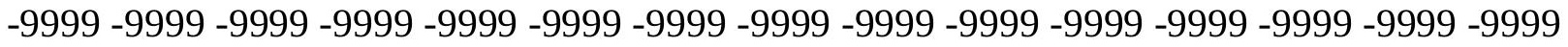
-9999 -9999 -9999 -9999 -9999 -9999 -9999 -9999 -9999 -9999 -9999 -9999 -9999 -9999 -9999 -

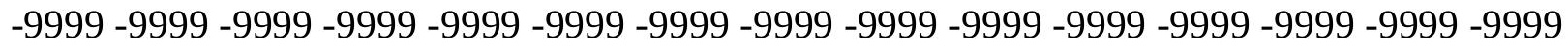

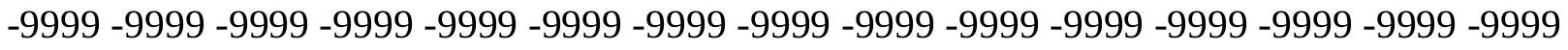
-9999 -9999 -9999 -9999 -9999 -9999 -9999 -9999 -9999 -9999 -9999 -9999 -9999 -9999 -9999 -9999 -9999 -9999 -9999 -9999 -9999 -9999 -9999 -9999-9999 -9999 -9999 -9999 -9999 -9999 -9999 -9999 -9999 -9999 -9999 -9999 -9999 -9999 -9999 -9999 -9999 -9999 -9999 -9999 -9999 -

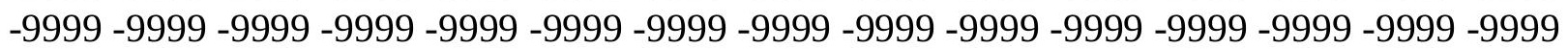


-9999 -9999 -9999 -9999 -9999 -9999 -9999 -9999 -9999 -9999 -9999 -9999 -9999 -9999 -9999 -9999 -9999 -9999 -9999 -9999 -9999 -9999 -9999 -9999 -9999 -9999 -9999 -9999 -9999 -9999 -

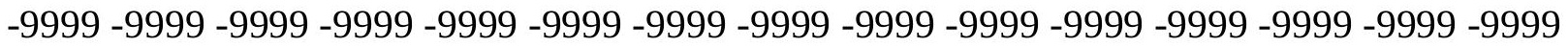
-9999 -9999 -9999 -9999 -9999 -9999 -9999 -9999 -9999 -9999 -9999 -9999 -9999 -9999 -9999 -9999 -9999 -9999 -9999 -9999 -9999 -9999 -9999 -9999-9999 -9999 -9999 -9999 -9999 -9999 -9999 -9999 -9999 -9999 -9999 -9999 -9999 -9999 -9999 -9999 -9999 -9999 -9999 -9999 -9999 -9999 -9999 -9999 -9999 -9999 -9999 -9999 -9999 -9999 -9999 -9999 -9999 -9999 -9999 -9999

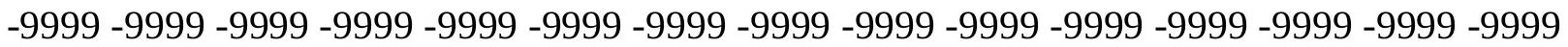

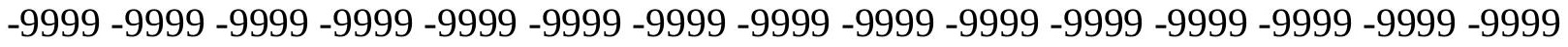
-9999 -9999 -9999 -9999 -9999 -9999 -9999 -9999 -9999 -9999 -9999 -9999 -9999 -9999 -9999 -9999 -9999 -9999 -9999 -9999 -9999 -9999 -9999 -9999 -9999 -9999 -9999 -9999 -9999 -9999 -9999 -9999 -9999 -9999 -9999 -9999 -9999 -9999 -9999 -9999 -9999 -9999 -9999 -9999 -9999 -9999 -9999 -9999 -9999 -9999 -9999 -9999 -9999 -9999 -9999 -9999 -9999 -9999 -9999 -9999 -9999 -9999 -9999 -9999 -9999 -9999 -9999 -9999 -9999 -9999 -9999 -9999 -9999 -9999 -9999 -9999 -9999 -9999 -9999 -9999 -9999 -9999 -9999 -9999 -9999 -9999 -9999 -9999 -9999

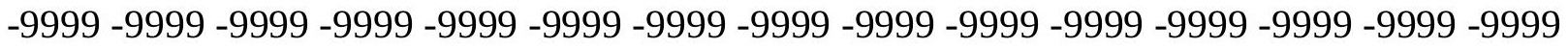
-9999 -9999 -9999 -9999 -9999 -9999 -9999 -9999 -9999 -9999 -9999 -9999 -9999 -9999 -9999 -9999 -9999 -9999 -9999 -9999 -9999 -9999 -9999 -9999 -9999 -9999 -9999 -9999 -9999 -9999 -9999 -9999 -9999 -9999 -9999 -9999 -9999 -9999 -9999 -9999 -9999 -9999 -9999 -9999 -9999 -

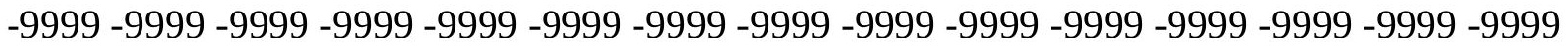

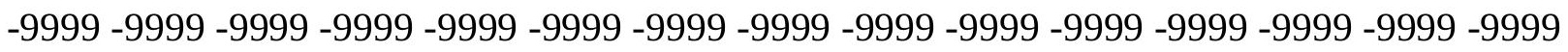
-9999 -9999 -9999 -9999 -9999 -9999 -9999 -9999 -9999 -9999 -9999 -9999 -9999 -9999 -9999 -9999 -9999 -9999 -9999 -9999 -9999 -9999 -9999 -9999 -9999 -9999 -9999 -9999 -9999 -9999 -9999 -9999 -9999 -9999 -9999 -9999 -9999 -9999 -9999 -9999 -9999 -9999 -9999 -9999 -9999 -

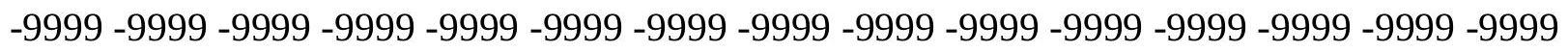
-9999 -9999 -9999 -9999 -9999 -9999 -9999 -9999 -9999 -9999 -9999 -9999 -9999 -9999 -9999 -9999 -9999 -9999 -9999 -9999 -9999 -9999 -9999 -9999 -9999 -9999 -9999 -9999 -9999 -9999 -

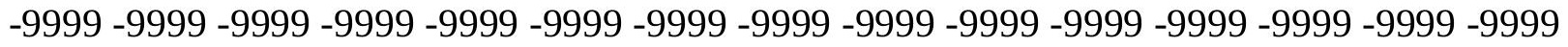
-9999 -9999 -9999 -9999 -9999 -9999 -9999 -9999 -9999 -9999 -9999 -9999 -9999 -9999 -9999 -9999 -9999 -9999 -9999 -9999 -9999 -9999 -9999 -9999 -9999 -9999 -9999 -9999 -9999 -999 -9999 -9999 -9999 -9999 -9999 -9999 -9999 -9999 -9999 -9999 -9999 -9999 -9999 -9999 -9999 -9999 -9999 -9999 -9999 -9999 -9999 -9999 -9999 -9999 -9999 -9999 -9999 -9999 -9999 -9999 -

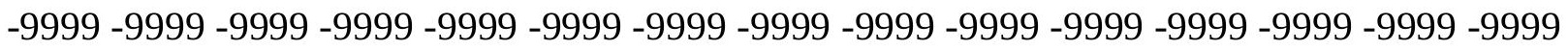

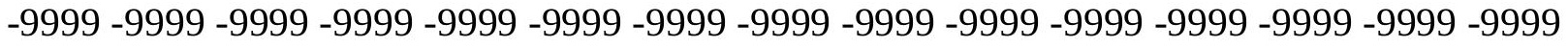

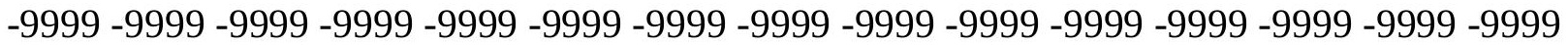

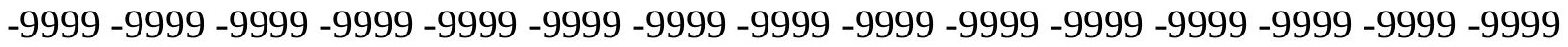

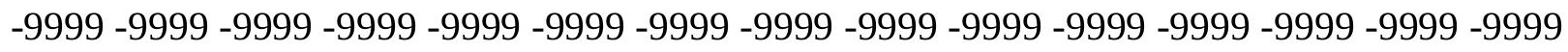

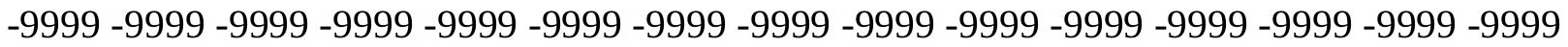
-9999 -9999 -9999 -9999 -9999 -9999 -9999 -9999 -9999 -9999 -9999 -9999 -9999 - 9999 - -999 -9999 -9999 -9999 -9999 -9999 -9999 -9999 -9999 -9999 -9999 -9999 -9999 -9999 -9999 - -999 -

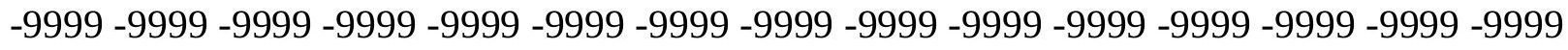

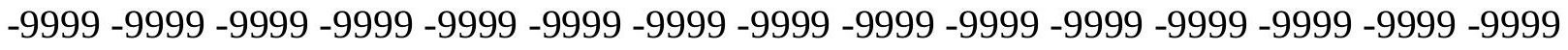
-9999 -9999 -9999 -9999 -9999 -9999 -9999 -9999 -9999 -9999 -9999 -9999 -9999 -9999 -9999 -9999 -9999 -9999 -9999 -9999 -9999 -9999 -9999 -9999-9999 -9999 -9999 -9999 -9999 -9999 -9999 -9999 -9999 -9999 -9999 -9999 -9999 -9999 -9999 -9999 -9999 -9999 -9999 -9999 -9999 -

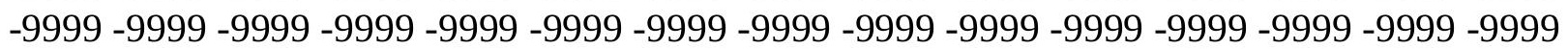


-9999 -9999 -9999 -9999 -9999 -9999 -9999 -9999 -9999 -9999 -9999 -9999 -9999 -9999 -9999 -9999 -9999 -9999 -9999 -9999 -9999 -9999 -9999 -9999 -9999 -9999 -9999 -9999 -9999 -9999 -9999 -9999 -9999 -9999 -9999 -9999 -9999 -9999 -9999 -9999 -9999 -9999 -9999 -9999 -9999 -9999 -9999 -9999 -9999 -9999 -9999 -9999 -9999 -9999 -9999 -9999 -9999 -9999 -9999 -9999 -9999 -9999 -9999 -9999 -9999 -9999 -9999 -9999 -9999 -9999 -9999 -9999 -9999 -9999 -9999 -9999 -9999 -9999 -9999 -9999 -9999 -9999 -9999 -9999 -9999 -9999 -9999 -9999 -9999 -9999 -9999 -9999 -9999 -9999 -9999 -9999 -9999 -9999 -9999 -9999 -9999 -9999 -9999 -9999 -9999 -

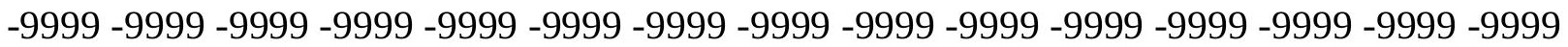
-9999 -9999 -9999 -9999 -9999 -9999 -9999 -9999 -9999 -9999 -9999 -9999 -9999 -9999 -9999 -9999 -9999 -9999 -9999 -9999 -9999 -9999 -9999 -9999 -9999 -9999 -9999 -9999 -9999 -9999 -

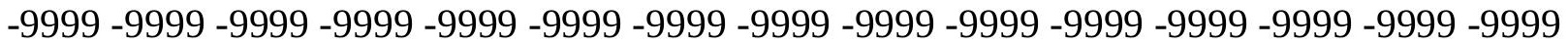
-9999 -9999 -9999 -9999 -9999 -9999 -9999 -9999 -9999 -9999 -9999 -9999 -9999 -9999 -9999 -9999 -9999 -9999 -9999 -9999 -9999 -9999 -9999 -9999 -9999 -9999 -9999 -9999 -9999 -9999 -9999 -9999 -9999 -9999 -9999 -9999 -9999 -9999 -9999 -9999 -9999 -9999 -9999 -9999 -9999 -9999 -9999 -9999 -9999 -9999 -9999 -9999 -9999 -9999 -9999 -9999 -9999 -9999 -9999 -9999

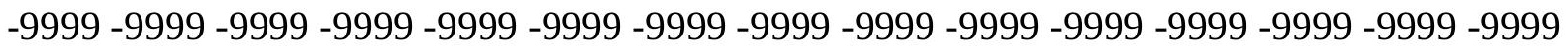
-9999 -9999 -9999 -9999 -9999 -9999 -9999 -9999 -9999 -9999 -9999 -9999 -9999 -9999 -9999 -9999 -9999 -9999 -9999 -9999 -9999 -9999 -9999 -9999 -9999 -9999 -9999 -9999 -9999 -9999 -9999 -9999 -9999 -9999 -9999 -9999 -9999 -9999 -9999 -9999 -9999 -9999 -9999 -9999 -9999 -9999 -9999 -9999 -9999 -9999 -9999 -9999 -9999 -9999 -9999 -9999 -9999 -9999 -9999 -9999 -9999 -9999 -9999 -9999 -9999 -9999 -9999 -9999 -9999 -9999 -9999 -9999 -9999 -9999 -9999 -9999 -9999 -9999 -9999 -9999 -9999 -9999 -9999 -9999 -9999 -9999 -9999 -9999 -9999 -9999 -9999 -9999 -9999 -9999 -9999 -9999 -9999 -9999 -9999 -9999 -9999 -9999 -9999 -9999 -9999 -9999 -9999 -9999 -9999 -9999 -9999 -9999 -9999 -9999 -9999 -9999 -9999 -9999 -9999 -9999 -9999 -9999 -9999 -9999 -9999 -9999 -9999 -9999 -9999 -9999 -9999 -9999 -9999 -9999 -9999 -9999 -9999 -9999 -9999 -9999 -9999 -9999 -9999 -9999 -9999 -9999 -9999 -9999 -9999 -9999 -9999 -9999 -9999 -9999 -9999 -9999 -9999 -9999 -9999 -9999 -9999 -9999 -9999 -9999 -9999 -9999 -9999 -9999 -9999 -9999 -9999 -9999 -9999 -9999 -9999 -9999 -9999 -9999 -9999

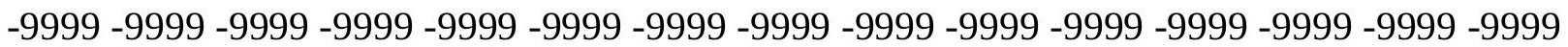
-9999 -9999 -9999 -9999 -9999 -9999 -9999 -9999 -9999 -9999 -9999 -9999 -9999 -9999 -9999 -9999 -9999 -9999 -9999 -9999 -9999 -9999 -9999 -9999 -9999 -9999 -9999 -9999 -9999 -9999 -

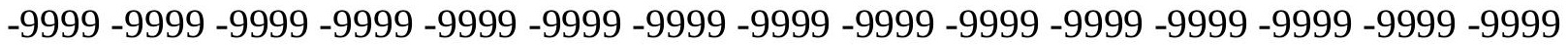
-9999 -9999 -9999 -9999 -9999 -9999 -9999 -9999 -9999 -9999 -9999 -9999 -9999 -9999 -9999 -9999 -9999 -9999 -9999 -9999 -9999 -9999 -9999 -9999 -9999 -9999 -9999 -9999 -9999 -9999 -9999 -9999 -9999 -9999 -9999 -9999 -9999 -9999 -9999 -9999 -9999 -9999 -9999 -9999 -9999 -9999 -9999 -9999 -9999 -9999 -9999 -9999 -9999 -9999 -9999 -9999 -9999 -9999 -9999 -9999 -9999 -9999 -9999 -9999 -9999 -9999 -9999 -9999 -9999 -9999 -9999 -9999 -9999 -9999 -9999

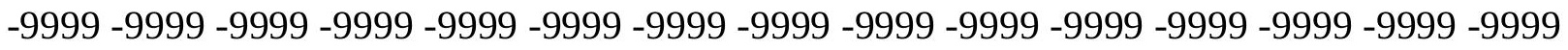
-9999 -9999 -9999 -9999 -9999 -9999 -9999 -9999 -9999 -9999 -9999 -9999 -9999 -9999 -9999 -9999 -9999 -9999 -9999 -9999 -9999 -9999 -9999 -9999 -9999 -9999 -9999 -9999 -9999 -9999 -9999 -9999 -9999 -9999 -9999 -9999 -9999 -9999 -9999 -9999 -9999 -9999 -9999 -9999 -9999 -999 -9999 -9999 -9999 -9999 -9999 -9999 -9999 -9999 -9999 -9999 -9999 -9999 -9999 -9999 -9999 -9999 -9999 -9999 -9999 -9999 -9999 -9999 -9999 -9999 -9999 -9999 -9999 -9999 -9999 -9999 -9999 -9999 -9999 -9999 -9999 -9999 -9999 -9999 -9999 -9999 -9999 -9999 -9999 -9999 -9999 -9999 -9999 -9999 -9999 -9999 -9999 -9999 -9999 -9999 -9999 -9999 -9999 -9999 -9999 -9999 -9999 -9999 -9999 -9999 -9999 -9999 -9999 -9999 -9999 -9999 -9999 -9999 -9999 -9999 
-9999 -9999 -9999 -9999 -9999 -9999 -9999 -9999 -9999 -9999 -9999 -9999 -9999 -9999 -9999 -9999 -9999 -9999 -9999 -9999 -9999 -9999 -9999 -9999 -9999 -9999 -9999 -9999 -9999 -9999 -

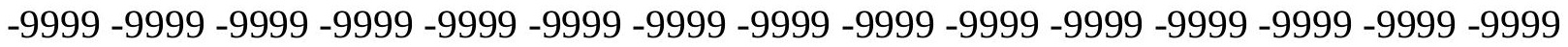
-9999 -9999 -9999 -9999 -9999 -9999 -9999 -9999 -9999 -9999 -9999 -9999 -9999 -9999 -9999 -9999 -9999 -9999 -9999 -9999 -9999 -9999 -9999 -9999-9999 -9999 -9999 -9999 -9999 -9999 -9999 -9999 -9999 -9999 -9999 -9999 -9999 -9999 -9999 -9999 -9999 -9999 -9999 -9999 -9999 -9999 -9999 -9999 -9999 -9999 -9999 -9999 -9999 -9999 -9999 -9999 -9999 -9999 -9999 -9999

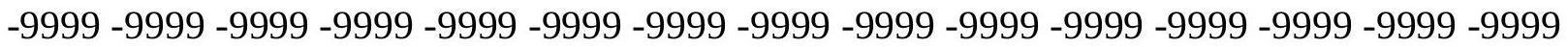

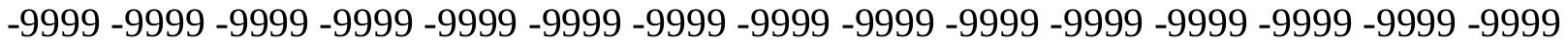
-9999 -9999 -9999 -9999 -9999 -9999 -9999 -9999 -9999 -9999 -9999 -9999 -9999 -9999 -9999 -9999 -9999 -9999 -9999 -9999 -9999 -9999 -9999 -9999 -9999 -9999 -9999 -9999 -9999 -9999 -9999 -9999 -9999 -9999 -9999 -9999 -9999 -9999 -9999 -9999 -9999 -9999 -9999 -9999 -9999 -9999 -9999 -9999 -9999 -9999 -9999 -9999 -9999 -9999 -9999 -9999 -9999 -9999 -9999 -9999 -

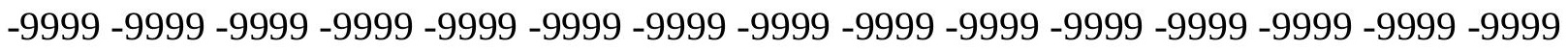
-9999 -9999 -9999 -9999 -9999 -9999 -9999 -9999 -9999 -9999 -9999 -9999 -9999 -9999 -9999 -

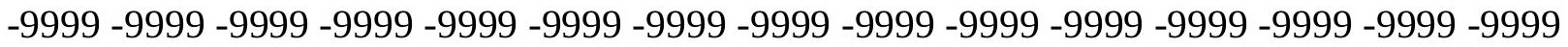
-9999 -9999 -9999 -9999 -9999 -9999 -9999 -9999 -9999 -9999 -9999 -9999 -9999 -9999 -9999 -9999 -9999 -9999 -9999 -9999 -9999 -9999 -9999 -9999 -9999 -9999 -9999 -9999 -9999 -9999 -9999 -9999 -9999 -9999 -9999 -9999 -9999 -9999 -9999 -9999 -9999 -9999 -9999 -9999 -9999 -

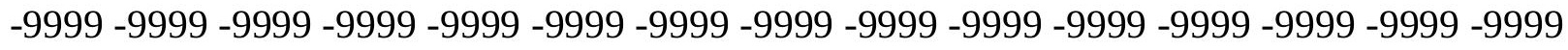

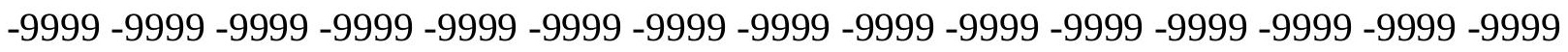

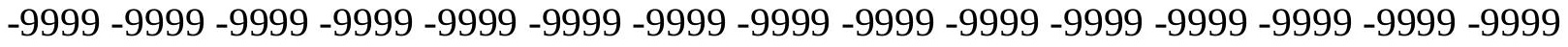
-9999 -9999 -9999 -9999 -9999 -9999 -9999 -9999 -9999 -9999 -9999 -9999 -9999 -9999 -9999 -9999 -9999 -9999 -9999 -9999 -9999 -9999 -9999 -9999 -9999 -9999 -9999 -9999 -9999 -9999 -

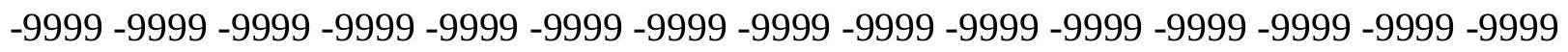
-9999 -9999 -9999 -9999 -9999 -9999 -9999 -9999 -9999 -9999 -9999 -9999 -9999 -9999 -9999 -9999 -9999 -9999 -9999 -9999 -9999 -9999 -9999 -9999 -9999 -9999 -9999 -9999 -9999 -

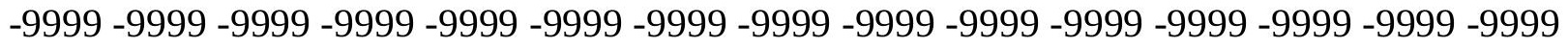
-9999 -9999 -9999 -9999 -9999 -9999 -9999 -9999 -9999 -9999 -9999 -9999 -9999 -9999 -9999 -9999 -9999 -9999 -9999 -9999 -9999 -9999 -9999 -9999 -9999 -9999 -9999 -9999 -9999 -999 -

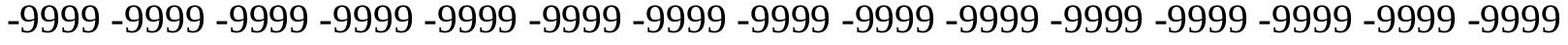
-9999 -9999 -9999 -9999 -9999 -9999 -9999 -9999 -9999 -9999 -9999 -9999 -9999 -9999 -9999 -

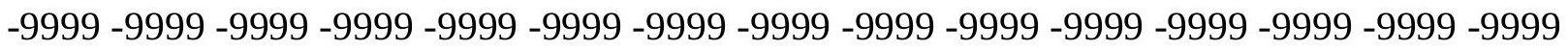

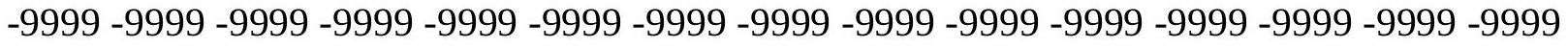

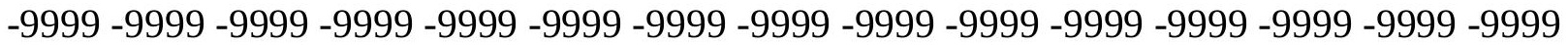
-9999 -9999 -9999 -9999 -9999 -9999 -9999 -9999 -9999 -9999 -9999 -9999 -9999 -9999 -9999

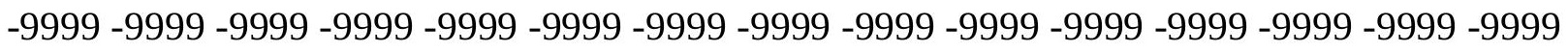

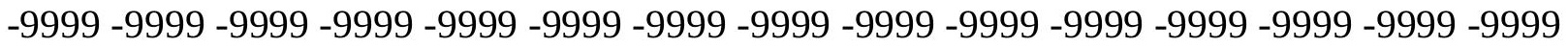
-9999 -9999 -9999 -9999 -9999 -9999 -9999 -9999 -9999 -9999 -9999 -9999 -9999 - 9999 - -999 -9999 -9999 -9999 -9999 -9999 -9999 -9999 -9999 -9999 -9999 -9999 -9999 -9999 -9999 -9999 -

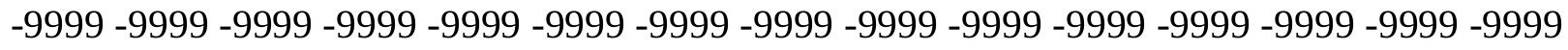

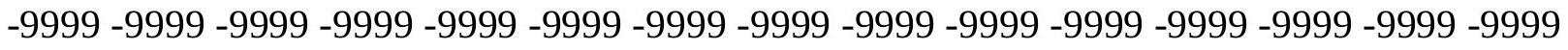
-9999 -9999 -9999 -9999 -9999 -9999 -9999 -9999 -9999 -9999 -9999 -9999 -9999 -9999 -9999 -9999 -9999 -9999 -9999 -9999 -9999 -9999 -9999 -9999-9999 -9999 -9999 -9999 -9999 -9999 -9999 -9999 -9999 -9999 -9999 -9999 -9999 -9999 -9999 -9999 -9999 -9999 -9999 -9999 -9999 -

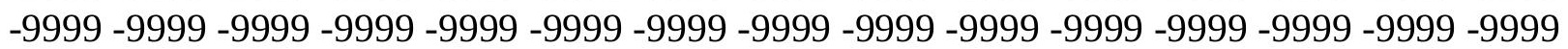


-9999 -9999 -9999 -9999 -9999 -9999 -9999 -9999 -9999 -9999 -9999 -9999 -9999 -9999 -9999 -9999 -9999 -9999 -9999 -9999 -9999 -9999 -9999 -9999 -9999 -9999 -9999 -9999 -9999 -9999 -9999 -9999 -9999 -9999 -9999 -9999 -9999 -9999 -9999 -9999 -9999 -9999 -9999 -9999 - 9999 -9999 -9999 -9999 -9999 -9999 -9999 -9999 -9999 -9999 -9999 -9999 -9999 -9999 -9999 -9999 -9999 -9999 -9999 -9999 -9999 -9999 -9999 -9999 -9999 -9999 -9999 -9999 -9999 -9999 - -9999 -9999 -9999 -9999 -9999 -9999 -9999 -9999 -9999 -9999 -9999 -9999 -9999 -9999 -9999 -9999 -9999 -9999 -9999 -9999 -9999 -9999 -9999 -9999 -9999 -9999 -9999 -9999 -9999 -9999

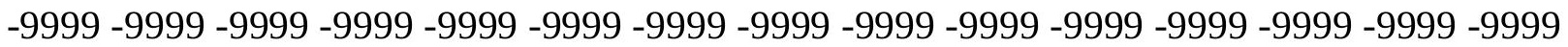

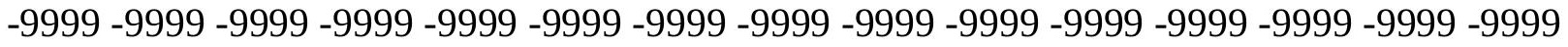
-9999 -9999 -9999 -9999 -9999 -9999 -9999 -9999 -9999 -9999 -9999 -9999 -9999 -9999 -9999

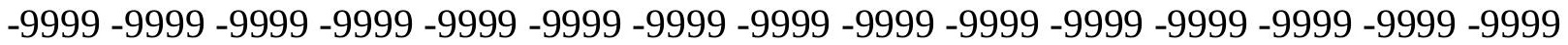
-9999 -9999 -9999 -9999 -9999 -9999 -9999 -9999 -9999 -9999 -9999 -9999 -9999 -9999 -9999 -9999 -9999 -9999 -9999 -9999 -9999 -9999 -9999 -9999 -9999 -9999 -9999 -9999 -9999 -9999 -9999 -9999 -9999 -9999 -9999 -9999 -9999 -9999 -9999 -9999 -9999 -9999 -9999 -9999 - -9999 -9999 -9999 -9999 -9999 -9999 -9999 -9999 -9999 -9999 -9999 -9999 -9999 -9999 -9999 -9999

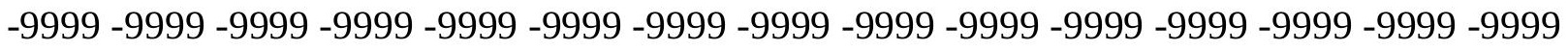
-9999 -9999 -9999 -9999 -9999 -9999 -9999 -9999 -9999 -9999 -9999 -9999 -9999 -9999 -9999 -9999 -9999 -9999 -9999 -9999 -9999 -9999 -9999 -9999 -9999 -9999 -9999 -9999 -9999 -9999 -9999 -9999 -9999 -9999 -9999 -9999 -9999 -9999 -9999 -9999 -9999 -9999 -9999 -9999 -9999 -

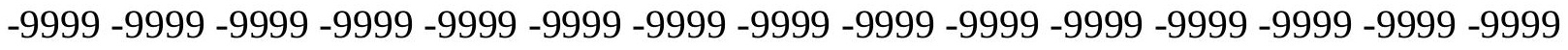
-9999 -9999 -9999 -9999 -9999 -9999 -9999 -9999 -9999 -9999 -9999 -9999 -9999 -9999 -9999 -999 -9999 -9999 -9999 -9999 -9999 -9999 -9999 -9999 -9999 -9999 -9999 -9999 -9999 -9999 -9999 -9999 -9999 -9999 -9999 -9999 -9999 -9999 -9999 -9999 -9999 -9999 -9999 -9999 -9999 -9999 -9999 -9999 -9999 -9999 -9999 -9999 -9999 -9999 -9999 -9999 -9999 -9999 -9999 -9999 -9999 -9999 -9999 -9999 -9999 -9999 -9999 -9999 -9999 -9999 -9999 -9999 -9999 -9999 -9999 -9999 -9999 -9999 -9999 -9999 -9999 -9999 -9999 -9999 -9999 -9999 -9999 -9999 -9999 -9999 -9999 -9999 -9999 -9999 -9999 -9999 -9999 -9999 -9999 -9999 -9999 -9999 -9999 -9999 -9999 -9999 -9999 -9999 -9999 -9999 -9999 -9999 -9999 -9999 -9999 -9999 -9999 -9999 -9999 -9999 -9999 -9999 -9999 -9999 -9999 -9999 -9999 -9999 -9999 -9999 -9999 -9999 -9999 -9999 -9999 -9999 -9999 -9999 -9999 -9999 -9999 -9999 -9999 -9999 -9999 -9999 -9999 -9999 -9999 -9999 -999 -9999 -9999 -9999 -9999 -9999 -9999 -9999 -9999 -9999 -9999 -9999 -9999 -9999 -9999 -9999 -9999 -9999 -9999 -9999 -9999 -9999 -9999 -9999 -9999 -9999 -9999 -9999 -9999 -9999 -

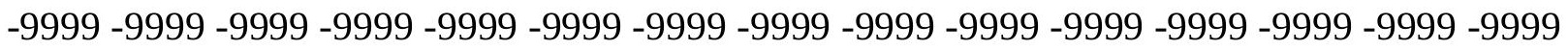

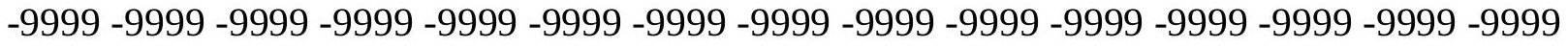

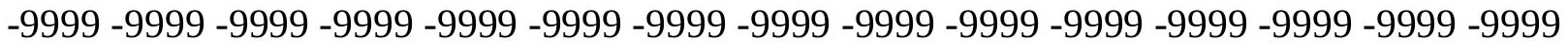
-9999 -9999 -9999 -9999 -9999 -9999 -9999 -9999 -9999 -9999 -9999 -9999 -9999 -9999 -9999 -

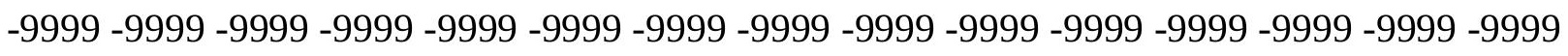

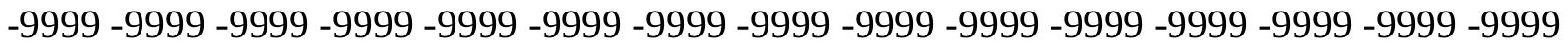

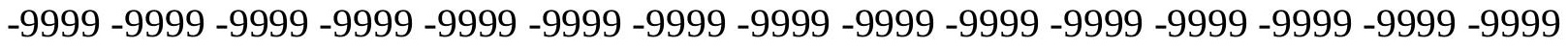
-9999 -9999 -9999 -9999 -9999 -9999 -9999 -9999 -9999 -9999 -9999 -9999 -9999 -9999 -9999 -

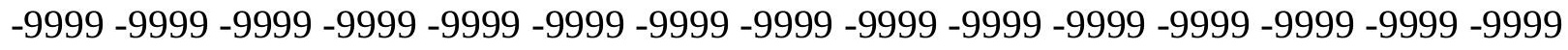

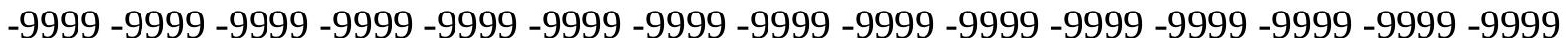
-9999 -9999 -9999 -9999 -9999 -9999 -9999 -9999 -9999 -9999 -9999 -9999 -9999 -9999 -9999 -9999 -9999 -9999 -9999 -9999 -9999 -9999 -9999 -9999-9999 -9999 -9999 -9999 -9999 -9999 -9999 -9999 -9999 -9999 -9999 -9999 -9999 -9999 -9999 -9999 -9999 -9999 -9999 -9999 -9999 -

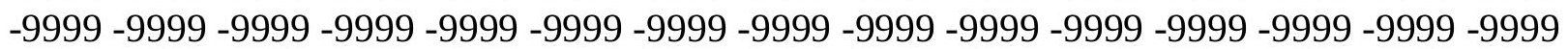


-9999 -9999 -9999 -9999 -9999 -9999 -9999 -9999 -9999 -9999 -9999 -9999 -9999 -9999 -9999 -9999 -9999 -9999 -9999 -9999 -9999 -9999 -9999 -9999 -9999 -9999 -9999 -9999 -9999 -9999 -

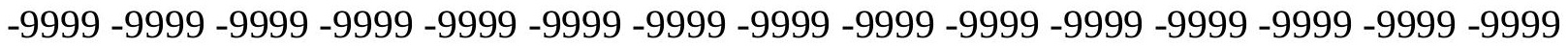
-9999 -9999 -9999 -9999 -9999 -9999 -9999 -9999 -9999 -9999 -9999 -9999 -9999 -9999 -9999 -9999 -9999 -9999 -9999 -9999 -9999 -9999 -9999 -9999-9999 -9999 -9999 -9999 -9999 -9999 -9999 -9999 -9999 -9999 -9999 -9999 -9999 -9999 -9999 -9999 -9999 -9999 -9999 -9999 -9999 -9999 -9999 -9999 -9999 -9999 -9999 -9999 -9999 -9999 -9999 -9999 -9999 -9999 -9999 -9999

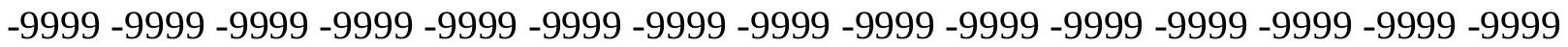

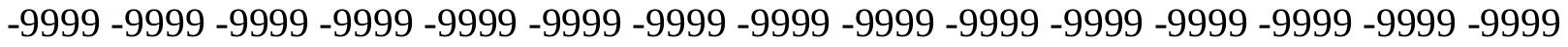
-9999 -9999 -9999 -9999 -9999 -9999 -9999 -9999 -9999 -9999 -9999 -9999 -9999 -9999 -9999 -9999 -9999 -9999 -9999 -9999 -9999 -9999 -9999 -9999 -9999 -9999 -9999 -9999 -9999 -9999 -9999 -9999 -9999 -9999 -9999 -9999 -9999 -9999 -9999 -9999 -9999 -9999 -9999 -9999 -9999 -9999 -9999 -9999 -9999 -9999 -9999 -9999 -9999 -9999 -9999 -9999 -9999 -9999 -9999 -9999 -9999 -9999 -9999 -9999 -9999 -9999 -9999 -9999 -9999 -9999 -9999 -9999 -9999 - 9999 -9999 -9999 -9999 -9999 -9999 -9999 -9999 -9999 -9999 -9999 -9999 -9999 -9999 -9999 -9999

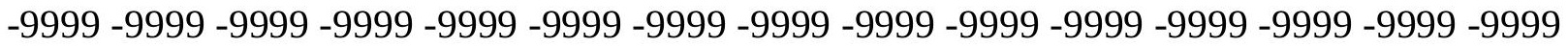
-9999 -9999 -9999 -9999 -9999 -9999 -9999 -9999 -9999 -9999 -9999 -9999 -9999 -9999 -9999 -9999 -9999 -9999 -9999 -9999 -9999 -9999 -9999 -9999 -9999 -9999 -9999 -9999 -9999 -9999 -9999 -9999 -9999 -9999 -9999 -9999 -9999 -9999 -9999 -9999 -9999 -9999 -9999 -9999 -9999 -

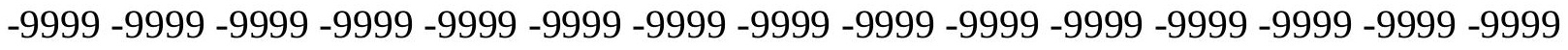

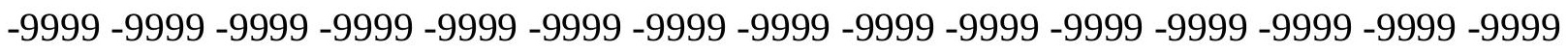
-9999 -9999 -9999 -9999 -9999 -9999 -9999 -9999 -9999 -9999 -9999 -9999 -9999 -9999 -9999 -9999 -9999 -9999 -9999 -9999 -9999 -9999 -9999 -9999 -9999 -9999 -9999 -9999 -9999 -9999 -9999 -9999 -9999 -9999 -9999 -9999 -9999 -9999 -9999 -9999 -9999 -9999 -9999 -9999 -9999 -

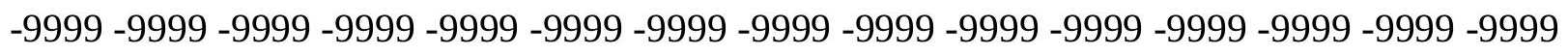
-9999 -9999 -9999 -9999 -9999 -9999 -9999 -9999 -9999 -9999 -9999 -9999 -9999 -9999 -9999 -9999 -9999 -9999 -9999 -9999 -9999 -9999 -9999 -9999 -9999 -9999 -9999 -9999 -9999 -9999 -

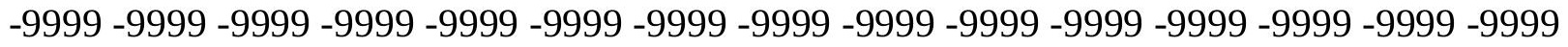
-9999 -9999 -9999 -9999 -9999 -9999 -9999 -9999 -9999 -9999 -9999 -9999 -9999 -9999 -9999 -9999 -9999 -9999 -9999 -9999 -9999 -9999 -9999 -9999 -9999 -9999 -9999 -9999 -9999 -999 -9999 -9999 -9999 -9999 -9999 -9999 -9999 -9999 -9999 -9999 -9999 -9999 -9999 -9999 -9999 -9999 -9999 -9999 -9999 -9999 -9999 -9999 -9999 -9999 -9999 -9999 -9999 -9999 -9999 -9999 -

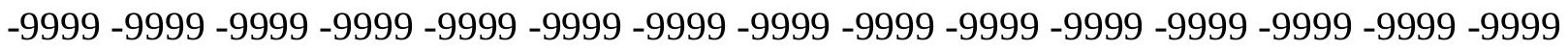

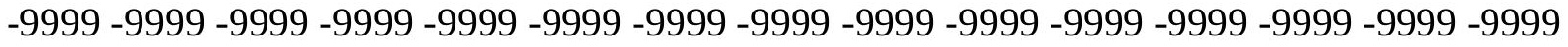

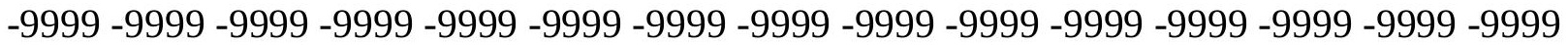

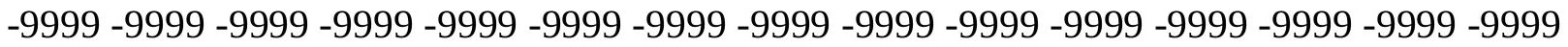

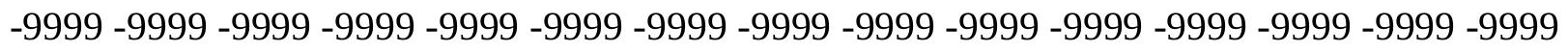

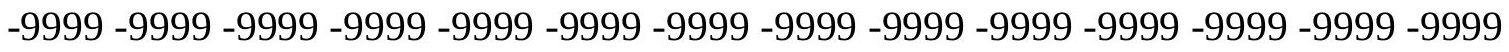
-9999 -9999 -9999 -9999 -9999 -9999 -9999 -9999 -9999 -9999 -9999 -9999 -9999 -9999 -9999 -9999 -9999 -9999 -9999 -9999 -9999 -9999 -9999 -9999 -9999 -9999 -9999 -9999 -9999 -9999 -

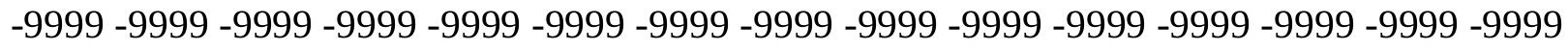

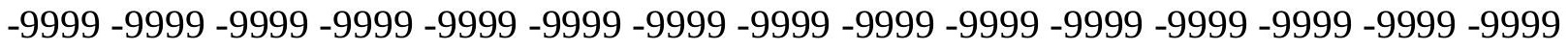
-9999 -9999 -9999 -9999 -9999 -9999 -9999 -9999 -9999 -9999 -9999 -9999 -9999 -9999 -9999 -9999 -9999 -9999 -9999 -9999 -9999 -9999 -9999 -9999-9999 -9999 -9999 -9999 -9999 -9999 -9999 -9999 -9999 -9999 -9999 -9999 -9999 -9999 -9999 -9999 -9999 -9999 -9999 -9999 -9999 -

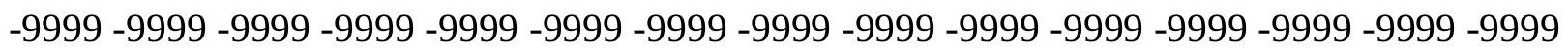


-9999 -9999 -9999 -9999 -9999 -9999 -9999 -9999 -9999 -9999 -9999 -9999 -9999 -9999 -9999 -9999 -9999 -9999 -9999 -9999 -9999 -9999 -9999 -9999 -9999 -9999 -9999 -9999 -9999 -9999 -9999 -9999 -9999 -9999 -9999 -9999 -9999 -9999 -9999 -9999 -9999 -9999 -9999 -9999 - 9999 -9999 -9999 -9999 -9999 -9999 -9999 -9999 -9999 -9999 -9999 -9999 -9999 -9999 -9999 -9999 -9999 -9999 -9999 -9999 -9999 -9999 -9999 -9999 -9999 -9999 -9999 -9999 -9999 -9999 -9999 -9999 -9999 -9999 -9999 -9999 -9999 -9999 -9999 -9999 -9999 -9999 -9999 -9999 -9999 -9999 -9999 -9999 -9999 -9999 -9999 -9999 -9999 -9999 -9999 -9999 -9999 -9999 -9999 -9999 -9999

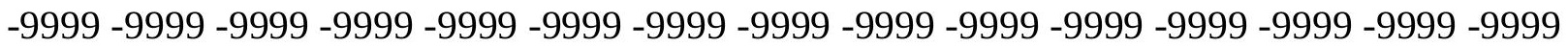
-9999 -9999 -9999 -9999 -9999 -9999 -9999 -9999 -9999 -9999 -9999 -9999 -9999 -9999 -9999 -9999 -9999 -9999 -9999 -9999 -9999 -9999 -9999 -9999 -9999 -9999 -9999 -9999 -9999 -9999

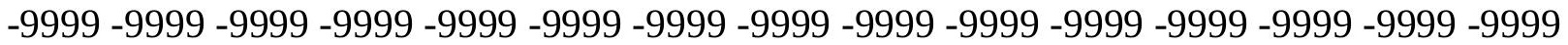
-9999 -9999 -9999 -9999 -9999 -9999 -9999 -9999 -9999 -9999 -9999 -9999 -9999 -9999 -9999 -9999 -9999 -9999 -9999 -9999 -9999 -9999 -9999 -9999 -9999 -9999 -9999 -9999 -9999 -9999 -

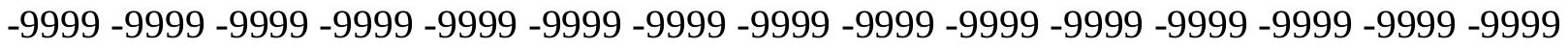
-9999 -9999 -9999 -9999 -9999 -9999 -9999 -9999 -9999 -9999 -9999 -9999 -9999 -9999 -9999

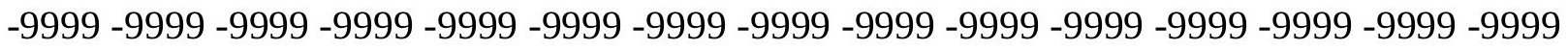
-9999 -9999 -9999 -9999 -9999 -9999 -9999 -9999 -9999 -9999 -9999 -9999 -9999 -9999 -9999 -9999 -9999 -9999 -9999 -9999 -9999 -9999 -9999 -9999 -9999 -9999 -9999 -9999 -9999 - -999 -9999 -9999 -9999 -9999 -9999 -9999 -9999 -9999 -9999 -9999 -9999 -9999 -9999 -9999 -9999 -9999 -9999 -9999 -9999 -9999 -9999 -9999 -9999 -9999 -9999 -9999 -9999 -9999 -9999 -9999 -9999 -9999 -9999 -9999 -9999 -9999 -9999 -9999 -9999 -9999 -9999 -9999 -9999 -9999 -9999 -999 -9999 -9999 -9999 -9999 -9999 -9999 -9999 -9999 -9999 -9999 -9999 -9999 -9999 -9999 -9999 -9999 -9999 -9999 -9999 -9999 -9999 -9999 -9999 -9999 -9999 -9999 -9999 -9999 -9999 -9999 -9999 -9999 -9999 -9999 -9999 -9999 -9999 -9999 -9999 -9999 -9999 -9999 -9999 -9999 -9999 -9999 -9999 -9999 -9999 -9999 -9999 -9999 -9999 -9999 -9999 -9999 -9999 -9999 -9999 -9999 -9999 -9999 -9999 -9999 -9999 -9999 -9999 -9999 -9999 -9999 -9999 -9999 -9999 -9999 -9999 -9999 -9999 -9999 -9999 -9999 -9999 -9999 -9999 -9999 -9999 -9999 -9999 -9999 -9999 -9999 -9999 -9999 -9999 -9999 -9999 -9999 -9999 -9999 -9999 -9999 -9999 -9999 -9999 -9999 -9999 -9999 -9999 -9999 -9999 -9999 -9999 -9999 -9999 -9999 -9999 -9999 -9999 -9999 -9999 -9999 -9999 -9999 -9999 -9999 -9999 -9999 -9999 -9999 -9999 -9999 -9999 -9999 -9999 -9999 -999 -9999 -9999 -9999 -9999 -9999 -9999 -9999 -9999 -9999 -9999 -9999 -9999 -9999 -9999 -9999 -9999 -9999 -9999 -9999 -9999 -9999 -9999 -9999 -9999 -9999 -9999 -9999 -9999 -9999 -9999 -

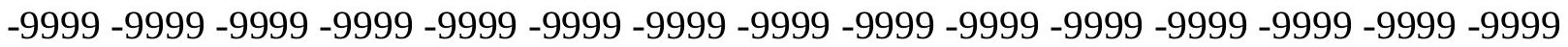

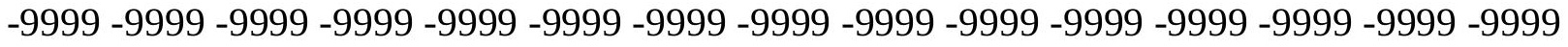

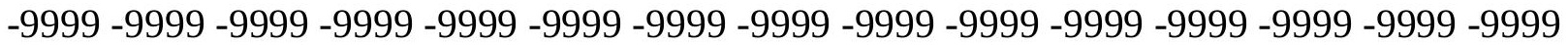
-9999 -9999 -9999 -9999 -9999 -9999 -9999 -9999 -9999 -9999 -9999 -9999 -9999 -9999 -9999

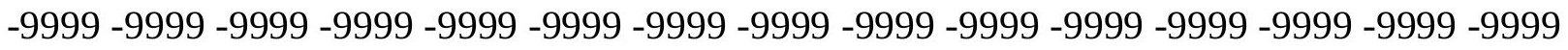

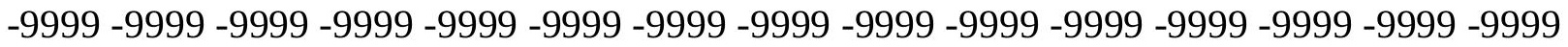

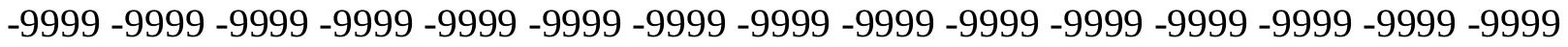
-9999 -9999 -9999 -9999 -9999 -9999 -9999 -9999 -9999 -9999 -9999 -9999 -9999 -9999 -9999 -

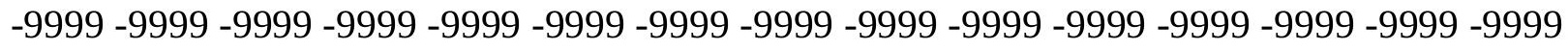

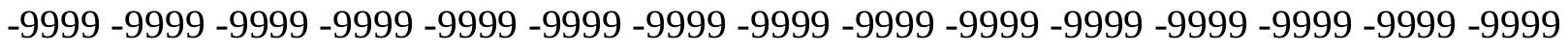
-9999 -9999 -9999 -9999 -9999 -9999 -9999 -9999 -9999 -9999 -9999 -9999 -9999 -9999 -9999 -9999 -9999 -9999 -9999 -9999 -9999 -9999 -9999 -9999 -9999 -9999 -9999 -9999 - -9999 -9999 -9999 -9999 -9999 -9999 -9999 -9999 -9999 -9999 -9999 -9999 -9999 -9999 -9999 -9999 -

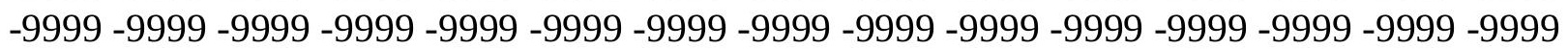


-9999 -9999 -9999 -9999 -9999 -9999 -9999 -9999 -9999 -9999 -9999 -9999 -9999 -9999 -9999 -9999 -9999 -9999 -9999 -9999 -9999 -9999 -9999 -9999 -9999 -9999 -9999 -9999 -9999 -9999 -9999 -9999 -9999 -9999 -9999 -9999 -9999 -9999 -9999 -9999 -9999 -9999 -9999 -9999 - 9999 -9999 -9999 -9999 -9999 -9999 -9999 -9999 -9999 -9999 -9999 -9999 -9999 -9999 -9999 -9999 -9999 -9999 -9999 -9999 -9999 -9999 -9999 -9999 -9999-9999 -9999 -9999 -9999 -9999 -9999 -9999 -9999 -9999 -9999 -9999 -9999 -9999 -9999 -9999 -9999 -9999 -9999 -9999 -9999 -9999 -9999 -9999 -9999 -9999 -9999 -9999 -9999 -9999 -9999 -9999 -9999 -9999 -9999 -9999 -9999

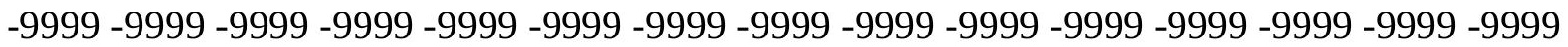

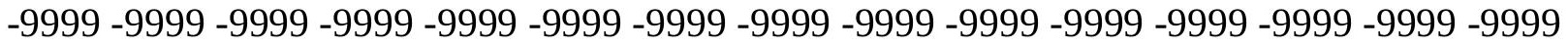
-9999 -9999 -9999 -9999 -9999 -9999 -9999 -9999 -9999 -9999 -9999 -9999 -9999 -9999 -9999

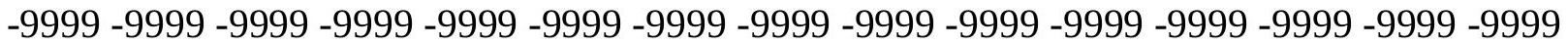
-9999 -9999 -9999 -9999 -9999 -9999 -9999 -9999 -9999 -9999 -9999 -9999 -9999 -9999 -9999 -9999 -9999 -9999 -9999 -9999 -9999 -9999 -9999 -9999 -9999 -9999 -9999 -9999 -9999 -9999 -

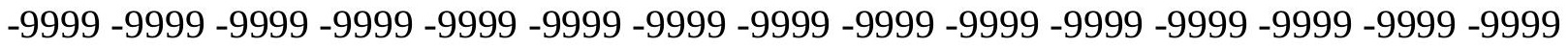
-9999 -9999 -9999 -9999 -9999 -9999 -9999 -9999 -9999 -9999 -9999 -9999 -9999 -9999 -9999

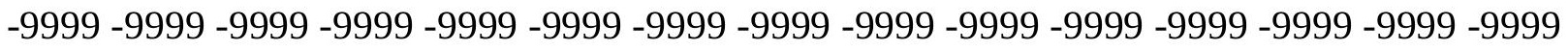
-9999 -9999 -9999 -9999 -9999 -9999 -9999 -9999 -9999 -9999 -9999 -9999 -9999 -9999 -9999 -9999 -9999 -9999 -9999 -9999 -9999 -9999 -9999 -9999 -9999 -9999 -9999 -9999 -9999 -9999 -9999 -9999 -9999 -9999 -9999 -9999 -9999 -9999 -9999 -9999 -9999 -9999 -9999 -9999 -9999 -9999 -9999 -9999 -9999 -9999 -9999 -9999 -9999 -9999 -9999 -9999 -9999 -9999 -9999 -9999 -9999 -9999 -9999 -9999 -9999 -9999 -9999 -9999 -9999 -9999 -9999 -9999 -9999 -9999 -9999 -999 -9999 -9999 -9999 -9999 -9999 -9999 -9999 -9999 -9999 -9999 -9999 -9999 -9999 -9999 -9999 -9999 -9999 -9999 -9999 -9999 -9999 -9999 -9999 -9999 -9999 -9999 -9999 -9999 -9999 -9999 -9999 -9999 -9999 -9999 -9999 -9999 -9999 -9999 -9999 -9999 -9999 -9999 -9999 -9999 -9999 -9999 -9999 -9999 -9999 -9999 -9999 -9999 -9999 -9999 -9999 -9999 -9999 -9999 -9999 -9999 -9999 -9999 -9999 -9999 -9999 -9999 -9999 -9999 -9999 -9999 -9999 -9999 -9999 -9999 -9999 -9999 -9999 -9999 -9999 -9999 -9999 -9999 -9999 -9999 -9999 -9999 -9999 -9999 -9999 -9999 -9999 -9999 -9999 -9999 -9999 -9999 -9999 -9999 -9999 -9999 -9999 -9999 -9999 -9999 -9999 -9999 -9999 -9999 -9999 -9999 -9999 -9999 -9999 -9999 -9999 -9999 -9999 -9999 -9999 -9999 -9999 -9999 -9999 -9999 -9999 -9999 -9999 -9999 -9999 -9999 -9999 -9999 -9999 -999 -9999 -9999 -9999 -9999 -9999 -9999 -9999 -9999 -9999 -9999 -9999 -9999 -9999 -9999 -9999 -9999 -9999 -9999 -9999 -9999 -9999 -9999 -9999 -9999 -9999 -9999 -9999 -9999 -9999 -9999 -

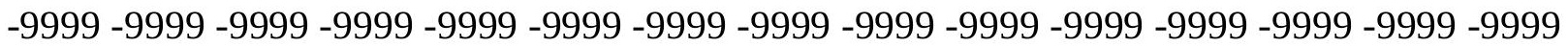

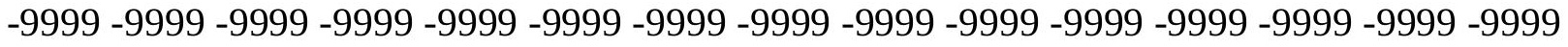

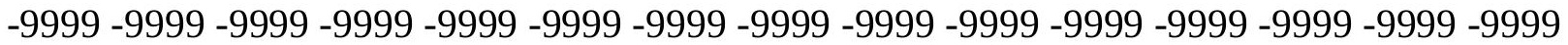
-9999 -9999 -9999 -9999 -9999 -9999 -9999 -9999 -9999 -9999 -9999 -9999 -9999 -9999 -9999

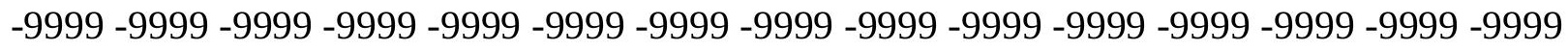

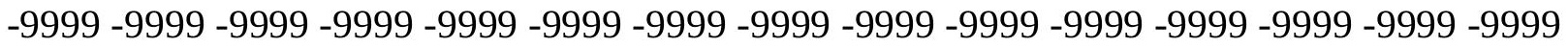
-9999 -9999 -9999 -9999 -9999 -9999 -9999 -9999 -9999 -9999 -9999 -9999 -9999 -9999 -9999 -9999 -9999 -9999 -9999 -9999 -9999 -9999 -9999 -9999 -9999 -9999 -9999 -9999 -9999 -9999 -

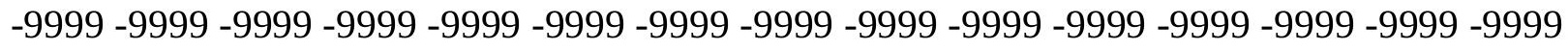

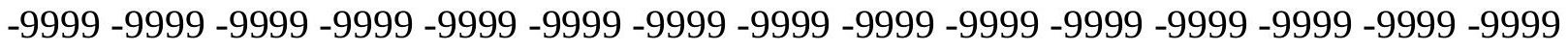
-9999 -9999 -9999 -9999 -9999 -9999 -9999 -9999 -9999 -9999 -9999 -9999 -9999 -9999 -9999 -9999 -9999 -9999 -9999 -9999 -9999 -9999 -9999 -9999-9999 -9999 -9999 -9999 -9999 -9999 -9999 -9999 -9999 -9999 -9999 -9999 -9999 -9999 -9999 -9999 -9999 -9999 -9999 -9999 -9999 -

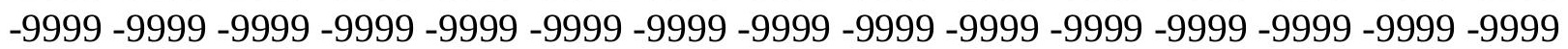


-9999 -9999 -9999 -9999 -9999 -9999 -9999 -9999 -9999 -9999 -9999 -9999 -9999 -9999 -9999 -9999 -9999 -9999 -9999 -9999 -9999 -9999 -9999 -9999 -9999 -9999 -9999 -9999 -9999 -9999 -9999 -9999 -9999 -9999 -9999 -9999 -9999 -9999 -9999 -9999 -9999 -9999 -9999 -9999 - 9999 -9999 -9999 -9999 -9999 -9999 -9999 -9999 -9999 -9999 -9999 -9999 -9999 -9999 -9999

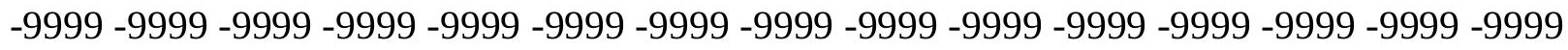
-9999 -9999 -9999 -9999 -9999 -9999 -9999 -9999 -9999 -9999 -9999 -9999 -9999 -9999 -9999 -9999 -9999 -9999 -9999 -9999 -9999 -9999 -9999 -9999 -9999 -9999 -9999 -9999 -9999 -9999

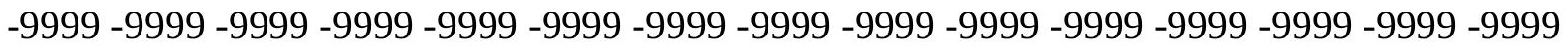

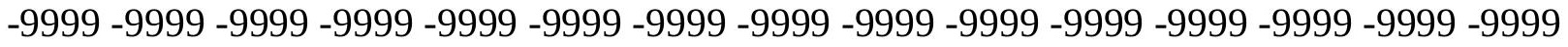
-9999 -9999 -9999 -9999 -9999 -9999 -9999 -9999 -9999 -9999 -9999 -9999 -9999 -9999 -9999 -9999 -9999 -9999 -9999 -9999 -9999 -9999 -9999 -9999 -9999 -9999 -9999 -9999 -9999 -9999 -9999 -9999 -9999 -9999 -9999 -9999 -9999 -9999 -9999 -9999 -9999 -9999 -9999 -9999 -9999 -9999 -9999 -9999 -9999 -9999 -9999 -9999 -9999 -9999 -9999 -9999 -9999 -9999 -9999 -9999 -

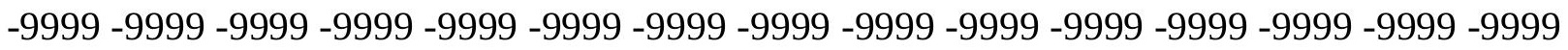
-9999 -9999 -9999 -9999 -9999 -9999 -9999 -9999 -9999 -9999 -9999 -9999 -9999 -9999 -9999 -

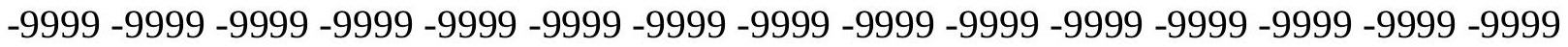
-9999 -9999 -9999 -9999 -9999 -9999 -9999 -9999 -9999 -9999 -9999 -9999 -9999 -9999 -9999 -9999 -9999 -9999 -9999 -9999 -9999 -9999 -9999 -9999 -9999 -9999 -9999 -9999 -9999 -9999 -9999 -9999 -9999 -9999 -9999 -9999 -9999 -9999 -9999 -9999 -9999 -9999 -9999 -9999 -9999 -

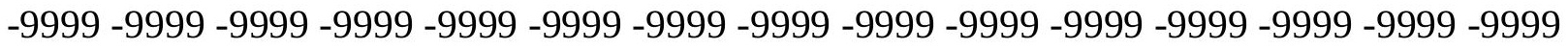
-9999 -9999 -9999 -9999 -9999 -9999 -9999 -9999 -9999 -9999 -9999 -9999 -9999 -9999 -9999

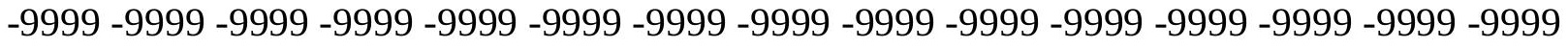
-9999 -9999 -9999 -9999 -9999 -9999 -9999 -9999 -9999 -9999 -9999 -9999 -9999 -9999 -9999 -9999 -9999 -9999 -9999 -9999 -9999 -9999 -9999 -9999 -9999 -9999 -9999 -9999 -9999 -9999 -9999 -9999 -9999 -9999 -9999 -9999 -9999 -9999 -9999 -9999 -9999 -9999 -9999 -9999 -9999 -9999 -9999 -9999 -9999 -9999 -9999 -9999 -9999 -9999 -9999 -9999 -9999 -9999 -9999 -9999 -9999 -9999 -9999 -9999 -9999 -9999 -9999 -9999 -9999 -9999 -9999 -9999 -9999 -9999 -9999 -9999 -9999 -9999 -9999 -9999 -9999 -9999 -9999 -9999 -9999 -9999 -9999 -9999 -9999 -9999 -9999 -9999 -9999 -9999 -9999 -9999 -9999 -9999 -9999 -9999 -9999 -9999 -9999 -9999 -9999 -9999 -9999 -9999 -9999 -9999 -9999 -9999 -9999 -9999 -9999 -9999 -9999 -9999 -9999 -9999 -9999 -9999 -9999 -9999 -9999 -9999 -9999 -9999 -9999 -9999 -9999 -9999 -9999 -9999 -9999 -9999 -9999 -9999 -9999 -9999 -9999 -9999 -9999 -9999 -9999 -9999 -9999 -9999 -9999 -

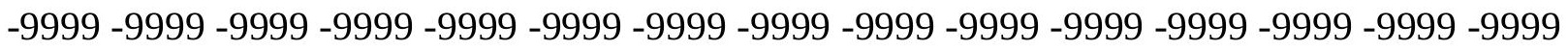

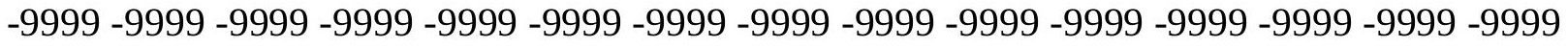
-9999 -9999 -9999 -9999 -9999 -9999 -9999 -9999 -9999 -9999 -9999 -9999 -9999 -9999 -9999 -

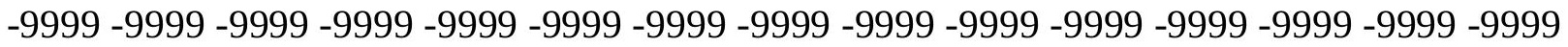

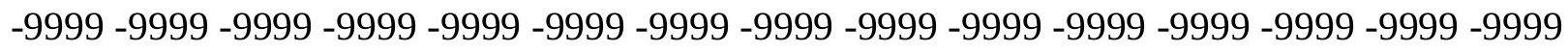

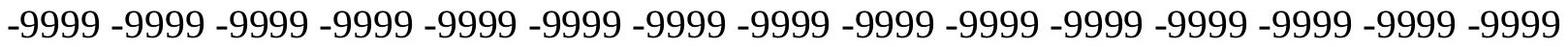

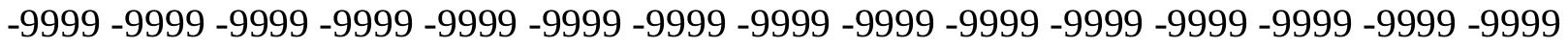
-9999 -9999 -9999 -9999 -9999 -9999 -9999 -9999 -9999 -9999 -9999 -9999 -9999 -9999 -9999 -

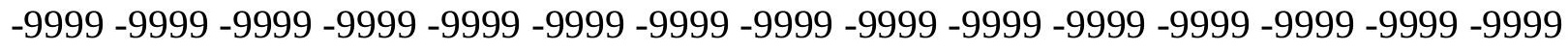

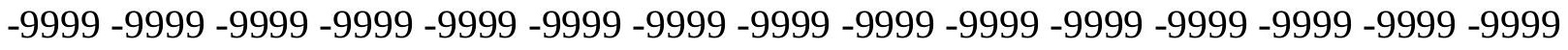
-9999 -9999 -9999 -9999 -9999 -9999 -9999 -9999 -9999 -9999 -9999 -9999 -9999 -9999 -9999 -9999 -9999 -9999 -9999 -9999 -9999 -9999 -9999 -9999-9999 -9999 -9999 -9999 -9999 -9999 -9999 -9999 -9999 -9999 -9999 -9999 -9999 -9999 -9999 -9999 -9999 -9999 -9999 -9999 -9999 -

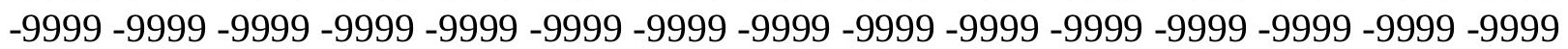


-9999 -9999 -9999 -9999 -9999 -9999 -9999 -9999 -9999 -9999 -9999 -9999 -9999 -9999 -9999 -9999 -9999 -9999 -9999 -9999 -9999 -9999 -9999 -9999 -9999 -9999 -9999 -9999 -9999 -9999 -9999 -9999 -9999 -9999 -9999 -9999 -9999 -9999 -9999 -9999 -9999 -9999 -9999 -9999 - 9999 -9999 -9999 -9999 -9999 -9999 -9999 -9999 -9999 -9999 -9999 -9999 -9999 -9999 -9999 -9999 -9999 -9999 -9999 -9999 -9999 -9999 -9999 -9999 -9999 -9999 -9999 -9999 -9999 -9999 -9999 -9999 -9999 -9999 -9999 -9999 -9999 -9999 -9999 -9999 -9999 -9999 -9999 -9999 -9999 -9999 -9999 -9999 -9999 -9999 -9999 -9999 -9999 -9999 -9999 -9999 -9999 -9999 -9999 -9999 -9999

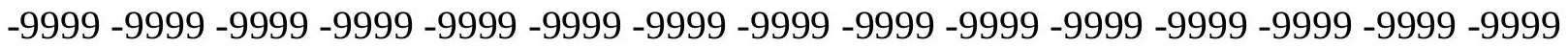

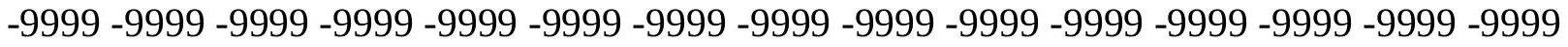
-9999 -9999 -9999 -9999 -9999 -9999 -9999 -9999 -9999 -9999 -9999 -9999 -9999 -9999 -9999 -9999 -9999 -9999 -9999 -9999 -9999 -9999 -9999 -9999 -9999 -9999 -9999 -9999 -9999 -9999 -9999 -9999 -9999 -9999 -9999 -9999 -9999 -9999 -9999 -9999 -9999 -9999 -9999 -9999 -9999 -9999 -9999 -9999 -9999 -9999 -9999 -9999 -9999 -9999 -9999 -9999 -9999 -9999 -9999 -9999 -9999 -9999 -9999 -9999 -9999 -9999 -9999 -9999 -9999 -9999 -9999 -9999 -9999 -9999 -9999 -9999 -9999 -9999 -9999 -9999 -9999 -9999 -9999 -9999 -9999 -9999 -9999 -9999 -9999 -

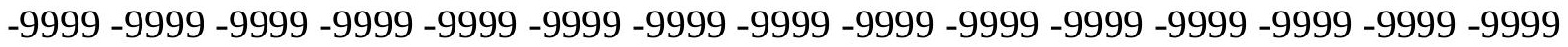
-9999 -9999 -9999 -9999 -9999 -9999 -9999 -9999 -9999 -9999 -9999 -9999 -9999 -9999 -9999 -9999 -9999 -9999 -9999 -9999 -9999 -9999 -9999 -9999 -9999 -9999 -9999 -9999 -9999 -9999 -9999 -9999 -9999 -9999 -9999 -9999 -9999 -9999 -9999 -9999 -9999 -9999 -9999 -9999 -9999 -9999 -9999 -9999 -9999 -9999 -9999 -9999 -9999 -9999 -9999 -9999 -9999 -9999 -9999 -9999 -9999 -9999 -9999 -9999 -9999 -9999 -9999 -9999 -9999 -9999 -9999 -9999 -9999 -9999 -9999 -999 -9999 -9999 -9999 -9999 -9999 -9999 -9999 -9999 -9999 -9999 -9999 -9999 -9999 -9999 -9999 -9999 -9999 -9999 -9999 -9999 -9999 -9999 -9999 -9999 -9999 -9999 -9999 -9999 -9999 -9999 -9999 -9999 -9999 -9999 -9999 -9999 -9999 -9999 -9999 -9999 -9999 -9999 -9999 -9999 -9999 -9999 -9999 -9999 -9999 -9999 -9999 -9999 -9999 -9999 -9999 -9999 -9999 -9999 -9999 -9999 -9999 -9999 -9999 -9999 -9999 -9999 -9999 -9999 -9999 -9999 -9999 -9999 -9999 -9999 -9999 -9999 -9999 -9999 -9999 -9999 -9999 -9999 -9999 -9999 -9999 -9999 -9999 -9999 -9999 -9999 -9999 -9999 -9999 -9999 -9999 -9999 -9999 -9999 -9999 -9999 -9999 -9999 -9999 -9999 -9999 -9999 -9999 -9999 -9999 -9999 -9999 -9999 -9999 -9999 -9999 -9999 -9999 -9999 -9999 -9999 -9999 -9999 -9999 -9999 -9999 -9999 -9999 -9999 -9999 -9999 -9999 -9999 -9999 -9999 -999 -9999 -9999 -9999 -9999 -9999 -9999 -9999 -9999 -9999 -9999 -9999 -9999 -9999 -9999 -9999 -9999 -9999 -9999 -9999 -9999 -9999 -9999 -9999 -9999 -9999 -9999 -9999 -9999 -9999 -9999 -

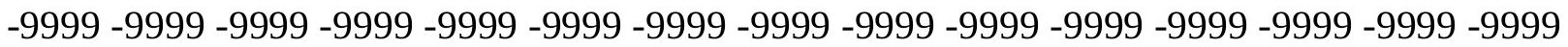

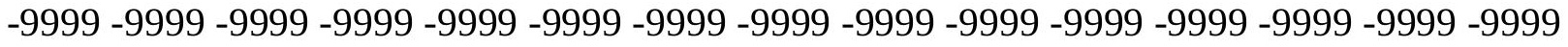

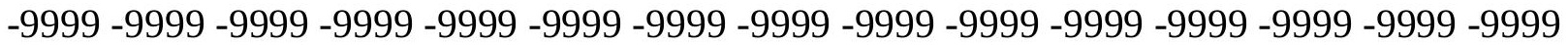
-9999 -9999 -9999 -9999 -9999 -9999 -9999 -9999 -9999 -9999 -9999 -9999 -9999 -9999 -9999 -9999 -9999 -9999 -9999 -9999 -9999 -9999 -9999 -9999 -9999 -9999 -9999 -9999 -9999 -

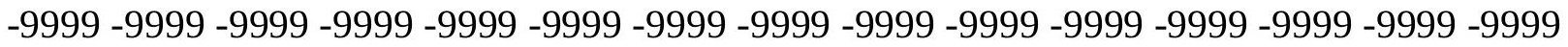
-9999 -9999 -9999 -9999 -9999 -9999 -9999 -9999 -9999 -9999 -9999 -9999 -9999 -9999 -9999 -9999 -9999 -9999 -9999 -9999 -9999 -9999 -9999 -9999 -9999 -9999 -9999 -9999 -9999 -9999 -

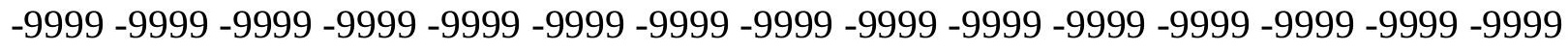

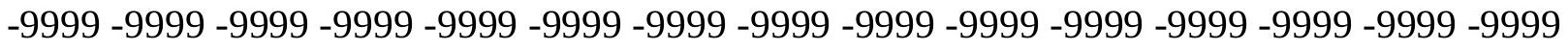
-9999 -9999 -9999 -9999 -9999 -9999 -9999 -9999 -9999 -9999 -9999 -9999 -9999 -9999 -9999 -9999 -9999 -9999 -9999 -9999 -9999 -9999 -9999 -9999-9999 -9999 -9999 -9999 -9999 -9999 -9999 -9999 -9999 -9999 -9999 -9999 -9999 -9999 -9999 -9999 -9999 -9999 -9999 -9999 -9999 -

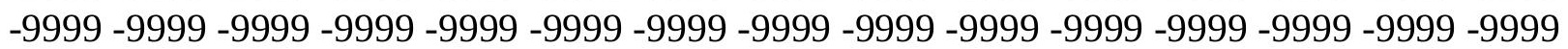


-9999 -9999 -9999 -9999 -9999 -9999 -9999 -9999 -9999 -9999 -9999 -9999 -9999 -9999 -9999 -9999 -9999 -9999 -9999 -9999 -9999 -9999 -9999 -9999 -9999 -9999 -9999 -9999 -9999 -9999 -

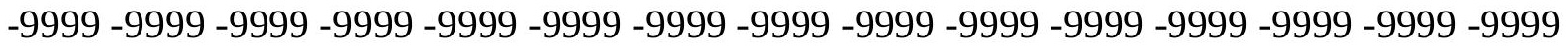
-9999 -9999 -9999 -9999 -9999 -9999 -9999 -9999 -9999 -9999 -9999 -9999 -9999 -9999 -9999 -9999 -9999 -9999 -9999 -9999 -9999 -9999 -9999 -9999-9999 -9999 -9999 -9999 -9999 -9999 -9999 -9999 -9999 -9999 -9999 -9999 -9999 -9999 -9999 -9999 -9999 -9999 -9999 -9999 -9999 -9999 -9999 -9999 -9999 -9999 -9999 -9999 -9999 -9999 -9999 -9999 -9999 -9999 -9999 -9999

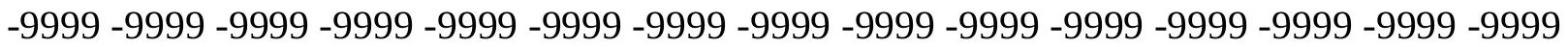

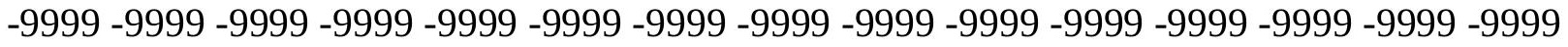
-9999 -9999 -9999 -9999 -9999 -9999 -9999 -9999 -9999 -9999 -9999 -9999 -9999 -9999 -9999 -9999 -9999 -9999 -9999 -9999 -9999 -9999 -9999 -9999 -9999 -9999 -9999 -9999 -9999 -9999 -9999 -9999 -9999 -9999 -9999 -9999 -9999 -9999 -9999 -9999 -9999 -9999 -9999 -9999 -9999 -9999 -9999 -9999 -9999 -9999 -9999 -9999 -9999 -9999 -9999 -9999 -9999 -9999 -9999 -9999 -9999 -9999 -9999 -9999 -9999 -9999 -9999 -9999 -9999 -9999 -9999 -9999 -9999 -9999 -9999 -9999 -9999 -9999 -9999 -9999 -9999 -9999 -9999 -9999 -9999 -9999 -9999 -9999 -9999 -9999 -

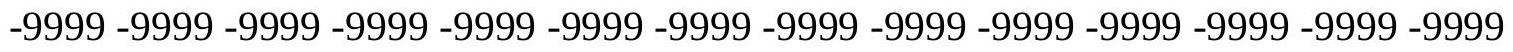
-9999 -9999 -9999 -9999 -9999 -9999 -9999 -9999 -9999 -9999 -9999 -9999 -9999 -9999 -9999 -9999 -9999 -9999 -9999 -9999 -9999 -9999 -9999 -9999 -9999 -9999 -9999 -9999 -9999 -9999 -9999 -9999 -9999 -9999 -9999 -9999 -9999 -9999 -9999 -9999 -9999 -9999 -9999 -9999 -9999 -

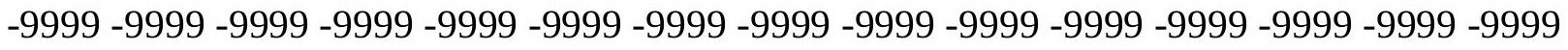

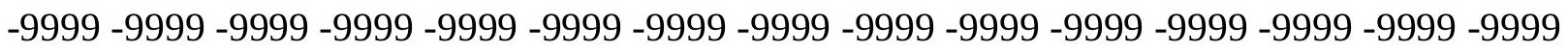
-9999 -9999 -9999 -9999 -9999 -9999 -9999 -9999 -9999 -9999 -9999 -9999 -9999 -9999 - 9999 -9999 -9999 -9999 -9999 -9999 -9999 -9999 -9999 -9999 -9999 -9999 -9999 -9999 -9999 -9999 -9999 -9999 -9999 -9999 -9999 -9999 -9999 -9999 -9999 -9999 -9999 -9999 -9999 -9999 -9999 -

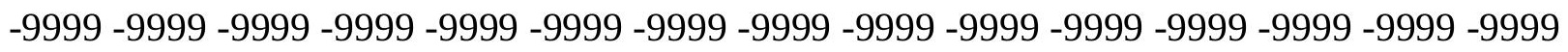
-9999 -9999 -9999 -9999 -9999 -9999 -9999 -9999 -9999 -9999 -9999 -9999 -9999 -9999 -9999 -9999 -9999 -9999 -9999 -9999 -9999 -9999 -9999 -9999 -9999 -9999 -9999 -9999 -9999 -9999 -

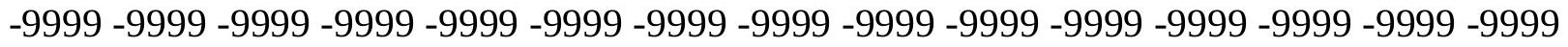
-9999 -9999 -9999 -9999 -9999 -9999 -9999 -9999 -9999 -9999 -9999 -9999 -9999 -9999 -9999 -9999 -9999 -9999 -9999 -9999 -9999 -9999 -9999 -9999 -9999 -9999 -9999 -9999 -9999 -999 -

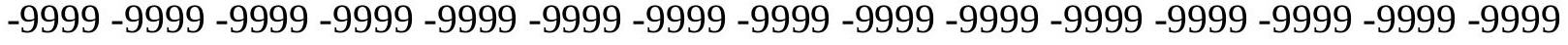
-9999 -9999 -9999 -9999 -9999 -9999 -9999 -9999 -9999 -9999 -9999 -9999 -9999 -9999 -9999 -

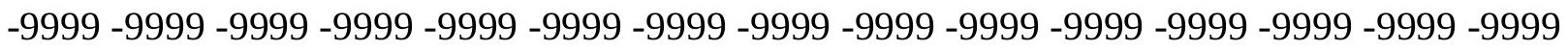

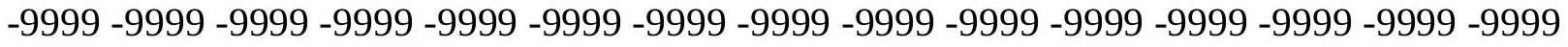

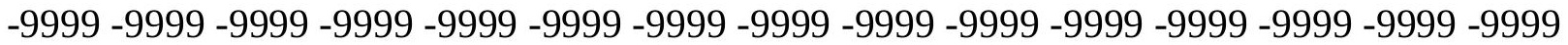
-9999 -9999 -9999 -9999 -9999 -9999 -9999 -9999 -9999 -9999 -9999 -9999 -9999 -9999 -9999 -

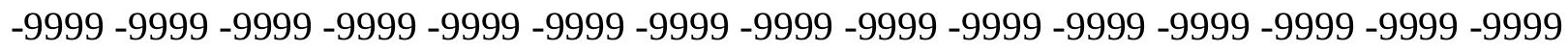

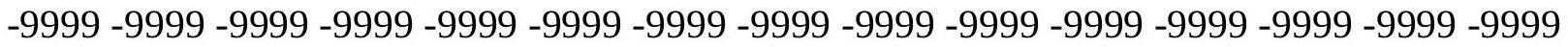
-9999 -9999 -9999 -9999 -9999 -9999 -9999 -9999 -9999 -9999 -9999 -9999 -9999 - 9999 - -999 -9999 -9999 -9999 -9999 -9999 -9999 -9999 -9999 -9999 -9999 -9999 -9999 -9999 -9999 -9999 -

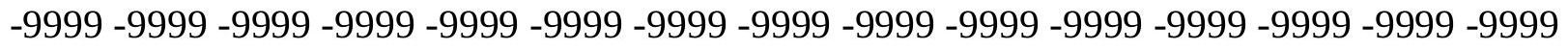

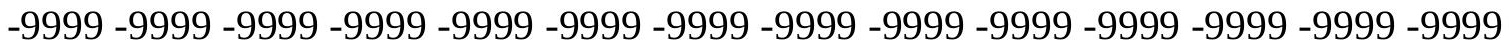
-9999 -9999 -9999 -9999 -9999 -9999 -9999 -9999 -9999 -9999 -9999 -9999 -9999 -9999 -9999 -9999 -9999 -9999 -9999 -9999 -9999 -9999 -9999 -9999-9999 -9999 -9999 -9999 -9999 -9999 -9999 -9999 -9999 -9999 -9999 -9999 -9999 -9999 -9999 -9999 -9999 -9999 -9999 -9999 -9999 -

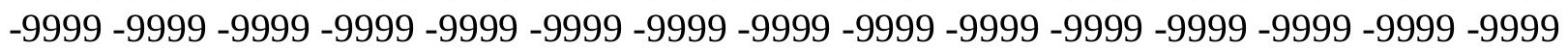


-9999 -9999 -9999 -9999 -9999 -9999 -9999 -9999 -9999 -9999 -9999 -9999 -9999 -9999 -9999 -9999 -9999 -9999 -9999 -9999 -9999 -9999 -9999 -9999 -9999 -9999 -9999 -9999 -9999 -9999 -

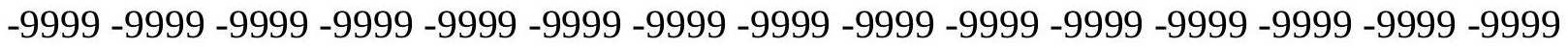
-9999 -9999 -9999 -9999 -9999 -9999 -9999 -9999 -9999 -9999 -9999 -9999 -9999 -9999 -9999 -9999 -9999 -9999 -9999 -9999 -9999 -9999 -9999 -9999-9999 -9999 -9999 -9999 -9999 -9999 -9999 -9999 -9999 -9999 -9999 -9999 -9999 -9999 -9999 -9999 -9999 -9999 -9999 -9999 -9999 -9999 -9999 -9999 -9999 -9999 -9999 -9999 -9999 -9999 -9999 -9999 -9999 -9999 -9999 -9999

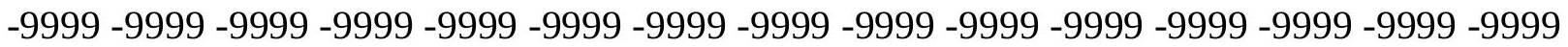

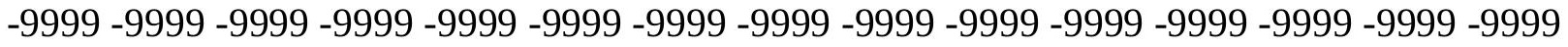
-9999 -9999 -9999 -9999 -9999 -9999 -9999 -9999 -9999 -9999 -9999 -9999 -9999 -9999 -9999 -9999 -9999 -9999 -9999 -9999 -9999 -9999 -9999 -9999 -9999 -9999 -9999 -9999 -9999 -9999 -9999 -9999 -9999 -9999 -9999 -9999 -9999 -9999 -9999 -9999 -9999 -9999 -9999 -9999 -9999 -9999 -9999 -9999 -9999 -9999 -9999 -9999 -9999 -9999 -9999 -9999 -9999 -9999 -9999 -9999 -

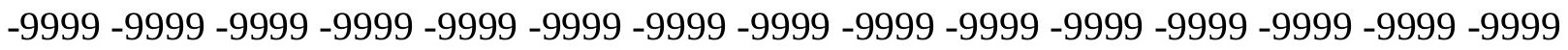
-9999 -9999 -9999 -9999 -9999 -9999 -9999 -9999 -9999 -9999 -9999 -9999 -9999 -9999 -9999 -

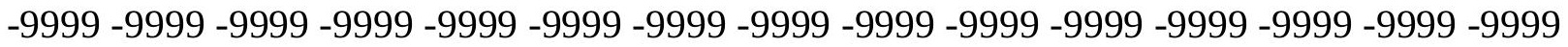
-9999 -9999 -9999 -9999 -9999 -9999 -9999 -9999 -9999 -9999 -9999 -9999 -9999 -9999 -9999 -9999 -9999 -9999 -9999 -9999 -9999 -9999 -9999 -9999 -9999 -9999 -9999 -9999 -9999 -9999 -9999 -9999 -9999 -9999 -9999 -9999 -9999 -9999 -9999 -9999 -9999 -9999 -9999 -9999 -9999 -

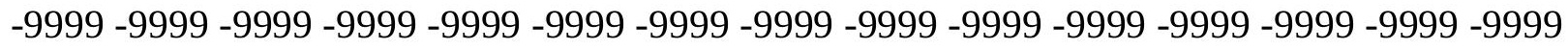

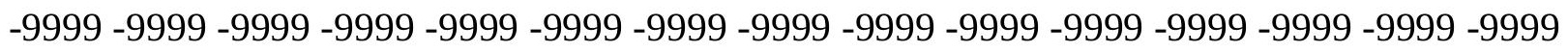
-9999 -9999 -9999 -9999 -9999 -9999 -9999 -9999 -9999 -9999 -9999 -9999 -9999 -9999 -9999 -9999 -9999 -9999 -9999 -9999 -9999 -9999 -9999 -9999 -9999 -9999 -9999 -9999 -9999 -9999 -9999 -9999 -9999 -9999 -9999 -9999 -9999 -9999 -9999 -9999 -9999 -9999 -9999 -9999 -

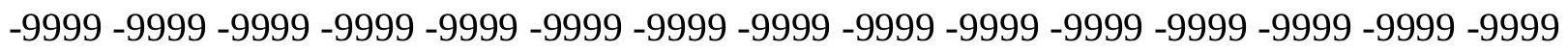
-9999 -9999 -9999 -9999 -9999 -9999 -9999 -9999 -9999 -9999 -9999 -9999 -9999 -9999 -9999 -9999 -9999 -9999 -9999 -9999 -9999 -9999 -9999 -9999 -9999 -9999 -9999 -9999 -9999 -9999 -

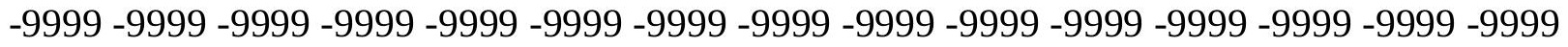
-9999 -9999 -9999 -9999 -9999 -9999 -9999 -9999 -9999 -9999 -9999 -9999 -9999 -9999 -9999 -9999 -9999 -9999 -9999 -9999 -9999 -9999 -9999 -9999 -9999 -9999 -9999 -9999 -9999 -999 -

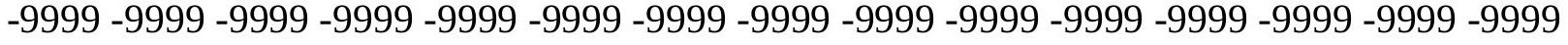
-9999 -9999 -9999 -9999 -9999 -9999 -9999 -9999 -9999 -9999 -9999 -9999 -9999 -9999 -9999 -

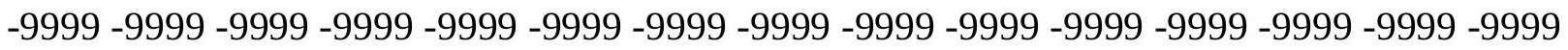

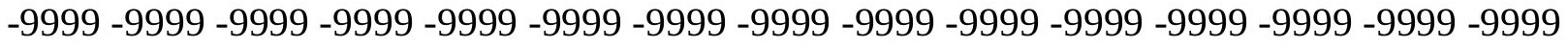

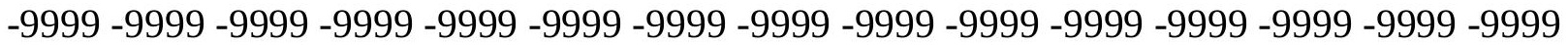

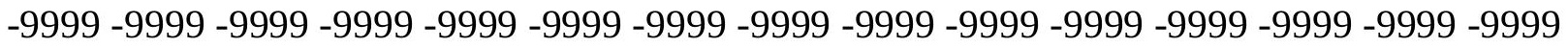

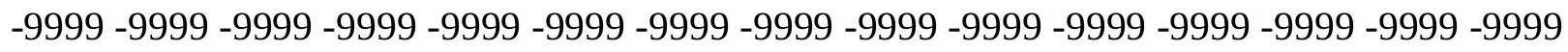

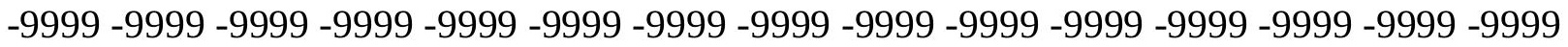

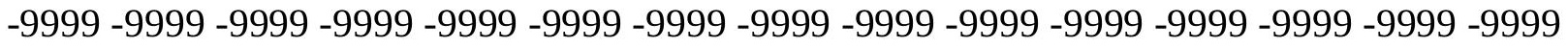
-9999 -9999 -9999 -9999 -9999 -9999 -9999 -9999 -9999 -9999 -9999 -9999 -9999 -9999 -9999 -

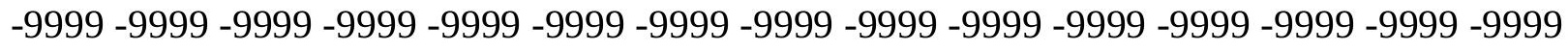

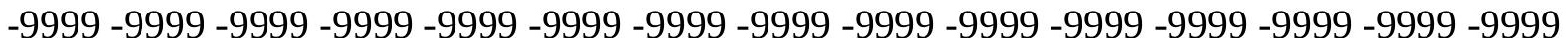
-9999 -9999 -9999 -9999 -9999 -9999 -9999 -9999 -9999 -9999 -9999 -9999 -9999 -9999 -9999 -9999 -9999 -9999 -9999 -9999 -9999 -9999 -9999 -9999-9999 -9999 -9999 -9999 -9999 -9999 -9999 -9999 -9999 -9999 -9999 -9999 -9999 -9999 -9999 -9999 -9999 -9999 -9999 -9999 -9999 -

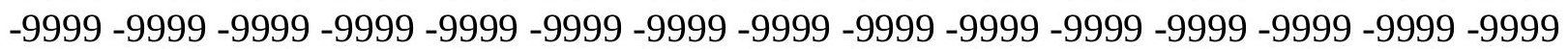


-9999 -9999 -9999 -9999 -9999 -9999 -9999 -9999 -9999 -9999 -9999 -9999 -9999 -9999 -9999 -9999 -9999 -9999 -9999 -9999 -9999 -9999 -9999 -9999 -9999 -9999 -9999 -9999 -9999 -

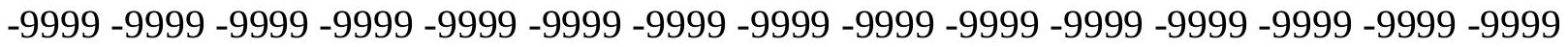
-9999 -9999 -9999 -9999 -9999 -9999 -9999 -9999 -9999 -9999 -9999 -9999 -9999 -9999 -9999 -9999 -9999 -9999 -9999 -9999 -9999 -9999 -9999 -9999 -9999 -9999 -9999 -9999 -9999 -9999 -9999 -9999 -9999 -9999 -9999 -9999 -9999 -9999 -9999 -9999 -9999 -9999 -9999 -9999 -9999 -9999 -9999 -9999 -9999 -9999 -9999 -9999 -9999 -9999 -9999 -9999 -9999 -9999 -9999 -9999

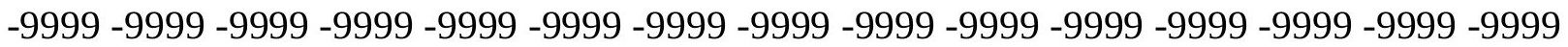

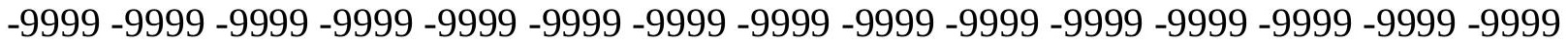
-9999 -9999 -9999 -9999 -9999 -9999 -9999 -9999 -9999 -9999 -9999 -9999 -9999 -9999 -9999 -9999 -9999 -9999 -9999 -9999 -9999 -9999 -9999 -9999 -9999 -9999 -9999 -9999 -9999 -9999 -9999 -9999 -9999 -9999 -9999 -9999 -9999 -9999 -9999 -9999 -9999 -9999 -9999 -9999 -9999 -9999 -9999 -9999 -9999 -9999 -9999 -9999 -9999 -9999 -9999 -9999 -9999 -9999 -9999 -9999 -9999 -9999 -9999 -9999 -9999 -9999 -9999 -9999 -9999 -9999 -9999 -9999 -9999 -9999 -9999 -9999 -9999 -9999 -9999 -9999 -9999 -9999 -9999 -9999 -9999 -9999 -9999 -9999 -9999 -9999 -

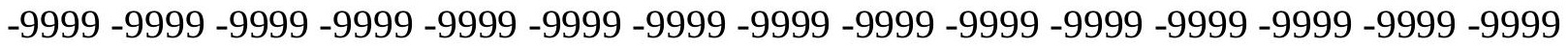
-9999 -9999 -9999 -9999 -9999 -9999 -9999 -9999 -9999 -9999 -9999 -9999 -9999 -9999 -9999 -9999 -9999 -9999 -9999 -9999 -9999 -9999 -9999 -9999 -9999 -9999 -9999 -9999 -9999 - 9999 -9999 -9999 -9999 -9999 -9999 -9999 -9999 -9999 -9999 -9999 -9999 -9999 -9999 -9999 -9999 -

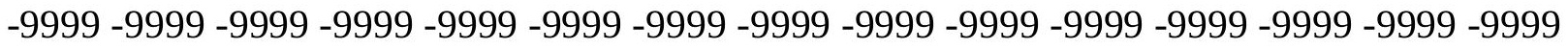

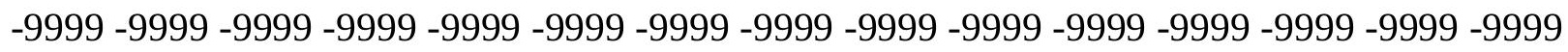

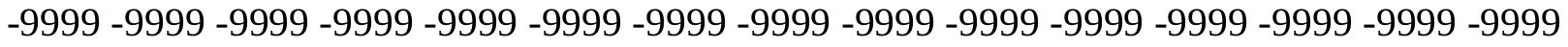
-9999 -9999 -9999 -9999 -9999 -9999 -9999 -9999 -9999 -9999 -9999 -9999 -9999 -9999 -9999 -9999 -9999 -9999 -9999 -9999 -9999 -9999 -9999 -9999 -9999 -9999 -9999 -9999 -9999 -9999 -

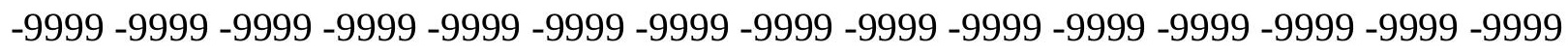
-9999 -9999 -9999 -9999 -9999 -9999 -9999 -9999 -9999 -9999 -9999 -9999 -9999 -9999 -9999 -9999 -9999 -9999 -9999 -9999 -9999 -9999 -9999 -9999 -9999 -9999 -9999 -9999 -9999 -9999 -9999 -9999 -9999 -9999 -9999 -9999 -9999 -9999 -9999 -9999 -9999 -9999 -9999 -9999 -9999 -9999 -9999 -9999 -9999 -9999 -9999 -9999 -9999 -9999 -9999 -9999 -9999 -9999 -9999 -9999 -9999 -9999 -9999 -9999 -9999 -9999 -9999 -9999 -9999 -9999 -9999 -9999 -9999 -999 -

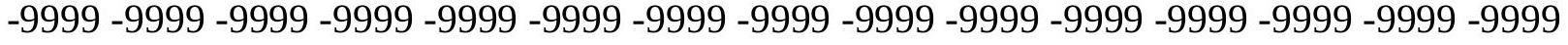
-9999 -9999 -9999 -9999 -9999 -9999 -9999 -9999 -9999 -9999 -9999 -9999 -9999 -9999 -9999 -

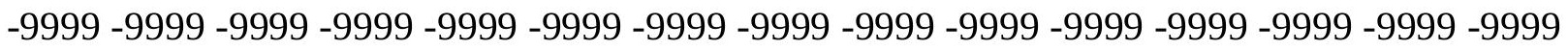

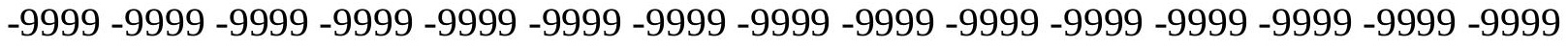

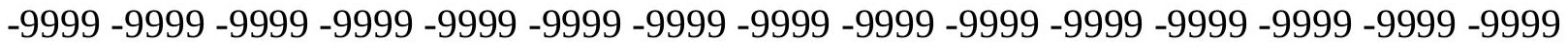

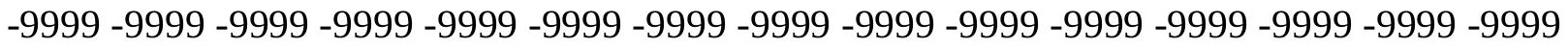

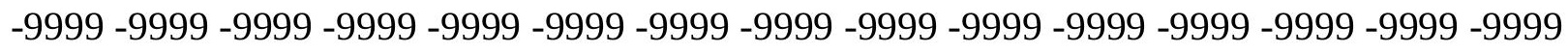

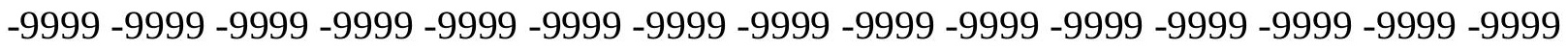

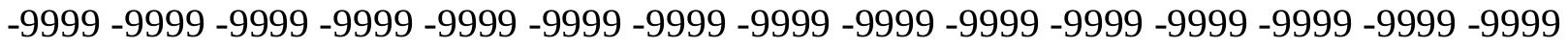
-9999 -9999 -9999 -9999 -9999 -9999 -9999 -9999 -9999 -9999 -9999 -9999 -9999 -9999 -9999 -

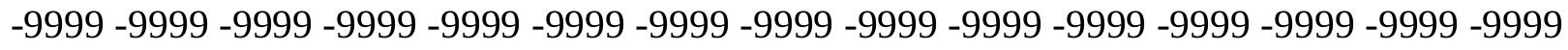

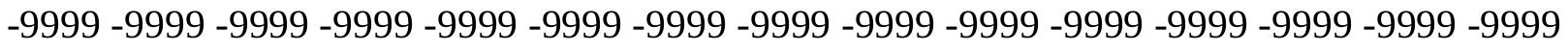
-9999 -9999 -9999 -9999 -9999 -9999 -9999 -9999 -9999 -9999 -9999 -9999 -9999 -9999 -9999 -9999 -9999 -9999 -9999 -9999 -9999 -9999 -9999 -9999-9999 -9999 -9999 -9999 -9999 -9999 -9999 -9999 -9999 -9999 -9999 -9999 -9999 -9999 -9999 -9999 -9999 -9999 -9999 -9999 -9999 -

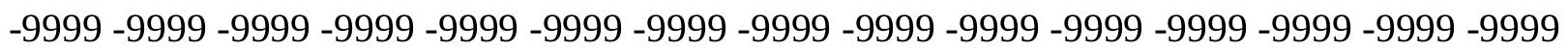


-9999 -9999 -9999 -9999 -9999 -9999 -9999 -9999 -9999 -9999 -9999 -9999 -9999 -9999 -9999 -9999 -9999 -9999 -9999 -9999 -9999 -9999 -9999 -9999 -9999 -9999 -9999 -9999 -9999 -9999 -

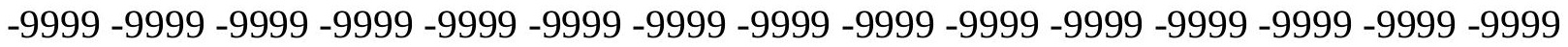
-9999 -9999 -9999 -9999 -9999 -9999 -9999 -9999 -9999 -9999 -9999 -9999 -9999 -9999 -9999 -9999 -9999 -9999 -9999 -9999 -9999 -9999 -9999 -9999-9999 -9999 -9999 -9999 -9999 -9999 -9999 -9999 -9999 -9999 -9999 -9999 -9999 -9999 -9999 -9999 -9999 -9999 -9999 -9999 -9999 -

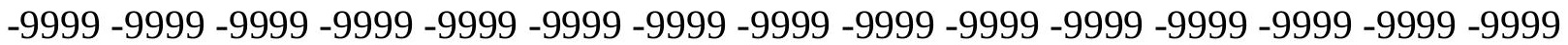
-9999 -9999 -9999 -9999 -9999 -9999 -9999 -9999 -9999 -9999 -9999 -9999 -9999 -9999 -9999 -9999 -9999 -9999 -9999 -9999 -9999 -9999 -9999 -9999 -9999 -9999 -9999 -9999 -9999 -9999 -9999 -9999 -9999 -9999 -9999 -9999 -9999 -9999 -9999 -9999 -9999 -9999 -9999 -9999 -9999 -9999 -9999 -9999 -9999 -9999 -9999 -9999 -9999 -9999 -9999 -9999 -9999 -9999 -9999 -9999 -9999 -9999 -9999 -9999 -9999 -9999 -9999 -9999 -9999 -9999 -9999 -9999 -9999 -9999 -9999 -9999 -9999 -9999 -9999 -9999 -9999 -9999 -9999 -9999 -9999 -9999 -9999 -9999 -9999 -9999 -9999 -9999 -9999 -9999 -9999 -9999 -9999 -9999 -9999 -9999 -9999 -9999 -9999 -9999 -9999 -9999 -9999 -9999 -9999 -9999 -9999 -9999 -9999 -9999 -9999 -9999 -9999 -9999 -9999 -

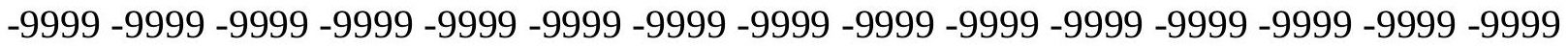
-9999 -9999 -9999 -9999 -9999 -9999 -9999 -9999 -9999 -9999 -9999 -9999 -9999 -9999 -9999 -9999 -9999 -9999 -9999 -9999 -9999 -9999 -9999 -9999 -9999 -9999 -9999 -9999 -9999 -9999 -9999 -9999 -9999 -9999 -9999 -9999 -9999 -9999 -9999 -9999 -9999 -9999 -9999 -9999 -9999 -

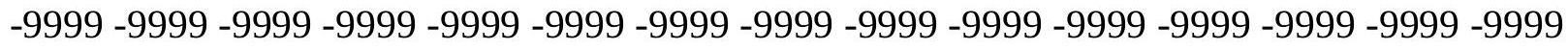

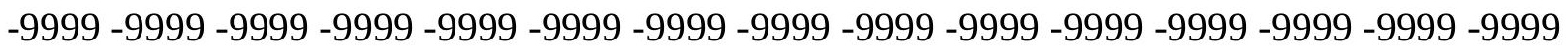
-9999 -9999 -9999 -9999 -9999 -9999 -9999 -9999 -9999 -9999 -9999 -9999 -9999 -9999 - 9999 -9999 -9999 -9999 -9999 -9999 -9999 -9999 -9999 -9999 -9999 -9999 -9999 -9999 -9999 -9999 -9999 -9999 -9999 -9999 -9999 -9999 -9999 -9999 -9999 -9999 -9999 -9999 -9999 -9999 -9999 -

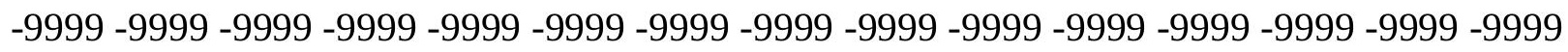
-9999 -9999 -9999 -9999 -9999 -9999 -9999 -9999 -9999 -9999 -9999 -9999 -9999 -9999 -9999 -9999 -9999 -9999 -9999 -9999 -9999 -9999 -9999 -9999 -9999 -9999 -9999 -9999 -9999 -9999 -

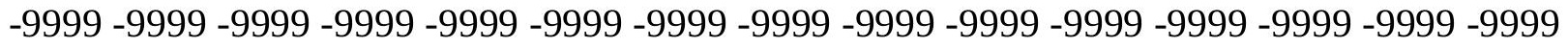
-9999 -9999 -9999 -9999 -9999 -9999 -9999 -9999 -9999 -9999 -9999 -9999 -9999 -9999 -9999 -9999 -9999 -9999 -9999 -9999 -9999 -9999 -9999 -9999 -9999 -9999 -9999 -9999 -9999 -999 -9999 -9999 -9999 -9999 -9999 -9999 -9999 -9999 -9999 -9999 -9999 -9999 -9999 -9999 -9999 -9999 -9999 -9999 -9999 -9999 -9999 -9999 -9999 -9999 -9999 -9999 -9999 -9999 -9999 -9999 -

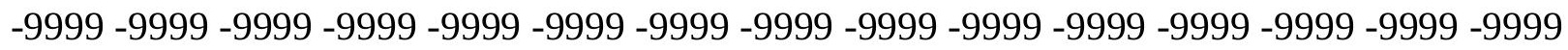

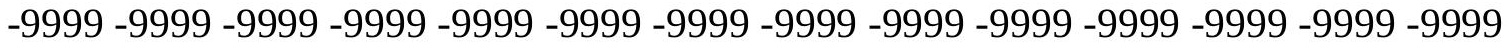
-9999 -9999 -9999 -9999 -9999 -9999 -9999 -9999 -9999 -9999 -9999 -9999 -9999 -9999 -9999

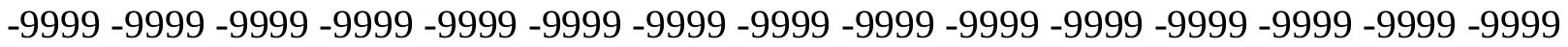

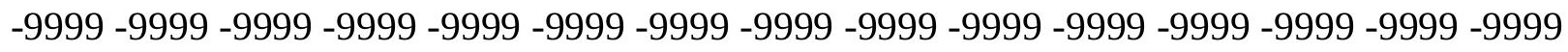

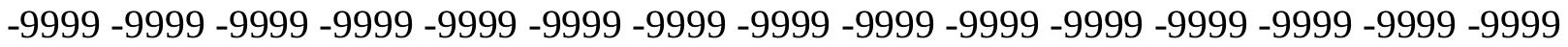

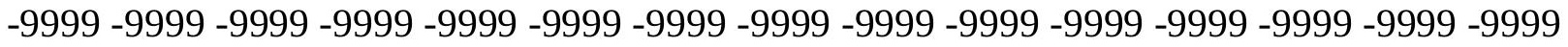
-9999 -9999 -9999 -9999 -9999 -9999 -9999 -9999 -9999 -9999 -9999 -9999 -9999 -9999 -9999 -

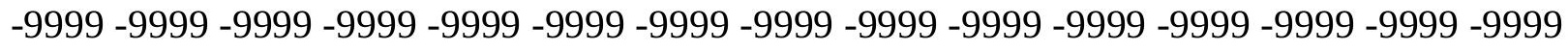

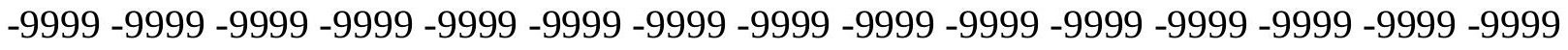
-9999 -9999 -9999 -9999 -9999 -9999 -9999 -9999 -9999 -9999 -9999 -9999 -9999 -9999 -9999 -9999 -9999 -9999 -9999 -9999 -9999 -9999 -9999 -9999-9999 -9999 -9999 -9999 -9999 -9999 -9999 -9999 -9999 -9999 -9999 -9999 -9999 -9999 -9999 -9999 -9999 -9999 -9999 -9999 -9999 -

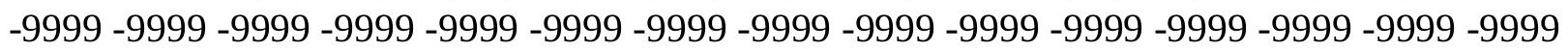


-9999 -9999 -9999 -9999 -9999 -9999 -9999 -9999 -9999 -9999 -9999 -9999 -9999 -9999 -9999 -9999 -9999 -9999 -9999 -9999 -9999 -9999 -9999 -9999 -9999 -9999 -9999 -9999 -9999 -9999 -

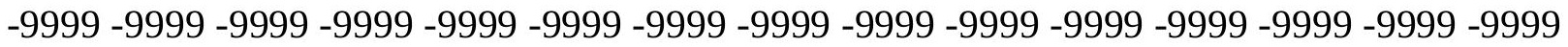
-9999 -9999 -9999 -9999 -9999 -9999 -9999 -9999 -9999 -9999 -9999 -9999 -9999 -9999 -9999 -9999 -9999 -9999 -9999 -9999 -9999 -9999 -9999 -9999-9999 -9999 -9999 -9999 -9999 -9999 -9999 -9999 -9999 -9999 -9999 -9999 -9999 -9999 -9999 -9999 -9999 -9999 -9999 -9999 -9999 -9999 -9999 -9999 -9999 -9999 -9999 -9999 -9999 -9999 -9999 -9999 -9999 -9999 -9999 -9999

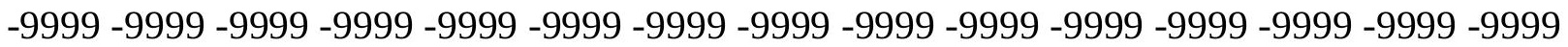

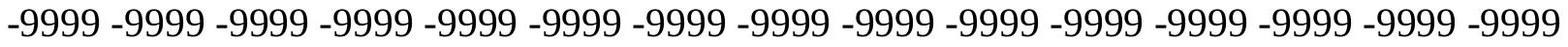
-9999 -9999 -9999 -9999 -9999 -9999 -9999 -9999 -9999 -9999 -9999 -9999 -9999 -9999 -9999 -9999 -9999 -9999 -9999 -9999 -9999 -9999 -9999 -9999 -9999 -9999 -9999 -9999 -9999 -9999 -9999 -9999 -9999 -9999 -9999 -9999 -9999 -9999 -9999 -9999 -9999 -9999 -9999 -9999 -9999 -9999 -9999 -9999 -9999 -9999 -9999 -9999 -9999 -9999 -9999 -9999 -9999 -9999 -9999 -9999 -9999 -9999 -9999 -9999 -9999 -9999 -9999 -9999 -9999 -9999 -9999 -9999 -9999 -9999 -9999 -9999 -9999 -9999 -9999 -9999 -9999 -9999 -9999 -9999 -9999 -9999 -9999 -9999 -9999

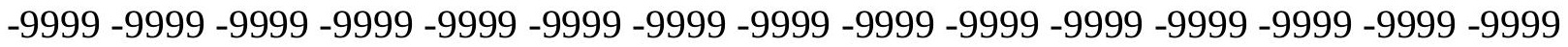
-9999 -9999 -9999 -9999 -9999 -9999 -9999 -9999 -9999 -9999 -9999 -9999 -9999 -9999 -9999 -9999 -9999 -9999 -9999 -9999 -9999 -9999 -9999 -9999 -9999 -9999 -9999 -9999 -9999 -9999 -9999 -9999 -9999 -9999 -9999 -9999 -9999 -9999 -9999 -9999 -9999 -9999 -9999 -9999 -9999 -

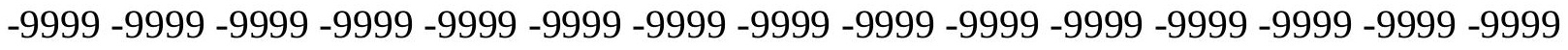

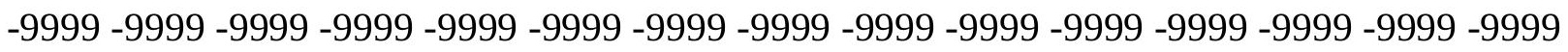
-9999 -9999 -9999 -9999 -9999 -9999 -9999 -9999 -9999 -9999 -9999 -9999 -9999 -9999 -9999 -9999 -9999 -9999 -9999 -9999 -9999 -9999 -9999 -9999 -9999 -9999 -9999 -9999 -9999 -9999 -9999 -9999 -9999 -9999 -9999 -9999 -9999 -9999 -9999 -9999 -9999 -9999 -9999 -9999 -9999 -

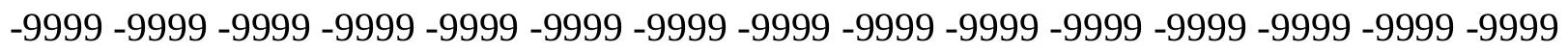
-9999 -9999 -9999 -9999 -9999 -9999 -9999 -9999 -9999 -9999 -9999 -9999 -9999 -9999 -9999 -9999 -9999 -9999 -9999 -9999 -9999 -9999 -9999 -9999 -9999 -9999 -9999 -9999 -9999 -9999 -

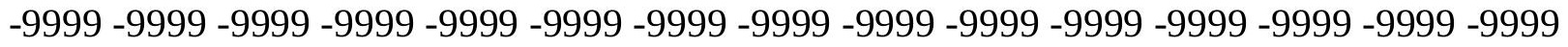
-9999 -9999 -9999 -9999 -9999 -9999 -9999 -9999 -9999 -9999 -9999 -9999 -9999 -9999 -9999 -9999 -9999 -9999 -9999 -9999 -9999 -9999 -9999 -9999 -9999 -9999 -9999 -9999 -9999 -999 -9999 -9999 -9999 -9999 -9999 -9999 -9999 -9999 -9999 -9999 -9999 -9999 -9999 -9999 -9999 -9999 -9999 -9999 -9999 -9999 -9999 -9999 -9999 -9999 -9999 -9999 -9999 -9999 -9999 -9999 -

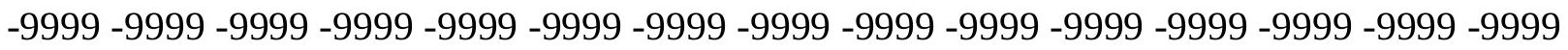

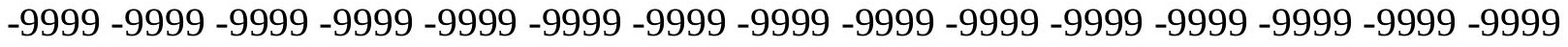

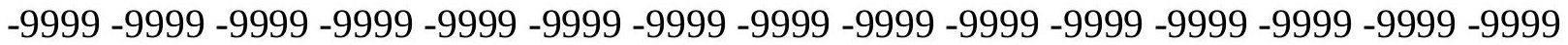

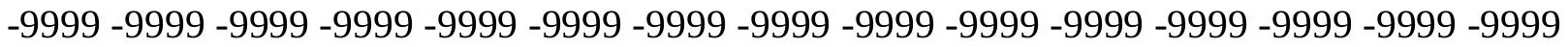

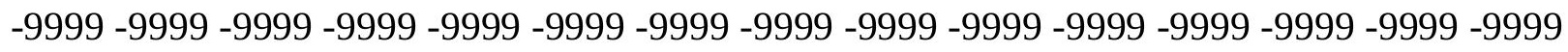

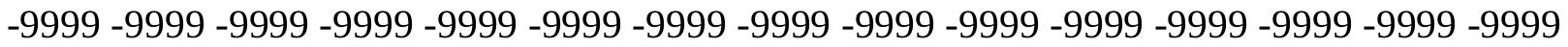
-9999 -9999 -9999 -9999 -9999 -9999 -9999 -9999 -9999 -9999 -9999 -9999 -9999 - 9999 - -999 -9999 -9999 -9999 -9999 -9999 -9999 -9999 -9999 -9999 -9999 -9999 -9999 -9999 -9999 - -999 -

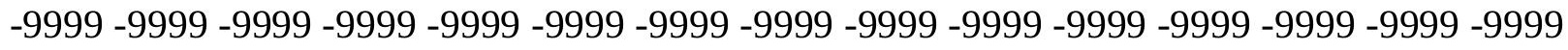

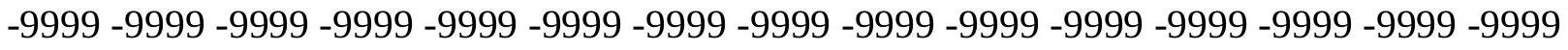
-9999 -9999 -9999 -9999 -9999 -9999 -9999 -9999 -9999 -9999 -9999 -9999 -9999 -9999 -9999 -9999 -9999 -9999 -9999 -9999 -9999 -9999 -9999 -9999-9999 -9999 -9999 -9999 -9999 -9999 -9999 -9999 -9999 -9999 -9999 -9999 -9999 -9999 -9999 -9999 -9999 -9999 -9999 -9999 -9999 -

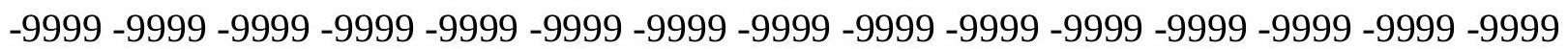


-9999 -9999 -9999 -9999 -9999 -9999 -9999 -9999 -9999 -9999 -9999 -9999 -9999 -9999 -9999 -9999 -9999 -9999 -9999 -9999 -9999 -9999 -9999 -9999 -9999 -9999 -9999 -9999 -9999 -9999 -9999 -9999 -9999 -9999 -9999 -9999 -9999 -9999 -9999 -9999 -9999 -9999 -9999 -9999 -9999 -9999 -9999 -9999 -9999 -9999 -9999 -9999 -9999 -9999 -9999 -9999 -9999 -9999 -9999 -9999 -9999 -9999 -9999 -9999 -9999 -9999 -9999 -9999 -9999 -9999 -9999 -9999 -9999 -9999 -9999 -9999 -9999 -9999 -9999 -9999 -9999 -9999 -9999 -9999 -9999 -9999 -9999 -9999 -9999 -9999 -9999 -9999 -9999 -9999 -9999 -9999 -9999 -9999 -9999 -9999 -9999 -9999 -9999 -9999 -9999 -

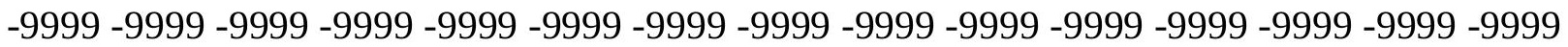
-9999 -9999 -9999 -9999 -9999 -9999 -9999 -9999 -9999 -9999 -9999 -9999 -9999 -9999 -9999 -9999 -9999 -9999 -9999 -9999 -9999 -9999 -9999 -9999 -9999 -9999 -9999 -9999 -9999 -9999 -

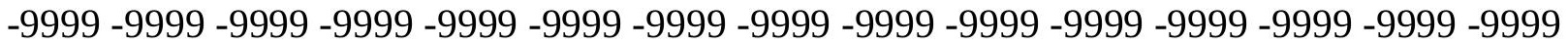
-9999 -9999 -9999 -9999 -9999 -9999 -9999 -9999 -9999 -9999 -9999 -9999 -9999 -9999 -9999 -9999 -9999 -9999 -9999 -9999 -9999 -9999 -9999 -9999 -9999 -9999 -9999 -9999 -9999 -9999 -9999 -9999 -9999 -9999 -9999 -9999 -9999 -9999 -9999 -9999 -9999 -9999 -9999 -9999 -9999 -9999 -9999 -9999 -9999 -9999 -9999 -9999 -9999 -9999 -9999 -9999 -9999 -9999 -9999 -9999

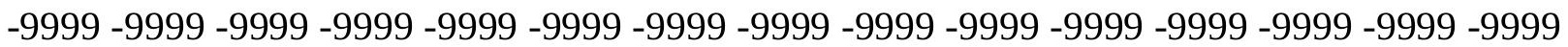
-9999 -9999 -9999 -9999 -9999 -9999 -9999 -9999 -9999 -9999 -9999 -9999 -9999 -9999 -9999 -9999 -9999 -9999 -9999 -9999 -9999 -9999 -9999 -9999 -9999 -9999 -9999 -9999 -9999 -9999 -9999 -9999 -9999 -9999 -9999 -9999 -9999 -9999 -9999 -9999 -9999 -9999 -9999 -9999 -9999 -9999 -9999 -9999 -9999 -9999 -9999 -9999 -9999 -9999 -9999 -9999 -9999 -9999 -9999 -9999 -9999 -9999 -9999 -9999 -9999 -9999 -9999 -9999 -9999 -9999 -9999 -9999 -9999 -9999 -9999 -9999 -9999 -9999 -9999 -9999 -9999 -9999 -9999 -9999 -9999 -9999 -9999 -9999 -9999 -9999 -9999 -9999 -9999 -9999 -9999 -9999 -9999 -9999 -9999 -9999 -9999 -9999 -9999 -9999 -9999 -9999 -9999 -9999 -9999 -9999 -9999 -9999 -9999 -9999 -9999 -9999 -9999 -9999 -9999 -9999 -9999 -9999 -9999 -9999 -9999 -9999 -9999 -9999 -9999 -9999 -9999 -9999 -9999 -9999 -9999 -9999 -9999 -9999 -9999 -9999 -9999 -9999 -9999 -9999 -9999 -9999 -9999 -9999 -9999 -9999 -9999 -9999 -9999 -9999 -9999 -9999 -9999 -9999 -9999 -9999 -9999 -9999 -9999 -9999 -9999 -9999 -9999 -9999 -9999 -9999 -9999 -9999 -9999 -9999 -9999 -9999 -9999 -9999 -9999

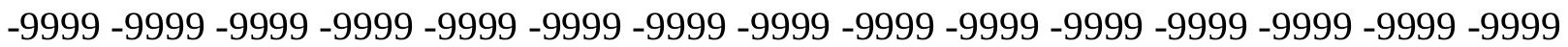
-9999 -9999 -9999 -9999 -9999 -9999 -9999 -9999 -9999 -9999 -9999 -9999 -9999 -9999 -9999 -9999 -9999 -9999 -9999 -9999 -9999 -9999 -9999 -9999 -9999 -9999 -9999 -9999 -9999 -9999 -

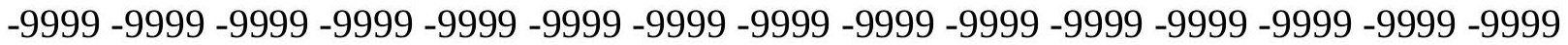
-9999 -9999 -9999 -9999 -9999 -9999 -9999 -9999 -9999 -9999 -9999 -9999 -9999 -9999 -9999 -9999 -9999 -9999 -9999 -9999 -9999 -9999 -9999 -9999 -9999 -9999 -9999 -9999 -9999 -9999 -9999 -9999 -9999 -9999 -9999 -9999 -9999 -9999 -9999 -9999 -9999 -9999 -9999 -9999 -9999 -9999 -9999 -9999 -9999 -9999 -9999 -9999 -9999 -9999 -9999 -9999 -9999 -9999 -9999 -9999 -9999 -9999 -9999 -9999 -9999 -9999 -9999 -9999 -9999 -9999 -9999 -9999 -9999 -9999 -9999

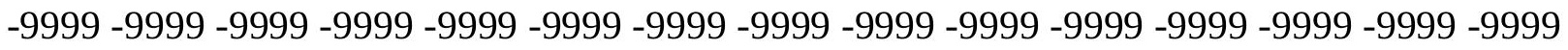
-9999 -9999 -9999 -9999 -9999 -9999 -9999 -9999 -9999 -9999 -9999 -9999 -9999 -9999 -9999 -9999 -9999 -9999 -9999 -9999 -9999 -9999 -9999 -9999 -9999 -9999 -9999 -9999 -9999 -9999 -9999 -9999 -9999 -9999 -9999 -9999 -9999 -9999 -9999 -9999 -9999 -9999 -9999 -9999 -9999 -999 -9999 -9999 -9999 -9999 -9999 -9999 -9999 -9999 -9999 -9999 -9999 -9999 -9999 -9999 -9999 -9999 -9999 -9999 -9999 -9999 -9999 -9999 -9999 -9999 -9999 -9999 -9999 -9999 -9999 -9999 -9999 -9999 -9999 -9999 -9999 -9999 -9999 -9999 -9999 -9999 -9999 -9999 -9999 -9999 -9999 -9999 -9999 -9999 -9999 -9999 -9999 -9999 -9999 -9999 -9999 -9999 -9999 -9999 -9999 -9999 -9999 -9999 -9999 -9999 -9999 -9999 -9999 -9999 -9999 -9999 -9999 -9999 -9999 -9999 
-9999 -9999 -9999 -9999 -9999 -9999 -9999 -9999 -9999 -9999 -9999 -9999 -9999 -9999 -9999 -9999 -9999 -9999 -9999 -9999 -9999 -9999 -9999 -9999 -9999 -9999 -9999 -9999 -9999 -9999 -

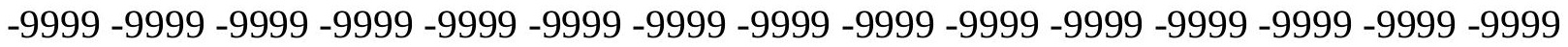
-9999 -9999 -9999 -9999 -9999 -9999 -9999 -9999 -9999 -9999 -9999 -9999 -9999 -9999 -9999 -9999 -9999 -9999 -9999 -9999 -9999 -9999 -9999 -9999-9999 -9999 -9999 -9999 -9999 -9999 -9999 -9999 -9999 -9999 -9999 -9999 -9999 -9999 -9999 -9999 -9999 -9999 -9999 -9999 -9999 -9999 -9999 -9999 -9999 -9999 -9999 -9999 -9999 -9999 -9999 -9999 -9999 -9999 -9999 -9999

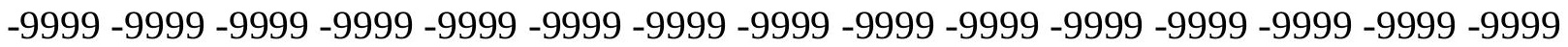

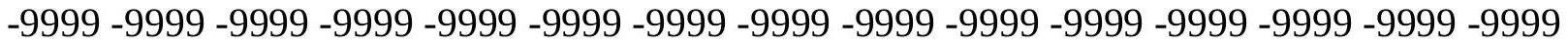
-9999 -9999 -9999 -9999 -9999 -9999 -9999 -9999 -9999 -9999 -9999 -9999 -9999 -9999 -9999 -9999 -9999 -9999 -9999 -9999 -9999 -9999 -9999 -9999 -9999 -9999 -9999 -9999 -9999 -9999 -9999 -9999 -9999 -9999 -9999 -9999 -9999 -9999 -9999 -9999 -9999 -9999 -9999 -9999 -9999 -9999 -9999 -9999 -9999 -9999 -9999 -9999 -9999 -9999 -9999 -9999 -9999 -9999 -9999 -9999 -

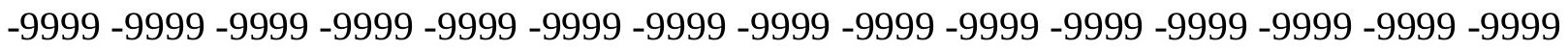
-9999 -9999 -9999 -9999 -9999 -9999 -9999 -9999 -9999 -9999 -9999 -9999 -9999 -9999 -9999 -

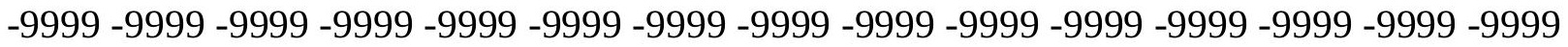
-9999 -9999 -9999 -9999 -9999 -9999 -9999 -9999 -9999 -9999 -9999 -9999 -9999 -9999 -9999 -9999 -9999 -9999 -9999 -9999 -9999 -9999 -9999 -9999 -9999 -9999 -9999 -9999 -9999 -9999 -9999 -9999 -9999 -9999 -9999 -9999 -9999 -9999 -9999 -9999 -9999 -9999 -9999 -9999 -9999 -

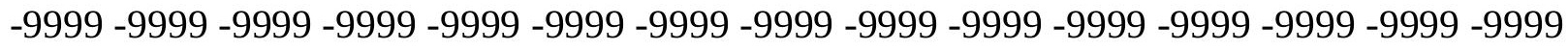

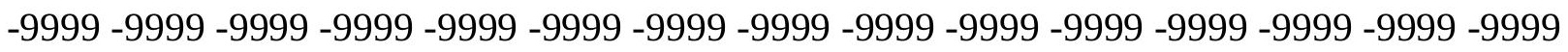

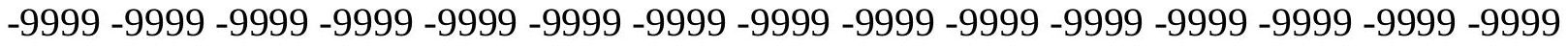
-9999 -9999 -9999 -9999 -9999 -9999 -9999 -9999 -9999 -9999 -9999 -9999 -9999 -9999 -9999 -9999 -9999 -9999 -9999 -9999 -9999 -9999 -9999 -9999 -9999 -9999 -9999 -9999 -9999 -9999 -

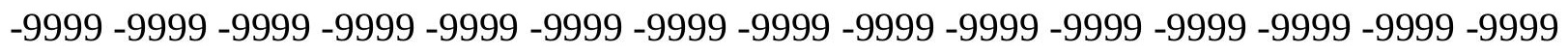
-9999 -9999 -9999 -9999 -9999 -9999 -9999 -9999 -9999 -9999 -9999 -9999 -9999 -9999 -9999 -9999 -9999 -9999 -9999 -9999 -9999 -9999 -9999 -9999 -9999 -9999 -9999 -9999 -9999 -

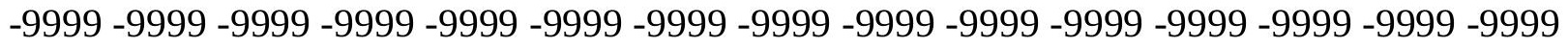
-9999 -9999 -9999 -9999 -9999 -9999 -9999 -9999 -9999 -9999 -9999 -9999 -9999 -9999 -9999 -9999 -9999 -9999 -9999 -9999 -9999 -9999 -9999 -9999 -9999 -9999 -9999 -9999 -9999 -999 -

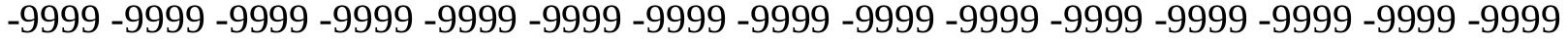
-9999 -9999 -9999 -9999 -9999 -9999 -9999 -9999 -9999 -9999 -9999 -9999 -9999 -9999 -9999 -

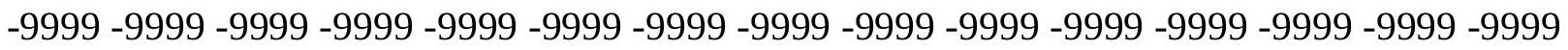

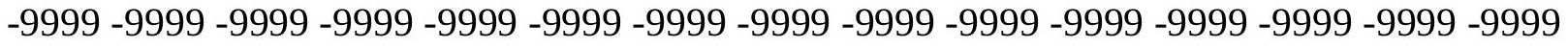

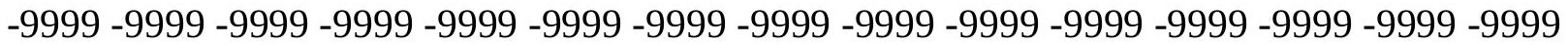
-9999 -9999 -9999 -9999 -9999 -9999 -9999 -9999 -9999 -9999 -9999 -9999 -9999 -9999 -9999

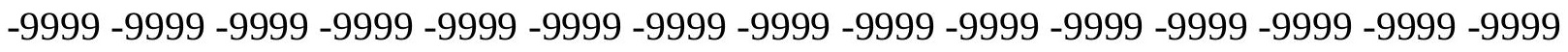

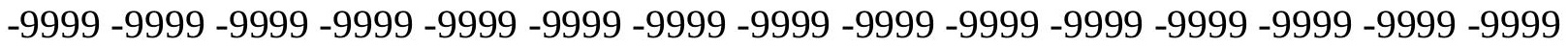
-9999 -9999 -9999 -9999 -9999 -9999 -9999 -9999 -9999 -9999 -9999 -9999 -9999 - 9999 - -999 -9999 -9999 -9999 -9999 -9999 -9999 -9999 -9999 -9999 -9999 -9999 -9999 -9999 -9999 -9999 -

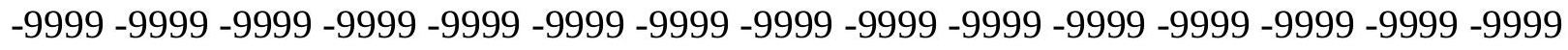

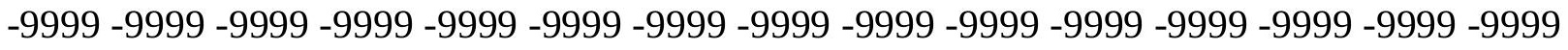
-9999 -9999 -9999 -9999 -9999 -9999 -9999 -9999 -9999 -9999 -9999 -9999 -9999 -9999 -9999 -9999 -9999 -9999 -9999 -9999 -9999 -9999 -9999 -9999-9999 -9999 -9999 -9999 -9999 -9999 -9999 -9999 -9999 -9999 -9999 -9999 -9999 -9999 -9999 -9999 -9999 -9999 -9999 -9999 -9999 -

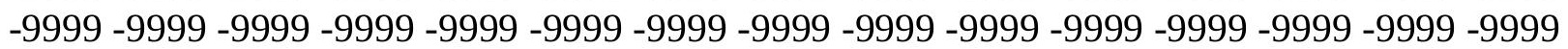


-9999 -9999 -9999 -9999 -9999 -9999 -9999 -9999 -9999 -9999 -9999 -9999 -9999 -9999 -9999 -9999 -9999 -9999 -9999 -9999 -9999 -9999 -9999 -9999 -9999 -9999 -9999 -9999 -9999 -9999 -9999 -9999 -9999 -9999 -9999 -9999 -9999 -9999 -9999 -9999 -9999 -9999 -9999 -9999 - 9999 -9999 -9999 -9999 -9999 -9999 -9999 -9999 -9999 -9999 -9999 -9999 -9999 -9999 -9999 -9999 -9999 -9999 -9999 -9999 -9999 -9999 -9999 -9999 -9999 -9999 -9999 -9999 -9999 -9999 - -9999 -9999 -9999 -9999 -9999 -9999 -9999 -9999 -9999 -9999 -9999 -9999 -9999 -9999 -9999 -9999 -9999 -9999 -9999 -9999 -9999 -9999 -9999 -9999 -9999 -9999 -9999 -9999 -9999 -9999

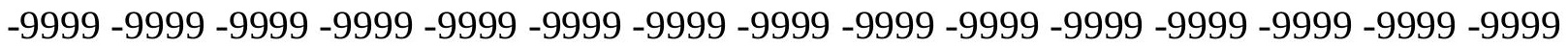

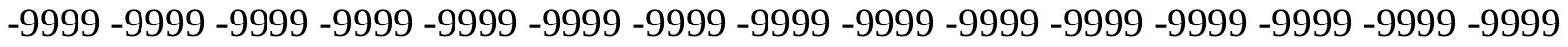
-9999 -9999 -9999 -9999 -9999 -9999 -9999 -9999 -9999 -9999 -9999 -9999 -9999 -9999 -9999

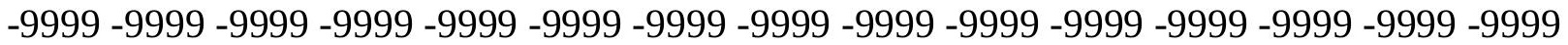
-9999 -9999 -9999 -9999 -9999 -9999 -9999 -9999 -9999 -9999 -9999 -9999 -9999 -9999 -9999 -9999 -9999 -9999 -9999 -9999 -9999 -9999 -9999 -9999 -9999 -9999 -9999 -9999 -9999 -9999 -9999 -9999 -9999 -9999 -9999 -9999 -9999 -9999 -9999 -9999 -9999 -9999 -9999 -9999 - -9999 -9999 -9999 -9999 -9999 -9999 -9999 -9999 -9999 -9999 -9999 -9999 -9999 -9999 -9999 -9999

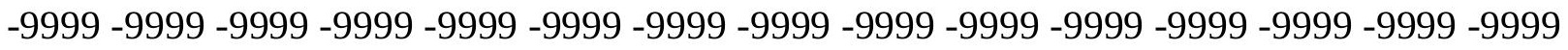
-9999 -9999 -9999 -9999 -9999 -9999 -9999 -9999 -9999 -9999 -9999 -9999 -9999 -9999 -9999 -9999 -9999 -9999 -9999 -9999 -9999 -9999 -9999 -9999 -9999 -9999 -9999 -9999 -9999 -9999 -9999 -9999 -9999 -9999 -9999 -9999 -9999 -9999 -9999 -9999 -9999 -9999 -9999 -9999 -9999 -

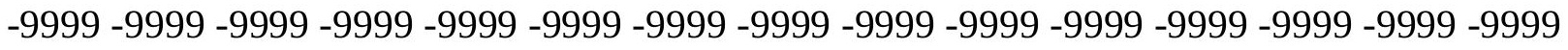
-9999 -9999 -9999 -9999 -9999 -9999 -9999 -9999 -9999 -9999 -9999 -9999 -9999 -9999 -9999 -999 -9999 -9999 -9999 -9999 -9999 -9999 -9999 -9999 -9999 -9999 -9999 -9999 -9999 -9999 -9999 -9999 -9999 -9999 -9999 -9999 -9999 -9999 -9999 -9999 -9999 -9999 -9999 -9999 -9999 -9999 -9999 -9999 -9999 -9999 -9999 -9999 -9999 -9999 -9999 -9999 -9999 -9999 -9999 -9999 -9999 -9999 -9999 -9999 -9999 -9999 -9999 -9999 -9999 -9999 -9999 -9999 -9999 -9999 -9999 -9999 -9999 -9999 -9999 -9999 -9999 -9999 -9999 -9999 -9999 -9999 -9999 -9999 -9999 -9999 -9999 -9999 -9999 -9999 -9999 -9999 -9999 -9999 -9999 -9999 -9999 -9999 -9999 -9999 -9999 -9999 -9999 -9999 -9999 -9999 -9999 -9999 -9999 -9999 -9999 -9999 -9999 -9999 -9999 -9999 -9999 -9999 -9999 -9999 -9999 -9999 -9999 -9999 -9999 -9999 -9999 -9999 -9999 -9999 -9999 -9999 -9999 -9999 -9999 -9999 -9999 -9999 -9999 -9999 -9999 -9999 -9999 -9999 -9999 -9999 -999 -9999 -9999 -9999 -9999 -9999 -9999 -9999 -9999 -9999 -9999 -9999 -9999 -9999 -9999 -9999 -9999 -9999 -9999 -9999 -9999 -9999 -9999 -9999 -9999 -9999 -9999 -9999 -9999 -9999 -

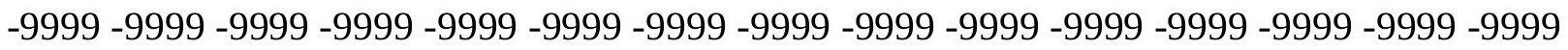

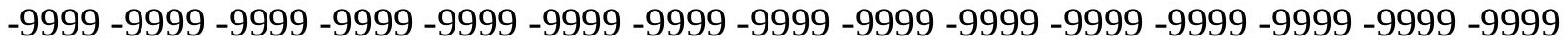

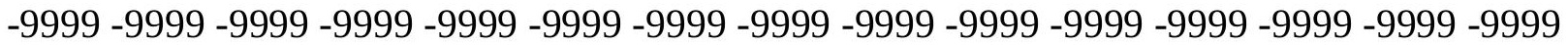
-9999 -9999 -9999 -9999 -9999 -9999 -9999 -9999 -9999 -9999 -9999 -9999 -9999 -9999 -9999 -

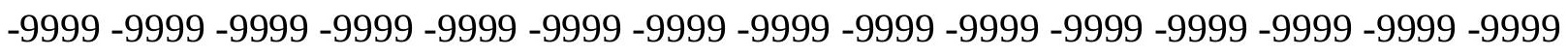

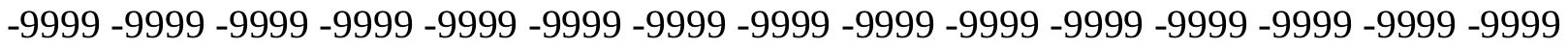

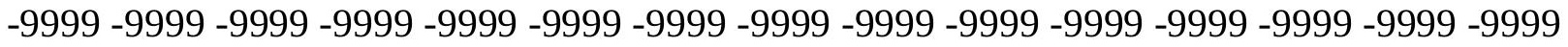
-9999 -9999 -9999 -9999 -9999 -9999 -9999 -9999 -9999 -9999 -9999 -9999 -9999 -9999 -9999 -

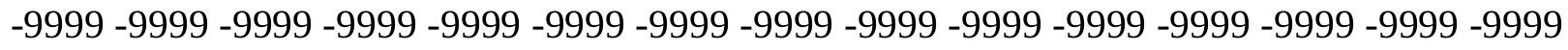

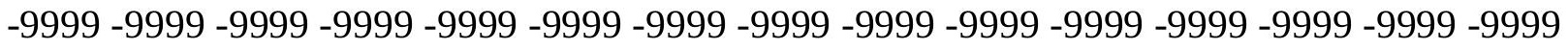
-9999 -9999 -9999 -9999 -9999 -9999 -9999 -9999 -9999 -9999 -9999 -9999 -9999 -9999 -9999 -9999 -9999 -9999 -9999 -9999 -9999 -9999 -9999 -9999-9999 -9999 -9999 -9999 -9999 -9999 -9999 -9999 -9999 -9999 -9999 -9999 -9999 -9999 -9999 -9999 -9999 -9999 -9999 -9999 -9999 -

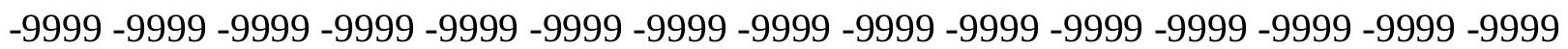


-9999 -9999 -9999 -9999 -9999 -9999 -9999 -9999 -9999 -9999 -9999 -9999 -9999 -9999 -9999 -9999 -9999 -9999 -9999 -9999 -9999 -9999 -9999 -9999 -9999 -9999 -9999 -9999 -9999 -9999 -

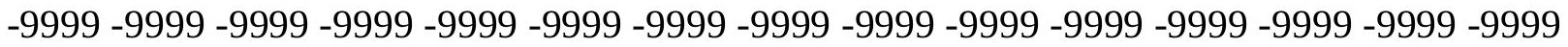
-9999 -9999 -9999 -9999 -9999 -9999 -9999 -9999 -9999 -9999 -9999 -9999 -9999 -9999 -9999 -9999 -9999 -9999 -9999 -9999 -9999 -9999 -9999 -9999-9999 -9999 -9999 -9999 -9999 -9999 -9999 -9999 -9999 -9999 -9999 -9999 -9999 -9999 -9999 -9999 -9999 -9999 -9999 -9999 -9999 -9999 -9999 -9999 -9999 -9999 -9999 -9999 -9999 -9999 -9999 -9999 -9999 -9999 -9999 -9999

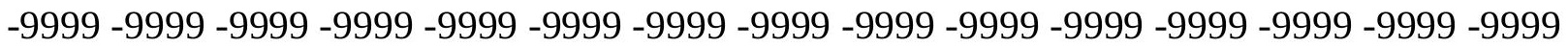

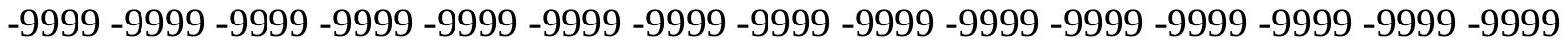
-9999 -9999 -9999 -9999 -9999 -9999 -9999 -9999 -9999 -9999 -9999 -9999 -9999 -9999 -9999 -9999 -9999 -9999 -9999 -9999 -9999 -9999 -9999 -9999 -9999 -9999 -9999 -9999 -9999 -9999 -9999 -9999 -9999 -9999 -9999 -9999 -9999 -9999 -9999 -9999 -9999 -9999 -9999 -9999 -9999 -9999 -9999 -9999 -9999 -9999 -9999 -9999 -9999 -9999 -9999 -9999 -9999 -9999 -9999 -9999 -9999 -9999 -9999 -9999 -9999 -9999 -9999 -9999 -9999 -9999 -9999 -9999 -9999 - 9999 -9999 -9999 -9999 -9999 -9999 -9999 -9999 -9999 -9999 -9999 -9999 -9999 -9999 -9999 -9999

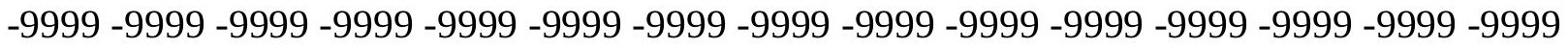
-9999 -9999 -9999 -9999 -9999 -9999 -9999 -9999 -9999 -9999 -9999 -9999 -9999 -9999 -9999 -9999 -9999 -9999 -9999 -9999 -9999 -9999 -9999 -9999 -9999 -9999 -9999 -9999 -9999 -9999 -9999 -9999 -9999 -9999 -9999 -9999 -9999 -9999 -9999 -9999 -9999 -9999 -9999 -9999 -9999 -

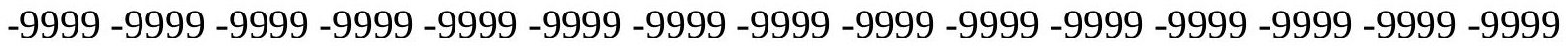

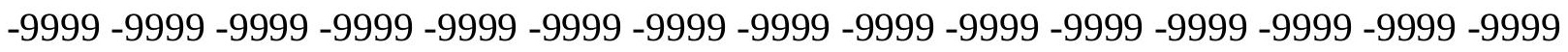
-9999 -9999 -9999 -9999 -9999 -9999 -9999 -9999 -9999 -9999 -9999 -9999 -9999 -9999 -9999 -9999 -9999 -9999 -9999 -9999 -9999 -9999 -9999 -9999 -9999 -9999 -9999 -9999 -9999 -9999 -9999 -9999 -9999 -9999 -9999 -9999 -9999 -9999 -9999 -9999 -9999 -9999 -9999 -9999 -9999 -

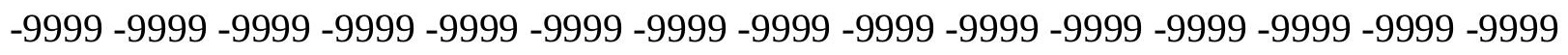
-9999 -9999 -9999 -9999 -9999 -9999 -9999 -9999 -9999 -9999 -9999 -9999 -9999 -9999 -9999 -9999 -9999 -9999 -9999 -9999 -9999 -9999 -9999 -9999 -9999 -9999 -9999 -9999 -9999 -9999 -

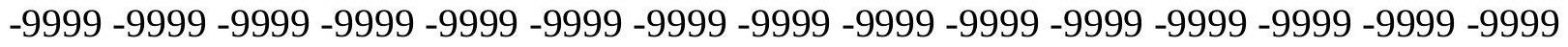
-9999 -9999 -9999 -9999 -9999 -9999 -9999 -9999 -9999 -9999 -9999 -9999 -9999 -9999 -9999 -9999 -9999 -9999 -9999 -9999 -9999 -9999 -9999 -9999 -9999 -9999 -9999 -9999 -9999 -999 -9999 -9999 -9999 -9999 -9999 -9999 -9999 -9999 -9999 -9999 -9999 -9999 -9999 -9999 -9999 -9999 -9999 -9999 -9999 -9999 -9999 -9999 -9999 -9999 -9999 -9999 -9999 -9999 -9999 -9999 -

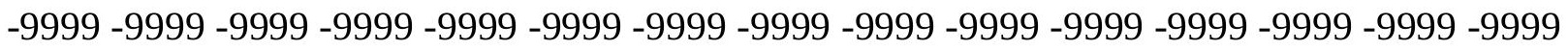

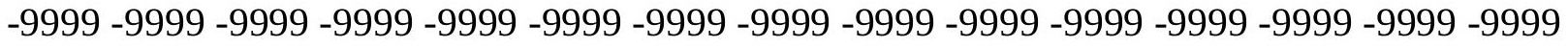

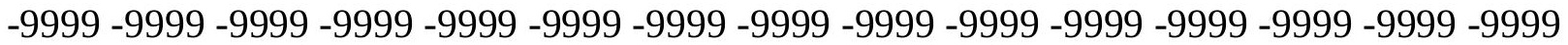

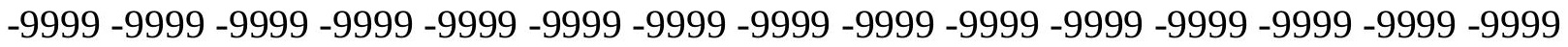

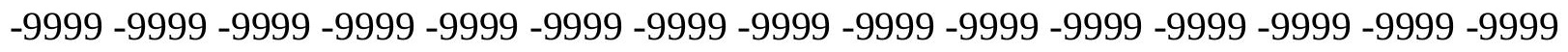

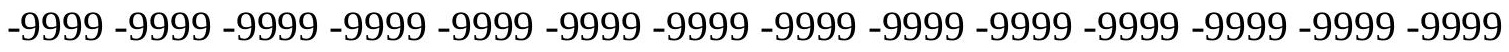
-9999 -9999 -9999 -9999 -9999 -9999 -9999 -9999 -9999 -9999 -9999 -9999 -9999 -9999 -9999 -9999 -9999 -9999 -9999 -9999 -9999 -9999 -9999 -9999 -9999 -9999 -9999 -9999 -9999 -9999 -

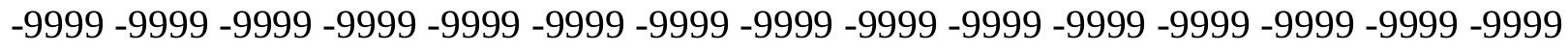

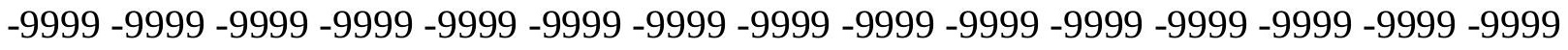
-9999 -9999 -9999 -9999 -9999 -9999 -9999 -9999 -9999 -9999 -9999 -9999 -9999 -9999 -9999 -9999 -9999 -9999 -9999 -9999 -9999 -9999 -9999 -9999-9999 -9999 -9999 -9999 -9999 -9999 -9999 -9999 -9999 -9999 -9999 -9999 -9999 -9999 -9999 -9999 -9999 -9999 -9999 -9999 -9999 -

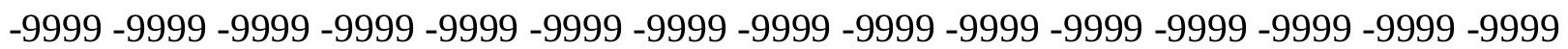


-9999 -9999 -9999 -9999 -9999 -9999 -9999 -9999 -9999 -9999 -9999 -9999 -9999 -9999 -9999 -9999 -9999 -9999 -9999 -9999 -9999 -9999 -9999 -9999 -9999 -9999 -9999 -9999 -9999 -9999 -9999 -9999 -9999 -9999 -9999 -9999 -9999 -9999 -9999 -9999 -9999 -9999 -9999 -9999 - 9999 -9999 -9999 -9999 -9999 -9999 -9999 -9999 -9999 -9999 -9999 -9999 -9999 -9999 -9999 -9999 -9999 -9999 -9999 -9999 -9999 -9999 -9999 -9999 -9999 -9999 -9999 -9999 -9999 -9999 -9999 -9999 -9999 -9999 -9999 -9999 -9999 -9999 -9999 -9999 -9999 -9999 -9999 -9999 -9999 -9999 -9999 -9999 -9999 -9999 -9999 -9999 -9999 -9999 -9999 -9999 -9999 -9999 -9999 -9999 -9999

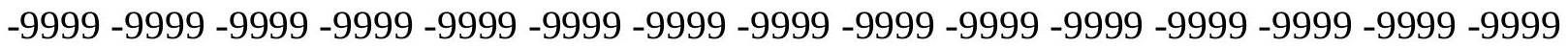
-9999 -9999 -9999 -9999 -9999 -9999 -9999 -9999 -9999 -9999 -9999 -9999 -9999 -9999 -9999 -9999 -9999 -9999 -9999 -9999 -9999 -9999 -9999 -9999 -9999 -9999 -9999 -9999 -9999 -9999

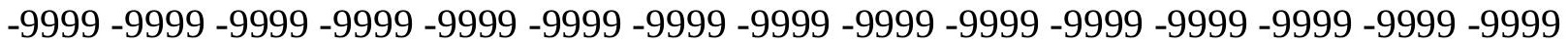
-9999 -9999 -9999 -9999 -9999 -9999 -9999 -9999 -9999 -9999 -9999 -9999 -9999 -9999 -9999 -9999 -9999 -9999 -9999 -9999 -9999 -9999 -9999 -9999 -9999 -9999 -9999 -9999 -9999 -9999 -

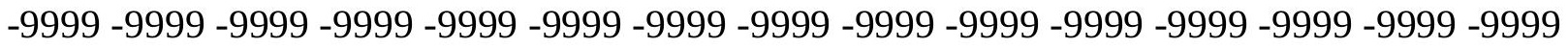
-9999 -9999 -9999 -9999 -9999 -9999 -9999 -9999 -9999 -9999 -9999 -9999 -9999 -9999 -9999

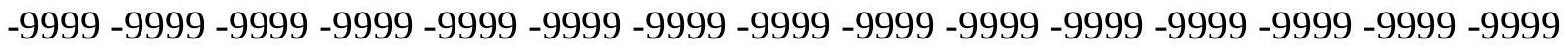
-9999 -9999 -9999 -9999 -9999 -9999 -9999 -9999 -9999 -9999 -9999 -9999 -9999 -9999 -9999 -9999 -9999 -9999 -9999 -9999 -9999 -9999 -9999 -9999 -9999 -9999 -9999 -9999 -9999 - -999 -9999 -9999 -9999 -9999 -9999 -9999 -9999 -9999 -9999 -9999 -9999 -9999 -9999 -9999 -9999 -9999 -9999 -9999 -9999 -9999 -9999 -9999 -9999 -9999 -9999 -9999 -9999 -9999 -9999 -9999 -9999 -9999 -9999 -9999 -9999 -9999 -9999 -9999 -9999 -9999 -9999 -9999 -9999 -9999 -9999 -999 -9999 -9999 -9999 -9999 -9999 -9999 -9999 -9999 -9999 -9999 -9999 -9999 -9999 -9999 -9999 -9999 -9999 -9999 -9999 -9999 -9999 -9999 -9999 -9999 -9999 -9999 -9999 -9999 -9999 -9999 -9999 -9999 -9999 -9999 -9999 -9999 -9999 -9999 -9999 -9999 -9999 -9999 -9999 -9999 -9999 -9999 -9999 -9999 -9999 -9999 -9999 -9999 -9999 -9999 -9999 -9999 -9999 -9999 -9999 -9999 -9999 -9999 -9999 -9999 -9999 -9999 -9999 -9999 -9999 -9999 -9999 -9999 -9999 -9999 -9999 -9999 -9999 -9999 -9999 -9999 -9999 -9999 -9999 -9999 -9999 -9999 -9999 -9999 -9999 -9999 -9999 -9999 -9999 -9999 -9999 -9999 -9999 -9999 -9999 -9999 -9999 -9999 -9999 -9999 -9999 -9999 -9999 -9999 -9999 -9999 -9999 -9999 -9999 -9999 -9999 -9999 -9999 -9999 -9999 -9999 -9999 -9999 -9999 -9999 -9999 -9999 -9999 -9999 -9999 -9999 -9999 -9999 -9999 -9999 -999 -9999 -9999 -9999 -9999 -9999 -9999 -9999 -9999 -9999 -9999 -9999 -9999 -9999 -9999 -9999 -9999 -9999 -9999 -9999 -9999 -9999 -9999 -9999 -9999 -9999 -9999 -9999 -9999 -9999 -9999 -

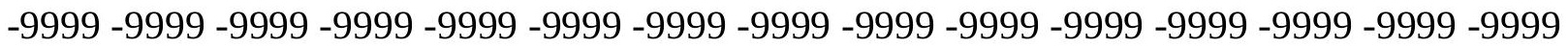

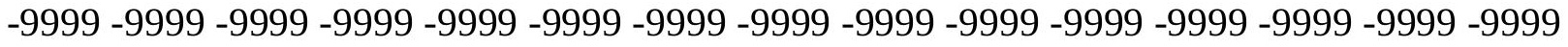

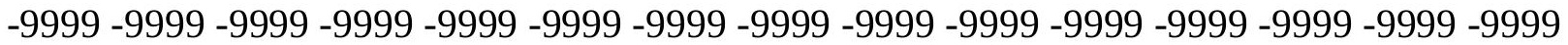
-9999 -9999 -9999 -9999 -9999 -9999 -9999 -9999 -9999 -9999 -9999 -9999 -9999 -9999 -9999

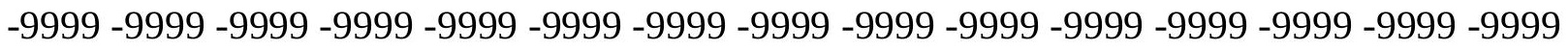

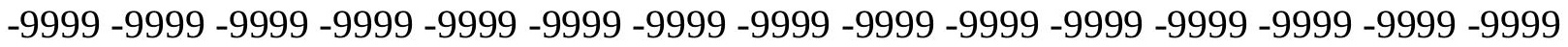

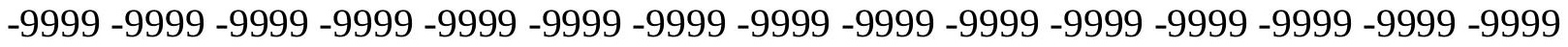
-9999 -9999 -9999 -9999 -9999 -9999 -9999 -9999 -9999 -9999 -9999 -9999 -9999 -9999 -9999 -

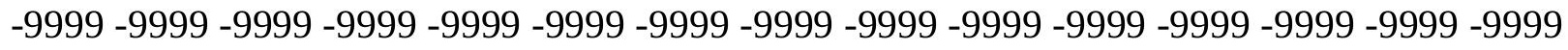

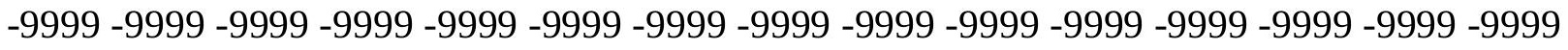
-9999 -9999 -9999 -9999 -9999 -9999 -9999 -9999 -9999 -9999 -9999 -9999 -9999 -9999 -9999 -9999 -9999 -9999 -9999 -9999 -9999 -9999 -9999 -9999 -9999 -9999 -9999 -9999 - -9999 -9999 -9999 -9999 -9999 -9999 -9999 -9999 -9999 -9999 -9999 -9999 -9999 -9999 -9999 -9999 -

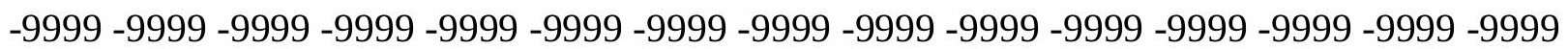


-9999 -9999 -9999 -9999 -9999 -9999 -9999 -9999 -9999 -9999 -9999 -9999 -9999 -9999 -9999 -9999 -9999 -9999 -9999 -9999 -9999 -9999 -9999 -9999 -9999 -9999 -9999 -9999 -9999 -9999 -9999 -9999 -9999 -9999 -9999 -9999 -9999 -9999 -9999 -9999 -9999 -9999 -9999 -9999 - 9999 -9999 -9999 -9999 -9999 -9999 -9999 -9999 -9999 -9999 -9999 -9999 -9999 -9999 -9999 -9999 -9999 -9999 -9999 -9999 -9999 -9999 -9999 -9999 -9999-9999 -9999 -9999 -9999 -9999 -9999 -9999 -9999 -9999 -9999 -9999 -9999 -9999 -9999 -9999 -9999 -9999 -9999 -9999 -9999 -9999 -9999 -9999 -9999 -9999 -9999 -9999 -9999 -9999 -9999 -9999 -9999 -9999 -9999 -9999 -9999

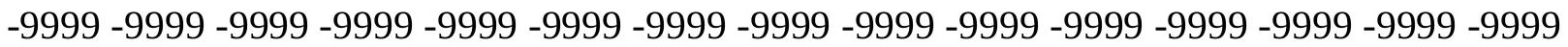

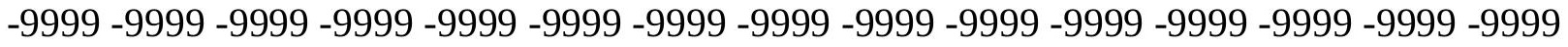
-9999 -9999 -9999 -9999 -9999 -9999 -9999 -9999 -9999 -9999 -9999 -9999 -9999 -9999 -9999

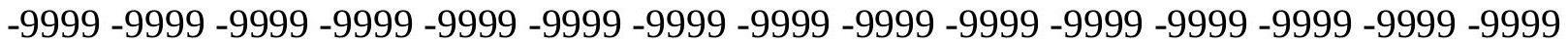
-9999 -9999 -9999 -9999 -9999 -9999 -9999 -9999 -9999 -9999 -9999 -9999 -9999 -9999 -9999 -9999 -9999 -9999 -9999 -9999 -9999 -9999 -9999 -9999 -9999 -9999 -9999 -9999 -9999 -9999 -

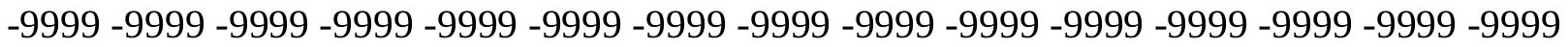
-9999 -9999 -9999 -9999 -9999 -9999 -9999 -9999 -9999 -9999 -9999 -9999 -9999 -9999 -9999

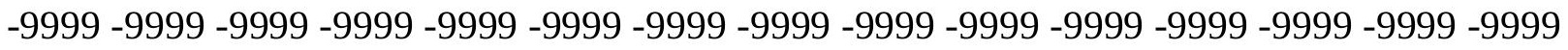
-9999 -9999 -9999 -9999 -9999 -9999 -9999 -9999 -9999 -9999 -9999 -9999 -9999 -9999 -9999 -9999 -9999 -9999 -9999 -9999 -9999 -9999 -9999 -9999 -9999 -9999 -9999 -9999 -9999 -9999 -9999 -9999 -9999 -9999 -9999 -9999 -9999 -9999 -9999 -9999 -9999 -9999 -9999 -9999 -9999 -9999 -9999 -9999 -9999 -9999 -9999 -9999 -9999 -9999 -9999 -9999 -9999 -9999 -9999 -9999 -9999 -9999 -9999 -9999 -9999 -9999 -9999 -9999 -9999 -9999 -9999 -9999 -9999 -9999 -9999 -999 -9999 -9999 -9999 -9999 -9999 -9999 -9999 -9999 -9999 -9999 -9999 -9999 -9999 -9999 -9999 -9999 -9999 -9999 -9999 -9999 -9999 -9999 -9999 -9999 -9999 -9999 -9999 -9999 -9999 -9999 -9999 -9999 -9999 -9999 -9999 -9999 -9999 -9999 -9999 -9999 -9999 -9999 -9999 -9999 -9999 -9999 -9999 -9999 -9999 -9999 -9999 -9999 -9999 -9999 -9999 -9999 -9999 -9999 -9999 -9999 -9999 -9999 -9999 -9999 -9999 -9999 -9999 -9999 -9999 -9999 -9999 -9999 -9999 -9999 -9999 -9999 -9999 -9999 -9999 -9999 -9999 -9999 -9999 -9999 -9999 -9999 -9999 -9999 -9999 -9999 -9999 -9999 -9999 -9999 -9999 -9999 -9999 -9999 -9999 -9999 -9999 -9999 -9999 -9999 -9999 -9999 -9999 -9999 -9999 -9999 -9999 -9999 -9999 -9999 -9999 -9999 -9999 -9999 -9999 -9999 -9999 -9999 -9999 -9999 -9999 -9999 -9999 -9999 -9999 -9999 -9999 -9999 -9999 -999 -9999 -9999 -9999 -9999 -9999 -9999 -9999 -9999 -9999 -9999 -9999 -9999 -9999 -9999 -9999 -9999 -9999 -9999 -9999 -9999 -9999 -9999 -9999 -9999 -9999 -9999 -9999 -9999 -9999 -9999 -

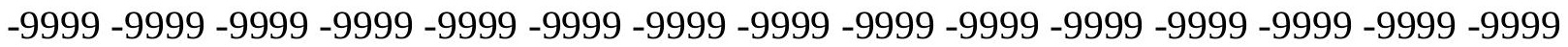

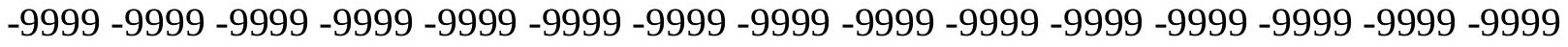

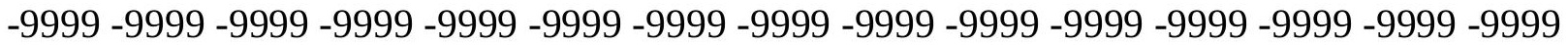
-9999 -9999 -9999 -9999 -9999 -9999 -9999 -9999 -9999 -9999 -9999 -9999 -9999 -9999 -9999

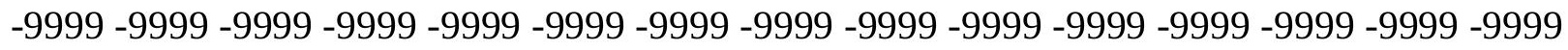

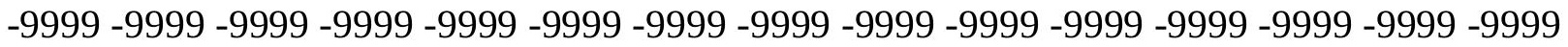
-9999 -9999 -9999 -9999 -9999 -9999 -9999 -9999 -9999 -9999 -9999 -9999 -9999 -9999 -9999 -9999 -9999 -9999 -9999 -9999 -9999 -9999 -9999 -9999 -9999 -9999 -9999 -9999 -9999 -9999 -

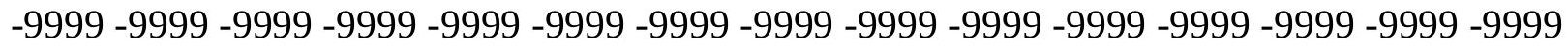

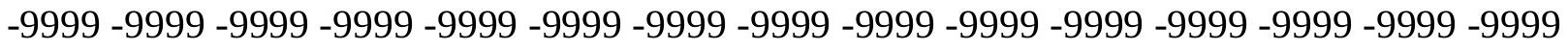
-9999 -9999 -9999 -9999 -9999 -9999 -9999 -9999 -9999 -9999 -9999 -9999 -9999 -9999 -9999 -9999 -9999 -9999 -9999 -9999 -9999 -9999 -9999 -9999-9999 -9999 -9999 -9999 -9999 -9999 -9999 -9999 -9999 -9999 -9999 -9999 -9999 -9999 -9999 -9999 -9999 -9999 -9999 -9999 -9999 -

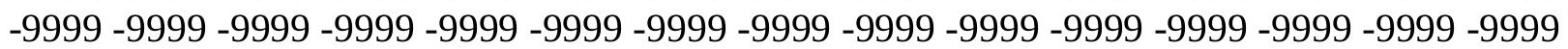


-9999 -9999 -9999 -9999 -9999 -9999 -9999 -9999 -9999 -9999 -9999 -9999 -9999 -9999 -9999 -9999 -9999 -9999 -9999 -9999 -9999 -9999 -9999 -9999 -9999 -9999 -9999 -9999 -9999 -9999 -9999 -9999 -9999 -9999 -9999 -9999 -9999 -9999 -9999 -9999 -9999 -9999 -9999 -9999 - 9999 -9999 -9999 -9999 -9999 -9999 -9999 -9999 -9999 -9999 -9999 -9999 -9999 -9999 -9999

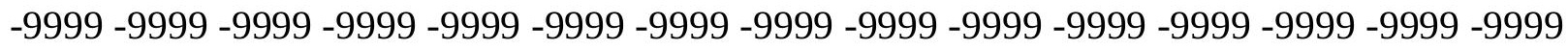
-9999 -9999 -9999 -9999 -9999 -9999 -9999 -9999 -9999 -9999 -9999 -9999 -9999 -9999 -9999 -9999 -9999 -9999 -9999 -9999 -9999 -9999 -9999 -9999 -9999 -9999 -9999 -9999 -9999 -9999

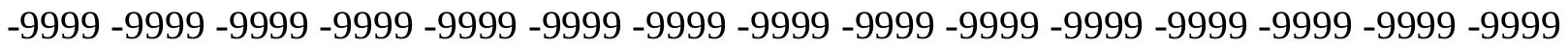

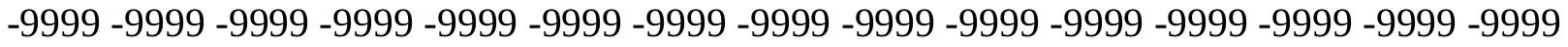
-9999 -9999 -9999 -9999 -9999 -9999 -9999 -9999 -9999 -9999 -9999 -9999 -9999 -9999 -9999 -9999 -9999 -9999 -9999 -9999 -9999 -9999 -9999 -9999 -9999 -9999 -9999 -9999 -9999 -9999 -9999 -9999 -9999 -9999 -9999 -9999 -9999 -9999 -9999 -9999 -9999 -9999 -9999 -9999 -9999 -9999 -9999 -9999 -9999 -9999 -9999 -9999 -9999 -9999 -9999 -9999 -9999 -9999 -9999 -9999 -

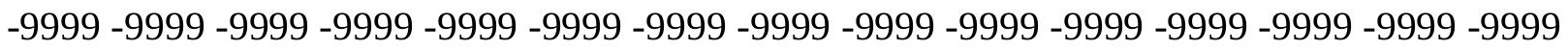
-9999 -9999 -9999 -9999 -9999 -9999 -9999 -9999 -9999 -9999 -9999 -9999 -9999 -9999 -9999 -

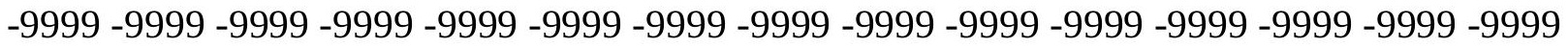
-9999 -9999 -9999 -9999 -9999 -9999 -9999 -9999 -9999 -9999 -9999 -9999 -9999 -9999 -9999 -9999 -9999 -9999 -9999 -9999 -9999 -9999 -9999 -9999 -9999 -9999 -9999 -9999 -9999 -9999 -9999 -9999 -9999 -9999 -9999 -9999 -9999 -9999 -9999 -9999 -9999 -9999 -9999 -9999 -9999 -

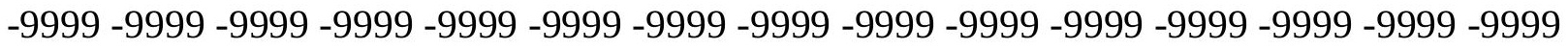
-9999 -9999 -9999 -9999 -9999 -9999 -9999 -9999 -9999 -9999 -9999 -9999 -9999 -9999 -9999

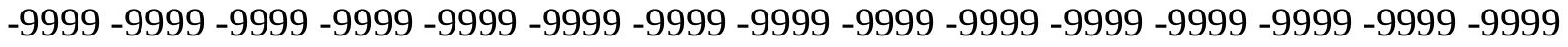
-9999 -9999 -9999 -9999 -9999 -9999 -9999 -9999 -9999 -9999 -9999 -9999 -9999 -9999 -9999 -9999 -9999 -9999 -9999 -9999 -9999 -9999 -9999 -9999 -9999 -9999 -9999 -9999 -9999 -9999 -9999 -9999 -9999 -9999 -9999 -9999 -9999 -9999 -9999 -9999 -9999 -9999 -9999 -9999 -9999 -9999 -9999 -9999 -9999 -9999 -9999 -9999 -9999 -9999 -9999 -9999 -9999 -9999 -9999 -9999 -9999 -9999 -9999 -9999 -9999 -9999 -9999 -9999 -9999 -9999 -9999 -9999 -9999 -9999 -9999 -9999 -9999 -9999 -9999 -9999 -9999 -9999 -9999 -9999 -9999 -9999 -9999 -9999 -9999 -9999 -9999 -9999 -9999 -9999 -9999 -9999 -9999 -9999 -9999 -9999 -9999 -9999 -9999 -9999 -9999 -9999 -9999 -9999 -9999 -9999 -9999 -9999 -9999 -9999 -9999 -9999 -9999 -9999 -9999 -9999 -9999 -9999 -9999 -9999 -9999 -9999 -9999 -9999 -9999 -9999 -9999 -9999 -9999 -9999 -9999 -9999 -9999 -9999 -9999 -9999 -9999 -9999 -9999 -9999 -9999 -9999 -9999 -9999 -9999 -

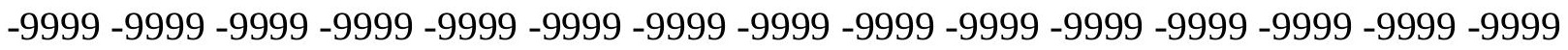

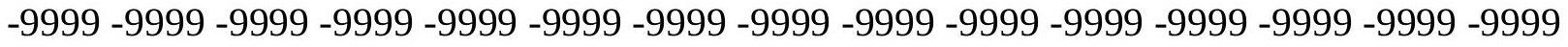
-9999 -9999 -9999 -9999 -9999 -9999 -9999 -9999 -9999 -9999 -9999 -9999 -9999 -9999 -9999 -

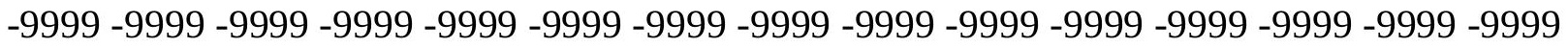

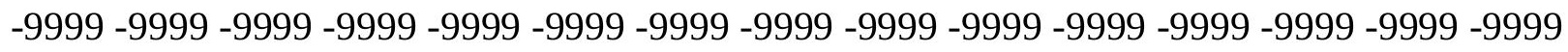

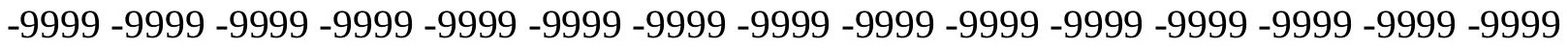

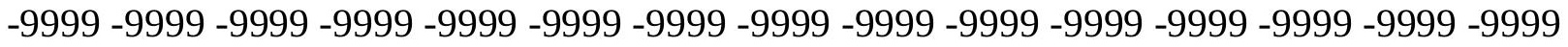
-9999 -9999 -9999 -9999 -9999 -9999 -9999 -9999 -9999 -9999 -9999 -9999 -9999 -9999 -9999 -

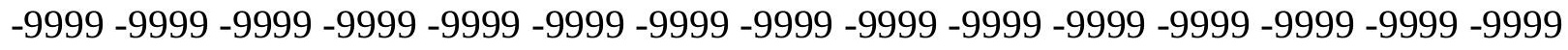

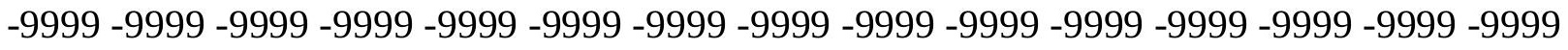
-9999 -9999 -9999 -9999 -9999 -9999 -9999 -9999 -9999 -9999 -9999 -9999 -9999 -9999 -9999 -9999 -9999 -9999 -9999 -9999 -9999 -9999 -9999 -9999-9999 -9999 -9999 -9999 -9999 -9999 -9999 -9999 -9999 -9999 -9999 -9999 -9999 -9999 -9999 -9999 -9999 -9999 -9999 -9999 -9999 -

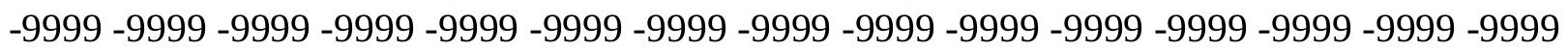


-9999 -9999 -9999 -9999 -9999 -9999 -9999 -9999 -9999 -9999 -9999 -9999 -9999 -9999 -9999 -9999 -9999 -9999 -9999 -9999 -9999 -9999 -9999 -9999 -9999 -9999 -9999 -9999 -9999 -9999 -9999 -9999 -9999 -9999 -9999 -9999 -9999 -9999 -9999 -9999 -9999 -9999 -9999 -9999 - 9999 -9999 -9999 -9999 -9999 -9999 -9999 -9999 -9999 -9999 -9999 -9999 -9999 -9999 -9999 -9999 -9999 -9999 -9999 -9999 -9999 -9999 -9999 -9999 -9999 -9999 -9999 -9999 -9999 -9999 -9999 -9999 -9999 -9999 -9999 -9999 -9999 -9999 -9999 -9999 -9999 -9999 -9999 -9999 -9999 -9999 -9999 -9999 -9999 -9999 -9999 -9999 -9999 -9999 -9999 -9999 -9999 -9999 -9999 -9999 -9999

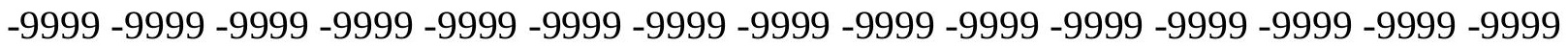

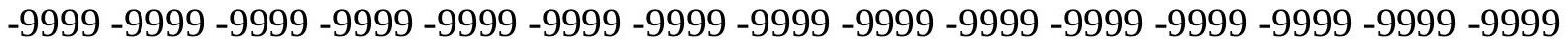
-9999 -9999 -9999 -9999 -9999 -9999 -9999 -9999 -9999 -9999 -9999 -9999 -9999 -9999 -9999 -9999 -9999 -9999 -9999 -9999 -9999 -9999 -9999 -9999 -9999 -9999 -9999 -9999 -9999 -9999 -9999 -9999 -9999 -9999 -9999 -9999 -9999 -9999 -9999 -9999 -9999 -9999 -9999 -9999 -9999 -9999 -9999 -9999 -9999 -9999 -9999 -9999 -9999 -9999 -9999 -9999 -9999 -9999 -9999 -9999 -9999 -9999 -9999 -9999 -9999 -9999 -9999 -9999 -9999 -9999 -9999 -9999 -9999 -9999 -9999 -9999 -9999 -9999 -9999 -9999 -9999 -9999 -9999 -9999 -9999 -9999 -9999 -9999 -9999 -

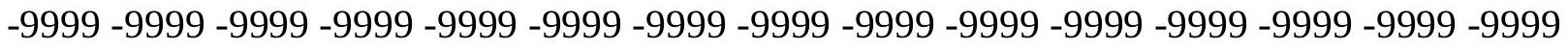
-9999 -9999 -9999 -9999 -9999 -9999 -9999 -9999 -9999 -9999 -9999 -9999 -9999 -9999 -9999 -9999 -9999 -9999 -9999 -9999 -9999 -9999 -9999 -9999 -9999 -9999 -9999 -9999 -9999 -9999 -9999 -9999 -9999 -9999 -9999 -9999 -9999 -9999 -9999 -9999 -9999 -9999 -9999 -9999 -9999 -9999 -9999 -9999 -9999 -9999 -9999 -9999 -9999 -9999 -9999 -9999 -9999 -9999 -9999 -9999 -9999 -9999 -9999 -9999 -9999 -9999 -9999 -9999 -9999 -9999 -9999 -9999 -9999 -9999 -9999 -999 -9999 -9999 -9999 -9999 -9999 -9999 -9999 -9999 -9999 -9999 -9999 -9999 -9999 -9999 -9999 -9999 -9999 -9999 -9999 -9999 -9999 -9999 -9999 -9999 -9999 -9999 -9999 -9999 -9999 -9999 -9999 -9999 -9999 -9999 -9999 -9999 -9999 -9999 -9999 -9999 -9999 -9999 -9999 -9999 -9999 -9999 -9999 -9999 -9999 -9999 -9999 -9999 -9999 -9999 -9999 -9999 -9999 -9999 -9999 -9999 -9999 -9999 -9999 -9999 -9999 -9999 -9999 -9999 -9999 -9999 -9999 -9999 -9999 -9999 -9999 -9999 -9999 -9999 -9999 -9999 -9999 -9999 -9999 -9999 -9999 -9999 -9999 -9999 -9999 -9999 -9999 -9999 -9999 -9999 -9999 -9999 -9999 -9999 -9999 -9999 -9999 -9999 -9999 -9999 -9999 -9999 -9999 -9999 -9999 -9999 -9999 -9999 -9999 -9999 -9999 -9999 -9999 -9999 -9999 -9999 -9999 -9999 -9999 -9999 -9999 -9999 -9999 -9999 -9999 -9999 -9999 -9999 -9999 -9999 -999 -9999 -9999 -9999 -9999 -9999 -9999 -9999 -9999 -9999 -9999 -9999 -9999 -9999 -9999 -9999 -9999 -9999 -9999 -9999 -9999 -9999 -9999 -9999 -9999 -9999 -9999 -9999 -9999 -9999 -9999 -

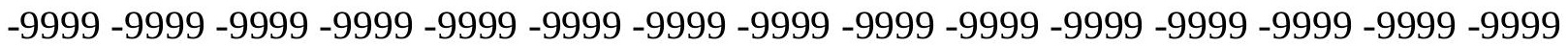

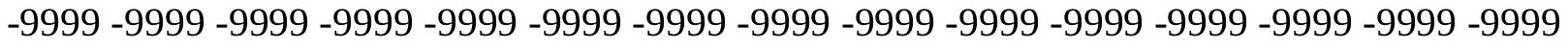

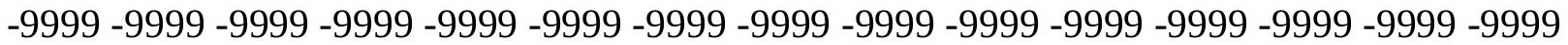
-9999 -9999 -9999 -9999 -9999 -9999 -9999 -9999 -9999 -9999 -9999 -9999 -9999 -9999 -9999 -9999 -9999 -9999 -9999 -9999 -9999 -9999 -9999 -9999 -9999 -9999 -9999 -9999 -9999 -

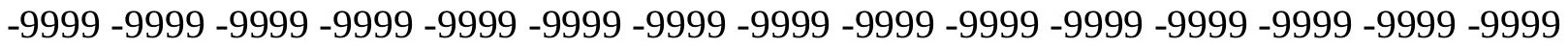
-9999 -9999 -9999 -9999 -9999 -9999 -9999 -9999 -9999 -9999 -9999 -9999 -9999 -9999 -9999 -9999 -9999 -9999 -9999 -9999 -9999 -9999 -9999 -9999 -9999 -9999 -9999 -9999 -9999 -9999 -

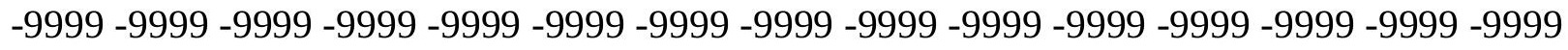

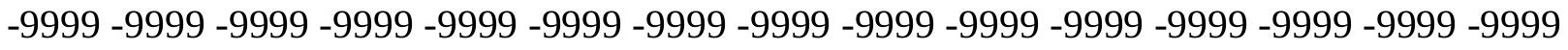
-9999 -9999 -9999 -9999 -9999 -9999 -9999 -9999 -9999 -9999 -9999 -9999 -9999 -9999 -9999 -9999 -9999 -9999 -9999 -9999 -9999 -9999 -9999 -9999-9999 -9999 -9999 -9999 -9999 -9999 -9999 -9999 -9999 -9999 -9999 -9999 -9999 -9999 -9999 -9999 -9999 -9999 -9999 -9999 -9999 -

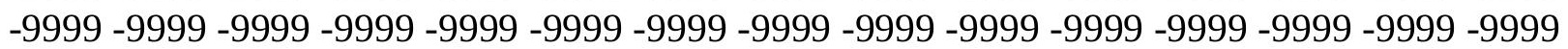


-9999 -9999 -9999 -9999 -9999 -9999 -9999 -9999 -9999 -9999 -9999 -9999 -9999 -9999 -9999 -9999 -9999 -9999 -9999 -9999 -9999 -9999 -9999 -9999 -9999 -9999 -9999 -9999 -9999 -9999 -

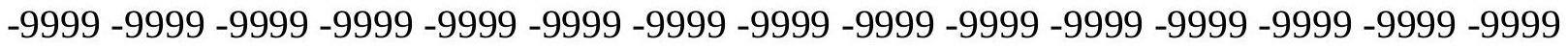
-9999 -9999 -9999 -9999 -9999 -9999 -9999 -9999 -9999 -9999 -9999 -9999 -9999 -9999 -9999 -9999 -9999 -9999 -9999 -9999 -9999 -9999 -9999 -9999-9999 -9999 -9999 -9999 -9999 -9999 -9999 -9999 -9999 -9999 -9999 -9999 -9999 -9999 -9999 -9999 -9999 -9999 -9999 -9999 -9999 -9999 -9999 -9999 -9999 -9999 -9999 -9999 -9999 -9999 -9999 -9999 -9999 -9999 -9999 -9999

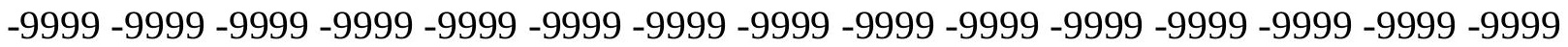

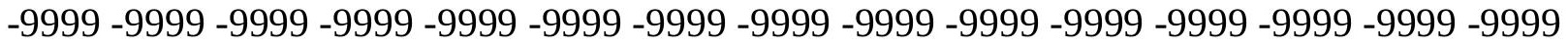
-9999 -9999 -9999 -9999 -9999 -9999 -9999 -9999 -9999 -9999 -9999 -9999 -9999 -9999 -9999 -9999 -9999 -9999 -9999 -9999 -9999 -9999 -9999 -9999 -9999 -9999 -9999 -9999 -9999 -9999 -9999 -9999 -9999 -9999 -9999 -9999 -9999 -9999 -9999 -9999 -9999 -9999 -9999 -9999 -9999 -9999 -9999 -9999 -9999 -9999 -9999 -9999 -9999 -9999 -9999 -9999 -9999 -9999 -9999 -9999 -9999 -9999 -9999 -9999 -9999 -9999 -9999 -9999 -9999 -9999 -9999 -9999 -9999 -9999 -9999 -9999 -9999 -9999 -9999 -9999 -9999 -9999 -9999 -9999 -9999 -9999 -9999 -9999 -9999 -9999 -

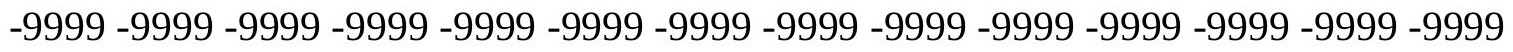
-9999 -9999 -9999 -9999 -9999 -9999 -9999 -9999 -9999 -9999 -9999 -9999 -9999 -9999 -9999 -9999 -9999 -9999 -9999 -9999 -9999 -9999 -9999 -9999 -9999 -9999 -9999 -9999 -9999 -9999 -9999 -9999 -9999 -9999 -9999 -9999 -9999 -9999 -9999 -9999 -9999 -9999 -9999 -9999 -9999 -

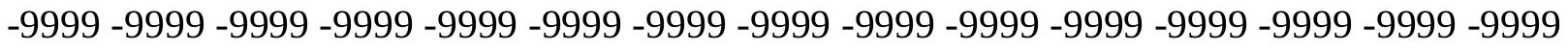

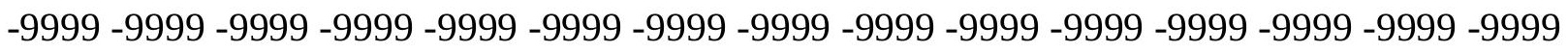
-9999 -9999 -9999 -9999 -9999 -9999 -9999 -9999 -9999 -9999 -9999 -9999 -9999 -9999 - 9999 -9999 -9999 -9999 -9999 -9999 -9999 -9999 -9999 -9999 -9999 -9999 -9999 -9999 -9999 -9999 -9999 -9999 -9999 -9999 -9999 -9999 -9999 -9999 -9999 -9999 -9999 -9999 -9999 -9999 -9999 -

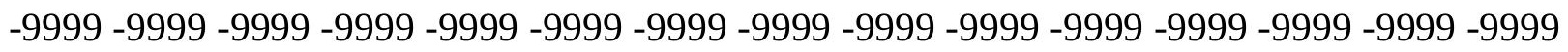
-9999 -9999 -9999 -9999 -9999 -9999 -9999 -9999 -9999 -9999 -9999 -9999 -9999 -9999 -9999 -9999 -9999 -9999 -9999 -9999 -9999 -9999 -9999 -9999 -9999 -9999 -9999 -9999 -9999 -9999 -

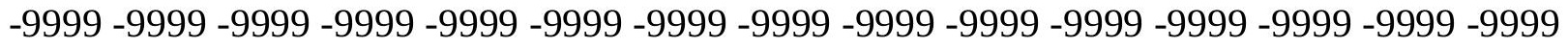
-9999 -9999 -9999 -9999 -9999 -9999 -9999 -9999 -9999 -9999 -9999 -9999 -9999 -9999 -9999 -9999 -9999 -9999 -9999 -9999 -9999 -9999 -9999 -9999 -9999 -9999 -9999 -9999 -9999 -999 -

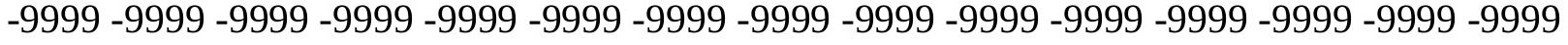
-9999 -9999 -9999 -9999 -9999 -9999 -9999 -9999 -9999 -9999 -9999 -9999 -9999 -9999 -9999 -

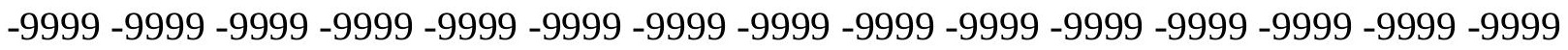

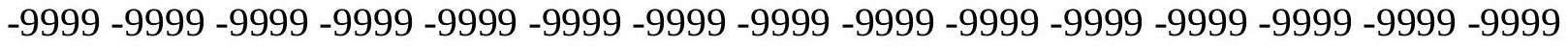

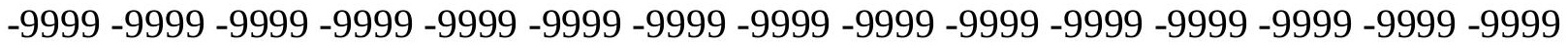
-9999 -9999 -9999 -9999 -9999 -9999 -9999 -9999 -9999 -9999 -9999 -9999 -9999 -9999 -9999 -

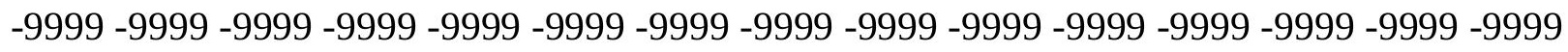

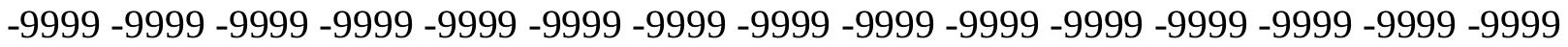
-9999 -9999 -9999 -9999 -9999 -9999 -9999 -9999 -9999 -9999 -9999 -9999 -9999 - 9999 - -999 -9999 -9999 -9999 -9999 -9999 -9999 -9999 -9999 -9999 -9999 -9999 -9999 -9999 -9999 -9999 -

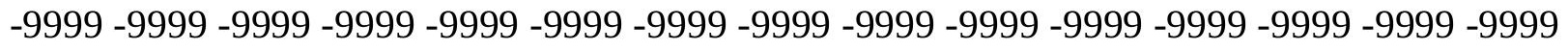

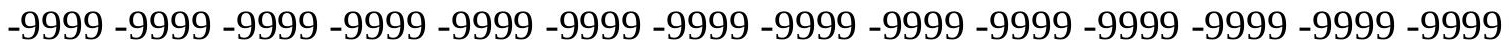
-9999 -9999 -9999 -9999 -9999 -9999 -9999 -9999 -9999 -9999 -9999 -9999 -9999 -9999 -9999 -9999 -9999 -9999 -9999 -9999 -9999 -9999 -9999 -9999-9999 -9999 -9999 -9999 -9999 -9999 -9999 -9999 -9999 -9999 -9999 -9999 -9999 -9999 -9999 -9999 -9999 -9999 -9999 -9999 -9999 -

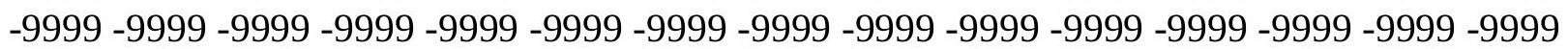


-9999 -9999 -9999 -9999 -9999 -9999 -9999 -9999 -9999 -9999 -9999 -9999 -9999 -9999 -9999 -9999 -9999 -9999 -9999 -9999 -9999 -9999 -9999 -9999 -9999 -9999 -9999 -9999 -9999 -9999 -

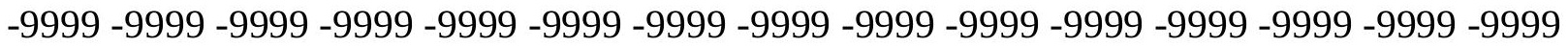
-9999 -9999 -9999 -9999 -9999 -9999 -9999 -9999 -9999 -9999 -9999 -9999 -9999 -9999 -9999 -9999 -9999 -9999 -9999 -9999 -9999 -9999 -9999 -9999-9999 -9999 -9999 -9999 -9999 -9999 -9999 -9999 -9999 -9999 -9999 -9999 -9999 -9999 -9999 -9999 -9999 -9999 -9999 -9999 -9999 -9999 -9999 -9999 -9999 -9999 -9999 -9999 -9999 -9999 -9999 -9999 -9999 -9999 -9999 -9999

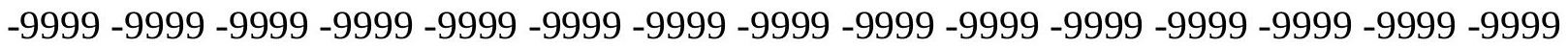

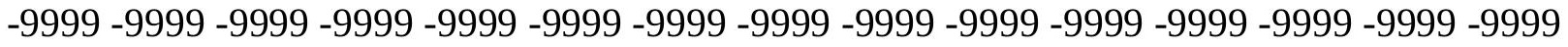
-9999 -9999 -9999 -9999 -9999 -9999 -9999 -9999 -9999 -9999 -9999 -9999 -9999 -9999 -9999 -9999 -9999 -9999 -9999 -9999 -9999 -9999 -9999 -9999 -9999 -9999 -9999 -9999 -9999 -9999 -9999 -9999 -9999 -9999 -9999 -9999 -9999 -9999 -9999 -9999 -9999 -9999 -9999 -9999 -9999 -9999 -9999 -9999 -9999 -9999 -9999 -9999 -9999 -9999 -9999 -9999 -9999 -9999 -9999 -9999 -

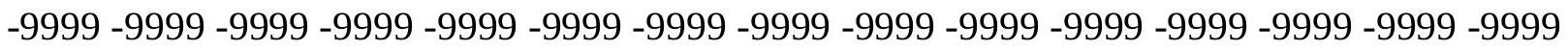
-9999 -9999 -9999 -9999 -9999 -9999 -9999 -9999 -9999 -9999 -9999 -9999 -9999 -9999 -9999 -

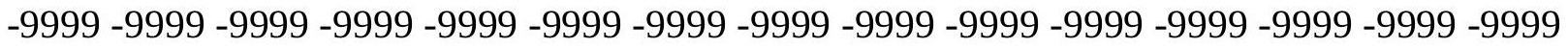
-9999 -9999 -9999 -9999 -9999 -9999 -9999 -9999 -9999 -9999 -9999 -9999 -9999 -9999 -9999 -9999 -9999 -9999 -9999 -9999 -9999 -9999 -9999 -9999 -9999 -9999 -9999 -9999 -9999 -9999 -9999 -9999 -9999 -9999 -9999 -9999 -9999 -9999 -9999 -9999 -9999 -9999 -9999 -9999 -9999 -

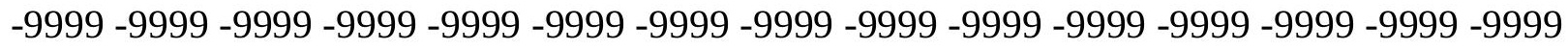

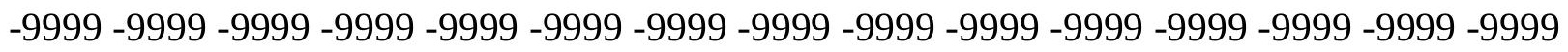
-9999 -9999 -9999 -9999 -9999 -9999 -9999 -9999 -9999 -9999 -9999 -9999 -9999 -9999 -9999 -9999 -9999 -9999 -9999 -9999 -9999 -9999 -9999 -9999 -9999 -9999 -9999 -9999 -9999 -9999 -9999 -9999 -9999 -9999 -9999 -9999 -9999 -9999 -9999 -9999 -9999 -9999 -9999 -9999 -

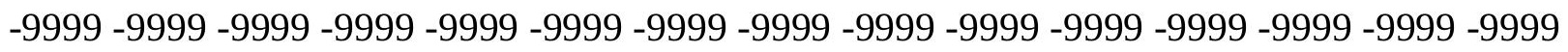
-9999 -9999 -9999 -9999 -9999 -9999 -9999 -9999 -9999 -9999 -9999 -9999 -9999 -9999 -9999 -9999 -9999 -9999 -9999 -9999 -9999 -9999 -9999 -9999 -9999 -9999 -9999 -9999 -9999 -9999 -

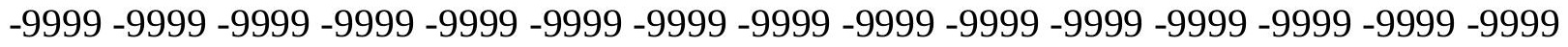
-9999 -9999 -9999 -9999 -9999 -9999 -9999 -9999 -9999 -9999 -9999 -9999 -9999 -9999 -9999 -9999 -9999 -9999 -9999 -9999 -9999 -9999 -9999 -9999 -9999 -9999 -9999 -9999 -9999 -999 -

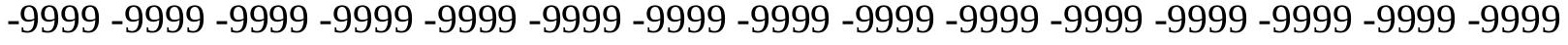
-9999 -9999 -9999 -9999 -9999 -9999 -9999 -9999 -9999 -9999 -9999 -9999 -9999 -9999 -9999 -

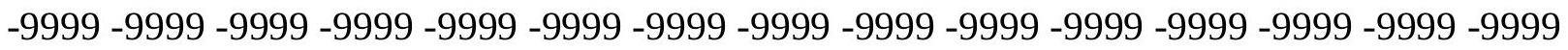

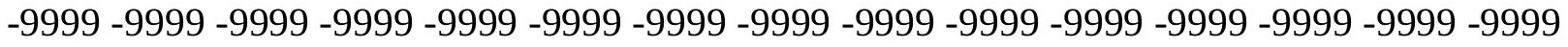

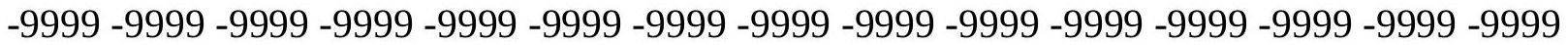

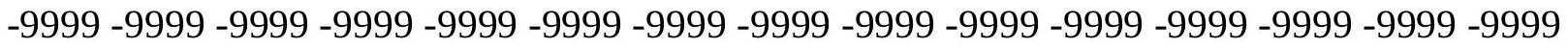

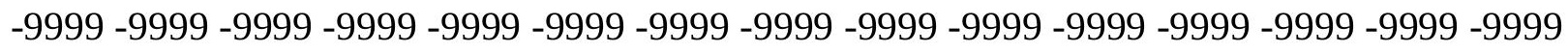

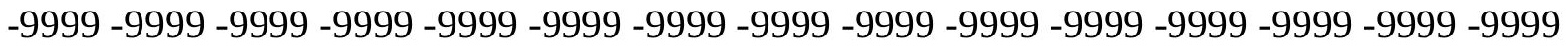

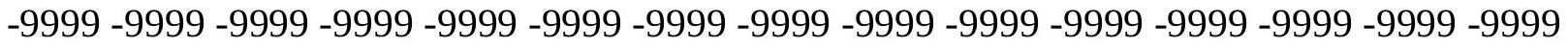
-9999 -9999 -9999 -9999 -9999 -9999 -9999 -9999 -9999 -9999 -9999 -9999 -9999 -9999 -9999 -

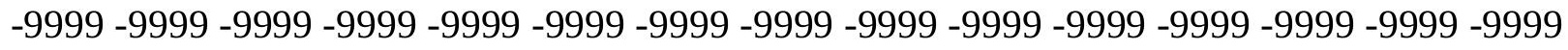

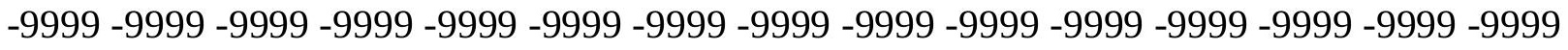
-9999 -9999 -9999 -9999 -9999 -9999 -9999 -9999 -9999 -9999 -9999 -9999 -9999 -9999 -9999 -9999 -9999 -9999 -9999 -9999 -9999 -9999 -9999 -9999-9999 -9999 -9999 -9999 -9999 -9999 -9999 -9999 -9999 -9999 -9999 -9999 -9999 -9999 -9999 -9999 -9999 -9999 -9999 -9999 -9999 -

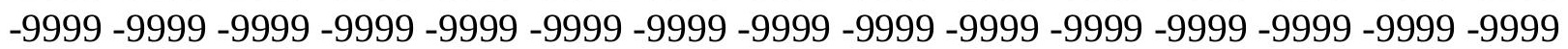


-9999 -9999 -9999 -9999 -9999 -9999 -9999 -9999 -9999 -9999 -9999 -9999 -9999 -9999 -9999 -9999 -9999 -9999 -9999 -9999 -9999 -9999 -9999 -9999 -9999 -9999 -9999 -9999 -9999 -

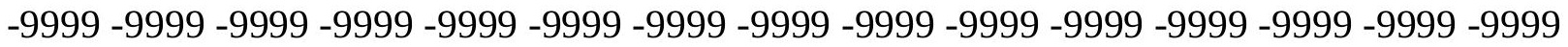
-9999 -9999 -9999 -9999 -9999 -9999 -9999 -9999 -9999 -9999 -9999 -9999 -9999 -9999 -9999 -9999 -9999 -9999 -9999 -9999 -9999 -9999 -9999 -9999 -9999 -9999 -9999 -9999 -9999 -9999 -9999 -9999 -9999 -9999 -9999 -9999 -9999 -9999 -9999 -9999 -9999 -9999 -9999 -9999 -9999 -9999 -9999 -9999 -9999 -9999 -9999 -9999 -9999 -9999 -9999 -9999 -9999 -9999 -9999 -9999

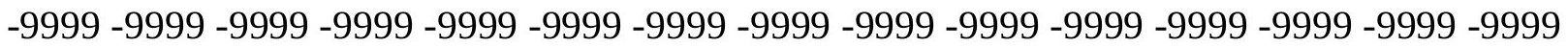

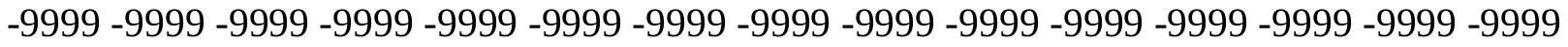
-9999 -9999 -9999 -9999 -9999 -9999 -9999 -9999 -9999 -9999 -9999 -9999 -9999 -9999 -9999 -9999 -9999 -9999 -9999 -9999 -9999 -9999 -9999 -9999 -9999 -9999 -9999 -9999 -9999 -9999 -9999 -9999 -9999 -9999 -9999 -9999 -9999 -9999 -9999 -9999 -9999 -9999 -9999 -9999 -9999 -9999 -9999 -9999 -9999 -9999 -9999 -9999 -9999 -9999 -9999 -9999 -9999 -9999 -9999 -9999 -9999 -9999 -9999 -9999 -9999 -9999 -9999 -9999 -9999 -9999 -9999 -9999 -9999 -9999 -9999 -9999 -9999 -9999 -9999 -9999 -9999 -9999 -9999 -9999 -9999 -9999 -9999 -9999 -9999 -9999 -

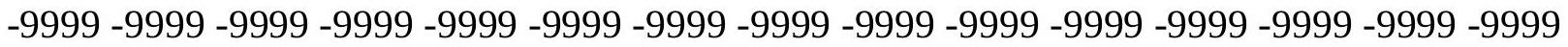
-9999 -9999 -9999 -9999 -9999 -9999 -9999 -9999 -9999 -9999 -9999 -9999 -9999 -9999 -9999 -9999 -9999 -9999 -9999 -9999 -9999 -9999 -9999 -9999 -9999 -9999 -9999 -9999 -9999 - 9999 -9999 -9999 -9999 -9999 -9999 -9999 -9999 -9999 -9999 -9999 -9999 -9999 -9999 -9999 -9999 -

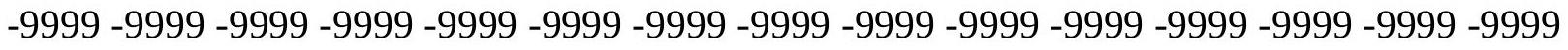

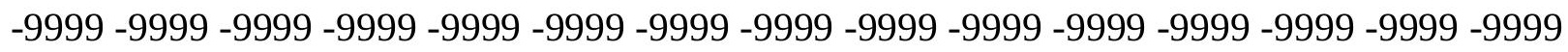

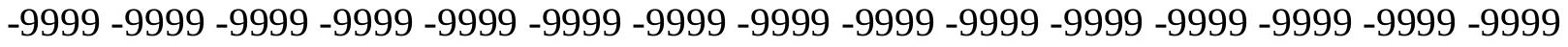
-9999 -9999 -9999 -9999 -9999 -9999 -9999 -9999 -9999 -9999 -9999 -9999 -9999 -9999 -9999 -9999 -9999 -9999 -9999 -9999 -9999 -9999 -9999 -9999 -9999 -9999 -9999 -9999 -9999 -9999 -

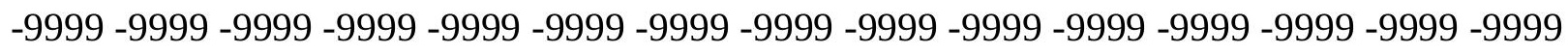
-9999 -9999 -9999 -9999 -9999 -9999 -9999 -9999 -9999 -9999 -9999 -9999 -9999 -9999 -9999 -9999 -9999 -9999 -9999 -9999 -9999 -9999 -9999 -9999 -9999 -9999 -9999 -9999 -9999 -9999 -9999 -9999 -9999 -9999 -9999 -9999 -9999 -9999 -9999 -9999 -9999 -9999 -9999 -9999 -9999 -9999 -9999 -9999 -9999 -9999 -9999 -9999 -9999 -9999 -9999 -9999 -9999 -9999 -9999 -9999 -9999 -9999 -9999 -9999 -9999 -9999 -9999 -9999 -9999 -9999 -9999 -9999 -9999 -999 -

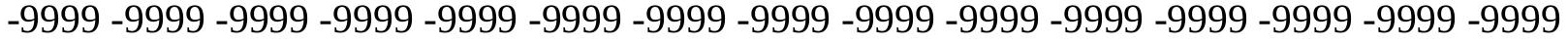
-9999 -9999 -9999 -9999 -9999 -9999 -9999 -9999 -9999 -9999 -9999 -9999 -9999 -9999 -9999 -

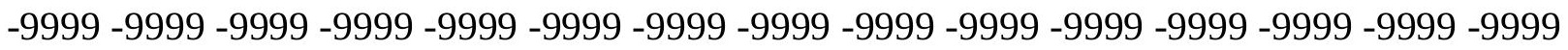

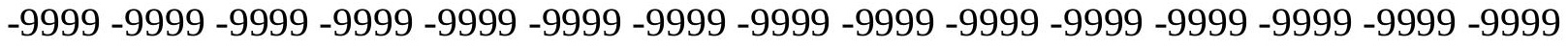

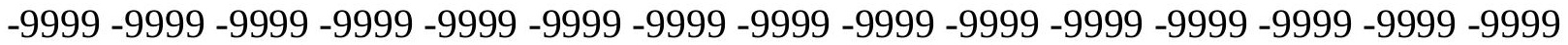

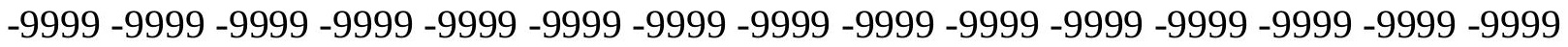

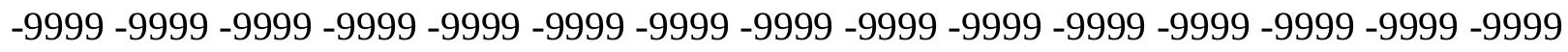

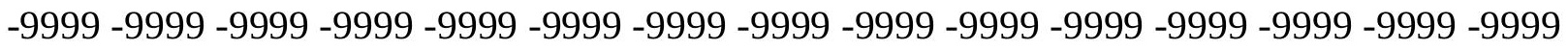

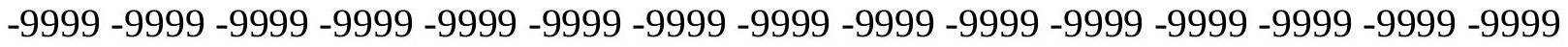
-9999 -9999 -9999 -9999 -9999 -9999 -9999 -9999 -9999 -9999 -9999 -9999 -9999 -9999 -9999 -

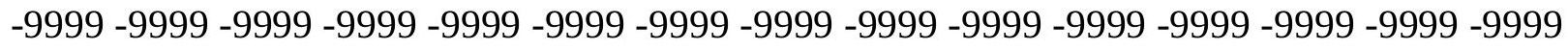

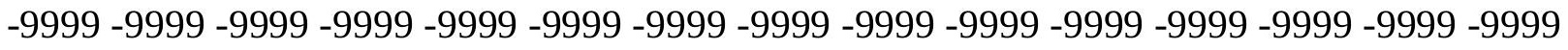
-9999 -9999 -9999 -9999 -9999 -9999 -9999 -9999 -9999 -9999 -9999 -9999 -9999 -9999 -9999 -9999 -9999 -9999 -9999 -9999 -9999 -9999 -9999 -9999-9999 -9999 -9999 -9999 -9999 -9999 -9999 -9999 -9999 -9999 -9999 -9999 -9999 -9999 -9999 -9999 -9999 -9999 -9999 -9999 -9999 -

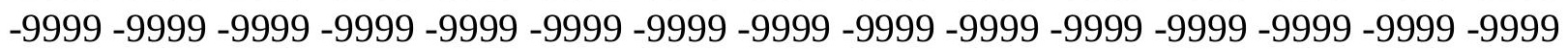


-9999 -9999 -9999 -9999 -9999 -9999 -9999 -9999 -9999 -9999 -9999 -9999 -9999 -9999 -9999 -9999 -9999 -9999 -9999 -9999 -9999 -9999 -9999 -9999 -9999 -9999 -9999 -9999 -9999 -9999 -

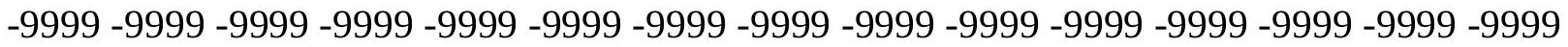
-9999 -9999 -9999 -9999 -9999 -9999 -9999 -9999 -9999 -9999 -9999 -9999 -9999 -9999 -9999 -9999 -9999 -9999 -9999 -9999 -9999 -9999 -9999 -9999-9999 -9999 -9999 -9999 -9999 -9999 -9999 -9999 -9999 -9999 -9999 -9999 -9999 -9999 -9999 -9999 -9999 -9999 -9999 -9999 -9999 -

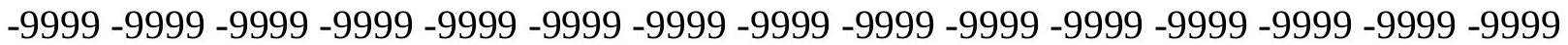
-9999 -9999 -9999 -9999 -9999 -9999 -9999 -9999 -9999 -9999 -9999 -9999 -9999 -9999 -9999 -9999 -9999 -9999 -9999 -9999 -9999 -9999 -9999 -9999 -9999 -9999 -9999 -9999 -9999 -9999 -9999 -9999 -9999 -9999 -9999 -9999 -9999 -9999 -9999 -9999 -9999 -9999 -9999 -9999 -9999 -9999 -9999 -9999 -9999 -9999 -9999 -9999 -9999 -9999 -9999 -9999 -9999 -9999 -9999 -9999 -9999 -9999 -9999 -9999 -9999 -9999 -9999 -9999 -9999 -9999 -9999 -9999 -9999 -9999 -9999 -9999 -9999 -9999 -9999 -9999 -9999 -9999 -9999 -9999 -9999 -9999 -9999 -9999 -9999 -9999 -9999 -9999 -9999 -9999 -9999 -9999 -9999 -9999 -9999 -9999 -9999 -9999 -9999 -9999 -9999 -9999 -9999 -9999 -9999 -9999 -9999 -9999 -9999 -9999 -9999 -9999 -9999 -9999 -9999 -

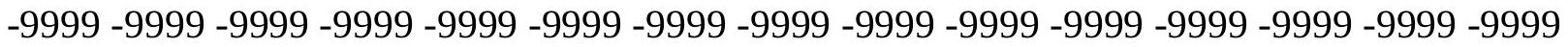
-9999 -9999 -9999 -9999 -9999 -9999 -9999 -9999 -9999 -9999 -9999 -9999 -9999 -9999 -9999 -9999 -9999 -9999 -9999 -9999 -9999 -9999 -9999 -9999 -9999 -9999 -9999 -9999 -9999 -9999 -9999 -9999 -9999 -9999 -9999 -9999 -9999 -9999 -9999 -9999 -9999 -9999 -9999 -9999 -9999 -

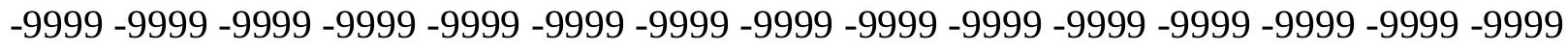

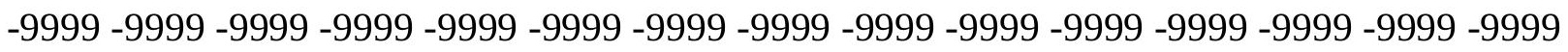
-9999 -9999 -9999 -9999 -9999 -9999 -9999 -9999 -9999 -9999 -9999 -9999 -9999 -9999 - 9999 -9999 -9999 -9999 -9999 -9999 -9999 -9999 -9999 -9999 -9999 -9999 -9999 -9999 -9999 -9999 -9999 -9999 -9999 -9999 -9999 -9999 -9999 -9999 -9999 -9999 -9999 -9999 -9999 -9999 -9999 -

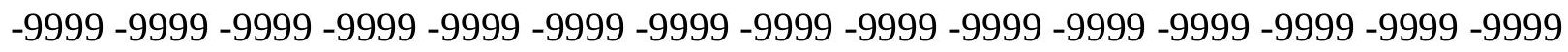
-9999 -9999 -9999 -9999 -9999 -9999 -9999 -9999 -9999 -9999 -9999 -9999 -9999 -9999 -9999 -9999 -9999 -9999 -9999 -9999 -9999 -9999 -9999 -9999 -9999 -9999 -9999 -9999 -9999 -9999 -

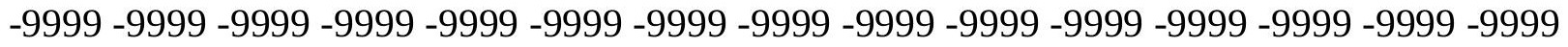
-9999 -9999 -9999 -9999 -9999 -9999 -9999 -9999 -9999 -9999 -9999 -9999 -9999 -9999 -9999 -9999 -9999 -9999 -9999 -9999 -9999 -9999 -9999 -9999 -9999 -9999 -9999 -9999 -9999 -999 -9999 -9999 -9999 -9999 -9999 -9999 -9999 -9999 -9999 -9999 -9999 -9999 -9999 -9999 -9999 -9999 -9999 -9999 -9999 -9999 -9999 -9999 -9999 -9999 -9999 -9999 -9999 -9999 -9999 -9999 -

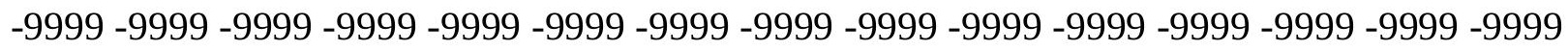

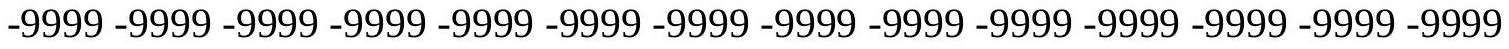
-9999 -9999 -9999 -9999 -9999 -9999 -9999 -9999 -9999 -9999 -9999 -9999 -9999 -9999 -9999

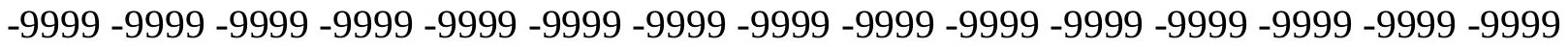

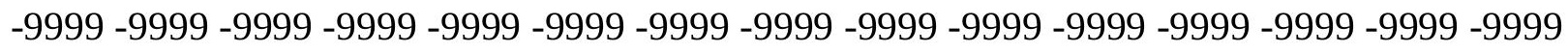

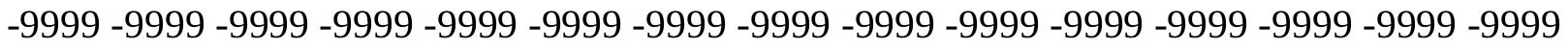

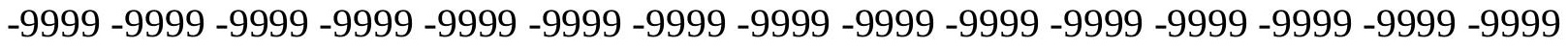
-9999 -9999 -9999 -9999 -9999 -9999 -9999 -9999 -9999 -9999 -9999 -9999 -9999 -9999 -9999 -

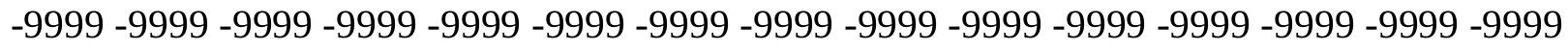

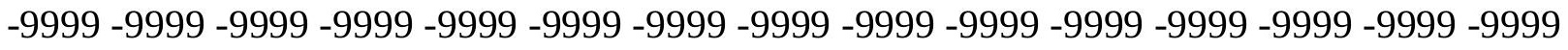
-9999 -9999 -9999 -9999 -9999 -9999 -9999 -9999 -9999 -9999 -9999 -9999 -9999 -9999 -9999 -9999 -9999 -9999 -9999 -9999 -9999 -9999 -9999 -9999-9999 -9999 -9999 -9999 -9999 -9999 -9999 -9999 -9999 -9999 -9999 -9999 -9999 -9999 -9999 -9999 -9999 -9999 -9999 -9999 -9999 -

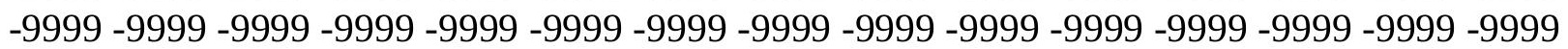


-9999 -9999 -9999 -9999 -9999 -9999 -9999 -9999 -9999 -9999 -9999 -9999 -9999 -9999 -9999 -9999 -9999 -9999 -9999 -9999 -9999 -9999 -9999 -9999 -9999 -9999 -9999 -9999 -9999 -9999 -

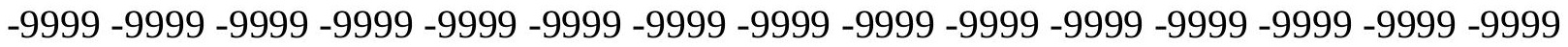
-9999 -9999 -9999 -9999 -9999 -9999 -9999 -9999 -9999 -9999 -9999 -9999 -9999 -9999 -9999 -9999 -9999 -9999 -9999 -9999 -9999 -9999 -9999 -9999-9999 -9999 -9999 -9999 -9999 -9999 -9999 -9999 -9999 -9999 -9999 -9999 -9999 -9999 -9999 -9999 -9999 -9999 -9999 -9999 -9999 -9999 -9999 -9999 -9999 -9999 -9999 -9999 -9999 -9999 -9999 -9999 -9999 -9999 -9999 -9999

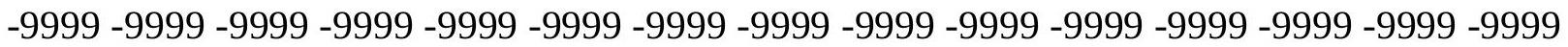

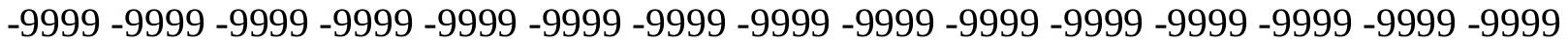
-9999 -9999 -9999 -9999 -9999 -9999 -9999 -9999 -9999 -9999 -9999 -9999 -9999 -9999 -9999 -9999 -9999 -9999 -9999 -9999 -9999 -9999 -9999 -9999 -9999 -9999 -9999 -9999 -9999 -9999 -9999 -9999 -9999 -9999 -9999 -9999 -9999 -9999 -9999 -9999 -9999 -9999 -9999 -9999 -9999 -9999 -9999 -9999 -9999 -9999 -9999 -9999 -9999 -9999 -9999 -9999 -9999 -9999 -9999 -9999 -9999 -9999 -9999 -9999 -9999 -9999 -9999 -9999 -9999 -9999 -9999 -9999 -9999 -9999 -9999 -9999 -9999 -9999 -9999 -9999 -9999 -9999 -9999 -9999 -9999 -9999 -9999 -9999 -9999

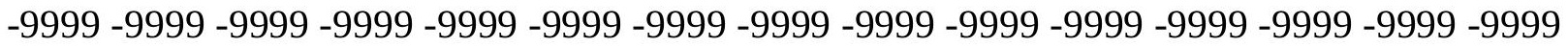
-9999 -9999 -9999 -9999 -9999 -9999 -9999 -9999 -9999 -9999 -9999 -9999 -9999 -9999 -9999 -9999 -9999 -9999 -9999 -9999 -9999 -9999 -9999 -9999 -9999 -9999 -9999 -9999 -9999 -9999 -9999 -9999 -9999 -9999 -9999 -9999 -9999 -9999 -9999 -9999 -9999 -9999 -9999 -9999 -9999 -

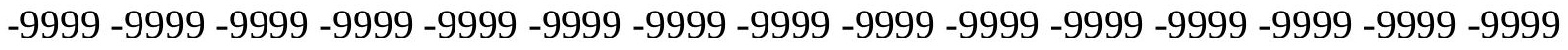

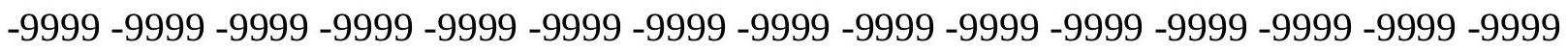
-9999 -9999 -9999 -9999 -9999 -9999 -9999 -9999 -9999 -9999 -9999 -9999 -9999 -9999 -9999 -9999 -9999 -9999 -9999 -9999 -9999 -9999 -9999 -9999 -9999 -9999 -9999 -9999 -9999 -9999 -9999 -9999 -9999 -9999 -9999 -9999 -9999 -9999 -9999 -9999 -9999 -9999 -9999 -9999 -9999 -

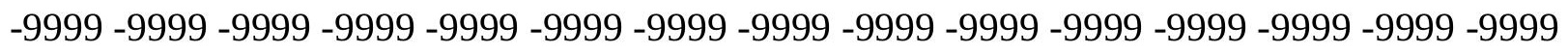
-9999 -9999 -9999 -9999 -9999 -9999 -9999 -9999 -9999 -9999 -9999 -9999 -9999 -9999 -9999 -9999 -9999 -9999 -9999 -9999 -9999 -9999 -9999 -9999 -9999 -9999 -9999 -9999 -9999 -9999 -

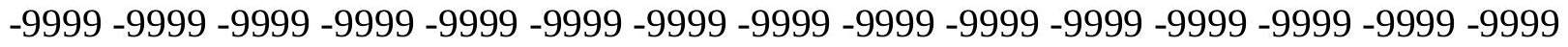
-9999 -9999 -9999 -9999 -9999 -9999 -9999 -9999 -9999 -9999 -9999 -9999 -9999 -9999 -9999 -9999 -9999 -9999 -9999 -9999 -9999 -9999 -9999 -9999 -9999 -9999 -9999 -9999 -9999 -999 -9999 -9999 -9999 -9999 -9999 -9999 -9999 -9999 -9999 -9999 -9999 -9999 -9999 -9999 -9999 -9999 -9999 -9999 -9999 -9999 -9999 -9999 -9999 -9999 -9999 -9999 -9999 -9999 -9999 -9999 -

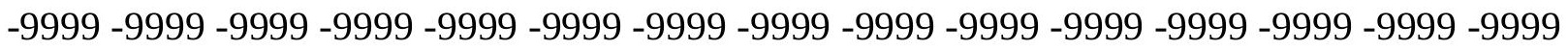

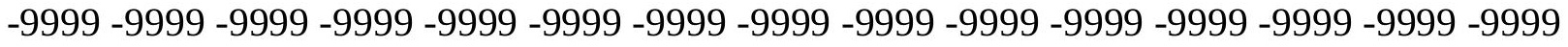

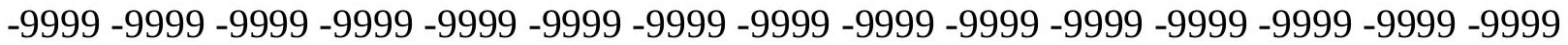

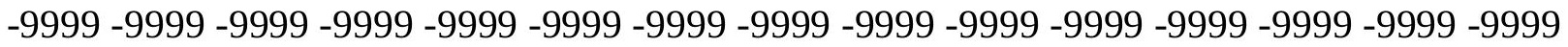

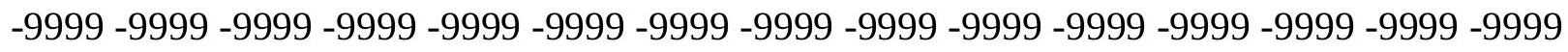

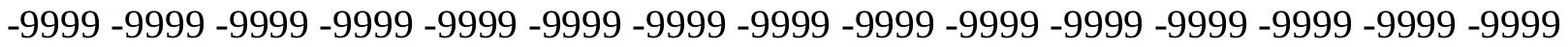
-9999 -9999 -9999 -9999 -9999 -9999 -9999 -9999 -9999 -9999 -9999 -9999 -9999 - 9999 - -999 -9999 -9999 -9999 -9999 -9999 -9999 -9999 -9999 -9999 -9999 -9999 -9999 -9999 -9999 - -999 -

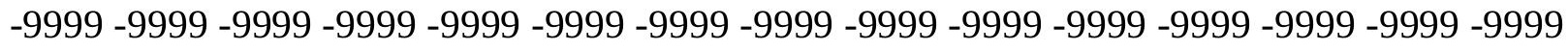

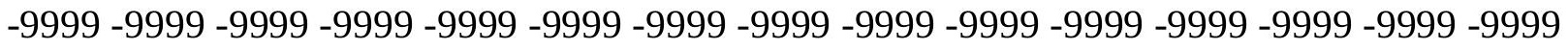
-9999 -9999 -9999 -9999 -9999 -9999 -9999 -9999 -9999 -9999 -9999 -9999 -9999 -9999 -9999 -9999 -9999 -9999 -9999 -9999 -9999 -9999 -9999 -9999-9999 -9999 -9999 -9999 -9999 -9999 -9999 -9999 -9999 -9999 -9999 -9999 -9999 -9999 -9999 -9999 -9999 -9999 -9999 -9999 -9999 -

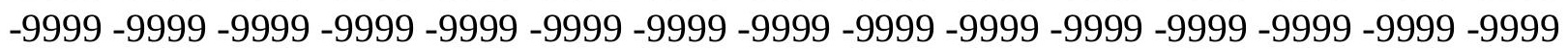


-9999 -9999 -9999 -9999 -9999 -9999 -9999 -9999 -9999 -9999 -9999 -9999 -9999 -9999 -9999 -9999 -9999 -9999 -9999 -9999 -9999 -9999 -9999 -9999 -9999 -9999 -9999 -9999 -9999 -9999 -9999 -9999 -9999 -9999 -9999 -9999 -9999 -9999 -9999 -9999 -9999 -9999 -9999 -9999 -9999 -9999 -9999 -9999 -9999 -9999 -9999 -9999 -9999 -9999 -9999 -9999 -9999 -9999 -9999 -9999 -9999 -9999 -9999 -9999 -9999 -9999 -9999 -9999 -9999 -9999 -9999 -9999 -9999 -9999 -9999 -9999 -9999 -9999 -9999 -9999 -9999 -9999 -9999 -9999 -9999 -9999 -9999 -9999 -9999 -9999 -9999 -9999 -9999 -9999 -9999 -9999 -9999 -9999 -9999 -9999 -9999 -9999 -9999 -9999 -9999 -

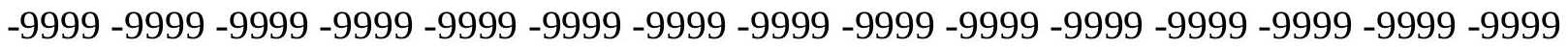
-9999 -9999 -9999 -9999 -9999 -9999 -9999 -9999 -9999 -9999 -9999 -9999 -9999 -9999 -9999 -9999 -9999 -9999 -9999 -9999 -9999 -9999 -9999 -9999 -9999 -9999 -9999 -9999 -9999 -9999 -

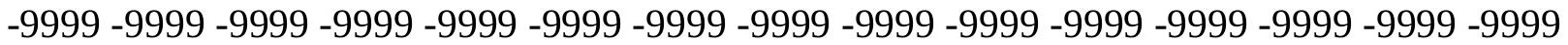
-9999 -9999 -9999 -9999 -9999 -9999 -9999 -9999 -9999 -9999 -9999 -9999 -9999 -9999 -9999 -9999 -9999 -9999 -9999 -9999 -9999 -9999 -9999 -9999 -9999 -9999 -9999 -9999 -9999 -9999 -9999 -9999 -9999 -9999 -9999 -9999 -9999 -9999 -9999 -9999 -9999 -9999 -9999 -9999 -9999 -9999 -9999 -9999 -9999 -9999 -9999 -9999 -9999 -9999 -9999 -9999 -9999 -9999 -9999 -9999

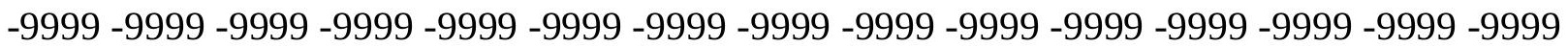
-9999 -9999 -9999 -9999 -9999 -9999 -9999 -9999 -9999 -9999 -9999 -9999 -9999 -9999 -9999 -9999 -9999 -9999 -9999 -9999 -9999 -9999 -9999 -9999 -9999 -9999 -9999 -9999 -9999 -9999 -9999 -9999 -9999 -9999 -9999 -9999 -9999 -9999 -9999 -9999 -9999 -9999 -9999 -9999 -9999 -9999 -9999 -9999 -9999 -9999 -9999 -9999 -9999 -9999 -9999 -9999 -9999 -9999 -9999 -9999 -9999 -9999 -9999 -9999 -9999 -9999 -9999 -9999 -9999 -9999 -9999 -9999 -9999 -9999 -9999 -9999 -9999 -9999 -9999 -9999 -9999 -9999 -9999 -9999 -9999 -9999 -9999 -9999 -9999 -9999 -9999 -9999 -9999 -9999 -9999 -9999 -9999 -9999 -9999 -9999 -9999 -9999 -9999 -9999 -9999 -9999 -9999 -9999 -9999 -9999 -9999 -9999 -9999 -9999 -9999 -9999 -9999 -9999 -9999 -9999 -9999 -9999 -9999 -9999 -9999 -9999 -9999 -9999 -9999 -9999 -9999 -9999 -9999 -9999 -9999 -9999 -9999 -9999 -9999 -9999 -9999 -9999 -9999 -9999 -9999 -9999 -9999 -9999 -9999 -9999 -9999 -9999 -9999 -9999 -9999 -9999 -9999 -9999 -9999 -9999 -9999 -9999 -9999 -9999 -9999 -9999 -9999 -9999 -9999 -9999 -9999 -9999 -9999 -9999 -9999 -9999 -9999 -9999 -9999

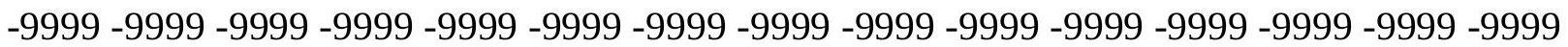
-9999 -9999 -9999 -9999 -9999 -9999 -9999 -9999 -9999 -9999 -9999 -9999 -9999 -9999 -9999 -9999 -9999 -9999 -9999 -9999 -9999 -9999 -9999 -9999 -9999 -9999 -9999 -9999 -9999 -9999 -

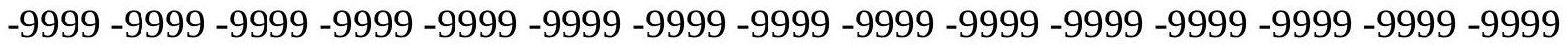
-9999 -9999 -9999 -9999 -9999 -9999 -9999 -9999 -9999 -9999 -9999 -9999 -9999 -9999 -9999 -9999 -9999 -9999 -9999 -9999 -9999 -9999 -9999 -9999 -9999 -9999 -9999 -9999 -9999 -9999 -9999 -9999 -9999 -9999 -9999 -9999 -9999 -9999 -9999 -9999 -9999 -9999 -9999 -9999 -9999 -9999 -9999 -9999 -9999 -9999 -9999 -9999 -9999 -9999 -9999 -9999 -9999 -9999 -9999 -9999 -9999 -9999 -9999 -9999 -9999 -9999 -9999 -9999 -9999 -9999 -9999 -9999 -9999 -9999 -9999

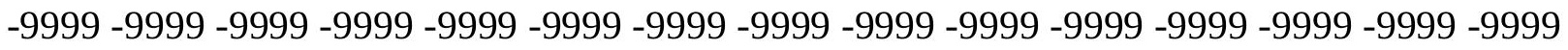
-9999 -9999 -9999 -9999 -9999 -9999 -9999 -9999 -9999 -9999 -9999 -9999 -9999 -9999 -9999 -9999 -9999 -9999 -9999 -9999 -9999 -9999 -9999 -9999 -9999 -9999 -9999 -9999 -9999 -9999 -9999 -9999 -9999 -9999 -9999 -9999 -9999 -9999 -9999 -9999 -9999 -9999 -9999 -9999 -9999 -999 -9999 -9999 -9999 -9999 -9999 -9999 -9999 -9999 -9999 -9999 -9999 -9999 -9999 -9999 -9999 -9999 -9999 -9999 -9999 -9999 -9999 -9999 -9999 -9999 -9999 -9999 -9999 -9999 -9999 -9999 -9999 -9999 -9999 -9999 -9999 -9999 -9999 -9999 -9999 -9999 -9999 -9999 -9999 -9999 -9999 -9999 -9999 -9999 -9999 -9999 -9999 -9999 -9999 -9999 -9999 -9999 -9999 -9999 -9999 -9999 -9999 -9999 -9999 -9999 -9999 -9999 -9999 -9999 -9999 -9999 -9999 -9999 -9999 -9999 
-9999 -9999 -9999 -9999 -9999 -9999 -9999 -9999 -9999 -9999 -9999 -9999 -9999 -9999 -9999 -9999 -9999 -9999 -9999 -9999 -9999 -9999 -9999 -9999 -9999 -9999 -9999 -9999 -9999 -9999 -

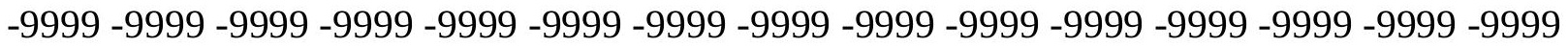
-9999 -9999 -9999 -9999 -9999 -9999 -9999 -9999 -9999 -9999 -9999 -9999 -9999 -9999 -9999 -9999 -9999 -9999 -9999 -9999 -9999 -9999 -9999 -9999-9999 -9999 -9999 -9999 -9999 -9999 -9999 -9999 -9999 -9999 -9999 -9999 -9999 -9999 -9999 -9999 -9999 -9999 -9999 -9999 -9999 -9999 -9999 -9999 -9999 -9999 -9999 -9999 -9999 -9999 -9999 -9999 -9999 -9999 -9999 -9999

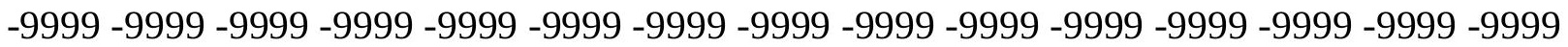

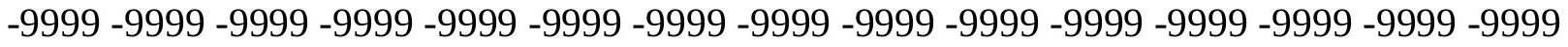
-9999 -9999 -9999 -9999 -9999 -9999 -9999 -9999 -9999 -9999 -9999 -9999 -9999 -9999 -9999 -9999 -9999 -9999 -9999 -9999 -9999 -9999 -9999 -9999 -9999 -9999 -9999 -9999 -9999 -9999 -9999 -9999 -9999 -9999 -9999 -9999 -9999 -9999 -9999 -9999 -9999 -9999 -9999 -9999 -9999 -9999 -9999 -9999 -9999 -9999 -9999 -9999 -9999 -9999 -9999 -9999 -9999 -9999 -9999 -9999 -

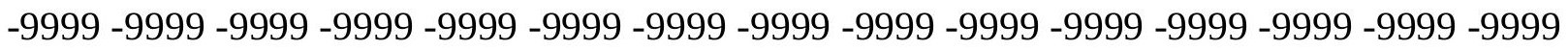
-9999 -9999 -9999 -9999 -9999 -9999 -9999 -9999 -9999 -9999 -9999 -9999 -9999 -9999 -9999 -

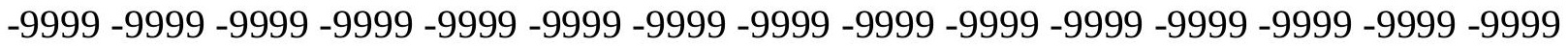
-9999 -9999 -9999 -9999 -9999 -9999 -9999 -9999 -9999 -9999 -9999 -9999 -9999 -9999 -9999 -9999 -9999 -9999 -9999 -9999 -9999 -9999 -9999 -9999 -9999 -9999 -9999 -9999 -9999 -9999 -9999 -9999 -9999 -9999 -9999 -9999 -9999 -9999 -9999 -9999 -9999 -9999 -9999 -9999 -9999 -

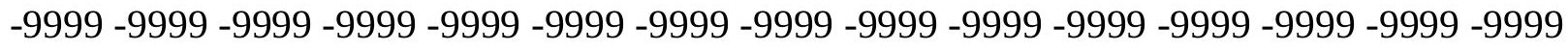

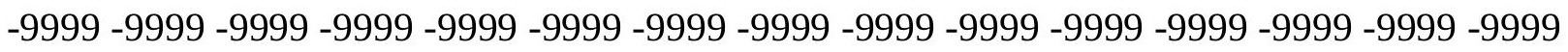

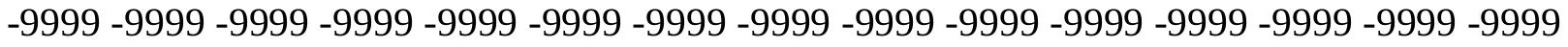
-9999 -9999 -9999 -9999 -9999 -9999 -9999 -9999 -9999 -9999 -9999 -9999 -9999 -9999 -9999 -9999 -9999 -9999 -9999 -9999 -9999 -9999 -9999 -9999 -9999 -9999 -9999 -9999 -9999 -9999 -

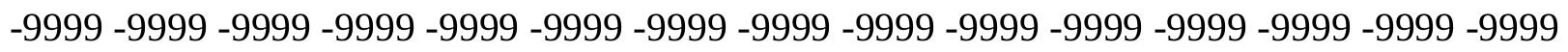
-9999 -9999 -9999 -9999 -9999 -9999 -9999 -9999 -9999 -9999 -9999 -9999 -9999 -9999 -9999 -9999 -9999 -9999 -9999 -9999 -9999 -9999 -9999 -9999 -9999 -9999 -9999 -9999 -9999 -

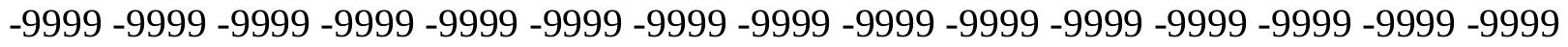
-9999 -9999 -9999 -9999 -9999 -9999 -9999 -9999 -9999 -9999 -9999 -9999 -9999 -9999 -9999 -9999 -9999 -9999 -9999 -9999 -9999 -9999 -9999 -9999 -9999 -9999 -9999 -9999 -9999 -999 -

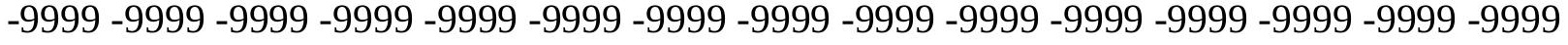
-9999 -9999 -9999 -9999 -9999 -9999 -9999 -9999 -9999 -9999 -9999 -9999 -9999 -9999 -9999 -

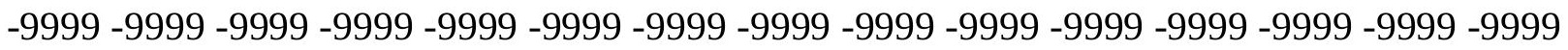

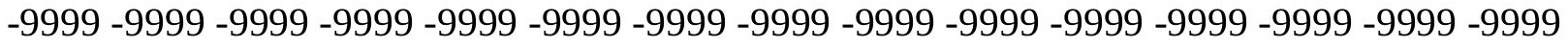

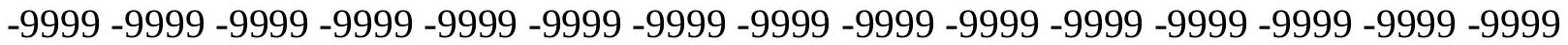
-9999 -9999 -9999 -9999 -9999 -9999 -9999 -9999 -9999 -9999 -9999 -9999 -9999 -9999 -9999

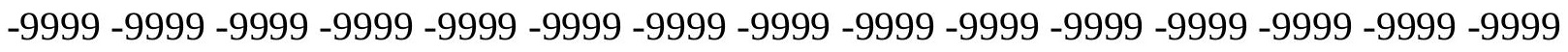

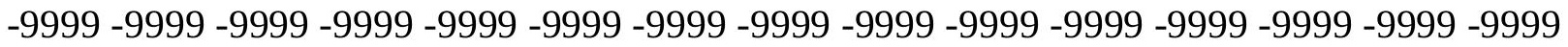
-9999 -9999 -9999 -9999 -9999 -9999 -9999 -9999 -9999 -9999 -9999 -9999 -9999 - 9999 - -999 -9999 -9999 -9999 -9999 -9999 -9999 -9999 -9999 -9999 -9999 -9999 -9999 -9999 -9999 -9999 -

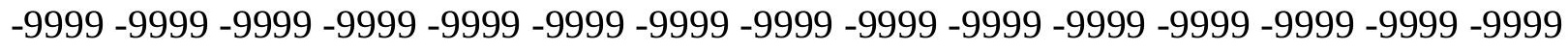

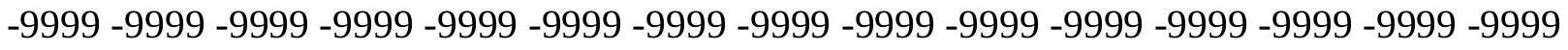
-9999 -9999 -9999 -9999 -9999 -9999 -9999 -9999 -9999 -9999 -9999 -9999 -9999 -9999 -9999 -9999 -9999 -9999 -9999 -9999 -9999 -9999 -9999 -9999-9999 -9999 -9999 -9999 -9999 -9999 -9999 -9999 -9999 -9999 -9999 -9999 -9999 -9999 -9999 -9999 -9999 -9999 -9999 -9999 -9999 -

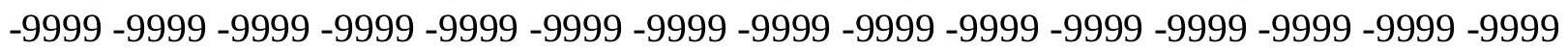


-9999 -9999 -9999 -9999 -9999 -9999 -9999 -9999 -9999 -9999 -9999 -9999 -9999 -9999 -9999 -9999 -9999 -9999 -9999 -9999 -9999 -9999 -9999 -9999 -9999 -9999 -9999 -9999 -9999 -9999 -9999 -9999 -9999 -9999 -9999 -9999 -9999 -9999 -9999 -9999 -9999 -9999 -9999 -9999 - 9999 -9999 -9999 -9999 -9999 -9999 -9999 -9999 -9999 -9999 -9999 -9999 -9999 -9999 -9999 -9999 -9999 -9999 -9999 -9999 -9999 -9999 -9999 -9999 -9999 -9999 -9999 -9999 -9999 -9999 - -9999 -9999 -9999 -9999 -9999 -9999 -9999 -9999 -9999 -9999 -9999 -9999 -9999 -9999 -9999 -9999 -9999 -9999 -9999 -9999 -9999 -9999 -9999 -9999 -9999 -9999 -9999 -9999 -9999 -9999

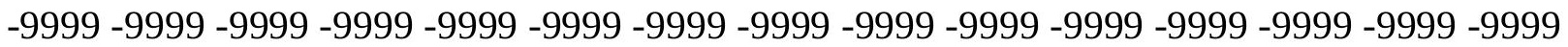

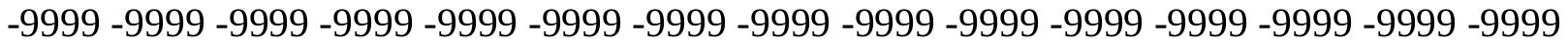
-9999 -9999 -9999 -9999 -9999 -9999 -9999 -9999 -9999 -9999 -9999 -9999 -9999 -9999 -9999

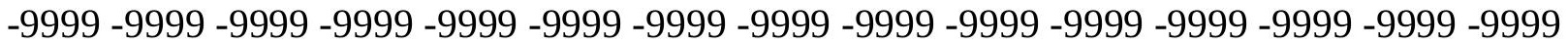
-9999 -9999 -9999 -9999 -9999 -9999 -9999 -9999 -9999 -9999 -9999 -9999 -9999 -9999 -9999 -9999 -9999 -9999 -9999 -9999 -9999 -9999 -9999 -9999 -9999 -9999 -9999 -9999 -9999 -9999 -9999 -9999 -9999 -9999 -9999 -9999 -9999 -9999 -9999 -9999 -9999 -9999 -9999 -9999 - -9999 -9999 -9999 -9999 -9999 -9999 -9999 -9999 -9999 -9999 -9999 -9999 -9999 -9999 -9999 -9999

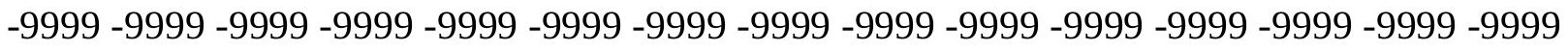
-9999 -9999 -9999 -9999 -9999 -9999 -9999 -9999 -9999 -9999 -9999 -9999 -9999 -9999 -9999 -9999 -9999 -9999 -9999 -9999 -9999 -9999 -9999 -9999 -9999 -9999 -9999 -9999 -9999 -9999 -9999 -9999 -9999 -9999 -9999 -9999 -9999 -9999 -9999 -9999 -9999 -9999 -9999 -9999 -9999 -

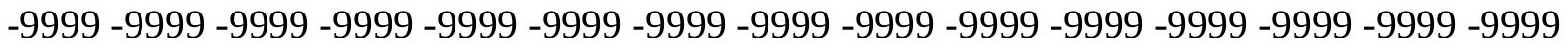
-9999 -9999 -9999 -9999 -9999 -9999 -9999 -9999 -9999 -9999 -9999 -9999 -9999 -9999 -9999 -999 -9999 -9999 -9999 -9999 -9999 -9999 -9999 -9999 -9999 -9999 -9999 -9999 -9999 -9999 -9999 -9999 -9999 -9999 -9999 -9999 -9999 -9999 -9999 -9999 -9999 -9999 -9999 -9999 -9999 -9999 -9999 -9999 -9999 -9999 -9999 -9999 -9999 -9999 -9999 -9999 -9999 -9999 -9999 -9999 -9999 -9999 -9999 -9999 -9999 -9999 -9999 -9999 -9999 -9999 -9999 -9999 -9999 -9999 -9999 -9999 -9999 -9999 -9999 -9999 -9999 -9999 -9999 -9999 -9999 -9999 -9999 -9999 -9999 -9999 -9999 -9999 -9999 -9999 -9999 -9999 -9999 -9999 -9999 -9999 -9999 -9999 -9999 -9999 -9999 -9999 -9999 -9999 -9999 -9999 -9999 -9999 -9999 -9999 -9999 -9999 -9999 -9999 -9999 -9999 -9999 -9999 -9999 -9999 -9999 -9999 -9999 -9999 -9999 -9999 -9999 -9999 -9999 -9999 -9999 -9999 -9999 -9999 -9999 -9999 -9999 -9999 -9999 -9999 -9999 -9999 -9999 -9999 -9999 -9999 -999 -9999 -9999 -9999 -9999 -9999 -9999 -9999 -9999 -9999 -9999 -9999 -9999 -9999 -9999 -9999 -9999 -9999 -9999 -9999 -9999 -9999 -9999 -9999 -9999 -9999 -9999 -9999 -9999 -9999 -

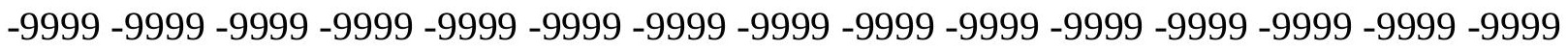

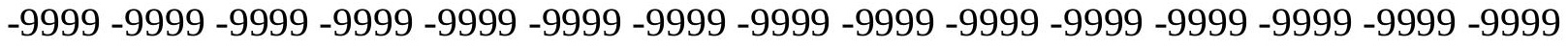

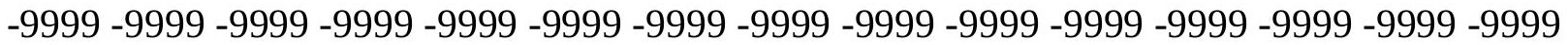
-9999 -9999 -9999 -9999 -9999 -9999 -9999 -9999 -9999 -9999 -9999 -9999 -9999 -9999 -9999 -

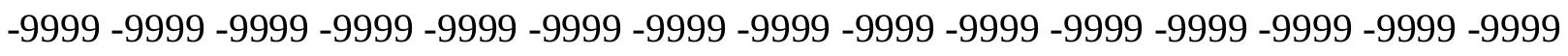

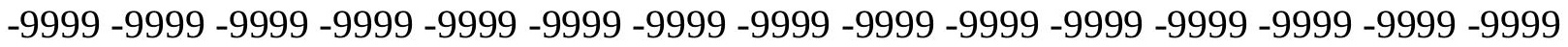

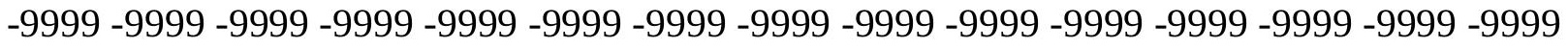
-9999 -9999 -9999 -9999 -9999 -9999 -9999 -9999 -9999 -9999 -9999 -9999 -9999 -9999 -9999 -

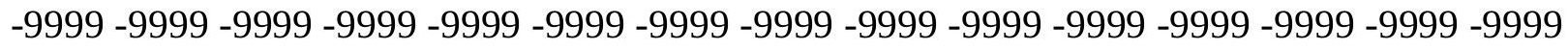

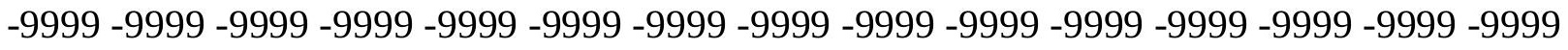
-9999 -9999 -9999 -9999 -9999 -9999 -9999 -9999 -9999 -9999 -9999 -9999 -9999 -9999 -9999 -9999 -9999 -9999 -9999 -9999 -9999 -9999 -9999 -9999-9999 -9999 -9999 -9999 -9999 -9999 -9999 -9999 -9999 -9999 -9999 -9999 -9999 -9999 -9999 -9999 -9999 -9999 -9999 -9999 -9999 -

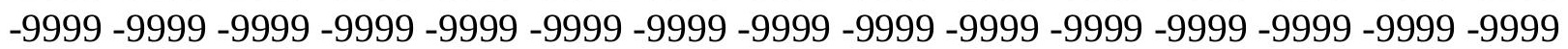


-9999 -9999 -9999 -9999 -9999 -9999 -9999 -9999 -9999 -9999 -9999 -9999 -9999 -9999 -9999 -9999 -9999 -9999 -9999 -9999 -9999 -9999 -9999 -9999 -9999 -9999 -9999 -9999 -9999 -9999 -

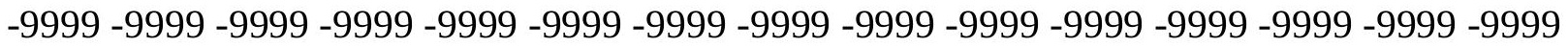
-9999 -9999 -9999 -9999 -9999 -9999 -9999 -9999 -9999 -9999 -9999 -9999 -9999 -9999 -9999 -9999 -9999 -9999 -9999 -9999 -9999 -9999 -9999 -9999-9999 -9999 -9999 -9999 -9999 -9999 -9999 -9999 -9999 -9999 -9999 -9999 -9999 -9999 -9999 -9999 -9999 -9999 -9999 -9999 -9999 -9999 -9999 -9999 -9999 -9999 -9999 -9999 -9999 -9999 -9999 -9999 -9999 -9999 -9999 -9999

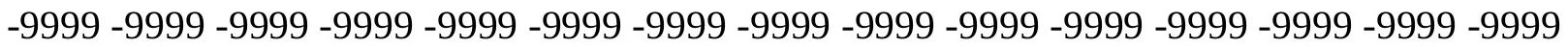

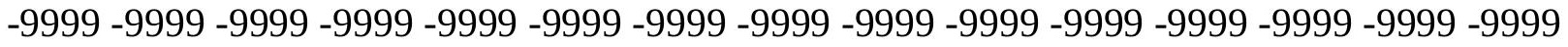
-9999 -9999 -9999 -9999 -9999 -9999 -9999 -9999 -9999 -9999 -9999 -9999 -9999 -9999 -9999 -9999 -9999 -9999 -9999 -9999 -9999 -9999 -9999 -9999 -9999 -9999 -9999 -9999 -9999 -9999 -9999 -9999 -9999 -9999 -9999 -9999 -9999 -9999 -9999 -9999 -9999 -9999 -9999 -9999 -9999 -9999 -9999 -9999 -9999 -9999 -9999 -9999 -9999 -9999 -9999 -9999 -9999 -9999 -9999 -9999 -9999 -9999 -9999 -9999 -9999 -9999 -9999 -9999 -9999 -9999 -9999 -9999 -9999 - 9999 -9999 -9999 -9999 -9999 -9999 -9999 -9999 -9999 -9999 -9999 -9999 -9999 -9999 -9999 -9999

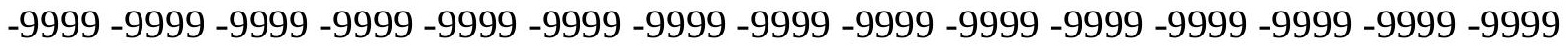
-9999 -9999 -9999 -9999 -9999 -9999 -9999 -9999 -9999 -9999 -9999 -9999 -9999 -9999 -9999 -9999 -9999 -9999 -9999 -9999 -9999 -9999 -9999 -9999 -9999 -9999 -9999 -9999 -9999 -9999 -9999 -9999 -9999 -9999 -9999 -9999 -9999 -9999 -9999 -9999 -9999 -9999 -9999 -9999 -9999 -

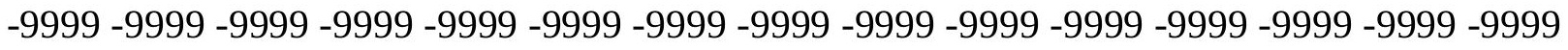

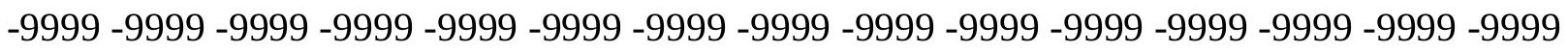
-9999 -9999 -9999 -9999 -9999 -9999 -9999 -9999 -9999 -9999 -9999 -9999 -9999 -9999 -9999 -9999 -9999 -9999 -9999 -9999 -9999 -9999 -9999 -9999 -9999 -9999 -9999 -9999 -9999 -9999 -9999 -9999 -9999 -9999 -9999 -9999 -9999 -9999 -9999 -9999 -9999 -9999 -9999 -9999 -9999 -

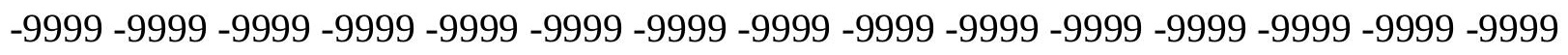
-9999 -9999 -9999 -9999 -9999 -9999 -9999 -9999 -9999 -9999 -9999 -9999 -9999 -9999 -9999 -9999 -9999 -9999 -9999 -9999 -9999 -9999 -9999 -9999 -9999 -9999 -9999 -9999 -9999 -9999 -

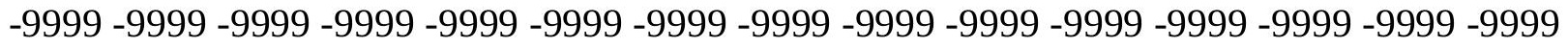
-9999 -9999 -9999 -9999 -9999 -9999 -9999 -9999 -9999 -9999 -9999 -9999 -9999 -9999 -9999 -9999 -9999 -9999 -9999 -9999 -9999 -9999 -9999 -9999 -9999 -9999 -9999 -9999 -9999 -999 -9999 -9999 -9999 -9999 -9999 -9999 -9999 -9999 -9999 -9999 -9999 -9999 -9999 -9999 -9999 -9999 -9999 -9999 -9999 -9999 -9999 -9999 -9999 -9999 -9999 -9999 -9999 -9999 -9999 -9999 -

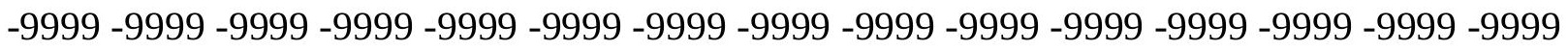

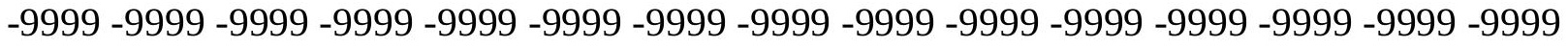

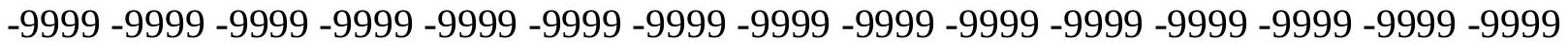

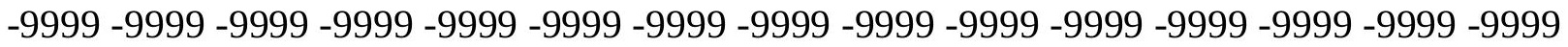

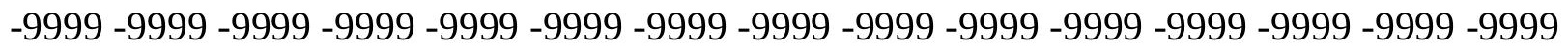

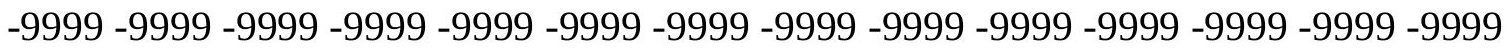
-9999 -9999 -9999 -9999 -9999 -9999 -9999 -9999 -9999 -9999 -9999 -9999 -9999 -9999 -9999 -9999 -9999 -9999 -9999 -9999 -9999 -9999 -9999 -9999 -9999 -9999 -9999 -9999 -9999 -9999 -

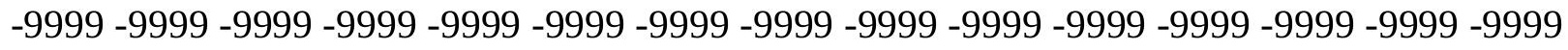

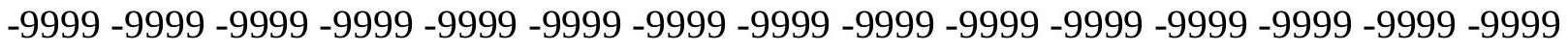
-9999 -9999 -9999 -9999 -9999 -9999 -9999 -9999 -9999 -9999 -9999 -9999 -9999 -9999 -9999 -9999 -9999 -9999 -9999 -9999 -9999 -9999 -9999 -9999-9999 -9999 -9999 -9999 -9999 -9999 -9999 -9999 -9999 -9999 -9999 -9999 -9999 -9999 -9999 -9999 -9999 -9999 -9999 -9999 -9999 -

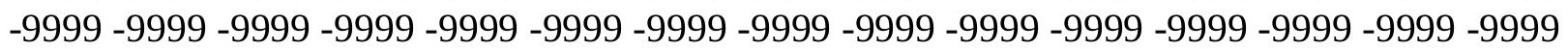


-9999 -9999 -9999 -9999 -9999 -9999 -9999 -9999 -9999 -9999 -9999 -9999 -9999 -9999 -9999 -9999 -9999 -9999 -9999 -9999 -9999 -9999 -9999 -9999 -9999 -9999 -9999 -9999 -9999 -9999 -9999 -9999 -9999 -9999 -9999 -9999 -9999 -9999 -9999 -9999 -9999 -9999 -9999 -9999 - 9999 -9999 -9999 -9999 -9999 -9999 -9999 -9999 -9999 -9999 -9999 -9999 -9999 -9999 -9999 -9999 -9999 -9999 -9999 -9999 -9999 -9999 -9999 -9999 -9999 -9999 -9999 -9999 -9999 -9999 -9999 -9999 -9999 -9999 -9999 -9999 -9999 -9999 -9999 -9999 -9999 -9999 -9999 -9999 -9999 -9999 -9999 -9999 -9999 -9999 -9999 -9999 -9999 -9999 -9999 -9999 -9999 -9999 -9999 -9999 -9999

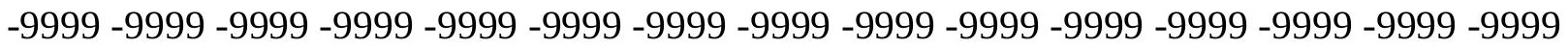
-9999 -9999 -9999 -9999 -9999 -9999 -9999 -9999 -9999 -9999 -9999 -9999 -9999 -9999 -9999 -9999 -9999 -9999 -9999 -9999 -9999 -9999 -9999 -9999 -9999 -9999 -9999 -9999 -9999 -9999

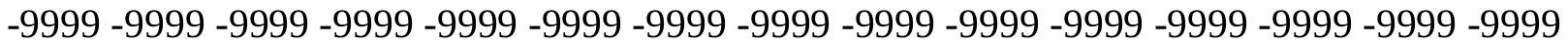
-9999 -9999 -9999 -9999 -9999 -9999 -9999 -9999 -9999 -9999 -9999 -9999 -9999 -9999 -9999 -9999 -9999 -9999 -9999 -9999 -9999 -9999 -9999 -9999 -9999 -9999 -9999 -9999 -9999 -9999 -

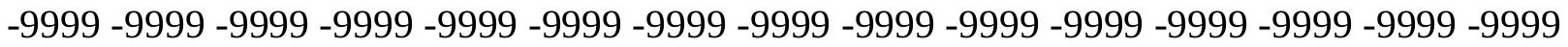
-9999 -9999 -9999 -9999 -9999 -9999 -9999 -9999 -9999 -9999 -9999 -9999 -9999 -9999 -9999

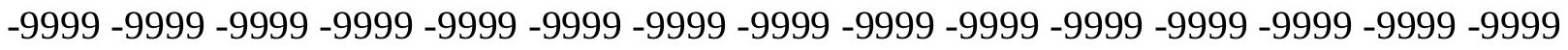
-9999 -9999 -9999 -9999 -9999 -9999 -9999 -9999 -9999 -9999 -9999 -9999 -9999 -9999 -9999 -9999 -9999 -9999 -9999 -9999 -9999 -9999 -9999 -9999 -9999 -9999 -9999 -9999 -9999 - -999 -9999 -9999 -9999 -9999 -9999 -9999 -9999 -9999 -9999 -9999 -9999 -9999 -9999 -9999 -9999 -9999 -9999 -9999 -9999 -9999 -9999 -9999 -9999 -9999 -9999 -9999 -9999 -9999 -9999 -9999 -9999 -9999 -9999 -9999 -9999 -9999 -9999 -9999 -9999 -9999 -9999 -9999 -9999 -9999 -9999 -999 -9999 -9999 -9999 -9999 -9999 -9999 -9999 -9999 -9999 -9999 -9999 -9999 -9999 -9999 -9999 -9999 -9999 -9999 -9999 -9999 -9999 -9999 -9999 -9999 -9999 -9999 -9999 -9999 -9999 -9999 -9999 -9999 -9999 -9999 -9999 -9999 -9999 -9999 -9999 -9999 -9999 -9999 -9999 -9999 -9999 -9999 -9999 -9999 -9999 -9999 -9999 -9999 -9999 -9999 -9999 -9999 -9999 -9999 -9999 -9999 -9999 -9999 -9999 -9999 -9999 -9999 -9999 -9999 -9999 -9999 -9999 -9999 -9999 -9999 -9999 -9999 -9999 -9999 -9999 -9999 -9999 -9999 -9999 -9999 -9999 -9999 -9999 -9999 -9999 -9999 -9999 -9999 -9999 -9999 -9999 -9999 -9999 -9999 -9999 -9999 -9999 -9999 -9999 -9999 -9999 -9999 -9999 -9999 -9999 -9999 -9999 -9999 -9999 -9999 -9999 -9999 -9999 -9999 -9999 -9999 -9999 -9999 -9999 -9999 -9999 -9999 -9999 -9999 -9999 -9999 -9999 -9999 -9999 -9999 -999 -9999 -9999 -9999 -9999 -9999 -9999 -9999 -9999 -9999 -9999 -9999 -9999 -9999 -9999 -9999 -9999 -9999 -9999 -9999 -9999 -9999 -9999 -9999 -9999 -9999 -9999 -9999 -9999 -9999 -9999 -

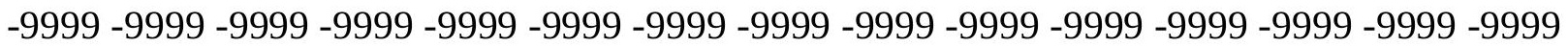

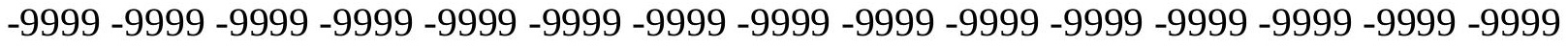

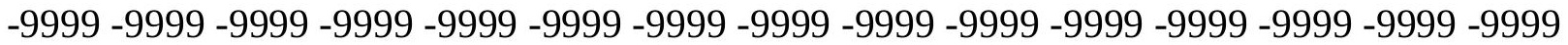
-9999 -9999 -9999 -9999 -9999 -9999 -9999 -9999 -9999 -9999 -9999 -9999 -9999 -9999 -9999

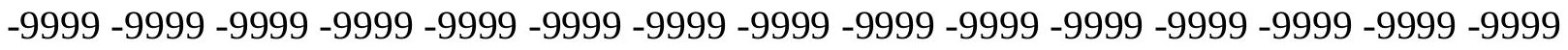

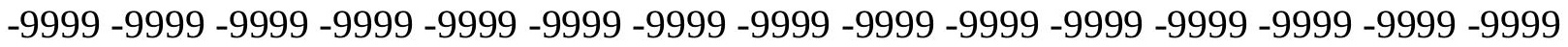

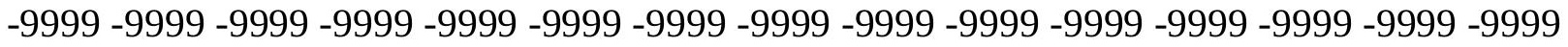
-9999 -9999 -9999 -9999 -9999 -9999 -9999 -9999 -9999 -9999 -9999 -9999 -9999 -9999 -9999 -

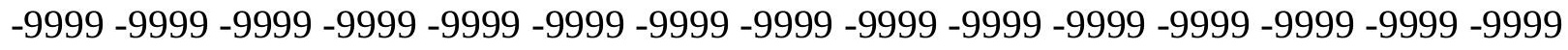

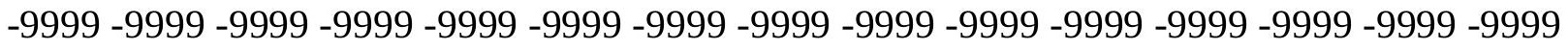
-9999 -9999 -9999 -9999 -9999 -9999 -9999 -9999 -9999 -9999 -9999 -9999 -9999 -9999 -9999 -9999 -9999 -9999 -9999 -9999 -9999 -9999 -9999 -9999 -9999 -9999 -9999 -9999 - -9999 -9999 -9999 -9999 -9999 -9999 -9999 -9999 -9999 -9999 -9999 -9999 -9999 -9999 -9999 -9999 -

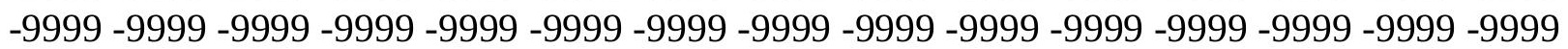


-9999 -9999 -9999 -9999 -9999 -9999 -9999 -9999 -9999 -9999 -9999 -9999 -9999 -9999 -9999 -9999 -9999 -9999 -9999 -9999 -9999 -9999 -9999 -9999 -9999 -9999 -9999 -9999 -9999 -9999 -9999 -9999 -9999 -9999 -9999 -9999 -9999 -9999 -9999 -9999 -9999 -9999 -9999 -9999 - 9999 -9999 -9999 -9999 -9999 -9999 -9999 -9999 -9999 -9999 -9999 -9999 -9999 -9999 -9999 -9999 -9999 -9999 -9999 -9999 -9999 -9999 -9999 -9999 -9999-9999 -9999 -9999 -9999 -9999 -9999 -9999 -9999 -9999 -9999 -9999 -9999 -9999 -9999 -9999 -9999 -9999 -9999 -9999 -9999 -9999 -9999 -9999 -9999 -9999 -9999 -9999 -9999 -9999 -9999 -9999 -9999 -9999 -9999 -9999 -9999

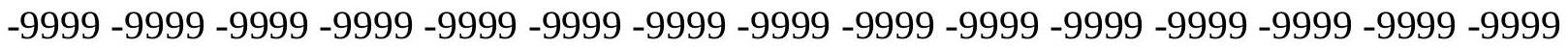

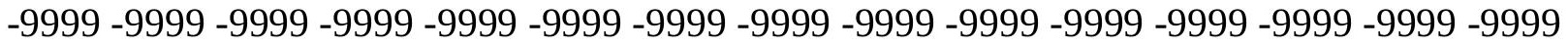
-9999 -9999 -9999 -9999 -9999 -9999 -9999 -9999 -9999 -9999 -9999 -9999 -9999 -9999 -9999

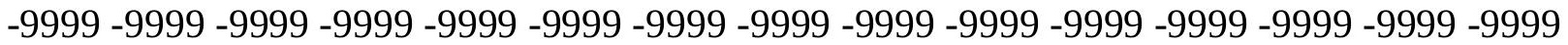
-9999 -9999 -9999 -9999 -9999 -9999 -9999 -9999 -9999 -9999 -9999 -9999 -9999 -9999 -9999 -9999 -9999 -9999 -9999 -9999 -9999 -9999 -9999 -9999 -9999 -9999 -9999 -9999 -9999 -9999 -

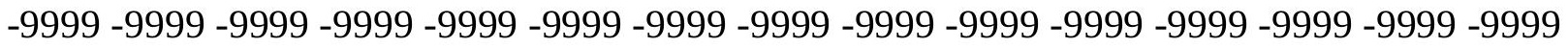
-9999 -9999 -9999 -9999 -9999 -9999 -9999 -9999 -9999 -9999 -9999 -9999 -9999 -9999 -9999

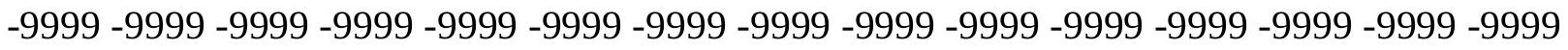
-9999 -9999 -9999 -9999 -9999 -9999 -9999 -9999 -9999 -9999 -9999 -9999 -9999 -9999 -9999 -9999 -9999 -9999 -9999 -9999 -9999 -9999 -9999 -9999 -9999 -9999 -9999 -9999 -9999 -9999 -9999 -9999 -9999 -9999 -9999 -9999 -9999 -9999 -9999 -9999 -9999 -9999 -9999 -9999 -9999 -9999 -9999 -9999 -9999 -9999 -9999 -9999 -9999 -9999 -9999 -9999 -9999 -9999 -9999 -9999 -9999 -9999 -9999 -9999 -9999 -9999 -9999 -9999 -9999 -9999 -9999 -9999 -9999 -9999 -9999 -999 -9999 -9999 -9999 -9999 -9999 -9999 -9999 -9999 -9999 -9999 -9999 -9999 -9999 -9999 -9999 -9999 -9999 -9999 -9999 -9999 -9999 -9999 -9999 -9999 -9999 -9999 -9999 -9999 -9999 -9999 -9999 -9999 -9999 -9999 -9999 -9999 -9999 -9999 -9999 -9999 -9999 -9999 -9999 -9999 -9999 -9999 -9999 -9999 -9999 -9999 -9999 -9999 -9999 -9999 -9999 -9999 -9999 -9999 -9999 -9999 -9999 -9999 -9999 -9999 -9999 -9999 -9999 -9999 -9999 -9999 -9999 -9999 -9999 -9999 -9999 -9999 -9999 -9999 -9999 -9999 -9999 -9999 -9999 -9999 -9999 -9999 -9999 -9999 -9999 -9999 -9999 -9999 -9999 -9999 -9999 -9999 -9999 -9999 -9999 -9999 -9999 -9999 -9999 -9999 -9999 -9999 -9999 -9999 -9999 -9999 -9999 -9999 -9999 -9999 -9999 -9999 -9999 -9999 -9999 -9999 -9999 -9999 -9999 -9999 -9999 -9999 -9999 -9999 -9999 -9999 -9999 -9999 -9999 -999 -9999 -9999 -9999 -9999 -9999 -9999 -9999 -9999 -9999 -9999 -9999 -9999 -9999 -9999 -9999 -9999 -9999 -9999 -9999 -9999 -9999 -9999 -9999 -9999 -9999 -9999 -9999 -9999 -9999 -9999 -

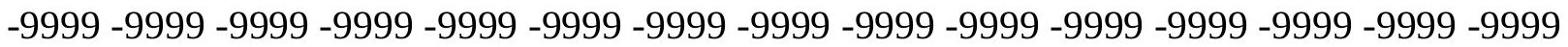

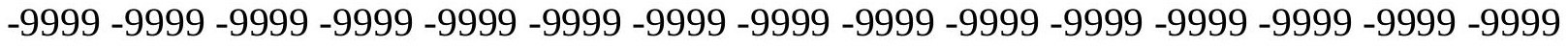

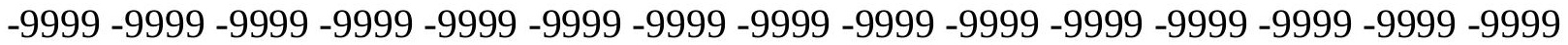
-9999 -9999 -9999 -9999 -9999 -9999 -9999 -9999 -9999 -9999 -9999 -9999 -9999 -9999 -9999

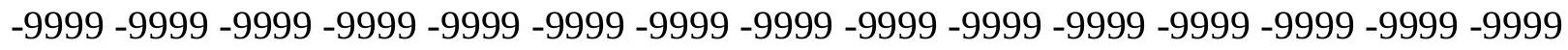

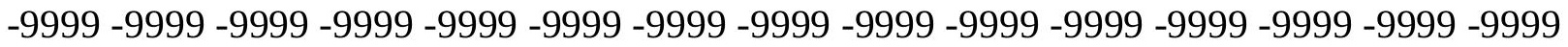
-9999 -9999 -9999 -9999 -9999 -9999 -9999 -9999 -9999 -9999 -9999 -9999 -9999 -9999 -9999 -9999 -9999 -9999 -9999 -9999 -9999 -9999 -9999 -9999 -9999 -9999 -9999 -9999 -9999 -9999 -

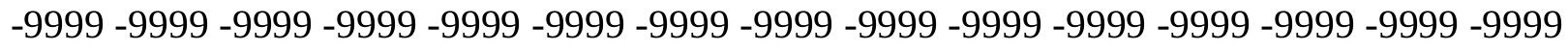

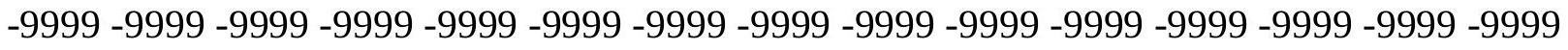
-9999 -9999 -9999 -9999 -9999 -9999 -9999 -9999 -9999 -9999 -9999 -9999 -9999 -9999 -9999 -9999 -9999 -9999 -9999 -9999 -9999 -9999 -9999 -9999-9999 -9999 -9999 -9999 -9999 -9999 -9999 -9999 -9999 -9999 -9999 -9999 -9999 -9999 -9999 -9999 -9999 -9999 -9999 -9999 -9999 -

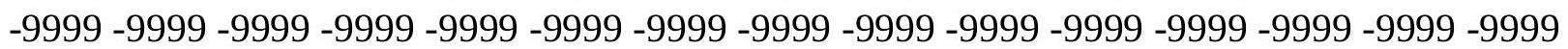


-9999 -9999 -9999 -9999 -9999 -9999 -9999 -9999 -9999 -9999 -9999 -9999 -9999 -9999 -9999 -9999 -9999 -9999 -9999 -9999 -9999 -9999 -9999 -9999 -9999 -9999 -9999 -9999 -9999 -9999 -9999 -9999 -9999 -9999 -9999 -9999 -9999 -9999 -9999 -9999 -9999 -9999 -9999 -9999 - 9999 -9999 -9999 -9999 -9999 -9999 -9999 -9999 -9999 -9999 -9999 -9999 -9999 -9999 -9999

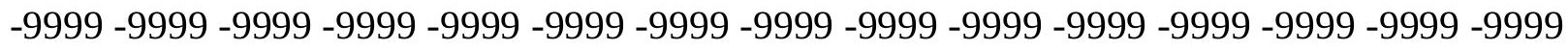
-9999 -9999 -9999 -9999 -9999 -9999 -9999 -9999 -9999 -9999 -9999 -9999 -9999 -9999 -9999 -9999 -9999 -9999 -9999 -9999 -9999 -9999 -9999 -9999 -9999 -9999 -9999 -9999 -9999 -9999

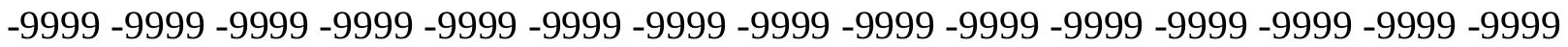

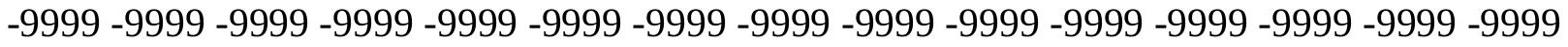
-9999 -9999 -9999 -9999 -9999 -9999 -9999 -9999 -9999 -9999 -9999 -9999 -9999 -9999 -9999 -9999 -9999 -9999 -9999 -9999 -9999 -9999 -9999 -9999 -9999 -9999 -9999 -9999 -9999 -9999 -9999 -9999 -9999 -9999 -9999 -9999 -9999 -9999 -9999 -9999 -9999 -9999 -9999 -9999 -9999 -9999 -9999 -9999 -9999 -9999 -9999 -9999 -9999 -9999 -9999 -9999 -9999 -9999 -9999 -9999 -

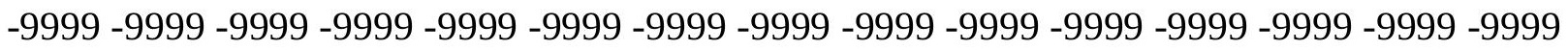
-9999 -9999 -9999 -9999 -9999 -9999 -9999 -9999 -9999 -9999 -9999 -9999 -9999 -9999 -9999 -

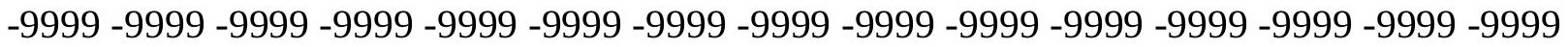
-9999 -9999 -9999 -9999 -9999 -9999 -9999 -9999 -9999 -9999 -9999 -9999 -9999 -9999 -9999 -9999 -9999 -9999 -9999 -9999 -9999 -9999 -9999 -9999 -9999 -9999 -9999 -9999 -9999 -9999 -9999 -9999 -9999 -9999 -9999 -9999 -9999 -9999 -9999 -9999 -9999 -9999 -9999 -9999 -9999 -

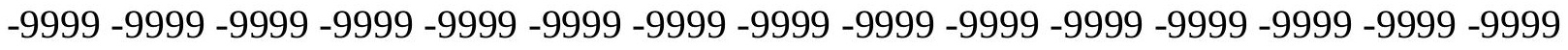
-9999 -9999 -9999 -9999 -9999 -9999 -9999 -9999 -9999 -9999 -9999 -9999 -9999 -9999 -9999

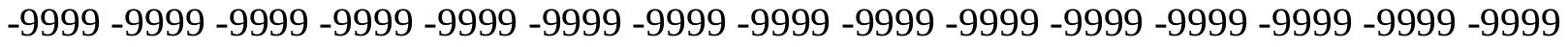
-9999 -9999 -9999 -9999 -9999 -9999 -9999 -9999 -9999 -9999 -9999 -9999 -9999 -9999 -9999 -9999 -9999 -9999 -9999 -9999 -9999 -9999 -9999 -9999 -9999 -9999 -9999 -9999 -9999 -9999 -9999 -9999 -9999 -9999 -9999 -9999 -9999 -9999 -9999 -9999 -9999 -9999 -9999 -9999 -9999 -9999 -9999 -9999 -9999 -9999 -9999 -9999 -9999 -9999 -9999 -9999 -9999 -9999 -9999 -9999 -9999 -9999 -9999 -9999 -9999 -9999 -9999 -9999 -9999 -9999 -9999 -9999 -9999 -9999 -9999 -9999 -9999 -9999 -9999 -9999 -9999 -9999 -9999 -9999 -9999 -9999 -9999 -9999 -9999 -9999 -9999 -9999 -9999 -9999 -9999 -9999 -9999 -9999 -9999 -9999 -9999 -9999 -9999 -9999 -9999 -9999 -9999 -9999 -9999 -9999 -9999 -9999 -9999 -9999 -9999 -9999 -9999 -9999 -9999 -9999 -9999 -9999 -9999 -9999 -9999 -9999 -9999 -9999 -9999 -9999 -9999 -9999 -9999 -9999 -9999 -9999 -9999 -9999 -9999 -9999 -9999 -9999 -9999 -9999 -9999 -9999 -9999 -9999 -9999 -

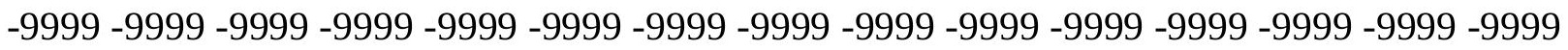

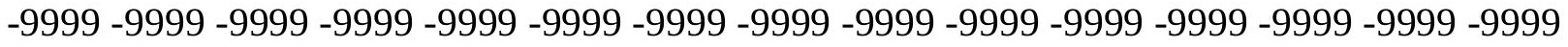
-9999 -9999 -9999 -9999 -9999 -9999 -9999 -9999 -9999 -9999 -9999 -9999 -9999 -9999 -9999 -

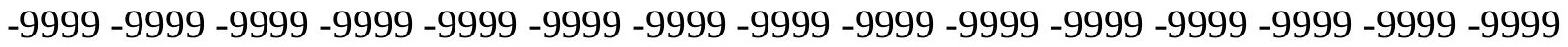

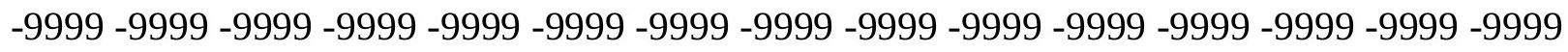

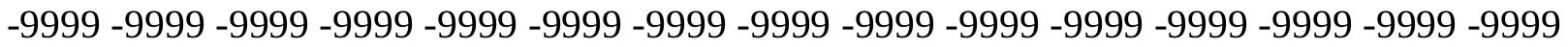

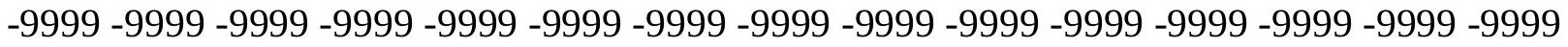
-9999 -9999 -9999 -9999 -9999 -9999 -9999 -9999 -9999 -9999 -9999 -9999 -9999 -9999 -9999 -

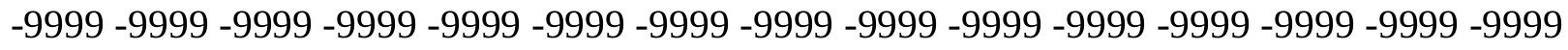

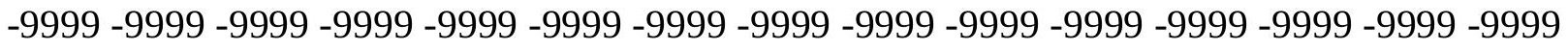
-9999 -9999 -9999 -9999 -9999 -9999 -9999 -9999 -9999 -9999 -9999 -9999 -9999 -9999 -9999 -9999 -9999 -9999 -9999 -9999 -9999 -9999 -9999 -9999-9999 -9999 -9999 -9999 -9999 -9999 -9999 -9999 -9999 -9999 -9999 -9999 -9999 -9999 -9999 -9999 -9999 -9999 -9999 -9999 -9999 -

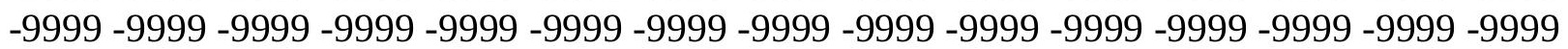


-9999 -9999 -9999 -9999 -9999 -9999 -9999 -9999 -9999 -9999 -9999 -9999 -9999 -9999 -9999 -9999 -9999 -9999 -9999 -9999 -9999 -9999 -9999 -9999 -9999 -9999 -9999 -9999 -9999 -9999 -9999 -9999 -9999 -9999 -9999 -9999 -9999 -9999 -9999 -9999 -9999 -9999 -9999 -9999 - 9999 -9999 -9999 -9999 -9999 -9999 -9999 -9999 -9999 -9999 -9999 -9999 -9999 -9999 -9999 -9999 -9999 -9999 -9999 -9999 -9999 -9999 -9999 -9999 -9999 -9999 -9999 -9999 -9999 -9999 -9999 -9999 -9999 -9999 -9999 -9999 -9999 -9999 -9999 -9999 -9999 -9999 -9999 -9999 -9999 -9999 -9999 -9999 -9999 -9999 -9999 -9999 -9999 -9999 -9999 -9999 -9999 -9999 -9999 -9999 -9999

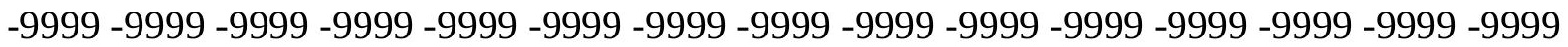

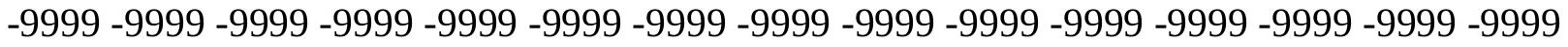
-9999 -9999 -9999 -9999 -9999 -9999 -9999 -9999 -9999 -9999 -9999 -9999 -9999 -9999 -9999 -9999 -9999 -9999 -9999 -9999 -9999 -9999 -9999 -9999 -9999 -9999 -9999 -9999 -9999 -9999 -9999 -9999 -9999 -9999 -9999 -9999 -9999 -9999 -9999 -9999 -9999 -9999 -9999 -9999 -9999 -9999 -9999 -9999 -9999 -9999 -9999 -9999 -9999 -9999 -9999 -9999 -9999 -9999 -9999 -9999 -9999 -9999 -9999 -9999 -9999 -9999 -9999 -9999 -9999 -9999 -9999 -9999 -9999 -9999 -9999 -9999 -9999 -9999 -9999 -9999 -9999 -9999 -9999 -9999 -9999 -9999 -9999 -9999 -9999 -

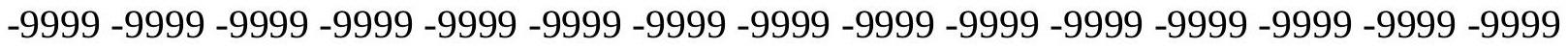
-9999 -9999 -9999 -9999 -9999 -9999 -9999 -9999 -9999 -9999 -9999 -9999 -9999 -9999 -9999 -9999 -9999 -9999 -9999 -9999 -9999 -9999 -9999 -9999 -9999 -9999 -9999 -9999 -9999 -9999 -9999 -9999 -9999 -9999 -9999 -9999 -9999 -9999 -9999 -9999 -9999 -9999 -9999 -9999 -9999 -9999 -9999 -9999 -9999 -9999 -9999 -9999 -9999 -9999 -9999 -9999 -9999 -9999 -9999 -9999 -9999 -9999 -9999 -9999 -9999 -9999 -9999 -9999 -9999 -9999 -9999 -9999 -9999 -9999 -9999 -999 -9999 -9999 -9999 -9999 -9999 -9999 -9999 -9999 -9999 -9999 -9999 -9999 -9999 -9999 -9999 -9999 -9999 -9999 -9999 -9999 -9999 -9999 -9999 -9999 -9999 -9999 -9999 -9999 -9999 -9999 -9999 -9999 -9999 -9999 -9999 -9999 -9999 -9999 -9999 -9999 -9999 -9999 -9999 -9999 -9999 -9999 -9999 -9999 -9999 -9999 -9999 -9999 -9999 -9999 -9999 -9999 -9999 -9999 -9999 -9999 -9999 -9999 -9999 -9999 -9999 -9999 -9999 -9999 -9999 -9999 -9999 -9999 -9999 -9999 -9999 -9999 -9999 -9999 -9999 -9999 -9999 -9999 -9999 -9999 -9999 -9999 -9999 -9999 -9999 -9999 -9999 -9999 -9999 -9999 -9999 -9999 -9999 -9999 -9999 -9999 -9999 -9999 -9999 -9999 -9999 -9999 -9999 -9999 -9999 -9999 -9999 -9999 -9999 -9999 -9999 -9999 -9999 -9999 -9999 -9999 -9999 -9999 -9999 -9999 -9999 -9999 -9999 -9999 -9999 -9999 -9999 -9999 -9999 -9999 -999 -9999 -9999 -9999 -9999 -9999 -9999 -9999 -9999 -9999 -9999 -9999 -9999 -9999 -9999 -9999 -9999 -9999 -9999 -9999 -9999 -9999 -9999 -9999 -9999 -9999 -9999 -9999 -9999 -9999 -9999 -

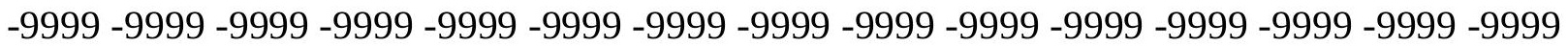

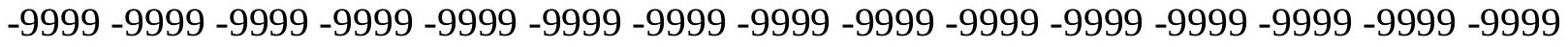

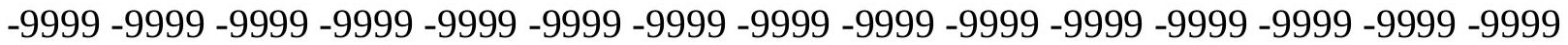
-9999 -9999 -9999 -9999 -9999 -9999 -9999 -9999 -9999 -9999 -9999 -9999 -9999 -9999 -9999 -9999 -9999 -9999 -9999 -9999 -9999 -9999 -9999 -9999 -9999 -9999 -9999 -9999 -9999 -

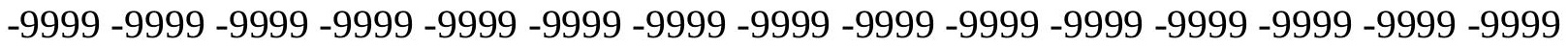
-9999 -9999 -9999 -9999 -9999 -9999 -9999 -9999 -9999 -9999 -9999 -9999 -9999 -9999 -9999 -9999 -9999 -9999 -9999 -9999 -9999 -9999 -9999 -9999 -9999 -9999 -9999 -9999 -9999 -9999 -

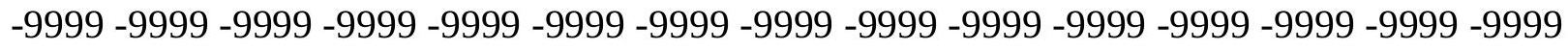

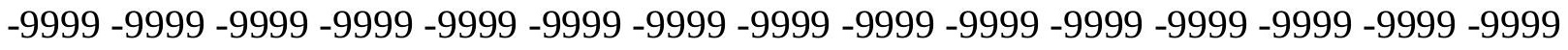
-9999 -9999 -9999 -9999 -9999 -9999 -9999 -9999 -9999 -9999 -9999 -9999 -9999 -9999 -9999 -9999 -9999 -9999 -9999 -9999 -9999 -9999 -9999 -9999-9999 -9999 -9999 -9999 -9999 -9999 -9999 -9999 -9999 -9999 -9999 -9999 -9999 -9999 -9999 -9999 -9999 -9999 -9999 -9999 -9999 -

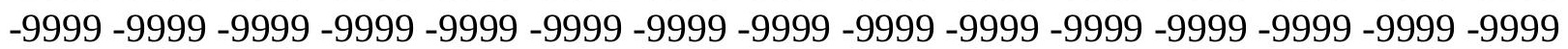


-9999 -9999 -9999 -9999 -9999 -9999 -9999 -9999 -9999 -9999 -9999 -9999 -9999 -9999 -9999 -9999 -9999 -9999 -9999 -9999 -9999 -9999 -9999 -9999 -9999 -9999 -9999 -9999 -9999 -9999 -

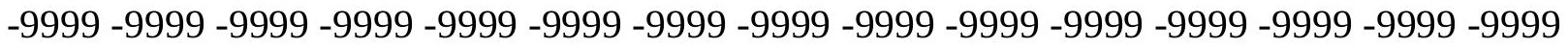
-9999 -9999 -9999 -9999 -9999 -9999 -9999 -9999 -9999 -9999 -9999 -9999 -9999 -9999 -9999 -9999 -9999 -9999 -9999 -9999 -9999 -9999 -9999 -9999-9999 -9999 -9999 -9999 -9999 -9999 -9999 -9999 -9999 -9999 -9999 -9999 -9999 -9999 -9999 -9999 -9999 -9999 -9999 -9999 -9999 -9999 -9999 -9999 -9999 -9999 -9999 -9999 -9999 -9999 -9999 -9999 -9999 -9999 -9999 -9999

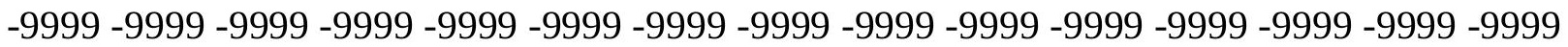

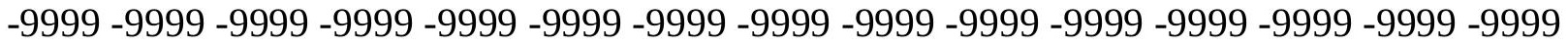
-9999 -9999 -9999 -9999 -9999 -9999 -9999 -9999 -9999 -9999 -9999 -9999 -9999 -9999 -9999 -9999 -9999 -9999 -9999 -9999 -9999 -9999 -9999 -9999 -9999 -9999 -9999 -9999 -9999 -9999 -9999 -9999 -9999 -9999 -9999 -9999 -9999 -9999 -9999 -9999 -9999 -9999 -9999 -9999 -9999 -9999 -9999 -9999 -9999 -9999 -9999 -9999 -9999 -9999 -9999 -9999 -9999 -9999 -9999 -9999 -9999 -9999 -9999 -9999 -9999 -9999 -9999 -9999 -9999 -9999 -9999 -9999 -9999 -9999 -9999 -9999 -9999 -9999 -9999 -9999 -9999 -9999 -9999 -9999 -9999 -9999 -9999 -9999 -9999 -9999 -

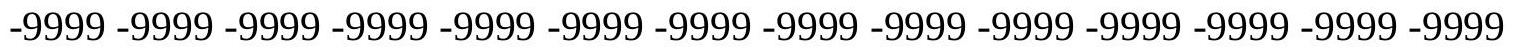
-9999 -9999 -9999 -9999 -9999 -9999 -9999 -9999 -9999 -9999 -9999 -9999 -9999 -9999 -9999 -9999 -9999 -9999 -9999 -9999 -9999 -9999 -9999 -9999 -9999 -9999 -9999 -9999 -9999 -9999 -9999 -9999 -9999 -9999 -9999 -9999 -9999 -9999 -9999 -9999 -9999 -9999 -9999 -9999 -9999 -

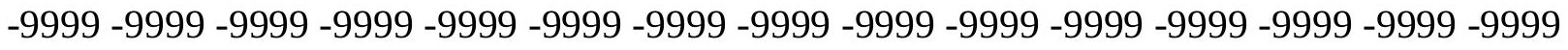

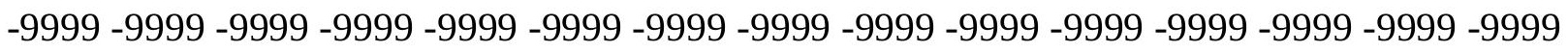
-9999 -9999 -9999 -9999 -9999 -9999 -9999 -9999 -9999 -9999 -9999 -9999 -9999 -9999 - 9999 -9999 -9999 -9999 -9999 -9999 -9999 -9999 -9999 -9999 -9999 -9999 -9999 -9999 -9999 -9999 -9999 -9999 -9999 -9999 -9999 -9999 -9999 -9999 -9999 -9999 -9999 -9999 -9999 -9999 -9999 -

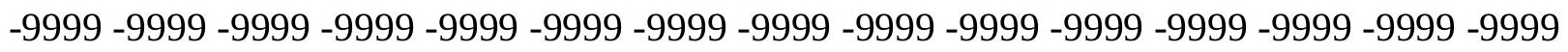
-9999 -9999 -9999 -9999 -9999 -9999 -9999 -9999 -9999 -9999 -9999 -9999 -9999 -9999 -9999 -9999 -9999 -9999 -9999 -9999 -9999 -9999 -9999 -9999 -9999 -9999 -9999 -9999 -9999 -9999 -

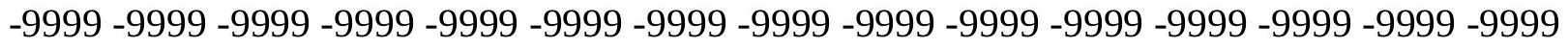
-9999 -9999 -9999 -9999 -9999 -9999 -9999 -9999 -9999 -9999 -9999 -9999 -9999 -9999 -9999 -9999 -9999 -9999 -9999 -9999 -9999 -9999 -9999 -9999 -9999 -9999 -9999 -9999 -9999 -999 -

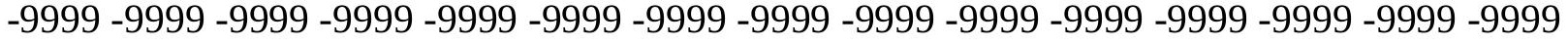
-9999 -9999 -9999 -9999 -9999 -9999 -9999 -9999 -9999 -9999 -9999 -9999 -9999 -9999 -9999 -

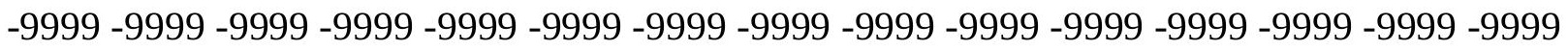

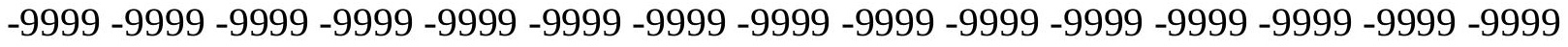

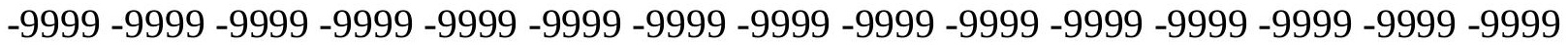
-9999 -9999 -9999 -9999 -9999 -9999 -9999 -9999 -9999 -9999 -9999 -9999 -9999 -9999 -9999 -

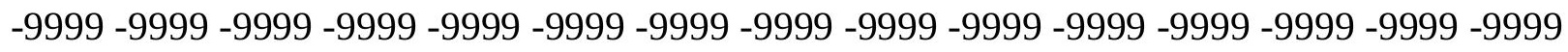

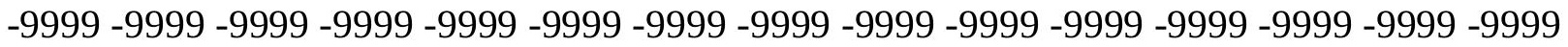
-9999 -9999 -9999 -9999 -9999 -9999 -9999 -9999 -9999 -9999 -9999 -9999 -9999 - 9999 - -999 -9999 -9999 -9999 -9999 -9999 -9999 -9999 -9999 -9999 -9999 -9999 -9999 -9999 -9999 -9999 -

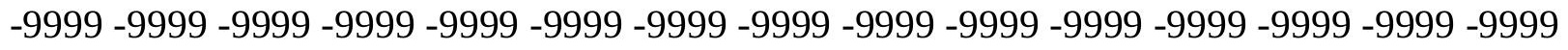

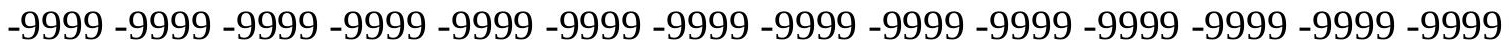
-9999 -9999 -9999 -9999 -9999 -9999 -9999 -9999 -9999 -9999 -9999 -9999 -9999 -9999 -9999 -9999 -9999 -9999 -9999 -9999 -9999 -9999 -9999 -9999-9999 -9999 -9999 -9999 -9999 -9999 -9999 -9999 -9999 -9999 -9999 -9999 -9999 -9999 -9999 -9999 -9999 -9999 -9999 -9999 -9999 -

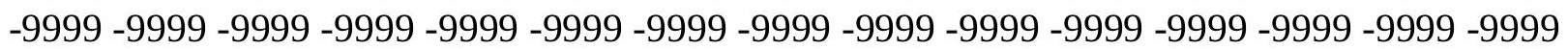


-9999 -9999 -9999 -9999 -9999 -9999 -9999 -9999 -9999 -9999 -9999 -9999 -9999 -9999 -9999 -9999 -9999 -9999 -9999 -9999 -9999 -9999 -9999 -9999 -9999 -9999 -9999 -9999 -9999 -9999 -

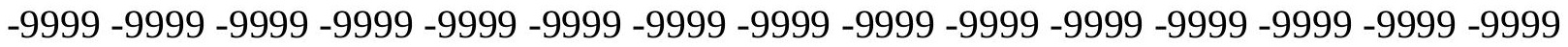
-9999 -9999 -9999 -9999 -9999 -9999 -9999 -9999 -9999 -9999 -9999 -9999 -9999 -9999 -9999 -9999 -9999 -9999 -9999 -9999 -9999 -9999 -9999 -9999-9999 -9999 -9999 -9999 -9999 -9999 -9999 -9999 -9999 -9999 -9999 -9999 -9999 -9999 -9999 -9999 -9999 -9999 -9999 -9999 -9999 -9999 -9999 -9999 -9999 -9999 -9999 -9999 -9999 -9999 -9999 -9999 -9999 -9999 -9999 -9999

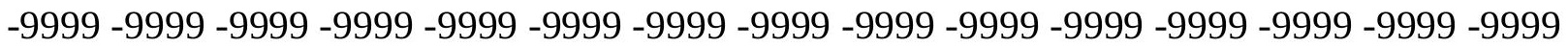

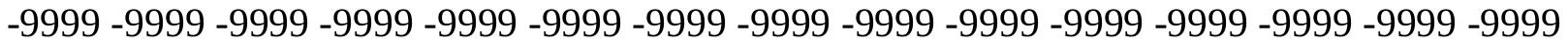
-9999 -9999 -9999 -9999 -9999 -9999 -9999 -9999 -9999 -9999 -9999 -9999 -9999 -9999 -9999 -9999 -9999 -9999 -9999 -9999 -9999 -9999 -9999 -9999 -9999 -9999 -9999 -9999 -9999 -9999 -9999 -9999 -9999 -9999 -9999 -9999 -9999 -9999 -9999 -9999 -9999 -9999 -9999 -9999 -9999 -9999 -9999 -9999 -9999 -9999 -9999 -9999 -9999 -9999 -9999 -9999 -9999 -9999 -9999 -9999 -

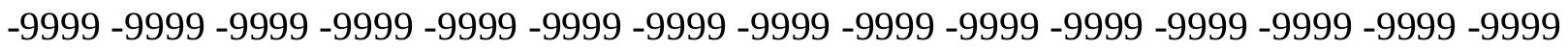
-9999 -9999 -9999 -9999 -9999 -9999 -9999 -9999 -9999 -9999 -9999 -9999 -9999 -9999 -9999 -

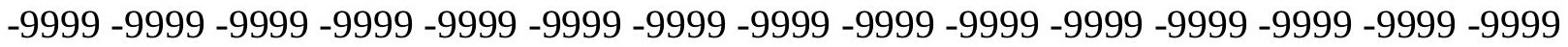
-9999 -9999 -9999 -9999 -9999 -9999 -9999 -9999 -9999 -9999 -9999 -9999 -9999 -9999 -9999 -9999 -9999 -9999 -9999 -9999 -9999 -9999 -9999 -9999 -9999 -9999 -9999 -9999 -9999 -9999 -9999 -9999 -9999 -9999 -9999 -9999 -9999 -9999 -9999 -9999 -9999 -9999 -9999 -9999 -9999 -

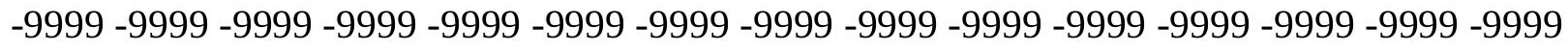

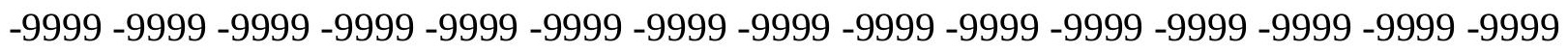
-9999 -9999 -9999 -9999 -9999 -9999 -9999 -9999 -9999 -9999 -9999 -9999 -9999 -9999 -9999 -9999 -9999 -9999 -9999 -9999 -9999 -9999 -9999 -9999 -9999 -9999 -9999 -9999 -9999 -9999 -9999 -9999 -9999 -9999 -9999 -9999 -9999 -9999 -9999 -9999 -9999 -9999 -9999 -9999 -

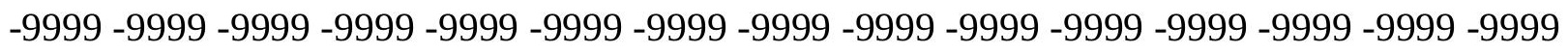
-9999 -9999 -9999 -9999 -9999 -9999 -9999 -9999 -9999 -9999 -9999 -9999 -9999 -9999 -9999 -9999 -9999 -9999 -9999 -9999 -9999 -9999 -9999 -9999 -9999 -9999 -9999 -9999 -9999 -9999 -

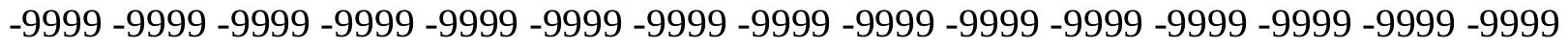
-9999 -9999 -9999 -9999 -9999 -9999 -9999 -9999 -9999 -9999 -9999 -9999 -9999 -9999 -9999 -9999 -9999 -9999 -9999 -9999 -9999 -9999 -9999 -9999 -9999 -9999 -9999 -9999 -9999 -999 -

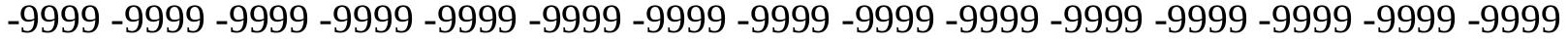
-9999 -9999 -9999 -9999 -9999 -9999 -9999 -9999 -9999 -9999 -9999 -9999 -9999 -9999 -9999 -

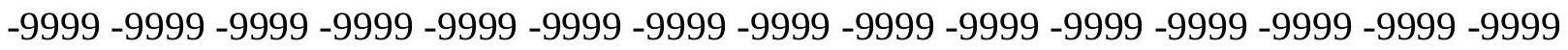

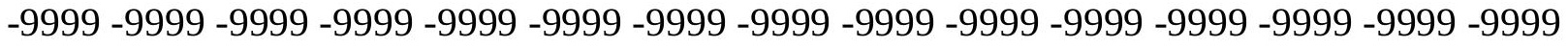

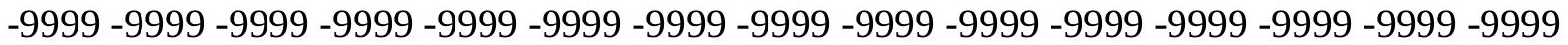

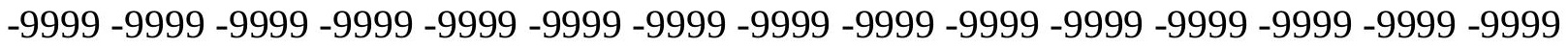

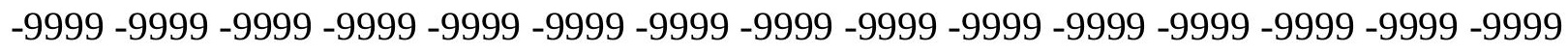

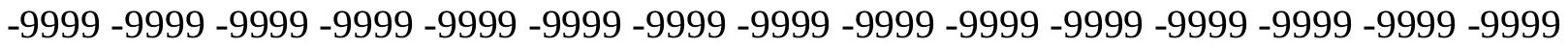

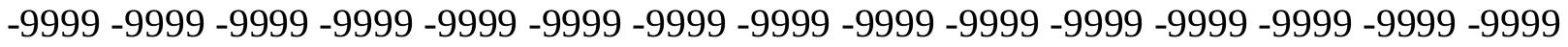
-9999 -9999 -9999 -9999 -9999 -9999 -9999 -9999 -9999 -9999 -9999 -9999 -9999 -9999 -9999 -

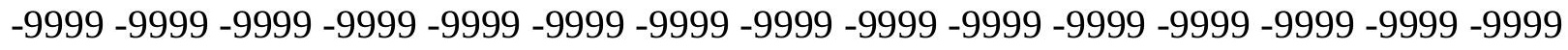

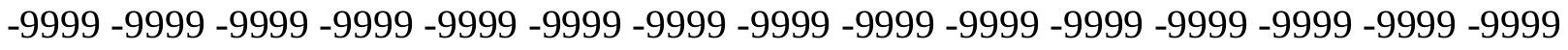
-9999 -9999 -9999 -9999 -9999 -9999 -9999 -9999 -9999 -9999 -9999 -9999 -9999 -9999 -9999 -9999 -9999 -9999 -9999 -9999 -9999 -9999 -9999 -9999-9999 -9999 -9999 -9999 -9999 -9999 -9999 -9999 -9999 -9999 -9999 -9999 -9999 -9999 -9999 -9999 -9999 -9999 -9999 -9999 -9999 -

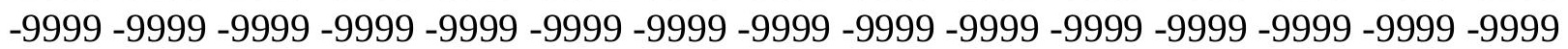


-9999 -9999 -9999 -9999 -9999 -9999 -9999 -9999 -9999 -9999 -9999 -9999 -9999 -9999 -9999 -9999 -9999 -9999 -9999 -9999 -9999 -9999 -9999 -9999 -9999 -9999 -9999 -9999 -9999 -

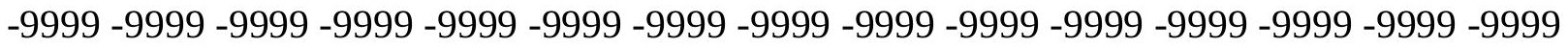
-9999 -9999 -9999 -9999 -9999 -9999 -9999 -9999 -9999 -9999 -9999 -9999 -9999 -9999 -9999 -9999 -9999 -9999 -9999 -9999 -9999 -9999 -9999 -9999 -9999 -9999 -9999 -9999 -9999 -9999 -9999 -9999 -9999 -9999 -9999 -9999 -9999 -9999 -9999 -9999 -9999 -9999 -9999 -9999 -9999 -9999 -9999 -9999 -9999 -9999 -9999 -9999 -9999 -9999 -9999 -9999 -9999 -9999 -9999 -9999

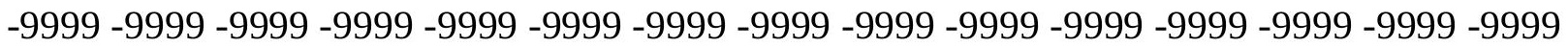

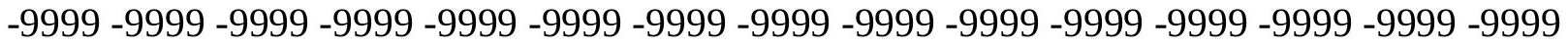
-9999 -9999 -9999 -9999 -9999 -9999 -9999 -9999 -9999 -9999 -9999 -9999 -9999 -9999 -9999 -9999 -9999 -9999 -9999 -9999 -9999 -9999 -9999 -9999 -9999 -9999 -9999 -9999 -9999 -9999 -9999 -9999 -9999 -9999 -9999 -9999 -9999 -9999 -9999 -9999 -9999 -9999 -9999 -9999 -9999 -9999 -9999 -9999 -9999 -9999 -9999 -9999 -9999 -9999 -9999 -9999 -9999 -9999 -9999 -9999 -9999 -9999 -9999 -9999 -9999 -9999 -9999 -9999 -9999 -9999 -9999 -9999 -9999 -9999 -9999 -9999 -9999 -9999 -9999 -9999 -9999 -9999 -9999 -9999 -9999 -9999 -9999 -9999 -9999 -9999 -

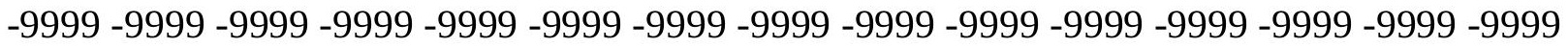
-9999 -9999 -9999 -9999 -9999 -9999 -9999 -9999 -9999 -9999 -9999 -9999 -9999 -9999 -9999 -9999 -9999 -9999 -9999 -9999 -9999 -9999 -9999 -9999 -9999 -9999 -9999 -9999 -9999 - 9999 -9999 -9999 -9999 -9999 -9999 -9999 -9999 -9999 -9999 -9999 -9999 -9999 -9999 -9999 -9999 -

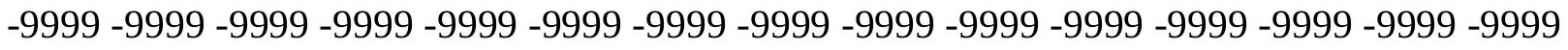

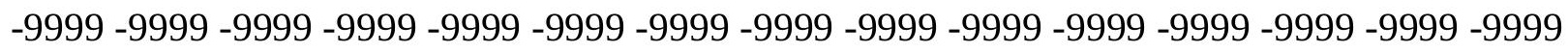

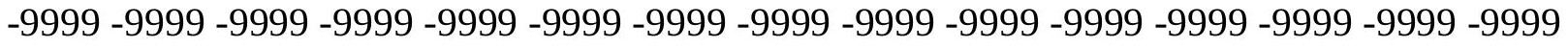
-9999 -9999 -9999 -9999 -9999 -9999 -9999 -9999 -9999 -9999 -9999 -9999 -9999 -9999 -9999 -9999 -9999 -9999 -9999 -9999 -9999 -9999 -9999 -9999 -9999 -9999 -9999 -9999 -9999 -9999 -

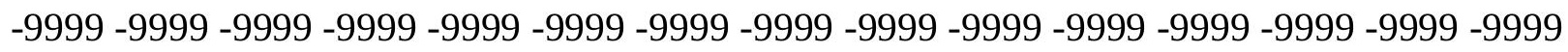
-9999 -9999 -9999 -9999 -9999 -9999 -9999 -9999 -9999 -9999 -9999 -9999 -9999 -9999 -9999 -9999 -9999 -9999 -9999 -9999 -9999 -9999 -9999 -9999 -9999 -9999 -9999 -9999 -9999 -9999 -9999 -9999 -9999 -9999 -9999 -9999 -9999 -9999 -9999 -9999 -9999 -9999 -9999 -9999 -9999 -9999 -9999 -9999 -9999 -9999 -9999 -9999 -9999 -9999 -9999 -9999 -9999 -9999 -9999 -9999 -9999 -9999 -9999 -9999 -9999 -9999 -9999 -9999 -9999 -9999 -9999 -9999 -9999 -999 -

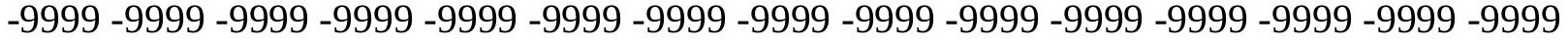
-9999 -9999 -9999 -9999 -9999 -9999 -9999 -9999 -9999 -9999 -9999 -9999 -9999 -9999 -9999 -

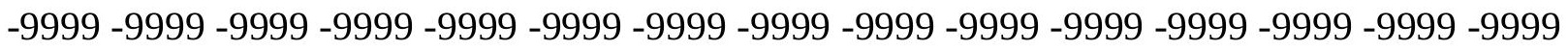

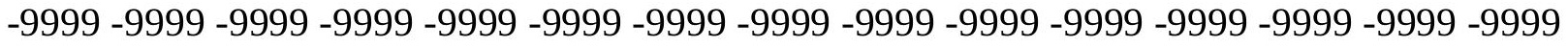

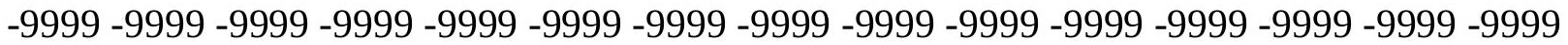

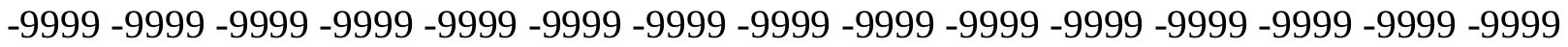

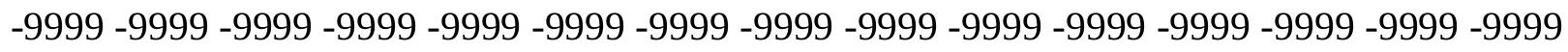

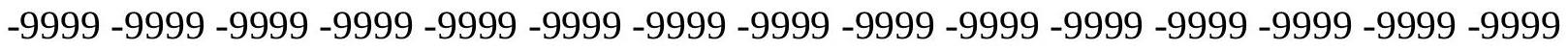

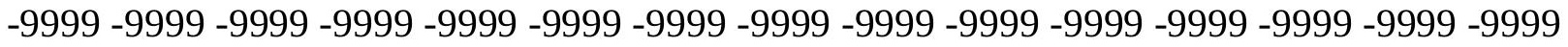
-9999 -9999 -9999 -9999 -9999 -9999 -9999 -9999 -9999 -9999 -9999 -9999 -9999 -9999 -9999 -

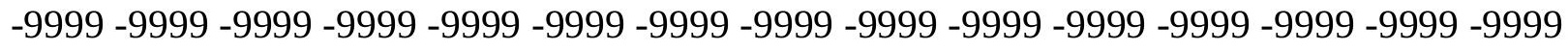

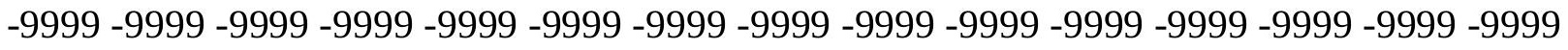
-9999 -9999 -9999 -9999 -9999 -9999 -9999 -9999 -9999 -9999 -9999 -9999 -9999 -9999 -9999 -9999 -9999 -9999 -9999 -9999 -9999 -9999 -9999 -9999-9999 -9999 -9999 -9999 -9999 -9999 -9999 -9999 -9999 -9999 -9999 -9999 -9999 -9999 -9999 -9999 -9999 -9999 -9999 -9999 -9999 -

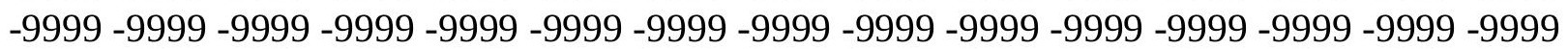


-9999 -9999 -9999 -9999 -9999 -9999 -9999 -9999 -9999 -9999 -9999 -9999 -9999 -9999 -9999 -9999 -9999 -9999 -9999 -9999 -9999 -9999 -9999 -9999 -9999 -9999 -9999 -9999 -9999 -9999 -

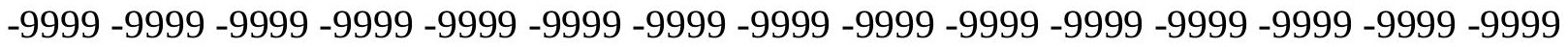
-9999 -9999 -9999 -9999 -9999 -9999 -9999 -9999 -9999 -9999 -9999 -9999 -9999 -9999 -9999 -9999 -9999 -9999 -9999 -9999 -9999 -9999 -9999 -9999-9999 -9999 -9999 -9999 -9999 -9999 -9999 -9999 -9999 -9999 -9999 -9999 -9999 -9999 -9999 -9999 -9999 -9999 -9999 -9999 -9999 -

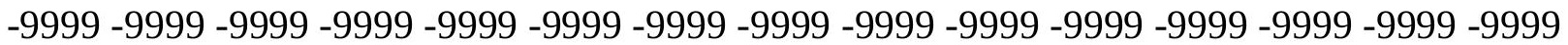
-9999 -9999 -9999 -9999 -9999 -9999 -9999 -9999 -9999 -9999 -9999 -9999 -9999 -9999 -9999 -9999 -9999 -9999 -9999 -9999 -9999 -9999 -9999 -9999 -9999 -9999 -9999 -9999 -9999 -9999 -9999 -9999 -9999 -9999 -9999 -9999 -9999 -9999 -9999 -9999 -9999 -9999 -9999 -9999 -9999 -9999 -9999 -9999 -9999 -9999 -9999 -9999 -9999 -9999 -9999 -9999 -9999 -9999 -9999 -9999 -9999 -9999 -9999 -9999 -9999 -9999 -9999 -9999 -9999 -9999 -9999 -9999 -9999 -9999 -9999 -9999 -9999 -9999 -9999 -9999 -9999 -9999 -9999 -9999 -9999 -9999 -9999 -9999 -9999 -9999 -9999 -9999 -9999 -9999 -9999 -9999 -9999 -9999 -9999 -9999 -9999 -9999 -9999 -9999 -9999 -9999 -9999 -9999 -9999 -9999 -9999 -9999 -9999 -9999 -9999 -9999 -9999 -9999 -9999 -

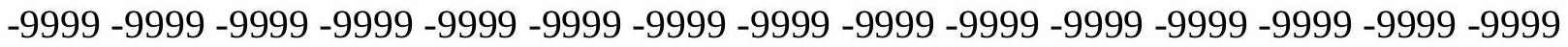
-9999 -9999 -9999 -9999 -9999 -9999 -9999 -9999 -9999 -9999 -9999 -9999 -9999 -9999 -9999 -9999 -9999 -9999 -9999 -9999 -9999 -9999 -9999 -9999 -9999 -9999 -9999 -9999 -9999 -9999 -9999 -9999 -9999 -9999 -9999 -9999 -9999 -9999 -9999 -9999 -9999 -9999 -9999 -9999 -9999 -

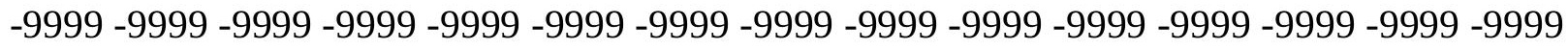

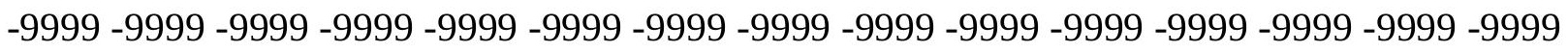
-9999 -9999 -9999 -9999 -9999 -9999 -9999 -9999 -9999 -9999 -9999 -9999 -9999 -9999 - 9999 -9999 -9999 -9999 -9999 -9999 -9999 -9999 -9999 -9999 -9999 -9999 -9999 -9999 -9999 -9999 -9999 -9999 -9999 -9999 -9999 -9999 -9999 -9999 -9999 -9999 -9999 -9999 -9999 -9999 -9999 -

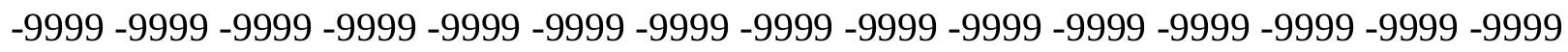
-9999 -9999 -9999 -9999 -9999 -9999 -9999 -9999 -9999 -9999 -9999 -9999 -9999 -9999 -9999 -9999 -9999 -9999 -9999 -9999 -9999 -9999 -9999 -9999 -9999 -9999 -9999 -9999 -9999 -9999 -

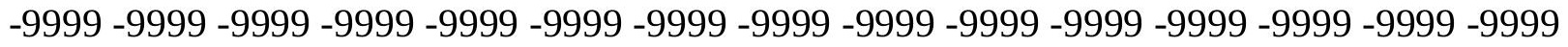
-9999 -9999 -9999 -9999 -9999 -9999 -9999 -9999 -9999 -9999 -9999 -9999 -9999 -9999 -9999 -9999 -9999 -9999 -9999 -9999 -9999 -9999 -9999 -9999 -9999 -9999 -9999 -9999 -9999 -999 -9999 -9999 -9999 -9999 -9999 -9999 -9999 -9999 -9999 -9999 -9999 -9999 -9999 -9999 -9999 -9999 -9999 -9999 -9999 -9999 -9999 -9999 -9999 -9999 -9999 -9999 -9999 -9999 -9999 -9999 -

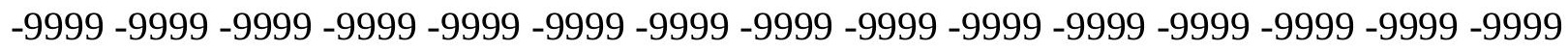

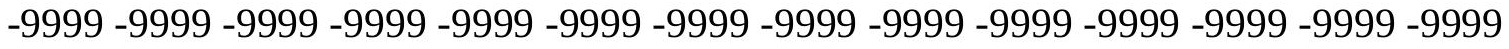
-9999 -9999 -9999 -9999 -9999 -9999 -9999 -9999 -9999 -9999 -9999 -9999 -9999 -9999 -9999

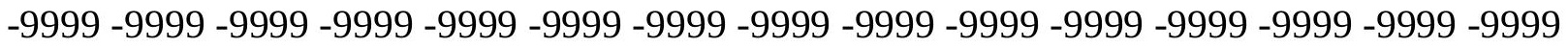

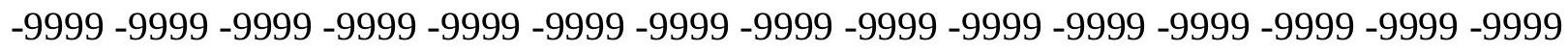

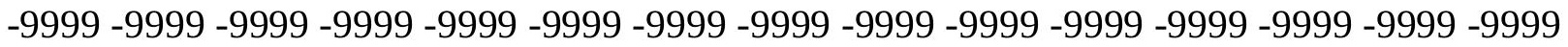

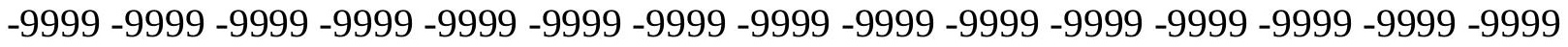
-9999 -9999 -9999 -9999 -9999 -9999 -9999 -9999 -9999 -9999 -9999 -9999 -9999 -9999 -9999 -

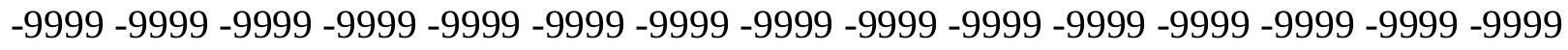

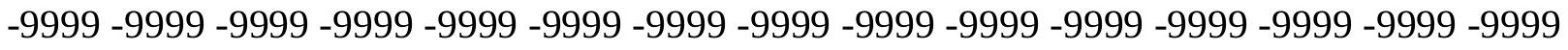
-9999 -9999 -9999 -9999 -9999 -9999 -9999 -9999 -9999 -9999 -9999 -9999 -9999 -9999 -9999 -9999 -9999 -9999 -9999 -9999 -9999 -9999 -9999 -9999-9999 -9999 -9999 -9999 -9999 -9999 -9999 -9999 -9999 -9999 -9999 -9999 -9999 -9999 -9999 -9999 -9999 -9999 -9999 -9999 -9999 -

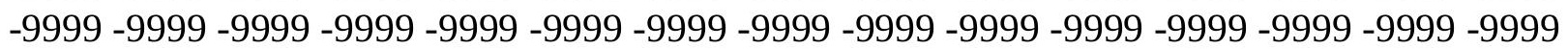


-9999 -9999 -9999 -9999 -9999 -9999 -9999 -9999 -9999 -9999 -9999 -9999 -9999 -9999 -9999 -9999 -9999 -9999 -9999 -9999 -9999 -9999 -9999 -9999 -9999 -9999 -9999 -9999 -9999 -9999 -

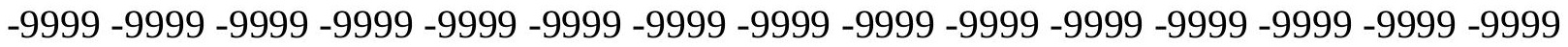
-9999 -9999 -9999 -9999 -9999 -9999 -9999 -9999 -9999 -9999 -9999 -9999 -9999 -9999 -9999 -9999 -9999 -9999 -9999 -9999 -9999 -9999 -9999 -9999-9999 -9999 -9999 -9999 -9999 -9999 -9999 -9999 -9999 -9999 -9999 -9999 -9999 -9999 -9999 -9999 -9999 -9999 -9999 -9999 -9999 -9999 -9999 -9999 -9999 -9999 -9999 -9999 -9999 -9999 -9999 -9999 -9999 -9999 -9999 -9999

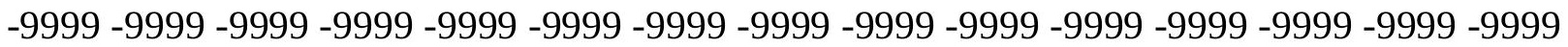

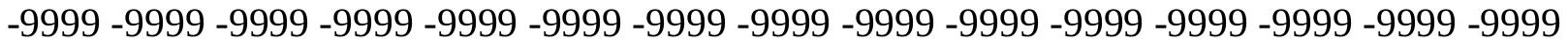
-9999 -9999 -9999 -9999 -9999 -9999 -9999 -9999 -9999 -9999 -9999 -9999 -9999 -9999 -9999 -9999 -9999 -9999 -9999 -9999 -9999 -9999 -9999 -9999 -9999 -9999 -9999 -9999 -9999 -9999 -9999 -9999 -9999 -9999 -9999 -9999 -9999 -9999 -9999 -9999 -9999 -9999 -9999 -9999 -9999 -9999 -9999 -9999 -9999 -9999 -9999 -9999 -9999 -9999 -9999 -9999 -9999 -9999 -9999 -9999 -9999 -9999 -9999 -9999 -9999 -9999 -9999 -9999 -9999 -9999 -9999 -9999 -9999 -9999 -9999 -9999 -9999 -9999 -9999 -9999 -9999 -9999 -9999 -9999 -9999 -9999 -9999 -9999 -9999

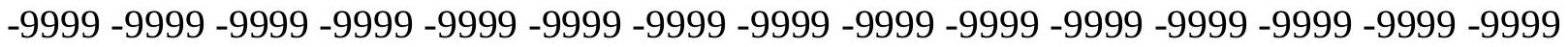
-9999 -9999 -9999 -9999 -9999 -9999 -9999 -9999 -9999 -9999 -9999 -9999 -9999 -9999 -9999 -9999 -9999 -9999 -9999 -9999 -9999 -9999 -9999 -9999 -9999 -9999 -9999 -9999 -9999 -9999 -9999 -9999 -9999 -9999 -9999 -9999 -9999 -9999 -9999 -9999 -9999 -9999 -9999 -9999 -9999 -

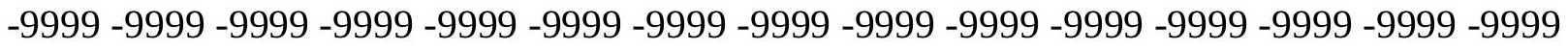

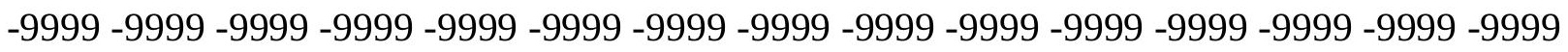
-9999 -9999 -9999 -9999 -9999 -9999 -9999 -9999 -9999 -9999 -9999 -9999 -9999 -9999 -9999 -9999 -9999 -9999 -9999 -9999 -9999 -9999 -9999 -9999 -9999 -9999 -9999 -9999 -9999 -9999 -9999 -9999 -9999 -9999 -9999 -9999 -9999 -9999 -9999 -9999 -9999 -9999 -9999 -9999 -9999 -

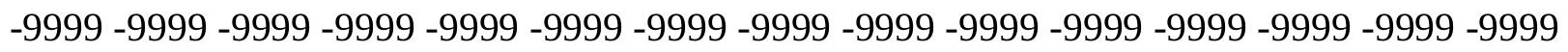
-9999 -9999 -9999 -9999 -9999 -9999 -9999 -9999 -9999 -9999 -9999 -9999 -9999 -9999 -9999 -9999 -9999 -9999 -9999 -9999 -9999 -9999 -9999 -9999 -9999 -9999 -9999 -9999 -9999 -9999 -

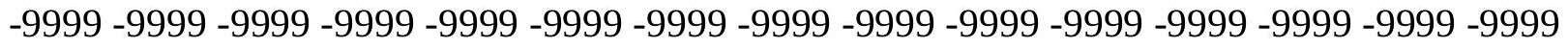
-9999 -9999 -9999 -9999 -9999 -9999 -9999 -9999 -9999 -9999 -9999 -9999 -9999 -9999 -9999 -9999 -9999 -9999 -9999 -9999 -9999 -9999 -9999 -9999 -9999 -9999 -9999 -9999 -9999 -999 -9999 -9999 -9999 -9999 -9999 -9999 -9999 -9999 -9999 -9999 -9999 -9999 -9999 -9999 -9999 -9999 -9999 -9999 -9999 -9999 -9999 -9999 -9999 -9999 -9999 -9999 -9999 -9999 -9999 -9999 -

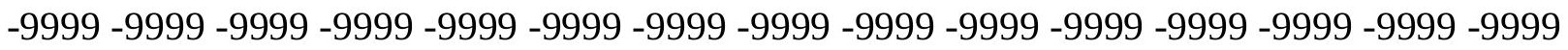

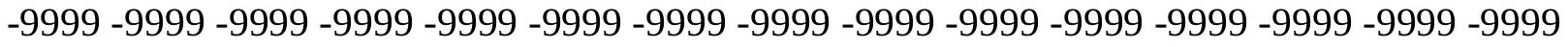

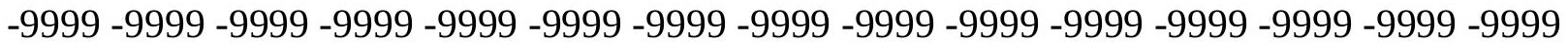

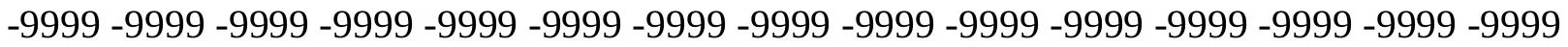

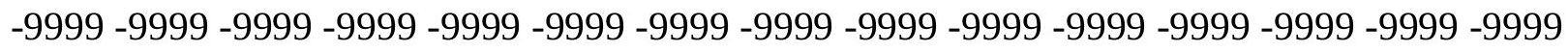

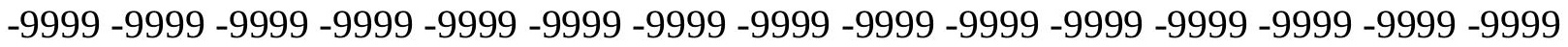
-9999 -9999 -9999 -9999 -9999 -9999 -9999 -9999 -9999 -9999 -9999 -9999 -9999 - 9999 - -999 -9999 -9999 -9999 -9999 -9999 -9999 -9999 -9999 -9999 -9999 -9999 -9999 -9999 -9999 - -999 -

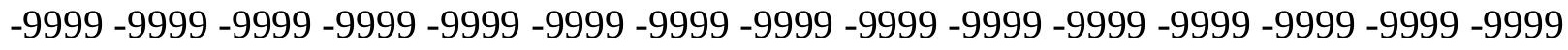

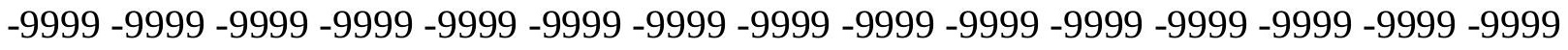
-9999 -9999 -9999 -9999 -9999 -9999 -9999 -9999 -9999 -9999 -9999 -9999 -9999 -9999 -9999 -9999 -9999 -9999 -9999 -9999 -9999 -9999 -9999 -9999-9999 -9999 -9999 -9999 -9999 -9999 -9999 -9999 -9999 -9999 -9999 -9999 -9999 -9999 -9999 -9999 -9999 -9999 -9999 -9999 -9999 -

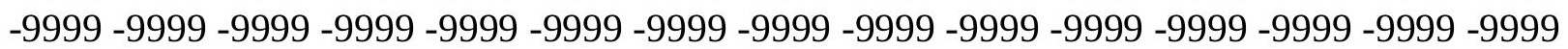


-9999 -9999 -9999 -9999 -9999 -9999 -9999 -9999 -9999 -9999 -9999 -9999 -9999 -9999 -9999 -9999 -9999 -9999 -9999 -9999 -9999 -9999 -9999 -9999 -9999 -9999 -9999 -9999 -9999 -9999 -9999 -9999 -9999 -9999 -9999 -9999 -9999 -9999 -9999 -9999 -9999 -9999 -9999 -9999 -9999 -9999 -9999 -9999 -9999 -9999 -9999 -9999 -9999 -9999 -9999 -9999 -9999 -9999 -9999 -9999 -9999 -9999 -9999 -9999 -9999 -9999 -9999 -9999 -9999 -9999 -9999 -9999 -9999 -9999 -9999 -9999 -9999 -9999 -9999 -9999 -9999 -9999 -9999 -9999 -9999 -9999 -9999 -9999 -9999 -9999 -9999 -9999 -9999 -9999 -9999 -9999 -9999 -9999 -9999 -9999 -9999 -9999 -9999 -9999 -9999 -

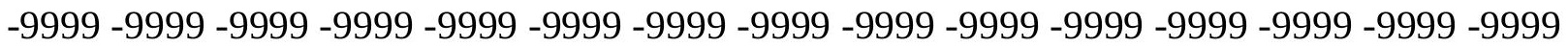
-9999 -9999 -9999 -9999 -9999 -9999 -9999 -9999 -9999 -9999 -9999 -9999 -9999 -9999 -9999 -9999 -9999 -9999 -9999 -9999 -9999 -9999 -9999 -9999 -9999 -9999 -9999 -9999 -9999 -9999 -

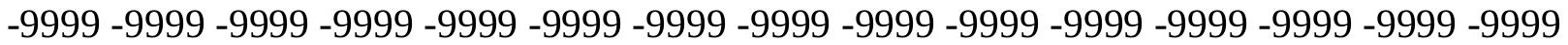
-9999 -9999 -9999 -9999 -9999 -9999 -9999 -9999 -9999 -9999 -9999 -9999 -9999 -9999 -9999 -9999 -9999 -9999 -9999 -9999 -9999 -9999 -9999 -9999 -9999 -9999 -9999 -9999 -9999 -9999 -9999 -9999 -9999 -9999 -9999 -9999 -9999 -9999 -9999 -9999 -9999 -9999 -9999 -9999 -9999 -9999 -9999 -9999 -9999 -9999 -9999 -9999 -9999 -9999 -9999 -9999 -9999 -9999 -9999 -9999

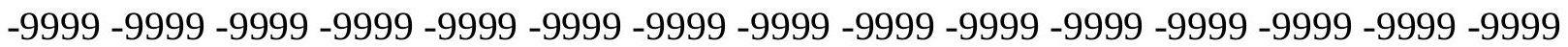
-9999 -9999 -9999 -9999 -9999 -9999 -9999 -9999 -9999 -9999 -9999 -9999 -9999 -9999 -9999 -9999 -9999 -9999 -9999 -9999 -9999 -9999 -9999 -9999 -9999 -9999 -9999 -9999 -9999 -9999 -9999 -9999 -9999 -9999 -9999 -9999 -9999 -9999 -9999 -9999 -9999 -9999 -9999 -9999 -9999 -9999 -9999 -9999 -9999 -9999 -9999 -9999 -9999 -9999 -9999 -9999 -9999 -9999 -9999 -9999 -9999 -9999 -9999 -9999 -9999 -9999 -9999 -9999 -9999 -9999 -9999 -9999 -9999 -9999 -9999 -9999 -9999 -9999 -9999 -9999 -9999 -9999 -9999 -9999 -9999 -9999 -9999 -9999 -9999 -9999 -9999 -9999 -9999 -9999 -9999 -9999 -9999 -9999 -9999 -9999 -9999 -9999 -9999 -9999 -9999 -9999 -9999 -9999 -9999 -9999 -9999 -9999 -9999 -9999 -9999 -9999 -9999 -9999 -9999 -9999 -9999 -9999 -9999 -9999 -9999 -9999 -9999 -9999 -9999 -9999 -9999 -9999 -9999 -9999 -9999 -9999 -9999 -9999 -9999 -9999 -9999 -9999 -9999 -9999 -9999 -9999 -9999 -9999 -9999 -9999 -9999 -9999 -9999 -9999 -9999 -9999 -9999 -9999 -9999 -9999 -9999 -9999 -9999 -9999 -9999 -9999 -9999 -9999 -9999 -9999 -9999 -9999 -9999 -9999 -9999 -9999 -9999 -9999 -9999

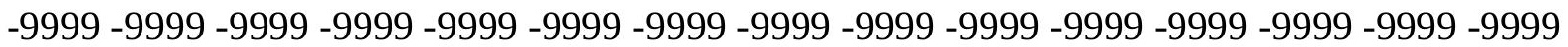
-9999 -9999 -9999 -9999 -9999 -9999 -9999 -9999 -9999 -9999 -9999 -9999 -9999 -9999 -9999 -9999 -9999 -9999 -9999 -9999 -9999 -9999 -9999 -9999 -9999 -9999 -9999 -9999 -9999 -9999 -

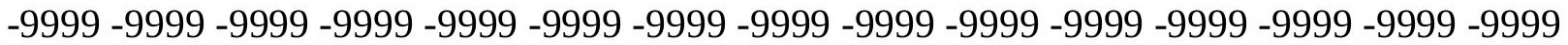
-9999 -9999 -9999 -9999 -9999 -9999 -9999 -9999 -9999 -9999 -9999 -9999 -9999 -9999 -9999 -9999 -9999 -9999 -9999 -9999 -9999 -9999 -9999 -9999 -9999 -9999 -9999 -9999 -9999 -9999 -9999 -9999 -9999 -9999 -9999 -9999 -9999 -9999 -9999 -9999 -9999 -9999 -9999 -9999 -9999 -9999 -9999 -9999 -9999 -9999 -9999 -9999 -9999 -9999 -9999 -9999 -9999 -9999 -9999 -9999 -9999 -9999 -9999 -9999 -9999 -9999 -9999 -9999 -9999 -9999 -9999 -9999 -9999 -9999 -9999

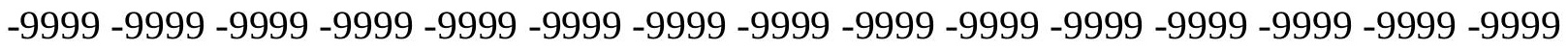
-9999 -9999 -9999 -9999 -9999 -9999 -9999 -9999 -9999 -9999 -9999 -9999 -9999 -9999 -9999 -9999 -9999 -9999 -9999 -9999 -9999 -9999 -9999 -9999 -9999 -9999 -9999 -9999 -9999 -9999 -9999 -9999 -9999 -9999 -9999 -9999 -9999 -9999 -9999 -9999 -9999 -9999 -9999 -9999 -9999 -999 -9999 -9999 -9999 -9999 -9999 -9999 -9999 -9999 -9999 -9999 -9999 -9999 -9999 -9999 -9999 -9999 -9999 -9999 -9999 -9999 -9999 -9999 -9999 -9999 -9999 -9999 -9999 -9999 -9999 -9999 -9999 -9999 -9999 -9999 -9999 -9999 -9999 -9999 -9999 -9999 -9999 -9999 -9999 -9999 -9999 -9999 -9999 -9999 -9999 -9999 -9999 -9999 -9999 -9999 -9999 -9999 -9999 -9999 -9999 -9999 -9999 -9999 -9999 -9999 -9999 -9999 -9999 -9999 -9999 -9999 -9999 -9999 -9999 -9999 
-9999 -9999 -9999 -9999 -9999 -9999 -9999 -9999 -9999 -9999 -9999 -9999 -9999 -9999 -9999 -9999 -9999 -9999 -9999 -9999 -9999 -9999 -9999 -9999 -9999 -9999 -9999 -9999 -9999 -9999 -

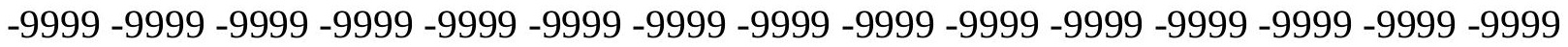
-9999 -9999 -9999 -9999 -9999 -9999 -9999 -9999 -9999 -9999 -9999 -9999 -9999 -9999 -9999 -9999 -9999 -9999 -9999 -9999 -9999 -9999 -9999 -9999-9999 -9999 -9999 -9999 -9999 -9999 -9999 -9999 -9999 -9999 -9999 -9999 -9999 -9999 -9999 -9999 -9999 -9999 -9999 -9999 -9999 -9999 -9999 -9999 -9999 -9999 -9999 -9999 -9999 -9999 -9999 -9999 -9999 -9999 -9999 -9999

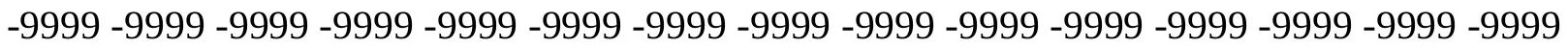

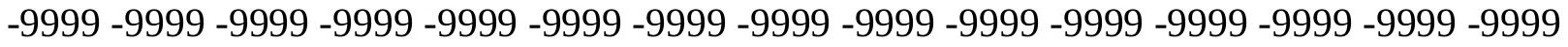
-9999 -9999 -9999 -9999 -9999 -9999 -9999 -9999 -9999 -9999 -9999 -9999 -9999 -9999 -9999 -9999 -9999 -9999 -9999 -9999 -9999 -9999 -9999 -9999 -9999 -9999 -9999 -9999 -9999 -9999 -9999 -9999 -9999 -9999 -9999 -9999 -9999 -9999 -9999 -9999 -9999 -9999 -9999 -9999 -9999 -9999 -9999 -9999 -9999 -9999 -9999 -9999 -9999 -9999 -9999 -9999 -9999 -9999 -9999 -9999 -

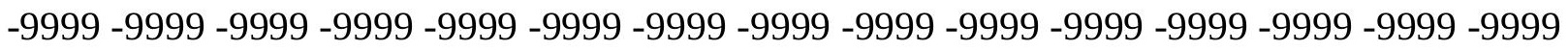
-9999 -9999 -9999 -9999 -9999 -9999 -9999 -9999 -9999 -9999 -9999 -9999 -9999 -9999 -9999 -

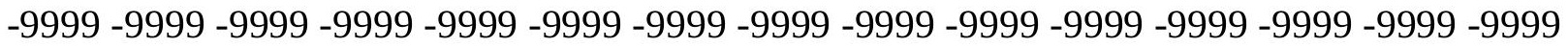
-9999 -9999 -9999 -9999 -9999 -9999 -9999 -9999 -9999 -9999 -9999 -9999 -9999 -9999 -9999 -9999 -9999 -9999 -9999 -9999 -9999 -9999 -9999 -9999 -9999 -9999 -9999 -9999 -9999 -9999 -9999 -9999 -9999 -9999 -9999 -9999 -9999 -9999 -9999 -9999 -9999 -9999 -9999 -9999 -9999 -

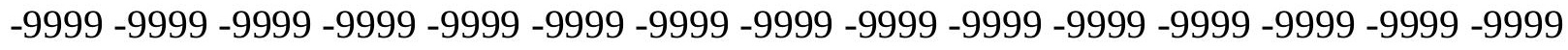

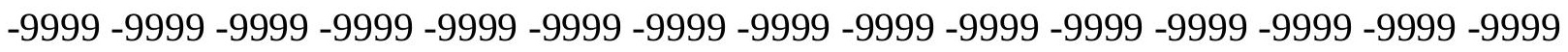

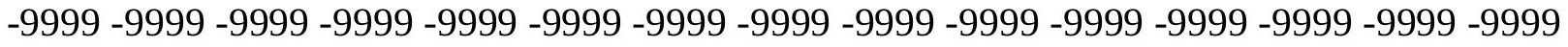
-9999 -9999 -9999 -9999 -9999 -9999 -9999 -9999 -9999 -9999 -9999 -9999 -9999 -9999 -9999 -9999 -9999 -9999 -9999 -9999 -9999 -9999 -9999 -9999 -9999 -9999 -9999 -9999 -9999 -9999 -

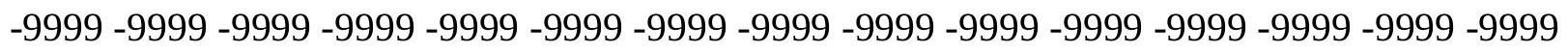
-9999 -9999 -9999 -9999 -9999 -9999 -9999 -9999 -9999 -9999 -9999 -9999 -9999 -9999 -9999 -9999 -9999 -9999 -9999 -9999 -9999 -9999 -9999 -9999 -9999 -9999 -9999 -9999 -9999 -

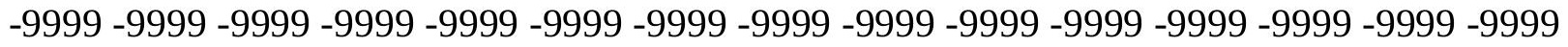
-9999 -9999 -9999 -9999 -9999 -9999 -9999 -9999 -9999 -9999 -9999 -9999 -9999 -9999 -9999 -9999 -9999 -9999 -9999 -9999 -9999 -9999 -9999 -9999 -9999 -9999 -9999 -9999 -9999 -999 -

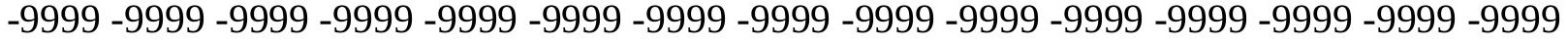
-9999 -9999 -9999 -9999 -9999 -9999 -9999 -9999 -9999 -9999 -9999 -9999 -9999 -9999 -9999 -

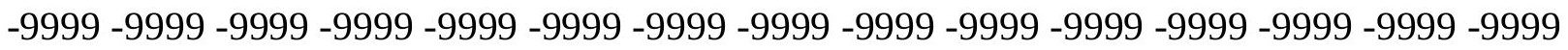

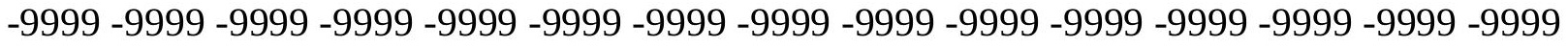

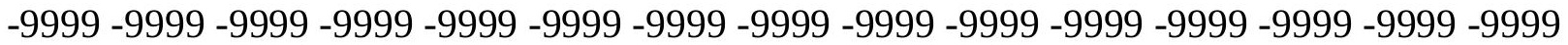
-9999 -9999 -9999 -9999 -9999 -9999 -9999 -9999 -9999 -9999 -9999 -9999 -9999 -9999 -9999

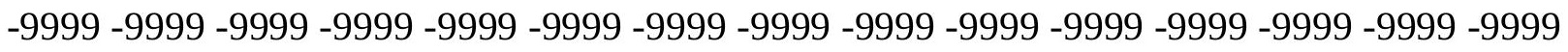

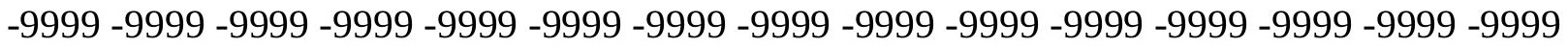
-9999 -9999 -9999 -9999 -9999 -9999 -9999 -9999 -9999 -9999 -9999 -9999 -9999 - 9999 - -999 -9999 -9999 -9999 -9999 -9999 -9999 -9999 -9999 -9999 -9999 -9999 -9999 -9999 -9999 -9999 -

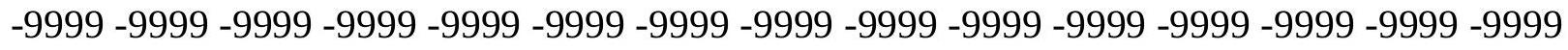

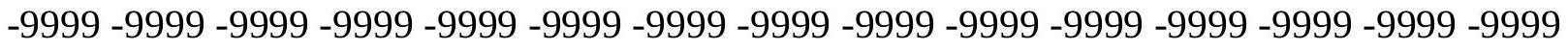
-9999 -9999 -9999 -9999 -9999 -9999 -9999 -9999 -9999 -9999 -9999 -9999 -9999 -9999 -9999 -9999 -9999 -9999 -9999 -9999 -9999 -9999 -9999 -9999-9999 -9999 -9999 -9999 -9999 -9999 -9999 -9999 -9999 -9999 -9999 -9999 -9999 -9999 -9999 -9999 -9999 -9999 -9999 -9999 -9999 -

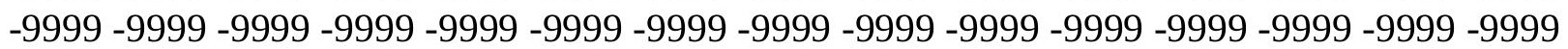


-9999 -9999 -9999 -9999 -9999 -9999 -9999 -9999 -9999 -9999 -9999 -9999 -9999 -9999 -9999 -9999 -9999 -9999 -9999 -9999 -9999 -9999 -9999 -9999 -9999 -9999 -9999 -9999 -9999 -9999 -9999 -9999 -9999 -9999 -9999 -9999 -9999 -9999 -9999 -9999 -9999 -9999 -9999 -9999 - 9999 -9999 -9999 -9999 -9999 -9999 -9999 -9999 -9999 -9999 -9999 -9999 -9999 -9999 -9999 -9999 -9999 -9999 -9999 -9999 -9999 -9999 -9999 -9999 -9999 -9999 -9999 -9999 -9999 -9999 - -9999 -9999 -9999 -9999 -9999 -9999 -9999 -9999 -9999 -9999 -9999 -9999 -9999 -9999 -9999 -9999 -9999 -9999 -9999 -9999 -9999 -9999 -9999 -9999 -9999 -9999 -9999 -9999 -9999 -9999

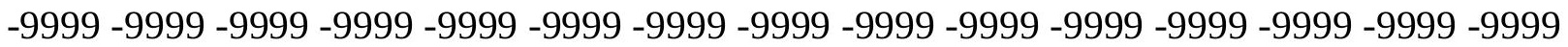

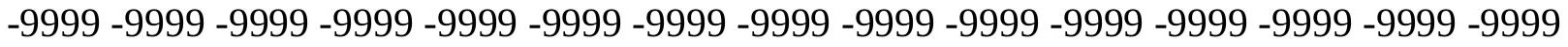
-9999 -9999 -9999 -9999 -9999 -9999 -9999 -9999 -9999 -9999 -9999 -9999 -9999 -9999 -9999

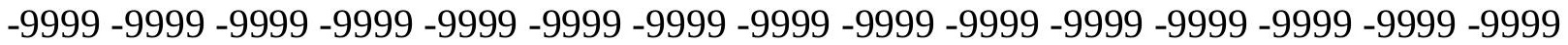
-9999 -9999 -9999 -9999 -9999 -9999 -9999 -9999 -9999 -9999 -9999 -9999 -9999 -9999 -9999 -9999 -9999 -9999 -9999 -9999 -9999 -9999 -9999 -9999 -9999 -9999 -9999 -9999 -9999 -9999 -9999 -9999 -9999 -9999 -9999 -9999 -9999 -9999 -9999 -9999 -9999 -9999 -9999 -9999 - -9999 -9999 -9999 -9999 -9999 -9999 -9999 -9999 -9999 -9999 -9999 -9999 -9999 -9999 -9999 -9999

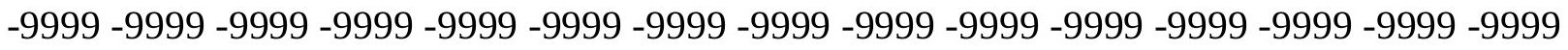
-9999 -9999 -9999 -9999 -9999 -9999 -9999 -9999 -9999 -9999 -9999 -9999 -9999 -9999 -9999 -9999 -9999 -9999 -9999 -9999 -9999 -9999 -9999 -9999 -9999 -9999 -9999 -9999 -9999 -9999 -9999 -9999 -9999 -9999 -9999 -9999 -9999 -9999 -9999 -9999 -9999 -9999 -9999 -9999 -9999 -

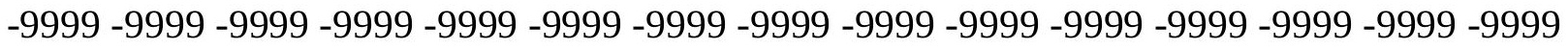
-9999 -9999 -9999 -9999 -9999 -9999 -9999 -9999 -9999 -9999 -9999 -9999 -9999 -9999 -9999 -999 -9999 -9999 -9999 -9999 -9999 -9999 -9999 -9999 -9999 -9999 -9999 -9999 -9999 -9999 -9999 -9999 -9999 -9999 -9999 -9999 -9999 -9999 -9999 -9999 -9999 -9999 -9999 -9999 -9999 -9999 -9999 -9999 -9999 -9999 -9999 -9999 -9999 -9999 -9999 -9999 -9999 -9999 -9999 -9999 -9999 -9999 -9999 -9999 -9999 -9999 -9999 -9999 -9999 -9999 -9999 -9999 -9999 -9999 -9999 -9999 -9999 -9999 -9999 -9999 -9999 -9999 -9999 -9999 -9999 -9999 -9999 -9999 -9999 -9999 -9999 -9999 -9999 -9999 -9999 -9999 -9999 -9999 -9999 -9999 -9999 -9999 -9999 -9999 -9999 -9999 -9999 -9999 -9999 -9999 -9999 -9999 -9999 -9999 -9999 -9999 -9999 -9999 -9999 -9999 -9999 -9999 -9999 -9999 -9999 -9999 -9999 -9999 -9999 -9999 -9999 -9999 -9999 -9999 -9999 -9999 -9999 -9999 -9999 -9999 -9999 -9999 -9999 -9999 -9999 -9999 -9999 -9999 -9999 -9999 -999 -9999 -9999 -9999 -9999 -9999 -9999 -9999 -9999 -9999 -9999 -9999 -9999 -9999 -9999 -9999 -9999 -9999 -9999 -9999 -9999 -9999 -9999 -9999 -9999 -9999 -9999 -9999 -9999 -9999 -

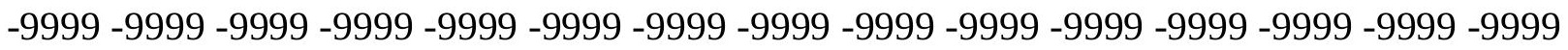

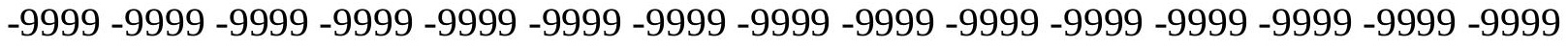

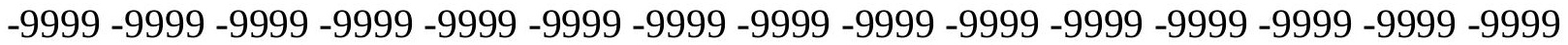
-9999 -9999 -9999 -9999 -9999 -9999 -9999 -9999 -9999 -9999 -9999 -9999 -9999 -9999 -9999 -

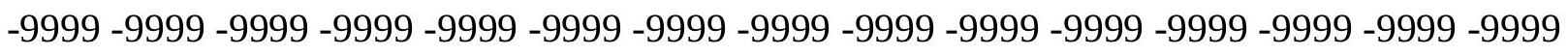

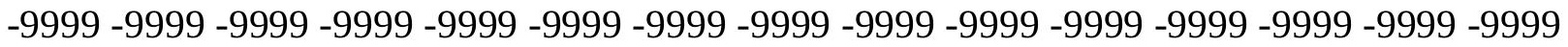

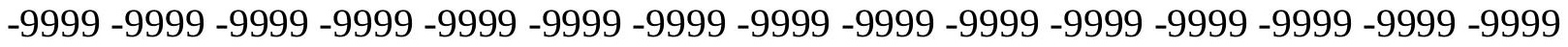
-9999 -9999 -9999 -9999 -9999 -9999 -9999 -9999 -9999 -9999 -9999 -9999 -9999 -9999 -9999 -

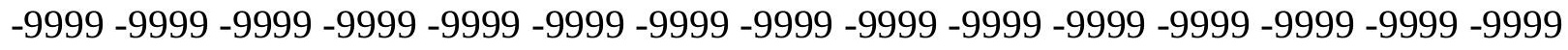

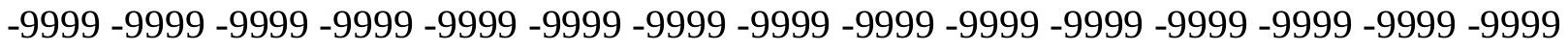
-9999 -9999 -9999 -9999 -9999 -9999 -9999 -9999 -9999 -9999 -9999 -9999 -9999 -9999 -9999 -9999 -9999 -9999 -9999 -9999 -9999 -9999 -9999 -9999-9999 -9999 -9999 -9999 -9999 -9999 -9999 -9999 -9999 -9999 -9999 -9999 -9999 -9999 -9999 -9999 -9999 -9999 -9999 -9999 -9999 -

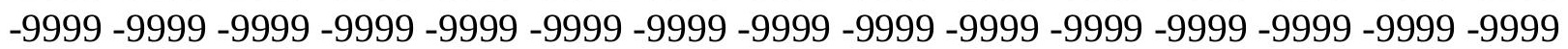


-9999 -9999 -9999 -9999 -9999 -9999 -9999 -9999 -9999 -9999 -9999 -9999 -9999 -9999 -9999 -9999 -9999 -9999 -9999 -9999 -9999 -9999 -9999 -9999 -9999 -9999 -9999 -9999 -9999 -9999 -

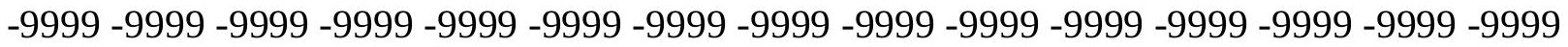
-9999 -9999 -9999 -9999 -9999 -9999 -9999 -9999 -9999 -9999 -9999 -9999 -9999 -9999 -9999 -9999 -9999 -9999 -9999 -9999 -9999 -9999 -9999 -9999-9999 -9999 -9999 -9999 -9999 -9999 -9999 -9999 -9999 -9999 -9999 -9999 -9999 -9999 -9999 -9999 -9999 -9999 -9999 -9999 -9999 -9999 -9999 -9999 -9999 -9999 -9999 -9999 -9999 -9999 -9999 -9999 -9999 -9999 -9999 -9999

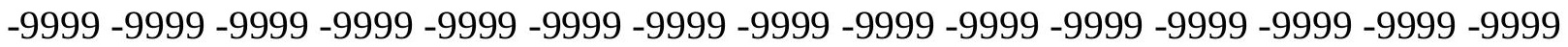

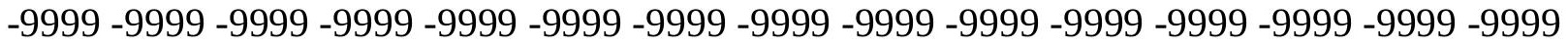
-9999 -9999 -9999 -9999 -9999 -9999 -9999 -9999 -9999 -9999 -9999 -9999 -9999 -9999 -9999 -9999 -9999 -9999 -9999 -9999 -9999 -9999 -9999 -9999 -9999 -9999 -9999 -9999 -9999 -9999 -9999 -9999 -9999 -9999 -9999 -9999 -9999 -9999 -9999 -9999 -9999 -9999 -9999 -9999 -9999 -9999 -9999 -9999 -9999 -9999 -9999 -9999 -9999 -9999 -9999 -9999 -9999 -9999 -9999 -9999 -9999 -9999 -9999 -9999 -9999 -9999 -9999 -9999 -9999 -9999 -9999 -9999 -9999 - 9999 -9999 -9999 -9999 -9999 -9999 -9999 -9999 -9999 -9999 -9999 -9999 -9999 -9999 -9999 -9999

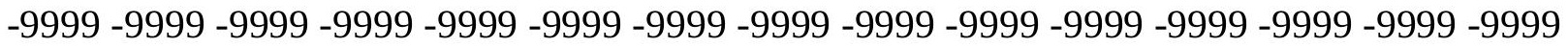
-9999 -9999 -9999 -9999 -9999 -9999 -9999 -9999 -9999 -9999 -9999 -9999 -9999 -9999 -9999 -9999 -9999 -9999 -9999 -9999 -9999 -9999 -9999 -9999 -9999 -9999 -9999 -9999 -9999 -9999 -9999 -9999 -9999 -9999 -9999 -9999 -9999 -9999 -9999 -9999 -9999 -9999 -9999 -9999 -9999 -

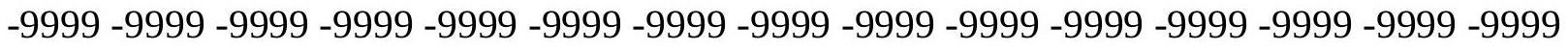

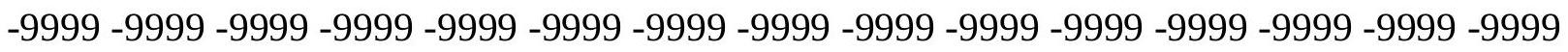
-9999 -9999 -9999 -9999 -9999 -9999 -9999 -9999 -9999 -9999 -9999 -9999 -9999 -9999 -9999 -9999 -9999 -9999 -9999 -9999 -9999 -9999 -9999 -9999 -9999 -9999 -9999 -9999 -9999 -9999 -9999 -9999 -9999 -9999 -9999 -9999 -9999 -9999 -9999 -9999 -9999 -9999 -9999 -9999 -9999 -

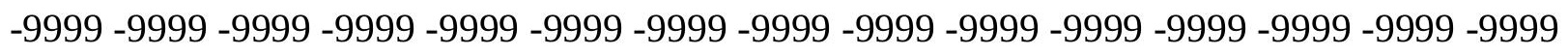
-9999 -9999 -9999 -9999 -9999 -9999 -9999 -9999 -9999 -9999 -9999 -9999 -9999 -9999 -9999 -9999 -9999 -9999 -9999 -9999 -9999 -9999 -9999 -9999 -9999 -9999 -9999 -9999 -9999 -9999 -

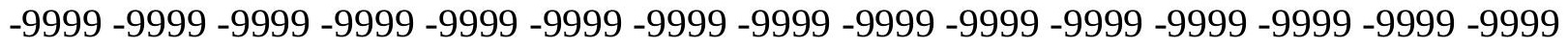
-9999 -9999 -9999 -9999 -9999 -9999 -9999 -9999 -9999 -9999 -9999 -9999 -9999 -9999 -9999 -9999 -9999 -9999 -9999 -9999 -9999 -9999 -9999 -9999 -9999 -9999 -9999 -9999 -9999 -999 -9999 -9999 -9999 -9999 -9999 -9999 -9999 -9999 -9999 -9999 -9999 -9999 -9999 -9999 -9999 -9999 -9999 -9999 -9999 -9999 -9999 -9999 -9999 -9999 -9999 -9999 -9999 -9999 -9999 -9999 -

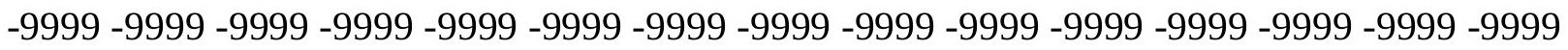

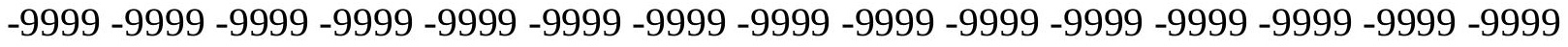

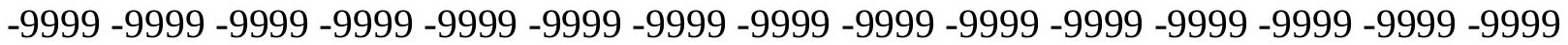

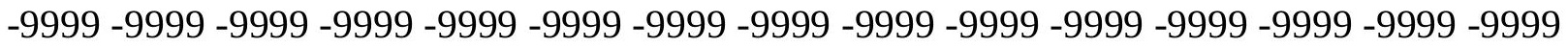

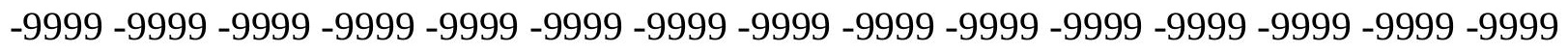

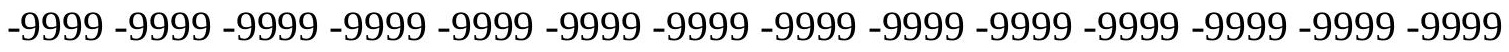
-9999 -9999 -9999 -9999 -9999 -9999 -9999 -9999 -9999 -9999 -9999 -9999 -9999 -9999 -9999 -9999 -9999 -9999 -9999 -9999 -9999 -9999 -9999 -9999 -9999 -9999 -9999 -9999 -9999 -9999 -

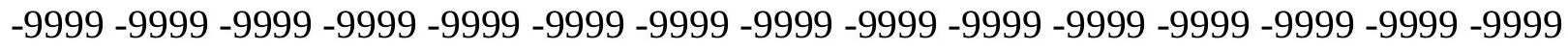

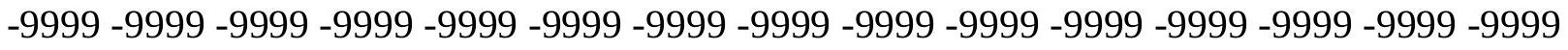
-9999 -9999 -9999 -9999 -9999 -9999 -9999 -9999 -9999 -9999 -9999 -9999 -9999 -9999 -9999 -9999 -9999 -9999 -9999 -9999 -9999 -9999 -9999 -9999-9999 -9999 -9999 -9999 -9999 -9999 -9999 -9999 -9999 -9999 -9999 -9999 -9999 -9999 -9999 -9999 -9999 -9999 -9999 -9999 -9999 -

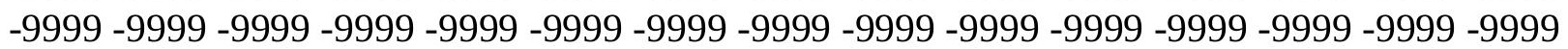


-9999 -9999 -9999 -9999 -9999 -9999 -9999 -9999 -9999 -9999 -9999 -9999 -9999 -9999 -9999 -9999 -9999 -9999 -9999 -9999 -9999 -9999 -9999 -9999 -9999 -9999 -9999 -9999 -9999 -9999 -9999 -9999 -9999 -9999 -9999 -9999 -9999 -9999 -9999 -9999 -9999 -9999 -9999 -9999 - 9999 -9999 -9999 -9999 -9999 -9999 -9999 -9999 -9999 -9999 -9999 -9999 -9999 -9999 -9999 -9999 -9999 -9999 -9999 -9999 -9999 -9999 -9999 -9999 -9999 -9999 -9999 -9999 -9999 -9999 -9999 -9999 -9999 -9999 -9999 -9999 -9999 -9999 -9999 -9999 -9999 -9999 -9999 -9999 -9999 -9999 -9999 -9999 -9999 -9999 -9999 -9999 -9999 -9999 -9999 -9999 -9999 -9999 -9999 -9999 -9999

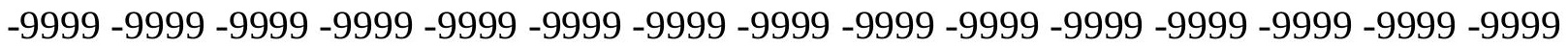
-9999 -9999 -9999 -9999 -9999 -9999 -9999 -9999 -9999 -9999 -9999 -9999 -9999 -9999 -9999 -9999 -9999 -9999 -9999 -9999 -9999 -9999 -9999 -9999 -9999 -9999 -9999 -9999 -9999 -9999

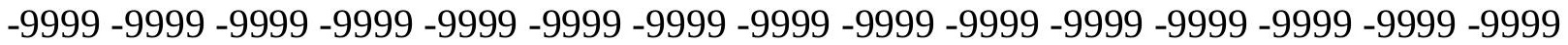
-9999 -9999 -9999 -9999 -9999 -9999 -9999 -9999 -9999 -9999 -9999 -9999 -9999 -9999 -9999 -9999 -9999 -9999 -9999 -9999 -9999 -9999 -9999 -9999 -9999 -9999 -9999 -9999 -9999 -9999 -

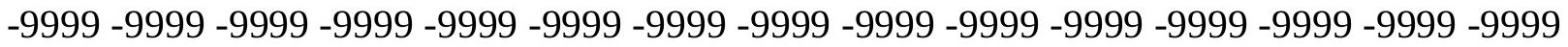
-9999 -9999 -9999 -9999 -9999 -9999 -9999 -9999 -9999 -9999 -9999 -9999 -9999 -9999 -9999

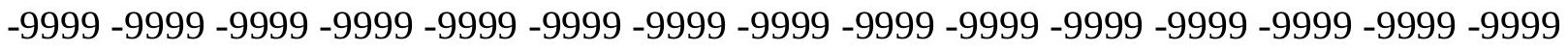
-9999 -9999 -9999 -9999 -9999 -9999 -9999 -9999 -9999 -9999 -9999 -9999 -9999 -9999 -9999 -9999 -9999 -9999 -9999 -9999 -9999 -9999 -9999 -9999 -9999 -9999 -9999 -9999 -9999 - -999 -9999 -9999 -9999 -9999 -9999 -9999 -9999 -9999 -9999 -9999 -9999 -9999 -9999 -9999 -9999 -9999 -9999 -9999 -9999 -9999 -9999 -9999 -9999 -9999 -9999 -9999 -9999 -9999 -9999 -9999 -9999 -9999 -9999 -9999 -9999 -9999 -9999 -9999 -9999 -9999 -9999 -9999 -9999 -9999 -9999 -999 -9999 -9999 -9999 -9999 -9999 -9999 -9999 -9999 -9999 -9999 -9999 -9999 -9999 -9999 -9999 -9999 -9999 -9999 -9999 -9999 -9999 -9999 -9999 -9999 -9999 -9999 -9999 -9999 -9999 -9999 -9999 -9999 -9999 -9999 -9999 -9999 -9999 -9999 -9999 -9999 -9999 -9999 -9999 -9999 -9999 -9999 -9999 -9999 -9999 -9999 -9999 -9999 -9999 -9999 -9999 -9999 -9999 -9999 -9999 -9999 -9999 -9999 -9999 -9999 -9999 -9999 -9999 -9999 -9999 -9999 -9999 -9999 -9999 -9999 -9999 -9999 -9999 -9999 -9999 -9999 -9999 -9999 -9999 -9999 -9999 -9999 -9999 -9999 -9999 -9999 -9999 -9999 -9999 -9999 -9999 -9999 -9999 -9999 -9999 -9999 -9999 -9999 -9999 -9999 -9999 -9999 -9999 -9999 -9999 -9999 -9999 -9999 -9999 -9999 -9999 -9999 -9999 -9999 -9999 -9999 -9999 -9999 -9999 -9999 -9999 -9999 -9999 -9999 -9999 -9999 -9999 -9999 -9999 -9999 -999 -9999 -9999 -9999 -9999 -9999 -9999 -9999 -9999 -9999 -9999 -9999 -9999 -9999 -9999 -9999 -9999 -9999 -9999 -9999 -9999 -9999 -9999 -9999 -9999 -9999 -9999 -9999 -9999 -9999 -9999 -

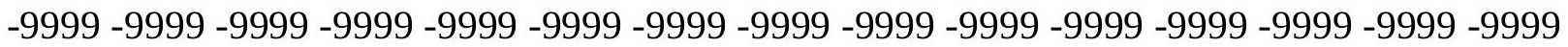

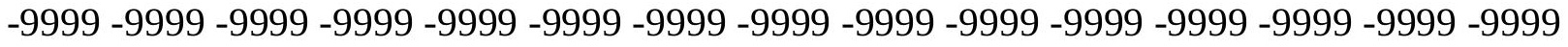

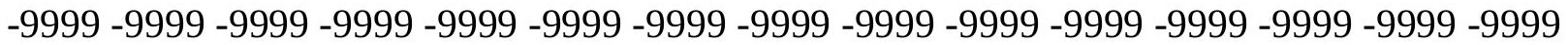
-9999 -9999 -9999 -9999 -9999 -9999 -9999 -9999 -9999 -9999 -9999 -9999 -9999 -9999 -9999

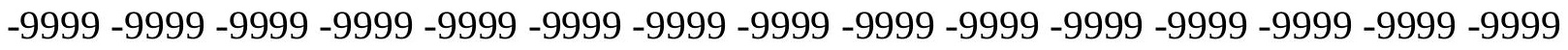

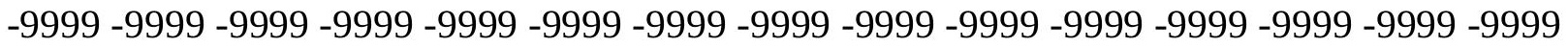

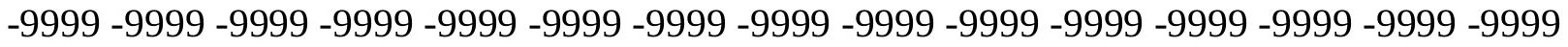
-9999 -9999 -9999 -9999 -9999 -9999 -9999 -9999 -9999 -9999 -9999 -9999 -9999 -9999 -9999 -

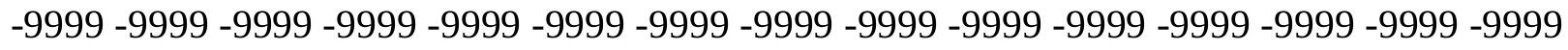

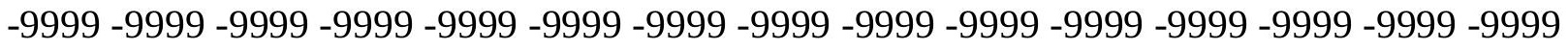
-9999 -9999 -9999 -9999 -9999 -9999 -9999 -9999 -9999 -9999 -9999 -9999 -9999 -9999 -9999 -9999 -9999 -9999 -9999 -9999 -9999 -9999 -9999 -9999 -9999 -9999 -9999 -9999 - -9999 -9999 -9999 -9999 -9999 -9999 -9999 -9999 -9999 -9999 -9999 -9999 -9999 -9999 -9999 -9999 -

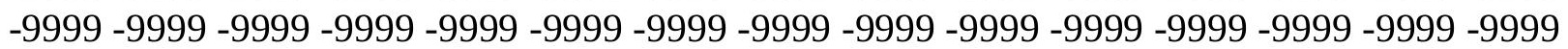


-9999 -9999 -9999 -9999 -9999 -9999 -9999 -9999 -9999 -9999 -9999 -9999 -9999 -9999 -9999 -9999 -9999 -9999 -9999 -9999 -9999 -9999 -9999 -9999 -9999 -9999 -9999 -9999 -9999 -9999 -9999 -9999 -9999 -9999 -9999 -9999 -9999 -9999 -9999 -9999 -9999 -9999 -9999 -9999 - 9999 -9999 -9999 -9999 -9999 -9999 -9999 -9999 -9999 -9999 -9999 -9999 -9999 -9999 -9999 -9999 -9999 -9999 -9999 -9999 -9999 -9999 -9999 -9999 -9999-9999 -9999 -9999 -9999 -9999 -9999 -9999 -9999 -9999 -9999 -9999 -9999 -9999 -9999 -9999 -9999 -9999 -9999 -9999 -9999 -9999 -9999 -9999 -9999 -9999 -9999 -9999 -9999 -9999 -9999 -9999 -9999 187.4429016113 189.2716064453 191.1002960205 192.9290008545195 .3672943115 -9999 -9999 -9999-9999 -9999 -9999 -9999 -9999 -9999 -9999 -9999 -9999 -9999 -9999 -9999 -9999 -9999 -9999 -9999 -9999 -9999 -9999 -9999 -9999 -9999 -9999 -9999 -9999 -9999 -9999 -9999 -9999 -9999 -9999 -

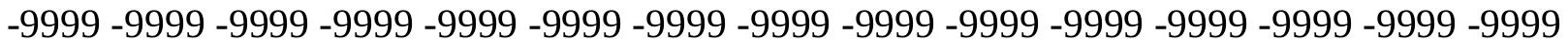
-9999 -9999 -9999 -9999 -9999 -9999 -9999 -9999 -9999 -9999 -9999 -9999 -9999 -9999 -9999 -9999 -9999 -9999 -9999 -9999 -9999 -9999 -9999 -9999 -9999 -9999 -9999 -9999 -9999 -9999 -9999 -9999 -9999 -9999 -9999 -9999 -9999 -9999 -9999 -9999 -9999 -9999 -9999 -9999 -9999 -9999 -9999 -9999 -9999 -9999 -9999 -9999 -9999 -9999 -9999 -9999 -9999 -9999 -9999 -9999 -9999 -9999 -9999 -9999 -9999 -9999 -9999 -9999 -9999 -9999 -9999 -9999 -9999 -9999 -9999 -9999 -9999 -9999 -9999 -9999 -9999 -9999 -9999 -9999 -9999 -9999 -9999 -9999 -9999 -9999 -9999 -9999 -9999 -9999 -9999 -9999 -9999 -9999 -9999 -9999 -9999 -9999 -9999 -9999 -9999 -9999 -9999 -9999 -9999 -9999 -9999 -9999 -9999 -9999 -9999 -9999 -9999 -9999 -9999 -9999 -9999 -9999 -9999 -9999 -9999 -9999 -9999 -9999 -9999 -9999 -9999 -9999 -9999 -9999 -9999 -9999 -9999 -9999 -9999 -9999 -9999 -9999 -9999 -9999 -9999 -9999 -9999 -9999 -9999 -9999 -9999 -9999 -9999 -9999 -9999 -9999 -9999 -9999 -9999 -9999 -9999 -9999 -9999 -9999 -9999 -9999 -9999 -9999 -9999 -9999 -9999 -9999 -9999 -9999 -9999 -9999 -9999 -9999 -9999 -9999 -9999 -9999 -9999 -9999 -9999 -9999 -9999 -9999 -9999 -9999 -9999 -9999 -9999 -9999 -9999 -9999 -9999 -9999 -9999 -9999 -9999 -9999 -9999 -9999

-9999 -9999 -9999 -9999 -9999 -9999 -9999 -9999 -9999 -9999 -9999 -9999 -9999 -9999 -9999 -9999 -9999 -9999 -9999 -9999 -9999 -9999 -9999 -9999 -9999 -9999 -9999 -9999 -9999 -9999 -9999 -9999 -9999 -9999 -9999 -9999 -9999 -9999 -9999 -9999 -9999 -9999 -9999 -9999 -9999

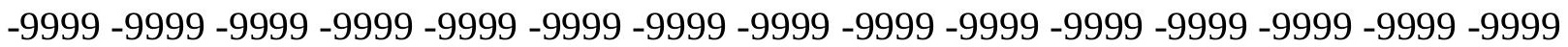
-9999 -9999 -9999 -9999 -9999 -9999 -9999 -9999 -9999 -9999 -9999 -9999 -9999 -9999 -9999 -9999 -9999 -9999 -9999 -9999 -9999 -9999 -9999 -9999 -9999 -9999 -9999 -9999 -9999 -9999 -

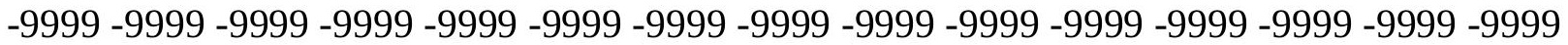
-9999 -9999 -9999 -9999 -9999 -9999 -9999 -9999 -9999 -9999 -9999 -9999 -9999 -9999 -9999 -9999 -9999-9999-9999-9999 188.3571929932188.966796875 189.5764007568 189.8811035156189 .8811035156189 .5764007568186 .8332977295189 .8811035156 191.1002960205193 .233795166195 .3672943115197 .500793457 -9999 -9999 -9999 -9999 -9999 -9999 -9999 -9999 -9999 -9999 -9999 -9999 -9999 -9999 -9999 -9999 -9999 -9999 -9999 -

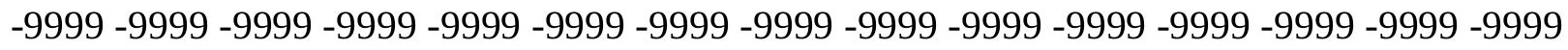
-9999 -9999 -9999 -9999 -9999 -9999 -9999 -9999 -9999 -9999 -9999 -9999 -9999 -9999 -9999 -9999 -9999 -9999 -9999 -9999 -9999 -9999 -9999 -9999 -9999 -9999 -9999 -9999 -9999 -9999 -9999 -9999 -9999 -9999 -9999 -9999 -9999 -9999 -9999 -9999 -9999 -9999 -9999 -9999 -9999 -999 -9999 -9999 -9999 -9999 -9999 -9999 -9999 -9999 -9999 -9999 -9999 -9999 -9999 -9999 -9999 -9999 -9999 -9999 -9999 -9999 -9999 -9999 -9999 -9999 -9999 -9999 -9999 -9999 -9999 -9999 -9999 -9999 -9999 -9999 -9999 -9999 -9999 -9999 -9999-9999 -9999 -9999 -9999 -9999 -9999 -9999 -9999 -9999 -9999 -9999 -9999 -9999 -9999 -9999 -9999 -9999 -9999 -9999 -9999 -9999

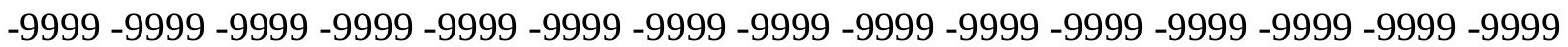


-9999 -9999 -9999 -9999 -9999 -9999 -9999 -9999 -9999 -9999 -9999 -9999 -9999 -9999 -9999 -9999 -9999 -9999 -9999 -9999 -9999 -9999 -9999 -9999 -9999 -9999 -9999 -9999 -9999 -9999 -9999 -9999 -9999 -9999 -9999 -9999 -9999 -9999 -9999 -9999 -9999 -9999 -9999 -9999 -9999 -9999 -9999 -9999 -9999 -9999 -9999 -9999 -9999 -9999 -9999 -9999 -9999 -9999 -9999 -9999 -9999 -9999 -9999 -9999 -9999 -9999 -9999 -9999 -9999 -9999 -9999 -9999 -9999 -9999 -9999 -9999 -9999 -9999 -9999 -9999 -9999 -9999 -9999 -9999 -9999 -9999 -9999 -9999 -9999 -9999 -9999 -9999 -9999 -9999 -9999 -9999 -9999 -9999

-9999 -9999 -9999 -9999 -9999 -9999 -9999 -9999 -9999 -9999 -9999 -9999 -9999 -9999 -9999 -9999 -9999 -9999 -9999 -9999 -9999 -9999 -9999 -9999 -9999 -9999 -9999 -9999 -9999 -9999 -9999 -9999 -9999 -9999 -9999 -9999 -9999 -9999 -9999 -9999 -9999 -9999 -9999 -9999 -9999 -

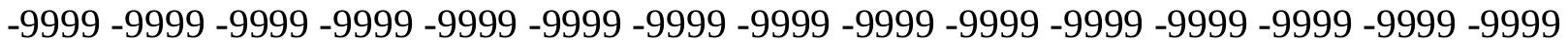
-9999 -9999 -9999 -9999 -9999 -9999 -9999 -9999 -9999 -9999 -9999 -9999 -9999 -9999 -9999

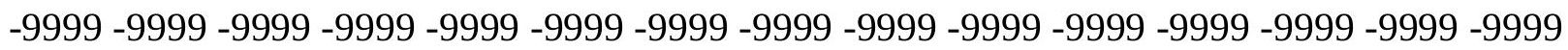
-9999 -9999 -9999 -9999 -9999 -9999 -9999 -9999 -9999 -9999 -9999 -9999 -9999 -9999 -9999 -9999 -9999 -9999 -9999 -9999 -9999 -9999 -9999 -9999 -9999 -9999 -9999 -9999 -9999 -9999 181.3471984863181 .6519012451181 .9566955566181 .9566955566181 .9566955566 181.9566955566181 .9566955566186 .8332977295186 .8332977295182 .5662994385 184.0901947021185 .9188995361187 .7476043701190 .4907073975192 .9290008545 193.8433074951195 .6721038818198 .4151000977 -9999 -9999 -9999 -9999 -9999 -9999 -9999 -9999 -9999 -9999 -9999 -9999 -9999 -9999 -9999 -9999 -9999 -9999 -9999 -9999 -9999 -9999

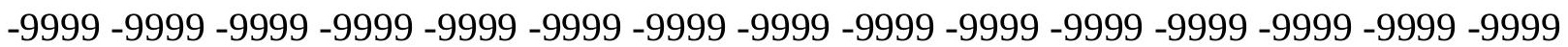
-9999 -9999 -9999 -9999 -9999 -9999 -9999 -9999 -9999 -9999 -9999 -9999 -9999 -9999 -9999 -9999 -9999 -9999 -9999 -9999 -9999 -9999 -9999 -9999 -9999 -9999 -9999 -9999 -9999 -9999 -9999 -9999 -9999 -9999 -9999 -9999 -9999 -9999 -9999 -9999 -9999 -9999 -9999 -9999 -9999

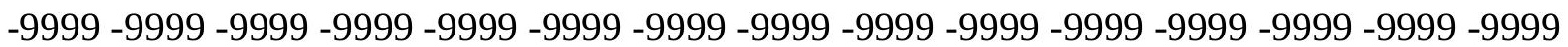
-9999 -9999 -9999 -9999 -9999 -9999 -9999 -9999 -9999 -9999 -9999 -9999 -9999 -9999 -9999 -9999 -9999 -9999 -9999 -9999 -9999 -9999 -9999 -9999 -9999 -9999 -9999 -9999 -9999 -9999 -9999 -9999 -9999 -9999 -9999 -9999 -9999 -9999 -9999 -9999 -9999 -9999 -9999 -9999 -9999 -9999 -9999 -9999 -9999 -9999 -9999 -9999 -9999 -9999 -9999 -9999 -9999 -9999 -9999 -9999 -9999 -9999 -9999 -9999 -9999 -9999 -9999 -9999 -9999 -9999 -9999 -9999 -9999 -9999 -9999 -9999 -9999 -9999 -9999 -9999 -9999 -9999 -9999 -9999 -9999 -9999 -9999 -9999 -9999 -9999 -9999 -9999 -9999 -9999 -9999 -9999 -9999 -9999 -9999 -9999 -9999 -9999 -9999 -9999 -9999 -9999 -9999 -9999 -9999 -9999 -9999 -9999 -9999 -9999 -9999 -9999 -9999 -9999 -9999 -9999 -9999 -9999 -9999 -9999 -9999 -9999 -9999 -9999 -9999 -9999 -9999 -9999 -9999 -9999 -9999 -

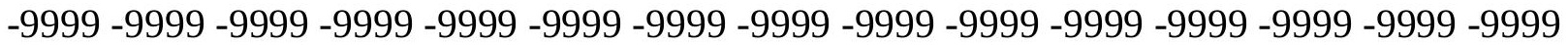
-9999 -9999 -9999-9999

-9999 -9999 -9999 -9999 -9999 -9999 -9999 -9999 -9999 -9999 -9999 -9999 -9999 -9999 -9999

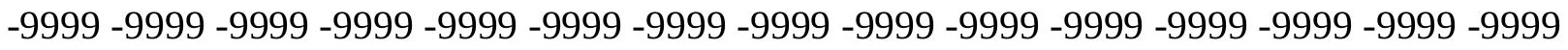
-9999 -9999 -9999 -9999 -9999 -9999 -9999 -9999 -9999 -9999 -9999 -9999 -9999 -9999 -9999 -9999 -9999 -9999 -9999 -9999 -9999 -9999 -9999 -9999 -9999 -9999 -9999 -9999 -9999 -9999 -9999 -9999 -9999 -9999 -9999 -9999 -9999 -9999 -9999 -9999 -9999 -9999 -9999 -9999 -9999 -999 -9999 -9999 -9999 -9999 -9999 -9999 -9999 -9999 -9999 -9999 -9999 -9999 -9999 -9999 -9999 -9999 -9999 -9999 -9999 -9999 -9999 -9999 -9999 -9999 -9999 -9999 -9999 -9999 -9999 -9999 -9999 -9999 -9999 -9999 -9999 -9999 -9999 -9999 -9999 182.261505127181 .6519012451 181.0424041748180 .432800293180 .1280059814179 .5184020996179 .2136993408 179.2136993408179 .5184020996179 .8231964111180 .1280059814180 .432800293 
180.432800293180 .7375946045181 .0424041748181 .9566955566183 .1759033203 184.699798584186 .2236938477189 .8811035156191 .7097930908193 .233795166 193.233795166195 .6721038818201 .158203125 -9999 -9999 -9999 -9999 -9999 -9999 -9999 -9999 -9999 -9999 -9999 -9999 -9999 -9999 -9999 -9999 -9999 -9999 -9999 -9999 -9999 -9999 -9999 -9999 -9999 -9999 -9999 -9999 -9999 -9999 -9999 -9999 -9999 -9999-9999 -9999 -9999 -9999 -9999 -9999 -9999 -9999 -9999 -9999 -9999 -9999 -9999 -9999 -9999 -9999 -9999 -9999 -

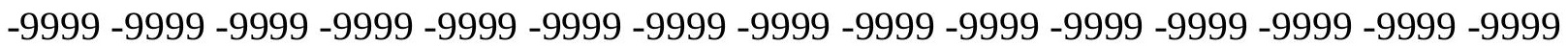

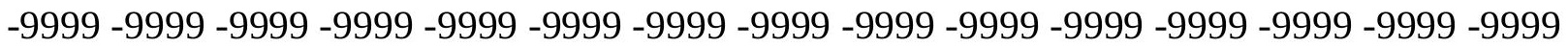

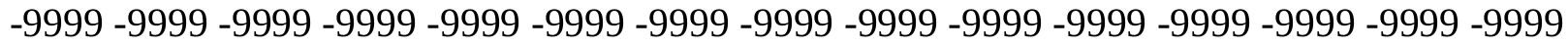
-9999 -9999 -9999 -9999 -9999 -9999 -9999 -9999 -9999 -9999 -9999 -9999 -9999 -9999 -9999

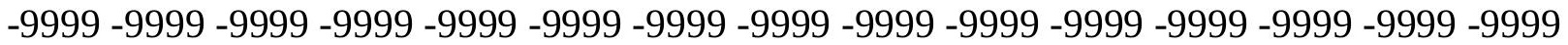
-9999 -9999 -9999 -9999 -9999 -9999 -9999 -9999 -9999 -9999 -9999 -9999 -9999 -9999 -9999 -9999 -9999 -9999 -9999 -9999 -9999 -9999 -9999 -9999 -9999 -9999 -9999 -9999 -9999 -9999 -9999 -9999 -9999 -9999 -9999 -9999 -9999 -9999 -9999 -9999 -9999 -9999 -9999 -9999 - 9999 -9999 -9999 -9999 -9999 -9999 -9999 -9999 -9999 -9999 -9999 -9999 -9999 -9999 -9999 -9999 -9999 -9999 -9999 -9999 -9999 -9999 -9999 -9999 -9999 -9999 -9999 -9999 -9999 - -9999 - -9999 -9999 -9999 -9999 -9999 -9999 -9999 -9999 -9999 -9999 -9999 -9999 -9999 -9999 -9999 -9999 -9999 -9999 -9999 -9999 -9999 -9999 -9999 -9999 -9999 -9999 -9999 -9999 -9999 -9999 -9999 -

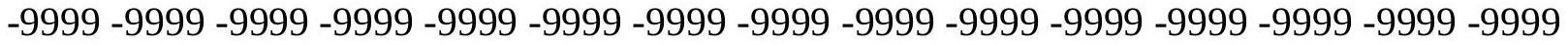
-9999 -9999-9999

-9999 -9999 -9999 -9999 -9999 -9999 -9999 -9999 -9999 -9999 -9999 -9999 -9999 -9999 -9999 -9999 -9999 -9999 -9999 -9999 -9999 -9999 -9999 -9999 -9999 -9999 -9999 -9999 -9999 -9999 -9999 -9999 -9999 -9999 -9999 -9999 -9999 -9999 -9999 -9999 -9999 -9999 -9999 -9999 -9999 -9999 -9999 -9999 -9999 -9999 -9999 -9999 -9999 -9999 -9999 -9999 -9999 -9999 -9999 -9999 -

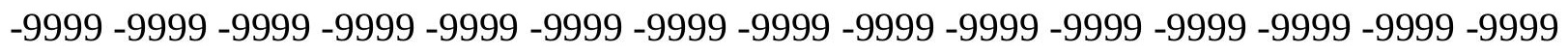
-9999 -9999 -9999 -9999 -9999 -9999 -9999 -9999 -9999 -9999 -9999 -9999 -9999 -9999 -9999 -9999 -9999 -9999 -9999 -9999 -9999 -9999 -9999 -9999 -9999 -9999 -9999 -9999 -9999 -9999 -9999 188.6620025635187.7476043701 186.528503418185.3094024658184.0901947021 182.87109375181 .6519012451180 .7375946045179 .8231964111179 .2136993408 178.604095459178 .2993011475177 .6896972656177 .3849029541177 .3849029541 177.3849029541177 .6896972656177 .9945068359178 .2993011475178 .604095459 179.2136993408179 .5184020996180 .1280059814181 .0424041748182 .261505127 183.7854003906185 .3094024658186 .8332977295189 .2716064453190 .4907073975 191.4051055908194 .1481018066196 .891204834198 .1103057861 -9999 -9999 -9999 -9999 -9999 -9999 -9999 -9999 -9999 -9999 -9999 -9999 -9999 -9999 -9999 -9999 -9999 -9999 -9999

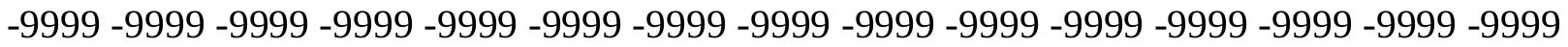

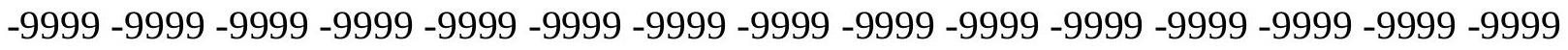

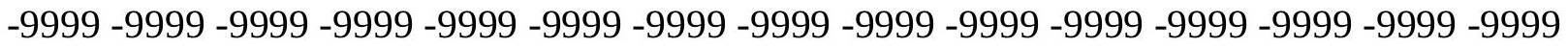
-9999 -9999 -9999 -9999 -9999 -9999 -9999 -9999 -9999 -9999 -9999 -9999 -9999 - 9999 - -999 -9999 -9999 -9999 -9999 -9999 -9999 -9999 -9999 -9999 -9999 -9999 -9999 -9999 -9999 -9999 -

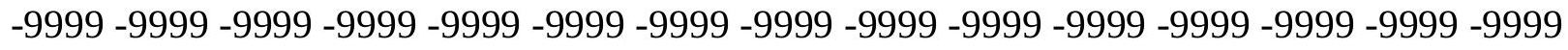

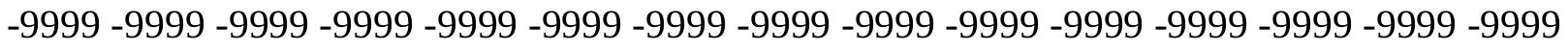
-9999 -9999 -9999 -9999 -9999 -9999 -9999 -9999 -9999 -9999 -9999 -9999 -9999 -9999 -9999 -9999 -9999 -9999 -9999 -9999 -9999 -9999 -9999 -9999-9999 -9999 -9999 -9999 -9999 -9999 -9999 -9999 -9999 -9999 -9999 -9999 -9999 -9999 -9999 -9999 -9999 -9999 -9999 -9999 -9999 -

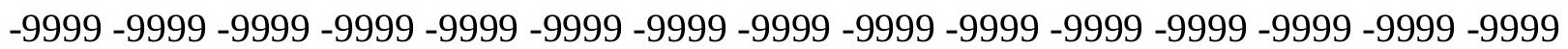


-9999 -9999 -9999 -9999 -9999 -9999 -9999 -9999 -9999 -9999 -9999 -9999 -9999 -9999 -9999 -9999 -9999 -9999 -9999 -9999 -9999 -9999 -9999 -9999 -9999 -9999 -9999 -9999 -9999 -9999 -9999 -9999 -9999 -9999 -9999 -9999 -9999 -9999 -9999 -9999 -9999 -9999 -9999 -9999 -9999

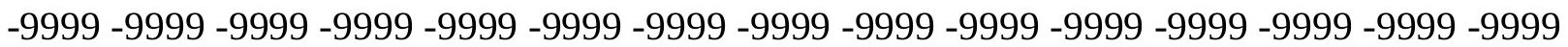
-9999 -9999-9999-9999-9999

-9999 -9999 -9999 -9999 -9999 -9999 -9999 -9999 -9999 -9999 -9999 -9999 -9999 -9999 -9999 -9999 -9999 -9999 -9999 -9999 -9999 -9999 -9999 -9999 -9999 -9999 -9999 -9999 -9999 -9999 -

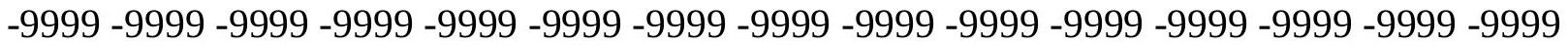
-9999 -9999 -9999 -9999 -9999 -9999 -9999 -9999 -9999 -9999 -9999 -9999 -9999 -9999 -9999 -9999 -9999 -9999 -9999 -9999 -9999 -9999 -9999 -9999 -9999 -9999 -9999 -9999 -9999 -9999 -

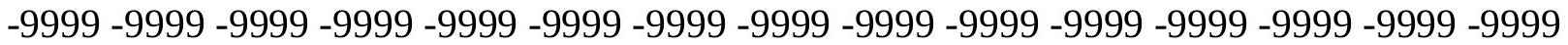
-9999 -9999 -9999 -9999 -9999 -9999 -9999 -9999 -9999 -9999 -9999 -9999 -9999 -9999 -9999 -9999 187.1381072998 185.9188995361 185.0045928955183.4806976318181.9566955566 180.432800293179 .2136993408178 .2993011475177 .6896972656177 .0802001953 176.4705963135176 .165802002175 .5561981201175 .5561981201175 .5561981201 175.5561981201175 .8609924316176 .165802002176 .7754058838177 .0802001953 177.6896972656178 .2993011475179 .2136993408180 .1280059814181 .3471984863 182.87109375183 .7854003906185 .0045928955186 .528503418188 .0523986816 $189.2716064453191 .4051055908193 .233795166193 .8433074951192 .9290008545-9999$ -9999 -9999 -9999 -9999 -9999 -9999 -9999 -9999 -9999 -9999 -9999 -9999 -9999 -9999 -9999

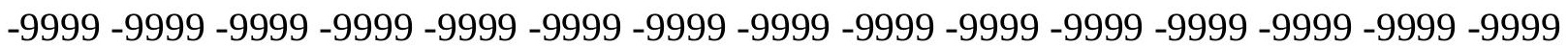
-9999 -9999 -9999 -9999 -9999 -9999 -9999 -9999 -9999 -9999 -9999 -9999 -9999 -9999 -9999 -9999 -9999 -9999 -9999 -9999 -9999 -9999 -9999 -9999 -9999 -9999 -9999 -9999 -9999 -9999 -9999 -9999 -9999 -9999 -9999 -9999 -9999 -9999 -9999 -9999 -9999 -9999 -9999 -9999 -9999

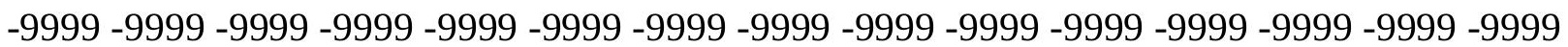
-9999 -9999 -9999 -9999 -9999 -9999 -9999 -9999 -9999 -9999 -9999 -9999 -9999 -9999 -9999 -9999 -9999 -9999 -9999 -9999 -9999 -9999 -9999 -9999 -9999 -9999 -9999 -9999 -9999 -9999 -9999 -9999 -9999 -9999 -9999 -9999 -9999 -9999 -9999 -9999 -9999 -9999 -9999 -9999 -9999 -9999 -9999 -9999 -9999 -9999 -9999 -9999 -9999 -9999 -9999 -9999 -9999 -9999 -9999 -9999 -9999 -9999 -9999 -9999 -9999 -9999 -9999 -9999 -9999 -9999 -9999 -9999 -9999 -9999 -9999 -9999 -9999 -9999 -9999 -9999 -9999 -9999 -9999 -9999 -9999 -9999 -9999 -9999 -9999 -9999 -

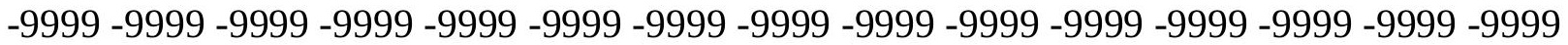
-9999 -9999 -9999 -9999 -9999 -9999 -9999 -9999 -9999 -9999 -9999 -9999 -9999 -9999 -9999 -9999 -9999 -9999 -9999 -9999 -9999 -9999 -9999 -9999 -9999 -9999 -9999 -9999 -9999 -9999 -

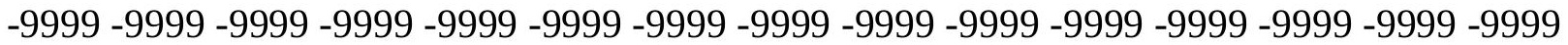
-9999 -9999 -9999 -9999-9999-9999 -9999

-9999 -9999 -9999 -9999 -9999 -9999 -9999 -9999 -9999 -9999 -9999 -9999 -9999 -9999 -9999

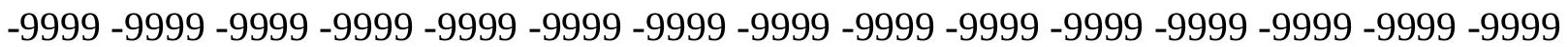
-9999 -9999 -9999 -9999 -9999 -9999 -9999 -9999 -9999 -9999 -9999 -9999 -9999 -9999 -9999 -9999 -9999 -9999 -9999 -9999 -9999 -9999 -9999 -9999 -9999 -9999 -9999 -9999 -9999 -9999 -9999 -9999 -9999 -9999 -9999 -9999 -9999 -9999 -9999 -9999 -9999 -9999 -9999 -9999 -9999 -999 -9999 -9999 -9999 -9999 -9999 -9999 -9999 -9999 -9999 -9999 -9999 -9999 -9999 -9999 -9999 -9999 -9999 -9999 -9999 -9999 -9999 -9999 -9999 -9999 -9999 -9999 -9999 -9999 -9999 -9999 -999 -9999 185.3094024658 184.3950042725 183.1759033203181 .9566955566180 .1280059814 178.604095459177 .0802001953175 .8609924316175 .2514038086174 .6419067383 174.337097168174 .0323028564173 .7274932861173 .7274932861173 .7274932861 
173.7274932861174 .0323028564174 .6419067383175 .2514038086175 .5561981201 176.165802002177 .0802001953177 .6896972656178 .604095459179 .5184020996 180.7375946045181 .9566955566182 .87109375184 .699798584186 .2236938477 187.4429016113188 .966796875189 .8811035156190 .1858978271190 .1858978271 190.4907073975 -9999 -9999 -9999 -9999 -9999 -9999 -9999 -9999 -9999 -9999 -9999 -9999 -9999 -9999 -9999 -9999 -9999 -9999 -9999 -9999 -9999 -9999 -9999 -9999 -9999 -9999 -9999 -9999 -9999 -9999 -9999 -9999 -9999 -9999 -9999 -9999 -9999 -9999 -9999 -9999 -9999 -9999

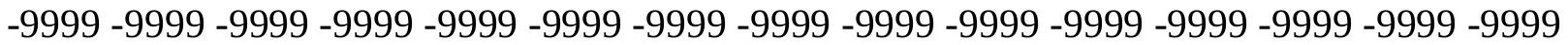

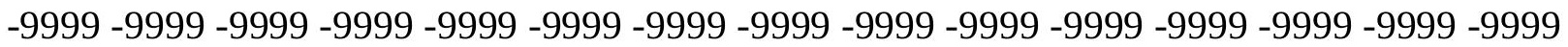
-9999 -9999 -9999 -9999 -9999 -9999 -9999 -9999 -9999 -9999 -9999 -9999 -9999 -9999 -9999 -

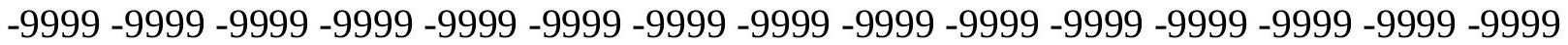
-9999 -9999 -9999 -9999 -9999 -9999 -9999 -9999 -9999 -9999 -9999 -9999 -9999 -9999 -9999 -9999 -9999 -9999 -9999 -9999 -9999 -9999 -9999 -9999 -9999 -9999 -9999 -9999 -9999 -9999 -9999 -9999 -9999 -9999 -9999 -9999 -9999 -9999 -9999 -9999 -9999 -9999 -9999 -9999 -9999 -9999 -9999 -9999 -9999 -9999 -9999 -9999 -9999 -9999 -9999 -9999 -9999 -9999 -9999 -9999

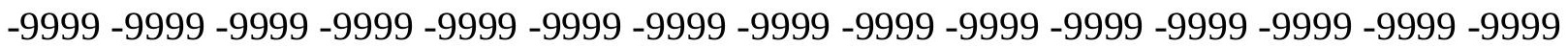

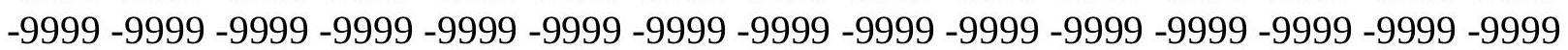
-9999 -9999 -9999 -9999 -9999 -9999 -9999 -9999 -9999 -9999 -9999 -9999 -9999 -9999 -9999 -9999 -9999 -9999 -9999 -9999 -9999 -9999 -9999 -9999 -9999 -9999 -9999 -9999 -9999 -9999 -9999 -9999 -9999 -9999 -9999 -9999 -9999 -9999 -9999 -9999 -9999 -9999 -9999 -9999 -9999 -9999 -9999 -9999 -9999 -9999 -9999 -9999 -9999 -9999 -9999

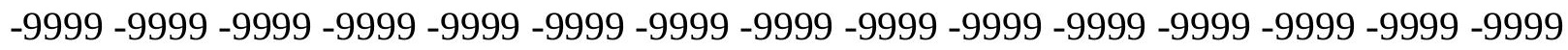
-9999 -9999 -9999 -9999 -9999 -9999 -9999 -9999 -9999 -9999 -9999 -9999 -9999 -9999 -9999 -9999 -9999 -9999 -9999 -9999 -9999 -9999 -9999 -9999 -9999 -9999 -9999 -9999 -9999 -9999

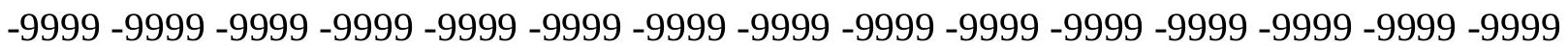
-9999 -9999 -9999 -9999 -9999 -9999 -9999 -9999 -9999 -9999 -9999 -9999 -9999 -9999 -9999 -9999 -9999 -9999 -9999 -9999 -9999 -9999 -9999 -9999 -9999 -9999 -9999 -9999 -9999 -9999 -9999 -9999 -9999 -9999 -9999 -9999 -9999 -9999 -9999 -9999 -9999 -9999 -9999 -9999 -9999 -9999 183.7854003906 182.5662994385181.3471984863180.1280059814178.604095459 177.0802001953175 .5561981201174 .337097168173 .1179962158172 .5084075928 172.2035980225173 .1179962158171 .8988037109171 .8988037109172 .2035980225 172.2035980225172 .5084075928173 .1179962158173 .7274932861174 .337097168 174.9467010498175 .5561981201176 .165802002176 .7754058838177 .3849029541 178.2993011475179 .2136993408181 .6519012451183 .1759033203185 .0045928955 186.2236938477186 .8332977295187 .1381072998187 .4429016113187 .4429016113 187.1381072998186 .528503418 -9999 -9999 -9999 -9999 -9999 -9999 -9999 -9999 -9999 -9999 -9999 -9999 -9999 -9999 -9999 -9999 -9999 -9999 -9999 -9999 -9999 -9999 -9999 -9999

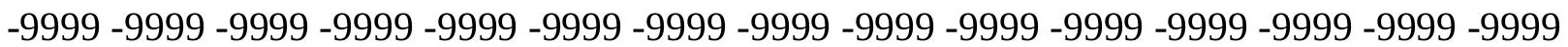
-9999 -9999 -9999 -9999 -9999 -9999 -9999 -9999 -9999 -9999 -9999 -9999 -9999 -9999 -9999 -9999 -9999 -9999 -9999 -9999 -9999 -9999 -9999 -9999 -9999 -9999 -9999 -9999 -9999 -9999 -9999 -9999 -9999 -9999 -9999 -9999 -9999 -9999 -9999 -9999 -9999 -9999 -9999 -9999 -9999

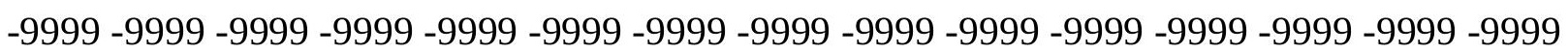
-9999 -9999 -9999 -9999 -9999 -9999 -9999 -9999 -9999 -9999 -9999 -9999 -9999 -9999 -9999 -9999 -9999 -9999 -9999 -9999 -9999 -9999 -9999 -9999 -9999 -9999 -9999 -9999 -9999 -9999 -9999 -9999 -9999 -9999 -9999 -9999 -9999 -9999 -9999 -9999 -9999 -9999 -9999 -9999 -9999

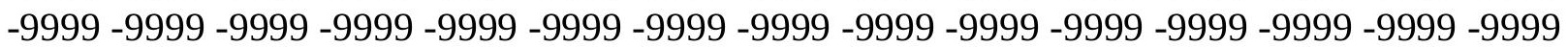


-9999 -9999 -9999 -9999 -9999 -9999 -9999 -9999 -9999 -9999 -9999 -9999 -9999 -9999 -9999 -9999 -9999 -9999 -9999 -9999 -9999 -9999 -9999 -9999 -9999 -9999 -9999 -9999 -9999 -9999 -9999 -9999 -9999 -9999 -9999 -9999 -9999 -9999 -9999 -9999 -9999 -9999 -9999 -9999 -9999 -9999 -9999 -9999 -9999 -9999 -9999 -9999 -9999 -9999 -9999 -9999 -9999 -9999 -9999 -9999 -9999 -9999 -9999 -9999 -9999 -9999 -9999 -9999 -9999 -9999 -9999 -9999 -9999 -9999 -9999 -9999 -9999 -9999 -9999 -9999 -9999 -9999 -9999 -9999 -9999 -9999 -9999

-9999 -9999 -9999 -9999 -9999 -9999 -9999 -9999 -9999 -9999 -9999 -9999 -9999 -9999 -9999

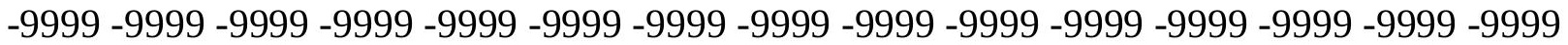
-9999 -9999 -9999 -9999 -9999 -9999 -9999 -9999 -9999 -9999 -9999 -9999 -9999 -9999 -9999 -9999 -9999 -9999 -9999 -9999 -9999 -9999 -9999 -9999 -9999 -9999 -9999 -9999 -9999 -9999 -

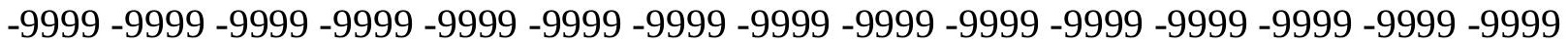
-9999 -9999 -9999 -9999 -9999 -9999 -9999 -9999 -9999 -9999 -9999 -9999 -9999 -9999 -9999 -9999 -9999 -9999 -9999 -9999 -9999 -9999 -9999 -9999 -9999 -9999 -9999 -9999 -9999 -9999 -9999 182.5662994385181.0424041748 179.8231964111178 .2993011475176 .7754058838 175.2514038086174 .0323028564172 .8132019043171 .8988037109171 .2891998291 171.2891998291171 .2891998291171 .2891998291171 .5939941406171 .8988037109 172.5084075928172 .8132019043173 .1179962158173 .4226989746174 .0323028564 174.337097168174 .9467010498175 .2514038086175 .5561981201175 .8609924316 176.4705963135177 .6896972656179 .8231964111181 .9566955566183 .4806976318 184.699798584185 .3094024658185 .9188995361186 .2236938477185 .6141052246 $184.699798584183 .1759033203181 .9566955566181 .0424041748180 .1280059814-9999$ -9999 -9999 -9999 -9999 -9999 -9999 -9999 -9999 -9999 -9999 -9999 -9999 -9999 -9999 -9999 -9999 -9999 -9999 -9999 -9999 -9999 -9999 -9999 -9999 -9999 -9999 -9999 -9999 -9999 -9999 -9999 -9999 -9999 -9999 -9999 -9999 -9999 -9999 -9999 -9999 -9999 -9999 -9999 -9999 -9999

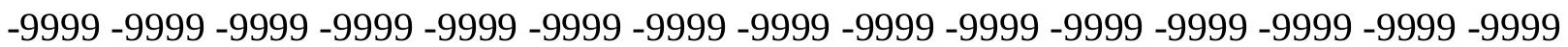
-9999 -9999 -9999 -9999 -9999 -9999 -9999 -9999 -9999 -9999 -9999 -9999 -9999 -9999 -9999 -9999 -9999 -9999 -9999 -9999 -9999 -9999 -9999 -9999 -9999 -9999 -9999 -9999 -9999 -9999 -9999 -9999 -9999 -9999 -9999 -9999 -9999 -9999 -9999 -9999 -9999 -9999 -9999 -9999 -9999 -9999 -9999 -9999 -9999 -9999 -9999 -9999 -9999 -9999 -9999 -9999 -9999 -9999 -9999 -9999

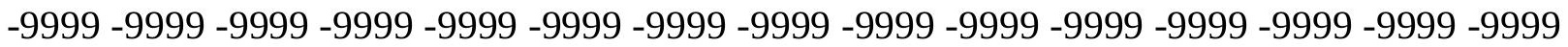
-9999 -9999 -9999 -9999 -9999 -9999 -9999 -9999 -9999 -9999 -9999 -9999 -9999 -9999 -9999 -

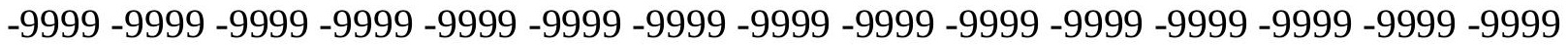
-9999 -9999 -9999 -9999 -9999 -9999 -9999 -9999 -9999 -9999 -9999 -9999 -9999 -9999 -9999 -9999 -9999 -9999 -9999 -9999 -9999 -9999 -9999 -9999 -9999 -9999 -9999 -9999 -9999 -9999 -

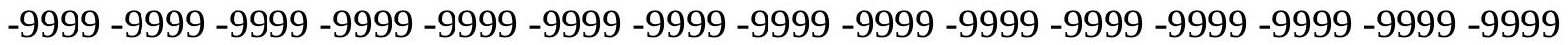
-9999 -9999 -9999 -9999 -9999 -9999 -9999 -9999 -9999 -9999 -9999 -9999 -9999 -9999 -9999 -9999 -9999 -9999 -9999 -9999 -9999 -9999 -9999 -9999 -9999 -9999 -9999 -9999 -9999 -9999 $-9999-9999$

-9999 -9999 -9999 -9999 -9999 -9999 -9999 -9999 -9999 -9999 -9999 -9999 -9999 -9999 -9999 -9999 -9999 -9999 -9999 -9999 -9999 -9999 -9999 -9999 -9999 -9999 -9999 -9999 -9999 -9999 -9999 -9999 -9999 -9999 -9999 -9999 -9999 -9999 -9999 -9999 -9999 -9999 -9999 -9999 -9999 -9999 -9999 -9999 -9999 -9999 -9999 -9999 -9999 -9999 -9999 -9999 -9999 -9999 -9999 -9999 -9999 -9999 -9999 -9999 -9999 -9999 -9999 -9999 -9999 -9999 -9999 -9999 -9999 -9999 -9999 -9999 -9999 -9999 -9999 -9999 -9999 -9999 -9999 -9999 -9999 -9999 -9999 -9999 -9999 -9999 -9999 -9999 -9999 -9999 -9999 -9999 -9999 -9999 -9999 -9999 -9999 -9999 -9999 -9999 -9999 -9999 -9999 179.8231964111 178.2993011475177.0802001953175.5561981201 
173.7274932861172 .5084075928171 .2891998291170 .6797027588170 .3748931885 170.3748931885170 .3748931885170 .9844970703171 .5939941406172 .5084075928 173.4226989746173 .4226989746173 .4226989746173 .4226989746173 .7274932861 174.0323028564174 .337097168174 .6419067383174 .6419067383174 .6419067383 174.9467010498175 .5561981201177 .3849029541180 .432800293182 .261505127 182.87109375184 .0901947021184 .699798584185 .6141052246185 .6141052246 185.0045928955183 .7854003906182 .5662994385179 .2136993408177 .9945068359 176.165802002173 .4226989746 -9999 -9999 -9999 -9999 -9999 -9999 -9999 -9999 -9999 -9999 -9999 -9999 -9999 -9999 -9999 -9999 -9999 -9999 -9999 -9999 -9999 -9999 -9999 -9999 -9999 -9999 -9999 -9999 -9999 -9999 -9999 -9999 -9999 -9999 -9999 -9999 -9999 -9999 -9999 -9999 -9999 -9999 -9999 -9999 -9999 -9999 -9999 -9999 -9999 -9999 -9999 -9999 -9999 -9999 -999 -9999 -9999 -9999 -9999 -9999 -9999 -9999 -9999 -9999 -9999 -9999 -9999 -9999 -9999 -9999 -9999 -9999 -9999 -9999 -9999 -9999 -9999 -9999 -9999 -9999 -9999 -9999 -9999 -9999 -9999 -9999 -9999 -9999 -9999 -9999 -9999 -9999 -9999 -9999 -9999 -9999 -9999 -9999 -9999 -9999 -9999 -9999 -9999 -9999 -9999 -9999 -9999 -9999 -9999 -9999 -9999 -9999 -9999 -9999 -9999

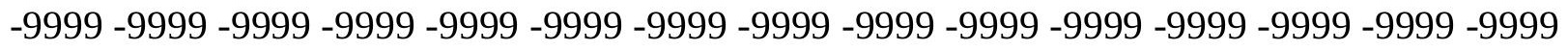
-9999 -9999 -9999 -9999 -9999 -9999 -9999 -9999 -9999 -9999 -9999 -9999 -9999 -9999 -9999 -9999 -9999 -9999 -9999 -9999 -9999 -9999 -9999 -9999 -9999 -9999 -9999 -9999 -9999 -9999 -

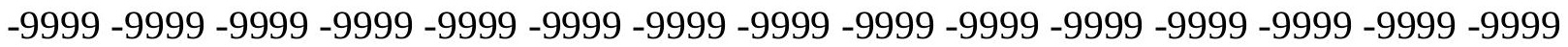

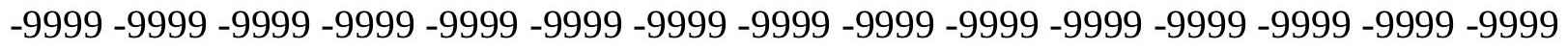

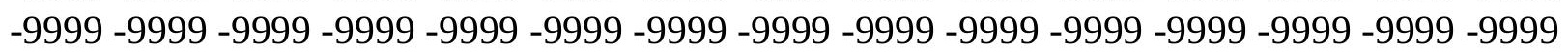

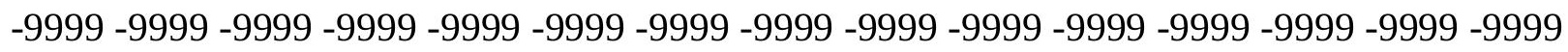

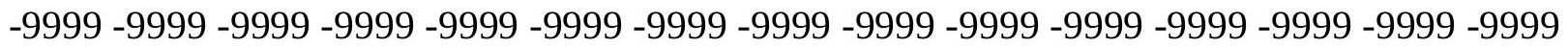
-9999 -9999 -9999 -9999-9999-9999-9999

-9999 -9999 -9999 -9999 -9999 -9999 -9999 -9999 -9999 -9999 -9999 -9999 -9999 -9999 -9999 -9999 -9999 -9999 -9999 -9999 -9999 -9999 -9999 -9999 -9999 -9999 -9999 -9999 -9999 -9999

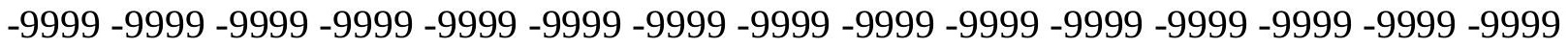

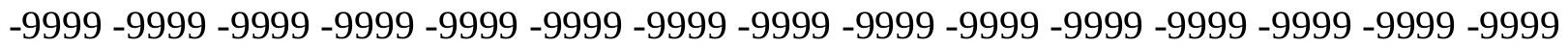

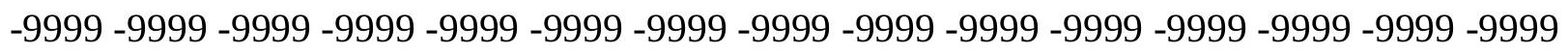

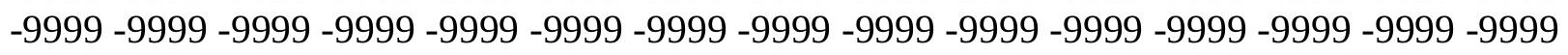
-9999 -9999 -9999 -9999 -9999 -9999 -9999 -9999 -9999 -9999 -9999 -9999 -9999 -9999 -9999 -9999 -9999 179.2136993408 177.3849029541 175.5561981201 174.0323028564 172.5084075928171 .2891998291170 .070098877169 .4604949951169 .4604949951 169.4604949951169 .7653045654170 .3748931885171 .2891998291172 .2035980225 173.1179962158173 .4226989746173 .4226989746173 .7274932861173 .7274932861 174.0323028564174 .0323028564174 .337097168174 .0323028564174 .0323028564 173.7274932861173 .7274932861174 .337097168180 .1280059814181 .0424041748 181.3471984863 182.261505127 183.1759033203 184.3950042725 185.3094024658 184.3950042725183 .7854003906182 .261505127179 .8231964111177 .0802001953 174.6419067383171 .5939941406167 .3269958496 -9999 -9999 -9999 -9999 -9999 -9999 -9999

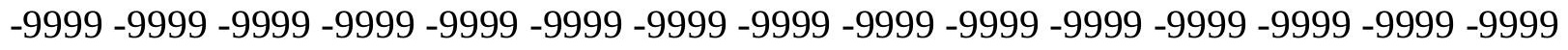

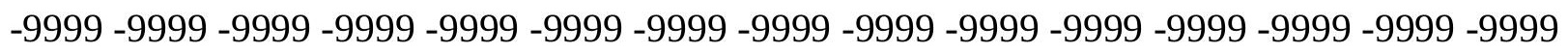

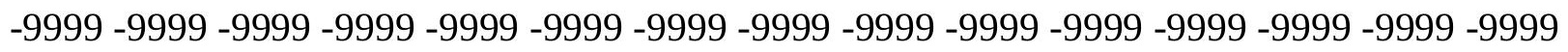
-9999 -9999 -9999 -9999 -9999 -9999 -9999 -9999 -9999 -9999 -9999 -9999 -9999 -9999 -9999 -

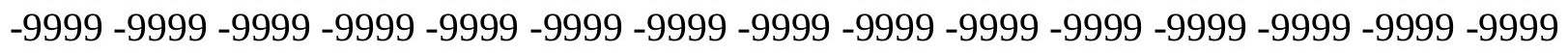

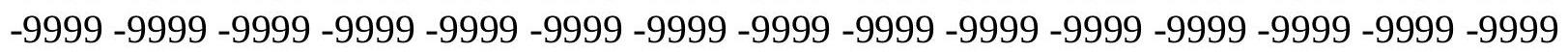


-9999 -9999 -9999 -9999 -9999 -9999 -9999 -9999 -9999 -9999 -9999 -9999 -9999 -9999 -9999 -9999 -9999 -9999 -9999 -9999 -9999 -9999 -9999 -9999 -9999 -9999 -9999 -9999 -9999 -9999 -9999 -9999 -9999 -9999 -9999 -9999 -9999 -9999 -9999 -9999 -9999 -9999 -9999 -9999 -9999 -9999 -9999 -9999 -9999 -9999 -9999 -9999 -9999 -9999 -9999 -9999 -9999 -9999 -9999 -9999 -9999 -9999 -9999 -9999 -9999 -9999 -9999 -9999 -9999 -9999 -9999 -9999 -9999 -9999 -9999 -9999 -9999 -9999 -9999 -9999 -9999 -9999 -9999 -9999 -9999 -9999 -9999 -9999 -9999 -9999 -9999 -9999 -9999 -9999 -9999 -9999 -9999 -9999 -9999 -9999 -9999 -9999 -9999 -9999 -9999

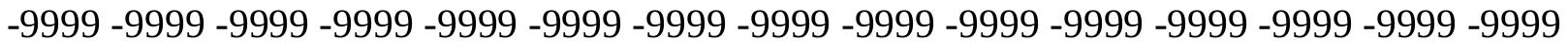

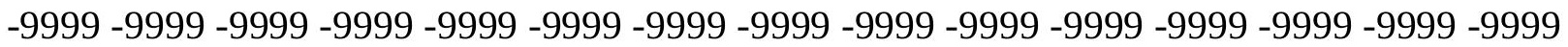
-9999 -9999 -9999 -9999 -9999 -9999 -9999 -9999

-9999 -9999 -9999 -9999 -9999 -9999 -9999 -9999 -9999 -9999 -9999 -9999 -9999 -9999 -9999 -9999 -9999 -9999 -9999 -9999 -9999 -9999 -9999 -9999 -9999 -9999 -9999 -9999 -9999 -9999

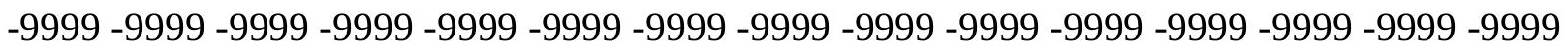
-9999 -9999 -9999 -9999 -9999 -9999 -9999 -9999 -9999 -9999 -9999 -9999 -9999 -9999 -9999 -9999 -9999 -9999 -9999 -9999 -9999 -9999 -9999 -9999 -9999 -9999 -9999 -9999 -9999 -9999 -9999 -9999 -9999 -9999 -9999 -9999 -9999 -9999 -9999 -9999 -9999 -9999 -9999 -9999 -9999 -9999 -9999 -9999 -9999 -9999 -9999 -9999 -9999 -9999 -9999 -9999 -9999 -9999 -9999 -9999 -9999 -9999-9999 176.7754058838174.6419067383172.8132019043171.2891998291 170.070098877169 .1557006836168 .8509979248168 .8509979248168 .8509979248 169.4604949951170 .070098877170 .6797027588171 .5939941406172 .5084075928 173.1179962158173 .4226989746173 .7274932861173 .7274932861174 .0323028564 174.0323028564174 .0323028564173 .7274932861173 .4226989746173 .1179962158 173.1179962158174 .337097168177 .0802001953178 .604095459179 .5184020996 180.432800293181 .3471984863182 .261505127182 .5662994385183 .1759033203 182.87109375181 .6519012451179 .8231964111177 .0802001953174 .0323028564 170.3748931885166 .4127044678161 .5361022949 -9999 -9999 -9999 -9999 -9999 -9999 -9999 -9999 -9999 -9999 -9999 -9999 -9999 -9999 -9999 -9999 -9999 -9999 -9999 -9999 -9999 -9999 -9999 -9999 -9999 -9999 -9999 -9999 -9999 -9999 -9999 -9999 -9999 -9999 -9999 -9999 -9999 -9999 -9999 -9999 -9999 -9999 -9999 -9999 -9999 -9999 -9999 -9999 -9999 -9999 -9999 -9999 -9999 -9999 -9999 -9999 -9999 -9999 -9999 -9999 -9999 -9999 -9999 -9999 -9999 -9999 -9999 -999 -9999 -9999 -9999 -9999 -9999 -9999 -9999 -9999 -9999 -9999 -9999 -9999 -9999 -9999 -9999 -

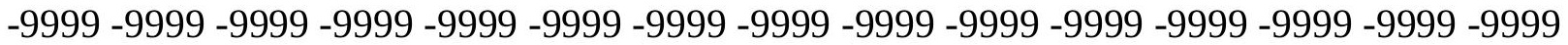
-9999 -9999 -9999 -9999 -9999 -9999 -9999 -9999 -9999 -9999 -9999 -9999 -9999 -9999 -9999 -9999 -9999 -9999 -9999 -9999 -9999 -9999 -9999 -9999 -9999 -9999 -9999 -9999 -9999 -9999 -

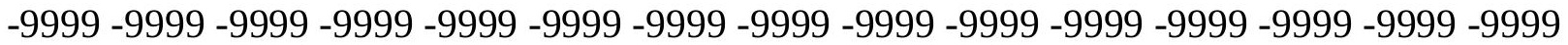
-9999 -9999 -9999 -9999 -9999 -9999 -9999 -9999 -9999 -9999 -9999 -9999 -9999 -9999 -9999 -9999 -9999 -9999 -9999 -9999 -9999 -9999 -9999 -9999 -9999 -9999 -9999 -9999 -9999 -9999

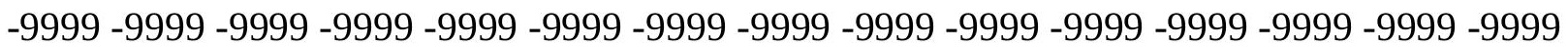
-9999 -9999 -9999 -9999 -9999 -9999 -9999 -9999 -9999 -9999 -9999 -9999 -9999 -9999 -9999 -9999 -9999 -9999 -9999 -9999 -9999 -9999 -9999 -9999 -9999 -9999 -9999 -9999 -9999 -9999 -

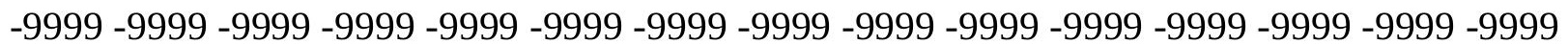
-9999 -9999 -9999 -9999 -9999-9999-9999 -9999 -9999 -9999 -9999 -9999 -9999 -9999 -9999 -9999 -9999 -9999 -9999 -9999 -9999 -9999 -9999 -9999 -9999 -9999 -9999 -9999 -9999 -9999 -9999 -9999 -9999 -9999 -9999 -9999 -9999 -9999 -9999 -9999 -9999 -9999 -9999 -9999 -9999 -9999 -9999 -9999 -9999 -9999 -9999 -9999

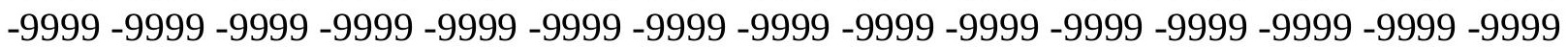


-9999 -9999 -9999 -9999 -9999 -9999 -9999 -9999 -9999 -9999 -9999 -9999 -9999 -9999 -9999 -9999 -9999 -9999 -9999 -9999 -9999 -9999 -9999 -9999 -9999 -9999 -9999 -9999 -9999 -9999 -9999 -9999 -9999 -9999 -9999 -9999 -9999 -9999 -9999 -9999 -9999 -9999 -9999 -9999 -9999 -9999 -9999 -9999-9999 174.337097168 172.5084075928170 .6797027588169 .1557006836 168.5462036133168 .241394043168 .241394043168 .5462036133168 .8509979248 169.4604949951170 .3748931885171 .2891998291172 .2035980225172 .8132019043 173.1179962158173 .7274932861173 .7274932861174 .0323028564174 .0323028564 174.0323028564173 .7274932861173 .4226989746173 .1179962158173 .1179962158 173.7274932861174 .6419067383175 .8609924316176 .7754058838177 .6896972656 178.9089050293180 .1280059814180 .7375946045181 .3471984863181 .6519012451 181.0424041748179 .5184020996177 .0802001953173 .7274932861169 .7653045654 166.7174987793161 .2312927246 -9999 -9999 -9999 -9999 -9999 -9999 -9999 -9999 -9999 -9999 -9999 -9999 -9999 -9999 -9999 -9999 -9999 -9999 -9999 -9999 -9999 -9999 -9999 -9999 -9999 -9999 -9999 -9999 -9999 -9999 -9999 -9999 -9999 -9999 -9999 -9999 -9999 -9999 -9999 -9999 -9999 -9999 -9999 -9999 -9999 -9999 -9999 -9999 -9999 -9999 -9999 -9999 -9999 -9999 -9999 -9999 -9999 -9999 -9999 -9999 -9999 -9999 -9999 -9999 -9999 -9999 -9999 -9999 -9999

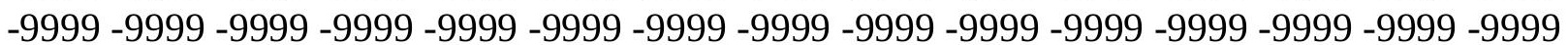
-9999 -9999 -9999 -9999 -9999 -9999 -9999 -9999 -9999 -9999 -9999 -9999 -9999 -9999 -9999 -9999 -9999 -9999 -9999 -9999 -9999 -9999 -9999 -9999 -9999 -9999 -9999 -9999 -9999 -9999 -9999 -9999 -9999 -9999 -9999 -9999 -9999 -9999 -9999 -9999 -9999 -9999 -9999 -9999 -9999

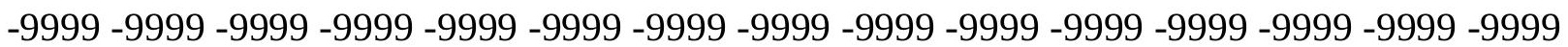
-9999 -9999 -9999 -9999 -9999 -9999 -9999 -9999 -9999 -9999 -9999 -9999 -9999 -9999 -9999 -9999 -9999 -9999 -9999 -9999 -9999 -9999 -9999 -9999 -9999 -9999 -9999 -9999 -9999 -9999 -9999 -9999 -9999 -9999 -9999 -9999 -9999 -9999 -9999 -9999 -9999 -9999 -9999 -9999 -9999

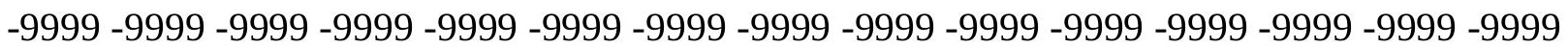
-9999 -9999 -9999 -9999 -9999 -9999 -9999 -9999 -9999 -9999 -9999 -9999 -9999 -9999 -9999 -9999 -9999 -9999 -9999 -9999 -9999 -9999 -9999 -9999 -9999 -9999 -9999 -9999 -9999 -9999 -9999 -9999-9999-9999-9999

-9999 -9999 -9999 -9999 -9999 -9999 -9999 -9999 -9999 -9999 -9999 -9999 -9999 -9999 -9999 -9999 -9999 -9999 -9999 -9999 -9999 -9999 -9999 -9999 -9999 -9999 -9999 -9999 -9999 -9999 -9999 -9999 -9999 -9999 -9999 -9999 -9999 -9999 -9999 -9999 -9999 -9999 -9999 -9999 -9999 -

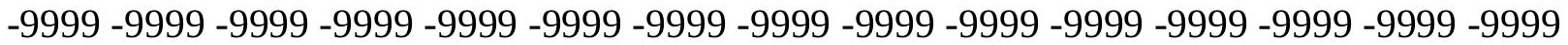
-9999 -9999 -9999 -9999 -9999 -9999 -9999 -9999 -9999 -9999 -9999 -9999 -9999 -9999 -9999 -9999 -9999 -9999 -9999 -9999 -9999 -9999 -9999 -9999 -9999 -9999 -9999 -9999 -9999 -9999 -9999 -9999 -9999 -9999 -9999 -9999 -9999 -9999 -9999 -9999 -9999 -9999 -9999 -9999 -9999 -9999 -9999 -9999 -9999 -9999 -9999 170.9844970703169 .4604949951168 .5462036133 167.9365997314167 .9365997314167 .9365997314168 .241394043168 .8509979248 169.7653045654170 .9844970703171 .8988037109172 .5084075928173 .1179962158 173.7274932861174 .0323028564174 .0323028564174 .0323028564173 .7274932861 173.4226989746173 .1179962158173 .1179962158172 .8132019043172 .8132019043 172.8132019043173 .1179962158174 .0323028564175 .2514038086176 .4705963135 177.9945068359178 .9089050293179 .8231964111180 .432800293180 .1280059814 178.9089050293177 .0802001953174 .0323028564170 .070098877165 .1934967041 160.6217956543155 .7451934814 -9999 -9999 -9999 -9999 -9999 -9999 -9999 -9999 -9999 -9999 -9999 -9999 -9999 -9999 -9999 -9999 -9999 -9999 -9999 -9999 -9999 -9999 -9999 -9999

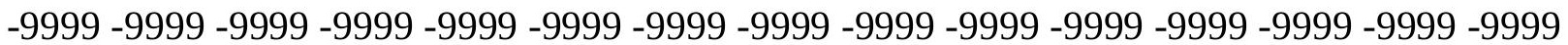


-9999 -9999 -9999 -9999 -9999 -9999 -9999 -9999 -9999 -9999 -9999 -9999 -9999 -9999 -9999 -9999 -9999 -9999 -9999 -9999 -9999 -9999 -9999 -9999 -9999 -9999 -9999 -9999 -9999 -9999 -9999 -9999 -9999 -9999 -9999 -9999 -9999 -9999 -9999 -9999 -9999 -9999 -9999 -9999 -9999 -9999 -9999 -9999 -9999 -9999 -9999 -9999 -9999 -9999 -9999 -9999 -9999 -9999 -9999 -9999 -9999 -9999 -9999 -9999 -9999 -9999 -9999 -9999 -9999 -9999 -9999 -9999 -9999 -9999 -9999 -9999 -9999 -9999 -9999 -9999 -9999 -9999 -9999 -9999 -9999 -9999 -9999 -9999 -9999 -9999 -9999 -9999 -9999 -9999 -9999 -9999 -9999 -9999 -9999 -9999 -9999 -9999 -9999 -9999 -9999

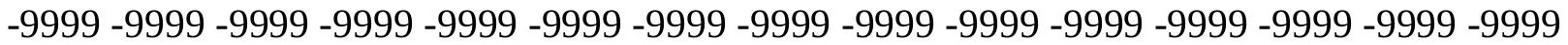
-9999 -9999 -9999 -9999 -9999 -9999 -9999 -9999 -9999 -9999 -9999 -9999 -9999 -9999 -9999 -9999 -9999 -9999 -9999 -9999 -9999 -9999 -9999 -9999 -9999 -9999 -9999 -9999 -9999 -9999 -

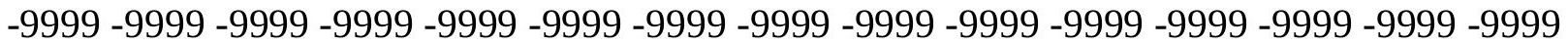
-9999 -9999 -9999 -9999 -9999 -9999 -9999 -9999 -9999 -9999 -9999 -9999 -9999 -9999 -9999 -9999 -9999 -9999 -9999 -9999 -9999 -9999 -9999 -9999 -9999 -9999 -9999 -9999 -9999 -9999 -9999 -9999-9999-9999

-9999 -9999 -9999 -9999 -9999 -9999 -9999 -9999 -9999 -9999 -9999 -9999 -9999 -9999 -9999 -9999 -9999 -9999 -9999 -9999 -9999 -9999 -9999 -9999 -9999 -9999 -9999 -9999 -9999 -9999 -9999 -9999 -9999 -9999 -9999 -9999 -9999 -9999 -9999 -9999 -9999 -9999 -9999 -9999 -9999 -9999 -9999 -9999 -9999 -9999 -9999 -9999 -9999 -9999 -9999 -9999 -9999 -9999 -9999 -9999 -9999 -9999 -9999 -9999 -9999 -9999 -9999 -9999 -9999 -9999 -9999 -9999 -9999 -9999 -9999 -9999 -9999 -9999 -9999 -9999 -9999 -9999 -9999 -9999 -9999 -9999 -9999 -9999 -9999 -9999 -9999 -9999 -9999 -9999 -9999 -9999 -9999 -9999 -9999 -9999 -9999 -9999 -9999 -9999 -9999 -9999 -9999-9999 -9999-9999 -9999-9999 -9999 168.8509979248168 .241394043 167.6318054199167 .6318054199167 .9365997314168 .5462036133169 .4604949951 170.6797027588171 .8988037109172 .8132019043173 .4226989746173 .7274932861 174.0323028564174 .0323028564174 .0323028564173 .7274932861173 .4226989746 173.1179962158172 .8132019043172 .5084075928171 .8988037109170 .9844970703 170.6797027588171 .2891998291172 .8132019043174 .337097168175 .8609924316 177.3849029541178 .2993011475178 .9089050293178 .9089050293178 .2993011475 177.0802001953174 .6419067383170 .6797027588165 .4983062744160 .9264984131 155.1356048584 -9999 -9999 -9999 -9999 -9999 -9999 -9999 -9999 -9999 -9999 -9999 -9999 -9999 -9999 -9999 -9999 -9999 -9999 -9999 -9999 -9999 -9999 -9999 -9999 -9999 -9999 -9999

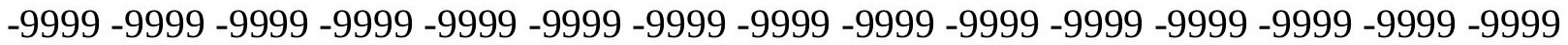
-9999 -9999 -9999 -9999 -9999 -9999 -9999 -9999 -9999 -9999 -9999 -9999 -9999 -9999 -9999 -9999 -9999 -9999 -9999 -9999 -9999 -9999 -9999 -9999 -9999 -9999 -9999 -9999 -9999 -9999 -

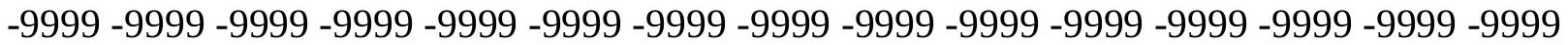
-9999 -9999 -9999 -9999 -9999 -9999 -9999 -9999 -9999 -9999 -9999 -9999 -9999 -9999 -9999 -9999 -9999 -9999 -9999 -9999 -9999 -9999 -9999 -9999 -9999 -9999 -9999 -9999 -9999 -9999

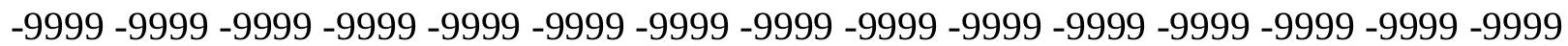
-9999 -9999 -9999 -9999 -9999 -9999 -9999 -9999 -9999 -9999 -9999 -9999 -9999 -9999 -9999 -9999 -9999 -9999 -9999 -9999 -9999 -9999 -9999 -9999 -9999 -9999 -9999 -9999 -9999 -9999 -9999 -9999 -9999 -9999 -9999 -9999 -9999 -9999 -9999 -9999 -9999 -9999 -9999 -9999 -9999

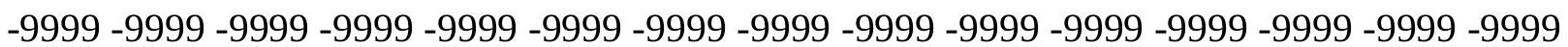
-9999 -9999 -9999 -9999 -9999 -9999 -9999 -9999 -9999 -9999 -9999 -9999 -9999 -9999 -9999 -9999 -9999 -9999 -9999 -9999 -9999 -9999 -9999 -9999 -9999 -9999 -9999 -9999 -9999 -9999 -9999 -9999 -9999 -9999 -9999 -9999 -9999 -9999 -9999 -9999 -9999 -9999 -9999 -9999 -9999 $-9999$ 
-9999 -9999 -9999 -9999 -9999 -9999 -9999 -9999 -9999 -9999 -9999 -9999 -9999 -9999 -9999 -9999 -9999 -9999 -9999 -9999 -9999 -9999 -9999 -9999 -9999 -9999 -9999 -9999 -9999 -9999 -9999 -9999 -9999 -9999 -9999 -9999 -9999 -9999 -9999 -9999 -9999 -9999 -9999 -9999 -9999 -9999 -9999 -9999 -9999 -9999 -9999 -9999 -9999 -9999 -9999 -9999 -9999 -9999 -9999 -9999 -9999 -9999 -9999 -9999 -9999 -9999 -9999 -9999 -9999 -9999 -9999 -9999 -9999 -9999 -9999 -9999 -9999 -9999 -9999 -9999 -9999 -9999 -9999 -9999 -9999 -9999 -9999 -9999 -9999 -9999 -9999 -9999 -9999 -9999 -9999 -9999 -9999 -9999 -9999 -9999 -9999 -9999 -9999 -9999 -9999 -9999 -9999 -9999 -9999 -9999 -9999 -9999 -9999 -9999 168.5462036133167 .9365997314 167.6318054199167 .6318054199167 .9365997314169 .4604949951170 .9844970703 172.2035980225173 .1179962158173 .7274932861174 .337097168174 .337097168 174.337097168173 .7274932861173 .4226989746173 .1179962158173 .1179962158 172.8132019043172 .5084075928171 .2891998291170 .070098877168 .241394043 169.1557006836170 .6797027588172 .5084075928174 .0323028564175 .5561981201 176.7754058838177 .3849029541177 .6896972656177 .3849029541176 .4705963135 174.9467010498171 .5939941406166 .1078948975159 .4026031494154 .2212982178 -9999 -9999 -9999 -9999 -9999 -9999 -9999 -9999 -9999 -9999 -9999 -9999 -9999 -9999 -9999 -9999 -9999 -9999 -9999 -9999 -9999 -9999 -9999 -9999 -9999 -9999 -9999 -9999 -9999 -9999 -9999 -9999 -9999 -9999 -9999 -9999 -9999 -9999 -9999 -9999 -9999 -9999 -9999 -9999 -9999 -9999 -9999 -9999 -9999 -9999 -9999 -9999 -9999 -9999 -9999 -9999 -9999 -9999 -9999 -9999 -9999 -9999 -9999 -9999 -9999 -9999 -9999 -9999 -9999 -9999 -9999 -9999 -9999 -9999 -9999 -9999

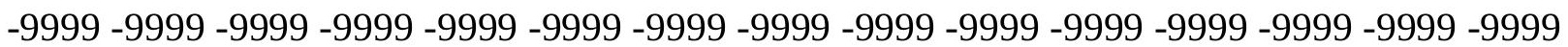
-9999 -9999 -9999 -9999 -9999 -9999 -9999 -9999 -9999 -9999 -9999 -9999 -9999 -9999 -9999 -9999 -9999 -9999 -9999 -9999 -9999 -9999 -9999 -9999 -9999 -9999 -9999 -9999 -9999 -9999 -9999 -9999 -9999 -9999 -9999 -9999 -9999 -9999 -9999 -9999 -9999 -9999 -9999 -9999 -9999

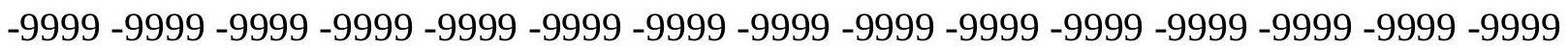
-9999 -9999 -9999 -9999 -9999 -9999 -9999 -9999 -9999 -9999 -9999 -9999 -9999 -9999 -9999 -9999 -9999 -9999 -9999 -9999 -9999 -9999 -9999 -9999 -9999 -9999 -9999 -9999 -9999 -9999 -9999 -9999 -9999 -9999 -9999 -9999 -9999 -9999 -9999 -9999 -9999 -9999 -9999 -9999 -9999 -9999 -9999 -9999 -9999 -9999 -9999 -9999 -9999 -9999 -9999 -9999 -9999 -9999 -9999 -9999

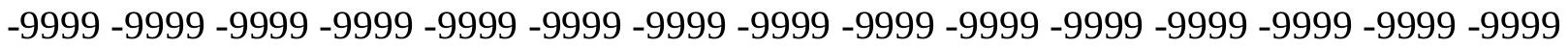
-9999 -9999 -9999 -9999 -9999 -9999 -9999 -9999 -9999 -9999 -9999 -9999 -

-9999 -9999 -9999 -9999 -9999 -9999 -9999 -9999 -9999 -9999 -9999 -9999 -9999 -9999 -9999 -9999 -9999 -9999 -9999 -9999 -9999 -9999 -9999 -9999 -9999 -9999 -9999 -9999 -9999 -9999 -9999 -9999 -9999 -9999 -9999 -9999 -9999 -9999 -9999 -9999 -9999 -9999 -9999 -9999 -9999 -

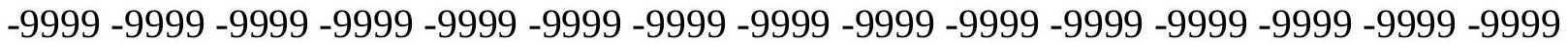
-9999 -9999 -9999 -9999 -9999 -9999 -9999 -9999 -9999 -9999 -9999 -9999 -9999 -9999 -9999 -9999 -9999 -9999 -9999 -9999 -9999 -9999 -9999 -9999 -9999 -9999 -9999 -9999 -9999 -9999

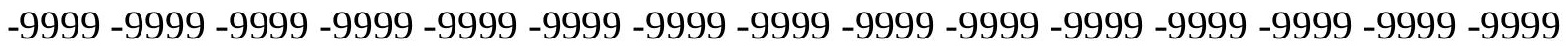
-9999 -9999 -9999 -9999 -9999 -9999 -9999 -9999 -9999 -9999 -9999 167.9365997314 167.6318054199168 .5462036133170 .3748931885172 .2035980225173 .1179962158 174.0323028564174 .337097168174 .6419067383174 .6419067383174 .337097168 173.7274932861173 .1179962158172 .8132019043172 .5084075928173 .1179962158 173.1179962158171 .2891998291168 .8509979248167 .0222015381167 .6318054199 169.4604949951171 .2891998291172 .5084075928174 .0323028564174 .9467010498 175.5561981201175 .8609924316175 .8609924316174 .9467010498174 .0323028564 172.5084075928165 .4983062744158 .7929992676152 .6972961426 -9999 -9999 -9999-9999 
-9999 -9999 -9999 -9999 -9999 -9999 -9999 -9999 -9999 -9999 -9999 -9999 -9999 -9999 -9999 -9999 -9999 -9999 -9999 -9999 -9999 -9999 -9999 -9999 -9999 -9999 -9999 -9999 -9999 -9999 -9999 -9999 -9999 -9999 -9999 -9999 -9999 -9999 -9999 -9999 -9999 -9999 -9999 -9999 -9999 -9999 -9999 -9999 -9999 -9999 -9999 -9999 -9999 -9999 -9999 -9999 -9999 -9999 -9999 -9999 -9999 -9999 -9999 -9999 -9999 -9999 -9999 -9999 -9999 -9999 -9999 -9999 -9999 -9999 -9999 -9999 -9999 -9999 -9999 -9999 -9999 -9999 -9999 -9999 -9999 -9999 -9999 -9999 -9999 -9999 -9999 -9999 -9999 -9999 -9999 -9999 -9999 -9999 -9999 -9999 -9999 -9999 -9999 -9999 -9999 -

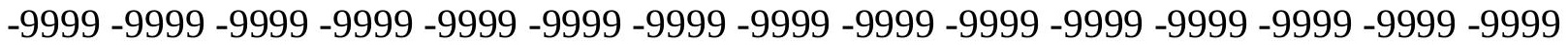
-9999 -9999 -9999 -9999 -9999 -9999 -9999 -9999 -9999 -9999 -9999 -9999 -9999 -9999 -9999 -9999 -9999 -9999 -9999 -9999 -9999 -9999 -9999 -9999 -9999 -9999 -9999 -9999 -9999 -9999 -

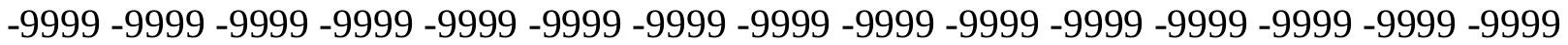
-9999 -9999 -9999 -9999 -9999 -9999 -9999 -9999 -9999 -9999 -9999 -9999 -9999 -9999 -9999

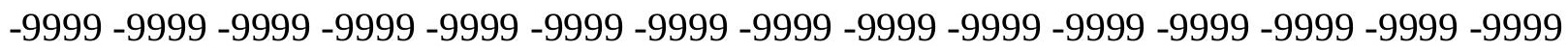
-9999 -9999 -9999 -9999 -9999 -9999 -9999 -9999 -9999 -9999 -9999 -9999 -9999 -9999 -9999 -9999 -9999 -9999 -9999 -9999 -9999 -9999 -9999 -9999 -9999 -9999 -9999 -9999 -9999 -9999 -9999 -9999 -9999 -9999 -9999 -9999 -9999 -9999 -9999

-9999 -9999 -9999 -9999 -9999 -9999 -9999 -9999 -9999 -9999 -9999 -9999 -9999 -9999 -9999 -9999 -9999 -9999 -9999 -9999 -9999 -9999 -9999 -9999 -9999 -9999 -9999 -9999 -9999 -9999 -9999 -9999 -9999 -9999 -9999 -9999 -9999 -9999 -9999 -9999 -9999 -9999 -9999 -9999 -9999 -9999 -9999 -9999 -9999 -9999 -9999 -9999 -9999 -9999 -9999 -9999 -9999 -9999 -9999 -9999

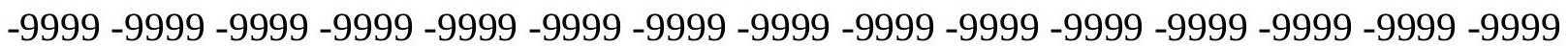
-9999 -9999 -9999 -9999 -9999 -9999 -9999 -9999 -9999 -9999 -9999 -9999 -9999 -9999 -9999 -9999 -9999 -9999 -9999 -9999 -9999 -9999 -9999 -9999 -9999 -9999 -9999 -9999 -9999 -9999 -9999 -9999 -9999 -9999 -9999 -9999 -9999 -9999 -9999 -9999 -9999 -9999 167.9365997314 167.6318054199172 .5084075928173 .4226989746174 .0323028564174 .6419067383 175.2514038086175 .2514038086175 .2514038086174 .6419067383174 .0323028564 173.1179962158172 .5084075928172 .2035980225174 .0323028564174 .9467010498 172.5084075928167 .3269958496167 .6318054199167 .0222015381168 .8509979248 170.070098877171 .2891998291172 .2035980225173 .1179962158173 .7274932861 174.0323028564173 .4226989746172 .5084075928170 .9844970703168 .241394043 163.3648071289157 .5738983154152 .6972961426 -9999 -9999 -9999 -9999 -9999 -9999 -9999 -9999 -9999 -9999 -9999 -9999 -9999 -9999 -9999 -9999 -9999 -9999 -9999 -9999 -9999 -9999

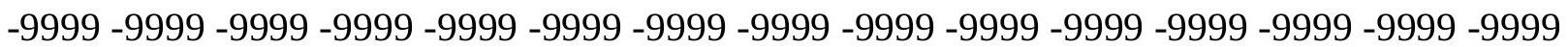
-9999 -9999 -9999 -9999 -9999 -9999 -9999 -9999 -9999 -9999 -9999 -9999 -9999 -9999 -9999 -

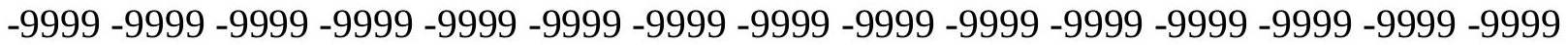
-9999 -9999 -9999 -9999 -9999 -9999 -9999 -9999 -9999 -9999 -9999 -9999 -9999 -9999 -9999 -9999 -9999 -9999 -9999 -9999 -9999 -9999 -9999 -9999 -9999 -9999 -9999 -9999 -9999 -9999

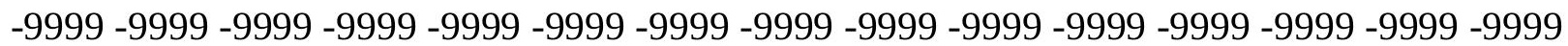
-9999 -9999 -9999 -9999 -9999 -9999 -9999 -9999 -9999 -9999 -9999 -9999 -9999 -9999 -9999 -9999 -9999 -9999 -9999 -9999 -9999 -9999 -9999 -9999 -9999 -9999 -9999 -9999 -9999 -9999 -9999 -9999 -9999 -9999 -9999 -9999 -9999 -9999 -9999 -9999 -9999 -9999 -9999 -9999 -9999

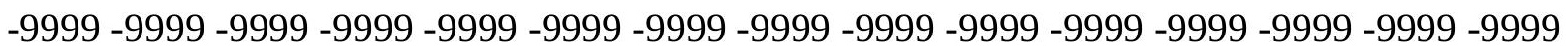
-9999 -9999 -9999 -9999 -9999 -9999 -9999 -9999 -9999 -9999 -9999 -9999 -9999 -9999 -9999 -9999 -9999 -9999 -9999 -9999 -9999 -9999 -9999 -9999 -9999 -9999 -9999 -9999 -9999 -9999 -9999 -9999 -9999 -9999 -9999 -9999 -9999 -9999 -9999 -9999 -9999 -9999 -9999 -9999 -9999

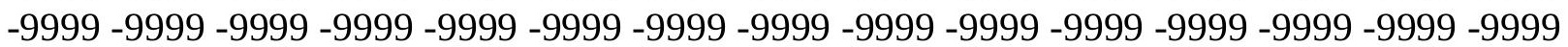


-9999 -9999 -9999 -9999-9999 -9999

-9999 -9999 -9999 -9999 -9999 -9999 -9999 -9999 -9999 -9999 -9999 -9999 -9999 -9999 -9999

-9999 -9999 -9999 -9999 -9999 -9999 -9999 -9999 -9999 -9999 -9999 -9999 -9999 -9999 -9999

-9999 -9999 -9999 -9999 -9999 -9999 -9999 -9999 -9999 -9999 -9999 -9999 -9999 -9999 -9999

-9999 -9999 -9999 -9999 -9999 -9999 -9999 -9999 -9999 -9999 -9999 -9999 -9999 -9999 -9999 -

-9999 -9999 -9999 -9999 -9999 -9999 -9999 -9999 -9999 -9999 -9999 -9999 -9999 -9999 -9999 -

-9999 -9999 -9999 -9999 -9999 -9999 -9999 -9999 -9999 -9999 -9999 -9999 -9999 -9999 -9999 -

-9999 -9999 -9999 -9999 -9999 -9999 -9999 -9999 -9999 -9999 -9999 -9999 -9999 -9999 -9999

-9999 -9999 -9999 -9999 -9999 -9999 -9999 -9999 -9999 -9999 -9999 -9999 -9999

172.8132019043173 .4226989746173 .7274932861174 .6419067383175 .2514038086

175.8609924316175 .8609924316175 .5561981201174 .6419067383174 .0323028564

173.4226989746172 .8132019043173 .1179962158174 .6419067383176 .4705963135

176.7754058838162 .4505004883163 .974395752167 .6318054199168 .241394043

168.8509979248169 .7653045654170 .6797027588171 .2891998291171 .8988037109

171.8988037109171 .2891998291169 .7653045654167 .0222015381164 .2792053223

160.6217956543156 .0500030518152 .0877990723 -9999 -9999 -9999 -9999 -9999 -9999 -9999

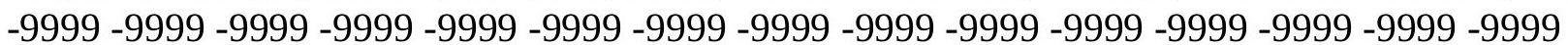

-9999 -9999 -9999 -9999 -9999 -9999 -9999 -9999 -9999 -9999 -9999 -9999 -9999 -9999 -9999 -

-9999 -9999 -9999 -9999 -9999 -9999 -9999 -9999 -9999 -9999 -9999 -9999 -9999 -9999 -9999 -

-9999 -9999 -9999 -9999 -9999 -9999 -9999 -9999 -9999 -9999 -9999 -9999 -9999 -9999 -9999 -

-9999 -9999 -9999 -9999 -9999 -9999 -9999 -9999 -9999 -9999 -9999 -9999 -9999 -9999 -9999 -999 -

-9999 -9999 -9999 -9999 -9999 -9999 -9999 -9999 -9999 -9999 -9999 -9999 -9999 -9999 -9999 -

-9999 -9999 -9999 -9999 -9999 -9999 -9999 -9999 -9999 -9999 -9999 -9999 -9999 -9999 -9999

-9999 -9999 -9999 -9999 -9999 -9999 -9999 -9999 -9999 -9999 -9999 -9999 -9999 -9999 -9999

-9999 -9999 -9999 -9999 -9999 -9999 -9999 -9999 -9999 -9999 -9999 -9999 -9999 -9999 -9999

-9999 -9999 -9999 -9999 -9999 -9999 -9999 -9999 -9999 -9999 -9999 -9999 -9999 -9999 -9999 -

-9999 -9999 -9999 -9999 -9999 -9999 -9999 -9999 -9999 -9999 -9999 -9999 -9999 -9999 -9999 -

-9999 -9999 -9999 -9999 -9999 -9999 -9999 -9999 -9999 -9999 -9999 -9999 -9999 -9999 -9999

-9999 -9999 -9999 -9999 -9999 -9999 -9999 -9999 -9999 -9999 -9999 -9999 -9999 -9999 -9999 -999 -

-9999 -9999 -9999 -9999 -9999 -9999 -9999 -9999 -9999 -9999 -9999 -9999 -9999 -9999 -9999 -

-9999 -9999 -9999 -9999 -9999 -9999 -9999 -9999 -9999 -9999 -9999 -9999 -9999 -9999 -9999 -

-9999 -9999 -9999-9999-9999-9999

-9999 -9999 -9999 -9999 -9999 -9999 -9999 -9999 -9999 -9999 -9999 -9999 -9999 -9999 -9999

-9999 -9999 -9999 -9999 -9999 -9999 -9999 -9999 -9999 -9999 -9999 -9999 -9999 -9999 -9999 -

-9999 -9999 -9999 -9999 -9999 -9999 -9999 -9999 -9999 -9999 -9999 -9999 -9999 -9999 -9999 -

-9999 -9999 -9999 -9999 -9999 -9999 -9999 -9999 -9999 -9999 -9999 -9999 -9999 -9999 -9999

-9999 -9999 -9999 -9999 -9999 -9999 -9999 -9999 -9999 -9999 -9999 -9999 -9999 -9999 -9999

-9999 -9999 -9999 -9999 -9999 -9999 -9999 -9999 -9999 -9999 -9999 -9999 -9999 -9999 -9999

-9999 -9999 -9999 -9999 -9999 -9999 -9999 -9999 -9999 -9999 -9999 -9999 -9999 -9999 -9999 -

-9999 -9999 -9999 -9999 -9999 -9999 -9999 -9999 -9999 -9999 -9999 -9999 -9999 -9999

174.337097168174 .6419067383174 .6419067383175 .5561981201176 .165802002

175.8609924316175 .5561981201174 .6419067383174 .0323028564173 .4226989746

173.1179962158173 .4226989746174 .337097168174 .6419067383171 .8988037109

166.4127044678164 .5839996338166 .1078948975167 .0222015381167 .6318054199

168.241394043168 .8509979248169 .4604949951170 .070098877170 .070098877

169.1557006836167 .6318054199165 .1934967041161 .8408966064158 .1835021973 
154.2212982178151 .1734008789 -9999 -9999 -9999 -9999 -9999 -9999 -9999 -9999 -9999 -9999 -9999 -9999 -9999 -9999 -9999 -9999 -9999 -9999 -9999 -9999 -9999 -9999 -9999 -9999

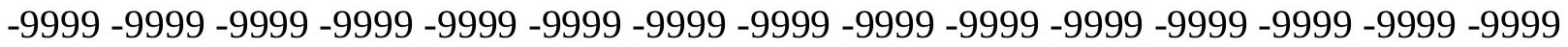
-9999 -9999 -9999 -9999 -9999 -9999 -9999 -9999 -9999 -9999 -9999 -9999 -9999 -9999 -9999 -9999 -9999 -9999 -9999 -9999 -9999 -9999 -9999 -9999-9999 -9999 -9999 -9999 -9999 -9999 -9999 -9999 -9999 -9999 -9999 -9999 -9999 -9999 -9999 -9999 -9999 -9999 -9999 -9999 -9999 -9999 -9999 -9999 -9999 -9999 -9999 -9999 -9999 -9999 -9999 -9999 -9999 -9999 -9999 -9999

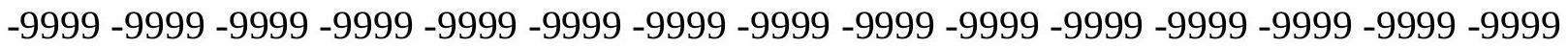

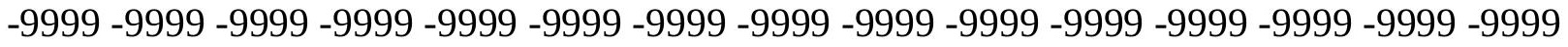
-9999 -9999 -9999 -9999 -9999 -9999 -9999 -9999 -9999 -9999 -9999 -9999 -9999 -9999 -9999 -9999 -9999 -9999 -9999 -9999 -9999 -9999 -9999 -9999 -9999 -9999 -9999 -9999 -9999 -9999 -9999 -9999 -9999 -9999 -9999 -9999 -9999 -9999 -9999 -9999 -9999 -9999 -9999 -9999 -9999 -9999 -9999 -9999 -9999 -9999 -9999 -9999 -9999 -9999 -9999 -9999 -9999 -9999 -9999 -9999 -

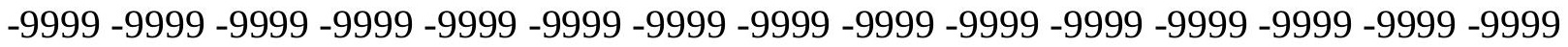
-9999 -9999 -9999 -9999 -9999 -9999 -9999 -9999 -9999 -9999 -9999 -9999 -9999 -9999 -9999 -

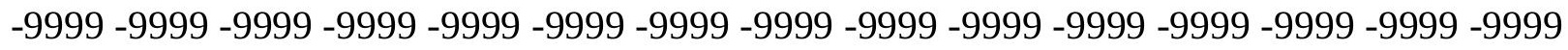
-9999 -9999-9999-9999

-9999 -9999 -9999 -9999 -9999 -9999 -9999 -9999 -9999 -9999 -9999 -9999 -9999 -9999 -9999 -9999 -9999 -9999 -9999 -9999 -9999 -9999 -9999 -9999 -9999 -9999 -9999 -9999 -9999 -9999 -

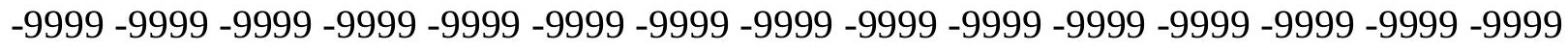
-9999 -9999 -9999 -9999 -9999 -9999 -9999 -9999 -9999 -9999 -9999 -9999 -9999 -9999 -9999 -999 -9999 -9999 -9999 -9999 -9999 -9999 -9999 -9999 -9999 -9999 -9999 -9999 -9999 -9999 -9999 -9999 -9999 -9999 -9999 -9999 -9999 -9999 -9999 -9999 -9999 -9999 -9999 -9999 -9999 -9999 -9999 -9999 -9999 -9999 -9999 -9999 -9999 -9999 -9999 -9999 -9999 -9999 -9999 -9999 -9999 -9999 -9999 -9999 -9999 -9999 -9999 -9999 -9999 -9999 -9999 -9999 -9999 -9999 -9999 -9999 175.5561981201175 .5561981201175 .2514038086175 .8609924316175 .5561981201 174.9467010498174 .0323028564173 .4226989746172 .8132019043172 .8132019043 172.8132019043172 .8132019043172 .2035980225169 .7653045654167 .0222015381 165.4983062744165 .4983062744166 .1078948975166 .4127044678166 .7174987793 167.3269958496167 .9365997314168 .5462036133168 .8509979248168 .241394043 166.4127044678163 .974395752160 .9264984131156 .9642944336153 .0021057129 150.2590942383 -9999 -9999 -9999 -9999 -9999 -9999 -9999 -9999 -9999 -9999 -9999 -9999 -9999 -9999 -9999 -9999 -9999 -9999 -9999 -9999 -9999 -9999 -9999 -9999 -9999 -9999 -9999 -9999 -9999 -9999 -9999 -9999 -9999 -9999 -9999 -9999 -9999 -9999 -9999 -9999 -9999 -9999 -9999 -9999 -9999 -9999 -9999 -9999 -9999 -9999 -9999 -9999 -9999 -9999 -9999 -9999 -9999 -9999 -9999 -9999 -9999 -9999 -9999 -9999 -9999 -9999 -9999 -9999 -9999 -9999 -9999 -9999

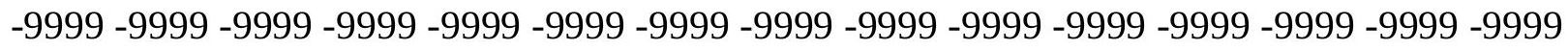

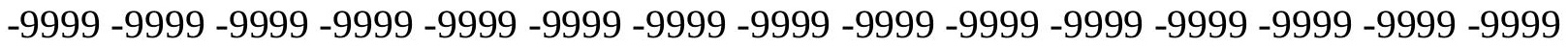
-9999 -9999 -9999 -9999 -9999 -9999 -9999 -9999 -9999 -9999 -9999 -9999 -9999 - 9999 - -999 -9999 -9999 -9999 -9999 -9999 -9999 -9999 -9999 -9999 -9999 -9999 -9999 -9999 -9999 -9999 -

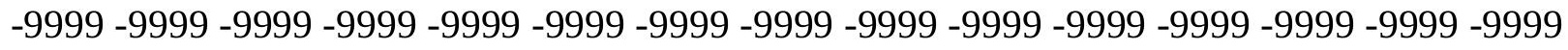

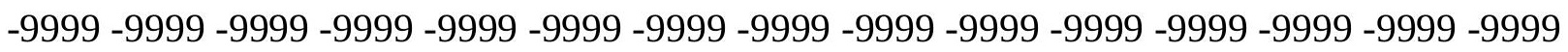
-9999 -9999 -9999 -9999 -9999 -9999 -9999 -9999 -9999 -9999 -9999 -9999 -9999 -9999 -9999 -9999 -9999 -9999 -9999 -9999 -9999 -9999 -9999 -9999-9999 -9999 -9999 -9999 -9999 -9999 -9999 -9999 -9999 -9999 -9999 -9999 -9999 -9999 -9999 -9999 -9999 -9999 -9999 -9999 -9999 -9999 -9999 -9999 -9999 -9999 -9999 -9999 -9999 -9999 -9999 -9999 -9999 -9999 -9999 -9999 
-9999 -9999 -9999 -9999 -9999 -9999 -9999 -9999 -9999 -9999 -9999 -9999 -9999 -9999 -9999 $-9999$

-9999 -9999 -9999 -9999 -9999 -9999 -9999 -9999 -9999 -9999 -9999 -9999 -9999 -9999 -9999 -9999 -9999 -9999 -9999 -9999 -9999 -9999 -9999 -9999 -9999 -9999 -9999 -9999 -9999 -9999 - -999 -

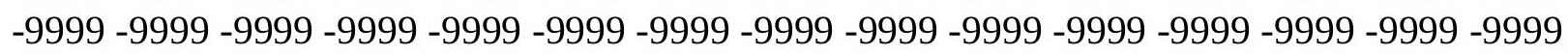

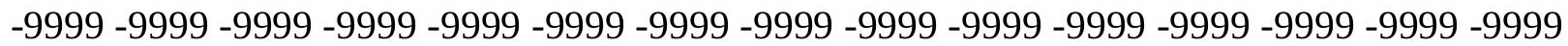

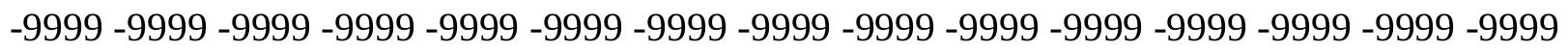
-9999 -9999 -9999 -9999 -9999 -9999 -9999 -9999 -9999 -9999 -9999 -9999 -9999 -9999 -9999

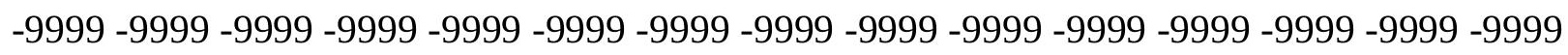
-9999 -9999 -9999 -9999 -9999 -9999 -9999 -9999 -9999 -9999 -9999 -9999 -9999 -9999 -9999 -9999 176.7754058838 175.8609924316 175.5561981201 174.337097168 173.4226989746 172.8132019043172 .5084075928172 .2035980225171 .8988037109171 .5939941406 171.5939941406170 .6797027588169 .1557006836167 .3269958496166 .1078948975 165.8031005859165 .8031005859165 .4983062744165 .4983062744165 .8031005859 166.7174987793167 .6318054199168 .241394043167 .6318054199166 .1078948975 $163.6696014404160 .6217956543157 .2691040039153 .9165039062149 .3446960449-9999$ -9999 -9999 -9999 -9999 -9999 -9999 -9999 -9999 -9999 -9999 -9999 -9999 -9999 -9999 -9999

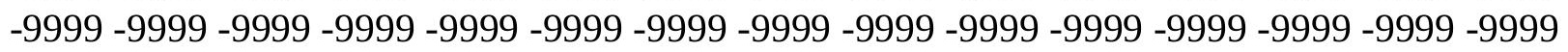

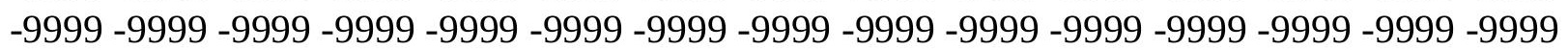

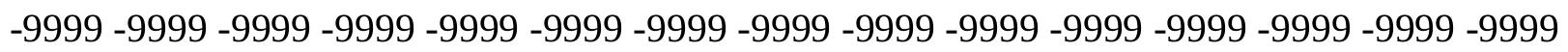

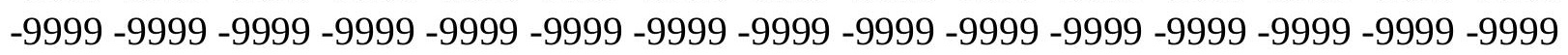

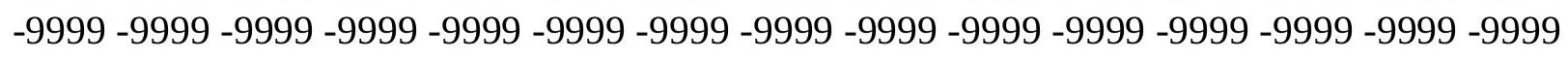
-9999 -9999 -9999 -9999 -9999 -9999 -9999 -9999 -9999 -9999 -9999 -9999 -9999 -9999 -9999 -

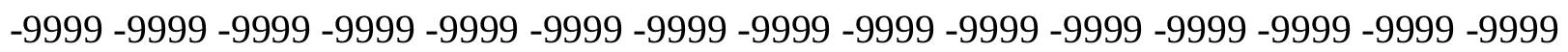

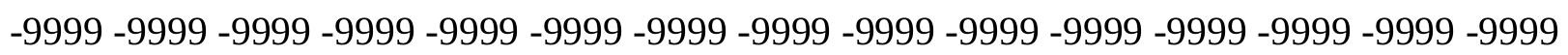

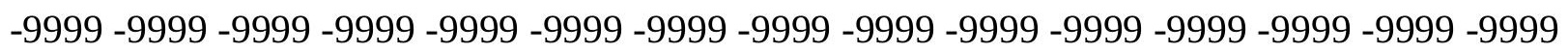

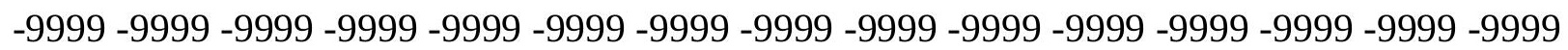

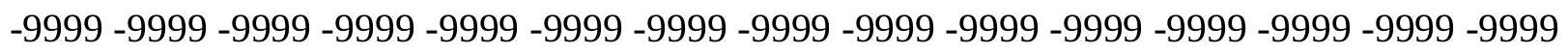

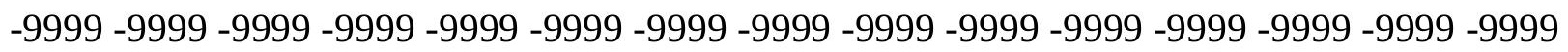

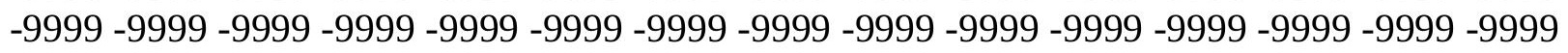

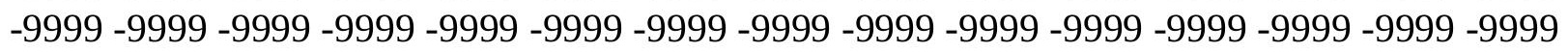
-9999 -9999 -9999 -9999 -9999 -9999 -9999 -9999 -9999 -9999 -9999 -9999 -

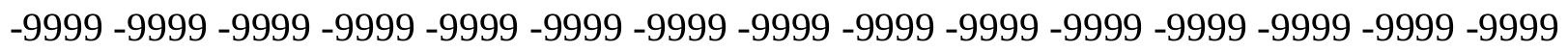

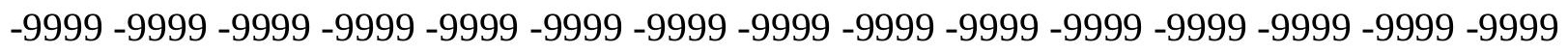

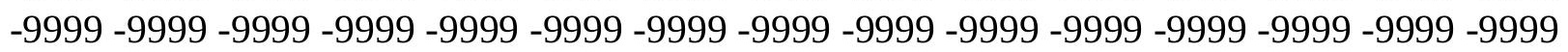

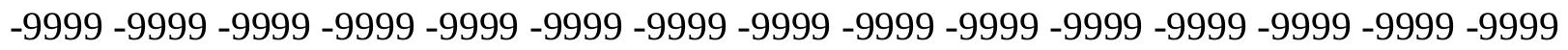

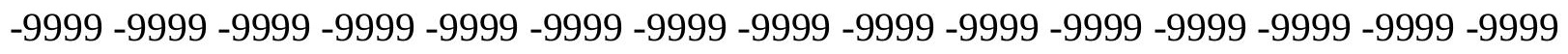

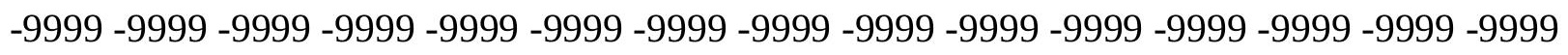

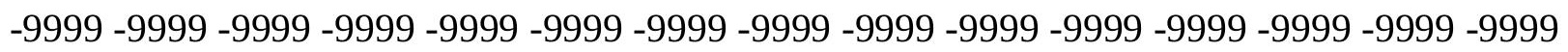
-9999 -9999 -9999 -9999 -9999 -9999 -9999 -9999 -9999 -9999 -9999 -9999 -9999 -9999 -9999 -9999-9999 177.0802001953 173.4226989746170.6797027588170.3748931885 170.9844970703170 .9844970703170 .6797027588170 .6797027588170 .3748931885 170.070098877169 .4604949951168 .5462036133167 .6318054199166 .7174987793 166.1078948975165 .4983062744165 .1934967041164 .8887023926164 .5839996338 166.1078948975167 .3269958496167 .9365997314167 .9365997314166 .4127044678 $164.2792053223161 .2312927246157 .878692627150 .5639038086148 .7351074219-9999$ 
-9999 -9999 -9999 -9999 -9999 -9999 -9999 -9999 -9999 -9999 -9999 -9999 -9999 -9999 -9999 -9999 -9999 -9999 -9999 -9999 -9999 -9999 -9999 -9999 -9999 -9999 -9999 -9999 -9999 -9999 -9999 -9999 -9999 -9999 -9999 -9999 -9999 -9999 -9999 -9999 -9999 -9999 -9999 -9999 -9999 -9999 -9999 -9999 -9999 -9999 -9999 -9999 -9999 -9999 -9999 -9999 -9999 -9999 -9999 -9999 -9999 -9999 -9999 -9999 -9999 -9999 -9999 -9999 -9999 -9999 -9999 -9999 -9999 -9999 -9999 -9999 -9999 -9999 -9999 -9999 -9999 -9999 -9999 -9999 -9999 -9999 -9999 -9999 -9999 -9999 -9999 -9999 -9999 -9999 -9999 -9999 -9999 -9999 -9999 -9999 -9999 -9999 -9999 -9999 -9999 -

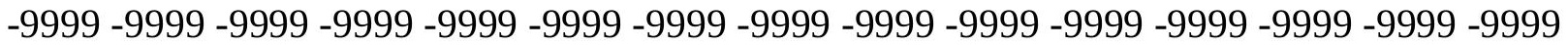
-9999 -9999 -9999 -9999 -9999 -9999 -9999 -9999 -9999 -9999 -9999 -9999 -9999 -9999 -9999 -9999 -9999 -9999 -9999 -9999 -9999 -9999 -9999 -9999 -9999 -9999 -9999 -9999 -9999 -9999 -

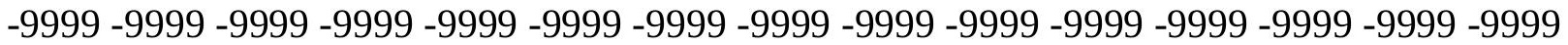
-9999 -9999 -9999 -9999 -9999 -9999 -9999 -9999 -9999 -9999 -9999 -9999 -9999 -9999 -9999

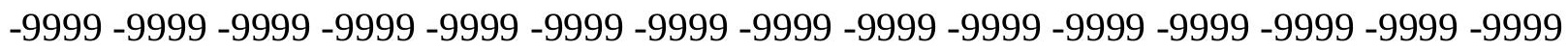
-9999 -9999 -9999 -9999 -9999 -9999 -9999 -9999 -9999 -9999 -9999 -9999 -9999 -9999 -9999 -9999 -9999 -9999 -9999 -9999 -9999 -9999 -9999 -9999 -9999 -9999 -9999 -9999 -9999 -9999 -9999 -9999 -9999 -9999 -9999 -9999 -9999 -9999 -9999 -9999 -9999 -9999

-9999 -9999 -9999 -9999 -9999 -9999 -9999 -9999 -9999 -9999 -9999 -9999 -9999 -9999 -9999 -9999 -9999 -9999 -9999 -9999 -9999 -9999 -9999 -9999 -9999 -9999 -9999 -9999 -9999 -9999 -9999 -9999 -9999 -9999 -9999 -9999 -9999 -9999 -9999 -9999 -9999 -9999 -9999 -9999 -9999 -9999 -9999 -9999 -9999 -9999 -9999 -9999 -9999 -9999 -9999 -9999 -9999 -9999 -9999 -9999

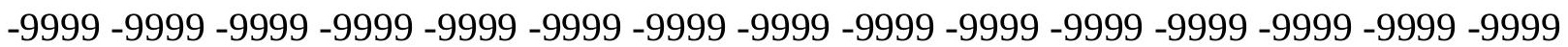
-9999 -9999 -9999 -9999 -9999 -9999 -9999 -9999 -9999 -9999 -9999 -9999 -9999 -9999 -9999 -9999 -9999 -9999 -9999 -9999 -9999 -9999 -9999 -9999 -9999 -9999 -9999 -9999 -9999 -9999 -9999 -9999 -9999 -9999 -9999 -9999 -9999 -9999 -9999 -9999 -9999 -9999 -9999 -9999 -9999 -9999 -9999-9999172.5084075928165.8031005859166.4127044678 167.9365997314 168.8509979248168 .8509979248169 .1557006836169 .1557006836169 .1557006836 168.8509979248168 .5462036133167 .9365997314167 .3269958496166 .4127044678 165.8031005859165 .1934967041164 .8887023926165 .1934967041166 .1078948975 167.3269958496168 .241394043168 .241394043166 .7174987793164 .5839996338 161.5361022949158 .7929992676150 .2590942383 -9999 -9999 -9999 -9999 -9999 -9999 -9999 -9999 -9999 -9999 -9999 -9999 -9999 -9999 -9999 -9999 -9999 -9999 -9999 -9999 -9999 -9999

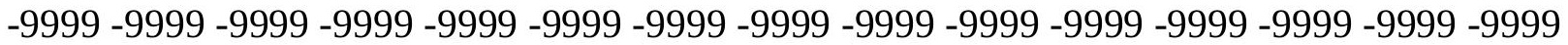
-9999 -9999 -9999 -9999 -9999 -9999 -9999 -9999 -9999 -9999 -9999 -9999 -9999 -9999 -9999 -9999 -9999 -9999 -9999 -9999 -9999 -9999 -9999 -9999 -9999 -9999 -9999 -9999 -9999 -9999 -

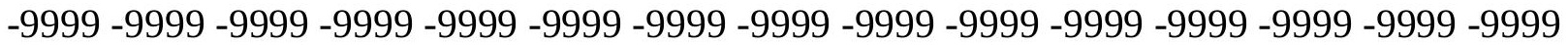
-9999 -9999 -9999 -9999 -9999 -9999 -9999 -9999 -9999 -9999 -9999 -9999 -9999 -9999 -9999 -9999 -9999 -9999 -9999 -9999 -9999 -9999 -9999 -9999 -9999 -9999 -9999 -9999 -9999 -9999

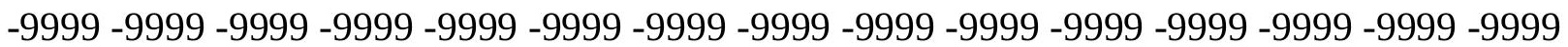
-9999 -9999 -9999 -9999 -9999 -9999 -9999 -9999 -9999 -9999 -9999 -9999 -9999 -9999 -9999 -9999 -9999 -9999 -9999 -9999 -9999 -9999 -9999 -9999 -9999 -9999 -9999 -9999 -9999 -9999 -9999 -9999 -9999 -9999 -9999 -9999 -9999 -9999 -9999 -9999 -9999 -9999 -9999 -9999 -9999 -999 -9999 -9999 -9999 -9999 -9999 -9999 -9999 -9999 -9999 -9999 -9999 -9999 -9999 -9999 -9999 -9999 -9999 -9999 -9999 -9999 -9999 -9999 -9999 -9999 -9999 -9999 -9999 -9999 -9999 -9999 -9999 -9999 -9999 -9999 -9999 -9999 -9999 -9999 -9999 -9999 -9999 -9999 -9999 -9999 -9999 -9999 -9999 -9999 -9999 -9999 -9999 -9999 -9999 -9999 -9999 -9999 -9999 -9999 -9999 -9999 -9999 -9999 -9999 -9999-9999 -9999 -9999 
-9999 -9999 -9999 -9999 -9999 -9999 -9999 -9999 -9999 -9999 -9999 -9999 -9999 -9999 -9999 -9999 -9999 -9999 -9999 -9999 -9999 -9999 -9999 -9999 -9999 -9999 -9999 -9999 -9999 -9999 -9999 -9999 -9999 -9999 -9999 -9999 -9999 -9999 -9999 -9999 -9999 -9999 -9999 -9999 -9999 -9999 -9999 -9999 -9999 -9999 -9999 -9999 -9999 -9999 -9999 -9999 -9999 -9999 -9999 -9999 -9999 -9999 -9999 -9999 -9999 -9999 -9999 -9999 -9999 -9999 -9999 -9999 -9999 -9999 -9999 -9999 -9999 -9999 -9999 -9999 -9999 -9999 -9999 -9999 -9999 -9999 -9999 -9999 -9999 -9999 -9999 -9999 -9999 -9999 -9999 -9999 -9999 -9999 -9999 -9999 -9999 -9999 -9999 -9999 -9999 -9999 -9999 -9999 -9999 -9999 -9999 -9999 -9999 -9999 -9999 -9999 -9999 -9999 -9999 -9999 -9999 -9999-9999 170.9844970703165.1934967041 165.8031005859165 .8031005859 166.7174987793167 .3269958496167 .6318054199167 .9365997314167 .9365997314 168.241394043168 .241394043168 .241394043167 .6318054199166 .7174987793 166.1078948975165 .4983062744165 .1934967041165 .4983062744166 .1078948975 167.0222015381167 .9365997314168 .5462036133166 .4127044678164 .2792053223 161.5361022949159 .0977935791149 .6495056152 -9999 -9999 -9999 -9999 -9999 -9999 -9999 -9999 -9999 -9999 -9999 -9999 -9999 -9999 -9999 -9999 -9999 -9999 -9999 -9999 -9999 -9999

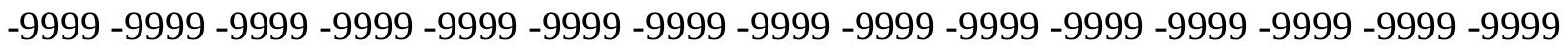
-9999 -9999 -9999 -9999 -9999 -9999 -9999 -9999 -9999 -9999 -9999 -9999 -9999 -9999 -9999 -9999 -9999 -9999 -9999 -9999 -9999 -9999 -9999 -9999 -9999 -9999 -9999 -9999 -9999 -9999 -9999 -9999 -9999 -9999 -9999 -9999 -9999 -9999 -9999 -9999 -9999 -9999 -9999 -9999 -9999 -9999 -9999 -9999 -9999 -9999 -9999 -9999 -9999 -9999 -9999 -9999 -9999 -9999 -9999 -9999

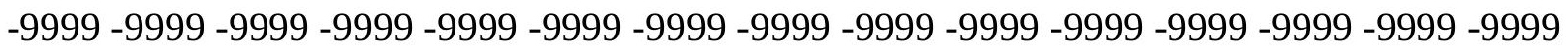
-9999 -9999 -9999 -9999 -9999 -9999 -9999 -9999 -9999 -9999 -9999 -9999 -9999 -9999 -9999 -9999 -9999 -9999 -9999 -9999 -9999 -9999 -9999 -9999 -9999 -9999 -9999 -9999 -9999 -9999 -9999 -9999 -9999 -9999 -9999 -9999 -9999 -9999 -9999 -9999 -9999 -9999 -9999 -9999 -9999

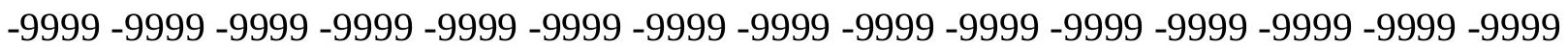
-9999 -9999 -9999 -9999 -9999 -9999 -9999 -9999 -9999 -9999 -9999 -9999 -9999 -9999 -9999 -9999 -9999 -9999 -9999 -9999 -9999 -9999 -9999 -9999 -9999 -9999 -9999 -9999 -9999 -9999 -9999 -9999 -9999 -9999 -9999 -9999 -9999 -9999 -9999 -9999 -9999 -9999 -9999 -9999 -9999

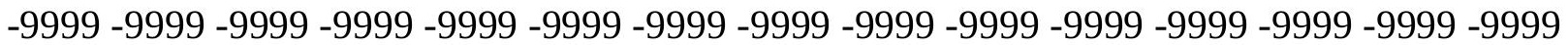
-9999 -9999 -9999 -9999 -9999 -9999 -9999 -9999 -9999 -9999 -9999 -9999 -9999 -9999 -9999 -9999 -9999 -9999 -9999 -9999 -9999 -9999

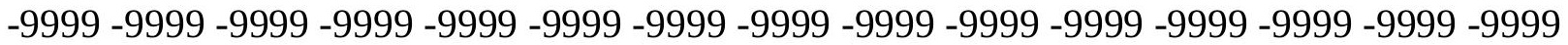
-9999 -9999 -9999 -9999 -9999 -9999 -9999 -9999 -9999 -9999 -9999 -9999 -9999 -9999 -9999 -9999 -9999 -9999 -9999 -9999 -9999 -9999 -9999 -9999 -9999 -9999 -9999 -9999 -9999 -9999 -

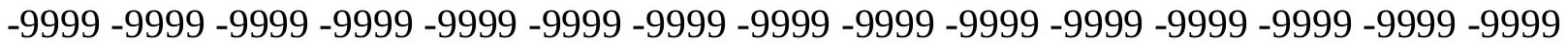
-9999 -9999 -9999 -9999 -9999 -9999 -9999 -9999 -9999 -9999 -9999 -9999 -9999 -9999 -9999 -9999 -9999 -9999 -9999 -9999 -9999 -9999 -9999 -9999 -9999 -9999 -9999 -9999 -9999 -9999 -9999 -9999 -9999 -9999 -9999 -9999 -9999 -9999 -9999 -9999 -9999 -9999 -9999 -9999 -9999 -9999 -9999 -9999 -9999 165.1934967041 164.5839996338 164.2792053223 164.8887023926 165.4983062744166 .1078948975166 .4127044678167 .0222015381167 .3269958496 167.9365997314168 .241394043167 .6318054199167 .0222015381166 .4127044678 165.8031005859165 .4983062744165 .1934967041165 .4983062744166 .1078948975 166.4127044678166 .4127044678164 .8887023926163 .0599975586160 .6217956543 150.2590942383148 .4304046631 -9999 -9999 -9999 -9999 -9999 -9999 -9999 -9999 -9999 -9999 -9999 -9999 -9999 -9999 -9999 -9999 -9999 -9999 -9999 -9999 -9999 -9999 -9999 -9999

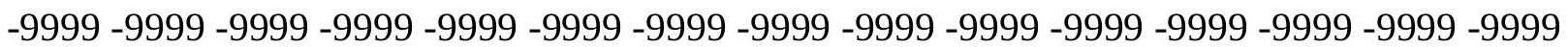


-9999 -9999 -9999 -9999 -9999 -9999 -9999 -9999 -9999 -9999 -9999 -9999 -9999 -9999 -9999 -9999 -9999 -9999 -9999 -9999 -9999 -9999 -9999 -9999 -9999 -9999 -9999 -9999 -9999 -9999 -9999 -9999 -9999 -9999 -9999 -9999 -9999 -9999 -9999 -9999 -9999 -9999 -9999 -9999 -9999 -9999 -9999 -9999 -9999 -9999 -9999 -9999 -9999 -9999 -9999 -9999 -9999 -9999 -9999 -9999 -9999 -9999 -9999 -9999 -9999 -9999 -9999 -9999 -9999 -9999 -9999 -9999 -9999 -9999 -9999 -9999 -9999 -9999 -9999 -9999 -9999 -9999 -9999 -9999 -9999 -9999 -9999 -9999 -9999 -9999 -9999 -9999 -9999 -9999 -9999 -9999 -9999 -9999 -9999 -9999 -9999 -9999 -9999 -9999 -9999 -

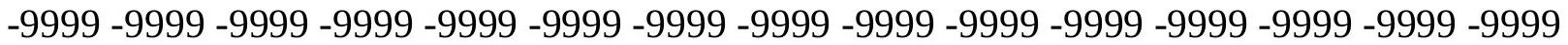
-9999 -9999 -9999 -9999 -9999 -9999 -9999 -9999 -9999 -9999 -9999 -9999 -9999 -9999 -9999 -9999 -9999 -9999 -9999 -9999 -9999 -9999 -9999 -9999 -9999 -9999 -9999 -9999 -9999 -9999 -9999 -9999 -9999 -9999 -9999 -9999 -9999 -9999 -9999 -9999 -9999 -9999 -9999 -9999 -9999 -9999 -9999 -9999 -9999 -9999 -9999 -9999 -9999 -9999 -9999 -9999 -9999 -9999 -9999 -9999

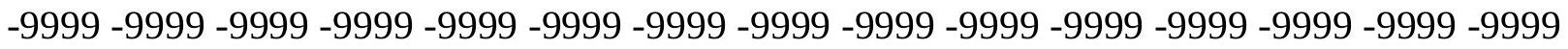
-9999 -9999 -9999-9999-9999

-9999 -9999 -9999 -9999 -9999 -9999 -9999 -9999 -9999 -9999 -9999 -9999 -9999 -9999 -9999 -9999 -9999 -9999 -9999 -9999 -9999 -9999 -9999 -9999 -9999 -9999 -9999 -9999 -9999 -9999 -9999 -9999 -9999 -9999 -9999 -9999 -9999 -9999 -9999 -9999 -9999 -9999 -9999 -9999 -9999 -9999 -9999 -9999 -9999 -9999 -9999 -9999 -9999 -9999 -9999 -9999 -9999 -9999 -9999 -9999 -9999 -9999 -9999 -9999 -9999 -9999 -9999 -9999 -9999 -9999 -9999 -9999 -9999 -9999 -9999 -9999 -9999 -9999 -9999 -9999 -9999 -9999 -9999 -9999 -9999 -9999 -9999 -9999 -9999 -9999

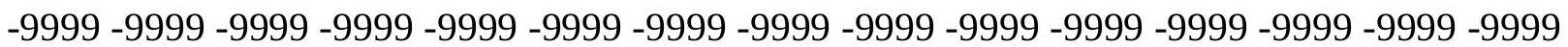
-9999 -9999 -9999 -9999 -9999 -9999 -9999 -9999 -9999 -9999 -9999 -9999 -9999 -9999 -9999 -9999 -9999 -9999 -9999-9999 164.5839996338163.974395752 163.3648071289 163.974395752164 .5839996338165 .1934967041165 .8031005859166 .4127044678 167.0222015381167 .3269958496167 .3269958496166 .7174987793166 .1078948975 165.4983062744165 .1934967041164 .5839996338164 .5839996338164 .2792053223 164.2792053223163 .6696014404162 .4505004883160 .6217956543158 .7929992676 149.0399017334 -9999 -9999 -9999 -9999 -9999 -9999 -9999 -9999 -9999 -9999 -9999 -9999 -9999 -9999 -9999 -9999 -9999 -9999 -9999 -9999 -9999 -9999 -9999 -9999 -9999 -9999 -9999 -9999 -9999 -9999 -9999 -9999 -9999 -9999 -9999 -9999 -9999 -9999 -9999 -9999 -9999 -9999 -9999 -9999 -9999 -9999 -9999 -9999 -9999 -9999 -9999 -9999 -9999 -9999 -9999 -9999 -9999 -

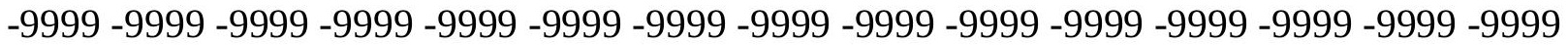
-9999 -9999 -9999 -9999 -9999 -9999 -9999 -9999 -9999 -9999 -9999 -9999 -9999 -9999 -9999 -9999 -9999 -9999 -9999 -9999 -9999 -9999 -9999 -9999 -9999 -9999 -9999 -9999 -9999 -9999 -

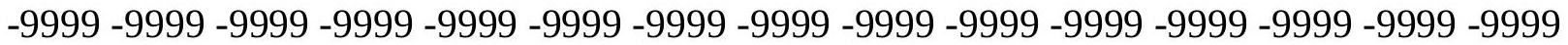
-9999 -9999 -9999 -9999 -9999 -9999 -9999 -9999 -9999 -9999 -9999 -9999 -9999 -9999 -9999 -9999 -9999 -9999 -9999 -9999 -9999 -9999 -9999 -9999 -9999 -9999 -9999 -9999 -9999 -9999

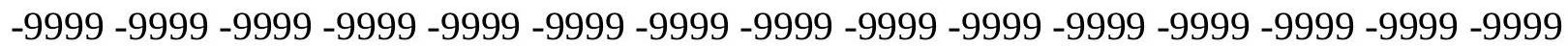
-9999 -9999 -9999 -9999 -9999 -9999 -9999 -9999 -9999 -9999 -9999 -9999 -9999 -9999 -9999 -9999 -9999 -9999 -9999 -9999 -9999 -9999 -9999 -9999 -9999 -9999 -9999 -9999 -9999 -9999 -9999 -9999 -9999 -9999 -9999 -9999 -9999 -9999 -9999 -9999 -9999 -9999 -9999 -9999 -9999

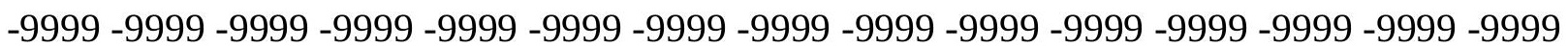

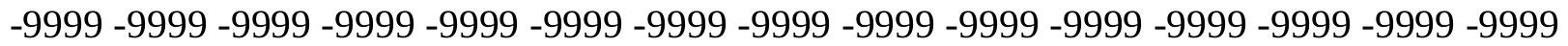
$-9999-9999-9999$

-9999 -9999 -9999 -9999 -9999 -9999 -9999 -9999 -9999 -9999 -9999 -9999 -9999 -9999 -9999

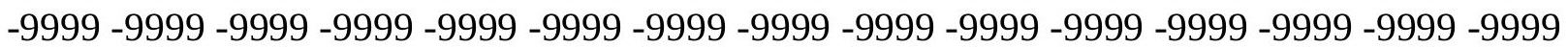


-9999 -9999 -9999 -9999 -9999 -9999 -9999 -9999 -9999 -9999 -9999 -9999 -9999 -9999 -9999 -9999 -9999 -9999 -9999 -9999 -9999 -9999 -9999 -9999 -9999 -9999 -9999 -9999 -9999 -9999 -9999 -9999 -9999 -9999 -9999 -9999 -9999 -9999 -9999 -9999 -9999 -9999 -9999 -9999 -9999 -9999 -9999 -9999 -9999 -9999 -9999 -9999 -9999 -9999 -9999 -9999 -9999 -9999 -9999 -9999

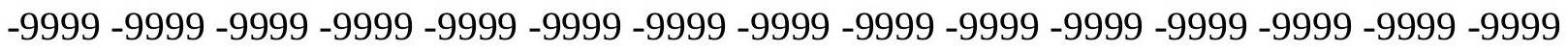
-9999 -9999 -9999 -9999 -9999 -9999 -9999 -9999 -9999 -9999 -9999 -9999 -9999 -9999 -9999 -9999 -9999 -9999 -9999 -9999 -9999 163.974395752163 .0599975586162 .7552947998 163.3648071289163 .974395752164 .5839996338165 .4983062744166 .1078948975 166.4127044678166 .7174987793166 .4127044678166 .1078948975165 .1934967041 164.5839996338163 .6696014404163 .0599975586162 .1457061768161 .5361022949 160.3170013428159 .4026031494158 .1835021973149 .3446960449147 .8208007812 -9999 -9999 -9999 -9999 -9999 -9999 -9999 -9999 -9999 -9999 -9999 -9999 -9999 -9999 -9999 -9999 -9999 -9999 -9999 -9999 -9999 -9999 -9999 -9999 -9999 -9999 -9999 -9999 -9999 -9999 -9999 -9999 -9999 -9999 -9999 -9999 -9999 -9999 -9999 -9999 -9999 -9999 -9999 -9999 -9999 -9999 -9999 -9999 -9999 -9999 -9999 -9999 -9999 -9999 -9999 -9999 -9999 -9999 -9999 -9999 -9999 -9999 -9999 -9999 -9999 -9999 -9999 -9999 -9999 -9999 -9999 -9999 -9999 -9999 -9999 -9999 -9999 -9999 -9999 -9999 -9999 -9999 -9999 -9999 -9999 -9999 -9999 -9999 -9999 -9999 -9999 -9999 -9999 -9999 -9999 -9999 -9999 -9999 -9999 -9999 -9999 -9999 -9999 -9999 -9999 -9999 -9999 -9999 -9999 -9999 -9999 -9999 -9999 -9999 -9999 -9999 -9999 -9999 -9999 -9999 -9999 -9999 -9999 -9999 -9999 -9999 -9999 -9999 -9999 -9999 -9999 -9999 -9999 -9999 -9999 -9999

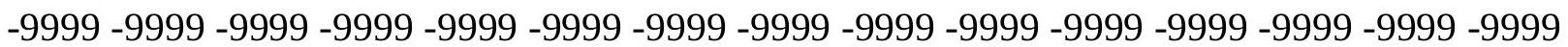
-9999 -9999 -9999 -9999 -9999 -9999 -9999 -9999 -9999 -9999 -9999 -9999 -9999 -9999 -9999 -9999 -9999 -9999 -9999 -9999 -9999 -9999 -9999 -9999 -9999 -9999 -9999 -9999 -9999 -9999 -9999 -9999 -9999 -9999 -9999 -9999 -9999 -9999 -9999 -9999 -9999 -9999 -9999 -9999 -9999

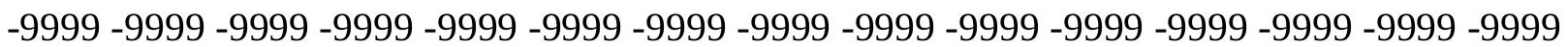
-9999 -9999 -9999 -9999 -9999 -9999 -9999 -9999 -9999 -9999 -9999 -9999 -9999 -9999 -9999 -9999 -9999 -9999 -9999 -9999 -9999 -9999 -9999 -9999 -9999 -9999 -9999 -9999 -9999 -9999 -9999 -9999 -9999 -9999 -9999 -9999 -9999 -9999 -9999 -9999 -9999 -9999 -9999 -9999

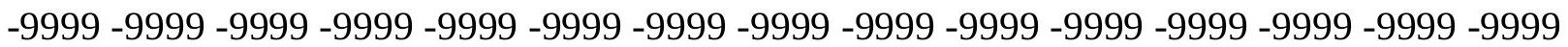
-9999 -9999 -9999 -9999 -9999 -9999 -9999 -9999 -9999 -9999 -9999 -9999 -9999 -9999 -9999 -9999 -9999 -9999 -9999 -9999 -9999 -9999 -9999 -9999 -9999 -9999 -9999 -9999 -9999 -9999 -

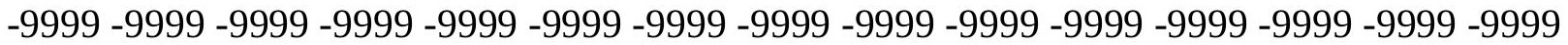
-9999 -9999 -9999 -9999 -9999 -9999 -9999 -9999 -9999 -9999 -9999 -9999 -9999 -9999 -9999 -9999 -9999 -9999 -9999 -9999 -9999 -9999 -9999 -9999 -9999 -9999 -9999 -9999 -9999 -9999 -9999 -9999 -9999 -9999 -9999 -9999 -9999 -9999 -9999 -9999 -9999 -9999 -9999 -9999 -9999 -9999 -9999 -9999 -9999 -9999 -9999 -9999 163.3648071289162 .4505004883161 .8408966064 162.4505004883163 .3648071289164 .2792053223164 .8887023926165 .4983062744 166.1078948975166 .1078948975165 .4983062744164 .8887023926163 .974395752 162.7552947998161 .2312927246160 .0122070312158 .4882965088157 .2691040039 156.0500030518149 .6495056152148 .4304046631 -9999 -9999 -9999 -9999 -9999 -9999 -9999 -9999 -9999 -9999 -9999 -9999 -9999 -9999 -9999 -9999 -9999 -9999 -9999 -9999 -9999 -9999 -9999 -9999 -9999 -9999 -9999 -9999 -9999 -9999 -9999 -9999 -9999 -9999 -9999 -9999 -9999 -9999 -9999 -9999 -9999 -9999 -9999 -9999 -9999 -9999 -9999 -9999 -9999 -9999 -9999 -9999 -9999 -9999 -9999 -9999 -9999 -9999 -9999 -9999 -9999 -9999 -9999 -9999 -9999 -9999 -9999 -9999 -9999 -9999 -9999 -9999 -9999 -9999 -9999 -9999 -9999 -9999 -9999 -9999 -9999 -9999

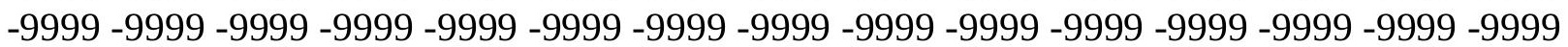


-9999 -9999 -9999 -9999 -9999 -9999 -9999 -9999 -9999 -9999 -9999 -9999 -9999 -9999 -9999 -9999 -9999 -9999 -9999 -9999 -9999 -9999 -9999 -9999 -9999 -9999 -9999 -9999 -9999 -9999 -9999 -9999 -9999 -9999 -9999 -9999 -9999 -9999 -9999 -9999 -9999 -9999 -9999 -9999 -9999 -9999 -9999 -9999 -9999 -9999 -9999 -9999 -9999 -9999 -9999 -9999 -9999 -9999 -9999 -9999 -9999 -9999 -9999 -9999 -9999 -9999 -9999 -9999 -9999 -9999 -9999 -9999 -9999 -9999 -9999 -9999 -9999 -9999 -9999 -9999 -9999 -9999 -9999 -9999 -9999 -9999 -9999 -9999 -9999 -9999 -9999 -9999 -9999 -9999 -9999 -9999 -9999 -9999 -9999 -9999 -9999 -9999 -9999 -9999 -9999 -

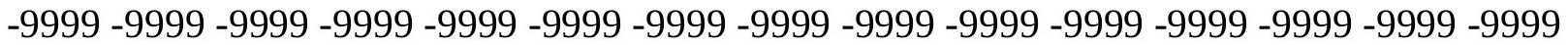

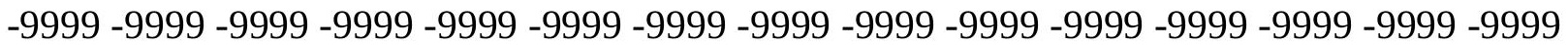
-9999 -9999 -9999 -9999 -9999 -9999 -9999 -9999 -9999

-9999 -9999 -9999 -9999 -9999 -9999 -9999 -9999 -9999 -9999 -9999 -9999 -9999 -9999 -9999 -9999 -9999 -9999 -9999 -9999 -9999 -9999 -9999 -9999 -9999 -9999 -9999 -9999 -9999 -9999 -9999 -9999 -9999 -9999 -9999 -9999 -9999 -9999 -9999 -9999 -9999 -9999 -9999 -9999 -9999 -9999 -9999 -9999 -9999 -9999 -9999 -9999 -9999 -9999 -9999 -9999 -9999 -9999 -9999 -9999 -9999 -9999 -9999 -9999 -9999 -9999 -9999 -9999 -9999 -9999 -9999 -9999 -9999 -9999 -9999 -9999 -9999 -9999 -9999 -9999 -9999 -9999 -9999 -9999 -9999 -9999 -9999 -9999 -9999 -9999 -9999 -9999 -9999 -9999 -9999 -9999 -9999 -9999 -9999 -9999 -9999 -9999 -9999 -9999 -9999 -9999 -9999 -9999 -9999 -9999 -9999 -9999 -9999 -9999 -9999 -9999 -9999 -9999 -9999 -9999 -9999 -9999 -9999 -9999 -9999 -9999 -9999 -9999 162.4505004883161 .8408966064 161.2312927246162 .1457061768163 .0599975586163 .974395752164 .8887023926 165.4983062744165 .8031005859165 .4983062744164 .5839996338163 .0599975586 161.5361022949159 .7073974609157 .5738983154155 .7451934814153 .9165039062 150.2590942383 149.0399017334 -9999 -9999 -9999 -9999 -9999 -9999 -9999 -9999 -9999 -9999 -9999 -9999 -9999 -9999 -9999 -9999 -9999 -9999 -9999 -9999 -9999 -9999 -9999 -9999

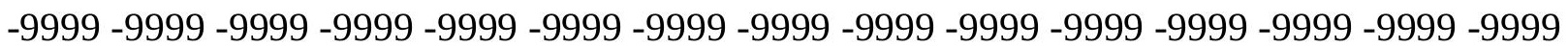
-9999 -9999 -9999 -9999 -9999 -9999 -9999 -9999 -9999 -9999 -9999 -9999 -9999 -9999 -9999 -9999 -9999 -9999 -9999 -9999 -9999 -9999 -9999 -9999 -9999 -9999 -9999 -9999 -9999 -9999 -9999 -9999 -9999 -9999 -9999 -9999 -9999 -9999 -9999 -9999 -9999 -9999 -9999 -9999 -9999 -9999 -9999 -9999 -9999 -9999 -9999 -9999 -9999 -9999 -9999 -9999 -9999 -9999 -9999 -9999 -9999 -9999 -9999 -9999 -9999 -9999 -9999 -9999 -9999 -9999 -9999 -9999 -9999 -9999 -9999 -9999 -9999 -9999 -9999 -9999 -9999 -9999 -9999 -9999 -9999 -9999 -9999 -9999 -9999 -9999 -

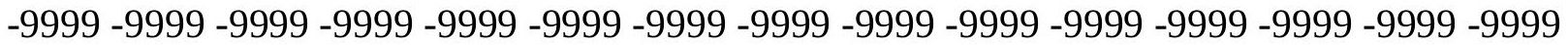
-9999 -9999 -9999 -9999 -9999 -9999 -9999 -9999 -9999 -9999 -9999 -9999 -9999 -9999 -9999 -9999 -9999 -9999 -9999 -9999 -9999 -9999 -9999 -9999 -9999 -9999 -9999 -9999 -9999 -9999 -

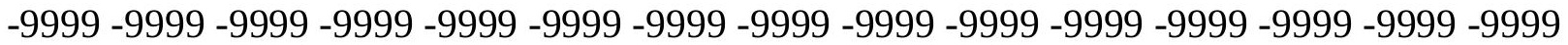
-9999 -9999 -9999 -9999 -9999 -9999 -9999 -9999 -9999 -9999 -9999 -9999 -9999 -9999 -9999 -9999 -9999 -9999 -9999 -9999 -9999 -9999 -9999 -9999 -9999 -9999 -9999 -9999 -9999 -9999

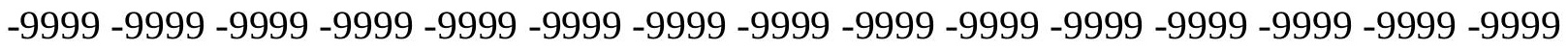
-9999 -9999 -9999 -9999 -9999 -9999 -9999 -9999

-9999 -9999 -9999 -9999 -9999 -9999 -9999 -9999 -9999 -9999 -9999 -9999 -9999 -9999 -9999 -9999 -9999 -9999 -9999 -9999 -9999 -9999 -9999 -9999 -9999 -9999 -9999 -9999 -9999 -9999 -9999 -9999 -9999 -9999 -9999 -9999 -9999 -9999 -9999 -9999 -9999 -9999 -9999 - -9999 - -9999 -9999 -9999 -9999 -9999 -9999 -9999 -9999 -9999 -9999 -9999 -9999 -9999 -9999 -9999 -9999 -9999 -9999 -9999 -9999 -9999 -9999 -9999 -9999 -9999 -9999 -9999 -9999 -9999 -9999 -9999 -9999 -9999 -9999 -9999 -9999 -9999 -9999 -9999 -9999 -9999 -9999 -9999 -9999 -9999 -9999

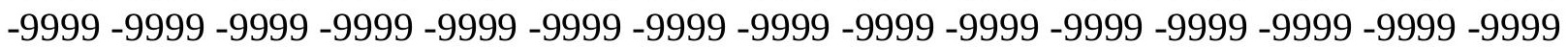


-9999 -9999 -9999 -9999 -9999 -9999 -9999 -9999 -9999 -9999 -9999 -9999 -9999 -9999 -9999 -9999 -9999 -9999 -9999 -9999 -9999 -9999 -9999 -9999 162.1457061768 161.2312927246 160.6217956543161 .5361022949162 .7552947998163 .974395752165 .1934967041 165.8031005859165 .1934967041164 .2792053223162 .4505004883160 .3170013428 $158.1835021973156 .0500030518153 .6116943359151 .1734008789149 .9542999268-9999$ -9999 -9999 -9999 -9999 -9999 -9999 -9999 -9999 -9999 -9999 -9999 -9999 -9999 -9999 -9999 -9999 -9999 -9999 -9999 -9999 -9999 -9999 -9999 -9999 -9999 -9999 -9999 -9999 -9999 -9999 -9999 -9999 -9999 -9999 -9999 -9999 -9999 -9999 -9999 -9999 -9999 -9999 -9999 -9999 -9999 -9999 -9999 -9999 -9999 -9999 -9999 -9999 -9999 -9999 -9999 -9999 -9999 -9999 -9999 -9999 -9999 -9999 -9999 -9999 -9999 -9999 -9999 -9999 -9999 -9999 -9999 -9999 -9999 -9999 -9999 -

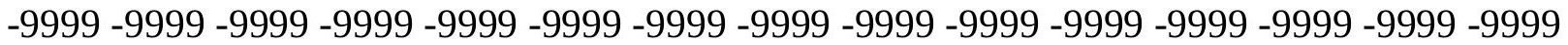
-9999 -9999 -9999 -9999 -9999 -9999 -9999 -9999 -9999 -9999 -9999 -9999 -9999 -9999 -9999 -9999 -9999 -9999 -9999 -9999 -9999 -9999 -9999 -9999 -9999 -9999 -9999 -9999 -9999 -9999 -9999 -9999 -9999 -9999 -9999 -9999 -9999 -9999 -9999 -9999 -9999 -9999 -9999 -9999 -9999 -9999 -9999 -9999 -9999 -9999 -9999 -9999 -9999 -9999 -9999 -9999 -9999 -9999 -9999 -9999

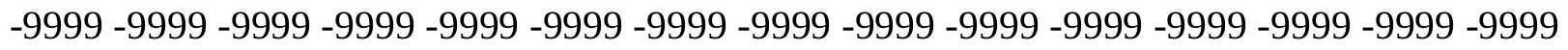
-9999 -9999 -9999 -9999 -9999 -9999 -9999 -9999 -9999 -9999 -9999 -9999 -9999 -9999 -9999 -9999 -9999 -9999 -9999 -9999 -9999 -9999 -9999 -9999 -9999 -9999 -9999 -9999 -9999 -9999 -

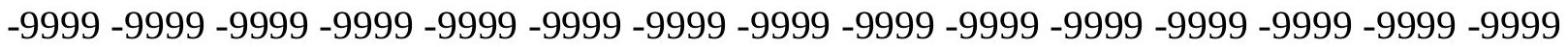

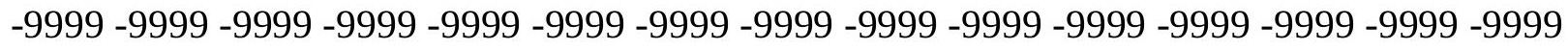

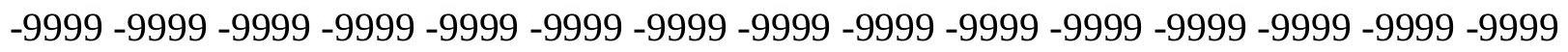
-9999-9999

-9999 -9999 -9999 -9999 -9999 -9999 -9999 -9999 -9999 -9999 -9999 -9999 -9999 -9999 -9999

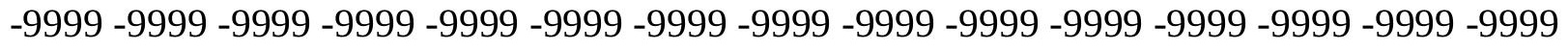

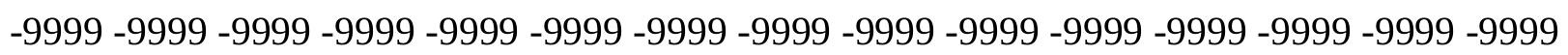
-9999 -9999 -9999 -9999 -9999 -9999 -9999 -9999 -9999 -9999 -9999 -9999 -9999 -9999 -9999

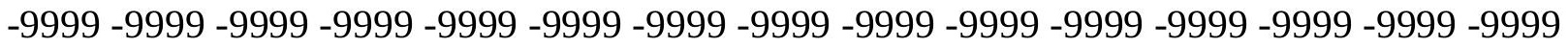

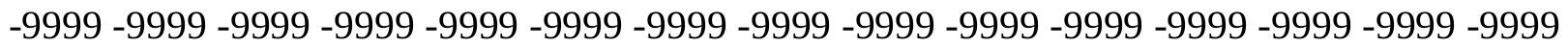

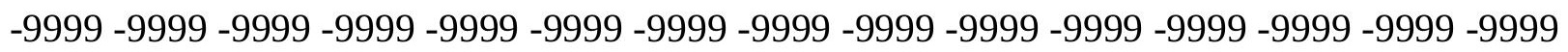

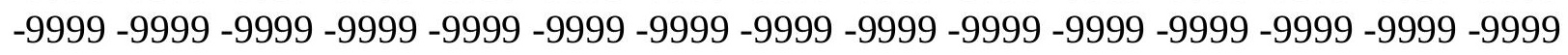
-9999 -9999 -9999 -9999 -9999 -9999 -9999 -9999 -9999 -9999 161.5361022949 160.9264984131160 .3170013428161 .5361022949163 .0599975586164 .8887023926 165.8031005859165 .4983062744163 .6696014404161 .5361022949159 .4026031494 156.9642944336 154.8307952881 152.6972961426151 .4781951904 -9999 -9999 -9999 -9999 -9999 -9999 -9999 -9999 -9999 -9999 -9999 -9999 -9999 -9999 -9999 -9999 -9999 -9999 -9999

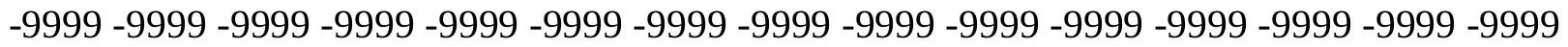

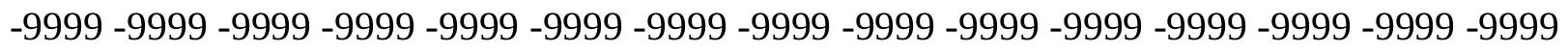

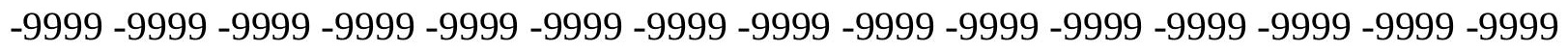
-9999 -9999 -9999 -9999 -9999 -9999 -9999 -9999 -9999 -9999 -9999 -9999 -9999 -9999 -9999 -9999 -9999 -9999 -9999 -9999 -9999 -9999 -9999 -9999 -9999 -9999 -9999 -9999 -9999 - -999 -

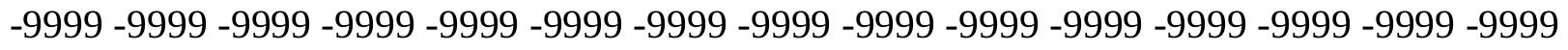

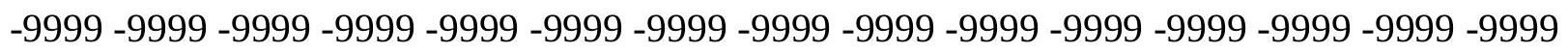

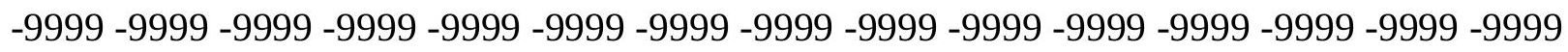
-9999 -9999 -9999 -9999 -9999 -9999 -9999 -9999 -9999 -9999 -9999 -9999 -9999 -9999 -9999 -

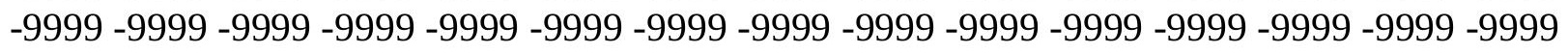

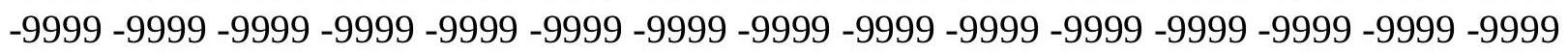


-9999 -9999 -9999 -9999 -9999 -9999 -9999 -9999 -9999 -9999 -9999 -9999 -9999 -9999 -9999 -9999 -9999 -9999 -9999 -9999 -9999 -9999 -9999 -9999 -9999 -9999 -9999 -9999 -9999 -9999 -9999 -9999 -9999 -9999 -9999 -9999 -9999 -9999 -9999 -9999 -9999 -9999 -9999 -9999 - 9999 -9999 -9999 -9999 -9999 -9999 -9999 -9999 -9999 -9999 -9999 -9999 -9999 -9999 -9999 -9999 -9999 -9999 -9999 -9999 -9999 -9999 -9999 -9999 -9999-9999 -9999 -9999 -9999 -9999 -9999 -9999 -9999 -9999 -9999 -9999 -9999 -9999 -9999 -9999 -9999 -9999 -9999 -9999 -9999 -9999 -9999 -9999 -9999 -9999 -9999 -9999 -9999 -9999 -9999 -9999 -9999 -9999 -9999 -9999 -9999

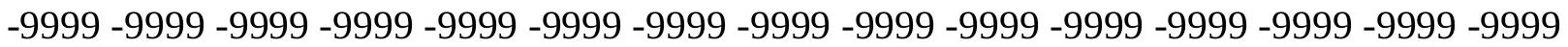

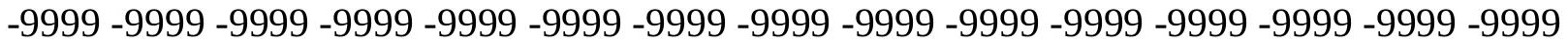
-9999 -9999 -9999 -9999 -9999 -9999 -9999 -9999 -9999 -9999 -9999 -9999 -9999 -9999 -9999 -9999 -9999 -9999 -9999 -9999 -9999 -9999 -9999 -9999 -9999 -9999 -9999 -9999 -9999 -9999 -9999 -9999 -9999 -9999 -9999 -9999 -9999 -9999 -9999 -9999 -9999 -9999 -9999 -9999 -9999 -9999 -9999 -9999 -9999 -9999 -9999 -9999 -9999 -9999 -9999 -9999 161.2312927246 160.6217956543160 .3170013428161 .8408966064164 .2792053223166 .1078948975 165.1934967041163 .0599975586160 .6217956543158 .1835021973155 .7451934814 154.2212982178 153.0021057129 -9999 -9999 -9999 -9999 -9999 -9999 -9999 -9999 -9999 -9999 -9999 -9999 -9999 -9999 -9999 -9999 -9999 -9999 -9999 -9999 -9999 -9999 -9999 -9999 -9999 -9999 -9999 -9999 -9999 -9999 -9999 -9999 -9999 -9999 -9999 -9999 -9999 -9999 -9999 -9999 -9999 -9999 -9999 -9999 -9999 -9999 -9999 -9999 -9999 -9999 -9999 -9999 -9999 -9999 -

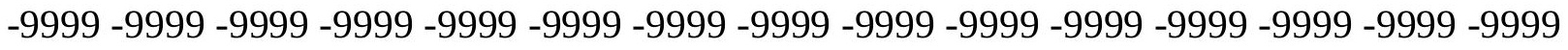

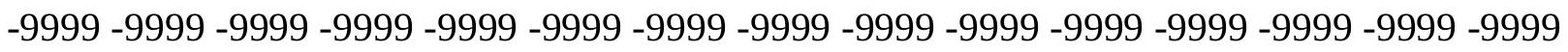
-9999 -9999 -9999 -9999 -9999 -9999 -9999 -9999 -9999 -9999 -9999 -9999 -9999 -9999 -9999 -9999 -9999 -9999 -9999 -9999 -9999 -9999 -9999 -9999 -9999 -9999 -9999 -9999 -9999 -9999 -9999 -9999 -9999 -9999 -9999 -9999 -9999 -9999 -9999 -9999 -9999 -9999 -9999 -9999 -9999 -

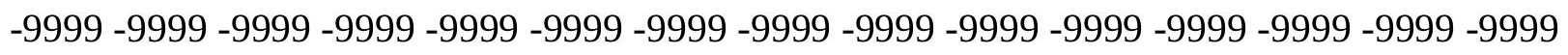
-9999 -9999 -9999 -9999 -9999 -9999 -9999 -9999 -9999 -9999 -9999 -9999 -9999 -9999 -9999 -9999 -9999 -9999 -9999 -9999 -9999 -9999 -9999 -9999 -9999 -9999 -9999 -9999 -9999 -9999 -

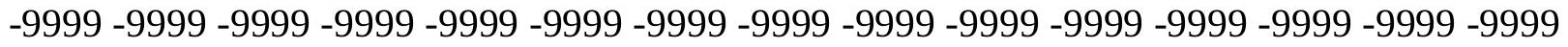
-9999 -9999 -9999 -9999 -9999 -9999 -9999 -9999 -9999 -9999 -9999 -9999 -9999 -9999 -9999 -9999 -9999 -9999 -9999 -9999 -9999 -9999 -9999 -9999 -9999 -9999 -9999 -9999 -9999 -999 -9999 -9999 -9999 -9999 -9999 -9999 -9999 -9999 -9999 -9999 -9999 -9999 -9999 -9999 -9999 -9999 -9999 -9999 -9999 -9999 -9999 -9999 -9999 -9999 -9999-9999

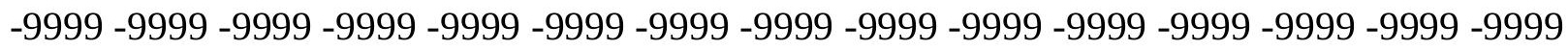
-9999 -9999 -9999 -9999 -9999 -9999 -9999 -9999 -9999 -9999 -9999 -9999 -9999 -9999 -9999 -9999 -9999 -9999 -9999 -9999 -9999 -9999 -9999 -9999 -9999 -9999 -9999 -9999 -9999 -9999 -

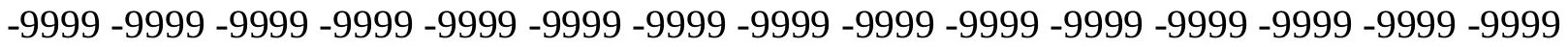

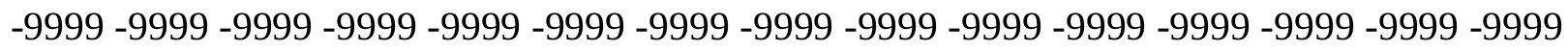

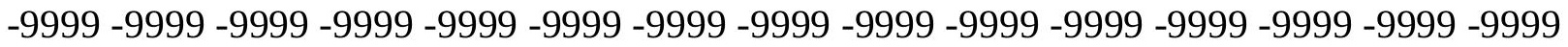

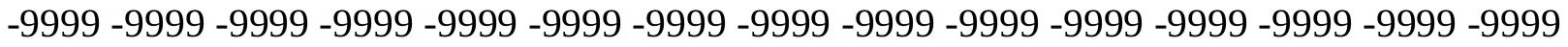
-9999 -9999 -9999 -9999 -9999 -9999 -9999 -9999 -9999 -9999 -9999 -9999 -9999 -9999 - -999 -9999 -9999 -9999 -9999 -9999 -9999 -9999 -9999 -9999 -9999 -9999 -9999 -999 160.3170013428160 .0122070312162 .1457061768166 .1078948975163 .3648071289 160.9264984131158 .7929992676156 .9642944336155 .7451934814154 .8307952881 -9999 -9999 -9999 -9999 -9999 -9999 -9999 -9999 -9999 -9999 -9999 -9999 -9999 -9999 -9999 -9999 -9999 -9999 -9999 -9999 -9999 -9999 -9999 -9999 -9999 -9999 -9999 -9999 -9999 -9999 -9999 -

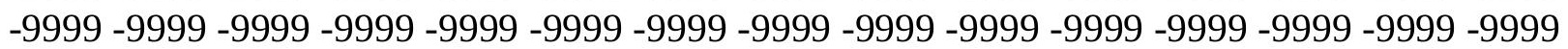


-9999 -9999 -9999 -9999 -9999 -9999 -9999 -9999 -9999 -9999 -9999 -9999 -9999 -9999 -9999 -9999 -9999 -9999 -9999 -9999 -9999 -9999 -9999 -9999 -9999 -9999 -9999 -9999 -9999 -9999 -9999 -9999 -9999 -9999 -9999 -9999 -9999 -9999 -9999 -9999 -9999 -9999 -9999 -9999 -9999 -9999 -9999 -9999 -9999 -9999 -9999 -9999 -9999 -9999 -9999 -9999 -9999 -9999 -9999 -9999 -9999 -9999 -9999 -9999 -9999 -9999 -9999 -9999 -9999 -9999 -9999 -9999 -9999 -9999 -9999 -9999 -9999 -9999 -9999 -9999 -9999 -9999 -9999 -9999 -9999 -9999 -9999 -9999 -9999 -9999 -9999 -9999 -9999 -9999 -9999 -9999 -9999 -9999 -9999 -9999 -9999 -9999 -9999 -9999 -9999 -

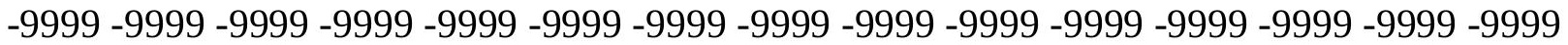
-9999 -9999 -9999 -9999 -9999 -9999 -9999 -9999 -9999 -9999 -9999 -9999 -9999 -9999 -9999 -9999 -9999 -9999 -9999 -9999 -9999 -9999 -9999 -9999 -9999 -9999 -9999 -9999 -9999 -9999 -

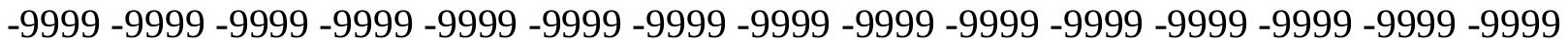
-9999 -9999 -9999 -9999 -9999 -9999 -9999 -9999 -9999 -9999 -9999 -9999 -9999 -9999 -9999

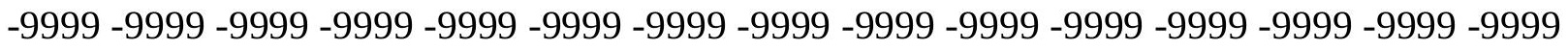
-9999 -9999-9999-9999-9999

-9999 -9999 -9999 -9999 -9999 -9999 -9999 -9999 -9999 -9999 -9999 -9999 -9999 -9999 -9999

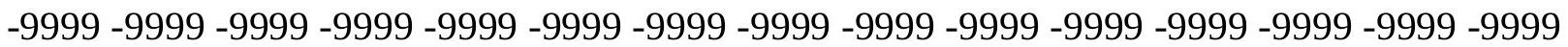
-9999 -9999 -9999 -9999 -9999 -9999 -9999 -9999 -9999 -9999 -9999 -9999 -9999 -9999 -9999 -9999 -9999 -9999 -9999 -9999 -9999 -9999 -9999 -9999 -9999 -9999 -9999 -9999 -9999 -9999 -9999 -9999 -9999 -9999 -9999 -9999 -9999 -9999 -9999 -9999 -9999 -9999 -9999 -9999 -9999 -9999 -9999 -9999 -9999 -9999 -9999 -9999 -9999 -9999 -9999 -9999 -9999 -9999 -9999 -9999

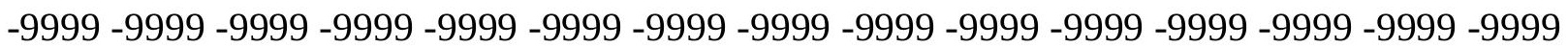

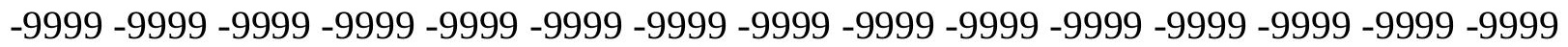
-9999 -9999 -9999 -9999 -9999 -9999 -9999 -9999 -9999 -9999 -9999 -9999 -9999 -9999 160.0122070312160 .0122070312159 .7073974609159 .7073974609158 .4882965088 157.5738983154156 .9642944336156 .0500030518 -9999 -9999 -9999 -9999 -9999 -9999 -9999 -9999 -9999 -9999 -9999 -9999 -9999 -9999 -9999 -9999 -9999 -9999 -9999 -9999 -9999 -9999 -9999 -9999 -9999 -9999 -9999 -9999 -9999 -9999 -9999 -9999 -9999 -9999 -9999 -9999 -9999 -9999 -9999 -9999 -9999 -9999 -9999 -9999 -9999 -9999 -9999 -9999 -9999 -9999 -9999 -9999 -9999 -9999 -9999 -9999 -9999 -9999 -9999 -9999 -9999 -9999 -9999 -9999 -9999 -9999 -9999 -9999 -9999 -9999 -9999 -9999 -9999 -9999 -9999 -9999 -9999 -9999 -9999 -9999 -9999 -9999 -9999 -9999 -9999 -9999 -9999 -9999 -9999 -9999 -9999 -9999 -9999 -9999 -9999 -9999 -9999 -

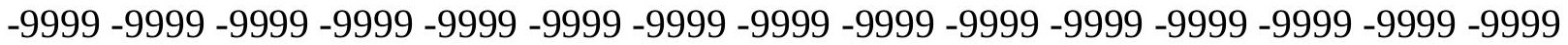
-9999 -9999 -9999 -9999 -9999 -9999 -9999 -9999 -9999 -9999 -9999 -9999 -9999 -9999 -9999 -9999 -9999 -9999 -9999 -9999 -9999 -9999 -9999 -9999 -9999 -9999 -9999 -9999 -9999 -9999 -

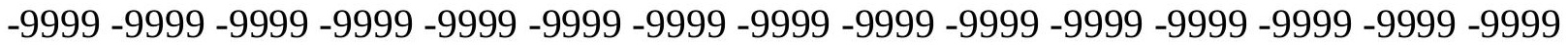
-9999 -9999 -9999 -9999 -9999 -9999 -9999 -9999 -9999 -9999 -9999 -9999 -9999 -9999 -9999 -9999 -9999 -9999 -9999 -9999 -9999 -9999 -9999 -9999 -9999 -9999 -9999 -9999 -9999 -9999

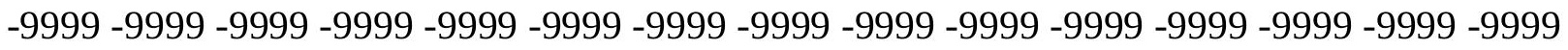
-9999 -9999 -9999 -9999 -9999 -9999 -9999 -9999 -9999 -9999 -9999 -9999 -9999 -9999 -9999 -9999 -9999 -9999 -9999 -9999 -9999 -9999 -9999 -9999 -9999 -9999 -9999 -9999 -9999 -9999 -9999 -9999 -9999 -9999 -9999 -9999 -9999 -9999 -9999 -9999 -9999 -9999 -9999 -9999 -9999 -9999 -9999 -9999 -9999 -9999 -9999 -9999 -9999 -9999 -9999 -9999 -9999 -9999 -9999 -9999 -9999 -9999 -9999 -9999 -9999 -9999 -9999 -9999 -9999 -9999 -9999 -9999 -9999 -9999 -9999 -9999 -9999 -9999 -9999 -9999 -9999 -9999 -9999 -9999 -9999 -9999 -9999 -9999 -9999 -9999 -9999 -9999 -9999 -9999 -9999 -9999 -9999 -9999 -9999 -9999 -9999 -9999 -9999 -9999 -9999

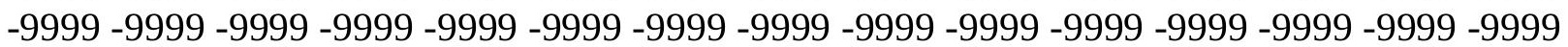


-9999 -9999 -9999 -9999 -9999 -9999 -9999 -9999 -9999 -9999 -9999 -9999 -9999 -9999 -9999 -9999 -9999 -9999 -9999 -9999 -9999 -9999 -9999 -9999 -9999 -9999 -9999 -9999 -9999 -9999 -9999 -9999 -9999 -9999 -9999 -9999 -9999 -9999 -9999 -9999 -9999 -9999 -9999 -9999 - 9999 -9999 -9999 -9999 -9999 -9999 -9999 -9999 -9999 -9999 -9999 -9999 -9999 -9999 -9999 -9999 -9999 159.4026031494 159.0977935791 158.4882965088 -9999 -9999 -9999 -9999 -9999 -9999 -9999 -9999 -9999 -9999 -9999 -9999 -9999 -9999 -9999 -9999 -9999 -9999 -9999 -9999 -9999 -9999 -9999 -9999 -9999 -9999 -9999 -9999 -9999 -9999 -9999 -9999 -9999 -9999 -9999 -9999

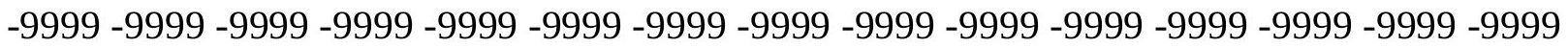

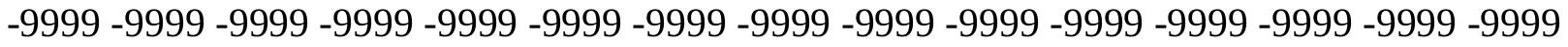
-9999 -9999 -9999 -9999 -9999 -9999 -9999 -9999 -9999 -9999 -9999 -9999 -9999 -9999 -9999 -9999 -9999 -9999 -9999 -9999 -9999 -9999 -9999 -9999 -9999 -9999 -9999 -9999 -9999 -9999 -9999 -9999 -9999 -9999 -9999 -9999 -9999 -9999 -9999 -9999 -9999 -9999 -9999 -9999 -9999 -9999 -9999 -9999 -9999 -9999 -9999 -9999 -9999 -9999 -9999 -9999 -9999 -9999 -9999 -9999 -9999 -9999 -9999 -9999 -9999 -9999 -9999 -9999 -9999 -9999 -9999 -9999 -9999 -9999 -9999 -9999 -9999 -9999 -9999 -9999 -9999 -9999 -9999 -9999 -9999 -9999 -9999 -9999 -9999 -9999 -

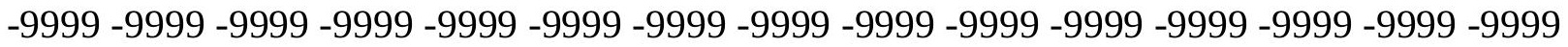
-9999 -9999 -9999 -9999 -9999 -9999 -9999 -9999 -9999 -9999 -9999 -9999 -9999 -9999 -9999 -9999 -9999 -9999 -9999 -9999 -9999 -9999 -9999 -9999 -9999 -9999 -9999 -9999 -9999 - 9999 -9999 -9999 -9999 -9999 -9999 -9999 -9999 -9999 -9999 -9999 -9999 -9999 -9999 -9999 -9999 -9999 -9999 -9999 -9999 -9999 -9999 -9999 -9999 -9999 -9999 -9999 -9999 -9999 -9999 -9999 -

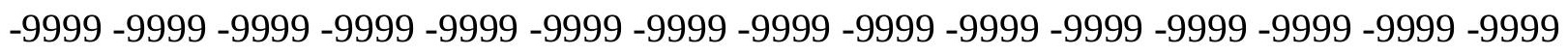
-9999 -9999-9999-9999

-9999 -9999 -9999 -9999 -9999 -9999 -9999 -9999 -9999 -9999 -9999 -9999 -9999 -9999 -9999 -9999 -9999 -9999 -9999 -9999 -9999 -9999 -9999 -9999 -9999 -9999 -9999 -9999 -9999 -9999 -

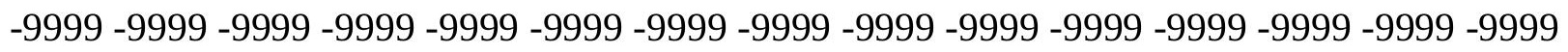
-9999 -9999 -9999 -9999 -9999 -9999 -9999 -9999 -9999 -9999 -9999 -9999 -9999 -9999 -9999 -9999 -9999 -9999 -9999 -9999 -9999 -9999 -9999 -9999 -9999 -9999 -9999 -9999 -9999 -9999 -

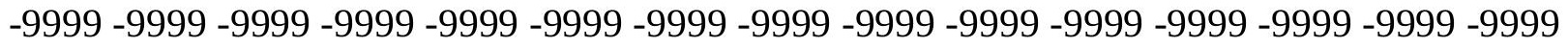
-9999 -9999 -9999 -9999 -9999 -9999 -9999 -9999 -9999 -9999 -9999 -9999 -9999 -9999 -9999 -9999 -9999 -9999 -9999 -9999 -9999 -9999 -9999 -9999 -9999 -9999 -9999 -9999 -9999 -999 -9999 -9999 -9999 -9999 -9999 -9999 -9999 -9999 -9999 -9999 -9999 -9999 -9999 -9999 -9999 -9999 -9999 -9999 -9999 -9999 -9999 -9999 -9999 -9999 -9999 -9999 -9999 -9999 -9999 -9999 -

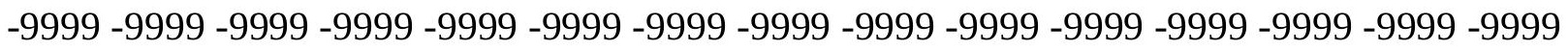

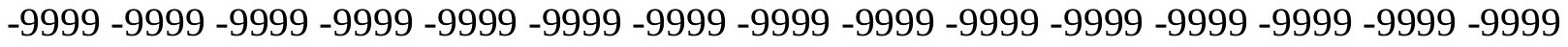

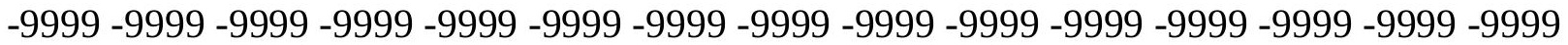

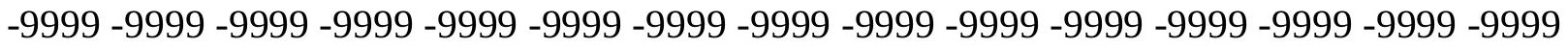

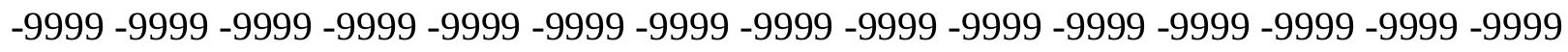

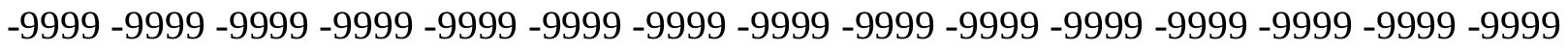

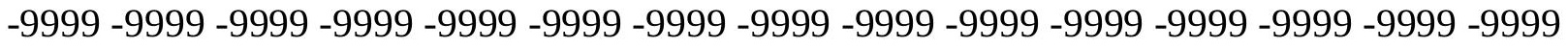
-9999 -9999 -9999 -9999 -9999 -9999 -9999 -9999 -9999 -9999 -9999 -9999 -9999 -9999 -9999 -

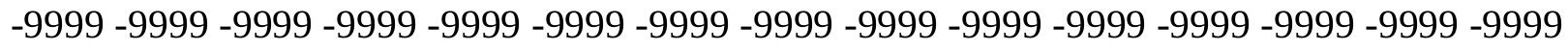

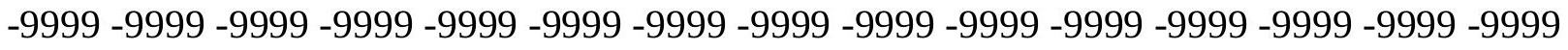
-9999 -9999 -9999 -9999 -9999 -9999 -9999 -9999 -9999 -9999 -9999 -9999 -9999 -9999 -9999 -9999 -9999 -9999 -9999 -9999 -9999 -9999 -9999 -9999-9999 -9999 -9999 -9999 -9999 -9999 -9999 -9999 -9999 -9999 -9999 -9999 -9999 -9999 -9999 -9999 -9999 -9999 -9999 -9999 -9999 -

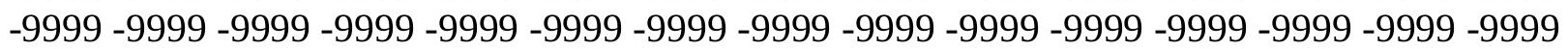


-9999 -9999 -9999 -9999 -9999 -9999 -9999 -9999 -9999 -9999 -9999 -9999 -9999 -9999 -9999 -9999 -9999 -9999 -9999 -9999 -9999 -9999 -9999 -9999 -9999 -9999 -9999 -9999 -9999 -

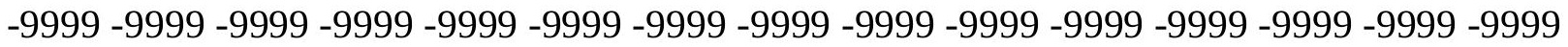
-9999 -9999 -9999 -9999 -9999 -9999 -9999 -9999 -9999 -9999 -9999 -9999 -9999 -9999 -9999 -9999 -9999 -9999 -9999 -9999 -9999 -9999 -9999 -9999 -9999 -9999 -9999 -9999 -9999 -9999 -9999 -9999 -9999 -9999 -9999 -9999 -9999 -9999 -9999 -9999 -9999 -9999 -9999 -9999 -9999 -9999 -9999 -9999 -9999 -9999 -9999 -9999 -9999 -9999 -9999 -9999 -9999 -9999 -9999 -9999

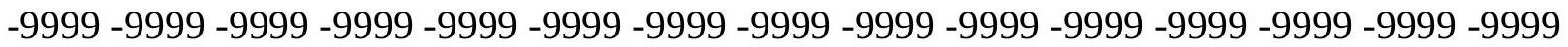

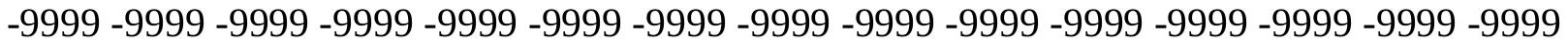
-9999 -9999 -9999 -9999 -9999 -9999 -9999 -9999 -9999 -9999 -9999 -9999 -9999 -9999 -9999 -9999 -9999 -9999 -9999 -9999 -9999 -9999 -9999 -9999 -9999 -9999 -9999 -9999 -9999 -9999 -9999 -9999 -9999 -9999 -9999 -9999 -9999 -9999 -9999 -9999 -9999 -9999 -9999 -9999 -9999 -9999 -9999 -9999 -9999 -9999 -9999 -9999 -9999 -9999 -9999 -9999 -9999 -9999 -9999 -9999 -9999 -9999 -9999 -9999 -9999 -9999 -9999 -9999 -9999 -9999 -9999 -9999 -9999 -9999 -9999 -9999 -9999 -9999 -9999 -9999 -9999 -9999 -9999 -9999 -9999 -9999 -9999 -9999 -9999 -9999 -

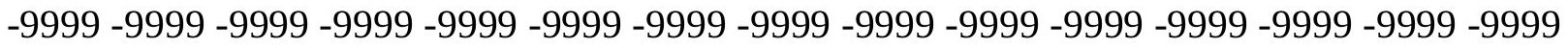
-9999 -9999 -9999 -9999 -9999 -9999 -9999 -9999 -9999 -9999 -9999 -9999 -9999 -9999 -9999 -9999 -9999 -9999 -9999 -9999 -9999 -9999 -9999 -9999 -9999 -9999 -9999 -9999 -9999 - 9999 -9999 -9999 -9999 -9999 -9999 -9999 -9999 -9999 -9999 -9999 -9999 -9999 -9999 -9999 -9999 -

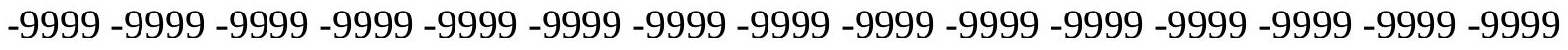

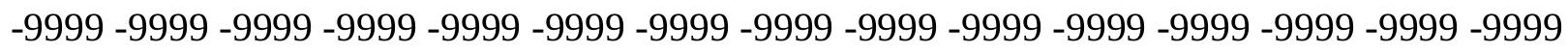

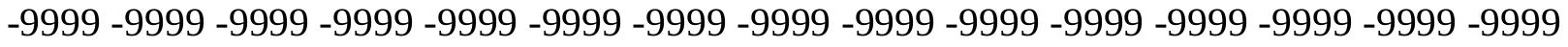
-9999 -9999 -9999 -9999 -9999 -9999 -9999 -9999 -9999 -9999 -9999 -9999 -9999 -9999 -9999 -9999 -9999 -9999 -9999 -9999 -9999 -9999 -9999 -9999 -9999 -9999 -9999 -9999 -9999 -9999 -

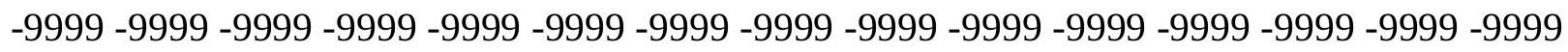
-9999 -9999 -9999 -9999 -9999 -9999 -9999 -9999 -9999 -9999 -9999 -9999 -9999 -9999 -9999 -9999 -9999 -9999 -9999 -9999 -9999 -9999 -9999 -9999 -9999 -9999 -9999 -9999 -9999 -9999 -9999 -9999 -9999 -9999 -9999 -9999 -9999 -9999 -9999 -9999 -9999 -9999 -9999 -9999 -9999 -9999 -9999 -9999 -9999 -9999 -9999 -9999 -9999 -9999 -9999 -9999 -9999 -9999 -9999 -9999 -9999 -9999 -9999 -9999 -9999 -9999 -9999 -9999 -9999 -9999 -9999 -9999 -9999 -999 -

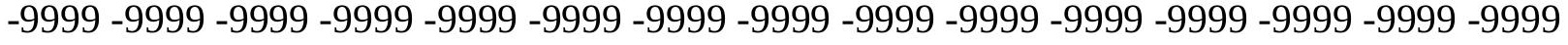
-9999 -9999 -9999 -9999 -9999 -9999 -9999 -9999 -9999 -9999 -9999 -9999 -9999 -9999 -9999 -

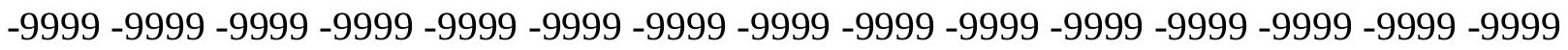

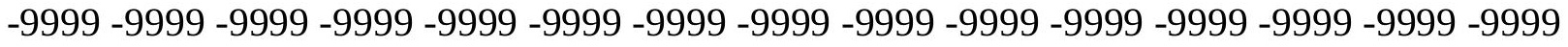

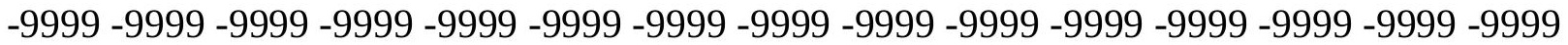

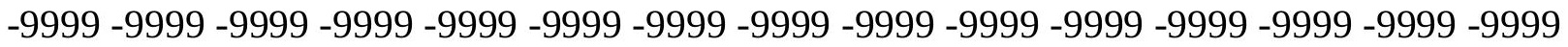

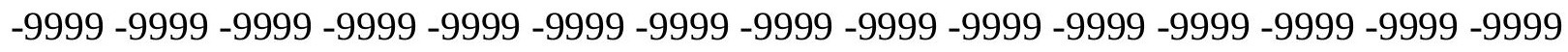

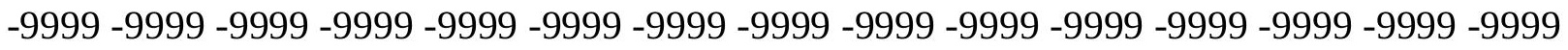

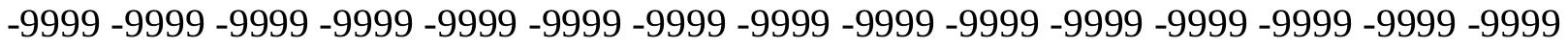
-9999 -9999 -9999 -9999 -9999 -9999 -9999 -9999 -9999 -9999 -9999 -9999 -9999 -9999 -9999 -

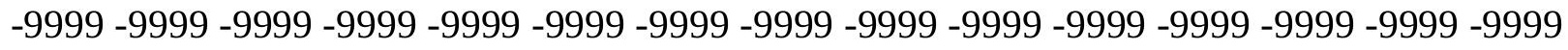

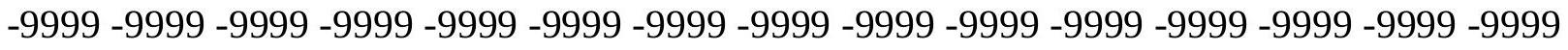
-9999 -9999 -9999 -9999 -9999 -9999 -9999 -9999 -9999 -9999 -9999 -9999 -9999 -9999 -9999 -9999 -9999 -9999 -9999 -9999 -9999 -9999 -9999 -9999-9999 -9999 -9999 -9999 -9999 -9999 -9999 -9999 -9999 -9999 -9999 -9999 -9999 -9999 -9999 -9999 -9999 -9999 -9999 -9999 -9999 -

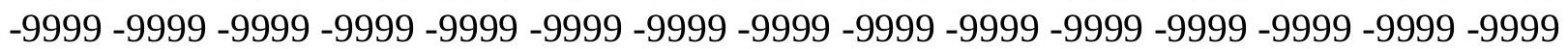


-9999 -9999 -9999 -9999 -9999 -9999 -9999 -9999 -9999 -9999 -9999 -9999 -9999 -9999 -9999 -9999 -9999 -9999 -9999 -9999 -9999 -9999 -9999 -9999 -9999 -9999 -9999 -9999 -9999 -9999 -

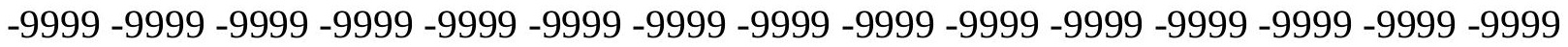
-9999 -9999 -9999 -9999 -9999 -9999 -9999 -9999 -9999 -9999 -9999 -9999 -9999 -9999 -9999 -9999 -9999 -9999 -9999 -9999 -9999 -9999 -9999 -9999-9999 -9999 -9999 -9999 -9999 -9999 -9999 -9999 -9999 -9999 -9999 -9999 -9999 -9999 -9999 -9999 -9999 -9999 -9999 -9999 -9999 -

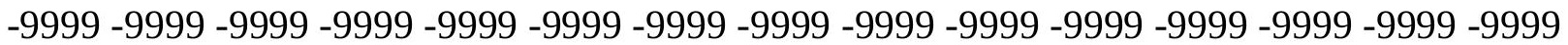
-9999 -9999 -9999 -9999 -9999 -9999 -9999 -9999 -9999 -9999 -9999 -9999 -9999 -9999 -9999 -9999 -9999 -9999 -9999 -9999 -9999 -9999 -9999 -9999 -9999 -9999 -9999 -9999 -9999 -9999 -9999 -9999 -9999 -9999 -9999 -9999 -9999 -9999 -9999 -9999 -9999 -9999 -9999 -9999 -9999 -9999 -9999 -9999 -9999 -9999 -9999 -9999 -9999 -9999 -9999 -9999 -9999 -9999 -9999 -9999 -9999 -9999 -9999 -9999 -9999 -9999 -9999 -9999 -9999 -9999 -9999 -9999 -9999 -9999 -9999 -9999 -9999 -9999 -9999 -9999 -9999 -9999 -9999 -9999 -9999 -9999 -9999 -9999 -9999 -9999 -9999 -9999 -9999 -9999 -9999 -9999 -9999 -9999 -9999 -9999 -9999 -9999 -9999 -9999 -9999 -9999 -9999 -9999 -9999 -9999 -9999 -9999 -9999 -9999 -9999 -9999 -9999 -9999 -9999 -

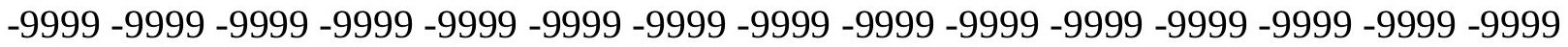
-9999 -9999 -9999 -9999 -9999 -9999 -9999 -9999 -9999 -9999 -9999 -9999 -9999 -9999 -9999 -9999 -9999 -9999 -9999 -9999 -9999 -9999 -9999 -9999 -9999 -9999 -9999 -9999 -9999 -9999 -9999 -9999 -9999 -9999 -9999 -9999 -9999 -9999 -9999 -9999 -9999 -9999 -9999 -9999 -9999 -

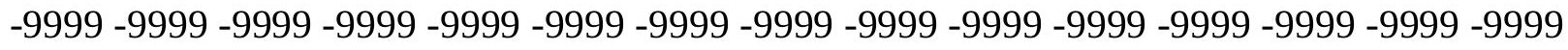

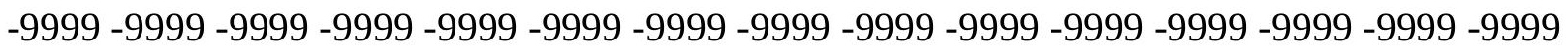
-9999 -9999 -9999 -9999 -9999 -9999 -9999 -9999 -9999 -9999 -9999 -9999 -9999 -9999 - 9999 -9999 -9999 -9999 -9999 -9999 -9999 -9999 -9999 -9999 -9999 -9999 -9999 -9999 -9999 -9999 -9999 -9999 -9999 -9999 -9999 -9999 -9999 -9999 -9999 -9999 -9999 -9999 -9999 -9999 -9999 -

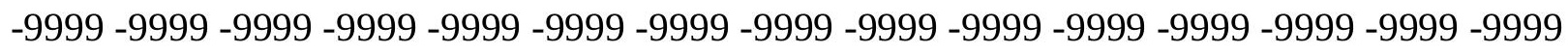
-9999 -9999 -9999 -9999 -9999 -9999 -9999 -9999 -9999 -9999 -9999 -9999 -9999 -9999 -9999 -9999 -9999 -9999 -9999 -9999 -9999 -9999 -9999 -9999 -9999 -9999 -9999 -9999 -9999 -9999 -

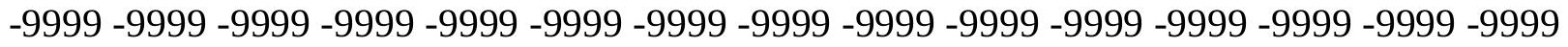
-9999 -9999 -9999 -9999 -9999 -9999 -9999 -9999 -9999 -9999 -9999 -9999 -9999 -9999 -9999 -9999 -9999 -9999 -9999 -9999 -9999 -9999 -9999 -9999 -9999 -9999 -9999 -9999 -9999 -999 -9999 -9999 -9999 -9999 -9999 -9999 -9999 -9999 -9999 -9999 -9999 -9999 -9999 -9999 -9999 -9999 -9999 -9999 -9999 -9999 -9999 -9999 -9999 -9999 -9999 -9999 -9999 -9999 -9999 -9999 -

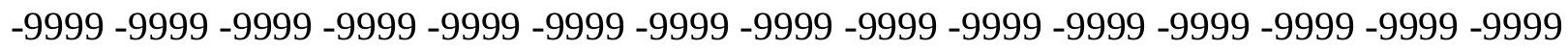

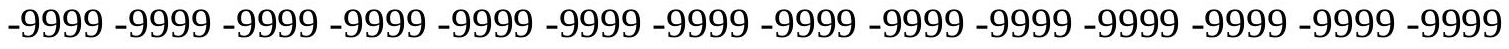
-9999 -9999 -9999 -9999 -9999 -9999 -9999 -9999 -9999 -9999 -9999 -9999 -9999 -9999 -9999

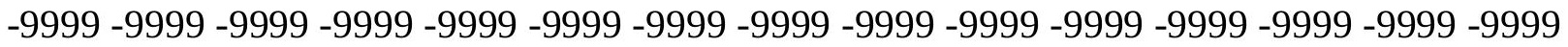

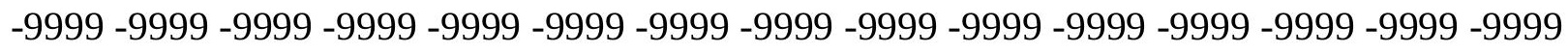

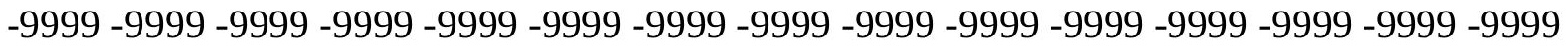

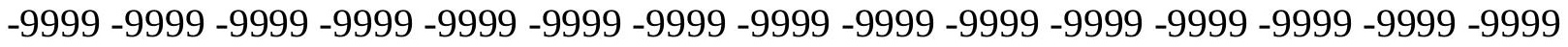
-9999 -9999 -9999 -9999 -9999 -9999 -9999 -9999 -9999 -9999 -9999 -9999 -9999 -9999 -9999 -

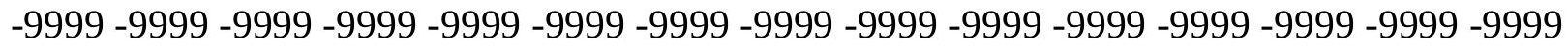

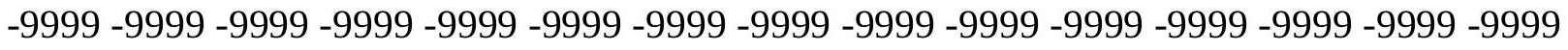
-9999 -9999 -9999 -9999 -9999 -9999 -9999 -9999 -9999 -9999 -9999 -9999 -9999 -9999 -9999 -9999 -9999 -9999 -9999 -9999 -9999 -9999 -9999 -9999-9999 -9999 -9999 -9999 -9999 -9999 -9999 -9999 -9999 -9999 -9999 -9999 -9999 -9999 -9999 -9999 -9999 -9999 -9999 -9999 -9999 -

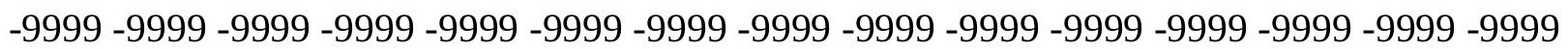


-9999 -9999 -9999 -9999 -9999 -9999 -9999 -9999 -9999 -9999 -9999 -9999 -9999 -9999 -9999 -9999 -9999 -9999 -9999 -9999 -9999 -9999 -9999 -9999 -9999 -9999 -9999 -9999 -9999 -9999 -

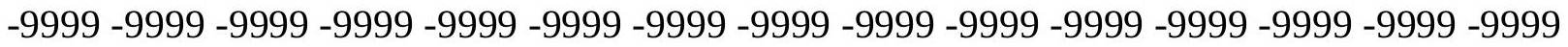
-9999 -9999 -9999 -9999 -9999 -9999 -9999 -9999 -9999 -9999 -9999 -9999 -9999 -9999 -9999 -9999 -9999 -9999 -9999 -9999 -9999 -9999 -9999 -9999-9999 -9999 -9999 -9999 -9999 -9999 -9999 -9999 -9999 -9999 -9999 -9999 -9999 -9999 -9999 -9999 -9999 -9999 -9999 -9999 -9999 -9999 -9999 -9999 -9999 -9999 -9999 -9999 -9999 -9999 -9999 -9999 -9999 -9999 -9999 -9999

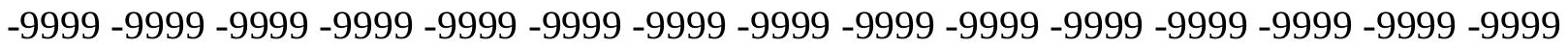

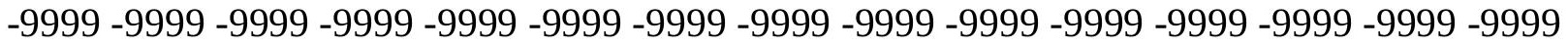
-9999 -9999 -9999 -9999 -9999 -9999 -9999 -9999 -9999 -9999 -9999 -9999 -9999 -9999 -9999 -9999 -9999 -9999 -9999 -9999 -9999 -9999 -9999 -9999 -9999 -9999 -9999 -9999 -9999 -9999 -9999 -9999 -9999 -9999 -9999 -9999 -9999 -9999 -9999 -9999 -9999 -9999 -9999 -9999 -9999 -9999 -9999 -9999 -9999 -9999 -9999 -9999 -9999 -9999 -9999 -9999 -9999 -9999 -9999 -9999 -9999 -9999 -9999 -9999 -9999 -9999 -9999 -9999 -9999 -9999 -9999 -9999 -9999 -9999 -9999 -9999 -9999 -9999 -9999 -9999 -9999 -9999 -9999 -9999 -9999 -9999 -9999 -9999 -9999

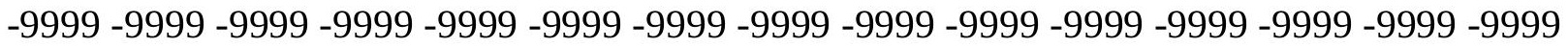
-9999 -9999 -9999 -9999 -9999 -9999 -9999 -9999 -9999 -9999 -9999 -9999 -9999 -9999 -9999 -9999 -9999 -9999 -9999 -9999 -9999 -9999 -9999 -9999 -9999 -9999 -9999 -9999 -9999 -9999 -9999 -9999 -9999 -9999 -9999 -9999 -9999 -9999 -9999 -9999 -9999 -9999 -9999 -9999 -9999 -

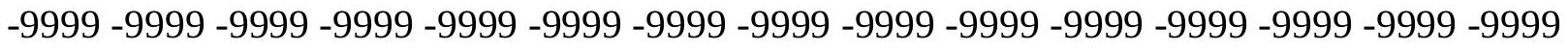

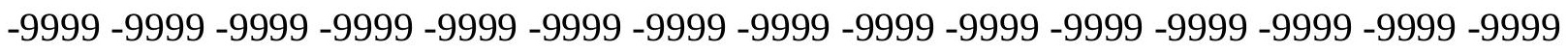
-9999 -9999 -9999 -9999 -9999 -9999 -9999 -9999 -9999 -9999 -9999 -9999 -9999 -9999 -9999 -9999 -9999 -9999 -9999 -9999 -9999 -9999 -9999 -9999 -9999 -9999 -9999 -9999 -9999 -9999 -9999 -9999 -9999 -9999 -9999 -9999 -9999 -9999 -9999 -9999 -9999 -9999 -9999 -9999 -9999 -

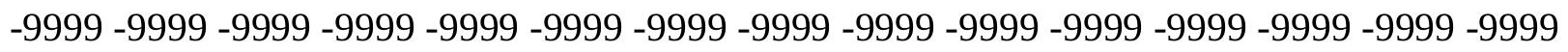
-9999 -9999 -9999 -9999 -9999 -9999 -9999 -9999 -9999 -9999 -9999 -9999 -9999 -9999 -9999 -9999 -9999 -9999 -9999 -9999 -9999 -9999 -9999 -9999 -9999 -9999 -9999 -9999 -9999 -9999 -

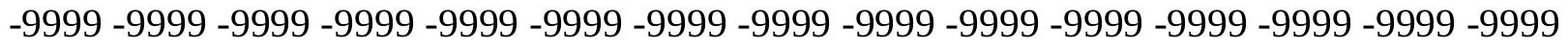
-9999 -9999 -9999 -9999 -9999 -9999 -9999 -9999 -9999 -9999 -9999 -9999 -9999 -9999 -9999 -9999 -9999 -9999 -9999 -9999 -9999 -9999 -9999 -9999 -9999 -9999 -9999 -9999 -9999 -999 -9999 -9999 -9999 -9999 -9999 -9999 -9999 -9999 -9999 -9999 -9999 -9999 -9999 -9999 -9999 -9999 -9999 -9999 -9999 -9999 -9999 -9999 -9999 -9999 -9999 -9999 -9999 -9999 -9999 -9999 -

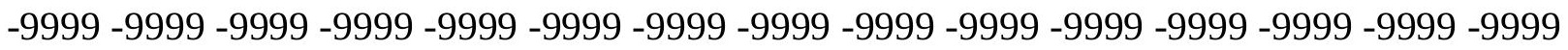

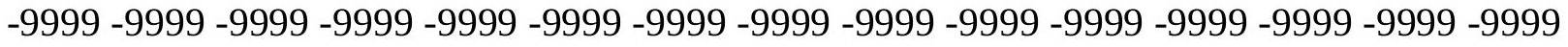

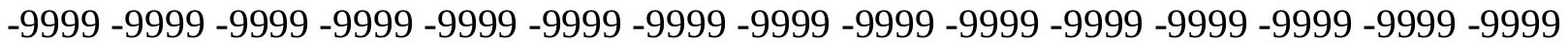

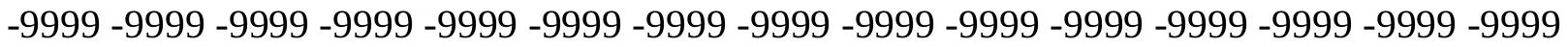

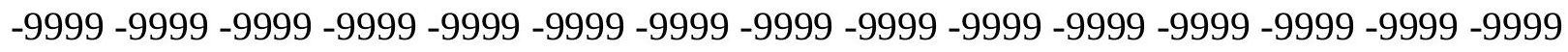

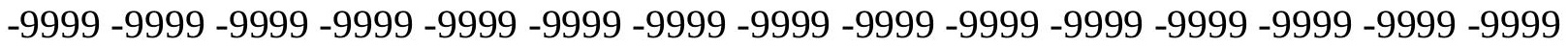
-9999 -9999 -9999 -9999 -9999 -9999 -9999 -9999 -9999 -9999 -9999 -9999 -9999 - 9999 - -999 -9999 -9999 -9999 -9999 -9999 -9999 -9999 -9999 -9999 -9999 -9999 -9999 -9999 -9999 - -999 -

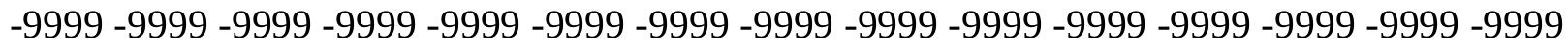

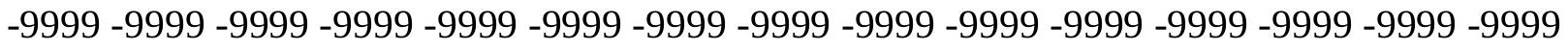
-9999 -9999 -9999 -9999 -9999 -9999 -9999 -9999 -9999 -9999 -9999 -9999 -9999 -9999 -9999 -9999 -9999 -9999 -9999 -9999 -9999 -9999 -9999 -9999-9999 -9999 -9999 -9999 -9999 -9999 -9999 -9999 -9999 -9999 -9999 -9999 -9999 -9999 -9999 -9999 -9999 -9999 -9999 -9999 -9999 -

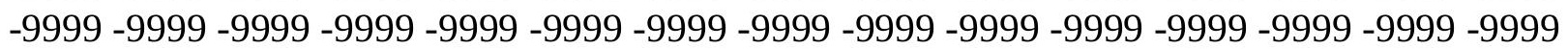


-9999 -9999 -9999 -9999 -9999 -9999 -9999 -9999 -9999 -9999 -9999 -9999 -9999 -9999 -9999 -9999 -9999 -9999 -9999 -9999 -9999 -9999 -9999 -9999 -9999 -9999 -9999 -9999 -9999 -9999 -9999 -9999 -9999 -9999 -9999 -9999 -9999 -9999 -9999 -9999 -9999 -9999 -9999 -9999 -9999 -9999 -9999 -9999 -9999 -9999 -9999 -9999 -9999 -9999 -9999 -9999 -9999 -9999 -9999 -9999 -9999 -9999 -9999 -9999 -9999 -9999 -9999 -9999 -9999 -9999 -9999 -9999 -9999 -9999 -9999 -9999 -9999 -9999 -9999 -9999 -9999 -9999 -9999 -9999 -9999 -9999 -9999 -9999 -9999 -9999 -9999 -9999 -9999 -9999 -9999 -9999 -9999 -9999 -9999 -9999 -9999 -9999 -9999 -9999 -9999 -

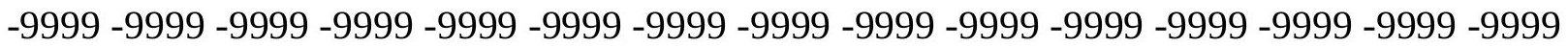
-9999 -9999 -9999 -9999 -9999 -9999 -9999 -9999 -9999 -9999 -9999 -9999 -9999 -9999 -9999 -9999 -9999 -9999 -9999 -9999 -9999 -9999 -9999 -9999 -9999 -9999 -9999 -9999 -9999 -9999 -

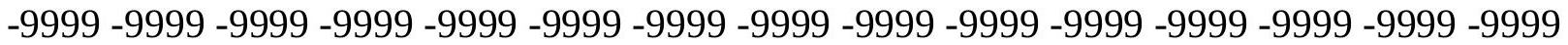
-9999 -9999 -9999 -9999 -9999 -9999 -9999 -9999 -9999 -9999 -9999 -9999 -9999 -9999 -9999 -9999 -9999 -9999 -9999 -9999 -9999 -9999 -9999 -9999 -9999 -9999 -9999 -9999 -9999 -9999 -9999 -9999 -9999 -9999 -9999 -9999 -9999 -9999 -9999 -9999 -9999 -9999 -9999 -9999 -9999 -9999 -9999 -9999 -9999 -9999 -9999 -9999 -9999 -9999 -9999 -9999 -9999 -9999 -9999 -9999

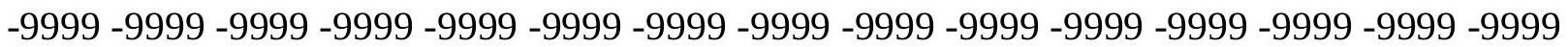
-9999 -9999 -9999 -9999 -9999 -9999 -9999 -9999 -9999 -9999 -9999 -9999 -9999 -9999 -9999 -9999 -9999 -9999 -9999 -9999 -9999 -9999 -9999 -9999 -9999 -9999 -9999 -9999 -9999 -9999 -9999 -9999 -9999 -9999 -9999 -9999 -9999 -9999 -9999 -9999 -9999 -9999 -9999 -9999 -9999 -9999 -9999 -9999 -9999 -9999 -9999 -9999 -9999 -9999 -9999 -9999 -9999 -9999 -9999 -9999 -9999 -9999 -9999 -9999 -9999 -9999 -9999 -9999 -9999 -9999 -9999 -9999 -9999 -9999 -9999 -9999 -9999 -9999 -9999 -9999 -9999 -9999 -9999 -9999 -9999 -9999 -9999 -9999 -9999 -9999 -9999 -9999 -9999 -9999 -9999 -9999 -9999 -9999 -9999 -9999 -9999 -9999 -9999 -9999 -9999 -9999 -9999 -9999 -9999 -9999 -9999 -9999 -9999 -9999 -9999 -9999 -9999 -9999 -9999 -9999 -9999 -9999 -9999 -9999 -9999 -9999 -9999 -9999 -9999 -9999 -9999 -9999 -9999 -9999 -9999 -9999 -9999 -9999 -9999 -9999 -9999 -9999 -9999 -9999 -9999 -9999 -9999 -9999 -9999 -9999 -9999 -9999 -9999 -9999 -9999 -9999 -9999 -9999 -9999 -9999 -9999 -9999 -9999 -9999 -9999 -9999 -9999 -9999 -9999 -9999 -9999 -9999 -9999 -9999 -9999 -9999 -9999 -9999 -9999

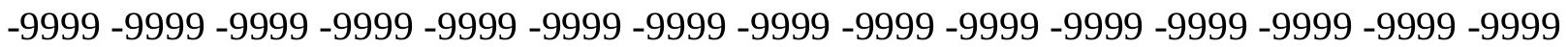
-9999 -9999 -9999 -9999 -9999 -9999 -9999 -9999 -9999 -9999 -9999 -9999 -9999 -9999 -9999 -9999 -9999 -9999 -9999 -9999 -9999 -9999 -9999 -9999 -9999 -9999 -9999 -9999 -9999 -9999 -

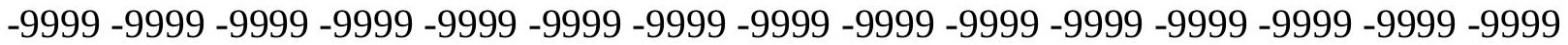
-9999 -9999 -9999 -9999 -9999 -9999 -9999 -9999 -9999 -9999 -9999 -9999 -9999 -9999 -9999 -9999 -9999 -9999 -9999 -9999 -9999 -9999 -9999 -9999 -9999 -9999 -9999 -9999 -9999 -9999 -9999 -9999 -9999 -9999 -9999 -9999 -9999 -9999 -9999 -9999 -9999 -9999 -9999 -9999 -9999 -9999 -9999 -9999 -9999 -9999 -9999 -9999 -9999 -9999 -9999 -9999 -9999 -9999 -9999 -9999 -9999 -9999 -9999 -9999 -9999 -9999 -9999 -9999 -9999 -9999 -9999 -9999 -9999 -9999 -9999

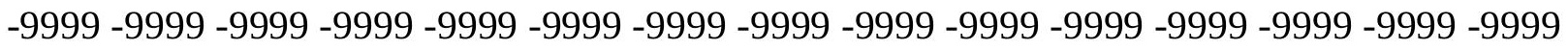
-9999 -9999 -9999 -9999 -9999 -9999 -9999 -9999 -9999 -9999 -9999 -9999 -9999 -9999 -9999 -9999 -9999 -9999 -9999 -9999 -9999 -9999 -9999 -9999 -9999 -9999 -9999 -9999 -9999 -9999 -9999 -9999 -9999 -9999 -9999 -9999 -9999 -9999 -9999 -9999 -9999 -9999 -9999 -9999 -9999 -999 -9999 -9999 -9999 -9999 -9999 -9999 -9999 -9999 -9999 -9999 -9999 -9999 -9999 -9999 -9999 -9999 -9999 -9999 -9999 -9999 -9999 -9999 -9999 -9999 -9999 -9999 -9999 -9999 -9999 -9999 -9999 -9999 -9999 -9999 -9999 -9999 -9999 -9999 -9999 -9999 -9999 -9999 -9999 -9999 -9999 -9999 -9999 -9999 -9999 -9999 -9999 -9999 -9999 -9999 -9999 -9999 -9999 -9999 -9999 -9999 -9999 -9999 -9999 -9999 -9999 -9999 -9999 -9999 -9999 -9999 -9999 -9999 -9999 -9999 
-9999 -9999 -9999 -9999 -9999 -9999 -9999 -9999 -9999 -9999 -9999 -9999 -9999 -9999 -9999 -9999 -9999 -9999 -9999 -9999 -9999 -9999 -9999 -9999 -9999 -9999 -9999 -9999 -9999 -9999 -

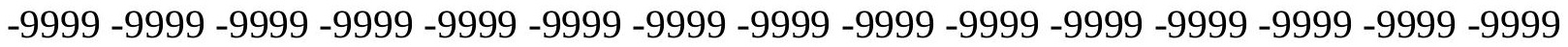
-9999 -9999 -9999 -9999 -9999 -9999 -9999 -9999 -9999 -9999 -9999 -9999 -9999 -9999 -9999 -9999 -9999 -9999 -9999 -9999 -9999 -9999 -9999 -9999-9999 -9999 -9999 -9999 -9999 -9999 -9999 -9999 -9999 -9999 -9999 -9999 -9999 -9999 -9999 -9999 -9999 -9999 -9999 -9999 -9999 -9999 -9999 -9999 -9999 -9999 -9999 -9999 -9999 -9999 -9999 -9999 -9999 -9999 -9999 -9999

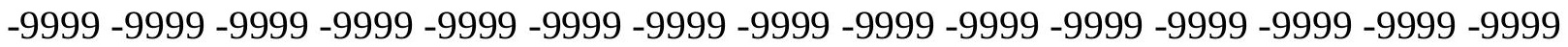

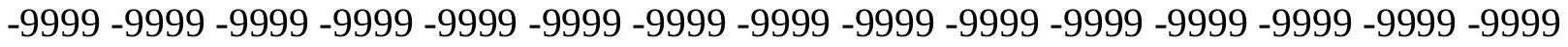
-9999 -9999 -9999 -9999 -9999 -9999 -9999 -9999 -9999 -9999 -9999 -9999 -9999 -9999 -9999 -9999 -9999 -9999 -9999 -9999 -9999 -9999 -9999 -9999 -9999 -9999 -9999 -9999 -9999 -9999 -9999 -9999 -9999 -9999 -9999 -9999 -9999 -9999 -9999 -9999 -9999 -9999 -9999 -9999 -9999 -9999 -9999 -9999 -9999 -9999 -9999 -9999 -9999 -9999 -9999 -9999 -9999 -9999 -9999 -9999 -

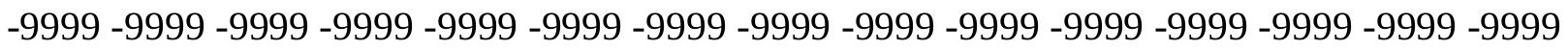
-9999 -9999 -9999 -9999 -9999 -9999 -9999 -9999 -9999 -9999 -9999 -9999 -9999 -9999 -9999 -

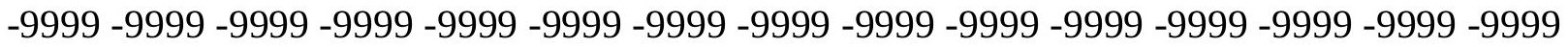
-9999 -9999 -9999 -9999 -9999 -9999 -9999 -9999 -9999 -9999 -9999 -9999 -9999 -9999 -9999 -9999 -9999 -9999 -9999 -9999 -9999 -9999 -9999 -9999 -9999 -9999 -9999 -9999 -9999 -9999 -9999 -9999 -9999 -9999 -9999 -9999 -9999 -9999 -9999 -9999 -9999 -9999 -9999 -9999 -9999 -

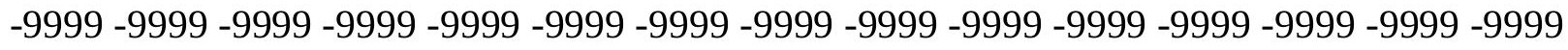

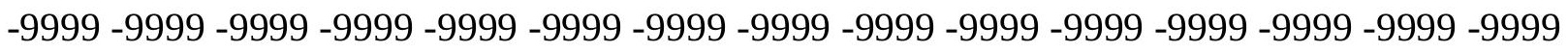

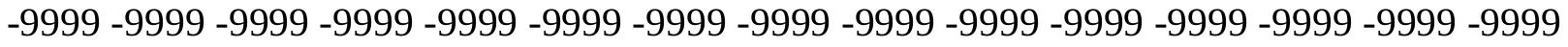
-9999 -9999 -9999 -9999 -9999 -9999 -9999 -9999 -9999 -9999 -9999 -9999 -9999 -9999 -9999 -9999 -9999 -9999 -9999 -9999 -9999 -9999 -9999 -9999 -9999 -9999 -9999 -9999 -9999 -9999 -

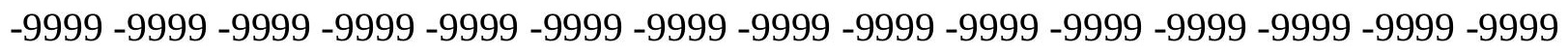
-9999 -9999 -9999 -9999 -9999 -9999 -9999 -9999 -9999 -9999 -9999 -9999 -9999 -9999 -9999 -9999 -9999 -9999 -9999 -9999 -9999 -9999 -9999 -9999 -9999 -9999 -9999 -9999 -9999 -

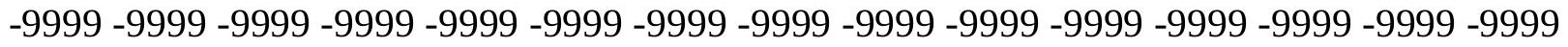
-9999 -9999 -9999 -9999 -9999 -9999 -9999 -9999 -9999 -9999 -9999 -9999 -9999 -9999 -9999 -9999 -9999 -9999 -9999 -9999 -9999 -9999 -9999 -9999 -9999 -9999 -9999 -9999 -9999 -999 -

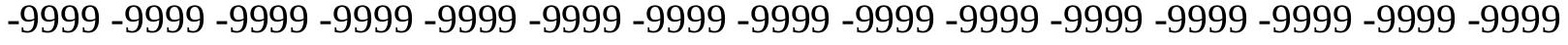
-9999 -9999 -9999 -9999 -9999 -9999 -9999 -9999 -9999 -9999 -9999 -9999 -9999 -9999 -9999 -

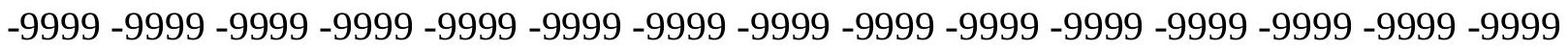

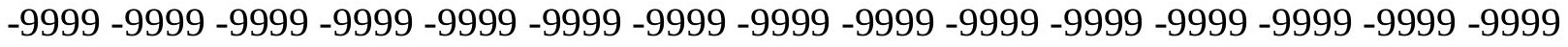

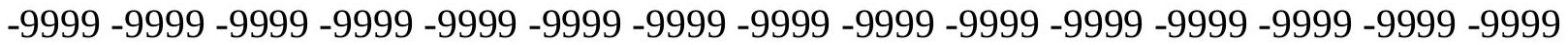
-9999 -9999 -9999 -9999 -9999 -9999 -9999 -9999 -9999 -9999 -9999 -9999 -9999 -9999 -9999

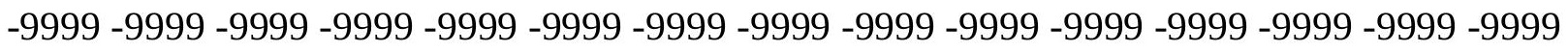

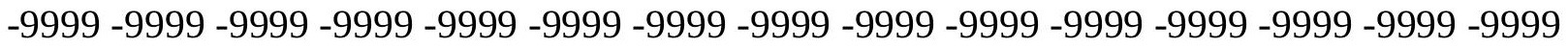
-9999 -9999 -9999 -9999 -9999 -9999 -9999 -9999 -9999 -9999 -9999 -9999 -9999 - 9999 - -999 -9999 -9999 -9999 -9999 -9999 -9999 -9999 -9999 -9999 -9999 -9999 -9999 -9999 -9999 -9999 -

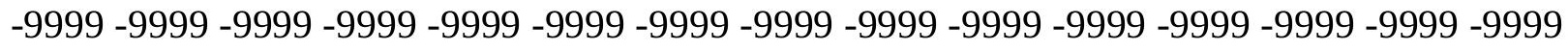

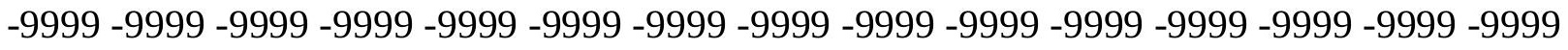
-9999 -9999 -9999 -9999 -9999 -9999 -9999 -9999 -9999 -9999 -9999 -9999 -9999 -9999 -9999 -9999 -9999 -9999 -9999 -9999 -9999 -9999 -9999 -9999-9999 -9999 -9999 -9999 -9999 -9999 -9999 -9999 -9999 -9999 -9999 -9999 -9999 -9999 -9999 -9999 -9999 -9999 -9999 -9999 -9999 -

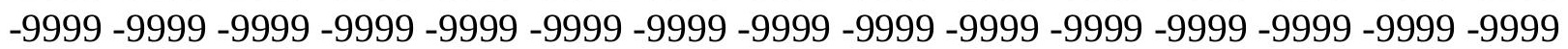


-9999 -9999 -9999 -9999 -9999 -9999 -9999 -9999 -9999 -9999 -9999 -9999 -9999 -9999 -9999 -9999 -9999 -9999 -9999 -9999 -9999 -9999 -9999 -9999 -9999 -9999 -9999 -9999 -9999 -9999 -9999 -9999 -9999 -9999 -9999 -9999 -9999 -9999 -9999 -9999 -9999 -9999 -9999 -9999 - 9999 -9999 -9999 -9999 -9999 -9999 -9999 -9999 -9999 -9999 -9999 -9999 -9999 -9999 -9999 -9999 -9999 -9999 -9999 -9999 -9999 -9999 -9999 -9999 -9999 -9999 -9999 -9999 -9999 -9999 - -9999 -9999 -9999 -9999 -9999 -9999 -9999 -9999 -9999 -9999 -9999 -9999 -9999 -9999 -9999 -9999 -9999 -9999 -9999 -9999 -9999 -9999 -9999 -9999 -9999 -9999 -9999 -9999 -9999 -9999

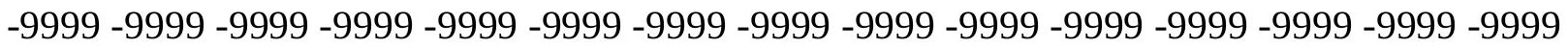

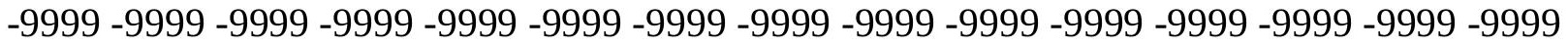
-9999 -9999 -9999 -9999 -9999 -9999 -9999 -9999 -9999 -9999 -9999 -9999 -9999 -9999 -9999

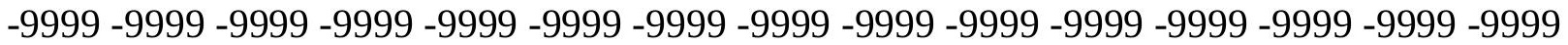
-9999 -9999 -9999 -9999 -9999 -9999 -9999 -9999 -9999 -9999 -9999 -9999 -9999 -9999 -9999 -9999 -9999 -9999 -9999 -9999 -9999 -9999 -9999 -9999 -9999 -9999 -9999 -9999 -9999 -9999 -9999 -9999 -9999 -9999 -9999 -9999 -9999 -9999 -9999 -9999 -9999 -9999 -9999 -9999 - -9999 -9999 -9999 -9999 -9999 -9999 -9999 -9999 -9999 -9999 -9999 -9999 -9999 -9999 -9999 -9999

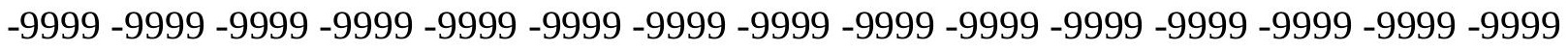
-9999 -9999 -9999 -9999 -9999 -9999 -9999 -9999 -9999 -9999 -9999 -9999 -9999 -9999 -9999 -9999 -9999 -9999 -9999 -9999 -9999 -9999 -9999 -9999 -9999 -9999 -9999 -9999 -9999 -9999 -9999 -9999 -9999 -9999 -9999 -9999 -9999 -9999 -9999 -9999 -9999 -9999 -9999 -9999 -9999 -

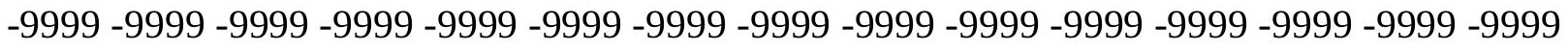
-9999 -9999 -9999 -9999 -9999 -9999 -9999 -9999 -9999 -9999 -9999 -9999 -9999 -9999 -9999 -999 -9999 -9999 -9999 -9999 -9999 -9999 -9999 -9999 -9999 -9999 -9999 -9999 -9999 -9999 -9999 -9999 -9999 -9999 -9999 -9999 -9999 -9999 -9999 -9999 -9999 -9999 -9999 -9999 -9999 -9999 -9999 -9999 -9999 -9999 -9999 -9999 -9999 -9999 -9999 -9999 -9999 -9999 -9999 -9999 -9999 -9999 -9999 -9999 -9999 -9999 -9999 -9999 -9999 -9999 -9999 -9999 -9999 -9999 -9999 -9999 -9999 -9999 -9999 -9999 -9999 -9999 -9999 -9999 -9999 -9999 -9999 -9999 -9999 -9999 -9999 -9999 -9999 -9999 -9999 -9999 -9999 -9999 -9999 -9999 -9999 -9999 -9999 -9999 -9999 -9999 -9999 -9999 -9999 -9999 -9999 -9999 -9999 -9999 -9999 -9999 -9999 -9999 -9999 -9999 -9999 -9999 -9999 -9999 -9999 -9999 -9999 -9999 -9999 -9999 -9999 -9999 -9999 -9999 -9999 -9999 -9999 -9999 -9999 -9999 -9999 -9999 -9999 -9999 -9999 -9999 -9999 -9999 -9999 -9999 -999 -9999 -9999 -9999 -9999 -9999 -9999 -9999 -9999 -9999 -9999 -9999 -9999 -9999 -9999 -9999 -9999 -9999 -9999 -9999 -9999 -9999 -9999 -9999 -9999 -9999 -9999 -9999 -9999 -9999 -

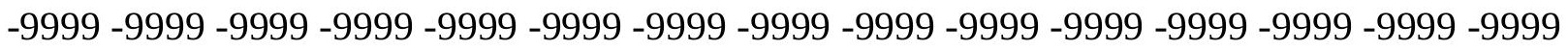

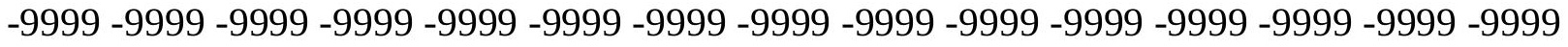

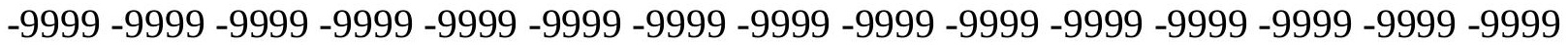
-9999 -9999 -9999 -9999 -9999 -9999 -9999 -9999 -9999 -9999 -9999 -9999 -9999 -9999 -9999 -

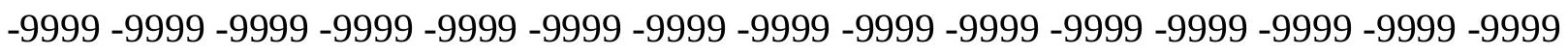

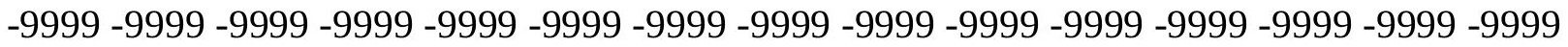

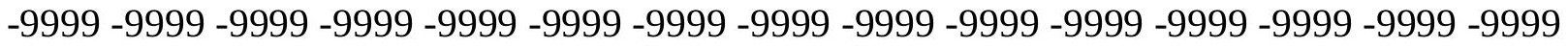
-9999 -9999 -9999 -9999 -9999 -9999 -9999 -9999 -9999 -9999 -9999 -9999 -9999 -9999 -9999 -

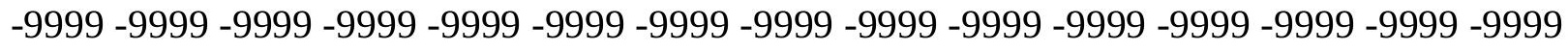

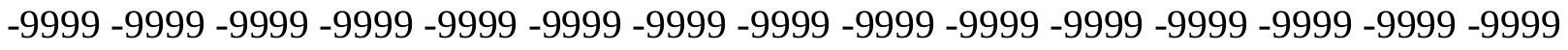
-9999 -9999 -9999 -9999 -9999 -9999 -9999 -9999 -9999 -9999 -9999 -9999 -9999 -9999 -9999 -9999 -9999 -9999 -9999 -9999 -9999 -9999 -9999 -9999-9999 -9999 -9999 -9999 -9999 -9999 -9999 -9999 -9999 -9999 -9999 -9999 -9999 -9999 -9999 -9999 -9999 -9999 -9999 -9999 -9999 -

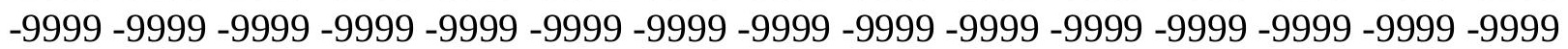


-9999 -9999 -9999 -9999 -9999 -9999 -9999 -9999 -9999 -9999 -9999 -9999 -9999 -9999 -9999 -9999 -9999 -9999 -9999 -9999 -9999 -9999 -9999 -9999 -9999 -9999 -9999 -9999 -9999 -9999 -

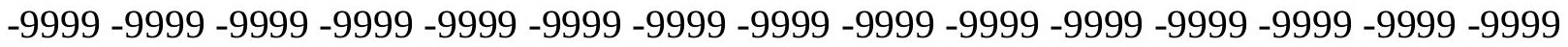
-9999 -9999 -9999 -9999 -9999 -9999 -9999 -9999 -9999 -9999 -9999 -9999 -9999 -9999 -9999 -9999 -9999 -9999 -9999 -9999 -9999 -9999 -9999 -9999-9999 -9999 -9999 -9999 -9999 -9999 -9999 -9999 -9999 -9999 -9999 -9999 -9999 -9999 -9999 -9999 -9999 -9999 -9999 -9999 -9999 -9999 -9999 -9999 -9999 -9999 -9999 -9999 -9999 -9999 -9999 -9999 -9999 -9999 -9999 -9999

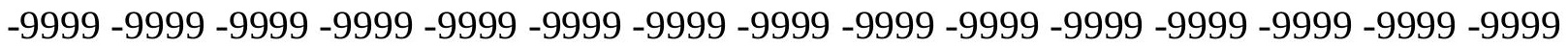

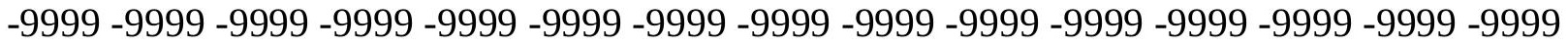
-9999 -9999 -9999 -9999 -9999 -9999 -9999 -9999 -9999 -9999 -9999 -9999 -9999 -9999 -9999 -9999 -9999 -9999 -9999 -9999 -9999 -9999 -9999 -9999 -9999 -9999 -9999 -9999 -9999 -9999 -9999 -9999 -9999 -9999 -9999 -9999 -9999 -9999 -9999 -9999 -9999 -9999 -9999 -9999 -9999 -9999 -9999 -9999 -9999 -9999 -9999 -9999 -9999 -9999 -9999 -9999 -9999 -9999 -9999 -9999 -9999 -9999 -9999 -9999 -9999 -9999 -9999 -9999 -9999 -9999 -9999 -9999 -9999 - 9999 -9999 -9999 -9999 -9999 -9999 -9999 -9999 -9999 -9999 -9999 -9999 -9999 -9999 -9999 -9999

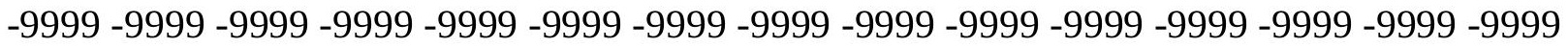
-9999 -9999 -9999 -9999 -9999 -9999 -9999 -9999 -9999 -9999 -9999 -9999 -9999 -9999 -9999 -9999 -9999 -9999 -9999 -9999 -9999 -9999 -9999 -9999 -9999 -9999 -9999 -9999 -9999 -9999 -9999 -9999 -9999 -9999 -9999 -9999 -9999 -9999 -9999 -9999 -9999 -9999 -9999 -9999 -9999 -

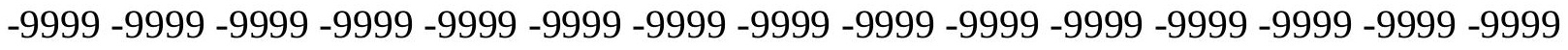

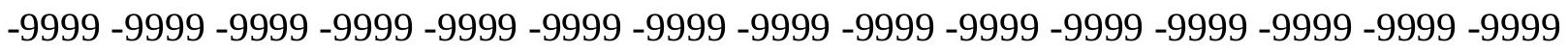
-9999 -9999 -9999 -9999 -9999 -9999 -9999 -9999 -9999 -9999 -9999 -9999 -9999 -9999 -9999 -9999 -9999 -9999 -9999 -9999 -9999 -9999 -9999 -9999 -9999 -9999 -9999 -9999 -9999 -9999 -9999 -9999 -9999 -9999 -9999 -9999 -9999 -9999 -9999 -9999 -9999 -9999 -9999 -9999 -9999 -

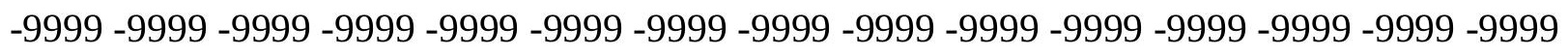
-9999 -9999 -9999 -9999 -9999 -9999 -9999 -9999 -9999 -9999 -9999 -9999 -9999 -9999 -9999 -9999 -9999 -9999 -9999 -9999 -9999 -9999 -9999 -9999 -9999 -9999 -9999 -9999 -9999 -9999 -

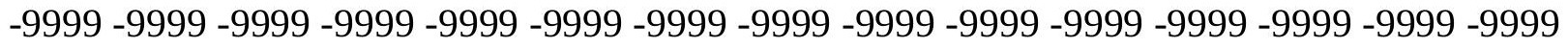
-9999 -9999 -9999 -9999 -9999 -9999 -9999 -9999 -9999 -9999 -9999 -9999 -9999 -9999 -9999 -9999 -9999 -9999 -9999 -9999 -9999 -9999 -9999 -9999 -9999 -9999 -9999 -9999 -9999 -999 -9999 -9999 -9999 -9999 -9999 -9999 -9999 -9999 -9999 -9999 -9999 -9999 -9999 -9999 -9999 -9999 -9999 -9999 -9999 -9999 -9999 -9999 -9999 -9999 -9999 -9999 -9999 -9999 -9999 -9999 -

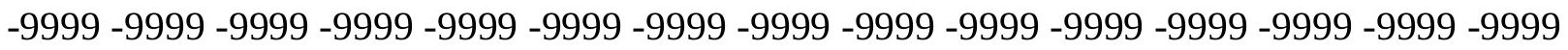

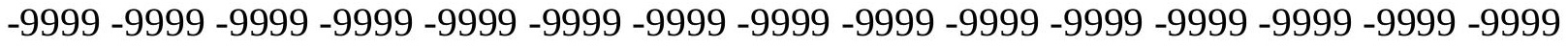

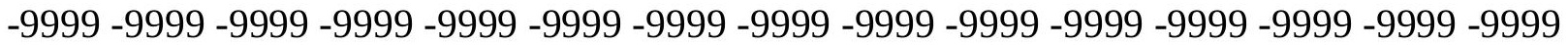

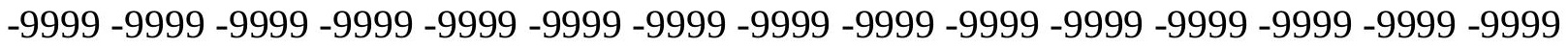

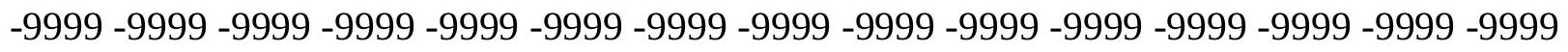

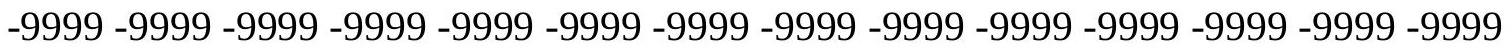
-9999 -9999 -9999 -9999 -9999 -9999 -9999 -9999 -9999 -9999 -9999 -9999 -9999 -9999 -9999 -9999 -9999 -9999 -9999 -9999 -9999 -9999 -9999 -9999 -9999 -9999 -9999 -9999 -9999 -9999 -

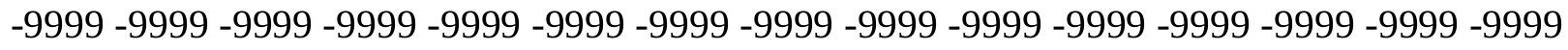

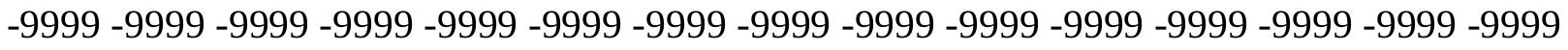
-9999 -9999 -9999 -9999 -9999 -9999 -9999 -9999 -9999 -9999 -9999 -9999 -9999 -9999 -9999 -9999 -9999 -9999 -9999 -9999 -9999 -9999 -9999 -9999-9999 -9999 -9999 -9999 -9999 -9999 -9999 -9999 -9999 -9999 -9999 -9999 -9999 -9999 -9999 -9999 -9999 -9999 -9999 -9999 -9999 -

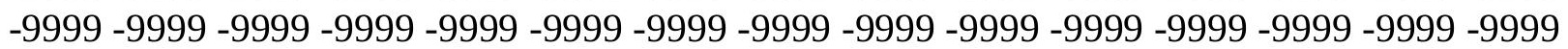


-9999 -9999 -9999 -9999 -9999 -9999 -9999 -9999 -9999 -9999 -9999 -9999 -9999 -9999 -9999 -9999 -9999 -9999 -9999 -9999 -9999 -9999 -9999 -9999 -9999 -9999 -9999 -9999 -9999 -9999 -9999 -9999 -9999 -9999 -9999 -9999 -9999 -9999 -9999 -9999 -9999 -9999 -9999 -9999 - 9999 -9999 -9999 -9999 -9999 -9999 -9999 -9999 -9999 -9999 -9999 -9999 -9999 -9999 -9999 -9999 -9999 -9999 -9999 -9999 -9999 -9999 -9999 -9999 -9999 -9999 -9999 -9999 -9999 -9999 -9999 -9999 -9999 -9999 -9999 -9999 -9999 -9999 -9999 -9999 -9999 -9999 -9999 -9999 -9999 -9999 -9999 -9999 -9999 -9999 -9999 -9999 -9999 -9999 -9999 -9999 -9999 -9999 -9999 -9999 -9999

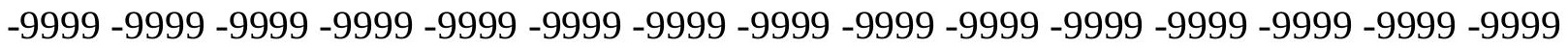
-9999 -9999 -9999 -9999 -9999 -9999 -9999 -9999 -9999 -9999 -9999 -9999 -9999 -9999 -9999 -9999 -9999 -9999 -9999 -9999 -9999 -9999 -9999 -9999 -9999 -9999 -9999 -9999 -9999 -9999

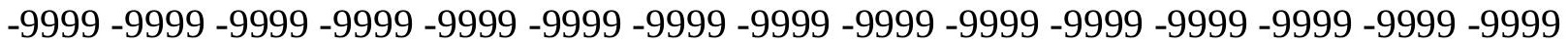
-9999 -9999 -9999 -9999 -9999 -9999 -9999 -9999 -9999 -9999 -9999 -9999 -9999 -9999 -9999 -9999 -9999 -9999 -9999 -9999 -9999 -9999 -9999 -9999 -9999 -9999 -9999 -9999 -9999 -9999 -

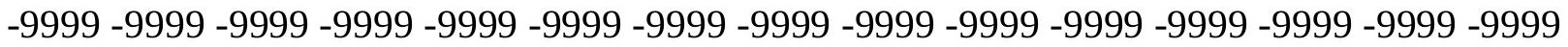
-9999 -9999 -9999 -9999 -9999 -9999 -9999 -9999 -9999 -9999 -9999 -9999 -9999 -9999 -9999

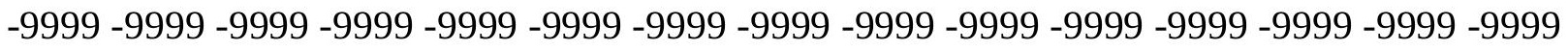
-9999 -9999 -9999 -9999 -9999 -9999 -9999 -9999 -9999 -9999 -9999 -9999 -9999 -9999 -9999 -9999 -9999 -9999 -9999 -9999 -9999 -9999 -9999 -9999 -9999 -9999 -9999 -9999 -9999 - -999 -9999 -9999 -9999 -9999 -9999 -9999 -9999 -9999 -9999 -9999 -9999 -9999 -9999 -9999 -9999 -9999 -9999 -9999 -9999 -9999 -9999 -9999 -9999 -9999 -9999 -9999 -9999 -9999 -9999 -9999 -9999 -9999 -9999 -9999 -9999 -9999 -9999 -9999 -9999 -9999 -9999 -9999 -9999 -9999 -9999 -999 -9999 -9999 -9999 -9999 -9999 -9999 -9999 -9999 -9999 -9999 -9999 -9999 -9999 -9999 -9999 -9999 -9999 -9999 -9999 -9999 -9999 -9999 -9999 -9999 -9999 -9999 -9999 -9999 -9999 -9999 -9999 -9999 -9999 -9999 -9999 -9999 -9999 -9999 -9999 -9999 -9999 -9999 -9999 -9999 -9999 -9999 -9999 -9999 -9999 -9999 -9999 -9999 -9999 -9999 -9999 -9999 -9999 -9999 -9999 -9999 -9999 -9999 -9999 -9999 -9999 -9999 -9999 -9999 -9999 -9999 -9999 -9999 -9999 -9999 -9999 -9999 -9999 -9999 -9999 -9999 -9999 -9999 -9999 -9999 -9999 -9999 -9999 -9999 -9999 -9999 -9999 -9999 -9999 -9999 -9999 -9999 -9999 -9999 -9999 -9999 -9999 -9999 -9999 -9999 -9999 -9999 -9999 -9999 -9999 -9999 -9999 -9999 -9999 -9999 -9999 -9999 -9999 -9999 -9999 -9999 -9999 -9999 -9999 -9999 -9999 -9999 -9999 -9999 -9999 -9999 -9999 -9999 -9999 -9999 -999 -9999 -9999 -9999 -9999 -9999 -9999 -9999 -9999 -9999 -9999 -9999 -9999 -9999 -9999 -9999 -9999 -9999 -9999 -9999 -9999 -9999 -9999 -9999 -9999 -9999 -9999 -9999 -9999 -9999 -9999 -

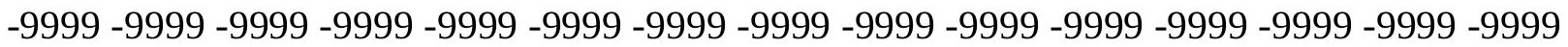

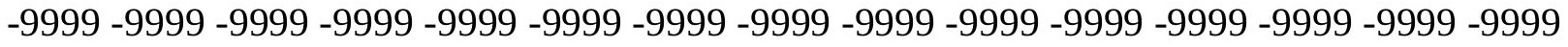

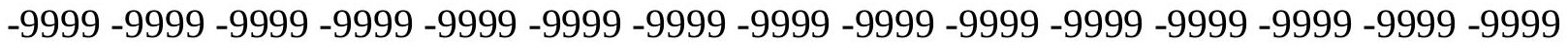
-9999 -9999 -9999 -9999 -9999 -9999 -9999 -9999 -9999 -9999 -9999 -9999 -9999 -9999 -9999

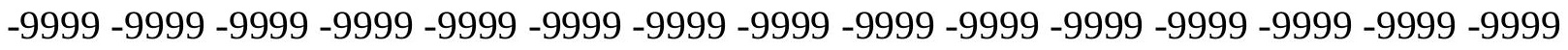

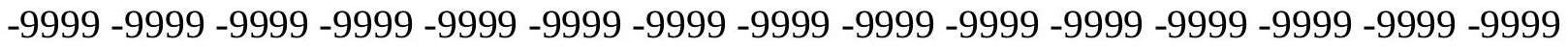

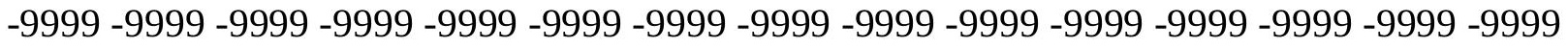
-9999 -9999 -9999 -9999 -9999 -9999 -9999 -9999 -9999 -9999 -9999 -9999 -9999 -9999 -9999 -

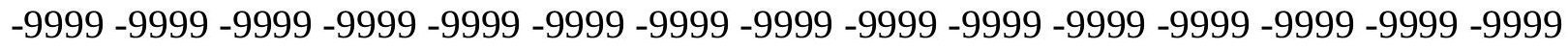

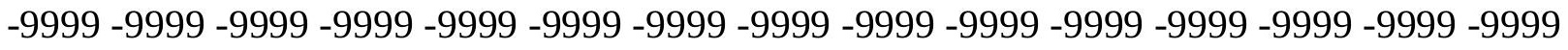
-9999 -9999 -9999 -9999 -9999 -9999 -9999 -9999 -9999 -9999 -9999 -9999 -9999 -9999 -9999 -9999 -9999 -9999 -9999 -9999 -9999 -9999 -9999 -9999 -9999 -9999 -9999 -9999 - -9999 -9999 -9999 -9999 -9999 -9999 -9999 -9999 -9999 -9999 -9999 -9999 -9999 -9999 -9999 -9999 -

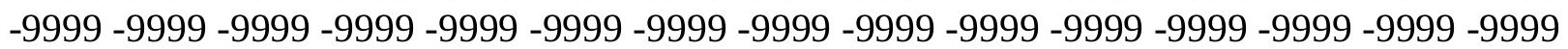


-9999 -9999 -9999 -9999 -9999 -9999 -9999 -9999 -9999 -9999 -9999 -9999 -9999 -9999 -9999 -9999 -9999 -9999 -9999 -9999 -9999 -9999 -9999 -9999 -9999 -9999 -9999 -9999 -9999 -9999 -9999 -9999 -9999 -9999 -9999 -9999 -9999 -9999 -9999 -9999 -9999 -9999 -9999 -9999 - 9999 -9999 -9999 -9999 -9999 -9999 -9999 -9999 -9999 -9999 -9999 -9999 -9999 -9999 -9999 -9999 -9999 -9999 -9999 -9999 -9999 -9999 -9999 -9999 -9999-9999 -9999 -9999 -9999 -9999 -9999 -9999 -9999 -9999 -9999 -9999 -9999 -9999 -9999 -9999 -9999 -9999 -9999 -9999 -9999 -9999 -9999 -9999 -9999 -9999 -9999 -9999 -9999 -9999 -9999 -9999 -9999 -9999 -9999 -9999 -9999

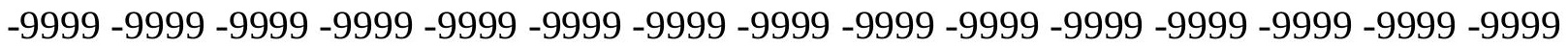

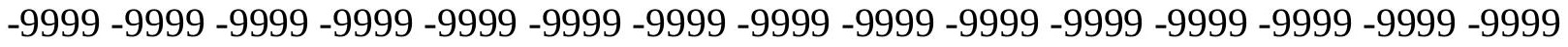
-9999 -9999 -9999 -9999 -9999 -9999 -9999 -9999 -9999 -9999 -9999 -9999 -9999 -9999 -9999

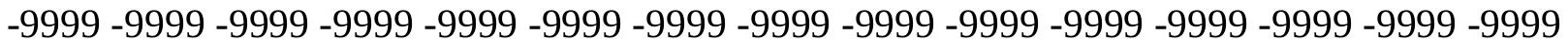
-9999 -9999 -9999 -9999 -9999 -9999 -9999 -9999 -9999 -9999 -9999 -9999 -9999 -9999 -9999 -9999 -9999 -9999 -9999 -9999 -9999 -9999 -9999 -9999 -9999 -9999 -9999 -9999 -9999 -9999 -

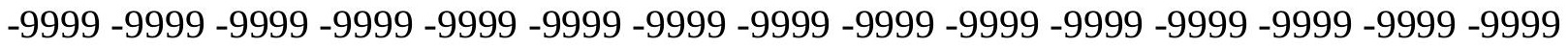
-9999 -9999 -9999 -9999 -9999 -9999 -9999 -9999 -9999 -9999 -9999 -9999 -9999 -9999 -9999

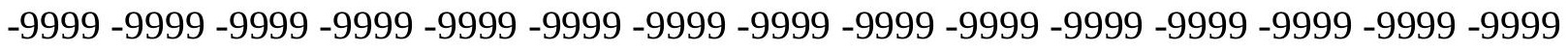
-9999 -9999 -9999 -9999 -9999 -9999 -9999 -9999 -9999 -9999 -9999 -9999 -9999 -9999 -9999 -9999 -9999 -9999 -9999 -9999 -9999 -9999 -9999 -9999 -9999 -9999 -9999 -9999 -9999 -9999 -9999 -9999 -9999 -9999 -9999 -9999 -9999 -9999 -9999 -9999 -9999 -9999 -9999 -9999 -9999 -9999 -9999 -9999 -9999 -9999 -9999 -9999 -9999 -9999 -9999 -9999 -9999 -9999 -9999 -9999 -9999 -9999 -9999 -9999 -9999 -9999 -9999 -9999 -9999 -9999 -9999 -9999 -9999 -9999 -9999 -999 -9999 -9999 -9999 -9999 -9999 -9999 -9999 -9999 -9999 -9999 -9999 -9999 -9999 -9999 -9999 -9999 -9999 -9999 -9999 -9999 -9999 -9999 -9999 -9999 -9999 -9999 -9999 -9999 -9999 -9999 -9999 -9999 -9999 -9999 -9999 -9999 -9999 -9999 -9999 -9999 -9999 -9999 -9999 -9999 -9999 -9999 -9999 -9999 -9999 -9999 -9999 -9999 -9999 -9999 -9999 -9999 -9999 -9999 -9999 -9999 -9999 -9999 -9999 -9999 -9999 -9999 -9999 -9999 -9999 -9999 -9999 -9999 -9999 -9999 -9999 -9999 -9999 -9999 -9999 -9999 -9999 -9999 -9999 -9999 -9999 -9999 -9999 -9999 -9999 -9999 -9999 -9999 -9999 -9999 -9999 -9999 -9999 -9999 -9999 -9999 -9999 -9999 -9999 -9999 -9999 -9999 -9999 -9999 -9999 -9999 -9999 -9999 -9999 -9999 -9999 -9999 -9999 -9999 -9999 -9999 -9999 -9999 -9999 -9999 -9999 -9999 -9999 -9999 -9999 -9999 -9999 -9999 -9999 -999 -9999 -9999 -9999 -9999 -9999 -9999 -9999 -9999 -9999 -9999 -9999 -9999 -9999 -9999 -9999 -9999 -9999 -9999 -9999 -9999 -9999 -9999 -9999 -9999 -9999 -9999 -9999 -9999 -9999 -9999 -

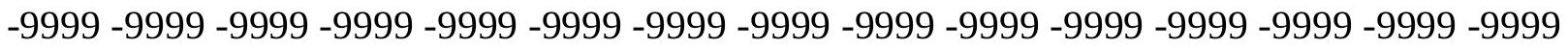

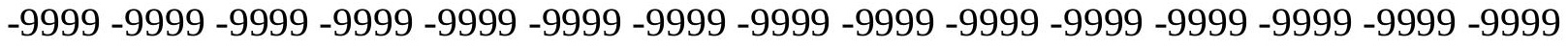

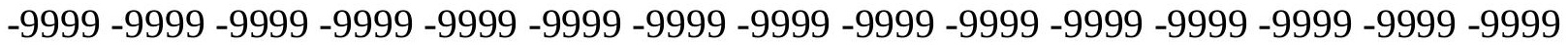
-9999 -9999 -9999 -9999 -9999 -9999 -9999 -9999 -9999 -9999 -9999 -9999 -9999 -9999 -9999

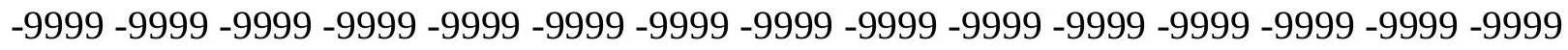

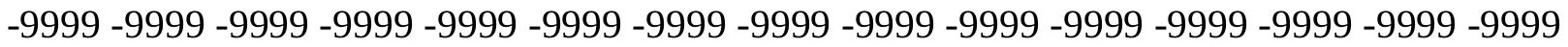
-9999 -9999 -9999 -9999 -9999 -9999 -9999 -9999 -9999 -9999 -9999 -9999 -9999 -9999 -9999 -9999 -9999 -9999 -9999 -9999 -9999 -9999 -9999 -9999 -9999 -9999 -9999 -9999 -9999 -9999 -

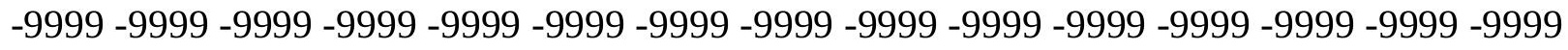

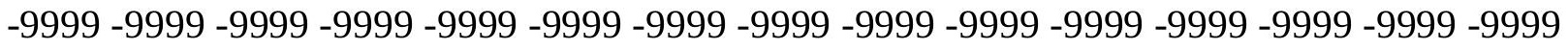
-9999 -9999 -9999 -9999 -9999 -9999 -9999 -9999 -9999 -9999 -9999 -9999 -9999 -9999 -9999 -9999 -9999 -9999 -9999 -9999 -9999 -9999 -9999 -9999-9999 -9999 -9999 -9999 -9999 -9999 -9999 -9999 -9999 -9999 -9999 -9999 -9999 -9999 -9999 -9999 -9999 -9999 -9999 -9999 -9999 -

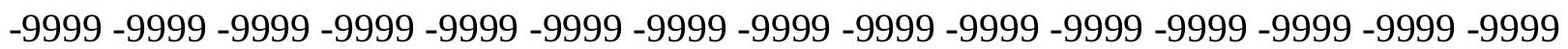


-9999 -9999 -9999 -9999 -9999 -9999 -9999 -9999 -9999 -9999 -9999 -9999 -9999 -9999 -9999 -9999 -9999 -9999 -9999 -9999 -9999 -9999 -9999 -9999 -9999 -9999 -9999 -9999 -9999 -9999 -9999 -9999 -9999 -9999 -9999 -9999 -9999 -9999 -9999 -9999 -9999 -9999 -9999 -9999 - 9999 -9999 -9999 -9999 -9999 -9999 -9999 -9999 -9999 -9999 -9999 -9999 -9999 -9999 -9999

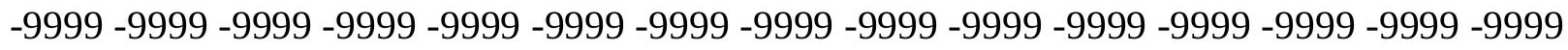
-9999 -9999 -9999 -9999 -9999 -9999 -9999 -9999 -9999 -9999 -9999 -9999 -9999 -9999 -9999 -9999 -9999 -9999 -9999 -9999 -9999 -9999 -9999 -9999 -9999 -9999 -9999 -9999 -9999 -9999

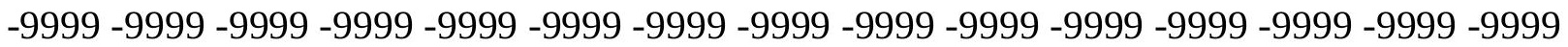

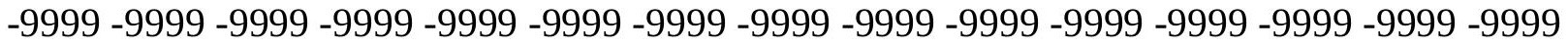
-9999 -9999 -9999 -9999 -9999 -9999 -9999 -9999 -9999 -9999 -9999 -9999 -9999 -9999 -9999 -9999 -9999 -9999 -9999 -9999 -9999 -9999 -9999 -9999 -9999 -9999 -9999 -9999 -9999 -9999 -9999 -9999 -9999 -9999 -9999 -9999 -9999 -9999 -9999 -9999 -9999 -9999 -9999 -9999 -9999 -9999 -9999 -9999 -9999 -9999 -9999 -9999 -9999 -9999 -9999 -9999 -9999 -9999 -9999 -9999 -

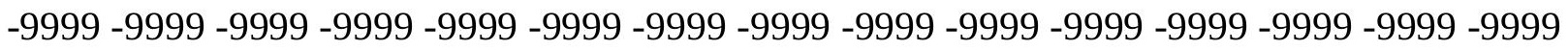
-9999 -9999 -9999 -9999 -9999 -9999 -9999 -9999 -9999 -9999 -9999 -9999 -9999 -9999 -9999 -

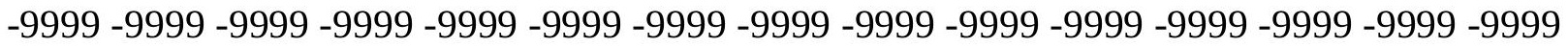
-9999 -9999 -9999 -9999 -9999 -9999 -9999 -9999 -9999 -9999 -9999 -9999 -9999 -9999 -9999 -9999 -9999 -9999 -9999 -9999 -9999 -9999 -9999 -9999 -9999 -9999 -9999 -9999 -9999 -9999 -9999 -9999 -9999 -9999 -9999 -9999 -9999 -9999 -9999 -9999 -9999 -9999 -9999 -9999 -9999 -

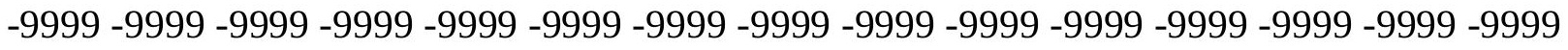
-9999 -9999 -9999 -9999 -9999 -9999 -9999 -9999 -9999 -9999 -9999 -9999 -9999 -9999 -9999

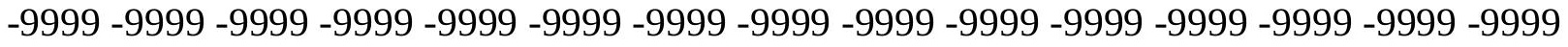
-9999 -9999 -9999 -9999 -9999 -9999 -9999 -9999 -9999 -9999 -9999 -9999 -9999 -9999 -9999 -9999 -9999 -9999 -9999 -9999 -9999 -9999 -9999 -9999 -9999 -9999 -9999 -9999 -9999 -9999 -9999 -9999 -9999 -9999 -9999 -9999 -9999 -9999 -9999 -9999 -9999 -9999 -9999 -9999 -9999 -9999 -9999 -9999 -9999 -9999 -9999 -9999 -9999 -9999 -9999 -9999 -9999 -9999 -9999 -9999 -9999 -9999 -9999 -9999 -9999 -9999 -9999 -9999 -9999 -9999 -9999 -9999 -9999 -9999 -9999 -9999 -9999 -9999 -9999 -9999 -9999 -9999 -9999 -9999 -9999 -9999 -9999 -9999 -9999 -9999 -9999 -9999 -9999 -9999 -9999 -9999 -9999 -9999 -9999 -9999 -9999 -9999 -9999 -9999 -9999 -9999 -9999 -9999 -9999 -9999 -9999 -9999 -9999 -9999 -9999 -9999 -9999 -9999 -9999 -9999 -9999 -9999 -9999 -9999 -9999 -9999 -9999 -9999 -9999 -9999 -9999 -9999 -9999 -9999 -9999 -9999 -9999 -9999 -9999 -9999 -9999 -9999 -9999 -9999 -9999 -9999 -9999 -9999 -9999 -

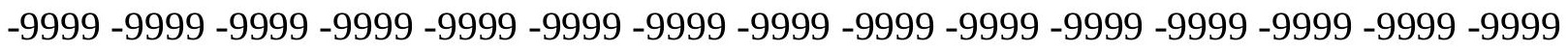

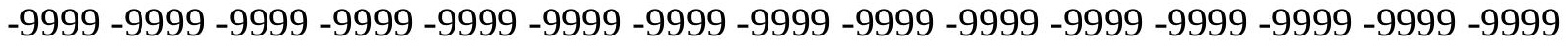
-9999 -9999 -9999 -9999 -9999 -9999 -9999 -9999 -9999 -9999 -9999 -9999 -9999 -9999 -9999 -

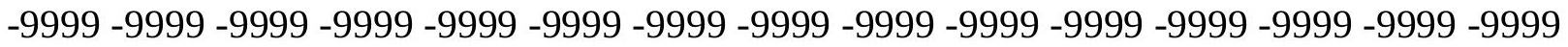

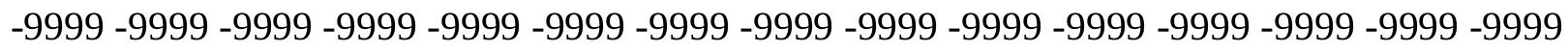

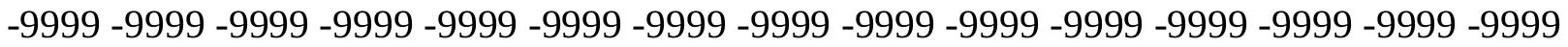

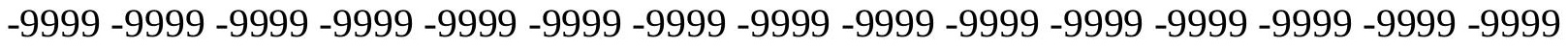
-9999 -9999 -9999 -9999 -9999 -9999 -9999 -9999 -9999 -9999 -9999 -9999 -9999 -9999 -9999 -

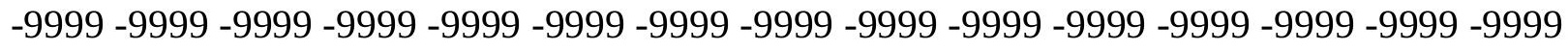

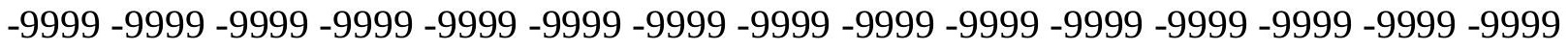
-9999 -9999 -9999 -9999 -9999 -9999 -9999 -9999 -9999 -9999 -9999 -9999 -9999 -9999 -9999 -9999 -9999 -9999 -9999 -9999 -9999 -9999 -9999 -9999-9999 -9999 -9999 -9999 -9999 -9999 -9999 -9999 -9999 -9999 -9999 -9999 -9999 -9999 -9999 -9999 -9999 -9999 -9999 -9999 -9999 -

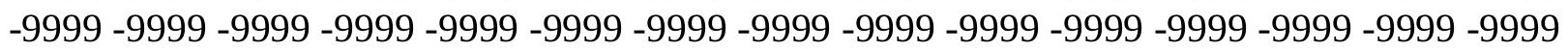


-9999 -9999 -9999 -9999 -9999 -9999 -9999 -9999 -9999 -9999 -9999 -9999 -9999 -9999 -9999 -9999 -9999 -9999 -9999 -9999 -9999 -9999 -9999 -9999 -9999 -9999 -9999 -9999 -9999 -9999 -9999 -9999 -9999 -9999 -9999 -9999 -9999 -9999 -9999 -9999 -9999 -9999 -9999 -9999 - 9999 -9999 -9999 -9999 -9999 -9999 -9999 -9999 -9999 -9999 -9999 -9999 -9999 -9999 -9999 -9999 -9999 -9999 -9999 -9999 -9999 -9999 -9999 -9999 -9999 -9999 -9999 -9999 -9999 -9999 -9999 -9999 -9999 -9999 -9999 -9999 -9999 -9999 -9999 -9999 -9999 -9999 -9999 -9999 -9999 -9999 -9999 -9999 -9999 -9999 -9999 -9999 -9999 -9999 -9999 -9999 -9999 -9999 -9999 -9999 -9999

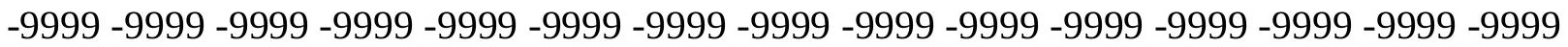

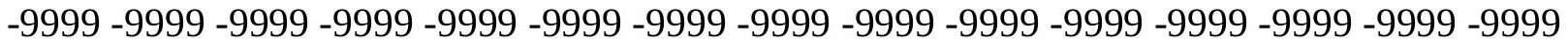
-9999 -9999 -9999 -9999 -9999 -9999 -9999 -9999 -9999 -9999 -9999 -9999 -9999 -9999 -9999 -9999 -9999 -9999 -9999 -9999 -9999 -9999 -9999 -9999 -9999 -9999 -9999 -9999 -9999 -9999 -9999 -9999 -9999 -9999 -9999 -9999 -9999 -9999 -9999 -9999 -9999 -9999 -9999 -9999 -9999 -9999 -9999 -9999 -9999 -9999 -9999 -9999 -9999 -9999 -9999 -9999 -9999 -9999 -9999 -9999 -9999 -9999 -9999 -9999 -9999 -9999 -9999 -9999 -9999 -9999 -9999 -9999 -9999 -9999 -9999 -9999 -9999 -9999 -9999 -9999 -9999 -9999 -9999 -9999 -9999 -9999 -9999 -9999 -9999 -

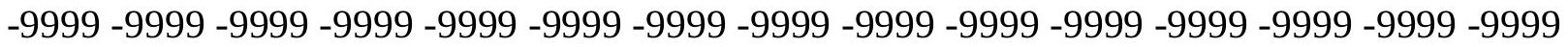
-9999 -9999 -9999 -9999 -9999 -9999 -9999 -9999 -9999 -9999 -9999 -9999 -9999 -9999 -9999 -9999 -9999 -9999 -9999 -9999 -9999 -9999 -9999 -9999 -9999 -9999 -9999 -9999 -9999 -9999 -9999 -9999 -9999 -9999 -9999 -9999 -9999 -9999 -9999 -9999 -9999 -9999 -9999 -9999 -9999 -9999 -9999 -9999 -9999 -9999 -9999 -9999 -9999 -9999 -9999 -9999 -9999 -9999 -9999 -9999 -9999 -9999 -9999 -9999 -9999 -9999 -9999 -9999 -9999 -9999 -9999 -9999 -9999 -9999 -9999 -999 -9999 -9999 -9999 -9999 -9999 -9999 -9999 -9999 -9999 -9999 -9999 -9999 -9999 -9999 -9999 -9999 -9999 -9999 -9999 -9999 -9999 -9999 -9999 -9999 -9999 -9999 -9999 -9999 -9999 -9999 -9999 -9999 -9999 -9999 -9999 -9999 -9999 -9999 -9999 -9999 -9999 -9999 -9999 -9999 -9999 -9999 -9999 -9999 -9999 -9999 -9999 -9999 -9999 -9999 -9999 -9999 -9999 -9999 -9999 -9999 -9999 -9999 -9999 -9999 -9999 -9999 -9999 -9999 -9999 -9999 -9999 -9999 -9999 -9999 -9999 -9999 -9999 -9999 -9999 -9999 -9999 -9999 -9999 -9999 -9999 -9999 -9999 -9999 -9999 -9999 -9999 -9999 -9999 -9999 -9999 -9999 -9999 -9999 -9999 -9999 -9999 -9999 -9999 -9999 -9999 -9999 -9999 -9999 -9999 -9999 -9999 -9999 -9999 -9999 -9999 -9999 -9999 -9999 -9999 -9999 -9999 -9999 -9999 -9999 -9999 -9999 -9999 -9999 -9999 -9999 -9999 -9999 -9999 -9999 -999 -9999 -9999 -9999 -9999 -9999 -9999 -9999 -9999 -9999 -9999 -9999 -9999 -9999 -9999 -9999 -9999 -9999 -9999 -9999 -9999 -9999 -9999 -9999 -9999 -9999 -9999 -9999 -9999 -9999 -9999 -

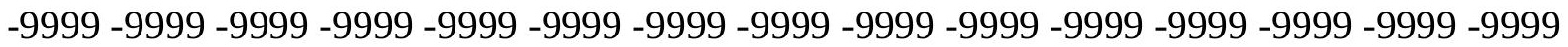

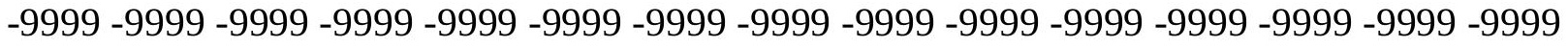

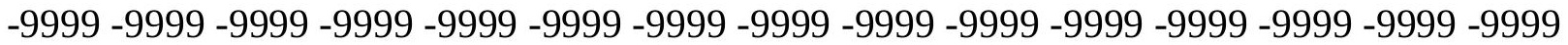
-9999 -9999 -9999 -9999 -9999 -9999 -9999 -9999 -9999 -9999 -9999 -9999 -9999 -9999 -9999 -9999 -9999 -9999 -9999 -9999 -9999 -9999 -9999 -9999 -9999 -9999 -9999 -9999 -9999 -

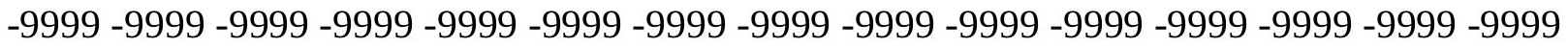
-9999 -9999 -9999 -9999 -9999 -9999 -9999 -9999 -9999 -9999 -9999 -9999 -9999 -9999 -9999 -9999 -9999 -9999 -9999 -9999 -9999 -9999 -9999 -9999 -9999 -9999 -9999 -9999 -9999 -9999 -

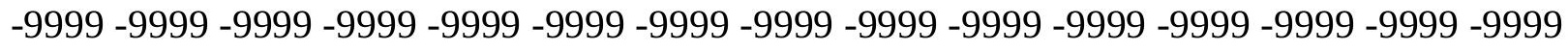

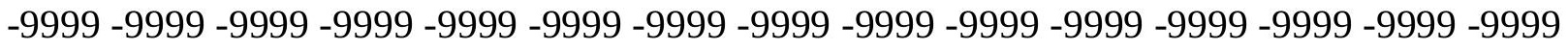
-9999 -9999 -9999 -9999 -9999 -9999 -9999 -9999 -9999 -9999 -9999 -9999 -9999 -9999 -9999 -9999 -9999 -9999 -9999 -9999 -9999 -9999 -9999 -9999-9999 -9999 -9999 -9999 -9999 -9999 -9999 -9999 -9999 -9999 -9999 -9999 -9999 -9999 -9999 -9999 -9999 -9999 -9999 -9999 -9999 -

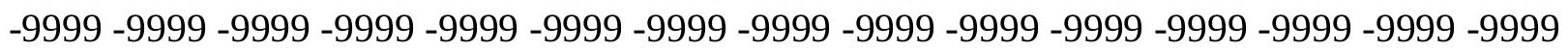


-9999 -9999 -9999 -9999 -9999 -9999 -9999 -9999 -9999 -9999 -9999 -9999 -9999 -9999 -9999 -9999 -9999 -9999 -9999 -9999 -9999 -9999 -9999 -9999 -9999 -9999 -9999 -9999 -9999 -9999 -

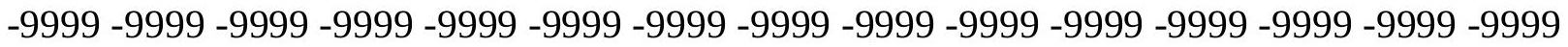
-9999 -9999 -9999 -9999 -9999 -9999 -9999 -9999 -9999 -9999 -9999 -9999 -9999 -9999 -9999 -9999 -9999 -9999 -9999 -9999 -9999 -9999 -9999 -9999-9999 -9999 -9999 -9999 -9999 -9999 -9999 -9999 -9999 -9999 -9999 -9999 -9999 -9999 -9999 -9999 -9999 -9999 -9999 -9999 -9999 -9999 -9999 -9999 -9999 -9999 -9999 -9999 -9999 -9999 -9999 -9999 -9999 -9999 -9999 -9999

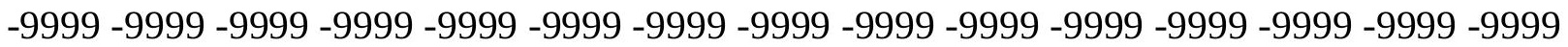

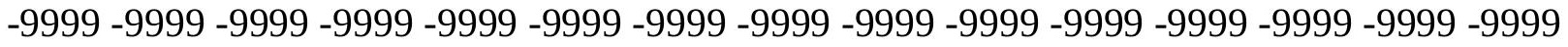
-9999 -9999 -9999 -9999 -9999 -9999 -9999 -9999 -9999 -9999 -9999 -9999 -9999 -9999 -9999 -9999 -9999 -9999 -9999 -9999 -9999 -9999 -9999 -9999 -9999 -9999 -9999 -9999 -9999 -9999 -9999 -9999 -9999 -9999 -9999 -9999 -9999 -9999 -9999 -9999 -9999 -9999 -9999 -9999 -9999 -9999 -9999 -9999 -9999 -9999 -9999 -9999 -9999 -9999 -9999 -9999 -9999 -9999 -9999 -9999 -9999 -9999 -9999 -9999 -9999 -9999 -9999 -9999 -9999 -9999 -9999 -9999 -9999 -9999 -9999 -9999 -9999 -9999 -9999 -9999 -9999 -9999 -9999 -9999 -9999 -9999 -9999 -9999 -9999 -9999 -

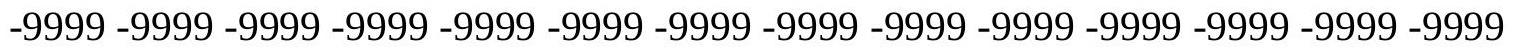
-9999 -9999 -9999 -9999 -9999 -9999 -9999 -9999 -9999 -9999 -9999 -9999 -9999 -9999 -9999 -9999 -9999 -9999 -9999 -9999 -9999 -9999 -9999 -9999 -9999 -9999 -9999 -9999 -9999 -9999 -9999 -9999 -9999 -9999 -9999 -9999 -9999 -9999 -9999 -9999 -9999 -9999 -9999 -9999 -9999 -

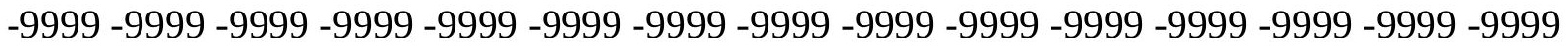

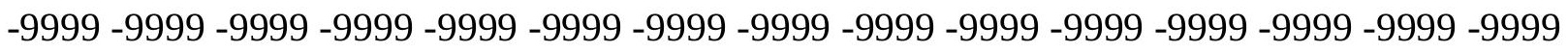
-9999 -9999 -9999 -9999 -9999 -9999 -9999 -9999 -9999 -9999 -9999 -9999 -9999 -9999 - 9999 -9999 -9999 -9999 -9999 -9999 -9999 -9999 -9999 -9999 -9999 -9999 -9999 -9999 -9999 -9999 -9999 -9999 -9999 -9999 -9999 -9999 -9999 -9999 -9999 -9999 -9999 -9999 -9999 -9999 -9999 -

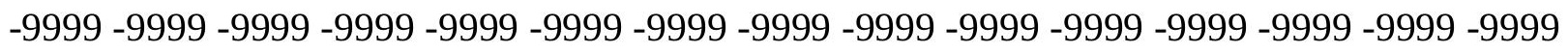
-9999 -9999 -9999 -9999 -9999 -9999 -9999 -9999 -9999 -9999 -9999 -9999 -9999 -9999 -9999 -9999 -9999 -9999 -9999 -9999 -9999 -9999 -9999 -9999 -9999 -9999 -9999 -9999 -9999 -9999 -

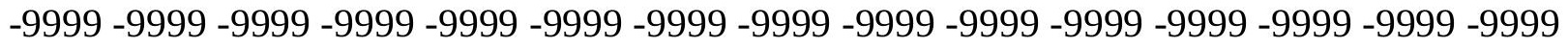
-9999 -9999 -9999 -9999 -9999 -9999 -9999 -9999 -9999 -9999 -9999 -9999 -9999 -9999 -9999 -9999 -9999 -9999 -9999 -9999 -9999 -9999 -9999 -9999 -9999 -9999 -9999 -9999 -9999 -999 -

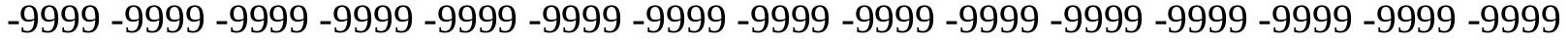
-9999 -9999 -9999 -9999 -9999 -9999 -9999 -9999 -9999 -9999 -9999 -9999 -9999 -9999 -9999 -

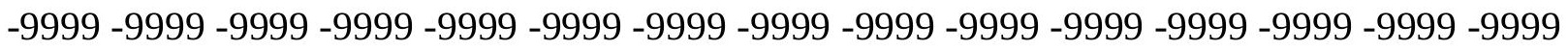

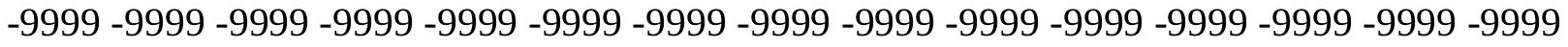

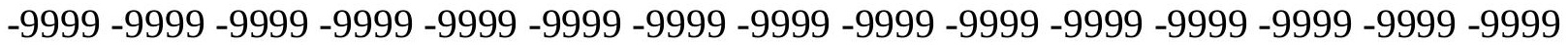
-9999 -9999 -9999 -9999 -9999 -9999 -9999 -9999 -9999 -9999 -9999 -9999 -9999 -9999 -9999 -

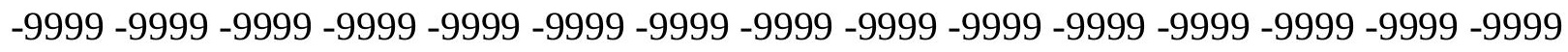

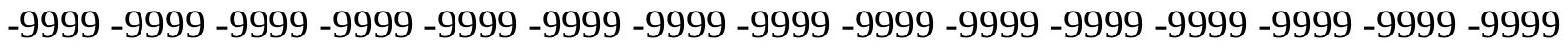
-9999 -9999 -9999 -9999 -9999 -9999 -9999 -9999 -9999 -9999 -9999 -9999 -9999 - 9999 - -999 -9999 -9999 -9999 -9999 -9999 -9999 -9999 -9999 -9999 -9999 -9999 -9999 -9999 -9999 -9999 -

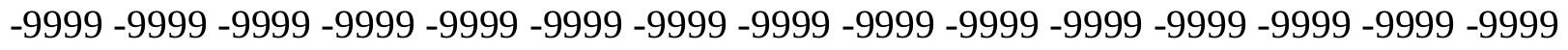

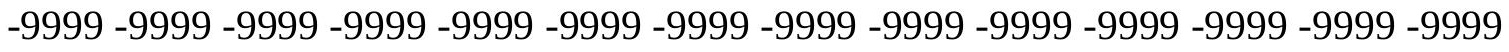
-9999 -9999 -9999 -9999 -9999 -9999 -9999 -9999 -9999 -9999 -9999 -9999 -9999 -9999 -9999 -9999 -9999 -9999 -9999 -9999 -9999 -9999 -9999 -9999-9999 -9999 -9999 -9999 -9999 -9999 -9999 -9999 -9999 -9999 -9999 -9999 -9999 -9999 -9999 -9999 -9999 -9999 -9999 -9999 -9999 -

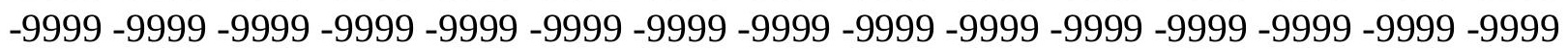


-9999 -9999 -9999 -9999 -9999 -9999 -9999 -9999 -9999 -9999 -9999 -9999 -9999 -9999 -9999 -9999 -9999 -9999 -9999 -9999 -9999 -9999 -9999 -9999 -9999 -9999 -9999 -9999 -9999 -9999 -

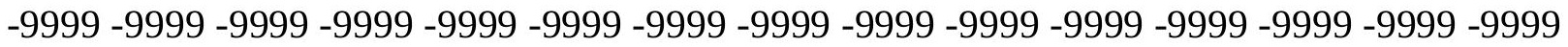
-9999 -9999 -9999 -9999 -9999 -9999 -9999 -9999 -9999 -9999 -9999 -9999 -9999 -9999 -9999 -9999 -9999 -9999 -9999 -9999 -9999 -9999 -9999 -9999-9999 -9999 -9999 -9999 -9999 -9999 -9999 -9999 -9999 -9999 -9999 -9999 -9999 -9999 -9999 -9999 -9999 -9999 -9999 -9999 -9999 -9999 -9999 -9999 -9999 -9999 -9999 -9999 -9999 -9999 -9999 -9999 -9999 -9999 -9999 -9999

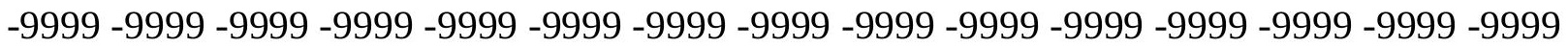

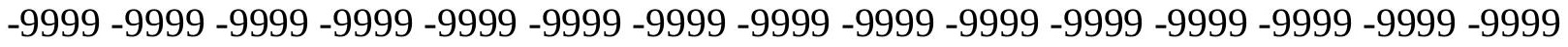
-9999 -9999 -9999 -9999 -9999 -9999 -9999 -9999 -9999 -9999 -9999 -9999 -9999 -9999 -9999 -9999 -9999 -9999 -9999 -9999 -9999 -9999 -9999 -9999 -9999 -9999 -9999 -9999 -9999 -9999 -9999 -9999 -9999 -9999 -9999 -9999 -9999 -9999 -9999 -9999 -9999 -9999 -9999 -9999 -9999 -9999 -9999 -9999 -9999 -9999 -9999 -9999 -9999 -9999 -9999 -9999 -9999 -9999 -9999 -9999 -

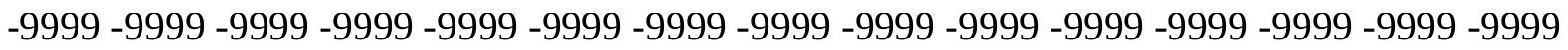
-9999 -9999 -9999 -9999 -9999 -9999 -9999 -9999 -9999 -9999 -9999 -9999 -9999 -9999 -9999 -

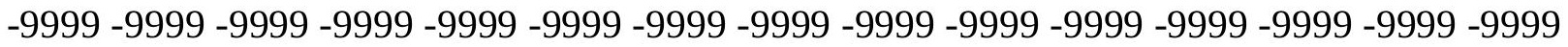
-9999 -9999 -9999 -9999 -9999 -9999 -9999 -9999 -9999 -9999 -9999 -9999 -9999 -9999 -9999 -9999 -9999 -9999 -9999 -9999 -9999 -9999 -9999 -9999 -9999 -9999 -9999 -9999 -9999 -9999 -9999 -9999 -9999 -9999 -9999 -9999 -9999 -9999 -9999 -9999 -9999 -9999 -9999 -9999 -9999 -

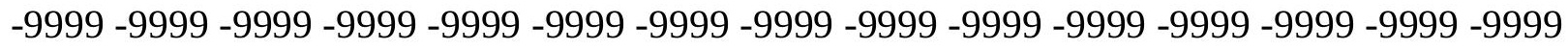

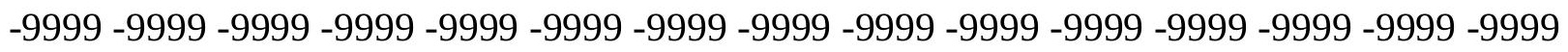
-9999 -9999 -9999 -9999 -9999 -9999 -9999 -9999 -9999 -9999 -9999 -9999 -9999 -9999 -9999 -9999 -9999 -9999 -9999 -9999 -9999 -9999 -9999 -9999 -9999 -9999 -9999 -9999 -9999 -9999 -9999 -9999 -9999 -9999 -9999 -9999 -9999 -9999 -9999 -9999 -9999 -9999 -9999 -9999 -

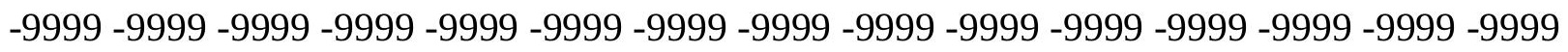
-9999 -9999 -9999 -9999 -9999 -9999 -9999 -9999 -9999 -9999 -9999 -9999 -9999 -9999 -9999 -9999 -9999 -9999 -9999 -9999 -9999 -9999 -9999 -9999 -9999 -9999 -9999 -9999 -9999 -9999 -

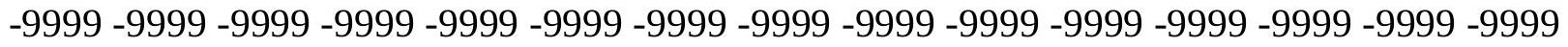
-9999 -9999 -9999 -9999 -9999 -9999 -9999 -9999 -9999 -9999 -9999 -9999 -9999 -9999 -9999 -9999 -9999 -9999 -9999 -9999 -9999 -9999 -9999 -9999 -9999 -9999 -9999 -9999 -9999 -999 -

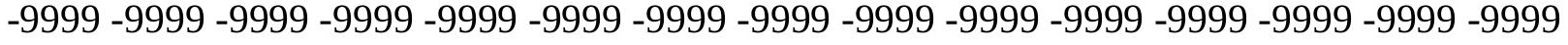
-9999 -9999 -9999 -9999 -9999 -9999 -9999 -9999 -9999 -9999 -9999 -9999 -9999 -9999 -9999 -

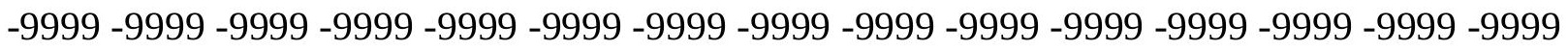

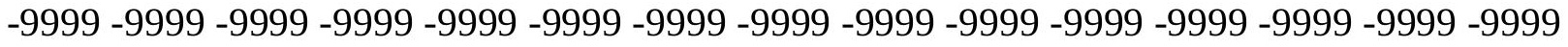

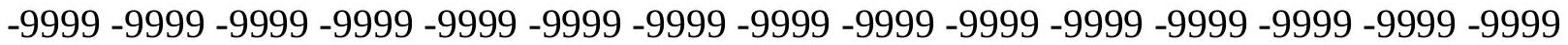

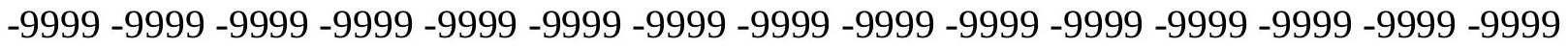

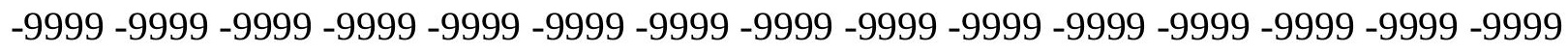

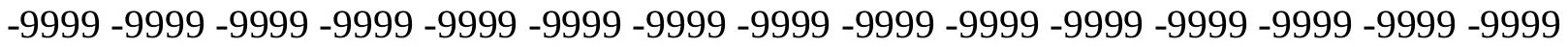

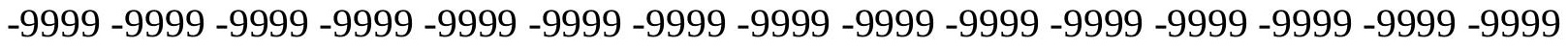
-9999 -9999 -9999 -9999 -9999 -9999 -9999 -9999 -9999 -9999 -9999 -9999 -9999 -9999 -9999 -

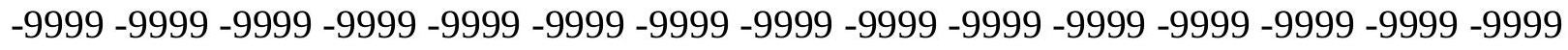

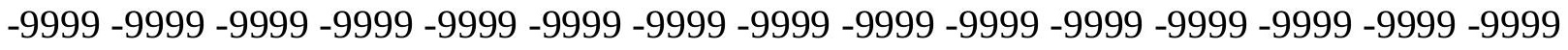
-9999 -9999 -9999 -9999 -9999 -9999 -9999 -9999 -9999 -9999 -9999 -9999 -9999 -9999 -9999 -9999 -9999 -9999 -9999 -9999 -9999 -9999 -9999 -9999-9999 -9999 -9999 -9999 -9999 -9999 -9999 -9999 -9999 -9999 -9999 -9999 -9999 -9999 -9999 -9999 -9999 -9999 -9999 -9999 -9999 -

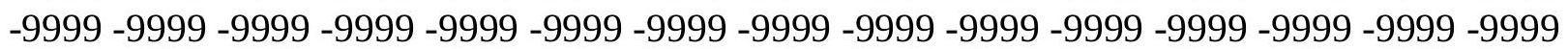


-9999 -9999 -9999 -9999 -9999 -9999 -9999 -9999 -9999 -9999 -9999 -9999 -9999 -9999 -9999 -9999 -9999 -9999 -9999 -9999 -9999 -9999 -9999 -9999 -9999 -9999 -9999 -9999 -9999 -

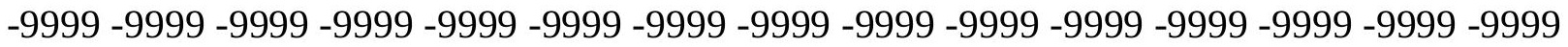
-9999 -9999 -9999 -9999 -9999 -9999 -9999 -9999 -9999 -9999 -9999 -9999 -9999 -9999 -9999 -9999 -9999 -9999 -9999 -9999 -9999 -9999 -9999 -9999 -9999 -9999 -9999 -9999 -9999 -9999 -9999 -9999 -9999 -9999 -9999 -9999 -9999 -9999 -9999 -9999 -9999 -9999 -9999 -9999 -9999 -9999 -9999 -9999 -9999 -9999 -9999 -9999 -9999 -9999 -9999 -9999 -9999 -9999 -9999 -9999

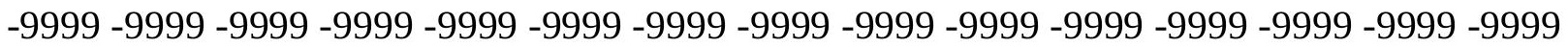

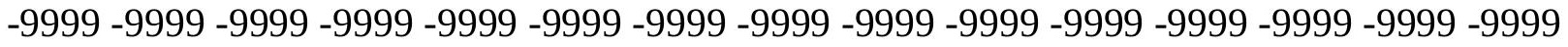
-9999 -9999 -9999 -9999 -9999 -9999 -9999 -9999 -9999 -9999 -9999 -9999 -9999 -9999 -9999 -9999 -9999 -9999 -9999 -9999 -9999 -9999 -9999 -9999 -9999 -9999 -9999 -9999 -9999 -9999 -9999 -9999 -9999 -9999 -9999 -9999 -9999 -9999 -9999 -9999 -9999 -9999 -9999 -9999 -9999 -9999 -9999 -9999 -9999 -9999 -9999 -9999 -9999 -9999 -9999 -9999 -9999 -9999 -9999 -9999 -9999 -9999 -9999 -9999 -9999 -9999 -9999 -9999 -9999 -9999 -9999 -9999 -9999 -9999 -9999 -9999 -9999 -9999 -9999 -9999 -9999 -9999 -9999 -9999 -9999 -9999 -9999 -9999 -9999 -9999 -

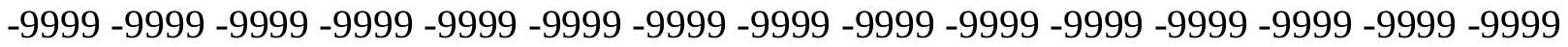
-9999 -9999 -9999 -9999 -9999 -9999 -9999 -9999 -9999 -9999 -9999 -9999 -9999 -9999 -9999 -9999 -9999 -9999 -9999 -9999 -9999 -9999 -9999 -9999 -9999 -9999 -9999 -9999 -9999 - 9999 -9999 -9999 -9999 -9999 -9999 -9999 -9999 -9999 -9999 -9999 -9999 -9999 -9999 -9999 -9999 -

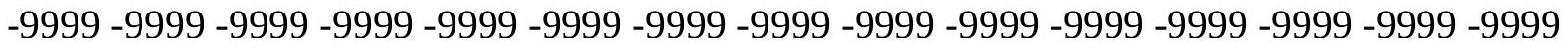

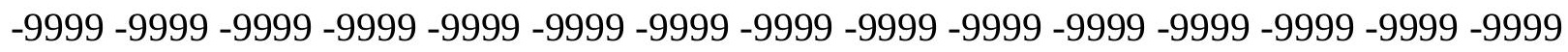

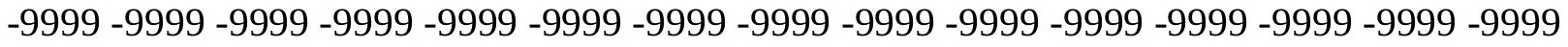
-9999 -9999 -9999 -9999 -9999 -9999 -9999 -9999 -9999 -9999 -9999 -9999 -9999 -9999 -9999 -9999 -9999 -9999 -9999 -9999 -9999 -9999 -9999 -9999 -9999 -9999 -9999 -9999 -9999 -9999 -

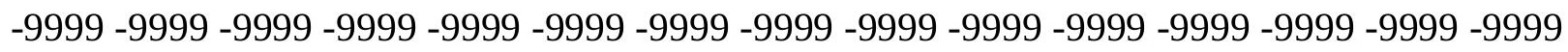
-9999 -9999 -9999 -9999 -9999 -9999 -9999 -9999 -9999 -9999 -9999 -9999 -9999 -9999 -9999 -9999 -9999 -9999 -9999 -9999 -9999 -9999 -9999 -9999 -9999 -9999 -9999 -9999 -9999 -9999 -9999 -9999 -9999 -9999 -9999 -9999 -9999 -9999 -9999 -9999 -9999 -9999 -9999 -9999 -9999 -9999 -9999 -9999 -9999 -9999 -9999 -9999 -9999 -9999 -9999 -9999 -9999 -9999 -9999 -9999 -9999 -9999 -9999 -9999 -9999 -9999 -9999 -9999 -9999 -9999 -9999 -9999 -9999 -999 -

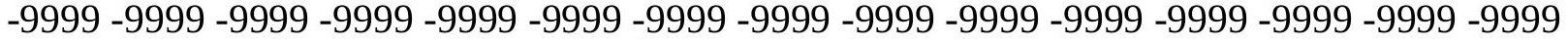
-9999 -9999 -9999 -9999 -9999 -9999 -9999 -9999 -9999 -9999 -9999 -9999 -9999 -9999 -9999 -

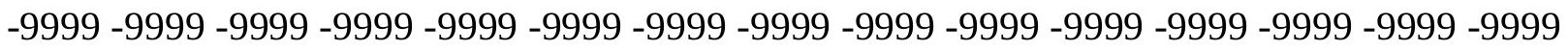

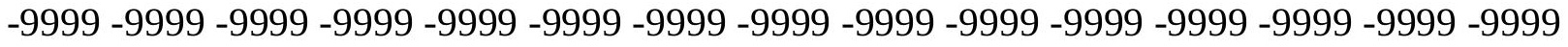

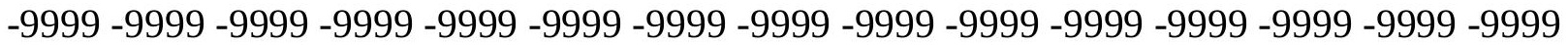

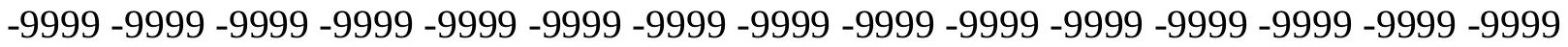

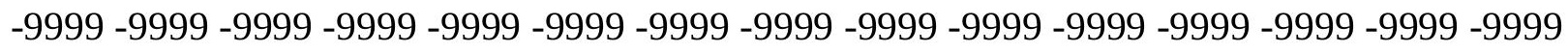

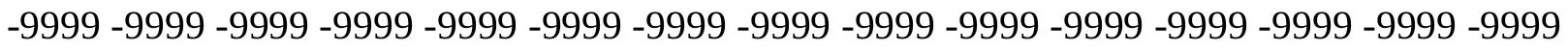

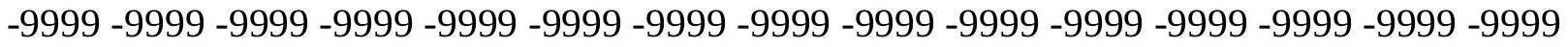
-9999 -9999 -9999 -9999 -9999 -9999 -9999 -9999 -9999 -9999 -9999 -9999 -9999 -9999 -9999 -

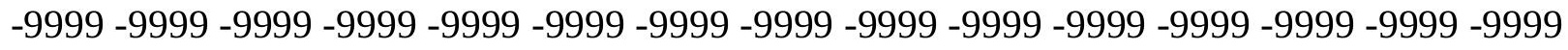

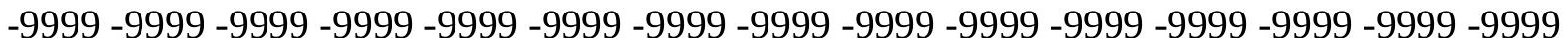
-9999 -9999 -9999 -9999 -9999 -9999 -9999 -9999 -9999 -9999 -9999 -9999 -9999 -9999 -9999 -9999 -9999 -9999 -9999 -9999 -9999 -9999 -9999 -9999-9999 -9999 -9999 -9999 -9999 -9999 -9999 -9999 -9999 -9999 -9999 -9999 -9999 -9999 -9999 -9999 -9999 -9999 -9999 -9999 -9999 -

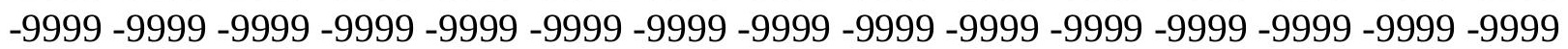


-9999 -9999 -9999 -9999 -9999 -9999 -9999 -9999 -9999 -9999 -9999 -9999 -9999 -9999 -9999 -9999 -9999 -9999 -9999 -9999 -9999 -9999 -9999 -9999 -9999 -9999 -9999 -9999 -9999 -9999 -

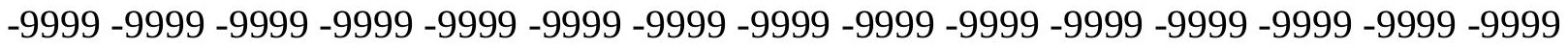
-9999 -9999 -9999 -9999 -9999 -9999 -9999 -9999 -9999 -9999 -9999 -9999 -9999 -9999 -9999 -9999 -9999 -9999 -9999 -9999 -9999 -9999 -9999 -9999-9999 -9999 -9999 -9999 -9999 -9999 -9999 -9999 -9999 -9999 -9999 -9999 -9999 -9999 -9999 -9999 -9999 -9999 -9999 -9999 -9999 -

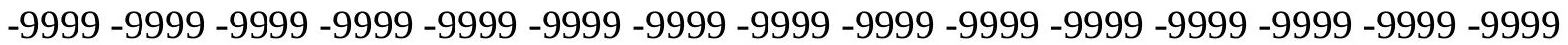
-9999 -9999 -9999 -9999 -9999 -9999 -9999 -9999 -9999 -9999 -9999 -9999 -9999 -9999 -9999 -9999 -9999 -9999 -9999 -9999 -9999 -9999 -9999 -9999 -9999 -9999 -9999 -9999 -9999 -9999 -9999 -9999 -9999 -9999 -9999 -9999 -9999 -9999 -9999 -9999 -9999 -9999 -9999 -9999 -9999 -9999 -9999 -9999 -9999 -9999 -9999 -9999 -9999 -9999 -9999 -9999 -9999 -9999 -9999 -9999 -9999 -9999 -9999 -9999 -9999 -9999 -9999 -9999 -9999 -9999 -9999 -9999 -9999 -9999 -9999 -9999 -9999 -9999 -9999 -9999 -9999 -9999 -9999 -9999 -9999 -9999 -9999 -9999 -9999 -9999 -9999 -9999 -9999 -9999 -9999 -9999 -9999 -9999 -9999 -9999 -9999 -9999 -9999 -9999 -9999 -9999 -9999 -9999 -9999 -9999 -9999 -9999 -9999 -9999 -9999 -9999 -9999 -9999 -9999 -

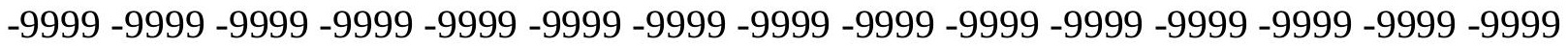
-9999 -9999 -9999 -9999 -9999 -9999 -9999 -9999 -9999 -9999 -9999 -9999 -9999 -9999 -9999 -9999 -9999 -9999 -9999 -9999 -9999 -9999 -9999 -9999 -9999 -9999 -9999 -9999 -9999 -9999 -9999 -9999 -9999 -9999 -9999 -9999 -9999 -9999 -9999 -9999 -9999 -9999 -9999 -9999 -9999 -

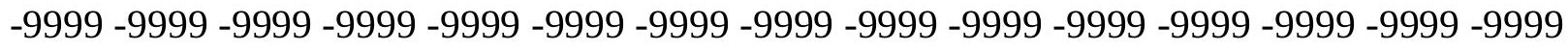

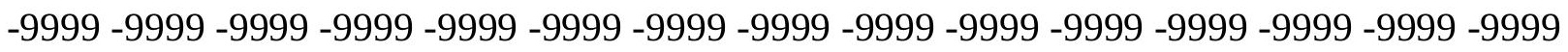
-9999 -9999 -9999 -9999 -9999 -9999 -9999 -9999 -9999 -9999 -9999 -9999 -9999 -9999 - 9999 -9999 -9999 -9999 -9999 -9999 -9999 -9999 -9999 -9999 -9999 -9999 -9999 -9999 -9999 -9999 -9999 -9999 -9999 -9999 -9999 -9999 -9999 -9999 -9999 -9999 -9999 -9999 -9999 -9999 -9999 -

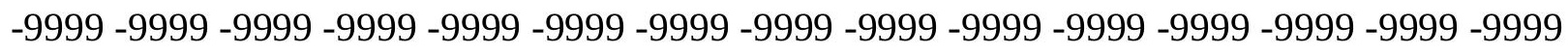
-9999 -9999 -9999 -9999 -9999 -9999 -9999 -9999 -9999 -9999 -9999 -9999 -9999 -9999 -9999 -9999 -9999 -9999 -9999 -9999 -9999 -9999 -9999 -9999 -9999 -9999 -9999 -9999 -9999 -9999 -

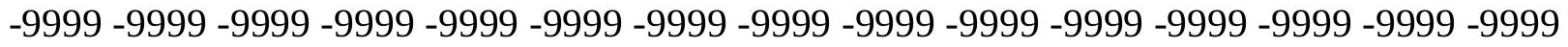
-9999 -9999 -9999 -9999 -9999 -9999 -9999 -9999 -9999 -9999 -9999 -9999 -9999 -9999 -9999 -9999 -9999 -9999 -9999 -9999 -9999 -9999 -9999 -9999 -9999 -9999 -9999 -9999 -9999 -999 -9999 -9999 -9999 -9999 -9999 -9999 -9999 -9999 -9999 -9999 -9999 -9999 -9999 -9999 -9999 -9999 -9999 -9999 -9999 -9999 -9999 -9999 -9999 -9999 -9999 -9999 -9999 -9999 -9999 -9999 -

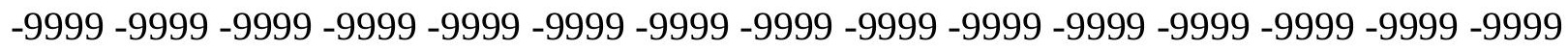

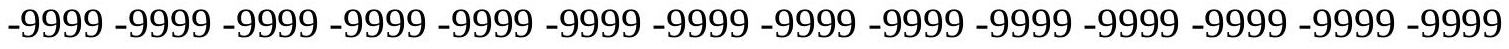
-9999 -9999 -9999 -9999 -9999 -9999 -9999 -9999 -9999 -9999 -9999 -9999 -9999 -9999 -9999

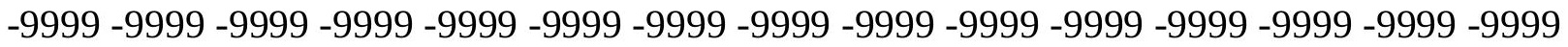

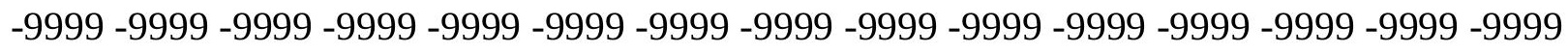

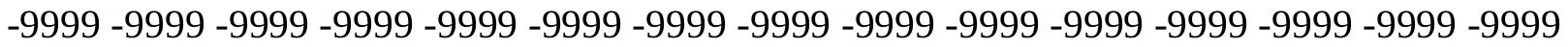

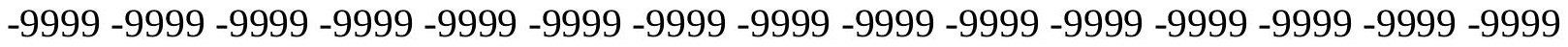
-9999 -9999 -9999 -9999 -9999 -9999 -9999 -9999 -9999 -9999 -9999 -9999 -9999 -9999 -9999 -

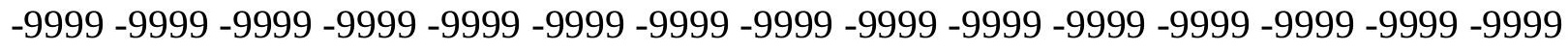

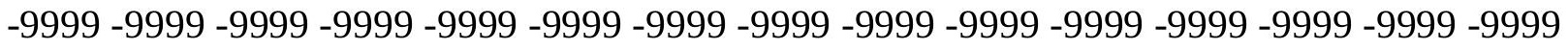
-9999 -9999 -9999 -9999 -9999 -9999 -9999 -9999 -9999 -9999 -9999 -9999 -9999 -9999 -9999 -9999 -9999 -9999 -9999 -9999 -9999 -9999 -9999 -9999-9999 -9999 -9999 -9999 -9999 -9999 -9999 -9999 -9999 -9999 -9999 -9999 -9999 -9999 -9999 -9999 -9999 -9999 -9999 -9999 -9999 -

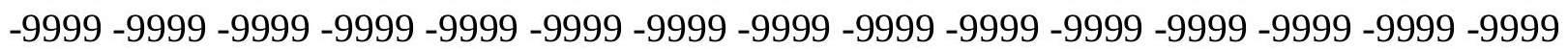


-9999 -9999 -9999 -9999 -9999 -9999 -9999 -9999 -9999 -9999 -9999 -9999 -9999 -9999 -9999 -9999 -9999 -9999 -9999 -9999 -9999 -9999 -9999 -9999 -9999 -9999 -9999 -9999 -9999 -9999 -

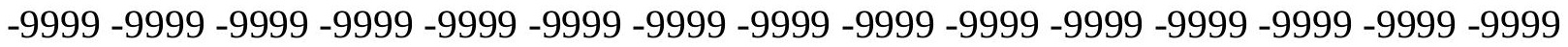
-9999 -9999 -9999 -9999 -9999 -9999 -9999 -9999 -9999 -9999 -9999 -9999 -9999 -9999 -9999 -9999 -9999 -9999 -9999 -9999 -9999 -9999 -9999 -9999-9999 -9999 -9999 -9999 -9999 -9999 -9999 -9999 -9999 -9999 -9999 -9999 -9999 -9999 -9999 -9999 -9999 -9999 -9999 -9999 -9999 -9999 -9999 -9999 -9999 -9999 -9999 -9999 -9999 -9999 -9999 -9999 -9999 -9999 -9999 -9999

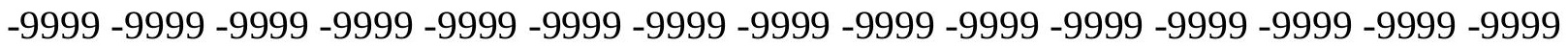

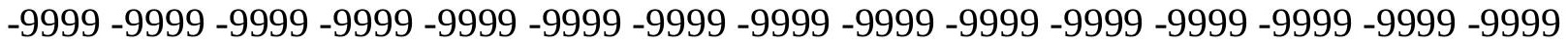
-9999 -9999 -9999 -9999 -9999 -9999 -9999 -9999 -9999 -9999 -9999 -9999 -9999 -9999 -9999 -9999 -9999 -9999 -9999 -9999 -9999 -9999 -9999 -9999 -9999 -9999 -9999 -9999 -9999 -9999 -9999 -9999 -9999 -9999 -9999 -9999 -9999 -9999 -9999 -9999 -9999 -9999 -9999 -9999 -9999 -9999 -9999 -9999 -9999 -9999 -9999 -9999 -9999 -9999 -9999 -9999 -9999 -9999 -9999 -9999 -9999 -9999 -9999 -9999 -9999 -9999 -9999 -9999 -9999 -9999 -9999 -9999 -9999 -9999 -9999 -9999 -9999 -9999 -9999 -9999 -9999 -9999 -9999 -9999 -9999 -9999 -9999 -9999 -9999

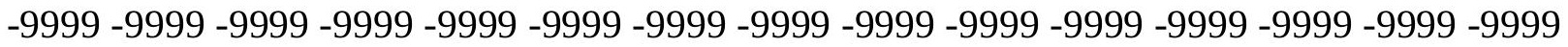
-9999 -9999 -9999 -9999 -9999 -9999 -9999 -9999 -9999 -9999 -9999 -9999 -9999 -9999 -9999 -9999 -9999 -9999 -9999 -9999 -9999 -9999 -9999 -9999 -9999 -9999 -9999 -9999 -9999 -9999 -9999 -9999 -9999 -9999 -9999 -9999 -9999 -9999 -9999 -9999 -9999 -9999 -9999 -9999 -9999 -

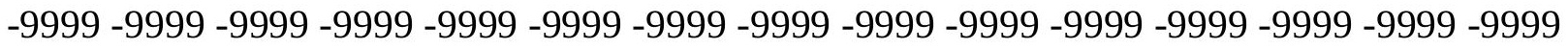

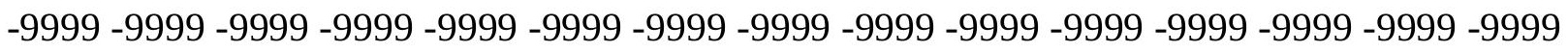
-9999 -9999 -9999 -9999 -9999 -9999 -9999 -9999 -9999 -9999 -9999 -9999 -9999 -9999 -9999 -9999 -9999 -9999 -9999 -9999 -9999 -9999 -9999 -9999 -9999 -9999 -9999 -9999 -9999 -9999 -9999 -9999 -9999 -9999 -9999 -9999 -9999 -9999 -9999 -9999 -9999 -9999 -9999 -9999 -9999 -

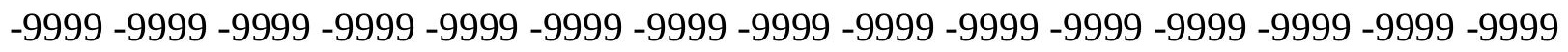
-9999 -9999 -9999 -9999 -9999 -9999 -9999 -9999 -9999 -9999 -9999 -9999 -9999 -9999 -9999 -9999 -9999 -9999 -9999 -9999 -9999 -9999 -9999 -9999 -9999 -9999 -9999 -9999 -9999 -9999 -

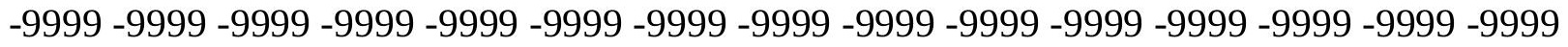
-9999 -9999 -9999 -9999 -9999 -9999 -9999 -9999 -9999 -9999 -9999 -9999 -9999 -9999 -9999 -9999 -9999 -9999 -9999 -9999 -9999 -9999 -9999 -9999 -9999 -9999 -9999 -9999 -9999 -999 -9999 -9999 -9999 -9999 -9999 -9999 -9999 -9999 -9999 -9999 -9999 -9999 -9999 -9999 -9999 -9999 -9999 -9999 -9999 -9999 -9999 -9999 -9999 -9999 -9999 -9999 -9999 -9999 -9999 -9999 -

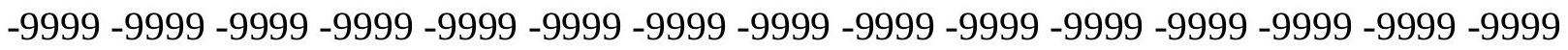

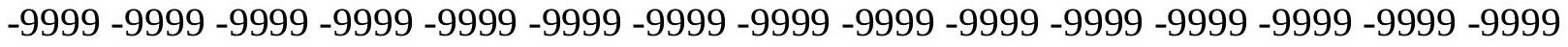

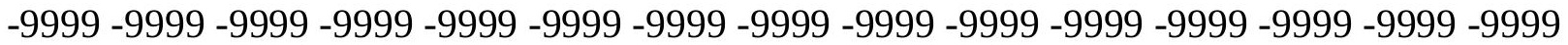

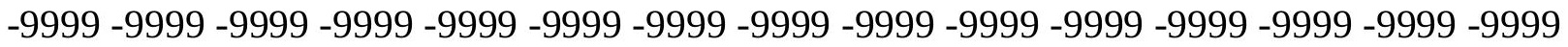

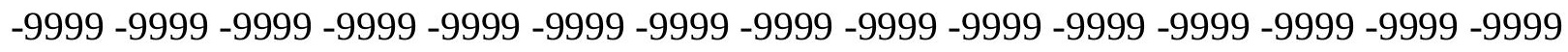

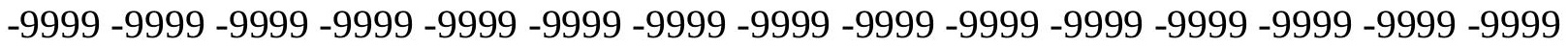
-9999 -9999 -9999 -9999 -9999 -9999 -9999 -9999 -9999 -9999 -9999 -9999 -9999 - 9999 - -999 -9999 -9999 -9999 -9999 -9999 -9999 -9999 -9999 -9999 -9999 -9999 -9999 -9999 -9999 - -999 -

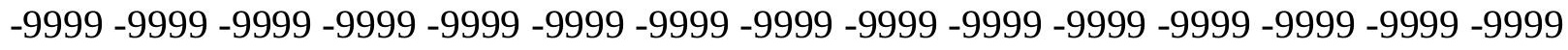

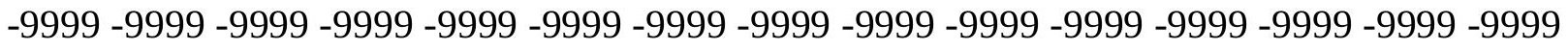
-9999 -9999 -9999 -9999 -9999 -9999 -9999 -9999 -9999 -9999 -9999 -9999 -9999 -9999 -9999 -9999 -9999 -9999 -9999 -9999 -9999 -9999 -9999 -9999-9999 -9999 -9999 -9999 -9999 -9999 -9999 -9999 -9999 -9999 -9999 -9999 -9999 -9999 -9999 -9999 -9999 -9999 -9999 -9999 -9999 -

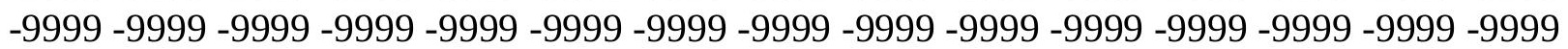


-9999 -9999 -9999 -9999 -9999 -9999 -9999 -9999 -9999 -9999 -9999 -9999 -9999 -9999 -9999 -9999 -9999 -9999 -9999 -9999 -9999 -9999 -9999 -9999 -9999 -9999 -9999 -9999 -9999 -9999 -9999 -9999 -9999 -9999 -9999 -9999 -9999 -9999 -9999 -9999 -9999 -9999 -9999 -9999 -9999 -9999 -9999 -9999 -9999 -9999 -9999 -9999 -9999 -9999 -9999 -9999 -9999 -9999 -9999 -9999 -9999 -9999 -9999 -9999 -9999 -9999 -9999 -9999 -9999 -9999 -9999 -9999 -9999 -9999 -9999 -9999 -9999 -9999 -9999 -9999 -9999 -9999 -9999 -9999 -9999 -9999 -9999 -9999 -9999 -9999 -9999 -9999 -9999 -9999 -9999 -9999 -9999 -9999 -9999 -9999 -9999 -9999 -9999 -9999 -9999 -

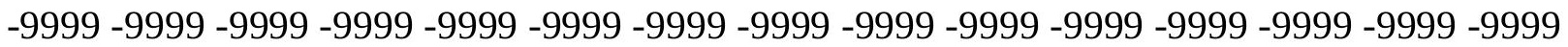
-9999 -9999 -9999 -9999 -9999 -9999 -9999 -9999 -9999 -9999 -9999 -9999 -9999 -9999 -9999 -9999 -9999 -9999 -9999 -9999 -9999 -9999 -9999 -9999 -9999 -9999 -9999 -9999 -9999 -9999 -

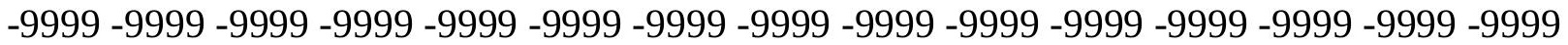
-9999 -9999 -9999 -9999 -9999 -9999 -9999 -9999 -9999 -9999 -9999 -9999 -9999 -9999 -9999 -9999 -9999 -9999 -9999 -9999 -9999 -9999 -9999 -9999 -9999 -9999 -9999 -9999 -9999 -9999 -9999 -9999 -9999 -9999 -9999 -9999 -9999 -9999 -9999 -9999 -9999 -9999 -9999 -9999 -9999 -9999 -9999 -9999 -9999 -9999 -9999 -9999 -9999 -9999 -9999 -9999 -9999 -9999 -9999 -9999

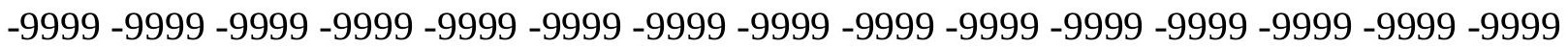
-9999 -9999 -9999 -9999 -9999 -9999 -9999 -9999 -9999 -9999 -9999 -9999 -9999 -9999 -9999 -9999 -9999 -9999 -9999 -9999 -9999 -9999 -9999 -9999 -9999 -9999 -9999 -9999 -9999 -9999 -9999 -9999 -9999 -9999 -9999 -9999 -9999 -9999 -9999 -9999 -9999 -9999 -9999 -9999 -9999 -9999 -9999 -9999 -9999 -9999 -9999 -9999 -9999 -9999 -9999 -9999 -9999 -9999 -9999 -9999 -9999 -9999 -9999 -9999 -9999 -9999 -9999 -9999 -9999 -9999 -9999 -9999 -9999 -9999 -9999 -9999 -9999 -9999 -9999 -9999 -9999 -9999 -9999 -9999 -9999 -9999 -9999 -9999 -9999 -9999 -9999 -9999 -9999 -9999 -9999 -9999 -9999 -9999 -9999 -9999 -9999 -9999 -9999 -9999 -9999 -9999 -9999 -9999 -9999 -9999 -9999 -9999 -9999 -9999 -9999 -9999 -9999 -9999 -9999 -9999 -9999 -9999 -9999 -9999 -9999 -9999 -9999 -9999 -9999 -9999 -9999 -9999 -9999 -9999 -9999 -9999 -9999 -9999 -9999 -9999 -9999 -9999 -9999 -9999 -9999 -9999 -9999 -9999 -9999 -9999 -9999 -9999 -9999 -9999 -9999 -9999 -9999 -9999 -9999 -9999 -9999 -9999 -9999 -9999 -9999 -9999 -9999 -9999 -9999 -9999 -9999 -9999 -9999 -9999 -9999 -9999 -9999 -9999 -9999

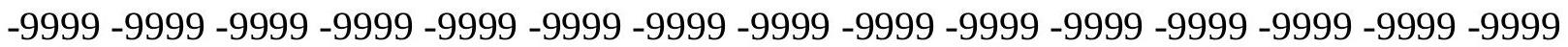
-9999 -9999 -9999 -9999 -9999 -9999 -9999 -9999 -9999 -9999 -9999 -9999 -9999 -9999 -9999 -9999 -9999 -9999 -9999 -9999 -9999 -9999 -9999 -9999 -9999 -9999 -9999 -9999 -9999 -9999 -

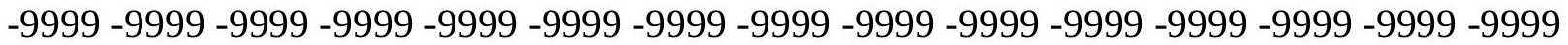
-9999 -9999 -9999 -9999 -9999 -9999 -9999 -9999 -9999 -9999 -9999 -9999 -9999 -9999 -9999 -9999 -9999 -9999 -9999 -9999 -9999 -9999 -9999 -9999 -9999 -9999 -9999 -9999 -9999 -9999 -9999 -9999 -9999 -9999 -9999 -9999 -9999 -9999 -9999 -9999 -9999 -9999 -9999 -9999 -9999 -9999 -9999 -9999 -9999 -9999 -9999 -9999 -9999 -9999 -9999 -9999 -9999 -9999 -9999 -9999 -9999 -9999 -9999 -9999 -9999 -9999 -9999 -9999 -9999 -9999 -9999 -9999 -9999 -9999 -9999

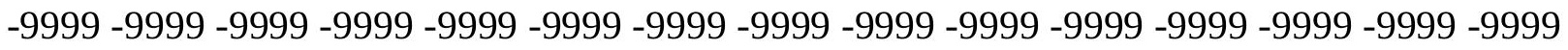
-9999 -9999 -9999 -9999 -9999 -9999 -9999 -9999 -9999 -9999 -9999 -9999 -9999 -9999 -9999 -9999 -9999 -9999 -9999 -9999 -9999 -9999 -9999 -9999 -9999 -9999 -9999 -9999 -9999 -9999 -9999 -9999 -9999 -9999 -9999 -9999 -9999 -9999 -9999 -9999 -9999 -9999 -9999 -9999 -9999 -999 -9999 -9999 -9999 -9999 -9999 -9999 -9999 -9999 -9999 -9999 -9999 -9999 -9999 -9999 -9999 -9999 -9999 -9999 -9999 -9999 -9999 -9999 -9999 -9999 -9999 -9999 -9999 -9999 -9999 -9999 -9999 -9999 -9999 -9999 -9999 -9999 -9999 -9999 -9999 -9999 -9999 -9999 -9999 -9999 -9999 -9999 -9999 -9999 -9999 -9999 -9999 -9999 -9999 -9999 -9999 -9999 -9999 -9999 -9999 -9999 -9999 -9999 -9999 -9999 -9999 -9999 -9999 -9999 -9999 -9999 -9999 -9999 -9999 -9999 
-9999 -9999 -9999 -9999 -9999 -9999 -9999 -9999 -9999 -9999 -9999 -9999 -9999 -9999 -9999 -9999 -9999 -9999 -9999 -9999 -9999 -9999 -9999 -9999 -9999 -9999 -9999 -9999 -9999 -9999 -

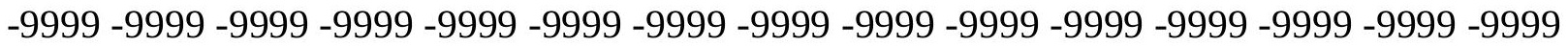
-9999 -9999 -9999 -9999 -9999 -9999 -9999 -9999 -9999 -9999 -9999 -9999 -9999 -9999 -9999 -9999 -9999 -9999 -9999 -9999 -9999 -9999 -9999 -9999-9999 -9999 -9999 -9999 -9999 -9999 -9999 -9999 -9999 -9999 -9999 -9999 -9999 -9999 -9999 -9999 -9999 -9999 -9999 -9999 -9999 -9999 -9999 -9999 -9999 -9999 -9999 -9999 -9999 -9999 -9999 -9999 -9999 -9999 -9999 -9999

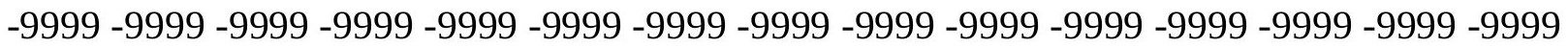

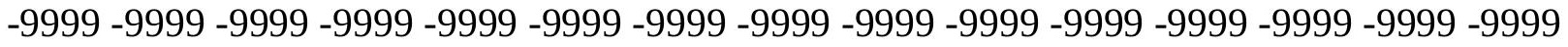
-9999 -9999 -9999 -9999 -9999 -9999 -9999 -9999 -9999 -9999 -9999 -9999 -9999 -9999 -9999 -9999 -9999 -9999 -9999 -9999 -9999 -9999 -9999 -9999 -9999 -9999 -9999 -9999 -9999 -9999 -9999 -9999 -9999 -9999 -9999 -9999 -9999 -9999 -9999 -9999 -9999 -9999 -9999 -9999 -9999 -9999 -9999 -9999 -9999 -9999 -9999 -9999 -9999 -9999 -9999 -9999 -9999 -9999 -9999 -9999 -

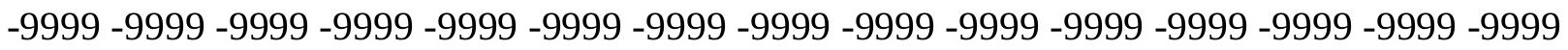
-9999 -9999 -9999 -9999 -9999 -9999 -9999 -9999 -9999 -9999 -9999 -9999 -9999 -9999 -9999 -

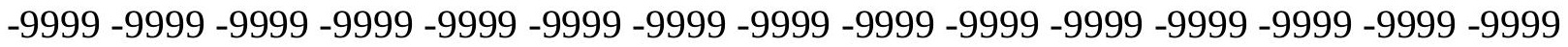
-9999 -9999 -9999 -9999 -9999 -9999 -9999 -9999 -9999 -9999 -9999 -9999 -9999 -9999 -9999 -9999 -9999 -9999 -9999 -9999 -9999 -9999 -9999 -9999 -9999 -9999 -9999 -9999 -9999 -9999 -9999 -9999 -9999 -9999 -9999 -9999 -9999 -9999 -9999 -9999 -9999 -9999 -9999 -9999 -9999 -

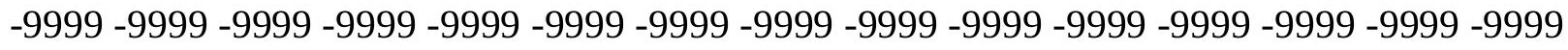

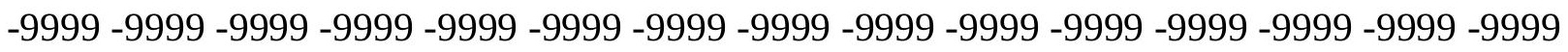

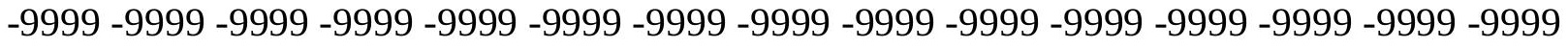
-9999 -9999 -9999 -9999 -9999 -9999 -9999 -9999 -9999 -9999 -9999 -9999 -9999 -9999 -9999 -9999 -9999 -9999 -9999 -9999 -9999 -9999 -9999 -9999 -9999 -9999 -9999 -9999 -9999 -9999 -

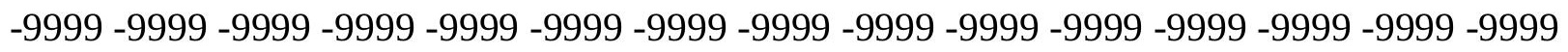
-9999 -9999 -9999 -9999 -9999 -9999 -9999 -9999 -9999 -9999 -9999 -9999 -9999 -9999 -9999 -9999 -9999 -9999 -9999 -9999 -9999 -9999 -9999 -9999 -9999 -9999 -9999 -9999 -9999 -

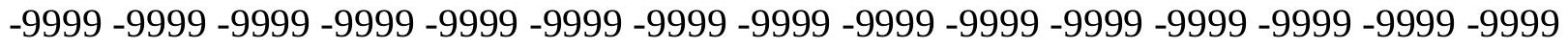
-9999 -9999 -9999 -9999 -9999 -9999 -9999 -9999 -9999 -9999 -9999 -9999 -9999 -9999 -9999 -9999 -9999 -9999 -9999 -9999 -9999 -9999 -9999 -9999 -9999 -9999 -9999 -9999 -9999 -999 -

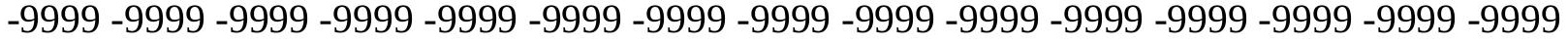
-9999 -9999 -9999 -9999 -9999 -9999 -9999 -9999 -9999 -9999 -9999 -9999 -9999 -9999 -9999 -

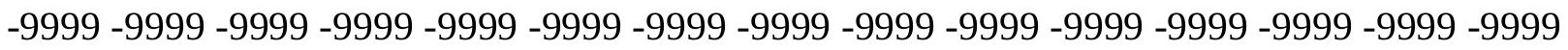

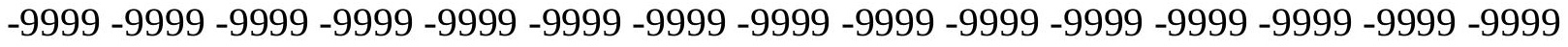

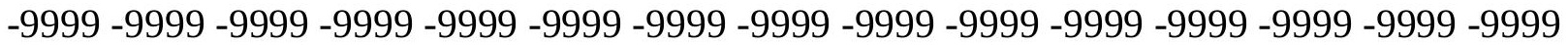
-9999 -9999 -9999 -9999 -9999 -9999 -9999 -9999 -9999 -9999 -9999 -9999 -9999 -9999 -9999

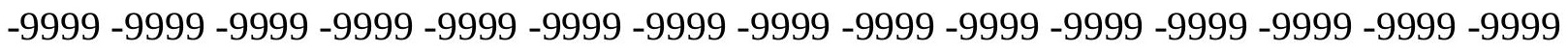

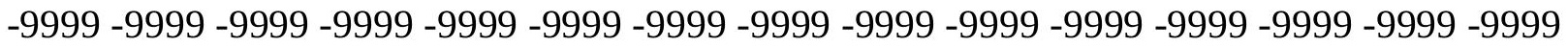
-9999 -9999 -9999 -9999 -9999 -9999 -9999 -9999 -9999 -9999 -9999 -9999 -9999 - 9999 - -999 -9999 -9999 -9999 -9999 -9999 -9999 -9999 -9999 -9999 -9999 -9999 -9999 -9999 -9999 -9999 -

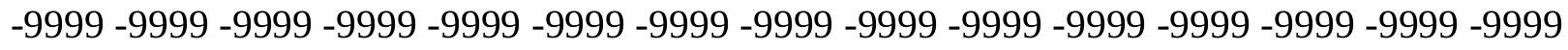

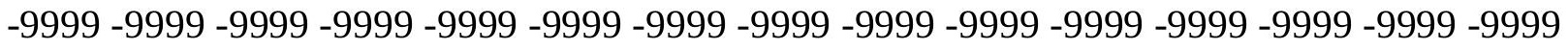
-9999 -9999 -9999 -9999 -9999 -9999 -9999 -9999 -9999 -9999 -9999 -9999 -9999 -9999 -9999 -9999 -9999 -9999 -9999 -9999 -9999 -9999 -9999 -9999-9999 -9999 -9999 -9999 -9999 -9999 -9999 -9999 -9999 -9999 -9999 -9999 -9999 -9999 -9999 -9999 -9999 -9999 -9999 -9999 -9999 -

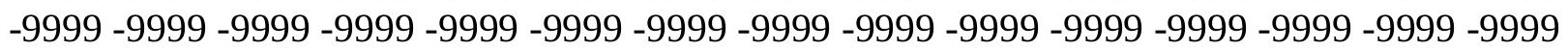


-9999 -9999 -9999 -9999 -9999 -9999 -9999 -9999 -9999 -9999 -9999 -9999 -9999 -9999 -9999 -9999 -9999 -9999 -9999 -9999 -9999 -9999 -9999 -9999 -9999 -9999 -9999 -9999 -9999 -9999 -9999 -9999 -9999 -9999 -9999 -9999 -9999 -9999 -9999 -9999 -9999 -9999 -9999 -9999 - 9999 -9999 -9999 -9999 -9999 -9999 -9999 -9999 -9999 -9999 -9999 -9999 -9999 -9999 -9999 -9999 -9999 -9999 -9999 -9999 -9999 -9999 -9999 -9999 -9999 -9999 -9999 -9999 -9999 -9999 - -9999 -9999 -9999 -9999 -9999 -9999 -9999 -9999 -9999 -9999 -9999 -9999 -9999 -9999 -9999 -9999 -9999 -9999 -9999 -9999 -9999 -9999 -9999 -9999 -9999 -9999 -9999 -9999 -9999 -9999

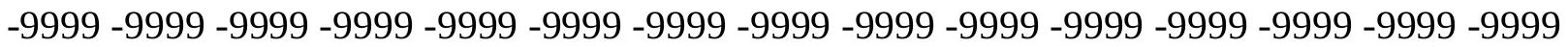

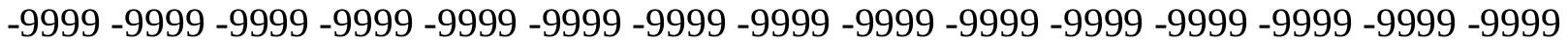
-9999 -9999 -9999 -9999 -9999 -9999 -9999 -9999 -9999 -9999 -9999 -9999 -9999 -9999 -9999

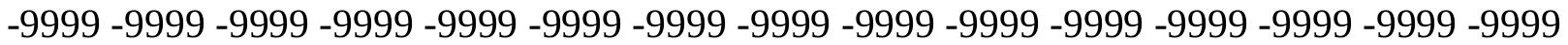
-9999 -9999 -9999 -9999 -9999 -9999 -9999 -9999 -9999 -9999 -9999 -9999 -9999 -9999 -9999 -9999 -9999 -9999 -9999 -9999 -9999 -9999 -9999 -9999 -9999 -9999 -9999 -9999 -9999 -9999 -9999 -9999 -9999 -9999 -9999 -9999 -9999 -9999 -9999 -9999 -9999 -9999 -9999 -9999 - -9999 -9999 -9999 -9999 -9999 -9999 -9999 -9999 -9999 -9999 -9999 -9999 -9999 -9999 -9999 -9999

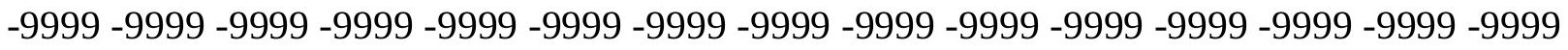
-9999 -9999 -9999 -9999 -9999 -9999 -9999 -9999 -9999 -9999 -9999 -9999 -9999 -9999 -9999 -9999 -9999 -9999 -9999 -9999 -9999 -9999 -9999 -9999 -9999 -9999 -9999 -9999 -9999 -9999 -9999 -9999 -9999 -9999 -9999 -9999 -9999 -9999 -9999 -9999 -9999 -9999 -9999 -9999 -9999 -

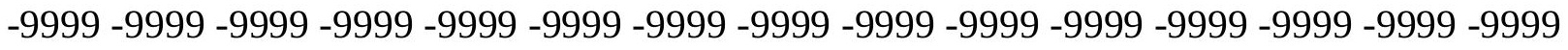
-9999 -9999 -9999 -9999 -9999 -9999 -9999 -9999 -9999 -9999 -9999 -9999 -9999 -9999 -9999 -999 -9999 -9999 -9999 -9999 -9999 -9999 -9999 -9999 -9999 -9999 -9999 -9999 -9999 -9999 -9999 -9999 -9999 -9999 -9999 -9999 -9999 -9999 -9999 -9999 -9999 -9999 -9999 -9999 -9999 -9999 -9999 -9999 -9999 -9999 -9999 -9999 -9999 -9999 -9999 -9999 -9999 -9999 -9999 -9999 -9999 -9999 -9999 -9999 -9999 -9999 -9999 -9999 -9999 -9999 -9999 -9999 -9999 -9999 -9999 -9999 -9999 -9999 -9999 -9999 -9999 -9999 -9999 -9999 -9999 -9999 -9999 -9999 -9999 -9999 -9999 -9999 -9999 -9999 -9999 -9999 -9999 -9999 -9999 -9999 -9999 -9999 -9999 -9999 -9999 -9999 -9999 -9999 -9999 -9999 -9999 -9999 -9999 -9999 -9999 -9999 -9999 -9999 -9999 -9999 -9999 -9999 -9999 -9999 -9999 -9999 -9999 -9999 -9999 -9999 -9999 -9999 -9999 -9999 -9999 -9999 -9999 -9999 -9999 -9999 -9999 -9999 -9999 -9999 -9999 -9999 -9999 -9999 -9999 -9999 -999 -9999 -9999 -9999 -9999 -9999 -9999 -9999 -9999 -9999 -9999 -9999 -9999 -9999 -9999 -9999 -9999 -9999 -9999 -9999 -9999 -9999 -9999 -9999 -9999 -9999 -9999 -9999 -9999 -9999 -

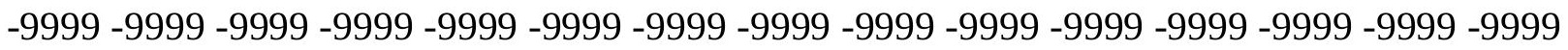

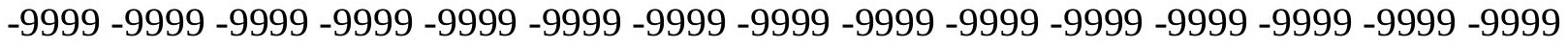

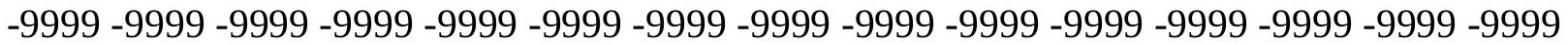
-9999 -9999 -9999 -9999 -9999 -9999 -9999 -9999 -9999 -9999 -9999 -9999 -9999 -9999 -9999 -

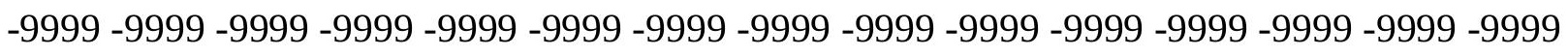

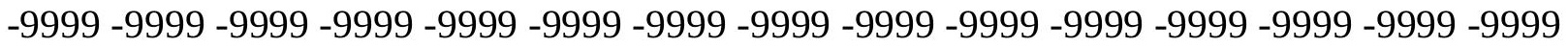

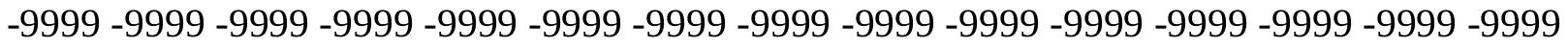
-9999 -9999 -9999 -9999 -9999 -9999 -9999 -9999 -9999 -9999 -9999 -9999 -9999 -9999 -9999 -

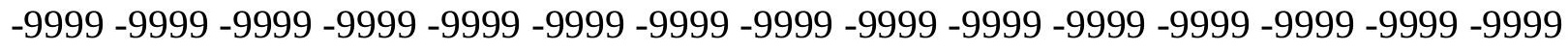

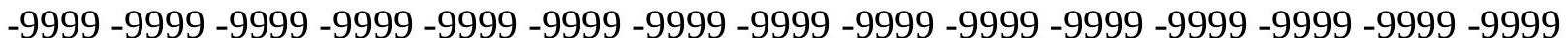
-9999 -9999 -9999 -9999 -9999 -9999 -9999 -9999 -9999 -9999 -9999 -9999 -9999 -9999 -9999 -9999 -9999 -9999 -9999 -9999 -9999 -9999 -9999 -9999-9999 -9999 -9999 -9999 -9999 -9999 -9999 -9999 -9999 -9999 -9999 -9999 -9999 -9999 -9999 -9999 -9999 -9999 -9999 -9999 -9999 -

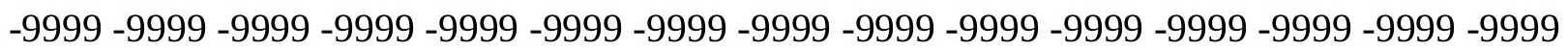


-9999 -9999 -9999 -9999 -9999 -9999 -9999 -9999 -9999 -9999 -9999 -9999 -9999 -9999 -9999 -9999 -9999 -9999 -9999 -9999 -9999 -9999 -9999 -9999 -9999 -9999 -9999 -9999 -9999 -9999 -

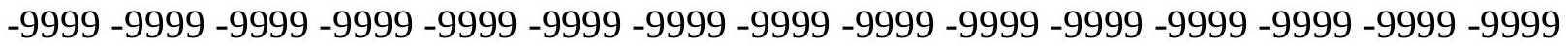
-9999 -9999 -9999 -9999 -9999 -9999 -9999 -9999 -9999 -9999 -9999 -9999 -9999 -9999 -9999 -9999 -9999 -9999 -9999 -9999 -9999 -9999 -9999 -9999-9999 -9999 -9999 -9999 -9999 -9999 -9999 -9999 -9999 -9999 -9999 -9999 -9999 -9999 -9999 -9999 -9999 -9999 -9999 -9999 -9999 -9999 -9999 -9999 -9999 -9999 -9999 -9999 -9999 -9999 -9999 -9999 -9999 -9999 -9999 -9999

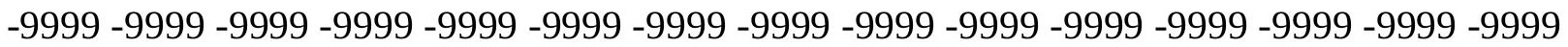

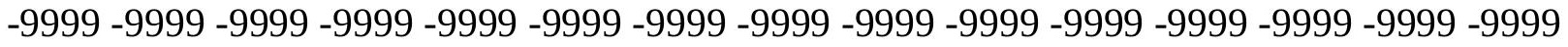
-9999 -9999 -9999 -9999 -9999 -9999 -9999 -9999 -9999 -9999 -9999 -9999 -9999 -9999 -9999 -9999 -9999 -9999 -9999 -9999 -9999 -9999 -9999 -9999 -9999 -9999 -9999 -9999 -9999 -9999 -9999 -9999 -9999 -9999 -9999 -9999 -9999 -9999 -9999 -9999 -9999 -9999 -9999 -9999 -9999 -9999 -9999 -9999 -9999 -9999 -9999 -9999 -9999 -9999 -9999 -9999 -9999 -9999 -9999 -9999 -9999 -9999 -9999 -9999 -9999 -9999 -9999 -9999 -9999 -9999 -9999 -9999 -9999 - 9999 -9999 -9999 -9999 -9999 -9999 -9999 -9999 -9999 -9999 -9999 -9999 -9999 -9999 -9999 -9999

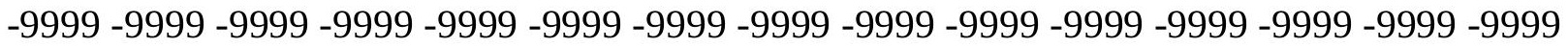
-9999 -9999 -9999 -9999 -9999 -9999 -9999 -9999 -9999 -9999 -9999 -9999 -9999 -9999 -9999 -9999 -9999 -9999 -9999 -9999 -9999 -9999 -9999 -9999 -9999 -9999 -9999 -9999 -9999 -9999 -9999 -9999 -9999 -9999 -9999 -9999 -9999 -9999 -9999 -9999 -9999 -9999 -9999 -9999 -9999 -

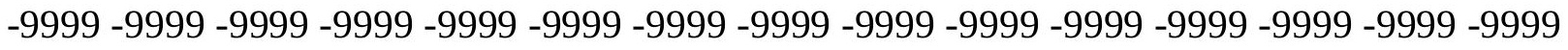

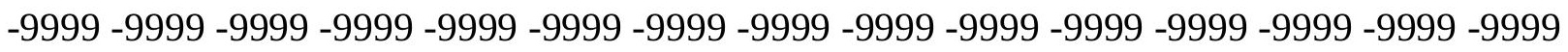
-9999 -9999 -9999 -9999 -9999 -9999 -9999 -9999 -9999 -9999 -9999 -9999 -9999 -9999 -9999 -9999 -9999 -9999 -9999 -9999 -9999 -9999 -9999 -9999 -9999 -9999 -9999 -9999 -9999 -9999 -9999 -9999 -9999 -9999 -9999 -9999 -9999 -9999 -9999 -9999 -9999 -9999 -9999 -9999 -9999 -

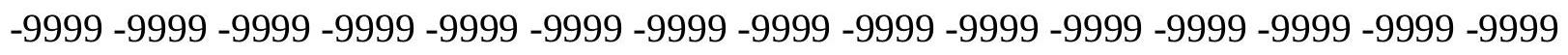
-9999 -9999 -9999 -9999 -9999 -9999 -9999 -9999 -9999 -9999 -9999 -9999 -9999 -9999 -9999 -9999 -9999 -9999 -9999 -9999 -9999 -9999 -9999 -9999 -9999 -9999 -9999 -9999 -9999 -9999 -

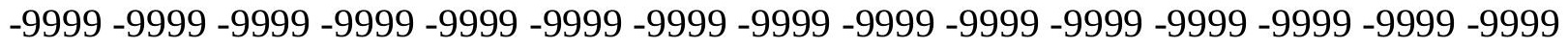
-9999 -9999 -9999 -9999 -9999 -9999 -9999 -9999 -9999 -9999 -9999 -9999 -9999 -9999 -9999 -9999 -9999 -9999 -9999 -9999 -9999 -9999 -9999 -9999 -9999 -9999 -9999 -9999 -9999 -999 -9999 -9999 -9999 -9999 -9999 -9999 -9999 -9999 -9999 -9999 -9999 -9999 -9999 -9999 -9999 -9999 -9999 -9999 -9999 -9999 -9999 -9999 -9999 -9999 -9999 -9999 -9999 -9999 -9999 -9999 -

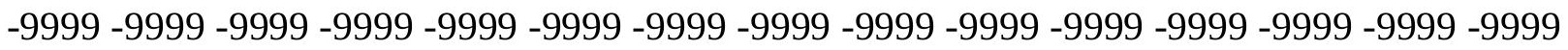

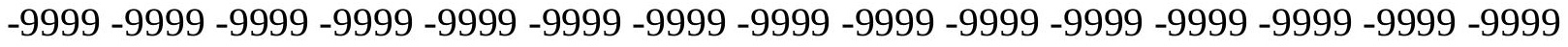

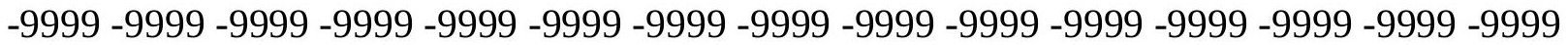

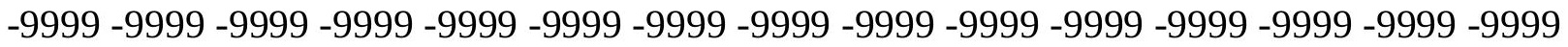

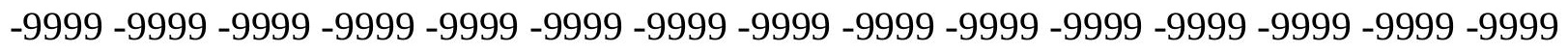

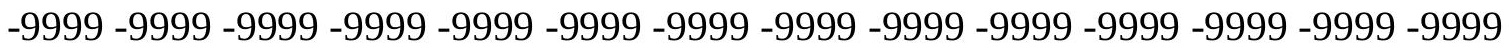
-9999 -9999 -9999 -9999 -9999 -9999 -9999 -9999 -9999 -9999 -9999 -9999 -9999 -9999 -9999 -9999 -9999 -9999 -9999 -9999 -9999 -9999 -9999 -9999 -9999 -9999 -9999 -9999 -9999 -9999 -

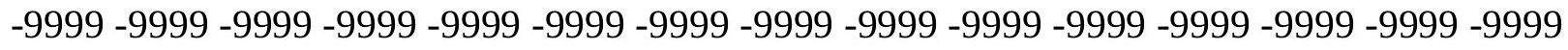

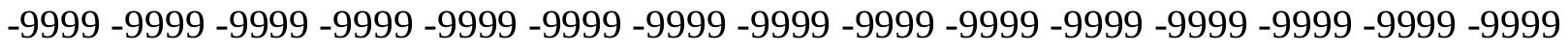
-9999 -9999 -9999 -9999 -9999 -9999 -9999 -9999 -9999 -9999 -9999 -9999 -9999 -9999 -9999 -9999 -9999 -9999 -9999 -9999 -9999 -9999 -9999 -9999-9999 -9999 -9999 -9999 -9999 -9999 -9999 -9999 -9999 -9999 -9999 -9999 -9999 -9999 -9999 -9999 -9999 -9999 -9999 -9999 -9999 -

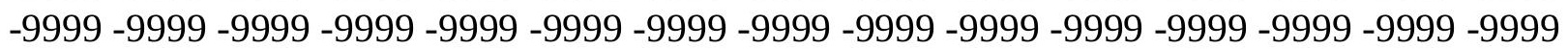


-9999 -9999 -9999 -9999 -9999 -9999 -9999 -9999 -9999 -9999 -9999 -9999 -9999 -9999 -9999 -9999 -9999 -9999 -9999 -9999 -9999 -9999 -9999 -9999 -9999 -9999 -9999 -9999 -9999 -9999 -9999 -9999 -9999 -9999 -9999 -9999 -9999 -9999 -9999 -9999 -9999 -9999 -9999 -9999 - 9999 -9999 -9999 -9999 -9999 -9999 -9999 -9999 -9999 -9999 -9999 -9999 -9999 -9999 -9999 -9999 -9999 -9999 -9999 -9999 -9999 -9999 -9999 -9999 -9999 -9999 -9999 -9999 -9999 -9999 -9999 -9999 -9999 -9999 -9999 -9999 -9999 -9999 -9999 -9999 -9999 -9999 -9999 -9999 -9999 -9999 -9999 -9999 -9999 -9999 -9999 -9999 -9999 -9999 -9999 -9999 -9999 -9999 -9999 -9999 -9999

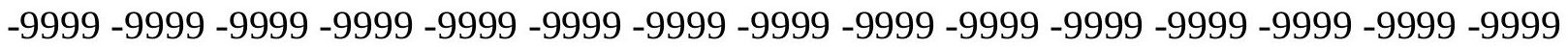
-9999 -9999 -9999 -9999 -9999 -9999 -9999 -9999 -9999 -9999 -9999 -9999 -9999 -9999 -9999 -9999 -9999 -9999 -9999 -9999 -9999 -9999 -9999 -9999 -9999 -9999 -9999 -9999 -9999 -9999

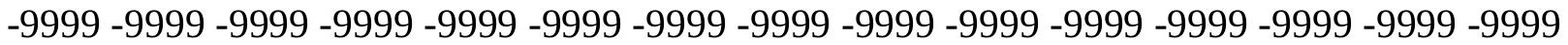
-9999 -9999 -9999 -9999 -9999 -9999 -9999 -9999 -9999 -9999 -9999 -9999 -9999 -9999 -9999 -9999 -9999 -9999 -9999 -9999 -9999 -9999 -9999 -9999 -9999 -9999 -9999 -9999 -9999 -9999 -

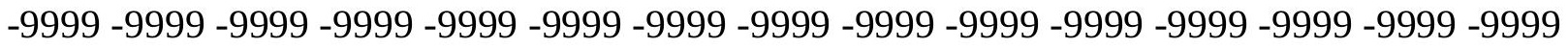
-9999 -9999 -9999 -9999 -9999 -9999 -9999 -9999 -9999 -9999 -9999 -9999 -9999 -9999 -9999

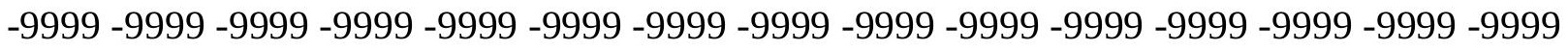
-9999 -9999 -9999 -9999 -9999 -9999 -9999 -9999 -9999 -9999 -9999 -9999 -9999 -9999 -9999 -9999 -9999 -9999 -9999 -9999 -9999 -9999 -9999 -9999 -9999 -9999 -9999 -9999 -9999 - -999 -9999 -9999 -9999 -9999 -9999 -9999 -9999 -9999 -9999 -9999 -9999 -9999 -9999 -9999 -9999 -9999 -9999 -9999 -9999 -9999 -9999 -9999 -9999 -9999 -9999 -9999 -9999 -9999 -9999 -9999 -9999 -9999 -9999 -9999 -9999 -9999 -9999 -9999 -9999 -9999 -9999 -9999 -9999 -9999 -9999 -999 -9999 -9999 -9999 -9999 -9999 -9999 -9999 -9999 -9999 -9999 -9999 -9999 -9999 -9999 -9999 -9999 -9999 -9999 -9999 -9999 -9999 -9999 -9999 -9999 -9999 -9999 -9999 -9999 -9999 -9999 -9999 -9999 -9999 -9999 -9999 -9999 -9999 -9999 -9999 -9999 -9999 -9999 -9999 -9999 -9999 -9999 -9999 -9999 -9999 -9999 -9999 -9999 -9999 -9999 -9999 -9999 -9999 -9999 -9999 -9999 -9999 -9999 -9999 -9999 -9999 -9999 -9999 -9999 -9999 -9999 -9999 -9999 -9999 -9999 -9999 -9999 -9999 -9999 -9999 -9999 -9999 -9999 -9999 -9999 -9999 -9999 -9999 -9999 -9999 -9999 -9999 -9999 -9999 -9999 -9999 -9999 -9999 -9999 -9999 -9999 -9999 -9999 -9999 -9999 -9999 -9999 -9999 -9999 -9999 -9999 -9999 -9999 -9999 -9999 -9999 -9999 -9999 -9999 -9999 -9999 -9999 -9999 -9999 -9999 -9999 -9999 -9999 -9999 -9999 -9999 -9999 -9999 -9999 -9999 -999 -9999 -9999 -9999 -9999 -9999 -9999 -9999 -9999 -9999 -9999 -9999 -9999 -9999 -9999 -9999 -9999 -9999 -9999 -9999 -9999 -9999 -9999 -9999 -9999 -9999 -9999 -9999 -9999 -9999 -9999 -

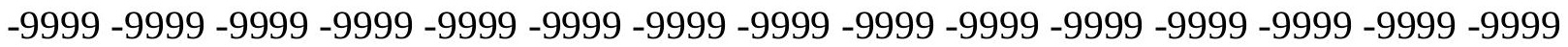

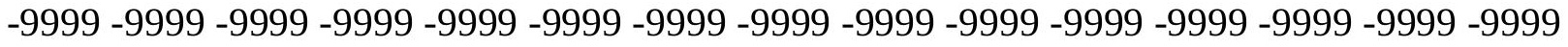

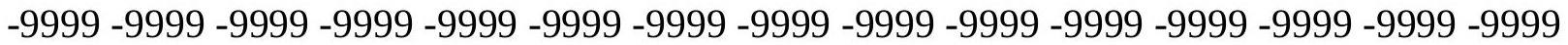
-9999 -9999 -9999 -9999 -9999 -9999 -9999 -9999 -9999 -9999 -9999 -9999 -9999 -9999 -9999

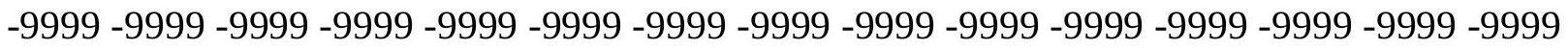

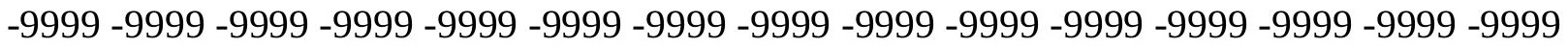

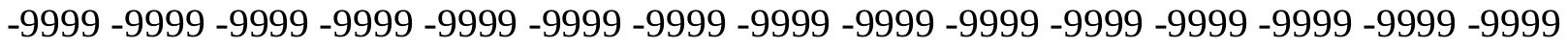
-9999 -9999 -9999 -9999 -9999 -9999 -9999 -9999 -9999 -9999 -9999 -9999 -9999 -9999 -9999 -

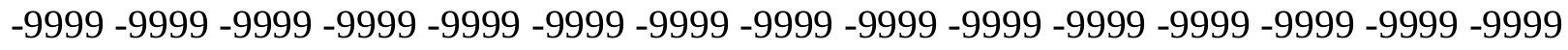

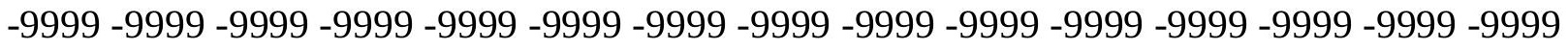
-9999 -9999 -9999 -9999 -9999 -9999 -9999 -9999 -9999 -9999 -9999 -9999 -9999 -9999 -9999 -9999 -9999 -9999 -9999 -9999 -9999 -9999 -9999 -9999 -9999 -9999 -9999 -9999 - -9999 -9999 -9999 -9999 -9999 -9999 -9999 -9999 -9999 -9999 -9999 -9999 -9999 -9999 -9999 -9999 -

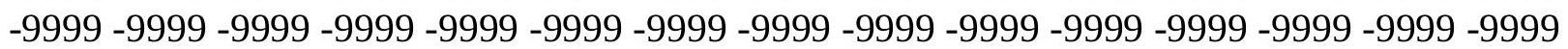


-9999 -9999 -9999 -9999 -9999 -9999 -9999 -9999 -9999 -9999 -9999 -9999 -9999 -9999 -9999 -9999 -9999 -9999 -9999 -9999 -9999 -9999 -9999 -9999 -9999 -9999 -9999 -9999 -9999 -9999 -9999 -9999 -9999 -9999 -9999 -9999 -9999 -9999 -9999 -9999 -9999 -9999 -9999 -9999 - 9999 -9999 -9999 -9999 -9999 -9999 -9999 -9999 -9999 -9999 -9999 -9999 -9999 -9999 -9999 -9999 -9999 -9999 -9999 -9999 -9999 -9999 -9999 -9999 -9999-9999 -9999 -9999 -9999 -9999 -9999 -9999 -9999 -9999 -9999 -9999 -9999 -9999 -9999 -9999 -9999 -9999 -9999 -9999 -9999 -9999 -9999 -9999 -9999 -9999 -9999 -9999 -9999 -9999 -9999 -9999 -9999 -9999 -9999 -9999 -9999

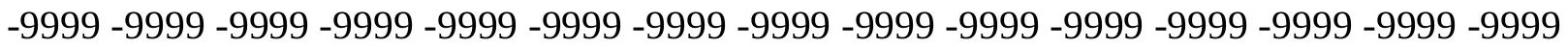

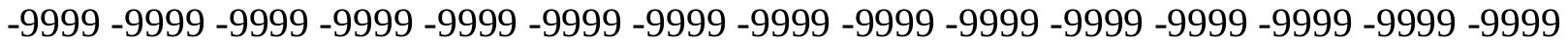
-9999 -9999 -9999 -9999 -9999 -9999 -9999 -9999 -9999 -9999 -9999 -9999 -9999 -9999 -9999

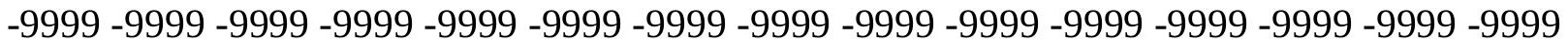
-9999 -9999 -9999 -9999 -9999 -9999 -9999 -9999 -9999 -9999 -9999 -9999 -9999 -9999 -9999 -9999 -9999 -9999 -9999 -9999 -9999 -9999 -9999 -9999 -9999 -9999 -9999 -9999 -9999 -9999 -

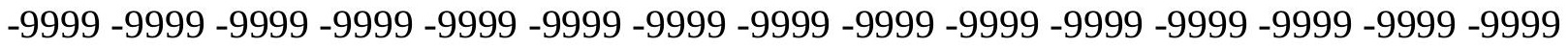
-9999 -9999 -9999 -9999 -9999 -9999 -9999 -9999 -9999 -9999 -9999 -9999 -9999 -9999 -9999

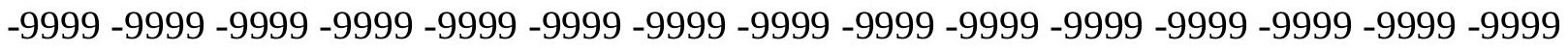
-9999 -9999 -9999 -9999 -9999 -9999 -9999 -9999 -9999 -9999 -9999 -9999 -9999 -9999 -9999 -9999 -9999 -9999 -9999 -9999 -9999 -9999 -9999 -9999 -9999 -9999 -9999 -9999 -9999 -9999 -9999 -9999 -9999 -9999 -9999 -9999 -9999 -9999 -9999 -9999 -9999 -9999 -9999 -9999 -9999 -9999 -9999 -9999 -9999 -9999 -9999 -9999 -9999 -9999 -9999 -9999 -9999 -9999 -9999 -9999 -9999 -9999 -9999 -9999 -9999 -9999 -9999 -9999 -9999 -9999 -9999 -9999 -9999 -9999 -9999 -999 -9999 -9999 -9999 -9999 -9999 -9999 -9999 -9999 -9999 -9999 -9999 -9999 -9999 -9999 -9999 -9999 -9999 -9999 -9999 -9999 -9999 -9999 -9999 -9999 -9999 -9999 -9999 -9999 -9999 -9999 -9999 -9999 -9999 -9999 -9999 -9999 -9999 -9999 -9999 -9999 -9999 -9999 -9999 -9999 -9999 -9999 -9999 -9999 -9999 -9999 -9999 -9999 -9999 -9999 -9999 -9999 -9999 -9999 -9999 -9999 -9999 -9999 -9999 -9999 -9999 -9999 -9999 -9999 -9999 -9999 -9999 -9999 -9999 -9999 -9999 -9999 -9999 -9999 -9999 -9999 -9999 -9999 -9999 -9999 -9999 -9999 -9999 -9999 -9999 -9999 -9999 -9999 -9999 -9999 -9999 -9999 -9999 -9999 -9999 -9999 -9999 -9999 -9999 -9999 -9999 -9999 -9999 -9999 -9999 -9999 -9999 -9999 -9999 -9999 -9999 -9999 -9999 -9999 -9999 -9999 -9999 -9999 -9999 -9999 -9999 -9999 -9999 -9999 -9999 -9999 -9999 -9999 -9999 -999 -9999 -9999 -9999 -9999 -9999 -9999 -9999 -9999 -9999 -9999 -9999 -9999 -9999 -9999 -9999 -9999 -9999 -9999 -9999 -9999 -9999 -9999 -9999 -9999 -9999 -9999 -9999 -9999 -9999 -9999 -

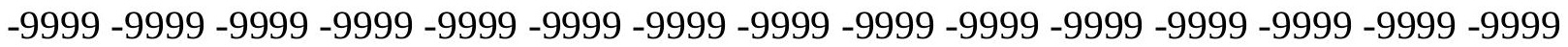

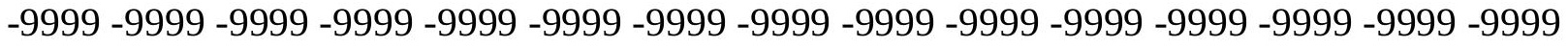

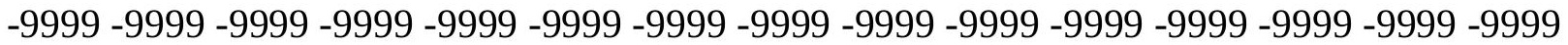
-9999 -9999 -9999 -9999 -9999 -9999 -9999 -9999 -9999 -9999 -9999 -9999 -9999 -9999 -9999

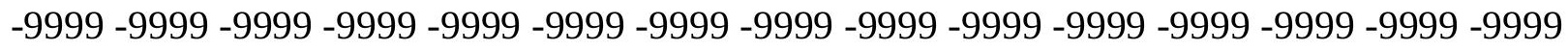

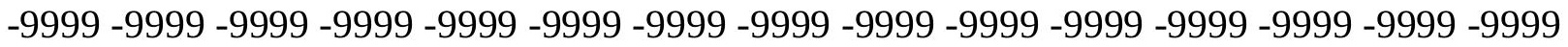
-9999 -9999 -9999 -9999 -9999 -9999 -9999 -9999 -9999 -9999 -9999 -9999 -9999 -9999 -9999 -9999 -9999 -9999 -9999 -9999 -9999 -9999 -9999 -9999 -9999 -9999 -9999 -9999 -9999 -9999 -

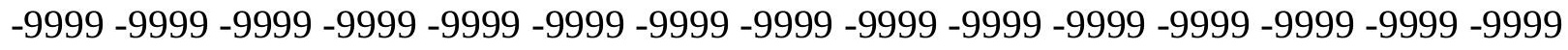

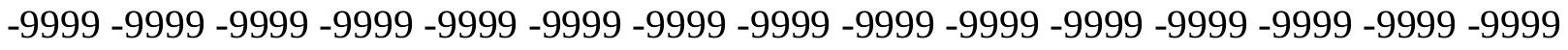
-9999 -9999 -9999 -9999 -9999 -9999 -9999 -9999 -9999 -9999 -9999 -9999 -9999 -9999 -9999 -9999 -9999 -9999 -9999 -9999 -9999 -9999 -9999 -9999-9999 -9999 -9999 -9999 -9999 -9999 -9999 -9999 -9999 -9999 -9999 -9999 -9999 -9999 -9999 -9999 -9999 -9999 -9999 -9999 -9999 -

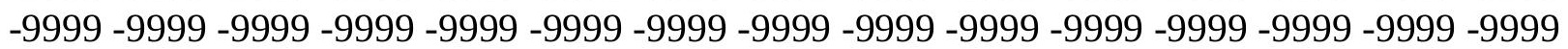


-9999 -9999 -9999 -9999 -9999 -9999 -9999 -9999 -9999 -9999 -9999 -9999 -9999 -9999 -9999 -9999 -9999 -9999 -9999 -9999 -9999 -9999 -9999 -9999 -9999 -9999 -9999 -9999 -9999 -9999 -9999 -9999 -9999 -9999 -9999 -9999 -9999 -9999 -9999 -9999 -9999 -9999 -9999 -9999 - 9999 -9999 -9999 -9999 -9999 -9999 -9999 -9999 -9999 -9999 -9999 -9999 -9999 -9999 -9999

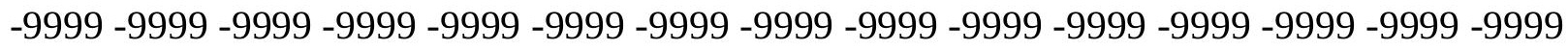
-9999 -9999 -9999 -9999 -9999 -9999 -9999 -9999 -9999 -9999 -9999 -9999 -9999 -9999 -9999 -9999 -9999 -9999 -9999 -9999 -9999 -9999 -9999 -9999 -9999 -9999 -9999 -9999 -9999 -9999

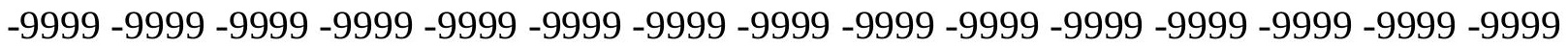

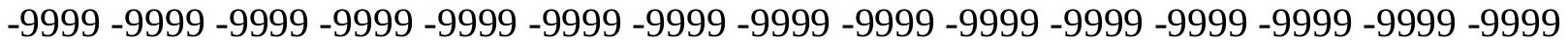
-9999 -9999 -9999 -9999 -9999 -9999 -9999 -9999 -9999 -9999 -9999 -9999 -9999 -9999 -9999 -9999 -9999 -9999 -9999 -9999 -9999 -9999 -9999 -9999 -9999 -9999 -9999 -9999 -9999 -9999 -9999 -9999 -9999 -9999 -9999 -9999 -9999 -9999 -9999 -9999 -9999 -9999 -9999 -9999 -9999 -9999 -9999 -9999 -9999 -9999 -9999 -9999 -9999 -9999 -9999 -9999 -9999 -9999 -9999 -9999 -

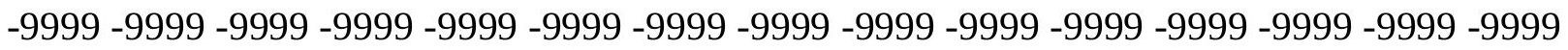
-9999 -9999 -9999 -9999 -9999 -9999 -9999 -9999 -9999 -9999 -9999 -9999 -9999 -9999 -9999 -

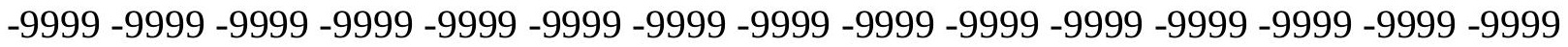
-9999 -9999 -9999 -9999 -9999 -9999 -9999 -9999 -9999 -9999 -9999 -9999 -9999 -9999 -9999 -9999 -9999 -9999 -9999 -9999 -9999 -9999 -9999 -9999 -9999 -9999 -9999 -9999 -9999 -9999 -9999 -9999 -9999 -9999 -9999 -9999 -9999 -9999 -9999 -9999 -9999 -9999 -9999 -9999 -9999 -

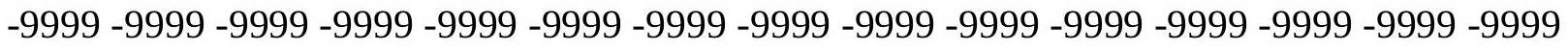
-9999 -9999 -9999 -9999 -9999 -9999 -9999 -9999 -9999 -9999 -9999 -9999 -9999 -9999 -9999

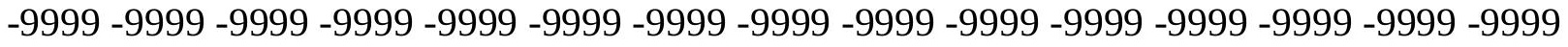
-9999 -9999 -9999 -9999 -9999 -9999 -9999 -9999 -9999 -9999 -9999 -9999 -9999 -9999 -9999 -9999 -9999 -9999 -9999 -9999 -9999 -9999 -9999 -9999 -9999 -9999 -9999 -9999 -9999 -9999 -9999 -9999 -9999 -9999 -9999 -9999 -9999 -9999 -9999 -9999 -9999 -9999 -9999 -9999 -9999 -9999 -9999 -9999 -9999 -9999 -9999 -9999 -9999 -9999 -9999 -9999 -9999 -9999 -9999 -9999 -9999 -9999 -9999 -9999 -9999 -9999 -9999 -9999 -9999 -9999 -9999 -9999 -9999 -9999 -9999 -9999 -9999 -9999 -9999 -9999 -9999 -9999 -9999 -9999 -9999 -9999 -9999 -9999 -9999 -9999 -9999 -9999 -9999 -9999 -9999 -9999 -9999 -9999 -9999 -9999 -9999 -9999 -9999 -9999 -9999 -9999 -9999 -9999 -9999 -9999 -9999 -9999 -9999 -9999 -9999 -9999 -9999 -9999 -9999 -9999 -9999 -9999 -9999 -9999 -9999 -9999 -9999 -9999 -9999 -9999 -9999 -9999 -9999 -9999 -9999 -9999 -9999 -9999 -9999 -9999 -9999 -9999 -9999 -9999 -9999 -9999 -9999 -9999 -9999 -

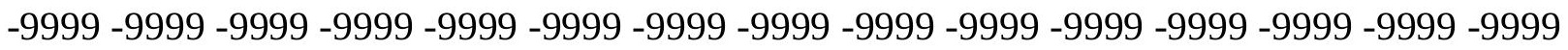

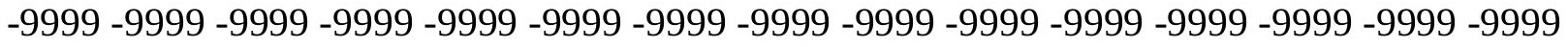
-9999 -9999 -9999 -9999 -9999 -9999 -9999 -9999 -9999 -9999 -9999 -9999 -9999 -9999 -9999 -

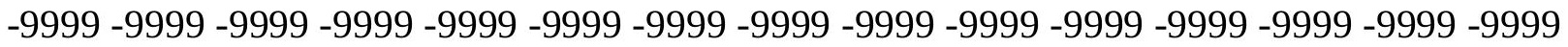

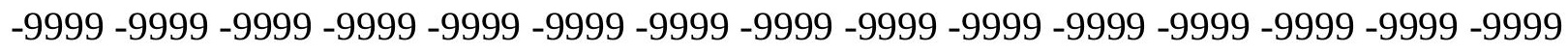

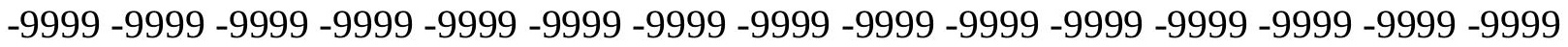

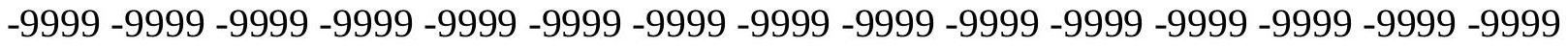
-9999 -9999 -9999 -9999 -9999 -9999 -9999 -9999 -9999 -9999 -9999 -9999 -9999 -9999 -9999 -

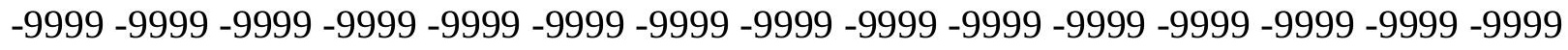

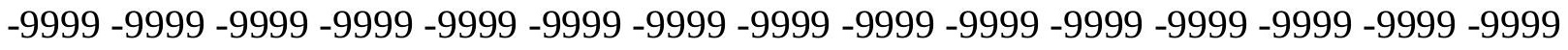
-9999 -9999 -9999 -9999 -9999 -9999 -9999 -9999 -9999 -9999 -9999 -9999 -9999 -9999 -9999 -9999 -9999 -9999 -9999 -9999 -9999 -9999 -9999 -9999-9999 -9999 -9999 -9999 -9999 -9999 -9999 -9999 -9999 -9999 -9999 -9999 -9999 -9999 -9999 -9999 -9999 -9999 -9999 -9999 -9999 -

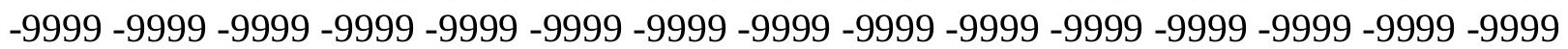


-9999 -9999 -9999 -9999 -9999 -9999 -9999 -9999 -9999 -9999 -9999 -9999 -9999 -9999 -9999 -9999 -9999 -9999 -9999 -9999 -9999 -9999 -9999 -9999 -9999 -9999 -9999 -9999 -9999 -9999 -9999 -9999 -9999 -9999 -9999 -9999 -9999 -9999 -9999 -9999 -9999 -9999 -9999 -9999 - 9999 -9999 -9999 -9999 -9999 -9999 -9999 -9999 -9999 -9999 -9999 -9999 -9999 -9999 -9999 -9999 -9999 -9999 -9999 -9999 -9999 -9999 -9999 -9999 -9999 -9999 -9999 -9999 -9999 -9999 -9999 -9999 -9999 -9999 -9999 -9999 -9999 -9999 -9999 -9999 -9999 -9999 -9999 -9999 -9999 -9999 -9999 -9999 -9999 -9999 -9999 -9999 -9999 -9999 -9999 -9999 -9999 -9999 -9999 -9999 -9999

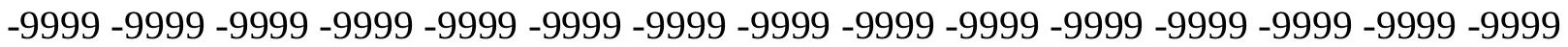

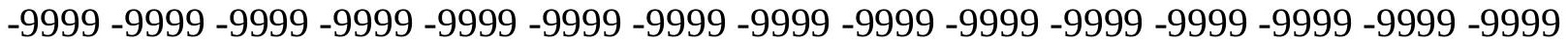
-9999 -9999 -9999 -9999 -9999 -9999 -9999 -9999 -9999 -9999 -9999 -9999 -9999 -9999 -9999 -9999 -9999 -9999 -9999 -9999 -9999 -9999 -9999 -9999 -9999 -9999 -9999 -9999 -9999 -9999 -9999 -9999 -9999 -9999 -9999 -9999 -9999 -9999 -9999 -9999 -9999 -9999 -9999 -9999 -9999 -9999 -9999 -9999 -9999 -9999 -9999 -9999 -9999 -9999 -9999 -9999 -9999 -9999 -9999 -9999 -9999 -9999 -9999 -9999 -9999 -9999 -9999 -9999 -9999 -9999 -9999 -9999 -9999 -9999 -9999 -9999 -9999 -9999 -9999 -9999 -9999 -9999 -9999 -9999 -9999 -9999 -9999 -9999 -9999 -

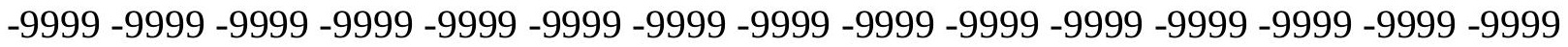
-9999 -9999 -9999 -9999 -9999 -9999 -9999 -9999 -9999 -9999 -9999 -9999 -9999 -9999 -9999 -9999 -9999 -9999 -9999 -9999 -9999 -9999 -9999 -9999 -9999 -9999 -9999 -9999 -9999 -9999 -9999 -9999 -9999 -9999 -9999 -9999 -9999 -9999 -9999 -9999 -9999 -9999 -9999 -9999 -9999 -9999 -9999 -9999 -9999 -9999 -9999 -9999 -9999 -9999 -9999 -9999 -9999 -9999 -9999 -9999 -9999 -9999 -9999 -9999 -9999 -9999 -9999 -9999 -9999 -9999 -9999 -9999 -9999 -9999 -9999 -999 -9999 -9999 -9999 -9999 -9999 -9999 -9999 -9999 -9999 -9999 -9999 -9999 -9999 -9999 -9999 -9999 -9999 -9999 -9999 -9999 -9999 -9999 -9999 -9999 -9999 -9999 -9999 -9999 -9999 -9999 -9999 -9999 -9999 -9999 -9999 -9999 -9999 -9999 -9999 -9999 -9999 -9999 -9999 -9999 -9999 -9999 -9999 -9999 -9999 -9999 -9999 -9999 -9999 -9999 -9999 -9999 -9999 -9999 -9999 -9999 -9999 -9999 -9999 -9999 -9999 -9999 -9999 -9999 -9999 -9999 -9999 -9999 -9999 -9999 -9999 -9999 -9999 -9999 -9999 -9999 -9999 -9999 -9999 -9999 -9999 -9999 -9999 -9999 -9999 -9999 -9999 -9999 -9999 -9999 -9999 -9999 -9999 -9999 -9999 -9999 -9999 -9999 -9999 -9999 -9999 -9999 -9999 -9999 -9999 -9999 -9999 -9999 -9999 -9999 -9999 -9999 -9999 -9999 -9999 -9999 -9999 -9999 -9999 -9999 -9999 -9999 -9999 -9999 -9999 -9999 -9999 -9999 -9999 -9999 -999 -9999 -9999 -9999 -9999 -9999 -9999 -9999 -9999 -9999 -9999 -9999 -9999 -9999 -9999 -9999 -9999 -9999 -9999 -9999 -9999 -9999 -9999 -9999 -9999 -9999 -9999 -9999 -9999 -9999 -9999 -

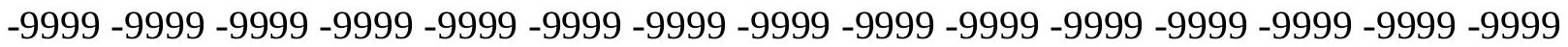

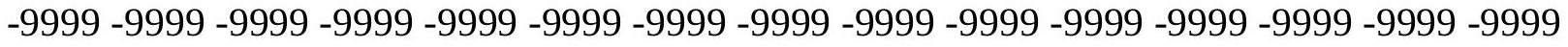

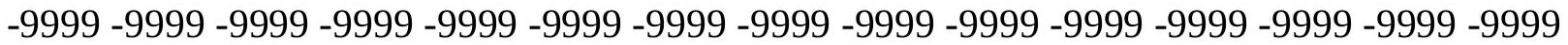
-9999 -9999 -9999 -9999 -9999 -9999 -9999 -9999 -9999 -9999 -9999 -9999 -9999 -9999 -9999 -9999 -9999 -9999 -9999 -9999 -9999 -9999 -9999 -9999 -9999 -9999 -9999 -9999 -9999 -

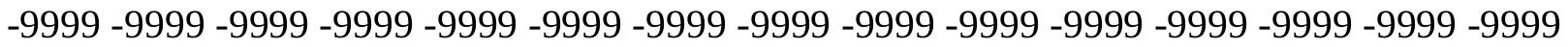
-9999 -9999 -9999 -9999 -9999 -9999 -9999 -9999 -9999 -9999 -9999 -9999 -9999 -9999 -9999 -9999 -9999 -9999 -9999 -9999 -9999 -9999 -9999 -9999 -9999 -9999 -9999 -9999 -9999 -9999 -

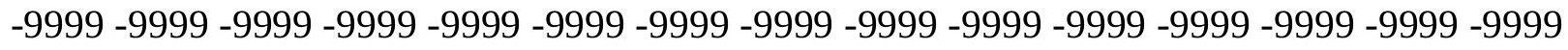

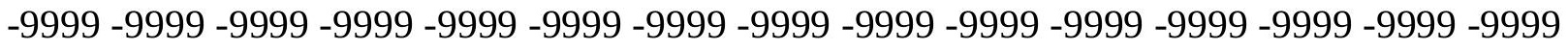
-9999 -9999 -9999 -9999 -9999 -9999 -9999 -9999 -9999 -9999 -9999 -9999 -9999 -9999 -9999 -9999 -9999 -9999 -9999 -9999 -9999 -9999 -9999 -9999-9999 -9999 -9999 -9999 -9999 -9999 -9999 -9999 -9999 -9999 -9999 -9999 -9999 -9999 -9999 -9999 -9999 -9999 -9999 -9999 -9999 -

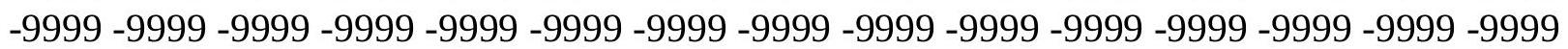


-9999 -9999 -9999 -9999 -9999 -9999 -9999 -9999 -9999 -9999 -9999 -9999 -9999 -9999 -9999 -9999 -9999 -9999 -9999 -9999 -9999 -9999 -9999 -9999 -9999 -9999 -9999 -9999 -9999 -9999 -

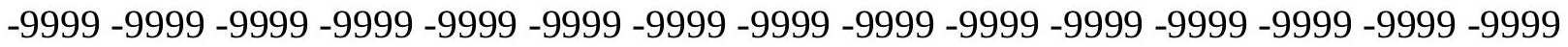
-9999 -9999 -9999 -9999 -9999 -9999 -9999 -9999 -9999 -9999 -9999 -9999 -9999 -9999 -9999 -9999 -9999 -9999 -9999 -9999 -9999 -9999 -9999 -9999-9999 -9999 -9999 -9999 -9999 -9999 -9999 -9999 -9999 -9999 -9999 -9999 -9999 -9999 -9999 -9999 -9999 -9999 -9999 -9999 -9999 -9999 -9999 -9999 -9999 -9999 -9999 -9999 -9999 -9999 -9999 -9999 -9999 -9999 -9999 -9999

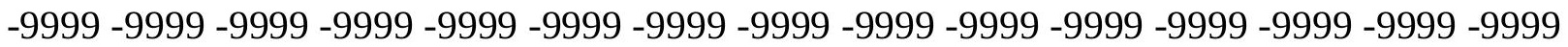

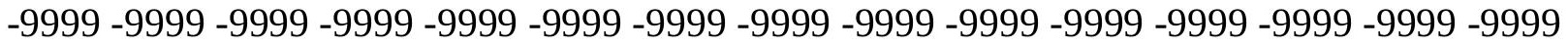
-9999 -9999 -9999 -9999 -9999 -9999 -9999 -9999 -9999 -9999 -9999 -9999 -9999 -9999 -9999 -9999 -9999 -9999 -9999 -9999 -9999 -9999 -9999 -9999 -9999 -9999 -9999 -9999 -9999 -9999 -9999 -9999 -9999 -9999 -9999 -9999 -9999 -9999 -9999 -9999 -9999 -9999 -9999 -9999 -9999 -9999 -9999 -9999 -9999 -9999 -9999 -9999 -9999 -9999 -9999 -9999 -9999 -9999 -9999 -9999 -9999 -9999 -9999 -9999 -9999 -9999 -9999 -9999 -9999 -9999 -9999 -9999 -9999 -9999 -9999 -9999 -9999 -9999 -9999 -9999 -9999 -9999 -9999 -9999 -9999 -9999 -9999 -9999 -9999 -9999 -

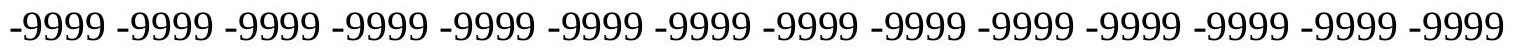
-9999 -9999 -9999 -9999 -9999 -9999 -9999 -9999 -9999 -9999 -9999 -9999 -9999 -9999 -9999 -9999 -9999 -9999 -9999 -9999 -9999 -9999 -9999 -9999 -9999 -9999 -9999 -9999 -9999 -9999 -9999 -9999 -9999 -9999 -9999 -9999 -9999 -9999 -9999 -9999 -9999 -9999 -9999 -9999 -9999 -

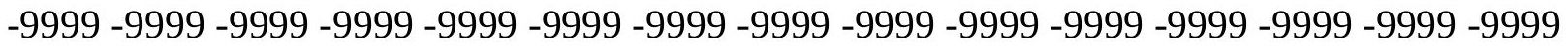

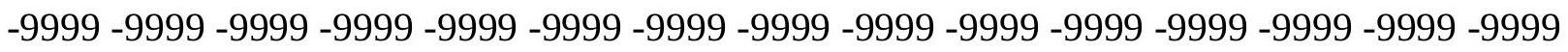
-9999 -9999 -9999 -9999 -9999 -9999 -9999 -9999 -9999 -9999 -9999 -9999 -9999 -9999 - 9999 -9999 -9999 -9999 -9999 -9999 -9999 -9999 -9999 -9999 -9999 -9999 -9999 -9999 -9999 -9999 -9999 -9999 -9999 -9999 -9999 -9999 -9999 -9999 -9999 -9999 -9999 -9999 -9999 -9999 -9999 -

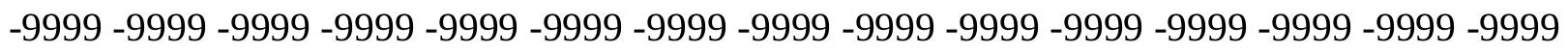
-9999 -9999 -9999 -9999 -9999 -9999 -9999 -9999 -9999 -9999 -9999 -9999 -9999 -9999 -9999 -9999 -9999 -9999 -9999 -9999 -9999 -9999 -9999 -9999 -9999 -9999 -9999 -9999 -9999 -9999 -

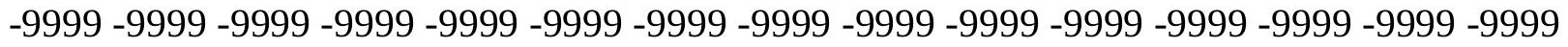
-9999 -9999 -9999 -9999 -9999 -9999 -9999 -9999 -9999 -9999 -9999 -9999 -9999 -9999 -9999 -9999 -9999 -9999 -9999 -9999 -9999 -9999 -9999 -9999 -9999 -9999 -9999 -9999 -9999 -999 -

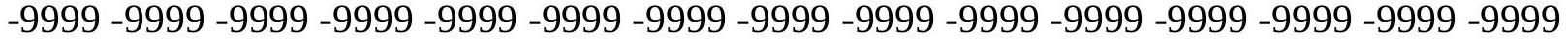
-9999 -9999 -9999 -9999 -9999 -9999 -9999 -9999 -9999 -9999 -9999 -9999 -9999 -9999 -9999 -

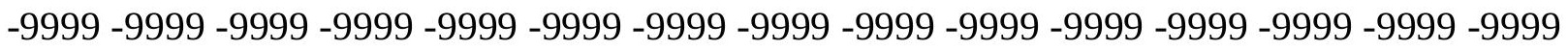

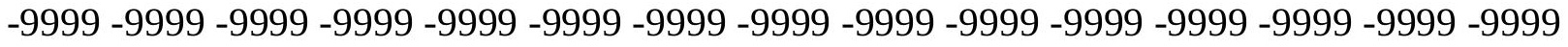

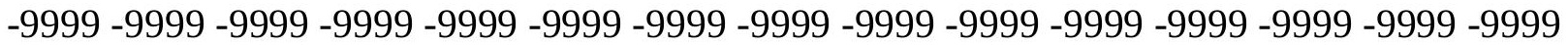
-9999 -9999 -9999 -9999 -9999 -9999 -9999 -9999 -9999 -9999 -9999 -9999 -9999 -9999 -9999 -

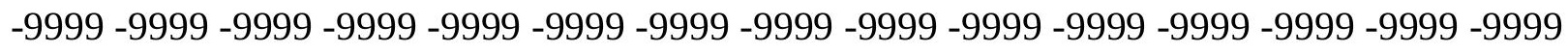

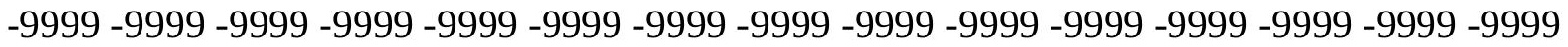
-9999 -9999 -9999 -9999 -9999 -9999 -9999 -9999 -9999 -9999 -9999 -9999 -9999 - 9999 - -999 -9999 -9999 -9999 -9999 -9999 -9999 -9999 -9999 -9999 -9999 -9999 -9999 -9999 -9999 -9999 -

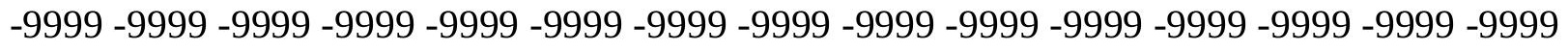

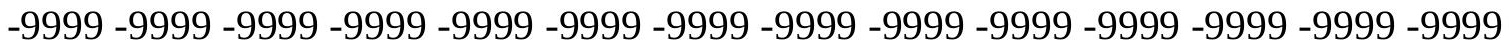
-9999 -9999 -9999 -9999 -9999 -9999 -9999 -9999 -9999 -9999 -9999 -9999 -9999 -9999 -9999 -9999 -9999 -9999 -9999 -9999 -9999 -9999 -9999 -9999-9999 -9999 -9999 -9999 -9999 -9999 -9999 -9999 -9999 -9999 -9999 -9999 -9999 -9999 -9999 -9999 -9999 -9999 -9999 -9999 -9999 -

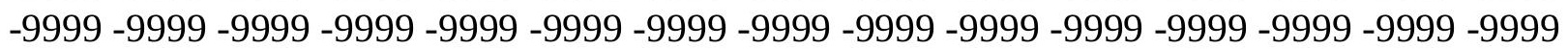


-9999 -9999 -9999 -9999 -9999 -9999 -9999 -9999 -9999 -9999 -9999 -9999 -9999 -9999 -9999 -9999 -9999 -9999 -9999 -9999 -9999 -9999 -9999 -9999 -9999 -9999 -9999 -9999 -9999 -9999 -

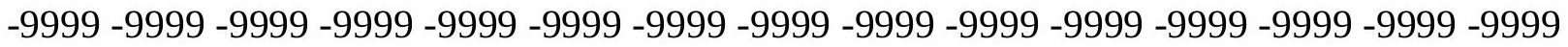
-9999 -9999 -9999 -9999 -9999 -9999 -9999 -9999 -9999 -9999 -9999 -9999 -9999 -9999 -9999 -9999 -9999 -9999 -9999 -9999 -9999 -9999 -9999 -9999-9999 -9999 -9999 -9999 -9999 -9999 -9999 -9999 -9999 -9999 -9999 -9999 -9999 -9999 -9999 -9999 -9999 -9999 -9999 -9999 -9999 -9999 -9999 -9999 -9999 -9999 -9999 -9999 -9999 -9999 -9999 -9999 -9999 -9999 -9999 -9999

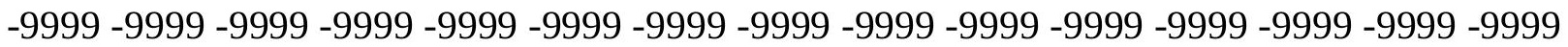

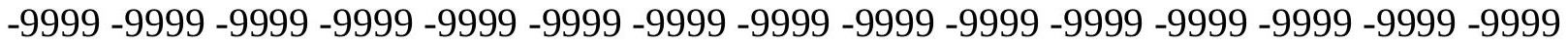
-9999 -9999 -9999 -9999 -9999 -9999 -9999 -9999 -9999 -9999 -9999 -9999 -9999 -9999 -9999 -9999 -9999 -9999 -9999 -9999 -9999 -9999 -9999 -9999 -9999 -9999 -9999 -9999 -9999 -9999 -9999 -9999 -9999 -9999 -9999 -9999 -9999 -9999 -9999 -9999 -9999 -9999 -9999 -9999 -9999 -9999 -9999 -9999 -9999 -9999 -9999 -9999 -9999 -9999 -9999 -9999 -9999 -9999 -9999 -9999 -

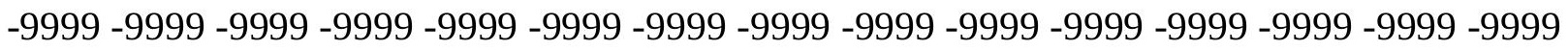
-9999 -9999 -9999 -9999 -9999 -9999 -9999 -9999 -9999 -9999 -9999 -9999 -9999 -9999 -9999 -

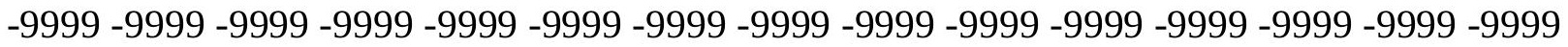
-9999 -9999 -9999 -9999 -9999 -9999 -9999 -9999 -9999 -9999 -9999 -9999 -9999 -9999 -9999 -9999 -9999 -9999 -9999 -9999 -9999 -9999 -9999 -9999 -9999 -9999 -9999 -9999 -9999 -9999 -9999 -9999 -9999 -9999 -9999 -9999 -9999 -9999 -9999 -9999 -9999 -9999 -9999 -9999 -9999 -

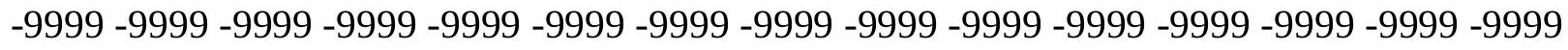

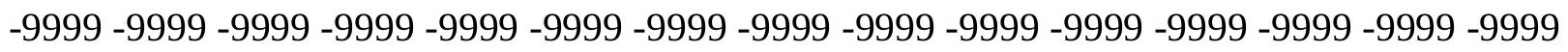
-9999 -9999 -9999 -9999 -9999 -9999 -9999 -9999 -9999 -9999 -9999 -9999 -9999 -9999 -9999 -9999 -9999 -9999 -9999 -9999 -9999 -9999 -9999 -9999 -9999 -9999 -9999 -9999 -9999 -9999 -9999 -9999 -9999 -9999 -9999 -9999 -9999 -9999 -9999 -9999 -9999 -9999 -9999 -9999 -

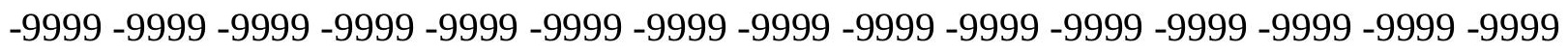
-9999 -9999 -9999 -9999 -9999 -9999 -9999 -9999 -9999 -9999 -9999 -9999 -9999 -9999 -9999 -9999 -9999 -9999 -9999 -9999 -9999 -9999 -9999 -9999 -9999 -9999 -9999 -9999 -9999 -9999 -

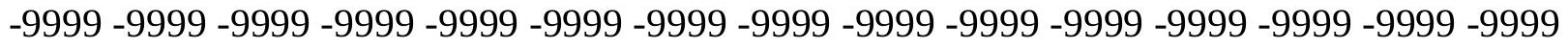
-9999 -9999 -9999 -9999 -9999 -9999 -9999 -9999 -9999 -9999 -9999 -9999 -9999 -9999 -9999 -9999 -9999 -9999 -9999 -9999 -9999 -9999 -9999 -9999 -9999 -9999 -9999 -9999 -9999 -999 -

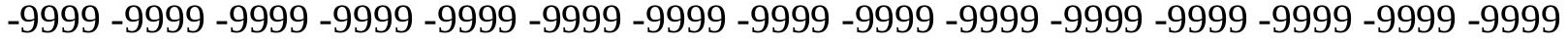
-9999 -9999 -9999 -9999 -9999 -9999 -9999 -9999 -9999 -9999 -9999 -9999 -9999 -9999 -9999 -

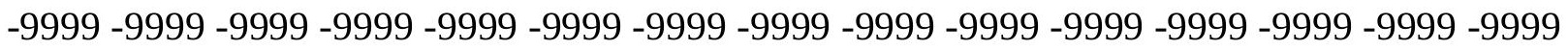

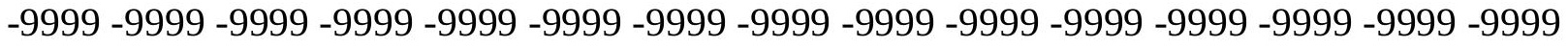

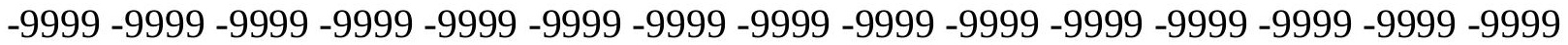

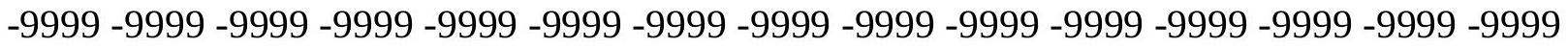

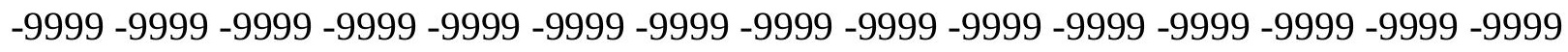

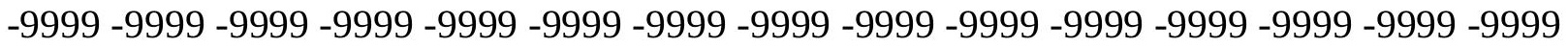

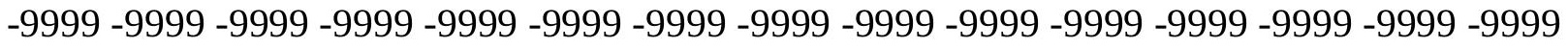
-9999 -9999 -9999 -9999 -9999 -9999 -9999 -9999 -9999 -9999 -9999 -9999 -9999 -9999 -9999 -

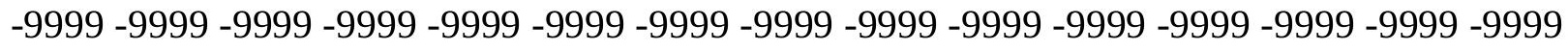

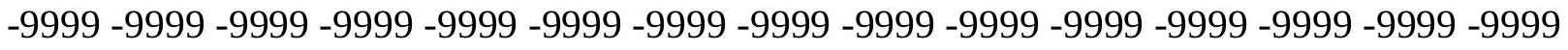
-9999 -9999 -9999 -9999 -9999 -9999 -9999 -9999 -9999 -9999 -9999 -9999 -9999 -9999 -9999 -9999 -9999 -9999 -9999 -9999 -9999 -9999 -9999 -9999-9999 -9999 -9999 -9999 -9999 -9999 -9999 -9999 -9999 -9999 -9999 -9999 -9999 -9999 -9999 -9999 -9999 -9999 -9999 -9999 -9999 -

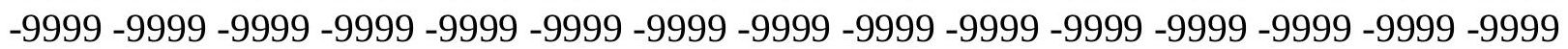


-9999 -9999 -9999 -9999 -9999 -9999 -9999 -9999 -9999 -9999 -9999 -9999 -9999 -9999 -9999 -9999 -9999 -9999 -9999 -9999 -9999 -9999 -9999 -9999 -9999 -9999 -9999 -9999 -9999 -

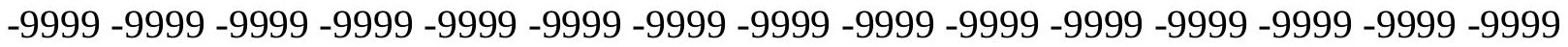
-9999 -9999 -9999 -9999 -9999 -9999 -9999 -9999 -9999 -9999 -9999 -9999 -9999 -9999 -9999 -9999 -9999 -9999 -9999 -9999 -9999 -9999 -9999 -9999 -9999 -9999 -9999 -9999 -9999 -9999 -9999 -9999 -9999 -9999 -9999 -9999 -9999 -9999 -9999 -9999 -9999 -9999 -9999 -9999 -9999 -9999 -9999 -9999 -9999 -9999 -9999 -9999 -9999 -9999 -9999 -9999 -9999 -9999 -9999 -9999

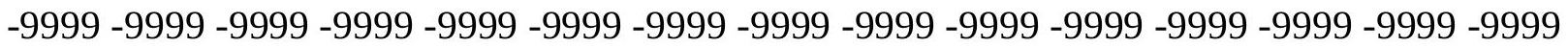

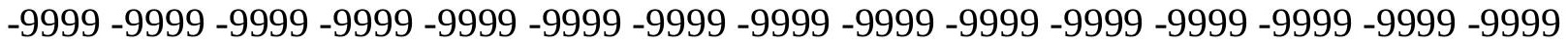
-9999 -9999 -9999 -9999 -9999 -9999 -9999 -9999 -9999 -9999 -9999 -9999 -9999 -9999 -9999 -9999 -9999 -9999 -9999 -9999 -9999 -9999 -9999 -9999 -9999 -9999 -9999 -9999 -9999 -9999 -9999 -9999 -9999 -9999 -9999 -9999 -9999 -9999 -9999 -9999 -9999 -9999 -9999 -9999 -9999 -9999 -9999 -9999 -9999 -9999 -9999 -9999 -9999 -9999 -9999 -9999 -9999 -9999 -9999 -9999 -9999 -9999 -9999 -9999 -9999 -9999 -9999 -9999 -9999 -9999 -9999 -9999 -9999 -9999 -9999 -9999 -9999 -9999 -9999 -9999 -9999 -9999 -9999 -9999 -9999 -9999 -9999 -9999 -9999 -9999 -

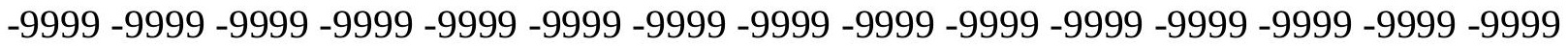
-9999 -9999 -9999 -9999 -9999 -9999 -9999 -9999 -9999 -9999 -9999 -9999 -9999 -9999 -9999 -9999 -9999 -9999 -9999 -9999 -9999 -9999 -9999 -9999 -9999 -9999 -9999 -9999 -9999 - 9999 -9999 -9999 -9999 -9999 -9999 -9999 -9999 -9999 -9999 -9999 -9999 -9999 -9999 -9999 -9999 -

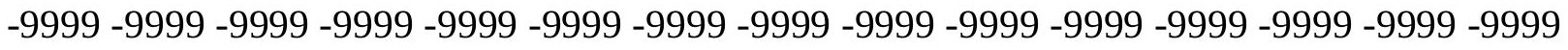

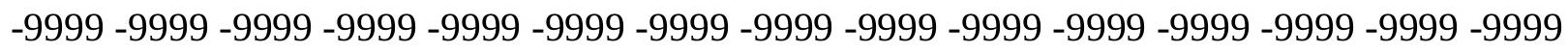

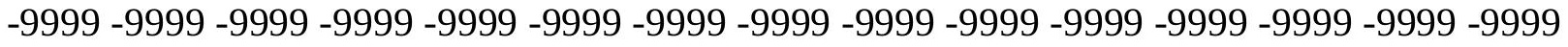
-9999 -9999 -9999 -9999 -9999 -9999 -9999 -9999 -9999 -9999 -9999 -9999 -9999 -9999 -9999 -9999 -9999 -9999 -9999 -9999 -9999 -9999 -9999 -9999 -9999 -9999 -9999 -9999 -9999 -9999 -

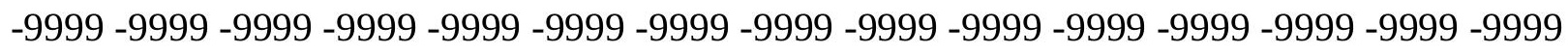
-9999 -9999 -9999 -9999 -9999 -9999 -9999 -9999 -9999 -9999 -9999 -9999 -9999 -9999 -9999 -9999 -9999 -9999 -9999 -9999 -9999 -9999 -9999 -9999 -9999 -9999 -9999 -9999 -9999 -9999 -9999 -9999 -9999 -9999 -9999 -9999 -9999 -9999 -9999 -9999 -9999 -9999 -9999 -9999 -9999 -9999 -9999 -9999 -9999 -9999 -9999 -9999 -9999 -9999 -9999 -9999 -9999 -9999 -9999 -9999 -9999 -9999 -9999 -9999 -9999 -9999 -9999 -9999 -9999 -9999 -9999 -9999 -9999 -999 -

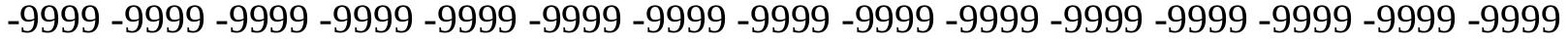
-9999 -9999 -9999 -9999 -9999 -9999 -9999 -9999 -9999 -9999 -9999 -9999 -9999 -9999 -9999 -

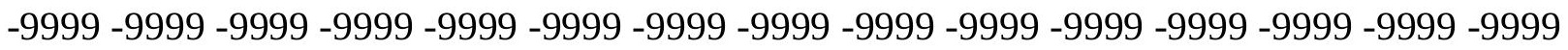

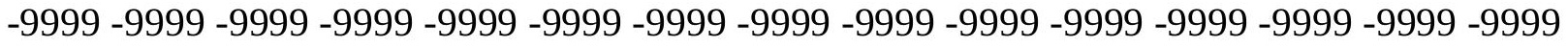

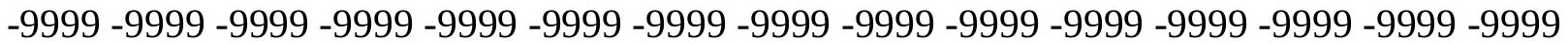

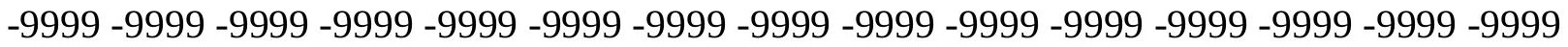

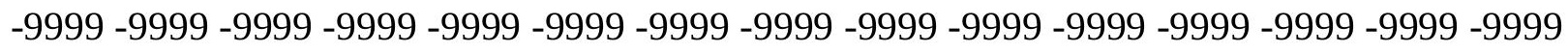

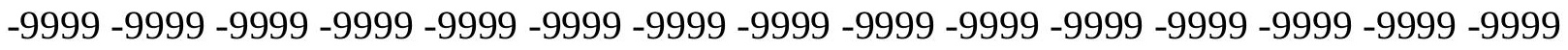

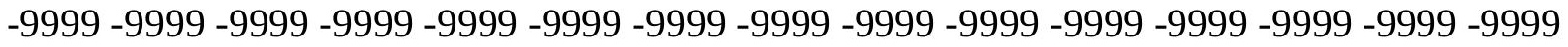
-9999 -9999 -9999 -9999 -9999 -9999 -9999 -9999 -9999 -9999 -9999 -9999 -9999 -9999 -9999 -

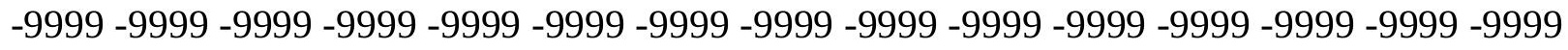

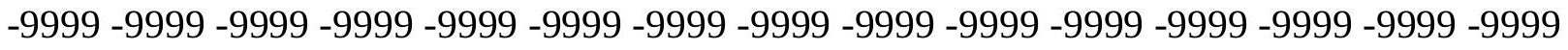
-9999 -9999 -9999 -9999 -9999 -9999 -9999 -9999 -9999 -9999 -9999 -9999 -9999 -9999 -9999 -9999 -9999 -9999 -9999 -9999 -9999 -9999 -9999 -9999-9999 -9999 -9999 -9999 -9999 -9999 -9999 -9999 -9999 -9999 -9999 -9999 -9999 -9999 -9999 -9999 -9999 -9999 -9999 -9999 -9999 -

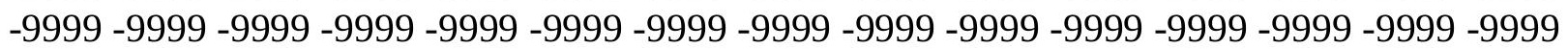


-9999 -9999 -9999 -9999 -9999 -9999 -9999 -9999 -9999 -9999 -9999 -9999 -9999 -9999 -9999 -9999 -9999 -9999 -9999 -9999 -9999 -9999 -9999 -9999 -9999 -9999 -9999 -9999 -9999 -9999 -

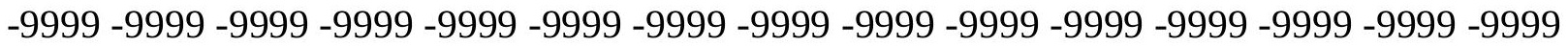
-9999 -9999 -9999 -9999 -9999 -9999 -9999 -9999 -9999 -9999 -9999 -9999 -9999 -9999 -9999 -9999 -9999 -9999 -9999 -9999 -9999 -9999 -9999 -9999-9999 -9999 -9999 -9999 -9999 -9999 -9999 -9999 -9999 -9999 -9999 -9999 -9999 -9999 -9999 -9999 -9999 -9999 -9999 -9999 -9999 -

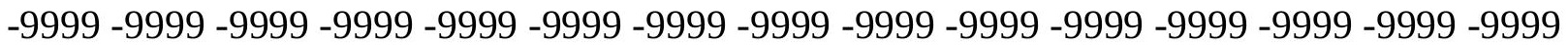
-9999 -9999 -9999 -9999 -9999 -9999 -9999 -9999 -9999 -9999 -9999 -9999 -9999 -9999 -9999 -9999 -9999 -9999 -9999 -9999 -9999 -9999 -9999 -9999 -9999 -9999 -9999 -9999 -9999 -9999 -9999 -9999 -9999 -9999 -9999 -9999 -9999 -9999 -9999 -9999 -9999 -9999 -9999 -9999 -9999 -9999 -9999 -9999 -9999 -9999 -9999 -9999 -9999 -9999 -9999 -9999 -9999 -9999 -9999 -9999 -9999 -9999 -9999 -9999 -9999 -9999 -9999 -9999 -9999 -9999 -9999 -9999 -9999 -9999 -9999 -9999 -9999 -9999 -9999 -9999 -9999 -9999 -9999 -9999 -9999 -9999 -9999 -9999 -9999 -9999 -9999 -9999 -9999 -9999 -9999 -9999 -9999 -9999 -9999 -9999 -9999 -9999 -9999 -9999 -9999 -9999 -9999 -9999 -9999 -9999 -9999 -9999 -9999 -9999 -9999 -9999 -9999 -9999 -9999 -

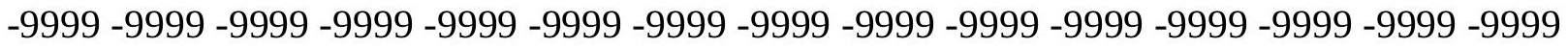
-9999 -9999 -9999 -9999 -9999 -9999 -9999 -9999 -9999 -9999 -9999 -9999 -9999 -9999 -9999 -9999 -9999 -9999 -9999 -9999 -9999 -9999 -9999 -9999 -9999 -9999 -9999 -9999 -9999 -9999 -9999 -9999 -9999 -9999 -9999 -9999 -9999 -9999 -9999 -9999 -9999 -9999 -9999 -9999 -9999 -

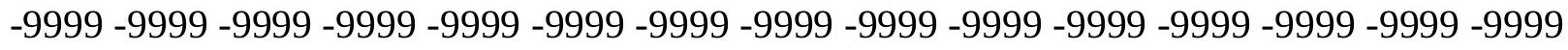

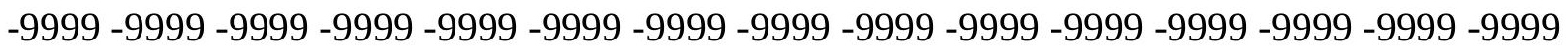
-9999 -9999 -9999 -9999 -9999 -9999 -9999 -9999 -9999 -9999 -9999 -9999 -9999 -9999 - 9999 -9999 -9999 -9999 -9999 -9999 -9999 -9999 -9999 -9999 -9999 -9999 -9999 -9999 -9999 -9999 -9999 -9999 -9999 -9999 -9999 -9999 -9999 -9999 -9999 -9999 -9999 -9999 -9999 -9999 -9999 -

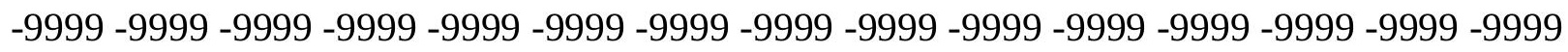
-9999 -9999 -9999 -9999 -9999 -9999 -9999 -9999 -9999 -9999 -9999 -9999 -9999 -9999 -9999 -9999 -9999 -9999 -9999 -9999 -9999 -9999 -9999 -9999 -9999 -9999 -9999 -9999 -9999 -9999 -

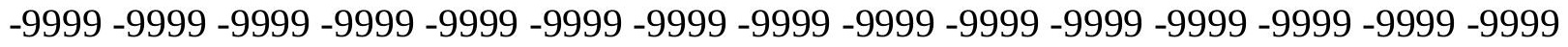
-9999 -9999 -9999 -9999 -9999 -9999 -9999 -9999 -9999 -9999 -9999 -9999 -9999 -9999 -9999 -9999 -9999 -9999 -9999 -9999 -9999 -9999 -9999 -9999 -9999 -9999 -9999 -9999 -9999 -999 -9999 -9999 -9999 -9999 -9999 -9999 -9999 -9999 -9999 -9999 -9999 -9999 -9999 -9999 -9999 -9999 -9999 -9999 -9999 -9999 -9999 -9999 -9999 -9999 -9999 -9999 -9999 -9999 -9999 -9999 -

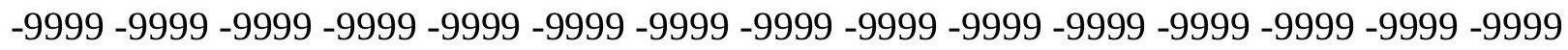

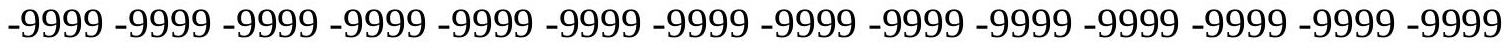
-9999 -9999 -9999 -9999 -9999 -9999 -9999 -9999 -9999 -9999 -9999 -9999 -9999 -9999 -9999

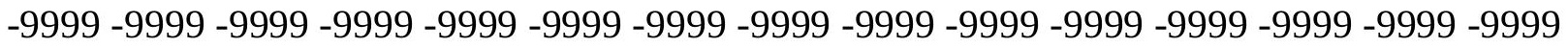

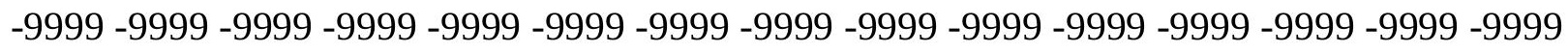

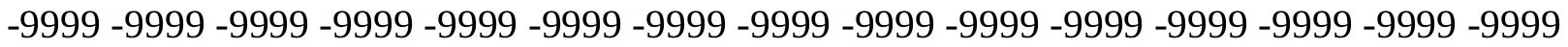

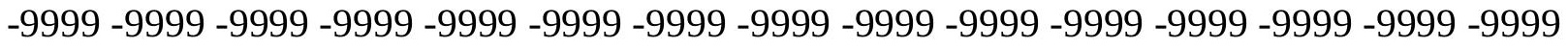
-9999 -9999 -9999 -9999 -9999 -9999 -9999 -9999 -9999 -9999 -9999 -9999 -9999 -9999 -9999 -

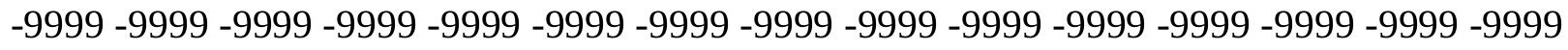

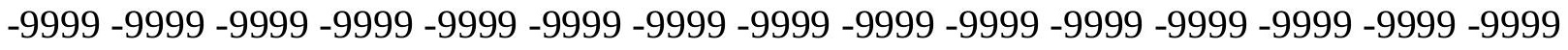
-9999 -9999 -9999 -9999 -9999 -9999 -9999 -9999 -9999 -9999 -9999 -9999 -9999 -9999 -9999 -9999 -9999 -9999 -9999 -9999 -9999 -9999 -9999 -9999-9999 -9999 -9999 -9999 -9999 -9999 -9999 -9999 -9999 -9999 -9999 -9999 -9999 -9999 -9999 -9999 -9999 -9999 -9999 -9999 -9999 -

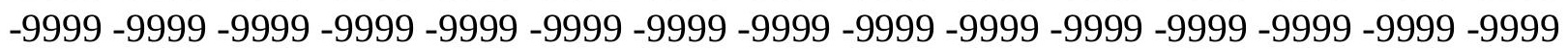


-9999 -9999 -9999 -9999 -9999 -9999 -9999 -9999 -9999 -9999 -9999 -9999 -9999 -9999 -9999 -9999 -9999 -9999 -9999 -9999 -9999 -9999 -9999 -9999 -9999 -9999 -9999 -9999 -9999 -9999 -

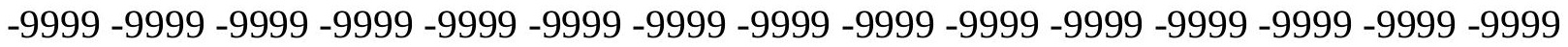
-9999 -9999 -9999 -9999 -9999 -9999 -9999 -9999 -9999 -9999 -9999 -9999 -9999 -9999 -9999 -9999 -9999 -9999 -9999 -9999 -9999 -9999 -9999 -9999-9999 -9999 -9999 -9999 -9999 -9999 -9999 -9999 -9999 -9999 -9999 -9999 -9999 -9999 -9999 -9999 -9999 -9999 -9999 -9999 -9999 -9999 -9999 -9999 -9999 -9999 -9999 -9999 -9999 -9999 -9999 -9999 -9999 -9999 -9999 -9999

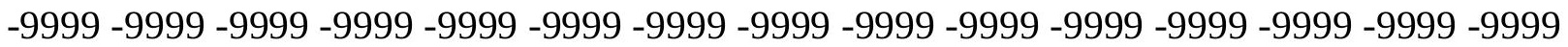

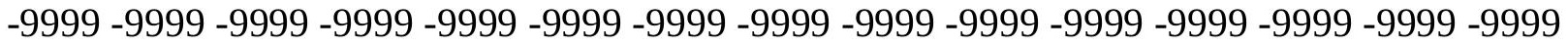
-9999 -9999 -9999 -9999 -9999 -9999 -9999 -9999 -9999 -9999 -9999 -9999 -9999 -9999 -9999 -9999 -9999 -9999 -9999 -9999 -9999 -9999 -9999 -9999 -9999 -9999 -9999 -9999 -9999 -9999 -9999 -9999 -9999 -9999 -9999 -9999 -9999 -9999 -9999 -9999 -9999 -9999 -9999 -9999 -9999 -9999 -9999 -9999 -9999 -9999 -9999 -9999 -9999 -9999 -9999 -9999 -9999 -9999 -9999 -9999 -9999 -9999 -9999 -9999 -9999 -9999 -9999 -9999 -9999 -9999 -9999 -9999 -9999 -9999 -9999 -9999 -9999 -9999 -9999 -9999 -9999 -9999 -9999 -9999 -9999 -9999 -9999 -9999 -9999

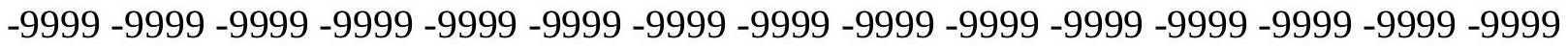
-9999 -9999 -9999 -9999 -9999 -9999 -9999 -9999 -9999 -9999 -9999 -9999 -9999 -9999 -9999 -9999 -9999 -9999 -9999 -9999 -9999 -9999 -9999 -9999 -9999 -9999 -9999 -9999 -9999 -9999 -9999 -9999 -9999 -9999 -9999 -9999 -9999 -9999 -9999 -9999 -9999 -9999 -9999 -9999 -9999 -

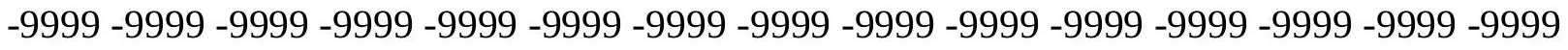

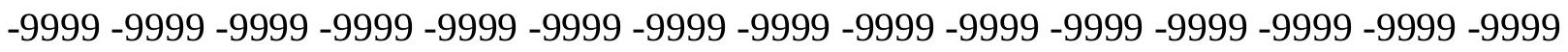
-9999 -9999 -9999 -9999 -9999 -9999 -9999 -9999 -9999 -9999 -9999 -9999 -9999 -9999 -9999 -9999 -9999 -9999 -9999 -9999 -9999 -9999 -9999 -9999 -9999 -9999 -9999 -9999 -9999 -9999 -9999 -9999 -9999 -9999 -9999 -9999 -9999 -9999 -9999 -9999 -9999 -9999 -9999 -9999 -9999 -

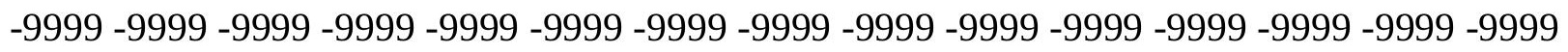
-9999 -9999 -9999 -9999 -9999 -9999 -9999 -9999 -9999 -9999 -9999 -9999 -9999 -9999 -9999 -9999 -9999 -9999 -9999 -9999 -9999 -9999 -9999 -9999 -9999 -9999 -9999 -9999 -9999 -9999 -

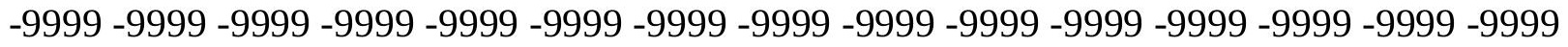
-9999 -9999 -9999 -9999 -9999 -9999 -9999 -9999 -9999 -9999 -9999 -9999 -9999 -9999 -9999 -9999 -9999 -9999 -9999 -9999 -9999 -9999 -9999 -9999 -9999 -9999 -9999 -9999 -9999 -999 -9999 -9999 -9999 -9999 -9999 -9999 -9999 -9999 -9999 -9999 -9999 -9999 -9999 -9999 -9999 -9999 -9999 -9999 -9999 -9999 -9999 -9999 -9999 -9999 -9999 -9999 -9999 -9999 -9999 -9999 -

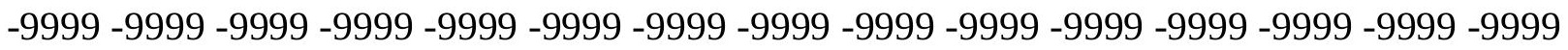

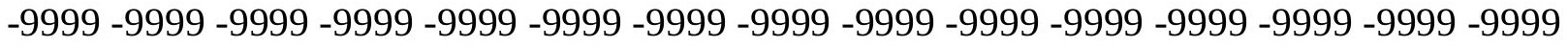

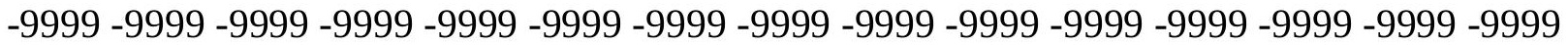

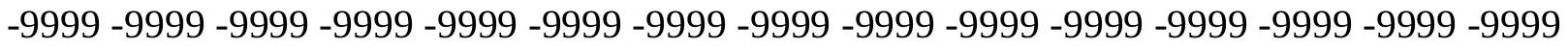

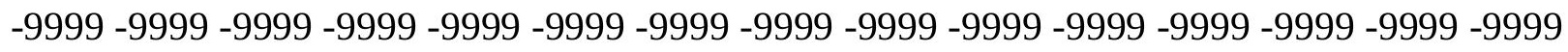

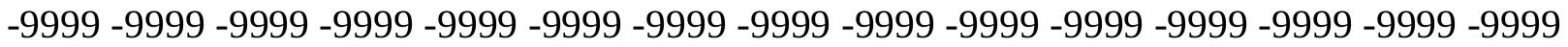
-9999 -9999 -9999 -9999 -9999 -9999 -9999 -9999 -9999 -9999 -9999 -9999 -9999 - 9999 - -999 -9999 -9999 -9999 -9999 -9999 -9999 -9999 -9999 -9999 -9999 -9999 -9999 -9999 -9999 - -999 -

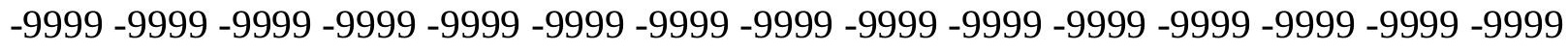

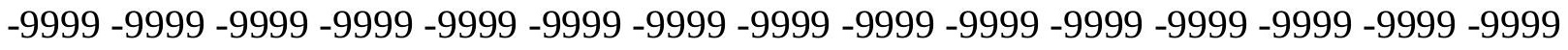
-9999 -9999 -9999 -9999 -9999 -9999 -9999 -9999 -9999 -9999 -9999 -9999 -9999 -9999 -9999 -9999 -9999 -9999 -9999 -9999 -9999 -9999 -9999 -9999-9999 -9999 -9999 -9999 -9999 -9999 -9999 -9999 -9999 -9999 -9999 -9999 -9999 -9999 -9999 -9999 -9999 -9999 -9999 -9999 -9999 -

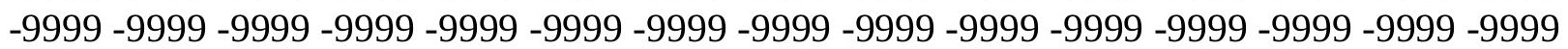


-9999 -9999 -9999 -9999 -9999 -9999 -9999 -9999 -9999 -9999 -9999 -9999 -9999 -9999 -9999 -9999 -9999 -9999 -9999 -9999 -9999 -9999 -9999 -9999 -9999 -9999 -9999 -9999 -9999 -9999 -9999 -9999 -9999 -9999 -9999 -9999 -9999 -9999 -9999 -9999 -9999 -9999 -9999 -9999 -9999 -9999 -9999 -9999 -9999 -9999 -9999 -9999 -9999 -9999 -9999 -9999 -9999 -9999 -9999 -9999 -9999 -9999 -9999 -9999 -9999 -9999 -9999 -9999 -9999 -9999 -9999 -9999 -9999 -9999 -9999 -9999 -9999 -9999 -9999 -9999 -9999 -9999 -9999 -9999 -9999 -9999 -9999 -9999 -9999 -9999 -9999 -9999 -9999 -9999 -9999 -9999 -9999 -9999 -9999 -9999 -9999 -9999 -9999 -9999 -9999 -

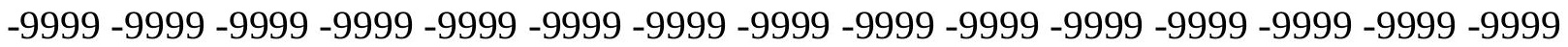
-9999 -9999 -9999 -9999 -9999 -9999 -9999 -9999 -9999 -9999 -9999 -9999 -9999 -9999 -9999 -9999 -9999 -9999 -9999 -9999 -9999 -9999 -9999 -9999 -9999 -9999 -9999 -9999 -9999 -9999 -

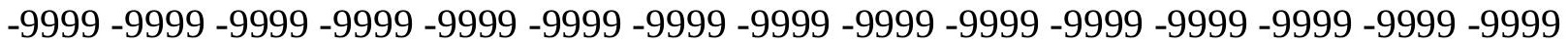
-9999 -9999 -9999 -9999 -9999 -9999 -9999 -9999 -9999 -9999 -9999 -9999 -9999 -9999 -9999 -9999 -9999 -9999 -9999 -9999 -9999 -9999 -9999 -9999 -9999 -9999 -9999 -9999 -9999 -9999 -9999 -9999 -9999 -9999 -9999 -9999 -9999 -9999 -9999 -9999 -9999 -9999 -9999 -9999 -9999 -9999 -9999 -9999 -9999 -9999 -9999 -9999 -9999 -9999 -9999 -9999 -9999 -9999 -9999 -9999

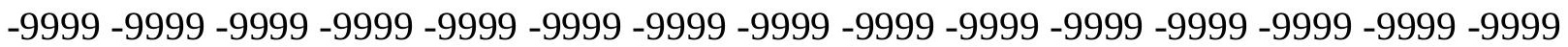
-9999 -9999 -9999 -9999 -9999 -9999 -9999 -9999 -9999 -9999 -9999 -9999 -9999 -9999 -9999 -9999 -9999 -9999 -9999 -9999 -9999 -9999 -9999 -9999 -9999 -9999 -9999 -9999 -9999 -9999 -9999 -9999 -9999 -9999 -9999 -9999 -9999 -9999 -9999 -9999 -9999 -9999 -9999 -9999 -9999 -9999 -9999 -9999 -9999 -9999 -9999 -9999 -9999 -9999 -9999 -9999 -9999 -9999 -9999 -9999 -9999 -9999 -9999 -9999 -9999 -9999 -9999 -9999 -9999 -9999 -9999 -9999 -9999 -9999 -9999 -9999 -9999 -9999 -9999 -9999 -9999 -9999 -9999 -9999 -9999 -9999 -9999 -9999 -9999 -9999 -9999 -9999 -9999 -9999 -9999 -9999 -9999 -9999 -9999 -9999 -9999 -9999 -9999 -9999 -9999 -9999 -9999 -9999 -9999 -9999 -9999 -9999 -9999 -9999 -9999 -9999 -9999 -9999 -9999 -9999 -9999 -9999 -9999 -9999 -9999 -9999 -9999 -9999 -9999 -9999 -9999 -9999 -9999 -9999 -9999 -9999 -9999 -9999 -9999 -9999 -9999 -9999 -9999 -9999 -9999 -9999 -9999 -9999 -9999 -9999 -9999 -9999 -9999 -9999 -9999 -9999 -9999 -9999 -9999 -9999 -9999 -9999 -9999 -9999 -9999 -9999 -9999 -9999 -9999 -9999 -9999 -9999 -9999 -9999 -9999 -9999 -9999 -9999 -9999

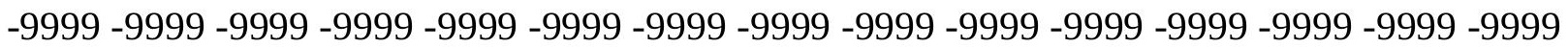
-9999 -9999 -9999 -9999 -9999 -9999 -9999 -9999 -9999 -9999 -9999 -9999 -9999 -9999 -9999 -9999 -9999 -9999 -9999 -9999 -9999 -9999 -9999 -9999 -9999 -9999 -9999 -9999 -9999 -9999 -

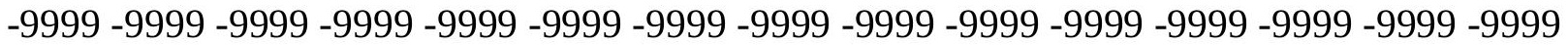
-9999 -9999 -9999 -9999 -9999 -9999 -9999 -9999 -9999 -9999 -9999 -9999 -9999 -9999 -9999 -9999 -9999 -9999 -9999 -9999 -9999 -9999 -9999 -9999 -9999 -9999 -9999 -9999 -9999 -9999 -9999 -9999 -9999 -9999 -9999 -9999 -9999 -9999 -9999 -9999 -9999 -9999 -9999 -9999 -9999 -9999 -9999 -9999 -9999 -9999 -9999 -9999 -9999 -9999 -9999 -9999 -9999 -9999 -9999 -9999 -9999 -9999 -9999 -9999 -9999 -9999 -9999 -9999 -9999 -9999 -9999 -9999 -9999 -9999 -9999

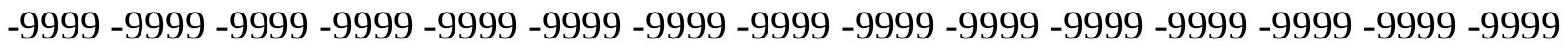
-9999 -9999 -9999 -9999 -9999 -9999 -9999 -9999 -9999 -9999 -9999 -9999 -9999 -9999 -9999 -9999 -9999 -9999 -9999 -9999 -9999 -9999 -9999 -9999 -9999 -9999 -9999 -9999 -9999 -9999 -9999 -9999 -9999 -9999 -9999 -9999 -9999 -9999 -9999 -9999 -9999 -9999 -9999 -9999 -9999 -999 -9999 -9999 -9999 -9999 -9999 -9999 -9999 -9999 -9999 -9999 -9999 -9999 -9999 -9999 -9999 -9999 -9999 -9999 -9999 -9999 -9999 -9999 -9999 -9999 -9999 -9999 -9999 -9999 -9999 -9999 -9999 -9999 -9999 -9999 -9999 -9999 -9999 -9999 -9999 -9999 -9999 -9999 -9999 -9999 -9999 -9999 -9999 -9999 -9999 -9999 -9999 -9999 -9999 -9999 -9999 -9999 -9999 -9999 -9999 -9999 -9999 -9999 -9999 -9999 -9999 -9999 -9999 -9999 -9999 -9999 -9999 -9999 -9999 -9999 
-9999 -9999 -9999 -9999 -9999 -9999 -9999 -9999 -9999 -9999 -9999 -9999 -9999 -9999 -9999 -9999 -9999 -9999 -9999 -9999 -9999 -9999 -9999 -9999 -9999 -9999 -9999 -9999 -9999 -9999 -

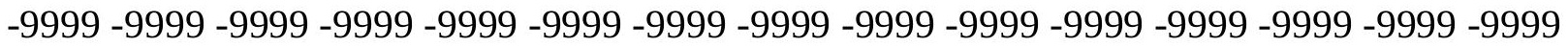
-9999 -9999 -9999 -9999 -9999 -9999 -9999 -9999 -9999 -9999 -9999 -9999 -9999 -9999 -9999 -9999 -9999 -9999 -9999 -9999 -9999 -9999 -9999 -9999-9999 -9999 -9999 -9999 -9999 -9999 -9999 -9999 -9999 -9999 -9999 -9999 -9999 -9999 -9999 -9999 -9999 -9999 -9999 -9999 -9999 -9999 -9999 -9999 -9999 -9999 -9999 -9999 -9999 -9999 -9999 -9999 -9999 -9999 -9999 -9999

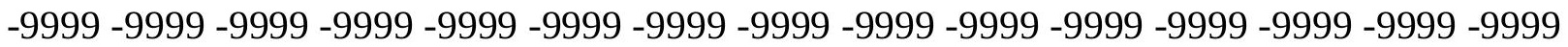

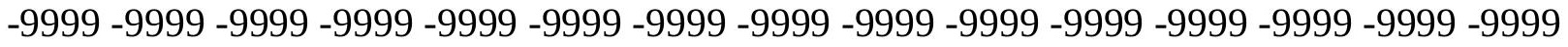
-9999 -9999 -9999 -9999 -9999 -9999 -9999 -9999 -9999 -9999 -9999 -9999 -9999 -9999 -9999 -9999 -9999 -9999 -9999 -9999 -9999 -9999 -9999 -9999 -9999 -9999 -9999 -9999 -9999 -9999 -9999 -9999 -9999 -9999 -9999 -9999 -9999 -9999 -9999 -9999 -9999 -9999 -9999 -9999 -9999 -9999 -9999 -9999 -9999 -9999 -9999 -9999 -9999 -9999 -9999 -9999 -9999 -9999 -9999 -9999 -

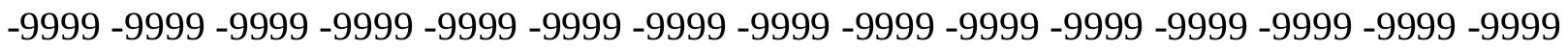
-9999 -9999 -9999 -9999 -9999 -9999 -9999 -9999 -9999 -9999 -9999 -9999 -9999 -9999 -9999 -

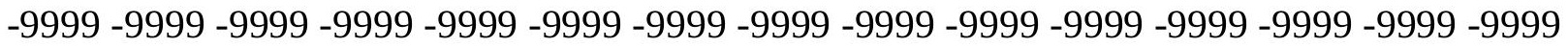
-9999 -9999 -9999 -9999 -9999 -9999 -9999 -9999 -9999 -9999 -9999 -9999 -9999 -9999 -9999 -9999 -9999 -9999 -9999 -9999 -9999 -9999 -9999 -9999 -9999 -9999 -9999 -9999 -9999 -9999 -9999 -9999 -9999 -9999 -9999 -9999 -9999 -9999 -9999 -9999 -9999 -9999 -9999 -9999 -9999 -

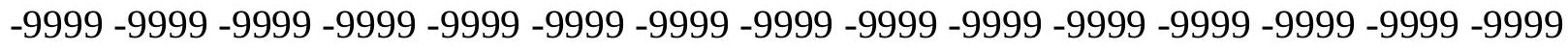

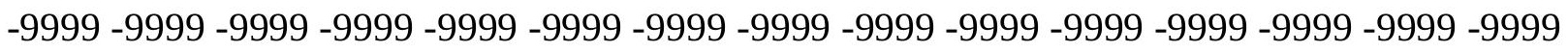

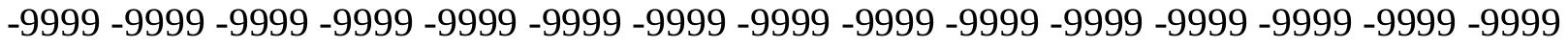
-9999 -9999 -9999 -9999 -9999 -9999 -9999 -9999 -9999 -9999 -9999 -9999 -9999 -9999 -9999 -9999 -9999 -9999 -9999 -9999 -9999 -9999 -9999 -9999 -9999 -9999 -9999 -9999 -9999 -9999 -

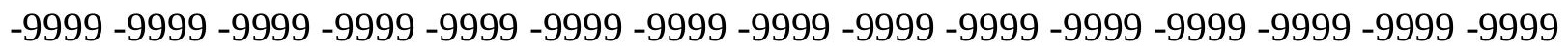
-9999 -9999 -9999 -9999 -9999 -9999 -9999 -9999 -9999 -9999 -9999 -9999 -9999 -9999 -9999 -9999 -9999 -9999 -9999 -9999 -9999 -9999 -9999 -9999 -9999 -9999 -9999 -9999 -9999 -

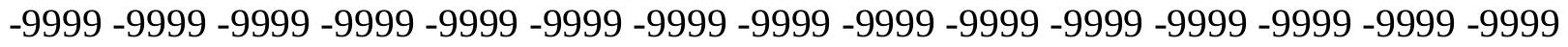
-9999 -9999 -9999 -9999 -9999 -9999 -9999 -9999 -9999 -9999 -9999 -9999 -9999 -9999 -9999 -9999 -9999 -9999 -9999 -9999 -9999 -9999 -9999 -9999 -9999 -9999 -9999 -9999 -9999 -999 -

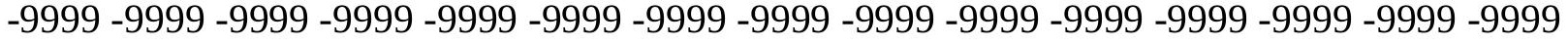
-9999 -9999 -9999 -9999 -9999 -9999 -9999 -9999 -9999 -9999 -9999 -9999 -9999 -9999 -9999 -

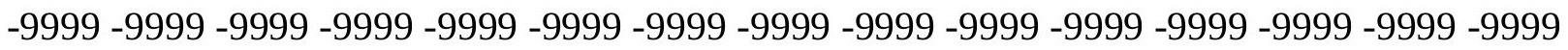

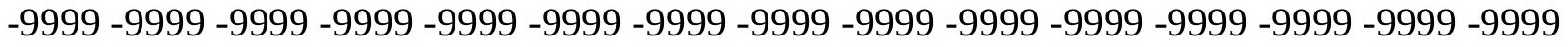

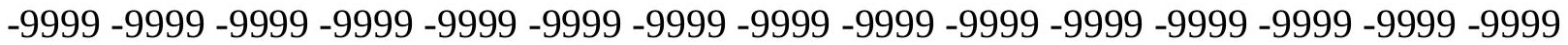
-9999 -9999 -9999 -9999 -9999 -9999 -9999 -9999 -9999 -9999 -9999 -9999 -9999 -9999 -9999

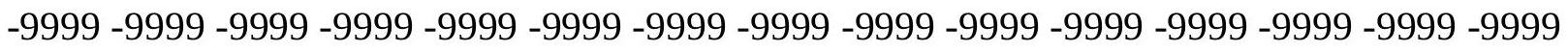

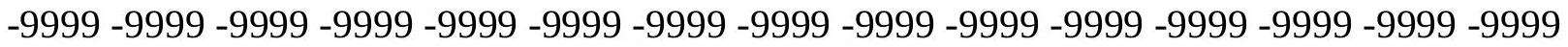
-9999 -9999 -9999 -9999 -9999 -9999 -9999 -9999 -9999 -9999 -9999 -9999 -9999 - 9999 - -999 -9999 -9999 -9999 -9999 -9999 -9999 -9999 -9999 -9999 -9999 -9999 -9999 -9999 -9999 -9999 -

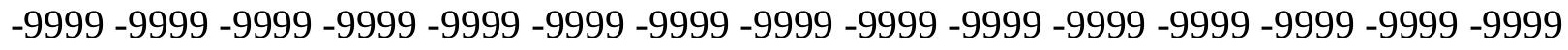

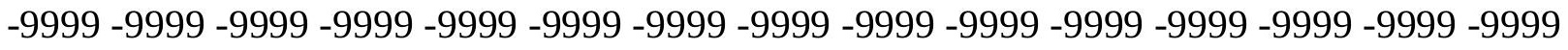
-9999 -9999 -9999 -9999 -9999 -9999 -9999 -9999 -9999 -9999 -9999 -9999 -9999 -9999 -9999 -9999 -9999 -9999 -9999 -9999 -9999 -9999 -9999 -9999-9999 -9999 -9999 -9999 -9999 -9999 -9999 -9999 -9999 -9999 -9999 -9999 -9999 -9999 -9999 -9999 -9999 -9999 -9999 -9999 -9999 -

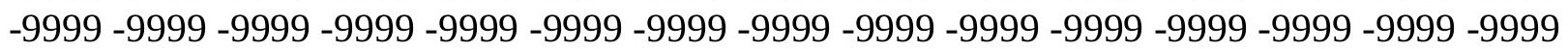


-9999 -9999 -9999 -9999 -9999 -9999 -9999 -9999 -9999 -9999 -9999 -9999 -9999 -9999 -9999 -9999 -9999 -9999 -9999 -9999 -9999 -9999 -9999 -9999 -9999 -9999 -9999 -9999 -9999 -9999 -9999 -9999 -9999 -9999 -9999 -9999 -9999 -9999 -9999 -9999 -9999 -9999 -9999 -9999 - 9999 -9999 -9999 -9999 -9999 -9999 -9999 -9999 -9999 -9999 -9999 -9999 -9999 -9999 -9999 -9999 -9999 -9999 -9999 -9999 -9999 -9999 -9999 -9999 -9999 -9999 -9999 -9999 -9999 -9999 - -9999 -9999 -9999 -9999 -9999 -9999 -9999 -9999 -9999 -9999 -9999 -9999 -9999 -9999 -9999 -9999 -9999 -9999 -9999 -9999 -9999 -9999 -9999 -9999 -9999 -9999 -9999 -9999 -9999 -9999

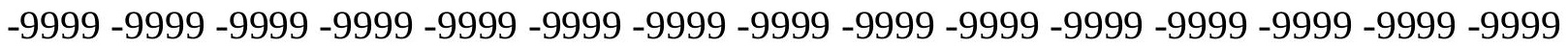

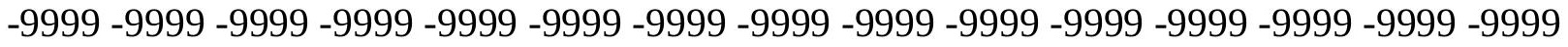
-9999 -9999 -9999 -9999 -9999 -9999 -9999 -9999 -9999 -9999 -9999 -9999 -9999 -9999 -9999

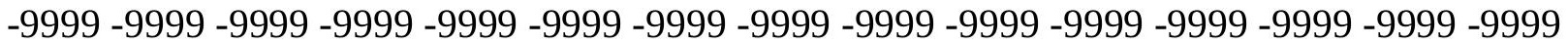
-9999 -9999 -9999 -9999 -9999 -9999 -9999 -9999 -9999 -9999 -9999 -9999 -9999 -9999 -9999 -9999 -9999 -9999 -9999 -9999 -9999 -9999 -9999 -9999 -9999 -9999 -9999 -9999 -9999 -9999 -9999 -9999 -9999 -9999 -9999 -9999 -9999 -9999 -9999 -9999 -9999 -9999 -9999 -9999 - -9999 -9999 -9999 -9999 -9999 -9999 -9999 -9999 -9999 -9999 -9999 -9999 -9999 -9999 -9999 -9999

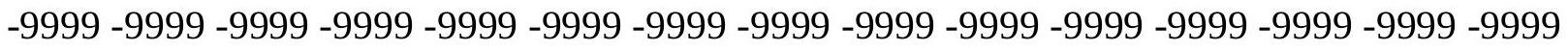
-9999 -9999 -9999 -9999 -9999 -9999 -9999 -9999 -9999 -9999 -9999 -9999 -9999 -9999 -9999 -9999 -9999 -9999 -9999 -9999 -9999 -9999 -9999 -9999 -9999 -9999 -9999 -9999 -9999 -9999 -9999 -9999 -9999 -9999 -9999 -9999 -9999 -9999 -9999 -9999 -9999 -9999 -9999 -9999 -9999 -

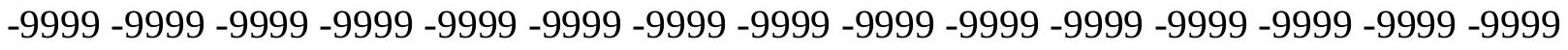
-9999 -9999 -9999 -9999 -9999 -9999 -9999 -9999 -9999 -9999 -9999 -9999 -9999 -9999 -9999 -999 -9999 -9999 -9999 -9999 -9999 -9999 -9999 -9999 -9999 -9999 -9999 -9999 -9999 -9999 -9999 -9999 -9999 -9999 -9999 -9999 -9999 -9999 -9999 -9999 -9999 -9999 -9999 -9999 -9999 -9999 -9999 -9999 -9999 -9999 -9999 -9999 -9999 -9999 -9999 -9999 -9999 -9999 -9999 -9999 -9999 -9999 -9999 -9999 -9999 -9999 -9999 -9999 -9999 -9999 -9999 -9999 -9999 -9999 -9999 -9999 -9999 -9999 -9999 -9999 -9999 -9999 -9999 -9999 -9999 -9999 -9999 -9999 -9999 -9999 -9999 -9999 -9999 -9999 -9999 -9999 -9999 -9999 -9999 -9999 -9999 -9999 -9999 -9999 -9999 -9999 -9999 -9999 -9999 -9999 -9999 -9999 -9999 -9999 -9999 -9999 -9999 -9999 -9999 -9999 -9999 -9999 -9999 -9999 -9999 -9999 -9999 -9999 -9999 -9999 -9999 -9999 -9999 -9999 -9999 -9999 -9999 -9999 -9999 -9999 -9999 -9999 -9999 -9999 -9999 -9999 -9999 -9999 -9999 -9999 -999 -9999 -9999 -9999 -9999 -9999 -9999 -9999 -9999 -9999 -9999 -9999 -9999 -9999 -9999 -9999 -9999 -9999 -9999 -9999 -9999 -9999 -9999 -9999 -9999 -9999 -9999 -9999 -9999 -9999 -

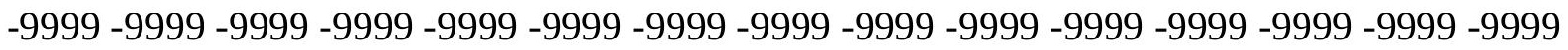

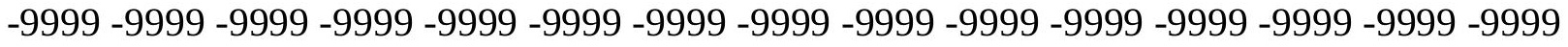

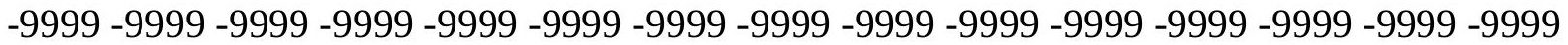
-9999 -9999 -9999 -9999 -9999 -9999 -9999 -9999 -9999 -9999 -9999 -9999 -9999 -9999 -9999 -

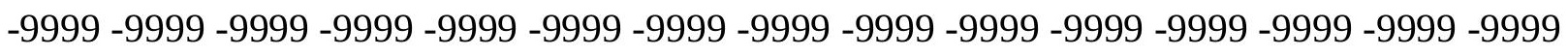

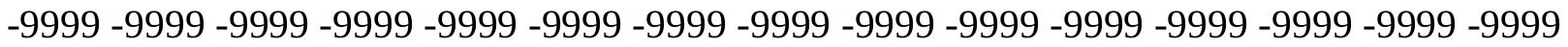

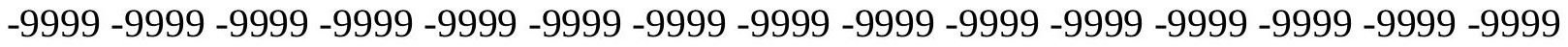
-9999 -9999 -9999 -9999 -9999 -9999 -9999 -9999 -9999 -9999 -9999 -9999 -9999 -9999 -9999 -

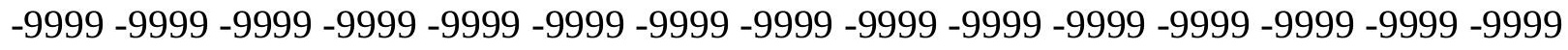

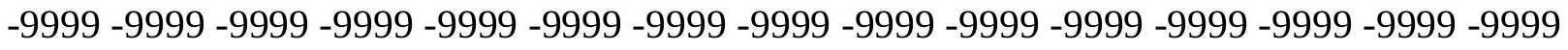
-9999 -9999 -9999 -9999 -9999 -9999 -9999 -9999 -9999 -9999 -9999 -9999 -9999 -9999 -9999 -9999 -9999 -9999 -9999 -9999 -9999 -9999 -9999 -9999-9999 -9999 -9999 -9999 -9999 -9999 -9999 -9999 -9999 -9999 -9999 -9999 -9999 -9999 -9999 -9999 -9999 -9999 -9999 -9999 -9999 -

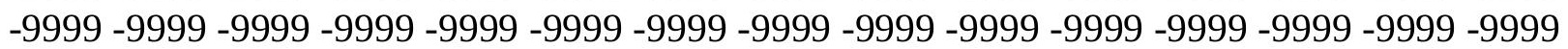


-9999 -9999 -9999 -9999 -9999 -9999 -9999 -9999 -9999 -9999 -9999 -9999 -9999 -9999 -9999 -9999 -9999 -9999 -9999 -9999 -9999 -9999 -9999 -9999 -9999 -9999 -9999 -9999 -9999 -9999 -

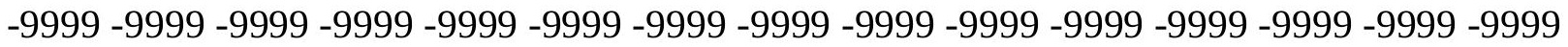
-9999 -9999 -9999 -9999 -9999 -9999 -9999 -9999 -9999 -9999 -9999 -9999 -9999 -9999 -9999 -9999 -9999 -9999 -9999 -9999 -9999 -9999 -9999 -9999-9999 -9999 -9999 -9999 -9999 -9999 -9999 -9999 -9999 -9999 -9999 -9999 -9999 -9999 -9999 -9999 -9999 -9999 -9999 -9999 -9999 -9999 -9999 -9999 -9999 -9999 -9999 -9999 -9999 -9999 -9999 -9999 -9999 -9999 -9999 -9999

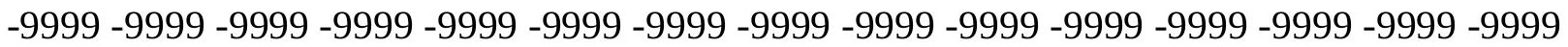

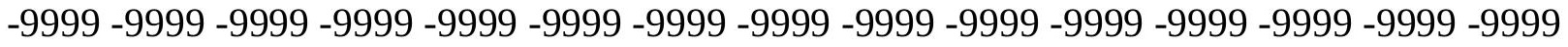
-9999 -9999 -9999 -9999 -9999 -9999 -9999 -9999 -9999 -9999 -9999 -9999 -9999 -9999 -9999 -9999 -9999 -9999 -9999 -9999 -9999 -9999 -9999 -9999 -9999 -9999 -9999 -9999 -9999 -9999 -9999 -9999 -9999 -9999 -9999 -9999 -9999 -9999 -9999 -9999 -9999 -9999 -9999 -9999 -9999 -9999 -9999 -9999 -9999 -9999 -9999 -9999 -9999 -9999 -9999 -9999 -9999 -9999 -9999 -9999 -9999 -9999 -9999 -9999 -9999 -9999 -9999 -9999 -9999 -9999 -9999 -9999 -9999 - 9999 -9999 -9999 -9999 -9999 -9999 -9999 -9999 -9999 -9999 -9999 -9999 -9999 -9999 -9999 -9999

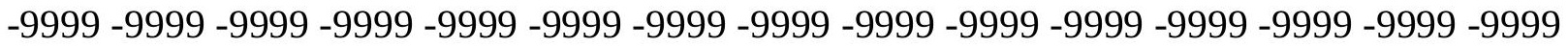
-9999 -9999 -9999 -9999 -9999 -9999 -9999 -9999 -9999 -9999 -9999 -9999 -9999 -9999 -9999 -9999 -9999 -9999 -9999 -9999 -9999 -9999 -9999 -9999 -9999 -9999 -9999 -9999 -9999 -9999 -9999 -9999 -9999 -9999 -9999 -9999 -9999 -9999 -9999 -9999 -9999 -9999 -9999 -9999 -9999 -

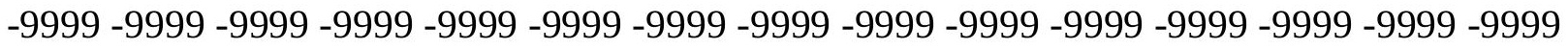

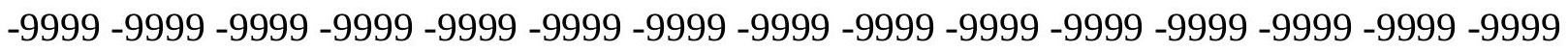
-9999 -9999 -9999 -9999 -9999 -9999 -9999 -9999 -9999 -9999 -9999 -9999 -9999 -9999 -9999 -9999 -9999 -9999 -9999 -9999 -9999 -9999 -9999 -9999 -9999 -9999 -9999 -9999 -9999 -9999 -9999 -9999 -9999 -9999 -9999 -9999 -9999 -9999 -9999 -9999 -9999 -9999 -9999 -9999 -9999 -

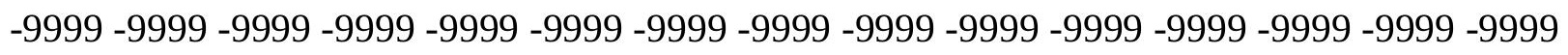
-9999 -9999 -9999 -9999 -9999 -9999 -9999 -9999 -9999 -9999 -9999 -9999 -9999 -9999 -9999 -9999 -9999 -9999 -9999 -9999 -9999 -9999 -9999 -9999 -9999 -9999 -9999 -9999 -9999 -9999 -

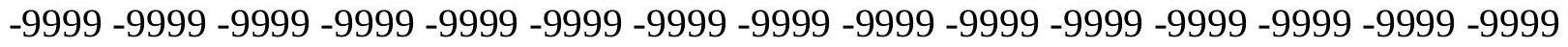
-9999 -9999 -9999 -9999 -9999 -9999 -9999 -9999 -9999 -9999 -9999 -9999 -9999 -9999 -9999 -9999 -9999 -9999 -9999 -9999 -9999 -9999 -9999 -9999 -9999 -9999 -9999 -9999 -9999 -999 -9999 -9999 -9999 -9999 -9999 -9999 -9999 -9999 -9999 -9999 -9999 -9999 -9999 -9999 -9999 -9999 -9999 -9999 -9999 -9999 -9999 -9999 -9999 -9999 -9999 -9999 -9999 -9999 -9999 -9999 -

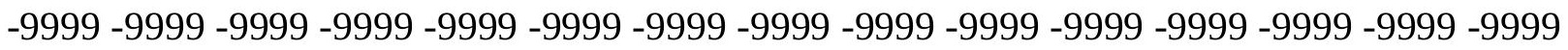

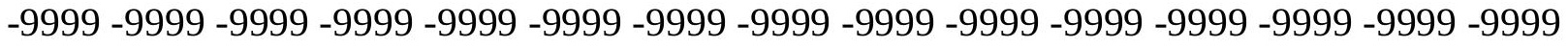

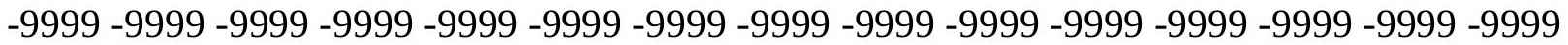

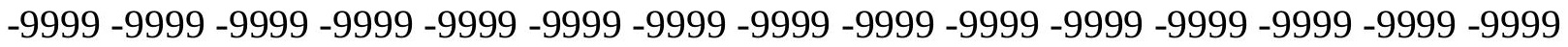

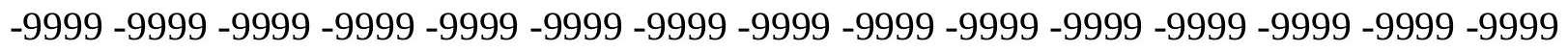

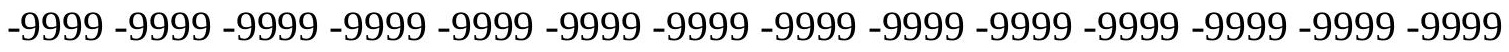
-9999 -9999 -9999 -9999 -9999 -9999 -9999 -9999 -9999 -9999 -9999 -9999 -9999 -9999 -9999 -9999 -9999 -9999 -9999 -9999 -9999 -9999 -9999 -9999 -9999 -9999 -9999 -9999 -9999 -9999 -

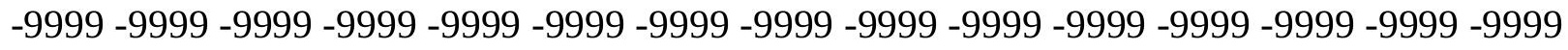

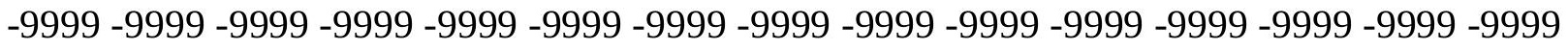
-9999 -9999 -9999 -9999 -9999 -9999 -9999 -9999 -9999 -9999 -9999 -9999 -9999 -9999 -9999 -9999 -9999 -9999 -9999 -9999 -9999 -9999 -9999 -9999-9999 -9999 -9999 -9999 -9999 -9999 -9999 -9999 -9999 -9999 -9999 -9999 -9999 -9999 -9999 -9999 -9999 -9999 -9999 -9999 -9999 -

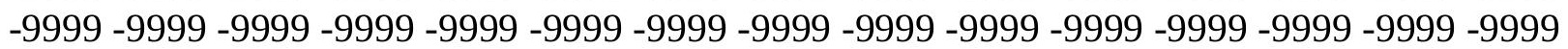


-9999 -9999 -9999 -9999 -9999 -9999 -9999 -9999 -9999 -9999 -9999 -9999 -9999 -9999 -9999 -9999 -9999 -9999 -9999 -9999 -9999 -9999 -9999 -9999 -9999 -9999 -9999 -9999 -9999 -9999 -9999 -9999 -9999 -9999 -9999 -9999 -9999 -9999 -9999 -9999 -9999 -9999 -9999 -9999 - 9999 -9999 -9999 -9999 -9999 -9999 -9999 -9999 -9999 -9999 -9999 -9999 -9999 -9999 -9999 -9999 -9999 -9999 -9999 -9999 -9999 -9999 -9999 -9999 -9999 -9999 -9999 -9999 -9999 -9999 -9999 -9999 -9999 -9999 -9999 -9999 -9999 -9999 -9999 -9999 -9999 -9999 -9999 -9999 -9999 -9999 -9999 -9999 -9999 -9999 -9999 -9999 -9999 -9999 -9999 -9999 -9999 -9999 -9999 -9999 -9999

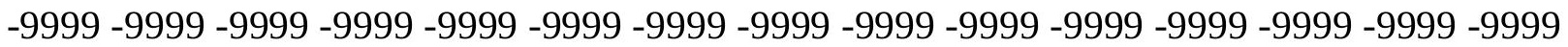
-9999 -9999 -9999 -9999 -9999 -9999 -9999 -9999 -9999 -9999 -9999 -9999 -9999 -9999 -9999 -9999 -9999 -9999 -9999 -9999 -9999 -9999 -9999 -9999 -9999 -9999 -9999 -9999 -9999 -9999

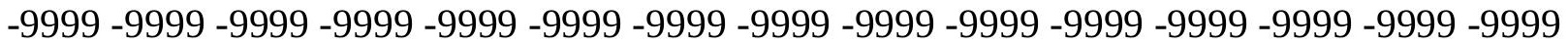
-9999 -9999 -9999 -9999 -9999 -9999 -9999 -9999 -9999 -9999 -9999 -9999 -9999 -9999 -9999 -9999 -9999 -9999 -9999 -9999 -9999 -9999 -9999 -9999 -9999 -9999 -9999 -9999 -9999 -9999 -

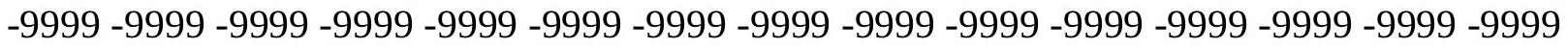
-9999 -9999 -9999 -9999 -9999 -9999 -9999 -9999 -9999 -9999 -9999 -9999 -9999 -9999 -9999

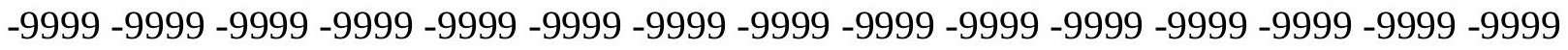
-9999 -9999 -9999 -9999 -9999 -9999 -9999 -9999 -9999 -9999 -9999 -9999 -9999 -9999 -9999 -9999 -9999 -9999 -9999 -9999 -9999 -9999 -9999 -9999 -9999 -9999 -9999 -9999 -9999 - -999 -9999 -9999 -9999 -9999 -9999 -9999 -9999 -9999 -9999 -9999 -9999 -9999 -9999 -9999 -9999 -9999 -9999 -9999 -9999 -9999 -9999 -9999 -9999 -9999 -9999 -9999 -9999 -9999 -9999 -9999 -9999 -9999 -9999 -9999 -9999 -9999 -9999 -9999 -9999 -9999 -9999 -9999 -9999 -9999 -9999 -999 -9999 -9999 -9999 -9999 -9999 -9999 -9999 -9999 -9999 -9999 -9999 -9999 -9999 -9999 -9999 -9999 -9999 -9999 -9999 -9999 -9999 -9999 -9999 -9999 -9999 -9999 -9999 -9999 -9999 -9999 -9999 -9999 -9999 -9999 -9999 -9999 -9999 -9999 -9999 -9999 -9999 -9999 -9999 -9999 -9999 -9999 -9999 -9999 -9999 -9999 -9999 -9999 -9999 -9999 -9999 -9999 -9999 -9999 -9999 -9999 -9999 -9999 -9999 -9999 -9999 -9999 -9999 -9999 -9999 -9999 -9999 -9999 -9999 -9999 -9999 -9999 -9999 -9999 -9999 -9999 -9999 -9999 -9999 -9999 -9999 -9999 -9999 -9999 -9999 -9999 -9999 -9999 -9999 -9999 -9999 -9999 -9999 -9999 -9999 -9999 -9999 -9999 -9999 -9999 -9999 -9999 -9999 -9999 -9999 -9999 -9999 -9999 -9999 -9999 -9999 -9999 -9999 -9999 -9999 -9999 -9999 -9999 -9999 -9999 -9999 -9999 -9999 -9999 -9999 -9999 -9999 -9999 -9999 -9999 -999 -9999 -9999 -9999 -9999 -9999 -9999 -9999 -9999 -9999 -9999 -9999 -9999 -9999 -9999 -9999 -9999 -9999 -9999 -9999 -9999 -9999 -9999 -9999 -9999 -9999 -9999 -9999 -9999 -9999 -9999 -

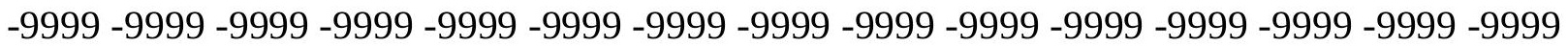

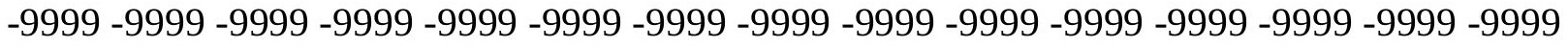

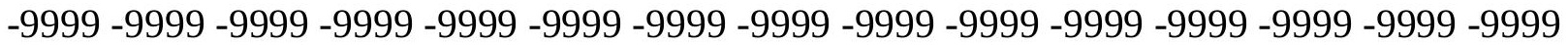
-9999 -9999 -9999 -9999 -9999 -9999 -9999 -9999 -9999 -9999 -9999 -9999 -9999 -9999 -9999

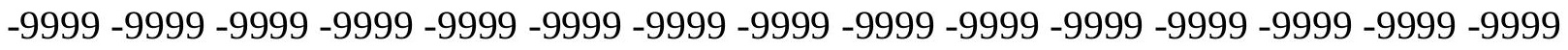

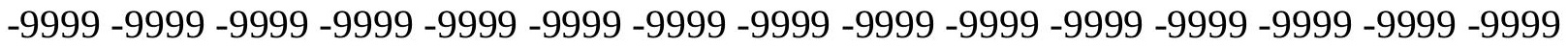

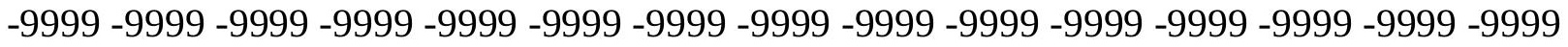
-9999 -9999 -9999 -9999 -9999 -9999 -9999 -9999 -9999 -9999 -9999 -9999 -9999 -9999 -9999 -

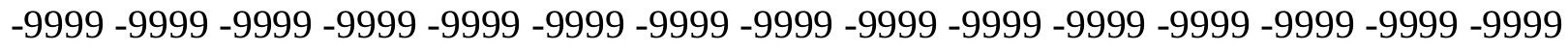

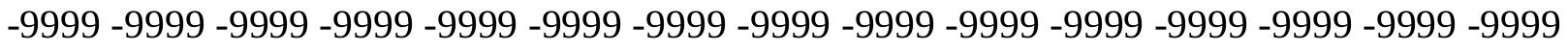
-9999 -9999 -9999 -9999 -9999 -9999 -9999 -9999 -9999 -9999 -9999 -9999 -9999 -9999 -9999 -9999 -9999 -9999 -9999 -9999 -9999 -9999 -9999 -9999 -9999 -9999 -9999 -9999 - -9999 -9999 -9999 -9999 -9999 -9999 -9999 -9999 -9999 -9999 -9999 -9999 -9999 -9999 -9999 -9999 -

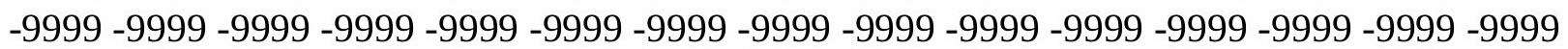


-9999 -9999 -9999 -9999 -9999 -9999 -9999 -9999 -9999 -9999 -9999 -9999 -9999 -9999 -9999 -9999 -9999 -9999 -9999 -9999 -9999 -9999 -9999 -9999 -9999 -9999 -9999 -9999 -9999 -9999 -9999 -9999 -9999 -9999 -9999 -9999 -9999 -9999 -9999 -9999 -9999 -9999 -9999 -9999 - 9999 -9999 -9999 -9999 -9999 -9999 -9999 -9999 -9999 -9999 -9999 -9999 -9999 -9999 -9999 -9999 -9999 -9999 -9999 -9999 -9999 -9999 -9999 -9999 -9999-9999 -9999 -9999 -9999 -9999 -9999 -9999 -9999 -9999 -9999 -9999 -9999 -9999 -9999 -9999 -9999 -9999 -9999 -9999 -9999 -9999 -9999 -9999 -9999 -9999 -9999 -9999 -9999 -9999 -9999 -9999 -9999 -9999 -9999 -9999 -9999

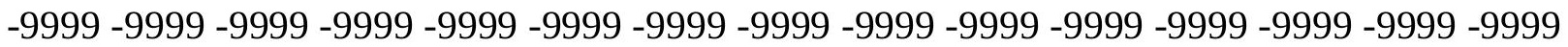

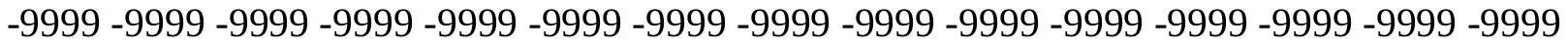
-9999 -9999 -9999 -9999 -9999 -9999 -9999 -9999 -9999 -9999 -9999 -9999 -9999 -9999 -9999

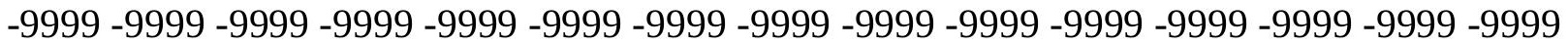
-9999 -9999 -9999 -9999 -9999 -9999 -9999 -9999 -9999 -9999 -9999 -9999 -9999 -9999 -9999 -9999 -9999 -9999 -9999 -9999 -9999 -9999 -9999 -9999 -9999 -9999 -9999 -9999 -9999 -9999 -

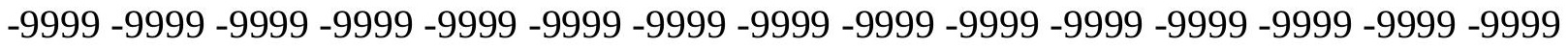
-9999 -9999 -9999 -9999 -9999 -9999 -9999 -9999 -9999 -9999 -9999 -9999 -9999 -9999 -9999

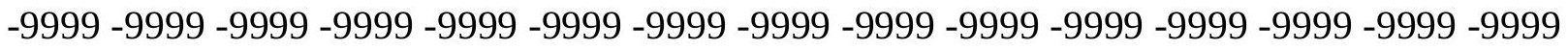
-9999 -9999 -9999 -9999 -9999 -9999 -9999 -9999 -9999 -9999 -9999 -9999 -9999 -9999 -9999 -9999 -9999 -9999 -9999 -9999 -9999 -9999 -9999 -9999 -9999 -9999 -9999 -9999 -9999 -9999 -9999 -9999 -9999 -9999 -9999 -9999 -9999 -9999 -9999 -9999 -9999 -9999 -9999 -9999 -9999 -9999 -9999 -9999 -9999 -9999 -9999 -9999 -9999 -9999 -9999 -9999 -9999 -9999 -9999 -9999 -9999 -9999 -9999 -9999 -9999 -9999 -9999 -9999 -9999 -9999 -9999 -9999 -9999 -9999 -9999 -999 -9999 -9999 -9999 -9999 -9999 -9999 -9999 -9999 -9999 -9999 -9999 -9999 -9999 -9999 -9999 -9999 -9999 -9999 -9999 -9999 -9999 -9999 -9999 -9999 -9999 -9999 -9999 -9999 -9999 -9999 -9999 -9999 -9999 -9999 -9999 -9999 -9999 -9999 -9999 -9999 -9999 -9999 -9999 -9999 -9999 -9999 -9999 -9999 -9999 -9999 -9999 -9999 -9999 -9999 -9999 -9999 -9999 -9999 -9999 -9999 -9999 -9999 -9999 -9999 -9999 -9999 -9999 -9999 -9999 -9999 -9999 -9999 -9999 -9999 -9999 -9999 -9999 -9999 -9999 -9999 -9999 -9999 -9999 -9999 -9999 -9999 -9999 -9999 -9999 -9999 -9999 -9999 -9999 -9999 -9999 -9999 -9999 -9999 -9999 -9999 -9999 -9999 -9999 -9999 -9999 -9999 -9999 -9999 -9999 -9999 -9999 -9999 -9999 -9999 -9999 -9999 -9999 -9999 -9999 -9999 -9999 -9999 -9999 -9999 -9999 -9999 -9999 -9999 -9999 -9999 -9999 -9999 -9999 -999 -9999 -9999 -9999 -9999 -9999 -9999 -9999 -9999 -9999 -9999 -9999 -9999 -9999 -9999 -9999 -9999 -9999 -9999 -9999 -9999 -9999 -9999 -9999 -9999 -9999 -9999 -9999 -9999 -9999 -9999 -

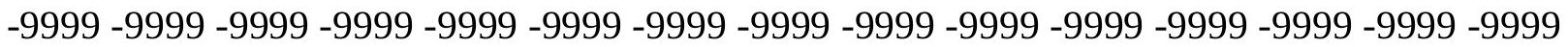

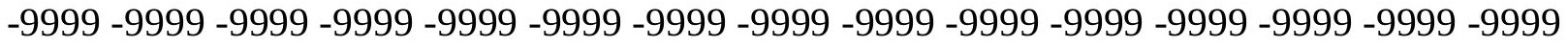

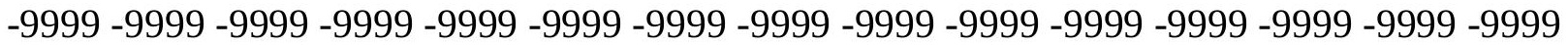
-9999 -9999 -9999 -9999 -9999 -9999 -9999 -9999 -9999 -9999 -9999 -9999 -9999 -9999 -9999

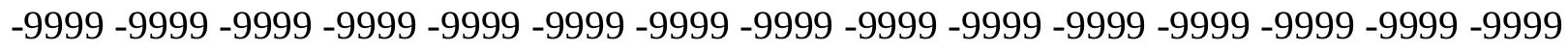

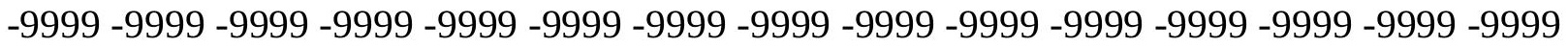
-9999 -9999 -9999 -9999 -9999 -9999 -9999 -9999 -9999 -9999 -9999 -9999 -9999 -9999 -9999 -9999 -9999 -9999 -9999 -9999 -9999 -9999 -9999 -9999 -9999 -9999 -9999 -9999 -9999 -9999 -

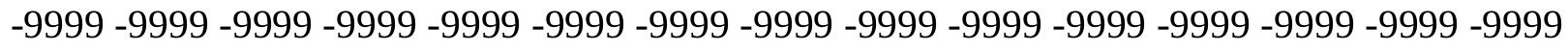

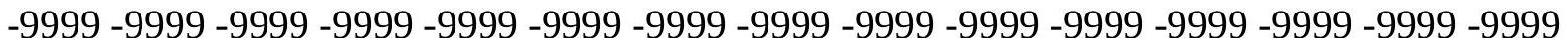
-9999 -9999 -9999 -9999 -9999 -9999 -9999 -9999 -9999 -9999 -9999 -9999 -9999 -9999 -9999 -9999 -9999 -9999 -9999 -9999 -9999 -9999 -9999 -9999-9999 -9999 -9999 -9999 -9999 -9999 -9999 -9999 -9999 -9999 -9999 -9999 -9999 -9999 -9999 -9999 -9999 -9999 -9999 -9999 -9999 -

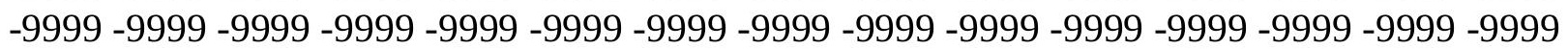


-9999 -9999 -9999 -9999 -9999 -9999 -9999 -9999 -9999 -9999 -9999 -9999 -9999 -9999 -9999 -9999 -9999 -9999 -9999 -9999 -9999 -9999 -9999 -9999 -9999 -9999 -9999 -9999 -9999 -9999 -9999 -9999 -9999 -9999 -9999 -9999 -9999 -9999 -9999 -9999 -9999 -9999 -9999 -9999 - 9999 -9999 -9999 -9999 -9999 -9999 -9999 -9999 -9999 -9999 -9999 -9999 -9999 -9999 -9999

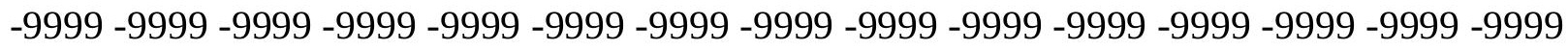
-9999 -9999 -9999 -9999 -9999 -9999 -9999 -9999 -9999 -9999 -9999 -9999 -9999 -9999 -9999 -9999 -9999 -9999 -9999 -9999 -9999 -9999 -9999 -9999 -9999 -9999 -9999 -9999 -9999 -9999

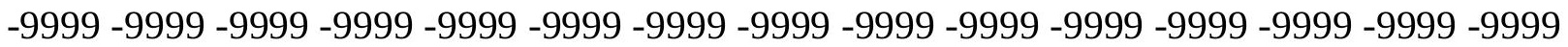

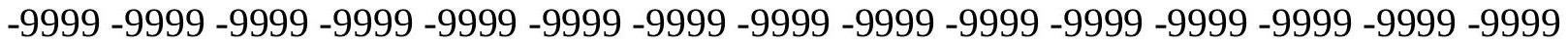
-9999 -9999 -9999 -9999 -9999 -9999 -9999 -9999 -9999 -9999 -9999 -9999 -9999 -9999 -9999 -9999 -9999 -9999 -9999 -9999 -9999 -9999 -9999 -9999 -9999 -9999 -9999 -9999 -9999 -9999 -9999 -9999 -9999 -9999 -9999 -9999 -9999 -9999 -9999 -9999 -9999 -9999 -9999 -9999 -9999 -9999 -9999 -9999 -9999 -9999 -9999 -9999 -9999 -9999 -9999 -9999 -9999 -9999 -9999 -9999 -

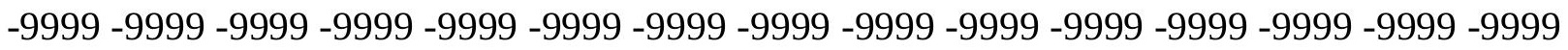
-9999 -9999 -9999 -9999 -9999 -9999 -9999 -9999 -9999 -9999 -9999 -9999 -9999 -9999 -9999 -

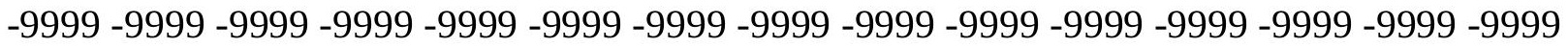
-9999 -9999 -9999 -9999 -9999 -9999 -9999 -9999 -9999 -9999 -9999 -9999 -9999 -9999 -9999 -9999 -9999 -9999 -9999 -9999 -9999 -9999 -9999 -9999 -9999 -9999 -9999 -9999 -9999 -9999 -9999 -9999 -9999 -9999 -9999 -9999 -9999 -9999 -9999 -9999 -9999 -9999 -9999 -9999 -9999 -

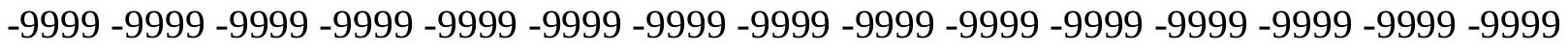
-9999 -9999 -9999 -9999 -9999 -9999 -9999 -9999 -9999 -9999 -9999 -9999 -9999 -9999 -9999

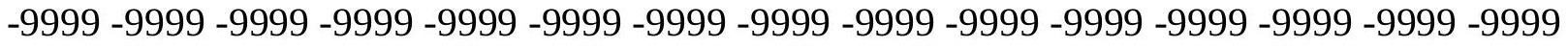
-9999 -9999 -9999 -9999 -9999 -9999 -9999 -9999 -9999 -9999 -9999 -9999 -9999 -9999 -9999 -9999 -9999 -9999 -9999 -9999 -9999 -9999 -9999 -9999 -9999 -9999 -9999 -9999 -9999 -9999 -9999 -9999 -9999 -9999 -9999 -9999 -9999 -9999 -9999 -9999 -9999 -9999 -9999 -9999 -9999 -9999 -9999 -9999 -9999 -9999 -9999 -9999 -9999 -9999 -9999 -9999 -9999 -9999 -9999 -9999 -9999 -9999 -9999 -9999 -9999 -9999 -9999 -9999 -9999 -9999 -9999 -9999 -9999 -9999 -9999 -9999 -9999 -9999 -9999 -9999 -9999 -9999 -9999 -9999 -9999 -9999 -9999 -9999 -9999 -9999 -9999 -9999 -9999 -9999 -9999 -9999 -9999 -9999 -9999 -9999 -9999 -9999 -9999 -9999 -9999 -9999 -9999 -9999 -9999 -9999 -9999 -9999 -9999 -9999 -9999 -9999 -9999 -9999 -9999 -9999 -9999 -9999 -9999 -9999 -9999 -9999 -9999 -9999 -9999 -9999 -9999 -9999 -9999 -9999 -9999 -9999 -9999 -9999 -9999 -9999 -9999 -9999 -9999 -9999 -9999 -9999 -9999 -9999 -9999 -

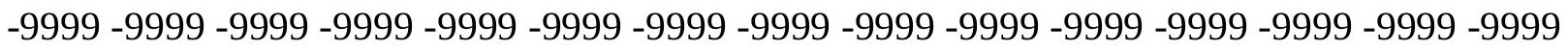

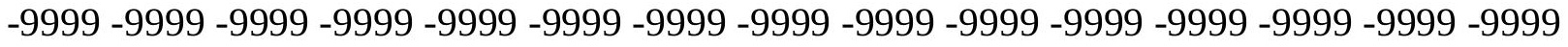
-9999 -9999 -9999 -9999 -9999 -9999 -9999 -9999 -9999 -9999 -9999 -9999 -9999 -9999 -9999 -

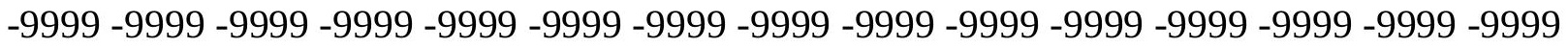

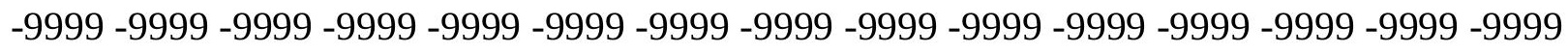

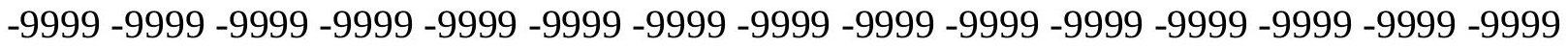

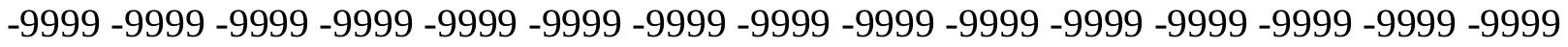
-9999 -9999 -9999 -9999 -9999 -9999 -9999 -9999 -9999 -9999 -9999 -9999 -9999 -9999 -9999 -

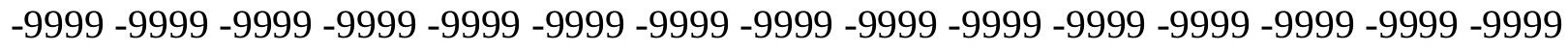

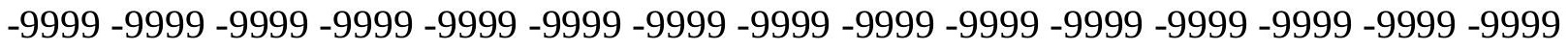
-9999 -9999 -9999 -9999 -9999 -9999 -9999 -9999 -9999 -9999 -9999 -9999 -9999 -9999 -9999 -9999 -9999 -9999 -9999 -9999 -9999 -9999 -9999 -9999-9999 -9999 -9999 -9999 -9999 -9999 -9999 -9999 -9999 -9999 -9999 -9999 -9999 -9999 -9999 -9999 -9999 -9999 -9999 -9999 -9999 -

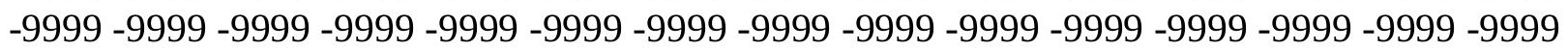


-9999 -9999 -9999 -9999 -9999 -9999 -9999 -9999 -9999 -9999 -9999 -9999 -9999 -9999 -9999 -9999 -9999 -9999 -9999 -9999 -9999 -9999 -9999 -9999 -9999 -9999 -9999 -9999 -9999 -9999 -9999 -9999 -9999 -9999 -9999 -9999 -9999 -9999 -9999 -9999 -9999 -9999 -9999 -9999 - 9999 -9999 -9999 -9999 -9999 -9999 -9999 -9999 -9999 -9999 -9999 -9999 -9999 -9999 -9999 -9999 -9999 -9999 -9999 -9999 -9999 -9999 -9999 -9999 -9999 -9999 -9999 -9999 -9999 -9999 -9999 -9999 -9999 -9999 -9999 -9999 -9999 -9999 -9999 -9999 -9999 -9999 -9999 -9999 -9999 -9999 -9999 -9999 -9999 -9999 -9999 -9999 -9999 -9999 -9999 -9999 -9999 -9999 -9999 -9999 -9999

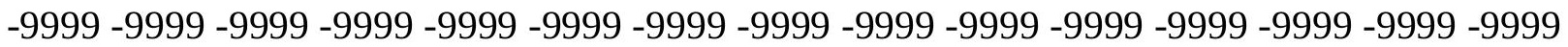

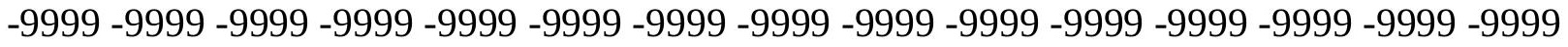
-9999 -9999 -9999 -9999 -9999 -9999 -9999 -9999 -9999 -9999 -9999 -9999 -9999 -9999 -9999 -9999 -9999 -9999 -9999 -9999 -9999 -9999 -9999 -9999 -9999 -9999 -9999 -9999 -9999 -9999 -9999 -9999 -9999 -9999 -9999 -9999 -9999 -9999 -9999 -9999 -9999 -9999 -9999 -9999 -9999 -9999 -9999 -9999 -9999 -9999 -9999 -9999 -9999 -9999 -9999 -9999 -9999 -9999 -9999 -9999 -9999 -9999 -9999 -9999 -9999 -9999 -9999 -9999 -9999 -9999 -9999 -9999 -9999 -9999 -9999 -9999 -9999 -9999 -9999 -9999 -9999 -9999 -9999 -9999 -9999 -9999 -9999 -9999 -9999 -

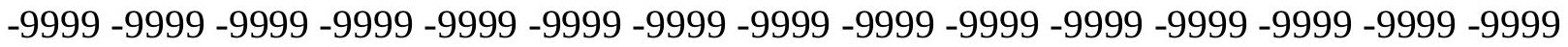
-9999 -9999 -9999 -9999 -9999 -9999 -9999 -9999 -9999 -9999 -9999 -9999 -9999 -9999 -9999 -9999 -9999 -9999 -9999 -9999 -9999 -9999 -9999 -9999 -9999 -9999 -9999 -9999 -9999 -9999 -9999 -9999 -9999 -9999 -9999 -9999 -9999 -9999 -9999 -9999 -9999 -9999 -9999 -9999 -9999 -9999 -9999 -9999 -9999 -9999 -9999 -9999 -9999 -9999 -9999 -9999 -9999 -9999 -9999 -9999 -9999 -9999 -9999 -9999 -9999 -9999 -9999 -9999 -9999 -9999 -9999 -9999 -9999 -9999 -9999 -999 -9999 -9999 -9999 -9999 -9999 -9999 -9999 -9999 -9999 -9999 -9999 -9999 -9999 -9999 -9999 -9999 -9999 -9999 -9999 -9999 -9999 -9999 -9999 -9999 -9999 -9999 -9999 -9999 -9999 -9999 -9999 -9999 -9999 -9999 -9999 -9999 -9999 -9999 -9999 -9999 -9999 -9999 -9999 -9999 -9999 -9999 -9999 -9999 -9999 -9999 -9999 -9999 -9999 -9999 -9999 -9999 -9999 -9999 -9999 -9999 -9999 -9999 -9999 -9999 -9999 -9999 -9999 -9999 -9999 -9999 -9999 -9999 -9999 -9999 -9999 -9999 -9999 -9999 -9999 -9999 -9999 -9999 -9999 -9999 -9999 -9999 -9999 -9999 -9999 -9999 -9999 -9999 -9999 -9999 -9999 -9999 -9999 -9999 -9999 -9999 -9999 -9999 -9999 -9999 -9999 -9999 -9999 -9999 -9999 -9999 -9999 -9999 -9999 -9999 -9999 -9999 -9999 -9999 -9999 -9999 -9999 -9999 -9999 -9999 -9999 -9999 -9999 -9999 -9999 -9999 -9999 -9999 -9999 -9999 -999 -9999 -9999 -9999 -9999 -9999 -9999 -9999 -9999 -9999 -9999 -9999 -9999 -9999 -9999 -9999 -9999 -9999 -9999 -9999 -9999 -9999 -9999 -9999 -9999 -9999 -9999 -9999 -9999 -9999 -9999 -

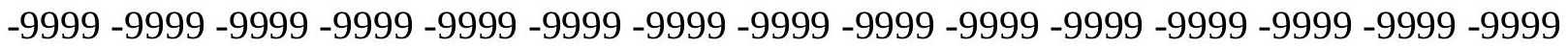

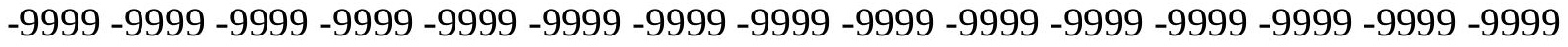

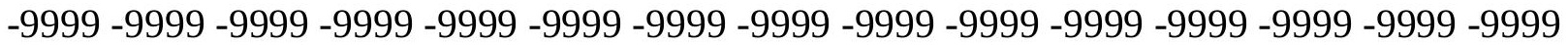
-9999 -9999 -9999 -9999 -9999 -9999 -9999 -9999 -9999 -9999 -9999 -9999 -9999 -9999 -9999 -9999 -9999 -9999 -9999 -9999 -9999 -9999 -9999 -9999 -9999 -9999 -9999 -9999 -9999 -

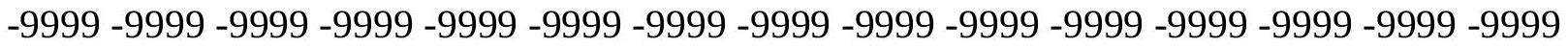
-9999 -9999 -9999 -9999 -9999 -9999 -9999 -9999 -9999 -9999 -9999 -9999 -9999 -9999 -9999 -9999 -9999 -9999 -9999 -9999 -9999 -9999 -9999 -9999 -9999 -9999 -9999 -9999 -9999 -9999 -

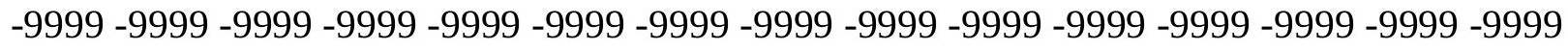

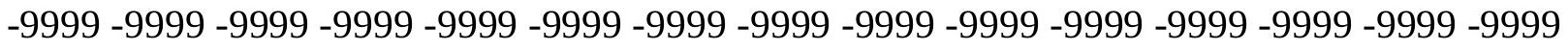
-9999 -9999 -9999 -9999 -9999 -9999 -9999 -9999 -9999 -9999 -9999 -9999 -9999 -9999 -9999 -9999 -9999 -9999 -9999 -9999 -9999 -9999 -9999 -9999-9999 -9999 -9999 -9999 -9999 -9999 -9999 -9999 -9999 -9999 -9999 -9999 -9999 -9999 -9999 -9999 -9999 -9999 -9999 -9999 -9999 -

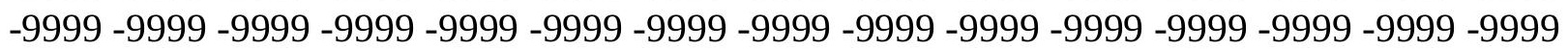


-9999 -9999 -9999 -9999 -9999 -9999 -9999 -9999 -9999 -9999 -9999 -9999 -9999 -9999 -9999 -9999 -9999 -9999 -9999 -9999 -9999 -9999 -9999 -9999 -9999 -9999 -9999 -9999 -9999 -9999 -

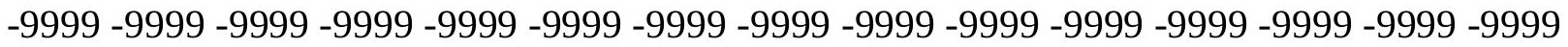
-9999 -9999 -9999 -9999 -9999 -9999 -9999 -9999 -9999 -9999 -9999 -9999 -9999 -9999 -9999 -9999 -9999 -9999 -9999 -9999 -9999 -9999 -9999 -9999-9999 -9999 -9999 -9999 -9999 -9999 -9999 -9999 -9999 -9999 -9999 -9999 -9999 -9999 -9999 -9999 -9999 -9999 -9999 -9999 -9999 -9999 -9999 -9999 -9999 -9999 -9999 -9999 -9999 -9999 -9999 -9999 -9999 -9999 -9999 -9999

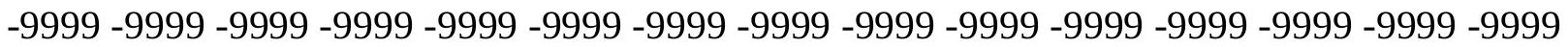

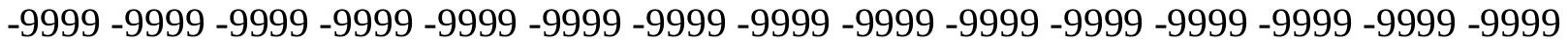
-9999 -9999 -9999 -9999 -9999 -9999 -9999 -9999 -9999 -9999 -9999 -9999 -9999 -9999 -9999 -9999 -9999 -9999 -9999 -9999 -9999 -9999 -9999 -9999 -9999 -9999 -9999 -9999 -9999 -9999 -9999 -9999 -9999 -9999 -9999 -9999 -9999 -9999 -9999 -9999 -9999 -9999 -9999 -9999 -9999 -9999 -9999 -9999 -9999 -9999 -9999 -9999 -9999 -9999 -9999 -9999 -9999 -9999 -9999 -9999 -9999 -9999 -9999 -9999 -9999 -9999 -9999 -9999 -9999 -9999 -9999 -9999 -9999 -9999 -9999 -9999 -9999 -9999 -9999 -9999 -9999 -9999 -9999 -9999 -9999 -9999 -9999 -9999 -9999 -9999 -

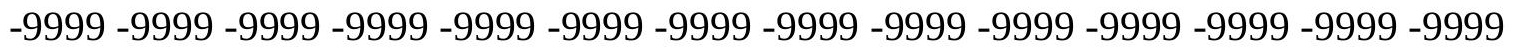
-9999 -9999 -9999 -9999 -9999 -9999 -9999 -9999 -9999 -9999 -9999 -9999 -9999 -9999 -9999 -9999 -9999 -9999 -9999 -9999 -9999 -9999 -9999 -9999 -9999 -9999 -9999 -9999 -9999 -9999 -9999 -9999 -9999 -9999 -9999 -9999 -9999 -9999 -9999 -9999 -9999 -9999 -9999 -9999 -9999 -

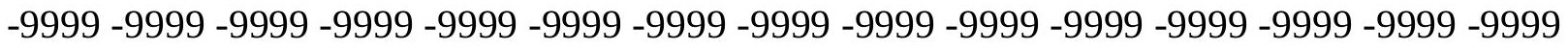

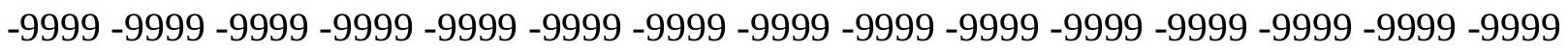
-9999 -9999 -9999 -9999 -9999 -9999 -9999 -9999 -9999 -9999 -9999 -9999 -9999 -9999 - 9999 -9999 -9999 -9999 -9999 -9999 -9999 -9999 -9999 -9999 -9999 -9999 -9999 -9999 -9999 -9999 -9999 -9999 -9999 -9999 -9999 -9999 -9999 -9999 -9999 -9999 -9999 -9999 -9999 -9999 -9999 -

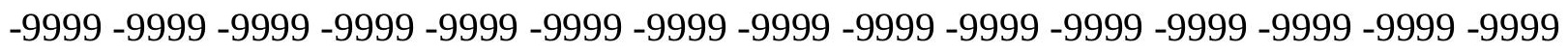
-9999 -9999 -9999 -9999 -9999 -9999 -9999 -9999 -9999 -9999 -9999 -9999 -9999 -9999 -9999 -9999 -9999 -9999 -9999 -9999 -9999 -9999 -9999 -9999 -9999 -9999 -9999 -9999 -9999 -9999 -

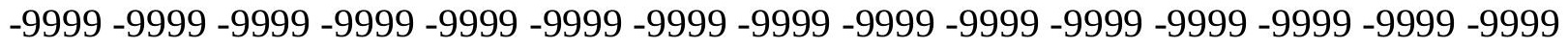
-9999 -9999 -9999 -9999 -9999 -9999 -9999 -9999 -9999 -9999 -9999 -9999 -9999 -9999 -9999 -9999 -9999 -9999 -9999 -9999 -9999 -9999 -9999 -9999 -9999 -9999 -9999 -9999 -9999 -999 -

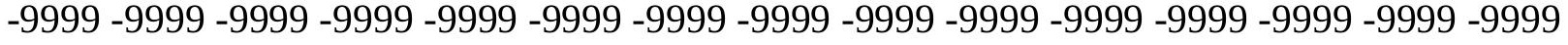
-9999 -9999 -9999 -9999 -9999 -9999 -9999 -9999 -9999 -9999 -9999 -9999 -9999 -9999 -9999 -

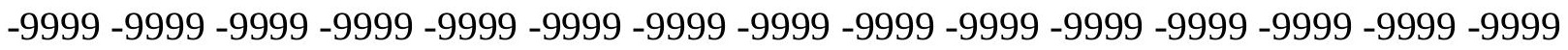

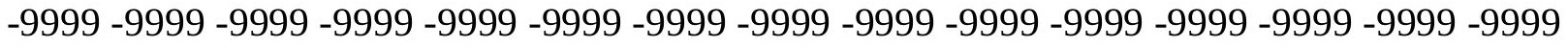

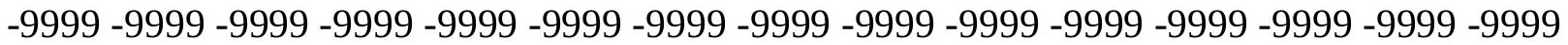
-9999 -9999 -9999 -9999 -9999 -9999 -9999 -9999 -9999 -9999 -9999 -9999 -9999 -9999 -9999 -

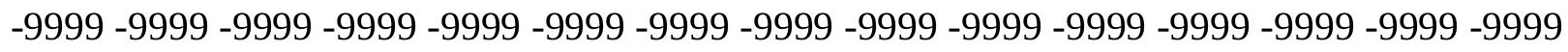

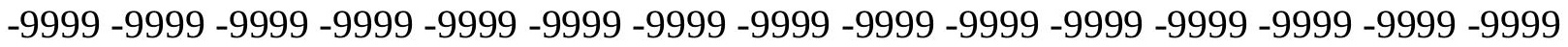
-9999 -9999 -9999 -9999 -9999 -9999 -9999 -9999 -9999 -9999 -9999 -9999 -9999 - 9999 - -999 -9999 -9999 -9999 -9999 -9999 -9999 -9999 -9999 -9999 -9999 -9999 -9999 -9999 -9999 -9999 -

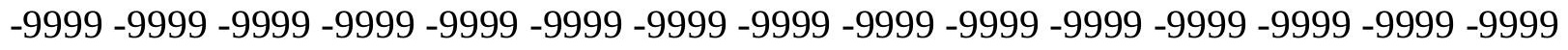

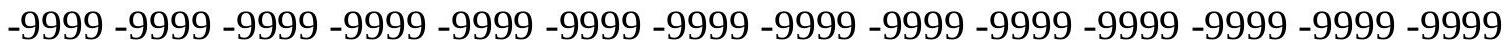
-9999 -9999 -9999 -9999 -9999 -9999 -9999 -9999 -9999 -9999 -9999 -9999 -9999 -9999 -9999 -9999 -9999 -9999 -9999 -9999 -9999 -9999 -9999 -9999-9999 -9999 -9999 -9999 -9999 -9999 -9999 -9999 -9999 -9999 -9999 -9999 -9999 -9999 -9999 -9999 -9999 -9999 -9999 -9999 -9999 -

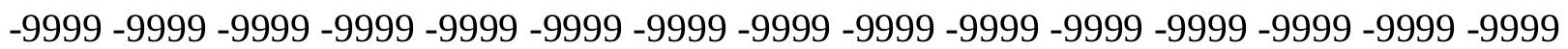


-9999 -9999 -9999 -9999 -9999 -9999 -9999 -9999 -9999 -9999 -9999 -9999 -9999 -9999 -9999 -9999 -9999 -9999 -9999 -9999 -9999 -9999 -9999 -9999 -9999 -9999 -9999 -9999 -9999 -9999 -

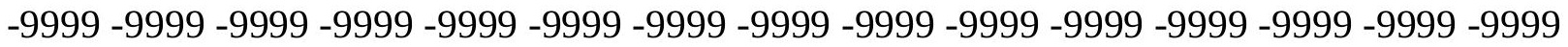
-9999 -9999 -9999 -9999 -9999 -9999 -9999 -9999 -9999 -9999 -9999 -9999 -9999 -9999 -9999 -9999 -9999 -9999 -9999 -9999 -9999 -9999 -9999 -9999-9999 -9999 -9999 -9999 -9999 -9999 -9999 -9999 -9999 -9999 -9999 -9999 -9999 -9999 -9999 -9999 -9999 -9999 -9999 -9999 -9999 -9999 -9999 -9999 -9999 -9999 -9999 -9999 -9999 -9999 -9999 -9999 -9999 -9999 -9999 -9999

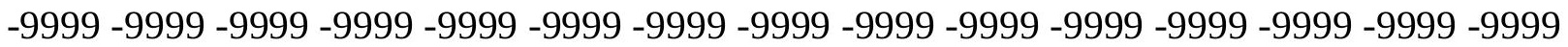

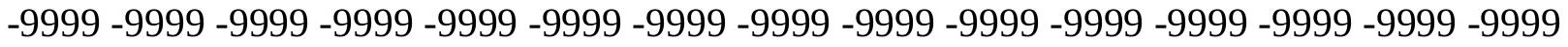
-9999 -9999 -9999 -9999 -9999 -9999 -9999 -9999 -9999 -9999 -9999 -9999 -9999 -9999 -9999 -9999 -9999 -9999 -9999 -9999 -9999 -9999 -9999 -9999 -9999 -9999 -9999 -9999 -9999 -9999 -9999 -9999 -9999 -9999 -9999 -9999 -9999 -9999 -9999 -9999 -9999 -9999 -9999 -9999 -9999 -9999 -9999 -9999 -9999 -9999 -9999 -9999 -9999 -9999 -9999 -9999 -9999 -9999 -9999 -9999 -

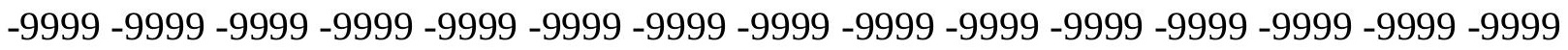
-9999 -9999 -9999 -9999 -9999 -9999 -9999 -9999 -9999 -9999 -9999 -9999 -9999 -9999 -9999 -

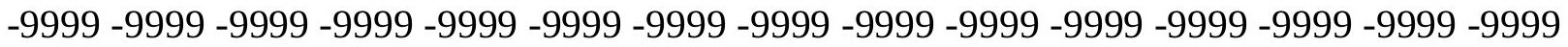
-9999 -9999 -9999 -9999 -9999 -9999 -9999 -9999 -9999 -9999 -9999 -9999 -9999 -9999 -9999 -9999 -9999 -9999 -9999 -9999 -9999 -9999 -9999 -9999 -9999 -9999 -9999 -9999 -9999 -9999 -9999 -9999 -9999 -9999 -9999 -9999 -9999 -9999 -9999 -9999 -9999 -9999 -9999 -9999 -9999 -

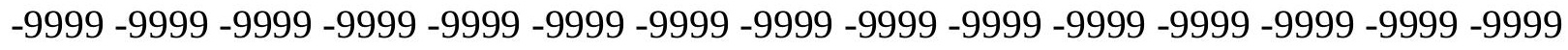

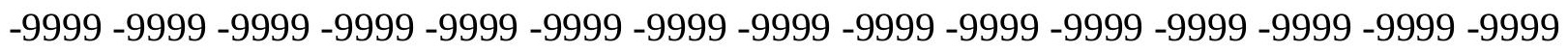
-9999 -9999 -9999 -9999 -9999 -9999 -9999 -9999 -9999 -9999 -9999 -9999 -9999 -9999 -9999 -9999 -9999 -9999 -9999 -9999 -9999 -9999 -9999 -9999 -9999 -9999 -9999 -9999 -9999 -9999 -9999 -9999 -9999 -9999 -9999 -9999 -9999 -9999 -9999 -9999 -9999 -9999 -9999 -9999 -

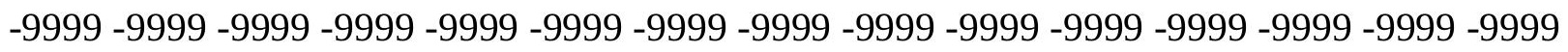
-9999 -9999 -9999 -9999 -9999 -9999 -9999 -9999 -9999 -9999 -9999 -9999 -9999 -9999 -9999 -9999 -9999 -9999 -9999 -9999 -9999 -9999 -9999 -9999 -9999 -9999 -9999 -9999 -9999 -9999 -

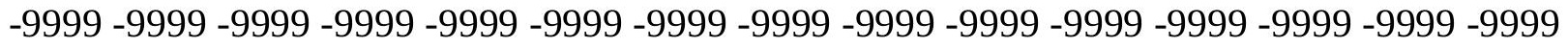
-9999 -9999 -9999 -9999 -9999 -9999 -9999 -9999 -9999 -9999 -9999 -9999 -9999 -9999 -9999 -9999 -9999 -9999 -9999 -9999 -9999 -9999 -9999 -9999 -9999 -9999 -9999 -9999 -9999 -999 -

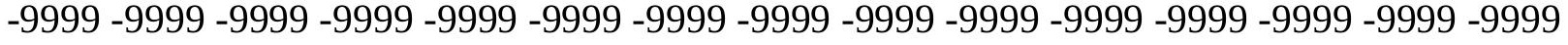
-9999 -9999 -9999 -9999 -9999 -9999 -9999 -9999 -9999 -9999 -9999 -9999 -9999 -9999 -9999 -

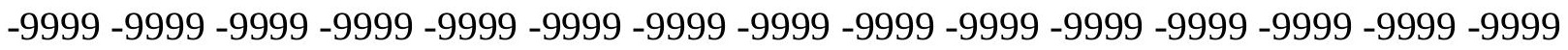

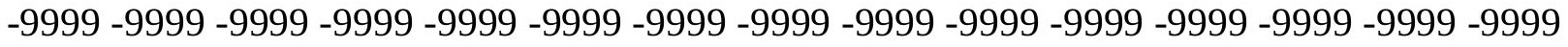

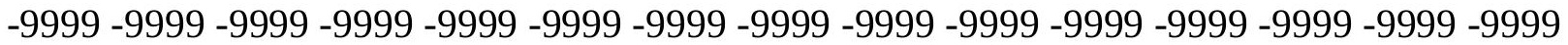

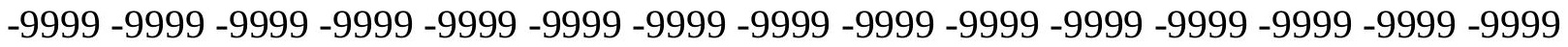

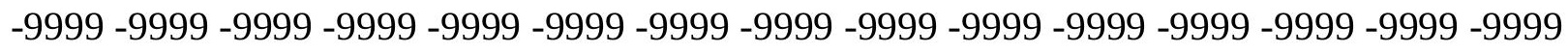

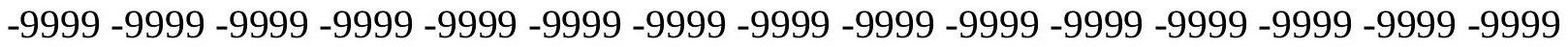

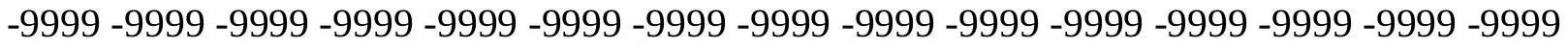
-9999 -9999 -9999 -9999 -9999 -9999 -9999 -9999 -9999 -9999 -9999 -9999 -9999 -9999 -9999 -

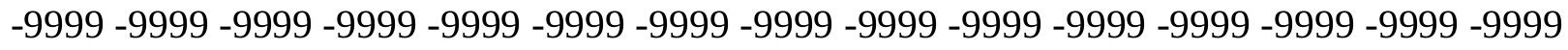

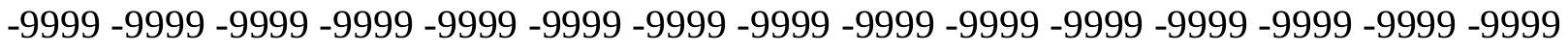
-9999 -9999 -9999 -9999 -9999 -9999 -9999 -9999 -9999 -9999 -9999 -9999 -9999 -9999 -9999 -9999 -9999 -9999 -9999 -9999 -9999 -9999 -9999 -9999-9999 -9999 -9999 -9999 -9999 -9999 -9999 -9999 -9999 -9999 -9999 -9999 -9999 -9999 -9999 -9999 -9999 -9999 -9999 -9999 -9999 -

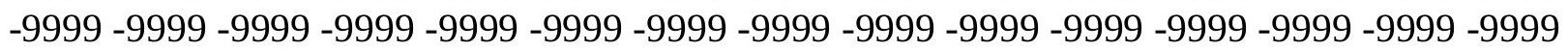


-9999 -9999 -9999 -9999 -9999 -9999 -9999 -9999 -9999 -9999 -9999 -9999 -9999 -9999 -9999 -9999 -9999 -9999 -9999 -9999 -9999 -9999 -9999 -9999 -9999 -9999 -9999 -9999 -9999 -

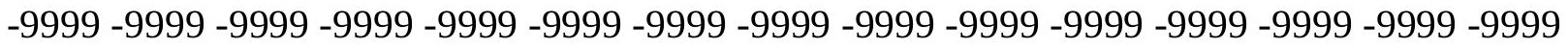
-9999 -9999 -9999 -9999 -9999 -9999 -9999 -9999 -9999 -9999 -9999 -9999 -9999 -9999 -9999 -9999 -9999 -9999 -9999 -9999 -9999 -9999 -9999 -9999 -9999 -9999 -9999 -9999 -9999 -9999 -9999 -9999 -9999 -9999 -9999 -9999 -9999 -9999 -9999 -9999 -9999 -9999 -9999 -9999 -9999 -9999 -9999 -9999 -9999 -9999 -9999 -9999 -9999 -9999 -9999 -9999 -9999 -9999 -9999 -9999

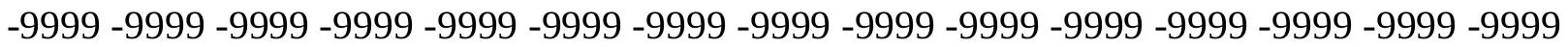

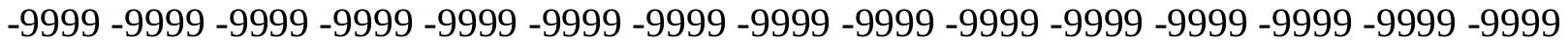
-9999 -9999 -9999 -9999 -9999 -9999 -9999 -9999 -9999 -9999 -9999 -9999 -9999 -9999 -9999 -9999 -9999 -9999 -9999 -9999 -9999 -9999 -9999 -9999 -9999 -9999 -9999 -9999 -9999 -9999 -9999 -9999 -9999 -9999 -9999 -9999 -9999 -9999 -9999 -9999 -9999 -9999 -9999 -9999 -9999 -9999 -9999 -9999 -9999 -9999 -9999 -9999 -9999 -9999 -9999 -9999 -9999 -9999 -9999 -9999 -9999 -9999 -9999 -9999 -9999 -9999 -9999 -9999 -9999 -9999 -9999 -9999 -9999 -9999 -9999 -9999 -9999 -9999 -9999 -9999 -9999 -9999 -9999 -9999 -9999 -9999 -9999 -9999 -9999 -9999 -

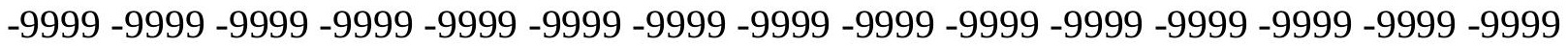
-9999 -9999 -9999 -9999 -9999 -9999 -9999 -9999 -9999 -9999 -9999 -9999 -9999 -9999 -9999 -9999 -9999 -9999 -9999 -9999 -9999 -9999 -9999 -9999 -9999 -9999 -9999 -9999 -9999 - 9999 -9999 -9999 -9999 -9999 -9999 -9999 -9999 -9999 -9999 -9999 -9999 -9999 -9999 -9999 -9999 -

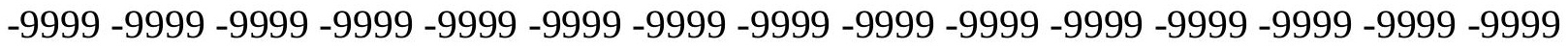

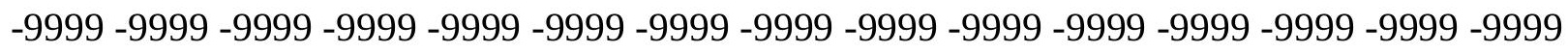

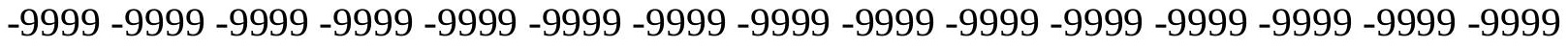
-9999 -9999 -9999 -9999 -9999 -9999 -9999 -9999 -9999 -9999 -9999 -9999 -9999 -9999 -9999 -9999 -9999 -9999 -9999 -9999 -9999 -9999 -9999 -9999 -9999 -9999 -9999 -9999 -9999 -9999 -

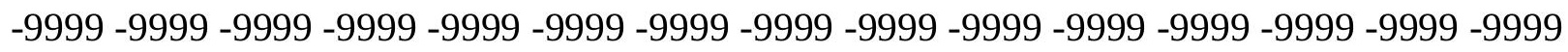
-9999 -9999 -9999 -9999 -9999 -9999 -9999 -9999 -9999 -9999 -9999 -9999 -9999 -9999 -9999 -9999 -9999 -9999 -9999 -9999 -9999 -9999 -9999 -9999 -9999 -9999 -9999 -9999 -9999 -9999 -9999 -9999 -9999 -9999 -9999 -9999 -9999 -9999 -9999 -9999 -9999 -9999 -9999 -9999 -9999 -9999 -9999 -9999 -9999 -9999 -9999 -9999 -9999 -9999 -9999 -9999 -9999 -9999 -9999 -9999 -9999 -9999 -9999 -9999 -9999 -9999 -9999 -9999 -9999 -9999 -9999 -9999 -9999 -999 -

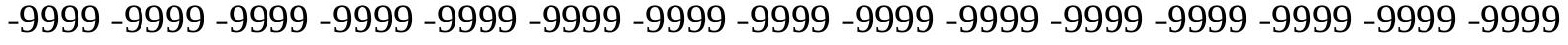
-9999 -9999 -9999 -9999 -9999 -9999 -9999 -9999 -9999 -9999 -9999 -9999 -9999 -9999 -9999 -

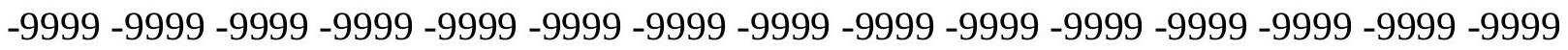

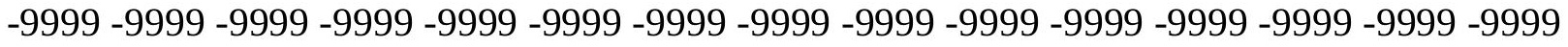

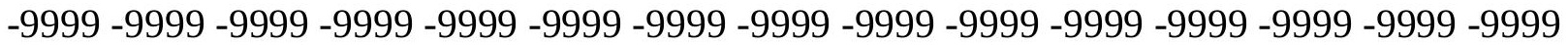

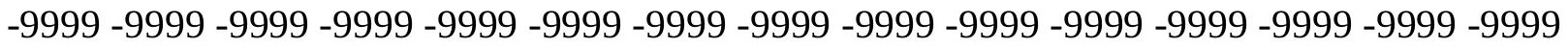

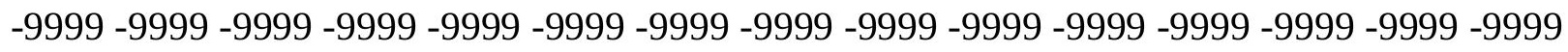

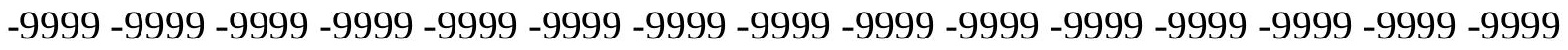

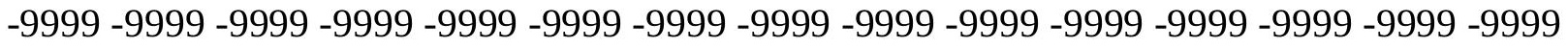
-9999 -9999 -9999 -9999 -9999 -9999 -9999 -9999 -9999 -9999 -9999 -9999 -9999 -9999 -9999 -

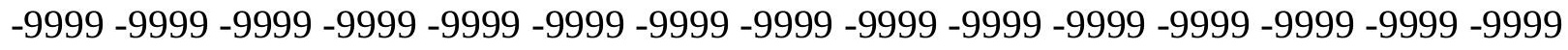

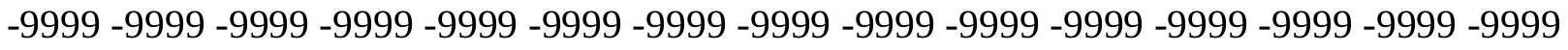
-9999 -9999 -9999 -9999 -9999 -9999 -9999 -9999 -9999 -9999 -9999 -9999 -9999 -9999 -9999 -9999 -9999 -9999 -9999 -9999 -9999 -9999 -9999 -9999-9999 -9999 -9999 -9999 -9999 -9999 -9999 -9999 -9999 -9999 -9999 -9999 -9999 -9999 -9999 -9999 -9999 -9999 -9999 -9999 -9999 -

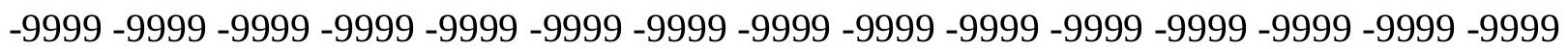


-9999 -9999 -9999 -9999 -9999 -9999 -9999 -9999 -9999 -9999 -9999 -9999 -9999 -9999 -9999 -9999 -9999 -9999 -9999 -9999 -9999 -9999 -9999 -9999 -9999 -9999 -9999 -9999 -9999 -9999 -

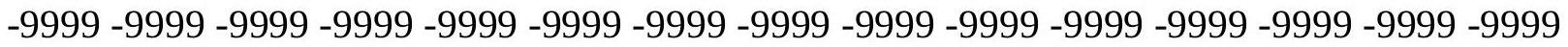
-9999 -9999 -9999 -9999 -9999 -9999 -9999 -9999 -9999 -9999 -9999 -9999 -9999 -9999 -9999 -9999 -9999 -9999 -9999 -9999 -9999 -9999 -9999 -9999-9999 -9999 -9999 -9999 -9999 -9999 -9999 -9999 -9999 -9999 -9999 -9999 -9999 -9999 -9999 -9999 -9999 -9999 -9999 -9999 -9999 -

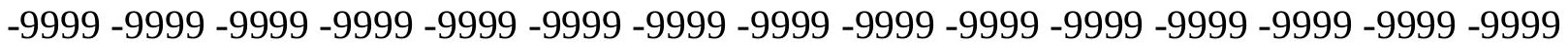
-9999 -9999 -9999 -9999 -9999 -9999 -9999 -9999 -9999 -9999 -9999 -9999 -9999 -9999 -9999 -9999 -9999 -9999 -9999 -9999 -9999 -9999 -9999 -9999 -9999 -9999 -9999 -9999 -9999 -9999 -9999 -9999 -9999 -9999 -9999 -9999 -9999 -9999 -9999 -9999 -9999 -9999 -9999 -9999 -9999 -9999 -9999 -9999 -9999 -9999 -9999 -9999 -9999 -9999 -9999 -9999 -9999 -9999 -9999 -9999 -9999 -9999 -9999 -9999 -9999 -9999 -9999 -9999 -9999 -9999 -9999 -9999 -9999 -9999 -9999 -9999 -9999 -9999 -9999 -9999 -9999 -9999 -9999 -9999 -9999 -9999 -9999 -9999 -9999 -9999 -9999 -9999 -9999 -9999 -9999 -9999 -9999 -9999 -9999 -9999 -9999 -9999 -9999 -9999 -9999 -9999 -9999 -9999 -9999 -9999 -9999 -9999 -9999 -9999 -9999 -9999 -9999 -9999 -9999 -

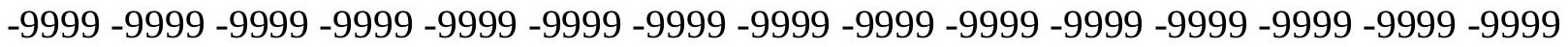
-9999 -9999 -9999 -9999 -9999 -9999 -9999 -9999 -9999 -9999 -9999 -9999 -9999 -9999 -9999 -9999 -9999 -9999 -9999 -9999 -9999 -9999 -9999 -9999 -9999 -9999 -9999 -9999 -9999 -9999 -9999 -9999 -9999 -9999 -9999 -9999 -9999 -9999 -9999 -9999 -9999 -9999 -9999 -9999 -9999 -

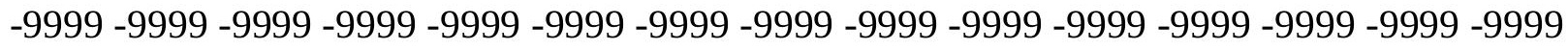

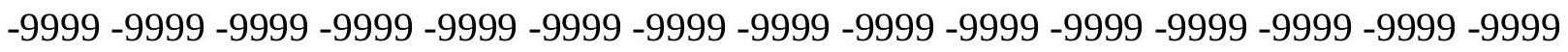
-9999 -9999 -9999 -9999 -9999 -9999 -9999 -9999 -9999 -9999 -9999 -9999 -9999 -9999 - 9999 -9999 -9999 -9999 -9999 -9999 -9999 -9999 -9999 -9999 -9999 -9999 -9999 -9999 -9999 -9999 -9999 -9999 -9999 -9999 -9999 -9999 -9999 -9999 -9999 -9999 -9999 -9999 -9999 -9999 -9999 -

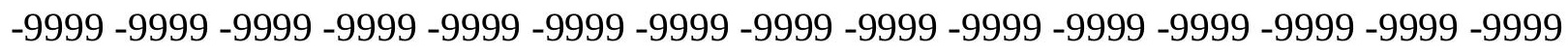
-9999 -9999 -9999 -9999 -9999 -9999 -9999 -9999 -9999 -9999 -9999 -9999 -9999 -9999 -9999 -9999 -9999 -9999 -9999 -9999 -9999 -9999 -9999 -9999 -9999 -9999 -9999 -9999 -9999 -9999 -

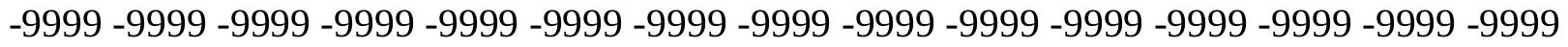
-9999 -9999 -9999 -9999 -9999 -9999 -9999 -9999 -9999 -9999 -9999 -9999 -9999 -9999 -9999 -9999 -9999 -9999 -9999 -9999 -9999 -9999 -9999 -9999 -9999 -9999 -9999 -9999 -9999 -999 -9999 -9999 -9999 -9999 -9999 -9999 -9999 -9999 -9999 -9999 -9999 -9999 -9999 -9999 -9999 -9999 -9999 -9999 -9999 -9999 -9999 -9999 -9999 -9999 -9999 -9999 -9999 -9999 -9999 -9999 -

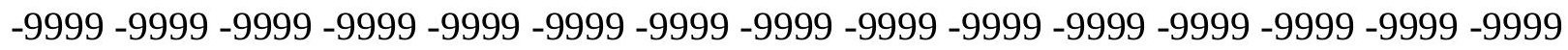

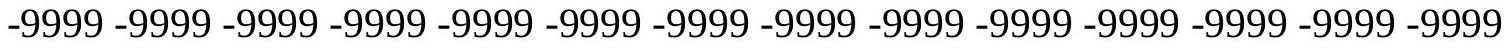
-9999 -9999 -9999 -9999 -9999 -9999 -9999 -9999 -9999 -9999 -9999 -9999 -9999 -9999 -9999

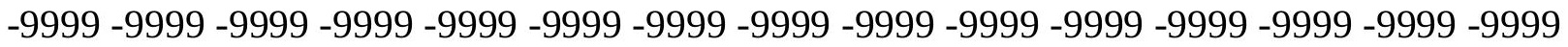

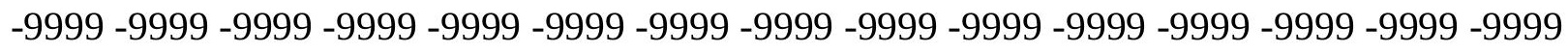

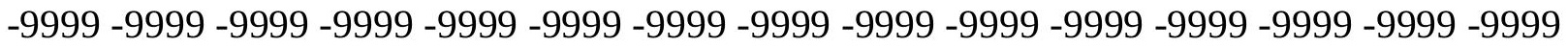

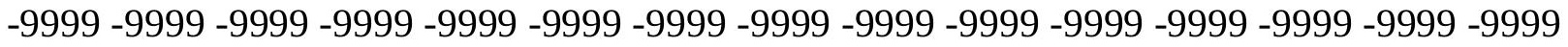
-9999 -9999 -9999 -9999 -9999 -9999 -9999 -9999 -9999 -9999 -9999 -9999 -9999 -9999 -9999 -

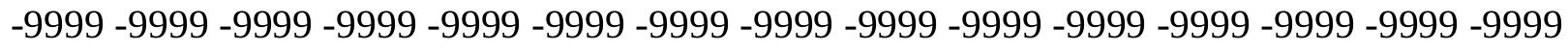

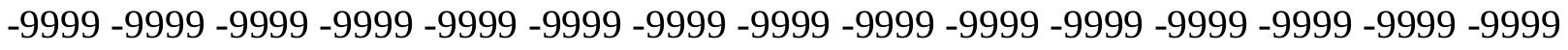
-9999 -9999 -9999 -9999 -9999 -9999 -9999 -9999 -9999 -9999 -9999 -9999 -9999 -9999 -9999 -9999 -9999 -9999 -9999 -9999 -9999 -9999 -9999 -9999-9999 -9999 -9999 -9999 -9999 -9999 -9999 -9999 -9999 -9999 -9999 -9999 -9999 -9999 -9999 -9999 -9999 -9999 -9999 -9999 -9999 -

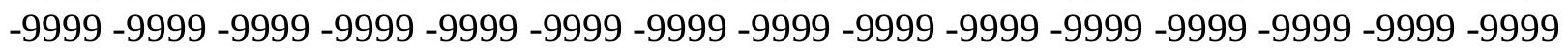


-9999 -9999 -9999 -9999 -9999 -9999 -9999 -9999 -9999 -9999 -9999 -9999 -9999 -9999 -9999 -9999 -9999 -9999 -9999 -9999 -9999 -9999 -9999 -9999 -9999 -9999 -9999 -9999 -9999 -9999 -

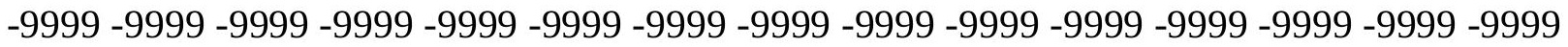
-9999 -9999 -9999 -9999 -9999 -9999 -9999 -9999 -9999 -9999 -9999 -9999 -9999 -9999 -9999 -9999 -9999 -9999 -9999 -9999 -9999 -9999 -9999 -9999-9999 -9999 -9999 -9999 -9999 -9999 -9999 -9999 -9999 -9999 -9999 -9999 -9999 -9999 -9999 -9999 -9999 -9999 -9999 -9999 -9999 -9999 -9999 -9999 -9999 -9999 -9999 -9999 -9999 -9999 -9999 -9999 -9999 -9999 -9999 -9999

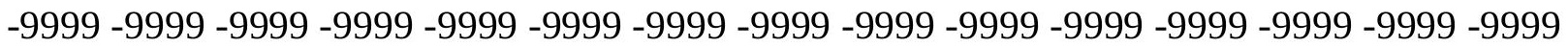

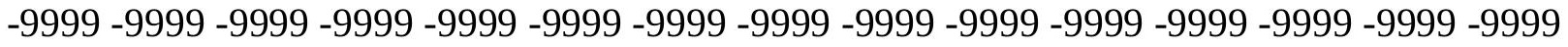
-9999 -9999 -9999 -9999 -9999 -9999 -9999 -9999 -9999 -9999 -9999 -9999 -9999 -9999 -9999 -9999 -9999 -9999 -9999 -9999 -9999 -9999 -9999 -9999 -9999 -9999 -9999 -9999 -9999 -9999 -9999 -9999 -9999 -9999 -9999 -9999 -9999 -9999 -9999 -9999 -9999 -9999 -9999 -9999 -9999 -9999 -9999 -9999 -9999 -9999 -9999 -9999 -9999 -9999 -9999 -9999 -9999 -9999 -9999 -9999 -9999 -9999 -9999 -9999 -9999 -9999 -9999 -9999 -9999 -9999 -9999 -9999 -9999 -9999 -9999 -9999 -9999 -9999 -9999 -9999 -9999 -9999 -9999 -9999 -9999 -9999 -9999 -9999 -9999

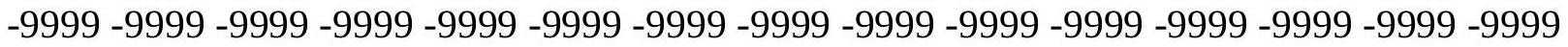
-9999 -9999 -9999 -9999 -9999 -9999 -9999 -9999 -9999 -9999 -9999 -9999 -9999 -9999 -9999 -9999 -9999 -9999 -9999 -9999 -9999 -9999 -9999 -9999 -9999 -9999 -9999 -9999 -9999 -9999 -9999 -9999 -9999 -9999 -9999 -9999 -9999 -9999 -9999 -9999 -9999 -9999 -9999 -9999 -9999 -

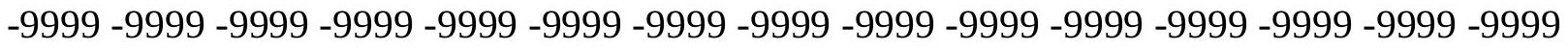

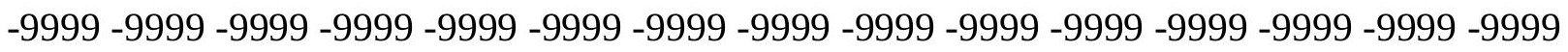
-9999 -9999 -9999 -9999 -9999 -9999 -9999 -9999 -9999 -9999 -9999 -9999 -9999 -9999 -9999 -9999 -9999 -9999 -9999 -9999 -9999 -9999 -9999 -9999 -9999 -9999 -9999 -9999 -9999 -9999 -9999 -9999 -9999 -9999 -9999 -9999 -9999 -9999 -9999 -9999 -9999 -9999 -9999 -9999 -9999 -

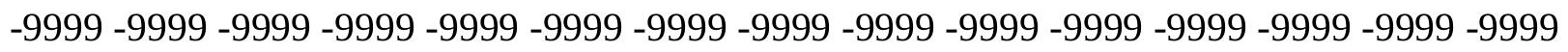
-9999 -9999 -9999 -9999 -9999 -9999 -9999 -9999 -9999 -9999 -9999 -9999 -9999 -9999 -9999 -9999 -9999 -9999 -9999 -9999 -9999 -9999 -9999 -9999 -9999 -9999 -9999 -9999 -9999 -9999 -

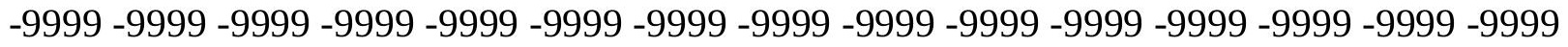
-9999 -9999 -9999 -9999 -9999 -9999 -9999 -9999 -9999 -9999 -9999 -9999 -9999 -9999 -9999 -9999 -9999 -9999 -9999 -9999 -9999 -9999 -9999 -9999 -9999 -9999 -9999 -9999 -9999 -999 -9999 -9999 -9999 -9999 -9999 -9999 -9999 -9999 -9999 -9999 -9999 -9999 -9999 -9999 -9999 -9999 -9999 -9999 -9999 -9999 -9999 -9999 -9999 -9999 -9999 -9999 -9999 -9999 -9999 -9999 -

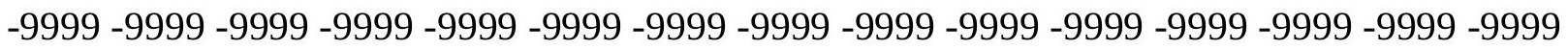

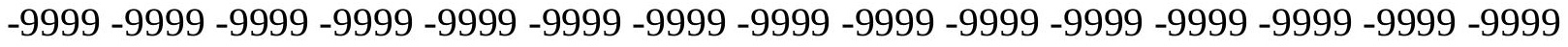

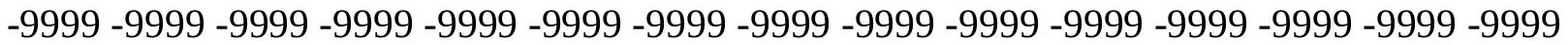

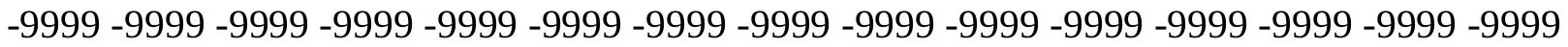

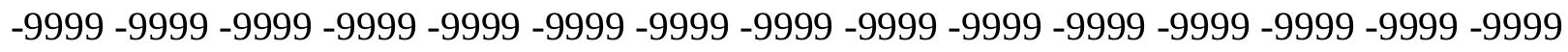

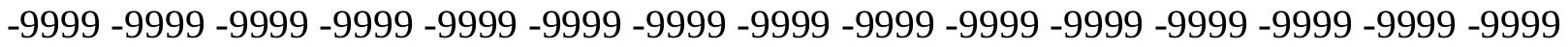
-9999 -9999 -9999 -9999 -9999 -9999 -9999 -9999 -9999 -9999 -9999 -9999 -9999 - 9999 - -999 -9999 -9999 -9999 -9999 -9999 -9999 -9999 -9999 -9999 -9999 -9999 -9999 -9999 -9999 - -999 -

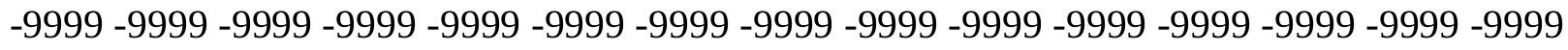

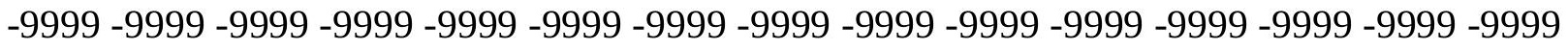
-9999 -9999 -9999 -9999 -9999 -9999 -9999 -9999 -9999 -9999 -9999 -9999 -9999 -9999 -9999 -9999 -9999 -9999 -9999 -9999 -9999 -9999 -9999 -9999-9999 -9999 -9999 -9999 -9999 -9999 -9999 -9999 -9999 -9999 -9999 -9999 -9999 -9999 -9999 -9999 -9999 -9999 -9999 -9999 -9999 -

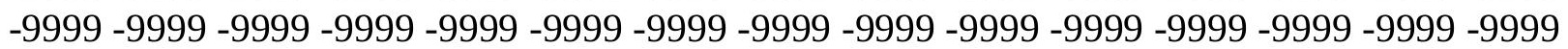


-9999 -9999 -9999 -9999 -9999 -9999 -9999 -9999 -9999 -9999 -9999 -9999 -9999 -9999 -9999 -9999 -9999 -9999 -9999 -9999 -9999 -9999 -9999 -9999 -9999 -9999 -9999 -9999 -9999 -9999 -9999 -9999 -9999 -9999 -9999 -9999 -9999 -9999 -9999 -9999 -9999 -9999 -9999 -9999 -9999 -9999 -9999 -9999 -9999 -9999 -9999 -9999 -9999 -9999 -9999 -9999 -9999 -9999 -9999 -9999 -9999 -9999 -9999 -9999 -9999 -9999 -9999 -9999 -9999 -9999 -9999 -9999 -9999 -9999 -9999 -9999 -9999 -9999 -9999 -9999 -9999 -9999 -9999 -9999 -9999 -9999 -9999 -9999 -9999 -9999 -9999 -9999 -9999 -9999 -9999 -9999 -9999 -9999 -9999 -9999 -9999 -9999 -9999 -9999 -9999 -

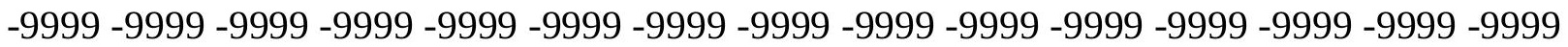
-9999 -9999 -9999 -9999 -9999 -9999 -9999 -9999 -9999 -9999 -9999 -9999 -9999 -9999 -9999 -9999 -9999 -9999 -9999 -9999 -9999 -9999 -9999 -9999 -9999 -9999 -9999 -9999 -9999 -9999 -

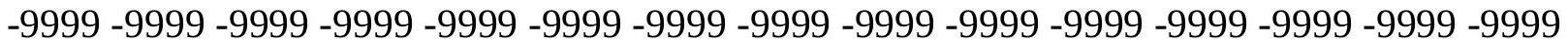
-9999 -9999 -9999 -9999 -9999 -9999 -9999 -9999 -9999 -9999 -9999 -9999 -9999 -9999 -9999 -9999 -9999 -9999 -9999 -9999 -9999 -9999 -9999 -9999 -9999 -9999 -9999 -9999 -9999 -9999 -9999 -9999 -9999 -9999 -9999 -9999 -9999 -9999 -9999 -9999 -9999 -9999 -9999 -9999 -9999 -9999 -9999 -9999 -9999 -9999 -9999 -9999 -9999 -9999 -9999 -9999 -9999 -9999 -9999 -9999

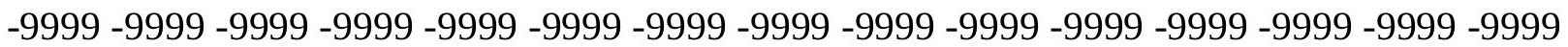
-9999 -9999 -9999 -9999 -9999 -9999 -9999 -9999 -9999 -9999 -9999 -9999 -9999 -9999 -9999 -9999 -9999 -9999 -9999 -9999 -9999 -9999 -9999 -9999 -9999 -9999 -9999 -9999 -9999 -9999 -9999 -9999 -9999 -9999 -9999 -9999 -9999 -9999 -9999 -9999 -9999 -9999 -9999 -9999 -9999 -9999 -9999 -9999 -9999 -9999 -9999 -9999 -9999 -9999 -9999 -9999 -9999 -9999 -9999 -9999 -9999 -9999 -9999 -9999 -9999 -9999 -9999 -9999 -9999 -9999 -9999 -9999 -9999 -9999 -9999 -9999 -9999 -9999 -9999 -9999 -9999 -9999 -9999 -9999 -9999 -9999 -9999 -9999 -9999 -9999 -9999 -9999 -9999 -9999 -9999 -9999 -9999 -9999 -9999 -9999 -9999 -9999 -9999 -9999 -9999 -9999 -9999 -9999 -9999 -9999 -9999 -9999 -9999 -9999 -9999 -9999 -9999 -9999 -9999 -9999 -9999 -9999 -9999 -9999 -9999 -9999 -9999 -9999 -9999 -9999 -9999 -9999 -9999 -9999 -9999 -9999 -9999 -9999 -9999 -9999 -9999 -9999 -9999 -9999 -9999 -9999 -9999 -9999 -9999 -9999 -9999 -9999 -9999 -9999 -9999 -9999 -9999 -9999 -9999 -9999 -9999 -9999 -9999 -9999 -9999 -9999 -9999 -9999 -9999 -9999 -9999 -9999 -9999 -9999 -9999 -9999 -9999 -9999 -9999

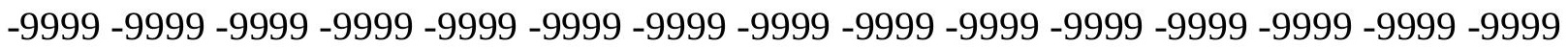
-9999 -9999 -9999 -9999 -9999 -9999 -9999 -9999 -9999 -9999 -9999 -9999 -9999 -9999 -9999 -9999 -9999 -9999 -9999 -9999 -9999 -9999 -9999 -9999 -9999 -9999 -9999 -9999 -9999 -9999 -

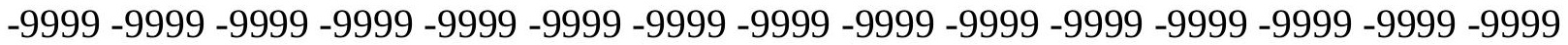
-9999 -9999 -9999 -9999 -9999 -9999 -9999 -9999 -9999 -9999 -9999 -9999 -9999 -9999 -9999 -9999 -9999 -9999 -9999 -9999 -9999 -9999 -9999 -9999 -9999 -9999 -9999 -9999 -9999 -9999 -9999 -9999 -9999 -9999 -9999 -9999 -9999 -9999 -9999 -9999 -9999 -9999 -9999 -9999 -9999 -9999 -9999 -9999 -9999 -9999 -9999 -9999 -9999 -9999 -9999 -9999 -9999 -9999 -9999 -9999 -9999 -9999 -9999 -9999 -9999 -9999 -9999 -9999 -9999 -9999 -9999 -9999 -9999 -9999 -9999

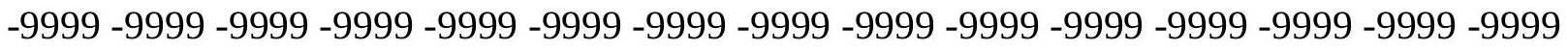
-9999 -9999 -9999 -9999 -9999 -9999 -9999 -9999 -9999 -9999 -9999 -9999 -9999 -9999 -9999 -9999 -9999 -9999 -9999 -9999 -9999 -9999 -9999 -9999 -9999 -9999 -9999 -9999 -9999 -9999 -9999 -9999 -9999 -9999 -9999 -9999 -9999 -9999 -9999 -9999 -9999 -9999 -9999 -9999 -9999 -999 -9999 -9999 -9999 -9999 -9999 -9999 -9999 -9999 -9999 -9999 -9999 -9999 -9999 -9999 -9999 -9999 -9999 -9999 -9999 -9999 -9999 -9999 -9999 -9999 -9999 -9999 -9999 -9999 -9999 -9999 -9999 -9999 -9999 -9999 -9999 -9999 -9999 -9999 -9999 -9999 -9999 -9999 -9999 -9999 -9999 -9999 -9999 -9999 -9999 -9999 -9999 -9999 -9999 -9999 -9999 -9999 -9999 -9999 -9999 -9999 -9999 -9999 -9999 -9999 -9999 -9999 -9999 -9999 -9999 -9999 -9999 -9999 -9999 -9999 
-9999 -9999 -9999 -9999 -9999 -9999 -9999 -9999 -9999 -9999 -9999 -9999 -9999 -9999 -9999 -9999 -9999 -9999 -9999 -9999 -9999 -9999 -9999 -9999 -9999 -9999 -9999 -9999 -9999 -9999 -

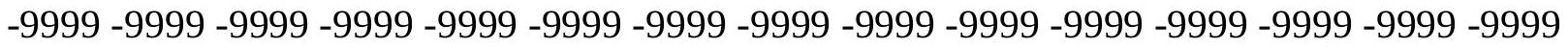
-9999 -9999 -9999 -9999 -9999 -9999 -9999 -9999 -9999 -9999 -9999 -9999 -9999 -9999 -9999 -9999 -9999 -9999 -9999 -9999 -9999 -9999 -9999 -9999-9999 -9999 -9999 -9999 -9999 -9999 -9999 -9999 -9999 -9999 -9999 -9999 -9999 -9999 -9999 -9999 -9999 -9999 -9999 -9999 -9999 -9999 -9999 -9999 -9999 -9999 -9999 -9999 -9999 -9999 -9999 -9999 -9999 -9999 -9999 -9999

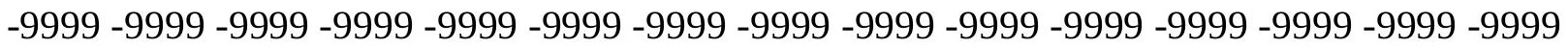

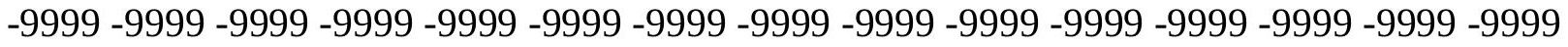
-9999 -9999 -9999 -9999 -9999 -9999 -9999 -9999 -9999 -9999 -9999 -9999 -9999 -9999 -9999 -9999 -9999 -9999 -9999 -9999 -9999 -9999 -9999 -9999 -9999 -9999 -9999 -9999 -9999 -9999 -9999 -9999 -9999 -9999 -9999 -9999 -9999 -9999 -9999 -9999 -9999 -9999 -9999 -9999 -9999 -9999 -9999 -9999 -9999 -9999 -9999 -9999 -9999 -9999 -9999 -9999 -9999 -9999 -9999 -9999 -

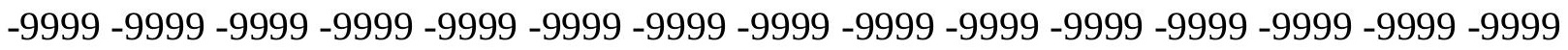
-9999 -9999 -9999 -9999 -9999 -9999 -9999 -9999 -9999 -9999 -9999 -9999 -9999 -9999 -9999 -

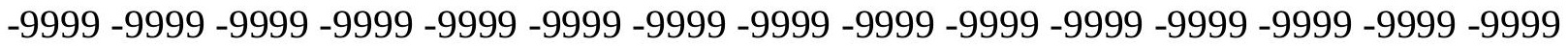
-9999 -9999 -9999 -9999 -9999 -9999 -9999 -9999 -9999 -9999 -9999 -9999 -9999 -9999 -9999 -9999 -9999 -9999 -9999 -9999 -9999 -9999 -9999 -9999 -9999 -9999 -9999 -9999 -9999 -9999 -9999 -9999 -9999 -9999 -9999 -9999 -9999 -9999 -9999 -9999 -9999 -9999 -9999 -9999 -9999 -

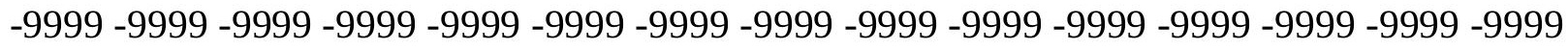

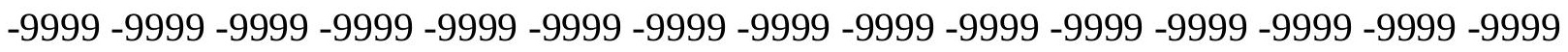

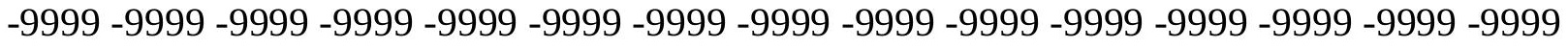
-9999 -9999 -9999 -9999 -9999 -9999 -9999 -9999 -9999 -9999 -9999 -9999 -9999 -9999 -9999 -9999 -9999 -9999 -9999 -9999 -9999 -9999 -9999 -9999 -9999 -9999 -9999 -9999 -9999 -9999 -

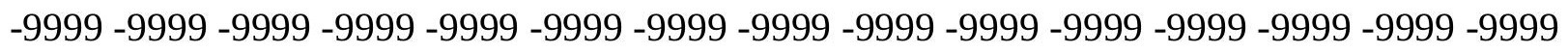
-9999 -9999 -9999 -9999 -9999 -9999 -9999 -9999 -9999 -9999 -9999 -9999 -9999 -9999 -9999 -9999 -9999 -9999 -9999 -9999 -9999 -9999 -9999 -9999 -9999 -9999 -9999 -9999 -9999 -

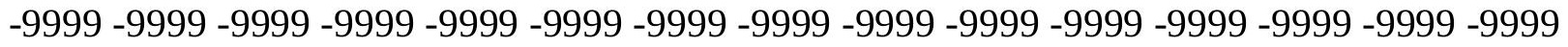
-9999 -9999 -9999 -9999 -9999 -9999 -9999 -9999 -9999 -9999 -9999 -9999 -9999 -9999 -9999 -9999 -9999 -9999 -9999 -9999 -9999 -9999 -9999 -9999 -9999 -9999 -9999 -9999 -9999 -999 -

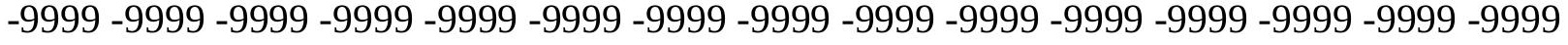
-9999 -9999 -9999 -9999 -9999 -9999 -9999 -9999 -9999 -9999 -9999 -9999 -9999 -9999 -9999 -

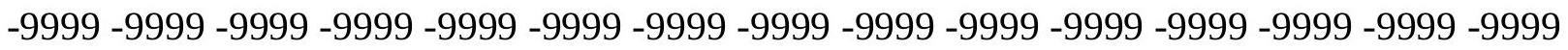

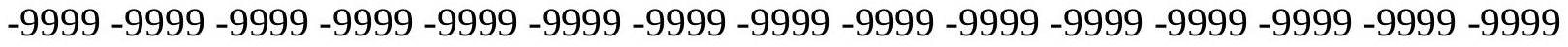

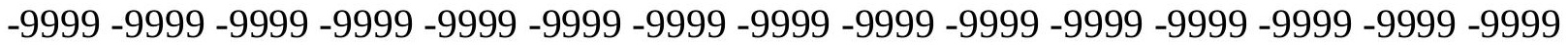
-9999 -9999 -9999 -9999 -9999 -9999 -9999 -9999 -9999 -9999 -9999 -9999 -9999 -9999 -9999

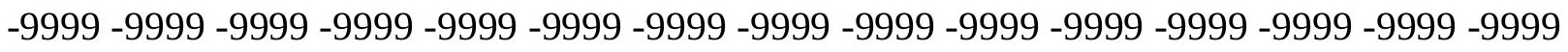

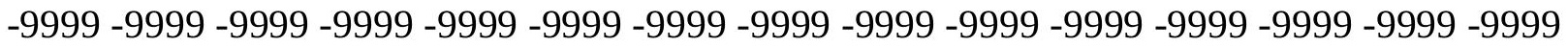
-9999 -9999 -9999 -9999 -9999 -9999 -9999 -9999 -9999 -9999 -9999 -9999 -9999 - 9999 - -999 -9999 -9999 -9999 -9999 -9999 -9999 -9999 -9999 -9999 -9999 -9999 -9999 -9999 -9999 -9999 -

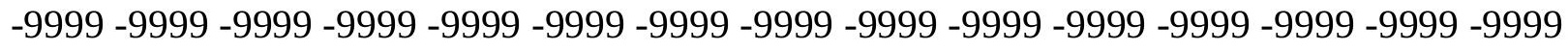

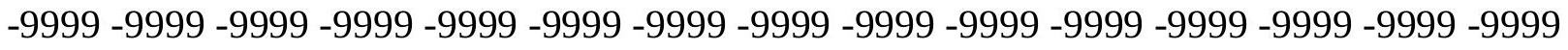
-9999 -9999 -9999 -9999 -9999 -9999 -9999 -9999 -9999 -9999 -9999 -9999 -9999 -9999 -9999 -9999 -9999 -9999 -9999 -9999 -9999 -9999 -9999 -9999-9999 -9999 -9999 -9999 -9999 -9999 -9999 -9999 -9999 -9999 -9999 -9999 -9999 -9999 -9999 -9999 -9999 -9999 -9999 -9999 -9999 -

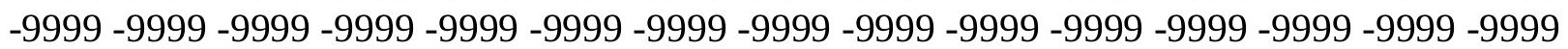


-9999 -9999 -9999 -9999 -9999 -9999 -9999 -9999 -9999 -9999 -9999 -9999 -9999 -9999 -9999 -9999 -9999 -9999 -9999 -9999 -9999 -9999 -9999 -9999 -9999 -9999 -9999 -9999 -9999 -9999 -9999 -9999 -9999 -9999 -9999 -9999 -9999 -9999 -9999 -9999 -9999 -9999 -9999 -9999 - 9999 -9999 -9999 -9999 -9999 -9999 -9999 -9999 -9999 -9999 -9999 -9999 -9999 -9999 -9999 -9999 -9999 -9999 -9999 -9999 -9999 -9999 -9999 -9999 -9999 -9999 -9999 -9999 -9999 -9999 - -9999 -9999 -9999 -9999 -9999 -9999 -9999 -9999 -9999 -9999 -9999 -9999 -9999 -9999 -9999 -9999 -9999 -9999 -9999 -9999 -9999 -9999 -9999 -9999 -9999 -9999 -9999 -9999 -9999 -9999

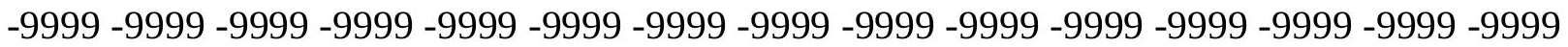

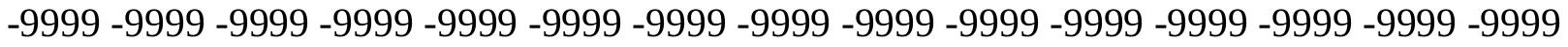
-9999 -9999 -9999 -9999 -9999 -9999 -9999 -9999 -9999 -9999 -9999 -9999 -9999 -9999 -9999

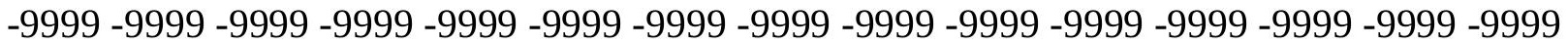
-9999 -9999 -9999 -9999 -9999 -9999 -9999 -9999 -9999 -9999 -9999 -9999 -9999 -9999 -9999 -9999 -9999 -9999 -9999 -9999 -9999 -9999 -9999 -9999 -9999 -9999 -9999 -9999 -9999 -9999 -9999 -9999 -9999 -9999 -9999 -9999 -9999 -9999 -9999 -9999 -9999 -9999 -9999 -9999 - -9999 -9999 -9999 -9999 -9999 -9999 -9999 -9999 -9999 -9999 -9999 -9999 -9999 -9999 -9999 -9999

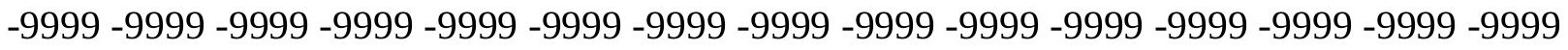
-9999 -9999 -9999 -9999 -9999 -9999 -9999 -9999 -9999 -9999 -9999 -9999 -9999 -9999 -9999 -9999 -9999 -9999 -9999 -9999 -9999 -9999 -9999 -9999 -9999 -9999 -9999 -9999 -9999 -9999 -9999 -9999 -9999 -9999 -9999 -9999 -9999 -9999 -9999 -9999 -9999 -9999 -9999 -9999 -9999 -

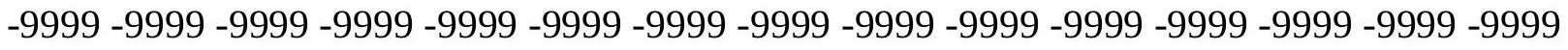
-9999 -9999 -9999 -9999 -9999 -9999 -9999 -9999 -9999 -9999 -9999 -9999 -9999 -9999 -9999 -999 -9999 -9999 -9999 -9999 -9999 -9999 -9999 -9999 -9999 -9999 -9999 -9999 -9999 -9999 -9999 -9999 -9999 -9999 -9999 -9999 -9999 -9999 -9999 -9999 -9999 -9999 -9999 -9999 -9999 -9999 -9999 -9999 -9999 -9999 -9999 -9999 -9999 -9999 -9999 -9999 -9999 -9999 -9999 -9999 -9999 -9999 -9999 -9999 -9999 -9999 -9999 -9999 -9999 -9999 -9999 -9999 -9999 -9999 -9999 -9999 -9999 -9999 -9999 -9999 -9999 -9999 -9999 -9999 -9999 -9999 -9999 -9999 -9999 -9999 -9999 -9999 -9999 -9999 -9999 -9999 -9999 -9999 -9999 -9999 -9999 -9999 -9999 -9999 -9999 -9999 -9999 -9999 -9999 -9999 -9999 -9999 -9999 -9999 -9999 -9999 -9999 -9999 -9999 -9999 -9999 -9999 -9999 -9999 -9999 -9999 -9999 -9999 -9999 -9999 -9999 -9999 -9999 -9999 -9999 -9999 -9999 -9999 -9999 -9999 -9999 -9999 -9999 -9999 -9999 -9999 -9999 -9999 -9999 -9999 -999 -9999 -9999 -9999 -9999 -9999 -9999 -9999 -9999 -9999 -9999 -9999 -9999 -9999 -9999 -9999 -9999 -9999 -9999 -9999 -9999 -9999 -9999 -9999 -9999 -9999 -9999 -9999 -9999 -9999 -

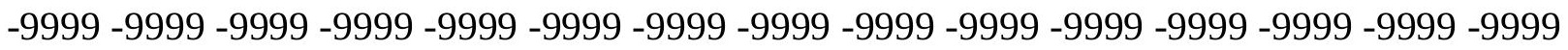

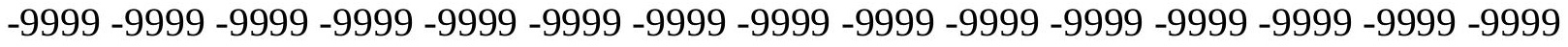

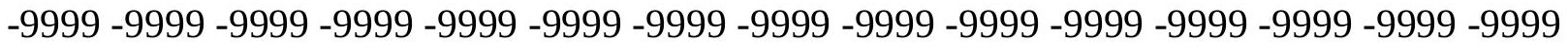
-9999 -9999 -9999 -9999 -9999 -9999 -9999 -9999 -9999 -9999 -9999 -9999 -9999 -9999 -9999 -

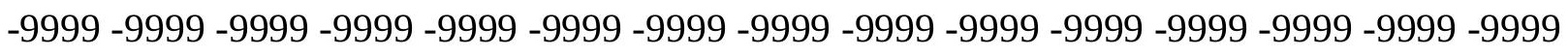

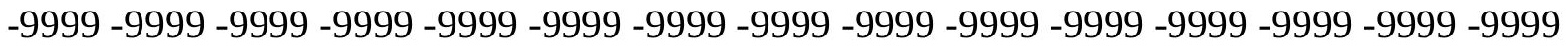

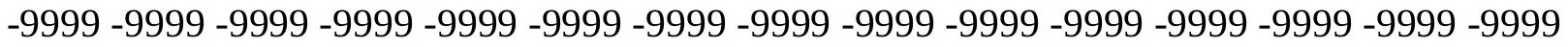
-9999 -9999 -9999 -9999 -9999 -9999 -9999 -9999 -9999 -9999 -9999 -9999 -9999 -9999 -9999 -

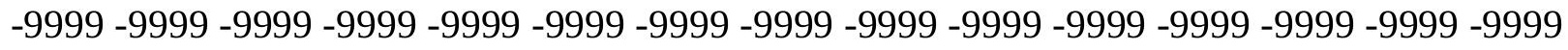

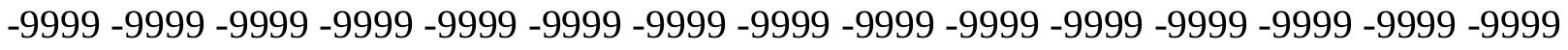
-9999 -9999 -9999 -9999 -9999 -9999 -9999 -9999 -9999 -9999 -9999 -9999 -9999 -9999 -9999 -9999 -9999 -9999 -9999 -9999 -9999 -9999 -9999 -9999-9999 -9999 -9999 -9999 -9999 -9999 -9999 -9999 -9999 -9999 -9999 -9999 -9999 -9999 -9999 -9999 -9999 -9999 -9999 -9999 -9999 -

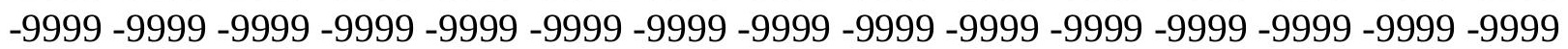


-9999 -9999 -9999 -9999 -9999 -9999 -9999 -9999 -9999 -9999 -9999 -9999 -9999 -9999 -9999 -9999 -9999 -9999 -9999 -9999 -9999 -9999 -9999 -9999 -9999 -9999 -9999 -9999 -9999 -9999 -

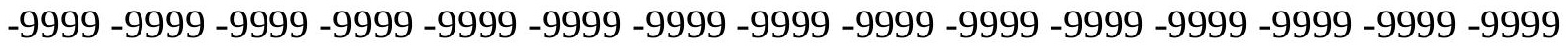
-9999 -9999 -9999 -9999 -9999 -9999 -9999 -9999 -9999 -9999 -9999 -9999 -9999 -9999 -9999 -9999 -9999 -9999 -9999 -9999 -9999 -9999 -9999 -9999-9999 -9999 -9999 -9999 -9999 -9999 -9999 -9999 -9999 -9999 -9999 -9999 -9999 -9999 -9999 -9999 -9999 -9999 -9999 -9999 -9999 -9999 -9999 -9999 -9999 -9999 -9999 -9999 -9999 -9999 -9999 -9999 -9999 -9999 -9999 -9999

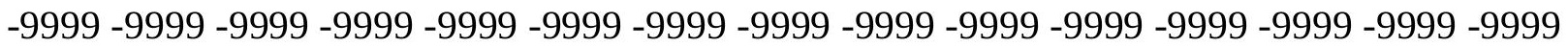

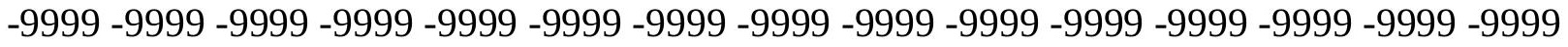
-9999 -9999 -9999 -9999 -9999 -9999 -9999 -9999 -9999 -9999 -9999 -9999 -9999 -9999 -9999 -9999 -9999 -9999 -9999 -9999 -9999 -9999 -9999 -9999 -9999 -9999 -9999 -9999 -9999 -9999 -9999 -9999 -9999 -9999 -9999 -9999 -9999 -9999 -9999 -9999 -9999 -9999 -9999 -9999 -9999 -9999 -9999 -9999 -9999 -9999 -9999 -9999 -9999 -9999 -9999 -9999 -9999 -9999 -9999 -9999 -9999 -9999 -9999 -9999 -9999 -9999 -9999 -9999 -9999 -9999 -9999 -9999 -9999 - 9999 -9999 -9999 -9999 -9999 -9999 -9999 -9999 -9999 -9999 -9999 -9999 -9999 -9999 -9999 -9999

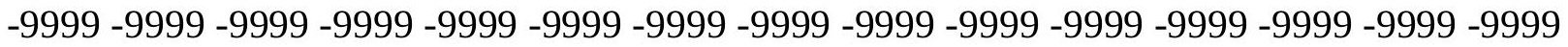
-9999 -9999 -9999 -9999 -9999 -9999 -9999 -9999 -9999 -9999 -9999 -9999 -9999 -9999 -9999 -9999 -9999 -9999 -9999 -9999 -9999 -9999 -9999 -9999 -9999 -9999 -9999 -9999 -9999 -9999 -9999 -9999 -9999 -9999 -9999 -9999 -9999 -9999 -9999 -9999 -9999 -9999 -9999 -9999 -9999 -

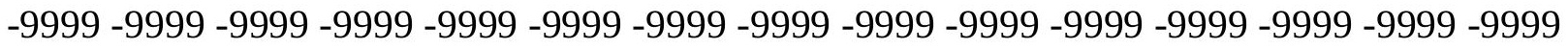

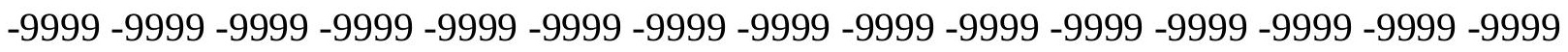
-9999 -9999 -9999 -9999 -9999 -9999 -9999 -9999 -9999 -9999 -9999 -9999 -9999 -9999 -9999 -9999 -9999 -9999 -9999 -9999 -9999 -9999 -9999 -9999 -9999 -9999 -9999 -9999 -9999 -9999 -9999 -9999 -9999 -9999 -9999 -9999 -9999 -9999 -9999 -9999 -9999 -9999 -9999 -9999 -9999 -

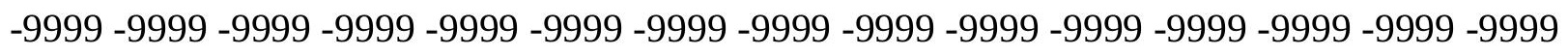
-9999 -9999 -9999 -9999 -9999 -9999 -9999 -9999 -9999 -9999 -9999 -9999 -9999 -9999 -9999 -9999 -9999 -9999 -9999 -9999 -9999 -9999 -9999 -9999 -9999 -9999 -9999 -9999 -9999 -9999 -

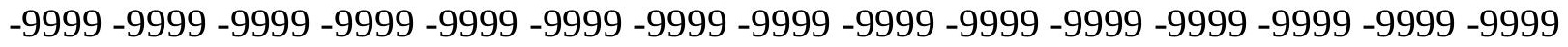
-9999 -9999 -9999 -9999 -9999 -9999 -9999 -9999 -9999 -9999 -9999 -9999 -9999 -9999 -9999 -9999 -9999 -9999 -9999 -9999 -9999 -9999 -9999 -9999 -9999 -9999 -9999 -9999 -9999 -999 -9999 -9999 -9999 -9999 -9999 -9999 -9999 -9999 -9999 -9999 -9999 -9999 -9999 -9999 -9999 -9999 -9999 -9999 -9999 -9999 -9999 -9999 -9999 -9999 -9999 -9999 -9999 -9999 -9999 -9999 -

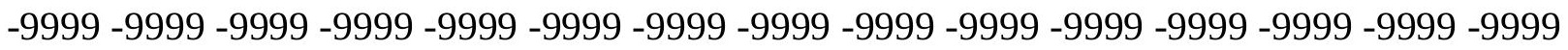

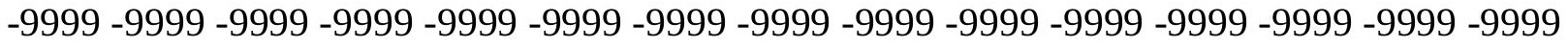

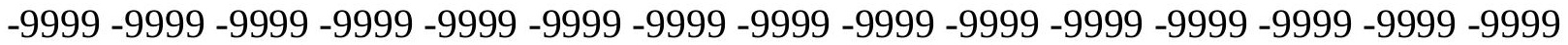

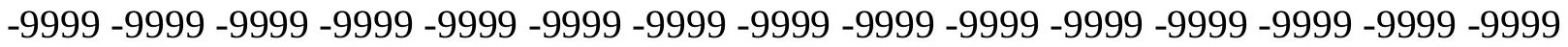

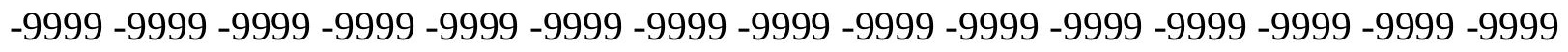

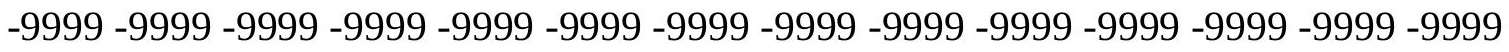
-9999 -9999 -9999 -9999 -9999 -9999 -9999 -9999 -9999 -9999 -9999 -9999 -9999 -9999 -9999 -9999 -9999 -9999 -9999 -9999 -9999 -9999 -9999 -9999 -9999 -9999 -9999 -9999 -9999 -9999 -

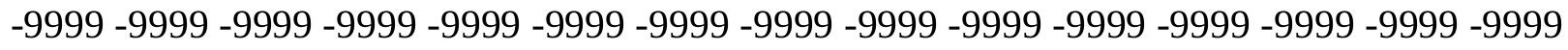

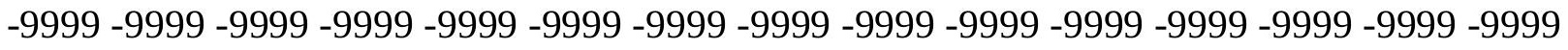
-9999 -9999 -9999 -9999 -9999 -9999 -9999 -9999 -9999 -9999 -9999 -9999 -9999 -9999 -9999 -9999 -9999 -9999 -9999 -9999 -9999 -9999 -9999 -9999-9999 -9999 -9999 -9999 -9999 -9999 -9999 -9999 -9999 -9999 -9999 -9999 -9999 -9999 -9999 -9999 -9999 -9999 -9999 -9999 -9999 -

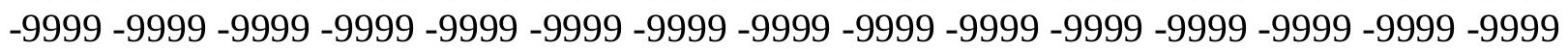


-9999 -9999 -9999 -9999 -9999 -9999 -9999 -9999 -9999 -9999 -9999 -9999 -9999 -9999 -9999 -9999 -9999 -9999 -9999 -9999 -9999 -9999 -9999 -9999 -9999 -9999 -9999 -9999 -9999 -9999 -9999 -9999 -9999 -9999 -9999 -9999 -9999 -9999 -9999 -9999 -9999 -9999 -9999 -9999 - 9999 -9999 -9999 -9999 -9999 -9999 -9999 -9999 -9999 -9999 -9999 -9999 -9999 -9999 -9999 -9999 -9999 -9999 -9999 -9999 -9999 -9999 -9999 -9999 -9999 -9999 -9999 -9999 -9999 -9999 -9999 -9999 -9999 -9999 -9999 -9999 -9999 -9999 -9999 -9999 -9999 -9999 -9999 -9999 -9999 -9999 -9999 -9999 -9999 -9999 -9999 -9999 -9999 -9999 -9999 -9999 -9999 -9999 -9999 -9999 -9999

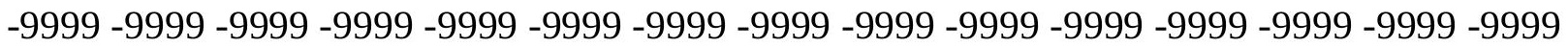
-9999 -9999 -9999 -9999 -9999 -9999 -9999 -9999 -9999 -9999 -9999 -9999 -9999 -9999 -9999 -9999 -9999 -9999 -9999 -9999 -9999 -9999 -9999 -9999 -9999 -9999 -9999 -9999 -9999 -9999

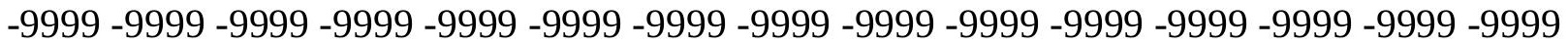
-9999 -9999 -9999 -9999 -9999 -9999 -9999 -9999 -9999 -9999 -9999 -9999 -9999 -9999 -9999 -9999 -9999 -9999 -9999 -9999 -9999 -9999 -9999 -9999 -9999 -9999 -9999 -9999 -9999 -9999 -

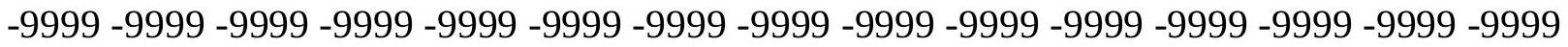
-9999 -9999 -9999 -9999 -9999 -9999 -9999 -9999 -9999 -9999 -9999 -9999 -9999 -9999 -9999

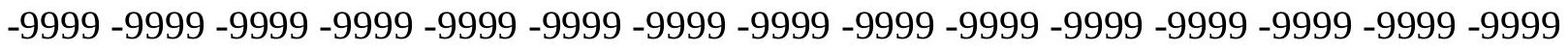
-9999 -9999 -9999 -9999 -9999 -9999 -9999 -9999 -9999 -9999 -9999 -9999 -9999 -9999 -9999 -9999 -9999 -9999 -9999 -9999 -9999 -9999 -9999 -9999 -9999 -9999 -9999 -9999 -9999 - -999 -9999 -9999 -9999 -9999 -9999 -9999 -9999 -9999 -9999 -9999 -9999 -9999 -9999 -9999 -9999 -9999 -9999 -9999 -9999 -9999 -9999 -9999 -9999 -9999 -9999 -9999 -9999 -9999 -9999 -9999 -9999 -9999 -9999 -9999 -9999 -9999 -9999 -9999 -9999 -9999 -9999 -9999 -9999 -9999 -9999 -999 -9999 -9999 -9999 -9999 -9999 -9999 -9999 -9999 -9999 -9999 -9999 -9999 -9999 -9999 -9999 -9999 -9999 -9999 -9999 -9999 -9999 -9999 -9999 -9999 -9999 -9999 -9999 -9999 -9999 -9999 -9999 -9999 -9999 -9999 -9999 -9999 -9999 -9999 -9999 -9999 -9999 -9999 -9999 -9999 -9999 -9999 -9999 -9999 -9999 -9999 -9999 -9999 -9999 -9999 -9999 -9999 -9999 -9999 -9999 -9999 -9999 -9999 -9999 -9999 -9999 -9999 -9999 -9999 -9999 -9999 -9999 -9999 -9999 -9999 -9999 -9999 -9999 -9999 -9999 -9999 -9999 -9999 -9999 -9999 -9999 -9999 -9999 -9999 -9999 -9999 -9999 -9999 -9999 -9999 -9999 -9999 -9999 -9999 -9999 -9999 -9999 -9999 -9999 -9999 -9999 -9999 -9999 -9999 -9999 -9999 -9999 -9999 -9999 -9999 -9999 -9999 -9999 -9999 -9999 -9999 -9999 -9999 -9999 -9999 -9999 -9999 -9999 -9999 -9999 -9999 -9999 -9999 -9999 -9999 -999 -9999 -9999 -9999 -9999 -9999 -9999 -9999 -9999 -9999 -9999 -9999 -9999 -9999 -9999 -9999 -9999 -9999 -9999 -9999 -9999 -9999 -9999 -9999 -9999 -9999 -9999 -9999 -9999 -9999 -9999 -

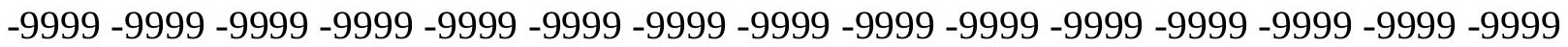

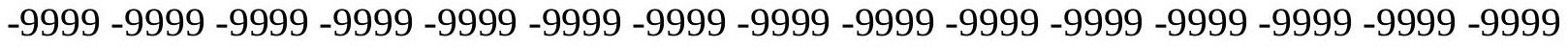

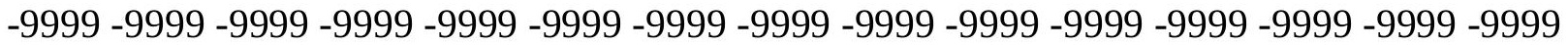
-9999 -9999 -9999 -9999 -9999 -9999 -9999 -9999 -9999 -9999 -9999 -9999 -9999 -9999 -9999

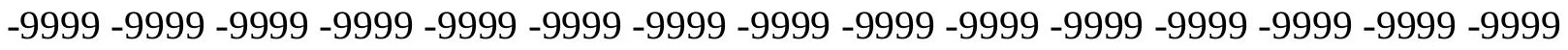

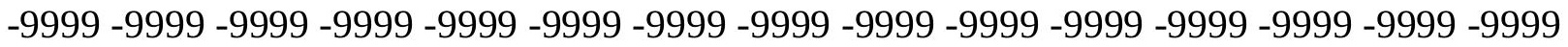

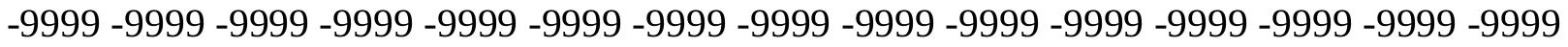
-9999 -9999 -9999 -9999 -9999 -9999 -9999 -9999 -9999 -9999 -9999 -9999 -9999 -9999 -9999 -

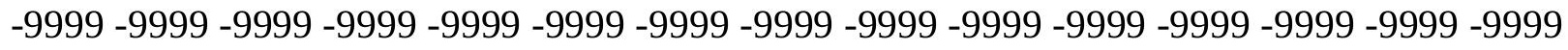

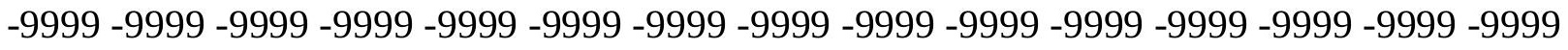
-9999 -9999 -9999 -9999 -9999 -9999 -9999 -9999 -9999 -9999 -9999 -9999 -9999 -9999 -9999 -9999 -9999 -9999 -9999 -9999 -9999 -9999 -9999 -9999 -9999 -9999 -9999 -9999 - -9999 -9999 -9999 -9999 -9999 -9999 -9999 -9999 -9999 -9999 -9999 -9999 -9999 -9999 -9999 -9999 -

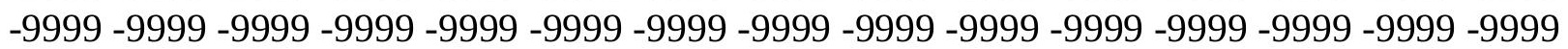


-9999 -9999 -9999 -9999 -9999 -9999 -9999 -9999 -9999 -9999 -9999 -9999 -9999 -9999 -9999 -9999 -9999 -9999 -9999 -9999 -9999 -9999 -9999 -9999 -9999 -9999 -9999 -9999 -9999 -9999 -9999 -9999 -9999 -9999 -9999 -9999 -9999 -9999 -9999 -9999 -9999 -9999 -9999 -9999 - 9999 -9999 -9999 -9999 -9999 -9999 -9999 -9999 -9999 -9999 -9999 -9999 -9999 -9999 -9999 -9999 -9999 -9999 -9999 -9999 -9999 -9999 -9999 -9999 -9999-9999 -9999 -9999 -9999 -9999 -9999 -9999 -9999 -9999 -9999 -9999 -9999 -9999 -9999 -9999 -9999 -9999 -9999 -9999 -9999 -9999 -9999 -9999 -9999 -9999 -9999 -9999 -9999 -9999 -9999 -9999 -9999 -9999 -9999 -9999 -9999

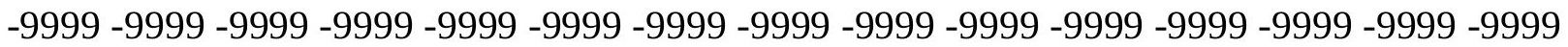

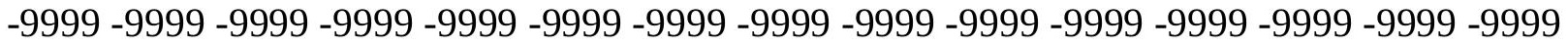
-9999 -9999 -9999 -9999 -9999 -9999 -9999 -9999 -9999 -9999 -9999 -9999 -9999 -9999 -9999

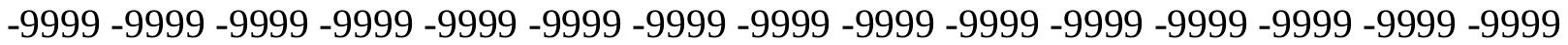
-9999 -9999 -9999 -9999 -9999 -9999 -9999 -9999 -9999 -9999 -9999 -9999 -9999 -9999 -9999 -9999 -9999 -9999 -9999 -9999 -9999 -9999 -9999 -9999 -9999 -9999 -9999 -9999 -9999 -9999 -

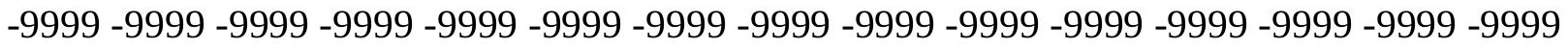
-9999 -9999 -9999 -9999 -9999 -9999 -9999 -9999 -9999 -9999 -9999 -9999 -9999 -9999 -9999

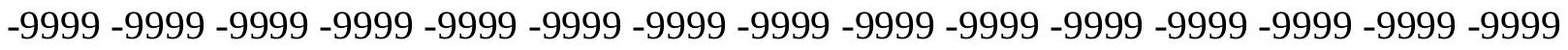
-9999 -9999 -9999 -9999 -9999 -9999 -9999 -9999 -9999 -9999 -9999 -9999 -9999 -9999 -9999 -9999 -9999 -9999 -9999 -9999 -9999 -9999 -9999 -9999 -9999 -9999 -9999 -9999 -9999 -9999 -9999 -9999 -9999 -9999 -9999 -9999 -9999 -9999 -9999 -9999 -9999 -9999 -9999 -9999 -9999 -9999 -9999 -9999 -9999 -9999 -9999 -9999 -9999 -9999 -9999 -9999 -9999 -9999 -9999 -9999 -9999 -9999 -9999 -9999 -9999 -9999 -9999 -9999 -9999 -9999 -9999 -9999 -9999 -9999 -9999 -999 -9999 -9999 -9999 -9999 -9999 -9999 -9999 -9999 -9999 -9999 -9999 -9999 -9999 -9999 -9999 -9999 -9999 -9999 -9999 -9999 -9999 -9999 -9999 -9999 -9999 -9999 -9999 -9999 -9999 -9999 -9999 -9999 -9999 -9999 -9999 -9999 -9999 -9999 -9999 -9999 -9999 -9999 -9999 -9999 -9999 -9999 -9999 -9999 -9999 -9999 -9999 -9999 -9999 -9999 -9999 -9999 -9999 -9999 -9999 -9999 -9999 -9999 -9999 -9999 -9999 -9999 -9999 -9999 -9999 -9999 -9999 -9999 -9999 -9999 -9999 -9999 -9999 -9999 -9999 -9999 -9999 -9999 -9999 -9999 -9999 -9999 -9999 -9999 -9999 -9999 -9999 -9999 -9999 -9999 -9999 -9999 -9999 -9999 -9999 -9999 -9999 -9999 -9999 -9999 -9999 -9999 -9999 -9999 -9999 -9999 -9999 -9999 -9999 -9999 -9999 -9999 -9999 -9999 -9999 -9999 -9999 -9999 -9999 -9999 -9999 -9999 -9999 -9999 -9999 -9999 -9999 -9999 -9999 -999 -9999 -9999 -9999 -9999 -9999 -9999 -9999 -9999 -9999 -9999 -9999 -9999 -9999 -9999 -9999 -9999 -9999 -9999 -9999 -9999 -9999 -9999 -9999 -9999 -9999 -9999 -9999 -9999 -9999 -9999 -

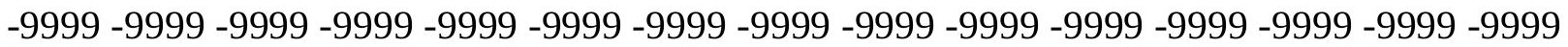

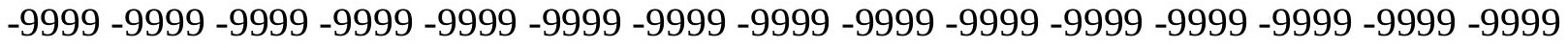

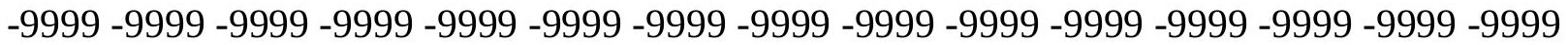
-9999 -9999 -9999 -9999 -9999 -9999 -9999 -9999 -9999 -9999 -9999 -9999 -9999 -9999 -9999

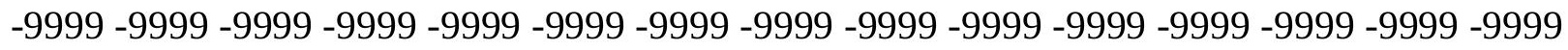

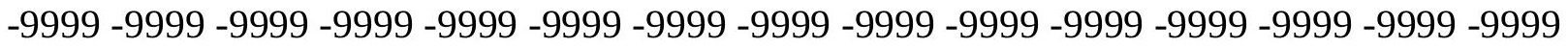
-9999 -9999 -9999 -9999 -9999 -9999 -9999 -9999 -9999 -9999 -9999 -9999 -9999 -9999 -9999 -9999 -9999 -9999 -9999 -9999 -9999 -9999 -9999 -9999 -9999 -9999 -9999 -9999 -9999 -9999 -

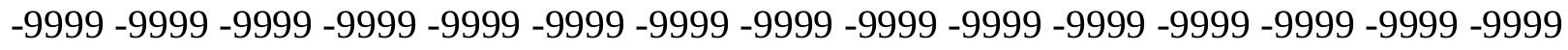

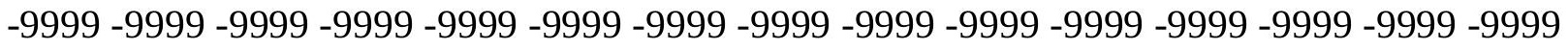
-9999 -9999 -9999 -9999 -9999 -9999 -9999 -9999 -9999 -9999 -9999 -9999 -9999 -9999 -9999 -9999 -9999 -9999 -9999 -9999 -9999 -9999 -9999 -9999-9999 -9999 -9999 -9999 -9999 -9999 -9999 -9999 -9999 -9999 -9999 -9999 -9999 -9999 -9999 -9999 -9999 -9999 -9999 -9999 -9999 -

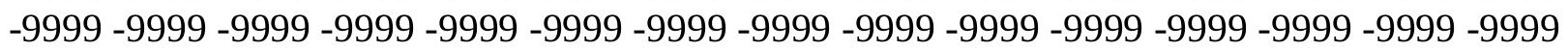


-9999 -9999 -9999 -9999 -9999 -9999 -9999 -9999 -9999 -9999 -9999 -9999 -9999 -9999 -9999 -9999 -9999 -9999 -9999 -9999 -9999 -9999 -9999 -9999 -9999 -9999 -9999 -9999 -9999 -9999 -9999 -9999 -9999 -9999 -9999 -9999 -9999 -9999 -9999 -9999 -9999 -9999 -9999 -9999 - 9999 -9999 -9999 -9999 -9999 -9999 -9999 -9999 -9999 -9999 -9999 -9999 -9999 -9999 -9999

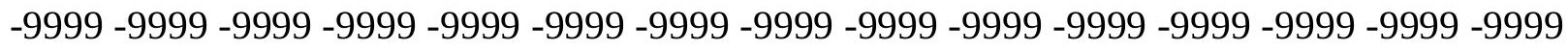
-9999 -9999 -9999 -9999 -9999 -9999 -9999 -9999 -9999 -9999 -9999 -9999 -9999 -9999 -9999 -9999 -9999 -9999 -9999 -9999 -9999 -9999 -9999 -9999 -9999 -9999 -9999 -9999 -9999 -9999

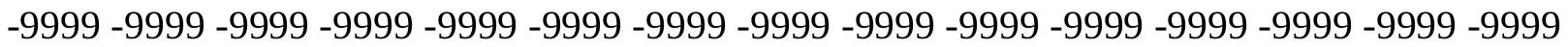

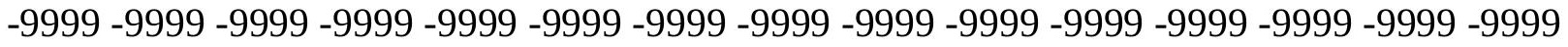
-9999 -9999 -9999 -9999 -9999 -9999 -9999 -9999 -9999 -9999 -9999 -9999 -9999 -9999 -9999 -9999 -9999 -9999 -9999 -9999 -9999 -9999 -9999 -9999 -9999 -9999 -9999 -9999 -9999 -9999 -9999 -9999 -9999 -9999 -9999 -9999 -9999 -9999 -9999 -9999 -9999 -9999 -9999 -9999 -9999 -9999 -9999 -9999 -9999 -9999 -9999 -9999 -9999 -9999 -9999 -9999 -9999 -9999 -9999 -9999 -

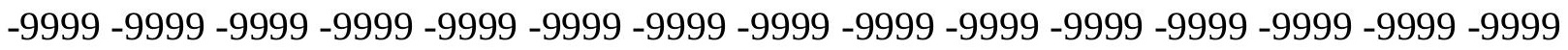
-9999 -9999 -9999 -9999 -9999 -9999 -9999 -9999 -9999 -9999 -9999 -9999 -9999 -9999 -9999 -

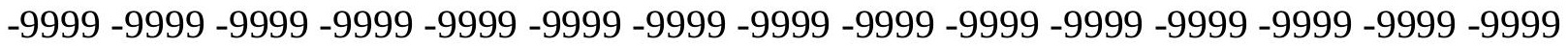
-9999 -9999 -9999 -9999 -9999 -9999 -9999 -9999 -9999 -9999 -9999 -9999 -9999 -9999 -9999 -9999 -9999 -9999 -9999 -9999 -9999 -9999 -9999 -9999 -9999 -9999 -9999 -9999 -9999 -9999 -9999 -9999 -9999 -9999 -9999 -9999 -9999 -9999 -9999 -9999 -9999 -9999 -9999 -9999 -9999 -

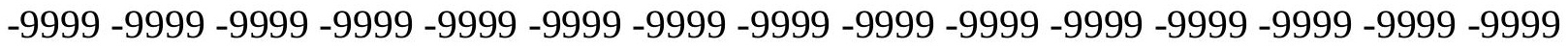
-9999 -9999 -9999 -9999 -9999 -9999 -9999 -9999 -9999 -9999 -9999 -9999 -9999 -9999 -9999

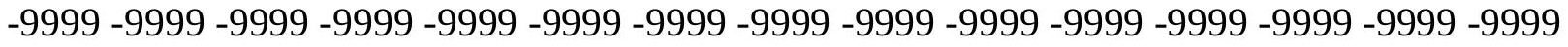
-9999 -9999 -9999 -9999 -9999 -9999 -9999 -9999 -9999 -9999 -9999 -9999 -9999 -9999 -9999 -9999 -9999 -9999 -9999 -9999 -9999 -9999 -9999 -9999 -9999 -9999 -9999 -9999 -9999 -9999 -9999 -9999 -9999 -9999 -9999 -9999 -9999 -9999 -9999 -9999 -9999 -9999 -9999 -9999 -9999 -9999 -9999 -9999 -9999 -9999 -9999 -9999 -9999 -9999 -9999 -9999 -9999 -9999 -9999 -9999 -9999 -9999 -9999 -9999 -9999 -9999 -9999 -9999 -9999 -9999 -9999 -9999 -9999 -9999 -9999 -9999 -9999 -9999 -9999 -9999 -9999 -9999 -9999 -9999 -9999 -9999 -9999 -9999 -9999 -9999 -9999 -9999 -9999 -9999 -9999 -9999 -9999 -9999 -9999 -9999 -9999 -9999 -9999 -9999 -9999 -9999 -9999 -9999 -9999 -9999 -9999 -9999 -9999 -9999 -9999 -9999 -9999 -9999 -9999 -9999 -9999 -9999 -9999 -9999 -9999 -9999 -9999 -9999 -9999 -9999 -9999 -9999 -9999 -9999 -9999 -9999 -9999 -9999 -9999 -9999 -9999 -9999 -9999 -9999 -9999 -9999 -9999 -9999 -9999 -

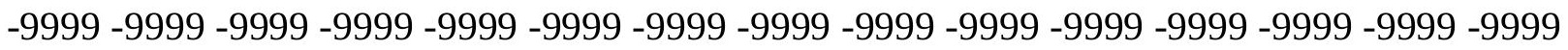

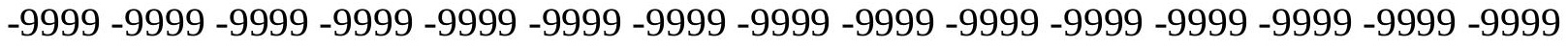
-9999 -9999 -9999 -9999 -9999 -9999 -9999 -9999 -9999 -9999 -9999 -9999 -9999 -9999 -9999 -

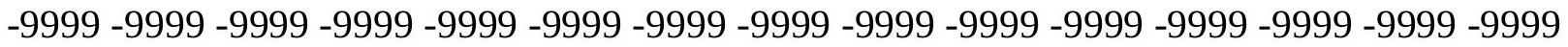

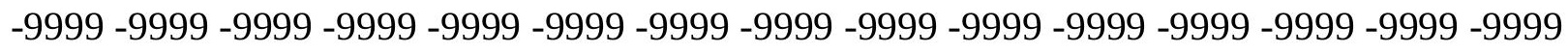

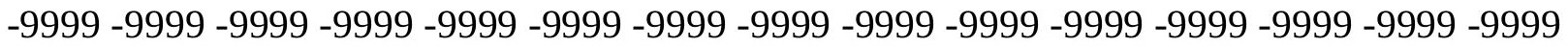

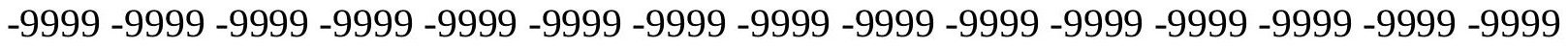
-9999 -9999 -9999 -9999 -9999 -9999 -9999 -9999 -9999 -9999 -9999 -9999 -9999 -9999 -9999 -

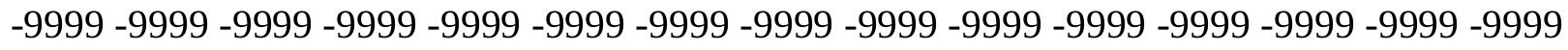

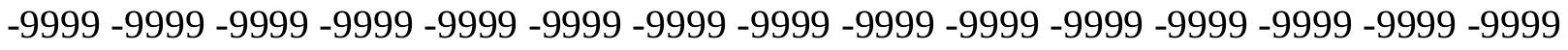
-9999 -9999 -9999 -9999 -9999 -9999 -9999 -9999 -9999 -9999 -9999 -9999 -9999 -9999 -9999 -9999 -9999 -9999 -9999 -9999 -9999 -9999 -9999 -9999-9999 -9999 -9999 -9999 -9999 -9999 -9999 -9999 -9999 -9999 -9999 -9999 -9999 -9999 -9999 -9999 -9999 -9999 -9999 -9999 -9999 -

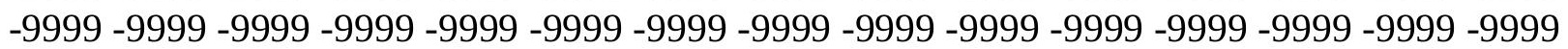


-9999 -9999 -9999 -9999 -9999 -9999 -9999 -9999 -9999 -9999 -9999 -9999 -9999 -9999 -9999 -9999 -9999 -9999 -9999 -9999 -9999 -9999 -9999 -9999 -9999 -9999 -9999 -9999 -9999 -9999 -9999 -9999 -9999 -9999 -9999 -9999 -9999 -9999 -9999 -9999 -9999 -9999 -9999 -9999 - 9999 -9999 -9999 -9999 -9999 -9999 -9999 -9999 -9999 -9999 -9999 -9999 -9999 -9999 -9999 -9999 -9999 -9999 -9999 -9999 -9999 -9999 -9999 -9999 -9999 -9999 -9999 -9999 -9999 -9999 -9999 -9999 -9999 -9999 -9999 -9999 -9999 -9999 -9999 -9999 -9999 -9999 -9999 -9999 -9999 -9999 -9999 -9999 -9999 -9999 -9999 -9999 -9999 -9999 -9999 -9999 -9999 -9999 -9999 -9999 -9999

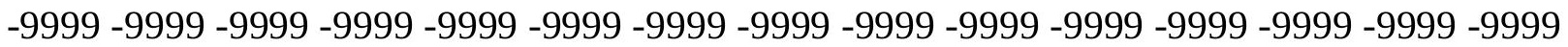

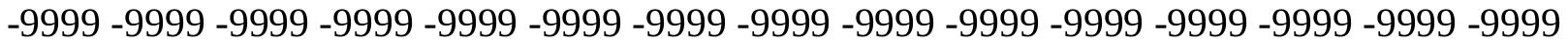
-9999 -9999 -9999 -9999 -9999 -9999 -9999 -9999 -9999 -9999 -9999 -9999 -9999 -9999 -9999 -9999 -9999 -9999 -9999 -9999 -9999 -9999 -9999 -9999 -9999 -9999 -9999 -9999 -9999 -9999 -9999 -9999 -9999 -9999 -9999 -9999 -9999 -9999 -9999 -9999 -9999 -9999 -9999 -9999 -9999 -9999 -9999 -9999 -9999 -9999 -9999 -9999 -9999 -9999 -9999 -9999 -9999 -9999 -9999 -9999 -9999 -9999 -9999 -9999 -9999 -9999 -9999 -9999 -9999 -9999 -9999 -9999 -9999 -9999 -9999 -9999 -9999 -9999 -9999 -9999 -9999 -9999 -9999 -9999 -9999 -9999 -9999 -9999 -9999 -

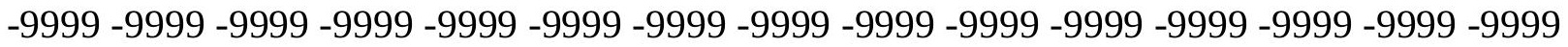
-9999 -9999 -9999 -9999 -9999 -9999 -9999 -9999 -9999 -9999 -9999 -9999 -9999 -9999 -9999 -9999 -9999 -9999 -9999 -9999 -9999 -9999 -9999 -9999 -9999 -9999 -9999 -9999 -9999 -9999 -9999 -9999 -9999 -9999 -9999 -9999 -9999 -9999 -9999 -9999 -9999 -9999 -9999 -9999 -9999 -9999 -9999 -9999 -9999 -9999 -9999 -9999 -9999 -9999 -9999 -9999 -9999 -9999 -9999 -9999 -9999 -9999 -9999 -9999 -9999 -9999 -9999 -9999 -9999 -9999 -9999 -9999 -9999 -9999 -9999 -999 -9999 -9999 -9999 -9999 -9999 -9999 -9999 -9999 -9999 -9999 -9999 -9999 -9999 -9999 -9999 -9999 -9999 -9999 -9999 -9999 -9999 -9999 -9999 -9999 -9999 -9999 -9999 -9999 -9999 -9999 -9999 -9999 -9999 -9999 -9999 -9999 -9999 -9999 -9999 -9999 -9999 -9999 -9999 -9999 -9999 -9999 -9999 -9999 -9999 -9999 -9999 -9999 -9999 -9999 -9999 -9999 -9999 -9999 -9999 -9999 -9999 -9999 -9999 -9999 -9999 -9999 -9999 -9999 -9999 -9999 -9999 -9999 -9999 -9999 -9999 -9999 -9999 -9999 -9999 -9999 -9999 -9999 -9999 -9999 -9999 -9999 -9999 -9999 -9999 -9999 -9999 -9999 -9999 -9999 -9999 -9999 -9999 -9999 -9999 -9999 -9999 -9999 -9999 -9999 -9999 -9999 -9999 -9999 -9999 -9999 -9999 -9999 -9999 -9999 -9999 -9999 -9999 -9999 -9999 -9999 -9999 -9999 -9999 -9999 -9999 -9999 -9999 -9999 -9999 -9999 -9999 -9999 -9999 -9999 -999 -9999 -9999 -9999 -9999 -9999 -9999 -9999 -9999 -9999 -9999 -9999 -9999 -9999 -9999 -9999 -9999 -9999 -9999 -9999 -9999 -9999 -9999 -9999 -9999 -9999 -9999 -9999 -9999 -9999 -9999 -

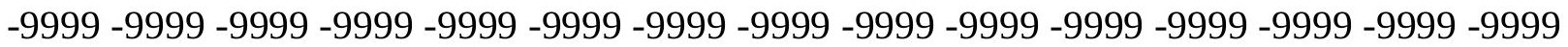

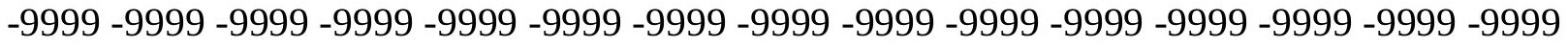

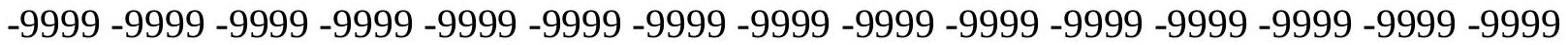
-9999 -9999 -9999 -9999 -9999 -9999 -9999 -9999 -9999 -9999 -9999 -9999 -9999 -9999 -9999 -9999 -9999 -9999 -9999 -9999 -9999 -9999 -9999 -9999 -9999 -9999 -9999 -9999 -9999 -

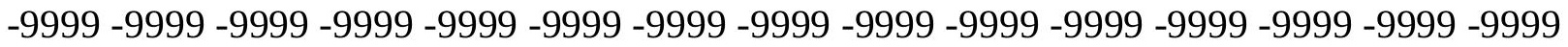
-9999 -9999 -9999 -9999 -9999 -9999 -9999 -9999 -9999 -9999 -9999 -9999 -9999 -9999 -9999 -9999 -9999 -9999 -9999 -9999 -9999 -9999 -9999 -9999 -9999 -9999 -9999 -9999 -9999 -9999 -

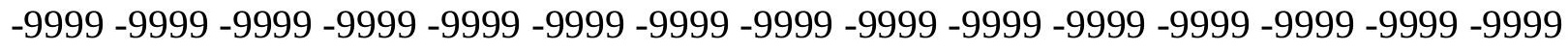

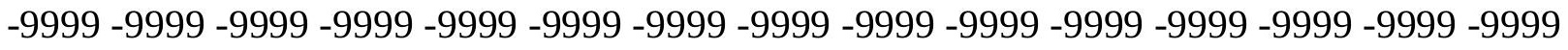
-9999 -9999 -9999 -9999 -9999 -9999 -9999 -9999 -9999 -9999 -9999 -9999 -9999 -9999 -9999 -9999 -9999 -9999 -9999 -9999 -9999 -9999 -9999 -9999-9999 -9999 -9999 -9999 -9999 -9999 -9999 -9999 -9999 -9999 -9999 -9999 -9999 -9999 -9999 -9999 -9999 -9999 -9999 -9999 -9999 -

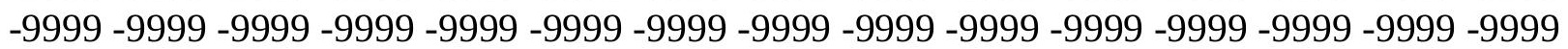


-9999 -9999 -9999 -9999 -9999 -9999 -9999 -9999 -9999 -9999 -9999 -9999 -9999 -9999 -9999 -9999 -9999 -9999 -9999 -9999 -9999 -9999 -9999 -9999 -9999 -9999 -9999 -9999 -9999 -9999 -

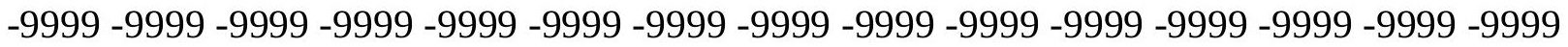
-9999 -9999 -9999 -9999 -9999 -9999 -9999 -9999 -9999 -9999 -9999 -9999 -9999 -9999 -9999 -9999 -9999 -9999 -9999 -9999 -9999 -9999 -9999 -9999-9999 -9999 -9999 -9999 -9999 -9999 -9999 -9999 -9999 -9999 -9999 -9999 -9999 -9999 -9999 -9999 -9999 -9999 -9999 -9999 -9999 -9999 -9999 -9999 -9999 -9999 -9999 -9999 -9999 -9999 -9999 -9999 -9999 -9999 -9999 -9999

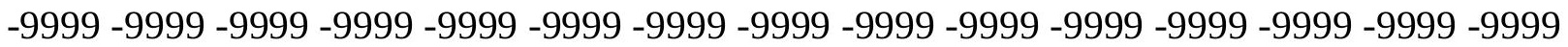

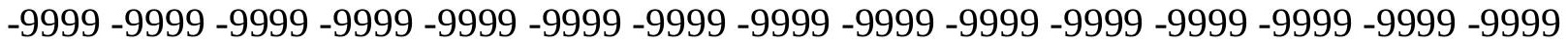
-9999 -9999 -9999 -9999 -9999 -9999 -9999 -9999 -9999 -9999 -9999 -9999 -9999 -9999 -9999 -9999 -9999 -9999 -9999 -9999 -9999 -9999 -9999 -9999 -9999 -9999 -9999 -9999 -9999 -9999 -9999 -9999 -9999 -9999 -9999 -9999 -9999 -9999 -9999 -9999 -9999 -9999 -9999 -9999 -9999 -9999 -9999 -9999 -9999 -9999 -9999 -9999 -9999 -9999 -9999 -9999 -9999 -9999 -9999 -9999 -9999 -9999 -9999 -9999 -9999 -9999 -9999 -9999 -9999 -9999 -9999 -9999 -9999 -9999 -9999 -9999 -9999 -9999 -9999 -9999 -9999 -9999 -9999 -9999 -9999 -9999 -9999 -9999 -9999 -9999 -

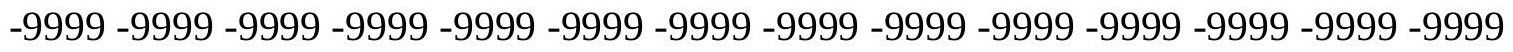
-9999 -9999 -9999 -9999 -9999 -9999 -9999 -9999 -9999 -9999 -9999 -9999 -9999 -9999 -9999 -9999 -9999 -9999 -9999 -9999 -9999 -9999 -9999 -9999 -9999 -9999 -9999 -9999 -9999 -9999 -9999 -9999 -9999 -9999 -9999 -9999 -9999 -9999 -9999 -9999 -9999 -9999 -9999 -9999 -9999 -

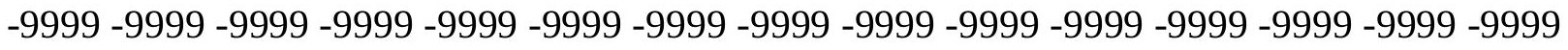

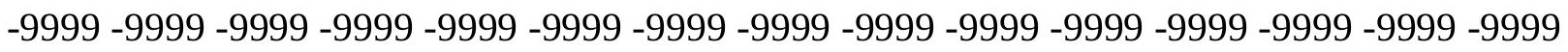
-9999 -9999 -9999 -9999 -9999 -9999 -9999 -9999 -9999 -9999 -9999 -9999 -9999 -9999 - 9999 -9999 -9999 -9999 -9999 -9999 -9999 -9999 -9999 -9999 -9999 -9999 -9999 -9999 -9999 -9999 -9999 -9999 -9999 -9999 -9999 -9999 -9999 -9999 -9999 -9999 -9999 -9999 -9999 -9999 -9999 -

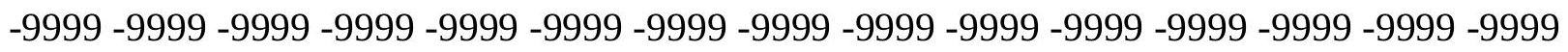
-9999 -9999 -9999 -9999 -9999 -9999 -9999 -9999 -9999 -9999 -9999 -9999 -9999 -9999 -9999 -9999 -9999 -9999 -9999 -9999 -9999 -9999 -9999 -9999 -9999 -9999 -9999 -9999 -9999 -9999 -

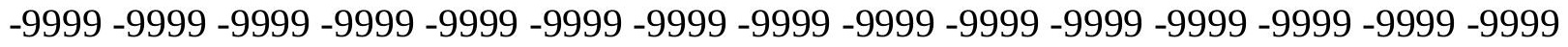
-9999 -9999 -9999 -9999 -9999 -9999 -9999 -9999 -9999 -9999 -9999 -9999 -9999 -9999 -9999 -9999 -9999 -9999 -9999 -9999 -9999 -9999 -9999 -9999 -9999 -9999 -9999 -9999 -9999 -999 -

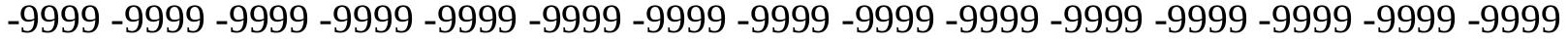
-9999 -9999 -9999 -9999 -9999 -9999 -9999 -9999 -9999 -9999 -9999 -9999 -9999 -9999 -9999 -

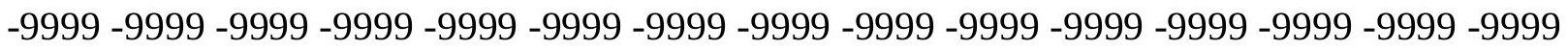

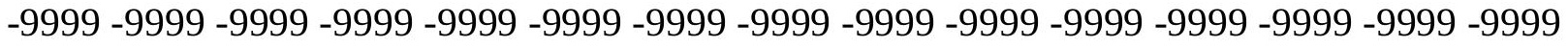

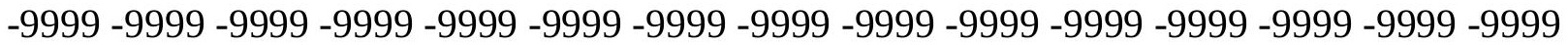
-9999 -9999 -9999 -9999 -9999 -9999 -9999 -9999 -9999 -9999 -9999 -9999 -9999 -9999 -9999 -

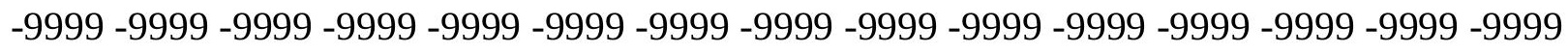

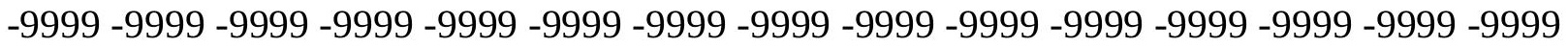
-9999 -9999 -9999 -9999 -9999 -9999 -9999 -9999 -9999 -9999 -9999 -9999 -9999 - 9999 - -999 -9999 -9999 -9999 -9999 -9999 -9999 -9999 -9999 -9999 -9999 -9999 -9999 -9999 -9999 -9999 -

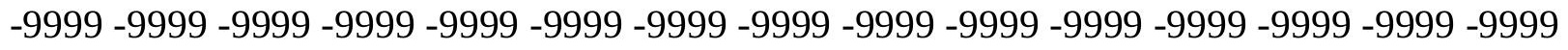

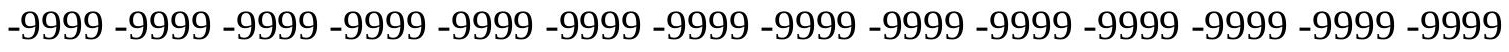
-9999 -9999 -9999 -9999 -9999 -9999 -9999 -9999 -9999 -9999 -9999 -9999 -9999 -9999 -9999 -9999 -9999 -9999 -9999 -9999 -9999 -9999 -9999 -9999-9999 -9999 -9999 -9999 -9999 -9999 -9999 -9999 -9999 -9999 -9999 -9999 -9999 -9999 -9999 -9999 -9999 -9999 -9999 -9999 -9999 -

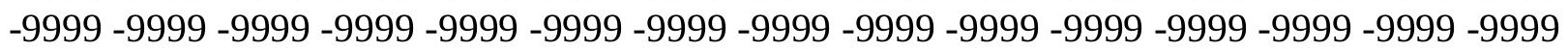


-9999 -9999 -9999 -9999 -9999 -9999 -9999 -9999 -9999 -9999 -9999 -9999 -9999 -9999 -9999 -9999 -9999 -9999 -9999 -9999 -9999 -9999 -9999 -9999 -9999 -9999 -9999 -9999 -9999 -9999 -

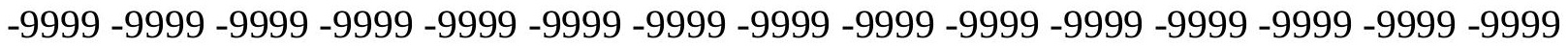
-9999 -9999 -9999 -9999 -9999 -9999 -9999 -9999 -9999 -9999 -9999 -9999 -9999 -9999 -9999 -9999 -9999 -9999 -9999 -9999 -9999 -9999 -9999 -9999-9999 -9999 -9999 -9999 -9999 -9999 -9999 -9999 -9999 -9999 -9999 -9999 -9999 -9999 -9999 -9999 -9999 -9999 -9999 -9999 -9999 -9999 -9999 -9999 -9999 -9999 -9999 -9999 -9999 -9999 -9999 -9999 -9999 -9999 -9999 -9999

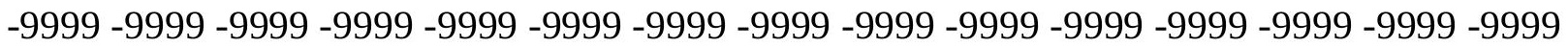

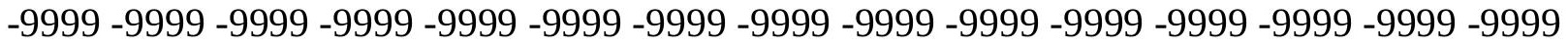
-9999 -9999 -9999 -9999 -9999 -9999 -9999 -9999 -9999 -9999 -9999 -9999 -9999 -9999 -9999 -9999 -9999 -9999 -9999 -9999 -9999 -9999 -9999 -9999 -9999 -9999 -9999 -9999 -9999 -9999 -9999 -9999 -9999 -9999 -9999 -9999 -9999 -9999 -9999 -9999 -9999 -9999 -9999 -9999 -9999 -9999 -9999 -9999 -9999 -9999 -9999 -9999 -9999 -9999 -9999 -9999 -9999 -9999 -9999 -9999 -

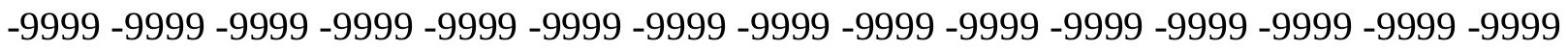
-9999 -9999 -9999 -9999 -9999 -9999 -9999 -9999 -9999 -9999 -9999 -9999 -9999 -9999 -9999 -

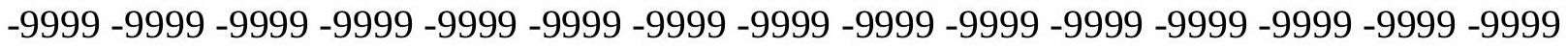
-9999 -9999 -9999 -9999 -9999 -9999 -9999 -9999 -9999 -9999 -9999 -9999 -9999 -9999 -9999 -9999 -9999 -9999 -9999 -9999 -9999 -9999 -9999 -9999 -9999 -9999 -9999 -9999 -9999 -9999 -9999 -9999 -9999 -9999 -9999 -9999 -9999 -9999 -9999 -9999 -9999 -9999 -9999 -9999 -9999 -

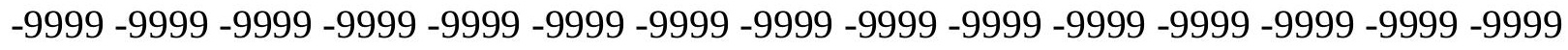

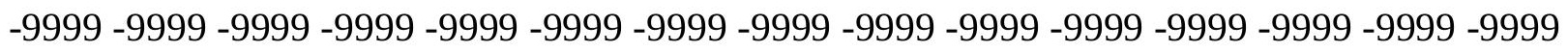
-9999 -9999 -9999 -9999 -9999 -9999 -9999 -9999 -9999 -9999 -9999 -9999 -9999 -9999 -9999 -9999 -9999 -9999 -9999 -9999 -9999 -9999 -9999 -9999 -9999 -9999 -9999 -9999 -9999 -9999 -9999 -9999 -9999 -9999 -9999 -9999 -9999 -9999 -9999 -9999 -9999 -9999 -9999 -9999 -

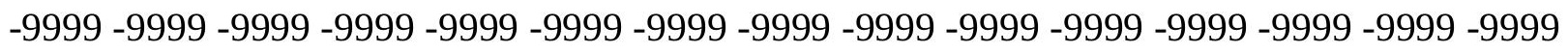
-9999 -9999 -9999 -9999 -9999 -9999 -9999 -9999 -9999 -9999 -9999 -9999 -9999 -9999 -9999 -9999 -9999 -9999 -9999 -9999 -9999 -9999 -9999 -9999 -9999 -9999 -9999 -9999 -9999 -9999 -

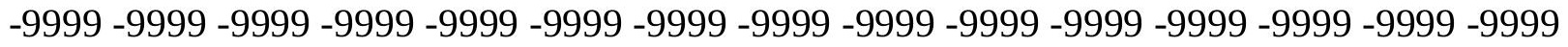
-9999 -9999 -9999 -9999 -9999 -9999 -9999 -9999 -9999 -9999 -9999 -9999 -9999 -9999 -9999 -9999 -9999 -9999 -9999 -9999 -9999 -9999 -9999 -9999 -9999 -9999 -9999 -9999 -9999 -999 -

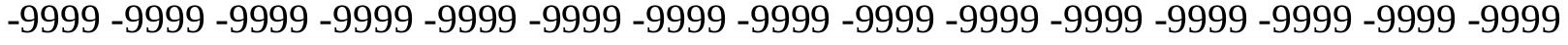
-9999 -9999 -9999 -9999 -9999 -9999 -9999 -9999 -9999 -9999 -9999 -9999 -9999 -9999 -9999 -

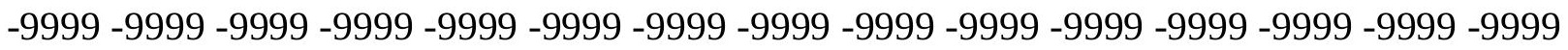

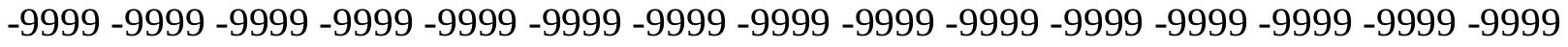

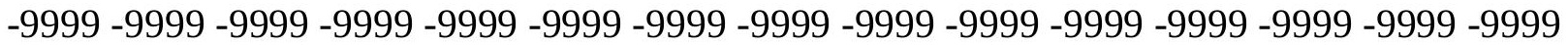

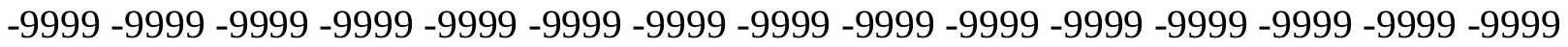

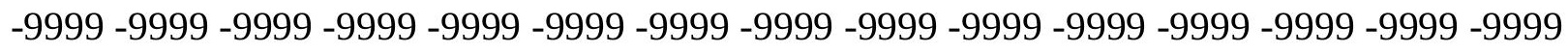

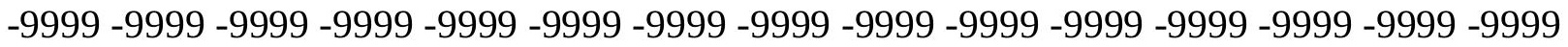

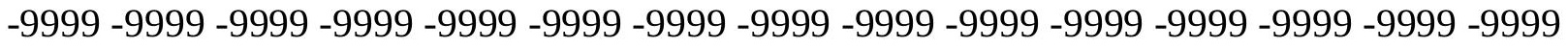
-9999 -9999 -9999 -9999 -9999 -9999 -9999 -9999 -9999 -9999 -9999 -9999 -9999 -9999 -9999 -

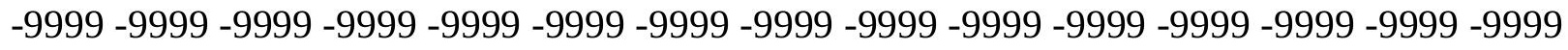

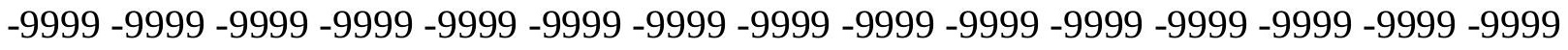
-9999 -9999 -9999 -9999 -9999 -9999 -9999 -9999 -9999 -9999 -9999 -9999 -9999 -9999 -9999 -9999 -9999 -9999 -9999 -9999 -9999 -9999 -9999 -9999-9999 -9999 -9999 -9999 -9999 -9999 -9999 -9999 -9999 -9999 -9999 -9999 -9999 -9999 -9999 -9999 -9999 -9999 -9999 -9999 -9999 -

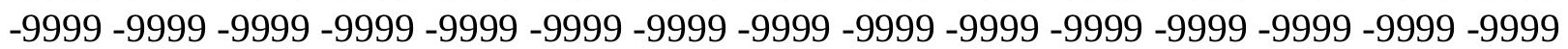


-9999 -9999 -9999 -9999 -9999 -9999 -9999 -9999 -9999 -9999 -9999 -9999 -9999 -9999 -9999 -9999 -9999 -9999 -9999 -9999 -9999 -9999 -9999 -9999 -9999 -9999 -9999 -9999 -9999 -

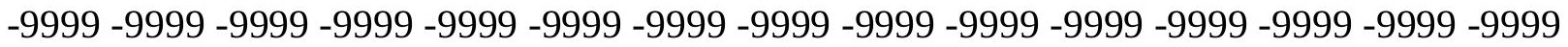
-9999 -9999 -9999 -9999 -9999 -9999 -9999 -9999 -9999 -9999 -9999 -9999 -9999 -9999 -9999 -9999 -9999 -9999 -9999 -9999 -9999 -9999 -9999 -9999 -9999 -9999 -9999 -9999 -9999 -9999 -9999 -9999 -9999 -9999 -9999 -9999 -9999 -9999 -9999 -9999 -9999 -9999 -9999 -9999 -9999 -9999 -9999 -9999 -9999 -9999 -9999 -9999 -9999 -9999 -9999 -9999 -9999 -9999 -9999 -9999

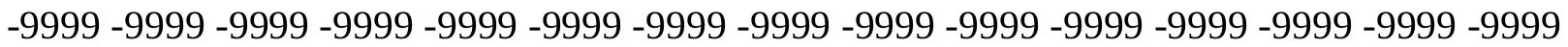

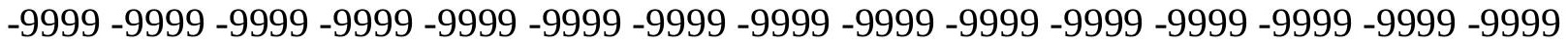
-9999 -9999 -9999 -9999 -9999 -9999 -9999 -9999 -9999 -9999 -9999 -9999 -9999 -9999 -9999 -9999 -9999 -9999 -9999 -9999 -9999 -9999 -9999 -9999 -9999 -9999 -9999 -9999 -9999 -9999 -9999 -9999 -9999 -9999 -9999 -9999 -9999 -9999 -9999 -9999 -9999 -9999 -9999 -9999 -9999 -9999 -9999 -9999 -9999 -9999 -9999 -9999 -9999 -9999 -9999 -9999 -9999 -9999 -9999 -9999 -9999 -9999 -9999 -9999 -9999 -9999 -9999 -9999 -9999 -9999 -9999 -9999 -9999 -9999 -9999 -9999 -9999 -9999 -9999 -9999 -9999 -9999 -9999 -9999 -9999 -9999 -9999 -9999 -9999 -9999 -

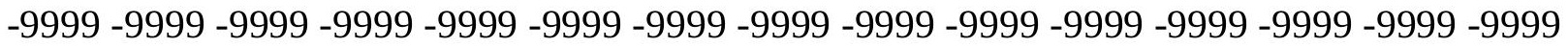
-9999 -9999 -9999 -9999 -9999 -9999 -9999 -9999 -9999 -9999 -9999 -9999 -9999 -9999 -9999 -9999 -9999 -9999 -9999 -9999 -9999 -9999 -9999 -9999 -9999 -9999 -9999 -9999 -9999 - 9999 -9999 -9999 -9999 -9999 -9999 -9999 -9999 -9999 -9999 -9999 -9999 -9999 -9999 -9999 -9999 -

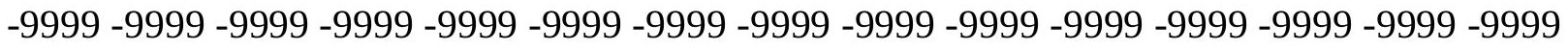

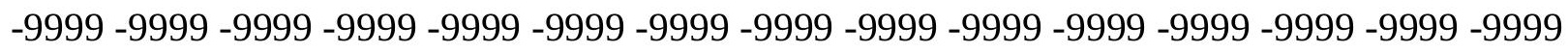

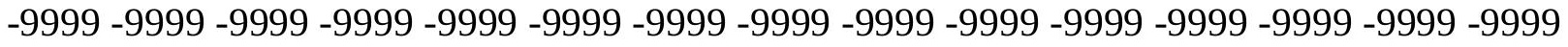
-9999 -9999 -9999 -9999 -9999 -9999 -9999 -9999 -9999 -9999 -9999 -9999 -9999 -9999 -9999 -9999 -9999 -9999 -9999 -9999 -9999 -9999 -9999 -9999 -9999 -9999 -9999 -9999 -9999 -9999 -

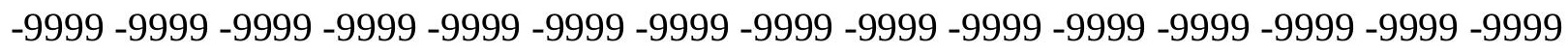
-9999 -9999 -9999 -9999 -9999 -9999 -9999 -9999 -9999 -9999 -9999 -9999 -9999 -9999 -9999 -9999 -9999 -9999 -9999 -9999 -9999 -9999 -9999 -9999 -9999 -9999 -9999 -9999 -9999 -9999 -9999 -9999 -9999 -9999 -9999 -9999 -9999 -9999 -9999 -9999 -9999 -9999 -9999 -9999 -9999 -9999 -9999 -9999 -9999 -9999 -9999 -9999 -9999 -9999 -9999 -9999 -9999 -9999 -9999 -9999 -9999 -9999 -9999 -9999 -9999 -9999 -9999 -9999 -9999 -9999 -9999 -9999 -9999 -999 -

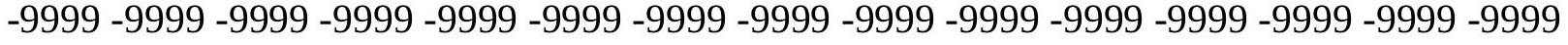
-9999 -9999 -9999 -9999 -9999 -9999 -9999 -9999 -9999 -9999 -9999 -9999 -9999 -9999 -9999 -

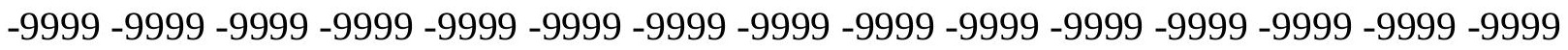

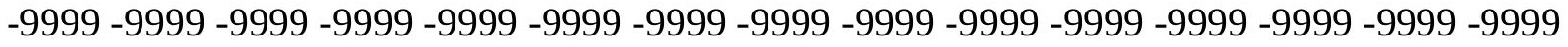

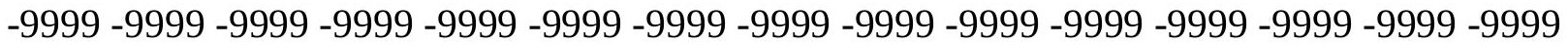

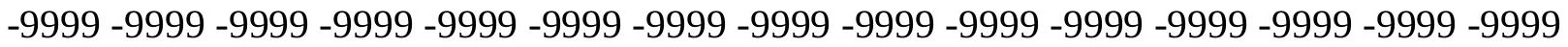

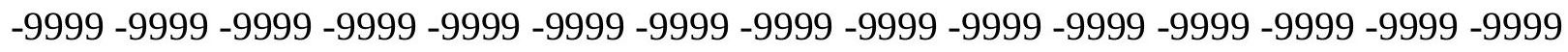

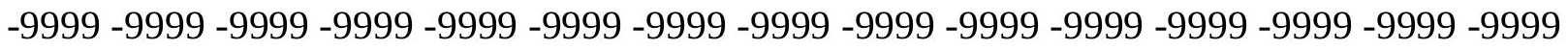

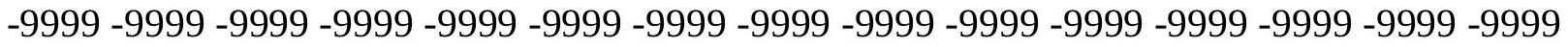
-9999 -9999 -9999 -9999 -9999 -9999 -9999 -9999 -9999 -9999 -9999 -9999 -9999 -9999 -9999 -

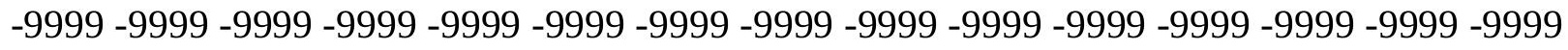

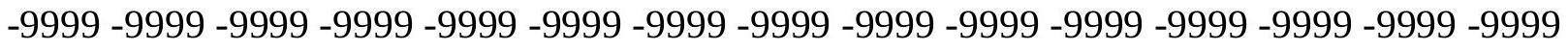
-9999 -9999 -9999 -9999 -9999 -9999 -9999 -9999 -9999 -9999 -9999 -9999 -9999 -9999 -9999 -9999 -9999 -9999 -9999 -9999 -9999 -9999 -9999 -9999-9999 -9999 -9999 -9999 -9999 -9999 -9999 -9999 -9999 -9999 -9999 -9999 -9999 -9999 -9999 -9999 -9999 -9999 -9999 -9999 -9999 -

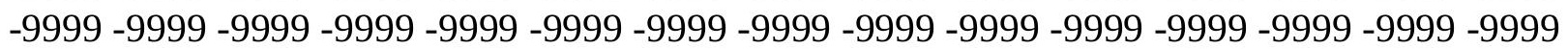


-9999 -9999 -9999 -9999 -9999 -9999 -9999 -9999 -9999 -9999 -9999 -9999 -9999 -9999 -9999 -9999 -9999 -9999 -9999 -9999 -9999 -9999 -9999 -9999 -9999 -9999 -9999 -9999 -9999 -9999 -

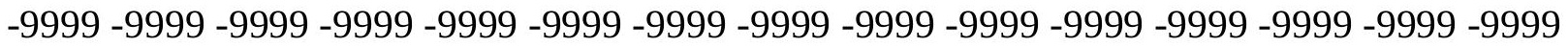
-9999 -9999 -9999 -9999 -9999 -9999 -9999 -9999 -9999 -9999 -9999 -9999 -9999 -9999 -9999 -9999 -9999 -9999 -9999 -9999 -9999 -9999 -9999 -9999-9999 -9999 -9999 -9999 -9999 -9999 -9999 -9999 -9999 -9999 -9999 -9999 -9999 -9999 -9999 -9999 -9999 -9999 -9999 -9999 -9999 -

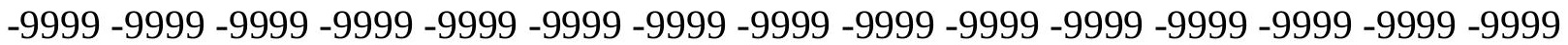
-9999 -9999 -9999 -9999 -9999 -9999 -9999 -9999 -9999 -9999 -9999 -9999 -9999 -9999 -9999 -9999 -9999 -9999 -9999 -9999 -9999 -9999 -9999 -9999 -9999 -9999 -9999 -9999 -9999 -9999 -9999 -9999 -9999 -9999 -9999 -9999 -9999 -9999 -9999 -9999 -9999 -9999 -9999 -9999 -9999 -9999 -9999 -9999 -9999 -9999 -9999 -9999 -9999 -9999 -9999 -9999 -9999 -9999 -9999 -9999 -9999 -9999 -9999 -9999 -9999 -9999 -9999 -9999 -9999 -9999 -9999 -9999 -9999 -9999 -9999 -9999 -9999 -9999 -9999 -9999 -9999 -9999 -9999 -9999 -9999 -9999 -9999 -9999 -9999 -9999 -9999 -9999 -9999 -9999 -9999 -9999 -9999 -9999 -9999 -9999 -9999 -9999 -9999 -9999 -9999 -9999 -9999 -9999 -9999 -9999 -9999 -9999 -9999 -9999 -9999 -9999 -9999 -9999 -9999 -

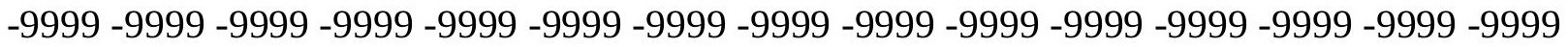
-9999 -9999 -9999 -9999 -9999 -9999 -9999 -9999 -9999 -9999 -9999 -9999 -9999 -9999 -9999 -9999 -9999 -9999 -9999 -9999 -9999 -9999 -9999 -9999 -9999 -9999 -9999 -9999 -9999 -9999 -9999 -9999 -9999 -9999 -9999 -9999 -9999 -9999 -9999 -9999 -9999 -9999 -9999 -9999 -9999 -

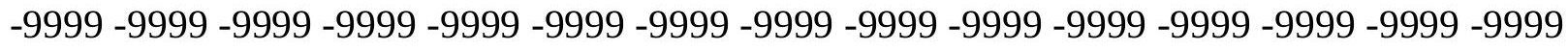

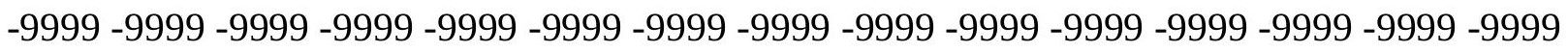
-9999 -9999 -9999 -9999 -9999 -9999 -9999 -9999 -9999 -9999 -9999 -9999 -9999 -9999 - 9999 -9999 -9999 -9999 -9999 -9999 -9999 -9999 -9999 -9999 -9999 -9999 -9999 -9999 -9999 -9999 -9999 -9999 -9999 -9999 -9999 -9999 -9999 -9999 -9999 -9999 -9999 -9999 -9999 -9999 -9999 -

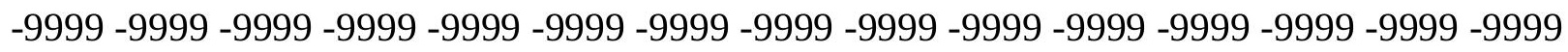
-9999 -9999 -9999 -9999 -9999 -9999 -9999 -9999 -9999 -9999 -9999 -9999 -9999 -9999 -9999 -9999 -9999 -9999 -9999 -9999 -9999 -9999 -9999 -9999 -9999 -9999 -9999 -9999 -9999 -9999 -

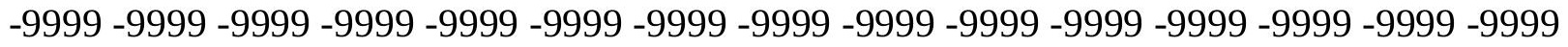
-9999 -9999 -9999 -9999 -9999 -9999 -9999 -9999 -9999 -9999 -9999 -9999 -9999 -9999 -9999 -9999 -9999 -9999 -9999 -9999 -9999 -9999 -9999 -9999 -9999 -9999 -9999 -9999 -9999 -999 -9999 -9999 -9999 -9999 -9999 -9999 -9999 -9999 -9999 -9999 -9999 -9999 -9999 -9999 -9999 -9999 -9999 -9999 -9999 -9999 -9999 -9999 -9999 -9999 -9999 -9999 -9999 -9999 -9999 -9999 -

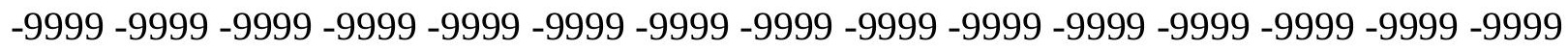

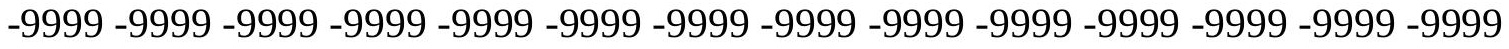
-9999 -9999 -9999 -9999 -9999 -9999 -9999 -9999 -9999 -9999 -9999 -9999 -9999 -9999 -9999

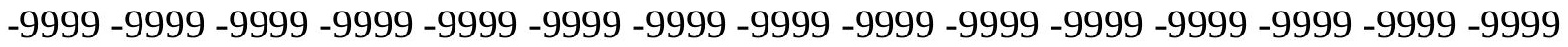

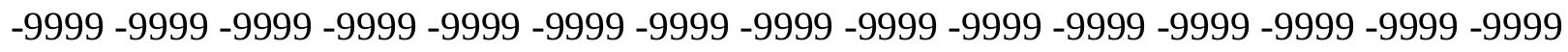

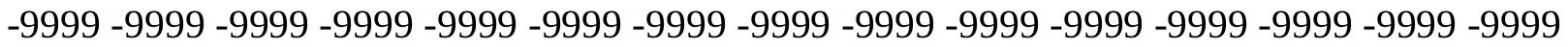

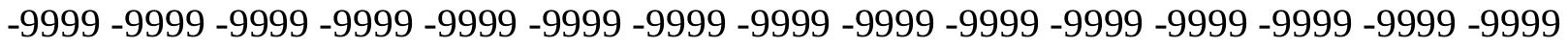
-9999 -9999 -9999 -9999 -9999 -9999 -9999 -9999 -9999 -9999 -9999 -9999 -9999 -9999 -9999 -

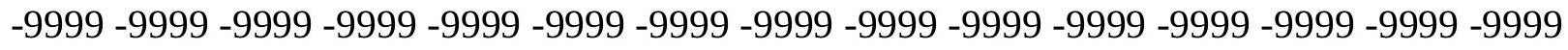

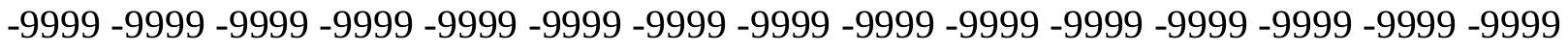
-9999 -9999 -9999 -9999 -9999 -9999 -9999 -9999 -9999 -9999 -9999 -9999 -9999 -9999 -9999 -9999 -9999 -9999 -9999 -9999 -9999 -9999 -9999 -9999-9999 -9999 -9999 -9999 -9999 -9999 -9999 -9999 -9999 -9999 -9999 -9999 -9999 -9999 -9999 -9999 -9999 -9999 -9999 -9999 -9999 -

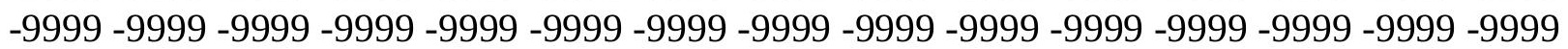


-9999 -9999 -9999 -9999 -9999 -9999 -9999 -9999 -9999 -9999 -9999 -9999 -9999 -9999 -9999 -9999 -9999 -9999 -9999 -9999 -9999 -9999 -9999 -9999 -9999 -9999 -9999 -9999 -9999 -9999 -

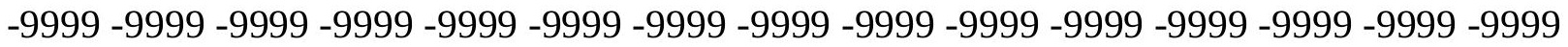
-9999 -9999 -9999 -9999 -9999 -9999 -9999 -9999 -9999 -9999 -9999 -9999 -9999 -9999 -9999 -9999 -9999 -9999 -9999 -9999 -9999 -9999 -9999 -9999-9999 -9999 -9999 -9999 -9999 -9999 -9999 -9999 -9999 -9999 -9999 -9999 -9999 -9999 -9999 -9999 -9999 -9999 -9999 -9999 -9999 -9999 -9999 -9999 -9999 -9999 -9999 -9999 -9999 -9999 -9999 -9999 -9999 -9999 -9999 -9999

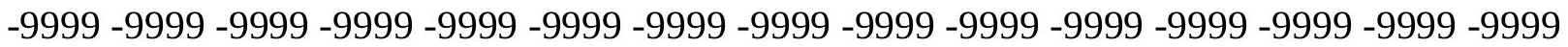

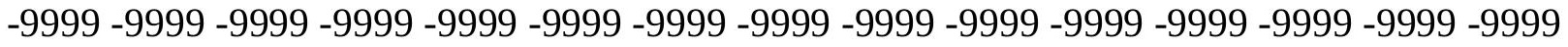
-9999 -9999 -9999 -9999 -9999 -9999 -9999 -9999 -9999 -9999 -9999 -9999 -9999 -9999 -9999 -9999 -9999 -9999 -9999 -9999 -9999 -9999 -9999 -9999 -9999 -9999 -9999 -9999 -9999 -9999 -9999 -9999 -9999 -9999 -9999 -9999 -9999 -9999 -9999 -9999 -9999 -9999 -9999 -9999 -9999 -9999 -9999 -9999 -9999 -9999 -9999 -9999 -9999 -9999 -9999 -9999 -9999 -9999 -9999 -9999 -9999 -9999 -9999 -9999 -9999 -9999 -9999 -9999 -9999 -9999 -9999 -9999 -9999 -9999 -9999 -9999 -9999 -9999 -9999 -9999 -9999 -9999 -9999 -9999 -9999 -9999 -9999 -9999 -9999

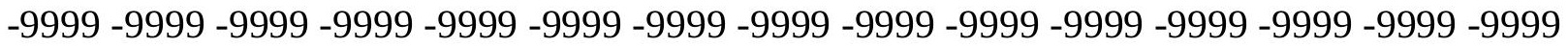
-9999 -9999 -9999 -9999 -9999 -9999 -9999 -9999 -9999 -9999 -9999 -9999 -9999 -9999 -9999 -9999 -9999 -9999 -9999 -9999 -9999 -9999 -9999 -9999 -9999 -9999 -9999 -9999 -9999 -9999 -9999 -9999 -9999 -9999 -9999 -9999 -9999 -9999 -9999 -9999 -9999 -9999 -9999 -9999 -9999 -

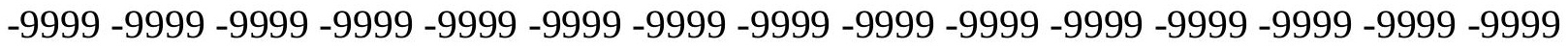

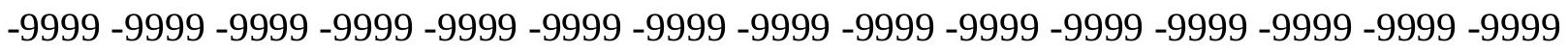
-9999 -9999 -9999 -9999 -9999 -9999 -9999 -9999 -9999 -9999 -9999 -9999 -9999 -9999 -9999 -9999 -9999 -9999 -9999 -9999 -9999 -9999 -9999 -9999 -9999 -9999 -9999 -9999 -9999 -9999 -9999 -9999 -9999 -9999 -9999 -9999 -9999 -9999 -9999 -9999 -9999 -9999 -9999 -9999 -9999 -

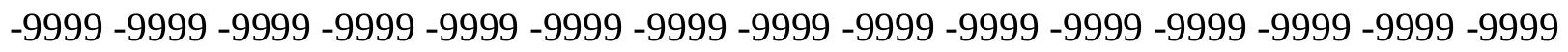
-9999 -9999 -9999 -9999 -9999 -9999 -9999 -9999 -9999 -9999 -9999 -9999 -9999 -9999 -9999 -9999 -9999 -9999 -9999 -9999 -9999 -9999 -9999 -9999 -9999 -9999 -9999 -9999 -9999 -9999 -

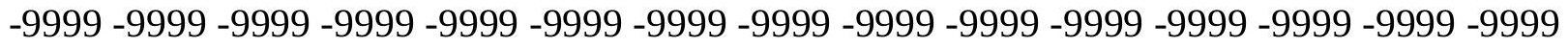
-9999 -9999 -9999 -9999 -9999 -9999 -9999 -9999 -9999 -9999 -9999 -9999 -9999 -9999 -9999 -9999 -9999 -9999 -9999 -9999 -9999 -9999 -9999 -9999 -9999 -9999 -9999 -9999 -9999 -999 -9999 -9999 -9999 -9999 -9999 -9999 -9999 -9999 -9999 -9999 -9999 -9999 -9999 -9999 -9999 -9999 -9999 -9999 -9999 -9999 -9999 -9999 -9999 -9999 -9999 -9999 -9999 -9999 -9999 -9999 -

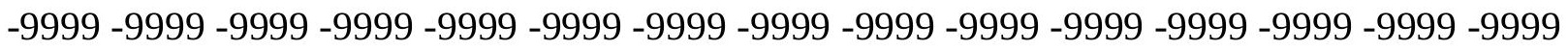

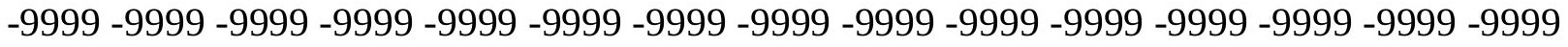

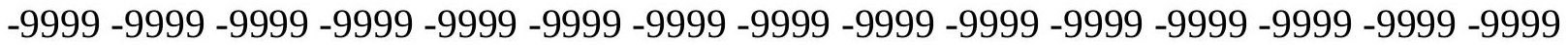

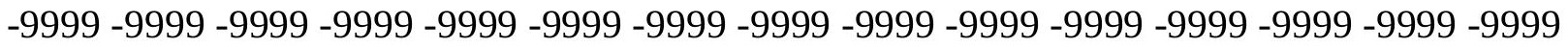

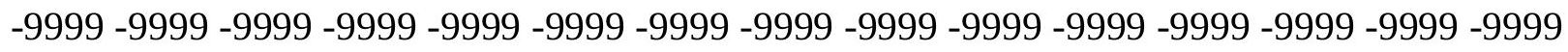

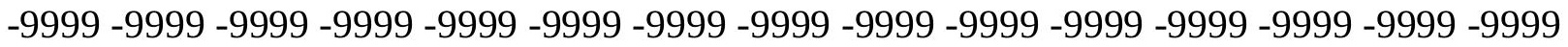
-9999 -9999 -9999 -9999 -9999 -9999 -9999 -9999 -9999 -9999 -9999 -9999 -9999 - 9999 - -999 -9999 -9999 -9999 -9999 -9999 -9999 -9999 -9999 -9999 -9999 -9999 -9999 -9999 -9999 - -999 -

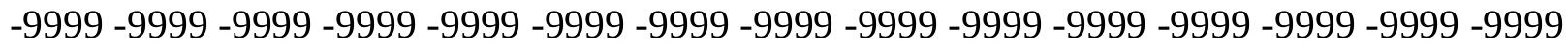

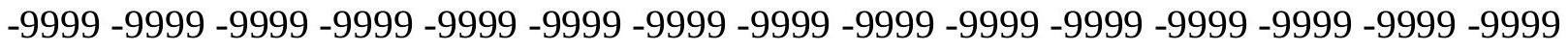
-9999 -9999 -9999 -9999 -9999 -9999 -9999 -9999 -9999 -9999 -9999 -9999 -9999 -9999 -9999 -9999 -9999 -9999 -9999 -9999 -9999 -9999 -9999 -9999-9999 -9999 -9999 -9999 -9999 -9999 -9999 -9999 -9999 -9999 -9999 -9999 -9999 -9999 -9999 -9999 -9999 -9999 -9999 -9999 -9999 -

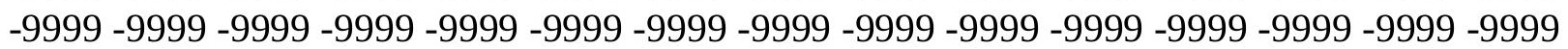


-9999 -9999 -9999 -9999 -9999 -9999 -9999 -9999 -9999 -9999 -9999 -9999 -9999 -9999 -9999 -9999 -9999 -9999 -9999 -9999 -9999 -9999 -9999 -9999 -9999 -9999 -9999 -9999 -9999 -9999 -9999 -9999 -9999 -9999 -9999 -9999 -9999 -9999 -9999 -9999 -9999 -9999 -9999 -9999 -9999 -9999 -9999 -9999 -9999 -9999 -9999 -9999 -9999 -9999 -9999 -9999 -9999 -9999 -9999 -9999 -9999 -9999 -9999 -9999 -9999 -9999 -9999 -9999 -9999 -9999 -9999 -9999 -9999 -9999 -9999 -9999 -9999 -9999 -9999 -9999 -9999 -9999 -9999 -9999 -9999 -9999 -9999 -9999 -9999 -9999 -9999 -9999 -9999 -9999 -9999 -9999 -9999 -9999 -9999 -9999 -9999 -9999 -9999 -9999 -9999 -

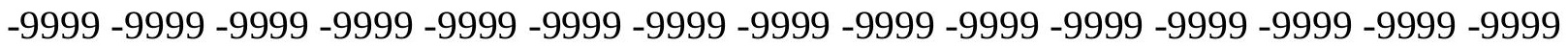
-9999 -9999 -9999 -9999 -9999 -9999 -9999 -9999 -9999 -9999 -9999 -9999 -9999 -9999 -9999 -9999 -9999 -9999 -9999 -9999 -9999 -9999 -9999 -9999 -9999 -9999 -9999 -9999 -9999 -9999 -

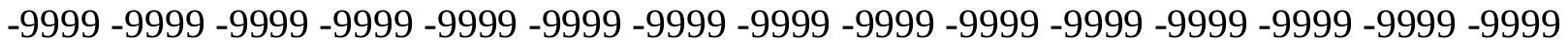
-9999 -9999 -9999 -9999 -9999 -9999 -9999 -9999 -9999 -9999 -9999 -9999 -9999 -9999 -9999 -9999 -9999 -9999 -9999 -9999 -9999 -9999 -9999 -9999 -9999 -9999 -9999 -9999 -9999 -9999 -9999 -9999 -9999 -9999 -9999 -9999 -9999 -9999 -9999 -9999 -9999 -9999 -9999 -9999 -9999 -9999 -9999 -9999 -9999 -9999 -9999 -9999 -9999 -9999 -9999 -9999 -9999 -9999 -9999 -9999

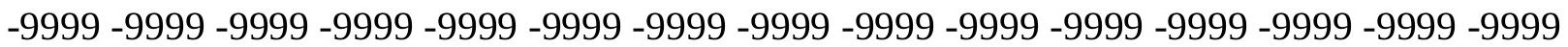
-9999 -9999 -9999 -9999 -9999 -9999 -9999 -9999 -9999 -9999 -9999 -9999 -9999 -9999 -9999 -9999 -9999 -9999 -9999 -9999 -9999 -9999 -9999 -9999 -9999 -9999 -9999 -9999 -9999 -9999 -9999 -9999 -9999 -9999 -9999 -9999 -9999 -9999 -9999 -9999 -9999 -9999 -9999 -9999 -9999 -9999 -9999 -9999 -9999 -9999 -9999 -9999 -9999 -9999 -9999 -9999 -9999 -9999 -9999 -9999 -9999 -9999 -9999 -9999 -9999 -9999 -9999 -9999 -9999 -9999 -9999 -9999 -9999 -9999 -9999 -9999 -9999 -9999 -9999 -9999 -9999 -9999 -9999 -9999 -9999 -9999 -9999 -9999 -9999 -9999 -9999 -9999 -9999 -9999 -9999 -9999 -9999 -9999 -9999 -9999 -9999 -9999 -9999 -9999 -9999 -9999 -9999 -9999 -9999 -9999 -9999 -9999 -9999 -9999 -9999 -9999 -9999 -9999 -9999 -9999 -9999 -9999 -9999 -9999 -9999 -9999 -9999 -9999 -9999 -9999 -9999 -9999 -9999 -9999 -9999 -9999 -9999 -9999 -9999 -9999 -9999 -9999 -9999 -9999 -9999 -9999 -9999 -9999 -9999 -9999 -9999 -9999 -9999 -9999 -9999 -9999 -9999 -9999 -9999 -9999 -9999 -9999 -9999 -9999 -9999 -9999 -9999 -9999 -9999 -9999 -9999 -9999 -9999 -9999 -9999 -9999 -9999 -9999 -9999

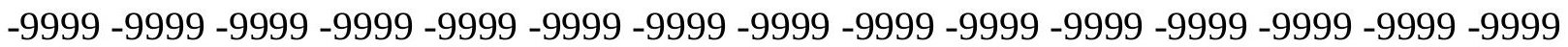
-9999 -9999 -9999 -9999 -9999 -9999 -9999 -9999 -9999 -9999 -9999 -9999 -9999 -9999 -9999 -9999 -9999 -9999 -9999 -9999 -9999 -9999 -9999 -9999 -9999 -9999 -9999 -9999 -9999 -9999 -

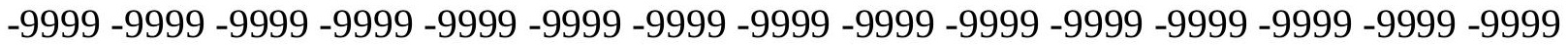
-9999 -9999 -9999 -9999 -9999 -9999 -9999 -9999 -9999 -9999 -9999 -9999 -9999 -9999 -9999 -9999 -9999 -9999 -9999 -9999 -9999 -9999 -9999 -9999 -9999 -9999 -9999 -9999 -9999 -9999 -9999 -9999 -9999 -9999 -9999 -9999 -9999 -9999 -9999 -9999 -9999 -9999 -9999 -9999 -9999 -9999 -9999 -9999 -9999 -9999 -9999 -9999 -9999 -9999 -9999 -9999 -9999 -9999 -9999 -9999 -9999 -9999 -9999 -9999 -9999 -9999 -9999 -9999 -9999 -9999 -9999 -9999 -9999 -9999 -9999

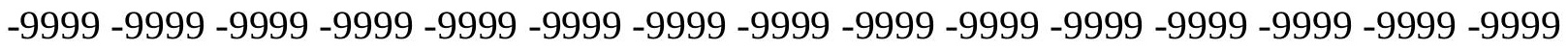
-9999 -9999 -9999 -9999 -9999 -9999 -9999 -9999 -9999 -9999 -9999 -9999 -9999 -9999 -9999 -9999 -9999 -9999 -9999 -9999 -9999 -9999 -9999 -9999 -9999 -9999 -9999 -9999 -9999 -9999 -9999 -9999 -9999 -9999 -9999 -9999 -9999 -9999 -9999 -9999 -9999 -9999 -9999 -9999 -9999 -999 -9999 -9999 -9999 -9999 -9999 -9999 -9999 -9999 -9999 -9999 -9999 -9999 -9999 -9999 -9999 -9999 -9999 -9999 -9999 -9999 -9999 -9999 -9999 -9999 -9999 -9999 -9999 -9999 -9999 -9999 -9999 -9999 -9999 -9999 -9999 -9999 -9999 -9999 -9999 -9999 -9999 -9999 -9999 -9999 -9999 -9999 -9999 -9999 -9999 -9999 -9999 -9999 -9999 -9999 -9999 -9999 -9999 -9999 -9999 -9999 -9999 -9999 -9999 -9999 -9999 -9999 -9999 -9999 -9999 -9999 -9999 -9999 -9999 -9999 
-9999 -9999 -9999 -9999 -9999 -9999 -9999 -9999 -9999 -9999 -9999 -9999 -9999 -9999 -9999 -9999 -9999 -9999 -9999 -9999 -9999 -9999 -9999 -9999 -9999 -9999 -9999 -9999 -9999 -9999 -

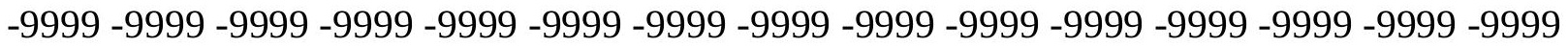
-9999 -9999 -9999 -9999 -9999 -9999 -9999 -9999 -9999 -9999 -9999 -9999 -9999 -9999 -9999 -9999 -9999 -9999 -9999 -9999 -9999 -9999 -9999 -9999-9999 -9999 -9999 -9999 -9999 -9999 -9999 -9999 -9999 -9999 -9999 -9999 -9999 -9999 -9999 -9999 -9999 -9999 -9999 -9999 -9999 -9999 -9999 -9999 -9999 -9999 -9999 -9999 -9999 -9999 -9999 -9999 -9999 -9999 -9999 -9999

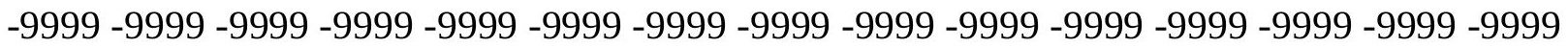

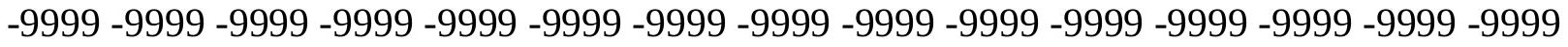
-9999 -9999 -9999 -9999 -9999 -9999 -9999 -9999 -9999 -9999 -9999 -9999 -9999 -9999 -9999 -9999 -9999 -9999 -9999 -9999 -9999 -9999 -9999 -9999 -9999 -9999 -9999 -9999 -9999 -9999 -9999 -9999 -9999 -9999 -9999 -9999 -9999 -9999 -9999 -9999 -9999 -9999 -9999 -9999 -9999 -9999 -9999 -9999 -9999 -9999 -9999 -9999 -9999 -9999 -9999 -9999 -9999 -9999 -9999 -9999 -

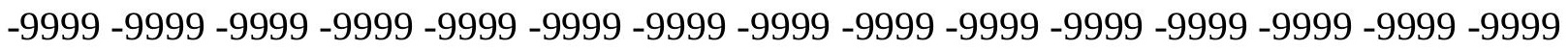
-9999 -9999 -9999 -9999 -9999 -9999 -9999 -9999 -9999 -9999 -9999 -9999 -9999 -9999 -9999 -

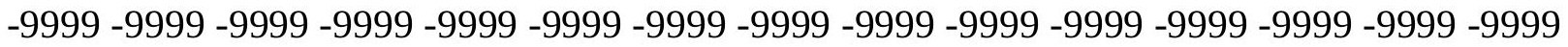
-9999 -9999 -9999 -9999 -9999 -9999 -9999 -9999 -9999 -9999 -9999 -9999 -9999 -9999 -9999 -9999 -9999 -9999 -9999 -9999 -9999 -9999 -9999 -9999 -9999 -9999 -9999 -9999 -9999 -9999 -9999 -9999 -9999 -9999 -9999 -9999 -9999 -9999 -9999 -9999 -9999 -9999 -9999 -9999 -9999 -

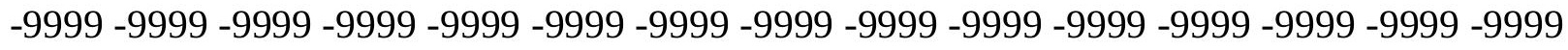

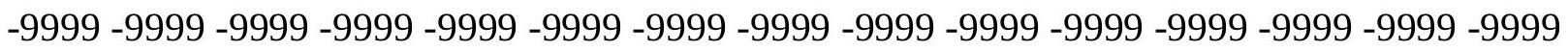

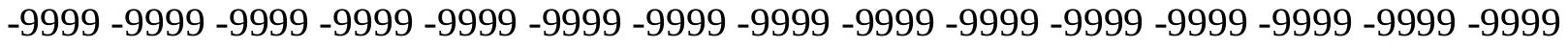
-9999 -9999 -9999 -9999 -9999 -9999 -9999 -9999 -9999 -9999 -9999 -9999 -9999 -9999 -9999 -9999 -9999 -9999 -9999 -9999 -9999 -9999 -9999 -9999 -9999 -9999 -9999 -9999 -9999 -9999 -

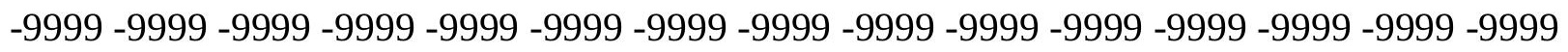
-9999 -9999 -9999 -9999 -9999 -9999 -9999 -9999 -9999 -9999 -9999 -9999 -9999 -9999 -9999 -9999 -9999 -9999 -9999 -9999 -9999 -9999 -9999 -9999 -9999 -9999 -9999 -9999 -9999 -

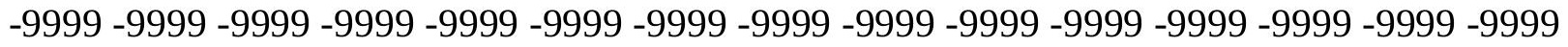
-9999 -9999 -9999 -9999 -9999 -9999 -9999 -9999 -9999 -9999 -9999 -9999 -9999 -9999 -9999 -9999 -9999 -9999 -9999 -9999 -9999 -9999 -9999 -9999 -9999 -9999 -9999 -9999 -9999 -999 -

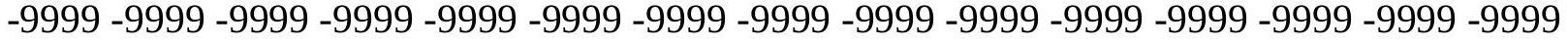
-9999 -9999 -9999 -9999 -9999 -9999 -9999 -9999 -9999 -9999 -9999 -9999 -9999 -9999 -9999 -

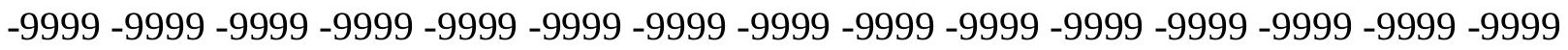

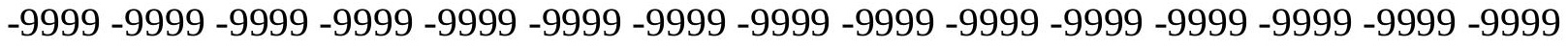

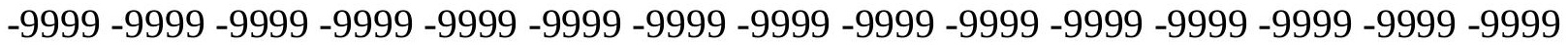
-9999 -9999 -9999 -9999 -9999 -9999 -9999 -9999 -9999 -9999 -9999 -9999 -9999 -9999 -9999

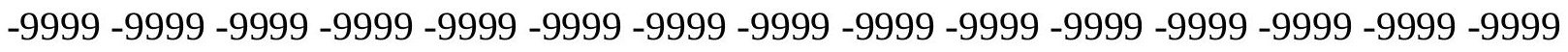

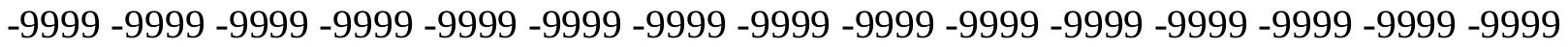
-9999 -9999 -9999 -9999 -9999 -9999 -9999 -9999 -9999 -9999 -9999 -9999 -9999 - 9999 - -999 -9999 -9999 -9999 -9999 -9999 -9999 -9999 -9999 -9999 -9999 -9999 -9999 -9999 -9999 -9999 -

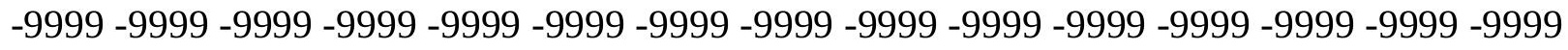

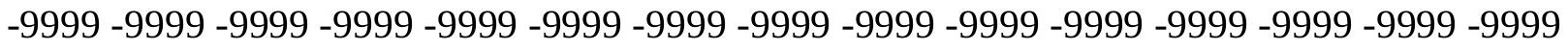
-9999 -9999 -9999 -9999 -9999 -9999 -9999 -9999 -9999 -9999 -9999 -9999 -9999 -9999 -9999 -9999 -9999 -9999 -9999 -9999 -9999 -9999 -9999 -9999-9999 -9999 -9999 -9999 -9999 -9999 -9999 -9999 -9999 -9999 -9999 -9999 -9999 -9999 -9999 -9999 -9999 -9999 -9999 -9999 -9999 -

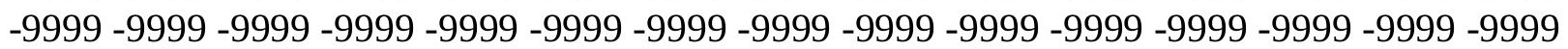


-9999 -9999 -9999 -9999 -9999 -9999 -9999 -9999 -9999 -9999 -9999 -9999 -9999 -9999 -9999 -9999 -9999 -9999 -9999 -9999 -9999 -9999 -9999 -9999 -9999 -9999 -9999 -9999 -9999 -9999 -9999 -9999 -9999 -9999 -9999 -9999 -9999 -9999 -9999 -9999 -9999 -9999 -9999 -9999 - 9999 -9999 -9999 -9999 -9999 -9999 -9999 -9999 -9999 -9999 -9999 -9999 -9999 -9999 -9999 -9999 -9999 -9999 -9999 -9999 -9999 -9999 -9999 -9999 -9999 -9999 -9999 -9999 -9999 -9999 - -9999 -9999 -9999 -9999 -9999 -9999 -9999 -9999 -9999 -9999 -9999 -9999 -9999 -9999 -9999 -9999 -9999 -9999 -9999 -9999 -9999 -9999 -9999 -9999 -9999 -9999 -9999 -9999 -9999 -9999

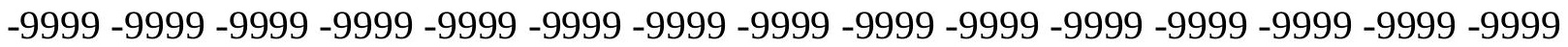

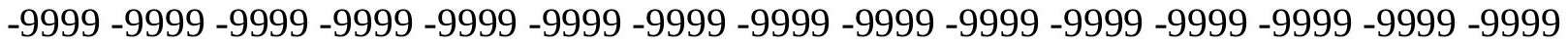
-9999 -9999 -9999 -9999 -9999 -9999 -9999 -9999 -9999 -9999 -9999 -9999 -9999 -9999 -9999

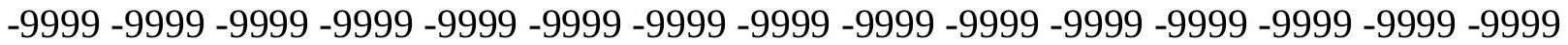
-9999 -9999 -9999 -9999 -9999 -9999 -9999 -9999 -9999 -9999 -9999 -9999 -9999 -9999 -9999 -9999 -9999 -9999 -9999 -9999 -9999 -9999 -9999 -9999 -9999 -9999 -9999 -9999 -9999 -9999 -9999 -9999 -9999 -9999 -9999 -9999 -9999 -9999 -9999 -9999 -9999 -9999 -9999 -9999 - -9999 -9999 -9999 -9999 -9999 -9999 -9999 -9999 -9999 -9999 -9999 -9999 -9999 -9999 -9999 -9999

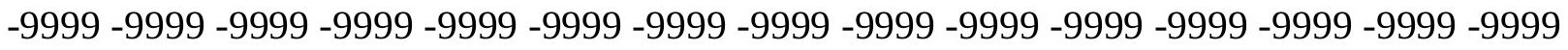
-9999 -9999 -9999 -9999 -9999 -9999 -9999 -9999 -9999 -9999 -9999 -9999 -9999 -9999 -9999 -9999 -9999 -9999 -9999 -9999 -9999 -9999 -9999 -9999 -9999 -9999 -9999 -9999 -9999 -9999 -9999 -9999 -9999 -9999 -9999 -9999 -9999 -9999 -9999 -9999 -9999 -9999 -9999 -9999 -9999 -

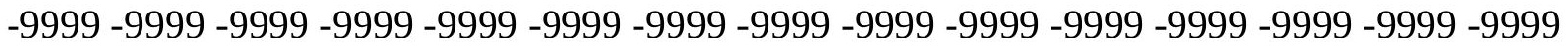
-9999 -9999 -9999 -9999 -9999 -9999 -9999 -9999 -9999 -9999 -9999 -9999 -9999 -9999 -9999 -999 -9999 -9999 -9999 -9999 -9999 -9999 -9999 -9999 -9999 -9999 -9999 -9999 -9999 -9999 -9999 -9999 -9999 -9999 -9999 -9999 -9999 -9999 -9999 -9999 -9999 -9999 -9999 -9999 -9999 -9999 -9999 -9999 -9999 -9999 -9999 -9999 -9999 -9999 -9999 -9999 -9999 -9999 -9999 -9999 -9999 -9999 -9999 -9999 -9999 -9999 -9999 -9999 -9999 -9999 -9999 -9999 -9999 -9999 -9999 -9999 -9999 -9999 -9999 -9999 -9999 -9999 -9999 -9999 -9999 -9999 -9999 -9999 -9999 -9999 -9999 -9999 -9999 -9999 -9999 -9999 -9999 -9999 -9999 -9999 -9999 -9999 -9999 -9999 -9999 -9999 -9999 -9999 -9999 -9999 -9999 -9999 -9999 -9999 -9999 -9999 -9999 -9999 -9999 -9999 -9999 -9999 -9999 -9999 -9999 -9999 -9999 -9999 -9999 -9999 -9999 -9999 -9999 -9999 -9999 -9999 -9999 -9999 -9999 -9999 -9999 -9999 -9999 -9999 -9999 -9999 -9999 -9999 -9999 -9999 -999 -9999 -9999 -9999 -9999 -9999 -9999 -9999 -9999 -9999 -9999 -9999 -9999 -9999 -9999 -9999 -9999 -9999 -9999 -9999 -9999 -9999 -9999 -9999 -9999 -9999 -9999 -9999 -9999 -9999 -

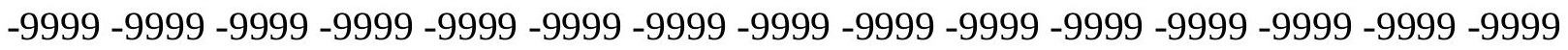

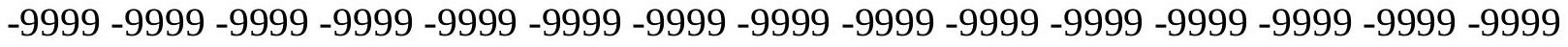

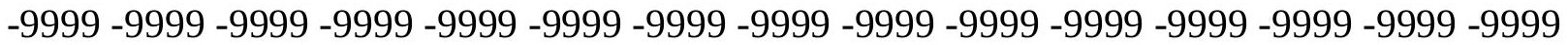
-9999 -9999 -9999 -9999 -9999 -9999 -9999 -9999 -9999 -9999 -9999 -9999 -9999 -9999 -9999 -

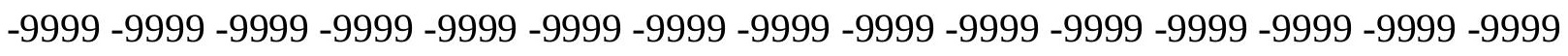

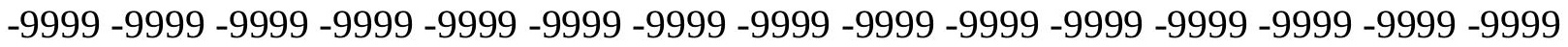

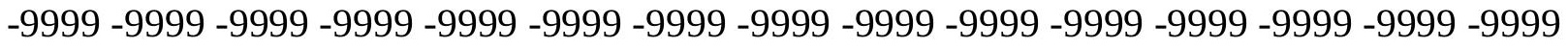
-9999 -9999 -9999 -9999 -9999 -9999 -9999 -9999 -9999 -9999 -9999 -9999 -9999 -9999 -9999 -

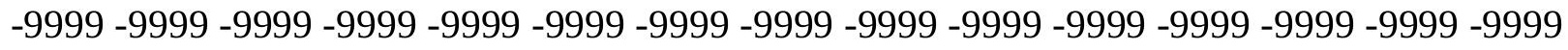

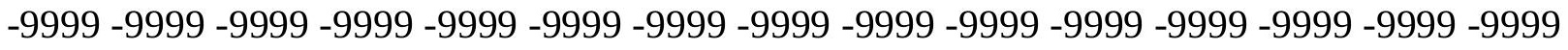
-9999 -9999 -9999 -9999 -9999 -9999 -9999 -9999 -9999 -9999 -9999 -9999 -9999 -9999 -9999 -9999 -9999 -9999 -9999 -9999 -9999 -9999 -9999 -9999-9999 -9999 -9999 -9999 -9999 -9999 -9999 -9999 -9999 -9999 -9999 -9999 -9999 -9999 -9999 -9999 -9999 -9999 -9999 -9999 -9999 -

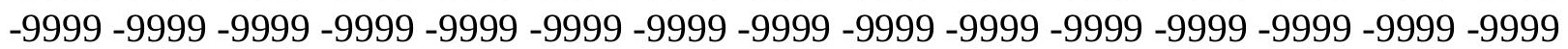


-9999 -9999 -9999 -9999 -9999 -9999 -9999 -9999 -9999 -9999 -9999 -9999 -9999 -9999 -9999 -9999 -9999 -9999 -9999 -9999 -9999 -9999 -9999 -9999 -9999 -9999 -9999 -9999 -9999 -9999 -

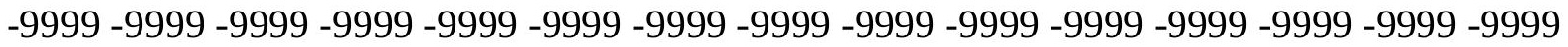
-9999 -9999 -9999 -9999 -9999 -9999 -9999 -9999 -9999 -9999 -9999 -9999 -9999 -9999 -9999 -9999 -9999 -9999 -9999 -9999 -9999 -9999 -9999 -9999-9999 -9999 -9999 -9999 -9999 -9999 -9999 -9999 -9999 -9999 -9999 -9999 -9999 -9999 -9999 -9999 -9999 -9999 -9999 -9999 -9999 -9999 -9999 -9999 -9999 -9999 -9999 -9999 -9999 -9999 -9999 -9999 -9999 -9999 -9999 -9999

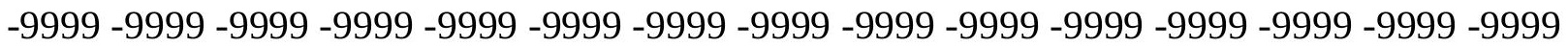

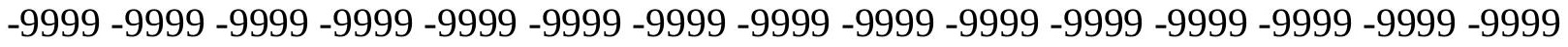
-9999 -9999 -9999 -9999 -9999 -9999 -9999 -9999 -9999 -9999 -9999 -9999 -9999 -9999 -9999 -9999 -9999 -9999 -9999 -9999 -9999 -9999 -9999 -9999 -9999 -9999 -9999 -9999 -9999 -9999 -9999 -9999 -9999 -9999 -9999 -9999 -9999 -9999 -9999 -9999 -9999 -9999 -9999 -9999 -9999 -9999 -9999 -9999 -9999 -9999 -9999 -9999 -9999 -9999 -9999 -9999 -9999 -9999 -9999 -9999 -9999 -9999 -9999 -9999 -9999 -9999 -9999 -9999 -9999 -9999 -9999 -9999 -9999 - 9999 -9999 -9999 -9999 -9999 -9999 -9999 -9999 -9999 -9999 -9999 -9999 -9999 -9999 -9999 -9999

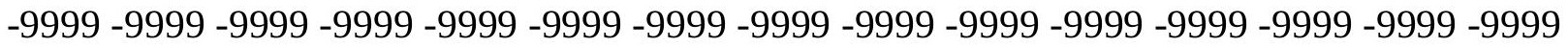
-9999 -9999 -9999 -9999 -9999 -9999 -9999 -9999 -9999 -9999 -9999 -9999 -9999 -9999 -9999 -9999 -9999 -9999 -9999 -9999 -9999 -9999 -9999 -9999 -9999 -9999 -9999 -9999 -9999 -9999 -9999 -9999 -9999 -9999 -9999 -9999 -9999 -9999 -9999 -9999 -9999 -9999 -9999 -9999 -9999 -

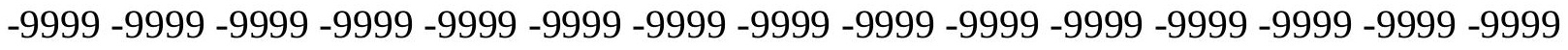

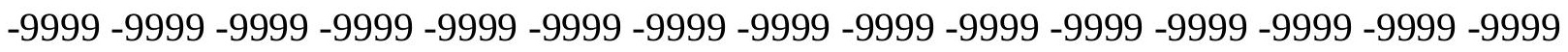
-9999 -9999 -9999 -9999 -9999 -9999 -9999 -9999 -9999 -9999 -9999 -9999 -9999 -9999 -9999 -9999 -9999 -9999 -9999 -9999 -9999 -9999 -9999 -9999 -9999 -9999 -9999 -9999 -9999 -9999 -9999 -9999 -9999 -9999 -9999 -9999 -9999 -9999 -9999 -9999 -9999 -9999 -9999 -9999 -9999 -

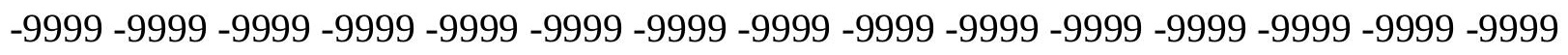
-9999 -9999 -9999 -9999 -9999 -9999 -9999 -9999 -9999 -9999 -9999 -9999 -9999 -9999 -9999 -9999 -9999 -9999 -9999 -9999 -9999 -9999 -9999 -9999 -9999 -9999 -9999 -9999 -9999 -9999 -

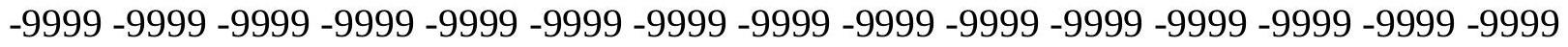
-9999 -9999 -9999 -9999 -9999 -9999 -9999 -9999 -9999 -9999 -9999 -9999 -9999 -9999 -9999 -9999 -9999 -9999 -9999 -9999 -9999 -9999 -9999 -9999 -9999 -9999 -9999 -9999 -9999 -999 -9999 -9999 -9999 -9999 -9999 -9999 -9999 -9999 -9999 -9999 -9999 -9999 -9999 -9999 -9999 -9999 -9999 -9999 -9999 -9999 -9999 -9999 -9999 -9999 -9999 -9999 -9999 -9999 -9999 -9999 -

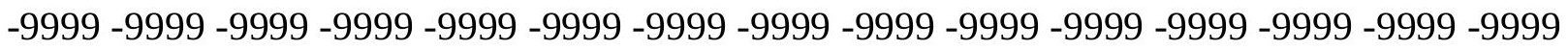

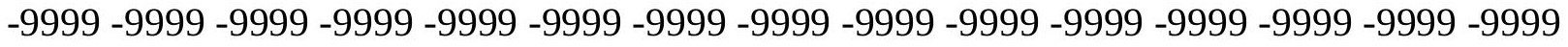

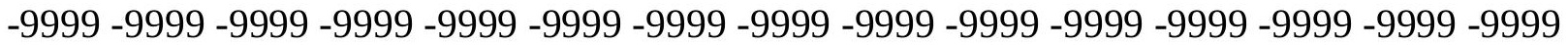

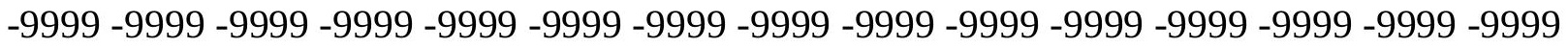

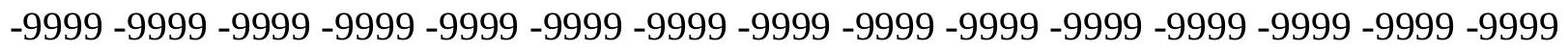

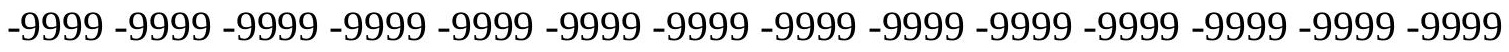
-9999 -9999 -9999 -9999 -9999 -9999 -9999 -9999 -9999 -9999 -9999 -9999 -9999 -9999 -9999 -9999 -9999 -9999 -9999 -9999 -9999 -9999 -9999 -9999 -9999 -9999 -9999 -9999 -9999 -9999 -

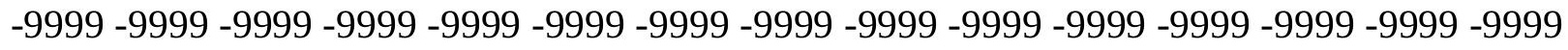

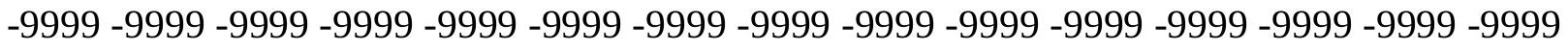
-9999 -9999 -9999 -9999 -9999 -9999 -9999 -9999 -9999 -9999 -9999 -9999 -9999 -9999 -9999 -9999 -9999 -9999 -9999 -9999 -9999 -9999 -9999 -9999-9999 -9999 -9999 -9999 -9999 -9999 -9999 -9999 -9999 -9999 -9999 -9999 -9999 -9999 -9999 -9999 -9999 -9999 -9999 -9999 -9999 -

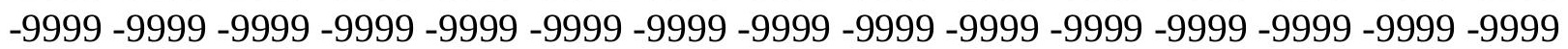


-9999 -9999 -9999 -9999 -9999 -9999 -9999 -9999 -9999 -9999 -9999 -9999 -9999 -9999 -9999 -9999 -9999 -9999 -9999 -9999 -9999 -9999 -9999 -9999 -9999 -9999 -9999 -9999 -9999 -9999 -9999 -9999 -9999 -9999 -9999 -9999 -9999 -9999 -9999 -9999 -9999 -9999 -9999 -9999 - 9999 -9999 -9999 -9999 -9999 -9999 -9999 -9999 -9999 -9999 -9999 -9999 -9999 -9999 -9999 -9999 -9999 -9999 -9999 -9999 -9999 -9999 -9999 -9999 -9999 -9999 -9999 -9999 -9999 -9999 -9999 -9999 -9999 -9999 -9999 -9999 -9999 -9999 -9999 -9999 -9999 -9999 -9999 -9999 -9999 -9999 -9999 -9999 -9999 -9999 -9999 -9999 -9999 -9999 -9999 -9999 -9999 -9999 -9999 -9999 -9999

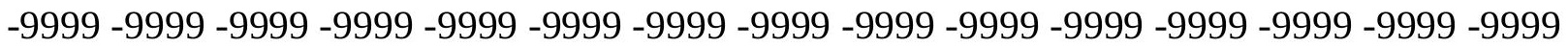
-9999 -9999 -9999 -9999 -9999 -9999 -9999 -9999 -9999 -9999 -9999 -9999 -9999 -9999 -9999 -9999 -9999 -9999 -9999 -9999 -9999 -9999 -9999 -9999 -9999 -9999 -9999 -9999 -9999 -9999

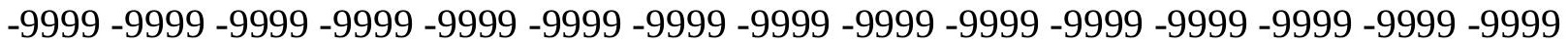
-9999 -9999 -9999 -9999 -9999 -9999 -9999 -9999 -9999 -9999 -9999 -9999 -9999 -9999 -9999 -9999 -9999 -9999 -9999 -9999 -9999 -9999 -9999 -9999 -9999 -9999 -9999 -9999 -9999 -9999 -

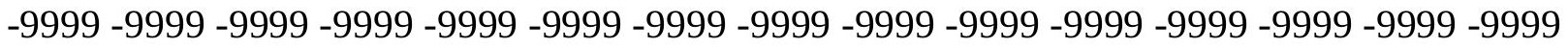
-9999 -9999 -9999 -9999 -9999 -9999 -9999 -9999 -9999 -9999 -9999 -9999 -9999 -9999 -9999

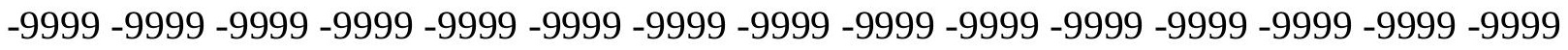
-9999 -9999 -9999 -9999 -9999 -9999 -9999 -9999 -9999 -9999 -9999 -9999 -9999 -9999 -9999 -9999 -9999 -9999 -9999 -9999 -9999 -9999 -9999 -9999 -9999 -9999 -9999 -9999 -9999 - -999 -9999 -9999 -9999 -9999 -9999 -9999 -9999 -9999 -9999 -9999 -9999 -9999 -9999 -9999 -9999 -9999 -9999 -9999 -9999 -9999 -9999 -9999 -9999 -9999 -9999 -9999 -9999 -9999 -9999 -9999 -9999 -9999 -9999 -9999 -9999 -9999 -9999 -9999 -9999 -9999 -9999 -9999 -9999 -9999 -9999 -999 -9999 -9999 -9999 -9999 -9999 -9999 -9999 -9999 -9999 -9999 -9999 -9999 -9999 -9999 -9999 -9999 -9999 -9999 -9999 -9999 -9999 -9999 -9999 -9999 -9999 -9999 -9999 -9999 -9999 -9999 -9999 -9999 -9999 -9999 -9999 -9999 -9999 -9999 -9999 -9999 -9999 -9999 -9999 -9999 -9999 -9999 -9999 -9999 -9999 -9999 -9999 -9999 -9999 -9999 -9999 -9999 -9999 -9999 -9999 -9999 -9999 -9999 -9999 -9999 -9999 -9999 -9999 -9999 -9999 -9999 -9999 -9999 -9999 -9999 -9999 -9999 -9999 -9999 -9999 -9999 -9999 -9999 -9999 -9999 -9999 -9999 -9999 -9999 -9999 -9999 -9999 -9999 -9999 -9999 -9999 -9999 -9999 -9999 -9999 -9999 -9999 -9999 -9999 -9999 -9999 -9999 -9999 -9999 -9999 -9999 -9999 -9999 -9999 -9999 -9999 -9999 -9999 -9999 -9999 -9999 -9999 -9999 -9999 -9999 -9999 -9999 -9999 -9999 -9999 -9999 -9999 -9999 -9999 -9999 -999 -9999 -9999 -9999 -9999 -9999 -9999 -9999 -9999 -9999 -9999 -9999 -9999 -9999 -9999 -9999 -9999 -9999 -9999 -9999 -9999 -9999 -9999 -9999 -9999 -9999 -9999 -9999 -9999 -9999 -9999 -

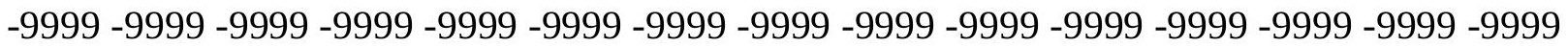

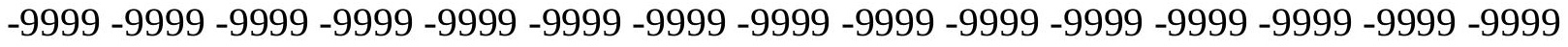

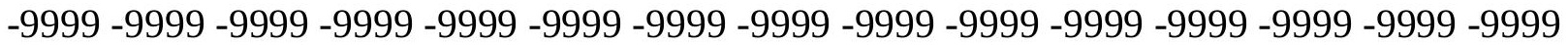
-9999 -9999 -9999 -9999 -9999 -9999 -9999 -9999 -9999 -9999 -9999 -9999 -9999 -9999 -9999

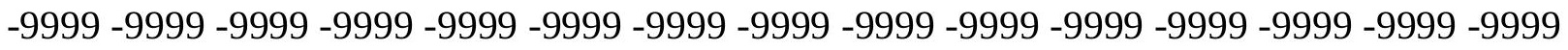

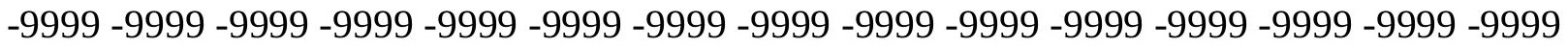

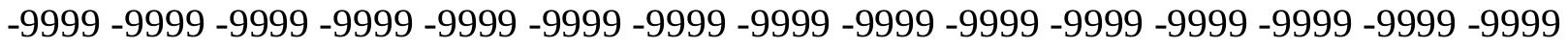
-9999 -9999 -9999 -9999 -9999 -9999 -9999 -9999 -9999 -9999 -9999 -9999 -9999 -9999 -9999 -

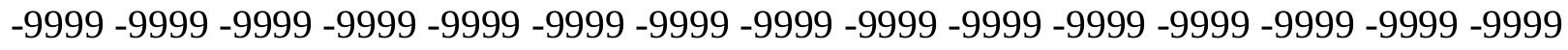

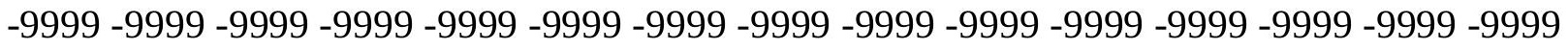
-9999 -9999 -9999 -9999 -9999 -9999 -9999 -9999 -9999 -9999 -9999 -9999 -9999 -9999 -9999 -9999 -9999 -9999 -9999 -9999 -9999 -9999 -9999 -9999 -9999 -9999 -9999 -9999 - -9999 -9999 -9999 -9999 -9999 -9999 -9999 -9999 -9999 -9999 -9999 -9999 -9999 -9999 -9999 -9999 -

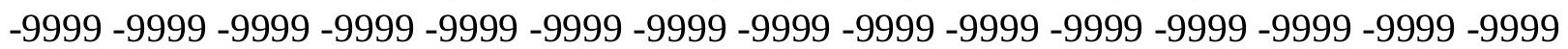


-9999 -9999 -9999 -9999 -9999 -9999 -9999 -9999 -9999 -9999 -9999 -9999 -9999 -9999 -9999 -9999 -9999 -9999 -9999 -9999 -9999 -9999 -9999 -9999 -9999 -9999 -9999 -9999 -9999 -9999 -9999 -9999 -9999 -9999 -9999 -9999 -9999 -9999 -9999 -9999 -9999 -9999 -9999 -9999 - 9999 -9999 -9999 -9999 -9999 -9999 -9999 -9999 -9999 -9999 -9999 -9999 -9999 -9999 -9999 -9999 -9999 -9999 -9999 -9999 -9999 -9999 -9999 -9999 -9999-9999 -9999 -9999 -9999 -9999 -9999 -9999 -9999 -9999 -9999 -9999 -9999 -9999 -9999 -9999 -9999 -9999 -9999 -9999 -9999 -9999 -9999 -9999 -9999 -9999 -9999 -9999 -9999 -9999 -9999 -9999 -9999 -9999 -9999 -9999 -9999

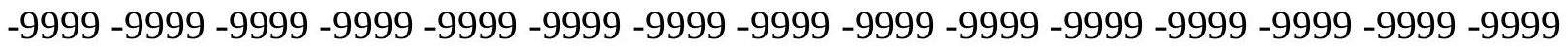

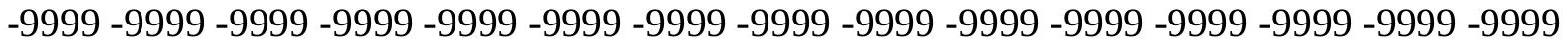
-9999 -9999 -9999 -9999 -9999 -9999 -9999 -9999 -9999 -9999 -9999 -9999 -9999 -9999 -9999

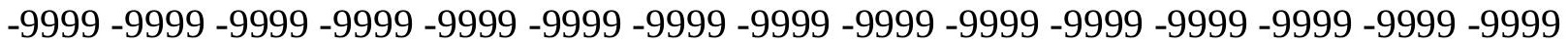
-9999 -9999 -9999 -9999 -9999 -9999 -9999 -9999 -9999 -9999 -9999 -9999 -9999 -9999 -9999 -9999 -9999 -9999 -9999 -9999 -9999 -9999 -9999 -9999 -9999 -9999 -9999 -9999 -9999 -9999 -

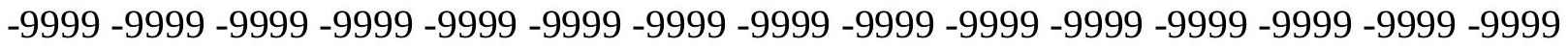
-9999 -9999 -9999 -9999 -9999 -9999 -9999 -9999 -9999 -9999 -9999 -9999 -9999 -9999 -9999

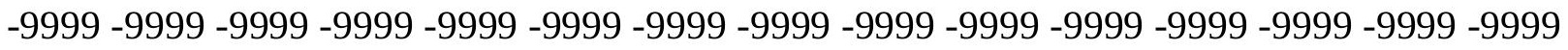
-9999 -9999 -9999 -9999 -9999 -9999 -9999 -9999 -9999 -9999 -9999 -9999 -9999 -9999 -9999 -9999 -9999 -9999 -9999 -9999 -9999 -9999 -9999 -9999 -9999 -9999 -9999 -9999 -9999 -9999 -9999 -9999 -9999 -9999 -9999 -9999 -9999 -9999 -9999 -9999 -9999 -9999 -9999 -9999 -9999 -9999 -9999 -9999 -9999 -9999 -9999 -9999 -9999 -9999 -9999 -9999 -9999 -9999 -9999 -9999 -9999 -9999 -9999 -9999 -9999 -9999 -9999 -9999 -9999 -9999 -9999 -9999 -9999 -9999 -9999 -999 -9999 -9999 -9999 -9999 -9999 -9999 -9999 -9999 -9999 -9999 -9999 -9999 -9999 -9999 -9999 -9999 -9999 -9999 -9999 -9999 -9999 -9999 -9999 -9999 -9999 -9999 -9999 -9999 -9999 -9999 -9999 -9999 -9999 -9999 -9999 -9999 -9999 -9999 -9999 -9999 -9999 -9999 -9999 -9999 -9999 -9999 -9999 -9999 -9999 -9999 -9999 -9999 -9999 -9999 -9999 -9999 -9999 -9999 -9999 -9999 -9999 -9999 -9999 -9999 -9999 -9999 -9999 -9999 -9999 -9999 -9999 -9999 -9999 -9999 -9999 -9999 -9999 -9999 -9999 -9999 -9999 -9999 -9999 -9999 -9999 -9999 -9999 -9999 -9999 -9999 -9999 -9999 -9999 -9999 -9999 -9999 -9999 -9999 -9999 -9999 -9999 -9999 -9999 -9999 -9999 -9999 -9999 -9999 -9999 -9999 -9999 -9999 -9999 -9999 -9999 -9999 -9999 -9999 -9999 -9999 -9999 -9999 -9999 -9999 -9999 -9999 -9999 -9999 -9999 -9999 -9999 -9999 -9999 -999 -9999 -9999 -9999 -9999 -9999 -9999 -9999 -9999 -9999 -9999 -9999 -9999 -9999 -9999 -9999 -9999 -9999 -9999 -9999 -9999 -9999 -9999 -9999 -9999 -9999 -9999 -9999 -9999 -9999 -9999 -

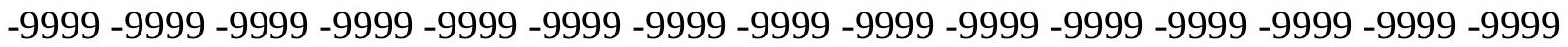

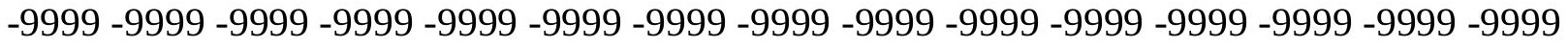

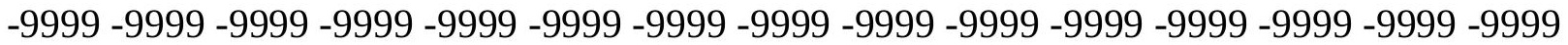
-9999 -9999 -9999 -9999 -9999 -9999 -9999 -9999 -9999 -9999 -9999 -9999 -9999 -9999 -9999

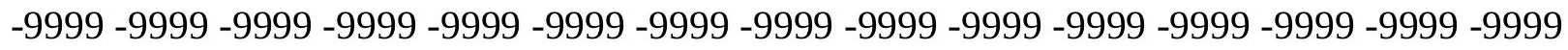

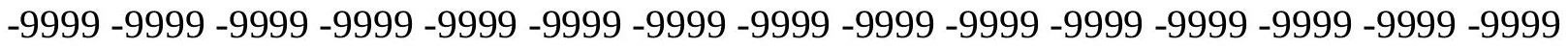
-9999 -9999 -9999 -9999 -9999 -9999 -9999 -9999 -9999 -9999 -9999 -9999 -9999 -9999 -9999 -9999 -9999 -9999 -9999 -9999 -9999 -9999 -9999 -9999 -9999 -9999 -9999 -9999 -9999 -9999 -

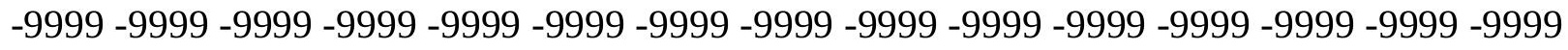

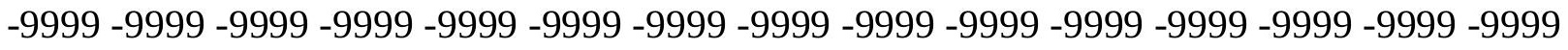
-9999 -9999 -9999 -9999 -9999 -9999 -9999 -9999 -9999 -9999 -9999 -9999 -9999 -9999 -9999 -9999 -9999 -9999 -9999 -9999 -9999 -9999 -9999 -9999-9999 -9999 -9999 -9999 -9999 -9999 -9999 -9999 -9999 -9999 -9999 -9999 -9999 -9999 -9999 -9999 -9999 -9999 -9999 -9999 -9999 -

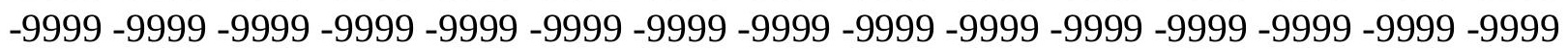


-9999 -9999 -9999 -9999 -9999 -9999 -9999 -9999 -9999 -9999 -9999 -9999 -9999 -9999 -9999 -9999 -9999 -9999 -9999 -9999 -9999 -9999 -9999 -9999 -9999 -9999 -9999 -9999 -9999 -9999 -9999 -9999 -9999 -9999 -9999 -9999 -9999 -9999 -9999 -9999 -9999 -9999 -9999 -9999 - 9999 -9999 -9999 -9999 -9999 -9999 -9999 -9999 -9999 -9999 -9999 -9999 -9999 -9999 -9999

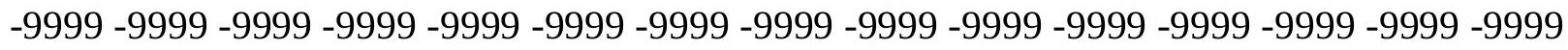
-9999 -9999 -9999 -9999 -9999 -9999 -9999 -9999 -9999 -9999 -9999 -9999 -9999 -9999 -9999 -9999 -9999 -9999 -9999 -9999 -9999 -9999 -9999 -9999 -9999 -9999 -9999 -9999 -9999 -9999

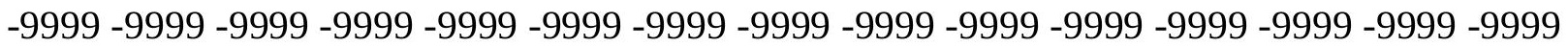

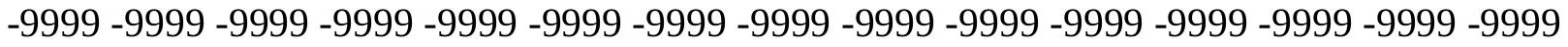
-9999 -9999 -9999 -9999 -9999 -9999 -9999 -9999 -9999 -9999 -9999 -9999 -9999 -9999 -9999 -9999 -9999 -9999 -9999 -9999 -9999 -9999 -9999 -9999 -9999 -9999 -9999 -9999 -9999 -9999 -9999 -9999 -9999 -9999 -9999 -9999 -9999 -9999 -9999 -9999 -9999 -9999 -9999 -9999 -9999 -9999 -9999 -9999 -9999 -9999 -9999 -9999 -9999 -9999 -9999 -9999 -9999 -9999 -9999 -9999 -

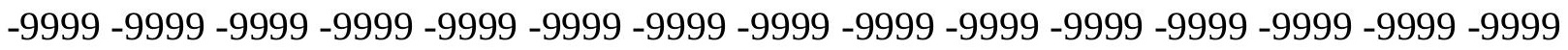
-9999 -9999 -9999 -9999 -9999 -9999 -9999 -9999 -9999 -9999 -9999 -9999 -9999 -9999 -9999 -

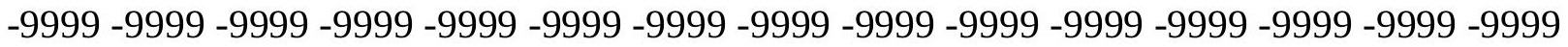
-9999 -9999 -9999 -9999 -9999 -9999 -9999 -9999 -9999 -9999 -9999 -9999 -9999 -9999 -9999 -9999 -9999 -9999 -9999 -9999 -9999 -9999 -9999 -9999 -9999 -9999 -9999 -9999 -9999 -9999 -9999 -9999 -9999 -9999 -9999 -9999 -9999 -9999 -9999 -9999 -9999 -9999 -9999 -9999 -9999 -

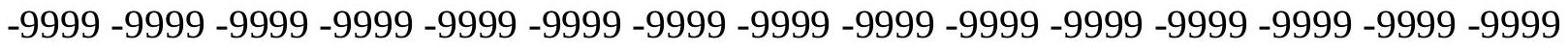
-9999 -9999 -9999 -9999 -9999 -9999 -9999 -9999 -9999 -9999 -9999 -9999 -9999 -9999 -9999

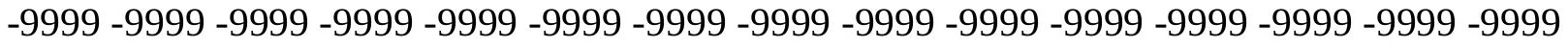
-9999 -9999 -9999 -9999 -9999 -9999 -9999 -9999 -9999 -9999 -9999 -9999 -9999 -9999 -9999 -9999 -9999 -9999 -9999 -9999 -9999 -9999 -9999 -9999 -9999 -9999 -9999 -9999 -9999 -9999 -9999 -9999 -9999 -9999 -9999 -9999 -9999 -9999 -9999 -9999 -9999 -9999 -9999 -9999 -9999 -9999 -9999 -9999 -9999 -9999 -9999 -9999 -9999 -9999 -9999 -9999 -9999 -9999 -9999 -9999 -9999 -9999 -9999 -9999 -9999 -9999 -9999 -9999 -9999 -9999 -9999 -9999 -9999 -9999 -9999 -9999 -9999 -9999 -9999 -9999 -9999 -9999 -9999 -9999 -9999 -9999 -9999 -9999 -9999 -9999 -9999 -9999 -9999 -9999 -9999 -9999 -9999 -9999 -9999 -9999 -9999 -9999 -9999 -9999 -9999 -9999 -9999 -9999 -9999 -9999 -9999 -9999 -9999 -9999 -9999 -9999 -9999 -9999 -9999 -9999 -9999 -9999 -9999 -9999 -9999 -9999 -9999 -9999 -9999 -9999 -9999 -9999 -9999 -9999 -9999 -9999 -9999 -9999 -9999 -9999 -9999 -9999 -9999 -9999 -9999 -9999 -9999 -9999 -9999 -

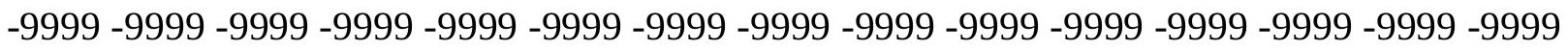

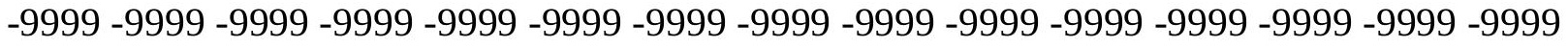
-9999 -9999 -9999 -9999 -9999 -9999 -9999 -9999 -9999 -9999 -9999 -9999 -9999 -9999 -9999 -

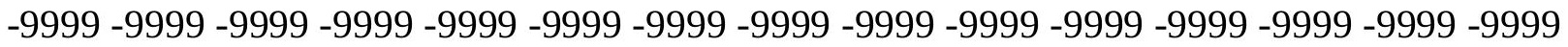

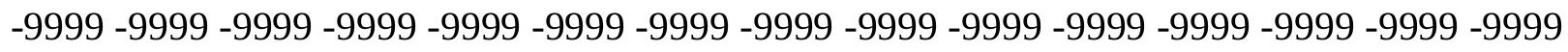

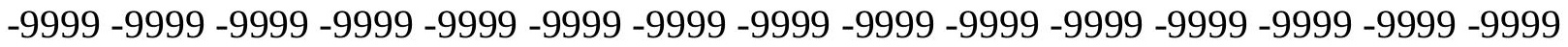

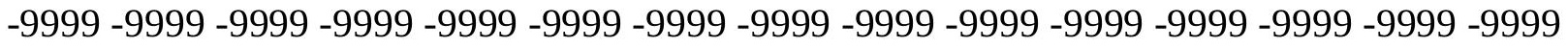
-9999 -9999 -9999 -9999 -9999 -9999 -9999 -9999 -9999 -9999 -9999 -9999 -9999 -9999 -9999 -

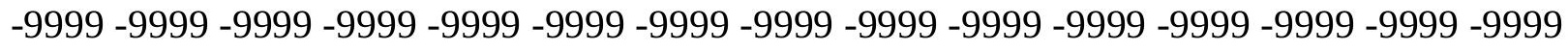

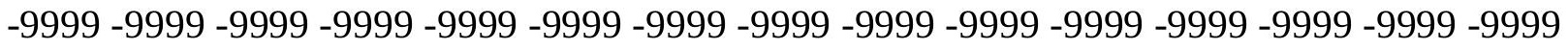
-9999 -9999 -9999 -9999 -9999 -9999 -9999 -9999 -9999 -9999 -9999 -9999 -9999 -9999 -9999 -9999 -9999 -9999 -9999 -9999 -9999 -9999 -9999 -9999-9999 -9999 -9999 -9999 -9999 -9999 -9999 -9999 -9999 -9999 -9999 -9999 -9999 -9999 -9999 -9999 -9999 -9999 -9999 -9999 -9999 -

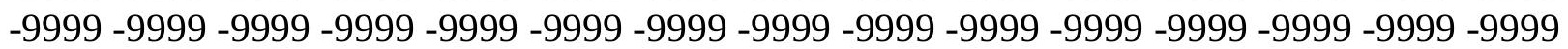


-9999 -9999 -9999 -9999 -9999 -9999 -9999 -9999 -9999 -9999 -9999 -9999 -9999 -9999 -9999 -9999 -9999 -9999 -9999 -9999 -9999 -9999 -9999 -9999 -9999 -9999 -9999 -9999 -9999 -9999 -9999 -9999 -9999 -9999 -9999 -9999 -9999 -9999 -9999 -9999 -9999 -9999 -9999 -9999 - 9999 -9999 -9999 -9999 -9999 -9999 -9999 -9999 -9999 -9999 -9999 -9999 -9999 -9999 -9999 -9999 -9999 -9999 -9999 -9999 -9999 -9999 -9999 -9999 -9999 -9999 -9999 -9999 -9999 -9999 -9999 -9999 -9999 -9999 -9999 -9999 -9999 -9999 -9999 -9999 -9999 -9999 -9999 -9999 -9999 -9999 -9999 -9999 -9999 -9999 -9999 -9999 -9999 -9999 -9999 -9999 -9999 -9999 -9999 -9999 -9999

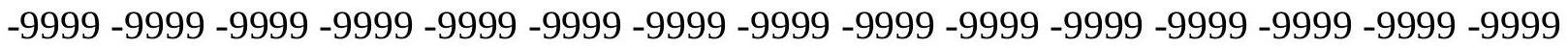

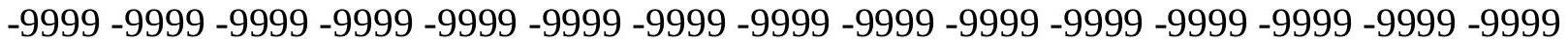
-9999 -9999 -9999 -9999 -9999 -9999 -9999 -9999 -9999 -9999 -9999 -9999 -9999 -9999 -9999 -9999 -9999 -9999 -9999 -9999 -9999 -9999 -9999 -9999 -9999 -9999 -9999 -9999 -9999 -9999 -9999 -9999 -9999 -9999 -9999 -9999 -9999 -9999 -9999 -9999 -9999 -9999 -9999 -9999 -9999 -9999 -9999 -9999 -9999 -9999 -9999 -9999 -9999 -9999 -9999 -9999 -9999 -9999 -9999 -9999 -9999 -9999 -9999 -9999 -9999 -9999 -9999 -9999 -9999 -9999 -9999 -9999 -9999 -9999 -9999 -9999 -9999 -9999 -9999 -9999 -9999 -9999 -9999 -9999 -9999 -9999 -9999 -9999 -9999 -

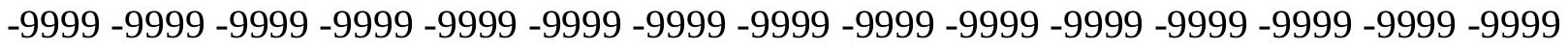
-9999 -9999 -9999 -9999 -9999 -9999 -9999 -9999 -9999 -9999 -9999 -9999 -9999 -9999 -9999 -9999 -9999 -9999 -9999 -9999 -9999 -9999 -9999 -9999 -9999 -9999 -9999 -9999 -9999 -9999 -9999 -9999 -9999 -9999 -9999 -9999 -9999 -9999 -9999 -9999 -9999 -9999 -9999 -9999 -9999 -9999 -9999 -9999 -9999 -9999 -9999 -9999 -9999 -9999 -9999 -9999 -9999 -9999 -9999 -9999 -9999 -9999 -9999 -9999 -9999 -9999 -9999 -9999 -9999 -9999 -9999 -9999 -9999 -9999 -9999 -999 -9999 -9999 -9999 -9999 -9999 -9999 -9999 -9999 -9999 -9999 -9999 -9999 -9999 -9999 -9999 -9999 -9999 -9999 -9999 -9999 -9999 -9999 -9999 -9999 -9999 -9999 -9999 -9999 -9999 -9999 -9999 -9999 -9999 -9999 -9999 -9999 -9999 -9999 -9999 -9999 -9999 -9999 -9999 -9999 -9999 -9999 -9999 -9999 -9999 -9999 -9999 -9999 -9999 -9999 -9999 -9999 -9999 -9999 -9999 -9999 -9999 -9999 -9999 -9999 -9999 -9999 -9999 -9999 -9999 -9999 -9999 -9999 -9999 -9999 -9999 -9999 -9999 -9999 -9999 -9999 -9999 -9999 -9999 -9999 -9999 -9999 -9999 -9999 -9999 -9999 -9999 -9999 -9999 -9999 -9999 -9999 -9999 -9999 -9999 -9999 -9999 -9999 -9999 -9999 -9999 -9999 -9999 -9999 -9999 -9999 -9999 -9999 -9999 -9999 -9999 -9999 -9999 -9999 -9999 -9999 -9999 -9999 -9999 -9999 -9999 -9999 -9999 -9999 -9999 -9999 -9999 -9999 -9999 -9999 -999 -9999 -9999 -9999 -9999 -9999 -9999 -9999 -9999 -9999 -9999 -9999 -9999 -9999 -9999 -9999 -9999 -9999 -9999 -9999 -9999 -9999 -9999 -9999 -9999 -9999 -9999 -9999 -9999 -9999 -9999 -

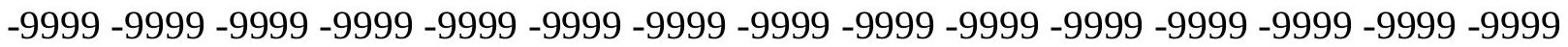

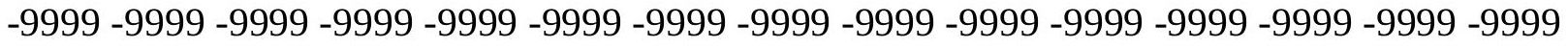

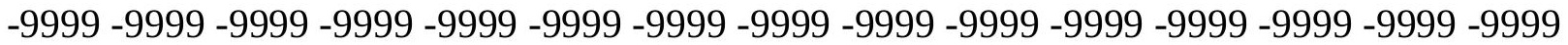
-9999 -9999 -9999 -9999 -9999 -9999 -9999 -9999 -9999 -9999 -9999 -9999 -9999 -9999 -9999 -9999 -9999 -9999 -9999 -9999 -9999 -9999 -9999 -9999 -9999 -9999 -9999 -9999 -9999 -

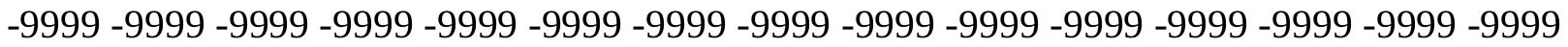
-9999 -9999 -9999 -9999 -9999 -9999 -9999 -9999 -9999 -9999 -9999 -9999 -9999 -9999 -9999 -9999 -9999 -9999 -9999 -9999 -9999 -9999 -9999 -9999 -9999 -9999 -9999 -9999 -9999 -9999 -

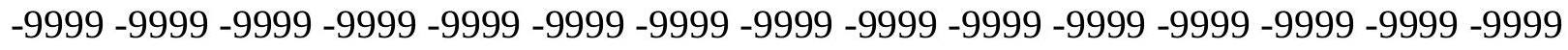

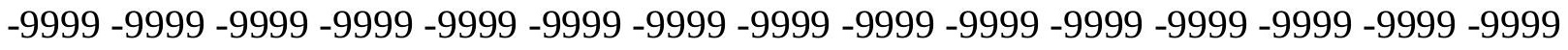
-9999 -9999 -9999 -9999 -9999 -9999 -9999 -9999 -9999 -9999 -9999 -9999 -9999 -9999 -9999 -9999 -9999 -9999 -9999 -9999 -9999 -9999 -9999 -9999-9999 -9999 -9999 -9999 -9999 -9999 -9999 -9999 -9999 -9999 -9999 -9999 -9999 -9999 -9999 -9999 -9999 -9999 -9999 -9999 -9999 -

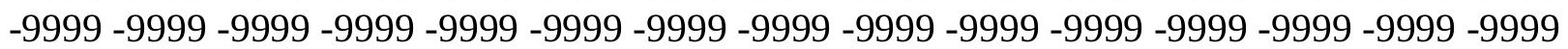


-9999 -9999 -9999 -9999 -9999 -9999 -9999 -9999 -9999 -9999 -9999 -9999 -9999 -9999 -9999 -9999 -9999 -9999 -9999 -9999 -9999 -9999 -9999 -9999 -9999 -9999 -9999 -9999 -9999 -9999 -

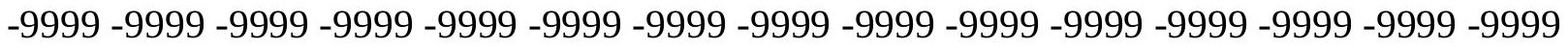
-9999 -9999 -9999 -9999 -9999 -9999 -9999 -9999 -9999 -9999 -9999 -9999 -9999 -9999 -9999 -9999 -9999 -9999 -9999 -9999 -9999 -9999 -9999 -9999-9999 -9999 -9999 -9999 -9999 -9999 -9999 -9999 -9999 -9999 -9999 -9999 -9999 -9999 -9999 -9999 -9999 -9999 -9999 -9999 -9999 -9999 -9999 -9999 -9999 -9999 -9999 -9999 -9999 -9999 -9999 -9999 -9999 -9999 -9999 -9999

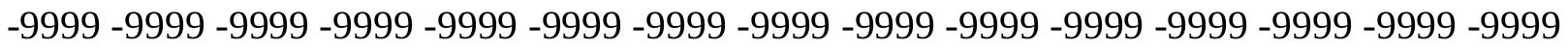

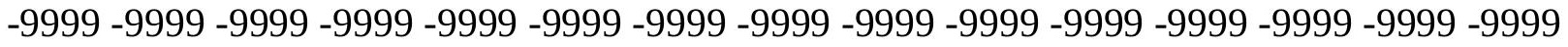
-9999 -9999 -9999 -9999 -9999 -9999 -9999 -9999 -9999 -9999 -9999 -9999 -9999 -9999 -9999 -9999 -9999 -9999 -9999 -9999 -9999 -9999 -9999 -9999 -9999 -9999 -9999 -9999 -9999 -9999 -9999 -9999 -9999 -9999 -9999 -9999 -9999 -9999 -9999 -9999 -9999 -9999 -9999 -9999 -9999 -9999 -9999 -9999 -9999 -9999 -9999 -9999 -9999 -9999 -9999 -9999 -9999 -9999 -9999 -9999 -9999 -9999 -9999 -9999 -9999 -9999 -9999 -9999 -9999 -9999 -9999 -9999 -9999 -9999 -9999 -9999 -9999 -9999 -9999 -9999 -9999 -9999 -9999 -9999 -9999 -9999 -9999 -9999 -9999 -9999 -

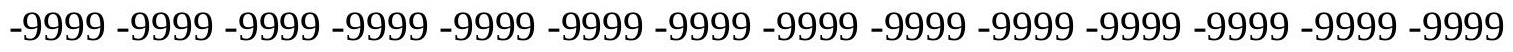
-9999 -9999 -9999 -9999 -9999 -9999 -9999 -9999 -9999 -9999 -9999 -9999 -9999 -9999 -9999 -9999 -9999 -9999 -9999 -9999 -9999 -9999 -9999 -9999 -9999 -9999 -9999 -9999 -9999 -9999 -9999 -9999 -9999 -9999 -9999 -9999 -9999 -9999 -9999 -9999 -9999 -9999 -9999 -9999 -9999 -

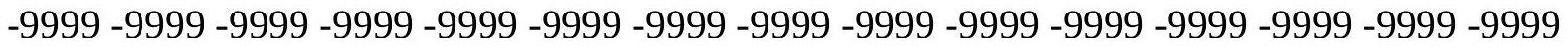

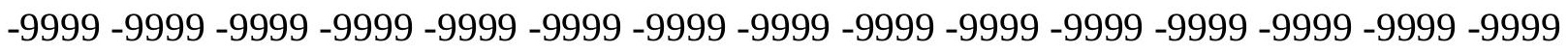
-9999 -9999 -9999 -9999 -9999 -9999 -9999 -9999 -9999 -9999 -9999 -9999 -9999 -9999 - 9999 -9999 -9999 -9999 -9999 -9999 -9999 -9999 -9999 -9999 -9999 -9999 -9999 -9999 -9999 -9999 -9999 -9999 -9999 -9999 -9999 -9999 -9999 -9999 -9999 -9999 -9999 -9999 -9999 -9999 -9999 -

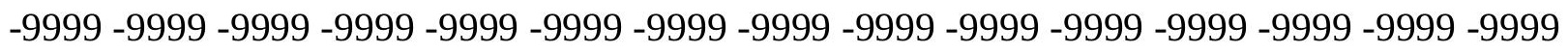
-9999 -9999 -9999 -9999 -9999 -9999 -9999 -9999 -9999 -9999 -9999 -9999 -9999 -9999 -9999 -9999 -9999 -9999 -9999 -9999 -9999 -9999 -9999 -9999 -9999 -9999 -9999 -9999 -9999 -9999 -

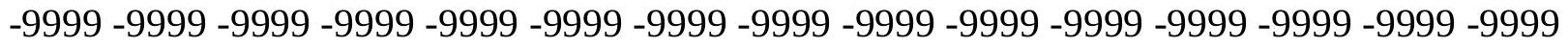
-9999 -9999 -9999 -9999 -9999 -9999 -9999 -9999 -9999 -9999 -9999 -9999 -9999 -9999 -9999 -9999 -9999 -9999 -9999 -9999 -9999 -9999 -9999 -9999 -9999 -9999 -9999 -9999 -9999 -999 -

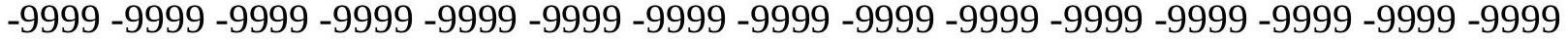
-9999 -9999 -9999 -9999 -9999 -9999 -9999 -9999 -9999 -9999 -9999 -9999 -9999 -9999 -9999 -

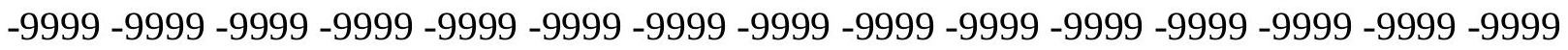

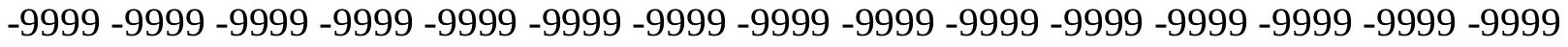

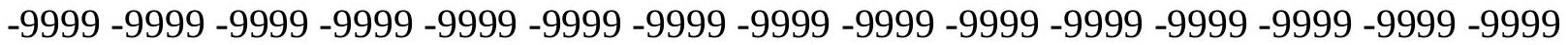
-9999 -9999 -9999 -9999 -9999 -9999 -9999 -9999 -9999 -9999 -9999 -9999 -9999 -9999 -9999 -

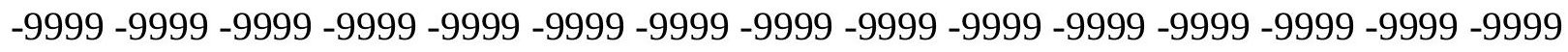

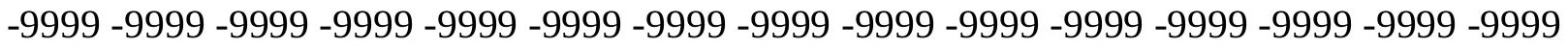
-9999 -9999 -9999 -9999 -9999 -9999 -9999 -9999 -9999 -9999 -9999 -9999 -9999 - 9999 - -999 -9999 -9999 -9999 -9999 -9999 -9999 -9999 -9999 -9999 -9999 -9999 -9999 -9999 -9999 -9999 -

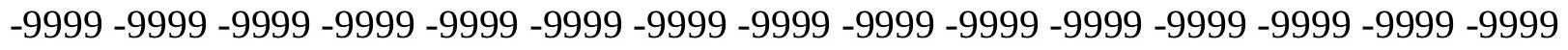

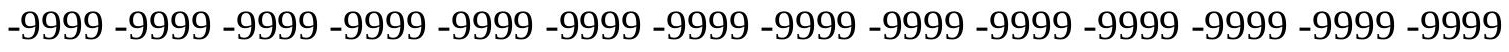
-9999 -9999 -9999 -9999 -9999 -9999 -9999 -9999 -9999 -9999 -9999 -9999 -9999 -9999 -9999 -9999 -9999 -9999 -9999 -9999 -9999 -9999 -9999 -9999-9999 -9999 -9999 -9999 -9999 -9999 -9999 -9999 -9999 -9999 -9999 -9999 -9999 -9999 -9999 -9999 -9999 -9999 -9999 -9999 -9999 -

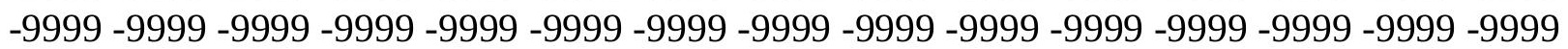


-9999 -9999 -9999 -9999 -9999 -9999 -9999 -9999 -9999 -9999 -9999 -9999 -9999 -9999 -9999 -9999 -9999 -9999 -9999 -9999 -9999 -9999 -9999 -9999 -9999 -9999 -9999 -9999 -9999 -9999 -

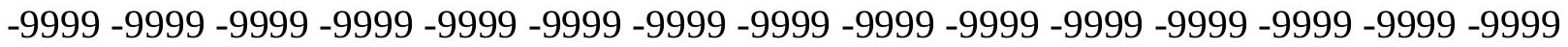
-9999 -9999 -9999 -9999 -9999 -9999 -9999 -9999 -9999 -9999 -9999 -9999 -9999 -9999 -9999 -9999 -9999 -9999 -9999 -9999 -9999 -9999 -9999 -9999-9999 -9999 -9999 -9999 -9999 -9999 -9999 -9999 -9999 -9999 -9999 -9999 -9999 -9999 -9999 -9999 -9999 -9999 -9999 -9999 -9999 -9999 -9999 -9999 -9999 -9999 -9999 -9999 -9999 -9999 -9999 -9999 -9999 -9999 -9999 -9999

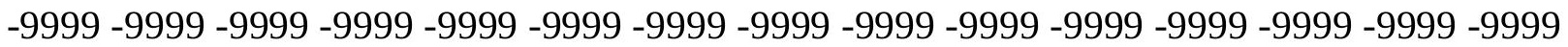

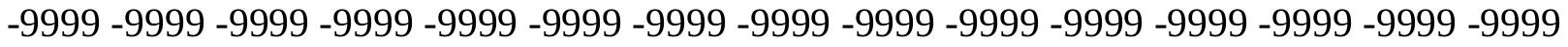
-9999 -9999 -9999 -9999 -9999 -9999 -9999 -9999 -9999 -9999 -9999 -9999 -9999 -9999 -9999 -9999 -9999 -9999 -9999 -9999 -9999 -9999 -9999 -9999 -9999 -9999 -9999 -9999 -9999 -9999 -9999 -9999 -9999 -9999 -9999 -9999 -9999 -9999 -9999 -9999 -9999 -9999 -9999 -9999 -9999 -9999 -9999 -9999 -9999 -9999 -9999 -9999 -9999 -9999 -9999 -9999 -9999 -9999 -9999 -9999 -

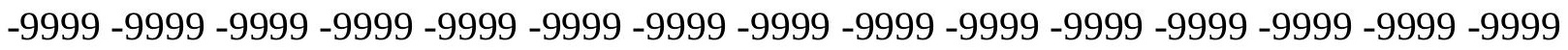
-9999 -9999 -9999 -9999 -9999 -9999 -9999 -9999 -9999 -9999 -9999 -9999 -9999 -9999 -9999 -

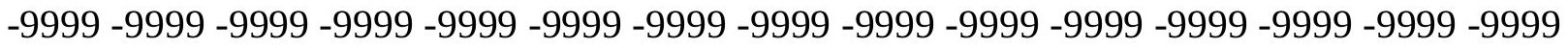
-9999 -9999 -9999 -9999 -9999 -9999 -9999 -9999 -9999 -9999 -9999 -9999 -9999 -9999 -9999 -9999 -9999 -9999 -9999 -9999 -9999 -9999 -9999 -9999 -9999 -9999 -9999 -9999 -9999 -9999 -9999 -9999 -9999 -9999 -9999 -9999 -9999 -9999 -9999 -9999 -9999 -9999 -9999 -9999 -9999 -

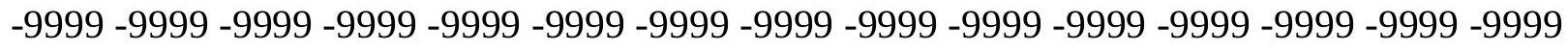

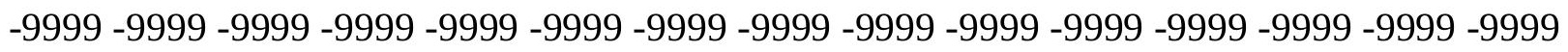
-9999 -9999 -9999 -9999 -9999 -9999 -9999 -9999 -9999 -9999 -9999 -9999 -9999 -9999 -9999 -9999 -9999 -9999 -9999 -9999 -9999 -9999 -9999 -9999 -9999 -9999 -9999 -9999 -9999 -9999 -9999 -9999 -9999 -9999 -9999 -9999 -9999 -9999 -9999 -9999 -9999 -9999 -9999 -9999 -

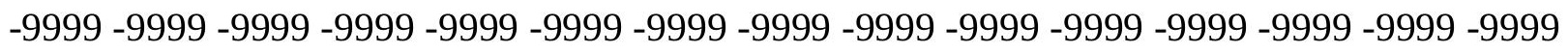
-9999 -9999 -9999 -9999 -9999 -9999 -9999 -9999 -9999 -9999 -9999 -9999 -9999 -9999 -9999 -9999 -9999 -9999 -9999 -9999 -9999 -9999 -9999 -9999 -9999 -9999 -9999 -9999 -9999 -9999 -

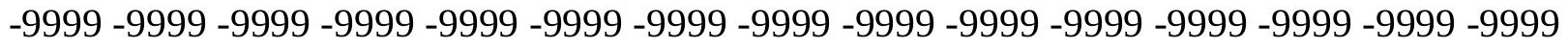
-9999 -9999 -9999 -9999 -9999 -9999 -9999 -9999 -9999 -9999 -9999 -9999 -9999 -9999 -9999 -9999 -9999 -9999 -9999 -9999 -9999 -9999 -9999 -9999 -9999 -9999 -9999 -9999 -9999 -999 -

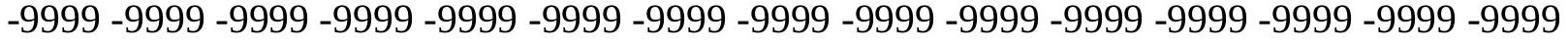
-9999 -9999 -9999 -9999 -9999 -9999 -9999 -9999 -9999 -9999 -9999 -9999 -9999 -9999 -9999 -

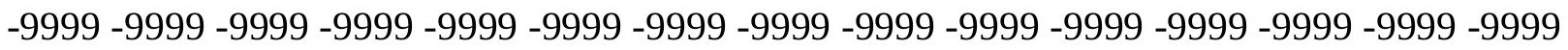

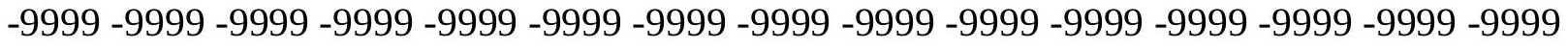

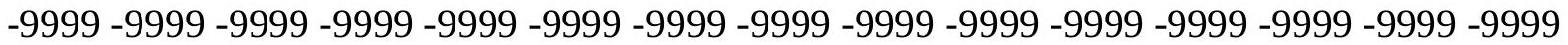

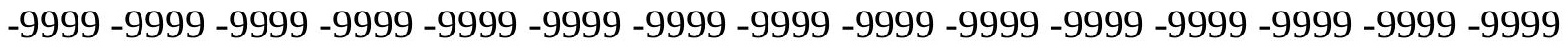

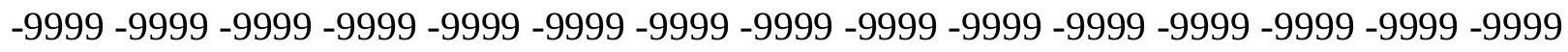

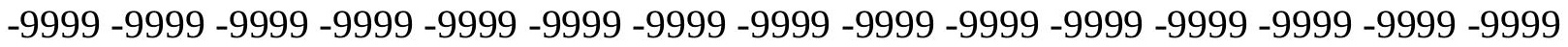

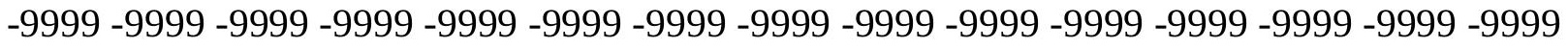
-9999 -9999 -9999 -9999 -9999 -9999 -9999 -9999 -9999 -9999 -9999 -9999 -9999 -9999 -9999 -

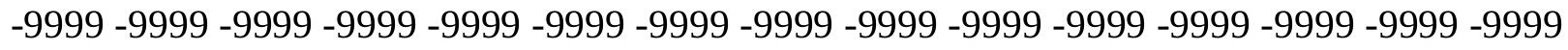

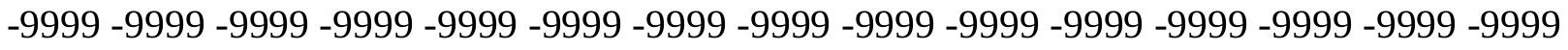
-9999 -9999 -9999 -9999 -9999 -9999 -9999 -9999 -9999 -9999 -9999 -9999 -9999 -9999 -9999 -9999 -9999 -9999 -9999 -9999 -9999 -9999 -9999 -9999-9999 -9999 -9999 -9999 -9999 -9999 -9999 -9999 -9999 -9999 -9999 -9999 -9999 -9999 -9999 -9999 -9999 -9999 -9999 -9999 -9999 -

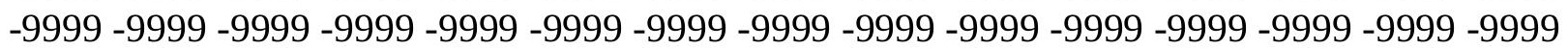


-9999 -9999 -9999 -9999 -9999 -9999 -9999 -9999 -9999 -9999 -9999 -9999 -9999 -9999 -9999 -9999 -9999 -9999 -9999 -9999 -9999 -9999 -9999 -9999 -9999 -9999 -9999 -9999 -9999 -

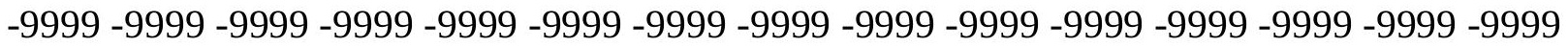
-9999 -9999 -9999 -9999 -9999 -9999 -9999 -9999 -9999 -9999 -9999 -9999 -9999 -9999 -9999 -9999 -9999 -9999 -9999 -9999 -9999 -9999 -9999 -9999 -9999 -9999 -9999 -9999 -9999 -9999 -9999 -9999 -9999 -9999 -9999 -9999 -9999 -9999 -9999 -9999 -9999 -9999 -9999 -9999 -9999 -9999 -9999 -9999 -9999 -9999 -9999 -9999 -9999 -9999 -9999 -9999 -9999 -9999 -9999 -9999

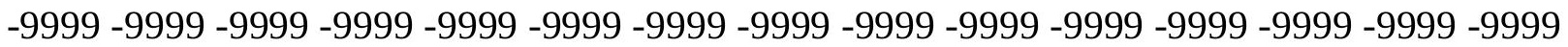

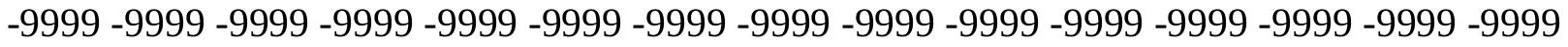
-9999 -9999 -9999 -9999 -9999 -9999 -9999 -9999 -9999 -9999 -9999 -9999 -9999 -9999 -9999 -9999 -9999 -9999 -9999 -9999 -9999 -9999 -9999 -9999 -9999 -9999 -9999 -9999 -9999 -9999 -9999 -9999 -9999 -9999 -9999 -9999 -9999 -9999 -9999 -9999 -9999 -9999 -9999 -9999 -9999 -9999 -9999 -9999 -9999 -9999 -9999 -9999 -9999 -9999 -9999 -9999 -9999 -9999 -9999 -9999 -9999 -9999 -9999 -9999 -9999 -9999 -9999 -9999 -9999 -9999 -9999 -9999 -9999 -9999 -9999 -9999 -9999 -9999 -9999 -9999 -9999 -9999 -9999 -9999 -9999 -9999 -9999 -9999 -9999 -9999 -

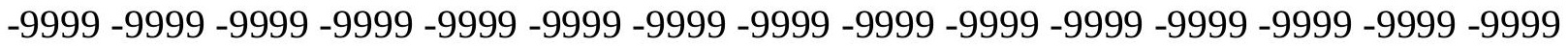
-9999 -9999 -9999 -9999 -9999 -9999 -9999 -9999 -9999 -9999 -9999 -9999 -9999 -9999 -9999 -9999 -9999 -9999 -9999 -9999 -9999 -9999 -9999 -9999 -9999 -9999 -9999 -9999 -9999 - 9999 -9999 -9999 -9999 -9999 -9999 -9999 -9999 -9999 -9999 -9999 -9999 -9999 -9999 -9999 -9999 -

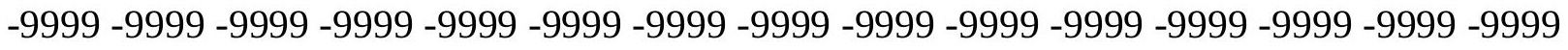

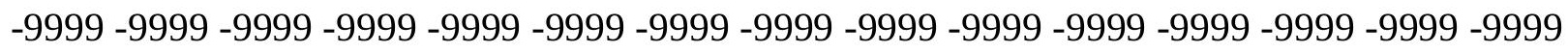

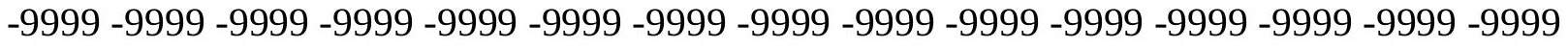
-9999 -9999 -9999 -9999 -9999 -9999 -9999 -9999 -9999 -9999 -9999 -9999 -9999 -9999 -9999 -9999 -9999 -9999 -9999 -9999 -9999 -9999 -9999 -9999 -9999 -9999 -9999 -9999 -9999 -9999 -

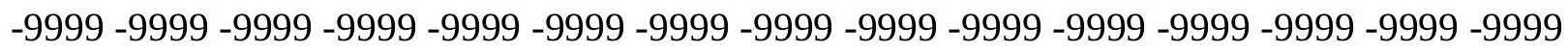
-9999 -9999 -9999 -9999 -9999 -9999 -9999 -9999 -9999 -9999 -9999 -9999 -9999 -9999 -9999 -9999 -9999 -9999 -9999 -9999 -9999 -9999 -9999 -9999 -9999 -9999 -9999 -9999 -9999 -9999 -9999 -9999 -9999 -9999 -9999 -9999 -9999 -9999 -9999 -9999 -9999 -9999 -9999 -9999 -9999 -9999 -9999 -9999 -9999 -9999 -9999 -9999 -9999 -9999 -9999 -9999 -9999 -9999 -9999 -9999 -9999 -9999 -9999 -9999 -9999 -9999 -9999 -9999 -9999 -9999 -9999 -9999 -9999 -999 -

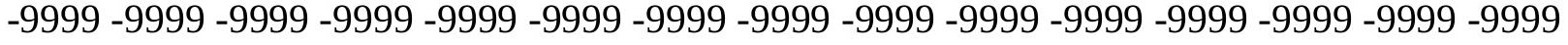
-9999 -9999 -9999 -9999 -9999 -9999 -9999 -9999 -9999 -9999 -9999 -9999 -9999 -9999 -9999 -

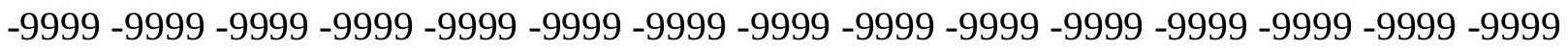

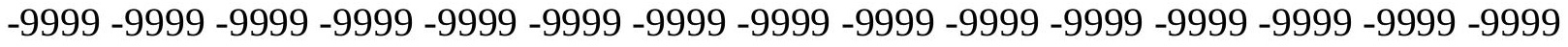

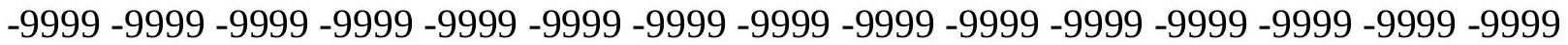

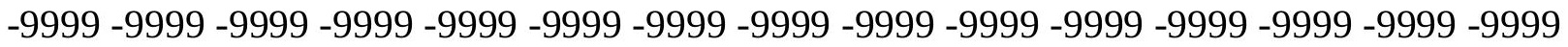

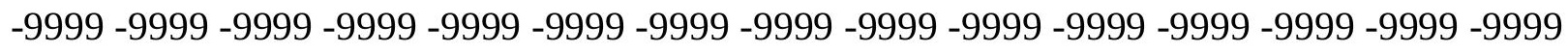

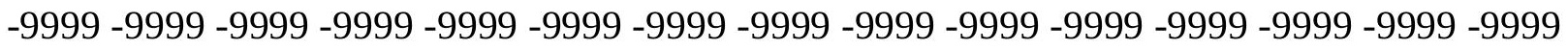

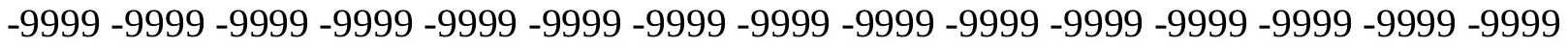
-9999 -9999 -9999 -9999 -9999 -9999 -9999 -9999 -9999 -9999 -9999 -9999 -9999 -9999 -9999 -

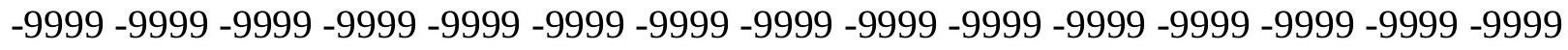

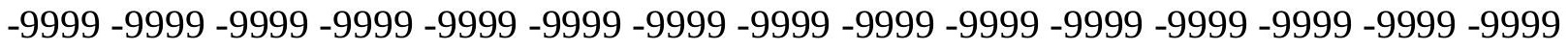
-9999 -9999 -9999 -9999 -9999 -9999 -9999 -9999 -9999 -9999 -9999 -9999 -9999 -9999 -9999 -9999 -9999 -9999 -9999 -9999 -9999 -9999 -9999 -9999-9999 -9999 -9999 -9999 -9999 -9999 -9999 -9999 -9999 -9999 -9999 -9999 -9999 -9999 -9999 -9999 -9999 -9999 -9999 -9999 -9999 -

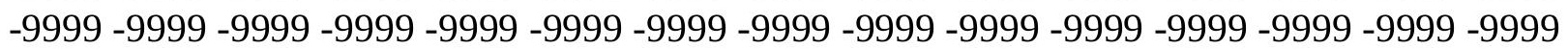


-9999 -9999 -9999 -9999 -9999 -9999 -9999 -9999 -9999 -9999 -9999 -9999 -9999 -9999 -9999 -9999 -9999 -9999 -9999 -9999 -9999 -9999 -9999 -9999 -9999 -9999 -9999 -9999 -9999 -9999 -

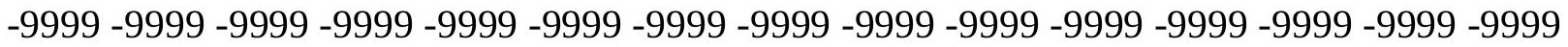
-9999 -9999 -9999 -9999 -9999 -9999 -9999 -9999 -9999 -9999 -9999 -9999 -9999 -9999 -9999 -9999 -9999 -9999 -9999 -9999 -9999 -9999 -9999 -9999-9999 -9999 -9999 -9999 -9999 -9999 -9999 -9999 -9999 -9999 -9999 -9999 -9999 -9999 -9999 -9999 -9999 -9999 -9999 -9999 -9999 -

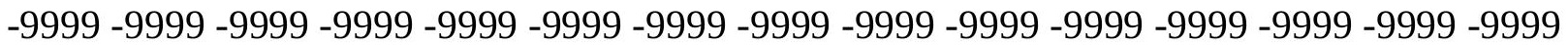
-9999 -9999 -9999 -9999 -9999 -9999 -9999 -9999 -9999 -9999 -9999 -9999 -9999 -9999 -9999 -9999 -9999 -9999 -9999 -9999 -9999 -9999 -9999 -9999 -9999 -9999 -9999 -9999 -9999 -9999 -9999 -9999 -9999 -9999 -9999 -9999 -9999 -9999 -9999 -9999 -9999 -9999 -9999 -9999 -9999 -9999 -9999 -9999 -9999 -9999 -9999 -9999 -9999 -9999 -9999 -9999 -9999 -9999 -9999 -9999 -9999 -9999 -9999 -9999 -9999 -9999 -9999 -9999 -9999 -9999 -9999 -9999 -9999 -9999 -9999 -9999 -9999 -9999 -9999 -9999 -9999 -9999 -9999 -9999 -9999 -9999 -9999 -9999 -9999 -9999 -9999 -9999 -9999 -9999 -9999 -9999 -9999 -9999 -9999 -9999 -9999 -9999 -9999 -9999 -9999 -9999 -9999 -9999 -9999 -9999 -9999 -9999 -9999 -9999 -9999 -9999 -9999 -9999 -9999 -

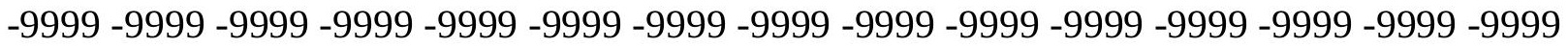
-9999 -9999 -9999 -9999 -9999 -9999 -9999 -9999 -9999 -9999 -9999 -9999 -9999 -9999 -9999 -9999 -9999 -9999 -9999 -9999 -9999 -9999 -9999 -9999 -9999 -9999 -9999 -9999 -9999 -9999 -9999 -9999 -9999 -9999 -9999 -9999 -9999 -9999 -9999 -9999 -9999 -9999 -9999 -9999 -9999 -

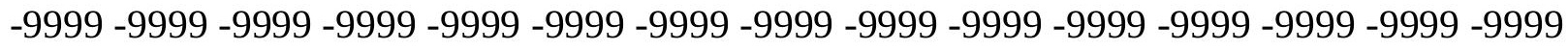

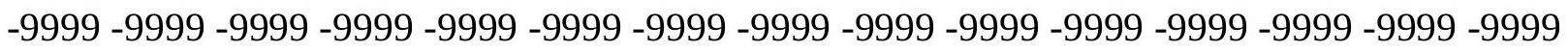
-9999 -9999 -9999 -9999 -9999 -9999 -9999 -9999 -9999 -9999 -9999 -9999 -9999 -9999 - 9999 -9999 -9999 -9999 -9999 -9999 -9999 -9999 -9999 -9999 -9999 -9999 -9999 -9999 -9999 -9999 -9999 -9999 -9999 -9999 -9999 -9999 -9999 -9999 -9999 -9999 -9999 -9999 -9999 -9999 -9999 -

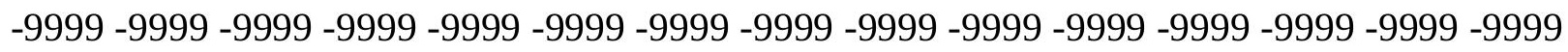
-9999 -9999 -9999 -9999 -9999 -9999 -9999 -9999 -9999 -9999 -9999 -9999 -9999 -9999 -9999 -9999 -9999 -9999 -9999 -9999 -9999 -9999 -9999 -9999 -9999 -9999 -9999 -9999 -9999 -9999 -

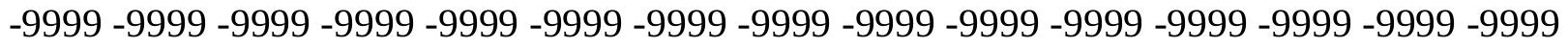
-9999 -9999 -9999 -9999 -9999 -9999 -9999 -9999 -9999 -9999 -9999 -9999 -9999 -9999 -9999 -9999 -9999 -9999 -9999 -9999 -9999 -9999 -9999 -9999 -9999 -9999 -9999 -9999 -9999 -999 -9999 -9999 -9999 -9999 -9999 -9999 -9999 -9999 -9999 -9999 -9999 -9999 -9999 -9999 -9999 -9999 -9999 -9999 -9999 -9999 -9999 -9999 -9999 -9999 -9999 -9999 -9999 -9999 -9999 -9999 -

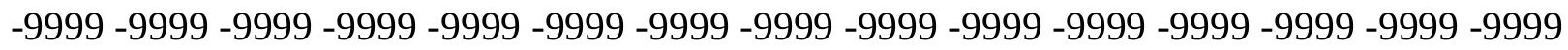

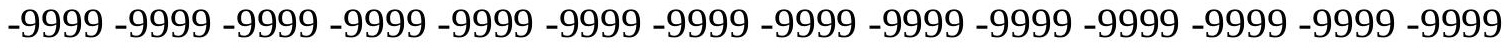
-9999 -9999 -9999 -9999 -9999 -9999 -9999 -9999 -9999 -9999 -9999 -9999 -9999 -9999 -9999

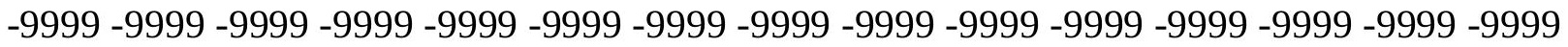

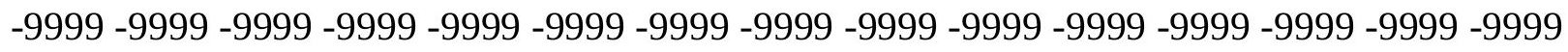

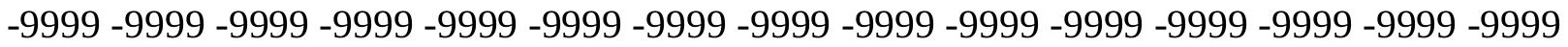

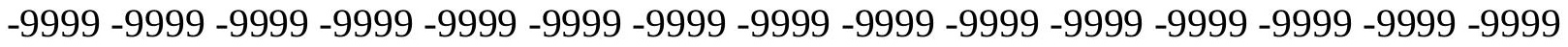
-9999 -9999 -9999 -9999 -9999 -9999 -9999 -9999 -9999 -9999 -9999 -9999 -9999 -9999 -9999 -

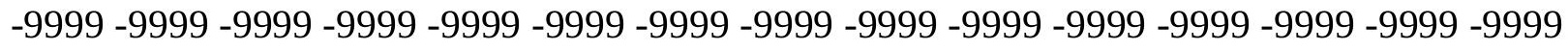

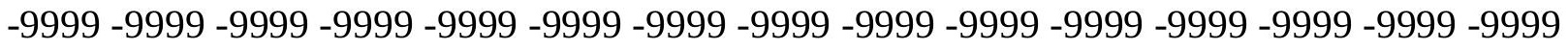
-9999 -9999 -9999 -9999 -9999 -9999 -9999 -9999 -9999 -9999 -9999 -9999 -9999 -9999 -9999 -9999 -9999 -9999 -9999 -9999 -9999 -9999 -9999 -9999-9999 -9999 -9999 -9999 -9999 -9999 -9999 -9999 -9999 -9999 -9999 -9999 -9999 -9999 -9999 -9999 -9999 -9999 -9999 -9999 -9999 -

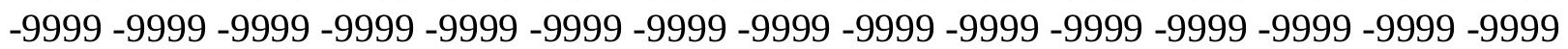


-9999 -9999 -9999 -9999 -9999 -9999 -9999 -9999 -9999 -9999 -9999 -9999 -9999 -9999 -9999 -9999 -9999 -9999 -9999 -9999 -9999 -9999 -9999 -9999 -9999 -9999 -9999 -9999 -9999 -9999 -

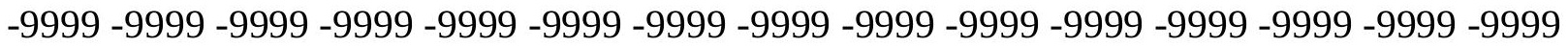
-9999 -9999 -9999 -9999 -9999 -9999 -9999 -9999 -9999 -9999 -9999 -9999 -9999 -9999 -9999 -9999 -9999 -9999 -9999 -9999 -9999 -9999 -9999 -9999-9999 -9999 -9999 -9999 -9999 -9999 -9999 -9999 -9999 -9999 -9999 -9999 -9999 -9999 -9999 -9999 -9999 -9999 -9999 -9999 -9999 -9999 -9999 -9999 -9999 -9999 -9999 -9999 -9999 -9999 -9999 -9999 -9999 -9999 -9999 -9999

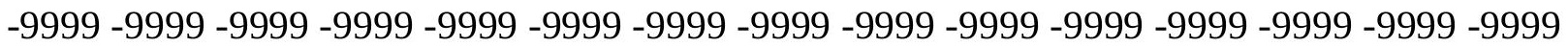

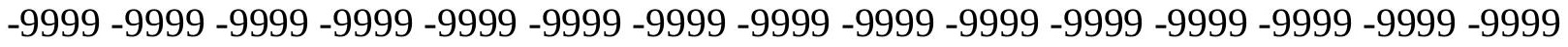
-9999 -9999 -9999 -9999 -9999 -9999 -9999 -9999 -9999 -9999 -9999 -9999 -9999 -9999 -9999 -9999 -9999 -9999 -9999 -9999 -9999 -9999 -9999 -9999 -9999 -9999 -9999 -9999 -9999 -9999 -9999 -9999 -9999 -9999 -9999 -9999 -9999 -9999 -9999 -9999 -9999 -9999 -9999 -9999 -9999 -9999 -9999 -9999 -9999 -9999 -9999 -9999 -9999 -9999 -9999 -9999 -9999 -9999 -9999 -9999 -9999 -9999 -9999 -9999 -9999 -9999 -9999 -9999 -9999 -9999 -9999 -9999 -9999 -9999 -9999 -9999 -9999 -9999 -9999 -9999 -9999 -9999 -9999 -9999 -9999 -9999 -9999 -9999 -9999

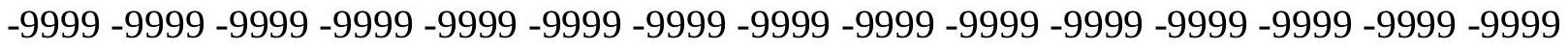
-9999 -9999 -9999 -9999 -9999 -9999 -9999 -9999 -9999 -9999 -9999 -9999 -9999 -9999 -9999 -9999 -9999 -9999 -9999 -9999 -9999 -9999 -9999 -9999 -9999 -9999 -9999 -9999 -9999 -9999 -9999 -9999 -9999 -9999 -9999 -9999 -9999 -9999 -9999 -9999 -9999 -9999 -9999 -9999 -9999 -

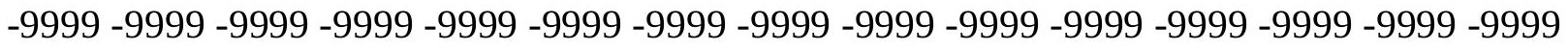

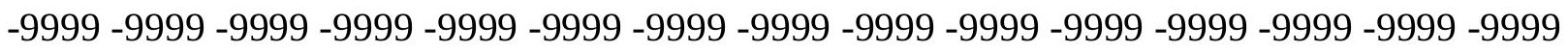
-9999 -9999 -9999 -9999 -9999 -9999 -9999 -9999 -9999 -9999 -9999 -9999 -9999 -9999 -9999 -9999 -9999 -9999 -9999 -9999 -9999 -9999 -9999 -9999 -9999 -9999 -9999 -9999 -9999 -9999 -9999 -9999 -9999 -9999 -9999 -9999 -9999 -9999 -9999 -9999 -9999 -9999 -9999 -9999 -9999 -

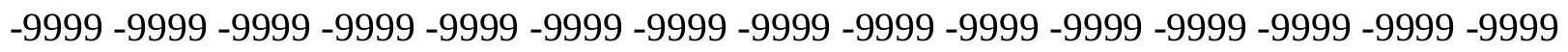
-9999 -9999 -9999 -9999 -9999 -9999 -9999 -9999 -9999 -9999 -9999 -9999 -9999 -9999 -9999 -9999 -9999 -9999 -9999 -9999 -9999 -9999 -9999 -9999 -9999 -9999 -9999 -9999 -9999 -9999 -

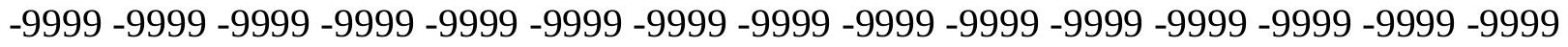
-9999 -9999 -9999 -9999 -9999 -9999 -9999 -9999 -9999 -9999 -9999 -9999 -9999 -9999 -9999 -9999 -9999 -9999 -9999 -9999 -9999 -9999 -9999 -9999 -9999 -9999 -9999 -9999 -9999 -999 -9999 -9999 -9999 -9999 -9999 -9999 -9999 -9999 -9999 -9999 -9999 -9999 -9999 -9999 -9999 -9999 -9999 -9999 -9999 -9999 -9999 -9999 -9999 -9999 -9999 -9999 -9999 -9999 -9999 -9999 -

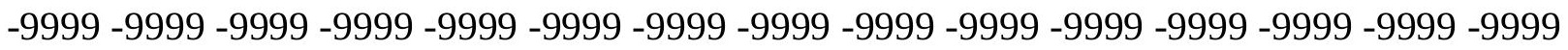

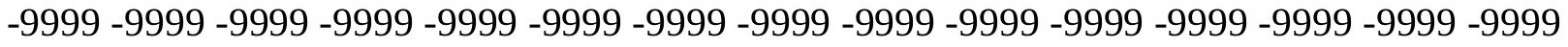

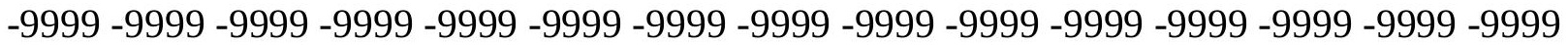

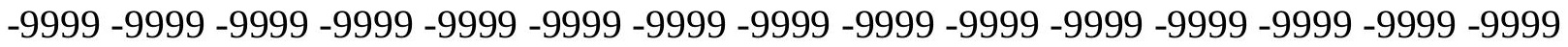

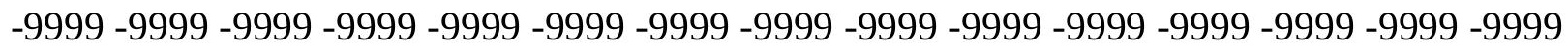

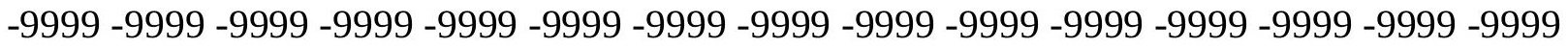
-9999 -9999 -9999 -9999 -9999 -9999 -9999 -9999 -9999 -9999 -9999 -9999 -9999 - 9999 - -999 -9999 -9999 -9999 -9999 -9999 -9999 -9999 -9999 -9999 -9999 -9999 -9999 -9999 -9999 - -999 -

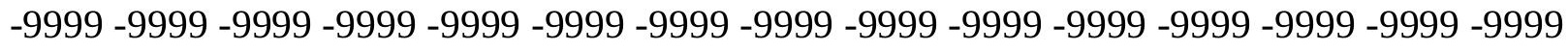

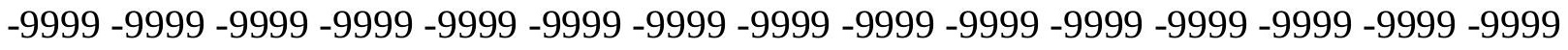
-9999 -9999 -9999 -9999 -9999 -9999 -9999 -9999 -9999 -9999 -9999 -9999 -9999 -9999 -9999 -9999 -9999 -9999 -9999 -9999 -9999 -9999 -9999 -9999-9999 -9999 -9999 -9999 -9999 -9999 -9999 -9999 -9999 -9999 -9999 -9999 -9999 -9999 -9999 -9999 -9999 -9999 -9999 -9999 -9999 -

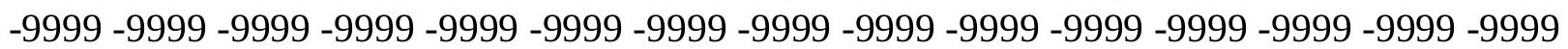


-9999 -9999 -9999 -9999 -9999 -9999 -9999 -9999 -9999 -9999 -9999 -9999 -9999 -9999 -9999 -9999 -9999 -9999 -9999 -9999 -9999 -9999 -9999 -9999 -9999 -9999 -9999 -9999 -9999 -9999 -9999 -9999 -9999 -9999 -9999 -9999 -9999 -9999 -9999 -9999 -9999 -9999 -9999 -9999 -9999 -9999 -9999 -9999 -9999 -9999 -9999 -9999 -9999 -9999 -9999 -9999 -9999 -9999 -9999 -9999 -9999 -9999 -9999 -9999 -9999 -9999 -9999 -9999 -9999 -9999 -9999 -9999 -9999 -9999 -9999 -9999 -9999 -9999 -9999 -9999 -9999 -9999 -9999 -9999 -9999 -9999 -9999 -9999 -9999 -9999 -9999 -9999 -9999 -9999 -9999 -9999 -9999 -9999 -9999 -9999 -9999 -9999 -9999 -9999 -9999 -

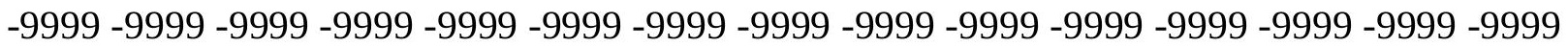
-9999 -9999 -9999 -9999 -9999 -9999 -9999 -9999 -9999 -9999 -9999 -9999 -9999 -9999 -9999 -9999 -9999 -9999 -9999 -9999 -9999 -9999 -9999 -9999 -9999 -9999 -9999 -9999 -9999 -9999 -

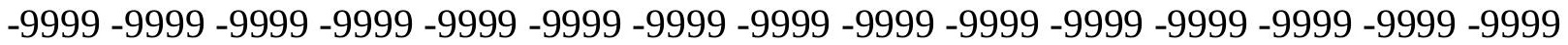
-9999 -9999 -9999 -9999 -9999 -9999 -9999 -9999 -9999 -9999 -9999 -9999 -9999 -9999 -9999 -9999 -9999 -9999 -9999 -9999 -9999 -9999 -9999 -9999 -9999 -9999 -9999 -9999 -9999 -9999 -9999 -9999 -9999 -9999 -9999 -9999 -9999 -9999 -9999 -9999 -9999 -9999 -9999 -9999 -9999 -9999 -9999 -9999 -9999 -9999 -9999 -9999 -9999 -9999 -9999 -9999 -9999 -9999 -9999 -9999

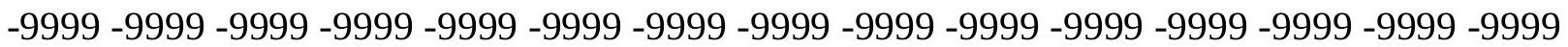
-9999 -9999 -9999 -9999 -9999 -9999 -9999 -9999 -9999 -9999 -9999 -9999 -9999 -9999 -9999 -9999 -9999 -9999 -9999 -9999 -9999 -9999 -9999 -9999 -9999 -9999 -9999 -9999 -9999 -9999 -9999 -9999 -9999 -9999 -9999 -9999 -9999 -9999 -9999 -9999 -9999 -9999 -9999 -9999 -9999 -9999 -9999 -9999 -9999 -9999 -9999 -9999 -9999 -9999 -9999 -9999 -9999 -9999 -9999 -9999 -9999 -9999 -9999 -9999 -9999 -9999 -9999 -9999 -9999 -9999 -9999 -9999 -9999 -9999 -9999 -9999 -9999 -9999 -9999 -9999 -9999 -9999 -9999 -9999 -9999 -9999 -9999 -9999 -9999 -9999 -9999 -9999 -9999 -9999 -9999 -9999 -9999 -9999 -9999 -9999 -9999 -9999 -9999 -9999 -9999 -9999 -9999 -9999 -9999 -9999 -9999 -9999 -9999 -9999 -9999 -9999 -9999 -9999 -9999 -9999 -9999 -9999 -9999 -9999 -9999 -9999 -9999 -9999 -9999 -9999 -9999 -9999 -9999 -9999 -9999 -9999 -9999 -9999 -9999 -9999 -9999 -9999 -9999 -9999 -9999 -9999 -9999 -9999 -9999 -9999 -9999 -9999 -9999 -9999 -9999 -9999 -9999 -9999 -9999 -9999 -9999 -9999 -9999 -9999 -9999 -9999 -9999 -9999 -9999 -9999 -9999 -9999 -9999 -9999 -9999 -9999 -9999 -9999 -9999

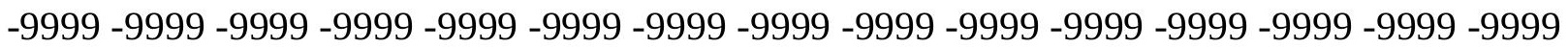
-9999 -9999 -9999 -9999 -9999 -9999 -9999 -9999 -9999 -9999 -9999 -9999 -9999 -9999 -9999 -9999 -9999 -9999 -9999 -9999 -9999 -9999 -9999 -9999 -9999 -9999 -9999 -9999 -9999 -9999 -

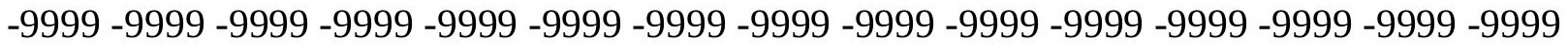
-9999 -9999 -9999 -9999 -9999 -9999 -9999 -9999 -9999 -9999 -9999 -9999 -9999 -9999 -9999 -9999 -9999 -9999 -9999 -9999 -9999 -9999 -9999 -9999 -9999 -9999 -9999 -9999 -9999 -9999 -9999 -9999 -9999 -9999 -9999 -9999 -9999 -9999 -9999 -9999 -9999 -9999 -9999 -9999 -9999 -9999 -9999 -9999 -9999 -9999 -9999 -9999 -9999 -9999 -9999 -9999 -9999 -9999 -9999 -9999 -9999 -9999 -9999 -9999 -9999 -9999 -9999 -9999 -9999 -9999 -9999 -9999 -9999 -9999 -9999

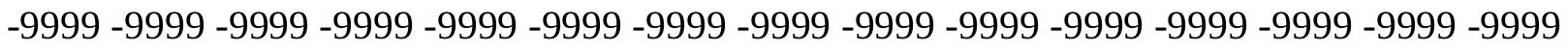
-9999 -9999 -9999 -9999 -9999 -9999 -9999 -9999 -9999 -9999 -9999 -9999 -9999 -9999 -9999 -9999 -9999 -9999 -9999 -9999 -9999 -9999 -9999 -9999 -9999 -9999 -9999 -9999 -9999 -9999 -9999 -9999 -9999 -9999 -9999 -9999 -9999 -9999 -9999 -9999 -9999 -9999 -9999 -9999 -9999 -999 -9999 -9999 -9999 -9999 -9999 -9999 -9999 -9999 -9999 -9999 -9999 -9999 -9999 -9999 -9999 -9999 -9999 -9999 -9999 -9999 -9999 -9999 -9999 -9999 -9999 -9999 -9999 -9999 -9999 -9999 -9999 -9999 -9999 -9999 -9999 -9999 -9999 -9999 -9999 -9999 -9999 -9999 -9999 -9999 -9999 -9999 -9999 -9999 -9999 -9999 -9999 -9999 -9999 -9999 -9999 -9999 -9999 -9999 -9999 -9999 -9999 -9999 -9999 -9999 -9999 -9999 -9999 -9999 -9999 -9999 -9999 -9999 -9999 -9999 
-9999 -9999 -9999 -9999 -9999 -9999 -9999 -9999 -9999 -9999 -9999 -9999 -9999 -9999 -9999 -9999 -9999 -9999 -9999 -9999 -9999 -9999 -9999 -9999 -9999 -9999 -9999 -9999 -9999 -9999 -

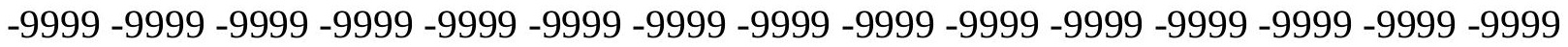
-9999 -9999 -9999 -9999 -9999 -9999 -9999 -9999 -9999 -9999 -9999 -9999 -9999 -9999 -9999 -9999 -9999 -9999 -9999 -9999 -9999 -9999 -9999 -9999-9999 -9999 -9999 -9999 -9999 -9999 -9999 -9999 -9999 -9999 -9999 -9999 -9999 -9999 -9999 -9999 -9999 -9999 -9999 -9999 -9999 -9999 -9999 -9999 -9999 -9999 -9999 -9999 -9999 -9999 -9999 -9999 -9999 -9999 -9999 -9999

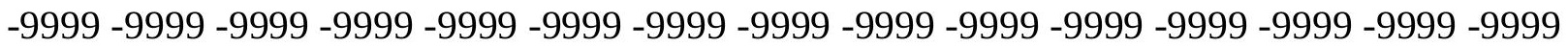

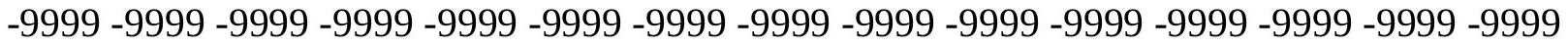
-9999 -9999 -9999 -9999 -9999 -9999 -9999 -9999 -9999 -9999 -9999 -9999 -9999 -9999 -9999 -9999 -9999 -9999 -9999 -9999 -9999 -9999 -9999 -9999 -9999 -9999 -9999 -9999 -9999 -9999 -9999 -9999 -9999 -9999 -9999 -9999 -9999 -9999 -9999 -9999 -9999 -9999 -9999 -9999 -9999 -9999 -9999 -9999 -9999 -9999 -9999 -9999 -9999 -9999 -9999 -9999 -9999 -9999 -9999 -9999 -

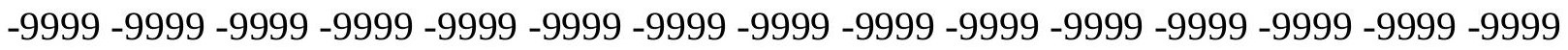
-9999 -9999 -9999 -9999 -9999 -9999 -9999 -9999 -9999 -9999 -9999 -9999 -9999 -9999 -9999 -

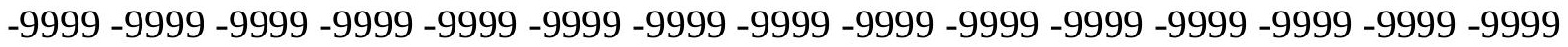
-9999 -9999 -9999 -9999 -9999 -9999 -9999 -9999 -9999 -9999 -9999 -9999 -9999 -9999 -9999 -9999 -9999 -9999 -9999 -9999 -9999 -9999 -9999 -9999 -9999 -9999 -9999 -9999 -9999 -9999 -9999 -9999 -9999 -9999 -9999 -9999 -9999 -9999 -9999 -9999 -9999 -9999 -9999 -9999 -9999 -

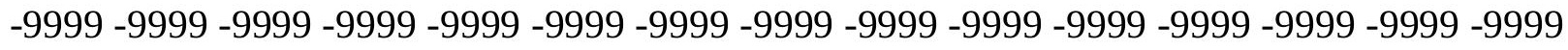

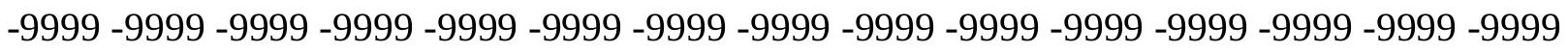

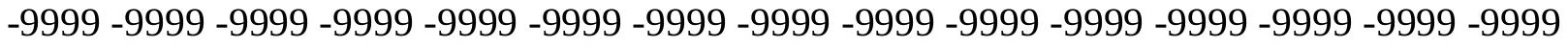
-9999 -9999 -9999 -9999 -9999 -9999 -9999 -9999 -9999 -9999 -9999 -9999 -9999 -9999 -9999 -9999 -9999 -9999 -9999 -9999 -9999 -9999 -9999 -9999 -9999 -9999 -9999 -9999 -9999 -9999 -

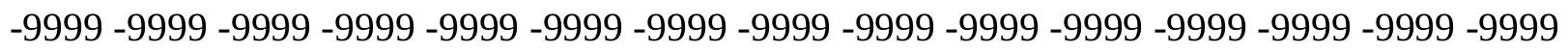
-9999 -9999 -9999 -9999 -9999 -9999 -9999 -9999 -9999 -9999 -9999 -9999 -9999 -9999 -9999 -9999 -9999 -9999 -9999 -9999 -9999 -9999 -9999 -9999 -9999 -9999 -9999 -9999 -9999 -

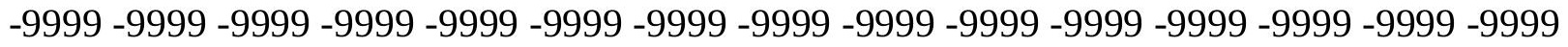
-9999 -9999 -9999 -9999 -9999 -9999 -9999 -9999 -9999 -9999 -9999 -9999 -9999 -9999 -9999 -9999 -9999 -9999 -9999 -9999 -9999 -9999 -9999 -9999 -9999 -9999 -9999 -9999 -9999 -999 -

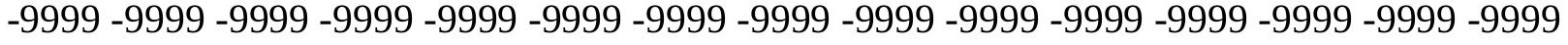
-9999 -9999 -9999 -9999 -9999 -9999 -9999 -9999 -9999 -9999 -9999 -9999 -9999 -9999 -9999 -

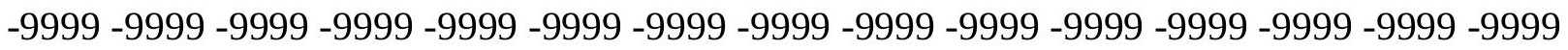

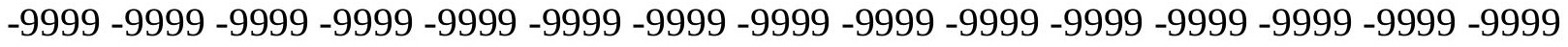

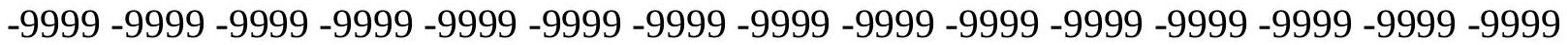
-9999 -9999 -9999 -9999 -9999 -9999 -9999 -9999 -9999 -9999 -9999 -9999 -9999 -9999 -9999

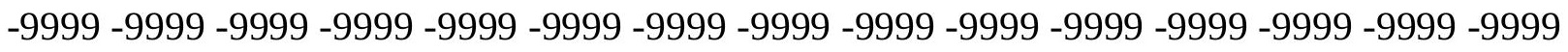

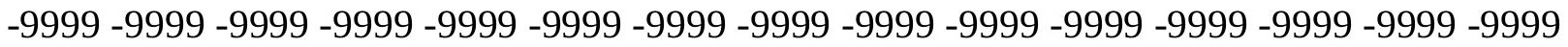
-9999 -9999 -9999 -9999 -9999 -9999 -9999 -9999 -9999 -9999 -9999 -9999 -9999 - 9999 - -999 -9999 -9999 -9999 -9999 -9999 -9999 -9999 -9999 -9999 -9999 -9999 -9999 -9999 -9999 -9999 -

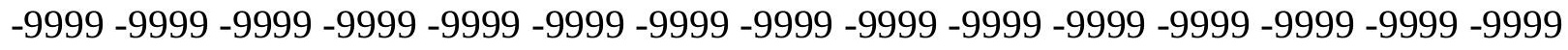

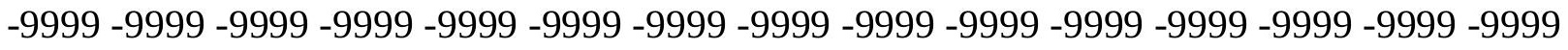
-9999 -9999 -9999 -9999 -9999 -9999 -9999 -9999 -9999 -9999 -9999 -9999 -9999 -9999 -9999 -9999 -9999 -9999 -9999 -9999 -9999 -9999 -9999 -9999-9999 -9999 -9999 -9999 -9999 -9999 -9999 -9999 -9999 -9999 -9999 -9999 -9999 -9999 -9999 -9999 -9999 -9999 -9999 -9999 -9999 -

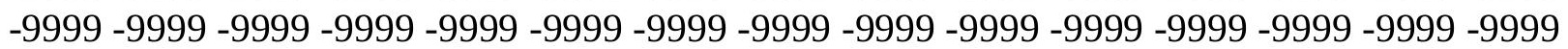


-9999 -9999 -9999 -9999 -9999 -9999 -9999 -9999 -9999 -9999 -9999 -9999 -9999 -9999 -9999 -9999 -9999 -9999 -9999 -9999 -9999 -9999 -9999 -9999 -9999 -9999 -9999 -9999 -9999 -9999 -9999 -9999 -9999 -9999 -9999 -9999 -9999 -9999 -9999 -9999 -9999 -9999 -9999 -9999 - 9999 -9999 -9999 -9999 -9999 -9999 -9999 -9999 -9999 -9999 -9999 -9999 -9999 -9999 -9999 -9999 -9999 -9999 -9999 -9999 -9999 -9999 -9999 -9999 -9999 -9999 -9999 -9999 -9999 -9999 - -9999 -9999 -9999 -9999 -9999 -9999 -9999 -9999 -9999 -9999 -9999 -9999 -9999 -9999 -9999 -9999 -9999 -9999 -9999 -9999 -9999 -9999 -9999 -9999 -9999 -9999 -9999 -9999 -9999 -9999

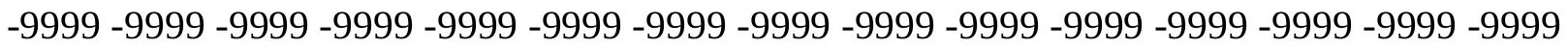

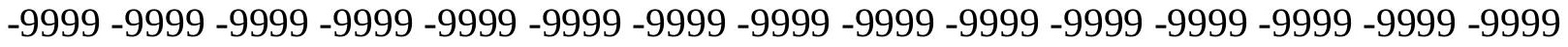
-9999 -9999 -9999 -9999 -9999 -9999 -9999 -9999 -9999 -9999 -9999 -9999 -9999 -9999 -9999

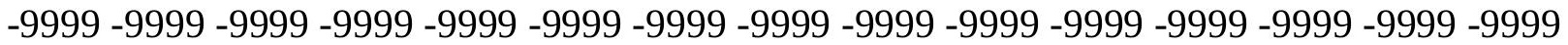
-9999 -9999 -9999 -9999 -9999 -9999 -9999 -9999 -9999 -9999 -9999 -9999 -9999 -9999 -9999 -9999 -9999 -9999 -9999 -9999 -9999 -9999 -9999 -9999 -9999 -9999 -9999 -9999 -9999 -9999 -9999 -9999 -9999 -9999 -9999 -9999 -9999 -9999 -9999 -9999 -9999 -9999 -9999 -9999 - -9999 -9999 -9999 -9999 -9999 -9999 -9999 -9999 -9999 -9999 -9999 -9999 -9999 -9999 -9999 -9999

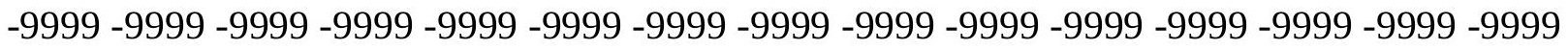
-9999 -9999 -9999 -9999 -9999 -9999 -9999 -9999 -9999 -9999 -9999 -9999 -9999 -9999 -9999 -9999 -9999 -9999 -9999 -9999 -9999 -9999 -9999 -9999 -9999 -9999 -9999 -9999 -9999 -9999 -9999 -9999 -9999 -9999 -9999 -9999 -9999 -9999 -9999 -9999 -9999 -9999 -9999 -9999 -9999 -

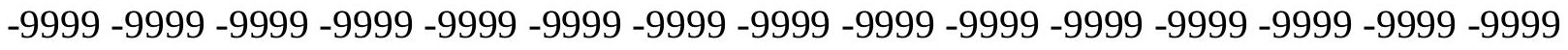
-9999 -9999 -9999 -9999 -9999 -9999 -9999 -9999 -9999 -9999 -9999 -9999 -9999 -9999 -9999 -999 -9999 -9999 -9999 -9999 -9999 -9999 -9999 -9999 -9999 -9999 -9999 -9999 -9999 -9999 -9999 -9999 -9999 -9999 -9999 -9999 -9999 -9999 -9999 -9999 -9999 -9999 -9999 -9999 -9999 -9999 -9999 -9999 -9999 -9999 -9999 -9999 -9999 -9999 -9999 -9999 -9999 -9999 -9999 -9999 -9999 -9999 -9999 -9999 -9999 -9999 -9999 -9999 -9999 -9999 -9999 -9999 -9999 -9999 -9999 -9999 -9999 -9999 -9999 -9999 -9999 -9999 -9999 -9999 -9999 -9999 -9999 -9999 -9999 -9999 -9999 -9999 -9999 -9999 -9999 -9999 -9999 -9999 -9999 -9999 -9999 -9999 -9999 -9999 -9999 -9999 -9999 -9999 -9999 -9999 -9999 -9999 -9999 -9999 -9999 -9999 -9999 -9999 -9999 -9999 -9999 -9999 -9999 -9999 -9999 -9999 -9999 -9999 -9999 -9999 -9999 -9999 -9999 -9999 -9999 -9999 -9999 -9999 -9999 -9999 -9999 -9999 -9999 -9999 -9999 -9999 -9999 -9999 -9999 -9999 -999 -9999 -9999 -9999 -9999 -9999 -9999 -9999 -9999 -9999 -9999 -9999 -9999 -9999 -9999 -9999 -9999 -9999 -9999 -9999 -9999 -9999 -9999 -9999 -9999 -9999 -9999 -9999 -9999 -9999 -

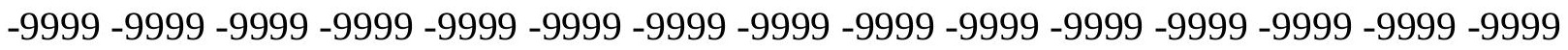

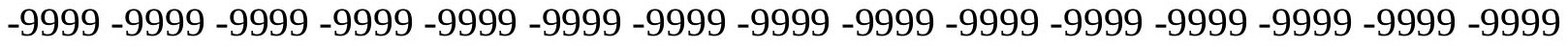

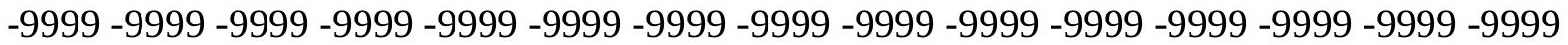
-9999 -9999 -9999 -9999 -9999 -9999 -9999 -9999 -9999 -9999 -9999 -9999 -9999 -9999 -9999 -

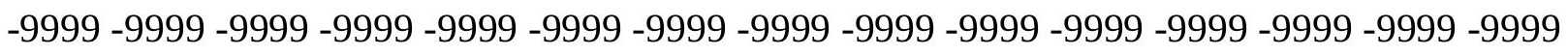

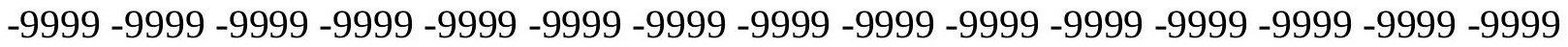

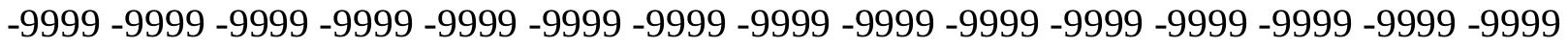
-9999 -9999 -9999 -9999 -9999 -9999 -9999 -9999 -9999 -9999 -9999 -9999 -9999 -9999 -9999 -

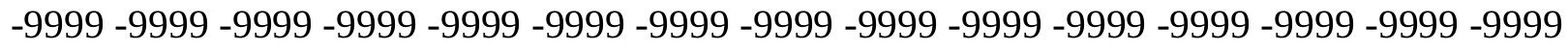

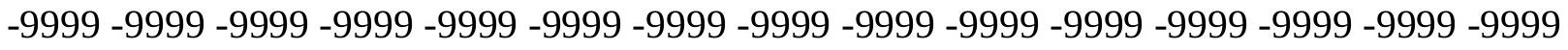
-9999 -9999 -9999 -9999 -9999 -9999 -9999 -9999 -9999 -9999 -9999 -9999 -9999 -9999 -9999 -9999 -9999 -9999 -9999 -9999 -9999 -9999 -9999 -9999-9999 -9999 -9999 -9999 -9999 -9999 -9999 -9999 -9999 -9999 -9999 -9999 -9999 -9999 -9999 -9999 -9999 -9999 -9999 -9999 -9999 -

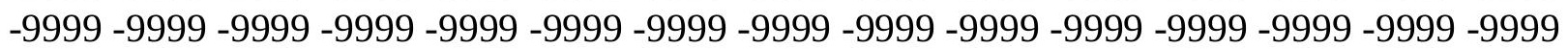


-9999 -9999 -9999 -9999 -9999 -9999 -9999 -9999 -9999 -9999 -9999 -9999 -9999 -9999 -9999 -9999 -9999 -9999 -9999 -9999 -9999 -9999 -9999 -9999 -9999 -9999 -9999 -9999 -9999 -9999 -

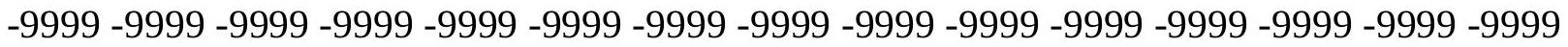
-9999 -9999 -9999 -9999 -9999 -9999 -9999 -9999 -9999 -9999 -9999 -9999 -9999 -9999 -9999 -9999 -9999 -9999 -9999 -9999 -9999 -9999 -9999 -9999-9999 -9999 -9999 -9999 -9999 -9999 -9999 -9999 -9999 -9999 -9999 -9999 -9999 -9999 -9999 -9999 -9999 -9999 -9999 -9999 -9999 -9999 -9999 -9999 -9999 -9999 -9999 -9999 -9999 -9999 -9999 -9999 -9999 -9999 -9999 -9999

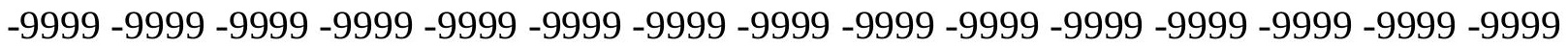

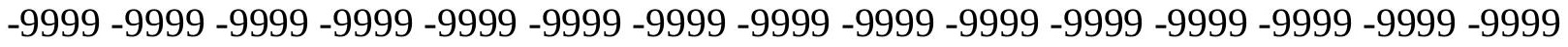
-9999 -9999 -9999 -9999 -9999 -9999 -9999 -9999 -9999 -9999 -9999 -9999 -9999 -9999 -9999 -9999 -9999 -9999 -9999 -9999 -9999 -9999 -9999 -9999 -9999 -9999 -9999 -9999 -9999 -9999 -9999 -9999 -9999 -9999 -9999 -9999 -9999 -9999 -9999 -9999 -9999 -9999 -9999 -9999 -9999 -9999 -9999 -9999 -9999 -9999 -9999 -9999 -9999 -9999 -9999 -9999 -9999 -9999 -9999 -9999 -9999 -9999 -9999 -9999 -9999 -9999 -9999 -9999 -9999 -9999 -9999 -9999 -9999 - 9999 -9999 -9999 -9999 -9999 -9999 -9999 -9999 -9999 -9999 -9999 -9999 -9999 -9999 -9999 -9999

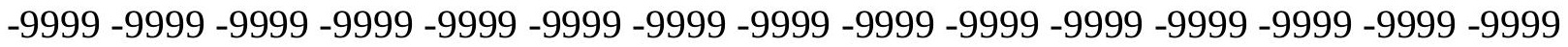
-9999 -9999 -9999 -9999 -9999 -9999 -9999 -9999 -9999 -9999 -9999 -9999 -9999 -9999 -9999 -9999 -9999 -9999 -9999 -9999 -9999 -9999 -9999 -9999 -9999 -9999 -9999 -9999 -9999 -9999 -9999 -9999 -9999 -9999 -9999 -9999 -9999 -9999 -9999 -9999 -9999 -9999 -9999 -9999 -9999 -

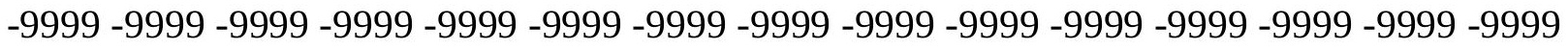

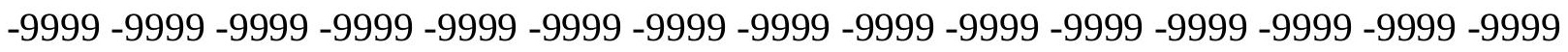
-9999 -9999 -9999 -9999 -9999 -9999 -9999 -9999 -9999 -9999 -9999 -9999 -9999 -9999 -9999 -9999 -9999 -9999 -9999 -9999 -9999 -9999 -9999 -9999 -9999 -9999 -9999 -9999 -9999 -9999 -9999 -9999 -9999 -9999 -9999 -9999 -9999 -9999 -9999 -9999 -9999 -9999 -9999 -9999 -9999 -

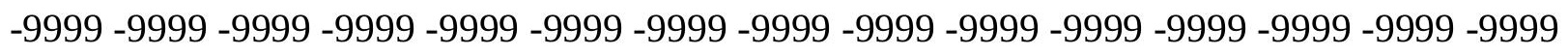
-9999 -9999 -9999 -9999 -9999 -9999 -9999 -9999 -9999 -9999 -9999 -9999 -9999 -9999 -9999 -9999 -9999 -9999 -9999 -9999 -9999 -9999 -9999 -9999 -9999 -9999 -9999 -9999 -9999 -9999 -

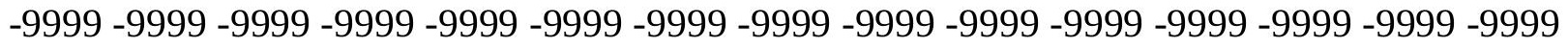
-9999 -9999 -9999 -9999 -9999 -9999 -9999 -9999 -9999 -9999 -9999 -9999 -9999 -9999 -9999 -9999 -9999 -9999 -9999 -9999 -9999 -9999 -9999 -9999 -9999 -9999 -9999 -9999 -9999 -999 -9999 -9999 -9999 -9999 -9999 -9999 -9999 -9999 -9999 -9999 -9999 -9999 -9999 -9999 -9999 -9999 -9999 -9999 -9999 -9999 -9999 -9999 -9999 -9999 -9999 -9999 -9999 -9999 -9999 -9999 -

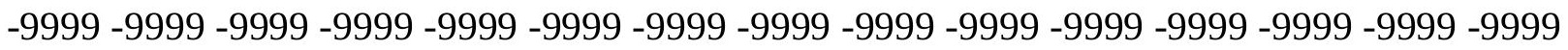

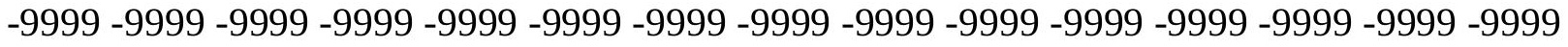

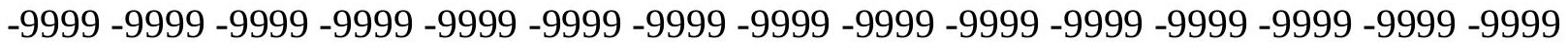

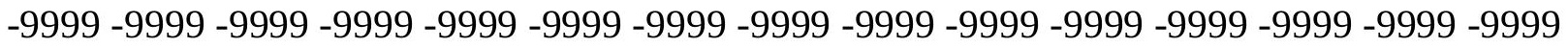

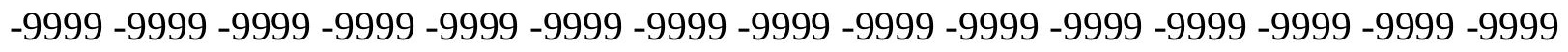

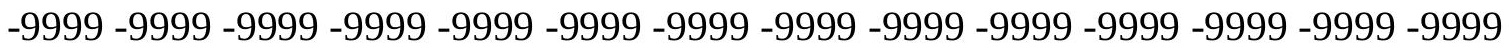
-9999 -9999 -9999 -9999 -9999 -9999 -9999 -9999 -9999 -9999 -9999 -9999 -9999 -9999 -9999 -9999 -9999 -9999 -9999 -9999 -9999 -9999 -9999 -9999 -9999 -9999 -9999 -9999 -9999 -9999 -

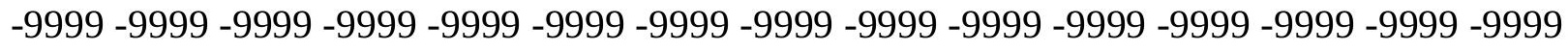

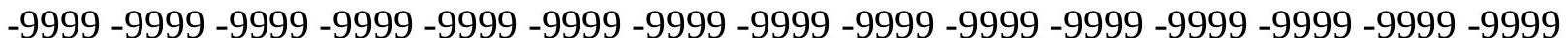
-9999 -9999 -9999 -9999 -9999 -9999 -9999 -9999 -9999 -9999 -9999 -9999 -9999 -9999 -9999 -9999 -9999 -9999 -9999 -9999 -9999 -9999 -9999 -9999-9999 -9999 -9999 -9999 -9999 -9999 -9999 -9999 -9999 -9999 -9999 -9999 -9999 -9999 -9999 -9999 -9999 -9999 -9999 -9999 -9999 -

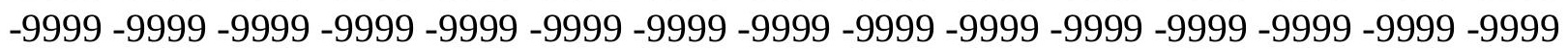


-9999 -9999 -9999 -9999 -9999 -9999 -9999 -9999 -9999 -9999 -9999 -9999 -9999 -9999 -9999 -9999 -9999 -9999 -9999 -9999 -9999 -9999 -9999 -9999 -9999 -9999 -9999 -9999 -9999 -9999 -9999 -9999 -9999 -9999 -9999 -9999 -9999 -9999 -9999 -9999 -9999 -9999 -9999 -9999 - 9999 -9999 -9999 -9999 -9999 -9999 -9999 -9999 -9999 -9999 -9999 -9999 -9999 -9999 -9999 -9999 -9999 -9999 -9999 -9999 -9999 -9999 -9999 -9999 -9999 -9999 -9999 -9999 -9999 -9999 -9999 -9999 -9999 -9999 -9999 -9999 -9999 -9999 -9999 -9999 -9999 -9999 -9999 -9999 -9999 -9999 -9999 -9999 -9999 -9999 -9999 -9999 -9999 -9999 -9999 -9999 -9999 -9999 -9999 -9999 -9999

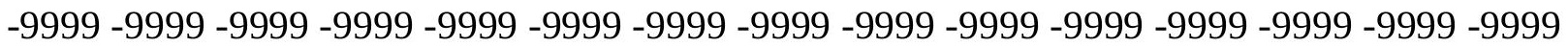
-9999 -9999 -9999 -9999 -9999 -9999 -9999 -9999 -9999 -9999 -9999 -9999 -9999 -9999 -9999 -9999 -9999 -9999 -9999 -9999 -9999 -9999 -9999 -9999 -9999 -9999 -9999 -9999 -9999 -9999

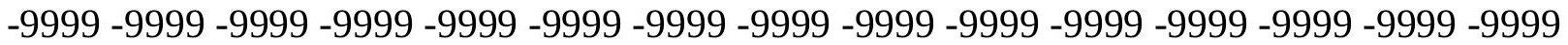
-9999 -9999 -9999 -9999 -9999 -9999 -9999 -9999 -9999 -9999 -9999 -9999 -9999 -9999 -9999 -9999 -9999 -9999 -9999 -9999 -9999 -9999 -9999 -9999 -9999 -9999 -9999 -9999 -9999 -9999 -

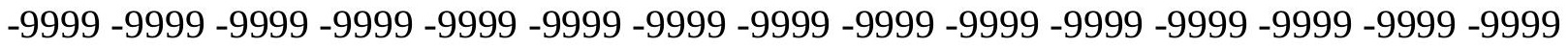
-9999 -9999 -9999 -9999 -9999 -9999 -9999 -9999 -9999 -9999 -9999 -9999 -9999 -9999 -9999

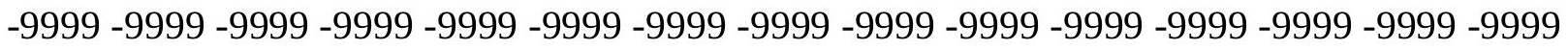
-9999 -9999 -9999 -9999 -9999 -9999 -9999 -9999 -9999 -9999 -9999 -9999 -9999 -9999 -9999 -9999 -9999 -9999 -9999 -9999 -9999 -9999 -9999 -9999 -9999 -9999 -9999 -9999 -9999 - -999 -9999 -9999 -9999 -9999 -9999 -9999 -9999 -9999 -9999 -9999 -9999 -9999 -9999 -9999 -9999 -9999 -9999 -9999 -9999 -9999 -9999 -9999 -9999 -9999 -9999 -9999 -9999 -9999 -9999 -9999 -9999 -9999 -9999 -9999 -9999 -9999 -9999 -9999 -9999 -9999 -9999 -9999 -9999 -9999 -9999 -999 -9999 -9999 -9999 -9999 -9999 -9999 -9999 -9999 -9999 -9999 -9999 -9999 -9999 -9999 -9999 -9999 -9999 -9999 -9999 -9999 -9999 -9999 -9999 -9999 -9999 -9999 -9999 -9999 -9999 -9999 -9999 -9999 -9999 -9999 -9999 -9999 -9999 -9999 -9999 -9999 -9999 -9999 -9999 -9999 -9999 -9999 -9999 -9999 -9999 -9999 -9999 -9999 -9999 -9999 -9999 -9999 -9999 -9999 -9999 -9999 -9999 -9999 -9999 -9999 -9999 -9999 -9999 -9999 -9999 -9999 -9999 -9999 -9999 -9999 -9999 -9999 -9999 -9999 -9999 -9999 -9999 -9999 -9999 -9999 -9999 -9999 -9999 -9999 -9999 -9999 -9999 -9999 -9999 -9999 -9999 -9999 -9999 -9999 -9999 -9999 -9999 -9999 -9999 -9999 -9999 -9999 -9999 -9999 -9999 -9999 -9999 -9999 -9999 -9999 -9999 -9999 -9999 -9999 -9999 -9999 -9999 -9999 -9999 -9999 -9999 -9999 -9999 -9999 -9999 -9999 -9999 -9999 -9999 -9999 -999 -9999 -9999 -9999 -9999 -9999 -9999 -9999 -9999 -9999 -9999 -9999 -9999 -9999 -9999 -9999 -9999 -9999 -9999 -9999 -9999 -9999 -9999 -9999 -9999 -9999 -9999 -9999 -9999 -9999 -9999 -

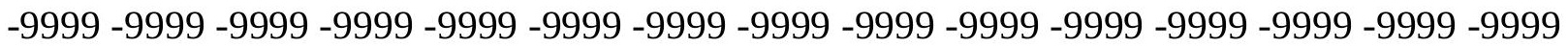

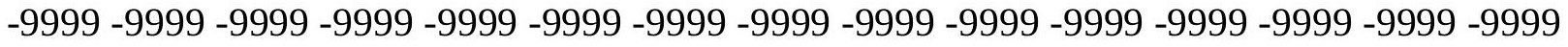

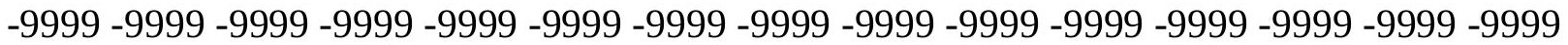
-9999 -9999 -9999 -9999 -9999 -9999 -9999 -9999 -9999 -9999 -9999 -9999 -9999 -9999 -9999

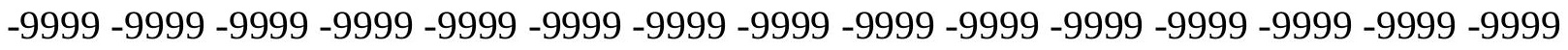

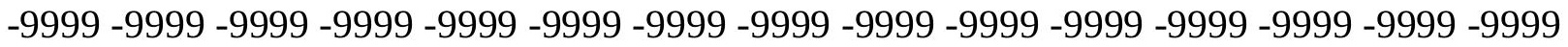

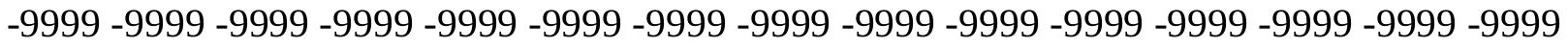
-9999 -9999 -9999 -9999 -9999 -9999 -9999 -9999 -9999 -9999 -9999 -9999 -9999 -9999 -9999 -

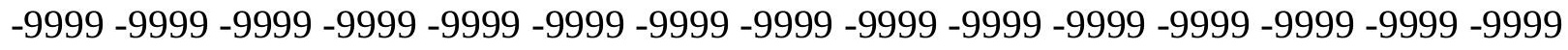

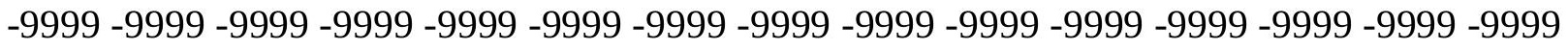
-9999 -9999 -9999 -9999 -9999 -9999 -9999 -9999 -9999 -9999 -9999 -9999 -9999 -9999 -9999 -9999 -9999 -9999 -9999 -9999 -9999 -9999 -9999 -9999 -9999 -9999 -9999 -9999 - -9999 -9999 -9999 -9999 -9999 -9999 -9999 -9999 -9999 -9999 -9999 -9999 -9999 -9999 -9999 -9999 -

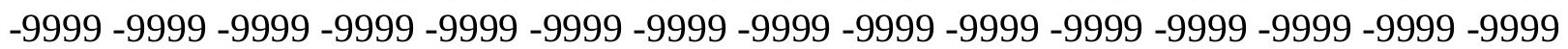


-9999 -9999 -9999 -9999 -9999 -9999 -9999 -9999 -9999 -9999 -9999 -9999 -9999 -9999 -9999 -9999 -9999 -9999 -9999 -9999 -9999 -9999 -9999 -9999 -9999 -9999 -9999 -9999 -9999 -9999 -9999 -9999 -9999 -9999 -9999 -9999 -9999 -9999 -9999 -9999 -9999 -9999 -9999 -9999 - 9999 -9999 -9999 -9999 -9999 -9999 -9999 -9999 -9999 -9999 -9999 -9999 -9999 -9999 -9999 -9999 -9999 -9999 -9999 -9999 -9999 -9999 -9999 -9999 -9999-9999 -9999 -9999 -9999 -9999 -9999 -9999 -9999 -9999 -9999 -9999 -9999 -9999 -9999 -9999 -9999 -9999 -9999 -9999 -9999 -9999 -9999 -9999 -9999 -9999 -9999 -9999 -9999 -9999 -9999 -9999 -9999 -9999 -9999 -9999 -9999

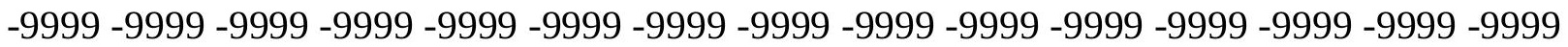

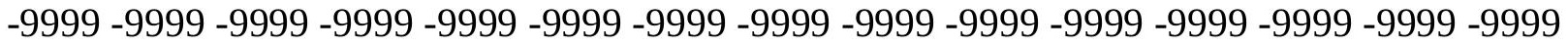
-9999 -9999 -9999 -9999 -9999 -9999 -9999 -9999 -9999 -9999 -9999 -9999 -9999 -9999 -9999

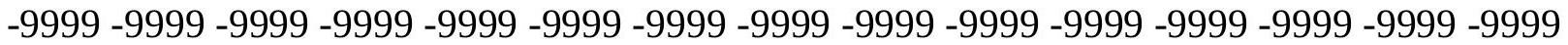
-9999 -9999 -9999 -9999 -9999 -9999 -9999 -9999 -9999 -9999 -9999 -9999 -9999 -9999 -9999 -9999 -9999 -9999 -9999 -9999 -9999 -9999 -9999 -9999 -9999 -9999 -9999 -9999 -9999 -9999 -

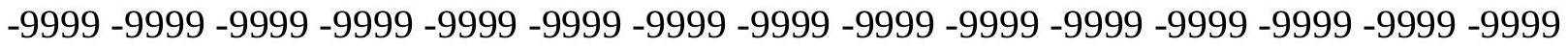
-9999 -9999 -9999 -9999 -9999 -9999 -9999 -9999 -9999 -9999 -9999 -9999 -9999 -9999 -9999

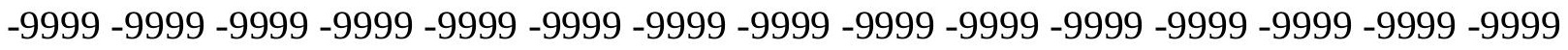
-9999 -9999 -9999 -9999 -9999 -9999 -9999 -9999 -9999 -9999 -9999 -9999 -9999 -9999 -9999 -9999 -9999 -9999 -9999 -9999 -9999 -9999 -9999 -9999 -9999 -9999 -9999 -9999 -9999 -9999 -9999 -9999 -9999 -9999 -9999 -9999 -9999 -9999 -9999 -9999 -9999 -9999 -9999 -9999 -9999 -9999 -9999 -9999 -9999 -9999 -9999 -9999 -9999 -9999 -9999 -9999 -9999 -9999 -9999 -9999 -9999 -9999 -9999 -9999 -9999 -9999 -9999 -9999 -9999 -9999 -9999 -9999 -9999 -9999 -9999 -999 -9999 -9999 -9999 -9999 -9999 -9999 -9999 -9999 -9999 -9999 -9999 -9999 -9999 -9999 -9999 -9999 -9999 -9999 -9999 -9999 -9999 -9999 -9999 -9999 -9999 -9999 -9999 -9999 -9999 -9999 -9999 -9999 -9999 -9999 -9999 -9999 -9999 -9999 -9999 -9999 -9999 -9999 -9999 -9999 -9999 -9999 -9999 -9999 -9999 -9999 -9999 -9999 -9999 -9999 -9999 -9999 -9999 -9999 -9999 -9999 -9999 -9999 -9999 -9999 -9999 -9999 -9999 -9999 -9999 -9999 -9999 -9999 -9999 -9999 -9999 -9999 -9999 -9999 -9999 -9999 -9999 -9999 -9999 -9999 -9999 -9999 -9999 -9999 -9999 -9999 -9999 -9999 -9999 -9999 -9999 -9999 -9999 -9999 -9999 -9999 -9999 -9999 -9999 -9999 -9999 -9999 -9999 -9999 -9999 -9999 -9999 -9999 -9999 -9999 -9999 -9999 -9999 -9999 -9999 -9999 -9999 -9999 -9999 -9999 -9999 -9999 -9999 -9999 -9999 -9999 -9999 -9999 -9999 -999 -9999 -9999 -9999 -9999 -9999 -9999 -9999 -9999 -9999 -9999 -9999 -9999 -9999 -9999 -9999 -9999 -9999 -9999 -9999 -9999 -9999 -9999 -9999 -9999 -9999 -9999 -9999 -9999 -9999 -9999 -

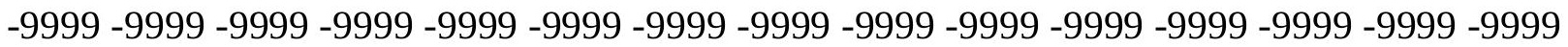

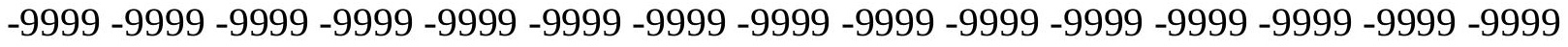

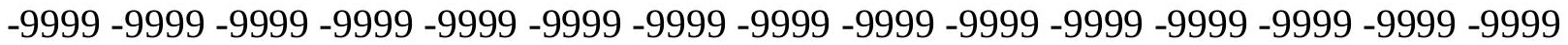
-9999 -9999 -9999 -9999 -9999 -9999 -9999 -9999 -9999 -9999 -9999 -9999 -9999 -9999 -9999

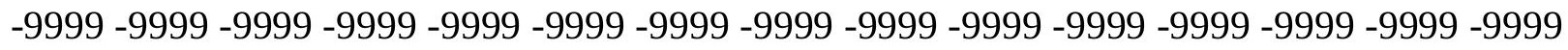

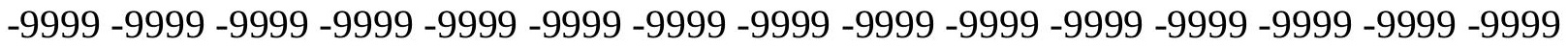
-9999 -9999 -9999 -9999 -9999 -9999 -9999 -9999 -9999 -9999 -9999 -9999 -9999 -9999 -9999 -9999 -9999 -9999 -9999 -9999 -9999 -9999 -9999 -9999 -9999 -9999 -9999 -9999 -9999 -9999 -

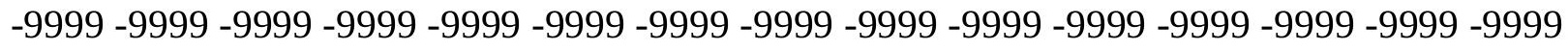

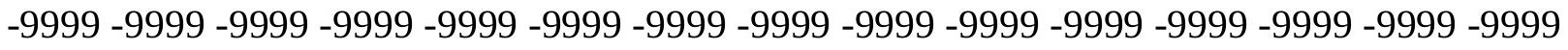
-9999 -9999 -9999 -9999 -9999 -9999 -9999 -9999 -9999 -9999 -9999 -9999 -9999 -9999 -9999 -9999 -9999 -9999 -9999 -9999 -9999 -9999 -9999 -9999-9999 -9999 -9999 -9999 -9999 -9999 -9999 -9999 -9999 -9999 -9999 -9999 -9999 -9999 -9999 -9999 -9999 -9999 -9999 -9999 -9999 -

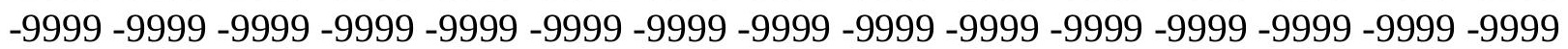


-9999 -9999 -9999 -9999 -9999 -9999 -9999 -9999 -9999 -9999 -9999 -9999 -9999 -9999 -9999 -9999 -9999 -9999 -9999 -9999 -9999 -9999 -9999 -9999 -9999 -9999 -9999 -9999 -9999 -9999 -9999 -9999 -9999 -9999 -9999 -9999 -9999 -9999 -9999 -9999 -9999 -9999 -9999 -9999 - 9999 -9999 -9999 -9999 -9999 -9999 -9999 -9999 -9999 -9999 -9999 -9999 -9999 -9999 -9999

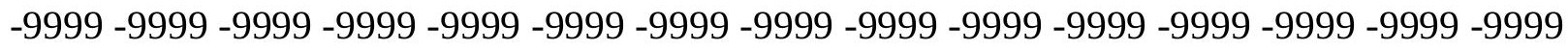
-9999 -9999 -9999 -9999 -9999 -9999 -9999 -9999 -9999 -9999 -9999 -9999 -9999 -9999 -9999 -9999 -9999 -9999 -9999 -9999 -9999 -9999 -9999 -9999 -9999 -9999 -9999 -9999 -9999 -9999

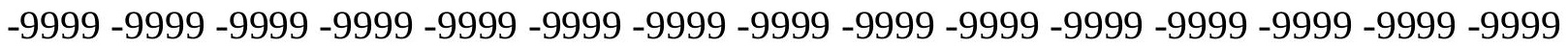

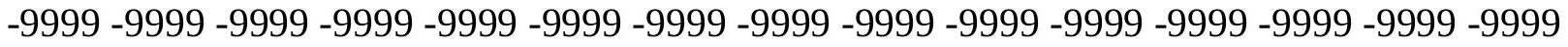
-9999 -9999 -9999 -9999 -9999 -9999 -9999 -9999 -9999 -9999 -9999 -9999 -9999 -9999 -9999 -9999 -9999 -9999 -9999 -9999 -9999 -9999 -9999 -9999 -9999 -9999 -9999 -9999 -9999 -9999 -9999 -9999 -9999 -9999 -9999 -9999 -9999 -9999 -9999 -9999 -9999 -9999 -9999 -9999 -9999 -9999 -9999 -9999 -9999 -9999 -9999 -9999 -9999 -9999 -9999 -9999 -9999 -9999 -9999 -9999 -

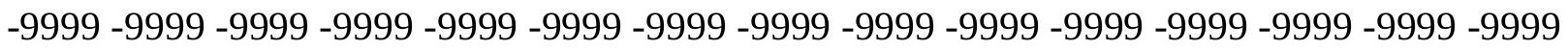
-9999 -9999 -9999 -9999 -9999 -9999 -9999 -9999 -9999 -9999 -9999 -9999 -9999 -9999 -9999 -

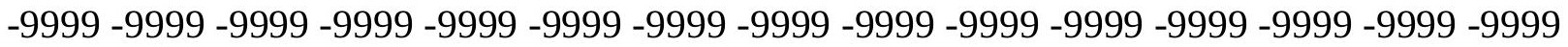
-9999 -9999 -9999 -9999 -9999 -9999 -9999 -9999 -9999 -9999 -9999 -9999 -9999 -9999 -9999 -9999 -9999 -9999 -9999 -9999 -9999 -9999 -9999 -9999 -9999 -9999 -9999 -9999 -9999 -9999 -9999 -9999 -9999 -9999 -9999 -9999 -9999 -9999 -9999 -9999 -9999 -9999 -9999 -9999 -9999 -

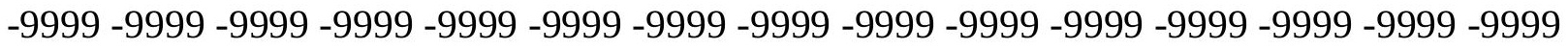
-9999 -9999 -9999 -9999 -9999 -9999 -9999 -9999 -9999 -9999 -9999 -9999 -9999 -9999 -9999

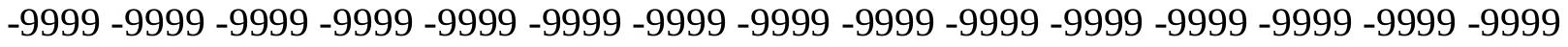
-9999 -9999 -9999 -9999 -9999 -9999 -9999 -9999 -9999 -9999 -9999 -9999 -9999 -9999 -9999 -9999 -9999 -9999 -9999 -9999 -9999 -9999 -9999 -9999 -9999 -9999 -9999 -9999 -9999 -9999 -9999 -9999 -9999 -9999 -9999 -9999 -9999 -9999 -9999 -9999 -9999 -9999 -9999 -9999 -9999 -9999 -9999 -9999 -9999 -9999 -9999 -9999 -9999 -9999 -9999 -9999 -9999 -9999 -9999 -9999 -9999 -9999 -9999 -9999 -9999 -9999 -9999 -9999 -9999 -9999 -9999 -9999 -9999 -9999 -9999 -9999 -9999 -9999 -9999 -9999 -9999 -9999 -9999 -9999 -9999 -9999 -9999 -9999 -9999 -9999 -9999 -9999 -9999 -9999 -9999 -9999 -9999 -9999 -9999 -9999 -9999 -9999 -9999 -9999 -9999 -9999 -9999 -9999 -9999 -9999 -9999 -9999 -9999 -9999 -9999 -9999 -9999 -9999 -9999 -9999 -9999 -9999 -9999 -9999 -9999 -9999 -9999 -9999 -9999 -9999 -9999 -9999 -9999 -9999 -9999 -9999 -9999 -9999 -9999 -9999 -9999 -9999 -9999 -9999 -9999 -9999 -9999 -9999 -9999 -

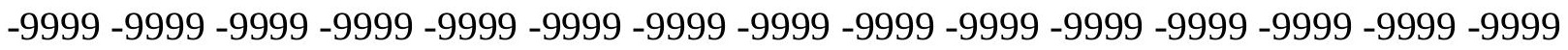

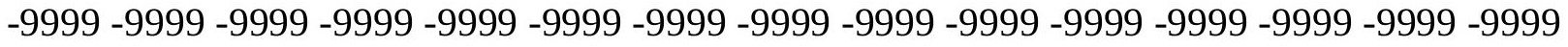
-9999 -9999 -9999 -9999 -9999 -9999 -9999 -9999 -9999 -9999 -9999 -9999 -9999 -9999 -9999 -

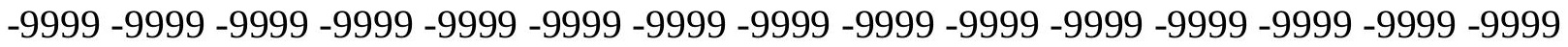

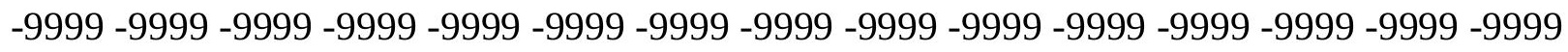

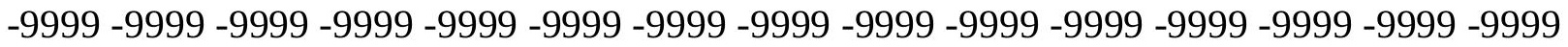

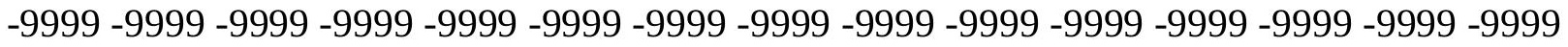
-9999 -9999 -9999 -9999 -9999 -9999 -9999 -9999 -9999 -9999 -9999 -9999 -9999 -9999 -9999 -

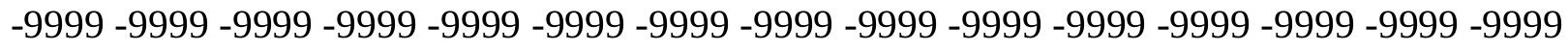

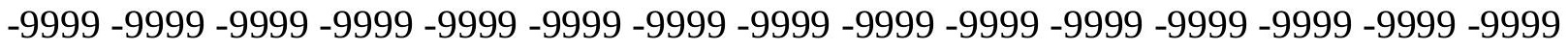
-9999 -9999 -9999 -9999 -9999 -9999 -9999 -9999 -9999 -9999 -9999 -9999 -9999 -9999 -9999 -9999 -9999 -9999 -9999 -9999 -9999 -9999 -9999 -9999-9999 -9999 -9999 -9999 -9999 -9999 -9999 -9999 -9999 -9999 -9999 -9999 -9999 -9999 -9999 -9999 -9999 -9999 -9999 -9999 -9999 -

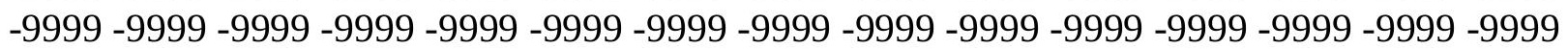


-9999 -9999 -9999 -9999 -9999 -9999 -9999 -9999 -9999 -9999 -9999 -9999 -9999 -9999 -9999 -9999 -9999 -9999 -9999 -9999 -9999 -9999 -9999 -9999 -9999 -9999 -9999 -9999 -9999 -9999 -9999 -9999 -9999 -9999 -9999 -9999 -9999 -9999 -9999 -9999 -9999 -9999 -9999 -9999 - 9999 -9999 -9999 -9999 -9999 -9999 -9999 -9999 -9999 -9999 -9999 -9999 -9999 -9999 -9999 -9999 -9999 -9999 -9999 -9999 -9999 -9999 -9999 -9999 -9999 -9999 -9999 -9999 -9999 -9999 -9999 -9999 -9999 -9999 -9999 -9999 -9999 -9999 -9999 -9999 -9999 -9999 -9999 -9999 -9999 -9999 -9999 -9999 -9999 -9999 -9999 -9999 -9999 -9999 -9999 -9999 -9999 -9999 -9999 -9999 -9999

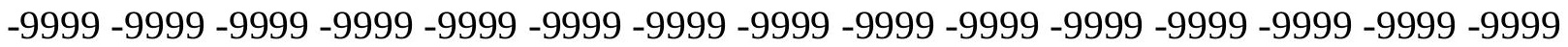

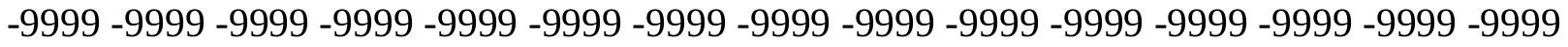
-9999 -9999 -9999 -9999 -9999 -9999 -9999 -9999 -9999 -9999 -9999 -9999 -9999 -9999 -9999 -9999 -9999 -9999 -9999 -9999 -9999 -9999 -9999 -9999 -9999 -9999 -9999 -9999 -9999 -9999 -9999 -9999 -9999 -9999 -9999 -9999 -9999 -9999 -9999 -9999 -9999 -9999 -9999 -9999 -9999 -9999 -9999 -9999 -9999 -9999 -9999 -9999 -9999 -9999 -9999 -9999 -9999 -9999 -9999 -9999 -9999 -9999 -9999 -9999 -9999 -9999 -9999 -9999 -9999 -9999 -9999 -9999 -9999 -9999 -9999 -9999 -9999 -9999 -9999 -9999 -9999 -9999 -9999 -9999 -9999 -9999 -9999 -9999 -9999 -

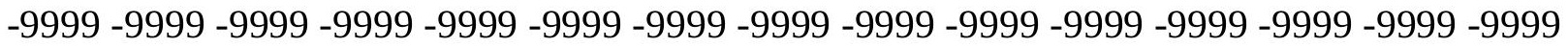
-9999 -9999 -9999 -9999 -9999 -9999 -9999 -9999 -9999 -9999 -9999 -9999 -9999 -9999 -9999 -9999 -9999 -9999 -9999 -9999 -9999 -9999 -9999 -9999 -9999 -9999 -9999 -9999 -9999 -9999 -9999 -9999 -9999 -9999 -9999 -9999 -9999 -9999 -9999 -9999 -9999 -9999 -9999 -9999 -9999 -9999 -9999 -9999 -9999 -9999 -9999 -9999 -9999 -9999 -9999 -9999 -9999 -9999 -9999 -9999 -9999 -9999 -9999 -9999 -9999 -9999 -9999 -9999 -9999 -9999 -9999 -9999 -9999 -9999 -9999 -999 -9999 -9999 -9999 -9999 -9999 -9999 -9999 -9999 -9999 -9999 -9999 -9999 -9999 -9999 -9999 -9999 -9999 -9999 -9999 -9999 -9999 -9999 -9999 -9999 -9999 -9999 -9999 -9999 -9999 -9999 -9999 -9999 -9999 -9999 -9999 -9999 -9999 -9999 -9999 -9999 -9999 -9999 -9999 -9999 -9999 -9999 -9999 -9999 -9999 -9999 -9999 -9999 -9999 -9999 -9999 -9999 -9999 -9999 -9999 -9999 -9999 -9999 -9999 -9999 -9999 -9999 -9999 -9999 -9999 -9999 -9999 -9999 -9999 -9999 -9999 -9999 -9999 -9999 -9999 -9999 -9999 -9999 -9999 -9999 -9999 -9999 -9999 -9999 -9999 -9999 -9999 -9999 -9999 -9999 -9999 -9999 -9999 -9999 -9999 -9999 -9999 -9999 -9999 -9999 -9999 -9999 -9999 -9999 -9999 -9999 -9999 -9999 -9999 -9999 -9999 -9999 -9999 -9999 -9999 -9999 -9999 -9999 -9999 -9999 -9999 -9999 -9999 -9999 -9999 -9999 -9999 -9999 -9999 -9999 -999 -9999 -9999 -9999 -9999 -9999 -9999 -9999 -9999 -9999 -9999 -9999 -9999 -9999 -9999 -9999 -9999 -9999 -9999 -9999 -9999 -9999 -9999 -9999 -9999 -9999 -9999 -9999 -9999 -9999 -9999 -

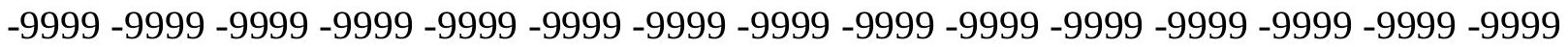

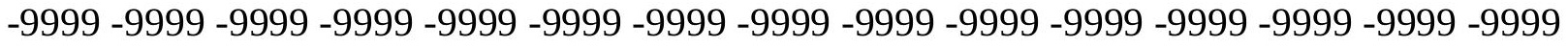

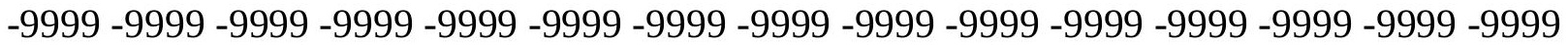
-9999 -9999 -9999 -9999 -9999 -9999 -9999 -9999 -9999 -9999 -9999 -9999 -9999 -9999 -9999 -9999 -9999 -9999 -9999 -9999 -9999 -9999 -9999 -9999 -9999 -9999 -9999 -9999 -9999 -

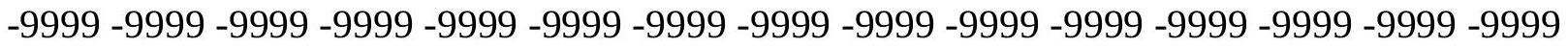
-9999 -9999 -9999 -9999 -9999 -9999 -9999 -9999 -9999 -9999 -9999 -9999 -9999 -9999 -9999 -9999 -9999 -9999 -9999 -9999 -9999 -9999 -9999 -9999 -9999 -9999 -9999 -9999 -9999 -9999 -

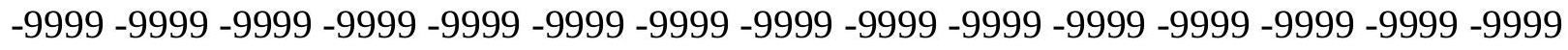

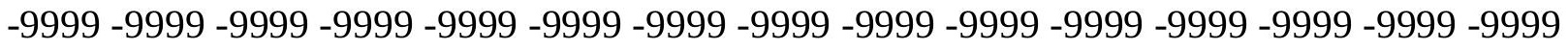
-9999 -9999 -9999 -9999 -9999 -9999 -9999 -9999 -9999 -9999 -9999 -9999 -9999 -9999 -9999 -9999 -9999 -9999 -9999 -9999 -9999 -9999 -9999 -9999-9999 -9999 -9999 -9999 -9999 -9999 -9999 -9999 -9999 -9999 -9999 -9999 -9999 -9999 -9999 -9999 -9999 -9999 -9999 -9999 -9999 -

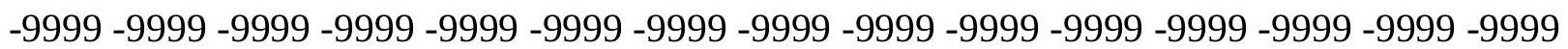


-9999 -9999 -9999 -9999 -9999 -9999 -9999 -9999 -9999 -9999 -9999 -9999 -9999 -9999 -9999 -9999 -9999 -9999 -9999 -9999 -9999 -9999 -9999 -9999 -9999 -9999 -9999 -9999 -9999 -9999 -

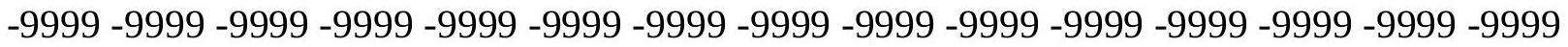
-9999 -9999 -9999 -9999 -9999 -9999 -9999 -9999 -9999 -9999 -9999 -9999 -9999 -9999 -9999 -9999 -9999 -9999 -9999 -9999 -9999 -9999 -9999 -9999-9999 -9999 -9999 -9999 -9999 -9999 -9999 -9999 -9999 -9999 -9999 -9999 -9999 -9999 -9999 -9999 -9999 -9999 -9999 -9999 -9999 -9999 -9999 -9999 -9999 -9999 -9999 -9999 -9999 -9999 -9999 -9999 -9999 -9999 -9999 -9999

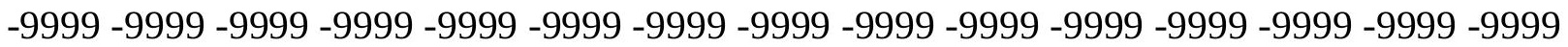

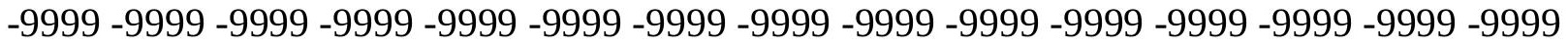
-9999 -9999 -9999 -9999 -9999 -9999 -9999 -9999 -9999 -9999 -9999 -9999 -9999 -9999 -9999 -9999 -9999 -9999 -9999 -9999 -9999 -9999 -9999 -9999 -9999 -9999 -9999 -9999 -9999 -9999 -9999 -9999 -9999 -9999 -9999 -9999 -9999 -9999 -9999 -9999 -9999 -9999 -9999 -9999 -9999 -9999 -9999 -9999 -9999 -9999 -9999 -9999 -9999 -9999 -9999 -9999 -9999 -9999 -9999 -9999 -9999 -9999 -9999 -9999 -9999 -9999 -9999 -9999 -9999 -9999 -9999 -9999 -9999 -9999 -9999 -9999 -9999 -9999 -9999 -9999 -9999 -9999 -9999 -9999 -9999 -9999 -9999 -9999 -9999 -9999 -

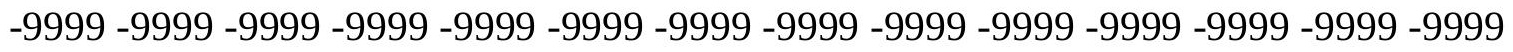
-9999 -9999 -9999 -9999 -9999 -9999 -9999 -9999 -9999 -9999 -9999 -9999 -9999 -9999 -9999 -9999 -9999 -9999 -9999 -9999 -9999 -9999 -9999 -9999 -9999 -9999 -9999 -9999 -9999 -9999 -9999 -9999 -9999 -9999 -9999 -9999 -9999 -9999 -9999 -9999 -9999 -9999 -9999 -9999 -9999 -

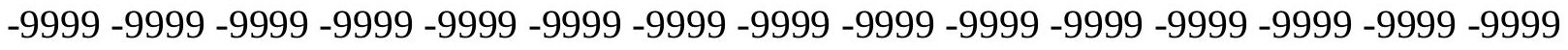

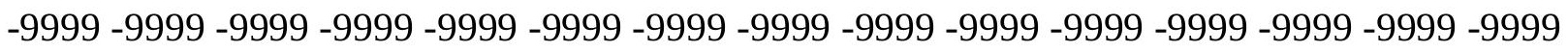
-9999 -9999 -9999 -9999 -9999 -9999 -9999 -9999 -9999 -9999 -9999 -9999 -9999 -9999 - 9999 -9999 -9999 -9999 -9999 -9999 -9999 -9999 -9999 -9999 -9999 -9999 -9999 -9999 -9999 -9999 -9999 -9999 -9999 -9999 -9999 -9999 -9999 -9999 -9999 -9999 -9999 -9999 -9999 -9999 -9999 -

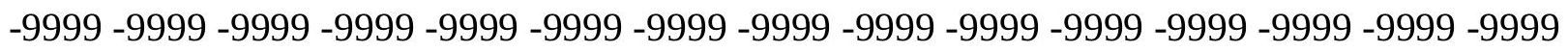
-9999 -9999 -9999 -9999 -9999 -9999 -9999 -9999 -9999 -9999 -9999 -9999 -9999 -9999 -9999 -9999 -9999 -9999 -9999 -9999 -9999 -9999 -9999 -9999 -9999 -9999 -9999 -9999 -9999 -9999 -

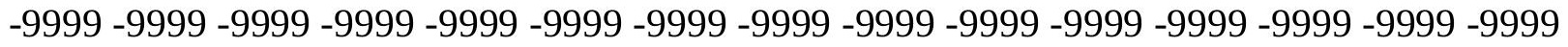
-9999 -9999 -9999 -9999 -9999 -9999 -9999 -9999 -9999 -9999 -9999 -9999 -9999 -9999 -9999 -9999 -9999 -9999 -9999 -9999 -9999 -9999 -9999 -9999 -9999 -9999 -9999 -9999 -9999 -999 -

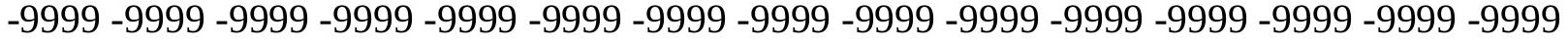
-9999 -9999 -9999 -9999 -9999 -9999 -9999 -9999 -9999 -9999 -9999 -9999 -9999 -9999 -9999 -

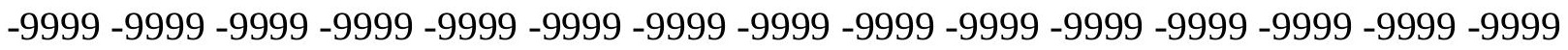

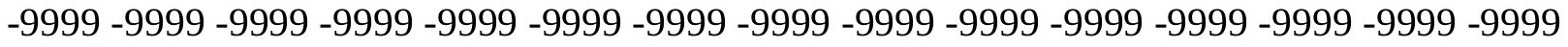

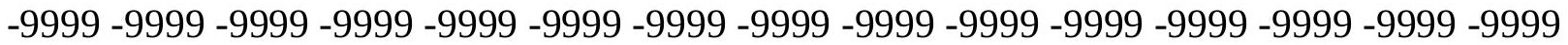
-9999 -9999 -9999 -9999 -9999 -9999 -9999 -9999 -9999 -9999 -9999 -9999 -9999 -9999 -9999 -

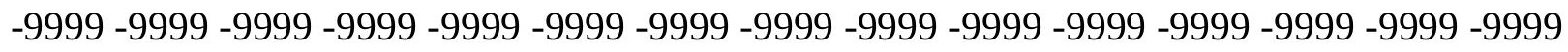

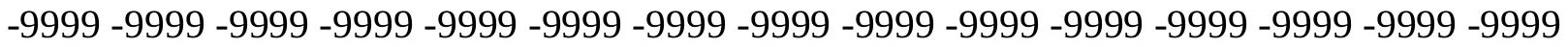
-9999 -9999 -9999 -9999 -9999 -9999 -9999 -9999 -9999 -9999 -9999 -9999 -9999 - 9999 - -999 -9999 -9999 -9999 -9999 -9999 -9999 -9999 -9999 -9999 -9999 -9999 -9999 -9999 -9999 -9999 -

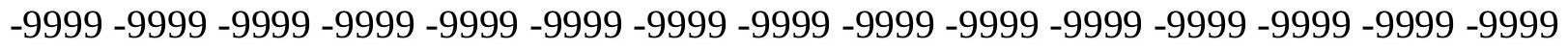

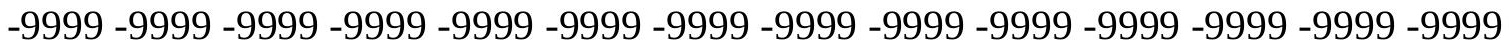
-9999 -9999 -9999 -9999 -9999 -9999 -9999 -9999 -9999 -9999 -9999 -9999 -9999 -9999 -9999 -9999 -9999 -9999 -9999 -9999 -9999 -9999 -9999 -9999-9999 -9999 -9999 -9999 -9999 -9999 -9999 -9999 -9999 -9999 -9999 -9999 -9999 -9999 -9999 -9999 -9999 -9999 -9999 -9999 -9999 -

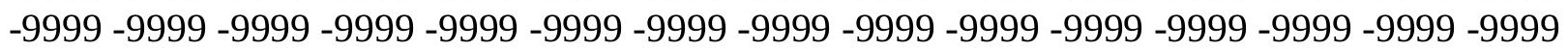


-9999 -9999 -9999 -9999 -9999 -9999 -9999 -9999 -9999 -9999 -9999 -9999 -9999 -9999 -9999 -9999 -9999 -9999 -9999 -9999 -9999 -9999 -9999 -9999 -9999 -9999 -9999 -9999 -9999 -9999 -

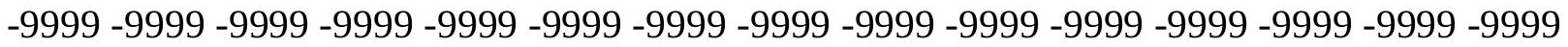
-9999 -9999 -9999 -9999 -9999 -9999 -9999 -9999 -9999 -9999 -9999 -9999 -9999 -9999 -9999 -9999 -9999 -9999 -9999 -9999 -9999 -9999 -9999 -9999-9999 -9999 -9999 -9999 -9999 -9999 -9999 -9999 -9999 -9999 -9999 -9999 -9999 -9999 -9999 -9999 -9999 -9999 -9999 -9999 -9999 -9999 -9999 -9999 -9999 -9999 -9999 -9999 -9999 -9999 -9999 -9999 -9999 -9999 -9999 -9999

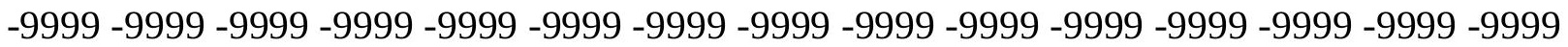

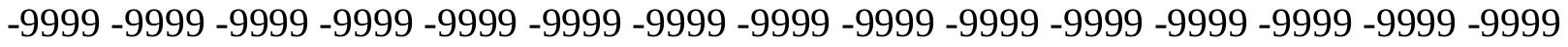
-9999 -9999 -9999 -9999 -9999 -9999 -9999 -9999 -9999 -9999 -9999 -9999 -9999 -9999 -9999 -9999 -9999 -9999 -9999 -9999 -9999 -9999 -9999 -9999 -9999 -9999 -9999 -9999 -9999 -9999 -9999 -9999 -9999 -9999 -9999 -9999 -9999 -9999 -9999 -9999 -9999 -9999 -9999 -9999 -9999 -9999 -9999 -9999 -9999 -9999 -9999 -9999 -9999 -9999 -9999 -9999 -9999 -9999 -9999 -9999 -

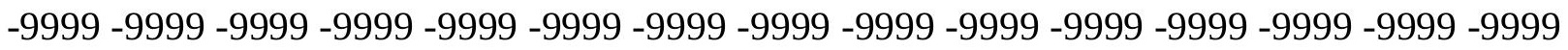
-9999 -9999 -9999 -9999 -9999 -9999 -9999 -9999 -9999 -9999 -9999 -9999 -9999 -9999 -9999 -

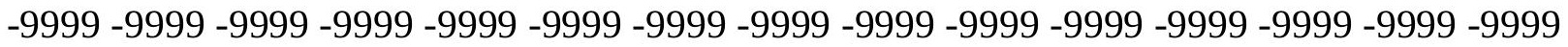
-9999 -9999 -9999 -9999 -9999 -9999 -9999 -9999 -9999 -9999 -9999 -9999 -9999 -9999 -9999 -9999 -9999 -9999 -9999 -9999 -9999 -9999 -9999 -9999 -9999 -9999 -9999 -9999 -9999 -9999 -9999 -9999 -9999 -9999 -9999 -9999 -9999 -9999 -9999 -9999 -9999 -9999 -9999 -9999 -9999 -

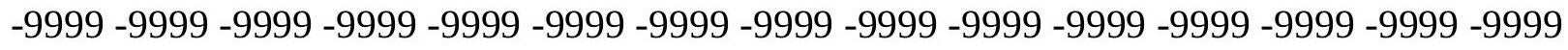

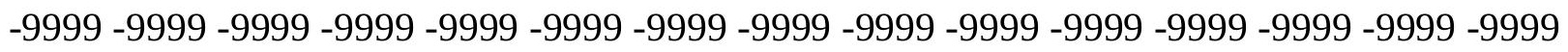
-9999 -9999 -9999 -9999 -9999 -9999 -9999 -9999 -9999 -9999 -9999 -9999 -9999 -9999 -9999 -9999 -9999 -9999 -9999 -9999 -9999 -9999 -9999 -9999 -9999 -9999 -9999 -9999 -9999 -9999 -9999 -9999 -9999 -9999 -9999 -9999 -9999 -9999 -9999 -9999 -9999 -9999 -9999 -9999 -

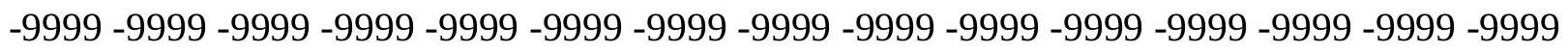
-9999 -9999 -9999 -9999 -9999 -9999 -9999 -9999 -9999 -9999 -9999 -9999 -9999 -9999 -9999 -9999 -9999 -9999 -9999 -9999 -9999 -9999 -9999 -9999 -9999 -9999 -9999 -9999 -9999 -9999 -

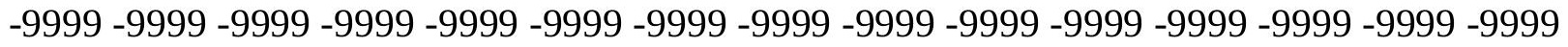
-9999 -9999 -9999 -9999 -9999 -9999 -9999 -9999 -9999 -9999 -9999 -9999 -9999 -9999 -9999 -9999 -9999 -9999 -9999 -9999 -9999 -9999 -9999 -9999 -9999 -9999 -9999 -9999 -9999 -999 -

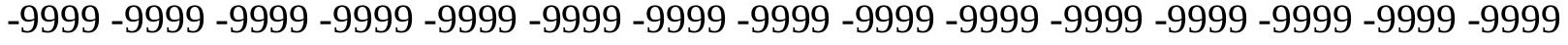
-9999 -9999 -9999 -9999 -9999 -9999 -9999 -9999 -9999 -9999 -9999 -9999 -9999 -9999 -9999 -

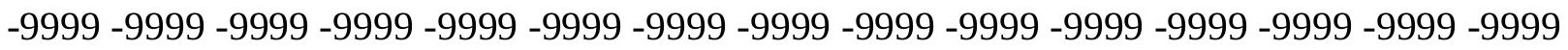

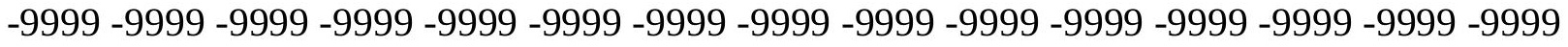

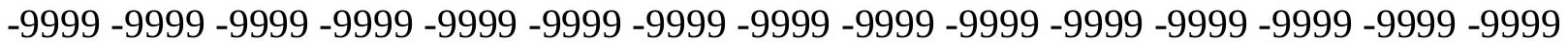

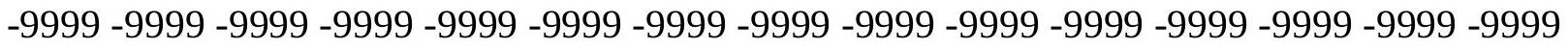

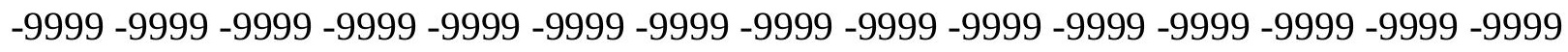

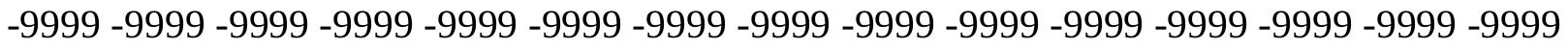

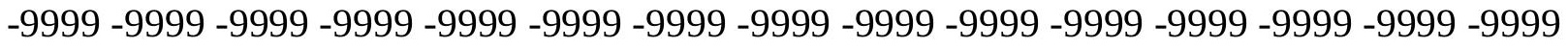
-9999 -9999 -9999 -9999 -9999 -9999 -9999 -9999 -9999 -9999 -9999 -9999 -9999 -9999 -9999 -

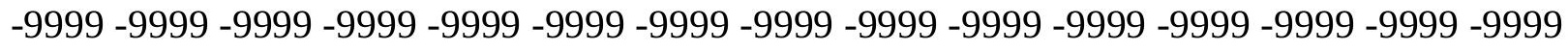

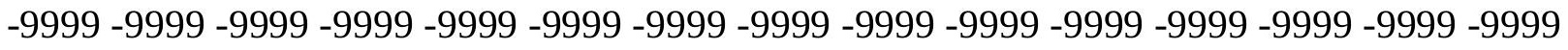
-9999 -9999 -9999 -9999 -9999 -9999 -9999 -9999 -9999 -9999 -9999 -9999 -9999 -9999 -9999 -9999 -9999 -9999 -9999 -9999 -9999 -9999 -9999 -9999-9999 -9999 -9999 -9999 -9999 -9999 -9999 -9999 -9999 -9999 -9999 -9999 -9999 -9999 -9999 -9999 -9999 -9999 -9999 -9999 -9999 -

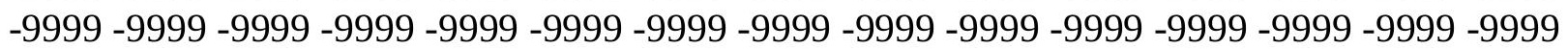


-9999 -9999 -9999 -9999 -9999 -9999 -9999 -9999 -9999 -9999 -9999 -9999 -9999 -9999 -9999 -9999 -9999 -9999 -9999 -9999 -9999 -9999 -9999 -9999 -9999 -9999 -9999 -9999 -9999 -

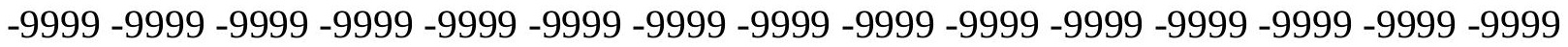
-9999 -9999 -9999 -9999 -9999 -9999 -9999 -9999 -9999 -9999 -9999 -9999 -9999 -9999 -9999 -9999 -9999 -9999 -9999 -9999 -9999 -9999 -9999 -9999 -9999 -9999 -9999 -9999 -9999 -9999 -9999 -9999 -9999 -9999 -9999 -9999 -9999 -9999 -9999 -9999 -9999 -9999 -9999 -9999 -9999 -9999 -9999 -9999 -9999 -9999 -9999 -9999 -9999 -9999 -9999 -9999 -9999 -9999 -9999 -9999

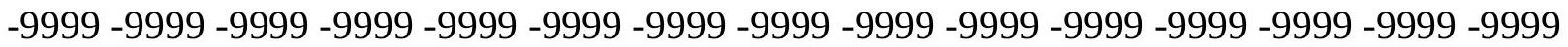

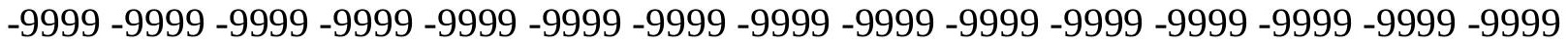
-9999 -9999 -9999 -9999 -9999 -9999 -9999 -9999 -9999 -9999 -9999 -9999 -9999 -9999 -9999 -9999 -9999 -9999 -9999 -9999 -9999 -9999 -9999 -9999 -9999 -9999 -9999 -9999 -9999 -9999 -9999 -9999 -9999 -9999 -9999 -9999 -9999 -9999 -9999 -9999 -9999 -9999 -9999 -9999 -9999 -9999 -9999 -9999 -9999 -9999 -9999 -9999 -9999 -9999 -9999 -9999 -9999 -9999 -9999 -9999 -9999 -9999 -9999 -9999 -9999 -9999 -9999 -9999 -9999 -9999 -9999 -9999 -9999 -9999 -9999 -9999 -9999 -9999 -9999 -9999 -9999 -9999 -9999 -9999 -9999 -9999 -9999 -9999 -9999 -9999 -

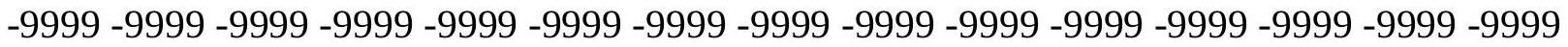
-9999 -9999 -9999 -9999 -9999 -9999 -9999 -9999 -9999 -9999 -9999 -9999 -9999 -9999 -9999 -9999 -9999 -9999 -9999 -9999 -9999 -9999 -9999 -9999 -9999 -9999 -9999 -9999 -9999 - 9999 -9999 -9999 -9999 -9999 -9999 -9999 -9999 -9999 -9999 -9999 -9999 -9999 -9999 -9999 -9999 -

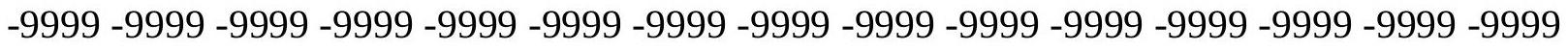

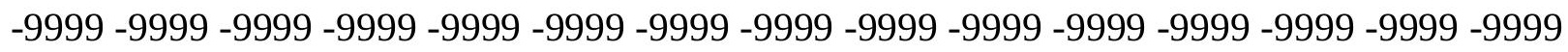

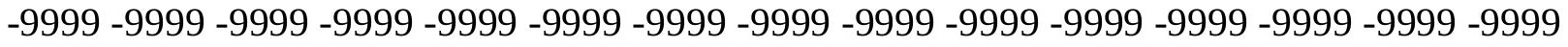
-9999 -9999 -9999 -9999 -9999 -9999 -9999 -9999 -9999 -9999 -9999 -9999 -9999 -9999 -9999 -9999 -9999 -9999 -9999 -9999 -9999 -9999 -9999 -9999 -9999 -9999 -9999 -9999 -9999 -9999 -

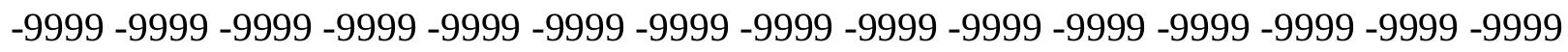
-9999 -9999 -9999 -9999 -9999 -9999 -9999 -9999 -9999 -9999 -9999 -9999 -9999 -9999 -9999 -9999 -9999 -9999 -9999 -9999 -9999 -9999 -9999 -9999 -9999 -9999 -9999 -9999 -9999 -9999 -9999 -9999 -9999 -9999 -9999 -9999 -9999 -9999 -9999 -9999 -9999 -9999 -9999 -9999 -9999 -9999 -9999 -9999 -9999 -9999 -9999 -9999 -9999 -9999 -9999 -9999 -9999 -9999 -9999 -9999 -9999 -9999 -9999 -9999 -9999 -9999 -9999 -9999 -9999 -9999 -9999 -9999 -9999 -999 -

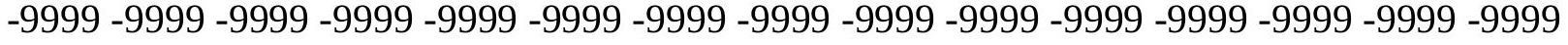
-9999 -9999 -9999 -9999 -9999 -9999 -9999 -9999 -9999 -9999 -9999 -9999 -9999 -9999 -9999 -

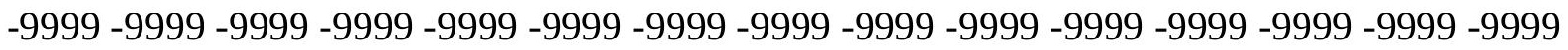

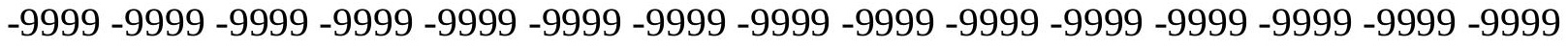

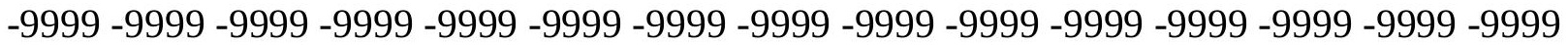

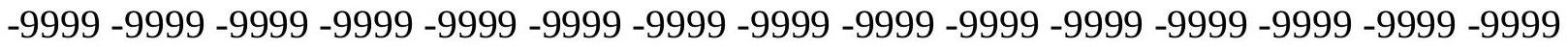

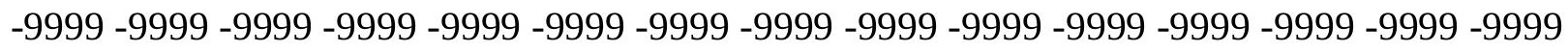

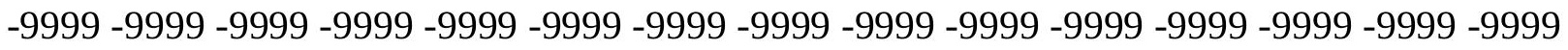

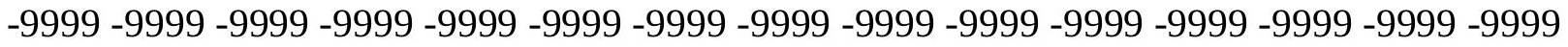
-9999 -9999 -9999 -9999 -9999 -9999 -9999 -9999 -9999 -9999 -9999 -9999 -9999 -9999 -9999 -

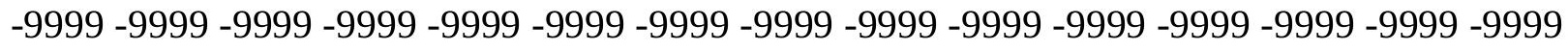

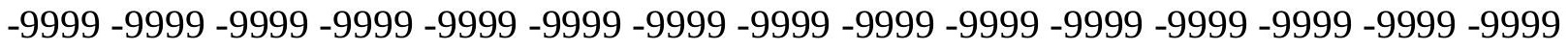
-9999 -9999 -9999 -9999 -9999 -9999 -9999 -9999 -9999 -9999 -9999 -9999 -9999 -9999 -9999 -9999 -9999 -9999 -9999 -9999 -9999 -9999 -9999 -9999-9999 -9999 -9999 -9999 -9999 -9999 -9999 -9999 -9999 -9999 -9999 -9999 -9999 -9999 -9999 -9999 -9999 -9999 -9999 -9999 -9999 -

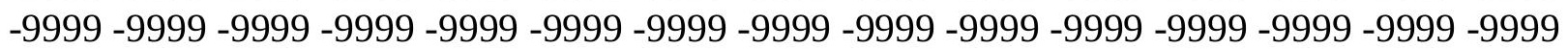


-9999 -9999 -9999 -9999 -9999 -9999 -9999 -9999 -9999 -9999 -9999 -9999 -9999 -9999 -9999 -9999 -9999 -9999 -9999 -9999 -9999 -9999 -9999 -9999 -9999 -9999 -9999 -9999 -9999 -9999 -

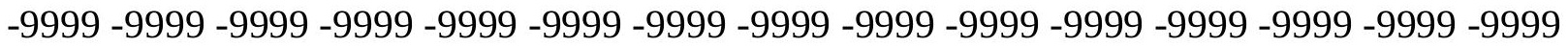
-9999 -9999 -9999 -9999 -9999 -9999 -9999 -9999 -9999 -9999 -9999 -9999 -9999 -9999 -9999 -9999 -9999 -9999 -9999 -9999 -9999 -9999 -9999 -9999-9999 -9999 -9999 -9999 -9999 -9999 -9999 -9999 -9999 -9999 -9999 -9999 -9999 -9999 -9999 -9999 -9999 -9999 -9999 -9999 -9999 -

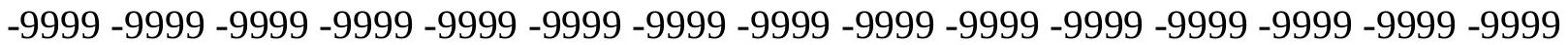
-9999 -9999 -9999 -9999 -9999 -9999 -9999 -9999 -9999 -9999 -9999 -9999 -9999 -9999 -9999 -9999 -9999 -9999 -9999 -9999 -9999 -9999 -9999 -9999 -9999 -9999 -9999 -9999 -9999 -9999 -9999 -9999 -9999 -9999 -9999 -9999 -9999 -9999 -9999 -9999 -9999 -9999 -9999 -9999 -9999 -9999 -9999 -9999 -9999 -9999 -9999 -9999 -9999 -9999 -9999 -9999 -9999 -9999 -9999 -9999 -9999 -9999 -9999 -9999 -9999 -9999 -9999 -9999 -9999 -9999 -9999 -9999 -9999 -9999 -9999 -9999 -9999 -9999 -9999 -9999 -9999 -9999 -9999 -9999 -9999 -9999 -9999 -9999 -9999 -9999 -9999 -9999 -9999 -9999 -9999 -9999 -9999 -9999 -9999 -9999 -9999 -9999 -9999 -9999 -9999 -9999 -9999 -9999 -9999 -9999 -9999 -9999 -9999 -9999 -9999 -9999 -9999 -9999 -9999 -

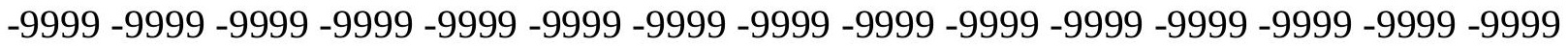
-9999 -9999 -9999 -9999 -9999 -9999 -9999 -9999 -9999 -9999 -9999 -9999 -9999 -9999 -9999 -9999 -9999 -9999 -9999 -9999 -9999 -9999 -9999 -9999 -9999 -9999 -9999 -9999 -9999 -9999 -9999 -9999 -9999 -9999 -9999 -9999 -9999 -9999 -9999 -9999 -9999 -9999 -9999 -9999 -9999 -

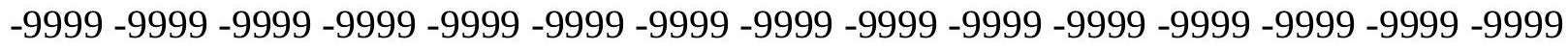

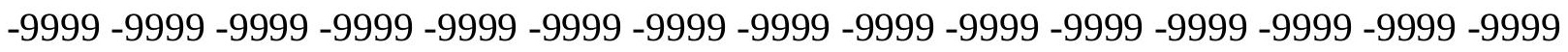
-9999 -9999 -9999 -9999 -9999 -9999 -9999 -9999 -9999 -9999 -9999 -9999 -9999 -9999 - 9999 -9999 -9999 -9999 -9999 -9999 -9999 -9999 -9999 -9999 -9999 -9999 -9999 -9999 -9999 -9999 -9999 -9999 -9999 -9999 -9999 -9999 -9999 -9999 -9999 -9999 -9999 -9999 -9999 -9999 -9999 -

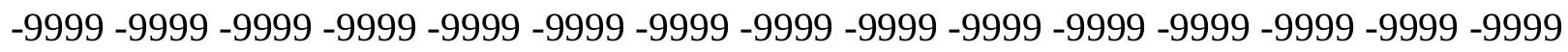
-9999 -9999 -9999 -9999 -9999 -9999 -9999 -9999 -9999 -9999 -9999 -9999 -9999 -9999 -9999 -9999 -9999 -9999 -9999 -9999 -9999 -9999 -9999 -9999 -9999 -9999 -9999 -9999 -9999 -9999 -

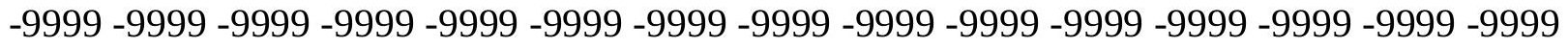
-9999 -9999 -9999 -9999 -9999 -9999 -9999 -9999 -9999 -9999 -9999 -9999 -9999 -9999 -9999 -9999 -9999 -9999 -9999 -9999 -9999 -9999 -9999 -9999 -9999 -9999 -9999 -9999 -9999 -999 -9999 -9999 -9999 -9999 -9999 -9999 -9999 -9999 -9999 -9999 -9999 -9999 -9999 -9999 -9999 -9999 -9999 -9999 -9999 -9999 -9999 -9999 -9999 -9999 -9999 -9999 -9999 -9999 -9999 -9999 -

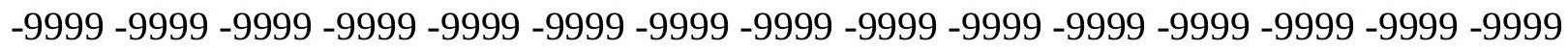

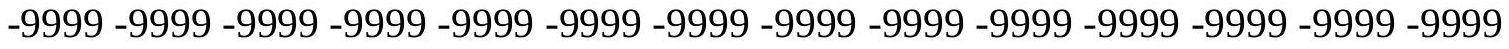
-9999 -9999 -9999 -9999 -9999 -9999 -9999 -9999 -9999 -9999 -9999 -9999 -9999 -9999 -9999

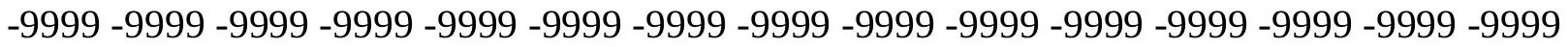

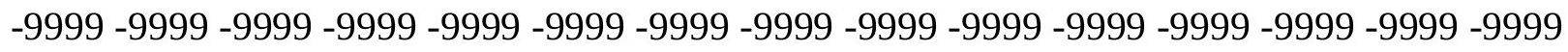

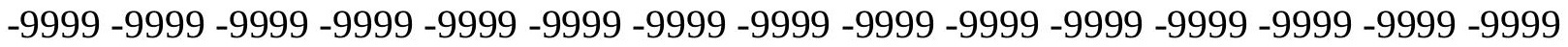

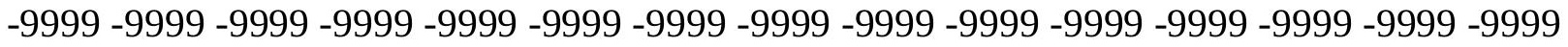
-9999 -9999 -9999 -9999 -9999 -9999 -9999 -9999 -9999 -9999 -9999 -9999 -9999 -9999 -9999 -

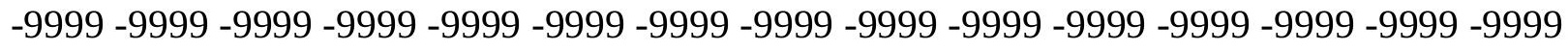

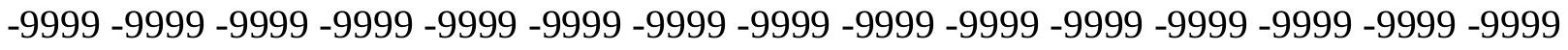
-9999 -9999 -9999 -9999 -9999 -9999 -9999 -9999 -9999 -9999 -9999 -9999 -9999 -9999 -9999 -9999 -9999 -9999 -9999 -9999 -9999 -9999 -9999 -9999-9999 -9999 -9999 -9999 -9999 -9999 -9999 -9999 -9999 -9999 -9999 -9999 -9999 -9999 -9999 -9999 -9999 -9999 -9999 -9999 -9999 -

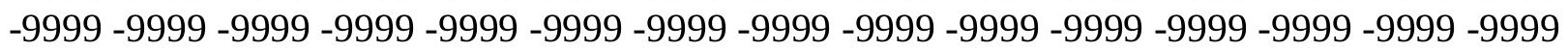


-9999 -9999 -9999 -9999 -9999 -9999 -9999 -9999 -9999 -9999 -9999 -9999 -9999 -9999 -9999 -9999 -9999 -9999 -9999 -9999 -9999 -9999 -9999 -9999 -9999 -9999 -9999 -9999 -9999 -9999 -

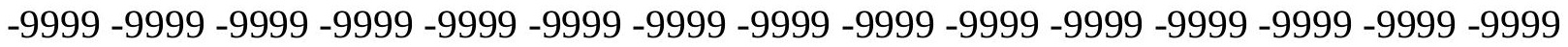
-9999 -9999 -9999 -9999 -9999 -9999 -9999 -9999 -9999 -9999 -9999 -9999 -9999 -9999 -9999 -9999 -9999 -9999 -9999 -9999 -9999 -9999 -9999 -9999-9999 -9999 -9999 -9999 -9999 -9999 -9999 -9999 -9999 -9999 -9999 -9999 -9999 -9999 -9999 -9999 -9999 -9999 -9999 -9999 -9999 -9999 -9999 -9999 -9999 -9999 -9999 -9999 -9999 -9999 -9999 -9999 -9999 -9999 -9999 -9999

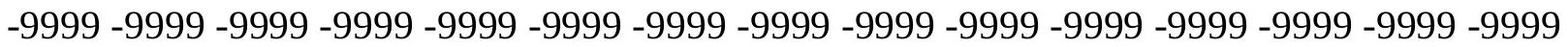

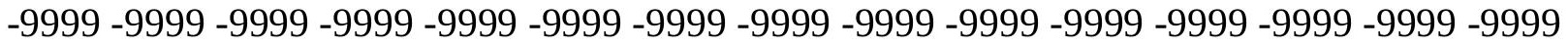
-9999 -9999 -9999 -9999 -9999 -9999 -9999 -9999 -9999 -9999 -9999 -9999 -9999 -9999 -9999 -9999 -9999 -9999 -9999 -9999 -9999 -9999 -9999 -9999 -9999 -9999 -9999 -9999 -9999 -9999 -9999 -9999 -9999 -9999 -9999 -9999 -9999 -9999 -9999 -9999 -9999 -9999 -9999 -9999 -9999 -9999 -9999 -9999 -9999 -9999 -9999 -9999 -9999 -9999 -9999 -9999 -9999 -9999 -9999 -9999 -9999 -9999 -9999 -9999 -9999 -9999 -9999 -9999 -9999 -9999 -9999 -9999 -9999 -9999 -9999 -9999 -9999 -9999 -9999 -9999 -9999 -9999 -9999 -9999 -9999 -9999 -9999 -9999 -9999

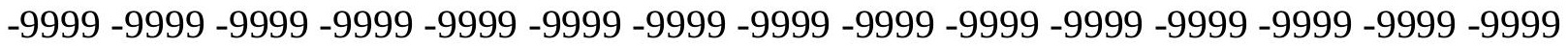
-9999 -9999 -9999 -9999 -9999 -9999 -9999 -9999 -9999 -9999 -9999 -9999 -9999 -9999 -9999 -9999 -9999 -9999 -9999 -9999 -9999 -9999 -9999 -9999 -9999 -9999 -9999 -9999 -9999 -9999 -9999 -9999 -9999 -9999 -9999 -9999 -9999 -9999 -9999 -9999 -9999 -9999 -9999 -9999 -9999 -

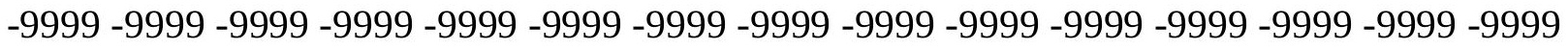

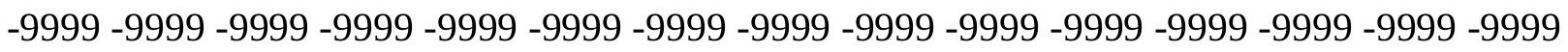
-9999 -9999 -9999 -9999 -9999 -9999 -9999 -9999 -9999 -9999 -9999 -9999 -9999 -9999 -9999 -9999 -9999 -9999 -9999 -9999 -9999 -9999 -9999 -9999 -9999 -9999 -9999 -9999 -9999 -9999 -9999 -9999 -9999 -9999 -9999 -9999 -9999 -9999 -9999 -9999 -9999 -9999 -9999 -9999 -9999 -

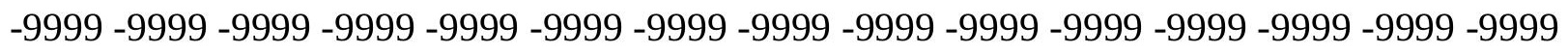
-9999 -9999 -9999 -9999 -9999 -9999 -9999 -9999 -9999 -9999 -9999 -9999 -9999 -9999 -9999 -9999 -9999 -9999 -9999 -9999 -9999 -9999 -9999 -9999 -9999 -9999 -9999 -9999 -9999 -9999 -

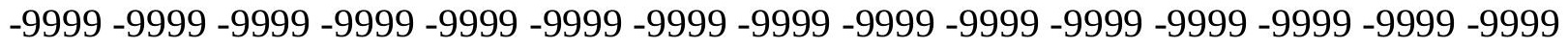
-9999 -9999 -9999 -9999 -9999 -9999 -9999 -9999 -9999 -9999 -9999 -9999 -9999 -9999 -9999 -9999 -9999 -9999 -9999 -9999 -9999 -9999 -9999 -9999 -9999 -9999 -9999 -9999 -9999 -999 -9999 -9999 -9999 -9999 -9999 -9999 -9999 -9999 -9999 -9999 -9999 -9999 -9999 -9999 -9999 -9999 -9999 -9999 -9999 -9999 -9999 -9999 -9999 -9999 -9999 -9999 -9999 -9999 -9999 -9999 -

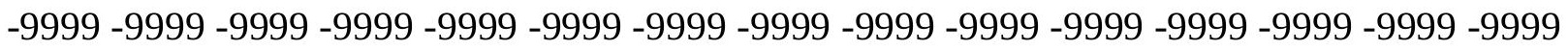

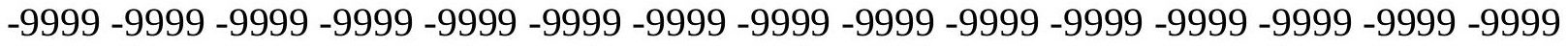

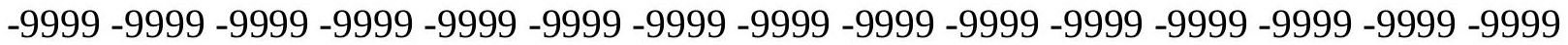

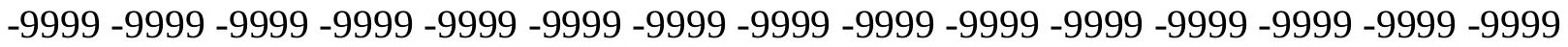

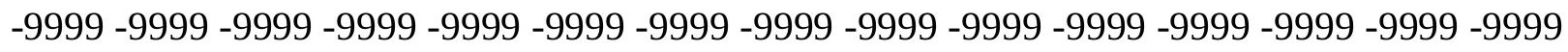

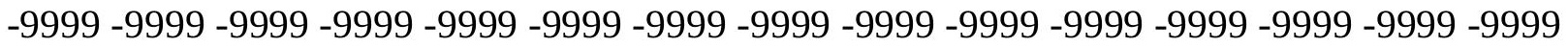
-9999 -9999 -9999 -9999 -9999 -9999 -9999 -9999 -9999 -9999 -9999 -9999 -9999 - 9999 - -999 -9999 -9999 -9999 -9999 -9999 -9999 -9999 -9999 -9999 -9999 -9999 -9999 -9999 -9999 - -999 -

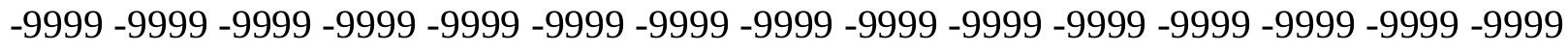

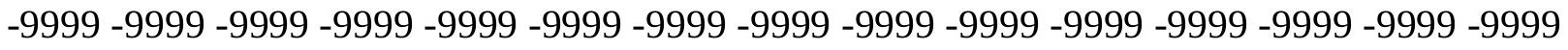
-9999 -9999 -9999 -9999 -9999 -9999 -9999 -9999 -9999 -9999 -9999 -9999 -9999 -9999 -9999 -9999 -9999 -9999 -9999 -9999 -9999 -9999 -9999 -9999-9999 -9999 -9999 -9999 -9999 -9999 -9999 -9999 -9999 -9999 -9999 -9999 -9999 -9999 -9999 -9999 -9999 -9999 -9999 -9999 -9999 -

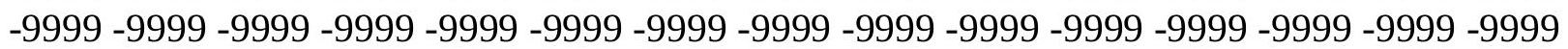


-9999 -9999 -9999 -9999 -9999 -9999 -9999 -9999 -9999 -9999 -9999 -9999 -9999 -9999 -9999 -9999 -9999 -9999 -9999 -9999 -9999 -9999 -9999 -9999 -9999 -9999 -9999 -9999 -9999 -9999 -9999 -9999 -9999 -9999 -9999 -9999 -9999 -9999 -9999 -9999 -9999 -9999 -9999 -9999 -9999 -9999 -9999 -9999 -9999 -9999 -9999 -9999 -9999 -9999 -9999 -9999 -9999 -9999 -9999 -9999 -9999 -9999 -9999 -9999 -9999 -9999 -9999 -9999 -9999 -9999 -9999 -9999 -9999 -9999 -9999 -9999 -9999 -9999 -9999 -9999 -9999 -9999 -9999 -9999 -9999 -9999 -9999 -9999 -9999 -9999 -9999 -9999 -9999 -9999 -9999 -9999 -9999 -9999 -9999 -9999 -9999 -9999 -9999 -9999 -9999 -

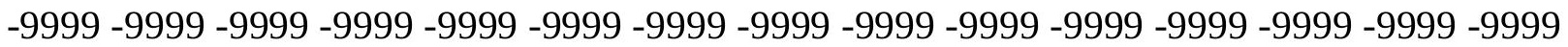
-9999 -9999 -9999 -9999 -9999 -9999 -9999 -9999 -9999 -9999 -9999 -9999 -9999 -9999 -9999 -9999 -9999 -9999 -9999 -9999 -9999 -9999 -9999 -9999 -9999 -9999 -9999 -9999 -9999 -9999 -

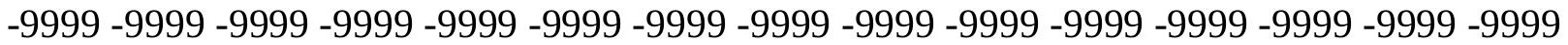
-9999 -9999 -9999 -9999 -9999 -9999 -9999 -9999 -9999 -9999 -9999 -9999 -9999 -9999 -9999 -9999 -9999 -9999 -9999 -9999 -9999 -9999 -9999 -9999 -9999 -9999 -9999 -9999 -9999 -9999 -9999 -9999 -9999 -9999 -9999 -9999 -9999 -9999 -9999 -9999 -9999 -9999 -9999 -9999 -9999 -9999 -9999 -9999 -9999 -9999 -9999 -9999 -9999 -9999 -9999 -9999 -9999 -9999 -9999 -9999

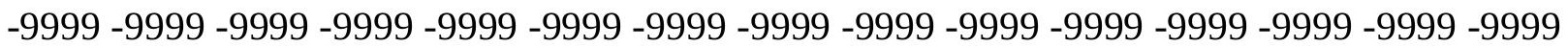
-9999 -9999 -9999 -9999 -9999 -9999 -9999 -9999 -9999 -9999 -9999 -9999 -9999 -9999 -9999 -9999 -9999 -9999 -9999 -9999 -9999 -9999 -9999 -9999 -9999 -9999 -9999 -9999 -9999 -9999 -9999 -9999 -9999 -9999 -9999 -9999 -9999 -9999 -9999 -9999 -9999 -9999 -9999 -9999 -9999 -9999 -9999 -9999 -9999 -9999 -9999 -9999 -9999 -9999 -9999 -9999 -9999 -9999 -9999 -9999 -9999 -9999 -9999 -9999 -9999 -9999 -9999 -9999 -9999 -9999 -9999 -9999 -9999 -9999 -9999 -9999 -9999 -9999 -9999 -9999 -9999 -9999 -9999 -9999 -9999 -9999 -9999 -9999 -9999 -9999 -9999 -9999 -9999 -9999 -9999 -9999 -9999 -9999 -9999 -9999 -9999 -9999 -9999 -9999 -9999 -9999 -9999 -9999 -9999 -9999 -9999 -9999 -9999 -9999 -9999 -9999 -9999 -9999 -9999 -9999 -9999 -9999 -9999 -9999 -9999 -9999 -9999 -9999 -9999 -9999 -9999 -9999 -9999 -9999 -9999 -9999 -9999 -9999 -9999 -9999 -9999 -9999 -9999 -9999 -9999 -9999 -9999 -9999 -9999 -9999 -9999 -9999 -9999 -9999 -9999 -9999 -9999 -9999 -9999 -9999 -9999 -9999 -9999 -9999 -9999 -9999 -9999 -9999 -9999 -9999 -9999 -9999 -9999 -9999 -9999 -9999 -9999 -9999 -9999

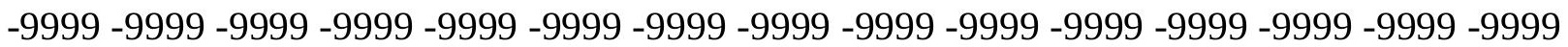
-9999 -9999 -9999 -9999 -9999 -9999 -9999 -9999 -9999 -9999 -9999 -9999 -9999 -9999 -9999 -9999 -9999 -9999 -9999 -9999 -9999 -9999 -9999 -9999 -9999 -9999 -9999 -9999 -9999 -9999 -

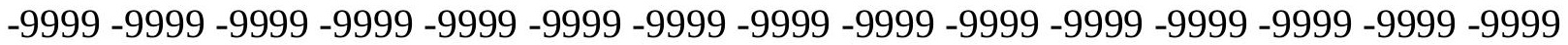
-9999 -9999 -9999 -9999 -9999 -9999 -9999 -9999 -9999 -9999 -9999 -9999 -9999 -9999 -9999 -9999 -9999 -9999 -9999 -9999 -9999 -9999 -9999 -9999 -9999 -9999 -9999 -9999 -9999 -9999 -9999 -9999 -9999 -9999 -9999 -9999 -9999 -9999 -9999 -9999 -9999 -9999 -9999 -9999 -9999 -9999 -9999 -9999 -9999 -9999 -9999 -9999 -9999 -9999 -9999 -9999 -9999 -9999 -9999 -9999 -9999 -9999 -9999 -9999 -9999 -9999 -9999 -9999 -9999 -9999 -9999 -9999 -9999 -9999 -9999

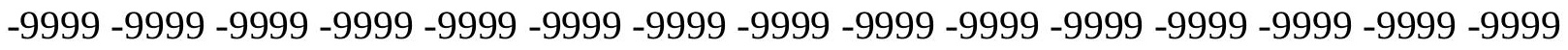
-9999 -9999 -9999 -9999 -9999 -9999 -9999 -9999 -9999 -9999 -9999 -9999 -9999 -9999 -9999 -9999 -9999 -9999 -9999 -9999 -9999 -9999 -9999 -9999 -9999 -9999 -9999 -9999 -9999 -9999 -9999 -9999 -9999 -9999 -9999 -9999 -9999 -9999 -9999 -9999 -9999 -9999 -9999 -9999 -9999 -999 -9999 -9999 -9999 -9999 -9999 -9999 -9999 -9999 -9999 -9999 -9999 -9999 -9999 -9999 -9999 -9999 -9999 -9999 -9999 -9999 -9999 -9999 -9999 -9999 -9999 -9999 -9999 -9999 -9999 -9999 -9999 -9999 -9999 -9999 -9999 -9999 -9999 -9999 -9999 -9999 -9999 -9999 -9999 -9999 -9999 -9999 -9999 -9999 -9999 -9999 -9999 -9999 -9999 -9999 -9999 -9999 -9999 -9999 -9999 -9999 -9999 -9999 -9999 -9999 -9999 -9999 -9999 -9999 -9999 -9999 -9999 -9999 -9999 -9999 
-9999 -9999 -9999 -9999 -9999 -9999 -9999 -9999 -9999 -9999 -9999 -9999 -9999 -9999 -9999 -9999 -9999 -9999 -9999 -9999 -9999 -9999 -9999 -9999 -9999 -9999 -9999 -9999 -9999 -9999 -

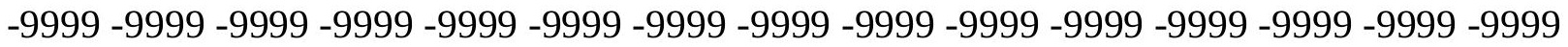
-9999 -9999 -9999 -9999 -9999 -9999 -9999 -9999 -9999 -9999 -9999 -9999 -9999 -9999 -9999 -9999 -9999 -9999 -9999 -9999 -9999 -9999 -9999 -9999-9999 -9999 -9999 -9999 -9999 -9999 -9999 -9999 -9999 -9999 -9999 -9999 -9999 -9999 -9999 -9999 -9999 -9999 -9999 -9999 -9999 -9999 -9999 -9999 -9999 -9999 -9999 -9999 -9999 -9999 -9999 -9999 -9999 -9999 -9999 -9999

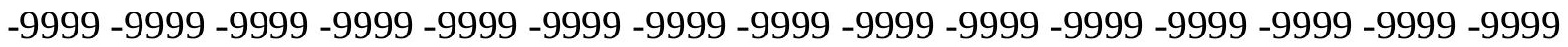

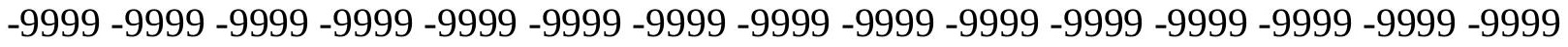
-9999 -9999 -9999 -9999 -9999 -9999 -9999 -9999 -9999 -9999 -9999 -9999 -9999 -9999 -9999 -9999 -9999 -9999 -9999 -9999 -9999 -9999 -9999 -9999 -9999 -9999 -9999 -9999 -9999 -9999 -9999 -9999 -9999 -9999 -9999 -9999 -9999 -9999 -9999 -9999 -9999 -9999 -9999 -9999 -9999 -9999 -9999 -9999 -9999 -9999 -9999 -9999 -9999 -9999 -9999 -9999 -9999 -9999 -9999 -9999 -

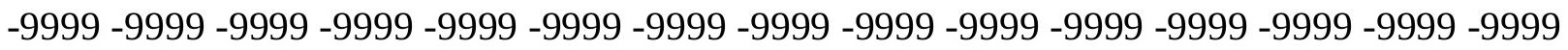
-9999 -9999 -9999 -9999 -9999 -9999 -9999 -9999 -9999 -9999 -9999 -9999 -9999 -9999 -9999 -

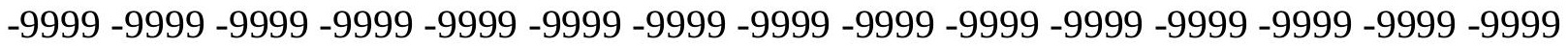
-9999 -9999 -9999 -9999 -9999 -9999 -9999 -9999 -9999 -9999 -9999 -9999 -9999 -9999 -9999 -9999 -9999 -9999 -9999 -9999 -9999 -9999 -9999 -9999 -9999 -9999 -9999 -9999 -9999 -9999 -9999 -9999 -9999 -9999 -9999 -9999 -9999 -9999 -9999 -9999 -9999 -9999 -9999 -9999 -9999 -

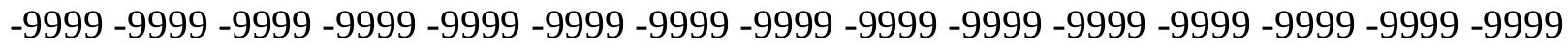

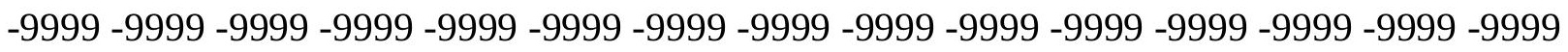

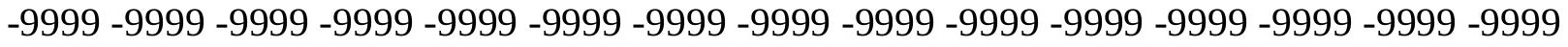
-9999 -9999 -9999 -9999 -9999 -9999 -9999 -9999 -9999 -9999 -9999 -9999 -9999 -9999 -9999 -9999 -9999 -9999 -9999 -9999 -9999 -9999 -9999 -9999 -9999 -9999 -9999 -9999 -9999 -9999 -

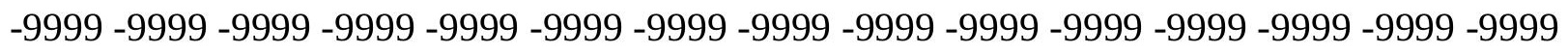
-9999 -9999 -9999 -9999 -9999 -9999 -9999 -9999 -9999 -9999 -9999 -9999 -9999 -9999 -9999 -9999 -9999 -9999 -9999 -9999 -9999 -9999 -9999 -9999 -9999 -9999 -9999 -9999 -9999 -

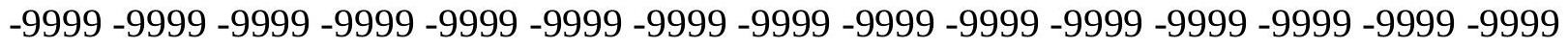
-9999 -9999 -9999 -9999 -9999 -9999 -9999 -9999 -9999 -9999 -9999 -9999 -9999 -9999 -9999 -9999 -9999 -9999 -9999 -9999 -9999 -9999 -9999 -9999 -9999 -9999 -9999 -9999 -9999 -999 -

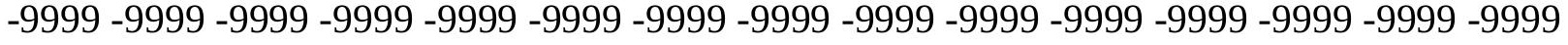
-9999 -9999 -9999 -9999 -9999 -9999 -9999 -9999 -9999 -9999 -9999 -9999 -9999 -9999 -9999 -

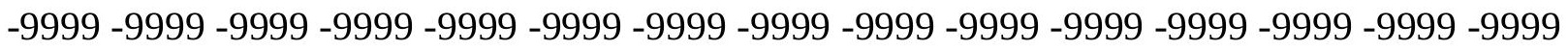

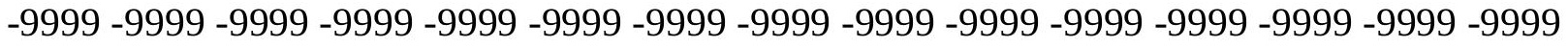

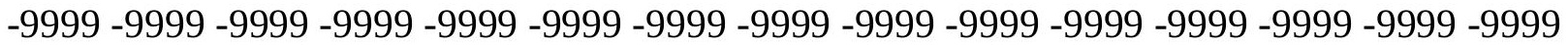
-9999 -9999 -9999 -9999 -9999 -9999 -9999 -9999 -9999 -9999 -9999 -9999 -9999 -9999 -9999

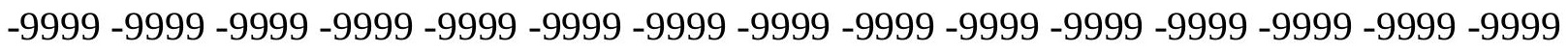

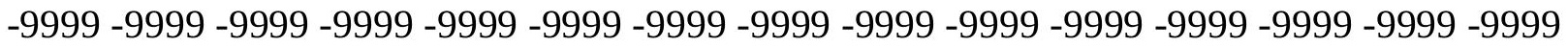
-9999 -9999 -9999 -9999 -9999 -9999 -9999 -9999 -9999 -9999 -9999 -9999 -9999 - 9999 - -999 -9999 -9999 -9999 -9999 -9999 -9999 -9999 -9999 -9999 -9999 -9999 -9999 -9999 -9999 -9999 -

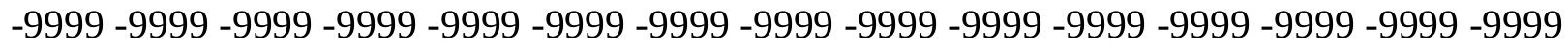

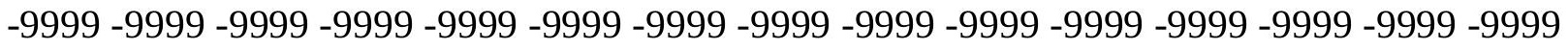
-9999 -9999 -9999 -9999 -9999 -9999 -9999 -9999 -9999 -9999 -9999 -9999 -9999 -9999 -9999 -9999 -9999 -9999 -9999 -9999 -9999 -9999 -9999 -9999-9999 -9999 -9999 -9999 -9999 -9999 -9999 -9999 -9999 -9999 -9999 -9999 -9999 -9999 -9999 -9999 -9999 -9999 -9999 -9999 -9999 -

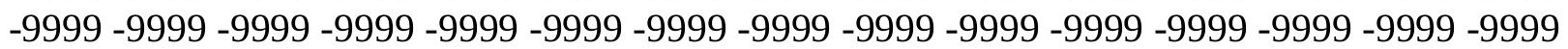


-9999 -9999 -9999 -9999 -9999 -9999 -9999 -9999 -9999 -9999 -9999 -9999 -9999 -9999 -9999 -9999 -9999 -9999 -9999 -9999 -9999 -9999 -9999 -9999 -9999 -9999 -9999 -9999 -9999 -9999 -9999 -9999 -9999 -9999 -9999 -9999 -9999 -9999 -9999 -9999 -9999 -9999 -9999 -9999 - 9999 -9999 -9999 -9999 -9999 -9999 -9999 -9999 -9999 -9999 -9999 -9999 -9999 -9999 -9999 -9999 -9999 -9999 -9999 -9999 -9999 -9999 -9999 -9999 -9999 -9999 -9999 -9999 -9999 -9999 - -9999 -9999 -9999 -9999 -9999 -9999 -9999 -9999 -9999 -9999 -9999 -9999 -9999 -9999 -9999 -9999 -9999 -9999 -9999 -9999 -9999 -9999 -9999 -9999 -9999 -9999 -9999 -9999 -9999 -9999

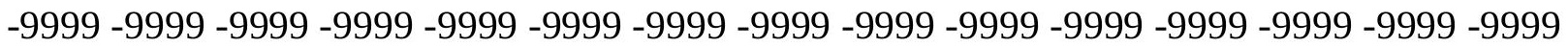

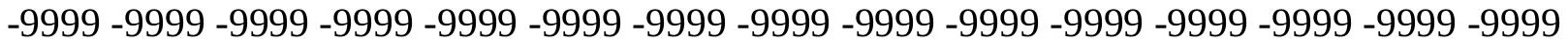
-9999 -9999 -9999 -9999 -9999 -9999 -9999 -9999 -9999 -9999 -9999 -9999 -9999 -9999 -9999

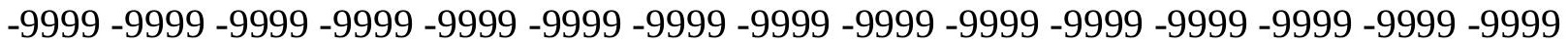
-9999 -9999 -9999 -9999 -9999 -9999 -9999 -9999 -9999 -9999 -9999 -9999 -9999 -9999 -9999 -9999 -9999 -9999 -9999 -9999 -9999 -9999 -9999 -9999 -9999 -9999 -9999 -9999 -9999 -9999 -9999 -9999 -9999 -9999 -9999 -9999 -9999 -9999 -9999 -9999 -9999 -9999 -9999 -9999 - -9999 -9999 -9999 -9999 -9999 -9999 -9999 -9999 -9999 -9999 -9999 -9999 -9999 -9999 -9999 -9999

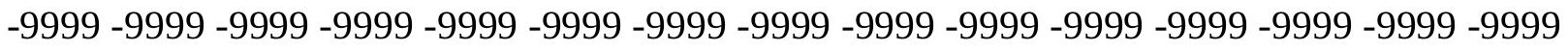
-9999 -9999 -9999 -9999 -9999 -9999 -9999 -9999 -9999 -9999 -9999 -9999 -9999 -9999 -9999 -9999 -9999 -9999 -9999 -9999 -9999 -9999 -9999 -9999 -9999 -9999 -9999 -9999 -9999 -9999 -9999 -9999 -9999 -9999 -9999 -9999 -9999 -9999 -9999 -9999 -9999 -9999 -9999 -9999 -9999 -

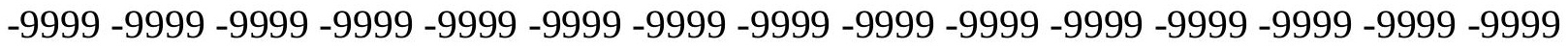
-9999 -9999 -9999 -9999 -9999 -9999 -9999 -9999 -9999 -9999 -9999 -9999 -9999 -9999 -9999 -999 -9999 -9999 -9999 -9999 -9999 -9999 -9999 -9999 -9999 -9999 -9999 -9999 -9999 -9999 -9999 -9999 -9999 -9999 -9999 -9999 -9999 -9999 -9999 -9999 -9999 -9999 -9999 -9999 -9999 -9999 -9999 -9999 -9999 -9999 -9999 -9999 -9999 -9999 -9999 -9999 -9999 -9999 -9999 -9999 -9999 -9999 -9999 -9999 -9999 -9999 -9999 -9999 -9999 -9999 -9999 -9999 -9999 -9999 -9999 -9999 -9999 -9999 -9999 -9999 -9999 -9999 -9999 -9999 -9999 -9999 -9999 -9999 -9999 -9999 -9999 -9999 -9999 -9999 -9999 -9999 -9999 -9999 -9999 -9999 -9999 -9999 -9999 -9999 -9999 -9999 -9999 -9999 -9999 -9999 -9999 -9999 -9999 -9999 -9999 -9999 -9999 -9999 -9999 -9999 -9999 -9999 -9999 -9999 -9999 -9999 -9999 -9999 -9999 -9999 -9999 -9999 -9999 -9999 -9999 -9999 -9999 -9999 -9999 -9999 -9999 -9999 -9999 -9999 -9999 -9999 -9999 -9999 -9999 -9999 -999 -9999 -9999 -9999 -9999 -9999 -9999 -9999 -9999 -9999 -9999 -9999 -9999 -9999 -9999 -9999 -9999 -9999 -9999 -9999 -9999 -9999 -9999 -9999 -9999 -9999 -9999 -9999 -9999 -9999 -

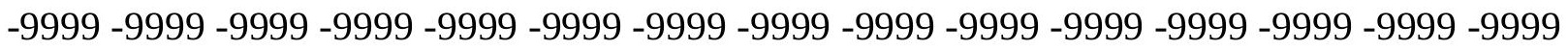

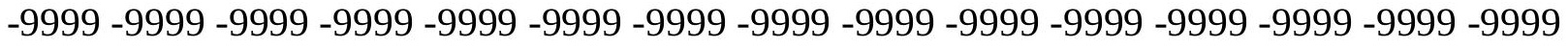

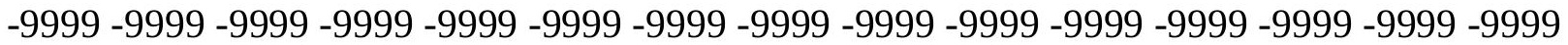
-9999 -9999 -9999 -9999 -9999 -9999 -9999 -9999 -9999 -9999 -9999 -9999 -9999 -9999 -9999 -

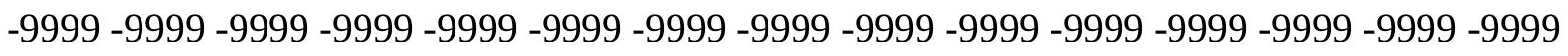

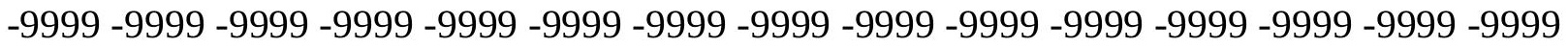

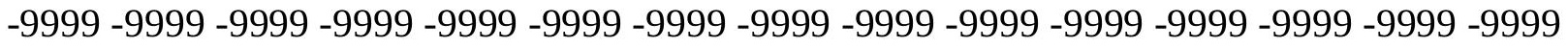
-9999 -9999 -9999 -9999 -9999 -9999 -9999 -9999 -9999 -9999 -9999 -9999 -9999 -9999 -9999 -

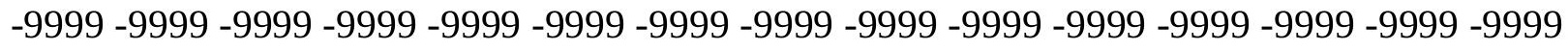

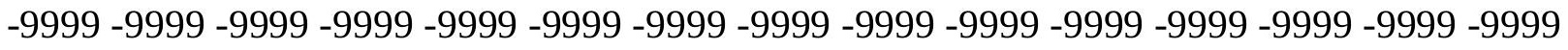
-9999 -9999 -9999 -9999 -9999 -9999 -9999 -9999 -9999 -9999 -9999 -9999 -9999 -9999 -9999 -9999 -9999 -9999 -9999 -9999 -9999 -9999 -9999 -9999-9999 -9999 -9999 -9999 -9999 -9999 -9999 -9999 -9999 -9999 -9999 -9999 -9999 -9999 -9999 -9999 -9999 -9999 -9999 -9999 -9999 -

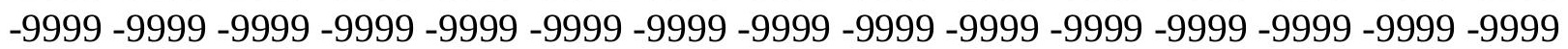


-9999 -9999 -9999 -9999 -9999 -9999 -9999 -9999 -9999 -9999 -9999 -9999 -9999 -9999 -9999 -9999 -9999 -9999 -9999 -9999 -9999 -9999 -9999 -9999 -9999 -9999 -9999 -9999 -9999 -9999 -

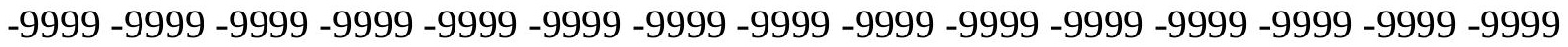
-9999 -9999 -9999 -9999 -9999 -9999 -9999 -9999 -9999 -9999 -9999 -9999 -9999 -9999 -9999 -9999 -9999 -9999 -9999 -9999 -9999 -9999 -9999 -9999-9999 -9999 -9999 -9999 -9999 -9999 -9999 -9999 -9999 -9999 -9999 -9999 -9999 -9999 -9999 -9999 -9999 -9999 -9999 -9999 -9999 -9999 -9999 -9999 -9999 -9999 -9999 -9999 -9999 -9999 -9999 -9999 -9999 -9999 -9999 -9999

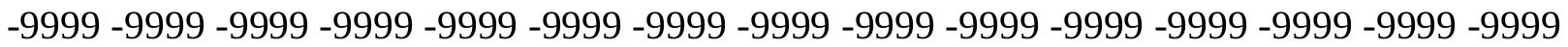

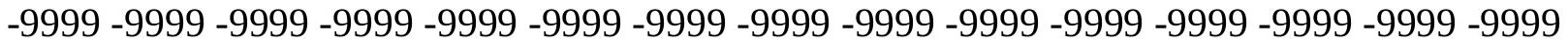
-9999 -9999 -9999 -9999 -9999 -9999 -9999 -9999 -9999 -9999 -9999 -9999 -9999 -9999 -9999 -9999 -9999 -9999 -9999 -9999 -9999 -9999 -9999 -9999 -9999 -9999 -9999 -9999 -9999 -9999 -9999 -9999 -9999 -9999 -9999 -9999 -9999 -9999 -9999 -9999 -9999 -9999 -9999 -9999 -9999 -9999 -9999 -9999 -9999 -9999 -9999 -9999 -9999 -9999 -9999 -9999 -9999 -9999 -9999 -9999 -9999 -9999 -9999 -9999 -9999 -9999 -9999 -9999 -9999 -9999 -9999 -9999 -9999 - 9999 -9999 -9999 -9999 -9999 -9999 -9999 -9999 -9999 -9999 -9999 -9999 -9999 -9999 -9999 -9999

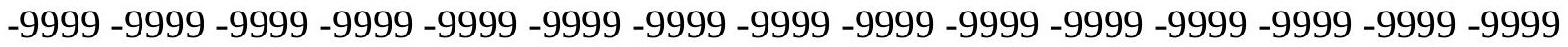
-9999 -9999 -9999 -9999 -9999 -9999 -9999 -9999 -9999 -9999 -9999 -9999 -9999 -9999 -9999 -9999 -9999 -9999 -9999 -9999 -9999 -9999 -9999 -9999 -9999 -9999 -9999 -9999 -9999 -9999 -9999 -9999 -9999 -9999 -9999 -9999 -9999 -9999 -9999 -9999 -9999 -9999 -9999 -9999 -9999 -

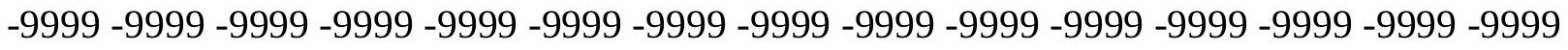

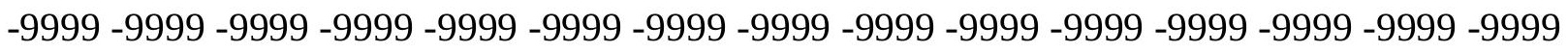
-9999 -9999 -9999 -9999 -9999 -9999 -9999 -9999 -9999 -9999 -9999 -9999 -9999 -9999 -9999 -9999 -9999 -9999 -9999 -9999 -9999 -9999 -9999 -9999 -9999 -9999 -9999 -9999 -9999 -9999 -9999 -9999 -9999 -9999 -9999 -9999 -9999 -9999 -9999 -9999 -9999 -9999 -9999 -9999 -9999 -

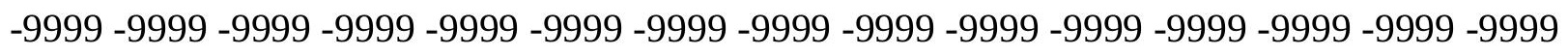
-9999 -9999 -9999 -9999 -9999 -9999 -9999 -9999 -9999 -9999 -9999 -9999 -9999 -9999 -9999 -9999 -9999 -9999 -9999 -9999 -9999 -9999 -9999 -9999 -9999 -9999 -9999 -9999 -9999 -9999 -

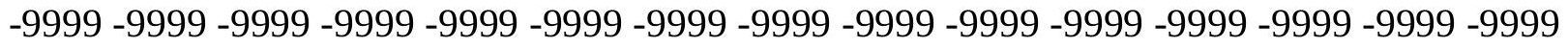
-9999 -9999 -9999 -9999 -9999 -9999 -9999 -9999 -9999 -9999 -9999 -9999 -9999 -9999 -9999 -9999 -9999 -9999 -9999 -9999 -9999 -9999 -9999 -9999 -9999 -9999 -9999 -9999 -9999 -999 -9999 -9999 -9999 -9999 -9999 -9999 -9999 -9999 -9999 -9999 -9999 -9999 -9999 -9999 -9999 -9999 -9999 -9999 -9999 -9999 -9999 -9999 -9999 -9999 -9999 -9999 -9999 -9999 -9999 -9999 -

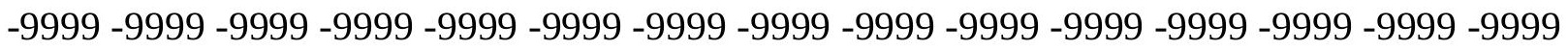

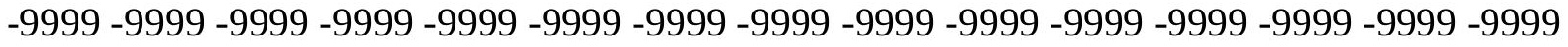

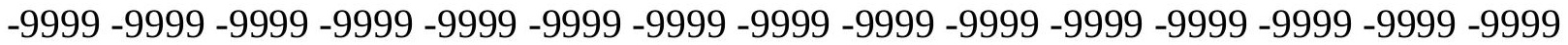

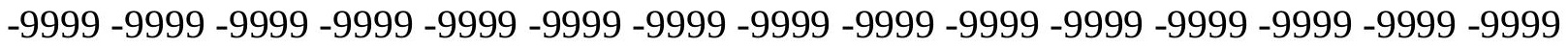

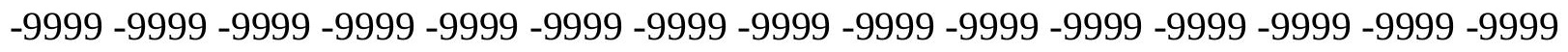

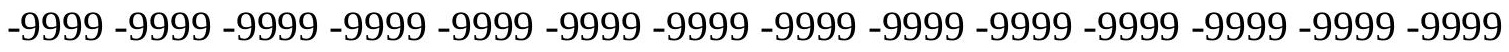
-9999 -9999 -9999 -9999 -9999 -9999 -9999 -9999 -9999 -9999 -9999 -9999 -9999 -9999 -9999 -9999 -9999 -9999 -9999 -9999 -9999 -9999 -9999 -9999 -9999 -9999 -9999 -9999 -9999 -9999 -

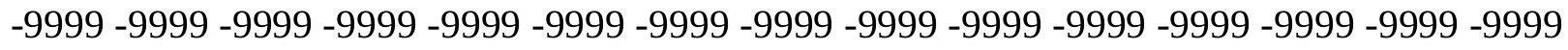

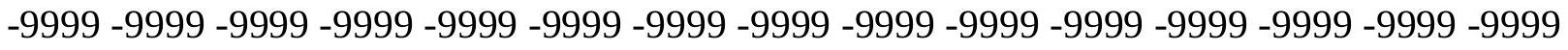
-9999 -9999 -9999 -9999 -9999 -9999 -9999 -9999 -9999 -9999 -9999 -9999 -9999 -9999 -9999 -9999 -9999 -9999 -9999 -9999 -9999 -9999 -9999 -9999-9999 -9999 -9999 -9999 -9999 -9999 -9999 -9999 -9999 -9999 -9999 -9999 -9999 -9999 -9999 -9999 -9999 -9999 -9999 -9999 -9999 -

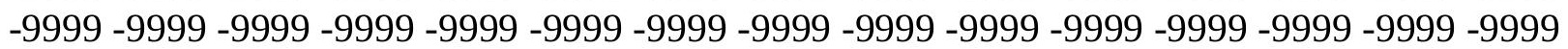


-9999 -9999 -9999 -9999 -9999 -9999 -9999 -9999 -9999 -9999 -9999 -9999 -9999 -9999 -9999 -9999 -9999 -9999 -9999 -9999 -9999 -9999 -9999 -9999 -9999 -9999 -9999 -9999 -9999 -9999 -9999 -9999 -9999 -9999 -9999 -9999 -9999 -9999 -9999 -9999 -9999 -9999 -9999 -9999 - 9999 -9999 -9999 -9999 -9999 -9999 -9999 -9999 -9999 -9999 -9999 -9999 -9999 -9999 -9999 -9999 -9999 -9999 -9999 -9999 -9999 -9999 -9999 -9999 -9999 -9999 -9999 -9999 -9999 -9999 -9999 -9999 -9999 -9999 -9999 -9999 -9999 -9999 -9999 -9999 -9999 -9999 -9999 -9999 -9999 -9999 -9999 -9999 -9999 -9999 -9999 -9999 -9999 -9999 -9999 -9999 -9999 -9999 -9999 -9999 -9999

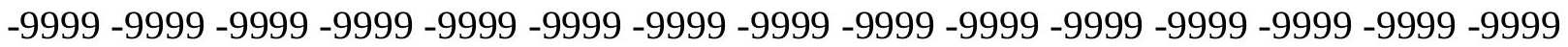
-9999 -9999 -9999 -9999 -9999 -9999 -9999 -9999 -9999 -9999 -9999 -9999 -9999 -9999 -9999 -9999 -9999 -9999 -9999 -9999 -9999 -9999 -9999 -9999 -9999 -9999 -9999 -9999 -9999 -9999

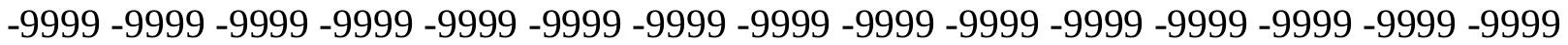
-9999 -9999 -9999 -9999 -9999 -9999 -9999 -9999 -9999 -9999 -9999 -9999 -9999 -9999 -9999 -9999 -9999 -9999 -9999 -9999 -9999 -9999 -9999 -9999 -9999 -9999 -9999 -9999 -9999 -9999 -

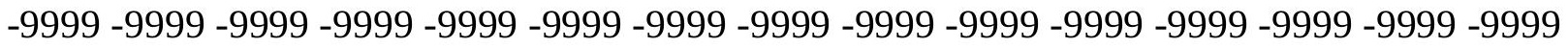
-9999 -9999 -9999 -9999 -9999 -9999 -9999 -9999 -9999 -9999 -9999 -9999 -9999 -9999 -9999

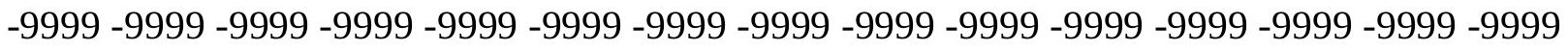
-9999 -9999 -9999 -9999 -9999 -9999 -9999 -9999 -9999 -9999 -9999 -9999 -9999 -9999 -9999 -9999 -9999 -9999 -9999 -9999 -9999 -9999 -9999 -9999 -9999 -9999 -9999 -9999 -9999 - -999 -9999 -9999 -9999 -9999 -9999 -9999 -9999 -9999 -9999 -9999 -9999 -9999 -9999 -9999 -9999 -9999 -9999 -9999 -9999 -9999 -9999 -9999 -9999 -9999 -9999 -9999 -9999 -9999 -9999 -9999 -9999 -9999 -9999 -9999 -9999 -9999 -9999 -9999 -9999 -9999 -9999 -9999 -9999 -9999 -9999 -999 -9999 -9999 -9999 -9999 -9999 -9999 -9999 -9999 -9999 -9999 -9999 -9999 -9999 -9999 -9999 -9999 -9999 -9999 -9999 -9999 -9999 -9999 -9999 -9999 -9999 -9999 -9999 -9999 -9999 -9999 -9999 -9999 -9999 -9999 -9999 -9999 -9999 -9999 -9999 -9999 -9999 -9999 -9999 -9999 -9999 -9999 -9999 -9999 -9999 -9999 -9999 -9999 -9999 -9999 -9999 -9999 -9999 -9999 -9999 -9999 -9999 -9999 -9999 -9999 -9999 -9999 -9999 -9999 -9999 -9999 -9999 -9999 -9999 -9999 -9999 -9999 -9999 -9999 -9999 -9999 -9999 -9999 -9999 -9999 -9999 -9999 -9999 -9999 -9999 -9999 -9999 -9999 -9999 -9999 -9999 -9999 -9999 -9999 -9999 -9999 -9999 -9999 -9999 -9999 -9999 -9999 -9999 -9999 -9999 -9999 -9999 -9999 -9999 -9999 -9999 -9999 -9999 -9999 -9999 -9999 -9999 -9999 -9999 -9999 -9999 -9999 -9999 -9999 -9999 -9999 -9999 -9999 -9999 -9999 -999 -9999 -9999 -9999 -9999 -9999 -9999 -9999 -9999 -9999 -9999 -9999 -9999 -9999 -9999 -9999 -9999 -9999 -9999 -9999 -9999 -9999 -9999 -9999 -9999 -9999 -9999 -9999 -9999 -9999 -9999 -

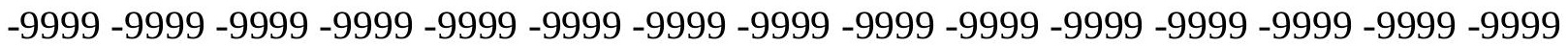

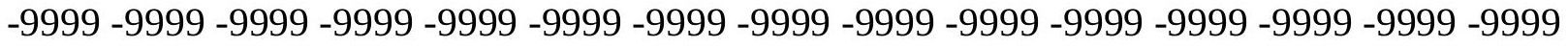

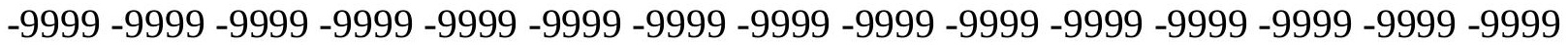
-9999 -9999 -9999 -9999 -9999 -9999 -9999 -9999 -9999 -9999 -9999 -9999 -9999 -9999 -9999

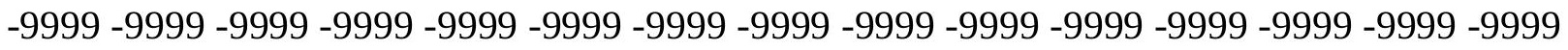

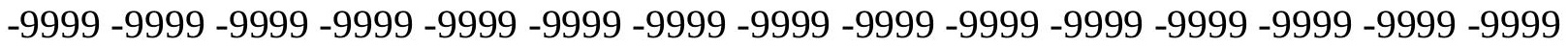

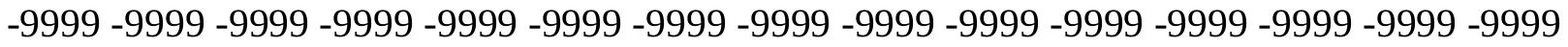
-9999 -9999 -9999 -9999 -9999 -9999 -9999 -9999 -9999 -9999 -9999 -9999 -9999 -9999 -9999 -

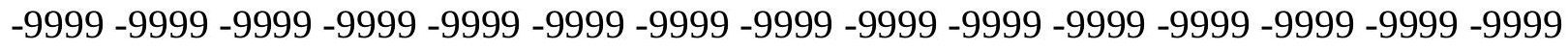

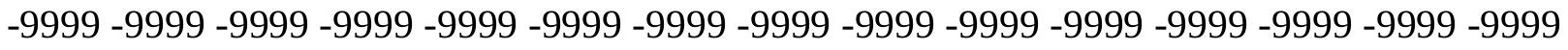
-9999 -9999 -9999 -9999 -9999 -9999 -9999 -9999 -9999 -9999 -9999 -9999 -9999 -9999 -9999 -9999 -9999 -9999 -9999 -9999 -9999 -9999 -9999 -9999 -9999 -9999 -9999 -9999 - -9999 -9999 -9999 -9999 -9999 -9999 -9999 -9999 -9999 -9999 -9999 -9999 -9999 -9999 -9999 -9999 -

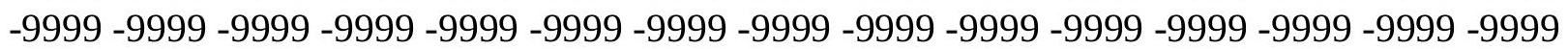


-9999 -9999 -9999 -9999 -9999 -9999 -9999 -9999 -9999 -9999 -9999 -9999 -9999 -9999 -9999 -9999 -9999 -9999 -9999 -9999 -9999 -9999 -9999 -9999 -9999 -9999 -9999 -9999 -9999 -9999 -9999 -9999 -9999 -9999 -9999 -9999 -9999 -9999 -9999 -9999 -9999 -9999 -9999 -9999 - 9999 -9999 -9999 -9999 -9999 -9999 -9999 -9999 -9999 -9999 -9999 -9999 -9999 -9999 -9999 -9999 -9999 -9999 -9999 -9999 -9999 -9999 -9999 -9999 -9999-9999 -9999 -9999 -9999 -9999 -9999 -9999 -9999 -9999 -9999 -9999 -9999 -9999 -9999 -9999 -9999 -9999 -9999 -9999 -9999 -9999 -9999 -9999 -9999 -9999 -9999 -9999 -9999 -9999 -9999 -9999 -9999 -9999 -9999 -9999 -9999

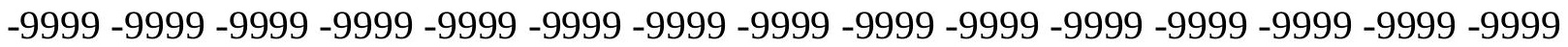

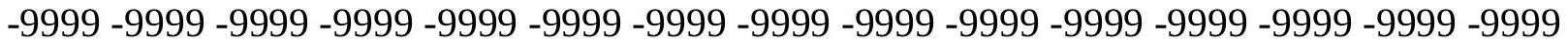
-9999 -9999 -9999 -9999 -9999 -9999 -9999 -9999 -9999 -9999 -9999 -9999 -9999 -9999 -9999

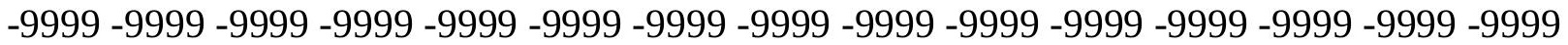
-9999 -9999 -9999 -9999 -9999 -9999 -9999 -9999 -9999 -9999 -9999 -9999 -9999 -9999 -9999 -9999 -9999 -9999 -9999 -9999 -9999 -9999 -9999 -9999 -9999 -9999 -9999 -9999 -9999 -9999 -

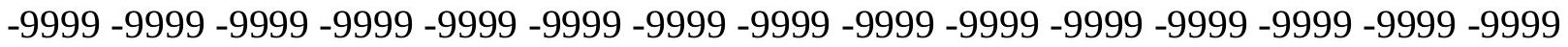
-9999 -9999 -9999 -9999 -9999 -9999 -9999 -9999 -9999 -9999 -9999 -9999 -9999 -9999 -9999

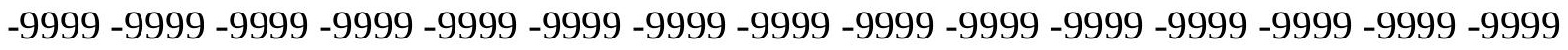
-9999 -9999 -9999 -9999 -9999 -9999 -9999 -9999 -9999 -9999 -9999 -9999 -9999 -9999 -9999 -9999 -9999 -9999 -9999 -9999 -9999 -9999 -9999 -9999 -9999 -9999 -9999 -9999 -9999 -9999 -9999 -9999 -9999 -9999 -9999 -9999 -9999 -9999 -9999 -9999 -9999 -9999 -9999 -9999 -9999 -9999 -9999 -9999 -9999 -9999 -9999 -9999 -9999 -9999 -9999 -9999 -9999 -9999 -9999 -9999 -9999 -9999 -9999 -9999 -9999 -9999 -9999 -9999 -9999 -9999 -9999 -9999 -9999 -9999 -9999 -999 -9999 -9999 -9999 -9999 -9999 -9999 -9999 -9999 -9999 -9999 -9999 -9999 -9999 -9999 -9999 -9999 -9999 -9999 -9999 -9999 -9999 -9999 -9999 -9999 -9999 -9999 -9999 -9999 -9999 -9999 -9999 -9999 -9999 -9999 -9999 -9999 -9999 -9999 -9999 -9999 -9999 -9999 -9999 -9999 -9999 -9999 -9999 -9999 -9999 -9999 -9999 -9999 -9999 -9999 -9999 -9999 -9999 -9999 -9999 -9999 -9999 -9999 -9999 -9999 -9999 -9999 -9999 -9999 -9999 -9999 -9999 -9999 -9999 -9999 -9999 -9999 -9999 -9999 -9999 -9999 -9999 -9999 -9999 -9999 -9999 -9999 -9999 -9999 -9999 -9999 -9999 -9999 -9999 -9999 -9999 -9999 -9999 -9999 -9999 -9999 -9999 -9999 -9999 -9999 -9999 -9999 -9999 -9999 -9999 -9999 -9999 -9999 -9999 -9999 -9999 -9999 -9999 -9999 -9999 -9999 -9999 -9999 -9999 -9999 -9999 -9999 -9999 -9999 -9999 -9999 -9999 -9999 -9999 -999 -9999 -9999 -9999 -9999 -9999 -9999 -9999 -9999 -9999 -9999 -9999 -9999 -9999 -9999 -9999 -9999 -9999 -9999 -9999 -9999 -9999 -9999 -9999 -9999 -9999 -9999 -9999 -9999 -9999 -9999 -

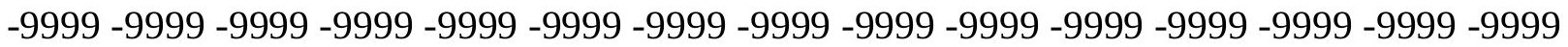

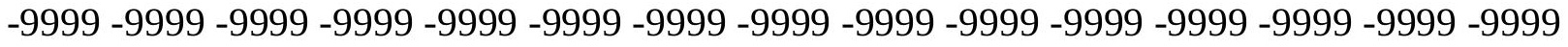

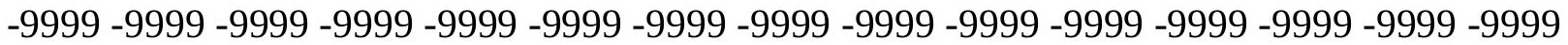
-9999 -9999 -9999 -9999 -9999 -9999 -9999 -9999 -9999 -9999 -9999 -9999 -9999 -9999 -9999

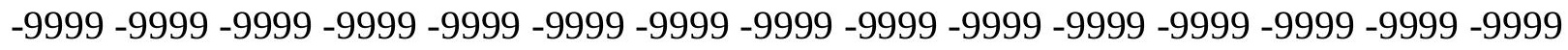

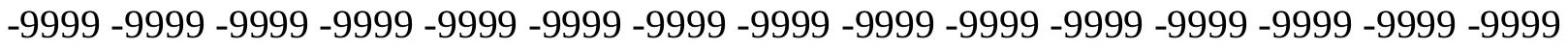
-9999 -9999 -9999 -9999 -9999 -9999 -9999 -9999 -9999 -9999 -9999 -9999 -9999 -9999 -9999 -9999 -9999 -9999 -9999 -9999 -9999 -9999 -9999 -9999 -9999 -9999 -9999 -9999 -9999 -9999 -

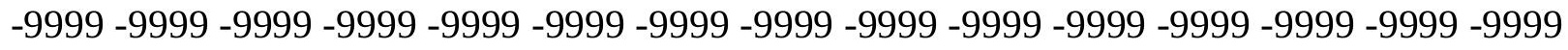

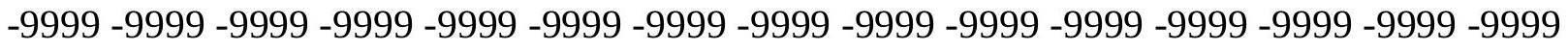
-9999 -9999 -9999 -9999 -9999 -9999 -9999 -9999 -9999 -9999 -9999 -9999 -9999 -9999 -9999 -9999 -9999 -9999 -9999 -9999 -9999 -9999 -9999 -9999-9999 -9999 -9999 -9999 -9999 -9999 -9999 -9999 -9999 -9999 -9999 -9999 -9999 -9999 -9999 -9999 -9999 -9999 -9999 -9999 -9999 -

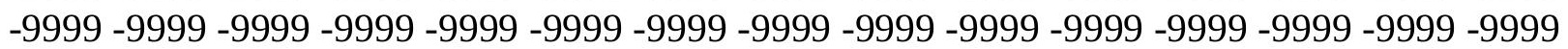


-9999 -9999 -9999 -9999 -9999 -9999 -9999 -9999 -9999 -9999 -9999 -9999 -9999 -9999 -9999 -9999 -9999 -9999 -9999 -9999 -9999 -9999 -9999 -9999 -9999 -9999 -9999 -9999 -9999 -9999 -9999 -9999 -9999 -9999 -9999 -9999 -9999 -9999 -9999 -9999 -9999 -9999 -9999 -9999 - 9999 -9999 -9999 -9999 -9999 -9999 -9999 -9999 -9999 -9999 -9999 -9999 -9999 -9999 -9999

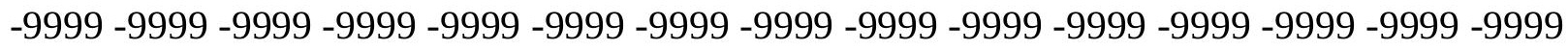
-9999 -9999 -9999 -9999 -9999 -9999 -9999 -9999 -9999 -9999 -9999 -9999 -9999 -9999 -9999 -9999 -9999 -9999 -9999 -9999 -9999 -9999 -9999 -9999 -9999 -9999 -9999 -9999 -9999 -9999

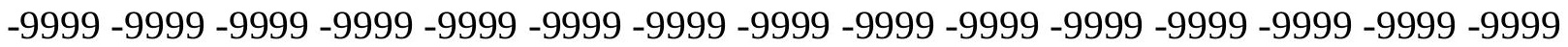

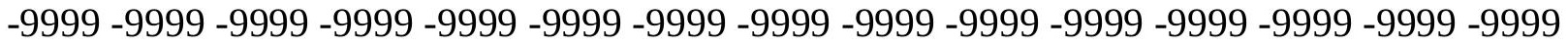
-9999 -9999 -9999 -9999 -9999 -9999 -9999 -9999 -9999 -9999 -9999 -9999 -9999 -9999 -9999 -9999 -9999 -9999 -9999 -9999 -9999 -9999 -9999 -9999 -9999 -9999 -9999 -9999 -9999 -9999 -9999 -9999 -9999 -9999 -9999 -9999 -9999 -9999 -9999 -9999 -9999 -9999 -9999 -9999 -9999 -9999 -9999 -9999 -9999 -9999 -9999 -9999 -9999 -9999 -9999 -9999 -9999 -9999 -9999 -9999 -

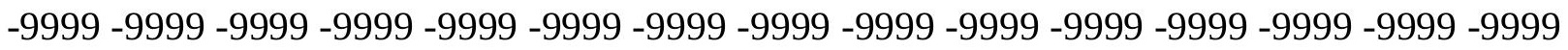
-9999 -9999 -9999 -9999 -9999 -9999 -9999 -9999 -9999 -9999 -9999 -9999 -9999 -9999 -9999 -

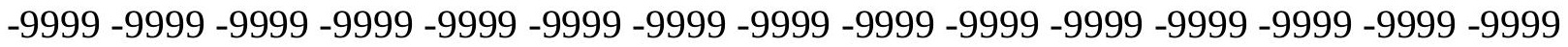
-9999 -9999 -9999 -9999 -9999 -9999 -9999 -9999 -9999 -9999 -9999 -9999 -9999 -9999 -9999 -9999 -9999 -9999 -9999 -9999 -9999 -9999 -9999 -9999 -9999 -9999 -9999 -9999 -9999 -9999 -9999 -9999 -9999 -9999 -9999 -9999 -9999 -9999 -9999 -9999 -9999 -9999 -9999 -9999 -9999 -

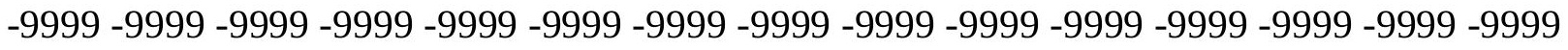
-9999 -9999 -9999 -9999 -9999 -9999 -9999 -9999 -9999 -9999 -9999 -9999 -9999 -9999 -9999

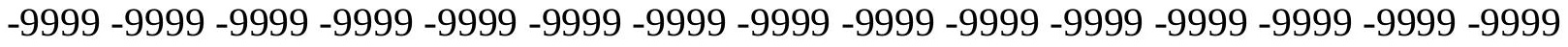
-9999 -9999 -9999 -9999 -9999 -9999 -9999 -9999 -9999 -9999 -9999 -9999 -9999 -9999 -9999 -9999 -9999 -9999 -9999 -9999 -9999 -9999 -9999 -9999 -9999 -9999 -9999 -9999 -9999 -9999 -9999 -9999 -9999 -9999 -9999 -9999 -9999 -9999 -9999 -9999 -9999 -9999 -9999 -9999 -9999 -9999 -9999 -9999 -9999 -9999 -9999 -9999 -9999 -9999 -9999 -9999 -9999 -9999 -9999 -9999 -9999 -9999 -9999 -9999 -9999 -9999 -9999 -9999 -9999 -9999 -9999 -9999 -9999 -9999 -9999 -9999 -9999 -9999 -9999 -9999 -9999 -9999 -9999 -9999 -9999 -9999 -9999 -9999 -9999 -9999 -9999 -9999 -9999 -9999 -9999 -9999 -9999 -9999 -9999 -9999 -9999 -9999 -9999 -9999 -9999 -9999 -9999 -9999 -9999 -9999 -9999 -9999 -9999 -9999 -9999 -9999 -9999 -9999 -9999 -9999 -9999 -9999 -9999 -9999 -9999 -9999 -9999 -9999 -9999 -9999 -9999 -9999 -9999 -9999 -9999 -9999 -9999 -9999 -9999 -9999 -9999 -9999 -9999 -9999 -9999 -9999 -9999 -9999 -9999 -

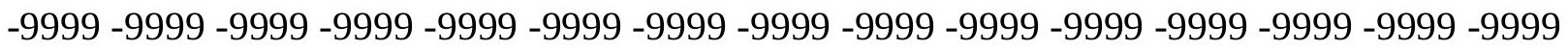

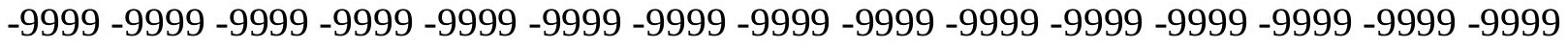
-9999 -9999 -9999 -9999 -9999 -9999 -9999 -9999 -9999 -9999 -9999 -9999 -9999 -9999 -9999 -

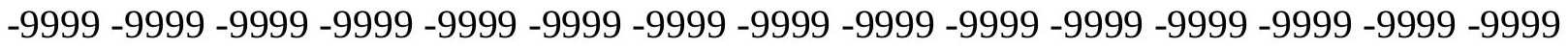

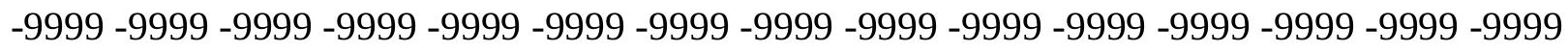

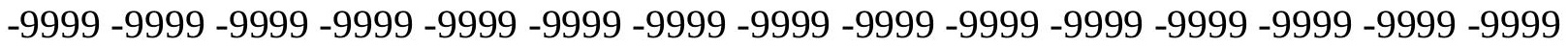

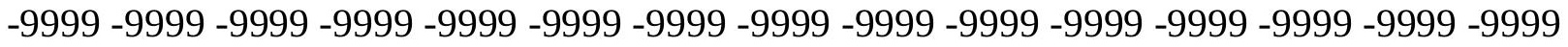
-9999 -9999 -9999 -9999 -9999 -9999 -9999 -9999 -9999 -9999 -9999 -9999 -9999 -9999 -9999 -

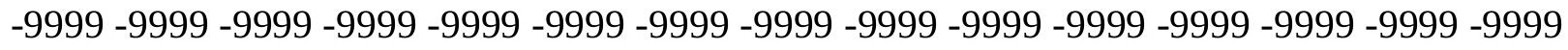

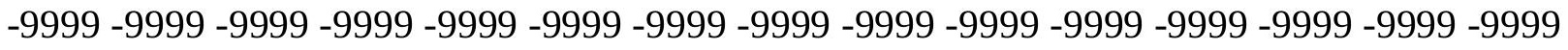
-9999 -9999 -9999 -9999 -9999 -9999 -9999 -9999 -9999 -9999 -9999 -9999 -9999 -9999 -9999 -9999 -9999 -9999 -9999 -9999 -9999 -9999 -9999 -9999-9999 -9999 -9999 -9999 -9999 -9999 -9999 -9999 -9999 -9999 -9999 -9999 -9999 -9999 -9999 -9999 -9999 -9999 -9999 -9999 -9999 -

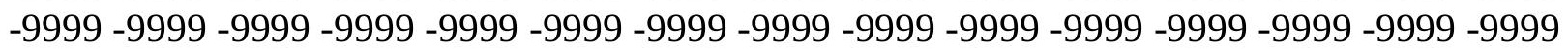


-9999 -9999 -9999 -9999 -9999 -9999 -9999 -9999 -9999 -9999 -9999 -9999 -9999 -9999 -9999 -9999 -9999 -9999 -9999 -9999 -9999 -9999 -9999 -9999 -9999 -9999 -9999 -9999 -9999 -9999 -9999 -9999 -9999 -9999 -9999 -9999 -9999 -9999 -9999 -9999 -9999 -9999 -9999 -9999 - 9999 -9999 -9999 -9999 -9999 -9999 -9999 -9999 -9999 -9999 -9999 -9999 -9999 -9999 -9999 -9999 -9999 -9999 -9999 -9999 -9999 -9999 -9999 -9999 -9999 -9999 -9999 -9999 -9999 -9999 -9999 -9999 -9999 -9999 -9999 -9999 -9999 -9999 -9999 -9999 -9999 -9999 -9999 -9999 -9999 -9999 -9999 -9999 -9999 -9999 -9999 -9999 -9999 -9999 -9999 -9999 -9999 -9999 -9999 -9999 -9999

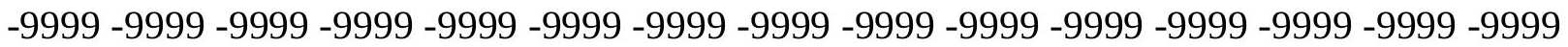

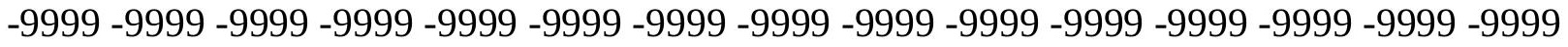
-9999 -9999 -9999 -9999 -9999 -9999 -9999 -9999 -9999 -9999 -9999 -9999 -9999 -9999 -9999 -9999 -9999 -9999 -9999 -9999 -9999 -9999 -9999 -9999 -9999 -9999 -9999 -9999 -9999 -9999 -9999 -9999 -9999 -9999 -9999 -9999 -9999 -9999 -9999 -9999 -9999 -9999 -9999 -9999 -9999 -9999 -9999 -9999 -9999 -9999 -9999 -9999 -9999 -9999 -9999 -9999 -9999 -9999 -9999 -9999 -9999 -9999 -9999 -9999 -9999 -9999 -9999 -9999 -9999 -9999 -9999 -9999 -9999 -9999 -9999 -9999 -9999 -9999 -9999 -9999 -9999 -9999 -9999 -9999 -9999 -9999 -9999 -9999 -9999 -

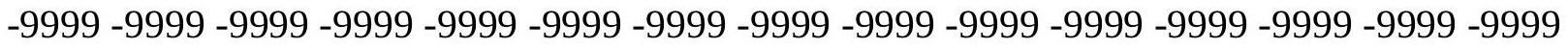
-9999 -9999 -9999 -9999 -9999 -9999 -9999 -9999 -9999 -9999 -9999 -9999 -9999 -9999 -9999 -9999 -9999 -9999 -9999 -9999 -9999 -9999 -9999 -9999 -9999 -9999 -9999 -9999 -9999 -9999 -9999 -9999 -9999 -9999 -9999 -9999 -9999 -9999 -9999 -9999 -9999 -9999 -9999 -9999 -9999 -9999 -9999 -9999 -9999 -9999 -9999 -9999 -9999 -9999 -9999 -9999 -9999 -9999 -9999 -9999 -9999 -9999 -9999 -9999 -9999 -9999 -9999 -9999 -9999 -9999 -9999 -9999 -9999 -9999 -9999 -999 -9999 -9999 -9999 -9999 -9999 -9999 -9999 -9999 -9999 -9999 -9999 -9999 -9999 -9999 -9999 -9999 -9999 -9999 -9999 -9999 -9999 -9999 -9999 -9999 -9999 -9999 -9999 -9999 -9999 -9999 -9999 -9999 -9999 -9999 -9999 -9999 -9999 -9999 -9999 -9999 -9999 -9999 -9999 -9999 -9999 -9999 -9999 -9999 -9999 -9999 -9999 -9999 -9999 -9999 -9999 -9999 -9999 -9999 -9999 -9999 -9999 -9999 -9999 -9999 -9999 -9999 -9999 -9999 -9999 -9999 -9999 -9999 -9999 -9999 -9999 -9999 -9999 -9999 -9999 -9999 -9999 -9999 -9999 -9999 -9999 -9999 -9999 -9999 -9999 -9999 -9999 -9999 -9999 -9999 -9999 -9999 -9999 -9999 -9999 -9999 -9999 -9999 -9999 -9999 -9999 -9999 -9999 -9999 -9999 -9999 -9999 -9999 -9999 -9999 -9999 -9999 -9999 -9999 -9999 -9999 -9999 -9999 -9999 -9999 -9999 -9999 -9999 -9999 -9999 -9999 -9999 -9999 -9999 -9999 -999 -9999 -9999 -9999 -9999 -9999 -9999 -9999 -9999 -9999 -9999 -9999 -9999 -9999 -9999 -9999 -9999 -9999 -9999 -9999 -9999 -9999 -9999 -9999 -9999 -9999 -9999 -9999 -9999 -9999 -9999 -

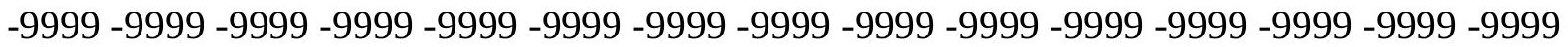

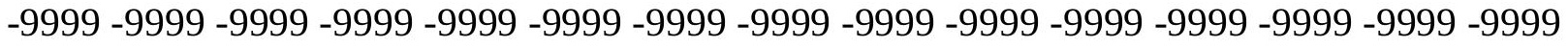

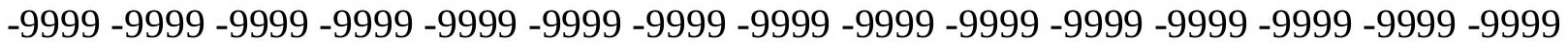
-9999 -9999 -9999 -9999 -9999 -9999 -9999 -9999 -9999 -9999 -9999 -9999 -9999 -9999 -9999 -9999 -9999 -9999 -9999 -9999 -9999 -9999 -9999 -9999 -9999 -9999 -9999 -9999 -9999 -

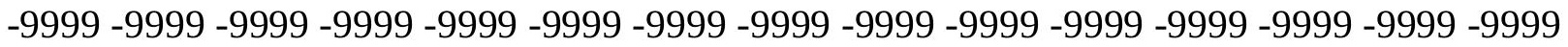
-9999 -9999 -9999 -9999 -9999 -9999 -9999 -9999 -9999 -9999 -9999 -9999 -9999 -9999 -9999 -9999 -9999 -9999 -9999 -9999 -9999 -9999 -9999 -9999 -9999 -9999 -9999 -9999 -9999 -9999 -

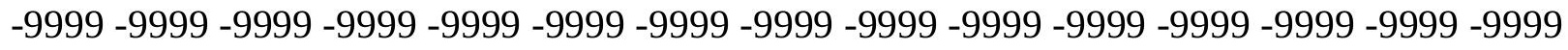

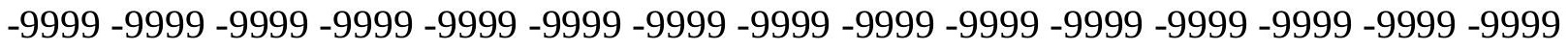
-9999 -9999 -9999 -9999 -9999 -9999 -9999 -9999 -9999 -9999 -9999 -9999 -9999 -9999 -9999 -9999 -9999 -9999 -9999 -9999 -9999 -9999 -9999 -9999-9999 -9999 -9999 -9999 -9999 -9999 -9999 -9999 -9999 -9999 -9999 -9999 -9999 -9999 -9999 -9999 -9999 -9999 -9999 -9999 -9999 -

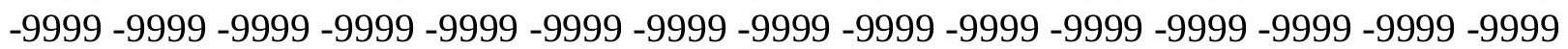


-9999 -9999 -9999 -9999 -9999 -9999 -9999 -9999 -9999 -9999 -9999 -9999 -9999 -9999 -9999 -9999 -9999 -9999 -9999 -9999 -9999 -9999 -9999 -9999 -9999 -9999 -9999 -9999 -9999 -9999 -

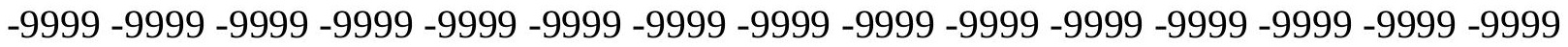
-9999 -9999 -9999 -9999 -9999 -9999 -9999 -9999 -9999 -9999 -9999 -9999 -9999 -9999 -9999 -9999 -9999 -9999 -9999 -9999 -9999 -9999 -9999 -9999-9999 -9999 -9999 -9999 -9999 -9999 -9999 -9999 -9999 -9999 -9999 -9999 -9999 -9999 -9999 -9999 -9999 -9999 -9999 -9999 -9999 -9999 -9999 -9999 -9999 -9999 -9999 -9999 -9999 -9999 -9999 -9999 -9999 -9999 -9999 -9999

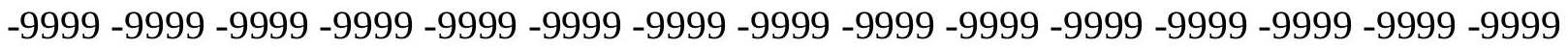

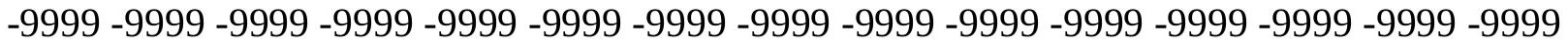
-9999 -9999 -9999 -9999 -9999 -9999 -9999 -9999 -9999 -9999 -9999 -9999 -9999 -9999 -9999 -9999 -9999 -9999 -9999 -9999 -9999 -9999 -9999 -9999 -9999 -9999 -9999 -9999 -9999 -9999 -9999 -9999 -9999 -9999 -9999 -9999 -9999 -9999 -9999 -9999 -9999 -9999 -9999 -9999 -9999 -9999 -9999 -9999 -9999 -9999 -9999 -9999 -9999 -9999 -9999 -9999 -9999 -9999 -9999 -9999 -9999 -9999 -9999 -9999 -9999 -9999 -9999 -9999 -9999 -9999 -9999 -9999 -9999 -9999 -9999 -9999 -9999 -9999 -9999 -9999 -9999 -9999 -9999 -9999 -9999 -9999 -9999 -9999 -9999 -9999 -

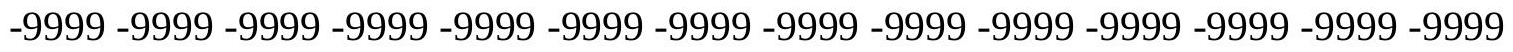
-9999 -9999 -9999 -9999 -9999 -9999 -9999 -9999 -9999 -9999 -9999 -9999 -9999 -9999 -9999 -9999 -9999 -9999 -9999 -9999 -9999 -9999 -9999 -9999 -9999 -9999 -9999 -9999 -9999 -9999 -9999 -9999 -9999 -9999 -9999 -9999 -9999 -9999 -9999 -9999 -9999 -9999 -9999 -9999 -9999 -

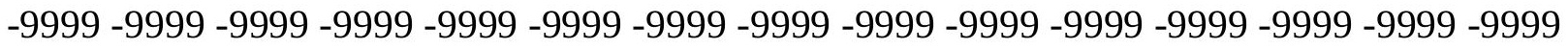

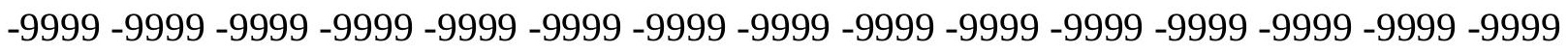
-9999 -9999 -9999 -9999 -9999 -9999 -9999 -9999 -9999 -9999 -9999 -9999 -9999 -9999 - 9999 -9999 -9999 -9999 -9999 -9999 -9999 -9999 -9999 -9999 -9999 -9999 -9999 -9999 -9999 -9999 -9999 -9999 -9999 -9999 -9999 -9999 -9999 -9999 -9999 -9999 -9999 -9999 -9999 -9999 -9999 -

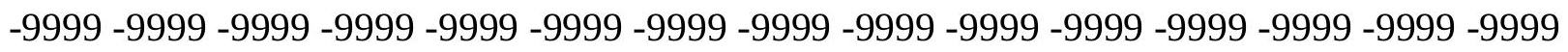
-9999 -9999 -9999 -9999 -9999 -9999 -9999 -9999 -9999 -9999 -9999 -9999 -9999 -9999 -9999 -9999 -9999 -9999 -9999 -9999 -9999 -9999 -9999 -9999 -9999 -9999 -9999 -9999 -9999 -9999 -

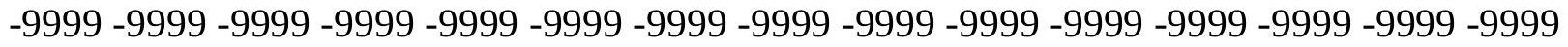
-9999 -9999 -9999 -9999 -9999 -9999 -9999 -9999 -9999 -9999 -9999 -9999 -9999 -9999 -9999 -9999 -9999 -9999 -9999 -9999 -9999 -9999 -9999 -9999 -9999 -9999 -9999 -9999 -9999 -999 -

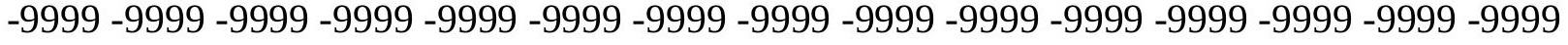
-9999 -9999 -9999 -9999 -9999 -9999 -9999 -9999 -9999 -9999 -9999 -9999 -9999 -9999 -9999 -

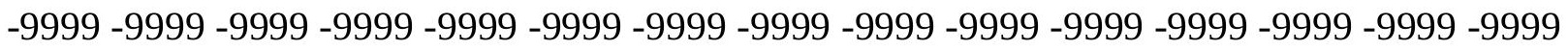

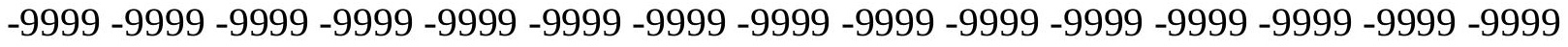

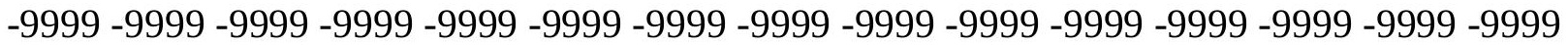
-9999 -9999 -9999 -9999 -9999 -9999 -9999 -9999 -9999 -9999 -9999 -9999 -9999 -9999 -9999 -

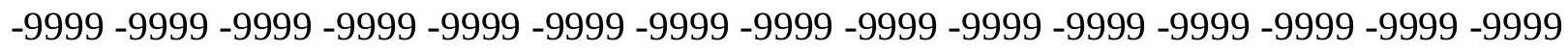

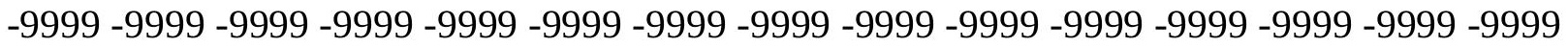
-9999 -9999 -9999 -9999 -9999 -9999 -9999 -9999 -9999 -9999 -9999 -9999 -9999 - 9999 - -999 -9999 -9999 -9999 -9999 -9999 -9999 -9999 -9999 -9999 -9999 -9999 -9999 -9999 -9999 -9999 -

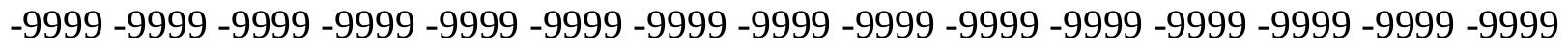

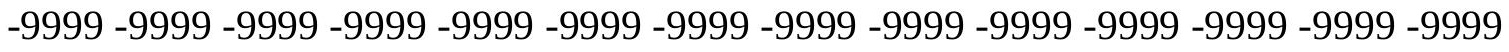
-9999 -9999 -9999 -9999 -9999 -9999 -9999 -9999 -9999 -9999 -9999 -9999 -9999 -9999 -9999 -9999 -9999 -9999 -9999 -9999 -9999 -9999 -9999 -9999-9999 -9999 -9999 -9999 -9999 -9999 -9999 -9999 -9999 -9999 -9999 -9999 -9999 -9999 -9999 -9999 -9999 -9999 -9999 -9999 -9999 -

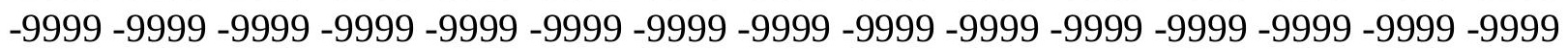


-9999 -9999 -9999 -9999 -9999 -9999 -9999 -9999 -9999 -9999 -9999 -9999 -9999 -9999 -9999 -9999 -9999 -9999 -9999 -9999 -9999 -9999 -9999 -9999 -9999 -9999 -9999 -9999 -9999 -9999 -

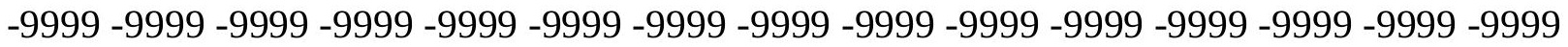
-9999 -9999 -9999 -9999 -9999 -9999 -9999 -9999 -9999 -9999 -9999 -9999 -9999 -9999 -9999 -9999 -9999 -9999 -9999 -9999 -9999 -9999 -9999 -9999-9999 -9999 -9999 -9999 -9999 -9999 -9999 -9999 -9999 -9999 -9999 -9999 -9999 -9999 -9999 -9999 -9999 -9999 -9999 -9999 -9999 -9999 -9999 -9999 -9999 -9999 -9999 -9999 -9999 -9999 -9999 -9999 -9999 -9999 -9999 -9999

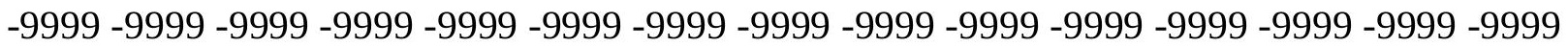

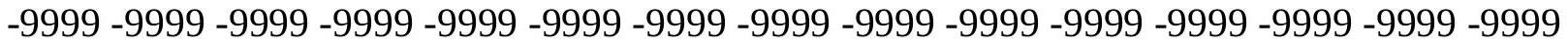
-9999 -9999 -9999 -9999 -9999 -9999 -9999 -9999 -9999 -9999 -9999 -9999 -9999 -9999 -9999 -9999 -9999 -9999 -9999 -9999 -9999 -9999 -9999 -9999 -9999 -9999 -9999 -9999 -9999 -9999 -9999 -9999 -9999 -9999 -9999 -9999 -9999 -9999 -9999 -9999 -9999 -9999 -9999 -9999 -9999 -9999 -9999 -9999 -9999 -9999 -9999 -9999 -9999 -9999 -9999 -9999 -9999 -9999 -9999 -9999 -

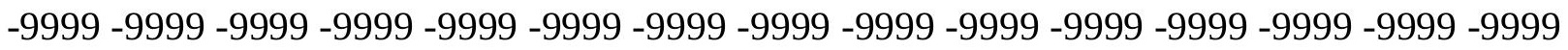
-9999 -9999 -9999 -9999 -9999 -9999 -9999 -9999 -9999 -9999 -9999 -9999 -9999 -9999 -9999 -

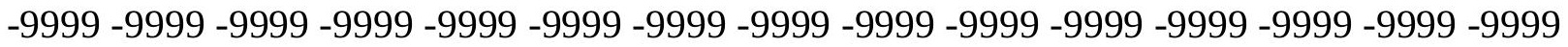
-9999 -9999 -9999 -9999 -9999 -9999 -9999 -9999 -9999 -9999 -9999 -9999 -9999 -9999 -9999 -9999 -9999 -9999 -9999 -9999 -9999 -9999 -9999 -9999 -9999 -9999 -9999 -9999 -9999 -9999 -9999 -9999 -9999 -9999 -9999 -9999 -9999 -9999 -9999 -9999 -9999 -9999 -9999 -9999 -9999 -

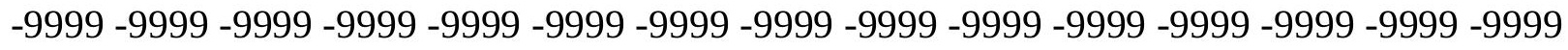

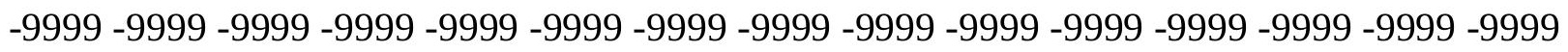
-9999 -9999 -9999 -9999 -9999 -9999 -9999 -9999 -9999 -9999 -9999 -9999 -9999 -9999 -9999 -9999 -9999 -9999 -9999 -9999 -9999 -9999 -9999 -9999 -9999 -9999 -9999 -9999 -9999 -9999 -9999 -9999 -9999 -9999 -9999 -9999 -9999 -9999 -9999 -9999 -9999 -9999 -9999 -9999 -

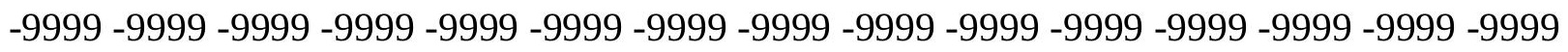
-9999 -9999 -9999 -9999 -9999 -9999 -9999 -9999 -9999 -9999 -9999 -9999 -9999 -9999 -9999 -9999 -9999 -9999 -9999 -9999 -9999 -9999 -9999 -9999 -9999 -9999 -9999 -9999 -9999 -9999 -

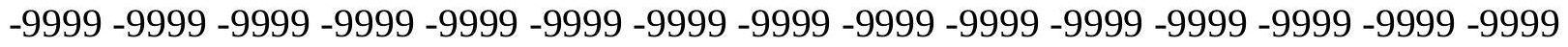
-9999 -9999 -9999 -9999 -9999 -9999 -9999 -9999 -9999 -9999 -9999 -9999 -9999 -9999 -9999 -9999 -9999 -9999 -9999 -9999 -9999 -9999 -9999 -9999 -9999 -9999 -9999 -9999 -9999 -999 -

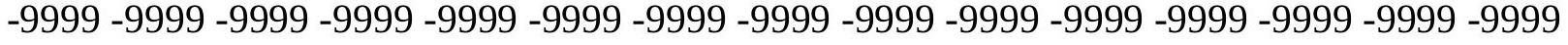
-9999 -9999 -9999 -9999 -9999 -9999 -9999 -9999 -9999 -9999 -9999 -9999 -9999 -9999 -9999 -

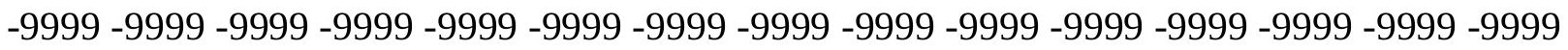

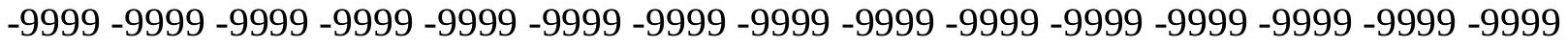

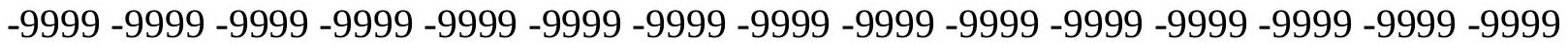

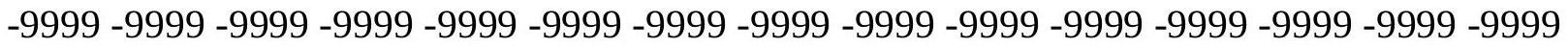

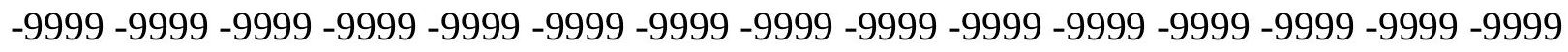

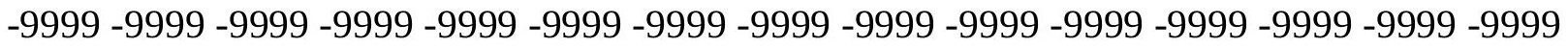

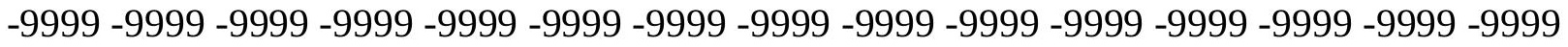
-9999 -9999 -9999 -9999 -9999 -9999 -9999 -9999 -9999 -9999 -9999 -9999 -9999 -9999 -9999 -

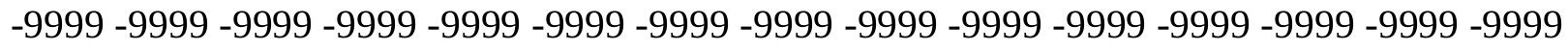

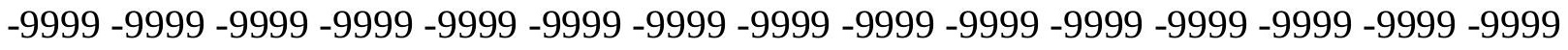
-9999 -9999 -9999 -9999 -9999 -9999 -9999 -9999 -9999 -9999 -9999 -9999 -9999 -9999 -9999 -9999 -9999 -9999 -9999 -9999 -9999 -9999 -9999 -9999-9999 -9999 -9999 -9999 -9999 -9999 -9999 -9999 -9999 -9999 -9999 -9999 -9999 -9999 -9999 -9999 -9999 -9999 -9999 -9999 -9999 -

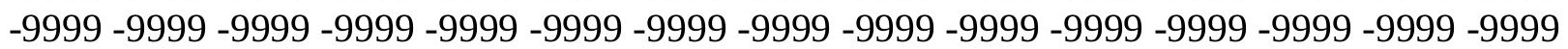


-9999 -9999 -9999 -9999 -9999 -9999 -9999 -9999 -9999 -9999 -9999 -9999 -9999 -9999 -9999 -9999 -9999 -9999 -9999 -9999 -9999 -9999 -9999 -9999 -9999 -9999 -9999 -9999 -9999 -

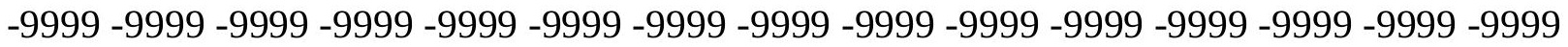
-9999 -9999 -9999 -9999 -9999 -9999 -9999 -9999 -9999 -9999 -9999 -9999 -9999 -9999 -9999 -9999 -9999 -9999 -9999 -9999 -9999 -9999 -9999 -9999 -9999 -9999 -9999 -9999 -9999 -9999 -9999 -9999 -9999 -9999 -9999 -9999 -9999 -9999 -9999 -9999 -9999 -9999 -9999 -9999 -9999 -9999 -9999 -9999 -9999 -9999 -9999 -9999 -9999 -9999 -9999 -9999 -9999 -9999 -9999 -9999

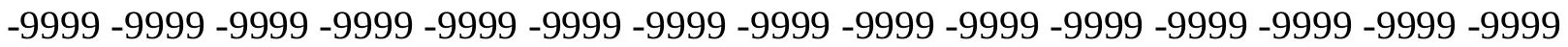

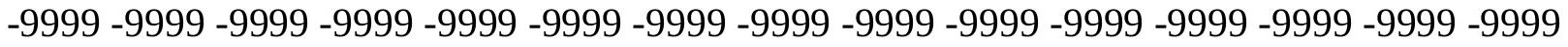
-9999 -9999 -9999 -9999 -9999 -9999 -9999 -9999 -9999 -9999 -9999 -9999 -9999 -9999 -9999 -9999 -9999 -9999 -9999 -9999 -9999 -9999 -9999 -9999 -9999 -9999 -9999 -9999 -9999 -9999 -9999 -9999 -9999 -9999 -9999 -9999 -9999 -9999 -9999 -9999 -9999 -9999 -9999 -9999 -9999 -9999 -9999 -9999 -9999 -9999 -9999 -9999 -9999 -9999 -9999 -9999 -9999 -9999 -9999 -9999 -9999 -9999 -9999 -9999 -9999 -9999 -9999 -9999 -9999 -9999 -9999 -9999 -9999 -9999 -9999 -9999 -9999 -9999 -9999 -9999 -9999 -9999 -9999 -9999 -9999 -9999 -9999 -9999 -9999 -9999 -

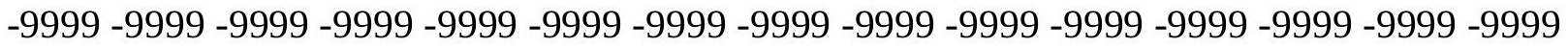
-9999 -9999 -9999 -9999 -9999 -9999 -9999 -9999 -9999 -9999 -9999 -9999 -9999 -9999 -9999 -9999 -9999 -9999 -9999 -9999 -9999 -9999 -9999 -9999 -9999 -9999 -9999 -9999 -9999 - 9999 -9999 -9999 -9999 -9999 -9999 -9999 -9999 -9999 -9999 -9999 -9999 -9999 -9999 -9999 -9999 -

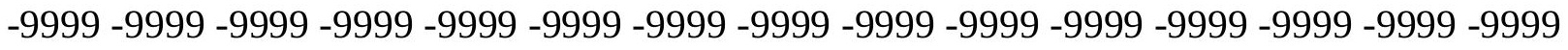

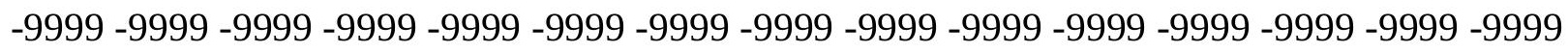

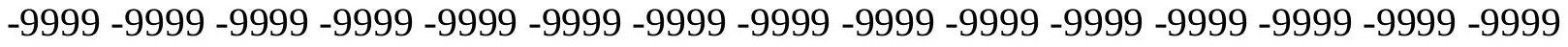
-9999 -9999 -9999 -9999 -9999 -9999 -9999 -9999 -9999 -9999 -9999 -9999 -9999 -9999 -9999 -9999 -9999 -9999 -9999 -9999 -9999 -9999 -9999 -9999 -9999 -9999 -9999 -9999 -9999 -9999 -

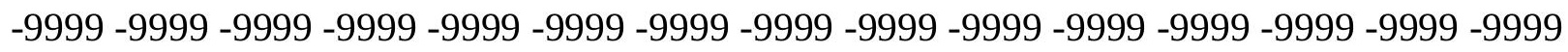
-9999 -9999 -9999 -9999 -9999 -9999 -9999 -9999 -9999 -9999 -9999 -9999 -9999 -9999 -9999 -9999 -9999 -9999 -9999 -9999 -9999 -9999 -9999 -9999 -9999 -9999 -9999 -9999 -9999 -9999 -9999 -9999 -9999 -9999 -9999 -9999 -9999 -9999 -9999 -9999 -9999 -9999 -9999 -9999 -9999 -9999 -9999 -9999 -9999 -9999 -9999 -9999 -9999 -9999 -9999 -9999 -9999 -9999 -9999 -9999 -9999 -9999 -9999 -9999 -9999 -9999 -9999 -9999 -9999 -9999 -9999 -9999 -9999 -999 -

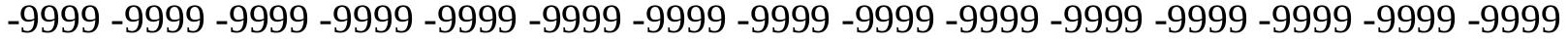
-9999 -9999 -9999 -9999 -9999 -9999 -9999 -9999 -9999 -9999 -9999 -9999 -9999 -9999 -9999 -

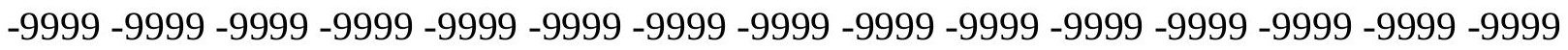

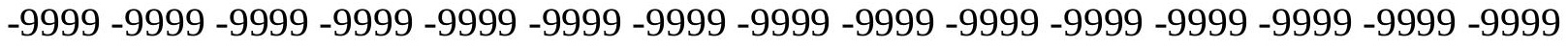

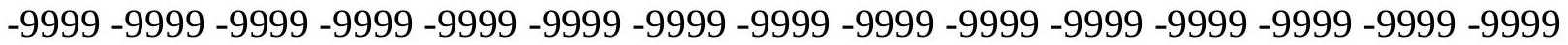

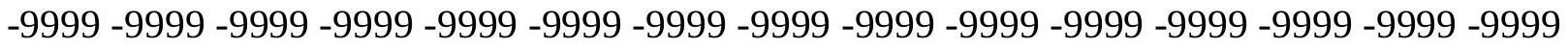

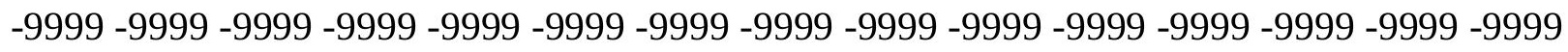

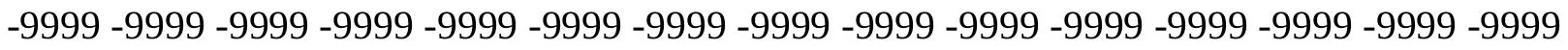

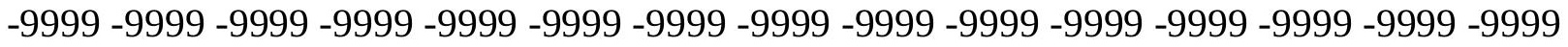
-9999 -9999 -9999 -9999 -9999 -9999 -9999 -9999 -9999 -9999 -9999 -9999 -9999 -9999 -9999 -

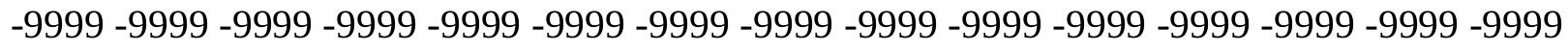

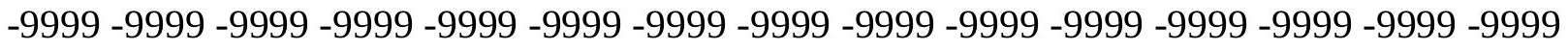
-9999 -9999 -9999 -9999 -9999 -9999 -9999 -9999 -9999 -9999 -9999 -9999 -9999 -9999 -9999 -9999 -9999 -9999 -9999 -9999 -9999 -9999 -9999 -9999-9999 -9999 -9999 -9999 -9999 -9999 -9999 -9999 -9999 -9999 -9999 -9999 -9999 -9999 -9999 -9999 -9999 -9999 -9999 -9999 -9999 -

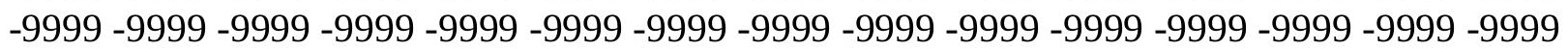


-9999 -9999 -9999 -9999 -9999 -9999 -9999 -9999 -9999 -9999 -9999 -9999 -9999 -9999 -9999 -9999 -9999 -9999 -9999 -9999 -9999 -9999 -9999 -9999 -9999 -9999 -9999 -9999 -9999 -9999 -

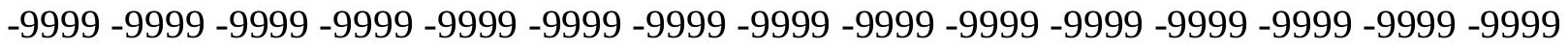
-9999 -9999 -9999 -9999 -9999 -9999 -9999 -9999 -9999 -9999 -9999 -9999 -9999 -9999 -9999 -9999 -9999 -9999 -9999 -9999 -9999 -9999 -9999 -9999-9999 -9999 -9999 -9999 -9999 -9999 -9999 -9999 -9999 -9999 -9999 -9999 -9999 -9999 -9999 -9999 -9999 -9999 -9999 -9999 -9999 -

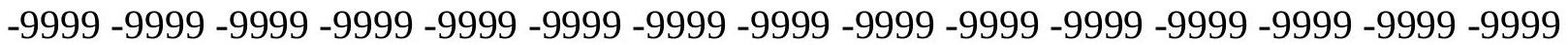
-9999 -9999 -9999 -9999 -9999 -9999 -9999 -9999 -9999 -9999 -9999 -9999 -9999 -9999 -9999 -9999 -9999 -9999 -9999 -9999 -9999 -9999 -9999 -9999 -9999 -9999 -9999 -9999 -9999 -9999 -9999 -9999 -9999 -9999 -9999 -9999 -9999 -9999 -9999 -9999 -9999 -9999 -9999 -9999 -9999 -9999 -9999 -9999 -9999 -9999 -9999 -9999 -9999 -9999 -9999 -9999 -9999 -9999 -9999 -9999 -9999 -9999 -9999 -9999 -9999 -9999 -9999 -9999 -9999 -9999 -9999 -9999 -9999 -9999 -9999 -9999 -9999 -9999 -9999 -9999 -9999 -9999 -9999 -9999 -9999 -9999 -9999 -9999 -9999 -9999 -9999 -9999 -9999 -9999 -9999 -9999 -9999 -9999 -9999 -9999 -9999 -9999 -9999 -9999 -9999 -9999 -9999 -9999 -9999 -9999 -9999 -9999 -9999 -9999 -9999 -9999 -9999 -9999 -9999 -

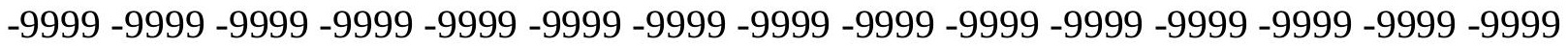
-9999 -9999 -9999 -9999 -9999 -9999 -9999 -9999 -9999 -9999 -9999 -9999 -9999 -9999 -9999 -9999 -9999 -9999 -9999 -9999 -9999 -9999 -9999 -9999 -9999 -9999 -9999 -9999 -9999 -9999 -9999 -9999 -9999 -9999 -9999 -9999 -9999 -9999 -9999 -9999 -9999 -9999 -9999 -9999 -9999 -

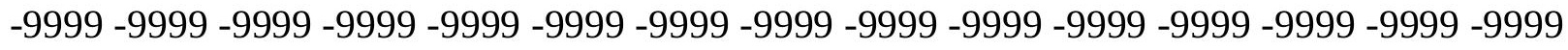

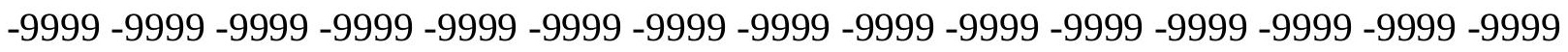
-9999 -9999 -9999 -9999 -9999 -9999 -9999 -9999 -9999 -9999 -9999 -9999 -9999 -9999 - 9999 -9999 -9999 -9999 -9999 -9999 -9999 -9999 -9999 -9999 -9999 -9999 -9999 -9999 -9999 -9999 -9999 -9999 -9999 -9999 -9999 -9999 -9999 -9999 -9999 -9999 -9999 -9999 -9999 -9999 -9999 -

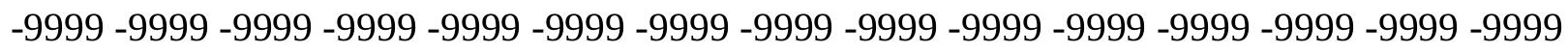
-9999 -9999 -9999 -9999 -9999 -9999 -9999 -9999 -9999 -9999 -9999 -9999 -9999 -9999 -9999 -9999 -9999 -9999 -9999 -9999 -9999 -9999 -9999 -9999 -9999 -9999 -9999 -9999 -9999 -9999 -

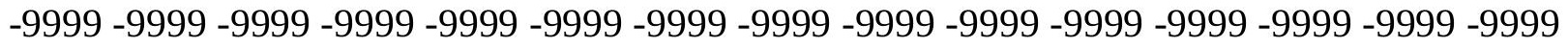
-9999 -9999 -9999 -9999 -9999 -9999 -9999 -9999 -9999 -9999 -9999 -9999 -9999 -9999 -9999 -9999 -9999 -9999 -9999 -9999 -9999 -9999 -9999 -9999 -9999 -9999 -9999 -9999 -9999 -999 -9999 -9999 -9999 -9999 -9999 -9999 -9999 -9999 -9999 -9999 -9999 -9999 -9999 -9999 -9999 -9999 -9999 -9999 -9999 -9999 -9999 -9999 -9999 -9999 -9999 -9999 -9999 -9999 -9999 -9999 -

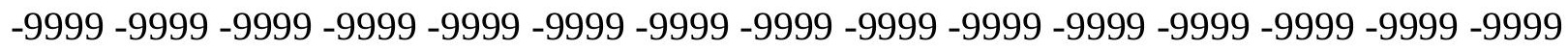

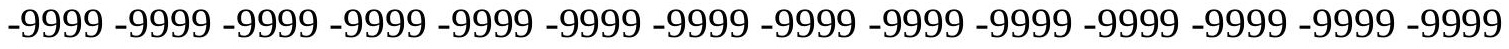
-9999 -9999 -9999 -9999 -9999 -9999 -9999 -9999 -9999 -9999 -9999 -9999 -9999 -9999 -9999

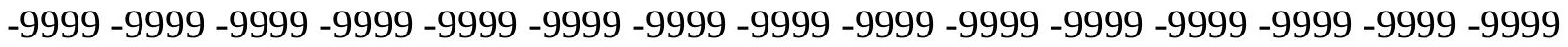

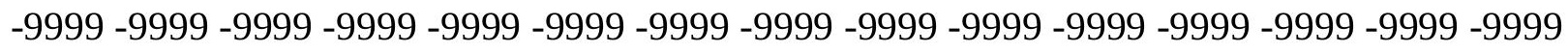

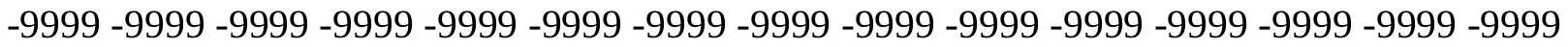

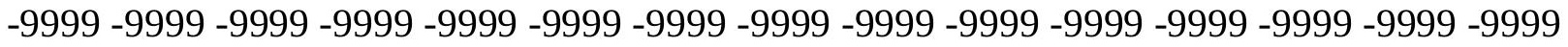
-9999 -9999 -9999 -9999 -9999 -9999 -9999 -9999 -9999 -9999 -9999 -9999 -9999 -9999 -9999 -

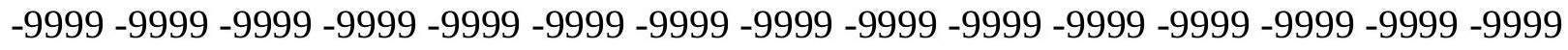

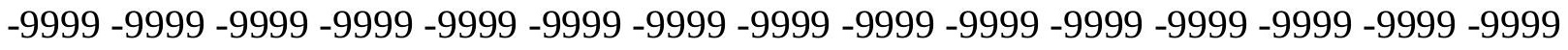
-9999 -9999 -9999 -9999 -9999 -9999 -9999 -9999 -9999 -9999 -9999 -9999 -9999 -9999 -9999 -9999 -9999 -9999 -9999 -9999 -9999 -9999 -9999 -9999-9999 -9999 -9999 -9999 -9999 -9999 -9999 -9999 -9999 -9999 -9999 -9999 -9999 -9999 -9999 -9999 -9999 -9999 -9999 -9999 -9999 -

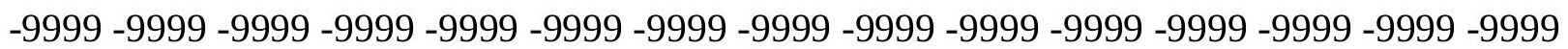


-9999 -9999 -9999 -9999 -9999 -9999 -9999 -9999 -9999 -9999 -9999 -9999 -9999 -9999 -9999 -9999 -9999 -9999 -9999 -9999 -9999 -9999 -9999 -9999 -9999 -9999 -9999 -9999 -9999 -9999 -

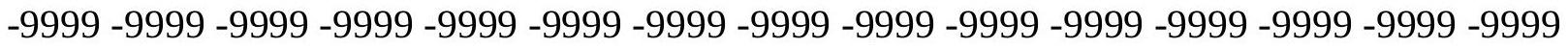
-9999 -9999 -9999 -9999 -9999 -9999 -9999 -9999 -9999 -9999 -9999 -9999 -9999 -9999 -9999 -9999 -9999 -9999 -9999 -9999 -9999 -9999 -9999 -9999-9999 -9999 -9999 -9999 -9999 -9999 -9999 -9999 -9999 -9999 -9999 -9999 -9999 -9999 -9999 -9999 -9999 -9999 -9999 -9999 -9999 -9999 -9999 -9999 -9999 -9999 -9999 -9999 -9999 -9999 -9999 -9999 -9999 -9999 -9999 -9999

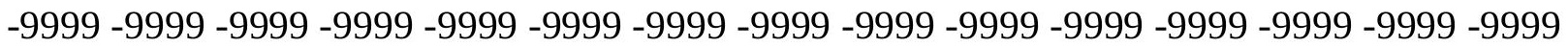

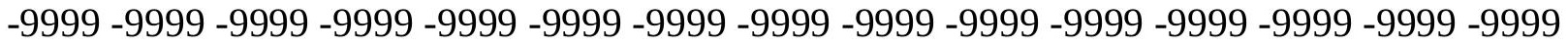
-9999 -9999 -9999 -9999 -9999 -9999 -9999 -9999 -9999 -9999 -9999 -9999 -9999 -9999 -9999 -9999 -9999 -9999 -9999 -9999 -9999 -9999 -9999 -9999 -9999 -9999 -9999 -9999 -9999 -9999 -9999 -9999 -9999 -9999 -9999 -9999 -9999 -9999 -9999 -9999 -9999 -9999 -9999 -9999 -9999 -9999 -9999 -9999 -9999 -9999 -9999 -9999 -9999 -9999 -9999 -9999 -9999 -9999 -9999 -9999 -9999 -9999 -9999 -9999 -9999 -9999 -9999 -9999 -9999 -9999 -9999 -9999 -9999 -9999 -9999 -9999 -9999 -9999 -9999 -9999 -9999 -9999 -9999 -9999 -9999 -9999 -9999 -9999 -9999

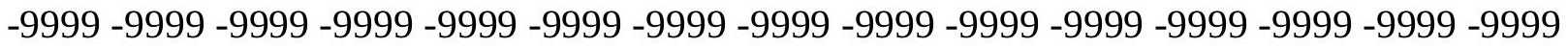
-9999 -9999 -9999 -9999 -9999 -9999 -9999 -9999 -9999 -9999 -9999 -9999 -9999 -9999 -9999 -9999 -9999 -9999 -9999 -9999 -9999 -9999 -9999 -9999 -9999 -9999 -9999 -9999 -9999 -9999 -9999 -9999 -9999 -9999 -9999 -9999 -9999 -9999 -9999 -9999 -9999 -9999 -9999 -9999 -9999 -

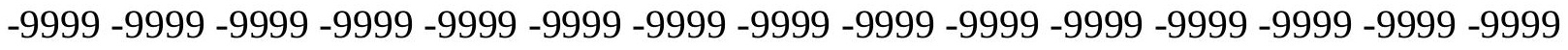

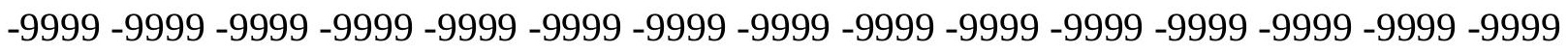
-9999 -9999 -9999 -9999 -9999 -9999 -9999 -9999 -9999 -9999 -9999 -9999 -9999 -9999 -9999 -9999 -9999 -9999 -9999 -9999 -9999 -9999 -9999 -9999 -9999 -9999 -9999 -9999 -9999 -9999 -9999 -9999 -9999 -9999 -9999 -9999 -9999 -9999 -9999 -9999 -9999 -9999 -9999 -9999 -9999 -

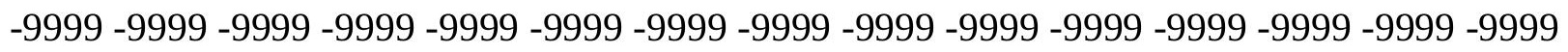
-9999 -9999 -9999 -9999 -9999 -9999 -9999 -9999 -9999 -9999 -9999 -9999 -9999 -9999 -9999 -9999 -9999 -9999 -9999 -9999 -9999 -9999 -9999 -9999 -9999 -9999 -9999 -9999 -9999 -9999 -

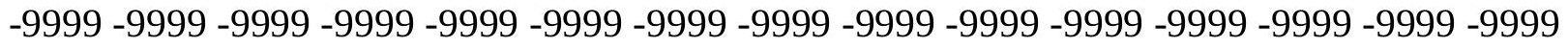
-9999 -9999 -9999 -9999 -9999 -9999 -9999 -9999 -9999 -9999 -9999 -9999 -9999 -9999 -9999 -9999 -9999 -9999 -9999 -9999 -9999 -9999 -9999 -9999 -9999 -9999 -9999 -9999 -9999 -999 -9999 -9999 -9999 -9999 -9999 -9999 -9999 -9999 -9999 -9999 -9999 -9999 -9999 -9999 -9999 -9999 -9999 -9999 -9999 -9999 -9999 -9999 -9999 -9999 -9999 -9999 -9999 -9999 -9999 -9999 -

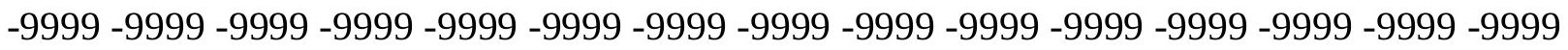

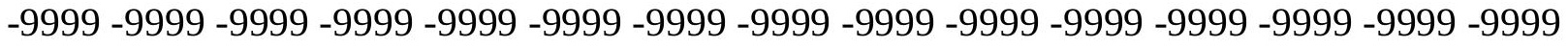

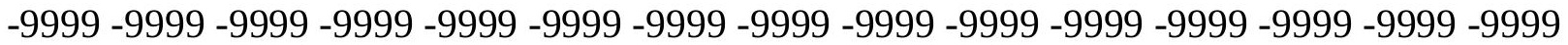

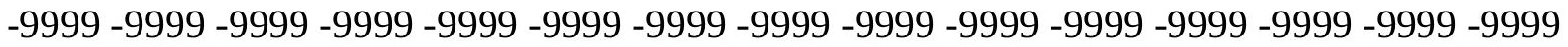

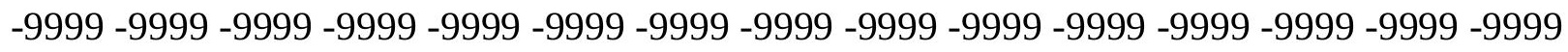

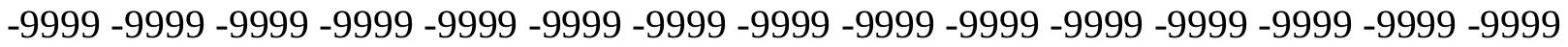
-9999 -9999 -9999 -9999 -9999 -9999 -9999 -9999 -9999 -9999 -9999 -9999 -9999 - 9999 - -999 -9999 -9999 -9999 -9999 -9999 -9999 -9999 -9999 -9999 -9999 -9999 -9999 -9999 -9999 - -999 -

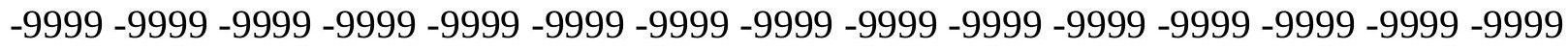

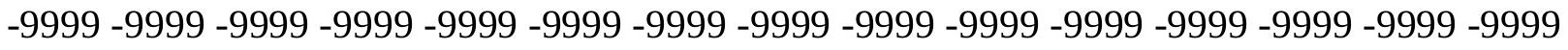
-9999 -9999 -9999 -9999 -9999 -9999 -9999 -9999 -9999 -9999 -9999 -9999 -9999 -9999 -9999 -9999 -9999 -9999 -9999 -9999 -9999 -9999 -9999 -9999-9999 -9999 -9999 -9999 -9999 -9999 -9999 -9999 -9999 -9999 -9999 -9999 -9999 -9999 -9999 -9999 -9999 -9999 -9999 -9999 -9999 -

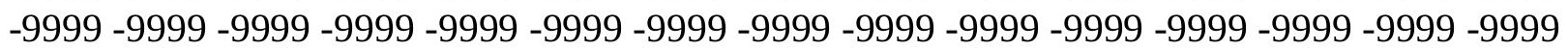


-9999 -9999 -9999 -9999 -9999 -9999 -9999 -9999 -9999 -9999 -9999 -9999 -9999 -9999 -9999 -9999 -9999 -9999 -9999 -9999 -9999 -9999 -9999 -9999 -9999 -9999 -9999 -9999 -9999 -9999 -9999 -9999 -9999 -9999 -9999 -9999 -9999 -9999 -9999 -9999 -9999 -9999 -9999 -9999 -9999 -9999 -9999 -9999 -9999 -9999 -9999 -9999 -9999 -9999 -9999 -9999 -9999 -9999 -9999 -9999 -9999 -9999 -9999 -9999 -9999 -9999 -9999 -9999 -9999 -9999 -9999 -9999 -9999 -9999 -9999 -9999 -9999 -9999 -9999 -9999 -9999 -9999 -9999 -9999 -9999 -9999 -9999 -9999 -9999 -9999 -9999 -9999 -9999 -9999 -9999 -9999 -9999 -9999 -9999 -9999 -9999 -9999 -9999 -9999 -9999 -

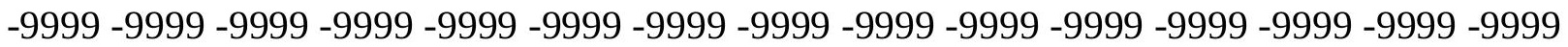
-9999 -9999 -9999 -9999 -9999 -9999 -9999 -9999 -9999 -9999 -9999 -9999 -9999 -9999 -9999 -9999 -9999 -9999 -9999 -9999 -9999 -9999 -9999 -9999 -9999 -9999 -9999 -9999 -9999 -9999 -

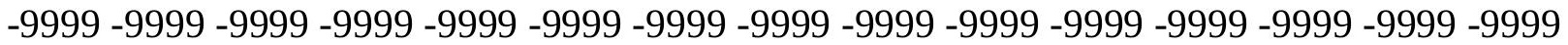
-9999 -9999 -9999 -9999 -9999 -9999 -9999 -9999 -9999 -9999 -9999 -9999 -9999 -9999 -9999 -9999 -9999 -9999 -9999 -9999 -9999 -9999 -9999 -9999 -9999 -9999 -9999 -9999 -9999 -9999 -9999 -9999 -9999 -9999 -9999 -9999 -9999 -9999 -9999 -9999 -9999 -9999 -9999 -9999 -9999 -9999 -9999 -9999 -9999 -9999 -9999 -9999 -9999 -9999 -9999 -9999 -9999 -9999 -9999 -9999

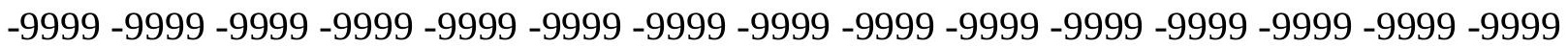
-9999 -9999 -9999 -9999 -9999 -9999 -9999 -9999 -9999 -9999 -9999 -9999 -9999 -9999 -9999 -9999 -9999 -9999 -9999 -9999 -9999 -9999 -9999 -9999 -9999 -9999 -9999 -9999 -9999 -9999 -9999 -9999 -9999 -9999 -9999 -9999 -9999 -9999 -9999 -9999 -9999 -9999 -9999 -9999 -9999 -9999 -9999 -9999 -9999 -9999 -9999 -9999 -9999 -9999 -9999 -9999 -9999 -9999 -9999 -9999 -9999 -9999 -9999 -9999 -9999 -9999 -9999 -9999 -9999 -9999 -9999 -9999 -9999 -9999 -9999 -9999 -9999 -9999 -9999 -9999 -9999 -9999 -9999 -9999 -9999 -9999 -9999 -9999 -9999 -9999 -9999 -9999 -9999 -9999 -9999 -9999 -9999 -9999 -9999 -9999 -9999 -9999 -9999 -9999 -9999 -9999 -9999 -9999 -9999 -9999 -9999 -9999 -9999 -9999 -9999 -9999 -9999 -9999 -9999 -9999 -9999 -9999 -9999 -9999 -9999 -9999 -9999 -9999 -9999 -9999 -9999 -9999 -9999 -9999 -9999 -9999 -9999 -9999 -9999 -9999 -9999 -9999 -9999 -9999 -9999 -9999 -9999 -9999 -9999 -9999 -9999 -9999 -9999 -9999 -9999 -9999 -9999 -9999 -9999 -9999 -9999 -9999 -9999 -9999 -9999 -9999 -9999 -9999 -9999 -9999 -9999 -9999 -9999 -9999 -9999 -9999 -9999 -9999 -9999

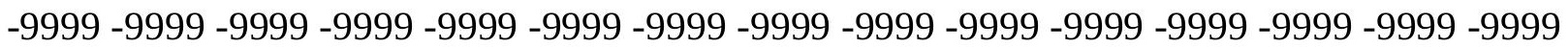
-9999 -9999 -9999 -9999 -9999 -9999 -9999 -9999 -9999 -9999 -9999 -9999 -9999 -9999 -9999 -9999 -9999 -9999 -9999 -9999 -9999 -9999 -9999 -9999 -9999 -9999 -9999 -9999 -9999 -9999 -

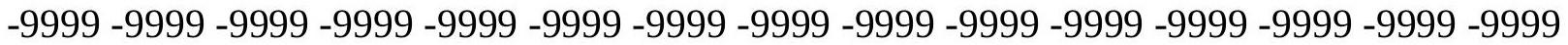
-9999 -9999 -9999 -9999 -9999 -9999 -9999 -9999 -9999 -9999 -9999 -9999 -9999 -9999 -9999 -9999 -9999 -9999 -9999 -9999 -9999 -9999 -9999 -9999 -9999 -9999 -9999 -9999 -9999 -9999 -9999 -9999 -9999 -9999 -9999 -9999 -9999 -9999 -9999 -9999 -9999 -9999 -9999 -9999 -9999 -9999 -9999 -9999 -9999 -9999 -9999 -9999 -9999 -9999 -9999 -9999 -9999 -9999 -9999 -9999 -9999 -9999 -9999 -9999 -9999 -9999 -9999 -9999 -9999 -9999 -9999 -9999 -9999 -9999 -9999

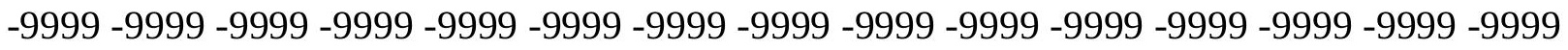
-9999 -9999 -9999 -9999 -9999 -9999 -9999 -9999 -9999 -9999 -9999 -9999 -9999 -9999 -9999 -9999 -9999 -9999 -9999 -9999 -9999 -9999 -9999 -9999 -9999 -9999 -9999 -9999 -9999 -9999 -9999 -9999 -9999 -9999 -9999 -9999 -9999 -9999 -9999 -9999 -9999 -9999 -9999 -9999 -9999 -999 -9999 -9999 -9999 -9999 -9999 -9999 -9999 -9999 -9999 -9999 -9999 -9999 -9999 -9999 -9999 -9999 -9999 -9999 -9999 -9999 -9999 -9999 -9999 -9999 -9999 -9999 -9999 -9999 -9999 -9999 -9999 -9999 -9999 -9999 -9999 -9999 -9999 -9999 -9999 -9999 -9999 -9999 -9999 -9999 -9999 -9999 -9999 -9999 -9999 -9999 -9999 -9999 -9999 -9999 -9999 -9999 -9999 -9999 -9999 -9999 -9999 -9999 -9999 -9999 -9999 -9999 -9999 -9999 -9999 -9999 -9999 -9999 -9999 -9999 
-9999 -9999 -9999 -9999 -9999 -9999 -9999 -9999 -9999 -9999 -9999 -9999 -9999 -9999 -9999 -9999 -9999 -9999 -9999 -9999 -9999 -9999 -9999 -9999 -9999 -9999 -9999 -9999 -9999 -9999 -

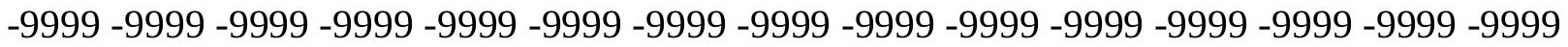
-9999 -9999 -9999 -9999 -9999 -9999 -9999 -9999 -9999 -9999 -9999 -9999 -9999 -9999 -9999 -9999 -9999 -9999 -9999 -9999 -9999 -9999 -9999 -9999-9999 -9999 -9999 -9999 -9999 -9999 -9999 -9999 -9999 -9999 -9999 -9999 -9999 -9999 -9999 -9999 -9999 -9999 -9999 -9999 -9999 -9999 -9999 -9999 -9999 -9999 -9999 -9999 -9999 -9999 -9999 -9999 -9999 -9999 -9999 -9999

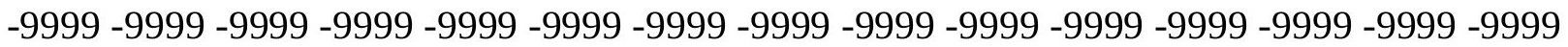

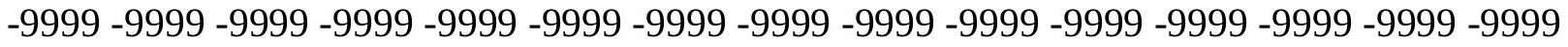
-9999 -9999 -9999 -9999 -9999 -9999 -9999 -9999 -9999 -9999 -9999 -9999 -9999 -9999 -9999 -9999 -9999 -9999 -9999 -9999 -9999 -9999 -9999 -9999 -9999 -9999 -9999 -9999 -9999 -9999 -9999 -9999 -9999 -9999 -9999 -9999 -9999 -9999 -9999 -9999 -9999 -9999 -9999 -9999 -9999 -9999 -9999 -9999 -9999 -9999 -9999 -9999 -9999 -9999 -9999 -9999 -9999 -9999 -9999 -9999 -

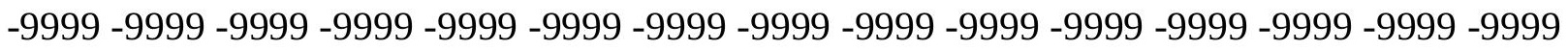
-9999 -9999 -9999 -9999 -9999 -9999 -9999 -9999 -9999 -9999 -9999 -9999 -9999 -9999 -9999 -

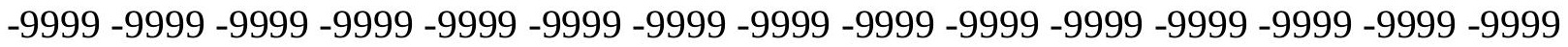
-9999 -9999 -9999 -9999 -9999 -9999 -9999 -9999 -9999 -9999 -9999 -9999 -9999 -9999 -9999 -9999 -9999 -9999 -9999 -9999 -9999 -9999 -9999 -9999 -9999 -9999 -9999 -9999 -9999 -9999 -9999 -9999 -9999 -9999 -9999 -9999 -9999 -9999 -9999 -9999 -9999 -9999 -9999 -9999 -9999 -

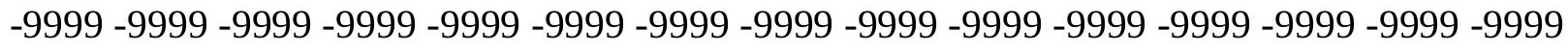

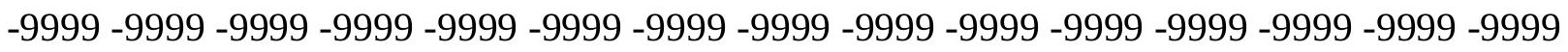

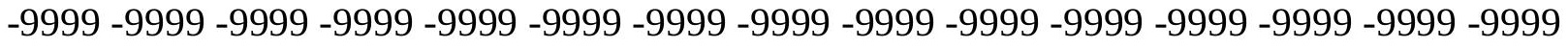
-9999 -9999 -9999 -9999 -9999 -9999 -9999 -9999 -9999 -9999 -9999 -9999 -9999 -9999 -9999 -9999 -9999 -9999 -9999 -9999 -9999 -9999 -9999 -9999 -9999 -9999 -9999 -9999 -9999 -9999 -

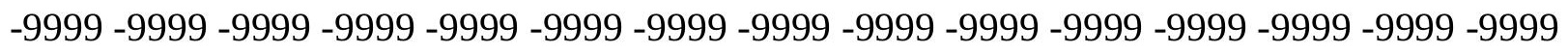
-9999 -9999 -9999 -9999 -9999 -9999 -9999 -9999 -9999 -9999 -9999 -9999 -9999 -9999 -9999 -9999 -9999 -9999 -9999 -9999 -9999 -9999 -9999 -9999 -9999 -9999 -9999 -9999 -9999 -

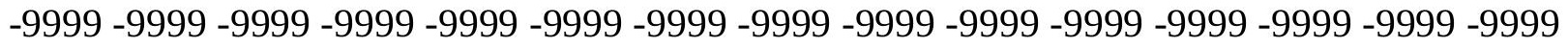
-9999 -9999 -9999 -9999 -9999 -9999 -9999 -9999 -9999 -9999 -9999 -9999 -9999 -9999 -9999 -9999 -9999 -9999 -9999 -9999 -9999 -9999 -9999 -9999 -9999 -9999 -9999 -9999 -9999 -999 -

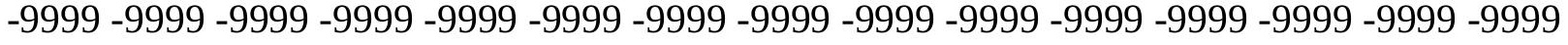
-9999 -9999 -9999 -9999 -9999 -9999 -9999 -9999 -9999 -9999 -9999 -9999 -9999 -9999 -9999 -

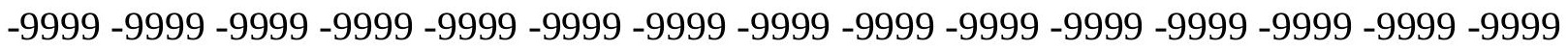

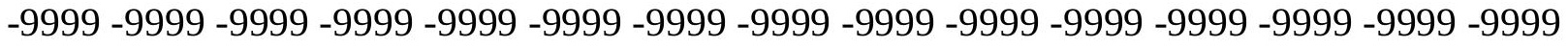

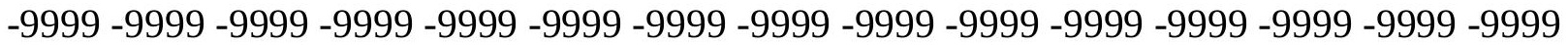
-9999 -9999 -9999 -9999 -9999 -9999 -9999 -9999 -9999 -9999 -9999 -9999 -9999 -9999 -9999

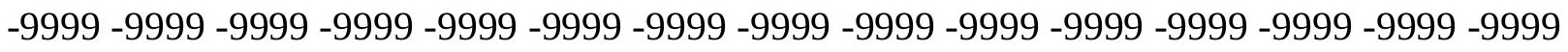

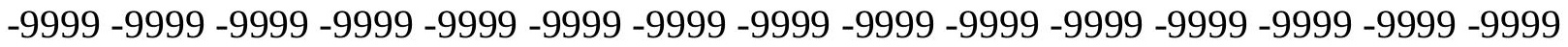
-9999 -9999 -9999 -9999 -9999 -9999 -9999 -9999 -9999 -9999 -9999 -9999 -9999 - 9999 - -999 -9999 -9999 -9999 -9999 -9999 -9999 -9999 -9999 -9999 -9999 -9999 -9999 -9999 -9999 -9999 -

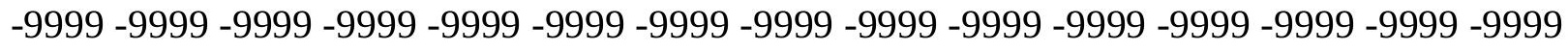

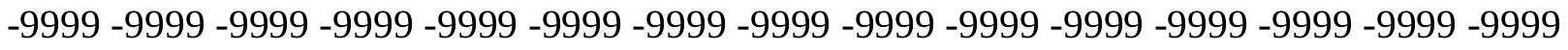
-9999 -9999 -9999 -9999 -9999 -9999 -9999 -9999 -9999 -9999 -9999 -9999 -9999 -9999 -9999 -9999 -9999 -9999 -9999 -9999 -9999 -9999 -9999 -9999-9999 -9999 -9999 -9999 -9999 -9999 -9999 -9999 -9999 -9999 -9999 -9999 -9999 -9999 -9999 -9999 -9999 -9999 -9999 -9999 -9999 -

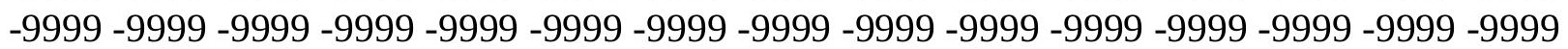


-9999 -9999 -9999 -9999 -9999 -9999 -9999 -9999 -9999 -9999 -9999 -9999 -9999 -9999 -9999 -9999 -9999 -9999 -9999 -9999 -9999 -9999 -9999 -9999 -9999 -9999 -9999 -9999 -9999 -9999 -9999 -9999 -9999 -9999 -9999 -9999 -9999 -9999 -9999 -9999 -9999 -9999 -9999 -9999 - 9999 -9999 -9999 -9999 -9999 -9999 -9999 -9999 -9999 -9999 -9999 -9999 -9999 -9999 -9999 -9999 -9999 -9999 -9999 -9999 -9999 -9999 -9999 -9999 -9999 -9999 -9999 -9999 -9999 -9999 - -9999 -9999 -9999 -9999 -9999 -9999 -9999 -9999 -9999 -9999 -9999 -9999 -9999 -9999 -9999 -9999 -9999 -9999 -9999 -9999 -9999 -9999 -9999 -9999 -9999 -9999 -9999 -9999 -9999 -9999

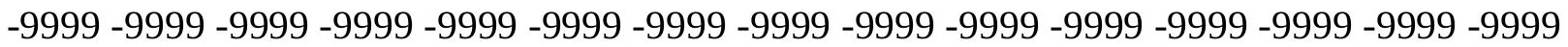

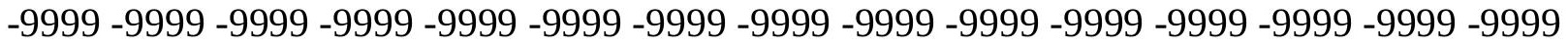
-9999 -9999 -9999 -9999 -9999 -9999 -9999 -9999 -9999 -9999 -9999 -9999 -9999 -9999 -9999

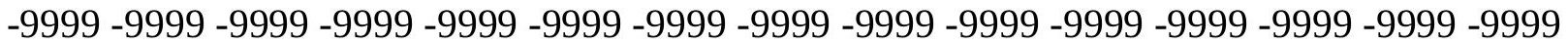
-9999 -9999 -9999 -9999 -9999 -9999 -9999 -9999 -9999 -9999 -9999 -9999 -9999 -9999 -9999 -9999 -9999 -9999 -9999 -9999 -9999 -9999 -9999 -9999 -9999 -9999 -9999 -9999 -9999 -9999 -9999 -9999 -9999 -9999 -9999 -9999 -9999 -9999 -9999 -9999 -9999 -9999 -9999 -9999 - -9999 -9999 -9999 -9999 -9999 -9999 -9999 -9999 -9999 -9999 -9999 -9999 -9999 -9999 -9999 -9999

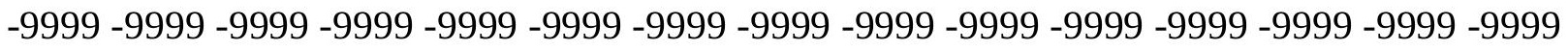
-9999 -9999 -9999 -9999 -9999 -9999 -9999 -9999 -9999 -9999 -9999 -9999 -9999 -9999 -9999 -9999 -9999 -9999 -9999 -9999 -9999 -9999 -9999 -9999 -9999 -9999 -9999 -9999 -9999 -9999 -9999 -9999 -9999 -9999 -9999 -9999 -9999 -9999 -9999 -9999 -9999 -9999 -9999 -9999 -9999 -

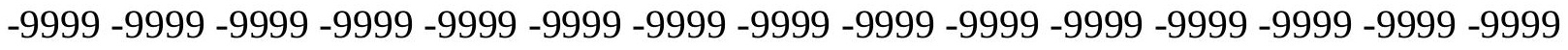
-9999 -9999 -9999 -9999 -9999 -9999 -9999 -9999 -9999 -9999 -9999 -9999 -9999 -9999 -9999 -999 -9999 -9999 -9999 -9999 -9999 -9999 -9999 -9999 -9999 -9999 -9999 -9999 -9999 -9999 -9999 -9999 -9999 -9999 -9999 -9999 -9999 -9999 -9999 -9999 -9999 -9999 -9999 -9999 -9999 -9999 -9999 -9999 -9999 -9999 -9999 -9999 -9999 -9999 -9999 -9999 -9999 -9999 -9999 -9999 -9999 -9999 -9999 -9999 -9999 -9999 -9999 -9999 -9999 -9999 -9999 -9999 -9999 -9999 -9999 -9999 -9999 -9999 -9999 -9999 -9999 -9999 -9999 -9999 -9999 -9999 -9999 -9999 -9999 -9999 -9999 -9999 -9999 -9999 -9999 -9999 -9999 -9999 -9999 -9999 -9999 -9999 -9999 -9999 -9999 -9999 -9999 -9999 -9999 -9999 -9999 -9999 -9999 -9999 -9999 -9999 -9999 -9999 -9999 -9999 -9999 -9999 -9999 -9999 -9999 -9999 -9999 -9999 -9999 -9999 -9999 -9999 -9999 -9999 -9999 -9999 -9999 -9999 -9999 -9999 -9999 -9999 -9999 -9999 -9999 -9999 -9999 -9999 -9999 -9999 -999 -9999 -9999 -9999 -9999 -9999 -9999 -9999 -9999 -9999 -9999 -9999 -9999 -9999 -9999 -9999 -9999 -9999 -9999 -9999 -9999 -9999 -9999 -9999 -9999 -9999 -9999 -9999 -9999 -9999 -

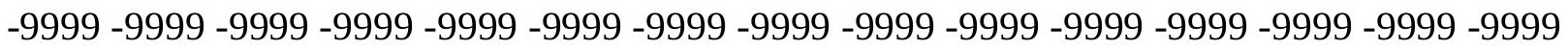

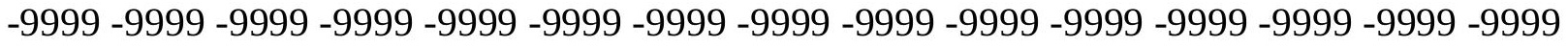

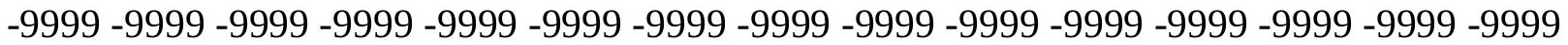
-9999 -9999 -9999 -9999 -9999 -9999 -9999 -9999 -9999 -9999 -9999 -9999 -9999 -9999 -9999 -

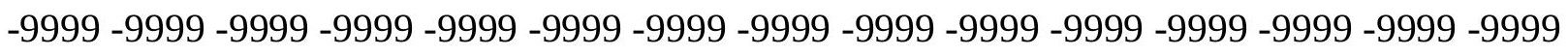

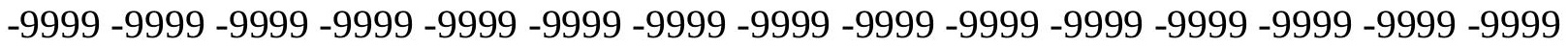

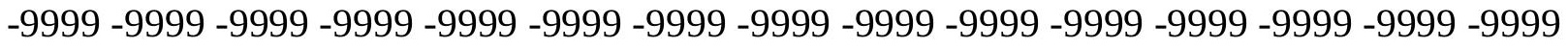
-9999 -9999 -9999 -9999 -9999 -9999 -9999 -9999 -9999 -9999 -9999 -9999 -9999 -9999 -9999 -

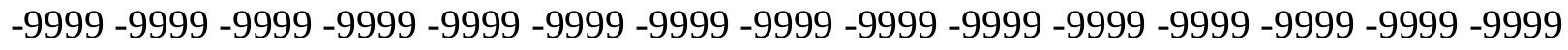

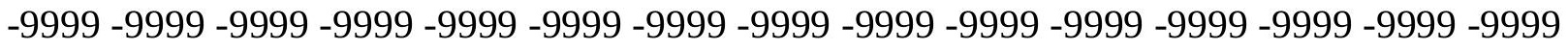
-9999 -9999 -9999 -9999 -9999 -9999 -9999 -9999 -9999 -9999 -9999 -9999 -9999 -9999 -9999 -9999 -9999 -9999 -9999 -9999 -9999 -9999 -9999 -9999-9999 -9999 -9999 -9999 -9999 -9999 -9999 -9999 -9999 -9999 -9999 -9999 -9999 -9999 -9999 -9999 -9999 -9999 -9999 -9999 -9999 -

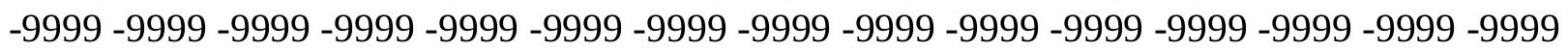


-9999 -9999 -9999 -9999 -9999 -9999 -9999 -9999 -9999 -9999 -9999 -9999 -9999 -9999 -9999 -9999 -9999 -9999 -9999 -9999 -9999 -9999 -9999 -9999 -9999 -9999 -9999 -9999 -9999 -9999 -

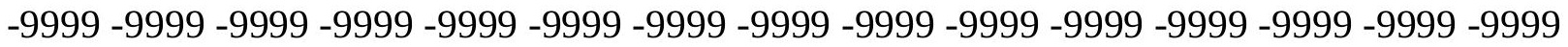
-9999 -9999 -9999 -9999 -9999 -9999 -9999 -9999 -9999 -9999 -9999 -9999 -9999 -9999 -9999 -9999 -9999 -9999 -9999 -9999 -9999 -9999 -9999 -9999-9999 -9999 -9999 -9999 -9999 -9999 -9999 -9999 -9999 -9999 -9999 -9999 -9999 -9999 -9999 -9999 -9999 -9999 -9999 -9999 -9999 -9999 -9999 -9999 -9999 -9999 -9999 -9999 -9999 -9999 -9999 -9999 -9999 -9999 -9999 -9999

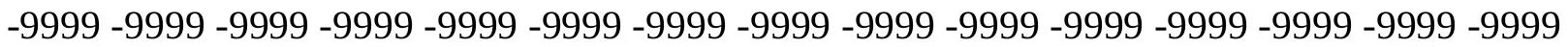

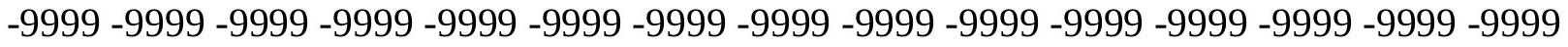
-9999 -9999 -9999 -9999 -9999 -9999 -9999 -9999 -9999 -9999 -9999 -9999 -9999 -9999 -9999 -9999 -9999 -9999 -9999 -9999 -9999 -9999 -9999 -9999 -9999 -9999 -9999 -9999 -9999 -9999 -9999 -9999 -9999 -9999 -9999 -9999 -9999 -9999 -9999 -9999 -9999 -9999 -9999 -9999 -9999 -9999 -9999 -9999 -9999 -9999 -9999 -9999 -9999 -9999 -9999 -9999 -9999 -9999 -9999 -9999 -9999 -9999 -9999 -9999 -9999 -9999 -9999 -9999 -9999 -9999 -9999 -9999 -9999 - 9999 -9999 -9999 -9999 -9999 -9999 -9999 -9999 -9999 -9999 -9999 -9999 -9999 -9999 -9999 -9999

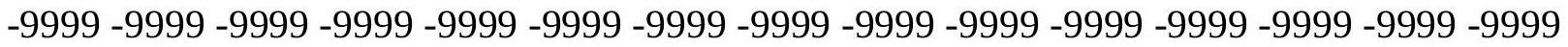
-9999 -9999 -9999 -9999 -9999 -9999 -9999 -9999 -9999 -9999 -9999 -9999 -9999 -9999 -9999 -9999 -9999 -9999 -9999 -9999 -9999 -9999 -9999 -9999 -9999 -9999 -9999 -9999 -9999 -9999 -9999 -9999 -9999 -9999 -9999 -9999 -9999 -9999 -9999 -9999 -9999 -9999 -9999 -9999 -9999 -

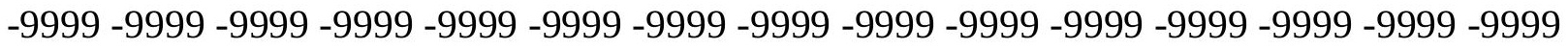

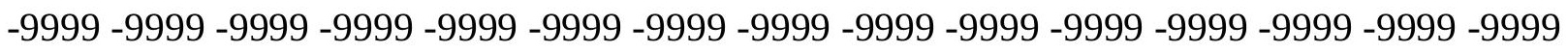
-9999 -9999 -9999 -9999 -9999 -9999 -9999 -9999 -9999 -9999 -9999 -9999 -9999 -9999 -9999 -9999 -9999 -9999 -9999 -9999 -9999 -9999 -9999 -9999 -9999 -9999 -9999 -9999 -9999 -9999 -9999 -9999 -9999 -9999 -9999 -9999 -9999 -9999 -9999 -9999 -9999 -9999 -9999 -9999 -9999 -

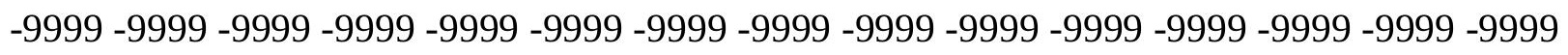
-9999 -9999 -9999 -9999 -9999 -9999 -9999 -9999 -9999 -9999 -9999 -9999 -9999 -9999 -9999 -9999 -9999 -9999 -9999 -9999 -9999 -9999 -9999 -9999 -9999 -9999 -9999 -9999 -9999 -9999 -

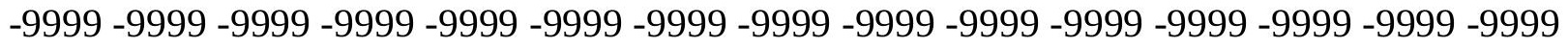
-9999 -9999 -9999 -9999 -9999 -9999 -9999 -9999 -9999 -9999 -9999 -9999 -9999 -9999 -9999 -9999 -9999 -9999 -9999 -9999 -9999 -9999 -9999 -9999 -9999 -9999 -9999 -9999 -9999 -999 -9999 -9999 -9999 -9999 -9999 -9999 -9999 -9999 -9999 -9999 -9999 -9999 -9999 -9999 -9999 -9999 -9999 -9999 -9999 -9999 -9999 -9999 -9999 -9999 -9999 -9999 -9999 -9999 -9999 -9999 -

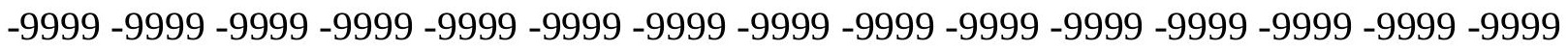

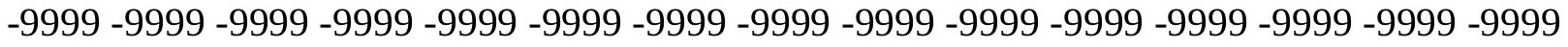

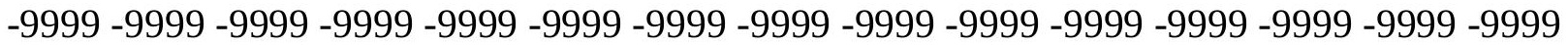

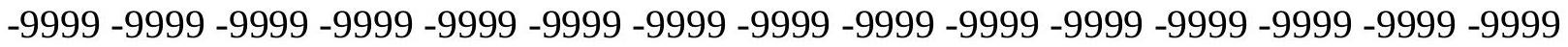

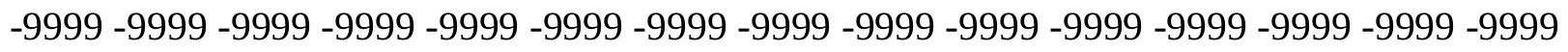

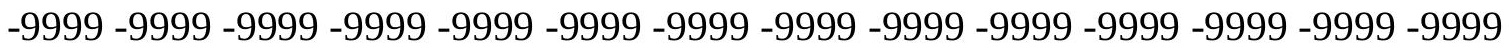
-9999 -9999 -9999 -9999 -9999 -9999 -9999 -9999 -9999 -9999 -9999 -9999 -9999 -9999 -9999 -9999 -9999 -9999 -9999 -9999 -9999 -9999 -9999 -9999 -9999 -9999 -9999 -9999 -9999 -9999 -

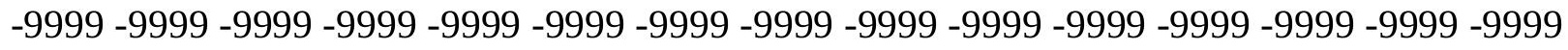

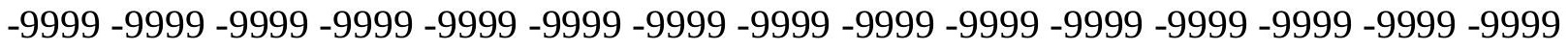
-9999 -9999 -9999 -9999 -9999 -9999 -9999 -9999 -9999 -9999 -9999 -9999 -9999 -9999 -9999 -9999 -9999 -9999 -9999 -9999 -9999 -9999 -9999 -9999-9999 -9999 -9999 -9999 -9999 -9999 -9999 -9999 -9999 -9999 -9999 -9999 -9999 -9999 -9999 -9999 -9999 -9999 -9999 -9999 -9999 -

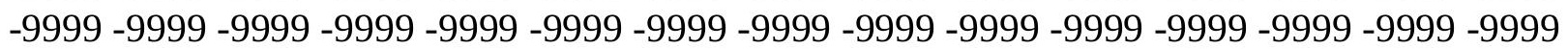


-9999 -9999 -9999 -9999 -9999 -9999 -9999 -9999 -9999 -9999 -9999 -9999 -9999 -9999 -9999 -9999 -9999 -9999 -9999 -9999 -9999 -9999 -9999 -9999 -9999 -9999 -9999 -9999 -9999 -9999 -9999 -9999 -9999 -9999 -9999 -9999 -9999 -9999 -9999 -9999 -9999 -9999 -9999 -9999 - 9999 -9999 -9999 -9999 -9999 -9999 -9999 -9999 -9999 -9999 -9999 -9999 -9999 -9999 -9999 -9999 -9999 -9999 -9999 -9999 -9999 -9999 -9999 -9999 -9999 -9999 -9999 -9999 -9999 -9999 -9999 -9999 -9999 -9999 -9999 -9999 -9999 -9999 -9999 -9999 -9999 -9999 -9999 -9999 -9999 -9999 -9999 -9999 -9999 -9999 -9999 -9999 -9999 -9999 -9999 -9999 -9999 -9999 -9999 -9999 -9999

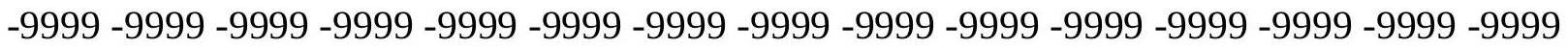
-9999 -9999 -9999 -9999 -9999 -9999 -9999 -9999 -9999 -9999 -9999 -9999 -9999 -9999 -9999 -9999 -9999 -9999 -9999 -9999 -9999 -9999 -9999 -9999 -9999 -9999 -9999 -9999 -9999 -9999

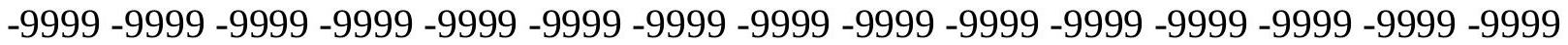
-9999 -9999 -9999 -9999 -9999 -9999 -9999 -9999 -9999 -9999 -9999 -9999 -9999 -9999 -9999 -9999 -9999 -9999 -9999 -9999 -9999 -9999 -9999 -9999 -9999 -9999 -9999 -9999 -9999 -9999 -

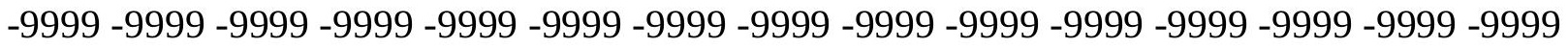
-9999 -9999 -9999 -9999 -9999 -9999 -9999 -9999 -9999 -9999 -9999 -9999 -9999 -9999 -9999

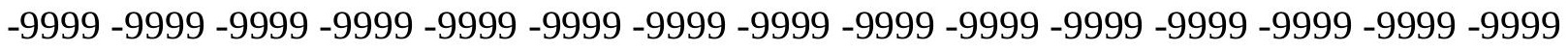
-9999 -9999 -9999 -9999 -9999 -9999 -9999 -9999 -9999 -9999 -9999 -9999 -9999 -9999 -9999 -9999 -9999 -9999 -9999 -9999 -9999 -9999 -9999 -9999 -9999 -9999 -9999 -9999 -9999 - -999 -9999 -9999 -9999 -9999 -9999 -9999 -9999 -9999 -9999 -9999 -9999 -9999 -9999 -9999 -9999 -9999 -9999 -9999 -9999 -9999 -9999 -9999 -9999 -9999 -9999 -9999 -9999 -9999 -9999 -9999 -9999 -9999 -9999 -9999 -9999 -9999 -9999 -9999 -9999 -9999 -9999 -9999 -9999 -9999 -9999 -999 -9999 -9999 -9999 -9999 -9999 -9999 -9999 -9999 -9999 -9999 -9999 -9999 -9999 -9999 -9999 -9999 -9999 -9999 -9999 -9999 -9999 -9999 -9999 -9999 -9999 -9999 -9999 -9999 -9999 -9999 -9999 -9999 -9999 -9999 -9999 -9999 -9999 -9999 -9999 -9999 -9999 -9999 -9999 -9999 -9999 -9999 -9999 -9999 -9999 -9999 -9999 -9999 -9999 -9999 -9999 -9999 -9999 -9999 -9999 -9999 -9999 -9999 -9999 -9999 -9999 -9999 -9999 -9999 -9999 -9999 -9999 -9999 -9999 -9999 -9999 -9999 -9999 -9999 -9999 -9999 -9999 -9999 -9999 -9999 -9999 -9999 -9999 -9999 -9999 -9999 -9999 -9999 -9999 -9999 -9999 -9999 -9999 -9999 -9999 -9999 -9999 -9999 -9999 -9999 -9999 -9999 -9999 -9999 -9999 -9999 -9999 -9999 -9999 -9999 -9999 -9999 -9999 -9999 -9999 -9999 -9999 -9999 -9999 -9999 -9999 -9999 -9999 -9999 -9999 -9999 -9999 -9999 -9999 -9999 -999 -9999 -9999 -9999 -9999 -9999 -9999 -9999 -9999 -9999 -9999 -9999 -9999 -9999 -9999 -9999 -9999 -9999 -9999 -9999 -9999 -9999 -9999 -9999 -9999 -9999 -9999 -9999 -9999 -9999 -9999 -

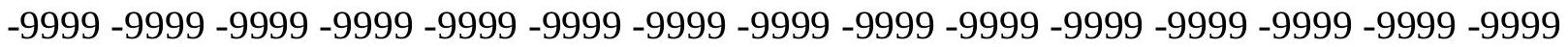

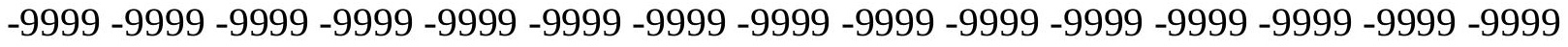

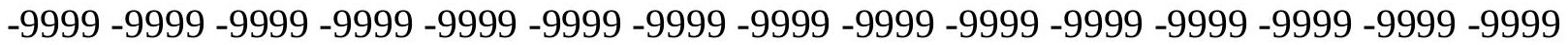
-9999 -9999 -9999 -9999 -9999 -9999 -9999 -9999 -9999 -9999 -9999 -9999 -9999 -9999 -9999

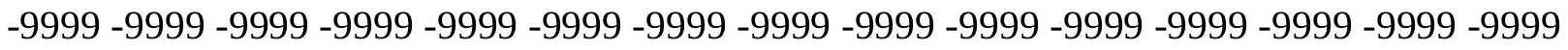

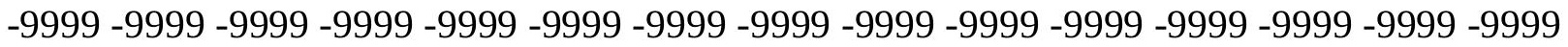

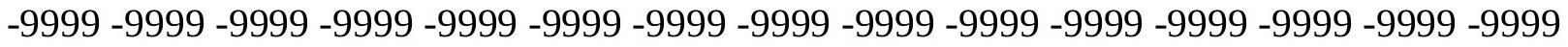
-9999 -9999 -9999 -9999 -9999 -9999 -9999 -9999 -9999 -9999 -9999 -9999 -9999 -9999 -9999 -

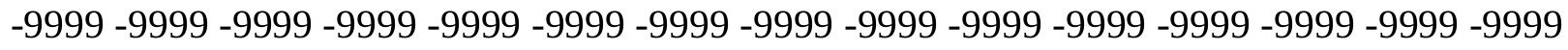

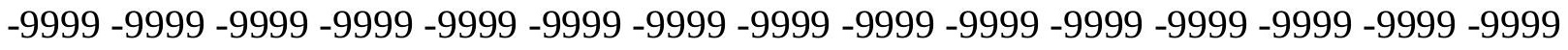
-9999 -9999 -9999 -9999 -9999 -9999 -9999 -9999 -9999 -9999 -9999 -9999 -9999 -9999 -9999 -9999 -9999 -9999 -9999 -9999 -9999 -9999 -9999 -9999 -9999 -9999 -9999 -9999 - -9999 -9999 -9999 -9999 -9999 -9999 -9999 -9999 -9999 -9999 -9999 -9999 -9999 -9999 -9999 -9999 -

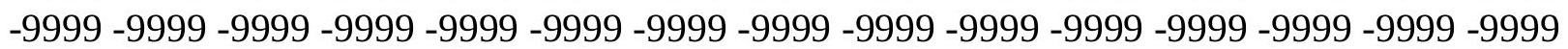


-9999 -9999 -9999 -9999 -9999 -9999 -9999 -9999 -9999 -9999 -9999 -9999 -9999 -9999 -9999 -9999 -9999 -9999 -9999 -9999 -9999 -9999 -9999 -9999 -9999 -9999 -9999 -9999 -9999 -9999 -9999 -9999 -9999 -9999 -9999 -9999 -9999 -9999 -9999 -9999 -9999 -9999 -9999 -9999 - 9999 -9999 -9999 -9999 -9999 -9999 -9999 -9999 -9999 -9999 -9999 -9999 -9999 -9999 -9999 -9999 -9999 -9999 -9999 -9999 -9999 -9999 -9999 -9999 -9999-9999 -9999 -9999 -9999 -9999 -9999 -9999 -9999 -9999 -9999 -9999 -9999 -9999 -9999 -9999 -9999 -9999 -9999 -9999 -9999 -9999 -9999 -9999 -9999 -9999 -9999 -9999 -9999 -9999 -9999 -9999 -9999 -9999 -9999 -9999 -9999

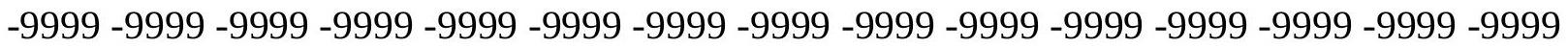

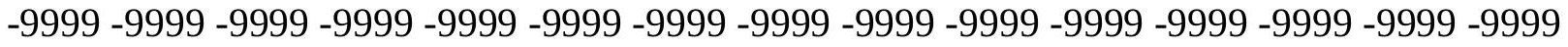
-9999 -9999 -9999 -9999 -9999 -9999 -9999 -9999 -9999 -9999 -9999 -9999 -9999 -9999 -9999

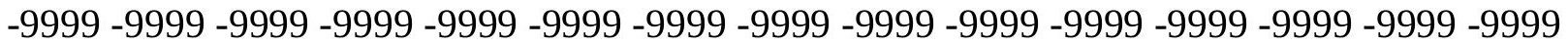
-9999 -9999 -9999 -9999 -9999 -9999 -9999 -9999 -9999 -9999 -9999 -9999 -9999 -9999 -9999 -9999 -9999 -9999 -9999 -9999 -9999 -9999 -9999 -9999 -9999 -9999 -9999 -9999 -9999 -9999 -

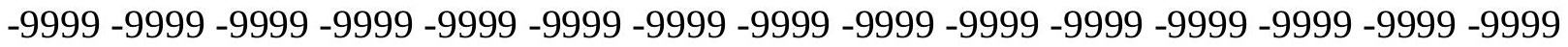
-9999 -9999 -9999 -9999 -9999 -9999 -9999 -9999 -9999 -9999 -9999 -9999 -9999 -9999 -9999

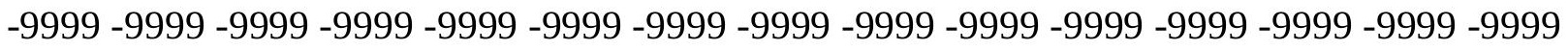
-9999 -9999 -9999 -9999 -9999 -9999 -9999 -9999 -9999 -9999 -9999 -9999 -9999 -9999 -9999 -9999 -9999 -9999 -9999 -9999 -9999 -9999 -9999 -9999 -9999 -9999 -9999 -9999 -9999 -9999 -9999 -9999 -9999 -9999 -9999 -9999 -9999 -9999 -9999 -9999 -9999 -9999 -9999 -9999 -9999 -9999 -9999 -9999 -9999 -9999 -9999 -9999 -9999 -9999 -9999 -9999 -9999 -9999 -9999 -9999 -9999 -9999 -9999 -9999 -9999 -9999 -9999 -9999 -9999 -9999 -9999 -9999 -9999 -9999 -9999 -999 -9999 -9999 -9999 -9999 -9999 -9999 -9999 -9999 -9999 -9999 -9999 -9999 -9999 -9999 -9999 -9999 -9999 -9999 -9999 -9999 -9999 -9999 -9999 -9999 -9999 -9999 -9999 -9999 -9999 -9999 -9999 -9999 -9999 -9999 -9999 -9999 -9999 -9999 -9999 -9999 -9999 -9999 -9999 -9999 -9999 -9999 -9999 -9999 -9999 -9999 -9999 -9999 -9999 -9999 -9999 -9999 -9999 -9999 -9999 -9999 -9999 -9999 -9999 -9999 -9999 -9999 -9999 -9999 -9999 -9999 -9999 -9999 -9999 -9999 -9999 -9999 -9999 -9999 -9999 -9999 -9999 -9999 -9999 -9999 -9999 -9999 -9999 -9999 -9999 -9999 -9999 -9999 -9999 -9999 -9999 -9999 -9999 -9999 -9999 -9999 -9999 -9999 -9999 -9999 -9999 -9999 -9999 -9999 -9999 -9999 -9999 -9999 -9999 -9999 -9999 -9999 -9999 -9999 -9999 -9999 -9999 -9999 -9999 -9999 -9999 -9999 -9999 -9999 -9999 -9999 -9999 -9999 -9999 -999 -9999 -9999 -9999 -9999 -9999 -9999 -9999 -9999 -9999 -9999 -9999 -9999 -9999 -9999 -9999 -9999 -9999 -9999 -9999 -9999 -9999 -9999 -9999 -9999 -9999 -9999 -9999 -9999 -9999 -9999 -

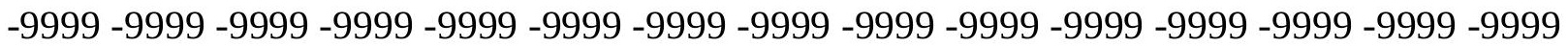

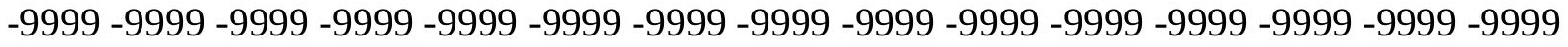

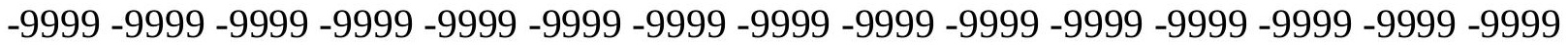
-9999 -9999 -9999 -9999 -9999 -9999 -9999 -9999 -9999 -9999 -9999 -9999 -9999 -9999 -9999

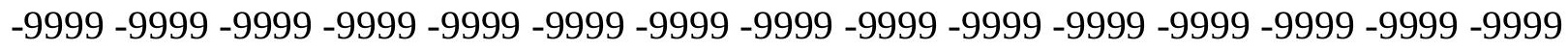

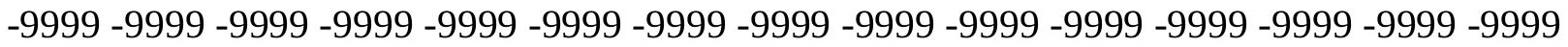
-9999 -9999 -9999 -9999 -9999 -9999 -9999 -9999 -9999 -9999 -9999 -9999 -9999 -9999 -9999 -9999 -9999 -9999 -9999 -9999 -9999 -9999 -9999 -9999 -9999 -9999 -9999 -9999 -9999 -9999 -

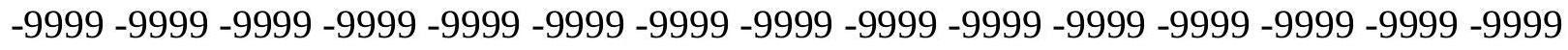

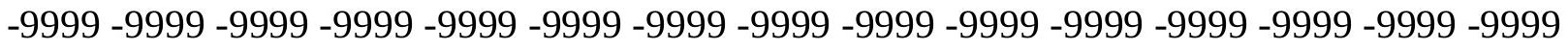
-9999 -9999 -9999 -9999 -9999 -9999 -9999 -9999 -9999 -9999 -9999 -9999 -9999 -9999 -9999 -9999 -9999 -9999 -9999 -9999 -9999 -9999 -9999 -9999-9999 -9999 -9999 -9999 -9999 -9999 -9999 -9999 -9999 -9999 -9999 -9999 -9999 -9999 -9999 -9999 -9999 -9999 -9999 -9999 -9999 -

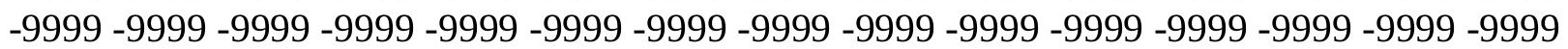


-9999 -9999 -9999 -9999 -9999 -9999 -9999 -9999 -9999 -9999 -9999 -9999 -9999 -9999 -9999 -9999 -9999 -9999 -9999 -9999 -9999 -9999 -9999 -9999 -9999 -9999 -9999 -9999 -9999 -9999 -9999 -9999 -9999 -9999 -9999 -9999 -9999 -9999 -9999 -9999 -9999 -9999 -9999 -9999 - 9999 -9999 -9999 -9999 -9999 -9999 -9999 -9999 -9999 -9999 -9999 -9999 -9999 -9999 -9999

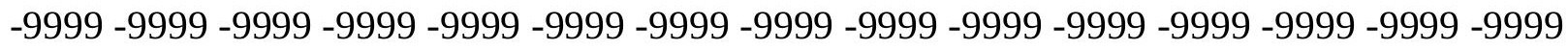
-9999 -9999 -9999 -9999 -9999 -9999 -9999 -9999 -9999 -9999 -9999 -9999 -9999 -9999 -9999 -9999 -9999 -9999 -9999 -9999 -9999 -9999 -9999 -9999 -9999 -9999 -9999 -9999 -9999 -9999

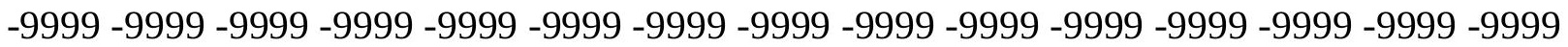

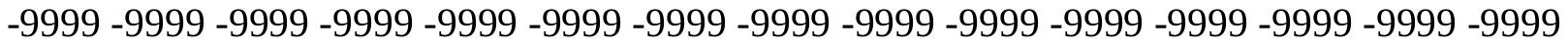
-9999 -9999 -9999 -9999 -9999 -9999 -9999 -9999 -9999 -9999 -9999 -9999 -9999 -9999 -9999 -9999 -9999 -9999 -9999 -9999 -9999 -9999 -9999 -9999 -9999 -9999 -9999 -9999 -9999 -9999 -9999 -9999 -9999 -9999 -9999 -9999 -9999 -9999 -9999 -9999 -9999 -9999 -9999 -9999 -9999 -9999 -9999 -9999 -9999 -9999 -9999 -9999 -9999 -9999 -9999 -9999 -9999 -9999 -9999 -9999 -

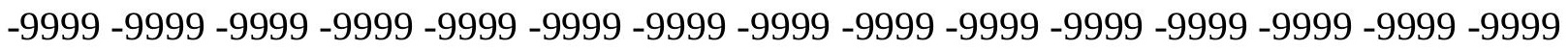
-9999 -9999 -9999 -9999 -9999 -9999 -9999 -9999 -9999 -9999 -9999 -9999 -9999 -9999 -9999 -

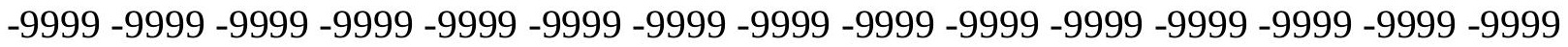
-9999 -9999 -9999 -9999 -9999 -9999 -9999 -9999 -9999 -9999 -9999 -9999 -9999 -9999 -9999 -9999 -9999 -9999 -9999 -9999 -9999 -9999 -9999 -9999 -9999 -9999 -9999 -9999 -9999 -9999 -9999 -9999 -9999 -9999 -9999 -9999 -9999 -9999 -9999 -9999 -9999 -9999 -9999 -9999 -9999 -

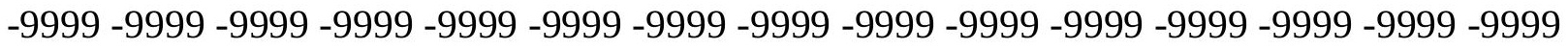
-9999 -9999 -9999 -9999 -9999 -9999 -9999 -9999 -9999 -9999 -9999 -9999 -9999 -9999 -9999

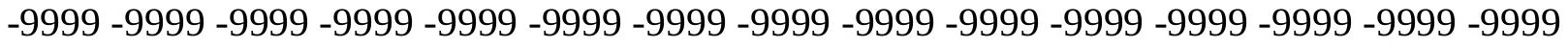
-9999 -9999 -9999 -9999 -9999 -9999 -9999 -9999 -9999 -9999 -9999 -9999 -9999 -9999 -9999 -9999 -9999 -9999 -9999 -9999 -9999 -9999 -9999 -9999 -9999 -9999 -9999 -9999 -9999 -9999 -9999 -9999 -9999 -9999 -9999 -9999 -9999 -9999 -9999 -9999 -9999 -9999 -9999 -9999 -9999 -9999 -9999 -9999 -9999 -9999 -9999 -9999 -9999 -9999 -9999 -9999 -9999 -9999 -9999 -9999 -9999 -9999 -9999 -9999 -9999 -9999 -9999 -9999 -9999 -9999 -9999 -9999 -9999 -9999 -9999 -9999 -9999 -9999 -9999 -9999 -9999 -9999 -9999 -9999 -9999 -9999 -9999 -9999 -9999 -9999 -9999 -9999 -9999 -9999 -9999 -9999 -9999 -9999 -9999 -9999 -9999 -9999 -9999 -9999 -9999 -9999 -9999 -9999 -9999 -9999 -9999 -9999 -9999 -9999 -9999 -9999 -9999 -9999 -9999 -9999 -9999 -9999 -9999 -9999 -9999 -9999 -9999 -9999 -9999 -9999 -9999 -9999 -9999 -9999 -9999 -9999 -9999 -9999 -9999 -9999 -9999 -9999 -9999 -9999 -9999 -9999 -9999 -9999 -9999 -

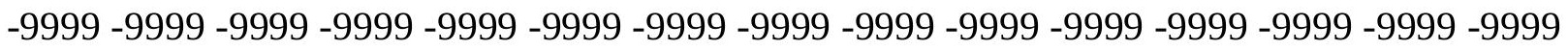

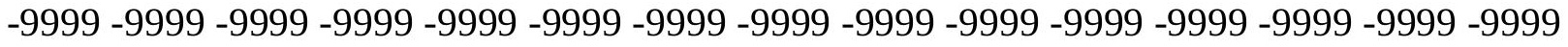
-9999 -9999 -9999 -9999 -9999 -9999 -9999 -9999 -9999 -9999 -9999 -9999 -9999 -9999 -9999 -

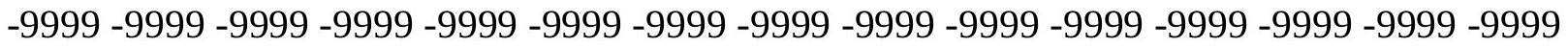

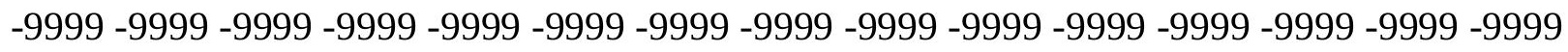

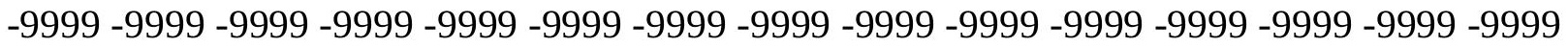

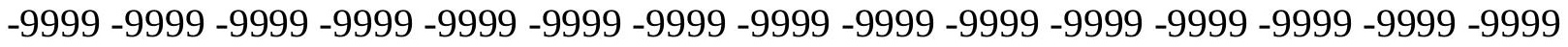
-9999 -9999 -9999 -9999 -9999 -9999 -9999 -9999 -9999 -9999 -9999 -9999 -9999 -9999 -9999 -

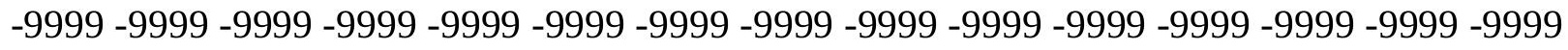

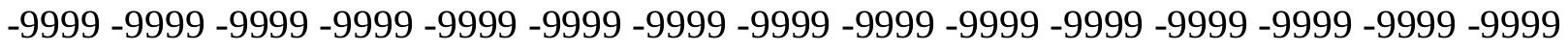
-9999 -9999 -9999 -9999 -9999 -9999 -9999 -9999 -9999 -9999 -9999 -9999 -9999 -9999 -9999 -9999 -9999 -9999 -9999 -9999 -9999 -9999 -9999 -9999-9999 -9999 -9999 -9999 -9999 -9999 -9999 -9999 -9999 -9999 -9999 -9999 -9999 -9999 -9999 -9999 -9999 -9999 -9999 -9999 -9999 -

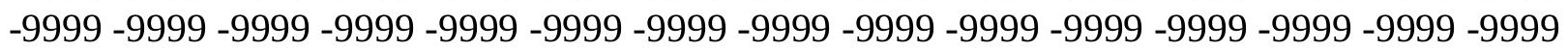


-9999 -9999 -9999 -9999 -9999 -9999 -9999 -9999 -9999 -9999 -9999 -9999 -9999 -9999 -9999 -9999 -9999 -9999 -9999 -9999 -9999 -9999 -9999 -9999 -9999 -9999 -9999 -9999 -9999 -9999 -9999 -9999 -9999 -9999 -9999 -9999 -9999 -9999 -9999 -9999 -9999 -9999 -9999 -9999 - 9999 -9999 -9999 -9999 -9999 -9999 -9999 -9999 -9999 -9999 -9999 -9999 -9999 -9999 -9999 -9999 -9999 -9999 -9999 -9999 -9999 -9999 -9999 -9999 -9999 -9999 -9999 -9999 -9999 -9999 -9999 -9999 -9999 -9999 -9999 -9999 -9999 -9999 -9999 -9999 -9999 -9999 -9999 -9999 -9999 -9999 -9999 -9999 -9999 -9999 -9999 -9999 -9999 -9999 -9999 -9999 -9999 -9999 -9999 -9999 -9999

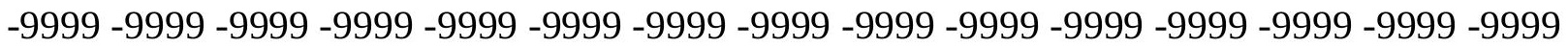

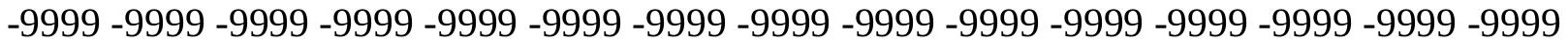
-9999 -9999 -9999 -9999 -9999 -9999 -9999 -9999 -9999 -9999 -9999 -9999 -9999 -9999 -9999 -9999 -9999 -9999 -9999 -9999 -9999 -9999 -9999 -9999 -9999 -9999 -9999 -9999 -9999 -9999 -9999 -9999 -9999 -9999 -9999 -9999 -9999 -9999 -9999 -9999 -9999 -9999 -9999 -9999 -9999 -9999 -9999 -9999 -9999 -9999 -9999 -9999 -9999 -9999 -9999 -9999 -9999 -9999 -9999 -9999 -9999 -9999 -9999 -9999 -9999 -9999 -9999 -9999 -9999 -9999 -9999 -9999 -9999 -9999 -9999 -9999 -9999 -9999 -9999 -9999 -9999 -9999 -9999 -9999 -9999 -9999 -9999 -9999 -9999 -

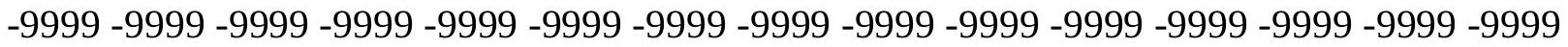
-9999 -9999 -9999 -9999 -9999 -9999 -9999 -9999 -9999 -9999 -9999 -9999 -9999 -9999 -9999 -9999 -9999 -9999 -9999 -9999 -9999 -9999 -9999 -9999 -9999 -9999 -9999 -9999 -9999 -9999 -9999 -9999 -9999 -9999 -9999 -9999 -9999 -9999 -9999 -9999 -9999 -9999 -9999 -9999 -9999 -9999 -9999 -9999 -9999 -9999 -9999 -9999 -9999 -9999 -9999 -9999 -9999 -9999 -9999 -9999 -9999 -9999 -9999 -9999 -9999 -9999 -9999 -9999 -9999 -9999 -9999 -9999 -9999 -9999 -9999 -999 -9999 -9999 -9999 -9999 -9999 -9999 -9999 -9999 -9999 -9999 -9999 -9999 -9999 -9999 -9999 -9999 -9999 -9999 -9999 -9999 -9999 -9999 -9999 -9999 -9999 -9999 -9999 -9999 -9999 -9999 -9999 -9999 -9999 -9999 -9999 -9999 -9999 -9999 -9999 -9999 -9999 -9999 -9999 -9999 -9999 -9999 -9999 -9999 -9999 -9999 -9999 -9999 -9999 -9999 -9999 -9999 -9999 -9999 -9999 -9999 -9999 -9999 -9999 -9999 -9999 -9999 -9999 -9999 -9999 -9999 -9999 -9999 -9999 -9999 -9999 -9999 -9999 -9999 -9999 -9999 -9999 -9999 -9999 -9999 -9999 -9999 -9999 -9999 -9999 -9999 -9999 -9999 -9999 -9999 -9999 -9999 -9999 -9999 -9999 -9999 -9999 -9999 -9999 -9999 -9999 -9999 -9999 -9999 -9999 -9999 -9999 -9999 -9999 -9999 -9999 -9999 -9999 -9999 -9999 -9999 -9999 -9999 -9999 -9999 -9999 -9999 -9999 -9999 -9999 -9999 -9999 -9999 -9999 -9999 -999 -9999 -9999 -9999 -9999 -9999 -9999 -9999 -9999 -9999 -9999 -9999 -9999 -9999 -9999 -9999 -9999 -9999 -9999 -9999 -9999 -9999 -9999 -9999 -9999 -9999 -9999 -9999 -9999 -9999 -9999 -

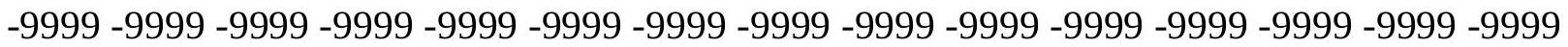

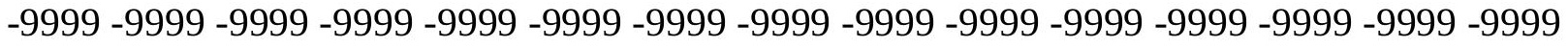

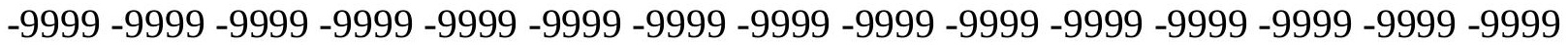
-9999 -9999 -9999 -9999 -9999 -9999 -9999 -9999 -9999 -9999 -9999 -9999 -9999 -9999 -9999 -9999 -9999 -9999 -9999 -9999 -9999 -9999 -9999 -9999 -9999 -9999 -9999 -9999 -9999 -

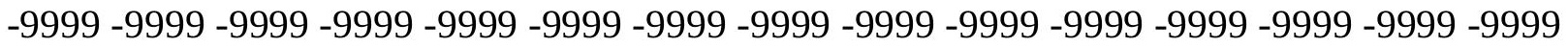
-9999 -9999 -9999 -9999 -9999 -9999 -9999 -9999 -9999 -9999 -9999 -9999 -9999 -9999 -9999 -9999 -9999 -9999 -9999 -9999 -9999 -9999 -9999 -9999 -9999 -9999 -9999 -9999 -9999 -9999 -

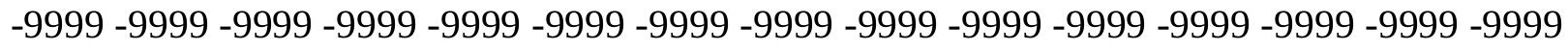

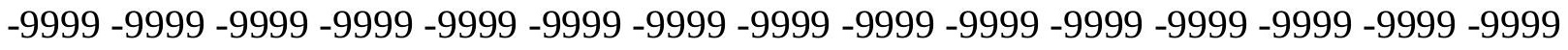
-9999 -9999 -9999 -9999 -9999 -9999 -9999 -9999 -9999 -9999 -9999 -9999 -9999 -9999 -9999 -9999 -9999 -9999 -9999 -9999 -9999 -9999 -9999 -9999-9999 -9999 -9999 -9999 -9999 -9999 -9999 -9999 -9999 -9999 -9999 -9999 -9999 -9999 -9999 -9999 -9999 -9999 -9999 -9999 -9999 -

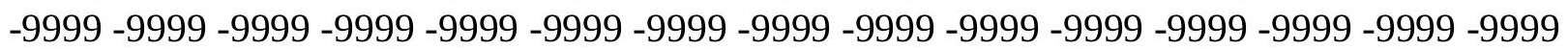


-9999 -9999 -9999 -9999 -9999 -9999 -9999 -9999 -9999 -9999 -9999 -9999 -9999 -9999 -9999 -9999 -9999 -9999 -9999 -9999 -9999 -9999 -9999 -9999 -9999 -9999 -9999 -9999 -9999 -9999 -

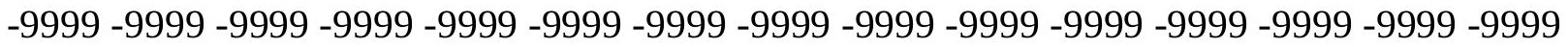
-9999 -9999 -9999 -9999 -9999 -9999 -9999 -9999 -9999 -9999 -9999 -9999 -9999 -9999 -9999 -9999 -9999 -9999 -9999 -9999 -9999 -9999 -9999 -9999-9999 -9999 -9999 -9999 -9999 -9999 -9999 -9999 -9999 -9999 -9999 -9999 -9999 -9999 -9999 -9999 -9999 -9999 -9999 -9999 -9999 -9999 -9999 -9999 -9999 -9999 -9999 -9999 -9999 -9999 -9999 -9999 -9999 -9999 -9999 -9999

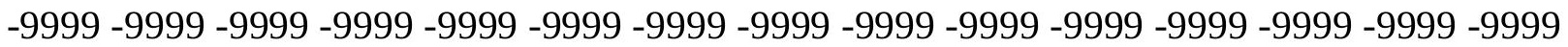

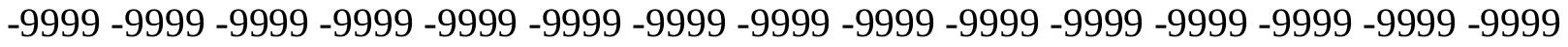
-9999 -9999 -9999 -9999 -9999 -9999 -9999 -9999 -9999 -9999 -9999 -9999 -9999 -9999 -9999 -9999 -9999 -9999 -9999 -9999 -9999 -9999 -9999 -9999 -9999 -9999 -9999 -9999 -9999 -9999 -9999 -9999 -9999 -9999 -9999 -9999 -9999 -9999 -9999 -9999 -9999 -9999 -9999 -9999 -9999 -9999 -9999 -9999 -9999 -9999 -9999 -9999 -9999 -9999 -9999 -9999 -9999 -9999 -9999 -9999 -9999 -9999 -9999 -9999 -9999 -9999 -9999 -9999 -9999 -9999 -9999 -9999 -9999 -9999 -9999 -9999 -9999 -9999 -9999 -9999 -9999 -9999 -9999 -9999 -9999 -9999 -9999 -9999 -9999 -9999 -

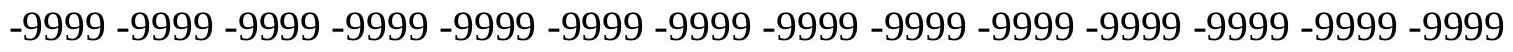
-9999 -9999 -9999 -9999 -9999 -9999 -9999 -9999 -9999 -9999 -9999 -9999 -9999 -9999 -9999 -9999 -9999 -9999 -9999 -9999 -9999 -9999 -9999 -9999 -9999 -9999 -9999 -9999 -9999 -9999 -9999 -9999 -9999 -9999 -9999 -9999 -9999 -9999 -9999 -9999 -9999 -9999 -9999 -9999 -9999 -

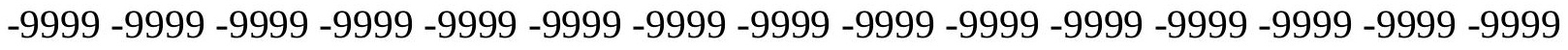

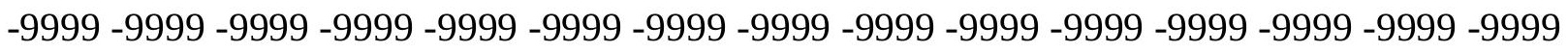
-9999 -9999 -9999 -9999 -9999 -9999 -9999 -9999 -9999 -9999 -9999 -9999 -9999 -9999 - 9999 -9999 -9999 -9999 -9999 -9999 -9999 -9999 -9999 -9999 -9999 -9999 -9999 -9999 -9999 -9999 -9999 -9999 -9999 -9999 -9999 -9999 -9999 -9999 -9999 -9999 -9999 -9999 -9999 -9999 -9999 -

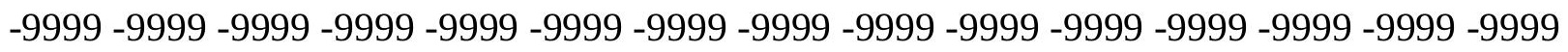
-9999 -9999 -9999 -9999 -9999 -9999 -9999 -9999 -9999 -9999 -9999 -9999 -9999 -9999 -9999 -9999 -9999 -9999 -9999 -9999 -9999 -9999 -9999 -9999 -9999 -9999 -9999 -9999 -9999 -9999 -

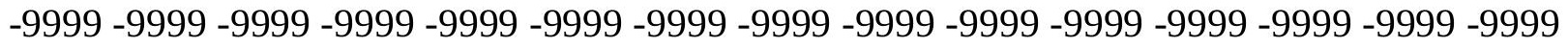
-9999 -9999 -9999 -9999 -9999 -9999 -9999 -9999 -9999 -9999 -9999 -9999 -9999 -9999 -9999 -9999 -9999 -9999 -9999 -9999 -9999 -9999 -9999 -9999 -9999 -9999 -9999 -9999 -9999 -999 -

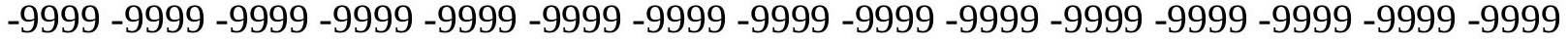
-9999 -9999 -9999 -9999 -9999 -9999 -9999 -9999 -9999 -9999 -9999 -9999 -9999 -9999 -9999 -

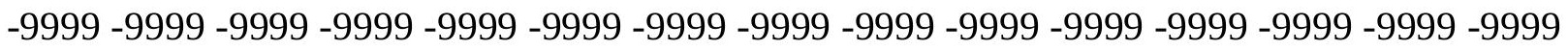

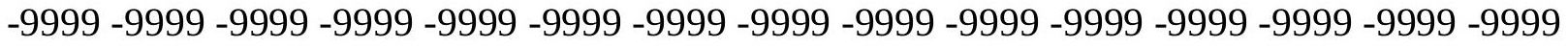

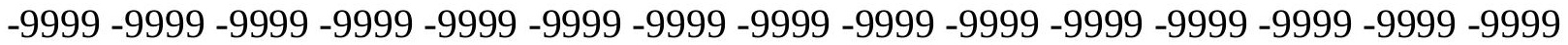
-9999 -9999 -9999 -9999 -9999 -9999 -9999 -9999 -9999 -9999 -9999 -9999 -9999 -9999 -9999 -

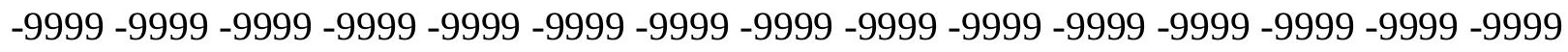

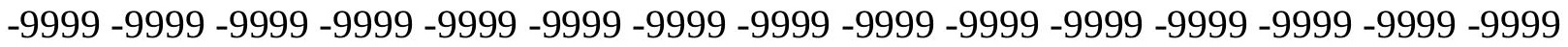
-9999 -9999 -9999 -9999 -9999 -9999 -9999 -9999 -9999 -9999 -9999 -9999 -9999 - 9999 - -999 -9999 -9999 -9999 -9999 -9999 -9999 -9999 -9999 -9999 -9999 -9999 -9999 -9999 -9999 -9999 -

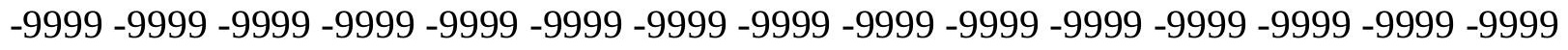

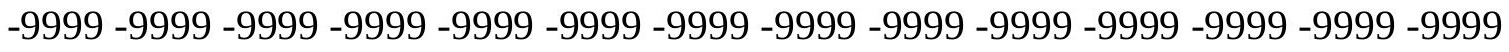
-9999 -9999 -9999 -9999 -9999 -9999 -9999 -9999 -9999 -9999 -9999 -9999 -9999 -9999 -9999 -9999 -9999 -9999 -9999 -9999 -9999 -9999 -9999 -9999-9999 -9999 -9999 -9999 -9999 -9999 -9999 -9999 -9999 -9999 -9999 -9999 -9999 -9999 -9999 -9999 -9999 -9999 -9999 -9999 -9999 -

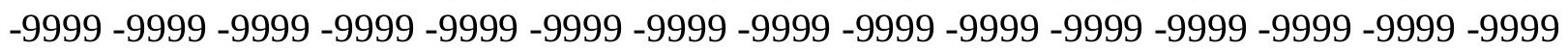


-9999 -9999 -9999 -9999 -9999 -9999 -9999 -9999 -9999 -9999 -9999 -9999 -9999 -9999 -9999 -9999 -9999 -9999 -9999 -9999 -9999 -9999 -9999 -9999 -9999 -9999 -9999 -9999 -9999 -9999 -

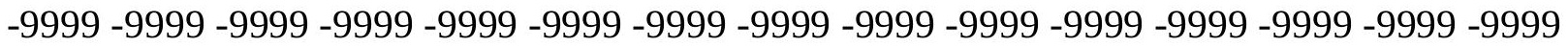
-9999 -9999 -9999 -9999 -9999 -9999 -9999 -9999 -9999 -9999 -9999 -9999 -9999 -9999 -9999 -9999 -9999 -9999 -9999 -9999 -9999 -9999 -9999 -9999-9999 -9999 -9999 -9999 -9999 -9999 -9999 -9999 -9999 -9999 -9999 -9999 -9999 -9999 -9999 -9999 -9999 -9999 -9999 -9999 -9999 -9999 -9999 -9999 -9999 -9999 -9999 -9999 -9999 -9999 -9999 -9999 -9999 -9999 -9999 -9999

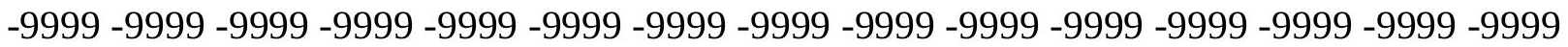

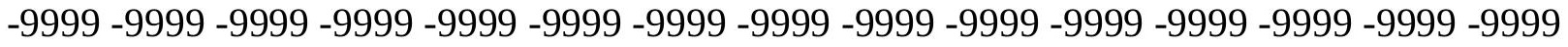
-9999 -9999 -9999 -9999 -9999 -9999 -9999 -9999 -9999 -9999 -9999 -9999 -9999 -9999 -9999 -9999 -9999 -9999 -9999 -9999 -9999 -9999 -9999 -9999 -9999 -9999 -9999 -9999 -9999 -9999 -9999 -9999 -9999 -9999 -9999 -9999 -9999 -9999 -9999 -9999 -9999 -9999 -9999 -9999 -9999 -9999 -9999 -9999 -9999 -9999 -9999 -9999 -9999 -9999 -9999 -9999 -9999 -9999 -9999 -9999 -

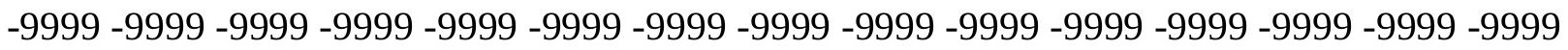
-9999 -9999 -9999 -9999 -9999 -9999 -9999 -9999 -9999 -9999 -9999 -9999 -9999 -9999 -9999 -

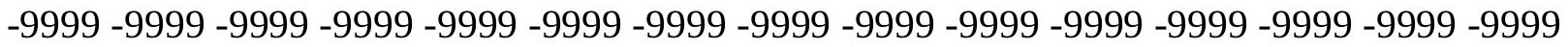
-9999 -9999 -9999 -9999 -9999 -9999 -9999 -9999 -9999 -9999 -9999 -9999 -9999 -9999 -9999 -9999 -9999 -9999 -9999 -9999 -9999 -9999 -9999 -9999 -9999 -9999 -9999 -9999 -9999 -9999 -9999 -9999 -9999 -9999 -9999 -9999 -9999 -9999 -9999 -9999 -9999 -9999 -9999 -9999 -9999 -

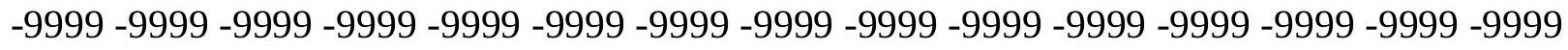

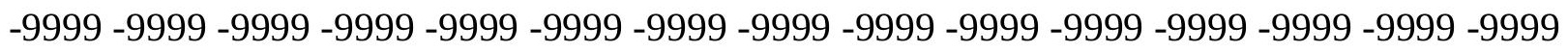
-9999 -9999 -9999 -9999 -9999 -9999 -9999 -9999 -9999 -9999 -9999 -9999 -9999 -9999 -9999 -9999 -9999 -9999 -9999 -9999 -9999 -9999 -9999 -9999 -9999 -9999 -9999 -9999 -9999 -9999 -9999 -9999 -9999 -9999 -9999 -9999 -9999 -9999 -9999 -9999 -9999 -9999 -9999 -9999 -

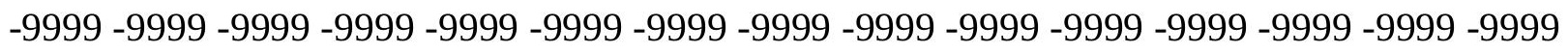
-9999 -9999 -9999 -9999 -9999 -9999 -9999 -9999 -9999 -9999 -9999 -9999 -9999 -9999 -9999 -9999 -9999 -9999 -9999 -9999 -9999 -9999 -9999 -9999 -9999 -9999 -9999 -9999 -9999 -9999 -

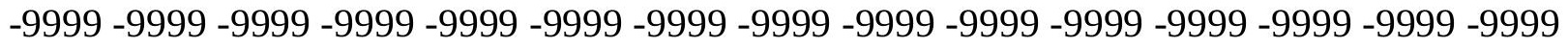
-9999 -9999 -9999 -9999 -9999 -9999 -9999 -9999 -9999 -9999 -9999 -9999 -9999 -9999 -9999 -9999 -9999 -9999 -9999 -9999 -9999 -9999 -9999 -9999 -9999 -9999 -9999 -9999 -9999 -999 -

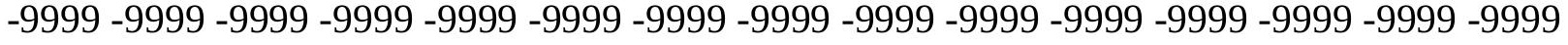
-9999 -9999 -9999 -9999 -9999 -9999 -9999 -9999 -9999 -9999 -9999 -9999 -9999 -9999 -9999 -

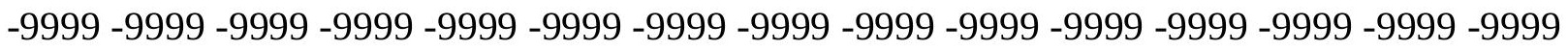

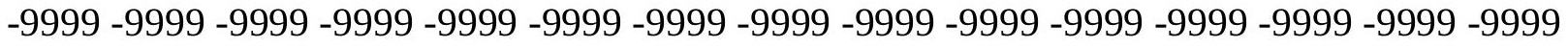

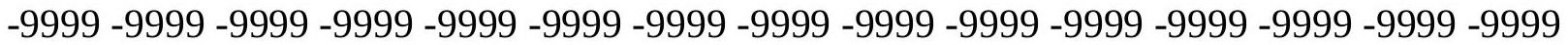

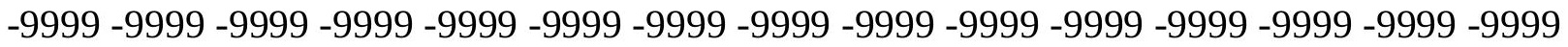

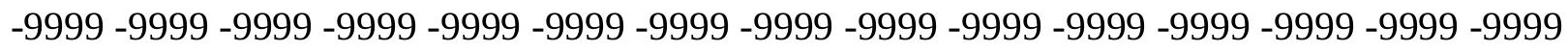

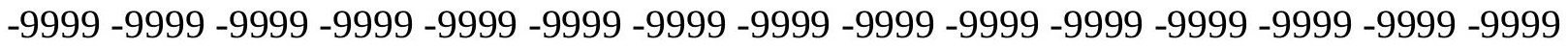

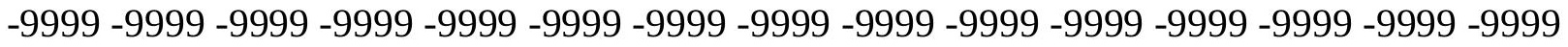
-9999 -9999 -9999 -9999 -9999 -9999 -9999 -9999 -9999 -9999 -9999 -9999 -9999 -9999 -9999 -

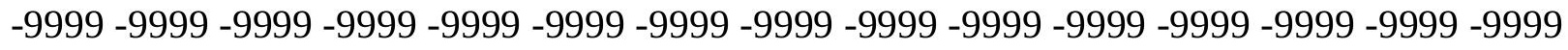

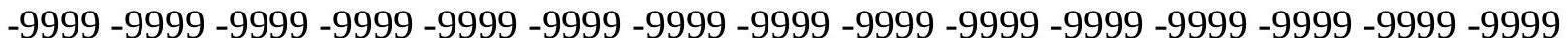
-9999 -9999 -9999 -9999 -9999 -9999 -9999 -9999 -9999 -9999 -9999 -9999 -9999 -9999 -9999 -9999 -9999 -9999 -9999 -9999 -9999 -9999 -9999 -9999-9999 -9999 -9999 -9999 -9999 -9999 -9999 -9999 -9999 -9999 -9999 -9999 -9999 -9999 -9999 -9999 -9999 -9999 -9999 -9999 -9999 -

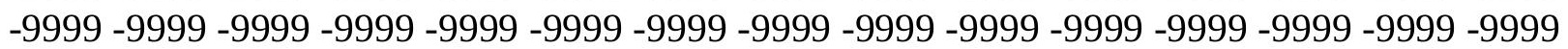


-9999 -9999 -9999 -9999 -9999 -9999 -9999 -9999 -9999 -9999 -9999 -9999 -9999 -9999 -9999 -9999 -9999 -9999 -9999 -9999 -9999 -9999 -9999 -9999 -9999 -9999 -9999 -9999 -9999 -

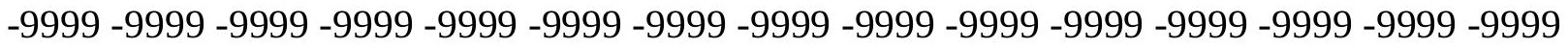
-9999 -9999 -9999 -9999 -9999 -9999 -9999 -9999 -9999 -9999 -9999 -9999 -9999 -9999 -9999 -9999 -9999 -9999 -9999 -9999 -9999 -9999 -9999 -9999 -9999 -9999 -9999 -9999 -9999 -9999 -9999 -9999 -9999 -9999 -9999 -9999 -9999 -9999 -9999 -9999 -9999 -9999 -9999 -9999 -9999 -9999 -9999 -9999 -9999 -9999 -9999 -9999 -9999 -9999 -9999 -9999 -9999 -9999 -9999 -9999

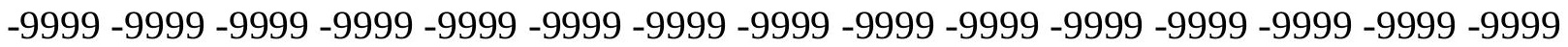

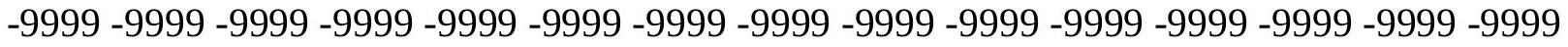
-9999 -9999 -9999 -9999 -9999 -9999 -9999 -9999 -9999 -9999 -9999 -9999 -9999 -9999 -9999 -9999 -9999 -9999 -9999 -9999 -9999 -9999 -9999 -9999 -9999 -9999 -9999 -9999 -9999 -9999 -9999 -9999 -9999 -9999 -9999 -9999 -9999 -9999 -9999 -9999 -9999 -9999 -9999 -9999 -9999 -9999 -9999 -9999 -9999 -9999 -9999 -9999 -9999 -9999 -9999 -9999 -9999 -9999 -9999 -9999 -9999 -9999 -9999 -9999 -9999 -9999 -9999 -9999 -9999 -9999 -9999 -9999 -9999 -9999 -9999 -9999 -9999 -9999 -9999 -9999 -9999 -9999 -9999 -9999 -9999 -9999 -9999 -9999 -9999 -9999 -

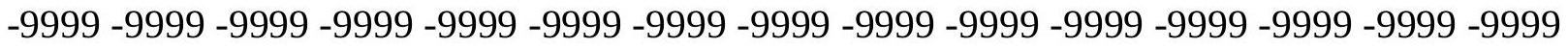
-9999 -9999 -9999 -9999 -9999 -9999 -9999 -9999 -9999 -9999 -9999 -9999 -9999 -9999 -9999 -9999 -9999 -9999 -9999 -9999 -9999 -9999 -9999 -9999 -9999 -9999 -9999 -9999 -9999 - 9999 -9999 -9999 -9999 -9999 -9999 -9999 -9999 -9999 -9999 -9999 -9999 -9999 -9999 -9999 -9999 -

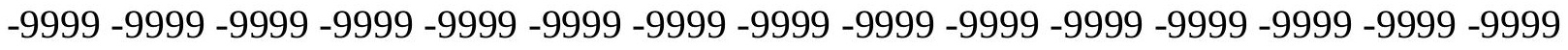

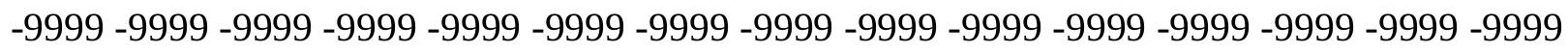

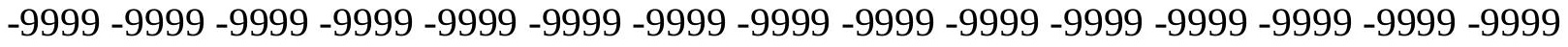
-9999 -9999 -9999 -9999 -9999 -9999 -9999 -9999 -9999 -9999 -9999 -9999 -9999 -9999 -9999 -9999 -9999 -9999 -9999 -9999 -9999 -9999 -9999 -9999 -9999 -9999 -9999 -9999 -9999 -9999 -

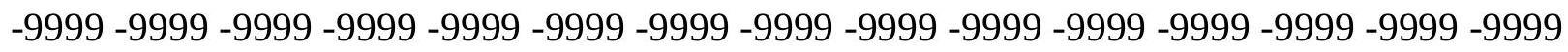
-9999 -9999 -9999 -9999 -9999 -9999 -9999 -9999 -9999 -9999 -9999 -9999 -9999 -9999 -9999 -9999 -9999 -9999 -9999 -9999 -9999 -9999 -9999 -9999 -9999 -9999 -9999 -9999 -9999 -9999 -9999 -9999 -9999 -9999 -9999 -9999 -9999 -9999 -9999 -9999 -9999 -9999 -9999 -9999 -9999 -9999 -9999 -9999 -9999 -9999 -9999 -9999 -9999 -9999 -9999 -9999 -9999 -9999 -9999 -9999 -9999 -9999 -9999 -9999 -9999 -9999 -9999 -9999 -9999 -9999 -9999 -9999 -9999 -999 -

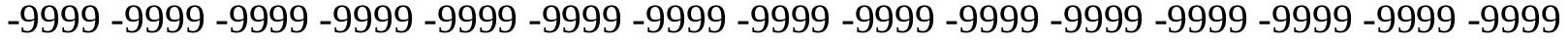
-9999 -9999 -9999 -9999 -9999 -9999 -9999 -9999 -9999 -9999 -9999 -9999 -9999 -9999 -9999 -

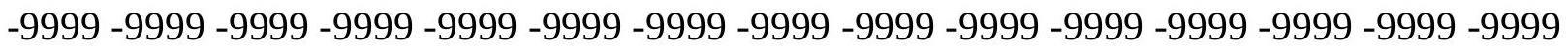

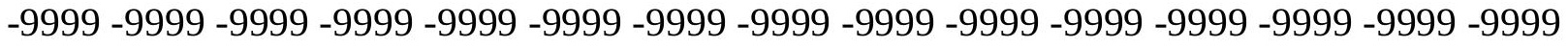

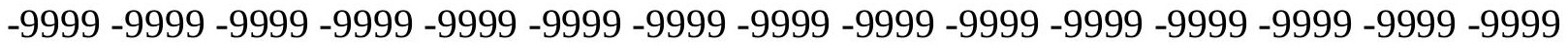

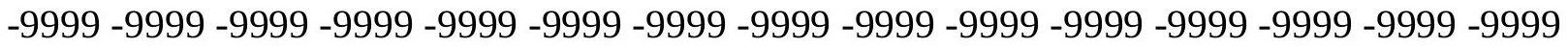

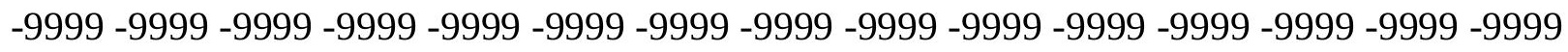

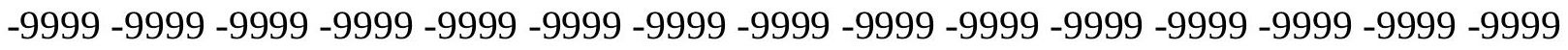

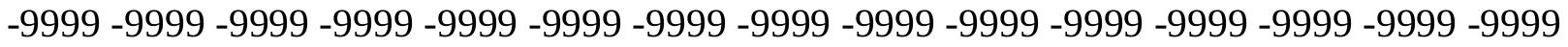
-9999 -9999 -9999 -9999 -9999 -9999 -9999 -9999 -9999 -9999 -9999 -9999 -9999 -9999 -9999 -

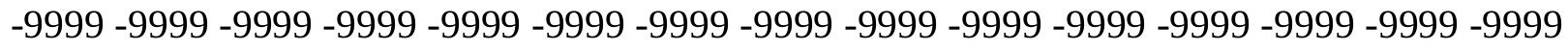

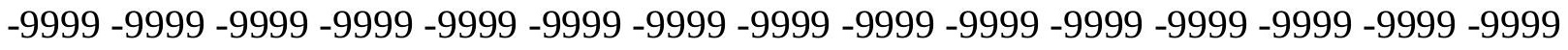
-9999 -9999 -9999 -9999 -9999 -9999 -9999 -9999 -9999 -9999 -9999 -9999 -9999 -9999 -9999 -9999 -9999 -9999 -9999 -9999 -9999 -9999 -9999 -9999-9999 -9999 -9999 -9999 -9999 -9999 -9999 -9999 -9999 -9999 -9999 -9999 -9999 -9999 -9999 -9999 -9999 -9999 -9999 -9999 -9999 -

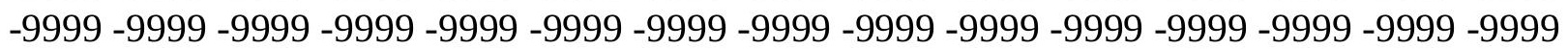


-9999 -9999 -9999 -9999 -9999 -9999 -9999 -9999 -9999 -9999 -9999 -9999 -9999 -9999 -9999 -9999 -9999 -9999 -9999 -9999 -9999 -9999 -9999 -9999 -9999 -9999 -9999 -9999 -9999 -9999 -

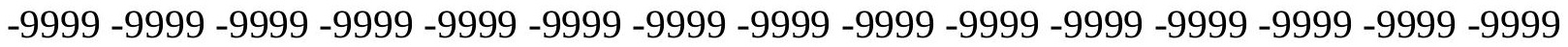
-9999 -9999 -9999 -9999 -9999 -9999 -9999 -9999 -9999 -9999 -9999 -9999 -9999 -9999 -9999 -9999 -9999 -9999 -9999 -9999 -9999 -9999 -9999 -9999-9999 -9999 -9999 -9999 -9999 -9999 -9999 -9999 -9999 -9999 -9999 -9999 -9999 -9999 -9999 -9999 -9999 -9999 -9999 -9999 -9999 -

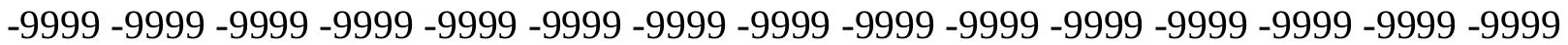
-9999 -9999 -9999 -9999 -9999 -9999 -9999 -9999 -9999 -9999 -9999 -9999 -9999 -9999 -9999 -9999 -9999 -9999 -9999 -9999 -9999 -9999 -9999 -9999 -9999 -9999 -9999 -9999 -9999 -9999 -9999 -9999 -9999 -9999 -9999 -9999 -9999 -9999 -9999 -9999 -9999 -9999 -9999 -9999 -9999 -9999 -9999 -9999 -9999 -9999 -9999 -9999 -9999 -9999 -9999 -9999 -9999 -9999 -9999 -9999 -9999 -9999 -9999 -9999 -9999 -9999 -9999 -9999 -9999 -9999 -9999 -9999 -9999 -9999 -9999 -9999 -9999 -9999 -9999 -9999 -9999 -9999 -9999 -9999 -9999 -9999 -9999 -9999 -9999 -9999 -9999 -9999 -9999 -9999 -9999 -9999 -9999 -9999 -9999 -9999 -9999 -9999 -9999 -9999 -9999 -9999 -9999 -9999 -9999 -9999 -9999 -9999 -9999 -9999 -9999 -9999 -9999 -9999 -9999 -

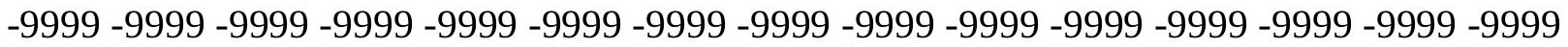
-9999 -9999 -9999 -9999 -9999 -9999 -9999 -9999 -9999 -9999 -9999 -9999 -9999 -9999 -9999 -9999 -9999 -9999 -9999 -9999 -9999 -9999 -9999 -9999 -9999 -9999 -9999 -9999 -9999 -9999 -9999 -9999 -9999 -9999 -9999 -9999 -9999 -9999 -9999 -9999 -9999 -9999 -9999 -9999 -9999 -

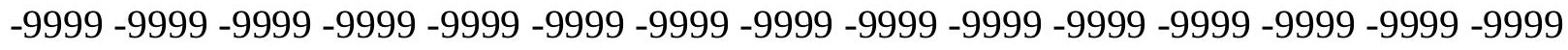

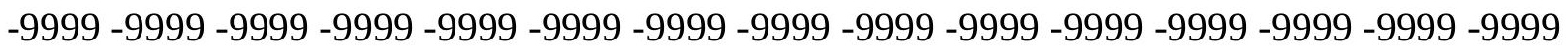
-9999 -9999 -9999 -9999 -9999 -9999 -9999 -9999 -9999 -9999 -9999 -9999 -9999 -9999 - 9999 -9999 -9999 -9999 -9999 -9999 -9999 -9999 -9999 -9999 -9999 -9999 -9999 -9999 -9999 -9999 -9999 -9999 -9999 -9999 -9999 -9999 -9999 -9999 -9999 -9999 -9999 -9999 -9999 -9999 -9999 -

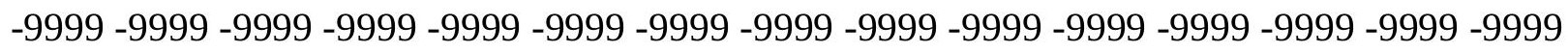
-9999 -9999 -9999 -9999 -9999 -9999 -9999 -9999 -9999 -9999 -9999 -9999 -9999 -9999 -9999 -9999 -9999 -9999 -9999 -9999 -9999 -9999 -9999 -9999 -9999 -9999 -9999 -9999 -9999 -9999 -

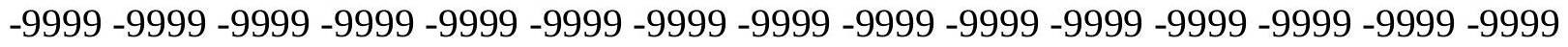
-9999 -9999 -9999 -9999 -9999 -9999 -9999 -9999 -9999 -9999 -9999 -9999 -9999 -9999 -9999 -9999 -9999 -9999 -9999 -9999 -9999 -9999 -9999 -9999 -9999 -9999 -9999 -9999 -9999 -999 -9999 -9999 -9999 -9999 -9999 -9999 -9999 -9999 -9999 -9999 -9999 -9999 -9999 -9999 -9999 -9999 -9999 -9999 -9999 -9999 -9999 -9999 -9999 -9999 -9999 -9999 -9999 -9999 -9999 -9999 -

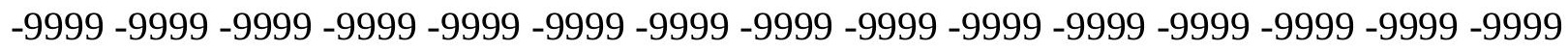

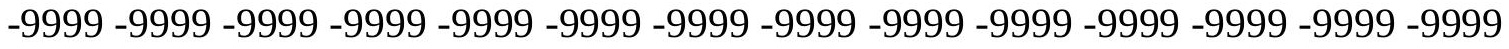
-9999 -9999 -9999 -9999 -9999 -9999 -9999 -9999 -9999 -9999 -9999 -9999 -9999 -9999 -9999

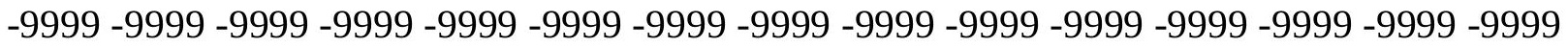

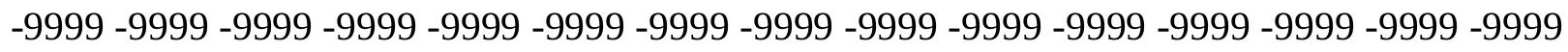

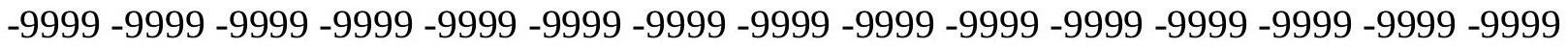

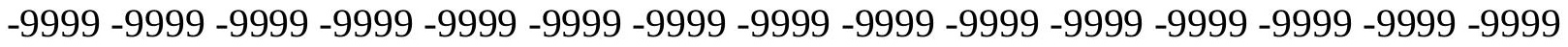
-9999 -9999 -9999 -9999 -9999 -9999 -9999 -9999 -9999 -9999 -9999 -9999 -9999 -9999 -9999 -

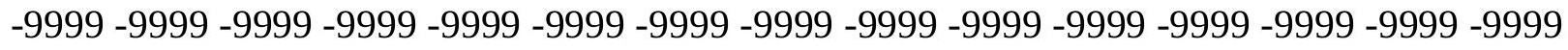

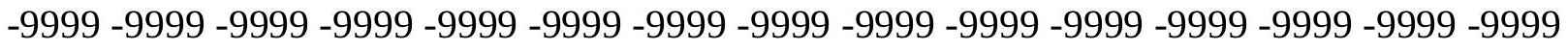
-9999 -9999 -9999 -9999 -9999 -9999 -9999 -9999 -9999 -9999 -9999 -9999 -9999 -9999 -9999 -9999 -9999 -9999 -9999 -9999 -9999 -9999 -9999 -9999-9999 -9999 -9999 -9999 -9999 -9999 -9999 -9999 -9999 -9999 -9999 -9999 -9999 -9999 -9999 -9999 -9999 -9999 -9999 -9999 -9999 -

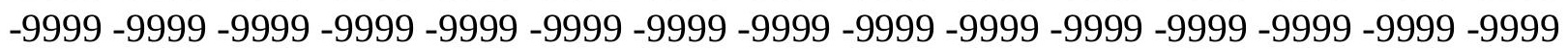


-9999 -9999 -9999 -9999 -9999 -9999 -9999 -9999 -9999 -9999 -9999 -9999 -9999 -9999 -9999 -9999 -9999 -9999 -9999 -9999 -9999 -9999 -9999 -9999 -9999 -9999 -9999 -9999 -9999 -9999 -

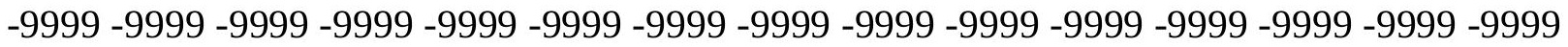
-9999 -9999 -9999 -9999 -9999 -9999 -9999 -9999 -9999 -9999 -9999 -9999 -9999 -9999 -9999 -9999 -9999 -9999 -9999 -9999 -9999 -9999 -9999 -9999-9999 -9999 -9999 -9999 -9999 -9999 -9999 -9999 -9999 -9999 -9999 -9999 -9999 -9999 -9999 -9999 -9999 -9999 -9999 -9999 -9999 -9999 -9999 -9999 -9999 -9999 -9999 -9999 -9999 -9999 -9999 -9999 -9999 -9999 -9999 -9999

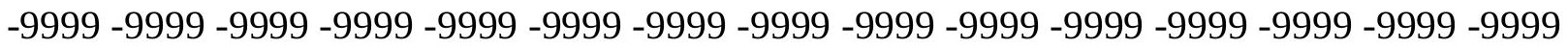

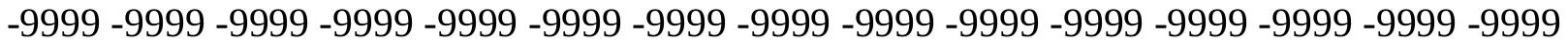
-9999 -9999 -9999 -9999 -9999 -9999 -9999 -9999 -9999 -9999 -9999 -9999 -9999 -9999 -9999 -9999 -9999 -9999 -9999 -9999 -9999 -9999 -9999 -9999 -9999 -9999 -9999 -9999 -9999 -9999 -9999 -9999 -9999 -9999 -9999 -9999 -9999 -9999 -9999 -9999 -9999 -9999 -9999 -9999 -9999 -9999 -9999 -9999 -9999 -9999 -9999 -9999 -9999 -9999 -9999 -9999 -9999 -9999 -9999 -9999 -9999 -9999 -9999 -9999 -9999 -9999 -9999 -9999 -9999 -9999 -9999 -9999 -9999 -9999 -9999 -9999 -9999 -9999 -9999 -9999 -9999 -9999 -9999 -9999 -9999 -9999 -9999 -9999 -9999

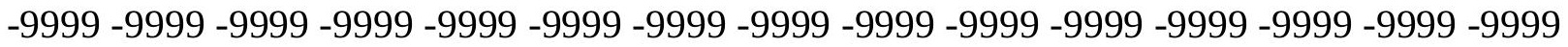
-9999 -9999 -9999 -9999 -9999 -9999 -9999 -9999 -9999 -9999 -9999 -9999 -9999 -9999 -9999 -9999 -9999 -9999 -9999 -9999 -9999 -9999 -9999 -9999 -9999 -9999 -9999 -9999 -9999 -9999 -9999 -9999 -9999 -9999 -9999 -9999 -9999 -9999 -9999 -9999 -9999 -9999 -9999 -9999 -9999 -

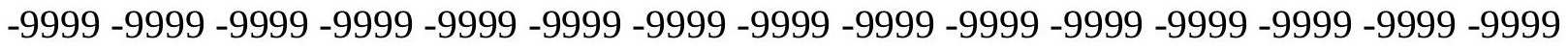

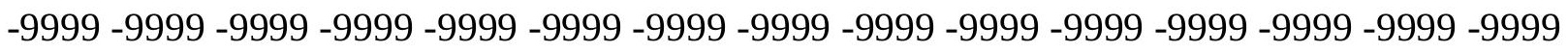
-9999 -9999 -9999 -9999 -9999 -9999 -9999 -9999 -9999 -9999 -9999 -9999 -9999 -9999 -9999 -9999 -9999 -9999 -9999 -9999 -9999 -9999 -9999 -9999 -9999 -9999 -9999 -9999 -9999 -9999 -9999 -9999 -9999 -9999 -9999 -9999 -9999 -9999 -9999 -9999 -9999 -9999 -9999 -9999 -9999 -

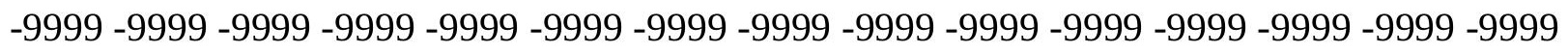
-9999 -9999 -9999 -9999 -9999 -9999 -9999 -9999 -9999 -9999 -9999 -9999 -9999 -9999 -9999 -9999 -9999 -9999 -9999 -9999 -9999 -9999 -9999 -9999 -9999 -9999 -9999 -9999 -9999 -9999 -

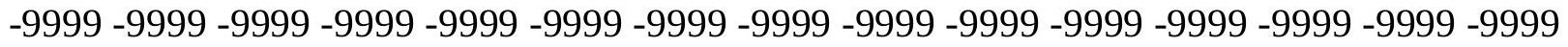
-9999 -9999 -9999 -9999 -9999 -9999 -9999 -9999 -9999 -9999 -9999 -9999 -9999 -9999 -9999 -9999 -9999 -9999 -9999 -9999 -9999 -9999 -9999 -9999 -9999 -9999 -9999 -9999 -9999 -999 -9999 -9999 -9999 -9999 -9999 -9999 -9999 -9999 -9999 -9999 -9999 -9999 -9999 -9999 -9999 -9999 -9999 -9999 -9999 -9999 -9999 -9999 -9999 -9999 -9999 -9999 -9999 -9999 -9999 -9999 -

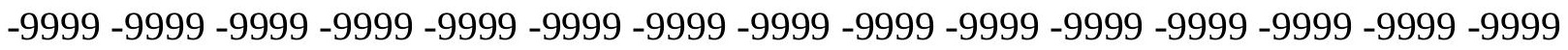

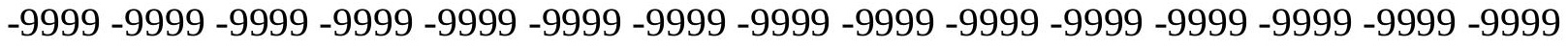

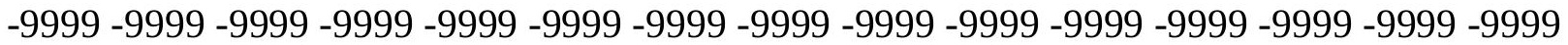

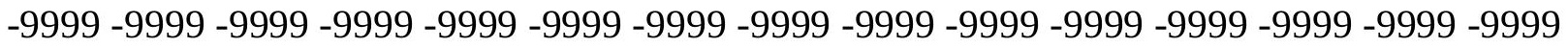

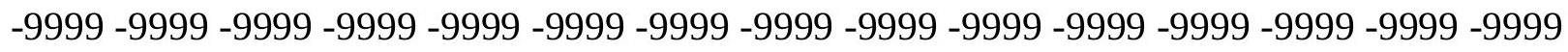

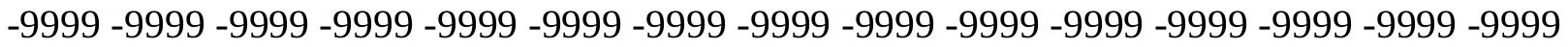
-9999 -9999 -9999 -9999 -9999 -9999 -9999 -9999 -9999 -9999 -9999 -9999 -9999 - 9999 - -999 -9999 -9999 -9999 -9999 -9999 -9999 -9999 -9999 -9999 -9999 -9999 -9999 -9999 -9999 - -999 -

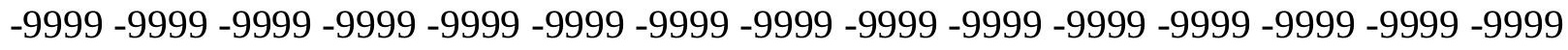

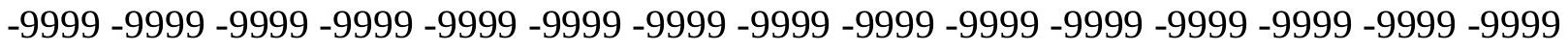
-9999 -9999 -9999 -9999 -9999 -9999 -9999 -9999 -9999 -9999 -9999 -9999 -9999 -9999 -9999 -9999 -9999 -9999 -9999 -9999 -9999 -9999 -9999 -9999-9999 -9999 -9999 -9999 -9999 -9999 -9999 -9999 -9999 -9999 -9999 -9999 -9999 -9999 -9999 -9999 -9999 -9999 -9999 -9999 -9999 -

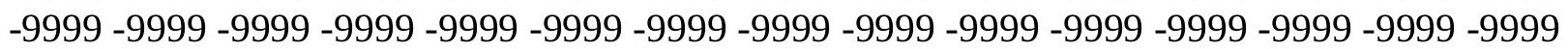


-9999 -9999 -9999 -9999 -9999 -9999 -9999 -9999 -9999 -9999 -9999 -9999 -9999 -9999 -9999 -9999 -9999 -9999 -9999 -9999 -9999 -9999 -9999 -9999 -9999 -9999 -9999 -9999 -9999 -9999 -9999 -9999 -9999 -9999 -9999 -9999 -9999 -9999 -9999 -9999 -9999 -9999 -9999 -9999 -9999 -9999 -9999 -9999 -9999 -9999 -9999 -9999 -9999 -9999 -9999 -9999 -9999 -9999 -9999 -9999 -9999 -9999 -9999 -9999 -9999 -9999 -9999 -9999 -9999 -9999 -9999 -9999 -9999 -9999 -9999 -9999 -9999 -9999 -9999 -9999 -9999 -9999 -9999 -9999 -9999 -9999 -9999 -9999 -9999 -9999 -9999 -9999 -9999 -9999 -9999 -9999 -9999 -9999 -9999 -9999 -9999 -9999 -9999 -9999 -9999 -

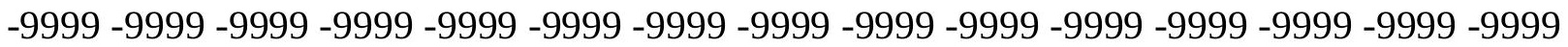
-9999 -9999 -9999 -9999 -9999 -9999 -9999 -9999 -9999 -9999 -9999 -9999 -9999 -9999 -9999 -9999 -9999 -9999 -9999 -9999 -9999 -9999 -9999 -9999 -9999 -9999 -9999 -9999 -9999 -9999 -

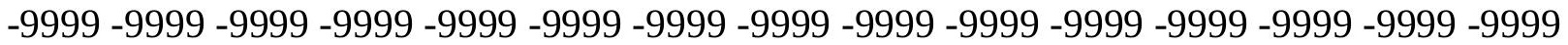
-9999 -9999 -9999 -9999 -9999 -9999 -9999 -9999 -9999 -9999 -9999 -9999 -9999 -9999 -9999 -9999 -9999 -9999 -9999 -9999 -9999 -9999 -9999 -9999 -9999 -9999 -9999 -9999 -9999 -9999 -9999 -9999 -9999 -9999 -9999 -9999 -9999 -9999 -9999 -9999 -9999 -9999 -9999 -9999 -9999 -9999 -9999 -9999 -9999 -9999 -9999 -9999 -9999 -9999 -9999 -9999 -9999 -9999 -9999 -9999

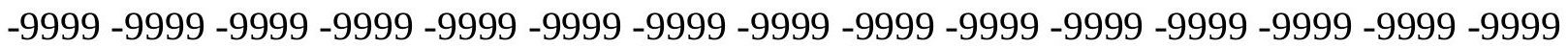
-9999 -9999 -9999 -9999 -9999 -9999 -9999 -9999 -9999 -9999 -9999 -9999 -9999 -9999 -9999 -9999 -9999 -9999 -9999 -9999 -9999 -9999 -9999 -9999 -9999 -9999 -9999 -9999 -9999 -9999 -9999 -9999 -9999 -9999 -9999 -9999 -9999 -9999 -9999 -9999 -9999 -9999 -9999 -9999 -9999 -9999 -9999 -9999 -9999 -9999 -9999 -9999 -9999 -9999 -9999 -9999 -9999 -9999 -9999 -9999 -9999 -9999 -9999 -9999 -9999 -9999 -9999 -9999 -9999 -9999 -9999 -9999 -9999 -9999 -9999 -9999 -9999 -9999 -9999 -9999 -9999 -9999 -9999 -9999 -9999 -9999 -9999 -9999 -9999 -9999 -9999 -9999 -9999 -9999 -9999 -9999 -9999 -9999 -9999 -9999 -9999 -9999 -9999 -9999 -9999 -9999 -9999 -9999 -9999 -9999 -9999 -9999 -9999 -9999 -9999 -9999 -9999 -9999 -9999 -9999 -9999 -9999 -9999 -9999 -9999 -9999 -9999 -9999 -9999 -9999 -9999 -9999 -9999 -9999 -9999 -9999 -9999 -9999 -9999 -9999 -9999 -9999 -9999 -9999 -9999 -9999 -9999 -9999 -9999 -9999 -9999 -9999 -9999 -9999 -9999 -9999 -9999 -9999 -9999 -9999 -9999 -9999 -9999 -9999 -9999 -9999 -9999 -9999 -9999 -9999 -9999 -9999 -9999 -9999 -9999 -9999 -9999 -9999 -9999

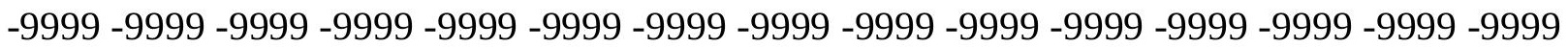
-9999 -9999 -9999 -9999 -9999 -9999 -9999 -9999 -9999 -9999 -9999 -9999 -9999 -9999 -9999 -9999 -9999 -9999 -9999 -9999 -9999 -9999 -9999 -9999 -9999 -9999 -9999 -9999 -9999 -9999 -

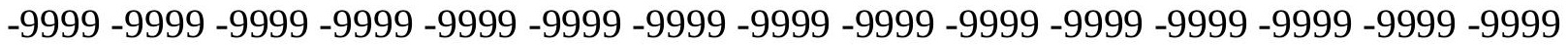
-9999 -9999 -9999 -9999 -9999 -9999 -9999 -9999 -9999 -9999 -9999 -9999 -9999 -9999 -9999 -9999 -9999 -9999 -9999 -9999 -9999 -9999 -9999 -9999 -9999 -9999 -9999 -9999 -9999 -9999 -9999 -9999 -9999 -9999 -9999 -9999 -9999 -9999 -9999 -9999 -9999 -9999 -9999 -9999 -9999 -9999 -9999 -9999 -9999 -9999 -9999 -9999 -9999 -9999 -9999 -9999 -9999 -9999 -9999 -9999 -9999 -9999 -9999 -9999 -9999 -9999 -9999 -9999 -9999 -9999 -9999 -9999 -9999 -9999 -9999

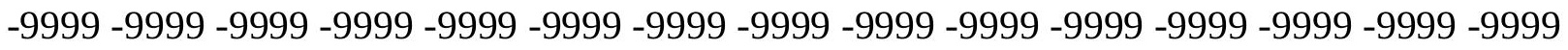
-9999 -9999 -9999 -9999 -9999 -9999 -9999 -9999 -9999 -9999 -9999 -9999 -9999 -9999 -9999 -9999 -9999 -9999 -9999 -9999 -9999 -9999 -9999 -9999 -9999 -9999 -9999 -9999 -9999 -9999 -9999 -9999 -9999 -9999 -9999 -9999 -9999 -9999 -9999 -9999 -9999 -9999 -9999 -9999 -9999 -999 -9999 -9999 -9999 -9999 -9999 -9999 -9999 -9999 -9999 -9999 -9999 -9999 -9999 -9999 -9999 -9999 -9999 -9999 -9999 -9999 -9999 -9999 -9999 -9999 -9999 -9999 -9999 -9999 -9999 -9999 -9999 -9999 -9999 -9999 -9999 -9999 -9999 -9999 -9999 -9999 -9999 -9999 -9999 -9999 -9999 -9999 -9999 -9999 -9999 -9999 -9999 -9999 -9999 -9999 -9999 -9999 -9999 -9999 -9999 -9999 -9999 -9999 -9999 -9999 -9999 -9999 -9999 -9999 -9999 -9999 -9999 -9999 -9999 -9999 
-9999 -9999 -9999 -9999 -9999 -9999 -9999 -9999 -9999 -9999 -9999 -9999 -9999 -9999 -9999 -9999 -9999 -9999 -9999 -9999 -9999 -9999 -9999 -9999 -9999 -9999 -9999 -9999 -9999 -9999 -

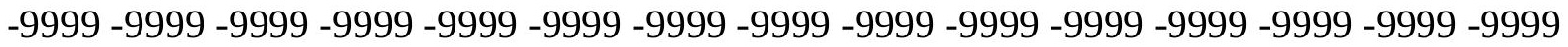
-9999 -9999 -9999 -9999 -9999 -9999 -9999 -9999 -9999 -9999 -9999 -9999 -9999 -9999 -9999 -9999 -9999 -9999 -9999 -9999 -9999 -9999 -9999 -9999-9999 -9999 -9999 -9999 -9999 -9999 -9999 -9999 -9999 -9999 -9999 -9999 -9999 -9999 -9999 -9999 -9999 -9999 -9999 -9999 -9999 -9999 -9999 -9999 -9999 -9999 -9999 -9999 -9999 -9999 -9999 -9999 -9999 -9999 -9999 -9999

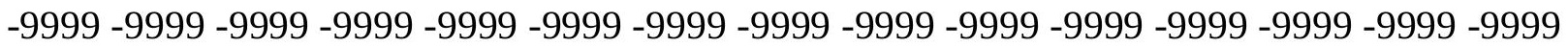

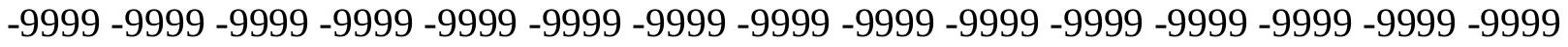
-9999 -9999 -9999 -9999 -9999 -9999 -9999 -9999 -9999 -9999 -9999 -9999 -9999 -9999 -9999 -9999 -9999 -9999 -9999 -9999 -9999 -9999 -9999 -9999 -9999 -9999 -9999 -9999 -9999 -9999 -9999 -9999 -9999 -9999 -9999 -9999 -9999 -9999 -9999 -9999 -9999 -9999 -9999 -9999 -9999 -9999 -9999 -9999 -9999 -9999 -9999 -9999 -9999 -9999 -9999 -9999 -9999 -9999 -9999 -9999 -

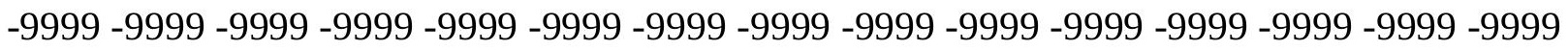
-9999 -9999 -9999 -9999 -9999 -9999 -9999 -9999 -9999 -9999 -9999 -9999 -9999 -9999 -9999 -

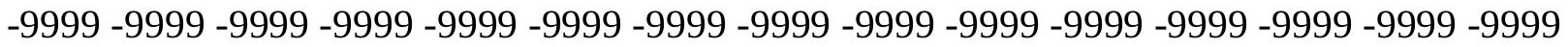
-9999 -9999 -9999 -9999 -9999 -9999 -9999 -9999 -9999 -9999 -9999 -9999 -9999 -9999 -9999 -9999 -9999 -9999 -9999 -9999 -9999 -9999 -9999 -9999 -9999 -9999 -9999 -9999 -9999 -9999 -9999 -9999 -9999 -9999 -9999 -9999 -9999 -9999 -9999 -9999 -9999 -9999 -9999 -9999 -9999 -

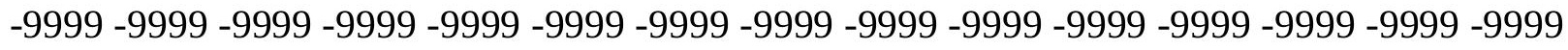

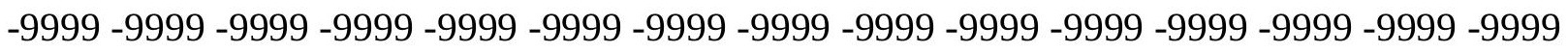

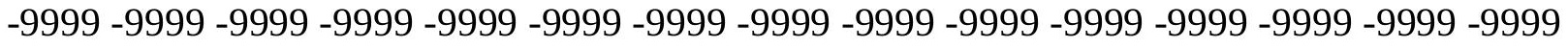
-9999 -9999 -9999 -9999 -9999 -9999 -9999 -9999 -9999 -9999 -9999 -9999 -9999 -9999 -9999 -9999 -9999 -9999 -9999 -9999 -9999 -9999 -9999 -9999 -9999 -9999 -9999 -9999 -9999 -9999 -

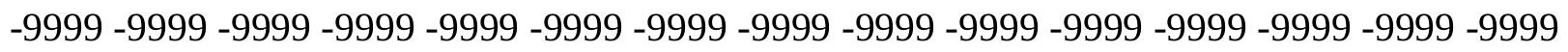
-9999 -9999 -9999 -9999 -9999 -9999 -9999 -9999 -9999 -9999 -9999 -9999 -9999 -9999 -9999 -9999 -9999 -9999 -9999 -9999 -9999 -9999 -9999 -9999 -9999 -9999 -9999 -9999 -9999 -

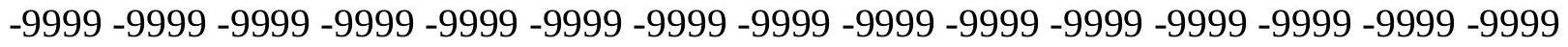
-9999 -9999 -9999 -9999 -9999 -9999 -9999 -9999 -9999 -9999 -9999 -9999 -9999 -9999 -9999 -9999 -9999 -9999 -9999 -9999 -9999 -9999 -9999 -9999 -9999 -9999 -9999 -9999 -9999 -999 -

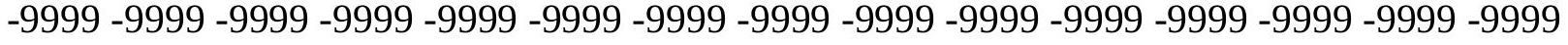
-9999 -9999 -9999 -9999 -9999 -9999 -9999 -9999 -9999 -9999 -9999 -9999 -9999 -9999 -9999 -

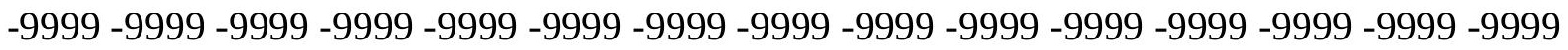

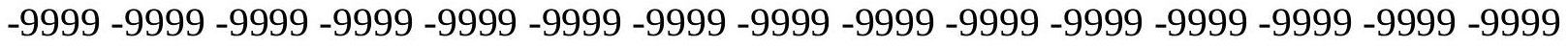

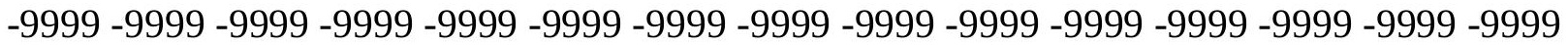
-9999 -9999 -9999 -9999 -9999 -9999 -9999 -9999 -9999 -9999 -9999 -9999 -9999 -9999 -9999

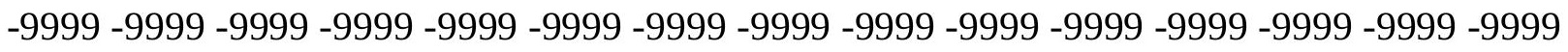

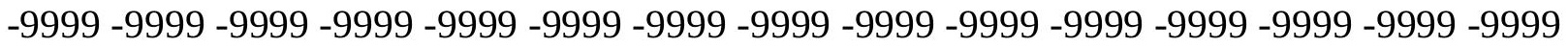
-9999 -9999 -9999 -9999 -9999 -9999 -9999 -9999 -9999 -9999 -9999 -9999 -9999 - 9999 - -999 -9999 -9999 -9999 -9999 -9999 -9999 -9999 -9999 -9999 -9999 -9999 -9999 -9999 -9999 -9999 -

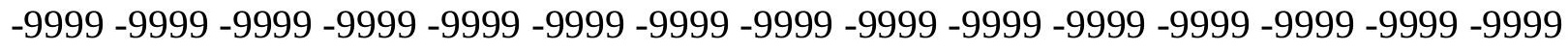

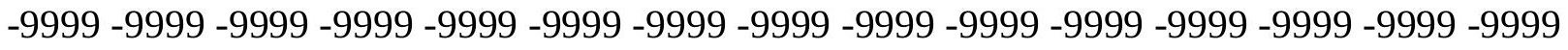
-9999 -9999 -9999 -9999 -9999 -9999 -9999 -9999 -9999 -9999 -9999 -9999 -9999 -9999 -9999 -9999 -9999 -9999 -9999 -9999 -9999 -9999 -9999 -9999-9999 -9999 -9999 -9999 -9999 -9999 -9999 -9999 -9999 -9999 -9999 -9999 -9999 -9999 -9999 -9999 -9999 -9999 -9999 -9999 -9999 -

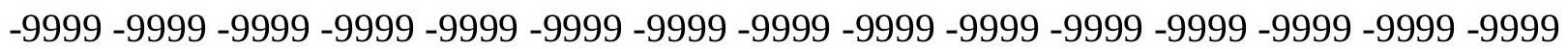


-9999 -9999 -9999 -9999 -9999 -9999 -9999 -9999 -9999 -9999 -9999 -9999 -9999 -9999 -9999 -9999 -9999 -9999 -9999 -9999 -9999 -9999 -9999 -9999 -9999 -9999 -9999 -9999 -9999 -9999 -9999 -9999 -9999 -9999 -9999 -9999 -9999 -9999 -9999 -9999 -9999 -9999 -9999 -9999 - 9999 -9999 -9999 -9999 -9999 -9999 -9999 -9999 -9999 -9999 -9999 -9999 -9999 -9999 -9999 -9999 -9999 -9999 -9999 -9999 -9999 -9999 -9999 -9999 -9999 -9999 -9999 -9999 -9999 -9999 - -9999 -9999 -9999 -9999 -9999 -9999 -9999 -9999 -9999 -9999 -9999 -9999 -9999 -9999 -9999 -9999 -9999 -9999 -9999 -9999 -9999 -9999 -9999 -9999 -9999 -9999 -9999 -9999 -9999 -9999

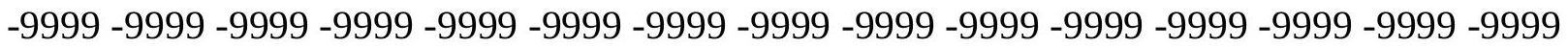

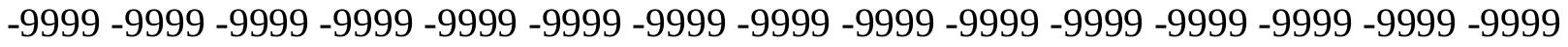
-9999 -9999 -9999 -9999 -9999 -9999 -9999 -9999 -9999 -9999 -9999 -9999 -9999 -9999 -9999

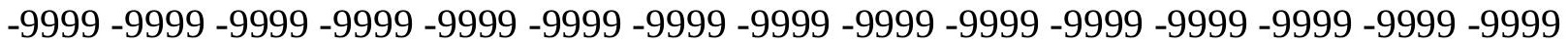
-9999 -9999 -9999 -9999 -9999 -9999 -9999 -9999 -9999 -9999 -9999 -9999 -9999 -9999 -9999 -9999 -9999 -9999 -9999 -9999 -9999 -9999 -9999 -9999 -9999 -9999 -9999 -9999 -9999 -9999 -9999 -9999 -9999 -9999 -9999 -9999 -9999 -9999 -9999 -9999 -9999 -9999 -9999 -9999 - -9999 -9999 -9999 -9999 -9999 -9999 -9999 -9999 -9999 -9999 -9999 -9999 -9999 -9999 -9999 -9999

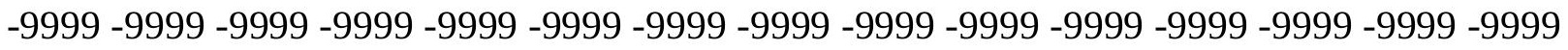
-9999 -9999 -9999 -9999 -9999 -9999 -9999 -9999 -9999 -9999 -9999 -9999 -9999 -9999 -9999 -9999 -9999 -9999 -9999 -9999 -9999 -9999 -9999 -9999 -9999 -9999 -9999 -9999 -9999 -9999 -9999 -9999 -9999 -9999 -9999 -9999 -9999 -9999 -9999 -9999 -9999 -9999 -9999 -9999 -9999 -

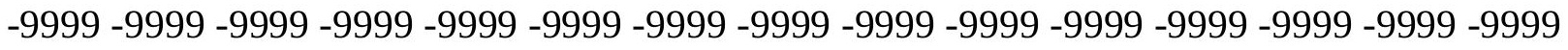
-9999 -9999 -9999 -9999 -9999 -9999 -9999 -9999 -9999 -9999 -9999 -9999 -9999 -9999 -9999 -999 -9999 -9999 -9999 -9999 -9999 -9999 -9999 -9999 -9999 -9999 -9999 -9999 -9999 -9999 -9999 -9999 -9999 -9999 -9999 -9999 -9999 -9999 -9999 -9999 -9999 -9999 -9999 -9999 -9999 -9999 -9999 -9999 -9999 -9999 -9999 -9999 -9999 -9999 -9999 -9999 -9999 -9999 -9999 -9999 -9999 -9999 -9999 -9999 -9999 -9999 -9999 -9999 -9999 -9999 -9999 -9999 -9999 -9999 -9999 -9999 -9999 -9999 -9999 -9999 -9999 -9999 -9999 -9999 -9999 -9999 -9999 -9999 -9999 -9999 -9999 -9999 -9999 -9999 -9999 -9999 -9999 -9999 -9999 -9999 -9999 -9999 -9999 -9999 -9999 -9999 -9999 -9999 -9999 -9999 -9999 -9999 -9999 -9999 -9999 -9999 -9999 -9999 -9999 -9999 -9999 -9999 -9999 -9999 -9999 -9999 -9999 -9999 -9999 -9999 -9999 -9999 -9999 -9999 -9999 -9999 -9999 -9999 -9999 -9999 -9999 -9999 -9999 -9999 -9999 -9999 -9999 -9999 -9999 -9999 -999 -9999 -9999 -9999 -9999 -9999 -9999 -9999 -9999 -9999 -9999 -9999 -9999 -9999 -9999 -9999 -9999 -9999 -9999 -9999 -9999 -9999 -9999 -9999 -9999 -9999 -9999 -9999 -9999 -9999 -

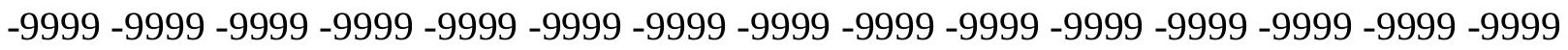

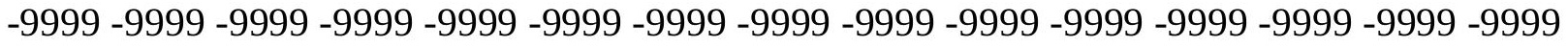

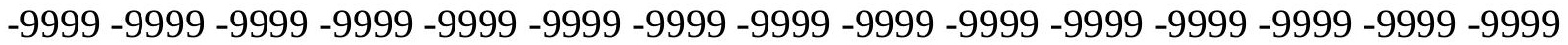
-9999 -9999 -9999 -9999 -9999 -9999 -9999 -9999 -9999 -9999 -9999 -9999 -9999 -9999 -9999 -

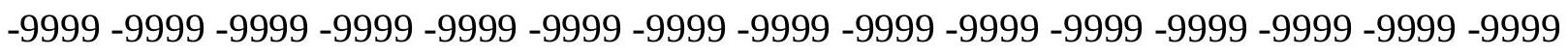

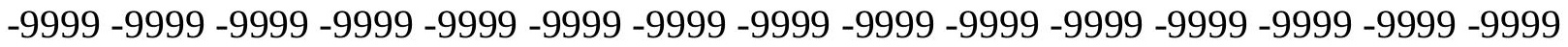

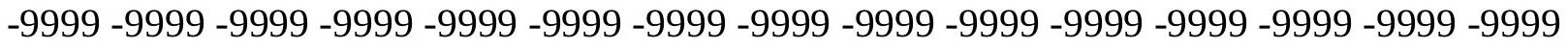
-9999 -9999 -9999 -9999 -9999 -9999 -9999 -9999 -9999 -9999 -9999 -9999 -9999 -9999 -9999 -

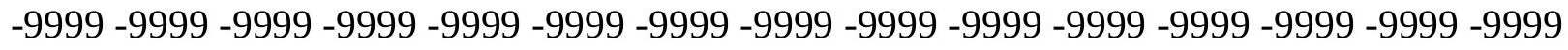

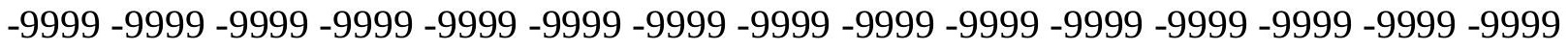
-9999 -9999 -9999 -9999 -9999 -9999 -9999 -9999 -9999 -9999 -9999 -9999 -9999 -9999 -9999 -9999 -9999 -9999 -9999 -9999 -9999 -9999 -9999 -9999-9999 -9999 -9999 -9999 -9999 -9999 -9999 -9999 -9999 -9999 -9999 -9999 -9999 -9999 -9999 -9999 -9999 -9999 -9999 -9999 -9999 -

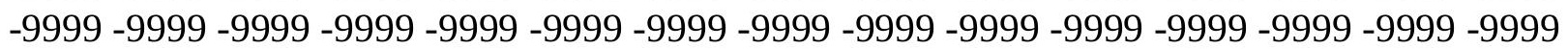


-9999 -9999 -9999 -9999 -9999 -9999 -9999 -9999 -9999 -9999 -9999 -9999 -9999 -9999 -9999 -9999 -9999 -9999 -9999 -9999 -9999 -9999 -9999 -9999 -9999 -9999 -9999 -9999 -9999 -9999 -

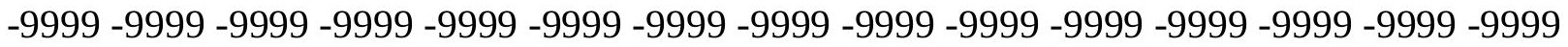
-9999 -9999 -9999 -9999 -9999 -9999 -9999 -9999 -9999 -9999 -9999 -9999 -9999 -9999 -9999 -9999 -9999 -9999 -9999 -9999 -9999 -9999 -9999 -9999-9999 -9999 -9999 -9999 -9999 -9999 -9999 -9999 -9999 -9999 -9999 -9999 -9999 -9999 -9999 -9999 -9999 -9999 -9999 -9999 -9999 -9999 -9999 -9999 -9999 -9999 -9999 -9999 -9999 -9999 -9999 -9999 -9999 -9999 -9999 -9999

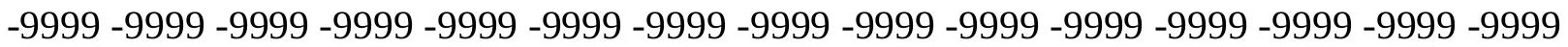

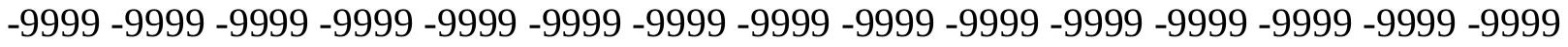
-9999 -9999 -9999 -9999 -9999 -9999 -9999 -9999 -9999 -9999 -9999 -9999 -9999 -9999 -9999 -9999 -9999 -9999 -9999 -9999 -9999 -9999 -9999 -9999 -9999 -9999 -9999 -9999 -9999 -9999 -9999 -9999 -9999 -9999 -9999 -9999 -9999 -9999 -9999 -9999 -9999 -9999 -9999 -9999 -9999 -9999 -9999 -9999 -9999 -9999 -9999 -9999 -9999 -9999 -9999 -9999 -9999 -9999 -9999 -9999 -9999 -9999 -9999 -9999 -9999 -9999 -9999 -9999 -9999 -9999 -9999 -9999 -9999 - 9999 -9999 -9999 -9999 -9999 -9999 -9999 -9999 -9999 -9999 -9999 -9999 -9999 -9999 -9999 -9999

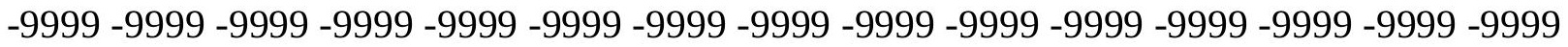
-9999 -9999 -9999 -9999 -9999 -9999 -9999 -9999 -9999 -9999 -9999 -9999 -9999 -9999 -9999 -9999 -9999 -9999 -9999 -9999 -9999 -9999 -9999 -9999 -9999 -9999 -9999 -9999 -9999 -9999 -9999 -9999 -9999 -9999 -9999 -9999 -9999 -9999 -9999 -9999 -9999 -9999 -9999 -9999 -9999 -

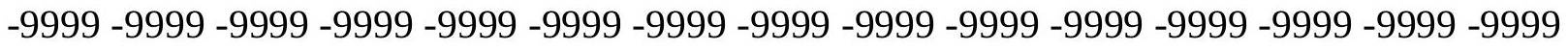

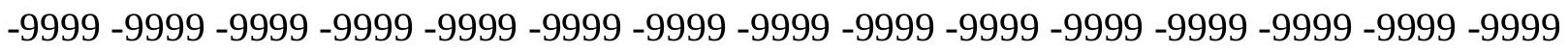
-9999 -9999 -9999 -9999 -9999 -9999 -9999 -9999 -9999 -9999 -9999 -9999 -9999 -9999 -9999 -9999 -9999 -9999 -9999 -9999 -9999 -9999 -9999 -9999 -9999 -9999 -9999 -9999 -9999 -9999 -9999 -9999 -9999 -9999 -9999 -9999 -9999 -9999 -9999 -9999 -9999 -9999 -9999 -9999 -9999 -

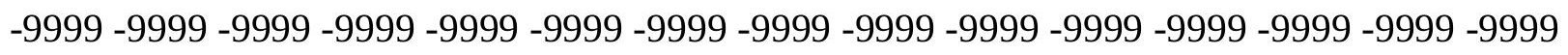
-9999 -9999 -9999 -9999 -9999 -9999 -9999 -9999 -9999 -9999 -9999 -9999 -9999 -9999 -9999 -9999 -9999 -9999 -9999 -9999 -9999 -9999 -9999 -9999 -9999 -9999 -9999 -9999 -9999 -9999 -

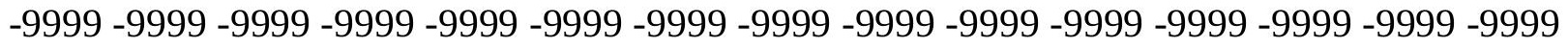
-9999 -9999 -9999 -9999 -9999 -9999 -9999 -9999 -9999 -9999 -9999 -9999 -9999 -9999 -9999 -9999 -9999 -9999 -9999 -9999 -9999 -9999 -9999 -9999 -9999 -9999 -9999 -9999 -9999 -999 -9999 -9999 -9999 -9999 -9999 -9999 -9999 -9999 -9999 -9999 -9999 -9999 -9999 -9999 -9999 -9999 -9999 -9999 -9999 -9999 -9999 -9999 -9999 -9999 -9999 -9999 -9999 -9999 -9999 -9999 -

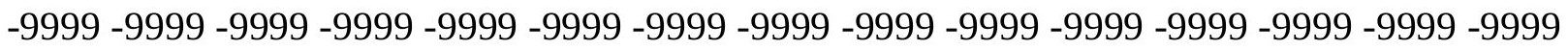

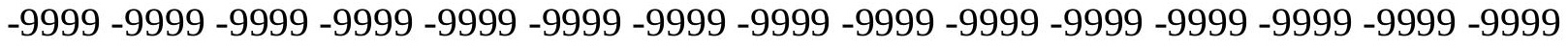

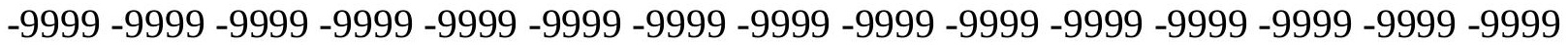

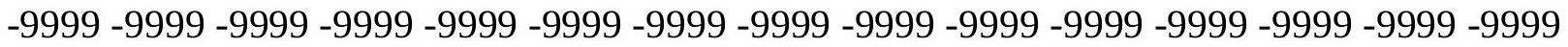

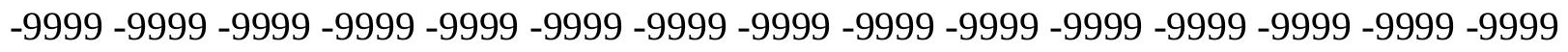

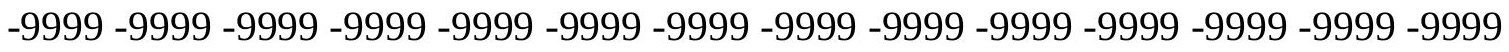
-9999 -9999 -9999 -9999 -9999 -9999 -9999 -9999 -9999 -9999 -9999 -9999 -9999 -9999 -9999 -9999 -9999 -9999 -9999 -9999 -9999 -9999 -9999 -9999 -9999 -9999 -9999 -9999 -9999 -9999 -

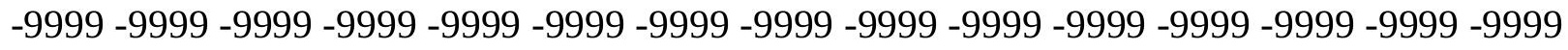

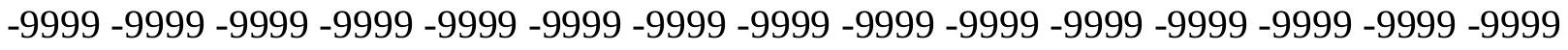
-9999 -9999 -9999 -9999 -9999 -9999 -9999 -9999 -9999 -9999 -9999 -9999 -9999 -9999 -9999 -9999 -9999 -9999 -9999 -9999 -9999 -9999 -9999 -9999-9999 -9999 -9999 -9999 -9999 -9999 -9999 -9999 -9999 -9999 -9999 -9999 -9999 -9999 -9999 -9999 -9999 -9999 -9999 -9999 -9999 -

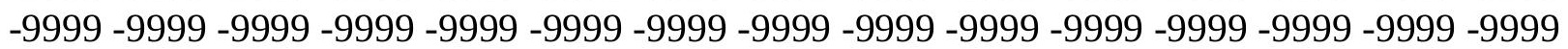


-9999 -9999 -9999 -9999 -9999 -9999 -9999 -9999 -9999 -9999 -9999 -9999 -9999 -9999 -9999 -9999 -9999 -9999 -9999 -9999 -9999 -9999 -9999 -9999 -9999 -9999 -9999 -9999 -9999 -9999 -9999 -9999 -9999 -9999 -9999 -9999 -9999 -9999 -9999 -9999 -9999 -9999 -9999 -9999 - 9999 -9999 -9999 -9999 -9999 -9999 -9999 -9999 -9999 -9999 -9999 -9999 -9999 -9999 -9999 -9999 -9999 -9999 -9999 -9999 -9999 -9999 -9999 -9999 -9999 -9999 -9999 -9999 -9999 -9999 -9999 -9999 -9999 -9999 -9999 -9999 -9999 -9999 -9999 -9999 -9999 -9999 -9999 -9999 -9999 -9999 -9999 -9999 -9999 -9999 -9999 -9999 -9999 -9999 -9999 -9999 -9999 -9999 -9999 -9999 -9999

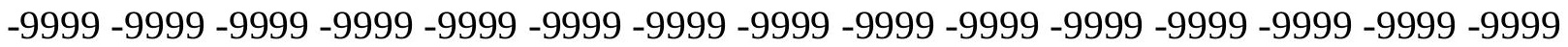
-9999 -9999 -9999 -9999 -9999 -9999 -9999 -9999 -9999 -9999 -9999 -9999 -9999 -9999 -9999 -9999 -9999 -9999 -9999 -9999 -9999 -9999 -9999 -9999 -9999 -9999 -9999 -9999 -9999 -9999

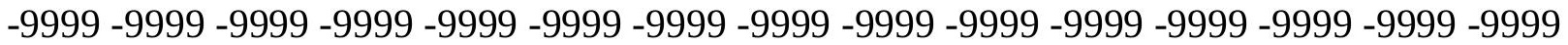
-9999 -9999 -9999 -9999 -9999 -9999 -9999 -9999 -9999 -9999 -9999 -9999 -9999 -9999 -9999 -9999 -9999 -9999 -9999 -9999 -9999 -9999 -9999 -9999 -9999 -9999 -9999 -9999 -9999 -9999 -

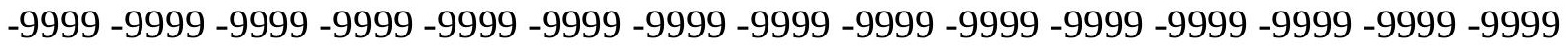
-9999 -9999 -9999 -9999 -9999 -9999 -9999 -9999 -9999 -9999 -9999 -9999 -9999 -9999 -9999

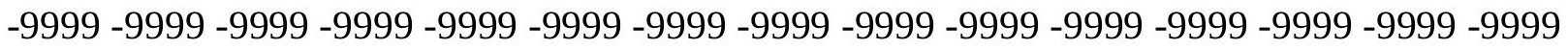
-9999 -9999 -9999 -9999 -9999 -9999 -9999 -9999 -9999 -9999 -9999 -9999 -9999 -9999 -9999 -9999 -9999 -9999 -9999 -9999 -9999 -9999 -9999 -9999 -9999 -9999 -9999 -9999 -9999 - -999 -9999 -9999 -9999 -9999 -9999 -9999 -9999 -9999 -9999 -9999 -9999 -9999 -9999 -9999 -9999 -9999 -9999 -9999 -9999 -9999 -9999 -9999 -9999 -9999 -9999 -9999 -9999 -9999 -9999 -9999 -9999 -9999 -9999 -9999 -9999 -9999 -9999 -9999 -9999 -9999 -9999 -9999 -9999 -9999 -9999 -999 -9999 -9999 -9999 -9999 -9999 -9999 -9999 -9999 -9999 -9999 -9999 -9999 -9999 -9999 -9999 -9999 -9999 -9999 -9999 -9999 -9999 -9999 -9999 -9999 -9999 -9999 -9999 -9999 -9999 -9999 -9999 -9999 -9999 -9999 -9999 -9999 -9999 -9999 -9999 -9999 -9999 -9999 -9999 -9999 -9999 -9999 -9999 -9999 -9999 -9999 -9999 -9999 -9999 -9999 -9999 -9999 -9999 -9999 -9999 -9999 -9999 -9999 -9999 -9999 -9999 -9999 -9999 -9999 -9999 -9999 -9999 -9999 -9999 -9999 -9999 -9999 -9999 -9999 -9999 -9999 -9999 -9999 -9999 -9999 -9999 -9999 -9999 -9999 -9999 -9999 -9999 -9999 -9999 -9999 -9999 -9999 -9999 -9999 -9999 -9999 -9999 -9999 -9999 -9999 -9999 -9999 -9999 -9999 -9999 -9999 -9999 -9999 -9999 -9999 -9999 -9999 -9999 -9999 -9999 -9999 -9999 -9999 -9999 -9999 -9999 -9999 -9999 -9999 -9999 -9999 -9999 -9999 -9999 -9999 -999 -9999 -9999 -9999 -9999 -9999 -9999 -9999 -9999 -9999 -9999 -9999 -9999 -9999 -9999 -9999 -9999 -9999 -9999 -9999 -9999 -9999 -9999 -9999 -9999 -9999 -9999 -9999 -9999 -9999 -9999 -

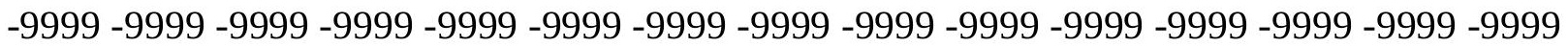

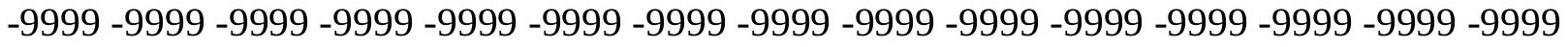

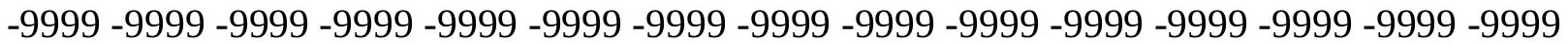
-9999 -9999 -9999 -9999 -9999 -9999 -9999 -9999 -9999 -9999 -9999 -9999 -9999 -9999 -9999

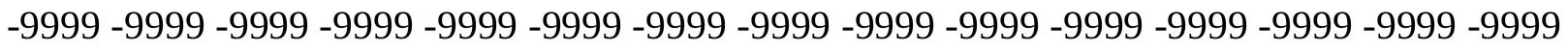

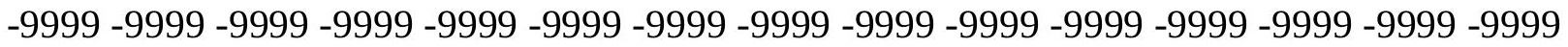

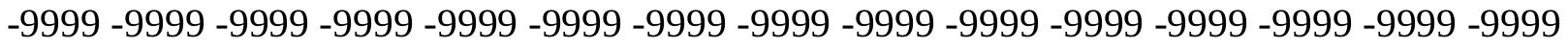
-9999 -9999 -9999 -9999 -9999 -9999 -9999 -9999 -9999 -9999 -9999 -9999 -9999 -9999 -9999 -

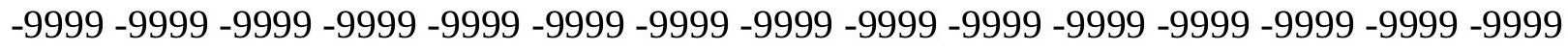

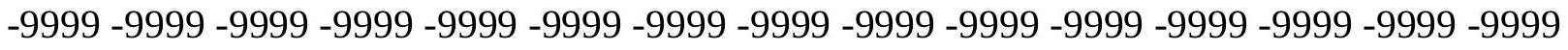
-9999 -9999 -9999 -9999 -9999 -9999 -9999 -9999 -9999 -9999 -9999 -9999 -9999 -9999 -9999 -9999 -9999 -9999 -9999 -9999 -9999 -9999 -9999 -9999 -9999 -9999 -9999 -9999 - -9999 -9999 -9999 -9999 -9999 -9999 -9999 -9999 -9999 -9999 -9999 -9999 -9999 -9999 -9999 -9999 -

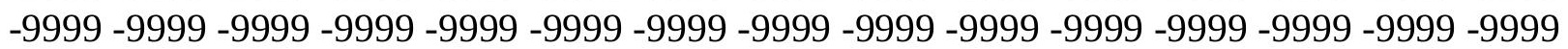


-9999 -9999 -9999 -9999 -9999 -9999 -9999 -9999 -9999 -9999 -9999 -9999 -9999 -9999 -9999 -9999 -9999 -9999 -9999 -9999 -9999 -9999 -9999 -9999 -9999 -9999 -9999 -9999 -9999 -9999 -9999 -9999 -9999 -9999 -9999 -9999 -9999 -9999 -9999 -9999 -9999 -9999 -9999 -9999 - 9999 -9999 -9999 -9999 -9999 -9999 -9999 -9999 -9999 -9999 -9999 -9999 -9999 -9999 -9999 -9999 -9999 -9999 -9999 -9999 -9999 -9999 -9999 -9999 -9999-9999 -9999 -9999 -9999 -9999 -9999 -9999 -9999 -9999 -9999 -9999 -9999 -9999 -9999 -9999 -9999 -9999 -9999 -9999 -9999 -9999 -9999 -9999 -9999 -9999 -9999 -9999 -9999 -9999 -9999 -9999 -9999 -9999 -9999 -9999 -9999

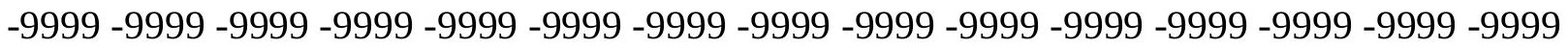

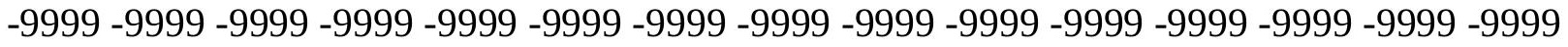
-9999 -9999 -9999 -9999 -9999 -9999 -9999 -9999 -9999 -9999 -9999 -9999 -9999 -9999 -9999

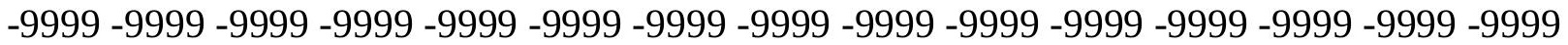
-9999 -9999 -9999 -9999 -9999 -9999 -9999 -9999 -9999 -9999 -9999 -9999 -9999 -9999 -9999 -9999 -9999 -9999 -9999 -9999 -9999 -9999 -9999 -9999 -9999 -9999 -9999 -9999 -9999 -9999 -

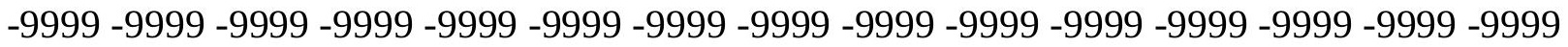
-9999 -9999 -9999 -9999 -9999 -9999 -9999 -9999 -9999 -9999 -9999 -9999 -9999 -9999 -9999

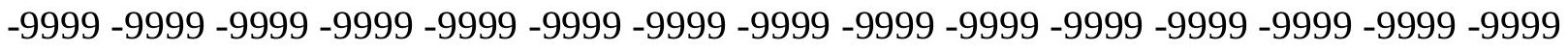
-9999 -9999 -9999 -9999 -9999 -9999 -9999 -9999 -9999 -9999 -9999 -9999 -9999 -9999 -9999 -9999 -9999 -9999 -9999 -9999 -9999 -9999 -9999 -9999 -9999 -9999 -9999 -9999 -9999 -9999 -9999 -9999 -9999 -9999 -9999 -9999 -9999 -9999 -9999 -9999 -9999 -9999 -9999 -9999 -9999 -9999 -9999 -9999 -9999 -9999 -9999 -9999 -9999 -9999 -9999 -9999 -9999 -9999 -9999 -9999 -9999 -9999 -9999 -9999 -9999 -9999 -9999 -9999 -9999 -9999 -9999 -9999 -9999 -9999 -9999 -999 -9999 -9999 -9999 -9999 -9999 -9999 -9999 -9999 -9999 -9999 -9999 -9999 -9999 -9999 -9999 -9999 -9999 -9999 -9999 -9999 -9999 -9999 -9999 -9999 -9999 -9999 -9999 -9999 -9999 -9999 -9999 -9999 -9999 -9999 -9999 -9999 -9999 -9999 -9999 -9999 -9999 -9999 -9999 -9999 -9999 -9999 -9999 -9999 -9999 -9999 -9999 -9999 -9999 -9999 -9999 -9999 -9999 -9999 -9999 -9999 -9999 -9999 -9999 -9999 -9999 -9999 -9999 -9999 -9999 -9999 -9999 -9999 -9999 -9999 -9999 -9999 -9999 -9999 -9999 -9999 -9999 -9999 -9999 -9999 -9999 -9999 -9999 -9999 -9999 -9999 -9999 -9999 -9999 -9999 -9999 -9999 -9999 -9999 -9999 -9999 -9999 -9999 -9999 -9999 -9999 -9999 -9999 -9999 -9999 -9999 -9999 -9999 -9999 -9999 -9999 -9999 -9999 -9999 -9999 -9999 -9999 -9999 -9999 -9999 -9999 -9999 -9999 -9999 -9999 -9999 -9999 -9999 -9999 -999 -9999 -9999 -9999 -9999 -9999 -9999 -9999 -9999 -9999 -9999 -9999 -9999 -9999 -9999 -9999 -9999 -9999 -9999 -9999 -9999 -9999 -9999 -9999 -9999 -9999 -9999 -9999 -9999 -9999 -9999 -

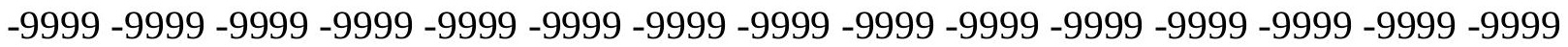

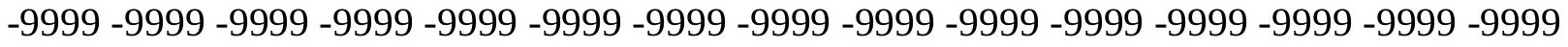

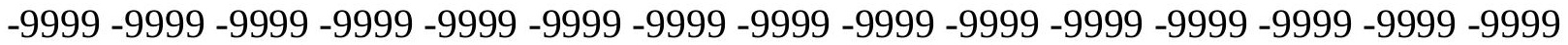
-9999 -9999 -9999 -9999 -9999 -9999 -9999 -9999 -9999 -9999 -9999 -9999 -9999 -9999 -9999

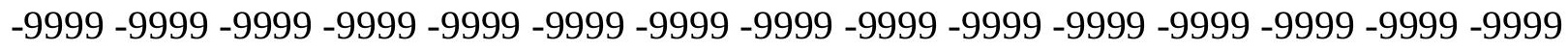

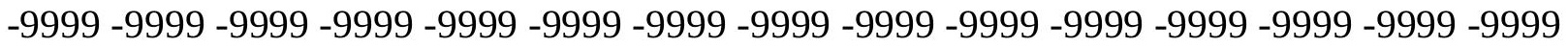
-9999 -9999 -9999 -9999 -9999 -9999 -9999 -9999 -9999 -9999 -9999 -9999 -9999 -9999 -9999 -9999 -9999 -9999 -9999 -9999 -9999 -9999 -9999 -9999 -9999 -9999 -9999 -9999 -9999 -9999 -

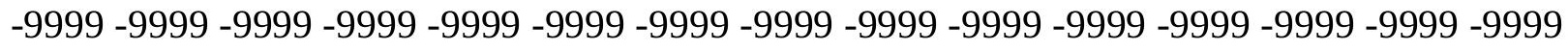

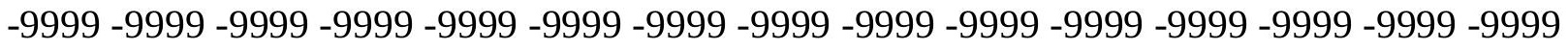
-9999 -9999 -9999 -9999 -9999 -9999 -9999 -9999 -9999 -9999 -9999 -9999 -9999 -9999 -9999 -9999 -9999 -9999 -9999 -9999 -9999 -9999 -9999 -9999-9999 -9999 -9999 -9999 -9999 -9999 -9999 -9999 -9999 -9999 -9999 -9999 -9999 -9999 -9999 -9999 -9999 -9999 -9999 -9999 -9999 -

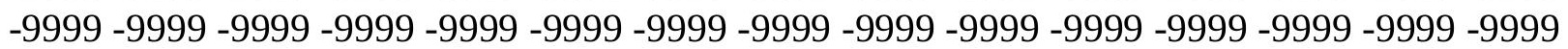


-9999 -9999 -9999 -9999 -9999 -9999 -9999 -9999 -9999 -9999 -9999 -9999 -9999 -9999 -9999 -9999 -9999 -9999 -9999 -9999 -9999 -9999 -9999 -9999 -9999 -9999 -9999 -9999 -9999 -9999 -9999 -9999 -9999 -9999 -9999 -9999 -9999 -9999 -9999 -9999 -9999 -9999 -9999 -9999 - 9999 -9999 -9999 -9999 -9999 -9999 -9999 -9999 -9999 -9999 -9999 -9999 -9999 -9999 -9999

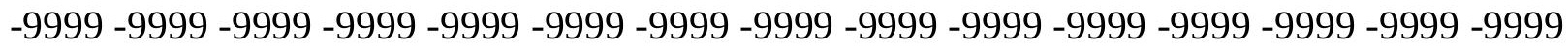
-9999 -9999 -9999 -9999 -9999 -9999 -9999 -9999 -9999 -9999 -9999 -9999 -9999 -9999 -9999 -9999 -9999 -9999 -9999 -9999 -9999 -9999 -9999 -9999 -9999 -9999 -9999 -9999 -9999 -9999

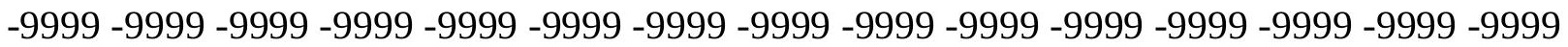

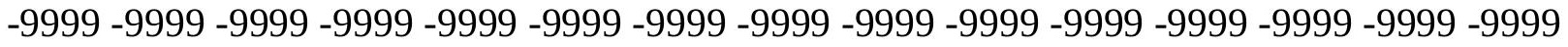
-9999 -9999 -9999 -9999 -9999 -9999 -9999 -9999 -9999 -9999 -9999 -9999 -9999 -9999 -9999 -9999 -9999 -9999 -9999 -9999 -9999 -9999 -9999 -9999 -9999 -9999 -9999 -9999 -9999 -9999 -9999 -9999 -9999 -9999 -9999 -9999 -9999 -9999 -9999 -9999 -9999 -9999 -9999 -9999 -9999 -9999 -9999 -9999 -9999 -9999 -9999 -9999 -9999 -9999 -9999 -9999 -9999 -9999 -9999 -9999 -

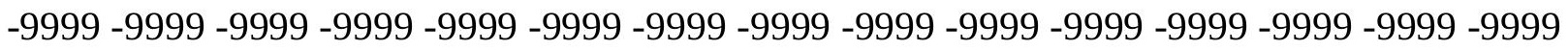
-9999 -9999 -9999 -9999 -9999 -9999 -9999 -9999 -9999 -9999 -9999 -9999 -9999 -9999 -9999 -

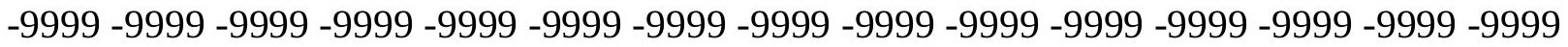
-9999 -9999 -9999 -9999 -9999 -9999 -9999 -9999 -9999 -9999 -9999 -9999 -9999 -9999 -9999 -9999 -9999 -9999 -9999 -9999 -9999 -9999 -9999 -9999 -9999 -9999 -9999 -9999 -9999 -9999 -9999 -9999 -9999 -9999 -9999 -9999 -9999 -9999 -9999 -9999 -9999 -9999 -9999 -9999 -9999 -

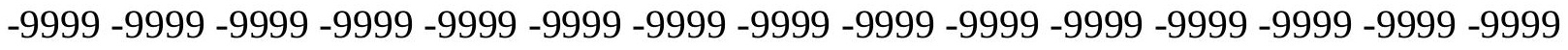
-9999 -9999 -9999 -9999 -9999 -9999 -9999 -9999 -9999 -9999 -9999 -9999 -9999 -9999 -9999

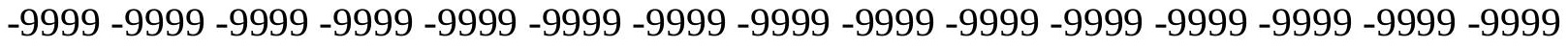
-9999 -9999 -9999 -9999 -9999 -9999 -9999 -9999 -9999 -9999 -9999 -9999 -9999 -9999 -9999 -9999 -9999 -9999 -9999 -9999 -9999 -9999 -9999 -9999 -9999 -9999 -9999 -9999 -9999 -9999 -9999 -9999 -9999 -9999 -9999 -9999 -9999 -9999 -9999 -9999 -9999 -9999 -9999 -9999 -9999 -9999 -9999 -9999 -9999 -9999 -9999 -9999 -9999 -9999 -9999 -9999 -9999 -9999 -9999 -9999 -9999 -9999 -9999 -9999 -9999 -9999 -9999 -9999 -9999 -9999 -9999 -9999 -9999 -9999 -9999 -9999 -9999 -9999 -9999 -9999 -9999 -9999 -9999 -9999 -9999 -9999 -9999 -9999 -9999 -9999 -9999 -9999 -9999 -9999 -9999 -9999 -9999 -9999 -9999 -9999 -9999 -9999 -9999 -9999 -9999 -9999 -9999 -9999 -9999 -9999 -9999 -9999 -9999 -9999 -9999 -9999 -9999 -9999 -9999 -9999 -9999 -9999 -9999 -9999 -9999 -9999 -9999 -9999 -9999 -9999 -9999 -9999 -9999 -9999 -9999 -9999 -9999 -9999 -9999 -9999 -9999 -9999 -9999 -9999 -9999 -9999 -9999 -9999 -9999 -

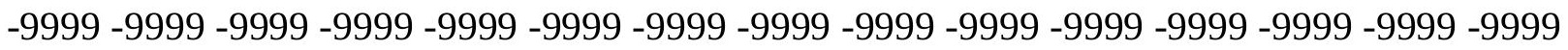

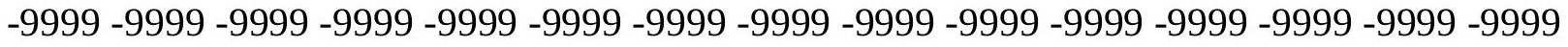
-9999 -9999 -9999 -9999 -9999 -9999 -9999 -9999 -9999 -9999 -9999 -9999 -9999 -9999 -9999 -

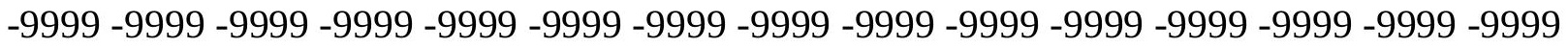

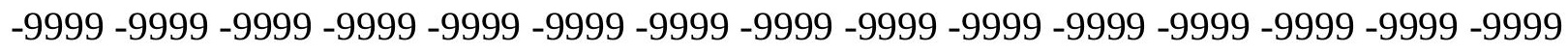

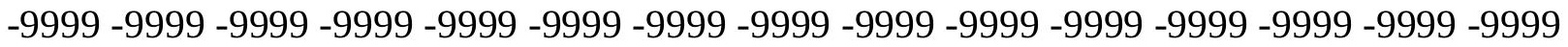

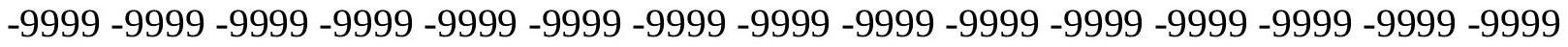
-9999 -9999 -9999 -9999 -9999 -9999 -9999 -9999 -9999 -9999 -9999 -9999 -9999 -9999 -9999 -

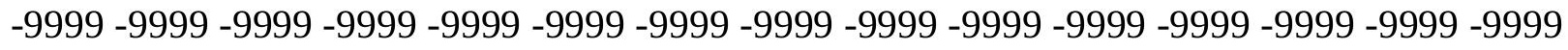

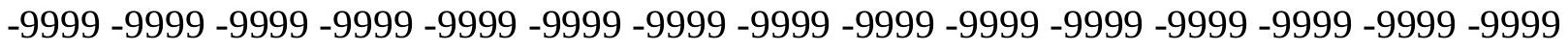
-9999 -9999 -9999 -9999 -9999 -9999 -9999 -9999 -9999 -9999 -9999 -9999 -9999 -9999 -9999 -9999 -9999 -9999 -9999 -9999 -9999 -9999 -9999 -9999-9999 -9999 -9999 -9999 -9999 -9999 -9999 -9999 -9999 -9999 -9999 -9999 -9999 -9999 -9999 -9999 -9999 -9999 -9999 -9999 -9999 -

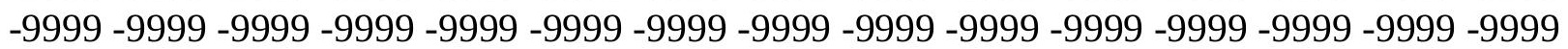


-9999 -9999 -9999 -9999 -9999 -9999 -9999 -9999 -9999 -9999 -9999 -9999 -9999 -9999 -9999 -9999 -9999 -9999 -9999 -9999 -9999 -9999 -9999 -9999 -9999 -9999 -9999 -9999 -9999 -9999 -9999 -9999 -9999 -9999 -9999 -9999 -9999 -9999 -9999 -9999 -9999 -9999 -9999 -9999 - 9999 -9999 -9999 -9999 -9999 -9999 -9999 -9999 -9999 -9999 -9999 -9999 -9999 -9999 -9999 -9999 -9999 -9999 -9999 -9999 -9999 -9999 -9999 -9999 -9999 -9999 -9999 -9999 -9999 -9999 -9999 -9999 -9999 -9999 -9999 -9999 -9999 -9999 -9999 -9999 -9999 -9999 -9999 -9999 -9999 -9999 -9999 -9999 -9999 -9999 -9999 -9999 -9999 -9999 -9999 -9999 -9999 -9999 -9999 -9999 -9999

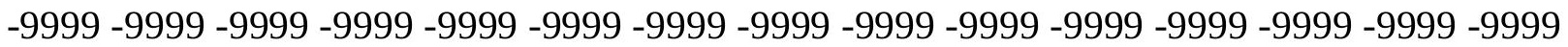

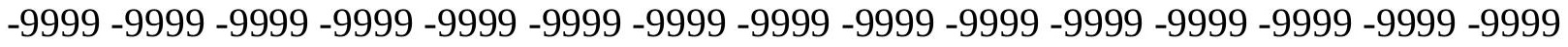
-9999 -9999 -9999 -9999 -9999 -9999 -9999 -9999 -9999 -9999 -9999 -9999 -9999 -9999 -9999 -9999 -9999 -9999 -9999 -9999 -9999 -9999 -9999 -9999 -9999 -9999 -9999 -9999 -9999 -9999 -9999 -9999 -9999 -9999 -9999 -9999 -9999 -9999 -9999 -9999 -9999 -9999 -9999 -9999 -9999 -9999 -9999 -9999 -9999 -9999 -9999 -9999 -9999 -9999 -9999 -9999 -9999 -9999 -9999 -9999 -9999 -9999 -9999 -9999 -9999 -9999 -9999 -9999 -9999 -9999 -9999 -9999 -9999 -9999 -9999 -9999 -9999 -9999 -9999 -9999 -9999 -9999 -9999 -9999 -9999 -9999 -9999 -9999 -9999 -

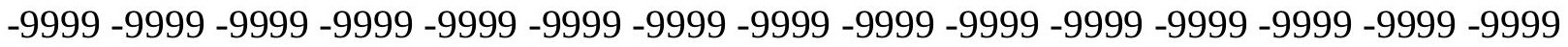
-9999 -9999 -9999 -9999 -9999 -9999 -9999 -9999 -9999 -9999 -9999 -9999 -9999 -9999 -9999 -9999 -9999 -9999 -9999 -9999 -9999 -9999 -9999 -9999 -9999 -9999 -9999 -9999 -9999 -9999 -9999 -9999 -9999 -9999 -9999 -9999 -9999 -9999 -9999 -9999 -9999 -9999 -9999 -9999 -9999 -9999 -9999 -9999 -9999 -9999 -9999 -9999 -9999 -9999 -9999 -9999 -9999 -9999 -9999 -9999 -9999 -9999 -9999 -9999 -9999 -9999 -9999 -9999 -9999 -9999 -9999 -9999 -9999 -9999 -9999 -999 -9999 -9999 -9999 -9999 -9999 -9999 -9999 -9999 -9999 -9999 -9999 -9999 -9999 -9999 -9999 -9999 -9999 -9999 -9999 -9999 -9999 -9999 -9999 -9999 -9999 -9999 -9999 -9999 -9999 -9999 -9999 -9999 -9999 -9999 -9999 -9999 -9999 -9999 -9999 -9999 -9999 -9999 -9999 -9999 -9999 -9999 -9999 -9999 -9999 -9999 -9999 -9999 -9999 -9999 -9999 -9999 -9999 -9999 -9999 -9999 -9999 -9999 -9999 -9999 -9999 -9999 -9999 -9999 -9999 -9999 -9999 -9999 -9999 -9999 -9999 -9999 -9999 -9999 -9999 -9999 -9999 -9999 -9999 -9999 -9999 -9999 -9999 -9999 -9999 -9999 -9999 -9999 -9999 -9999 -9999 -9999 -9999 -9999 -9999 -9999 -9999 -9999 -9999 -9999 -9999 -9999 -9999 -9999 -9999 -9999 -9999 -9999 -9999 -9999 -9999 -9999 -9999 -9999 -9999 -9999 -9999 -9999 -9999 -9999 -9999 -9999 -9999 -9999 -9999 -9999 -9999 -9999 -9999 -9999 -999 -9999 -9999 -9999 -9999 -9999 -9999 -9999 -9999 -9999 -9999 -9999 -9999 -9999 -9999 -9999 -9999 -9999 -9999 -9999 -9999 -9999 -9999 -9999 -9999 -9999 -9999 -9999 -9999 -9999 -9999 -

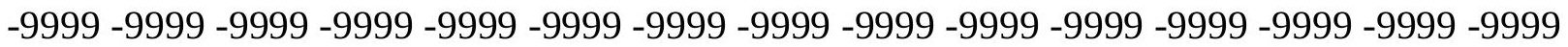

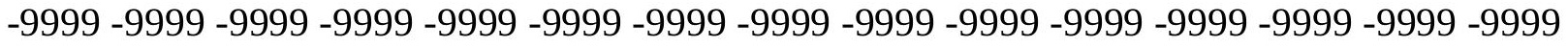

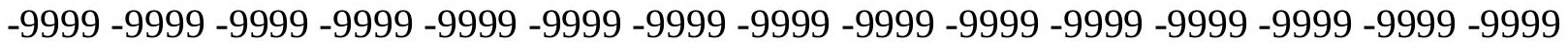
-9999 -9999 -9999 -9999 -9999 -9999 -9999 -9999 -9999 -9999 -9999 -9999 -9999 -9999 -9999 -9999 -9999 -9999 -9999 -9999 -9999 -9999 -9999 -9999 -9999 -9999 -9999 -9999 -9999 -

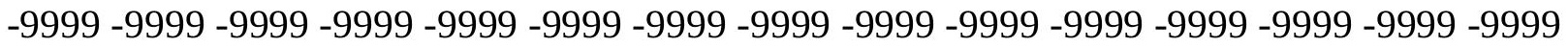
-9999 -9999 -9999 -9999 -9999 -9999 -9999 -9999 -9999 -9999 -9999 -9999 -9999 -9999 -9999 -9999 -9999 -9999 -9999 -9999 -9999 -9999 -9999 -9999 -9999 -9999 -9999 -9999 -9999 -9999 -

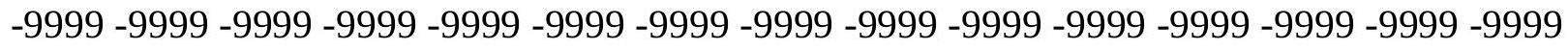

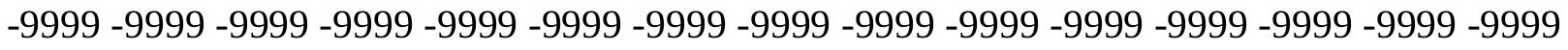
-9999 -9999 -9999 -9999 -9999 -9999 -9999 -9999 -9999 -9999 -9999 -9999 -9999 -9999 -9999 -9999 -9999 -9999 -9999 -9999 -9999 -9999 -9999 -9999-9999 -9999 -9999 -9999 -9999 -9999 -9999 -9999 -9999 -9999 -9999 -9999 -9999 -9999 -9999 -9999 -9999 -9999 -9999 -9999 -9999 -

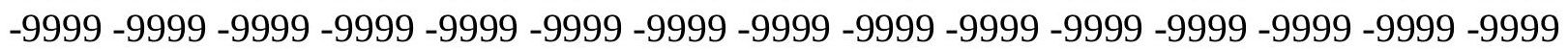


-9999 -9999 -9999 -9999 -9999 -9999 -9999 -9999 -9999 -9999 -9999 -9999 -9999 -9999 -9999 -9999 -9999 -9999 -9999 -9999 -9999 -9999 -9999 -9999 -9999 -9999 -9999 -9999 -9999 -9999 -

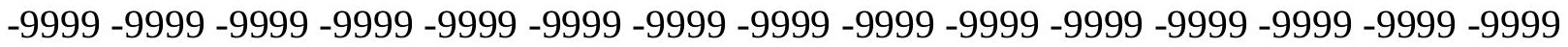
-9999 -9999 -9999 -9999 -9999 -9999 -9999 -9999 -9999 -9999 -9999 -9999 -9999 -9999 -9999 -9999 -9999 -9999 -9999 -9999 -9999 -9999 -9999 -9999-9999 -9999 -9999 -9999 -9999 -9999 -9999 -9999 -9999 -9999 -9999 -9999 -9999 -9999 -9999 -9999 -9999 -9999 -9999 -9999 -9999 -9999 -9999 -9999 -9999 -9999 -9999 -9999 -9999 -9999 -9999 -9999 -9999 -9999 -9999 -9999

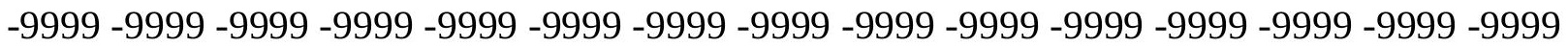

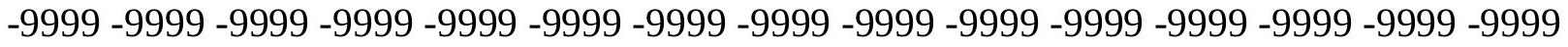
-9999 -9999 -9999 -9999 -9999 -9999 -9999 -9999 -9999 -9999 -9999 -9999 -9999 -9999 -9999 -9999 -9999 -9999 -9999 -9999 -9999 -9999 -9999 -9999 -9999 -9999 -9999 -9999 -9999 -9999 -9999 -9999 -9999 -9999 -9999 -9999 -9999 -9999 -9999 -9999 -9999 -9999 -9999 -9999 -9999 -9999 -9999 -9999 -9999 -9999 -9999 -9999 -9999 -9999 -9999 -9999 -9999 -9999 -9999 -9999 -9999 -9999 -9999 -9999 -9999 -9999 -9999 -9999 -9999 -9999 -9999 -9999 -9999 -9999 -9999 -9999 -9999 -9999 -9999 -9999 -9999 -9999 -9999 -9999 -9999 -9999 -9999 -9999 -9999 -9999 -

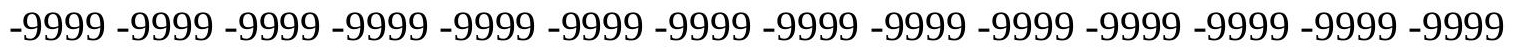
-9999 -9999 -9999 -9999 -9999 -9999 -9999 -9999 -9999 -9999 -9999 -9999 -9999 -9999 -9999 -9999 -9999 -9999 -9999 -9999 -9999 -9999 -9999 -9999 -9999 -9999 -9999 -9999 -9999 -9999 -9999 -9999 -9999 -9999 -9999 -9999 -9999 -9999 -9999 -9999 -9999 -9999 -9999 -9999 -9999 -

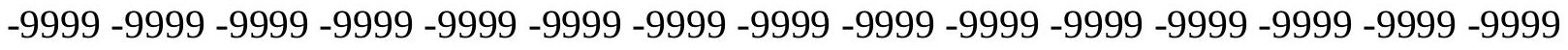

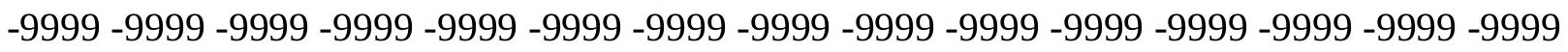
-9999 -9999 -9999 -9999 -9999 -9999 -9999 -9999 -9999 -9999 -9999 -9999 -9999 -9999 - 9999 -9999 -9999 -9999 -9999 -9999 -9999 -9999 -9999 -9999 -9999 -9999 -9999 -9999 -9999 -9999 -9999 -9999 -9999 -9999 -9999 -9999 -9999 -9999 -9999 -9999 -9999 -9999 -9999 -9999 -9999 -

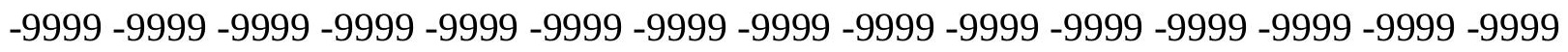
-9999 -9999 -9999 -9999 -9999 -9999 -9999 -9999 -9999 -9999 -9999 -9999 -9999 -9999 -9999 -9999 -9999 -9999 -9999 -9999 -9999 -9999 -9999 -9999 -9999 -9999 -9999 -9999 -9999 -9999 -

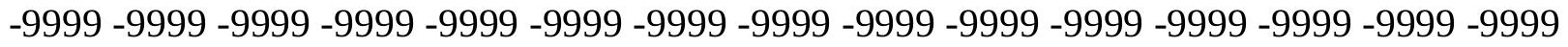
-9999 -9999 -9999 -9999 -9999 -9999 -9999 -9999 -9999 -9999 -9999 -9999 -9999 -9999 -9999 -9999 -9999 -9999 -9999 -9999 -9999 -9999 -9999 -9999 -9999 -9999 -9999 -9999 -9999 -999 -

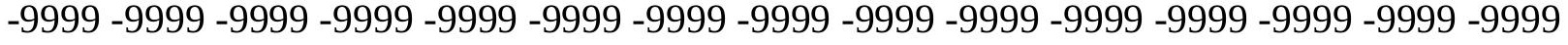
-9999 -9999 -9999 -9999 -9999 -9999 -9999 -9999 -9999 -9999 -9999 -9999 -9999 -9999 -9999 -

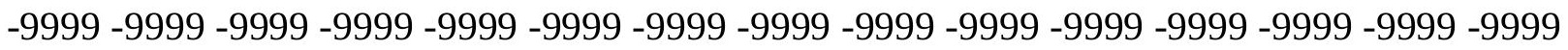

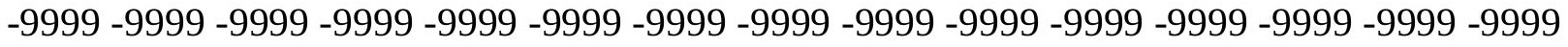

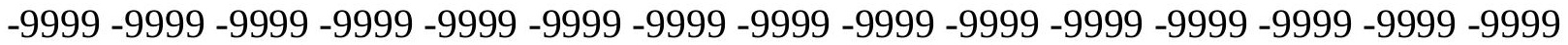
-9999 -9999 -9999 -9999 -9999 -9999 -9999 -9999 -9999 -9999 -9999 -9999 -9999 -9999 -9999 -

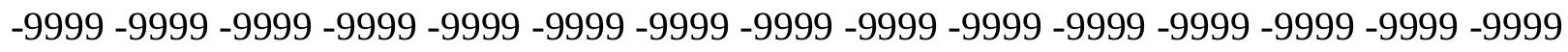

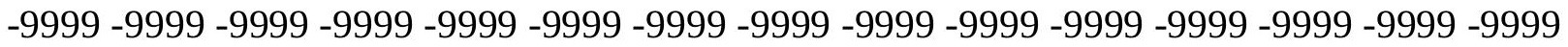
-9999 -9999 -9999 -9999 -9999 -9999 -9999 -9999 -9999 -9999 -9999 -9999 -9999 - 9999 - -999 -9999 -9999 -9999 -9999 -9999 -9999 -9999 -9999 -9999 -9999 -9999 -9999 -9999 -9999 -9999 -

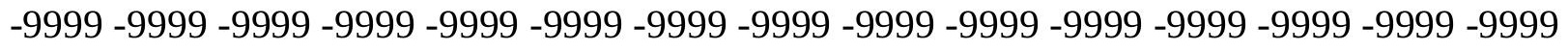

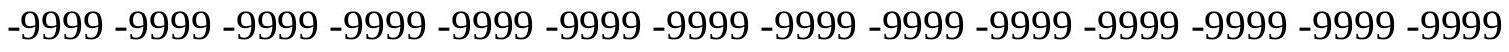
-9999 -9999 -9999 -9999 -9999 -9999 -9999 -9999 -9999 -9999 -9999 -9999 -9999 -9999 -9999 -9999 -9999 -9999 -9999 -9999 -9999 -9999 -9999 -9999-9999 -9999 -9999 -9999 -9999 -9999 -9999 -9999 -9999 -9999 -9999 -9999 -9999 -9999 -9999 -9999 -9999 -9999 -9999 -9999 -9999 -

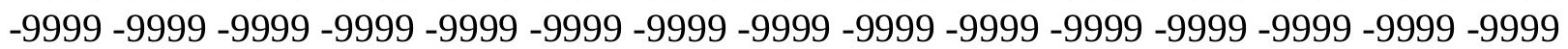


-9999 -9999 -9999 -9999 -9999 -9999 -9999 -9999 -9999 -9999 -9999 -9999 -9999 -9999 -9999 -9999 -9999 -9999 -9999 -9999 -9999 -9999 -9999 -9999 -9999 -9999 -9999 -9999 -9999 -9999 -

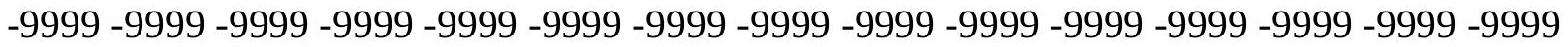
-9999 -9999 -9999 -9999 -9999 -9999 -9999 -9999 -9999 -9999 -9999 -9999 -9999 -9999 -9999 -9999 -9999 -9999 -9999 -9999 -9999 -9999 -9999 -9999-9999 -9999 -9999 -9999 -9999 -9999 -9999 -9999 -9999 -9999 -9999 -9999 -9999 -9999 -9999 -9999 -9999 -9999 -9999 -9999 -9999 -9999 -9999 -9999 -9999 -9999 -9999 -9999 -9999 -9999 -9999 -9999 -9999 -9999 -9999 -9999

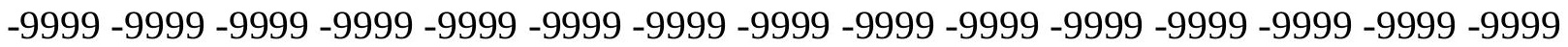

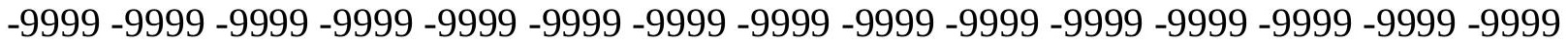
-9999 -9999 -9999 -9999 -9999 -9999 -9999 -9999 -9999 -9999 -9999 -9999 -9999 -9999 -9999 -9999 -9999 -9999 -9999 -9999 -9999 -9999 -9999 -9999 -9999 -9999 -9999 -9999 -9999 -9999 -9999 -9999 -9999 -9999 -9999 -9999 -9999 -9999 -9999 -9999 -9999 -9999 -9999 -9999 -9999 -9999 -9999 -9999 -9999 -9999 -9999 -9999 -9999 -9999 -9999 -9999 -9999 -9999 -9999 -9999 -

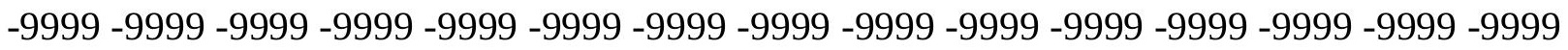
-9999 -9999 -9999 -9999 -9999 -9999 -9999 -9999 -9999 -9999 -9999 -9999 -9999 -9999 -9999 -

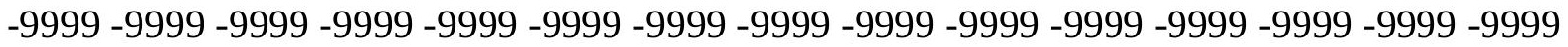
-9999 -9999 -9999 -9999 -9999 -9999 -9999 -9999 -9999 -9999 -9999 -9999 -9999 -9999 -9999 -9999 -9999 -9999 -9999 -9999 -9999 -9999 -9999 -9999 -9999 -9999 -9999 -9999 -9999 -9999 -9999 -9999 -9999 -9999 -9999 -9999 -9999 -9999 -9999 -9999 -9999 -9999 -9999 -9999 -9999 -

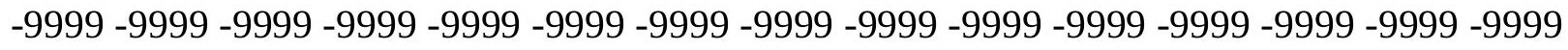

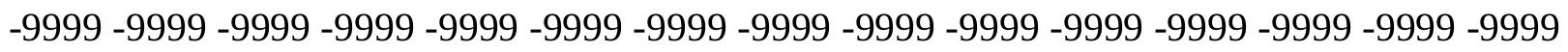
-9999 -9999 -9999 -9999 -9999 -9999 -9999 -9999 -9999 -9999 -9999 -9999 -9999 -9999 -9999 -9999 -9999 -9999 -9999 -9999 -9999 -9999 -9999 -9999 -9999 -9999 -9999 -9999 -9999 -9999 -9999 -9999 -9999 -9999 -9999 -9999 -9999 -9999 -9999 -9999 -9999 -9999 -9999 -9999 -

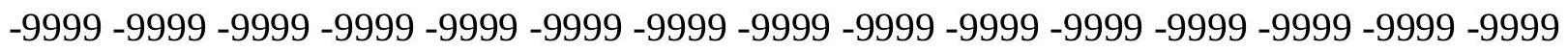
-9999 -9999 -9999 -9999 -9999 -9999 -9999 -9999 -9999 -9999 -9999 -9999 -9999 -9999 -9999 -9999 -9999 -9999 -9999 -9999 -9999 -9999 -9999 -9999 -9999 -9999 -9999 -9999 -9999 -9999 -

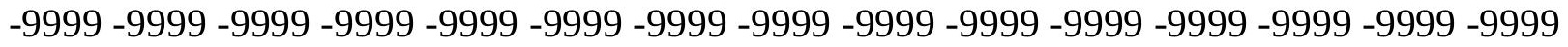
-9999 -9999 -9999 -9999 -9999 -9999 -9999 -9999 -9999 -9999 -9999 -9999 -9999 -9999 -9999 -9999 -9999 -9999 -9999 -9999 -9999 -9999 -9999 -9999 -9999 -9999 -9999 -9999 -9999 -999 -

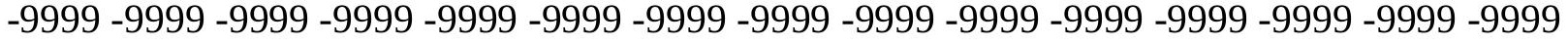
-9999 -9999 -9999 -9999 -9999 -9999 -9999 -9999 -9999 -9999 -9999 -9999 -9999 -9999 -9999 -

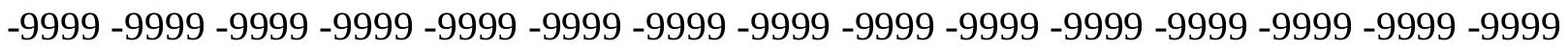

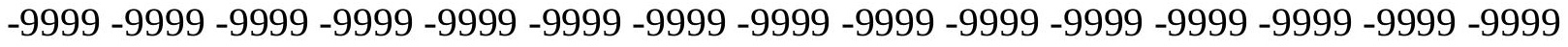

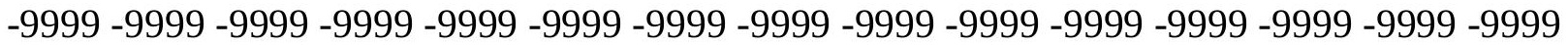

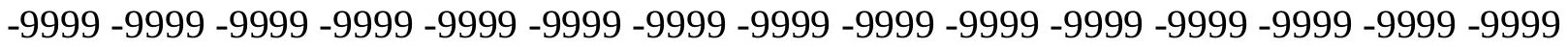

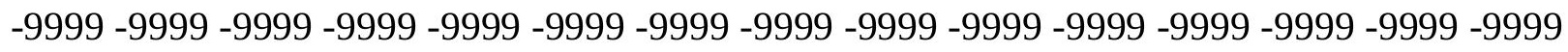

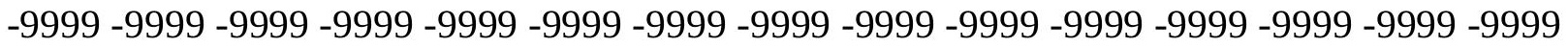

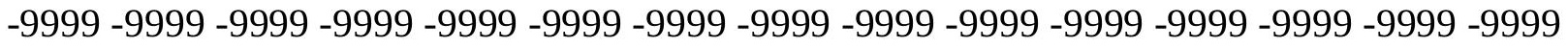
-9999 -9999 -9999 -9999 -9999 -9999 -9999 -9999 -9999 -9999 -9999 -9999 -9999 -9999 -9999 -

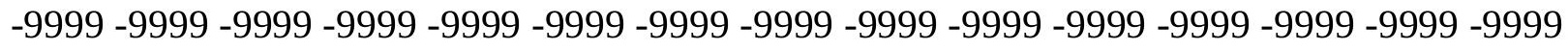

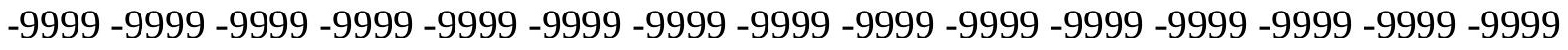
-9999 -9999 -9999 -9999 -9999 -9999 -9999 -9999 -9999 -9999 -9999 -9999 -9999 -9999 -9999 -9999 -9999 -9999 -9999 -9999 -9999 -9999 -9999 -9999-9999 -9999 -9999 -9999 -9999 -9999 -9999 -9999 -9999 -9999 -9999 -9999 -9999 -9999 -9999 -9999 -9999 -9999 -9999 -9999 -9999 -

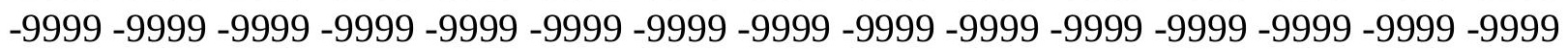


-9999 -9999 -9999 -9999 -9999 -9999 -9999 -9999 -9999 -9999 -9999 -9999 -9999 -9999 -9999 -9999 -9999 -9999 -9999 -9999 -9999 -9999 -9999 -9999 -9999 -9999 -9999 -9999 -9999 -

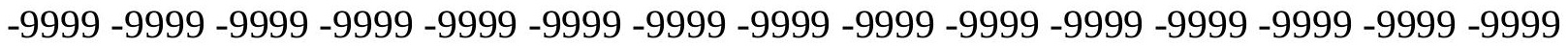
-9999 -9999 -9999 -9999 -9999 -9999 -9999 -9999 -9999 -9999 -9999 -9999 -9999 -9999 -9999 -9999 -9999 -9999 -9999 -9999 -9999 -9999 -9999 -9999 -9999 -9999 -9999 -9999 -9999 -9999 -9999 -9999 -9999 -9999 -9999 -9999 -9999 -9999 -9999 -9999 -9999 -9999 -9999 -9999 -9999 -9999 -9999 -9999 -9999 -9999 -9999 -9999 -9999 -9999 -9999 -9999 -9999 -9999 -9999 -9999

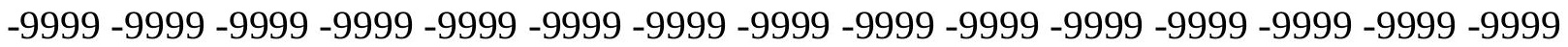

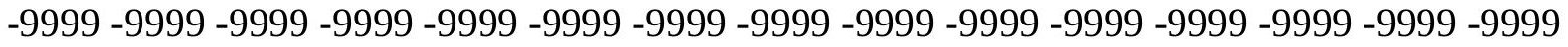
-9999 -9999 -9999 -9999 -9999 -9999 -9999 -9999 -9999 -9999 -9999 -9999 -9999 -9999 -9999 -9999 -9999 -9999 -9999 -9999 -9999 -9999 -9999 -9999 -9999 -9999 -9999 -9999 -9999 -9999 -9999 -9999 -9999 -9999 -9999 -9999 -9999 -9999 -9999 -9999 -9999 -9999 -9999 -9999 -9999 -9999 -9999 -9999 -9999 -9999 -9999 -9999 -9999 -9999 -9999 -9999 -9999 -9999 -9999 -9999 -9999 -9999 -9999 -9999 -9999 -9999 -9999 -9999 -9999 -9999 -9999 -9999 -9999 -9999 -9999 -9999 -9999 -9999 -9999 -9999 -9999 -9999 -9999 -9999 -9999 -9999 -9999 -9999 -9999 -9999 -

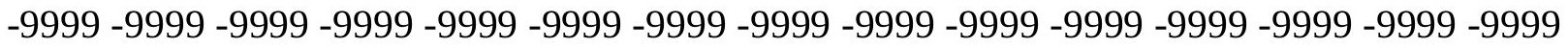
-9999 -9999 -9999 -9999 -9999 -9999 -9999 -9999 -9999 -9999 -9999 -9999 -9999 -9999 -9999 -9999 -9999 -9999 -9999 -9999 -9999 -9999 -9999 -9999 -9999 -9999 -9999 -9999 -9999 - 9999 -9999 -9999 -9999 -9999 -9999 -9999 -9999 -9999 -9999 -9999 -9999 -9999 -9999 -9999 -9999 -

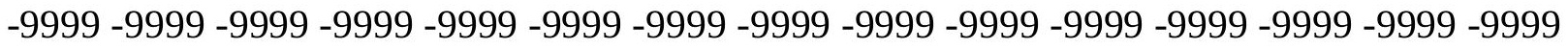

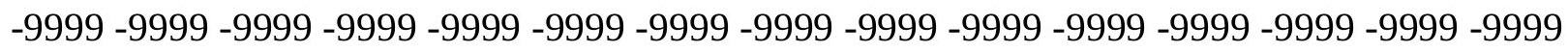

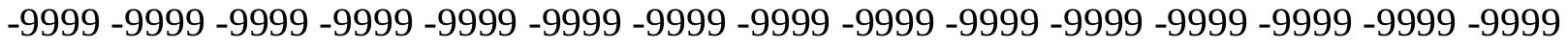
-9999 -9999 -9999 -9999 -9999 -9999 -9999 -9999 -9999 -9999 -9999 -9999 -9999 -9999 -9999 -9999 -9999 -9999 -9999 -9999 -9999 -9999 -9999 -9999 -9999 -9999 -9999 -9999 -9999 -9999 -

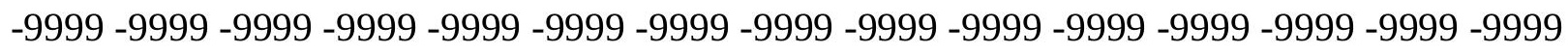
-9999 -9999 -9999 -9999 -9999 -9999 -9999 -9999 -9999 -9999 -9999 -9999 -9999 -9999 -9999 -9999 -9999 -9999 -9999 -9999 -9999 -9999 -9999 -9999 -9999 -9999 -9999 -9999 -9999 -9999 -9999 -9999 -9999 -9999 -9999 -9999 -9999 -9999 -9999 -9999 -9999 -9999 -9999 -9999 -9999 -9999 -9999 -9999 -9999 -9999 -9999 -9999 -9999 -9999 -9999 -9999 -9999 -9999 -9999 -9999 -9999 -9999 -9999 -9999 -9999 -9999 -9999 -9999 -9999 -9999 -9999 -9999 -9999 -999 -

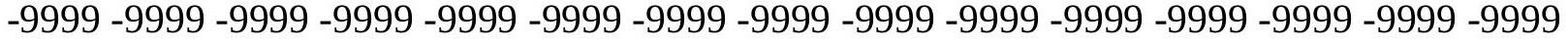
-9999 -9999 -9999 -9999 -9999 -9999 -9999 -9999 -9999 -9999 -9999 -9999 -9999 -9999 -9999 -

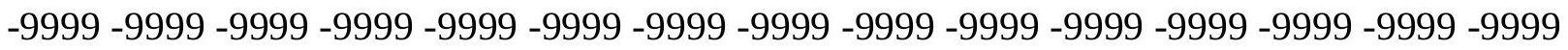

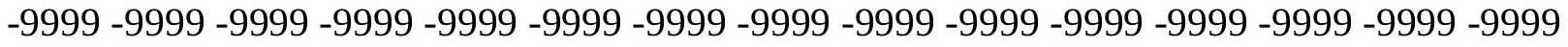

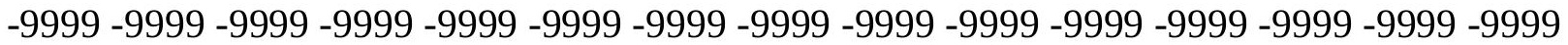

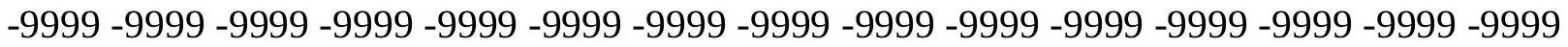

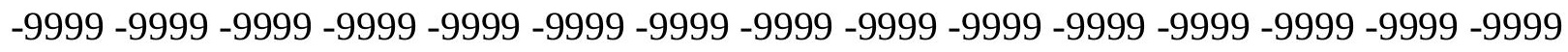

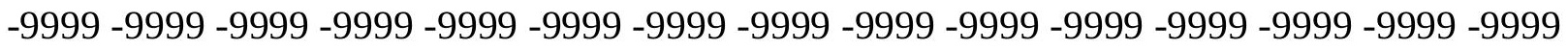

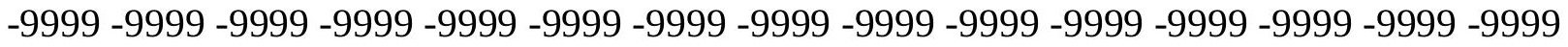
-9999 -9999 -9999 -9999 -9999 -9999 -9999 -9999 -9999 -9999 -9999 -9999 -9999 -9999 -9999 -

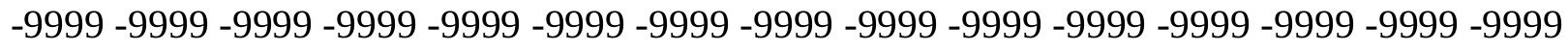

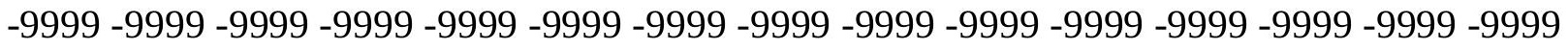
-9999 -9999 -9999 -9999 -9999 -9999 -9999 -9999 -9999 -9999 -9999 -9999 -9999 -9999 -9999 -9999 -9999 -9999 -9999 -9999 -9999 -9999 -9999 -9999-9999 -9999 -9999 -9999 -9999 -9999 -9999 -9999 -9999 -9999 -9999 -9999 -9999 -9999 -9999 -9999 -9999 -9999 -9999 -9999 -9999 -

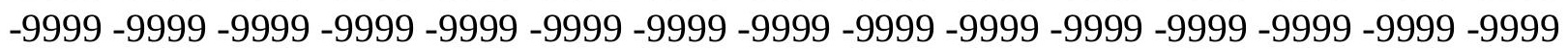


-9999 -9999 -9999 -9999 -9999 -9999 -9999 -9999 -9999 -9999 -9999 -9999 -9999 -9999 -9999 -9999 -9999 -9999 -9999 -9999 -9999 -9999 -9999 -9999 -9999 -9999 -9999 -9999 -9999 -9999 -

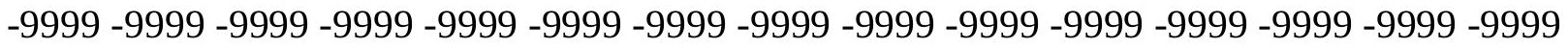
-9999 -9999 -9999 -9999 -9999 -9999 -9999 -9999 -9999 -9999 -9999 -9999 -9999 -9999 -9999 -9999 -9999 -9999 -9999 -9999 -9999 -9999 -9999 -9999-9999 -9999 -9999 -9999 -9999 -9999 -9999 -9999 -9999 -9999 -9999 -9999 -9999 -9999 -9999 -9999 -9999 -9999 -9999 -9999 -9999 -

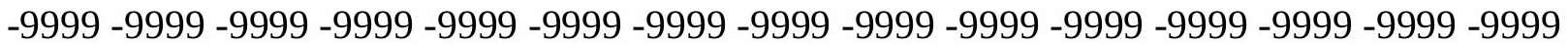
-9999 -9999 -9999 -9999 -9999 -9999 -9999 -9999 -9999 -9999 -9999 -9999 -9999 -9999 -9999 -9999 -9999 -9999 -9999 -9999 -9999 -9999 -9999 -9999 -9999 -9999 -9999 -9999 -9999 -9999 -9999 -9999 -9999 -9999 -9999 -9999 -9999 -9999 -9999 -9999 -9999 -9999 -9999 -9999 -9999 -9999 -9999 -9999 -9999 -9999 -9999 -9999 -9999 -9999 -9999 -9999 -9999 -9999 -9999 -9999 -9999 -9999 -9999 -9999 -9999 -9999 -9999 -9999 -9999 -9999 -9999 -9999 -9999 -9999 -9999 -9999 -9999 -9999 -9999 -9999 -9999 -9999 -9999 -9999 -9999 -9999 -9999 -9999 -9999 -9999 -9999 -9999 -9999 -9999 -9999 -9999 -9999 -9999 -9999 -9999 -9999 -9999 -9999 -9999 -9999 -9999 -9999 -9999 -9999 -9999 -9999 -9999 -9999 -9999 -9999 -9999 -9999 -9999 -9999 -

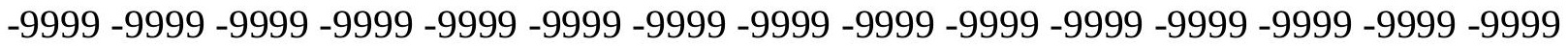
-9999 -9999 -9999 -9999 -9999 -9999 -9999 -9999 -9999 -9999 -9999 -9999 -9999 -9999 -9999 -9999 -9999 -9999 -9999 -9999 -9999 -9999 -9999 -9999 -9999 -9999 -9999 -9999 -9999 -9999 -9999 -9999 -9999 -9999 -9999 -9999 -9999 -9999 -9999 -9999 -9999 -9999 -9999 -9999 -9999 -

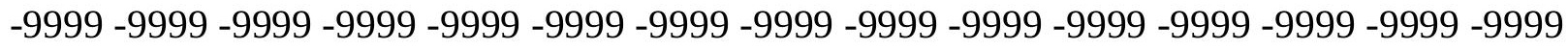

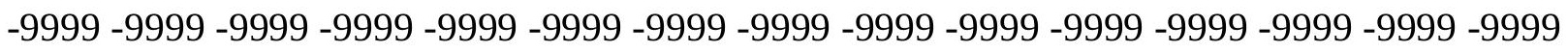
-9999 -9999 -9999 -9999 -9999 -9999 -9999 -9999 -9999 -9999 -9999 -9999 -9999 -9999 - 9999 -9999 -9999 -9999 -9999 -9999 -9999 -9999 -9999 -9999 -9999 -9999 -9999 -9999 -9999 -9999 -9999 -9999 -9999 -9999 -9999 -9999 -9999 -9999 -9999 -9999 -9999 -9999 -9999 -9999 -9999 -

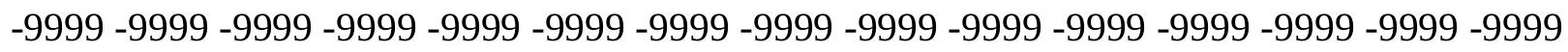
-9999 -9999 -9999 -9999 -9999 -9999 -9999 -9999 -9999 -9999 -9999 -9999 -9999 -9999 -9999 -9999 -9999 -9999 -9999 -9999 -9999 -9999 -9999 -9999 -9999 -9999 -9999 -9999 -9999 -9999 -

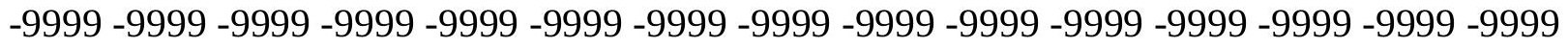
-9999 -9999 -9999 -9999 -9999 -9999 -9999 -9999 -9999 -9999 -9999 -9999 -9999 -9999 -9999 -9999 -9999 -9999 -9999 -9999 -9999 -9999 -9999 -9999 -9999 -9999 -9999 -9999 -9999 -999 -9999 -9999 -9999 -9999 -9999 -9999 -9999 -9999 -9999 -9999 -9999 -9999 -9999 -9999 -9999 -9999 -9999 -9999 -9999 -9999 -9999 -9999 -9999 -9999 -9999 -9999 -9999 -9999 -9999 -9999 -

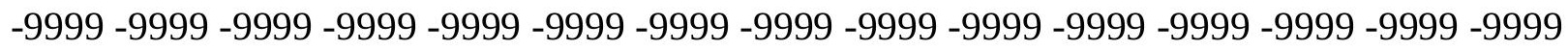

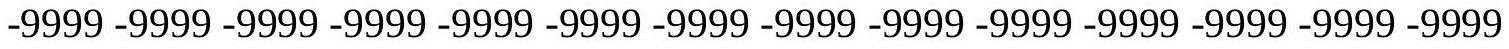
-9999 -9999 -9999 -9999 -9999 -9999 -9999 -9999 -9999 -9999 -9999 -9999 -9999 -9999 -9999

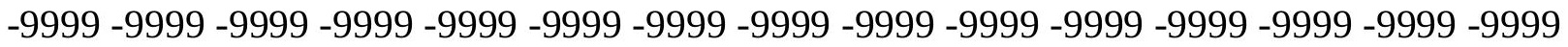

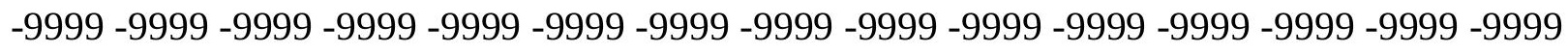

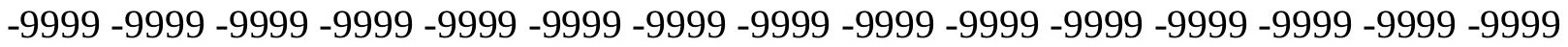

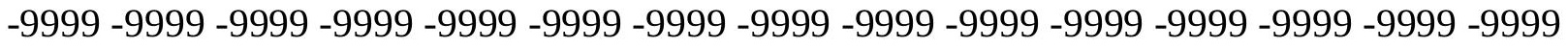
-9999 -9999 -9999 -9999 -9999 -9999 -9999 -9999 -9999 -9999 -9999 -9999 -9999 -9999 -9999 -

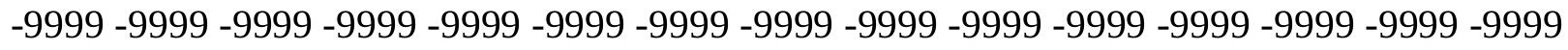

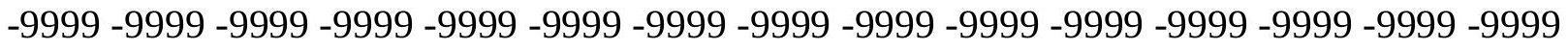
-9999 -9999 -9999 -9999 -9999 -9999 -9999 -9999 -9999 -9999 -9999 -9999 -9999 -9999 -9999 -9999 -9999 -9999 -9999 -9999 -9999 -9999 -9999 -9999-9999 -9999 -9999 -9999 -9999 -9999 -9999 -9999 -9999 -9999 -9999 -9999 -9999 -9999 -9999 -9999 -9999 -9999 -9999 -9999 -9999 -

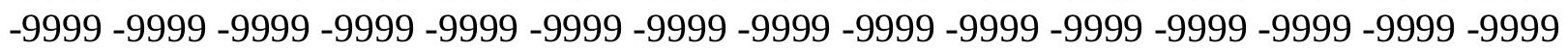




$$
\begin{aligned}
& \text {-9999 -9999 -9999 -9999 -9999 -9999 -9999 -9999 -9999 -9999 -9999 -9999 -9999 -9999 -9999 } \\
& \text {-9999 -9999 -9999 -9999 -9999 -9999 -9999 -9999 -9999 -9999 -9999 -9999 -9999 -9999 -9999 - } \\
& \text {-9999 -9999 -9999 -9999 -9999 -9999 -9999 -9999 -9999 -9999 -9999 -9999 -9999 -9999 - 9999 - } \\
& \text {-9999 -9999 -9999 -9999 -9999 -9999 -9999 -9999 -9999 -9999 -9999 -9999 -9999 -9999 -9999 } \\
& \text {-9999 -9999 -9999 -9999 -9999 -9999 -9999 -9999 -9999 -9999 -9999 -9999 -9999 -9999 -9999 - } \\
& \text {-9999 -9999 -9999 -9999 -9999 -9999 -9999 -9999 -9999 -9999 -9999 -9999 -9999 -9999 -9999 - } \\
& \text {-9999 -9999 -9999 -9999 -9999 -9999 -9999 -9999 -9999 -9999 -9999 -9999 -9999 -9999 - -999 - }
\end{aligned}
$$

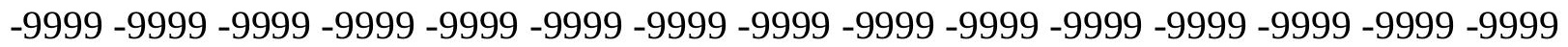

$$
\begin{aligned}
& \text {-9999 -9999 -9999 -9999 -9999 -9999 -9999 -9999 -9999 -9999 -9999 -9999 -9999 -9999 -9999 - } \\
& \text {-9999 -9999 -9999 -9999 -9999 -9999 -9999 -9999 -9999 -9999 -9999 -9999 -9999 -9999 -9999 - } \\
& \text {-9999 -9999 -9999 -9999 -9999 -9999 -9999 -9999 -9999 -9999 -9999 -9999 -9999 -9999 -9999 - } \\
& \text {-9999 -9999 -9999 -9999 -9999 -9999 -9999 -9999 -9999 -9999 -9999 -9999 -9999 -9999 -9999 - } \\
& \text {-9999 -9999 -9999 -9999 -9999 -9999 -9999 -9999 -9999 -9999 -9999 -9999 -9999 -9999 -9999 - } \\
& \text {-9999 -9999 -9999 -9999 -9999 -9999 -9999 -9999 -9999 -9999 -9999 -9999 -9999 -9999 - }
\end{aligned}
$$


u3top_elev 


$\begin{array}{ll}\text { ncols } & 389 \\ \text { nrows } & 437 \\ \text { xllcorner } & 545925 \\ \text { yllcorner } & 100925 \\ \text { cellsize } & 150\end{array}$

NODATA_value -9999

-9999 -9999 -9999 -9999 -9999 -9999 -9999 -9999 -9999 -9999 -9999 -9999 -9999 -9999 -9999 -9999 -9999 -9999 -9999 -9999 -9999 -9999 -9999 -9999 -9999 -9999 -9999 -9999 -9999 -9999 -999 -9999 -9999 -9999 -9999 -9999 -9999 -9999 -9999 -9999 -9999 -9999 -9999 -9999 -9999 -9999 -9999 -9999 -9999 -9999 -9999 -9999 -9999 -9999 -9999 -9999 -9999 -9999 -9999 -9999 -9999

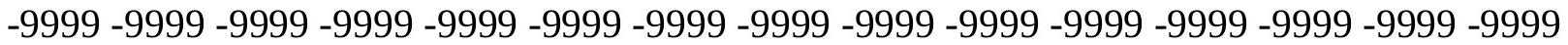
-9999 -9999 -9999 -9999 -9999 -9999 -9999 -9999 -9999 -9999 -9999 -9999 -9999 -9999 -9999 -9999 -9999 -9999 -9999 -9999 -9999 -9999 -9999 -9999 -9999 -9999 -9999 -9999 -9999 -9999 -9999 -9999 -9999 -9999 -9999 -9999 -9999 -9999 -9999 -9999 -9999 -9999 -9999 -9999 - 9999 -9999 -9999 -9999 -9999 -9999 -9999 -9999 -9999 -9999 -9999 -9999 -9999 -9999 -9999 -9999

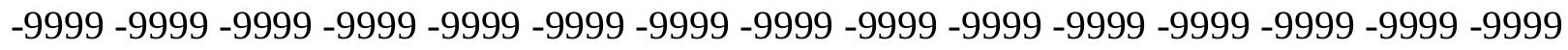
-9999 -9999 -9999 -9999 -9999 -9999 -9999 -9999 -9999 -9999 -9999 -9999 -9999 -9999 -9999 -9999 -9999 -9999 -9999 -9999 -9999 -9999 -9999 -9999 -9999 -9999 -9999 -9999 -9999 -9999 -999 -9999 -9999 -9999 -9999 -9999 -9999 -9999 -9999 -9999 -9999 -9999 -9999 -9999 -9999 -9999 -9999 -9999 -9999 -9999 -9999 -9999 -9999 -9999 -9999 -9999 -9999 -9999 -9999 -9999 -9999 -9999 -9999 -9999 -9999 -9999 -9999 -9999 -9999 -9999 -9999 -9999 -9999 -9999 -9999 -9999 -9999 -9999 -9999 -9999 -9999 -9999 -9999 -9999 -9999 -9999 -9999 -9999 -9999 -9999 -9999 -9999 -9999 -9999 -9999 -9999 -9999 -9999 -9999 -9999 -9999 -9999 -9999 -9999 -9999 -9999 -9999 -9999 -9999 -9999 -9999 -9999 -9999 -9999 -9999 -9999 -9999 -9999 -9999 -9999 -9999 -9999 -9999 -9999 -9999 -9999 -9999 -9999 -9999 -9999 -9999 -9999 -9999 -9999 -9999 -9999 -9999 -9999 -9999 -9999 -9999 -9999 -9999 -9999 -9999 -9999 -9999 -9999 -9999 -9999 -9999 -9999 -9999 -9999 -9999 -9999 -9999 -9999 -9999 -9999 -9999 -9999 -9999 -9999 -9999 -9999 -9999 -9999 -9999 -9999 -9999 -9999 -9999 -9999 -9999 -9999 -9999 -9999 -9999 -9999 -9999 -9999 -9999 -9999 -9999 -9999 -9999 -9999 -9999 -9999 -9999 -9999 -9999 -9999 -9999 -9999 -9999 -9999 -9999 -9999 -9999 -9999 -9999 -9999 -9999 -9999 -9999 -9999 -9999 -9999 -999 -9999 -9999 -9999 -9999 -9999 -9999 -9999 -9999 -9999 -9999 -9999 -9999 -9999 -9999 -9999 -9999 -9999 -9999 -9999 -9999 -9999 -9999 -9999 -9999 -9999 -9999 -9999 -9999 -9999 -

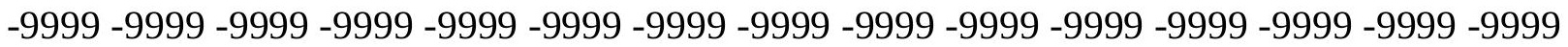
-9999 -9999 -9999 -9999 -9999 -9999 -9999 -9999 -9999 -9999 -9999 -9999 -9999 -9999 -9999 -9999 -9999 -9999 -9999 -9999 -9999 -9999 -9999 -9999 -9999 -9999 -9999 -9999 -9999 -9999 -

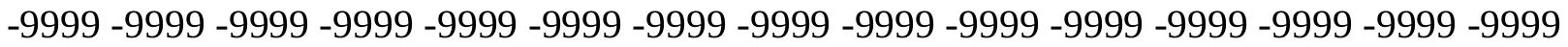

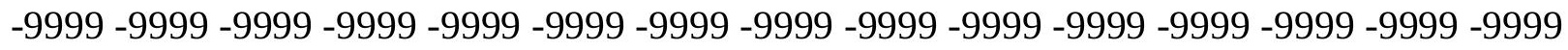
-9999 -9999 -9999 -9999 -9999 -9999 -9999 -9999 -9999 -9999 -9999 -9999 -9999 - 9999 - -9999 -9999 -9999 -9999 -9999 -9999 -9999 -9999 -9999 -9999 -9999 -9999 -9999 -9999 - 9999 - -999 -9999 -9999 -9999 -9999 -9999 -9999 -9999 -9999 -9999 -9999 -9999 -9999 -9999 -9999 -9999 -

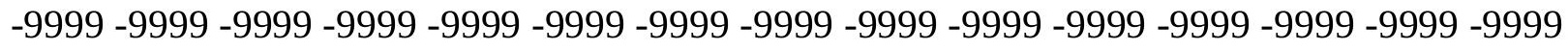

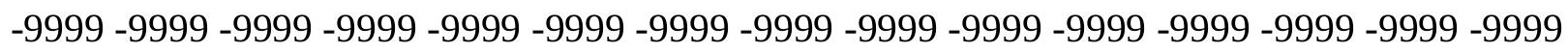
-9999 -9999 -9999 -9999 -9999 -9999 -9999 -9999 -9999 -9999 -9999 -9999 -9999 -9999 -9999 -9999 -9999 -9999 -9999 -9999 -9999 -9999 -9999 -9999-9999 -9999 -9999 -9999 -9999 -9999 -9999 -9999 -9999 -9999 -9999 -9999 -9999 -9999 -9999 -9999 -9999 -9999 -9999 -9999 -9999 -

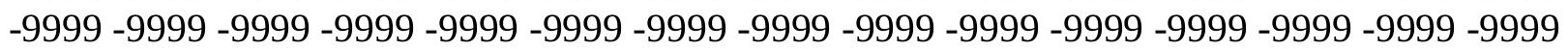


-9999 -9999 -9999 -9999 -9999 -9999 -9999 -9999 -9999 -9999 -9999 -9999 -9999 -9999 -9999 -9999 -9999 -9999 -9999 -9999 -9999 -9999 -9999 -9999 -9999 -9999 -9999 -9999 -9999 -9999 -

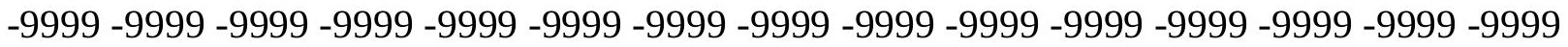
-9999 -9999 -9999 -9999 -9999 -9999 -9999 -9999 -9999 -9999 -9999 -9999 -9999 -9999 -9999 -9999 -9999 -9999 -9999 -9999 -9999 -9999 -9999 -9999-9999 -9999 -9999 -9999 -9999 -9999 -9999 -9999 -9999 -9999 -9999 -9999 -9999 -9999 -9999 -9999 -9999 -9999 -9999 -9999 -9999 -9999 -9999 -9999 -9999 -9999 -9999 -9999 -9999 -9999 -9999 -9999 -9999 -9999 -9999 -9999

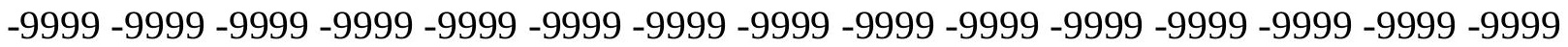

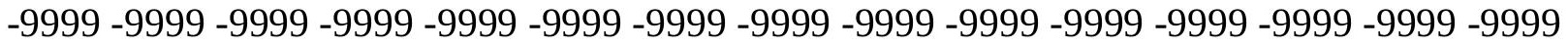
-9999 -9999 -9999 -9999 -9999 -9999 -9999 -9999 -9999 -9999 -9999 -9999 -9999 -9999 -9999 -9999 -9999 -9999 -9999 -9999 -9999 -9999 -9999 -9999 -9999 -9999 -9999 -9999 -9999 -9999 -9999 -9999 -9999 -9999 -9999 -9999 -9999 -9999 -9999 -9999 -9999 -9999 -9999 -9999 -9999 -9999 -9999 -9999 -9999 -9999 -9999 -9999 -9999 -9999 -9999 -9999 -9999 -9999 -9999 -9999 -9999 -9999 -9999 -9999 -9999 -9999 -9999 -9999 -9999 -9999 -9999 -9999 -9999 - 9999 -9999 -9999 -9999 -9999 -9999 -9999 -9999 -9999 -9999 -9999 -9999 -9999 -9999 -9999 -9999

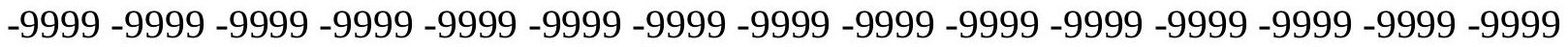
-9999 -9999 -9999 -9999 -9999 -9999 -9999 -9999 -9999 -9999 -9999 -9999 -9999 -9999 -9999 -9999 -9999 -9999 -9999 -9999 -9999 -9999 -9999 -9999 -9999 -9999 -9999 -9999 -9999 -9999 -9999 -9999 -9999 -9999 -9999 -9999 -9999 -9999 -9999 -9999 -9999 -9999 -9999 -9999 -9999 -

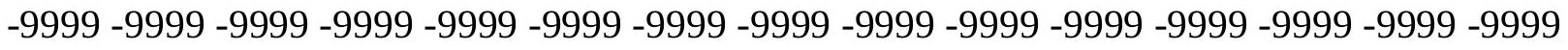

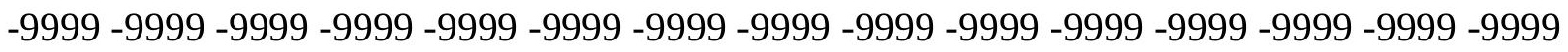
-9999 -9999 -9999 -9999 -9999 -9999 -9999 -9999 -9999 -9999 -9999 -9999 -9999 -9999 -9999 -9999 -9999 -9999 -9999 -9999 -9999 -9999 -9999 -9999 -9999 -9999 -9999 -9999 -9999 -9999 -9999 -9999 -9999 -9999 -9999 -9999 -9999 -9999 -9999 -9999 -9999 -9999 -9999 -9999 -9999 -

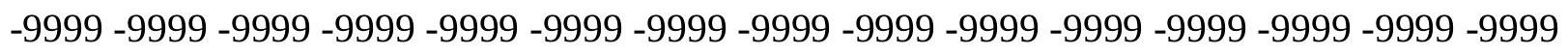
-9999 -9999 -9999 -9999 -9999 -9999 -9999 -9999 -9999 -9999 -9999 -9999 -9999 -9999 -9999 -9999 -9999 -9999 -9999 -9999 -9999 -9999 -9999 -9999 -9999 -9999 -9999 -9999 -9999 -9999 -

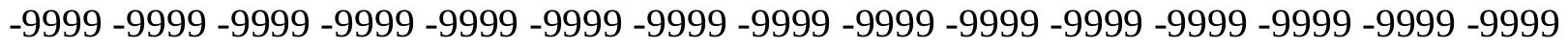
-9999 -9999 -9999 -9999 -9999 -9999 -9999 -9999 -9999 -9999 -9999 -9999 -9999 -9999 -9999 -9999 -9999 -9999 -9999 -9999 -9999 -9999 -9999 -9999 -9999 -9999 -9999 -9999 -9999 -999 -9999 -9999 -9999 -9999 -9999 -9999 -9999 -9999 -9999 -9999 -9999 -9999 -9999 -9999 -9999 -9999 -9999 -9999 -9999 -9999 -9999 -9999 -9999 -9999 -9999 -9999 -9999 -9999 -9999 -9999 -

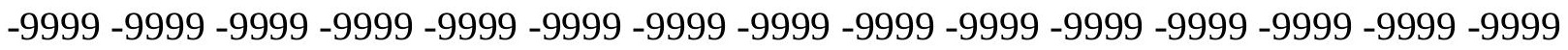

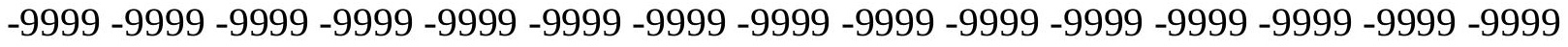

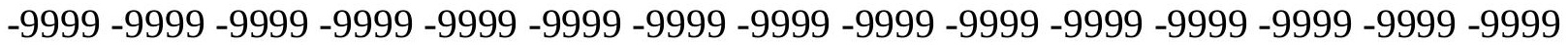

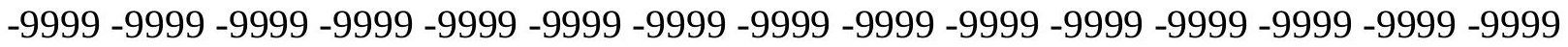

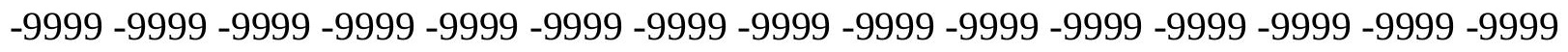

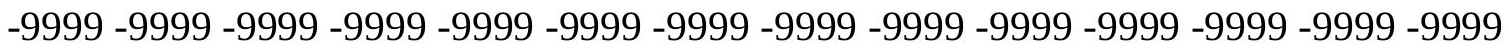
-9999 -9999 -9999 -9999 -9999 -9999 -9999 -9999 -9999 -9999 -9999 -9999 -9999 -9999 -9999 -9999 -9999 -9999 -9999 -9999 -9999 -9999 -9999 -9999 -9999 -9999 -9999 -9999 -9999 -9999 -

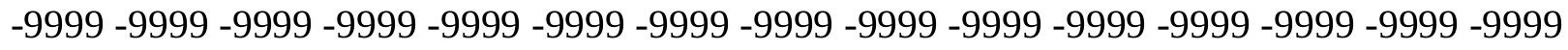

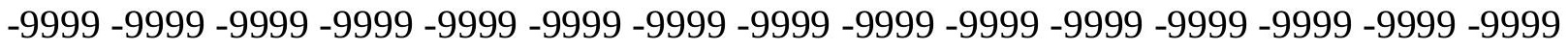
-9999 -9999 -9999 -9999 -9999 -9999 -9999 -9999 -9999 -9999 -9999 -9999 -9999 -9999 -9999 -9999 -9999 -9999 -9999 -9999 -9999 -9999 -9999 -9999-9999 -9999 -9999 -9999 -9999 -9999 -9999 -9999 -9999 -9999 -9999 -9999 -9999 -9999 -9999 -9999 -9999 -9999 -9999 -9999 -9999 -

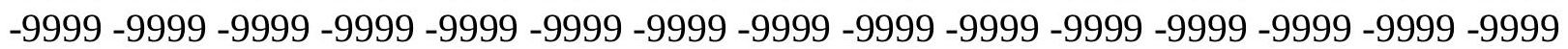


-9999 -9999 -9999 -9999 -9999 -9999 -9999 -9999 -9999 -9999 -9999 -9999 -9999 -9999 -9999 -9999 -9999 -9999 -9999 -9999 -9999 -9999 -9999 -9999 -9999 -9999 -9999 -9999 -9999 -9999 -9999 -9999 -9999 -9999 -9999 -9999 -9999 -9999 -9999 -9999 -9999 -9999 -9999 -9999 - 9999 -9999 -9999 -9999 -9999 -9999 -9999 -9999 -9999 -9999 -9999 -9999 -9999 -9999 -9999 -9999 -9999 -9999 -9999 -9999 -9999 -9999 -9999 -9999 -9999 -9999 -9999 -9999 -9999 -9999 -9999 -9999 -9999 -9999 -9999 -9999 -9999 -9999 -9999 -9999 -9999 -9999 -9999 -9999 -9999 -9999 -9999 -9999 -9999 -9999 -9999 -9999 -9999 -9999 -9999 -9999 -9999 -9999 -9999 -9999 -9999

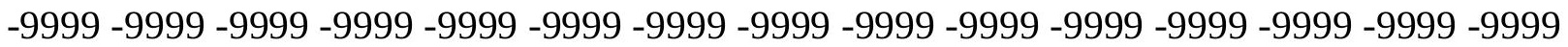
-9999 -9999 -9999 -9999 -9999 -9999 -9999 -9999 -9999 -9999 -9999 -9999 -9999 -9999 -9999 -9999 -9999 -9999 -9999 -9999 -9999 -9999 -9999 -9999 -9999 -9999 -9999 -9999 -9999 -9999

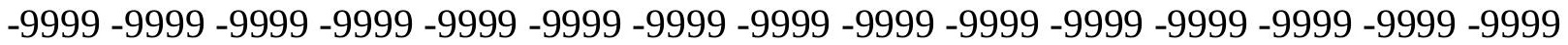
-9999 -9999 -9999 -9999 -9999 -9999 -9999 -9999 -9999 -9999 -9999 -9999 -9999 -9999 -9999 -9999 -9999 -9999 -9999 -9999 -9999 -9999 -9999 -9999 -9999 -9999 -9999 -9999 -9999 -9999 -

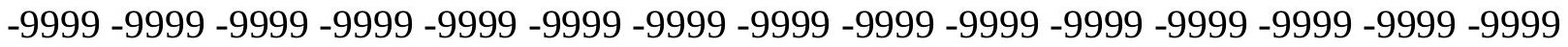
-9999 -9999 -9999 -9999 -9999 -9999 -9999 -9999 -9999 -9999 -9999 -9999 -9999 -9999 -9999

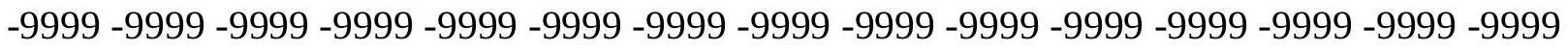
-9999 -9999 -9999 -9999 -9999 -9999 -9999 -9999 -9999 -9999 -9999 -9999 -9999 -9999 -9999 -9999 -9999 -9999 -9999 -9999 -9999 -9999 -9999 -9999 -9999 -9999 -9999 -9999 -9999 - -999 -9999 -9999 -9999 -9999 -9999 -9999 -9999 -9999 -9999 -9999 -9999 -9999 -9999 -9999 -9999 -9999 -9999 -9999 -9999 -9999 -9999 -9999 -9999 -9999 -9999 -9999 -9999 -9999 -9999 -9999 -9999 -9999 -9999 -9999 -9999 -9999 -9999 -9999 -9999 -9999 -9999 -9999 -9999 -9999 -9999 -999 -9999 -9999 -9999 -9999 -9999 -9999 -9999 -9999 -9999 -9999 -9999 -9999 -9999 -9999 -9999 -9999 -9999 -9999 -9999 -9999 -9999 -9999 -9999 -9999 -9999 -9999 -9999 -9999 -9999 -9999 -9999 -9999 -9999 -9999 -9999 -9999 -9999 -9999 -9999 -9999 -9999 -9999 -9999 -9999 -9999 -9999 -9999 -9999 -9999 -9999 -9999 -9999 -9999 -9999 -9999 -9999 -9999 -9999 -9999 -9999 -9999 -9999 -9999 -9999 -9999 -9999 -9999 -9999 -9999 -9999 -9999 -9999 -9999 -9999 -9999 -9999 -9999 -9999 -9999 -9999 -9999 -9999 -9999 -9999 -9999 -9999 -9999 -9999 -9999 -9999 -9999 -9999 -9999 -9999 -9999 -9999 -9999 -9999 -9999 -9999 -9999 -9999 -9999 -9999 -9999 -9999 -9999 -9999 -9999 -9999 -9999 -9999 -9999 -9999 -9999 -9999 -9999 -9999 -9999 -9999 -9999 -9999 -9999 -9999 -9999 -9999 -9999 -9999 -9999 -9999 -9999 -9999 -9999 -9999 -999 -9999 -9999 -9999 -9999 -9999 -9999 -9999 -9999 -9999 -9999 -9999 -9999 -9999 -9999 -9999 -9999 -9999 -9999 -9999 -9999 -9999 -9999 -9999 -9999 -9999 -9999 -9999 -9999 -9999 -9999 -

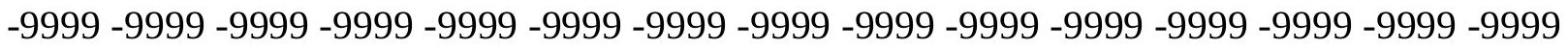

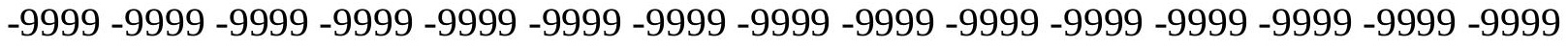

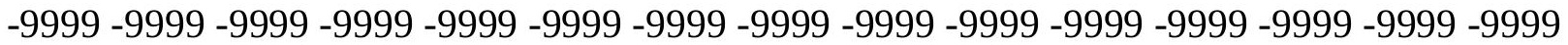
-9999 -9999 -9999 -9999 -9999 -9999 -9999 -9999 -9999 -9999 -9999 -9999 -9999 -9999 -9999

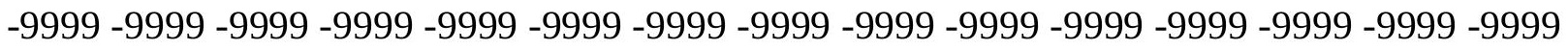

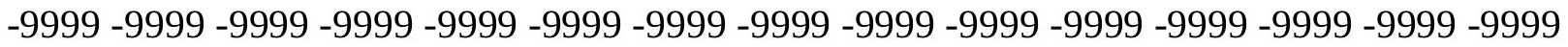

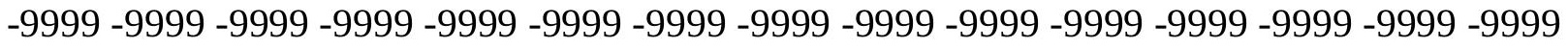
-9999 -9999 -9999 -9999 -9999 -9999 -9999 -9999 -9999 -9999 -9999 -9999 -9999 -9999 -9999 -

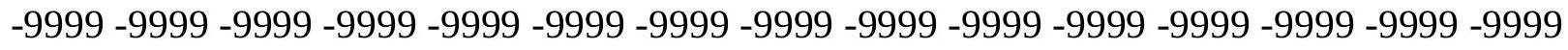

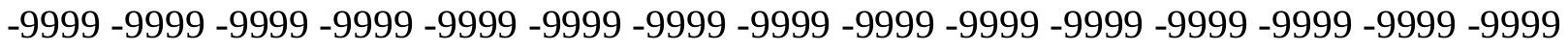
-9999 -9999 -9999 -9999 -9999 -9999 -9999 -9999 -9999 -9999 -9999 -9999 -9999 -9999 -9999 -9999 -9999 -9999 -9999 -9999 -9999 -9999 -9999 -9999 -9999 -9999 -9999 -9999 - -9999 -9999 -9999 -9999 -9999 -9999 -9999 -9999 -9999 -9999 -9999 -9999 -9999 -9999 -9999 -9999 -

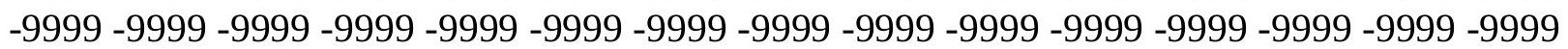


-9999 -9999 -9999 -9999 -9999 -9999 -9999 -9999 -9999 -9999 -9999 -9999 -9999 -9999 -9999 -9999 -9999 -9999 -9999 -9999 -9999 -9999 -9999 -9999 -9999 -9999 -9999 -9999 -9999 -9999 -9999 -9999 -9999 -9999 -9999 -9999 -9999 -9999 -9999 -9999 -9999 -9999 -9999 -9999 - 9999 -9999 -9999 -9999 -9999 -9999 -9999 -9999 -9999 -9999 -9999 -9999 -9999 -9999 -9999 -9999 -9999 -9999 -9999 -9999 -9999 -9999 -9999 -9999 -9999-9999 -9999 -9999 -9999 -9999 -9999 -9999 -9999 -9999 -9999 -9999 -9999 -9999 -9999 -9999 -9999 -9999 -9999 -9999 -9999 -9999 -9999 -9999 -9999 -9999 -9999 -9999 -9999 -9999 -9999 -9999 -9999 -9999 -9999 -9999 -9999

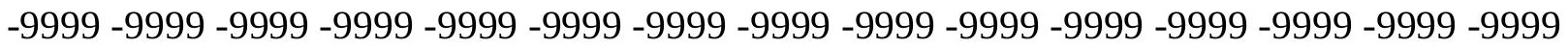

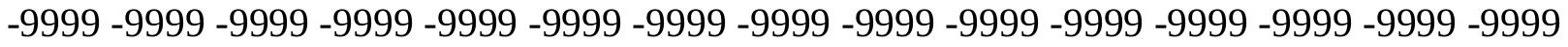
-9999 -9999 -9999 -9999 -9999 -9999 -9999 -9999 -9999 -9999 -9999 -9999 -9999 -9999 -9999

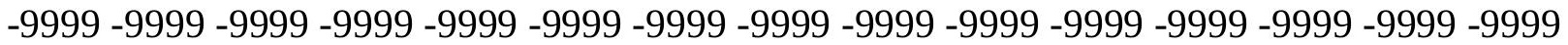
-9999 -9999 -9999 -9999 -9999 -9999 -9999 -9999 -9999 -9999 -9999 -9999 -9999 -9999 -9999 -9999 -9999 -9999 -9999 -9999 -9999 -9999 -9999 -9999 -9999 -9999 -9999 -9999 -9999 -9999 -

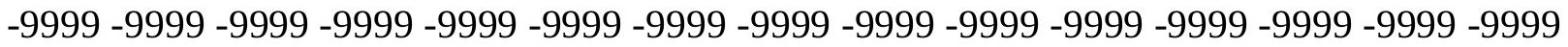
-9999 -9999 -9999 -9999 -9999 -9999 -9999 -9999 -9999 -9999 -9999 -9999 -9999 -9999 -9999

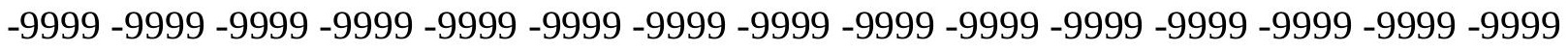
-9999 -9999 -9999 -9999 -9999 -9999 -9999 -9999 -9999 -9999 -9999 -9999 -9999 -9999 -9999 -9999 -9999 -9999 -9999 -9999 -9999 -9999 -9999 -9999 -9999 -9999 -9999 -9999 -9999 -9999 -9999 -9999 -9999 -9999 -9999 -9999 -9999 -9999 -9999 -9999 -9999 -9999 -9999 -9999 -9999 -9999 -9999 -9999 -9999 -9999 -9999 -9999 -9999 -9999 -9999 -9999 -9999 -9999 -9999 -9999 -9999 -9999 -9999 -9999 -9999 -9999 -9999 -9999 -9999 -9999 -9999 -9999 -9999 -9999 -9999 -999 -9999 -9999 -9999 -9999 -9999 -9999 -9999 -9999 -9999 -9999 -9999 -9999 -9999 -9999 -9999 -9999 -9999 -9999 -9999 -9999 -9999 -9999 -9999 -9999 -9999 -9999 -9999 -9999 -9999 -9999 -9999 -9999 -9999 -9999 -9999 -9999 -9999 -9999 -9999 -9999 -9999 -9999 -9999 -9999 -9999 -9999 -9999 -9999 -9999 -9999 -9999 -9999 -9999 -9999 -9999 -9999 -9999 -9999 -9999 -9999 -9999 -9999 -9999 -9999 -9999 -9999 -9999 -9999 -9999 -9999 -9999 -9999 -9999 -9999 -9999 -9999 -9999 -9999 -9999 -9999 -9999 -9999 -9999 -9999 -9999 -9999 -9999 -9999 -9999 -9999 -9999 -9999 -9999 -9999 -9999 -9999 -9999 -9999 -9999 -9999 -9999 -9999 -9999 -9999 -9999 -9999 -9999 -9999 -9999 -9999 -9999 -9999 -9999 -9999 -9999 -9999 -9999 -9999 -9999 -9999 -9999 -9999 -9999 -9999 -9999 -9999 -9999 -9999 -9999 -9999 -9999 -9999 -9999 -999 -9999 -9999 -9999 -9999 -9999 -9999 -9999 -9999 -9999 -9999 -9999 -9999 -9999 -9999 -9999 -9999 -9999 -9999 -9999 -9999 -9999 -9999 -9999 -9999 -9999 -9999 -9999 -9999 -9999 -9999 -

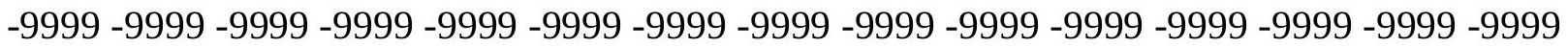

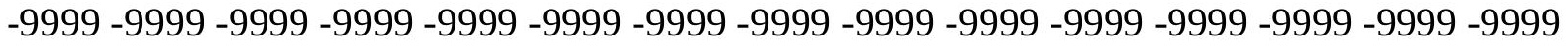

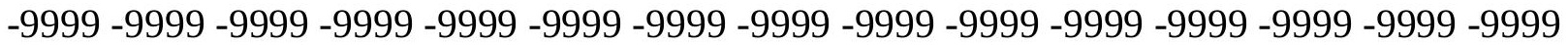
-9999 -9999 -9999 -9999 -9999 -9999 -9999 -9999 -9999 -9999 -9999 -9999 -9999 -9999 -9999

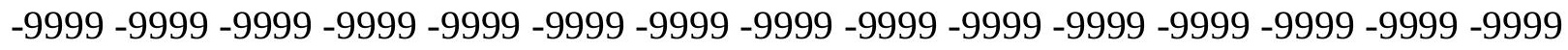

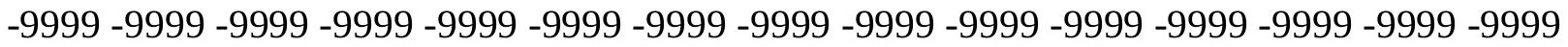
-9999 -9999 -9999 -9999 -9999 -9999 -9999 -9999 -9999 -9999 -9999 -9999 -9999 -9999 -9999 -9999 -9999 -9999 -9999 -9999 -9999 -9999 -9999 -9999 -9999 -9999 -9999 -9999 -9999 -9999 -

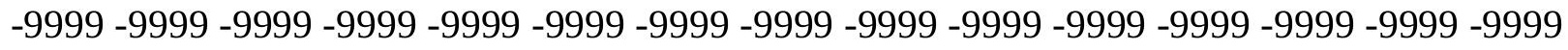

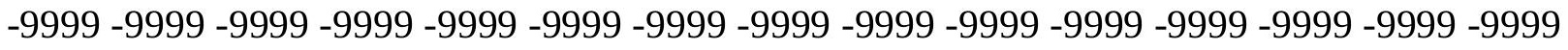
-9999 -9999 -9999 -9999 -9999 -9999 -9999 -9999 -9999 -9999 -9999 -9999 -9999 -9999 -9999 -9999 -9999 -9999 -9999 -9999 -9999 -9999 -9999 -9999-9999 -9999 -9999 -9999 -9999 -9999 -9999 -9999 -9999 -9999 -9999 -9999 -9999 -9999 -9999 -9999 -9999 -9999 -9999 -9999 -9999 -

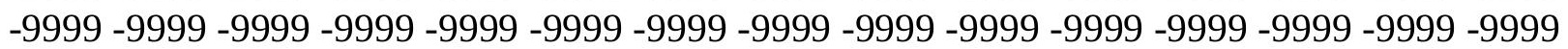


-9999 -9999 -9999 -9999 -9999 -9999 -9999 -9999 -9999 -9999 -9999 -9999 -9999 -9999 -9999 -9999 -9999 -9999 -9999 -9999 -9999 -9999 -9999 -9999 -9999 -9999 -9999 -9999 -9999 -9999 -9999 -9999 -9999 -9999 -9999 -9999 -9999 -9999 -9999 -9999 -9999 -9999 -9999 -9999 - 9999 -9999 -9999 -9999 -9999 -9999 -9999 -9999 -9999 -9999 -9999 -9999 -9999 -9999 -9999

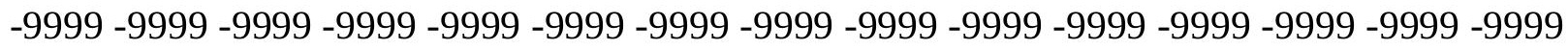
-9999 -9999 -9999 -9999 -9999 -9999 -9999 -9999 -9999 -9999 -9999 -9999 -9999 -9999 -9999 -9999 -9999 -9999 -9999 -9999 -9999 -9999 -9999 -9999 -9999 -9999 -9999 -9999 -9999 -9999

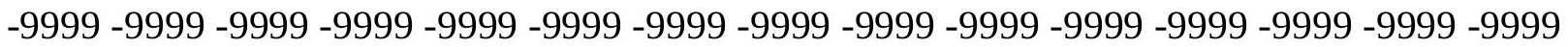

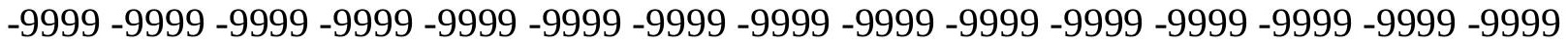
-9999 -9999 -9999 -9999 -9999 -9999 -9999 -9999 -9999 -9999 -9999 -9999 -9999 -9999 -9999 -9999 -9999 -9999 -9999 -9999 -9999 -9999 -9999 -9999 -9999 -9999 -9999 -9999 -9999 -9999 -9999 -9999 -9999 -9999 -9999 -9999 -9999 -9999 -9999 -9999 -9999 -9999 -9999 -9999 -9999 -9999 -9999 -9999 -9999 -9999 -9999 -9999 -9999 -9999 -9999 -9999 -9999 -9999 -9999 -9999 -

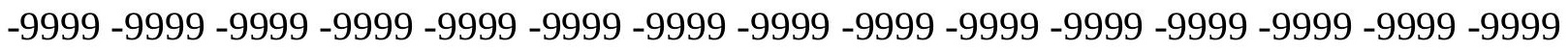
-9999 -9999 -9999 -9999 -9999 -9999 -9999 -9999 -9999 -9999 -9999 -9999 -9999 -9999 -9999 -

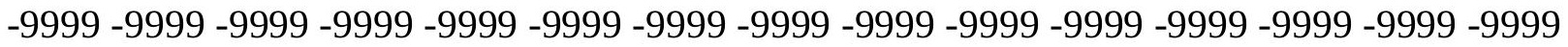
-9999 -9999 -9999 -9999 -9999 -9999 -9999 -9999 -9999 -9999 -9999 -9999 -9999 -9999 -9999 -9999 -9999 -9999 -9999 -9999 -9999 -9999 -9999 -9999 -9999 -9999 -9999 -9999 -9999 -9999 -9999 -9999 -9999 -9999 -9999 -9999 -9999 -9999 -9999 -9999 -9999 -9999 -9999 -9999 -9999 -

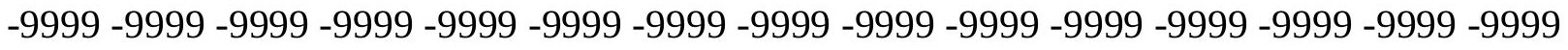
-9999 -9999 -9999 -9999 -9999 -9999 -9999 -9999 -9999 -9999 -9999 -9999 -9999 -9999 -9999

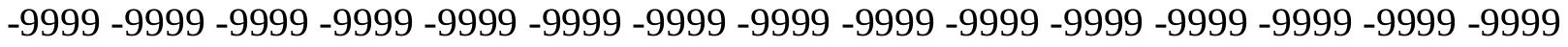
-9999 -9999 -9999 -9999 -9999 -9999 -9999 -9999 -9999 -9999 -9999 -9999 -9999 -9999 -9999 -9999 -9999 -9999 -9999 -9999 -9999 -9999 -9999 -9999 -9999 -9999 -9999 -9999 -9999 -9999 -9999 -9999 -9999 -9999 -9999 -9999 -9999 -9999 -9999 -9999 -9999 -9999 -9999 -9999 -9999 -9999 -9999 -9999 -9999 -9999 -9999 -9999 -9999 -9999 -9999 -9999 -9999 -9999 -9999 -9999 -9999 -9999 -9999 -9999 -9999 -9999 -9999 -9999 -9999 -9999 -9999 -9999 -9999 -9999 -9999 -9999 -9999 -9999 -9999 -9999 -9999 -9999 -9999 -9999 -9999 -9999 -9999 -9999 -9999 -9999 -9999 -9999 -9999 -9999 -9999 -9999 -9999 -9999 -9999 -9999 -9999 -9999 -9999 -9999 -9999 -9999 -9999 -9999 -9999 -9999 -9999 -9999 -9999 -9999 -9999 -9999 -9999 -9999 -9999 -9999 -9999 -9999 -9999 -9999 -9999 -9999 -9999 -9999 -9999 -9999 -9999 -9999 -9999 -9999 -9999 -9999 -9999 -9999 -9999 -9999 -9999 -9999 -9999 -9999 -9999 -9999 -9999 -9999 -9999 -

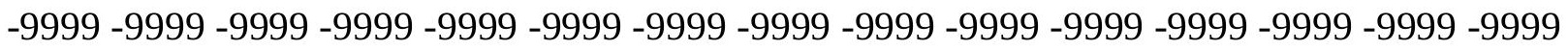

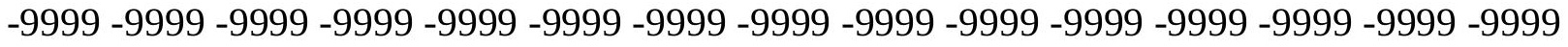
-9999 -9999 -9999 -9999 -9999 -9999 -9999 -9999 -9999 -9999 -9999 -9999 -9999 -9999 -9999 -

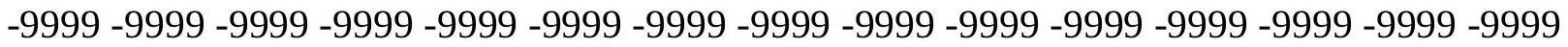

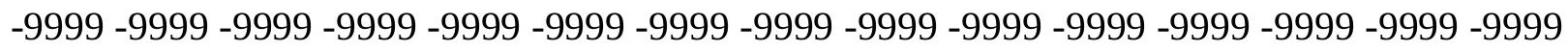

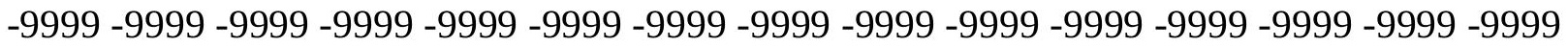

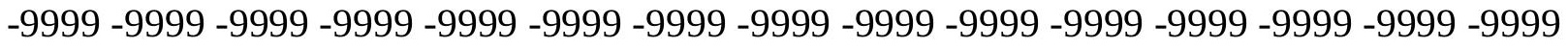
-9999 -9999 -9999 -9999 -9999 -9999 -9999 -9999 -9999 -9999 -9999 -9999 -9999 -9999 -9999 -

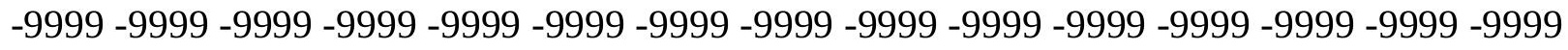

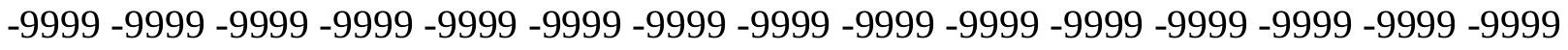
-9999 -9999 -9999 -9999 -9999 -9999 -9999 -9999 -9999 -9999 -9999 -9999 -9999 -9999 -9999 -9999 -9999 -9999 -9999 -9999 -9999 -9999 -9999 -9999-9999 -9999 -9999 -9999 -9999 -9999 -9999 -9999 -9999 -9999 -9999 -9999 -9999 -9999 -9999 -9999 -9999 -9999 -9999 -9999 -9999 -

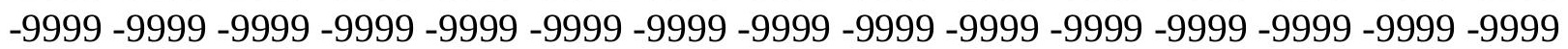


-9999 -9999 -9999 -9999 -9999 -9999 -9999 -9999 -9999 -9999 -9999 -9999 -9999 -9999 -9999 -9999 -9999 -9999 -9999 -9999 -9999 -9999 -9999 -9999 -9999 -9999 -9999 -9999 -9999 -9999 -9999 -9999 -9999 -9999 -9999 -9999 -9999 -9999 -9999 -9999 -9999 -9999 -9999 -9999 - 9999 -9999 -9999 -9999 -9999 -9999 -9999 -9999 -9999 -9999 -9999 -9999 -9999 -9999 -9999 -9999 -9999 -9999 -9999 -9999 -9999 -9999 -9999 -9999 -9999 -9999 -9999 -9999 -9999 -9999 -9999 -9999 -9999 -9999 -9999 -9999 -9999 -9999 -9999 -9999 -9999 -9999 -9999 -9999 -9999 -9999 -9999 -9999 -9999 -9999 -9999 -9999 -9999 -9999 -9999 -9999 -9999 -9999 -9999 -9999 -9999

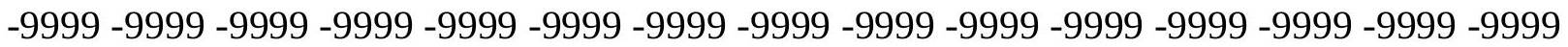

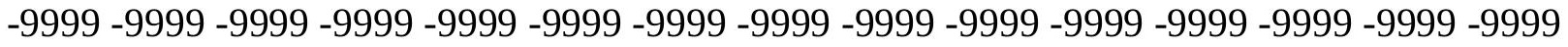
-9999 -9999 -9999 -9999 -9999 -9999 -9999 -9999 -9999 -9999 -9999 -9999 -9999 -9999 -9999 -9999 -9999 -9999 -9999 -9999 -9999 -9999 -9999 -9999 -9999 -9999 -9999 -9999 -9999 -9999 -9999 -9999 -9999 -9999 -9999 -9999 -9999 -9999 -9999 -9999 -9999 -9999 -9999 -9999 -9999 -9999 -9999 -9999 -9999 -9999 -9999 -9999 -9999 -9999 -9999 -9999 -9999 -9999 -9999 -9999 -9999 -9999 -9999 -9999 -9999 -9999 -9999 -9999 -9999 -9999 -9999 -9999 -9999 -9999 -9999 -9999 -9999 -9999 -9999 -9999 -9999 -9999 -9999 -9999 -9999 -9999 -9999 -9999 -9999 -

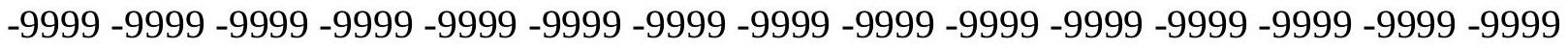
-9999 -9999 -9999 -9999 -9999 -9999 -9999 -9999 -9999 -9999 -9999 -9999 -9999 -9999 -9999 -9999 -9999 -9999 -9999 -9999 -9999 -9999 -9999 -9999 -9999 -9999 -9999 -9999 -9999 -9999 -9999 -9999 -9999 -9999 -9999 -9999 -9999 -9999 -9999 -9999 -9999 -9999 -9999 -9999 -9999 -9999 -9999 -9999 -9999 -9999 -9999 -9999 -9999 -9999 -9999 -9999 -9999 -9999 -9999 -9999 -9999 -9999 -9999 -9999 -9999 -9999 -9999 -9999 -9999 -9999 -9999 -9999 -9999 -9999 -9999 -999 -9999 -9999 -9999 -9999 -9999 -9999 -9999 -9999 -9999 -9999 -9999 -9999 -9999 -9999 -9999 -9999 -9999 -9999 -9999 -9999 -9999 -9999 -9999 -9999 -9999 -9999 -9999 -9999 -9999 -9999 -9999 -9999 -9999 -9999 -9999 -9999 -9999 -9999 -9999 -9999 -9999 -9999 -9999 -9999 -9999 -9999 -9999 -9999 -9999 -9999 -9999 -9999 -9999 -9999 -9999 -9999 -9999 -9999 -9999 -9999 -9999 -9999 -9999 -9999 -9999 -9999 -9999 -9999 -9999 -9999 -9999 -9999 -9999 -9999 -9999 -9999 -9999 -9999 -9999 -9999 -9999 -9999 -9999 -9999 -9999 -9999 -9999 -9999 -9999 -9999 -9999 -9999 -9999 -9999 -9999 -9999 -9999 -9999 -9999 -9999 -9999 -9999 -9999 -9999 -9999 -9999 -9999 -9999 -9999 -9999 -9999 -9999 -9999 -9999 -9999 -9999 -9999 -9999 -9999 -9999 -9999 -9999 -9999 -9999 -9999 -9999 -9999 -9999 -9999 -9999 -9999 -9999 -9999 -9999 -999 -9999 -9999 -9999 -9999 -9999 -9999 -9999 -9999 -9999 -9999 -9999 -9999 -9999 -9999 -9999 -9999 -9999 -9999 -9999 -9999 -9999 -9999 -9999 -9999 -9999 -9999 -9999 -9999 -9999 -9999 -

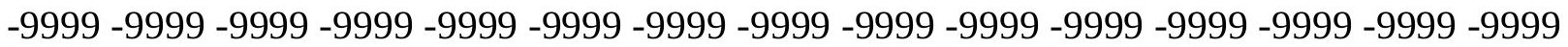

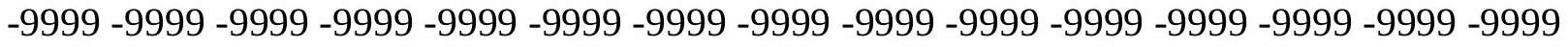

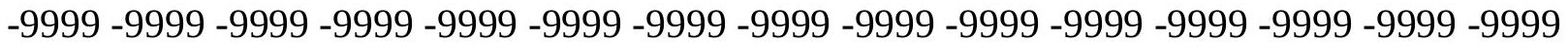
-9999 -9999 -9999 -9999 -9999 -9999 -9999 -9999 -9999 -9999 -9999 -9999 -9999 -9999 -9999 -9999 -9999 -9999 -9999 -9999 -9999 -9999 -9999 -9999 -9999 -9999 -9999 -9999 -9999 -

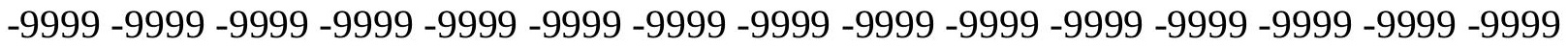
-9999 -9999 -9999 -9999 -9999 -9999 -9999 -9999 -9999 -9999 -9999 -9999 -9999 -9999 -9999 -9999 -9999 -9999 -9999 -9999 -9999 -9999 -9999 -9999 -9999 -9999 -9999 -9999 -9999 -9999 -

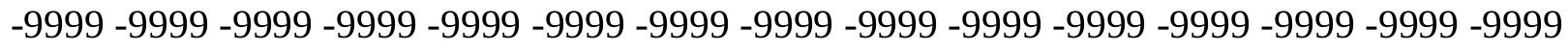

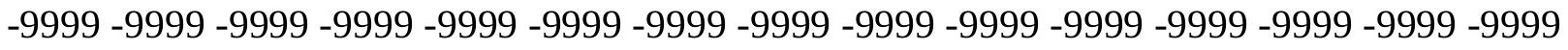
-9999 -9999 -9999 -9999 -9999 -9999 -9999 -9999 -9999 -9999 -9999 -9999 -9999 -9999 -9999 -9999 -9999 -9999 -9999 -9999 -9999 -9999 -9999 -9999-9999 -9999 -9999 -9999 -9999 -9999 -9999 -9999 -9999 -9999 -9999 -9999 -9999 -9999 -9999 -9999 -9999 -9999 -9999 -9999 -9999 -

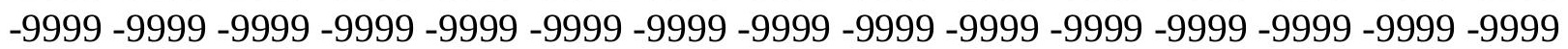


-9999 -9999 -9999 -9999 -9999 -9999 -9999 -9999 -9999 -9999 -9999 -9999 -9999 -9999 -9999 -9999 -9999 -9999 -9999 -9999 -9999 -9999 -9999 -9999 -9999 -9999 -9999 -9999 -9999 -9999 -

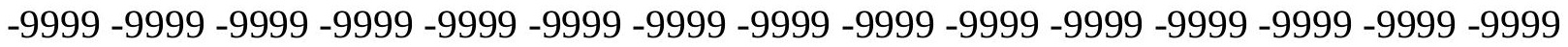
-9999 -9999 -9999 -9999 -9999 -9999 -9999 -9999 -9999 -9999 -9999 -9999 -9999 -9999 -9999 -9999 -9999 -9999 -9999 -9999 -9999 -9999 -9999 -9999-9999 -9999 -9999 -9999 -9999 -9999 -9999 -9999 -9999 -9999 -9999 -9999 -9999 -9999 -9999 -9999 -9999 -9999 -9999 -9999 -9999 -9999 -9999 -9999 -9999 -9999 -9999 -9999 -9999 -9999 -9999 -9999 -9999 -9999 -9999 -9999

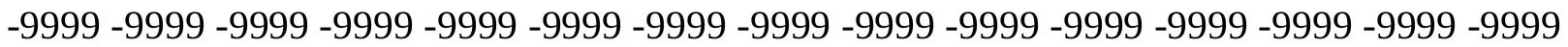

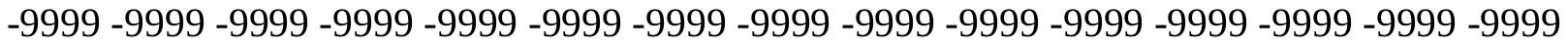
-9999 -9999 -9999 -9999 -9999 -9999 -9999 -9999 -9999 -9999 -9999 -9999 -9999 -9999 -9999 -9999 -9999 -9999 -9999 -9999 -9999 -9999 -9999 -9999 -9999 -9999 -9999 -9999 -9999 -9999 -9999 -9999 -9999 -9999 -9999 -9999 -9999 -9999 -9999 -9999 -9999 -9999 -9999 -9999 -9999 -9999 -9999 -9999 -9999 -9999 -9999 -9999 -9999 -9999 -9999 -9999 -9999 -9999 -9999 -9999 -9999 -9999 -9999 -9999 -9999 -9999 -9999 -9999 -9999 -9999 -9999 -9999 -9999 -9999 -9999 -9999 -9999 -9999 -9999 -9999 -9999 -9999 -9999 -9999 -9999 -9999 -9999 -9999 -9999 -9999 -

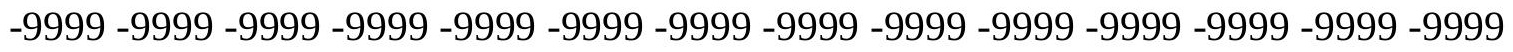
-9999 -9999 -9999 -9999 -9999 -9999 -9999 -9999 -9999 -9999 -9999 -9999 -9999 -9999 -9999 -9999 -9999 -9999 -9999 -9999 -9999 -9999 -9999 -9999 -9999 -9999 -9999 -9999 -9999 -9999 -9999 -9999 -9999 -9999 -9999 -9999 -9999 -9999 -9999 -9999 -9999 -9999 -9999 -9999 -9999 -

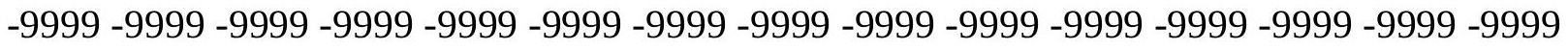

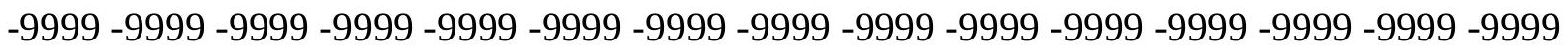
-9999 -9999 -9999 -9999 -9999 -9999 -9999 -9999 -9999 -9999 -9999 -9999 -9999 -9999 - 9999 -9999 -9999 -9999 -9999 -9999 -9999 -9999 -9999 -9999 -9999 -9999 -9999 -9999 -9999 -9999 -9999 -9999 -9999 -9999 -9999 -9999 -9999 -9999 -9999 -9999 -9999 -9999 -9999 -9999 -9999 -

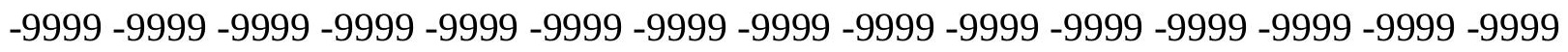
-9999 -9999 -9999 -9999 -9999 -9999 -9999 -9999 -9999 -9999 -9999 -9999 -9999 -9999 -9999 -9999 -9999 -9999 -9999 -9999 -9999 -9999 -9999 -9999 -9999 -9999 -9999 -9999 -9999 -9999 -

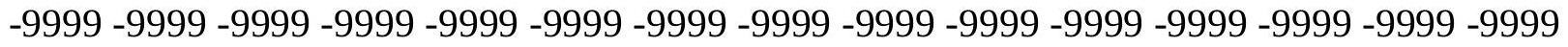
-9999 -9999 -9999 -9999 -9999 -9999 -9999 -9999 -9999 -9999 -9999 -9999 -9999 -9999 -9999 -9999 -9999 -9999 -9999 -9999 -9999 -9999 -9999 -9999 -9999 -9999 -9999 -9999 -9999 -999 -

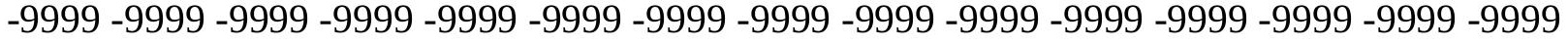
-9999 -9999 -9999 -9999 -9999 -9999 -9999 -9999 -9999 -9999 -9999 -9999 -9999 -9999 -9999 -

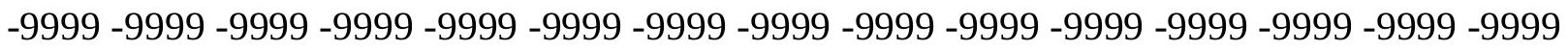

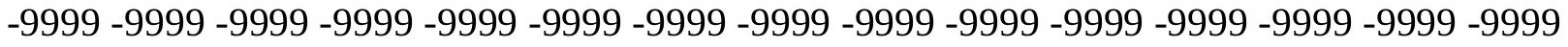

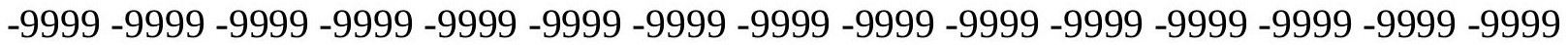
-9999 -9999 -9999 -9999 -9999 -9999 -9999 -9999 -9999 -9999 -9999 -9999 -9999 -9999 -9999 -

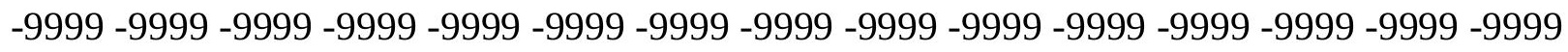

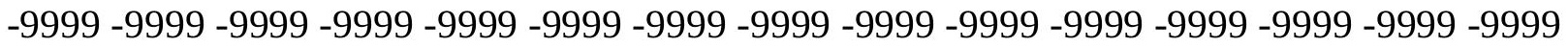
-9999 -9999 -9999 -9999 -9999 -9999 -9999 -9999 -9999 -9999 -9999 -9999 -9999 - 9999 - -999 -9999 -9999 -9999 -9999 -9999 -9999 -9999 -9999 -9999 -9999 -9999 -9999 -9999 -9999 -9999 -

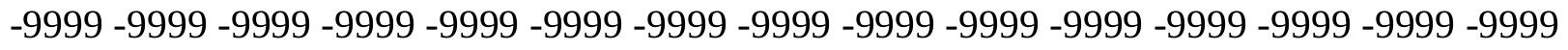

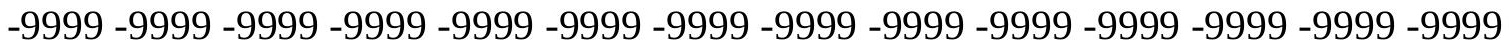
-9999 -9999 -9999 -9999 -9999 -9999 -9999 -9999 -9999 -9999 -9999 -9999 -9999 -9999 -9999 -9999 -9999 -9999 -9999 -9999 -9999 -9999 -9999 -9999-9999 -9999 -9999 -9999 -9999 -9999 -9999 -9999 -9999 -9999 -9999 -9999 -9999 -9999 -9999 -9999 -9999 -9999 -9999 -9999 -9999 -

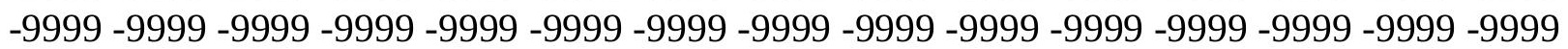


-9999 -9999 -9999 -9999 -9999 -9999 -9999 -9999 -9999 -9999 -9999 -9999 -9999 -9999 -9999 -9999 -9999 -9999 -9999 -9999 -9999 -9999 -9999 -9999 -9999 -9999 -9999 -9999 -9999 -9999 -

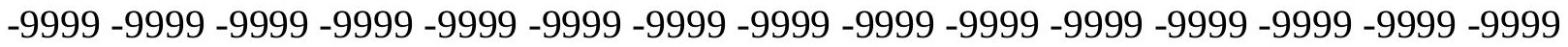
-9999 -9999 -9999 -9999 -9999 -9999 -9999 -9999 -9999 -9999 -9999 -9999 -9999 -9999 -9999 -9999 -9999 -9999 -9999 -9999 -9999 -9999 -9999 -9999-9999 -9999 -9999 -9999 -9999 -9999 -9999 -9999 -9999 -9999 -9999 -9999 -9999 -9999 -9999 -9999 -9999 -9999 -9999 -9999 -9999 -9999 -9999 -9999 -9999 -9999 -9999 -9999 -9999 -9999 -9999 -9999 -9999 -9999 -9999 -9999

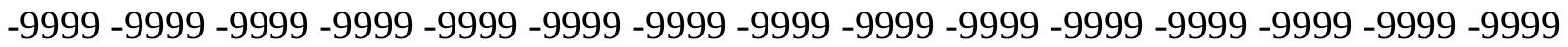

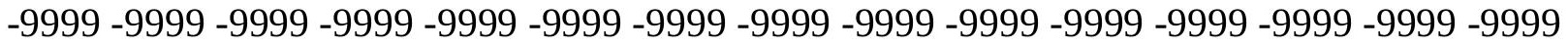
-9999 -9999 -9999 -9999 -9999 -9999 -9999 -9999 -9999 -9999 -9999 -9999 -9999 -9999 -9999 -9999 -9999 -9999 -9999 -9999 -9999 -9999 -9999 -9999 -9999 -9999 -9999 -9999 -9999 -9999 -9999 -9999 -9999 -9999 -9999 -9999 -9999 -9999 -9999 -9999 -9999 -9999 -9999 -9999 -9999 -9999 -9999 -9999 -9999 -9999 -9999 -9999 -9999 -9999 -9999 -9999 -9999 -9999 -9999 -9999 -

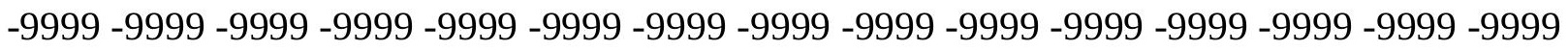
-9999 -9999 -9999 -9999 -9999 -9999 -9999 -9999 -9999 -9999 -9999 -9999 -9999 -9999 -9999 -

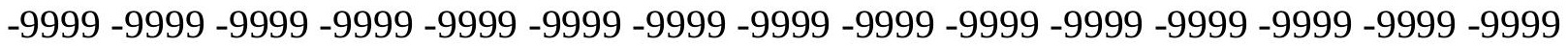
-9999 -9999 -9999 -9999 -9999 -9999 -9999 -9999 -9999 -9999 -9999 -9999 -9999 -9999 -9999 -9999 -9999 -9999 -9999 -9999 -9999 -9999 -9999 -9999 -9999 -9999 -9999 -9999 -9999 -9999 -9999 -9999 -9999 -9999 -9999 -9999 -9999 -9999 -9999 -9999 -9999 -9999 -9999 -9999 -9999 -

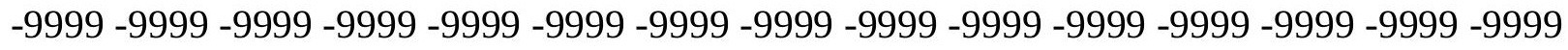

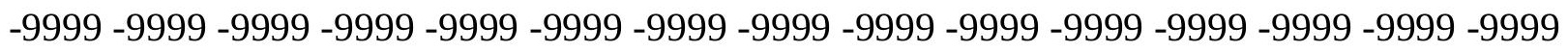
-9999 -9999 -9999 -9999 -9999 -9999 -9999 -9999 -9999 -9999 -9999 -9999 -9999 -9999 -9999 -9999 -9999 -9999 -9999 -9999 -9999 -9999 -9999 -9999 -9999 -9999 -9999 -9999 -9999 -9999 -9999 -9999 -9999 -9999 -9999 -9999 -9999 -9999 -9999 -9999 -9999 -9999 -9999 -9999 -

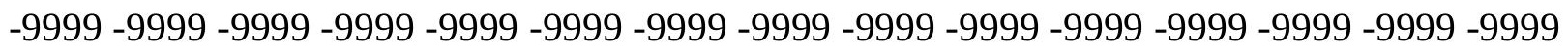
-9999 -9999 -9999 -9999 -9999 -9999 -9999 -9999 -9999 -9999 -9999 -9999 -9999 -9999 -9999 -9999 -9999 -9999 -9999 -9999 -9999 -9999 -9999 -9999 -9999 -9999 -9999 -9999 -9999 -9999 -

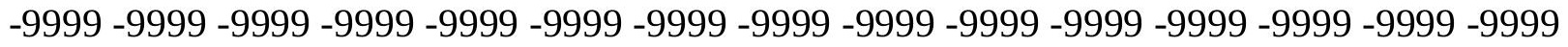
-9999 -9999 -9999 -9999 -9999 -9999 -9999 -9999 -9999 -9999 -9999 -9999 -9999 -9999 -9999 -9999 -9999 -9999 -9999 -9999 -9999 -9999 -9999 -9999 -9999 -9999 -9999 -9999 -9999 -999 -

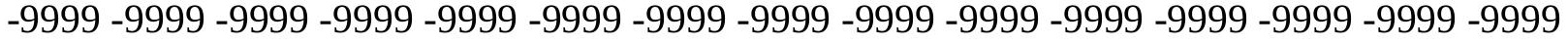
-9999 -9999 -9999 -9999 -9999 -9999 -9999 -9999 -9999 -9999 -9999 -9999 -9999 -9999 -9999 -

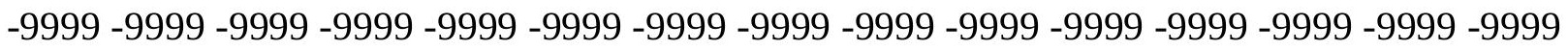

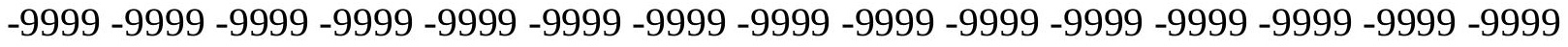

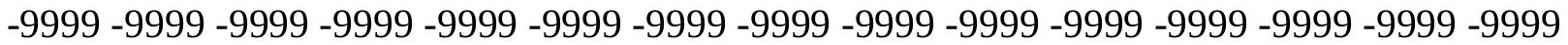

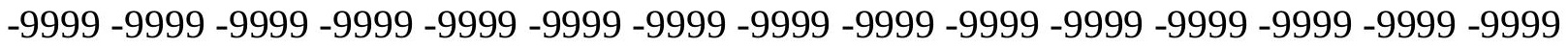

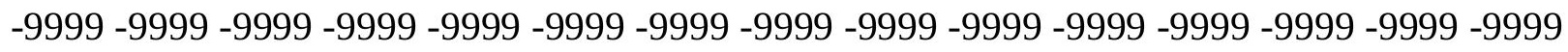

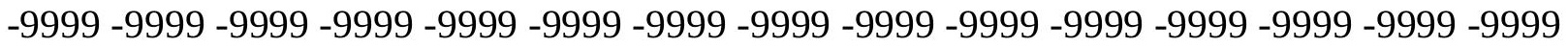

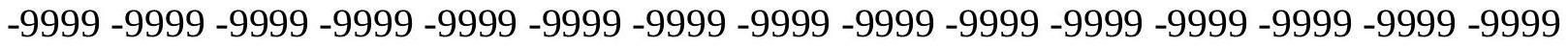
-9999 -9999 -9999 -9999 -9999 -9999 -9999 -9999 -9999 -9999 -9999 -9999 -9999 -9999 -9999 -

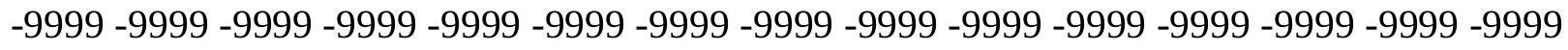

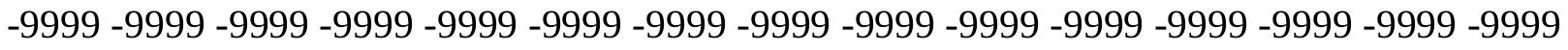
-9999 -9999 -9999 -9999 -9999 -9999 -9999 -9999 -9999 -9999 -9999 -9999 -9999 -9999 -9999 -9999 -9999 -9999 -9999 -9999 -9999 -9999 -9999 -9999-9999 -9999 -9999 -9999 -9999 -9999 -9999 -9999 -9999 -9999 -9999 -9999 -9999 -9999 -9999 -9999 -9999 -9999 -9999 -9999 -9999 -

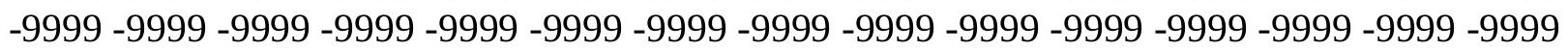


-9999 -9999 -9999 -9999 -9999 -9999 -9999 -9999 -9999 -9999 -9999 -9999 -9999 -9999 -9999 -9999 -9999 -9999 -9999 -9999 -9999 -9999 -9999 -9999 -9999 -9999 -9999 -9999 -9999 -

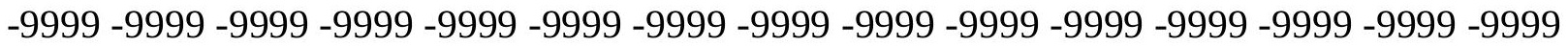
-9999 -9999 -9999 -9999 -9999 -9999 -9999 -9999 -9999 -9999 -9999 -9999 -9999 -9999 -9999 -9999 -9999 -9999 -9999 -9999 -9999 -9999 -9999 -9999 -9999 -9999 -9999 -9999 -9999 -9999 -9999 -9999 -9999 -9999 -9999 -9999 -9999 -9999 -9999 -9999 -9999 -9999 -9999 -9999 -9999 -9999 -9999 -9999 -9999 -9999 -9999 -9999 -9999 -9999 -9999 -9999 -9999 -9999 -9999 -9999

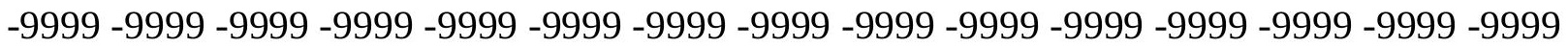

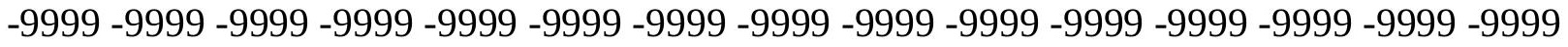
-9999 -9999 -9999 -9999 -9999 -9999 -9999 -9999 -9999 -9999 -9999 -9999 -9999 -9999 -9999 -9999 -9999 -9999 -9999 -9999 -9999 -9999 -9999 -9999 -9999 -9999 -9999 -9999 -9999 -9999 -9999 -9999 -9999 -9999 -9999 -9999 -9999 -9999 -9999 -9999 -9999 -9999 -9999 -9999 -9999 -9999 -9999 -9999 -9999 -9999 -9999 -9999 -9999 -9999 -9999 -9999 -9999 -9999 -9999 -9999 -9999 -9999 -9999 -9999 -9999 -9999 -9999 -9999 -9999 -9999 -9999 -9999 -9999 -9999 -9999 -9999 -9999 -9999 -9999 -9999 -9999 -9999 -9999 -9999 -9999 -9999 -9999 -9999 -9999 -9999 -

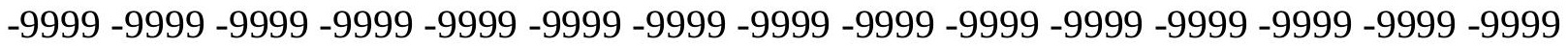
-9999 -9999 -9999 -9999 -9999 -9999 -9999 -9999 -9999 -9999 -9999 -9999 -9999 -9999 -9999 -9999 -9999 -9999 -9999 -9999 -9999 -9999 -9999 -9999 -9999 -9999 -9999 -9999 -9999 - 9999 -9999 -9999 -9999 -9999 -9999 -9999 -9999 -9999 -9999 -9999 -9999 -9999 -9999 -9999 -9999 -

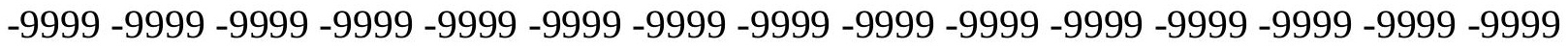

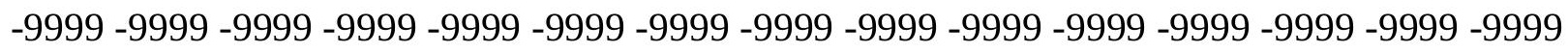

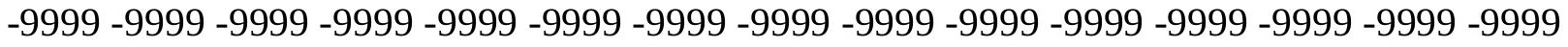
-9999 -9999 -9999 -9999 -9999 -9999 -9999 -9999 -9999 -9999 -9999 -9999 -9999 -9999 -9999 -9999 -9999 -9999 -9999 -9999 -9999 -9999 -9999 -9999 -9999 -9999 -9999 -9999 -9999 -9999 -

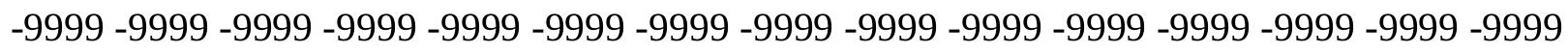
-9999 -9999 -9999 -9999 -9999 -9999 -9999 -9999 -9999 -9999 -9999 -9999 -9999 -9999 -9999 -9999 -9999 -9999 -9999 -9999 -9999 -9999 -9999 -9999 -9999 -9999 -9999 -9999 -9999 -9999 -9999 -9999 -9999 -9999 -9999 -9999 -9999 -9999 -9999 -9999 -9999 -9999 -9999 -9999 -9999 -9999 -9999 -9999 -9999 -9999 -9999 -9999 -9999 -9999 -9999 -9999 -9999 -9999 -9999 -9999 -9999 -9999 -9999 -9999 -9999 -9999 -9999 -9999 -9999 -9999 -9999 -9999 -9999 -999 -

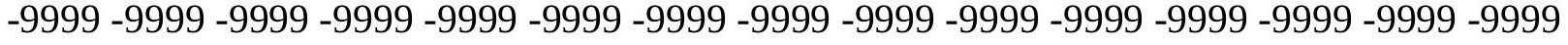
-9999 -9999 -9999 -9999 -9999 -9999 -9999 -9999 -9999 -9999 -9999 -9999 -9999 -9999 -9999 -

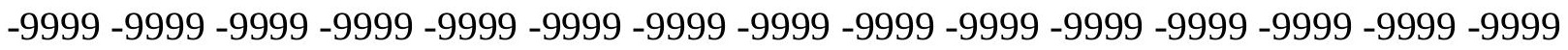

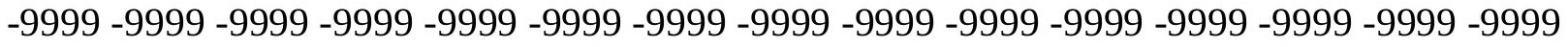

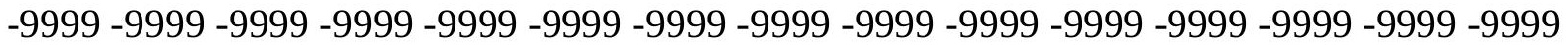

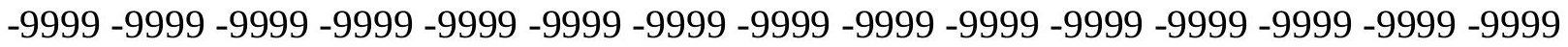

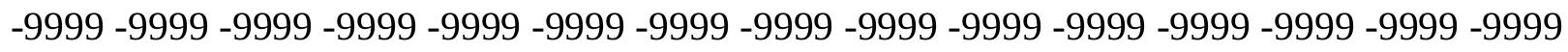

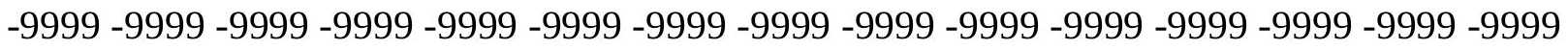

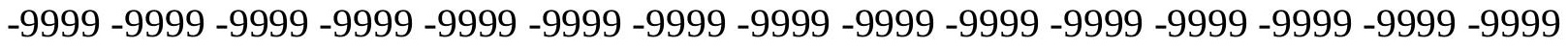
-9999 -9999 -9999 -9999 -9999 -9999 -9999 -9999 -9999 -9999 -9999 -9999 -9999 -9999 -9999 -

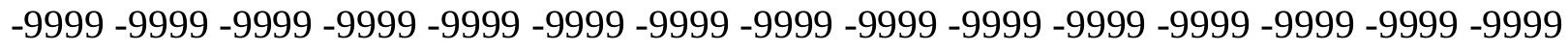

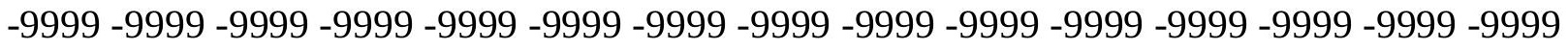
-9999 -9999 -9999 -9999 -9999 -9999 -9999 -9999 -9999 -9999 -9999 -9999 -9999 -9999 -9999 -9999 -9999 -9999 -9999 -9999 -9999 -9999 -9999 -9999-9999 -9999 -9999 -9999 -9999 -9999 -9999 -9999 -9999 -9999 -9999 -9999 -9999 -9999 -9999 -9999 -9999 -9999 -9999 -9999 -9999 -

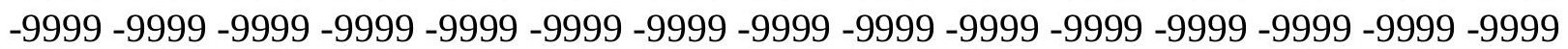


-9999 -9999 -9999 -9999 -9999 -9999 -9999 -9999 -9999 -9999 -9999 -9999 -9999 -9999 -9999 -9999 -9999 -9999 -9999 -9999 -9999 -9999 -9999 -9999 -9999 -9999 -9999 -9999 -9999 -9999 -

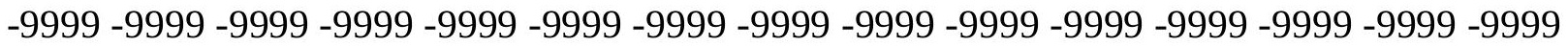
-9999 -9999 -9999 -9999 -9999 -9999 -9999 -9999 -9999 -9999 -9999 -9999 -9999 -9999 -9999 -9999 -9999 -9999 -9999 -9999 -9999 -9999 -9999 -9999-9999 -9999 -9999 -9999 -9999 -9999 -9999 -9999 -9999 -9999 -9999 -9999 -9999 -9999 -9999 -9999 -9999 -9999 -9999 -9999 -9999 -

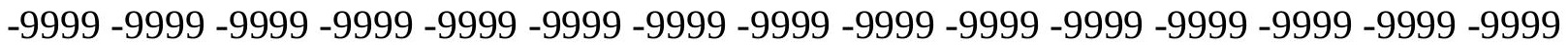
-9999 -9999 -9999 -9999 -9999 -9999 -9999 -9999 -9999 -9999 -9999 -9999 -9999 -9999 -9999 -9999 -9999 -9999 -9999 -9999 -9999 -9999 -9999 -9999 -9999 -9999 -9999 -9999 -9999 -9999 -9999 -9999 -9999 -9999 -9999 -9999 -9999 -9999 -9999 -9999 -9999 -9999 -9999 -9999 -9999 -9999 -9999 -9999 -9999 -9999 -9999 -9999 -9999 -9999 -9999 -9999 -9999 -9999 -9999 -9999 -9999 -9999 -9999 -9999 -9999 -9999 -9999 -9999 -9999 -9999 -9999 -9999 -9999 -9999 -9999 -9999 -9999 -9999 -9999 -9999 -9999 -9999 -9999 -9999 -9999 -9999 -9999 -9999 -9999 -9999 -9999 -9999 -9999 -9999 -9999 -9999 -9999 -9999 -9999 -9999 -9999 -9999 -9999 -9999 -9999 -9999 -9999 -9999 -9999 -9999 -9999 -9999 -9999 -9999 -9999 -9999 -9999 -9999 -9999 -

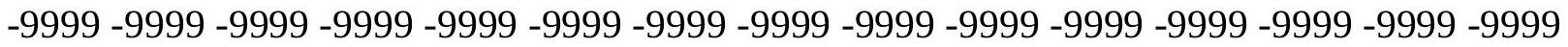
-9999 -9999 -9999 -9999 -9999 -9999 -9999 -9999 -9999 -9999 -9999 -9999 -9999 -9999 -9999 -9999 -9999 -9999 -9999 -9999 -9999 -9999 -9999 -9999 -9999 -9999 -9999 -9999 -9999 -9999 -9999 -9999 -9999 -9999 -9999 -9999 -9999 -9999 -9999 -9999 -9999 -9999 -9999 -9999 -9999 -

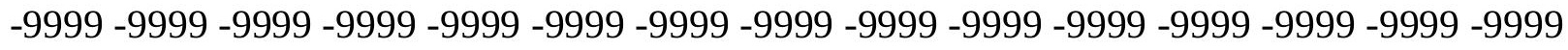

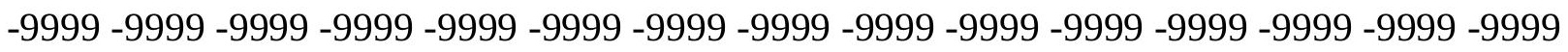
-9999 -9999 -9999 -9999 -9999 -9999 -9999 -9999 -9999 -9999 -9999 -9999 -9999 -9999 - 9999 -9999 -9999 -9999 -9999 -9999 -9999 -9999 -9999 -9999 -9999 -9999 -9999 -9999 -9999 -9999 -9999 -9999 -9999 -9999 -9999 -9999 -9999 -9999 -9999 -9999 -9999 -9999 -9999 -9999 -9999 -

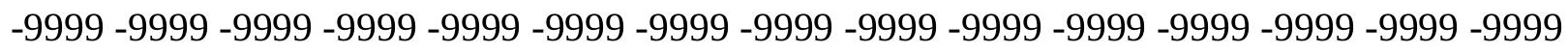
-9999 -9999 -9999 -9999 -9999 -9999 -9999 -9999 -9999 -9999 -9999 -9999 -9999 -9999 -9999 -9999 -9999 -9999 -9999 -9999 -9999 -9999 -9999 -9999 -9999 -9999 -9999 -9999 -9999 -9999 -

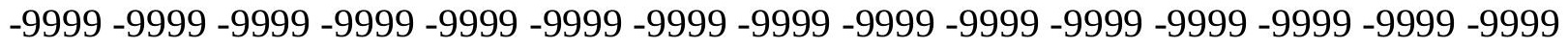
-9999 -9999 -9999 -9999 -9999 -9999 -9999 -9999 -9999 -9999 -9999 -9999 -9999 -9999 -9999 -9999 -9999 -9999 -9999 -9999 -9999 -9999 -9999 -9999 -9999 -9999 -9999 -9999 -9999 -999 -9999 -9999 -9999 -9999 -9999 -9999 -9999 -9999 -9999 -9999 -9999 -9999 -9999 -9999 -9999 -9999 -9999 -9999 -9999 -9999 -9999 -9999 -9999 -9999 -9999 -9999 -9999 -9999 -9999 -9999 -

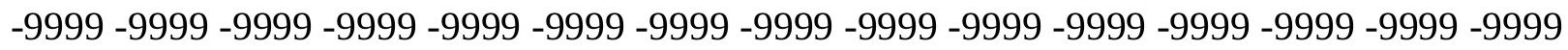

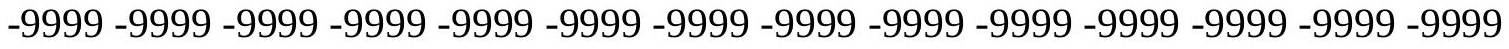
-9999 -9999 -9999 -9999 -9999 -9999 -9999 -9999 -9999 -9999 -9999 -9999 -9999 -9999 -9999

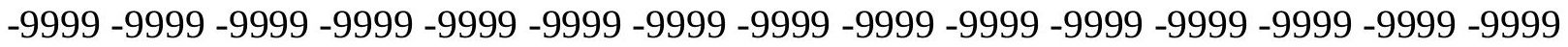

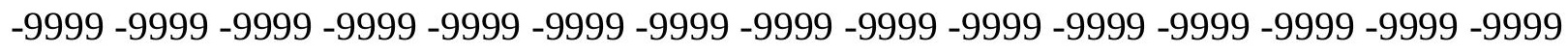

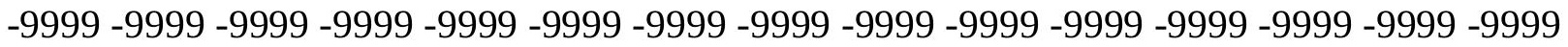

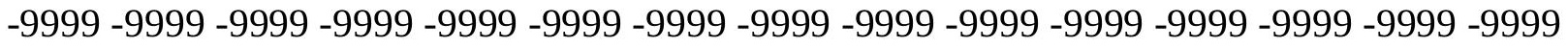
-9999 -9999 -9999 -9999 -9999 -9999 -9999 -9999 -9999 -9999 -9999 -9999 -9999 -9999 -9999 -

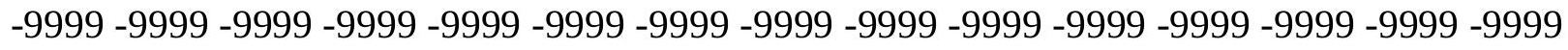

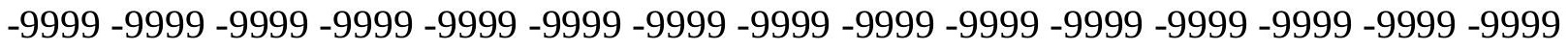
-9999 -9999 -9999 -9999 -9999 -9999 -9999 -9999 -9999 -9999 -9999 -9999 -9999 -9999 -9999 -9999 -9999 -9999 -9999 -9999 -9999 -9999 -9999 -9999-9999 -9999 -9999 -9999 -9999 -9999 -9999 -9999 -9999 -9999 -9999 -9999 -9999 -9999 -9999 -9999 -9999 -9999 -9999 -9999 -9999 -

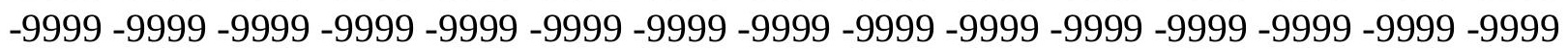


-9999 -9999 -9999 -9999 -9999 -9999 -9999 -9999 -9999 -9999 -9999 -9999 -9999 -9999 -9999 -9999 -9999 -9999 -9999 -9999 -9999 -9999 -9999 -9999 -9999 -9999 -9999 -9999 -9999 -9999 -

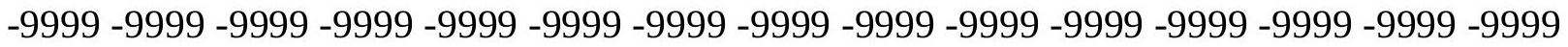
-9999 -9999 -9999 -9999 -9999 -9999 -9999 -9999 -9999 -9999 -9999 -9999 -9999 -9999 -9999 -9999 -9999 -9999 -9999 -9999 -9999 -9999 -9999 -9999-9999 -9999 -9999 -9999 -9999 -9999 -9999 -9999 -9999 -9999 -9999 -9999 -9999 -9999 -9999 -9999 -9999 -9999 -9999 -9999 -9999 -9999 -9999 -9999 -9999 -9999 -9999 -9999 -9999 -9999 -9999 -9999 -9999 -9999 -9999 -9999

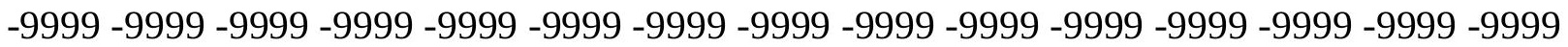

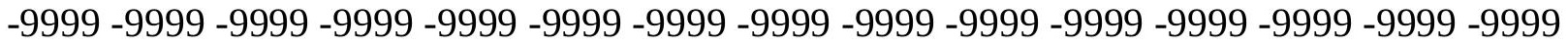
-9999 -9999 -9999 -9999 -9999 -9999 -9999 -9999 -9999 -9999 -9999 -9999 -9999 -9999 -9999 -9999 -9999 -9999 -9999 -9999 -9999 -9999 -9999 -9999 -9999 -9999 -9999 -9999 -9999 -9999 -9999 -9999 -9999 -9999 -9999 -9999 -9999 -9999 -9999 -9999 -9999 -9999 -9999 -9999 -9999 -9999 -9999 -9999 -9999 -9999 -9999 -9999 -9999 -9999 -9999 -9999 -9999 -9999 -9999 -9999 -9999 -9999 -9999 -9999 -9999 -9999 -9999 -9999 -9999 -9999 -9999 -9999 -9999 -9999 -9999 -9999 -9999 -9999 -9999 -9999 -9999 -9999 -9999 -9999 -9999 -9999 -9999 -9999 -9999

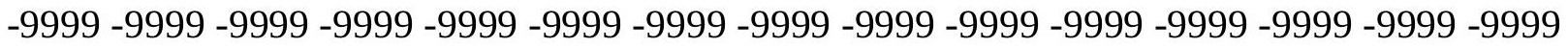
-9999 -9999 -9999 -9999 -9999 -9999 -9999 -9999 -9999 -9999 -9999 -9999 -9999 -9999 -9999 -9999 -9999 -9999 -9999 -9999 -9999 -9999 -9999 -9999 -9999 -9999 -9999 -9999 -9999 -9999 -9999 -9999 -9999 -9999 -9999 -9999 -9999 -9999 -9999 -9999 -9999 -9999 -9999 -9999 -9999 -

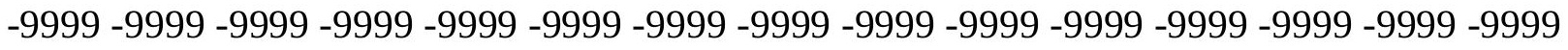

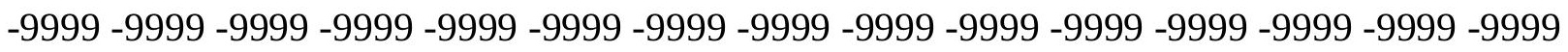
-9999 -9999 -9999 -9999 -9999 -9999 -9999 -9999 -9999 -9999 -9999 -9999 -9999 -9999 -9999 -9999 -9999 -9999 -9999 -9999 -9999 -9999 -9999 -9999 -9999 -9999 -9999 -9999 -9999 -9999 -9999 -9999 -9999 -9999 -9999 -9999 -9999 -9999 -9999 -9999 -9999 -9999 -9999 -9999 -9999 -

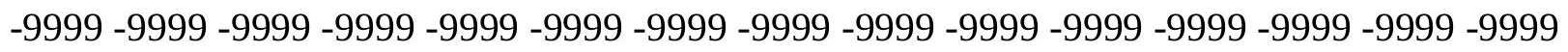
-9999 -9999 -9999 -9999 -9999 -9999 -9999 -9999 -9999 -9999 -9999 -9999 -9999 -9999 -9999 -9999 -9999 -9999 -9999 -9999 -9999 -9999 -9999 -9999 -9999 -9999 -9999 -9999 -9999 -9999 -

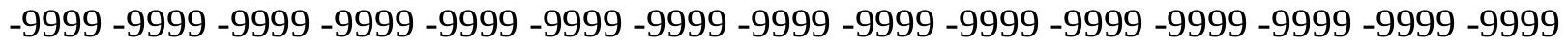
-9999 -9999 -9999 -9999 -9999 -9999 -9999 -9999 -9999 -9999 -9999 -9999 -9999 -9999 -9999 -9999 -9999 -9999 -9999 -9999 -9999 -9999 -9999 -9999 -9999 -9999 -9999 -9999 -9999 -999 -9999 -9999 -9999 -9999 -9999 -9999 -9999 -9999 -9999 -9999 -9999 -9999 -9999 -9999 -9999 -9999 -9999 -9999 -9999 -9999 -9999 -9999 -9999 -9999 -9999 -9999 -9999 -9999 -9999 -9999 -

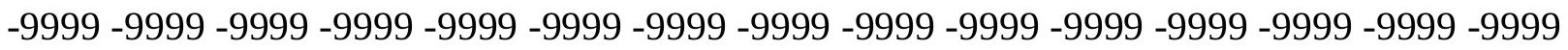

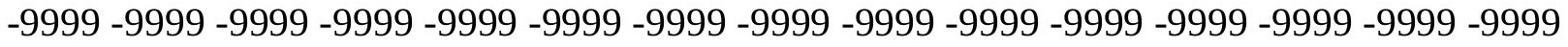

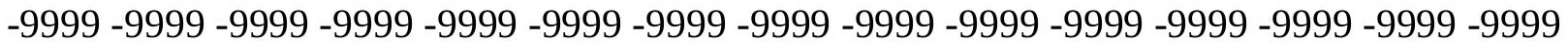

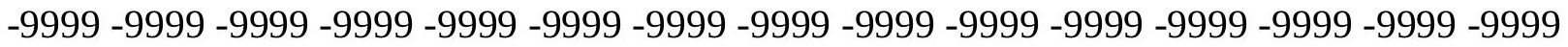

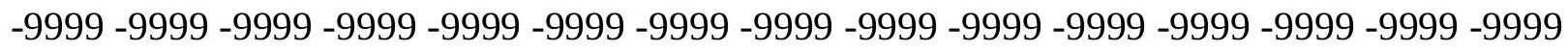

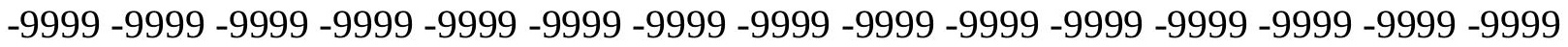
-9999 -9999 -9999 -9999 -9999 -9999 -9999 -9999 -9999 -9999 -9999 -9999 -9999 - 9999 - -999 -9999 -9999 -9999 -9999 -9999 -9999 -9999 -9999 -9999 -9999 -9999 -9999 -9999 -9999 - -999 -

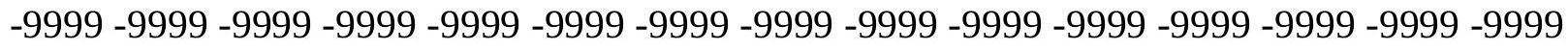

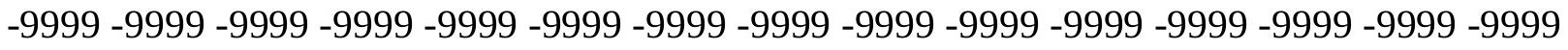
-9999 -9999 -9999 -9999 -9999 -9999 -9999 -9999 -9999 -9999 -9999 -9999 -9999 -9999 -9999 -9999 -9999 -9999 -9999 -9999 -9999 -9999 -9999 -9999-9999 -9999 -9999 -9999 -9999 -9999 -9999 -9999 -9999 -9999 -9999 -9999 -9999 -9999 -9999 -9999 -9999 -9999 -9999 -9999 -9999 -

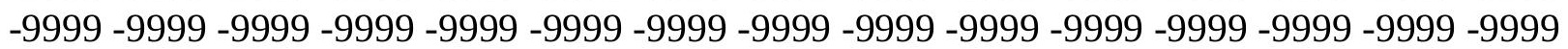


-9999 -9999 -9999 -9999 -9999 -9999 -9999 -9999 -9999 -9999 -9999 -9999 -9999 -9999 -9999 -9999 -9999 -9999 -9999 -9999 -9999 -9999 -9999 -9999 -9999 -9999 -9999 -9999 -9999 -9999 -9999 -9999 -9999 -9999 -9999 -9999 -9999 -9999 -9999 -9999 -9999 -9999 -9999 -9999 -9999 -9999 -9999 -9999 -9999 -9999 -9999 -9999 -9999 -9999 -9999 -9999 -9999 -9999 -9999 -9999 -9999 -9999 -9999 -9999 -9999 -9999 -9999 -9999 -9999 -9999 -9999 -9999 -9999 -9999 -9999 -9999 -9999 -9999 -9999 -9999 -9999 -9999 -9999 -9999 -9999 -9999 -9999 -9999 -9999 -9999 -9999 -9999 -9999 -9999 -9999 -9999 -9999 -9999 -9999 -9999 -9999 -9999 -9999 -9999 -9999 -

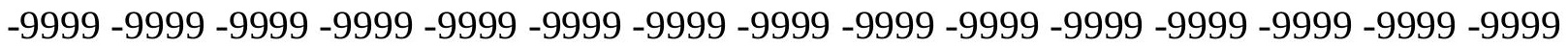
-9999 -9999 -9999 -9999 -9999 -9999 -9999 -9999 -9999 -9999 -9999 -9999 -9999 -9999 -9999 -9999 -9999 -9999 -9999 -9999 -9999 -9999 -9999 -9999 -9999 -9999 -9999 -9999 -9999 -9999 -

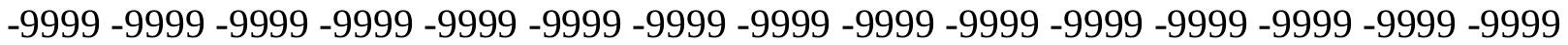
-9999 -9999 -9999 -9999 -9999 -9999 -9999 -9999 -9999 -9999 -9999 -9999 -9999 -9999 -9999 -9999 -9999 -9999 -9999 -9999 -9999 -9999 -9999 -9999 -9999 -9999 -9999 -9999 -9999 -9999 -9999 -9999 -9999 -9999 -9999 -9999 -9999 -9999 -9999 -9999 -9999 -9999 -9999 -9999 -9999 -9999 -9999 -9999 -9999 -9999 -9999 -9999 -9999 -9999 -9999 -9999 -9999 -9999 -9999 -9999

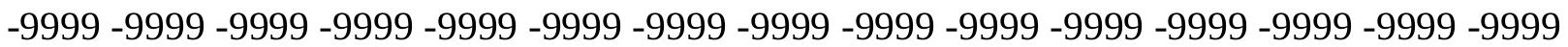
-9999 -9999 -9999 -9999 -9999 -9999 -9999 -9999 -9999 -9999 -9999 -9999 -9999 -9999 -9999 -9999 -9999 -9999 -9999 -9999 -9999 -9999 -9999 -9999 -9999 -9999 -9999 -9999 -9999 -9999 -9999 -9999 -9999 -9999 -9999 -9999 -9999 -9999 -9999 -9999 -9999 -9999 -9999 -9999 -9999 -9999 -9999 -9999 -9999 -9999 -9999 -9999 -9999 -9999 -9999 -9999 -9999 -9999 -9999 -9999 -9999 -9999 -9999 -9999 -9999 -9999 -9999 -9999 -9999 -9999 -9999 -9999 -9999 -9999 -9999 -9999 -9999 -9999 -9999 -9999 -9999 -9999 -9999 -9999 -9999 -9999 -9999 -9999 -9999 -9999 -9999 -9999 -9999 -9999 -9999 -9999 -9999 -9999 -9999 -9999 -9999 -9999 -9999 -9999 -9999 -9999 -9999 -9999 -9999 -9999 -9999 -9999 -9999 -9999 -9999 -9999 -9999 -9999 -9999 -9999 -9999 -9999 -9999 -9999 -9999 -9999 -9999 -9999 -9999 -9999 -9999 -9999 -9999 -9999 -9999 -9999 -9999 -9999 -9999 -9999 -9999 -9999 -9999 -9999 -9999 -9999 -9999 -9999 -9999 -9999 -9999 -9999 -9999 -9999 -9999 -9999 -9999 -9999 -9999 -9999 -9999 -9999 -9999 -9999 -9999 -9999 -9999 -9999 -9999 -9999 -9999 -9999 -9999 -9999 -9999 -9999 -9999 -9999 -9999

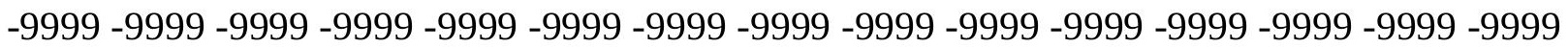
-9999 -9999 -9999 -9999 -9999 -9999 -9999 -9999 -9999 -9999 -9999 -9999 -9999 -9999 -9999 -9999 -9999 -9999 -9999 -9999 -9999 -9999 -9999 -9999 -9999 -9999 -9999 -9999 -9999 -9999 -

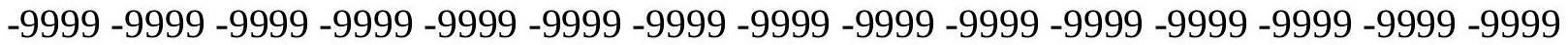
-9999 -9999 -9999 -9999 -9999 -9999 -9999 -9999 -9999 -9999 -9999 -9999 -9999 -9999 -9999 -9999 -9999 -9999 -9999 -9999 -9999 -9999 -9999 -9999 -9999 -9999 -9999 -9999 -9999 -9999 -9999 -9999 -9999 -9999 -9999 -9999 -9999 -9999 -9999 -9999 -9999 -9999 -9999 -9999 -9999 -9999 -9999 -9999 -9999 -9999 -9999 -9999 -9999 -9999 -9999 -9999 -9999 -9999 -9999 -9999 -9999 -9999 -9999 -9999 -9999 -9999 -9999 -9999 -9999 -9999 -9999 -9999 -9999 -9999 -9999

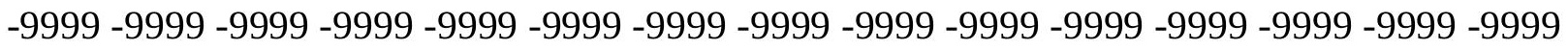
-9999 -9999 -9999 -9999 -9999 -9999 -9999 -9999 -9999 -9999 -9999 -9999 -9999 -9999 -9999 -9999 -9999 -9999 -9999 -9999 -9999 -9999 -9999 -9999 -9999 -9999 -9999 -9999 -9999 -9999 -9999 -9999 -9999 -9999 -9999 -9999 -9999 -9999 -9999 -9999 -9999 -9999 -9999 -9999 -9999 -999 -9999 -9999 -9999 -9999 -9999 -9999 -9999 -9999 -9999 -9999 -9999 -9999 -9999 -9999 -9999 -9999 -9999 -9999 -9999 -9999 -9999 -9999 -9999 -9999 -9999 -9999 -9999 -9999 -9999 -9999 -9999 -9999 -9999 -9999 -9999 -9999 -9999 -9999 -9999 -9999 -9999 -9999 -9999 -9999 -9999 -9999 -9999 -9999 -9999 -9999 -9999 -9999 -9999 -9999 -9999 -9999 -9999 -9999 -9999 -9999 -9999 -9999 -9999 -9999 -9999 -9999 -9999 -9999 -9999 -9999 -9999 -9999 -9999 -9999 
-9999 -9999 -9999 -9999 -9999 -9999 -9999 -9999 -9999 -9999 -9999 -9999 -9999 -9999 -9999 -9999 -9999 -9999 -9999 -9999 -9999 -9999 -9999 -9999 -9999 -9999 -9999 -9999 -9999 -9999 -

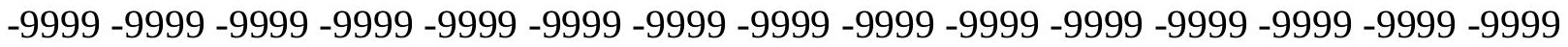
-9999 -9999 -9999 -9999 -9999 -9999 -9999 -9999 -9999 -9999 -9999 -9999 -9999 -9999 -9999 -9999 -9999 -9999 -9999 -9999 -9999 -9999 -9999 -9999-9999 -9999 -9999 -9999 -9999 -9999 -9999 -9999 -9999 -9999 -9999 -9999 -9999 -9999 -9999 -9999 -9999 -9999 -9999 -9999 -9999 -9999 -9999 -9999 -9999 -9999 -9999 -9999 -9999 -9999 -9999 -9999 -9999 -9999 -9999 -9999

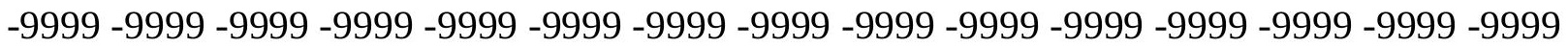

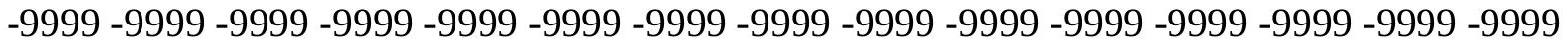
-9999 -9999 -9999 -9999 -9999 -9999 -9999 -9999 -9999 -9999 -9999 -9999 -9999 -9999 -9999 -9999 -9999 -9999 -9999 -9999 -9999 -9999 -9999 -9999 -9999 -9999 -9999 -9999 -9999 -9999 -9999 -9999 -9999 -9999 -9999 -9999 -9999 -9999 -9999 -9999 -9999 -9999 -9999 -9999 -9999 -9999 -9999 -9999 -9999 -9999 -9999 -9999 -9999 -9999 -9999 -9999 -9999 -9999 -9999 -9999 -

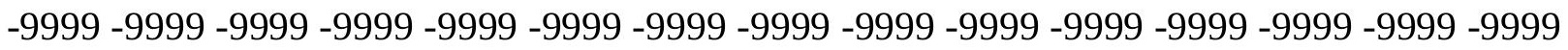
-9999 -9999 -9999 -9999 -9999 -9999 -9999 -9999 -9999 -9999 -9999 -9999 -9999 -9999 -9999 -

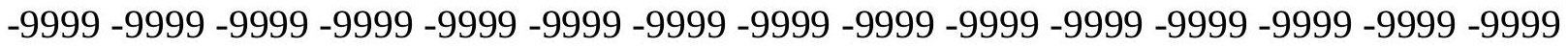
-9999 -9999 -9999 -9999 -9999 -9999 -9999 -9999 -9999 -9999 -9999 -9999 -9999 -9999 -9999 -9999 -9999 -9999 -9999 -9999 -9999 -9999 -9999 -9999 -9999 -9999 -9999 -9999 -9999 -9999 -9999 -9999 -9999 -9999 -9999 -9999 -9999 -9999 -9999 -9999 -9999 -9999 -9999 -9999 -9999 -

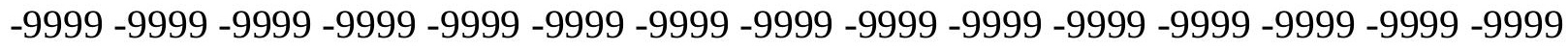

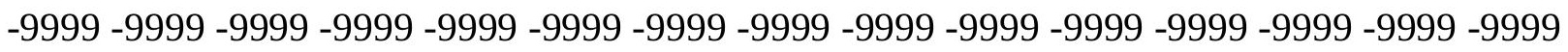

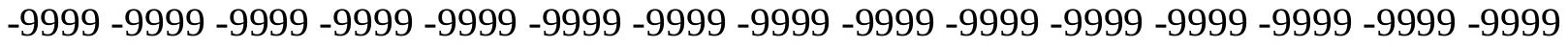
-9999 -9999 -9999 -9999 -9999 -9999 -9999 -9999 -9999 -9999 -9999 -9999 -9999 -9999 -9999 -9999 -9999 -9999 -9999 -9999 -9999 -9999 -9999 -9999 -9999 -9999 -9999 -9999 -9999 -9999 -

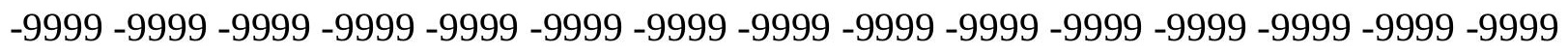
-9999 -9999 -9999 -9999 -9999 -9999 -9999 -9999 -9999 -9999 -9999 -9999 -9999 -9999 -9999 -9999 -9999 -9999 -9999 -9999 -9999 -9999 -9999 -9999 -9999 -9999 -9999 -9999 -9999 -

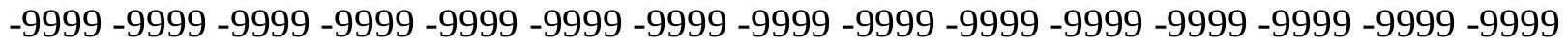
-9999 -9999 -9999 -9999 -9999 -9999 -9999 -9999 -9999 -9999 -9999 -9999 -9999 -9999 -9999 -9999 -9999 -9999 -9999 -9999 -9999 -9999 -9999 -9999 -9999 -9999 -9999 -9999 -9999 -999 -

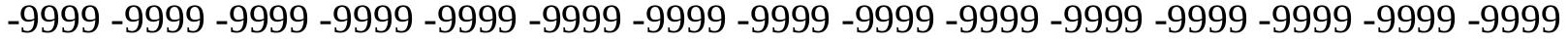
-9999 -9999 -9999 -9999 -9999 -9999 -9999 -9999 -9999 -9999 -9999 -9999 -9999 -9999 -9999 -

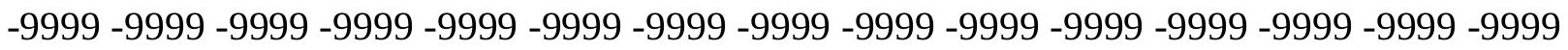

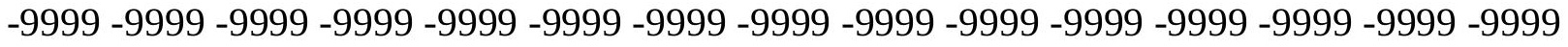

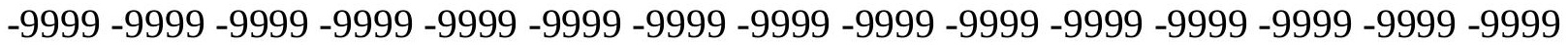
-9999 -9999 -9999 -9999 -9999 -9999 -9999 -9999 -9999 -9999 -9999 -9999 -9999 -9999 -9999

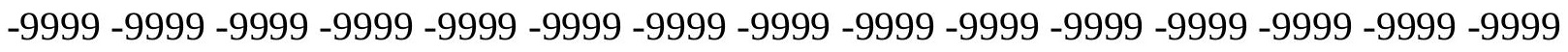

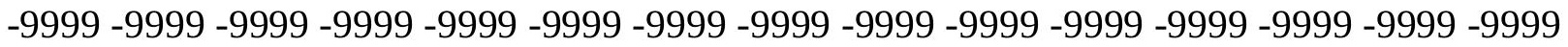
-9999 -9999 -9999 -9999 -9999 -9999 -9999 -9999 -9999 -9999 -9999 -9999 -9999 - 9999 - -999 -9999 -9999 -9999 -9999 -9999 -9999 -9999 -9999 -9999 -9999 -9999 -9999 -9999 -9999 -9999 -

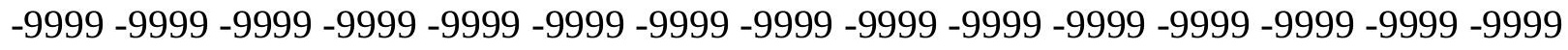

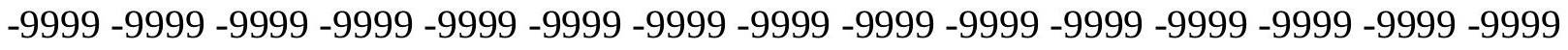
-9999 -9999 -9999 -9999 -9999 -9999 -9999 -9999 -9999 -9999 -9999 -9999 -9999 -9999 -9999 -9999 -9999 -9999 -9999 -9999 -9999 -9999 -9999 -9999-9999 -9999 -9999 -9999 -9999 -9999 -9999 -9999 -9999 -9999 -9999 -9999 -9999 -9999 -9999 -9999 -9999 -9999 -9999 -9999 -9999 -

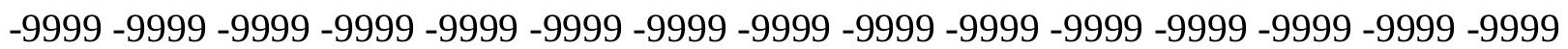


-9999 -9999 -9999 -9999 -9999 -9999 -9999 -9999 -9999 -9999 -9999 -9999 -9999 -9999 -9999 -9999 -9999 -9999 -9999 -9999 -9999 -9999 -9999 -9999 -9999 -9999 -9999 -9999 -9999 -9999 -9999 -9999 -9999 -9999 -9999 -9999 -9999 -9999 -9999 -9999 -9999 -9999 -9999 -9999 - 9999 -9999 -9999 -9999 -9999 -9999 -9999 -9999 -9999 -9999 -9999 -9999 -9999 -9999 -9999 -9999 -9999 -9999 -9999 -9999 -9999 -9999 -9999 -9999 -9999 -9999 -9999 -9999 -9999 -9999 - -9999 -9999 -9999 -9999 -9999 -9999 -9999 -9999 -9999 -9999 -9999 -9999 -9999 -9999 -9999 -9999 -9999 -9999 -9999 -9999 -9999 -9999 -9999 -9999 -9999 -9999 -9999 -9999 -9999 -9999

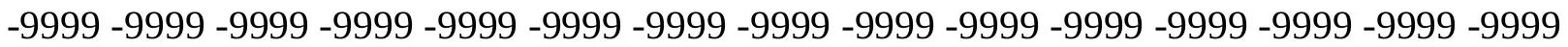

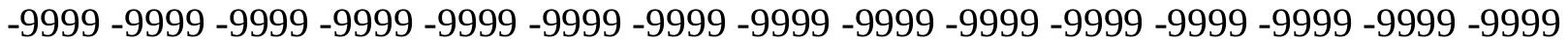
-9999 -9999 -9999 -9999 -9999 -9999 -9999 -9999 -9999 -9999 -9999 -9999 -9999 -9999 -9999

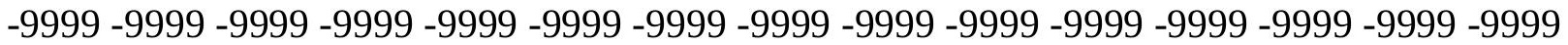
-9999 -9999 -9999 -9999 -9999 -9999 -9999 -9999 -9999 -9999 -9999 -9999 -9999 -9999 -9999 -9999 -9999 -9999 -9999 -9999 -9999 -9999 -9999 -9999 -9999 -9999 -9999 -9999 -9999 -9999 -9999 -9999 -9999 -9999 -9999 -9999 -9999 -9999 -9999 -9999 -9999 -9999 -9999 -9999 - -9999 -9999 -9999 -9999 -9999 -9999 -9999 -9999 -9999 -9999 -9999 -9999 -9999 -9999 -9999 -9999

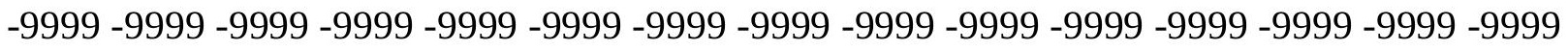
-9999 -9999 -9999 -9999 -9999 -9999 -9999 -9999 -9999 -9999 -9999 -9999 -9999 -9999 -9999 -9999 -9999 -9999 -9999 -9999 -9999 -9999 -9999 -9999 -9999 -9999 -9999 -9999 -9999 -9999 -9999 -9999 -9999 -9999 -9999 -9999 -9999 -9999 -9999 -9999 -9999 -9999 -9999 -9999 -9999 -

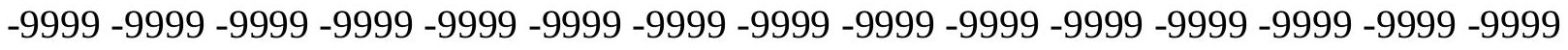
-9999 -9999 -9999 -9999 -9999 -9999 -9999 -9999 -9999 -9999 -9999 -9999 -9999 -9999 -9999 -999 -9999 -9999 -9999 -9999 -9999 -9999 -9999 -9999 -9999 -9999 -9999 -9999 -9999 -9999 -9999 -9999 -9999 -9999 -9999 -9999 -9999 -9999 -9999 -9999 -9999 -9999 -9999 -9999 -9999 -9999 -9999 -9999 -9999 -9999 -9999 -9999 -9999 -9999 -9999 -9999 -9999 -9999 -9999 -9999 -9999 -9999 -9999 -9999 -9999 -9999 -9999 -9999 -9999 -9999 -9999 -9999 -9999 -9999 -9999 -9999 -9999 -9999 -9999 -9999 -9999 -9999 -9999 -9999 -9999 -9999 -9999 -9999 -9999 -9999 -9999 -9999 -9999 -9999 -9999 -9999 -9999 -9999 -9999 -9999 -9999 -9999 -9999 -9999 -9999 -9999 -9999 -9999 -9999 -9999 -9999 -9999 -9999 -9999 -9999 -9999 -9999 -9999 -9999 -9999 -9999 -9999 -9999 -9999 -9999 -9999 -9999 -9999 -9999 -9999 -9999 -9999 -9999 -9999 -9999 -9999 -9999 -9999 -9999 -9999 -9999 -9999 -9999 -9999 -9999 -9999 -9999 -9999 -9999 -9999 -999 -9999 -9999 -9999 -9999 -9999 -9999 -9999 -9999 -9999 -9999 -9999 -9999 -9999 -9999 -9999 -9999 -9999 -9999 -9999 -9999 -9999 -9999 -9999 -9999 -9999 -9999 -9999 -9999 -9999 -

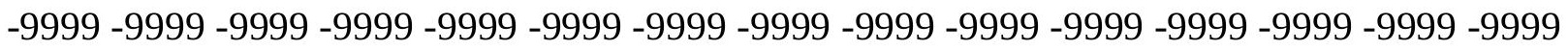

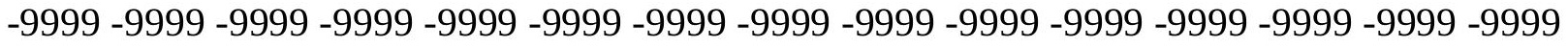

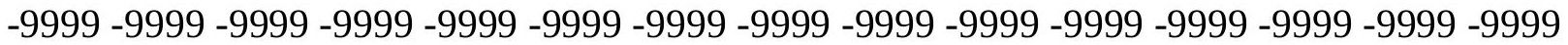
-9999 -9999 -9999 -9999 -9999 -9999 -9999 -9999 -9999 -9999 -9999 -9999 -9999 -9999 -9999 -

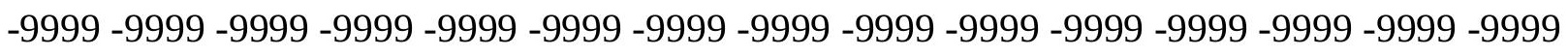

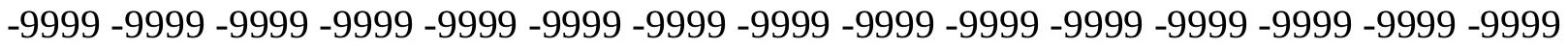

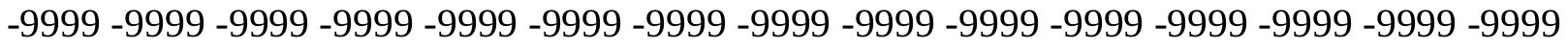
-9999 -9999 -9999 -9999 -9999 -9999 -9999 -9999 -9999 -9999 -9999 -9999 -9999 -9999 -9999 -

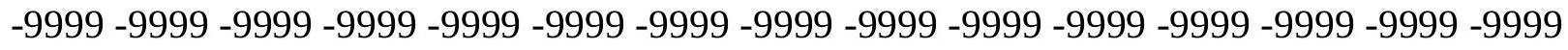

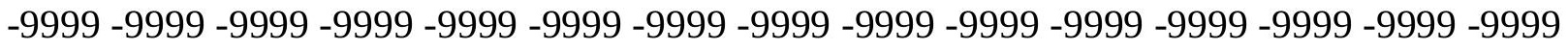
-9999 -9999 -9999 -9999 -9999 -9999 -9999 -9999 -9999 -9999 -9999 -9999 -9999 -9999 -9999 -9999 -9999 -9999 -9999 -9999 -9999 -9999 -9999 -9999-9999 -9999 -9999 -9999 -9999 -9999 -9999 -9999 -9999 -9999 -9999 -9999 -9999 -9999 -9999 -9999 -9999 -9999 -9999 -9999 -9999 -

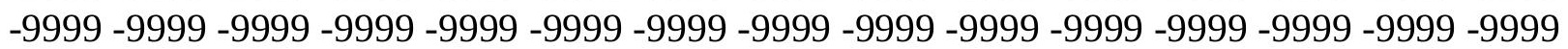


-9999 -9999 -9999 -9999 -9999 -9999 -9999 -9999 -9999 -9999 -9999 -9999 -9999 -9999 -9999 -9999 -9999 -9999 -9999 -9999 -9999 -9999 -9999 -9999 -9999 -9999 -9999 -9999 -9999 -9999 -

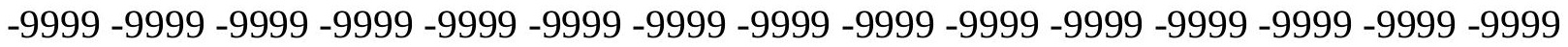
-9999 -9999 -9999 -9999 -9999 -9999 -9999 -9999 -9999 -9999 -9999 -9999 -9999 -9999 -9999 -9999 -9999 -9999 -9999 -9999 -9999 -9999 -9999 -9999-9999 -9999 -9999 -9999 -9999 -9999 -9999 -9999 -9999 -9999 -9999 -9999 -9999 -9999 -9999 -9999 -9999 -9999 -9999 -9999 -9999 -9999 -9999 -9999 -9999 -9999 -9999 -9999 -9999 -9999 -9999 -9999 -9999 -9999 -9999 -9999

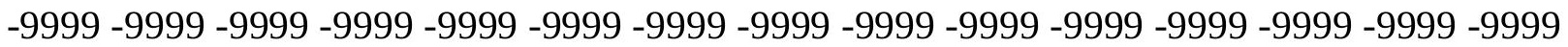

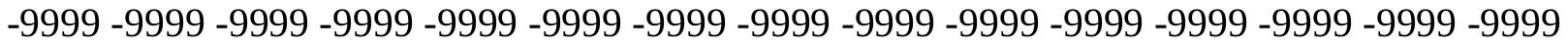
-9999 -9999 -9999 -9999 -9999 -9999 -9999 -9999 -9999 -9999 -9999 -9999 -9999 -9999 -9999 -9999 -9999 -9999 -9999 -9999 -9999 -9999 -9999 -9999 -9999 -9999 -9999 -9999 -9999 -9999 -9999 -9999 -9999 -9999 -9999 -9999 -9999 -9999 -9999 -9999 -9999 -9999 -9999 -9999 -9999 -9999 -9999 -9999 -9999 -9999 -9999 -9999 -9999 -9999 -9999 -9999 -9999 -9999 -9999 -9999 -9999 -9999 -9999 -9999 -9999 -9999 -9999 -9999 -9999 -9999 -9999 -9999 -9999 - 9999 -9999 -9999 -9999 -9999 -9999 -9999 -9999 -9999 -9999 -9999 -9999 -9999 -9999 -9999 -9999

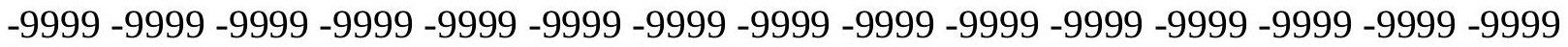
-9999 -9999 -9999 -9999 -9999 -9999 -9999 -9999 -9999 -9999 -9999 -9999 -9999 -9999 -9999 -9999 -9999 -9999 -9999 -9999 -9999 -9999 -9999 -9999 -9999 -9999 -9999 -9999 -9999 -9999 -9999 -9999 -9999 -9999 -9999 -9999 -9999 -9999 -9999 -9999 -9999 -9999 -9999 -9999 -9999 -

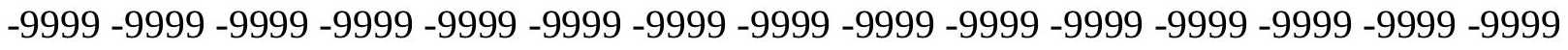

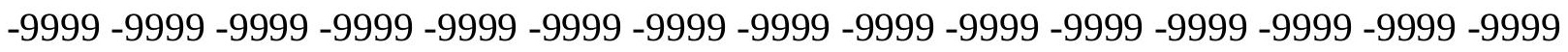
-9999 -9999 -9999 -9999 -9999 -9999 -9999 -9999 -9999 -9999 -9999 -9999 -9999 -9999 -9999 -9999 -9999 -9999 -9999 -9999 -9999 -9999 -9999 -9999 -9999 -9999 -9999 -9999 -9999 -9999 -9999 -9999 -9999 -9999 -9999 -9999 -9999 -9999 -9999 -9999 -9999 -9999 -9999 -9999 -9999 -

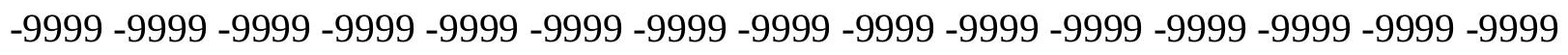
-9999 -9999 -9999 -9999 -9999 -9999 -9999 -9999 -9999 -9999 -9999 -9999 -9999 -9999 -9999 -9999 -9999 -9999 -9999 -9999 -9999 -9999 -9999 -9999 -9999 -9999 -9999 -9999 -9999 -9999 -

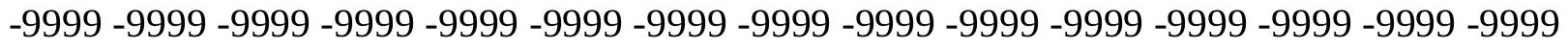
-9999 -9999 -9999 -9999 -9999 -9999 -9999 -9999 -9999 -9999 -9999 -9999 -9999 -9999 -9999 -9999 -9999 -9999 -9999 -9999 -9999 -9999 -9999 -9999 -9999 -9999 -9999 -9999 -9999 -999 -9999 -9999 -9999 -9999 -9999 -9999 -9999 -9999 -9999 -9999 -9999 -9999 -9999 -9999 -9999 -9999 -9999 -9999 -9999 -9999 -9999 -9999 -9999 -9999 -9999 -9999 -9999 -9999 -9999 -9999 -

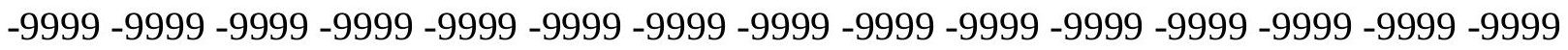

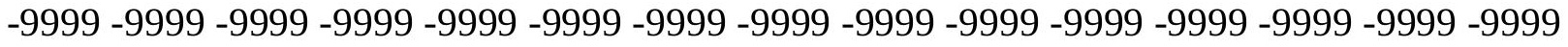

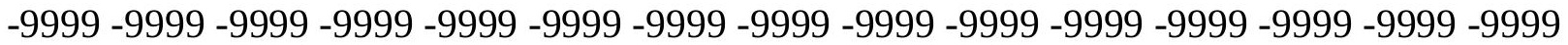

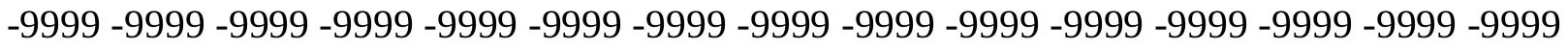

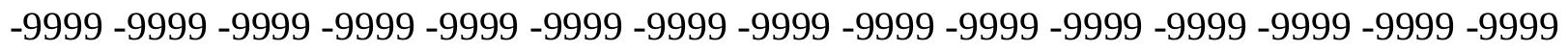

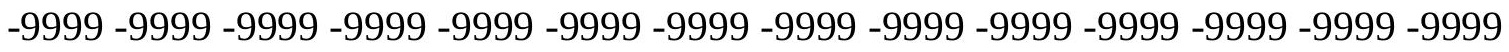
-9999 -9999 -9999 -9999 -9999 -9999 -9999 -9999 -9999 -9999 -9999 -9999 -9999 -9999 -9999 -9999 -9999 -9999 -9999 -9999 -9999 -9999 -9999 -9999 -9999 -9999 -9999 -9999 -9999 -9999 -

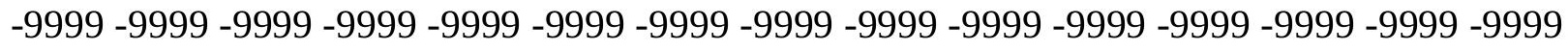

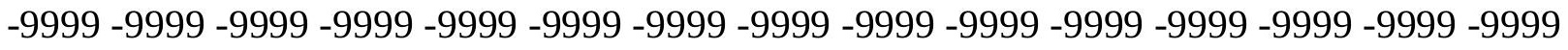
-9999 -9999 -9999 -9999 -9999 -9999 -9999 -9999 -9999 -9999 -9999 -9999 -9999 -9999 -9999 -9999 -9999 -9999 -9999 -9999 -9999 -9999 -9999 -9999-9999 -9999 -9999 -9999 -9999 -9999 -9999 -9999 -9999 -9999 -9999 -9999 -9999 -9999 -9999 -9999 -9999 -9999 -9999 -9999 -9999 -

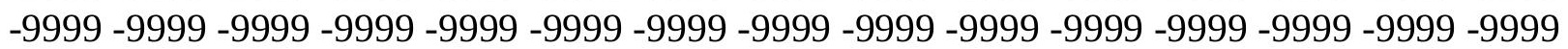


-9999 -9999 -9999 -9999 -9999 -9999 -9999 -9999 -9999 -9999 -9999 -9999 -9999 -9999 -9999 -9999 -9999 -9999 -9999 -9999 -9999 -9999 -9999 -9999 -9999 -9999 -9999 -9999 -9999 -9999 -9999 -9999 -9999 -9999 -9999 -9999 -9999 -9999 -9999 -9999 -9999 -9999 -9999 -9999 - 9999 -9999 -9999 -9999 -9999 -9999 -9999 -9999 -9999 -9999 -9999 -9999 -9999 -9999 -9999 -9999 -9999 -9999 -9999 -9999 -9999 -9999 -9999 -9999 -9999 -9999 -9999 -9999 -9999 -9999 -9999 -9999 -9999 -9999 -9999 -9999 -9999 -9999 -9999 -9999 -9999 -9999 -9999 -9999 -9999 -9999 -9999 -9999 -9999 -9999 -9999 -9999 -9999 -9999 -9999 -9999 -9999 -9999 -9999 -9999 -9999

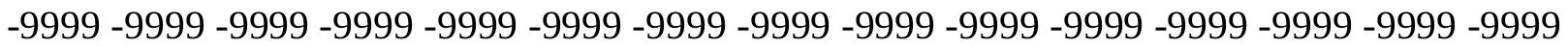
-9999 -9999 -9999 -9999 -9999 -9999 -9999 -9999 -9999 -9999 -9999 -9999 -9999 -9999 -9999 -9999 -9999 -9999 -9999 -9999 -9999 -9999 -9999 -9999 -9999 -9999 -9999 -9999 -9999 -9999

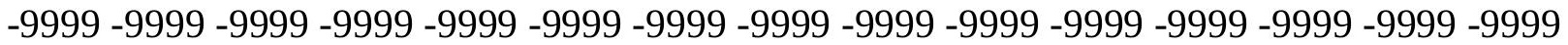
-9999 -9999 -9999 -9999 -9999 -9999 -9999 -9999 -9999 -9999 -9999 -9999 -9999 -9999 -9999 -9999 -9999 -9999 -9999 -9999 -9999 -9999 -9999 -9999 -9999 -9999 -9999 -9999 -9999 -9999 -

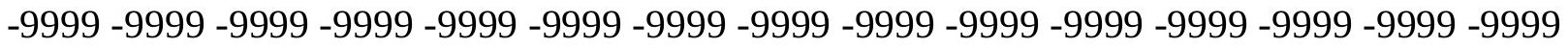
-9999 -9999 -9999 -9999 -9999 -9999 -9999 -9999 -9999 -9999 -9999 -9999 -9999 -9999 -9999

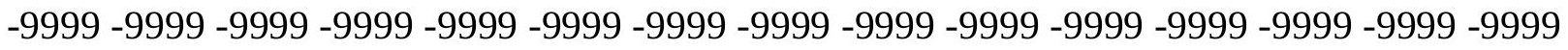
-9999 -9999 -9999 -9999 -9999 -9999 -9999 -9999 -9999 -9999 -9999 -9999 -9999 -9999 -9999 -9999 -9999 -9999 -9999 -9999 -9999 -9999 -9999 -9999 -9999 -9999 -9999 -9999 -9999 - -999 -9999 -9999 -9999 -9999 -9999 -9999 -9999 -9999 -9999 -9999 -9999 -9999 -9999 -9999 -9999 -9999 -9999 -9999 -9999 -9999 -9999 -9999 -9999 -9999 -9999 -9999 -9999 -9999 -9999 -9999 -9999 -9999 -9999 -9999 -9999 -9999 -9999 -9999 -9999 -9999 -9999 -9999 -9999 -9999 -9999 -999 -9999 -9999 -9999 -9999 -9999 -9999 -9999 -9999 -9999 -9999 -9999 -9999 -9999 -9999 -9999 -9999 -9999 -9999 -9999 -9999 -9999 -9999 -9999 -9999 -9999 -9999 -9999 -9999 -9999 -9999 -9999 -9999 -9999 -9999 -9999 -9999 -9999 -9999 -9999 -9999 -9999 -9999 -9999 -9999 -9999 -9999 -9999 -9999 -9999 -9999 -9999 -9999 -9999 -9999 -9999 -9999 -9999 -9999 -9999 -9999 -9999 -9999 -9999 -9999 -9999 -9999 -9999 -9999 -9999 -9999 -9999 -9999 -9999 -9999 -9999 -9999 -9999 -9999 -9999 -9999 -9999 -9999 -9999 -9999 -9999 -9999 -9999 -9999 -9999 -9999 -9999 -9999 -9999 -9999 -9999 -9999 -9999 -9999 -9999 -9999 -9999 -9999 -9999 -9999 -9999 -9999 -9999 -9999 -9999 -9999 -9999 -9999 -9999 -9999 -9999 -9999 -9999 -9999 -9999 -9999 -9999 -9999 -9999 -9999 -9999 -9999 -9999 -9999 -9999 -9999 -9999 -9999 -9999 -9999 -999 -9999 -9999 -9999 -9999 -9999 -9999 -9999 -9999 -9999 -9999 -9999 -9999 -9999 -9999 -9999 -9999 -9999 -9999 -9999 -9999 -9999 -9999 -9999 -9999 -9999 -9999 -9999 -9999 -9999 -9999 -

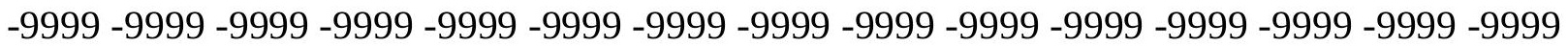

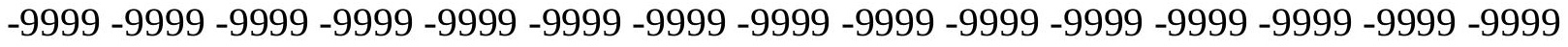

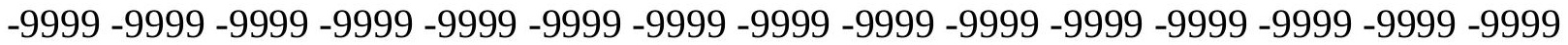
-9999 -9999 -9999 -9999 -9999 -9999 -9999 -9999 -9999 -9999 -9999 -9999 -9999 -9999 -9999

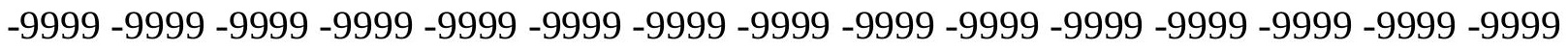

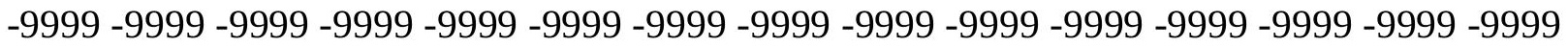

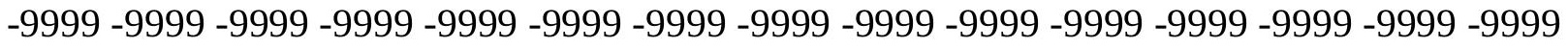
-9999 -9999 -9999 -9999 -9999 -9999 -9999 -9999 -9999 -9999 -9999 -9999 -9999 -9999 -9999 -

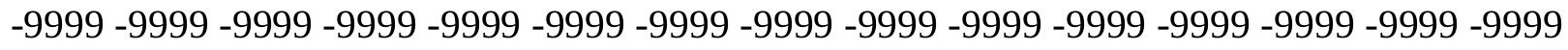

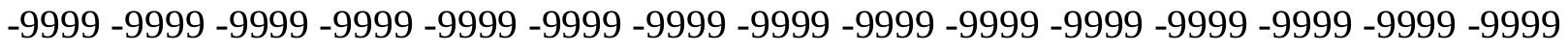
-9999 -9999 -9999 -9999 -9999 -9999 -9999 -9999 -9999 -9999 -9999 -9999 -9999 -9999 -9999 -9999 -9999 -9999 -9999 -9999 -9999 -9999 -9999 -9999 -9999 -9999 -9999 -9999 - -9999 -9999 -9999 -9999 -9999 -9999 -9999 -9999 -9999 -9999 -9999 -9999 -9999 -9999 -9999 -9999 -

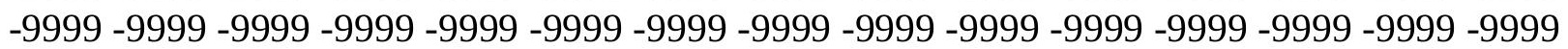


-9999 -9999 -9999 -9999 -9999 -9999 -9999 -9999 -9999 -9999 -9999 -9999 -9999 -9999 -9999 -9999 -9999 -9999 -9999 -9999 -9999 -9999 -9999 -9999 -9999 -9999 -9999 -9999 -9999 -9999 -9999 -9999 -9999 -9999 -9999 -9999 -9999 -9999 -9999 -9999 -9999 -9999 -9999 -9999 - 9999 -9999 -9999 -9999 -9999 -9999 -9999 -9999 -9999 -9999 -9999 -9999 -9999 -9999 -9999 -9999 -9999 -9999 -9999 -9999 -9999 -9999 -9999 -9999 -9999-9999 -9999 -9999 -9999 -9999 -9999 -9999 -9999 -9999 -9999 -9999 -9999 -9999 -9999 -9999 -9999 -9999 -9999 -9999 -9999 -9999 -9999 -9999 -9999 -9999 -9999 -9999 -9999 -9999 -9999 -9999 -9999 -9999 -9999 -9999 -9999

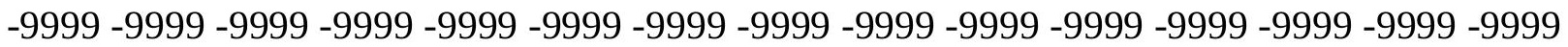

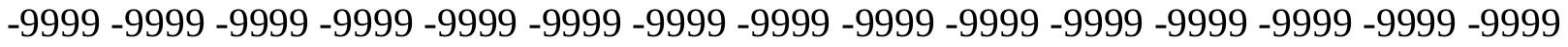
-9999 -9999 -9999 -9999 -9999 -9999 -9999 -9999 -9999 -9999 -9999 -9999 -9999 -9999 -9999

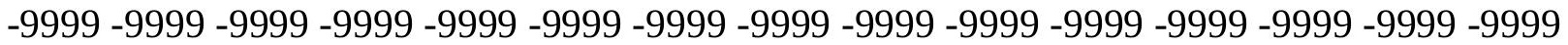
-9999 -9999 -9999 -9999 -9999 -9999 -9999 -9999 -9999 -9999 -9999 -9999 -9999 -9999 -9999 -9999 -9999 -9999 -9999 -9999 -9999 -9999 -9999 -9999 -9999 -9999 -9999 -9999 -9999 -9999 -

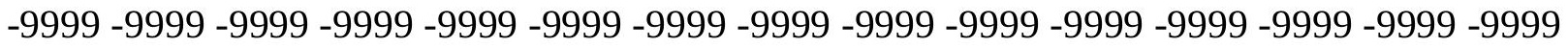
-9999 -9999 -9999 -9999 -9999 -9999 -9999 -9999 -9999 -9999 -9999 -9999 -9999 -9999 -9999

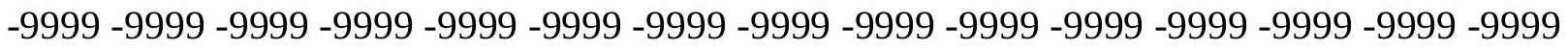
-9999 -9999 -9999 -9999 -9999 -9999 -9999 -9999 -9999 -9999 -9999 -9999 -9999 -9999 -9999 -9999 -9999 -9999 -9999 -9999 -9999 -9999 -9999 -9999 -9999 -9999 -9999 -9999 -9999 -9999 -9999 -9999 -9999 -9999 -9999 -9999 -9999 -9999 -9999 -9999 -9999 -9999 -9999 -9999 -9999 -9999 -9999 -9999 -9999 -9999 -9999 -9999 -9999 -9999 -9999 -9999 -9999 -9999 -9999 -9999 -9999 -9999 -9999 -9999 -9999 -9999 -9999 -9999 -9999 -9999 -9999 -9999 -9999 -9999 -9999 -999 -9999 -9999 -9999 -9999 -9999 -9999 -9999 -9999 -9999 -9999 -9999 -9999 -9999 -9999 -9999 -9999 -9999 -9999 -9999 -9999 -9999 -9999 -9999 -9999 -9999 -9999 -9999 -9999 -9999 -9999 -9999 -9999 -9999 -9999 -9999 -9999 -9999 -9999 -9999 -9999 -9999 -9999 -9999 -9999 -9999 -9999 -9999 -9999 -9999 -9999 -9999 -9999 -9999 -9999 -9999 -9999 -9999 -9999 -9999 -9999 -9999 -9999 -9999 -9999 -9999 -9999 -9999 -9999 -9999 -9999 -9999 -9999 -9999 -9999 -9999 -9999 -9999 -9999 -9999 -9999 -9999 -9999 -9999 -9999 -9999 -9999 -9999 -9999 -9999 -9999 -9999 -9999 -9999 -9999 -9999 -9999 -9999 -9999 -9999 -9999 -9999 -9999 -9999 -9999 -9999 -9999 -9999 -9999 -9999 -9999 -9999 -9999 -9999 -9999 -9999 -9999 -9999 -9999 -9999 -9999 -9999 -9999 -9999 -9999 -9999 -9999 -9999 -9999 -9999 -9999 -9999 -9999 -9999 -999 -9999 -9999 -9999 -9999 -9999 -9999 -9999 -9999 -9999 -9999 -9999 -9999 -9999 -9999 -9999 -9999 -9999 -9999 -9999 -9999 -9999 -9999 -9999 -9999 -9999 -9999 -9999 -9999 -9999 -9999 -

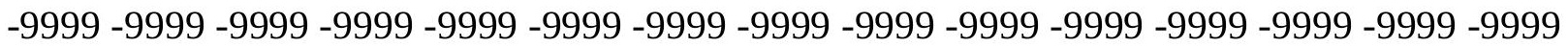

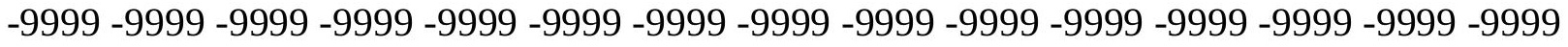

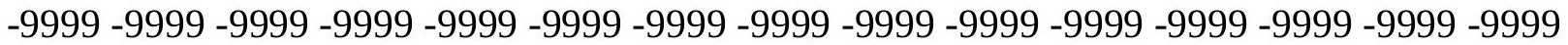
-9999 -9999 -9999 -9999 -9999 -9999 -9999 -9999 -9999 -9999 -9999 -9999 -9999 -9999 -9999

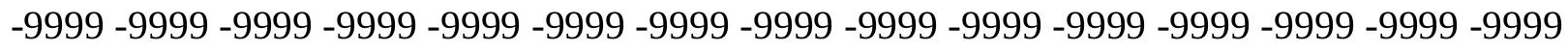

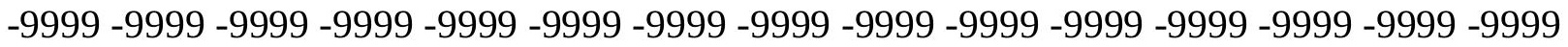
-9999 -9999 -9999 -9999 -9999 -9999 -9999 -9999 -9999 -9999 -9999 -9999 -9999 -9999 -9999 -9999 -9999 -9999 -9999 -9999 -9999 -9999 -9999 -9999 -9999 -9999 -9999 -9999 -9999 -9999 -

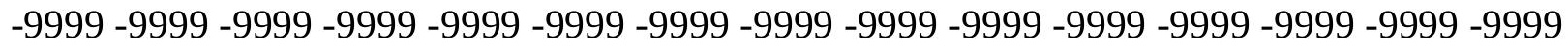

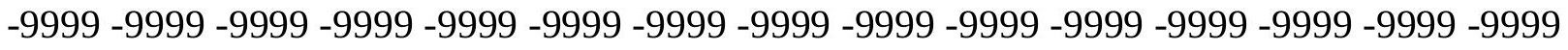
-9999 -9999 -9999 -9999 -9999 -9999 -9999 -9999 -9999 -9999 -9999 -9999 -9999 -9999 -9999 -9999 -9999 -9999 -9999 -9999 -9999 -9999 -9999 -9999-9999 -9999 -9999 -9999 -9999 -9999 -9999 -9999 -9999 -9999 -9999 -9999 -9999 -9999 -9999 -9999 -9999 -9999 -9999 -9999 -9999 -

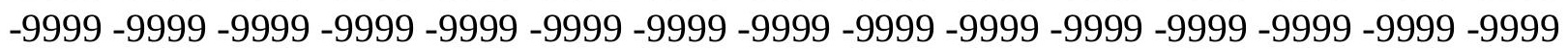


-9999 -9999 -9999 -9999 -9999 -9999 -9999 -9999 -9999 -9999 -9999 -9999 -9999 -9999 -9999 -9999 -9999 -9999 -9999 -9999 -9999 -9999 -9999 -9999 -9999 -9999 -9999 -9999 -9999 -9999 -9999 -9999 -9999 -9999 -9999 -9999 -9999 -9999 -9999 -9999 -9999 -9999 -9999 -9999 - 9999 -9999 -9999 -9999 -9999 -9999 -9999 -9999 -9999 -9999 -9999 -9999 -9999 -9999 -9999

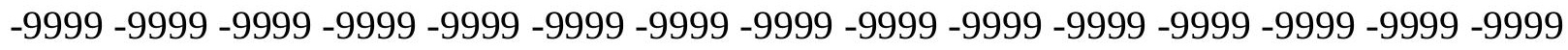
-9999 -9999 -9999 -9999 -9999 -9999 -9999 -9999 -9999 -9999 -9999 -9999 -9999 -9999 -9999 -9999 -9999 -9999 -9999 -9999 -9999 -9999 -9999 -9999 -9999 -9999 -9999 -9999 -9999 -9999

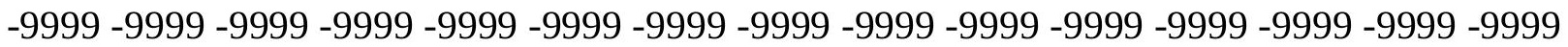

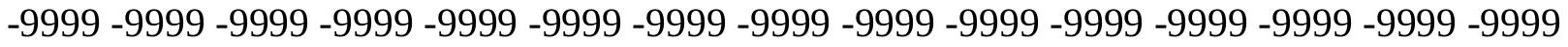
-9999 -9999 -9999 -9999 -9999 -9999 -9999 -9999 -9999 -9999 -9999 -9999 -9999 -9999 -9999 -9999 -9999 -9999 -9999 -9999 -9999 -9999 -9999 -9999 -9999 -9999 -9999 -9999 -9999 -9999 -9999 -9999 -9999 -9999 -9999 -9999 -9999 -9999 -9999 -9999 -9999 -9999 -9999 -9999 -9999 -9999 -9999 -9999 -9999 -9999 -9999 -9999 -9999 -9999 -9999 -9999 -9999 -9999 -9999 -9999 -

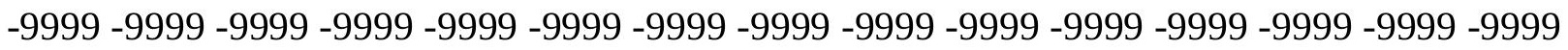
-9999 -9999 -9999 -9999 -9999 -9999 -9999 -9999 -9999 -9999 -9999 -9999 -9999 -9999 -9999 -

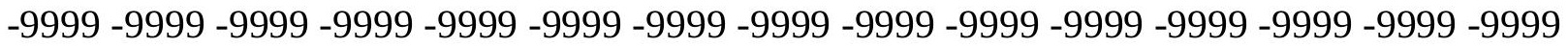
-9999 -9999 -9999 -9999 -9999 -9999 -9999 -9999 -9999 -9999 -9999 -9999 -9999 -9999 -9999 -9999 -9999 -9999 -9999 -9999 -9999 -9999 -9999 -9999 -9999 -9999 -9999 -9999 -9999 -9999 -9999 -9999 -9999 -9999 -9999 -9999 -9999 -9999 -9999 -9999 -9999 -9999 -9999 -9999 -9999 -

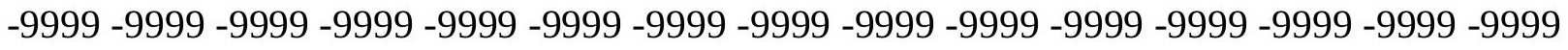
-9999 -9999 -9999 -9999 -9999 -9999 -9999 -9999 -9999 -9999 -9999 -9999 -9999 -9999 -9999

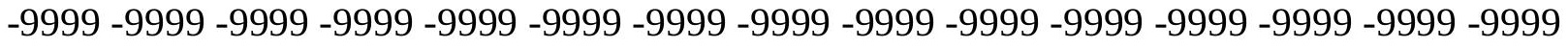
-9999 -9999 -9999 -9999 -9999 -9999 -9999 -9999 -9999 -9999 -9999 -9999 -9999 -9999 -9999 -9999 -9999 -9999 -9999 -9999 -9999 -9999 -9999 -9999 -9999 -9999 -9999 -9999 -9999 -9999 -9999 -9999 -9999 -9999 -9999 -9999 -9999 -9999 -9999 -9999 -9999 -9999 -9999 -9999 -9999 -9999 -9999 -9999 -9999 -9999 -9999 -9999 -9999 -9999 -9999 -9999 -9999 -9999 -9999 -9999 -9999 -9999 -9999 -9999 -9999 -9999 -9999 -9999 -9999 -9999 -9999 -9999 -9999 -9999 -9999 -9999 -9999 -9999 -9999 -9999 -9999 -9999 -9999 -9999 -9999 -9999 -9999 -9999 -9999 -9999 -9999 -9999 -9999 -9999 -9999 -9999 -9999 -9999 -9999 -9999 -9999 -9999 -9999 -9999 -9999 -9999 -9999 -9999 -9999 -9999 -9999 -9999 -9999 -9999 -9999 -9999 -9999 -9999 -9999 -9999 -9999 -9999 -9999 -9999 -9999 -9999 -9999 -9999 -9999 -9999 -9999 -9999 -9999 -9999 -9999 -9999 -9999 -9999 -9999 -9999 -9999 -9999 -9999 -9999 -9999 -9999 -9999 -9999 -9999 -

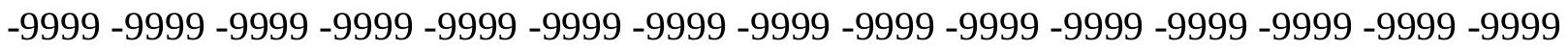

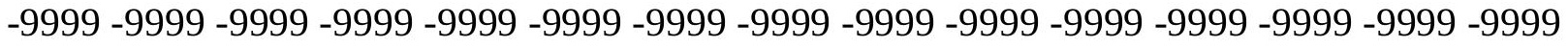
-9999 -9999 -9999 -9999 -9999 -9999 -9999 -9999 -9999 -9999 -9999 -9999 -9999 -9999 -9999 -

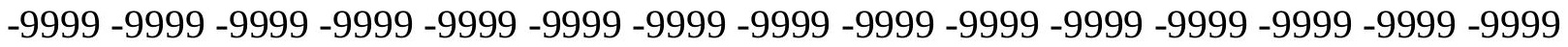

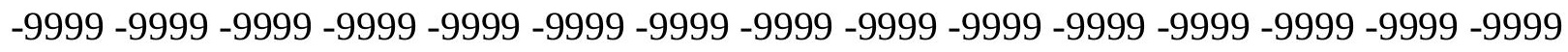

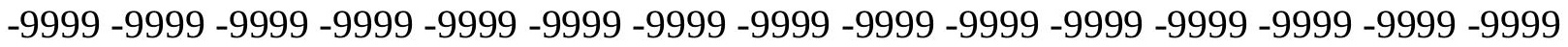

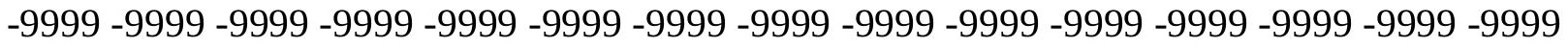
-9999 -9999 -9999 -9999 -9999 -9999 -9999 -9999 -9999 -9999 -9999 -9999 -9999 -9999 -9999 -

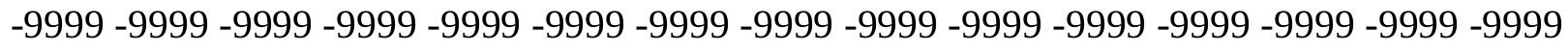

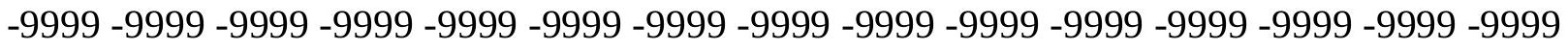
-9999 -9999 -9999 -9999 -9999 -9999 -9999 -9999 -9999 -9999 -9999 -9999 -9999 -9999 -9999 -9999 -9999 -9999 -9999 -9999 -9999 -9999 -9999 -9999-9999 -9999 -9999 -9999 -9999 -9999 -9999 -9999 -9999 -9999 -9999 -9999 -9999 -9999 -9999 -9999 -9999 -9999 -9999 -9999 -9999 -

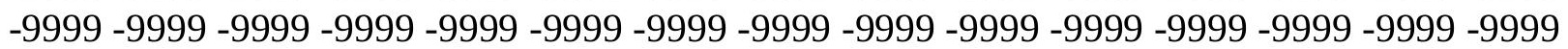


-9999 -9999 -9999 -9999 -9999 -9999 -9999 -9999 -9999 -9999 -9999 -9999 -9999 -9999 -9999 -9999 -9999 -9999 -9999 -9999 -9999 -9999 -9999 -9999 -9999 -9999 -9999 -9999 -9999 -9999 -9999 -9999 -9999 -9999 -9999 -9999 -9999 -9999 -9999 -9999 -9999 -9999 -9999 -9999 - 9999 -9999 -9999 -9999 -9999 -9999 -9999 -9999 -9999 -9999 -9999 -9999 -9999 -9999 -9999 -9999 -9999 -9999 -9999 -9999 -9999 -9999 -9999 -9999 -9999 -9999 -9999 -9999 -9999 -9999 -9999 -9999 -9999 -9999 -9999 -9999 -9999 -9999 -9999 -9999 -9999 -9999 -9999 -9999 -9999 -9999 -9999 -9999 -9999 -9999 -9999 -9999 -9999 -9999 -9999 -9999 -9999 -9999 -9999 -9999 -9999

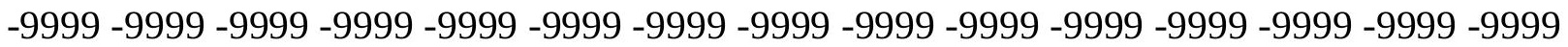

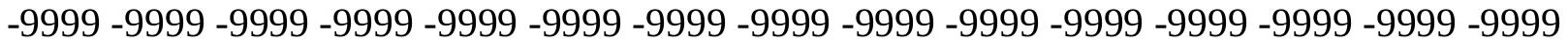
-9999 -9999 -9999 -9999 -9999 -9999 -9999 -9999 -9999 -9999 -9999 -9999 -9999 -9999 -9999 -9999 -9999 -9999 -9999 -9999 -9999 -9999 -9999 -9999 -9999 -9999 -9999 -9999 -9999 -9999 -9999 -9999 -9999 -9999 -9999 -9999 -9999 -9999 -9999 -9999 -9999 -9999 -9999 -9999 -9999 -9999 -9999 -9999 -9999 -9999 -9999 -9999 -9999 -9999 -9999 -9999 -9999 -9999 -9999 -9999 -9999 -9999 -9999 -9999 -9999 -9999 -9999 -9999 -9999 -9999 -9999 -9999 -9999 -9999 -9999 -9999 -9999 -9999 -9999 -9999 -9999 -9999 -9999 -9999 -9999 -9999 -9999 -9999 -9999 -

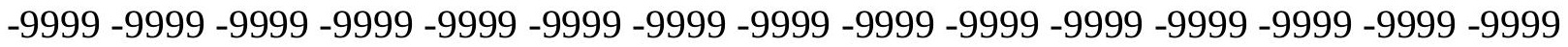
-9999 -9999 -9999 -9999 -9999 -9999 -9999 -9999 -9999 -9999 -9999 -9999 -9999 -9999 -9999 -9999 -9999 -9999 -9999 -9999 -9999 -9999 -9999 -9999 -9999 -9999 -9999 -9999 -9999 -9999 -9999 -9999 -9999 -9999 -9999 -9999 -9999 -9999 -9999 -9999 -9999 -9999 -9999 -9999 -9999 -9999 -9999 -9999 -9999 -9999 -9999 -9999 -9999 -9999 -9999 -9999 -9999 -9999 -9999 -9999 -9999 -9999 -9999 -9999 -9999 -9999 -9999 -9999 -9999 -9999 -9999 -9999 -9999 -9999 -9999 -999 -9999 -9999 -9999 -9999 -9999 -9999 -9999 -9999 -9999 -9999 -9999 -9999 -9999 -9999 -9999 -9999 -9999 -9999 -9999 -9999 -9999 -9999 -9999 -9999 -9999 -9999 -9999 -9999 -9999 -9999 -9999 -9999 -9999 -9999 -9999 -9999 -9999 -9999 -9999 -9999 -9999 -9999 -9999 -9999 -9999 -9999 -9999 -9999 -9999 -9999 -9999 -9999 -9999 -9999 -9999 -9999 -9999 -9999 -9999 -9999 -9999 -9999 -9999 -9999 -9999 -9999 -9999 -9999 -9999 -9999 -9999 -9999 -9999 -9999 -9999 -9999 -9999 -9999 -9999 -9999 -9999 -9999 -9999 -9999 -9999 -9999 -9999 -9999 -9999 -9999 -9999 -9999 -9999 -9999 -9999 -9999 -9999 -9999 -9999 -9999 -9999 -9999 -9999 -9999 -9999 -9999 -9999 -9999 -9999 -9999 -9999 -9999 -9999 -9999 -9999 -9999 -9999 -9999 -9999 -9999 -9999 -9999 -9999 -9999 -9999 -9999 -9999 -9999 -9999 -9999 -9999 -9999 -9999 -9999 -999 -9999 -9999 -9999 -9999 -9999 -9999 -9999 -9999 -9999 -9999 -9999 -9999 -9999 -9999 -9999 -9999 -9999 -9999 -9999 -9999 -9999 -9999 -9999 -9999 -9999 -9999 -9999 -9999 -9999 -9999 -

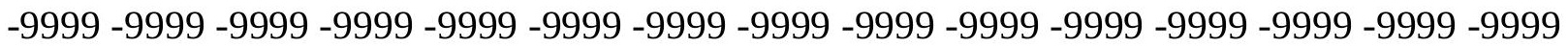

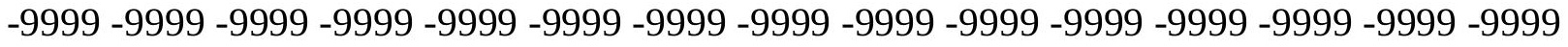

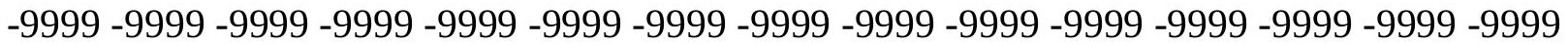
-9999 -9999 -9999 -9999 -9999 -9999 -9999 -9999 -9999 -9999 -9999 -9999 -9999 -9999 -9999 -9999 -9999 -9999 -9999 -9999 -9999 -9999 -9999 -9999 -9999 -9999 -9999 -9999 -9999 -

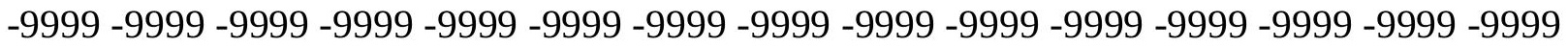
-9999 -9999 -9999 -9999 -9999 -9999 -9999 -9999 -9999 -9999 -9999 -9999 -9999 -9999 -9999 -9999 -9999 -9999 -9999 -9999 -9999 -9999 -9999 -9999 -9999 -9999 -9999 -9999 -9999 -9999 -

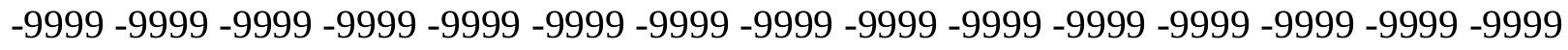

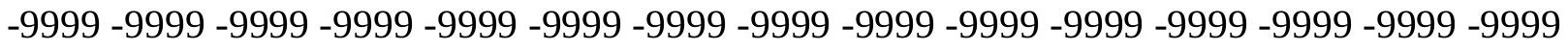
-9999 -9999 -9999 -9999 -9999 -9999 -9999 -9999 -9999 -9999 -9999 -9999 -9999 -9999 -9999 -9999 -9999 -9999 -9999 -9999 -9999 -9999 -9999 -9999-9999 -9999 -9999 -9999 -9999 -9999 -9999 -9999 -9999 -9999 -9999 -9999 -9999 -9999 -9999 -9999 -9999 -9999 -9999 -9999 -9999 -

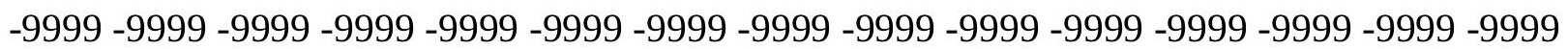


-9999 -9999 -9999 -9999 -9999 -9999 -9999 -9999 -9999 -9999 -9999 -9999 -9999 -9999 -9999 -9999 -9999 -9999 -9999 -9999 -9999 -9999 -9999 -9999 -9999 -9999 -9999 -9999 -9999 -9999 -

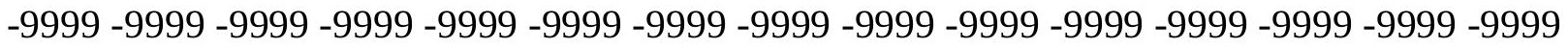
-9999 -9999 -9999 -9999 -9999 -9999 -9999 -9999 -9999 -9999 -9999 -9999 -9999 -9999 -9999 -9999 -9999 -9999 -9999 -9999 -9999 -9999 -9999 -9999-9999 -9999 -9999 -9999 -9999 -9999 -9999 -9999 -9999 -9999 -9999 -9999 -9999 -9999 -9999 -9999 -9999 -9999 -9999 -9999 -9999 -9999 -9999 -9999 -9999 -9999 -9999 -9999 -9999 -9999 -9999 -9999 -9999 -9999 -9999 -9999

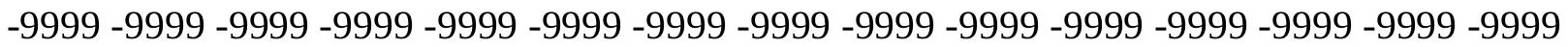

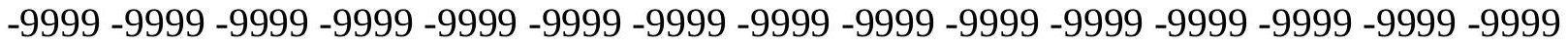
-9999 -9999 -9999 -9999 -9999 -9999 -9999 -9999 -9999 -9999 -9999 -9999 -9999 -9999 -9999 -9999 -9999 -9999 -9999 -9999 -9999 -9999 -9999 -9999 -9999 -9999 -9999 -9999 -9999 -9999 -9999 -9999 -9999 -9999 -9999 -9999 -9999 -9999 -9999 -9999 -9999 -9999 -9999 -9999 -9999 -9999 -9999 -9999 -9999 -9999 -9999 -9999 -9999 -9999 -9999 -9999 -9999 -9999 -9999 -9999 -9999 -9999 -9999 -9999 -9999 -9999 -9999 -9999 -9999 -9999 -9999 -9999 -9999 -9999 -9999 -9999 -9999 -9999 -9999 -9999 -9999 -9999 -9999 -9999 -9999 -9999 -9999 -9999 -9999 -9999 -

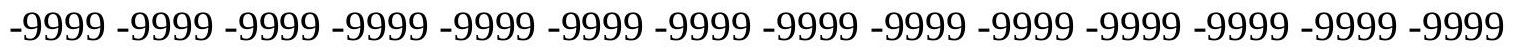
-9999 -9999 -9999 -9999 -9999 -9999 -9999 -9999 -9999 -9999 -9999 -9999 -9999 -9999 -9999 -9999 -9999 -9999 -9999 -9999 -9999 -9999 -9999 -9999 -9999 -9999 -9999 -9999 -9999 -9999 -9999 -9999 -9999 -9999 -9999 -9999 -9999 -9999 -9999 -9999 -9999 -9999 -9999 -9999 -9999 -

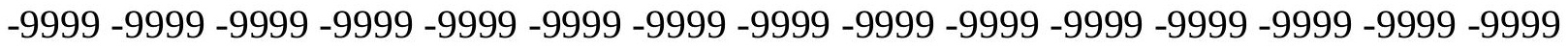

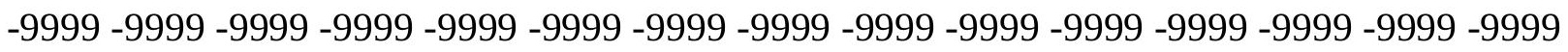
-9999 -9999 -9999 -9999 -9999 -9999 -9999 -9999 -9999 -9999 -9999 -9999 -9999 -9999 - 9999 -9999 -9999 -9999 -9999 -9999 -9999 -9999 -9999 -9999 -9999 -9999 -9999 -9999 -9999 -9999 -9999 -9999 -9999 -9999 -9999 -9999 -9999 -9999 -9999 -9999 -9999 -9999 -9999 -9999 -9999 -

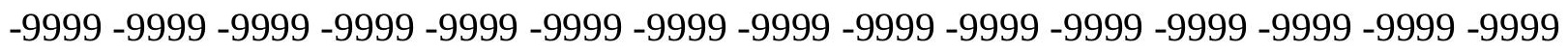
-9999 -9999 -9999 -9999 -9999 -9999 -9999 -9999 -9999 -9999 -9999 -9999 -9999 -9999 -9999 -9999 -9999 -9999 -9999 -9999 -9999 -9999 -9999 -9999 -9999 -9999 -9999 -9999 -9999 -9999 -

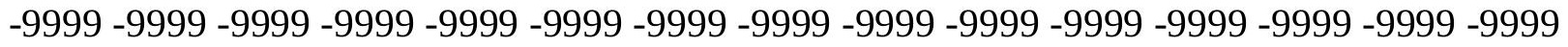
-9999 -9999 -9999 -9999 -9999 -9999 -9999 -9999 -9999 -9999 -9999 -9999 -9999 -9999 -9999 -9999 -9999 -9999 -9999 -9999 -9999 -9999 -9999 -9999 -9999 -9999 -9999 -9999 -9999 -999 -

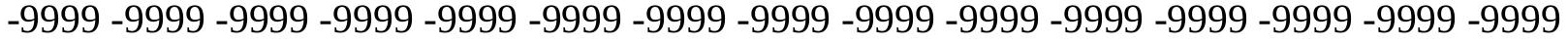
-9999 -9999 -9999 -9999 -9999 -9999 -9999 -9999 -9999 -9999 -9999 -9999 -9999 -9999 -9999 -

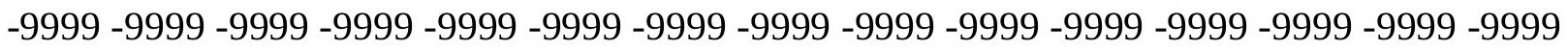

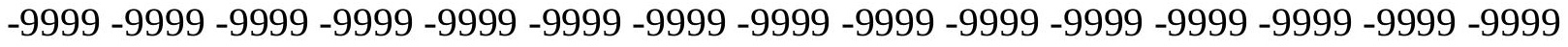

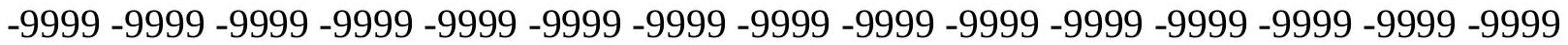
-9999 -9999 -9999 -9999 -9999 -9999 -9999 -9999 -9999 -9999 -9999 -9999 -9999 -9999 -9999 -

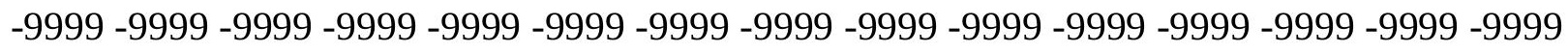

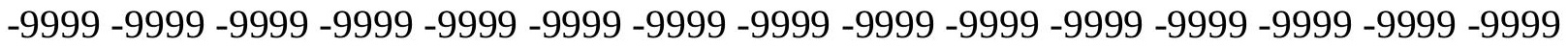
-9999 -9999 -9999 -9999 -9999 -9999 -9999 -9999 -9999 -9999 -9999 -9999 -9999 - 9999 - -999 -9999 -9999 -9999 -9999 -9999 -9999 -9999 -9999 -9999 -9999 -9999 -9999 -9999 -9999 -9999 -

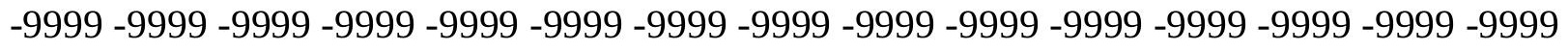

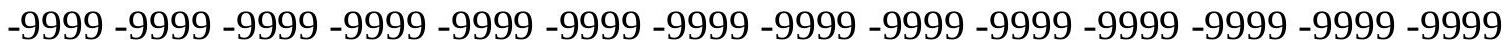
-9999 -9999 -9999 -9999 -9999 -9999 -9999 -9999 -9999 -9999 -9999 -9999 -9999 -9999 -9999 -9999 -9999 -9999 -9999 -9999 -9999 -9999 -9999 -9999-9999 -9999 -9999 -9999 -9999 -9999 -9999 -9999 -9999 -9999 -9999 -9999 -9999 -9999 -9999 -9999 -9999 -9999 -9999 -9999 -9999 -

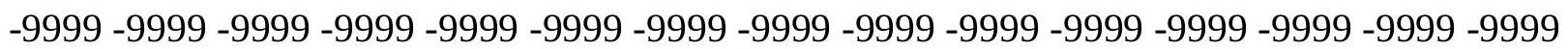


-9999 -9999 -9999 -9999 -9999 -9999 -9999 -9999 -9999 -9999 -9999 -9999 -9999 -9999 -9999 -9999 -9999 -9999 -9999 -9999 -9999 -9999 -9999 -9999 -9999 -9999 -9999 -9999 -9999 -9999 -

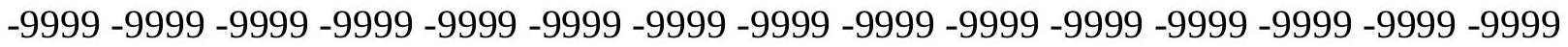
-9999 -9999 -9999 -9999 -9999 -9999 -9999 -9999 -9999 -9999 -9999 -9999 -9999 -9999 -9999 -9999 -9999 -9999 -9999 -9999 -9999 -9999 -9999 -9999-9999 -9999 -9999 -9999 -9999 -9999 -9999 -9999 -9999 -9999 -9999 -9999 -9999 -9999 -9999 -9999 -9999 -9999 -9999 -9999 -9999 -9999 -9999 -9999 -9999 -9999 -9999 -9999 -9999 -9999 -9999 -9999 -9999 -9999 -9999 -9999

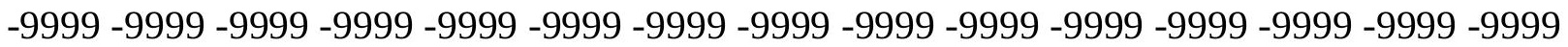

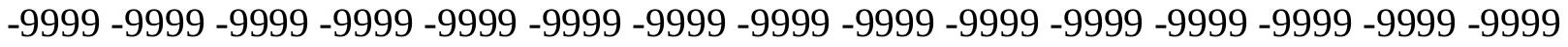
-9999 -9999 -9999 -9999 -9999 -9999 -9999 -9999 -9999 -9999 -9999 -9999 -9999 -9999 -9999 -9999 -9999 -9999 -9999 -9999 -9999 -9999 -9999 -9999 -9999 -9999 -9999 -9999 -9999 -9999 -9999 -9999 -9999 -9999 -9999 -9999 -9999 -9999 -9999 -9999 -9999 -9999 -9999 -9999 -9999 -9999 -9999 -9999 -9999 -9999 -9999 -9999 -9999 -9999 -9999 -9999 -9999 -9999 -9999 -9999 -

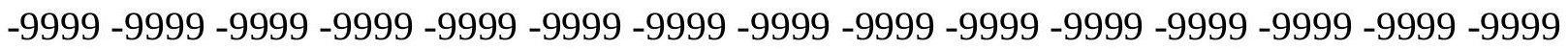
-9999 -9999 -9999 -9999 -9999 -9999 -9999 -9999 -9999 -9999 -9999 -9999 -9999 -9999 -9999 -

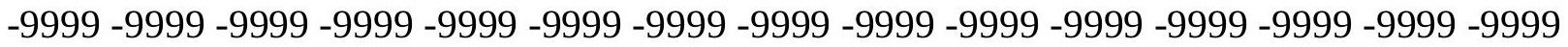
-9999 -9999 -9999 -9999 -9999 -9999 -9999 -9999 -9999 -9999 -9999 -9999 -9999 -9999 -9999 -9999 -9999 -9999 -9999 -9999 -9999 -9999 -9999 -9999 -9999 -9999 -9999 -9999 -9999 -9999 -9999 -9999 -9999 -9999 -9999 -9999 -9999 -9999 -9999 -9999 -9999 -9999 -9999 -9999 -9999 -

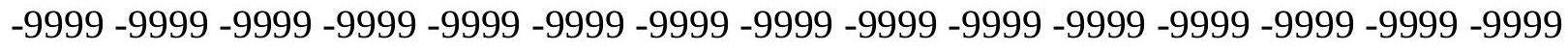

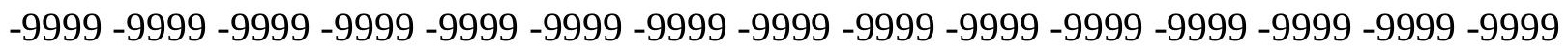
-9999 -9999 -9999 -9999 -9999 -9999 -9999 -9999 -9999 -9999 -9999 -9999 -9999 -9999 -9999 -9999 -9999 -9999 -9999 -9999 -9999 -9999 -9999 -9999 -9999 -9999 -9999 -9999 -9999 -9999 -9999 -9999 -9999 -9999 -9999 -9999 -9999 -9999 -9999 -9999 -9999 -9999 -9999 -9999 -

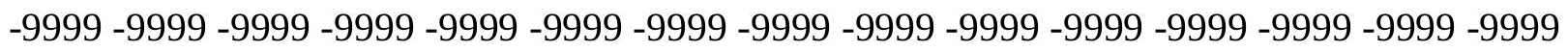
-9999 -9999 -9999 -9999 -9999 -9999 -9999 -9999 -9999 -9999 -9999 -9999 -9999 -9999 -9999 -9999 -9999 -9999 -9999 -9999 -9999 -9999 -9999 -9999 -9999 -9999 -9999 -9999 -9999 -9999 -

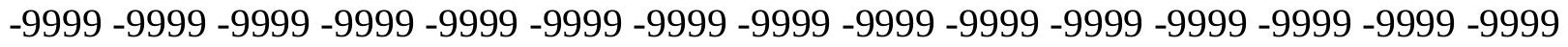
-9999 -9999 -9999 -9999 -9999 -9999 -9999 -9999 -9999 -9999 -9999 -9999 -9999 -9999 -9999 -9999 -9999 -9999 -9999 -9999 -9999 -9999 -9999 -9999 -9999 -9999 -9999 -9999 -9999 -999 -

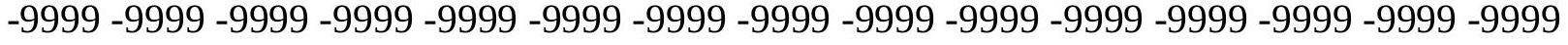
-9999 -9999 -9999 -9999 -9999 -9999 -9999 -9999 -9999 -9999 -9999 -9999 -9999 -9999 -9999 -

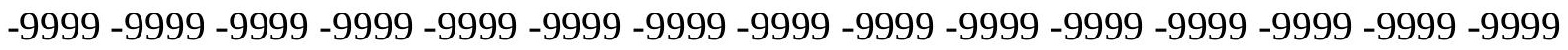

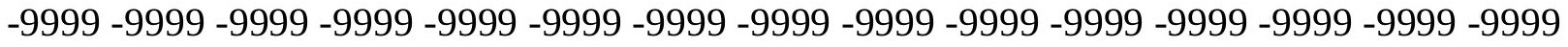

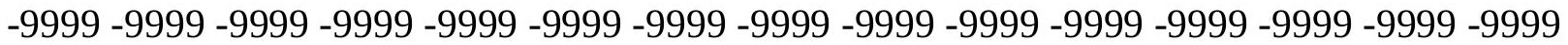

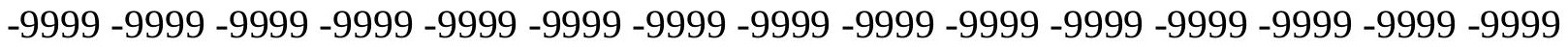

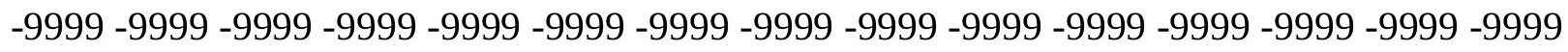

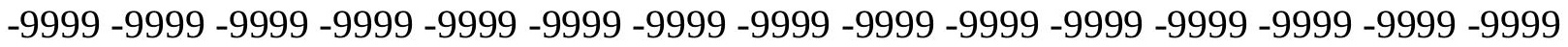

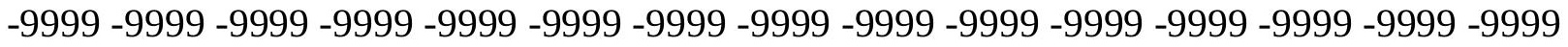
-9999 -9999 -9999 -9999 -9999 -9999 -9999 -9999 -9999 -9999 -9999 -9999 -9999 -9999 -9999 -

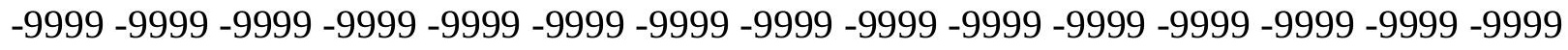

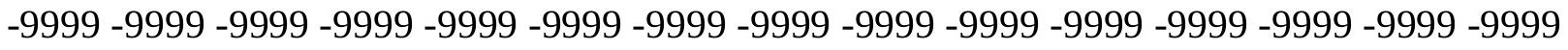
-9999 -9999 -9999 -9999 -9999 -9999 -9999 -9999 -9999 -9999 -9999 -9999 -9999 -9999 -9999 -9999 -9999 -9999 -9999 -9999 -9999 -9999 -9999 -9999-9999 -9999 -9999 -9999 -9999 -9999 -9999 -9999 -9999 -9999 -9999 -9999 -9999 -9999 -9999 -9999 -9999 -9999 -9999 -9999 -9999 -

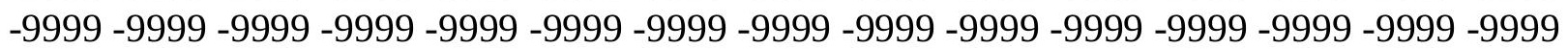


-9999 -9999 -9999 -9999 -9999 -9999 -9999 -9999 -9999 -9999 -9999 -9999 -9999 -9999 -9999 -9999 -9999 -9999 -9999 -9999 -9999 -9999 -9999 -9999 -9999 -9999 -9999 -9999 -9999 -

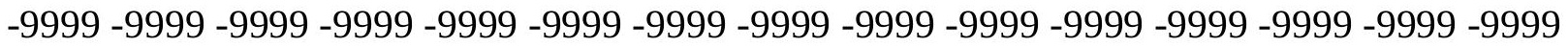
-9999 -9999 -9999 -9999 -9999 -9999 -9999 -9999 -9999 -9999 -9999 -9999 -9999 -9999 -9999 -9999 -9999 -9999 -9999 -9999 -9999 -9999 -9999 -9999 -9999 -9999 -9999 -9999 -9999 -9999 -9999 -9999 -9999 -9999 -9999 -9999 -9999 -9999 -9999 -9999 -9999 -9999 -9999 -9999 -9999 -9999 -9999 -9999 -9999 -9999 -9999 -9999 -9999 -9999 -9999 -9999 -9999 -9999 -9999 -9999

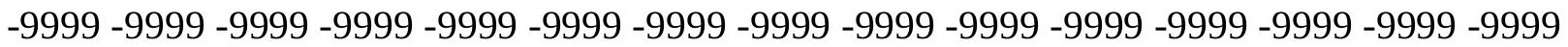

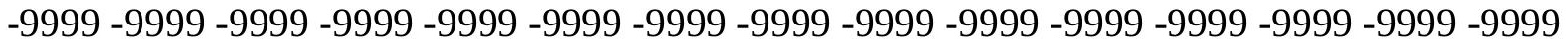
-9999 -9999 -9999 -9999 -9999 -9999 -9999 -9999 -9999 -9999 -9999 -9999 -9999 -9999 -9999 -9999 -9999 -9999 -9999 -9999 -9999 -9999 -9999 -9999 -9999 -9999 -9999 -9999 -9999 -9999 -9999 -9999 -9999 -9999 -9999 -9999 -9999 -9999 -9999 -9999 -9999 -9999 -9999 -9999 -9999 -9999 -9999 -9999 -9999 -9999 -9999 -9999 -9999 -9999 -9999 -9999 -9999 -9999 -9999 -9999 -9999 -9999 -9999 -9999 -9999 -9999 -9999 -9999 -9999 -9999 -9999 -9999 -9999 -9999 -9999 -9999 -9999 -9999 -9999 -9999 -9999 -9999 -9999 -9999 -9999 -9999 -9999 -9999 -9999 -9999 -

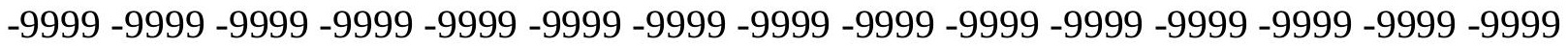
-9999 -9999 -9999 -9999 -9999 -9999 -9999 -9999 -9999 -9999 -9999 -9999 -9999 -9999 -9999 -9999 -9999 -9999 -9999 -9999 -9999 -9999 -9999 -9999 -9999 -9999 -9999 -9999 -9999 - 9999 -9999 -9999 -9999 -9999 -9999 -9999 -9999 -9999 -9999 -9999 -9999 -9999 -9999 -9999 -9999 -

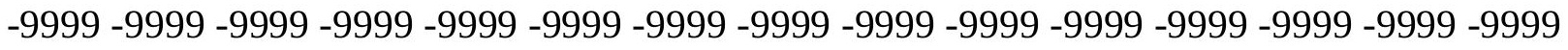

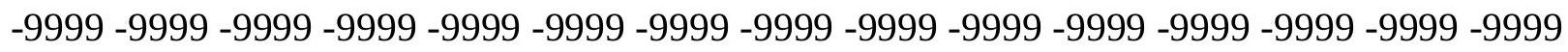

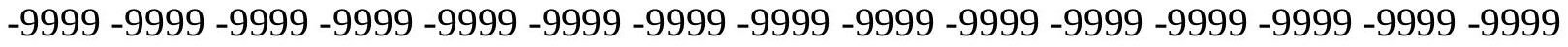
-9999 -9999 -9999 -9999 -9999 -9999 -9999 -9999 -9999 -9999 -9999 -9999 -9999 -9999 -9999 -9999 -9999 -9999 -9999 -9999 -9999 -9999 -9999 -9999 -9999 -9999 -9999 -9999 -9999 -9999 -

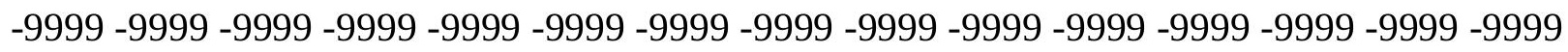
-9999 -9999 -9999 -9999 -9999 -9999 -9999 -9999 -9999 -9999 -9999 -9999 -9999 -9999 -9999 -9999 -9999 -9999 -9999 -9999 -9999 -9999 -9999 -9999 -9999 -9999 -9999 -9999 -9999 -9999 -9999 -9999 -9999 -9999 -9999 -9999 -9999 -9999 -9999 -9999 -9999 -9999 -9999 -9999 -9999 -9999 -9999 -9999 -9999 -9999 -9999 -9999 -9999 -9999 -9999 -9999 -9999 -9999 -9999 -9999 -9999 -9999 -9999 -9999 -9999 -9999 -9999 -9999 -9999 -9999 -9999 -9999 -9999 -999 -

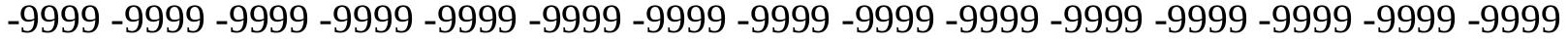
-9999 -9999 -9999 -9999 -9999 -9999 -9999 -9999 -9999 -9999 -9999 -9999 -9999 -9999 -9999 -

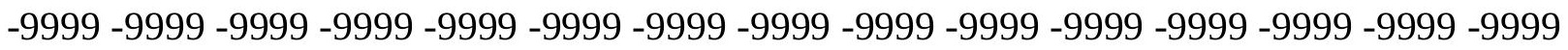

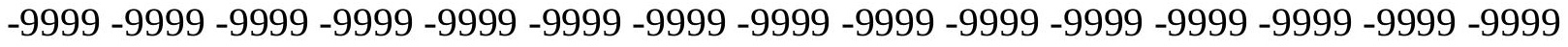

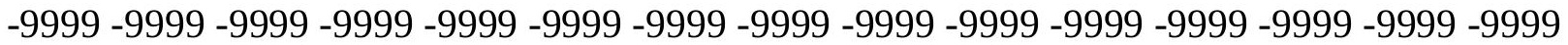

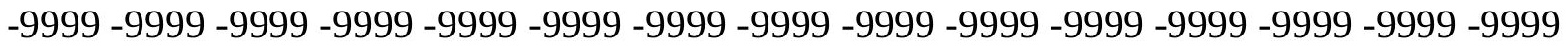

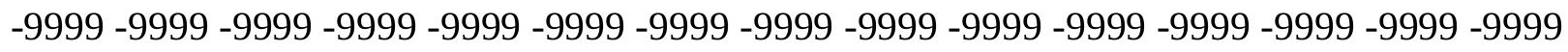

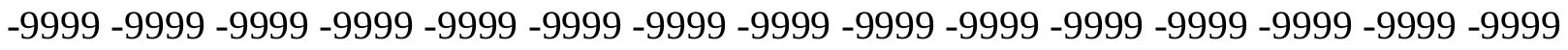

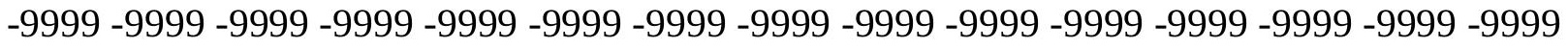
-9999 -9999 -9999 -9999 -9999 -9999 -9999 -9999 -9999 -9999 -9999 -9999 -9999 -9999 -9999 -

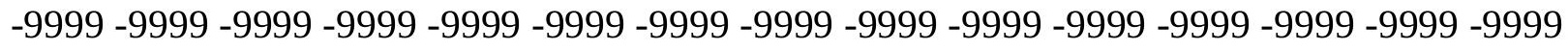

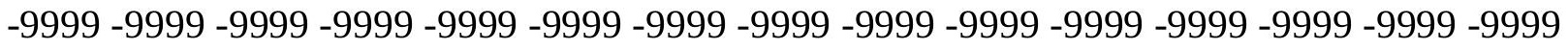
-9999 -9999 -9999 -9999 -9999 -9999 -9999 -9999 -9999 -9999 -9999 -9999 -9999 -9999 -9999 -9999 -9999 -9999 -9999 -9999 -9999 -9999 -9999 -9999-9999 -9999 -9999 -9999 -9999 -9999 -9999 -9999 -9999 -9999 -9999 -9999 -9999 -9999 -9999 -9999 -9999 -9999 -9999 -9999 -9999 -

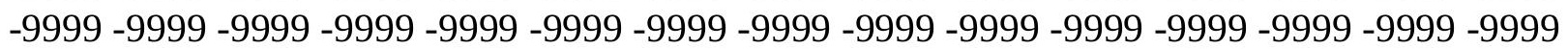


-9999 -9999 -9999 -9999 -9999 -9999 -9999 -9999 -9999 -9999 -9999 -9999 -9999 -9999 -9999 -9999 -9999 -9999 -9999 -9999 -9999 -9999 -9999 -9999 -9999 -9999 -9999 -9999 -9999 -9999 -

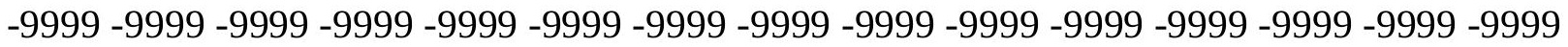
-9999 -9999 -9999 -9999 -9999 -9999 -9999 -9999 -9999 -9999 -9999 -9999 -9999 -9999 -9999 -9999 -9999 -9999 -9999 -9999 -9999 -9999 -9999 -9999-9999 -9999 -9999 -9999 -9999 -9999 -9999 -9999 -9999 -9999 -9999 -9999 -9999 -9999 -9999 -9999 -9999 -9999 -9999 -9999 -9999 -

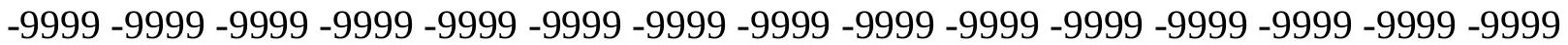
-9999 -9999 -9999 -9999 -9999 -9999 -9999 -9999 -9999 -9999 -9999 -9999 -9999 -9999 -9999 -9999 -9999 -9999 -9999 -9999 -9999 -9999 -9999 -9999 -9999 -9999 -9999 -9999 -9999 -9999 -9999 -9999 -9999 -9999 -9999 -9999 -9999 -9999 -9999 -9999 -9999 -9999 -9999 -9999 -9999 -9999 -9999 -9999 -9999 -9999 -9999 -9999 -9999 -9999 -9999 -9999 -9999 -9999 -9999 -9999 -9999 -9999 -9999 -9999 -9999 -9999 -9999 -9999 -9999 -9999 -9999 -9999 -9999 -9999 -9999 -9999 -9999 -9999 -9999 -9999 -9999 -9999 -9999 -9999 -9999 -9999 -9999 -9999 -9999 -9999 -9999 -9999 -9999 -9999 -9999 -9999 -9999 -9999 -9999 -9999 -9999 -9999 -9999 -9999 -9999 -9999 -9999 -9999 -9999 -9999 -9999 -9999 -9999 -9999 -9999 -9999 -9999 -9999 -9999 -

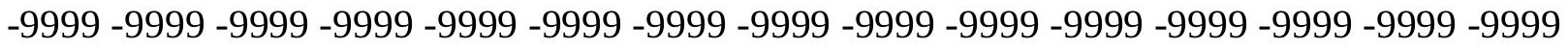
-9999 -9999 -9999 -9999 -9999 -9999 -9999 -9999 -9999 -9999 -9999 -9999 -9999 -9999 -9999 -9999 -9999 -9999 -9999 -9999 -9999 -9999 -9999 -9999 -9999 -9999 -9999 -9999 -9999 -9999 -9999 -9999 -9999 -9999 -9999 -9999 -9999 -9999 -9999 -9999 -9999 -9999 -9999 -9999 -9999 -

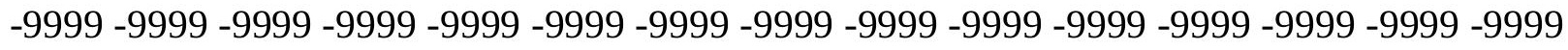

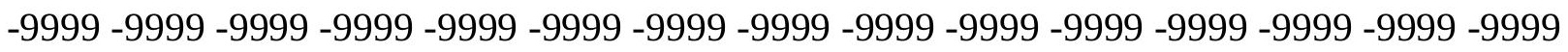
-9999 -9999 -9999 -9999 -9999 -9999 -9999 -9999 -9999 -9999 -9999 -9999 -9999 -9999 - 9999 -9999 -9999 -9999 -9999 -9999 -9999 -9999 -9999 -9999 -9999 -9999 -9999 -9999 -9999 -9999 -9999 -9999 -9999 -9999 -9999 -9999 -9999 -9999 -9999 -9999 -9999 -9999 -9999 -9999 -9999 -

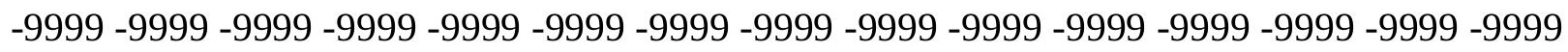
-9999 -9999 -9999 -9999 -9999 -9999 -9999 -9999 -9999 -9999 -9999 -9999 -9999 -9999 -9999 -9999 -9999 -9999 -9999 -9999 -9999 -9999 -9999 -9999 -9999 -9999 -9999 -9999 -9999 -9999 -

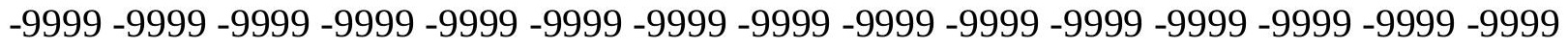
-9999 -9999 -9999 -9999 -9999 -9999 -9999 -9999 -9999 -9999 -9999 -9999 -9999 -9999 -9999 -9999 -9999 -9999 -9999 -9999 -9999 -9999 -9999 -9999 -9999 -9999 -9999 -9999 -9999 -999 -9999 -9999 -9999 -9999 -9999 -9999 -9999 -9999 -9999 -9999 -9999 -9999 -9999 -9999 -9999 -9999 -9999 -9999 -9999 -9999 -9999 -9999 -9999 -9999 -9999 -9999 -9999 -9999 -9999 -9999 -

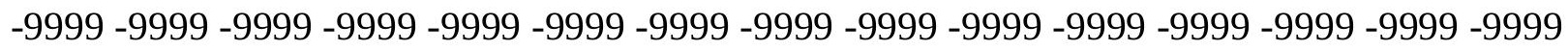

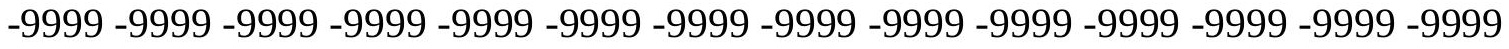
-9999 -9999 -9999 -9999 -9999 -9999 -9999 -9999 -9999 -9999 -9999 -9999 -9999 -9999 -9999

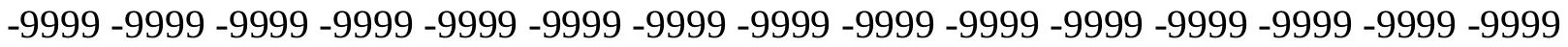

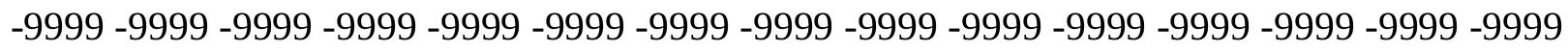

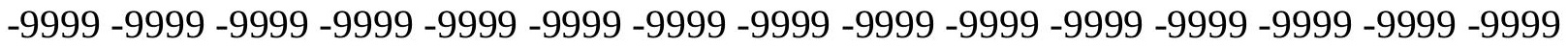

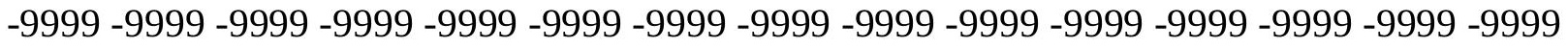
-9999 -9999 -9999 -9999 -9999 -9999 -9999 -9999 -9999 -9999 -9999 -9999 -9999 -9999 -9999 -

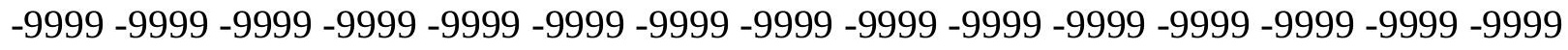

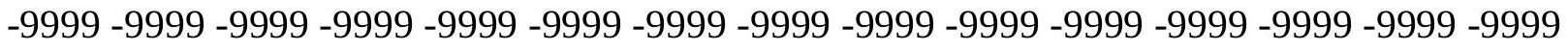
-9999 -9999 -9999 -9999 -9999 -9999 -9999 -9999 -9999 -9999 -9999 -9999 -9999 -9999 -9999 -9999 -9999 -9999 -9999 -9999 -9999 -9999 -9999 -9999-9999 -9999 -9999 -9999 -9999 -9999 -9999 -9999 -9999 -9999 -9999 -9999 -9999 -9999 -9999 -9999 -9999 -9999 -9999 -9999 -9999 -

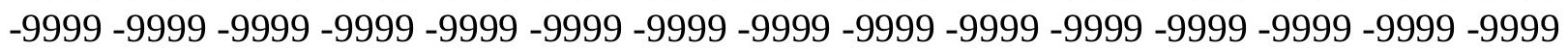


-9999 -9999 -9999 -9999 -9999 -9999 -9999 -9999 -9999 -9999 -9999 -9999 -9999 -9999 -9999 -9999 -9999 -9999 -9999 -9999 -9999 -9999 -9999 -9999 -9999 -9999 -9999 -9999 -9999 -9999 -

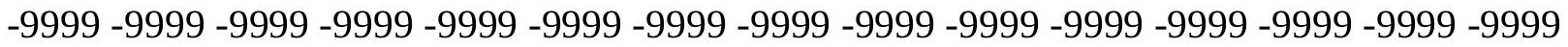
-9999 -9999 -9999 -9999 -9999 -9999 -9999 -9999 -9999 -9999 -9999 -9999 -9999 -9999 -9999 -9999 -9999 -9999 -9999 -9999 -9999 -9999 -9999 -9999-9999 -9999 -9999 -9999 -9999 -9999 -9999 -9999 -9999 -9999 -9999 -9999 -9999 -9999 -9999 -9999 -9999 -9999 -9999 -9999 -9999 -9999 -9999 -9999 -9999 -9999 -9999 -9999 -9999 -9999 -9999 -9999 -9999 -9999 -9999 -9999

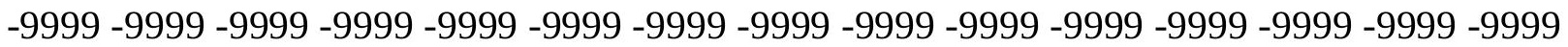

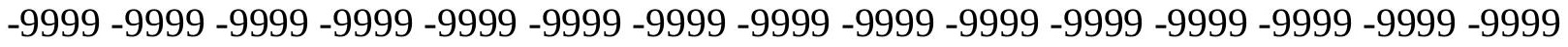
-9999 -9999 -9999 -9999 -9999 -9999 -9999 -9999 -9999 -9999 -9999 -9999 -9999 -9999 -9999 -9999 -9999 -9999 -9999 -9999 -9999 -9999 -9999 -9999 -9999 -9999 -9999 -9999 -9999 -9999 -9999 -9999 -9999 -9999 -9999 -9999 -9999 -9999 -9999 -9999 -9999 -9999 -9999 -9999 -9999 -9999 -9999 -9999 -9999 -9999 -9999 -9999 -9999 -9999 -9999 -9999 -9999 -9999 -9999 -9999 -9999 -9999 -9999 -9999 -9999 -9999 -9999 -9999 -9999 -9999 -9999 -9999 -9999 -9999 -9999 -9999 -9999 -9999 -9999 -9999 -9999 -9999 -9999 -9999 -9999 -9999 -9999 -9999 -9999

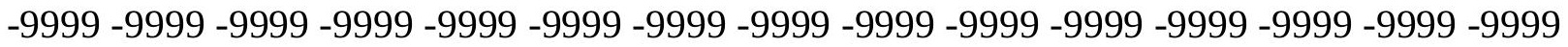
-9999 -9999 -9999 -9999 -9999 -9999 -9999 -9999 -9999 -9999 -9999 -9999 -9999 -9999 -9999 -9999 -9999 -9999 -9999 -9999 -9999 -9999 -9999 -9999 -9999 -9999 -9999 -9999 -9999 -9999 -9999 -9999 -9999 -9999 -9999 -9999 -9999 -9999 -9999 -9999 -9999 -9999 -9999 -9999 -9999 -

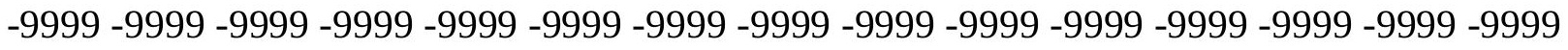

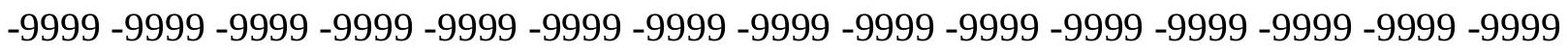
-9999 -9999 -9999 -9999 -9999 -9999 -9999 -9999 -9999 -9999 -9999 -9999 -9999 -9999 -9999 -9999 -9999 -9999 -9999 -9999 -9999 -9999 -9999 -9999 -9999 -9999 -9999 -9999 -9999 -9999 -9999 -9999 -9999 -9999 -9999 -9999 -9999 -9999 -9999 -9999 -9999 -9999 -9999 -9999 -9999 -

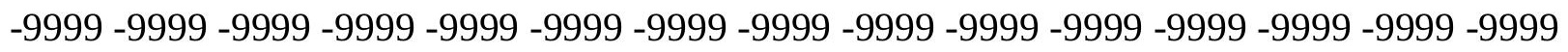
-9999 -9999 -9999 -9999 -9999 -9999 -9999 -9999 -9999 -9999 -9999 -9999 -9999 -9999 -9999 -9999 -9999 -9999 -9999 -9999 -9999 -9999 -9999 -9999 -9999 -9999 -9999 -9999 -9999 -9999 -

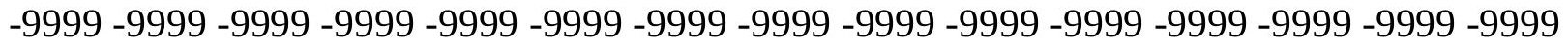
-9999 -9999 -9999 -9999 -9999 -9999 -9999 -9999 -9999 -9999 -9999 -9999 -9999 -9999 -9999 -9999 -9999 -9999 -9999 -9999 -9999 -9999 -9999 -9999 -9999 -9999 -9999 -9999 -9999 -999 -9999 -9999 -9999 -9999 -9999 -9999 -9999 -9999 -9999 -9999 -9999 -9999 -9999 -9999 -9999 -9999 -9999 -9999 -9999 -9999 -9999 -9999 -9999 -9999 -9999 -9999 -9999 -9999 -9999 -9999 -

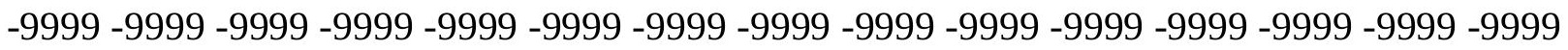

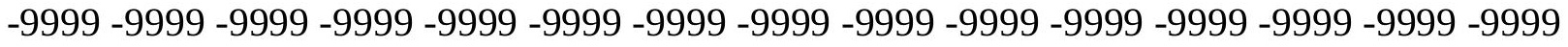

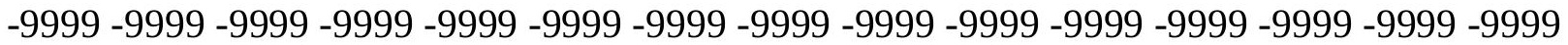

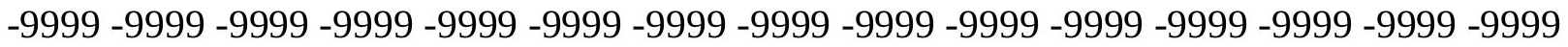

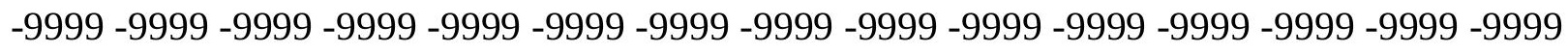

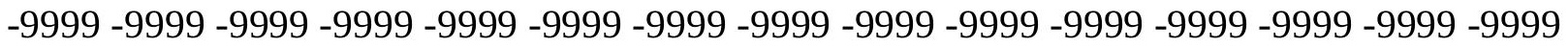
-9999 -9999 -9999 -9999 -9999 -9999 -9999 -9999 -9999 -9999 -9999 -9999 -9999 - 9999 - -999 -9999 -9999 -9999 -9999 -9999 -9999 -9999 -9999 -9999 -9999 -9999 -9999 -9999 -9999 - -999 -

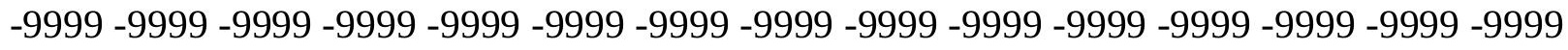

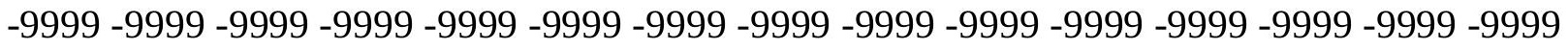
-9999 -9999 -9999 -9999 -9999 -9999 -9999 -9999 -9999 -9999 -9999 -9999 -9999 -9999 -9999 -9999 -9999 -9999 -9999 -9999 -9999 -9999 -9999 -9999-9999 -9999 -9999 -9999 -9999 -9999 -9999 -9999 -9999 -9999 -9999 -9999 -9999 -9999 -9999 -9999 -9999 -9999 -9999 -9999 -9999 -

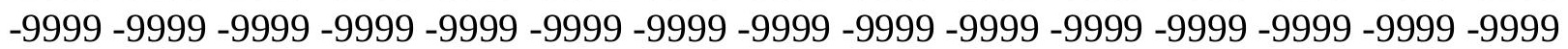


-9999 -9999 -9999 -9999 -9999 -9999 -9999 -9999 -9999 -9999 -9999 -9999 -9999 -9999 -9999 -9999 -9999 -9999 -9999 -9999 -9999 -9999 -9999 -9999 -9999 -9999 -9999 -9999 -9999 -9999 -9999 -9999 -9999 -9999 -9999 -9999 -9999 -9999 -9999 -9999 -9999 -9999 -9999 -9999 -9999 -9999 -9999 -9999 -9999 -9999 -9999 -9999 -9999 -9999 -9999 -9999 -9999 -9999 -9999 -9999 -9999 -9999 -9999 -9999 -9999 -9999 -9999 -9999 -9999 -9999 -9999 -9999 -9999 -9999 -9999 -9999 -9999 -9999 -9999 -9999 -9999 -9999 -9999 -9999 -9999 -9999 -9999 -9999 -9999 -9999 -9999 -9999 -9999 -9999 -9999 -9999 -9999 -9999 -9999 -9999 -9999 -9999 -9999 -9999 -9999 -

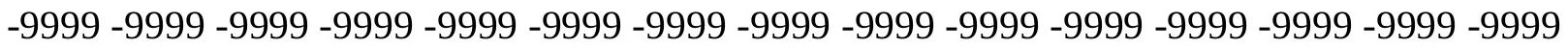
-9999 -9999 -9999 -9999 -9999 -9999 -9999 -9999 -9999 -9999 -9999 -9999 -9999 -9999 -9999 -9999 -9999 -9999 -9999 -9999 -9999 -9999 -9999 -9999 -9999 -9999 -9999 -9999 -9999 -9999 -

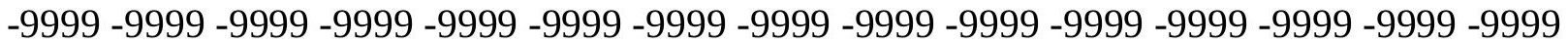
-9999 -9999 -9999 -9999 -9999 -9999 -9999 -9999 -9999 -9999 -9999 -9999 -9999 -9999 -9999 -9999 -9999 -9999 -9999 -9999 -9999 -9999 -9999 -9999 -9999 -9999 -9999 -9999 -9999 -9999 -9999 -9999 -9999 -9999 -9999 -9999 -9999 -9999 -9999 -9999 -9999 -9999 -9999 -9999 -9999 -9999 -9999 -9999 -9999 -9999 -9999 -9999 -9999 -9999 -9999 -9999 -9999 -9999 -9999 -9999

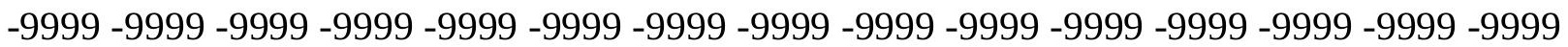
-9999 -9999 -9999 -9999 -9999 -9999 -9999 -9999 -9999 -9999 -9999 -9999 -9999 -9999 -9999 -9999 -9999 -9999 -9999 -9999 -9999 -9999 -9999 -9999 -9999 -9999 -9999 -9999 -9999 -9999 -9999 -9999 -9999 -9999 -9999 -9999 -9999 -9999 -9999 -9999 -9999 -9999 -9999 -9999 -9999 -9999 -9999 -9999 -9999 -9999 -9999 -9999 -9999 -9999 -9999 -9999 -9999 -9999 -9999 -9999 -9999 -9999 -9999 -9999 -9999 -9999 -9999 -9999 -9999 -9999 -9999 -9999 -9999 -9999 -9999 -9999 -9999 -9999 -9999 -9999 -9999 -9999 -9999 -9999 -9999 -9999 -9999 -9999 -9999 -9999 -9999 -9999 -9999 -9999 -9999 -9999 -9999 -9999 -9999 -9999 -9999 -9999 -9999 -9999 -9999 -9999 -9999 -9999 -9999 -9999 -9999 -9999 -9999 -9999 -9999 -9999 -9999 -9999 -9999 -9999 -9999 -9999 -9999 -9999 -9999 -9999 -9999 -9999 -9999 -9999 -9999 -9999 -9999 -9999 -9999 -9999 -9999 -9999 -9999 -9999 -9999 -9999 -9999 -9999 -9999 -9999 -9999 -9999 -9999 -9999 -9999 -9999 -9999 -9999 -9999 -9999 -9999 -9999 -9999 -9999 -9999 -9999 -9999 -9999 -9999 -9999 -9999 -9999 -9999 -9999 -9999 -9999 -9999 -9999 -9999 -9999 -9999 -9999 -9999

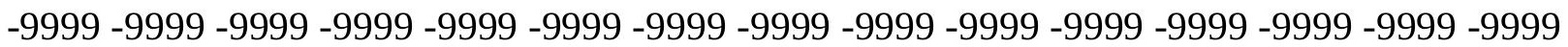
-9999 -9999 -9999 -9999 -9999 -9999 -9999 -9999 -9999 -9999 -9999 -9999 -9999 -9999 -9999 -9999 -9999 -9999 -9999 -9999 -9999 -9999 -9999 -9999 -9999 -9999 -9999 -9999 -9999 -9999 -

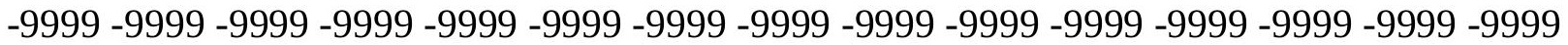
-9999 -9999 -9999 -9999 -9999 -9999 -9999 -9999 -9999 -9999 -9999 -9999 -9999 -9999 -9999 -9999 -9999 -9999 -9999 -9999 -9999 -9999 -9999 -9999 -9999 -9999 -9999 -9999 -9999 -9999 -9999 -9999 -9999 -9999 -9999 -9999 -9999 -9999 -9999 -9999 -9999 -9999 -9999 -9999 -9999 -9999 -9999 -9999 -9999 -9999 -9999 -9999 -9999 -9999 -9999 -9999 -9999 -9999 -9999 -9999 -9999 -9999 -9999 -9999 -9999 -9999 -9999 -9999 -9999 -9999 -9999 -9999 -9999 -9999 -9999

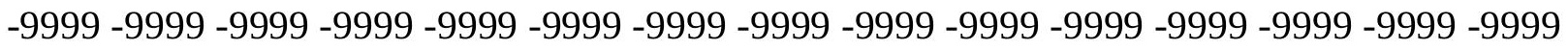
-9999 -9999 -9999 -9999 -9999 -9999 -9999 -9999 -9999 -9999 -9999 -9999 -9999 -9999 -9999 -9999 -9999 -9999 -9999 -9999 -9999 -9999 -9999 -9999 -9999 -9999 -9999 -9999 -9999 -9999 -9999 -9999 -9999 -9999 -9999 -9999 -9999 -9999 -9999 -9999 -9999 -9999 -9999 -9999 -9999 -999 -9999 -9999 -9999 -9999 -9999 -9999 -9999 -9999 -9999 -9999 -9999 -9999 -9999 -9999 -9999 -9999 -9999 -9999 -9999 -9999 -9999 -9999 -9999 -9999 -9999 -9999 -9999 -9999 -9999 -9999 -9999 -9999 -9999 -9999 -9999 -9999 -9999 -9999 -9999 -9999 -9999 -9999 -9999 -9999 -9999 -9999 -9999 -9999 -9999 -9999 -9999 -9999 -9999 -9999 -9999 -9999 -9999 -9999 -9999 -9999 -9999 -9999 -9999 -9999 -9999 -9999 -9999 -9999 -9999 -9999 -9999 -9999 -9999 -9999 
-9999 -9999 -9999 -9999 -9999 -9999 -9999 -9999 -9999 -9999 -9999 -9999 -9999 -9999 -9999 -9999 -9999 -9999 -9999 -9999 -9999 -9999 -9999 -9999 -9999 -9999 -9999 -9999 -9999 -9999 -

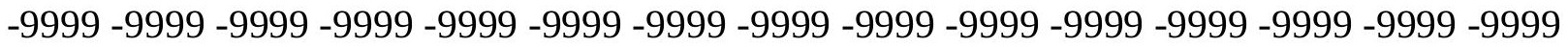
-9999 -9999 -9999 -9999 -9999 -9999 -9999 -9999 -9999 -9999 -9999 -9999 -9999 -9999 -9999 -9999 -9999 -9999 -9999 -9999 -9999 -9999 -9999 -9999-9999 -9999 -9999 -9999 -9999 -9999 -9999 -9999 -9999 -9999 -9999 -9999 -9999 -9999 -9999 -9999 -9999 -9999 -9999 -9999 -9999 -9999 -9999 -9999 -9999 -9999 -9999 -9999 -9999 -9999 -9999 -9999 -9999 -9999 -9999 -9999

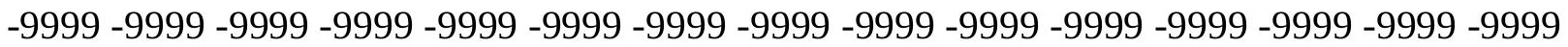

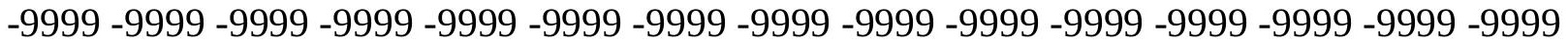
-9999 -9999 -9999 -9999 -9999 -9999 -9999 -9999 -9999 -9999 -9999 -9999 -9999 -9999 -9999 -9999 -9999 -9999 -9999 -9999 -9999 -9999 -9999 -9999 -9999 -9999 -9999 -9999 -9999 -9999 -9999 -9999 -9999 -9999 -9999 -9999 -9999 -9999 -9999 -9999 -9999 -9999 -9999 -9999 -9999 -9999 -9999 -9999 -9999 -9999 -9999 -9999 -9999 -9999 -9999 -9999 -9999 -9999 -9999 -9999 -

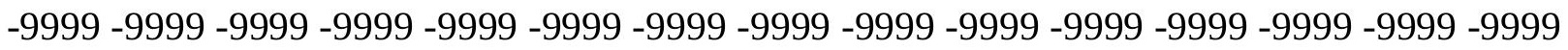
-9999 -9999 -9999 -9999 -9999 -9999 -9999 -9999 -9999 -9999 -9999 -9999 -9999 -9999 -9999 -

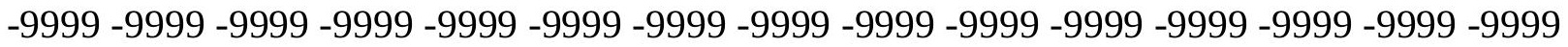
-9999 -9999 -9999 -9999 -9999 -9999 -9999 -9999 -9999 -9999 -9999 -9999 -9999 -9999 -9999 -9999 -9999 -9999 -9999 -9999 -9999 -9999 -9999 -9999 -9999 -9999 -9999 -9999 -9999 -9999 -9999 -9999 -9999 -9999 -9999 -9999 -9999 -9999 -9999 -9999 -9999 -9999 -9999 -9999 -9999 -

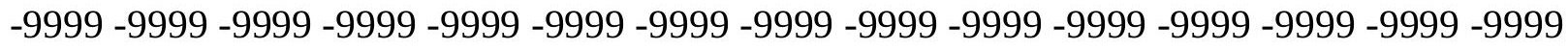

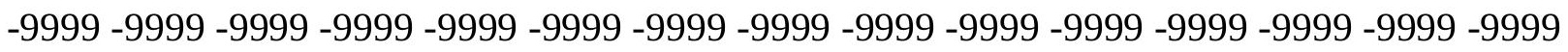

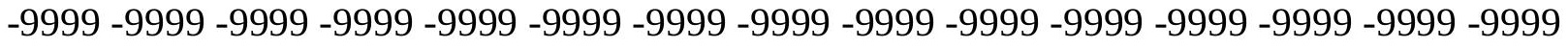
-9999 -9999 -9999 -9999 -9999 -9999 -9999 -9999 -9999 -9999 -9999 -9999 -9999 -9999 -9999 -9999 -9999 -9999 -9999 -9999 -9999 -9999 -9999 -9999 -9999 -9999 -9999 -9999 -9999 -9999 -

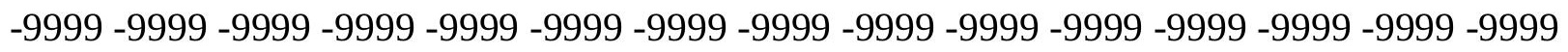
-9999 -9999 -9999 -9999 -9999 -9999 -9999 -9999 -9999 -9999 -9999 -9999 -9999 -9999 -9999 -9999 -9999 -9999 -9999 -9999 -9999 -9999 -9999 -9999 -9999 -9999 -9999 -9999 -9999 -

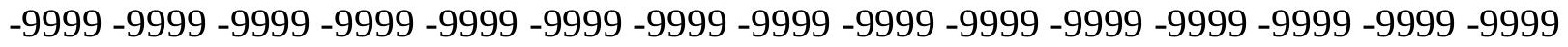
-9999 -9999 -9999 -9999 -9999 -9999 -9999 -9999 -9999 -9999 -9999 -9999 -9999 -9999 -9999 -9999 -9999 -9999 -9999 -9999 -9999 -9999 -9999 -9999 -9999 -9999 -9999 -9999 -9999 -999 -

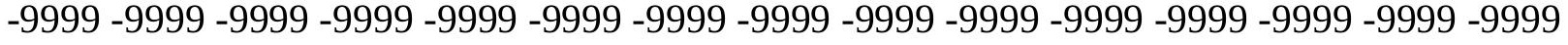
-9999 -9999 -9999 -9999 -9999 -9999 -9999 -9999 -9999 -9999 -9999 -9999 -9999 -9999 -9999 -

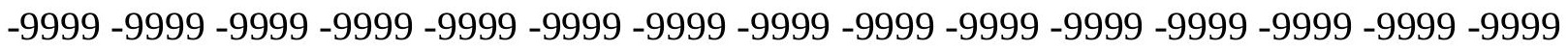

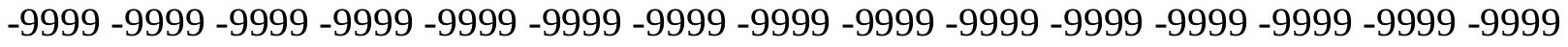

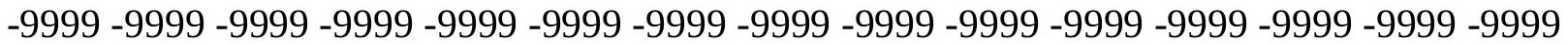
-9999 -9999 -9999 -9999 -9999 -9999 -9999 -9999 -9999 -9999 -9999 -9999 -9999 -9999 -9999

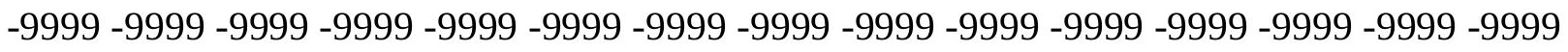

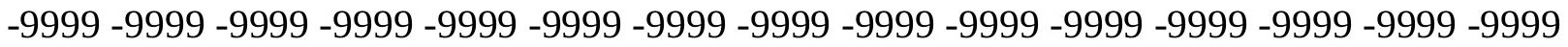
-9999 -9999 -9999 -9999 -9999 -9999 -9999 -9999 -9999 -9999 -9999 -9999 -9999 - 9999 - -999 -9999 -9999 -9999 -9999 -9999 -9999 -9999 -9999 -9999 -9999 -9999 -9999 -9999 -9999 -9999 -

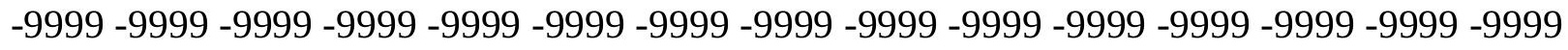

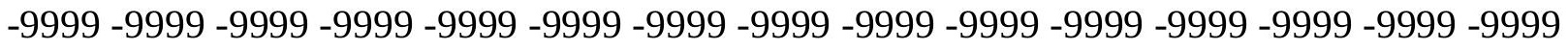
-9999 -9999 -9999 -9999 -9999 -9999 -9999 -9999 -9999 -9999 -9999 -9999 -9999 -9999 -9999 -9999 -9999 -9999 -9999 -9999 -9999 -9999 -9999 -9999-9999 -9999 -9999 -9999 -9999 -9999 -9999 -9999 -9999 -9999 -9999 -9999 -9999 -9999 -9999 -9999 -9999 -9999 -9999 -9999 -9999 -

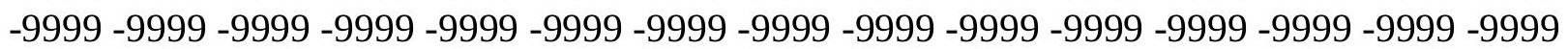


-9999 -9999 -9999 -9999 -9999 -9999 -9999 -9999 -9999 -9999 -9999 -9999 -9999 -9999 -9999 -9999 -9999 -9999 -9999 -9999 -9999 -9999 -9999 -9999 -9999 -9999 -9999 -9999 -9999 -9999 -9999 -9999 -9999 -9999 -9999 -9999 -9999 -9999 -9999 -9999 -9999 -9999 -9999 -9999 - 9999 -9999 -9999 -9999 -9999 -9999 -9999 -9999 -9999 -9999 -9999 -9999 -9999 -9999 -9999 -9999 -9999 -9999 -9999 -9999 -9999 -9999 -9999 -9999 -9999 -9999 -9999 -9999 -9999 -9999 - -9999 -9999 -9999 -9999 -9999 -9999 -9999 -9999 -9999 -9999 -9999 -9999 -9999 -9999 -9999 -9999 -9999 -9999 -9999 -9999 -9999 -9999 -9999 -9999 -9999 -9999 -9999 -9999 -9999 -9999

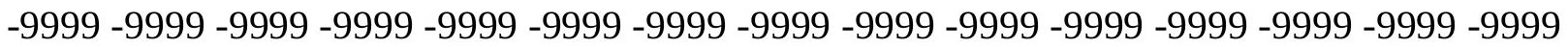

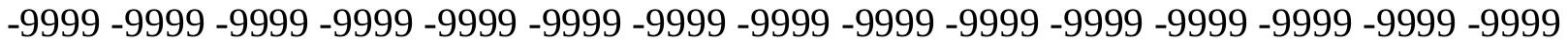
-9999 -9999 -9999 -9999 -9999 -9999 -9999 -9999 -9999 -9999 -9999 -9999 -9999 -9999 -9999

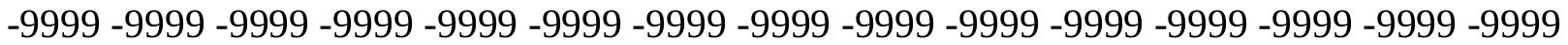
-9999 -9999 -9999 -9999 -9999 -9999 -9999 -9999 -9999 -9999 -9999 -9999 -9999 -9999 -9999 -9999 -9999 -9999 -9999 -9999 -9999 -9999 -9999 -9999 -9999 -9999 -9999 -9999 -9999 -9999 -9999 -9999 -9999 -9999 -9999 -9999 -9999 -9999 -9999 -9999 -9999 -9999 -9999 -9999 - -9999 -9999 -9999 -9999 -9999 -9999 -9999 -9999 -9999 -9999 -9999 -9999 -9999 -9999 -9999 -9999

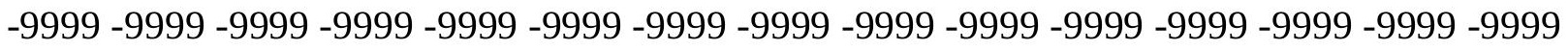
-9999 -9999 -9999 -9999 -9999 -9999 -9999 -9999 -9999 -9999 -9999 -9999 -9999 -9999 -9999 -9999 -9999 -9999 -9999 -9999 -9999 -9999 -9999 -9999 -9999 -9999 -9999 -9999 -9999 -9999 -9999 -9999 -9999 -9999 -9999 -9999 -9999 -9999 -9999 -9999 -9999 -9999 -9999 -9999 -9999 -

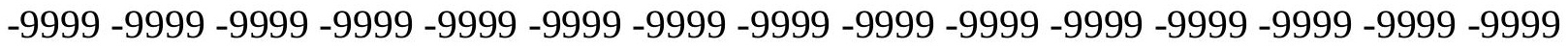
-9999 -9999 -9999 -9999 -9999 -9999 -9999 -9999 -9999 -9999 -9999 -9999 -9999 -9999 -9999 -999 -9999 -9999 -9999 -9999 -9999 -9999 -9999 -9999 -9999 -9999 -9999 -9999 -9999 -9999 -9999 -9999 -9999 -9999 -9999 -9999 -9999 -9999 -9999 -9999 -9999 -9999 -9999 -9999 -9999 -9999 -9999 -9999 -9999 -9999 -9999 -9999 -9999 -9999 -9999 -9999 -9999 -9999 -9999 -9999 -9999 -9999 -9999 -9999 -9999 -9999 -9999 -9999 -9999 -9999 -9999 -9999 -9999 -9999 -9999 -9999 -9999 -9999 -9999 -9999 -9999 -9999 -9999 -9999 -9999 -9999 -9999 -9999 -9999 -9999 -9999 -9999 -9999 -9999 -9999 -9999 -9999 -9999 -9999 -9999 -9999 -9999 -9999 -9999 -9999 -9999 -9999 -9999 -9999 -9999 -9999 -9999 -9999 -9999 -9999 -9999 -9999 -9999 -9999 -9999 -9999 -9999 -9999 -9999 -9999 -9999 -9999 -9999 -9999 -9999 -9999 -9999 -9999 -9999 -9999 -9999 -9999 -9999 -9999 -9999 -9999 -9999 -9999 -9999 -9999 -9999 -9999 -9999 -9999 -9999 -999 -9999 -9999 -9999 -9999 -9999 -9999 -9999 -9999 -9999 -9999 -9999 -9999 -9999 -9999 -9999 -9999 -9999 -9999 -9999 -9999 -9999 -9999 -9999 -9999 -9999 -9999 -9999 -9999 -9999 -

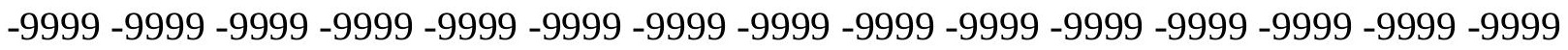

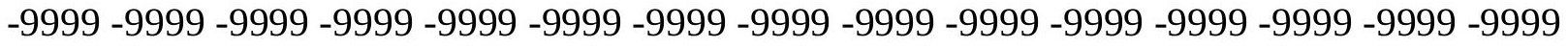

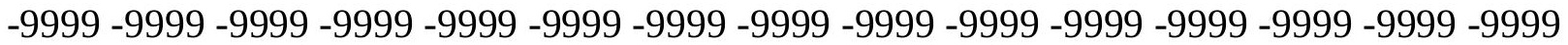
-9999 -9999 -9999 -9999 -9999 -9999 -9999 -9999 -9999 -9999 -9999 -9999 -9999 -9999 -9999 -

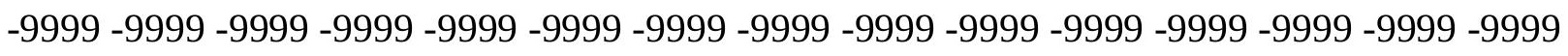

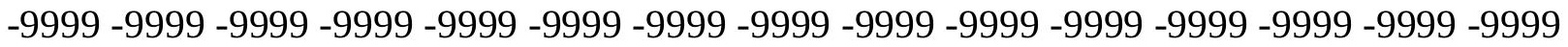

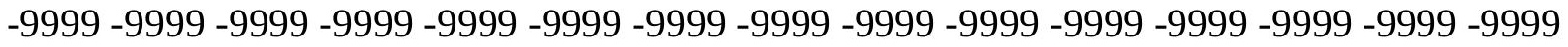
-9999 -9999 -9999 -9999 -9999 -9999 -9999 -9999 -9999 -9999 -9999 -9999 -9999 -9999 -9999 -

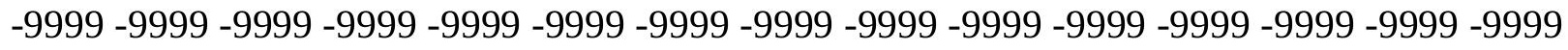

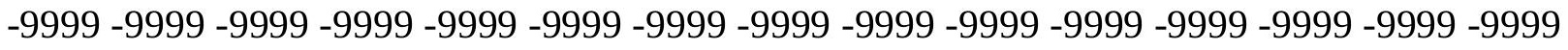
-9999 -9999 -9999 -9999 -9999 -9999 -9999 -9999 -9999 -9999 -9999 -9999 -9999 -9999 -9999 -9999 -9999 -9999 -9999 -9999 -9999 -9999 -9999 -9999-9999 -9999 -9999 -9999 -9999 -9999 -9999 -9999 -9999 -9999 -9999 -9999 -9999 -9999 -9999 -9999 -9999 -9999 -9999 -9999 -9999 -

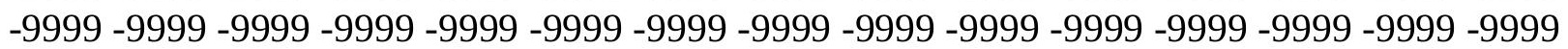


-9999 -9999 -9999 -9999 -9999 -9999 -9999 -9999 -9999 -9999 -9999 -9999 -9999 -9999 -9999 -9999 -9999 -9999 -9999 -9999 -9999 -9999 -9999 -9999 -9999 -9999 -9999 -9999 -9999 -9999 -

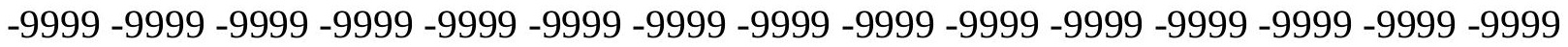
-9999 -9999 -9999 -9999 -9999 -9999 -9999 -9999 -9999 -9999 -9999 -9999 -9999 -9999 -9999 -9999 -9999 -9999 -9999 -9999 -9999 -9999 -9999 -9999-9999 -9999 -9999 -9999 -9999 -9999 -9999 -9999 -9999 -9999 -9999 -9999 -9999 -9999 -9999 -9999 -9999 -9999 -9999 -9999 -9999 -9999 -9999 -9999 -9999 -9999 -9999 -9999 -9999 -9999 -9999 -9999 -9999 -9999 -9999 -9999

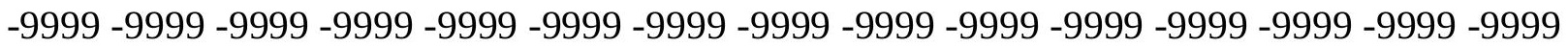

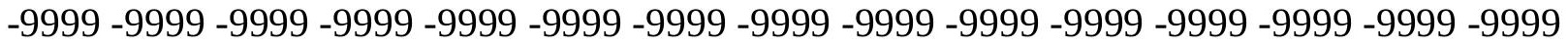
-9999 -9999 -9999 -9999 -9999 -9999 -9999 -9999 -9999 -9999 -9999 -9999 -9999 -9999 -9999 -9999 -9999 -9999 -9999 -9999 -9999 -9999 -9999 -9999 -9999 -9999 -9999 -9999 -9999 -9999 -9999 -9999 -9999 -9999 -9999 -9999 -9999 -9999 -9999 -9999 -9999 -9999 -9999 -9999 -9999 -9999 -9999 -9999 -9999 -9999 -9999 -9999 -9999 -9999 -9999 -9999 -9999 -9999 -9999 -9999 -9999 -9999 -9999 -9999 -9999 -9999 -9999 -9999 -9999 -9999 -9999 -9999 -9999 - 9999 -9999 -9999 -9999 -9999 -9999 -9999 -9999 -9999 -9999 -9999 -9999 -9999 -9999 -9999 -9999

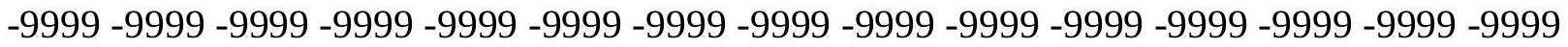
-9999 -9999 -9999 -9999 -9999 -9999 -9999 -9999 -9999 -9999 -9999 -9999 -9999 -9999 -9999 -9999 -9999 -9999 -9999 -9999 -9999 -9999 -9999 -9999 -9999 -9999 -9999 -9999 -9999 -9999 -9999 -9999 -9999 -9999 -9999 -9999 -9999 -9999 -9999 -9999 -9999 -9999 -9999 -9999 -9999 -

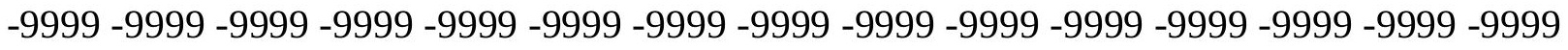

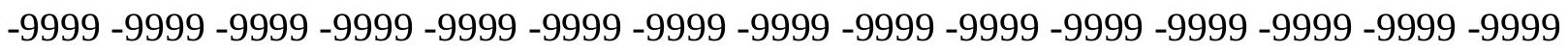
-9999 -9999 -9999 -9999 -9999 -9999 -9999 -9999 -9999 -9999 -9999 -9999 -9999 -9999 -9999 -9999 -9999 -9999 -9999 -9999 -9999 -9999 -9999 -9999 -9999 -9999 -9999 -9999 -9999 -9999 -9999 -9999 -9999 -9999 -9999 -9999 -9999 -9999 -9999 -9999 -9999 -9999 -9999 -9999 -9999 -

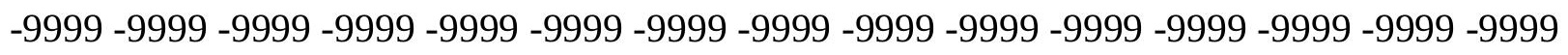
-9999 -9999 -9999 -9999 -9999 -9999 -9999 -9999 -9999 -9999 -9999 -9999 -9999 -9999 -9999 -9999 -9999 -9999 -9999 -9999 -9999 -9999 -9999 -9999 -9999 -9999 -9999 -9999 -9999 -9999 -

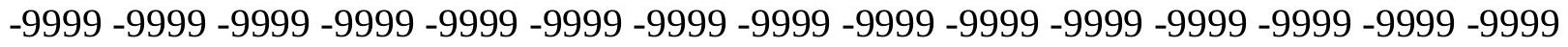
-9999 -9999 -9999 -9999 -9999 -9999 -9999 -9999 -9999 -9999 -9999 -9999 -9999 -9999 -9999 -9999 -9999 -9999 -9999 -9999 -9999 -9999 -9999 -9999 -9999 -9999 -9999 -9999 -9999 -999 -9999 -9999 -9999 -9999 -9999 -9999 -9999 -9999 -9999 -9999 -9999 -9999 -9999 -9999 -9999 -9999 -9999 -9999 -9999 -9999 -9999 -9999 -9999 -9999 -9999 -9999 -9999 -9999 -9999 -9999 -

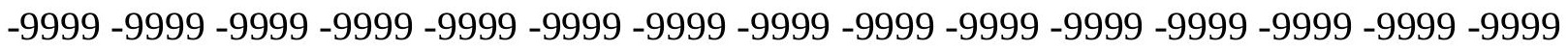

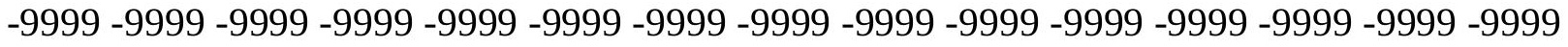

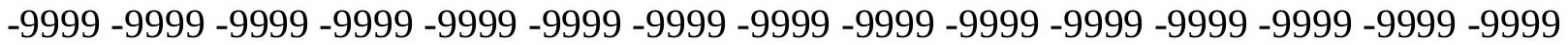

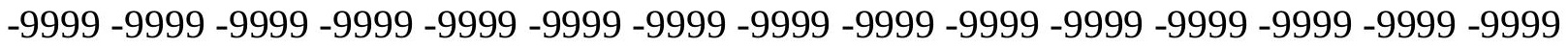

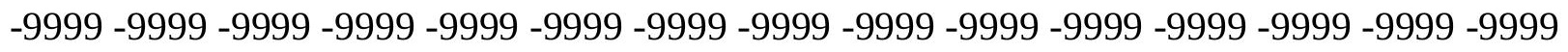

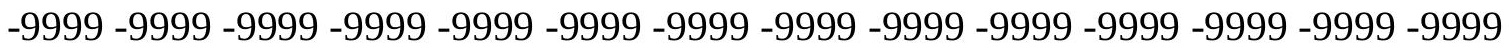
-9999 -9999 -9999 -9999 -9999 -9999 -9999 -9999 -9999 -9999 -9999 -9999 -9999 -9999 -9999 -9999 -9999 -9999 -9999 -9999 -9999 -9999 -9999 -9999 -9999 -9999 -9999 -9999 -9999 -9999 -

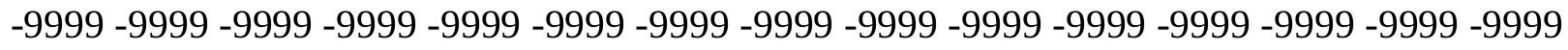

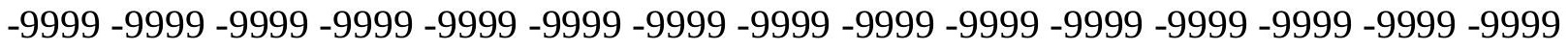
-9999 -9999 -9999 -9999 -9999 -9999 -9999 -9999 -9999 -9999 -9999 -9999 -9999 -9999 -9999 -9999 -9999 -9999 -9999 -9999 -9999 -9999 -9999 -9999-9999 -9999 -9999 -9999 -9999 -9999 -9999 -9999 -9999 -9999 -9999 -9999 -9999 -9999 -9999 -9999 -9999 -9999 -9999 -9999 -9999 -

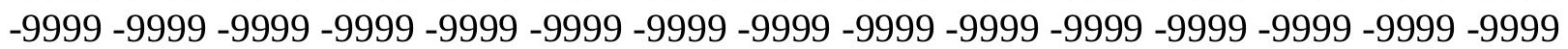


-9999 -9999 -9999 -9999 -9999 -9999 -9999 -9999 -9999 -9999 -9999 -9999 -9999 -9999 -9999 -9999 -9999 -9999 -9999 -9999 -9999 -9999 -9999 -9999 -9999 -9999 -9999 -9999 -9999 -9999 -9999 -9999 -9999 -9999 -9999 -9999 -9999 -9999 -9999 -9999 -9999 -9999 -9999 -9999 - 9999 -9999 -9999 -9999 -9999 -9999 -9999 -9999 -9999 -9999 -9999 -9999 -9999 -9999 -9999 -9999 -9999 -9999 -9999 -9999 -9999 -9999 -9999 -9999 -9999 -9999 -9999 -9999 -9999 -9999 -9999 -9999 -9999 -9999 -9999 -9999 -9999 -9999 -9999 -9999 -9999 -9999 -9999 -9999 -9999 -9999 -9999 -9999 -9999 -9999 -9999 -9999 -9999 -9999 -9999 -9999 -9999 -9999 -9999 -9999 -9999

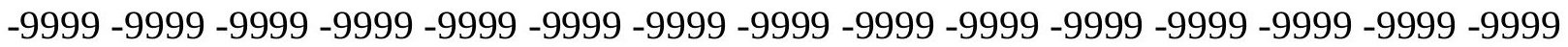
-9999 -9999 -9999 -9999 -9999 -9999 -9999 -9999 -9999 -9999 -9999 -9999 -9999 -9999 -9999 -9999 -9999 -9999 -9999 -9999 -9999 -9999 -9999 -9999 -9999 -9999 -9999 -9999 -9999 -9999

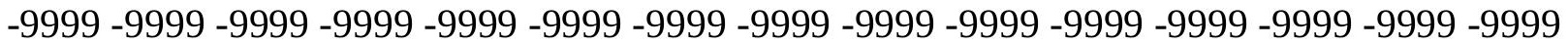
-9999 -9999 -9999 -9999 -9999 -9999 -9999 -9999 -9999 -9999 -9999 -9999 -9999 -9999 -9999 -9999 -9999 -9999 -9999 -9999 -9999 -9999 -9999 -9999 -9999 -9999 -9999 -9999 -9999 -9999 -

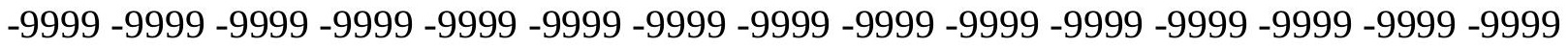
-9999 -9999 -9999 -9999 -9999 -9999 -9999 -9999 -9999 -9999 -9999 -9999 -9999 -9999 -9999

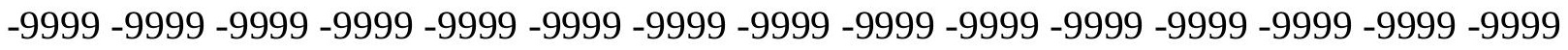
-9999 -9999 -9999 -9999 -9999 -9999 -9999 -9999 -9999 -9999 -9999 -9999 -9999 -9999 -9999 -9999 -9999 -9999 -9999 -9999 -9999 -9999 -9999 -9999 -9999 -9999 -9999 -9999 -9999 - -999 -9999 -9999 -9999 -9999 -9999 -9999 -9999 -9999 -9999 -9999 -9999 -9999 -9999 -9999 -9999 -9999 -9999 -9999 -9999 -9999 -9999 -9999 -9999 -9999 -9999 -9999 -9999 -9999 -9999 -9999 -9999 -9999 -9999 -9999 -9999 -9999 -9999 -9999 -9999 -9999 -9999 -9999 -9999 -9999 -9999 -999 -9999 -9999 -9999 -9999 -9999 -9999 -9999 -9999 -9999 -9999 -9999 -9999 -9999 -9999 -9999 -9999 -9999 -9999 -9999 -9999 -9999 -9999 -9999 -9999 -9999 -9999 -9999 -9999 -9999 -9999 -9999 -9999 -9999 -9999 -9999 -9999 -9999 -9999 -9999 -9999 -9999 -9999 -9999 -9999 -9999 -9999 -9999 -9999 -9999 -9999 -9999 -9999 -9999 -9999 -9999 -9999 -9999 -9999 -9999 -9999 -9999 -9999 -9999 -9999 -9999 -9999 -9999 -9999 -9999 -9999 -9999 -9999 -9999 -9999 -9999 -9999 -9999 -9999 -9999 -9999 -9999 -9999 -9999 -9999 -9999 -9999 -9999 -9999 -9999 -9999 -9999 -9999 -9999 -9999 -9999 -9999 -9999 -9999 -9999 -9999 -9999 -9999 -9999 -9999 -9999 -9999 -9999 -9999 -9999 -9999 -9999 -9999 -9999 -9999 -9999 -9999 -9999 -9999 -9999 -9999 -9999 -9999 -9999 -9999 -9999 -9999 -9999 -9999 -9999 -9999 -9999 -9999 -9999 -9999 -999 -9999 -9999 -9999 -9999 -9999 -9999 -9999 -9999 -9999 -9999 -9999 -9999 -9999 -9999 -9999 -9999 -9999 -9999 -9999 -9999 -9999 -9999 -9999 -9999 -9999 -9999 -9999 -9999 -9999 -9999 -

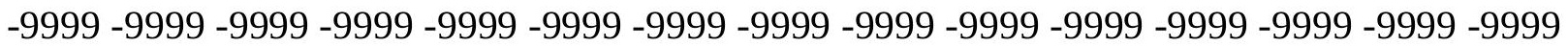

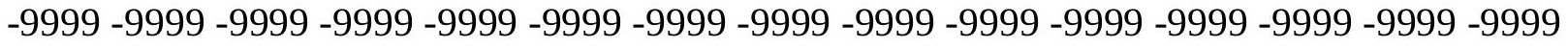

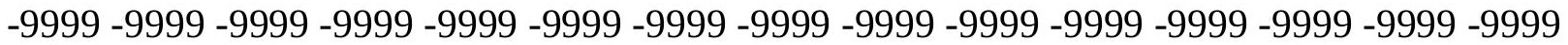
-9999 -9999 -9999 -9999 -9999 -9999 -9999 -9999 -9999 -9999 -9999 -9999 -9999 -9999 -9999

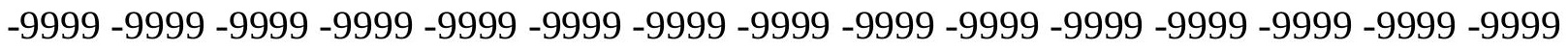

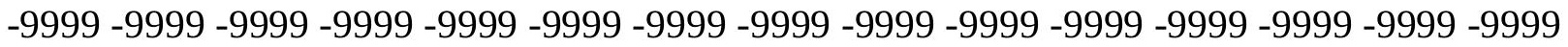

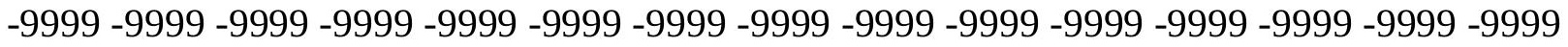
-9999 -9999 -9999 -9999 -9999 -9999 -9999 -9999 -9999 -9999 -9999 -9999 -9999 -9999 -9999 -

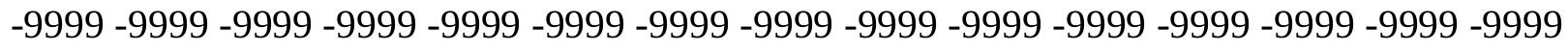

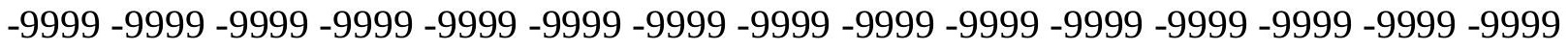
-9999 -9999 -9999 -9999 -9999 -9999 -9999 -9999 -9999 -9999 -9999 -9999 -9999 -9999 -9999 -9999 -9999 -9999 -9999 -9999 -9999 -9999 -9999 -9999 -9999 -9999 -9999 -9999 - -9999 -9999 -9999 -9999 -9999 -9999 -9999 -9999 -9999 -9999 -9999 -9999 -9999 -9999 -9999 -9999 -

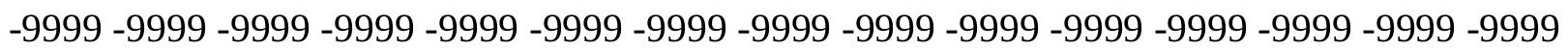


-9999 -9999 -9999 -9999 -9999 -9999 -9999 -9999 -9999 -9999 -9999 -9999 -9999 -9999 -9999 -9999 -9999 -9999 -9999 -9999 -9999 -9999 -9999 -9999 -9999 -9999 -9999 -9999 -9999 -9999 -9999 -9999 -9999 -9999 -9999 -9999 -9999 -9999 -9999 -9999 -9999 -9999 -9999 -9999 - 9999 -9999 -9999 -9999 -9999 -9999 -9999 -9999 -9999 -9999 -9999 -9999 -9999 -9999 -9999 -9999 -9999 -9999 -9999 -9999 -9999 -9999 -9999 -9999 -9999-9999 -9999 -9999 -9999 -9999 -9999 -9999 -9999 -9999 -9999 -9999 -9999 -9999 -9999 -9999 -9999 -9999 -9999 -9999 -9999 -9999 -9999 -9999 -9999 -9999 -9999 -9999 -9999 -9999 -9999 -9999 -9999 -9999 -9999 -9999 -9999

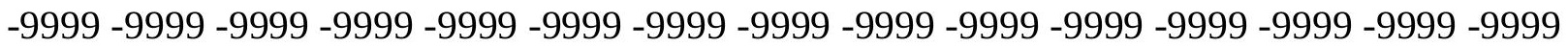

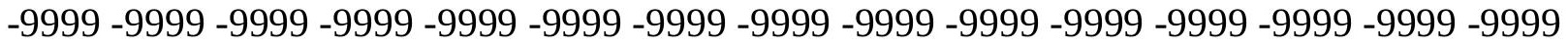
-9999 -9999 -9999 -9999 -9999 -9999 -9999 -9999 -9999 -9999 -9999 -9999 -9999 -9999 -9999

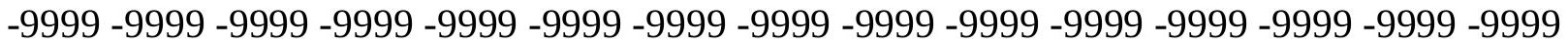
-9999 -9999 -9999 -9999 -9999 -9999 -9999 -9999 -9999 -9999 -9999 -9999 -9999 -9999 -9999 -9999 -9999 -9999 -9999 -9999 -9999 -9999 -9999 -9999 -9999 -9999 -9999 -9999 -9999 -9999 -

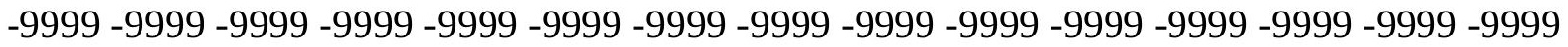
-9999 -9999 -9999 -9999 -9999 -9999 -9999 -9999 -9999 -9999 -9999 -9999 -9999 -9999 -9999

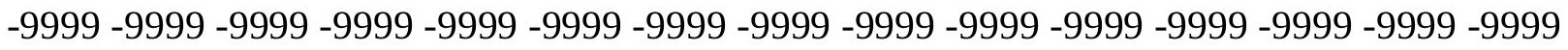
-9999 -9999 -9999 -9999 -9999 -9999 -9999 -9999 -9999 -9999 -9999 -9999 -9999 -9999 -9999 -9999 -9999 -9999 -9999 -9999 -9999 -9999 -9999 -9999 -9999 -9999 -9999 -9999 -9999 -9999 -9999 -9999 -9999 -9999 -9999 -9999 -9999 -9999 -9999 -9999 -9999 -9999 -9999 -9999 -9999 -9999 -9999 -9999 -9999 -9999 -9999 -9999 -9999 -9999 -9999 -9999 -9999 -9999 -9999 -9999 -9999 -9999 -9999 -9999 -9999 -9999 -9999 -9999 -9999 -9999 -9999 -9999 -9999 -9999 -9999 -999 -9999 -9999 -9999 -9999 -9999 -9999 -9999 -9999 -9999 -9999 -9999 -9999 -9999 -9999 -9999 -9999 -9999 -9999 -9999 -9999 -9999 -9999 -9999 -9999 -9999 -9999 -9999 -9999 -9999 -9999 -9999 -9999 -9999 -9999 -9999 -9999 -9999 -9999 -9999 -9999 -9999 -9999 -9999 -9999 -9999 -9999 -9999 -9999 -9999 -9999 -9999 -9999 -9999 -9999 -9999 -9999 -9999 -9999 -9999 -9999 -9999 -9999 -9999 -9999 -9999 -9999 -9999 -9999 -9999 -9999 -9999 -9999 -9999 -9999 -9999 -9999 -9999 -9999 -9999 -9999 -9999 -9999 -9999 -9999 -9999 -9999 -9999 -9999 -9999 -9999 -9999 -9999 -9999 -9999 -9999 -9999 -9999 -9999 -9999 -9999 -9999 -9999 -9999 -9999 -9999 -9999 -9999 -9999 -9999 -9999 -9999 -9999 -9999 -9999 -9999 -9999 -9999 -9999 -9999 -9999 -9999 -9999 -9999 -9999 -9999 -9999 -9999 -9999 -9999 -9999 -9999 -9999 -9999 -999 -9999 -9999 -9999 -9999 -9999 -9999 -9999 -9999 -9999 -9999 -9999 -9999 -9999 -9999 -9999 -9999 -9999 -9999 -9999 -9999 -9999 -9999 -9999 -9999 -9999 -9999 -9999 -9999 -9999 -9999 -

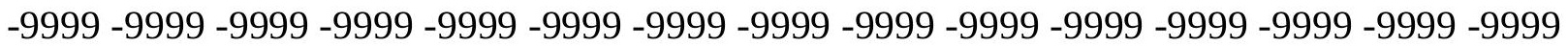

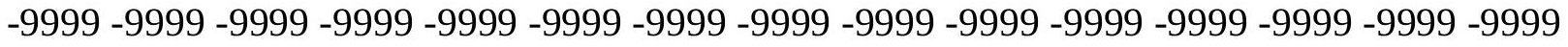

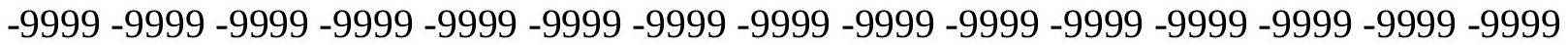
-9999 -9999 -9999 -9999 -9999 -9999 -9999 -9999 -9999 -9999 -9999 -9999 -9999 -9999 -9999

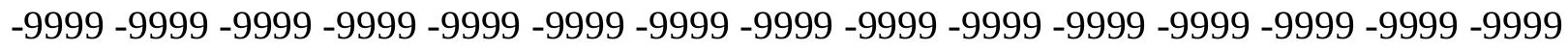

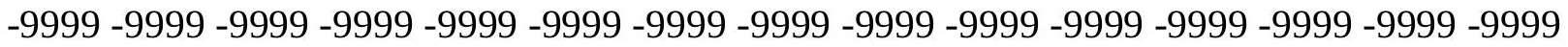
-9999 -9999 -9999 -9999 -9999 -9999 -9999 -9999 -9999 -9999 -9999 -9999 -9999 -9999 -9999 -9999 -9999 -9999 -9999 -9999 -9999 -9999 -9999 -9999 -9999 -9999 -9999 -9999 -9999 -9999 -

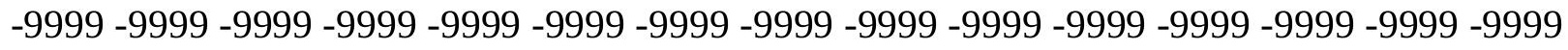

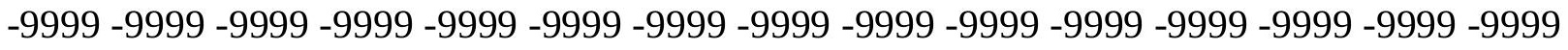
-9999 -9999 -9999 -9999 -9999 -9999 -9999 -9999 -9999 -9999 -9999 -9999 -9999 -9999 -9999 -9999 -9999 -9999 -9999 -9999 -9999 -9999 -9999 -9999-9999 -9999 -9999 -9999 -9999 -9999 -9999 -9999 -9999 -9999 -9999 -9999 -9999 -9999 -9999 -9999 -9999 -9999 -9999 -9999 -9999 -

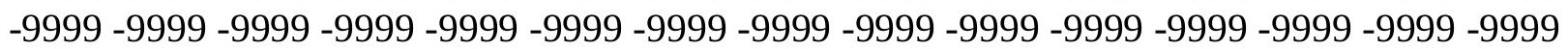


-9999 -9999 -9999 -9999 -9999 -9999 -9999 -9999 -9999 -9999 -9999 -9999 -9999 -9999 -9999 -9999 -9999 -9999 -9999 -9999 -9999 -9999 -9999 -9999 -9999 -9999 -9999 -9999 -9999 -9999 -9999 -9999 -9999 -9999 -9999 -9999 -9999 -9999 -9999 -9999 -9999 -9999 -9999 -9999 - 9999 -9999 -9999 -9999 -9999 -9999 -9999 -9999 -9999 -9999 -9999 -9999 -9999 -9999 -9999

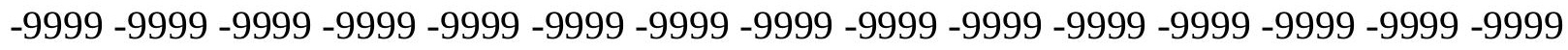
-9999 -9999 -9999 -9999 -9999 -9999 -9999 -9999 -9999 -9999 -9999 -9999 -9999 -9999 -9999 -9999 -9999 -9999 -9999 -9999 -9999 -9999 -9999 -9999 -9999 -9999 -9999 -9999 -9999 -9999

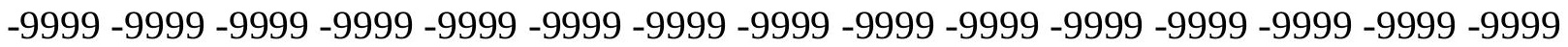

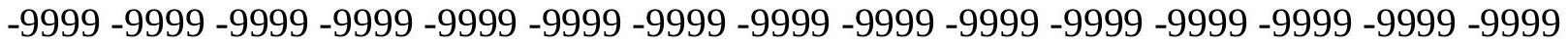
-9999 -9999 -9999 -9999 -9999 -9999 -9999 -9999 -9999 -9999 -9999 -9999 -9999 -9999 -9999 -9999 -9999 -9999 -9999 -9999 -9999 -9999 -9999 -9999 -9999 -9999 -9999 -9999 -9999 -9999 -9999 -9999 -9999 -9999 -9999 -9999 -9999 -9999 -9999 -9999 -9999 -9999 -9999 -9999 -9999 -9999 -9999 -9999 -9999 -9999 -9999 -9999 -9999 -9999 -9999 -9999 -9999 -9999 -9999 -9999 -

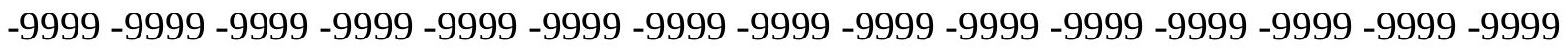
-9999 -9999 -9999 -9999 -9999 -9999 -9999 -9999 -9999 -9999 -9999 -9999 -9999 -9999 -9999 -

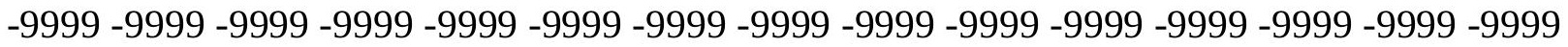
-9999 -9999 -9999 -9999 -9999 -9999 -9999 -9999 -9999 -9999 -9999 -9999 -9999 -9999 -9999 -9999 -9999 -9999 -9999 -9999 -9999 -9999 -9999 -9999 -9999 -9999 -9999 -9999 -9999 -9999 -9999 -9999 -9999 -9999 -9999 -9999 -9999 -9999 -9999 -9999 -9999 -9999 -9999 -9999 -9999 -

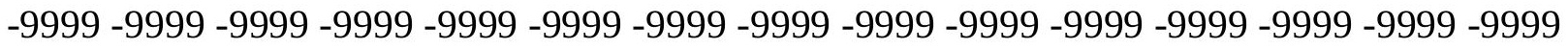
-9999 -9999 -9999 -9999 -9999 -9999 -9999 -9999 -9999 -9999 -9999 -9999 -9999 -9999 -9999

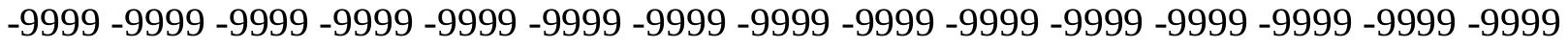
-9999 -9999 -9999 -9999 -9999 -9999 -9999 -9999 -9999 -9999 -9999 -9999 -9999 -9999 -9999 -9999 -9999 -9999 -9999 -9999 -9999 -9999 -9999 -9999 -9999 -9999 -9999 -9999 -9999 -9999 -9999 -9999 -9999 -9999 -9999 -9999 -9999 -9999 -9999 -9999 -9999 -9999 -9999 -9999 -9999 -9999 -9999 -9999 -9999 -9999 -9999 -9999 -9999 -9999 -9999 -9999 -9999 -9999 -9999 -9999 -9999 -9999 -9999 -9999 -9999 -9999 -9999 -9999 -9999 -9999 -9999 -9999 -9999 -9999 -9999 -9999 -9999 -9999 -9999 -9999 -9999 -9999 -9999 -9999 -9999 -9999 -9999 -9999 -9999 -9999 -9999 -9999 -9999 -9999 -9999 -9999 -9999 -9999 -9999 -9999 -9999 -9999 -9999 -9999 -9999 -9999 -9999 -9999 -9999 -9999 -9999 -9999 -9999 -9999 -9999 -9999 -9999 -9999 -9999 -9999 -9999 -9999 -9999 -9999 -9999 -9999 -9999 -9999 -9999 -9999 -9999 -9999 -9999 -9999 -9999 -9999 -9999 -9999 -9999 -9999 -9999 -9999 -9999 -9999 -9999 -9999 -9999 -9999 -9999 -

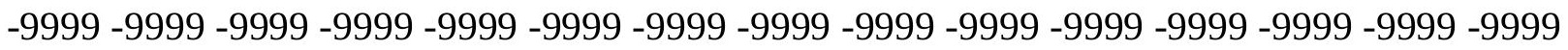

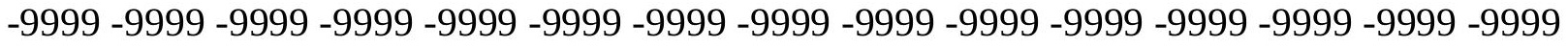
-9999 -9999 -9999 -9999 -9999 -9999 -9999 -9999 -9999 -9999 -9999 -9999 -9999 -9999 -9999 -

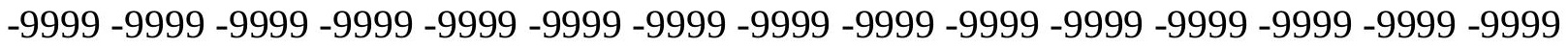

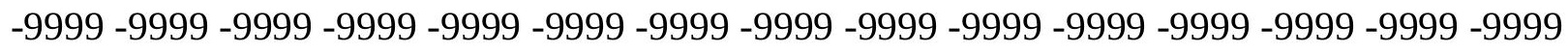

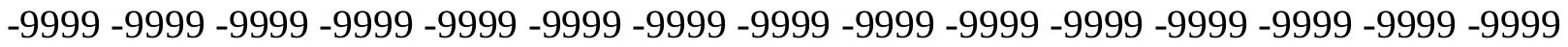

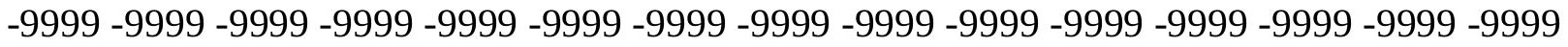
-9999 -9999 -9999 -9999 -9999 -9999 -9999 -9999 -9999 -9999 -9999 -9999 -9999 -9999 -9999 -

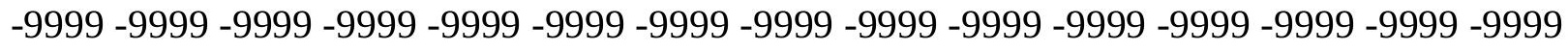

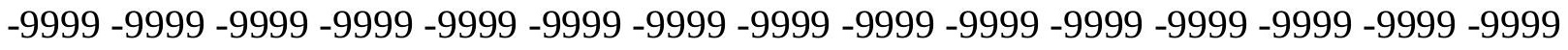
-9999 -9999 -9999 -9999 -9999 -9999 -9999 -9999 -9999 -9999 -9999 -9999 -9999 -9999 -9999 -9999 -9999 -9999 -9999 -9999 -9999 -9999 -9999 -9999-9999 -9999 -9999 -9999 -9999 -9999 -9999 -9999 -9999 -9999 -9999 -9999 -9999 -9999 -9999 -9999 -9999 -9999 -9999 -9999 -9999 -

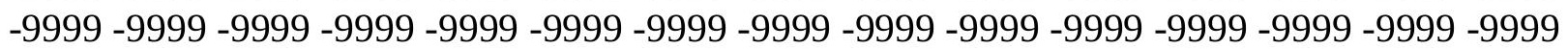


-9999 -9999 -9999 -9999 -9999 -9999 -9999 -9999 -9999 -9999 -9999 -9999 -9999 -9999 -9999 -9999 -9999 -9999 -9999 -9999 -9999 -9999 -9999 -9999 -9999 -9999 -9999 -9999 -9999 -9999 -9999 -9999 -9999 -9999 -9999 -9999 -9999 -9999 -9999 -9999 -9999 -9999 -9999 -9999 - 9999 -9999 -9999 -9999 -9999 -9999 -9999 -9999 -9999 -9999 -9999 -9999 -9999 -9999 -9999 -9999 -9999 -9999 -9999 -9999 -9999 -9999 -9999 -9999 -9999 -9999 -9999 -9999 -9999 -9999 -9999 -9999 -9999 -9999 -9999 -9999 -9999 -9999 -9999 -9999 -9999 -9999 -9999 -9999 -9999 -9999 -9999 -9999 -9999 -9999 -9999 -9999 -9999 -9999 -9999 -9999 -9999 -9999 -9999 -9999 -9999

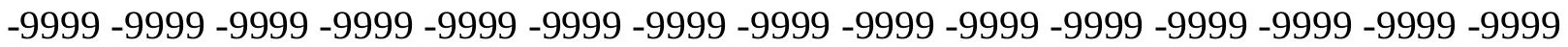

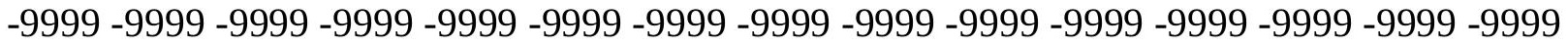
-9999 -9999 -9999 -9999 -9999 -9999 -9999 -9999 -9999 -9999 -9999 -9999 -9999 -9999 -9999 -9999 -9999 -9999 -9999 -9999 -9999 -9999 -9999 -9999 -9999 -9999 -9999 -9999 -9999 -9999 -9999 -9999 -9999 -9999 -9999 -9999 -9999 -9999 -9999 -9999 -9999 -9999 -9999 -9999 -9999 -9999 -9999 -9999 -9999 -9999 -9999 -9999 -9999 -9999 -9999 -9999 -9999 -9999 -9999 -9999 -9999 -9999 -9999 -9999 -9999 -9999 -9999 -9999 -9999 -9999 -9999 -9999 -9999 -9999 -9999 -9999 -9999 -9999 -9999 -9999 -9999 -9999 -9999 -9999 -9999 -9999 -9999 -9999 -9999 -

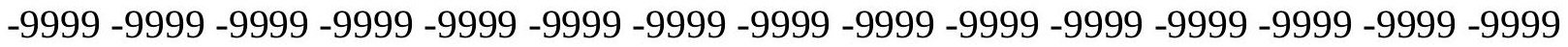
-9999 -9999 -9999 -9999 -9999 -9999 -9999 -9999 -9999 -9999 -9999 -9999 -9999 -9999 -9999 -9999 -9999 -9999 -9999 -9999 -9999 -9999 -9999 -9999 -9999 -9999 -9999 -9999 -9999 -9999 -9999 -9999 -9999 -9999 -9999 -9999 -9999 -9999 -9999 -9999 -9999 -9999 -9999 -9999 -9999 -9999 -9999 -9999 -9999 -9999 -9999 -9999 -9999 -9999 -9999 -9999 -9999 -9999 -9999 -9999 -9999 -9999 -9999 -9999 -9999 -9999 -9999 -9999 -9999 -9999 -9999 -9999 -9999 -9999 -9999 -999 -9999 -9999 -9999 -9999 -9999 -9999 -9999 -9999 -9999 -9999 -9999 -9999 -9999 -9999 -9999 -9999 -9999 -9999 -9999 -9999 -9999 -9999 -9999 -9999 -9999 -9999 -9999 -9999 -9999 -9999 -9999 -9999 -9999 -9999 -9999 -9999 -9999 -9999 -9999 -9999 -9999 -9999 -9999 -9999 -9999 -9999 -9999 -9999 -9999 -9999 -9999 -9999 -9999 -9999 -9999 -9999 -9999 -9999 -9999 -9999 -9999 -9999 -9999 -9999 -9999 -9999 -9999 -9999 -9999 -9999 -9999 -9999 -9999 -9999 -9999 -9999 -9999 -9999 -9999 -9999 -9999 -9999 -9999 -9999 -9999 -9999 -9999 -9999 -9999 -9999 -9999 -9999 -9999 -9999 -9999 -9999 -9999 -9999 -9999 -9999 -9999 -9999 -9999 -9999 -9999 -9999 -9999 -9999 -9999 -9999 -9999 -9999 -9999 -9999 -9999 -9999 -9999 -9999 -9999 -9999 -9999 -9999 -9999 -9999 -9999 -9999 -9999 -9999 -9999 -9999 -9999 -9999 -9999 -9999 -999 -9999 -9999 -9999 -9999 -9999 -9999 -9999 -9999 -9999 -9999 -9999 -9999 -9999 -9999 -9999 -9999 -9999 -9999 -9999 -9999 -9999 -9999 -9999 -9999 -9999 -9999 -9999 -9999 -9999 -9999 -

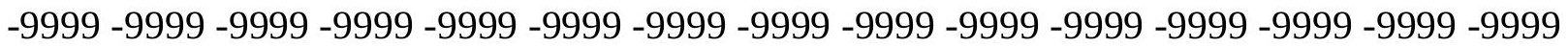

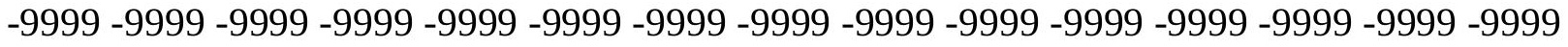

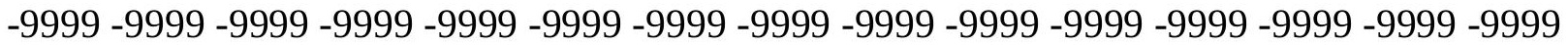
-9999 -9999 -9999 -9999 -9999 -9999 -9999 -9999 -9999 -9999 -9999 -9999 -9999 -9999 -9999 -9999 -9999 -9999 -9999 -9999 -9999 -9999 -9999 -9999 -9999 -9999 -9999 -9999 -9999 -

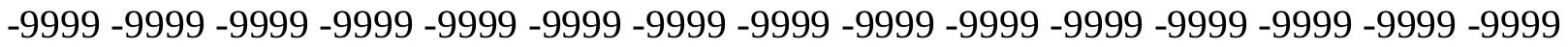
-9999 -9999 -9999 -9999 -9999 -9999 -9999 -9999 -9999 -9999 -9999 -9999 -9999 -9999 -9999 -9999 -9999 -9999 -9999 -9999 -9999 -9999 -9999 -9999 -9999 -9999 -9999 -9999 -9999 -9999 -

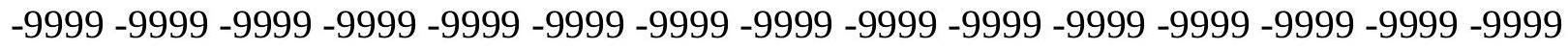

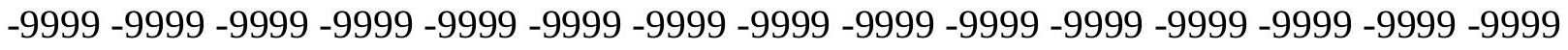
-9999 -9999 -9999 -9999 -9999 -9999 -9999 -9999 -9999 -9999 -9999 -9999 -9999 -9999 -9999 -9999 -9999 -9999 -9999 -9999 -9999 -9999 -9999 -9999-9999 -9999 -9999 -9999 -9999 -9999 -9999 -9999 -9999 -9999 -9999 -9999 -9999 -9999 -9999 -9999 -9999 -9999 -9999 -9999 -9999 -

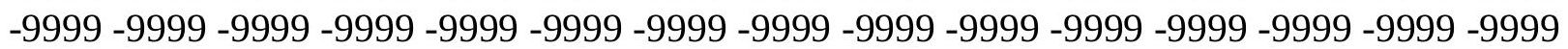


-9999 -9999 -9999 -9999 -9999 -9999 -9999 -9999 -9999 -9999 -9999 -9999 -9999 -9999 -9999 -9999 -9999 -9999 -9999 -9999 -9999 -9999 -9999 -9999 -9999 -9999 -9999 -9999 -9999 -9999 -

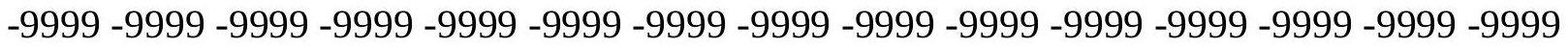
-9999 -9999 -9999 -9999 -9999 -9999 -9999 -9999 -9999 -9999 -9999 -9999 -9999 -9999 -9999 -9999 -9999 -9999 -9999 -9999 -9999 -9999 -9999 -9999-9999 -9999 -9999 -9999 -9999 -9999 -9999 -9999 -9999 -9999 -9999 -9999 -9999 -9999 -9999 -9999 -9999 -9999 -9999 -9999 -9999 -9999 -9999 -9999 -9999 -9999 -9999 -9999 -9999 -9999 -9999 -9999 -9999 -9999 -9999 -9999

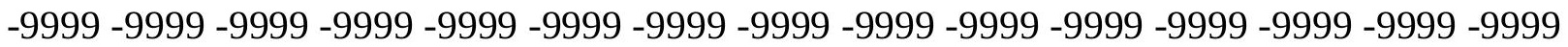

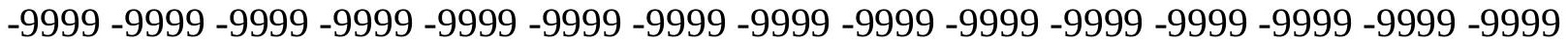
-9999 -9999 -9999 -9999 -9999 -9999 -9999 -9999 -9999 -9999 -9999 -9999 -9999 -9999 -9999 -9999 -9999 -9999 -9999 -9999 -9999 -9999 -9999 -9999 -9999 -9999 -9999 -9999 -9999 -9999 -9999 -9999 -9999 -9999 -9999 -9999 -9999 -9999 -9999 -9999 -9999 -9999 -9999 -9999 -9999 -9999 -9999 -9999 -9999 -9999 -9999 -9999 -9999 -9999 -9999 -9999 -9999 -9999 -9999 -9999 -9999 -9999 -9999 -9999 -9999 -9999 -9999 -9999 -9999 -9999 -9999 -9999 -9999 -9999 -9999 -9999 -9999 -9999 -9999 -9999 -9999 -9999 -9999 -9999 -9999 -9999 -9999 -9999 -9999 -9999 -

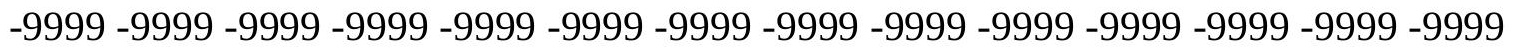
-9999 -9999 -9999 -9999 -9999 -9999 -9999 -9999 -9999 -9999 -9999 -9999 -9999 -9999 -9999 -9999 -9999 -9999 -9999 -9999 -9999 -9999 -9999 -9999 -9999 -9999 -9999 -9999 -9999 -9999 -9999 -9999 -9999 -9999 -9999 -9999 -9999 -9999 -9999 -9999 -9999 -9999 -9999 -9999 -9999 -

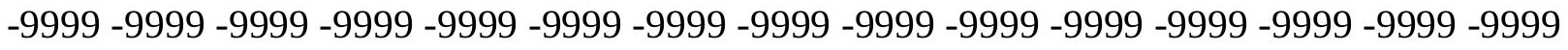

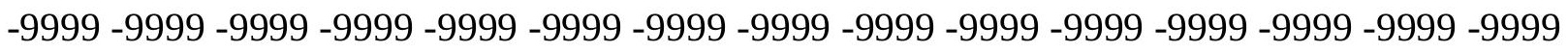
-9999 -9999 -9999 -9999 -9999 -9999 -9999 -9999 -9999 -9999 -9999 -9999 -9999 -9999 - 9999 -9999 -9999 -9999 -9999 -9999 -9999 -9999 -9999 -9999 -9999 -9999 -9999 -9999 -9999 -9999 -9999 -9999 -9999 -9999 -9999 -9999 -9999 -9999 -9999 -9999 -9999 -9999 -9999 -9999 -9999 -

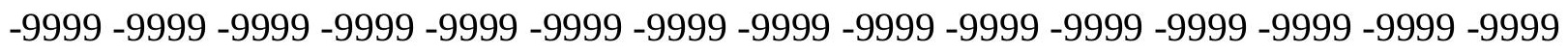
-9999 -9999 -9999 -9999 -9999 -9999 -9999 -9999 -9999 -9999 -9999 -9999 -9999 -9999 -9999 -9999 -9999 -9999 -9999 -9999 -9999 -9999 -9999 -9999 -9999 -9999 -9999 -9999 -9999 -9999 -

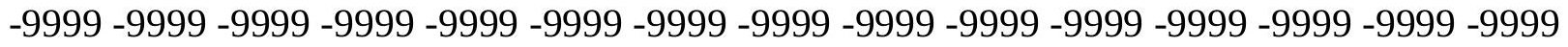
-9999 -9999 -9999 -9999 -9999 -9999 -9999 -9999 -9999 -9999 -9999 -9999 -9999 -9999 -9999 -9999 -9999 -9999 -9999 -9999 -9999 -9999 -9999 -9999 -9999 -9999 -9999 -9999 -9999 -999 -

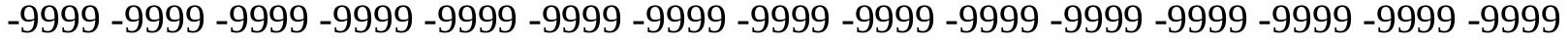
-9999 -9999 -9999 -9999 -9999 -9999 -9999 -9999 -9999 -9999 -9999 -9999 -9999 -9999 -9999 -

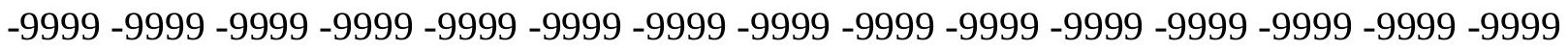

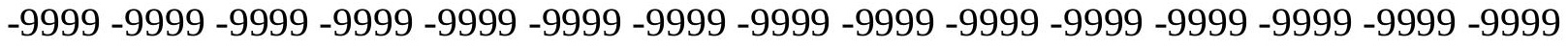

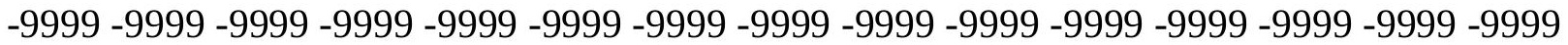
-9999 -9999 -9999 -9999 -9999 -9999 -9999 -9999 -9999 -9999 -9999 -9999 -9999 -9999 -9999 -

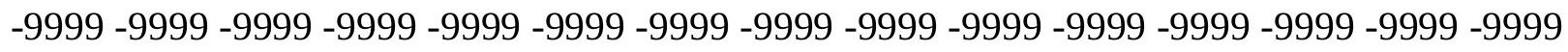

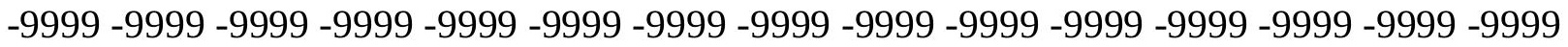
-9999 -9999 -9999 -9999 -9999 -9999 -9999 -9999 -9999 -9999 -9999 -9999 -9999 - 9999 - -999 -9999 -9999 -9999 -9999 -9999 -9999 -9999 -9999 -9999 -9999 -9999 -9999 -9999 -9999 -9999 -

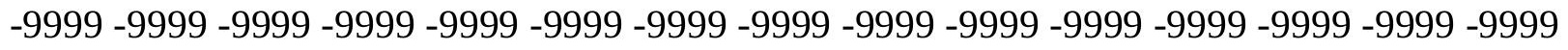

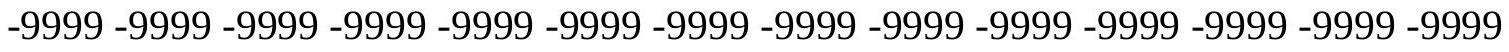
-9999 -9999 -9999 -9999 -9999 -9999 -9999 -9999 -9999 -9999 -9999 -9999 -9999 -9999 -9999 -9999 -9999 -9999 -9999 -9999 -9999 -9999 -9999 -9999-9999 -9999 -9999 -9999 -9999 -9999 -9999 -9999 -9999 -9999 -9999 -9999 -9999 -9999 -9999 -9999 -9999 -9999 -9999 -9999 -9999 -

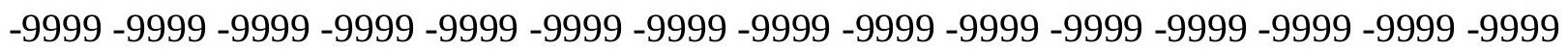


-9999 -9999 -9999 -9999 -9999 -9999 -9999 -9999 -9999 -9999 -9999 -9999 -9999 -9999 -9999 -9999 -9999 -9999 -9999 -9999 -9999 -9999 -9999 -9999 -9999 -9999 -9999 -9999 -9999 -9999 -

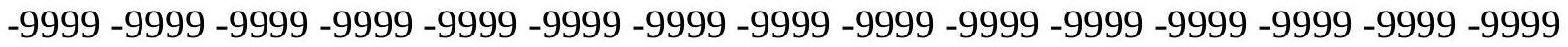
-9999 -9999 -9999 -9999 -9999 -9999 -9999 -9999 -9999 -9999 -9999 -9999 -9999 -9999 -9999 -9999 -9999 -9999 -9999 -9999 -9999 -9999 -9999 -9999-9999 -9999 -9999 -9999 -9999 -9999 -9999 -9999 -9999 -9999 -9999 -9999 -9999 -9999 -9999 -9999 -9999 -9999 -9999 -9999 -9999 -9999 -9999 -9999 -9999 -9999 -9999 -9999 -9999 -9999 -9999 -9999 -9999 -9999 -9999 -9999

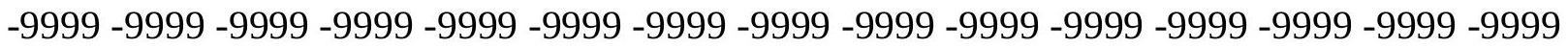

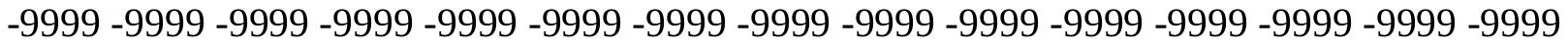
-9999 -9999 -9999 -9999 -9999 -9999 -9999 -9999 -9999 -9999 -9999 -9999 -9999 -9999 -9999 -9999 -9999 -9999 -9999 -9999 -9999 -9999 -9999 -9999 -9999 -9999 -9999 -9999 -9999 -9999 -9999 -9999 -9999 -9999 -9999 -9999 -9999 -9999 -9999 -9999 -9999 -9999 -9999 -9999 -9999 -9999 -9999 -9999 -9999 -9999 -9999 -9999 -9999 -9999 -9999 -9999 -9999 -9999 -9999 -9999 -

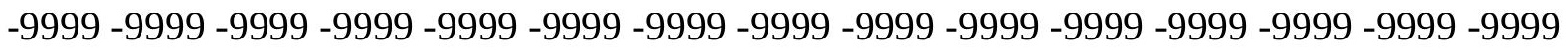
-9999 -9999 -9999 -9999 -9999 -9999 -9999 -9999 -9999 -9999 -9999 -9999 -9999 -9999 -9999 -

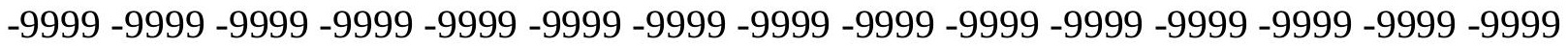
-9999 -9999 -9999 -9999 -9999 -9999 -9999 -9999 -9999 -9999 -9999 -9999 -9999 -9999 -9999 -9999 -9999 -9999 -9999 -9999 -9999 -9999 -9999 -9999 -9999 -9999 -9999 -9999 -9999 -9999 -9999 -9999 -9999 -9999 -9999 -9999 -9999 -9999 -9999 -9999 -9999 -9999 -9999 -9999 -9999 -

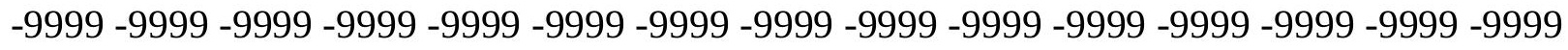

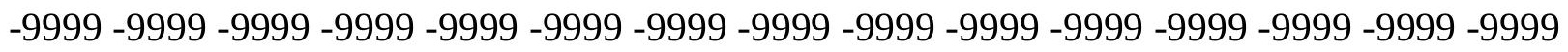
-9999 -9999 -9999 -9999 -9999 -9999 -9999 -9999 -9999 -9999 -9999 -9999 -9999 -9999 -9999 -9999 -9999 -9999 -9999 -9999 -9999 -9999 -9999 -9999 -9999 -9999 -9999 -9999 -9999 -9999 -9999 -9999 -9999 -9999 -9999 -9999 -9999 -9999 -9999 -9999 -9999 -9999 -9999 -9999 -

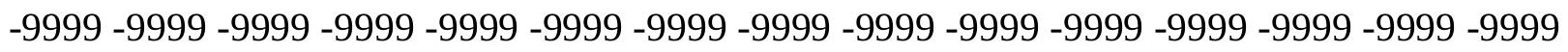
-9999 -9999 -9999 -9999 -9999 -9999 -9999 -9999 -9999 -9999 -9999 -9999 -9999 -9999 -9999 -9999 -9999 -9999 -9999 -9999 -9999 -9999 -9999 -9999 -9999 -9999 -9999 -9999 -9999 -9999 -

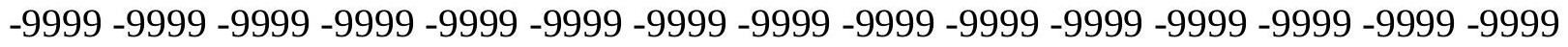
-9999 -9999 -9999 -9999 -9999 -9999 -9999 -9999 -9999 -9999 -9999 -9999 -9999 -9999 -9999 -9999 -9999 -9999 -9999 -9999 -9999 -9999 -9999 -9999 -9999 -9999 -9999 -9999 -9999 -999 -

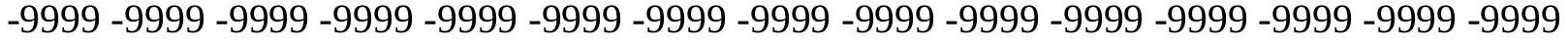
-9999 -9999 -9999 -9999 -9999 -9999 -9999 -9999 -9999 -9999 -9999 -9999 -9999 -9999 -9999 -

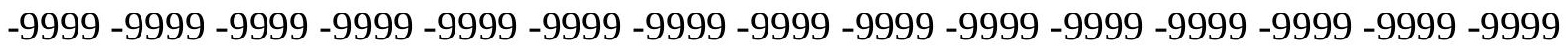

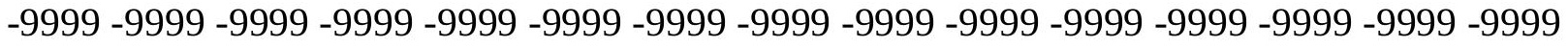

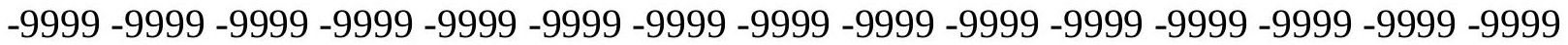

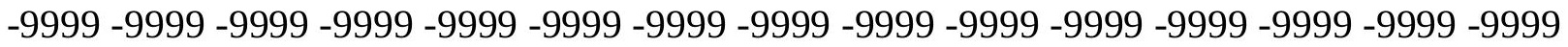

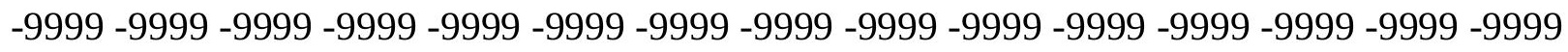

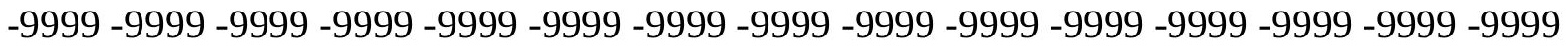

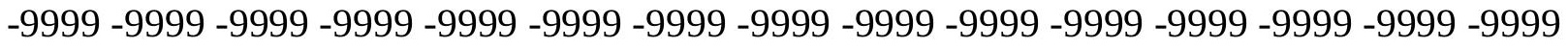
-9999 -9999 -9999 -9999 -9999 -9999 -9999 -9999 -9999 -9999 -9999 -9999 -9999 -9999 -9999 -

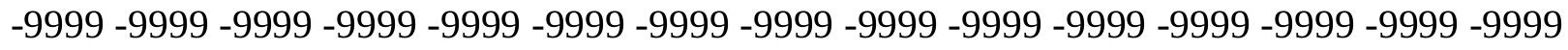

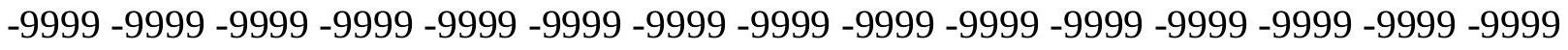
-9999 -9999 -9999 -9999 -9999 -9999 -9999 -9999 -9999 -9999 -9999 -9999 -9999 -9999 -9999 -9999 -9999 -9999 -9999 -9999 -9999 -9999 -9999 -9999-9999 -9999 -9999 -9999 -9999 -9999 -9999 -9999 -9999 -9999 -9999 -9999 -9999 -9999 -9999 -9999 -9999 -9999 -9999 -9999 -9999 -

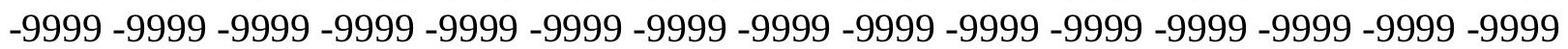


-9999 -9999 -9999 -9999 -9999 -9999 -9999 -9999 -9999 -9999 -9999 -9999 -9999 -9999 -9999 -9999 -9999 -9999 -9999 -9999 -9999 -9999 -9999 -9999 -9999 -9999 -9999 -9999 -9999 -

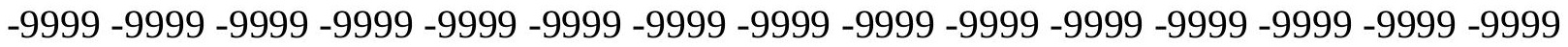
-9999 -9999 -9999 -9999 -9999 -9999 -9999 -9999 -9999 -9999 -9999 -9999 -9999 -9999 -9999 -9999 -9999 -9999 -9999 -9999 -9999 -9999 -9999 -9999 -9999 -9999 -9999 -9999 -9999 -9999 -9999 -9999 -9999 -9999 -9999 -9999 -9999 -9999 -9999 -9999 -9999 -9999 -9999 -9999 -9999 -9999 -9999 -9999 -9999 -9999 -9999 -9999 -9999 -9999 -9999 -9999 -9999 -9999 -9999 -9999

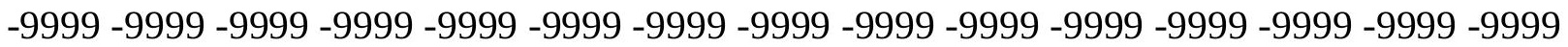

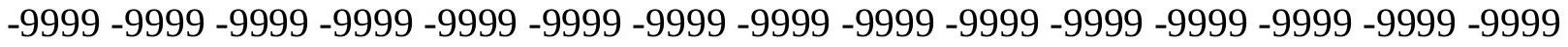
-9999 -9999 -9999 -9999 -9999 -9999 -9999 -9999 -9999 -9999 -9999 -9999 -9999 -9999 -9999 -9999 -9999 -9999 -9999 -9999 -9999 -9999 -9999 -9999 -9999 -9999 -9999 -9999 -9999 -9999 -9999 -9999 -9999 -9999 -9999 -9999 -9999 -9999 -9999 -9999 -9999 -9999 -9999 -9999 -9999 -9999 -9999 -9999 -9999 -9999 -9999 -9999 -9999 -9999 -9999 -9999 -9999 -9999 -9999 -9999 -9999 -9999 -9999 -9999 -9999 -9999 -9999 -9999 -9999 -9999 -9999 -9999 -9999 -9999 -9999 -9999 -9999 -9999 -9999 -9999 -9999 -9999 -9999 -9999 -9999 -9999 -9999 -9999 -9999 -9999 -

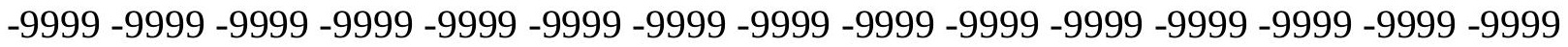
-9999 -9999 -9999 -9999 -9999 -9999 -9999 -9999 -9999 -9999 -9999 -9999 -9999 -9999 -9999 -9999 -9999 -9999 -9999 -9999 -9999 -9999 -9999 -9999 -9999 -9999 -9999 -9999 -9999 - 9999 -9999 -9999 -9999 -9999 -9999 -9999 -9999 -9999 -9999 -9999 -9999 -9999 -9999 -9999 -9999 -

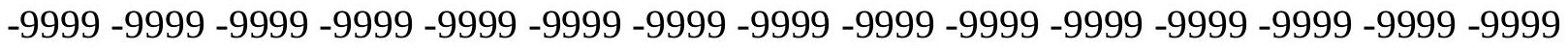

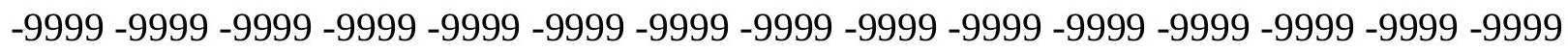

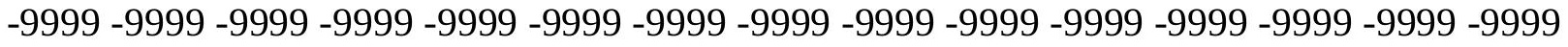
-9999 -9999 -9999 -9999 -9999 -9999 -9999 -9999 -9999 -9999 -9999 -9999 -9999 -9999 -9999 -9999 -9999 -9999 -9999 -9999 -9999 -9999 -9999 -9999 -9999 -9999 -9999 -9999 -9999 -9999 -

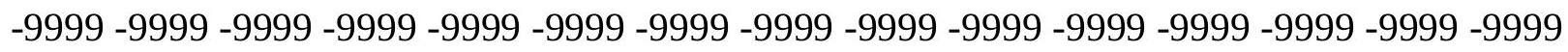
-9999 -9999 -9999 -9999 -9999 -9999 -9999 -9999 -9999 -9999 -9999 -9999 -9999 -9999 -9999 -9999 -9999 -9999 -9999 -9999 -9999 -9999 -9999 -9999 -9999 -9999 -9999 -9999 -9999 -9999 -9999 -9999 -9999 -9999 -9999 -9999 -9999 -9999 -9999 -9999 -9999 -9999 -9999 -9999 -9999 -9999 -9999 -9999 -9999 -9999 -9999 -9999 -9999 -9999 -9999 -9999 -9999 -9999 -9999 -9999 -9999 -9999 -9999 -9999 -9999 -9999 -9999 -9999 -9999 -9999 -9999 -9999 -9999 -999 -

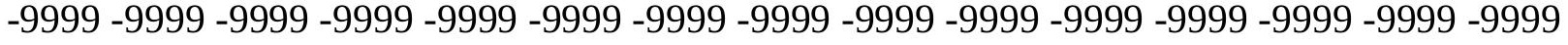
-9999 -9999 -9999 -9999 -9999 -9999 -9999 -9999 -9999 -9999 -9999 -9999 -9999 -9999 -9999 -

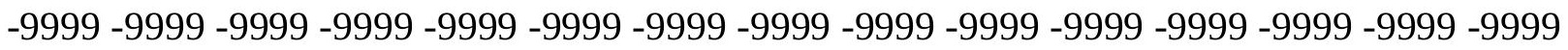

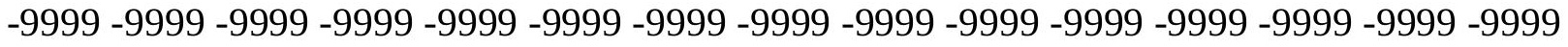

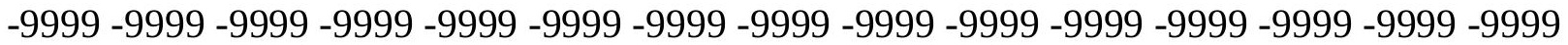

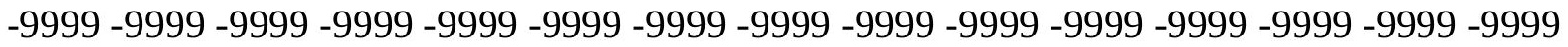

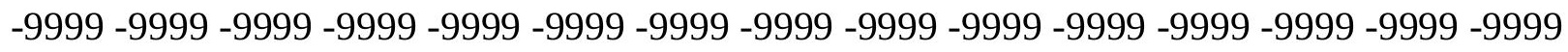

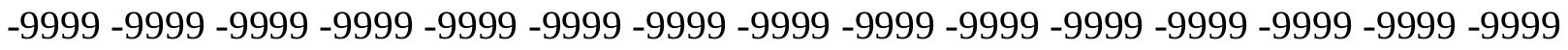

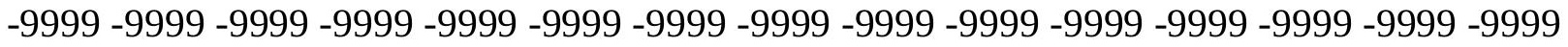
-9999 -9999 -9999 -9999 -9999 -9999 -9999 -9999 -9999 -9999 -9999 -9999 -9999 -9999 -9999 -

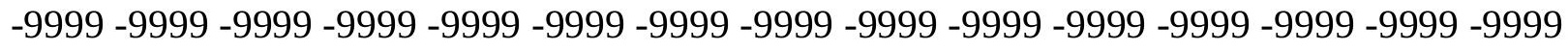

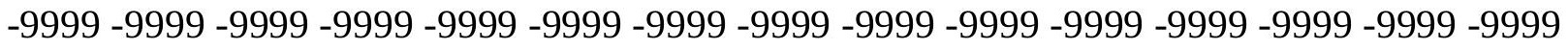
-9999 -9999 -9999 -9999 -9999 -9999 -9999 -9999 -9999 -9999 -9999 -9999 -9999 -9999 -9999 -9999 -9999 -9999 -9999 -9999 -9999 -9999 -9999 -9999-9999 -9999 -9999 -9999 -9999 -9999 -9999 -9999 -9999 -9999 -9999 -9999 -9999 -9999 -9999 -9999 -9999 -9999 -9999 -9999 -9999 -

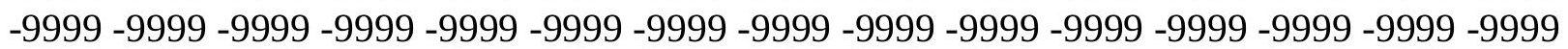


-9999 -9999 -9999 -9999 -9999 -9999 -9999 -9999 -9999 -9999 -9999 -9999 -9999 -9999 -9999 -9999 -9999 -9999 -9999 -9999 -9999 -9999 -9999 -9999 -9999 -9999 -9999 -9999 -9999 -9999 -

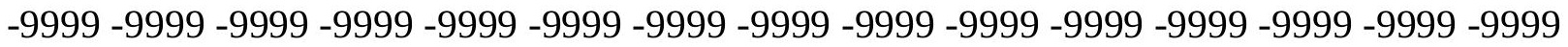
-9999 -9999 -9999 -9999 -9999 -9999 -9999 -9999 -9999 -9999 -9999 -9999 -9999 -9999 -9999 -9999 -9999 -9999 -9999 -9999 -9999 -9999 -9999 -9999-9999 -9999 -9999 -9999 -9999 -9999 -9999 -9999 -9999 -9999 -9999 -9999 -9999 -9999 -9999 -9999 -9999 -9999 -9999 -9999 -9999 -

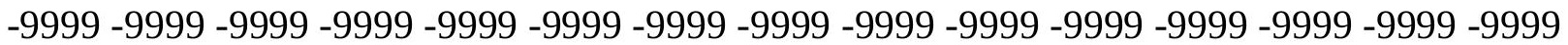
-9999 -9999 -9999 -9999 -9999 -9999 -9999 -9999 -9999 -9999 -9999 -9999 -9999 -9999 -9999 -9999 -9999 -9999 -9999 -9999 -9999 -9999 -9999 -9999 -9999 -9999 -9999 -9999 -9999 -9999 -9999 -9999 -9999 -9999 -9999 -9999 -9999 -9999 -9999 -9999 -9999 -9999 -9999 -9999 -9999 -9999 -9999 -9999 -9999 -9999 -9999 -9999 -9999 -9999 -9999 -9999 -9999 -9999 -9999 -9999 -9999 -9999 -9999 -9999 -9999 -9999 -9999 -9999 -9999 -9999 -9999 -9999 -9999 -9999 -9999 -9999 -9999 -9999 -9999 -9999 -9999 -9999 -9999 -9999 -9999 -9999 -9999 -9999 -9999 -9999 -9999 -9999 -9999 -9999 -9999 -9999 -9999 -9999 -9999 -9999 -9999 -9999 -9999 -9999 -9999 -9999 -9999 -9999 -9999 -9999 -9999 -9999 -9999 -9999 -9999 -9999 -9999 -9999 -9999 -

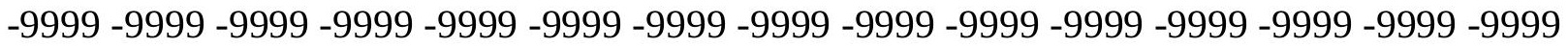
-9999 -9999 -9999 -9999 -9999 -9999 -9999 -9999 -9999 -9999 -9999 -9999 -9999 -9999 -9999 -9999 -9999 -9999 -9999 -9999 -9999 -9999 -9999 -9999 -9999 -9999 -9999 -9999 -9999 -9999 -9999 -9999 -9999 -9999 -9999 -9999 -9999 -9999 -9999 -9999 -9999 -9999 -9999 -9999 -9999 -

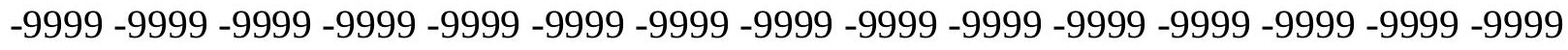

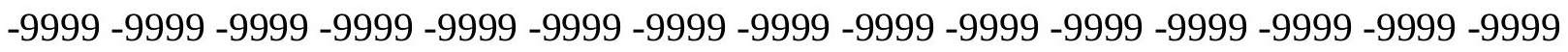
-9999 -9999 -9999 -9999 -9999 -9999 -9999 -9999 -9999 -9999 -9999 -9999 -9999 -9999 - 9999 -9999 -9999 -9999 -9999 -9999 -9999 -9999 -9999 -9999 -9999 -9999 -9999 -9999 -9999 -9999 -9999 -9999 -9999 -9999 -9999 -9999 -9999 -9999 -9999 -9999 -9999 -9999 -9999 -9999 -9999 -

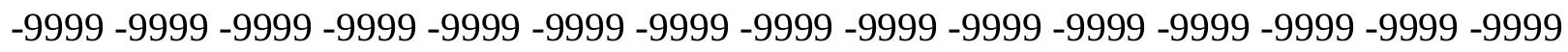
-9999 -9999 -9999 -9999 -9999 -9999 -9999 -9999 -9999 -9999 -9999 -9999 -9999 -9999 -9999 -9999 -9999 -9999 -9999 -9999 -9999 -9999 -9999 -9999 -9999 -9999 -9999 -9999 -9999 -9999 -

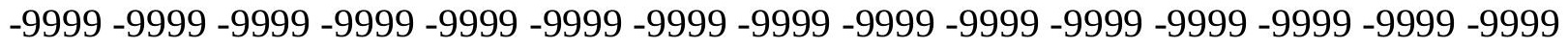
-9999 -9999 -9999 -9999 -9999 -9999 -9999 -9999 -9999 -9999 -9999 -9999 -9999 -9999 -9999 -9999 -9999 -9999 -9999 -9999 -9999 -9999 -9999 -9999 -9999 -9999 -9999 -9999 -9999 -999 -9999 -9999 -9999 -9999 -9999 -9999 -9999 -9999 -9999 -9999 -9999 -9999 -9999 -9999 -9999 -9999 -9999 -9999 -9999 -9999 -9999 -9999 -9999 -9999 -9999 -9999 -9999 -9999 -9999 -9999 -

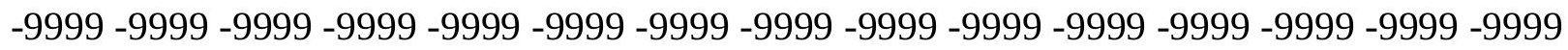

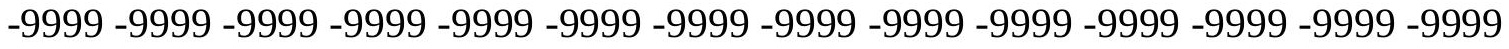
-9999 -9999 -9999 -9999 -9999 -9999 -9999 -9999 -9999 -9999 -9999 -9999 -9999 -9999 -9999

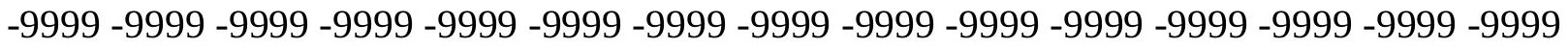

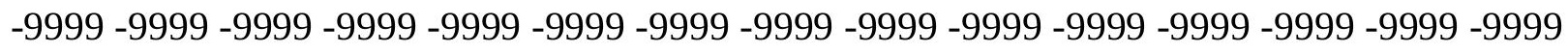

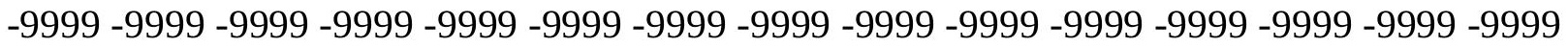

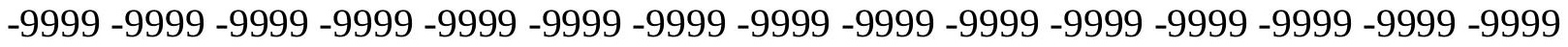
-9999 -9999 -9999 -9999 -9999 -9999 -9999 -9999 -9999 -9999 -9999 -9999 -9999 -9999 -9999 -

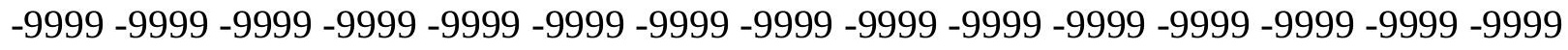

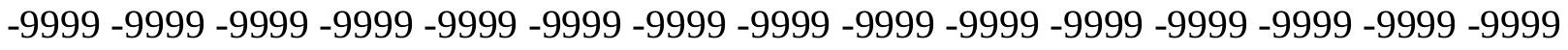
-9999 -9999 -9999 -9999 -9999 -9999 -9999 -9999 -9999 -9999 -9999 -9999 -9999 -9999 -9999 -9999 -9999 -9999 -9999 -9999 -9999 -9999 -9999 -9999-9999 -9999 -9999 -9999 -9999 -9999 -9999 -9999 -9999 -9999 -9999 -9999 -9999 -9999 -9999 -9999 -9999 -9999 -9999 -9999 -9999 -

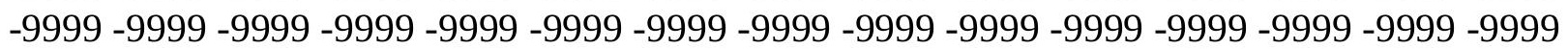


-9999 -9999 -9999 -9999 -9999 -9999 -9999 -9999 -9999 -9999 -9999 -9999 -9999 -9999 -9999 -9999 -9999 -9999 -9999 -9999 -9999 -9999 -9999 -9999 -9999 -9999 -9999 -9999 -9999 -9999 -

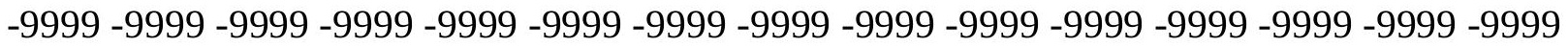
-9999 -9999 -9999 -9999 -9999 -9999 -9999 -9999 -9999 -9999 -9999 -9999 -9999 -9999 -9999 -9999 -9999 -9999 -9999 -9999 -9999 -9999 -9999 -9999-9999 -9999 -9999 -9999 -9999 -9999 -9999 -9999 -9999 -9999 -9999 -9999 -9999 -9999 -9999 -9999 -9999 -9999 -9999 -9999 -9999 -9999 -9999 -9999 -9999 -9999 -9999 -9999 -9999 -9999 -9999 -9999 -9999 -9999 -9999 -9999

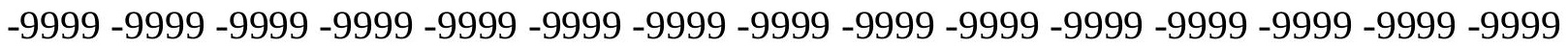

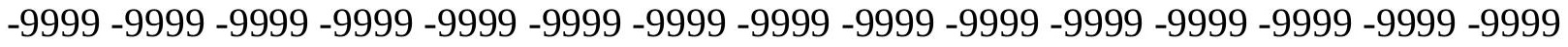
-9999 -9999 -9999 -9999 -9999 -9999 -9999 -9999 -9999 -9999 -9999 -9999 -9999 -9999 -9999 -9999 -9999 -9999 -9999 -9999 -9999 -9999 -9999 -9999 -9999 -9999 -9999 -9999 -9999 -9999 -9999 -9999 -9999 -9999 -9999 -9999 -9999 -9999 -9999 -9999 -9999 -9999 -9999 -9999 -9999 -9999 -9999 -9999 -9999 -9999 -9999 -9999 -9999 -9999 -9999 -9999 -9999 -9999 -9999 -9999 -9999 -9999 -9999 -9999 -9999 -9999 -9999 -9999 -9999 -9999 -9999 -9999 -9999 -9999 -9999 -9999 -9999 -9999 -9999 -9999 -9999 -9999 -9999 -9999 -9999 -9999 -9999 -9999 -9999

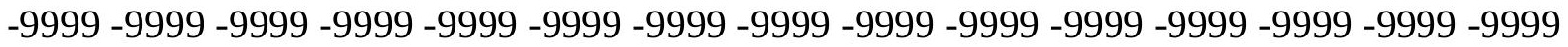
-9999 -9999 -9999 -9999 -9999 -9999 -9999 -9999 -9999 -9999 -9999 -9999 -9999 -9999 -9999 -9999 -9999 -9999 -9999 -9999 -9999 -9999 -9999 -9999 -9999 -9999 -9999 -9999 -9999 -9999 -9999 -9999 -9999 -9999 -9999 -9999 -9999 -9999 -9999 -9999 -9999 -9999 -9999 -9999 -9999 -

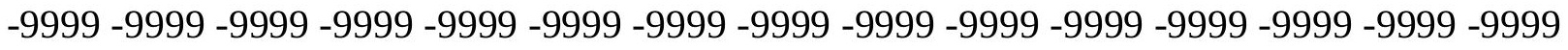

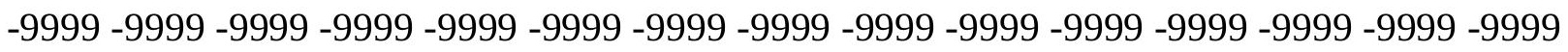
-9999 -9999 -9999 -9999 -9999 -9999 -9999 -9999 -9999 -9999 -9999 -9999 -9999 -9999 -9999 -9999 -9999 -9999 -9999 -9999 -9999 -9999 -9999 -9999 -9999 -9999 -9999 -9999 -9999 -9999 -9999 -9999 -9999 -9999 -9999 -9999 -9999 -9999 -9999 -9999 -9999 -9999 -9999 -9999 -9999 -

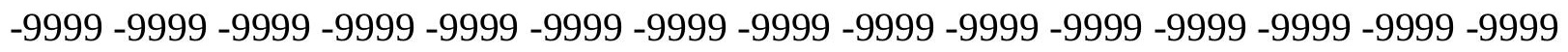
-9999 -9999 -9999 -9999 -9999 -9999 -9999 -9999 -9999 -9999 -9999 -9999 -9999 -9999 -9999 -9999 -9999 -9999 -9999 -9999 -9999 -9999 -9999 -9999 -9999 -9999 -9999 -9999 -9999 -9999 -

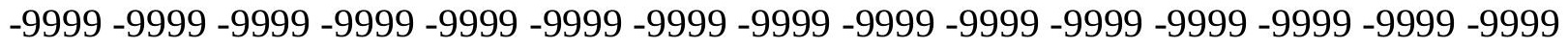
-9999 -9999 -9999 -9999 -9999 -9999 -9999 -9999 -9999 -9999 -9999 -9999 -9999 -9999 -9999 -9999 -9999 -9999 -9999 -9999 -9999 -9999 -9999 -9999 -9999 -9999 -9999 -9999 -9999 -999 -9999 -9999 -9999 -9999 -9999 -9999 -9999 -9999 -9999 -9999 -9999 -9999 -9999 -9999 -9999 -9999 -9999 -9999 -9999 -9999 -9999 -9999 -9999 -9999 -9999 -9999 -9999 -9999 -9999 -9999 -

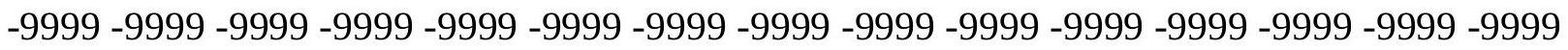

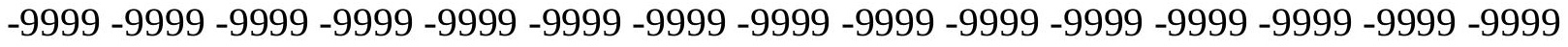

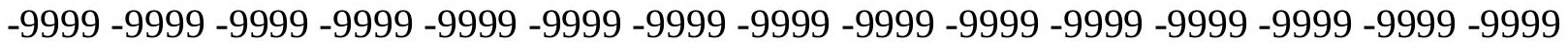

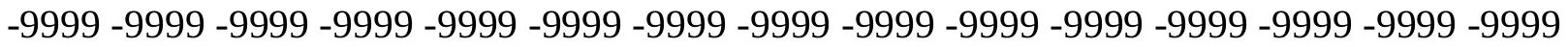

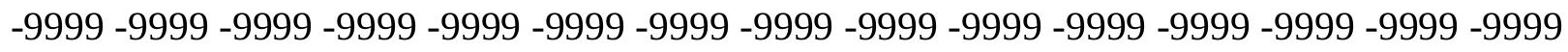

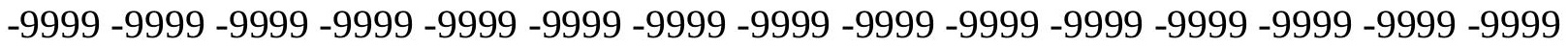
-9999 -9999 -9999 -9999 -9999 -9999 -9999 -9999 -9999 -9999 -9999 -9999 -9999 - 9999 - -999 -9999 -9999 -9999 -9999 -9999 -9999 -9999 -9999 -9999 -9999 -9999 -9999 -9999 -9999 - -999 -

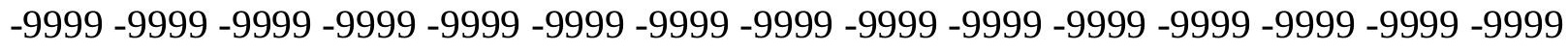

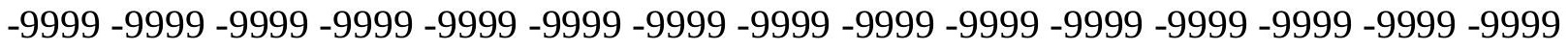
-9999 -9999 -9999 -9999 -9999 -9999 -9999 -9999 -9999 -9999 -9999 -9999 -9999 -9999 -9999 -9999 -9999 -9999 -9999 -9999 -9999 -9999 -9999 -9999-9999 -9999 -9999 -9999 -9999 -9999 -9999 -9999 -9999 -9999 -9999 -9999 -9999 -9999 -9999 -9999 -9999 -9999 -9999 -9999 -9999 -

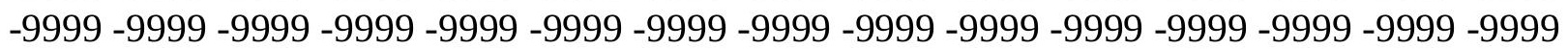


-9999 -9999 -9999 -9999 -9999 -9999 -9999 -9999 -9999 -9999 -9999 -9999 -9999 -9999 -9999 -9999 -9999 -9999 -9999 -9999 -9999 -9999 -9999 -9999 -9999 -9999 -9999 -9999 -9999 -9999 -9999 -9999 -9999 -9999 -9999 -9999 -9999 -9999 -9999 -9999 -9999 -9999 -9999 -9999 -9999 -9999 -9999 -9999 -9999 -9999 -9999 -9999 -9999 -9999 -9999 -9999 -9999 -9999 -9999 -9999 -9999 -9999 -9999 -9999 -9999 -9999 -9999 -9999 -9999 -9999 -9999 -9999 -9999 -9999 -9999 -9999 -9999 -9999 -9999 -9999 -9999 -9999 -9999 -9999 -9999 -9999 -9999 -9999 -9999 -9999 -9999 -9999 -9999 -9999 -9999 -9999 -9999 -9999 -9999 -9999 -9999 -9999 -9999 -9999 -9999 -

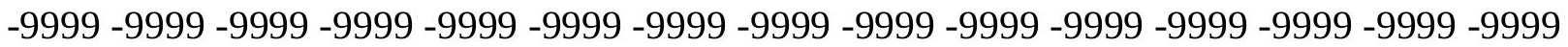
-9999 -9999 -9999 -9999 -9999 -9999 -9999 -9999 -9999 -9999 -9999 -9999 -9999 -9999 -9999 -9999 -9999 -9999 -9999 -9999 -9999 -9999 -9999 -9999 -9999 -9999 -9999 -9999 -9999 -9999 -

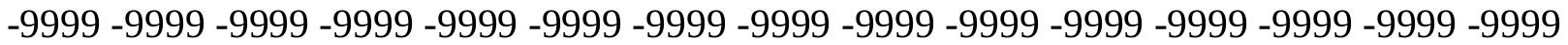
-9999 -9999 -9999 -9999 -9999 -9999 -9999 -9999 -9999 -9999 -9999 -9999 -9999 -9999 -9999 -9999 -9999 -9999 -9999 -9999 -9999 -9999 -9999 -9999 -9999 -9999 -9999 -9999 -9999 -9999 -9999 -9999 -9999 -9999 -9999 -9999 -9999 -9999 -9999 -9999 -9999 -9999 -9999 -9999 -9999 -9999 -9999 -9999 -9999 -9999 -9999 -9999 -9999 -9999 -9999 -9999 -9999 -9999 -9999 -9999

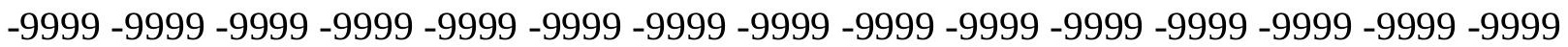
-9999 -9999 -9999 -9999 -9999 -9999 -9999 -9999 -9999 -9999 -9999 -9999 -9999 -9999 -9999 -9999 -9999 -9999 -9999 -9999 -9999 -9999 -9999 -9999 -9999 -9999 -9999 -9999 -9999 -9999 -9999 -9999 -9999 -9999 -9999 -9999 -9999 -9999 -9999 -9999 -9999 -9999 -9999 -9999 -9999 -9999 -9999 -9999 -9999 -9999 -9999 -9999 -9999 -9999 -9999 -9999 -9999 -9999 -9999 -9999 -9999 -9999 -9999 -9999 -9999 -9999 -9999 -9999 -9999 -9999 -9999 -9999 -9999 -9999 -9999 -9999 -9999 -9999 -9999 -9999 -9999 -9999 -9999 -9999 -9999 -9999 -9999 -9999 -9999 -9999 -9999 -9999 -9999 -9999 -9999 -9999 -9999 -9999 -9999 -9999 -9999 -9999 -9999 -9999 -9999 -9999 -9999 -9999 -9999 -9999 -9999 -9999 -9999 -9999 -9999 -9999 -9999 -9999 -9999 -9999 -9999 -9999 -9999 -9999 -9999 -9999 -9999 -9999 -9999 -9999 -9999 -9999 -9999 -9999 -9999 -9999 -9999 -9999 -9999 -9999 -9999 -9999 -9999 -9999 -9999 -9999 -9999 -9999 -9999 -9999 -9999 -9999 -9999 -9999 -9999 -9999 -9999 -9999 -9999 -9999 -9999 -9999 -9999 -9999 -9999 -9999 -9999 -9999 -9999 -9999 -9999 -9999 -9999 -9999 -9999 -9999 -9999 -9999 -9999

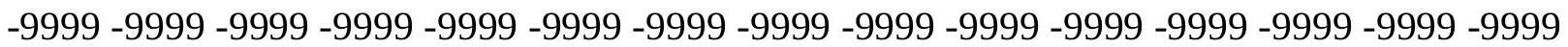
-9999 -9999 -9999 -9999 -9999 -9999 -9999 -9999 -9999 -9999 -9999 -9999 -9999 -9999 -9999 -9999 -9999 -9999 -9999 -9999 -9999 -9999 -9999 -9999 -9999 -9999 -9999 -9999 -9999 -9999 -

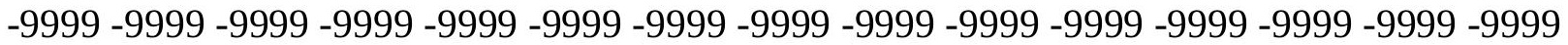
-9999 -9999 -9999 -9999 -9999 -9999 -9999 -9999 -9999 -9999 -9999 -9999 -9999 -9999 -9999 -9999 -9999 -9999 -9999 -9999 -9999 -9999 -9999 -9999 -9999 -9999 -9999 -9999 -9999 -9999 -9999 -9999 -9999 -9999 -9999 -9999 -9999 -9999 -9999 -9999 -9999 -9999 -9999 -9999 -9999 -9999 -9999 -9999 -9999 -9999 -9999 -9999 -9999 -9999 -9999 -9999 -9999 -9999 -9999 -9999 -9999 -9999 -9999 -9999 -9999 -9999 -9999 -9999 -9999 -9999 -9999 -9999 -9999 -9999 -9999

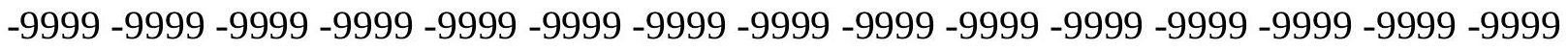
-9999 -9999 -9999 -9999 -9999 -9999 -9999 -9999 -9999 -9999 -9999 -9999 -9999 -9999 -9999 -9999 -9999 -9999 -9999 -9999 -9999 -9999 -9999 -9999 -9999 -9999 -9999 -9999 -9999 -9999 -9999 -9999 -9999 -9999 -9999 -9999 -9999 -9999 -9999 -9999 -9999 -9999 -9999 -9999 -9999 -999 -9999 -9999 -9999 -9999 -9999 -9999 -9999 -9999 -9999 -9999 -9999 -9999 -9999 -9999 -9999 -9999 -9999 -9999 -9999 -9999 -9999 -9999 -9999 -9999 -9999 -9999 -9999 -9999 -9999 -9999 -9999 -9999 -9999 -9999 -9999 -9999 -9999 -9999 -9999 -9999 -9999 -9999 -9999 -9999 -9999 -9999 -9999 -9999 -9999 -9999 -9999 -9999 -9999 -9999 -9999 -9999 -9999 -9999 -9999 -9999 -9999 -9999 -9999 -9999 -9999 -9999 -9999 -9999 -9999 -9999 -9999 -9999 -9999 -9999 
-9999 -9999 -9999 -9999 -9999 -9999 -9999 -9999 -9999 -9999 -9999 -9999 -9999 -9999 -9999 -9999 -9999 -9999 -9999 -9999 -9999 -9999 -9999 -9999 -9999 -9999 -9999 -9999 -9999 -9999 -

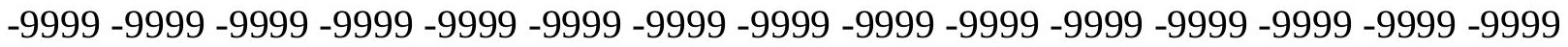
-9999 -9999 -9999 -9999 -9999 -9999 -9999 -9999 -9999 -9999 -9999 -9999 -9999 -9999 -9999 -9999 -9999 -9999 -9999 -9999 -9999 -9999 -9999 -9999-9999 -9999 -9999 -9999 -9999 -9999 -9999 -9999 -9999 -9999 -9999 -9999 -9999 -9999 -9999 -9999 -9999 -9999 -9999 -9999 -9999 -9999 -9999 -9999 -9999 -9999 -9999 -9999 -9999 -9999 -9999 -9999 -9999 -9999 -9999 -9999

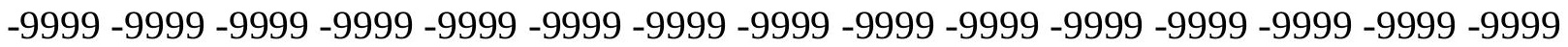

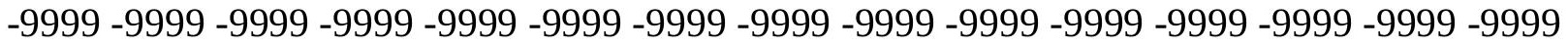
-9999 -9999 -9999 -9999 -9999 -9999 -9999 -9999 -9999 -9999 -9999 -9999 -9999 -9999 -9999 -9999 -9999 -9999 -9999 -9999 -9999 -9999 -9999 -9999 -9999 -9999 -9999 -9999 -9999 -9999 -9999 -9999 -9999 -9999 -9999 -9999 -9999 -9999 -9999 -9999 -9999 -9999 -9999 -9999 -9999 -9999 -9999 -9999 -9999 -9999 -9999 -9999 -9999 -9999 -9999 -9999 -9999 -9999 -9999 -9999 -

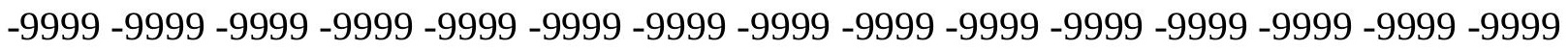
-9999 -9999 -9999 -9999 -9999 -9999 -9999 -9999 -9999 -9999 -9999 -9999 -9999 -9999 -9999 -

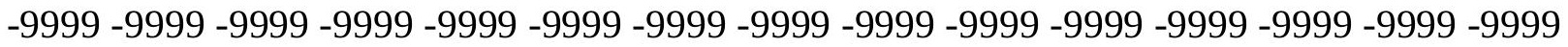
-9999 -9999 -9999 -9999 -9999 -9999 -9999 -9999 -9999 -9999 -9999 -9999 -9999 -9999 -9999 -9999 -9999 -9999 -9999 -9999 -9999 -9999 -9999 -9999 -9999 -9999 -9999 -9999 -9999 -9999 -9999 -9999 -9999 -9999 -9999 -9999 -9999 -9999 -9999 -9999 -9999 -9999 -9999 -9999 -9999 -

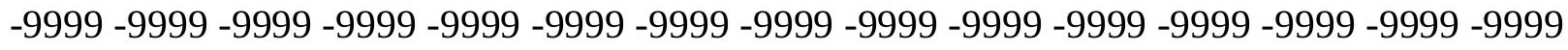

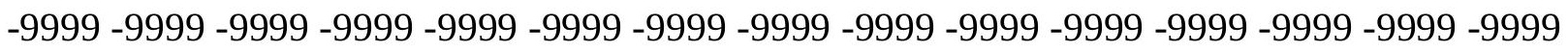

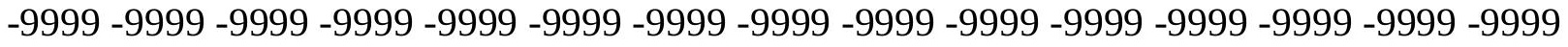
-9999 -9999 -9999 -9999 -9999 -9999 -9999 -9999 -9999 -9999 -9999 -9999 -9999 -9999 -9999 -9999 -9999 -9999 -9999 -9999 -9999 -9999 -9999 -9999 -9999 -9999 -9999 -9999 -9999 -9999 -

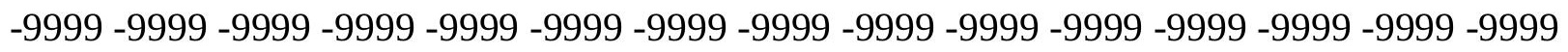
-9999 -9999 -9999 -9999 -9999 -9999 -9999 -9999 -9999 -9999 -9999 -9999 -9999 -9999 -9999 -9999 -9999 -9999 -9999 -9999 -9999 -9999 -9999 -9999 -9999 -9999 -9999 -9999 -9999 -

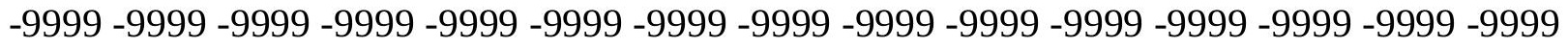
-9999 -9999 -9999 -9999 -9999 -9999 -9999 -9999 -9999 -9999 -9999 -9999 -9999 -9999 -9999 -9999 -9999 -9999 -9999 -9999 -9999 -9999 -9999 -9999 -9999 -9999 -9999 -9999 -9999 -999 -

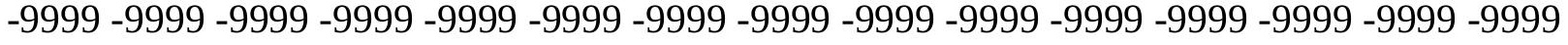
-9999 -9999 -9999 -9999 -9999 -9999 -9999 -9999 -9999 -9999 -9999 -9999 -9999 -9999 -9999 -

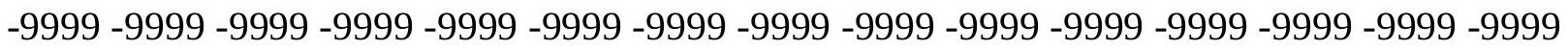

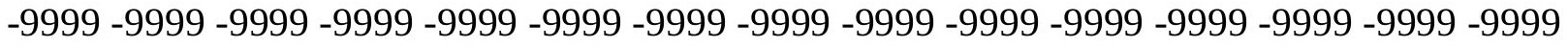

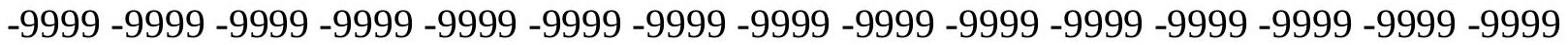
-9999 -9999 -9999 -9999 -9999 -9999 -9999 -9999 -9999 -9999 -9999 -9999 -9999 -9999 -9999

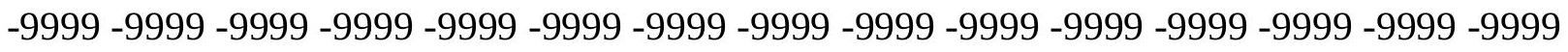

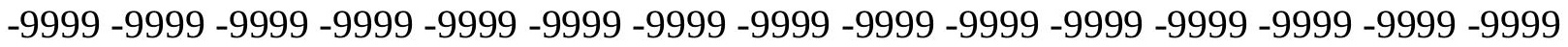
-9999 -9999 -9999 -9999 -9999 -9999 -9999 -9999 -9999 -9999 -9999 -9999 -9999 - 9999 - -999 -9999 -9999 -9999 -9999 -9999 -9999 -9999 -9999 -9999 -9999 -9999 -9999 -9999 -9999 -9999 -

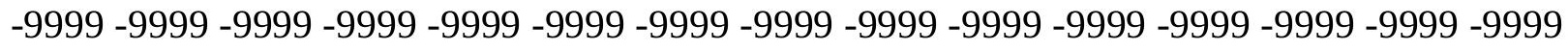

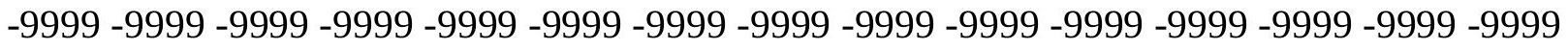
-9999 -9999 -9999 -9999 -9999 -9999 -9999 -9999 -9999 -9999 -9999 -9999 -9999 -9999 -9999 -9999 -9999 -9999 -9999 -9999 -9999 -9999 -9999 -9999-9999 -9999 -9999 -9999 -9999 -9999 -9999 -9999 -9999 -9999 -9999 -9999 -9999 -9999 -9999 -9999 -9999 -9999 -9999 -9999 -9999 -

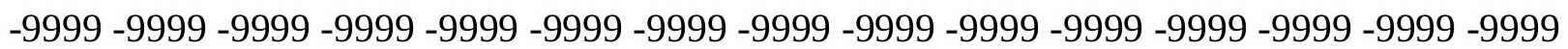


-9999 -9999 -9999 -9999 -9999 -9999 -9999 -9999 -9999 -9999 -9999 -9999 -9999 -9999 -9999 -9999 -9999 -9999 -9999 -9999 -9999 -9999 -9999 -9999 -9999 -9999 -9999 -9999 -9999 -9999 -9999 -9999 -9999 -9999 -9999 -9999 -9999 -9999 -9999 -9999 -9999 -9999 -9999 -9999 - 9999 -9999 -9999 -9999 -9999 -9999 -9999 -9999 -9999 -9999 -9999 -9999 -9999 -9999 -9999 -9999 -9999 -9999 -9999 -9999 -9999 -9999 -9999 -9999 -9999 -9999 -9999 -9999 -9999 -9999 - -9999 -9999 -9999 -9999 -9999 -9999 -9999 -9999 -9999 -9999 -9999 -9999 -9999 -9999 -9999 -9999 -9999 -9999 -9999 -9999 -9999 -9999 -9999 -9999 -9999 -9999 -9999 -9999 -9999 -9999

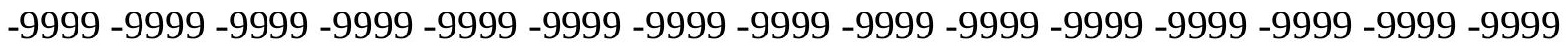

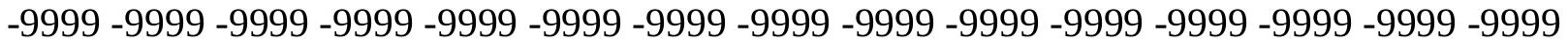
-9999 -9999 -9999 -9999 -9999 -9999 -9999 -9999 -9999 -9999 -9999 -9999 -9999 -9999 -9999

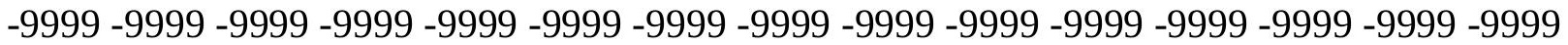
-9999 -9999 -9999 -9999 -9999 -9999 -9999 -9999 -9999 -9999 -9999 -9999 -9999 -9999 -9999 -9999 -9999 -9999 -9999 -9999 -9999 -9999 -9999 -9999 -9999 -9999 -9999 -9999 -9999 -9999 -9999 -9999 -9999 -9999 -9999 -9999 -9999 -9999 -9999 -9999 -9999 -9999 -9999 -9999 - -9999 -9999 -9999 -9999 -9999 -9999 -9999 -9999 -9999 -9999 -9999 -9999 -9999 -9999 -9999 -9999

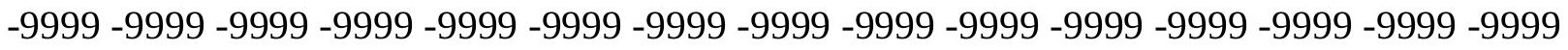
-9999 -9999 -9999 -9999 -9999 -9999 -9999 -9999 -9999 -9999 -9999 -9999 -9999 -9999 -9999 -9999 -9999 -9999 -9999 -9999 -9999 -9999 -9999 -9999 -9999 -9999 -9999 -9999 -9999 -9999 -9999 -9999 -9999 -9999 -9999 -9999 -9999 -9999 -9999 -9999 -9999 -9999 -9999 -9999 -9999 -

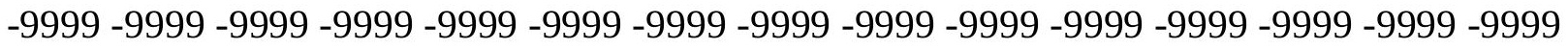
-9999 -9999 -9999 -9999 -9999 -9999 -9999 -9999 -9999 -9999 -9999 -9999 -9999 -9999 -9999 -999 -9999 -9999 -9999 -9999 -9999 -9999 -9999 -9999 -9999 -9999 -9999 -9999 -9999 -9999 -9999 -9999 -9999 -9999 -9999 -9999 -9999 -9999 -9999 -9999 -9999 -9999 -9999 -9999 -9999 -9999 -9999 -9999 -9999 -9999 -9999 -9999 -9999 -9999 -9999 -9999 -9999 -9999 -9999 -9999 -9999 -9999 -9999 -9999 -9999 -9999 -9999 -9999 -9999 -9999 -9999 -9999 -9999 -9999 -9999 -9999 -9999 -9999 -9999 -9999 -9999 -9999 -9999 -9999 -9999 -9999 -9999 -9999 -9999 -9999 -9999 -9999 -9999 -9999 -9999 -9999 -9999 -9999 -9999 -9999 -9999 -9999 -9999 -9999 -9999 -9999 -9999 -9999 -9999 -9999 -9999 -9999 -9999 -9999 -9999 -9999 -9999 -9999 -9999 -9999 -9999 -9999 -9999 -9999 -9999 -9999 -9999 -9999 -9999 -9999 -9999 -9999 -9999 -9999 -9999 -9999 -9999 -9999 -9999 -9999 -9999 -9999 -9999 -9999 -9999 -9999 -9999 -9999 -9999 -9999 -999 -9999 -9999 -9999 -9999 -9999 -9999 -9999 -9999 -9999 -9999 -9999 -9999 -9999 -9999 -9999 -9999 -9999 -9999 -9999 -9999 -9999 -9999 -9999 -9999 -9999 -9999 -9999 -9999 -9999 -

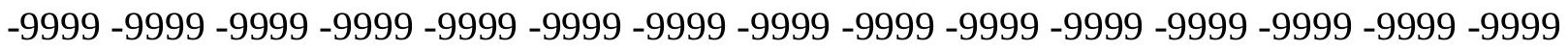

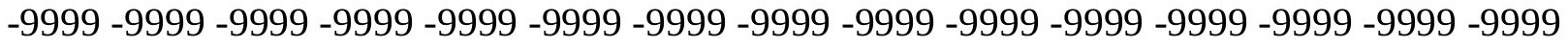

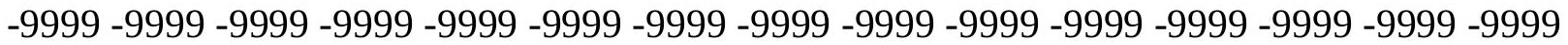
-9999 -9999 -9999 -9999 -9999 -9999 -9999 -9999 -9999 -9999 -9999 -9999 -9999 -9999 -9999 -

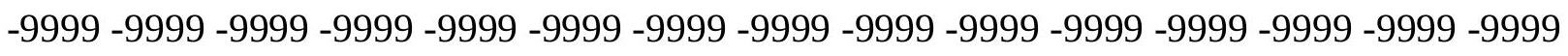

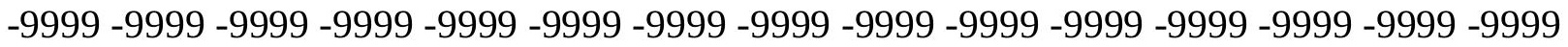

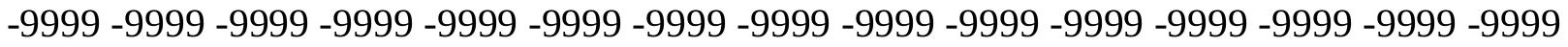
-9999 -9999 -9999 -9999 -9999 -9999 -9999 -9999 -9999 -9999 -9999 -9999 -9999 -9999 -9999 -

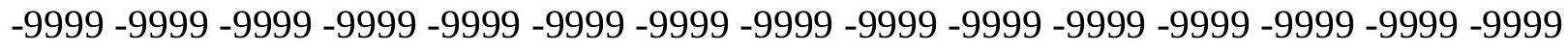

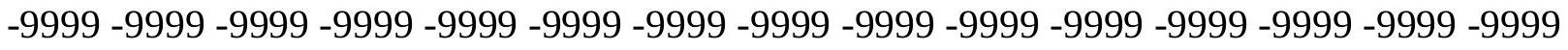
-9999 -9999 -9999 -9999 -9999 -9999 -9999 -9999 -9999 -9999 -9999 -9999 -9999 -9999 -9999 -9999 -9999 -9999 -9999 -9999 -9999 -9999 -9999 -9999-9999 -9999 -9999 -9999 -9999 -9999 -9999 -9999 -9999 -9999 -9999 -9999 -9999 -9999 -9999 -9999 -9999 -9999 -9999 -9999 -9999 -

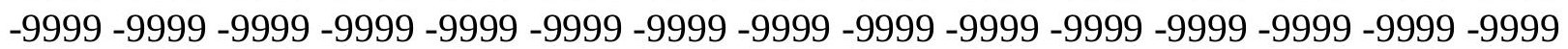


-9999 -9999 -9999 -9999 -9999 -9999 -9999 -9999 -9999 -9999 -9999 -9999 -9999 -9999 -9999 -9999 -9999 -9999 -9999 -9999 -9999 -9999 -9999 -9999 -9999 -9999 -9999 -9999 -9999 -9999 -

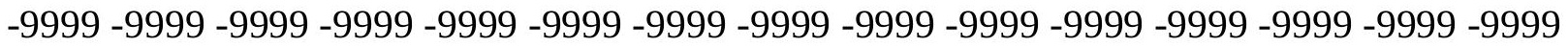
-9999 -9999 -9999 -9999 -9999 -9999 -9999 -9999 -9999 -9999 -9999 -9999 -9999 -9999 -9999 -9999 -9999 -9999 -9999 -9999 -9999 -9999 -9999 -9999-9999 -9999 -9999 -9999 -9999 -9999 -9999 -9999 -9999 -9999 -9999 -9999 -9999 -9999 -9999 -9999 -9999 -9999 -9999 -9999 -9999 -9999 -9999 -9999 -9999 -9999 -9999 -9999 -9999 -9999 -9999 -9999 -9999 -9999 -9999 -9999

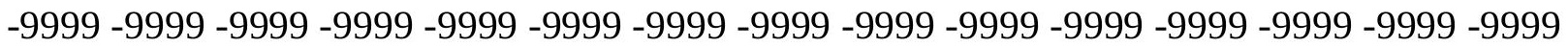

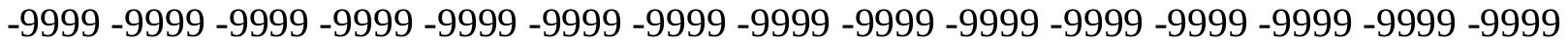
-9999 -9999 -9999 -9999 -9999 -9999 -9999 -9999 -9999 -9999 -9999 -9999 -9999 -9999 -9999 -9999 -9999 -9999 -9999 -9999 -9999 -9999 -9999 -9999 -9999 -9999 -9999 -9999 -9999 -9999 -9999 -9999 -9999 -9999 -9999 -9999 -9999 -9999 -9999 -9999 -9999 -9999 -9999 -9999 -9999 -9999 -9999 -9999 -9999 -9999 -9999 -9999 -9999 -9999 -9999 -9999 -9999 -9999 -9999 -9999 -9999 -9999 -9999 -9999 -9999 -9999 -9999 -9999 -9999 -9999 -9999 -9999 -9999 - 9999 -9999 -9999 -9999 -9999 -9999 -9999 -9999 -9999 -9999 -9999 -9999 -9999 -9999 -9999 -9999

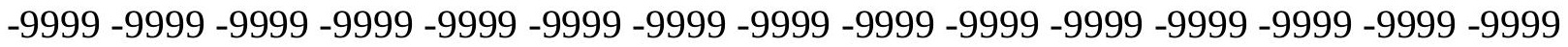
-9999 -9999 -9999 -9999 -9999 -9999 -9999 -9999 -9999 -9999 -9999 -9999 -9999 -9999 -9999 -9999 -9999 -9999 -9999 -9999 -9999 -9999 -9999 -9999 -9999 -9999 -9999 -9999 -9999 -9999 -9999 -9999 -9999 -9999 -9999 -9999 -9999 -9999 -9999 -9999 -9999 -9999 -9999 -9999 -9999 -

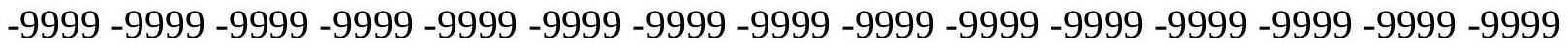

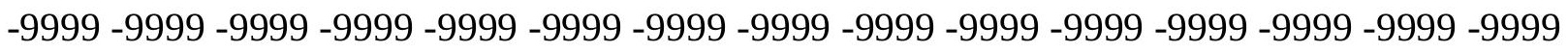
-9999 -9999 -9999 -9999 -9999 -9999 -9999 -9999 -9999 -9999 -9999 -9999 -9999 -9999 -9999 -9999 -9999 -9999 -9999 -9999 -9999 -9999 -9999 -9999 -9999 -9999 -9999 -9999 -9999 -9999 -9999 -9999 -9999 -9999 -9999 -9999 -9999 -9999 -9999 -9999 -9999 -9999 -9999 -9999 -9999 -

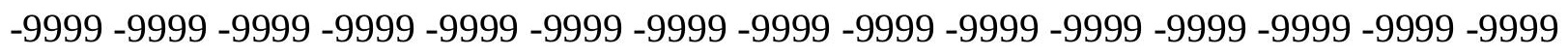
-9999 -9999 -9999 -9999 -9999 -9999 -9999 -9999 -9999 -9999 -9999 -9999 -9999 -9999 -9999 -9999 -9999 -9999 -9999 -9999 -9999 -9999 -9999 -9999 -9999 -9999 -9999 -9999 -9999 -9999 -

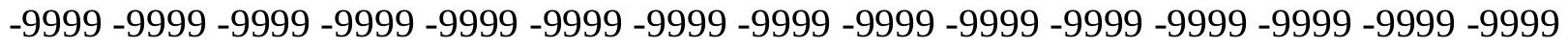
-9999 -9999 -9999 -9999 -9999 -9999 -9999 -9999 -9999 -9999 -9999 -9999 -9999 -9999 -9999 -9999 -9999 -9999 -9999 -9999 -9999 -9999 -9999 -9999 -9999 -9999 -9999 -9999 -9999 -999 -9999 -9999 -9999 -9999 -9999 -9999 -9999 -9999 -9999 -9999 -9999 -9999 -9999 -9999 -9999 -9999 -9999 -9999 -9999 -9999 -9999 -9999 -9999 -9999 -9999 -9999 -9999 -9999 -9999 -9999 -

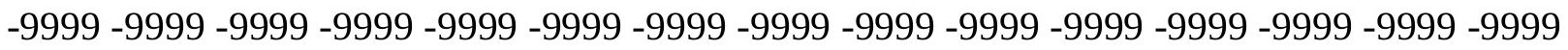

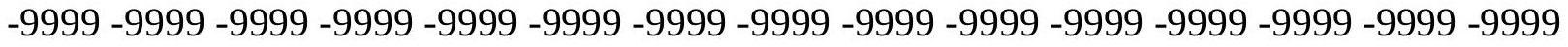

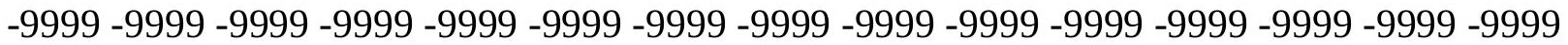

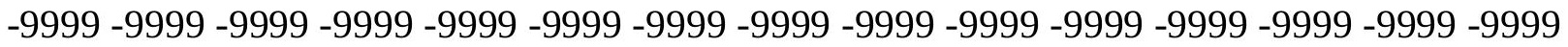

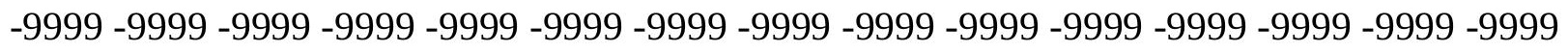

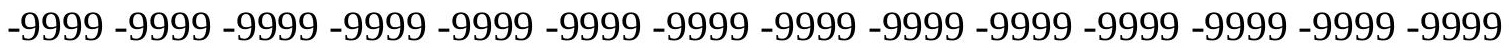
-9999 -9999 -9999 -9999 -9999 -9999 -9999 -9999 -9999 -9999 -9999 -9999 -9999 -9999 -9999 -9999 -9999 -9999 -9999 -9999 -9999 -9999 -9999 -9999 -9999 -9999 -9999 -9999 -9999 -9999 -

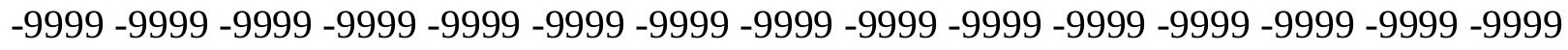

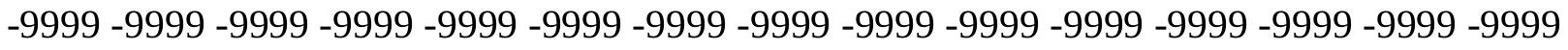
-9999 -9999 -9999 -9999 -9999 -9999 -9999 -9999 -9999 -9999 -9999 -9999 -9999 -9999 -9999 -9999 -9999 -9999 -9999 -9999 -9999 -9999 -9999 -9999-9999 -9999 -9999 -9999 -9999 -9999 -9999 -9999 -9999 -9999 -9999 -9999 -9999 -9999 -9999 -9999 -9999 -9999 -9999 -9999 -9999 -

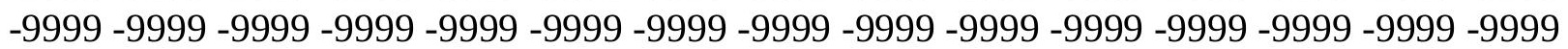


-9999 -9999 -9999 -9999 -9999 -9999 -9999 -9999 -9999 -9999 -9999 -9999 -9999 -9999 -9999 -9999 -9999 -9999 -9999 -9999 -9999 -9999 -9999 -9999 -9999 -9999 -9999 -9999 -9999 -9999 -9999 -9999 -9999 -9999 -9999 -9999 -9999 -9999 -9999 -9999 -9999 -9999 -9999 -9999 - 9999 -9999 -9999 -9999 -9999 -9999 -9999 -9999 -9999 -9999 -9999 -9999 -9999 -9999 -9999 -9999 -9999 -9999 -9999 -9999 -9999 -9999 -9999 -9999 -9999 -9999 -9999 -9999 -9999 -9999 -9999 -9999 -9999 -9999 -9999 -9999 -9999 -9999 -9999 -9999 -9999 -9999 -9999 -9999 -9999 -9999 -9999 -9999 -9999 -9999 -9999 -9999 -9999 -9999 -9999 -9999 -9999 -9999 -9999 -9999 -9999

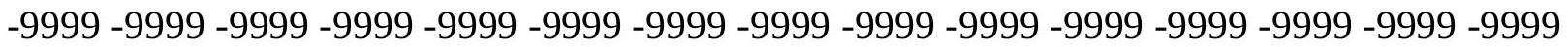
-9999 -9999 -9999 -9999 -9999 -9999 -9999 -9999 -9999 -9999 -9999 -9999 -9999 -9999 -9999 -9999 -9999 -9999 -9999 -9999 -9999 -9999 -9999 -9999 -9999 -9999 -9999 -9999 -9999 -9999

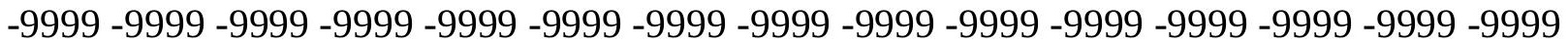
-9999 -9999 -9999 -9999 -9999 -9999 -9999 -9999 -9999 -9999 -9999 -9999 -9999 -9999 -9999 -9999 -9999 -9999 -9999 -9999 -9999 -9999 -9999 -9999 -9999 -9999 -9999 -9999 -9999 -9999 -

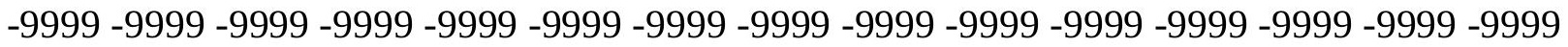
-9999 -9999 -9999 -9999 -9999 -9999 -9999 -9999 -9999 -9999 -9999 -9999 -9999 -9999 -9999

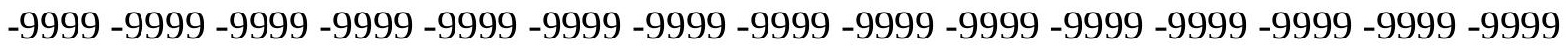
-9999 -9999 -9999 -9999 -9999 -9999 -9999 -9999 -9999 -9999 -9999 -9999 -9999 -9999 -9999 -9999 -9999 -9999 -9999 -9999 -9999 -9999 -9999 -9999 -9999 -9999 -9999 -9999 -9999 - -999 -9999 -9999 -9999 -9999 -9999 -9999 -9999 -9999 -9999 -9999 -9999 -9999 -9999 -9999 -9999 -9999 -9999 -9999 -9999 -9999 -9999 -9999 -9999 -9999 -9999 -9999 -9999 -9999 -9999 -9999 -9999 -9999 -9999 -9999 -9999 -9999 -9999 -9999 -9999 -9999 -9999 -9999 -9999 -9999 -9999 -999 -9999 -9999 -9999 -9999 -9999 -9999 -9999 -9999 -9999 -9999 -9999 -9999 -9999 -9999 -9999 -9999 -9999 -9999 -9999 -9999 -9999 -9999 -9999 -9999 -9999 -9999 -9999 -9999 -9999 -9999 -9999 -9999 -9999 -9999 -9999 -9999 -9999 -9999 -9999 -9999 -9999 -9999 -9999 -9999 -9999 -9999 -9999 -9999 -9999 -9999 -9999 -9999 -9999 -9999 -9999 -9999 -9999 -9999 -9999 -9999 -9999 -9999 -9999 -9999 -9999 -9999 -9999 -9999 -9999 -9999 -9999 -9999 -9999 -9999 -9999 -9999 -9999 -9999 -9999 -9999 -9999 -9999 -9999 -9999 -9999 -9999 -9999 -9999 -9999 -9999 -9999 -9999 -9999 -9999 -9999 -9999 -9999 -9999 -9999 -9999 -9999 -9999 -9999 -9999 -9999 -9999 -9999 -9999 -9999 -9999 -9999 -9999 -9999 -9999 -9999 -9999 -9999 -9999 -9999 -9999 -9999 -9999 -9999 -9999 -9999 -9999 -9999 -9999 -9999 -9999 -9999 -9999 -9999 -9999 -999 -9999 -9999 -9999 -9999 -9999 -9999 -9999 -9999 -9999 -9999 -9999 -9999 -9999 -9999 -9999 -9999 -9999 -9999 -9999 -9999 -9999 -9999 -9999 -9999 -9999 -9999 -9999 -9999 -9999 -9999 -

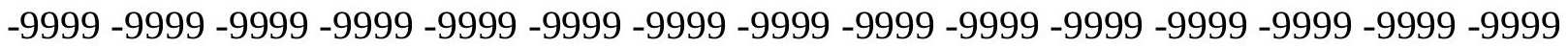

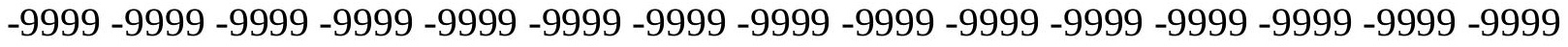

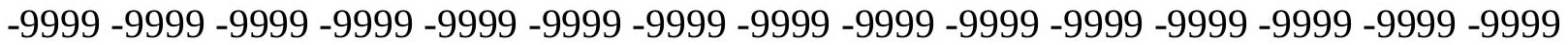
-9999 -9999 -9999 -9999 -9999 -9999 -9999 -9999 -9999 -9999 -9999 -9999 -9999 -9999 -9999

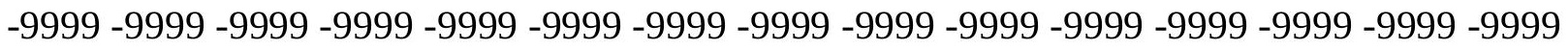

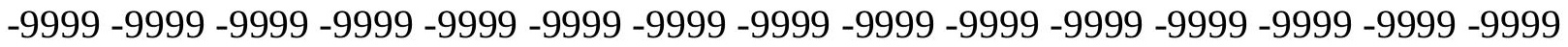

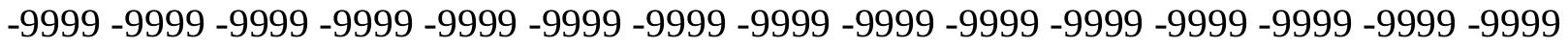
-9999 -9999 -9999 -9999 -9999 -9999 -9999 -9999 -9999 -9999 -9999 -9999 -9999 -9999 -9999 -

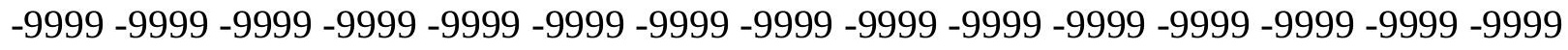

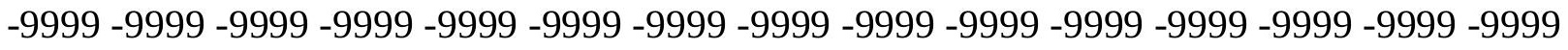
-9999 -9999 -9999 -9999 -9999 -9999 -9999 -9999 -9999 -9999 -9999 -9999 -9999 -9999 -9999 -9999 -9999 -9999 -9999 -9999 -9999 -9999 -9999 -9999 -9999 -9999 -9999 -9999 - -9999 -9999 -9999 -9999 -9999 -9999 -9999 -9999 -9999 -9999 -9999 -9999 -9999 -9999 -9999 -9999 -

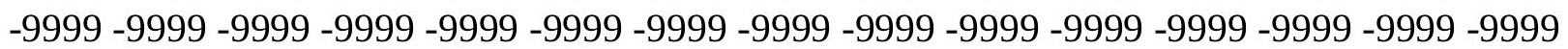


-9999 -9999 -9999 -9999 -9999 -9999 -9999 -9999 -9999 -9999 -9999 -9999 -9999 -9999 -9999 -9999 -9999 -9999 -9999 -9999 -9999 -9999 -9999 -9999 -9999 -9999 -9999 -9999 -9999 -9999 -9999 -9999 -9999 -9999 -9999 -9999 -9999 -9999 -9999 -9999 -9999 -9999 -9999 -9999 - 9999 -9999 -9999 -9999 -9999 -9999 -9999 -9999 -9999 -9999 -9999 -9999 -9999 -9999 -9999 -9999 -9999 -9999 -9999 -9999 -9999 -9999 -9999 -9999 -9999-9999 -9999 -9999 -9999 -9999 -9999 -9999 -9999 -9999 -9999 -9999 -9999 -9999 -9999 -9999 -9999 -9999 -9999 -9999 -9999 -9999 -9999 -9999 -9999 -9999 -9999 -9999 -9999 -9999 -9999 -9999 -9999 -9999 -9999 -9999 -9999

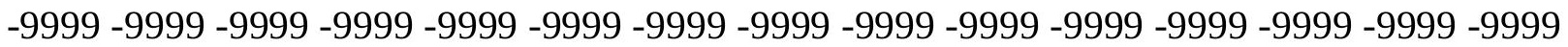

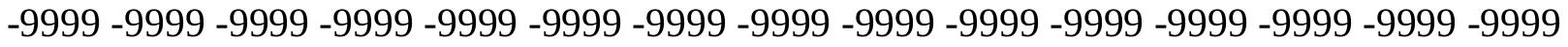
-9999 -9999 -9999 -9999 -9999 -9999 -9999 -9999 -9999 -9999 -9999 -9999 -9999 -9999 -9999

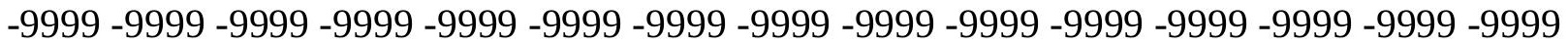
-9999 -9999 -9999 -9999 -9999 -9999 -9999 -9999 -9999 -9999 -9999 -9999 -9999 -9999 -9999 -9999 -9999 -9999 -9999 -9999 -9999 -9999 -9999 -9999 -9999 -9999 -9999 -9999 -9999 -9999 -

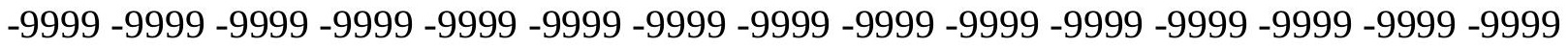
-9999 -9999 -9999 -9999 -9999 -9999 -9999 -9999 -9999 -9999 -9999 -9999 -9999 -9999 -9999

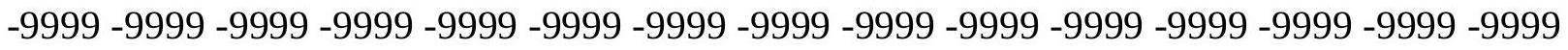
-9999 -9999 -9999 -9999 -9999 -9999 -9999 -9999 -9999 -9999 -9999 -9999 -9999 -9999 -9999 -9999 -9999 -9999 -9999 -9999 -9999 -9999 -9999 -9999 -9999 -9999 -9999 -9999 -9999 -9999 -9999 -9999 -9999 -9999 -9999 -9999 -9999 -9999 -9999 -9999 -9999 -9999 -9999 -9999 -9999 -9999 -9999 -9999 -9999 -9999 -9999 -9999 -9999 -9999 -9999 -9999 -9999 -9999 -9999 -9999 -9999 -9999 -9999 -9999 -9999 -9999 -9999 -9999 -9999 -9999 -9999 -9999 -9999 -9999 -9999 -999 -9999 -9999 -9999 -9999 -9999 -9999 -9999 -9999 -9999 -9999 -9999 -9999 -9999 -9999 -9999 -9999 -9999 -9999 -9999 -9999 -9999 -9999 -9999 -9999 -9999 -9999 -9999 -9999 -9999 -9999 -9999 -9999 -9999 -9999 -9999 -9999 -9999 -9999 -9999 -9999 -9999 -9999 -9999 -9999 -9999 -9999 -9999 -9999 -9999 -9999 -9999 -9999 -9999 -9999 -9999 -9999 -9999 -9999 -9999 -9999 -9999 -9999 -9999 -9999 -9999 -9999 -9999 -9999 -9999 -9999 -9999 -9999 -9999 -9999 -9999 -9999 -9999 -9999 -9999 -9999 -9999 -9999 -9999 -9999 -9999 -9999 -9999 -9999 -9999 -9999 -9999 -9999 -9999 -9999 -9999 -9999 -9999 -9999 -9999 -9999 -9999 -9999 -9999 -9999 -9999 -9999 -9999 -9999 -9999 -9999 -9999 -9999 -9999 -9999 -9999 -9999 -9999 -9999 -9999 -9999 -9999 -9999 -9999 -9999 -9999 -9999 -9999 -9999 -9999 -9999 -9999 -9999 -9999 -999 -9999 -9999 -9999 -9999 -9999 -9999 -9999 -9999 -9999 -9999 -9999 -9999 -9999 -9999 -9999 -9999 -9999 -9999 -9999 -9999 -9999 -9999 -9999 -9999 -9999 -9999 -9999 -9999 -9999 -9999 -

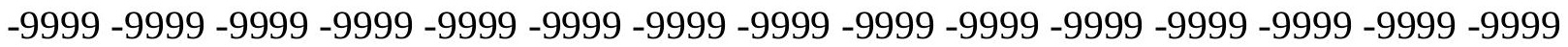

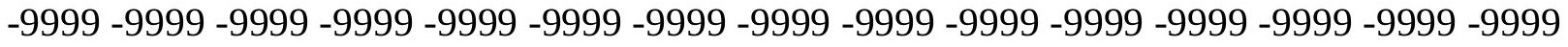

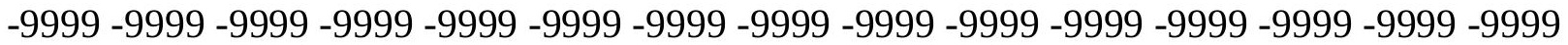
-9999 -9999 -9999 -9999 -9999 -9999 -9999 -9999 -9999 -9999 -9999 -9999 -9999 -9999 -9999

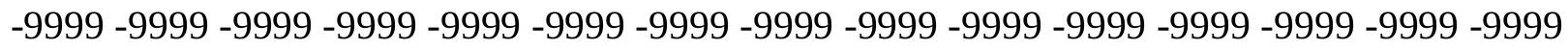

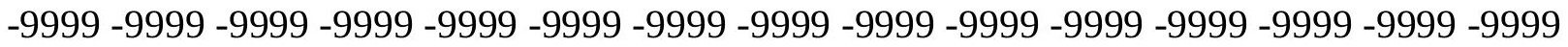
-9999 -9999 -9999 -9999 -9999 -9999 -9999 -9999 -9999 -9999 -9999 -9999 -9999 -9999 -9999 -9999 -9999 -9999 -9999 -9999 -9999 -9999 -9999 -9999 -9999 -9999 -9999 -9999 -9999 -9999 -

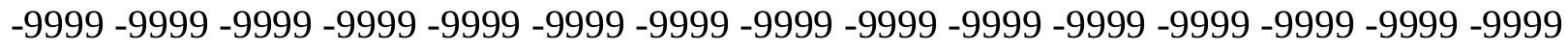

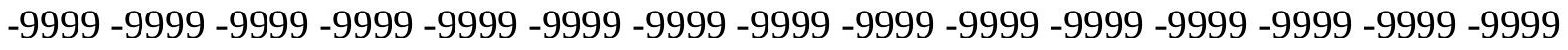
-9999 -9999 -9999 -9999 -9999 -9999 -9999 -9999 -9999 -9999 -9999 -9999 -9999 -9999 -9999 -9999 -9999 -9999 -9999 -9999 -9999 -9999 -9999 -9999-9999 -9999 -9999 -9999 -9999 -9999 -9999 -9999 -9999 -9999 -9999 -9999 -9999 -9999 -9999 -9999 -9999 -9999 -9999 -9999 -9999 -

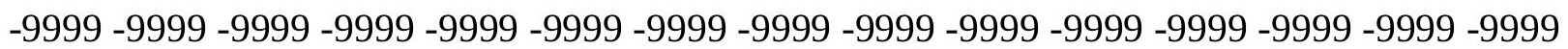


-9999 -9999 -9999 -9999 -9999 -9999 -9999 -9999 -9999 -9999 -9999 -9999 -9999 -9999 -9999 -9999 -9999 -9999 -9999 -9999 -9999 -9999 -9999 -9999 -9999 -9999 -9999 -9999 -9999 -9999 -9999 -9999 -9999 -9999 -9999 -9999 -9999 -9999 -9999 -9999 -9999 -9999 -9999 -9999 - 9999 -9999 -9999 -9999 -9999 -9999 -9999 -9999 -9999 -9999 -9999 -9999 -9999 -9999 -9999

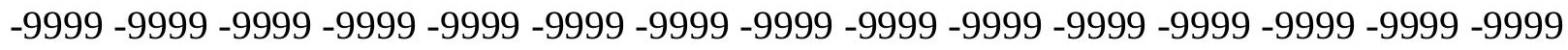
-9999 -9999 -9999 -9999 -9999 -9999 -9999 -9999 -9999 -9999 -9999 -9999 -9999 -9999 -9999 -9999 -9999 -9999 -9999 -9999 -9999 -9999 -9999 -9999 -9999 -9999 -9999 -9999 -9999 -9999

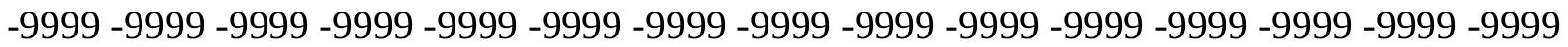

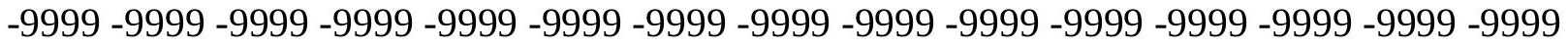
-9999 -9999 -9999 -9999 -9999 -9999 -9999 -9999 -9999 -9999 -9999 -9999 -9999 -9999 -9999 -9999 -9999 -9999 -9999 -9999 -9999 -9999 -9999 -9999 -9999 -9999 -9999 -9999 -9999 -9999 -9999 -9999 -9999 -9999 -9999 -9999 -9999 -9999 -9999 -9999 -9999 -9999 -9999 -9999 -9999 -9999 -9999 -9999 -9999 -9999 -9999 -9999 -9999 -9999 -9999 -9999 -9999 -9999 -9999 -9999 -

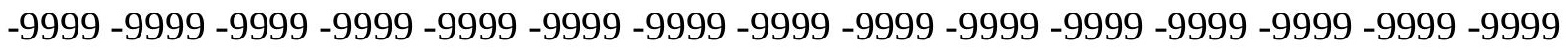
-9999 -9999 -9999 -9999 -9999 -9999 -9999 -9999 -9999 -9999 -9999 -9999 -9999 -9999 -9999 -

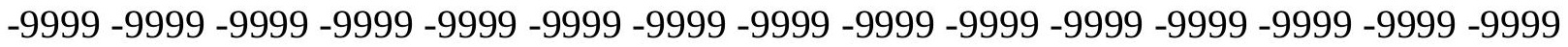
-9999 -9999 -9999 -9999 -9999 -9999 -9999 -9999 -9999 -9999 -9999 -9999 -9999 -9999 -9999 -9999 -9999 -9999 -9999 -9999 -9999 -9999 -9999 -9999 -9999 -9999 -9999 -9999 -9999 -9999 -9999 -9999 -9999 -9999 -9999 -9999 -9999 -9999 -9999 -9999 -9999 -9999 -9999 -9999 -9999 -

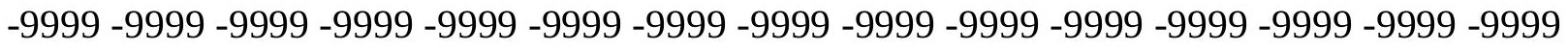
-9999 -9999 -9999 -9999 -9999 -9999 -9999 -9999 -9999 -9999 -9999 -9999 -9999 -9999 -9999

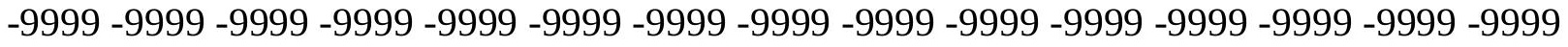
-9999 -9999 -9999 -9999 -9999 -9999 -9999 -9999 -9999 -9999 -9999 -9999 -9999 -9999 -9999 -9999 -9999 -9999 -9999 -9999 -9999 -9999 -9999 -9999 -9999 -9999 -9999 -9999 -9999 -9999 -9999 -9999 -9999 -9999 -9999 -9999 -9999 -9999 -9999 -9999 -9999 -9999 -9999 -9999 -9999 -9999 -9999 -9999 -9999 -9999 -9999 -9999 -9999 -9999 -9999 -9999 -9999 -9999 -9999 -9999 -9999 -9999 -9999 -9999 -9999 -9999 -9999 -9999 -9999 -9999 -9999 -9999 -9999 -9999 -9999 -9999 -9999 -9999 -9999 -9999 -9999 -9999 -9999 -9999 -9999 -9999 -9999 -9999 -9999 -9999 -9999 -9999 -9999 -9999 -9999 -9999 -9999 -9999 -9999 -9999 -9999 -9999 -9999 -9999 -9999 -9999 -9999 -9999 -9999 -9999 -9999 -9999 -9999 -9999 -9999 -9999 -9999 -9999 -9999 -9999 -9999 -9999 -9999 -9999 -9999 -9999 -9999 -9999 -9999 -9999 -9999 -9999 -9999 -9999 -9999 -9999 -9999 -9999 -9999 -9999 -9999 -9999 -9999 -9999 -9999 -9999 -9999 -9999 -9999 -

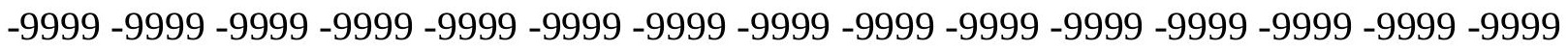

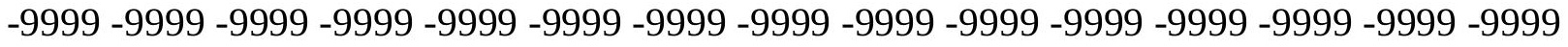
-9999 -9999 -9999 -9999 -9999 -9999 -9999 -9999 -9999 -9999 -9999 -9999 -9999 -9999 -9999 -

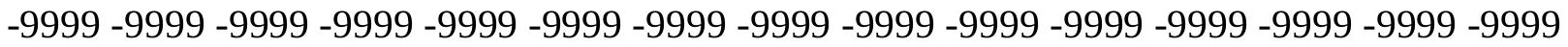

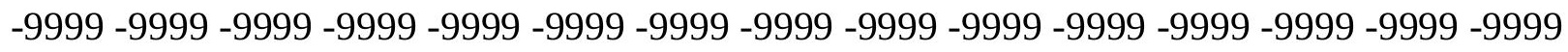

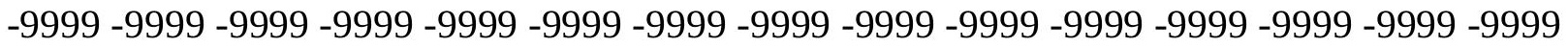

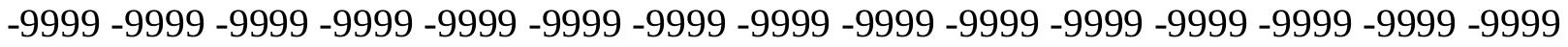
-9999 -9999 -9999 -9999 -9999 -9999 -9999 -9999 -9999 -9999 -9999 -9999 -9999 -9999 -9999 -

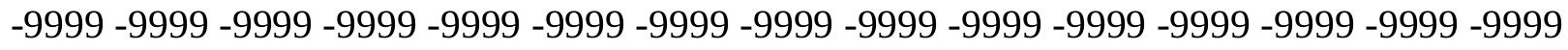

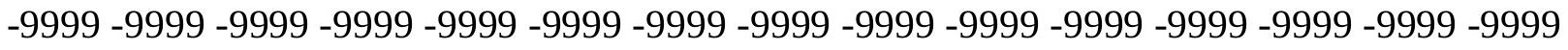
-9999 -9999 -9999 -9999 -9999 -9999 -9999 -9999 -9999 -9999 -9999 -9999 -9999 -9999 -9999 -9999 -9999 -9999 -9999 -9999 -9999 -9999 -9999 -9999-9999 -9999 -9999 -9999 -9999 -9999 -9999 -9999 -9999 -9999 -9999 -9999 -9999 -9999 -9999 -9999 -9999 -9999 -9999 -9999 -9999 -

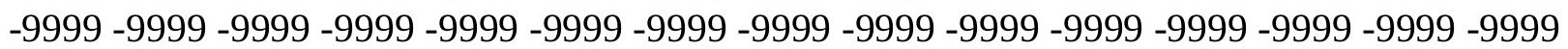


-9999 -9999 -9999 -9999 -9999 -9999 -9999 -9999 -9999 -9999 -9999 -9999 -9999 -9999 -9999 -9999 -9999 -9999 -9999 -9999 -9999 -9999 -9999 -9999 -9999 -9999 -9999 -9999 -9999 -9999 -9999 -9999 -9999 -9999 -9999 -9999 -9999 -9999 -9999 -9999 -9999 -9999 -9999 -9999 - 9999 -9999 -9999 -9999 -9999 -9999 -9999 -9999 -9999 -9999 -9999 -9999 -9999 -9999 -9999 -9999 -9999 -9999 -9999 -9999 -9999 -9999 -9999 -9999 -9999 -9999 -9999 -9999 -9999 -9999 -9999 -9999 -9999 -9999 -9999 -9999 -9999 -9999 -9999 -9999 -9999 -9999 -9999 -9999 -9999 -9999 -9999 -9999 -9999 -9999 -9999 -9999 -9999 -9999 -9999 -9999 -9999 -9999 -9999 -9999 -9999

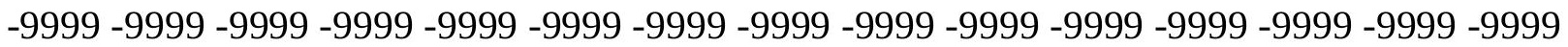

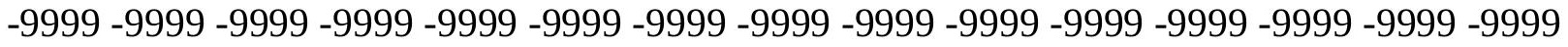
-9999 -9999 -9999 -9999 -9999 -9999 -9999 -9999 -9999 -9999 -9999 -9999 -9999 -9999 -9999 -9999 -9999 -9999 -9999 -9999 -9999 -9999 -9999 -9999 -9999 -9999 -9999 -9999 -9999 -9999 -9999 -9999 -9999 -9999 -9999 -9999 -9999 -9999 -9999 -9999 -9999 -9999 -9999 -9999 -9999 -9999 -9999 -9999 -9999 -9999 -9999 -9999 -9999 -9999 -9999 -9999 -9999 -9999 -9999 -9999 -9999 -9999 -9999 -9999 -9999 -9999 -9999 -9999 -9999 -9999 -9999 -9999 -9999 -9999 -9999 -9999 -9999 -9999 -9999 -9999 -9999 -9999 -9999 -9999 -9999 -9999 -9999 -9999 -9999 -

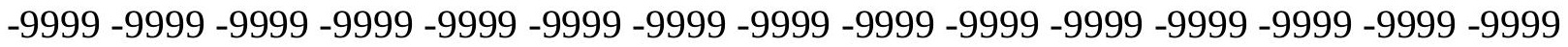
-9999 -9999 -9999 -9999 -9999 -9999 -9999 -9999 -9999 -9999 -9999 -9999 -9999 -9999 -9999 -9999 -9999 -9999 -9999 -9999 -9999 -9999 -9999 -9999 -9999 -9999 -9999 -9999 -9999 -9999 -9999 -9999 -9999 -9999 -9999 -9999 -9999 -9999 -9999 -9999 -9999 -9999 -9999 -9999 -9999 -9999 -9999 -9999 -9999 -9999 -9999 -9999 -9999 -9999 -9999 -9999 -9999 -9999 -9999 -9999 -9999 -9999 -9999 -9999 -9999 -9999 -9999 -9999 -9999 -9999 -9999 -9999 -9999 -9999 -9999 -999 -9999 -9999 -9999 -9999 -9999 -9999 -9999 -9999 -9999 -9999 -9999 -9999 -9999 -9999 -9999 -9999 -9999 -9999 -9999 -9999 -9999 -9999 -9999 -9999 -9999 -9999 -9999 -9999 -9999 -9999 -9999 -9999 -9999 -9999 -9999 -9999 -9999 -9999 -9999 -9999 -9999 -9999 -9999 -9999 -9999 -9999 -9999 -9999 -9999 -9999 -9999 -9999 -9999 -9999 -9999 -9999 -9999 -9999 -9999 -9999 -9999 -9999 -9999 -9999 -9999 -9999 -9999 -9999 -9999 -9999 -9999 -9999 -9999 -9999 -9999 -9999 -9999 -9999 -9999 -9999 -9999 -9999 -9999 -9999 -9999 -9999 -9999 -9999 -9999 -9999 -9999 -9999 -9999 -9999 -9999 -9999 -9999 -9999 -9999 -9999 -9999 -9999 -9999 -9999 -9999 -9999 -9999 -9999 -9999 -9999 -9999 -9999 -9999 -9999 -9999 -9999 -9999 -9999 -9999 -9999 -9999 -9999 -9999 -9999 -9999 -9999 -9999 -9999 -9999 -9999 -9999 -9999 -9999 -9999 -999 -9999 -9999 -9999 -9999 -9999 -9999 -9999 -9999 -9999 -9999 -9999 -9999 -9999 -9999 -9999 -9999 -9999 -9999 -9999 -9999 -9999 -9999 -9999 -9999 -9999 -9999 -9999 -9999 -9999 -9999 -

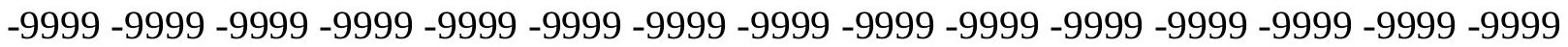

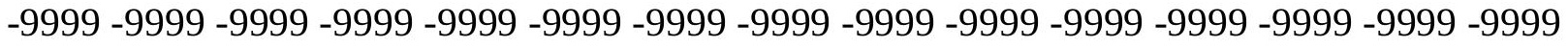

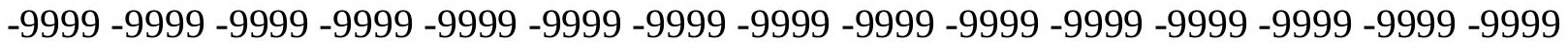
-9999 -9999 -9999 -9999 -9999 -9999 -9999 -9999 -9999 -9999 -9999 -9999 -9999 -9999 -9999 -9999 -9999 -9999 -9999 -9999 -9999 -9999 -9999 -9999 -9999 -9999 -9999 -9999 -9999 -

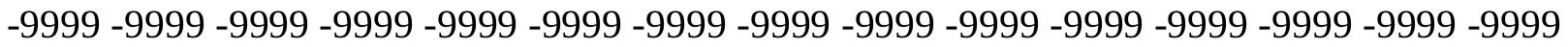
-9999 -9999 -9999 -9999 -9999 -9999 -9999 -9999 -9999 -9999 -9999 -9999 -9999 -9999 -9999 -9999 -9999 -9999 -9999 -9999 -9999 -9999 -9999 -9999 -9999 -9999 -9999 -9999 -9999 -9999 -

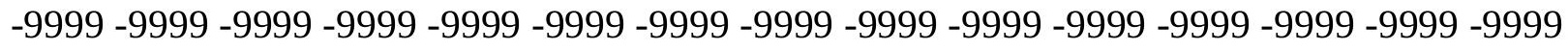

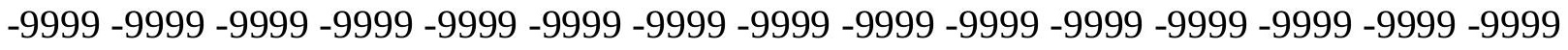
-9999 -9999 -9999 -9999 -9999 -9999 -9999 -9999 -9999 -9999 -9999 -9999 -9999 -9999 -9999 -9999 -9999 -9999 -9999 -9999 -9999 -9999 -9999 -9999-9999 -9999 -9999 -9999 -9999 -9999 -9999 -9999 -9999 -9999 -9999 -9999 -9999 -9999 -9999 -9999 -9999 -9999 -9999 -9999 -9999 -

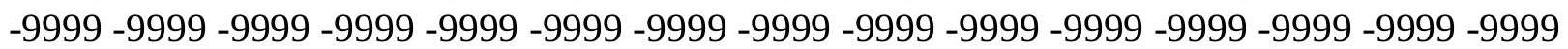


-9999 -9999 -9999 -9999 -9999 -9999 -9999 -9999 -9999 -9999 -9999 -9999 -9999 -9999 -9999 -9999 -9999 -9999 -9999 -9999 -9999 -9999 -9999 -9999 -9999 -9999 -9999 -9999 -9999 -9999 -

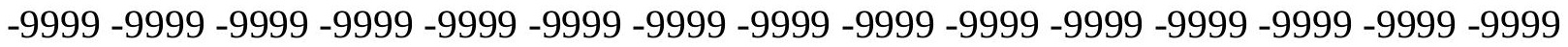
-9999 -9999 -9999 -9999 -9999 -9999 -9999 -9999 -9999 -9999 -9999 -9999 -9999 -9999 -9999 -9999 -9999 -9999 -9999 -9999 -9999 -9999 -9999 -9999-9999 -9999 -9999 -9999 -9999 -9999 -9999 -9999 -9999 -9999 -9999 -9999 -9999 -9999 -9999 -9999 -9999 -9999 -9999 -9999 -9999 -9999 -9999 -9999 -9999 -9999 -9999 -9999 -9999 -9999 -9999 -9999 -9999 -9999 -9999 -9999

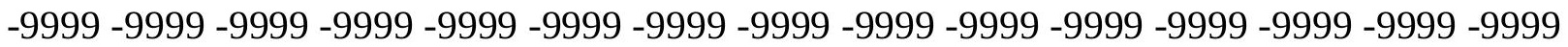

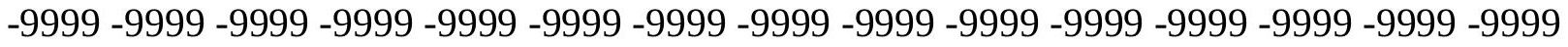
-9999 -9999 -9999 -9999 -9999 -9999 -9999 -9999 -9999 -9999 -9999 -9999 -9999 -9999 -9999 -9999 -9999 -9999 -9999 -9999 -9999 -9999 -9999 -9999 -9999 -9999 -9999 -9999 -9999 -9999 -9999 -9999 -9999 -9999 -9999 -9999 -9999 -9999 -9999 -9999 -9999 -9999 -9999 -9999 -9999 -9999 -9999 -9999 -9999 -9999 -9999 -9999 -9999 -9999 -9999 -9999 -9999 -9999 -9999 -9999 -9999 -9999 -9999 -9999 -9999 -9999 -9999 -9999 -9999 -9999 -9999 -9999 -9999 -9999 -9999 -9999 -9999 -9999 -9999 -9999 -9999 -9999 -9999 -9999 -9999 -9999 -9999 -9999 -9999 -9999 -

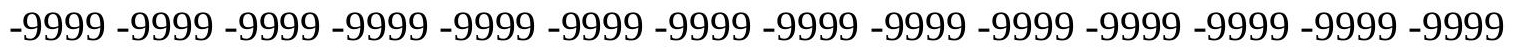
-9999 -9999 -9999 -9999 -9999 -9999 -9999 -9999 -9999 -9999 -9999 -9999 -9999 -9999 -9999 -9999 -9999 -9999 -9999 -9999 -9999 -9999 -9999 -9999 -9999 -9999 -9999 -9999 -9999 -9999 -9999 -9999 -9999 -9999 -9999 -9999 -9999 -9999 -9999 -9999 -9999 -9999 -9999 -9999 -9999 -

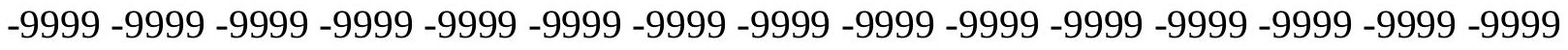

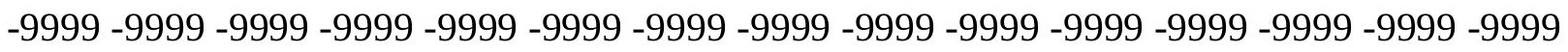
-9999 -9999 -9999 -9999 -9999 -9999 -9999 -9999 -9999 -9999 -9999 -9999 -9999 -9999 - 9999 -9999 -9999 -9999 -9999 -9999 -9999 -9999 -9999 -9999 -9999 -9999 -9999 -9999 -9999 -9999 -9999 -9999 -9999 -9999 -9999 -9999 -9999 -9999 -9999 -9999 -9999 -9999 -9999 -9999 -9999 -

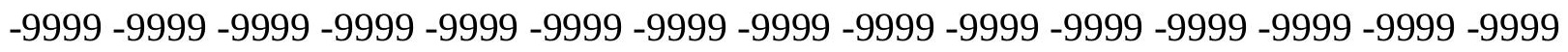
-9999 -9999 -9999 -9999 -9999 -9999 -9999 -9999 -9999 -9999 -9999 -9999 -9999 -9999 -9999 -9999 -9999 -9999 -9999 -9999 -9999 -9999 -9999 -9999 -9999 -9999 -9999 -9999 -9999 -9999 -

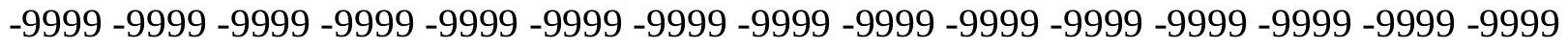
-9999 -9999 -9999 -9999 -9999 -9999 -9999 -9999 -9999 -9999 -9999 -9999 -9999 -9999 -9999 -9999 -9999 -9999 -9999 -9999 -9999 -9999 -9999 -9999 -9999 -9999 -9999 -9999 -9999 -999 -

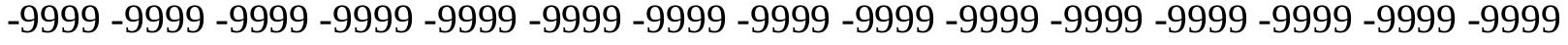
-9999 -9999 -9999 -9999 -9999 -9999 -9999 -9999 -9999 -9999 -9999 -9999 -9999 -9999 -9999 -

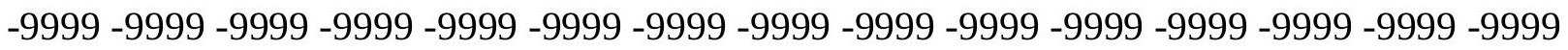

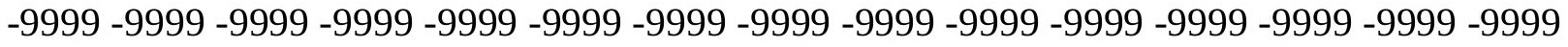

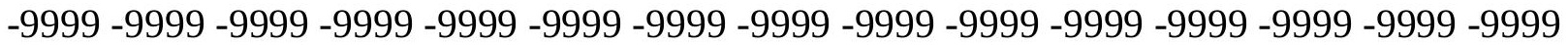
-9999 -9999 -9999 -9999 -9999 -9999 -9999 -9999 -9999 -9999 -9999 -9999 -9999 -9999 -9999 -

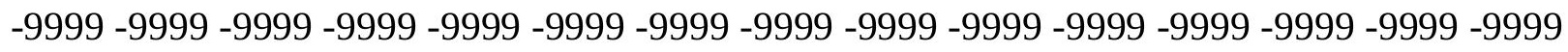

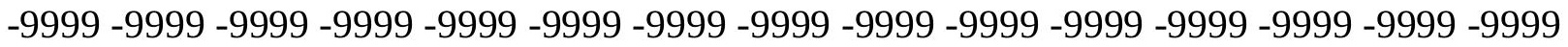
-9999 -9999 -9999 -9999 -9999 -9999 -9999 -9999 -9999 -9999 -9999 -9999 -9999 - 9999 - -999 -9999 -9999 -9999 -9999 -9999 -9999 -9999 -9999 -9999 -9999 -9999 -9999 -9999 -9999 -9999 -

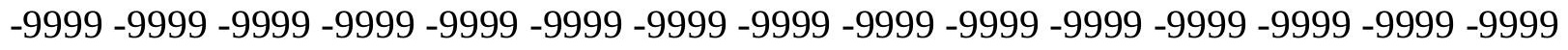

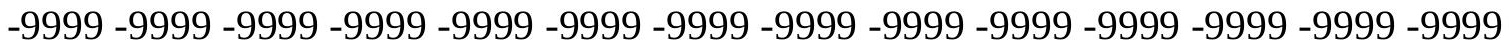
-9999 -9999 -9999 -9999 -9999 -9999 -9999 -9999 -9999 -9999 -9999 -9999 -9999 -9999 -9999 -9999 -9999 -9999 -9999 -9999 -9999 -9999 -9999 -9999-9999 -9999 -9999 -9999 -9999 -9999 -9999 -9999 -9999 -9999 -9999 -9999 -9999 -9999 -9999 -9999 -9999 -9999 -9999 -9999 -9999 -

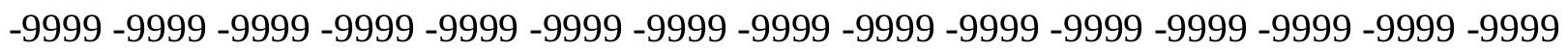


-9999 -9999 -9999 -9999 -9999 -9999 -9999 -9999 -9999 -9999 -9999 -9999 -9999 -9999 -9999 -9999 -9999 -9999 -9999 -9999 -9999 -9999 -9999 -9999 -9999 -9999 -9999 -9999 -9999 -9999 -

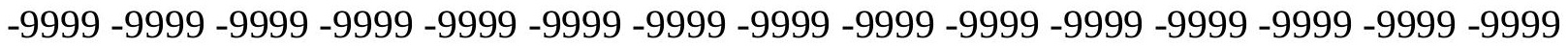
-9999 -9999 -9999 -9999 -9999 -9999 -9999 -9999 -9999 -9999 -9999 -9999 -9999 -9999 -9999 -9999 -9999 -9999 -9999 -9999 -9999 -9999 -9999 -9999-9999 -9999 -9999 -9999 -9999 -9999 -9999 -9999 -9999 -9999 -9999 -9999 -9999 -9999 -9999 -9999 -9999 -9999 -9999 -9999 -9999 -9999 -9999 -9999 -9999 -9999 -9999 -9999 -9999 -9999 -9999 -9999 -9999 -9999 -9999 -9999

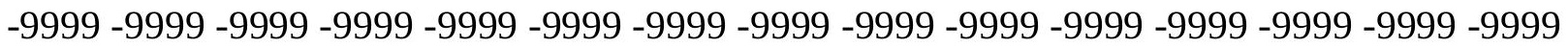

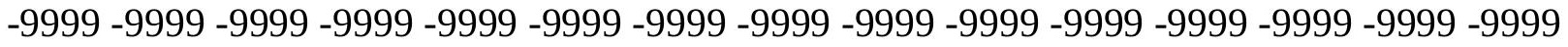
-9999 -9999 -9999 -9999 -9999 -9999 -9999 -9999 -9999 -9999 -9999 -9999 -9999 -9999 -9999 -9999 -9999 -9999 -9999 -9999 -9999 -9999 -9999 -9999 -9999 -9999 -9999 -9999 -9999 -9999 -9999 -9999 -9999 -9999 -9999 -9999 -9999 -9999 -9999 -9999 -9999 -9999 -9999 -9999 -9999 -9999 -9999 -9999 -9999 -9999 -9999 -9999 -9999 -9999 -9999 -9999 -9999 -9999 -9999 -9999 -

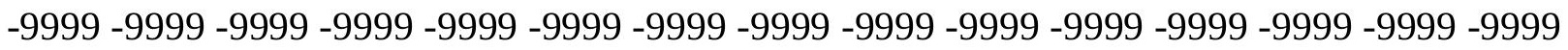
-9999 -9999 -9999 -9999 -9999 -9999 -9999 -9999 -9999 -9999 -9999 -9999 -9999 -9999 -9999 -

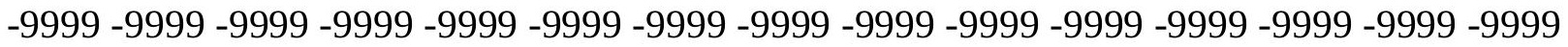
-9999 -9999 -9999 -9999 -9999 -9999 -9999 -9999 -9999 -9999 -9999 -9999 -9999 -9999 -9999 -9999 -9999 -9999 -9999 -9999 -9999 -9999 -9999 -9999 -9999 -9999 -9999 -9999 -9999 -9999 -9999 -9999 -9999 -9999 -9999 -9999 -9999 -9999 -9999 -9999 -9999 -9999 -9999 -9999 -9999 -

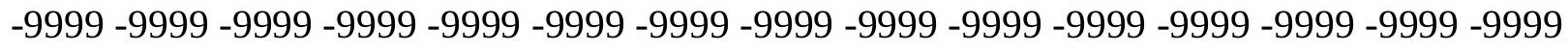

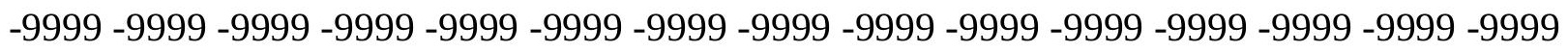
-9999 -9999 -9999 -9999 -9999 -9999 -9999 -9999 -9999 -9999 -9999 -9999 -9999 -9999 -9999 -9999 -9999 -9999 -9999 -9999 -9999 -9999 -9999 -9999 -9999 -9999 -9999 -9999 -9999 -9999 -9999 -9999 -9999 -9999 -9999 -9999 -9999 -9999 -9999 -9999 -9999 -9999 -9999 -9999 -

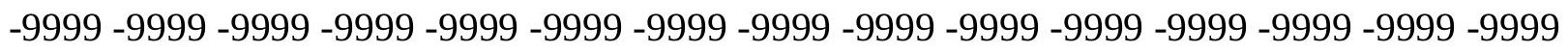
-9999 -9999 -9999 -9999 -9999 -9999 -9999 -9999 -9999 -9999 -9999 -9999 -9999 -9999 -9999 -9999 -9999 -9999 -9999 -9999 -9999 -9999 -9999 -9999 -9999 -9999 -9999 -9999 -9999 -9999 -

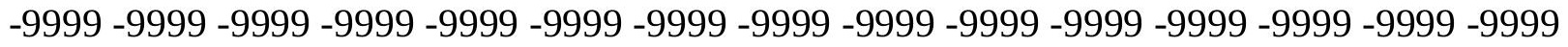
-9999 -9999 -9999 -9999 -9999 -9999 -9999 -9999 -9999 -9999 -9999 -9999 -9999 -9999 -9999 -9999 -9999 -9999 -9999 -9999 -9999 -9999 -9999 -9999 -9999 -9999 -9999 -9999 -9999 -999 -

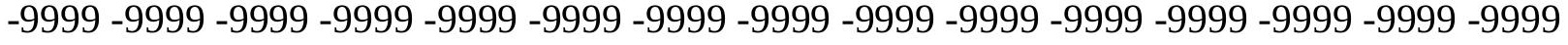
-9999 -9999 -9999 -9999 -9999 -9999 -9999 -9999 -9999 -9999 -9999 -9999 -9999 -9999 -9999 -

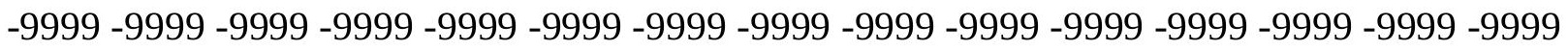

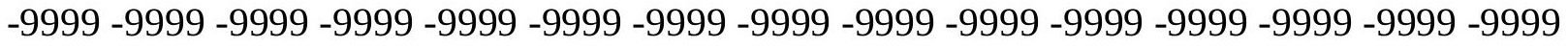

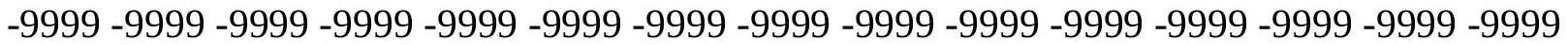

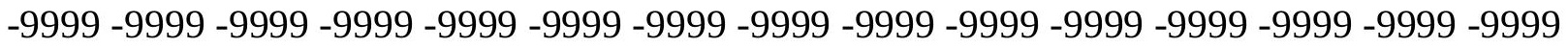

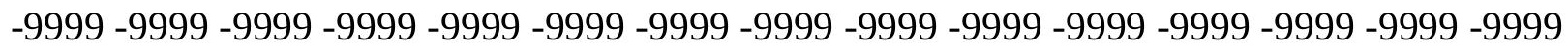

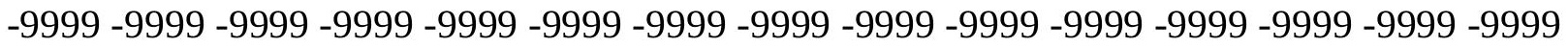

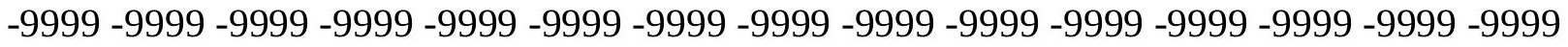
-9999 -9999 -9999 -9999 -9999 -9999 -9999 -9999 -9999 -9999 -9999 -9999 -9999 -9999 -9999 -

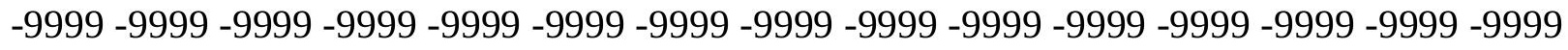

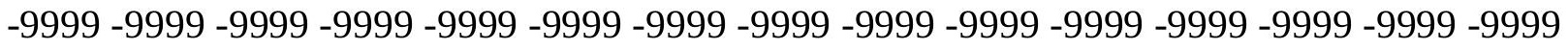
-9999 -9999 -9999 -9999 -9999 -9999 -9999 -9999 -9999 -9999 -9999 -9999 -9999 -9999 -9999 -9999 -9999 -9999 -9999 -9999 -9999 -9999 -9999 -9999-9999 -9999 -9999 -9999 -9999 -9999 -9999 -9999 -9999 -9999 -9999 -9999 -9999 -9999 -9999 -9999 -9999 -9999 -9999 -9999 -9999 -

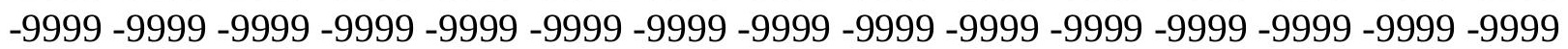


-9999 -9999 -9999 -9999 -9999 -9999 -9999 -9999 -9999 -9999 -9999 -9999 -9999 -9999 -9999 -9999 -9999 -9999 -9999 -9999 -9999 -9999 -9999 -9999 -9999 -9999 -9999 -9999 -9999 -

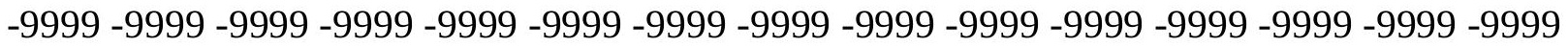
-9999 -9999 -9999 -9999 -9999 -9999 -9999 -9999 -9999 -9999 -9999 -9999 -9999 -9999 -9999 -9999 -9999 -9999 -9999 -9999 -9999 -9999 -9999 -9999 -9999 -9999 -9999 -9999 -9999 -9999 -9999 -9999 -9999 -9999 -9999 -9999 -9999 -9999 -9999 -9999 -9999 -9999 -9999 -9999 -9999 -9999 -9999 -9999 -9999 -9999 -9999 -9999 -9999 -9999 -9999 -9999 -9999 -9999 -9999 -9999

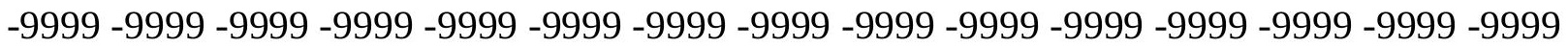

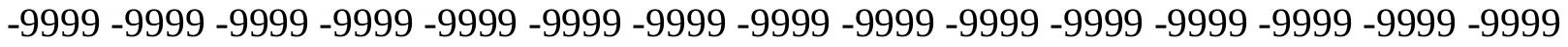
-9999 -9999 -9999 -9999 -9999 -9999 -9999 -9999 -9999 -9999 -9999 -9999 -9999 -9999 -9999 -9999 -9999 -9999 -9999 -9999 -9999 -9999 -9999 -9999 -9999 -9999 -9999 -9999 -9999 -9999 -9999 -9999 -9999 -9999 -9999 -9999 -9999 -9999 -9999 -9999 -9999 -9999 -9999 -9999 -9999 -9999 -9999 -9999 -9999 -9999 -9999 -9999 -9999 -9999 -9999 -9999 -9999 -9999 -9999 -9999 -9999 -9999 -9999 -9999 -9999 -9999 -9999 -9999 -9999 -9999 -9999 -9999 -9999 -9999 -9999 -9999 -9999 -9999 -9999 -9999 -9999 -9999 -9999 -9999 -9999 -9999 -9999 -9999 -9999 -9999 -

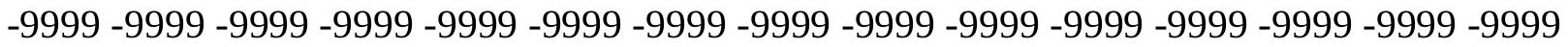
-9999 -9999 -9999 -9999 -9999 -9999 -9999 -9999 -9999 -9999 -9999 -9999 -9999 -9999 -9999 -9999 -9999 -9999 -9999 -9999 -9999 -9999 -9999 -9999 -9999 -9999 -9999 -9999 -9999 - 9999 -9999 -9999 -9999 -9999 -9999 -9999 -9999 -9999 -9999 -9999 -9999 -9999 -9999 -9999 -9999 -

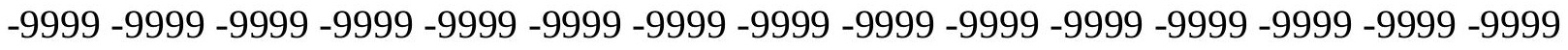

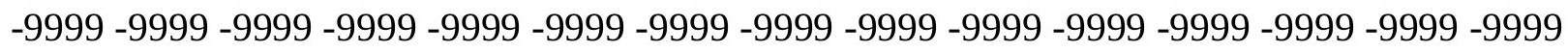

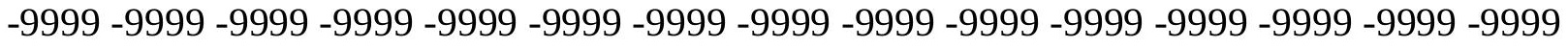
-9999 -9999 -9999 -9999 -9999 -9999 -9999 -9999 -9999 -9999 -9999 -9999 -9999 -9999 -9999 -9999 -9999 -9999 -9999 -9999 -9999 -9999 -9999 -9999 -9999 -9999 -9999 -9999 -9999 -9999 -

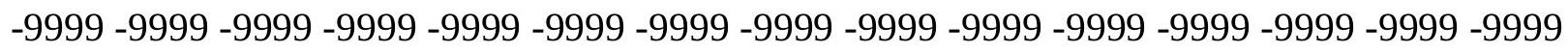
-9999 -9999 -9999 -9999 -9999 -9999 -9999 -9999 -9999 -9999 -9999 -9999 -9999 -9999 -9999 -9999 -9999 -9999 -9999 -9999 -9999 -9999 -9999 -9999 -9999 -9999 -9999 -9999 -9999 -9999 -9999 -9999 -9999 -9999 -9999 -9999 -9999 -9999 -9999 -9999 -9999 -9999 -9999 -9999 -9999 -9999 -9999 -9999 -9999 -9999 -9999 -9999 -9999 -9999 -9999 -9999 -9999 -9999 -9999 -9999 -9999 -9999 -9999 -9999 -9999 -9999 -9999 -9999 -9999 -9999 -9999 -9999 -9999 -999 -

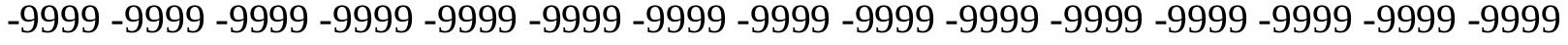
-9999 -9999 -9999 -9999 -9999 -9999 -9999 -9999 -9999 -9999 -9999 -9999 -9999 -9999 -9999 -

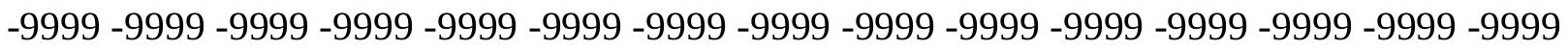

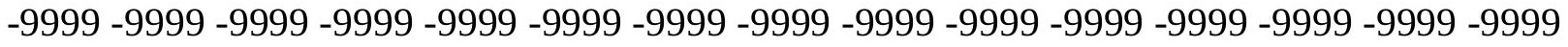

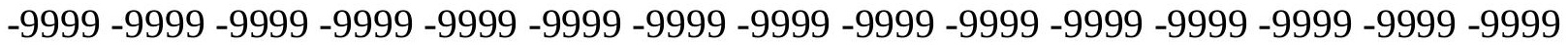

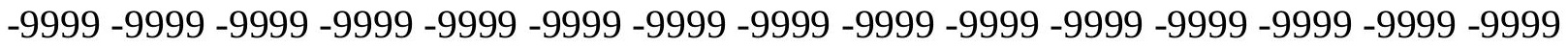

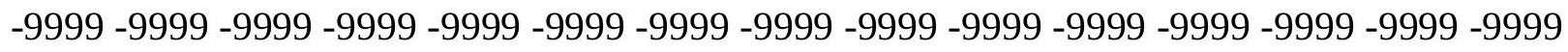

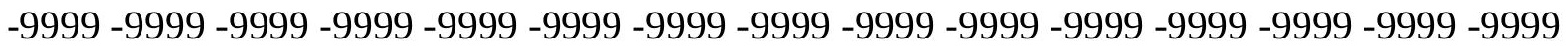

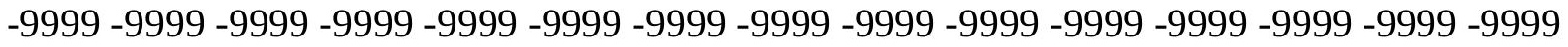
-9999 -9999 -9999 -9999 -9999 -9999 -9999 -9999 -9999 -9999 -9999 -9999 -9999 -9999 -9999 -

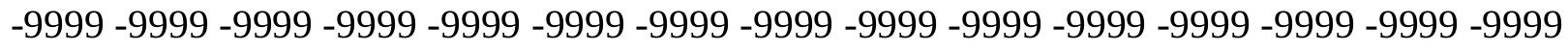

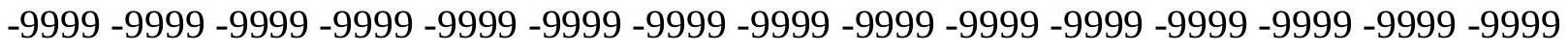
-9999 -9999 -9999 -9999 -9999 -9999 -9999 -9999 -9999 -9999 -9999 -9999 -9999 -9999 -9999 -9999 -9999 -9999 -9999 -9999 -9999 -9999 -9999 -9999-9999 -9999 -9999 -9999 -9999 -9999 -9999 -9999 -9999 -9999 -9999 -9999 -9999 -9999 -9999 -9999 -9999 -9999 -9999 -9999 -9999 -

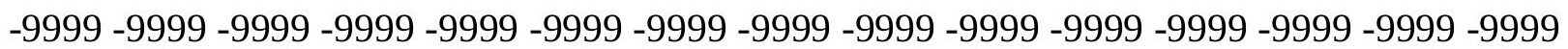


-9999 -9999 -9999 -9999 -9999 -9999 -9999 -9999 -9999 -9999 -9999 -9999 -9999 -9999 -9999 -9999 -9999 -9999 -9999 -9999 -9999 -9999 -9999 -9999 -9999 -9999 -9999 -9999 -9999 -9999 -

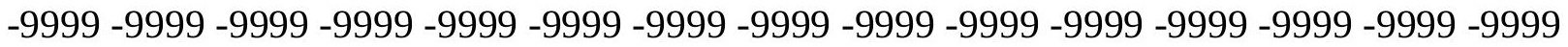
-9999 -9999 -9999 -9999 -9999 -9999 -9999 -9999 -9999 -9999 -9999 -9999 -9999 -9999 -9999 -9999 -9999 -9999 -9999 -9999 -9999 -9999 -9999 -9999-9999 -9999 -9999 -9999 -9999 -9999 -9999 -9999 -9999 -9999 -9999 -9999 -9999 -9999 -9999 -9999 -9999 -9999 -9999 -9999 -9999 -

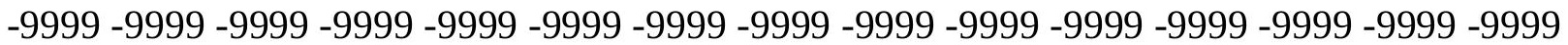
-9999 -9999 -9999 -9999 -9999 -9999 -9999 -9999 -9999 -9999 -9999 -9999 -9999 -9999 -9999 -9999 -9999 -9999 -9999 -9999 -9999 -9999 -9999 -9999 -9999 -9999 -9999 -9999 -9999 -9999 -9999 -9999 -9999 -9999 -9999 -9999 -9999 -9999 -9999 -9999 -9999 -9999 -9999 -9999 -9999 -9999 -9999 -9999 -9999 -9999 -9999 -9999 -9999 -9999 -9999 -9999 -9999 -9999 -9999 -9999 -9999 -9999 -9999 -9999 -9999 -9999 -9999 -9999 -9999 -9999 -9999 -9999 -9999 -9999 -9999 -9999 -9999 -9999 -9999 -9999 -9999 -9999 -9999 -9999 -9999 -9999 -9999 -9999 -9999 -9999 -9999 -9999 -9999 -9999 -9999 -9999 -9999 -9999 -9999 -9999 -9999 -9999 -9999 -9999 -9999 -9999 -9999 -9999 -9999 -9999 -9999 -9999 -9999 -9999 -9999 -9999 -9999 -9999 -9999 -

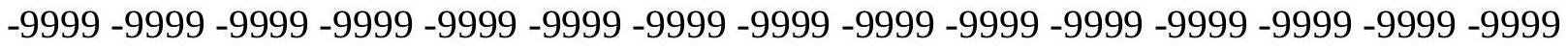
-9999 -9999 -9999 -9999 -9999 -9999 -9999 -9999 -9999 -9999 -9999 -9999 -9999 -9999 -9999 -9999 -9999 -9999 -9999 -9999 -9999 -9999 -9999 -9999 -9999 -9999 -9999 -9999 -9999 -9999 -9999 -9999 -9999 -9999 -9999 -9999 -9999 -9999 -9999 -9999 -9999 -9999 -9999 -9999 -9999 -

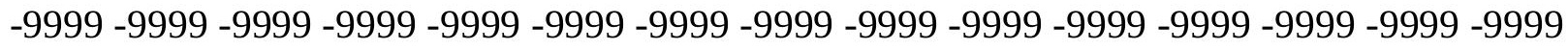

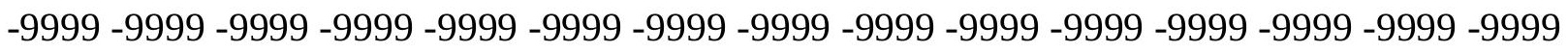
-9999 -9999 -9999 -9999 -9999 -9999 -9999 -9999 -9999 -9999 -9999 -9999 -9999 -9999 - 9999 -9999 -9999 -9999 -9999 -9999 -9999 -9999 -9999 -9999 -9999 -9999 -9999 -9999 -9999 -9999 -9999 -9999 -9999 -9999 -9999 -9999 -9999 -9999 -9999 -9999 -9999 -9999 -9999 -9999 -9999 -

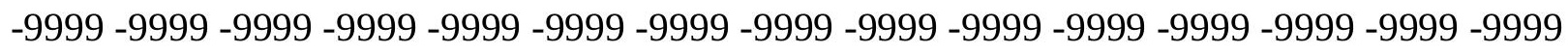
-9999 -9999 -9999 -9999 -9999 -9999 -9999 -9999 -9999 -9999 -9999 -9999 -9999 -9999 -9999 -9999 -9999 -9999 -9999 -9999 -9999 -9999 -9999 -9999 -9999 -9999 -9999 -9999 -9999 -9999 -

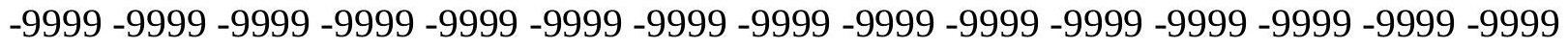
-9999 -9999 -9999 -9999 -9999 -9999 -9999 -9999 -9999 -9999 -9999 -9999 -9999 -9999 -9999 -9999 -9999 -9999 -9999 -9999 -9999 -9999 -9999 -9999 -9999 -9999 -9999 -9999 -9999 -999 -9999 -9999 -9999 -9999 -9999 -9999 -9999 -9999 -9999 -9999 -9999 -9999 -9999 -9999 -9999 -9999 -9999 -9999 -9999 -9999 -9999 -9999 -9999 -9999 -9999 -9999 -9999 -9999 -9999 -9999 -

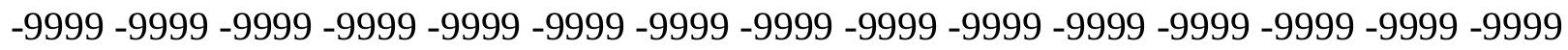

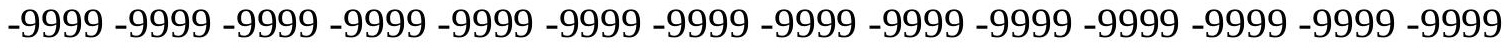
-9999 -9999 -9999 -9999 -9999 -9999 -9999 -9999 -9999 -9999 -9999 -9999 -9999 -9999 -9999

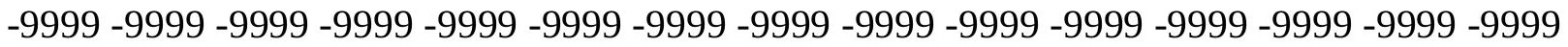

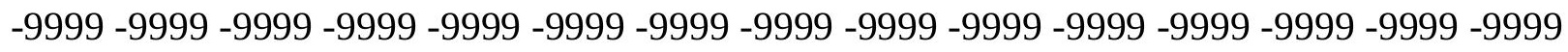

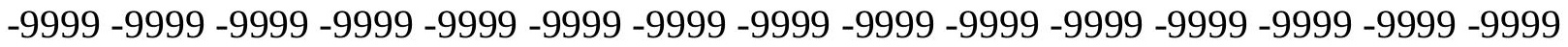

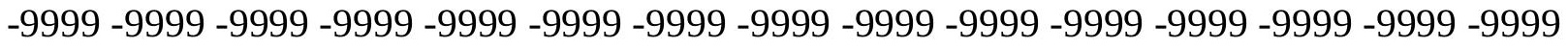
-9999 -9999 -9999 -9999 -9999 -9999 -9999 -9999 -9999 -9999 -9999 -9999 -9999 -9999 -9999 -

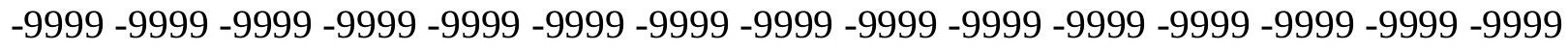

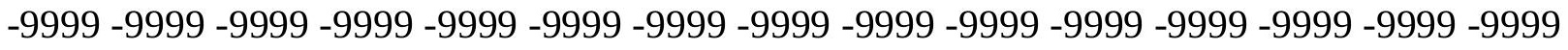
-9999 -9999 -9999 -9999 -9999 -9999 -9999 -9999 -9999 -9999 -9999 -9999 -9999 -9999 -9999 -9999 -9999 -9999 -9999 -9999 -9999 -9999 -9999 -9999-9999 -9999 -9999 -9999 -9999 -9999 -9999 -9999 -9999 -9999 -9999 -9999 -9999 -9999 -9999 -9999 -9999 -9999 -9999 -9999 -9999 -

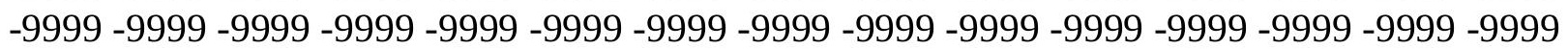


-9999 -9999 -9999 -9999 -9999 -9999 -9999 -9999 -9999 -9999 -9999 -9999 -9999 -9999 -9999 -9999 -9999 -9999 -9999 -9999 -9999 -9999 -9999 -9999 -9999 -9999 -9999 -9999 -9999 -9999 -

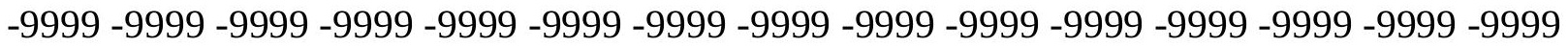
-9999 -9999 -9999 -9999 -9999 -9999 -9999 -9999 -9999 -9999 -9999 -9999 -9999 -9999 -9999 -9999 -9999 -9999 -9999 -9999 -9999 -9999 -9999 -9999-9999 -9999 -9999 -9999 -9999 -9999 -9999 -9999 -9999 -9999 -9999 -9999 -9999 -9999 -9999 -9999 -9999 -9999 -9999 -9999 -9999 -9999 -9999 -9999 -9999 -9999 -9999 -9999 -9999 -9999 -9999 -9999 -9999 -9999 -9999 -9999

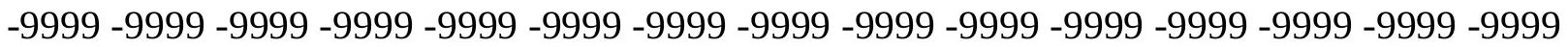

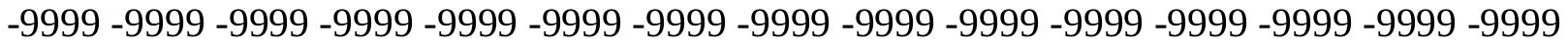
-9999 -9999 -9999 -9999 -9999 -9999 -9999 -9999 -9999 -9999 -9999 -9999 -9999 -9999 -9999 -9999 -9999 -9999 -9999 -9999 -9999 -9999 -9999 -9999 -9999 -9999 -9999 -9999 -9999 -9999 -9999 -9999 -9999 -9999 -9999 -9999 -9999 -9999 -9999 -9999 -9999 -9999 -9999 -9999 -9999 -9999 -9999 -9999 -9999 -9999 -9999 -9999 -9999 -9999 -9999 -9999 -9999 -9999 -9999 -9999 -9999 -9999 -9999 -9999 -9999 -9999 -9999 -9999 -9999 -9999 -9999 -9999 -9999 -9999 -9999 -9999 -9999 -9999 -9999 -9999 -9999 -9999 -9999 -9999 -9999 -9999 -9999 -9999 -9999

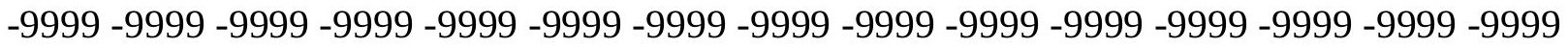
-9999 -9999 -9999 -9999 -9999 -9999 -9999 -9999 -9999 -9999 -9999 -9999 -9999 -9999 -9999 -9999 -9999 -9999 -9999 -9999 -9999 -9999 -9999 -9999 -9999 -9999 -9999 -9999 -9999 -9999 -9999 -9999 -9999 -9999 -9999 -9999 -9999 -9999 -9999 -9999 -9999 -9999 -9999 -9999 -9999 -

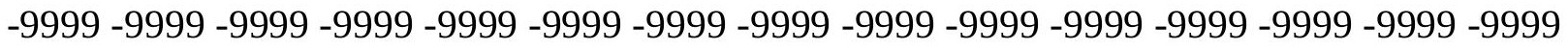

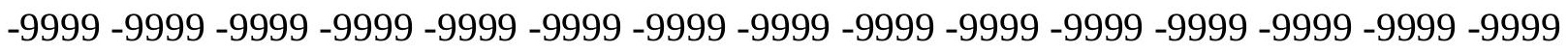
-9999 -9999 -9999 -9999 -9999 -9999 -9999 -9999 -9999 -9999 -9999 -9999 -9999 -9999 -9999 -9999 -9999 -9999 -9999 -9999 -9999 -9999 -9999 -9999 -9999 -9999 -9999 -9999 -9999 -9999 -9999 -9999 -9999 -9999 -9999 -9999 -9999 -9999 -9999 -9999 -9999 -9999 -9999 -9999 -9999 -

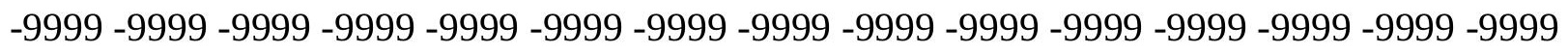
-9999 -9999 -9999 -9999 -9999 -9999 -9999 -9999 -9999 -9999 -9999 -9999 -9999 -9999 -9999 -9999 -9999 -9999 -9999 -9999 -9999 -9999 -9999 -9999 -9999 -9999 -9999 -9999 -9999 -9999 -

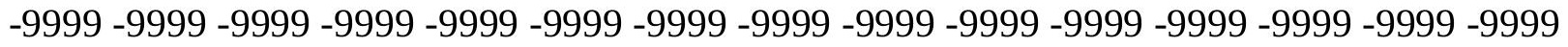
-9999 -9999 -9999 -9999 -9999 -9999 -9999 -9999 -9999 -9999 -9999 -9999 -9999 -9999 -9999 -9999 -9999 -9999 -9999 -9999 -9999 -9999 -9999 -9999 -9999 -9999 -9999 -9999 -9999 -999 -9999 -9999 -9999 -9999 -9999 -9999 -9999 -9999 -9999 -9999 -9999 -9999 -9999 -9999 -9999 -9999 -9999 -9999 -9999 -9999 -9999 -9999 -9999 -9999 -9999 -9999 -9999 -9999 -9999 -9999 -

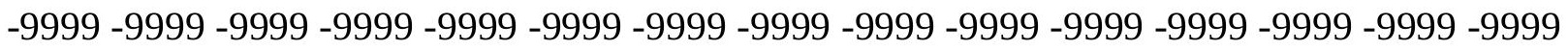

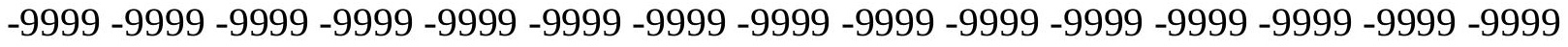

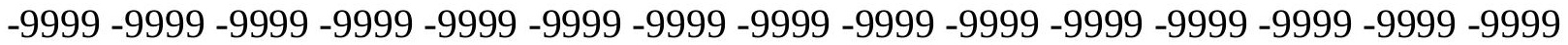

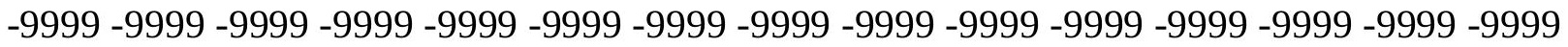

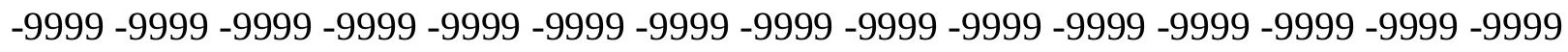

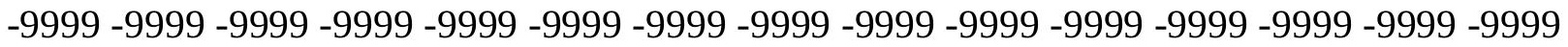
-9999 -9999 -9999 -9999 -9999 -9999 -9999 -9999 -9999 -9999 -9999 -9999 -9999 - 9999 - -999 -9999 -9999 -9999 -9999 -9999 -9999 -9999 -9999 -9999 -9999 -9999 -9999 -9999 -9999 - -999 -

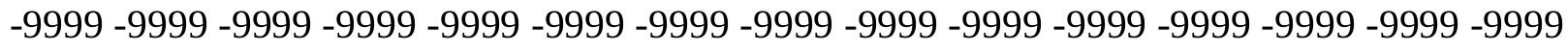

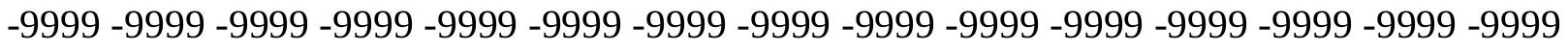
-9999 -9999 -9999 -9999 -9999 -9999 -9999 -9999 -9999 -9999 -9999 -9999 -9999 -9999 -9999 -9999 -9999 -9999 -9999 -9999 -9999 -9999 -9999 -9999-9999 -9999 -9999 -9999 -9999 -9999 -9999 -9999 -9999 -9999 -9999 -9999 -9999 -9999 -9999 -9999 -9999 -9999 -9999 -9999 -9999 -

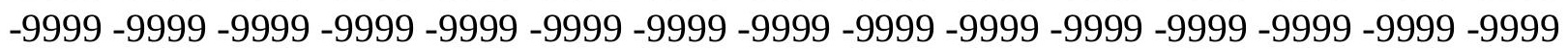


-9999 -9999 -9999 -9999 -9999 -9999 -9999 -9999 -9999 -9999 -9999 -9999 -9999 -9999 -9999 -9999 -9999 -9999 -9999 -9999 -9999 -9999 -9999 -9999 -9999 -9999 -9999 -9999 -9999 -9999 -9999 -9999 -9999 -9999 -9999 -9999 -9999 -9999 -9999 -9999 -9999 -9999 -9999 -9999 -9999 -9999 -9999 -9999 -9999 -9999 -9999 -9999 -9999 -9999 -9999 -9999 -9999 -9999 -9999 -9999 -9999 -9999 -9999 -9999 -9999 -9999 -9999 -9999 -9999 -9999 -9999 -9999 -9999 -9999 -9999 -9999 -9999 -9999 -9999 -9999 -9999 -9999 -9999 -9999 -9999 -9999 -9999 -9999 -9999 -9999 -9999 -9999 -9999 -9999 -9999 -9999 -9999 -9999 -9999 -9999 -9999 -9999 -9999 -9999 -9999 -

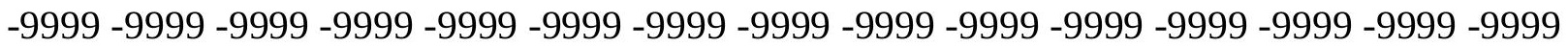
-9999 -9999 -9999 -9999 -9999 -9999 -9999 -9999 -9999 -9999 -9999 -9999 -9999 -9999 -9999 -9999 -9999 -9999 -9999 -9999 -9999 -9999 -9999 -9999 -9999 -9999 -9999 -9999 -9999 -9999 -

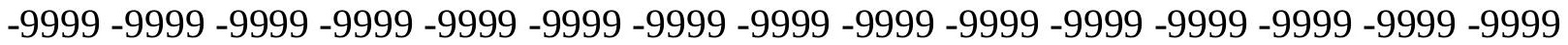
-9999 -9999 -9999 -9999 -9999 -9999 -9999 -9999 -9999 -9999 -9999 -9999 -9999 -9999 -9999 -9999 -9999 -9999 -9999 -9999 -9999 -9999 -9999 -9999 -9999 -9999 -9999 -9999 -9999 -9999 -9999 -9999 -9999 -9999 -9999 -9999 -9999 -9999 -9999 -9999 -9999 -9999 -9999 -9999 -9999 -9999 -9999 -9999 -9999 -9999 -9999 -9999 -9999 -9999 -9999 -9999 -9999 -9999 -9999 -9999

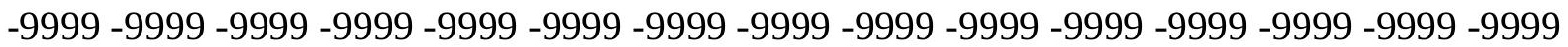
-9999 -9999 -9999 -9999 -9999 -9999 -9999 -9999 -9999 -9999 -9999 -9999 -9999 -9999 -9999 -9999 -9999 -9999 -9999 -9999 -9999 -9999 -9999 -9999 -9999 -9999 -9999 -9999 -9999 -9999 -9999 -9999 -9999 -9999 -9999 -9999 -9999 -9999 -9999 -9999 -9999 -9999 -9999 -9999 -9999 -9999 -9999 -9999 -9999 -9999 -9999 -9999 -9999 -9999 -9999 -9999 -9999 -9999 -9999 -9999 -9999 -9999 -9999 -9999 -9999 -9999 -9999 -9999 -9999 -9999 -9999 -9999 -9999 -9999 -9999 -9999 -9999 -9999 -9999 -9999 -9999 -9999 -9999 -9999 -9999 -9999 -9999 -9999 -9999 -9999 -9999 -9999 -9999 -9999 -9999 -9999 -9999 -9999 -9999 -9999 -9999 -9999 -9999 -9999 -9999 -9999 -9999 -9999 -9999 -9999 -9999 -9999 -9999 -9999 -9999 -9999 -9999 -9999 -9999 -9999 -9999 -9999 -9999 -9999 -9999 -9999 -9999 -9999 -9999 -9999 -9999 -9999 -9999 -9999 -9999 -9999 -9999 -9999 -9999 -9999 -9999 -9999 -9999 -9999 -9999 -9999 -9999 -9999 -9999 -9999 -9999 -9999 -9999 -9999 -9999 -9999 -9999 -9999 -9999 -9999 -9999 -9999 -9999 -9999 -9999 -9999 -9999 -9999 -9999 -9999 -9999 -9999 -9999 -9999 -9999 -9999 -9999 -9999 -9999

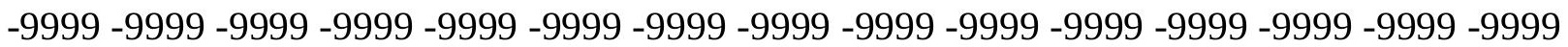
-9999 -9999 -9999 -9999 -9999 -9999 -9999 -9999 -9999 -9999 -9999 -9999 -9999 -9999 -9999 -9999 -9999 -9999 -9999 -9999 -9999 -9999 -9999 -9999 -9999 -9999 -9999 -9999 -9999 -9999 -

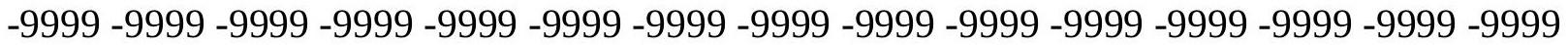
-9999 -9999 -9999 -9999 -9999 -9999 -9999 -9999 -9999 -9999 -9999 -9999 -9999 -9999 -9999 -9999 -9999 -9999 -9999 -9999 -9999 -9999 -9999 -9999 -9999 -9999 -9999 -9999 -9999 -9999 -9999 -9999 -9999 -9999 -9999 -9999 -9999 -9999 -9999 -9999 -9999 -9999 -9999 -9999 -9999 -9999 -9999 -9999 -9999 -9999 -9999 -9999 -9999 -9999 -9999 -9999 -9999 -9999 -9999 -9999 -9999 -9999 -9999 -9999 -9999 -9999 -9999 -9999 -9999 -9999 -9999 -9999 -9999 -9999 -9999

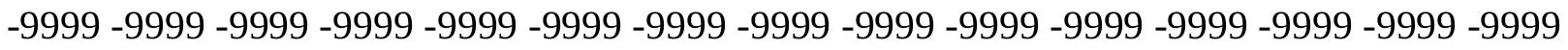
-9999 -9999 -9999 -9999 -9999 -9999 -9999 -9999 -9999 -9999 -9999 -9999 -9999 -9999 -9999 -9999 -9999 -9999 -9999 -9999 -9999 -9999 -9999 -9999 -9999 -9999 -9999 -9999 -9999 -9999 -9999 -9999 -9999 -9999 -9999 -9999 -9999 -9999 -9999 -9999 -9999 -9999 -9999 -9999 -9999 -999 -9999 -9999 -9999 -9999 -9999 -9999 -9999 -9999 -9999 -9999 -9999 -9999 -9999 -9999 -9999 -9999 -9999 -9999 -9999 -9999 -9999 -9999 -9999 -9999 -9999 -9999 -9999 -9999 -9999 -9999 -9999 -9999 -9999 -9999 -9999 -9999 -9999 -9999 -9999 -9999 -9999 -9999 -9999 -9999 -9999 -9999 -9999 -9999 -9999 -9999 -9999 -9999 -9999 -9999 -9999 -9999 -9999 -9999 -9999 -9999 -9999 -9999 -9999 -9999 -9999 -9999 -9999 -9999 -9999 -9999 -9999 -9999 -9999 -9999 
-9999 -9999 -9999 -9999 -9999 -9999 -9999 -9999 -9999 -9999 -9999 -9999 -9999 -9999 -9999 -9999 -9999 -9999 -9999 -9999 -9999 -9999 -9999 -9999 -9999 -9999 -9999 -9999 -9999 -9999 -

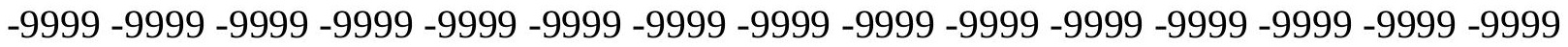
-9999 -9999 -9999 -9999 -9999 -9999 -9999 -9999 -9999 -9999 -9999 -9999 -9999 -9999 -9999 -9999 -9999 -9999 -9999 -9999 -9999 -9999 -9999 -9999-9999 -9999 -9999 -9999 -9999 -9999 -9999 -9999 -9999 -9999 -9999 -9999 -9999 -9999 -9999 -9999 -9999 -9999 -9999 -9999 -9999 -9999 -9999 -9999 -9999 -9999 -9999 -9999 -9999 -9999 -9999 -9999 -9999 -9999 -9999 -9999

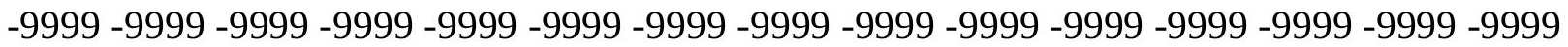

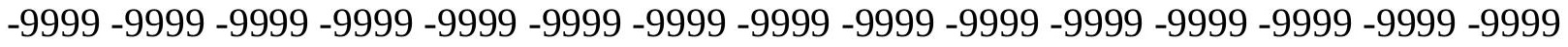
-9999 -9999 -9999 -9999 -9999 -9999 -9999 -9999 -9999 -9999 -9999 -9999 -9999 -9999 -9999 -9999 -9999 -9999 -9999 -9999 -9999 -9999 -9999 -9999 -9999 -9999 -9999 -9999 -9999 -9999 -9999 -9999 -9999 -9999 -9999 -9999 -9999 -9999 -9999 -9999 -9999 -9999 -9999 -9999 -9999 -9999 -9999 -9999 -9999 -9999 -9999 -9999 -9999 -9999 -9999 -9999 -9999 -9999 -9999 -9999 -

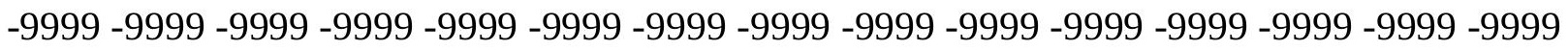
-9999 -9999 -9999 -9999 -9999 -9999 -9999 -9999 -9999 -9999 -9999 -9999 -9999 -9999 -9999 -

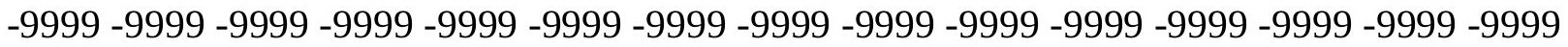
-9999 -9999 -9999 -9999 -9999 -9999 -9999 -9999 -9999 -9999 -9999 -9999 -9999 -9999 -9999 -9999 -9999 -9999 -9999 -9999 -9999 -9999 -9999 -9999 -9999 -9999 -9999 -9999 -9999 -9999 -9999 -9999 -9999 -9999 -9999 -9999 -9999 -9999 -9999 -9999 -9999 -9999 -9999 -9999 -9999 -

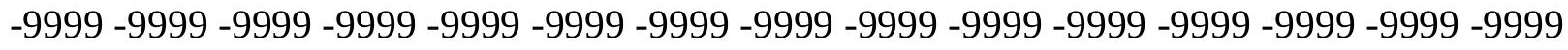

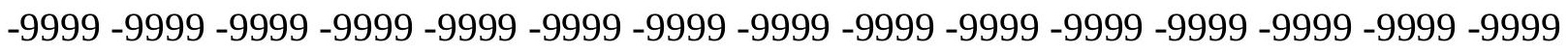

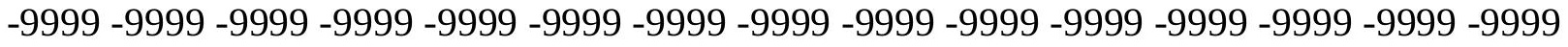
-9999 -9999 -9999 -9999 -9999 -9999 -9999 -9999 -9999 -9999 -9999 -9999 -9999 -9999 -9999 -9999 -9999 -9999 -9999 -9999 -9999 -9999 -9999 -9999 -9999 -9999 -9999 -9999 -9999 -9999 -

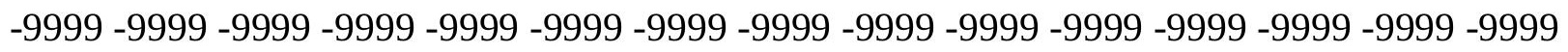
-9999 -9999 -9999 -9999 -9999 -9999 -9999 -9999 -9999 -9999 -9999 -9999 -9999 -9999 -9999 -9999 -9999 -9999 -9999 -9999 -9999 -9999 -9999 -9999 -9999 -9999 -9999 -9999 -9999 -

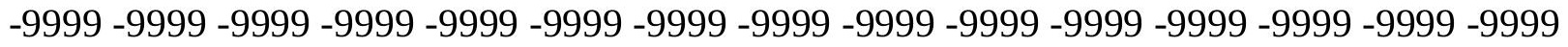
-9999 -9999 -9999 -9999 -9999 -9999 -9999 -9999 -9999 -9999 -9999 -9999 -9999 -9999 -9999 -9999 -9999 -9999 -9999 -9999 -9999 -9999 -9999 -9999 -9999 -9999 -9999 -9999 -9999 -999 -

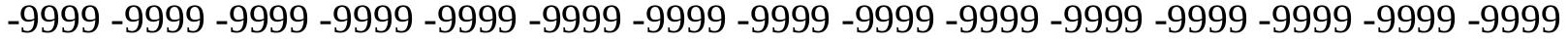
-9999 -9999 -9999 -9999 -9999 -9999 -9999 -9999 -9999 -9999 -9999 -9999 -9999 -9999 -9999 -

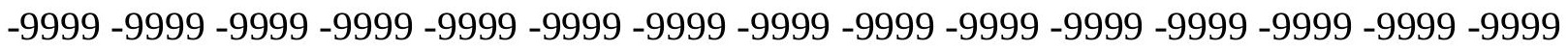

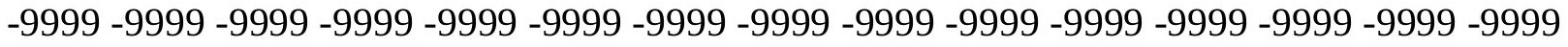

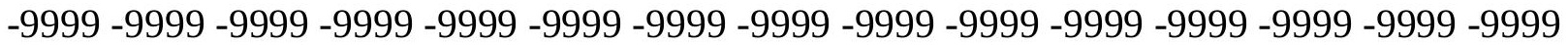
-9999 -9999 -9999 -9999 -9999 -9999 -9999 -9999 -9999 -9999 -9999 -9999 -9999 -9999 -9999

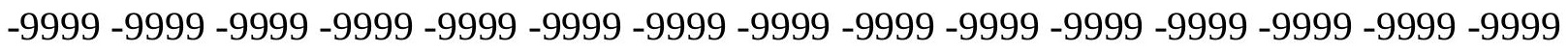

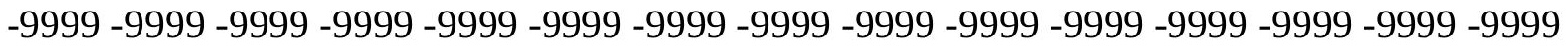
-9999 -9999 -9999 -9999 -9999 -9999 -9999 -9999 -9999 -9999 -9999 -9999 -9999 - 9999 - -999 -9999 -9999 -9999 -9999 -9999 -9999 -9999 -9999 -9999 -9999 -9999 -9999 -9999 -9999 -9999 -

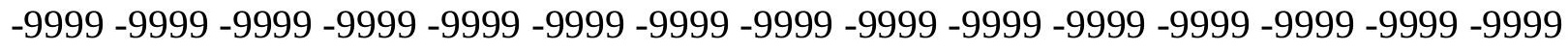

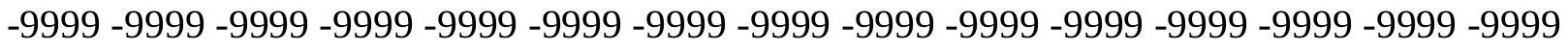
-9999 -9999 -9999 -9999 -9999 -9999 -9999 -9999 -9999 -9999 -9999 -9999 -9999 -9999 -9999 -9999 -9999 -9999 -9999 -9999 -9999 -9999 -9999 -9999-9999 -9999 -9999 -9999 -9999 -9999 -9999 -9999 -9999 -9999 -9999 -9999 -9999 -9999 -9999 -9999 -9999 -9999 -9999 -9999 -9999 -

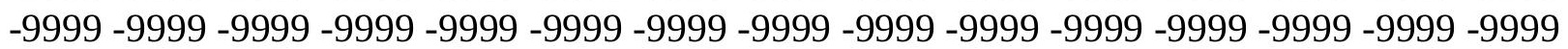


-9999 -9999 -9999 -9999 -9999 -9999 -9999 -9999 -9999 -9999 -9999 -9999 -9999 -9999 -9999 -9999 -9999 -9999 -9999 -9999 -9999 -9999 -9999 -9999 -9999 -9999 -9999 -9999 -9999 -9999 -9999 -9999 -9999 -9999 -9999 -9999 -9999 -9999 -9999 -9999 -9999 -9999 -9999 -9999 - 9999 -9999 -9999 -9999 -9999 -9999 -9999 -9999 -9999 -9999 -9999 -9999 -9999 -9999 -9999 -9999 -9999 -9999 -9999 -9999 -9999 -9999 -9999 -9999 -9999 -9999 -9999 -9999 -9999 -9999 - -9999 -9999 -9999 -9999 -9999 -9999 -9999 -9999 -9999 -9999 -9999 -9999 -9999 -9999 -9999 -9999 -9999 -9999 -9999 -9999 -9999 -9999 -9999 -9999 -9999 -9999 -9999 -9999 -9999 -9999

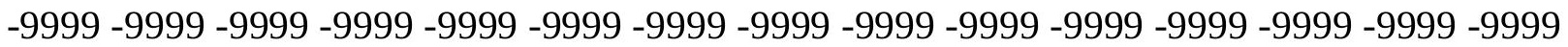

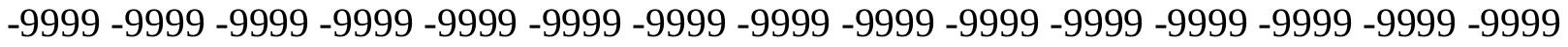
-9999 -9999 -9999 -9999 -9999 -9999 -9999 -9999 -9999 -9999 -9999 -9999 -9999 -9999 -9999

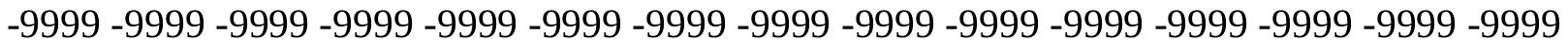
-9999 -9999 -9999 -9999 -9999 -9999 -9999 -9999 -9999 -9999 -9999 -9999 -9999 -9999 -9999 -9999 -9999 -9999 -9999 -9999 -9999 -9999 -9999 -9999 -9999 -9999 -9999 -9999 -9999 -9999 -9999 -9999 -9999 -9999 -9999 -9999 -9999 -9999 -9999 -9999 -9999 -9999 -9999 -9999 - -9999 -9999 -9999 -9999 -9999 -9999 -9999 -9999 -9999 -9999 -9999 -9999 -9999 -9999 -9999 -9999

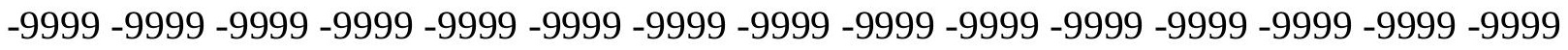
-9999 -9999 -9999 -9999 -9999 -9999 -9999 -9999 -9999 -9999 -9999 -9999 -9999 -9999 -9999 -9999 -9999 -9999 -9999 -9999 -9999 -9999 -9999 -9999 -9999 -9999 -9999 -9999 -9999 -9999 -9999 -9999 -9999 -9999 -9999 -9999 -9999 -9999 -9999 -9999 -9999 -9999 -9999 -9999 -9999 -

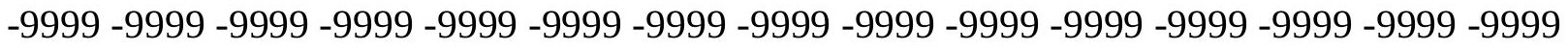
-9999 -9999 -9999 -9999 -9999 -9999 -9999 -9999 -9999 -9999 -9999 -9999 -9999 -9999 -9999 -999 -9999 -9999 -9999 -9999 -9999 -9999 -9999 -9999 -9999 -9999 -9999 -9999 -9999 -9999 -9999 -9999 -9999 -9999 -9999 -9999 -9999 -9999 -9999 -9999 -9999 -9999 -9999 -9999 -9999 -9999 -9999 -9999 -9999 -9999 -9999 -9999 -9999 -9999 -9999 -9999 -9999 -9999 -9999 -9999 -9999 -9999 -9999 -9999 -9999 -9999 -9999 -9999 -9999 -9999 -9999 -9999 -9999 -9999 -9999 -9999 -9999 -9999 -9999 -9999 -9999 -9999 -9999 -9999 -9999 -9999 -9999 -9999 -9999 -9999 -9999 -9999 -9999 -9999 -9999 -9999 -9999 -9999 -9999 -9999 -9999 -9999 -9999 -9999 -9999 -9999 -9999 -9999 -9999 -9999 -9999 -9999 -9999 -9999 -9999 -9999 -9999 -9999 -9999 -9999 -9999 -9999 -9999 -9999 -9999 -9999 -9999 -9999 -9999 -9999 -9999 -9999 -9999 -9999 -9999 -9999 -9999 -9999 -9999 -9999 -9999 -9999 -9999 -9999 -9999 -9999 -9999 -9999 -9999 -9999 -999 -9999 -9999 -9999 -9999 -9999 -9999 -9999 -9999 -9999 -9999 -9999 -9999 -9999 -9999 -9999 -9999 -9999 -9999 -9999 -9999 -9999 -9999 -9999 -9999 -9999 -9999 -9999 -9999 -9999 -

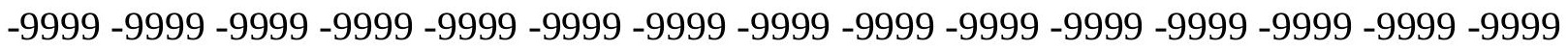

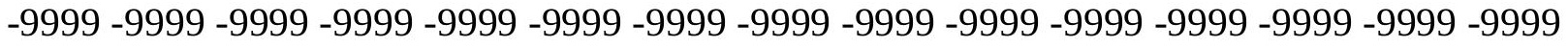

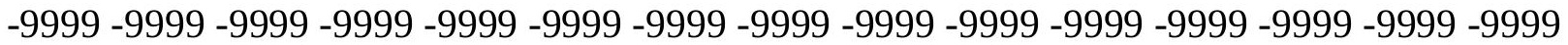
-9999 -9999 -9999 -9999 -9999 -9999 -9999 -9999 -9999 -9999 -9999 -9999 -9999 -9999 -9999 -

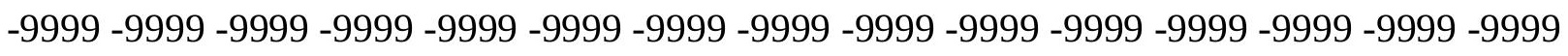

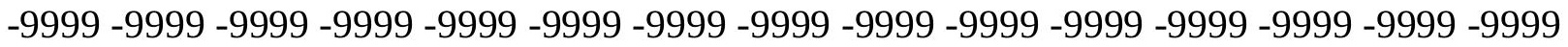

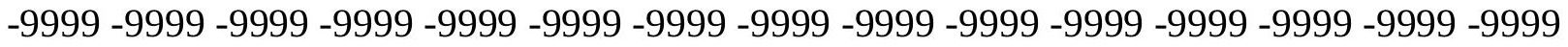
-9999 -9999 -9999 -9999 -9999 -9999 -9999 -9999 -9999 -9999 -9999 -9999 -9999 -9999 -9999 -

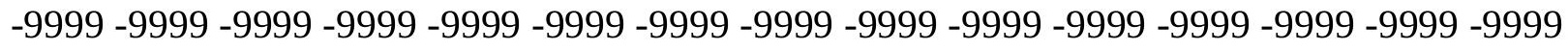

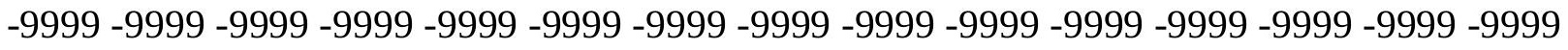
-9999 -9999 -9999 -9999 -9999 -9999 -9999 -9999 -9999 -9999 -9999 -9999 -9999 -9999 -9999 -9999 -9999 -9999 -9999 -9999 -9999 -9999 -9999 -9999-9999 -9999 -9999 -9999 -9999 -9999 -9999 -9999 -9999 -9999 -9999 -9999 -9999 -9999 -9999 -9999 -9999 -9999 -9999 -9999 -9999 -

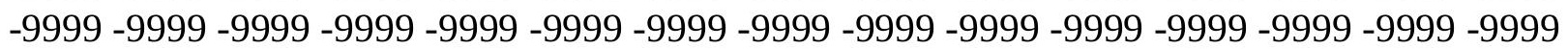


-9999 -9999 -9999 -9999 -9999 -9999 -9999 -9999 -9999 -9999 -9999 -9999 -9999 -9999 -9999 -9999 -9999 -9999 -9999 -9999 -9999 -9999 -9999 -9999 -9999 -9999 -9999 -9999 -9999 -9999 -

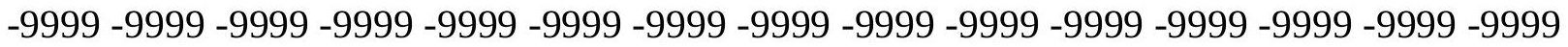
-9999 -9999 -9999 -9999 -9999 -9999 -9999 -9999 -9999 -9999 -9999 -9999 -9999 -9999 -9999 -9999 -9999 -9999 -9999 -9999 -9999 -9999 -9999 -9999-9999 -9999 -9999 -9999 -9999 -9999 -9999 -9999 -9999 -9999 -9999 -9999 -9999 -9999 -9999 -9999 -9999 -9999 -9999 -9999 -9999 -9999 -9999 -9999 -9999 -9999 -9999 -9999 -9999 -9999 -9999 -9999 -9999 -9999 -9999 -9999

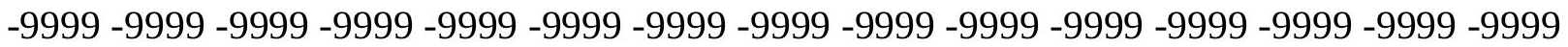

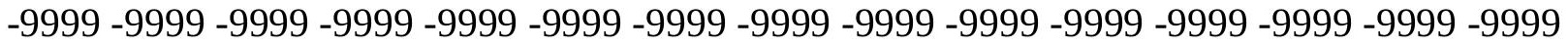
-9999 -9999 -9999 -9999 -9999 -9999 -9999 -9999 -9999 -9999 -9999 -9999 -9999 -9999 -9999 -9999 -9999 -9999 -9999 -9999 -9999 -9999 -9999 -9999 -9999 -9999 -9999 -9999 -9999 -9999 -9999 -9999 -9999 -9999 -9999 -9999 -9999 -9999 -9999 -9999 -9999 -9999 -9999 -9999 -9999 -9999 -9999 -9999 -9999 -9999 -9999 -9999 -9999 -9999 -9999 -9999 -9999 -9999 -9999 -9999 -9999 -9999 -9999 -9999 -9999 -9999 -9999 -9999 -9999 -9999 -9999 -9999 -9999 - 9999 -9999 -9999 -9999 -9999 -9999 -9999 -9999 -9999 -9999 -9999 -9999 -9999 -9999 -9999 -9999

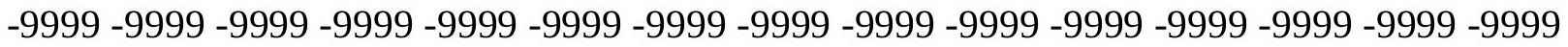
-9999 -9999 -9999 -9999 -9999 -9999 -9999 -9999 -9999 -9999 -9999 -9999 -9999 -9999 -9999 -9999 -9999 -9999 -9999 -9999 -9999 -9999 -9999 -9999 -9999 -9999 -9999 -9999 -9999 -9999 -9999 -9999 -9999 -9999 -9999 -9999 -9999 -9999 -9999 -9999 -9999 -9999 -9999 -9999 -9999 -

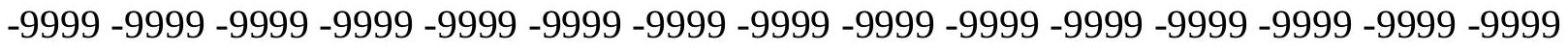

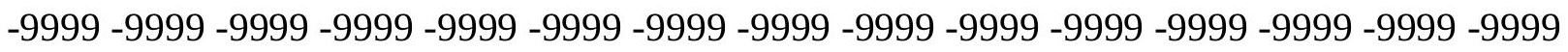
-9999 -9999 -9999 -9999 -9999 -9999 -9999 -9999 -9999 -9999 -9999 -9999 -9999 -9999 -9999 -9999 -9999 -9999 -9999 -9999 -9999 -9999 -9999 -9999 -9999 -9999 -9999 -9999 -9999 -9999 -9999 -9999 -9999 -9999 -9999 -9999 -9999 -9999 -9999 -9999 -9999 -9999 -9999 -9999 -9999 -

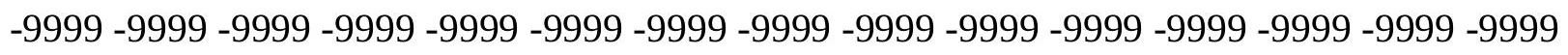
-9999 -9999 -9999 -9999 -9999 -9999 -9999 -9999 -9999 -9999 -9999 -9999 -9999 -9999 -9999 -9999 -9999 -9999 -9999 -9999 -9999 -9999 -9999 -9999 -9999 -9999 -9999 -9999 -9999 -9999 -

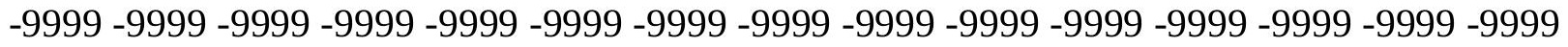
-9999 -9999 -9999 -9999 -9999 -9999 -9999 -9999 -9999 -9999 -9999 -9999 -9999 -9999 -9999 -9999 -9999 -9999 -9999 -9999 -9999 -9999 -9999 -9999 -9999 -9999 -9999 -9999 -9999 -999 -9999 -9999 -9999 -9999 -9999 -9999 -9999 -9999 -9999 -9999 -9999 -9999 -9999 -9999 -9999 -9999 -9999 -9999 -9999 -9999 -9999 -9999 -9999 -9999 -9999 -9999 -9999 -9999 -9999 -9999 -

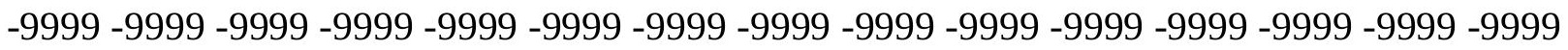

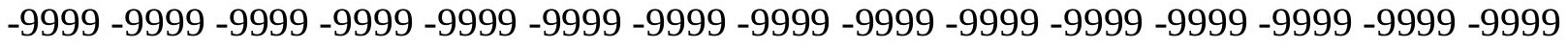

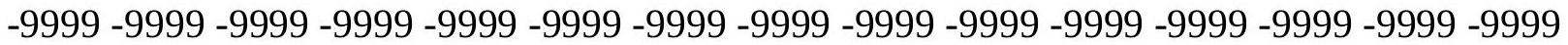

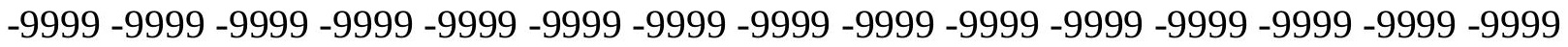

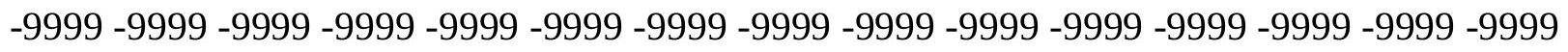

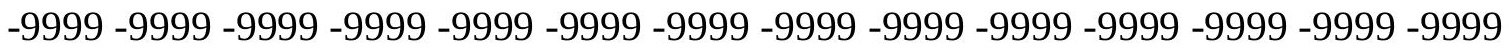
-9999 -9999 -9999 -9999 -9999 -9999 -9999 -9999 -9999 -9999 -9999 -9999 -9999 -9999 -9999 -9999 -9999 -9999 -9999 -9999 -9999 -9999 -9999 -9999 -9999 -9999 -9999 -9999 -9999 -9999 -

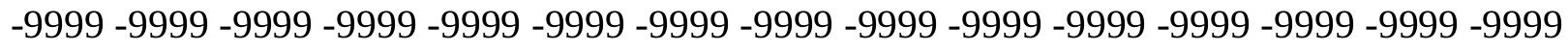

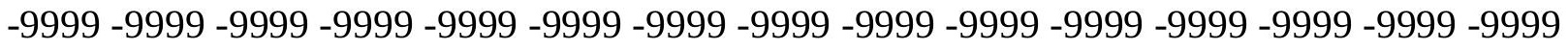
-9999 -9999 -9999 -9999 -9999 -9999 -9999 -9999 -9999 -9999 -9999 -9999 -9999 -9999 -9999 -9999 -9999 -9999 -9999 -9999 -9999 -9999 -9999 -9999-9999 -9999 -9999 -9999 -9999 -9999 -9999 -9999 -9999 -9999 -9999 -9999 -9999 -9999 -9999 -9999 -9999 -9999 -9999 -9999 -9999 -

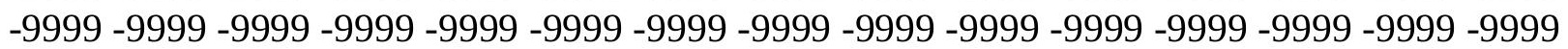


-9999 -9999 -9999 -9999 -9999 -9999 -9999 -9999 -9999 -9999 -9999 -9999 -9999 -9999 -9999 -9999 -9999 -9999 -9999 -9999 -9999 -9999 -9999 -9999 -9999 -9999 -9999 -9999 -9999 -9999 -9999 -9999 -9999 -9999 -9999 -9999 -9999 -9999 -9999 -9999 -9999 -9999 -9999 -9999 - 9999 -9999 -9999 -9999 -9999 -9999 -9999 -9999 -9999 -9999 -9999 -9999 -9999 -9999 -9999 -9999 -9999 -9999 -9999 -9999 -9999 -9999 -9999 -9999 -9999 -9999 -9999 -9999 -9999 -9999 -9999 -9999 -9999 -9999 -9999 -9999 -9999 -9999 -9999 -9999 -9999 -9999 -9999 -9999 -9999 -9999 -9999 -9999 -9999 -9999 -9999 -9999 -9999 -9999 -9999 -9999 -9999 -9999 -9999 -9999 -9999

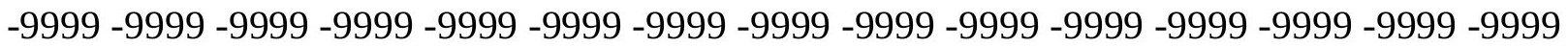
-9999 -9999 -9999 -9999 -9999 -9999 -9999 -9999 -9999 -9999 -9999 -9999 -9999 -9999 -9999 -9999 -9999 -9999 -9999 -9999 -9999 -9999 -9999 -9999 -9999 -9999 -9999 -9999 -9999 -9999

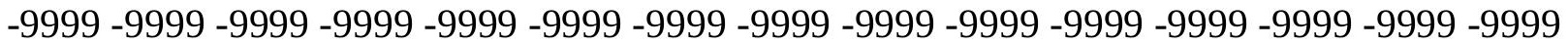
-9999 -9999 -9999 -9999 -9999 -9999 -9999 -9999 -9999 -9999 -9999 -9999 -9999 -9999 -9999 -9999 -9999 -9999 -9999 -9999 -9999 -9999 -9999 -9999 -9999 -9999 -9999 -9999 -9999 -9999 -

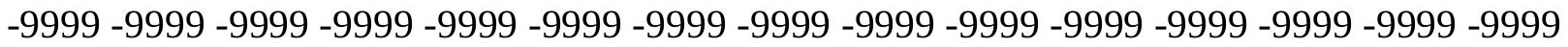
-9999 -9999 -9999 -9999 -9999 -9999 -9999 -9999 -9999 -9999 -9999 -9999 -9999 -9999 -9999

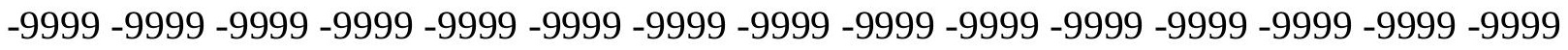
-9999 -9999 -9999 -9999 -9999 -9999 -9999 -9999 -9999 -9999 -9999 -9999 -9999 -9999 -9999 -9999 -9999 -9999 -9999 -9999 -9999 -9999 -9999 -9999 -9999 -9999 -9999 -9999 -9999 - -999 -9999 -9999 -9999 -9999 -9999 -9999 -9999 -9999 -9999 -9999 -9999 -9999 -9999 -9999 -9999 -9999 -9999 -9999 -9999 -9999 -9999 -9999 -9999 -9999 -9999 -9999 -9999 -9999 -9999 -9999 -9999 -9999 -9999 -9999 -9999 -9999 -9999 -9999 -9999 -9999 -9999 -9999 -9999 -9999 -9999 -999 -9999 -9999 -9999 -9999 -9999 -9999 -9999 -9999 -9999 -9999 -9999 -9999 -9999 -9999 -9999 -9999 -9999 -9999 -9999 -9999 -9999 -9999 -9999 -9999 -9999 -9999 -9999 -9999 -9999 -9999 -9999 -9999 -9999 -9999 -9999 -9999 -9999 -9999 -9999 -9999 -9999 -9999 -9999 -9999 -9999 -9999 -9999 -9999 -9999 -9999 -9999 -9999 -9999 -9999 -9999 -9999 -9999 -9999 -9999 -9999 -9999 -9999 -9999 -9999 -9999 -9999 -9999 -9999 -9999 -9999 -9999 -9999 -9999 -9999 -9999 -9999 -9999 -9999 -9999 -9999 -9999 -9999 -9999 -9999 -9999 -9999 -9999 -9999 -9999 -9999 -9999 -9999 -9999 -9999 -9999 -9999 -9999 -9999 -9999 -9999 -9999 -9999 -9999 -9999 -9999 -9999 -9999 -9999 -9999 -9999 -9999 -9999 -9999 -9999 -9999 -9999 -9999 -9999 -9999 -9999 -9999 -9999 -9999 -9999 -9999 -9999 -9999 -9999 -9999 -9999 -9999 -9999 -9999 -9999 -999 -9999 -9999 -9999 -9999 -9999 -9999 -9999 -9999 -9999 -9999 -9999 -9999 -9999 -9999 -9999 -9999 -9999 -9999 -9999 -9999 -9999 -9999 -9999 -9999 -9999 -9999 -9999 -9999 -9999 -9999 -

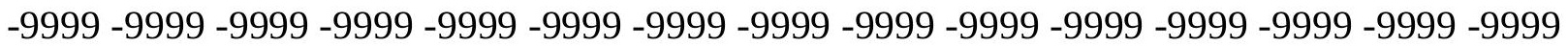

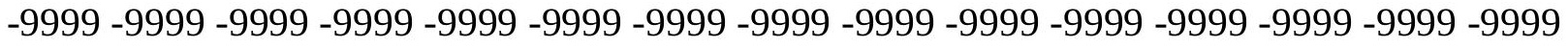

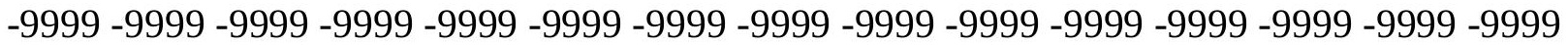
-9999 -9999 -9999 -9999 -9999 -9999 -9999 -9999 -9999 -9999 -9999 -9999 -9999 -9999 -9999

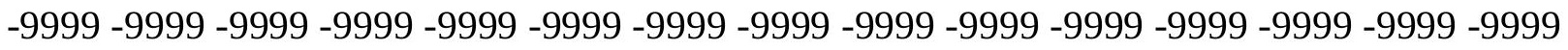

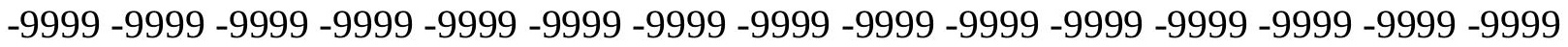

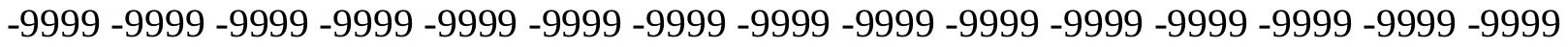
-9999 -9999 -9999 -9999 -9999 -9999 -9999 -9999 -9999 -9999 -9999 -9999 -9999 -9999 -9999 -

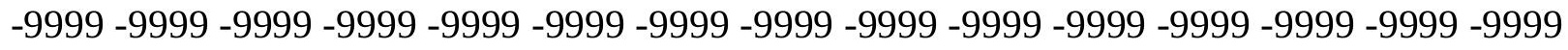

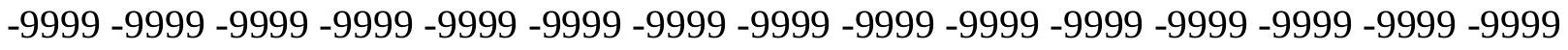
-9999 -9999 -9999 -9999 -9999 -9999 -9999 -9999 -9999 -9999 -9999 -9999 -9999 -9999 -9999 -9999 -9999 -9999 -9999 -9999 -9999 -9999 -9999 -9999 -9999 -9999 -9999 -9999 - -9999 -9999 -9999 -9999 -9999 -9999 -9999 -9999 -9999 -9999 -9999 -9999 -9999 -9999 -9999 -9999 -

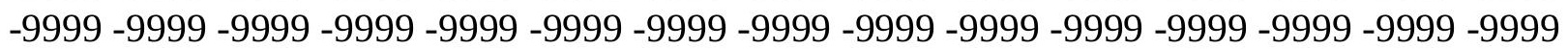


-9999 -9999 -9999 -9999 -9999 -9999 -9999 -9999 -9999 -9999 -9999 -9999 -9999 -9999 -9999 -9999 -9999 -9999 -9999 -9999 -9999 -9999 -9999 -9999 -9999 -9999 -9999 -9999 -9999 -9999 -9999 -9999 -9999 -9999 -9999 -9999 -9999 -9999 -9999 -9999 -9999 -9999 -9999 -9999 - 9999 -9999 -9999 -9999 -9999 -9999 -9999 -9999 -9999 -9999 -9999 -9999 -9999 -9999 -9999 -9999 -9999 -9999 -9999 -9999 -9999 -9999 -9999 -9999 -9999-9999 -9999 -9999 -9999 -9999 -9999 -9999 -9999 -9999 -9999 -9999 -9999 -9999 -9999 -9999 -9999 -9999 -9999 -9999 -9999 -9999 -9999 -9999 -9999 -9999 -9999 -9999 -9999 -9999 -9999 -9999 -9999 -9999 -9999 -9999 -9999

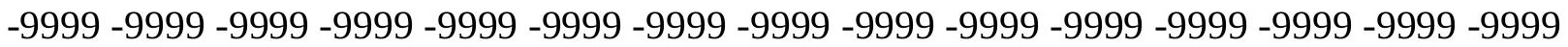

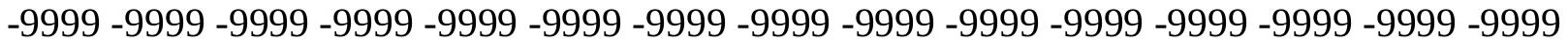
-9999 -9999 -9999 -9999 -9999 -9999 -9999 -9999 -9999 -9999 -9999 -9999 -9999 -9999 -9999

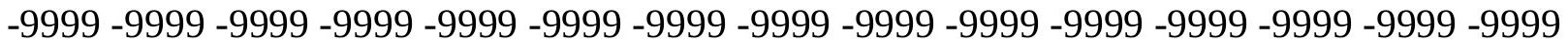
-9999 -9999 -9999 -9999 -9999 -9999 -9999 -9999 -9999 -9999 -9999 -9999 -9999 -9999 -9999 -9999 -9999 -9999 -9999 -9999 -9999 -9999 -9999 -9999 -9999 -9999 -9999 -9999 -9999 -9999 -

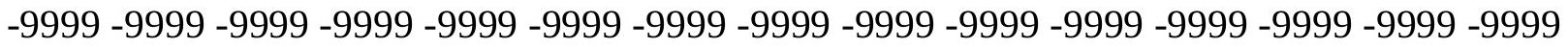
-9999 -9999 -9999 -9999 -9999 -9999 -9999 -9999 -9999 -9999 -9999 -9999 -9999 -9999 -9999

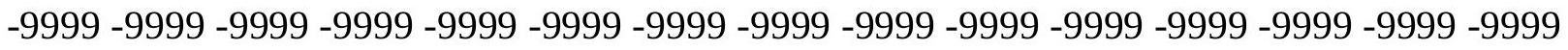
-9999 -9999 -9999 -9999 -9999 -9999 -9999 -9999 -9999 -9999 -9999 -9999 -9999 -9999 -9999 -9999 -9999 -9999 -9999 -9999 -9999 -9999 -9999 -9999 -9999 -9999 -9999 -9999 -9999 -9999 -9999 -9999 -9999 -9999 -9999 -9999 -9999 -9999 -9999 -9999 -9999 -9999 -9999 -9999 -9999 -9999 -9999 -9999 -9999 -9999 -9999 -9999 -9999 -9999 -9999 -9999 -9999 -9999 -9999 -9999 -9999 -9999 -9999 -9999 -9999 -9999 -9999 -9999 -9999 -9999 -9999 -9999 -9999 -9999 -9999 -999 -9999 -9999 -9999 -9999 -9999 -9999 -9999 -9999 -9999 -9999 -9999 -9999 -9999 -9999 -9999 -9999 -9999 -9999 -9999 -9999 -9999 -9999 -9999 -9999 -9999 -9999 -9999 -9999 -9999 -9999 -9999 -9999 -9999 -9999 -9999 -9999 -9999 -9999 -9999 -9999 -9999 -9999 -9999 -9999 -9999 -9999 -9999 -9999 -9999 -9999 -9999 -9999 -9999 -9999 -9999 -9999 -9999 -9999 -9999 -9999 -9999 -9999 -9999 -9999 -9999 -9999 -9999 -9999 -9999 -9999 -9999 -9999 -9999 -9999 -9999 -9999 -9999 -9999 -9999 -9999 -9999 -9999 -9999 -9999 -9999 -9999 -9999 -9999 -9999 -9999 -9999 -9999 -9999 -9999 -9999 -9999 -9999 -9999 -9999 -9999 -9999 -9999 -9999 -9999 -9999 -9999 -9999 -9999 -9999 -9999 -9999 -9999 -9999 -9999 -9999 -9999 -9999 -9999 -9999 -9999 -9999 -9999 -9999 -9999 -9999 -9999 -9999 -9999 -9999 -9999 -9999 -9999 -9999 -999 -9999 -9999 -9999 -9999 -9999 -9999 -9999 -9999 -9999 -9999 -9999 -9999 -9999 -9999 -9999 -9999 -9999 -9999 -9999 -9999 -9999 -9999 -9999 -9999 -9999 -9999 -9999 -9999 -9999 -9999 -

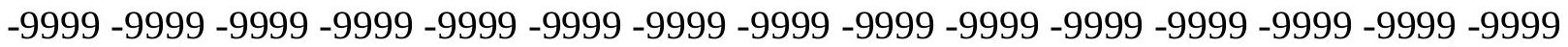

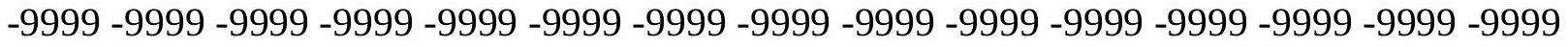

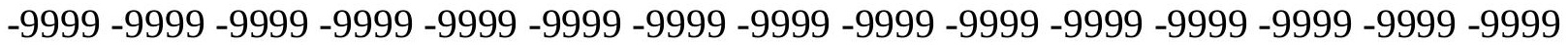
-9999 -9999 -9999 -9999 -9999 -9999 -9999 -9999 -9999 -9999 -9999 -9999 -9999 -9999 -9999

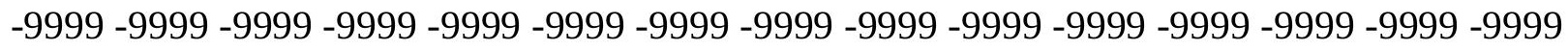

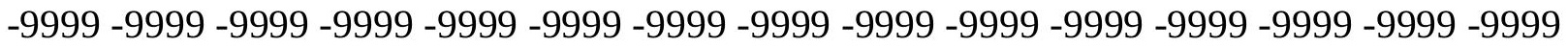
-9999 -9999 -9999 -9999 -9999 -9999 -9999 -9999 -9999 -9999 -9999 -9999 -9999 -9999 -9999 -9999 -9999 -9999 -9999 -9999 -9999 -9999 -9999 -9999 -9999 -9999 -9999 -9999 -9999 -9999 -

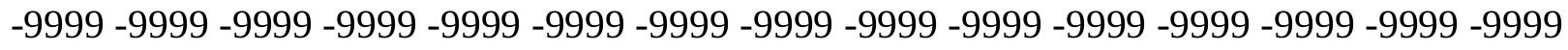

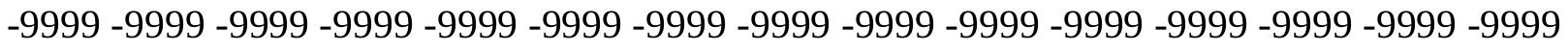
-9999 -9999 -9999 -9999 -9999 -9999 -9999 -9999 -9999 -9999 -9999 -9999 -9999 -9999 -9999 -9999 -9999 -9999 -9999 -9999 -9999 -9999 -9999 -9999-9999 -9999 -9999 -9999 -9999 -9999 -9999 -9999 -9999 -9999 -9999 -9999 -9999 -9999 -9999 -9999 -9999 -9999 -9999 -9999 -9999 -

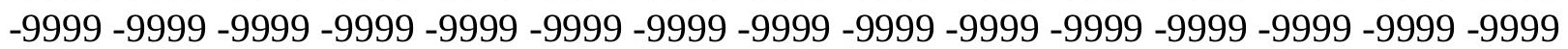


-9999 -9999 -9999 -9999 -9999 -9999 -9999 -9999 -9999 -9999 -9999 -9999 -9999 -9999 -9999 -9999 -9999 -9999 -9999 -9999 -9999 -9999 -9999 -9999 -9999 -9999 -9999 -9999 -9999 -9999 -9999 -9999 -9999 -9999 -9999 -9999 -9999 -9999 -9999 -9999 -9999 -9999 -9999 -9999 - 9999 -9999 -9999 -9999 -9999 -9999 -9999 -9999 -9999 -9999 -9999 -9999 -9999 -9999 -9999

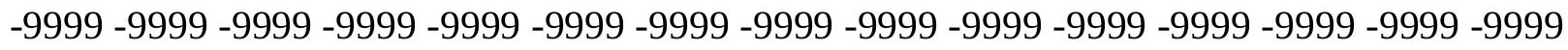
-9999 -9999 -9999 -9999 -9999 -9999 -9999 -9999 -9999 -9999 -9999 -9999 -9999 -9999 -9999 -9999 -9999 -9999 -9999 -9999 -9999 -9999 -9999 -9999 -9999 -9999 -9999 -9999 -9999 -9999

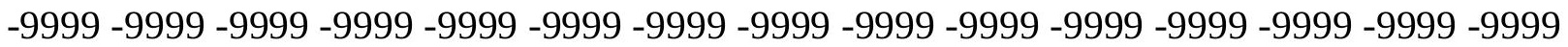

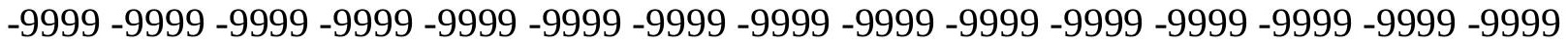
-9999 -9999 -9999 -9999 -9999 -9999 -9999 -9999 -9999 -9999 -9999 -9999 -9999 -9999 -9999 -9999 -9999 -9999 -9999 -9999 -9999 -9999 -9999 -9999 -9999 -9999 -9999 -9999 -9999 -9999 -9999 -9999 -9999 -9999 -9999 -9999 -9999 -9999 -9999 -9999 -9999 -9999 -9999 -9999 -9999 -9999 -9999 -9999 -9999 -9999 -9999 -9999 -9999 -9999 -9999 -9999 -9999 -9999 -9999 -9999 -

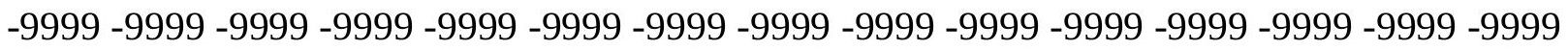
-9999 -9999 -9999 -9999 -9999 -9999 -9999 -9999 -9999 -9999 -9999 -9999 -9999 -9999 -9999 -

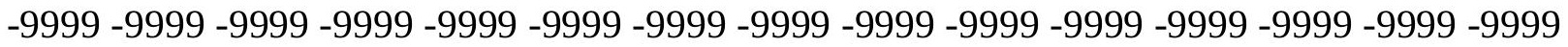
-9999 -9999 -9999 -9999 -9999 -9999 -9999 -9999 -9999 -9999 -9999 -9999 -9999 -9999 -9999 -9999 -9999 -9999 -9999 -9999 -9999 -9999 -9999 -9999 -9999 -9999 -9999 -9999 -9999 -9999 -9999 -9999 -9999 -9999 -9999 -9999 -9999 -9999 -9999 -9999 -9999 -9999 -9999 -9999 -9999 -

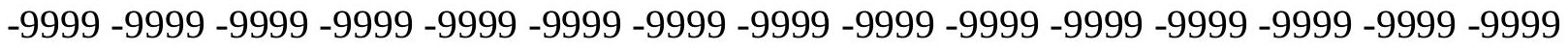
-9999 -9999 -9999 -9999 -9999 -9999 -9999 -9999 -9999 -9999 -9999 -9999 -9999 -9999 -9999

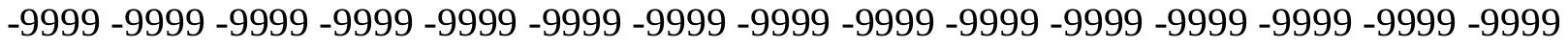
-9999 -9999 -9999 -9999 -9999 -9999 -9999 -9999 -9999 -9999 -9999 -9999 -9999 -9999 -9999 -9999 -9999 -9999 -9999 -9999 -9999 -9999 -9999 -9999 -9999 -9999 -9999 -9999 -9999 -9999 -9999 -9999 -9999 -9999 -9999 -9999 -9999 -9999 -9999 -9999 -9999 -9999 -9999 -9999 -9999 -9999 -9999 -9999 -9999 -9999 -9999 -9999 -9999 -9999 -9999 -9999 -9999 -9999 -9999 -9999 -9999 -9999 -9999 -9999 -9999 -9999 -9999 -9999 -9999 -9999 -9999 -9999 -9999 -9999 -9999 -9999 -9999 -9999 -9999 -9999 -9999 -9999 -9999 -9999 -9999 -9999 -9999 -9999 -9999 -9999 -9999 -9999 -9999 -9999 -9999 -9999 -9999 -9999 -9999 -9999 -9999 -9999 -9999 -9999 -9999 -9999 -9999 -9999 -9999 -9999 -9999 -9999 -9999 -9999 -9999 -9999 -9999 -9999 -9999 -9999 -9999 -9999 -9999 -9999 -9999 -9999 -9999 -9999 -9999 -9999 -9999 -9999 -9999 -9999 -9999 -9999 -9999 -9999 -9999 -9999 -9999 -9999 -9999 -9999 -9999 -9999 -9999 -9999 -9999 -

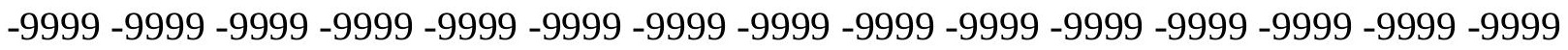

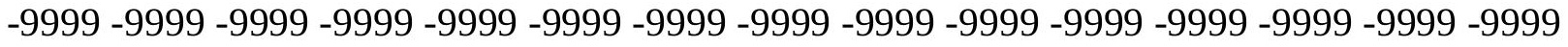
-9999 -9999 -9999 -9999 -9999 -9999 -9999 -9999 -9999 -9999 -9999 -9999 -9999 -9999 -9999 -

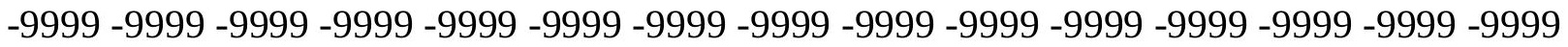

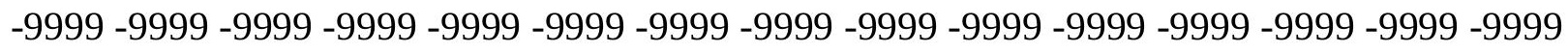

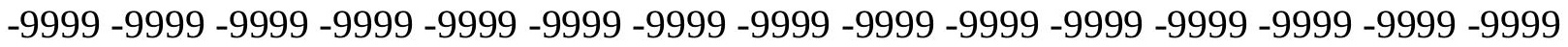

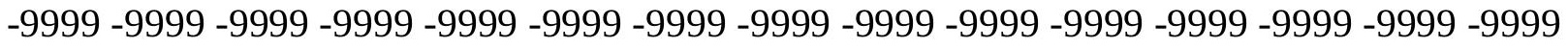
-9999 -9999 -9999 -9999 -9999 -9999 -9999 -9999 -9999 -9999 -9999 -9999 -9999 -9999 -9999 -

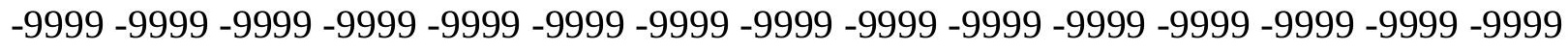

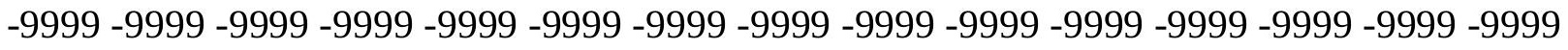
-9999 -9999 -9999 -9999 -9999 -9999 -9999 -9999 -9999 -9999 -9999 -9999 -9999 -9999 -9999 -9999 -9999 -9999 -9999 -9999 -9999 -9999 -9999 -9999-9999 -9999 -9999 -9999 -9999 -9999 -9999 -9999 -9999 -9999 -9999 -9999 -9999 -9999 -9999 -9999 -9999 -9999 -9999 -9999 -9999 -

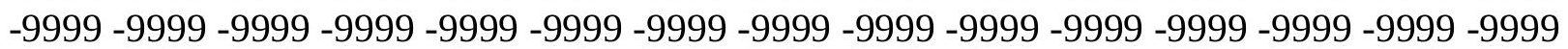


-9999 -9999 -9999 -9999 -9999 -9999 -9999 -9999 -9999 -9999 -9999 -9999 -9999 -9999 -9999 -9999 -9999 -9999 -9999 -9999 -9999 -9999 -9999 -9999 -9999 -9999 -9999 -9999 -9999 -9999 -9999 -9999 -9999 -9999 -9999 -9999 -9999 -9999 -9999 -9999 -9999 -9999 -9999 -9999 - 9999 -9999 -9999 -9999 -9999 -9999 -9999 -9999 -9999 -9999 -9999 -9999 -9999 -9999 -9999 -9999 -9999 -9999 -9999 -9999 -9999 -9999 -9999 -9999 -9999 -9999 -9999 -9999 -9999 -9999 -9999 -9999 -9999 -9999 -9999 -9999 -9999 -9999 -9999 -9999 -9999 -9999 -9999 -9999 -9999 -9999 -9999 -9999 -9999 -9999 -9999 -9999 -9999 -9999 -9999 -9999 -9999 -9999 -9999 -9999 -9999

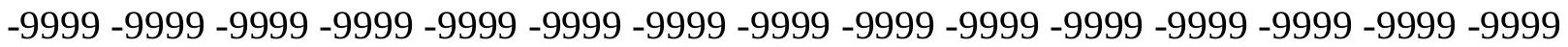

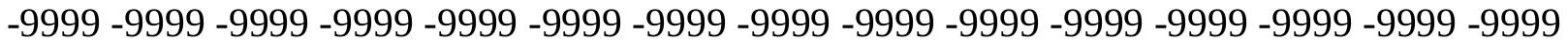
-9999 -9999 -9999 -9999 -9999 -9999 -9999 -9999 -9999 -9999 -9999 -9999 -9999 -9999 -9999 -9999 -9999 -9999 -9999 -9999 -9999 -9999 -9999 -9999 -9999 -9999 -9999 -9999 -9999 -9999 -9999 -9999 -9999 -9999 -9999 -9999 -9999 -9999 -9999 -9999 -9999 -9999 -9999 -9999 -9999 -9999 -9999 -9999 -9999 -9999 -9999 -9999 -9999 -9999 -9999 -9999 -9999 -9999 -9999 -9999 -9999 -9999 -9999 -9999 -9999 -9999 -9999 -9999 -9999 -9999 -9999 -9999 -9999 -9999 -9999 -9999 -9999 -9999 -9999 -9999 -9999 -9999 -9999 -9999 -9999 -9999 -9999 -9999 -9999 -

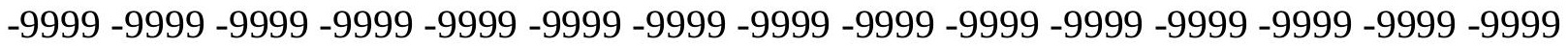
-9999 -9999 -9999 -9999 -9999 -9999 -9999 -9999 -9999 -9999 -9999 -9999 -9999 -9999 -9999 -9999 -9999 -9999 -9999 -9999 -9999 -9999 -9999 -9999 -9999 -9999 -9999 -9999 -9999 -9999 -9999 -9999 -9999 -9999 -9999 -9999 -9999 -9999 -9999 -9999 -9999 -9999 -9999 -9999 -9999 -9999 -9999 -9999 -9999 -9999 -9999 -9999 -9999 -9999 -9999 -9999 -9999 -9999 -9999 -9999 -9999 -9999 -9999 -9999 -9999 -9999 -9999 -9999 -9999 -9999 -9999 -9999 -9999 -9999 -9999 -999 -9999 -9999 -9999 -9999 -9999 -9999 -9999 -9999 -9999 -9999 -9999 -9999 -9999 -9999 -9999 -9999 -9999 -9999 -9999 -9999 -9999 -9999 -9999 -9999 -9999 -9999 -9999 -9999 -9999 -9999 -9999 -9999 -9999 -9999 -9999 -9999 -9999 -9999 -9999 -9999 -9999 -9999 -9999 -9999 -9999 -9999 -9999 -9999 -9999 -9999 -9999 -9999 -9999 -9999 -9999 -9999 -9999 -9999 -9999 -9999 -9999 -9999 -9999 -9999 -9999 -9999 -9999 -9999 -9999 -9999 -9999 -9999 -9999 -9999 -9999 -9999 -9999 -9999 -9999 -9999 -9999 -9999 -9999 -9999 -9999 -9999 -9999 -9999 -9999 -9999 -9999 -9999 -9999 -9999 -9999 -9999 -9999 -9999 -9999 -9999 -9999 -9999 -9999 -9999 -9999 -9999 -9999 -9999 -9999 -9999 -9999 -9999 -9999 -9999 -9999 -9999 -9999 -9999 -9999 -9999 -9999 -9999 -9999 -9999 -9999 -9999 -9999 -9999 -9999 -9999 -9999 -9999 -9999 -9999 -999 -9999 -9999 -9999 -9999 -9999 -9999 -9999 -9999 -9999 -9999 -9999 -9999 -9999 -9999 -9999 -9999 -9999 -9999 -9999 -9999 -9999 -9999 -9999 -9999 -9999 -9999 -9999 -9999 -9999 -9999 -

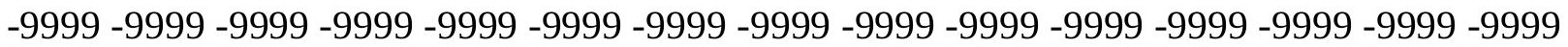

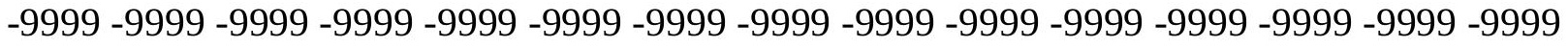

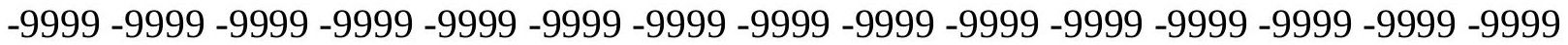
-9999 -9999 -9999 -9999 -9999 -9999 -9999 -9999 -9999 -9999 -9999 -9999 -9999 -9999 -9999 -9999 -9999 -9999 -9999 -9999 -9999 -9999 -9999 -9999 -9999 -9999 -9999 -9999 -9999 -

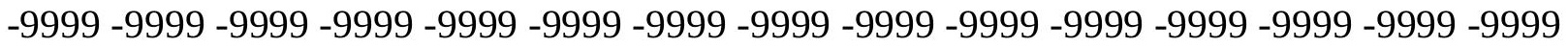
-9999 -9999 -9999 -9999 -9999 -9999 -9999 -9999 -9999 -9999 -9999 -9999 -9999 -9999 -9999 -9999 -9999 -9999 -9999 -9999 -9999 -9999 -9999 -9999 -9999 -9999 -9999 -9999 -9999 -9999 -

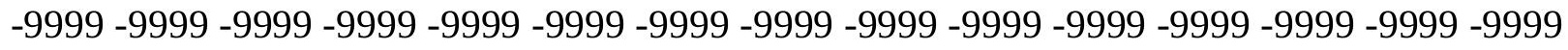

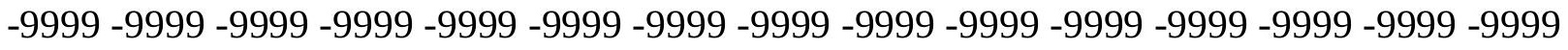
-9999 -9999 -9999 -9999 -9999 -9999 -9999 -9999 -9999 -9999 -9999 -9999 -9999 -9999 -9999 -9999 -9999 -9999 -9999 -9999 -9999 -9999 -9999 -9999-9999 -9999 -9999 -9999 -9999 -9999 -9999 -9999 -9999 -9999 -9999 -9999 -9999 -9999 -9999 -9999 -9999 -9999 -9999 -9999 -9999 -

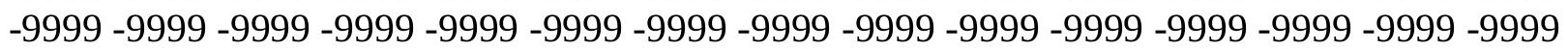


-9999 -9999 -9999 -9999 -9999 -9999 -9999 -9999 -9999 -9999 -9999 -9999 -9999 -9999 -9999 -9999 -9999 -9999 -9999 -9999 -9999 -9999 -9999 -9999 -9999 -9999 -9999 -9999 -9999 -9999 -

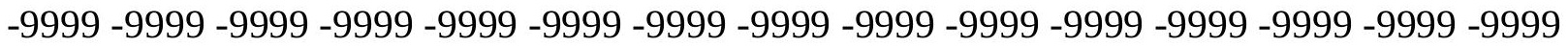
-9999 -9999 -9999 -9999 -9999 -9999 -9999 -9999 -9999 -9999 -9999 -9999 -9999 -9999 -9999 -9999 -9999 -9999 -9999 -9999 -9999 -9999 -9999 -9999-9999 -9999 -9999 -9999 -9999 -9999 -9999 -9999 -9999 -9999 -9999 -9999 -9999 -9999 -9999 -9999 -9999 -9999 -9999 -9999 -9999 -9999 -9999 -9999 -9999 -9999 -9999 -9999 -9999 -9999 -9999 -9999 -9999 -9999 -9999 -9999

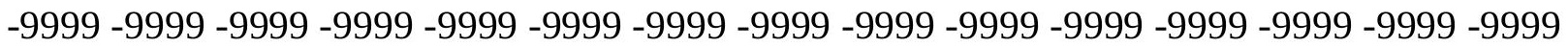

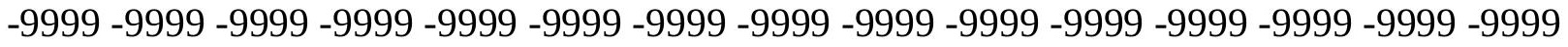
-9999 -9999 -9999 -9999 -9999 -9999 -9999 -9999 -9999 -9999 -9999 -9999 -9999 -9999 -9999 -9999 -9999 -9999 -9999 -9999 -9999 -9999 -9999 -9999 -9999 -9999 -9999 -9999 -9999 -9999 -9999 -9999 -9999 -9999 -9999 -9999 -9999 -9999 -9999 -9999 -9999 -9999 -9999 -9999 -9999 -9999 -9999 -9999 -9999 -9999 -9999 -9999 -9999 -9999 -9999 -9999 -9999 -9999 -9999 -9999 -9999 -9999 -9999 -9999 -9999 -9999 -9999 -9999 -9999 -9999 -9999 -9999 -9999 -9999 -9999 -9999 -9999 -9999 -9999 -9999 -9999 -9999 -9999 -9999 -9999 -9999 -9999 -9999 -9999 -9999 -

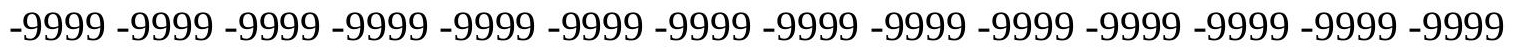
-9999 -9999 -9999 -9999 -9999 -9999 -9999 -9999 -9999 -9999 -9999 -9999 -9999 -9999 -9999 -9999 -9999 -9999 -9999 -9999 -9999 -9999 -9999 -9999 -9999 -9999 -9999 -9999 -9999 -9999 -9999 -9999 -9999 -9999 -9999 -9999 -9999 -9999 -9999 -9999 -9999 -9999 -9999 -9999 -9999 -

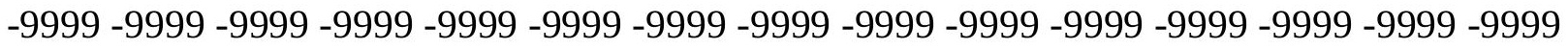

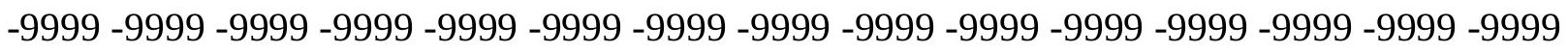
-9999 -9999 -9999 -9999 -9999 -9999 -9999 -9999 -9999 -9999 -9999 -9999 -9999 -9999 - 9999 -9999 -9999 -9999 -9999 -9999 -9999 -9999 -9999 -9999 -9999 -9999 -9999 -9999 -9999 -9999 -9999 -9999 -9999 -9999 -9999 -9999 -9999 -9999 -9999 -9999 -9999 -9999 -9999 -9999 -9999 -

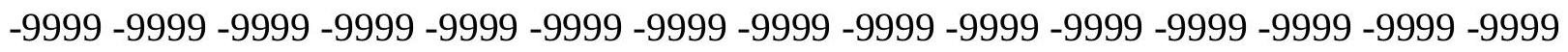
-9999 -9999 -9999 -9999 -9999 -9999 -9999 -9999 -9999 -9999 -9999 -9999 -9999 -9999 -9999 -9999 -9999 -9999 -9999 -9999 -9999 -9999 -9999 -9999 -9999 -9999 -9999 -9999 -9999 -9999 -

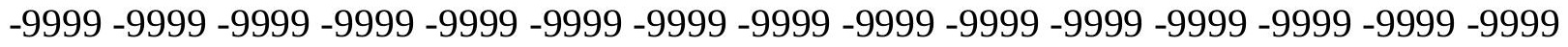
-9999 -9999 -9999 -9999 -9999 -9999 -9999 -9999 -9999 -9999 -9999 -9999 -9999 -9999 -9999 -9999 -9999 -9999 -9999 -9999 -9999 -9999 -9999 -9999 -9999 -9999 -9999 -9999 -9999 -999 -

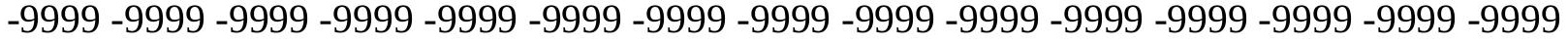
-9999 -9999 -9999 -9999 -9999 -9999 -9999 -9999 -9999 -9999 -9999 -9999 -9999 -9999 -9999 -

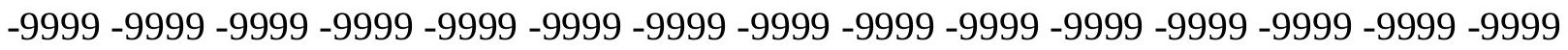

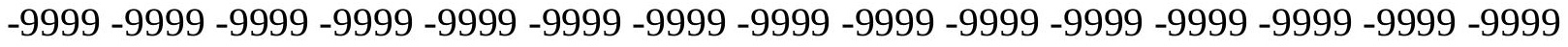

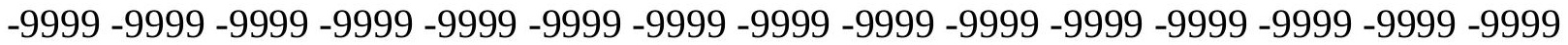
-9999 -9999 -9999 -9999 -9999 -9999 -9999 -9999 -9999 -9999 -9999 -9999 -9999 -9999 -9999 -

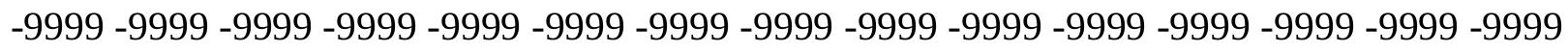

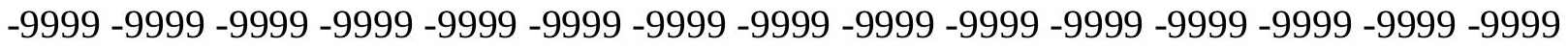
-9999 -9999 -9999 -9999 -9999 -9999 -9999 -9999 -9999 -9999 -9999 -9999 -9999 - 9999 - -999 -9999 -9999 -9999 -9999 -9999 -9999 -9999 -9999 -9999 -9999 -9999 -9999 -9999 -9999 -9999 -

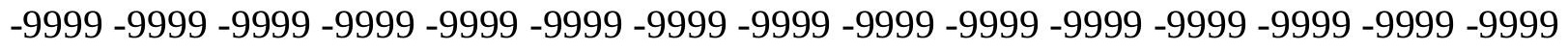

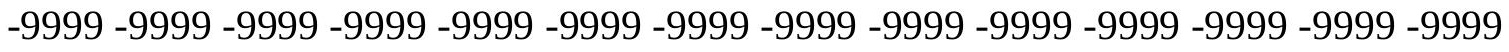
-9999 -9999 -9999 -9999 -9999 -9999 -9999 -9999 -9999 -9999 -9999 -9999 -9999 -9999 -9999 -9999 -9999 -9999 -9999 -9999 -9999 -9999 -9999 -9999-9999 -9999 -9999 -9999 -9999 -9999 -9999 -9999 -9999 -9999 -9999 -9999 -9999 -9999 -9999 -9999 -9999 -9999 -9999 -9999 -9999 -

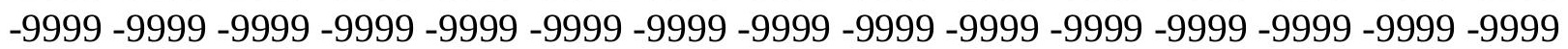


-9999 -9999 -9999 -9999 -9999 -9999 -9999 -9999 -9999 -9999 -9999 -9999 -9999 -9999 -9999 -9999 -9999 -9999 -9999 -9999 -9999 -9999 -9999 -9999 -9999 -9999 -9999 -9999 -9999 -9999 -

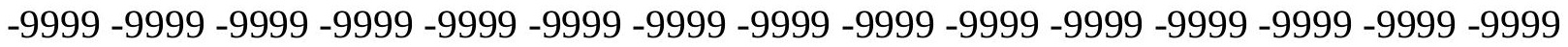
-9999 -9999 -9999 -9999 -9999 -9999 -9999 -9999 -9999 -9999 -9999 -9999 -9999 -9999 -9999 -9999 -9999 -9999 -9999 -9999 -9999 -9999 -9999 -9999-9999 -9999 -9999 -9999 -9999 -9999 -9999 -9999 -9999 -9999 -9999 -9999 -9999 -9999 -9999 -9999 -9999 -9999 -9999 -9999 -9999 -9999 -9999 -9999 -9999 -9999 -9999 -9999 -9999 -9999 -9999 -9999 -9999 -9999 -9999 -9999

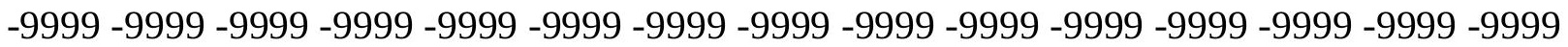

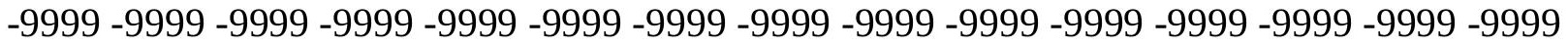
-9999 -9999 -9999 -9999 -9999 -9999 -9999 -9999 -9999 -9999 -9999 -9999 -9999 -9999 -9999 -9999 -9999 -9999 -9999 -9999 -9999 -9999 -9999 -9999 -9999 -9999 -9999 -9999 -9999 -9999 -9999 -9999 -9999 -9999 -9999 -9999 -9999 -9999 -9999 -9999 -9999 -9999 -9999 -9999 -9999 -9999 -9999 -9999 -9999 -9999 -9999 -9999 -9999 -9999 -9999 -9999 -9999 -9999 -9999 -9999 -

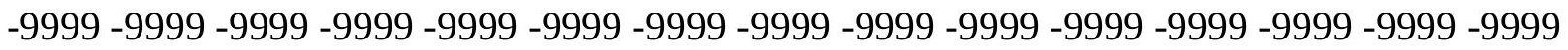
-9999 -9999 -9999 -9999 -9999 -9999 -9999 -9999 -9999 -9999 -9999 -9999 -9999 -9999 -9999 -

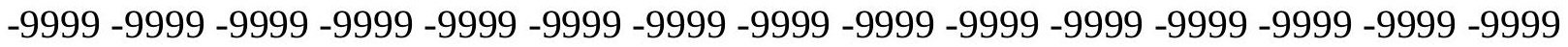
-9999 -9999 -9999 -9999 -9999 -9999 -9999 -9999 -9999 -9999 -9999 -9999 -9999 -9999 -9999 -9999 -9999 -9999 -9999 -9999 -9999 -9999 -9999 -9999 -9999 -9999 -9999 -9999 -9999 -9999 -9999 -9999 -9999 -9999 -9999 -9999 -9999 -9999 -9999 -9999 -9999 -9999 -9999 -9999 -9999 -

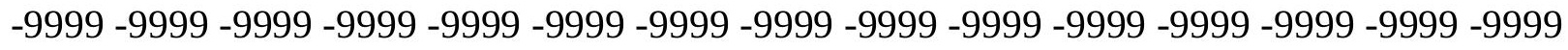

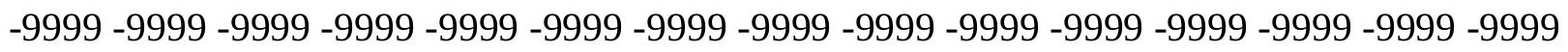
-9999 -9999 -9999 -9999 -9999 -9999 -9999 -9999 -9999 -9999 -9999 -9999 -9999 -9999 -9999 -9999 -9999 -9999 -9999 -9999 -9999 -9999 -9999 -9999 -9999 -9999 -9999 -9999 -9999 -9999 -9999 -9999 -9999 -9999 -9999 -9999 -9999 -9999 -9999 -9999 -9999 -9999 -9999 -9999 -

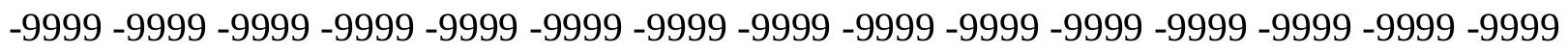
-9999 -9999 -9999 -9999 -9999 -9999 -9999 -9999 -9999 -9999 -9999 -9999 -9999 -9999 -9999 -9999 -9999 -9999 -9999 -9999 -9999 -9999 -9999 -9999 -9999 -9999 -9999 -9999 -9999 -9999 -

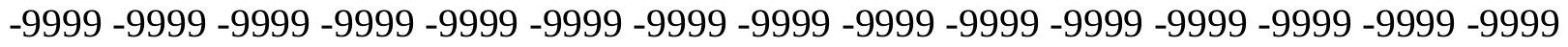
-9999 -9999 -9999 -9999 -9999 -9999 -9999 -9999 -9999 -9999 -9999 -9999 -9999 -9999 -9999 -9999 -9999 -9999 -9999 -9999 -9999 -9999 -9999 -9999 -9999 -9999 -9999 -9999 -9999 -999 -

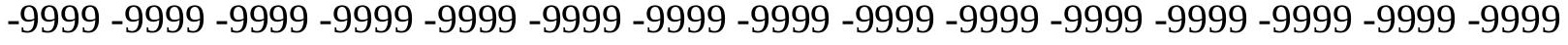
-9999 -9999 -9999 -9999 -9999 -9999 -9999 -9999 -9999 -9999 -9999 -9999 -9999 -9999 -9999 -

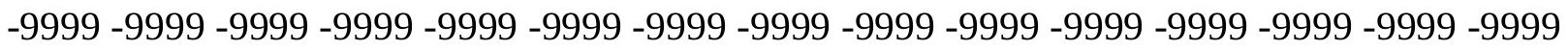

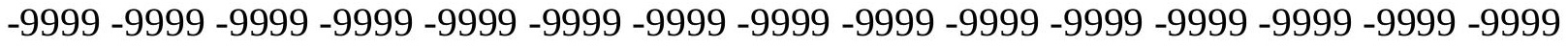

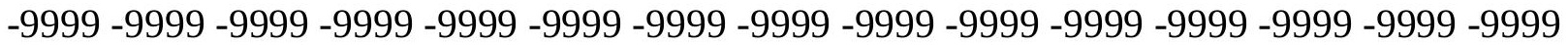

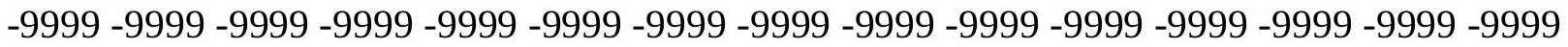

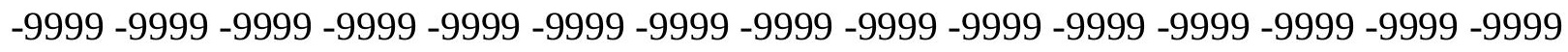

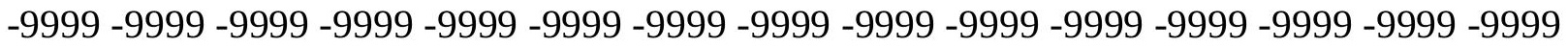

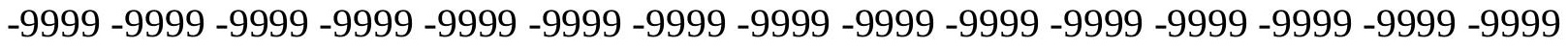
-9999 -9999 -9999 -9999 -9999 -9999 -9999 -9999 -9999 -9999 -9999 -9999 -9999 -9999 -9999 -

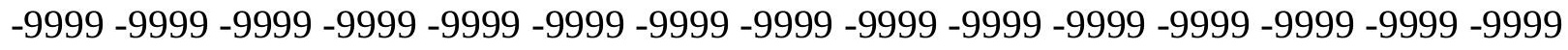

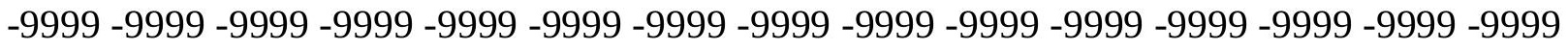
-9999 -9999 -9999 -9999 -9999 -9999 -9999 -9999 -9999 -9999 -9999 -9999 -9999 -9999 -9999 -9999 -9999 -9999 -9999 -9999 -9999 -9999 -9999 -9999-9999 -9999 -9999 -9999 -9999 -9999 -9999 -9999 -9999 -9999 -9999 -9999 -9999 -9999 -9999 -9999 -9999 -9999 -9999 -9999 -9999 -

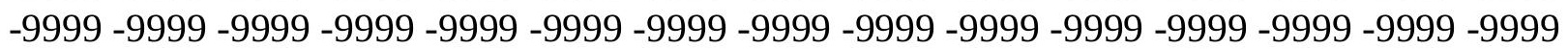


-9999 -9999 -9999 -9999 -9999 -9999 -9999 -9999 -9999 -9999 -9999 -9999 -9999 -9999 -9999 -9999 -9999 -9999 -9999 -9999 -9999 -9999 -9999 -9999 -9999 -9999 -9999 -9999 -9999 -

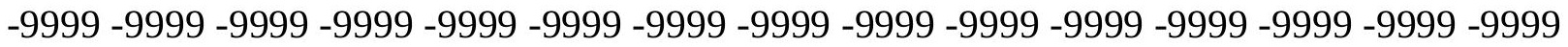
-9999 -9999 -9999 -9999 -9999 -9999 -9999 -9999 -9999 -9999 -9999 -9999 -9999 -9999 -9999 -9999 -9999 -9999 -9999 -9999 -9999 -9999 -9999 -9999 -9999 -9999 -9999 -9999 -9999 -9999 -9999 -9999 -9999 -9999 -9999 -9999 -9999 -9999 -9999 -9999 -9999 -9999 -9999 -9999 -9999 -9999 -9999 -9999 -9999 -9999 -9999 -9999 -9999 -9999 -9999 -9999 -9999 -9999 -9999 -9999

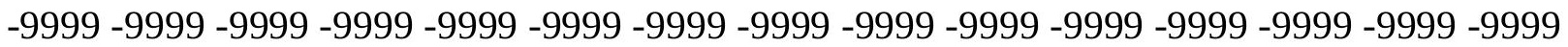

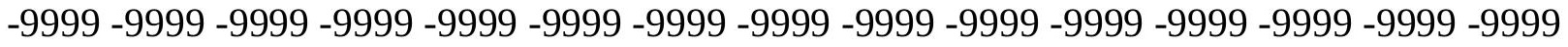
-9999 -9999 -9999 -9999 -9999 -9999 -9999 -9999 -9999 -9999 -9999 -9999 -9999 -9999 -9999 -9999 -9999 -9999 -9999 -9999 -9999 -9999 -9999 -9999 -9999 -9999 -9999 -9999 -9999 -9999 -9999 -9999 -9999 -9999 -9999 -9999 -9999 -9999 -9999 -9999 -9999 -9999 -9999 -9999 -9999 -9999 -9999 -9999 -9999 -9999 -9999 -9999 -9999 -9999 -9999 -9999 -9999 -9999 -9999 -9999 -9999 -9999 -9999 -9999 -9999 -9999 -9999 -9999 -9999 -9999 -9999 -9999 -9999 -9999 -9999 -9999 -9999 -9999 -9999 -9999 -9999 -9999 -9999 -9999 -9999 -9999 -9999 -9999 -9999 -9999 -

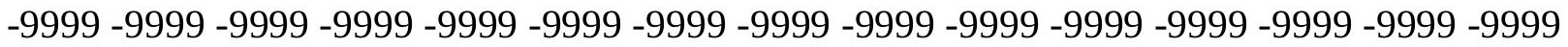
-9999 -9999 -9999 -9999 -9999 -9999 -9999 -9999 -9999 -9999 -9999 -9999 -9999 -9999 -9999 -9999 -9999 -9999 -9999 -9999 -9999 -9999 -9999 -9999 -9999 -9999 -9999 -9999 -9999 - 9999 -9999 -9999 -9999 -9999 -9999 -9999 -9999 -9999 -9999 -9999 -9999 -9999 -9999 -9999 -9999 -

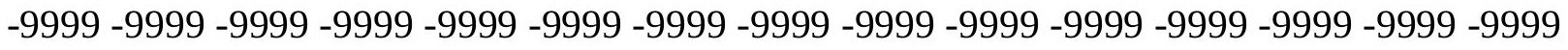

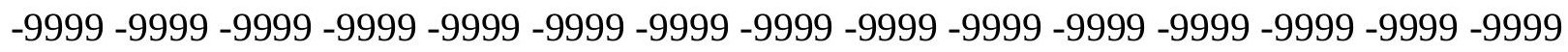

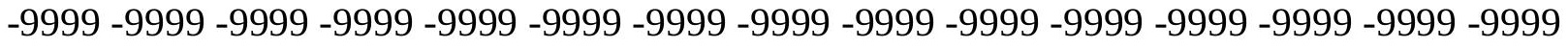
-9999 -9999 -9999 -9999 -9999 -9999 -9999 -9999 -9999 -9999 -9999 -9999 -9999 -9999 -9999 -9999 -9999 -9999 -9999 -9999 -9999 -9999 -9999 -9999 -9999 -9999 -9999 -9999 -9999 -9999 -

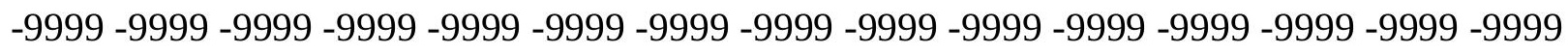
-9999 -9999 -9999 -9999 -9999 -9999 -9999 -9999 -9999 -9999 -9999 -9999 -9999 -9999 -9999 -9999 -9999 -9999 -9999 -9999 -9999 -9999 -9999 -9999 -9999 -9999 -9999 -9999 -9999 -9999 -9999 -9999 -9999 -9999 -9999 -9999 -9999 -9999 -9999 -9999 -9999 -9999 -9999 -9999 -9999 -9999 -9999 -9999 -9999 -9999 -9999 -9999 -9999 -9999 -9999 -9999 -9999 -9999 -9999 -9999 -9999 -9999 -9999 -9999 -9999 -9999 -9999 -9999 -9999 -9999 -9999 -9999 -9999 -999 -

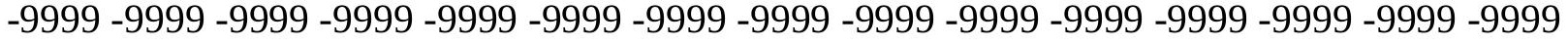
-9999 -9999 -9999 -9999 -9999 -9999 -9999 -9999 -9999 -9999 -9999 -9999 -9999 -9999 -9999 -

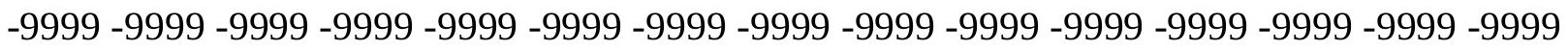

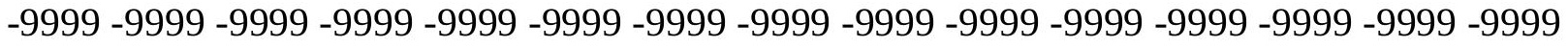

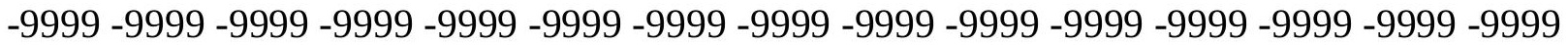

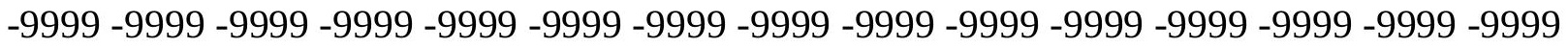

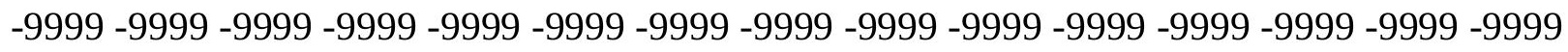

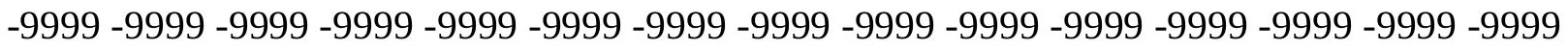

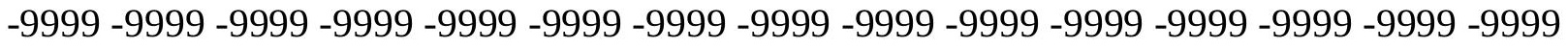
-9999 -9999 -9999 -9999 -9999 -9999 -9999 -9999 -9999 -9999 -9999 -9999 -9999 -9999 -9999 -

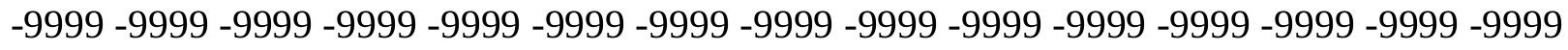

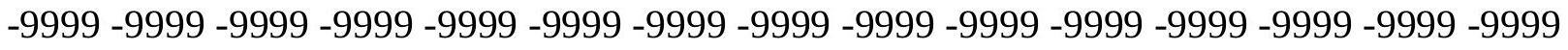
-9999 -9999 -9999 -9999 -9999 -9999 -9999 -9999 -9999 -9999 -9999 -9999 -9999 -9999 -9999 -9999 -9999 -9999 -9999 -9999 -9999 -9999 -9999 -9999-9999 -9999 -9999 -9999 -9999 -9999 -9999 -9999 -9999 -9999 -9999 -9999 -9999 -9999 -9999 -9999 -9999 -9999 -9999 -9999 -9999 -

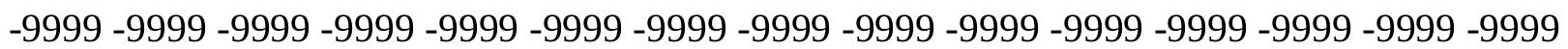


-9999 -9999 -9999 -9999 -9999 -9999 -9999 -9999 -9999 -9999 -9999 -9999 -9999 -9999 -9999 -9999 -9999 -9999 -9999 -9999 -9999 -9999 -9999 -9999 -9999 -9999 -9999 -9999 -9999 -9999 -

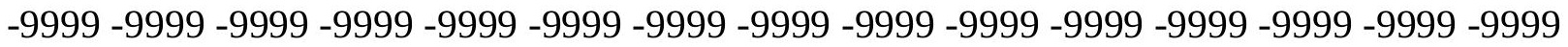
-9999 -9999 -9999 -9999 -9999 -9999 -9999 -9999 -9999 -9999 -9999 -9999 -9999 -9999 -9999 -9999 -9999 -9999 -9999 -9999 -9999 -9999 -9999 -9999-9999 -9999 -9999 -9999 -9999 -9999 -9999 -9999 -9999 -9999 -9999 -9999 -9999 -9999 -9999 -9999 -9999 -9999 -9999 -9999 -9999 -

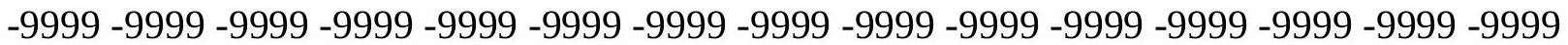
-9999 -9999 -9999 -9999 -9999 -9999 -9999 -9999 -9999 -9999 -9999 -9999 -9999 -9999 -9999 -9999 -9999 -9999 -9999 -9999 -9999 -9999 -9999 -9999 -9999 -9999 -9999 -9999 -9999 -9999 -9999 -9999 -9999 -9999 -9999 -9999 -9999 -9999 -9999 -9999 -9999 -9999 -9999 -9999 -9999 -9999 -9999 -9999 -9999 -9999 -9999 -9999 -9999 -9999 -9999 -9999 -9999 -9999 -9999 -9999 -9999 -9999 -9999 -9999 -9999 -9999 -9999 -9999 -9999 -9999 -9999 -9999 -9999 -9999 -9999 -9999 -9999 -9999 -9999 -9999 -9999 -9999 -9999 -9999 -9999 -9999 -9999 -9999 -9999 -9999 -9999 -9999 -9999 -9999 -9999 -9999 -9999 -9999 -9999 -9999 -9999 -9999 -9999 -9999 -9999 -9999 -9999 -9999 -9999 -9999 -9999 -9999 -9999 -9999 -9999 -9999 -9999 -9999 -9999 -

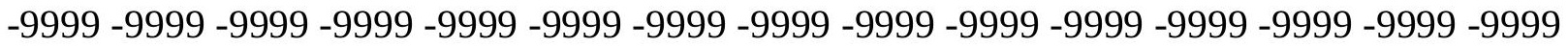
-9999 -9999 -9999 -9999 -9999 -9999 -9999 -9999 -9999 -9999 -9999 -9999 -9999 -9999 -9999 -9999 -9999 -9999 -9999 -9999 -9999 -9999 -9999 -9999 -9999 -9999 -9999 -9999 -9999 -9999 -9999 -9999 -9999 -9999 -9999 -9999 -9999 -9999 -9999 -9999 -9999 -9999 -9999 -9999 -9999 -

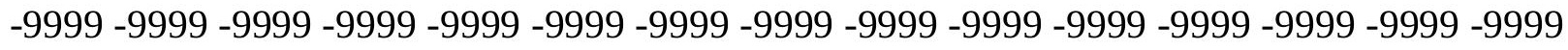

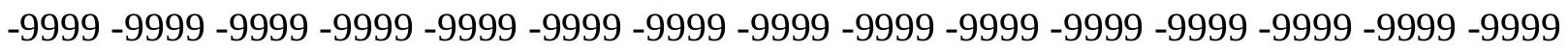
-9999 -9999 -9999 -9999 -9999 -9999 -9999 -9999 -9999 -9999 -9999 -9999 -9999 -9999 - 9999 -9999 -9999 -9999 -9999 -9999 -9999 -9999 -9999 -9999 -9999 -9999 -9999 -9999 -9999 -9999 -9999 -9999 -9999 -9999 -9999 -9999 -9999 -9999 -9999 -9999 -9999 -9999 -9999 -9999 -9999 -

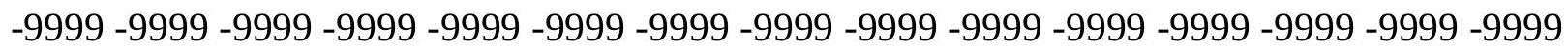
-9999 -9999 -9999 -9999 -9999 -9999 -9999 -9999 -9999 -9999 -9999 -9999 -9999 -9999 -9999 -9999 -9999 -9999 -9999 -9999 -9999 -9999 -9999 -9999 -9999 -9999 -9999 -9999 -9999 -9999 -

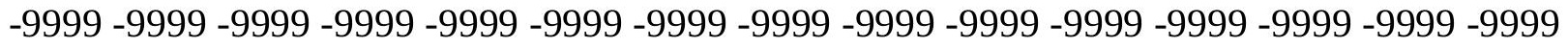
-9999 -9999 -9999 -9999 -9999 -9999 -9999 -9999 -9999 -9999 -9999 -9999 -9999 -9999 -9999 -9999 -9999 -9999 -9999 -9999 -9999 -9999 -9999 -9999 -9999 -9999 -9999 -9999 -9999 -999 -9999 -9999 -9999 -9999 -9999 -9999 -9999 -9999 -9999 -9999 -9999 -9999 -9999 -9999 -9999 -9999 -9999 -9999 -9999 -9999 -9999 -9999 -9999 -9999 -9999 -9999 -9999 -9999 -9999 -9999 -

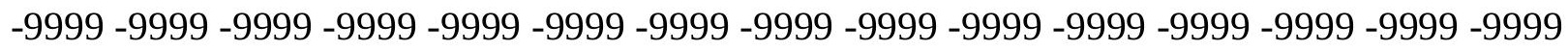

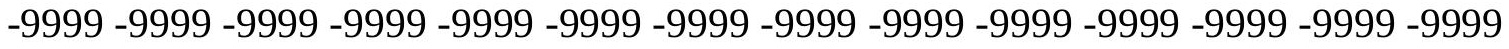
-9999 -9999 -9999 -9999 -9999 -9999 -9999 -9999 -9999 -9999 -9999 -9999 -9999 -9999 -9999

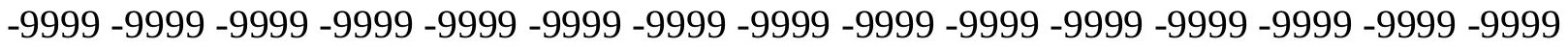

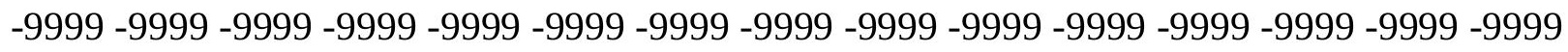

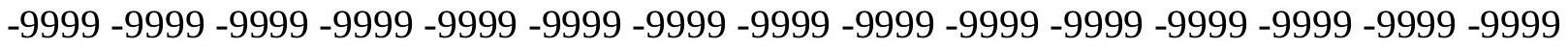

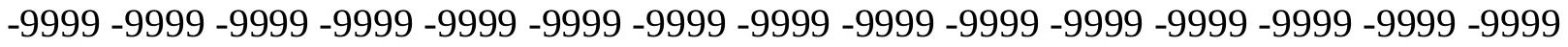
-9999 -9999 -9999 -9999 -9999 -9999 -9999 -9999 -9999 -9999 -9999 -9999 -9999 -9999 -9999 -

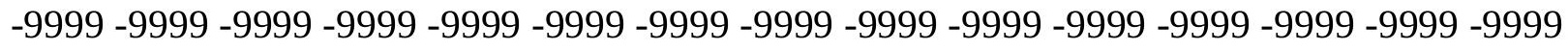

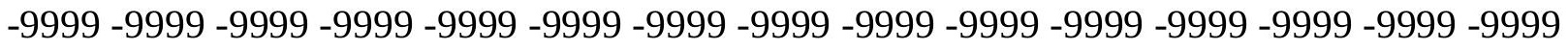
-9999 -9999 -9999 -9999 -9999 -9999 -9999 -9999 -9999 -9999 -9999 -9999 -9999 -9999 -9999 -9999 -9999 -9999 -9999 -9999 -9999 -9999 -9999 -9999-9999 -9999 -9999 -9999 -9999 -9999 -9999 -9999 -9999 -9999 -9999 -9999 -9999 -9999 -9999 -9999 -9999 -9999 -9999 -9999 -9999 -

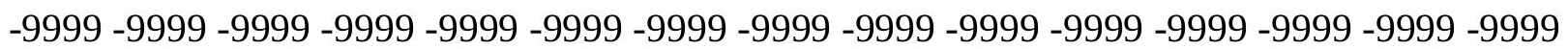


-9999 -9999 -9999 -9999 -9999 -9999 -9999 -9999 -9999 -9999 -9999 -9999 -9999 -9999 -9999 -9999 -9999 -9999 -9999 -9999 -9999 -9999 -9999 -9999 -9999 -9999 -9999 -9999 -9999 -9999 -

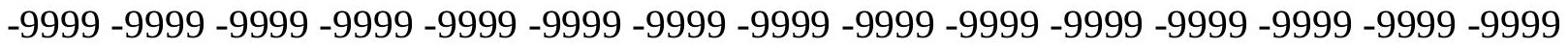
-9999 -9999 -9999 -9999 -9999 -9999 -9999 -9999 -9999 -9999 -9999 -9999 -9999 -9999 -9999 -9999 -9999 -9999 -9999 -9999 -9999 -9999 -9999 -9999-9999 -9999 -9999 -9999 -9999 -9999 -9999 -9999 -9999 -9999 -9999 -9999 -9999 -9999 -9999 -9999 -9999 -9999 -9999 -9999 -9999 -9999 -9999 -9999 -9999 -9999 -9999 -9999 -9999 -9999 -9999 -9999 -9999 -9999 -9999 -9999

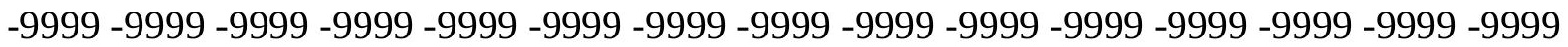

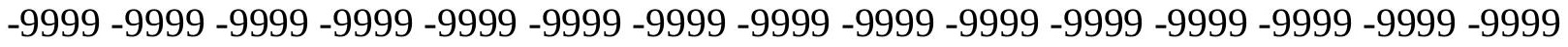
-9999 -9999 -9999 -9999 -9999 -9999 -9999 -9999 -9999 -9999 -9999 -9999 -9999 -9999 -9999 -9999 -9999 -9999 -9999 -9999 -9999 -9999 -9999 -9999 -9999 -9999 -9999 -9999 -9999 -9999 -9999 -9999 -9999 -9999 -9999 -9999 -9999 -9999 -9999 -9999 -9999 -9999 -9999 -9999 -9999 -9999 -9999 -9999 -9999 -9999 -9999 -9999 -9999 -9999 -9999 -9999 -9999 -9999 -9999 -9999 -9999 -9999 -9999 -9999 -9999 -9999 -9999 -9999 -9999 -9999 -9999 -9999 -9999 -9999 -9999 -9999 -9999 -9999 -9999 -9999 -9999 -9999 -9999 -9999 -9999 -9999 -9999 -9999 -9999

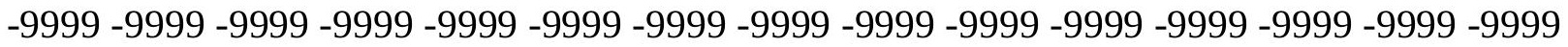
-9999 -9999 -9999 -9999 -9999 -9999 -9999 -9999 -9999 -9999 -9999 -9999 -9999 -9999 -9999 -9999 -9999 -9999 -9999 -9999 -9999 -9999 -9999 -9999 -9999 -9999 -9999 -9999 -9999 -9999 -9999 -9999 -9999 -9999 -9999 -9999 -9999 -9999 -9999 -9999 -9999 -9999 -9999 -9999 -9999 -

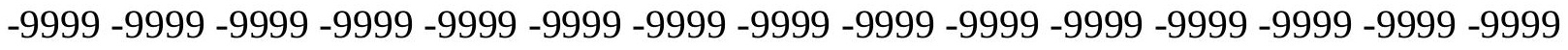

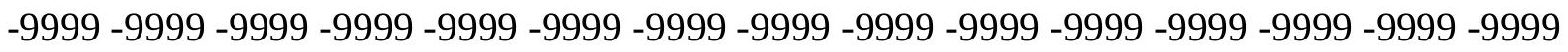
-9999 -9999 -9999 -9999 -9999 -9999 -9999 -9999 -9999 -9999 -9999 -9999 -9999 -9999 -9999 -9999 -9999 -9999 -9999 -9999 -9999 -9999 -9999 -9999 -9999 -9999 -9999 -9999 -9999 -9999 -9999 -9999 -9999 -9999 -9999 -9999 -9999 -9999 -9999 -9999 -9999 -9999 -9999 -9999 -9999 -

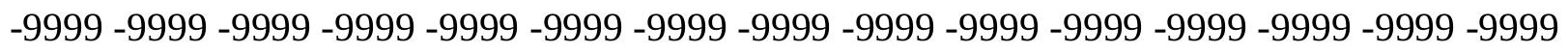
-9999 -9999 -9999 -9999 -9999 -9999 -9999 -9999 -9999 -9999 -9999 -9999 -9999 -9999 -9999 -9999 -9999 -9999 -9999 -9999 -9999 -9999 -9999 -9999 -9999 -9999 -9999 -9999 -9999 -9999 -

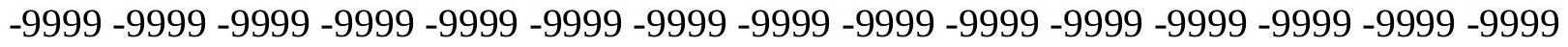
-9999 -9999 -9999 -9999 -9999 -9999 -9999 -9999 -9999 -9999 -9999 -9999 -9999 -9999 -9999 -9999 -9999 -9999 -9999 -9999 -9999 -9999 -9999 -9999 -9999 -9999 -9999 -9999 -9999 -999 -9999 -9999 -9999 -9999 -9999 -9999 -9999 -9999 -9999 -9999 -9999 -9999 -9999 -9999 -9999 -9999 -9999 -9999 -9999 -9999 -9999 -9999 -9999 -9999 -9999 -9999 -9999 -9999 -9999 -9999 -

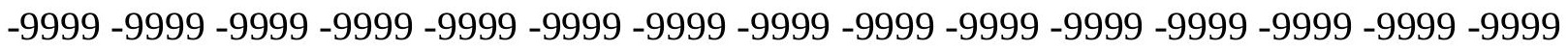

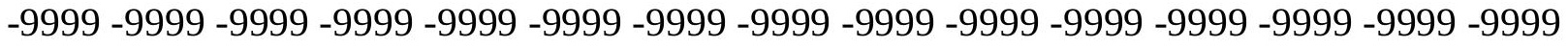

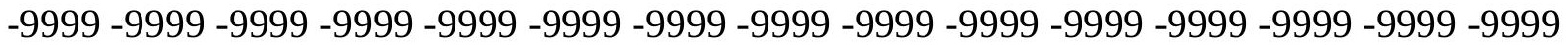

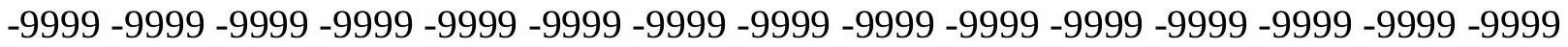

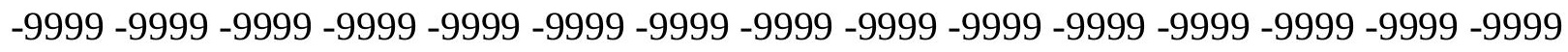

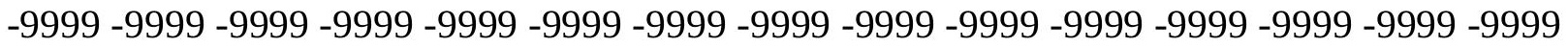
-9999 -9999 -9999 -9999 -9999 -9999 -9999 -9999 -9999 -9999 -9999 -9999 -9999 - 9999 - -999 -9999 -9999 -9999 -9999 -9999 -9999 -9999 -9999 -9999 -9999 -9999 -9999 -9999 -9999 - -999 -

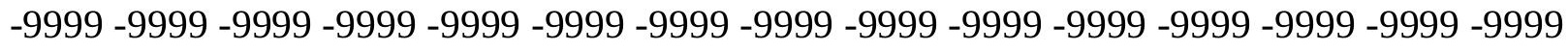

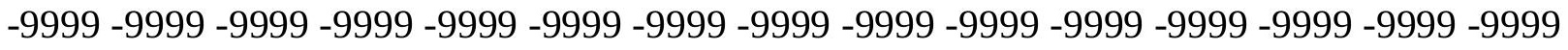
-9999 -9999 -9999 -9999 -9999 -9999 -9999 -9999 -9999 -9999 -9999 -9999 -9999 -9999 -9999 -9999 -9999 -9999 -9999 -9999 -9999 -9999 -9999 -9999-9999 -9999 -9999 -9999 -9999 -9999 -9999 -9999 -9999 -9999 -9999 -9999 -9999 -9999 -9999 -9999 -9999 -9999 -9999 -9999 -9999 -

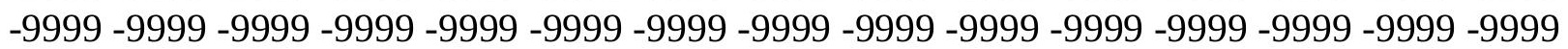


-9999 -9999 -9999 -9999 -9999 -9999 -9999 -9999 -9999 -9999 -9999 -9999 -9999 -9999 -9999 -9999 -9999 -9999 -9999 -9999 -9999 -9999 -9999 -9999 -9999 -9999 -9999 -9999 -9999 -9999 -9999 -9999 -9999 -9999 -9999 -9999 -9999 -9999 -9999 -9999 -9999 -9999 -9999 -9999 -9999 -9999 -9999 -9999 -9999 -9999 -9999 -9999 -9999 -9999 -9999 -9999 -9999 -9999 -9999 -9999 -9999 -9999 -9999 -9999 -9999 -9999 -9999 -9999 -9999 -9999 -9999 -9999 -9999 -9999 -9999 -9999 -9999 -9999 -9999 -9999 -9999 -9999 -9999 -9999 -9999 -9999 -9999 -9999 -9999 -9999 -9999 -9999 -9999 -9999 -9999 -9999 -9999 -9999 -9999 -9999 -9999 -9999 -9999 -9999 -9999 -

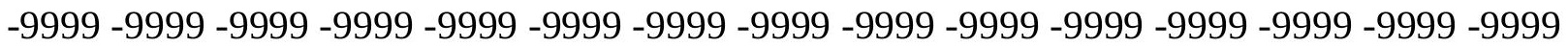
-9999 -9999 -9999 -9999 -9999 -9999 -9999 -9999 -9999 -9999 -9999 -9999 -9999 -9999 -9999 -9999 -9999 -9999 -9999 -9999 -9999 -9999 -9999 -9999 -9999 -9999 -9999 -9999 -9999 -9999 -

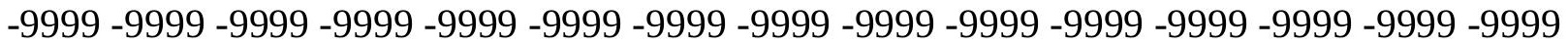
-9999 -9999 -9999 -9999 -9999 -9999 -9999 -9999 -9999 -9999 -9999 -9999 -9999 -9999 -9999 -9999 -9999 -9999 -9999 -9999 -9999 -9999 -9999 -9999 -9999 -9999 -9999 -9999 -9999 -9999 -9999 -9999 -9999 -9999 -9999 -9999 -9999 -9999 -9999 -9999 -9999 -9999 -9999 -9999 -9999 -9999 -9999 -9999 -9999 -9999 -9999 -9999 -9999 -9999 -9999 -9999 -9999 -9999 -9999 -9999

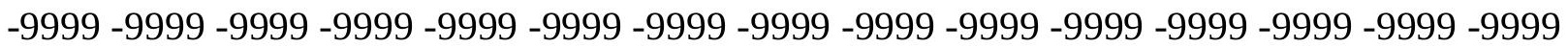
-9999 -9999 -9999 -9999 -9999 -9999 -9999 -9999 -9999 -9999 -9999 -9999 -9999 -9999 -9999 -9999 -9999 -9999 -9999 -9999 -9999 -9999 -9999 -9999 -9999 -9999 -9999 -9999 -9999 -9999 -9999 -9999 -9999 -9999 -9999 -9999 -9999 -9999 -9999 -9999 -9999 -9999 -9999 -9999 -9999 -9999 -9999 -9999 -9999 -9999 -9999 -9999 -9999 -9999 -9999 -9999 -9999 -9999 -9999 -9999 -9999 -9999 -9999 -9999 -9999 -9999 -9999 -9999 -9999 -9999 -9999 -9999 -9999 -9999 -9999 -9999 -9999 -9999 -9999 -9999 -9999 -9999 -9999 -9999 -9999 -9999 -9999 -9999 -9999 -9999 -9999 -9999 -9999 -9999 -9999 -9999 -9999 -9999 -9999 -9999 -9999 -9999 -9999 -9999 -9999 -9999 -9999 -9999 -9999 -9999 -9999 -9999 -9999 -9999 -9999 -9999 -9999 -9999 -9999 -9999 -9999 -9999 -9999 -9999 -9999 -9999 -9999 -9999 -9999 -9999 -9999 -9999 -9999 -9999 -9999 -9999 -9999 -9999 -9999 -9999 -9999 -9999 -9999 -9999 -9999 -9999 -9999 -9999 -9999 -9999 -9999 -9999 -9999 -9999 -9999 -9999 -9999 -9999 -9999 -9999 -9999 -9999 -9999 -9999 -9999 -9999 -9999 -9999 -9999 -9999 -9999 -9999 -9999 -9999 -9999 -9999 -9999 -9999 -9999

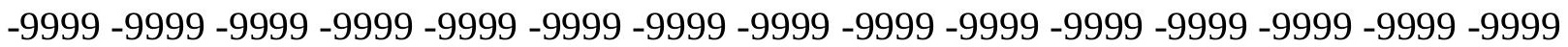
-9999 -9999 -9999 -9999 -9999 -9999 -9999 -9999 -9999 -9999 -9999 -9999 -9999 -9999 -9999 -9999 -9999 -9999 -9999 -9999 -9999 -9999 -9999 -9999 -9999 -9999 -9999 -9999 -9999 -9999 -

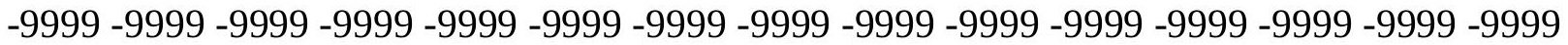
-9999 -9999 -9999 -9999 -9999 -9999 -9999 -9999 -9999 -9999 -9999 -9999 -9999 -9999 -9999 -9999 -9999 -9999 -9999 -9999 -9999 -9999 -9999 -9999 -9999 -9999 -9999 -9999 -9999 -9999 -9999 -9999 -9999 -9999 -9999 -9999 -9999 -9999 -9999 -9999 -9999 -9999 -9999 -9999 -9999 -9999 -9999 -9999 -9999 -9999 -9999 -9999 -9999 -9999 -9999 -9999 -9999 -9999 -9999 -9999 -9999 -9999 -9999 -9999 -9999 -9999 -9999 -9999 -9999 -9999 -9999 -9999 -9999 -9999 -9999

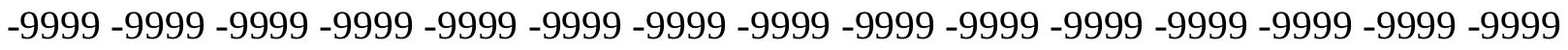
-9999 -9999 -9999 -9999 -9999 -9999 -9999 -9999 -9999 -9999 -9999 -9999 -9999 -9999 -9999 -9999 -9999 -9999 -9999 -9999 -9999 -9999 -9999 -9999 -9999 -9999 -9999 -9999 -9999 -9999 -9999 -9999 -9999 -9999 -9999 -9999 -9999 -9999 -9999 -9999 -9999 -9999 -9999 -9999 -9999 -999 -9999 -9999 -9999 -9999 -9999 -9999 -9999 -9999 -9999 -9999 -9999 -9999 -9999 -9999 -9999 -9999 -9999 -9999 -9999 -9999 -9999 -9999 -9999 -9999 -9999 -9999 -9999 -9999 -9999 -9999 -9999 -9999 -9999 -9999 -9999 -9999 -9999 -9999 -9999 -9999 -9999 -9999 -9999 -9999 -9999 -9999 -9999 -9999 -9999 -9999 -9999 -9999 -9999 -9999 -9999 -9999 -9999 -9999 -9999 -9999 -9999 -9999 -9999 -9999 -9999 -9999 -9999 -9999 -9999 -9999 -9999 -9999 -9999 -9999 
-9999 -9999 -9999 -9999 -9999 -9999 -9999 -9999 -9999 -9999 -9999 -9999 -9999 -9999 -9999 -9999 -9999 -9999 -9999 -9999 -9999 -9999 -9999 -9999 -9999 -9999 -9999 -9999 -9999 -9999 -

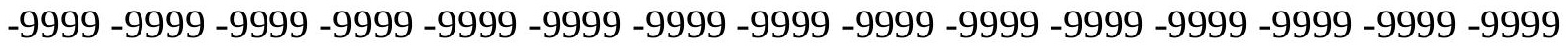
-9999 -9999 -9999 -9999 -9999 -9999 -9999 -9999 -9999 -9999 -9999 -9999 -9999 -9999 -9999 -9999 -9999 -9999 -9999 -9999 -9999 -9999 -9999 -9999-9999 -9999 -9999 -9999 -9999 -9999 -9999 -9999 -9999 -9999 -9999 -9999 -9999 -9999 -9999 -9999 -9999 -9999 -9999 -9999 -9999 -9999 -9999 -9999 -9999 -9999 -9999 -9999 -9999 -9999 -9999 -9999 -9999 -9999 -9999 -9999

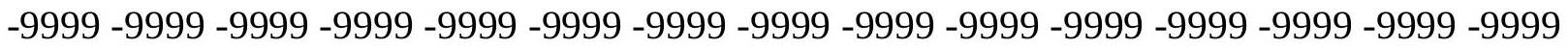

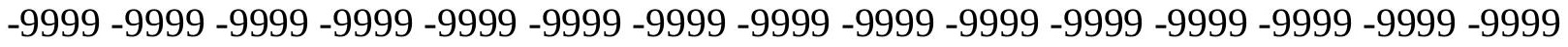
-9999 -9999 -9999 -9999 -9999 -9999 -9999 -9999 -9999 -9999 -9999 -9999 -9999 -9999 -9999 -9999 -9999 -9999 -9999 -9999 -9999 -9999 -9999 -9999 -9999 -9999 -9999 -9999 -9999 -9999 -9999 -9999 -9999 -9999 -9999 -9999 -9999 -9999 -9999 -9999 -9999 -9999 -9999 -9999 -9999 -9999 -9999 -9999 -9999 -9999 -9999 -9999 -9999 -9999 -9999 -9999 -9999 -9999 -9999 -9999 -

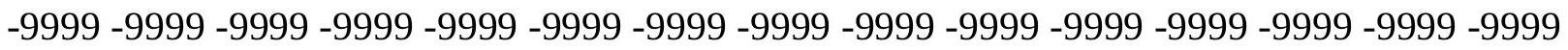
-9999 -9999 -9999 -9999 -9999 -9999 -9999 -9999 -9999 -9999 -9999 -9999 -9999 -9999 -9999 -

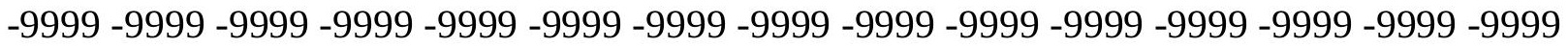
-9999 -9999 -9999 -9999 -9999 -9999 -9999 -9999 -9999 -9999 -9999 -9999 -9999 -9999 -9999 -9999 -9999 -9999 -9999 -9999 -9999 -9999 -9999 -9999 -9999 -9999 -9999 -9999 -9999 -9999 -9999 -9999 -9999 -9999 -9999 -9999 -9999 -9999 -9999 -9999 -9999 -9999 -9999 -9999 -9999 -

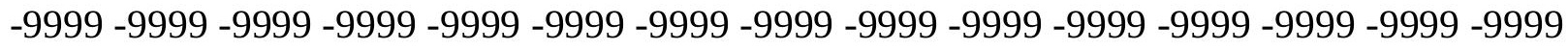

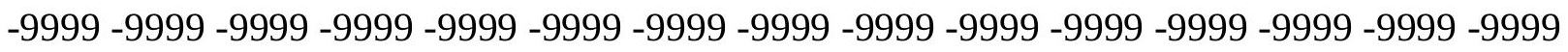

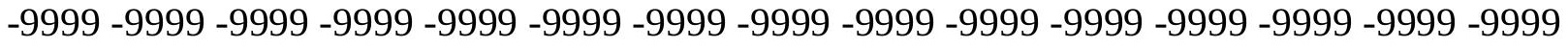
-9999 -9999 -9999 -9999 -9999 -9999 -9999 -9999 -9999 -9999 -9999 -9999 -9999 -9999 -9999 -9999 -9999 -9999 -9999 -9999 -9999 -9999 -9999 -9999 -9999 -9999 -9999 -9999 -9999 -9999 -

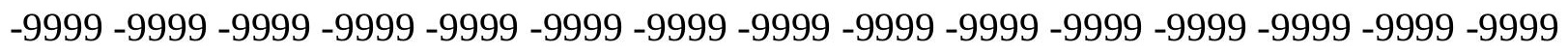
-9999 -9999 -9999 -9999 -9999 -9999 -9999 -9999 -9999 -9999 -9999 -9999 -9999 -9999 -9999 -9999 -9999 -9999 -9999 -9999 -9999 -9999 -9999 -9999 -9999 -9999 -9999 -9999 -9999 -

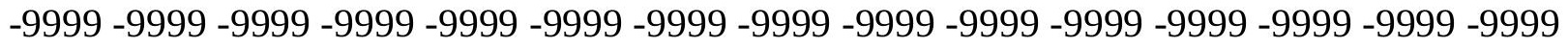
-9999 -9999 -9999 -9999 -9999 -9999 -9999 -9999 -9999 -9999 -9999 -9999 -9999 -9999 -9999 -9999 -9999 -9999 -9999 -9999 -9999 -9999 -9999 -9999 -9999 -9999 -9999 -9999 -9999 -999 -

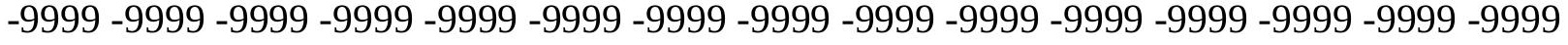
-9999 -9999 -9999 -9999 -9999 -9999 -9999 -9999 -9999 -9999 -9999 -9999 -9999 -9999 -9999 -

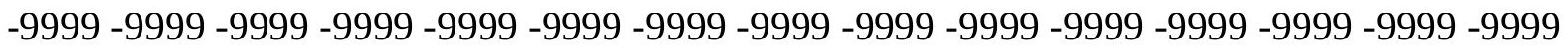

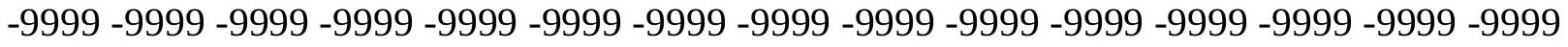

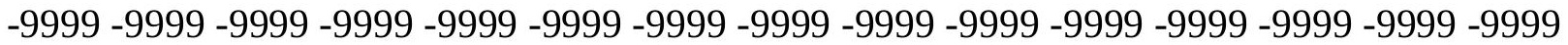
-9999 -9999 -9999 -9999 -9999 -9999 -9999 -9999 -9999 -9999 -9999 -9999 -9999 -9999 -9999

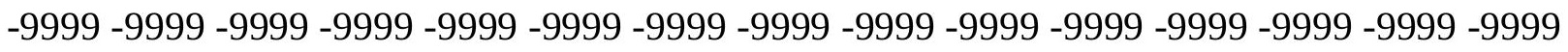

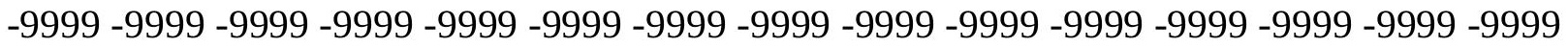
-9999 -9999 -9999 -9999 -9999 -9999 -9999 -9999 -9999 -9999 -9999 -9999 -9999 - 9999 - -999 -9999 -9999 -9999 -9999 -9999 -9999 -9999 -9999 -9999 -9999 -9999 -9999 -9999 -9999 -9999 -

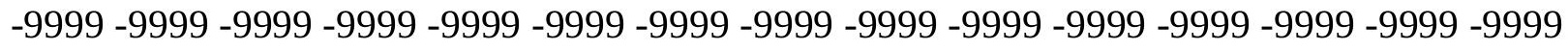

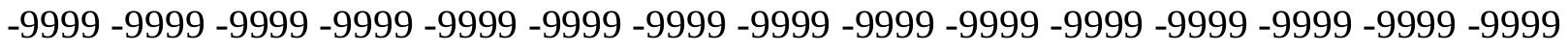
-9999 -9999 -9999 -9999 -9999 -9999 -9999 -9999 -9999 -9999 -9999 -9999 -9999 -9999 -9999 -9999 -9999 -9999 -9999 -9999 -9999 -9999 -9999 -9999-9999 -9999 -9999 -9999 -9999 -9999 -9999 -9999 -9999 -9999 -9999 -9999 -9999 -9999 -9999 -9999 -9999 -9999 -9999 -9999 -9999 -

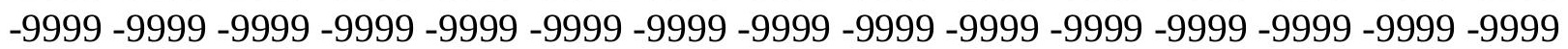


-9999 -9999 -9999 -9999 -9999 -9999 -9999 -9999 -9999 -9999 -9999 -9999 -9999 -9999 -9999 -9999 -9999 -9999 -9999 -9999 -9999 -9999 -9999 -9999 -9999 -9999 -9999 -9999 -9999 -9999 -9999 -9999 -9999 -9999 -9999 -9999 -9999 -9999 -9999 -9999 -9999 -9999 -9999 -9999 - 9999 -9999 -9999 -9999 -9999 -9999 -9999 -9999 -9999 -9999 -9999 -9999 -9999 -9999 -9999 -9999 -9999 -9999 -9999 -9999 -9999 -9999 -9999 -9999 -9999 -9999 -9999 -9999 -9999 -9999 - -9999 -9999 -9999 -9999 -9999 -9999 -9999 -9999 -9999 -9999 -9999 -9999 -9999 -9999 -9999 -9999 -9999 -9999 -9999 -9999 -9999 -9999 -9999 -9999 -9999 -9999 -9999 -9999 -9999 -9999

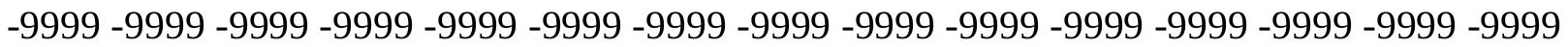

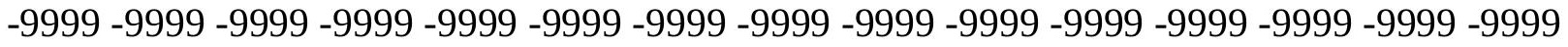
-9999 -9999 -9999 -9999 -9999 -9999 -9999 -9999 -9999 -9999 -9999 -9999 -9999 -9999 -9999

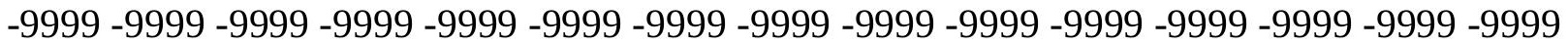
-9999 -9999 -9999 -9999 -9999 -9999 -9999 -9999 -9999 -9999 -9999 -9999 -9999 -9999 -9999 -9999 -9999 -9999 -9999 -9999 -9999 -9999 -9999 -9999 -9999 -9999 -9999 -9999 -9999 -9999 -9999 -9999 -9999 -9999 -9999 -9999 -9999 -9999 -9999 -9999 -9999 -9999 -9999 -9999 - -9999 -9999 -9999 -9999 -9999 -9999 -9999 -9999 -9999 -9999 -9999 -9999 -9999 -9999 -9999 -9999

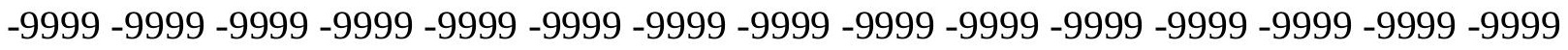
-9999 -9999 -9999 -9999 -9999 -9999 -9999 -9999 -9999 -9999 -9999 -9999 -9999 -9999 -9999 -9999 -9999 -9999 -9999 -9999 -9999 -9999 -9999 -9999 -9999 -9999 -9999 -9999 -9999 -9999 -9999 -9999 -9999 -9999 -9999 -9999 -9999 -9999 -9999 -9999 -9999 -9999 -9999 -9999 -9999 -

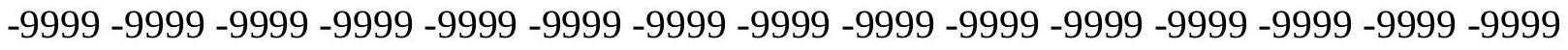
-9999 -9999 -9999 -9999 -9999 -9999 -9999 -9999 -9999 -9999 -9999 -9999 -9999 -9999 -9999 -999 -9999 -9999 -9999 -9999 -9999 -9999 -9999 -9999 -9999 -9999 -9999 -9999 -9999 -9999 -9999 -9999 -9999 -9999 -9999 -9999 -9999 -9999 -9999 -9999 -9999 -9999 -9999 -9999 -9999 -9999 -9999 -9999 -9999 -9999 -9999 -9999 -9999 -9999 -9999 -9999 -9999 -9999 -9999 -9999 -9999 -9999 -9999 -9999 -9999 -9999 -9999 -9999 -9999 -9999 -9999 -9999 -9999 -9999 -9999 -9999 -9999 -9999 -9999 -9999 -9999 -9999 -9999 -9999 -9999 -9999 -9999 -9999 -9999 -9999 -9999 -9999 -9999 -9999 -9999 -9999 -9999 -9999 -9999 -9999 -9999 -9999 -9999 -9999 -9999 -9999 -9999 -9999 -9999 -9999 -9999 -9999 -9999 -9999 -9999 -9999 -9999 -9999 -9999 -9999 -9999 -9999 -9999 -9999 -9999 -9999 -9999 -9999 -9999 -9999 -9999 -9999 -9999 -9999 -9999 -9999 -9999 -9999 -9999 -9999 -9999 -9999 -9999 -9999 -9999 -9999 -9999 -9999 -9999 -9999 -999 -9999 -9999 -9999 -9999 -9999 -9999 -9999 -9999 -9999 -9999 -9999 -9999 -9999 -9999 -9999 -9999 -9999 -9999 -9999 -9999 -9999 -9999 -9999 -9999 -9999 -9999 -9999 -9999 -9999 -

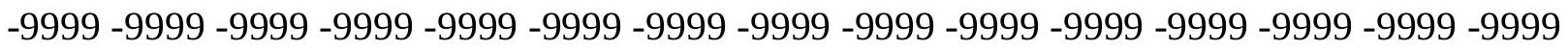

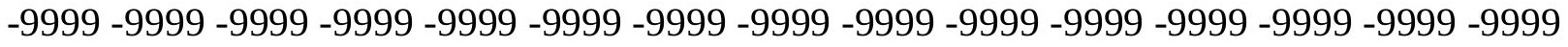

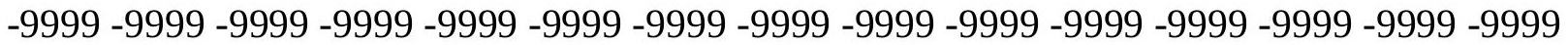
-9999 -9999 -9999 -9999 -9999 -9999 -9999 -9999 -9999 -9999 -9999 -9999 -9999 -9999 -9999 -

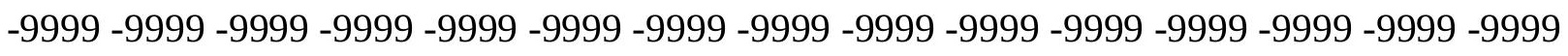

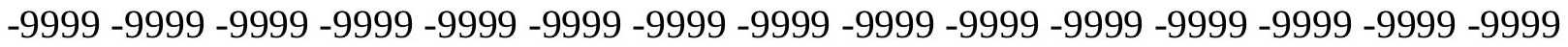

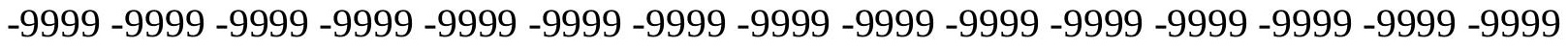
-9999 -9999 -9999 -9999 -9999 -9999 -9999 -9999 -9999 -9999 -9999 -9999 -9999 -9999 -9999 -

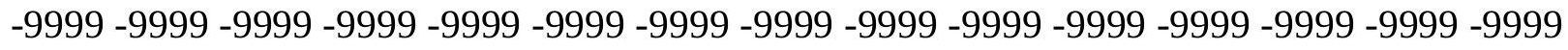

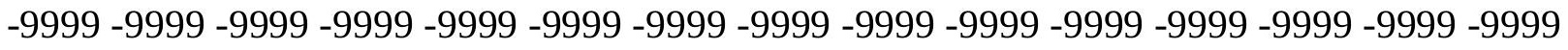
-9999 -9999 -9999 -9999 -9999 -9999 -9999 -9999 -9999 -9999 -9999 -9999 -9999 -9999 -9999 -9999 -9999 -9999 -9999 -9999 -9999 -9999 -9999 -9999-9999 -9999 -9999 -9999 -9999 -9999 -9999 -9999 -9999 -9999 -9999 -9999 -9999 -9999 -9999 -9999 -9999 -9999 -9999 -9999 -9999 -

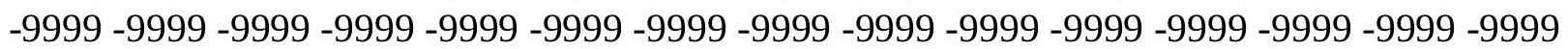


-9999 -9999 -9999 -9999 -9999 -9999 -9999 -9999 -9999 -9999 -9999 -9999 -9999 -9999 -9999 -9999 -9999 -9999 -9999 -9999 -9999 -9999 -9999 -9999 -9999 -9999 -9999 -9999 -9999 -9999 -

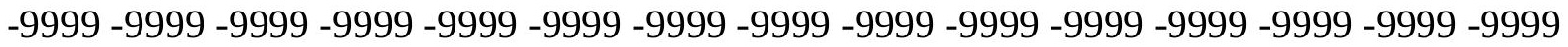
-9999 -9999 -9999 -9999 -9999 -9999 -9999 -9999 -9999 -9999 -9999 -9999 -9999 -9999 -9999 -9999 -9999 -9999 -9999 -9999 -9999 -9999 -9999 -9999-9999 -9999 -9999 -9999 -9999 -9999 -9999 -9999 -9999 -9999 -9999 -9999 -9999 -9999 -9999 -9999 -9999 -9999 -9999 -9999 -9999 -9999 -9999 -9999 -9999 -9999 -9999 -9999 -9999 -9999 -9999 -9999 -9999 -9999 -9999 -9999

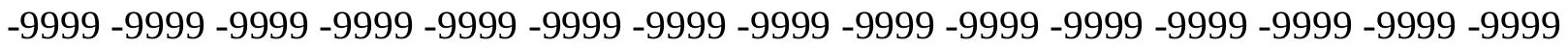

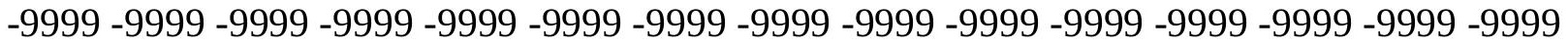
-9999 -9999 -9999 -9999 -9999 -9999 -9999 -9999 -9999 -9999 -9999 -9999 -9999 -9999 -9999 -9999 -9999 -9999 -9999 -9999 -9999 -9999 -9999 -9999 -9999 -9999 -9999 -9999 -9999 -9999 -9999 -9999 -9999 -9999 -9999 -9999 -9999 -9999 -9999 -9999 -9999 -9999 -9999 -9999 -9999 -9999 -9999 -9999 -9999 -9999 -9999 -9999 -9999 -9999 -9999 -9999 -9999 -9999 -9999 -9999 -9999 -9999 -9999 -9999 -9999 -9999 -9999 -9999 -9999 -9999 -9999 -9999 -9999 - 9999 -9999 -9999 -9999 -9999 -9999 -9999 -9999 -9999 -9999 -9999 -9999 -9999 -9999 -9999 -9999

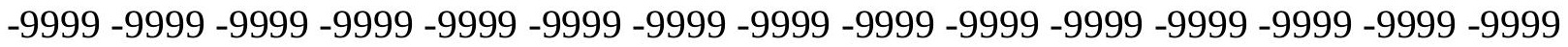
-9999 -9999 -9999 -9999 -9999 -9999 -9999 -9999 -9999 -9999 -9999 -9999 -9999 -9999 -9999 -9999 -9999 -9999 -9999 -9999 -9999 -9999 -9999 -9999 -9999 -9999 -9999 -9999 -9999 -9999 -9999 -9999 -9999 -9999 -9999 -9999 -9999 -9999 -9999 -9999 -9999 -9999 -9999 -9999 -9999 -

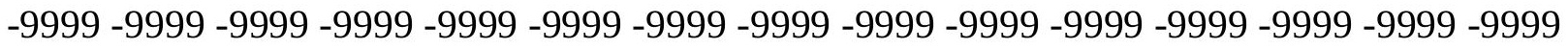

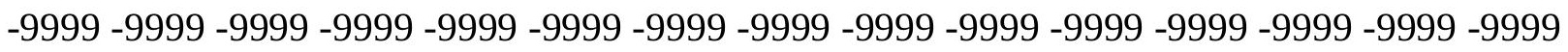
-9999 -9999 -9999 -9999 -9999 -9999 -9999 -9999 -9999 -9999 -9999 -9999 -9999 -9999 -9999 -9999 -9999 -9999 -9999 -9999 -9999 -9999 -9999 -9999 -9999 -9999 -9999 -9999 -9999 -9999 -9999 -9999 -9999 -9999 -9999 -9999 -9999 -9999 -9999 -9999 -9999 -9999 -9999 -9999 -9999 -

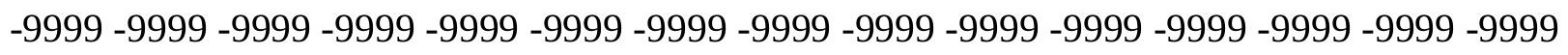
-9999 -9999 -9999 -9999 -9999 -9999 -9999 -9999 -9999 -9999 -9999 -9999 -9999 -9999 -9999 -9999 -9999 -9999 -9999 -9999 -9999 -9999 -9999 -9999 -9999 -9999 -9999 -9999 -9999 -9999 -

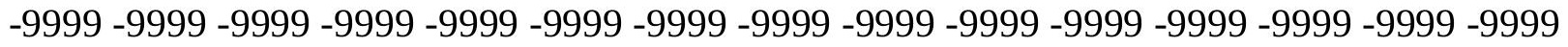
-9999 -9999 -9999 -9999 -9999 -9999 -9999 -9999 -9999 -9999 -9999 -9999 -9999 -9999 -9999 -9999 -9999 -9999 -9999 -9999 -9999 -9999 -9999 -9999 -9999 -9999 -9999 -9999 -9999 -999 -9999 -9999 -9999 -9999 -9999 -9999 -9999 -9999 -9999 -9999 -9999 -9999 -9999 -9999 -9999 -9999 -9999 -9999 -9999 -9999 -9999 -9999 -9999 -9999 -9999 -9999 -9999 -9999 -9999 -9999 -

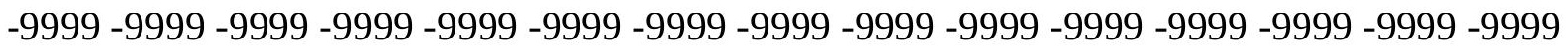

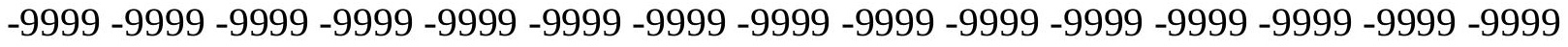

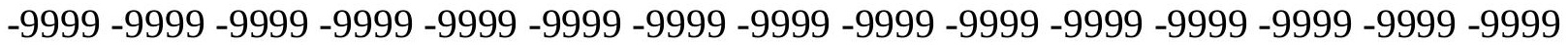

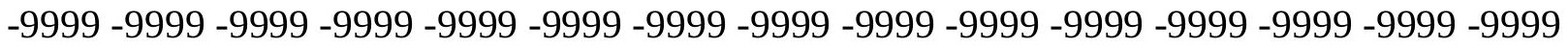

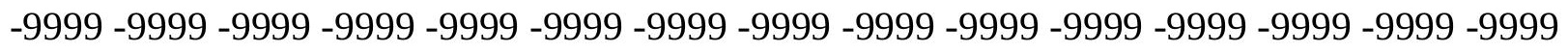

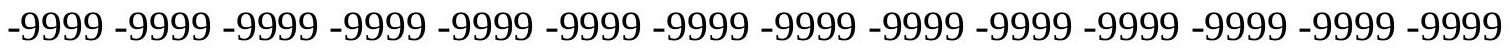
-9999 -9999 -9999 -9999 -9999 -9999 -9999 -9999 -9999 -9999 -9999 -9999 -9999 -9999 -9999 -9999 -9999 -9999 -9999 -9999 -9999 -9999 -9999 -9999 -9999 -9999 -9999 -9999 -9999 -9999 -

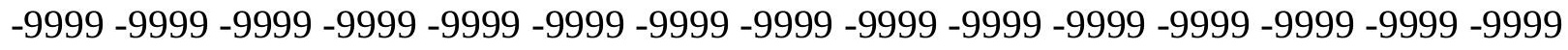

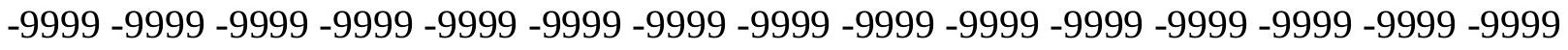
-9999 -9999 -9999 -9999 -9999 -9999 -9999 -9999 -9999 -9999 -9999 -9999 -9999 -9999 -9999 -9999 -9999 -9999 -9999 -9999 -9999 -9999 -9999 -9999-9999 -9999 -9999 -9999 -9999 -9999 -9999 -9999 -9999 -9999 -9999 -9999 -9999 -9999 -9999 -9999 -9999 -9999 -9999 -9999 -9999 -

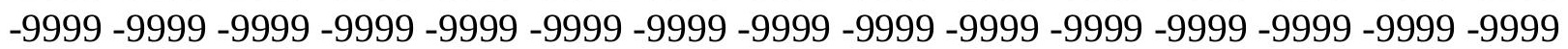


-9999 -9999 -9999 -9999 -9999 -9999 -9999 -9999 -9999 -9999 -9999 -9999 -9999 -9999 -9999 -9999 -9999 -9999 -9999 -9999 -9999 -9999 -9999 -9999 -9999 -9999 -9999 -9999 -9999 -9999 -9999 -9999 -9999 -9999 -9999 -9999 -9999 -9999 -9999 -9999 -9999 -9999 -9999 -9999 - 9999 -9999 -9999 -9999 -9999 -9999 -9999 -9999 -9999 -9999 -9999 -9999 -9999 -9999 -9999 -9999 -9999 -9999 -9999 -9999 -9999 -9999 -9999 -9999 -9999 -9999 -9999 -9999 -9999 -9999 -9999 -9999 -9999 -9999 -9999 -9999 -9999 -9999 -9999 -9999 -9999 -9999 -9999 -9999 -9999 -9999 -9999 -9999 -9999 -9999 -9999 -9999 -9999 -9999 -9999 -9999 -9999 -9999 -9999 -9999 -9999

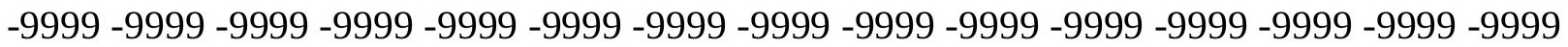
-9999 -9999 -9999 -9999 -9999 -9999 -9999 -9999 -9999 -9999 -9999 -9999 -9999 -9999 -9999 -9999 -9999 -9999 -9999 -9999 -9999 -9999 -9999 -9999 -9999 -9999 -9999 -9999 -9999 -9999

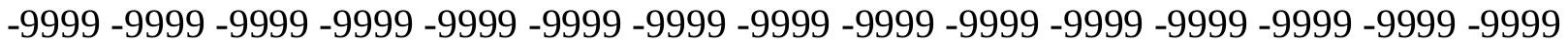
-9999 -9999 -9999 -9999 -9999 -9999 -9999 -9999 -9999 -9999 -9999 -9999 -9999 -9999 -9999 -9999 -9999 -9999 -9999 -9999 -9999 -9999 -9999 -9999 -9999 -9999 -9999 -9999 -9999 -9999 -

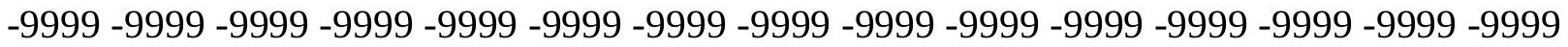
-9999 -9999 -9999 -9999 -9999 -9999 -9999 -9999 -9999 -9999 -9999 -9999 -9999 -9999 -9999

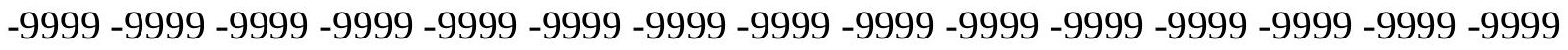
-9999 -9999 -9999 -9999 -9999 -9999 -9999 -9999 -9999 -9999 -9999 -9999 -9999 -9999 -9999 -9999 -9999 -9999 -9999 -9999 -9999 -9999 -9999 -9999 -9999 -9999 -9999 -9999 -9999 - -999 -9999 -9999 -9999 -9999 -9999 -9999 -9999 -9999 -9999 -9999 -9999 -9999 -9999 -9999 -9999 -9999 -9999 -9999 -9999 -9999 -9999 -9999 -9999 -9999 -9999 -9999 -9999 -9999 -9999 -9999 -9999 -9999 -9999 -9999 -9999 -9999 -9999 -9999 -9999 -9999 -9999 -9999 -9999 -9999 -9999 -999 -9999 -9999 -9999 -9999 -9999 -9999 -9999 -9999 -9999 -9999 -9999 -9999 -9999 -9999 -9999 -9999 -9999 -9999 -9999 -9999 -9999 -9999 -9999 -9999 -9999 -9999 -9999 -9999 -9999 -9999 -9999 -9999 -9999 -9999 -9999 -9999 -9999 -9999 -9999 -9999 -9999 -9999 -9999 -9999 -9999 -9999 -9999 -9999 -9999 -9999 -9999 -9999 -9999 -9999 -9999 -9999 -9999 -9999 -9999 -9999 -9999 -9999 -9999 -9999 -9999 -9999 -9999 -9999 -9999 -9999 -9999 -9999 -9999 -9999 -9999 -9999 -9999 -9999 -9999 -9999 -9999 -9999 -9999 -9999 -9999 -9999 -9999 -9999 -9999 -9999 -9999 -9999 -9999 -9999 -9999 -9999 -9999 -9999 -9999 -9999 -9999 -9999 -9999 -9999 -9999 -9999 -9999 -9999 -9999 -9999 -9999 -9999 -9999 -9999 -9999 -9999 -9999 -9999 -9999 -9999 -9999 -9999 -9999 -9999 -9999 -9999 -9999 -9999 -9999 -9999 -9999 -9999 -9999 -9999 -999 -9999 -9999 -9999 -9999 -9999 -9999 -9999 -9999 -9999 -9999 -9999 -9999 -9999 -9999 -9999 -9999 -9999 -9999 -9999 -9999 -9999 -9999 -9999 -9999 -9999 -9999 -9999 -9999 -9999 -9999 -

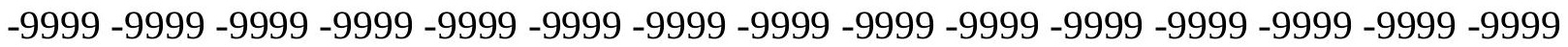

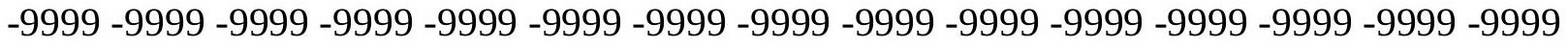

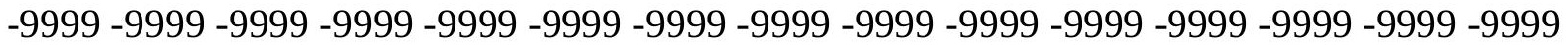
-9999 -9999 -9999 -9999 -9999 -9999 -9999 -9999 -9999 -9999 -9999 -9999 -9999 -9999 -9999

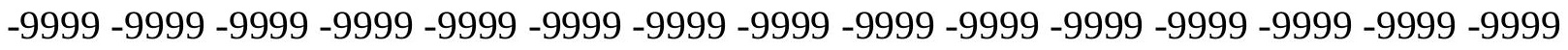

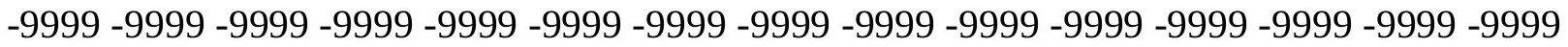

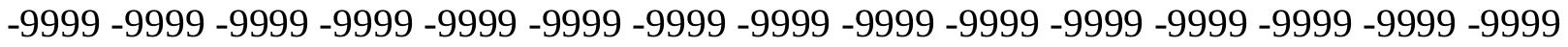
-9999 -9999 -9999 -9999 -9999 -9999 -9999 -9999 -9999 -9999 -9999 -9999 -9999 -9999 -9999 -

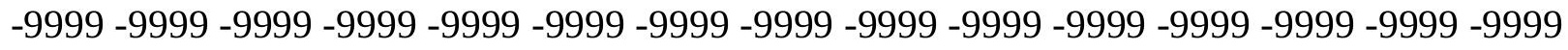

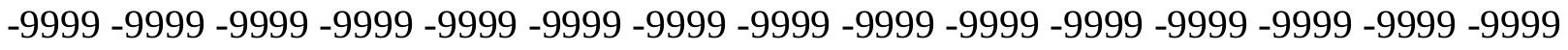
-9999 -9999 -9999 -9999 -9999 -9999 -9999 -9999 -9999 -9999 -9999 -9999 -9999 -9999 -9999 -9999 -9999 -9999 -9999 -9999 -9999 -9999 -9999 -9999 -9999 -9999 -9999 -9999 - -9999 -9999 -9999 -9999 -9999 -9999 -9999 -9999 -9999 -9999 -9999 -9999 -9999 -9999 -9999 -9999 -

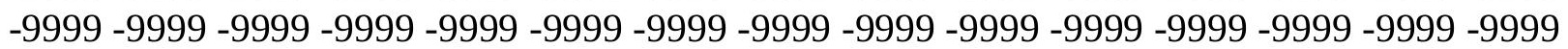


-9999 -9999 -9999 -9999 -9999 -9999 -9999 -9999 -9999 -9999 -9999 -9999 -9999 -9999 -9999 -9999 -9999 -9999 -9999 -9999 -9999 -9999 -9999 -9999 -9999 -9999 -9999 -9999 -9999 -9999 -9999 -9999 -9999 -9999 -9999 -9999 -9999 -9999 -9999 -9999 -9999 -9999 -9999 -9999 - 9999 -9999 -9999 -9999 -9999 -9999 -9999 -9999 -9999 -9999 -9999 -9999 -9999 -9999 -9999 -9999 -9999 -9999 -9999 -9999 -9999 -9999 -9999 -9999 -9999-9999 -9999 -9999 -9999 -9999 -9999 -9999 -9999 -9999 -9999 -9999 -9999 -9999 -9999 -9999 -9999 -9999 -9999 -9999 -9999 -9999 -9999 -9999 -9999 -9999 -9999 -9999 -9999 -9999 -9999 -9999 -9999 -9999 -9999 -9999 -9999

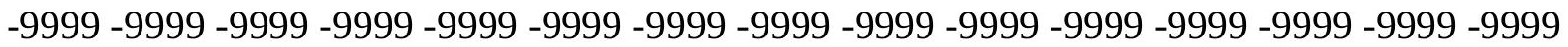

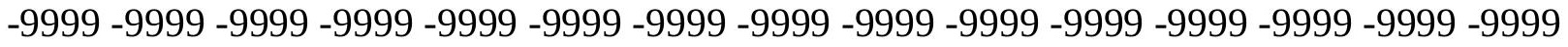
-9999 -9999 -9999 -9999 -9999 -9999 -9999 -9999 -9999 -9999 -9999 -9999 -9999 -9999 -9999

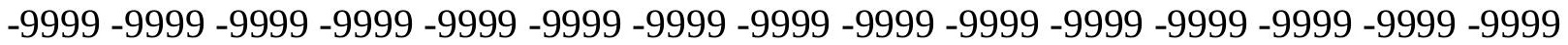
-9999 -9999 -9999 -9999 -9999 -9999 -9999 -9999 -9999 -9999 -9999 -9999 -9999 -9999 -9999 -9999 -9999 -9999 -9999 -9999 -9999 -9999 -9999 -9999 -9999 -9999 -9999 -9999 -9999 -9999 -

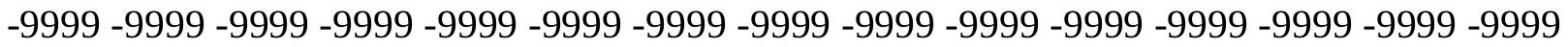
-9999 -9999 -9999 -9999 -9999 -9999 -9999 -9999 -9999 -9999 -9999 -9999 -9999 -9999 -9999

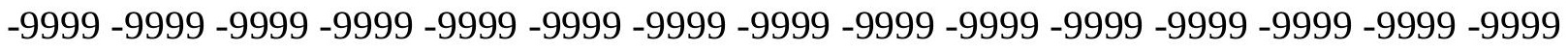
-9999 -9999 -9999 -9999 -9999 -9999 -9999 -9999 -9999 -9999 -9999 -9999 -9999 -9999 -9999 -9999 -9999 -9999 -9999 -9999 -9999 -9999 -9999 -9999 -9999 -9999 -9999 -9999 -9999 -9999 -9999 -9999 -9999 -9999 -9999 -9999 -9999 -9999 -9999 -9999 -9999 -9999 -9999 -9999 -9999 -9999 -9999 -9999 -9999 -9999 -9999 -9999 -9999 -9999 -9999 -9999 -9999 -9999 -9999 -9999 -9999 -9999 -9999 -9999 -9999 -9999 -9999 -9999 -9999 -9999 -9999 -9999 -9999 -9999 -9999 -999 -9999 -9999 -9999 -9999 -9999 -9999 -9999 -9999 -9999 -9999 -9999 -9999 -9999 -9999 -9999 -9999 -9999 -9999 -9999 -9999 -9999 -9999 -9999 -9999 -9999 -9999 -9999 -9999 -9999 -9999 -9999 -9999 -9999 -9999 -9999 -9999 -9999 -9999 -9999 -9999 -9999 -9999 -9999 -9999 -9999 -9999 -9999 -9999 -9999 -9999 -9999 -9999 -9999 -9999 -9999 -9999 -9999 -9999 -9999 -9999 -9999 -9999 -9999 -9999 -9999 -9999 -9999 -9999 -9999 -9999 -9999 -9999 -9999 -9999 -9999 -9999 -9999 -9999 -9999 -9999 -9999 -9999 -9999 -9999 -9999 -9999 -9999 -9999 -9999 -9999 -9999 -9999 -9999 -9999 -9999 -9999 -9999 -9999 -9999 -9999 -9999 -9999 -9999 -9999 -9999 -9999 -9999 -9999 -9999 -9999 -9999 -9999 -9999 -9999 -9999 -9999 -9999 -9999 -9999 -9999 -9999 -9999 -9999 -9999 -9999 -9999 -9999 -9999 -9999 -9999 -9999 -9999 -9999 -999 -9999 -9999 -9999 -9999 -9999 -9999 -9999 -9999 -9999 -9999 -9999 -9999 -9999 -9999 -9999 -9999 -9999 -9999 -9999 -9999 -9999 -9999 -9999 -9999 -9999 -9999 -9999 -9999 -9999 -9999 -

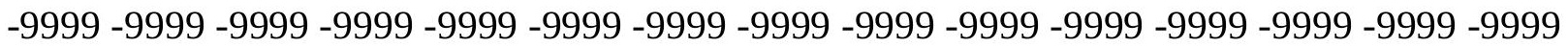

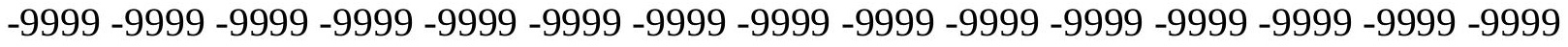

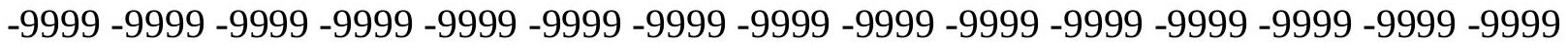
-9999 -9999 -9999 -9999 -9999 -9999 -9999 -9999 -9999 -9999 -9999 -9999 -9999 -9999 -9999

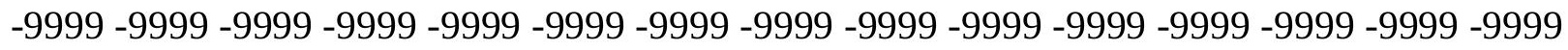

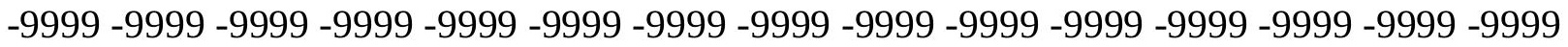
-9999 -9999 -9999 -9999 -9999 -9999 -9999 -9999 -9999 -9999 -9999 -9999 -9999 -9999 -9999 -9999 -9999 -9999 -9999 -9999 -9999 -9999 -9999 -9999 -9999 -9999 -9999 -9999 -9999 -9999 -

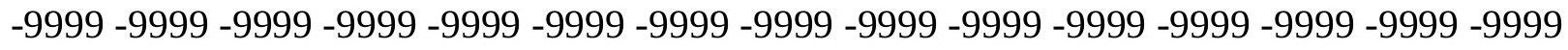

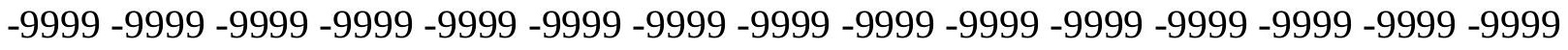
-9999 -9999 -9999 -9999 -9999 -9999 -9999 -9999 -9999 -9999 -9999 -9999 -9999 -9999 -9999 -9999 -9999 -9999 -9999 -9999 -9999 -9999 -9999 -9999-9999 -9999 -9999 -9999 -9999 -9999 -9999 -9999 -9999 -9999 -9999 -9999 -9999 -9999 -9999 -9999 -9999 -9999 -9999 -9999 -9999 -

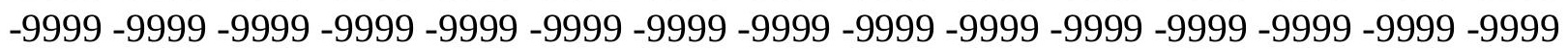


-9999 -9999 -9999 -9999 -9999 -9999 -9999 -9999 -9999 -9999 -9999 -9999 -9999 -9999 -9999 -9999 -9999 -9999 -9999 -9999 -9999 -9999 -9999 -9999 -9999 -9999 -9999 -9999 -9999 -9999 -9999 -9999 -9999 -9999 -9999 -9999 -9999 -9999 -9999 -9999 -9999 -9999 -9999 -9999 - 9999 -9999 -9999 -9999 -9999 -9999 -9999 -9999 -9999 -9999 -9999 -9999 -9999 -9999 -9999

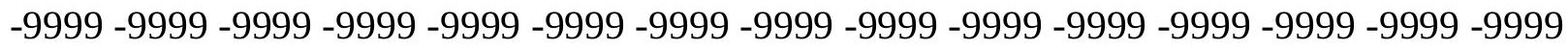
-9999 -9999 -9999 -9999 -9999 -9999 -9999 -9999 -9999 -9999 -9999 -9999 -9999 -9999 -9999 -9999 -9999 -9999 -9999 -9999 -9999 -9999 -9999 -9999 -9999 -9999 -9999 -9999 -9999 -9999

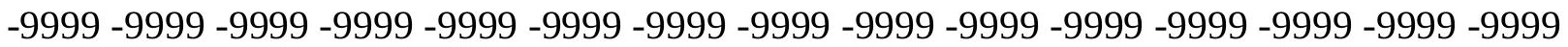

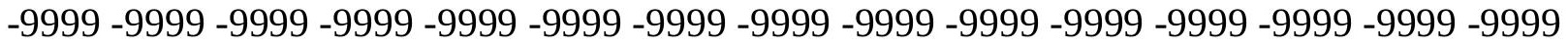
-9999 -9999 -9999 -9999 -9999 -9999 -9999 -9999 -9999 -9999 -9999 -9999 -9999 -9999 -9999 -9999 -9999 -9999 -9999 -9999 -9999 -9999 -9999 -9999 -9999 -9999 -9999 -9999 -9999 -9999 -9999 -9999 -9999 -9999 -9999 -9999 -9999 -9999 -9999 -9999 -9999 -9999 -9999 -9999 -9999 -9999 -9999 -9999 -9999 -9999 -9999 -9999 -9999 -9999 -9999 -9999 -9999 -9999 -9999 -9999 -

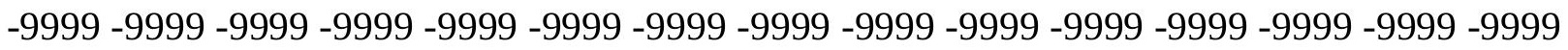
-9999 -9999 -9999 -9999 -9999 -9999 -9999 -9999 -9999 -9999 -9999 -9999 -9999 -9999 -9999 -

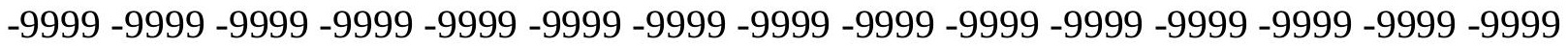
-9999 -9999 -9999 -9999 -9999 -9999 -9999 -9999 -9999 -9999 -9999 -9999 -9999 -9999 -9999 -9999 -9999 -9999 -9999 -9999 -9999 -9999 -9999 -9999 -9999 -9999 -9999 -9999 -9999 -9999 -9999 -9999 -9999 -9999 -9999 -9999 -9999 -9999 -9999 -9999 -9999 -9999 -9999 -9999 -9999 -

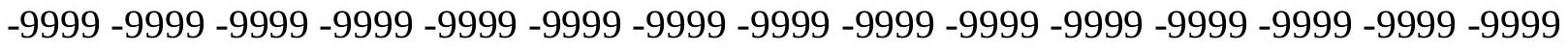
-9999 -9999 -9999 -9999 -9999 -9999 -9999 -9999 -9999 -9999 -9999 -9999 -9999 -9999 -9999

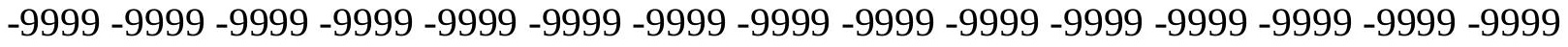
-9999 -9999 -9999 -9999 -9999 -9999 -9999 -9999 -9999 -9999 -9999 -9999 -9999 -9999 -9999 -9999 -9999 -9999 -9999 -9999 -9999 -9999 -9999 -9999 -9999 -9999 -9999 -9999 -9999 -9999 -9999 -9999 -9999 -9999 -9999 -9999 -9999 -9999 -9999 -9999 -9999 -9999 -9999 -9999 -9999 -9999 -9999 -9999 -9999 -9999 -9999 -9999 -9999 -9999 -9999 -9999 -9999 -9999 -9999 -9999 -9999 -9999 -9999 -9999 -9999 -9999 -9999 -9999 -9999 -9999 -9999 -9999 -9999 -9999 -9999 -9999 -9999 -9999 -9999 -9999 -9999 -9999 -9999 -9999 -9999 -9999 -9999 -9999 -9999 -9999 -9999 -9999 -9999 -9999 -9999 -9999 -9999 -9999 -9999 -9999 -9999 -9999 -9999 -9999 -9999 -9999 -9999 -9999 -9999 -9999 -9999 -9999 -9999 -9999 -9999 -9999 -9999 -9999 -9999 -9999 -9999 -9999 -9999 -9999 -9999 -9999 -9999 -9999 -9999 -9999 -9999 -9999 -9999 -9999 -9999 -9999 -9999 -9999 -9999 -9999 -9999 -9999 -9999 -9999 -9999 -9999 -9999 -9999 -9999 -

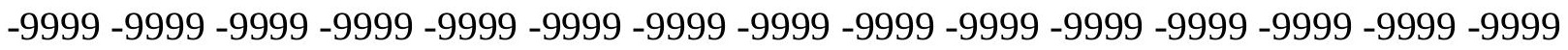

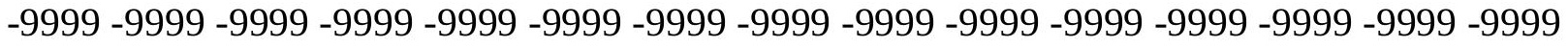
-9999 -9999 -9999 -9999 -9999 -9999 -9999 -9999 -9999 -9999 -9999 -9999 -9999 -9999 -9999 -

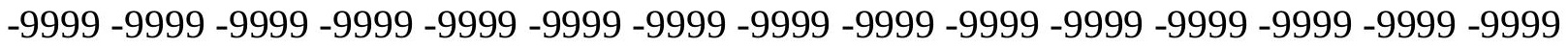

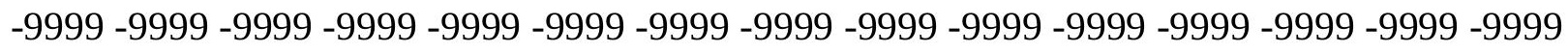

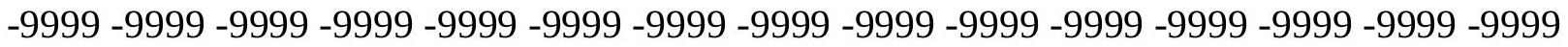

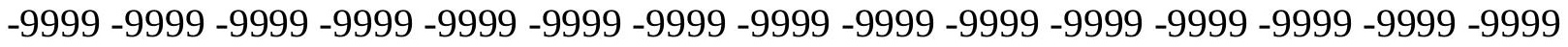
-9999 -9999 -9999 -9999 -9999 -9999 -9999 -9999 -9999 -9999 -9999 -9999 -9999 -9999 -9999 -

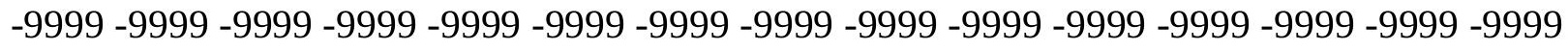

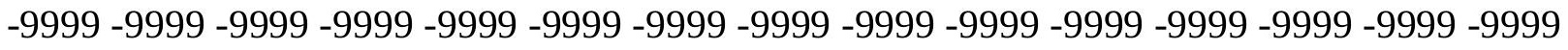
-9999 -9999 -9999 -9999 -9999 -9999 -9999 -9999 -9999 -9999 -9999 -9999 -9999 -9999 -9999 -9999 -9999 -9999 -9999 -9999 -9999 -9999 -9999 -9999-9999 -9999 -9999 -9999 -9999 -9999 -9999 -9999 -9999 -9999 -9999 -9999 -9999 -9999 -9999 -9999 -9999 -9999 -9999 -9999 -9999 -

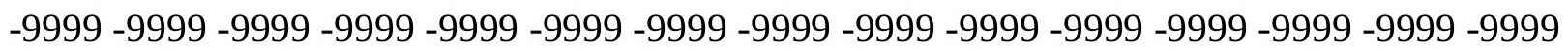


-9999 -9999 -9999 -9999 -9999 -9999 -9999 -9999 -9999 -9999 -9999 -9999 -9999 -9999 -9999 -9999 -9999 -9999 -9999 -9999 -9999 -9999 -9999 -9999 -9999 -9999 -9999 -9999 -9999 -9999 -9999 -9999 -9999 -9999 -9999 -9999 -9999 -9999 -9999 -9999 -9999 -9999 -9999 -9999 - 9999 -9999 -9999 -9999 -9999 -9999 -9999 -9999 -9999 -9999 -9999 -9999 -9999 -9999 -9999 -9999 -9999 -9999 -9999 -9999 -9999 -9999 -9999 -9999 -9999 -9999 -9999 -9999 -9999 -9999 -9999 -9999 -9999 -9999 -9999 -9999 -9999 -9999 -9999 -9999 -9999 -9999 -9999 -9999 -9999 -9999 -9999 -9999 -9999 -9999 -9999 -9999 -9999 -9999 -9999 -9999 -9999 -9999 -9999 -9999 -9999

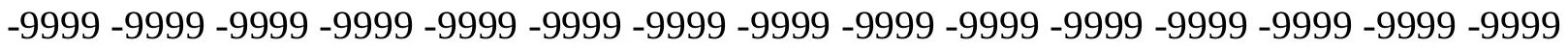

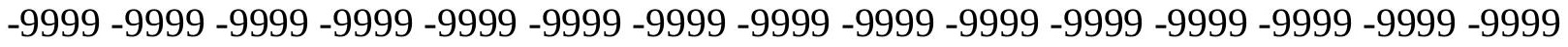
-9999 -9999 -9999 -9999 -9999 -9999 -9999 -9999 -9999 -9999 -9999 -9999 -9999 -9999 -9999 -9999 -9999 -9999 -9999 -9999 -9999 -9999 -9999 -9999 -9999 -9999 -9999 -9999 -9999 -9999 -9999 -9999 -9999 -9999 -9999 -9999 -9999 -9999 -9999 -9999 -9999 -9999 -9999 -9999 -9999 -9999 -9999 -9999 -9999 -9999 -9999 -9999 -9999 -9999 -9999 -9999 -9999 -9999 -9999 -9999 -9999 -9999 -9999 -9999 -9999 -9999 -9999 -9999 -9999 -9999 -9999 -9999 -9999 -9999 -9999 -9999 -9999 -9999 -9999 -9999 -9999 -9999 -9999 -9999 -9999 -9999 -9999 -9999 -9999 -

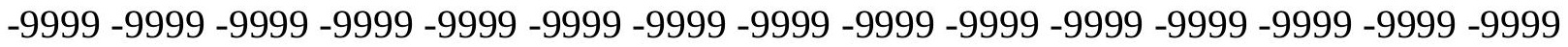
-9999 -9999 -9999 -9999 -9999 -9999 -9999 -9999 -9999 -9999 -9999 -9999 -9999 -9999 -9999 -9999 -9999 -9999 -9999 -9999 -9999 -9999 -9999 -9999 -9999 -9999 -9999 -9999 -9999 -9999 -9999 -9999 -9999 -9999 -9999 -9999 -9999 -9999 -9999 -9999 -9999 -9999 -9999 -9999 -9999 -9999 -9999 -9999 -9999 -9999 -9999 -9999 -9999 -9999 -9999 -9999 -9999 -9999 -9999 -9999 -9999 -9999 -9999 -9999 -9999 -9999 -9999 -9999 -9999 -9999 -9999 -9999 -9999 -9999 -9999 -999 -9999 -9999 -9999 -9999 -9999 -9999 -9999 -9999 -9999 -9999 -9999 -9999 -9999 -9999 -9999 -9999 -9999 -9999 -9999 -9999 -9999 -9999 -9999 -9999 -9999 -9999 -9999 -9999 -9999 -9999 -9999 -9999 -9999 -9999 -9999 -9999 -9999 -9999 -9999 -9999 -9999 -9999 -9999 -9999 -9999 -9999 -9999 -9999 -9999 -9999 -9999 -9999 -9999 -9999 -9999 -9999 -9999 -9999 -9999 -9999 -9999 -9999 -9999 -9999 -9999 -9999 -9999 -9999 -9999 -9999 -9999 -9999 -9999 -9999 -9999 -9999 -9999 -9999 -9999 -9999 -9999 -9999 -9999 -9999 -9999 -9999 -9999 -9999 -9999 -9999 -9999 -9999 -9999 -9999 -9999 -9999 -9999 -9999 -9999 -9999 -9999 -9999 -9999 -9999 -9999 -9999 -9999 -9999 -9999 -9999 -9999 -9999 -9999 -9999 -9999 -9999 -9999 -9999 -9999 -9999 -9999 -9999 -9999 -9999 -9999 -9999 -9999 -9999 -9999 -9999 -9999 -9999 -9999 -9999 -999 -9999 -9999 -9999 -9999 -9999 -9999 -9999 -9999 -9999 -9999 -9999 -9999 -9999 -9999 -9999 -9999 -9999 -9999 -9999 -9999 -9999 -9999 -9999 -9999 -9999 -9999 -9999 -9999 -9999 -9999 -

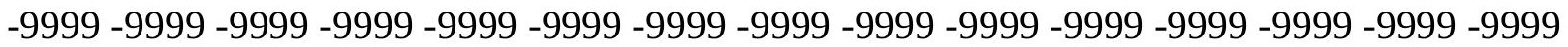

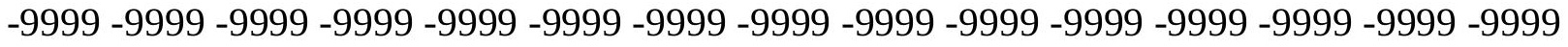

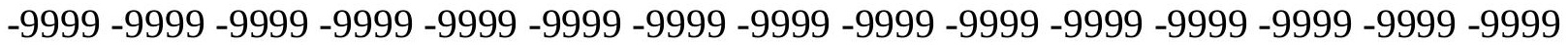
-9999 -9999 -9999 -9999 -9999 -9999 -9999 -9999 -9999 -9999 -9999 -9999 -9999 -9999 -9999 -9999 -9999 -9999 -9999 -9999 -9999 -9999 -9999 -9999 -9999 -9999 -9999 -9999 -9999 -

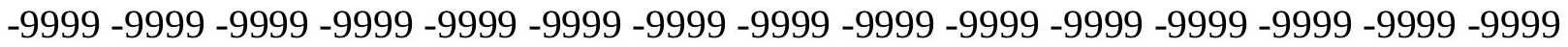
-9999 -9999 -9999 -9999 -9999 -9999 -9999 -9999 -9999 -9999 -9999 -9999 -9999 -9999 -9999 -9999 -9999 -9999 -9999 -9999 -9999 -9999 -9999 -9999 -9999 -9999 -9999 -9999 -9999 -9999 -

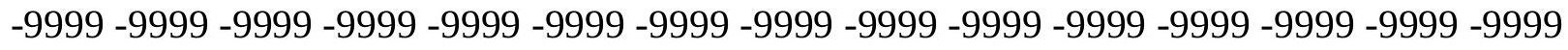

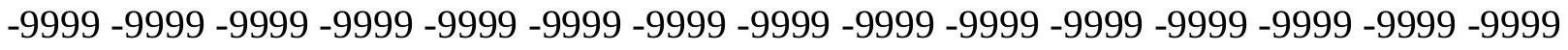
-9999 -9999 -9999 -9999 -9999 -9999 -9999 -9999 -9999 -9999 -9999 -9999 -9999 -9999 -9999 -9999 -9999 -9999 -9999 -9999 -9999 -9999 -9999 -9999-9999 -9999 -9999 -9999 -9999 -9999 -9999 -9999 -9999 -9999 -9999 -9999 -9999 -9999 -9999 -9999 -9999 -9999 -9999 -9999 -9999 -

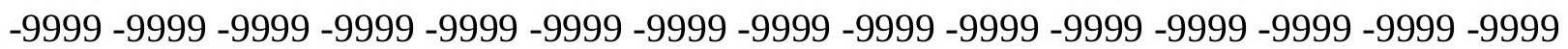


-9999 -9999 -9999 -9999 -9999 -9999 -9999 -9999 -9999 -9999 -9999 -9999 -9999 -9999 -9999 -9999 -9999 -9999 -9999 -9999 -9999 -9999 -9999 -9999 -9999 -9999 -9999 -9999 -9999 -9999 -

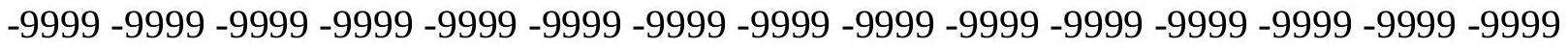
-9999 -9999 -9999 -9999 -9999 -9999 -9999 -9999 -9999 -9999 -9999 -9999 -9999 -9999 -9999 -9999 -9999 -9999 -9999 -9999 -9999 -9999 -9999 -9999-9999 -9999 -9999 -9999 -9999 -9999 -9999 -9999 -9999 -9999 -9999 -9999 -9999 -9999 -9999 -9999 -9999 -9999 -9999 -9999 -9999 -9999 -9999 -9999 -9999 -9999 -9999 -9999 -9999 -9999 -9999 -9999 -9999 -9999 -9999 -9999

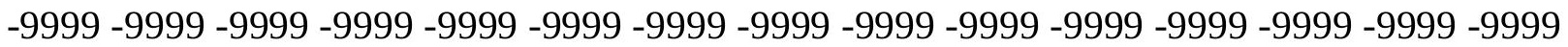

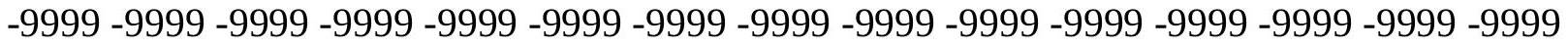
-9999 -9999 -9999 -9999 -9999 -9999 -9999 -9999 -9999 -9999 -9999 -9999 -9999 -9999 -9999 -9999 -9999 -9999 -9999 -9999 -9999 -9999 -9999 -9999 -9999 -9999 -9999 -9999 -9999 -9999 -9999 -9999 -9999 -9999 -9999 -9999 -9999 -9999 -9999 -9999 -9999 -9999 -9999 -9999 -9999 -9999 -9999 -9999 -9999 -9999 -9999 -9999 -9999 -9999 -9999 -9999 -9999 -9999 -9999 -9999 -9999 -9999 -9999 -9999 -9999 -9999 -9999 -9999 -9999 -9999 -9999 -9999 -9999 -9999 -9999 -9999 -9999 -9999 -9999 -9999 -9999 -9999 -9999 -9999 -9999 -9999 -9999 -9999 -9999 -9999 -

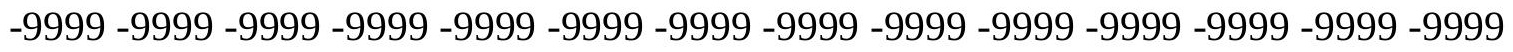
-9999 -9999 -9999 -9999 -9999 -9999 -9999 -9999 -9999 -9999 -9999 -9999 -9999 -9999 -9999 -9999 -9999 -9999 -9999 -9999 -9999 -9999 -9999 -9999 -9999 -9999 -9999 -9999 -9999 -9999 -9999 -9999 -9999 -9999 -9999 -9999 -9999 -9999 -9999 -9999 -9999 -9999 -9999 -9999 -9999 -

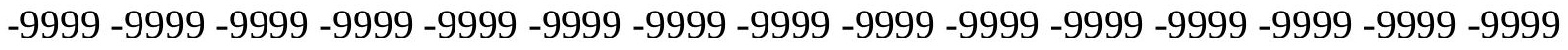

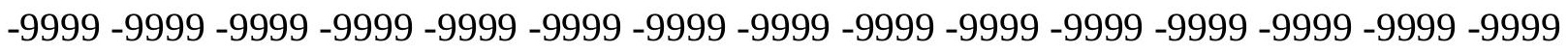
-9999 -9999 -9999 -9999 -9999 -9999 -9999 -9999 -9999 -9999 -9999 -9999 -9999 -9999 - 9999 -9999 -9999 -9999 -9999 -9999 -9999 -9999 -9999 -9999 -9999 -9999 -9999 -9999 -9999 -9999 -9999 -9999 -9999 -9999 -9999 -9999 -9999 -9999 -9999 -9999 -9999 -9999 -9999 -9999 -9999 -

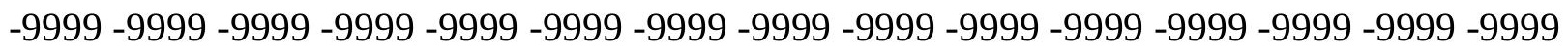
-9999 -9999 -9999 -9999 -9999 -9999 -9999 -9999 -9999 -9999 -9999 -9999 -9999 -9999 -9999 -9999 -9999 -9999 -9999 -9999 -9999 -9999 -9999 -9999 -9999 -9999 -9999 -9999 -9999 -9999 -

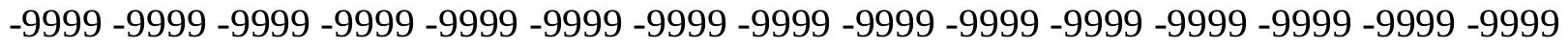
-9999 -9999 -9999 -9999 -9999 -9999 -9999 -9999 -9999 -9999 -9999 -9999 -9999 -9999 -9999 -9999 -9999 -9999 -9999 -9999 -9999 -9999 -9999 -9999 -9999 -9999 -9999 -9999 -9999 -999 -

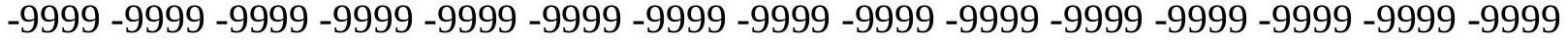
-9999 -9999 -9999 -9999 -9999 -9999 -9999 -9999 -9999 -9999 -9999 -9999 -9999 -9999 -9999 -

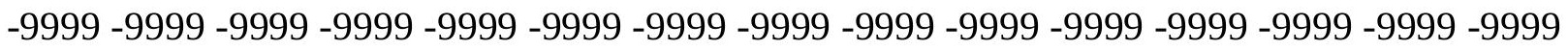

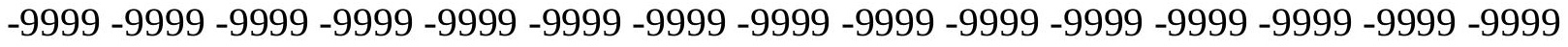

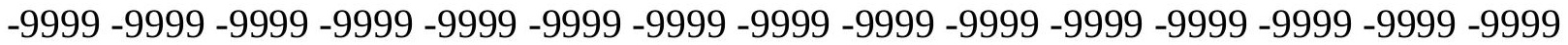
-9999 -9999 -9999 -9999 -9999 -9999 -9999 -9999 -9999 -9999 -9999 -9999 -9999 -9999 -9999 -

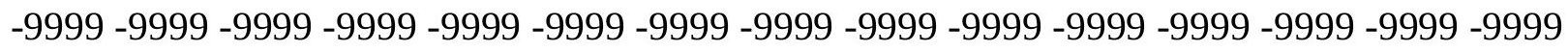

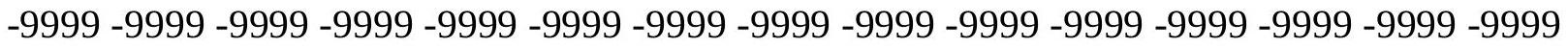
-9999 -9999 -9999 -9999 -9999 -9999 -9999 -9999 -9999 -9999 -9999 -9999 -9999 - 9999 - -999 -9999 -9999 -9999 -9999 -9999 -9999 -9999 -9999 -9999 -9999 -9999 -9999 -9999 -9999 -9999 -

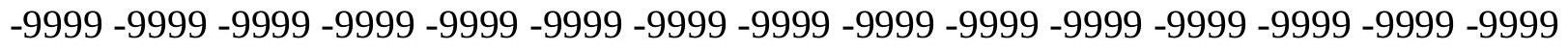

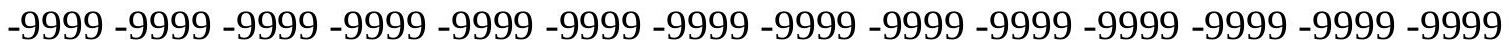
-9999 -9999 -9999 -9999 -9999 -9999 -9999 -9999 -9999 -9999 -9999 -9999 -9999 -9999 -9999 -9999 -9999 -9999 -9999 -9999 -9999 -9999 -9999 -9999-9999 -9999 -9999 -9999 -9999 -9999 -9999 -9999 -9999 -9999 -9999 -9999 -9999 -9999 -9999 -9999 -9999 -9999 -9999 -9999 -9999 -

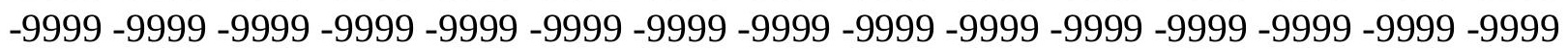


-9999 -9999 -9999 -9999 -9999 -9999 -9999 -9999 -9999 -9999 -9999 -9999 -9999 -9999 -9999 -9999 -9999 -9999 -9999 -9999 -9999 -9999 -9999 -9999 -9999 -9999 -9999 -9999 -9999 -9999 -

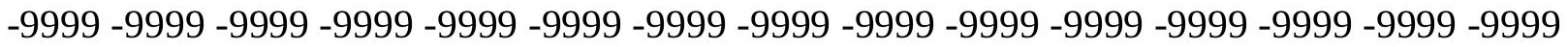
-9999 -9999 -9999 -9999 -9999 -9999 -9999 -9999 -9999 -9999 -9999 -9999 -9999 -9999 -9999 -9999 -9999 -9999 -9999 -9999 -9999 -9999 -9999 -9999-9999 -9999 -9999 -9999 -9999 -9999 -9999 -9999 -9999 -9999 -9999 -9999 -9999 -9999 -9999 -9999 -9999 -9999 -9999 -9999 -9999 -9999 -9999 -9999 -9999 -9999 -9999 -9999 -9999 -9999 -9999 -9999 -9999 -9999 -9999 -9999

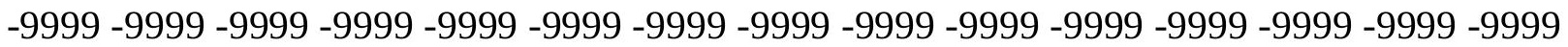

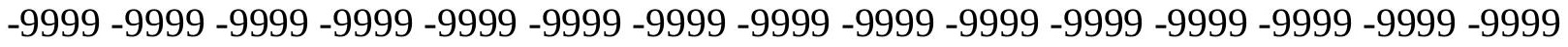
-9999 -9999 -9999 -9999 -9999 -9999 -9999 -9999 -9999 -9999 -9999 -9999 -9999 -9999 -9999 -9999 -9999 -9999 -9999 -9999 -9999 -9999 -9999 -9999 -9999 -9999 -9999 -9999 -9999 -9999 -9999 -9999 -9999 -9999 -9999 -9999 -9999 -9999 -9999 -9999 -9999 -9999 -9999 -9999 -9999 -9999 -9999 -9999 -9999 -9999 -9999 -9999 -9999 -9999 -9999 -9999 -9999 -9999 -9999 -9999 -

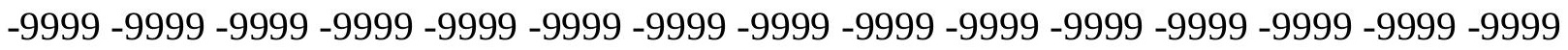
-9999 -9999 -9999 -9999 -9999 -9999 -9999 -9999 -9999 -9999 -9999 -9999 -9999 -9999 -9999 -

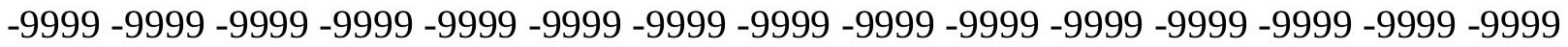
-9999 -9999 -9999 -9999 -9999 -9999 -9999 -9999 -9999 -9999 -9999 -9999 -9999 -9999 -9999 -9999 -9999 -9999 -9999 -9999 -9999 -9999 -9999 -9999 -9999 -9999 -9999 -9999 -9999 -9999 -9999 -9999 -9999 -9999 -9999 -9999 -9999 -9999 -9999 -9999 -9999 -9999 -9999 -9999 -9999 -

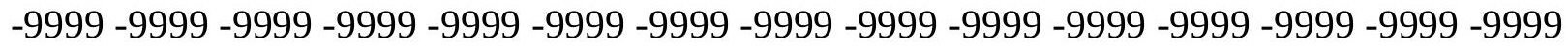

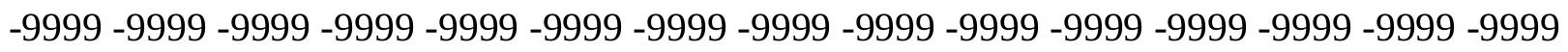
-9999 -9999 -9999 -9999 -9999 -9999 -9999 -9999 -9999 -9999 -9999 -9999 -9999 -9999 -9999 -9999 -9999 -9999 -9999 -9999 -9999 -9999 -9999 -9999 -9999 -9999 -9999 -9999 -9999 -9999 -9999 -9999 -9999 -9999 -9999 -9999 -9999 -9999 -9999 -9999 -9999 -9999 -9999 -9999 -

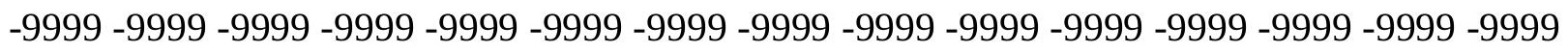
-9999 -9999 -9999 -9999 -9999 -9999 -9999 -9999 -9999 -9999 -9999 -9999 -9999 -9999 -9999 -9999 -9999 -9999 -9999 -9999 -9999 -9999 -9999 -9999 -9999 -9999 -9999 -9999 -9999 -9999 -

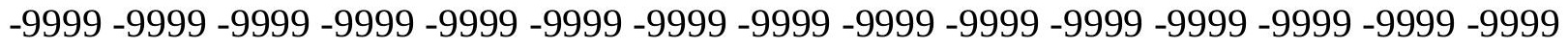
-9999 -9999 -9999 -9999 -9999 -9999 -9999 -9999 -9999 -9999 -9999 -9999 -9999 -9999 -9999 -9999 -9999 -9999 -9999 -9999 -9999 -9999 -9999 -9999 -9999 -9999 -9999 -9999 -9999 -999 -

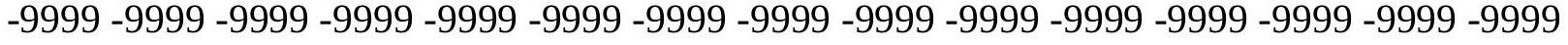
-9999 -9999 -9999 -9999 -9999 -9999 -9999 -9999 -9999 -9999 -9999 -9999 -9999 -9999 -9999 -

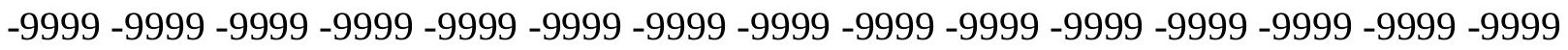

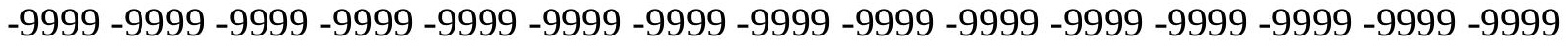

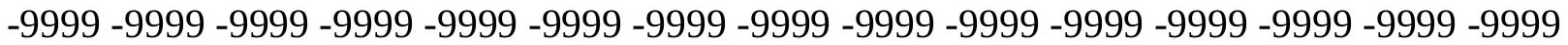

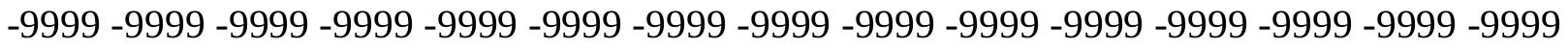

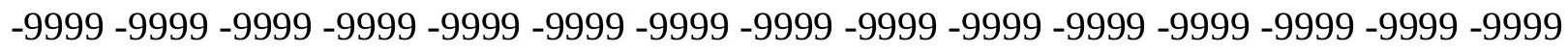

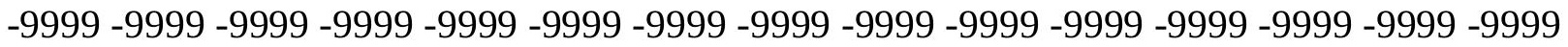

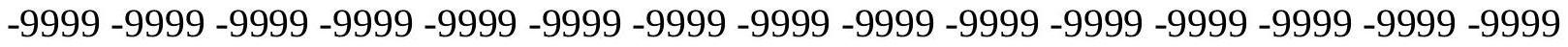
-9999 -9999 -9999 -9999 -9999 -9999 -9999 -9999 -9999 -9999 -9999 -9999 -9999 -9999 -9999 -

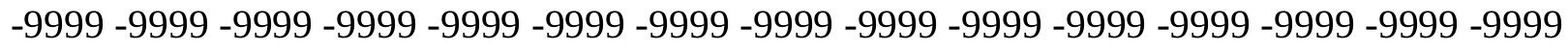

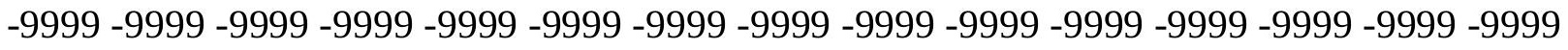
-9999 -9999 -9999 -9999 -9999 -9999 -9999 -9999 -9999 -9999 -9999 -9999 -9999 -9999 -9999 -9999 -9999 -9999 -9999 -9999 -9999 -9999 -9999 -9999-9999 -9999 -9999 -9999 -9999 -9999 -9999 -9999 -9999 -9999 -9999 -9999 -9999 -9999 -9999 -9999 -9999 -9999 -9999 -9999 -9999 -

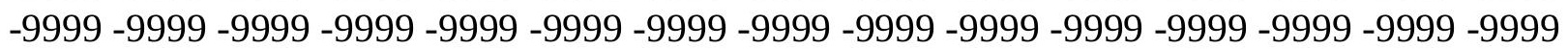


-9999 -9999 -9999 -9999 -9999 -9999 -9999 -9999 -9999 -9999 -9999 -9999 -9999 -9999 -9999 -9999 -9999 -9999 -9999 -9999 -9999 -9999 -9999 -9999 -9999 -9999 -9999 -9999 -9999 -

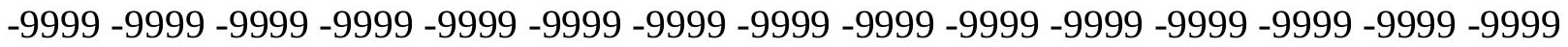
-9999 -9999 -9999 -9999 -9999 -9999 -9999 -9999 -9999 -9999 -9999 -9999 -9999 -9999 -9999 -9999 -9999 -9999 -9999 -9999 -9999 -9999 -9999 -9999 -9999 -9999 -9999 -9999 -9999 -9999 -9999 -9999 -9999 -9999 -9999 -9999 -9999 -9999 -9999 -9999 -9999 -9999 -9999 -9999 -9999 -9999 -9999 -9999 -9999 -9999 -9999 -9999 -9999 -9999 -9999 -9999 -9999 -9999 -9999 -9999

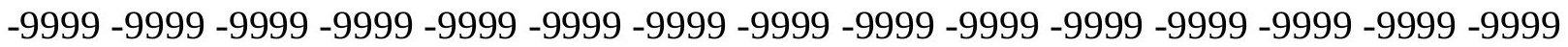

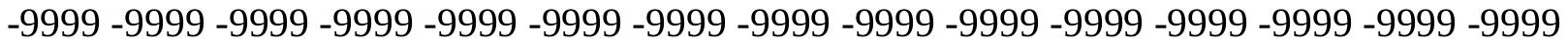
-9999 -9999 -9999 -9999 -9999 -9999 -9999 -9999 -9999 -9999 -9999 -9999 -9999 -9999 -9999 -9999 -9999 -9999 -9999 -9999 -9999 -9999 -9999 -9999 -9999 -9999 -9999 -9999 -9999 -9999 -9999 -9999 -9999 -9999 -9999 -9999 -9999 -9999 -9999 -9999 -9999 -9999 -9999 -9999 -9999 -9999 -9999 -9999 -9999 -9999 -9999 -9999 -9999 -9999 -9999 -9999 -9999 -9999 -9999 -9999 -9999 -9999 -9999 -9999 -9999 -9999 -9999 -9999 -9999 -9999 -9999 -9999 -9999 -9999 -9999 -9999 -9999 -9999 -9999 -9999 -9999 -9999 -9999 -9999 -9999 -9999 -9999 -9999 -9999 -9999 -

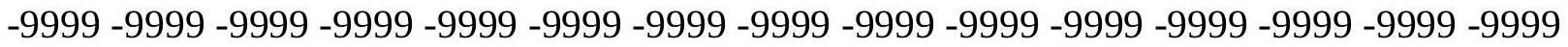
-9999 -9999 -9999 -9999 -9999 -9999 -9999 -9999 -9999 -9999 -9999 -9999 -9999 -9999 -9999 -9999 -9999 -9999 -9999 -9999 -9999 -9999 -9999 -9999 -9999 -9999 -9999 -9999 -9999 - 9999 -9999 -9999 -9999 -9999 -9999 -9999 -9999 -9999 -9999 -9999 -9999 -9999 -9999 -9999 -9999 -

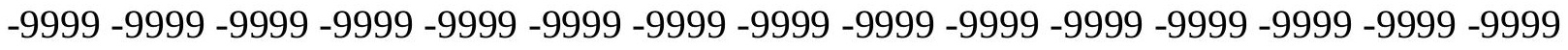

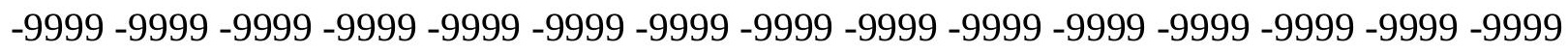

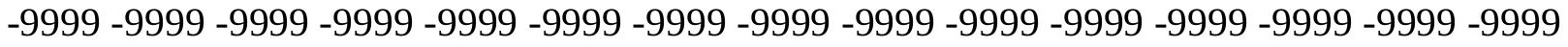
-9999 -9999 -9999 -9999 -9999 -9999 -9999 -9999 -9999 -9999 -9999 -9999 -9999 -9999 -9999 -9999 -9999 -9999 -9999 -9999 -9999 -9999 -9999 -9999 -9999 -9999 -9999 -9999 -9999 -9999 -

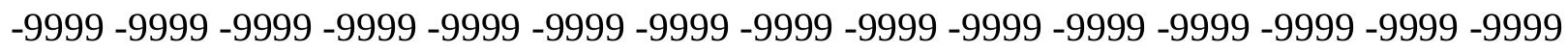
-9999 -9999 -9999 -9999 -9999 -9999 -9999 -9999 -9999 -9999 -9999 -9999 -9999 -9999 -9999 -9999 -9999 -9999 -9999 -9999 -9999 -9999 -9999 -9999 -9999 -9999 -9999 -9999 -9999 -9999 -9999 -9999 -9999 -9999 -9999 -9999 -9999 -9999 -9999 -9999 -9999 -9999 -9999 -9999 -9999 -9999 -9999 -9999 -9999 -9999 -9999 -9999 -9999 -9999 -9999 -9999 -9999 -9999 -9999 -9999 -9999 -9999 -9999 -9999 -9999 -9999 -9999 -9999 -9999 -9999 -9999 -9999 -9999 -999 -

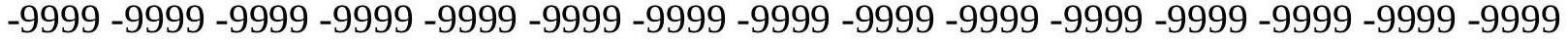
-9999 -9999 -9999 -9999 -9999 -9999 -9999 -9999 -9999 -9999 -9999 -9999 -9999 -9999 -9999 -

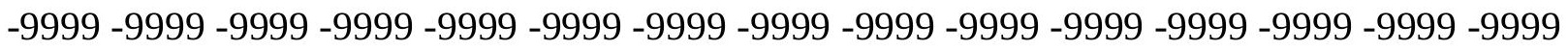

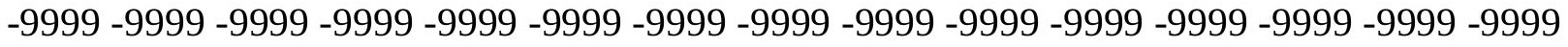

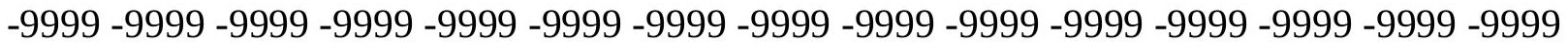

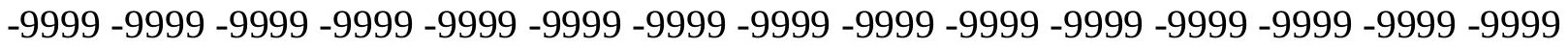

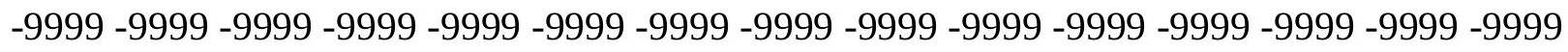

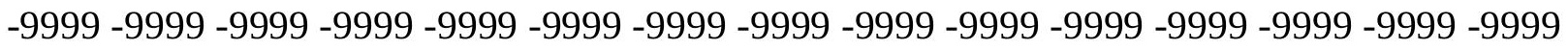

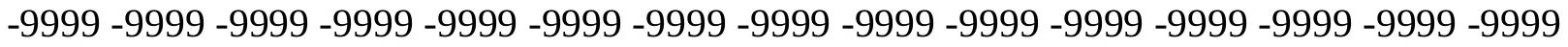
-9999 -9999 -9999 -9999 -9999 -9999 -9999 -9999 -9999 -9999 -9999 -9999 -9999 -9999 -9999 -

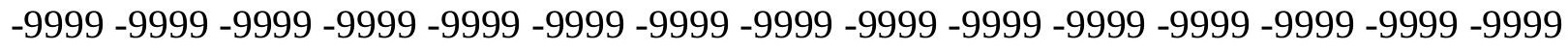

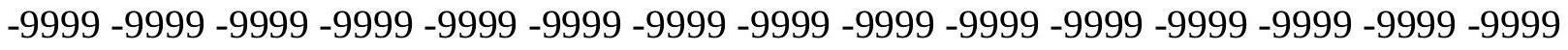
-9999 -9999 -9999 -9999 -9999 -9999 -9999 -9999 -9999 -9999 -9999 -9999 -9999 -9999 -9999 -9999 -9999 -9999 -9999 -9999 -9999 -9999 -9999 -9999-9999 -9999 -9999 -9999 -9999 -9999 -9999 -9999 -9999 -9999 -9999 -9999 -9999 -9999 -9999 -9999 -9999 -9999 -9999 -9999 -9999 -

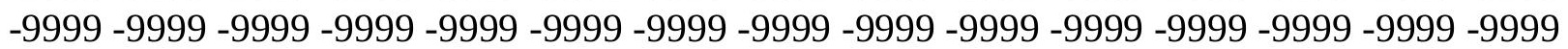


-9999 -9999 -9999 -9999 -9999 -9999 -9999 -9999 -9999 -9999 -9999 -9999 -9999 -9999 -9999 -9999 -9999 -9999 -9999 -9999 -9999 -9999 -9999 -9999 -9999 -9999 -9999 -9999 -9999 -9999 -

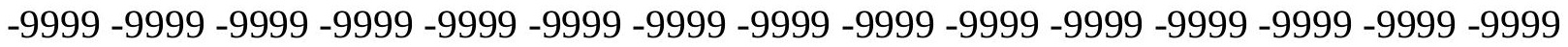
-9999 -9999 -9999 -9999 -9999 -9999 -9999 -9999 -9999 -9999 -9999 -9999 -9999 -9999 -9999 -9999 -9999 -9999 -9999 -9999 -9999 -9999 -9999 -9999-9999 -9999 -9999 -9999 -9999 -9999 -9999 -9999 -9999 -9999 -9999 -9999 -9999 -9999 -9999 -9999 -9999 -9999 -9999 -9999 -9999 -

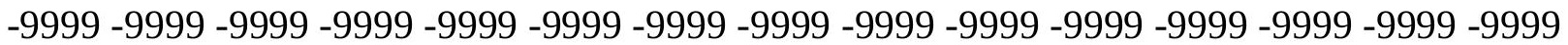
-9999 -9999 -9999 -9999 -9999 -9999 -9999 -9999 -9999 -9999 -9999 -9999 -9999 -9999 -9999 -9999 -9999 -9999 -9999 -9999 -9999 -9999 -9999 -9999 -9999 -9999 -9999 -9999 -9999 -9999 -9999 -9999 -9999 -9999 -9999 -9999 -9999 -9999 -9999 -9999 -9999 -9999 -9999 -9999 -9999 -9999 -9999 -9999 -9999 -9999 -9999 -9999 -9999 -9999 -9999 -9999 -9999 -9999 -9999 -9999 -9999 -9999 -9999 -9999 -9999 -9999 -9999 -9999 -9999 -9999 -9999 -9999 -9999 -9999 -9999 -9999 -9999 -9999 -9999 -9999 -9999 -9999 -9999 -9999 -9999 -9999 -9999 -9999 -9999 -9999 -9999 -9999 -9999 -9999 -9999 -9999 -9999 -9999 -9999 -9999 -9999 -9999 -9999 -9999 -9999 -9999 -9999 -9999 -9999 -9999 -9999 -9999 -9999 -9999 -9999 -9999 -9999 -9999 -9999 -

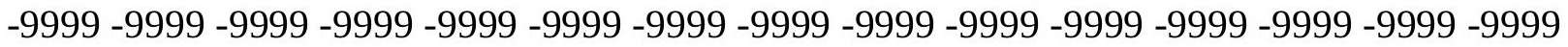
-9999 -9999 -9999 -9999 -9999 -9999 -9999 -9999 -9999 -9999 -9999 -9999 -9999 -9999 -9999 -9999 -9999 -9999 -9999 -9999 -9999 -9999 -9999 -9999 -9999 -9999 -9999 -9999 -9999 -9999 -9999 -9999 -9999 -9999 -9999 -9999 -9999 -9999 -9999 -9999 -9999 -9999 -9999 -9999 -9999 -

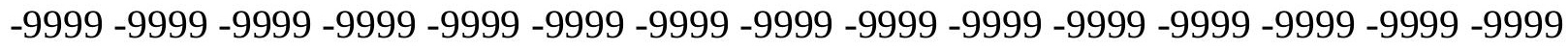

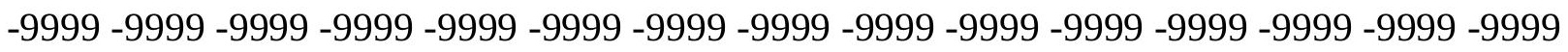
-9999 -9999 -9999 -9999 -9999 -9999 -9999 -9999 -9999 -9999 -9999 -9999 -9999 -9999 - 9999 -9999 -9999 -9999 -9999 -9999 -9999 -9999 -9999 -9999 -9999 -9999 -9999 -9999 -9999 -9999 -9999 -9999 -9999 -9999 -9999 -9999 -9999 -9999 -9999 -9999 -9999 -9999 -9999 -9999 -9999 -

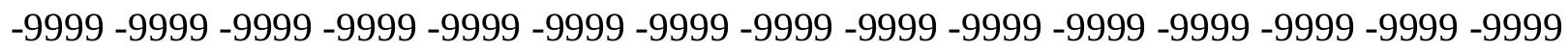
-9999 -9999 -9999 -9999 -9999 -9999 -9999 -9999 -9999 -9999 -9999 -9999 -9999 -9999 -9999 -9999 -9999 -9999 -9999 -9999 -9999 -9999 -9999 -9999 -9999 -9999 -9999 -9999 -9999 -9999 -

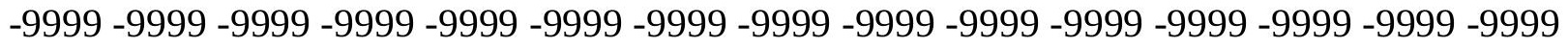
-9999 -9999 -9999 -9999 -9999 -9999 -9999 -9999 -9999 -9999 -9999 -9999 -9999 -9999 -9999 -9999 -9999 -9999 -9999 -9999 -9999 -9999 -9999 -9999 -9999 -9999 -9999 -9999 -9999 -999 -9999 -9999 -9999 -9999 -9999 -9999 -9999 -9999 -9999 -9999 -9999 -9999 -9999 -9999 -9999 -9999 -9999 -9999 -9999 -9999 -9999 -9999 -9999 -9999 -9999 -9999 -9999 -9999 -9999 -9999 -

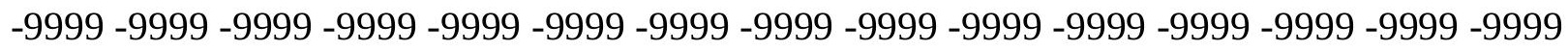

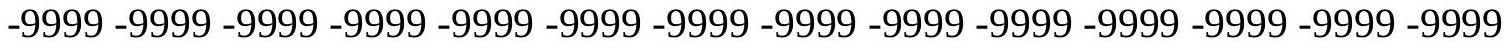
-9999 -9999 -9999 -9999 -9999 -9999 -9999 -9999 -9999 -9999 -9999 -9999 -9999 -9999 -9999

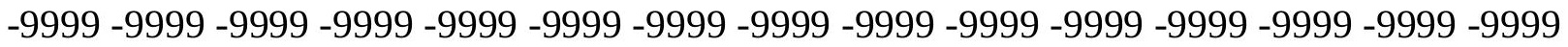

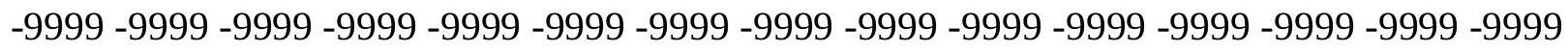

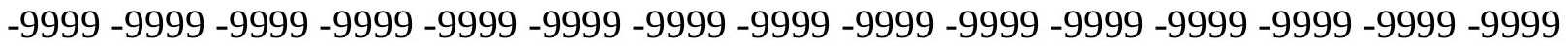

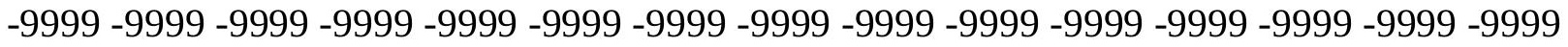
-9999 -9999 -9999 -9999 -9999 -9999 -9999 -9999 -9999 -9999 -9999 -9999 -9999 -9999 -9999 -

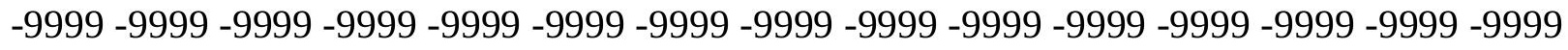

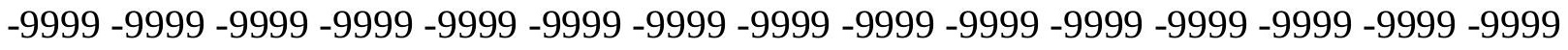
-9999 -9999 -9999 -9999 -9999 -9999 -9999 -9999 -9999 -9999 -9999 -9999 -9999 -9999 -9999 -9999 -9999 -9999 -9999 -9999 -9999 -9999 -9999 -9999-9999 -9999 -9999 -9999 -9999 -9999 -9999 -9999 -9999 -9999 -9999 -9999 -9999 -9999 -9999 -9999 -9999 -9999 -9999 -9999 -9999 -

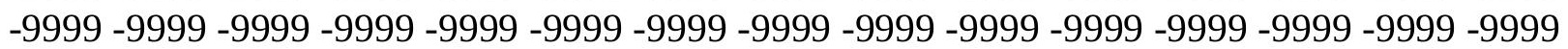


-9999 -9999 -9999 -9999 -9999 -9999 -9999 -9999 -9999 -9999 -9999 -9999 -9999 -9999 -9999 -9999 -9999 -9999 -9999 -9999 -9999 -9999 -9999 -9999 -9999 -9999 -9999 -9999 -9999 -9999 -

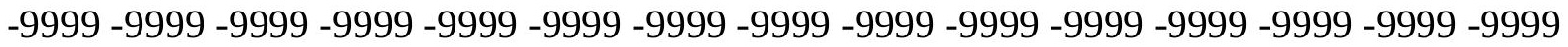
-9999 -9999 -9999 -9999 -9999 -9999 -9999 -9999 -9999 -9999 -9999 -9999 -9999 -9999 -9999 -9999 -9999 -9999 -9999 -9999 -9999 -9999 -9999 -9999-9999 -9999 -9999 -9999 -9999 -9999 -9999 -9999 -9999 -9999 -9999 -9999 -9999 -9999 -9999 -9999 -9999 -9999 -9999 -9999 -9999 -9999 -9999 -9999 -9999 -9999 -9999 -9999 -9999 -9999 -9999 -9999 -9999 -9999 -9999 -9999

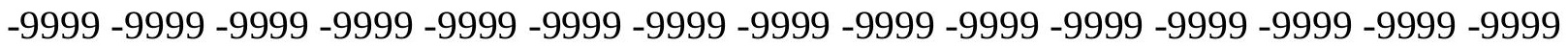

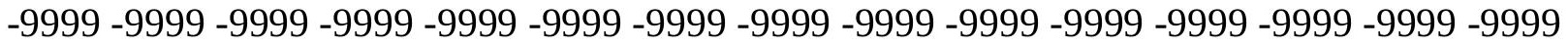
-9999 -9999 -9999 -9999 -9999 -9999 -9999 -9999 -9999 -9999 -9999 -9999 -9999 -9999 -9999 -9999 -9999 -9999 -9999 -9999 -9999 -9999 -9999 -9999 -9999 -9999 -9999 -9999 -9999 -9999 -9999 -9999 -9999 -9999 -9999 -9999 -9999 -9999 -9999 -9999 -9999 -9999 -9999 -9999 -9999 -9999 -9999 -9999 -9999 -9999 -9999 -9999 -9999 -9999 -9999 -9999 -9999 -9999 -9999 -9999 -9999 -9999 -9999 -9999 -9999 -9999 -9999 -9999 -9999 -9999 -9999 -9999 -9999 -9999 -9999 -9999 -9999 -9999 -9999 -9999 -9999 -9999 -9999 -9999 -9999 -9999 -9999 -9999 -9999

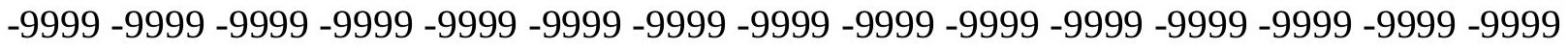
-9999 -9999 -9999 -9999 -9999 -9999 -9999 -9999 -9999 -9999 -9999 -9999 -9999 -9999 -9999 -9999 -9999 -9999 -9999 -9999 -9999 -9999 -9999 -9999 -9999 -9999 -9999 -9999 -9999 -9999 -9999 -9999 -9999 -9999 -9999 -9999 -9999 -9999 -9999 -9999 -9999 -9999 -9999 -9999 -9999 -

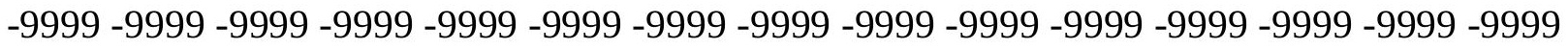

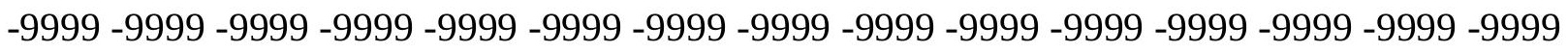
-9999 -9999 -9999 -9999 -9999 -9999 -9999 -9999 -9999 -9999 -9999 -9999 -9999 -9999 -9999 -9999 -9999 -9999 -9999 -9999 -9999 -9999 -9999 -9999 -9999 -9999 -9999 -9999 -9999 -9999 -9999 -9999 -9999 -9999 -9999 -9999 -9999 -9999 -9999 -9999 -9999 -9999 -9999 -9999 -9999 -

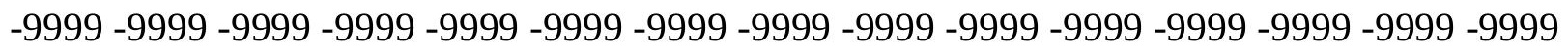
-9999 -9999 -9999 -9999 -9999 -9999 -9999 -9999 -9999 -9999 -9999 -9999 -9999 -9999 -9999 -9999 -9999 -9999 -9999 -9999 -9999 -9999 -9999 -9999 -9999 -9999 -9999 -9999 -9999 -9999 -

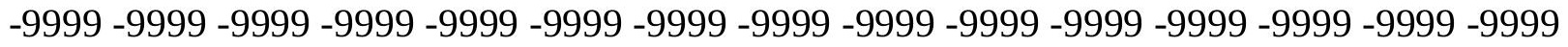
-9999 -9999 -9999 -9999 -9999 -9999 -9999 -9999 -9999 -9999 -9999 -9999 -9999 -9999 -9999 -9999 -9999 -9999 -9999 -9999 -9999 -9999 -9999 -9999 -9999 -9999 -9999 -9999 -9999 -999 -9999 -9999 -9999 -9999 -9999 -9999 -9999 -9999 -9999 -9999 -9999 -9999 -9999 -9999 -9999 -9999 -9999 -9999 -9999 -9999 -9999 -9999 -9999 -9999 -9999 -9999 -9999 -9999 -9999 -9999 -

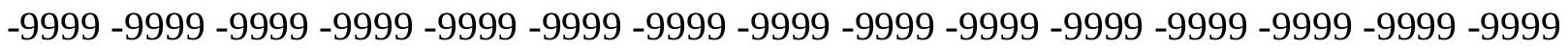

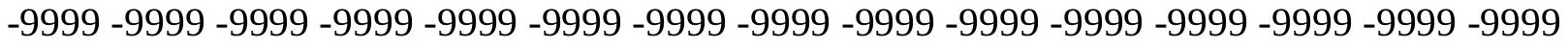

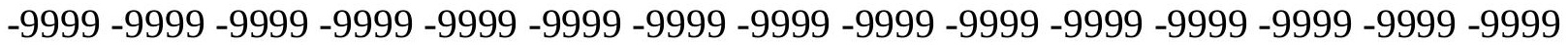

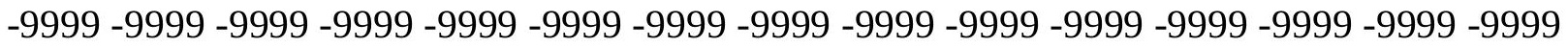

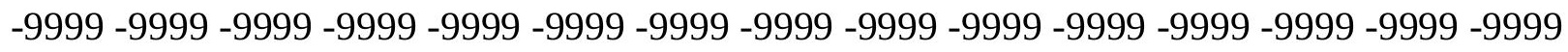

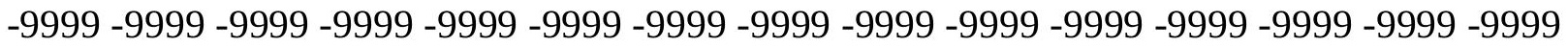
-9999 -9999 -9999 -9999 -9999 -9999 -9999 -9999 -9999 -9999 -9999 -9999 -9999 - 9999 - -999 -9999 -9999 -9999 -9999 -9999 -9999 -9999 -9999 -9999 -9999 -9999 -9999 -9999 -9999 - -999 -

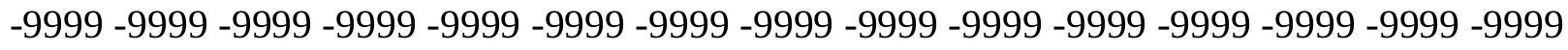

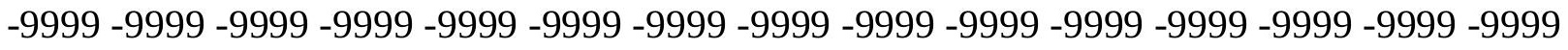
-9999 -9999 -9999 -9999 -9999 -9999 -9999 -9999 -9999 -9999 -9999 -9999 -9999 -9999 -9999 -9999 -9999 -9999 -9999 -9999 -9999 -9999 -9999 -9999-9999 -9999 -9999 -9999 -9999 -9999 -9999 -9999 -9999 -9999 -9999 -9999 -9999 -9999 -9999 -9999 -9999 -9999 -9999 -9999 -9999 -

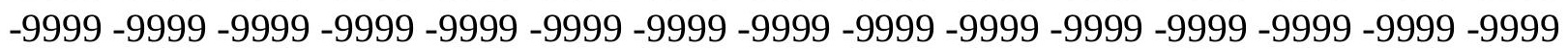


-9999 -9999 -9999 -9999 -9999 -9999 -9999 -9999 -9999 -9999 -9999 -9999 -9999 -9999 -9999 -9999 -9999 -9999 -9999 -9999 -9999 -9999 -9999 -9999 -9999 -9999 -9999 -9999 -9999 -9999 -9999 -9999 -9999 -9999 -9999 -9999 -9999 -9999 -9999 -9999 -9999 -9999 -9999 -9999 -9999 -9999 -9999 -9999 -9999 -9999 -9999 -9999 -9999 -9999 -9999 -9999 -9999 -9999 -9999 -9999 -9999 -9999 -9999 -9999 -9999 -9999 -9999 -9999 -9999 -9999 -9999 -9999 -9999 -9999 -9999 -9999 -9999 -9999 -9999 -9999 -9999 -9999 -9999 -9999 -9999 -9999 -9999 -9999 -9999 -9999 -9999 -9999 -9999 -9999 -9999 -9999 -9999 -9999 -9999 -9999 -9999 -9999 -9999 -9999 -9999 -

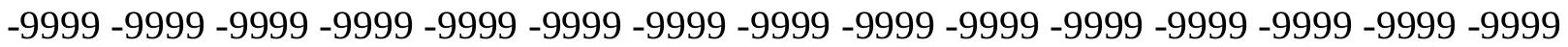
-9999 -9999 -9999 -9999 -9999 -9999 -9999 -9999 -9999 -9999 -9999 -9999 -9999 -9999 -9999 -9999 -9999 -9999 -9999 -9999 -9999 -9999 -9999 -9999 -9999 -9999 -9999 -9999 -9999 -9999 -

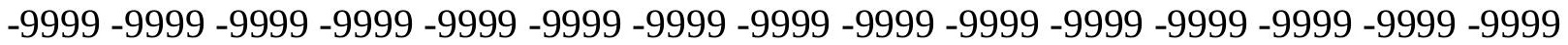
-9999 -9999 -9999 -9999 -9999 -9999 -9999 -9999 -9999 -9999 -9999 -9999 -9999 -9999 -9999 -9999 -9999 -9999 -9999 -9999 -9999 -9999 -9999 -9999 -9999 -9999 -9999 -9999 -9999 -9999 -9999 -9999 -9999 -9999 -9999 -9999 -9999 -9999 -9999 -9999 -9999 -9999 -9999 -9999 -9999 -9999 -9999 -9999 -9999 -9999 -9999 -9999 -9999 -9999 -9999 -9999 -9999 -9999 -9999 -9999

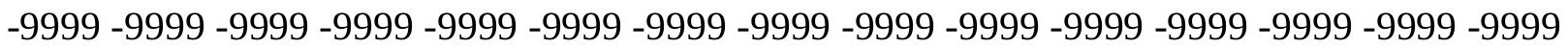
-9999 -9999 -9999 -9999 -9999 -9999 -9999 -9999 -9999 -9999 -9999 -9999 -9999 -9999 -9999 -9999 -9999 -9999 -9999 -9999 -9999 -9999 -9999 -9999 -9999 -9999 -9999 -9999 -9999 -9999 -9999 -9999 -9999 -9999 -9999 -9999 -9999 -9999 -9999 -9999 -9999 -9999 -9999 -9999 -9999 -9999 -9999 -9999 -9999 -9999 -9999 -9999 -9999 -9999 -9999 -9999 -9999 -9999 -9999 -9999 -9999 -9999 -9999 -9999 -9999 -9999 -9999 -9999 -9999 -9999 -9999 -9999 -9999 -9999 -9999 -9999 -9999 -9999 -9999 -9999 -9999 -9999 -9999 -9999 -9999 -9999 -9999 -9999 -9999 -9999 -9999 -9999 -9999 -9999 -9999 -9999 -9999 -9999 -9999 -9999 -9999 -9999 -9999 -9999 -9999 -9999 -9999 -9999 -9999 -9999 -9999 -9999 -9999 -9999 -9999 -9999 -9999 -9999 -9999 -9999 -9999 -9999 -9999 -9999 -9999 -9999 -9999 -9999 -9999 -9999 -9999 -9999 -9999 -9999 -9999 -9999 -9999 -9999 -9999 -9999 -9999 -9999 -9999 -9999 -9999 -9999 -9999 -9999 -9999 -9999 -9999 -9999 -9999 -9999 -9999 -9999 -9999 -9999 -9999 -9999 -9999 -9999 -9999 -9999 -9999 -9999 -9999 -9999 -9999 -9999 -9999 -9999 -9999 -9999 -9999 -9999 -9999 -9999 -9999

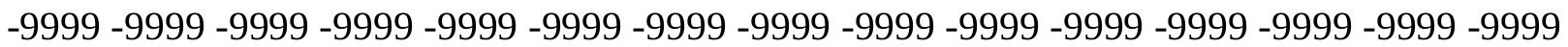
-9999 -9999 -9999 -9999 -9999 -9999 -9999 -9999 -9999 -9999 -9999 -9999 -9999 -9999 -9999 -9999 -9999 -9999 -9999 -9999 -9999 -9999 -9999 -9999 -9999 -9999 -9999 -9999 -9999 -9999 -

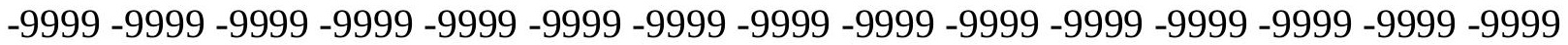
-9999 -9999 -9999 -9999 -9999 -9999 -9999 -9999 -9999 -9999 -9999 -9999 -9999 -9999 -9999 -9999 -9999 -9999 -9999 -9999 -9999 -9999 -9999 -9999 -9999 -9999 -9999 -9999 -9999 -9999 -9999 -9999 -9999 -9999 -9999 -9999 -9999 -9999 -9999 -9999 -9999 -9999 -9999 -9999 -9999 -9999 -9999 -9999 -9999 -9999 -9999 -9999 -9999 -9999 -9999 -9999 -9999 -9999 -9999 -9999 -9999 -9999 -9999 -9999 -9999 -9999 -9999 -9999 -9999 -9999 -9999 -9999 -9999 -9999 -9999

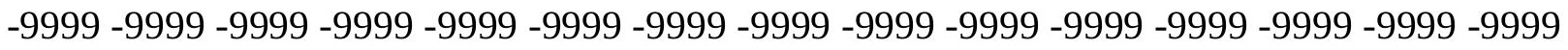
-9999 -9999 -9999 -9999 -9999 -9999 -9999 -9999 -9999 -9999 -9999 -9999 -9999 -9999 -9999 -9999 -9999 -9999 -9999 -9999 -9999 -9999 -9999 -9999 -9999 -9999 -9999 -9999 -9999 -9999 -9999 -9999 -9999 -9999 -9999 -9999 -9999 -9999 -9999 -9999 -9999 -9999 -9999 -9999 -9999 -999 -9999 -9999 -9999 -9999 -9999 -9999 -9999 -9999 -9999 -9999 -9999 -9999 -9999 -9999 -9999 -9999 -9999 -9999 -9999 -9999 -9999 -9999 -9999 -9999 -9999 -9999 -9999 -9999 -9999 -9999 -9999 -9999 -9999 -9999 -9999 -9999 -9999 -9999 -9999 -9999 -9999 -9999 -9999 -9999 -9999 -9999 -9999 -9999 -9999 -9999 -9999 -9999 -9999 -9999 -9999 -9999 -9999 -9999 -9999 -9999 -9999 -9999 -9999 -9999 -9999 -9999 -9999 -9999 -9999 -9999 -9999 -9999 -9999 -9999 
-9999 -9999 -9999 -9999 -9999 -9999 -9999 -9999 -9999 -9999 -9999 -9999 -9999 -9999 -9999 -9999 -9999 -9999 -9999 -9999 -9999 -9999 -9999 -9999 -9999 -9999 -9999 -9999 -9999 -9999 -

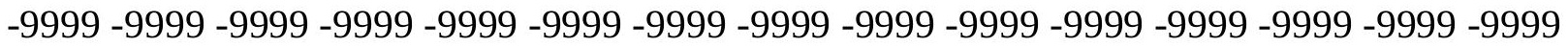
-9999 -9999 -9999 -9999 -9999 -9999 -9999 -9999 -9999 -9999 -9999 -9999 -9999 -9999 -9999 -9999 -9999 -9999 -9999 -9999 -9999 -9999 -9999 -9999-9999 -9999 -9999 -9999 -9999 -9999 -9999 -9999 -9999 -9999 -9999 -9999 -9999 -9999 -9999 -9999 -9999 -9999 -9999 -9999 -9999 -9999 -9999 -9999 -9999 -9999 -9999 -9999 -9999 -9999 -9999 -9999 -9999 -9999 -9999 -9999

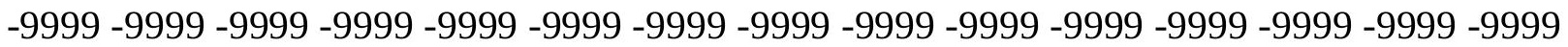

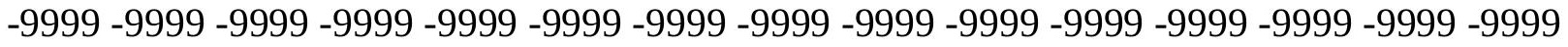
-9999 -9999 -9999 -9999 -9999 -9999 -9999 -9999 -9999 -9999 -9999 -9999 -9999 -9999 -9999 -9999 -9999 -9999 -9999 -9999 -9999 -9999 -9999 -9999 -9999 -9999 -9999 -9999 -9999 -9999 -9999 -9999 -9999 -9999 -9999 -9999 -9999 -9999 -9999 -9999 -9999 -9999 -9999 -9999 -9999 -9999 -9999 -9999 -9999 -9999 -9999 -9999 -9999 -9999 -9999 -9999 -9999 -9999 -9999 -9999 -

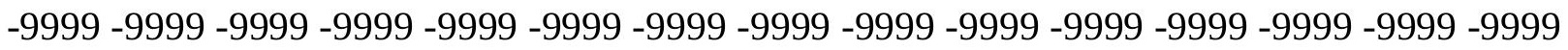
-9999 -9999 -9999 -9999 -9999 -9999 -9999 -9999 -9999 -9999 -9999 -9999 -9999 -9999 -9999 -

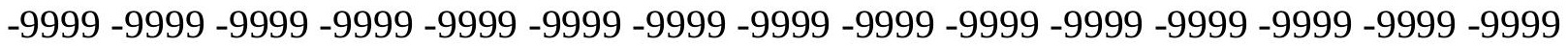
-9999 -9999 -9999 -9999 -9999 -9999 -9999 -9999 -9999 -9999 -9999 -9999 -9999 -9999 -9999 -9999 -9999 -9999 -9999 -9999 -9999 -9999 -9999 -9999 -9999 -9999 -9999 -9999 -9999 -9999 -9999 -9999 -9999 -9999 -9999 -9999 -9999 -9999 -9999 -9999 -9999 -9999 -9999 -9999 -9999 -

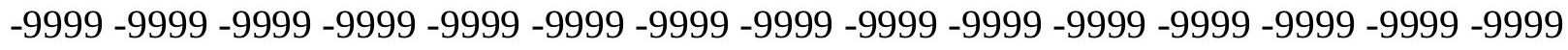

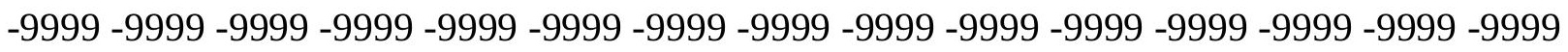

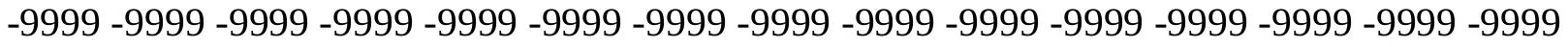
-9999 -9999 -9999 -9999 -9999 -9999 -9999 -9999 -9999 -9999 -9999 -9999 -9999 -9999 -9999 -9999 -9999 -9999 -9999 -9999 -9999 -9999 -9999 -9999 -9999 -9999 -9999 -9999 -9999 -9999 -

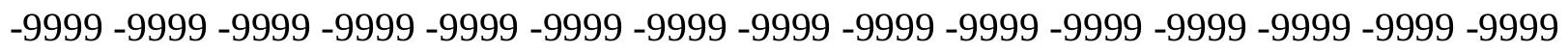
-9999 -9999 -9999 -9999 -9999 -9999 -9999 -9999 -9999 -9999 -9999 -9999 -9999 -9999 -9999 -9999 -9999 -9999 -9999 -9999 -9999 -9999 -9999 -9999 -9999 -9999 -9999 -9999 -9999 -

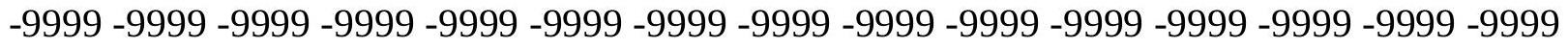
-9999 -9999 -9999 -9999 -9999 -9999 -9999 -9999 -9999 -9999 -9999 -9999 -9999 -9999 -9999 -9999 -9999 -9999 -9999 -9999 -9999 -9999 -9999 -9999 -9999 -9999 -9999 -9999 -9999 -999 -

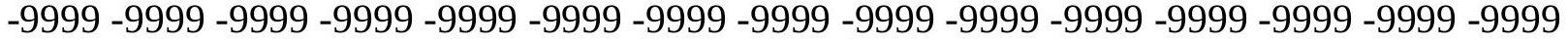
-9999 -9999 -9999 -9999 -9999 -9999 -9999 -9999 -9999 -9999 -9999 -9999 -9999 -9999 -9999 -

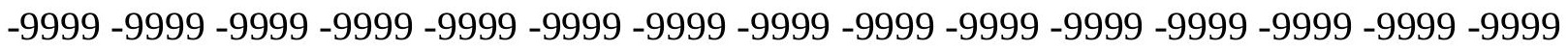

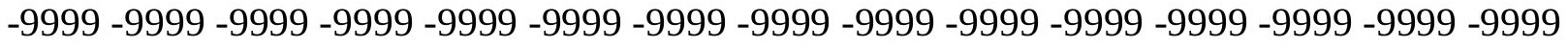

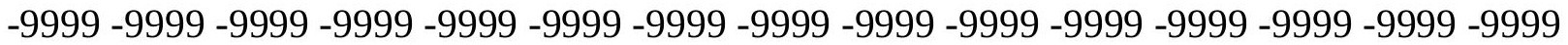
-9999 -9999 -9999 -9999 -9999 -9999 -9999 -9999 -9999 -9999 -9999 -9999 -9999 -9999 -9999

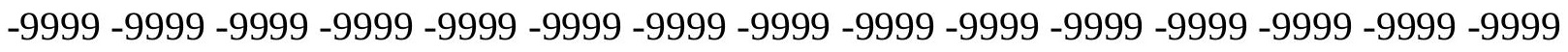

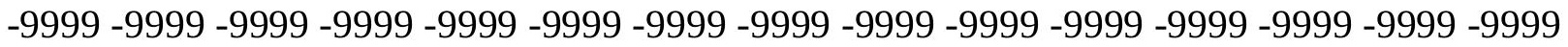
-9999 -9999 -9999 -9999 -9999 -9999 -9999 -9999 -9999 -9999 -9999 -9999 -9999 - 9999 - -999 -9999 -9999 -9999 -9999 -9999 -9999 -9999 -9999 -9999 -9999 -9999 -9999 -9999 -9999 -9999 -

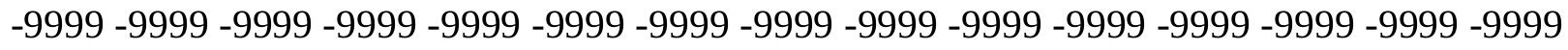

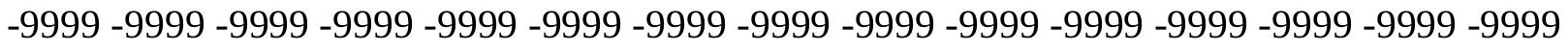
-9999 -9999 -9999 -9999 -9999 -9999 -9999 -9999 -9999 -9999 -9999 -9999 -9999 -9999 -9999 -9999 -9999 -9999 -9999 -9999 -9999 -9999 -9999 -9999-9999 -9999 -9999 -9999 -9999 -9999 -9999 -9999 -9999 -9999 -9999 -9999 -9999 -9999 -9999 -9999 -9999 -9999 -9999 -9999 -9999 -

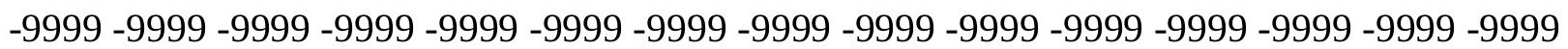


-9999 -9999 -9999 -9999 -9999 -9999 -9999 -9999 -9999 -9999 -9999 -9999 -9999 -9999 -9999 -9999 -9999 -9999 -9999 -9999 -9999 -9999 -9999 -9999 -9999 -9999 -9999 -9999 -9999 -9999 -9999 -9999 -9999 -9999 -9999 -9999 -9999 -9999 -9999 -9999 -9999 -9999 -9999 -9999 - 9999 -9999 -9999 -9999 -9999 -9999 -9999 -9999 -9999 -9999 -9999 -9999 -9999 -9999 -9999 -9999 -9999 -9999 -9999 -9999 -9999 -9999 -9999 -9999 -9999 -9999 -9999 -9999 -9999 -9999 - -9999 -9999 -9999 -9999 -9999 -9999 -9999 -9999 -9999 -9999 -9999 -9999 -9999 -9999 -9999 -9999 -9999 -9999 -9999 -9999 -9999 -9999 -9999 -9999 -9999 -9999 -9999 -9999 -9999 -9999

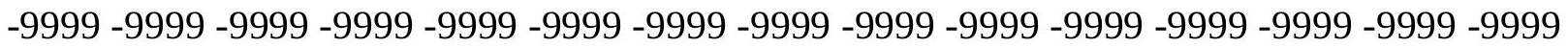

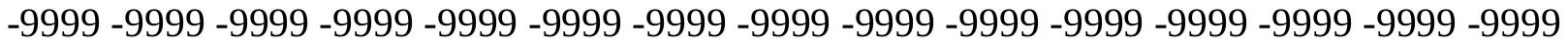
-9999 -9999 -9999 -9999 -9999 -9999 -9999 -9999 -9999 -9999 -9999 -9999 -9999 -9999 -9999

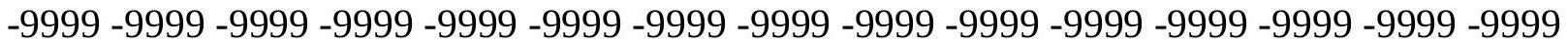
-9999 -9999 -9999 -9999 -9999 -9999 -9999 -9999 -9999 -9999 -9999 -9999 -9999 -9999 -9999 -9999 -9999 -9999 -9999 -9999 -9999 -9999 -9999 -9999 -9999 -9999 -9999 -9999 -9999 -9999 -9999 -9999 -9999 -9999 -9999 -9999 -9999 -9999 -9999 -9999 -9999 -9999 -9999 -9999 - -9999 -9999 -9999 -9999 -9999 -9999 -9999 -9999 -9999 -9999 -9999 -9999 -9999 -9999 -9999 -9999

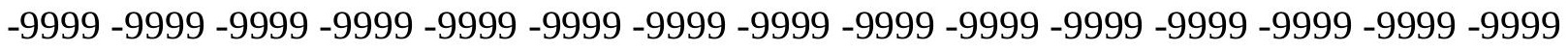
-9999 -9999 -9999 -9999 -9999 -9999 -9999 -9999 -9999 -9999 -9999 -9999 -9999 -9999 -9999 -9999 -9999 -9999 -9999 -9999 -9999 -9999 -9999 -9999 -9999 -9999 -9999 -9999 -9999 -9999 -9999 -9999 -9999 -9999 -9999 -9999 -9999 -9999 -9999 -9999 -9999 -9999 -9999 -9999 -9999 -

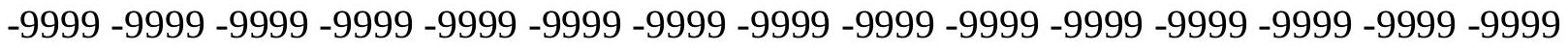
-9999 -9999 -9999 -9999 -9999 -9999 -9999 -9999 -9999 -9999 -9999 -9999 -9999 -9999 -9999 -999 -9999 -9999 -9999 -9999 -9999 -9999 -9999 -9999 -9999 -9999 -9999 -9999 -9999 -9999 -9999 -9999 -9999 -9999 -9999 -9999 -9999 -9999 -9999 -9999 -9999 -9999 -9999 -9999 -9999 -9999 -9999 -9999 -9999 -9999 -9999 -9999 -9999 -9999 -9999 -9999 -9999 -9999 -9999 -9999 -9999 -9999 -9999 -9999 -9999 -9999 -9999 -9999 -9999 -9999 -9999 -9999 -9999 -9999 -9999 -9999 -9999 -9999 -9999 -9999 -9999 -9999 -9999 -9999 -9999 -9999 -9999 -9999 -9999 -9999 -9999 -9999 -9999 -9999 -9999 -9999 -9999 -9999 -9999 -9999 -9999 -9999 -9999 -9999 -9999 -9999 -9999 -9999 -9999 -9999 -9999 -9999 -9999 -9999 -9999 -9999 -9999 -9999 -9999 -9999 -9999 -9999 -9999 -9999 -9999 -9999 -9999 -9999 -9999 -9999 -9999 -9999 -9999 -9999 -9999 -9999 -9999 -9999 -9999 -9999 -9999 -9999 -9999 -9999 -9999 -9999 -9999 -9999 -9999 -9999 -999 -9999 -9999 -9999 -9999 -9999 -9999 -9999 -9999 -9999 -9999 -9999 -9999 -9999 -9999 -9999 -9999 -9999 -9999 -9999 -9999 -9999 -9999 -9999 -9999 -9999 -9999 -9999 -9999 -9999 -

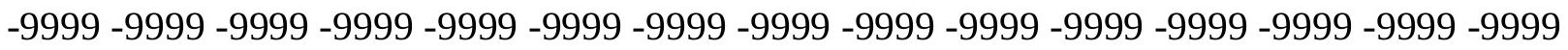

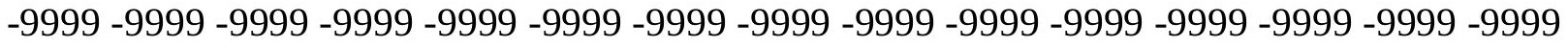

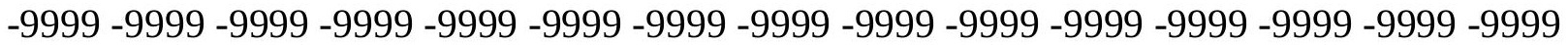
-9999 -9999 -9999 -9999 -9999 -9999 -9999 -9999 -9999 -9999 -9999 -9999 -9999 -9999 -9999 -

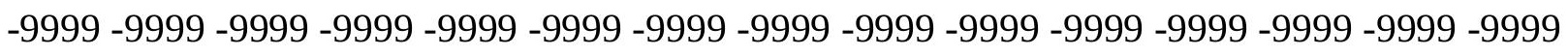

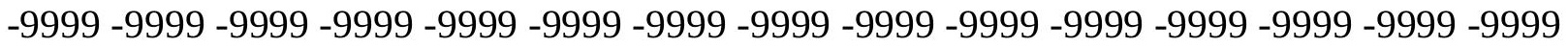

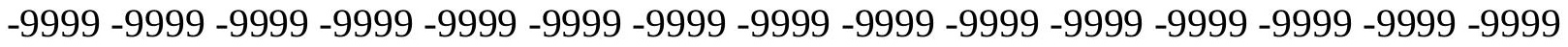
-9999 -9999 -9999 -9999 -9999 -9999 -9999 -9999 -9999 -9999 -9999 -9999 -9999 -9999 -9999 -

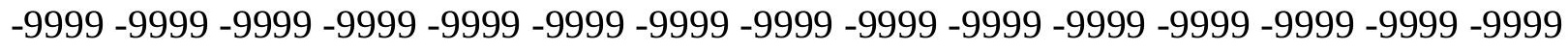

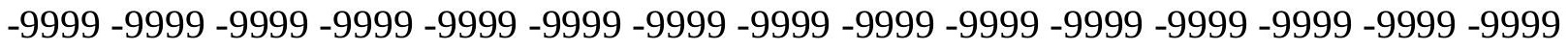
-9999 -9999 -9999 -9999 -9999 -9999 -9999 -9999 -9999 -9999 -9999 -9999 -9999 -9999 -9999 -9999 -9999 -9999 -9999 -9999 -9999 -9999 -9999 -9999-9999 -9999 -9999 -9999 -9999 -9999 -9999 -9999 -9999 -9999 -9999 -9999 -9999 -9999 -9999 -9999 -9999 -9999 -9999 -9999 -9999 -

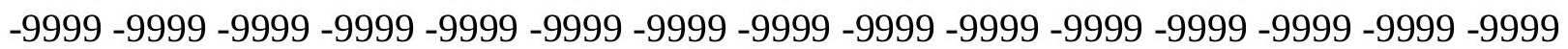


-9999 -9999 -9999 -9999 -9999 -9999 -9999 -9999 -9999 -9999 -9999 -9999 -9999 -9999 -9999 -9999 -9999 -9999 -9999 -9999 -9999 -9999 -9999 -9999 -9999 -9999 -9999 -9999 -9999 -9999 -

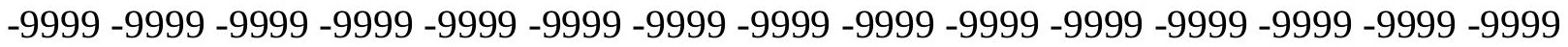
-9999 -9999 -9999 -9999 -9999 -9999 -9999 -9999 -9999 -9999 -9999 -9999 -9999 -9999 -9999 -9999 -9999 -9999 -9999 -9999 -9999 -9999 -9999 -9999-9999 -9999 -9999 -9999 -9999 -9999 -9999 -9999 -9999 -9999 -9999 -9999 -9999 -9999 -9999 -9999 -9999 -9999 -9999 -9999 -9999 -9999 -9999 -9999 -9999 -9999 -9999 -9999 -9999 -9999 -9999 -9999 -9999 -9999 -9999 -9999

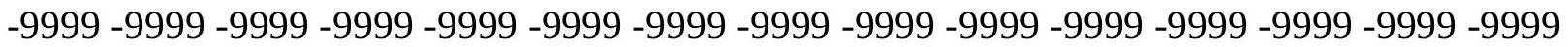

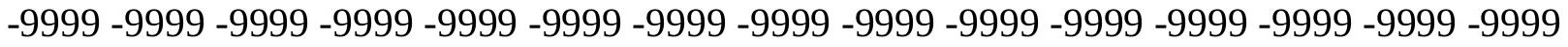
-9999 -9999 -9999 -9999 -9999 -9999 -9999 -9999 -9999 -9999 -9999 -9999 -9999 -9999 -9999 -9999 -9999 -9999 -9999 -9999 -9999 -9999 -9999 -9999 -9999 -9999 -9999 -9999 -9999 -9999 -9999 -9999 -9999 -9999 -9999 -9999 -9999 -9999 -9999 -9999 -9999 -9999 -9999 -9999 -9999 -9999 -9999 -9999 -9999 -9999 -9999 -9999 -9999 -9999 -9999 -9999 -9999 -9999 -9999 -9999 -9999 -9999 -9999 -9999 -9999 -9999 -9999 -9999 -9999 -9999 -9999 -9999 -9999 - 9999 -9999 -9999 -9999 -9999 -9999 -9999 -9999 -9999 -9999 -9999 -9999 -9999 -9999 -9999 -9999

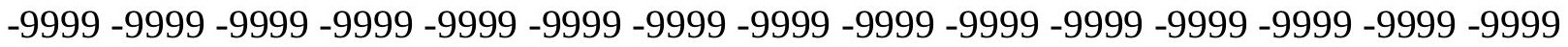
-9999 -9999 -9999 -9999 -9999 -9999 -9999 -9999 -9999 -9999 -9999 -9999 -9999 -9999 -9999 -9999 -9999 -9999 -9999 -9999 -9999 -9999 -9999 -9999 -9999 -9999 -9999 -9999 -9999 -9999 -9999 -9999 -9999 -9999 -9999 -9999 -9999 -9999 -9999 -9999 -9999 -9999 -9999 -9999 -9999 -

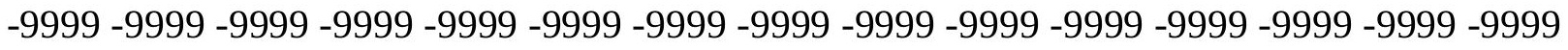

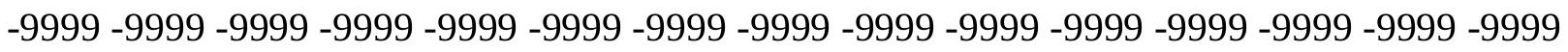
-9999 -9999 -9999 -9999 -9999 -9999 -9999 -9999 -9999 -9999 -9999 -9999 -9999 -9999 -9999 -9999 -9999 -9999 -9999 -9999 -9999 -9999 -9999 -9999 -9999 -9999 -9999 -9999 -9999 -9999 -9999 -9999 -9999 -9999 -9999 -9999 -9999 -9999 -9999 -9999 -9999 -9999 -9999 -9999 -9999 -

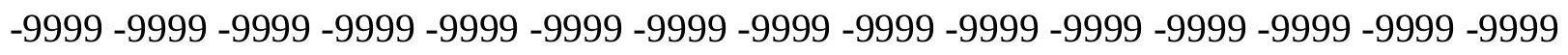
-9999 -9999 -9999 -9999 -9999 -9999 -9999 -9999 -9999 -9999 -9999 -9999 -9999 -9999 -9999 -9999 -9999 -9999 -9999 -9999 -9999 -9999 -9999 -9999 -9999 -9999 -9999 -9999 -9999 -9999 -

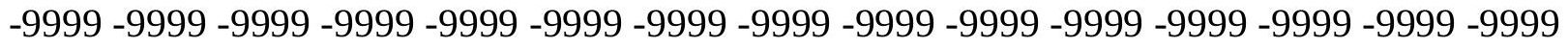
-9999 -9999 -9999 -9999 -9999 -9999 -9999 -9999 -9999 -9999 -9999 -9999 -9999 -9999 -9999 -9999 -9999 -9999 -9999 -9999 -9999 -9999 -9999 -9999 -9999 -9999 -9999 -9999 -9999 -999 -9999 -9999 -9999 -9999 -9999 -9999 -9999 -9999 -9999 -9999 -9999 -9999 -9999 -9999 -9999 -9999 -9999 -9999 -9999 -9999 -9999 -9999 -9999 -9999 -9999 -9999 -9999 -9999 -9999 -9999 -

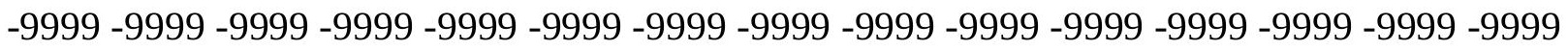

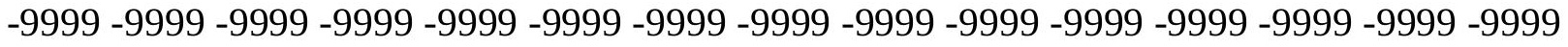

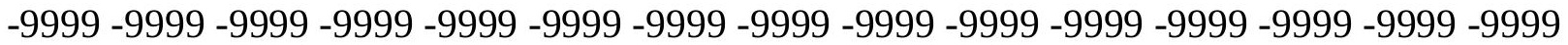

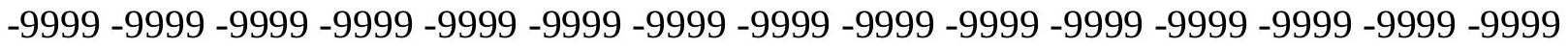

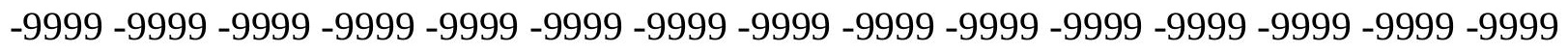

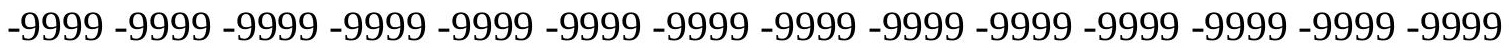
-9999 -9999 -9999 -9999 -9999 -9999 -9999 -9999 -9999 -9999 -9999 -9999 -9999 -9999 -9999 -9999 -9999 -9999 -9999 -9999 -9999 -9999 -9999 -9999 -9999 -9999 -9999 -9999 -9999 -9999 -

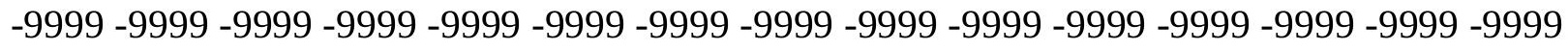

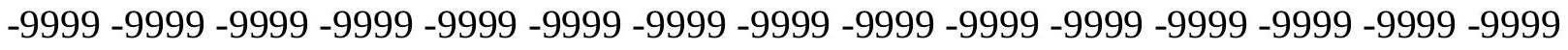
-9999 -9999 -9999 -9999 -9999 -9999 -9999 -9999 -9999 -9999 -9999 -9999 -9999 -9999 -9999 -9999 -9999 -9999 -9999 -9999 -9999 -9999 -9999 -9999-9999 -9999 -9999 -9999 -9999 -9999 -9999 -9999 -9999 -9999 -9999 -9999 -9999 -9999 -9999 -9999 -9999 -9999 -9999 -9999 -9999 -

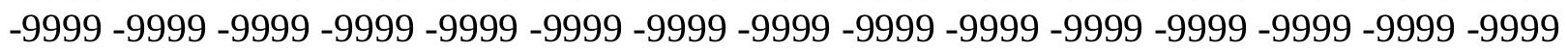


-9999 -9999 -9999 -9999 -9999 -9999 -9999 -9999 -9999 -9999 -9999 -9999 -9999 -9999 -9999 -9999 -9999 -9999 -9999 -9999 -9999 -9999 -9999 -9999 -9999 -9999 -9999 -9999 -9999 -9999 -9999 -9999 -9999 -9999 -9999 -9999 -9999 -9999 -9999 -9999 -9999 -9999 -9999 -9999 - 9999 -9999 -9999 -9999 -9999 -9999 -9999 -9999 -9999 -9999 -9999 -9999 -9999 -9999 -9999 -9999 -9999 -9999 -9999 -9999 -9999 -9999 -9999 -9999 -9999 -9999 -9999 -9999 -9999 -9999 -9999 -9999 -9999 -9999 -9999 -9999 -9999 -9999 -9999 -9999 -9999 -9999 -9999 -9999 -9999 -9999 -9999 -9999 -9999 -9999 -9999 -9999 -9999 -9999 -9999 -9999 -9999 -9999 -9999 -9999 -9999

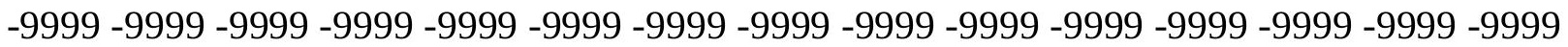
-9999 -9999 -9999 -9999 -9999 -9999 -9999 -9999 -9999 -9999 -9999 -9999 -9999 -9999 -9999 -9999 -9999 -9999 -9999 -9999 -9999 -9999 -9999 -9999 -9999 -9999 -9999 -9999 -9999 -9999

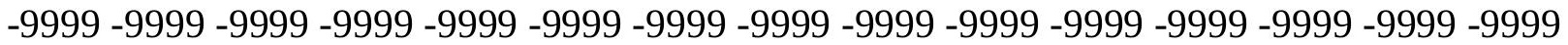
-9999 -9999 -9999 -9999 -9999 -9999 -9999 -9999 -9999 -9999 -9999 -9999 -9999 -9999 -9999 -9999 -9999 -9999 -9999 -9999 -9999 -9999 -9999 -9999 -9999 -9999 -9999 -9999 -9999 -9999 -

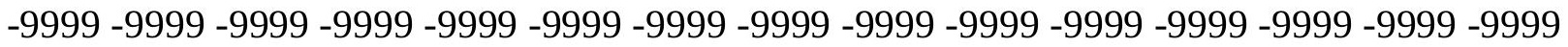
-9999 -9999 -9999 -9999 -9999 -9999 -9999 -9999 -9999 -9999 -9999 -9999 -9999 -9999 -9999

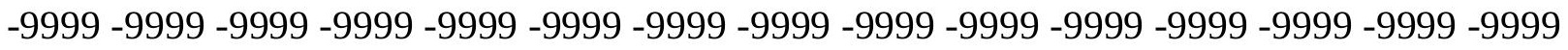
-9999 -9999 -9999 -9999 -9999 -9999 -9999 -9999 -9999 -9999 -9999 -9999 -9999 -9999 -9999 -9999 -9999 -9999 -9999 -9999 -9999 -9999 -9999 -9999 -9999 -9999 -9999 -9999 -9999 - -999 -9999 -9999 -9999 -9999 -9999 -9999 -9999 -9999 -9999 -9999 -9999 -9999 -9999 -9999 -9999 -9999 -9999 -9999 -9999 -9999 -9999 -9999 -9999 -9999 -9999 -9999 -9999 -9999 -9999 -9999 -9999 -9999 -9999 -9999 -9999 -9999 -9999 -9999 -9999 -9999 -9999 -9999 -9999 -9999 -9999 -999 -9999 -9999 -9999 -9999 -9999 -9999 -9999 -9999 -9999 -9999 -9999 -9999 -9999 -9999 -9999 -9999 -9999 -9999 -9999 -9999 -9999 -9999 -9999 -9999 -9999 -9999 -9999 -9999 -9999 -9999 -9999 -9999 -9999 -9999 -9999 -9999 -9999 -9999 -9999 -9999 -9999 -9999 -9999 -9999 -9999 -9999 -9999 -9999 -9999 -9999 -9999 -9999 -9999 -9999 -9999 -9999 -9999 -9999 -9999 -9999 -9999 -9999 -9999 -9999 -9999 -9999 -9999 -9999 -9999 -9999 -9999 -9999 -9999 -9999 -9999 -9999 -9999 -9999 -9999 -9999 -9999 -9999 -9999 -9999 -9999 -9999 -9999 -9999 -9999 -9999 -9999 -9999 -9999 -9999 -9999 -9999 -9999 -9999 -9999 -9999 -9999 -9999 -9999 -9999 -9999 -9999 -9999 -9999 -9999 -9999 -9999 -9999 -9999 -9999 -9999 -9999 -9999 -9999 -9999 -9999 -9999 -9999 -9999 -9999 -9999 -9999 -9999 -9999 -9999 -9999 -9999 -9999 -9999 -9999 -999 -9999 -9999 -9999 -9999 -9999 -9999 -9999 -9999 -9999 -9999 -9999 -9999 -9999 -9999 -9999 -9999 -9999 -9999 -9999 -9999 -9999 -9999 -9999 -9999 -9999 -9999 -9999 -9999 -9999 -9999 -

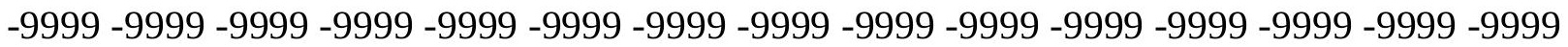

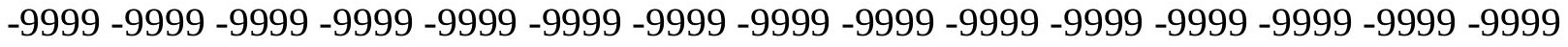

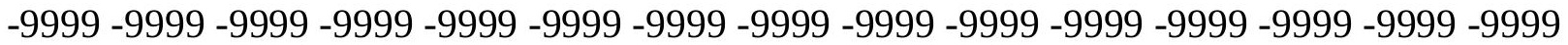
-9999 -9999 -9999 -9999 -9999 -9999 -9999 -9999 -9999 -9999 -9999 -9999 -9999 -9999 -9999

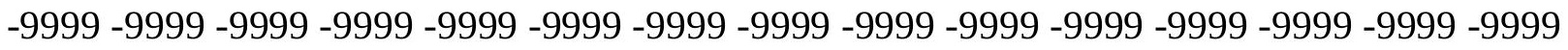

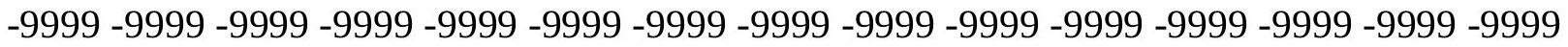

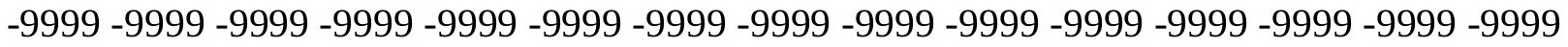
-9999 -9999 -9999 -9999 -9999 -9999 -9999 -9999 -9999 -9999 -9999 -9999 -9999 -9999 -9999 -

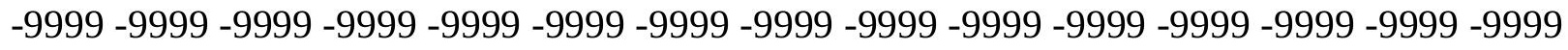

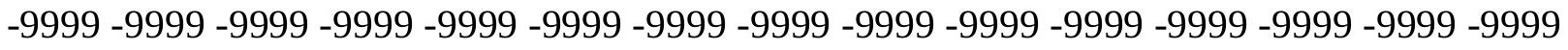
-9999 -9999 -9999 -9999 -9999 -9999 -9999 -9999 -9999 -9999 -9999 -9999 -9999 -9999 -9999 -9999 -9999 -9999 -9999 -9999 -9999 -9999 -9999 -9999 -9999 -9999 -9999 -9999 - -9999 -9999 -9999 -9999 -9999 -9999 -9999 -9999 -9999 -9999 -9999 -9999 -9999 -9999 -9999 -9999 -

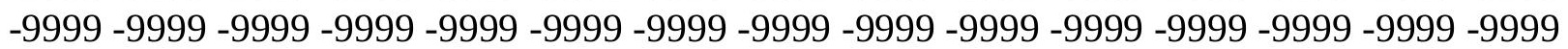


-9999 -9999 -9999 -9999 -9999 -9999 -9999 -9999 -9999 -9999 -9999 -9999 -9999 -9999 -9999 -9999 -9999 -9999 -9999 -9999 -9999 -9999 -9999 -9999 -9999 -9999 -9999 -9999 -9999 -9999 -9999 -9999 -9999 -9999 -9999 -9999 -9999 -9999 -9999 -9999 -9999 -9999 -9999 -9999 - 9999 -9999 -9999 -9999 -9999 -9999 -9999 -9999 -9999 -9999 -9999 -9999 -9999 -9999 -9999 -9999 -9999 -9999 -9999 -9999 -9999 -9999 -9999 -9999 -9999-9999 -9999 -9999 -9999 -9999 -9999 -9999 -9999 -9999 -9999 -9999 -9999 -9999 -9999 -9999 -9999 -9999 -9999 -9999 -9999 -9999 -9999 -9999 -9999 -9999 -9999 -9999 -9999 -9999 -9999 -9999 -9999 -9999 -9999 -9999 -9999

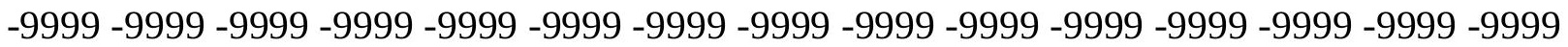

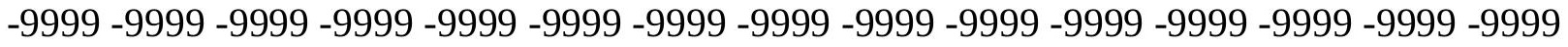
-9999 -9999 -9999 -9999 -9999 -9999 -9999 -9999 -9999 -9999 -9999 -9999 -9999 -9999 -9999

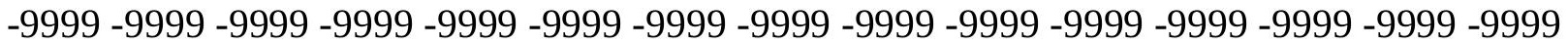
-9999 -9999 -9999 -9999 -9999 -9999 -9999 -9999 -9999 -9999 -9999 -9999 -9999 -9999 -9999 -9999 -9999 -9999 -9999 -9999 -9999 -9999 -9999 -9999 -9999 -9999 -9999 -9999 -9999 -9999 -

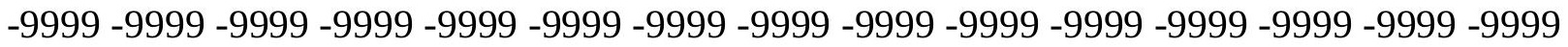
-9999 -9999 -9999 -9999 -9999 -9999 -9999 -9999 -9999 -9999 -9999 -9999 -9999 -9999 -9999

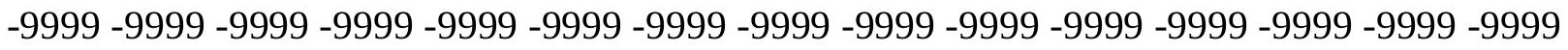
-9999 -9999 -9999 -9999 -9999 -9999 -9999 -9999 -9999 -9999 -9999 -9999 -9999 -9999 -9999 -9999 -9999 -9999 -9999 -9999 -9999 -9999 -9999 -9999 -9999 -9999 -9999 -9999 -9999 -9999 -9999 -9999 -9999 -9999 -9999 -9999 -9999 -9999 -9999 -9999 -9999 -9999 -9999 -9999 -9999 -9999 -9999 -9999 -9999 -9999 -9999 -9999 -9999 -9999 -9999 -9999 -9999 -9999 -9999 -9999 -9999 -9999 -9999 -9999 -9999 -9999 -9999 -9999 -9999 -9999 -9999 -9999 -9999 -9999 -9999 -999 -9999 -9999 -9999 -9999 -9999 -9999 -9999 -9999 -9999 -9999 -9999 -9999 -9999 -9999 -9999 -9999 -9999 -9999 -9999 -9999 -9999 -9999 -9999 -9999 -9999 -9999 -9999 -9999 -9999 -9999 -9999 -9999 -9999 -9999 -9999 -9999 -9999 -9999 -9999 -9999 -9999 -9999 -9999 -9999 -9999 -9999 -9999 -9999 -9999 -9999 -9999 -9999 -9999 -9999 -9999 -9999 -9999 -9999 -9999 -9999 -9999 -9999 -9999 -9999 -9999 -9999 -9999 -9999 -9999 -9999 -9999 -9999 -9999 -9999 -9999 -9999 -9999 -9999 -9999 -9999 -9999 -9999 -9999 -9999 -9999 -9999 -9999 -9999 -9999 -9999 -9999 -9999 -9999 -9999 -9999 -9999 -9999 -9999 -9999 -9999 -9999 -9999 -9999 -9999 -9999 -9999 -9999 -9999 -9999 -9999 -9999 -9999 -9999 -9999 -9999 -9999 -9999 -9999 -9999 -9999 -9999 -9999 -9999 -9999 -9999 -9999 -9999 -9999 -9999 -9999 -9999 -9999 -9999 -999 -9999 -9999 -9999 -9999 -9999 -9999 -9999 -9999 -9999 -9999 -9999 -9999 -9999 -9999 -9999 -9999 -9999 -9999 -9999 -9999 -9999 -9999 -9999 -9999 -9999 -9999 -9999 -9999 -9999 -9999 -

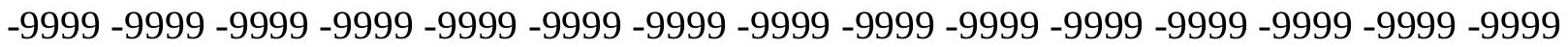

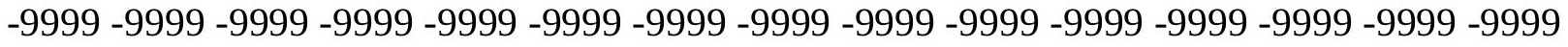

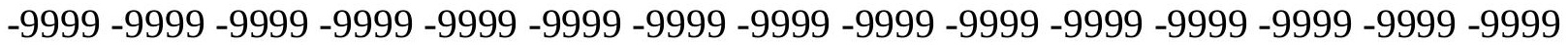
-9999 -9999 -9999 -9999 -9999 -9999 -9999 -9999 -9999 -9999 -9999 -9999 -9999 -9999 -9999

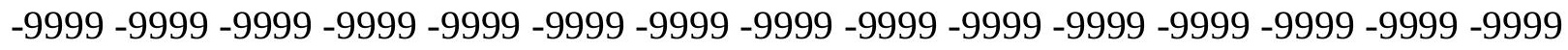

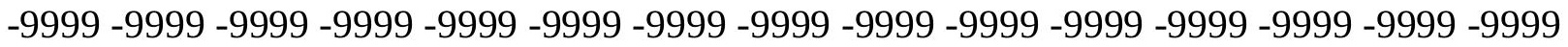
-9999 -9999 -9999 -9999 -9999 -9999 -9999 -9999 -9999 -9999 -9999 -9999 -9999 -9999 -9999 -9999 -9999 -9999 -9999 -9999 -9999 -9999 -9999 -9999 -9999 -9999 -9999 -9999 -9999 -9999 -

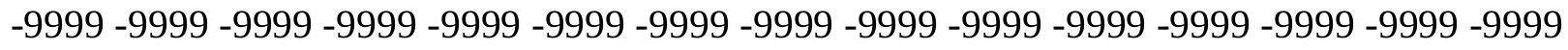

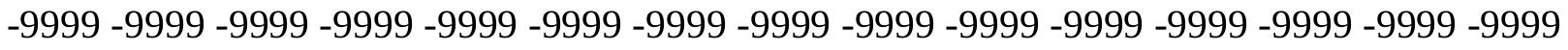
-9999 -9999 -9999 -9999 -9999 -9999 -9999 -9999 -9999 -9999 -9999 -9999 -9999 -9999 -9999 -9999 -9999 -9999 -9999 -9999 -9999 -9999 -9999 -9999-9999 -9999 -9999 -9999 -9999 -9999 -9999 -9999 -9999 -9999 -9999 -9999 -9999 -9999 -9999 -9999 -9999 -9999 -9999 -9999 -9999 -

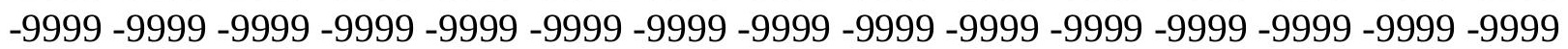


-9999 -9999 -9999 -9999 -9999 -9999 -9999 -9999 -9999 -9999 -9999 -9999 -9999 -9999 -9999 -9999 -9999 -9999 -9999 -9999 -9999 -9999 -9999 -9999 -9999 -9999 -9999 -9999 -9999 -9999 -9999 -9999 -9999 -9999 -9999 -9999 -9999 -9999 -9999 -9999 -9999 -9999 -9999 -9999 - 9999 -9999 -9999 -9999 -9999 -9999 -9999 -9999 -9999 -9999 -9999 -9999 -9999 -9999 -9999

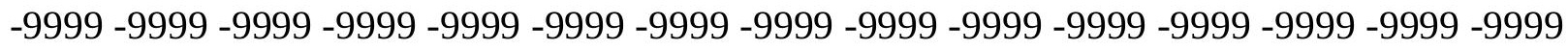
-9999 -9999 -9999 -9999 -9999 -9999 -9999 -9999 -9999 -9999 -9999 -9999 -9999 -9999 -9999 -9999 -9999 -9999 -9999 -9999 -9999 -9999 -9999 -9999 -9999 -9999 -9999 -9999 -9999 -9999

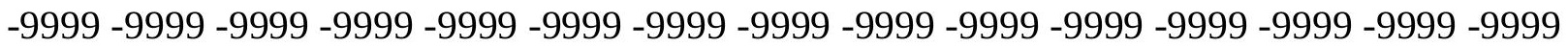

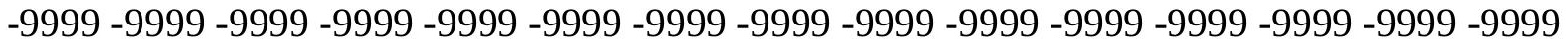
-9999 -9999 -9999 -9999 -9999 -9999 -9999 -9999 -9999 -9999 -9999 -9999 -9999 -9999 -9999 -9999 -9999 -9999 -9999 -9999 -9999 -9999 -9999 -9999 -9999 -9999 -9999 -9999 -9999 -9999 -9999 -9999 -9999 -9999 -9999 -9999 -9999 -9999 -9999 -9999 -9999 -9999 -9999 -9999 -9999 -9999 -9999 -9999 -9999 -9999 -9999 -9999 -9999 -9999 -9999 -9999 -9999 -9999 -9999 -9999 -

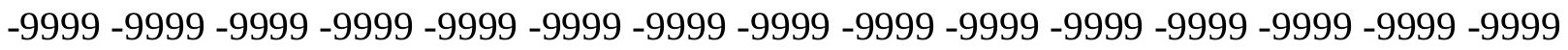
-9999 -9999 -9999 -9999 -9999 -9999 -9999 -9999 -9999 -9999 -9999 -9999 -9999 -9999 -9999 -

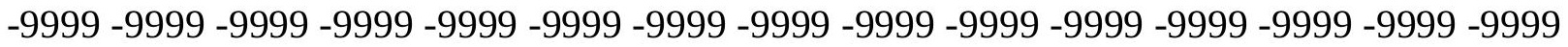
-9999 -9999 -9999 -9999 -9999 -9999 -9999 -9999 -9999 -9999 -9999 -9999 -9999 -9999 -9999 -9999 -9999 -9999 -9999 -9999 -9999 -9999 -9999 -9999 -9999 -9999 -9999 -9999 -9999 -9999 -9999 -9999 -9999 -9999 -9999 -9999 -9999 -9999 -9999 -9999 -9999 -9999 -9999 -9999 -9999 -

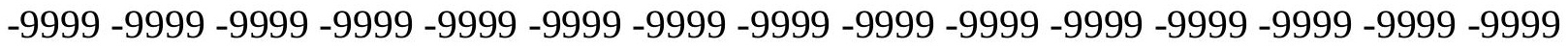
-9999 -9999 -9999 -9999 -9999 -9999 -9999 -9999 -9999 -9999 -9999 -9999 -9999 -9999 -9999

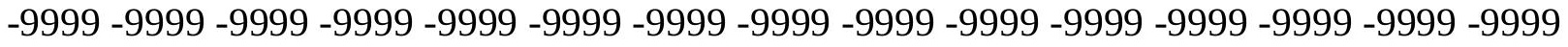
-9999 -9999 -9999 -9999 -9999 -9999 -9999 -9999 -9999 -9999 -9999 -9999 -9999 -9999 -9999 -9999 -9999 -9999 -9999 -9999 -9999 -9999 -9999 -9999 -9999 -9999 -9999 -9999 -9999 -9999 -9999 -9999 -9999 -9999 -9999 -9999 -9999 -9999 -9999 -9999 -9999 -9999 -9999 -9999 -9999 -9999 -9999 -9999 -9999 -9999 -9999 -9999 -9999 -9999 -9999 -9999 -9999 -9999 -9999 -9999 -9999 -9999 -9999 -9999 -9999 -9999 -9999 -9999 -9999 -9999 -9999 -9999 -9999 -9999 -9999 -9999 -9999 -9999 -9999 -9999 -9999 -9999 -9999 -9999 -9999 -9999 -9999 -9999 -9999 -9999 -9999 -9999 -9999 -9999 -9999 -9999 -9999 -9999 -9999 -9999 -9999 -9999 -9999 -9999 -9999 -9999 -9999 -9999 -9999 -9999 -9999 -9999 -9999 -9999 -9999 -9999 -9999 -9999 -9999 -9999 -9999 -9999 -9999 -9999 -9999 -9999 -9999 -9999 -9999 -9999 -9999 -9999 -9999 -9999 -9999 -9999 -9999 -9999 -9999 -9999 -9999 -9999 -9999 -9999 -9999 -9999 -9999 -9999 -9999 -

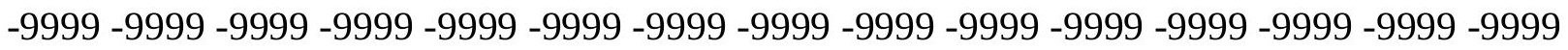

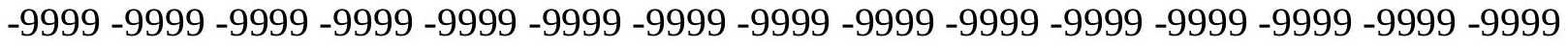
-9999 -9999 -9999 -9999 -9999 -9999 -9999 -9999 -9999 -9999 -9999 -9999 -9999 -9999 -9999 -

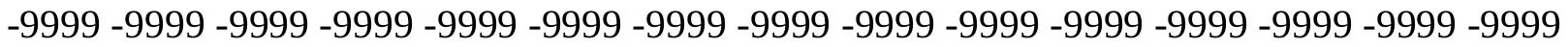

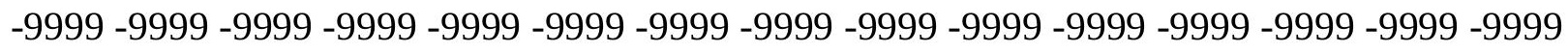

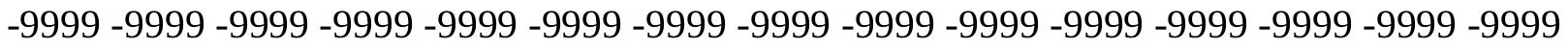

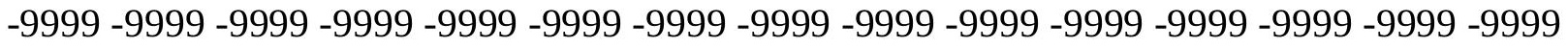
-9999 -9999 -9999 -9999 -9999 -9999 -9999 -9999 -9999 -9999 -9999 -9999 -9999 -9999 -9999 -

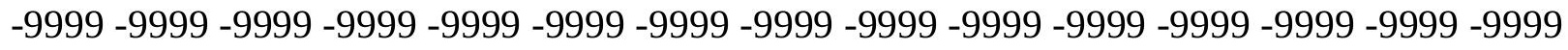

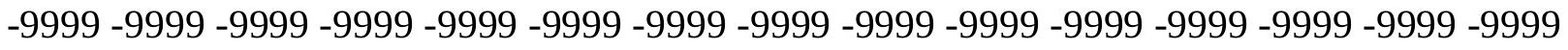
-9999 -9999 -9999 -9999 -9999 -9999 -9999 -9999 -9999 -9999 -9999 -9999 -9999 -9999 -9999 -9999 -9999 -9999 -9999 -9999 -9999 -9999 -9999 -9999-9999 -9999 -9999 -9999 -9999 -9999 -9999 -9999 -9999 -9999 -9999 -9999 -9999 -9999 -9999 -9999 -9999 -9999 -9999 -9999 -9999 -

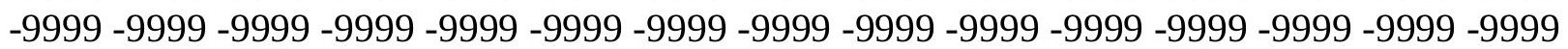


-9999 -9999 -9999 -9999 -9999 -9999 -9999 -9999 -9999 -9999 -9999 -9999 -9999 -9999 -9999 -9999 -9999 -9999 -9999 -9999 -9999 -9999 -9999 -9999 -9999 -9999 -9999 -9999 -9999 -9999 -9999 -9999 -9999 -9999 -9999 -9999 -9999 -9999 -9999 -9999 -9999 -9999 -9999 -9999 - 9999 -9999 -9999 -9999 -9999 -9999 -9999 -9999 -9999 -9999 -9999 -9999 -9999 -9999 -9999 -9999 -9999 -9999 -9999 -9999 -9999 -9999 -9999 -9999 -9999 -9999 -9999 -9999 -9999 -9999 -9999 -9999 -9999 -9999 -9999 -9999 -9999 -9999 -9999 -9999 -9999 -9999 -9999 -9999 -9999 -9999 -9999 -9999 -9999 -9999 -9999 -9999 -9999 -9999 -9999 -9999 -9999 -9999 -9999 -9999 -9999

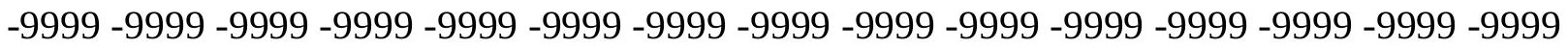

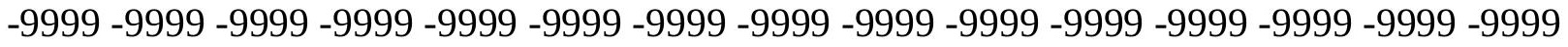
-9999 -9999 -9999 -9999 -9999 -9999 -9999 -9999 -9999 -9999 -9999 -9999 -9999 -9999 -9999 -9999 -9999 -9999 -9999 -9999 -9999 -9999 -9999 -9999 -9999 -9999 -9999 -9999 -9999 -9999 -9999 -9999 -9999 -9999 -9999 -9999 -9999 -9999 -9999 -9999 -9999 -9999 -9999 -9999 -9999 -9999 -9999 -9999 -9999 -9999 -9999 -9999 -9999 -9999 -9999 -9999 -9999 -9999 -9999 -9999 -9999 -9999 -9999 -9999 -9999 -9999 -9999 -9999 -9999 -9999 -9999 -9999 -9999 -9999 -9999 -9999 -9999 -9999 -9999 -9999 -9999 -9999 -9999 -9999 -9999 -9999 -9999 -9999 -9999 -

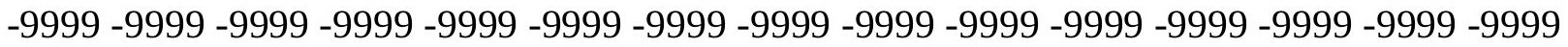
-9999 -9999 -9999 -9999 -9999 -9999 -9999 -9999 -9999 -9999 -9999 -9999 -9999 -9999 -9999 -9999 -9999 -9999 -9999 -9999 -9999 -9999 -9999 -9999 -9999 -9999 -9999 -9999 -9999 -9999 -9999 -9999 -9999 -9999 -9999 -9999 -9999 -9999 -9999 -9999 -9999 -9999 -9999 -9999 -9999 -9999 -9999 -9999 -9999 -9999 -9999 -9999 -9999 -9999 -9999 -9999 -9999 -9999 -9999 -9999 -9999 -9999 -9999 -9999 -9999 -9999 -9999 -9999 -9999 -9999 -9999 -9999 -9999 -9999 -9999 -999 -9999 -9999 -9999 -9999 -9999 -9999 -9999 -9999 -9999 -9999 -9999 -9999 -9999 -9999 -9999 -9999 -9999 -9999 -9999 -9999 -9999 -9999 -9999 -9999 -9999 -9999 -9999 -9999 -9999 -9999 -9999 -9999 -9999 -9999 -9999 -9999 -9999 -9999 -9999 -9999 -9999 -9999 -9999 -9999 -9999 -9999 -9999 -9999 -9999 -9999 -9999 -9999 -9999 -9999 -9999 -9999 -9999 -9999 -9999 -9999 -9999 -9999 -9999 -9999 -9999 -9999 -9999 -9999 -9999 -9999 -9999 -9999 -9999 -9999 -9999 -9999 -9999 -9999 -9999 -9999 -9999 -9999 -9999 -9999 -9999 -9999 -9999 -9999 -9999 -9999 -9999 -9999 -9999 -9999 -9999 -9999 -9999 -9999 -9999 -9999 -9999 -9999 -9999 -9999 -9999 -9999 -9999 -9999 -9999 -9999 -9999 -9999 -9999 -9999 -9999 -9999 -9999 -9999 -9999 -9999 -9999 -9999 -9999 -9999 -9999 -9999 -9999 -9999 -9999 -9999 -9999 -9999 -9999 -9999 -999 -9999 -9999 -9999 -9999 -9999 -9999 -9999 -9999 -9999 -9999 -9999 -9999 -9999 -9999 -9999 -9999 -9999 -9999 -9999 -9999 -9999 -9999 -9999 -9999 -9999 -9999 -9999 -9999 -9999 -9999 -

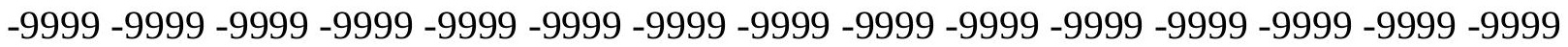

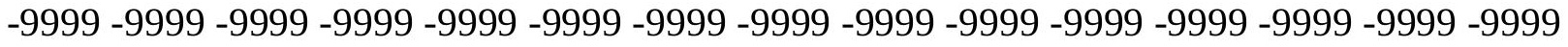

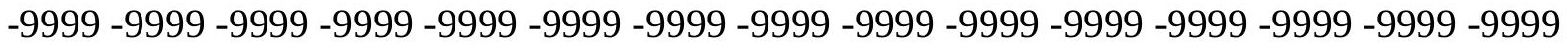
-9999 -9999 -9999 -9999 -9999 -9999 -9999 -9999 -9999 -9999 -9999 -9999 -9999 -9999 -9999 -9999 -9999 -9999 -9999 -9999 -9999 -9999 -9999 -9999 -9999 -9999 -9999 -9999 -9999 -

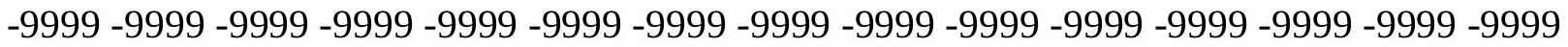
-9999 -9999 -9999 -9999 -9999 -9999 -9999 -9999 -9999 -9999 -9999 -9999 -9999 -9999 -9999 -9999 -9999 -9999 -9999 -9999 -9999 -9999 -9999 -9999 -9999 -9999 -9999 -9999 -9999 -9999 -

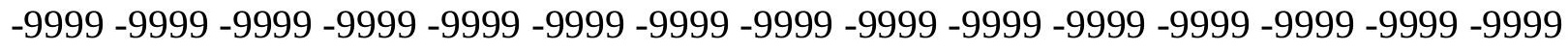

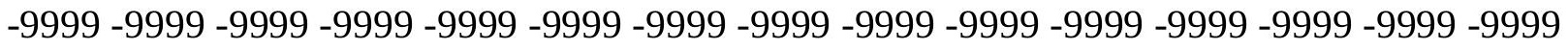
-9999 -9999 -9999 -9999 -9999 -9999 -9999 -9999 -9999 -9999 -9999 -9999 -9999 -9999 -9999 -9999 -9999 -9999 -9999 -9999 -9999 -9999 -9999 -9999-9999 -9999 -9999 -9999 -9999 -9999 -9999 -9999 -9999 -9999 -9999 -9999 -9999 -9999 -9999 -9999 -9999 -9999 -9999 -9999 -9999 -

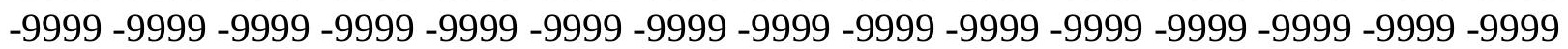


-9999 -9999 -9999 -9999 -9999 -9999 -9999 -9999 -9999 -9999 -9999 -9999 -9999 -9999 -9999 -9999 -9999 -9999 -9999 -9999 -9999 -9999 -9999 -9999 -9999 -9999 -9999 -9999 -9999 -9999 -

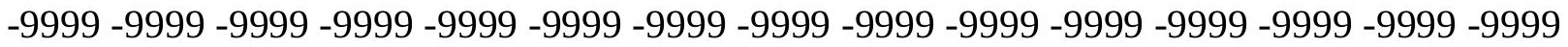
-9999 -9999 -9999 -9999 -9999 -9999 -9999 -9999 -9999 -9999 -9999 -9999 -9999 -9999 -9999 -9999 -9999 -9999 -9999 -9999 -9999 -9999 -9999 -9999-9999 -9999 -9999 -9999 -9999 -9999 -9999 -9999 -9999 -9999 -9999 -9999 -9999 -9999 -9999 -9999 -9999 -9999 -9999 -9999 -9999 -9999 -9999 -9999 -9999 -9999 -9999 -9999 -9999 -9999 -9999 -9999 -9999 -9999 -9999 -9999

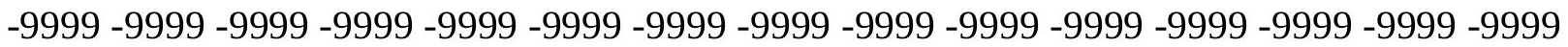

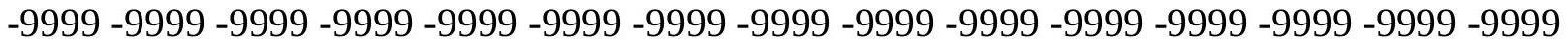
-9999 -9999 -9999 -9999 -9999 -9999 -9999 -9999 -9999 -9999 -9999 -9999 -9999 -9999 -9999 -9999 -9999 -9999 -9999 -9999 -9999 -9999 -9999 -9999 -9999 -9999 -9999 -9999 -9999 -9999 -9999 -9999 -9999 -9999 -9999 -9999 -9999 -9999 -9999 -9999 -9999 -9999 -9999 -9999 -9999 -9999 -9999 -9999 -9999 -9999 -9999 -9999 -9999 -9999 -9999 -9999 -9999 -9999 -9999 -9999 -9999 -9999 -9999 -9999 -9999 -9999 -9999 -9999 -9999 -9999 -9999 -9999 -9999 -9999 -9999 -9999 -9999 -9999 -9999 -9999 -9999 -9999 -9999 -9999 -9999 -9999 -9999 -9999 -9999 -9999 -

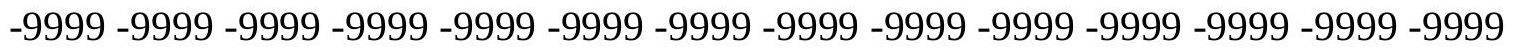
-9999 -9999 -9999 -9999 -9999 -9999 -9999 -9999 -9999 -9999 -9999 -9999 -9999 -9999 -9999 -9999 -9999 -9999 -9999 -9999 -9999 -9999 -9999 -9999 -9999 -9999 -9999 -9999 -9999 -9999 -9999 -9999 -9999 -9999 -9999 -9999 -9999 -9999 -9999 -9999 -9999 -9999 -9999 -9999 -9999 -

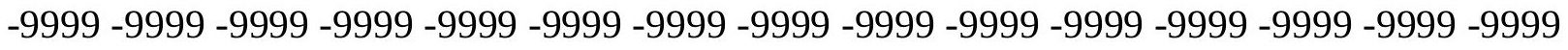

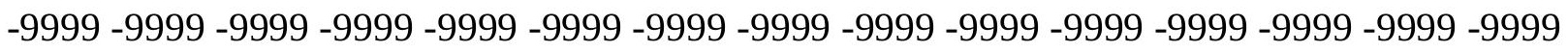
-9999 -9999 -9999 -9999 -9999 -9999 -9999 -9999 -9999 -9999 -9999 -9999 -9999 -9999 - 9999 -9999 -9999 -9999 -9999 -9999 -9999 -9999 -9999 -9999 -9999 -9999 -9999 -9999 -9999 -9999 -9999 -9999 -9999 -9999 -9999 -9999 -9999 -9999 -9999 -9999 -9999 -9999 -9999 -9999 -9999 -

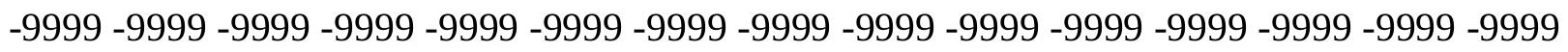
-9999 -9999 -9999 -9999 -9999 -9999 -9999 -9999 -9999 -9999 -9999 -9999 -9999 -9999 -9999 -9999 -9999 -9999 -9999 -9999 -9999 -9999 -9999 -9999 -9999 -9999 -9999 -9999 -9999 -9999 -

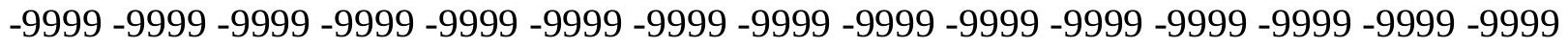
-9999 -9999 -9999 -9999 -9999 -9999 -9999 -9999 -9999 -9999 -9999 -9999 -9999 -9999 -9999 -9999 -9999 -9999 -9999 -9999 -9999 -9999 -9999 -9999 -9999 -9999 -9999 -9999 -9999 -999 -

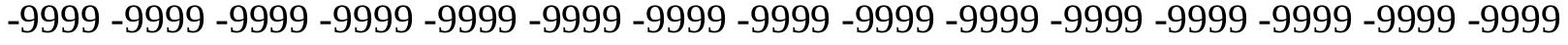
-9999 -9999 -9999 -9999 -9999 -9999 -9999 -9999 -9999 -9999 -9999 -9999 -9999 -9999 -9999 -

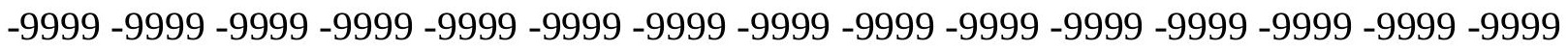

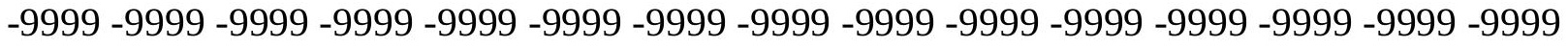

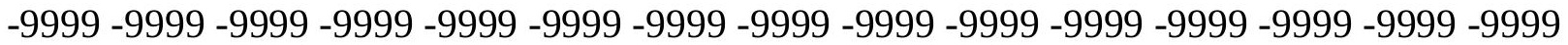
-9999 -9999 -9999 -9999 -9999 -9999 -9999 -9999 -9999 -9999 -9999 -9999 -9999 -9999 -9999 -

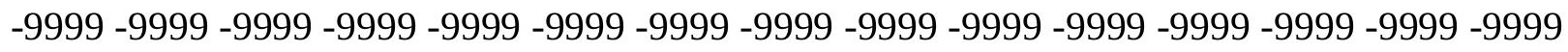

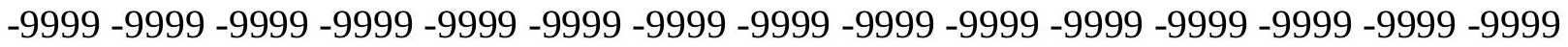
-9999 -9999 -9999 -9999 -9999 -9999 -9999 -9999 -9999 -9999 -9999 -9999 -9999 - 9999 - -999 -9999 -9999 -9999 -9999 -9999 -9999 -9999 -9999 -9999 -9999 -9999 -9999 -9999 -9999 -9999 -

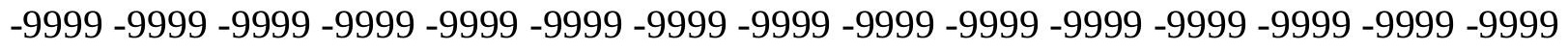

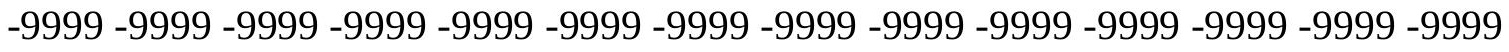
-9999 -9999 -9999 -9999 -9999 -9999 -9999 -9999 -9999 -9999 -9999 -9999 -9999 -9999 -9999 -9999 -9999 -9999 -9999 -9999 -9999 -9999 -9999 -9999-9999 -9999 -9999 -9999 -9999 -9999 -9999 -9999 -9999 -9999 -9999 -9999 -9999 -9999 -9999 -9999 -9999 -9999 -9999 -9999 -9999 -

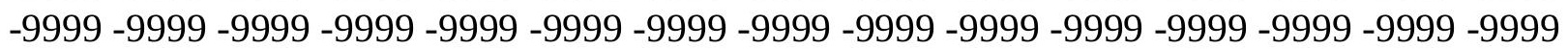


-9999 -9999 -9999 -9999 -9999 -9999 -9999 -9999 -9999 -9999 -9999 -9999 -9999 -9999 -9999 -9999 -9999 -9999 -9999 -9999 -9999 -9999 -9999 -9999 -9999 -9999 -9999 -9999 -9999 -9999 -

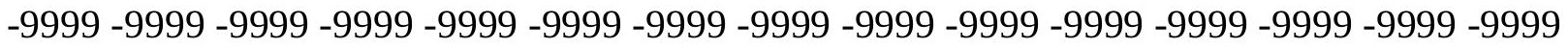
-9999 -9999 -9999 -9999 -9999 -9999 -9999 -9999 -9999 -9999 -9999 -9999 -9999 -9999 -9999 -9999 -9999 -9999 -9999 -9999 -9999 -9999 -9999 -9999-9999 -9999 -9999 -9999 -9999 -9999 -9999 -9999 -9999 -9999 -9999 -9999 -9999 -9999 -9999 -9999 -9999 -9999 -9999 -9999 -9999 -9999 -9999 -9999 -9999 -9999 -9999 -9999 -9999 -9999 -9999 -9999 -9999 -9999 -9999 -9999

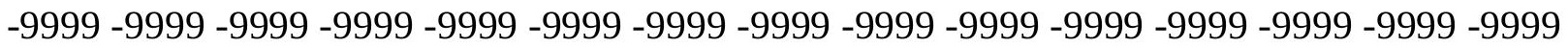

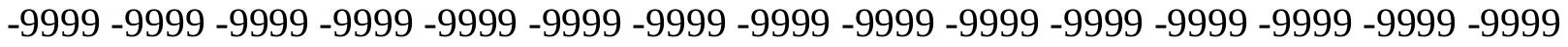
-9999 -9999 -9999 -9999 -9999 -9999 -9999 -9999 -9999 -9999 -9999 -9999 -9999 -9999 -9999 -9999 -9999 -9999 -9999 -9999 -9999 -9999 -9999 -9999 -9999 -9999 -9999 -9999 -9999 -9999 -9999 -9999 -9999 -9999 -9999 -9999 -9999 -9999 -9999 -9999 -9999 -9999 -9999 -9999 -9999 -9999 -9999 -9999 -9999 -9999 -9999 -9999 -9999 -9999 -9999 -9999 -9999 -9999 -9999 -9999 -

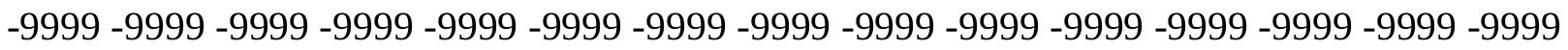
-9999 -9999 -9999 -9999 -9999 -9999 -9999 -9999 -9999 -9999 -9999 -9999 -9999 -9999 -9999 -

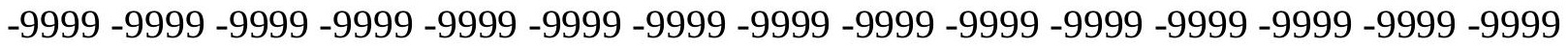
-9999 -9999 -9999 -9999 -9999 -9999 -9999 -9999 -9999 -9999 -9999 -9999 -9999 -9999 -9999 -9999 -9999 -9999 -9999 -9999 -9999 -9999 -9999 -9999 -9999 -9999 -9999 -9999 -9999 -9999 -9999 -9999 -9999 -9999 -9999 -9999 -9999 -9999 -9999 -9999 -9999 -9999 -9999 -9999 -9999 -

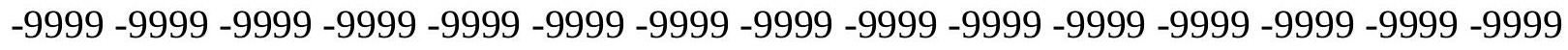

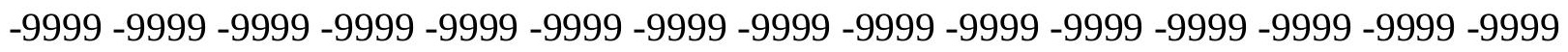
-9999 -9999 -9999 -9999 -9999 -9999 -9999 -9999 -9999 -9999 -9999 -9999 -9999 -9999 -9999 -9999 -9999 -9999 -9999 -9999 -9999 -9999 -9999 -9999 -9999 -9999 -9999 -9999 -9999 -9999 -9999 -9999 -9999 -9999 -9999 -9999 -9999 -9999 -9999 -9999 -9999 -9999 -9999 -9999 -

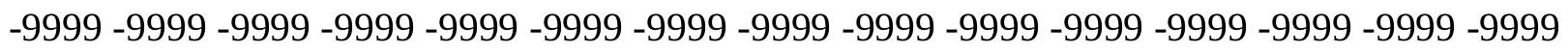
-9999 -9999 -9999 -9999 -9999 -9999 -9999 -9999 -9999 -9999 -9999 -9999 -9999 -9999 -9999 -9999 -9999 -9999 -9999 -9999 -9999 -9999 -9999 -9999 -9999 -9999 -9999 -9999 -9999 -9999 -

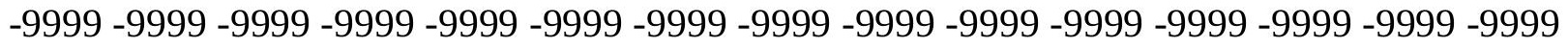
-9999 -9999 -9999 -9999 -9999 -9999 -9999 -9999 -9999 -9999 -9999 -9999 -9999 -9999 -9999 -9999 -9999 -9999 -9999 -9999 -9999 -9999 -9999 -9999 -9999 -9999 -9999 -9999 -9999 -999 -

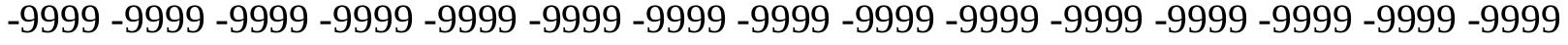
-9999 -9999 -9999 -9999 -9999 -9999 -9999 -9999 -9999 -9999 -9999 -9999 -9999 -9999 -9999 -

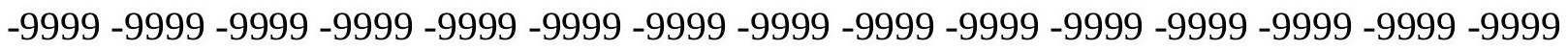

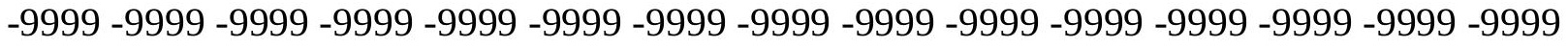

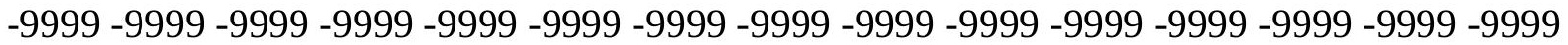

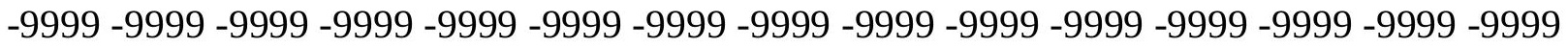

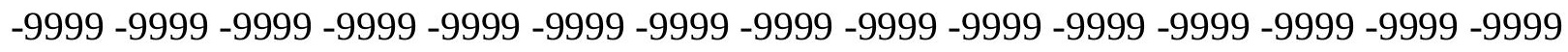

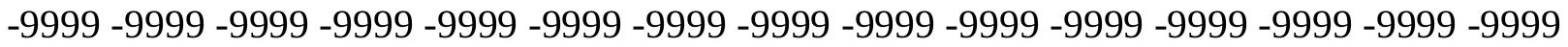

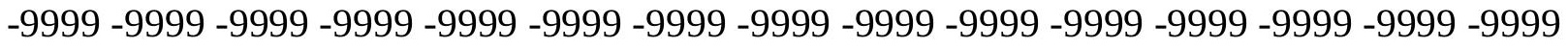
-9999 -9999 -9999 -9999 -9999 -9999 -9999 -9999 -9999 -9999 -9999 -9999 -9999 -9999 -9999 -

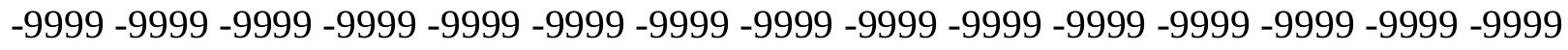

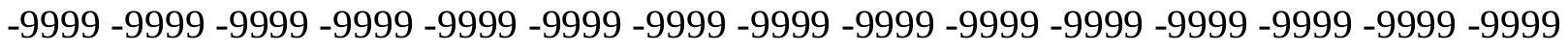
-9999 -9999 -9999 -9999 -9999 -9999 -9999 -9999 -9999 -9999 -9999 -9999 -9999 -9999 -9999 -9999 -9999 -9999 -9999 -9999 -9999 -9999 -9999 -9999-9999 -9999 -9999 -9999 -9999 -9999 -9999 -9999 -9999 -9999 -9999 -9999 -9999 -9999 -9999 -9999 -9999 -9999 -9999 -9999 -9999 -

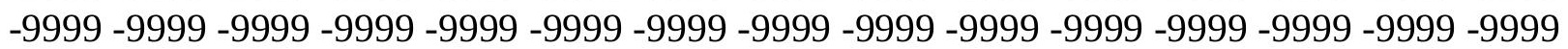


-9999 -9999 -9999 -9999 -9999 -9999 -9999 -9999 -9999 -9999 -9999 -9999 -9999 -9999 -9999 -9999 -9999 -9999 -9999 -9999 -9999 -9999 -9999 -9999 -9999 -9999 -9999 -9999 -9999 -

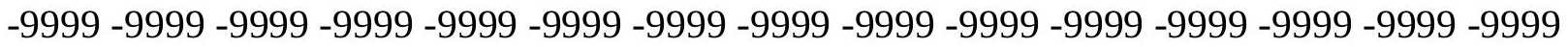
-9999 -9999 -9999 -9999 -9999 -9999 -9999 -9999 -9999 -9999 -9999 -9999 -9999 -9999 -9999 -9999 -9999 -9999 -9999 -9999 -9999 -9999 -9999 -9999 -9999 -9999 -9999 -9999 -9999 -9999 -9999 -9999 -9999 -9999 -9999 -9999 -9999 -9999 -9999 -9999 -9999 -9999 -9999 -9999 -9999 -9999 -9999 -9999 -9999 -9999 -9999 -9999 -9999 -9999 -9999 -9999 -9999 -9999 -9999 -9999

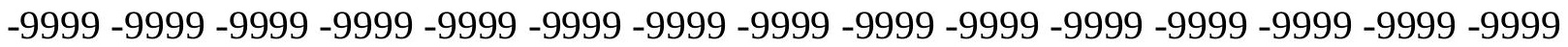

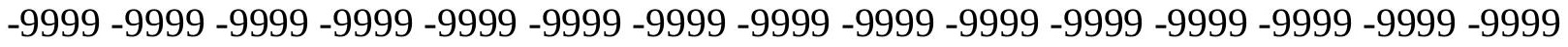
-9999 -9999 -9999 -9999 -9999 -9999 -9999 -9999 -9999 -9999 -9999 -9999 -9999 -9999 -9999 -9999 -9999 -9999 -9999 -9999 -9999 -9999 -9999 -9999 -9999 -9999 -9999 -9999 -9999 -9999 -9999 -9999 -9999 -9999 -9999 -9999 -9999 -9999 -9999 -9999 -9999 -9999 -9999 -9999 -9999 -9999 -9999 -9999 -9999 -9999 -9999 -9999 -9999 -9999 -9999 -9999 -9999 -9999 -9999 -9999 -9999 -9999 -9999 -9999 -9999 -9999 -9999 -9999 -9999 -9999 -9999 -9999 -9999 -9999 -9999 -9999 -9999 -9999 -9999 -9999 -9999 -9999 -9999 -9999 -9999 -9999 -9999 -9999 -9999 -9999 -

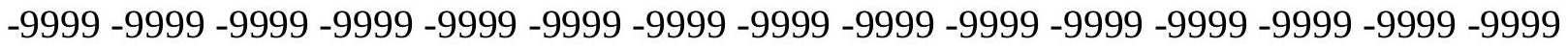
-9999 -9999 -9999 -9999 -9999 -9999 -9999 -9999 -9999 -9999 -9999 -9999 -9999 -9999 -9999 -9999 -9999 -9999 -9999 -9999 -9999 -9999 -9999 -9999 -9999 -9999 -9999 -9999 -9999 - 9999 -9999 -9999 -9999 -9999 -9999 -9999 -9999 -9999 -9999 -9999 -9999 -9999 -9999 -9999 -9999 -

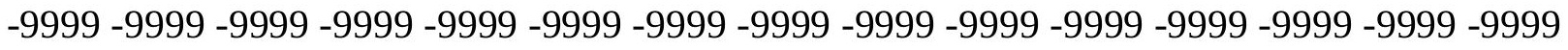

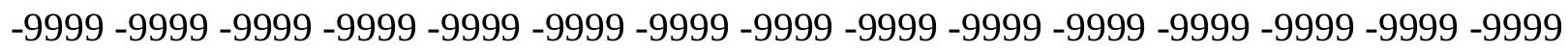

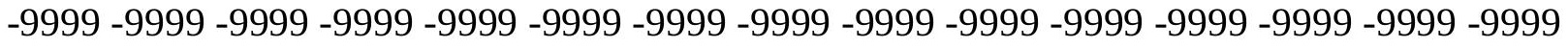
-9999 -9999 -9999 -9999 -9999 -9999 -9999 -9999 -9999 -9999 -9999 -9999 -9999 -9999 -9999 -9999 -9999 -9999 -9999 -9999 -9999 -9999 -9999 -9999 -9999 -9999 -9999 -9999 -9999 -9999 -

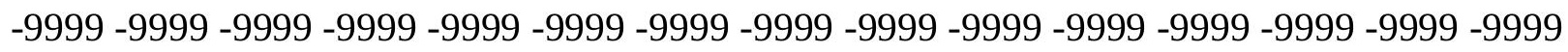
-9999 -9999 -9999 -9999 -9999 -9999 -9999 -9999 -9999 -9999 -9999 -9999 -9999 -9999 -9999 -9999 -9999 -9999 -9999 -9999 -9999 -9999 -9999 -9999 -9999 -9999 -9999 -9999 -9999 -9999 -9999 -9999 -9999 -9999 -9999 -9999 -9999 -9999 -9999 -9999 -9999 -9999 -9999 -9999 -9999 -9999 -9999 -9999 -9999 -9999 -9999 -9999 -9999 -9999 -9999 -9999 -9999 -9999 -9999 -9999 -9999 -9999 -9999 -9999 -9999 -9999 -9999 -9999 -9999 -9999 -9999 -9999 -9999 -999 -

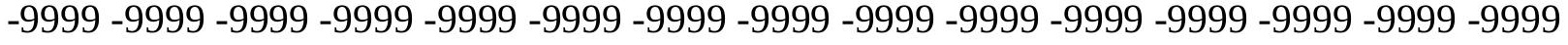
-9999 -9999 -9999 -9999 -9999 -9999 -9999 -9999 -9999 -9999 -9999 -9999 -9999 -9999 -9999 -

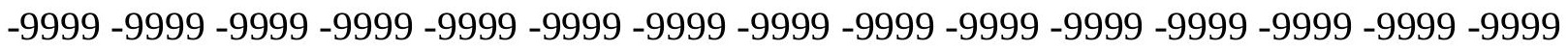

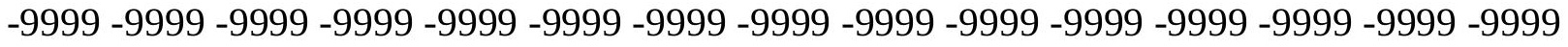

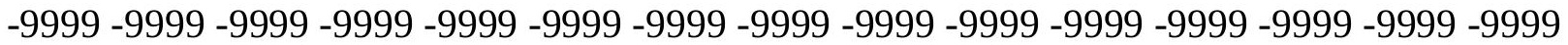

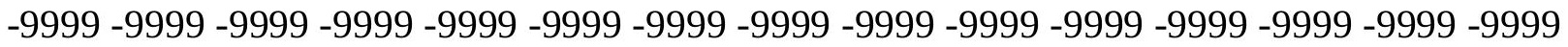

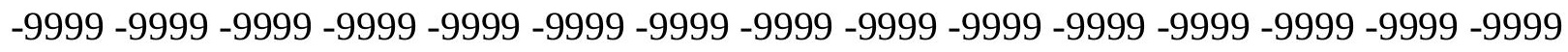

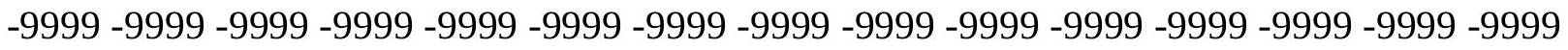

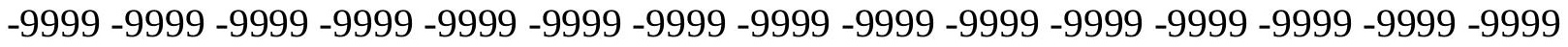
-9999 -9999 -9999 -9999 -9999 -9999 -9999 -9999 -9999 -9999 -9999 -9999 -9999 -9999 -9999 -

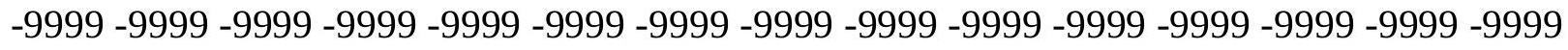

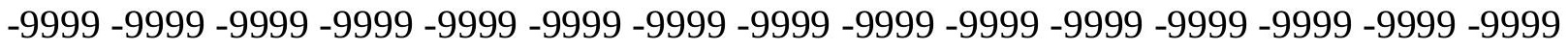
-9999 -9999 -9999 -9999 -9999 -9999 -9999 -9999 -9999 -9999 -9999 -9999 -9999 -9999 -9999 -9999 -9999 -9999 -9999 -9999 -9999 -9999 -9999 -9999-9999 -9999 -9999 -9999 -9999 -9999 -9999 -9999 -9999 -9999 -9999 -9999 -9999 -9999 -9999 -9999 -9999 -9999 -9999 -9999 -9999 -

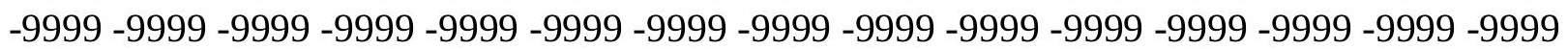


-9999 -9999 -9999 -9999 -9999 -9999 -9999 -9999 -9999 -9999 -9999 -9999 -9999 -9999 -9999 -9999 -9999 -9999 -9999 -9999 -9999 -9999 -9999 -9999 -9999 -9999 -9999 -9999 -9999 -9999 -

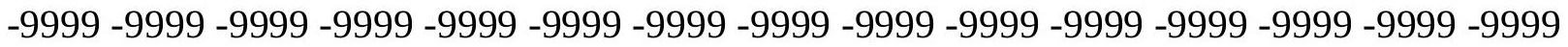
-9999 -9999 -9999 -9999 -9999 -9999 -9999 -9999 -9999 -9999 -9999 -9999 -9999 -9999 -9999 -9999 -9999 -9999 -9999 -9999 -9999 -9999 -9999 -9999-9999 -9999 -9999 -9999 -9999 -9999 -9999 -9999 -9999 -9999 -9999 -9999 -9999 -9999 -9999 -9999 -9999 -9999 -9999 -9999 -9999 -

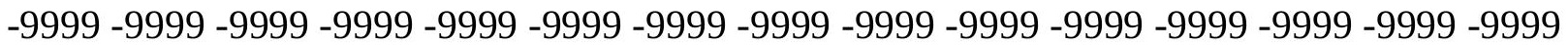
-9999 -9999 -9999 -9999 -9999 -9999 -9999 -9999 -9999 -9999 -9999 -9999 -9999 -9999 -9999 -9999 -9999 -9999 -9999 -9999 -9999 -9999 -9999 -9999 -9999 -9999 -9999 -9999 -9999 -9999 -9999 -9999 -9999 -9999 -9999 -9999 -9999 -9999 -9999 -9999 -9999 -9999 -9999 -9999 -9999 -9999 -9999 -9999 -9999 -9999 -9999 -9999 -9999 -9999 -9999 -9999 -9999 -9999 -9999 -9999 -9999 -9999 -9999 -9999 -9999 -9999 -9999 -9999 -9999 -9999 -9999 -9999 -9999 -9999 -9999 -9999 -9999 -9999 -9999 -9999 -9999 -9999 -9999 -9999 -9999 -9999 -9999 -9999 -9999 -9999 -9999 -9999 -9999 -9999 -9999 -9999 -9999 -9999 -9999 -9999 -9999 -9999 -9999 -9999 -9999 -9999 -9999 -9999 -9999 -9999 -9999 -9999 -9999 -9999 -9999 -9999 -9999 -9999 -9999 -

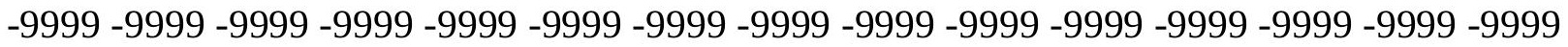
-9999 -9999 -9999 -9999 -9999 -9999 -9999 -9999 -9999 -9999 -9999 -9999 -9999 -9999 -9999 -9999 -9999 -9999 -9999 -9999 -9999 -9999 -9999 -9999 -9999 -9999 -9999 -9999 -9999 -9999 -9999 -9999 -9999 -9999 -9999 -9999 -9999 -9999 -9999 -9999 -9999 -9999 -9999 -9999 -9999 -

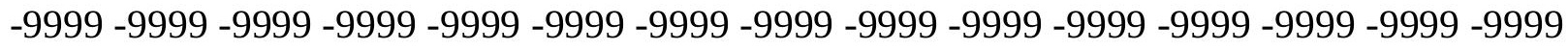

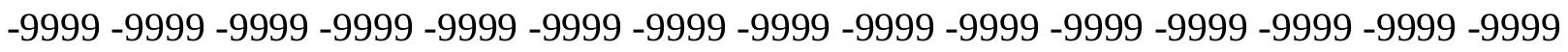
-9999 -9999 -9999 -9999 -9999 -9999 -9999 -9999 -9999 -9999 -9999 -9999 -9999 -9999 - 9999 -9999 -9999 -9999 -9999 -9999 -9999 -9999 -9999 -9999 -9999 -9999 -9999 -9999 -9999 -9999 -9999 -9999 -9999 -9999 -9999 -9999 -9999 -9999 -9999 -9999 -9999 -9999 -9999 -9999 -9999 -

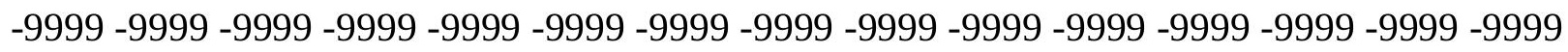
-9999 -9999 -9999 -9999 -9999 -9999 -9999 -9999 -9999 -9999 -9999 -9999 -9999 -9999 -9999 -9999 -9999 -9999 -9999 -9999 -9999 -9999 -9999 -9999 -9999 -9999 -9999 -9999 -9999 -9999 -

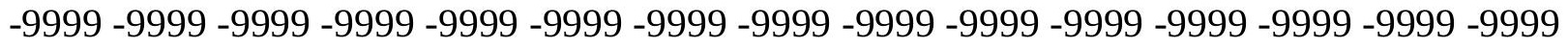
-9999 -9999 -9999 -9999 -9999 -9999 -9999 -9999 -9999 -9999 -9999 -9999 -9999 -9999 -9999 -9999 -9999 -9999 -9999 -9999 -9999 -9999 -9999 -9999 -9999 -9999 -9999 -9999 -9999 -999 -9999 -9999 -9999 -9999 -9999 -9999 -9999 -9999 -9999 -9999 -9999 -9999 -9999 -9999 -9999 -9999 -9999 -9999 -9999 -9999 -9999 -9999 -9999 -9999 -9999 -9999 -9999 -9999 -9999 -9999 -

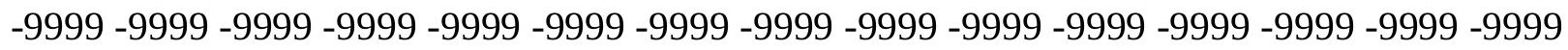

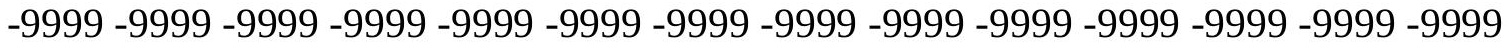
-9999 -9999 -9999 -9999 -9999 -9999 -9999 -9999 -9999 -9999 -9999 -9999 -9999 -9999 -9999

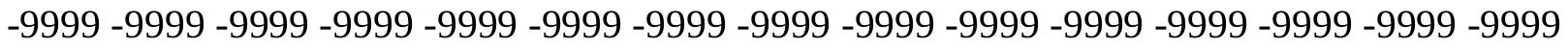

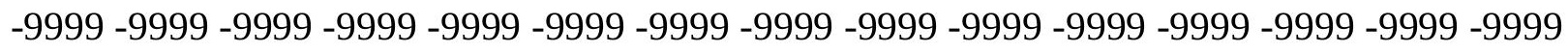

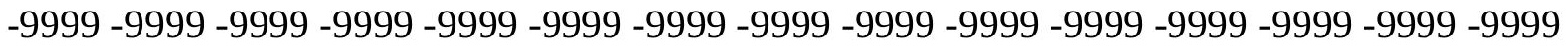

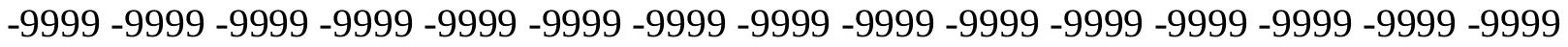
-9999 -9999 -9999 -9999 -9999 -9999 -9999 -9999 -9999 -9999 -9999 -9999 -9999 -9999 -9999 -

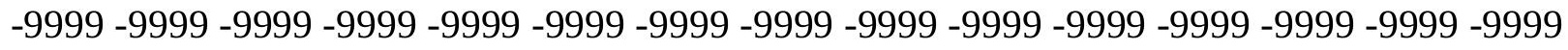

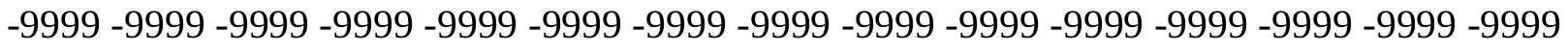
-9999 -9999 -9999 -9999 -9999 -9999 -9999 -9999 -9999 -9999 -9999 -9999 -9999 -9999 -9999 -9999 -9999 -9999 -9999 -9999 -9999 -9999 -9999 -9999-9999 -9999 -9999 -9999 -9999 -9999 -9999 -9999 -9999 -9999 -9999 -9999 -9999 -9999 -9999 -9999 -9999 -9999 -9999 -9999 -9999 -

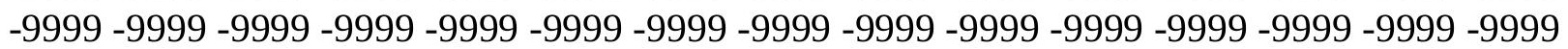


-9999 -9999 -9999 -9999 -9999 -9999 -9999 -9999 -9999 -9999 -9999 -9999 -9999 -9999 -9999 -9999 -9999 -9999 -9999 -9999 -9999 -9999 -9999 -9999 -9999 -9999 -9999 -9999 -9999 -9999 -

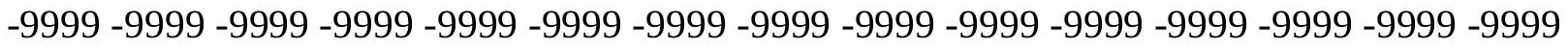
-9999 -9999 -9999 -9999 -9999 -9999 -9999 -9999 -9999 -9999 -9999 -9999 -9999 -9999 -9999 -9999 -9999 -9999 -9999 -9999 -9999 -9999 -9999 -9999-9999 -9999 -9999 -9999 -9999 -9999 -9999 -9999 -9999 -9999 -9999 -9999 -9999 -9999 -9999 -9999 -9999 -9999 -9999 -9999 -9999 -9999 -9999 -9999 -9999 -9999 -9999 -9999 -9999 -9999 -9999 -9999 -9999 -9999 -9999 -9999

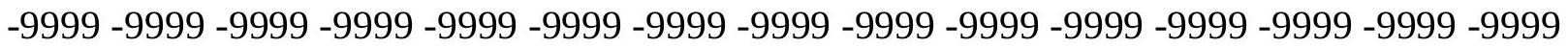

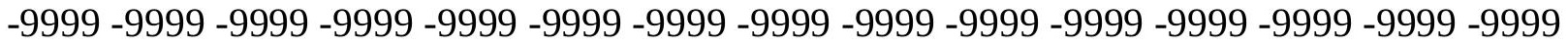
-9999 -9999 -9999 -9999 -9999 -9999 -9999 -9999 -9999 -9999 -9999 -9999 -9999 -9999 -9999 -9999 -9999 -9999 -9999 -9999 -9999 -9999 -9999 -9999 -9999 -9999 -9999 -9999 -9999 -9999 -9999 -9999 -9999 -9999 -9999 -9999 -9999 -9999 -9999 -9999 -9999 -9999 -9999 -9999 -9999 -9999 -9999 -9999 -9999 -9999 -9999 -9999 -9999 -9999 -9999 -9999 -9999 -9999 -9999 -9999 -9999 -9999 -9999 -9999 -9999 -9999 -9999 -9999 -9999 -9999 -9999 -9999 -9999 -9999 -9999 -9999 -9999 -9999 -9999 -9999 -9999 -9999 -9999 -9999 -9999 -9999 -9999 -9999 -9999

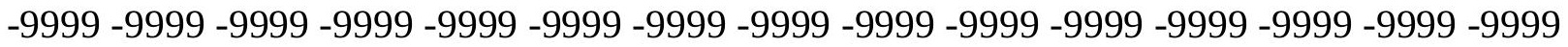
-9999 -9999 -9999 -9999 -9999 -9999 -9999 -9999 -9999 -9999 -9999 -9999 -9999 -9999 -9999 -9999 -9999 -9999 -9999 -9999 -9999 -9999 -9999 -9999 -9999 -9999 -9999 -9999 -9999 -9999 -9999 -9999 -9999 -9999 -9999 -9999 -9999 -9999 -9999 -9999 -9999 -9999 -9999 -9999 -9999 -

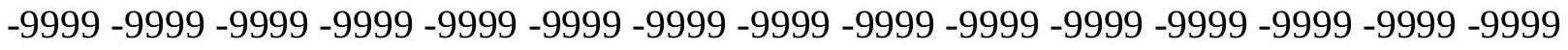

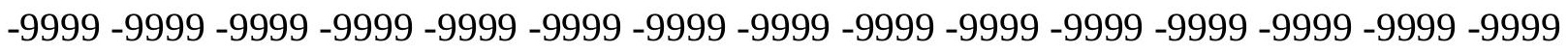
-9999 -9999 -9999 -9999 -9999 -9999 -9999 -9999 -9999 -9999 -9999 -9999 -9999 -9999 -9999 -9999 -9999 -9999 -9999 -9999 -9999 -9999 -9999 -9999 -9999 -9999 -9999 -9999 -9999 -9999 -9999 -9999 -9999 -9999 -9999 -9999 -9999 -9999 -9999 -9999 -9999 -9999 -9999 -9999 -9999 -

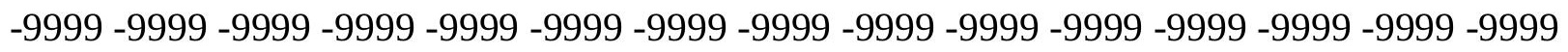
-9999 -9999 -9999 -9999 -9999 -9999 -9999 -9999 -9999 -9999 -9999 -9999 -9999 -9999 -9999 -9999 -9999 -9999 -9999 -9999 -9999 -9999 -9999 -9999 -9999 -9999 -9999 -9999 -9999 -9999 -

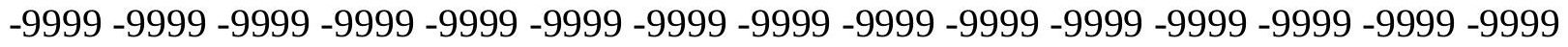
-9999 -9999 -9999 -9999 -9999 -9999 -9999 -9999 -9999 -9999 -9999 -9999 -9999 -9999 -9999 -9999 -9999 -9999 -9999 -9999 -9999 -9999 -9999 -9999 -9999 -9999 -9999 -9999 -9999 -999 -9999 -9999 -9999 -9999 -9999 -9999 -9999 -9999 -9999 -9999 -9999 -9999 -9999 -9999 -9999 -9999 -9999 -9999 -9999 -9999 -9999 -9999 -9999 -9999 -9999 -9999 -9999 -9999 -9999 -9999 -

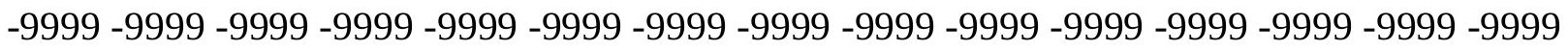

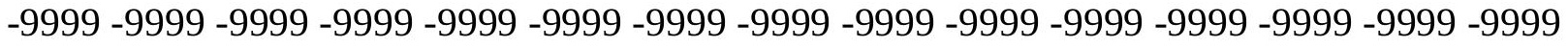

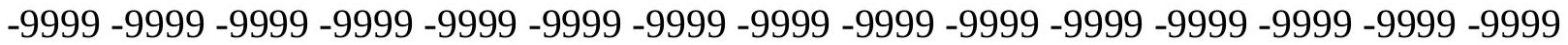

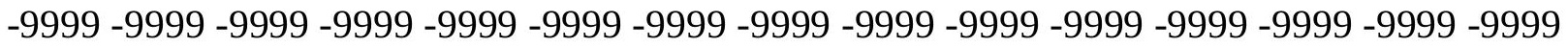

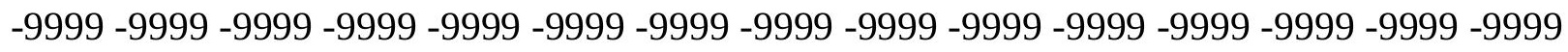

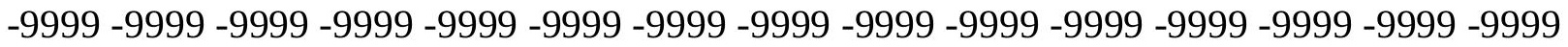
-9999 -9999 -9999 -9999 -9999 -9999 -9999 -9999 -9999 -9999 -9999 -9999 -9999 - 9999 - -999 -9999 -9999 -9999 -9999 -9999 -9999 -9999 -9999 -9999 -9999 -9999 -9999 -9999 -9999 - -999 -

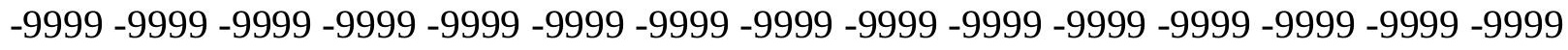

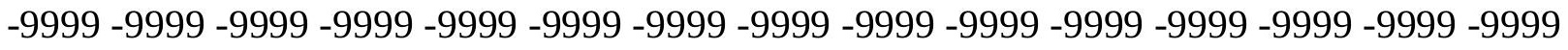
-9999 -9999 -9999 -9999 -9999 -9999 -9999 -9999 -9999 -9999 -9999 -9999 -9999 -9999 -9999 -9999 -9999 -9999 -9999 -9999 -9999 -9999 -9999 -9999-9999 -9999 -9999 -9999 -9999 -9999 -9999 -9999 -9999 -9999 -9999 -9999 -9999 -9999 -9999 -9999 -9999 -9999 -9999 -9999 -9999 -

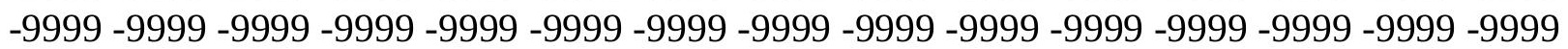


-9999 -9999 -9999 -9999 -9999 -9999 -9999 -9999 -9999 -9999 -9999 -9999 -9999 -9999 -9999 -9999 -9999 -9999 -9999 -9999 -9999 -9999 -9999 -9999 -9999 -9999 -9999 -9999 -9999 -9999 -9999 -9999 -9999 -9999 -9999 -9999 -9999 -9999 -9999 -9999 -9999 -9999 -9999 -9999 -9999 -9999 -9999 -9999 -9999 -9999 -9999 -9999 -9999 -9999 -9999 -9999 -9999 -9999 -9999 -9999 -9999 -9999 -9999 -9999 -9999 -9999 -9999 -9999 -9999 -9999 -9999 -9999 -9999 -9999 -9999 -9999 -9999 -9999 -9999 -9999 -9999 -9999 -9999 -9999 -9999 -9999 -9999 -9999 -9999 -9999 -9999 -9999 -9999 -9999 -9999 -9999 -9999 -9999 -9999 -9999 -9999 -9999 -9999 -9999 -9999 -

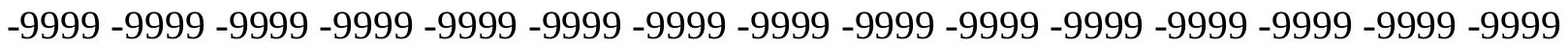
-9999 -9999 -9999 -9999 -9999 -9999 -9999 -9999 -9999 -9999 -9999 -9999 -9999 -9999 -9999 -9999 -9999 -9999 -9999 -9999 -9999 -9999 -9999 -9999 -9999 -9999 -9999 -9999 -9999 -9999 -

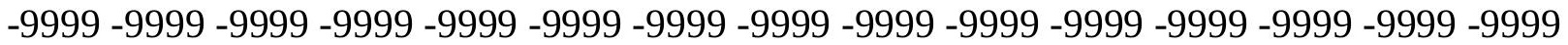
-9999 -9999 -9999 -9999 -9999 -9999 -9999 -9999 -9999 -9999 -9999 -9999 -9999 -9999 -9999 -9999 -9999 -9999 -9999 -9999 -9999 -9999 -9999 -9999 -9999 -9999 -9999 -9999 -9999 -9999 -9999 -9999 -9999 -9999 -9999 -9999 -9999 -9999 -9999 -9999 -9999 -9999 -9999 -9999 -9999 -9999 -9999 -9999 -9999 -9999 -9999 -9999 -9999 -9999 -9999 -9999 -9999 -9999 -9999 -9999

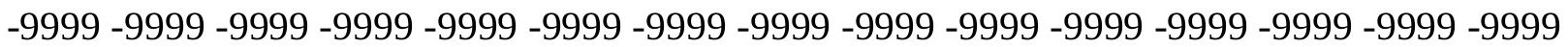
-9999 -9999 -9999 -9999 -9999 -9999 -9999 -9999 -9999 -9999 -9999 -9999 -9999 -9999 -9999 -9999 -9999 -9999 -9999 -9999 -9999 -9999 -9999 -9999 -9999 -9999 -9999 -9999 -9999 -9999 -9999 -9999 -9999 -9999 -9999 -9999 -9999 -9999 -9999 -9999 -9999 -9999 -9999 -9999 -9999 -9999 -9999 -9999 -9999 -9999 -9999 -9999 -9999 -9999 -9999 -9999 -9999 -9999 -9999 -9999 -9999 -9999 -9999 -9999 -9999 -9999 -9999 -9999 -9999 -9999 -9999 -9999 -9999 -9999 -9999 -9999 -9999 -9999 -9999 -9999 -9999 -9999 -9999 -9999 -9999 -9999 -9999 -9999 -9999 -9999 -9999 -9999 -9999 -9999 -9999 -9999 -9999 -9999 -9999 -9999 -9999 -9999 -9999 -9999 -9999 -9999 -9999 -9999 -9999 -9999 -9999 -9999 -9999 -9999 -9999 -9999 -9999 -9999 -9999 -9999 -9999 -9999 -9999 -9999 -9999 -9999 -9999 -9999 -9999 -9999 -9999 -9999 -9999 -9999 -9999 -9999 -9999 -9999 -9999 -9999 -9999 -9999 -9999 -9999 -9999 -9999 -9999 -9999 -9999 -9999 -9999 -9999 -9999 -9999 -9999 -9999 -9999 -9999 -9999 -9999 -9999 -9999 -9999 -9999 -9999 -9999 -9999 -9999 -9999 -9999 -9999 -9999 -9999 -9999 -9999 -9999 -9999 -9999 -9999

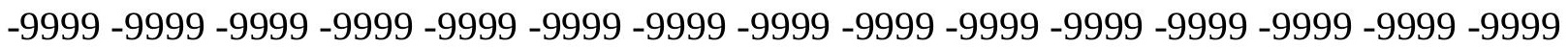
-9999 -9999 -9999 -9999 -9999 -9999 -9999 -9999 -9999 -9999 -9999 -9999 -9999 -9999 -9999 -9999 -9999 -9999 -9999 -9999 -9999 -9999 -9999 -9999 -9999 -9999 -9999 -9999 -9999 -9999 -

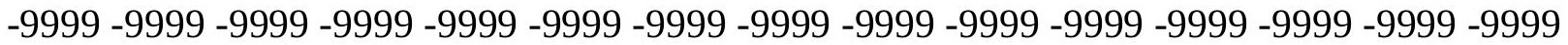
-9999 -9999 -9999 -9999 -9999 -9999 -9999 -9999 -9999 -9999 -9999 -9999 -9999 -9999 -9999 -9999 -9999 -9999 -9999 -9999 -9999 -9999 -9999 -9999 -9999 -9999 -9999 -9999 -9999 -9999 -9999 -9999 -9999 -9999 -9999 -9999 -9999 -9999 -9999 -9999 -9999 -9999 -9999 -9999 -9999 -9999 -9999 -9999 -9999 -9999 -9999 -9999 -9999 -9999 -9999 -9999 -9999 -9999 -9999 -9999 -9999 -9999 -9999 -9999 -9999 -9999 -9999 -9999 -9999 -9999 -9999 -9999 -9999 -9999 -9999

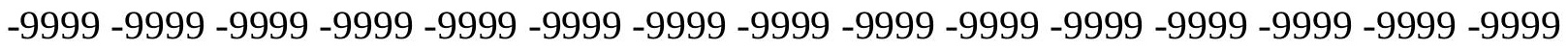
-9999 -9999 -9999 -9999 -9999 -9999 -9999 -9999 -9999 -9999 -9999 -9999 -9999 -9999 -9999 -9999 -9999 -9999 -9999 -9999 -9999 -9999 -9999 -9999 -9999 -9999 -9999 -9999 -9999 -9999 -9999 -9999 -9999 -9999 -9999 -9999 -9999 -9999 -9999 -9999 -9999 -9999 -9999 -9999 -9999 -999 -9999 -9999 -9999 -9999 -9999 -9999 -9999 -9999 -9999 -9999 -9999 -9999 -9999 -9999 -9999 -9999 -9999 -9999 -9999 -9999 -9999 -9999 -9999 -9999 -9999 -9999 -9999 -9999 -9999 -9999 -9999 -9999 -9999 -9999 -9999 -9999 -9999 -9999 -9999 -9999 -9999 -9999 -9999 -9999 -9999 -9999 -9999 -9999 -9999 -9999 -9999 -9999 -9999 -9999 -9999 -9999 -9999 -9999 -9999 -9999 -9999 -9999 -9999 -9999 -9999 -9999 -9999 -9999 -9999 -9999 -9999 -9999 -9999 -9999 
-9999 -9999 -9999 -9999 -9999 -9999 -9999 -9999 -9999 -9999 -9999 -9999 -9999 -9999 -9999 -9999 -9999 -9999 -9999 -9999 -9999 -9999 -9999 -9999 -9999 -9999 -9999 -9999 -9999 -9999 -

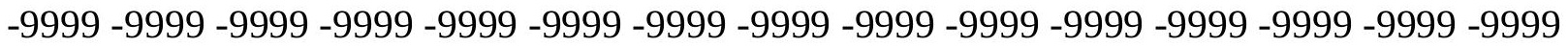
-9999 -9999 -9999 -9999 -9999 -9999 -9999 -9999 -9999 -9999 -9999 -9999 -9999 -9999 -9999 -9999 -9999 -9999 -9999 -9999 -9999 -9999 -9999 -9999-9999 -9999 -9999 -9999 -9999 -9999 -9999 -9999 -9999 -9999 -9999 -9999 -9999 -9999 -9999 -9999 -9999 -9999 -9999 -9999 -9999 -9999 -9999 -9999 -9999 -9999 -9999 -9999 -9999 -9999 -9999 -9999 -9999 -9999 -9999 -9999

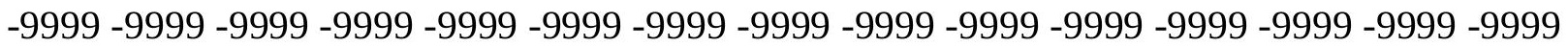

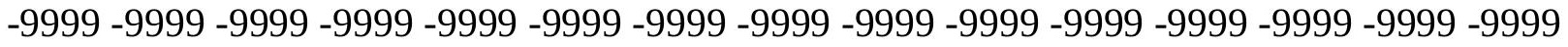
-9999 -9999 -9999 -9999 -9999 -9999 -9999 -9999 -9999 -9999 -9999 -9999 -9999 -9999 -9999 -9999 -9999 -9999 -9999 -9999 -9999 -9999 -9999 -9999 -9999 -9999 -9999 -9999 -9999 -9999 -9999 -9999 -9999 -9999 -9999 -9999 -9999 -9999 -9999 -9999 -9999 -9999 -9999 -9999 -9999 -9999 -9999 -9999 -9999 -9999 -9999 -9999 -9999 -9999 -9999 -9999 -9999 -9999 -9999 -9999 -

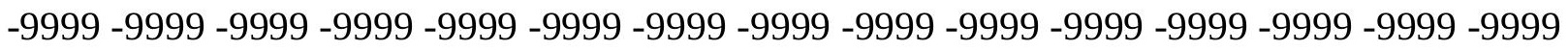
-9999 -9999 -9999 -9999 -9999 -9999 -9999 -9999 -9999 -9999 -9999 -9999 -9999 -9999 -9999 -

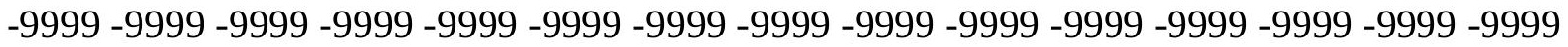
-9999 -9999 -9999 -9999 -9999 -9999 -9999 -9999 -9999 -9999 -9999 -9999 -9999 -9999 -9999 -9999 -9999 -9999 -9999 -9999 -9999 -9999 -9999 -9999 -9999 -9999 -9999 -9999 -9999 -9999 -9999 -9999 -9999 -9999 -9999 -9999 -9999 -9999 -9999 -9999 -9999 -9999 -9999 -9999 -9999 -

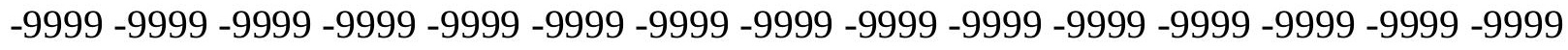

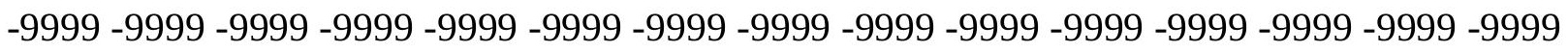

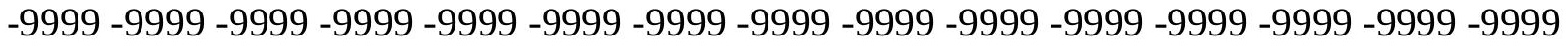
-9999 -9999 -9999 -9999 -9999 -9999 -9999 -9999 -9999 -9999 -9999 -9999 -9999 -9999 -9999 -9999 -9999 -9999 -9999 -9999 -9999 -9999 -9999 -9999 -9999 -9999 -9999 -9999 -9999 -9999 -

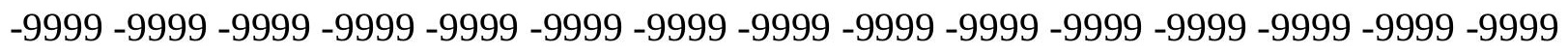
-9999 -9999 -9999 -9999 -9999 -9999 -9999 -9999 -9999 -9999 -9999 -9999 -9999 -9999 -9999 -9999 -9999 -9999 -9999 -9999 -9999 -9999 -9999 -9999 -9999 -9999 -9999 -9999 -9999 -

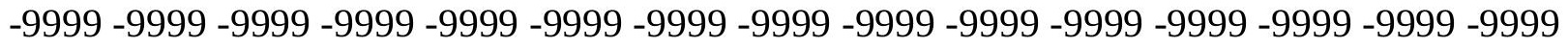
-9999 -9999 -9999 -9999 -9999 -9999 -9999 -9999 -9999 -9999 -9999 -9999 -9999 -9999 -9999 -9999 -9999 -9999 -9999 -9999 -9999 -9999 -9999 -9999 -9999 -9999 -9999 -9999 -9999 -999 -

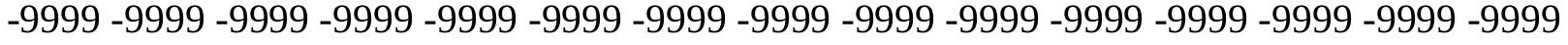
-9999 -9999 -9999 -9999 -9999 -9999 -9999 -9999 -9999 -9999 -9999 -9999 -9999 -9999 -9999 -

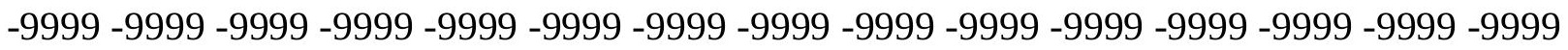

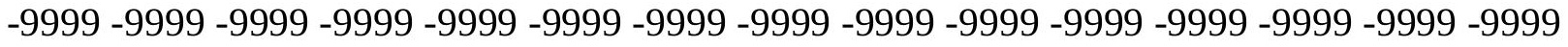

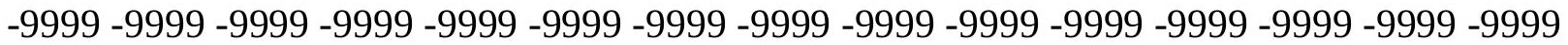
-9999 -9999 -9999 -9999 -9999 -9999 -9999 -9999 -9999 -9999 -9999 -9999 -9999 -9999 -9999

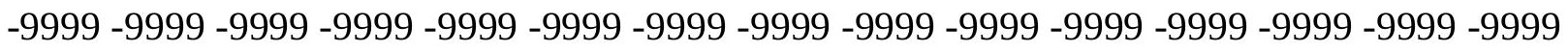

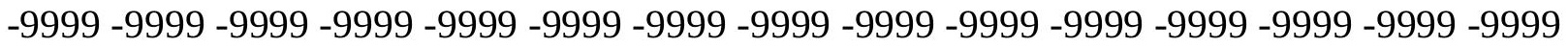
-9999 -9999 -9999 -9999 -9999 -9999 -9999 -9999 -9999 -9999 -9999 -9999 -9999 - 9999 - -999 -9999 -9999 -9999 -9999 -9999 -9999 -9999 -9999 -9999 -9999 -9999 -9999 -9999 -9999 -9999 -

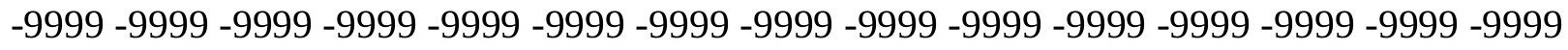

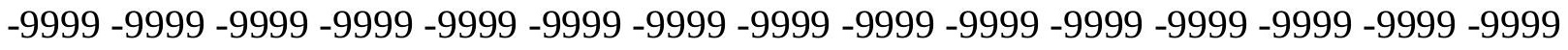
-9999 -9999 -9999 -9999 -9999 -9999 -9999 -9999 -9999 -9999 -9999 -9999 -9999 -9999 -9999 -9999 -9999 -9999 -9999 -9999 -9999 -9999 -9999 -9999-9999 -9999 -9999 -9999 -9999 -9999 -9999 -9999 -9999 -9999 -9999 -9999 -9999 -9999 -9999 -9999 -9999 -9999 -9999 -9999 -9999 -

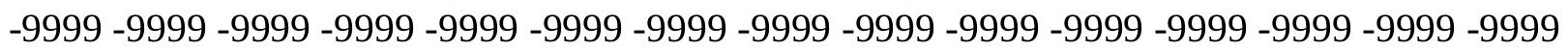


-9999 -9999 -9999 -9999 -9999 -9999 -9999 -9999 -9999 -9999 -9999 -9999 -9999 -9999 -9999 -9999 -9999 -9999 -9999 -9999 -9999 -9999 -9999 -9999 -9999 -9999 -9999 -9999 -9999 -9999 -9999 -9999 -9999 -9999 -9999 -9999 -9999 -9999 -9999 -9999 -9999 -9999 -9999 -9999 - 9999 -9999 -9999 -9999 -9999 -9999 -9999 -9999 -9999 -9999 -9999 -9999 -9999 -9999 -9999 -9999 -9999 -9999 -9999 -9999 -9999 -9999 -9999 -9999 -9999 -9999 -9999 -9999 -9999 -9999 - -9999 -9999 -9999 -9999 -9999 -9999 -9999 -9999 -9999 -9999 -9999 -9999 -9999 -9999 -9999 -9999 -9999 -9999 -9999 -9999 -9999 -9999 -9999 -9999 -9999 -9999 -9999 -9999 -9999 -9999

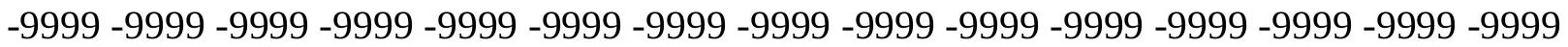

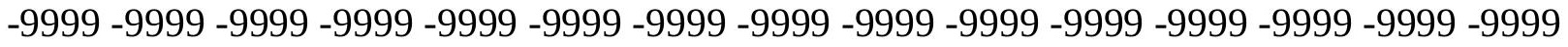
-9999 -9999 -9999 -9999 -9999 -9999 -9999 -9999 -9999 -9999 -9999 -9999 -9999 -9999 -9999

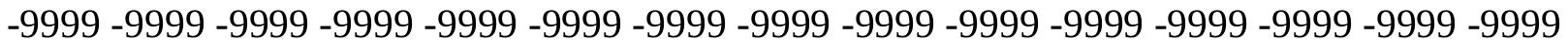
-9999 -9999 -9999 -9999 -9999 -9999 -9999 -9999 -9999 -9999 -9999 -9999 -9999 -9999 -9999 -9999 -9999 -9999 -9999 -9999 -9999 -9999 -9999 -9999 -9999 -9999 -9999 -9999 -9999 -9999 -9999 -9999 -9999 -9999 -9999 -9999 -9999 -9999 -9999 -9999 -9999 -9999 -9999 -9999 - -9999 -9999 -9999 -9999 -9999 -9999 -9999 -9999 -9999 -9999 -9999 -9999 -9999 -9999 -9999 -9999

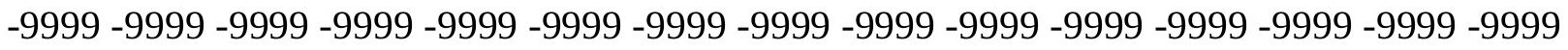
-9999 -9999 -9999 -9999 -9999 -9999 -9999 -9999 -9999 -9999 -9999 -9999 -9999 -9999 -9999 -9999 -9999 -9999 -9999 -9999 -9999 -9999 -9999 -9999 -9999 -9999 -9999 -9999 -9999 -9999 -9999 -9999 -9999 -9999 -9999 -9999 -9999 -9999 -9999 -9999 -9999 -9999 -9999 -9999 -9999 -

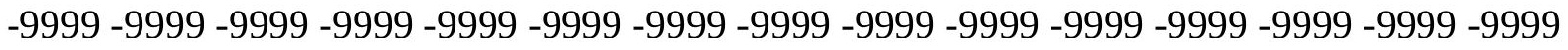
-9999 -9999 -9999 -9999 -9999 -9999 -9999 -9999 -9999 -9999 -9999 -9999 -9999 -9999 -9999 -999 -9999 -9999 -9999 -9999 -9999 -9999 -9999 -9999 -9999 -9999 -9999 -9999 -9999 -9999 -9999 -9999 -9999 -9999 -9999 -9999 -9999 -9999 -9999 -9999 -9999 -9999 -9999 -9999 -9999 -9999 -9999 -9999 -9999 -9999 -9999 -9999 -9999 -9999 -9999 -9999 -9999 -9999 -9999 -9999 -9999 -9999 -9999 -9999 -9999 -9999 -9999 -9999 -9999 -9999 -9999 -9999 -9999 -9999 -9999 -9999 -9999 -9999 -9999 -9999 -9999 -9999 -9999 -9999 -9999 -9999 -9999 -9999 -9999 -9999 -9999 -9999 -9999 -9999 -9999 -9999 -9999 -9999 -9999 -9999 -9999 -9999 -9999 -9999 -9999 -9999 -9999 -9999 -9999 -9999 -9999 -9999 -9999 -9999 -9999 -9999 -9999 -9999 -9999 -9999 -9999 -9999 -9999 -9999 -9999 -9999 -9999 -9999 -9999 -9999 -9999 -9999 -9999 -9999 -9999 -9999 -9999 -9999 -9999 -9999 -9999 -9999 -9999 -9999 -9999 -9999 -9999 -9999 -9999 -9999 -999 -9999 -9999 -9999 -9999 -9999 -9999 -9999 -9999 -9999 -9999 -9999 -9999 -9999 -9999 -9999 -9999 -9999 -9999 -9999 -9999 -9999 -9999 -9999 -9999 -9999 -9999 -9999 -9999 -9999 -

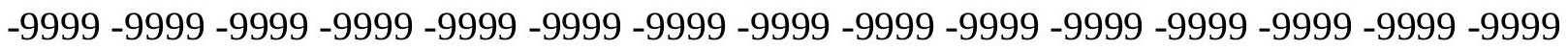

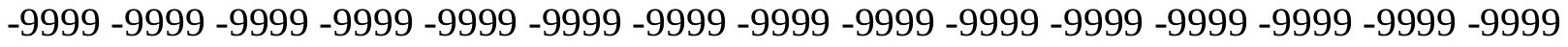

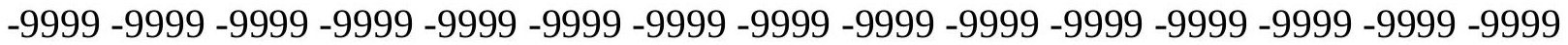
-9999 -9999 -9999 -9999 -9999 -9999 -9999 -9999 -9999 -9999 -9999 -9999 -9999 -9999 -9999 -

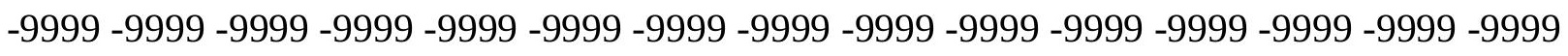

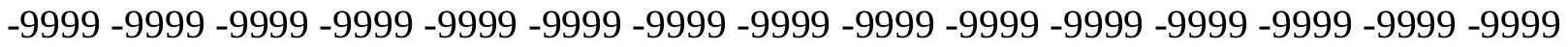

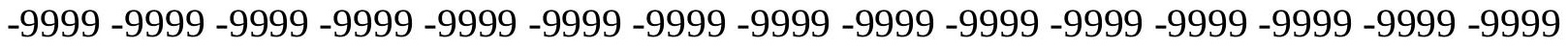
-9999 -9999 -9999 -9999 -9999 -9999 -9999 -9999 -9999 -9999 -9999 -9999 -9999 -9999 -9999 -

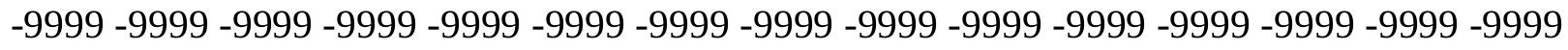

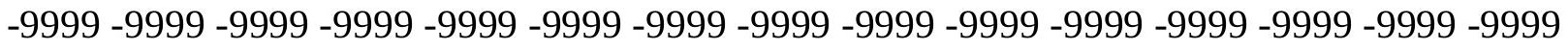
-9999 -9999 -9999 -9999 -9999 -9999 -9999 -9999 -9999 -9999 -9999 -9999 -9999 -9999 -9999 -9999 -9999 -9999 -9999 -9999 -9999 -9999 -9999 -9999-9999 -9999 -9999 -9999 -9999 -9999 -9999 -9999 -9999 -9999 -9999 -9999 -9999 -9999 -9999 -9999 -9999 -9999 -9999 -9999 -9999 -

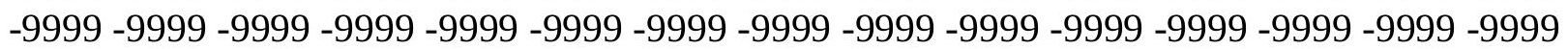


-9999 -9999 -9999 -9999 -9999 -9999 -9999 -9999 -9999 -9999 -9999 -9999 -9999 -9999 -9999 -9999 -9999 -9999 -9999 -9999 -9999 -9999 -9999 -9999 -9999 -9999 -9999 -9999 -9999 -9999 -

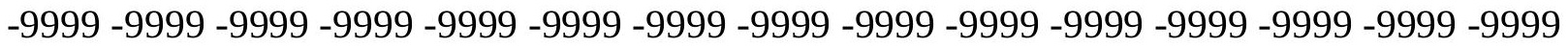
-9999 -9999 -9999 -9999 -9999 -9999 -9999 -9999 -9999 -9999 -9999 -9999 -9999 -9999 -9999 -9999 -9999 -9999 -9999 -9999 -9999 -9999 -9999 -9999-9999 -9999 -9999 -9999 -9999 -9999 -9999 -9999 -9999 -9999 -9999 -9999 -9999 -9999 -9999 -9999 -9999 -9999 -9999 -9999 -9999 -9999 -9999 -9999 -9999 -9999 -9999 -9999 -9999 -9999 -9999 -9999 -9999 -9999 -9999 -9999

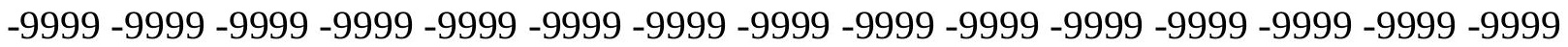

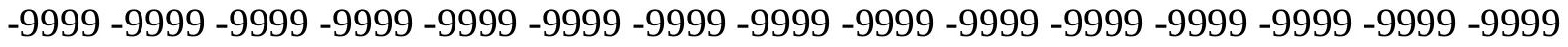
-9999 -9999 -9999 -9999 -9999 -9999 -9999 -9999 -9999 -9999 -9999 -9999 -9999 -9999 -9999 -9999 -9999 -9999 -9999 -9999 -9999 -9999 -9999 -9999 -9999 -9999 -9999 -9999 -9999 -9999 -9999 -9999 -9999 -9999 -9999 -9999 -9999 -9999 -9999 -9999 -9999 -9999 -9999 -9999 -9999 -9999 -9999 -9999 -9999 -9999 -9999 -9999 -9999 -9999 -9999 -9999 -9999 -9999 -9999 -9999 -9999 -9999 -9999 -9999 -9999 -9999 -9999 -9999 -9999 -9999 -9999 -9999 -9999 - 9999 -9999 -9999 -9999 -9999 -9999 -9999 -9999 -9999 -9999 -9999 -9999 -9999 -9999 -9999 -9999

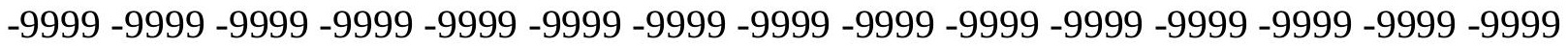
-9999 -9999 -9999 -9999 -9999 -9999 -9999 -9999 -9999 -9999 -9999 -9999 -9999 -9999 -9999 -9999 -9999 -9999 -9999 -9999 -9999 -9999 -9999 -9999 -9999 -9999 -9999 -9999 -9999 -9999 -9999 -9999 -9999 -9999 -9999 -9999 -9999 -9999 -9999 -9999 -9999 -9999 -9999 -9999 -9999 -

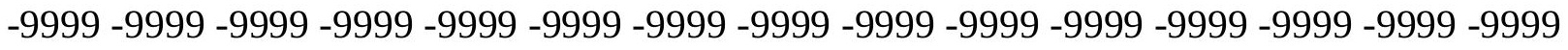

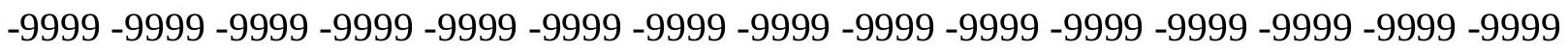
-9999 -9999 -9999 -9999 -9999 -9999 -9999 -9999 -9999 -9999 -9999 -9999 -9999 -9999 -9999 -9999 -9999 -9999 -9999 -9999 -9999 -9999 -9999 -9999 -9999 -9999 -9999 -9999 -9999 -9999 -9999 -9999 -9999 -9999 -9999 -9999 -9999 -9999 -9999 -9999 -9999 -9999 -9999 -9999 -9999 -

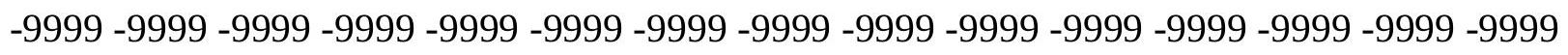
-9999 -9999 -9999 -9999 -9999 -9999 -9999 -9999 -9999 -9999 -9999 -9999 -9999 -9999 -9999 -9999 -9999 -9999 -9999 -9999 -9999 -9999 -9999 -9999 -9999 -9999 -9999 -9999 -9999 -9999 -

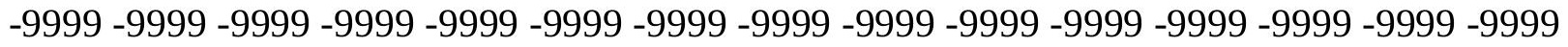
-9999 -9999 -9999 -9999 -9999 -9999 -9999 -9999 -9999 -9999 -9999 -9999 -9999 -9999 -9999 -9999 -9999 -9999 -9999 -9999 -9999 -9999 -9999 -9999 -9999 -9999 -9999 -9999 -9999 -999 -9999 -9999 -9999 -9999 -9999 -9999 -9999 -9999 -9999 -9999 -9999 -9999 -9999 -9999 -9999 -9999 -9999 -9999 -9999 -9999 -9999 -9999 -9999 -9999 -9999 -9999 -9999 -9999 -9999 -9999 -

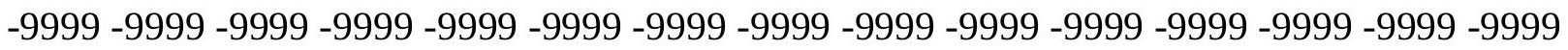

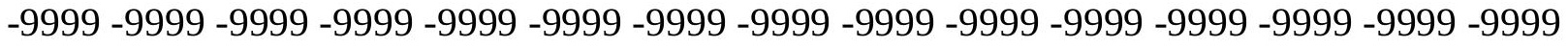

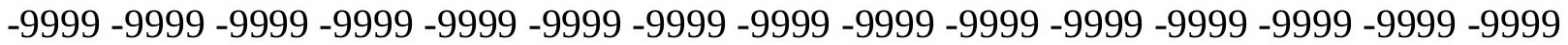

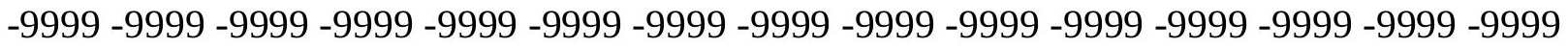

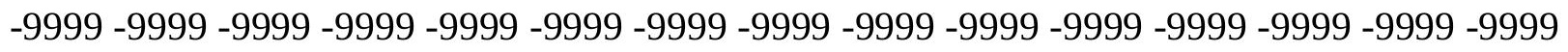

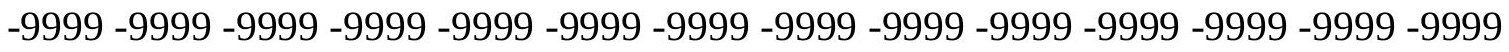
-9999 -9999 -9999 -9999 -9999 -9999 -9999 -9999 -9999 -9999 -9999 -9999 -9999 -9999 -9999 -9999 -9999 -9999 -9999 -9999 -9999 -9999 -9999 -9999 -9999 -9999 -9999 -9999 -9999 -9999 -

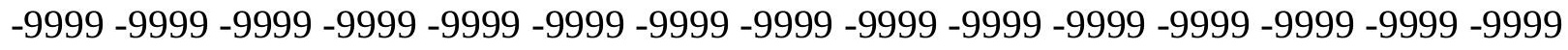

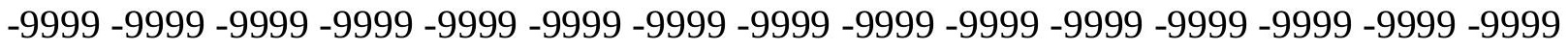
-9999 -9999 -9999 -9999 -9999 -9999 -9999 -9999 -9999 -9999 -9999 -9999 -9999 -9999 -9999 -9999 -9999 -9999 -9999 -9999 -9999 -9999 -9999 -9999-9999 -9999 -9999 -9999 -9999 -9999 -9999 -9999 -9999 -9999 -9999 -9999 -9999 -9999 -9999 -9999 -9999 -9999 -9999 -9999 -9999 -

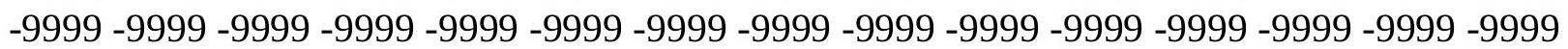


-9999 -9999 -9999 -9999 -9999 -9999 -9999 -9999 -9999 -9999 -9999 -9999 -9999 -9999 -9999 -9999 -9999 -9999 -9999 -9999 -9999 -9999 -9999 -9999 -9999 -9999 -9999 -9999 -9999 -9999 -9999 -9999 -9999 -9999 -9999 -9999 -9999 -9999 -9999 -9999 -9999 -9999 -9999 -9999 - 9999 -9999 -9999 -9999 -9999 -9999 -9999 -9999 -9999 -9999 -9999 -9999 -9999 -9999 -9999 -9999 -9999 -9999 -9999 -9999 -9999 -9999 -9999 -9999 -9999 -9999 -9999 -9999 -9999 -9999 -9999 -9999 -9999 -9999 -9999 -9999 -9999 -9999 -9999 -9999 -9999 -9999 -9999 -9999 -9999 -9999 -9999 -9999 -9999 -9999 -9999 -9999 -9999 -9999 -9999 -9999 -9999 -9999 -9999 -9999 -9999

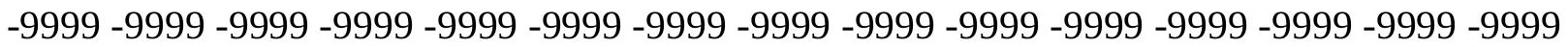
-9999 -9999 -9999 -9999 -9999 -9999 -9999 -9999 -9999 -9999 -9999 -9999 -9999 -9999 -9999 -9999 -9999 -9999 -9999 -9999 -9999 -9999 -9999 -9999 -9999 -9999 -9999 -9999 -9999 -9999

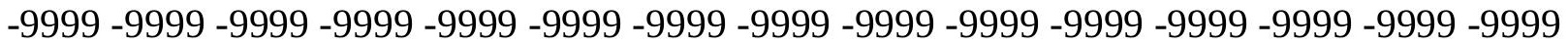
-9999 -9999 -9999 -9999 -9999 -9999 -9999 -9999 -9999 -9999 -9999 -9999 -9999 -9999 -9999 -9999 -9999 -9999 -9999 -9999 -9999 -9999 -9999 -9999 -9999 -9999 -9999 -9999 -9999 -9999 -

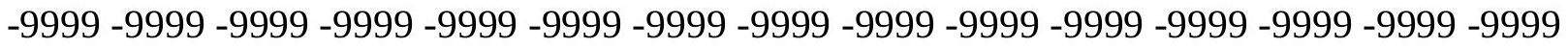
-9999 -9999 -9999 -9999 -9999 -9999 -9999 -9999 -9999 -9999 -9999 -9999 -9999 -9999 -9999

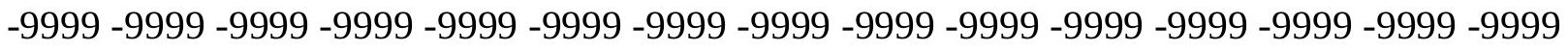
-9999 -9999 -9999 -9999 -9999 -9999 -9999 -9999 -9999 -9999 -9999 -9999 -9999 -9999 -9999 -9999 -9999 -9999 -9999 -9999 -9999 -9999 -9999 -9999 -9999 -9999 -9999 -9999 -9999 - -999 -9999 -9999 -9999 -9999 -9999 -9999 -9999 -9999 -9999 -9999 -9999 -9999 -9999 -9999 -9999 -9999 -9999 -9999 -9999 -9999 -9999 -9999 -9999 -9999 -9999 -9999 -9999 -9999 -9999 -9999 -9999 -9999 -9999 -9999 -9999 -9999 -9999 -9999 -9999 -9999 -9999 -9999 -9999 -9999 -9999 -999 -9999 -9999 -9999 -9999 -9999 -9999 -9999 -9999 -9999 -9999 -9999 -9999 -9999 -9999 -9999 -9999 -9999 -9999 -9999 -9999 -9999 -9999 -9999 -9999 -9999 -9999 -9999 -9999 -9999 -9999 -9999 -9999 -9999 -9999 -9999 -9999 -9999 -9999 -9999 -9999 -9999 -9999 -9999 -9999 -9999 -9999 -9999 -9999 -9999 -9999 -9999 -9999 -9999 -9999 -9999 -9999 -9999 -9999 -9999 -9999 -9999 -9999 -9999 -9999 -9999 -9999 -9999 -9999 -9999 -9999 -9999 -9999 -9999 -9999 -9999 -9999 -9999 -9999 -9999 -9999 -9999 -9999 -9999 -9999 -9999 -9999 -9999 -9999 -9999 -9999 -9999 -9999 -9999 -9999 -9999 -9999 -9999 -9999 -9999 -9999 -9999 -9999 -9999 -9999 -9999 -9999 -9999 -9999 -9999 -9999 -9999 -9999 -9999 -9999 -9999 -9999 -9999 -9999 -9999 -9999 -9999 -9999 -9999 -9999 -9999 -9999 -9999 -9999 -9999 -9999 -9999 -9999 -9999 -9999 -999 -9999 -9999 -9999 -9999 -9999 -9999 -9999 -9999 -9999 -9999 -9999 -9999 -9999 -9999 -9999 -9999 -9999 -9999 -9999 -9999 -9999 -9999 -9999 -9999 -9999 -9999 -9999 -9999 -9999 -9999 -

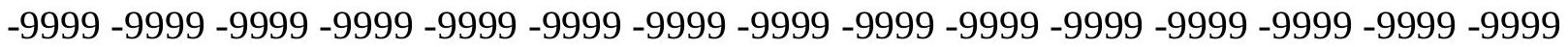

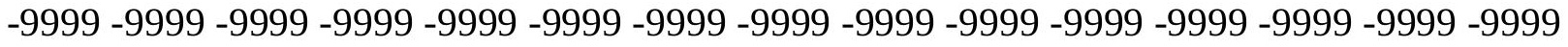

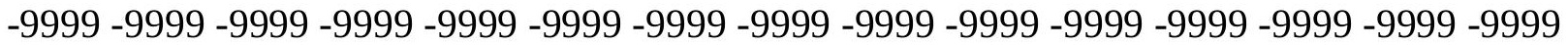
-9999 -9999 -9999 -9999 -9999 -9999 -9999 -9999 -9999 -9999 -9999 -9999 -9999 -9999 -9999

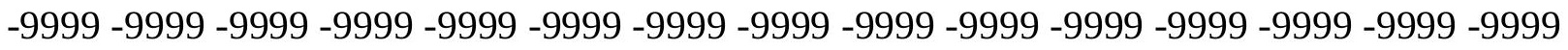

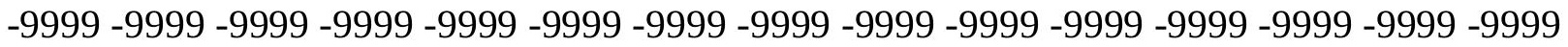

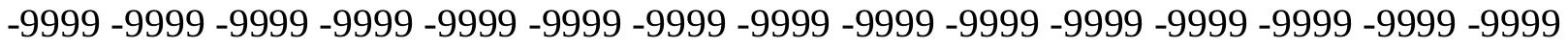
-9999 -9999 -9999 -9999 -9999 -9999 -9999 -9999 -9999 -9999 -9999 -9999 -9999 -9999 -9999 -

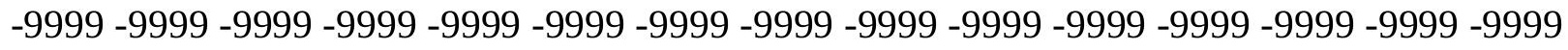

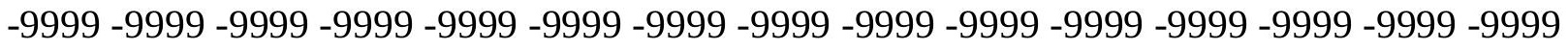
-9999 -9999 -9999 -9999 -9999 -9999 -9999 -9999 -9999 -9999 -9999 -9999 -9999 -9999 -9999 -9999 -9999 -9999 -9999 -9999 -9999 -9999 -9999 -9999 -9999 -9999 -9999 -9999 - -9999 -9999 -9999 -9999 -9999 -9999 -9999 -9999 -9999 -9999 -9999 -9999 -9999 -9999 -9999 -9999 -

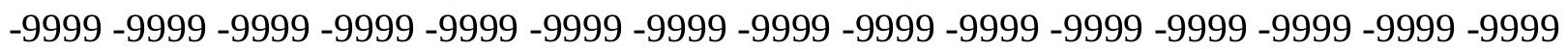


-9999 -9999 -9999 -9999 -9999 -9999 -9999 -9999 -9999 -9999 -9999 -9999 -9999 -9999 -9999 -9999 -9999 -9999 -9999 -9999 -9999 -9999 -9999 -9999 -9999 -9999 -9999 -9999 -9999 -9999 -9999 -9999 -9999 -9999 -9999 -9999 -9999 -9999 -9999 -9999 -9999 -9999 -9999 -9999 - 9999 -9999 -9999 -9999 -9999 -9999 -9999 -9999 -9999 -9999 -9999 -9999 -9999 -9999 -9999 -9999 -9999 -9999 -9999 -9999 -9999 -9999 -9999 -9999 -9999-9999 -9999 -9999 -9999 -9999 -9999 -9999 -9999 -9999 -9999 -9999 -9999 -9999 -9999 -9999 -9999 -9999 -9999 -9999 -9999 -9999 -9999 -9999 -9999 -9999 -9999 -9999 -9999 -9999 -9999 -9999 -9999 -9999 -9999 -9999 -9999

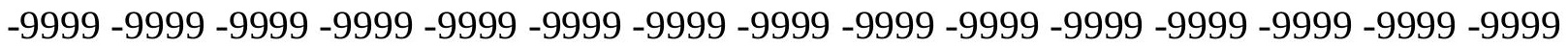

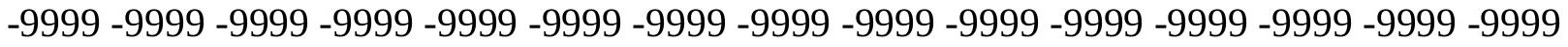
-9999 -9999 -9999 -9999 -9999 -9999 -9999 -9999 -9999 -9999 -9999 -9999 -9999 -9999 -9999

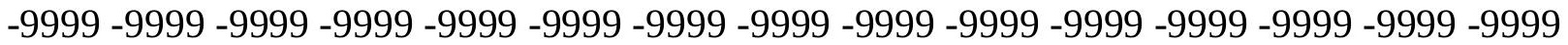
-9999 -9999 -9999 -9999 -9999 -9999 -9999 -9999 -9999 -9999 -9999 -9999 -9999 -9999 -9999 -9999 -9999 -9999 -9999 -9999 -9999 -9999 -9999 -9999 -9999 -9999 -9999 -9999 -9999 -9999 -

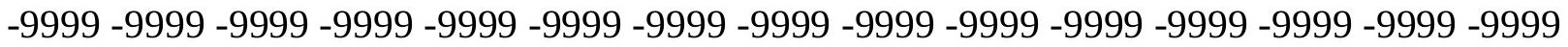
-9999 -9999 -9999 -9999 -9999 -9999 -9999 -9999 -9999 -9999 -9999 -9999 -9999 -9999 -9999

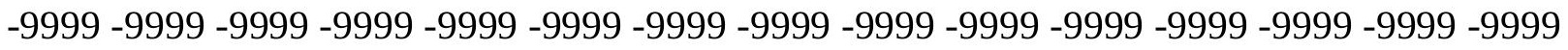
-9999 -9999 -9999 -9999 -9999 -9999 -9999 -9999 -9999 -9999 -9999 -9999 -9999 -9999 -9999 -9999 -9999 -9999 -9999 -9999 -9999 -9999 -9999 -9999 -9999 -9999 -9999 -9999 -9999 -9999 -9999 -9999 -9999 -9999 -9999 -9999 -9999 -9999 -9999 -9999 -9999 -9999 -9999 -9999 -9999 -9999 -9999 -9999 -9999 -9999 -9999 -9999 -9999 -9999 -9999 -9999 -9999 -9999 -9999 -9999 -9999 -9999 -9999 -9999 -9999 -9999 -9999 -9999 -9999 -9999 -9999 -9999 -9999 -9999 -9999 -999 -9999 -9999 -9999 -9999 -9999 -9999 -9999 -9999 -9999 -9999 -9999 -9999 -9999 -9999 -9999 -9999 -9999 -9999 -9999 -9999 -9999 -9999 -9999 -9999 -9999 -9999 -9999 -9999 -9999 -9999 -9999 -9999 -9999 -9999 -9999 -9999 -9999 -9999 -9999 -9999 -9999 -9999 -9999 -9999 -9999 -9999 -9999 -9999 -9999 -9999 -9999 -9999 -9999 -9999 -9999 -9999 -9999 -9999 -9999 -9999 -9999 -9999 -9999 -9999 -9999 -9999 -9999 -9999 -9999 -9999 -9999 -9999 -9999 -9999 -9999 -9999 -9999 -9999 -9999 -9999 -9999 -9999 -9999 -9999 -9999 -9999 -9999 -9999 -9999 -9999 -9999 -9999 -9999 -9999 -9999 -9999 -9999 -9999 -9999 -9999 -9999 -9999 -9999 -9999 -9999 -9999 -9999 -9999 -9999 -9999 -9999 -9999 -9999 -9999 -9999 -9999 -9999 -9999 -9999 -9999 -9999 -9999 -9999 -9999 -9999 -9999 -9999 -9999 -9999 -9999 -9999 -9999 -9999 -999 -9999 -9999 -9999 -9999 -9999 -9999 -9999 -9999 -9999 -9999 -9999 -9999 -9999 -9999 -9999 -9999 -9999 -9999 -9999 -9999 -9999 -9999 -9999 -9999 -9999 -9999 -9999 -9999 -9999 -9999 -

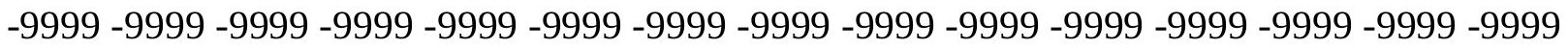

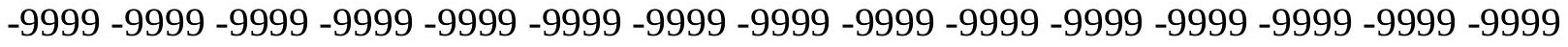

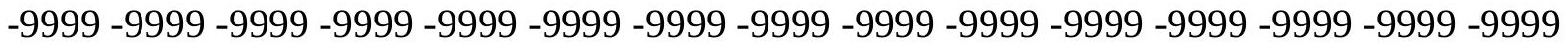
-9999 -9999 -9999 -9999 -9999 -9999 -9999 -9999 -9999 -9999 -9999 -9999 -9999 -9999 -9999

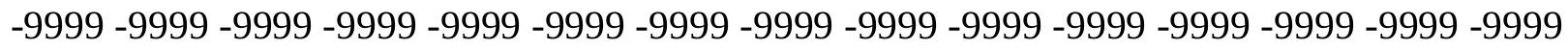

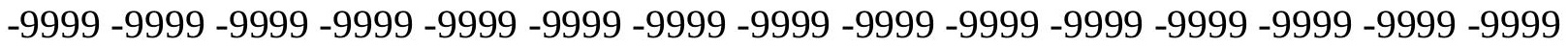
-9999 -9999 -9999 -9999 -9999 -9999 -9999 -9999 -9999 -9999 -9999 -9999 -9999 -9999 -9999 -9999 -9999 -9999 -9999 -9999 -9999 -9999 -9999 -9999 -9999 -9999 -9999 -9999 -9999 -9999 -

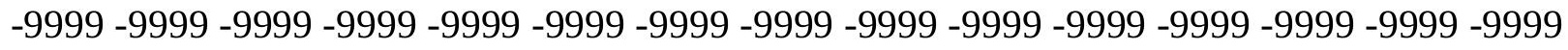

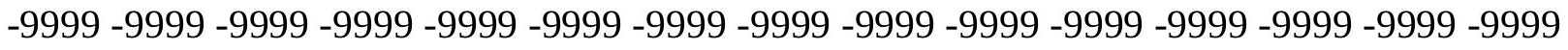
-9999 -9999 -9999 -9999 -9999 -9999 -9999 -9999 -9999 -9999 -9999 -9999 -9999 -9999 -9999 -9999 -9999 -9999 -9999 -9999 -9999 -9999 -9999 -9999-9999 -9999 -9999 -9999 -9999 -9999 -9999 -9999 -9999 -9999 -9999 -9999 -9999 -9999 -9999 -9999 -9999 -9999 -9999 -9999 -9999 -

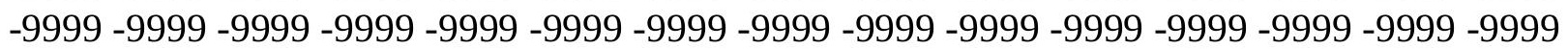


-9999 -9999 -9999 -9999 -9999 -9999 -9999 -9999 -9999 -9999 -9999 -9999 -9999 -9999 -9999 -9999 -9999 -9999 -9999 -9999 -9999 -9999 -9999 -9999 -9999 -9999 -9999 -9999 -9999 -9999 -9999 -9999 -9999 -9999 -9999 -9999 -9999 -9999 -9999 -9999 -9999 -9999 -9999 -9999 - 9999 -9999 -9999 -9999 -9999 -9999 -9999 -9999 -9999 -9999 -9999 -9999 -9999 -9999 -9999

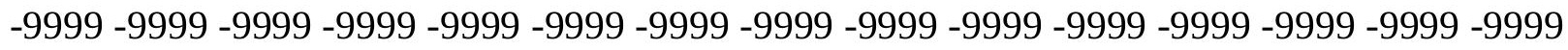
-9999 -9999 -9999 -9999 -9999 -9999 -9999 -9999 -9999 -9999 -9999 -9999 -9999 -9999 -9999 -9999 -9999 -9999 -9999 -9999 -9999 -9999 -9999 -9999 -9999 -9999 -9999 -9999 -9999 -9999

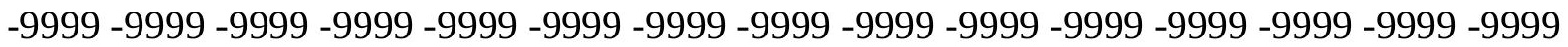

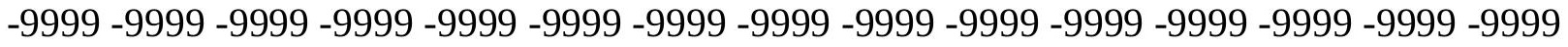
-9999 -9999 -9999 -9999 -9999 -9999 -9999 -9999 -9999 -9999 -9999 -9999 -9999 -9999 -9999 -9999 -9999 -9999 -9999 -9999 -9999 -9999 -9999 -9999 -9999 -9999 -9999 -9999 -9999 -9999 -9999 -9999 -9999 -9999 -9999 -9999 -9999 -9999 -9999 -9999 -9999 -9999 -9999 -9999 -9999 -9999 -9999 -9999 -9999 -9999 -9999 -9999 -9999 -9999 -9999 -9999 -9999 -9999 -9999 -9999 -

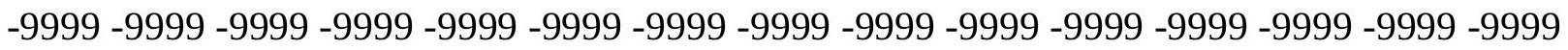
-9999 -9999 -9999 -9999 -9999 -9999 -9999 -9999 -9999 -9999 -9999 -9999 -9999 -9999 -9999 -

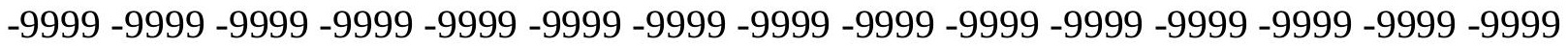
-9999 -9999 -9999 -9999 -9999 -9999 -9999 -9999 -9999 -9999 -9999 -9999 -9999 -9999 -9999 -9999 -9999 -9999 -9999 -9999 -9999 -9999 -9999 -9999 -9999 -9999 -9999 -9999 -9999 -9999 -9999 -9999 -9999 -9999 -9999 -9999 -9999 -9999 -9999 -9999 -9999 -9999 -9999 -9999 -9999 -

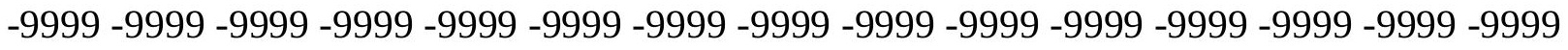
-9999 -9999 -9999 -9999 -9999 -9999 -9999 -9999 -9999 -9999 -9999 -9999 -9999 -9999 -9999

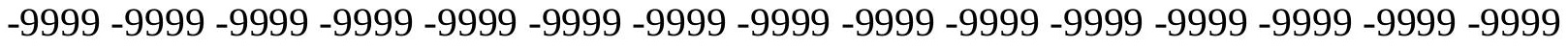
-9999 -9999 -9999 -9999 -9999 -9999 -9999 -9999 -9999 -9999 -9999 -9999 -9999 -9999 -9999 -9999 -9999 -9999 -9999 -9999 -9999 -9999 -9999 -9999 -9999 -9999 -9999 -9999 -9999 -9999 -9999 -9999 -9999 -9999 -9999 -9999 -9999 -9999 -9999 -9999 -9999 -9999 -9999 -9999 -9999 -9999 -9999 -9999 -9999 -9999 -9999 -9999 -9999 -9999 -9999 -9999 -9999 -9999 -9999 -9999 -9999 -9999 -9999 -9999 -9999 -9999 -9999 -9999 -9999 -9999 -9999 -9999 -9999 -9999 -9999 -9999 -9999 -9999 -9999 -9999 -9999 -9999 -9999 -9999 -9999 -9999 -9999 -9999 -9999 -9999 -9999 -9999 -9999 -9999 -9999 -9999 -9999 -9999 -9999 -9999 -9999 -9999 -9999 -9999 -9999 -9999 -9999 -9999 -9999 -9999 -9999 -9999 -9999 -9999 -9999 -9999 -9999 -9999 -9999 -9999 -9999 -9999 -9999 -9999 -9999 -9999 -9999 -9999 -9999 -9999 -9999 -9999 -9999 -9999 -9999 -9999 -9999 -9999 -9999 -9999 -9999 -9999 -9999 -9999 -9999 -9999 -9999 -9999 -9999 -

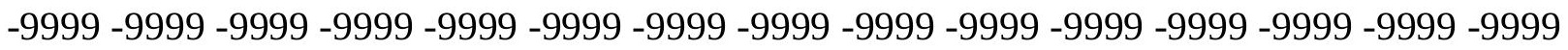

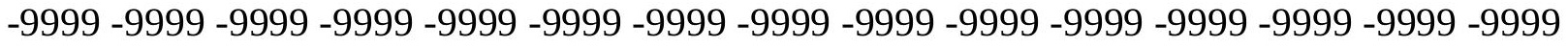
-9999 -9999 -9999 -9999 -9999 -9999 -9999 -9999 -9999 -9999 -9999 -9999 -9999 -9999 -9999 -

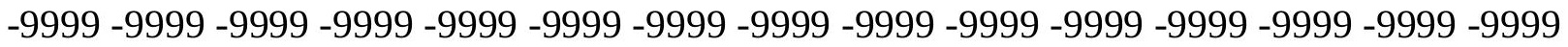

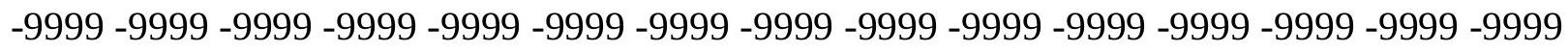

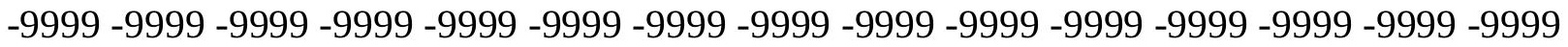

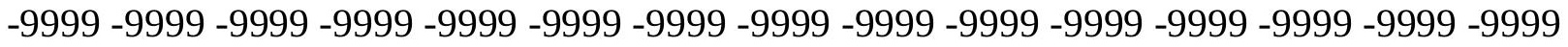
-9999 -9999 -9999 -9999 -9999 -9999 -9999 -9999 -9999 -9999 -9999 -9999 -9999 -9999 -9999 -

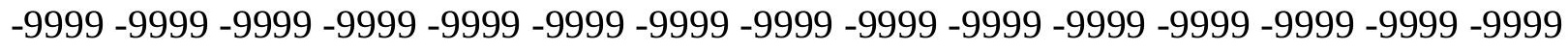

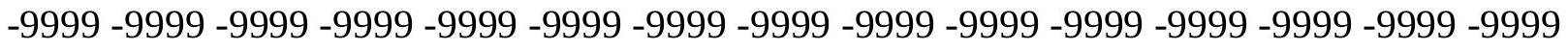
-9999 -9999 -9999 -9999 -9999 -9999 -9999 -9999 -9999 -9999 -9999 -9999 -9999 -9999 -9999 -9999 -9999 -9999 -9999 -9999 -9999 -9999 -9999 -9999-9999 -9999 -9999 -9999 -9999 -9999 -9999 -9999 -9999 -9999 -9999 -9999 -9999 -9999 -9999 -9999 -9999 -9999 -9999 -9999 -9999 -

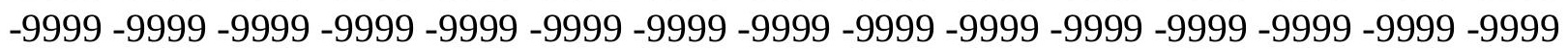


-9999 -9999 -9999 -9999 -9999 -9999 -9999 -9999 -9999 -9999 -9999 -9999 -9999 -9999 -9999 -9999 -9999 -9999 -9999 -9999 -9999 -9999 -9999 -9999 -9999 -9999 -9999 -9999 -9999 -9999 -9999 -9999 -9999 -9999 -9999 -9999 -9999 -9999 -9999 -9999 -9999 -9999 -9999 -9999 - 9999 -9999 -9999 -9999 -9999 -9999 -9999 -9999 -9999 -9999 -9999 -9999 -9999 -9999 -9999 -9999 -9999 -9999 -9999 -9999 -9999 -9999 -9999 -9999 -9999-9999 -9999 -9999 -9999 -9999 -9999 -9999 -9999 -9999 -9999 -9999 -9999 -9999 -9999 -9999 -9999 -9999 -9999 -9999 -9999 -9999 -9999 -9999 -9999 -9999 -9999 -9999 -9999 -9999 -9999 -9999 -9999 -9999 -9999 -9999 -9999

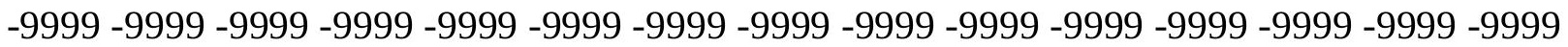

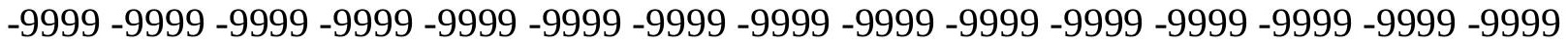
-9999 -9999 -9999 -9999 -9999 -9999 -9999 -9999 -9999 -9999 -9999 -9999 -9999 -9999 -9999 -9999 -9999 -9999 -9999 -9999 -9999 -9999 -9999 -9999 -9999 -9999 -9999 -9999 -9999 -9999 -9999 -9999 -9999 -9999 -9999 -9999 -9999 -9999 -9999 -9999 -9999 -9999 -9999 -9999 -9999 -9999 -9999 -9999 -9999 -9999 -9999 -9999 -9999 -9999 -9999 -9999 -9999 -9999 -9999 -9999 -9999 -9999 -9999 -9999 -9999 -9999 -9999 -9999 -9999 -9999 -9999 -9999 -9999 -9999 -9999 -9999 -9999 -9999 -9999 -9999 -9999 -9999 -9999 -9999 -9999 -9999 -9999 -9999 -9999

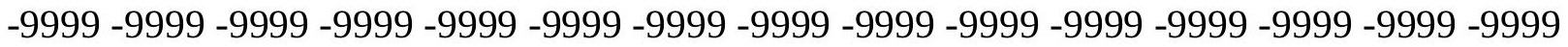
-9999 -9999 -9999 -9999 -9999 -9999 -9999 -9999 -9999 -9999 -9999 -9999 -9999 -9999 -9999 -9999 -9999 -9999 -9999 -9999 -9999 -9999 -9999 133.1911010742131 .6672058105 130.1432037354128 .6192932129 -9999 -9999 -9999 -9999 -9999 -9999 -9999 -9999 -9999

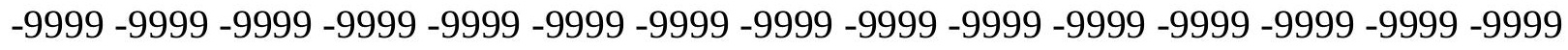

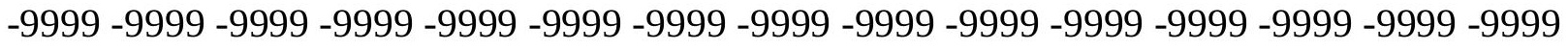

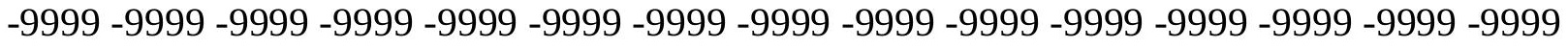
-9999 -9999 -9999 -9999 -9999 -9999 -9999 -9999 -9999 -9999 -9999 -9999 -9999 -9999 -9999 -

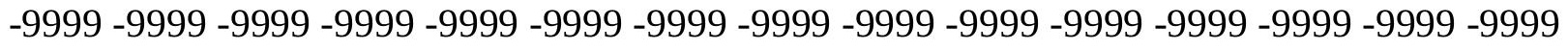

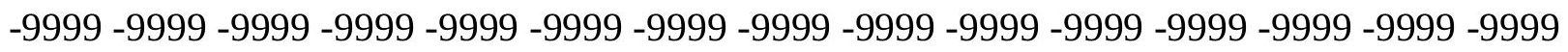
-9999 -9999 -9999 -9999 -9999 -9999 -9999 -9999 -9999 -9999 -9999 -9999 -9999 -9999 -9999 -9999 -9999 -9999 -9999 -9999 -9999 -9999 -9999 -9999 -9999 -9999 -9999 -9999 -9999 -9999 -

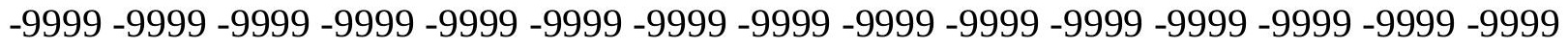
-9999 -9999 -9999 -9999 -9999 -9999 -9999 -9999 -9999 -9999 -9999 -9999 -9999 -9999 -9999 -9999 -9999 -9999 -9999 -9999 -9999 -9999 -9999 -9999 -9999 -9999 -9999 -9999 -9999 -999 -

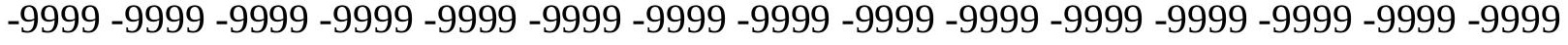
-9999 -9999 -9999 -9999 -9999 -9999 -9999 -9999 -9999 -9999 -9999 -9999 -9999 -9999 -9999 -

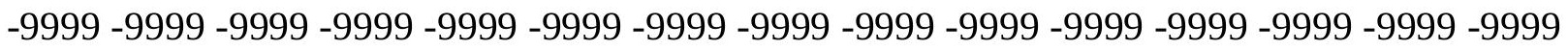

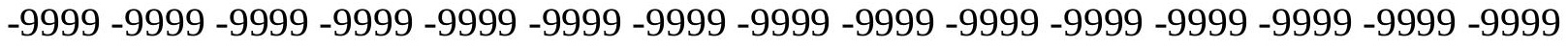

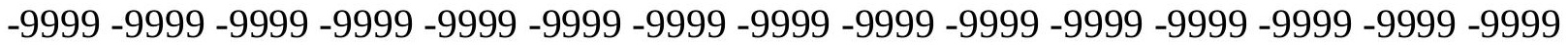

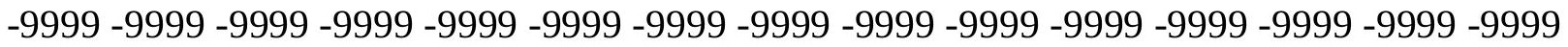
-9999 -9999 -9999-9999-9999 -9999-9999-9999

-9999 -9999 -9999 -9999 -9999 -9999 -9999 -9999 -9999 -9999 -9999 -9999 -9999 -9999 - -999 -

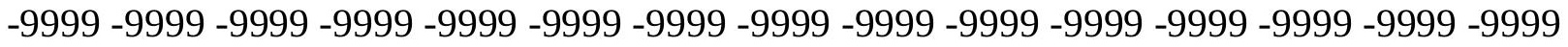
-9999 -9999 -9999 -9999 -9999 -9999 -9999 -9999 -9999 -9999 -9999 -9999 -9999 -9999 - -999 -

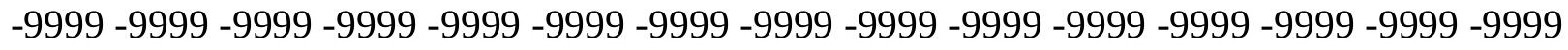

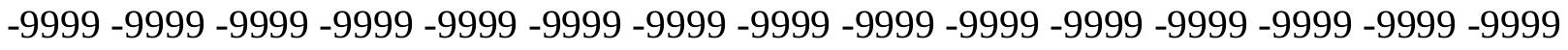
-9999 -9999 -9999 -9999 -9999 -9999 -9999 -9999 -9999 -9999 -9999 -9999 -9999 -9999 - 9999 -

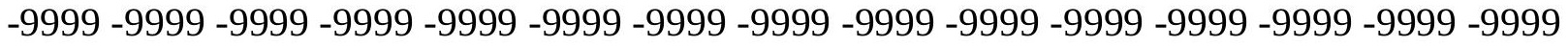
-9999 -9999 -9999 -9999 -9999 142.0299072266 140.2012023926138.3724975586 136.8484954834139 .8963928223133 .8007049561132 .5814971924131 .6672058105 
131.3623962402131 .6672058105132 .2767028809133 .8007049561135 .6293945312 114.2944030762 -9999 -9999 -9999 -9999 -9999 -9999 -9999 -9999 -9999 -9999 -9999 -9999 -9999 -9999 -9999 -9999 -9999 -9999 -9999 -9999 -9999 -9999 -9999 -9999 -9999 -9999 -9999 -9999 -9999 -9999 -9999 -9999 -9999 -9999 -9999 -9999 -9999 -9999 -9999 -9999 -9999 -9999 -9999 -9999 -9999 -9999 -9999 -9999 -9999 -9999 -9999-9999 -9999 -9999 -9999 -9999 -9999 -9999 -9999 -9999 -9999 -9999 -9999 -9999 -9999 -9999 -9999 -9999 -9999 -9999 -9999 -9999 -

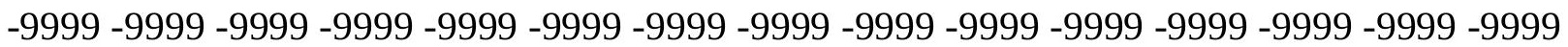

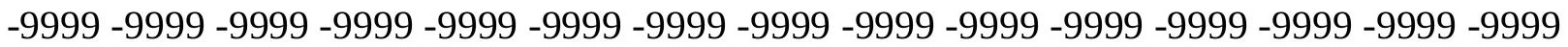

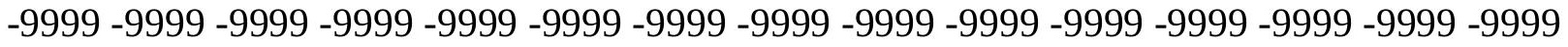
-9999 -9999 -9999 -9999 -9999 -9999 -9999 -9999 -9999 -9999 -9999 -9999 -9999 -9999 -9999

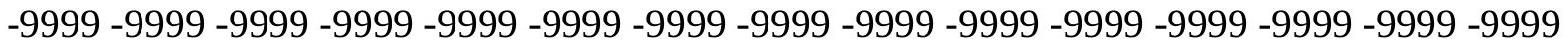
-9999 -9999 -9999 -9999 -9999 -9999 -9999 -9999 -9999 -9999 -9999 -9999 -9999 -9999 -9999 -9999 -9999 -9999 -9999 -9999 -9999 -9999 -9999 -9999 -9999 -9999 -9999 -9999 -9999 -9999 -

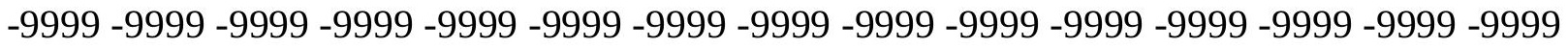
-9999 -9999 -9999 -9999 -9999 -9999 -9999 -9999 -9999 -9999 -9999 -9999 -9999 -9999 -9999

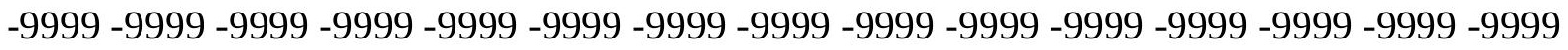
-9999 -9999 -9999 -9999 -9999 -9999 -9999 -9999 -9999 -9999 -9999 -9999 -9999 -9999 -9999 -9999 -9999 -9999 -9999 -9999 -9999 -9999 -9999 -9999 -9999 -9999 -9999 -9999 -9999 -9999 -9999 -9999 -9999 -9999 -9999 -9999 -9999 -9999 -9999 -9999 -9999 -9999 -9999 -

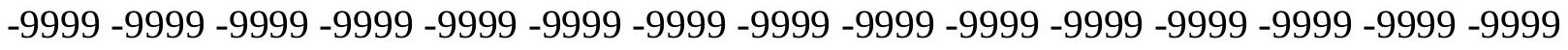

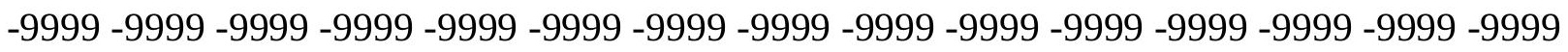

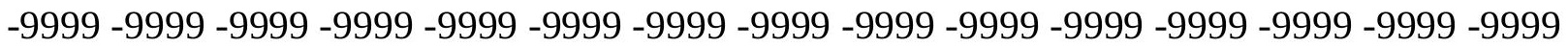
-9999 -9999 -9999 -9999 -9999 -9999 -9999 -9999 -9999 -9999 -9999 -9999 -9999 -9999 -9999 -9999 -9999 -9999 -9999 -9999 -9999 -9999 -9999 -9999 -9999 -9999 -9999 -9999 -9999 -9999 -9999 -9999 -9999 -9999 -9999 -9999 -9999 -9999 -9999 -9999 -9999 -9999 -9999 -9999 -9999 -9999 -9999 -9999 -9999 -9999 -9999 -9999 -9999 -9999 -9999 -9999 -9999 -9999 -9999 -9999 -9999 -9999 -9999 149.6495056152146.9064025879 145.0776977539147 .8208007812 146.2969055176145 .0776977539143 .5538024902142 .0299072266140 .8106994629 139.8963928223139 .5915985107139 .5915985107140 .2012023926141 .1154937744 138.0677032471139 .8963928223141 .420303344797 .8360290527389 .60682678223 78.3297805786179 .5489196777382 .5967712402385 .3398437588 .38768768311 91.4355392456194 .7881774902398 .14080810547101 .4934005737104 .2365036011 106.3700027466 107.2844009399 107.2844009399 -9999 -9999 -9999 -9999 -9999 -9999 -9999 -9999 -9999 -9999 -9999 -9999 -9999 -9999 -9999 -9999 -9999 -9999 -9999 -9999 -9999 -9999 -9999 -9999 -9999 -9999 -9999 -9999 -9999 -9999 -9999 -9999 -9999 -9999 -9999 -9999 -9999 -9999 -9999 -9999 -9999 -9999 -9999 -9999 -9999 -9999 -9999 -9999 -9999 -9999 -9999 -9999

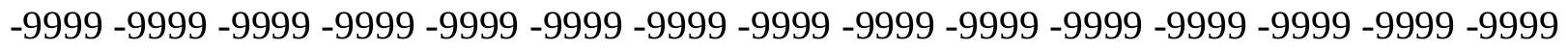

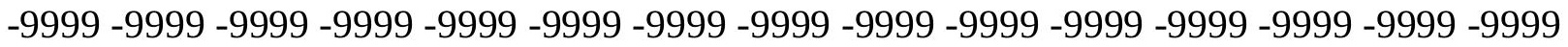
-9999 -9999 -9999 -9999 -9999 -9999 -9999 -9999 -9999 -9999 -9999 -9999 -9999 - 9999 - -999 -9999 -9999 -9999 -9999 -9999 -9999 -9999 -9999 -9999 -9999 -9999 -9999 -9999 -9999 -9999 -

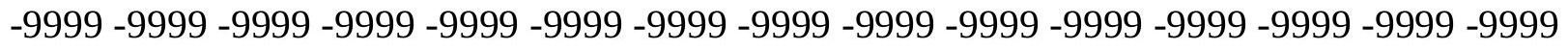

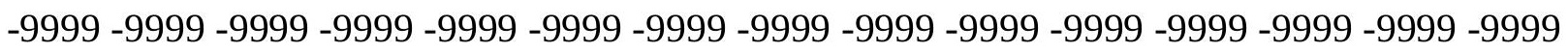
-9999 -9999 -9999 -9999 -9999 -9999 -9999 -9999 -9999 -9999 -9999 -9999 -9999 -9999 -9999 -9999 -9999 -9999 -9999 -9999 -9999 -9999 -9999 -9999-9999 -9999 -9999 -9999 -9999 -9999 -9999 -9999 -9999 -9999 -9999 -9999 -9999 -9999 -9999 -9999 -9999 -9999 -9999 -9999 -9999 -

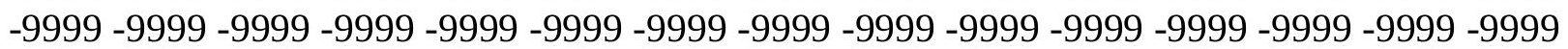


-9999 -9999 -9999 -9999 -9999 -9999 -9999 -9999 -9999 -9999 -9999 -9999 -9999 -9999 -9999 -9999 -9999 -9999 -9999 -9999 -9999 -9999 -9999 -9999 -9999 -9999 -9999 -9999 -9999 -9999 -9999 -9999 -9999 -9999 -9999 -9999 -9999 -9999 -9999 -9999 -9999 -9999 -9999 -9999 -9999 -9999-9999

-9999 -9999 -9999 -9999 -9999 -9999 -9999 -9999 -9999 -9999 -9999 -9999 -9999 -9999 -9999 -9999 -9999 -9999 -9999 -9999 -9999 -9999 -9999 -9999 -9999 -9999 -9999 -9999 -9999 -9999 -9999 -9999 -9999 -9999 -9999 -9999 -9999 -9999 -9999 -9999 -9999 -9999 -9999 -9999 -9999

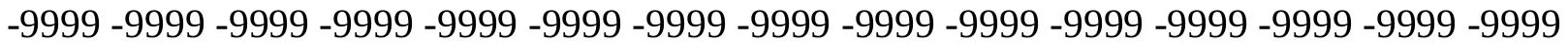

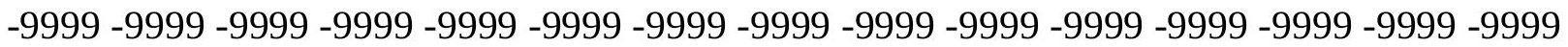
-9999 -9999 -9999 -9999 -9999 -9999 -9999 -9999 -9999 -9999 -9999 -9999 -9999 -9999 -9999 -9999 -9999 -9999 -9999 -9999 -9999 -9999 -9999 -9999 -9999 -9999 -9999 -9999 -9999 -9999 -9999 -9999 154.8307952881 151.4781951904149.6495056152147.8208007812 146.2969055176149 .6495056152148 .4304046631146 .9064025879145 .3825073242 144.1634063721143 .2489929199142 .6394042969142 .6394042969142 .9441986084 143.8585968018145 .0776977539146 .2969055176142 .9441986084144 .1634063721 145.0776977539145 .3825073242145 .6873016357145 .3825073242144 .7729034424 143.5538024902142 .0299072266140 .2012023926138 .3724975586136 .2389984131 134.7149963379133 .4958953857133 .1911010742108 .1986999512107 .5891036987 -9999 -9999 -9999 -9999 -9999 -9999 -9999 -9999 -9999 -9999 -9999 -9999 -9999 -9999 -9999 -9999 -9999 -9999 -9999 -9999 -9999 -9999 -9999 -9999 -9999 -9999 -9999 -9999 -9999 -9999 -9999

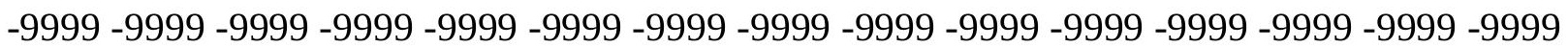
-9999 -9999 -9999 -9999 -9999 -9999 -9999 -9999 -9999 -9999 -9999 -9999 -9999 -9999 -9999 -9999 -9999 -9999 -9999 -9999 -9999 -9999 -9999 -9999 -9999 -9999 -9999 -9999 -9999 -9999 -9999 -9999 -9999 -9999 -9999 -9999 -9999 -9999 -9999 -9999 -9999 -9999 -9999 -9999 -9999

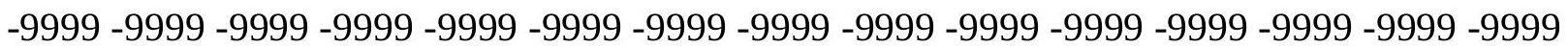
-9999 -9999 -9999 -9999 -9999 -9999 -9999 -9999 -9999 -9999 -9999 -9999 -9999 -9999 -9999 -9999 -9999 -9999 -9999 -9999 -9999 -9999 -9999 -9999 -9999 -9999 -9999 -9999 -9999 -9999 -9999 -9999 -9999 -9999 -9999 -9999 -9999 -9999 -9999 -9999 -9999 -9999 -9999 -9999 -9999 -9999 -9999 -9999 -9999 -9999 -9999 -9999 -9999 -9999 -9999 -9999 -9999 -9999 -9999 -9999 -9999 -9999 -9999 -9999 -9999 -9999 -9999 -9999 -9999 -9999 -9999 -9999 -9999 -9999 -9999 -9999 -9999 -9999 -9999 -9999 -9999 -9999 -9999 -9999 -9999 -9999 -9999 -9999 -9999 -9999 -9999 -9999 -9999 -9999 -9999 -9999 -9999 -9999 -9999 -9999 -9999 -9999 -9999 -9999 -9999 -9999 -9999 -9999 -9999 -9999 -9999 -9999 -9999 -9999 -9999 -9999 -9999 -9999 -9999 -9999 -

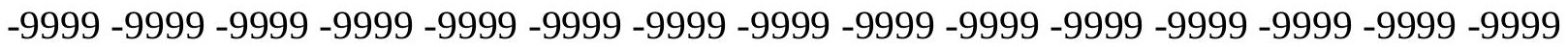
-9999 -9999 -9999 -9999 -9999 -9999 -9999

-9999 -9999 -9999 -9999 -9999 -9999 -9999 -9999 -9999 -9999 -9999 -9999 -9999 -9999 -9999 -9999 -9999 -9999 -9999 -9999 -9999 -9999 -9999 -9999 -9999 -9999 -9999 -9999 -9999 -9999

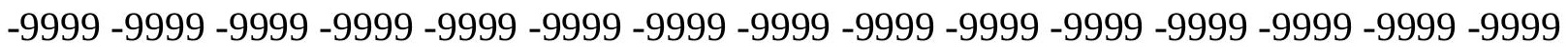
-9999 -9999 -9999 -9999 -9999 -9999 -9999 -9999 -9999 -9999 -9999 -9999 -9999 -9999 -9999 -9999 -9999 -9999 -9999 -9999 -9999 -9999 -9999 -9999 -9999 -9999 -9999 -9999 -9999 -9999 -9999 -9999 -9999 -9999 -9999 -9999 -9999 -9999 -9999 -9999 -9999 -9999 -9999 -9999 -9999 -9999 -9999 -9999 -9999 -9999 -9999 -9999 -9999 -9999 -9999 -9999 -9999 -9999 -9999 -9999 -9999 160.3170013428 156.3547973633153.9165039062 152.3925933838150.8686065674 149.3446960449148 .1255950928147 .2111968994145 .3825073242148 .4304046631 147.2111968994146 .2969055176145 .6873016357145 .3825073242145 .6873016357 146.2969055176147 .2111968994148 .1255950928144 .4682006836145 .3825073242 
145.9920959473146 .2969055176146 .6015930176146 .2969055176145 .3825073242 144.4682006836142 .9441986084141 .4203033447139 .5915985107137 .4580993652 135.6293945312133 .8007049561132 .2767028809134 .1054992676135 .0198059082 137.1533050537 -9999 -9999 -9999 -9999 -9999 -9999 -9999 -9999 -9999 -9999 -9999 -9999 -9999 -9999 -9999 -9999 -9999 -9999 -9999 -9999 -9999 -9999 -9999 -9999 -9999 -9999 -9999 -9999 -9999 -9999 -9999 -9999 -9999 -9999 -9999 -9999 -9999 -9999 -9999 -9999 -9999 -9999 -9999 -9999 -9999 -9999 -9999 -9999 -9999 -9999 -9999 -9999 -9999 -9999 -9999 -9999 -9999 -9999 -9999 -9999 -9999 -9999 -9999 -9999 -9999 -9999 -9999 -9999 -9999 -9999 -9999 -9999 -9999 -9999 -9999 -9999 -9999 -9999 -9999 -9999 -9999 -9999 -9999 -9999 -9999 -9999 -9999 -9999 -9999 -9999 -9999 -9999 -9999 -9999 -9999 -9999 -9999 -9999 -9999 -9999 -9999 -9999 -9999 -9999 -9999 -9999 -9999 -9999 -9999 -9999 -9999 -9999 -9999 -9999 -9999 -9999 -9999 -999 -9999 -9999 -9999 -9999 -9999 -9999 -9999 -9999 -9999 -9999 -9999 -9999 -9999 -9999 -9999 -9999 -9999 -9999 -9999 -9999 -9999 -9999 -9999 -9999 -9999 -9999 -9999 -9999 -9999 -9999 -9999 -9999 -9999 -9999 -9999 -9999 -9999 -9999 -9999 -9999 -9999 -9999 -9999 -9999 -9999 -9999 -9999 -9999 -9999 -9999 -9999 -9999 -9999 -9999 -9999 -9999 -9999 -9999 -9999 -9999

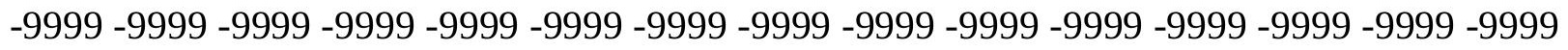

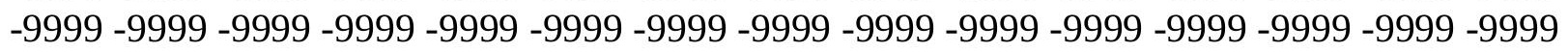

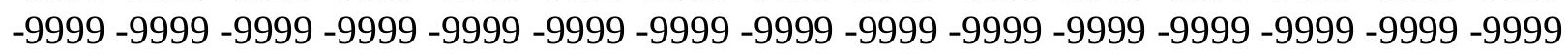

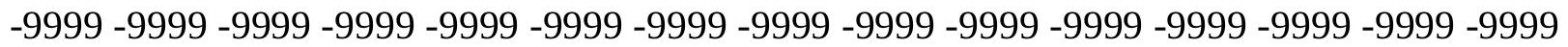
-9999 -9999 -9999 -9999-9999 -9999-9999 -9999 -9999 -9999

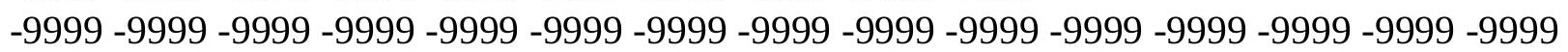

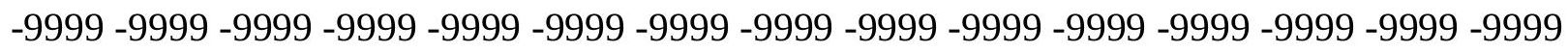
-9999 -9999 -9999 -9999 -9999 -9999 -9999 -9999 -9999 -9999 -9999 -9999 -9999 -9999 -9999 -9999 -9999 -9999 -9999 -9999 -9999 -9999 -9999 -9999 -9999 -9999 -9999 -9999 -9999 -9999 -

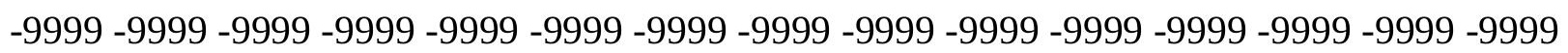
-9999 -9999 -9999 -9999 -9999 -9999 -9999 -9999 -9999 -9999 -9999 -9999 -9999 -9999 -9999 -9999 -9999 -9999 -9999 -9999 -9999 -9999 -9999 -9999 -9999 -9999 -9999 -9999 -9999 -9999 165.8031005859161 .5361022949158 .4882965088157 .2691040039155 .7451934814 154.2212982178152 .6972961426152 .0877990723151 .1734008789149 .6495056152 147.8208007812146 .2969055176145 .0776977539144 .1634063721143 .8585968018 148.1255950928148 .4304046631149 .0399017334149 .6495056152145 .6873016357 146.6015930176147 .2111968994147 .2111968994147 .2111968994146 .9064025879 145.9920959473145 .0776977539143 .8585968018142 .6394042969140 .8106994629 138.9819946289137 .1533050537135 .6293945312134 .7149963379135 .0198059082 135.3246002197136 .8484954834 -9999 -9999 -9999 -9999 -9999 -9999 -9999 -9999 -9999

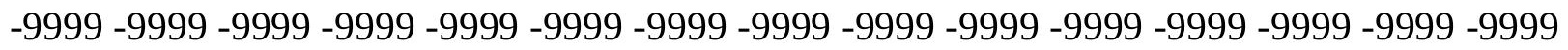

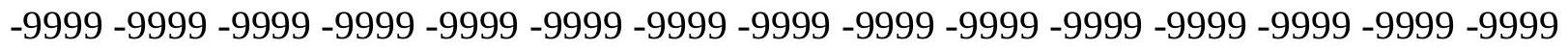

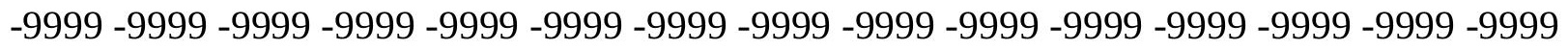

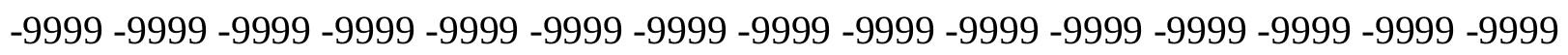
-9999 -9999 -9999 -9999 -9999 -9999 -9999 -9999 -9999 -9999 -9999 -9999 -9999 -9999 -9999 -

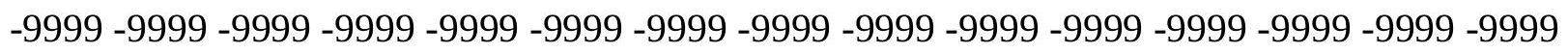

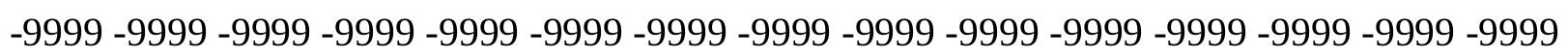

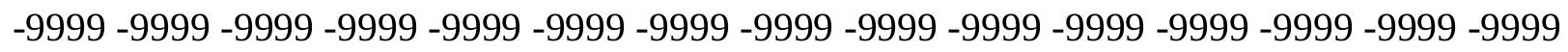
-9999 -9999 -9999 -9999 -9999 -9999 -9999 -9999 -9999 -9999 -9999 -9999 -9999 -9999 -9999 -

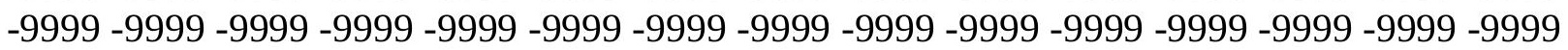

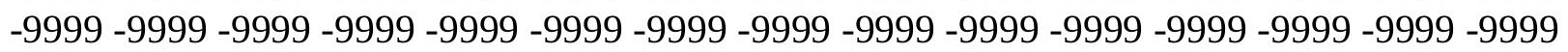


-9999 -9999 -9999 -9999 -9999 -9999 -9999 -9999 -9999 -9999 -9999 -9999 -9999 -9999 -9999 -9999 -9999 -9999 -9999 -9999 -9999 -9999 -9999 -9999 -9999 -9999 -9999 -9999 -9999 -9999 -9999 -9999 -9999 -9999 -9999 -9999 -9999 -9999 -9999 -9999 -9999 -9999 -9999 -9999 -9999 -9999 -9999 -9999 -9999 -9999 -9999 -9999 -9999 -9999 -9999 -9999 -9999 -9999 -9999 -9999 -9999 -9999 -9999 -9999 -9999 -9999 -9999 -9999 -9999 -9999 -9999 -9999 -9999 -9999 -9999 -9999 -9999 -9999 -9999 -9999 -9999 -9999 -9999 -9999 -9999 -9999 -9999 -9999 -9999 -9999 -9999 -9999 -9999 -9999 -9999 -9999 -9999 -9999 -9999 -9999 -9999 -9999 -9999

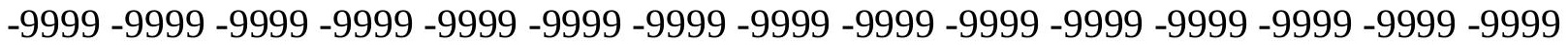
-9999 -9999 -9999 -9999 -9999 -9999 -9999 -9999 -9999 -9999 -9999 -9999 -9999 -9999 -9999 -9999 -9999 -9999 -9999 -9999 -9999 -9999 -9999 -9999 -9999 -9999 -9999 -9999 -9999 -9999 -

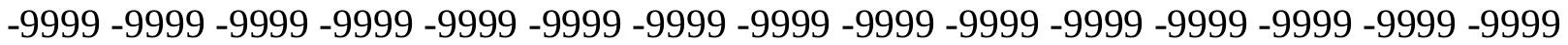
-9999 -9999 -9999 -9999 -9999 -9999 -9999 -9999 -9999 -9999 -9999 -9999 -9999 -9999 -9999 166.4127044678162 .7552947998161 .8408966064160 .6217956543159 .4026031494 157.878692627156 .6596069336155 .7451934814154 .8307952881153 .6116943359 151.7830047607150 .5639038086149 .3446960449148 .4304046631147 .5160064697 146.9064025879146 .6015930176151 .1734008789151 .4781951904147 .5160064697 148.1255950928148 .4304046631148 .4304046631148 .1255950928147 .5160064697 146.6015930176145 .9920959473145 .0776977539143 .8585968018142 .6394042969 141.1154937744139 .5915985107138 .3724975586137 .4580993652137 .1533050537 137.1533050537137 .7628936768 -9999 -9999 -9999 -9999 -9999 -9999 -9999 -9999 -9999 -9999 -9999 -9999 -9999 -9999 -9999 -9999 -9999 -9999 -9999 -9999 -9999 -9999 -9999 -9999 -9999 -9999 -9999 -9999 -9999 -9999 -9999 -9999 -9999 -9999 -9999 -9999 -9999 -9999 -9999 -9999 -9999 -9999 -9999 -9999 -9999 -9999 -9999 -9999 -9999 -9999 -9999 -9999 -9999 -9999 -9999 -9999 -9999 -9999 -9999 -9999 -9999 -9999 -9999 -9999 -9999 -9999 -9999 -9999 -9999

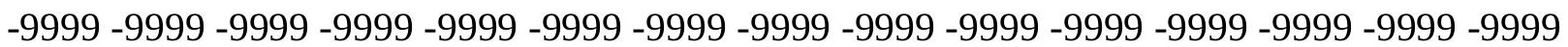
-9999 -9999 -9999 -9999 -9999 -9999 -9999 -9999 -9999 -9999 -9999 -9999 -9999 -9999 -9999 -9999 -9999 -9999 -9999 -9999 -9999 -9999 -9999 -9999 -9999 -9999 -9999 -9999 -9999 -9999 -9999 -9999 -9999 -9999 -9999 -9999 -9999 -9999 -9999 -9999 -9999 -9999 -9999 -9999 -9999 -9999 -9999 -9999 -9999 -9999 -9999 -9999 -9999 -9999 -9999 -9999 -9999 -9999 -9999 -9999 -9999 -9999 -9999 -9999 -9999 -9999 -9999 -9999 -9999 -9999 -9999 -9999 -9999 -9999 -9999 -9999 -9999 -9999 -9999 -9999 -9999 -9999 -9999 -9999 -9999 -9999 -9999 -9999 -9999 -9999 -

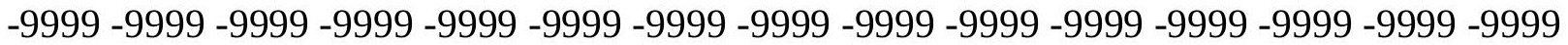
-9999 -9999 -9999 -9999 -9999 -9999 -9999 -9999 -9999 -9999 -9999 -9999 -9999 -9999 -9999 -9999 -9999 -9999 -9999 -9999 -9999 -9999 -9999 -9999 -9999 -9999 -9999 -9999 -9999 -9999 -

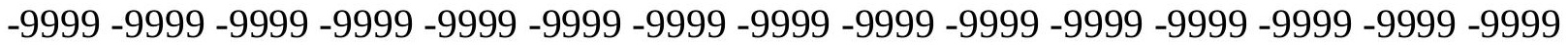
-9999 -9999 -9999 -9999 -9999 -9999 -9999 -9999 -9999 -9999 -9999 -9999 -9999 -9999 -9999 -9999 -9999 -9999 -9999 -9999 -9999 -9999 -9999 -9999 -9999 -9999 -9999 -9999

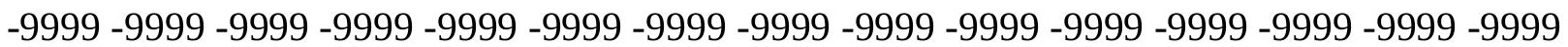
-9999 -9999 -9999 -9999 -9999 -9999 -9999 -9999 -9999 -9999 -9999 -9999 -9999 -9999 -9999 -9999 -9999 -9999 -9999 -9999 -9999 -9999 -9999 -9999 -9999 -9999 -9999 -9999 -9999 -9999 -9999 -9999 -9999 -9999 -9999 -9999 -9999 -9999 -9999 -9999 -9999 -9999 -9999 -9999 -9999 -9999 -9999 -9999 -9999 -9999 -9999 -9999 -9999 -9999 -9999 -9999 -9999 -9999 -9999 -9999 -9999 -9999 -9999 -9999 -9999 -9999 -9999 -9999 -9999 -9999 -9999 -9999 -9999 -9999 170.070098877166 .7174987793165 .8031005859165 .1934967041163 .974395752 163.0599975586161 .8408966064160 .9264984131160 .0122070312158 .7929992676 157.5738983154156 .3547973633154 .8307952881153 .9165039062153 .0021057129 
151.7830047607150 .8686065674149 .9542999268149 .3446960449149 .3446960449 149.6495056152149 .9542999268150 .2590942383149 .6495056152149 .0399017334 148.4304046631147 .5160064697146 .9064025879146 .2969055176145 .6873016357 144.7729034424143 .8585968018142 .6394042969141 .4203033447140 .5059967041 139.8963928223 139.5915985107 139.8963928223 -9999 -9999 -9999 -9999 -9999 -9999-9999 -9999 -9999 -9999 -9999 -9999 -9999 -9999 -9999 -9999 -9999 -9999 -9999 -9999 -9999 -9999 -9999 -9999 -9999 -9999 -9999 -9999 -9999 -9999 -9999 -9999 -9999 -9999 -9999 -9999 -9999 -

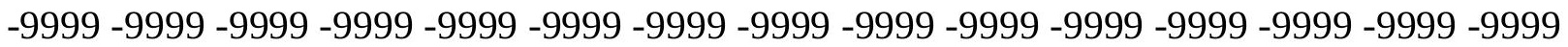

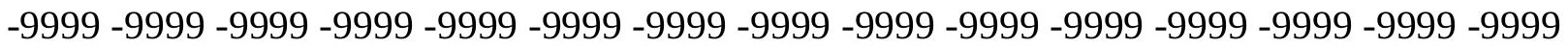
-9999 -9999 -9999 -9999 -9999 -9999 -9999 -9999 -9999 -9999 -9999 -9999 -9999 -9999 -9999 -

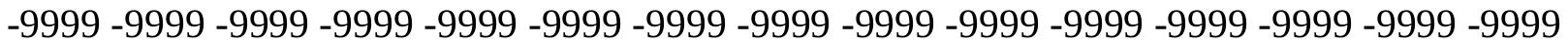
-9999 -9999 -9999 -9999 -9999 -9999 -9999 -9999 -9999 -9999 -9999 -9999 -9999 -9999 -9999 -9999 -9999 -9999 -9999 -9999 -9999 -9999 -9999 -9999 -9999 -9999 -9999 -9999 -9999 -9999 -9999 -9999 -9999 -9999 -9999 -9999 -9999 -9999 -9999 -9999 -9999 -9999 -9999 -9999 - 9999 -9999 -9999 -9999 -9999 -9999 -9999 -9999 -9999 -9999 -9999 -9999 -9999 -9999 -9999 -9999

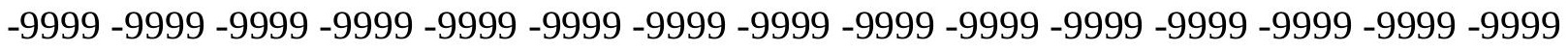
-9999 -9999 -9999 -9999 -9999 -9999 -9999 -9999 -9999 -9999 -9999 -9999 -9999 -9999 -9999 -9999 -9999 -9999 -9999 -9999 -9999 -9999 -9999 -9999 -9999 -9999 -9999 -9999 -9999 -9999 -999 -9999 -9999 -9999 -9999 -9999 -9999 -9999 -9999 -9999 -9999 -9999 -9999 -9999 -9999 -9999 -9999 -9999 -9999 -9999 -9999 -9999 -9999 -9999 -9999 -9999 -9999 -9999 -9999 -9999 -9999 -9999 -9999 -9999 -9999 -9999 -9999 -9999 -9999 -9999 -9999 -9999 -9999 -9999 -9999 -9999 -9999 -9999 -9999 -9999 -9999 -9999 -9999 -9999 -9999 -9999 -9999 -9999 -9999 -9999 -9999 -9999 -9999 -9999 -9999 -9999 -9999 -9999 -9999 -9999 -9999 -9999 -9999 -9999 -9999 -9999 -9999 -9999 -9999 -9999 -9999 -9999 -9999 -9999 -9999 -9999 -9999 -9999 -9999 -9999 -9999 -9999 -9999 -9999 -9999 -9999 -9999 -9999 -9999 -9999 -9999 -9999 -9999 -9999 -9999 -9999 -9999 -9999 -9999 -9999 -9999 -9999 -9999 -9999 -9999 -9999 -9999 -9999 -9999 -9999 -9999 -9999 -9999 -9999 -9999 -9999 -9999 -9999 -9999 -9999 -9999 -9999 -9999 -9999 -9999 -9999 -9999 -9999 -9999 -9999 -9999 -9999 -9999 -9999 -9999 -9999 -9999 -9999 -9999 172.8132019043169 .4604949951168 .8509979248168 .8509979248168 .241394043 167.3269958496166 .4127044678165 .8031005859164 .8887023926163 .974395752 163.0599975586162 .1457061768160 .9264984131159 .7073974609158 .7929992676 157.878692627156 .9642944336155 .4403991699153 .9165039062152 .3925933838 152.6972961426152 .6972961426152 .6972961426152 .3925933838151 .7830047607 150.8686065674149 .6495056152153 .6116943359148 .4304046631148 .4304046631 148.1255950928147 .5160064697146 .6015930176145 .6873016357144 .7729034424 $143.8585968018142 .9441986084142 .3347015381142 .3347015381142 .3347015381-9999$ -9999 -9999 -9999 -9999 -9999 -9999 -9999 -9999 -9999 -9999 -9999 -9999 -9999 -9999 -9999

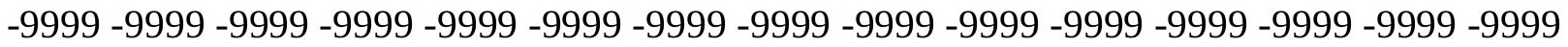
-9999 -9999 -9999 -9999 -9999 -9999 -9999 -9999 -9999 -9999 -9999 -9999 -9999 -9999 -9999 -9999 -9999 -9999 -9999 -9999 -9999 -9999 -9999 -9999 -9999 -9999 -9999 -9999 -9999 -9999 -

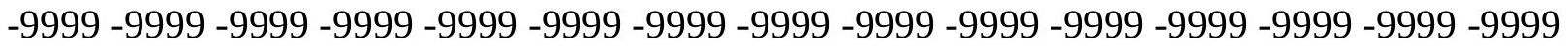

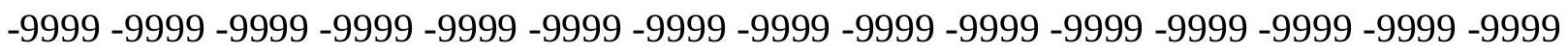
-9999 -9999 -9999 -9999 -9999 -9999 -9999 -9999 -9999 -9999 -9999 -9999 -9999 -9999 -9999 -9999 -9999 -9999 -9999 -9999 -9999 -9999 -9999 -9999 -9999 -9999 -9999 -9999 -9999 -9999 -9999 -9999 -9999 -9999 -9999 -9999 -9999 -9999 -9999 -9999 -9999 -9999 -9999 -9999 -9999 -

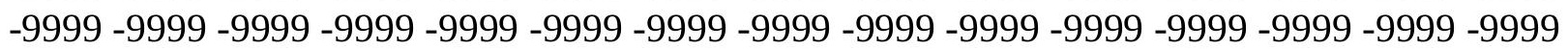


-9999 -9999 -9999 -9999 -9999 -9999 -9999 -9999 -9999 -9999 -9999 -9999 -9999 -9999 -9999 -9999 -9999 -9999 -9999 -9999 -9999 -9999 -9999 -9999 -9999 -9999 -9999 -9999 -9999 -9999 -9999 -9999 -9999 -9999 -9999 -9999 -9999 -9999 -9999 -9999 -9999 -9999 -9999 -9999 -9999 -9999 -9999 -9999 -9999 -9999 -9999 -9999 -9999 -9999 -9999 -9999 -9999 -9999 -9999 -9999 -9999 -9999 -9999 -9999 -9999 -9999 -9999 -9999 -9999-9999 -9999 -9999 -9999 -9999 -9999 -

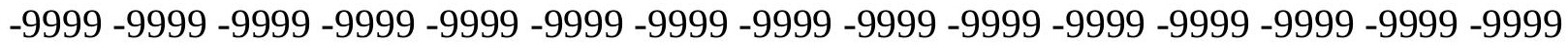
-9999 -9999-9999-9999-9999

-9999 -9999 -9999 -9999 -9999 -9999 -9999 -9999 -9999 -9999 -9999 -9999 -9999 -9999 -9999

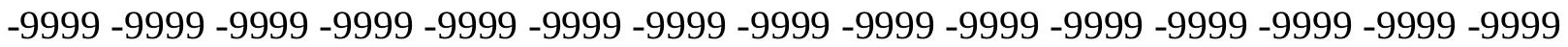
-9999 -9999 -9999 -9999 -9999 -9999 -9999 -9999 -9999 -9999 -9999 -9999 -9999 -9999 -9999 -

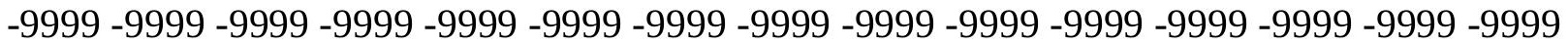
-9999 -9999 -9999 -9999 -9999 -9999 -9999 -9999 -9999 -9999 -9999 -9999 -9999 -9999 -9999 -9999 -9999 -9999 -9999 -9999 -9999 -9999 -9999 -9999 -9999 -9999 -9999 -9999 -9999 -9999 -9999 -9999 -9999 -9999 -9999 -9999 -9999 -9999 -9999 -9999 -9999 -9999 173.7274932861 171.2891998291170 .6797027588171 .2891998291171 .2891998291170 .9844970703 170.6797027588170 .070098877169 .4604949951168 .8509979248167 .9365997314 167.3269958496166 .4127044678165 .4983062744164 .8887023926163 .974395752 163.3648071289162 .1457061768160 .9264984131159 .4026031494157 .878692627 157.2691040039156 .6596069336156 .3547973633155 .4403991699154 .5260925293 153.3069000244152 .0877990723155 .4403991699150 .8686065674151 .1734008789 151.1734008789150 .8686065674150 .2590942383149 .3446960449148 .4304046631 $147.8208007812146 .6015930176145 .9920959473145 .6873016357145 .0776977539-9999$ -9999 -9999 -9999 -9999 -9999 -9999 -9999 -9999 -9999 -9999 -9999 -9999 -9999 -9999 -9999 -9999 -9999 -9999 -9999 -9999 -9999 -9999 -9999 -9999 -9999 -9999 -9999 -9999 -9999 -9999

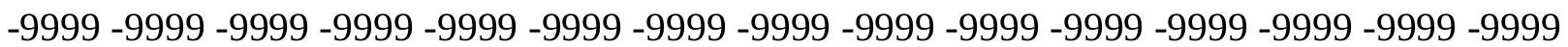
-9999 -9999 -9999 -9999 -9999 -9999 -9999 -9999 -9999 -9999 -9999 -9999 -9999 -9999 -9999 -9999 -9999 -9999 -9999 -9999 -9999 -9999 -9999 -9999 -9999 -9999 -9999 -9999 -9999 -9999 -9999 -9999 -9999 -9999 -9999 -9999 -9999 -9999 -9999 -9999 -9999 -9999 -9999 -9999 -9999 -9999 -9999 -9999 -9999 -9999 -9999 -9999 -9999 -9999 -9999 -9999 -9999 -9999 -9999 -9999 -9999 -9999 -9999 -9999 -9999 -9999 -9999 -9999 -9999 -9999 -9999 -9999 -9999 -9999 -9999 -9999 -9999 -9999 -9999 -9999 -9999 -9999 -9999 -9999 -9999 -9999 -9999 -9999 -9999 -9999 -

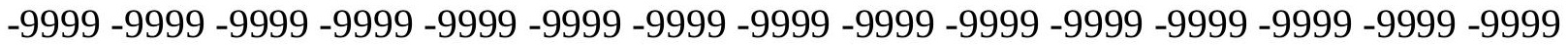
-9999 -9999 -9999 -9999 -9999 -9999 -9999 -9999 -9999 -9999 -9999 -9999 -9999 -9999 -9999 -9999 -9999 -9999 -9999 -9999 -9999 -9999 -9999 -9999 -9999 -9999 -9999 -9999 -9999 -9999 -

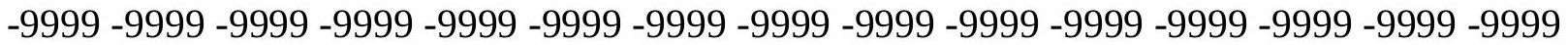
-9999 -9999 -9999 -9999 -9999 -9999 -9999 -9999 -9999 -9999 -9999 -9999 -9999 -9999 -9999 -9999 -9999 -9999 -9999 -9999 -9999 -9999 -9999 -9999 -9999 -9999 -9999 -9999 -9999 -9999

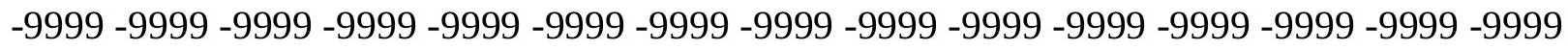
-9999 -9999-9999-9999-9999

-9999 -9999 -9999 -9999 -9999 -9999 -9999 -9999 -9999 -9999 -9999 -9999 -9999 -9999 -9999 -9999 -9999 -9999 -9999 -9999 -9999 -9999 -9999 -9999 -9999 -9999 -9999 -9999 -9999 -9999 -999 -9999 -9999 -9999 -9999 -9999 -9999 -9999 -9999 -9999 -9999 -9999 -9999 -9999 -9999 -9999 -9999 -9999 -9999 -9999 -9999 -9999 -9999 -9999 -9999 -9999 -9999 -9999 -9999 -9999 -9999 -9999 -9999 -9999 -9999 -9999 -9999 -9999 -9999 -9999 -9999 -9999 -9999 -9999 -9999 -9999 -9999 -9999 -9999 -9999 -9999 -9999 -9999 -9999 -9999 -9999 -9999 -9999 -9999 -9999 -9999 -9999 -9999 -9999 -9999 -9999 -9999 -9999 -9999 -9999 -9999 -9999 173.1179962158 
171.8988037109171 .2891998291172 .8132019043173 .4226989746173 .7274932861 173.7274932861173 .4226989746173 .1179962158172 .8132019043172 .5084075928 171.8988037109171 .2891998291170 .6797027588170 .070098877169 .7653045654 169.1557006836168 .8509979248167 .9365997314166 .7174987793165 .4983062744 163.974395752162 .4505004883161 .5361022949160 .3170013428159 .4026031494 157.878692627156 .6596069336155 .4403991699154 .5260925293154 .5260925293 154.5260925293154 .8307952881154 .8307952881154 .2212982178153 .3069000244 152.3925933838151 .7830047607151 .1734008789150 .2590942383149 .0399017334 147.8208007812 -9999 -9999 -9999 -9999 -9999 -9999 -9999 -9999 -9999 -9999 -9999 -9999 -9999 -9999 -9999 -9999 -9999 -9999 -9999 -9999 -9999 -9999 -9999 -9999 -9999 -9999 -9999

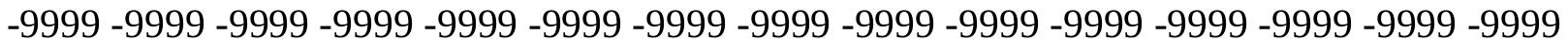
-9999 -9999 -9999 -9999 -9999 -9999 -9999 -9999 -9999 -9999 -9999 -9999 -9999 -9999 -9999 -9999 -9999 -9999 -9999 -9999 -9999 -9999 -9999 -9999 -9999 -9999 -9999 -9999 -9999 -9999 -9999 -9999 -9999 -9999 -9999 -9999 -9999 -9999 -9999 -9999 -9999 -9999 -9999 -9999 -9999 -9999 -9999 -9999 -9999 -9999 -9999 -9999 -9999 -9999 -9999 -9999 -9999 -9999 -9999 -9999

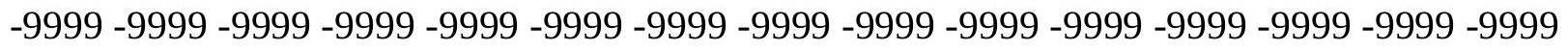
-9999 -9999 -9999 -9999 -9999 -9999 -9999 -9999 -9999 -9999 -9999 -9999 -9999 -9999 -9999 -9999 -9999 -9999 -9999 -9999 -9999 -9999 -9999 -9999 -9999 -9999 -9999 -9999 -9999 -9999 -

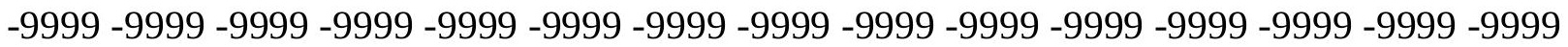

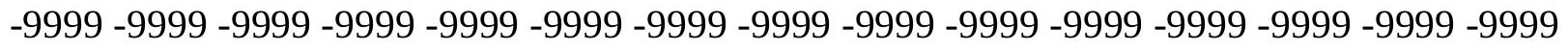

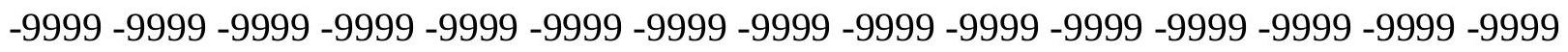
-9999 -9999 -9999 -9999 -9999 -9999 -9999 -9999 -9999 -9999 -9999 -9999 -9999 -9999 -9999 -9999 -9999 -9999 -9999 -9999 -9999 -9999 -9999 -9999 -9999 -9999 -9999 -9999 -9999 -9999 -

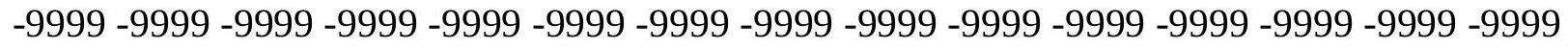
-9999-9999 -9999-9999-9999-9999-9999-9999 -9999

-9999 -9999 -9999 -9999 -9999 -9999 -9999 -9999 -9999 -9999 -9999 -9999 -9999 -9999 -9999 -9999 -9999 -9999 -9999 -9999 -9999 -9999 -9999 -9999 -9999 -9999 -9999 -9999 -9999 -9999 -

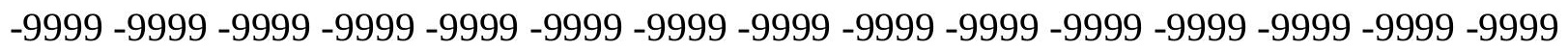
-9999 -9999 -9999 -9999 -9999 -9999 -9999 -9999 -9999 -9999 -9999 -9999 -9999 -9999 -9999 -9999 -9999 -9999 -9999 -9999 -9999 -9999 -9999 -9999 -9999 -9999 -9999 -9999 -9999 -9999 -9999 -9999 -9999 -9999 -9999 -9999 -9999 -9999 -9999 -9999 -9999 -9999 -9999 -9999 -9999 -9999 -9999 -9999 -9999 -9999 -9999 -9999 -9999 -9999 -9999 -9999 171.5939941406 170.9844970703173 .1179962158174 .6419067383175 .5561981201175 .8609924316 176.165802002176 .165802002176 .165802002176 .165802002175 .8609924316 175.5561981201175 .2514038086174 .9467010498174 .337097168174 .0323028564 174.0323028564174 .0323028564173 .7274932861173 .1179962158171 .5939941406 169.7653045654167 .9365997314166 .4127044678164 .8887023926163 .3648071289 162.1457061768160 .6217956543159 .7073974609158 .7929992676158 .7929992676 158.7929992676159 .0977935791159 .4026031494159 .0977935791158 .1835021973 156.9642944336161 .2312927246156 .0500030518155 .1356048584153 .3069000244 150.5639038086 149.0399017334 -9999 -9999-9999 -9999 -9999 -9999 -9999 -9999 -9999 -9999 -9999 -9999 -9999 -9999 -9999 -9999 -9999 -9999 -9999 -9999 -9999 -9999 -9999 -9999 -9999 -9999 -9999 -9999 -9999 -9999 -9999 -9999 -9999 -9999 -9999 -9999 -9999 -9999 -9999 -9999 -9999 -9999 -9999 -9999 -9999 -9999 -9999 -9999 -9999 -9999 -9999 -9999 -9999 -9999 -

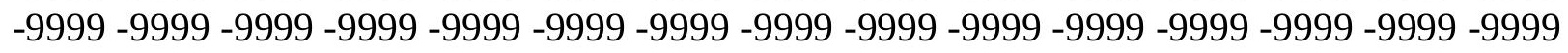

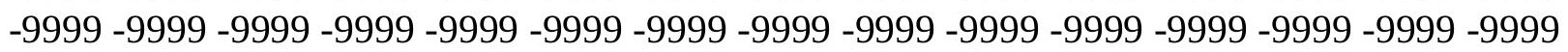


-9999 -9999 -9999 -9999 -9999 -9999 -9999 -9999 -9999 -9999 -9999 -9999 -9999 -9999 -9999 -9999 -9999 -9999 -9999 -9999 -9999 -9999 -9999 -9999 -9999 -9999 -9999 -9999 -9999 -9999 -9999 -9999 -9999 -9999 -9999 -9999 -9999 -9999 -9999 -9999 -9999 -9999 -9999 -9999 -9999 -9999 -9999 -9999 -9999 -9999 -9999 -9999 -9999 -9999 -9999 -9999 -9999 -9999 -9999 -9999 -9999 -9999 -9999 -9999 -9999 -9999 -9999 -9999 -9999 -9999 -9999 -9999 -9999 -9999 -9999 -9999 -9999 -9999 -9999 -9999 -9999 -9999 -9999 -9999 -9999 -9999 -9999 -9999 -9999 -9999 -9999 -9999 -9999 -9999 -9999 -9999 -9999 -9999 -9999 -9999 -9999 -9999 -9999 -9999 -9999

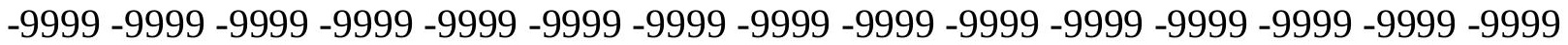
-9999 -9999 -9999 -9999 -9999 -9999 -9999 -9999 -9999 -9999 -9999 -9999 -9999 -9999 -9999 -9999 -9999 -9999 -9999 -9999 -9999 -9999 -9999 -9999 -9999 -9999 -9999 -9999 -9999 -9999 -9999 -9999 -9999 -9999 -9999 -9999 -9999 -9999 -9999 -9999 -9999

-9999 -9999 -9999 -9999 -9999 -9999 -9999 -9999 -9999 -9999 -9999 -9999 -9999 -9999 -9999

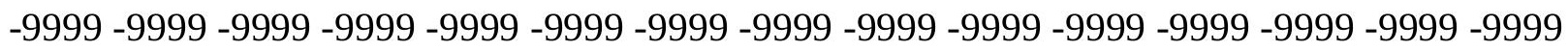
-9999 -9999 -9999 -9999 -9999 -9999 -9999 -9999 -9999 -9999 -9999 -9999 -9999 -9999 -9999 -9999 -9999 -9999 -9999 -9999 -9999 -9999 -9999 -9999 -9999 -9999 -9999 -9999 -9999 -9999 -9999 -9999 -9999 -9999 -9999 -9999 -9999 -9999 -9999 -9999 -9999 -9999 -9999 -9999 -9999 -

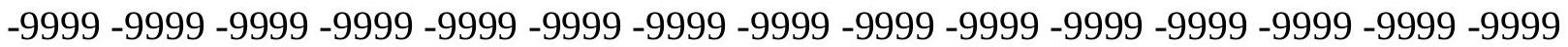
-9999 -9999 -9999 -9999 -9999 -9999 -9999 -9999 -9999 -9999 171.2891998291 170.6797027588172 .2035980225174 .9467010498176 .4705963135177 .6896972656 177.9945068359178 .2993011475178 .604095459178 .9089050293179 .2136993408 179.2136993408178 .9089050293178 .604095459178 .604095459178 .2993011475 178.2993011475178 .604095459179 .2136993408179 .5184020996179 .2136993408 177.6896972656175 .5561981201173 .1179962158171 .2891998291169 .4604949951 167.9365997314166 .4127044678165 .1934967041163 .974395752163 .3648071289 163.3648071289163 .3648071289163 .974395752164 .2792053223164 .5839996338 163.974395752163 .0599975586161 .8408966064161 .2312927246160 .3170013428 157.5738983154154 .5260925293151 .7830047607 -9999 -9999 -9999 -9999 -9999 -9999-9999 -9999 -9999 -9999 -9999 -9999 -9999 -9999 -9999 -9999 -9999 -9999 -9999 -9999 -9999 -9999

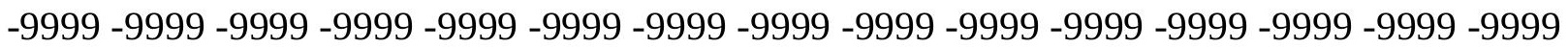

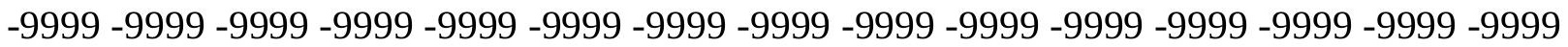
-9999 -9999 -9999 -9999 -9999 -9999 -9999 -9999 -9999 -9999 -9999 -9999 -9999 -9999 -9999 -9999 -9999 -9999 -9999 -9999 -9999 -9999 -9999 -9999 -9999 -9999 -9999 -9999 -9999 -9999 -9999 -9999 -9999 -9999 -9999 -9999 -9999 -9999 -9999 -9999 -9999 -9999 -9999 -9999 -9999 -9999 -9999 -9999 -9999 -9999 -9999 -9999 -9999 -9999 -9999 -9999 -9999 -9999 -9999 -9999 -

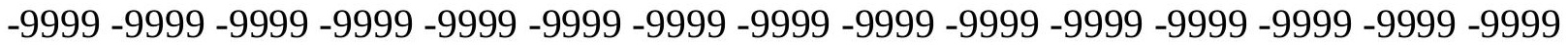
-9999 -9999 -9999 -9999 -9999 -9999 -9999 -9999 -9999 -9999 -9999 -9999 -9999 -9999 -9999 -9999 -9999 -9999 -9999 -9999 -9999 -9999 -9999 -9999 -9999 -9999 -9999 -9999 -9999 -9999

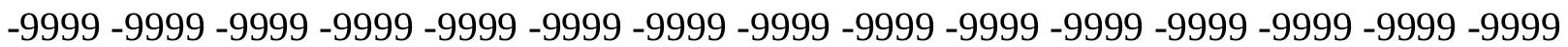
-9999 -9999 -9999 -9999 -9999 -9999 -9999 -9999 -9999 -9999 -9999 -9999 -9999 -9999 -9999 -9999 -9999 -9999 -9999 -9999 -9999 -9999 -9999 -9999 -9999 -9999 -9999 -9999 -9999 -9999 -9999 -9999 -9999 -9999 -9999 -9999 -9999 -9999 -9999 -9999 -9999 -9999 -9999 -9999 -9999 -999 -9999 -9999 -9999 -9999 -9999 -9999 -9999 -9999 -9999 -9999 -9999 -9999 -9999 -9999 -9999 -9999 -9999 -9999 -9999 -9999 -9999 -9999 -9999 -9999 -9999 -9999 -9999 -9999 -9999 -9999 -9999 -9999 -9999 -9999 -9999 -9999 -9999 -9999 -9999 -9999 -9999 -9999 -9999 -9999 -9999 -9999 -9999 -9999 -9999 -9999 -9999 -9999 -9999 -9999 -9999 -9999 -9999 -9999

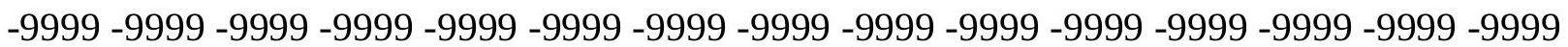


-9999 -9999 -9999 -9999 -9999 -9999 -9999 -9999 -9999 -9999 -9999 -9999 -9999 -9999 -9999 -9999 -9999 -9999 -9999 -9999 -9999 -9999 -9999 -9999 -9999 -9999 -9999 -9999 -9999 -9999 -9999 -9999 -9999 -9999 -9999 -9999 -9999 -9999 -9999 -9999 -9999 -9999 -9999 -9999 -9999 -9999 -9999 -9999 -9999 -9999 -9999 -9999 -9999 -9999 -9999 170.6797027588 170.6797027588174 .6419067383177 .3849029541178 .9089050293179 .8231964111 180.1280059814180 .7375946045181 .0424041748181 .3471984863181 .6519012451 181.9566955566181 .9566955566181 .6519012451181 .6519012451181 .6519012451 181.9566955566182 .261505127184 .0901947021185 .3094024658185 .6141052246 183.7854003906180 .7375946045177 .9945068359175 .8609924316174 .0323028564 172.2035980225170 .6797027588169 .4604949951168 .5462036133167 .9365997314 167.9365997314168 .241394043168 .8509979248169 .7653045654170 .3748931885 170.6797027588170 .070098877168 .8509979248166 .4127044678165 .1934967041 161.8408966064158 .1835021973154 .5260925293151 .4781951904 -9999 -9999 -9999 -9999 -9999 -9999 -9999 -9999 -9999 -9999 -9999 -9999 -9999 -9999 -9999 -9999 -9999 -9999 -9999 -9999 -9999 -9999 -9999 -9999 -9999 -9999 -9999 -9999 -9999 -9999 -9999 -9999 -9999 -9999 -9999 -9999 -9999 -9999 -9999 -9999 -9999 -9999 -9999 -9999 -9999 -9999 -9999 -9999 -9999

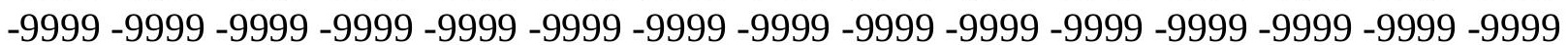
-9999 -9999 -9999 -9999 -9999 -9999 -9999 -9999 -9999 -9999 -9999 -9999 -9999 -9999 -9999 -9999 -9999 -9999 -9999 -9999 -9999 -9999 -9999 -9999 -9999 -9999 -9999 -9999 -9999 -9999 -9999 -9999 -9999 -9999 -9999 -9999 -9999 -9999 -9999 -9999 -9999 -9999 -9999 -9999 -9999

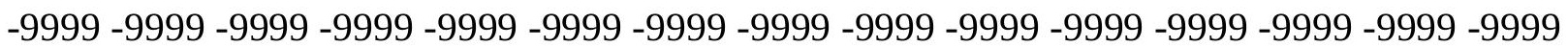
-9999 -9999 -9999 -9999 -9999 -9999 -9999 -9999 -9999 -9999 -9999 -9999 -9999 -9999 -9999 -9999 -9999 -9999 -9999 -9999 -9999 -9999 -9999 -9999 -9999 -9999 -9999 -9999 -9999 -9999 -9999 -9999 -9999 -9999 -9999 -9999 -9999 -9999 -9999 -9999 -9999 -9999 -9999 -9999 -9999

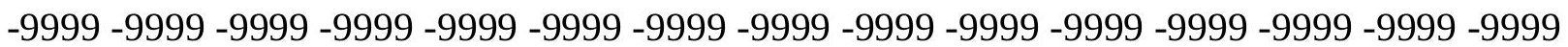
-9999 -9999 -9999 -9999 -9999 -9999 -9999 -9999 -9999 -9999 -9999 -9999 -9999 -9999 -9999 -9999 -9999 -9999 -9999 -9999 -9999 -9999 -9999 -9999 -9999 -9999 -9999 -9999 -9999 -9999 -9999 -9999 -9999 -9999 -9999 -9999 -9999 -9999 -9999 -9999 -9999 -9999 -9999 -9999 -9999 -9999 -9999 -9999 -9999 -9999 -9999 -9999 -9999 -9999 -9999 -9999 -9999 -9999 -9999 -9999 -9999 -9999 -9999 -9999 -9999 -9999 -9999 -9999 -9999 -9999 -9999 -9999 -9999 -9999 -9999 -9999 -9999 -9999 -9999 -9999 -9999 -9999 -9999 -9999 -9999 -9999 -9999 -9999 -9999 -9999 -9999 -9999 -9999 -9999 -9999 -9999 -9999 -9999 -9999 -9999 -9999 -9999 -9999 -9999 -9999 -9999 -9999 -9999 -9999 -9999 -9999 -9999 -9999 -9999 -9999 -9999 -9999 -9999 -9999 -9999 -9999 -9999 -9999 -9999 -9999 -9999 -9999 -9999 -9999 -9999 -9999 -9999 -9999 -9999 -9999

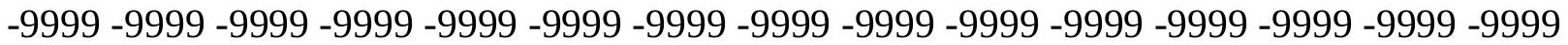
-9999 -9999 -9999 -9999 -9999 -9999 -9999 -9999 -9999 170.9844970703170 .3748931885 174.337097168178 .604095459180 .7375946045181 .9566955566182 .261505127 182.261505127182 .87109375183 .4806976318183 .7854003906184 .0901947021 184.3950042725184 .3950042725184 .3950042725184 .3950042725184 .699798584 185.3094024658186 .2236938477188 .3571929932190 .4907073975191 .7097930908 190.4907073975185 .0045928955182 .87109375180 .432800293178 .2993011475 176.4705963135174 .9467010498173 .7274932861172 .8132019043172 .2035980225 172.2035980225172 .8132019043173 .4226989746174 .6419067383175 .8609924316 177.0802001953177 .0802001953175 .5561981201171 .2891998291167 .9365997314 164.8887023926160 .9264984131156 .9642944336153 .3069000244 -9999 -9999 -9999 -9999 -9999 -9999 -9999 -9999 -9999 -9999 -9999 -9999 -9999 -9999 -9999 -9999 -9999 -9999 -9999 
-9999 -9999 -9999 -9999 -9999 -9999 -9999 -9999 -9999 -9999 -9999 -9999 -9999 -9999 -9999 -9999 -9999 -9999 -9999 -9999 -9999 -9999 -9999 -9999 -9999 -9999 -9999 -9999 -9999 -9999 -9999 -9999 -9999 -9999 -9999 -9999 -9999 -9999 -9999 -9999 -9999 -9999 -9999 -9999 -9999 -9999 -9999 -9999 -9999 -9999 -9999 -9999 -9999 -9999 -9999 -9999 -9999 -9999 -9999 -9999 -9999 -9999 -9999 -9999 -9999 -9999 -9999 -9999 -9999 -9999 -9999 -9999 -9999 -9999 -9999 -9999 -9999 -9999 -9999 -9999 -9999 -9999 -9999 -9999 -9999 -9999 -9999 -9999 -9999 -9999 -9999 -9999 -9999 -9999 -9999 -9999 -9999 -9999 -9999 -9999 -9999 -9999 -9999 -9999 -9999

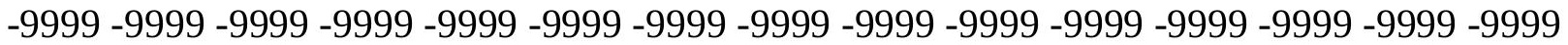
-9999 -9999 -9999 -9999 -9999 -9999 -9999 -9999 -9999 -9999 -9999 -9999 -9999 -9999 -9999 -9999 -9999 -9999 -9999 -9999 -9999 -9999 -9999 -9999 -9999 -9999 -9999 -9999 -9999 -9999 -9999 -9999 -9999 -9999 -9999 -9999 -9999 -9999 -9999 -9999 -9999 -9999 -9999 -9999 -9999 -9999 -9999 -9999 -9999 -9999 -9999 -9999 -9999 -9999 -9999 -9999 -9999 -9999 -9999 -9999

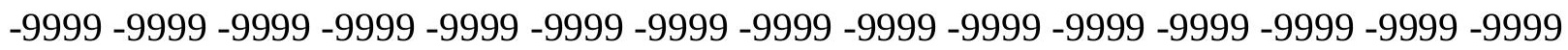
-9999 -9999 -9999 -9999 -9999 -9999 -9999 -9999 -9999 -9999 -9999 -9999 -9999 -9999 -9999 -9999 -9999 -9999 -9999 -9999 -9999 -9999 -9999 -9999 -9999 -9999 -9999 -9999 -9999 -9999 -9999 -9999 -9999 -9999 -9999 -9999 -9999 -9999 -9999 -9999 -9999 -9999 -9999 -9999 -9999 -9999 -9999 -9999 -9999 -9999 -9999 -9999 -9999 -9999 -9999 -9999 -9999 -9999 -9999 -9999 -9999 -9999 -9999 -9999 -9999 -9999 -9999 -9999 -9999 -9999 -9999 -9999 -9999 -9999 -9999 -9999 -9999 -9999 -9999 -9999 -9999 -9999 -9999 -9999 -9999 -9999 -9999 -9999 -9999 -9999 -9999 -9999 -9999 -9999 -9999 -9999 -9999 -9999 -9999 -9999 -9999 -9999 -9999 -9999 -9999 -9999 -9999 -9999 -9999 -9999 -9999 -9999 -9999 -9999 -9999 -9999 -9999 -9999 -9999 -9999 -9999 -9999 -9999 -9999 -9999 -9999-9999 -9999 -9999 170.6797027588 171.2891998291 180.432800293182 .5662994385183 .7854003906184 .699798584185 .0045928955 185.0045928955185 .3094024658185 .6141052246185 .9188995361185 .9188995361 186.2236938477186 .2236938477186 .2236938477186 .528503418186 .8332977295 187.7476043701189 .2716064453191 .4051055908193 .8433074951196 .2816009521 198.1103057861191 .7097930908187 .1381072998184 .0901947021181 .6519012451 179.8231964111178 .604095459177 .3849029541176 .4705963135176 .165802002 176.4705963135176 .7754058838177 .9945068359179 .5184020996181 .3471984863 182.87109375183 .4806976318182 .5662994385176 .165802002170 .3748931885 167.3269958496163 .3648071289159 .0977935791154 .8307952881 -9999 -9999 -9999 -9999 -9999 -9999 -9999 -9999 -9999 -9999 -9999 -9999 -9999 -9999 -9999 -9999 -9999 -9999 -9999 -9999 -9999 -9999 -9999 -9999 -9999 -9999 -9999 -9999 -9999 -9999 -9999 -9999 -9999 -9999 -9999 -9999 -9999 -9999 -9999 -9999 -9999 -9999 -9999 -9999 -9999 -9999 -9999 -9999 -9999 -

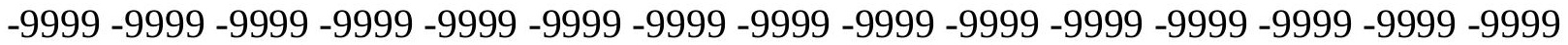
-9999 -9999 -9999 -9999 -9999 -9999 -9999 -9999 -9999 -9999 -9999 -9999 -9999 -9999 -9999 -9999 -9999 -9999 -9999 -9999 -9999 -9999 -9999 -9999 -9999 -9999 -9999 -9999 -9999 -9999

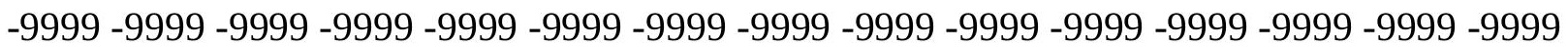
-9999 -9999 -9999 -9999 -9999 -9999 -9999 -9999 -9999 -9999 -9999 -9999 -9999 -9999 -9999 -9999 -9999 -9999 -9999 -9999 -9999 -9999 -9999 -9999 -9999 -9999 -9999 -9999 -9999 -9999 -9999 -9999 -9999 -9999 -9999 -9999 -9999 -9999 -9999 -9999 -9999 -9999 -9999 -9999 -9999 -999 -9999 -9999 -9999 -9999 -9999 -9999 -9999 -9999 -9999 -9999 -9999 -9999 -9999 -9999 -9999 -9999 -9999 -9999 -9999 -9999 -9999 -9999 -9999 -9999 -9999 -9999 -9999 -9999 -9999 -9999 -9999 -9999 -9999 -9999 -9999 -9999 -9999 -9999 -9999 -9999 -9999 -9999 -9999 -9999 -9999 -9999 -9999 -9999 -9999 -9999 -9999 -9999 -9999 -9999 -9999 -9999 -9999 -9999 -9999 -9999

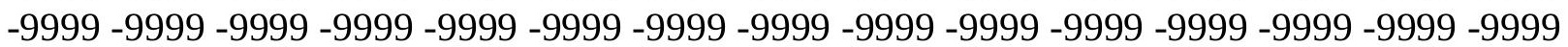


-9999 -9999 -9999 -9999 -9999 -9999 -9999 -9999 -9999 -9999 -9999 -9999 -9999 -9999 -9999 -9999 -9999 -9999 -9999 -9999 -9999 -9999 -9999 -9999 -9999 -9999 -9999 -9999 -9999 -9999 -9999 -9999 -9999 -9999 -9999 -9999 -9999 -9999 -9999 -9999 -9999 -9999 -9999 -9999 -9999 -9999 -9999 -9999 -9999 -9999 -9999 -9999 -9999 -9999 -9999 -9999 -9999 -9999 -9999 -9999 -9999 -9999 -9999 -9999 -9999 -9999 -9999 -9999 -9999 -9999 -9999 -9999 -9999 -9999 -9999 -9999 -9999 -9999 -9999 -9999 -9999 -9999 -9999 -9999 -9999 -9999 -9999 -9999 -9999 -9999 -9999 -9999 -9999 -9999 -9999 -9999 -9999 -9999 -9999 -9999 -9999 -9999 -9999 -9999 -9999 -9999 -9999 -9999 -9999 -9999 -9999 -9999 -9999 170.9844970703170 .6797027588 176.4705963135181 .0424041748184 .699798584186 .528503418187 .4429016113 187.7476043701187 .7476043701187 .7476043701187 .7476043701187 .7476043701 187.7476043701187 .4429016113187 .4429016113187 .4429016113187 .7476043701 188.3571929932189 .2716064453190 .795501709192 .624206543195 .0625196 .891204834 196.891204834193 .8433074951189 .8811035156186 .528503418184 .3950042725 182.5662994385181 .3471984863180 .432800293179 .8231964111179 .8231964111 180.1280059814180 .432800293181 .6519012451183 .4806976318185 .9188995361 187.7476043701188 .0523986816185 .9188995361181 .0424041748174 .6419067383 $169.7653045654165 .8031005859161 .2312927246156 .6596069336152 .0877990723-9999$ -9999 -9999 -9999 -9999 -9999 -9999 -9999 -9999 -9999 -9999 -9999 -9999 -9999 -9999 -9999 -9999 -9999 -9999 -9999 -9999 -9999 -9999 -9999 -9999 -9999 -9999 -9999 -9999 -9999 -9999 -9999 -9999 -9999 -9999 -9999 -9999 -9999 -9999 -9999 -9999 -9999 -9999 -9999 -9999 -9999

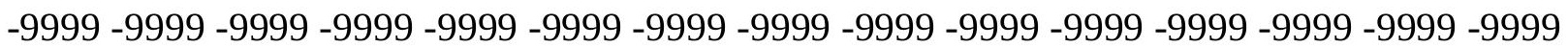
-9999 -9999 -9999 -9999 -9999 -9999 -9999 -9999 -9999 -9999 -9999 -9999 -9999 -9999 -9999 -9999 -9999 -9999 -9999 -9999 -9999 -9999 -9999 -9999 -9999 -9999 -9999 -9999 -9999 -9999 -9999 -9999 -9999 -9999 -9999 -9999 -9999 -9999 -9999 -9999 -9999 -9999 -9999 -9999 -9999

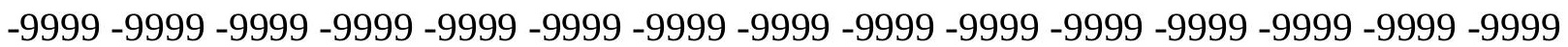
-9999 -9999 -9999 -9999 -9999 -9999 -9999 -9999 -9999 -9999 -9999 -9999 -9999 -9999 -9999 -9999 -9999 -9999 -9999 -9999 -9999 -9999 -9999 -9999 -9999 -9999 -9999 -9999 -9999 -9999 -9999 -9999 -9999 -9999 -9999 -9999 -9999 -9999 -9999 -9999 -9999 -9999 -9999 -9999 -9999 -9999 -9999 -9999 -9999 -9999 -9999 -9999 -9999 -9999 -9999 -9999 -9999 -9999 -9999 -9999 -9999 -9999 -9999 -9999 -9999 -9999 -9999 -9999 -9999 -9999 -9999 -9999 -9999 -9999 -9999 -9999 -9999 -9999 -9999 -9999 -9999 -9999 -9999 -9999 -9999 -9999 -9999 -9999 -9999 -9999 -

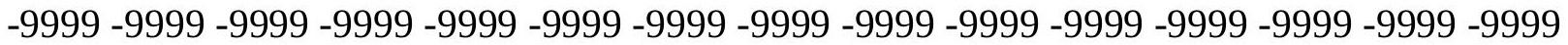

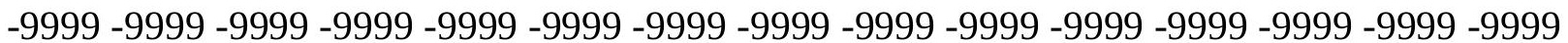
-9999 -9999

-9999 -9999 -9999 -9999 -9999 -9999 -9999 -9999 -9999 -9999 -9999 -9999 -9999 -9999 -9999 -9999 -9999 -9999 -9999 -9999 -9999 -9999 -9999 -9999 -9999 -9999 -9999 -9999 -9999 -9999 -9999 -9999 -9999 -9999 -9999 -9999 -9999 -9999 -9999 -9999 -9999 -9999 -9999 -9999 -9999

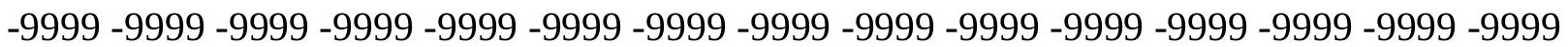
-9999 -9999 -9999 -9999 -9999 -9999 -9999 -9999 -9999 -9999 -9999 -9999 -9999 -9999 -9999 -9999 -9999 -9999 -9999 -9999 -9999 -9999 -9999 -9999 -9999 -9999 -9999 -9999 -9999 -9999 -999 -9999 -9999 -9999 -9999 -9999-9999-9999 171.8988037109172 .5084075928173 .7274932861 178.604095459182 .5662994385185 .9188995361188 .0523986816189 .2716064453 189.8811035156189 .8811035156189 .5764007568189 .2716064453188 .966796875 188.6620025635188 .3571929932188 .3571929932188 .3571929932188 .3571929932 188.6620025635189 .5764007568190 .795501709192 .3193969727193 .8433074951 194.7577056885194 .4528961182192 .9290008545190 .1858978271187 .4429016113 
185.6141052246184 .0901947021182 .87109375187 .7476043701189 .5764007568 182.87109375183 .4806976318184 .3950042725184 .3950042725187 .1381072998 189.8811035156191 .7097930908192 .0146026611189 .8811035156185 .6141052246 180.432800293174 .337097168168 .5462036133163 .974395752159 .0977935791 154.8307952881 -9999 -9999 -9999 -9999 -9999 -9999 -9999 -9999 -9999 -9999 -9999 -9999 -9999 -9999 -9999 -9999 -9999 -9999 -9999 -9999 -9999 -9999 -9999 -9999 -9999 -9999 -9999

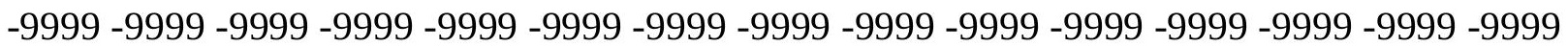

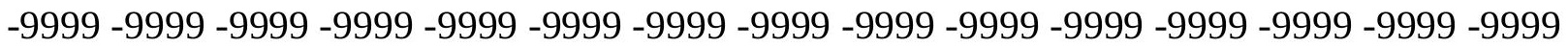
-9999 -9999 -9999 -9999 -9999 -9999 -9999 -9999 -9999 -9999 -9999 -9999 -9999 -9999 -9999 -9999 -9999 -9999 -9999 -9999 -9999 -9999 -9999 -9999 -9999 -9999 -9999 -9999 -9999 -9999 -9999 -9999 -9999 -9999 -9999 -9999 -9999 -9999 -9999 -9999 -9999 -9999 -9999 -9999 -9999 -999 -9999 -9999 -9999 -9999 -9999 -9999 -9999 -9999 -9999 -9999 -9999 -9999 -9999 -9999 -9999 -9999 -9999 -9999 -9999 -9999 -9999 -9999 -9999 -9999 -9999 -9999 -9999 -9999 -9999 -9999 -9999 -9999 -9999 -9999 -9999 -9999 -9999 -9999 -9999 -9999 -9999 -9999 -9999 -9999 -9999 -9999 -9999 -9999 -9999 -9999 -9999 -9999 -9999 -9999 -9999 -9999 -9999 -9999 -9999 -9999

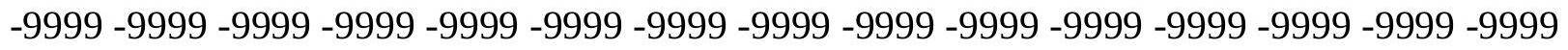
-9999 -9999 -9999 -9999 -9999 -9999 -9999 -9999 -9999 -9999 -9999 -9999 -9999 -9999 -9999 -

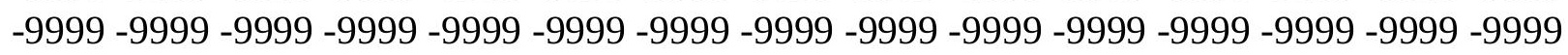

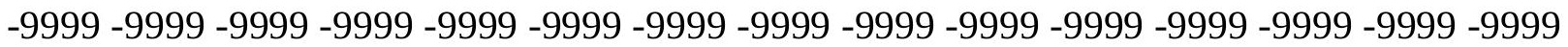
-9999 -9999 -9999 -9999 -9999 -9999 -9999 -9999 -9999 -9999 -9999 -9999 -9999 -9999 -9999 -9999 -9999 -9999 -9999-9999-9999

-9999 -9999 -9999 -9999 -9999 -9999 -9999 -9999 -9999 -9999 -9999 -9999 -9999 -9999 -9999 -9999 -9999 -9999 -9999 -9999 -9999 -9999 -9999 -9999 -9999 -9999 -9999 -9999 -9999 -9999 -9999 -9999 -9999 -9999 -9999 -9999 -9999 -9999 -9999 -9999 -9999 -9999 -9999 -9999 -9999 -

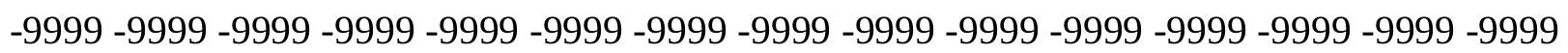
-9999 -9999 -9999 -9999 -9999 -9999 -9999 -9999 -9999 -9999 -9999 -9999 -9999 -9999 -9999

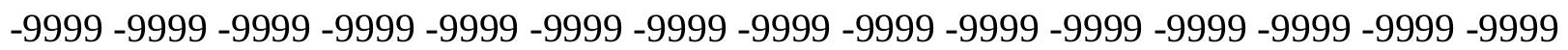
-9999 -9999 -9999 -9999 -9999-9999 173.1179962158 174.0323028564 174.9467010498 177.0802001953180 .432800293184 .0901947021187 .1381072998189 .5764007568 190.795501709191 .4051055908191 .4051055908191 .1002960205190 .4907073975 189.8811035156189 .2716064453188 .6620025635188 .3571929932188 .3571929932 188.0523986816188 .3571929932188 .966796875189 .5764007568190 .4907073975 191.4051055908191 .7097930908191 .4051055908190 .4907073975188 .6620025635 187.1381072998190 .795501709190 .4907073975190 .795501709191 .7097930908 192.0146026611190 .795501709186 .2236938477188 .6620025635188 .966796875 190.795501709193 .233795166195 .3672943115195 .3672943115193 .8433074951 190.4907073975185 .9188995361180 .432800293174 .0323028564167 .6318054199 162.1457061768157 .878692627154 .2212982178 -9999 -9999 -9999 -9999 -9999 -9999 -9999 -9999 -9999 -9999 -9999 -9999 -9999 -9999 -9999 -9999 -9999 -9999 -9999 -9999 -9999 -9999 -9999 -9999 -9999 -9999 -9999 -9999 -9999 -9999 -9999 -9999 -9999 -9999 -9999 -9999 -9999 -

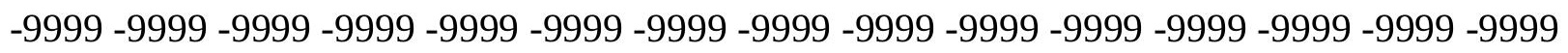

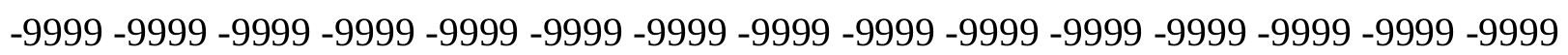
-9999 -9999 -9999 -9999 -9999 -9999 -9999 -9999 -9999 -9999 -9999 -9999 -9999 -9999 -9999 -9999 -9999 -9999 -9999 -9999 -9999 -9999 -9999 -9999 -9999 -9999 -9999 -9999 -9999 -9999 -

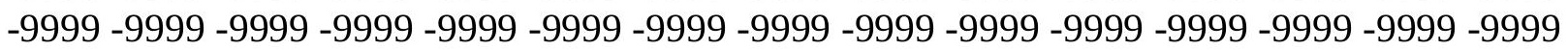

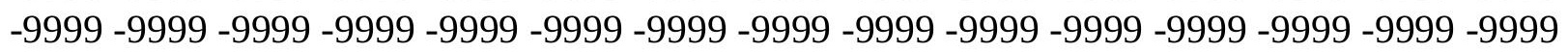


-9999 -9999 -9999 -9999 -9999 -9999 -9999 -9999 -9999 -9999 -9999 -9999 -9999 -9999 -9999 -9999 -9999 -9999 -9999 -9999 -9999 -9999 -9999 -9999 -9999 -9999 -9999 -9999 -9999 -9999 -

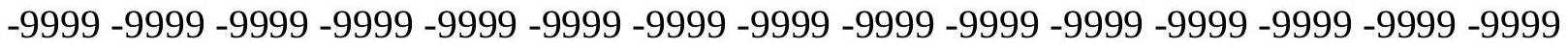
-9999 -9999 -9999 -9999 -9999 -9999 -9999 -9999 -9999 -9999 -9999 -9999 -9999 -9999 -9999 -9999 -9999 -9999 -9999 -9999 -9999 -9999 -9999 -9999-9999 -9999 -9999 -9999 -9999 -9999 -9999 -9999 -9999 -9999 -9999 -9999 -9999 -9999 -9999 -9999 -9999 -9999 -9999 -9999 -9999 -

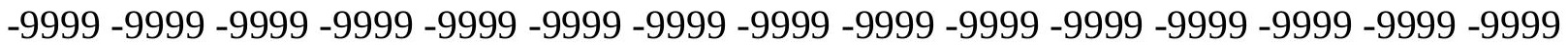
-9999 -9999 -9999 -9999-9999 -9999-9999 -9999 -9999-9999

-9999 -9999 -9999 -9999 -9999 -9999 -9999 -9999 -9999 -9999 -9999 -9999 -9999 -9999 -9999 -9999 -9999 -9999 -9999 -9999 -9999 -9999 -9999 -9999 -9999 -9999 -9999 -9999 -9999 -9999 -9999 -9999 -9999 -9999 -9999 -9999 -9999 -9999 -9999 -9999 -9999 -9999 -9999 -9999 -9999 -9999 -9999 -9999 -9999 -9999 -9999 -9999 -9999 -9999 -9999 -9999 -9999 -9999 -9999 -9999 -9999 -9999 -9999 -9999 -9999 -9999 -9999 -9999 -9999 -9999 -9999 -9999 -9999 -9999 -9999 -9999 -9999 -9999 -9999 -9999 -9999 -9999 -9999 -9999 -9999 -9999 -9999 -9999 -9999 -9999 -9999 -9999 -9999 -9999 -9999 -9999 174.9467010498175 .8609924316177 .3849029541 179.8231964111182 .5662994385185 .6141052246188 .0523986816190 .1858978271 191.7097930908192 .3193969727192 .3193969727192 .0146026611191 .1002960205 190.1858978271189 .2716064453188 .6620025635188 .0523986816187 .7476043701 187.4429016113187 .1381072998187 .4429016113187 .7476043701188 .0523986816 188.0523986816188 .3571929932188 .0523986816187 .4429016113186 .528503418 185.6141052246190 .1858978271190 .4907073975191 .1002960205191 .7097930908 192.0146026611191 .7097930908187 .4429016113189 .2716064453191 .1002960205 192.9290008545194 .8256378174198 .1103057861198 .1103057861196 .891204834 194.7577056885191 .1002960205186 .2236938477180 .432800293174 .0323028564 167.3269958496165 .1934967041156 .3547973633153 .0021057129 -9999 -9999 -9999 -9999 -9999 -9999 -9999 -9999 -9999 -9999 -9999 -9999 -9999 -9999 -9999 -9999 -9999 -9999 -9999 -9999 -9999 -9999 -9999 -9999 -9999 -9999 -9999 -9999 -9999 -9999 -9999 -9999 -9999 -9999 -9999 -9999 -9999 -9999 -9999 -9999 -9999 -9999 -9999 -9999 -9999 -9999 -9999 -9999 -9999 -9999 -9999 -9999 -9999 -9999 -9999 -9999 -9999 -9999 -9999 -9999 -9999 -9999 -9999 -9999 -9999 -9999 -9999 -9999 -9999 -9999 -9999 -9999 -9999 -9999 -9999 -9999 -9999 -9999 -999 -9999 -9999 -9999 -9999 -9999 -9999 -9999 -9999 -9999 -9999 -9999 -9999 -9999 -9999 -9999 -9999 -9999 -9999 -9999 -9999 -9999 -9999 -9999 -9999 -9999 -9999 -9999 -9999 -9999 -9999 -

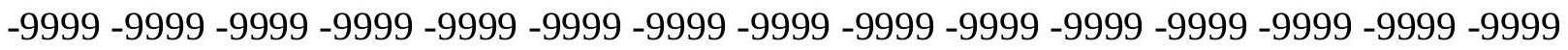

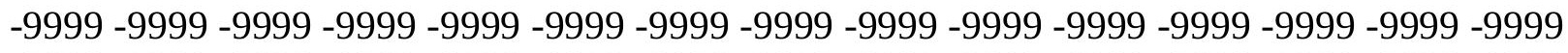
-9999 -9999 -9999 -9999 -9999 -9999 -9999 -9999 -9999 -9999 -9999 -9999 -9999 -9999 -9999 -

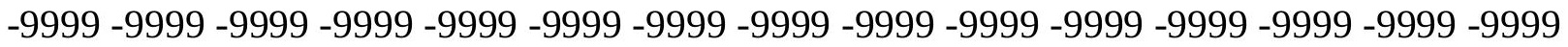

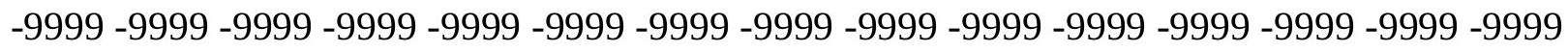

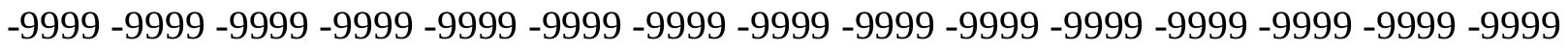
-9999 -9999 -9999 -9999 -9999 -9999 -9999 -9999 -9999 -9999 -9999 -9999 -9999 - 9999 - -999 -9999 -9999 -9999 -9999 -9999 -9999 -9999 -9999 -9999 -9999 -9999 -9999 -9999 -9999 - -9999 -9999 -9999 -9999 -9999 -9999 -9999 -9999 -9999 -9999 -9999 -9999 -9999 -

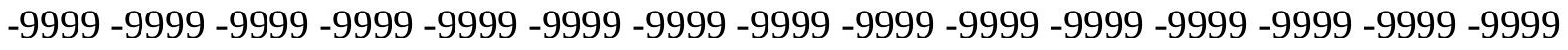
-9999 -9999 -9999 -9999 -9999 -9999 -9999 -9999 -9999 -9999 -9999 -9999 -9999 -9999 -9999 -9999 -9999 -9999 -9999 -9999 -9999 -9999 -9999 -9999-9999 -9999 -9999 -9999 -9999 -9999 -9999 -9999 -9999 -9999 -9999 -9999 -9999 -9999 -9999 -9999 -9999 -9999 -9999 -9999 -9999 -

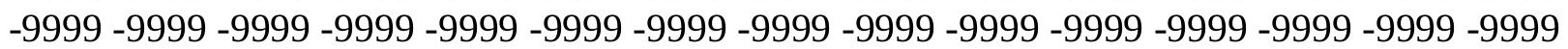


-9999 -9999 -9999 -9999 -9999 -9999 -9999 -9999 -9999 -9999 -9999 -9999 -9999 -9999 -9999 -9999 -9999 -9999 -9999 -9999 176.165802002176 .7754058838177 .9945068359 179.8231964111181 .9566955566184 .0901947021186 .528503418188 .966796875 190.4907073975191 .7097930908192 .624206543192 .624206543192 .0146026611 190.795501709189 .8811035156188 .6620025635187 .7476043701187 .1381072998 186.528503418185 .9188995361185 .6141052246185 .6141052246185 .3094024658 185.0045928955185 .0045928955184 .699798584184 .699798584184 .699798584 184.3950042725183 .7854003906183 .0897674561183 .6764984131184 .3280792236 185.0425567627185 .8273162842186 .7016601562186 .8332977295188 .966796875 191.1002960205192 .9290008545194 .2620544434194 .8188476562199 .0247039795 199.329498291 198.4151000977195.6721038818191.7097930908 186.528503418 180.432800293174 .0323028564167 .3269958496160 .0122070312154 .5260925293 150.8686065674148 .4304046631 -9999 -9999 -9999 -9999 -9999 -9999 -9999 -9999 -9999 -9999 -9999 -9999 -9999 -9999 -9999 -9999 -9999 -9999 -9999 -9999 -9999 -9999 -9999 -9999 -9999 -9999 -9999 -9999 -9999 -9999 -9999 -9999 -9999 -9999 -9999 -9999 -9999 -9999 -9999

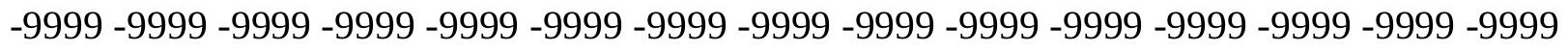
-9999 -9999 -9999 -9999 -9999 -9999 -9999 -9999 -9999 -9999 -9999 -9999 -9999 -9999 -9999 -9999 -9999 -9999 -9999 -9999 -9999 -9999 -9999 -9999 -9999 -9999 -9999 -9999 -9999 -9999 -

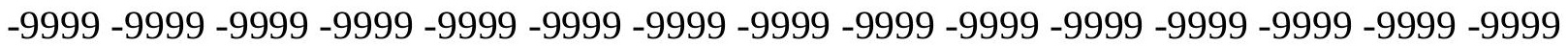

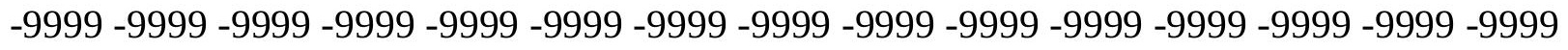

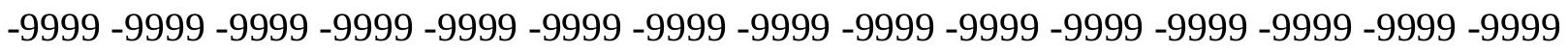
-9999 -9999 -9999 -9999 -9999 -9999 -9999 -9999 -9999 -9999 -9999 -9999 -9999 -9999 -9999 -9999 -9999 -9999 -9999 -9999 -9999 -9999 -9999 -9999 -9999 -9999 -9999 -9999 -9999 -9999 -

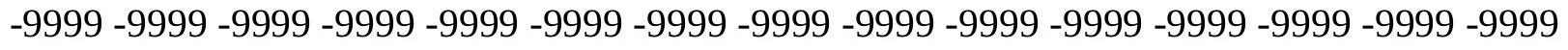

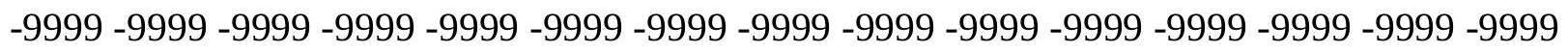
-9999 -9999 -9999 -9999 -9999 -9999 -9999 -9999 -9999 -9999 -9999 -9999 -9999 -9999 -9999

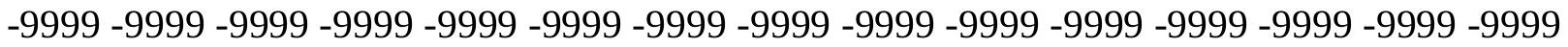

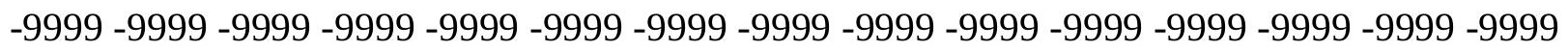
-9999 -9999 -9999 -9999-9999

-9999 -9999 -9999 -9999 -9999 -9999 -9999 -9999 -9999 -9999 -9999 -9999 -9999 -9999 -9999 -9999 -9999 -9999 -9999 -9999 -9999 -9999 -9999 -9999-9999 -9999 -9999 -9999 -9999 -9999 -9999 -9999 -9999 -9999 -9999 -9999 -9999 -9999 -9999 -9999 -9999 -9999 -9999 -9999 -9999 -

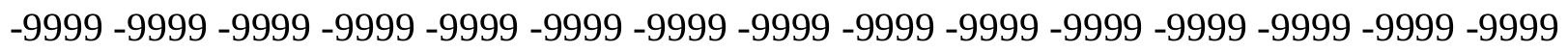
-9999 -9999 -9999 -9999 -9999 -9999 -9999 -9999 -9999 -9999 -9999 -9999 -9999 -9999 -9999 -9999 -9999 -9999 -9999 -9999 -9999 -9999 -9999 -9999 -9999 -9999 -9999 -9999 -9999 -9999 -9999 -9999-9999-9999 177.3849029541 177.6896972656178.604095459 179.8231964111 181.6519012451183 .4806976318185 .3094024658187 .4429016113189 .2716064453 190.4907073975191 .4051055908192 .0146026611191 .7097930908191 .1002960205 189.8811035156188 .6620025635187 .4429016113186 .528503418185 .6141052246 185.0045928955184 .3950042725183 .7854003906183 .1759033203182 .87109375 182.5662994385181 .9566955566179 .8751068115179 .990020752180 .2264251709 180.5758666992181 .0233917236181 .5544281006181 .9566955566182 .829208374 183.5686187744182 .5662994385184 .0901947021185 .9188995361187 .7476043701 189.8811035156191 .7097930908193 .5386047363193 .7780151367193 .8272857666 200.5485992432200 .8533935547199 .329498291195 .9768066406191 .7097930908 186.2236938477180 .432800293174 .337097168167 .6318054199160 .0122070312 
152.0877990723149 .0399017334 -9999 -9999 -9999 -9999 -9999 -9999 -9999 -9999 -9999 -9999 -9999 -9999 -9999 -9999 -9999 -9999 -9999 -9999 -9999 -9999 -9999 -9999 -9999 -9999

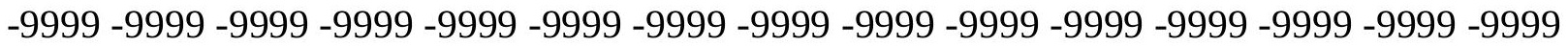
-9999 -9999 -9999 -9999 -9999 -9999 -9999 -9999 -9999 -9999 -9999 -9999 -9999 -9999 -9999 -9999 -9999 -9999 -9999 -9999 -9999 -9999 -9999 -9999-9999 -9999 -9999 -9999 -9999 -9999 -9999 -9999 -9999 -9999 -9999 -9999 -9999 -9999 -9999 -9999 -9999 -9999 -9999 -9999 -9999 -9999 -9999 -9999 -9999 -9999 -9999 -9999 -9999 -9999 -9999 -9999 -9999 -9999 -9999 -9999 -999 -

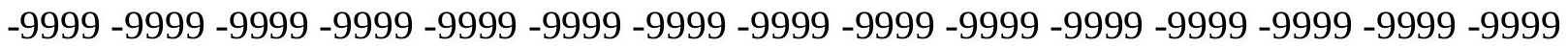
-9999 -9999 -9999 -9999 -9999 -9999 -9999 -9999 -9999 -9999 -9999 -9999 -9999 -9999 -9999 -9999 -9999 -9999 -9999 -9999 -9999 -9999 -9999 -9999 -9999 -9999 -9999 -9999 -9999 -9999 -9999 -9999 -9999 -9999 -9999 -9999 -9999 -9999 -9999 -9999 -9999 -9999 -9999 -9999 -9999 -9999 -9999 -9999 -9999 -9999 -9999 -9999 -9999 -9999 -9999 -9999 -9999 -9999 -9999 -9999 -9999 -9999 -9999 -9999 -9999 -9999 -9999 -9999 -9999 -9999 -9999 -9999 -9999 -9999 -9999 -

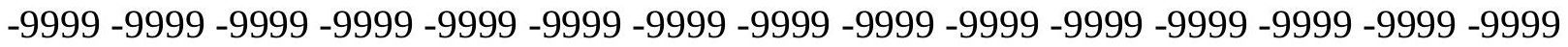
-9999 -9999 -9999 -9999 -9999 -9999 -9999 -9999 -9999 -9999 -9999 -9999 -9999 -9999 -9999 -

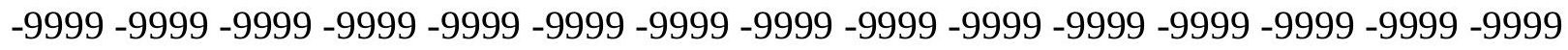
-9999 -9999-9999-9999-9999

-9999 -9999 -9999 -9999 -9999 -9999 -9999 -9999 -9999 -9999 -9999 -9999 -9999 -9999 -9999 -9999 -9999 -9999 -9999 -9999 -9999 -9999 -9999 -9999 -9999 -9999 -9999 -9999 -9999 -9999 -9999 -9999 -9999 -9999 -9999 -9999 -9999 -9999 -9999 -9999 -9999 -9999 -9999 -9999 -9999 -9999 -9999 -9999 -9999 -9999 -9999 -9999 -9999 -9999 -9999 -9999 -9999 -9999 -9999 -9999 -999 -9999 -9999 -9999 -9999 -9999 -9999 -9999 -9999 -9999 -9999 -9999 -9999 -9999 -9999 -9999 -9999 -9999 -9999 -9999 -9999 -9999 -9999 -9999 -9999 -9999 -9999 -9999 -9999 -9999 -9999 -9999 -9999 -9999-9999 178.9089050293 179.2136993408 180.432800293181.6519012451 182.87109375184 .3950042725186 .2236938477187 .7476043701188 .966796875 189.8811035156190 .4907073975190 .795501709190 .4907073975189 .5764007568 188.3571929932187 .1381072998185 .9188995361184 .699798584183 .7854003906 182.87109375180 .5134124756179 .7512664795179 .1588287354178 .7261810303 178.4398956299178 .2927246094178 .2801513672178 .4003143311178 .6485595703 179.0159606934179 .4842376709180 .0358123779180 .432800293180 .7375946045 181.0424041748181 .9566955566183 .1759033203184 .699798584186 .2236938477 188.966796875189 .8811035156191 .1002960205192 .1416168213192 .5443267822 192.5272521973201 .158203125200 .5485992432199 .0247039795195 .3672943115 190.4907073975185 .6141052246181 .0424041748175 .8609924316169 .1557006836 162.1457061768 149.9542999268 147.8208007812 -9999 -9999 -9999 -9999 -9999 -9999 -9999 -9999 -9999 -9999 -9999 -9999 -9999 -9999 -9999 -9999 -9999 -9999 -9999 -9999 -9999 -9999

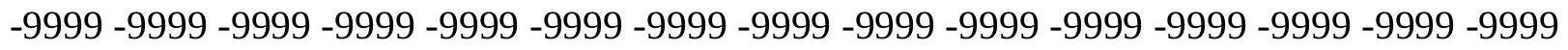

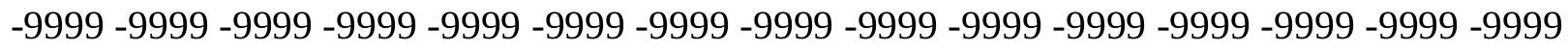
-9999 -9999 -9999 -9999 -9999 -9999 -9999 -9999 -9999 -9999 -9999 -9999 -9999 - 9999 - -999 -9999 -9999 -9999 -9999 -9999 -9999 -9999 -9999 -9999 -9999 -9999 -9999 -9999 -9999 -9999 -

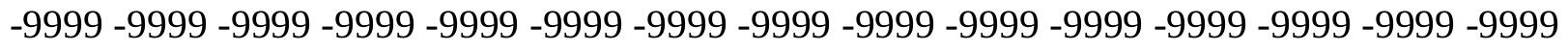

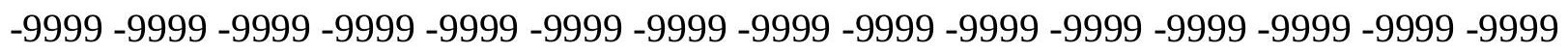
-9999 -9999 -9999 -9999 -9999 -9999 -9999 -9999 -9999 -9999 -9999 -9999 -9999 -9999 -9999 -9999 -9999 -9999 -9999 -9999 -9999 -9999 -9999 -9999-9999 -9999 -9999 -9999 -9999 -9999 -9999 -9999 -9999 -9999 -9999 -9999 -9999 -9999 -9999 -9999 -9999 -9999 -9999 -9999 -9999 -

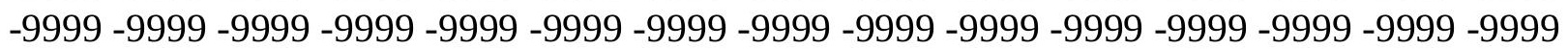


-9999 -9999 -9999 -9999 -9999 -9999 -9999 -9999 -9999 -9999 -9999 -9999 -9999 -9999 -9999 -9999 -9999 -9999 -9999 -9999 -9999 -9999 -9999 -9999 -9999 -9999 -9999 -9999 -9999 -9999 -9999 -9999 -9999 -9999 -9999 -9999 -9999 -9999 -9999 -9999 -9999 -9999 -9999 -9999 -9999 -9999 -9999 -9999 -9999 -9999 -9999 -9999 -9999 -9999 -9999 -9999 -9999 -9999 -9999 -9999 -9999 -9999 -9999-9999-9999-9999

-9999 -9999 -9999 -9999 -9999 -9999 -9999 -9999 -9999 -9999 -9999 -9999 -9999 -9999 -9999 -9999 -9999 -9999 -9999 -9999 -9999 -9999 -9999 -9999 -9999 -9999 -9999 -9999 -9999 -9999 -

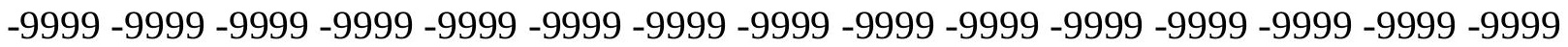

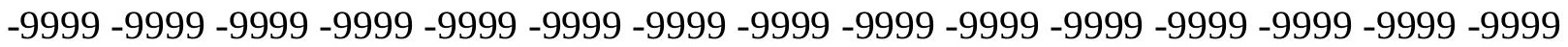
-9999 -9999 -9999 -9999 -9999 -9999 -9999 -9999 -9999 -9999 -9999 -9999 -9999 -9999 -9999 -9999 -9999 -9999 -9999 -9999 -9999 -9999 -9999 -9999 -9999 -9999 -9999 -9999 -9999 -9999 -9999 -9999-9999 -9999 180.1280059814 180.7375946045181 .6519012451182 .5662994385 183.7854003906185 .0045928955186 .528503418187 .4429016113188 .6620025635 189.2716064453189 .5764007568189 .2716064453187 .7252502441187 .0762023926 186.0965881348184 .8744354248183 .5982818604182 .2525787354180 .9615631104 179.8143768311178 .8535461426178 .091003418177 .5191040039177 .1067047119 176.8352813721176 .6951599121176 .6884765625176 .8194122314177 .0850067139 177.4791870117177 .9752502441178 .5492248535179 .187713623179 .5184020996 180.1280059814181 .0424041748182 .261505127183 .7854003906185 .3094024658 186.8332977295188 .0523986816189 .2716064453190 .4474639893191 .1091461182 191.2767486572191 .0633850098198 .7198944092200 .2438049316196 .2816009521 192.0146026611188 .3571929932185 .6141052246183 .4806976318178 .604095459 168.5462036133153 .9165039062148 .4304046631 -9999 -9999 -9999 -9999 -9999 -9999 -9999 -9999 -9999 -9999 -9999 -9999 -9999 -9999 -9999 -9999 -9999 -9999 -9999 -9999 -9999 -9999

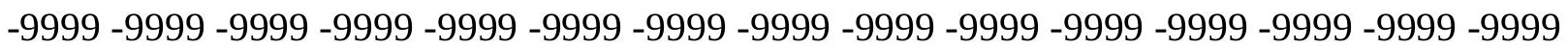
-9999 -9999 -9999 -9999 -9999 -9999 -9999 -9999 -9999 -9999 -9999 -9999 -9999 -9999 -9999 -9999 -9999 -9999 -9999 -9999 -9999 -9999 -9999 -9999 -9999 -9999 -9999 -9999 -9999 -9999 -9999 -9999 -9999 -9999 -9999 -9999 -9999 -9999 -9999 -9999 -9999 -9999 -9999 -9999 -9999

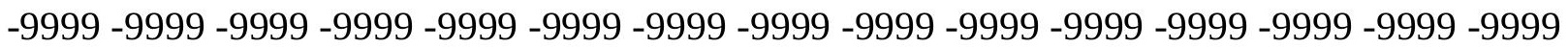

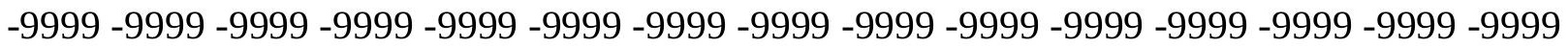
-9999 -9999 -9999 -9999 -9999 -9999 -9999 -9999 -9999 -9999 -9999 -9999 -9999 -9999 -9999 -

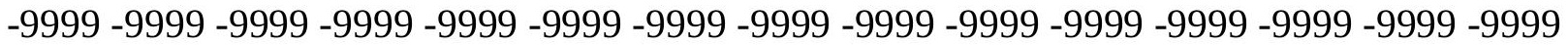
-9999 -9999 -9999 -9999 -9999 -9999 -9999 -9999 -9999 -9999 -9999 -9999 -9999 -9999 -9999 -9999 -9999 -9999 -9999 -9999 -9999 -9999 -9999 -9999 -9999 -9999 -9999 -9999 -9999 -9999 -

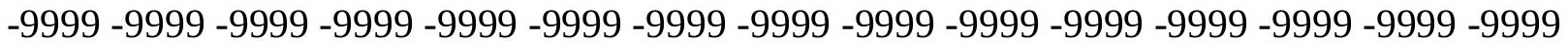
-9999 -9999 -9999 -9999 -9999 -9999 -9999 -9999 -9999 -9999 -9999 -9999 -9999 -9999 -9999 -9999 -9999 -9999 -9999 -9999 -9999 -9999 -9999 -9999 -9999 -9999 -9999 -9999 -9999 -9999

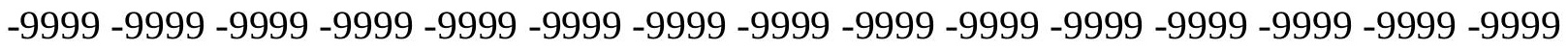
-9999-9999-9999-9999-9999-9999

-9999 -9999 -9999 -9999 -9999 -9999 -9999 -9999 -9999 -9999 -9999 -9999 -9999 -9999 -9999 -9999 -9999 -9999 -9999 -9999 -9999 -9999 -9999 -9999 -9999 -9999 -9999 -9999 -9999 -9999 -999 -9999 -9999 -9999 -9999 -9999 -9999 -9999 -9999 -9999 -9999 -9999 -9999 -9999 -9999 -9999 -9999 -9999 -9999 -9999 -9999 -9999 -9999 -9999 -9999 -9999 -9999 -9999 -9999 -9999 -9999 -9999 -9999 -9999 -9999 -9999 -9999 -9999 -9999 -9999 -9999 -9999 -9999 -9999 -9999 -9999 -9999 -9999 -9999 -9999 -9999 -9999 -9999 -9999 -9999 -9999 -9999 -9999 -9999 -9999 -9999 -9999 -9999 -9999-9999 181.3471984863181.9566955566182.5662994385183.4806976318 
184.3950042725185 .6141052246186 .528503418187 .1381072998188 .0523986816 188.3571929932188 .3571929932187 .7476043701186 .5696716309185 .9188995361 184.699798584183 .1759033203181 .9566955566180 .432800293179 .1363067627 177.9755249023177 .0358428955176 .3197937012175 .8221893311175 .46434021 175.23097229175 .1043243408175 .1130065918175 .262298584175 .5568084717 175.9825134277176 .5112609863177 .0802001953177 .6896972656178 .2993011475 179.1922912598180 .035446167181 .0144195557182 .1798095703183 .5163269043 184.8654174805186 .2236938477187 .7476043701188 .9225769043189 .6779174805 189.958770752 189.8371429443189.3654174805 195.0625193 .8433074951191 .1002960205 188.3571929932186 .528503418187 .1381072998187 .4429016113173 .4226989746 159.0977935791 148.7351074219 146.6015930176 -9999 -9999 -9999 -9999 -9999 -9999 -9999 -9999 -9999 -9999 -9999 -9999 -9999 -9999 -9999 -9999 -9999 -9999 -9999 -9999 -9999 -9999 -9999 -9999 -9999 -9999 -9999 -9999 -9999 -9999 -9999 -9999 -9999 -9999 -9999 -9999 -9999 -9999 -9999 -9999 -9999 -9999 -9999 -9999 -9999 -9999 -9999 -9999 -9999 -9999 -9999 - 9999 -9999 -9999 -9999 -9999 -9999 -9999 -9999 -9999 -9999 -9999 -9999 -9999 -9999 -9999 -9999

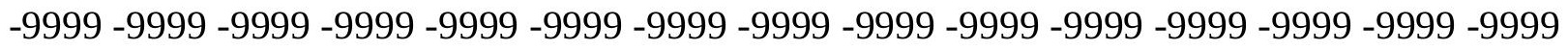

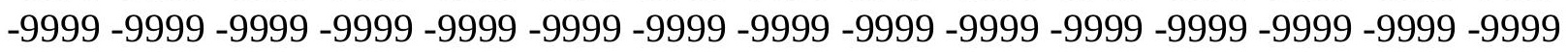
-9999 -9999 -9999 -9999 -9999 -9999 -9999 -9999 -9999 -9999 -9999 -9999 -9999 -9999 -9999 -999 -9999 -9999 -9999 -9999 -9999 -9999 -9999 -9999 -9999 -9999 -9999 -9999 -9999 -9999 -9999 -9999 -9999 -9999 -9999 -9999 -9999 -9999 -9999 -9999 -9999 -9999 -9999 -9999 -9999 -9999 -9999 -9999 -9999 -9999 -9999 -9999 -9999 -9999 -9999 -9999 -9999 -9999 -9999 -9999 -9999 -9999 -9999 -9999 -9999 -9999 -9999 -9999 -9999 -9999 -9999 -9999 -9999 -9999 -9999 -9999 -9999 -9999 -9999 -9999 -9999 -9999 -9999 -9999 -9999 -9999 -9999 -9999 -9999 -9999 -9999 -9999 -9999 -9999 -9999 -9999 -9999 -9999 -9999 -9999 -9999 -9999 -9999 -9999 -9999 -9999 -9999 -9999 -9999 -9999 -9999 -9999 -9999 -9999 -9999 -9999 -9999 -9999 -9999 -9999 -9999 -9999 -9999 -9999 -9999 -9999 -9999 -9999 -9999 -9999 -9999 -9999 -9999-9999 -9999 - -9999 -9999 -9999-9999-9999-9999

-9999 -9999 -9999 -9999 -9999 -9999 -9999 -9999 -9999 -9999 -9999 -9999 -9999 -9999 -9999 -9999 -9999 -9999 -9999 -9999 -9999 -9999 -9999 -9999 -9999 -9999 -9999 -9999 -9999 -9999 -9999 -9999 -9999 -9999 -9999 -9999 -9999 -9999 -9999 -9999 -9999 -9999 -9999 -9999 -9999 -9999 -9999 -9999 -9999 -9999 -9999 -9999 -9999 -9999 -9999 -9999 -9999 -9999 -9999 -9999

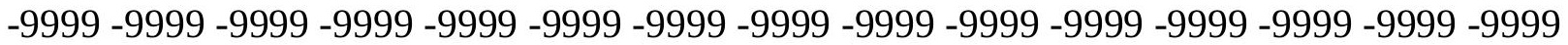

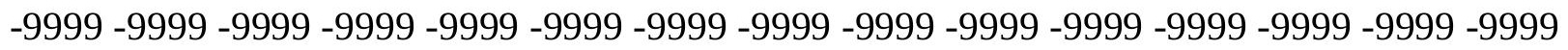
-9999 -9999 -9999 182.261505127 181.9566955566 182.5662994385183.1759033203 184.0901947021184 .699798584185 .6141052246186 .2236938477186 .8332977295 187.1381072998187 .1381072998186 .8332977295186 .2236938477185 .0953063965 184.0901947021182 .5662994385181 .0424041748179 .5184020996178 .2993011475 177.0802001953175 .8609924316175 .0250091553174 .4450073242174 .0612792969 173.8204803467173 .6337585449173 .5291595459173 .5716705322173 .7274932861 174.0323028564174 .5367736816175 .1063079834175 .5561981201176 .165802002 177.0063781738177 .6861877441178 .434463501179 .2627105713180 .2440490723 181.4641876221182 .8676757812184 .3950042725185 .9188995361187 .4429016113 188.1928253174188 .536605835188 .4984130859188 .0832672119187 .2829742432 190.1858978271188 .3571929932185 .9188995361183 .4806976318185 .0045928955 183.1759033203174 .337097168162 .7552947998152 .0877990723146 .6015930176 145.0776977539 -9999 -9999 -9999 -9999 -9999 -9999 -9999 -9999 -9999 -9999 -9999 -9999 
-9999 -9999 -9999 -9999 -9999 -9999 -9999 -9999 -9999 -9999 -9999 -9999 -9999 -9999 -9999 -9999 -9999 -9999 -9999 -9999 -9999 -9999 -9999 -9999 -9999 -9999 -9999 -9999 -9999 -9999 -9999 -9999 -9999 -9999 -9999 -9999 -9999 -9999 -9999 -9999 -9999 -9999 -9999 -9999 -9999 -9999 -9999 -9999 -9999 -9999 -9999 -9999 -9999 -9999 -9999 -9999 -9999 -9999 -9999 -9999 -9999 -9999 -9999 -9999 -9999 -9999 -9999 -9999 -9999 -9999 -9999 -9999 -9999 -9999 -9999 -9999 -9999 -9999 -9999 -9999 -9999 -9999 -9999 -9999 -9999 -9999 -9999 -9999 -9999 -9999 -9999 -9999 -9999 -9999 -9999 -9999 -9999 -9999 -9999 -9999 -9999 -9999 -9999 -9999 -9999

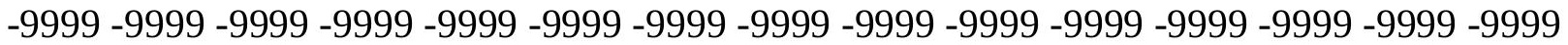
-9999 -9999 -9999 -9999 -9999 -9999 -9999 -9999 -9999 -9999 -9999 -9999 -9999 -9999 -9999 -9999 -9999 -9999 -9999 -9999 -9999 -9999 -9999 -9999 -9999 -9999 -9999 -9999 -9999 -9999 -

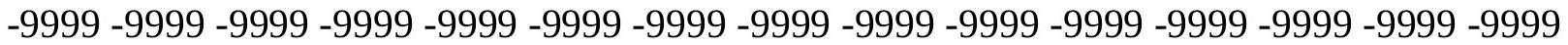
-9999 -9999 -9999 -9999 -9999 -9999 -9999 -9999 -9999 -9999 -9999 -9999 -9999 -9999 -9999

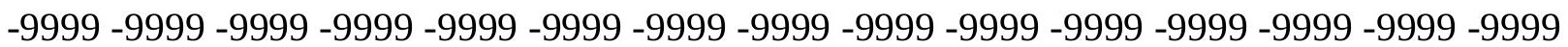
-9999 -9999 -9999 -9999 -9999 -9999 -9999 -9999 -9999 -9999 -9999 -9999 -9999 -9999 -9999 -9999 -9999 -9999 -9999 -9999 -9999 -9999 -9999 -9999 -9999 -9999 -9999 -9999 -9999 -9999 -9999 -9999 -9999 -9999 -9999 -9999 -9999 -9999 -9999 -9999 -9999 -9999 -9999 -9999 -9999 -9999 -9999 -9999 -9999 -9999 -9999 -9999 -9999 -9999 -9999 -9999 -9999 -9999 -9999 -9999 -9999 -9999 -9999 -9999 -9999 -9999 -9999 -9999 -9999 -9999 -9999 -9999 -9999 -9999 -9999 -9999 -9999 -9999 -9999 -9999 -9999 -9999 -9999 -9999 -9999 -9999 -9999 -9999 -9999 -9999 -9999 -9999 -9999 -9999 -9999 -9999 -9999 -9999 -9999 -9999 -9999 -9999 -9999 -9999 -9999 -9999 -9999 -9999 -9999 -9999 -9999 -9999 -9999 -9999 -9999 -9999 -9999 -9999 -9999 -9999 -9999 -9999 182.87109375182.5662994385183.1759033203 183.7854003906 184.3950042725185 .0045928955185 .6141052246185 .9188995361186 .2236938477 186.528503418186 .2236938477185 .9188995361185 .0045928955183 .4907226562 182.261505127180 .7375946045179 .2136993408177 .6896972656175 .8609924316 174.6419067383173 .7274932861172 .8132019043172 .5084075928172 .2035980225 172.2035980225 171.8988037109 171.8988037109 172.0877075195 172.2035980225 172.5084075928173 .1179962158173 .7274932861174 .337097168174 .9467010498 175.5503692627176 .1525421143176 .7404937744177 .3430480957178 .0485229492 179.1050415039180 .7375946045182 .5662994385184 .0901947021185 .6141052246 186.528503418186 .9340667725186 .9459838867186 .6056365967185 .820022583 184.5892486572185 .0045928955183 .4806976318182 .261505127181 .6519012451 178.9089050293172 .5084075928163 .974395752154 .8307952881147 .2111968994 145.0776977539 -9999 -9999 -9999 -9999 -9999 -9999 -9999 -9999 -9999 -9999 -9999 -9999 -9999 -9999 -9999 -9999 -9999 -9999 -9999 -9999 -9999 -9999 -9999 -9999 -9999 -9999 -9999 -9999 -9999 -9999 -9999 -9999 -9999 -9999 -9999 -9999 -9999 -9999 -9999 -9999 -9999 -9999 -9999 -9999 -9999 -9999 -9999 -9999 -9999 -9999 -9999 -9999 -9999 -9999 -9999 -9999 -9999

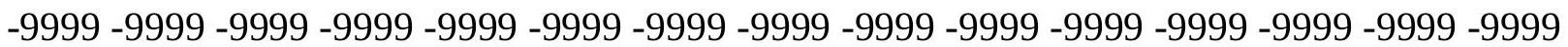
-9999 -9999 -9999 -9999 -9999 -9999 -9999 -9999 -9999 -9999 -9999 -9999 -9999 -9999 -9999 -9999 -9999 -9999 -9999 -9999 -9999 -9999 -9999 -9999 -9999 -9999 -9999 -9999 -9999 -9999 -9999 -9999 -9999 -9999 -9999 -9999 -9999 -9999 -9999 -9999 -9999 -9999 -9999 -9999 -9999

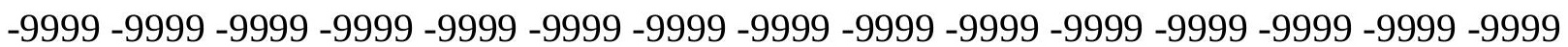
-9999 -9999 -9999 -9999 -9999 -9999 -9999 -9999 -9999 -9999 -9999 -9999 -9999 -9999 -9999 -9999 -9999 -9999 -9999 -9999 -9999 -9999 -9999 -9999 -9999 -9999 -9999 -9999 -9999 -9999 -9999 -9999 -9999 -9999 -9999 -9999 -9999 -9999 -9999 -9999 -9999 -9999 -9999 -9999 -9999

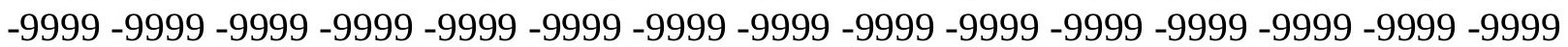


-9999 -9999 -9999 -9999 -9999 -9999 -9999 -9999 -9999 -9999 -9999 -9999 -9999 -9999 -9999 -9999 -9999 -9999 -9999 -9999 -9999 -9999 -9999 -9999 -9999 -9999 -9999 -9999 -9999 -9999 -9999 -9999 -9999 -9999 -9999 -9999 -9999 -9999 -9999 -9999 -9999 -9999 -9999 -9999 -9999 -9999 -9999 -9999 -9999 -9999 -9999 -9999 -9999 -9999 -9999 -9999 -9999 -9999 -9999 -9999 -9999 -9999 -9999 -9999 -9999 -9999 -9999 -9999-9999 -9999 -9999 -9999 -9999 -9999 -9999 -9999 -9999 -9999 -9999 -9999 -9999 -9999 -9999 -9999 -9999 -9999 -9999 -9999 -9999 -

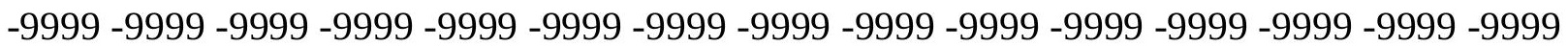

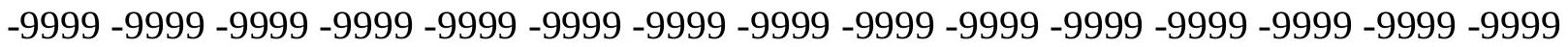

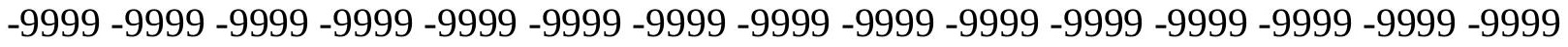
-9999 -9999 -9999 182.87109375182.87109375 183.1759033203183 .7854003906 184.3950042725185 .0045928955185 .3094024658185 .6141052246185 .9188995361 185.9188995361185 .6141052246185 .0045928955183 .7854003906181 .9815826416 180.740020752179 .2136993408177 .3849029541175 .8609924316174 .0323028564 172.5084075928171 .2891998291170 .6797027588170 .3748931885170 .3748931885 170.3748931885170 .3748931885170 .6797027588170 .6797027588170 .9844970703 171.2891998291171 .8988037109172 .5084075928173 .1179962158173 .7274932861 174.0323028564174 .6419067383174 .9467010498175 .2514038086175 .5561981201 176.165802002178 .2993011475180 .432800293182 .87109375184 .0901947021 184.699798584185 .0045928955185 .0045928955184 .699798584184 .0901947021 182.6316833496181 .2656097412180 .1898040771178 .9641418457178 .604095459 175.5561981201170 .6797027588163 .6696014404156 .0500030518148 .7351074219 145.0776977539 -9999 -9999 -9999 -9999 -9999 -9999 -9999 -9999 -9999 -9999 -9999 -9999 -9999 -9999 -9999 -9999 -9999 -9999 -9999 -9999 -9999 -9999 -9999 -9999 -9999 -9999 -9999 -

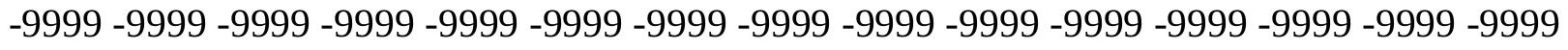

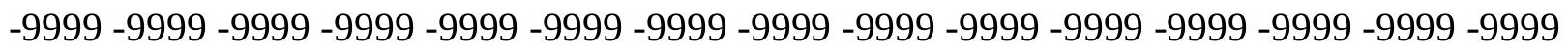
-9999 -9999 -9999 -9999 -9999 -9999 -9999 -9999 -9999 -9999 -9999 -9999 -9999 -9999 -9999 -9999 -9999 -9999 -9999 -9999 -9999 -9999 -9999 -9999 -9999 -9999 -9999 -9999 -9999 -9999 -

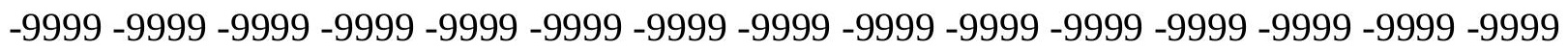
-9999 -9999 -9999 -9999 -9999 -9999 -9999 -9999 -9999 -9999 -9999 -9999 -9999 -9999 -9999 -9999 -9999 -9999 -9999 -9999 -9999 -9999 -9999 -9999 -9999 -9999 -9999 -9999 -9999 -9999 -9999 -9999 -9999 -9999 -9999 -9999 -9999 -9999 -9999-9999 -9999 -9999 -9999 -9999 -9999 -9999 -9999 -9999 -9999 -9999 -9999 -9999 -9999 -9999 -9999 -9999 -9999 -9999 -9999 -9999 -

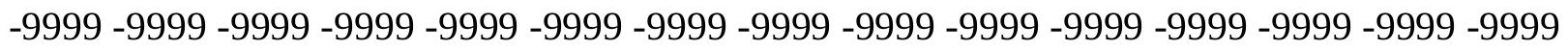
-9999 -9999 -9999 -9999 -9999 -9999 -9999 -9999 -9999 -9999 -9999 -9999 -9999 -9999 -9999 -9999 -9999 -9999 -9999 -9999 -9999 -9999 -9999 -9999 -9999 -9999 -9999 -9999 -9999 -9999 -

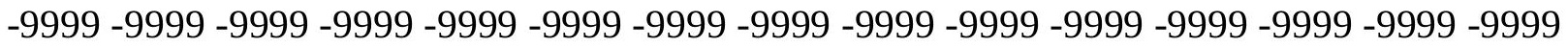

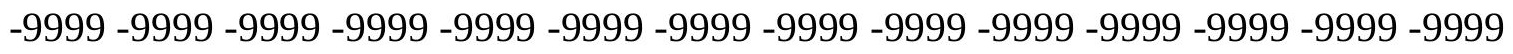

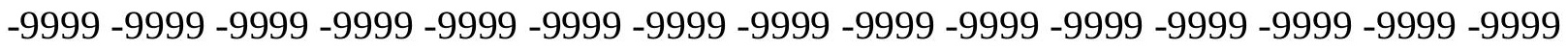
-9999 -9999 -9999 -9999 -9999 -9999 -9999 -9999 -9999 -9999 -9999 -9999 -9999 - 9999 - -999 -9999 -9999 -9999 -9999 -9999 -9999 -9999 -9999 -9999 -9999 -9999 -9999 -9999 -9999 - -999 -

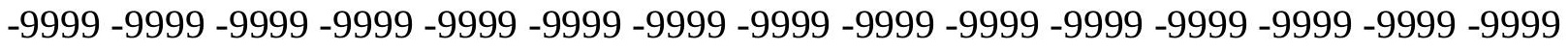

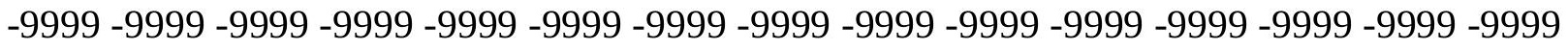
-9999 -9999 -9999 -9999 -9999 -9999 -9999 -9999 -9999 -9999 -9999 -9999 -9999 -9999 -9999 -9999 -9999 -9999 182.5662994385182.5662994385183.1759033203183.7854003906 184.3950042725184 .699798584185 .3094024658185 .6141052246185 .6141052246 185.3094024658185 .0045928955184 .0901947021183 .1759033203181 .6519012451 
179.4101104736177 .9945068359176 .165802002174 .337097168172 .5084075928 170.6797027588169 .4604949951168 .8509979248168 .8509979248168 .8509979248 169.1557006836169 .1557006836169 .4604949951169 .4604949951169 .7653045654 170.3748931885170 .6797027588171 .2891998291171 .8988037109172 .2035980225 172.8132019043173 .1179962158173 .1179962158172 .8132019043172 .5084075928 172.8132019043174 .9467010498179 .2136993408181 .6519012451182 .5662994385 182.5662994385182 .5662994385182 .5662994385181 .9566955566181 .3471984863 180.432800293178 .9089050293178 .604095459177 .4538574219175 .8388214111 173.4226989746168 .8509979248163 .0599975586156 .3547973633149 .6495056152 145.0776977539 -9999 -9999 -9999 -9999 -9999 -9999 -9999 -9999 -9999 -9999 -9999 -9999 -9999 -9999 -9999 -9999 -9999 -9999 -9999 -9999 -9999 -9999 -9999 -9999 -9999 -9999 -9999 -9999 -9999 -9999 -9999 -9999 -9999 -9999 -9999 -9999 -9999 -9999 -9999 -9999 -9999 -9999 -9999 -9999 -9999 -9999 -9999 -9999 -9999 -9999 -9999 -9999 -9999 -9999 -9999 -9999 -9999 -9999 -9999 -9999 -9999 -9999 -9999 -9999 -9999 -9999 -9999 -9999 -9999 -9999 -9999 -9999 -9999 -9999 -9999 -9999 -9999 -9999 -9999 -9999 -9999 -9999 -9999 -9999 -9999 -9999 -9999 -9999 -9999 -9999 -9999 -9999 -9999 -9999 -9999 -9999 -9999 -9999 -9999 -9999 -9999 -9999

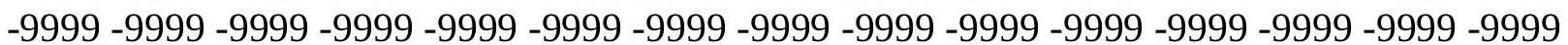
-9999 -9999 -9999 -9999 -9999 -9999 -9999 -9999 -9999 -9999 -9999 -9999 -9999 -9999 -9999 -9999 -9999 -9999 -9999 -9999 -9999 -9999 -9999 -9999 -9999 -9999 -9999 -9999 -9999 -9999 -9999 -9999 -9999 -9999 -9999 -9999 -9999 -9999 -9999 -9999 -9999 -9999 -9999 -9999 -9999

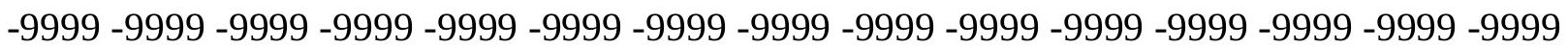
-9999 -9999 -9999 -9999 -9999 -9999 -9999 -9999 -9999 -9999 -9999 -9999 -9999 -9999 -9999 -9999 -9999 -9999 -9999 -9999 -9999 -9999 -9999 -9999 -9999 -9999 -9999 -9999 -9999 -9999 -9999 -9999 -9999 -9999 -9999 -9999 -9999 -9999 -9999 -9999 -9999 -9999 -9999 -9999 -9999 -9999 -9999 -9999 -9999 -9999 -9999 -9999 -9999 -9999 -9999 -9999 -9999 -9999 -9999 -9999 -9999 -9999 -9999 -9999 -9999 -9999 -9999 -9999 -9999 -9999 -9999 -9999 -9999 -9999 -9999 -9999 -9999 -9999 -9999 -9999 -9999 -9999 -9999 -9999 -9999 -9999 -9999 -9999 -9999 -9999 -9999 -9999 -9999 -9999 -9999 -9999 -9999 -9999 -9999 -9999 -9999 -9999 -9999 -9999 -9999 -9999 -9999 -9999 -9999 -9999 -9999 -9999 -9999 -9999 -9999 -9999 -9999 -9999 -9999 -9999 -9999 -9999 -9999 -9999 -9999 -9999 -9999 -9999 -9999 -9999 -9999 -9999 -9999 -9999 -9999 -9999 -9999 -9999 -9999 -9999 -9999 -9999 -9999 -9999 -9999 -9999 -9999 -9999 -9999 -9999 -9999 -9999 181.9566955566 182.261505127183.1759033203183.7854003906 184.3950042725184 .699798584185 .0045928955185 .3094024658185 .3094024658 185.0045928955184 .699798584183 .7854003906182 .5662994385181 .0424041748 178.194732666176 .8467102051175 .2514038086173 .1179962158171 .2891998291 169.4604949951167 .9365997314167 .6318054199167 .9365997314167 .9365997314 168.241394043168 .5462036133168 .5462036133168 .8509979248169 .1557006836 169.4604949951170 .070098877170 .3748931885170 .9844970703171 .2891998291 171.5939941406171 .5939941406171 .2891998291170 .9844970703170 .3748931885 170.070098877170 .3748931885179 .2136993408180 .1280059814180 .432800293 180.432800293180 .1280059814180 .1280059814179 .5184020996178 .9089050293 178.2993011475177 .3849029541176 .7754058838176 .165802002174 .337097168 171.5939941406167 .3269958496162 .1457061768156 .3547973633150 .2590942383 145.0776977539143 .8585968018 -9999 -9999 -9999 -9999 -9999 -9999 -9999 -9999 -9999 -9999 -9999 -9999 -9999 -9999 -9999 -9999 -9999 -9999 -9999 -9999 -9999 -9999 -9999 -9999

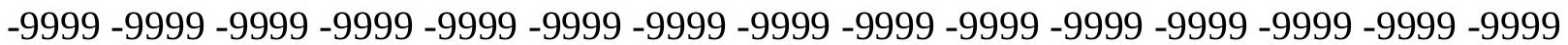


-9999 -9999 -9999 -9999 -9999 -9999 -9999 -9999 -9999 -9999 -9999 -9999 -9999 -9999 -9999 -9999 -9999 -9999 -9999 -9999 -9999 -9999 -9999 -9999 -9999 -9999 -9999 -9999 -9999 -9999 -9999 -9999 -9999 -9999 -9999 -9999 -9999 -9999 -9999 -9999 -9999 -9999 -9999 -9999 -9999 -9999 -9999 -9999 -9999 -9999 -9999 -9999 -9999 -9999 -9999 -9999 -9999 -9999 -9999 -9999 -9999 -9999 -9999 -9999 -9999 -9999 -9999 -9999 -9999 -9999 -9999 -9999 -9999 -9999 -9999 -9999 -9999 -9999 -9999 -9999 -9999 -9999 -9999 -9999 -9999 -9999 -9999 -9999 -9999 -9999 -9999 -9999 -9999 -9999 -9999 -9999 -9999 -9999 -9999 -9999 -9999 -9999 -9999 -9999 -9999

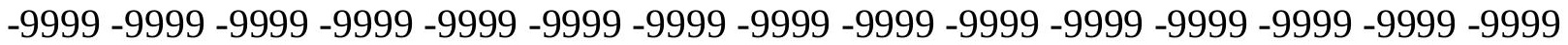
-9999 -9999 -9999 -9999 -9999 -9999 -9999 -9999 -9999 -9999 -9999 -9999 -9999 -9999 -9999 -9999 -9999 -9999 -9999 -9999 -9999 -9999 -9999 -9999 -9999 -9999 -9999 -9999 -9999 -9999 -

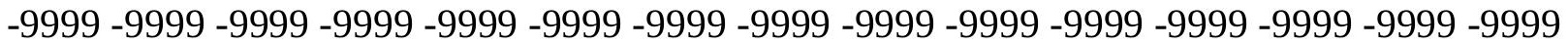
-9999 -9999 -9999 -9999 -9999 -9999 -9999 -9999 -9999 -9999 -9999 -9999 -9999 -9999 -9999 -9999 -9999 -9999 -9999 -9999 -9999 -9999 -9999 -9999 -9999 -9999 -9999 -9999 -9999 -9999 $-9999$

-9999 -9999 -9999 -9999 -9999 -9999 -9999 -9999 -9999 -9999 -9999 -9999 -9999 -9999 -9999 -9999 -9999 -9999 -9999 -9999 -9999 -9999 -9999 -9999 -9999 -9999 -9999 -9999 -9999 -9999

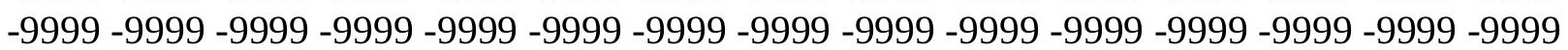
-9999 -9999 -9999 -9999 -9999 -9999 -9999 -9999 -9999 -9999 -9999 -9999 -9999 -9999 -9999 -999 -9999 -9999 -9999 -9999 -9999 -9999 -9999 -9999 -9999 -9999 -9999 -9999 -9999 -9999 -9999 -9999 -9999 -9999 -9999 -9999 -9999 -9999 -9999 -9999 -9999 -9999 -9999 -9999 -9999 -9999 -9999 -9999 182.261505127 181.0424041748182.5662994385183.4806976318 184.0901947021184 .3950042725185 .0045928955185 .3094024658185 .3094024658 185.3094024658185 .0045928955184 .3950042725183 .4806976318182 .261505127 180.432800293178 .604095459175 .8103637695174 .3764953613172 .8132019043 170.6797027588169 .1557006836167 .9365997314167 .3269958496167 .3269958496 167.3269958496167 .6318054199167 .9365997314168 .241394043168 .241394043 168.5462036133168 .8509979248169 .4604949951169 .7653045654170 .070098877 170.3748931885170 .3748931885170 .3748931885170 .070098877169 .7653045654 169.1557006836169 .4604949951171 .2891998291174 .9467010498177 .3849029541 177.9945068359177 .9945068359177 .6896972656177 .6896972656177 .3849029541 177.0802001953176 .7754058838176 .165802002175 .8609924316174 .9467010498 173.1179962158170 .3748931885166 .4127044678161 .5361022949156 .3547973633 150.8686065674145 .3825073242143 .8585968018 -9999 -9999 -9999 -9999 -9999 -9999 -9999 -9999 -9999 -9999 -9999 -9999 -9999 -9999 -9999 -9999 -9999 -9999 -9999 -9999 -9999 -9999

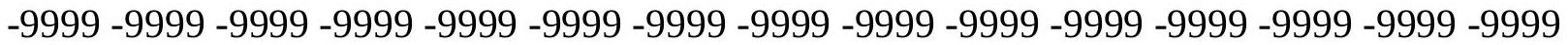
-9999 -9999 -9999 -9999 -9999 -9999 -9999 -9999 -9999 -9999 -9999 -9999 -9999 -9999 -9999 -9999 -9999 -9999 -9999 -9999 -9999 -9999 -9999 -9999 -9999 -9999 -9999 -9999 -9999 -9999

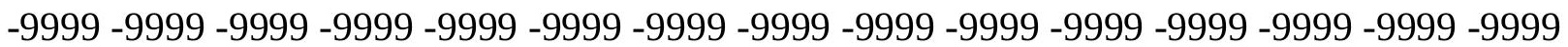
-9999 -9999 -9999 -9999 -9999 -9999 -9999 -9999 -9999 -9999 -9999 -9999 -9999 -9999 -9999 -9999 -9999 -9999 -9999 -9999 -9999 -9999 -9999 -9999 -9999 -9999 -9999 -9999 -9999 -9999 -9999 -9999 -9999 -9999 -9999 -9999 -9999 -9999 -9999 -9999 -9999 -9999 -9999 -9999 -9999

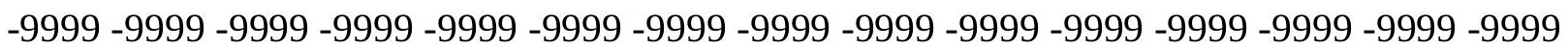
-9999 -9999 -9999 -9999 -9999 -9999 -9999 -9999 -9999 -9999 -9999 -9999 -9999 -9999 -9999 -9999 -9999 -9999 -9999 -9999 -9999 -9999 -9999 -9999 -9999 -9999 -9999 -9999 -9999 -9999 -9999 -9999 -9999 -9999 -9999 -9999 -9999 -9999 -9999 -9999 -9999 -9999 -9999 -9999 -9999

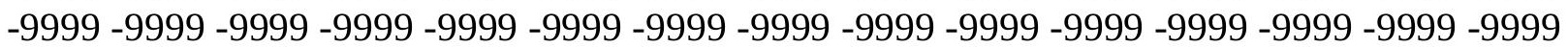


-9999 -9999 -9999 -9999 -9999 -9999 -9999 -9999 -9999 -9999 -9999 -9999 -9999 -9999 -9999 -9999 -9999 -9999 -9999 -9999 -9999 -9999 -9999 -9999 -9999 -9999 -9999 -9999 -9999 -9999 -9999-9999-9999

-9999 -9999 -9999 -9999 -9999 -9999 -9999 -9999 -9999 -9999 -9999 -9999 -9999 -9999 -9999 -9999 -9999 -9999 -9999 -9999 -9999 -9999 -9999 -9999 -9999 -9999 -9999-9999 -9999 -9999 -9999 -9999 -9999 -9999 -9999 -9999 -9999 -9999 -9999 -9999 -9999 -9999 -9999 -9999 -9999 -

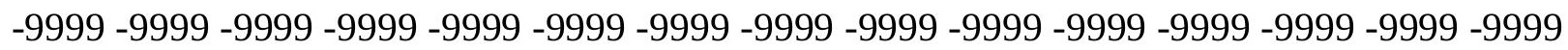
-9999 -9999 -9999 -9999 -9999 -9999 -9999 -9999 -9999 -9999 -9999 -9999 -9999 -9999 -9999 -999 -9999 -9999 -9999 -9999 -9999-9999 -9999 -9999 -9999 -9999 -9999 -9999 -9999 -9999 -9999 -9999 -9999 184.3950042725183.7854003906183.7854003906184.0901947021 184.699798584185 .0045928955185 .0045928955185 .3094024658185 .3094024658 185.0045928955184 .699798584184 .0901947021183 .4806976318181 .9566955566 180.1280059814178 .2993011475176 .4705963135173 .5871124268172 .1202545166 170.5257720947169 .1557006836167 .9365997314167 .3269958496167 .0222015381 167.3269958496167 .3269958496167 .6318054199167 .9365997314168 .241394043 168.5462036133168 .8509979248168 .8509979248169 .1557006836169 .4604949951 169.4604949951169 .4604949951169 .4604949951169 .1557006836168 .8509979248 168.5462036133169 .1557006836170 .6797027588172 .5084075928174 .0323028564 174.9467010498175 .2514038086175 .2514038086175 .2514038086175 .2514038086 175.2514038086175 .2514038086175 .2514038086174 .9467010498174 .0323028564 172.2035980225169 .4604949951165 .8031005859161 .2312927246156 .0500030518 151.1734008789146 .2969055176144 .1634063721 -9999 -9999 -9999 -9999 -9999 -9999 -9999 -9999 -9999 -9999 -9999 -9999 -9999 -9999 -9999 -9999 -9999 -9999 -9999 -9999 -9999 -9999 -9999 -9999 -9999 -9999 -9999 -9999 -9999 -9999 -9999 -9999 -9999 -9999 -9999 -9999 -9999

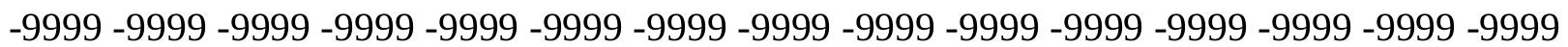
-9999 -9999 -9999 -9999 -9999 -9999 -9999 -9999 -9999 -9999 -9999 -9999 -9999 -9999 -9999 -9999 -9999 -9999 -9999 -9999 -9999 -9999 -9999 -9999 -9999 -9999 -9999 -9999 -9999 -9999

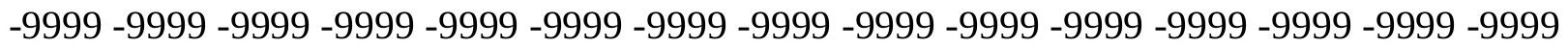

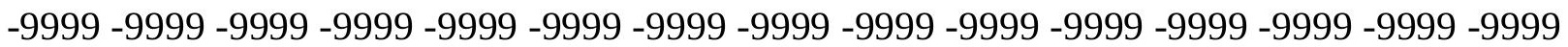

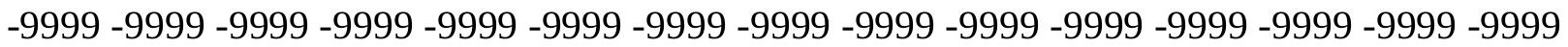
-9999 -9999 -9999 -9999 -9999 -9999 -9999 -9999 -9999 -9999 -9999 -9999 -9999 -9999 -9999 -

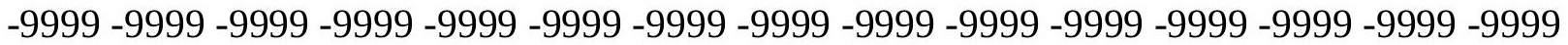
-9999 -9999 -9999 -9999 -9999 -9999 -9999 -9999 -9999 -9999 -9999 -9999 -9999 -9999 -9999 -9999 -9999 -9999 -9999 -9999 -9999 -9999 -9999 -9999 -9999 -9999 -9999 -9999 -9999 -9999 -9999 -9999 -9999 -9999 -9999 -9999 -9999 -9999 -9999 -9999 -9999 -9999 -9999 -9999 -9999 -9999 -9999 -9999 -9999 -9999 -9999 -9999 -9999 -9999 -9999 -9999 -9999 -9999 -9999 -9999

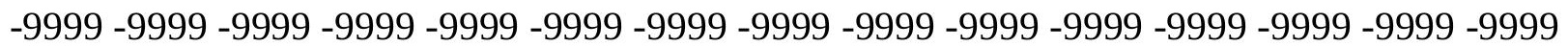
$-9999-9999-9999$

-9999 -9999 -9999 -9999 -9999 -9999 -9999 -9999 -9999 -9999 -9999 -9999 -9999 -9999 -9999 -9999 -9999 -9999 -9999 -9999 -9999 -9999 -9999 -9999 -9999 -9999 -9999 -9999 -9999 -9999 -9999 -9999 -9999 -9999 -9999 -9999 -9999 -9999 -9999 -9999 -9999 -9999 -9999 -9999 -9999 -999 -9999 -9999 -9999 -9999 -9999 -9999 -9999 -9999 -9999 -9999 -9999 -9999 -9999 -9999 -9999 -9999 -9999 -9999 -9999 -9999 -9999 -9999 -9999 -9999 -9999 -9999 -9999 -9999 -9999 -9999 -9999 -9999 -9999 -9999 -9999 -9999 -9999 -9999 -9999 -9999 -9999 -9999 -9999 -9999 -9999 -9999 -9999 185.6141052246185.3094024658 185.3094024658 185.3094024658 185.3094024658185 .3094024658185 .6141052246185 .6141052246185 .3094024658 
185.0045928955184 .699798584184 .0901947021183 .1759033203181 .6519012451 180.1280059814178 .2993011475176 .4705963135174 .337097168172 .5084075928 170.3388061523169 .1457672119168 .1999359131167 .6318054199167 .3269958496 167.3269958496167 .3269958496167 .6318054199167 .6318054199167 .9365997314 168.241394043168 .5462036133168 .8509979248168 .8509979248168 .8509979248 168.8509979248168 .5462036133168 .5462036133168 .241394043167 .9365997314 167.9365997314168 .5462036133169 .4604949951170 .6797027588171 .5939941406 171.8988037109172 .5084075928172 .8132019043172 .8132019043173 .1179962158 173.4226989746173 .7274932861174 .0323028564174 .0323028564173 .1179962158 171.5939941406168 .8509979248165 .1934967041160 .6217956543155 .7451934814 151.1734008789146 .9064025879144 .1634063721 -9999 -9999 -9999 -9999 -9999 -9999 -9999 -9999 -9999 -9999 -9999 -9999 -9999 -9999 -9999 -9999 -9999 -9999 -9999 -9999 -9999 -9999 -9999 -9999 -9999 -9999 -9999 -9999 -9999 -9999 -9999 -9999 -9999 -9999 -9999 -9999 -9999 -9999 -9999 -9999 -9999 -9999 -9999 -9999 -9999 -9999 -9999 -9999 -9999 -9999 -9999 -9999 -9999 -9999 -9999 -9999 -9999 -9999 -9999 -9999 -9999 -9999 -9999 -9999 -9999 -9999 -9999

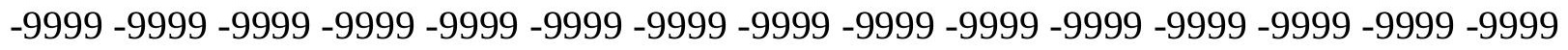

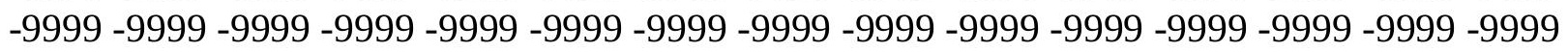

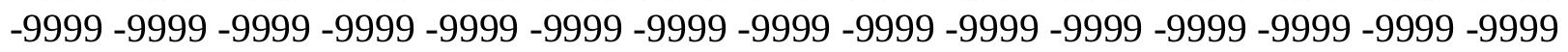

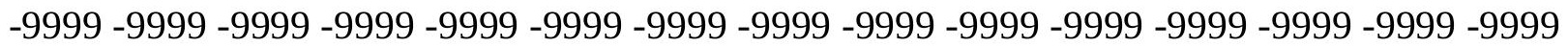

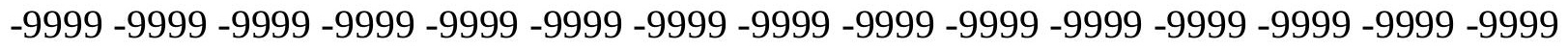

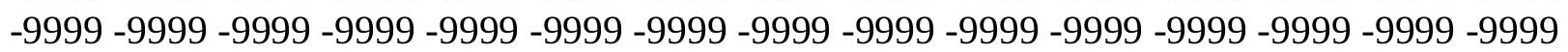

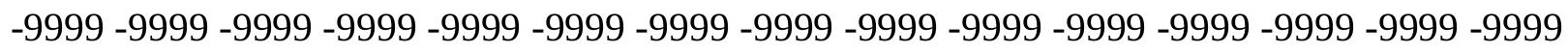
-9999 -9999 -9999 -9999 -9999 -9999 -9999 -9999 -9999 -9999 -9999 -9999 -9999 -9999 -9999 -

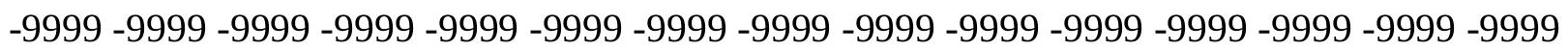

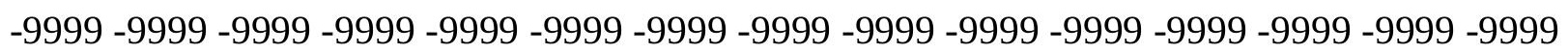
-9999 -9999 -9999 -9999 -9999 -9999 -9999 -9999 -9999 -9999 -9999 -9999 -9999 -9999 -9999 -9999-9999-9999

-9999 -9999 -9999 -9999 -9999 -9999 -9999 -9999 -9999 -9999 -9999 -9999 -9999 -9999 -9999

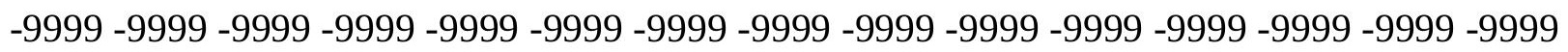

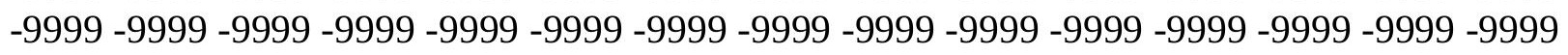
-9999 -9999 -9999 -9999 -9999 -9999 -9999 -9999 -9999 -9999 -9999 -9999 -9999 -9999 -9999 -9999 -9999 -9999 -9999 -9999 -9999 -9999 -9999 -9999 -9999 -9999 -9999 -9999 -9999 -9999 -

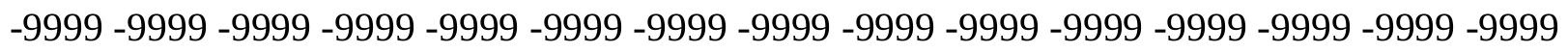
-9999 -9999 186.8332977295 186.528503418 186.2236938477 186.2236938477 185.9188995361185 .9188995361185 .9188995361185 .6141052246185 .6141052246 185.3094024658184 .699798584183 .7854003906182 .87109375181 .6519012451 179.8231964111178 .2993011475176 .4705963135174 .6419067383172 .8132019043 171.2891998291170 .070098877168 .4716339111167 .9396362305167 .6318054199 167.3269958496167 .3269958496167 .6318054199167 .6318054199167 .9365997314 168.241394043168 .5462036133168 .5462036133168 .241394043168 .241394043 167.9365997314167 .9365997314167 .6318054199167 .3269958496167 .0222015381 167.0222015381167 .3269958496168 .241394043168 .8509979248169 .1557006836 169.4604949951170 .3748931885170 .6797027588170 .9844970703171 .2891998291 171.5939941406172 .2035980225172 .8132019043172 .8132019043172 .5084075928 171.2891998291168 .5462036133164 .8887023926160 .0122070312155 .1356048584 150.8686065674146 .9064025879144 .4682006836 -9999 -9999 -9999 -9999 -9999 -9999 -9999 
-9999 -9999 -9999 -9999 -9999 -9999 -9999 -9999 -9999 -9999 -9999 -9999 -9999 -9999 -9999 -9999 -9999 -9999 -9999 -9999 -9999 -9999 -9999 -9999 -9999 -9999 -9999 -9999 -9999 -9999 -9999 -9999 -9999 -9999 -9999 -9999 -9999 -9999 -9999 -9999 -9999 -9999 -9999 -9999 -9999 -9999 -9999 -9999 -9999 -9999 -9999 -9999 -9999 -9999 -9999 -9999 -9999 -9999 -9999 -9999 -9999 -9999 -9999 -9999 -9999 -9999 -9999 -9999 -9999 -9999 -9999 -9999 -9999 -9999 -9999 -9999 -9999 -9999 -9999 -9999 -9999 -9999 -9999 -9999 -9999 -9999 -9999 -9999 -9999 -9999 -9999 -9999 -9999 -9999 -9999 -9999 -9999 -9999 -9999 -9999 -9999 -9999 -9999 -9999 -9999

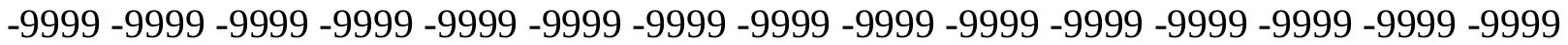
-9999 -9999 -9999 -9999 -9999 -9999 -9999 -9999 -9999 -9999 -9999 -9999 -9999 -9999 -9999 -9999 -9999 -9999 -9999 -9999 -9999 -9999 -9999 -9999 -9999 -9999 -9999 -9999 -9999 -9999 -

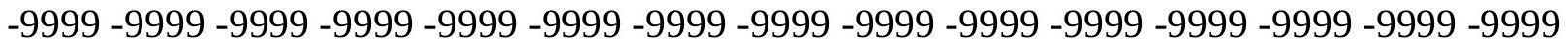
-9999 -9999 -9999 -9999 -9999 -9999 -9999 -9999 -9999 -9999 -9999 -9999 -9999 -9999 -9999

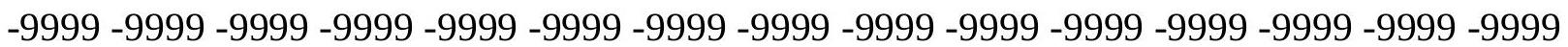
-9999 -9999 -9999 -9999 -9999 -9999 -9999 -9999 -9999 -9999 -9999 -9999 -9999 -9999 -9999 -9999 -9999 -9999 -9999 -9999 -9999 -9999 -9999 -9999 -9999 -9999 -9999 -9999 -9999 -9999 -9999-9999-9999

-9999 -9999 -9999 -9999 -9999 -9999 -9999 -9999 -9999 -9999 -9999 -9999 -9999 -9999 -9999 -9999 -9999 -9999 -9999 -9999 -9999 -9999 -9999 -9999 -9999 -9999 -9999 -9999 -9999 -9999 -9999 -9999 -9999 -9999 -9999 -9999 -9999 -9999 -9999 -9999 -9999 -9999 -9999 -9999 -9999 -9999 -9999 -9999 -9999 -9999 -9999 -9999 -9999 -9999 -9999 -9999 -9999 -9999 -9999 -9999

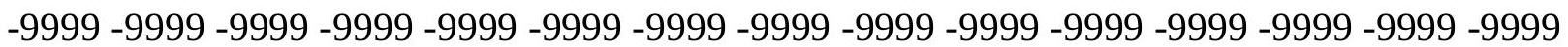
-9999 -9999 -9999 -9999 -9999 -9999 -9999 -9999 -9999 -9999 -9999 -9999 -9999 -9999 -9999 -9999 -9999 187.7476043701 187.4429016113187.4429016113187.1381072998 186.8332977295186 .528503418186 .2236938477185 .9188995361185 .6141052246 185.3094024658184 .699798584183 .7854003906182 .87109375181 .3471984863 179.8231964111178 .2993011475176 .4705963135174 .9467010498173 .1179962158 171.5939941406170 .3748931885169 .4604949951168 .2928466797167 .9365997314 167.6318054199167 .6318054199167 .6318054199167 .6318054199167 .9365997314 168.241394043168 .5462036133168 .241394043167 .9365997314167 .6318054199 167.3269958496167 .0222015381166 .7174987793166 .4127044678166 .1078948975 165.8031005859165 .8031005859166 .4127044678167 .9365997314166 .4127044678 167.6318054199168 .8509979248169 .1557006836169 .1557006836169 .1557006836 169.7653045654170 .6797027588171 .2891998291171 .5939941406171 .5939941406 170.6797027588168 .5462036133164 .2792053223159 .0977935791154 .2212982178 150.2590942383 146.9064025879 144.7729034424 -9999 -9999 -9999 -9999 -9999 -9999 -9999 -9999 -9999 -9999 -9999 -9999 -9999 -9999 -9999 -9999 -9999 -9999 -9999 -9999 -9999 -9999 -9999 -9999 -9999 -9999 -9999 -9999 -9999 -9999 -9999 -9999 -9999 -9999 -9999 -9999 -9999

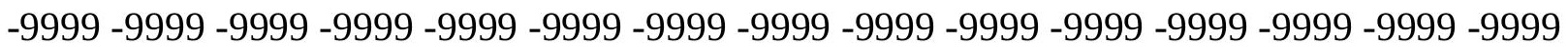
-9999 -9999 -9999 -9999 -9999 -9999 -9999 -9999 -9999 -9999 -9999 -9999 -9999 -9999 -9999 -9999 -9999 -9999 -9999 -9999 -9999 -9999 -9999 -9999 -9999 -9999 -9999 -9999 -9999 -9999 -9999 -9999 -9999 -9999 -9999 -9999 -9999 -9999 -9999 -9999 -9999 -9999 -9999 -9999 -9999

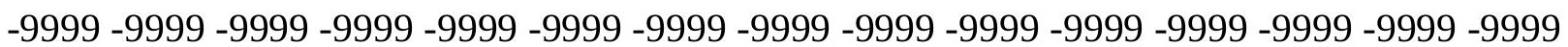

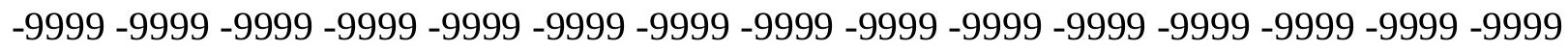
-9999 -9999 -9999 -9999 -9999 -9999 -9999 -9999 -9999 -9999 -9999 -9999 -9999 -9999 -9999 -9999 -9999 -9999 -9999 -9999 -9999 -9999 -9999 -9999 -9999 -9999 -9999 -9999 -9999 -9999

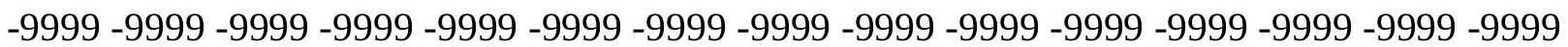


-9999 -9999 -9999 -9999 -9999 -9999 -9999 -9999 -9999 -9999 -9999 -9999 -9999 -9999 -9999 -9999 -9999 -9999 -9999 -9999 -9999 -9999 -9999 -9999 -9999 -9999 -9999 -9999 -9999 -9999 -9999 -9999 -9999 -9999 -9999 -9999 -9999 -9999 -9999 -9999 -9999 -9999 -9999 -9999 -9999 -9999 -9999 -9999 -9999 -9999 -9999 -9999 -9999 -9999 -9999 -9999 -9999 -9999 -9999 -9999 -9999 -9999-9999

-9999 -9999 -9999 -9999 -9999 -9999 -9999 -9999 -9999 -9999 -9999 -9999 -9999 -9999 -9999 -9999 -9999 -9999 -9999 -9999 -9999 -9999 -9999 -9999 -9999 -9999 -9999 -9999 -9999 -9999 -9999 -9999 -9999 -9999 -9999 -9999 -9999 -9999 -9999 -9999 -9999 -9999 -9999 -9999 -9999

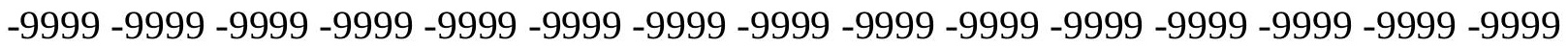
-9999 -9999 -9999 -9999 -9999 -9999 -9999 -9999 -9999 -9999 -9999 -9999 -9999 -9999 -9999 -9999 -9999 -9999 -9999 -9999 -9999 -9999 -9999 -9999 -9999 -9999 -9999 -9999 -9999 -9999 -9999 -9999 188.6620025635188.3571929932188.0523986816187.7476043701 187.4429016113186 .8332977295186 .528503418186 .2236938477185 .9188995361 185.3094024658184 .699798584183 .7854003906182 .87109375181 .6519012451 180.1280059814178 .2993011475176 .7754058838175 .2514038086173 .4226989746 172.2035980225170 .9844970703169 .7653045654168 .8509979248168 .241394043 167.9365997314167 .6318054199167 .6318054199167 .6318054199167 .9365997314 167.9365997314167 .9365997314167 .9365997314167 .6318054199167 .3269958496 166.7174987793166 .4127044678166 .1078948975165 .4983062744165 .1934967041 164.5839996338163 .974395752163 .6696014404163 .0599975586165 .8031005859 167.3269958496167 .9365997314167 .9365997314167 .6318054199167 .3269958496 168.241394043168 .8509979248169 .7653045654170 .070098877170 .070098877 169.4604949951168 .241394043163 .3648071289158 .1835021973152 .6972961426 149.6495056152 146.6015930176 145.0776977539 -9999 -9999 -9999 -9999 -9999 -9999 -9999 -9999 -9999 -9999 -9999 -9999 -9999 -9999 -9999 -9999 -9999 -9999 -9999 -9999 -9999 -9999 -9999 -9999 -9999 -9999 -9999 -9999 -9999 -9999 -9999 -9999 -9999 -9999 -9999 -9999 -9999 -9999 -9999 -9999 -9999 -9999 -9999 -9999 -9999 -9999 -9999 -9999 -9999 -9999 -9999 -9999

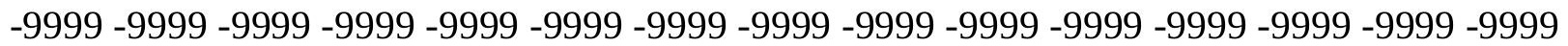
-9999 -9999 -9999 -9999 -9999 -9999 -9999 -9999 -9999 -9999 -9999 -9999 -9999 -9999 -9999 -9999 -9999 -9999 -9999 -9999 -9999 -9999 -9999 -9999 -9999 -9999 -9999 -9999 -9999 -9999 -9999 -9999 -9999 -9999 -9999 -9999 -9999 -9999 -9999 -9999 -9999 -9999 -9999 -9999 -9999 -9999 -9999 -9999 -9999 -9999 -9999 -9999 -9999 -9999 -9999 -9999 -9999 -9999 -9999 -9999

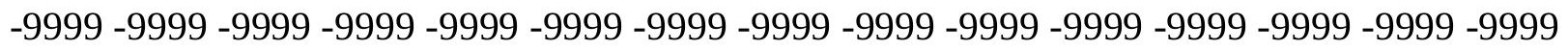
-9999 -9999 -9999 -9999 -9999 -9999 -9999 -9999 -9999 -9999 -9999 -9999 -9999 -9999 -9999 -9999 -9999 -9999 -9999 -9999 -9999 -9999 -9999 -9999 -9999 -9999 -9999 -9999 -9999-999 -999 -9999 -9999 -9999 -9999 -9999 -9999 -9999 -9999 -9999 -9999 -9999 -9999 -9999 -9999 -9999

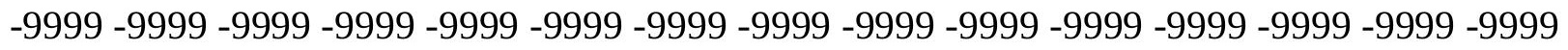

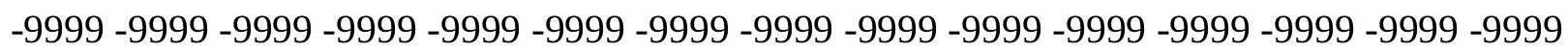

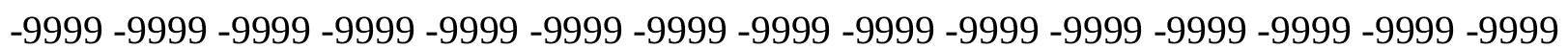
-9999-9999-9999

-9999 -9999 -9999 -9999 -9999 -9999 -9999 -9999 -9999 -9999 -9999 -9999 -9999 -9999 -9999 -9999 -9999 -9999 -9999 -9999 -9999 -9999 -9999 -9999 -9999 -9999 -9999 -9999 -9999 -9999 -9999 -9999 -9999 -9999 -9999 -9999 -9999 -9999 -9999 -9999 -9999 -9999 -9999 -9999 -9999 -9999 -9999 -9999 -9999 -9999 -9999 -9999 -9999 -9999 -9999 -9999 -9999 -9999 -9999 -9999

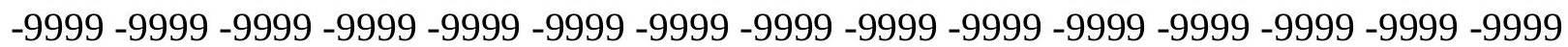

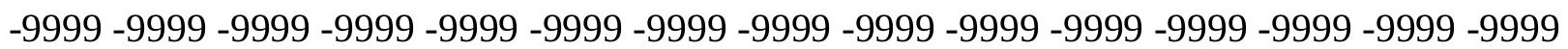


-9999 -9999 189.2716064453188.966796875188.6620025635188.3571929932 187.7476043701187 .1381072998186 .8332977295186 .2236938477185 .9188995361 185.3094024658184 .699798584183 .7854003906182 .87109375181 .6519012451 180.1280059814178 .604095459177 .0802001953175 .5561981201174 .0323028564 172.5084075928171 .2891998291170 .070098877169 .1557006836168 .5462036133 168.241394043167 .9365997314167 .6318054199170 .9890594482172 .8132019043 167.6318054199167 .6318054199167 .3269958496167 .0222015381166 .7174987793 166.1078948975165 .8031005859165 .1934967041164 .8887023926164 .2792053223 163.3648071289162 .7552947998162 .1457061768162 .7552947998166 .7174987793 167.0222015381167 .3269958496167 .3269958496166 .7174987793166 .4127044678 166.7174987793167 .3269958496167 .9365997314168 .241394043167 .9365997314 167.3269958496165 .1934967041161 .5361022949156 .9642944336152 .6972961426 149.3446960449 146.6015930176 145.3825073242 -9999 -9999 -9999 -9999 -9999 -9999 -9999 -9999 -9999 -9999 -9999 -9999 -9999 -9999 -9999 -9999 -9999 -9999 -9999 -9999 -9999 -9999 -9999 -9999 -9999 -9999 -9999 -9999 -9999 -9999 -9999 -9999 -9999 -9999 -9999 -9999 -9999 -

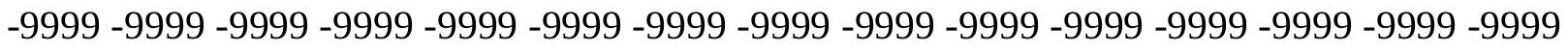
-9999 -9999 -9999 -9999 -9999 -9999 -9999 -9999 -9999 -9999 -9999 -9999 -9999 -9999 -9999 -9999 -9999 -9999 -9999 -9999 -9999 -9999 -9999 -9999 -9999 -9999 -9999 -9999 -9999 -9999 -999 -9999 -9999 -9999 -9999 -9999 -9999 -9999 -9999 -9999 -9999 -9999 -9999 -9999 -9999 -9999 -9999 -9999 -9999 -9999 -9999 -9999 -9999 -9999 -9999 -9999 -9999 -9999 -9999 -9999 -9999 -9999 -9999 -9999 -9999 -9999 -9999 -9999 -9999 -9999 -9999 -9999 -9999 -9999 -9999 -9999

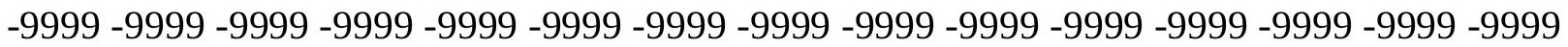
-9999 -9999 -9999 -9999 -9999 -9999 -9999 -9999 -9999 -9999 -9999 -9999 -9999 -9999 -9999 -9999 -9999 -9999 -9999 -9999 -9999 -9999 -9999 -9999 -9999 -9999 -9999 -9999 -9999 -9999 -9999 -9999 -9999 -9999 -9999 -9999 -9999 -9999 -9999 -9999 -9999 -9999 -9999 -9999 -9999 -9999 -9999 -9999 -9999 -9999 -9999 -9999 -9999 -9999 -9999 -9999 -9999 -9999 -9999 -9999 -9999 -9999 -9999 -9999 -9999 -9999 -9999 -9999 -9999 -9999 -9999 -9999 -9999 -9999 -9999 -

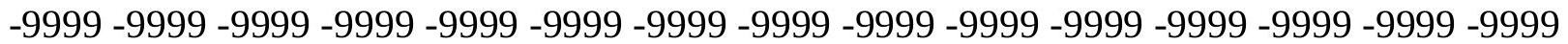
-9999-9999-9999

-9999 -9999 -9999 -9999 -9999 -9999 -9999 -9999 -9999 -9999 -9999 -9999 -9999 -9999 -9999 -9999 -9999 -9999 -9999 -9999 -9999 -9999 -9999 -9999 -9999 -9999 -9999 -9999 -9999 -9999

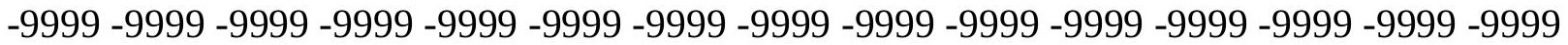

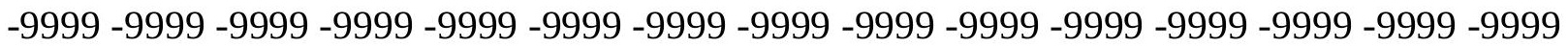
-9999 -9999 -9999 -9999 -9999 -9999 -9999 -9999 -9999 -9999 -9999 -9999 -9999 -9999 -9999 -9999 -9999 -9999 -9999 -9999 -9999 -9999 -9999 -9999 -9999 -9999 -9999 -9999 -9999 -9999 -9999 -9999 189.5764007568 189.2716064453 189.2716064453 188.6620025635 188.0523986816187 .4429016113186 .8332977295186 .2236938477185 .9188995361 185.3094024658184 .699798584183 .7854003906182 .87109375181 .6519012451 180.432800293178 .9089050293177 .3849029541175 .8609924316174 .337097168 172.8132019043171 .5939941406170 .6797027588169 .7653045654168 .8509979248 168.241394043167 .9365997314171 .946182251173 .149230957173 .7274932861 173.1179962158171 .8988037109167 .0222015381166 .7174987793166 .1078948975 165.8031005859165 .1934967041164 .5839996338163 .974395752163 .3648071289 162.7552947998162 .1457061768161 .5361022949160 .6217956543163 .974395752 166.1078948975166 .1078948975165 .8031005859165 .4983062744165 .1934967041 165.1934967041165 .4983062744165 .8031005859165 .8031005859165 .4983062744 
164.2792053223162 .4505004883159 .4026031494155 .7451934814152 .0877990723 149.0399017334 146.2969055176 145.3825073242 -9999 -9999 -9999 -9999 -9999 -9999 -9999 -9999 -9999 -9999 -9999 -9999 -9999 -9999 -9999 -9999 -9999 -9999 -9999 -9999 -9999 -9999 -9999 -9999 -9999 -9999 -9999 -9999 -9999 -9999 -9999 -9999 -9999 -9999 -9999 -9999 -9999 -9999 -9999 -9999 -9999 -9999 -9999 -9999 -9999 -9999-9999 -9999 -9999 -9999 -9999 -9999 -9999 -9999 -9999 -9999 -9999 -9999 -9999 -9999 -9999 -9999 -9999 -9999 -9999 -9999 -9999 -9999 -9999 -9999 -9999 -9999 -9999 -9999 -9999 -9999 -9999 -9999 -9999 -9999 -9999 -9999

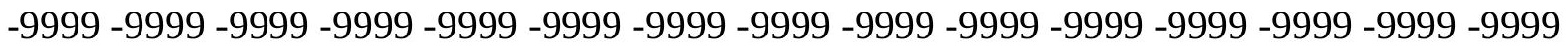

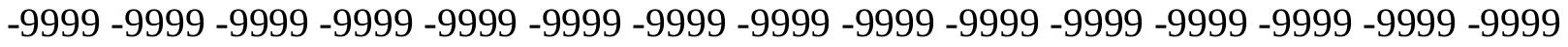
-9999 -9999 -9999 -9999 -9999 -9999 -9999 -9999 -9999 -9999 -9999 -9999 -9999 -9999 -9999

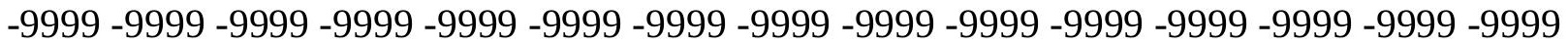
-9999 -9999 -9999 -9999 -9999 -9999 -9999 -9999 -9999 -9999 -9999 -9999 -9999 -9999 -9999 -9999 -9999 -9999 -9999 -9999 -9999 -9999 -9999 -9999 -9999 -9999 -9999 -9999 -9999 -9999 -9999 -9999 -9999 -9999 -9999 -9999 -9999 -9999 -9999 -9999 -9999 -9999 -9999 -9999 - 9999 -9999 -9999 -9999 -9999 -9999 -9999 -9999 -9999 -9999 -9999 -9999 -9999 -9999 -9999 -9999

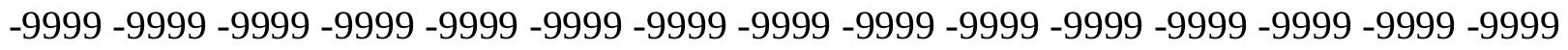
-9999 -9999 -9999 -9999 -9999 -9999 -9999 -9999 -9999 -9999 -9999 -9999 -9999 -9999 -9999 -9999 -9999-9999

-9999 -9999 -9999 -9999 -9999 -9999 -9999 -9999 -9999 -9999 -9999 -9999 -9999 -9999 -9999

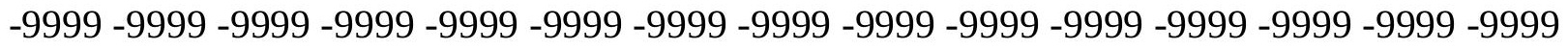

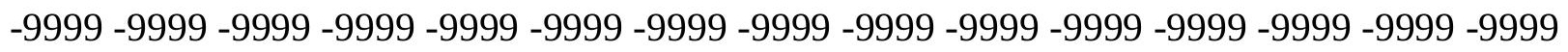
-9999 -9999 -9999 -9999 -9999 -9999 -9999 -9999 -9999 -9999 -9999 -9999 -9999 -9999 -9999 -9999 -9999 -9999 -9999 -9999 -9999 -9999 -9999 -9999 -9999 -9999 -9999 -9999 -9999 -9999 -9999 -9999 -9999 -9999 -9999 -9999 -9999 -9999 -9999 -9999 -9999 -9999 -9999 -9999 -9999 -9999-9999 189.5764007568189.5764007568 189.2716064453 188.6620025635 187.7476043701187 .1381072998186 .528503418186 .2236938477185 .6141052246 185.3094024658184 .699798584184 .0901947021183 .1759033203181 .9566955566 180.432800293179 .2136993408177 .6896972656176 .165802002174 .6419067383 173.4226989746171 .8988037109170 .9844970703169 .7653045654169 .1557006836 168.5462036133167 .9365997314173 .4226989746174 .337097168174 .6419067383 174.337097168173 .1179962158166 .7174987793166 .4127044678165 .8031005859 165.4983062744164 .8887023926164 .2792053223163 .3648071289162 .7552947998 162.1457061768161 .5361022949161 .2312927246161 .5361022949162 .7552947998 163.974395752164 .5839996338164 .2792053223163 .974395752163 .6696014404 163.6696014404163 .6696014404163 .6696014404163 .3648071289162 .7552947998 161.5361022949159 .7073974609156 .9642944336154 .2212982178151 .1734008789 148.4304046631 145.9920959473145 .3825073242 -9999 -9999 -9999 -9999 -9999 -9999 -9999

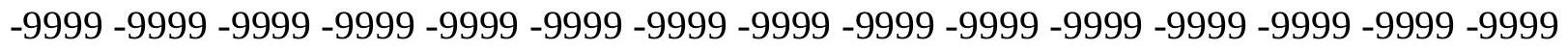
-9999 -9999 -9999 -9999 -9999 -9999 -9999 -9999 -9999 -9999 -9999 -9999 -9999 - 9999 - -999 -9999 -9999 -9999 -9999 -9999 -9999 -9999 -9999 -9999 -9999 -9999 -9999 -9999 -9999 -9999 -

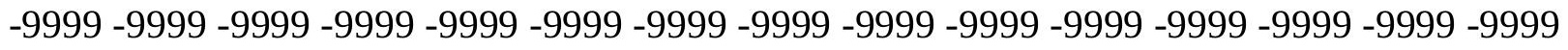

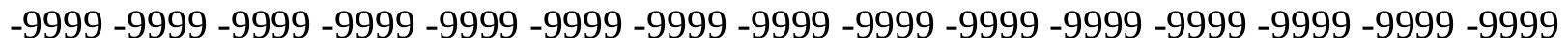
-9999 -9999 -9999 -9999 -9999 -9999 -9999 -9999 -9999 -9999 -9999 -9999 -9999 -9999 -9999 -9999 -9999 -9999 -9999 -9999 -9999 -9999 -9999 -9999-9999 -9999 -9999 -9999 -9999 -9999 -9999 -9999 -9999 -9999 -9999 -9999 -9999 -9999 -9999 -9999 -9999 -9999 -9999 -9999 -9999 -

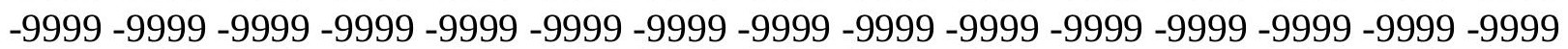


-9999 -9999 -9999 -9999 -9999 -9999 -9999 -9999 -9999 -9999 -9999 -9999 -9999 -9999 -9999 -9999 -9999 -9999 -9999 -9999 -9999 -9999 -9999 -9999 -9999 -9999 -9999 -9999 -9999 -9999 -9999 -9999 -9999 -9999 -9999 -9999 -9999 -9999 -9999 -9999 -9999 -9999 -9999 -9999 -9999 -9999 -9999 -9999 -9999 -9999 -9999 -9999 -9999 -9999 -9999 -9999 -9999 -9999 -9999 -9999 -9999 -9999 -9999 -9999 -9999 -9999 -9999 -9999 -9999 -9999 -9999 -9999 -9999 -9999 -9999

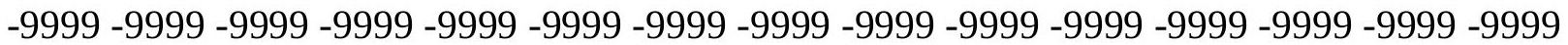
-9999 -9999 -9999

-9999 -9999 -9999 -9999 -9999 -9999 -9999 -9999 -9999 -9999 -9999 -9999 -9999 -9999 -9999

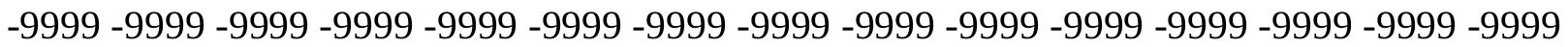
-9999 -9999 -9999 -9999 -9999 -9999 -9999 -9999 -9999 -9999 -9999 -9999 -9999 -9999 -9999 -

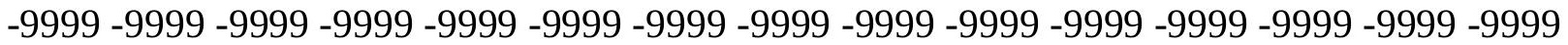
-9999 -9999 -9999 -9999 -9999 -9999 -9999 -9999 -9999 -9999 -9999 -9999 -9999 -9999 -9999

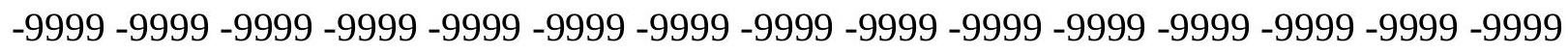
-9999 -9999 189.2716064453 189.5764007568 188.966796875 188.0523986816 187.4429016113186 .8332977295186 .2236938477185 .9188995361185 .6141052246 185.0045928955184 .699798584184 .0901947021183 .1759033203181 .9566955566 180.7375946045179 .5184020996177 .9945068359176 .4705963135174 .9467010498 173.7274932861172 .2035980225171 .2891998291170 .070098877169 .4604949951 168.5462036133168 .241394043173 .7274932861174 .9467010498175 .498260498 175.3793792725174 .337097168171 .8988037109166 .1078948975165 .4983062744 165.1934967041164 .5839996338163 .6696014404163 .0599975586162 .4505004883 161.8408966064161 .5361022949161 .2312927246161 .8408966064162 .1457061768 162.7552947998162 .7552947998162 .7552947998162 .4505004883161 .8408966064 161.8408966064161 .8408966064161 .5361022949161 .2312927246160 .3170013428 159.0977935791157 .2691040039154 .8307952881152 .6972961426150 .2590942383 147.8208007812145 .3825073242145 .0776977539145 .0776977539 -9999 -9999-9999-9999 -9999 -9999 -9999 -9999 -9999 -9999 -9999 -9999 -9999 -9999 -9999 -9999 -9999 -9999 -9999 -9999 -9999 -9999 -9999 -9999 -9999 -9999 -9999 -9999 -9999 -9999 -9999 -9999 -9999 -9999 -9999 -9999 -9999 -9999 -9999 -9999 -9999 -9999 -9999 -9999 -9999 -9999 -9999 -9999 -9999

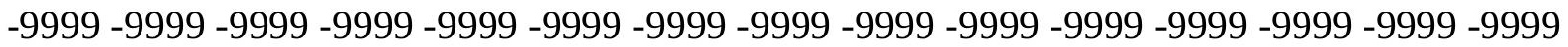
-9999 -9999 -9999 -9999 -9999 -9999 -9999 -9999 -9999 -9999 -9999 -9999 -9999 -9999 -9999 -

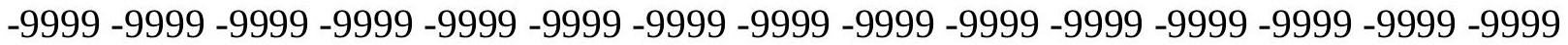
-9999 -9999 -9999 -9999 -9999 -9999 -9999 -9999 -9999 -9999 -9999 -9999 -9999 -9999 -9999 -9999 -9999 -9999 -9999 -9999 -9999 -9999 -9999 -9999 -9999 -9999 -9999 -9999 -9999 -9999 -

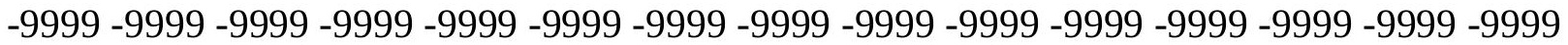
-9999 -9999 -9999 -9999 -9999 -9999 -9999 -9999 -9999 -9999 -9999 -9999 -9999 -9999 -9999 -9999 -9999 -9999 -9999 -9999 -9999 -9999 -9999 -9999 -9999 -9999 -9999 -9999 -9999 -9999

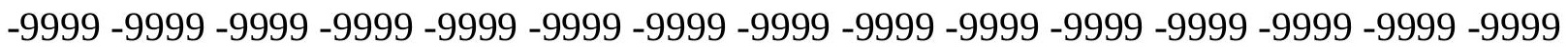
-9999 -9999 -9999 -9999 -9999 -9999 -9999 -9999 -9999 -9999 -9999 -9999 -9999 -9999 -9999 -9999 -9999 -9999 -9999 -9999 -9999 -9999 -9999 -9999 -9999 -9999 -9999 -9999 -9999 -9999 -

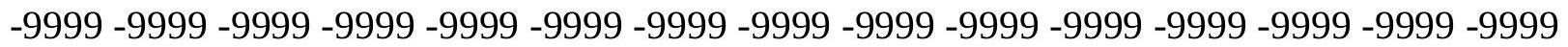
$-9999-9999-9999-9999-9999$

-9999 -9999 -9999 -9999 -9999 -9999 -9999 -9999 -9999 -9999 -9999 -9999 -9999 -9999 -9999 -9999 -9999 -9999 -9999 -9999 -9999 -9999 -9999 -9999 -9999 -9999 -9999 -9999 -9999 -9999 -9999 -9999 -9999 -9999 -9999 -9999 -9999 -9999 -9999 -9999 -9999 -9999 -9999 -9999 -9999

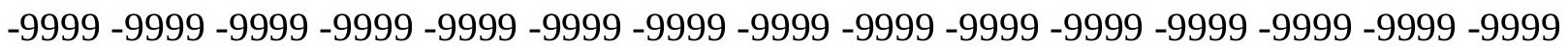


-9999 -9999 -9999 -9999 -9999 -9999 -9999 -9999 -9999 -9999 -9999 -9999 -9999 -9999 -9999 -9999 -9999 -9999 -9999 -9999 -9999 -9999 -9999 -9999 -9999 -9999 -9999 -9999 -9999 -9999 -9999 -9999 188.0523986816188.0523986816187.4429016113186.8332977295 186.528503418186 .2236938477185 .9188995361185 .6141052246185 .3094024658 185.0045928955184 .699798584184 .0901947021183 .1759033203182 .261505127 181.0424041748179 .5184020996178 .2993011475176 .7754058838175 .2514038086 174.0323028564172 .8132019043171 .5939941406170 .3748931885169 .4604949951 168.8509979248168 .241394043173 .7274932861174 .9467010498176 .165802002 175.3937225342174 .6175231934173 .1179962158165 .8031005859165 .4983062744 164.8887023926164 .2792053223163 .3648071289162 .7552947998162 .1457061768 161.5361022949161 .2312927246161 .2312927246161 .2312927246161 .2312927246 161.5361022949161 .2312927246160 .9264984131160 .6217956543160 .3170013428 160.0122070312160 .0122070312159 .7073974609159 .0977935791158 .4882965088 156.9642944336155 .1356048584153 .0021057129151 .4781951904149 .3446960449 147.2111968994 145.3825073242 145.0776977539 145.0776977539 -9999 -9999-9999-9999 -9999 -9999 -9999 -9999 -9999 -9999 -9999 -9999 -9999 -9999 -9999 -9999 -9999 -9999 -9999

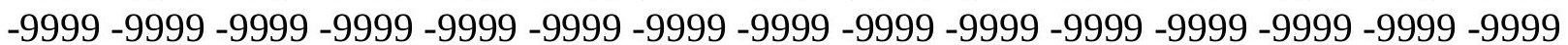
-9999 -9999 -9999 -9999 -9999 -9999 -9999 -9999 -9999 -9999 -9999 -9999 -9999 -9999 -9999 -9999 -9999 -9999 -9999 -9999 -9999 -9999 -9999 -9999 -9999 -9999 -9999 -9999 -9999 -9999 -9999 -9999 -9999 -9999 -9999 -9999 -9999 -9999 -9999 -9999 -9999 -9999 -9999 -9999 -9999

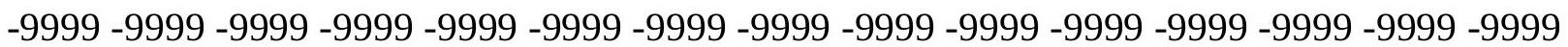
-9999 -9999 -9999 -9999 -9999 -9999 -9999 -9999 -9999 -9999 -9999 -9999 -9999 -9999 -9999 -9999 -9999 -9999 -9999 -9999 -9999 -9999 -9999 -9999 -9999 -9999 -9999 -9999 -9999 -9999 -9999 -9999 -9999 -9999 -9999 -9999 -9999 -9999 -9999 -9999 -9999 -9999 -9999 -9999 -9999

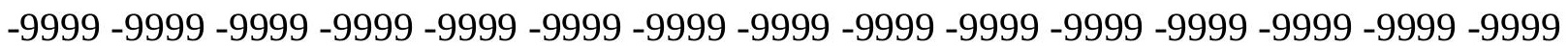
-9999 -9999 -9999 -9999 -9999 -9999 -9999 -9999 -9999 -9999 -9999 -9999 -9999 -9999 -9999 -9999 -9999 -9999 -9999 -9999 -9999 -9999 -9999 -9999 -9999 -9999 -9999 -9999 -9999 -9999 -9999 -9999 -9999 -9999 -9999 -9999 -9999 -9999 -9999 -9999 -9999 -9999 -9999 -9999 -9999 -9999 -9999 -9999 -9999 -9999 -9999 -9999 -9999 -9999 -9999 -9999 -9999 -9999 -9999 -9999

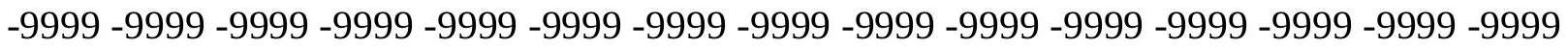
-9999 -9999 -9999-9999-9999

-9999 -9999 -9999 -9999 -9999 -9999 -9999 -9999 -9999 -9999 -9999 -9999 -9999 -9999 -9999 -9999 -9999 -9999 -9999 -9999 -9999 -9999 -9999 -9999 -9999 -9999 -9999 -9999 -9999 -9999 -9999 -9999 -9999 -9999 -9999 -9999 -9999 -9999 -9999 -9999 -9999 -9999 -9999 -9999 -9999 -

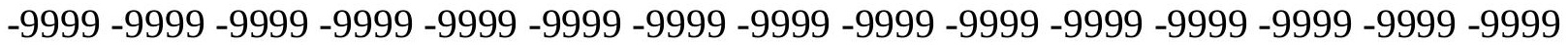
-9999 -9999 -9999 -9999 -9999 -9999 -9999 -9999 -9999 -9999 -9999 -9999 -9999 -9999 -9999 -9999 -9999 -9999 -9999 -9999 -9999 -9999 -9999 -9999 -9999 -9999 -9999 -9999 -9999 -9999 -9999 -9999 184.699798584189.8811035156185.3094024658185.3094024658 185.3094024658185 .3094024658185 .3094024658185 .3094024658185 .0045928955 185.0045928955184 .699798584184 .0901947021183 .4806976318182 .5662994385 181.3471984863179 .8231964111178 .604095459177 .0802001953175 .8609924316 174.337097168173 .1179962158171 .8988037109170 .6797027588169 .7653045654 168.8509979248168 .241394043173 .1179962158174 .6419067383176 .165802002 177.0802001953172 .9769134521169 .8481445312165 .4983062744165 .1934967041 164.8887023926163 .974395752163 .3648071289162 .4505004883161 .8408966064 161.2312927246160 .9264984131160 .6217956543160 .3170013428160 .3170013428 
160.3170013428160 .0122070312159 .7073974609159 .0977935791158 .4882965088 158.4882965088158 .4882965088158 .1835021973157 .5738983154156 .6596069336 155.4403991699154 .2212982178152 .3925933838150 .5639038086148 .7351074219 $146.6015930176144 .7729034424144 .7729034424144 .7729034424144 .7729034424-9999$ -9999 -9999 -9999 -9999 -9999 -9999 -9999 -9999 -9999 -9999 -9999 -9999 -9999 -9999 -9999 -9999 -9999 -9999 -9999 -9999 -9999 -9999 -9999 -9999 -9999 -9999 -9999 -9999 -9999 -9999

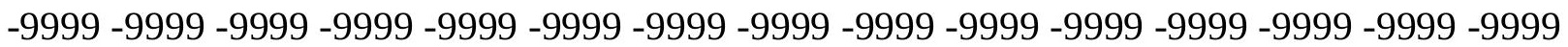

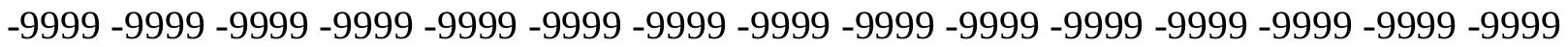
-9999 -9999 -9999 -9999 -9999 -9999 -9999 -9999 -9999 -9999 -9999 -9999 -9999 -9999 -9999 -9999 -9999 -9999 -9999 -9999 -9999 -9999 -9999 -9999 -9999 -9999 -9999 -9999 -9999 -9999 -9999 -9999 -9999 -9999 -9999 -9999 -9999 -9999 -9999 -9999 -9999 -9999 -9999 -9999 -9999 -9999 -9999 -9999 -9999 -9999 -9999 -9999 -9999 -9999 -9999 -9999 -9999 -9999 -9999 -9999 -9999 -9999 -9999 -9999 -9999 -9999 -9999 -9999 -9999 -9999 -9999 -9999 -9999 -9999 -9999 -9999 -9999 -9999 -9999 -9999 -9999 -9999 -9999 -9999 -9999 -9999 -9999 -9999 -9999 -9999 -9999 -9999 -9999 -9999 -9999 -9999 -9999 -9999 -9999 -9999 -9999 -9999 -9999 -9999 -9999

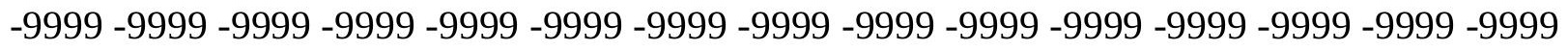
-9999 -9999 -9999 -9999 -9999 -9999 -9999 -9999 -9999 -9999 -9999 -9999 -9999 -9999 -9999 -

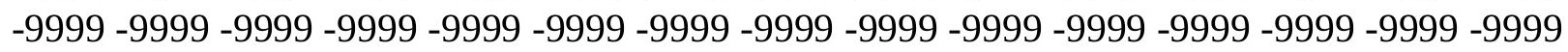

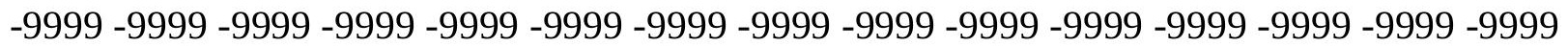
-9999 -9999 -9999 -9999 -9999 -9999-9999

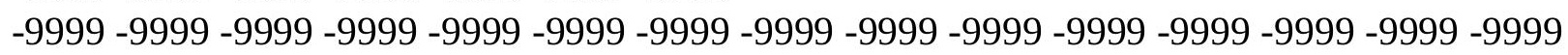

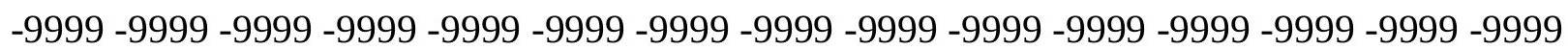
-9999 -9999 -9999 -9999 -9999 -9999 -9999 -9999 -9999 -9999 -9999 -9999 -9999 -9999 -9999 -

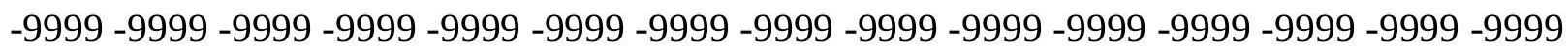

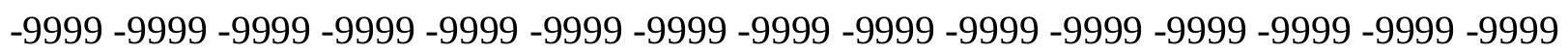

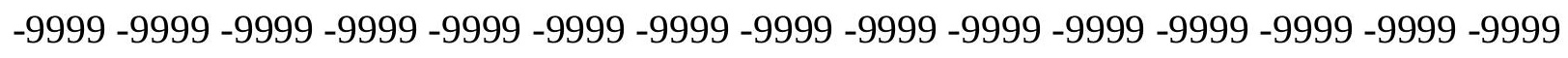
-9999-9999 182.5662994385 187.1381072998 183.1759033203183.7854003906 184.0901947021184 .3950042725184 .699798584185 .0045928955185 .0045928955 184.699798584184 .699798584184 .0901947021183 .7854003906183 .1759033203 181.3471984863180 .1280059814178 .9089050293177 .6896972656176 .165802002 174.6419067383173 .4226989746171 .8988037109170 .9844970703169 .7653045654 168.8509979248168 .241394043167 .6318054199173 .7274932861174 .9467010498 175.5561981201174 .9467010498168 .176071167165 .4983062744164 .8887023926 164.5839996338163 .6696014404163 .0599975586162 .1457061768161 .5361022949 160.9264984131160 .3170013428160 .0122070312159 .7073974609159 .4026031494 159.0977935791158 .7929992676158 .4882965088157 .878692627157 .5738983154 157.2691040039156 .9642944336156 .6596069336156 .3547973633155 .4403991699 154.5260925293153 .3069000244152 .0877990723150 .2590942383148 .1255950928 $145.9920959473144 .4682006836144 .4682006836144 .4682006836144 .7729034424-9999$ -9999 -9999 -9999 -9999 -9999 -9999 -9999 -9999 -9999 -9999 -9999 -9999 -9999 -9999 -9999

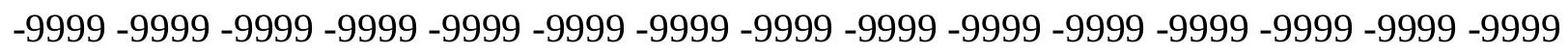

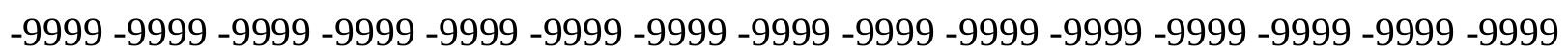
-9999 -9999 -9999 -9999 -9999 -9999 -9999 -9999 -9999 -9999 -9999 -9999 -9999 -9999 -9999 -9999 -9999 -9999 -9999 -9999 -9999 -9999 -9999 -9999 -9999 -9999 -9999 -9999 -9999 -9999 -

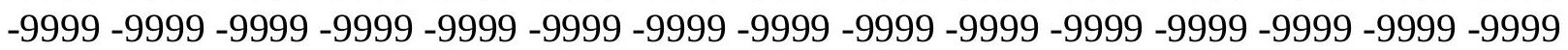

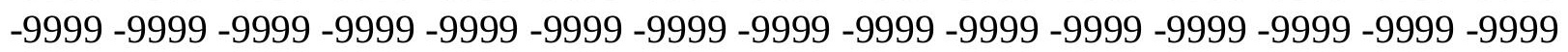


-9999 -9999 -9999 -9999 -9999 -9999 -9999 -9999 -9999 -9999 -9999 -9999 -9999 -9999 -9999 -9999 -9999 -9999 -9999 -9999 -9999 -9999 -9999 -9999 -9999 -9999 -9999 -9999 -9999 -9999 -9999 -9999 -9999 -9999 -9999 -9999 -9999 -9999 -9999 -9999 -9999 -9999 -9999 -9999 -9999 -9999 -9999 -9999 -9999 -9999 -9999 -9999 -9999 -9999 -9999 -9999 -9999 -9999 -9999 -9999 -9999 -9999 -9999 -9999 -9999 -9999 -9999 -9999 -9999 -9999 -9999 -9999 -9999 -9999 -9999 -9999 -9999 -9999 -9999 -9999 -9999 -9999 -9999 -9999 -9999 -9999 -9999 -9999 -9999 -9999 -9999 -9999 -9999 -9999 -9999 -9999 -9999 -9999 -9999 -9999 -9999 -9999 -9999 -9999 -9999

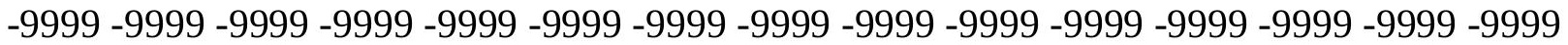
-9999 -9999 -9999 -9999 -9999 -9999 -9999

-9999 -9999 -9999 -9999 -9999 -9999 -9999 -9999 -9999 -9999 -9999 -9999 -9999 -9999 -9999 -9999 -9999 -9999 -9999 -9999 -9999 -9999 -9999 -9999 -9999 -9999 -9999 -9999 -9999 -9999 -9999 -9999 -9999 -9999 -9999 -9999 -9999 -9999 -9999 -9999 -9999 -9999 -9999 -9999 -9999

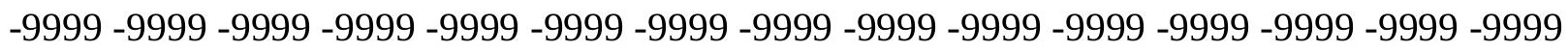
-9999 -9999 -9999 -9999 -9999 -9999 -9999 -9999 -9999 -9999 -9999 -9999 -9999 -9999 -9999 -9999 -9999 -9999 -9999 -9999 -9999 -9999 -9999 -9999 -9999 -9999 -9999 -9999 -9999 -9999 -9999 -9999 184.3950042725 181.3471984863181.9566955566182.5662994385 183.1759033203183 .7854003906184 .3950042725184 .699798584185 .0045928955 185.0045928955184 .699798584184 .3950042725183 .7854003906183 .1759033203 181.9566955566180 .7375946045179 .5184020996177 .9945068359176 .7754058838 174.9467010498173 .7274932861172 .2035980225170 .9844970703170 .070098877 169.1557006836168 .241394043167 .6318054199172 .2035980225173 .1179962158 173.4226989746172 .8132019043167 .5480041504165 .1934967041164 .8887023926 164.2792053223163 .6696014404162 .7552947998162 .1457061768161 .2312927246 160.6217956543160 .0122070312159 .4026031494158 .7929992676158 .4882965088 158.1835021973158 .1835021973157 .5738983154157 .2691040039156 .9642944336 156.3547973633156 .0500030518155 .7451934814155 .1356048584154 .5260925293 153.3069000244152 .3925933838151 .7830047607149 .6495056152147 .2111968994 145.0776977539144 .1634063721144 .1634063721144 .1634063721144 .4682006836 -9999 -9999 -9999 -9999 -9999 -9999 -9999 -9999 -9999 -9999 -9999 -9999 -9999 -9999 -9999 -9999 -9999 -9999 -9999 -9999 -9999 -9999 -9999 -9999 -9999 -9999 -9999 -9999 -9999 -9999 -9999 -9999 -9999 -9999 -9999 -9999 -9999 -9999 -9999 -9999 -9999 -9999 -9999 -9999 -9999 -9999 -9999 -9999 -9999 -9999 -9999 -9999 -9999 -9999 -9999 -9999 -9999 -9999 -9999 -9999 -9999 -9999 -9999 -9999 -9999 -9999 -9999 -9999 -9999 -9999 -9999 -9999 -9999 -9999 -9999 -9999 -9999 -9999 -9999 -9999 -9999 -9999 -9999 -9999 -9999 -9999 -9999 -9999 -9999 -9999 -9999 -

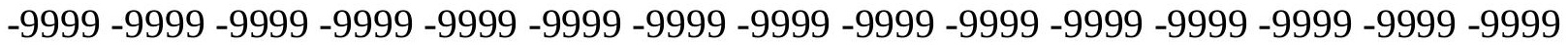
-9999 -9999 -9999 -9999 -9999 -9999 -9999 -9999 -9999 -9999 -9999 -9999 -9999 -9999 -9999 -9999 -9999 -9999 -9999 -9999 -9999 -9999 -9999 -9999 -9999 -9999 -9999 -9999 -9999 -9999

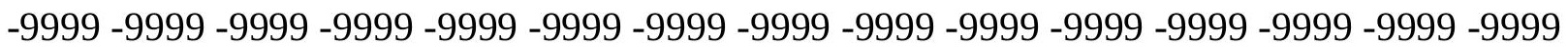
-9999 -9999 -9999 -9999 -9999 -9999 -9999 -9999 -9999 -9999 -9999 -9999 -9999 -9999 -9999 -9999 -9999 -9999 -9999 -9999 -9999 -9999 -9999 -9999 -9999 -9999 -9999 -9999 -9999 -9999 -9999 -9999 -9999 -9999 -9999 -9999 -9999 -9999 -9999 -9999 -9999 -9999 -9999 -9999 -9999

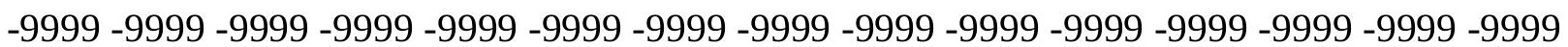

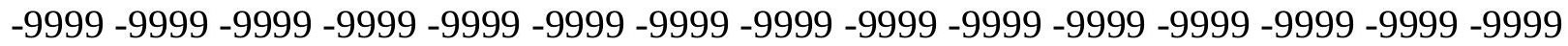
-9999 -9999 -9999 -9999 -9999 -9999 -9999 -9999 -9999 -9999 -9999 -9999 -9999 -9999 -9999 -9999 -9999 -9999 -9999 -9999 -9999 -9999

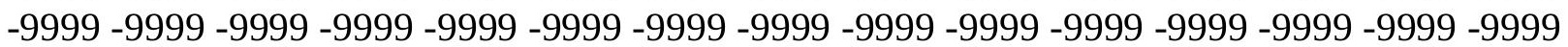


-9999 -9999 -9999 -9999 -9999 -9999 -9999 -9999 -9999 -9999 -9999 -9999 -9999 -9999 -9999 -9999 -9999 -9999 -9999 -9999 -9999 -9999 -9999 -9999 -9999 -9999 -9999 -9999 -9999 -9999 -9999 -9999 -9999 -9999 -9999 -9999 -9999 -9999 -9999 -9999 -9999 -9999 -9999 -9999 -9999 -9999 -9999 -9999 -9999 -9999 -9999 -9999 -9999 -9999 -9999 -9999 -9999 -9999 -9999 -9999 -9999 -9999 185.3094024658 181.3471984863181.3471984863181.9566955566 182.5662994385183 .4806976318184 .3950042725184 .699798584185 .0045928955 185.3094024658185 .0045928955184 .699798584184 .0901947021183 .4806976318 182.5662994385181 .6519012451180 .1280059814178 .604095459177 .0802001953 175.5561981201174 .0323028564172 .5084075928171 .2891998291170 .070098877 169.1557006836168 .5462036133167 .9365997314167 .3269958496166 .7174987793 171.2891998291170 .6797027588165 .4983062744165 .1934967041164 .5839996338 163.974395752163 .3648071289162 .7552947998161 .8408966064161 .2312927246 160.3170013428159 .7073974609158 .7929992676158 .1835021973157 .878692627 157.878692627157 .5738983154157 .2691040039156 .6596069336156 .3547973633 155.7451934814155 .4403991699154 .8307952881154 .2212982178153 .3069000244 152.3925933838151 .4781951904150 .2590942383148 .4304046631146 .2969055176 144.1634063721143 .5538024902143 .8585968018143 .8585968018144 .1634063721 144.4682006836 -9999 -9999 -9999 -9999 -9999 -9999 -9999 -9999 -9999 -9999 -9999 -9999 -9999 -9999 -9999 -9999 -9999 -9999 -9999 -9999 -9999 -9999 -9999 -9999 -9999 -9999 -9999 -9999 -9999 -9999 -9999 -9999 -9999 -9999 -9999 -9999 -9999 -9999 -9999 -9999 -9999 -9999 -9999 -9999 -9999 -9999 -9999 -9999 -9999 -9999 -9999 -9999 -9999 -9999 -9999 -9999 -9999 -999 -9999 -9999 -9999 -9999 -9999 -9999 -9999 -9999 -9999 -9999 -9999 -9999 -9999 -9999 -9999 -9999 -9999 -9999 -9999 -9999 -9999 -9999 -9999 -9999 -9999 -9999 -9999 -9999 -9999 -9999 -9999 -9999 -9999 -9999 -9999 -9999 -9999 -9999 -9999 -9999 -9999 -9999 -9999 -9999 -9999 -9999 -9999 -9999 -9999 -9999 -9999 -9999 -9999 -9999 -9999 -9999 -9999 -9999 -9999 -9999 -9999 -9999 -9999 -9999 -9999 -9999 -9999 -9999 -9999 -9999 -9999 -9999 -9999 -9999 -9999 -9999 -9999 -9999 -9999 -9999 -9999 -9999 -9999 -9999 -9999 -9999 -9999 -9999 -9999 -9999 -9999 -9999 -9999 -9999 -9999 -9999 -9999 -9999 -9999 -9999 -9999 -9999 -9999 -9999 -9999 -9999 -9999 -9999 -9999 -9999 -9999 -9999 -9999 -9999 -9999 -9999 -9999 -9999 -9999 -9999 -9999 -9999 -9999 -9999 -9999 -9999 -9999 -9999 -9999 -9999 -9999 -9999 -9999 -9999 -9999 -9999 -9999 -9999 -9999 -9999 -9999 -9999 -9999 -9999 -9999 -9999 -9999 -9999 -9999 -9999 -9999 -9999 -9999 -9999 -9999 -9999 -9999 -9999 -9999 -9999 -9999 -9999 -9999 -9999 -9999 -9999 -9999 -9999 -9999 -9999 -9999 -9999 -9999 -9999 -9999

-9999 -9999 -9999 -9999 -9999 -9999 -9999 -9999 -9999 -9999 -9999 -9999 -9999 -9999 -9999 -9999 -9999 -9999 -9999 -9999 -9999 -9999 -9999 -9999 -9999 -9999 -9999 -9999 -9999 -9999 -9999 -9999 -9999 -9999 -9999 -9999 -9999 -9999 -9999 -9999 -9999 -9999 -9999 -9999 -9999

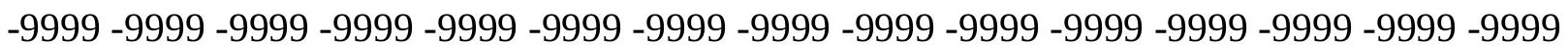

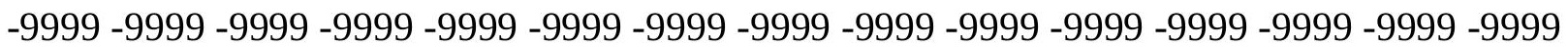
-9999 -9999 -9999 -9999 -9999 -9999 -9999 -9999 -9999 -9999 -9999 -9999 -9999 -9999 -9999 -9999 -9999 184.3950042725 180.432800293180.7375946045181.6519012451 182.5662994385183 .7854003906184 .699798584185 .3094024658185 .6141052246 185.6141052246185 .6141052246185 .3094024658184 .699798584184 .0901947021 183.4806976318182 .261505127181 .0424041748179 .2136993408177 .6896972656 175.8609924316174 .337097168172 .8132019043171 .2891998291170 .3748931885 169.4604949951168 .8509979248167 .9365997314167 .3269958496167 .0222015381 166.4127044678166 .1078948975170 .6797027588165 .1934967041164 .5839996338 
163.974395752163 .3648071289162 .4505004883161 .8408966064160 .9264984131 160.3170013428159 .4026031494158 .7929992676158 .1835021973157 .878692627 157.5738983154157 .2691040039156 .6596069336156 .3547973633155 .7451934814 155.4403991699154 .8307952881154 .2212982178153 .3069000244152 .3925933838 151.4781951904150 .2590942383149 .0399017334147 .2111968994145 .3825073242 143.2489929199143 .2489929199143 .5538024902143 .8585968018143 .8585968018 144.1634063721 -9999 -9999 -9999 -9999 -9999 -9999 -9999 -9999 -9999 -9999 -9999 -9999 -9999 -9999 -9999 -9999 -9999 -9999 -9999 -9999 -9999 -9999 -9999 -9999 -9999 -9999 -9999

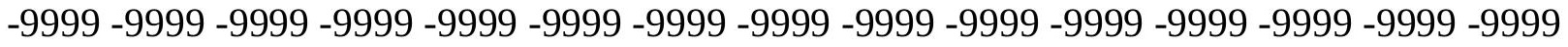
-9999 -9999 -9999 -9999 -9999 -9999 -9999 -9999 -9999 -9999 -9999 -9999 -9999 -9999 -9999 -9999 -9999 -9999 -9999 -9999 -9999 -9999 -9999 -9999 -9999 -9999 -9999 -9999 -9999 -9999 -9999 -9999 -9999 -9999 -9999 -9999 -9999 -9999 -9999 -9999 -9999 -9999 -9999 -9999 -9999 -9999 -9999 -9999 -9999 -9999 -9999 -9999 -9999 -9999 -9999 -9999 -9999 -9999 -9999 -9999 -9999 -9999 -9999 -9999 -9999 -9999 -9999 -9999 -9999 -9999 -9999 -9999 -9999 -9999 - 9999 -9999 -9999 -9999 -9999 -9999 -9999 -9999 -9999 -9999 -9999 -9999 -9999 -9999 -9999 -9999

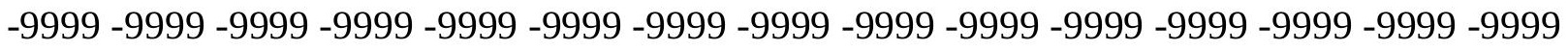
-9999 -9999 -9999 -9999 -9999 -9999 -9999 -9999 -9999 -9999 -9999 -9999 -9999 -9999 -9999 -9999 -9999 -9999 -9999 -9999 -9999 -9999 -9999 -9999 -9999 -9999 -9999 -9999 -9999 -9999 -9999 -9999 -9999 -9999 -9999 -9999 -9999 -9999 -9999 -9999 -9999 -9999 -9999 -9999 -9999 -

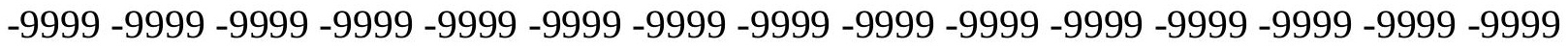

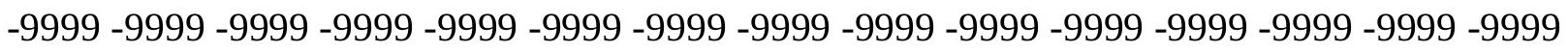
-9999 -9999-9999-9999-9999-9999-9999-9999-9999-9999 -9999 -9999 -9999 -9999 -9999 -9999 -9999 -9999 -9999 -9999 -9999 -9999 -9999 -9999 -9999

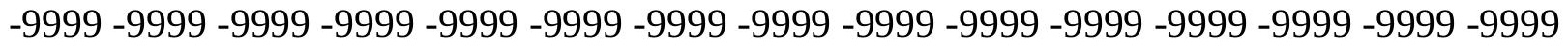

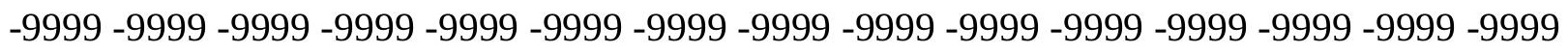
-9999 -9999 -9999 -9999 -9999 -9999 -9999 -9999 -9999 -9999 -9999 -9999 -9999 -9999 -9999 -9999 -9999 -9999 -9999 -9999 -9999 -9999 -9999 -9999 -9999 -9999 -9999 -9999 -9999 -9999 -9999 -9999 -9999 -9999 -9999-9999 -9999 -9999 -9999 -9999 -9999 -9999 -9999 -9999 - -999 -9999-9999 182.5662994385179.2136993408 180.1280059814181.9566955566 183.4806976318184 .699798584185 .3094024658185 .9188995361186 .2236938477 186.2236938477186 .2236938477185 .9188995361185 .6141052246185 .0045928955 184.0901947021182 .87109375181 .6519012451180 .1280059814178 .2993011475 176.4705963135174 .6419067383173 .1179962158171 .8988037109170 .6797027588 169.7653045654168 .8509979248168 .241394043167 .6318054199167 .0222015381 166.7174987793166 .1078948975165 .4983062744165 .1934967041164 .5839996338 163.9439086914163 .0599975586162 .4505004883161 .8408966064160 .9264984131 160.3170013428159 .4026031494158 .7929992676158 .1835021973157 .878692627 157.5738983154156 .9642944336156 .6596069336156 .0500030518155 .7451934814 154.8307952881154 .2212982178153 .6116943359152 .6972961426151 .4781951904 150.5639038086149 .3446960449147 .8208007812146 .2969055176144 .4682006836 142.6394042969142 .9441986084143 .2489929199143 .5538024902143 .8585968018 144.1634063721 144.1634063721 -9999 -9999 -9999 -9999 -9999 -9999 -9999 -9999 -9999 -9999 -9999 -9999 -9999 -9999 -9999 -9999 -9999 -9999 -9999 -9999 -9999 -9999 -9999 -9999 -9999 -9999 -9999 -9999 -9999 -9999 -9999 -9999 -9999-9999 -9999 -9999 -9999 -9999 -9999 -9999 -9999 -9999 -9999 -9999 -9999 -9999 -9999 -9999 -9999 -9999 -9999 -9999 -9999 -9999 -

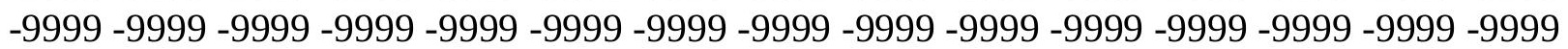


-9999 -9999 -9999 -9999 -9999 -9999 -9999 -9999 -9999 -9999 -9999 -9999 -9999 -9999 -9999 -9999 -9999 -9999 -9999 -9999 -9999 -9999 -9999 -9999 -9999 -9999 -9999 -9999 -9999 -9999 -9999 -9999 -9999 -9999 -9999 -9999 -9999 -9999 -9999 -9999 -9999 -9999 -9999 -9999 -9999 -9999 -9999 -9999 -9999 -9999 -9999 -9999 -9999 -9999 -9999 -9999 -9999 -9999 -9999 -9999 -9999 -9999 -9999 -9999 -9999 -9999 -9999 -9999 -9999 -9999 -9999 -9999 -9999 -9999 -9999 -9999 -9999 -9999 -9999 -9999 -9999 -9999 -9999 -9999 -9999 -9999 -9999 -9999 -9999 -9999 -9999 -9999 -9999 -9999 -9999 -9999 -9999 -9999 -9999 -9999 -9999 -9999 -9999 -9999 -9999

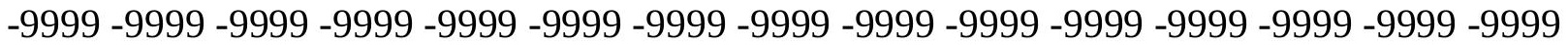
-9999 -9999 -9999 -9999 -9999 -9999 -9999 -9999 -9999 -9999 -9999 -9999 -9999 -9999 -9999 -9999 -9999 -9999 -9999 -9999 -9999 -9999 -9999 -9999 -9999 -9999 -9999 -9999 -9999 -9999 -9999 -9999 -9999 -9999 -9999 -9999 -9999 -9999 -9999 -9999 -9999 -9999

-9999 -9999 -9999 -9999 -9999 -9999 -9999 -9999 -9999 -9999 -9999 -9999 -9999 -9999 -9999

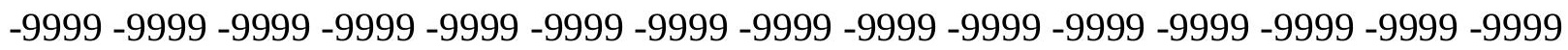
-9999 -9999 -9999 -9999 -9999 -9999 -9999 -9999 -9999 -9999 -9999 -9999 -9999 -9999 -9999 -9999 -9999 -9999 -9999 -9999 -9999 -9999 -9999 -9999 -9999 -9999 -9999 -9999 -9999 -9999 -9999 -9999 -9999 -9999 -9999 -9999 -9999 -9999 -9999 -9999 -9999 -9999 -9999 -9999 -9999 -9999 -9999 -9999 -9999 -9999 -9999 -9999 -9999 -9999 -9999 -9999 -9999 -9999 -9999 -9999 -9999 -9999 181.3471984863184.0901947021 181.3471984863183.4806976318 185.3094024658186 .2236938477186 .8332977295187 .1381072998187 .1381072998 187.1381072998187 .1381072998186 .528503418186 .2236938477185 .6141052246 184.699798584183 .7854003906182 .261505127180 .7375946045178 .9089050293 177.0802001953175 .2514038086173 .7274932861172 .2035980225171 .2891998291 170.070098877169 .4604949951168 .5462036133167 .9365997314167 .3269958496 166.7174987793166 .1078948975165 .8031005859165 .1934967041164 .5839996338 163.974395752163 .1609649658162 .4505004883161 .8408966064160 .9264984131 160.3170013428159 .7073974609159 .0977935791158 .4882965088158 .1835021973 157.5738983154157 .2691040039156 .6596069336156 .0500030518155 .4403991699 154.8307952881153 .9165039062153 .0021057129152 .0877990723150 .8686065674 149.6495056152148 .4304046631146 .9064025879145 .3825073242143 .8585968018 142.6394042969142 .9441986084143 .2489929199143 .5538024902143 .5538024902 143.8585968018144 .1634063721 -9999 -9999 -9999 -9999 -9999 -9999 -9999 -9999 -9999 -9999 -9999 -9999 -9999 -9999 -9999 -9999 -9999 -9999 -9999 -9999 -9999 -9999 -9999 -9999 -9999 -9999 -9999 -9999 -9999 -9999 -9999 -9999 -9999 -9999 -9999 -9999 -9999 -9999 -9999 -9999 -9999 -9999 -9999 -9999 -9999 -9999 -9999 -9999 -9999 -9999 -9999 -9999 -9999 -9999 -

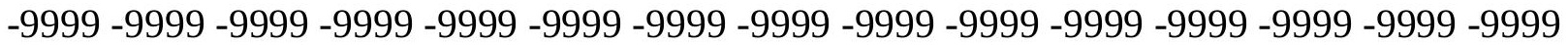
-9999 -9999 -9999 -9999 -9999 -9999 -9999 -9999 -9999 -9999 -9999 -9999 -9999 -9999 -9999 -9999 -9999 -9999 -9999 -9999 -9999 -9999 -9999 -9999 -9999 -9999 -9999 -9999 -9999 -9999

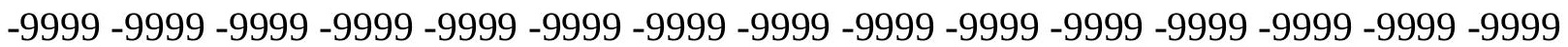
-9999 -9999 -9999 -9999 -9999 -9999 -9999 -9999 -9999 -9999 -9999 -9999 -9999 -9999 -9999 -9999 -9999 -9999 -9999 -9999 -9999 -9999 -9999 -9999 -9999 -9999 -9999 -9999 -9999 -9999 -

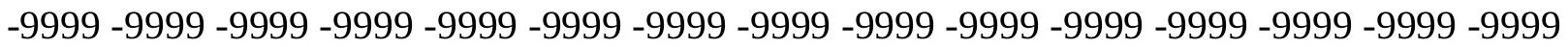
-9999 -9999 -9999 -9999 -9999 -9999 -9999 -9999 -9999 -9999 -9999 -9999 -9999 -9999 -9999 -9999 -9999 -9999 -9999 -9999 -9999 -9999 -9999 -9999 -9999 -9999 -9999 -9999 -9999 -9999 -9999 -9999 -9999 -9999 -9999 -9999 -9999 -9999 -9999 -9999 -9999 -9999 -9999 -9999 -9999 -9999 -9999 -9999 -9999 -9999 -9999 -9999 -9999 -9999 -9999 -9999 -9999 -9999 -9999 -9999 -9999 -9999 -9999 -9999 -9999 -9999 -9999 -9999 -9999 -9999 -9999 -9999 
-9999 -9999 -9999 -9999 -9999 -9999 -9999 -9999 -9999 -9999 -9999 -9999 -9999 -9999 -9999 -9999 -9999 -9999 -9999 -9999 -9999 -9999 -9999 -9999 -9999 -9999 -9999 -9999 -9999 -9999 -9999 -9999 -9999 -9999 -9999 -9999 -9999 -9999 -9999 -9999 -9999 -9999 -9999 -9999 -9999 -9999 -9999 -9999 -9999 -9999 -9999 -9999 -9999 -9999 -9999 -9999 -9999 -9999 -9999 -9999 -9999 -9999 -9999 -9999 -9999 -9999 -9999 -9999 -9999 -9999 -9999 -9999 -9999 -9999 -9999 -9999 -9999 -9999 -9999 -9999 -9999 -9999 -9999 -9999 -9999 -9999 -9999 -9999 -9999 -9999 -9999 -9999 183.7854003906 182.87109375 185.0045928955187 .1381072998188 .3571929932 188.6620025635188 .6620025635188 .3571929932188 .3571929932188 .0523986816 187.7476043701187 .4429016113187 .1381072998186 .2236938477185 .3094024658 184.3950042725183 .1759033203181 .3471984863179 .5184020996177 .9945068359 176.165802002174 .337097168173 .1179962158171 .8988037109170 .6797027588 169.7653045654168 .8509979248168 .241394043167 .6318054199167 .0222015381 166.4127044678165 .8031005859165 .1934967041164 .5839996338163 .974395752 163.3648071289162 .4505004883161 .8378143311161 .2312927246160 .6217956543 160.0122070312159 .4026031494158 .7929992676158 .4882965088157 .878692627 157.5738983154156 .9642944336156 .0500030518155 .4403991699154 .5260925293 153.6116943359152 .6972961426151 .4781951904150 .2590942383149 .0399017334 147.8208007812146 .2969055176144 .7729034424143 .2489929199142 .6394042969 142.9441986084143 .2489929199143 .2489929199143 .5538024902143 .8585968018 144.1634063721144 .4682006836 -9999 -9999 -9999 -9999 -9999 -9999 -9999 -9999 -9999 -9999 -9999 -9999 -9999 -9999 -9999 -9999 -9999 -9999 -9999 -9999 -9999 -9999 -9999 -9999 -9999 -9999 -9999 -9999 -9999 -9999 -9999 -9999 -9999 -9999 -9999 -9999 -9999 -9999 -9999 -9999 -9999 -9999 -9999 -9999 -9999 -9999 -9999 -9999 -9999 -9999 -9999 -9999 -9999 -9999 -9999 -9999 -9999 -9999 -9999 -9999 -9999 -9999 -9999 -9999 -9999 -9999 -9999 -9999 -9999 -9999 -9999 -9999 -9999 -9999 -9999 -9999 -9999 -9999 -9999 -9999 -9999 -9999 -9999 -9999 -9999 -9999 -9999 -9999 -9999 -9999 -9999 -9999 -9999 -9999 -9999 -9999 -9999 -9999 -9999 -9999 -9999 -9999 -9999 -9999 -9999 -9999 -9999 -9999 -9999 -9999 -9999 -9999 -9999 -9999 -9999 -9999 -9999 -9999 -9999 -9999 -9999 -9999 -9999 -9999 -9999 -9999 -9999 -9999 -9999 -9999 -9999 -9999 -9999 -9999 -9999 -9999 -9999 -9999 -9999 -9999 -9999 -9999 -9999 -9999 -9999 -9999 -9999 -9999 -9999 -9999 -9999 -9999 -9999 -9999 -9999 -9999 -9999 -9999 -9999 -9999 -9999 -9999 -9999 -9999 -9999 -9999 -9999 -9999 -9999 -9999 -9999 -9999 -9999 -9999 -9999 -9999 -9999 -9999 -9999 -9999 -9999 -9999 -9999 -9999 -9999 -9999 -9999 -9999 -9999 -9999 -9999 -9999 -9999 -9999 -9999 -9999 -9999 -9999 -9999 -9999 -9999 -9999 -9999 -9999 -9999 -9999 -9999 -9999 -9999 -9999 -9999 -9999 -9999 -9999 -9999 -9999 -9999 -9999 -9999 -9999 -9999 -9999 -9999 -9999 -9999 -9999 -9999 -9999 -9999 -9999

-9999 -9999 -9999 -9999 -9999 -9999 -9999 -9999 -9999 -9999 -9999 -9999 -9999 -9999 -9999 -9999 -9999 -9999 -9999 -9999 -9999 -9999 -9999 -9999 -9999 -9999 -9999 -9999 -9999 -9999 -9999 -9999 -9999 -9999 -9999 -9999 -9999 -9999 -9999 -9999 -9999 -9999 -9999 -9999 -9999 -9999 -9999 -9999 -9999 -9999 -9999 -9999 -9999 -9999 -9999 -9999 -9999 -9999 -9999 -9999 -9999 -9999 -9999 -9999 -9999 -9999 -9999 -9999 -9999 -9999 -9999 -9999 -9999 -9999 -9999 -9999 -9999 -9999 -9999 -9999 -9999 -9999 -9999 -9999 -9999 -9999 -9999 -9999 -9999 -9999 -9999 -9999-9999 190.795501709 191.4051055908 192.3193969727 192.0146026611 191.4051055908190 .4907073975189 .8811035156189 .5764007568188 .966796875 188.6620025635188 .3571929932187 .7476043701187 .1381072998186 .2236938477 185.0045928955183 .7854003906182 .261505127180 .432800293178 .604095459 176.7754058838175 .2514038086173 .7274932861172 .5084075928171 .2891998291 
170.3748931885169 .4604949951168 .8509979248167 .9365997314167 .3269958496 166.7174987793166 .1078948975165 .4983062744164 .8887023926164 .2792053223 163.3648071289162 .7552947998161 .8511962891161 .2312927246160 .6217956543 160.0122070312159 .7073974609159 .0977935791158 .7929992676158 .1835021973 157.878692627157 .2691040039156 .3547973633155 .4403991699154 .5260925293 153.6116943359152 .6972961426151 .1734008789149 .9542999268148 .7351074219 147.2111968994145 .9920959473144 .7729034424143 .2489929199142 .9441986084 142.9441986084143 .2489929199143 .5538024902143 .5538024902143 .8585968018 144.1634063721 144.1634063721 -9999 -9999 -9999 -9999 -9999 -9999 -9999 -9999 -9999 -9999 -9999 -9999 -9999 -9999 -9999 -9999 -9999 -9999 -9999 -9999 -9999 -9999 -9999 -9999 -9999 -9999 -9999 -9999 -9999 -9999 -9999 -9999 -9999 -9999 -9999 -9999 -9999 -9999 -9999 -9999 -9999 -9999 -9999 -9999 -9999 -9999 -9999 -9999 -9999 -9999 -9999 -9999 -9999 -9999 -999 -9999 -9999 -9999 -9999 -9999 -9999 -9999 -9999 -9999 -9999 -9999 -9999 -9999 -9999 -9999 -9999 -9999 -9999 -9999 -9999 -9999 -9999 -9999 -9999 -9999 -9999 -9999 -9999 -9999 -9999 -9999 -9999 -9999 -9999 -9999 -9999 -9999 -9999 -9999 -9999 -9999 -9999 -9999 -9999 -9999

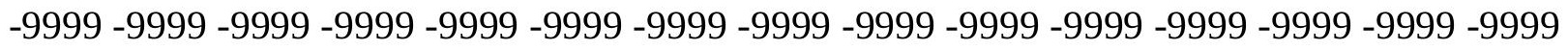
-9999 -9999 -9999 -9999 -9999 -9999 -9999 -9999 -9999 -9999 -9999 -9999 -9999 -9999 -9999 -9999 -9999 -9999 -9999 -9999 -9999 -9999 -9999 -9999 -9999 -9999 -9999 -9999 -9999 -9999 -

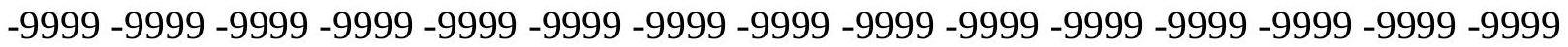

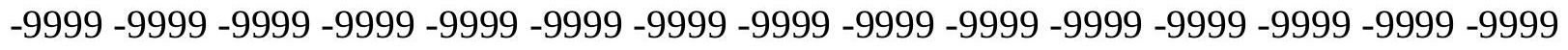

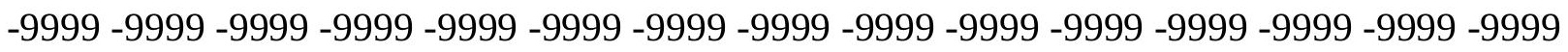
-9999 -9999 -9999 -9999 -9999 -9999 -9999 -9999 -9999 -9999 -9999 -9999 -9999 -9999 -9999 -9999 -9999 -9999 -9999 -9999 -9999 -9999 -9999 -9999 -9999 -9999 -9999 -9999 -9999 -999 -999 -9999 -9999 -9999 -9999 -9999 -9999 -9999 -9999 -9999 -9999 -9999 -

-9999 -9999 -9999 -9999 -9999 -9999 -9999 -9999 -9999 -9999 -9999 -9999 -9999 -9999 -9999 -9999 -9999 -9999 -9999 -9999 -9999 -9999 -9999 -9999 -9999 -9999 -9999 -9999 -9999 -9999

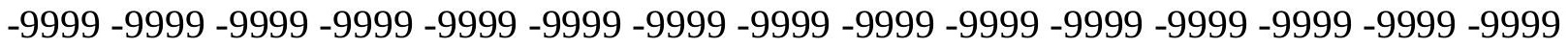

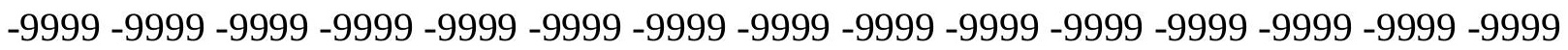
-9999 -9999 -9999 -9999 -9999 -9999 -9999 -9999 -9999 -9999 -9999 -9999 -9999 -9999 -9999

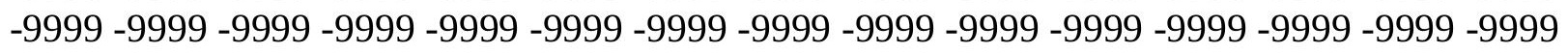
-9999 -9999 -9999 208.4730072021 198.7198944092 197.1959991455 195.3672943115 193.8433074951192 .3193969727191 .4051055908190 .795501709190 .1858978271 189.5764007568189 .2716064453188 .6620025635188 .0523986816187 .1381072998 185.9188995361184 .3950042725182 .87109375181 .0424041748179 .5184020996 177.6896972656175 .8609924316174 .337097168173 .1179962158171 .8988037109 170.9844970703170 .070098877169 .1557006836168 .5462036133167 .6318054199 167.0222015381166 .4127044678165 .8031005859165 .1934967041164 .5839996338 163.6696014404163 .0599975586162 .1457061768161 .292388916160 .7651672363 160.3170013428160 .0122070312159 .7073974609159 .0977935791158 .7929992676 158.1835021973157 .5738983154156 .6596069336155 .7451934814154 .8307952881 153.9165039062152 .6972961426151 .4781951904149 .9542999268148 .4304046631 147.5160064697146 .2969055176144 .7729034424143 .5538024902143 .2489929199 143.2489929199143 .5538024902143 .5538024902143 .5538024902143 .8585968018 143.8585968018144 .1634063721144 .4682006836 -9999 -9999 -9999 -9999-9999 -9999 -9999 -9999 -9999 -9999 -9999 -9999 -9999 -9999 -9999 -9999 -9999 -9999 -9999 -9999 -9999 -9999 -

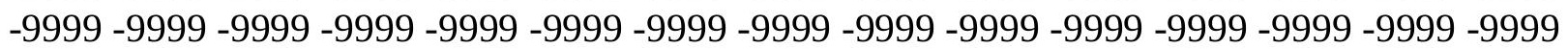


-9999 -9999 -9999 -9999 -9999 -9999 -9999 -9999 -9999 -9999 -9999 -9999 -9999 -9999 -9999 -9999 -9999 -9999 -9999 -9999 -9999 -9999 -9999 -9999 -9999 -9999 -9999 -9999 -9999 -9999 -9999 -9999 -9999 -9999 -9999 -9999 -9999 -9999 -9999 -9999 -9999 -9999 -9999 -9999 -9999 -9999 -9999 -9999 -9999 -9999 -9999 -9999 -9999 -9999 -9999 -9999 -9999 -9999 -9999 -9999 -9999 -9999 -9999 -9999 -9999 -9999 -9999 -9999 -9999 -9999 -9999 -9999 -9999 -9999 -9999 -9999 -9999 -9999 -9999 -9999 -9999 -9999 -9999 -9999 -9999 -9999 -9999 -9999 -9999 -9999 -9999 -9999 -9999 -9999 -9999 -9999 -9999 -9999 -9999 -9999 -9999 -9999 -9999 -9999 -9999

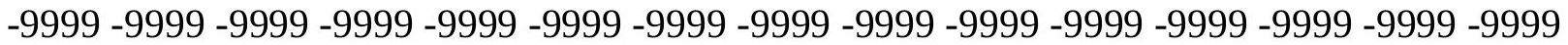
-9999 -9999 -9999 -9999 -9999 -9999 -9999 -9999 -9999 -9999 -9999 -9999 -9999 -9999 -9999 -9999 -9999 -9999 -9999 -9999 -9999 -9999 -9999 -9999 -9999 -9999 -9999 -9999 -9999 -9999 -

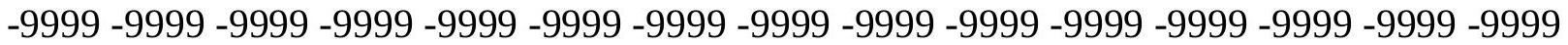
-9999 -9999 -9999 -9999 -9999 -9999 -9999 -9999 -9999 -9999 -9999 -9999 -9999 -9999 -9999 -

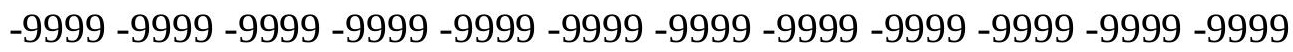
-9999 -9999 -9999 -9999 -9999 -9999 -9999 -9999 -9999 -9999 -9999 -9999 -9999 -9999 -9999 -9999 -9999 -9999 -9999 -9999 -9999 -9999 -9999 -9999 -9999 -9999 -9999 -9999 -9999 -9999

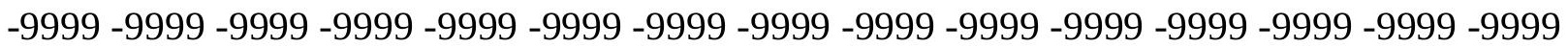
-9999 -9999 -9999 -9999 -9999 -9999 -9999 -9999 -9999 -9999 -9999 -9999 -9999 -9999 -9999 -9999 -9999 -9999 -9999 -9999 -9999 -9999 -9999 -9999 -9999 -9999 -9999 -9999 -9999 -9999 -9999 -9999 -9999 -9999 -9999 -9999 -9999 -9999 -9999 -9999 -9999 -9999 -9999 -9999 -9999 -9999 -9999-9999 232.246307373203.596496582 200.2438049316197.8054962158 195.6721038818193 .8433074951192 .624206543191 .7097930908191 .1002960205 190.4907073975190 .1858978271189 .5764007568188 .966796875187 .7476043701 186.8332977295185 .3094024658183 .7854003906181 .9566955566180 .1280059814 178.2993011475176 .7754058838175 .2514038086173 .7274932861172 .5084075928 171.2891998291170 .3748931885169 .7653045654168 .8509979248168 .241394043 167.6318054199167 .0222015381166 .1078948975165 .4983062744164 .8887023926 163.974395752163 .0599975586162 .4505004883161 .8408966064160 .9313201904 160.5894470215160 .2977905273160 .0122070312159 .7073974609159 .4026031494 158.4882965088157 .878692627156 .9642944336156 .0500030518155 .1356048584 154.0602874756152 .8993988037151 .7830047607150 .5639038086149 .3446960449 148.1255950928146 .9064025879145 .3825073242144 .1634063721143 .8585968018 143.5538024902143 .5538024902143 .5538024902143 .5538024902143 .5538024902 143.8585968018144 .1634063721144 .4682006836 -9999 -9999 -9999 -9999 -9999 -9999 -9999 -9999 -9999 -9999 -9999 -9999 -9999 -9999 -9999 -9999 -9999 -9999 -9999 -9999 -9999 -9999

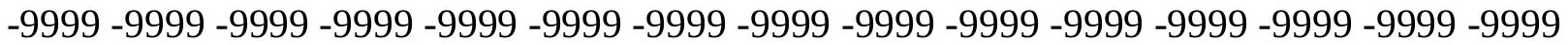
-9999 -9999 -9999 -9999 -9999 -9999 -9999 -9999 -9999 -9999 -9999 -9999 -9999 -9999 -9999

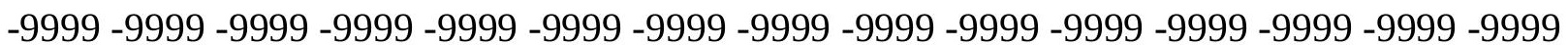

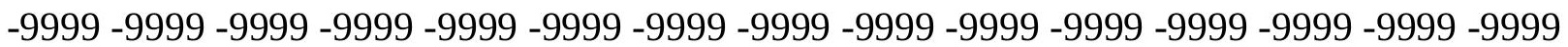
-9999 -9999 -9999 -9999 -9999 -9999 -9999 -9999 -9999 -9999 -9999 -9999 -9999 -9999 -9999 -9999 -9999 -9999 -9999 -9999 -9999 -9999 -9999 -9999 -9999 -9999 -9999 -9999 -9999 -9999 -9999 -9999 -9999 -9999 -9999 -9999 -9999 -9999 -9999 -9999 -9999 -9999 -9999 -9999 -9999

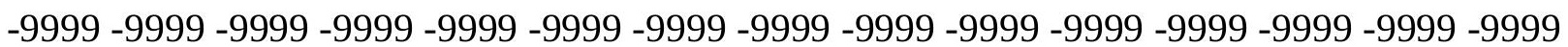
-9999 -9999 -9999 -9999 -9999 -9999 -9999 -9999 -9999 -9999 -9999 -9999 -9999 -9999 -9999 -9999 -9999 -9999 -9999 -9999 -9999 -9999 -9999 -9999 -9999 -9999 -9999 -9999 -9999 -9999 -9999 -9999 -9999 -9999 -9999 -9999 -9999 -9999 -9999 -9999 -9999 -9999 -9999 -9999 -9999

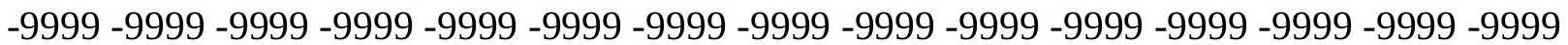


-9999 -9999 -9999 -9999 -9999 -9999 -9999 -9999 -9999 -9999 -9999 -9999 -9999 -9999 -9999 -9999 -9999 -9999 -9999 -9999 -9999 -9999 -9999 -9999 -9999 -9999 -9999 -

-9999 -9999 -9999 -9999 -9999 -9999 -9999 -9999 -9999 -9999 -9999 -9999 -9999 -9999 -9999 -9999 -9999 -9999 -9999 -9999 -9999 -9999 -9999 -9999 -9999 -9999 -9999 -9999 -9999 -9999 -9999 -9999 -9999 -9999 -9999 -9999 -9999 -9999 -9999-9999 -9999 -9999 -9999 -9999 -9999 -9999 -9999 -9999 -9999 -9999 -9999 -9999 -9999 -9999 -9999 -9999 -9999 -9999 -9999 -9999 -

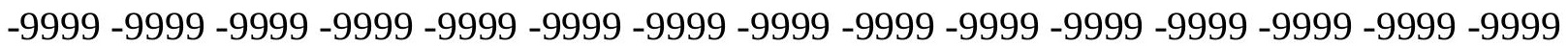
-9999 -9999 -9999 -9999 -9999 -9999 -9999 -9999 -9999 -9999 -9999 -9999 -9999 -9999 -9999 -9999 -9999 -9999 -9999 220.054901123 201.158203125 198.4151000977 196.2816009521 194.7577056885193 .5386047363192 .624206543192 .0146026611191 .7097930908 191.1002960205190 .4907073975189 .8811035156188 .966796875187 .7476043701 186.2236938477 184.3950042725 182.87109375 180.7375946045 179.2136993408 177.3849029541175 .8609924316174 .337097168173 .1179962158171 .8988037109 170.9844970703170 .070098877169 .4604949951168 .5462036133167 .9365997314 167.3269958496166 .7174987793165 .8031005859165 .1934967041164 .2792053223 163.3648071289162 .7552947998161 .8408966064161 .2312927246160 .6217956543 160.3170013428160 .0122070312160 .0122070312159 .7073974609159 .0977935791 158.1835021973157 .2691040039156 .3547973633155 .2781524658154 .1412353516 153.6116943359152 .6972961426151 .4781951904150 .2590942383149 .0399017334 147.8208007812146 .2969055176145 .0776977539144 .1634063721144 .1634063721 143.8585968018143 .8585968018143 .5538024902143 .5538024902143 .8585968018 143.8585968018144 .1634063721144 .7729034424 -9999 -9999 -9999 -9999 -9999 -9999 -9999 -9999 -9999 -9999 -9999 -9999 -9999 -9999 -9999 -9999 -9999 -9999 -9999 -9999 -9999 -9999

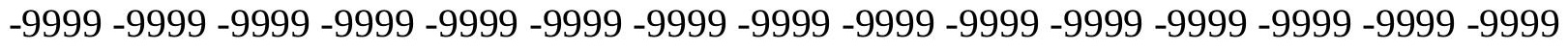

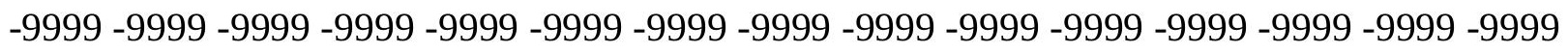
-9999 -9999 -9999 -9999 -9999 -9999 -9999 -9999 -9999 -9999 -9999 -9999 -9999 -9999 -9999 -9999 -9999 -9999 -9999 -9999 -9999 -9999 -9999 -9999 -9999 -9999 -9999 -9999 -9999 -9999 -

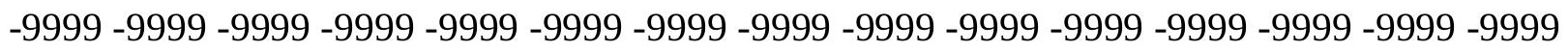
-9999 -9999 -9999 -9999 -9999 -9999 -9999 -9999 -9999 -9999 -9999 -9999 -9999 -9999 -9999 -9999 -9999 -9999 -9999 -9999 -9999 -9999 -9999 -9999 -9999 -9999 -9999 -9999 -9999 -9999 -9999 -9999 -9999 -9999 -9999 -9999 -9999 -9999 -9999-9999 -9999 -9999 -9999 -9999 -9999 -9999 -9999 -9999 -9999 -9999 -9999 -9999 -9999 -9999 -9999 -9999 -9999 -9999 -9999 -9999 -

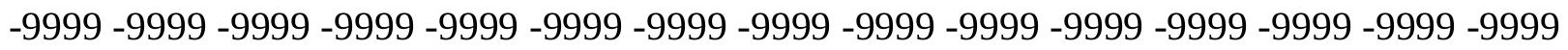
-9999 -9999 -9999 -9999 -9999 -9999 -9999 -9999 -9999 -9999 -9999 -9999 -9999 -9999 -9999 -9999 -9999 -9999 -9999 -9999 -9999 -9999 -9999 -9999 -9999 -9999 -9999 -9999 -9999 -9999 -

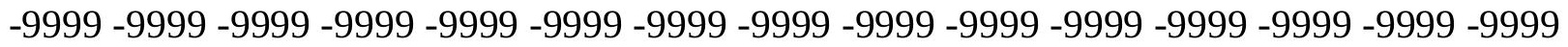

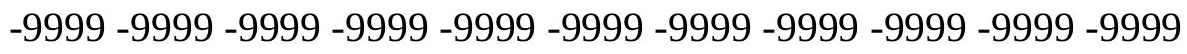

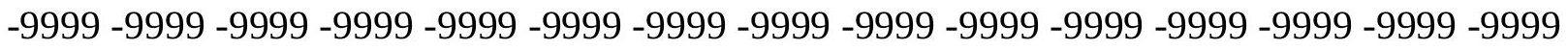
-9999 -9999 -9999 -9999 -9999 -9999 -9999 -9999 -9999 -9999 -9999 -9999 -9999 - 9999 - -999 -9999 -9999 -9999 -9999 -9999 -9999 -9999 -9999 -9999 -9999 -9999 -9999 -9999 -9999 - -999 -

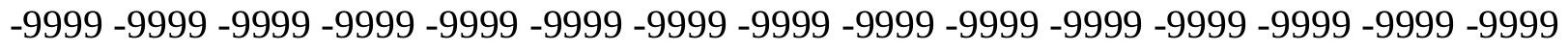

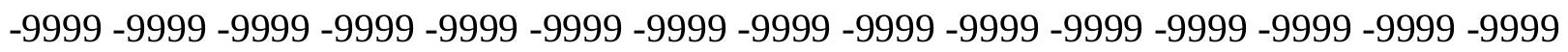
-9999 -9999 -9999 -9999 -9999 -9999 -9999 -9999 -9999 -9999 -9999 -9999 -9999 -9999 -9999 -9999 -9999 -9999 -9999 233.4653930664 202.6820983887 198.1103057861 196.891204834 195.3672943115 194.1481018066193 .5386047363193 .233795166192 .624206543 192.3193969727191 .7097930908191 .1002960205189 .8811035156188 .6620025635 
187.1381072998185 .3094024658183 .4806976318181 .6519012451179 .8231964111 177.9945068359176 .4705963135174 .9467010498173 .7274932861172 .5084075928 171.5939941406170 .6797027588169 .7653045654169 .1557006836168 .5462036133 167.9365997314167 .0222015381166 .4127044678165 .4983062744164 .5839996338 163.6696014404162 .7552947998162 .1457061768161 .5361022949160 .9264984131 160.3170013428160 .0122070312160 .0122070312159 .7045440674159 .0977935791 158.286315918157 .3706512451156 .377532959155 .292175293155 .1356048584 154.5260925293153 .6116943359152 .6972961426151 .1734008789149 .9542999268 148.7351074219147 .5160064697145 .9920959473144 .7729034424144 .4682006836 144.1634063721143 .8585968018143 .5538024902143 .5538024902143 .5538024902 143.5538024902144 .1634063721144 .4682006836 -9999 -9999 -9999 -9999 -9999 -9999 -9999 -9999 -9999 -9999 -9999 -9999 -9999 -9999 -9999 -9999 -9999 -9999 -9999 -9999 -9999 -9999 -9999 -9999 -9999 -9999 -9999 -9999 -9999 -9999 -9999 -9999 -9999 -9999 -9999 -9999 -9999 -9999 -9999 -9999 -9999 -9999 -9999 -9999 -9999 -9999 -9999 -9999 -9999 -9999 -9999 -9999 -9999 -9999 -9999 -9999 -9999 -9999 -9999 -9999 -9999 -9999 -9999 -9999 -9999 -9999 -9999

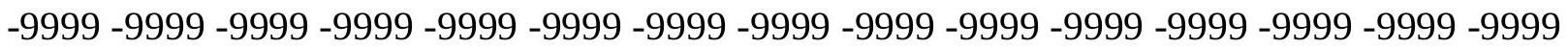

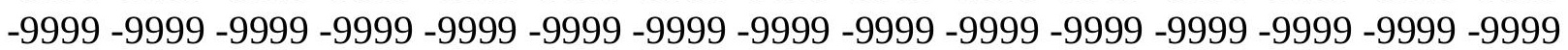
-9999 -9999 -9999 -9999 -9999 -9999 -9999 -9999 -9999 -9999 -9999 -9999 -9999 -9999 -9999 -999 -9999 -9999 -9999 -9999 -9999 -9999 -9999 -9999 -9999 -9999 -9999 -9999 -9999 -9999 -9999 -9999 -9999 -9999 -9999 -9999 -9999 -9999 -9999 -9999 -9999 -9999 -9999 -9999 -9999 -9999

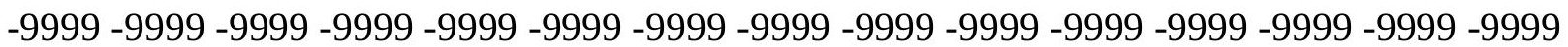
-9999 -9999 -9999 -9999 -9999 -9999 -9999 -9999 -9999 -9999 -9999 -9999 -9999 -9999 -9999 -9999 -9999 -9999 -9999 -9999 -9999 -9999 -9999 -9999 -9999 -9999 -9999 -9999 -9999 -9999 -9999 -9999 -9999 -9999 -9999 -9999 -9999 -9999 -9999 -9999 -9999 -9999 -9999 -9999 -9999

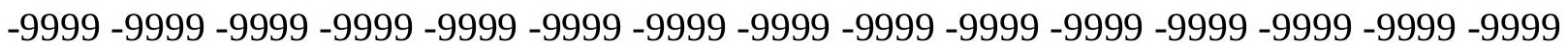
-9999 -9999 -9999 -9999 -9999 -9999 -9999 -9999 -9999 -9999-9999 -9999 -9999 -9999 -9999 -9999 -9999 -9999 -9999 -9999 -9999 -9999 -9999 -9999 -9999 -9999 -9999 -9999 -9999 -9999 -9999 -9999 -9999 -9999 -9999 -9999 -9999 -9999 -9999 -9999 -9999

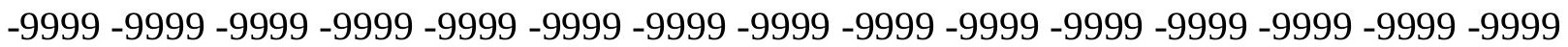

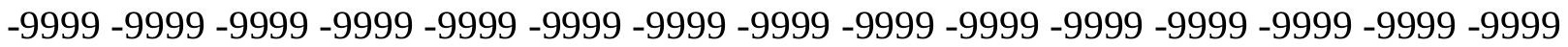
-9999 -9999 -9999 -9999 -9999 -9999 -9999 -9999 -9999 -9999 -9999 -9999 -9999 -9999 -9999 -9999 -9999 -9999 -9999 -9999 -9999 -9999 -9999 -9999 -9999 -9999 -9999 -9999 -9999 -9999 -9999 -9999 -9999 -9999-9999 219.4452972412 198.4151000977 197.1959991455 195.6721038818194 .7577056885194 .4528961182194 .4528961182194 .1481018066 193.8433074951193 .233795166192 .3193969727191 .1002960205189 .8811035156 188.0523986816186 .2236938477184 .3950042725182 .261505127180 .432800293 178.604095459177 .0802001953175 .5561981201174 .337097168173 .1179962158 172.2035980225170 .9844970703170 .3748931885169 .7653045654168 .8509979248 168.241394043167 .6318054199166 .7174987793165 .8031005859164 .8887023926 163.974395752163 .0599975586162 .1457061768161 .5361022949160 .9264984131 160.3170013428160 .0122070312159 .7073974609159 .4026031494158 .9373168945 158.1662445068157 .878692627157 .2691040039156 .6596069336156 .0500030518 155.1356048584154 .2212982178153 .3069000244152 .0877990723150 .8686065674 149.9542999268148 .7351074219147 .2111968994145 .6873016357144 .7729034424 144.1634063721143 .8585968018143 .2489929199143 .2489929199143 .2489929199 143.2489929199143 .5538024902144 .1634063721144 .7729034424 -9999 -9999 -9999 -9999 
-9999 -9999 -9999 -9999 -9999 -9999 -9999 -9999 -9999 -9999 -9999 -9999 -9999 -9999 -9999 -9999 -9999 -9999 -9999 -9999 -9999 -9999 -9999 -9999 -9999 -9999 -9999 -9999 -9999 -9999 -9999 -9999 -9999 -9999 -9999 -9999 -9999 -9999 -9999 -9999 -9999 -9999 -9999 -9999 -9999 -9999 -9999 -9999 -9999 -9999 -9999 -9999 -9999 -9999 -9999 -9999 -9999 -9999 -9999 -9999 -9999 -9999 -9999 -9999 -9999 -9999 -9999 -9999 -9999 -9999 -9999 -9999 -9999 -9999 -9999 -9999 -9999 -9999 -9999 -9999 -9999 -9999 -9999 -9999 -9999 -9999 -9999 -9999 -9999 -9999 -9999 -9999 -9999 -9999 -9999 -9999 -9999 -9999 -9999 -9999 -9999 -9999 -9999 -9999 -9999

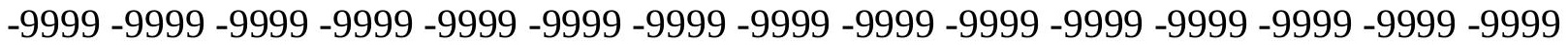
-9999 -9999 -9999 -9999 -9999 -9999 -9999 -9999 -9999 -9999 -9999 -9999 -9999 -9999 -9999 -9999 -9999 -9999 -9999 -9999 -9999 -9999 -9999 -9999 -9999 -9999 -9999 -9999 -9999 -9999 -9999 -9999 -9999 -9999 -9999 -9999 -9999 -9999 -9999 -9999 -9999 -9999 -9999 -9999 -9999 -9999 -9999 -9999 -9999 -9999 -9999 -9999 -9999 -9999 -9999 -9999 -9999 -9999 -9999 -9999

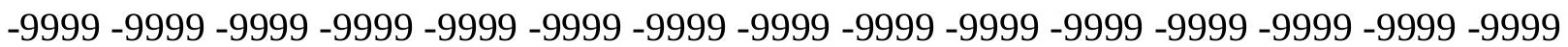
-9999 -9999 -9999 -9999 -9999 -9999 -9999 -9999 -9999 -9999 -9999 -9999 -9999 -9999 -9999 -9999 -9999 -9999 -9999 -9999 -9999 -9999 -9999 -9999 -9999 -9999 -9999 -9999

-9999 -9999 -9999 -9999 -9999 -9999 -9999 -9999 -9999 -9999 -9999 -9999 -9999 -9999 -9999

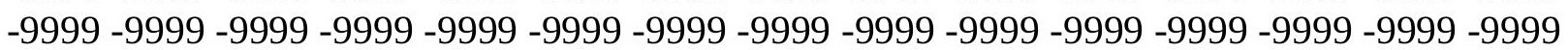
-9999 -9999 -9999 -9999 -9999 -9999 -9999 -9999 -9999 -9999 -9999 -9999 -9999 -9999 -9999 -9999 -9999 -9999 -9999 -9999 -9999 -9999 -9999 -9999 -9999 -9999 -9999 -9999 -9999 -9999 -9999 -9999 -9999 -9999 -9999 -9999 -9999 -9999 -9999 -9999 -9999 -9999 -9999 -9999 -9999 -9999 -9999 -9999 -9999 -9999 -9999 -9999 -9999 -9999 -9999 -9999 -9999 -9999 -9999 -9999 -9999 -9999 -9999 -9999 -9999 233.4653930664206.9490966797 196.5863952637 195.0625 195.6721038818195 .9768066406196 .2816009521195 .9768066406195 .3672943115 194.7577056885193 .8433074951192 .624206543191 .1002960205189 .2716064453 187.1381072998185 .0045928955183 .1759033203181 .3471984863179 .5184020996 177.9945068359176 .4705963135174 .9467010498173 .7274932861172 .5084075928 171.5939941406170 .6797027588170 .070098877169 .4604949951168 .5462036133 167.9365997314167 .0222015381166 .1078948975165 .1934967041164 .2792053223 163.3648071289162 .4505004883161 .8408966064160 .9264984131160 .3170013428 160.0122070312159 .4026031494159 .4026031494159 .0977935791158 .7929992676 158.1835021973157 .878692627157 .2691040039156 .6596069336155 .7451934814 155.1356048584153 .9165039062152 .6972961426152 .0877990723151 .1734008789 149.9542999268148 .4304046631146 .6015930176145 .0776977539144 .1634063721 143.5538024902142 .9441986084142 .6394042969142 .6394042969142 .9441986084 143.2489929199143 .8585968018144 .4682006836 -9999 -9999 -9999 -9999 -9999 -9999 -9999 -9999 -9999 -9999 -9999 -9999 -9999 -9999 -9999 -9999 -9999 -9999 -9999 -9999 -9999 -9999

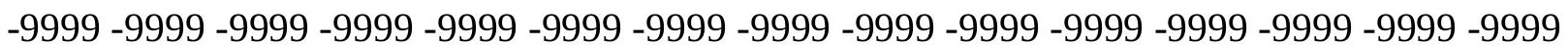

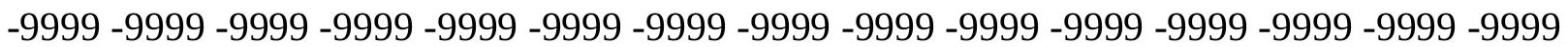
-9999 -9999 -9999 -9999 -9999 -9999 -9999 -9999 -9999 -9999 -9999 -9999 -9999 -9999 -9999 -9999 -9999 -9999 -9999 -9999 -9999 -9999 -9999 -9999 -9999 -9999 -9999 -9999 -9999 -9999 -9999 -9999 -9999 -9999 -9999 -9999 -9999 -9999 -9999 -9999 -9999 -9999 -9999 -9999 -9999

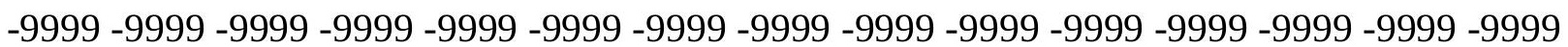
-9999 -9999 -9999 -9999 -9999 -9999 -9999 -9999 -9999 -9999 -9999 -9999 -9999 -9999 -9999 -9999 -9999 -9999 -9999 -9999 -9999 -9999 -9999 -9999 -9999 -9999 -9999 -9999 -9999 -9999 -9999 -9999 -9999 -9999 -9999 -9999 -9999 -9999 -9999 -9999 -9999 -9999 -9999 -9999 -9999

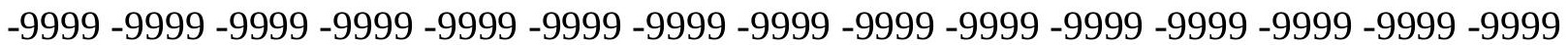


-9999 -9999 -9999 -9999 -9999 -9999 -9999 -9999 -9999 -9999 -9999 -9999 -9999 -9999 -9999 -9999 -9999 -9999 -9999 -9999 -9999 -9999 -9999 -9999 -9999 -9999 -9999 -9999 -9999 -9999 -9999 -9999 -9999 -9999 -9999 -9999 -9999 -9999 -9999 -9999 -9999 -9999 -9999 -9999 -9999 -9999 -9999 -9999 -9999 -9999 -9999 -9999 -9999 -9999 -9999

-9999 -9999 -9999 -9999 -9999 -9999 -9999 -9999 -9999 -9999 -9999 -9999 -9999 -9999 -9999 -9999 -9999 -9999 -9999 -9999 -9999 -9999 -9999 -9999 -9999 -9999 -9999 -9999 -9999 -9999 -9999 -9999 -9999 -9999 -9999 -9999 -9999 -9999 -9999 -9999 -9999 -9999 -9999 -9999 -9999

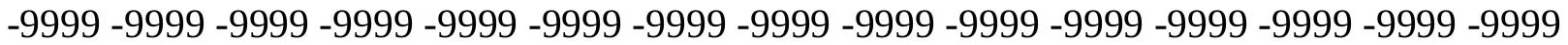

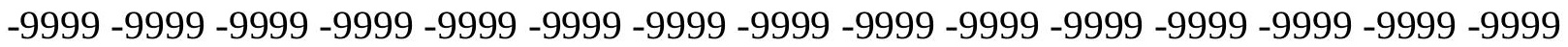
-9999 -9999 -9999 -9999 -9999 -9999 -9999 -9999 -9999 -9999 -9999 -9999 -9999 -9999 -9999 -999 -9999 -9999 -9999 -9999 -9999 -9999 219.4452972412 192.3193969727195 .3672943115 197.8054962158198 .7198944092198 .7198944092198 .1103057861197 .500793457 196.2816009521195 .3672943115193 .8433074951192 .3193969727190 .4907073975 188.3571929932186 .2236938477183 .7854003906181 .9566955566180 .432800293 178.604095459177 .0802001953175 .5561981201174 .337097168173 .1179962158 171.8988037109170 .9844970703170 .3748931885169 .7653045654169 .1557006836 168.241394043167 .3269958496166 .4127044678165 .4983062744164 .5839996338 163.6696014404162 .7552947998161 .8408966064161 .2312927246160 .6217956543 160.0122070312159 .4026031494159 .4026031494159 .0977935791159 .0977935791 158.7929992676158 .4882965088157 .878692627157 .2691040039156 .6596069336 155.7451934814155 .1356048584154 .2212982178153 .3069000244152 .6972961426 151.4781951904149 .6495056152147 .5160064697145 .0776977539144 .1634063721 143.2489929199142 .6394042969142 .3347015381142 .0299072266142 .3347015381 142.6394042969143 .2489929199143 .8585968018 -9999 -9999 -9999 -9999 -9999 -9999 -9999 -9999 -9999 -9999 -9999 -9999 -9999 -9999 -9999 -9999 -9999 -9999 -9999 -9999 -9999 -9999 -9999 -9999 -9999 -9999 -9999 -9999 -9999 -9999 -9999 -9999 -9999 -9999 -9999 -9999 -9999 -9999 -9999 -9999 -9999 -9999 -9999 -9999 -9999 -9999 -9999 -9999 -9999 -9999 -9999 -9999 -9999 -9999 -9999 -9999 -9999 -9999 -9999 -9999 -9999 -9999 -9999 -9999 -9999 -9999 -9999 -9999 -9999 -9999 -9999 -9999 -9999 -9999 -9999 -9999 -9999 -9999 -9999 -9999 -9999 -9999

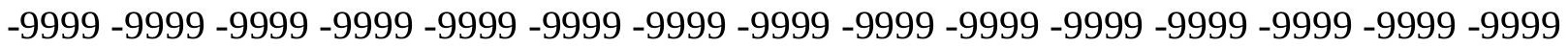
-9999 -9999 -9999 -9999 -9999 -9999 -9999 -9999 -9999 -9999 -9999 -9999 -9999 -9999 -9999

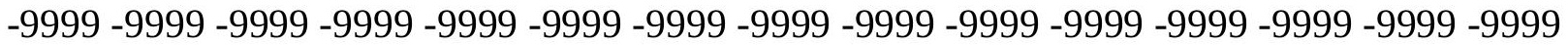

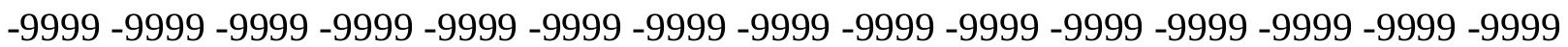
-9999 -9999 -9999 -9999 -9999 -9999 -9999 -9999 -9999 -9999 -9999 -9999 -9999 -9999 -9999 -9999 -9999 -9999 -9999 -9999 -9999 -9999 -9999 -9999 -9999 -9999 -9999 -9999 -9999 -9999 -9999 -9999 -9999 -9999 -9999 -9999 -9999 -9999 -9999 -9999 -9999 -9999 -9999 -9999 -9999 -9999 -9999 -9999 -9999 -9999 -9999 -9999 -9999 -9999 -9999 -9999 -9999 -9999 -9999 -9999

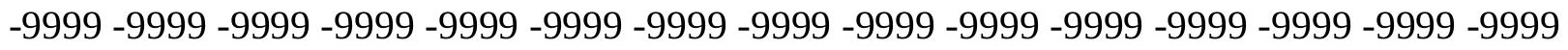
-9999 -9999 -9999 -9999 -9999 -9999 -9999 -9999 -9999-9999 -9999 -9999 -9999 -9999 -9999 -9999 -9999 -9999 -9999 -9999 -9999 -9999 -9999 -9999 -9999 -9999 -9999 -9999 -9999 -9999 -9999 -9999 -9999 -9999 -9999 -9999 -9999 -9999 -9999 -9999 -999 -9999 -9999 -9999 -9999 -9999 -9999 -9999 -9999 -9999 -9999 -9999 -9999 -9999 -9999 -9999 -9999 -9999 -9999 -9999 -9999 -9999 -9999 -9999 -9999 -9999 -9999 -9999 -9999 -9999 -9999 -9999 -9999 -9999 -9999 -9999 -9999 -9999 -9999 -9999 -9999 -9999 -9999 -9999 -9999 -9999 -9999 -9999 -9999 -9999 -9999 -9999 -9999 -9999 -9999 -9999 -9999 -9999 -9999 -9999 -9999 -9999 -9999 -9999 -9999 -9999 -9999 234.0749969482 204.2059936523 199.6342926025 
201.7678070068202 .0724945068201 .158203125200 .2438049316199 .329498291 198.1103057861196 .891204834195 .3672943115193 .5386047363191 .7097930908 189.5764007568187 .4429016113185 .3094024658183 .1759033203181 .3471984863 179.5184020996177 .6896972656176 .165802002174 .6419067383173 .4226989746 172.2035980225171 .2891998291170 .3748931885169 .7653045654169 .4604949951 168.5462036133167 .3269958496166 .4127044678165 .8031005859164 .8887023926 163.974395752163 .0599975586162 .4505004883161 .5361022949160 .9264984131 160.0122070312159 .7073974609159 .4026031494159 .4026031494159 .4026031494 159.0977935791159 .0977935791158 .4882965088157 .878692627157 .5738983154 156.6596069336156 .0500030518155 .4403991699154 .8307952881153 .9165039062 152.6972961426150 .8686065674148 .4304046631145 .3825073242143 .5538024902 142.6394042969142 .0299072266141 .7250976562141 .4203033447141 .7250976562 142.0299072266 142.6394042969 143.2489929199144 .1634063721 -9999 -9999 -9999 -9999 -9999 -9999 -9999 -9999 -9999 -9999 -9999 -9999 -9999 -9999 -9999 -9999 -9999 -9999 -9999 -9999 -9999 -9999 -9999 -9999 -9999 -9999 -9999 -9999 -9999 -9999 -9999 -9999 -9999 -9999

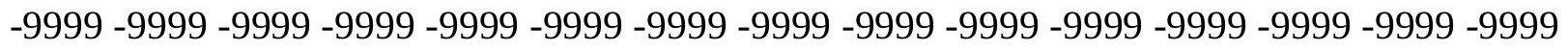
-9999 -9999 -9999 -9999 -9999 -9999 -9999 -9999 -9999 -9999 -9999 -9999 -9999 -9999 -9999 -

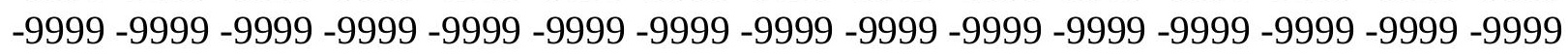
-9999 -9999 -9999 -9999 -9999 -9999 -9999 -9999 -9999 -9999 -9999 -9999 -9999 -9999 -9999 -999 -

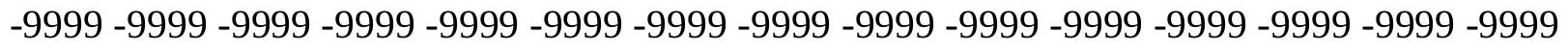

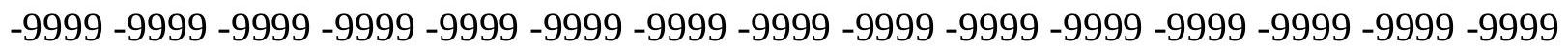

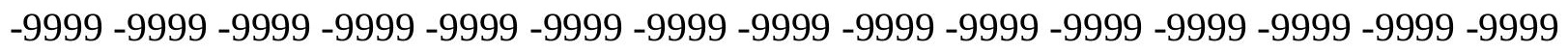
-9999 -9999 -9999 -9999 -9999 -9999 -9999 -9999 -9999 -9999 -9999 -9999 -9999 -9999 -9999 -

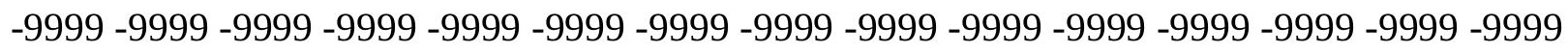

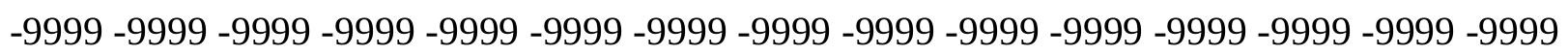
-9999 -9999 -9999 -9999 -9999 -9999 -9999 -9999 -9999 -9999 -9999 -9999 -9999 -9999 -9999 -9999 -9999 -9999 -9999 -9999 -9999 -9999 -9999 -9999 -9999 -9999 -9999 -9999 -9999 -9999 -9999 -9999 -9999 -9999 -9999 -9999 -9999 -9999 -9999 -9999 -9999 -9999

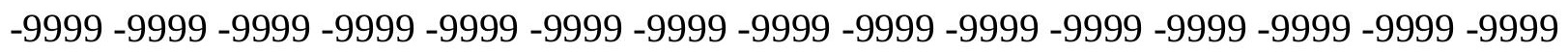

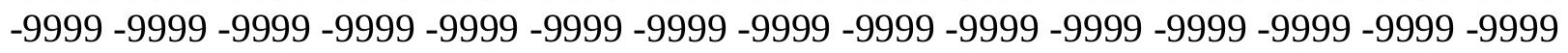
-9999 -9999 -9999 -9999 -9999 -9999 -9999 -9999 -9999 -9999 -9999 -9999 -9999 -9999 -9999 -9999 -9999 -9999 -9999 -9999 -9999 -9999 -9999 -9999 -9999 -9999 -9999 -9999 -9999 -9999 -

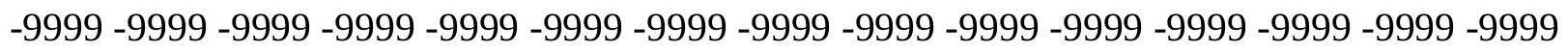

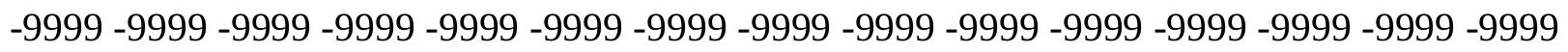
-9999 -9999 -9999 -9999 -9999 -9999-9999 221.883605957 207.25390625 206.6443023682 205.425201416203.9011993408202.3773040771201.158203125199.9389953613 198.4151000977196 .891204834195 .0625192 .9290008545190 .795501709188 .6620025635 186.528503418184 .3950042725182 .261505127180 .432800293178 .604095459 176.7754058838175 .2514038086173 .7274932861172 .5084075928171 .2891998291 170.3748931885169 .7653045654169 .1557006836168 .241394043167 .3269958496 166.7174987793165 .8031005859165 .1934967041164 .2792053223163 .6696014404 162.7552947998162 .1457061768161 .5361022949160 .9264984131160 .3170013428 160.0122070312160 .0122070312160 .0122070312160 .0122070312159 .7073974609 159.0977935791158 .7929992676158 .1835021973157 .5738983154156 .9642944336 156.3547973633155 .7451934814154 .8307952881153 .9165039062152 .0877990723 149.0399017334145 .3825073242142 .6394042969141 .7250976562141 .1154937744 
140.8106994629140 .8106994629141 .1154937744141 .4203033447142 .0299072266 142.9441986084143 .5538024902 -9999 -9999 -9999 -9999 -9999 -9999 -9999 -9999 -9999 -9999 -9999 -9999 -9999 -9999 -9999 -9999 -9999 -9999 -9999 -9999 -9999 -9999 -9999 -9999 -9999 -9999 -9999 -9999 -9999 -9999 -9999 -9999 -9999 -9999 -9999 -9999 -9999 -9999 -9999 -9999 -9999 -9999 -9999 -9999 -9999 -9999 -9999 -9999-9999 -9999 -9999 -9999 -9999 -9999 -9999 -9999 -9999 -9999 -9999 -9999 -9999 -9999 -9999 -9999 -9999 -9999 -9999 -9999 -9999 -9999 -9999 -9999 -9999 -9999 -9999 -9999 -9999 -9999 -9999 -9999 -9999 -9999 -9999 -9999

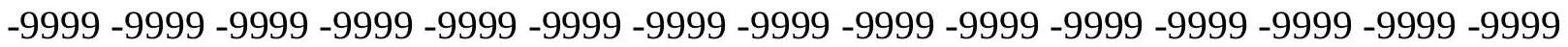

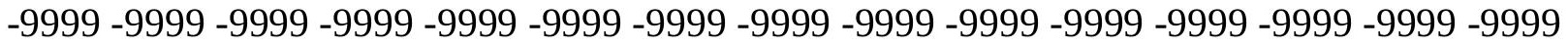
-9999 -9999 -9999 -9999 -9999 -9999 -9999 -9999 -9999 -9999 -9999 -9999 -9999 -9999 -9999

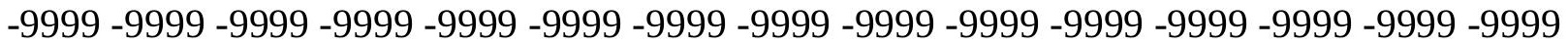
-9999 -9999 -9999 -9999 -9999 -9999 -9999 -9999 -9999 -9999 -9999 -9999 -9999 -9999 -9999 -9999 -9999 -9999 -9999 -9999 -9999 -9999 -9999 -9999 -9999 -9999 -9999 -9999 -9999 -9999 -

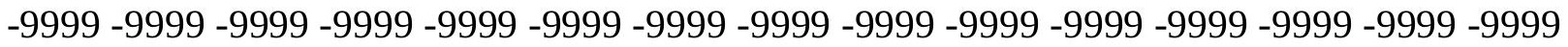
-9999 -9999 -9999 -9999 -9999 -9999 -9999 -9999 -9999 -9999 -9999 -9999 -9999 -9999 -9999

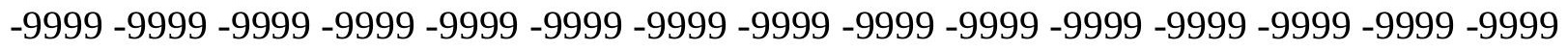
-9999 -9999 -9999 -9999-9999 -9999 -9999

-9999 -9999 -9999 -9999 -9999 -9999 -9999 -9999 -9999 -9999 -9999 -9999 -9999 -9999 -9999 -9999 -9999 -9999 -9999 -9999 -9999 -9999 -9999 -9999 -9999 -9999 -9999 -9999 -9999 -9999 -

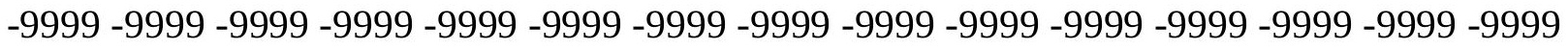

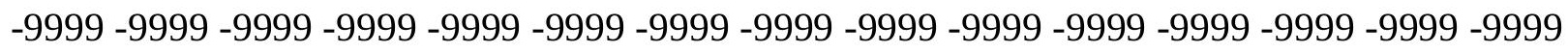
-9999 -9999 -9999 -9999 -9999 -9999 -9999 -9999 -9999 -9999 -9999 -9999 -9999 -9999 -9999 -9999 -9999 -9999 -9999 -9999 -9999 -9999 -9999 -9999 -9999 -9999 -9999 -9999 -9999 -9999 -9999 -9999 -9999 -9999 -9999 -9999 -9999 232.8558044434 211.520904541209.9969024658 207.25390625 205.425201416203.9011993408202.6820983887201.158203125 199.6342926025198 .1103057861196 .2816009521194 .1481018066192 .0146026611 189.8811035156187 .7476043701185 .6141052246183 .4806976318181 .3471984863 179.5184020996177 .3849029541175 .5561981201174 .0323028564172 .5084075928 171.2891998291170 .3748931885169 .4604949951168 .8509979248167 .9365997314 167.3269958496 166.7174987793165.8031005859165.4983062744 164.8887023926 164.2792053223 163.6696014404163.0599975586162.4505004883161.8408966064 161.2312927246160 .9264984131160 .9264984131160 .9264984131160 .6217956543 160.3170013428159 .7073974609159 .4026031494158 .7929992676158 .1835021973 157.5738983154156 .9642944336156 .3547973633155 .4403991699154 .2212982178 152.3925933838149 .0399017334145 .0776977539141 .4203033447140 .5059967041 140.2012023926139 .8963928223140 .2012023926140 .5059967041141 .1154937744 141.7250976562142 .6394042969143 .2489929199144 .1634063721 -9999 -9999 -9999-9999 -9999 -9999 -9999 -9999 -9999 -9999 -9999 -9999 -9999 -9999 -9999 -9999 -9999 -9999 -9999 -9999 -9999 -9999 -9999 -9999 -9999 -9999 -9999 -9999 -9999 -9999 -9999 -9999 - 9999 - -999 -9999 -9999 -9999 -9999 -9999 -9999 -9999 -9999 -9999 -9999 -9999 -9999 -9999 -9999 -9999 -

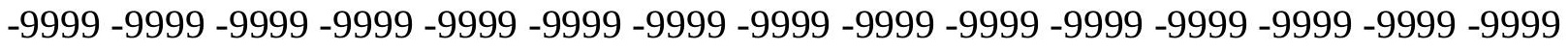

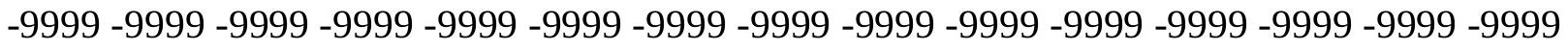
-9999 -9999 -9999 -9999 -9999 -9999 -9999 -9999 -9999 -9999 -9999 -9999 -9999 -9999 -9999 -9999 -9999 -9999 -9999 -9999 -9999 -9999 -9999 -9999-9999 -9999 -9999 -9999 -9999 -9999 -9999 -9999 -9999 -9999 -9999 -9999 -9999 -9999 -9999 -9999 -9999 -9999 -9999 -9999 -9999 -

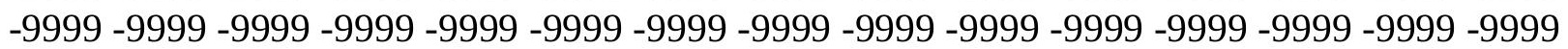


-9999 -9999 -9999 -9999 -9999 -9999 -9999 -9999 -9999 -9999 -9999 -9999 -9999 -9999 -9999 -9999 -9999 -9999 -9999 -9999 -9999 -9999 -9999 -9999 -9999 -9999 -9999 -9999 -9999 -9999 -9999 -9999 -9999 -9999 -9999 -9999 -9999 -9999 -9999 -9999 -9999 -9999 -9999 -9999 -9999 -9999 -9999 -9999 -9999 -9999 -9999 -9999 -9999 -9999 -9999 -9999 -9999 -9999 -9999 -9999 -9999 -9999 -9999 -9999 -9999 -9999 -9999 -9999 -9999 -9999 -9999 -9999 -9999 -9999 -9999 -9999 -9999 -9999 -9999 -9999 -9999 -9999 -9999 -9999 -9999 -9999

-9999 -9999 -9999 -9999 -9999 -9999 -9999 -9999 -9999 -9999 -9999 -9999 -9999 -9999 -9999

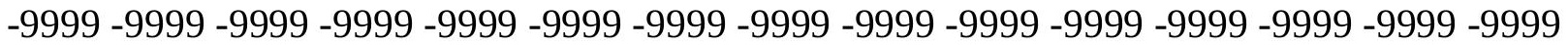
-9999 -9999 -9999 -9999 -9999 -9999 -9999 -9999 -9999 -9999 -9999 -9999 -9999 -9999 -9999 -9999 -9999 -9999 -9999 -9999 -9999 -9999 -9999 -9999 -9999 -9999 -9999 -9999 -9999 -9999 -9999 -9999 -9999 -9999 -9999 -9999 -9999 -9999 -9999 -9999 -9999 -9999 -9999 -9999 -9999 -9999 -9999 -9999 -9999 -9999 -9999 -9999 -9999 -9999 -9999 -9999 -9999 -9999 -9999 -9999 -9999 -9999 -9999 -9999 -9999 -9999-9999 240.7801971436220.3596038818 209.3874053955 206.9490966797205 .7299957275204 .5108032227203 .596496582202 .3773040771 200.8533935547199 .0247039795197 .1959991455195 .3672943115193 .233795166 191.1002960205188 .966796875186 .8332977295184 .699798584182 .261505127 180.1280059814178 .2993011475176 .165802002174 .0323028564172 .5084075928 170.9844970703170 .070098877169 .1557006836168 .241394043167 .6318054199 167.0222015381166 .4127044678166 .1078948975165 .8031005859165 .4983062744 165.1934967041164 .8887023926164 .2792053223163 .6696014404162 .7552947998 162.4505004883162 .1457061768161 .8408966064161 .8408966064161 .5361022949 160.9264984131160 .3170013428159 .7073974609159 .0977935791158 .4882965088 157.878692627157 .2691040039156 .3547973633155 .4403991699154 .2212982178 152.3925933838148 .4304046631144 .1634063721140 .5059967041139 .2868041992 138.9819946289139 .2868041992139 .5915985107140 .2012023926140 .8106994629 141.4203033447142 .3347015381143 .2489929199144 .1634063721 -9999 -9999 -9999 -9999 -9999 -9999 -9999 -9999 -9999 -9999 -9999 -9999 -9999 -9999 -9999 -9999 -9999 -9999 -9999 -9999 -9999 -9999 -9999 -9999 -9999 -9999 -9999 -9999 -9999 -9999 -9999 -9999 -9999 -9999 -9999 -9999 -9999 -9999 -9999 -9999 -9999 -9999 -9999 -9999 -9999 -9999 -9999 -9999 -9999

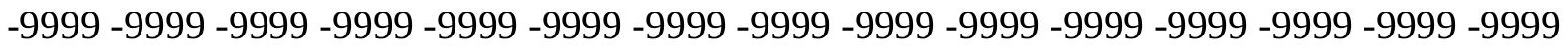
-9999 -9999 -9999 -9999 -9999 -9999 -9999 -9999 -9999 -9999 -9999 -9999 -9999 -9999 -9999 -

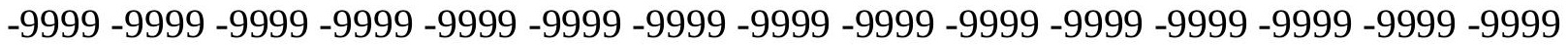
-9999 -9999 -9999 -9999 -9999 -9999 -9999 -9999 -9999 -9999 -9999 -9999 -9999 -9999 -9999 -9999 -9999 -9999 -9999 -9999 -9999 -9999 -9999 -9999 -9999 -9999 -9999 -9999 -9999 -9999 -

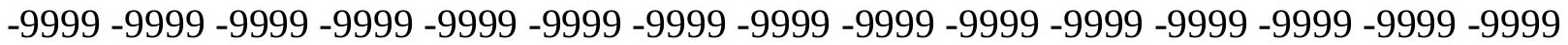
-9999 -9999 -9999 -9999 -9999 -9999 -9999 -9999 -9999 -9999 -9999 -9999 -9999 -9999 -9999 -9999 -9999 -9999 -9999 -9999 -9999 -9999 -9999 -9999 -9999 -9999 -9999 -9999 -9999 -9999

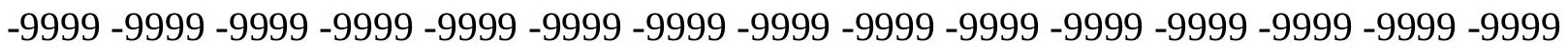
-9999 -9999 -9999 -9999 -9999 -9999 -9999 -9999 -9999 -9999 -9999 -9999 -9999 -9999 -9999 -9999 -9999 -9999 -9999 -9999 -9999 -9999 -9999 -9999 -9999 -9999 -9999 -9999 -9999 -9999 -999 -9999 -9999 -9999 -9999 -9999 -9999 -9999 -9999 -9999 -9999 -9999

-9999 -9999 -9999 -9999 -9999 -9999 -9999 -9999 -9999 -9999 -9999 -9999 -9999 -9999 -9999 -9999 -9999 -9999 -9999 -9999 -9999 -9999 -9999 -9999 -9999 -9999 -9999 -9999 -9999 -9999 -9999 -9999 -9999 -9999 -9999 -9999 -9999 -9999 -9999 -9999 -9999 -9999 -9999 -9999 -9999 -9999 -9999 -9999 -9999 -9999 -9999 -9999 -9999 -9999 -9999 -9999 -9999 -9999 -9999 -9999

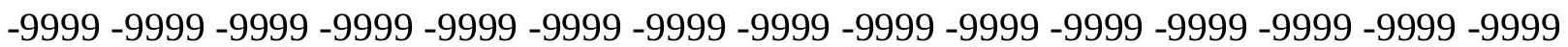


-9999 -9999 -9999 -9999 -9999 -9999 -9999 -9999 -9999 -9999 -9999 -9999 -9999 -9999 -9999 -9999 -9999 -9999 -9999 -9999 -9999 -9999 248.0950927734 224.0171051025 205.425201416 205.1204071045205 .425201416205 .1204071045204 .2059936523202 .9868927002 201.7678070068199 .9389953613198 .1103057861195 .9768066406193 .8433074951 192.0146026611189 .8811035156187 .7476043701185 .6141052246183 .4806976318 181.3471984863178 .9089050293176 .7754058838174 .337097168172 .5084075928 170.9844970703169 .7653045654168 .8509979248168 .241394043167 .3269958496 167.0222015381166 .4127044678166 .1078948975166 .1078948975166 .4127044678 166.4127044678166 .4127044678165 .8031005859164 .8887023926164 .2792053223 163.6696014404163 .3648071289163 .0599975586162 .7552947998162 .4505004883 161.5361022949160 .6217956543159 .7073974609159 .0977935791158 .1835021973 157.5738983154156 .9642944336156 .0500030518154 .8307952881153 .0021057129 150.5639038086146 .9064025879142 .9441986084139 .2868041992138 .0677032471 138.0677032471138 .6772003174138 .9819946289139 .8963928223140 .5059967041 $141.4203033447142 .3347015381143 .2489929199144 .1634063721145 .0776977539-9999$ -9999 -9999 -9999 -9999 -9999 -9999 -9999 -9999 -9999 -9999 -9999 -9999 -9999 -9999 -9999 -9999 -9999 -9999 -9999 -9999 -9999 -9999 -9999 -9999 -9999 -9999 -9999 -9999 -9999 -9999 -9999 -9999 -9999 -9999 -9999 -9999 -9999 -9999 -9999 -9999 -9999 -9999 -9999 -9999 -9999 -9999 -9999 -9999 -9999 -9999 -9999 -9999 -9999 -9999 -9999 -9999 -9999 -9999 -9999 -9999 -9999 -9999 -9999 -9999 -9999 -9999 -9999 -9999 -9999 -9999 -9999 -9999 -9999 -9999 -9999 -9999 -9999 -9999 -9999 -9999 -9999 -9999 -9999 -9999 -9999 -9999 -9999 -9999 -9999 -9999 -9999 -9999 -9999 -9999 -9999 -9999 -9999 -9999 -9999 -9999 -9999 -9999 -9999 -9999 -9999 -9999 -9999 -9999 -9999 -9999 -9999 -9999 -9999 -9999 -9999 -9999 -9999 -9999 -9999 -9999 -9999 -9999 -9999 -9999 -9999 -9999 -9999 -9999 -9999 -9999 -9999 -9999 -9999 -9999 -9999 -9999 -9999 -9999 -9999 -9999 -9999 -9999 -9999 -9999 -9999 -9999 -9999 -9999 -9999 -9999 -9999 -9999 -9999 -9999 -9999 -9999 -9999 -9999 -9999 -9999 -9999 -9999 -9999 -9999 -9999 -9999 -9999 -9999 -9999 -9999 -9999 -9999 -9999 -9999 -9999 -9999 -9999 -9999 -9999 -9999 -

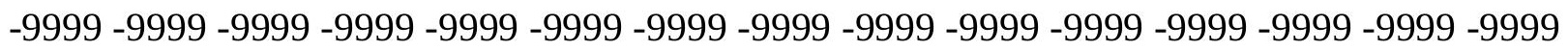

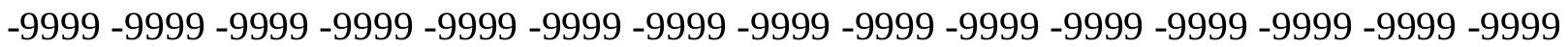
-9999 -9999 -9999 -9999 -9999 -9999 -9999 -9999 -9999 -9999 -9999 -9999 -9999 -9999 -9999 -9999 -9999 -9999 -9999 -9999 -9999 -9999 -9999 -9999 -9999 -9999 -9999 -9999

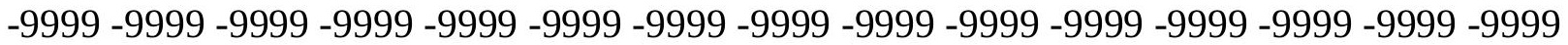

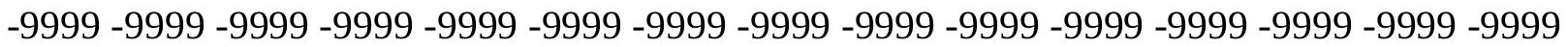
-9999 -9999 -9999 -9999 -9999 -9999 -9999 -9999 -9999 -9999 -9999 -9999 -9999 -9999 -9999 -

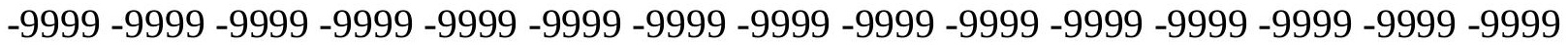
-9999 -9999 -9999 -9999 -9999 -9999 -9999 -9999 -9999 -9999 -9999 -9999 -9999 -9999 -9999 -9999 -9999-9999 -9999 -9999-9999-9999 256.0195007324 227.0648956299 202.9868927002 204.2059936523205.425201416205.425201416204.8155975342 203.596496582 202.0724945068200 .2438049316198 .4151000977196 .2816009521194 .4528961182 192.624206543190 .795501709188 .6620025635186 .528503418184 .3950042725 182.261505127179 .8231964111177 .3849029541174 .6419067383172 .5084075928 170.6797027588169 .4604949951168 .5462036133167 .9365997314167 .3269958496 166.7174987793166 .4127044678166 .1078948975166 .4127044678167 .3269958496 168.241394043168 .5462036133167 .9365997314166 .4127044678165 .4983062744 164.5839996338164 .5839996338164 .2792053223163 .974395752163 .3648071289 162.4505004883161 .2312927246159 .7073974609158 .4882965088157 .5738983154 
156.9642944336156 .3547973633155 .4403991699153 .9165039062151 .4781951904 149.0399017334145 .3825073242141 .1154937744137 .4580993652137 .1533050537 137.4580993652138 .0677032471138 .9819946289139 .8963928223140 .8106994629 $141.7250976562142 .9441986084143 .8585968018144 .7729034424145 .6873016357-9999$ -9999 -9999 -9999 -9999 -9999 -9999 -9999 -9999 -9999 -9999 -9999 -9999 -9999 -9999 -9999 -9999 -9999 -9999 -9999 -9999 -9999 -9999 -9999 -9999 -9999 -9999 -9999 -9999 -9999 -9999

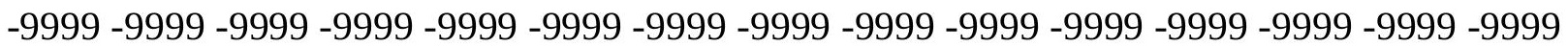

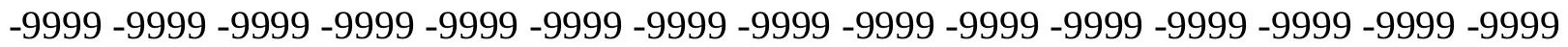
-9999 -9999 -9999 -9999 -9999 -9999 -9999 -9999 -9999 -9999 -9999 -9999 -9999 -9999 -9999 -9999 -9999 -9999 -9999 -9999 -9999 -9999 -9999 -9999 -9999 -9999 -9999 -9999 -9999 -9999 -

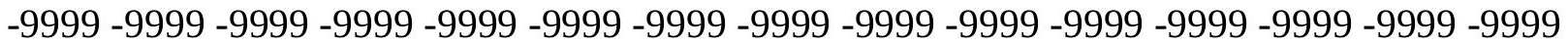
-9999 -9999 -9999 -9999 -9999 -9999 -9999 -9999 -9999 -9999 -9999 -9999 -9999 -9999 -9999 -9999 -9999 -9999 -9999 -9999 -9999 -9999 -9999 -9999 -9999 -9999 -9999 -9999 -9999 -9999 -9999 -9999 -9999 -9999 -9999 -9999 -9999 -9999 -9999 -9999 -9999 -9999 -9999 -9999 -9999 -9999 -9999 -9999 -9999 -9999 -9999 -9999 -9999 -9999 -9999 -9999 -9999 -9999 -9999 -9999

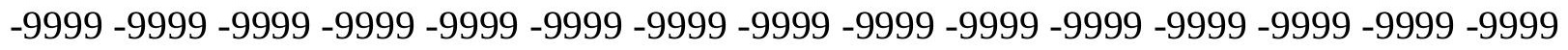
-9999 -9999 -9999 -9999 -9999 -9999 -9999 -9999 -9999 -9999 -9999 -9999 -9999 -9999 -9999 -

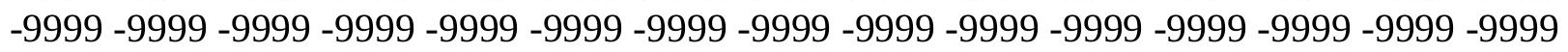
-9999 -9999 -9999 -9999 -9999 -9999 -9999 -9999 -9999 -9999 -9999 -9999 -9999 -

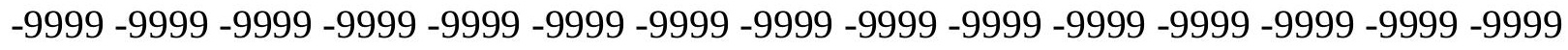

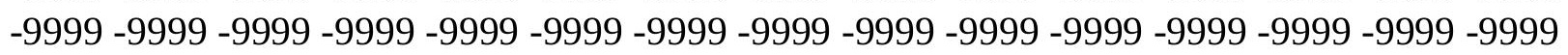

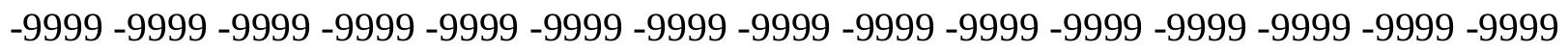
-9999 -9999 -9999 -9999 -9999 -9999 -9999 -9999 -9999 -9999 -9999 -9999 -9999 -9999 -9999 -

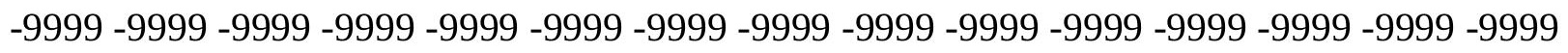

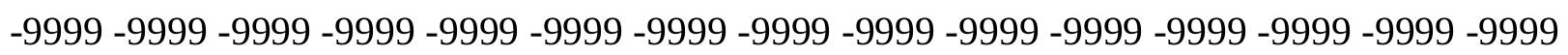
-9999 -9999 -9999 -9999-9999-9999-9999 269.7348022461236.8179931641206.6443023682 205.7299957275206 .3394927979206 .0346984863205 .1204071045203 .596496582 201.7678070068199 .9389953613198 .1103057861196 .2816009521194 .4528961182 192.624206543191 .1002960205189 .2716064453187 .4429016113185 .6141052246 183.4806976318180 .7375946045177 .9945068359174 .9467010498172 .5084075928 170.6797027588169 .4604949951168 .5462036133174 .337097168174 .6419067383 172.5084075928166 .4127044678166 .1078948975166 .7174987793168 .5462036133 170.6797027588171 .2891998291170 .070098877167 .9365997314166 .1078948975 165.4983062744165 .8031005859165 .8031005859165 .4983062744164 .5839996338 163.0599975586161 .2312927246159 .4026031494157 .878692627156 .6596069336 156.0500030518155 .4403991699154 .8307952881153 .6116943359151 .7830047607 148.1255950928143 .5538024902138 .6772003174135 .9342041016136 .5437011719 137.4580993652138 .3724975586139 .2868041992140 .2012023926141 .4203033447 142.6394042969143 .5538024902144 .7729034424145 .6873016357146 .2969055176 146.9064025879 -9999 -9999 -9999 -9999 -9999 -9999 -9999 -9999 -9999 -9999 -9999 -9999

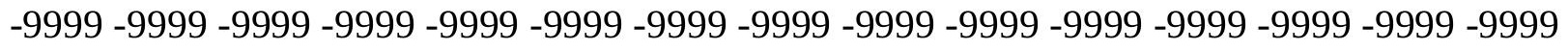

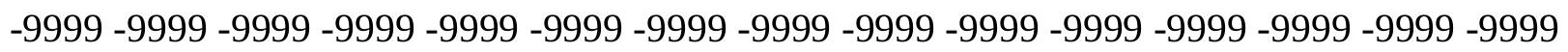
-9999 -9999 -9999 -9999 -9999 -9999 -9999 -9999 -9999 -9999 -9999 -9999 -9999 -9999 -9999 -9999 -9999 -9999 -9999 -9999 -9999 -9999 -9999 -9999 -9999 -9999 -9999 -9999 -9999 -9999 -

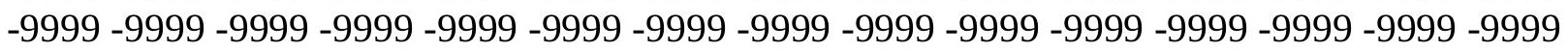

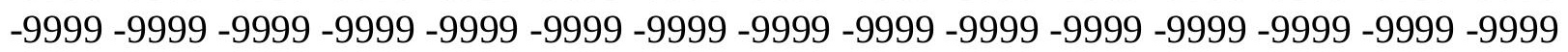


-9999 -9999 -9999 -9999 -9999 -9999 -9999 -9999 -9999 -9999 -9999 -9999 -9999 -9999 -9999 -9999 -9999 -9999 -9999 -9999 -9999 -9999 -9999 -9999 -9999 -9999 -9999 -9999 -9999 -9999 -9999 -9999 -9999 -9999 -9999 -9999 -9999 -9999 -9999 -9999 -9999 -9999 -9999 -9999 -9999 -9999 -9999 -9999 -9999 -9999 -9999 -9999 -9999 -9999 -9999 -9999 -9999 -9999 -9999 -9999 -9999 -9999 -9999 -9999 -9999 -9999 -9999 -9999 -9999 -9999 -9999 -9999 -9999 -9999 -9999 -9999 -9999 -9999 -9999 -9999 -9999 -9999 -9999 -9999 -9999 -9999 -9999 -9999 -9999 -9999 -9999 -9999 -9999 -9999 -9999 -9999 -9999 -9999 -9999 -9999 -9999 -9999 -9999 -9999 -9999 -9999 -9999 -9999 -9999 -9999 -9999 -9999 -9999 -9999 -9999 -9999 -9999 -9999 -9999 -9999 $-9999$

-9999 -9999 -9999 -9999 -9999 -9999 -9999 -9999 -9999 -9999 -9999 -9999 -9999 -9999 -9999

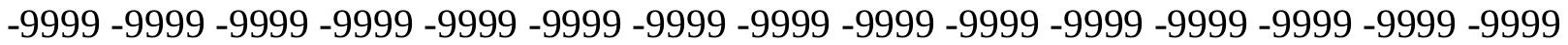
-9999 -9999 -9999 -9999 -9999 -9999 -9999 -9999 -9999 -9999 -9999 -9999 -9999-9999-9999 -9999 -9999 -9999 -9999 -9999 -9999 -9999 -9999 -9999 -9999 -9999 -9999 -9999 -9999 -9999 -9999 -9999 -9999 -9999 -9999 -9999 -9999 -9999 -9999 -9999 -9999 -9999 -9999 -9999 -9999 -9999 -9999 -9999 -9999 -9999 -9999 -9999 -9999 -9999 -9999 -9999 -9999 -9999 -9999 -9999 -9999 -9999 -9999 -9999 -9999-9999 312.7352905273 283.1453857422 247.1806945801 215.787902832208 .1681976318207 .8634033203206 .3394927979204 .8155975342 202.9868927002201 .158203125199 .329498291197 .500793457195 .9768066406 194.1481018066192 .624206543191 .1002960205189 .5764007568188 .0523986816 186.2236938477184 .3950042725181 .9566955566178 .9089050293175 .5561981201 172.2035980225170 .3748931885169 .4604949951173 .7274932861175 .8609924316 177.6896972656174 .0323028564167 .6318054199166 .4127044678166 .7174987793 169.4604949951173 .4226989746174 .9467010498172 .2035980225168 .5462036133 166.4127044678166 .4127044678167 .0222015381167 .6318054199167 .3269958496 166.1078948975163 .974395752161 .5361022949158 .7929992676156 .3547973633 154.8307952881154 .2212982178153 .9165039062153 .3069000244152 .6972961426 151.7830047607148 .7351074219141 .7250976562135 .6293945312136 .2389984131 136.8484954834137 .7628936768138 .6772003174139 .8963928223141 .1154937744 142.3347015381143 .5538024902144 .7729034424145 .9920959473146 .9064025879 147.5160064697148 .1255950928 -9999 -9999 -9999 -9999 -9999 -9999 -9999 -9999 -9999 -9999 -9999 -9999 -9999 -9999 -9999 -9999 -9999 -9999 -9999 -9999 -9999 -9999 -9999 -9999 -9999 -9999 -9999 -9999 -9999 -9999 -9999 -9999 -9999 -9999 -9999 -9999 -9999 -9999 -9999 -9999 -9999 -9999 -9999 -9999 -9999 -9999 -9999 -9999 -9999 -9999 -9999 -9999 -9999 -9999 -9999 -9999 -9999 -9999 -9999 -9999 -9999 -9999 -9999 -9999 -9999 -9999 -9999 -9999 -9999 -

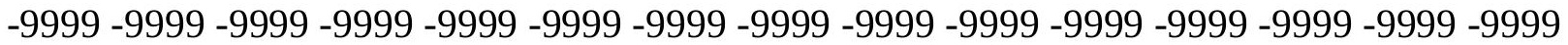
-9999 -9999 -9999 -9999 -9999 -9999 -9999 -9999 -9999 -9999 -9999 -9999 -9999 -9999 -9999 -9999 -9999 -9999 -9999 -9999 -9999 -9999 -9999 -9999 -9999 -9999 -9999 -9999 -9999 -9999

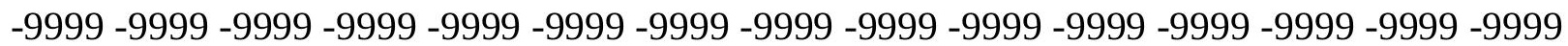
-9999 -9999 -9999 -9999 -9999 -9999 -9999 -9999 -9999 -9999 -9999 -9999 -9999 -9999 -9999 -9999 -9999 -9999 -9999 -9999 -9999 -9999 -9999 -9999 -9999 -9999 -9999 -9999 -9999 -9999 -9999 -9999 -9999 -9999 -9999 -9999 -9999 -9999 -9999 -9999 -9999 -9999 -9999 -9999 -9999

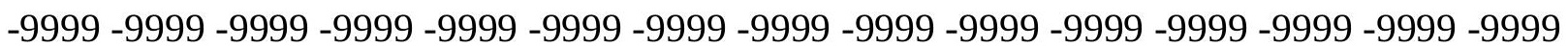
-9999 -9999 -9999 -9999 -9999 -9999 -9999 -9999 -9999 -9999 -9999 -9999 -9999 -9999 -9999 -

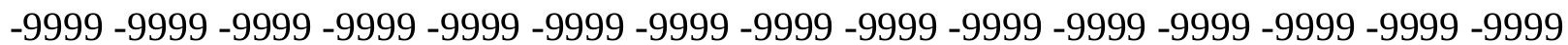
-9999 -9999-9999-9999

-9999 -9999 -9999 -9999 -9999 -9999 -9999 -9999 -9999 -9999 -9999 -9999 -9999 -9999 -9999 
-9999 -9999 -9999 -9999 -9999 -9999 -9999 -9999 -9999 -9999 -9999 -9999 -9999 -9999 -9999 -9999 -9999 -9999 -9999 -9999 -9999 -9999 -9999 -9999 -9999 -9999 -9999 -9999 -9999 -9999 -9999 -9999 -9999 -9999 -9999 -9999 -9999 -9999 -9999 -9999 -9999 -9999 -9999 -9999 -9999 -9999 -9999 -9999 -9999 -9999 -9999 -9999 -9999 -9999 -9999 -9999 -9999 -9999 -9999 -9999 -9999 -9999 -9999 -9999 -9999 -9999 -9999 -9999 -9999 -9999 -9999 -9999 -9999 -9999 -9999 -9999 -9999 -9999 -9999 -9999 -9999 323.9866027832290 .1553955078255 .1051025391 224.0171051025210 .6065063477208 .1681976318205 .7299957275203 .596496582 201.4629974365199 .9389953613198 .1103057861196 .5863952637195 .0625193 .5386047363 192.0146026611190 .795501709189 .5764007568188 .3571929932186 .8332977295 185.3094024658183 .4806976318180 .1280059814175 .8609924316171 .5939941406 169.4604949951169 .4604949951170 .070098877174 .9467010498169 .4604949951 170.6797027588170 .3748931885167 .9365997314166 .4127044678170 .6797027588 176.165802002179 .8231964111172 .8132019043167 .0222015381165 .8031005859 167.3269958496168 .8509979248169 .7653045654169 .4604949951167 .6318054199 165.1934967041161 .8408966064158 .1835021973154 .8307952881152 .6972961426 151.7830047607152 .0877990723150 .8686065674150 .2590942383149 .9542999268 150.2590942383137 .7628936768136 .5437011719137 .1533050537138 .0677032471 138.9819946289139 .8963928223141 .1154937744142 .3347015381143 .8585968018 145.0776977539146 .6015930176147 .8208007812148 .7351074219149 .3446960449 149.6495056152 149.6495056152 -9999 -9999 -9999 -9999 -9999 -9999 -9999 -9999 -9999 -9999 -9999 -9999 -9999 -9999 -9999 -9999 -9999 -9999 -9999 -9999 -9999 -9999 -9999 -9999 -9999 -9999 -9999 -9999 -9999 -9999 -9999 -9999 -9999 -9999 -9999 -9999 -9999 -9999 -9999 -9999 -9999 -9999 -9999 -9999 -9999 -9999 -9999 -9999 -9999 -9999 -9999 -9999 -9999 -9999 -9999 -9999 -9999 -9999 -9999 -9999 -9999 -9999 -9999 -9999 -9999 -9999 -9999 -9999 -9999

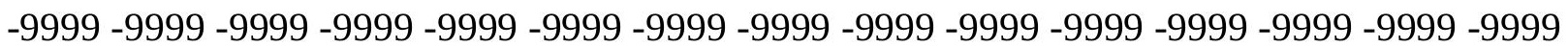
-9999 -9999 -9999 -9999 -9999 -9999 -9999 -9999 -9999 -9999 -9999 -9999 -9999 -9999 -9999 -9999 -9999 -9999 -9999 -9999 -9999 -9999 -9999 -9999 -9999 -9999 -9999 -9999 -9999 -9999 -9999 -9999 -9999 -9999 -9999 -9999 -9999 -9999 -9999 -9999 -9999 -9999 -9999 -9999 -9999 -9999 -9999 -9999 -9999 -9999 -9999 -9999 -9999 -9999 -9999 -9999 -9999 -9999 -9999 -9999 -9999 -9999 -9999 -9999 -9999 -9999 -9999 -9999 -9999 -9999 -9999 -9999 -9999 -9999 -9999 -9999 -9999 -9999 -9999 -9999 -9999 -9999 -9999 -9999 -9999 -9999 -9999 -9999 -9999 -9999 -9999 -9999 -9999 -9999 -9999 -9999 -9999 -9999 -9999 -9999 -9999 -9999 -9999 -9999 -9999 -9999 -9999 -9999 -9999 -9999 -9999 -9999 -9999 -9999 -9999 -9999 -9999 -9999 -9999 -9999 -

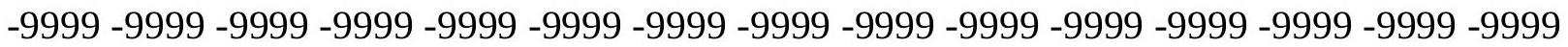
-9999 -9999-9999

-9999 -9999 -9999 -9999 -9999 -9999 -9999 -9999 -9999 -9999 -9999 -9999 -9999 -9999 -9999 -9999 -9999 -9999 -9999 -9999 -9999 -9999 -9999 -9999 -9999 -9999 -9999 -9999 -9999 -9999

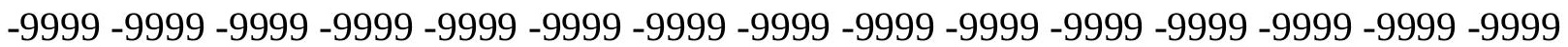
-9999 -9999 -9999 -9999 -9999 -9999 -9999 -9999 -9999 -9999 -9999 -9999 -9999 -9999 -9999 -9999 -9999 -9999 -9999 -9999 -9999 -9999 -9999 -9999 -9999 -9999 -9999 -9999 -9999 -9999 -

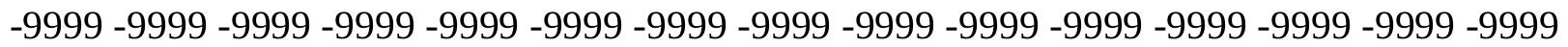
-9999 -9999 -9999 -9999 -9999-9999 319.7196044922 289.8505859375257 .5433959961 227.9792938232208 .7778015137205 .425201416202 .9868927002200 .8533935547 199.329498291197 .8054962158196 .2816009521195 .0625193 .5386047363192 .3193969727 191.1002960205189 .8811035156188 .966796875188 .0523986816187 .1381072998 186.2236938477184 .699798584181 .9566955566176 .4705963135170 .070098877 
167.0222015381169 .1557006836173 .1179962158170 .9844970703170 .3748931885 175.8609924316180 .1280059814176 .165802002172 .2035980225176 .165802002 179.5184020996178 .604095459174 .0323028564169 .1557006836168 .5462036133 170.070098877171 .8988037109172 .8132019043172 .2035980225170 .070098877 166.7174987793162 .1457061768157 .5738983154153 .6116943359150 .2590942383 148.4304046631148 .1255950928147 .5160064697146 .9064025879145 .3825073242 140.2012023926138 .6772003174138 .9819946289139 .5915985107139 .8963928223 140.5059967041141 .4203033447142 .3347015381143 .8585968018145 .3825073242 147.2111968994148 .7351074219149 .6495056152150 .5639038086151 .1734008789 151.4781951904151 .1734008789 -9999 -9999 -9999 -9999 -9999 -9999 -9999 -9999 -9999 -9999 -9999 -9999 -9999 -9999 -9999 -9999 -9999 -9999 -9999 -9999 -9999 -9999 -9999 -9999

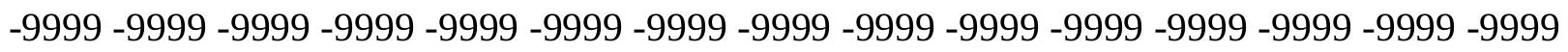
-9999 -9999 -9999 -9999 -9999 -9999 -9999 -9999 -9999 -9999 -9999 -9999 -9999 -9999 -9999 -9999 -9999 -9999 -9999 -9999 -9999 -9999 -9999 -9999 -9999 -9999 -9999 -9999 -9999 -9999 -9999 -9999 -9999 -9999 -9999 -9999 -9999 -9999 -9999 -9999 -9999 -9999 -9999 -9999 -9999

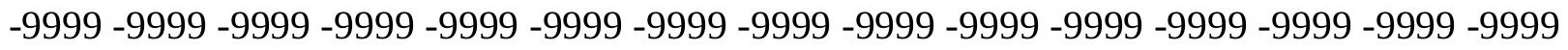
-9999 -9999 -9999 -9999 -9999 -9999 -9999 -9999 -9999 -9999 -9999 -9999 -9999 -9999 -9999 -9999 -9999 -9999 -9999 -9999 -9999 -9999 -9999 -9999 -9999 -9999 -9999 -9999 -9999 -9999 -

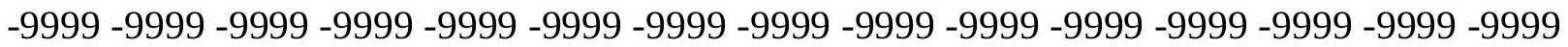

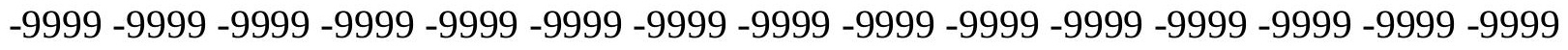

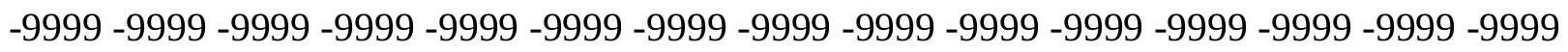
-9999 -9999 -9999 -9999 -9999 -9999 -9999 -9999 -9999 -9999 -9999 -9999 -9999 -9999 -9999 -9999 -9999 -9999 -9999 -9999 -9999 -9999 -9999 -9999 -9999 -9999 -9999 -9999 -9999 -9999 -9999 -9999-9999 -9999 -9999 -9999 -9999 -9999 -9999 -9999 -9999 -9999 -9999 -999 -999 -999 $-9999-9999-9999$

-9999 -9999 -9999 -9999 -9999 -9999 -9999 -9999 -9999 -9999 -9999 -9999 -9999 -9999 -9999

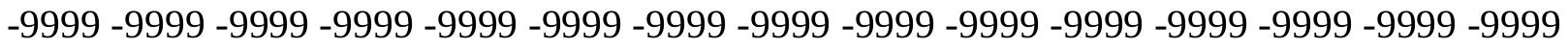

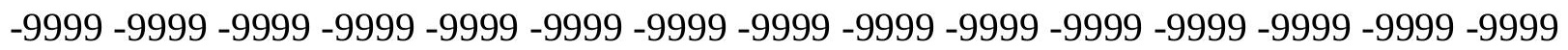
-9999 -9999 -9999 -9999 -9999 -9999 -9999 -9999 -9999 -9999 -9999 -9999 -9999 -9999 -9999 -9999 -9999 -9999 -9999 -9999 -9999 -9999 -9999 -9999 -9999 -9999 -9999 -9999 -9999 -9999 -9999 -9999 -9999 -9999 -9999 -9999 -9999 -9999 -9999 -9999 -9999 -9999 -9999 -9999 -9999 -9999 -9999 -9999 -9999 -9999 -9999 302.6516113281277 .6592102051249 .3141937256 223.1027069092200 .8533935547199 .9389953613199 .0247039795197 .8054962158 196.5863952637 195.3672943115 194.1481018066192.9290008545191.7097930908 190.795501709189 .8811035156188 .966796875188 .3571929932187 .4429016113 186.8332977295186 .2236938477185 .0045928955183 .7854003906177 .3849029541 170.070098877169 .1557006836179 .5184020996190 .4907073975190 .795501709 188.0523986816181 .7653503418179 .6631317139177 .9656219482177 .1969604492 178.7022399902180 .2108459473179 .462600708177 .7122650146177 .6743011475 181.9566955566178 .2993011475179 .2136993408179 .5184020996178 .9089050293 175.5561981201170 .6797027588165 .1934967041159 .7073974609155 .1356048584 151.4781951904149 .0399017334147 .5160064697146 .6015930176145 .6873016357 144.4682006836143 .5538024902143 .2489929199142 .9441986084142 .6394042969 142.6394042969142 .6394042969142 .9441986084144 .1634063721145 .6873016357 147.5160064697149 .3446960449150 .8686065674152 .3925933838153 .0021057129 153.6116943359 153.3069000244 153.0021057129 -9999 -9999 -9999 -9999 -9999 -9999 -9999 
-9999 -9999 -9999 -9999 -9999 -9999 -9999 -9999 -9999 -9999 -9999 -9999 -9999 -9999 -9999 -9999 -9999 -9999 -9999 -9999 -9999 -9999 -9999 -9999 -9999 -9999 -9999 -9999 -9999 -9999 -9999 -9999 -9999 -9999 -9999 -9999 -9999 -9999 -9999 -9999 -9999 -9999 -9999 -9999 -9999 -9999 -9999 -9999 -9999 -9999 -9999 -9999 -9999 -9999 -9999 -9999 -9999 -9999 -9999 -9999 -9999 -9999 -9999 -9999 -9999 -9999 -9999 -9999 -9999 -9999 -9999 -9999 -9999 -9999 -9999 -9999 -9999 -9999 -9999 -9999 -9999 -9999 -9999 -9999 -9999 -9999 -9999 -9999 -9999 -9999 -9999 -9999 -9999 -9999 -9999 -9999 -9999 -9999 -9999 -9999 -9999 -9999 -9999 -9999 -9999

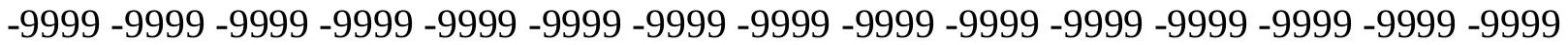
-9999 -9999 -9999 -9999 -9999 -9999 -9999 -9999 -9999 -9999 -9999 -9999 -9999 -9999 -9999 -9999 -9999 -9999 -9999 -9999 -9999 -9999 -9999 -9999 -9999 -9999 -9999 -9999 -9999 -9999 -

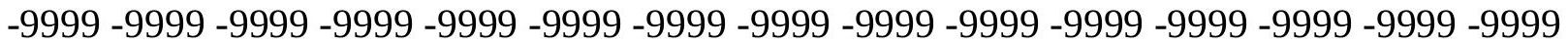
-9999 -9999 -9999 -9999 -9999 -9999 -9999 -9999 -9999 -9999 -9999 -9999 -9999 -9999 -9999

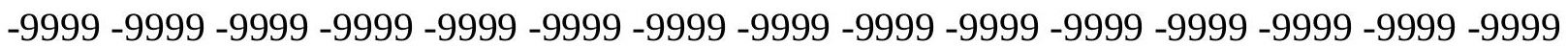
-9999 -9999 -9999 -9999 -9999 -9999 -9999 -9999 -9999 -9999 -9999 -9999 -9999 -9999 -9999 -9999 -9999-9999-9999-9999

-9999 -9999 -9999 -9999 -9999 -9999 -9999 -9999 -9999 -9999 -9999 -9999 -9999 -9999 -9999 -9999 -9999 -9999 -9999 -9999 -9999 -9999 -9999 -9999 -9999 -9999 -9999 -9999 -9999 -9999 -9999 -9999 -9999 -9999 -9999 -9999 -9999 -9999 -9999 -9999 -9999 -9999 -9999 -9999 -9999 -9999 -9999 -9999 -9999 -9999 -9999 -9999 -9999 -9999 -9999 -9999 -9999 -9999 -9999 -9999 -9999 -9999 -9999 -9999 -9999 -9999 -9999 -9999 -9999 -9999 -9999 -9999 -9999 -9999 -9999

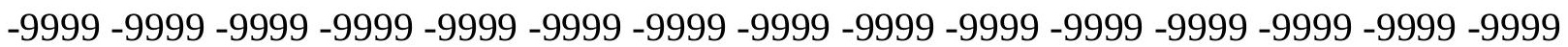
-9999 -9999 -9999 -9999 -9999-9999 277.9641113281257.8482055664 235.5989074707 213.6544036865195 .9768066406195 .3672943115195 .0625194 .1481018066193 .5386047363 192.624206543191 .7097930908190 .795501709189 .8811035156188 .966796875 188.3571929932187 .7476043701187 .1381072998186 .8332977295186 .2236938477 185.6141052246184 .0901947021180 .432800293184 .3950042725179 .8231964111 176.165802002185 .9188995361195 .9768066406194 .4528961182190 .1858978271 181.8563079834178 .0631408691177 .2467346191178 .7194671631180 .3645019531 181.0713653564180 .9806365967181 .1063995361182 .2694396973183 .490020752 183.188949585183 .6289520264184 .7870635986184 .0901947021178 .9089050293 172.8132019043167 .0222015381161 .5361022949156 .6596069336152 .6972961426 151.1734008789150 .8686065674150 .8686065674150 .5639038086149 .9542999268 149.3446960449148 .4304046631147 .5160064697146 .6015930176145 .6873016357 145.0776977539145 .0776977539145 .6873016357147 .5160064697149 .6495056152 151.7830047607153 .6116943359155 .1356048584155 .7451934814156 .0500030518 155.7451934814155 .1356048584154 .2212982178 -9999 -9999 -9999 -9999 -9999 -9999 -9999 -9999 -9999 -9999 -9999 -9999 -9999 -9999 -9999 -9999 -9999 -9999 -9999 -9999 -9999 -9999

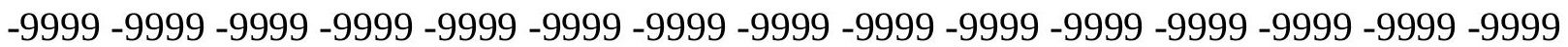
-9999 -9999 -9999 -9999 -9999 -9999 -9999 -9999 -9999 -9999 -9999 -9999 -9999 -9999 -9999 -9999 -9999 -9999 -9999 -9999 -9999 -9999 -9999 -9999 -9999 -9999 -9999 -9999 -9999 -9999 -9999 -9999 -9999 -9999 -9999 -9999 -9999 -9999 -9999 -9999 -9999 -9999 -9999 -9999 -9999

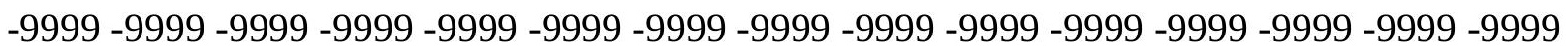
-9999 -9999 -9999 -9999 -9999 -9999 -9999 -9999 -9999 -9999 -9999 -9999 -9999 -9999 -9999 -999 -9999 -9999 -9999 -9999 -9999 -9999 -9999 -9999 -9999 -9999 -9999 -9999 -9999 -9999 -9999 -9999 -9999 -9999 -9999 -9999 -9999 -9999 -9999 -9999 -9999 -9999 -9999 -9999 -9999 -9999

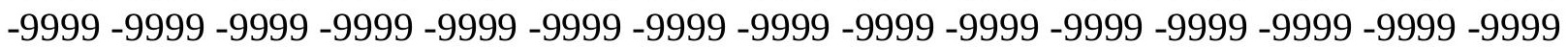


-9999 -9999 -9999 -9999 -9999 -9999 -9999 -9999 -9999 -9999 -9999 -9999 -9999 -9999 -9999 -9999 -9999 -9999 -9999 -9999 -9999 -9999 -9999 -9999 -9999 -9999 -9999 -9999 -9999 -9999 -9999 -9999 -9999 -9999 -9999 -9999 -9999 -9999 -9999 -9999 -9999 -9999 -9999 -9999 -9999 -9999 -9999 -9999 -9999 -9999 -9999 -9999 -9999 -9999 -9999 -9999 -9999 -9999 -9999 -9999 -9999 -9999-9999-9999

-9999 -9999 -9999 -9999 -9999 -9999 -9999 -9999 -9999 -9999 -9999 -9999 -9999 -9999 -9999 -9999 -9999 -9999 -9999 -9999 -9999 -9999 -9999 -9999 -9999 -9999 -9999 -9999 -9999 -9999 -9999 -9999 -9999 -9999 -9999 -9999 -9999 -9999 -9999 -9999 -9999 -9999 -9999 -9999 -9999 -9999 -9999 -9999 -9999 -9999 -9999 -9999 -9999 -9999 -9999 -9999 -9999 -9999 -9999 -9999 -9999 -9999 -9999 -9999 -9999 -9999 -9999 -9999 -9999 -9999 -9999 -9999 -9999 -9999 -9999 -9999 -9999 -9999 -9999 -9999 -9999 -9999 -9999 -9999 -9999 -9999 -9999 -9999 -9999 -9999 -9999 -9999 -9999 -9999 -9999 -9999 244.4376983643 231.9414978027 218.2261962891 203.9011993408197 .1959991455193 .5386047363191 .7097930908191 .1002960205 190.1858978271189 .8811035156189 .2716064453188 .6620025635188 .0523986816 187.4429016113186 .8332977295186 .2236938477185 .9188995361185 .6141052246 185.3094024658184 .3950042725183 .4806976318182 .261505127177 .9945068359 172.8132019043166 .7174987793174 .337097168179 .5184020996184 .0901947021 181.3471984863178 .604095459177 .9945068359176 .7754058838179 .5184020996 181.9566955566181 .4408111572181 .7147521973182 .6525878906183 .6088562012 183.5785217285183 .2559661865184 .0419158936186 .6814422607188 .6620025635 181.9566955566172 .8132019043167 .6318054199163 .3648071289158 .7929992676 155.7451934814154 .2212982178155 .4403991699156 .0500030518156 .3547973633 156.0500030518155 .1356048584154 .2212982178153 .0021057129151 .1734008789 149.6495056152148 .1255950928147 .2111968994147 .5160064697149 .3446960449 151.7830047607154 .5260925293156 .9642944336158 .1835021973158 .7929992676 158.7929992676158 .1835021973156 .9642944336155 .7451934814 -9999 -9999 -9999 -9999 -9999 -9999 -9999 -9999 -9999 -9999 -9999 -9999 -9999 -9999 -9999 -9999 -9999 -9999 -9999

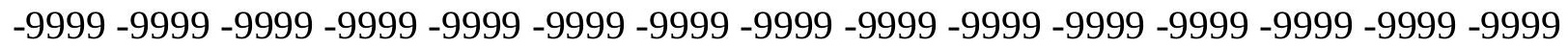
-9999 -9999 -9999 -9999 -9999 -9999 -9999 -9999 -9999 -9999 -9999 -9999 -9999 -9999 -9999 -9999 -9999 -9999 -9999 -9999 -9999 -9999 -9999 -9999 -9999 -9999 -9999 -9999 -9999 -9999 -9999 -9999 -9999 -9999 -9999 -9999 -9999 -9999 -9999 -9999 -9999 -9999 -9999 -9999 -9999

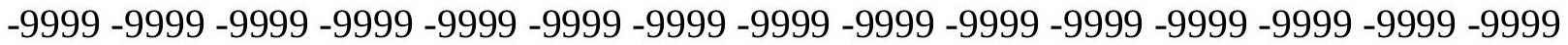

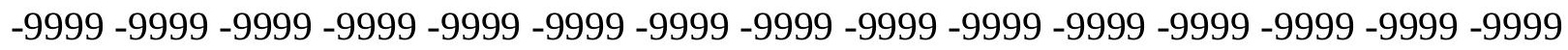
-9999 -9999 -9999 -9999 -9999 -9999 -9999 -9999 -9999 -9999 -9999 -9999 -9999 -9999 -9999 -9999 -9999 -9999 -9999 -9999 -9999 -9999 -9999 -9999 -9999 -9999 -9999 -9999 -9999 -9999 -9999 -9999 -9999 -9999 -9999 -9999 -9999 -9999 -9999 -9999 -9999 -9999 -9999 -9999 -9999

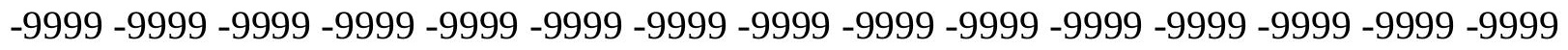

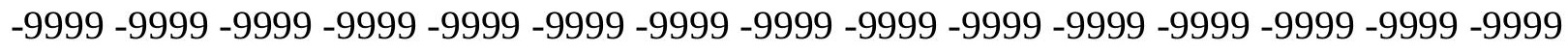
-9999 -9999 -9999 -9999 -9999 -9999 -9999 -9999 -9999 -9999 -9999 -9999 -9999 -9999 -9999 -9999 -9999 -9999 -9999 -9999 -9999 -9999 -9999 -9999 -9999 -9999 -9999 -9999 -9999 -9999 -9999 -9999 -9999 -9999 -9999 -9999 -9999

-9999 -9999 -9999 -9999 -9999 -9999 -9999 -9999 -9999 -9999 -9999 -9999 -9999 -9999 -9999 -9999 -9999 -9999 -9999 -9999 -9999 -9999 -9999 -9999 -9999 -9999 -9999 -9999 -9999 -9999 -9999 -9999 -9999 -9999 -9999 -9999 -9999 -9999 -9999 -9999 -9999 -9999 -9999 -9999 -9999 -9999 -9999 -9999 -9999 -9999 -9999 -9999 -9999 -9999 -9999 -9999 -9999 -9999 -9999 -9999 -

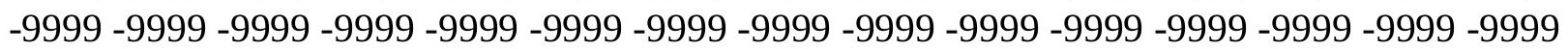


-9999 -9999 -9999 -9999 -9999 -9999 -9999 -9999 -9999 -9999 -9999 -9999 -9999 -9999 -9999 -9999 -9999 -9999 -9999 -9999 -9999 213.0447998047 207.25390625 201.158203125 198.7198944092195 .0625191 .4051055908189 .2716064453188 .0523986816187 .4429016113 187.1381072998186 .8332977295186 .528503418185 .9188995361185 .6141052246 185.3094024658184 .699798584184 .699798584184 .3950042725184 .0901947021 183.4806976318182 .5662994385181 .0424041748177 .9945068359179 .2136993408 177.9945068359181 .3471984863185 .9188995361188 .6620025635188 .0523986816 186.2236938477184 .699798584183 .7854003906179 .2136993408180 .1280059814 181.0424041748181 .9566955566183 .4806976318184 .0901947021183 .4806976318 181.0424041748181 .3471984863184 .3950042725185 .6141052246180 .432800293 173.7274932861169 .1557006836165 .8031005859163 .6696014404162 .1457061768 160.9264984131159 .7073974609161 .5361022949162 .1457061768161 .8408966064 161.2312927246160 .3170013428158 .7929992676156 .6596069336154 .2212982178 151.4781951904149 .6495056152149 .6495056152151 .4781951904154 .8307952881 157.878692627160 .3170013428161 .5361022949161 .8408966064161 .2312927246 160.3170013428159 .0977935791157 .2691040039155 .7451934814 -9999 -9999-9999-9999 -9999 -9999 -9999 -9999 -9999 -9999 -9999 -9999 -9999 -9999 -9999 -9999 -9999 -9999-9999 -9999 -9999 -9999 -9999 -9999 -9999 -9999 -9999 -9999 -9999 -9999 -9999 -9999 -9999 -9999 -999 -9999 -9999 -9999 -9999 -9999 -9999 -9999 -9999 -9999 -9999 -9999 -9999 -9999 -9999 -9999 -9999 -9999 -9999 -9999 -9999 -9999 -9999 -9999 -9999 -9999 -9999 -9999 -9999 -9999 -9999 -9999 -9999 -9999 -9999 -9999 -9999 -9999 -9999 -9999 -9999 -9999 -9999 -9999 -9999 -9999 -9999 -9999 -9999 -9999 -9999 -9999 -9999 -9999 -9999 -9999 -9999 -9999 -9999 -9999 -9999 -9999 -9999 -9999 -9999 -9999 -9999 -9999 -9999 -9999 -9999 -9999 -9999 -9999 -9999 -9999 -9999 -9999 -9999 -9999 -9999 -9999 -9999 -9999 -9999 -9999 -9999 -9999 -9999 -9999 -9999 -9999 -9999 -9999 -9999 -9999 -9999 -9999 -9999 -9999 -9999 -9999 -9999 -9999 -9999 -9999 -9999 -9999 -9999 -9999 -9999 -9999 -9999 -9999 -9999 -9999 -9999 -9999 -9999 -9999 -9999 -9999 -9999 -9999 -9999 -9999 -9999 -9999 -9999 -9999 -9999 -9999 -9999 -9999 -9999 -9999 -

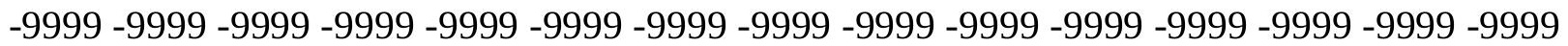

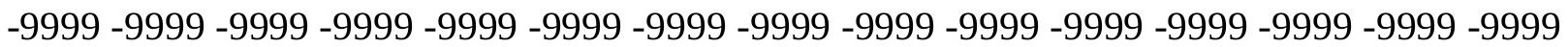
-9999 -9999 -9999 -9999 -9999 -9999 -9999 -9999 -9999 -9999 -9999 -9999 -9999 -9999 -9999 -9999 -9999-9999-9999-9999-9999

-9999 -9999 -9999 -9999 -9999 -9999 -9999 -9999 -9999 -9999 -9999 -9999 -9999 -9999 -9999 -9999 -9999 -9999 -9999 -9999 -9999 -9999 -9999 -9999-9999 -9999 -9999 -9999-9999-999 - -999 -9999 -9999 -9999 -9999 -9999 -9999 -9999 -9999 -9999 -9999 -9999 -9999 -9999 -9999 -9999 -9999 -9999 -9999 -9999 -9999 -9999 -9999 -9999 -9999 -9999 -9999 -9999 -9999 -9999 -9999 -9999 -9999 -9999 -9999 -9999 -9999 -9999 -9999 -9999 -9999 -9999 -9999 -9999 -9999 -9999

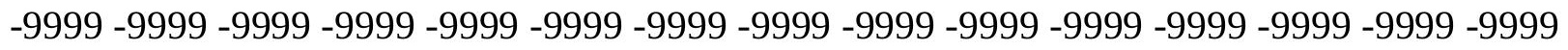
-9999 -9999 -9999 -9999-9999 203.2917022705 196.5863952637192 .624206543 192.3193969727192 .624206543191 .1002960205188 .6620025635186 .528503418 185.3094024658185 .0045928955184 .699798584184 .699798584184 .3950042725 184.3950042725184 .0901947021183 .7854003906183 .4806976318183 .1759033203 182.87109375182 .5662994385182 .261505127181 .3471984863179 .8231964111 182.5662994385181 .6519012451181 .6519012451183 .4806976318186 .2236938477 188.0523986816188 .3571929932187 .4429016113186 .2236938477185 .3094024658 180.7375946045181 .3471984863182 .5662994385183 .4806976318184 .3950042725 184.3950042725183 .1759033203181 .6519012451180 .432800293179 .8231964111 
178.2993011475174 .337097168169 .4604949951163 .974395752163 .0599975586 162.7552947998162 .1457061768163 .3648071289164 .2792053223165 .8031005859 168.241394043167 .0222015381167 .0222015381166 .4127044678164 .5839996338 162.1457061768159 .4026031494156 .3547973633153 .3069000244152 .0877990723 154.8307952881159 .0977935791162 .4505004883164 .2792053223164 .8887023926 164.5839996338163 .6696014404162 .4505004883160 .6217956543158 .7929992676 156.6596069336 -9999 -9999 -9999 -9999 -9999 -9999 -9999 -9999 -9999 -9999 -9999 -9999

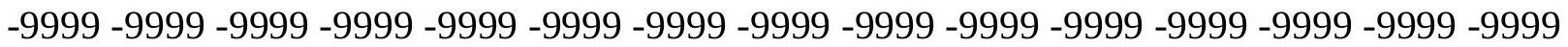
-9999 -9999 -9999 -9999 -9999 -9999 -9999 -9999 -9999 -9999 -9999 -9999 -9999 -9999 -9999 -9999 -9999 -9999 -9999 -9999 -9999 -9999 -9999 -9999 -9999 -9999 -9999 -9999 -9999 -9999 -9999 -9999 -9999 -9999 -9999 -9999 -9999 -9999 -9999 -9999 -9999 -9999 -9999 -9999 -9999 -9999 -9999 -9999 -9999 -9999 -9999 -9999 -9999 -9999 -9999 -9999 -9999 -9999 -9999 -9999 -9999 -9999 -9999 -9999 -9999 -9999 -9999 -9999 -9999 -9999 -9999 -9999 -9999 -9999 -9999 -9999 -9999 -9999 -9999 -9999 -9999 -9999 -9999 -9999 -9999 -9999 -9999 -9999 -9999 -9999 -9999 -9999 -9999 -9999 -9999 -9999 -9999 -9999 -9999 -9999 -9999 -9999 -9999 -9999 -9999

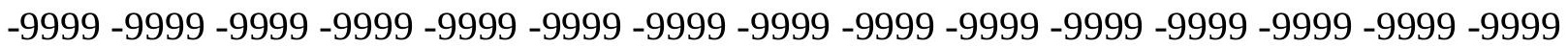

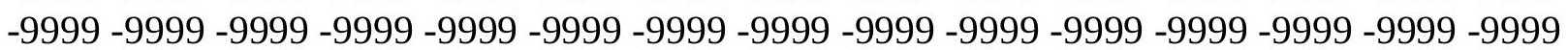
-9999 -9999 -9999 -9999 -9999 -9999 -9999 -9999 -9999 -9999 -9999 -9999 -9999 -9999 -9999 -999 -9999 -9999 -9999 -9999 -9999 -9999 -9999 -9999 -9999 -9999 -9999 -9999 -9999 -9999 -9999 -9999 -9999 -9999 -9999 -9999 -9999 -9999 -9999 -9999 -9999 -9999 -9999 -9999 -9999 -9999 -9999 -9999 -9999 -9999 -9999 -9999 -9999 -9999 -9999 -9999 -9999 -9999 -9999 -

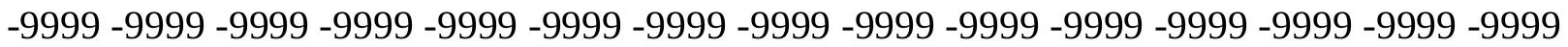
-9999 -9999 -9999 -9999 -9999 -9999 -9999 -9999 -9999 -9999 -9999 -9999 -9999 -9999 -9999 -9999 -9999 -9999 -9999 -9999 -9999 -9999 -9999 -9999 -9999 -9999 -9999 -9999 -9999 -9999 -9999 -9999 -9999 -9999 -9999 -9999 -9999 -9999 -9999 -9999 -9999 -9999 -9999 -9999 -9999 -9999 -9999 -9999 -9999 -9999 -9999 -9999 -9999 -9999 -9999 -9999 -9999 -9999 -9999 -9999 -9999 -9999 -9999 -9999 -9999 -9999 -9999 -9999 -9999 -9999 -9999 -9999 -9999 -9999 -9999 -9999 -9999 -9999 -9999 -9999 191.4051055908188 .0523986816185 .9188995361 186.8332977295187 .4429016113186 .8332977295185 .3094024658184 .0901947021 183.1759033203182 .87109375183 .1759033203183 .1759033203183 .1759033203 183.1759033203182 .87109375182 .5662994385182 .261505127181 .9566955566 181.9566955566181 .3471984863181 .0424041748180 .1280059814179 .2136993408 183.1759033203183 .1759033203183 .4806976318184 .699798584186 .528503418 187.4429016113188 .0523986816187 .4429016113186 .8332977295181 .6519012451 181.9566955566182 .5662994385183 .4806976318184 .3950042725184 .699798584 184.699798584183 .7854003906182 .5662994385181 .3471984863179 .5184020996 177.0802001953173 .4226989746168 .5462036133168 .8509979248161 .5361022949 160.6217956543160 .3170013428161 .2312927246162 .1457061768166 .7174987793 168.8509979248171 .5939941406172 .5084075928172 .5084075928170 .070098877 166.7174987793164 .5839996338163 .6696014404160 .6217956543155 .7451934814 161.8408966064166 .1078948975167 .9365997314168 .5462036133168 .241394043 167.3269958496165.8031005859 164.2792053223162.1457061768 160.0122070312 157.5738983154155 .4403991699 -9999 -9999 -9999 -9999 -9999 -9999 -9999 -9999 -9999 -9999 -9999 -9999 -9999 -9999 -9999 -9999 -9999 -9999 -9999 -9999 -9999 -9999 -9999 -9999 -9999 -9999 -9999 -9999 -9999 -9999 -9999 -9999 -9999 -9999 -9999 -9999 -9999 -9999 -9999

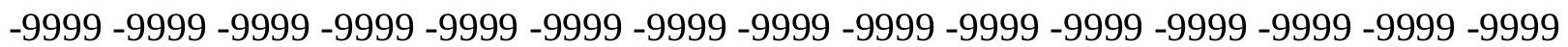


-9999 -9999 -9999 -9999 -9999 -9999 -9999 -9999 -9999 -9999 -9999 -9999 -9999 -9999 -9999 -9999 -9999 -9999 -9999 -9999 -9999 -9999 -9999 -9999 -9999 -9999 -9999 -9999 -9999 -9999 -9999 -9999 -9999 -9999 -9999 -9999 -9999 -9999 -9999 -9999 -9999 -9999 -9999 -9999 -9999 -9999 -9999 -9999 -9999 -9999 -9999 -9999 -9999 -9999 -9999 -9999 -9999 -9999 -9999 -9999 -9999 -9999 -9999 -9999 -9999 -9999 -9999 -9999 -9999 -9999 -9999 -9999 -9999 -9999 -9999 -9999 -9999 -9999 -9999 -9999 -9999 -9999 -9999 -9999 -9999 -9999 -9999 -9999 -9999 -9999 -9999 -9999 -9999 -9999 -9999 -9999 -9999 -9999 -9999 -9999 -9999 -9999 -9999 -9999 -9999

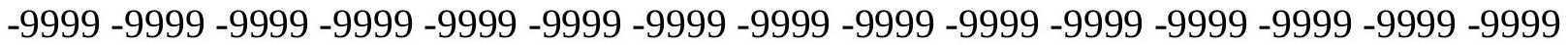
-9999 -9999 -9999 -9999 -9999 -9999 -9999 -9999 -9999 -9999 -9999 -9999 -9999 -9999 -9999 -9999 -9999 -9999 -9999 -9999 -9999 -9999 -9999 -9999 -9999 -9999 -9999 -9999 -9999 -9999 -

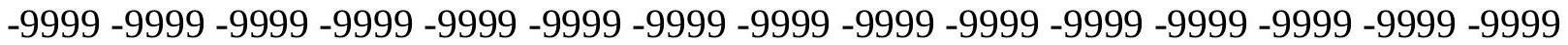
-9999 -9999 -9999 -9999 -9999 -9999 -9999 -9999 -9999 -9999 -9999 -9999 -9999 -9999 -9999

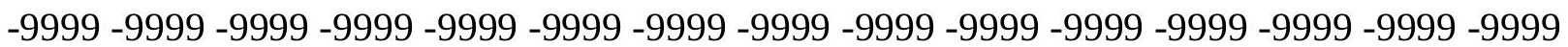
-9999 -9999 -9999 -9999 -9999 -9999 -9999 -9999 -9999 -9999 -9999 -9999 -9999 -9999 -9999 -9999 -9999 -9999 -9999 -9999 -9999 -9999 -9999 -9999 -9999 -9999 -9999 -9999 -9999 -9999 -9999 -9999 -9999 -9999 -9999 -9999 -9999 -9999 -9999 -9999 -9999 -9999 -9999 -9999 -9999 -9999 -9999 -9999 -9999 -9999 -9999 -9999 -9999 -9999 -9999 -9999 -9999 -9999 -9999 -9999 -9999 -9999 -9999 -9999 -9999 185.6141052246183 .1759033203183 .4806976318 183.7854003906184 .0901947021183 .7854003906182 .87109375182 .261505127 181.9566955566181 .9566955566181 .9566955566182 .261505127182 .261505127 182.261505127181 .9566955566181 .6519012451181 .3471984863181 .0424041748 180.7375946045180 .432800293179 .8231964111179 .2136993408183 .4806976318 183.4806976318183 .7854003906184 .3950042725185 .3094024658186 .2236938477 187.1381072998187 .4429016113187 .1381072998182 .5662994385182 .5662994385 182.87109375183 .4806976318184 .0901947021184 .699798584185 .0045928955 184.699798584184 .0901947021182 .87109375181 .3471984863179 .5184020996 176.7754058838173 .4226989746169 .4604949951165 .8031005859163 .3648071289 162.1457061768161 .8408966064162 .1457061768163 .3648071289165 .4983062744 168.5462036133174 .9467010498180 .432800293177 .6087646484173 .1515197754 169.6430969238168 .5462036133171 .5939941406173 .4226989746173 .4226989746 174.0323028564174 .337097168173 .4226989746172 .2035980225170 .6797027588 169.1557006836167 .3269958496165 .4983062744163 .0599975586160 .6217956543 158.1835021973155 .7451934814 -9999 -9999 -9999 -9999 -9999 -9999 -9999 -9999 -9999 -9999 -9999 -9999 -9999 -9999 -9999 -9999 -9999 -9999 -9999 -9999 -9999 -9999 -9999 -9999

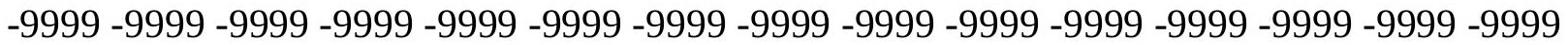
-9999 -9999 -9999 -9999 -9999 -9999 -9999 -9999 -9999 -9999 -9999 -9999 -9999 -9999 -9999

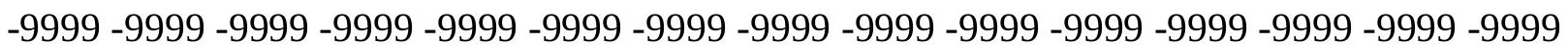

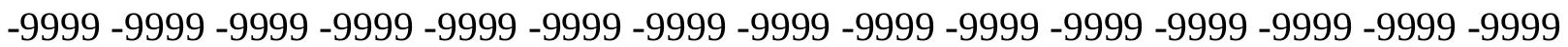
-9999 -9999 -9999 -9999 -9999 -9999 -9999 -9999 -9999 -9999 -9999 -9999 -9999 -9999 -9999 -9999 -9999 -9999 -9999 -9999 -9999 -9999 -9999 -9999 -9999 -9999 -9999 -9999 -9999 -9999 -9999 -9999 -9999 -9999 -9999 -9999 -9999 -9999 -9999 -9999 -9999 -9999 -9999 -9999 -9999

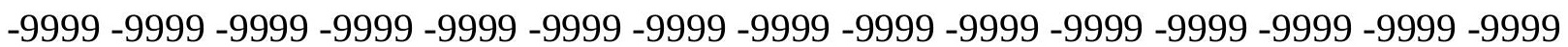
-9999 -9999 -9999 -9999 -9999 -9999 -9999 -9999 -9999 -9999 -9999 -9999 -9999 -9999 -9999 -9999 -9999 -9999 -9999 -9999 -9999 -9999 -9999 -9999 -9999 -9999 -9999 -9999 -9999 -9999 -9999 -9999 -9999 -9999 -9999 -9999 -9999 -9999 -9999 -9999 -9999 -9999 -9999 -9999 -9999

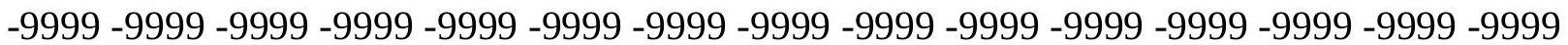


-9999 -9999 -9999 -9999 -9999 -9999 -9999 -9999 -9999 -9999 -9999 -9999 -9999 -9999 -9999 -9999 -9999 -9999 -9999 -9999 -9999 -9999 -9999 -9999 -9999 -9999 -9999 -9999 -9999 -9999 -9999 -9999 -9999 -9999 -9999 -9999 -9999 -9999 -9999 -9999 -9999 -9999 -9999 -9999 -9999 -9999 -9999 -9999 -9999 -9999 -9999 -9999 -9999 -9999 -9999 -9999 -9999 -9999 -9999 -9999 -9999 -9999 -9999 -9999 -9999 -9999 -9999 -9999 -9999 -9999 -9999 -9999 -9999 -9999 -9999 -9999 -9999 -9999 -9999 -9999 -9999 -9999 -9999 -9999 -9999 -9999 -9999 -9999 -9999 -9999 -9999 -9999 -9999 -9999 -9999 -9999 -9999 -9999 -9999 -9999 -9999 -9999 -9999 -9999 -9999 -9999 -9999 -9999 -9999 -9999 184.699798584 182.87109375183 .1759033203 183.4806976318183 .1759033203182 .5662994385181 .9566955566181 .6519012451 181.3471984863181 .6519012451181 .9566955566181 .9566955566182 .261505127 182.261505127181 .9566955566181 .6519012451181 .0424041748180 .432800293 179.8231964111179 .5184020996178 .9089050293178 .2993011475182 .87109375 183.4806976318183 .7854003906184 .3950042725185 .0045928955185 .9188995361 186.2236938477186 .528503418182 .261505127182 .5662994385182 .87109375 183.1759033203183 .4806976318184 .0901947021184 .3950042725184 .699798584 184.3950042725183 .7854003906182 .87109375181 .3471984863179 .2136993408 176.7754058838173 .7274932861170 .3748931885167 .6318054199165 .4983062744 164.2792053223163 .974395752164 .5839996338165 .8031005859168 .241394043 171.5939941406176 .165802002180 .1280059814179 .8231964111173 .1368865967 169.2893981934170 .612121582174 .0422668457177 .6461029053181 .456237793 184.699798584181 .6519012451178 .2993011475174 .6419067383172 .2035980225 170.3748931885168 .241394043166 .1078948975163 .6696014404160 .9264984131 158.1835021973155 .4403991699153 .0021057129 -9999 -9999 -9999 -9999 -9999 -9999 -9999 -9999 -9999 -9999 -9999 -9999 -9999 -9999 -9999 -9999 -9999 -9999 -9999 -9999 -9999 -9999 -9999 -9999 -9999 -9999 -9999 -9999 -9999 -9999 -9999 -9999 -9999 -9999 -9999 -9999 -9999 -9999 -9999 -9999 -9999 -9999 -9999 -9999 -9999 -9999 -9999 -9999 -9999 -9999 -9999 -9999 -9999 -9999 -9999 -9999 -9999 -9999 -9999 -9999 -9999 -9999 -9999 -9999 -9999 -9999 -9999 -9999 -9999 -9999 -9999 -9999 -9999 -9999 -9999 -9999 -9999 -9999 -9999 -9999 -9999 -9999 -9999 -9999 -9999 -9999 -9999 -9999 -9999 -9999 -9999 -9999 -9999 -9999 -9999 -9999 -9999 -9999 -9999 -9999 -9999 -9999 -9999 -9999 -9999 -9999 -9999 -9999 -9999 -9999 -9999 -9999 -9999 -9999 -9999 -9999 -9999 -9999 -9999 -9999 -9999 -9999 -9999 -9999 -9999 -9999 -9999 -9999 -9999 -9999 -9999 -9999 -9999 -9999 -9999 -9999 -9999 -9999 -9999 -9999 -9999-9999 -999 -9999 -9999 -9999 -9999 -9999 -9999 -9999 -9999 -9999 -9999 -9999 -9999 -9999 -9999 -9999 -9999 -9999 -9999 -9999 -9999 -9999 -9999 -9999 -9999 -9999 -9999 -9999 -9999 -9999 -9999 -9999 -9999 -9999 -9999 -9999 -9999 -9999 -9999 -9999 -9999 -9999 -9999 -9999 -9999 -9999 -9999 -9999 -9999 -9999 -9999 -9999 -9999 -9999 -9999 -9999 -9999 -9999 -9999 -9999 -9999 -

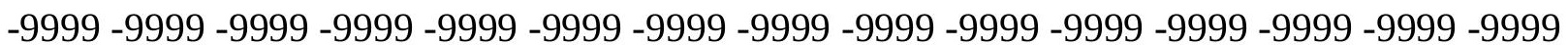
$-9999$

-9999 -9999 -9999 -9999 -9999 -9999 -9999 -9999 -9999 -9999 -9999 -9999 -9999 -9999 -9999 -9999 -9999 -9999 -9999 -9999 -9999 -9999 -9999 -9999 -9999 -9999 -9999 -9999 -9999 -9999 -9999 -9999 -9999 -9999 -9999 -9999 -9999 -9999 -9999 -9999 -9999 -9999 -9999 -9999 -9999

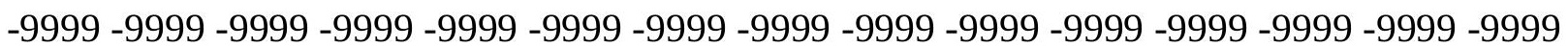
-9999 -9999 -9999 -9999 -9999 -9999 -9999 -9999 -9999 -9999 -9999 -9999 -9999 -9999 -9999 -9999 -9999 -9999 -9999 -9999 -9999 -9999 -9999 -9999 -9999 -9999 -9999 -9999 -9999 -9999 -9999 -9999 -9999 -9999 -9999 -9999 186.528503418 186.2236938477 185.9188995361 185.0045928955183 .1759033203182 .5662994385182 .261505127181 .9566955566 
182.261505127 182.5662994385182.87109375 182.87109375 182.5662994385 182.261505127 181.6519012451181 .0424041748180 .1280059814179 .5184020996178 .604095459 177.9945068359177 .6896972656182 .261505127182 .87109375183 .4806976318 184.0901947021184 .699798584185 .0045928955185 .3094024658181 .3471984863 181.9566955566182 .261505127182 .5662994385183 .1759033203183 .4806976318 183.7854003906184 .0901947021184 .0901947021183 .7854003906183 .1759033203 182.261505127180 .7375946045178 .9089050293176 .4705963135174 .0323028564 171.2891998291168 .8509979248167 .0222015381165 .8031005859165 .8031005859 166.4127044678167 .9365997314170 .3748931885173 .7274932861177 .3849029541 179.8231964111176 .4705963135170 .070098877165 .1934967041170 .9844970703 172.8916625977177 .1568145752182 .2613220215186 .6003570557189 .2716064453 181.6519012451175 .2514038086173 .1179962158170 .9844970703168 .8509979248 166.4127044678163 .6696014404160 .9264984131158 .1835021973155 .1356048584 152.6972961426 -9999 -9999 -9999 -9999 -9999 -9999 -9999 -9999 -9999 -9999 -9999 -9999 -9999 -9999 -9999 -9999 -9999 -9999 -9999 -9999 -9999 -9999 -9999 -9999 -9999 -9999 -9999

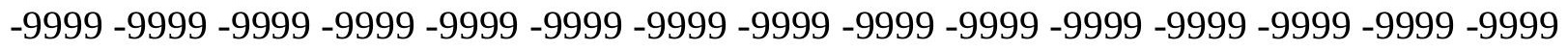
-9999 -9999 -9999 -9999 -9999 -9999 -9999 -9999 -9999 -9999 -9999 -9999 -9999 -9999 -9999 -9999 -9999 -9999 -9999 -9999 -9999 -9999 -9999 -9999 -9999 -9999 -9999 -9999 -9999 -9999 -

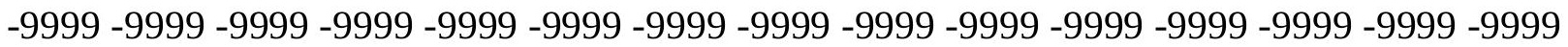

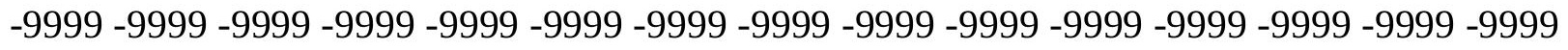

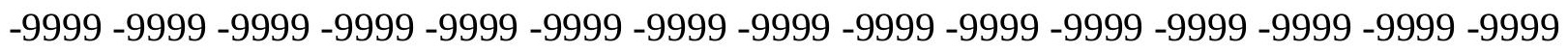

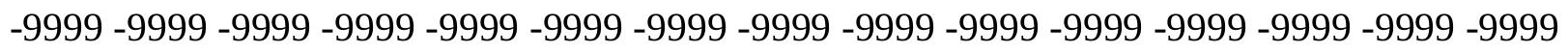
-9999 -9999 -9999 -9999 -9999 -9999 -9999 -9999 -9999 -9999 -9999 -9999 -9999 -9999 -9999 -

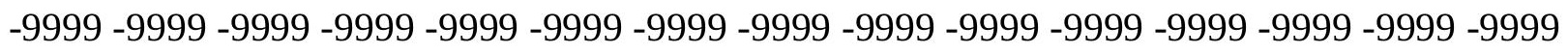

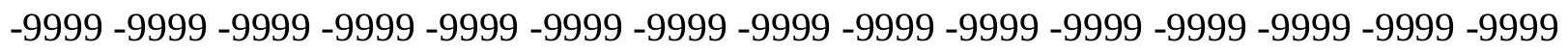
-9999 -9999 -9999 -9999 -9999 -9999 -9999 -9999 -9999 -9999 -9999 -9999 -9999 -9999 -9999

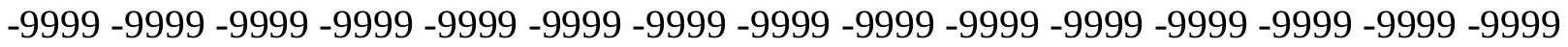
-9999 -9999 -9999 -9999 -9999 -9999 -9999 -9999 -9999 -9999-9999

-9999 -9999 -9999 -9999 -9999 -9999 -9999 -9999 -9999 -9999 -9999 -9999 -9999 -9999 -9999

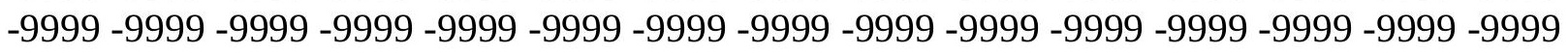
-9999 -9999 -9999 -9999 -9999 -9999 -9999 -9999 -9999 -9999 -9999 -9999 -9999 -9999 -9999 -9999 -9999 -9999 -9999 -9999 -9999 -9999 -9999 -9999 -9999 -9999 -9999 -9999 -9999 -9999 -

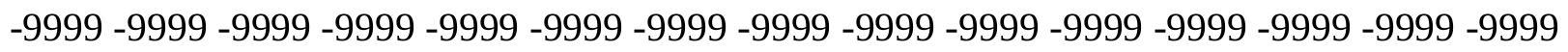

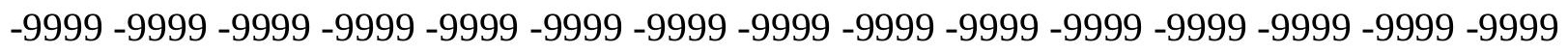
-9999 -9999-9999-9999-9999-9999 193.5386047363 190.795501709 190.1858978271 189.5764007568187 .4429016113185 .6141052246184 .0901947021183 .4806976318 183.4806976318183 .7854003906184 .0901947021184 .0901947021183 .7854003906 183.1759033203182 .5662994385181 .3471984863180 .432800293179 .2136993408 178.2993011475177 .6896972656177 .3849029541177 .3849029541181 .9566955566 182.5662994385183 .1759033203183 .7854003906184 .0901947021180 .1280059814 180.7375946045181 .3471984863181 .9566955566182 .261505127182 .87109375 183.1759033203183 .1759033203183 .4806976318183 .4806976318183 .1759033203 182.5662994385181 .6519012451180 .1280059814178 .2993011475176 .4705963135 174.0323028564171 .8988037109169 .7653045654168 .241394043167 .3269958496 167.0222015381167 .3269958496168 .8509979248170 .6797027588173 .4226989746 175.8609924316176 .7754058838174 .337097168170 .070098877167 .3269958496 
167.3269958496168 .8509979248174 .8535308838179 .2181091309182 .5980682373 184.9354553223185 .3094024658177 .3849029541173 .7274932861170 .9844970703 168.8509979248166 .4127044678163 .6696014404160 .6217956543157 .5738983154 154.8307952881152 .0877990723149 .6495056152 -9999 -9999 -9999 -9999 -9999 -9999 -9999 -9999 -9999 -9999 -9999 -9999 -9999 -9999 -9999 -9999 -9999 -9999 -9999 -9999 -9999 -9999 -9999 -9999 -9999 -9999 -9999 -9999 -9999 -9999 -9999 -9999 -9999 -9999 -9999 -9999 -9999 -9999 -9999 -9999 -9999 -9999 -9999 -9999 -9999 -9999 -9999 -9999 -9999 -9999 -9999 -9999 -9999 -9999 -9999 -9999 -9999 -9999 -9999 -9999 -9999 -9999 -9999 -9999 -9999 -9999 -9999 -9999 -9999 -9999 -9999 -9999 -9999 -9999 -9999 -9999 -9999 -9999 -9999 -9999 -9999 -9999 -9999 -9999 -9999 -9999 -9999 -9999 -9999 -9999 -9999 -9999 -9999 -9999 -9999 -9999 -9999 -9999 -9999 -9999 -9999 -9999 -9999 -9999 -9999 -9999 -9999 -9999 -9999 -9999 -9999 -9999 -999 -9999 -9999 -9999 -9999 -9999 -9999 -9999 -9999 -9999 -9999 -9999 -9999 -9999 -9999 -9999 -9999 -9999 -9999 -9999 -9999 -9999 -9999 -9999 -9999 -9999 -9999 -9999 -9999 -9999 -9999 -9999 -9999 -9999 -9999 -9999 -9999 -9999 -9999 -9999 -9999 -9999 -9999 -9999 -9999 -9999 -9999 -9999 -9999 -9999 -9999 -9999 -9999 -9999 -9999 -9999 -9999 -9999 -9999 -9999 -9999

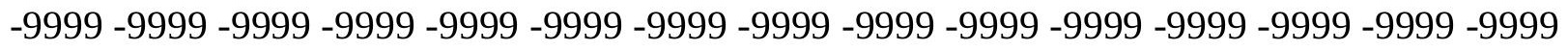
-9999 -9999 -9999 -9999 -9999 -9999 -9999 -9999 -9999 -9999 -9999 -9999 -9999 -9999 -9999 -

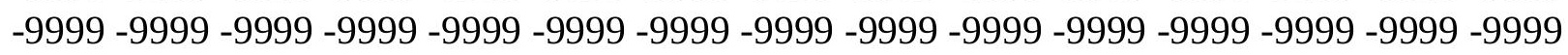

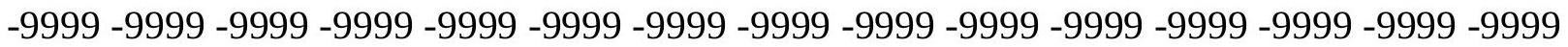

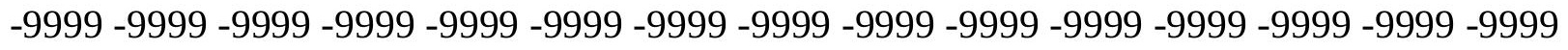

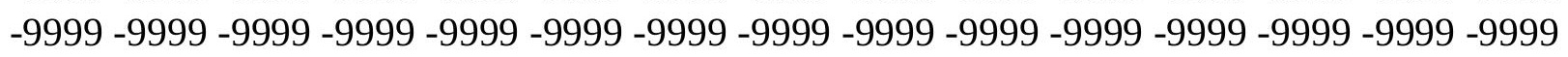

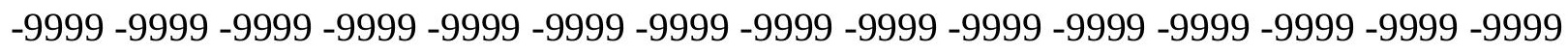
-9999 -9999 -9999 -9999 -9999 -9999 -9999 -9999 -9999 -9999 -9999 -9999 -9999 -9999 -9999 -9999 -9999 -9999 -9999 -9999 -9999 -9999 -9999 -9999 -9999 -9999 -9999 -9999 -9999 -9999 -9999 -9999 -9999 -9999 -9999 -9999 204.5108032227 201.158203125 197.1959991455 195.9768066406193 .233795166188 .6620025635186 .2236938477185 .6141052246 185.9188995361186 .2236938477186 .2236938477185 .9188995361185 .6141052246 184.699798584183 .4806976318182 .261505127180 .7375946045179 .2136993408 177.9945068359177 .6896972656177 .3849029541177 .0802001953177 .3849029541 177.3849029541177 .9945068359178 .2993011475178 .9089050293179 .5184020996 180.1280059814180 .7375946045181 .3471984863181 .6519012451182 .261505127 182.5662994385182 .5662994385182 .5662994385182 .5662994385182 .261505127 181.6519012451180 .7375946045179 .5184020996177 .9945068359176 .165802002 174.0323028564172 .2035980225170 .3748931885168 .8509979248167 .9365997314 167.6318054199172 .5084075928173 .4226989746174 .6419067383171 .5939941406 172.8132019043172 .8132019043171 .5939941406169 .4604949951168 .241394043 168.5462036133170 .6797027588174 .0323028564174 .6419067383176 .4705963135 177.3849029541176 .4705963135175 .8609924316173 .1179962158170 .6797027588 168.241394043165 .8031005859163 .0599975586160 .3170013428157 .2691040039 154.2212982178 151.1734008789 149.3446960449 -9999 -9999 -9999 -9999 -9999 -9999 -9999

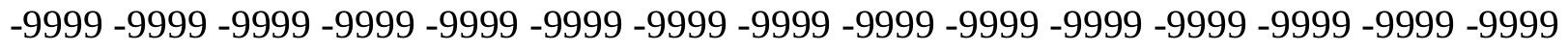

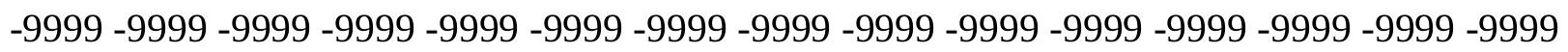
-9999 -9999 -9999 -9999 -9999 -9999 -9999 -9999 -9999 -9999 -9999 -9999 -9999 -9999 -9999 -9999 -9999 -9999 -9999 -9999 -9999 -9999 -9999 -9999 -9999 -9999 -9999 -9999 -9999 -9999 -9999 -9999 -9999 -9999 -9999 -9999 -9999 -9999 -9999 -9999 -9999 -9999 -9999 -9999 -9999 -

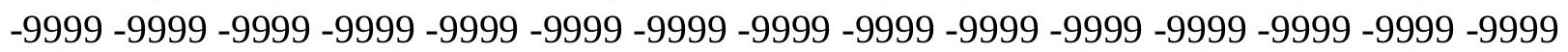


-9999 -9999 -9999 -9999 -9999 -9999 -9999 -9999 -9999 -9999 -9999 -9999 -9999 -9999 -9999 -9999 -9999 -9999 -9999 -9999 -9999 -9999 -9999 -9999 -9999 -9999 -9999 -9999 -9999 -9999 -9999 -9999 -9999 -9999 -9999 -9999 -9999 -9999 -9999 -9999 -9999 -9999 -9999 -9999 -9999 -9999 -9999 -9999 -9999 -9999 -9999 -9999 -9999 -9999 -9999 -9999 -9999 -9999 -9999 -9999 -9999 -9999 -9999 -9999 -9999 -9999 -9999 -9999 -9999 -9999 -9999 -9999 -9999 -9999 -9999 -9999 -9999 -9999 -9999 -9999 -9999 -9999 -9999 -9999 -9999 -9999 -9999 -9999 -9999 -9999 -9999 -9999 -9999 -9999 -9999 -9999 -9999 -9999 -9999 -9999 -9999 -9999 -9999 -9999 -9999

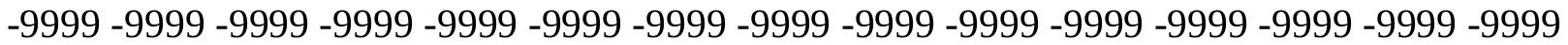
-9999 -9999 -9999 -9999 -9999 -9999 -9999 -9999 -9999 -9999 -9999 -9999 -9999 -9999 -9999 -9999 -9999 -9999 -9999 -9999 -9999 -9999 -9999 -9999 -9999 -9999 -9999 -9999 -9999 -9999 -

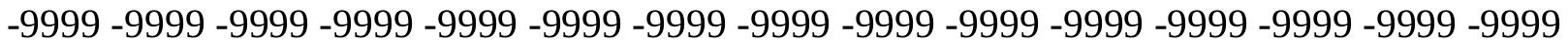
-9999 -9999 -9999 -9999 -9999 -9999 -9999 -9999 -9999 -9999 -9999 -9999 -9999 -9999 -9999

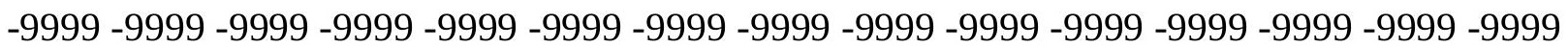
-9999 -9999 -9999 -9999 -9999 -9999 -9999 -9999 -9999 -9999 -9999 -9999 -9999 -9999 -9999 -9999 -9999 -9999 -9999 -9999 -9999 -9999 -9999 212.4351959229 208.7778015137 203.596496582198 .4151000977189 .2716064453188 .966796875188 .966796875 188.966796875188 .966796875188 .3571929932187 .4429016113186 .528503418 185.0045928955183 .4806976318181 .6519012451180 .1280059814178 .9089050293 177.9945068359177 .3849029541177 .3849029541177 .3849029541177 .3849029541 177.6896972656177 .9945068359178 .604095459178 .9089050293179 .5184020996 180.1280059814180 .7375946045181 .0424041748181 .3471984863181 .6519012451 181.9566955566181 .9566955566181 .6519012451181 .3471984863180 .7375946045 179.8231964111178 .604095459177 .3849029541175 .5561981201174 .0323028564 172.2035980225170 .6797027588169 .4604949951168 .241394043167 .6318054199 172.2035980225172 .8132019043173 .4226989746173 .7274932861169 .4604949951 169.4604949951168 .5462036133167 .9365997314167 .6318054199168 .5462036133 170.6797027588172 .8132019043173 .7274932861173 .4226989746171 .5939941406 172.2035980225172 .5084075928171 .5939941406169 .4604949951167 .3269958496 165.1934967041162 .4505004883161 .8408966064160 .6217956543154 .2212982178 151.4781951904149 .3446960449147 .2111968994 -9999 -9999 -9999 -9999 -9999 -9999 -9999 -9999 -9999 -9999 -9999 -9999 -9999 -9999 -9999 -9999 -9999 -9999 -9999 -9999 -9999 -9999

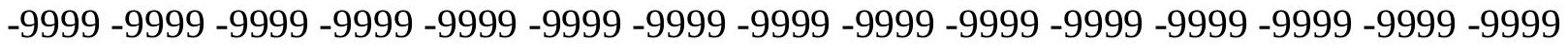
-9999 -9999 -9999 -9999 -9999 -9999 -9999 -9999 -9999 -9999 -9999 -9999 -9999 -9999 -9999 -9999 -9999 -9999 -9999 -9999 -9999 -9999 -9999 -9999 -9999 -9999 -9999 -9999 -9999 -9999 -

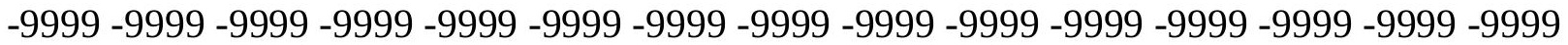
-9999 -9999 -9999 -9999 -9999 -9999 -9999 -9999 -9999 -9999 -9999 -9999 -9999 -9999 -9999 -9999 -9999 -9999 -9999 -9999 -9999 -9999 -9999 -9999 -9999 -9999 -9999 -9999 -9999 -9999

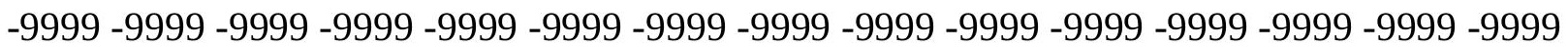
-9999 -9999 -9999 -9999 -9999 -9999 -9999 -9999 -9999 -9999 -9999 -9999 -9999 -9999 -9999 -9999 -9999 -9999 -9999 -9999 -9999 -9999 -9999 -9999 -9999 -9999 -9999 -9999 -9999 -9999 -

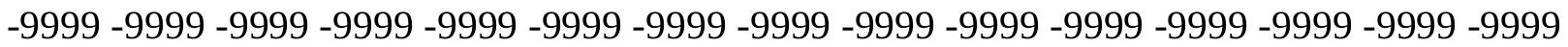
-9999 -9999 -9999 -9999 -9999 -9999 -9999 -9999 -9999 -9999 -9999 -9999 -9999 -9999 -9999 -9999 -9999 -9999 -9999 -9999 -9999 -9999 -9999 -9999 -9999 -9999 -9999 -9999 -9999 -9999 -9999 -9999 -9999 -9999 -9999 -9999 -9999 -9999 -9999 -9999 -9999 -9999 -9999 -9999 -9999 -9999 -9999 -9999 -9999 -9999 -9999 -9999 -9999 -9999 -9999 -9999 -9999 -9999 -9999

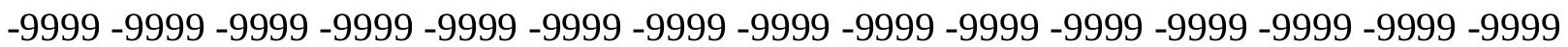


-9999 -9999 -9999 -9999 -9999 -9999 -9999 -9999 -9999 -9999 -9999 -9999 -9999 -9999 -9999 -9999 -9999 -9999 -9999 -9999 -9999 -9999 -9999 -9999 -9999 -9999 -9999 -9999 -9999 -9999 -9999 -9999 -9999 -9999 -9999 -9999 -9999 -9999 -9999 -9999 -9999 -9999 -9999 -9999 -9999 -9999 -9999 -9999 -9999 -9999 -9999 -9999 -9999 -9999 -9999 -9999 -9999 -9999 -9999 -9999 -9999 -9999 -9999 -9999 -9999 -9999 -9999 -9999 -9999 -9999 215.1782989502 208.1681976318200 .2438049316197 .1959991455192 .624206543192 .3193969727 192.0146026611191 .1002960205189 .8811035156188 .3571929932186 .8332977295 184.699798584182 .87109375181 .3471984863179 .8231964111178 .604095459 177.9945068359177 .6896972656177 .3849029541177 .3849029541177 .3849029541 177.6896972656177 .9945068359178 .2993011475178 .9089050293179 .5184020996 179.8231964111180 .1280059814180 .432800293180 .7375946045181 .0424041748 181.0424041748180 .7375946045180 .432800293179 .8231964111178 .9089050293 177.6896972656176 .4705963135175 .2514038086173 .7274932861172 .2035980225 170.6797027588169 .4604949951168 .241394043167 .6318054199167 .0222015381 166.7174987793171 .2891998291171 .2891998291166 .4127044678166 .1078948975 165.8031005859165 .8031005859166 .4127044678167 .6318054199169 .4604949951 171.2891998291172 .2035980225172 .2035980225171 .5939941406170 .9844970703 170.3748931885169 .4604949951168 .241394043166 .4127044678164 .2792053223 161.8408966064159 .4026031494156 .6596069336154 .2212982178151 .4781951904 149.3446960449 147.2111968994 -9999 -9999 -9999 -9999 -9999 -9999 -9999 -9999 -9999 -9999 -9999 -9999 -9999 -9999 -9999 -9999 -9999 -9999 -9999 -9999 -9999 -9999 -9999 -9999 -9999 -9999 -9999 -9999 -9999 -9999 -9999 -9999 -9999 -9999 -9999 -9999 -9999 -9999 -9999 -9999 -9999 -9999 -9999 -9999 -9999 -9999 -9999 -9999 -9999 -9999 -9999 -9999 -9999 -9999 -9999 -9999 -9999 -9999 -9999 -9999 -9999 -9999 -9999 -9999 -9999 -9999 -9999 -9999 -9999

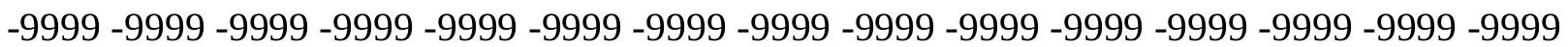
-9999 -9999 -9999 -9999 -9999 -9999 -9999 -9999 -9999 -9999 -9999 -9999 -9999 -9999 -9999 -9999 -9999 -9999 -9999 -9999 -9999 -9999 -9999 -9999 -9999 -9999 -9999 -9999 -9999 -9999 -9999 -9999 -9999 -9999 -9999 -9999 -9999 -9999 -9999 -9999 -9999 -9999 -9999 -9999 -9999 -9999 -9999 -9999 -9999 -9999 -9999 -9999 -9999 -9999 -9999 -9999 -9999 -9999 -9999 -9999 -9999 -9999 -9999 -9999 -9999 -9999 -9999 -9999 -9999 -9999 -9999 -9999 -9999 -9999 -9999 -9999 -9999 -9999 -9999 -9999 -9999 -9999 -9999 -9999 -9999 -9999 -9999 -9999 -9999 -9999 -9999 -9999 -9999 -9999 -9999 -9999 -9999 -9999 -9999 -9999 -9999 -9999 -9999 -9999 -9999 -9999 -9999 -9999 -9999 -9999 -9999 -9999 -9999 -9999 -9999 -9999 -9999 -9999 -9999 -9999 -9999 -9999 -9999 -9999 -9999 -9999 -9999 -9999 -9999 -9999 -9999 -9999 -9999 -9999 -9999 -9999 -9999 -9999 -9999 -9999 -9999 -9999 -9999 -9999 -9999 -9999 -9999 -9999 -9999 -9999 -9999 -9999 -9999 -9999 -9999 -9999 -9999 -9999 -9999 -9999 -9999 -9999 -9999 -9999 -9999 -9999 -9999 -9999 -9999 -9999 -9999 -9999 -9999 -9999 -9999 -9999 -9999

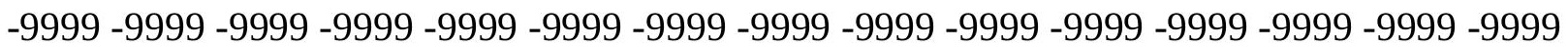
-9999 -9999 -9999 -9999 -9999 -9999 -9999 -9999 -9999 -9999 -9999 -9999 -9999 -9999 -9999 -9999 -9999 -9999 -9999 -9999 -9999 -9999 -9999 -9999 -9999 -9999 -9999 -9999 -9999 -9999 -9999 -9999 -9999 -9999 -9999 -9999 -9999 -9999 -9999 -9999 -9999 -9999 216.3973999023 208.7778015137199 .9389953613195 .6721038818194 .7577056885193 .5386047363 192.0146026611190 .4907073975188 .3571929932186 .2236938477184 .3950042725 182.261505127180 .7375946045179 .5184020996178 .604095459177 .9945068359 177.3849029541177 .3849029541177 .3849029541177 .3849029541177 .6896972656 177.9945068359178 .2993011475178 .604095459179 .2136993408179 .5184020996 
179.8231964111180 .1280059814180 .1280059814180 .1280059814179 .8231964111 179.5184020996178 .9089050293177 .9945068359177 .0802001953175 .8609924316 174.6419067383173 .1179962158171 .8988037109170 .6797027588169 .1557006836 168.241394043167 .0222015381166 .4127044678165 .4983062744165 .1934967041 164.5839996338163 .974395752163 .3648071289163 .3648071289163 .6696014404 164.8887023926166 .4127044678168 .241394043169 .7653045654170 .6797027588 170.9844970703170 .9844970703170 .6797027588169 .7653045654168 .5462036133 166.7174987793164 .8887023926163 .0599975586160 .9264984131158 .4882965088 $156.3547973633153 .9165039062151 .4781951904149 .3446960449147 .2111968994-9999$ -9999 -9999 -9999 -9999 -9999 -9999 -9999 -9999 -9999 -9999 -9999 -9999 -9999 -9999 -9999

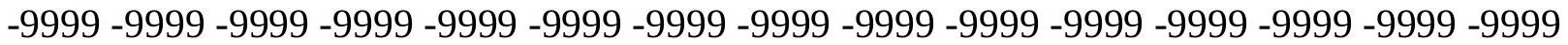
-9999 -9999 -9999 -9999 -9999 -9999 -9999 -9999 -9999 -9999 -9999 -9999 -9999 -9999 -9999 -9999 -9999 -9999 -9999 -9999 -9999 -9999 -9999 -9999 -9999 -9999 -9999 -9999 -9999 -9999 -

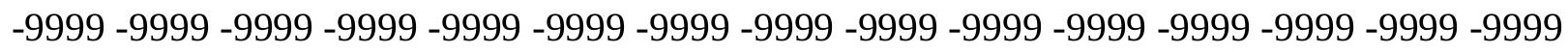
-9999 -9999 -9999 -9999 -9999 -9999 -9999 -9999 -9999 -9999 -9999 -9999 -9999 -9999 -9999

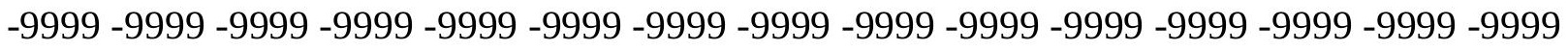
-9999 -9999 -9999 -9999 -9999 -9999 -9999 -9999 -9999 -9999 -9999 -9999 -9999 -9999 -9999 -9999 -9999 -9999 -9999 -9999 -9999 -9999 -9999 -9999 -9999 -9999 -9999 -9999 -9999 -9999 -9999 -9999 -9999 -9999 -9999 -9999 -9999 -9999 -9999 -9999 -9999 -9999 -9999 -9999 -9999 -

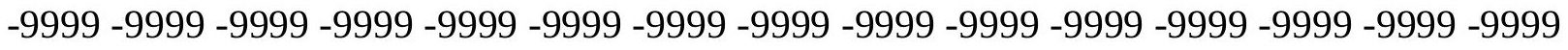

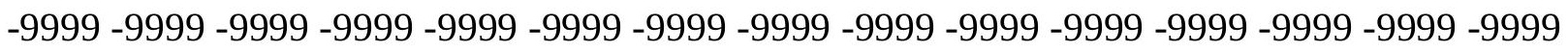
-9999 -9999 -9999 -9999 -9999 -9999 -9999 -9999 -9999 -9999 -9999 -9999 -9999 -9999 -9999 -9999 -9999 -9999 -9999 -9999 -9999 -9999 -9999 -9999 -9999 -9999 -9999 -9999 -9999 -9999 -9999 -9999-9999-9999-9999

-9999 -9999 -9999 -9999 -9999 -9999 -9999 -9999 -9999 -9999 -9999 -9999 -9999 -9999 -9999 -9999 -9999 -9999 -9999 -9999 -9999 -9999 -9999 -9999 -9999 -9999 -9999 -9999 -9999 -9999 -

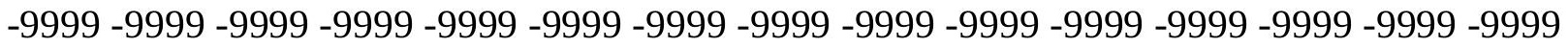

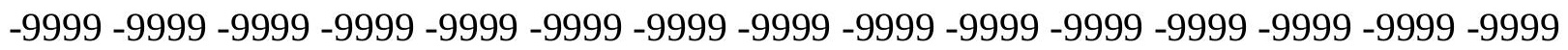
-9999 -9999 -9999 -9999 -9999 -9999 -9999 -9999 -9999 -9999 -9999 -9999 -9999 -9999 -9999 -9999 -9999 -9999 -9999 -9999 -9999 -9999 -9999 -9999 -9999 -9999 -9999 -9999 -9999 -9999 -9999 -9999 -9999 -9999 -9999 -9999 -9999 -9999 -9999 -9999 -9999 -9999 -9999 -9999 213.6544036865205 .425201416197 .1959991455195 .9768066406194 .1481018066 192.3193969727190 .1858978271187 .7476043701185 .6141052246183 .4806976318 181.6519012451180 .1280059814179 .2136993408178 .2993011475177 .6896972656 177.3849029541177 .0802001953177 .0802001953177 .0802001953177 .3849029541 177.6896972656177 .9945068359178 .2993011475178 .604095459178 .9089050293 179.2136993408 179.2136993408 179.2136993408178.9089050293178.604095459 177.9945068359177 .0802001953176 .165802002175 .2514038086174 .0323028564 172.8132019043171 .5939941406170 .3748931885169 .1557006836167 .9365997314 166.7174987793165 .8031005859164 .8887023926163 .6696014404162 .7552947998 162.1457061768161 .2312927246161 .2312927246161 .8408966064163 .3648071289 165.1934967041166 .7174987793168 .241394043169 .4604949951170 .070098877 170.070098877169 .7653045654169 .1557006836167 .9365997314166 .4127044678 164.2792053223161 .8408966064159 .7073974609157 .5738983154155 .7451934814 $153.6116943359151 .1734008789148 .7351074219146 .6015930176144 .7729034424-9999$ -9999 -9999 -9999 -9999 -9999 -9999 -9999 -9999 -9999 -9999 -9999 -9999 -9999 -9999 -9999 
-9999 -9999 -9999 -9999 -9999 -9999 -9999 -9999 -9999 -9999 -9999 -9999 -9999 -9999 -9999 -9999 -9999 -9999 -9999 -9999 -9999 -9999 -9999 -9999 -9999 -9999 -9999 -9999 -9999 -9999 -9999 -9999 -9999 -9999 -9999 -9999 -9999 -9999 -9999 -9999 -9999 -9999 -9999 -9999 -9999 -9999 -9999 -9999 -9999 -9999 -9999 -9999 -9999 -9999 -9999 -9999 -9999 -9999 -9999 -9999 -9999 -9999 -9999 -9999 -9999 -9999 -9999 -9999 -9999 -9999 -9999 -9999 -9999 -9999 -9999 -9999 -9999 -9999 -9999 -9999 -9999 -9999 -9999 -9999 -9999 -9999 -9999 -9999 -9999 -9999 -9999 -9999 -9999 -9999 -9999 -9999 -9999 -9999 -9999 -9999 -9999 -9999 -9999 -9999 -9999

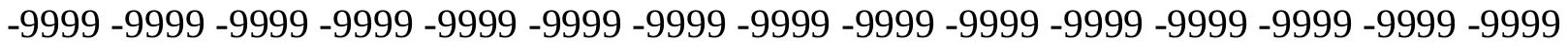
-9999 -9999 -9999 -9999 -9999 -9999 -9999 -9999 -9999 -9999 -9999 -9999 -9999 -9999 -9999 -9999 -9999 -9999 -9999 -9999 -9999 -9999 -9999 -9999 -9999 -9999 -9999 -9999 -9999 -9999 -

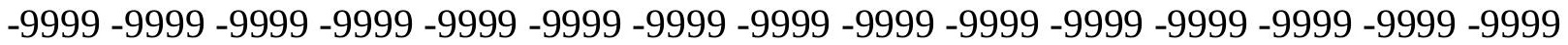
-9999 -9999 -9999 -9999 -9999 -9999 -9999 -9999 -9999 -9999 -9999 -9999 -9999 -9999 -9999 -9999 -9999 -9999 -9999 -9999 -9999 -9999 -9999 -9999 -9999 -9999 -9999 -9999 -9999 -9999 -9999 -9999-9999-9999

-9999 -9999 -9999 -9999 -9999 -9999 -9999 -9999 -9999 -9999 -9999 -9999 -9999 -9999 -9999 -9999 -9999 -9999 -9999 -9999 -9999 -9999 -9999 -9999 -9999 -9999 -9999 -9999 -9999 -9999

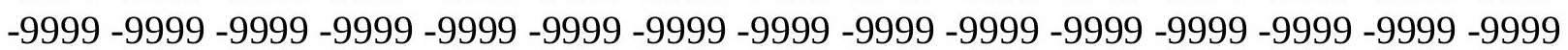
-9999 -9999 -9999 -9999 -9999 -9999 -9999 -9999 -9999 -9999 -9999 -9999 -9999 -9999 -9999 -9999 -9999 -9999 -9999 -9999 -9999 -9999 -9999 -9999 -9999 -9999 -9999 -9999 -9999 -9999 -9999 -9999 -9999 -9999 -9999 -9999 -9999 -9999 -9999 -9999 -9999 -9999 -9999 -9999 -9999 -9999 -9999 -9999 -9999 -9999 -9999 -9999 -9999 -9999 -9999 -9999 -9999 -9999 -9999 -9999 217.3117980957 208.7778015137200.5485992432195.9768066406 193.8433074951 191.4051055908188 .966796875186 .528503418184 .3950042725182 .5662994385 180.7375946045179 .5184020996178 .604095459177 .6896972656177 .0802001953 176.7754058838176 .4705963135176 .4705963135176 .7754058838176 .7754058838 177.3849029541 177.6896972656177.9945068359 178.2993011475 178.2993011475 178.604095459178 .2993011475178 .2993011475177 .6896972656177 .0802001953 176.4705963135175 .5561981201174 .6419067383173 .7274932861172 .5084075928 171.2891998291170 .070098877168 .8509979248167 .6318054199166 .4127044678 165.1934967041164 .2792053223163 .0599975586161 .8408966064160 .9264984131 160.0122070312159 .4026031494160 .9264984131162 .4505004883163 .974395752 165.8031005859167 .3269958496168 .241394043168 .8509979248169 .1557006836 168.8509979248168 .241394043167 .3269958496165 .8031005859163 .6696014404 161.2312927246158 .7929992676156 .3547973633154 .2212982178152 .6972961426 150.2590942383147 .8208007812145 .6873016357143 .8585968018 -9999 -9999 -9999 -9999 -9999 -9999 -9999 -9999 -9999 -9999 -9999 -9999 -9999 -9999 -9999 -9999 -9999 -9999 -9999 -9999 -9999 -9999 -9999 -9999 -9999 -9999 -9999 -9999 -9999 -9999 -9999 -9999 -9999 -9999

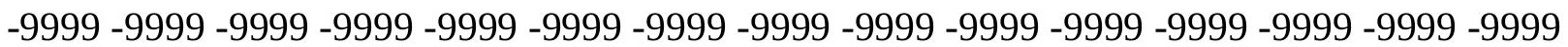
-9999 -9999 -9999 -9999 -9999 -9999 -9999 -9999 -9999 -9999 -9999 -9999 -9999 -9999 -9999 -9999 -9999 -9999 -9999 -9999 -9999 -9999 -9999 -9999 -9999 -9999 -9999 -9999 -9999 -9999 -9999 -9999 -9999 -9999 -9999 -9999 -9999 -9999 -9999 -9999 -9999 -9999 -9999 -9999 -9999

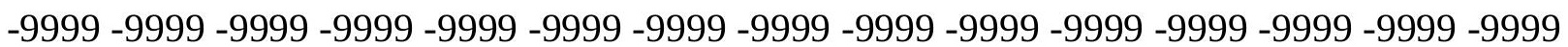
-9999 -9999 -9999 -9999 -9999 -9999 -9999 -9999 -9999 -9999 -9999 -9999 -9999 -9999 -9999 -999 -9999 -9999 -9999 -9999 -9999 -9999 -9999 -9999 -9999 -9999 -9999 -9999 -9999 -9999 -9999 -9999 -9999 -9999 -9999 -9999 -9999 -9999 -9999 -9999 -9999 -9999 -9999 -9999 -9999 -9999

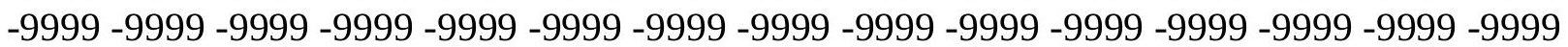


-9999 -9999 -9999 -9999 -9999 -9999 -9999 -9999 -9999 -9999 -9999 -9999 -9999 -9999 -9999 -9999 -9999 -9999 -9999 -9999 -9999 -9999 -9999 -9999 -9999 -9999 -9999 -9999 -9999 -9999

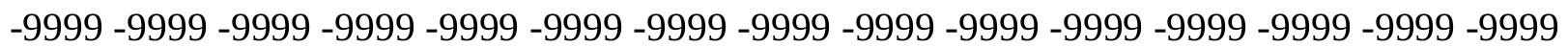
$-9999$

-9999 -9999 -9999 -9999 -9999 -9999 -9999 -9999 -9999 -9999 -9999 -9999 -9999 -9999 -9999 -9999 -9999 -9999 -9999 -9999 -9999 -9999 -9999 -9999 -9999 -9999 -9999 -9999 -9999 -9999 -9999 -9999 -9999 -9999 -9999 -9999 -9999 -9999 -9999 -9999 -9999 -9999 -9999 -9999 -9999 -999 -9999 -9999 -9999 -9999 -9999 -9999 -9999 -9999 -9999 -9999 -9999 -9999 -9999 -9999 -9999 -9999 -9999 -9999 -9999 -9999 -9999 -9999 -9999 -9999 -9999 -9999 -9999 -9999 -9999 -9999 -9999 -9999 -9999 -9999 -9999 -9999 -9999 -9999 -9999 -9999 -9999 -9999 -9999 -9999 -9999 -9999 -9999 -9999 -9999 -9999 -9999 -9999 -9999 -9999 -9999 -9999 -9999 -9999 -9999 -9999 -9999 -9999 211.2160949707 203.596496582195.0625192.3193969727 189.8811035156 187.4429016113185 .0045928955182 .87109375181 .3471984863179 .8231964111 178.9089050293177 .9945068359177 .0802001953176 .4705963135176 .165802002 176.165802002176 .165802002176 .165802002176 .4705963135177 .0802001953 177.3849029541177 .6896972656177 .6896972656177 .9945068359177 .6896972656 177.3849029541177 .0802001953176 .4705963135175 .8609924316174 .9467010498 174.0323028564173 .1179962158172 .2035980225170 .9844970703169 .7653045654 168.8509979248167 .6318054199166 .4127044678165 .1934967041163 .974395752 162.7552947998161 .5361022949160 .6217956543160 .0122070312159 .7073974609 160.6217956543162 .1457061768163 .6696014404165 .1934967041166 .4127044678 167.3269958496167 .9365997314168 .241394043167 .9365997314167 .3269958496 166.4127044678164 .8887023926163 .0599975586160 .9264984131158 .4882965088 156.0500030518153 .6116943359150 .8686065674148 .1255950928145 .9920959473 144.1634063721142 .3347015381141 .1154937744 -9999 -9999 -9999 -9999 -9999 -9999 -9999 -9999 -9999 -9999 -9999 -9999 -9999 -9999 -9999 -9999 -9999 -9999 -9999 -9999 -9999 -9999 -9999 -9999 -9999 -9999 -9999 -9999 -9999 -9999 -9999 -9999 -9999 -9999 -9999 -9999 -9999 -9999 -9999 -9999 -9999 -9999 -9999 -9999 -9999 -9999 -9999 -9999 -9999 -9999 -9999 -9999 -9999 -9999 -9999 -9999 -9999 -9999 -9999 -9999 -9999 -9999 -9999 -9999 -9999 -9999 -9999 -9999 -9999 -9999 -9999 -9999 -9999 -9999 -9999 -9999 -9999 -9999 -9999 -9999 -9999 -9999 -9999 -9999 -9999 -9999 -9999 -9999 -9999 -9999 -9999 -9999 -9999 -9999 -9999 -9999 -9999 -9999 -9999 -9999 -9999 -9999 -9999 -9999 -9999 -9999 -9999 -9999 -9999 -9999 -9999 -9999

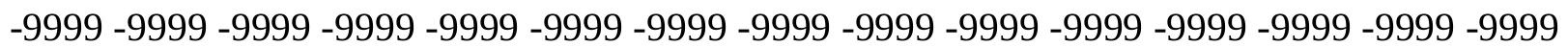
-9999 -9999 -9999 -9999 -9999 -9999 -9999 -9999 -9999 -9999 -9999 -9999 -9999 -9999 -9999 -9999 -9999 -9999 -9999 -9999 -9999 -9999 -9999 -9999 -9999 -9999 -9999 -9999 -9999-999 -999 -

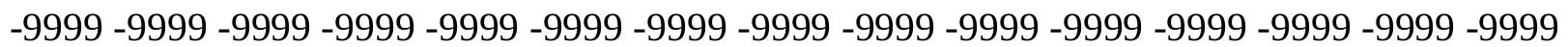
-9999 -9999 -9999 -9999 -9999 -9999 -9999 -9999 -9999 -9999 -9999 -9999 -9999 -9999 -9999

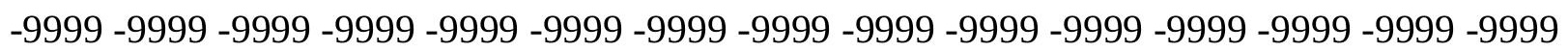
-9999 -9999 -9999 -9999 -9999 -9999 -9999 -9999 -9999 -9999 -9999 -9999 -9999 -9999 -9999 -9999 -9999 -9999 -9999 -9999 -9999 -9999 -9999 -9999 -9999 -9999 -9999

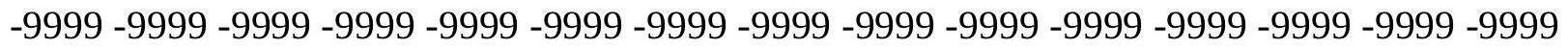
-9999 -9999 -9999 -9999 -9999 -9999 -9999 -9999 -9999 -9999 -9999 -9999 -9999 -9999 -9999 -9999 -9999 -9999 -9999 -9999 -9999 -9999 -9999 -9999 -9999 -9999 -9999 -9999 -9999 -9999 -9999 -9999 -9999 -9999 -9999 -9999 -9999 -9999 -9999 -9999 -9999 -9999 -9999 -9999 -9999 -9999 -9999 -9999 -9999 -9999 -9999 -9999 -9999 -9999 -9999 -9999 -9999 -9999 -9999-999 -

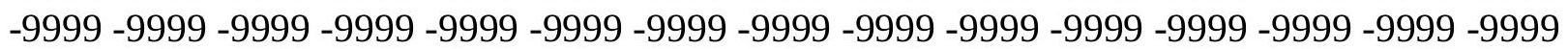


-9999 -9999 -9999 213.3495941162 205.425201416 197.1959991455 190.1858978271 187.7476043701185 .3094024658183 .1759033203181 .6519012451180 .432800293 178.9089050293177 .9945068359176 .7754058838176 .165802002175 .5561981201 175.5561981201175 .5561981201175 .5561981201175 .8609924316176 .4705963135 176.7754058838177 .0802001953177 .3849029541177 .3849029541177 .3849029541 177.0802001953176 .4705963135175 .8609924316175 .2514038086174 .6419067383 173.7274932861172 .8132019043171 .8988037109170 .9844970703169 .7653045654 168.5462036133167 .6318054199166 .4127044678165 .1934967041163 .974395752 162.7552947998161 .8408966064160 .9264984131160 .6217956543160 .6217956543 161.2312927246162 .1457061768163 .3648071289164 .8887023926165 .8031005859 166.7174987793167 .3269958496167 .3269958496167 .3269958496166 .7174987793 165.4983062744164 .2792053223162 .4505004883160 .3170013428158 .1835021973 155.7451934814153 .0021057129150 .2590942383146 .9064025879143 .8585968018 142.0299072266140 .5059967041139 .2868041992 -9999 -9999 -9999 -9999 -9999 -9999 -9999 -9999 -9999 -9999 -9999 -9999 -9999 -9999 -9999 -9999 -9999 -9999 -9999 -9999 -9999 -9999 -9999 -9999 -9999 -9999 -9999 -9999 -9999 -9999 -9999 -9999 -9999 -9999 -9999 -9999 -9999 -

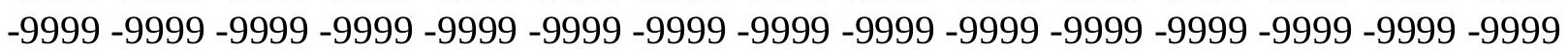
-9999 -9999 -9999 -9999 -9999 -9999 -9999 -9999 -9999 -9999 -9999 -9999 -9999 -9999 -9999 -999 -9999 -9999 -9999 -9999 -9999 -9999 -9999 -9999 -9999 -9999 -9999 -9999 -9999 -9999 -9999 -9999 -9999 -9999 -9999 -9999 -9999 -9999 -9999 -9999 -9999 -9999 -9999 -9999 -9999 -9999 -9999 -9999 -9999 -9999 -9999 -9999 -9999 -9999 -9999 -9999 -9999 -9999 -9999 -9999 -9999 -9999 -9999 -9999 -9999 -9999 -9999 -9999 -9999 -9999 -9999 -9999 -9999 -9999 -9999 -9999 -9999 -9999 -9999 -9999 -9999 -9999 -9999 -9999 -9999 -9999 -9999 -9999 -9999 -9999 -9999 -9999 -9999 -9999 -9999 -9999 -9999 -9999 -9999 -9999 -9999 -9999 -9999 -9999 -9999 -9999 -9999 -9999 -9999 -9999 -9999 -9999 -9999 -9999 -9999 -9999 -9999 -9999 -9999 -9999 -9999 -9999 -9999 -9999 -9999 -9999 -9999 -9999 -9999 -9999 -9999 -9999 -9999 -9999 -9999 -9999 -9999 -9999 -9999 -9999 -9999 -9999 -9999 -9999 -9999 -9999 -9999 -9999 -9999 -9999 -9999 -9999 -9999 -9999 -9999 -9999 -9999 -9999 -9999 -9999 -9999 -9999 -9999

-9999 -9999 -9999 -9999 -9999 -9999 -9999 -9999 -9999 -9999 -9999 -9999 -9999 -9999 -9999 -9999 -9999 -9999 -9999 -9999 -9999 -9999 -9999 -9999 -9999 -9999 -9999 -9999 -9999 -9999 -9999 -9999 -9999 -9999 -9999 -9999 -9999 -9999 -9999 -9999 -9999 -9999 -9999 -9999 -9999

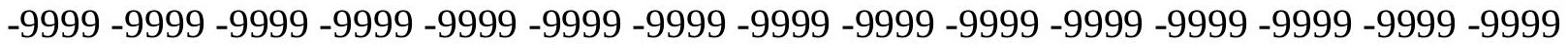

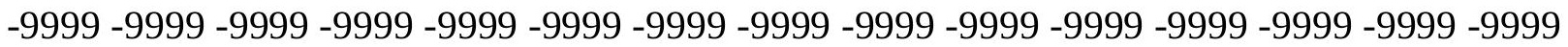
-9999 -9999 -9999 -9999 -9999 -9999 -9999 -9999 -9999 -9999 -9999 -9999 -9999 -9999 -9999 -9999 -9999 -9999 -9999 -9999 -9999 -9999 -9999 -9999 -9999 -9999 -9999 -9999 -9999 -9999 -9999 -9999 -9999 -9999 -9999 206.3394927979 198.7198944092191 .1002960205 184.699798584182 .87109375181 .6519012451180 .7375946045179 .2136993408 177.6896972656176 .4705963135175 .5561981201175 .2514038086174 .9467010498 174.9467010498175 .2514038086175 .5561981201175 .8609924316176 .4705963135 176.7754058838177 .0802001953177 .0802001953176 .7754058838176 .4705963135 176.165802002175 .5561981201174 .9467010498174 .0323028564173 .4226989746 172.5084075928171 .8988037109170 .6797027588169 .7653045654168 .8509979248 167.6318054199166 .7174987793165 .4983062744164 .2792053223163 .3648071289 162.4505004883161 .8408966064161 .5361022949161 .5361022949161 .8408966064 162.7552947998163 .6696014404164 .5839996338165 .4983062744166 .1078948975 166.7174987793166 .7174987793166 .4127044678165 .8031005859164 .8887023926 
163.6696014404161 .8408966064160 .0122070312157 .5738983154155 .1356048584 152.6972961426149 .6495056152146 .6015930176143 .5538024902140 .8106994629 138.3724975586 137.4580993652 136.8484954834 -9999 -9999 -9999 -9999 -9999 -9999 -9999 -9999 -9999 -9999 -9999 -9999 -9999 -9999 -9999 -9999 -9999 -9999 -9999 -9999 -9999 -9999 -9999 -9999 -9999 -9999 -9999 -9999 -9999 -9999 -9999 -9999 -9999 -9999-9999 -9999 -9999 -9999 -9999 -9999 -9999 -9999 -9999 -9999 -9999 -9999 -9999 -9999 -9999 -9999 -9999 -9999 -9999 -9999 -9999 -9999 -9999 -9999 -9999 -9999 -9999 -9999 -9999 -9999 -9999 -9999 -9999 -

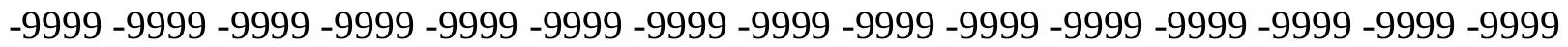

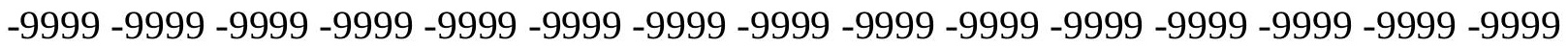
-9999 -9999 -9999 -9999 -9999 -9999 -9999 -9999 -9999 -9999 -9999 -9999 -9999 -9999 -9999 -

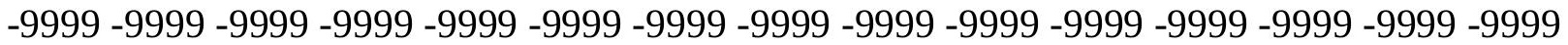
-9999 -9999 -9999 -9999 -9999 -9999 -9999 -9999 -9999 -9999 -9999 -9999 -9999 -9999 -9999 -9999 -9999 -9999 -9999 -9999 -9999 -9999 -9999 -9999 -9999 -9999 -9999 -9999 -9999 -9999 -9999 -9999 -9999 -9999 -9999 -9999 -9999 -9999 -9999 -9999 -9999 -9999 -9999 -9999 - 9999 -9999 -9999 -9999 -9999 -9999 -9999 -9999 -9999 -9999 -9999 -9999 -9999 -9999 -9999 -9999

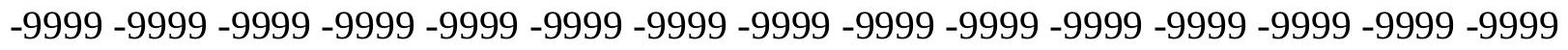
-9999 -9999 -9999 -9999 -9999 -9999 -9999 -9999 -9999 -9999 -9999 -9999 -9999 -9999 -9999 -9999 -9999 -9999 -9999 -9999 -9999 -9999 -9999 -9999 -9999 -9999 -9999 -9999 -9999 -9999 -9999 -9999 -9999 -9999 -9999 -9999 -9999 -9999 -9999 -9999 -9999 -9999 -9999 -9999 -9999 -9999 -9999 -9999 -9999 -9999 -9999 -9999 -9999 -9999 -9999 -9999 -9999 -9999 -9999 -9999 -9999 -9999 -9999 -9999 -9999 -9999 -9999 -9999 -9999 -9999 -9999 -9999 -9999 -9999 -9999 -9999 -9999 -9999 -9999 -9999 -9999 -9999 -9999 -9999 -9999 -9999 -9999 -9999 -9999 -9999 -9999 -9999 -9999 -9999 -9999 -9999 -9999 -9999 -9999 -9999 -9999 -9999 -9999 -9999 -9999 -9999 -9999 -9999 -9999 -9999 -9999 -9999 -9999 -9999 -9999 -9999 -9999 -9999 -9999 -9999 -9999 -9999 -9999 199.9389953613192 .0146026611184 .699798584 182.261505127 181.0424041748 179.2136993408177.6896972656176.165802002 175.2514038086174 .6419067383174 .337097168174 .337097168174 .6419067383 174.9467010498175 .5561981201176 .165802002176 .4705963135176 .7754058838 176.7754058838176 .7754058838176 .165802002175 .8609924316175 .2514038086 174.6419067383173 .7274932861173 .1179962158172 .5084075928171 .5939941406 170.9844970703170 .070098877169 .1557006836167 .9365997314167 .0222015381 166.1078948975164 .8887023926163 .974395752163 .3648071289162 .7552947998 162.4505004883162 .4505004883162 .7552947998163 .3648071289163 .974395752 164.8887023926165 .4983062744165 .8031005859166 .1078948975166 .1078948975 165.8031005859165 .1934967041164 .2792053223163 .0599975586161 .2312927246 159.4026031494157 .2691040039154 .8307952881152 .0877990723149 .3446960449 146.6015930176143 .5538024902140 .8106994629138 .0677032471135 .9342041016 134.7149963379 134.7149963379 -9999 -9999 -9999 -9999 -9999 -9999 -9999 -9999 -9999 -9999 -9999 -9999 -9999 -9999 -9999 -9999 -9999 -9999 -9999 -9999 -9999 -9999 -9999 -9999 -9999 -9999 -9999 -9999 -9999 -9999 -9999 -9999 -9999 -9999 -9999 -9999 -9999 -9999 -9999 -

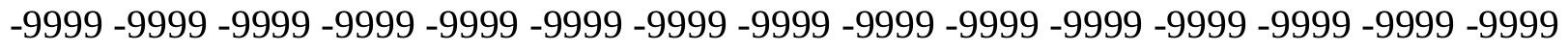
-9999 -9999 -9999 -9999 -9999 -9999 -9999 -9999 -9999 -9999 -9999 -9999 -9999 -9999 -9999 -9999 -9999 -9999 -9999 -9999 -9999 -9999 -9999 -9999 -9999 -9999 -9999 -9999 -9999 -9999 -9999 -9999 -9999 -9999 -9999 -9999 -9999 -9999 -9999 -9999 -9999 -9999 -9999 -9999 -9999 -9999 -9999 -9999 -9999 -9999 -9999 -9999 -9999 -9999 -9999 -9999 -9999 -9999 -9999 -9999 -

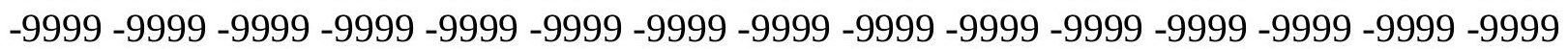


-9999 -9999 -9999 -9999 -9999 -9999 -9999 -9999 -9999 -9999 -9999 -9999 -9999 -9999 -9999 -9999 -9999 -9999 -9999 -9999 -9999 -9999 -9999 -9999 -9999 -9999 -9999 -9999 -9999 -9999 -9999 -9999 -9999 -9999 -9999 -9999 -9999 -9999 -9999 -9999 -9999 -9999 -9999 -9999 -9999 -9999 -9999 -9999 -9999 -9999 -9999 -9999 -9999 -9999 -9999 -9999 -9999 -9999 -9999 -9999

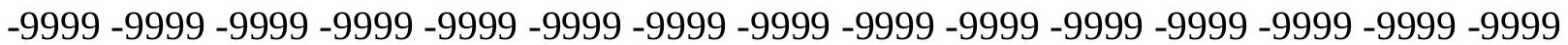
-9999 -9999 -9999 -9999 -9999 -9999 -9999 -9999

-9999 -9999 -9999 -9999 -9999 -9999 -9999 -9999 -9999 -9999 -9999 -9999 -9999 -9999 -9999

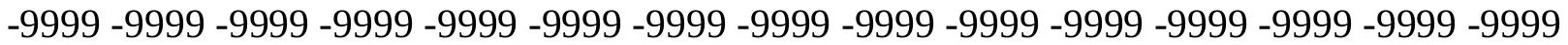
-9999 -9999 -9999 -9999 -9999 -9999 -9999 -9999 -9999 -9999 -9999 -9999 -9999 -9999 -9999 -9999 -9999 -9999 -9999 -9999 -9999 -9999 -9999 -9999 -9999 -9999 -9999 -9999 -9999 -9999 -

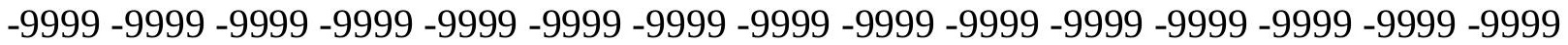
-9999 -9999 -9999 -9999 -9999 -9999 -9999 -9999 -9999 -9999 -9999 -9999 -9999 -9999 -9999

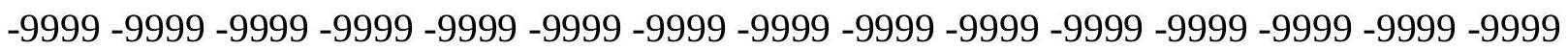
-9999 -9999 -9999 -9999 -9999 -9999 -9999 -9999 -9999 195.0625189 .5764007568 185.0045928955180 .7375946045177 .0802001953175 .8609924316174 .9467010498 174.0323028564173 .7274932861173 .7274932861174 .337097168174 .6419067383 175.2514038086175 .8609924316176 .4705963135176 .7754058838176 .7754058838 176.4705963135176 .165802002175 .5561981201174 .9467010498174 .337097168 173.7274932861173 .1179962158172 .5084075928171 .8988037109170 .9844970703 170.3748931885169 .4604949951168 .5462036133167 .6318054199166 .7174987793 165.8031005859164 .8887023926164 .2792053223163 .974395752163 .6696014404 163.6696014404163 .6696014404163 .974395752164 .5839996338164 .8887023926 165.4983062744165 .8031005859165 .8031005859165 .8031005859165 .4983062744 164.5839996338163 .6696014404162 .4505004883160 .9264984131159 .0977935791 156.9642944336154 .5260925293152 .0877990723149 .3446960449146 .6015930176 143.5538024902140 .8106994629138 .3724975586135 .9342041016133 .4958953857 132.5814971924132 .8863067627 -9999 -9999 -9999 -9999 -9999 -9999 -9999 -9999 -9999 -9999 -9999 -9999 -9999 -9999 -9999 -9999 -9999 -9999 -9999 -9999 -9999 -9999 -9999 -9999 -9999 -9999 -9999 -9999 -9999 -9999 -9999 -9999 -9999 -9999 -9999 -9999 -9999 -9999 -9999

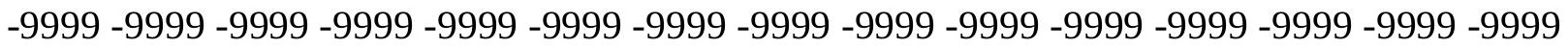
-9999 -9999 -9999 -9999 -9999 -9999 -9999 -9999 -9999 -9999 -9999 -9999 -9999 -9999 -9999 -

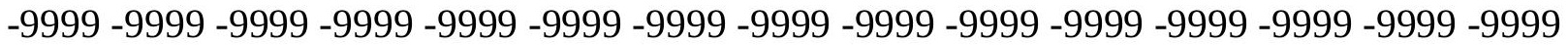
-9999 -9999 -9999 -9999 -9999 -9999 -9999 -9999 -9999 -9999 -9999 -9999 -9999 -9999 -9999 -9999 -9999 -9999 -9999 -9999 -9999 -9999 -9999 -9999 -9999 -9999 -9999 -9999 -9999 -9999 -

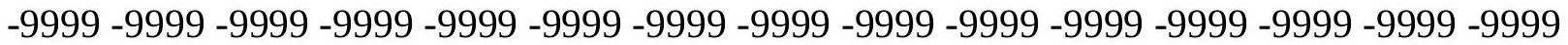
-9999 -9999 -9999 -9999 -9999 -9999 -9999 -9999 -9999 -9999 -9999 -9999 -9999 -9999 -9999 -9999 -9999 -9999 -9999 -9999 -9999 -9999 -9999 -9999 -9999 -9999 -9999 -9999 -9999 -9999

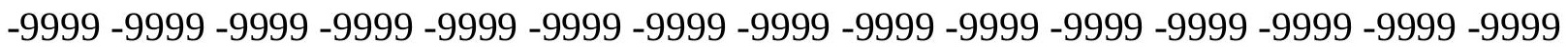
-9999 -9999 -9999 -9999 -9999 -9999 -9999 -9999 -9999 -9999 -9999 -9999 -9999 -9999 -9999 -9999 -9999 -9999 -9999 -9999 -9999 -9999 -9999 -9999 -9999 -9999 -9999 -9999 -9999 -9999 -9999 -9999 -9999 -9999 -9999-9999-9999

-9999 -9999 -9999 -9999 -9999 -9999 -9999 -9999 -9999 -9999 -9999 -9999 -9999 -9999 -9999 -9999 -9999 -9999 -9999 -9999 -9999 -9999 -9999 -9999 -9999 -9999 -9999 -9999 -9999 -9999 -9999 -9999 -9999 -9999 -9999 -9999 -9999 -9999 -9999 -9999 -9999 -9999 -9999 -9999 -9999 -9999 -9999 -9999 -9999 -9999 -9999 -9999 -9999 -9999 -9999 -9999 -9999 -9999 -9999 -9999

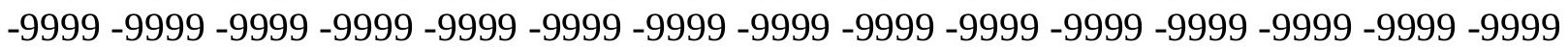


-9999 -9999 -9999 -9999 -9999 -9999 -9999 -9999 -9999 -9999 -9999 -9999 -9999 -9999 -9999 -9999 -9999 -9999 -9999 -9999 -9999 -9999 -9999 -9999 -9999 -9999 -9999 -9999 -9999 -9999 -9999 -9999 -9999 -9999 -9999 -9999 -9999 -9999 -9999 -9999 -9999 -9999 189.2716064453 185.0045928955181 .3471984863178 .2993011475175 .5561981201173 .4226989746 173.7274932861174 .0323028564174 .6419067383175 .2514038086176 .165802002 176.7754058838177 .0802001953177 .0802001953176 .7754058838175 .8609924316 175.2514038086174 .6419067383174 .0323028564173 .4226989746173 .1179962158 172.5084075928171 .8988037109171 .2891998291170 .6797027588170 .070098877 169.1557006836168 .241394043167 .3269958496166 .7174987793166 .1078948975 165.4983062744164 .8887023926164 .5839996338164 .5839996338164 .5839996338 164.8887023926165 .1934967041165 .1934967041165 .4983062744165 .8031005859 165.8031005859165 .4983062744164 .8887023926164 .2792053223163 .3648071289 162.1457061768160 .6217956543158 .7929992676156 .6596069336154 .2212982178 151.7830047607149 .3446960449146 .6015930176143 .8585968018141 .1154937744 138.3724975586136.2389984131 133.8007049561131 .9720001221131 .0576019287 131.3623962402 -9999 -9999 -9999 -9999 -9999 -9999 -9999 -9999 -9999 -9999 -9999 -9999 -9999 -9999 -9999 -9999 -9999 -9999 -9999 -9999 -9999 -9999 -9999 -9999 -9999 -9999 -9999 -9999 -9999 -9999 -9999 -9999 -9999 -9999 -9999 -9999 -9999 -9999 -9999 -9999 -9999 -9999 -9999 -9999 -9999 -9999 -9999 -9999 -9999 -9999 -9999 -9999 -9999 -9999 -9999 -9999 -9999 -9999 -9999 -9999 -9999 -9999 -9999 -9999 -9999 -9999 -9999 -9999 -9999 -9999 -9999 -9999 -9999 -9999 -9999 -9999 -9999 -9999 -9999 -9999 -9999 -9999 -9999 -9999 -9999 -9999 -9999 -9999 -9999 -9999 -9999 -9999 -9999 -9999 -9999 -9999 -9999 -9999 -9999 -9999 -9999 -9999 -9999 -9999 -9999 -9999 -9999 -9999 -9999 -9999 -9999 -9999 -9999 -9999 -9999 -9999 -9999 -9999 -9999 -9999 -9999 -9999 -9999 -9999 -9999 -9999 -9999 -9999 -9999 -9999 -9999 -9999 -9999 -9999 -9999 -9999 -9999 -9999 -9999 -9999 -9999 -9999 -9999 -9999 -9999 -9999 -9999 -9999 -9999 -9999 -9999 -9999 -9999 -9999 -9999 -9999 -9999 -9999 -9999 -9999 -9999 -9999 -9999 -9999 -9999 -9999 -9999 -9999 -9999 -9999 -9999 -9999 -9999 -9999 -9999 -9999 -9999 -

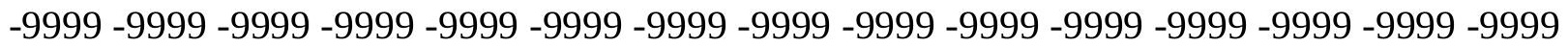
-9999 -9999 -9999 -9999 -9999 -9999 -9999 -9999 -9999 -9999 -9999 -9999 -9999 -9999 -9999 -9999 -9999-9999

-9999 -9999 -9999 -9999 -9999 -9999 -9999 -9999 -9999 -9999 -9999 -9999 -9999 -9999 -9999 -9999 -9999 -9999 -9999 -9999 -9999 -9999 -9999 -9999 -9999 -9999 -9999 -9999 -9999 -9999

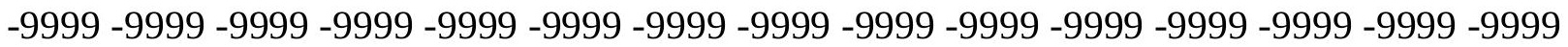
-9999 -9999 -9999 -9999 -9999 -9999 -9999 -9999 -9999 -9999 -9999 -9999 -9999 -9999 -9999 -9999 -9999 -9999 -9999 -9999 -9999 -9999 -9999 -9999 -9999 -9999 -9999 -9999 -9999 -9999 -9999 -9999 -9999 -9999 -9999 -9999 -9999 -9999 -9999 -9999 -9999 -9999 -9999 -9999 -9999

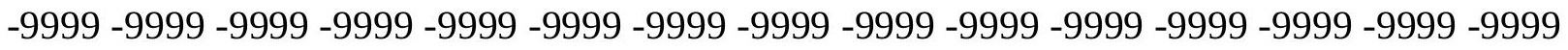

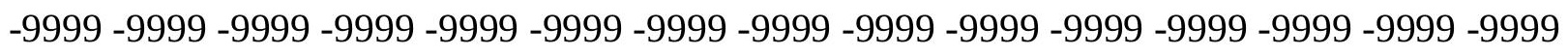
186.8332977295184 .0901947021181 .6519012451179 .5184020996177 .6896972656 176.165802002175 .2514038086176 .165802002177 .0802001953177 .6896972656 177.3849029541 176.7754058838175.8609924316174.9467010498174.337097168 173.7274932861173 .1179962158172 .8132019043172 .8132019043172 .2035980225 171.8988037109171 .2891998291170 .6797027588169 .7653045654169 .1557006836 168.241394043167 .6318054199167 .0222015381166 .4127044678166 .1078948975 165.8031005859165 .4983062744165 .4983062744165 .4983062744165 .4983062744 165.8031005859165 .8031005859165 .8031005859165 .4983062744165 .1934967041 
164.5839996338163 .974395752163 .0599975586161 .8408966064160 .3170013428 158.4882965088156 .3547973633154 .2212982178151 .7830047607149 .3446960449 146.6015930176143 .8585968018141 .1154937744138 .6772003174136 .2389984131 134.1054992676132 .2767028809130 .7528076172129 .533706665 -9999 -9999 -9999 -9999 -9999 -9999 -9999 -9999 -9999 -9999 -9999 -9999 -9999 -9999 -9999 -9999 -9999 -9999 -9999 -9999 -9999 -9999 -9999 -9999 -9999 -9999 -9999 -9999 -9999 -9999 -9999 -9999 -9999 -9999

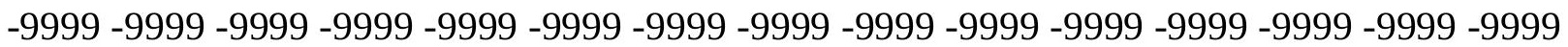

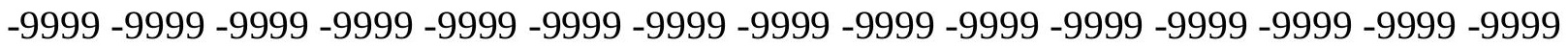
-9999 -9999 -9999 -9999 -9999 -9999 -9999 -9999 -9999 -9999 -9999 -9999 -9999 -9999 -9999 -9999 -9999 -9999 -9999 -9999 -9999 -9999 -9999 -9999 -9999 -9999 -9999 -9999 -9999 -9999 -

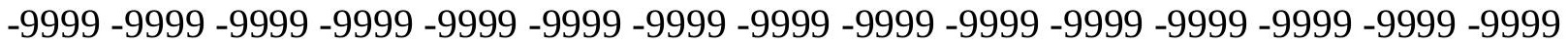
-9999 -9999 -9999 -9999 -9999 -9999 -9999 -9999 -9999 -9999 -9999 -9999 -9999 -9999 -9999 -9999 -9999 -9999 -9999 -9999 -9999 -9999 -9999 -9999 -9999 -9999 -9999 -9999 -9999 -9999 -9999 -9999 -9999 -9999 -9999 -9999 -9999 -9999 -9999 -9999 -9999 -9999 -9999 -9999 -9999 -9999 -9999 -9999 -9999 -9999 -9999 -9999 -9999 -9999 -9999 -9999 -9999 -9999 -9999 -9999

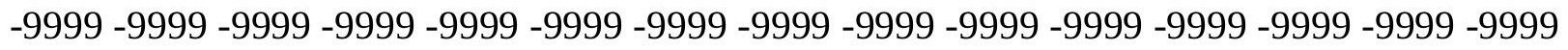
-9999 -9999 -9999 -9999 -9999 -9999 -9999 -9999 -9999 -9999 -9999 -9999 -9999 -9999 -9999 -9999 -9999 -9999 -9999 -9999 -9999 -9999 -9999 -9999 -9999 -9999

-9999 -9999 -9999 -9999 -9999 -9999 -9999 -9999 -9999 -9999 -9999 -9999 -9999 -9999 -9999

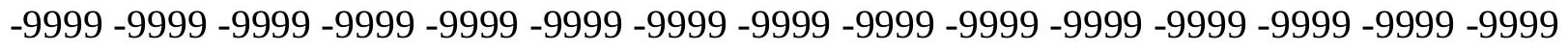

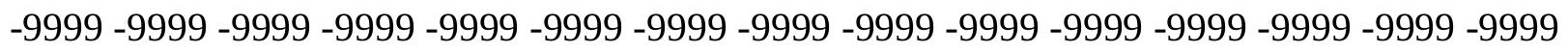

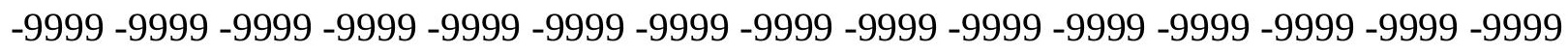
-9999 -9999 -9999 -9999 -9999 -9999 -9999 -9999 -9999 -9999 -9999 -9999 -9999 -9999 -9999 -

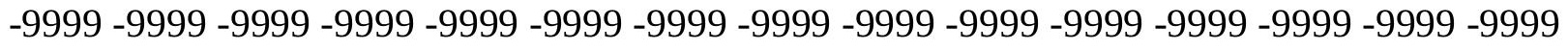

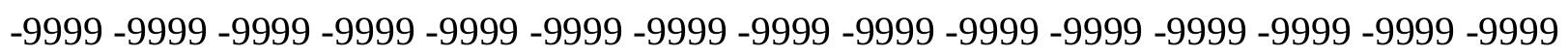

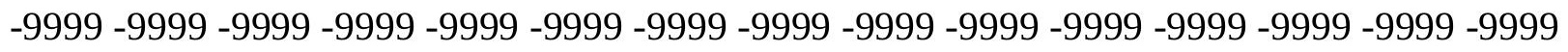
-9999 -9999 -9999-9999 186.528503418 185.0045928955183 .7854003906182 .87109375 181.6519012451179 .5184020996177 .9945068359176 .7754058838175 .5561981201 174.6419067383174 .0323028564173 .4226989746173 .1179962158173 .1179962158 172.8132019043172 .8132019043172 .5084075928171 .8988037109171 .2891998291 170.3748931885169 .7653045654169 .1557006836168 .5462036133167 .9365997314 167.6318054199167 .0222015381166 .7174987793166 .4127044678166 .4127044678 166.1078948975166 .1078948975166 .1078948975165 .8031005859165 .8031005859 165.4983062744165 .1934967041164 .5839996338163 .6696014404162 .7552947998 161.5361022949160 .0122070312158 .1835021973156 .3547973633154 .2212982178 151.7830047607149 .3446960449146 .6015930176143 .8585968018141 .4203033447 138.6772003174136 .2389984131133 .8007049561131 .9720001221129 .533706665 127.7050018311128 .3144989014 -9999 -9999 -9999 -9999 -9999 -9999 -9999 -9999 -9999 -9999 -9999 -9999 -9999 -9999 -9999 -9999 -9999 -9999 -9999 -9999 -9999 -9999 -9999 -9999 -9999 -9999 -9999 -9999 -9999 -9999 -9999 -9999 -9999 -9999 -9999 -9999 -9999 -9999 -9999 -

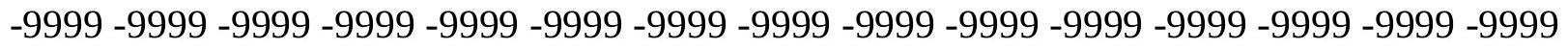

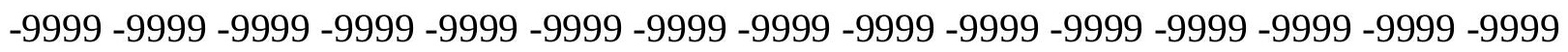

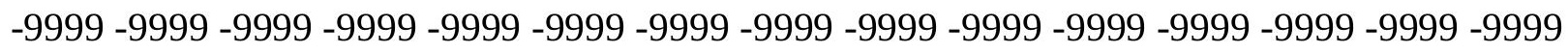
-9999 -9999 -9999 -9999 -9999 -9999 -9999 -9999 -9999 -9999 -9999 -9999 -9999 -9999 -9999 -

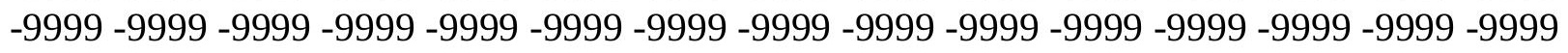

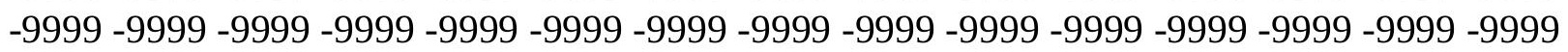


-9999 -9999 -9999 -9999 -9999 -9999 -9999 -9999 -9999 -9999 -9999 -9999 -9999 -9999 -9999 -9999 -9999 -9999 -9999 -9999 -9999 -9999 -9999 -9999 -9999 -9999 -9999 -9999 -9999 -9999 -9999 -9999 -9999 -9999 -9999 -9999 -9999 -9999 -9999 -9999 -9999 -9999 -9999 -9999 -9999 -9999 -9999 -9999 -9999 -9999 -9999 -9999 -9999 -9999 -9999 -9999 -9999 -9999 -9999 -9999

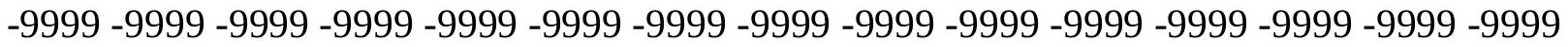
-9999 -9999-9999-9999-9999

-9999 -9999 -9999 -9999 -9999 -9999 -9999 -9999 -9999 -9999 -9999 -9999 -9999 -9999 -9999

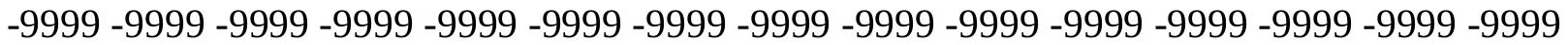

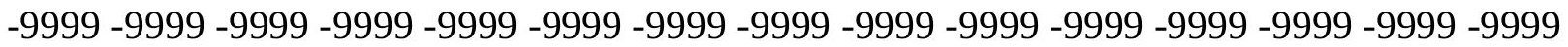
-9999 -9999 -9999 -9999 -9999 -9999 -9999 -9999 -9999 -9999 -9999 -9999 -9999 -9999 -9999 -

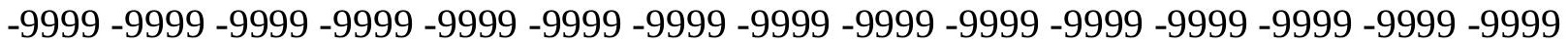
-9999 -9999 -9999 -9999 -9999 -9999 -9999 -9999 -9999 -9999 -9999 -9999 -9999 -9999 -9999 -9999 -9999 -9999 -9999 -9999 -9999 -9999 -9999 -9999 -9999 -9999 -9999 -9999 -9999 -9999 -9999 -9999 -9999 -9999 -9999 -9999 -9999 -9999 -9999 -9999 -9999 -9999 -9999 -9999 -9999 -9999 -9999 -9999 -9999 -9999 -9999 -9999 -9999 190.1858978271188 .3571929932 185.9188995361183 .4806976318180 .7375946045178 .2993011475176 .165802002 174.0323028564173 .1179962158173 .1179962158173 .1179962158173 .1179962158 173.1179962158172 .5084075928171 .8988037109170 .9844970703170 .6797027588 170.070098877169 .4604949951169 .1557006836168 .5462036133168 .241394043 167.9365997314167 .3269958496167 .0222015381166 .7174987793166 .7174987793 166.4127044678166 .1078948975165 .8031005859165 .4983062744165 .1934967041 164.5839996338163 .6696014404162 .7552947998161 .2312927246160 .0122070312 158.1835021973156 .3547973633154 .2212982178152 .0877990723149 .6495056152 146.9064025879144 .1634063721141 .4203033447138 .6772003174135 .9342041016 $133.1911010742130 .7528076172128 .3144989014125 .8762969971126 .1809997559-9999$ -9999 -9999 -9999 -9999 -9999 -9999 -9999 -9999 -9999 -9999 -9999 -9999 -9999 -9999 -9999 -9999 -9999 -9999 -9999 -9999 -9999 -9999 -9999 -9999 -9999 -9999 -9999 -9999 -9999 -9999

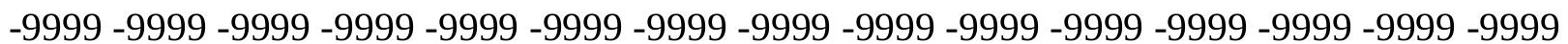
-9999 -9999 -9999 -9999 -9999 -9999 -9999 -9999 -9999 -9999 -9999 -9999 -9999 -9999 -9999

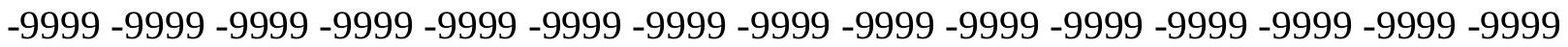
-9999 -9999 -9999 -9999 -9999 -9999 -9999 -9999 -9999 -9999 -9999 -9999 -9999 -9999 -9999 -

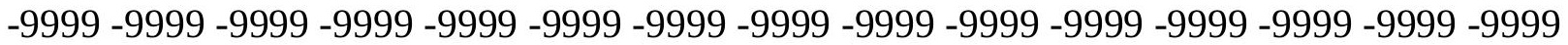
-9999 -9999 -9999 -9999 -9999 -9999 -9999 -9999 -9999 -9999 -9999 -9999 -9999 -9999 -9999 -9999 -9999 -9999 -9999 -9999 -9999 -9999 -9999 -9999 -9999 -9999 -9999 -9999 -9999 -9999 -9999 -9999 -9999 -9999 -9999 -9999 -9999 -9999 -9999 -9999 -9999 -9999 -9999 -9999 -9999 -9999 -9999 -9999 -9999 -9999 -9999 -9999 -9999 -9999 -9999 -9999 -9999 -9999 -9999 -9999 -9999 -9999 -9999 -9999 -9999 -9999 -9999 -9999 -9999 -9999 -9999 -9999 -9999 -9999 -9999

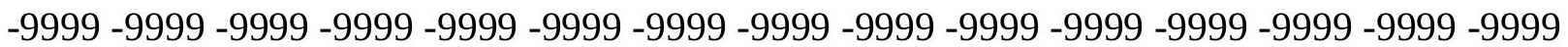
-9999 -9999 -9999 -9999 -9999 -9999 -9999 -9999 -9999 -9999 -9999 -9999 -9999 -9999 -9999 -9999 -9999 -9999 -9999 -9999 -9999 -9999 -9999 -9999 -9999 -9999 -9999 -9999 -9999 -9999 -9999 -9999 -9999 -9999 -9999 -9999 -9999 -9999 -9999 -9999 -9999 -9999 -9999

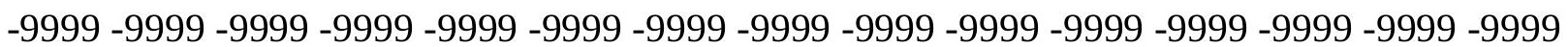
-9999 -9999 -9999 -9999 -9999 -9999 -9999 -9999 -9999 -9999 -9999 -9999 -9999 -9999 -9999 -9999 -9999 -9999 -9999 -9999 -9999 -9999 -9999 -9999 -9999 -9999 -9999 -9999 -9999 -9999 -999 -9999 -9999 -9999 -9999 -9999 -9999 -9999 -9999 -9999 -9999 -9999 -9999 -9999 -9999 -9999

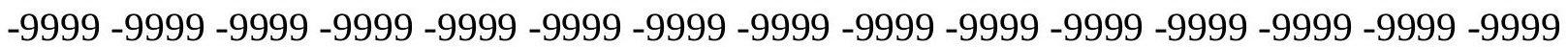


-9999 -9999 -9999 -9999 -9999 -9999 -9999 -9999 -9999 -9999 -9999 -9999 -9999 -9999 -9999 -9999 -9999 -9999 -9999 -9999 -9999 -9999 -9999 -9999 -9999 -9999 -9999 -9999 -9999 185.6141052246183 .4806976318181 .6519012451180 .1280059814178 .604095459 177.3849029541175 .8609924316173 .7274932861172 .2035980225171 .5939941406 171.2891998291170 .6797027588170 .3748931885170 .070098877169 .7653045654 169.1557006836168 .8509979248168 .241394043167 .9365997314167 .3269958496 167.0222015381166 .7174987793166 .4127044678166 .1078948975165 .8031005859 165.1934967041164 .5839996338163 .6696014404162 .4505004883161 .2312927246 160.0122070312158 .1835021973156 .3547973633154 .5260925293152 .0877990723 149.6495056152 147.2111968994 144.4682006836141.4203033447138.3724975586 135.6293945312132 .5814971924129 .533706665126 .7906036377124 .3523025513 123.43800354 -9999 -9999 -9999 -9999 -9999 -9999 -9999 -9999 -9999 -9999 -9999 -9999 -9999 -9999 -9999 -9999 -9999 -9999 -9999 -9999 -9999 -9999 -9999 -9999 -9999 -9999 -9999 -9999 -9999 -9999 -9999 -9999 -9999 -9999 -9999 -9999 -9999 -9999 -9999 -9999 -9999 -9999 -9999 -9999 -9999 -9999 -9999 -9999 -9999 -9999 -9999 -9999 -9999 -9999 -9999 -9999 -9999 -9999 -9999 -9999 -9999 -9999 -9999 -9999 -9999 -9999 -9999 -9999 -9999 -9999 -9999 -9999 -9999 -9999 -9999 -9999 -9999 -9999 -9999 -9999 -9999 -9999 -9999 -9999 -9999 -9999 -9999 -9999 -9999 -9999 -9999 -9999 -9999 -9999 -9999 -9999 -9999 -9999 -9999 -9999 -9999 -9999 -9999 -9999 -9999 -9999 -9999 -9999 -9999 -9999 -9999 -9999 -9999 -9999 -9999 -9999 -9999 -9999 -9999 -9999 -9999 -9999 -9999 -9999 -9999 -9999 -9999 -9999 -9999 -9999 -9999 -9999 -9999 -9999 -9999 -9999 -9999 -9999 -9999 -9999 -9999 -9999 -9999 -9999 -9999 -9999 -9999 -9999 -9999 -9999 -9999 -9999 -9999 -9999 -9999 -9999 -9999 -9999 -9999 -9999 -9999 -9999 -9999 -9999 -9999 -9999 -9999 -9999 -9999 -9999 -9999 -9999 -9999 -9999 -9999 -9999 -9999 -9999 -9999 -9999 -9999 -9999 -9999 -9999 -9999 -9999 -9999 -9999 -9999 -9999 -9999 -9999 -9999 -9999 -9999 -9999 -9999 -9999 -9999 -9999 -9999 -9999 -9999 -9999 -9999 -9999 -9999 -9999-9999

-9999 -9999 -9999 -9999 -9999 -9999 -9999 -9999 -9999 -9999 -9999 -9999 -9999 -9999 -9999 -9999 -9999 -9999 -9999 -9999 -9999 -9999 -9999 -9999 -9999 -9999 -9999 -9999 -9999 -9999

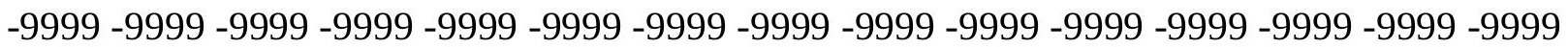

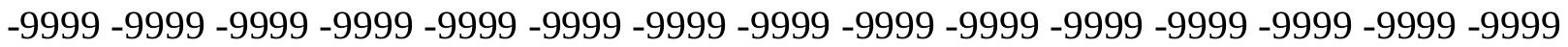
-9999 -9999 -9999 -9999 -9999 -9999 -9999 -9999 -9999 -9999 -9999 -9999 -9999 -9999 -9999 -

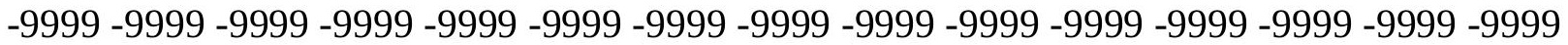
-9999 -9999 -9999 -9999 -9999 -9999 -9999 -9999 -9999 -9999 -9999 -9999 -9999 -9999 -9999 -9999 -9999 -9999 -9999 -9999 -9999 -9999 -9999 -9999 -9999 -9999 -9999 -9999 -9999 -9999 -9999 -9999 -9999 -9999 -9999 -9999 -9999 -9999 -9999 -9999 -9999 -9999 -9999 -9999 -9999 -9999 -9999 -9999 -9999-9999 184.3950042725 182.5662994385180 .432800293 177.9945068359175 .5561981201173 .4226989746171 .2891998291170 .9844970703 170.6797027588170 .070098877169 .4604949951169 .1557006836168 .5462036133 167.9365997314167 .3269958496167 .0222015381166 .7174987793166 .1078948975 165.8031005859165 .1934967041164 .5839996338163 .6696014404162 .4505004883 161.2312927246160 .0122070312158 .4882965088156 .6596069336154 .5260925293 152.3925933838149 .9542999268147 .5160064697144 .7729034424141 .7250976562 138.3724975586135 .0198059082131 .6672058105128 .3144989014124 .9618988037 122.2188034058120 .3900985718121 .6092987061 -9999 -9999 -9999 -9999 -9999 -9999 -9999 -9999 -9999 -9999 -9999 -9999 -9999 -9999 -9999 -9999 -9999 -9999 -9999 -9999 -9999 -9999

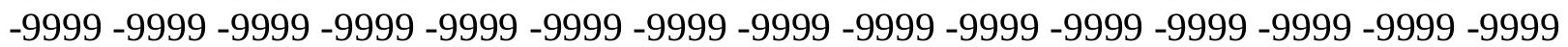


-9999 -9999 -9999 -9999 -9999 -9999 -9999 -9999 -9999 -9999 -9999 -9999 -9999 -9999 -9999 -9999 -9999 -9999 -9999 -9999 -9999 -9999 -9999 -9999 -9999 -9999 -9999 -9999 -9999 -9999 -9999 -9999 -9999 -9999 -9999 -9999 -9999 -9999 -9999 -9999 -9999 -9999 -9999 -9999 -9999 -9999 -9999 -9999 -9999 -9999 -9999 -9999 -9999 -9999 -9999 -9999 -9999 -9999 -9999 -9999 -9999 -9999 -9999 -9999 -9999 -9999 -9999 -9999 -9999 -9999 -9999 -9999 -9999 -9999 -9999 -9999 -9999 -9999 -9999 -9999 -9999 -9999 -9999 -9999 -9999 -9999 -9999 -9999 -9999 -9999 -9999 -9999 -9999 -9999 -9999 -9999 -9999 -9999 -9999 -9999 -9999 -9999 -9999 -9999 -9999 -

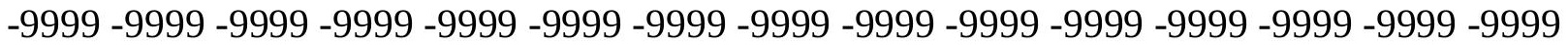
-9999 -9999 -9999 -9999 -9999 -9999 -9999 -9999 -9999 -9999 -9999 -9999 -9999 -9999 -9999 -9999 -9999 -9999 -9999 -9999 -9999 -9999 -9999 -9999 -9999 -9999 -9999 -9999 -9999 -9999 -

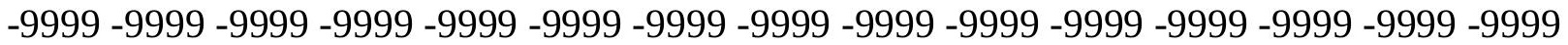
-9999 -9999 -9999-9999-9999-9999

-9999 -9999 -9999 -9999 -9999 -9999 -9999 -9999 -9999 -9999 -9999 -9999 -9999 -9999 -9999 -9999 -9999 -9999 -9999 -9999 -9999 -9999 -9999 -9999 -9999 -9999 -9999 -9999 -9999 -9999 -9999 -9999 -9999 -9999 -9999 -9999 -9999 -9999 -9999 -9999 -9999 -9999 -9999 -9999 -9999

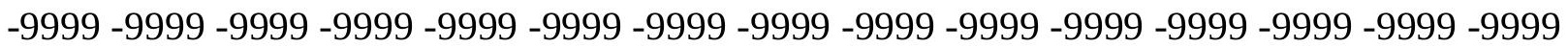
-9999 -9999 -9999 -9999 -9999 -9999 -9999 -9999 -9999 -9999 -9999 -9999 -9999 -9999 -9999 -9999 -9999 -9999 -9999 -9999 -9999 -9999 -9999 -9999 -9999 -9999 -9999 -9999 -9999 -9999 -9999 -9999 -9999 -9999 -9999 -9999 -9999 -9999 -9999 -9999 -9999 -9999 -9999 -9999 -9999 -9999 -9999 -9999 -9999 -9999 -9999 -9999 -9999 -9999 -9999 -9999 -9999 -9999 -9999 -9999

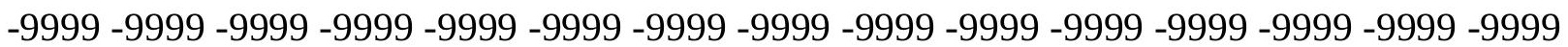
-9999 -9999 -9999 -9999 -9999 -9999-9999 -9999 -9999 184.3950042725 181.9566955566 179.8231964111177 .6896972656175 .5561981201173 .1179962158170 .9844970703 169.7653045654168 .8509979248168 .241394043167 .9365997314167 .3269958496 167.0222015381166 .4127044678165 .8031005859165 .1934967041164 .5839996338 163.6696014404162 .4505004883161 .2312927246160 .0122070312158 .4882965088 156.6596069336154 .8307952881152 .6972961426150 .5639038086148 .1255950928 145.0776977539142 .0299072266138 .6772003174135 .0198059082131 .0576019287 127.0953979492123 .43800354119 .7806015015117 .0374984741117 .9517974854 -9999 -9999 -9999 -9999 -9999 -9999 -9999 -9999 -9999 -9999 -9999 -9999 -9999 -9999 -9999 -9999 -9999 -9999 -9999 -9999 -9999 -9999 -9999 -9999 -9999 -9999 -9999 -9999 -9999 -9999 -9999 -9999 -

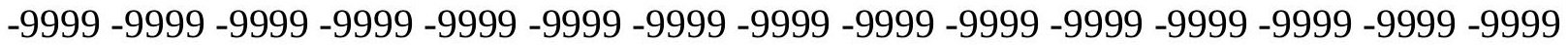

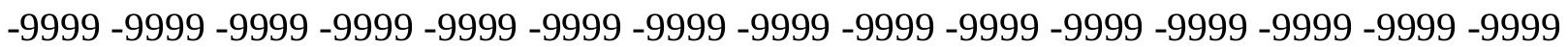
-9999 -9999 -9999 -9999 -9999 -9999 -9999 -9999 -9999 -9999 -9999 -9999 -9999 -9999 -9999 -

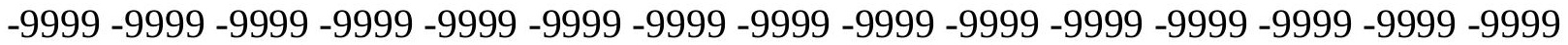
-9999 -9999 -9999 -9999 -9999 -9999 -9999 -9999 -9999 -9999 -9999 -9999 -9999 -9999 -9999 -9999 -9999 -9999 -9999 -9999 -9999 -9999 -9999 -9999 -9999 -9999 -9999 -9999 -9999 -9999

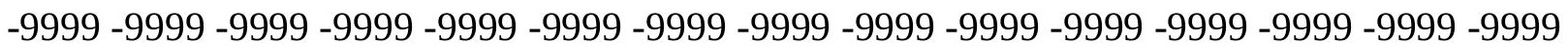
-9999 -9999 -9999 -9999 -9999 -9999 -9999 -9999 -9999 -9999 -9999 -9999 -9999 -9999 -9999 -9999 -9999 -9999 -9999 -9999 -9999 -9999 -9999 -9999 -9999 -9999 -9999 -9999 -9999 -9999 -9999 -9999 -9999 -9999 -9999 -9999 -9999 -9999 -9999 -9999 -9999 -9999 -9999 -9999 -9999 -999 -9999 -9999 -9999 -9999 -9999 -9999 -9999 -9999 -9999 -9999 -9999 -9999 -9999 -9999 -9999 -9999 -9999 -9999 -9999 -9999 -9999-9999 -9999 -9999 -9999 -9999 -9999 -9999 -9999 -9999 -9999 -9999 -9999 -9999 -9999 -9999 -9999 -9999 -9999 -9999 -9999 -9999 -9999 -9999 -9999 -9999 -9999 -9999 -9999 -9999 -9999 -9999 -9999 -9999 -9999 -9999

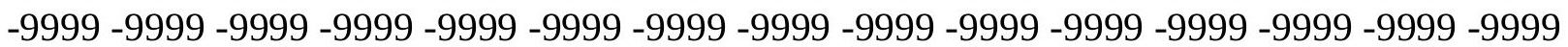


-9999 -9999 -9999 -9999 -9999 -9999 -9999 -9999 -9999 -9999 -9999 -9999 -9999 -9999 -9999 -9999 -9999 -9999 -9999 -9999 -9999 -9999 -9999 -9999 -9999 -9999 -9999 -9999 -9999 -9999 -9999 -9999 -9999 -9999 -9999 -9999 -9999 -9999 -9999 -9999 -9999 -9999 -9999 -9999 -9999 -9999 -9999 -9999 -9999 -9999 -9999 -9999 -9999 -9999 -9999 -9999 -9999 -9999 -9999 -9999 -9999 -9999 -9999 -9999 -9999 -9999 -9999 -9999 -9999 -9999 -9999 -9999 -9999 -9999 -9999 -9999 -9999 -9999 -9999 -9999 -9999 -9999 -9999 -9999 -9999 -9999 -9999 -9999 -9999 -9999 -9999 -9999 -9999 -9999 -9999 -9999 -9999 -9999 -9999 -9999 -9999 -9999 -9999 -9999 181.6519012451179 .2136993408176 .4705963135174 .0323028564171 .5939941406 169.1557006836167 .6318054199167 .0222015381166 .7174987793166 .1078948975 165.4983062744164 .5839996338163 .6696014404162 .7552947998161 .5361022949 160.0122070312158 .7929992676156 .9642944336155 .1356048584153 .3069000244 151.1734008789148 .7351074219145 .9920959473142 .6394042969139 .2868041992 135.3246002197131 .0576019287126 .4858016968122 .2188034058117 .9517974854 115.2088012695113 .9896011353 -9999 -9999 -9999 -9999 -9999 -9999 -9999 -9999 -9999 -9999 -9999 -9999 -9999 -9999 -9999 -9999 -9999 -9999 -9999 -9999 -9999 -9999 -9999 -9999

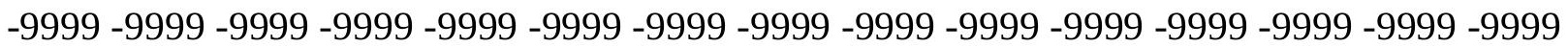
-9999 -9999 -9999 -9999 -9999 -9999 -9999 -9999 -9999 -9999 -9999 -9999 -9999 -9999 -9999 -9999 -9999 -9999 -9999 -9999 -9999 -9999 -9999 -9999 -9999 -9999 -9999 -9999 -9999 -9999 -9999 -9999 -9999 -9999 -9999 -9999 -9999 -9999 -9999 -9999 -9999 -9999 -9999 -9999 -9999 -9999 -9999 -9999 -9999 -9999 -9999 -9999 -9999 -9999 -9999 -9999 -9999 -9999 -9999 -9999

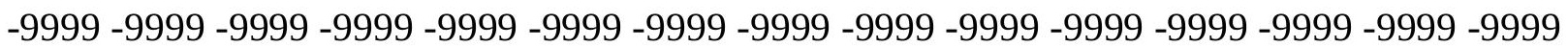
-9999 -9999 -9999 -9999 -9999 -9999 -9999 -9999 -9999 -9999 -9999 -9999 -9999 -9999 -9999 -9999 -9999 -9999 -9999 -9999 -9999 -9999 -9999 -9999 -9999 -9999 -9999 -9999 -9999 -9999 -9999 -9999 -9999 -9999 -9999 -9999 -9999 -9999 -9999 -9999 -9999 -9999 -9999 -9999 -9999

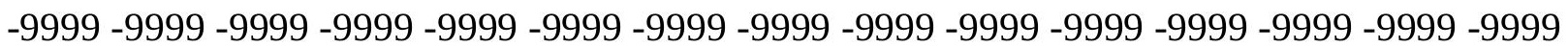
-9999 -9999 -9999 -9999 -9999 -9999 -9999 -9999 -9999 -9999 -9999 -9999 -9999 -9999 -9999 -9999 -9999 -9999 -9999 -9999 -9999 -9999 -9999 -9999 -9999 -9999 -9999 -9999 -9999 -9999 -9999 -9999 -9999-9999

-9999 -9999 -9999 -9999 -9999 -9999 -9999 -9999 -9999 -9999 -9999 -9999 -9999 -9999 -9999 -9999 -9999 -9999 -9999 -9999 -9999 -9999 -9999 -9999 -9999 -9999 -9999 -9999 -9999 -9999 -9999 -9999 -9999 -9999 -9999 -9999 -9999 -9999 -9999 -9999 -9999 -9999 -9999 -9999 -9999 -

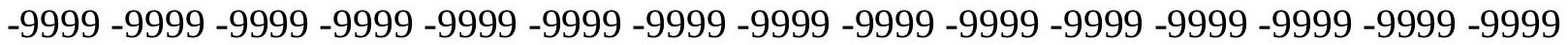
-9999 -9999 -9999 -9999 -9999 -9999 -9999 -9999 -9999 -9999 -9999 -9999 -9999 -9999 -9999 -9999 -9999 -9999 -9999 -9999 -9999 -9999 -9999 -9999 -9999 -9999 -9999 -9999 -9999 -9999 -9999 -9999 -9999 -9999 -9999 -9999 -9999 -9999 -9999 -9999 -9999 -9999 -9999 -9999 -9999 -9999 -9999 -9999 -9999 -9999 -9999 -9999 -9999 -9999 -9999 -9999 -9999 -9999 -9999 -9999 -9999 -9999 -9999 -9999 -9999 -9999 -9999 -9999 -9999 -9999 -9999 -9999 -9999 -9999 -9999 -9999 -9999 -9999 -9999 -9999 -9999 -9999 -9999 -9999 -9999 -9999 -9999 -9999 -9999 -9999 -9999 -9999-9999 179.2136993408176.4705963135174.0323028564171.5939941406 169.1557006836167 .0222015381165 .4983062744164 .5839996338163 .6696014404 162.7552947998161 .5361022949160 .3170013428158 .7929992676157 .2691040039 155.7451934814153 .9165039062151 .7830047607149 .3446960449146 .9064025879 143.8585968018140 .2012023926135 .9342041016131 .3623962402126 .7906036377 122.2188034058117 .9517974854116 .1231002808 -9999 -9999 -9999 -9999 -9999 -9999 -9999 -9999 -9999 -9999 -9999 -9999 -9999 -9999 -9999 -9999 -9999 -9999 -9999 -9999 -9999 -9999

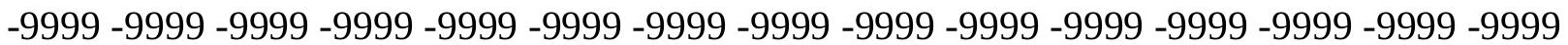


-9999 -9999 -9999 -9999 -9999 -9999 -9999 -9999 -9999 -9999 -9999 -9999 -9999 -9999 -9999 -9999 -9999 -9999 -9999 -9999 -9999 -9999 -9999 -9999 -9999 -9999 -9999 -9999 -9999 -9999 -9999 -9999 -9999 -9999 -9999 -9999 -9999 -9999 -9999 -9999 -9999 -9999 -9999 -9999 - 9999 -9999 -9999 -9999 -9999 -9999 -9999 -9999 -9999 -9999 -9999 -9999 -9999 -9999 -9999 -9999 -9999 -9999 -9999 -9999 -9999 -9999 -9999 -9999 -9999-9999 -9999 -9999 -9999 -9999 -9999 -9999 -9999 -9999 -9999 -9999 -9999 -9999 -9999 -9999 -9999 -9999 -9999 -9999 -9999 -9999 -9999 -9999 -9999 -9999 -9999 -9999 -9999 -9999 -9999 -9999 -9999 -9999 -9999 -9999 -9999

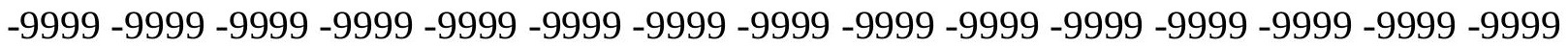
-9999 -9999 -9999 -9999 -9999 -9999 -9999 -9999 -9999 -9999 -9999 -9999 -9999 -9999 -9999 -9999 -9999 -9999 -9999 -9999 -9999 -9999 -9999 -9999 -9999 -9999 -9999 -9999 -9999 -9999 -9999 -9999 -9999 -9999 -9999 -9999 -9999 -9999 -9999 -9999 -9999 -9999 -9999 -9999 -9999 -9999 -9999 -9999 -9999-9999-9999-9999

-9999 -9999 -9999 -9999 -9999 -9999 -9999 -9999 -9999 -9999 -9999 -9999 -9999 -9999 -9999 -9999 -9999 -9999 -9999 -9999 -9999 -9999 -9999 -9999 -9999 -9999 -9999 -9999 -9999 - 9999 -9999 -9999 -9999 -9999 -9999 -9999 -9999 -9999 -9999 -9999 -9999 -9999 -9999 -9999 -9999

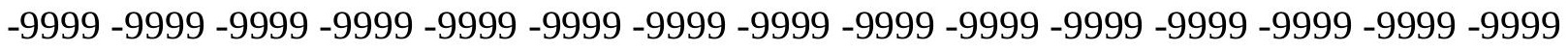
-9999 -9999 -9999 -9999 -9999 -9999 -9999 -9999 -9999 -9999 -9999 -9999 -9999 -9999 -9999 -9999 -9999 -9999 -9999 -9999 -9999 -9999 -9999 -9999 -9999 -9999 -9999 -9999 -9999 -9999 -9999 -9999 -9999 -9999 -9999 -9999 -9999 -9999 -9999 -9999 -9999 -9999 -9999 -9999 -9999 -9999 -9999 -9999 -9999 -9999 -9999 -9999 -9999 -9999 -9999 -9999 -9999 -9999 -9999 -9999 -9999 -9999 -9999 -9999 -9999 -9999 -9999 -9999 -9999 -9999 -9999 -9999 -9999 -9999 -9999 -999 -9999 -9999 -9999 -9999 -9999 -9999 -9999 -9999 -9999 -9999 -9999 -9999 -9999 -9999 -9999 -9999 -9999-9999 -9999 -9999-9999 -9999 176.165802002173 .7274932861170 .9844970703 168.5462036133165 .8031005859163 .0599975586161 .5361022949160 .3170013428 159.0977935791157 .5738983154156 .0500030518154 .5260925293152 .3925933838 150.5639038086148 .1255950928145 .0776977539141 .7250976562137 .4580993652 $132.5814971924127 .7050018311122 .8283996582119 .7806015015117 .647102356-9999$ -9999 -9999 -9999 -9999 -9999 -9999 -9999 -9999 -9999 -9999 -9999 -9999 -9999 -9999 -9999 -9999 -9999 -9999 -9999 -9999 -9999 -9999 -9999 -9999 -9999 -9999 -9999 -9999 -9999 -9999 -9999 -9999 -9999 -9999 -9999 -9999 -9999 -9999 -9999 -9999 -9999 -9999 -9999 -9999 -999 -9999 -9999 -9999 -9999 -9999 -9999 -9999 -9999 -9999 -9999 -9999 -9999 -9999 -9999 -9999 -9999 -9999 -9999 -9999 -9999 -9999 -9999 -9999 -9999 -9999 -9999 -9999 -9999 -9999 -9999

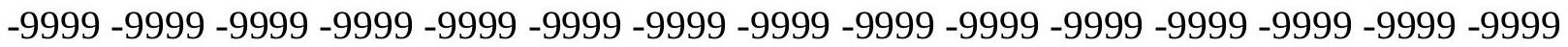
-9999 -9999 -9999 -9999 -9999 -9999 -9999 -9999 -9999 -9999 -9999 -9999 -9999 -9999 -9999 -9999 -9999 -9999 -9999 -9999 -9999 -9999 -9999 -9999 -9999 -9999 -9999 -9999 -9999 -9999 -9999 -9999 -9999 -9999 -9999 -9999 -9999 -9999 -9999 -9999 -9999 -9999 -9999 -9999 -9999

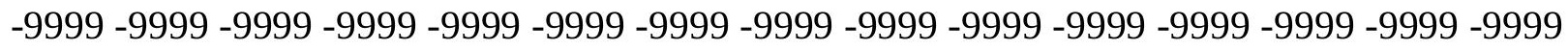

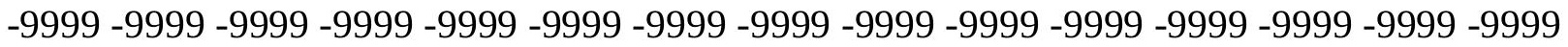

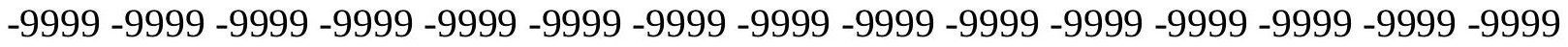
-9999 -9999 -9999 -9999 -9999 -9999 -9999 -9999 -9999 -9999 -9999 -9999 -9999 -9999 -9999 -

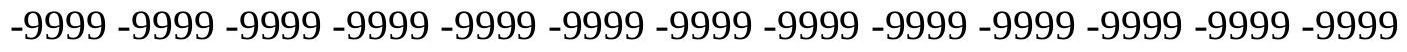

-9999 -9999 -9999 -9999 -9999 -9999 -9999 -9999 -9999 -9999 -9999 -9999 -9999 -9999 -9999 -9999 -9999 -9999 -9999 -9999 -9999 -9999 -9999 -9999 -9999 -9999 -9999 -9999 -9999 -9999 -9999 -9999 -9999 -9999 -9999 -9999 -9999 -9999 -9999-9999 -9999 -9999 -9999 -9999 -9999 -9999 -9999 -9999 -9999 -9999 -9999 -9999 -9999 -9999 -9999 -9999 -9999 -9999 -9999 -9999 -9999 -9999 -9999 -9999 -9999 -9999 -9999 -9999 -9999 -9999 -9999 -9999 -9999 -9999 -9999 
-9999 -9999 -9999 -9999 -9999 -9999 -9999 -9999 -9999 -9999 -9999 -9999 -9999 -9999 -9999 -9999 -9999 -9999 -9999 -9999 -9999 -9999 -9999 -9999 -9999 -9999 -9999 -9999 -9999 -9999 -9999 -9999 -9999 -9999 -9999 -9999 -9999 -9999 -9999 -9999 -9999 -9999 -9999 -9999 -9999 -9999 -9999 -9999 -9999 -9999 -9999 -9999 -9999 -9999 -9999 -9999 -9999 -9999 -9999 -9999 -9999 -9999 -9999 -9999 -9999 -9999 -9999 -9999 -9999 -9999 -9999 -9999 -9999 -9999 -9999 -9999 -9999 -9999 -9999 -9999 -9999 -9999 -9999 -9999 -9999 -9999 171.8988037109 169.1557006836166 .7174987793163 .974395752161 .2312927246158 .1835021973 156.6596069336154 .8307952881153 .3069000244151 .4781951904149 .3446960449 146.9064025879143 .5538024902138 .9819946289134 .1054992676128 .9241027832 125.5715026855122 .2188034058 -9999 -9999 -9999 -9999 -9999 -9999 -9999 -9999 -9999 -9999 -9999 -9999 -9999 -9999 -9999 -9999 -9999 -9999 -9999 -9999 -9999 -9999 -9999 -9999 -9999 -9999 -9999 -9999 -9999 -9999 -9999 -9999 -9999 -9999 -9999 -9999 -9999 -9999 -9999 -9999 -9999 -9999 -9999 -9999 -9999 -9999 -9999 -9999 -9999 -9999 -9999 -9999 -9999 -9999 -9999 -9999 -9999 -9999 -9999 -9999 -9999 -9999 -9999 -9999 -9999 -9999 -9999 -9999 -9999 -9999 -9999 -9999 -9999 -9999 -9999 -9999 -9999 -9999 -9999 -9999 -9999 -9999 -9999 -9999 -9999 -9999 -9999 -9999 -9999 -9999 -9999 -9999 -9999 -9999 -9999 -9999 -9999 -9999 -9999 -9999 -9999 -9999 -9999 -9999 -9999 -9999 -9999 -9999 -9999 -9999 -9999 -9999 -9999 -9999 -9999 -9999 -9999 -9999 -9999 -9999 -9999 -9999 -9999 -9999 -9999 -9999 -9999 -9999 -9999 -9999 -9999 -9999 -9999 -9999 -9999 -9999 -9999 -9999 -9999 -9999 -9999 -9999 -9999 -9999 -9999 -9999 -9999 -9999 -9999 -9999 -9999 -9999 -9999 -9999 -9999 -9999 -9999 -9999 -9999

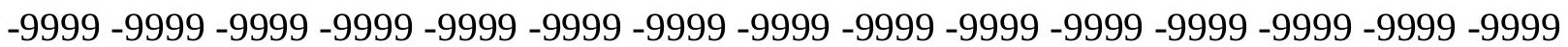
-9999 -9999 -9999 -9999 -9999 -9999 -9999 -9999 -9999 -9999 -9999 -9999 -9999 -9999 -9999 -9999 -9999 -9999 -9999 -9999 -9999 -9999 -9999 -9999 -9999 -9999 -9999 -9999 -9999 -9999 -9999 -9999 -9999 -9999-9999 -9999

-9999 -9999 -9999 -9999 -9999 -9999 -9999 -9999 -9999 -9999 -9999 -9999 -9999 -9999 -9999 -9999 -9999 -9999 -9999 -9999 -9999 -9999 -9999 -9999 -9999 -9999 -9999 -9999 -9999 -9999 -9999 -9999 -9999 -9999 -9999 -9999 -9999 -9999 -9999 -9999 -9999 -9999 -9999 -9999 -9999 -9999 -9999 -9999 -9999 -9999 -9999 -9999 -9999 -9999 -9999 -9999 -9999 -9999 -9999 -9999 -9999 -9999 -9999 -9999 -9999 -9999 -9999 -9999 -9999 -9999 -9999 -9999 -9999 -9999 -9999 -9999 -9999 -9999 -9999 -9999 -9999 -9999 -9999 -9999 -9999 -9999 -9999 -9999 -9999 -9999 -9999 -9999 -9999 -9999 -9999 -9999 -9999 -9999 -9999 -9999 -9999 -9999 -9999 -9999 -9999 -

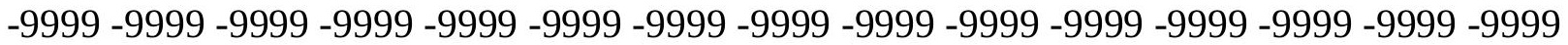
-9999 -9999 -9999 -9999 -9999 -9999 -9999 -9999 -9999 -9999 -9999 -9999 -9999 -9999 -9999 -9999 -9999 -9999 -9999 -9999 -9999 -9999 -9999 -9999 -9999 -9999 -9999 -9999 -9999 -9999 -9999 -9999 -9999 -9999 -9999 -9999 -9999 -9999 -9999 -9999 -9999 -9999 -9999 -9999 -9999 167.3269958496164 .2792053223161 .5361022949158 .4882965088155 .4403991699 152.3925933838150 .8686065674149 .0399017334145 .6873016357140 .8106994629 137.1533050537 134.1054992676 130.7528076172 -9999 -9999 -9999 -9999 -9999 -9999 -9999 -9999 -9999 -9999 -9999 -9999 -9999 -9999 -9999 -9999 -9999 -9999 -9999 -9999 -9999 -9999 -9999 -9999 -9999 -9999 -9999 -9999 -9999 -9999 -9999 -9999 -9999 -9999 -9999 -9999 -9999 -9999 -9999 -9999 -9999 -9999 -9999 -9999 -9999 -9999 -9999 -9999 -9999 -9999 -9999 -9999 -9999 -9999 -9999 -9999 -9999 -9999 -9999 -9999 -9999 -9999 -9999 -9999 -9999 -9999 -9999 -9999 -9999 -9999 -9999 -9999 -9999 -9999 -9999 -9999 -9999 -9999 -9999 -9999 -9999 -9999 -9999 -9999 -9999 -9999 -9999 -9999 -9999 -9999 -9999 -9999 -9999 -9999 -9999 -9999 -9999 -9999 -9999 -9999 -9999 -9999 -9999 -9999 -9999 -9999 -9999 -9999 -9999 -9999 -9999 -9999

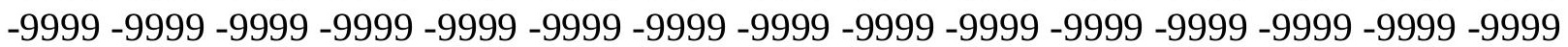


-9999 -9999 -9999 -9999 -9999 -9999 -9999 -9999 -9999 -9999 -9999 -9999 -9999 -9999 -9999 -9999 -9999 -9999 -9999 -9999 -9999 -9999 -9999 -9999 -9999 -9999 -9999 -9999 -9999 -9999 -9999 -9999 -9999 -9999 -9999 -9999 -9999 -9999 -9999 -9999 -9999 -9999 -9999 -9999 -9999 -9999 -9999 -9999 -9999 -9999 -9999 -9999 -9999 -9999 -9999 -9999 -9999 -9999 -9999 -9999

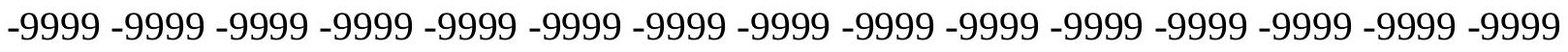
-9999 -9999 -9999 -9999 -9999 -9999 -9999 -9999 -9999

-9999 -9999 -9999 -9999 -9999 -9999 -9999 -9999 -9999 -9999 -9999 -9999 -9999 -9999 -9999

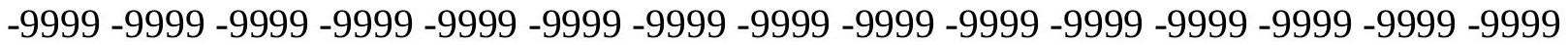
-9999 -9999 -9999 -9999 -9999 -9999 -9999 -9999 -9999 -9999 -9999 -9999 -9999 -9999 -9999 -9999 -9999 -9999 -9999 -9999 -9999 -9999 -9999 -9999 -9999 -9999 -9999 -9999 -9999 -9999 -

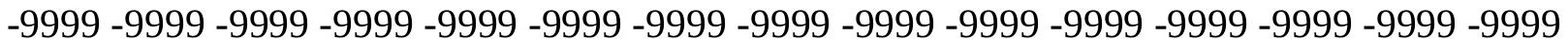
-9999 -9999 -9999 -9999 -9999 -9999 -9999 -9999 -9999 -9999 -9999 -9999 -9999 -9999 -9999

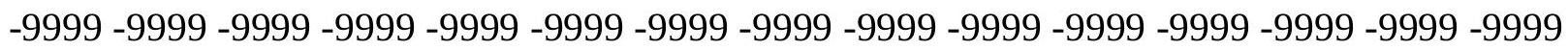
-9999 -9999 -9999 -9999 -9999 -9999 -9999 -9999 -9999 -9999 -9999 -9999 -9999 -9999 -9999 -9999 -9999 -9999 -9999 -9999 -9999 -9999 -9999 -9999 -9999 -9999 -9999 -9999 -9999 -9999 -9999 -9999 -9999 -9999 -9999 -9999 -9999 -9999 -9999 -9999 -9999 -9999 -9999 -9999 -9999 -9999 -9999 -9999 -9999 -9999 -9999 -9999 -9999 -9999 -9999 -9999 -9999 -9999 -9999 -9999 -9999 -9999 -9999 -9999 161.5361022949158 .4882965088155 .7451934814153 .0021057129 149.6495056152 145.9920959473142 .6394042969 -9999 -9999 -9999 -9999 -9999 -9999-9999 -9999 -9999 -9999 -9999 -9999 -9999 -9999 -9999 -9999 -9999 -9999 -9999 -9999 -9999 -9999

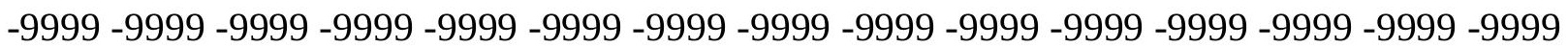
-9999 -9999 -9999 -9999 -9999 -9999 -9999 -9999 -9999 -9999 -9999 -9999 -9999 -9999 -9999 -9999 -9999 -9999 -9999 -9999 -9999 -9999 -9999 -9999 -9999 -9999 -9999 -9999 -9999 -9999 -9999 -9999 -9999 -9999 -9999 -9999 -9999 -9999 -9999 -9999 -9999 -9999 -9999 -9999 -9999

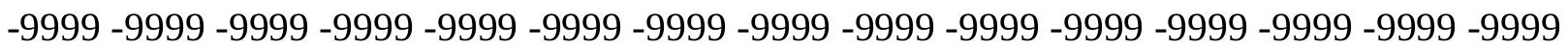
-9999 -9999 -9999 -9999 -9999 -9999 -9999 -9999 -9999 -9999 -9999 -9999 -9999 -9999 -9999 -9999 -9999 -9999 -9999 -9999 -9999 -9999 -9999 -9999 -9999 -9999 -9999 -9999 -9999 -9999 -9999 -9999 -9999 -9999 -9999 -9999 -9999 -9999 -9999 -9999 -9999 -9999 -9999 -9999 -9999 -9999 -9999 -9999 -9999 -9999 -9999 -9999 -9999 -9999 -9999 -9999 -9999 -9999 -9999 -9999 -999 -9999 -9999 -9999 -9999 -9999 -9999 -9999 -9999 -9999 -9999 -9999 -9999 -9999 -9999 -9999 -9999 -9999 -9999 -9999 -9999 -9999 -9999 -9999 -9999 -9999 -9999 -9999 -9999 -9999 -9999 -9999 -9999 -9999 -9999 -9999 -9999 -9999 -9999 -9999 -9999 -9999 -9999 -9999-9999 -9999 -9999 -9999 -9999 -9999 -9999 -9999 -9999 -9999 -9999 -9999 -9999

-9999 -9999 -9999 -9999 -9999 -9999 -9999 -9999 -9999 -9999 -9999 -9999 -9999 -9999 -9999

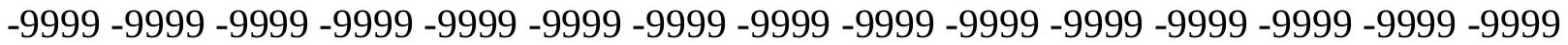
-9999 -9999 -9999 -9999 -9999 -9999 -9999 -9999 -9999 -9999 -9999 -9999 -9999 -9999 -9999 -9999 -9999 -9999 -9999 -9999 -9999 -9999 -9999 -9999 -9999 -9999 -9999 -9999 -9999 -9999

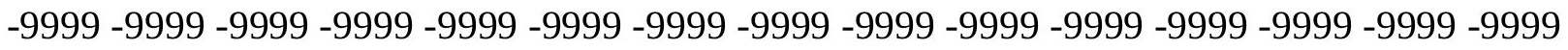
-9999 -9999 -9999 -9999 -9999 -9999 -9999 -9999 -9999 -9999 -9999 -9999 -9999 -9999 -9999 -9999 -9999 -9999 -9999 -9999 -9999 -9999 -9999 -9999 -9999 -9999 -9999 -9999 -9999 -9999 -9999 -9999 -9999 -9999 -9999 -9999 -9999 -9999 -9999 -9999 -9999 -9999 -9999 -9999 -9999 -999 -9999 -9999 -9999 -9999 -9999 -9999 -9999 -9999 -9999 -9999 -9999 -9999 -9999 -9999 -9999 -9999 -9999 -9999 -9999 -9999 -9999 -9999 -9999 -9999 -9999 -9999 -9999 -9999 -9999 -9999 -9999 -9999 -9999 -9999 -9999 -9999 -9999 -9999 -9999 -9999 -9999 -9999 -9999 -9999 -9999 -9999 -9999 -9999 -9999 -9999 -9999 -9999 -9999 -9999 -9999 -9999 -9999 -9999 -9999 -9999

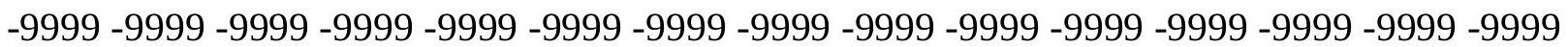


-9999 -9999 -9999 -9999 -9999 -9999 -9999 -9999 -9999 -9999 -9999 -9999 -9999 -9999 -9999 -9999 -9999 -9999 -9999 -9999 -9999 -9999 -9999 -9999 -9999 -9999 -9999 -9999 -9999 -9999 -

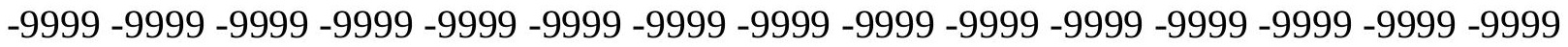
-9999 -9999 -9999 -9999 -9999 -9999 -9999 -9999 -9999 -9999 -9999 -9999 -9999 -9999 -9999 -9999 -9999 -9999 -9999 -9999 -9999 -9999 -9999 -9999-9999 -9999 -9999 -9999 -9999 -9999 -9999 -9999 -9999 -9999 -9999 -9999 -9999 -9999 -9999 -9999 -9999 -9999 -9999 -9999 -9999 -9999 -9999 -9999 -9999 -9999 -9999 -9999 -9999 -9999 -9999 -9999 -9999 -9999 -9999 -9999

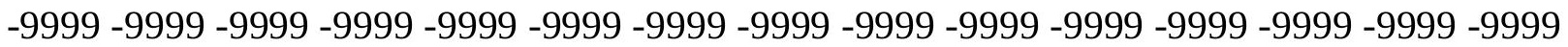

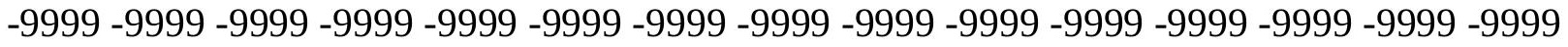
-9999 -9999 -9999 -9999 -9999 -9999 -9999 -9999 -9999 -9999 -9999 -9999 -9999 -9999 -9999 -9999 -9999 -9999 -9999 -9999 -9999 -9999 -9999 -9999 -9999 -9999 -9999 -9999 -9999 -9999 -9999 -9999 -9999 -9999 -9999 -9999 -9999 -9999 -9999 -9999 -9999 -9999 -9999 -9999 -9999 -9999 -9999 -9999 -9999 -9999 -9999 -9999 -9999 -9999 -9999 -9999 -9999 -9999 -9999 -9999 -9999 -9999 -9999 -9999 -9999 -9999 -9999 -9999 -9999 -9999 -9999 -9999 -9999 -9999 -9999 -9999 -9999 -9999 -9999 -9999 -9999 -9999 -9999 -9999 -9999 -9999 -9999 -9999 -9999 -

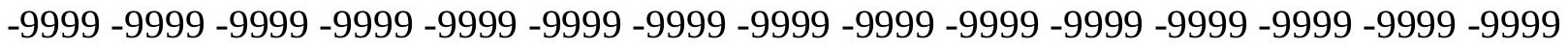
-9999 -9999 -9999 -9999 -9999 -9999 -9999 -9999 -9999 -9999 -9999 -9999 -9999 -9999 -9999 -9999 -9999 -9999 -9999 -9999 -9999 -9999 -9999 -9999 -9999 -9999 -9999 -9999 -9999 -9999 -9999 -9999 -9999 -9999 -9999 -9999 -9999 -9999 -9999 -9999 -9999 -9999 -9999 -9999 -9999 -

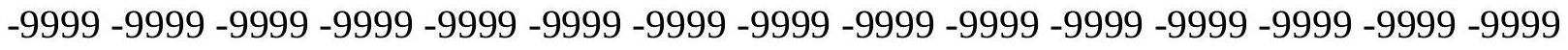
-9999 -9999 -9999 -9999 -9999 -9999 -9999 -9999 -9999 -9999 -9999 -9999 -9999 -9999 -9999

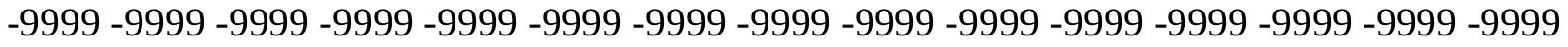
-9999 -9999 -9999 -9999 -9999 -9999 -9999 -9999 -9999 -9999 -9999 -9999 -9999 -9999 -9999 -9999 -9999 -9999 -9999 -9999 -9999 -9999 -9999 -9999 -9999 -9999 -9999 -9999 -9999 -9999 -

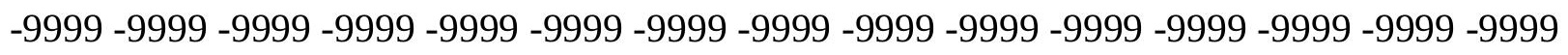
-9999 -9999 -9999 -9999 -9999 -9999 -9999 -9999 -9999 -9999 -9999 -9999 -9999 -9999 -9999 -9999 -9999 -9999 -9999 -9999 -9999 -9999 -9999 -9999 -9999 -9999 -9999 -9999 -9999 -9999 -

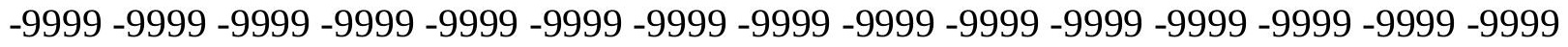
-9999 -9999 -9999 -9999 -9999 -9999 -9999 -9999 -9999 -9999 -9999 -9999 -9999 -9999 -9999 -9999 -9999 -9999 -9999 -9999 -9999 -9999 -9999 -9999 -9999 -9999 -9999 -9999 -9999 -999 -9999 -9999 -9999 -9999 -9999 -9999 -9999 -9999 -9999 -9999 -9999 -9999 -9999 -9999 -9999 -9999 -9999 -9999 -9999 -9999 -9999 -9999 -9999 -9999 -9999 -9999 -9999 -9999 -9999 -9999 -

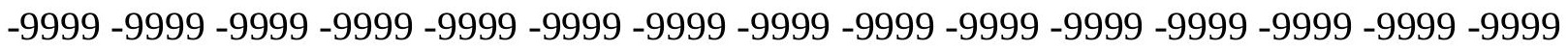

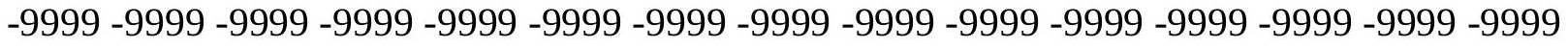

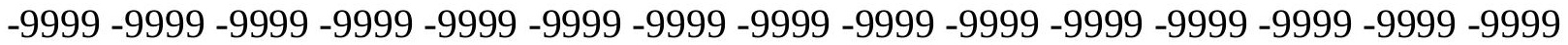
-9999 -9999 -9999 -9999 -9999 -9999 -9999 -9999 -9999 -9999 -9999 -9999 -9999 -9999 -9999 -

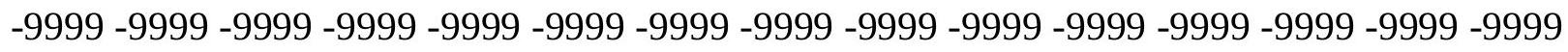

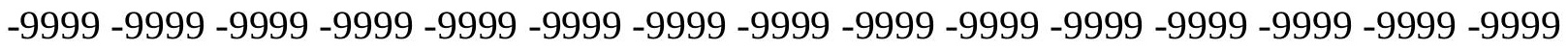
-9999 -9999 -9999 -9999 -9999 -9999 -9999 -9999 -9999 -9999 -9999 -9999 -9999 -9999 - -999 -9999 -9999 -9999 -9999 -9999 -9999 -9999 -9999 -9999 -9999 -9999 -9999 -9999 -9999 -9999 -

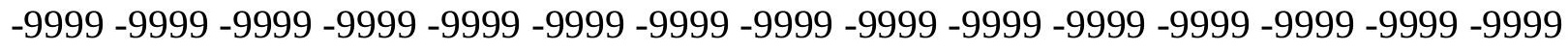

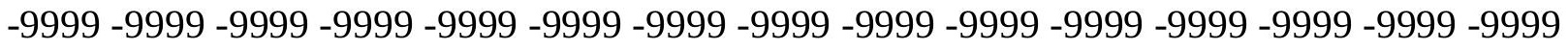
-9999 -9999 -9999 -9999 -9999 -9999 -9999 -9999 -9999 -9999 -9999 -9999 -9999 -9999 -9999 -9999 -9999 -9999 -9999 -9999 -9999 -9999 -9999 -9999-9999 -9999 -9999 -9999 -9999 -9999 -9999 -9999 -9999 -9999 -9999 -9999 -9999 -9999 -9999 -9999 -9999 -9999 -9999 -9999 -9999 -

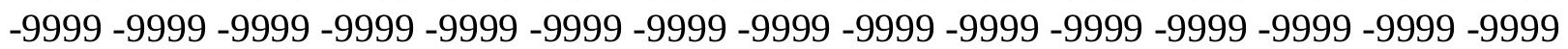


-9999 -9999 -9999 -9999 -9999 -9999 -9999 -9999 -9999 -9999 -9999 -9999 -9999 -9999 -9999 -9999 -9999 -9999 -9999 -9999 -9999 -9999 -9999 -9999 -9999 -9999 -9999 -9999 -9999 -9999 -

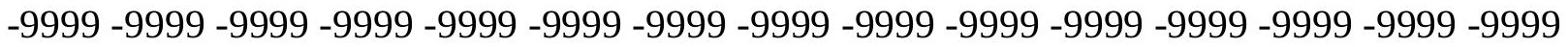
-9999 -9999 -9999 -9999 -9999 -9999 -9999 -9999 -9999 -9999 -9999 -9999 -9999 -9999 -9999 -9999 -9999 -9999 -9999 -9999 -9999 -9999 -9999 -9999-9999 -9999 -9999 -9999 -9999 -9999 -9999 -9999 -9999 -9999 -9999 -9999 -9999 -9999 -9999 -9999 -9999 -9999 -9999 -9999 -9999 -9999 -9999 -9999 -9999 -9999 -9999 -9999 -9999 -9999 -9999 -9999 -9999 -9999 -9999 -9999

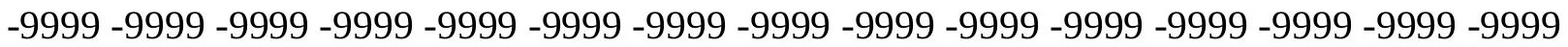

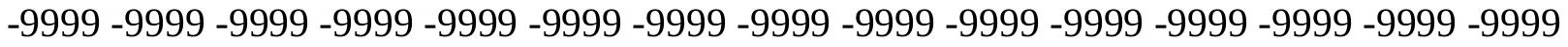
-9999 -9999 -9999 -9999 -9999 -9999 -9999 -9999 -9999 -9999 -9999 -9999 -9999 -9999 -9999 -9999 -9999 -9999 -9999 -9999 -9999 -9999 -9999 -9999 -9999 -9999 -9999 -9999 -9999 -9999 -9999 -9999 -9999 -9999 -9999 -9999 -9999 -9999 -9999 -9999 -9999 -9999 -9999 -9999 -9999 -9999 -9999 -9999 -9999 -9999 -9999 -9999 -9999 -9999 -9999 -9999 -9999 -9999 -9999 -9999 -

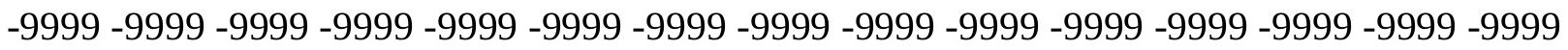
-9999 -9999 -9999 -9999 -9999 -9999 -9999 -9999 -9999 -9999 -9999 -9999 -9999 -9999 -9999 -

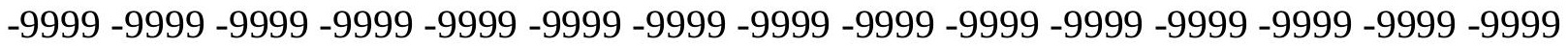
-9999 -9999 -9999 -9999 -9999 -9999 -9999 -9999 -9999 -9999 -9999 -9999 -9999 -9999 -9999 -9999 -9999 -9999 -9999 -9999 -9999 -9999 -9999 -9999 -9999 -9999 -9999 -9999 -9999 -9999 -9999 -9999 -9999 -9999 -9999 -9999 -9999 -9999 -9999 -9999 -9999 -9999 -9999 -9999 - -999 -

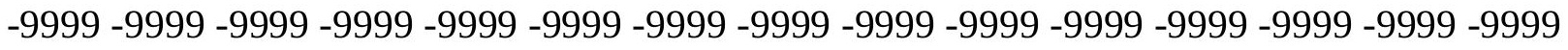

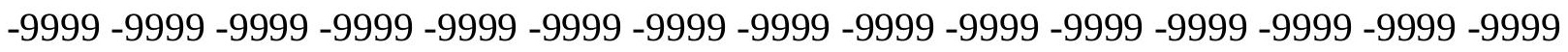
-9999 -9999 -9999 -9999 -9999 -9999 -9999 -9999 -9999 -9999 -9999 -9999 -9999 -9999 -9999 -9999 -9999 -9999 -9999 -9999 -9999 -9999 -9999 -9999 -9999 -9999 -9999 -9999 -9999 -9999 -9999 -9999 -9999 -9999 -9999 -9999 -9999 -9999 -9999 -9999 -9999 -9999 -9999 -9999 -9999 -

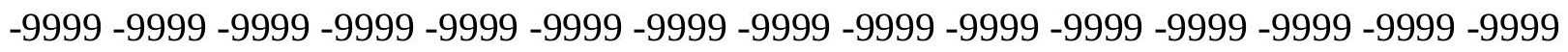
-9999 -9999 -9999 -9999 -9999 -9999 -9999 -9999 -9999 -9999 -9999 -9999 -9999 -9999 -9999 -9999 -9999 -9999 -9999 -9999 -9999 -9999 -9999 -9999 -9999 -9999 -9999 -9999 -9999 -9999 -

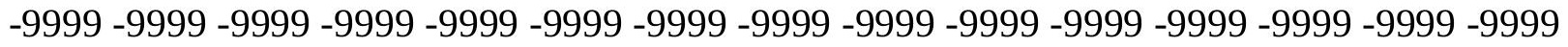
-9999 -9999 -9999 -9999 -9999 -9999 -9999 -9999 -9999 -9999 -9999 -9999 -9999 -9999 -9999 -9999 -9999 -9999 -9999 -9999 -9999 -9999 -9999 -9999 -9999 -9999 -9999 -9999 -9999 -999 -

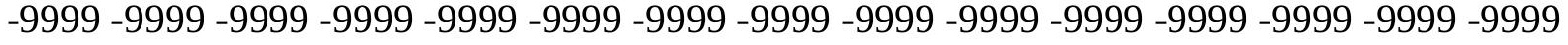
-9999 -9999 -9999 -9999 -9999 -9999 -9999 -9999 -9999 -9999 -9999 -9999 -9999 -9999 -9999 -

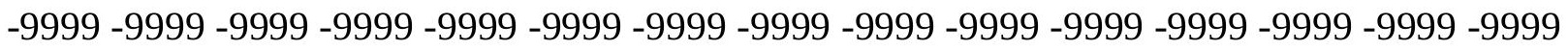

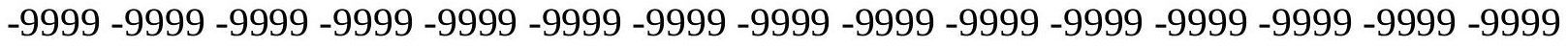

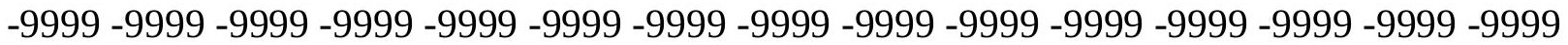

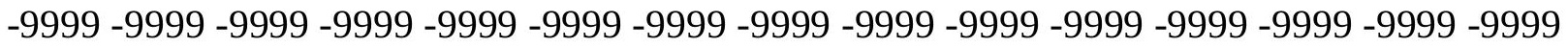

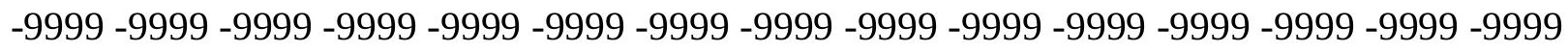

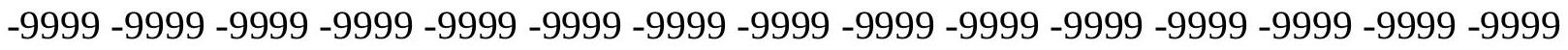

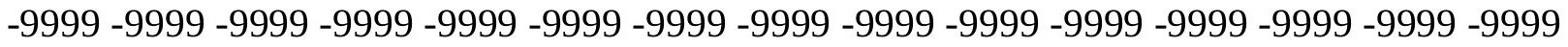
-9999 -9999 -9999 -9999 -9999 -9999 -9999 -9999 -9999 -9999 -9999 -9999 -9999 -9999 -9999 -

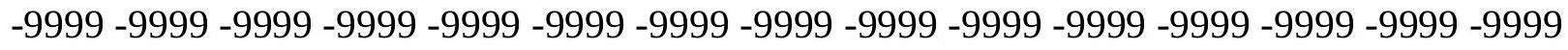

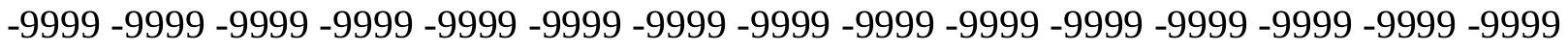
-9999 -9999 -9999 -9999 -9999 -9999 -9999 -9999 -9999 -9999 -9999 -9999 -9999 -9999 -9999 -9999 -9999 -9999 -9999 -9999 -9999 -9999 -9999 -9999 -9999 -9999 -9999 -9999 -9999 -9999 -9999 -9999 -9999 -9999 -9999 -9999 -9999 -9999 -9999 -9999 -9999 -9999 -9999 -9999 -

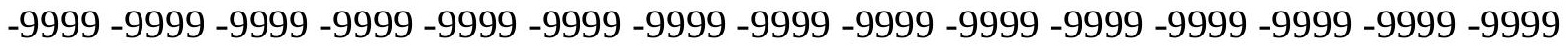


-9999 -9999 -9999 -9999 -9999 -9999 -9999 -9999 -9999 -9999 -9999 -9999 -9999 -9999 -9999 -9999 -9999 -9999 -9999 -9999 -9999 -9999 -9999 -9999 -9999 -9999 -9999 -9999 -9999 -9999 -

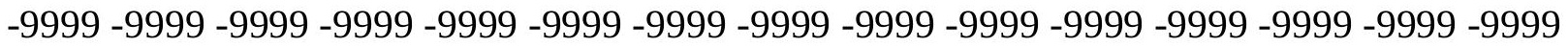
-9999 -9999 -9999 -9999 -9999 -9999 -9999 -9999 -9999 -9999 -9999 -9999 -9999 -9999 -9999 -9999 -9999 -9999 -9999 -9999 -9999 -9999 -9999 -9999-9999 -9999 -9999 -9999 -9999 -9999 -9999 -9999 -9999 -9999 -9999 -9999 -9999 -9999 -9999 -9999 -9999 -9999 -9999 -9999 -9999 -9999 -9999 -9999 -9999 -9999 -9999 -9999 -9999 -9999 -9999 -9999 -9999 -9999 -9999 -9999

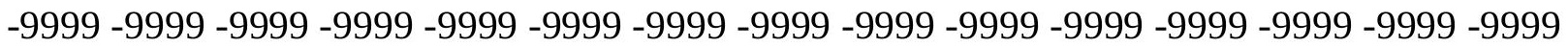

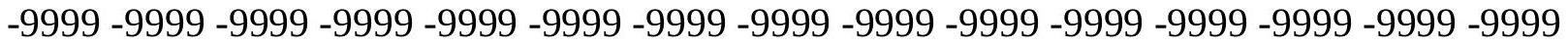
-9999 -9999 -9999 -9999 -9999 -9999 -9999 -9999 -9999 -9999 -9999 -9999 -9999 -9999 -9999 -9999 -9999 -9999 -9999 -9999 -9999 -9999 -9999 -9999 -9999 -9999 -9999 -9999 -9999 -9999 -9999 -9999 -9999 -9999 -9999 -9999 -9999 -9999 -9999 -9999 -9999 -9999 -9999 -9999 -9999 -9999 -9999 -9999 -9999 -9999 -9999 -9999 -9999 -9999 -9999 -9999 -9999 -9999 -9999 -9999 -

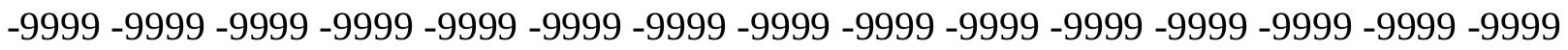
-9999 -9999 -9999 -9999 -9999 -9999 -9999 -9999 -9999 -9999 -9999 -9999 -9999 -9999 -9999 -

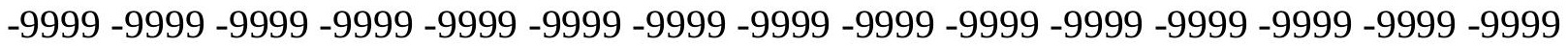
-9999 -9999 -9999 -9999 -9999 -9999 -9999 -9999 -9999 -9999 -9999 -9999 -9999 -9999 -9999 -9999 -9999 -9999 -9999 -9999 -9999 -9999 -9999 -9999 -9999 -9999 -9999 -9999 -9999 - 9999 -9999 -9999 -9999 -9999 -9999 -9999 -9999 -9999 -9999 -9999 -9999 -9999 -9999 -9999 -9999 -

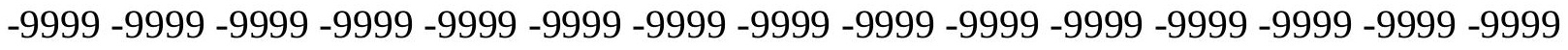

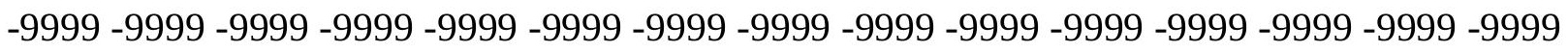
-9999 -9999 -9999 -9999 -9999 -9999 -9999 -9999 -9999 -9999 -9999 -9999 -9999 -9999 - 9999 -9999 -9999 -9999 -9999 -9999 -9999 -9999 -9999 -9999 -9999 -9999 -9999 -9999 -9999 -9999 -9999 -9999 -9999 -9999 -9999 -9999 -9999 -9999 -9999 -9999 -9999 -9999 -9999 -9999 -9999 -9999 -9999 -9999 -9999 -9999 -9999 -9999 -9999 -9999 -9999 -9999 -9999 -9999 -9999 -9999 -9999 -9999 -9999 -9999 -9999 -9999 -9999 -9999 -9999 -9999 -9999 -9999 -9999 -9999 -9999 -9999 -9999 -9999 -9999 -9999 -9999 -9999 -9999 -9999 -9999 -9999 -9999 -9999 -9999 -

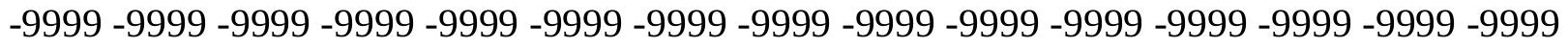
-9999 -9999 -9999 -9999 -9999 -9999 -9999 -9999 -9999 -9999 -9999 -9999 -9999 -9999 -9999 -9999 -9999 -9999 -9999 -9999 -9999 -9999 -9999 -9999 -9999 -9999 -9999 -9999 -9999 -999 -9999 -9999 -9999 -9999 -9999 -9999 -9999 -9999 -9999 -9999 -9999 -9999 -9999 -9999 -9999 -9999 -9999 -9999 -9999 -9999 -9999 -9999 -9999 -9999 -9999 -9999 -9999 -9999 -9999 -9999 -

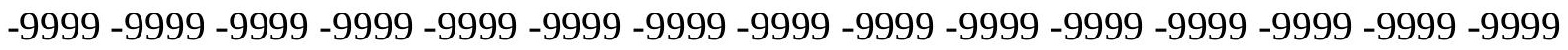

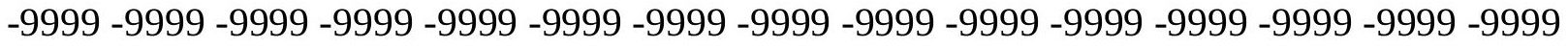

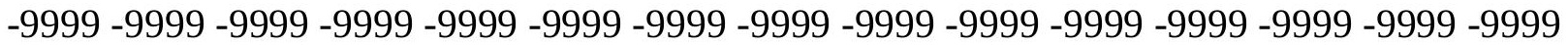

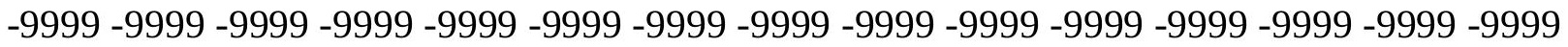

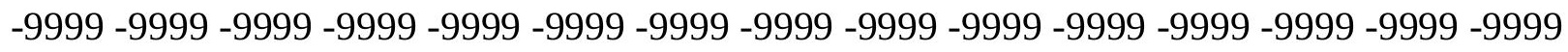

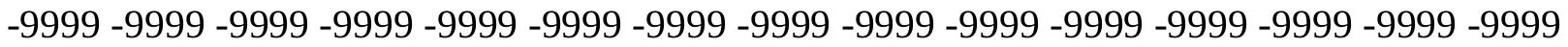

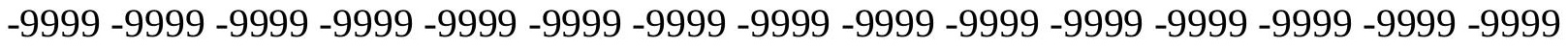
-9999 -9999 -9999 -9999 -9999 -9999 -9999 -9999 -9999 -9999 -9999 -9999 -9999 -9999 -9999 -

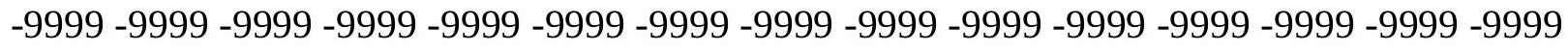

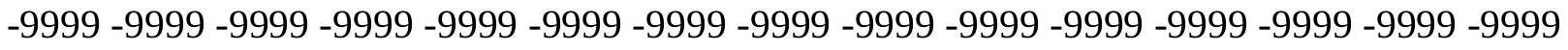
-9999 -9999 -9999 -9999 -9999 -9999 -9999 -9999 -9999 -9999 -9999 -9999 -9999 -9999 -9999 -9999 -9999 -9999 -9999 -9999 -9999 -9999 -9999 -9999-9999 -9999 -9999 -9999 -9999 -9999 -9999 -9999 -9999 -9999 -9999 -9999 -9999 -9999 -9999 -9999 -9999 -9999 -9999 -9999 -9999 -

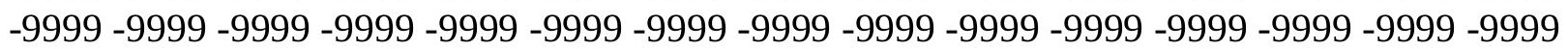


-9999 -9999 -9999 -9999 -9999 -9999 -9999 -9999 -9999 -9999 -9999 -9999 -9999 -9999 -9999 -9999 -9999 -9999 -9999 -9999 -9999 -9999 -9999 -9999 -9999 -9999 -9999 -9999 -9999 -9999 -9999 -9999 -9999 -9999 -9999 -9999 -9999 -9999 -9999 -9999 -9999 -9999 -9999 -9999 - 9999 -9999 -9999 -9999 -9999 -9999 -9999 -9999 -9999 -9999 -9999 -9999 -9999 -9999 -9999 -9999 -9999 -9999 -9999 -9999 -9999 -9999 -9999 -9999 -9999 -9999 -9999 -9999 -9999 -9999 -9999 -9999 -9999 -9999 -9999 -9999 -9999 -9999 -9999 -9999 -9999 -9999 -9999 -9999 -9999 -9999 -9999 -9999 -9999 -9999 -9999 -9999 -9999 -9999 -9999 -9999 -9999 -9999 -9999 -9999

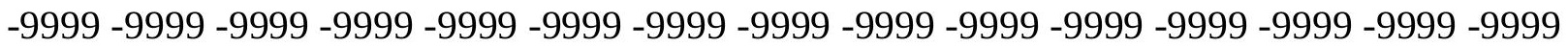

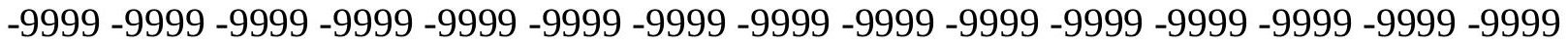
-9999 -9999 -9999 -9999 -9999 -9999 -9999 -9999 -9999 -9999 -9999 -9999 -9999 -9999 -9999 -9999 -9999 -9999 -9999 -9999 -9999 -9999 -9999 -9999 -9999 -9999 -9999 -9999 -9999 -9999 -9999 -9999 -9999 -9999 -9999 -9999 -9999 -9999 -9999 -9999 -9999 -9999 -9999 -9999 -9999 -9999 -9999 -9999 -9999 -9999 -9999 -9999 -9999 -9999 -9999 -9999 -9999 -9999 -9999 -9999 -9999 -9999 -9999 -9999 -9999 -9999 -9999 -9999 -9999 -9999 -9999 -9999 -9999 -9999 -9999 -9999 -9999 -9999 -9999 -9999 -9999 -9999 -9999 -9999 -9999 -9999 -9999 -9999 -9999 -9999 -

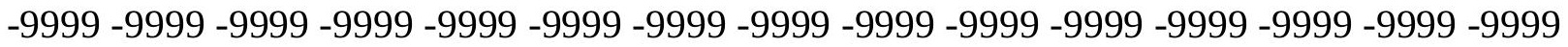
-9999 -9999 -9999 -9999 -9999 -9999 -9999 -9999 -9999 -9999 -9999 -9999 -9999 -9999 -9999 -9999 -9999 -9999 -9999 -9999 -9999 -9999 -9999 -9999 -9999 -9999 -9999 -9999 -9999 - 9999 -9999 -9999 -9999 -9999 -9999 -9999 -9999 -9999 -9999 -9999 -9999 -9999 -9999 -9999 -9999 -

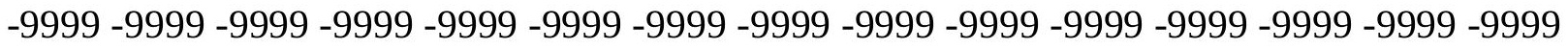

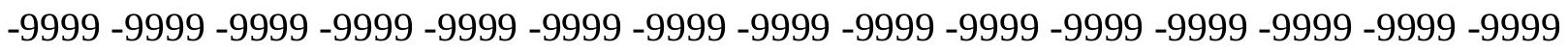

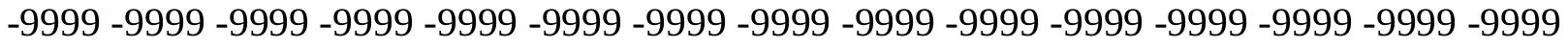
-9999 -9999 -9999 -9999 -9999 -9999 -9999 -9999 -9999 -9999 -9999 -9999 -9999 -9999 -9999 -9999 -9999 -9999 -9999 -9999 -9999 -9999 -9999 -9999 -9999 -9999 -9999 -9999 -9999 -9999 -

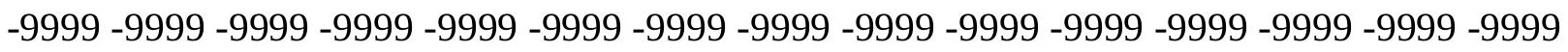
-9999 -9999 -9999 -9999 -9999 -9999 -9999 -9999 -9999 -9999 -9999 -9999 -9999 -9999 -9999 -9999 -9999 -9999 -9999 -9999 -9999 -9999 -9999 -9999 -9999 -9999 -9999 -9999 -9999 -9999 -

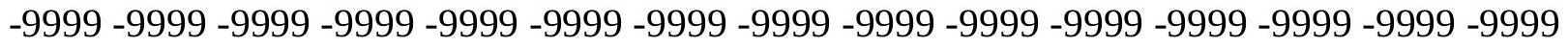
-9999 -9999 -9999 -9999 -9999 -9999 -9999 -9999 -9999 -9999 -9999 -9999 -9999 -9999 -9999 -9999 -9999 -9999 -9999 -9999 -9999 -9999 -9999 -9999 -9999 -9999 -9999 -9999 -9999 -999 -9999 -9999 -9999 -9999 -9999 -9999 -9999 -9999 -9999 -9999 -9999 -9999 -9999 -9999 -9999 -9999 -9999 -9999 -9999 -9999 -9999 -9999 -9999 -9999 -9999 -9999 -9999 -9999 -9999 -

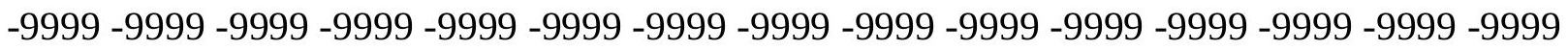

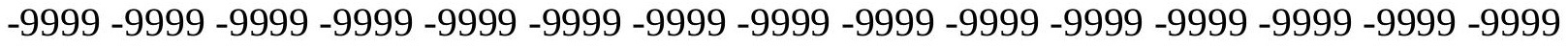

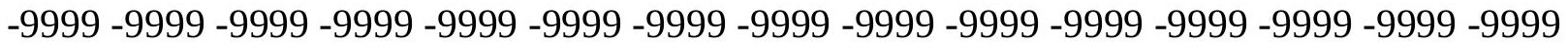

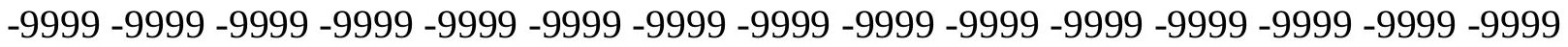

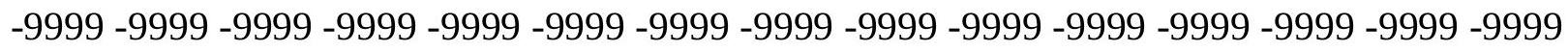

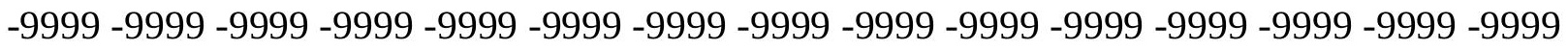

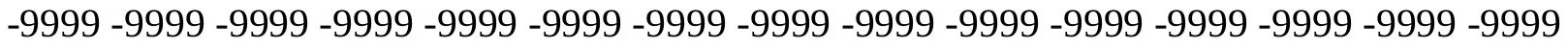
-9999 -9999 -9999 -9999 -9999 -9999 -9999 -9999 -9999 -9999 -9999 -9999 -9999 -9999 -9999 -

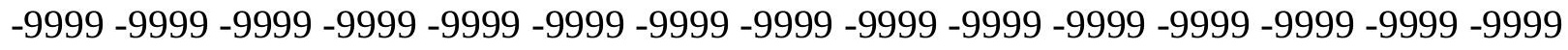

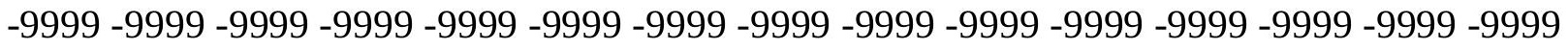
-9999 -9999 -9999 -9999 -9999 -9999 -9999 -9999 -9999 -9999 -9999 -9999 -9999 -9999 -9999 -9999 -9999 -9999 -9999 -9999 -9999 -9999 -9999 -9999-9999 -9999 -9999 -9999 -9999 -9999 -9999 -9999 -9999 -9999 -9999 -9999 -9999 -9999 -9999 -9999 -9999 -9999 -9999 -9999 -9999 -

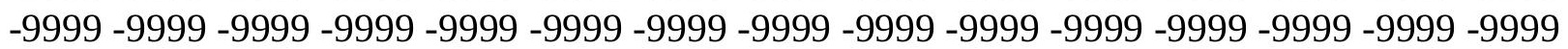


-9999 -9999 -9999 -9999 -9999 -9999 -9999 -9999 -9999 -9999 -9999 -9999 -9999 -9999 -9999 -9999 -9999 -9999 -9999 -9999 -9999 -9999 -9999 -9999 -9999 -9999 -9999 -9999 -9999 -9999 -

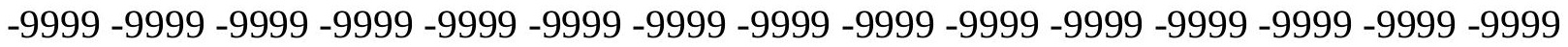
-9999 -9999 -9999 -9999 -9999 -9999 -9999 -9999 -9999 -9999 -9999 -9999 -9999 -9999 -9999 -9999 -9999 -9999 -9999 -9999 -9999 -9999 -9999 -9999-9999 -9999 -9999 -9999 -9999 -9999 -9999 -9999 -9999 -9999 -9999 -9999 -9999 -9999 -9999 -9999 -9999 -9999 -9999 -9999 -9999 -9999 -9999 -9999 -9999 -9999 -9999 -9999 -9999 -9999 -9999 -9999 -9999 -9999 -9999 -9999

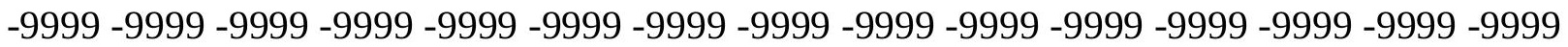

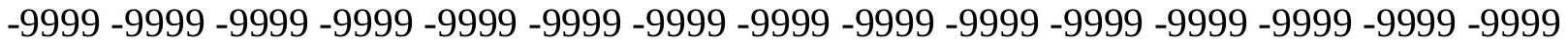

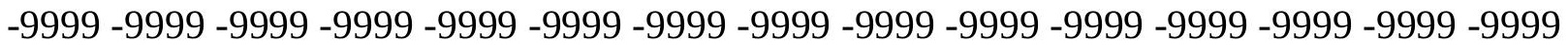
-9999 -9999 -9999 -9999 -9999 -9999 -9999 -9999 -9999 -9999 -9999 -9999 -9999 -9999 -9999 -9999 -9999 -9999 -9999 -9999 -9999 -9999 -9999 -9999 -9999 -9999 -9999 -9999 -9999 -9999 -9999 -9999 -9999 -9999 -9999 -9999 -9999 -9999 -9999 -9999 -9999 -9999 -9999 -9999 -

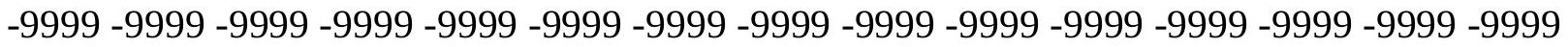
-9999 -9999 -9999 -9999 -9999 -9999 -9999 -9999 -9999 -9999 -9999 -9999 -9999 -9999 -9999 -

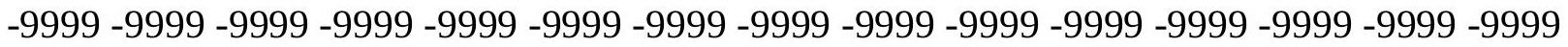
-9999 -9999 -9999 -9999 -9999 -9999 -9999 -9999 -9999 -9999 -9999 -9999 -9999 -9999 -9999 -9999 -9999 -9999 -9999 -9999 -9999 -9999 -9999 -9999 -9999 -9999 -9999 -9999 -9999 -9999 -9999 -9999 -9999 -9999 -9999 -9999 -9999 -9999 -9999 -9999 -9999 -9999 -9999 -9999 -9999 -

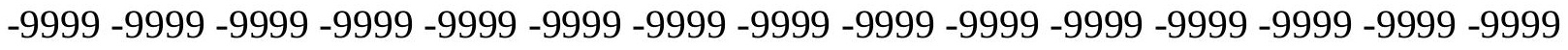

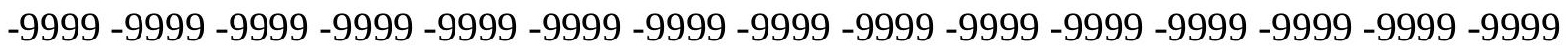
-9999 -9999 -9999 -9999 -9999 -9999 -9999 -9999 -9999 -9999 -9999 -9999 -9999 -9999 -9999 -9999 -9999 -9999 -9999 -9999 -9999 -9999 -9999 -9999 -9999 -9999 -9999 -9999 -9999 -9999 -9999 -9999 -9999 -9999 -9999 -9999 -9999 -9999 -9999 -9999 -9999 -9999 -9999 -9999 -9999 -

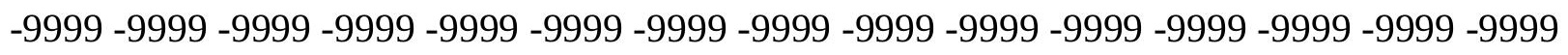
-9999 -9999 -9999 -9999 -9999 -9999 -9999 -9999 -9999 -9999 -9999 -9999 -9999 -9999 -9999 -9999 -9999 -9999 -9999 -9999 -9999 -9999 -9999 -9999 -9999 -9999 -9999 -9999 -9999 -9999 -

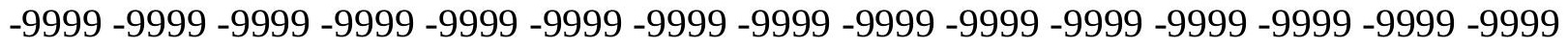
-9999 -9999 -9999 -9999 -9999 -9999 -9999 -9999 -9999 -9999 -9999 -9999 -9999 -9999 -9999 -9999 -9999 -9999 -9999 -9999 -9999 -9999 -9999 -9999 -9999 -9999 -9999 -9999 -9999 -999 -9999 -9999 -9999 -9999 -9999 -9999 -9999 -9999 -9999 -9999 -9999 -9999 -9999 -9999 -9999 -9999 -9999 -9999 -9999 -9999 -9999 -9999 -9999 -9999 -9999 -9999 -9999 -9999 -9999 -9999 -

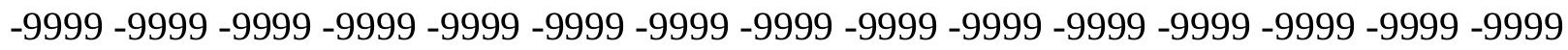

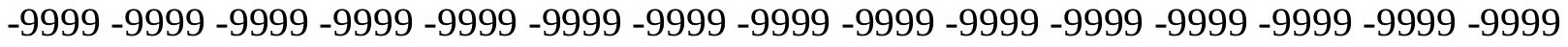

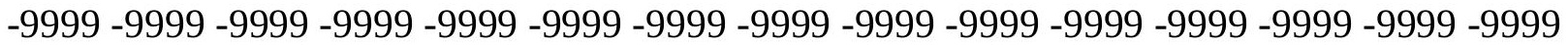
-9999 -9999 -9999 -9999 -9999 -9999 -9999 -9999 -9999 -9999 -9999 -9999 -9999 -9999 -9999 -

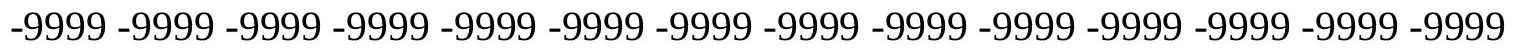

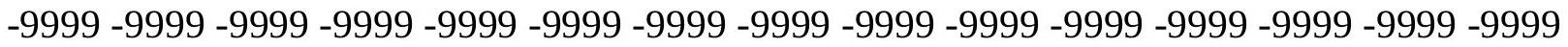
-9999 -9999 -9999 -9999 -9999 -9999 -9999 -9999 -9999 -9999 -9999 -9999 -9999 - 9999 - -999 -9999 -9999 -9999 -9999 -9999 -9999 -9999 -9999 -9999 -9999 -9999 -9999 -9999 -9999 -9999 -

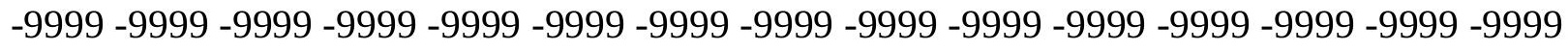

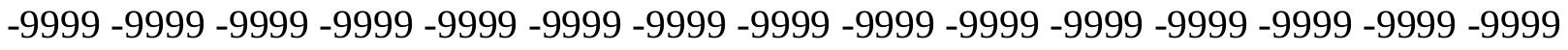
-9999 -9999 -9999 -9999 -9999 -9999 -9999 -9999 -9999 -9999 -9999 -9999 -9999 -9999 -9999 -9999 -9999 -9999 -9999 -9999 -9999 -9999 -9999 -9999-9999 -9999 -9999 -9999 -9999 -9999 -9999 -9999 -9999 -9999 -9999 -9999 -9999 -9999 -9999 -9999 -9999 -9999 -9999 -9999 -9999 -

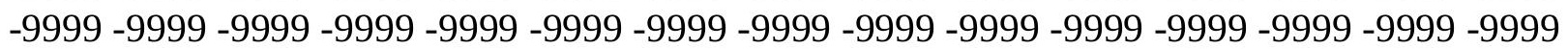


-9999 -9999 -9999 -9999 -9999 -9999 -9999 -9999 -9999 -9999 -9999 -9999 -9999 -9999 -9999 -9999 -9999 -9999 -9999 -9999 -9999 -9999 -9999 -9999 -9999 -9999 -9999 -9999 -9999 -9999 -

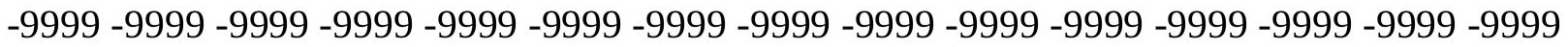
-9999 -9999 -9999 -9999 -9999 -9999 -9999 -9999 -9999 -9999 -9999 -9999 -9999 -9999 -9999 -9999 -9999 -9999 -9999 -9999 -9999 -9999 -9999 -9999-9999 -9999 -9999 -9999 -9999 -9999 -9999 -9999 -9999 -9999 -9999 -9999 -9999 -9999 -9999 -9999 -9999 -9999 -9999 -9999 -9999 -9999 -9999 -9999 -9999 -9999 -9999 -9999 -9999 -9999 -9999 -9999 -9999 -9999 -9999 -9999

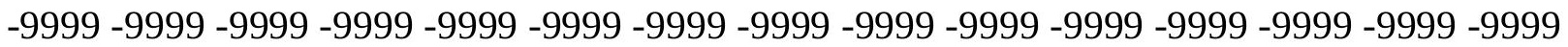

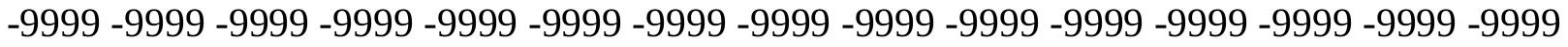
-9999 -9999 -9999 -9999 -9999 -9999 -9999 -9999 -9999 -9999 -9999 -9999 -9999 -9999 -9999 -9999 -9999 -9999 -9999 -9999 -9999 -9999 -9999 -9999 -9999 -9999 -9999 -9999 -9999 -9999 -9999 -9999 -9999 -9999 -9999 -9999 -9999 -9999 -9999 -9999 -9999 -9999 -9999 -9999 -9999 -9999 -9999 -9999 -9999 -9999 -9999 -9999 -9999 -9999 -9999 -9999 -9999 -9999 -9999 -9999 -9999 -9999 -9999 -9999 -9999 -9999 -9999 -9999 -9999 -9999 -9999 -9999 -9999 -9999 -9999 -9999 -9999 -9999 -9999 -9999 -9999 -9999 -9999 -9999 -9999 -9999 -9999 -9999 -9999 -9999 -

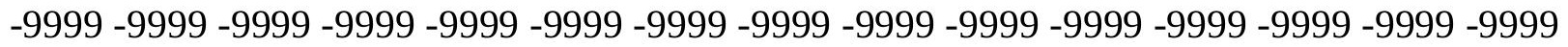
-9999 -9999 -9999 -9999 -9999 -9999 -9999 -9999 -9999 -9999 -9999 -9999 -9999 -9999 -9999 -9999 -9999 -9999 -9999 -9999 -9999 -9999 -9999 -9999 -9999 -9999 -9999 -9999 -9999 -9999 -9999 -9999 -9999 -9999 -9999 -9999 -9999 -9999 -9999 -9999 -9999 -9999 -9999 -9999 -

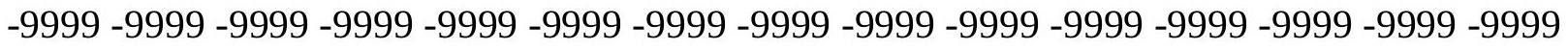
-9999 -9999 -9999 -9999 -9999 -9999 -9999 -9999 -9999 -9999 -9999 -9999 -9999 -9999 -9999 -999 -

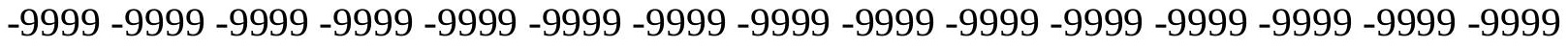
-9999 -9999 -9999 -9999 -9999 -9999 -9999 -9999 -9999 -9999 -9999 -9999 -9999 -9999 -9999 -9999 -9999 -9999 -9999 -9999 -9999 -9999 -9999 -9999 -9999 -9999 -9999 -9999 -9999 -9999 -9999 -9999 -9999 -9999 -9999 -9999 -9999 -9999 -9999 -9999 -9999 -9999 -9999 -9999 -9999 -9999 -9999 -9999 -9999 -9999 -9999 -9999 -9999 -9999 -9999 -9999 -9999 -9999 -9999 -9999 -9999 -9999 -9999 -9999 -9999 -9999 -9999 -9999 -9999 -9999 -9999 -9999 -9999 -9999 -9999 -

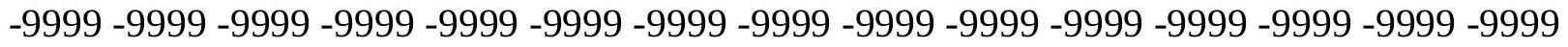
-9999 -9999 -9999 -9999 -9999 -9999 -9999 -9999 -9999 -9999 -9999 -9999 -9999 -9999 -9999 -9999 -9999 -9999 -9999 -9999 -9999 -9999 -9999 -9999 -9999 -9999 -9999 -9999 -9999 -999 -9999 -9999 -9999 -9999 -9999 -9999 -9999 -9999 -9999 -9999 -9999 -9999 -9999 -9999 -9999 -9999 -9999 -9999 -9999 -9999 -9999 -9999 -9999 -9999 -9999 -9999 -9999 -9999 -9999 -9999 -

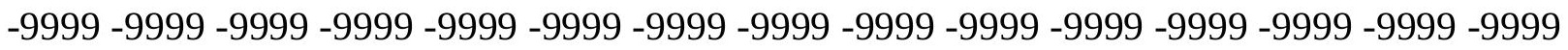

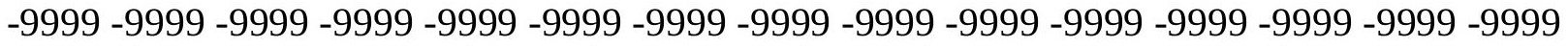

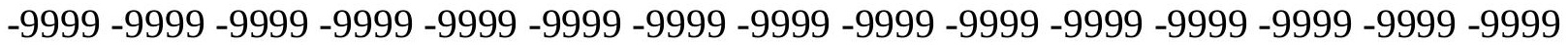
-9999 -9999 -9999 -9999 -9999 -9999 -9999 -9999 -9999 -9999 -9999 -9999 -9999 -9999 -9999

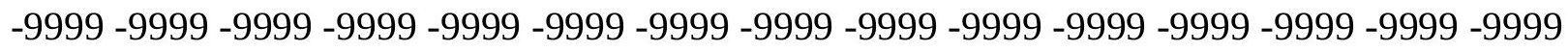

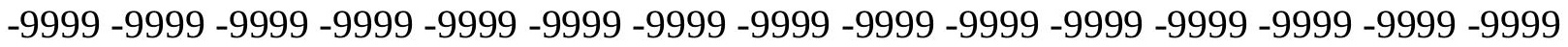
-9999 -9999 -9999 -9999 -9999 -9999 -9999 -9999 -9999 -9999 -9999 -9999 -9999 - 9999 - -999 -9999 -9999 -9999 -9999 -9999 -9999 -9999 -9999 -9999 -9999 -9999 -9999 -9999 -9999 -9999 -

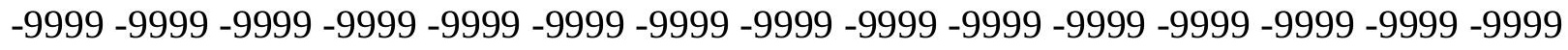

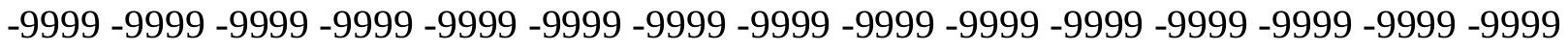
-9999 -9999 -9999 -9999 -9999 -9999 -9999 -9999 -9999 -9999 -9999 -9999 -9999 -9999 -9999 -9999 -9999 -9999 -9999 -9999 -9999 -9999 -9999 -9999 -9999 -9999 -9999 -9999 -9999 -9999 -9999 -9999 -9999 -9999 -9999 -9999 -9999 -9999 -9999 -9999 -9999 -9999 -9999 -9999 -

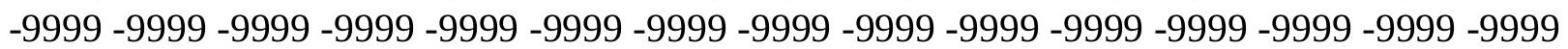


-9999 -9999 -9999 -9999 -9999 -9999 -9999 -9999 -9999 -9999 -9999 -9999 -9999 -9999 -9999 -9999 -9999 -9999 -9999 -9999 -9999 -9999 -9999 -9999 -9999 -9999 -9999 -9999 -9999 -9999 -9999 -9999 -9999 -9999 -9999 -9999 -9999 -9999 -9999 -9999 -9999 -9999 -9999 -9999 - 9999 -9999 -9999 -9999 -9999 -9999 -9999 -9999 -9999 -9999 -9999 -9999 -9999 -9999 -9999 -9999 -9999 -9999 -9999 -9999 -9999 -9999 -9999 -9999 -9999-9999 -9999 -9999 -9999 -9999 -9999 -9999 -9999 -9999 -9999 -9999 -9999 -9999 -9999 -9999 -9999 -9999 -9999 -9999 -9999 -9999 -9999 -9999 -9999 -9999 -9999 -9999 -9999 -9999 -9999 -9999 -9999 -9999 -9999 -9999 -9999

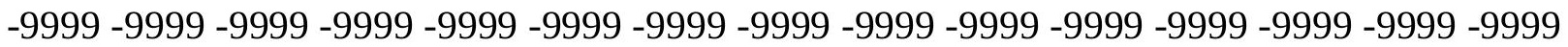

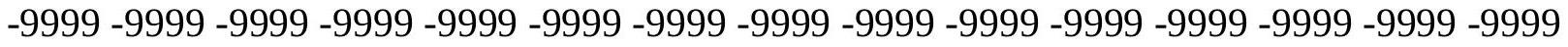
-9999 -9999 -9999 -9999 -9999 -9999 -9999 -9999 -9999 -9999 -9999 -9999 -9999 -9999 -9999 -9999 -9999 -9999 -9999 -9999 -9999 -9999 -9999 -9999 -9999 -9999 -9999 -9999 -9999 -9999 -9999 -9999 -9999 -9999 -9999 -9999 -9999 -9999 -9999 -9999 -9999 -9999 -9999 -9999 -9999 -9999 -9999 -9999 -9999 -9999 -9999 -9999 -9999 -9999 -9999 -9999 -9999 -9999 -9999 -9999 -

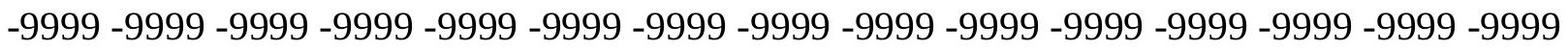
-9999 -9999 -9999 -9999 -9999 -9999 -9999 -9999 -9999 -9999 -9999 -9999 -9999 -9999 -9999 -

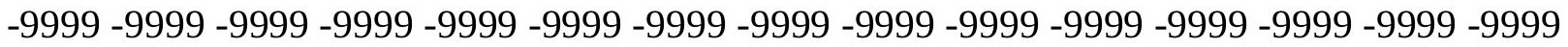
-9999 -9999 -9999 -9999 -9999 -9999 -9999 -9999 -9999 -9999 -9999 -9999 -9999 -9999 -9999 -9999 -9999 -9999 -9999 -9999 -9999 -9999 -9999 -9999 -9999 -9999 -9999 -9999 -9999 -9999 -9999 -9999 -9999 -9999 -9999 -9999 -9999 -9999 -9999 -9999 -9999 -9999 -9999 -9999 -9999 -

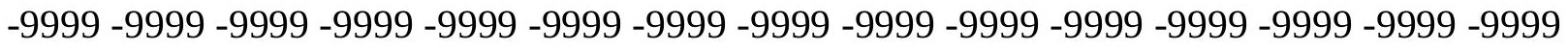
-9999 -9999 -9999 -9999 -9999 -9999 -9999 -9999 -9999 -9999 -9999 -9999 -9999 -9999 -9999 -999 -9999 -9999 -9999 -9999 -9999 -9999 -9999 -9999 -9999 -9999 -9999 -9999 -9999 -9999 - 9999 -9999 -9999 -9999 -9999 -9999 -9999 -9999 -9999 -9999 -9999 -9999 -9999 -9999 -9999 -

-9999 -9999 -9999 -9999 -9999 -9999 -9999 -9999 -9999 -9999 -9999 -9999 -9999 -9999 -9999 -

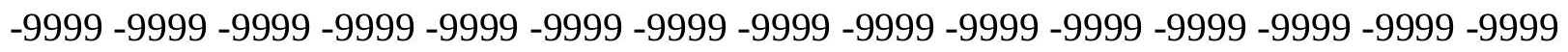
-9999 -9999 -9999 -9999 -9999 -9999 -9999 -9999 -9999 -9999 -9999 -9999 -9999 -9999 -9999 -9999 -9999 -9999 -9999 -9999 -9999 -9999 -9999 -9999 -9999 -9999 -9999 -9999 -9999 -9999 -

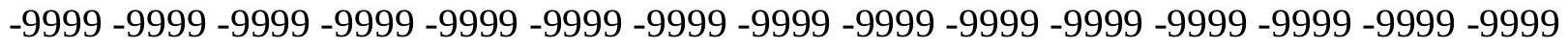
-9999 -9999 -9999 -9999 -9999 -9999 -9999 -9999 -9999 -9999 -9999 -9999 -9999 -9999 -9999 -9999 -9999 -9999 -9999 -9999 -9999 -9999 -9999 -9999 -9999 -9999 -9999 -9999 -9999 -999 -

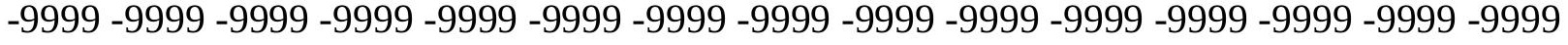
-9999 -9999 -9999 -9999 -9999 -9999 -9999 -9999 -9999 -9999 -9999 -9999 -9999 -9999 -9999 -

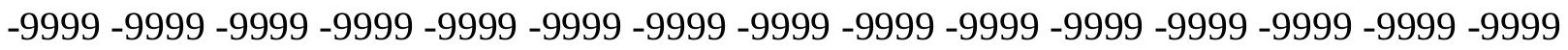

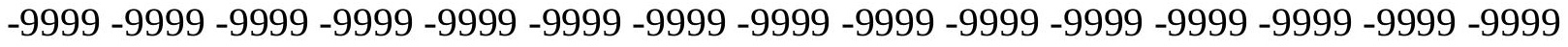

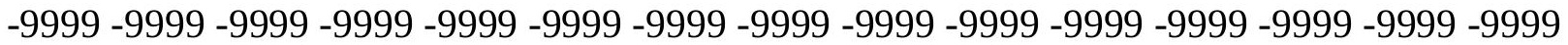

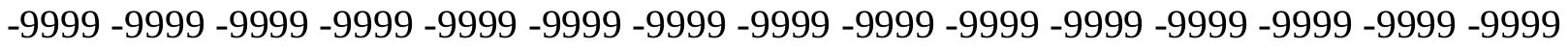

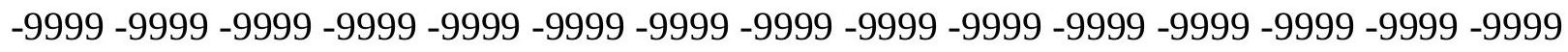

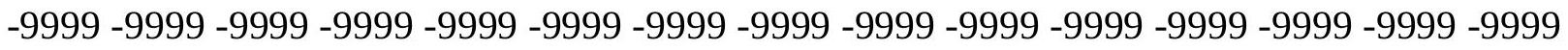

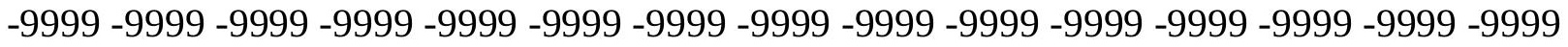
-9999 -9999 -9999 -9999 -9999 -9999 -9999 -9999 -9999 -9999 -9999 -9999 -9999 -9999 -9999 -

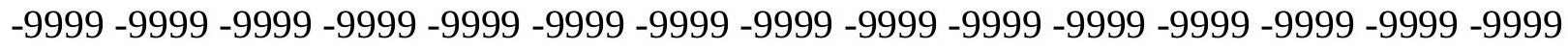

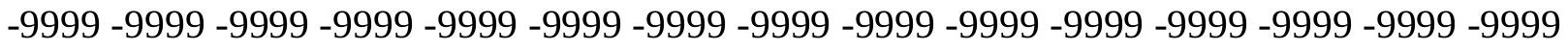
-9999 -9999 -9999 -9999 -9999 -9999 -9999 -9999 -9999 -9999 -9999 -9999 -9999 -9999 -9999 -9999 -9999 -9999 -9999 -9999 -9999 -9999 -9999 -9999-9999 -9999 -9999 -9999 -9999 -9999 -9999 -9999 -9999 -9999 -9999 -9999 -9999 -9999 -9999 -9999 -9999 -9999 -9999 -9999 -9999 -

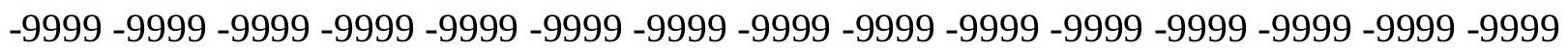


-9999 -9999 -9999 -9999 -9999 -9999 -9999 -9999 -9999 -9999 -9999 -9999 -9999 -9999 -9999 -9999 -9999 -9999 -9999 -9999 -9999 -9999 -9999 -9999 -9999 -9999 -9999 -9999 -9999 -9999 -9999 -9999 -9999 -9999 -9999 -9999 -9999 -9999 -9999 -9999 -9999 -9999 -9999 -9999 -9999 -9999 -9999 -9999 -9999 -9999 -9999 -9999 -9999 -9999 -9999 -9999 -9999 -9999 -9999 -9999 -9999 -9999 -9999 -9999 -9999 -9999 -9999 -9999-9999 -9999 -9999 -9999 -9999 -9999 -9999 -9999 -9999 -9999 -9999 -9999 -9999 -9999 -9999 -9999 -9999 -9999 -9999 -9999 -9999 -9999 -9999 -9999 -9999 -9999 -9999 -9999 -9999 -9999 -9999 -9999 -9999 -9999 -9999 -9999

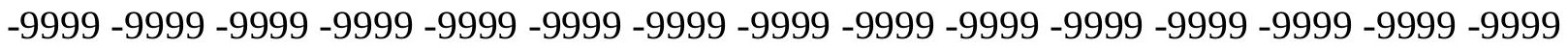

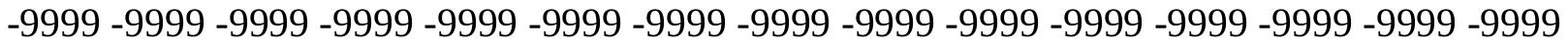
-9999 -9999 -9999 -9999 -9999 -9999 -9999 -9999 -9999 -9999 -9999 -9999 -9999 -9999 -9999 -9999 -9999 -9999 -9999 -9999 -9999 -9999 -9999 -9999 -9999 -9999 -9999 -9999 -9999 -9999 -9999 -9999 -9999 -9999 -9999 -9999 -9999 -9999 -9999 -9999 -9999 -9999 -9999 -9999 -9999 -9999 -9999 -9999 -9999 -9999 -9999 -9999 -9999 -9999 -9999 -9999 -9999 -9999 -9999 -9999 -

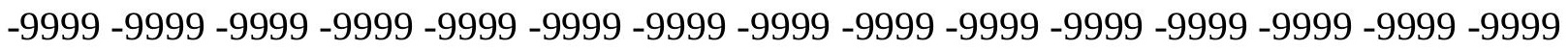
-9999 -9999 -9999 -9999 -9999 -9999 -9999 -9999 -9999 -9999 -9999 -9999 -9999 -9999 -9999 -

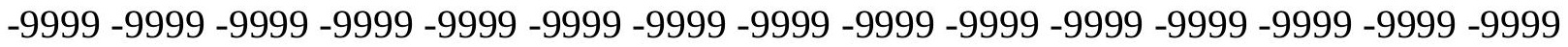
-9999 -9999 -9999 -9999 -9999 -9999 -9999 -9999 -9999 -9999 -9999 -9999 -9999 -9999 -9999 -9999 -9999 -9999 -9999 -9999 -9999 -9999 -9999 -9999 -9999 -9999 -9999 -9999 -9999 -9999 -9999 -9999 -9999 -9999 -9999 -9999 -9999 -9999 -9999 -9999 -9999 -9999 -9999 -9999 -9999 -

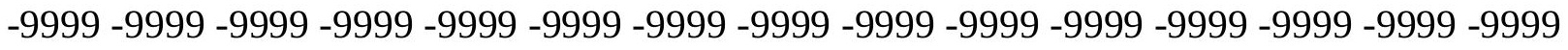

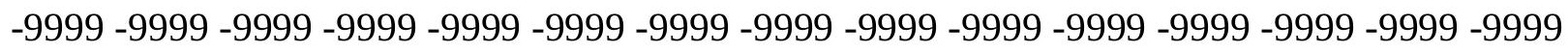
-9999 -9999 -9999 -9999 -9999 -9999 -9999 -9999 -9999 -9999 -9999 -9999 -9999 -9999 -9999 -9999 -9999 -9999 -9999 -9999 -9999 -9999 -9999 -9999 -9999 -9999 -9999 -9999 -9999 -9999 -9999 -9999 -9999 -9999 -9999 -9999 -9999 -9999 -9999 -9999 -9999 -9999 -9999 -9999 -9999 -

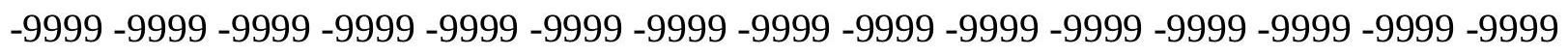
-9999 -9999 -9999 -9999 -9999 -9999 -9999 -9999 -9999 -9999 -9999 -9999 -9999 -9999 -9999 -9999 -9999 -9999 -9999 -9999 -9999 -9999 -9999 -9999 -9999 -9999 -9999 -9999 -9999 -9999 -

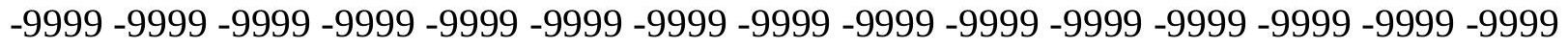
-9999 -9999 -9999 -9999 -9999 -9999 -9999 -9999 -9999 -9999 -9999 -9999 -9999 -9999 -9999 -9999 -9999 -9999 -9999 -9999 -9999 -9999 -9999 -9999 -9999 -9999 -9999 -9999 - -999 -

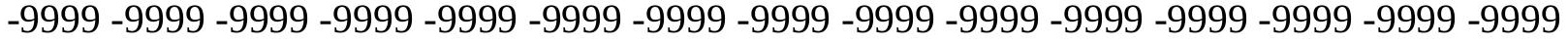
-9999 -9999 -9999 -9999 -9999 -9999 -9999 -9999 -9999 -9999 -9999 -9999 -9999 -9999 -9999 -

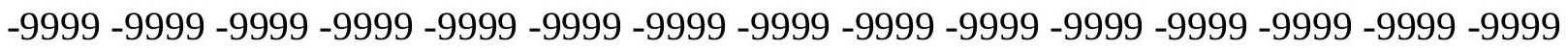

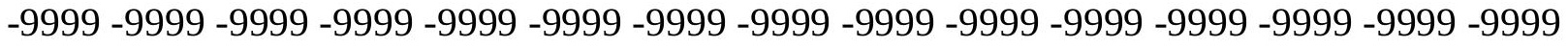

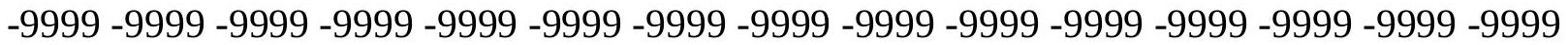

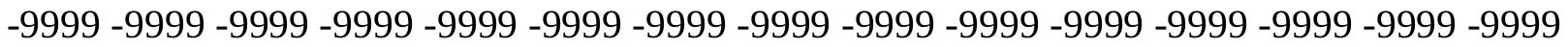

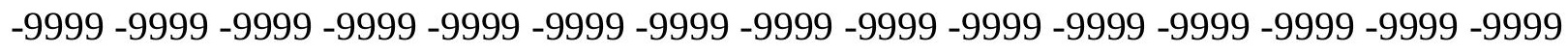

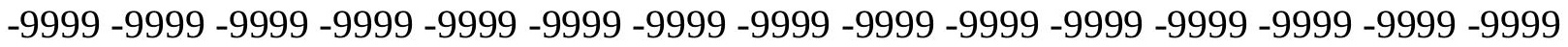

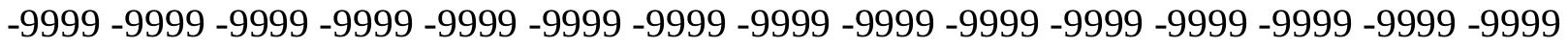
-9999 -9999 -9999 -9999 -9999 -9999 -9999 -9999 -9999 -9999 -9999 -9999 -9999 -9999 -9999 -

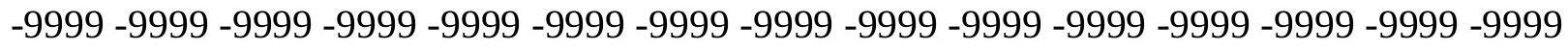

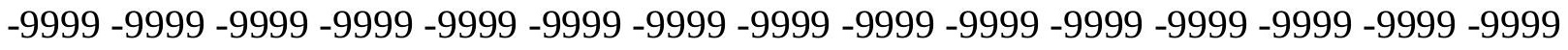
-9999 -9999 -9999 -9999 -9999 -9999 -9999 -9999 -9999 -9999 -9999 -9999 -9999 -9999 -9999 -9999 -9999 -9999 -9999 -9999 -9999 -9999 -9999 -9999-9999 -9999 -9999 -9999 -9999 -9999 -9999 -9999 -9999 -9999 -9999 -9999 -9999 -9999 -9999 -9999 -9999 -9999 -9999 -9999 -9999 -

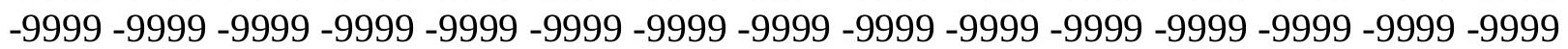


-9999 -9999 -9999 -9999 -9999 -9999 -9999 -9999 -9999 -9999 -9999 -9999 -9999 -9999 -9999 -9999 -9999 -9999 -9999 -9999 -9999 -9999 -9999 -9999 -9999 -9999 -9999 -9999 -9999 -9999 -

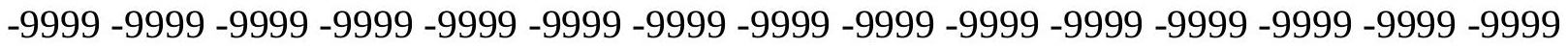
-9999 -9999 -9999 -9999 -9999 -9999 -9999 -9999 -9999 -9999 -9999 -9999 -9999 -9999 -9999 -9999 -9999 -9999 -9999 -9999 -9999 -9999 -9999 -9999-9999 -9999 -9999 -9999 -9999 -9999 -9999 -9999 -9999 -9999 -9999 -9999 -9999 -9999 -9999 -9999 -9999 -9999 -9999 -9999 -9999 -9999 -9999 -9999 -9999 -9999 -9999 -9999 -9999 -9999 -9999 -9999 -9999 -9999 -9999 -9999

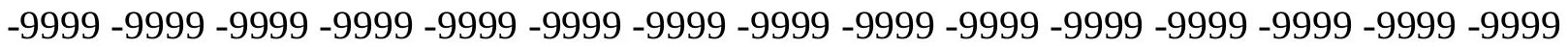
-9999 -9999 -9999 -9999 -9999 -9999 -9999 -9999 -9999 -9999 -9999 -9999 -9999 -9999 -9999 -9999 -9999 -9999 -9999 -9999 -9999 -9999 -9999 -9999 -9999 -9999 -9999 -9999 -9999

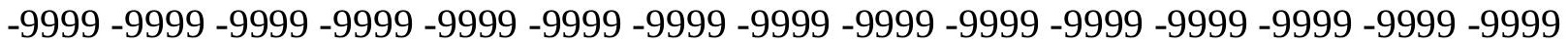
-9999 -9999 -9999 -9999 -9999 -9999 -9999 -9999 -9999 -9999 -9999 -9999 -9999 -9999 -9999 -9999 -9999 -9999 -9999 -9999 -9999 -9999 -9999 -9999 -9999 -9999 -9999 -9999 -9999 -9999 -9999 -9999 -9999 -9999 -9999 -9999 -9999 -9999 -9999 -9999 -9999 -9999 -9999 -9999 - 9999 -9999 -9999 -9999 -9999 -9999 -9999 -9999 -9999 -9999 -9999 -9999 -9999 -9999 -9999 -9999

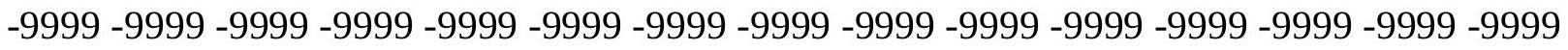
-9999 -9999 -9999 -9999 -9999 -9999 -9999 -9999 -9999 -9999 -9999 -9999 -9999 -9999 -9999 -9999 -9999 -9999 -9999 -9999 -9999 -9999 -9999 -9999 -9999 -9999 -9999 -9999 -9999 -9999 -9999 -9999 -9999 -9999 -9999 -9999 -9999 -9999 -9999 -9999 -9999 -9999 -9999 -9999 -9999 -

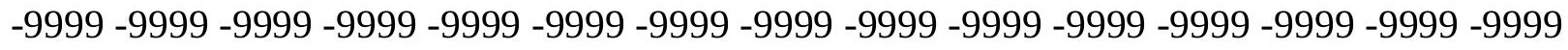

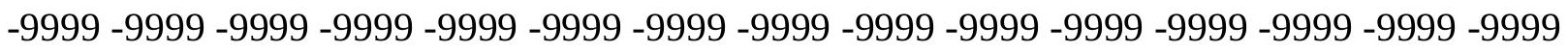
-9999 -9999 -9999 -9999 -9999 -9999 -9999 -9999 -9999 -9999 -9999 -9999 -9999 -9999 -9999 -9999 -9999 -9999 -9999 -9999 -9999 -9999 -9999 -9999 -9999 -9999 -9999 -9999 -9999 -9999 -9999 -9999 -9999 -9999 -9999 -9999 -9999 -9999 -9999 -9999 -9999 -9999 -9999 -9999 -9999 -

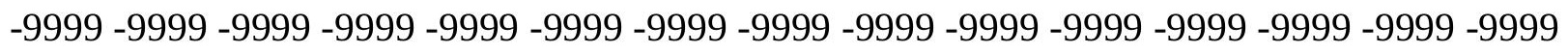
-9999 -9999 -9999 -9999 -9999 -9999 -9999 -9999 -9999 -9999 -9999 -9999 -9999 -9999 -9999 -9999 -9999 -9999 -9999 -9999 -9999 -9999 -9999 -9999 -9999 -9999 -9999 -9999 -9999 -9999 -

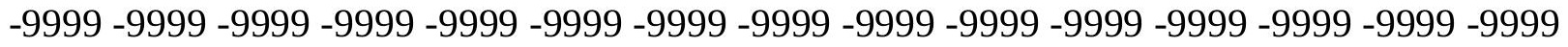
-9999 -9999 -9999 -9999 -9999 -9999 -9999 -9999 -9999 -9999 -9999 -9999 -9999 -9999 -9999 -9999 -9999 -9999 -9999 -9999 -9999 -9999 -9999 -9999 -9999 -9999 -9999 -9999 -9999 -999 -9999 -9999 -9999 -9999 -9999 -9999 -9999 -9999 -9999 -9999 -9999 -9999 -9999 -9999 -9999 -9999 -9999 -9999 -9999 -9999 -9999 -9999 -9999 -9999 -9999 -9999 -9999 -9999 -9999 -9999 -

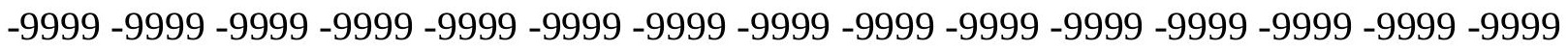

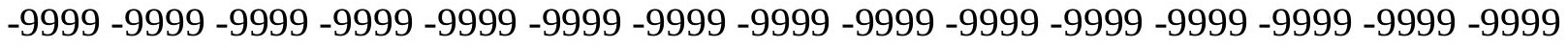
-9999 -9999 -9999 -9999 -9999 -9999 -9999 -9999 -9999 -9999 -9999 -9999 -9999 -9999 -

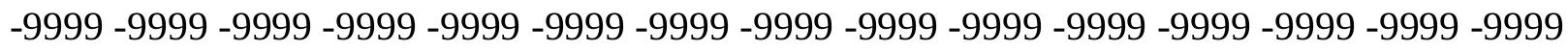

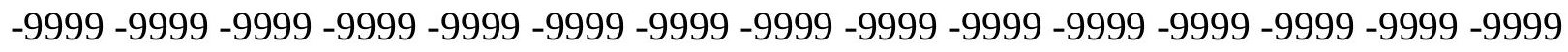

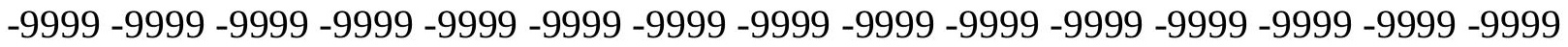
-9999 -9999 -9999 -9999 -9999 -9999 -9999 -9999 -9999 -9999 -9999 -9999 -9999 - 9999 - -999 -9999 -9999 -9999 -9999 -9999 -9999 -9999 -9999 -9999 -9999 -9999 -9999 -9999 -9999 -9999 -

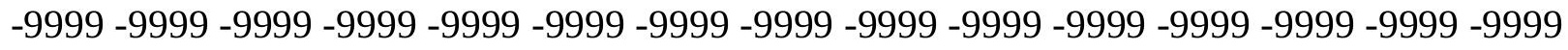

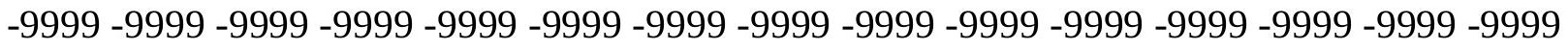
-9999 -9999 -9999 -9999 -9999 -9999 -9999 -9999 -9999 -9999 -9999 -9999 -9999 -9999 -9999 -9999 -9999 -9999 -9999 -9999 -9999 -9999 -9999 -9999-9999 -9999 -9999 -9999 -9999 -9999 -9999 -9999 -9999 -9999 -9999 -9999 -9999 -9999 -9999 -9999 -9999 -9999 -9999 -9999 -9999 -

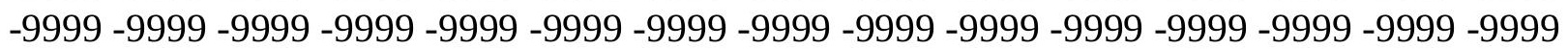


-9999 -9999 -9999 -9999 -9999 -9999 -9999 -9999 -9999 -9999 -9999 -9999 -9999 -9999 -9999 -9999 -9999 -9999 -9999 -9999 -9999 -9999 -9999 -9999 -9999 -9999 -9999 -9999 -9999 -9999 -

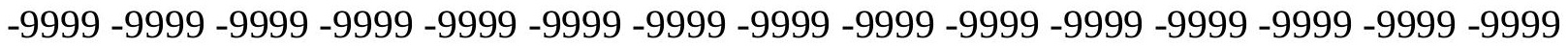
-9999 -9999 -9999 -9999 -9999 -9999 -9999 -9999 -9999 -9999 -9999 -9999 -9999 -9999 -9999 -9999 -9999 -9999 -9999 -9999 -9999 -9999 -9999 -9999-9999 -9999 -9999 -9999 -9999 -9999 -9999 -9999 -9999 -9999 -9999 -9999 -9999 -9999 -9999 -9999 -9999 -9999 -9999 -9999 -9999 -9999 -9999 -9999 -9999 -9999 -9999 -9999 -9999 -9999 -9999 -9999 -9999 -9999 -9999 -9999

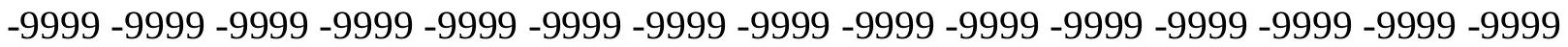

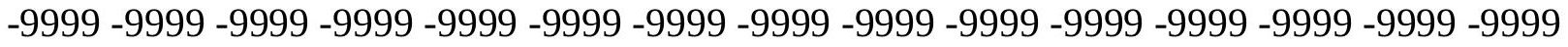
-9999 -9999 -9999 -9999 -9999 -9999 -9999 -9999 -9999 -9999 -9999 -9999 -9999 -9999 -9999 -9999 -9999 -9999 -9999 -9999 -9999 -9999 -9999 -9999 -9999 -9999 -9999 -9999 -9999 -9999 -9999 -9999 -9999 -9999 -9999 -9999 -9999 -9999 -9999 -9999 -9999 -9999 -9999 -9999 -9999 -9999 -9999 -9999 -9999 -9999 -9999 -9999 -9999 -9999 -9999 -9999 -9999 -9999 -9999 -9999 -9999 -9999 -9999 -9999 -9999 -9999 -9999 -9999 -9999 -9999 -9999 -9999 -9999 -9999 -9999 -9999 -9999 -9999 -9999 -9999 -9999 -9999 -9999 -9999 -9999 -9999 -9999 -9999 -9999 -9999 -9999 -9999 -9999 -9999 -9999 -9999 -9999 -9999 -9999 -9999 -9999 -9999 - 9999 - -999 -

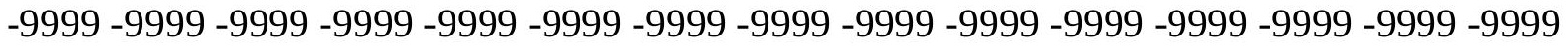
-9999 -9999 -9999 -9999 -9999 -9999 -9999 -9999 -9999 -9999 -9999 -9999 -9999 -9999 -9999 -9999 -9999 -9999 -9999 -9999 -9999 -9999 -9999 -9999 -9999 -9999 -9999 -9999 -9999 -9999 -

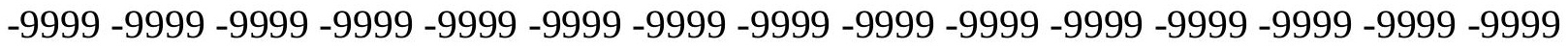
-9999 -9999 -9999 -9999 -9999 -9999 -9999 -9999 -9999 -9999 -9999 -9999 -9999 -9999 -9999

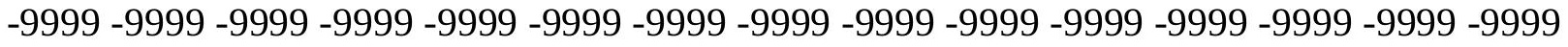
-9999 -9999 -9999 -9999 -9999 -9999 -9999 -9999 -9999 -9999 -9999 -9999 -9999 -9999 -9999 -9999 -9999 -9999 -9999 -9999 -9999 -9999 -9999 -9999 -9999 -9999 -9999 -9999 -9999 -9999 -

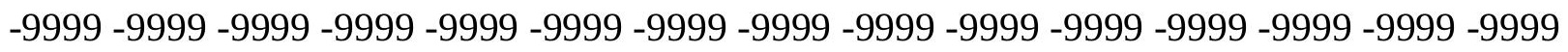
-9999 -9999 -9999 -9999 -9999 -9999 -9999 -9999 -9999 -9999 -9999 -9999 -9999 -9999 -9999 -9999 -9999 -9999 -9999 -9999 -9999 -9999 -9999 -9999 -9999 -9999 -9999 -9999 -9999 -9999 -

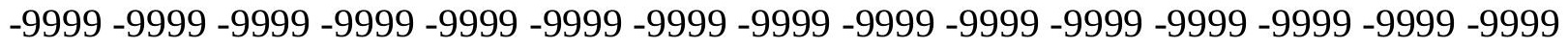
-9999 -9999 -9999 -9999 -9999 -9999 -9999 -9999 -9999 -9999 -9999 -9999 -9999 -9999 -9999 -9999 -9999 -9999 -9999 -9999 -9999 -9999 -9999 -9999 -9999 -9999 -9999 -9999 -9999 -999 -

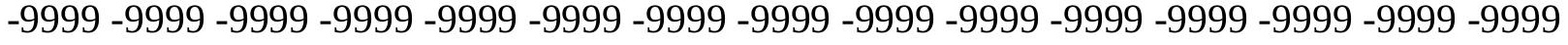
-9999 -9999 -9999 -9999 -9999 -9999 -9999 -9999 -9999 -9999 -9999 -9999 -9999 -9999 -9999 -

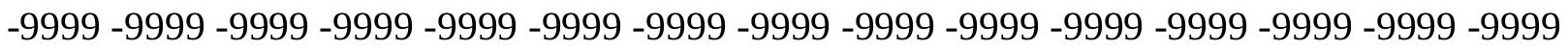

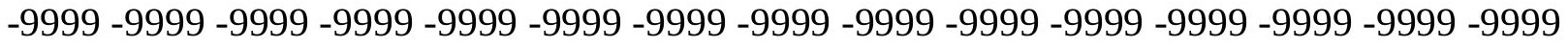

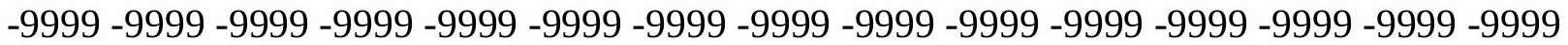
-9999 -9999 -9999 -9999 -9999 -9999 -9999 -9999 -9999 -9999 -9999 -9999 -9999 -9999 -9999 -

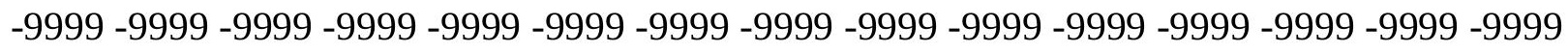

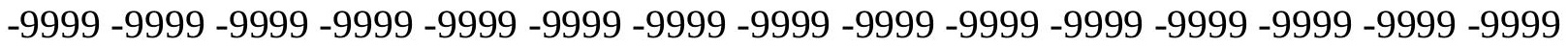
-9999 -9999 -9999 -9999 -9999 -9999 -9999 -9999 -9999 -9999 -9999 -9999 -9999 - 9999 - -999 -9999 -9999 -9999 -9999 -9999 -9999 -9999 -9999 -9999 -9999 -9999 -9999 -9999 -9999 -9999 -

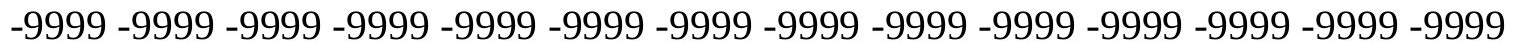

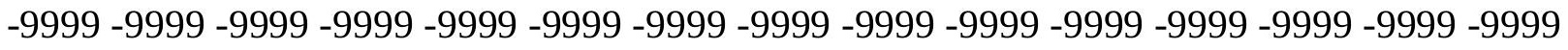
-9999 -9999 -9999 -9999 -9999 -9999 -9999 -9999 -9999 -9999 -9999 -9999 -9999 -9999 -9999 -9999 -9999 -9999 -9999 -9999 -9999 -9999 -9999 -9999-9999 -9999 -9999 -9999 -9999 -9999 -9999 -9999 -9999 -9999 -9999 -9999 -9999 -9999 -9999 -9999 -9999 -9999 -9999 -9999 -9999 -

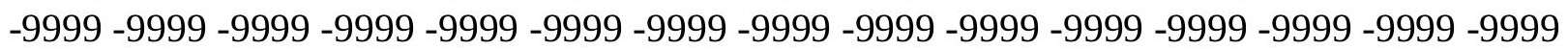


-9999 -9999 -9999 -9999 -9999 -9999 -9999 -9999 -9999 -9999 -9999 -9999 -9999 -9999 -9999 -9999 -9999 -9999 -9999 -9999 -9999 -9999 -9999 -9999 -9999 -9999 -9999 -9999 -9999 -9999 -9999 -9999 -9999 -9999 -9999 -9999 -9999 -9999 -9999 -9999 -9999 -9999 -9999 -9999 - 9999 -9999 -9999 -9999 -9999 -9999 -9999 -9999 -9999 -9999 -9999 -9999 -9999 -9999 -9999 -9999 -9999 -9999 -9999 -9999 -9999 -9999 -9999 -9999 -9999-9999 -9999 -9999 -9999 -9999 -9999 -9999 -9999 -9999 -9999 -9999 -9999 -9999 -9999 -9999 -9999 -9999 -9999 -9999 -9999 -9999 -9999 -9999 -9999 -9999 -9999 -9999 -9999 -9999 -9999 -9999 -9999 -9999 -9999 -9999 -9999

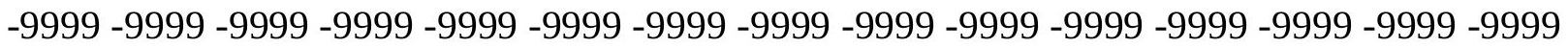
-9999 -9999 -9999 -9999 -9999 -9999 -9999 -9999 -9999 -9999 -9999 -9999 -9999 -9999 -9999 -9999 -9999 -9999 -9999 -9999 -9999 -9999 -9999 -9999 -9999 -9999 -9999 -9999 -9999 -9999

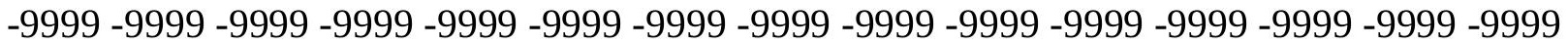
-9999 -9999 -9999 -9999 -9999 -9999 -9999 -9999 -9999 -9999 -9999 -9999 -9999 -9999 -9999 -9999 -9999 -9999 -9999 -9999 -9999 -9999 -9999 -9999 -9999 -9999 -9999 -9999 -9999 -9999 -

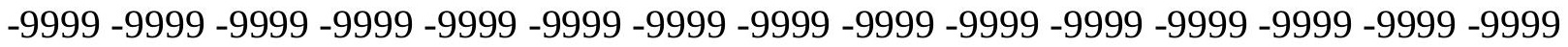
-9999 -9999 -9999 -9999 -9999 -9999 -9999 -9999 -9999 -9999 -9999 -9999 -9999 -9999 -9999

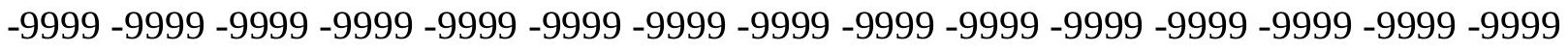
-9999 -9999 -9999 -9999 -9999 -9999 -9999 -9999 -9999 -9999 -9999 -9999 -9999 -9999 -9999 -9999 -9999 -9999 -9999 -9999 -9999 -9999 -9999 -9999 -9999 -9999 -9999 -9999 -9999 - 9999 -9999 -9999 -9999 -9999 -9999 -9999 -9999 -9999 -9999 -9999 -9999 -9999 -9999 -9999 -9999 -9999 -9999 -9999 -9999 -9999 -9999 -9999 -9999 -9999 -9999 -9999 -9999 -9999 -9999 -9999 -9999 -9999 -9999 -9999 -9999 -9999 -9999 -9999 -9999 -9999 -9999 -9999 -9999 -9999 -9999 -9999 -9999 -9999 -9999 -9999 -9999 -9999 -9999 -9999 -9999 -9999 -9999 -9999 -9999 -9999 -9999 -9999 -9999 -9999 -9999 -9999 -9999 -9999 -9999 -9999 -9999 -9999 -9999 -9999 -9999 -9999 -9999 -9999 -9999 -9999 -9999 -9999 -9999 -9999 -9999 -9999 -9999 -9999 -9999 -9999 -9999 -9999 -9999 -9999 -9999 -9999 -9999 -9999 -9999 -9999 -9999 -9999 -9999 -9999 -9999 -9999 -9999 -9999 -9999 -9999 -9999 -9999 -9999 -9999 -9999 -9999 -9999 -9999 -9999 -9999 -9999 -9999 -9999 -9999 -9999 -9999 -9999 -9999 -9999 -9999 -9999 -9999 -9999 -9999 -9999 -9999 -9999 -9999 -9999 -9999 -9999 -9999 -9999 -9999 -9999 -9999 -9999 -9999 -9999 -9999 -9999 -9999 -9999 -9999 -9999 -9999 -9999 -9999 -9999 -9999 -9999 -9999 -9999 -9999 -9999 -9999 -9999 -9999 -9999 -9999 -9999 -9999 -9999 -9999 -9999 -9999 -9999 -9999 -999 -9999 -9999 -9999 -9999 -9999 -9999 -9999 -9999 -9999 -9999 -9999 -9999 -9999 -9999 -9999 -9999 -9999 -9999 -9999 -9999 -9999 -9999 -9999 -9999 -9999 -9999 -9999 -9999 -9999 -9999 -

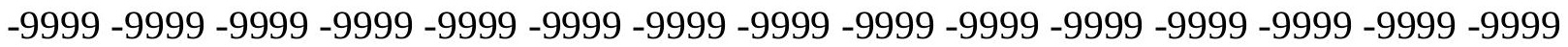

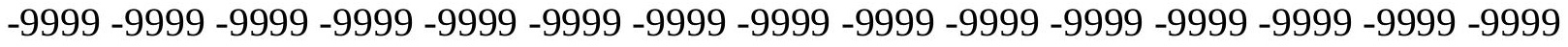

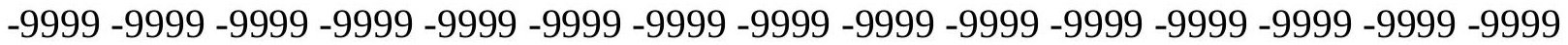
-9999 -9999 -9999 -9999 -9999 -9999 -9999 -9999 -9999 -9999 -9999 -9999 -9999 -9999 -9999

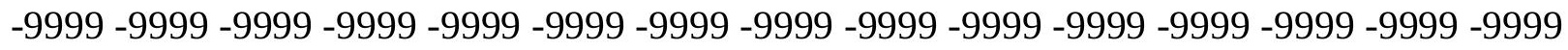

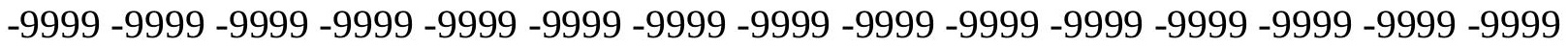

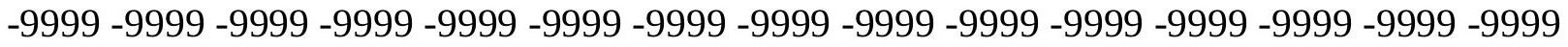
-9999 -9999 -9999 -9999 -9999 -9999 -9999 -9999 -9999 -9999 -9999 -9999 -9999 -9999 -9999 -

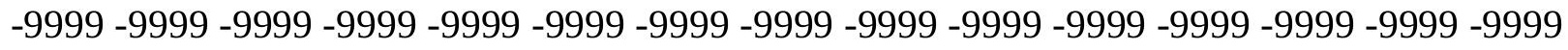

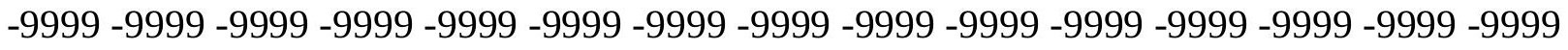
-9999 -9999 -9999 -9999 -9999 -9999 -9999 -9999 -9999 -9999 -9999 -9999 -9999 -9999 -9999 -9999 -9999 -9999 -9999 -9999 -9999 -9999 -9999 -9999-9999 -9999 -9999 -9999 -9999 -9999 -9999 -9999 -9999 -9999 -9999 -9999 -9999 -9999 -9999 -9999 -9999 -9999 -9999 -9999 -9999 -

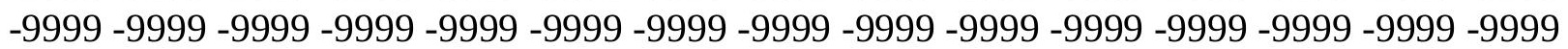


-9999 -9999 -9999 -9999 -9999 -9999 -9999 -9999 -9999 -9999 -9999 -9999 -9999 -9999 -9999 -9999 -9999 -9999 -9999 -9999 -9999 -9999 -9999 -9999 -9999 -9999 -9999 -9999 -9999 -9999 -9999 -9999 -9999 -9999 -9999 -9999 -9999 -9999 -9999 -9999 -9999 -9999 -9999 -9999 -9999 -9999 -9999 -9999 -9999 -9999 -9999 -9999 -9999 -9999 -9999 -9999 -9999 -9999 -9999 -9999 -9999 -9999 -9999 -9999 -9999 -9999 -9999 -9999 -9999 -9999 -9999 -9999 -9999 -9999 -9999 -9999 -9999 -9999 -9999 -9999 -9999 -9999 -9999 -9999 -9999 -9999 -9999 -9999 -9999 -9999 -9999 -9999 -9999 -9999 -9999 -9999 -9999 -9999 -9999 -9999 -9999 -9999 -9999 -9999 -

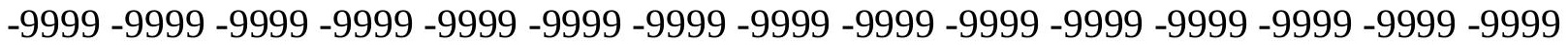
-9999 -9999 -9999 -9999 -9999 -9999 -9999 -9999 -9999 -9999 -9999 -9999 -9999 -9999 -9999 -9999 -9999 -9999 -9999 -9999 -9999 -9999 -9999 -9999 -9999 -9999 -9999 -9999 -9999 -9999 -

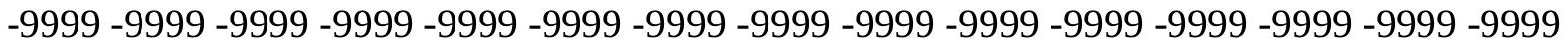
-9999 -9999 -9999 -9999 -9999 -9999 -9999 -9999 -9999 -9999 -9999 -9999 -9999 -9999 -9999 -9999 -9999 -9999 -9999 -9999 -9999 -9999 -9999 -9999 -9999 -9999 -9999 -9999 -9999 -9999 -9999 -9999 -9999 -9999 -9999 -9999 -9999 -9999 -9999 -9999 -9999 -9999 -9999 -9999 -9999 -9999 -9999 -9999 -9999 -9999 -9999 -9999 -9999 -9999 -9999 -9999 -9999 -9999 -9999 -9999 -9999 -9999 -9999 -9999 -9999 -9999 -9999 -9999 -9999 -9999 -9999 -9999 -9999 -9999 -9999 -9999 -9999 -9999 -9999 -9999 -9999 -9999 -9999 -9999 -9999 -9999 -9999 -9999 -9999 -9999 -9999 -9999 -9999 -9999 -9999 -9999 -9999 -9999 -9999 -9999 -9999 -9999 -9999 -9999 -9999 -9999 -9999 -9999 -9999 -9999 -9999 -9999 -9999 -9999 -9999 -9999 -9999 -9999 -9999 -9999 -9999 -9999 -9999 -9999 -9999 -9999 -9999 -9999 -9999 -9999 -9999 -9999 -9999 -9999 -9999

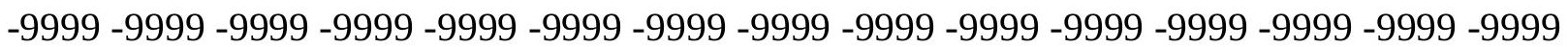
-9999 -9999 -9999 -9999 -9999 -9999 -9999 -9999 -9999 -9999 -9999 -9999 -9999 -9999 -9999 -9999 -9999 -9999 -9999 -9999 -9999 -9999 -9999 -9999 -9999 -9999 -9999 -9999 -9999 -9999 -9999 -9999 -9999 -9999 -9999 -9999 -9999 -9999 -9999 -9999 -9999 -9999 -9999 -9999 -9999

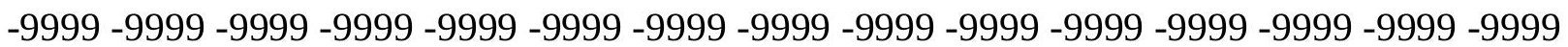
-9999 -9999 -9999 -9999 -9999 -9999 -9999 -9999 -9999 -9999 -9999 -9999 -9999 -9999 -9999 -9999 -9999 -9999 -9999 -9999 -9999 -9999 -9999 -9999 -9999 -9999 -9999 -9999 -9999 -9999 -9999 -9999 -9999 -9999 -9999 -9999 -9999 -9999 -9999 -9999 -9999 -9999 -9999 -9999

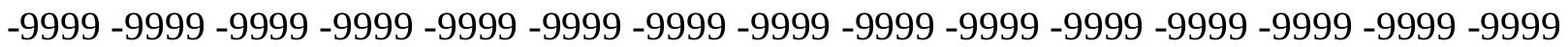
-9999 -9999 -9999 -9999 -9999 -9999 -9999 -9999 -9999 -9999 -9999 -9999 -9999 -9999 -9999 -9999 -9999 -9999 -9999 -9999 -9999 -9999 -9999 -9999 -9999 -9999 -9999 -9999 -9999 -9999 -

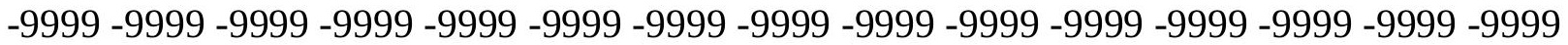
-9999 -9999 -9999 -9999 -9999 -9999 -9999 -9999 -9999 -9999 -9999 -9999 -9999 -9999 -9999 -9999 -9999 -9999 -9999 -9999 -9999 -9999 -9999 -9999 -9999 -9999 -9999 -9999 -9999 -9999 -9999 -9999 -9999 -9999 -9999 -9999 -9999 -9999 -9999 -9999 -9999 -9999 -9999 -9999 -9999 -9999 -9999 -9999 -9999 -9999 -9999 -9999 -9999 -9999 -9999 -9999 -9999 -9999 -9999 -9999 -9999 -9999 -9999 -9999 -9999 -9999 -9999 -9999 -9999 -9999 -9999 -9999 -9999 -9999 -9999

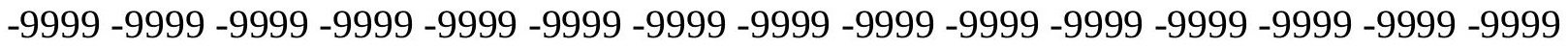
-9999 -9999 -9999 -9999 -9999 -9999 -9999 -9999 -9999 -9999 -9999 -9999 -9999 -9999 -9999 -9999 -9999 -9999 -9999 -9999 -9999 -9999 -9999 -9999 -9999 -9999 -9999 -9999 -9999 -9999 -

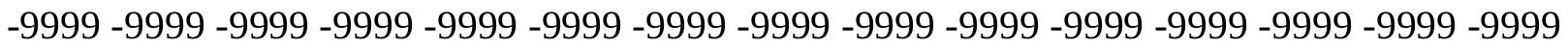
-9999 -9999 -9999 -9999 -9999 -9999 -9999 -9999 -9999 -9999 -9999 -9999 -9999 -9999 -9999 -9999 -9999 -9999 -9999 -9999 -9999 -9999 -9999 -9999 -9999 -9999 -9999 -9999 -9999 -9999 -9999 -9999 -9999 -9999 -9999 -9999 -9999 -9999 -9999 -9999 -9999 -9999 -9999 -9999 -9999 -9999 -9999 -9999 -9999 -9999 -9999 -9999 -9999 -9999 -9999 -9999 -9999 -9999 -9999 -9999

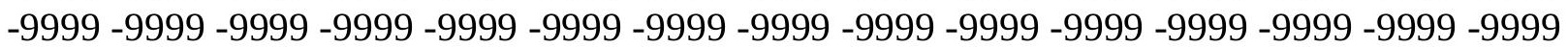


-9999 -9999 -9999 -9999 -9999 -9999 -9999 -9999 -9999 -9999 -9999 -9999 -9999 -9999 -9999 -9999 -9999 -9999 -9999 -9999 -9999 -9999 -9999 -9999 -9999 -9999 -9999 -9999 -9999 -9999 -

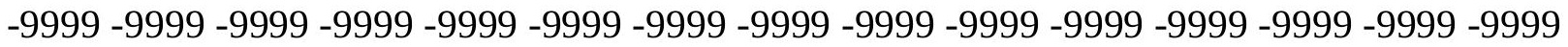
-9999 -9999 -9999 -9999 -9999 -9999 -9999 -9999 -9999 -9999 -9999 -9999 -9999 -9999 -9999 -9999 -9999 -9999 -9999 -9999 -9999 -9999 -9999 -9999-9999 -9999 -9999 -9999 -9999 -9999 -9999 -9999 -9999 -9999 -9999 -9999 -9999 -9999 -9999 -9999 -9999 -9999 -9999 -9999 -9999 -9999 -9999 -9999 -9999 -9999 -9999 -9999 -9999 -9999 -9999 -9999 -9999 -9999 -9999 -

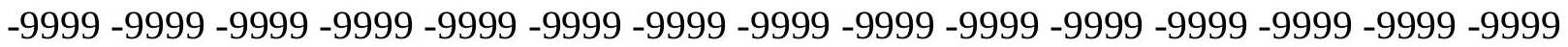

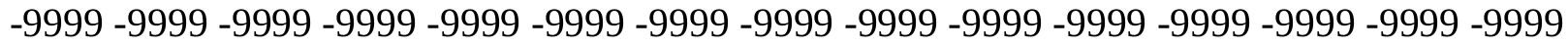
-9999 -9999 -9999 -9999 -9999 -9999 -9999 -9999 -9999 -9999 -9999 -9999 -9999 -9999 -9999 -9999 -9999 -9999 -9999 -9999 -9999 -9999 -9999 -9999 -9999 -9999 -9999 -9999 -9999 -9999 -9999 -9999 -9999 -9999 -9999 -9999 -9999 -9999 -9999 -9999 -9999 -9999 -9999 -9999 -9999 -9999 -9999 -9999 -9999 -9999 -9999 -9999 -9999 -9999 -9999 -9999 -9999 -9999 -9999 -9999 -9999 -9999 -9999 -9999 -9999 -9999 -9999 -9999 -9999 -9999 -9999 -9999 -9999 -9999 -9999 -9999 -9999 -9999 -9999 -9999 -9999 -9999 -9999 -9999 -9999 -9999 -9999 -9999 -9999 -9999 -

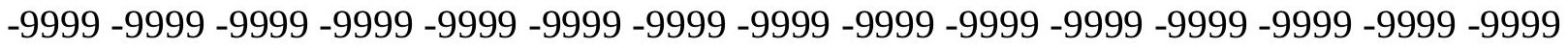
-9999 -9999 -9999 -9999 -9999 -9999 -9999 -9999 -9999 -9999 -9999 -9999 -9999 -9999 -9999 -9999 -9999 -9999 -9999 -9999 -9999 -9999 -9999 -9999 -9999 -9999 -9999 -9999 -9999 -9999 -9999 -9999 -9999 -9999 -9999 -9999 -9999 -9999 -9999 -9999 -9999 -9999 -9999 -9999 -9999 -

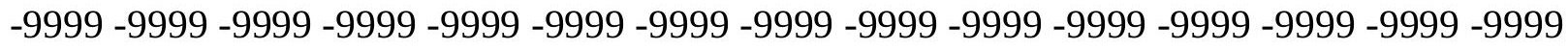

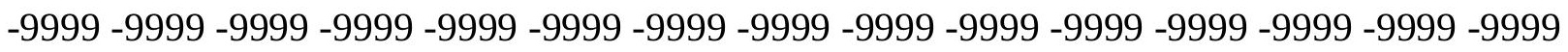

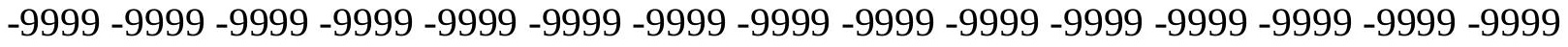
-9999 -9999 -9999 -9999 -9999 -9999 -9999 -9999 -9999 -9999 -9999 -9999 -9999 -9999 -9999 -9999 -9999 -9999 -9999 -9999 -9999 -9999 -9999 -9999 -9999 -9999 -9999 -9999 -9999 -9999 -

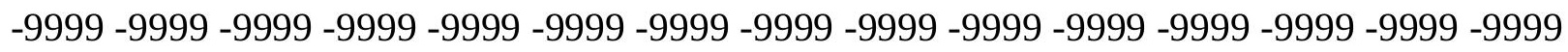
-9999 -9999 -9999 -9999 -9999 -9999 -9999 -9999 -9999 -9999 -9999 -9999 -9999 -9999 -9999 -9999 -9999 -9999 -9999 -9999 -9999 -9999 -9999 -9999 -9999 -9999 -9999 -9999 -9999 -9999 -

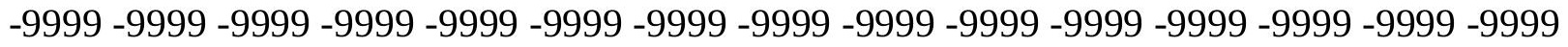
-9999 -9999 -9999 -9999 -9999 -9999 -9999 -9999 -9999 -9999 -9999 -9999 -9999 -9999 -9999 -9999 -9999 -9999 -9999 -9999 -9999 -9999 -9999 -9999 -9999 -9999 -9999 -9999 -9999 -999 -9999 -9999 -9999 -9999 -9999 -9999 -9999 -9999 -9999 -9999 -9999 -9999 -9999 -9999 -9999 -

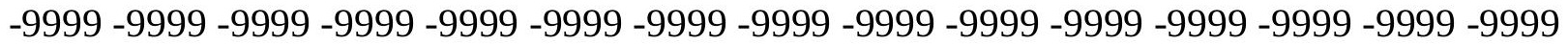

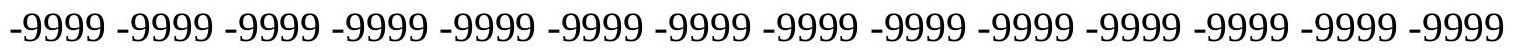

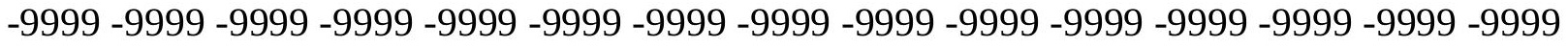

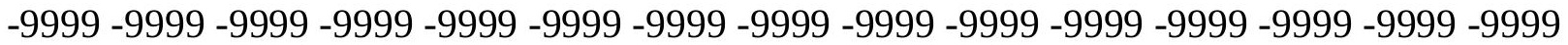

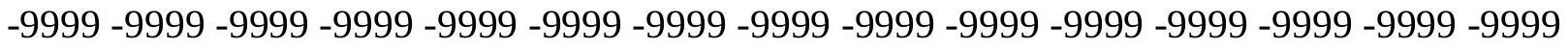

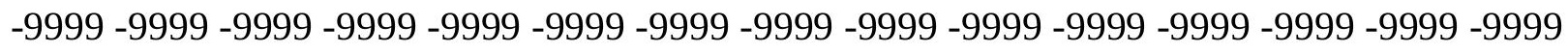

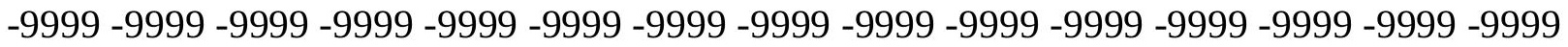

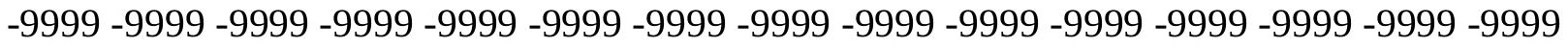
-9999 -9999 -9999 -9999 -9999 -9999 -9999 -9999 -9999 -9999 -9999 -9999 -9999 -9999 -9999 -

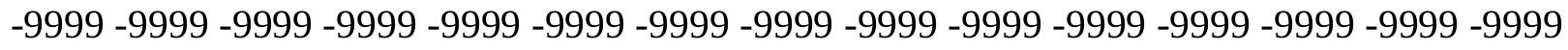

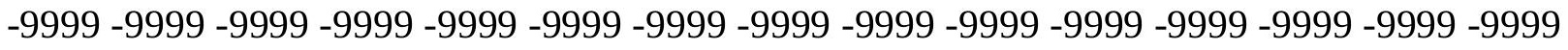
-9999 -9999 -9999 -9999 -9999 -9999 -9999 -9999 -9999 -9999 -9999 -9999 -9999 -9999 -9999 -9999 -9999 -9999 -9999 -9999 -9999 -9999 -9999 -9999-9999 -9999 -9999 -9999 -9999 -9999 -9999 -9999 -9999 -9999 -9999 -9999 -9999 -9999 -9999 -9999 -9999 -9999 -9999 -9999 -9999 -

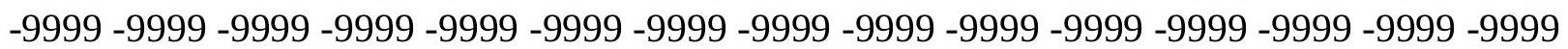


-9999 -9999 -9999 -9999 -9999 -9999 -9999 -9999 -9999 -9999 -9999 -9999 -9999 -9999 -9999 -9999 -9999 -9999 -9999 -9999 -9999 -9999 -9999 -9999 -9999 -9999 -9999 -9999 -9999 -9999 -

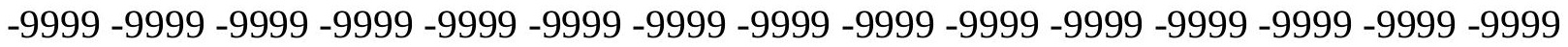
-9999 -9999 -9999 -9999 -9999 -9999 -9999 -9999 -9999 -9999 -9999 -9999 -9999 -9999 -9999 -9999 -9999 -9999 -9999 -9999 -9999 -9999 -9999 -9999-9999 -9999 -9999 -9999 -9999 -9999 -9999 -9999 -9999 -9999 -9999 -9999 -9999 -9999 -9999 -9999 -9999 -9999 -9999 -9999 -9999 -9999 -9999 -9999 -9999 -9999 -9999 -9999 -9999 -9999 -9999 -9999 -9999 -9999 -9999 -9999

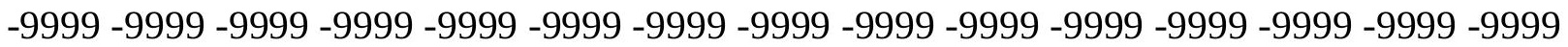

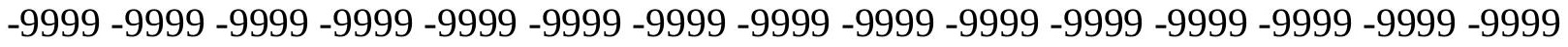
-9999 -9999 -9999 -9999 -9999 -9999 -9999 -9999 -9999 -9999 -9999 -9999 -9999 -9999 -9999 -9999 -9999 -9999 -9999 -9999 -9999 -9999 -9999 -9999 -9999 -9999 -9999 -9999 -9999 -9999 -9999 -9999 -9999 -9999 -9999 -9999 -9999 -9999 -9999 -9999 -9999 -9999 -9999 -9999 -9999 -9999 -9999 -9999 -9999 -9999 -9999 -9999 -9999 -9999 -9999 -9999 -9999 -9999 -9999 -9999 -9999 -9999 -9999 -9999 -9999 -9999 -9999 -9999 -9999 -9999 -9999 -9999 -9999 -9999 -9999 -9999 -9999 -9999 -9999 -9999 -9999 -9999 -9999 -9999 -9999 -9999 -9999 -9999 -9999 -

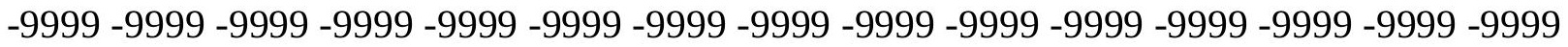
-9999 -9999 -9999 -9999 -9999 -9999 -9999 -9999 -9999 -9999 -9999 -9999 -9999 -9999 -9999 -9999 -9999 -9999 -9999 -9999 -9999 -9999 -9999 -9999 -9999 -9999 -9999 -9999 -9999 -9999 -9999 -9999 -9999 -9999 -9999 -9999 -9999 -9999 -9999 -9999 -9999 -9999 -9999 -9999 -9999 -

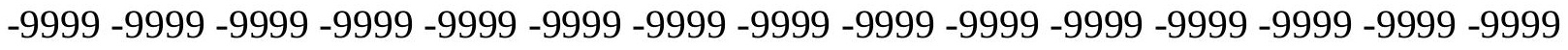
-9999 -9999 -9999 -9999 -9999 -9999 -9999 -9999 -9999 -9999 -9999 -9999 -9999 -9999 -9999

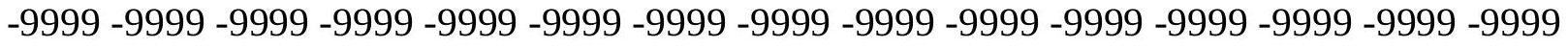
-9999 -9999 -9999 -9999 -9999 -9999 -9999 -9999 -9999 -9999 -9999 -9999 -9999 -9999 -9999 -9999 -9999 -9999 -9999 -9999 -9999 -9999 -9999 -9999 -9999 -9999 -9999 -9999 -9999 -9999 -

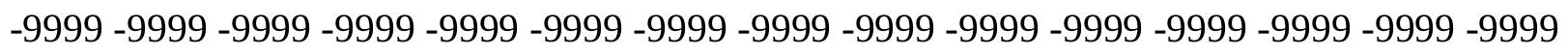
-9999 -9999 -9999 -9999 -9999 -9999 -9999 -9999 -9999 -9999 -9999 -9999 -9999 -9999 -9999 -9999 -9999 -9999 -9999 -9999 -9999 -9999 -9999 -9999 -9999 -9999 -9999 -9999 -9999 -9999 -

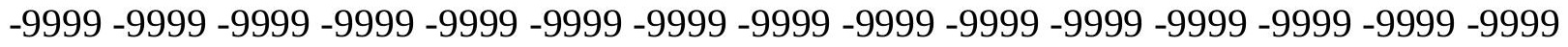
-9999 -9999 -9999 -9999 -9999 -9999 -9999 -9999 -9999 -9999 -9999 -9999 -9999 -9999 -9999 -9999 -9999 -9999 -9999 -9999 -9999 -9999 -9999 -9999 -9999 -9999 -9999 -9999 -9999 -999 -9999 -9999 -9999 -9999 -9999 -9999 -9999 -9999 -9999 -9999 -9999 -9999 -9999 -9999 -9999 -9999 -9999 -9999 -9999 -9999 -9999 -9999 -9999 -9999 -9999 -9999 -9999 -9999 -9999 -9999 -

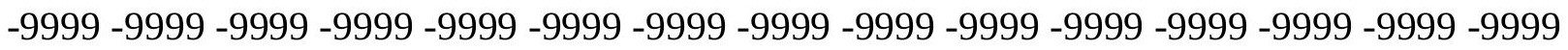

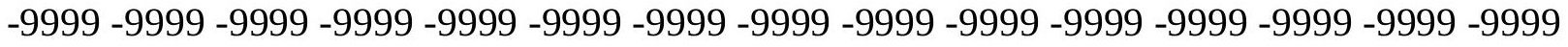

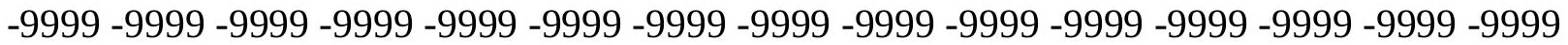
-9999 -9999 -9999 -9999 -9999 -9999 -9999 -9999 -9999 -9999 -9999 -9999 -9999 -9999 -9999 -

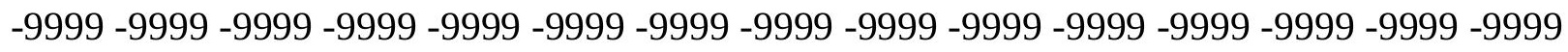

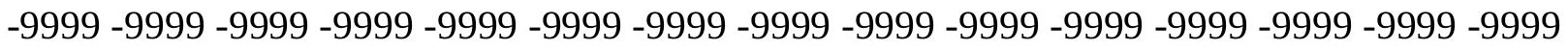
-9999 -9999 -9999 -9999 -9999 -9999 -9999 -9999 -9999 -9999 -9999 -9999 -9999 -9999 - -999 -9999 -9999 -9999 -9999 -9999 -9999 -9999 -9999 -9999 -9999 -9999 -9999 -9999 -9999 -9999 -

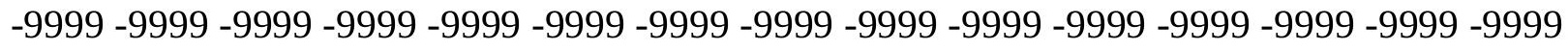

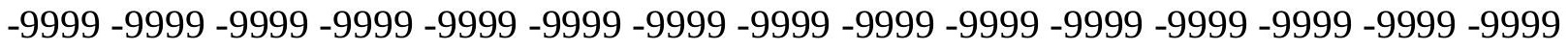
-9999 -9999 -9999 -9999 -9999 -9999 -9999 -9999 -9999 -9999 -9999 -9999 -9999 -9999 -9999 -9999 -9999 -9999 -9999 -9999 -9999 -9999 -9999 -9999-9999 -9999 -9999 -9999 -9999 -9999 -9999 -9999 -9999 -9999 -9999 -9999 -9999 -9999 -9999 -9999 -9999 -9999 -9999 -9999 -9999 -

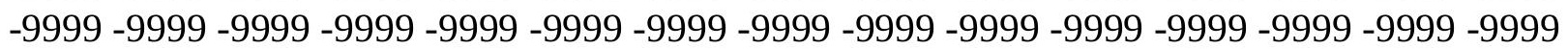


-9999 -9999 -9999 -9999 -9999 -9999 -9999 -9999 -9999 -9999 -9999 -9999 -9999 -9999 -9999 -9999 -9999 -9999 -9999 -9999 -9999 -9999 -9999 -9999 -9999 -9999 -9999 -9999 -9999 -9999 -

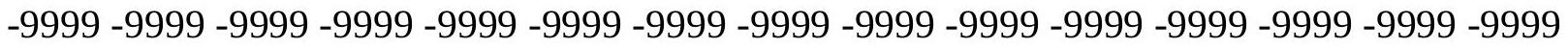
-9999 -9999 -9999 -9999 -9999 -9999 -9999 -9999 -9999 -9999 -9999 -9999 -9999 -9999 -9999 -9999 -9999 -9999 -9999 -9999 -9999 -9999 -9999 -9999-9999 -9999 -9999 -9999 -9999 -9999 -9999 -9999 -9999 -9999 -9999 -9999 -9999 -9999 -9999 -9999 -9999 -9999 -9999 -9999 -9999 -9999 -9999 -9999 -9999 -9999 -9999 -9999 -9999 -9999 -9999 -9999 -9999 -9999 -9999 -9999

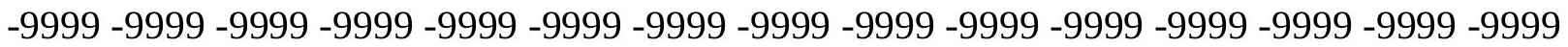

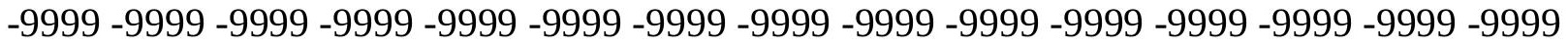
-9999 -9999 -9999 -9999 -9999 -9999 -9999 -9999 -9999 -9999 -9999 -9999 -9999 -9999 -9999 -9999 -9999 -9999 -9999 -9999 -9999 -9999 -9999 -9999 -9999 -9999 -9999 -9999 -9999 -9999 -9999 -9999 -9999 -9999 -9999 -9999 -9999 -9999 -9999 -9999 -9999 -9999 -9999 -9999 -9999 -9999 -9999 -9999 -9999 -9999 -9999 -9999 -9999 -9999 -9999 -9999 -9999 -9999 -9999 -9999 -

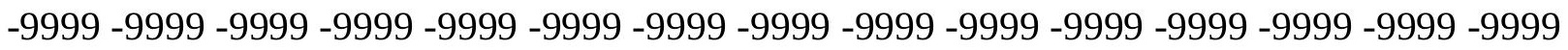
-9999 -9999 -9999 -9999 -9999 -9999 -9999 -9999 -9999 -9999 -9999 -9999 -9999 -9999 -9999 -

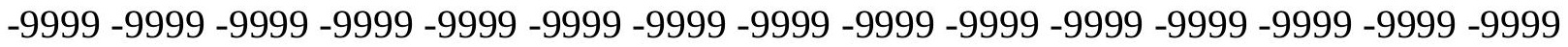
-9999 -9999 -9999 -9999 -9999 -9999 -9999 -9999 -9999 -9999 -9999 -9999 -9999 -9999 -9999 -9999 -9999 -9999 -9999 -9999 -9999 -9999 -9999 -9999 -9999 -9999 -9999 -9999 -9999 -9999 -9999 -9999 -9999 -9999 -9999 -9999 -9999 -9999 -9999 -9999 -9999 -9999 -9999 -9999 - -999 -

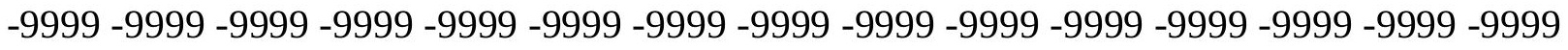

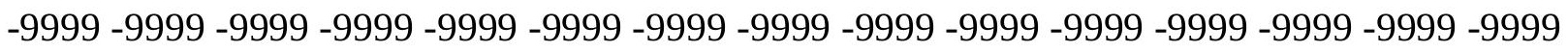
-9999 -9999 -9999 -9999 -9999 -9999 -9999 -9999 -9999 -9999 -9999 -9999 -9999 -9999 -9999 -9999 -9999 -9999 -9999 -9999 -9999 -9999 -9999 -9999 -9999 -9999 -9999 -9999 -9999 -9999 -9999 -9999 -9999 -9999 -9999 -9999 -9999 -9999 -9999 -9999 -9999 -9999 -9999 -9999 -9999 -

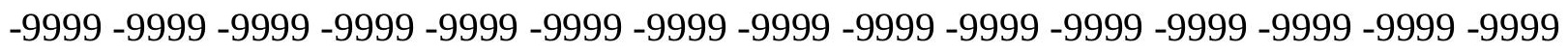
-9999 -9999 -9999 -9999 -9999 -9999 -9999 -9999 -9999 -9999 -9999 -9999 -9999 -9999 -9999 -9999 -9999 -9999 -9999 -9999 -9999 -9999 -9999 -9999 -9999 -9999 -9999 -9999 -9999 -9999 -

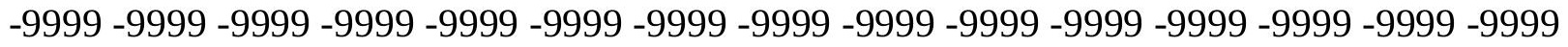
-9999 -9999 -9999 -9999 -9999 -9999 -9999 -9999 -9999 -9999 -9999 -9999 -9999 -9999 -9999 -9999 -9999 -9999 -9999 -9999 -9999 -9999 -9999 -9999 -9999 -9999 -9999 -9999 -9999 -999 -

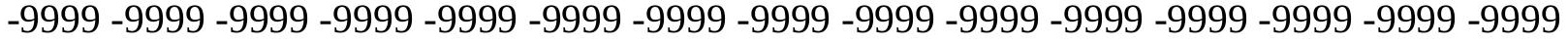
-9999 -9999 -9999 -9999 -9999 -9999 -9999 -9999 -9999 -9999 -9999 -9999 -9999 -9999 -9999 -

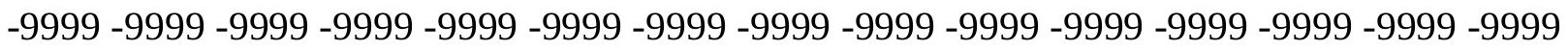

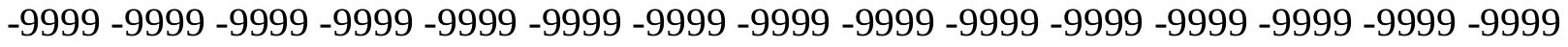

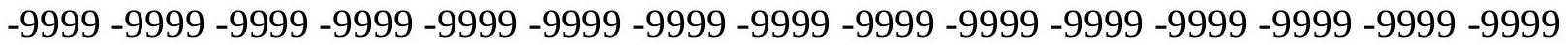

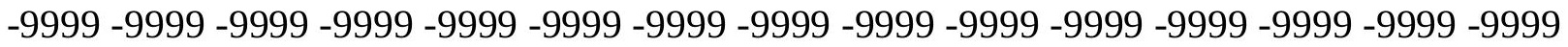

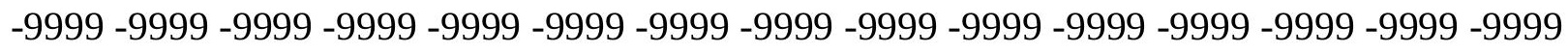

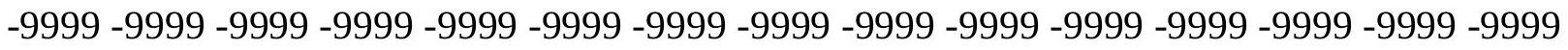

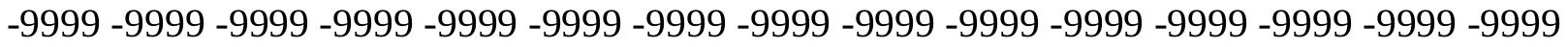
-9999 -9999 -9999 -9999 -9999 -9999 -9999 -9999 -9999 -9999 -9999 -9999 -9999 -9999 -9999 -

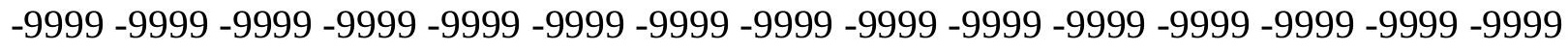

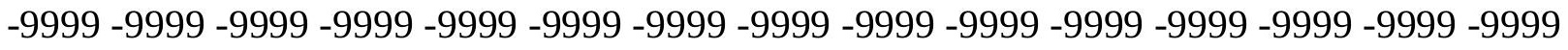
-9999 -9999 -9999 -9999 -9999 -9999 -9999 -9999 -9999 -9999 -9999 -9999 -9999 -9999 -9999 -9999 -9999 -9999 -9999 -9999 -9999 -9999 -9999 -9999 -9999 -9999 -9999 -9999 -9999 -9999 -9999 -9999 -9999 -9999 -9999 -9999 -9999 -9999 -9999 -9999 -9999 -9999 -9999 -9999 -

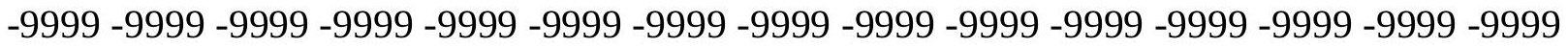


-9999 -9999 -9999 -9999 -9999 -9999 -9999 -9999 -9999 -9999 -9999 -9999 -9999 -9999 -9999 -9999 -9999 -9999 -9999 -9999 -9999 -9999 -9999 -9999 -9999 -9999 -9999 -9999 -9999 -9999 -

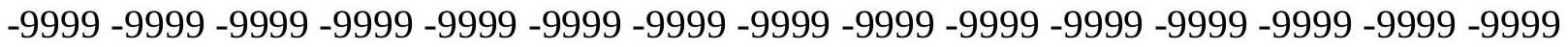
-9999 -9999 -9999 -9999 -9999 -9999 -9999 -9999 -9999 -9999 -9999 -9999 -9999 -9999 -9999 -9999 -9999 -9999 -9999 -9999 -9999 -9999 -9999 -9999-9999 -9999 -9999 -9999 -9999 -9999 -9999 -9999 -9999 -9999 -9999 -9999 -9999 -9999 -9999 -9999 -9999 -9999 -9999 -9999 -9999 -9999 -9999 -9999 -9999 -9999 -9999 -9999 -9999 -9999 -9999 -9999 -9999 -9999 -9999 -9999

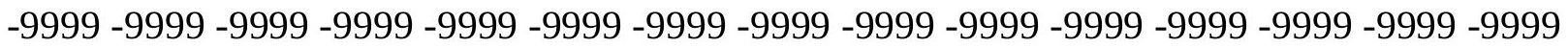

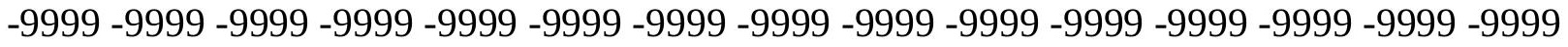
-9999 -9999 -9999 -9999 -9999 -9999 -9999 -9999 -9999 -9999 -9999 -9999 -9999 -9999 -9999 -9999 -9999 -9999 -9999 -9999 -9999 -9999 -9999 -9999 -9999 -9999 -9999 -9999 -9999 -9999 -9999 -9999 -9999 -9999 -9999 -9999 -9999 -9999 -9999 -9999 -9999 -9999 -9999 -9999 -9999 -9999 -9999 -9999 -9999 -9999 -9999 -9999 -9999 -9999 -9999 -9999 -9999 -9999 -9999 -9999 -

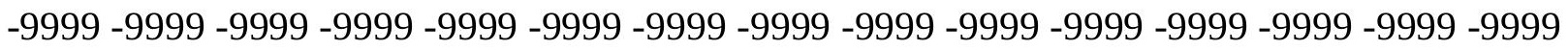
-9999 -9999 -9999 -9999 -9999 -9999 -9999 -9999 -9999 -9999 -9999 -9999 -9999 -9999 -9999 -

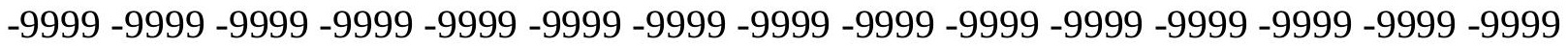
-9999 -9999 -9999 -9999 -9999 -9999 -9999 -9999 -9999 -9999 -9999 -9999 -9999 -9999 -9999 -9999 -9999 -9999 -9999 -9999 -9999 -9999 -9999 -9999 -9999 -9999 -9999 -9999 -9999 - 9999 -9999 -9999 -9999 -9999 -9999 -9999 -9999 -9999 -9999 -9999 -9999 -9999 -9999 -9999 -9999 -

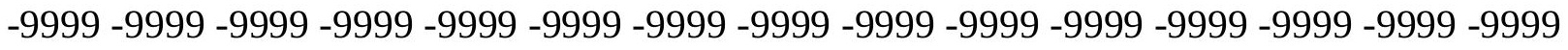

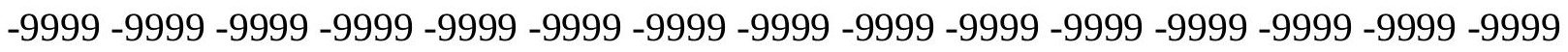
-9999 -9999 -9999 -9999 -9999 -9999 -9999 -9999 -9999 -9999 -9999 -9999 -9999 -9999 - 9999 -9999 -9999 -9999 -9999 -9999 -9999 -9999 -9999 -9999 -9999 -9999 -9999 -9999 -9999 -9999 -9999 -9999 -9999 -9999 -9999 -9999 -9999 -9999 -9999 -9999 -9999 -9999 -9999 -9999 -9999 -9999 -9999 -9999 -9999 -9999 -9999 -9999 -9999 -9999 -9999 -9999 -9999 -9999 -9999 -9999 -9999 -9999 -9999 -9999 -9999 -9999 -9999 -9999 -9999 -9999 -9999 -9999 -9999 -9999 -9999 -9999 -9999 -9999 -9999 -9999 -9999 -9999 -9999 -9999 -9999 -9999 -9999 -9999 -9999 -

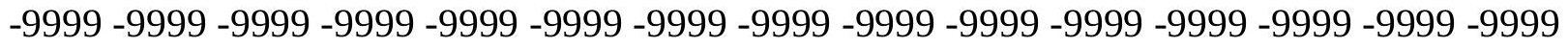
-9999 -9999 -9999 -9999 -9999 -9999 -9999 -9999 -9999 -9999 -9999 -9999 -9999 -9999 -9999 -9999 -9999 -9999 -9999 -9999 -9999 -9999 -9999 -9999 -9999 -9999 -9999 -9999 -9999 -999 -9999 -9999 -9999 -9999 -9999 -9999 -9999 -9999 -9999 -9999 -9999 -9999 -9999 -9999 -9999 -9999 -9999 -9999 -9999 -9999 -9999 -9999 -9999 -9999 -9999 -9999 -9999 -9999 -9999 -9999 -

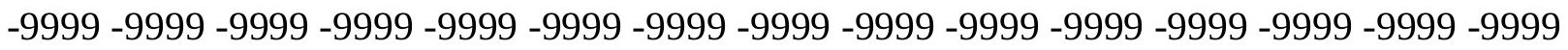

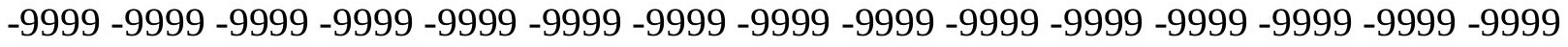

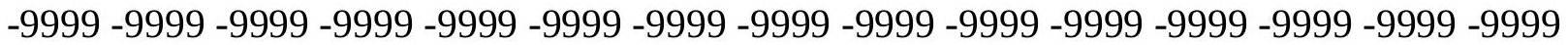

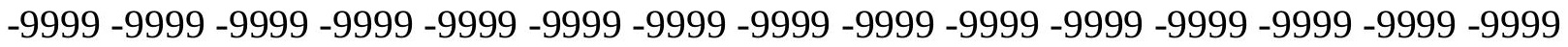

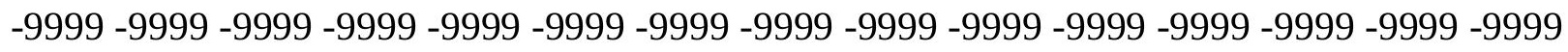

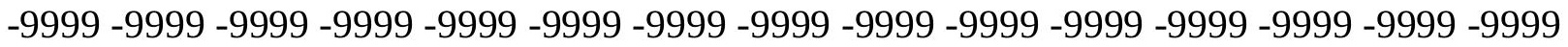

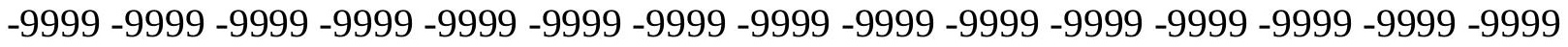
-9999 -9999 -9999 -9999 -9999 -9999 -9999 -9999 -9999 -9999 -9999 -9999 -9999 -9999 -9999 -

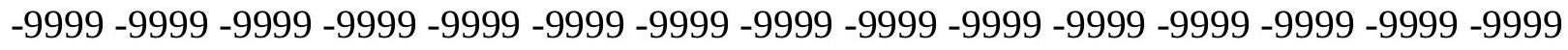

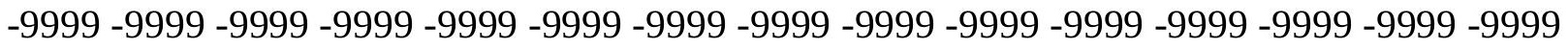
-9999 -9999 -9999 -9999 -9999 -9999 -9999 -9999 -9999 -9999 -9999 -9999 -9999 -9999 -9999 -9999 -9999 -9999 -9999 -9999 -9999 -9999 -9999 -9999-9999 -9999 -9999 -9999 -9999 -9999 -9999 -9999 -9999 -9999 -9999 -9999 -9999 -9999 -9999 -9999 -9999 -9999 -9999 -9999 -9999 -

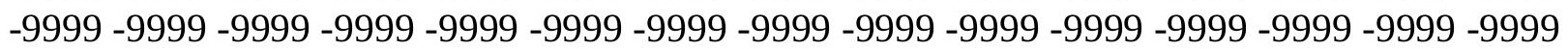


-9999 -9999 -9999 -9999 -9999 -9999 -9999 -9999 -9999 -9999 -9999 -9999 -9999 -9999 -9999 -9999 -9999 -9999 -9999 -9999 -9999 -9999 -9999 -9999 -9999 -9999 -9999 -9999 -9999 -9999 -9999 -9999 -9999 -9999 -9999 -9999 -9999 -9999 -9999 -9999 -9999 -9999 -9999 -9999 - 9999 -9999 -9999 -9999 -9999 -9999 -9999 -9999 -9999 -9999 -9999 -9999 -9999 -9999 -9999 -9999 -9999 -9999 -9999 -9999 -9999 -9999 -9999 -9999 -9999 -9999 -9999 -9999 -9999 -9999 -9999 -9999 -9999 -9999 -9999 -9999 -9999 -9999 -9999 -9999 -9999 -9999 -9999 -9999 -9999 -9999 -9999 -9999 -9999 -9999 -9999 -9999 -9999 -9999 -9999 -9999 -9999 -9999 -9999 -9999

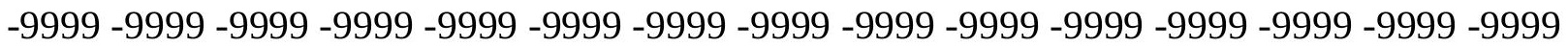

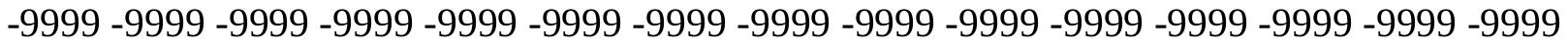
-9999 -9999 -9999 -9999 -9999 -9999 -9999 -9999 -9999 -9999 -9999 -9999 -9999 -9999 -9999 -9999 -9999 -9999 -9999 -9999 -9999 -9999 -9999 -9999 -9999 -9999 -9999 -9999 -9999 -9999 -9999 -9999 -9999 -9999 -9999 -9999 -9999 -9999 -9999 -9999 -9999 -9999 -9999 -9999 -9999 -9999 -9999 -9999 -9999 -9999 -9999 -9999 -9999 -9999 -9999 -9999 -9999 -9999 -9999 -9999 -9999 -9999 -9999 -9999 -9999 -9999 -9999 -9999 -9999 -9999 -9999 -9999 -9999 -9999 -9999 -9999 -9999 -9999 -9999 -9999 -9999 -9999 -9999 -9999 -9999 -9999 -9999 -9999 -9999 -9999 -

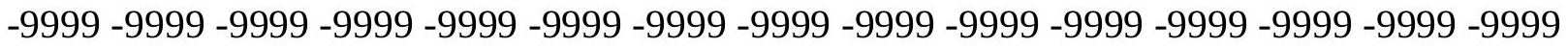
-9999 -9999 -9999 -9999 -9999 -9999 -9999 -9999 -9999 -9999 -9999 -9999 -9999 -9999 -9999 -9999 -9999 -9999 -9999 -9999 -9999 -9999 -9999 -9999 -9999 -9999 -9999 -9999 -9999 - 9999 -9999 -9999 -9999 -9999 -9999 -9999 -9999 -9999 -9999 -9999 -9999 -9999 -9999 -9999 -9999 -

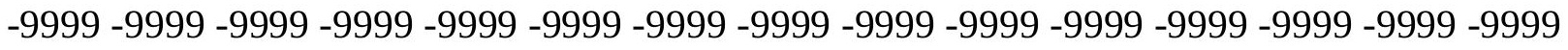

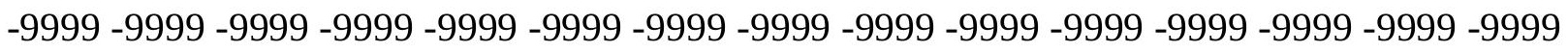

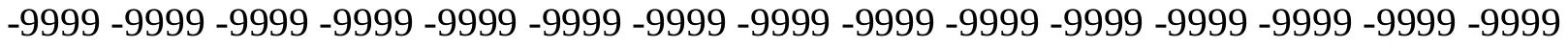
-9999 -9999 -9999 -9999 -9999 -9999 -9999 -9999 -9999 -9999 -9999 -9999 -9999 -9999 -9999 -9999 -9999 -9999 -9999 -9999 -9999 -9999 -9999 -9999 -9999 -9999 -9999 -9999 -9999 -9999 -

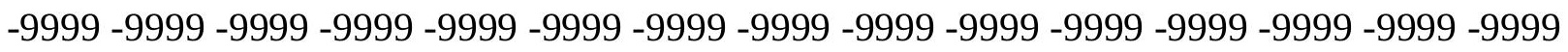
-9999 -9999 -9999 -9999 -9999 -9999 -9999 -9999 -9999 -9999 -9999 -9999 -9999 -9999 -9999 -9999 -9999 -9999 -9999 -9999 -9999 -9999 -9999 -9999 -9999 -9999 -9999 -9999 -9999 -9999 -

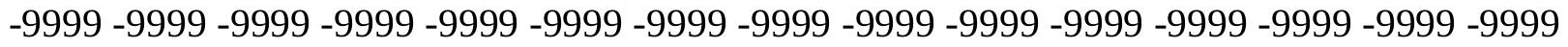
-9999 -9999 -9999 -9999 -9999 -9999 -9999 -9999 -9999 -9999 -9999 -9999 -9999 -9999 -9999 -9999 -9999 -9999 -9999 -9999 -9999 -9999 -9999 -9999 -9999 -9999 -9999 -9999 -9999 -999 -9999 -9999 -9999 -9999 -9999 -9999 -9999 -9999 -9999 -9999 -9999 -9999 -9999 -9999 -9999 -9999 -9999 -9999 -9999 -9999 -9999 -9999 -9999 -9999 -9999 -9999 -9999 -9999 -9999 -

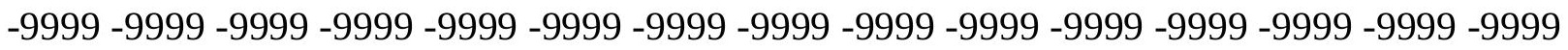

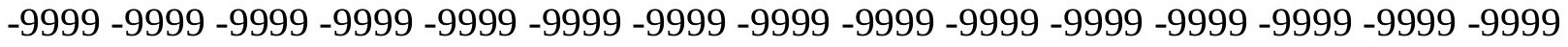

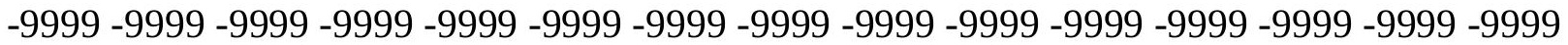

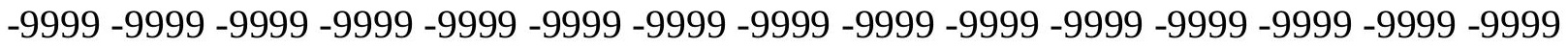

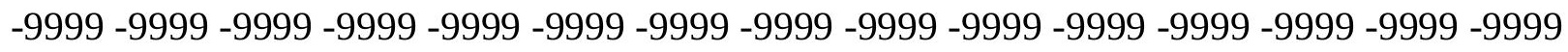

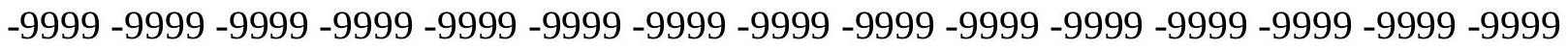

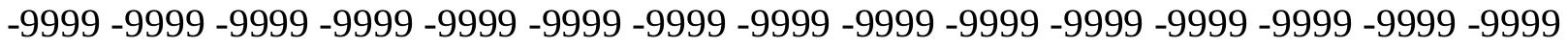
-9999 -9999 -9999 -9999 -9999 -9999 -9999 -9999 -9999 -9999 -9999 -9999 -9999 -9999 -9999 -

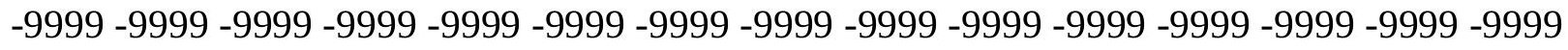

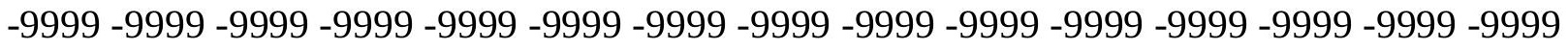
-9999 -9999 -9999 -9999 -9999 -9999 -9999 -9999 -9999 -9999 -9999 -9999 -9999 -9999 -9999 -9999 -9999 -9999 -9999 -9999 -9999 -9999 -9999 -9999-9999 -9999 -9999 -9999 -9999 -9999 -9999 -9999 -9999 -9999 -9999 -9999 -9999 -9999 -9999 -9999 -9999 -9999 -9999 -9999 -9999 -

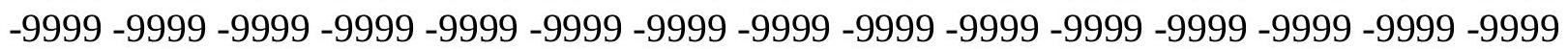


-9999 -9999 -9999 -9999 -9999 -9999 -9999 -9999 -9999 -9999 -9999 -9999 -9999 -9999 -9999 -9999 -9999 -9999 -9999 -9999 -9999 -9999 -9999 -9999 -9999 -9999 -9999 -9999 -9999 -9999 -

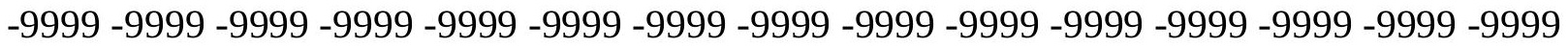
-9999 -9999 -9999 -9999 -9999 -9999 -9999 -9999 -9999 -9999 -9999 -9999 -9999 -9999 -9999 -9999 -9999 -9999 -9999 -9999 -9999 -9999 -9999 -9999-9999 -9999 -9999 -9999 -9999 -9999 -9999 -9999 -9999 -9999 -9999 -9999 -9999 -9999 -9999 -9999 -9999 -9999 -9999 -9999 -9999 -9999 -9999 -9999 -9999 -9999 -9999 -9999 -9999 -9999 -9999 -9999 -9999 -9999 -9999 -9999

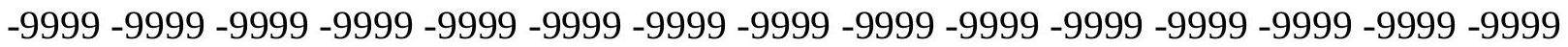

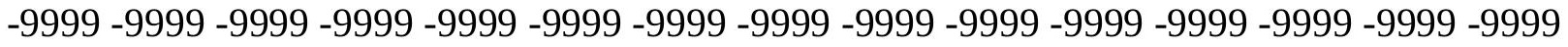

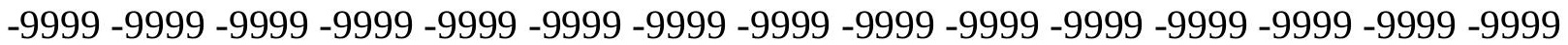
-9999 -9999 -9999 -9999 -9999 -9999 -9999 -9999 -9999 -9999 -9999 -9999 -9999 -9999 -9999 -9999 -9999 -9999 -9999 -9999 -9999 -9999 -9999 -9999 -9999 -9999 -9999 -9999 -9999 -9999 -9999 -9999 -9999 -9999 -9999 -9999 -9999 -9999 -9999 -9999 -9999 -9999 -9999 -9999 -

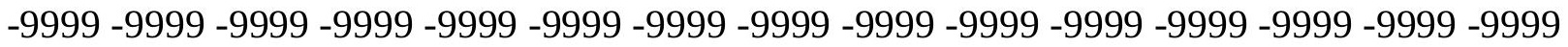
-9999 -9999 -9999 -9999 -9999 -9999 -9999 -9999 -9999 -9999 -9999 -9999 -9999 -9999 -9999 -

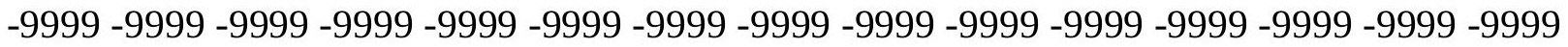
-9999 -9999 -9999 -9999 -9999 -9999 -9999 -9999 -9999 -9999 -9999 -9999 -9999 -9999 -9999 -9999 -9999 -9999 -9999 -9999 -9999 -9999 -9999 -9999 -9999 -9999 -9999 -9999 -9999 -9999 -9999 -9999 -9999 -9999 -9999 -9999 -9999 -9999 -9999 -9999 -9999 -9999 -9999 -9999 -9999 -

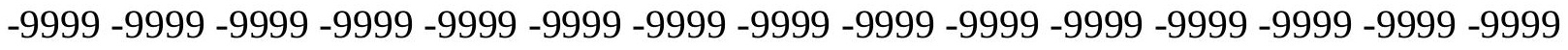

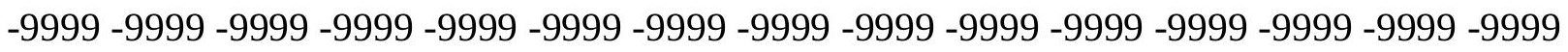
-9999 -9999 -9999 -9999 -9999 -9999 -9999 -9999 -9999 -9999 -9999 -9999 -9999 -9999 -9999 -9999 -9999 -9999 -9999 -9999 -9999 -9999 -9999 -9999 -9999 -9999 -9999 -9999 -9999 -9999 -9999 -9999 -9999 -9999 -9999 -9999 -9999 -9999 -9999 -9999 -9999 -9999 -9999 -9999 -9999 -

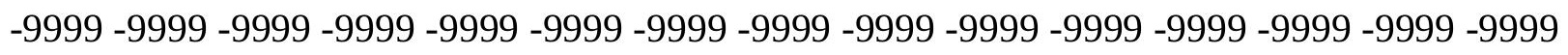
-9999 -9999 -9999 -9999 -9999 -9999 -9999 -9999 -9999 -9999 -9999 -9999 -9999 -9999 -9999 -9999 -9999 -9999 -9999 -9999 -9999 -9999 -9999 -9999 -9999 -9999 -9999 -9999 -9999 -9999 -

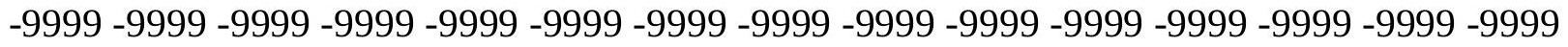
-9999 -9999 -9999 -9999 -9999 -9999 -9999 -9999 -9999 -9999 -9999 -9999 -9999 -9999 -9999 -9999 -9999 -9999 -9999 -9999 -9999 -9999 -9999 -9999 -9999 -9999 -9999 -9999 -9999 -999 -9999 -9999 -9999 -9999 -9999 -9999 -9999 -9999 -9999 -9999 -9999 -9999 -9999 -9999 -9999 -9999 -9999 -9999 -9999 -9999 -9999 -9999 -9999 -9999 -9999 -9999 -9999 -9999 -9999 -9999 -

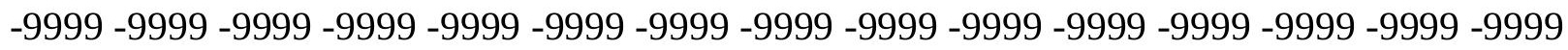

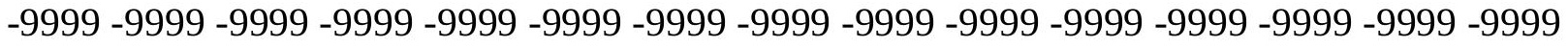

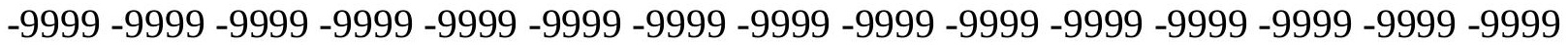
-9999 -9999 -9999 -9999 -9999 -9999 -9999 -9999 -9999 -9999 -9999 -9999 -9999 -9999 -9999 -

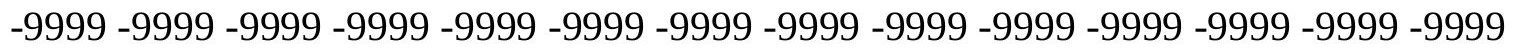

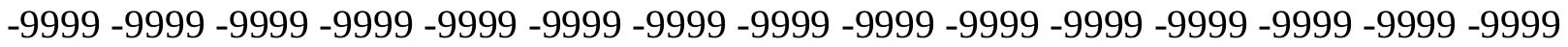
-9999 -9999 -9999 -9999 -9999 -9999 -9999 -9999 -9999 -9999 -9999 -9999 -9999 - 9999 - -999 -9999 -9999 -9999 -9999 -9999 -9999 -9999 -9999 -9999 -9999 -9999 -9999 -9999 -9999 -9999 -

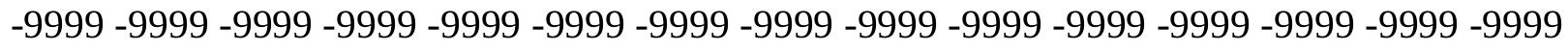

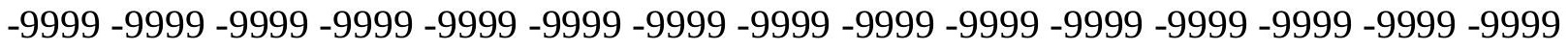
-9999 -9999 -9999 -9999 -9999 -9999 -9999 -9999 -9999 -9999 -9999 -9999 -9999 -9999 -9999 -9999 -9999 -9999 -9999 -9999 -9999 -9999 -9999 -9999-9999 -9999 -9999 -9999 -9999 -9999 -9999 -9999 -9999 -9999 -9999 -9999 -9999 -9999 -9999 -9999 -9999 -9999 -9999 -9999 -9999 -

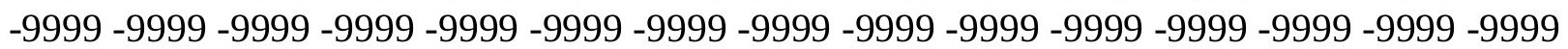


-9999 -9999 -9999 -9999 -9999 -9999 -9999 -9999 -9999 -9999 -9999 -9999 -9999 -9999 -9999 -9999 -9999 -9999 -9999 -9999 -9999 -9999 -9999 -9999 -9999 -9999 -9999 -9999 -9999 -9999 -

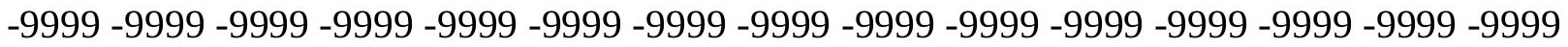
-9999 -9999 -9999 -9999 -9999 -9999 -9999 -9999 -9999 -9999 -9999 -9999 -9999 -9999 -9999 -9999 -9999 -9999 -9999 -9999 -9999 -9999 -9999 -9999-9999 -9999 -9999 -9999 -9999 -9999 -9999 -9999 -9999 -9999 -9999 -9999 -9999 -9999 -9999 -9999 -9999 -9999 -9999 -9999 -9999 -9999 -9999 -9999 -9999 -9999 -9999 -9999 -9999 -9999 -9999 -9999 -9999 -9999 -9999 -9999

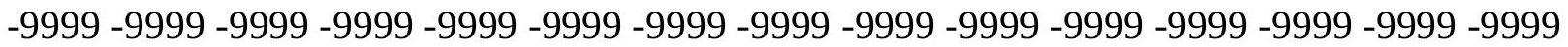

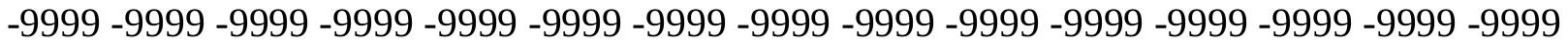
-9999 -9999 -9999 -9999 -9999 -9999 -9999 -9999 -9999 -9999 -9999 -9999 -9999 -9999 -9999 -9999 -9999 -9999 -9999 -9999 -9999 -9999 -9999 -9999 -9999 -9999 -9999 -9999 -9999 -9999 -9999 -9999 -9999 -9999 -9999 -9999 -9999 -9999 -9999 -9999 -9999 -9999 -9999 -9999 -9999 -9999 -9999 -9999 -9999 -9999 -9999 -9999 -9999 -9999 -9999 -9999 -9999 -9999 -9999 -9999 -9999 -9999 -9999 -9999 -9999 -9999 -9999 -9999 -9999 -9999 -9999 -9999 -9999 -9999 -9999 -9999 -9999 -9999 -9999 -9999 -9999 -9999 -9999 -9999 -9999 -9999 -9999 -9999 -9999 -9999 -

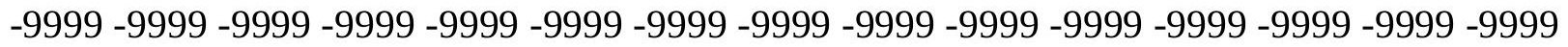
-9999 -9999 -9999 -9999 -9999 -9999 -9999 -9999 -9999 -9999 -9999 -9999 -9999 -9999 -9999 -9999 -9999 -9999 -9999 -9999 -9999 -9999 -9999 -9999 -9999 -9999 -9999 -9999 -9999 -9999 -9999 -9999 -9999 -9999 -9999 -9999 -9999 -9999 -9999 -9999 -9999 -9999 -9999 -9999 -

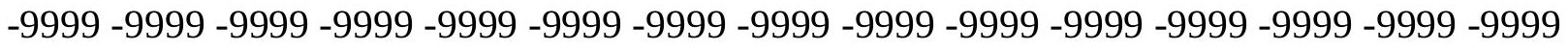
-9999 -9999 -9999 -9999 -9999 -9999 -9999 -9999 -9999 -9999 -9999 -9999 -9999 -9999 -9999 -999 -

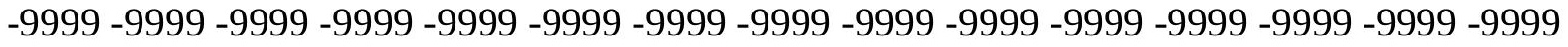
-9999 -9999 -9999 -9999 -9999 -9999 -9999 -9999 -9999 -9999 -9999 -9999 -9999 -9999 -9999 -9999 -9999 -9999 -9999 -9999 -9999 -9999 -9999 -9999 -9999 -9999 -9999 -9999 -9999 -9999 -9999 -9999 -9999 -9999 -9999 -9999 -9999 -9999 -9999 -9999 -9999 -9999 -9999 -9999 -9999 -9999 -9999 -9999 -9999 -9999 -9999 -9999 -9999 -9999 -9999 -9999 -9999 -9999 -9999 -9999 -9999 -9999 -9999 -9999 -9999 -9999 -9999 -9999 -9999 -9999 -9999 -9999 -9999 -9999 -9999 -

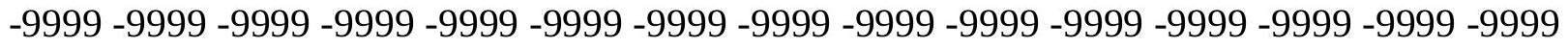
-9999 -9999 -9999 -9999 -9999 -9999 -9999 -9999 -9999 -9999 -9999 -9999 -9999 -9999 -9999 -9999 -9999 -9999 -9999 -9999 -9999 -9999 -9999 -9999 -9999 -9999 -9999 -9999 -9999 -999 -9999 -9999 -9999 -9999 -9999 -9999 -9999 -9999 -9999 -9999 -9999 -9999 -9999 -9999 -9999 -9999 -9999 -9999 -9999 -9999 -9999 -9999 -9999 -9999 -9999 -9999 -9999 -9999 -9999 -9999 -

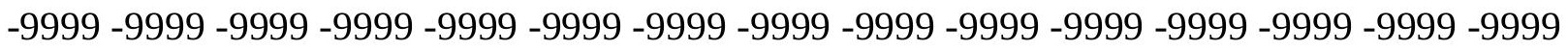

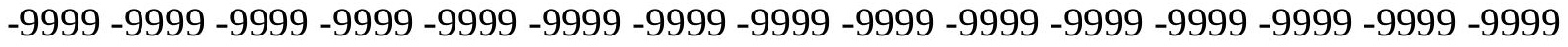

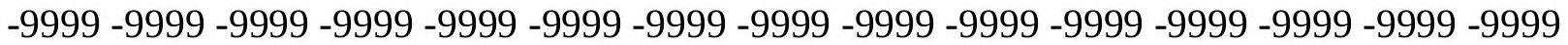
-9999 -9999 -9999 -9999 -9999 -9999 -9999 -9999 -9999 -9999 -9999 -9999 -9999 -9999 -9999

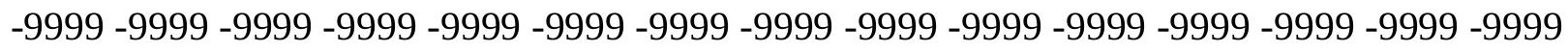

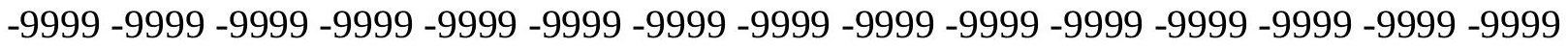
-9999 -9999 -9999 -9999 -9999 -9999 -9999 -9999 -9999 -9999 -9999 -9999 -9999 - 9999 - -999 -9999 -9999 -9999 -9999 -9999 -9999 -9999 -9999 -9999 -9999 -9999 -9999 -9999 -9999 -9999 -

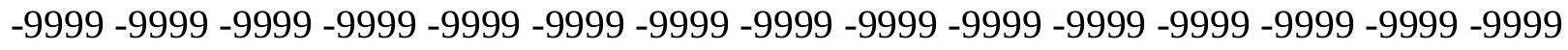

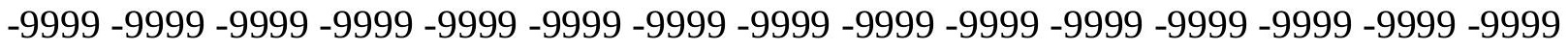
-9999 -9999 -9999 -9999 -9999 -9999 -9999 -9999 -9999 -9999 -9999 -9999 -9999 -9999 -9999 -9999 -9999 -9999 -9999 -9999 -9999 -9999 -9999 -9999 -9999 -9999 -9999 -9999 -9999 -9999 -9999 -9999 -9999 -9999 -9999 -9999 -9999 -9999 -9999 -9999 -9999 -9999 -9999 -9999 -

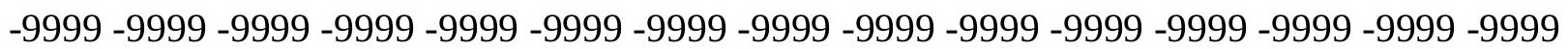


-9999 -9999 -9999 -9999 -9999 -9999 -9999 -9999 -9999 -9999 -9999 -9999 -9999 -9999 -9999 -9999 -9999 -9999 -9999 -9999 -9999 -9999 -9999 -9999 -9999 -9999 -9999 -9999 -9999 -9999 -9999 -9999 -9999 -9999 -9999 -9999 -9999 -9999 -9999 -9999 -9999 -9999 -9999 -9999 - 9999 -9999 -9999 -9999 -9999 -9999 -9999 -9999 -9999 -9999 -9999 -9999 -9999 -9999 -9999 -9999 -9999 -9999 -9999 -9999 -9999 -9999 -9999 -9999 -9999-9999 -9999 -9999 -9999 -9999 -9999 -9999 -9999 -9999 -9999 -9999 -9999 -9999 -9999 -9999 -9999 -9999 -9999 -9999 -9999 -9999 -9999 -9999 -9999 -9999 -9999 -9999 -9999 -9999 -9999 -9999 -9999 -9999 -9999 -9999 -9999

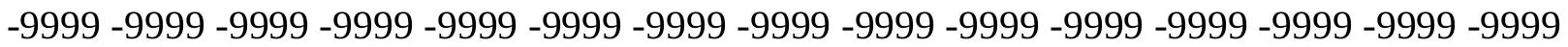

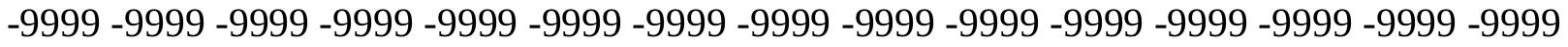
-9999 -9999 -9999 -9999 -9999 -9999 -9999 -9999 -9999 -9999 -9999 -9999 -9999 -9999 -9999 -9999 -9999 -9999 -9999 -9999 -9999 -9999 -9999 -9999 -9999 -9999 -9999 -9999 -9999 -9999 -9999 -9999 -9999 -9999 -9999 -9999 -9999 -9999 -9999 -9999 -9999 -9999 -9999 -9999 -9999 -9999 -9999 -9999 -9999 -9999 -9999 -9999 -9999 -9999 -9999 -9999 -9999 -9999 -9999 -9999 -

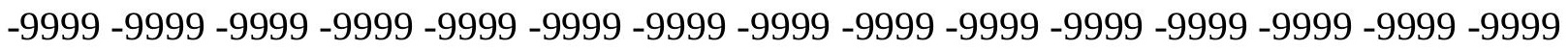
-9999 -9999 -9999 -9999 -9999 -9999 -9999 -9999 -9999 -9999 -9999 -9999 -9999 -9999 -9999 -

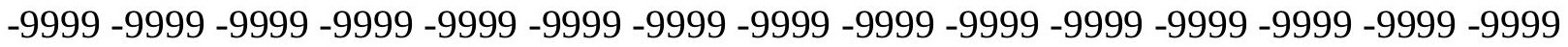
-9999 -9999 -9999 -9999 -9999 -9999 -9999 -9999 -9999 -9999 -9999 -9999 -9999 -9999 -9999 -9999 -9999 -9999 -9999 -9999 -9999 -9999 -9999 -9999 -9999 -9999 -9999 -9999 -9999 -9999 -9999 -9999 -9999 -9999 -9999 -9999 -9999 -9999 -9999 -9999 -9999 -9999 -9999 -9999 -9999 -

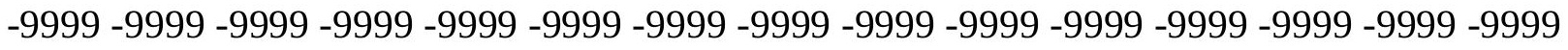
-9999 -9999 -9999 -9999 -9999 -9999 -9999 -9999 -9999 -9999 -9999 -9999 -9999 -9999 -9999 -999 -9999 -9999 -9999 -9999 -9999 -9999 -9999 -9999 -9999 -9999 -9999 -9999 -9999 -9999 - 9999 -9999 -9999 -9999 -9999 -9999 -9999 -9999 -9999 -9999 -9999 -9999 -9999 -9999 -9999 -

-9999 -9999 -9999 -9999 -9999 -9999 -9999 -9999 -9999 -9999 -9999 -9999 -9999 -9999 -9999 -

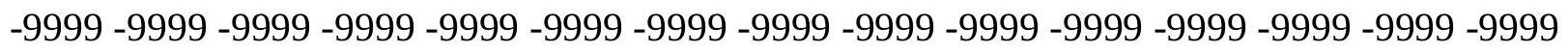
-9999 -9999 -9999 -9999 -9999 -9999 -9999 -9999 -9999 -9999 -9999 -9999 -9999 -9999 -9999 -9999 -9999 -9999 -9999 -9999 -9999 -9999 -9999 -9999 -9999 -9999 -9999 -9999 -9999 -9999 -

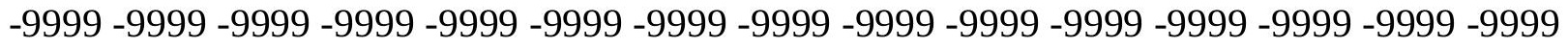
-9999 -9999 -9999 -9999 -9999 -9999 -9999 -9999 -9999 -9999 -9999 -9999 -9999 -9999 -9999 -9999 -9999 -9999 -9999 -9999 -9999 -9999 -9999 -9999 -9999 -9999 -9999 -9999 -9999 -999 -

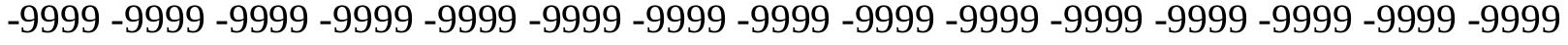
-9999 -9999 -9999 -9999 -9999 -9999 -9999 -9999 -9999 -9999 -9999 -9999 -9999 -9999 -9999 -

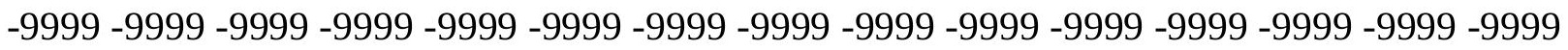

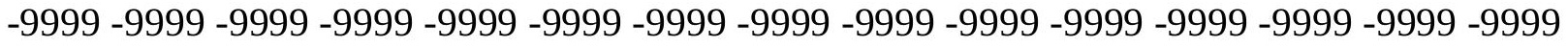

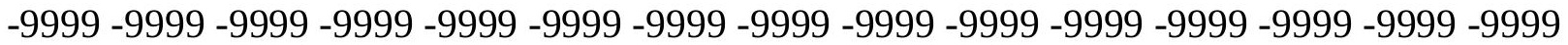

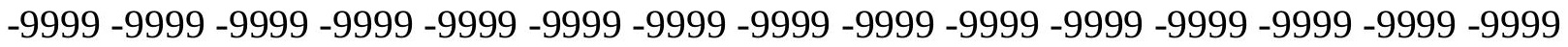

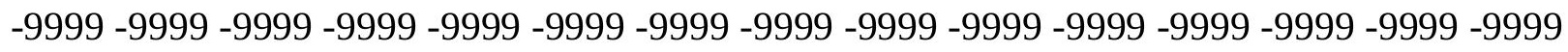

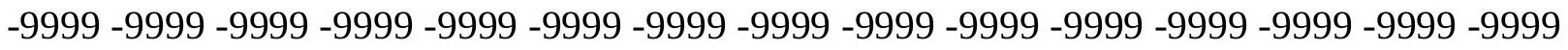

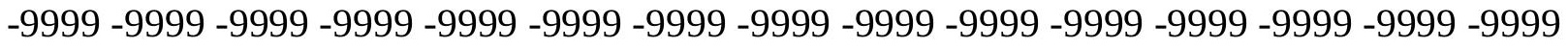
-9999 -9999 -9999 -9999 -9999 -9999 -9999 -9999 -9999 -9999 -9999 -9999 -9999 -9999 -9999 -

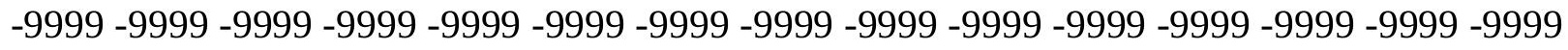

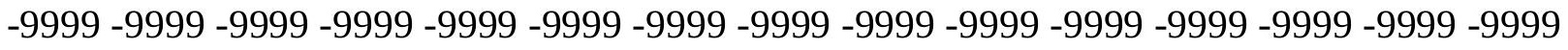
-9999 -9999 -9999 -9999 -9999 -9999 -9999 -9999 -9999 -9999 -9999 -9999 -9999 -9999 -9999 -9999 -9999 -9999 -9999 -9999 -9999 -9999 -9999 -9999-9999 -9999 -9999 -9999 -9999 -9999 -9999 -9999 -9999 -9999 -9999 -9999 -9999 -9999 -9999 -9999 -9999 -9999 -9999 -9999 -9999 -

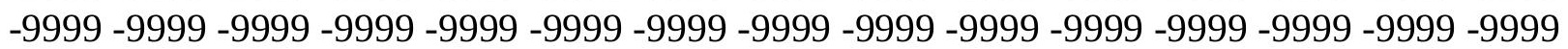


-9999 -9999 -9999 -9999 -9999 -9999 -9999 -9999 -9999 -9999 -9999 -9999 -9999 -9999 -9999 -9999 -9999 -9999 -9999 -9999 -9999 -9999 -9999 -9999 -9999 -9999 -9999 -9999 -9999 -9999 -9999 -9999 -9999 -9999 -9999 -9999 -9999 -9999 -9999 -9999 -9999 -9999 -9999 -9999 -9999 -9999 -9999 -9999 -9999 -9999 -9999 -9999 -9999 -9999 -9999 -9999 -9999 -9999 -9999 -9999 -9999 -9999 -9999 -9999 -9999 -9999 -9999 -9999-9999 -9999 -9999 -9999 -9999 -9999 -9999 -9999 -9999 -9999 -9999 -9999 -9999 -9999 -9999 -9999 -9999 -9999 -9999 -9999 -9999 -9999 -9999 -9999 -9999 -9999 -9999 -9999 -9999 -9999 -9999 -9999 -9999 -9999 -9999 -9999

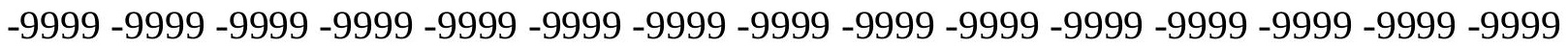

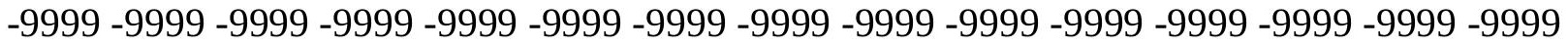
-9999 -9999 -9999 -9999 -9999 -9999 -9999 -9999 -9999 -9999 -9999 -9999 -9999 -9999 -9999 -9999 -9999 -9999 -9999 -9999 -9999 -9999 -9999 -9999 -9999 -9999 -9999 -9999 -9999 -9999 -9999 -9999 -9999 -9999 -9999 -9999 -9999 -9999 -9999 -9999 -9999 -9999 -9999 -9999 -9999 -9999 -9999 -9999 -9999 -9999 -9999 -9999 -9999 -9999 -9999 -9999 -9999 -9999 -9999 -9999 -

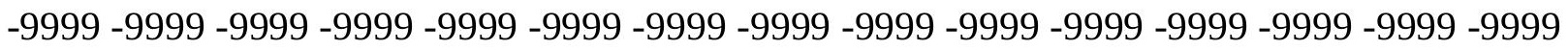
-9999 -9999 -9999 -9999 -9999 -9999 -9999 -9999 -9999 -9999 -9999 -9999 -9999 -9999 -9999 -

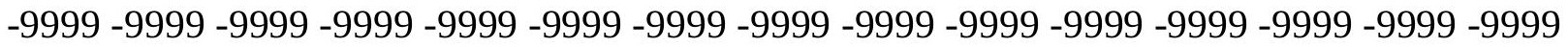
-9999 -9999 -9999 -9999 -9999 -9999 -9999 -9999 -9999 -9999 -9999 -9999 -9999 -9999 -9999 -9999 -9999 -9999 -9999 -9999 -9999 -9999 -9999 -9999 -9999 -9999 -9999 -9999 -9999 -9999 -9999 -9999 -9999 -9999 -9999 -9999 -9999 -9999 -9999 -9999 -9999 -9999 -9999 -9999 -9999 -

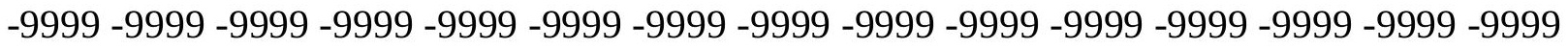

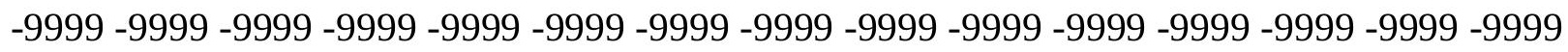
-9999 -9999 -9999 -9999 -9999 -9999 -9999 -9999 -9999 -9999 -9999 -9999 -9999 -9999 -9999 -9999 -9999 -9999 -9999 -9999 -9999 -9999 -9999 -9999 -9999 -9999 -9999 -9999 -9999 -9999 -9999 -9999 -9999 -9999 -9999 -9999 -9999 -9999 -9999 -9999 -9999 -9999 -9999 -9999 -9999 -

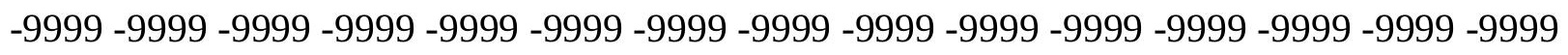
-9999 -9999 -9999 -9999 -9999 -9999 -9999 -9999 -9999 -9999 -9999 -9999 -9999 -9999 -9999 -9999 -9999 -9999 -9999 -9999 -9999 -9999 -9999 -9999 -9999 -9999 -9999 -9999 -9999 -9999 -

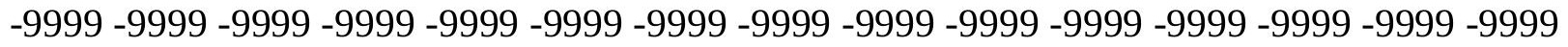
-9999 -9999 -9999 -9999 -9999 -9999 -9999 -9999 -9999 -9999 -9999 -9999 -9999 -9999 -9999 -9999 -9999 -9999 -9999 -9999 -9999 -9999 -9999 -9999 -9999 -9999 -9999 -9999 - -999 -

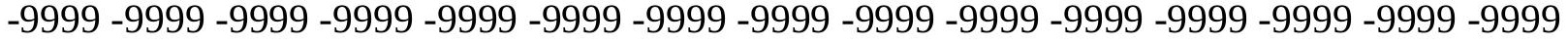
-9999 -9999 -9999 -9999 -9999 -9999 -9999 -9999 -9999 -9999 -9999 -9999 -9999 -9999 -9999 -

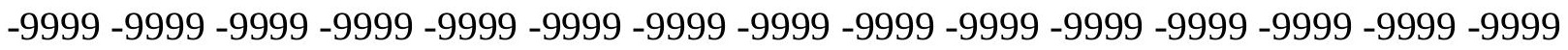

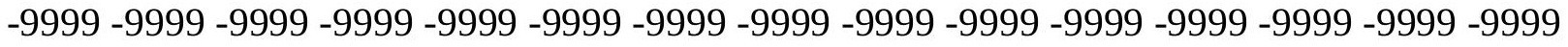

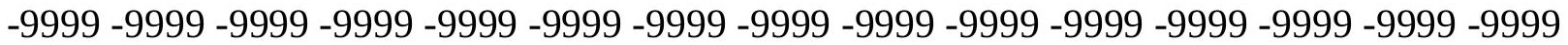

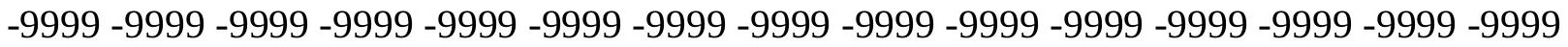

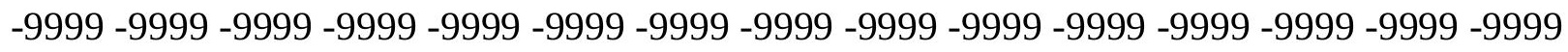

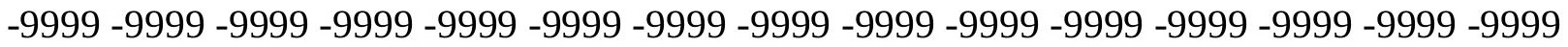

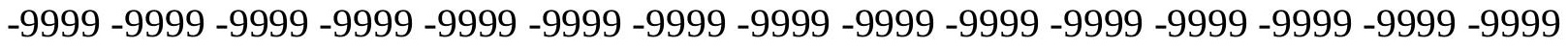
-9999 -9999 -9999 -9999 -9999 -9999 -9999 -9999 -9999 -9999 -9999 -9999 -9999 -9999 -9999 -

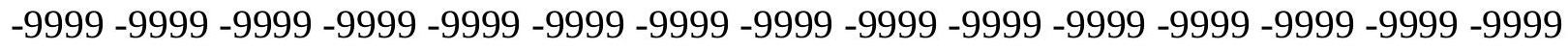

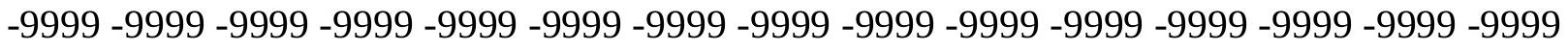
-9999 -9999 -9999 -9999 -9999 -9999 -9999 -9999 -9999 -9999 -9999 -9999 -9999 -9999 -9999 -9999 -9999 -9999 -9999 -9999 -9999 -9999 -9999 -9999-9999 -9999 -9999 -9999 -9999 -9999 -9999 -9999 -9999 -9999 -9999 -9999 -9999 -9999 -9999 -9999 -9999 -9999 -9999 -9999 -9999 -

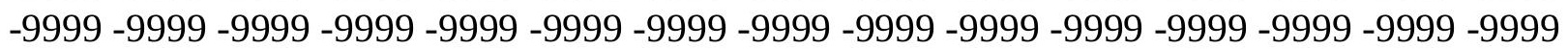


-9999 -9999 -9999 -9999 -9999 -9999 -9999 -9999 -9999 -9999 -9999 -9999 -9999 -9999 -9999 -9999 -9999 -9999 -9999 -9999 -9999 -9999 -9999 -9999 -9999 -9999 -9999 -9999 -9999 -9999 -

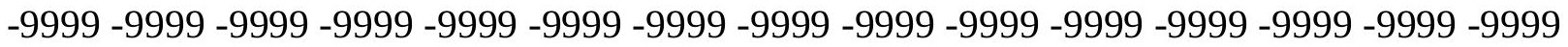
-9999 -9999 -9999 -9999 -9999 -9999 -9999 -9999 -9999 -9999 -9999 -9999 -9999 -9999 -9999 -9999 -9999 -9999 -9999 -9999 -9999 -9999 -9999 -9999-9999 -9999 -9999 -9999 -9999 -9999 -9999 -9999 -9999 -9999 -9999 -9999 -9999 -9999 -9999 -9999 -9999 -9999 -9999 -9999 -9999 -9999 -9999 -9999 -9999 -9999 -9999 -9999 -9999 -9999 -9999 -9999 -9999 -9999 -9999 -9999

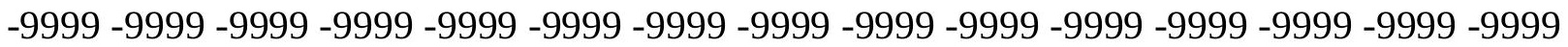
-9999 -9999 -9999 -9999 -9999 -9999 -9999 -9999 -9999 -9999 -9999 -9999 -9999 -9999 -9999 -9999 -9999 -9999 -9999 -9999 -9999 -9999 -9999 -9999 -9999 -9999 -9999 -9999 -9999

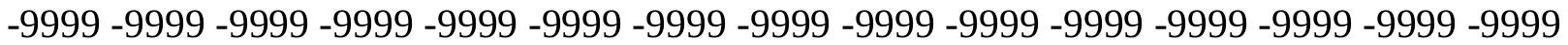
-9999 -9999 -9999 -9999 -9999 -9999 -9999 -9999 -9999 -9999 -9999 -9999 -9999 -9999 -9999 -9999 -9999 -9999 -9999 -9999 -9999 -9999 -9999 -9999 -9999 -9999 -9999 -9999 -9999 -9999 -9999 -9999 -9999 -9999 -9999 -9999 -9999 -9999 -9999 -9999 -9999 -9999 -9999 -9999 - 9999 -9999 -9999 -9999 -9999 -9999 -9999 -9999 -9999 -9999 -9999 -9999 -9999 -9999 -9999 -9999

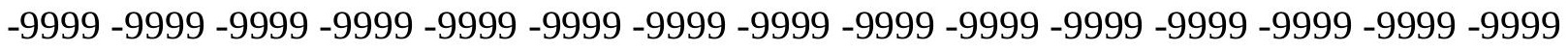
-9999 -9999 -9999 -9999 -9999 -9999 -9999 -9999 -9999 -9999 -9999 -9999 -9999 -9999 -9999 -9999 -9999 -9999 -9999 -9999 -9999 -9999 -9999 -9999 -9999 -9999 -9999 -9999 -9999 -9999 -9999 -9999 -9999 -9999 -9999 -9999 -9999 -9999 -9999 -9999 -9999 -9999 -9999 -9999 -9999 -

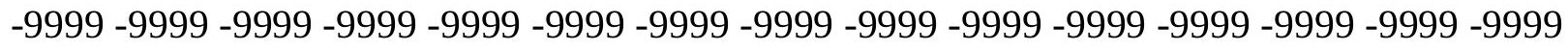

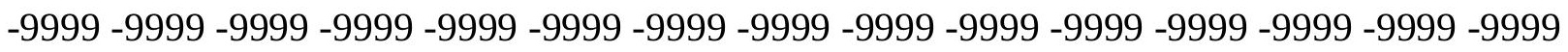
-9999 -9999 -9999 -9999 -9999 -9999 -9999 -9999 -9999 -9999 -9999 -9999 -9999 -9999 -9999 -9999 -9999 -9999 -9999 -9999 -9999 -9999 -9999 -9999 -9999 -9999 -9999 -9999 -9999 -9999 -9999 -9999 -9999 -9999 -9999 -9999 -9999 -9999 -9999 -9999 -9999 -9999 -9999 -9999 -9999 -

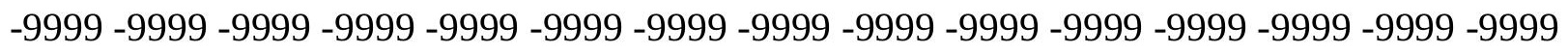
-9999 -9999 -9999 -9999 -9999 -9999 -9999 -9999 -9999 -9999 -9999 -9999 -9999 -9999 -9999 -9999 -9999 -9999 -9999 -9999 -9999 -9999 -9999 -9999 -9999 -9999 -9999 -9999 -9999 -9999 -

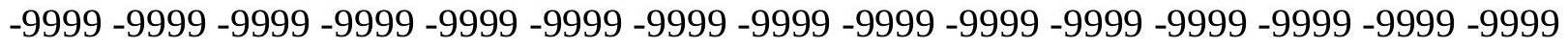
-9999 -9999 -9999 -9999 -9999 -9999 -9999 -9999 -9999 -9999 -9999 -9999 -9999 -9999 -9999 -9999 -9999 -9999 -9999 -9999 -9999 -9999 -9999 -9999 -9999 -9999 -9999 -9999 -9999 -999 -9999 -9999 -9999 -9999 -9999 -9999 -9999 -9999 -9999 -9999 -9999 -9999 -9999 -9999 -9999 -9999 -9999 -9999 -9999 -9999 -9999 -9999 -9999 -9999 -9999 -9999 -9999 -9999 -9999 -9999 -

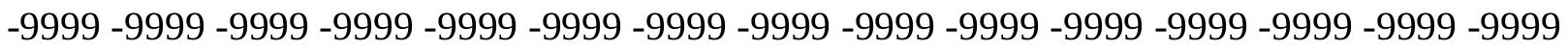

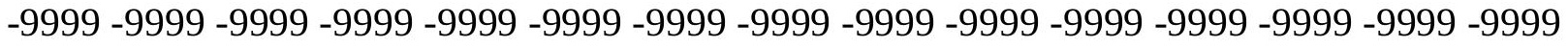
-9999 -9999 -9999 -9999 -9999 -9999 -9999 -9999 -9999 -9999 -9999 -9999 -9999 -9999 -

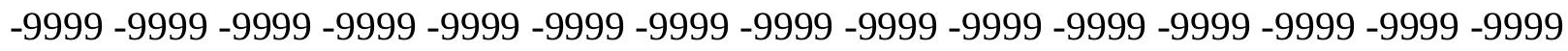

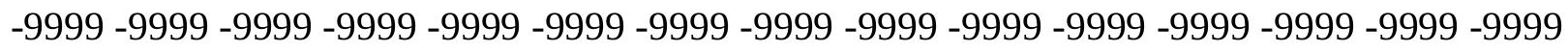

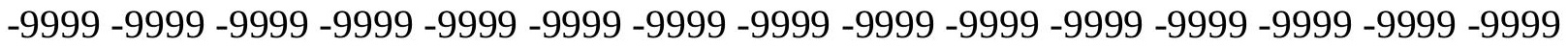
-9999 -9999 -9999 -9999 -9999 -9999 -9999 -9999 -9999 -9999 -9999 -9999 -9999 - 9999 - -999 -9999 -9999 -9999 -9999 -9999 -9999 -9999 -9999 -9999 -9999 -9999 -9999 -9999 -9999 -9999 -

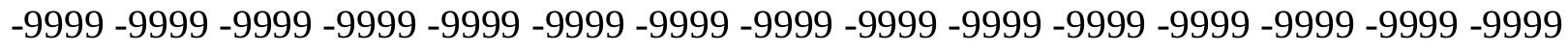

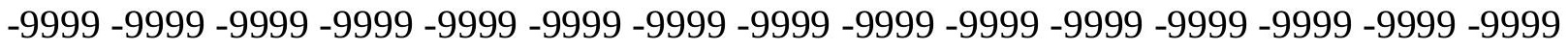
-9999 -9999 -9999 -9999 -9999 -9999 -9999 -9999 -9999 -9999 -9999 -9999 -9999 -9999 -9999 -9999 -9999 -9999 -9999 -9999 -9999 -9999 -9999 -9999-9999 -9999 -9999 -9999 -9999 -9999 -9999 -9999 -9999 -9999 -9999 -9999 -9999 -9999 -9999 -9999 -9999 -9999 -9999 -9999 -9999 -

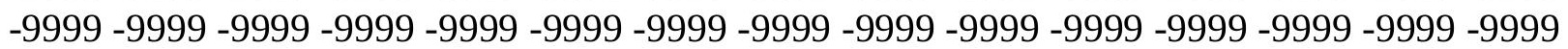


-9999 -9999 -9999 -9999 -9999 -9999 -9999 -9999 -9999 -9999 -9999 -9999 -9999 -9999 -9999 -9999 -9999 -9999 -9999 -9999 -9999 -9999 -9999 -9999 -9999 -9999 -9999 -9999 -9999 -9999 -

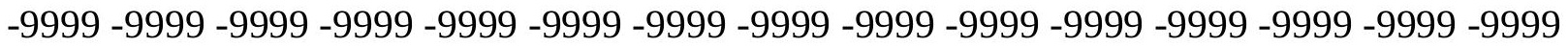
-9999 -9999 -9999 -9999 -9999 -9999 -9999 -9999 -9999 -9999 -9999 -9999 -9999 -9999 -9999 -9999 -9999 -9999 -9999 -9999 -9999 -9999 -9999 -9999-9999 -9999 -9999 -9999 -9999 -9999 -9999 -9999 -9999 -9999 -9999 -9999 -9999 -9999 -9999 -9999 -9999 -9999 -9999 -9999 -9999 -9999 -9999 -9999 -9999 -9999 -9999 -9999 -9999 -9999 -9999 -9999 -9999 -9999 -9999 -9999

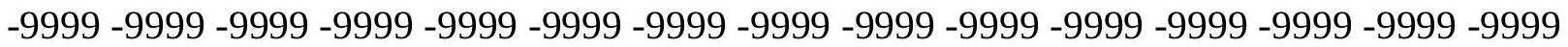

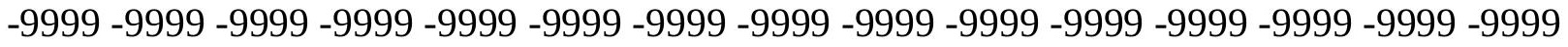
-9999 -9999 -9999 -9999 -9999 -9999 -9999 -9999 -9999 -9999 -9999 -9999 -9999 -9999 -9999 -9999 -9999 -9999 -9999 -9999 -9999 -9999 -9999 -9999 -9999 -9999 -9999 -9999 -9999 -9999 -9999 -9999 -9999 -9999 -9999 -9999 -9999 -9999 -9999 -9999 -9999 -9999 -9999 -9999 -9999 -9999 -9999 -9999 -9999 -9999 -9999 -9999 -9999 -9999 -9999 -9999 -9999 -9999 -9999 -9999 -9999 -9999 -9999 -9999 -9999 -9999 -9999 -9999 -9999 -9999 -9999 -9999 -9999 -9999 -9999 -9999 -9999 -9999 -9999 -9999 -9999 -9999 -9999 -9999 -9999 -9999 -9999 -9999 -9999 -9999 -9999 -9999 -9999 -9999 -9999 -9999 -9999 -9999 -9999 -9999 -9999 -9999 - 9999 - -999 -

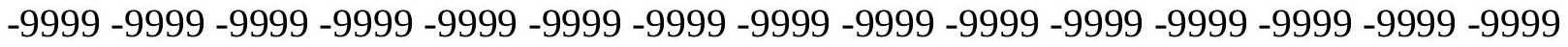
-9999 -9999 -9999 -9999 -9999 -9999 -9999 -9999 -9999 -9999 -9999 -9999 -9999 -9999 -9999 -9999 -9999 -9999 -9999 -9999 -9999 -9999 -9999 -9999 -9999 -9999 -9999 -9999 -9999 -9999 -

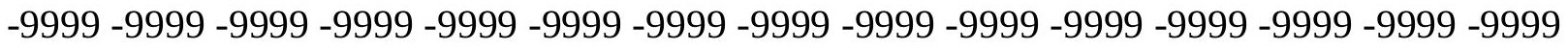
-9999 -9999 -9999 -9999 -9999 -9999 -9999 -9999 -9999 -9999 -9999 -9999 -9999 -9999 -9999

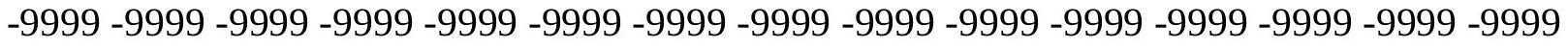
-9999 -9999 -9999 -9999 -9999 -9999 -9999 -9999 -9999 -9999 -9999 -9999 -9999 -9999 -9999 -9999 -9999 -9999 -9999 -9999 -9999 -9999 -9999 -9999 -9999 -9999 -9999 -9999 -9999 -9999 -

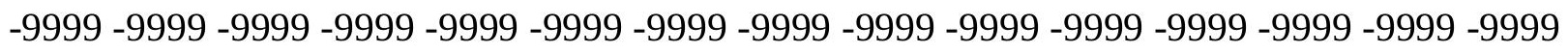
-9999 -9999 -9999 -9999 -9999 -9999 -9999 -9999 -9999 -9999 -9999 -9999 -9999 -9999 -9999 -9999 -9999 -9999 -9999 -9999 -9999 -9999 -9999 -9999 -9999 -9999 -9999 -9999 -9999 -9999 -

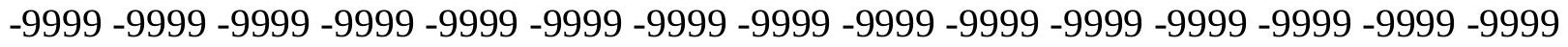
-9999 -9999 -9999 -9999 -9999 -9999 -9999 -9999 -9999 -9999 -9999 -9999 -9999 -9999 -9999 -9999 -9999 -9999 -9999 -9999 -9999 -9999 -9999 -9999 -9999 -9999 -9999 -9999 -9999 -999 -

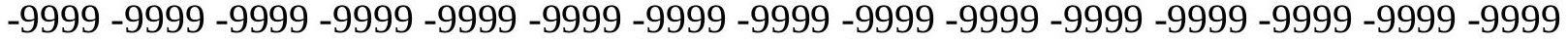
-9999 -9999 -9999 -9999 -9999 -9999 -9999 -9999 -9999 -9999 -9999 -9999 -9999 -9999 -9999 -

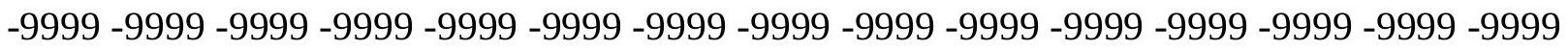

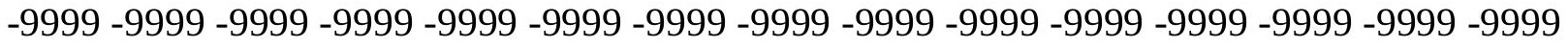

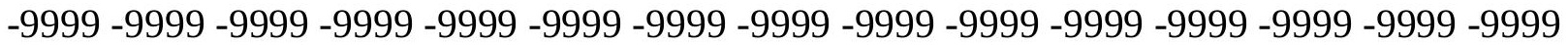
-9999 -9999 -9999 -9999 -9999 -9999 -9999 -9999 -9999 -9999 -9999 -9999 -9999 -9999 -9999 -

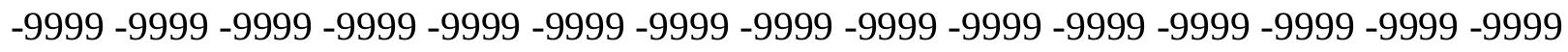

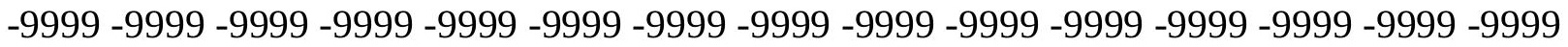
-9999 -9999 -9999 -9999 -9999 -9999 -9999 -9999 -9999 -9999 -9999 -9999 -9999 - 9999 - -999 -9999 -9999 -9999 -9999 -9999 -9999 -9999 -9999 -9999 -9999 -9999 -9999 -9999 -9999 -9999 -

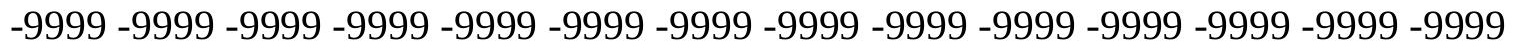

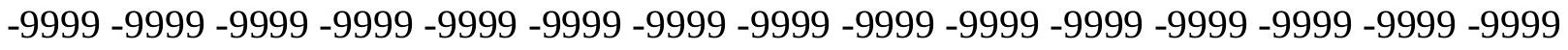
-9999 -9999 -9999 -9999 -9999 -9999 -9999 -9999 -9999 -9999 -9999 -9999 -9999 -9999 -9999 -9999 -9999 -9999 -9999 -9999 -9999 -9999 -9999 -9999-9999 -9999 -9999 -9999 -9999 -9999 -9999 -9999 -9999 -9999 -9999 -9999 -9999 -9999 -9999 -9999 -9999 -9999 -9999 -9999 -9999 -

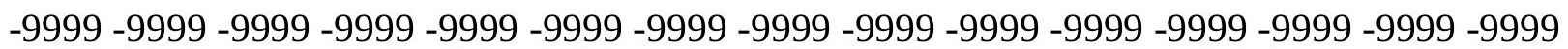


-9999 -9999 -9999 -9999 -9999 -9999 -9999 -9999 -9999 -9999 -9999 -9999 -9999 -9999 -9999 -9999 -9999 -9999 -9999 -9999 -9999 -9999 -9999 -9999 -9999 -9999 -9999 -9999 -9999 -9999 -9999 -9999 -9999 -9999 -9999 -9999 -9999 -9999 -9999 -9999 -9999 -9999 -9999 -9999 - 9999 -9999 -9999 -9999 -9999 -9999 -9999 -9999 -9999 -9999 -9999 -9999 -9999 -9999 -9999 -9999 -9999 -9999 -9999 -9999 -9999 -9999 -9999 -9999 -9999-9999 -9999 -9999 -9999 -9999 -9999 -9999 -9999 -9999 -9999 -9999 -9999 -9999 -9999 -9999 -9999 -9999 -9999 -9999 -9999 -9999 -9999 -9999 -9999 -9999 -9999 -9999 -9999 -9999 -9999 -9999 -9999 -9999 -9999 -9999 -9999

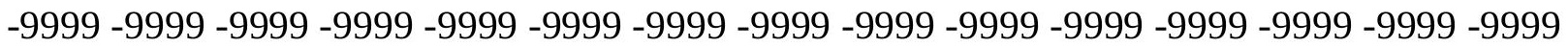
-9999 -9999 -9999 -9999 -9999 -9999 -9999 -9999 -9999 -9999 -9999 -9999 -9999 -9999 -9999 -9999 -9999 -9999 -9999 -9999 -9999 -9999 -9999 -9999 -9999 -9999 -9999 -9999 -9999 -9999

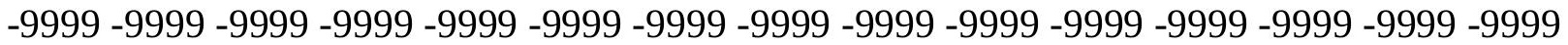
-9999 -9999 -9999 -9999 -9999 -9999 -9999 -9999 -9999 -9999 -9999 -9999 -9999 -9999 -9999 -9999 -9999 -9999 -9999 -9999 -9999 -9999 -9999 -9999 -9999 -9999 -9999 -9999 -9999 -9999 -

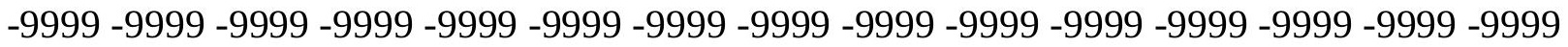
-9999 -9999 -9999 -9999 -9999 -9999 -9999 -9999 -9999 -9999 -9999 -9999 -9999 -9999 -9999

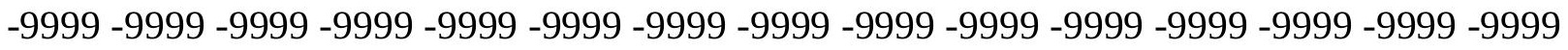
-9999 -9999 -9999 -9999 -9999 -9999 -9999 -9999 -9999 -9999 -9999 -9999 -9999 -9999 -9999 -9999 -9999 -9999 -9999 -9999 -9999 -9999 -9999 -9999 -9999 -9999 -9999 -9999 -9999 - 9999 -9999 -9999 -9999 -9999 -9999 -9999 -9999 -9999 -9999 -9999 -9999 -9999 -9999 -9999 -9999 -9999 -9999 -9999 -9999 -9999 -9999 -9999 -9999 -9999 -9999 -9999 -9999 -9999 -9999 -9999 -9999 -9999 -9999 -9999 -9999 -9999 -9999 -9999 -9999 -9999 -9999 -9999 -9999 -9999 -9999 -9999 -9999 -9999 -9999 -9999 -9999 -9999 -9999 -9999 -9999 -9999 -9999 -9999 -9999 -9999 -9999 -9999 -9999 -9999 -9999 -9999 -9999 -9999 -9999 -9999 -9999 -9999 -9999 -9999 -9999 -9999 -9999 -9999 -9999 -9999 -9999 -9999 -9999 -9999 -9999 -9999 -9999 -9999 -9999 -9999 -9999 -9999 -9999 -9999 -9999 -9999 -9999 -9999 -9999 -9999 -9999 -9999 -9999 -9999 -9999 -9999 -9999 -9999 -9999 -9999 -9999 -9999 -9999 -9999 -9999 -9999 -9999 -9999 -9999 -9999 -9999 -9999 -9999 -9999 -9999 -9999 -9999 -9999 -9999 -9999 -9999 -9999 -9999 -9999 -9999 -9999 -9999 -9999 -9999 -9999 -9999 -9999 -9999 -9999 -9999 -9999 -9999 -9999 -9999 -9999 -9999 -9999 -9999 -9999 -9999 -9999 -9999 -9999 -9999 -9999 -9999 -9999 -9999 -9999 -9999 -9999 -9999 -9999 -9999 -9999 -9999 -9999 -9999 -9999 -9999 -9999 -9999 -9999 -999 -9999 -9999 -9999 -9999 -9999 -9999 -9999 -9999 -9999 -9999 -9999 -9999 -9999 -9999 -9999 -9999 -9999 -9999 -9999 -9999 -9999 -9999 -9999 -9999 -9999 -9999 -9999 -9999 -9999 -9999 -

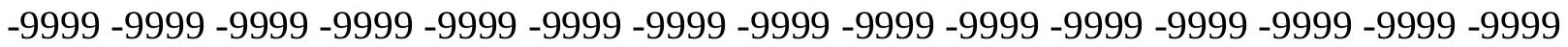

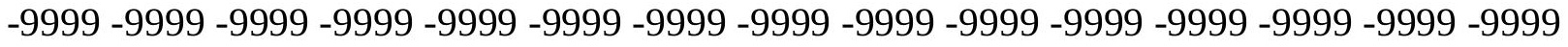

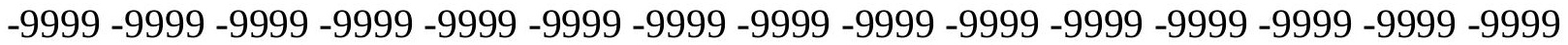
-9999 -9999 -9999 -9999 -9999 -9999 -9999 -9999 -9999 -9999 -9999 -9999 -9999 -9999 -9999

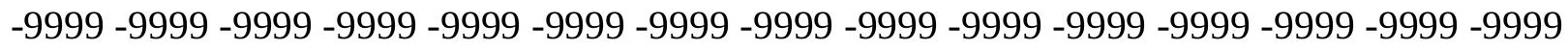

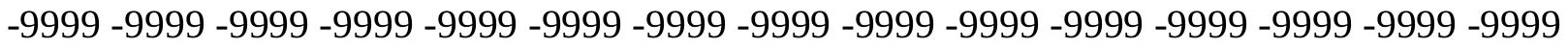

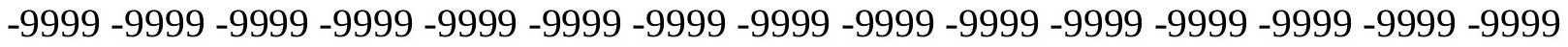
-9999 -9999 -9999 -9999 -9999 -9999 -9999 -9999 -9999 -9999 -9999 -9999 -9999 -9999 -9999 -

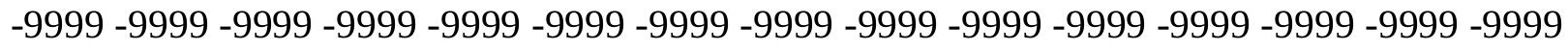

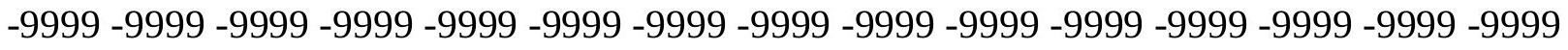
-9999 -9999 -9999 -9999 -9999 -9999 -9999 -9999 -9999 -9999 -9999 -9999 -9999 -9999 -9999 -9999 -9999 -9999 -9999 -9999 -9999 -9999 -9999 -9999-9999 -9999 -9999 -9999 -9999 -9999 -9999 -9999 -9999 -9999 -9999 -9999 -9999 -9999 -9999 -9999 -9999 -9999 -9999 -9999 -9999 -

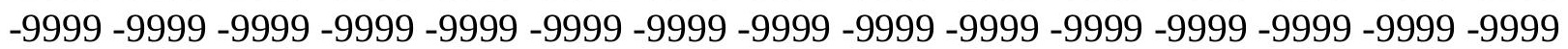


-9999 -9999 -9999 -9999 -9999 -9999 -9999 -9999 -9999 -9999 -9999 -9999 -9999 -9999 -9999 -9999 -9999 -9999 -9999 -9999 -9999 -9999 -9999 -9999 -9999 -9999 -9999 -9999 -9999 -9999 -9999 -9999 -9999 -9999 -9999 -9999 -9999 -9999 -9999 -9999 -9999 -9999 -9999 -9999 -9999 -9999 -9999 -9999 -9999 -9999 -9999 -9999 -9999 -9999 -9999 -9999 -9999 -9999 -9999 -9999 -9999 -9999 -9999 -9999 -9999 -9999 -9999 -9999 -9999 -9999 -9999 -9999 -9999 -9999 -9999 -9999 -9999 -9999 -9999 -9999 -9999 -9999 -9999 -9999 -9999 -9999 -9999 -9999 -9999 -9999 -9999 -9999 -9999 -9999 -9999 -9999 -9999 -9999 -9999 -9999 -9999 -9999 -9999 -9999 -

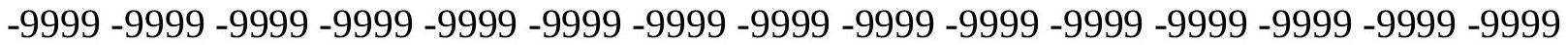
-9999 -9999 -9999 -9999 -9999 -9999 -9999 -9999 -9999 -9999 -9999 -9999 -9999 -9999 -9999 -9999 -9999 -9999 -9999 -9999 -9999 -9999 -9999 -9999 -9999 -9999 -9999 -9999 -9999 -9999 -

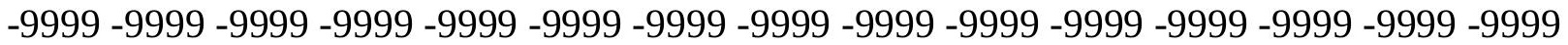
-9999 -9999 -9999 -9999 -9999 -9999 -9999 -9999 -9999 -9999 -9999 -9999 -9999 -9999 -9999 -9999 -9999 -9999 -9999 -9999 -9999 -9999 -9999 -9999 -9999 -9999 -9999 -9999 -9999 -9999 -9999 -9999 -9999 -9999 -9999 -9999 -9999 -9999 -9999 -9999 -9999 -9999 -9999 -9999 -9999 -9999 -9999 -9999 -9999 -9999 -9999 -9999 -9999 -9999 -9999 -9999 -9999 -9999 -9999 -9999 -9999 -9999 -9999 -9999 -9999 -9999 -9999 -9999 -9999 -9999 -9999 -9999 -9999 -9999 -9999 -9999 -9999 -9999 -9999 -9999 -9999 -9999 -9999 -9999 -9999 -9999 -9999 -9999 -9999 -9999 -9999 -9999 -9999 -9999 -9999 -9999 -9999 -9999 -9999 -9999 -9999 -9999 -9999 -9999 -9999 -9999 -9999 -9999 -9999 -9999 -9999 -9999 -9999 -9999 -9999 -9999 -9999 -9999 -9999 -9999 -9999 -9999 -9999 -9999 -9999 -9999 -9999 -9999 -9999 -9999 -9999 -9999 -9999 -9999 -9999

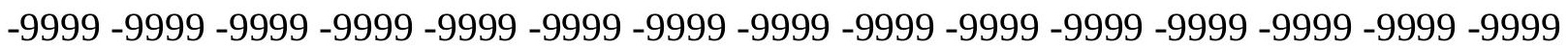
-9999 -9999 -9999 -9999 -9999 -9999 -9999 -9999 -9999 -9999 -9999 -9999 -9999 -9999 -9999 -9999 -9999 -9999 -9999 -9999 -9999 -9999 -9999 -9999 -9999 -9999 -9999 -9999 -9999 -9999 -9999 -9999 -9999 -9999 -9999 -9999 -9999 -9999 -9999 -9999 -9999 -9999 -9999 -9999 -9999

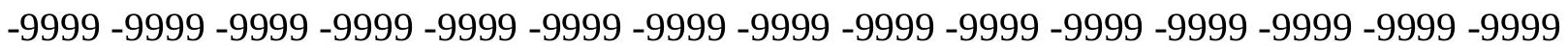
-9999 -9999 -9999 -9999 -9999 -9999 -9999 -9999 -9999 -9999 -9999 -9999 -9999 -9999 -9999 -9999 -9999 -9999 -9999 -9999 -9999 -9999 -9999 -9999 -9999 -9999 -9999 -9999 -9999 -9999 -9999 -9999 -9999 -9999 -9999 -9999 -9999 -9999 -9999 -9999 -9999 -9999 -9999 -9999

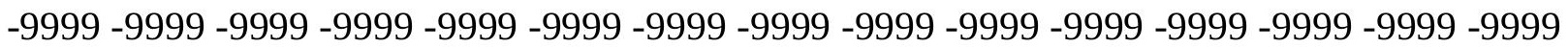
-9999 -9999 -9999 -9999 -9999 -9999 -9999 -9999 -9999 -9999 -9999 -9999 -9999 -9999 -9999 -9999 -9999 -9999 -9999 -9999 -9999 -9999 -9999 -9999 -9999 -9999 -9999 -9999 -9999 -9999 -

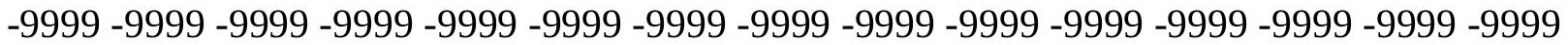
-9999 -9999 -9999 -9999 -9999 -9999 -9999 -9999 -9999 -9999 -9999 -9999 -9999 -9999 -9999 -9999 -9999 -9999 -9999 -9999 -9999 -9999 -9999 -9999 -9999 -9999 -9999 -9999 -9999 -9999 -9999 -9999 -9999 -9999 -9999 -9999 -9999 -9999 -9999 -9999 -9999 -9999 -9999 -9999 -9999 -9999 -9999 -9999 -9999 -9999 -9999 -9999 -9999 -9999 -9999 -9999 -9999 -9999 -9999 -9999 -9999 -9999 -9999 -9999 -9999 -9999 -9999 -9999 -9999 -9999 -9999 -9999 -9999 -9999 -9999

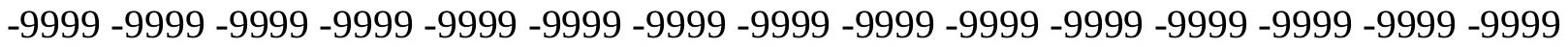
-9999 -9999 -9999 -9999 -9999 -9999 -9999 -9999 -9999 -9999 -9999 -9999 -9999 -9999 -9999 -9999 -9999 -9999 -9999 -9999 -9999 -9999 -9999 -9999 -9999 -9999 -9999 -9999 -9999 -9999 -

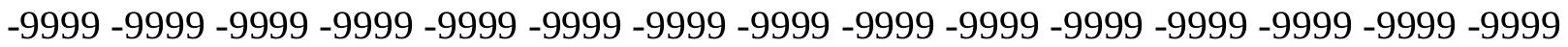
-9999 -9999 -9999 -9999 -9999 -9999 -9999 -9999 -9999 -9999 -9999 -9999 -9999 -9999 -9999 -9999 -9999 -9999 -9999 -9999 -9999 -9999 -9999 -9999 -9999 -9999 -9999 -9999 -9999 -9999 -9999 -9999 -9999 -9999 -9999 -9999 -9999 -9999 -9999 -9999 -9999 -9999 -9999 -9999 -9999 -9999 -9999 -9999 -9999 -9999 -9999 -9999 -9999 -9999 -9999 -9999 -9999 -9999 -9999 -9999

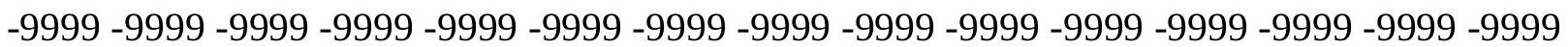


-9999 -9999 -9999 -9999 -9999 -9999 -9999 -9999 -9999 -9999 -9999 -9999 -9999 -9999 -9999 -9999 -9999 -9999 -9999 -9999 -9999 -9999 -9999 -9999 -9999 -9999 -9999 -9999 -9999 -9999 -

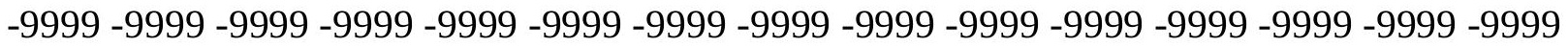
-9999 -9999 -9999 -9999 -9999 -9999 -9999 -9999 -9999 -9999 -9999 -9999 -9999 -9999 -9999 -9999 -9999 -9999 -9999 -9999 -9999 -9999 -9999 -9999-9999 -9999 -9999 -9999 -9999 -9999 -9999 -9999 -9999 -9999 -9999 -9999 -9999 -9999 -9999 -9999 -9999 -9999 -9999 -9999 -9999 -9999 -9999 -9999 -9999 -9999 -9999 -9999 -9999 -9999 -9999 -9999 -9999 -9999 -9999 -

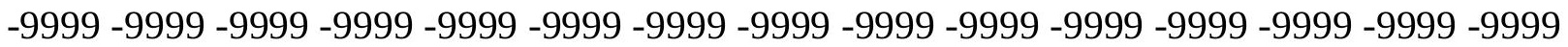

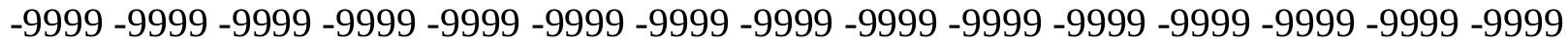
-9999 -9999 -9999 -9999 -9999 -9999 -9999 -9999 -9999 -9999 -9999 -9999 -9999 -9999 -9999 -9999 -9999 -9999 -9999 -9999 -9999 -9999 -9999 -9999 -9999 -9999 -9999 -9999 -9999 -9999 -9999 -9999 -9999 -9999 -9999 -9999 -9999 -9999 -9999 -9999 -9999 -9999 -9999 -9999 -9999 -9999 -9999 -9999 -9999 -9999 -9999 -9999 -9999 -9999 -9999 -9999 -9999 -9999 -9999 -9999 -9999 -9999 -9999 -9999 -9999 -9999 -9999 -9999 -9999 -9999 -9999 -9999 -9999 -9999 -9999 -9999 -9999 -9999 -9999 -9999 -9999 -9999 -9999 -9999 -9999 -9999 -9999 -9999 -9999 -9999 -

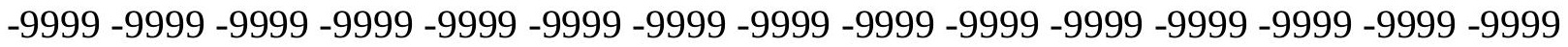
-9999 -9999 -9999 -9999 -9999 -9999 -9999 -9999 -9999 -9999 -9999 -9999 -9999 -9999 -9999 -9999 -9999 -9999 -9999 -9999 -9999 -9999 -9999 -9999 -9999 -9999 -9999 -9999 -9999 -9999 -9999 -9999 -9999 -9999 -9999 -9999 -9999 -9999 -9999 -9999 -9999 -9999 -9999 -9999 -9999 -

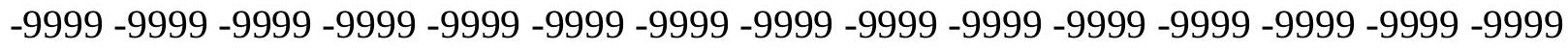

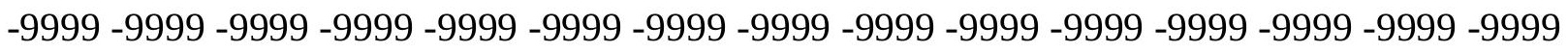

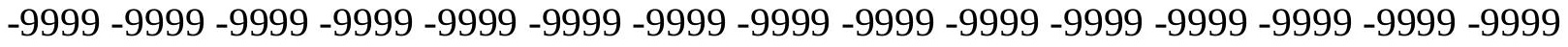
-9999 -9999 -9999 -9999 -9999 -9999 -9999 -9999 -9999 -9999 -9999 -9999 -9999 -9999 -9999 -9999 -9999 -9999 -9999 -9999 -9999 -9999 -9999 -9999 -9999 -9999 -9999 -9999 -9999 -9999 -

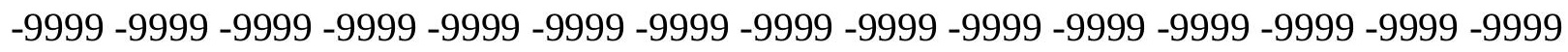
-9999 -9999 -9999 -9999 -9999 -9999 -9999 -9999 -9999 -9999 -9999 -9999 -9999 -9999 -9999 -9999 -9999 -9999 -9999 -9999 -9999 -9999 -9999 -9999 -9999 -9999 -9999 -9999 -9999 -9999 -

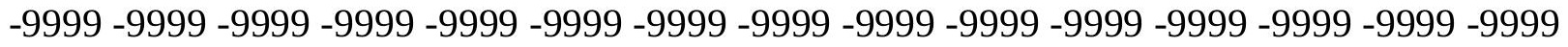
-9999 -9999 -9999 -9999 -9999 -9999 -9999 -9999 -9999 -9999 -9999 -9999 -9999 -9999 -9999 -9999 -9999 -9999 -9999 -9999 -9999 -9999 -9999 -9999 -9999 -9999 -9999 -9999 -9999 -999 -9999 -9999 -9999 -9999 -9999 -9999 -9999 -9999 -9999 -9999 -9999 -9999 -9999 -9999 -9999 -

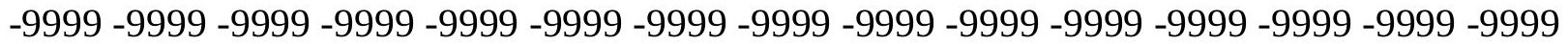

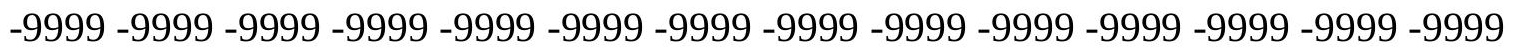

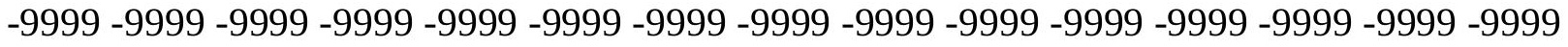

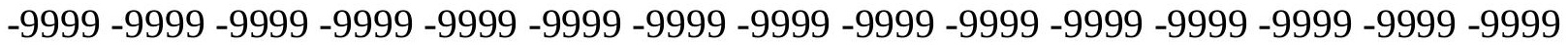

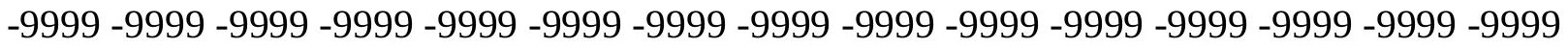

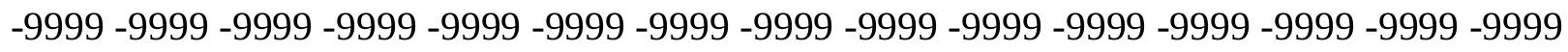

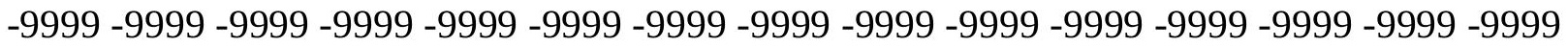

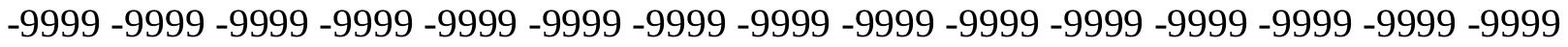
-9999 -9999 -9999 -9999 -9999 -9999 -9999 -9999 -9999 -9999 -9999 -9999 -9999 -9999 -9999 -

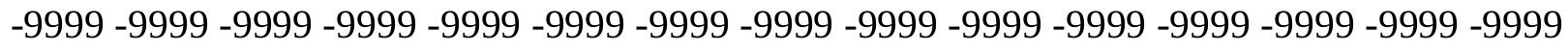

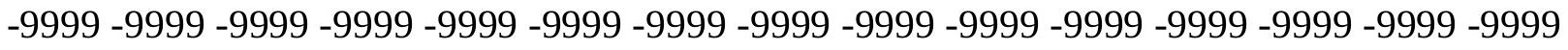
-9999 -9999 -9999 -9999 -9999 -9999 -9999 -9999 -9999 -9999 -9999 -9999 -9999 -9999 -9999 -9999 -9999 -9999 -9999 -9999 -9999 -9999 -9999 -9999-9999 -9999 -9999 -9999 -9999 -9999 -9999 -9999 -9999 -9999 -9999 -9999 -9999 -9999 -9999 -9999 -9999 -9999 -9999 -9999 -9999 -

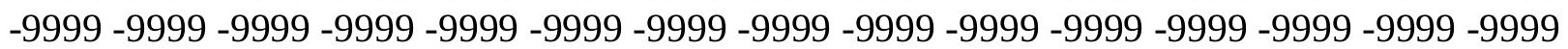


-9999 -9999 -9999 -9999 -9999 -9999 -9999 -9999 -9999 -9999 -9999 -9999 -9999 -9999 -9999 -9999 -9999 -9999 -9999 -9999 -9999 -9999 -9999 -9999 -9999 -9999 -9999 -9999 -9999 -9999 -

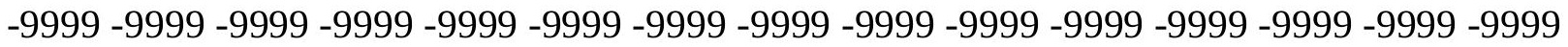
-9999 -9999 -9999 -9999 -9999 -9999 -9999 -9999 -9999 -9999 -9999 -9999 -9999 -9999 -9999 -9999 -9999 -9999 -9999 -9999 -9999 -9999 -9999 -9999-9999 -9999 -9999 -9999 -9999 -9999 -9999 -9999 -9999 -9999 -9999 -9999 -9999 -9999 -9999 -9999 -9999 -9999 -9999 -9999 -9999 -9999 -9999 -9999 -9999 -9999 -9999 -9999 -9999 -9999 -9999 -9999 -9999 -9999 -9999 -9999

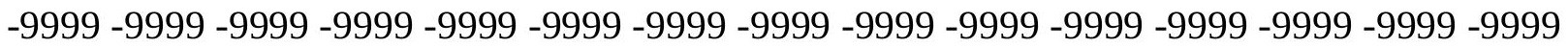

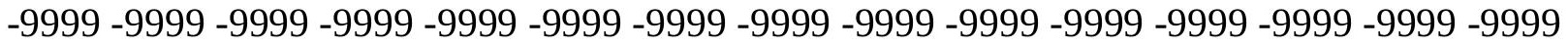
-9999 -9999 -9999 -9999 -9999 -9999 -9999 -9999 -9999 -9999 -9999 -9999 -9999 -9999 -9999 -9999 -9999 -9999 -9999 -9999 -9999 -9999 -9999 -9999 -9999 -9999 -9999 -9999 -9999 -9999 -9999 -9999 -9999 -9999 -9999 -9999 -9999 -9999 -9999 -9999 -9999 -9999 -9999 -9999 -9999 -9999 -9999 -9999 -9999 -9999 -9999 -9999 -9999 -9999 -9999 -9999 -9999 -9999 -9999 -9999 -9999 -9999 -9999 -9999 -9999 -9999 -9999 -9999 -9999 -9999 -9999 -9999 -9999 -9999 -9999 -9999 -9999 -9999 -9999 -9999 -9999 -9999 -9999 -9999 -9999 -9999 -9999 -9999 -9999 -

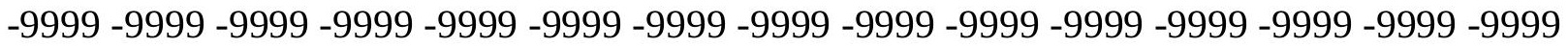
-9999 -9999 -9999 -9999 -9999 -9999 -9999 -9999 -9999 -9999 -9999 -9999 -9999 -9999 -9999 -9999 -9999 -9999 -9999 -9999 -9999 -9999 -9999 -9999 -9999 -9999 -9999 -9999 -9999 -9999 -9999 -9999 -9999 -9999 -9999 -9999 -9999 -9999 -9999 -9999 -9999 -9999 -9999 -9999 -9999 -

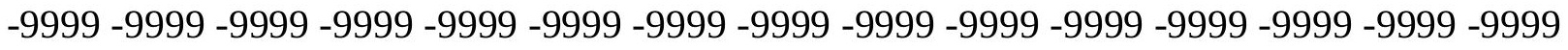
-9999 -9999 -9999 -9999 -9999 -9999 -9999 -9999 -9999 -9999 -9999 -9999 -9999 -9999 -9999

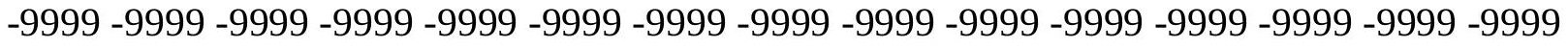
-9999 -9999 -9999 -9999 -9999 -9999 -9999 -9999 -9999 -9999 -9999 -9999 -9999 -9999 -9999 -9999 -9999 -9999 -9999 -9999 -9999 -9999 -9999 -9999 -9999 -9999 -9999 -9999 -9999 -9999 -

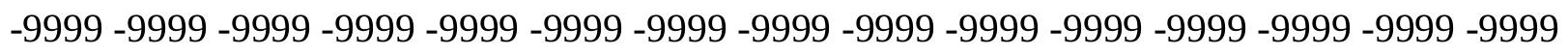
-9999 -9999 -9999 -9999 -9999 -9999 -9999 -9999 -9999 -9999 -9999 -9999 -9999 -9999 -9999 -9999 -9999 -9999 -9999 -9999 -9999 -9999 -9999 -9999 -9999 -9999 -9999 -9999 -9999 -9999 -

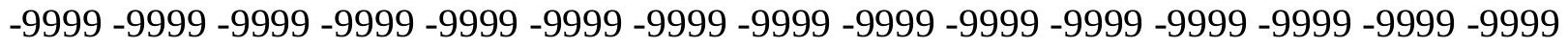
-9999 -9999 -9999 -9999 -9999 -9999 -9999 -9999 -9999 -9999 -9999 -9999 -9999 -9999 -9999 -9999 -9999 -9999 -9999 -9999 -9999 -9999 -9999 -9999 -9999 -9999 -9999 -9999 -9999 -999 -9999 -9999 -9999 -9999 -9999 -9999 -9999 -9999 -9999 -9999 -9999 -9999 -9999 -9999 -9999 -9999 -9999 -9999 -9999 -9999 -9999 -9999 -9999 -9999 -9999 -9999 -9999 -9999 -9999 -9999 -

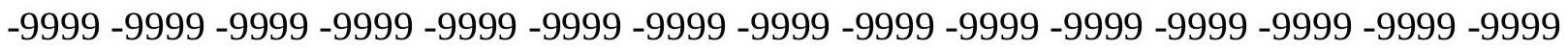

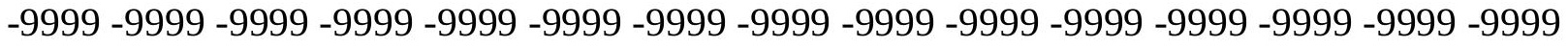

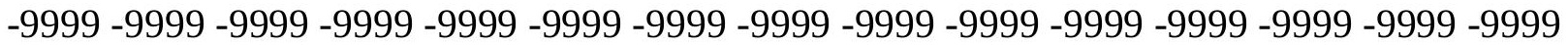
-9999 -9999 -9999 -9999 -9999 -9999 -9999 -9999 -9999 -9999 -9999 -9999 -9999 -9999 -9999 -

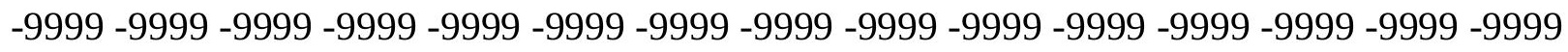

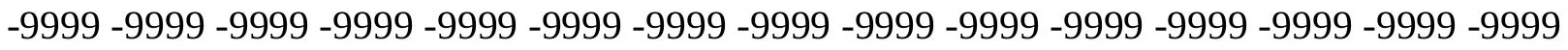
-9999 -9999 -9999 -9999 -9999 -9999 -9999 -9999 -9999 -9999 -9999 -9999 -9999 -9999 - -999 -9999 -9999 -9999 -9999 -9999 -9999 -9999 -9999 -9999 -9999 -9999 -9999 -9999 -9999 -9999 -

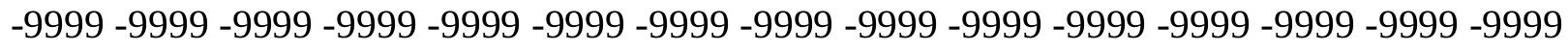

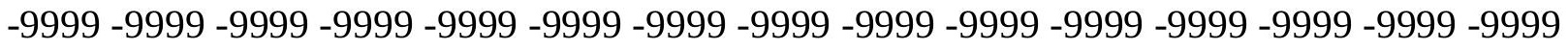
-9999 -9999 -9999 -9999 -9999 -9999 -9999 -9999 -9999 -9999 -9999 -9999 -9999 -9999 -9999 -9999 -9999 -9999 -9999 -9999 -9999 -9999 -9999 -9999-9999 -9999 -9999 -9999 -9999 -9999 -9999 -9999 -9999 -9999 -9999 -9999 -9999 -9999 -9999 -9999 -9999 -9999 -9999 -9999 -9999 -

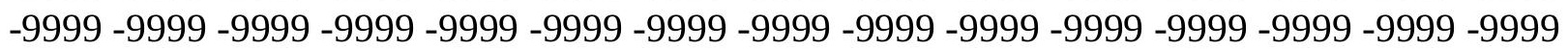


-9999 -9999 -9999 -9999 -9999 -9999 -9999 -9999 -9999 -9999 -9999 -9999 -9999 -9999 -9999 -9999 -9999 -9999 -9999 -9999 -9999 -9999 -9999 -9999 -9999 -9999 -9999 -9999 -9999 -9999 -

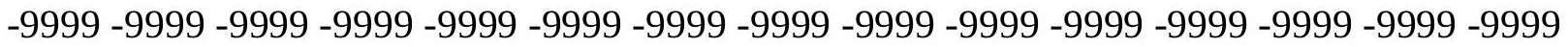
-9999 -9999 -9999 -9999 -9999 -9999 -9999 -9999 -9999 -9999 -9999 -9999 -9999 -9999 -9999 -9999 -9999 -9999 -9999 -9999 -9999 -9999 -9999 -9999-9999 -9999 -9999 -9999 -9999 -9999 -9999 -9999 -9999 -9999 -9999 -9999 -9999 -9999 -9999 -9999 -9999 -9999 -9999 -9999 -9999 -9999 -9999 -9999 -9999 -9999 -9999 -9999 -9999 -9999 -9999 -9999 -9999 -9999 -9999 -9999

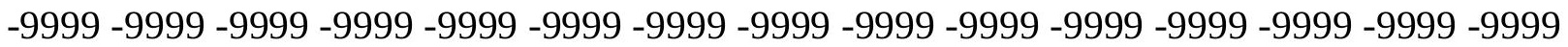

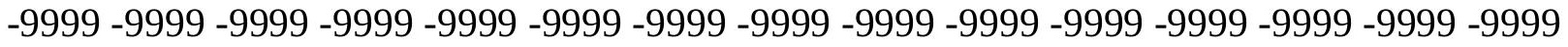
-9999 -9999 -9999 -9999 -9999 -9999 -9999 -9999 -9999 -9999 -9999 -9999 -9999 -9999 -9999 -9999 -9999 -9999 -9999 -9999 -9999 -9999 -9999 -9999 -9999 -9999 -9999 -9999 -9999 -9999 -9999 -9999 -9999 -9999 -9999 -9999 -9999 -9999 -9999 -9999 -9999 -9999 -9999 -9999 -9999 -9999 -9999 -9999 -9999 -9999 -9999 -9999 -9999 -9999 -9999 -9999 -9999 -9999 -9999 -9999 -

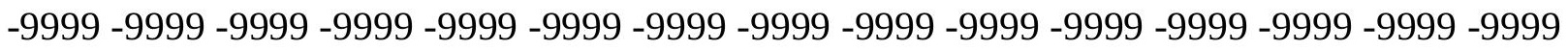
-9999 -9999 -9999 -9999 -9999 -9999 -9999 -9999 -9999 -9999 -9999 -9999 -9999 -9999 -9999 -

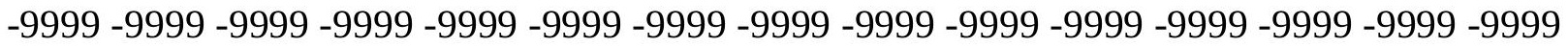
-9999 -9999 -9999 -9999 -9999 -9999 -9999 -9999 -9999 -9999 -9999 -9999 -9999 -9999 -9999 -9999 -9999 -9999 -9999 -9999 -9999 -9999 -9999 -9999 -9999 -9999 -9999 -9999 -9999 -9999 -9999 -9999 -9999 -9999 -9999 -9999 -9999 -9999 -9999 -9999 -9999 -9999 -9999 -9999 - -999 -

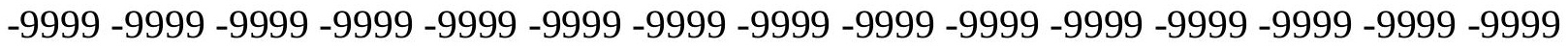

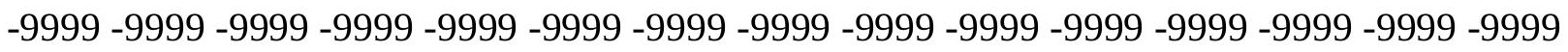
-9999 -9999 -9999 -9999 -9999 -9999 -9999 -9999 -9999 -9999 -9999 -9999 -9999 -9999 -9999 -9999 -9999 -9999 -9999 -9999 -9999 -9999 -9999 -9999 -9999 -9999 -9999 -9999 -9999 -9999 -9999 -9999 -9999 -9999 -9999 -9999 -9999 -9999 -9999 -9999 -9999 -9999 -9999 -9999 -9999 -

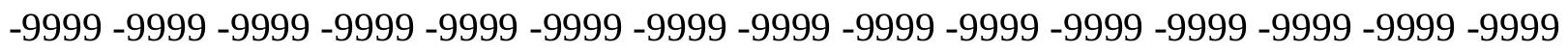
-9999 -9999 -9999 -9999 -9999 -9999 -9999 -9999 -9999 -9999 -9999 -9999 -9999 -9999 -9999 -9999 -9999 -9999 -9999 -9999 -9999 -9999 -9999 -9999 -9999 -9999 -9999 -9999 -9999 -9999 -

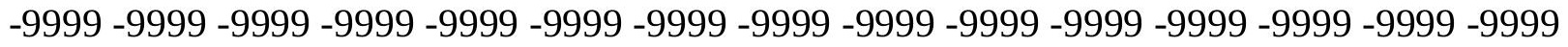
-9999 -9999 -9999 -9999 -9999 -9999 -9999 -9999 -9999 -9999 -9999 -9999 -9999 -9999 -9999 -9999 -9999 -9999 -9999 -9999 -9999 -9999 -9999 -9999 -9999 -9999 -9999 -9999 -9999 -999 -

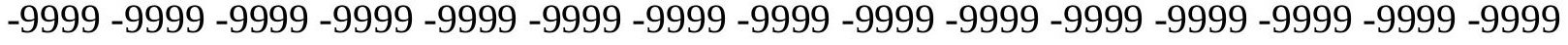
-9999 -9999 -9999 -9999 -9999 -9999 -9999 -9999 -9999 -9999 -9999 -9999 -9999 -9999 -9999 -

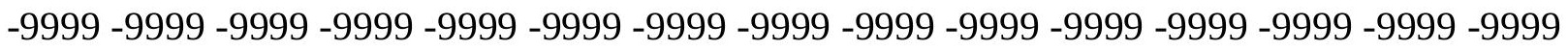

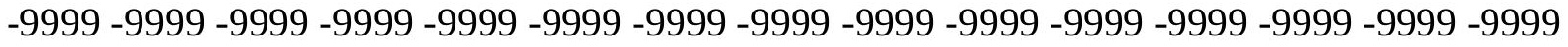

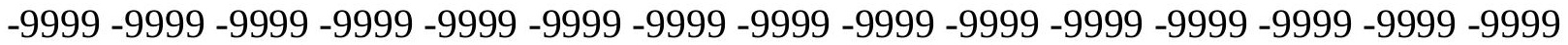

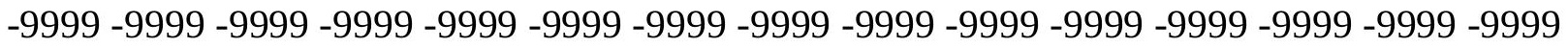

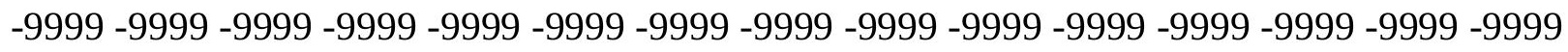

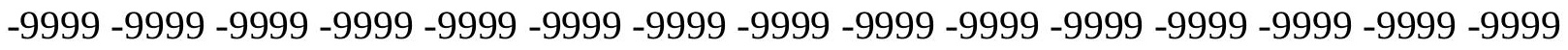

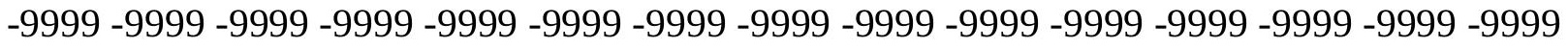
-9999 -9999 -9999 -9999 -9999 -9999 -9999 -9999 -9999 -9999 -9999 -9999 -9999 -9999 -9999 -

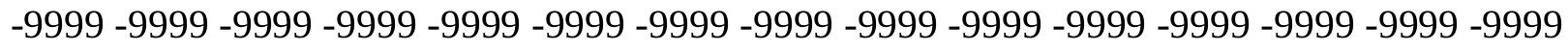

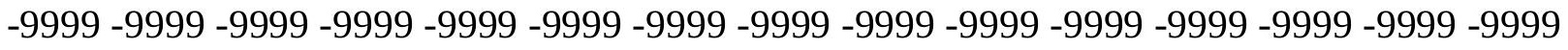
-9999 -9999 -9999 -9999 -9999 -9999 -9999 -9999 -9999 -9999 -9999 -9999 -9999 -9999 -9999 -9999 -9999 -9999 -9999 -9999 -9999 -9999 -9999 -9999 -9999 -9999 -9999 -9999 -9999 -9999 -9999 -9999 -9999 -9999 -9999 -9999 -9999 -9999 -9999 -9999 -9999 -9999 -9999 -9999 -

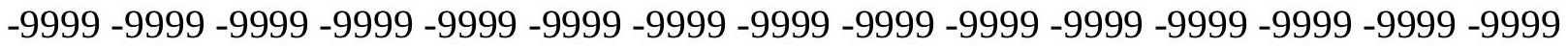


-9999 -9999 -9999 -9999 -9999 -9999 -9999 -9999 -9999 -9999 -9999 -9999 -9999 -9999 -9999 -9999 -9999 -9999 -9999 -9999 -9999 -9999 -9999 -9999 -9999 -9999 -9999 -9999 -9999 -9999 -

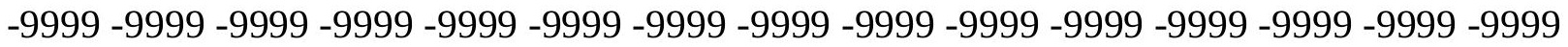
-9999 -9999 -9999 -9999 -9999 -9999 -9999 -9999 -9999 -9999 -9999 -9999 -9999 -9999 -9999 -9999 -9999 -9999 -9999 -9999 -9999 -9999 -9999 -9999-9999 -9999 -9999 -9999 -9999 -9999 -9999 -9999 -9999 -9999 -9999 -9999 -9999 -9999 -9999 -9999 -9999 -9999 -9999 -9999 -9999 -9999 -9999 -9999 -9999 -9999 -9999 -9999 -9999 -9999 -9999 -9999 -9999 -9999 -9999 -9999

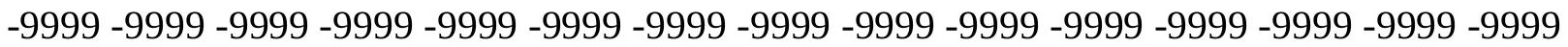

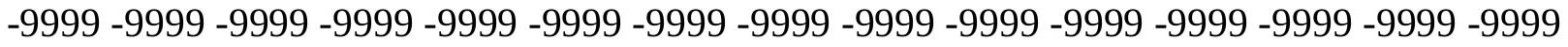
-9999 -9999 -9999 -9999 -9999 -9999 -9999 -9999 -9999 -9999 -9999 -9999 -9999 -9999 -9999 -9999 -9999 -9999 -9999 -9999 -9999 -9999 -9999 -9999 -9999 -9999 -9999 -9999 -9999 -9999 -9999 -9999 -9999 -9999 -9999 -9999 -9999 -9999 -9999 -9999 -9999 -9999 -9999 -9999 -9999 -9999 -9999 -9999 -9999 -9999 -9999 -9999 -9999 -9999 -9999 -9999 -9999 -9999 -9999 -9999 -

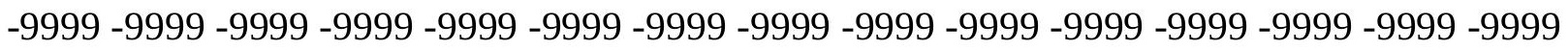
-9999 -9999 -9999 -9999 -9999 -9999 -9999 -9999 -9999 -9999 -9999 -9999 -9999 -9999 -9999 -

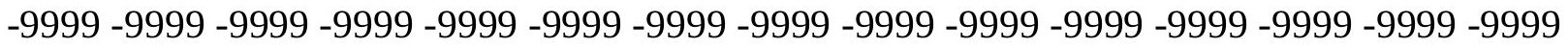
-9999 -9999 -9999 -9999 -9999 -9999 -9999 -9999 -9999 -9999 -9999 -9999 -9999 -9999 -9999 -9999 -9999 -9999 -9999 -9999 -9999 -9999 -9999 -9999 -9999 -9999 -9999 -9999 -9999 - 9999 -9999 -9999 -9999 -9999 -9999 -9999 -9999 -9999 -9999 -9999 -9999 -9999 -9999 -9999 -9999 -

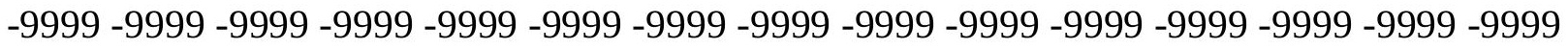

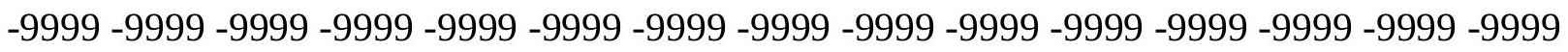
-9999 -9999 -9999 -9999 -9999 -9999 -9999 -9999 -9999 -9999 -9999 -9999 -9999 -9999 - 9999 -9999 -9999 -9999 -9999 -9999 -9999 -9999 -9999 -9999 -9999 -9999 -9999 -9999 -9999 -9999 -9999 -9999 -9999 -9999 -9999 -9999 -9999 -9999 -9999 -9999 -9999 -9999 -9999 -9999 -9999 -9999 -9999 -9999 -9999 -9999 -9999 -9999 -9999 -9999 -9999 -9999 -9999 -9999 -9999 -9999 -9999 -9999 -9999 -9999 -9999 -9999 -9999 -9999 -9999 -9999 -9999 -9999 -9999 -9999 -9999 -9999 -9999 -9999 -9999 -9999 -9999 -9999 -9999 -9999 -9999 -9999 -9999 -9999 -9999 -

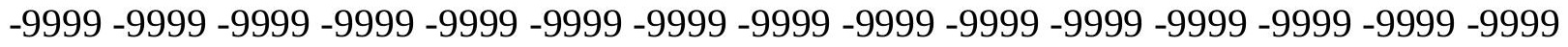
-9999 -9999 -9999 -9999 -9999 -9999 -9999 -9999 -9999 -9999 -9999 -9999 -9999 -9999 -9999 -9999 -9999 -9999 -9999 -9999 -9999 -9999 -9999 -9999 -9999 -9999 -9999 -9999 -9999 -999 -9999 -9999 -9999 -9999 -9999 -9999 -9999 -9999 -9999 -9999 -9999 -9999 -9999 -9999 -9999 -9999 -9999 -9999 -9999 -9999 -9999 -9999 -9999 -9999 -9999 -9999 -9999 -9999 -9999 -9999 -

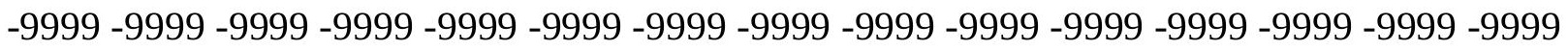

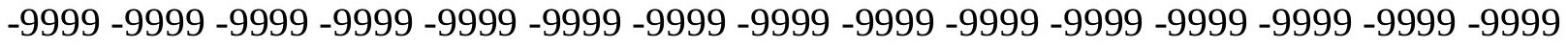

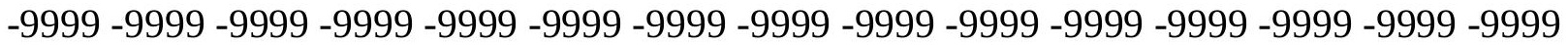

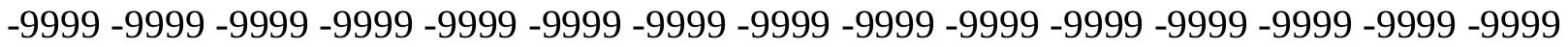

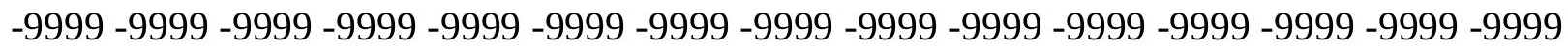

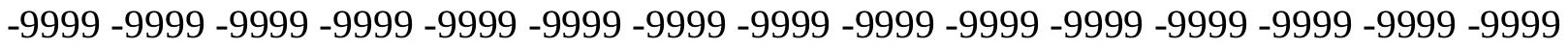

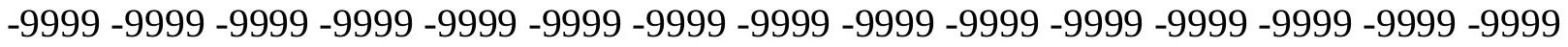
-9999 -9999 -9999 -9999 -9999 -9999 -9999 -9999 -9999 -9999 -9999 -9999 -9999 -9999 -9999 -

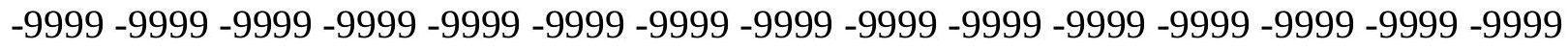

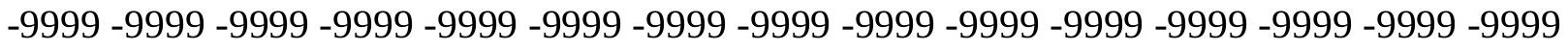
-9999 -9999 -9999 -9999 -9999 -9999 -9999 -9999 -9999 -9999 -9999 -9999 -9999 -9999 -9999 -9999 -9999 -9999 -9999 -9999 -9999 -9999 -9999 -9999-9999 -9999 -9999 -9999 -9999 -9999 -9999 -9999 -9999 -9999 -9999 -9999 -9999 -9999 -9999 -9999 -9999 -9999 -9999 -9999 -9999 -

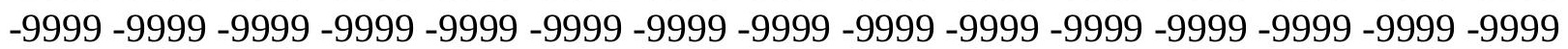


-9999 -9999 -9999 -9999 -9999 -9999 -9999 -9999 -9999 -9999 -9999 -9999 -9999 -9999 -9999 -9999 -9999 -9999 -9999 -9999 -9999 -9999 -9999 -9999 -9999 -9999 -9999 -9999 -9999 -9999 -9999 -9999 -9999 -9999 -9999 -9999 -9999 -9999 -9999 -9999 -9999 -9999 -9999 -9999 - 9999 -9999 -9999 -9999 -9999 -9999 -9999 -9999 -9999 -9999 -9999 -9999 -9999 -9999 -9999 -9999 -9999 -9999 -9999 -9999 -9999 -9999 -9999 -9999 -9999 -9999 -9999 -9999 -9999 -9999 -9999 -9999 -9999 -9999 -9999 -9999 -9999 -9999 -9999 -9999 -9999 -9999 -9999 -9999 -9999 -9999 -9999 -9999 -9999 -9999 -9999 -9999 -9999 -9999 -9999 -9999 -9999 -9999 -9999 -9999

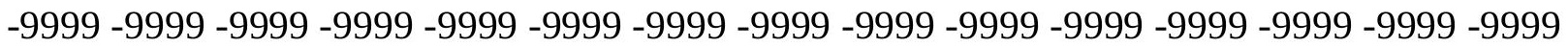

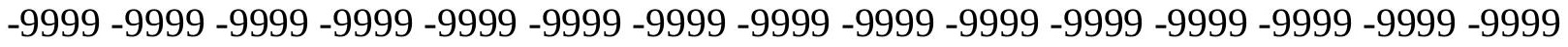
-9999 -9999 -9999 -9999 -9999 -9999 -9999 -9999 -9999 -9999 -9999 -9999 -9999 -9999 -9999 -9999 -9999 -9999 -9999 -9999 -9999 -9999 -9999 -9999 -9999 -9999 -9999 -9999 -9999 -9999 -9999 -9999 -9999 -9999 -9999 -9999 -9999 -9999 -9999 -9999 -9999 -9999 -9999 -9999 -9999 -9999 -9999 -9999 -9999 -9999 -9999 -9999 -9999 -9999 -9999 -9999 -9999 -9999 -9999 -9999 -9999 -9999 -9999 -9999 -9999 -9999 -9999 -9999 -9999 -9999 -9999 -9999 -9999 -9999 -9999 -9999 -9999 -9999 -9999 -9999 -9999 -9999 -9999 -9999 -9999 -9999 -9999 -9999 -9999 -9999 -

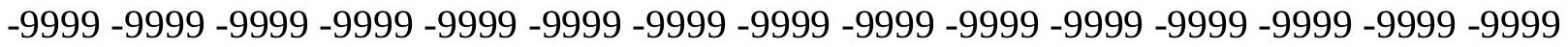
-9999 -9999 -9999 -9999 -9999 -9999 -9999 -9999 -9999 -9999 -9999 -9999 -9999 -9999 -9999 -9999 -9999 -9999 -9999 -9999 -9999 -9999 -9999 -9999 -9999 -9999 -9999 -9999 -9999 - 9999 -9999 -9999 -9999 -9999 -9999 -9999 -9999 -9999 -9999 -9999 -9999 -9999 -9999 -9999 -9999 -

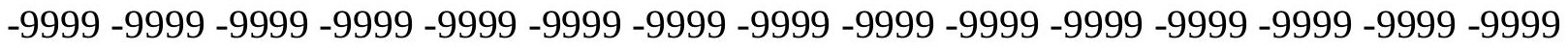

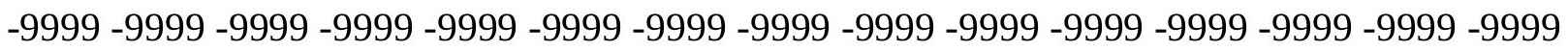

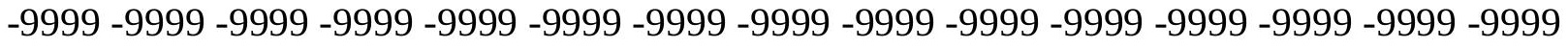
-9999 -9999 -9999 -9999 -9999 -9999 -9999 -9999 -9999 -9999 -9999 -9999 -9999 -9999 -9999 -9999 -9999 -9999 -9999 -9999 -9999 -9999 -9999 -9999 -9999 -9999 -9999 -9999 -9999 -9999 -

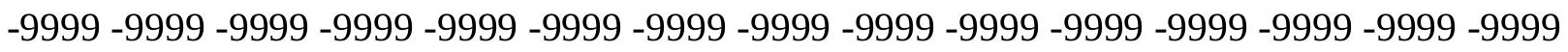
-9999 -9999 -9999 -9999 -9999 -9999 -9999 -9999 -9999 -9999 -9999 -9999 -9999 -9999 -9999 -9999 -9999 -9999 -9999 -9999 -9999 -9999 -9999 -9999 -9999 -9999 -9999 -9999 -9999 -9999 -

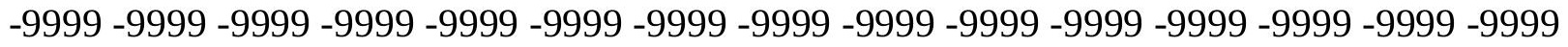
-9999 -9999 -9999 -9999 -9999 -9999 -9999 -9999 -9999 -9999 -9999 -9999 -9999 -9999 -9999 -9999 -9999 -9999 -9999 -9999 -9999 -9999 -9999 -9999 -9999 -9999 -9999 -9999 -9999 -999 -9999 -9999 -9999 -9999 -9999 -9999 -9999 -9999 -9999 -9999 -9999 -9999 -9999 -9999 -9999 -9999 -9999 -9999 -9999 -9999 -9999 -9999 -9999 -9999 -9999 -9999 -9999 -9999 -9999 -

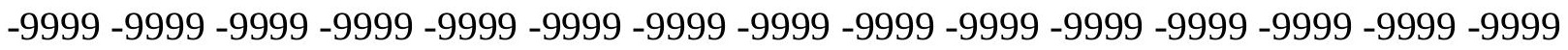

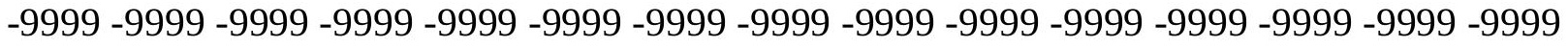

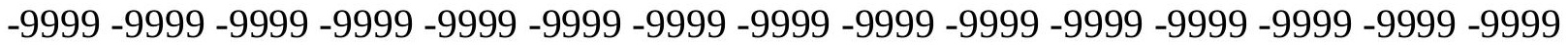

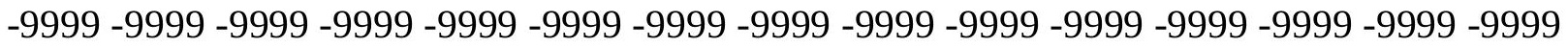

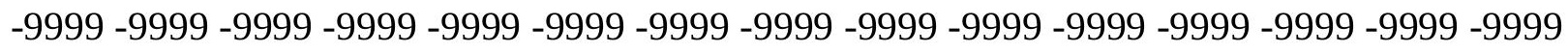

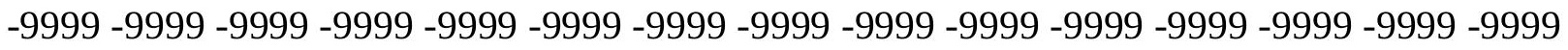

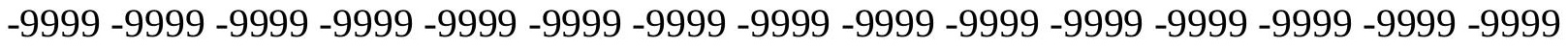
-9999 -9999 -9999 -9999 -9999 -9999 -9999 -9999 -9999 -9999 -9999 -9999 -9999 -9999 -9999 -

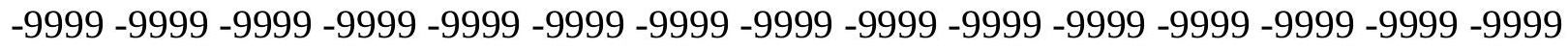

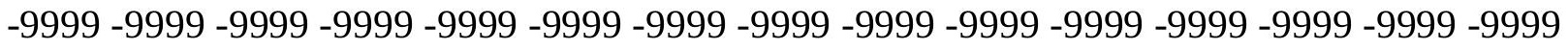
-9999 -9999 -9999 -9999 -9999 -9999 -9999 -9999 -9999 -9999 -9999 -9999 -9999 -9999 -9999 -9999 -9999 -9999 -9999 -9999 -9999 -9999 -9999 -9999-9999 -9999 -9999 -9999 -9999 -9999 -9999 -9999 -9999 -9999 -9999 -9999 -9999 -9999 -9999 -9999 -9999 -9999 -9999 -9999 -9999 -

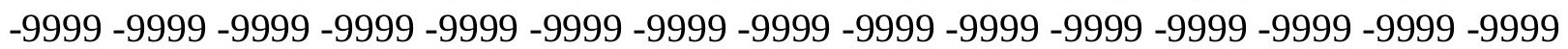


-9999 -9999 -9999 -9999 -9999 -9999 -9999 -9999 -9999 -9999 -9999 -9999 -9999 -9999 -9999 -9999 -9999 -9999 -9999 -9999 -9999 -9999 -9999 -9999 -9999 -9999 -9999 -9999 -9999 -9999 -

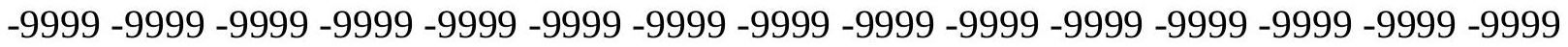
-9999 -9999 -9999 -9999 -9999 -9999 -9999 -9999 -9999 -9999 -9999 -9999 -9999 -9999 -9999 -9999 -9999 -9999 -9999 -9999 -9999 -9999 -9999 -9999-9999 -9999 -9999 -9999 -9999 -9999 -9999 -9999 -9999 -9999 -9999 -9999 -9999 -9999 -9999 -9999 -9999 -9999 -9999 -9999 -9999 -9999 -9999 -9999 -9999 -9999 -9999 -9999 -9999 -9999 -9999 -9999 -9999 -9999 -9999 -9999

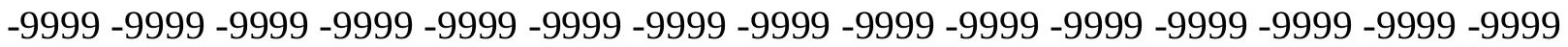

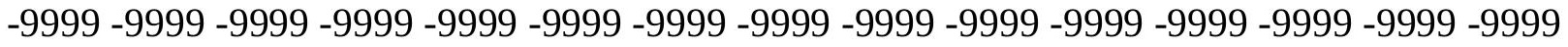

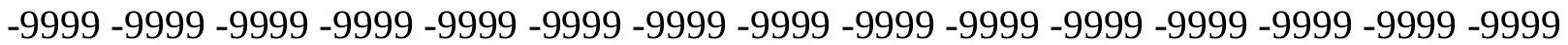
-9999 -9999 -9999 -9999 -9999 -9999 -9999 -9999 -9999 -9999 -9999 -9999 -9999 -9999 -9999 -9999 -9999 -9999 -9999 -9999 -9999 -9999 -9999 -9999 -9999 -9999 -9999 -9999 -9999 -9999 -9999 -9999 -9999 -9999 -9999 -9999 -9999 -9999 -9999 -9999 -9999 -9999 -9999 -9999 -

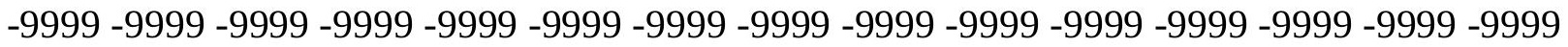
-9999 -9999 -9999 -9999 -9999 -9999 -9999 -9999 -9999 -9999 -9999 -9999 -9999 -9999 -9999 -

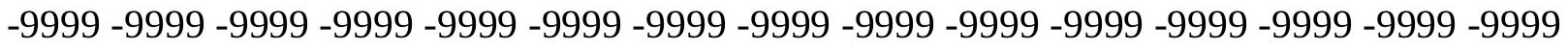
-9999 -9999 -9999 -9999 -9999 -9999 -9999 -9999 -9999 -9999 -9999 -9999 -9999 -9999 -9999 -9999 -9999 -9999 -9999 -9999 -9999 -9999 -9999 -9999 -9999 -9999 -9999 -9999 -9999 -9999 -9999 -9999 -9999 -9999 -9999 -9999 -9999 -9999 -9999 -9999 -9999 -9999 -9999 -9999 -9999 -

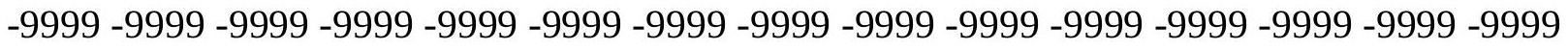

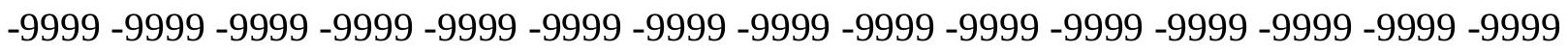
-9999 -9999 -9999 -9999 -9999 -9999 -9999 -9999 -9999 -9999 -9999 -9999 -9999 -9999 -9999 -9999 -9999 -9999 -9999 -9999 -9999 -9999 -9999 -9999 -9999 -9999 -9999 -9999 -9999 -9999 -9999 -9999 -9999 -9999 -9999 -9999 -9999 -9999 -9999 -9999 -9999 -9999 -9999 -9999 -9999 -

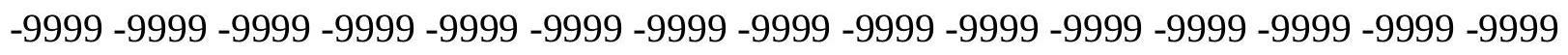
-9999 -9999 -9999 -9999 -9999 -9999 -9999 -9999 -9999 -9999 -9999 -9999 -9999 -9999 -9999 -9999 -9999 -9999 -9999 -9999 -9999 -9999 -9999 -9999 -9999 -9999 -9999 -9999 -9999 -9999 -

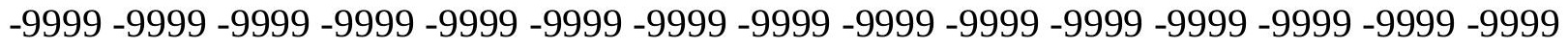
-9999 -9999 -9999 -9999 -9999 -9999 -9999 -9999 -9999 -9999 -9999 -9999 -9999 -9999 -9999 -9999 -9999 -9999 -9999 -9999 -9999 -9999 -9999 -9999 -9999 -9999 -9999 -9999 -9999 -999 -9999 -9999 -9999 -9999 -9999 -9999 -9999 -9999 -9999 -9999 -9999 -9999 -9999 -9999 -9999 -9999 -9999 -9999 -9999 -9999 -9999 -9999 -9999 -9999 -9999 -9999 -9999 -9999 -9999 -9999 -

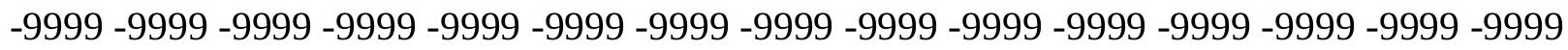

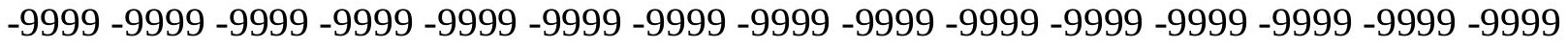

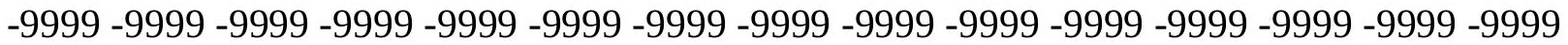
-9999 -9999 -9999 -9999 -9999 -9999 -9999 -9999 -9999 -9999 -9999 -9999 -9999 -9999 -9999 -

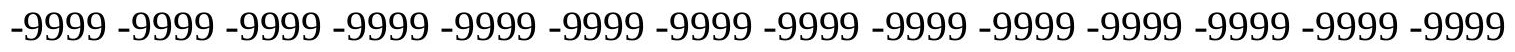

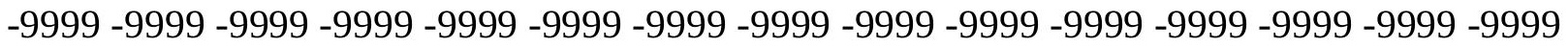
-9999 -9999 -9999 -9999 -9999 -9999 -9999 -9999 -9999 -9999 -9999 -9999 -9999 - 9999 - -999 -9999 -9999 -9999 -9999 -9999 -9999 -9999 -9999 -9999 -9999 -9999 -9999 -9999 -9999 -9999 -

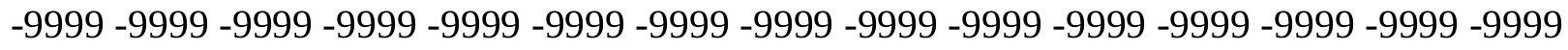

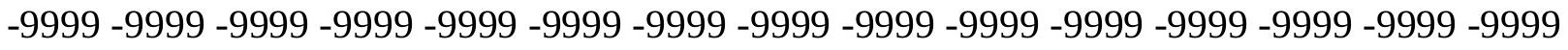
-9999 -9999 -9999 -9999 -9999 -9999 -9999 -9999 -9999 -9999 -9999 -9999 -9999 -9999 -9999 -9999 -9999 -9999 -9999 -9999 -9999 -9999 -9999 -9999-9999 -9999 -9999 -9999 -9999 -9999 -9999 -9999 -9999 -9999 -9999 -9999 -9999 -9999 -9999 -9999 -9999 -9999 -9999 -9999 -9999 -

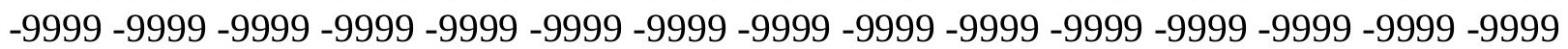


-9999 -9999 -9999 -9999 -9999 -9999 -9999 -9999 -9999 -9999 -9999 -9999 -9999 -9999 -9999 -9999 -9999 -9999 -9999 -9999 -9999 -9999 -9999 -9999 -9999 -9999 -9999 -9999 -9999 -9999 -

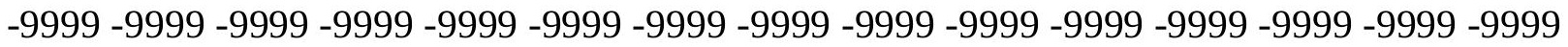
-9999 -9999 -9999 -9999 -9999 -9999 -9999 -9999 -9999 -9999 -9999 -9999 -9999 -9999 -9999 -9999 -9999 -9999 -9999 -9999 -9999 -9999 -9999 -9999-9999 -9999 -9999 -9999 -9999 -9999 -9999 -9999 -9999 -9999 -9999 -9999 -9999 -9999 -9999 -9999 -9999 -9999 -9999 -9999 -9999 -9999 -9999 -9999 -9999 -9999 -9999 -9999 -9999 -9999 -9999 -9999 -9999 -9999 -9999 -9999

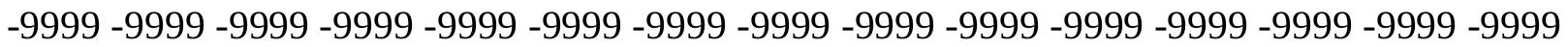

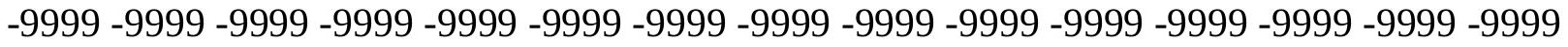
-9999 -9999 -9999 -9999 -9999 -9999 -9999 -9999 -9999 -9999 -9999 -9999 -9999 -9999 -9999 -9999 -9999 -9999 -9999 -9999 -9999 -9999 -9999 -9999 -9999 -9999 -9999 -9999 -9999 -9999 -9999 -9999 -9999 -9999 -9999 -9999 -9999 -9999 -9999 -9999 -9999 -9999 -9999 -9999 -9999 -9999 -9999 -9999 -9999 -9999 -9999 -9999 -9999 -9999 -9999 -9999 -9999 -9999 -9999 -9999 -9999 -9999 -9999 -9999 -9999 -9999 -9999 -9999 -9999 -9999 -9999 -9999 -9999 -9999 -9999 -9999 -9999 -9999 -9999 -9999 -9999 -9999 -9999 -9999 -9999 -9999 -9999 -9999 -9999 -9999 -

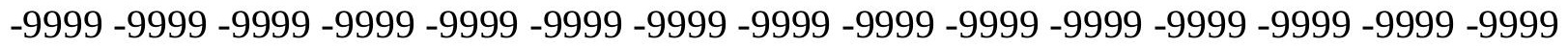
-9999 -9999 -9999 -9999 -9999 -9999 -9999 -9999 -9999 -9999 -9999 -9999 -9999 -9999 -9999 -9999 -9999 -9999 -9999 -9999 -9999 -9999 -9999 -9999 -9999 -9999 -9999 -9999 -9999 -9999 -9999 -9999 -9999 -9999 -9999 -9999 -9999 -9999 -9999 -9999 -9999 -9999 -9999 -9999 -

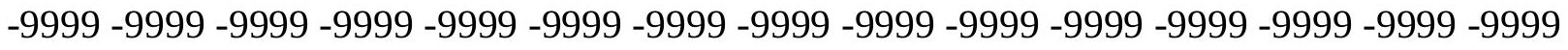
-9999 -9999 -9999 -9999 -9999 -9999 -9999 -9999 -9999 -9999 -9999 -9999 -9999 -9999 -9999 -999 -

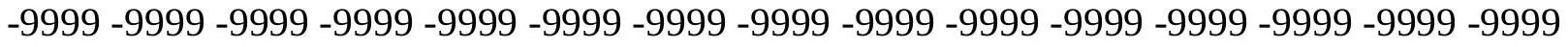
-9999 -9999 -9999 -9999 -9999 -9999 -9999 -9999 -9999 -9999 -9999 -9999 -9999 -9999 -9999 -9999 -9999 -9999 -9999 -9999 -9999 -9999 -9999 -9999 -9999 -9999 -9999 -9999 -9999 -9999 -9999 -9999 -9999 -9999 -9999 -9999 -9999 -9999 -9999 -9999 -9999 -9999 -9999 -9999 -9999 -9999 -9999 -9999 -9999 -9999 -9999 -9999 -9999 -9999 -9999 -9999 -9999 -9999 -9999 -9999 -9999 -9999 -9999 -9999 -9999 -9999 -9999 -9999 -9999 -9999 -9999 -9999 -9999 -9999 -9999 -

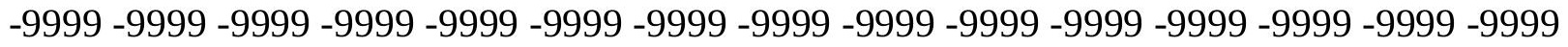
-9999 -9999 -9999 -9999 -9999 -9999 -9999 -9999 -9999 -9999 -9999 -9999 -9999 -9999 -9999 -9999 -9999 -9999 -9999 -9999 -9999 -9999 -9999 -9999 -9999 -9999 -9999 -9999 -9999 -999 -9999 -9999 -9999 -9999 -9999 -9999 -9999 -9999 -9999 -9999 -9999 -9999 -9999 -9999 -9999 -9999 -9999 -9999 -9999 -9999 -9999 -9999 -9999 -9999 -9999 -9999 -9999 -9999 -9999 -9999 -

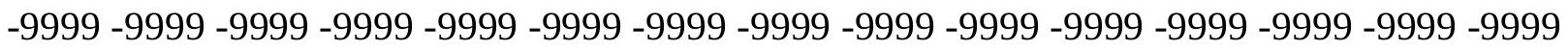

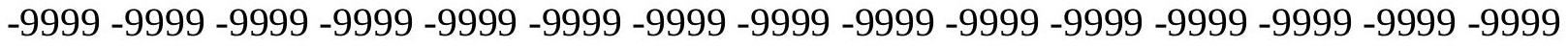

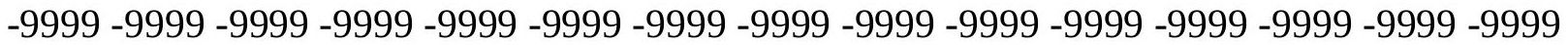
-9999 -9999 -9999 -9999 -9999 -9999 -9999 -9999 -9999 -9999 -9999 -9999 -9999 -9999 -9999

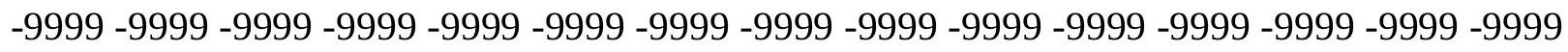

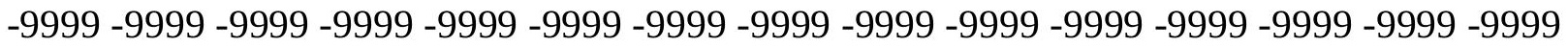
-9999 -9999 -9999 -9999 -9999 -9999 -9999 -9999 -9999 -9999 -9999 -9999 -9999 - 9999 - -999 -9999 -9999 -9999 -9999 -9999 -9999 -9999 -9999 -9999 -9999 -9999 -9999 -9999 -9999 -9999 -

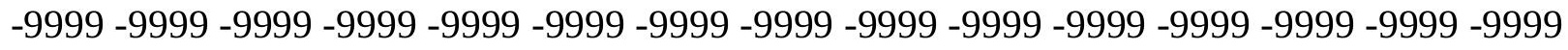

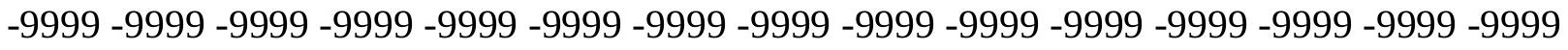
-9999 -9999 -9999 -9999 -9999 -9999 -9999 -9999 -9999 -9999 -9999 -9999 -9999 -9999 -9999 -9999 -9999 -9999 -9999 -9999 -9999 -9999 -9999 -9999 -9999 -9999 -9999 -9999 -9999 -9999 -9999 -9999 -9999 -9999 -9999 -9999 -9999 -9999 -9999 -9999 -9999 -9999 -9999 -9999 -

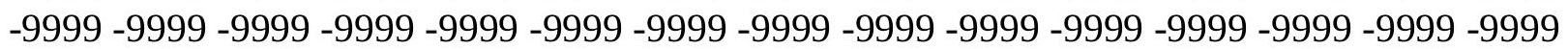


-9999 -9999 -9999 -9999 -9999 -9999 -9999 -9999 -9999 -9999 -9999 -9999 -9999 -9999 -9999 -9999 -9999 -9999 -9999 -9999 -9999 -9999 -9999 -9999 -9999 -9999 -9999 -9999 -9999 -9999 -9999 -9999 -9999 -9999 -9999 -9999 -9999 -9999 -9999 -9999 -9999 -9999 -9999 -9999 - 9999 -9999 -9999 -9999 -9999 -9999 -9999 -9999 -9999 -9999 -9999 -9999 -9999 -9999 -9999 -9999 -9999 -9999 -9999 -9999 -9999 -9999 -9999 -9999 -9999-9999 -9999 -9999 -9999 -9999 -9999 -9999 -9999 -9999 -9999 -9999 -9999 -9999 -9999 -9999 -9999 -9999 -9999 -9999 -9999 -9999 -9999 -9999 -9999 -9999 -9999 -9999 -9999 -9999 -9999 -9999 -9999 -9999 -9999 -9999 -9999

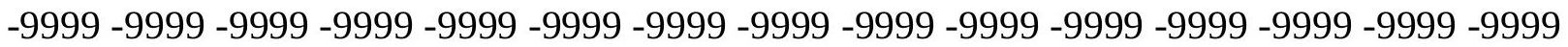

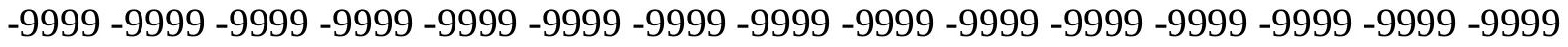
-9999 -9999 -9999 -9999 -9999 -9999 -9999 -9999 -9999 -9999 -9999 -9999 -9999 -9999 -9999 -9999 -9999 -9999 -9999 -9999 -9999 -9999 -9999 -9999 -9999 -9999 -9999 -9999 -9999 -9999 -9999 -9999 -9999 -9999 -9999 -9999 -9999 -9999 -9999 -9999 -9999 -9999 -9999 -9999 -9999 -9999 -9999 -9999 -9999 -9999 -9999 -9999 -9999 -9999 -9999 -9999 -9999 -9999 -9999 -9999 -

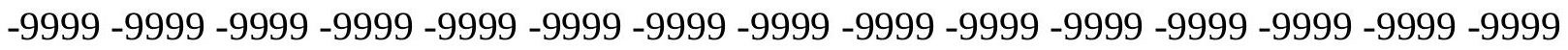
-9999 -9999 -9999 -9999 -9999 -9999 -9999 -9999 -9999 -9999 -9999 -9999 -9999 -9999 -9999 -

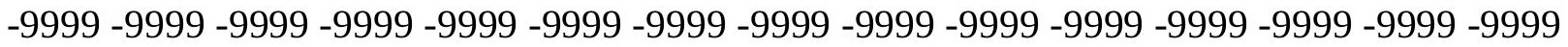
-9999 -9999 -9999 -9999 -9999 -9999 -9999 -9999 -9999 -9999 -9999 -9999 -9999 -9999 -9999 -9999 -9999 -9999 -9999 -9999 -9999 -9999 -9999 -9999 -9999 -9999 -9999 -9999 -9999 -9999 -9999 -9999 -9999 -9999 -9999 -9999 -9999 -9999 -9999 -9999 -9999 -9999 -9999 -9999 -9999 -

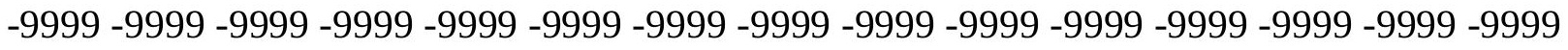
-9999 -9999 -9999 -9999 -9999 -9999 -9999 -9999 -9999 -9999 -9999 -9999 -9999 -9999 -9999 -999 -9999 -9999 -9999 -9999 -9999 -9999 -9999 -9999 -9999 -9999 -9999 -9999 -9999 -9999 - 9999 -9999 -9999 -9999 -9999 -9999 -9999 -9999 -9999 -9999 -9999 -9999 -9999 -9999 -9999 -

-9999 -9999 -9999 -9999 -9999 -9999 -9999 -9999 -9999 -9999 -9999 -9999 -9999 -9999 -9999 -

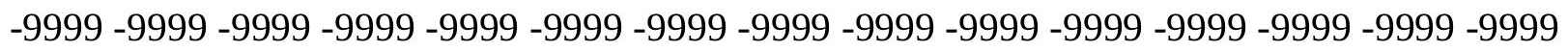
-9999 -9999 -9999 -9999 -9999 -9999 -9999 -9999 -9999 -9999 -9999 -9999 -9999 -9999 -9999 -9999 -9999 -9999 -9999 -9999 -9999 -9999 -9999 -9999 -9999 -9999 -9999 -9999 -9999 -9999 -

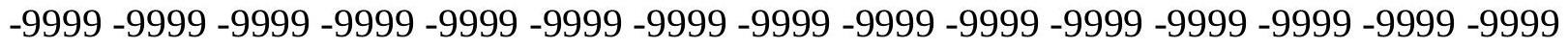
-9999 -9999 -9999 -9999 -9999 -9999 -9999 -9999 -9999 -9999 -9999 -9999 -9999 -9999 -9999 -9999 -9999 -9999 -9999 -9999 -9999 -9999 -9999 -9999 -9999 -9999 -9999 -9999 -9999 -999 -

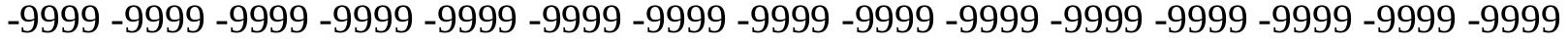
-9999 -9999 -9999 -9999 -9999 -9999 -9999 -9999 -9999 -9999 -9999 -9999 -9999 -9999 -9999 -

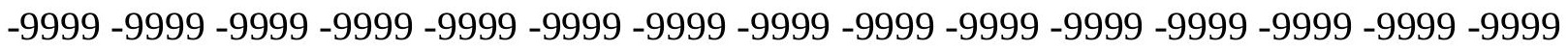

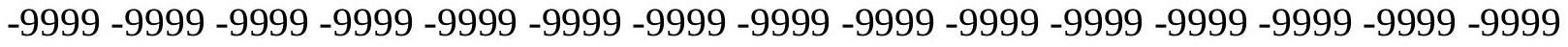

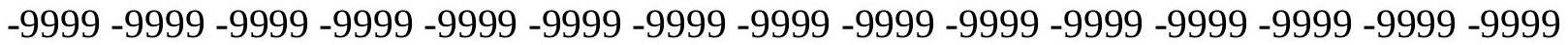

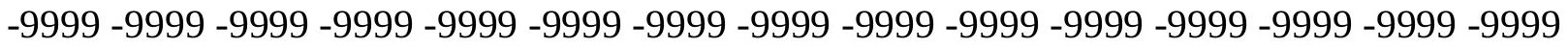

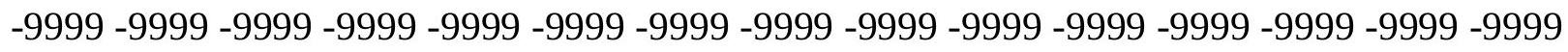

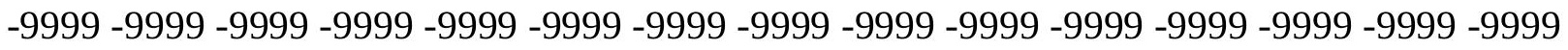

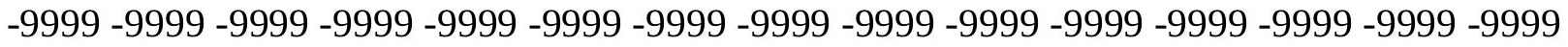
-9999 -9999 -9999 -9999 -9999 -9999 -9999 -9999 -9999 -9999 -9999 -9999 -9999 -9999 -9999 -

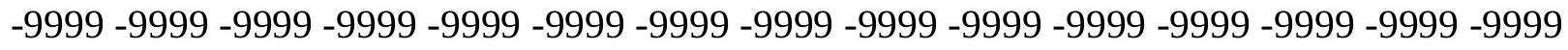

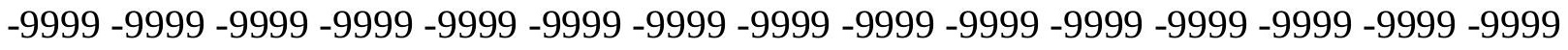
-9999 -9999 -9999 -9999 -9999 -9999 -9999 -9999 -9999 -9999 -9999 -9999 -9999 -9999 -9999 -9999 -9999 -9999 -9999 -9999 -9999 -9999 -9999 -9999-9999 -9999 -9999 -9999 -9999 -9999 -9999 -9999 -9999 -9999 -9999 -9999 -9999 -9999 -9999 -9999 -9999 -9999 -9999 -9999 -9999 -

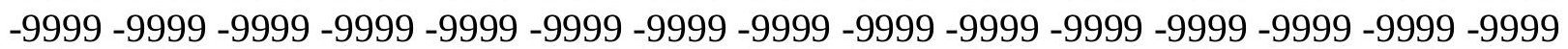


-9999 -9999 -9999 -9999 -9999 -9999 -9999 -9999 -9999 -9999 -9999 -9999 -9999 -9999 -9999 -9999 -9999 -9999 -9999 -9999 -9999 -9999 -9999 -9999 -9999 -9999 -9999 -9999 -9999 -9999 -9999 -9999 -9999 -9999 -9999 -9999 -9999 -9999 -9999 -9999 -9999 -9999 -9999 -9999 -9999 -9999 -9999 -9999 -9999 -9999 -9999 -9999 -9999 -9999 -9999 -9999 -9999 -9999 -9999 -9999 -9999 -9999 -9999 -9999 -9999 -9999 -9999 -9999-9999 -9999 -9999 -9999 -9999 -9999 -9999 -9999 -9999 -9999 -9999 -9999 -9999 -9999 -9999 -9999 -9999 -9999 -9999 -9999 -9999 -9999 -9999 -9999 -9999 -9999 -9999 -9999 -9999 -9999 -9999 -9999 -9999 -9999 -9999 -9999

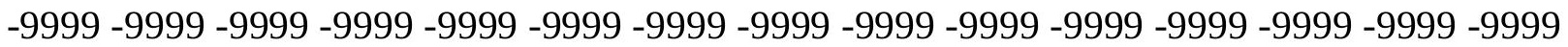

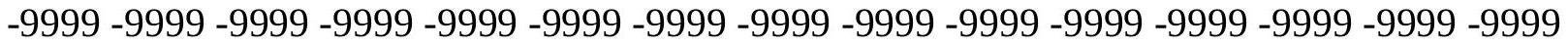
-9999 -9999 -9999 -9999 -9999 -9999 -9999 -9999 -9999 -9999 -9999 -9999 -9999 -9999 -9999 -9999 -9999 -9999 -9999 -9999 -9999 -9999 -9999 -9999 -9999 -9999 -9999 -9999 -9999 -9999 -9999 -9999 -9999 -9999 -9999 -9999 -9999 -9999 -9999 -9999 -9999 -9999 -9999 -9999 -9999 -9999 -9999 -9999 -9999 -9999 -9999 -9999 -9999 -9999 -9999 -9999 -9999 -9999 -9999 -9999 -

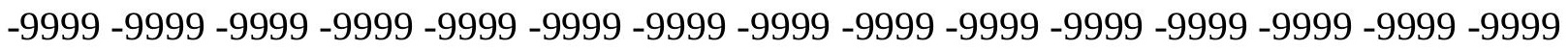
-9999 -9999 -9999 -9999 -9999 -9999 -9999 -9999 -9999 -9999 -9999 -9999 -9999 -9999 -9999 -

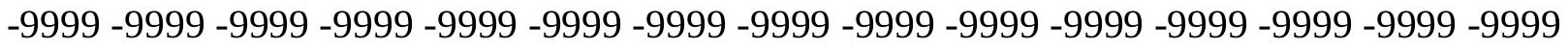
-9999 -9999 -9999 -9999 -9999 -9999 -9999 -9999 -9999 -9999 -9999 -9999 -9999 -9999 -9999 -9999 -9999 -9999 -9999 -9999 -9999 -9999 -9999 -9999 -9999 -9999 -9999 -9999 -9999 -9999 -9999 -9999 -9999 -9999 -9999 -9999 -9999 -9999 -9999 -9999 -9999 -9999 -9999 -9999 -9999 -

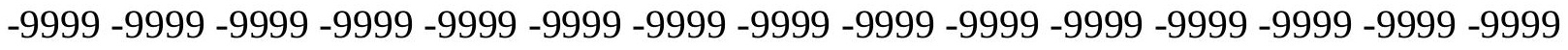

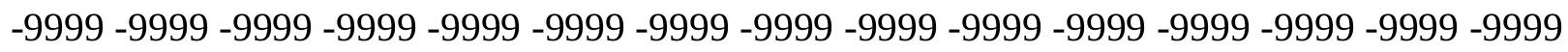
-9999 -9999 -9999 -9999 -9999 -9999 -9999 -9999 -9999 -9999 -9999 -9999 -9999 -9999 -9999 -9999 -9999 -9999 -9999 -9999 -9999 -9999 -9999 -9999 -9999 -9999 -9999 -9999 -9999 -9999 -9999 -9999 -9999 -9999 -9999 -9999 -9999 -9999 -9999 -9999 -9999 -9999 -9999 -9999 -9999 -

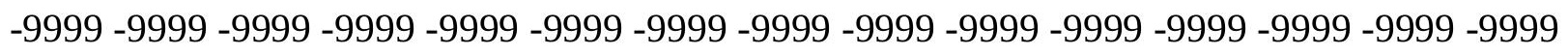
-9999 -9999 -9999 -9999 -9999 -9999 -9999 -9999 -9999 -9999 -9999 -9999 -9999 -9999 -9999 -9999 -9999 -9999 -9999 -9999 -9999 -9999 -9999 -9999 -9999 -9999 -9999 -9999 -9999 -9999 -

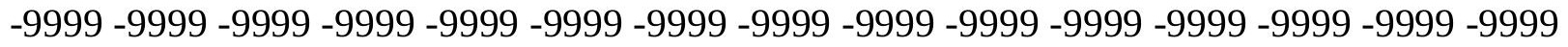
-9999 -9999 -9999 -9999 -9999 -9999 -9999 -9999 -9999 -9999 -9999 -9999 -9999 -9999 -9999 -9999 -9999 -9999 -9999 -9999 -9999 -9999 -9999 -9999 -9999 -9999 -9999 -9999 - -999 -

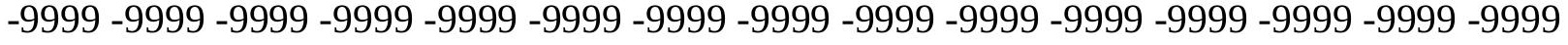
-9999 -9999 -9999 -9999 -9999 -9999 -9999 -9999 -9999 -9999 -9999 -9999 -9999 -9999 -9999 -

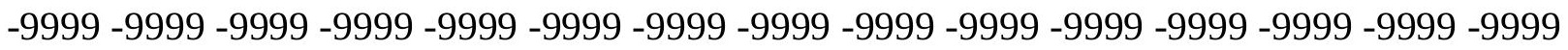

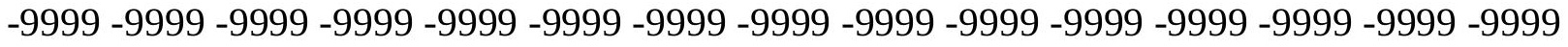

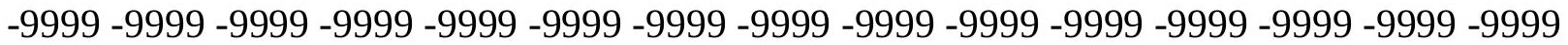

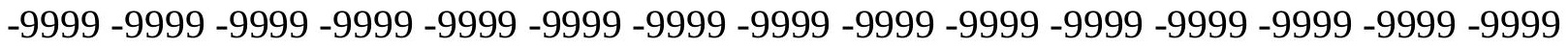

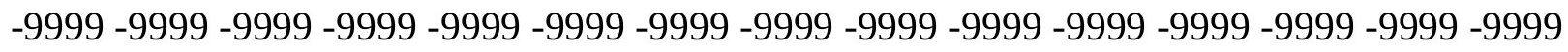

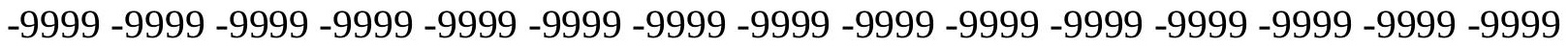

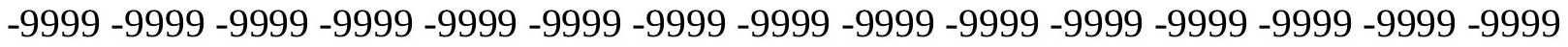
-9999 -9999 -9999 -9999 -9999 -9999 -9999 -9999 -9999 -9999 -9999 -9999 -9999 -9999 -9999 -

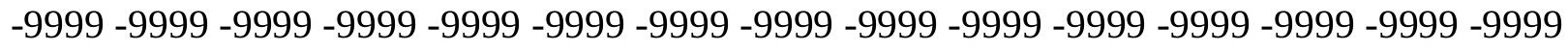

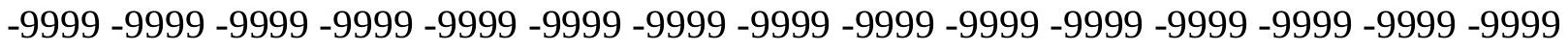
-9999 -9999 -9999 -9999 -9999 -9999 -9999 -9999 -9999 -9999 -9999 -9999 -9999 -9999 -9999 -9999 -9999 -9999 -9999 -9999 -9999 -9999 -9999 -9999-9999 -9999 -9999 -9999 -9999 -9999 -9999 -9999 -9999 -9999 -9999 -9999 -9999 -9999 -9999 -9999 -9999 -9999 -9999 -9999 -9999 -

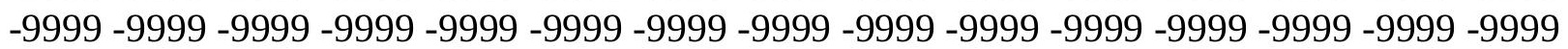


-9999 -9999 -9999 -9999 -9999 -9999 -9999 -9999 -9999 -9999 -9999 -9999 -9999 -9999 -9999 -9999 -9999 -9999 -9999 -9999 -9999 -9999 -9999 -9999 -9999 -9999 -9999 -9999 -9999 -9999 -

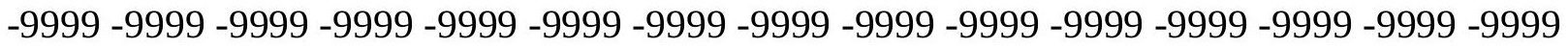
-9999 -9999 -9999 -9999 -9999 -9999 -9999 -9999 -9999 -9999 -9999 -9999 -9999 -9999 -9999 -9999 -9999 -9999 -9999 -9999 -9999 -9999 -9999 -9999-9999 -9999 -9999 -9999 -9999 -9999 -9999 -9999 -9999 -9999 -9999 -9999 -9999 -9999 -9999 -9999 -9999 -9999 -9999 -9999 -9999 -9999 -9999 -9999 -9999 -9999 -9999 -9999 -9999 -9999 -9999 -9999 -9999 -9999 -9999 -9999

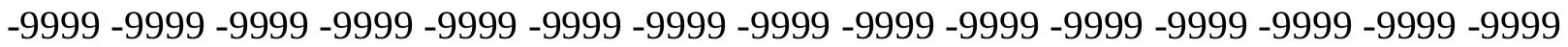
-9999 -9999 -9999 -9999 -9999 -9999 -9999 -9999 -9999 -9999 -9999 -9999 -9999 -9999 -9999 -9999 -9999 -9999 -9999 -9999 -9999 -9999 -9999 -9999 -9999 -9999 -9999 -9999 -9999

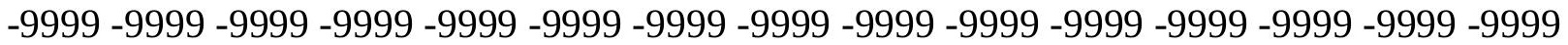
-9999 -9999 -9999 -9999 -9999 -9999 -9999 -9999 -9999 -9999 -9999 -9999 -9999 -9999 -9999 -9999 -9999 -9999 -9999 -9999 -9999 -9999 -9999 -9999 -9999 -9999 -9999 -9999 -9999 -9999 -9999 -9999 -9999 -9999 -9999 -9999 -9999 -9999 -9999 -9999 -9999 -9999 -9999 -9999 - 9999 -9999 -9999 -9999 -9999 -9999 -9999 -9999 -9999 -9999 -9999 -9999 -9999 -9999 -9999 -9999

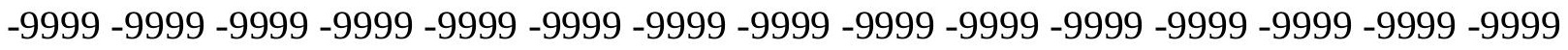
-9999 -9999 -9999 -9999 -9999 -9999 -9999 -9999 -9999 -9999 -9999 -9999 -9999 -9999 -9999 -9999 -9999 -9999 -9999 -9999 -9999 -9999 -9999 -9999 -9999 -9999 -9999 -9999 -9999 -9999 -9999 -9999 -9999 -9999 -9999 -9999 -9999 -9999 -9999 -9999 -9999 -9999 -9999 -9999 -9999 -

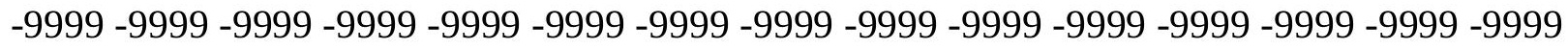

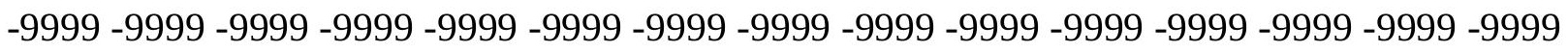
-9999 -9999 -9999 -9999 -9999 -9999 -9999 -9999 -9999 -9999 -9999 -9999 -9999 -9999 -9999 -9999 -9999 -9999 -9999 -9999 -9999 -9999 -9999 -9999 -9999 -9999 -9999 -9999 -9999 -9999 -9999 -9999 -9999 -9999 -9999 -9999 -9999 -9999 -9999 -9999 -9999 -9999 -9999 -9999 -9999 -

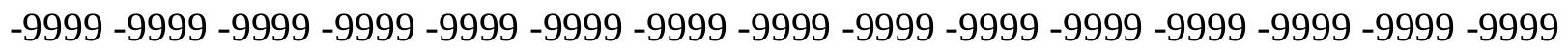
-9999 -9999 -9999 -9999 -9999 -9999 -9999 -9999 -9999 -9999 -9999 -9999 -9999 -9999 -9999 -9999 -9999 -9999 -9999 -9999 -9999 -9999 -9999 -9999 -9999 -9999 -9999 -9999 -9999 -9999 -

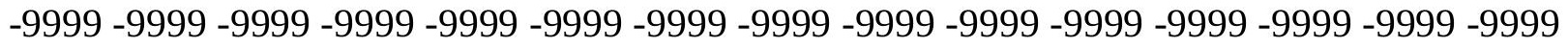
-9999 -9999 -9999 -9999 -9999 -9999 -9999 -9999 -9999 -9999 -9999 -9999 -9999 -9999 -9999 -9999 -9999 -9999 -9999 -9999 -9999 -9999 -9999 -9999 -9999 -9999 -9999 -9999 -9999 -999 -9999 -9999 -9999 -9999 -9999 -9999 -9999 -9999 -9999 -9999 -9999 -9999 -9999 -9999 -9999 -9999 -9999 -9999 -9999 -9999 -9999 -9999 -9999 -9999 -9999 -9999 -9999 -9999 -9999 -9999 -

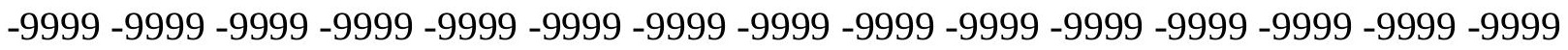

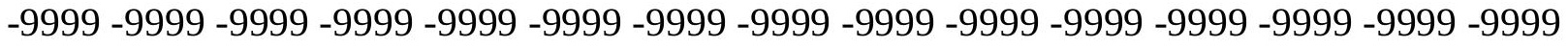
-9999 -9999 -9999 -9999 -9999 -9999 -9999 -9999 -9999 -9999 -9999 -9999 -9999 -9999 -

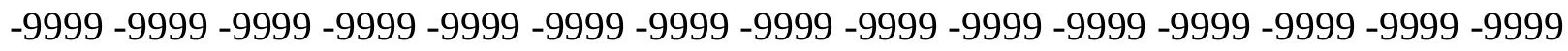

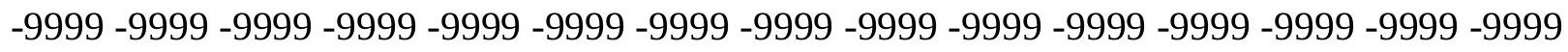

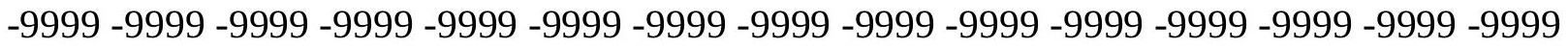
-9999 -9999 -9999 -9999 -9999 -9999 -9999 -9999 -9999 -9999 -9999 -9999 -9999 - 9999 - -999 -9999 -9999 -9999 -9999 -9999 -9999 -9999 -9999 -9999 -9999 -9999 -9999 -9999 -9999 -9999 -

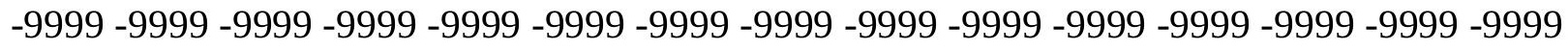

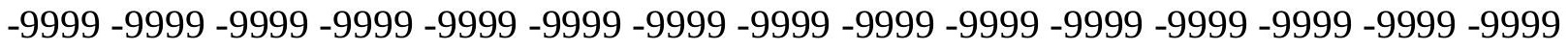
-9999 -9999 -9999 -9999 -9999 -9999 -9999 -9999 -9999 -9999 -9999 -9999 -9999 -9999 -9999 -9999 -9999 -9999 -9999 -9999 -9999 -9999 -9999 -9999-9999 -9999 -9999 -9999 -9999 -9999 -9999 -9999 -9999 -9999 -9999 -9999 -9999 -9999 -9999 -9999 -9999 -9999 -9999 -9999 -9999 -

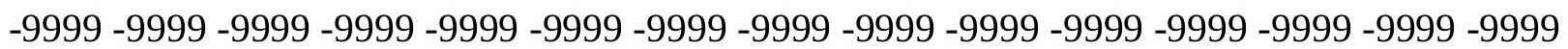


-9999 -9999 -9999 -9999 -9999 -9999 -9999 -9999 -9999 -9999 -9999 -9999 -9999 -9999 -9999 -9999 -9999 -9999 -9999 -9999 -9999 -9999 -9999 -9999 -9999 -9999 -9999 -9999 -9999 -9999 -

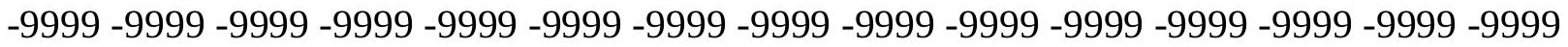
-9999 -9999 -9999 -9999 -9999 -9999 -9999 -9999 -9999 -9999 -9999 -9999 -9999 -9999 -9999 -9999 -9999 -9999 -9999 -9999 -9999 -9999 -9999 -9999-9999 -9999 -9999 -9999 -9999 -9999 -9999 -9999 -9999 -9999 -9999 -9999 -9999 -9999 -9999 -9999 -9999 -9999 -9999 -9999 -9999 -9999 -9999 -9999 -9999 -9999 -9999 -9999 -9999 -9999 -9999 -9999 -9999 -9999 -9999 -9999

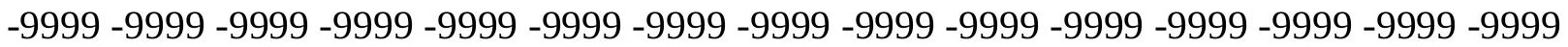

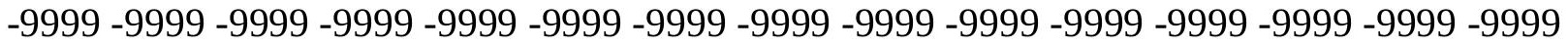
-9999 -9999 -9999 -9999 -9999 -9999 -9999 -9999 -9999 -9999 -9999 -9999 -9999 -9999 -9999 -9999 -9999 -9999 -9999 -9999 -9999 -9999 -9999 -9999 -9999 -9999 -9999 -9999 -9999 -9999 -9999 -9999 -9999 -9999 -9999 -9999 -9999 -9999 -9999 -9999 -9999 -9999 -9999 -9999 -9999 -9999 -9999 -9999 -9999 -9999 -9999 -9999 -9999 -9999 -9999 -9999 -9999 -9999 -9999 -9999 -9999 -9999 -9999 -9999 -9999 -9999 -9999 -9999 -9999 -9999 -9999 -9999 -9999 -9999 -9999 -9999 -9999 -9999 -9999 -9999 -9999 -9999 -9999 -9999 -9999 -9999 -9999 -9999 -9999 -9999 -9999 -9999 -9999 -9999 -9999 -9999 -9999 -9999 -9999 -9999 -9999 -9999 - 9999 - -999 -

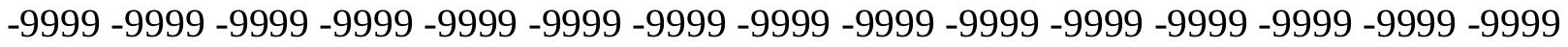
-9999 -9999 -9999 -9999 -9999 -9999 -9999 -9999 -9999 -9999 -9999 -9999 -9999 -9999 -9999 -9999 -9999 -9999 -9999 -9999 -9999 -9999 -9999 -9999 -9999 -9999 -9999 -9999 -9999 -9999 -

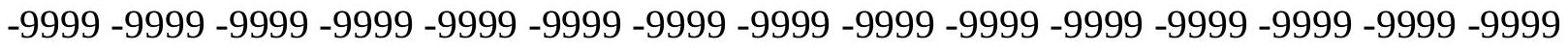
-9999 -9999 -9999 -9999 -9999 -9999 -9999 -9999 -9999 -9999 -9999 -9999 -9999 -9999 -9999

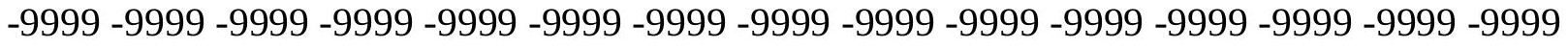
-9999 -9999 -9999 -9999 -9999 -9999 -9999 -9999 -9999 -9999 -9999 -9999 -9999 -9999 -9999 -9999 -9999 -9999 -9999 -9999 -9999 -9999 -9999 -9999 -9999 -9999 -9999 -9999 -9999 -9999 -

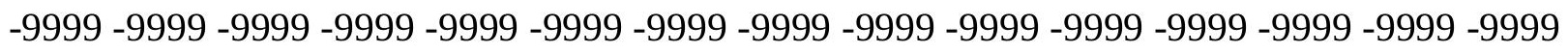
-9999 -9999 -9999 -9999 -9999 -9999 -9999 -9999 -9999 -9999 -9999 -9999 -9999 -9999 -9999 -9999 -9999 -9999 -9999 -9999 -9999 -9999 -9999 -9999 -9999 -9999 -9999 -9999 -9999 -9999 -

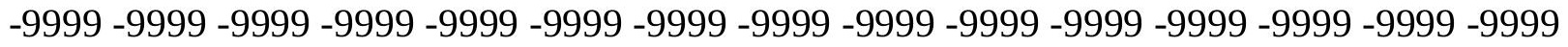
-9999 -9999 -9999 -9999 -9999 -9999 -9999 -9999 -9999 -9999 -9999 -9999 -9999 -9999 -9999 -9999 -9999 -9999 -9999 -9999 -9999 -9999 -9999 -9999 -9999 -9999 -9999 -9999 -9999 -999 -

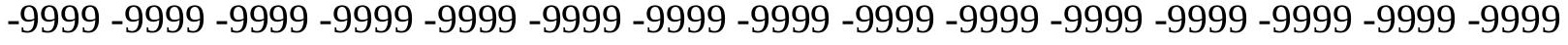
-9999 -9999 -9999 -9999 -9999 -9999 -9999 -9999 -9999 -9999 -9999 -9999 -9999 -9999 -9999 -

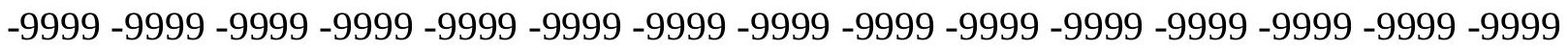

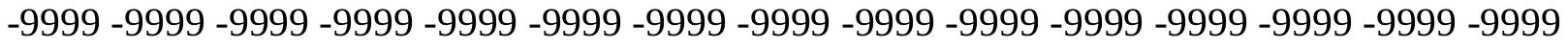

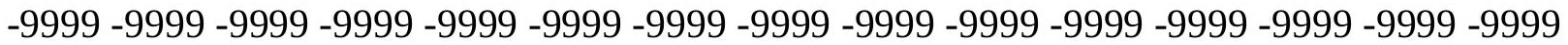
-9999 -9999 -9999 -9999 -9999 -9999 -9999 -9999 -9999 -9999 -9999 -9999 -9999 -9999 -9999 -

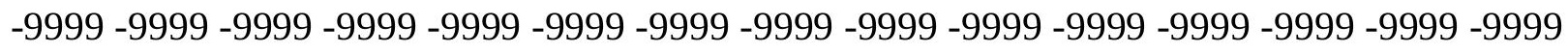

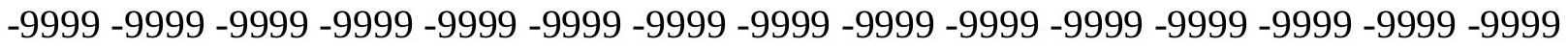
-9999 -9999 -9999 -9999 -9999 -9999 -9999 -9999 -9999 -9999 -9999 -9999 -9999 - 9999 - -999 -9999 -9999 -9999 -9999 -9999 -9999 -9999 -9999 -9999 -9999 -9999 -9999 -9999 -9999 -9999 -

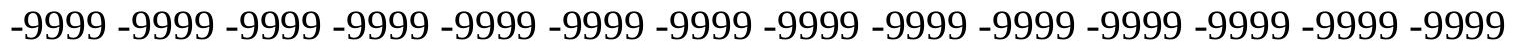

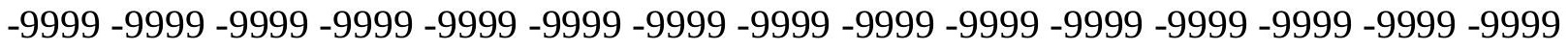
-9999 -9999 -9999 -9999 -9999 -9999 -9999 -9999 -9999 -9999 -9999 -9999 -9999 -9999 -9999 -9999 -9999 -9999 -9999 -9999 -9999 -9999 -9999 -9999-9999 -9999 -9999 -9999 -9999 -9999 -9999 -9999 -9999 -9999 -9999 -9999 -9999 -9999 -9999 -9999 -9999 -9999 -9999 -9999 -9999 -

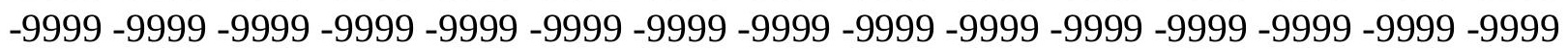


-9999 -9999 -9999 -9999 -9999 -9999 -9999 -9999 -9999 -9999 -9999 -9999 -9999 -9999 -9999 -9999 -9999 -9999 -9999 -9999 -9999 -9999 -9999 -9999 -9999 -9999 -9999 -9999 -9999 -9999 -9999 -9999 -9999 -9999 -9999 -9999 -9999 -9999 -9999 -9999 -9999 -9999 -9999 -9999 - 9999 -9999 -9999 -9999 -9999 -9999 -9999 -9999 -9999 -9999 -9999 -9999 -9999 -9999 -9999 -9999 -9999 -9999 -9999 -9999 -9999 -9999 -9999 -9999 -9999-9999 -9999 -9999 -9999 -9999 -9999 -9999 -9999 -9999 -9999 -9999 -9999 -9999 -9999 -9999 -9999 -9999 -9999 -9999 -9999 -9999 -9999 -9999 -9999 -9999 -9999 -9999 -9999 -9999 -9999 -9999 -9999 -9999 -9999 -9999 -9999

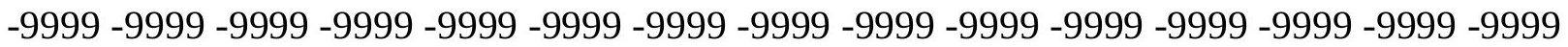
-9999 -9999 -9999 -9999 -9999 -9999 -9999 -9999 -9999 -9999 -9999 -9999 -9999 -9999 -9999 -9999 -9999 -9999 -9999 -9999 -9999 -9999 -9999 -9999 -9999 -9999 -9999 -9999 -9999 -9999

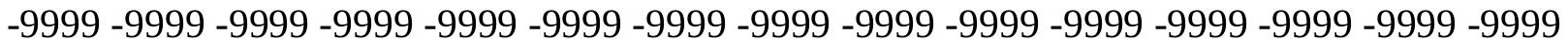
-9999 -9999 -9999 -9999 -9999 -9999 -9999 -9999 -9999 -9999 -9999 -9999 -9999 -9999 -9999 -9999 -9999 -9999 -9999 -9999 -9999 -9999 -9999 -9999 -9999 -9999 -9999 -9999 -9999 -9999 -

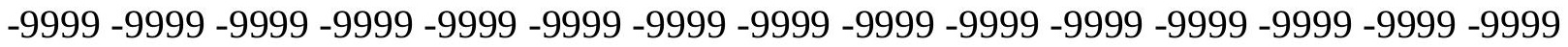
-9999 -9999 -9999 -9999 -9999 -9999 -9999 -9999 -9999 -9999 -9999 -9999 -9999 -9999 -9999

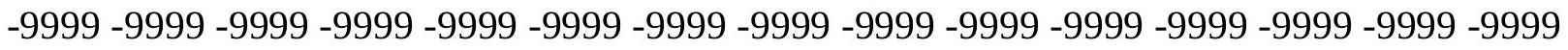
-9999 -9999 -9999 -9999 -9999 -9999 -9999 -9999 -9999 -9999 -9999 -9999 -9999 -9999 -9999 -9999 -9999 -9999 -9999 -9999 -9999 -9999 -9999 -9999 -9999 -9999 -9999 -9999 -9999 - 9999 -9999 -9999 -9999 -9999 -9999 -9999 -9999 -9999 -9999 -9999 -9999 -9999 -9999 -9999 -9999 -9999 -9999 -9999 -9999 -9999 -9999 -9999 -9999 -9999 -9999 -9999 -9999 -9999 -9999 -9999 -9999 -9999 -9999 -9999 -9999 -9999 -9999 -9999 -9999 -9999 -9999 -9999 -9999 -9999 -9999 -9999 -9999 -9999 -9999 -9999 -9999 -9999 -9999 -9999 -9999 -9999 -9999 -9999 -9999 -9999 -9999 -9999 -9999 -9999 -9999 -9999 -9999 -9999 -9999 -9999 -9999 -9999 -9999 -9999 -9999 -9999 -9999 -9999 -9999 -9999 -9999 -9999 -9999 -9999 -9999 -9999 -9999 -9999 -9999 -9999 -9999 -9999 -9999 -9999 -9999 -9999 -9999 -9999 -9999 -9999 -9999 -9999 -9999 -9999 -9999 -9999 -9999 -9999 -9999 -9999 -9999 -9999 -9999 -9999 -9999 -9999 -9999 -9999 -9999 -9999 -9999 -9999 -9999 -9999 -9999 -9999 -9999 -9999 -9999 -9999 -9999 -9999 -9999 -9999 -9999 -9999 -9999 -9999 -9999 -9999 -9999 -9999 -9999 -9999 -9999 -9999 -9999 -9999 -9999 -9999 -9999 -9999 -9999 -9999 -9999 -9999 -9999 -9999 -9999 -9999 -9999 -9999 -9999 -9999 -9999 -9999 -9999 -9999 -9999 -9999 -9999 -9999 -9999 -9999 -9999 -9999 -9999 -9999 -999 -9999 -9999 -9999 -9999 -9999 -9999 -9999 -9999 -9999 -9999 -9999 -9999 -9999 -9999 -9999 -9999 -9999 -9999 -9999 -9999 -9999 -9999 -9999 -9999 -9999 -9999 -9999 -9999 -9999 -9999 -

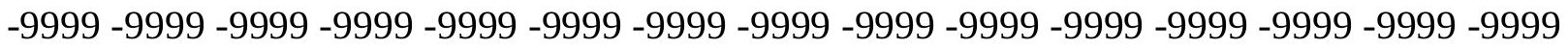

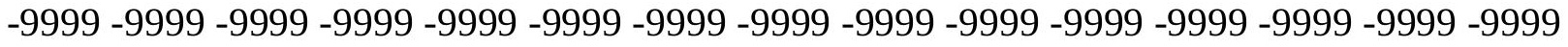

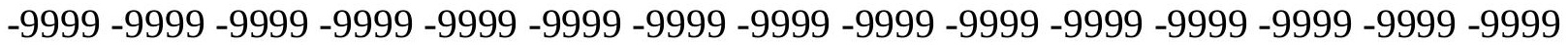
-9999 -9999 -9999 -9999 -9999 -9999 -9999 -9999 -9999 -9999 -9999 -9999 -9999 -9999 -9999

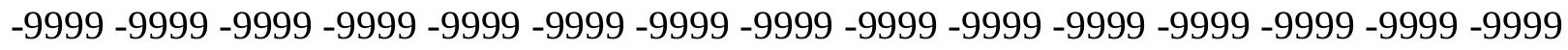

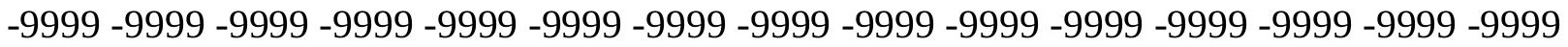

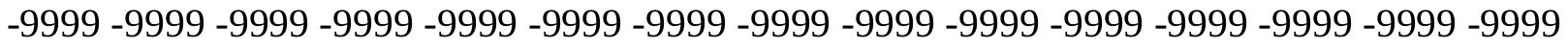
-9999 -9999 -9999 -9999 -9999 -9999 -9999 -9999 -9999 -9999 -9999 -9999 -9999 -9999 -9999 -

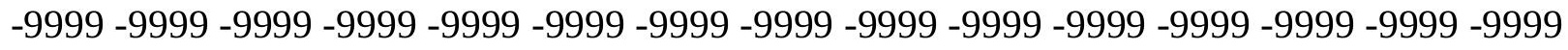

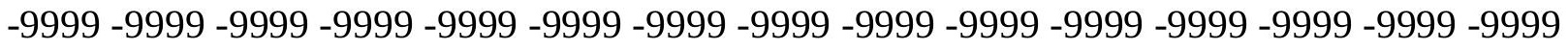
-9999 -9999 -9999 -9999 -9999 -9999 -9999 -9999 -9999 -9999 -9999 -9999 -9999 -9999 -9999 -9999 -9999 -9999 -9999 -9999 -9999 -9999 -9999 -9999-9999 -9999 -9999 -9999 -9999 -9999 -9999 -9999 -9999 -9999 -9999 -9999 -9999 -9999 -9999 -9999 -9999 -9999 -9999 -9999 -9999 -

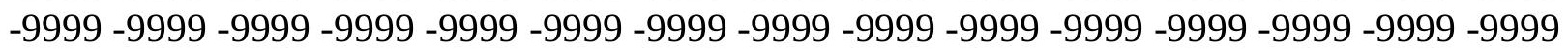


-9999 -9999 -9999 -9999 -9999 -9999 -9999 -9999 -9999 -9999 -9999 -9999 -9999 -9999 -9999 -9999 -9999 -9999 -9999 -9999 -9999 -9999 -9999 -9999 -9999 -9999 -9999 -9999 -9999 -9999 -9999 -9999 -9999 -9999 -9999 -9999 -9999 -9999 -9999 -9999 -9999 -9999 -9999 -9999 -9999 -9999 -9999 -9999 -9999 -9999 -9999 -9999 -9999 -9999 -9999 -9999 -9999 -9999 -9999 -9999 -9999 -9999 -9999 -9999 -9999 -9999 -9999 -9999 -9999 -9999 -9999 -9999 -9999 -9999 -9999 -9999 -9999 -9999 -9999 -9999 -9999 -9999 -9999 -9999 -9999 -9999 -9999 -9999 -9999 -9999 -9999 -9999 -9999 -9999 -9999 -9999 -9999 -9999 -9999 -9999 -9999 -9999 -9999 -9999 -

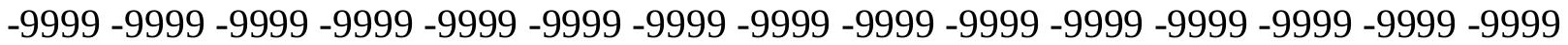
-9999 -9999 -9999 -9999 -9999 -9999 -9999 -9999 -9999 -9999 -9999 -9999 -9999 -9999 -9999 -9999 -9999 -9999 -9999 -9999 -9999 -9999 -9999 -9999 -9999 -9999 -9999 -9999 -9999 -9999 -

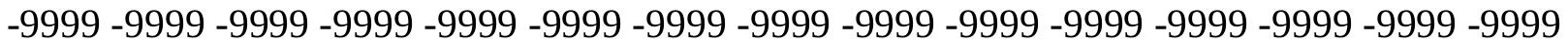
-9999 -9999 -9999 -9999 -9999 -9999 -9999 -9999 -9999 -9999 -9999 -9999 -9999 -9999 -9999 -9999 -9999 -9999 -9999 -9999 -9999 -9999 -9999 -9999 -9999 -9999 -9999 -9999 -9999 -9999 -9999 -9999 -9999 -9999 -9999 -9999 -9999 -9999 -9999 -9999 -9999 -9999 -9999 -9999 -9999 -9999 -9999 -9999 -9999 -9999 -9999 -9999 -9999 -9999 -9999 -9999 -9999 -9999 -9999 -9999 -9999 -9999 -9999 -9999 -9999 -9999 -9999 -9999 -9999 -9999 -9999 -9999 -9999 -9999 -9999 -9999 -9999 -9999 -9999 -9999 -9999 -9999 -9999 -9999 -9999 -9999 -9999 -9999 -9999 -9999 -9999 -9999 -9999 -9999 -9999 -9999 -9999 -9999 -9999 -9999 -9999 -9999 -9999 -9999 -9999 -9999 -9999 -9999 -9999 -9999 -9999 -9999 -9999 -9999 -9999 -9999 -9999 -9999 -9999 -9999 -9999 -9999 -9999 -9999 -9999 -9999 -9999 -9999 -9999 -9999 -9999 -9999 -9999 -9999 -9999

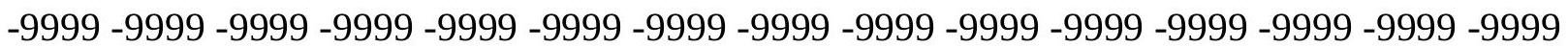
-9999 -9999 -9999 -9999 -9999 -9999 -9999 -9999 -9999 -9999 -9999 -9999 -9999 -9999 -9999 -9999 -9999 -9999 -9999 -9999 -9999 -9999 -9999 -9999 -9999 -9999 -9999 -9999 -9999 -9999 -9999 -9999 -9999 -9999 -9999 -9999 -9999 -9999 -9999 -9999 -9999 -9999 -9999 -9999 -9999

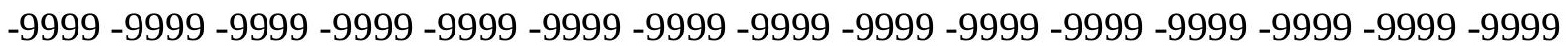
-9999 -9999 -9999 -9999 -9999 -9999 -9999 -9999 -9999 -9999 -9999 -9999 -9999 -9999 -9999 -9999 -9999 -9999 -9999 -9999 -9999 -9999 -9999 -9999 -9999 -9999 -9999 -9999 -9999 -9999 -9999 -9999 -9999 -9999 -9999 -9999 -9999 -9999 -9999 -9999 -9999 -9999 -9999 -9999

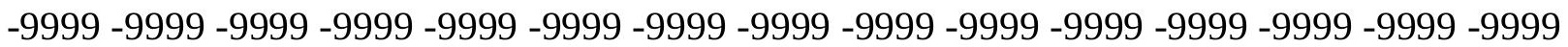
-9999 -9999 -9999 -9999 -9999 -9999 -9999 -9999 -9999 -9999 -9999 -9999 -9999 -9999 -9999 -9999 -9999 -9999 -9999 -9999 -9999 -9999 -9999 -9999 -9999 -9999 -9999 -9999 -9999 -9999 -

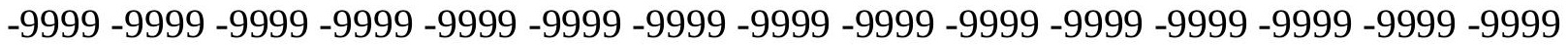
-9999 -9999 -9999 -9999 -9999 -9999 -9999 -9999 -9999 -9999 -9999 -9999 -9999 -9999 -9999 -9999 -9999 -9999 -9999 -9999 -9999 -9999 -9999 -9999 -9999 -9999 -9999 -9999 -9999 -9999 -9999 -9999 -9999 -9999 -9999 -9999 -9999 -9999 -9999 -9999 -9999 -9999 -9999 -9999 -9999 -9999 -9999 -9999 -9999 -9999 -9999 -9999 -9999 -9999 -9999 -9999 -9999 -9999 -9999 -9999 -9999 -9999 -9999 -9999 -9999 -9999 -9999 -9999 -9999 -9999 -9999 -9999 -9999 -9999 -9999

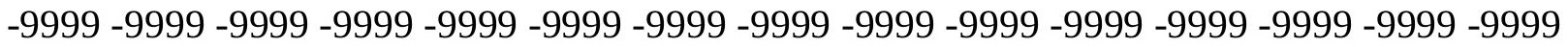
-9999 -9999 -9999 -9999 -9999 -9999 -9999 -9999 -9999 -9999 -9999 -9999 -9999 -9999 -9999 -9999 -9999 -9999 -9999 -9999 -9999 -9999 -9999 -9999 -9999 -9999 -9999 -9999 -9999 -9999 -

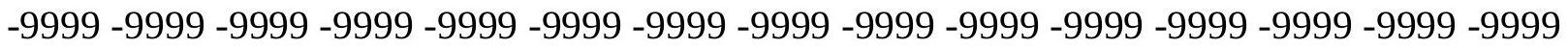
-9999 -9999 -9999 -9999 -9999 -9999 -9999 -9999 -9999 -9999 -9999 -9999 -9999 -9999 -9999 -9999 -9999 -9999 -9999 -9999 -9999 -9999 -9999 -9999 -9999 -9999 -9999 -9999 -9999 -9999 -9999 -9999 -9999 -9999 -9999 -9999 -9999 -9999 -9999 -9999 -9999 -9999 -9999 -9999 -9999 -9999 -9999 -9999 -9999 -9999 -9999 -9999 -9999 -9999 -9999 -9999 -9999 -9999 -9999 -9999

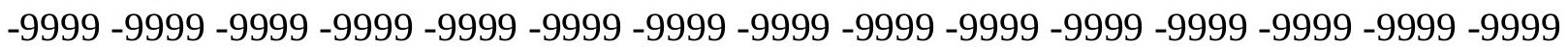


-9999 -9999 -9999 -9999 -9999 -9999 -9999 -9999 -9999 -9999 -9999 -9999 -9999 -9999 -9999 -9999 -9999 -9999 -9999 -9999 -9999 -9999 -9999 -9999 -9999 -9999 -9999 -9999 -9999 -9999 -

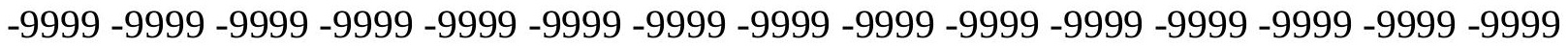
-9999 -9999 -9999 -9999 -9999 -9999 -9999 -9999 -9999 -9999 -9999 -9999 -9999 -9999 -9999 -9999 -9999 -9999 -9999 -9999 -9999 -9999 -9999 -9999-9999 -9999 -9999 -9999 -9999 -9999 -9999 -9999 -9999 -9999 -9999 -9999 -9999 -9999 -9999 -9999 -9999 -9999 -9999 -9999 -9999 -9999 -9999 -9999 -9999 -9999 -9999 -9999 -9999 -9999 -9999 -9999 -9999 -9999 -9999 -

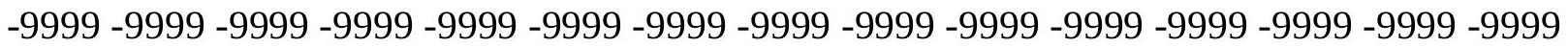

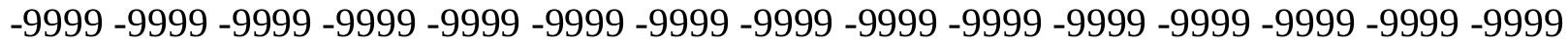
-9999 -9999 -9999 -9999 -9999 -9999 -9999 -9999 -9999 -9999 -9999 -9999 -9999 -9999 -9999 -9999 -9999 -9999 -9999 -9999 -9999 -9999 -9999 -9999 -9999 -9999 -9999 -9999 -9999 -9999 -9999 -9999 -9999 -9999 -9999 -9999 -9999 -9999 -9999 -9999 -9999 -9999 -9999 -9999 -9999 -9999 -9999 -9999 -9999 -9999 -9999 -9999 -9999 -9999 -9999 -9999 -9999 -9999 -9999 -9999 -9999 -9999 -9999 -9999 -9999 -9999 -9999 -9999 -9999 -9999 -9999 -9999 -9999 -9999 -9999 -9999 -9999 -9999 -9999 -9999 -9999 -9999 -9999 -9999 -9999 -9999 -9999 -9999 -9999 -9999 -

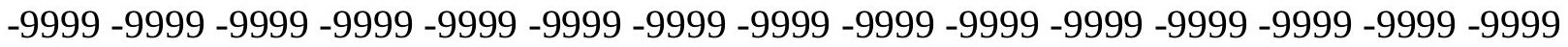
-9999 -9999 -9999 -9999 -9999 -9999 -9999 -9999 -9999 -9999 -9999 -9999 -9999 -9999 -9999 -9999 -9999 -9999 -9999 -9999 -9999 -9999 -9999 -9999 -9999 -9999 -9999 -9999 -9999 -9999 -9999 -9999 -9999 -9999 -9999 -9999 -9999 -9999 -9999 -9999 -9999 -9999 -9999 -9999 -9999 -

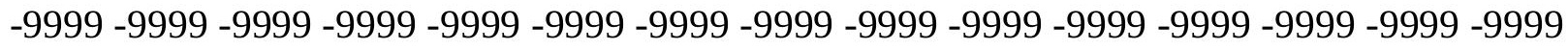

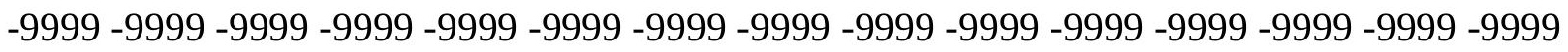

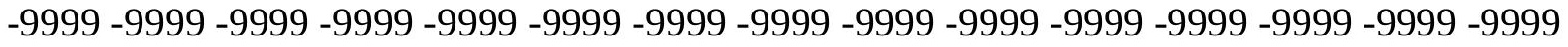
-9999 -9999 -9999 -9999 -9999 -9999 -9999 -9999 -9999 -9999 -9999 -9999 -9999 -9999 -9999 -9999 -9999 -9999 -9999 -9999 -9999 -9999 -9999 -9999 -9999 -9999 -9999 -9999 -9999 -9999 -

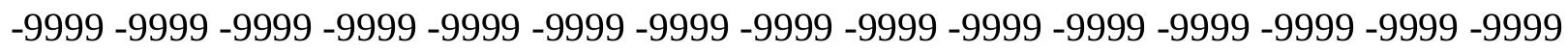
-9999 -9999 -9999 -9999 -9999 -9999 -9999 -9999 -9999 -9999 -9999 -9999 -9999 -9999 -9999 -9999 -9999 -9999 -9999 -9999 -9999 -9999 -9999 -9999 -9999 -9999 -9999 -9999 -9999 -9999 -

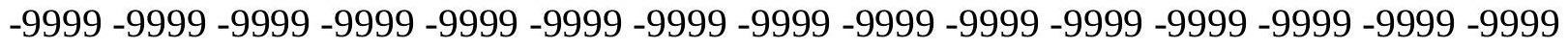
-9999 -9999 -9999 -9999 -9999 -9999 -9999 -9999 -9999 -9999 -9999 -9999 -9999 -9999 -9999 -9999 -9999 -9999 -9999 -9999 -9999 -9999 -9999 -9999 -9999 -9999 -9999 -9999 -9999 -999 -9999 -9999 -9999 -9999 -9999 -9999 -9999 -9999 -9999 -9999 -9999 -9999 -9999 -9999 -9999 -

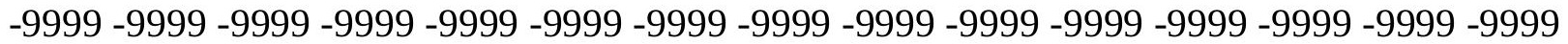

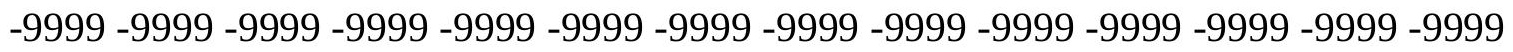

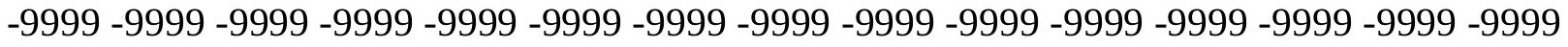

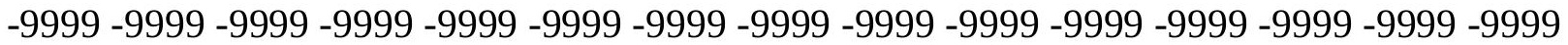

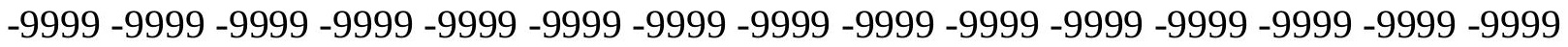

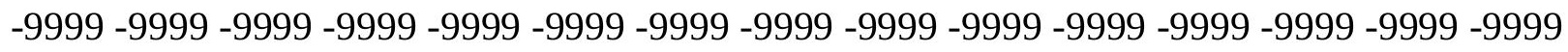

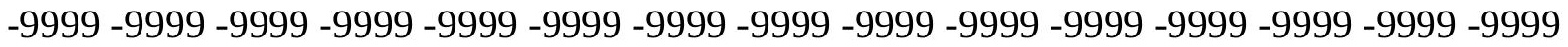

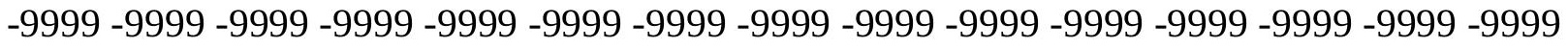
-9999 -9999 -9999 -9999 -9999 -9999 -9999 -9999 -9999 -9999 -9999 -9999 -9999 -9999 -9999 -

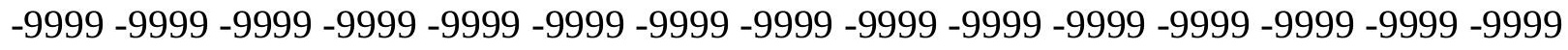

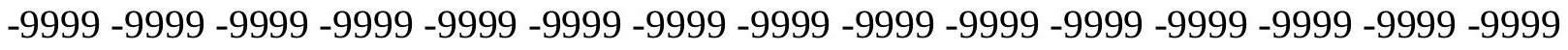
-9999 -9999 -9999 -9999 -9999 -9999 -9999 -9999 -9999 -9999 -9999 -9999 -9999 -9999 -9999 -9999 -9999 -9999 -9999 -9999 -9999 -9999 -9999 -9999-9999 -9999 -9999 -9999 -9999 -9999 -9999 -9999 -9999 -9999 -9999 -9999 -9999 -9999 -9999 -9999 -9999 -9999 -9999 -9999 -9999 -

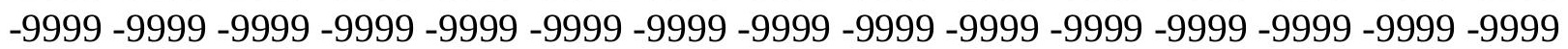


-9999 -9999 -9999 -9999 -9999 -9999 -9999 -9999 -9999 -9999 -9999 -9999 -9999 -9999 -9999 -9999 -9999 -9999 -9999 -9999 -9999 -9999 -9999 -9999 -9999 -9999 -9999 -9999 -9999 -9999 -

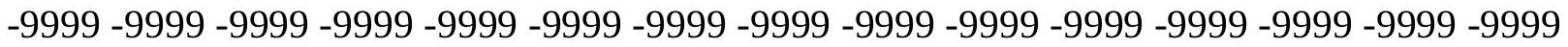
-9999 -9999 -9999 -9999 -9999 -9999 -9999 -9999 -9999 -9999 -9999 -9999 -9999 -9999 -9999 -9999 -9999 -9999 -9999 -9999 -9999 -9999 -9999 -9999-9999 -9999 -9999 -9999 -9999 -9999 -9999 -9999 -9999 -9999 -9999 -9999 -9999 -9999 -9999 -9999 -9999 -9999 -9999 -9999 -9999 -9999 -9999 -9999 -9999 -9999 -9999 -9999 -9999 -9999 -9999 -9999 -9999 -9999 -9999 -9999

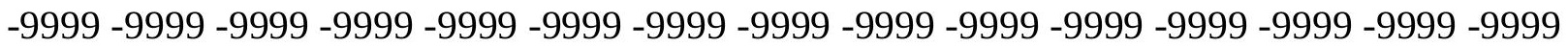

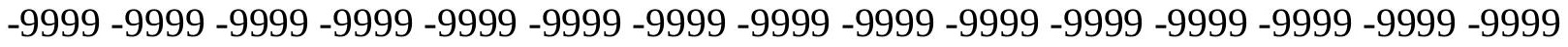
-9999 -9999 -9999 -9999 -9999 -9999 -9999 -9999 -9999 -9999 -9999 -9999 -9999 -9999 -9999 -9999 -9999 -9999 -9999 -9999 -9999 -9999 -9999 -9999 -9999 -9999 -9999 -9999 -9999 -9999 -9999 -9999 -9999 -9999 -9999 -9999 -9999 -9999 -9999 -9999 -9999 -9999 -9999 -9999 -9999 -9999 -9999 -9999 -9999 -9999 -9999 -9999 -9999 -9999 -9999 -9999 -9999 -9999 -9999 -9999 -9999 -9999 -9999 -9999 -9999 -9999 -9999 -9999 -9999 -9999 -9999 -9999 -9999 -9999 -9999 -9999 -9999 -9999 -9999 -9999 -9999 -9999 -9999 -9999 -9999 -9999 -9999 -9999 -9999 -

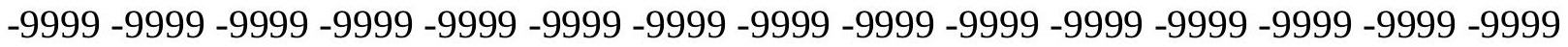
-9999 -9999 -9999 -9999 -9999 -9999 -9999 -9999 -9999 -9999 -9999 -9999 -9999 -9999 -9999 -9999 -9999 -9999 -9999 -9999 -9999 -9999 -9999 -9999 -9999 -9999 -9999 -9999 -9999 -9999 -9999 -9999 -9999 -9999 -9999 -9999 -9999 -9999 -9999 -9999 -9999 -9999 -9999 -9999 -9999 -

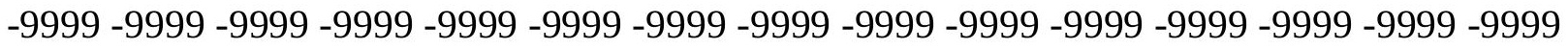
-9999 -9999 -9999 -9999 -9999 -9999 -9999 -9999 -9999 -9999 -9999 -9999 -9999 -9999 -9999

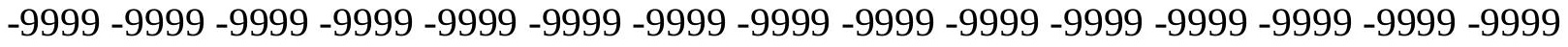
-9999 -9999 -9999 -9999 -9999 -9999 -9999 -9999 -9999 -9999 -9999 -9999 -9999 -9999 -9999 -9999 -9999 -9999 -9999 -9999 -9999 -9999 -9999 -9999 -9999 -9999 -9999 -9999 -9999 -9999 -

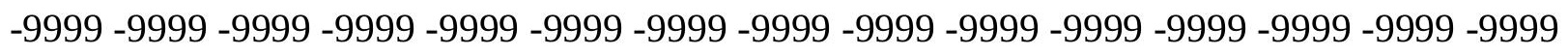
-9999 -9999 -9999 -9999 -9999 -9999 -9999 -9999 -9999 -9999 -9999 -9999 -9999 -9999 -9999 -9999 -9999 -9999 -9999 -9999 -9999 -9999 -9999 -9999 -9999 -9999 -9999 -9999 -9999 -9999 -

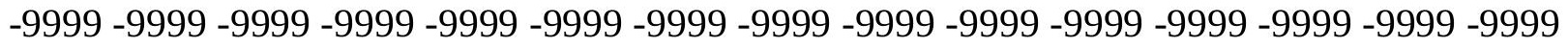
-9999 -9999 -9999 -9999 -9999 -9999 -9999 -9999 -9999 -9999 -9999 -9999 -9999 -9999 -9999 -9999 -9999 -9999 -9999 -9999 -9999 -9999 -9999 -9999 -9999 -9999 -9999 -9999 -9999 -999 -9999 -9999 -9999 -9999 -9999 -9999 -9999 -9999 -9999 -9999 -9999 -9999 -9999 -9999 -9999 -9999 -9999 -9999 -9999 -9999 -9999 -9999 -9999 -9999 -9999 -9999 -9999 -9999 -9999 -9999 -

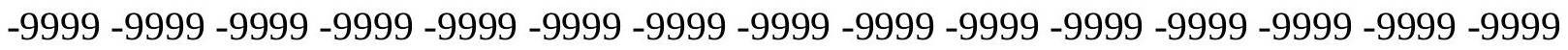

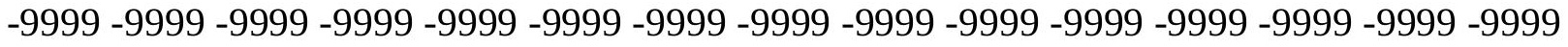

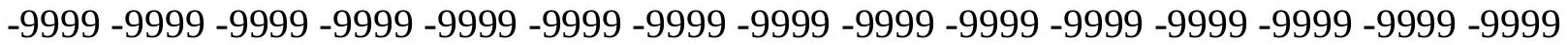
-9999 -9999 -9999 -9999 -9999 -9999 -9999 -9999 -9999 -9999 -9999 -9999 -9999 -9999 -9999 -

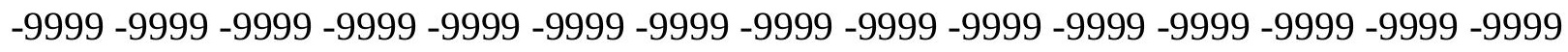

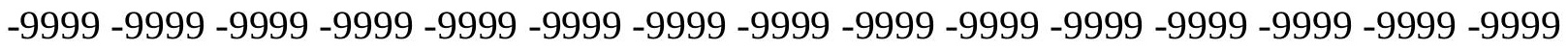
-9999 -9999 -9999 -9999 -9999 -9999 -9999 -9999 -9999 -9999 -9999 -9999 -9999 -9999 - -999 -9999 -9999 -9999 -9999 -9999 -9999 -9999 -9999 -9999 -9999 -9999 -9999 -9999 -9999 -9999 -

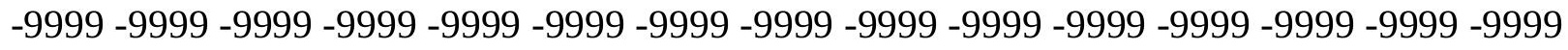

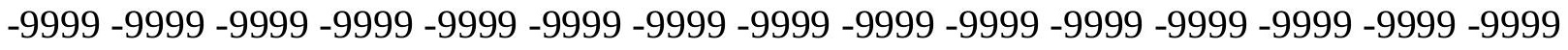
-9999 -9999 -9999 -9999 -9999 -9999 -9999 -9999 -9999 -9999 -9999 -9999 -9999 -9999 -9999 -9999 -9999 -9999 -9999 -9999 -9999 -9999 -9999 -9999-9999 -9999 -9999 -9999 -9999 -9999 -9999 -9999 -9999 -9999 -9999 -9999 -9999 -9999 -9999 -9999 -9999 -9999 -9999 -9999 -9999 -

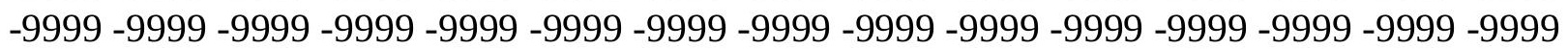


-9999 -9999 -9999 -9999 -9999 -9999 -9999 -9999 -9999 -9999 -9999 -9999 -9999 -9999 -9999 -9999 -9999 -9999 -9999 -9999 -9999 -9999 -9999 -9999 -9999 -9999 -9999 -9999 -9999 -9999 -

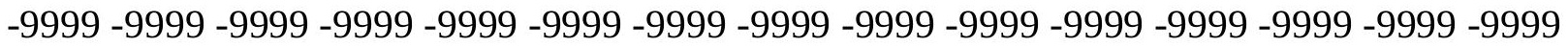
-9999 -9999 -9999 -9999 -9999 -9999 -9999 -9999 -9999 -9999 -9999 -9999 -9999 -9999 -9999 -9999 -9999 -9999 -9999 -9999 -9999 -9999 -9999 -9999-9999 -9999 -9999 -9999 -9999 -9999 -9999 -9999 -9999 -9999 -9999 -9999 -9999 -9999 -9999 -9999 -9999 -9999 -9999 -9999 -9999 -9999 -9999 -9999 -9999 -9999 -9999 -9999 -9999 -9999 -9999 -9999 -9999 -9999 -9999 -9999

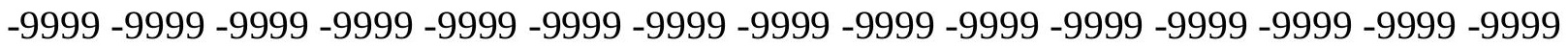

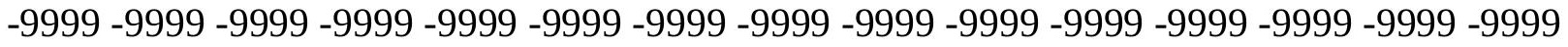
-9999 -9999 -9999 -9999 -9999 -9999 -9999 -9999 -9999 -9999 -9999 -9999 -9999 -9999 -9999 -9999 -9999 -9999 -9999 -9999 -9999 -9999 -9999 -9999 -9999 -9999 -9999 -9999 -9999 -9999 -9999 -9999 -9999 -9999 -9999 -9999 -9999 -9999 -9999 -9999 -9999 -9999 -9999 -9999 -9999 -9999 -9999 -9999 -9999 -9999 -9999 -9999 -9999 -9999 -9999 -9999 -9999 -9999 -9999 -9999 -

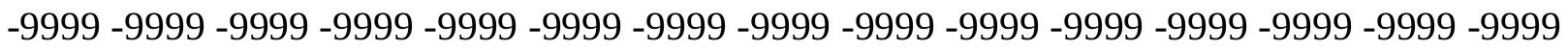
-9999 -9999 -9999 -9999 -9999 -9999 -9999 -9999 -9999 -9999 -9999 -9999 -9999 -9999 -9999 -

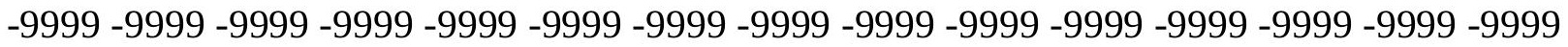
-9999 -9999 -9999 -9999 -9999 -9999 -9999 -9999 -9999 -9999 -9999 -9999 -9999 -9999 -9999 -9999 -9999 -9999 -9999 -9999 -9999 -9999 -9999 -9999 -9999 -9999 -9999 -9999 -9999 -9999 -9999 -9999 -9999 -9999 -9999 -9999 -9999 -9999 -9999 -9999 -9999 -9999 -9999 -9999 - -999 -

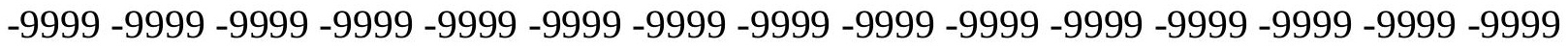

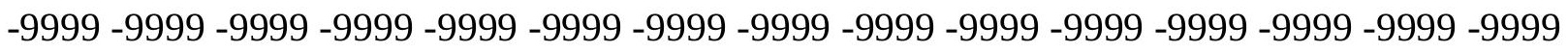
-9999 -9999 -9999 -9999 -9999 -9999 -9999 -9999 -9999 -9999 -9999 -9999 -9999 -9999 -9999 -9999 -9999 -9999 -9999 -9999 -9999 -9999 -9999 -9999 -9999 -9999 -9999 -9999 -9999 -9999 -9999 -9999 -9999 -9999 -9999 -9999 -9999 -9999 -9999 -9999 -9999 -9999 -9999 -9999 -9999 -

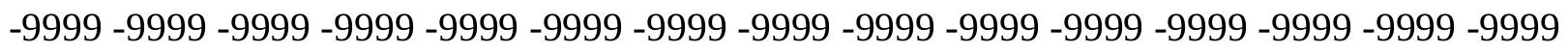
-9999 -9999 -9999 -9999 -9999 -9999 -9999 -9999 -9999 -9999 -9999 -9999 -9999 -9999 -9999 -9999 -9999 -9999 -9999 -9999 -9999 -9999 -9999 -9999 -9999 -9999 -9999 -9999 -9999 -9999 -

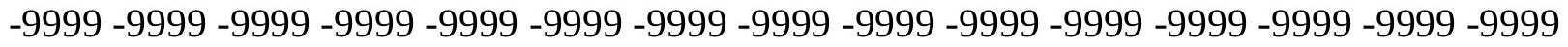
-9999 -9999 -9999 -9999 -9999 -9999 -9999 -9999 -9999 -9999 -9999 -9999 -9999 -9999 -9999 -9999 -9999 -9999 -9999 -9999 -9999 -9999 -9999 -9999 -9999 -9999 -9999 -9999 -9999 -999 -

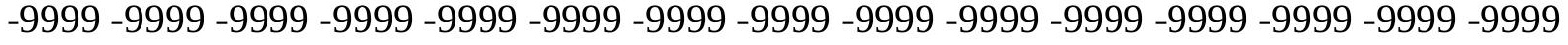
-9999 -9999 -9999 -9999 -9999 -9999 -9999 -9999 -9999 -9999 -9999 -9999 -9999 -9999 -9999 -

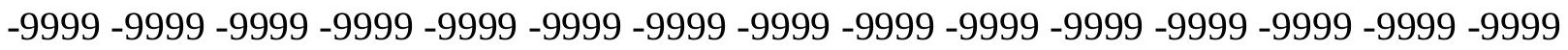

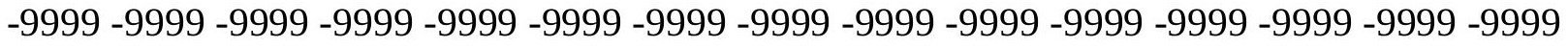

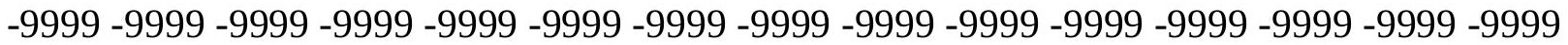

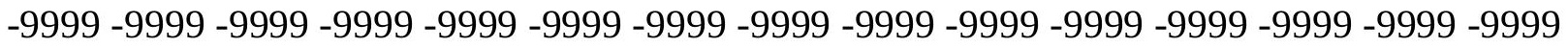

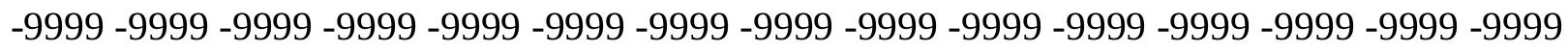

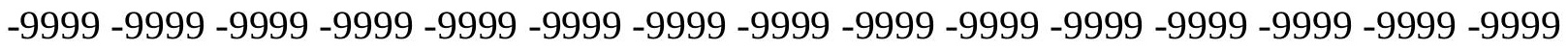

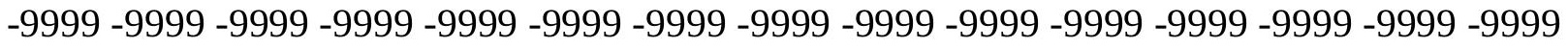
-9999 -9999 -9999 -9999 -9999 -9999 -9999 -9999 -9999 -9999 -9999 -9999 -9999 -9999 -9999 -

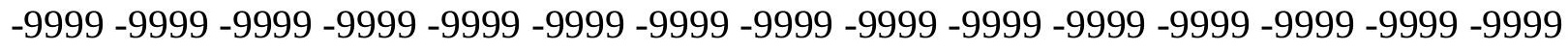

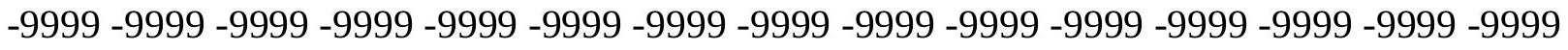
-9999 -9999 -9999 -9999 -9999 -9999 -9999 -9999 -9999 -9999 -9999 -9999 -9999 -9999 -9999 -9999 -9999 -9999 -9999 -9999 -9999 -9999 -9999 -9999 -9999 -9999 -9999 -9999 -9999 -9999 -9999 -9999 -9999 -9999 -9999 -9999 -9999 -9999 -9999 -9999 -9999 -9999 -9999 -9999 -

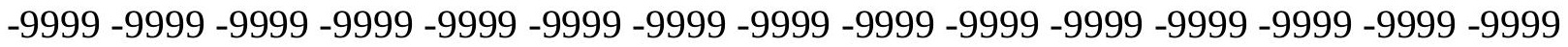


-9999 -9999 -9999 -9999 -9999 -9999 -9999 -9999 -9999 -9999 -9999 -9999 -9999 -9999 -9999 -9999 -9999 -9999 -9999 -9999 -9999 -9999 -9999 -9999 -9999 -9999 -9999 -9999 -9999 -9999 -

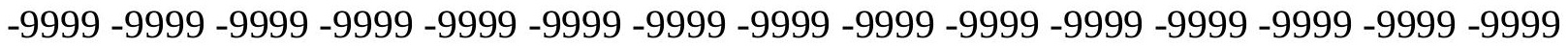
-9999 -9999 -9999 -9999 -9999 -9999 -9999 -9999 -9999 -9999 -9999 -9999 -9999 -9999 -9999 -9999 -9999 -9999 -9999 -9999 -9999 -9999 -9999 -9999-9999 -9999 -9999 -9999 -9999 -9999 -9999 -9999 -9999 -9999 -9999 -9999 -9999 -9999 -9999 -9999 -9999 -9999 -9999 -9999 -9999 -9999 -9999 -9999 -9999 -9999 -9999 -9999 -9999 -9999 -9999 -9999 -9999 -9999 -9999 -9999

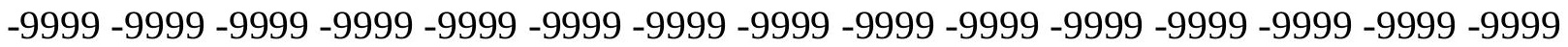

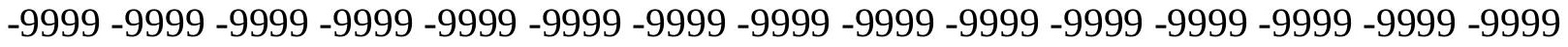
-9999 -9999 -9999 -9999 -9999 -9999 -9999 -9999 -9999 -9999 -9999 -9999 -9999 -9999 -9999 -9999 -9999 -9999 -9999 -9999 -9999 -9999 -9999 -9999 -9999 -9999 -9999 -9999 -9999 -9999 -9999 -9999 -9999 -9999 -9999 -9999 -9999 -9999 -9999 -9999 -9999 -9999 -9999 -9999 -9999 -9999 -9999 -9999 -9999 -9999 -9999 -9999 -9999 -9999 -9999 -9999 -9999 -9999 -9999 -9999 -

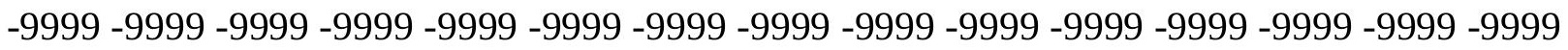
-9999 -9999 -9999 -9999 -9999 -9999 -9999 -9999 -9999 -9999 -9999 -9999 -9999 -9999 -9999 -

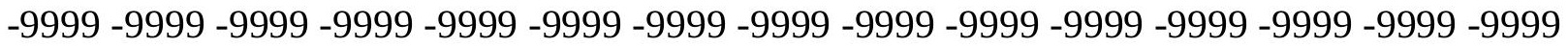
-9999 -9999 -9999 -9999 -9999 -9999 -9999 -9999 -9999 -9999 -9999 -9999 -9999 -9999 -9999 -9999 -9999 -9999 -9999 -9999 -9999 -9999 -9999 -9999 -9999 -9999 -9999 -9999 -9999 - 9999 -9999 -9999 -9999 -9999 -9999 -9999 -9999 -9999 -9999 -9999 -9999 -9999 -9999 -9999 -9999 -

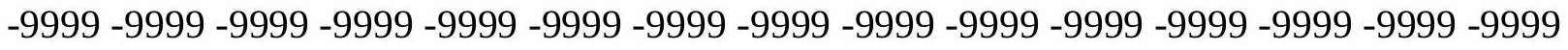

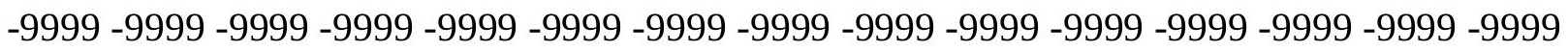
-9999 -9999 -9999 -9999 -9999 -9999 -9999 -9999 -9999 -9999 -9999 -9999 -9999 -9999 - 9999 -9999 -9999 -9999 -9999 -9999 -9999 -9999 -9999 -9999 -9999 -9999 -9999 -9999 -9999 -9999 -9999 -9999 -9999 -9999 -9999 -9999 -9999 -9999 -9999 -9999 -9999 -9999 -9999 -9999 -9999 -9999 -9999 -9999 -9999 -9999 -9999 -9999 -9999 -9999 -9999 -9999 -9999 -9999 -9999 -9999 -9999 -9999 -9999 -9999 -9999 -9999 -9999 -9999 -9999 -9999 -9999 -9999 -9999 -9999 -9999 -9999 -9999 -9999 -9999 -9999 -9999 -9999 -9999 -9999 -9999 -9999 -9999 -9999 -9999 -

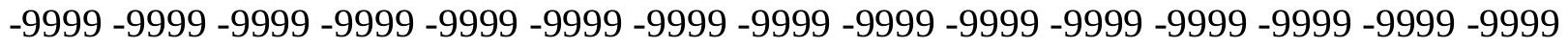
-9999 -9999 -9999 -9999 -9999 -9999 -9999 -9999 -9999 -9999 -9999 -9999 -9999 -9999 -9999 -9999 -9999 -9999 -9999 -9999 -9999 -9999 -9999 -9999 -9999 -9999 -9999 -9999 -9999 -999 -9999 -9999 -9999 -9999 -9999 -9999 -9999 -9999 -9999 -9999 -9999 -9999 -9999 -9999 -9999 -9999 -9999 -9999 -9999 -9999 -9999 -9999 -9999 -9999 -9999 -9999 -9999 -9999 -9999 -9999 -

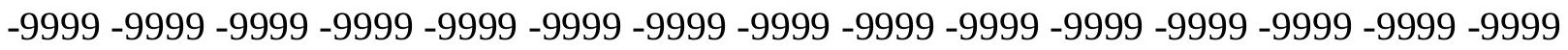

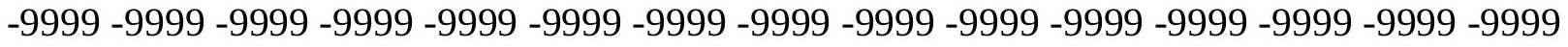

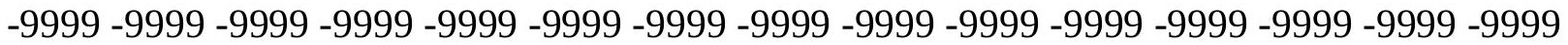

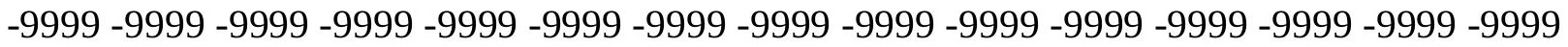

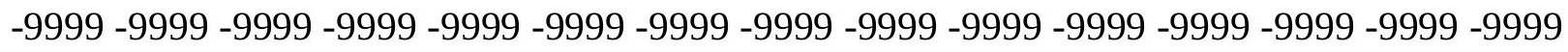

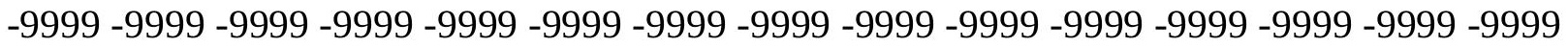

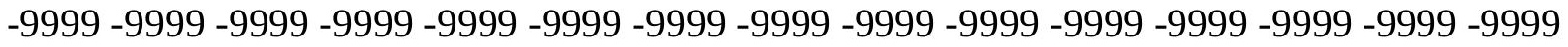
-9999 -9999 -9999 -9999 -9999 -9999 -9999 -9999 -9999 -9999 -9999 -9999 -9999 -9999 -9999 -

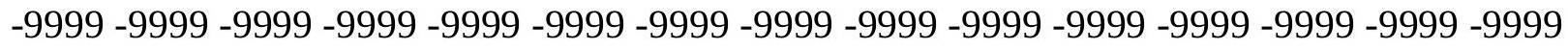

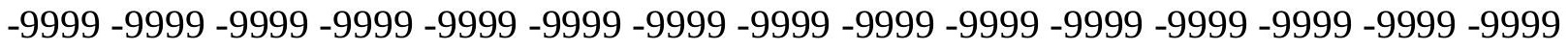
-9999 -9999 -9999 -9999 -9999 -9999 -9999 -9999 -9999 -9999 -9999 -9999 -9999 -9999 -9999 -9999 -9999 -9999 -9999 -9999 -9999 -9999 -9999 -9999-9999 -9999 -9999 -9999 -9999 -9999 -9999 -9999 -9999 -9999 -9999 -9999 -9999 -9999 -9999 -9999 -9999 -9999 -9999 -9999 -9999 -

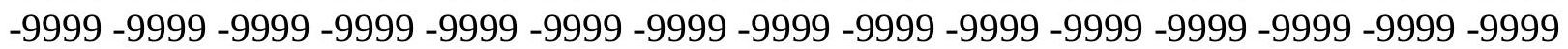


-9999 -9999 -9999 -9999 -9999 -9999 -9999 -9999 -9999 -9999 -9999 -9999 -9999 -9999 -9999 -9999 -9999 -9999 -9999 -9999 -9999 -9999 -9999 -9999 -9999 -9999 -9999 -9999 -9999 -9999 -9999 -9999 -9999 -9999 -9999 -9999 -9999 -9999 -9999 -9999 -9999 -9999 -9999 -9999 - 9999 -9999 -9999 -9999 -9999 -9999 -9999 -9999 -9999 -9999 -9999 -9999 -9999 -9999 -9999 -9999 -9999 -9999 -9999 -9999 -9999 -9999 -9999 -9999 -9999 -9999 -9999 -9999 -9999 -9999 -9999 -9999 -9999 -9999 -9999 -9999 -9999 -9999 -9999 -9999 -9999 -9999 -9999 -9999 -9999 -9999 -9999 -9999 -9999 -9999 -9999 -9999 -9999 -9999 -9999 -9999 -9999 -9999 -9999 -9999

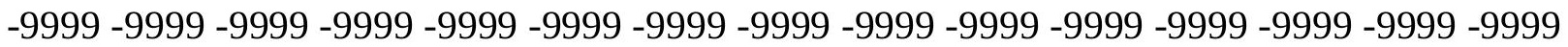

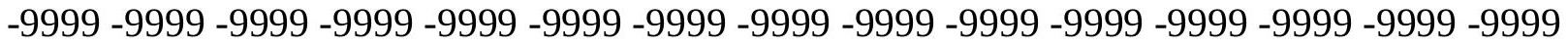
-9999 -9999 -9999 -9999 -9999 -9999 -9999 -9999 -9999 -9999 -9999 -9999 -9999 -9999 -9999 -9999 -9999 -9999 -9999 -9999 -9999 -9999 -9999 -9999 -9999 -9999 -9999 -9999 -9999 -9999 -9999 -9999 -9999 -9999 -9999 -9999 -9999 -9999 -9999 -9999 -9999 -9999 -9999 -9999 -9999 -9999 -9999 -9999 -9999 -9999 -9999 -9999 -9999 -9999 -9999 -9999 -9999 -9999 -9999 -9999 -9999 -9999 -9999 -9999 -9999 -9999 -9999 -9999 -9999 -9999 -9999 -9999 -9999 -9999 -9999 -9999 -9999 -9999 -9999 -9999 -9999 -9999 -9999 -9999 -9999 -9999 -9999 -9999 -9999 -9999 -

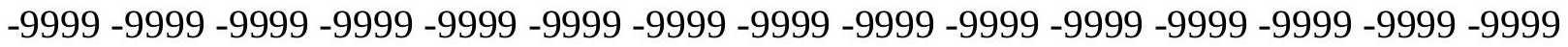
-9999 -9999 -9999 -9999 -9999 -9999 -9999 -9999 -9999 -9999 -9999 -9999 -9999 -9999 -9999 -9999 -9999 -9999 -9999 -9999 -9999 -9999 -9999 -9999 -9999 -9999 -9999 -9999 -9999 - 9999 -9999 -9999 -9999 -9999 -9999 -9999 -9999 -9999 -9999 -9999 -9999 -9999 -9999 -9999 -9999 -

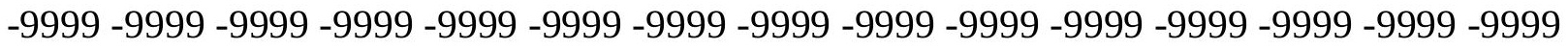

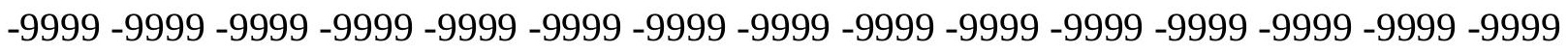

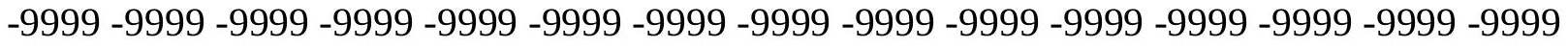
-9999 -9999 -9999 -9999 -9999 -9999 -9999 -9999 -9999 -9999 -9999 -9999 -9999 -9999 -9999 -9999 -9999 -9999 -9999 -9999 -9999 -9999 -9999 -9999 -9999 -9999 -9999 -9999 -9999 -9999 -

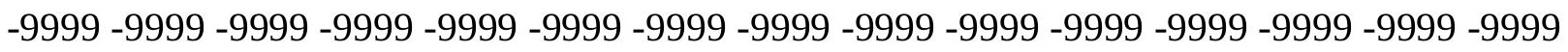
-9999 -9999 -9999 -9999 -9999 -9999 -9999 -9999 -9999 -9999 -9999 -9999 -9999 -9999 -9999 -9999 -9999 -9999 -9999 -9999 -9999 -9999 -9999 -9999 -9999 -9999 -9999 -9999 -9999 -9999 -

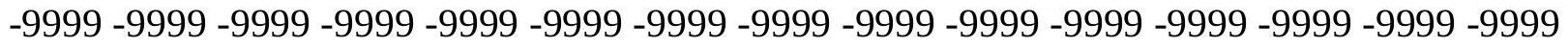
-9999 -9999 -9999 -9999 -9999 -9999 -9999 -9999 -9999 -9999 -9999 -9999 -9999 -9999 -9999 -9999 -9999 -9999 -9999 -9999 -9999 -9999 -9999 -9999 -9999 -9999 -9999 -9999 -9999 -999 -9999 -9999 -9999 -9999 -9999 -9999 -9999 -9999 -9999 -9999 -9999 -9999 -9999 -9999 -9999 -9999 -9999 -9999 -9999 -9999 -9999 -9999 -9999 -9999 -9999 -9999 -9999 -9999 -9999 -

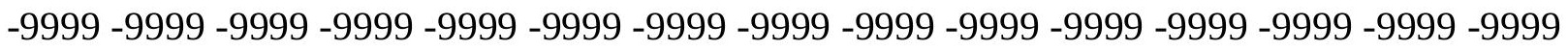

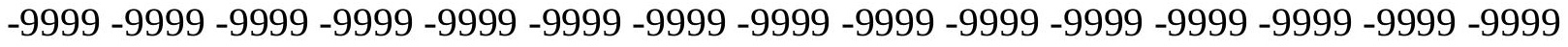

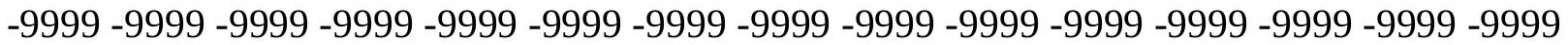

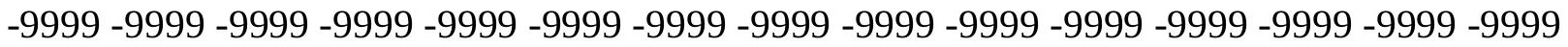

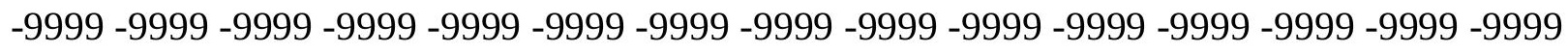

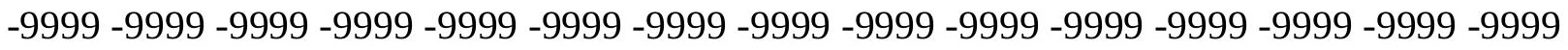

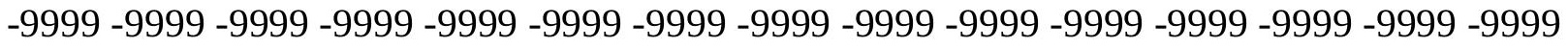
-9999 -9999 -9999 -9999 -9999 -9999 -9999 -9999 -9999 -9999 -9999 -9999 -9999 -9999 -9999 -

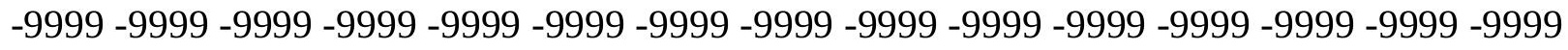

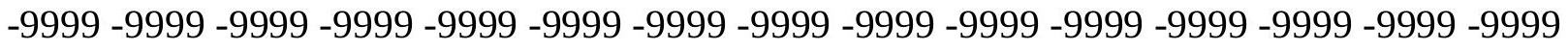
-9999 -9999 -9999 -9999 -9999 -9999 -9999 -9999 -9999 -9999 -9999 -9999 -9999 -9999 -9999 -9999 -9999 -9999 -9999 -9999 -9999 -9999 -9999 -9999-9999 -9999 -9999 -9999 -9999 -9999 -9999 -9999 -9999 -9999 -9999 -9999 -9999 -9999 -9999 -9999 -9999 -9999 -9999 -9999 -9999 -

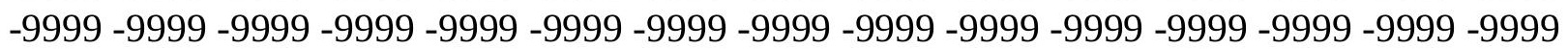


-9999 -9999 -9999 -9999 -9999 -9999 -9999 -9999 -9999 -9999 -9999 -9999 -9999 -9999 -9999 -9999 -9999 -9999 -9999 -9999 -9999 -9999 -9999 -9999 -9999 -9999 -9999 -9999 -9999 -9999 -

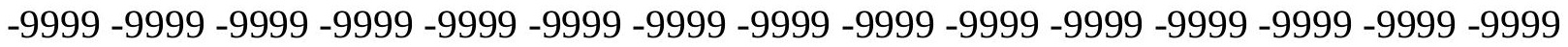
-9999 -9999 -9999 -9999 -9999 -9999 -9999 -9999 -9999 -9999 -9999 -9999 -9999 -9999 -9999 -9999 -9999 -9999 -9999 -9999 -9999 -9999 -9999 -9999-9999 -9999 -9999 -9999 -9999 -9999 -9999 -9999 -9999 -9999 -9999 -9999 -9999 -9999 -9999 -9999 -9999 -9999 -9999 -9999 -9999 -9999 -9999 -9999 -9999 -9999 -9999 -9999 -9999 -9999 -9999 -9999 -9999 -9999 -9999 -9999

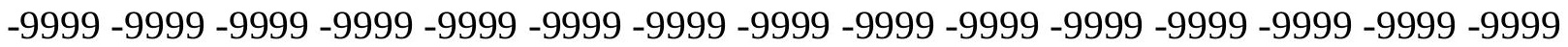

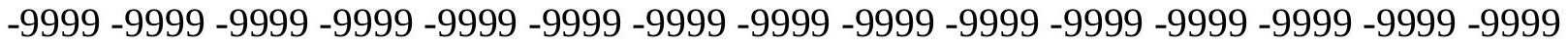

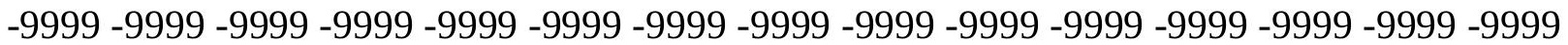
-9999 -9999 -9999 -9999 -9999 -9999 -9999 -9999 -9999 -9999 -9999 -9999 -9999 -9999 -9999 -9999 -9999 -9999 -9999 -9999 -9999 -9999 -9999 -9999 -9999 -9999 -9999 -9999 -9999 -9999 -9999 -9999 -9999 -9999 -9999 -9999 -9999 -9999 -9999 -9999 -9999 -9999 -9999 -9999 -

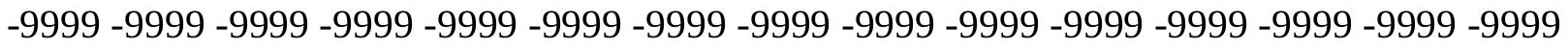
-9999 -9999 -9999 -9999 -9999 -9999 -9999 -9999 -9999 -9999 -9999 -9999 -9999 -9999 -9999 -

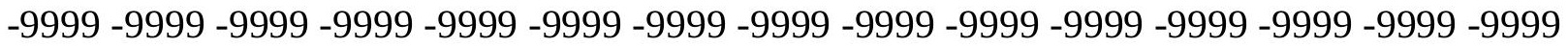
-9999 -9999 -9999 -9999 -9999 -9999 -9999 -9999 -9999 -9999 -9999 -9999 -9999 -9999 -9999 -9999 -9999 -9999 -9999 -9999 -9999 -9999 -9999 -9999 -9999 -9999 -9999 -9999 -9999 -9999 -9999 -9999 -9999 -9999 -9999 -9999 -9999 -9999 -9999 -9999 -9999 -9999 -9999 -9999 -9999 -

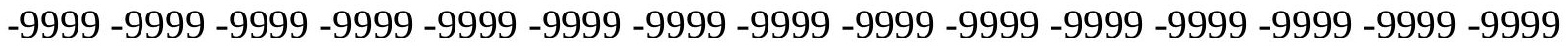

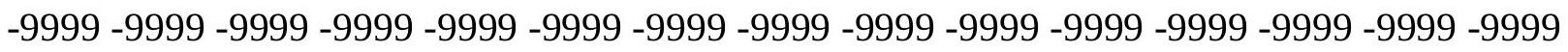
-9999 -9999 -9999 -9999 -9999 -9999 -9999 -9999 -9999 -9999 -9999 -9999 -9999 -9999 -9999 -9999 -9999 -9999 -9999 -9999 -9999 -9999 -9999 -9999 -9999 -9999 -9999 -9999 -9999 -9999 -9999 -9999 -9999 -9999 -9999 -9999 -9999 -9999 -9999 -9999 -9999 -9999 -9999 -9999 -9999 -

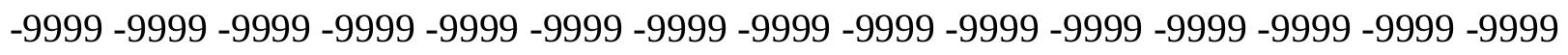
-9999 -9999 -9999 -9999 -9999 -9999 -9999 -9999 -9999 -9999 -9999 -9999 -9999 -9999 -9999 -9999 -9999 -9999 -9999 -9999 -9999 -9999 -9999 -9999 -9999 -9999 -9999 -9999 -9999 -9999 -

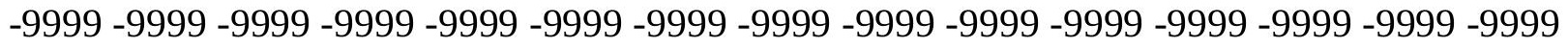
-9999 -9999 -9999 -9999 -9999 -9999 -9999 -9999 -9999 -9999 -9999 -9999 -9999 -9999 -9999 -9999 -9999 -9999 -9999 -9999 -9999 -9999 -9999 -9999 -9999 -9999 -9999 -9999 -9999 -999 -9999 -9999 -9999 -9999 -9999 -9999 -9999 -9999 -9999 -9999 -9999 -9999 -9999 -9999 -9999 -9999 -9999 -9999 -9999 -9999 -9999 -9999 -9999 -9999 -9999 -9999 -9999 -9999 -9999 -9999 -

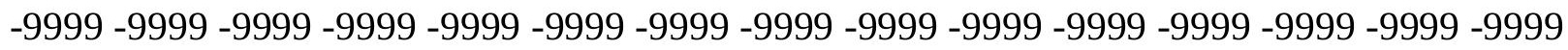

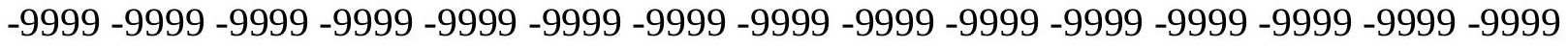

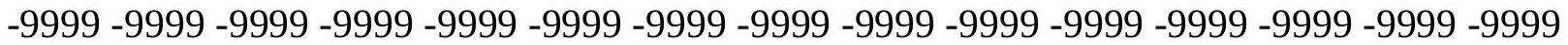
-9999 -9999 -9999 -9999 -9999 -9999 -9999 -9999 -9999 -9999 -9999 -9999 -9999 -9999 -9999 -

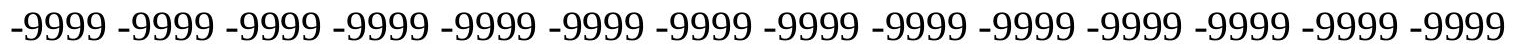

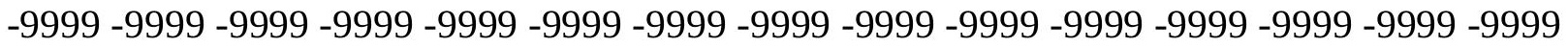
-9999 -9999 -9999 -9999 -9999 -9999 -9999 -9999 -9999 -9999 -9999 -9999 -9999 - 9999 - -999 -9999 -9999 -9999 -9999 -9999 -9999 -9999 -9999 -9999 -9999 -9999 -9999 -9999 -9999 -9999 -

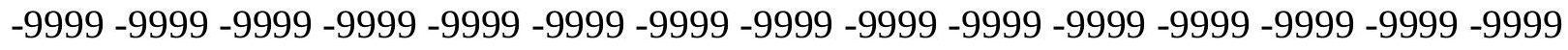

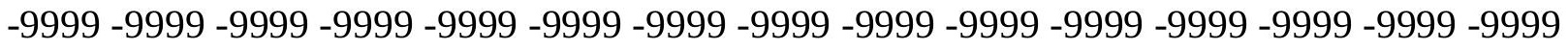
-9999 -9999 -9999 -9999 -9999 -9999 -9999 -9999 -9999 -9999 -9999 -9999 -9999 -9999 -9999 -9999 -9999 -9999 -9999 -9999 -9999 -9999 -9999 -9999-9999 -9999 -9999 -9999 -9999 -9999 -9999 -9999 -9999 -9999 -9999 -9999 -9999 -9999 -9999 -9999 -9999 -9999 -9999 -9999 -9999 -

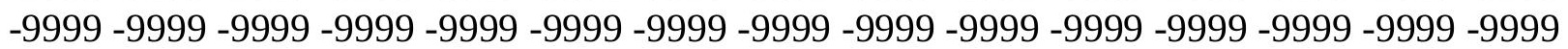


-9999 -9999 -9999 -9999 -9999 -9999 -9999 -9999 -9999 -9999 -9999 -9999 -9999 -9999 -9999 -9999 -9999 -9999 -9999 -9999 -9999 -9999 -9999 -9999 -9999 -9999 -9999 -9999 -9999 -9999 -

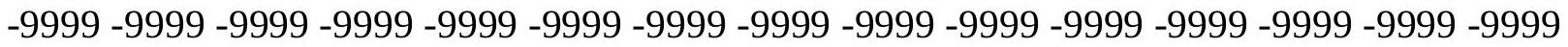
-9999 -9999 -9999 -9999 -9999 -9999 -9999 -9999 -9999 -9999 -9999 -9999 -9999 -9999 -9999 -9999 -9999 -9999 -9999 -9999 -9999 -9999 -9999 -9999-9999 -9999 -9999 -9999 -9999 -9999 -9999 -9999 -9999 -9999 -9999 -9999 -9999 -9999 -9999 -9999 -9999 -9999 -9999 -9999 -9999 -9999 -9999 -9999 -9999 -9999 -9999 -9999 -9999 -9999 -9999 -9999 -9999 -9999 -9999 -9999

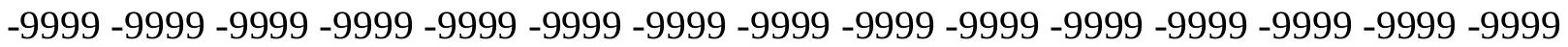

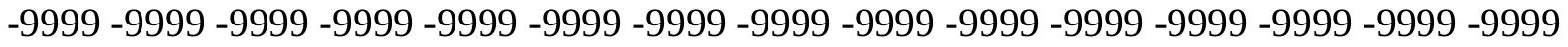
-9999 -9999 -9999 -9999 -9999 -9999 -9999 -9999 -9999 -9999 -9999 -9999 -9999 -9999 -9999 -9999 -9999 -9999 -9999 -9999 -9999 -9999 -9999 -9999 -9999 -9999 -9999 -9999 -9999 -9999 -9999 -9999 -9999 -9999 -9999 -9999 -9999 -9999 -9999 -9999 -9999 -9999 -9999 -9999 -9999 -9999 -9999 -9999 -9999 -9999 -9999 -9999 -9999 -9999 -9999 -9999 -9999 -9999 -9999 -9999 -9999 -9999 -9999 -9999 -9999 -9999 -9999 -9999 -9999 -9999 -9999 -9999 -9999 -9999 -9999 -9999 -9999 -9999 -9999 -9999 -9999 -9999 -9999 -9999 -9999 -9999 -9999 -9999 -9999 -9999 -

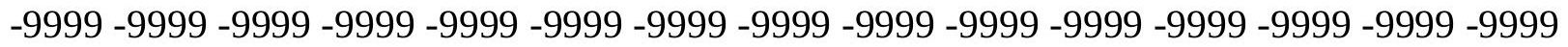
-9999 -9999 -9999 -9999 -9999 -9999 -9999 -9999 -9999 -9999 -9999 -9999 -9999 -9999 -9999 -9999 -9999 -9999 -9999 -9999 -9999 -9999 -9999 -9999 -9999 -9999 -9999 -9999 -9999 -9999 -9999 -9999 -9999 -9999 -9999 -9999 -9999 -9999 -9999 -9999 -9999 -9999 -9999 -9999 -

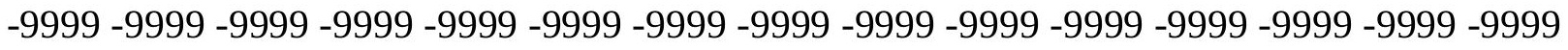
-9999 -9999 -9999 -9999 -9999 -9999 -9999 -9999 -9999 -9999 -9999 -9999 -9999 -9999 -9999 -999 -

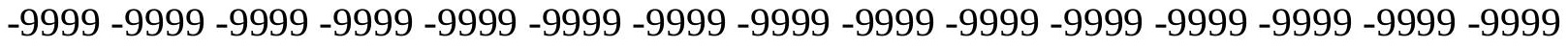
-9999 -9999 -9999 -9999 -9999 -9999 -9999 -9999 -9999 -9999 -9999 -9999 -9999 -9999 -9999 -9999 -9999 -9999 -9999 -9999 -9999 -9999 -9999 -9999 -9999 -9999 -9999 -9999 -9999 -9999 -9999 -9999 -9999 -9999 -9999 -9999 -9999 -9999 -9999 -9999 -9999 -9999 -9999 -9999 -9999 -9999 -9999 -9999 -9999 -9999 -9999 -9999 -9999 -9999 -9999 -9999 -9999 -9999 -9999 -9999 -9999 -9999 -9999 -9999 -9999 -9999 -9999 -9999 -9999 -9999 -9999 -9999 -9999 -9999 -9999 -

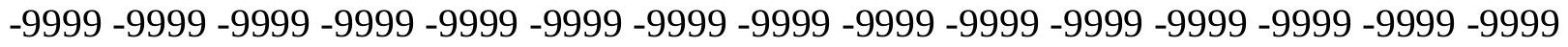
-9999 -9999 -9999 -9999 -9999 -9999 -9999 -9999 -9999 -9999 -9999 -9999 -9999 -9999 -9999 -9999 -9999 -9999 -9999 -9999 -9999 -9999 -9999 -9999 -9999 -9999 -9999 -9999 -9999 -999 -9999 -9999 -9999 -9999 -9999 -9999 -9999 -9999 -9999 -9999 -9999 -9999 -9999 -9999 -9999 -9999 -9999 -9999 -9999 -9999 -9999 -9999 -9999 -9999 -9999 -9999 -9999 -9999 -9999 -9999 -

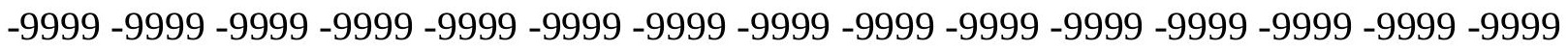

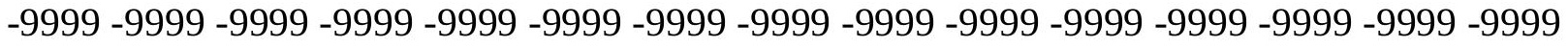

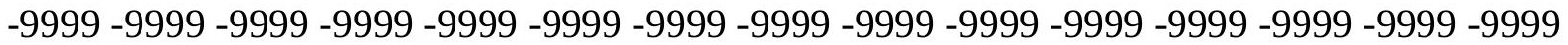
-9999 -9999 -9999 -9999 -9999 -9999 -9999 -9999 -9999 -9999 -9999 -9999 -9999 -9999 -9999

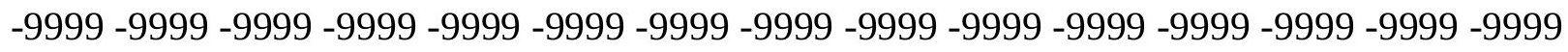

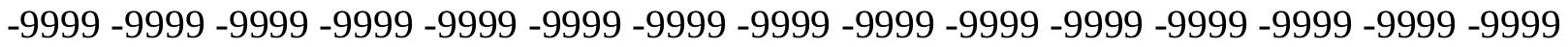
-9999 -9999 -9999 -9999 -9999 -9999 -9999 -9999 -9999 -9999 -9999 -9999 -9999 - 9999 - -999 -9999 -9999 -9999 -9999 -9999 -9999 -9999 -9999 -9999 -9999 -9999 -9999 -9999 -9999 -9999 -

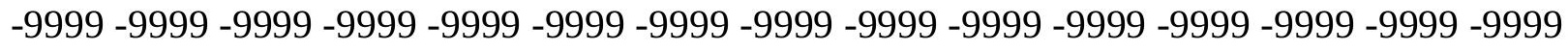

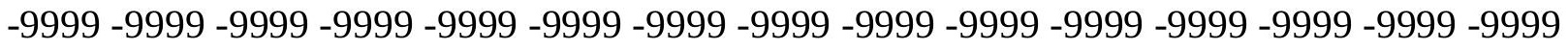
-9999 -9999 -9999 -9999 -9999 -9999 -9999 -9999 -9999 -9999 -9999 -9999 -9999 -9999 -9999 -9999 -9999 -9999 -9999 -9999 -9999 -9999 -9999 -9999 -9999 -9999 -9999 -9999 -9999 -9999 -9999 -9999 -9999 -9999 -9999 -9999 -9999 -9999 -9999 -9999 -9999 -9999 -9999 -9999 -

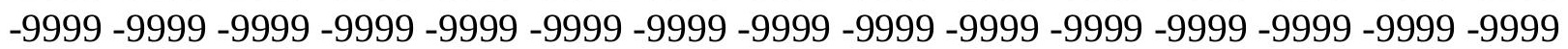


-9999 -9999 -9999 -9999 -9999 -9999 -9999 -9999 -9999 -9999 -9999 -9999 -9999 -9999 -9999 -9999 -9999 -9999 -9999 -9999 -9999 -9999 -9999 -9999 -9999 -9999 -9999 -9999 -9999 -9999 -9999 -9999 -9999 -9999 -9999 -9999 -9999 -9999 -9999 -9999 -9999 -9999 -9999 -9999 - 9999 -9999 -9999 -9999 -9999 -9999 -9999 -9999 -9999 -9999 -9999 -9999 -9999 -9999 -9999 -9999 -9999 -9999 -9999 -9999 -9999 -9999 -9999 -9999 -9999-9999 -9999 -9999 -9999 -9999 -9999 -9999 -9999 -9999 -9999 -9999 -9999 -9999 -9999 -9999 -9999 -9999 -9999 -9999 -9999 -9999 -9999 -9999 -9999 -9999 -9999 -9999 -9999 -9999 -9999 -9999 -9999 -9999 -9999 -9999 -9999

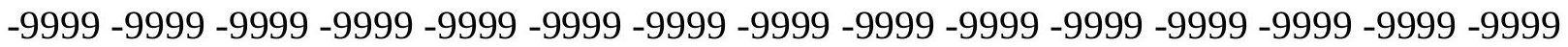

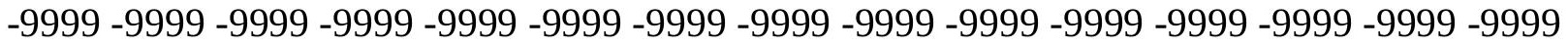
-9999 -9999 -9999 -9999 -9999 -9999 -9999 -9999 -9999 -9999 -9999 -9999 -9999 -9999 -9999 -9999 -9999 -9999 -9999 -9999 -9999 -9999 -9999 -9999 -9999 -9999 -9999 -9999 -9999 -9999 -9999 -9999 -9999 -9999 -9999 -9999 -9999 -9999 -9999 -9999 -9999 -9999 -9999 -9999 -9999 -9999 -9999 -9999 -9999 -9999 -9999 -9999 -9999 -9999 -9999 -9999 -9999 -9999 -9999 -9999 -

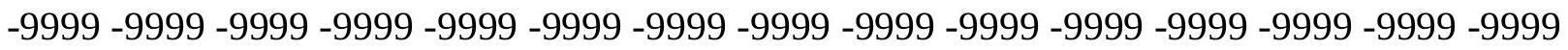
-9999 -9999 -9999 -9999 -9999 -9999 -9999 -9999 -9999 -9999 -9999 -9999 -9999 -9999 -9999 -

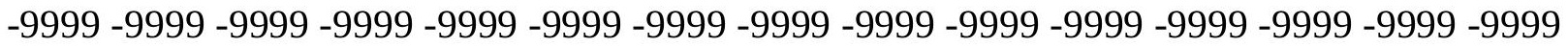
-9999 -9999 -9999 -9999 -9999 -9999 -9999 -9999 -9999 -9999 -9999 -9999 -9999 -9999 -9999 -9999 -9999 -9999 -9999 -9999 -9999 -9999 -9999 -9999 -9999 -9999 -9999 -9999 -9999 -9999 -9999 -9999 -9999 -9999 -9999 -9999 -9999 -9999 -9999 -9999 -9999 -9999 -9999 -9999 -9999 -

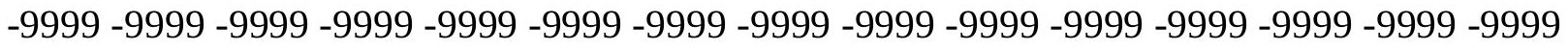
-9999 -9999 -9999 -9999 -9999 -9999 -9999 -9999 -9999 -9999 -9999 -9999 -9999 -9999 -9999 -999 -9999 -9999 -9999 -9999 -9999 -9999 -9999 -9999 -9999 -9999 -9999 -9999 -9999 -9999 - 9999 -9999 -9999 -9999 -9999 -9999 -9999 -9999 -9999 -9999 -9999 -9999 -9999 -9999 -9999 -

-9999 -9999 -9999 -9999 -9999 -9999 -9999 -9999 -9999 -9999 -9999 -9999 -9999 -9999 -9999 -

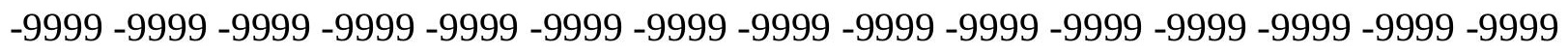
-9999 -9999 -9999 -9999 -9999 -9999 -9999 -9999 -9999 -9999 -9999 -9999 -9999 -9999 -9999 -9999 -9999 -9999 -9999 -9999 -9999 -9999 -9999 -9999 -9999 -9999 -9999 -9999 -9999 -9999 -

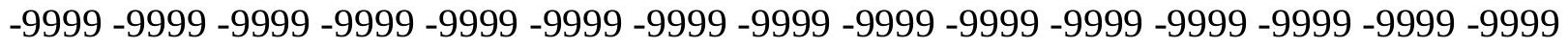
-9999 -9999 -9999 -9999 -9999 -9999 -9999 -9999 -9999 -9999 -9999 -9999 -9999 -9999 -9999 -9999 -9999 -9999 -9999 -9999 -9999 -9999 -9999 -9999 -9999 -9999 -9999 -9999 -9999 -999 -

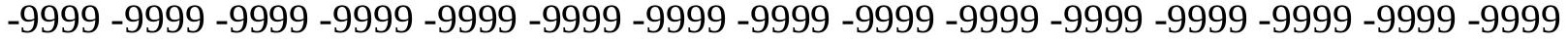
-9999 -9999 -9999 -9999 -9999 -9999 -9999 -9999 -9999 -9999 -9999 -9999 -9999 -9999 -9999 -

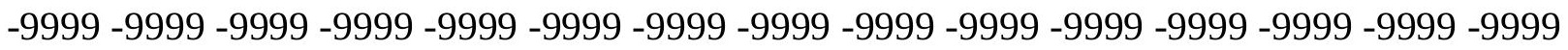

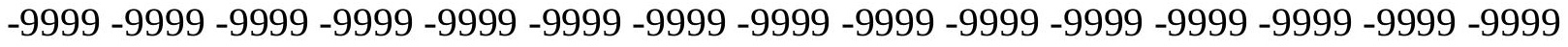

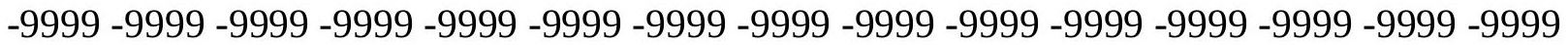

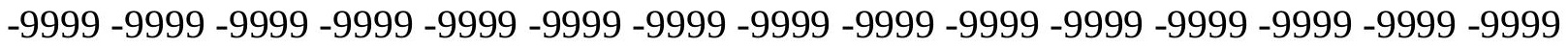

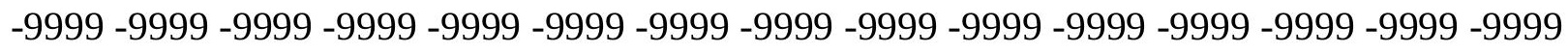

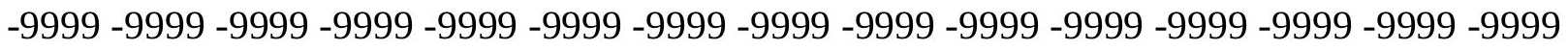

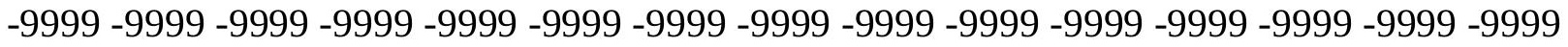
-9999 -9999 -9999 -9999 -9999 -9999 -9999 -9999 -9999 -9999 -9999 -9999 -9999 -9999 -9999 -

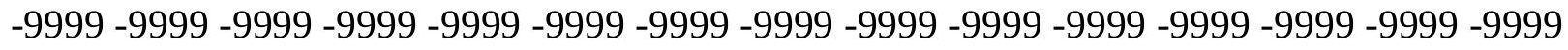

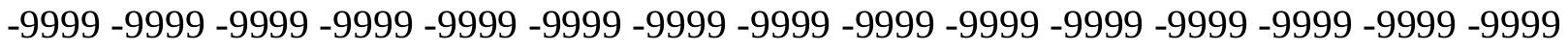
-9999 -9999 -9999 -9999 -9999 -9999 -9999 -9999 -9999 -9999 -9999 -9999 -9999 -9999 -9999 -9999 -9999 -9999 -9999 -9999 -9999 -9999 -9999 -9999-9999 -9999 -9999 -9999 -9999 -9999 -9999 -9999 -9999 -9999 -9999 -9999 -9999 -9999 -9999 -9999 -9999 -9999 -9999 -9999 -9999 -

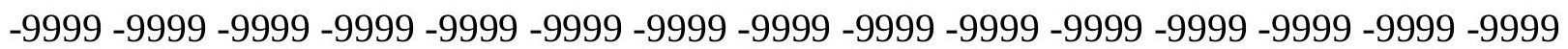


-9999 -9999 -9999 -9999 -9999 -9999 -9999 -9999 -9999 -9999 -9999 -9999 -9999 -9999 -9999 -9999 -9999 -9999 -9999 -9999 -9999 -9999 -9999 -9999 -9999 -9999 -9999 -9999 -9999 -9999 -9999 -9999 -9999 -9999 -9999 -9999 -9999 -9999 -9999 -9999 -9999 -9999 -9999 -9999 -9999 -9999 -9999 -9999 -9999 -9999 -9999 -9999 -9999 -9999 -9999 -9999 -9999 -9999 -9999 -9999 -9999 -9999 -9999 -9999 -9999 -9999 -9999 -9999-9999 -9999 -9999 -9999 -9999 -9999 -9999 -9999 -9999 -9999 -9999 -9999 -9999 -9999 -9999 -9999 -9999 -9999 -9999 -9999 -9999 -9999 -9999 -9999 -9999 -9999 -9999 -9999 -9999 -9999 -9999 -9999 -9999 -9999 -9999 -9999

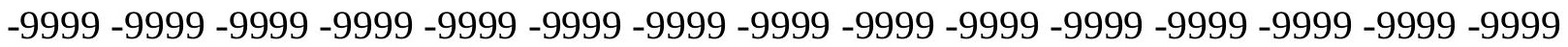

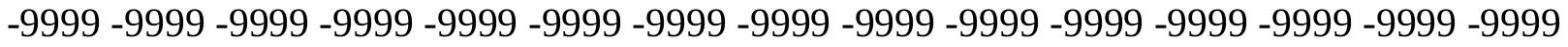
-9999 -9999 -9999 -9999 -9999 -9999 -9999 -9999 -9999 -9999 -9999 -9999 -9999 -9999 -9999 -9999 -9999 -9999 -9999 -9999 -9999 -9999 -9999 -9999 -9999 -9999 -9999 -9999 -9999 -9999 -9999 -9999 -9999 -9999 -9999 -9999 -9999 -9999 -9999 -9999 -9999 -9999 -9999 -9999 -9999 -9999 -9999 -9999 -9999 -9999 -9999 -9999 -9999 -9999 -9999 -9999 -9999 -9999 -9999 -9999 -

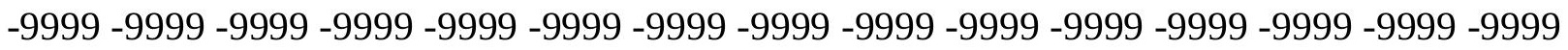
-9999 -9999 -9999 -9999 -9999 -9999 -9999 -9999 -9999 -9999 -9999 -9999 -9999 -9999 -9999 -

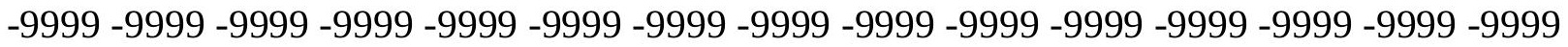
-9999 -9999 -9999 -9999 -9999 -9999 -9999 -9999 -9999 -9999 -9999 -9999 -9999 -9999 -9999 -9999 -9999 -9999 -9999 -9999 -9999 -9999 -9999 -9999 -9999 -9999 -9999 -9999 -9999 -9999 -9999 -9999 -9999 -9999 -9999 -9999 -9999 -9999 -9999 -9999 -9999 -9999 -9999 -9999 -9999 -

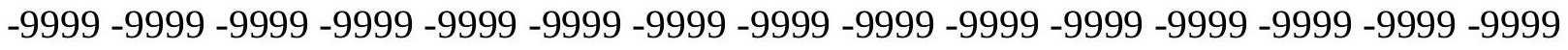

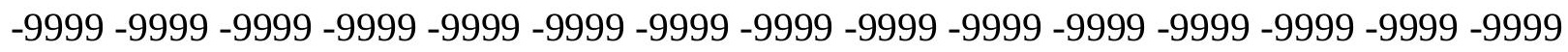
-9999 -9999 -9999 -9999 -9999 -9999 -9999 -9999 -9999 -9999 -9999 -9999 -9999 -9999 -9999 -9999 -9999 -9999 -9999 -9999 -9999 -9999 -9999 -9999 -9999 -9999 -9999 -9999 -9999 -9999 -9999 -9999 -9999 -9999 -9999 -9999 -9999 -9999 -9999 -9999 -9999 -9999 -9999 -9999 -9999 -

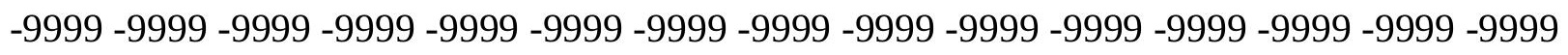
-9999 -9999 -9999 -9999 -9999 -9999 -9999 -9999 -9999 -9999 -9999 -9999 -9999 -9999 -9999 -9999 -9999 -9999 -9999 -9999 -9999 -9999 -9999 -9999 -9999 -9999 -9999 -9999 -9999 -9999 -

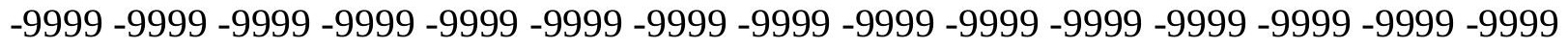
-9999 -9999 -9999 -9999 -9999 -9999 -9999 -9999 -9999 -9999 -9999 -9999 -9999 -9999 -9999 -9999 -9999 -9999 -9999 -9999 -9999 -9999 -9999 -9999 -9999 -9999 -9999 -9999 - -999 -

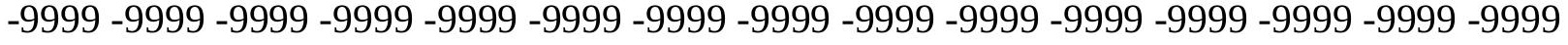
-9999 -9999 -9999 -9999 -9999 -9999 -9999 -9999 -9999 -9999 -9999 -9999 -9999 -9999 -9999 -

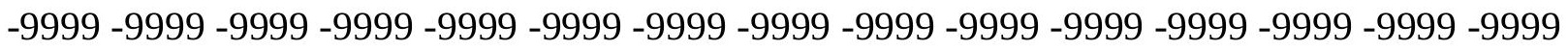

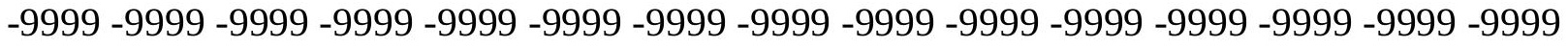

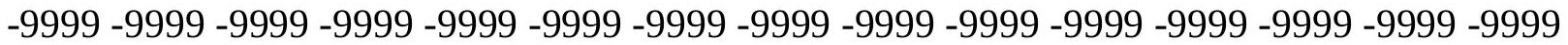

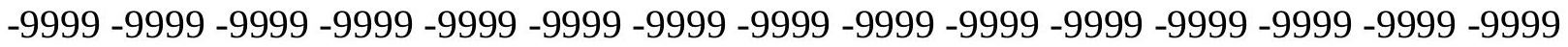

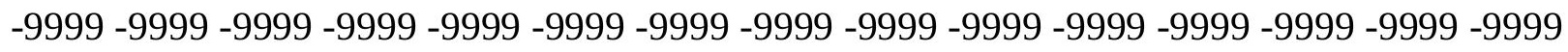

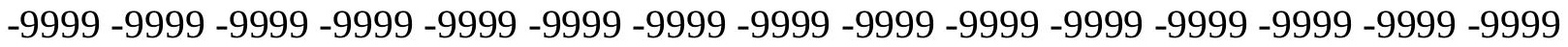

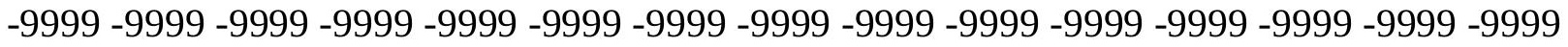
-9999 -9999 -9999 -9999 -9999 -9999 -9999 -9999 -9999 -9999 -9999 -9999 -9999 -9999 -9999 -

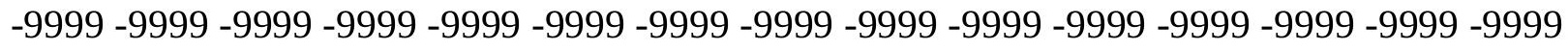

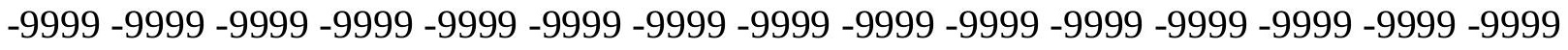
-9999 -9999 -9999 -9999 -9999 -9999 -9999 -9999 -9999 -9999 -9999 -9999 -9999 -9999 -9999 -9999 -9999 -9999 -9999 -9999 -9999 -9999 -9999 -9999-9999 -9999 -9999 -9999 -9999 -9999 -9999 -9999 -9999 -9999 -9999 -9999 -9999 -9999 -9999 -9999 -9999 -9999 -9999 -9999 -9999 -

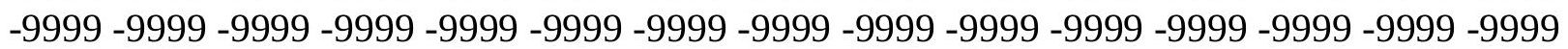


-9999 -9999 -9999 -9999 -9999 -9999 -9999 -9999 -9999 -9999 -9999 -9999 -9999 -9999 -9999 -9999 -9999 -9999 -9999 -9999 -9999 -9999 -9999 -9999 -9999 -9999 -9999 -9999 -9999 -9999 -

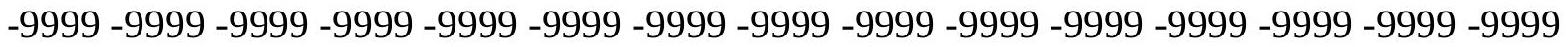
-9999 -9999 -9999 -9999 -9999 -9999 -9999 -9999 -9999 -9999 -9999 -9999 -9999 -9999 -9999 -9999 -9999 -9999 -9999 -9999 -9999 -9999 -9999 -9999-9999 -9999 -9999 -9999 -9999 -9999 -9999 -9999 -9999 -9999 -9999 -9999 -9999 -9999 -9999 -9999 -9999 -9999 -9999 -9999 -9999 -9999 -9999 -9999 -9999 -9999 -9999 -9999 -9999 -9999 -9999 -9999 -9999 -9999 -9999 -9999

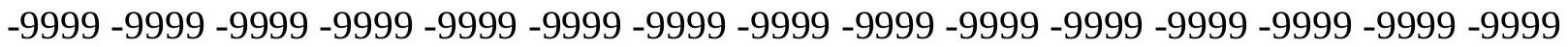
-9999 -9999 -9999 -9999 -9999 -9999 -9999 -9999 -9999 -9999 -9999 -9999 -9999 -9999 -9999 -9999 -9999 -9999 -9999 -9999 -9999 -9999 -9999 -9999 -9999 -9999 -9999 -9999 -9999

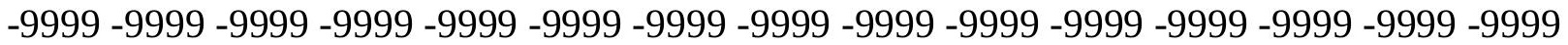
-9999 -9999 -9999 -9999 -9999 -9999 -9999 -9999 -9999 -9999 -9999 -9999 -9999 -9999 -9999 -9999 -9999 -9999 -9999 -9999 -9999 -9999 -9999 -9999 -9999 -9999 -9999 -9999 -9999 -9999 -9999 -9999 -9999 -9999 -9999 -9999 -9999 -9999 -9999 -9999 -9999 -9999 -9999 -9999 - 9999 -9999 -9999 -9999 -9999 -9999 -9999 -9999 -9999 -9999 -9999 -9999 -9999 -9999 -9999 -9999

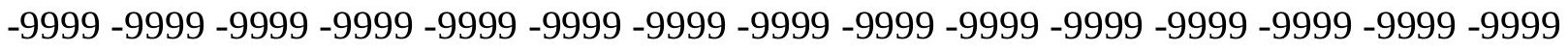
-9999 -9999 -9999 -9999 -9999 -9999 -9999 -9999 -9999 -9999 -9999 -9999 -9999 -9999 -9999 -9999 -9999 -9999 -9999 -9999 -9999 -9999 -9999 -9999 -9999 -9999 -9999 -9999 -9999 -9999 -9999 -9999 -9999 -9999 -9999 -9999 -9999 -9999 -9999 -9999 -9999 -9999 -9999 -9999 -9999 -

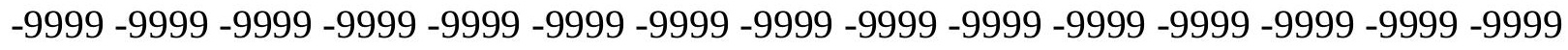

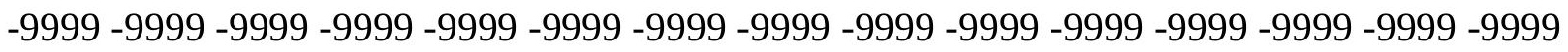
-9999 -9999 -9999 -9999 -9999 -9999 -9999 -9999 -9999 -9999 -9999 -9999 -9999 -9999 -9999 -9999 -9999 -9999 -9999 -9999 -9999 -9999 -9999 -9999 -9999 -9999 -9999 -9999 -9999 -9999 -9999 -9999 -9999 -9999 -9999 -9999 -9999 -9999 -9999 -9999 -9999 -9999 -9999 -9999 -9999 -

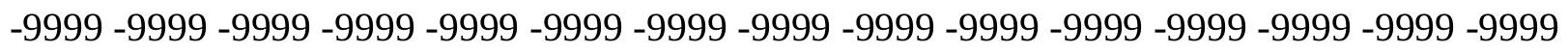
-9999 -9999 -9999 -9999 -9999 -9999 -9999 -9999 -9999 -9999 -9999 -9999 -9999 -9999 -9999 -9999 -9999 -9999 -9999 -9999 -9999 -9999 -9999 -9999 -9999 -9999 -9999 -9999 -9999 -9999 -

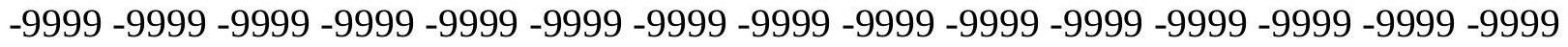
-9999 -9999 -9999 -9999 -9999 -9999 -9999 -9999 -9999 -9999 -9999 -9999 -9999 -9999 -9999 -9999 -9999 -9999 -9999 -9999 -9999 -9999 -9999 -9999 -9999 -9999 -9999 -9999 -9999 -999 -9999 -9999 -9999 -9999 -9999 -9999 -9999 -9999 -9999 -9999 -9999 -9999 -9999 -9999 -9999 -9999 -9999 -9999 -9999 -9999 -9999 -9999 -9999 -9999 -9999 -9999 -9999 -9999 -9999 -9999 -

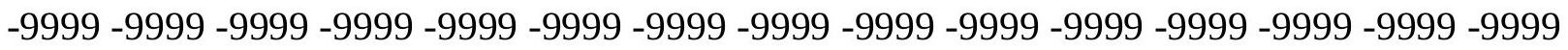

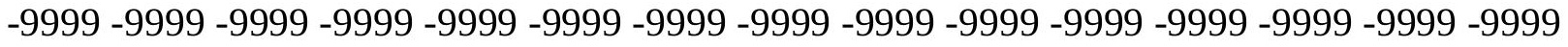
-9999 -9999 -9999 -9999 -9999 -9999 -9999 -9999 -9999 -9999 -9999 -9999 -9999 -9999 -

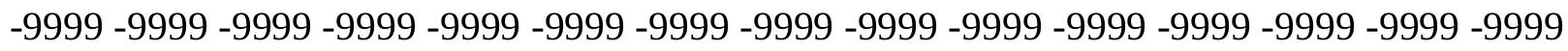

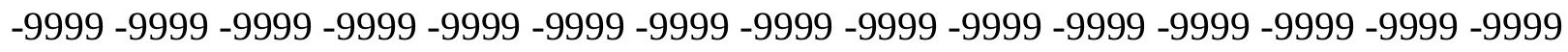

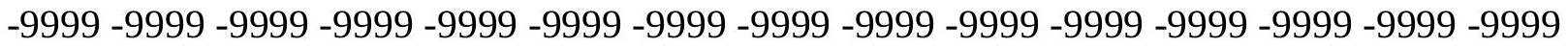
-9999 -9999 -9999 -9999 -9999 -9999 -9999 -9999 -9999 -9999 -9999 -9999 -9999 - 9999 - -999 -9999 -9999 -9999 -9999 -9999 -9999 -9999 -9999 -9999 -9999 -9999 -9999 -9999 -9999 -9999 -

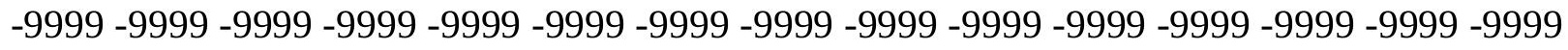

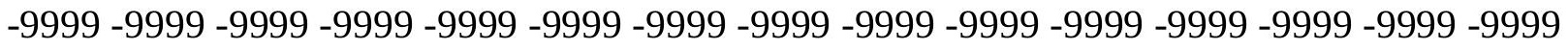
-9999 -9999 -9999 -9999 -9999 -9999 -9999 -9999 -9999 -9999 -9999 -9999 -9999 -9999 -9999 -9999 -9999 -9999 -9999 -9999 -9999 -9999 -9999 -9999-9999 -9999 -9999 -9999 -9999 -9999 -9999 -9999 -9999 -9999 -9999 -9999 -9999 -9999 -9999 -9999 -9999 -9999 -9999 -9999 -9999 -

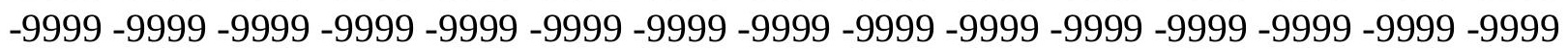


-9999 -9999 -9999 -9999 -9999 -9999 -9999 -9999 -9999 -9999 -9999 -9999 -9999 -9999 -9999 -9999 -9999 -9999 -9999 -9999 -9999 -9999 -9999 -9999 -9999 -9999 -9999 -9999 -9999 -9999 -

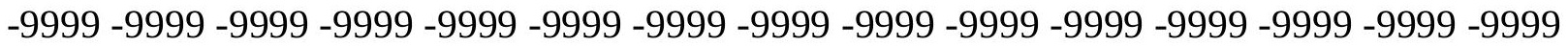
-9999 -9999 -9999 -9999 -9999 -9999 -9999 -9999 -9999 -9999 -9999 -9999 -9999 -9999 -9999 -9999 -9999 -9999 -9999 -9999 -9999 -9999 -9999 -9999-9999 -9999 -9999 -9999 -9999 -9999 -9999 -9999 -9999 -9999 -9999 -9999 -9999 -9999 -9999 -9999 -9999 -9999 -9999 -9999 -9999 -9999 -9999 -9999 -9999 -9999 -9999 -9999 -9999 -9999 -9999 -9999 -9999 -9999 -9999 -9999

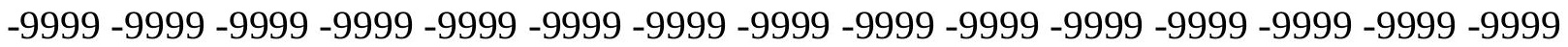

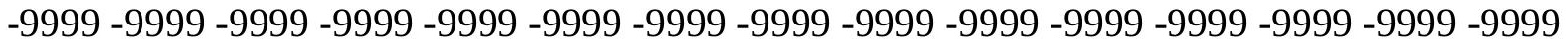
-9999 -9999 -9999 -9999 -9999 -9999 -9999 -9999 -9999 -9999 -9999 -9999 -9999 -9999 -9999 -9999 -9999 -9999 -9999 -9999 -9999 -9999 -9999 -9999 -9999 -9999 -9999 -9999 -9999 -9999 -9999 -9999 -9999 -9999 -9999 -9999 -9999 -9999 -9999 -9999 -9999 -9999 -9999 -9999 -9999 -9999 -9999 -9999 -9999 -9999 -9999 -9999 -9999 -9999 -9999 -9999 -9999 -9999 -9999 -9999 -9999 -9999 -9999 -9999 -9999 -9999 -9999 -9999 -9999 -9999 -9999 -9999 -9999 -9999 -9999 -9999 -9999 -9999 -9999 -9999 -9999 -9999 -9999 -9999 -9999 -9999 -9999 -9999 -9999 -9999 -9999 -9999 -9999 -9999 -9999 -9999 -9999 -9999 -9999 -9999 -9999 -9999 - 9999 - -999 -

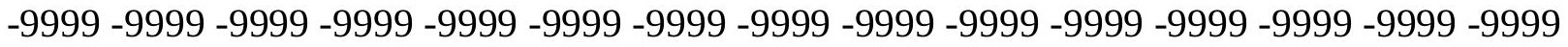
-9999 -9999 -9999 -9999 -9999 -9999 -9999 -9999 -9999 -9999 -9999 -9999 -9999 -9999 -9999 -9999 -9999 -9999 -9999 -9999 -9999 -9999 -9999 -9999 -9999 -9999 -9999 -9999 -9999 -9999 -

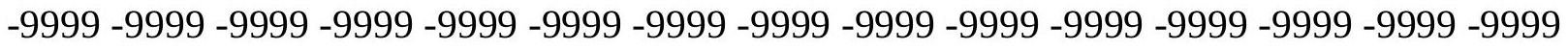
-9999 -9999 -9999 -9999 -9999 -9999 -9999 -9999 -9999 -9999 -9999 -9999 -9999 -9999 -9999

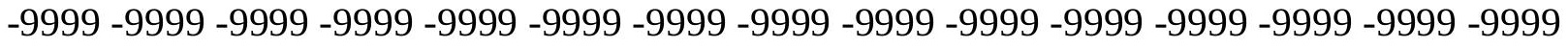
-9999 -9999 -9999 -9999 -9999 -9999 -9999 -9999 -9999 -9999 -9999 -9999 -9999 -9999 -9999 -9999 -9999 -9999 -9999 -9999 -9999 -9999 -9999 -9999 -9999 -9999 -9999 -9999 -9999 -9999 -

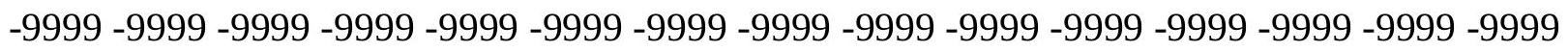
-9999 -9999 -9999 -9999 -9999 -9999 -9999 -9999 -9999 -9999 -9999 -9999 -9999 -9999 -9999 -9999 -9999 -9999 -9999 -9999 -9999 -9999 -9999 -9999 -9999 -9999 -9999 -9999 -9999 -9999 -

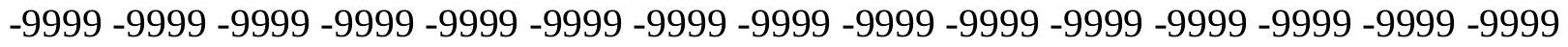
-9999 -9999 -9999 -9999 -9999 -9999 -9999 -9999 -9999 -9999 -9999 -9999 -9999 -9999 -9999 -9999 -9999 -9999 -9999 -9999 -9999 -9999 -9999 -9999 -9999 -9999 -9999 -9999 -9999 -999 -

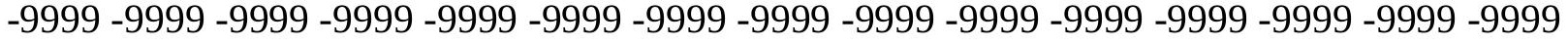
-9999 -9999 -9999 -9999 -9999 -9999 -9999 -9999 -9999 -9999 -9999 -9999 -9999 -9999 -9999 -

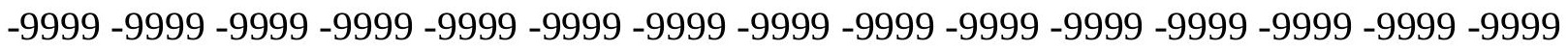

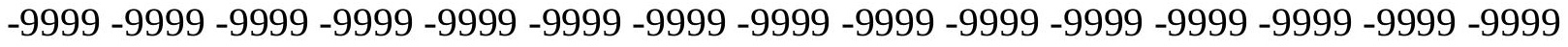

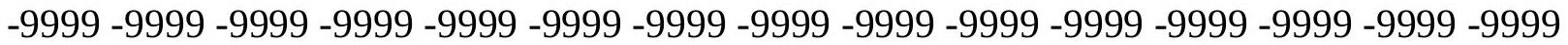
-9999 -9999 -9999 -9999 -9999 -9999 -9999 -9999 -9999 -9999 -9999 -9999 -9999 -9999 -9999 -

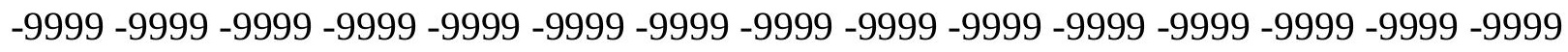

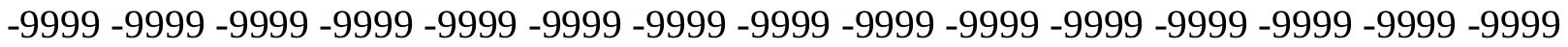
-9999 -9999 -9999 -9999 -9999 -9999 -9999 -9999 -9999 -9999 -9999 -9999 -9999 - 9999 - -999 -9999 -9999 -9999 -9999 -9999 -9999 -9999 -9999 -9999 -9999 -9999 -9999 -9999 -9999 -9999 -

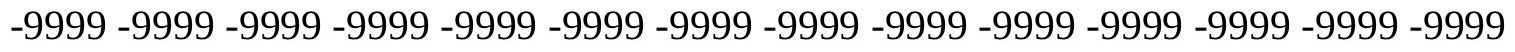

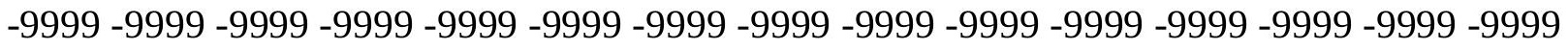
-9999 -9999 -9999 -9999 -9999 -9999 -9999 -9999 -9999 -9999 -9999 -9999 -9999 -9999 -9999 -9999 -9999 -9999 -9999 -9999 -9999 -9999 -9999 -9999-9999 -9999 -9999 -9999 -9999 -9999 -9999 -9999 -9999 -9999 -9999 -9999 -9999 -9999 -9999 -9999 -9999 -9999 -9999 -9999 -9999 -

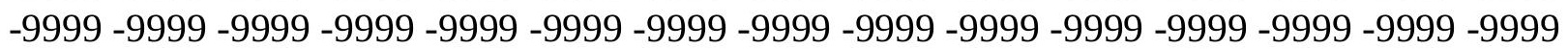


-9999 -9999 -9999 -9999 -9999 -9999 -9999 -9999 -9999 -9999 -9999 -9999 -9999 -9999 -9999 -9999 -9999 -9999 -9999 -9999 -9999 -9999 -9999 -9999 -9999 -9999 -9999 -9999 -9999 -9999 -9999 -9999 -9999 -9999 -9999 -9999 -9999 -9999 -9999 -9999 -9999 -9999 -9999 -9999 - 9999 -9999 -9999 -9999 -9999 -9999 -9999 -9999 -9999 -9999 -9999 -9999 -9999 -9999 -9999 -9999 -9999 -9999 -9999 -9999 -9999 -9999 -9999 -9999 -9999-9999 -9999 -9999 -9999 -9999 -9999 -9999 -9999 -9999 -9999 -9999 -9999 -9999 -9999 -9999 -9999 -9999 -9999 -9999 -9999 -9999 -9999 -9999 -9999 -9999 -9999 -9999 -9999 -9999 -9999 -9999 -9999 -9999 -9999 -9999 -9999

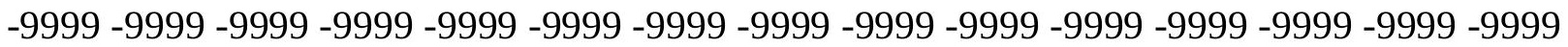
-9999 -9999 -9999 -9999 -9999 -9999 -9999 -9999 -9999 -9999 -9999 -9999 -9999 -9999 -9999 -9999 -9999 -9999 -9999 -9999 -9999 -9999 -9999 -9999 -9999 -9999 -9999 -9999 -9999 -9999

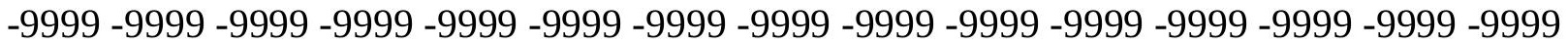
-9999 -9999 -9999 -9999 -9999 -9999 -9999 -9999 -9999 -9999 -9999 -9999 -9999 -9999 -9999 -9999 -9999 -9999 -9999 -9999 -9999 -9999 -9999 -9999 -9999 -9999 -9999 -9999 -9999 -9999 -

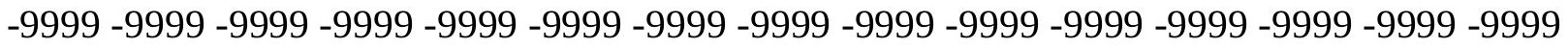
-9999 -9999 -9999 -9999 -9999 -9999 -9999 -9999 -9999 -9999 -9999 -9999 -9999 -9999 -9999

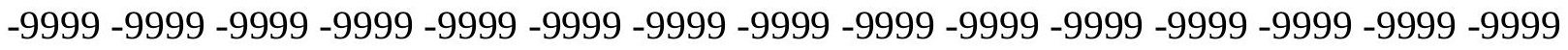
-9999 -9999 -9999 -9999 -9999 -9999 -9999 -9999 -9999 -9999 -9999 -9999 -9999 -9999 -9999 -9999 -9999 -9999 -9999 -9999 -9999 -9999 -9999 -9999 -9999 -9999 -9999 -9999 -9999 - 9999 -9999 -9999 -9999 -9999 -9999 -9999 -9999 -9999 -9999 -9999 -9999 -9999 -9999 -9999 -9999 -9999 -9999 -9999 -9999 -9999 -9999 -9999 -9999 -9999 -9999 -9999 -9999 -9999 -9999 -9999 -9999 -9999 -9999 -9999 -9999 -9999 -9999 -9999 -9999 -9999 -9999 -9999 -9999 -9999 -9999 -9999 -9999 -9999 -9999 -9999 -9999 -9999 -9999 -9999 -9999 -9999 -9999 -9999 -9999 -9999 -9999 -9999 -9999 -9999 -9999 -9999 -9999 -9999 -9999 -9999 -9999 -9999 -9999 -9999 -9999 -9999 -9999 -9999 -9999 -9999 -9999 -9999 -9999 -9999 -9999 -9999 -9999 -9999 -9999 -9999 -9999 -9999 -9999 -9999 -9999 -9999 -9999 -9999 -9999 -9999 -9999 -9999 -9999 -9999 -9999 -9999 -9999 -9999 -9999 -9999 -9999 -9999 -9999 -9999 -9999 -9999 -9999 -9999 -9999 -9999 -9999 -9999 -9999 -9999 -9999 -9999 -9999 -9999 -9999 -9999 -9999 -9999 -9999 -9999 -9999 -9999 -9999 -9999 -9999 -9999 -9999 -9999 -9999 -9999 -9999 -9999 -9999 -9999 -9999 -9999 -9999 -9999 -9999 -9999 -9999 -9999 -9999 -9999 -9999 -9999 -9999 -9999 -9999 -9999 -9999 -9999 -9999 -9999 -9999 -9999 -9999 -9999 -9999 -9999 -9999 -9999 -9999 -9999 -999 -9999 -9999 -9999 -9999 -9999 -9999 -9999 -9999 -9999 -9999 -9999 -9999 -9999 -9999 -9999 -9999 -9999 -9999 -9999 -9999 -9999 -9999 -9999 -9999 -9999 -9999 -9999 -9999 -9999 -9999 -

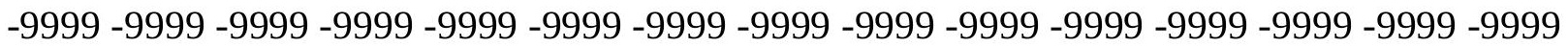

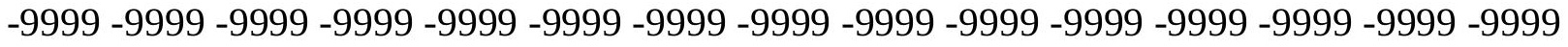

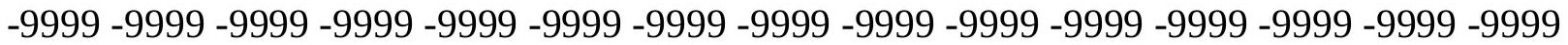
-9999 -9999 -9999 -9999 -9999 -9999 -9999 -9999 -9999 -9999 -9999 -9999 -9999 -9999 -9999

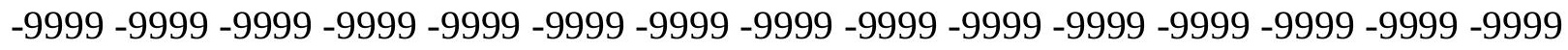

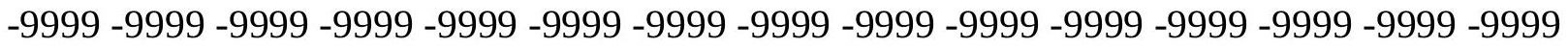

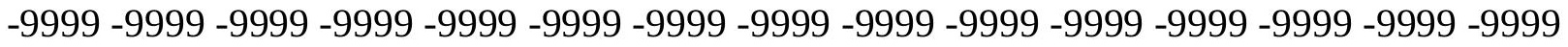
-9999 -9999 -9999 -9999 -9999 -9999 -9999 -9999 -9999 -9999 -9999 -9999 -9999 -9999 -9999 -

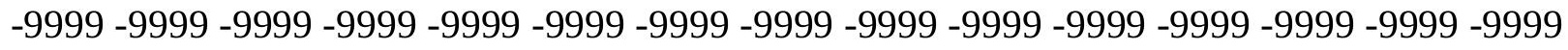

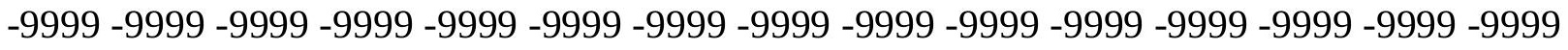
-9999 -9999 -9999 -9999 -9999 -9999 -9999 -9999 -9999 -9999 -9999 -9999 -9999 -9999 -9999 -9999 -9999 -9999 -9999 -9999 -9999 -9999 -9999 -9999-9999 -9999 -9999 -9999 -9999 -9999 -9999 -9999 -9999 -9999 -9999 -9999 -9999 -9999 -9999 -9999 -9999 -9999 -9999 -9999 -9999 -

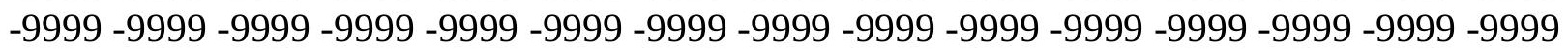


-9999 -9999 -9999 -9999 -9999 -9999 -9999 -9999 -9999 -9999 -9999 -9999 -9999 -9999 -9999 -9999 -9999 -9999 -9999 -9999 -9999 -9999 -9999 -9999 -9999 -9999 -9999 -9999 -9999 -9999 -9999 -9999 -9999 -9999 -9999 -9999 -9999 -9999 -9999 -9999 -9999 -9999 -9999 -9999 -9999 -9999 -9999 -9999 -9999 -9999 -9999 -9999 -9999 -9999 -9999 -9999 -9999 -9999 -9999 -9999 -9999 -9999 -9999 -9999 -9999 -9999 -9999 -9999 -9999 -9999 -9999 -9999 -9999 -9999 -9999 -9999 -9999 -9999 -9999 -9999 -9999 -9999 -9999 -9999 -9999 -9999 -9999 -9999 -9999 -9999 -9999 -9999 -9999 -9999 -9999 -9999 -9999 -9999 -9999 -9999 -9999 -9999 -9999 -9999 -

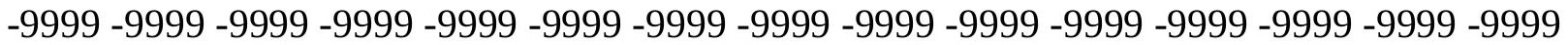
-9999 -9999 -9999 -9999 -9999 -9999 -9999 -9999 -9999 -9999 -9999 -9999 -9999 -9999 -9999 -9999 -9999 -9999 -9999 -9999 -9999 -9999 -9999 -9999 -9999 -9999 -9999 -9999 -9999 -9999 -

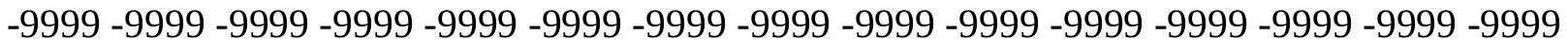
-9999 -9999 -9999 -9999 -9999 -9999 -9999 -9999 -9999 -9999 -9999 -9999 -9999 -9999 -9999 -9999 -9999 -9999 -9999 -9999 -9999 -9999 -9999 -9999 -9999 -9999 -9999 -9999 -9999 -9999 -9999 -9999 -9999 -9999 -9999 -9999 -9999 -9999 -9999 -9999 -9999 -9999 -9999 -9999 -9999 -9999 -9999 -9999 -9999 -9999 -9999 -9999 -9999 -9999 -9999 -9999 -9999 -9999 -9999 -9999 -9999 -9999 -9999 -9999 -9999 -9999 -9999 -9999 -9999 -9999 -9999 -9999 -9999 -9999 -9999 -9999 -9999 -9999 -9999 -9999 -9999 -9999 -9999 -9999 -9999 -9999 -9999 -9999 -9999 -9999 -9999 -9999 -9999 -9999 -9999 -9999 -9999 -9999 -9999 -9999 -9999 -9999 -9999 -9999 -9999 -9999 -9999 -9999 -9999 -9999 -9999 -9999 -9999 -9999 -9999 -9999 -9999 -9999 -9999 -9999 -9999 -9999 -9999 -9999 -9999 -9999 -9999 -9999 -9999 -9999 -9999 -9999 -9999 -9999 -9999

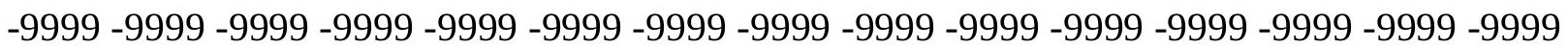
-9999 -9999 -9999 -9999 -9999 -9999 -9999 -9999 -9999 -9999 -9999 -9999 -9999 -9999 -9999 -9999 -9999 -9999 -9999 -9999 -9999 -9999 -9999 -9999 -9999 -9999 -9999 -9999 -9999 -9999 -9999 -9999 -9999 -9999 -9999 -9999 -9999 -9999 -9999 -9999 -9999 -9999 -9999 -9999 -9999

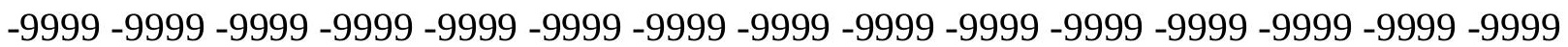
-9999 -9999 -9999 -9999 -9999 -9999 -9999 -9999 -9999 -9999 -9999 -9999 -9999 -9999 -9999 -9999 -9999 -9999 -9999 -9999 -9999 -9999 -9999 -9999 -9999 -9999 -9999 -9999 -9999 -9999 -9999 -9999 -9999 -9999 -9999 -9999 -9999 -9999 -9999 -9999 -9999 -9999 -9999 -9999

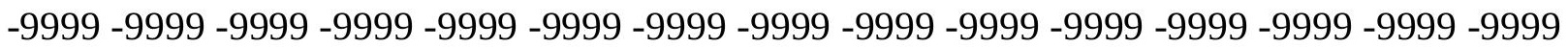
-9999 -9999 -9999 -9999 -9999 -9999 -9999 -9999 -9999 -9999 -9999 -9999 -9999 -9999 -9999 -9999 -9999 -9999 -9999 -9999 -9999 -9999 -9999 -9999 -9999 -9999 -9999 -9999 -9999 -9999 -

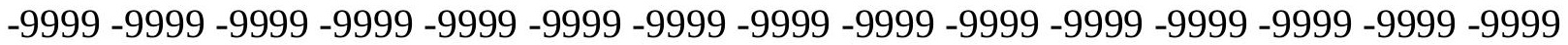
-9999 -9999 -9999 -9999 -9999 -9999 -9999 -9999 -9999 -9999 -9999 -9999 -9999 -9999 -9999 -9999 -9999 -9999 -9999 -9999 -9999 -9999 -9999 -9999 -9999 -9999 -9999 -9999 -9999 -9999 -9999 -9999 -9999 -9999 -9999 -9999 -9999 -9999 -9999 -9999 -9999 -9999 -9999 -9999 -9999 -9999 -9999 -9999 -9999 -9999 -9999 -9999 -9999 -9999 -9999 -9999 -9999 -9999 -9999 -9999 -9999 -9999 -9999 -9999 -9999 -9999 -9999 -9999 -9999 -9999 -9999 -9999 -9999 -9999 -9999

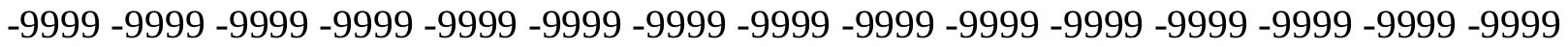
-9999 -9999 -9999 -9999 -9999 -9999 -9999 -9999 -9999 -9999 -9999 -9999 -9999 -9999 -9999 -9999 -9999 -9999 -9999 -9999 -9999 -9999 -9999 -9999 -9999 -9999 -9999 -9999 -9999 -9999 -

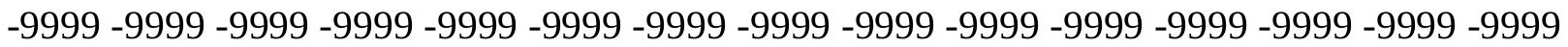
-9999 -9999 -9999 -9999 -9999 -9999 -9999 -9999 -9999 -9999 -9999 -9999 -9999 -9999 -9999 -9999 -9999 -9999 -9999 -9999 -9999 -9999 -9999 -9999 -9999 -9999 -9999 -9999 -9999 -9999 -9999 -9999 -9999 -9999 -9999 -9999 -9999 -9999 -9999 -9999 -9999 -9999 -9999 -9999 -9999 -9999 -9999 -9999 -9999 -9999 -9999 -9999 -9999 -9999 -9999 -9999 -9999 -9999 -9999 -9999

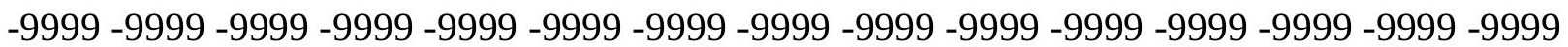


-9999 -9999 -9999 -9999 -9999 -9999 -9999 -9999 -9999 -9999 -9999 -9999 -9999 -9999 -9999 -9999 -9999 -9999 -9999 -9999 -9999 -9999 -9999 -9999 -9999 -9999 -9999 -9999 -9999 -9999 -

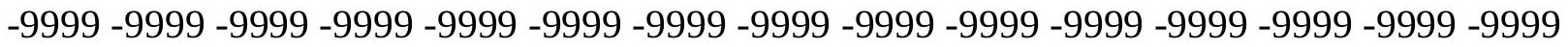
-9999 -9999 -9999 -9999 -9999 -9999 -9999 -9999 -9999 -9999 -9999 -9999 -9999 -9999 -9999 -9999 -9999 -9999 -9999 -9999 -9999 -9999 -9999 -9999-9999 -9999 -9999 -9999 -9999 -9999 -9999 -9999 -9999 -9999 -9999 -9999 -9999 -9999 -9999 -9999 -9999 -9999 -9999 -9999 -9999 -9999 -9999 -9999 -9999 -9999 -9999 -9999 -9999 -9999 -9999 -9999 -9999 -9999 -9999 -

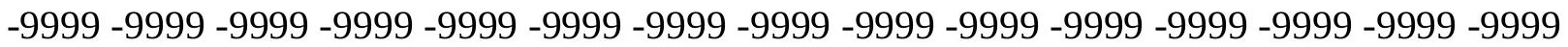

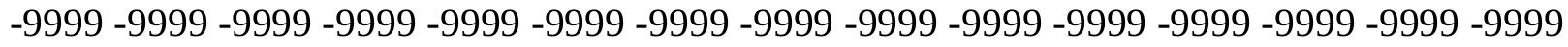
-9999 -9999 -9999 -9999 -9999 -9999 -9999 -9999 -9999 -9999 -9999 -9999 -9999 -9999 -9999 -9999 -9999 -9999 -9999 -9999 -9999 -9999 -9999 -9999 -9999 -9999 -9999 -9999 -9999 -9999 -9999 -9999 -9999 -9999 -9999 -9999 -9999 -9999 -9999 -9999 -9999 -9999 -9999 -9999 -9999 -9999 -9999 -9999 -9999 -9999 -9999 -9999 -9999 -9999 -9999 -9999 -9999 -9999 -9999 -9999 -9999 -9999 -9999 -9999 -9999 -9999 -9999 -9999 -9999 -9999 -9999 -9999 -9999 -9999 -9999 -9999 -9999 -9999 -9999 -9999 -9999 -9999 -9999 -9999 -9999 -9999 -9999 -9999 -9999 -9999 -

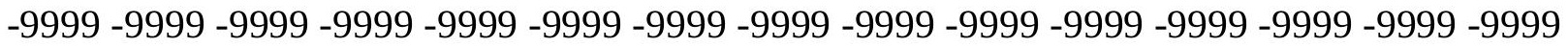
-9999 -9999 -9999 -9999 -9999 -9999 -9999 -9999 -9999 -9999 -9999 -9999 -9999 -9999 -9999 -9999 -9999 -9999 -9999 -9999 -9999 -9999 -9999 -9999 -9999 -9999 -9999 -9999 -9999 -9999 -9999 -9999 -9999 -9999 -9999 -9999 -9999 -9999 -9999 -9999 -9999 -9999 -9999 -9999 -9999 -

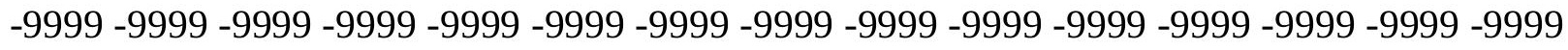

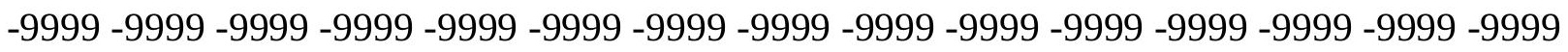

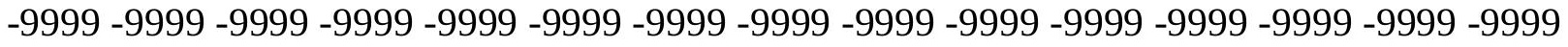
-9999 -9999 -9999 -9999 -9999 -9999 -9999 -9999 -9999 -9999 -9999 -9999 -9999 -9999 -9999 -9999 -9999 -9999 -9999 -9999 -9999 -9999 -9999 -9999 -9999 -9999 -9999 -9999 -9999 -9999 -

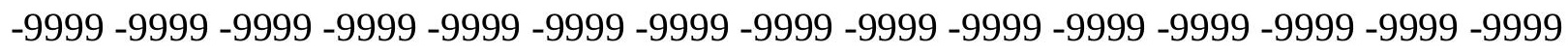
-9999 -9999 -9999 -9999 -9999 -9999 -9999 -9999 -9999 -9999 -9999 -9999 -9999 -9999 -9999 -9999 -9999 -9999 -9999 -9999 -9999 -9999 -9999 -9999 -9999 -9999 -9999 -9999 -9999 -9999 -

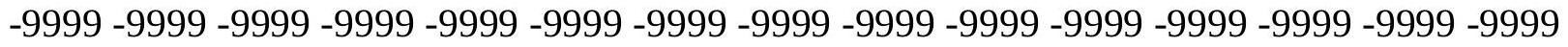
-9999 -9999 -9999 -9999 -9999 -9999 -9999 -9999 -9999 -9999 -9999 -9999 -9999 -9999 -9999 -9999 -9999 -9999 -9999 -9999 -9999 -9999 -9999 -9999 -9999 -9999 -9999 -9999 -9999 -999 -9999 -9999 -9999 -9999 -9999 -9999 -9999 -9999 -9999 -9999 -9999 -9999 -9999 -9999 -9999 -

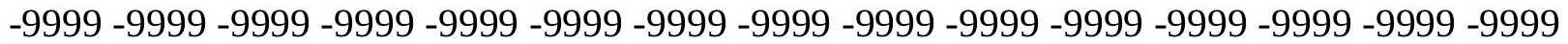

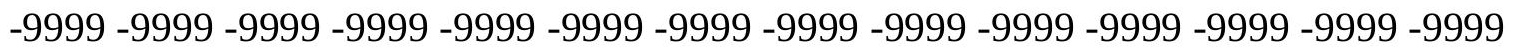

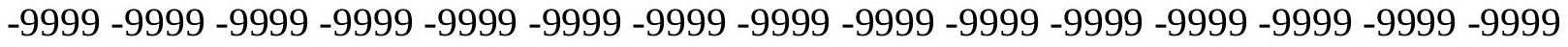

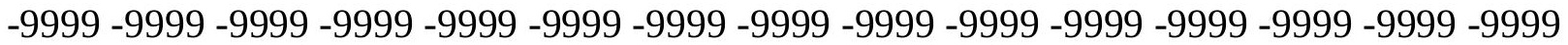

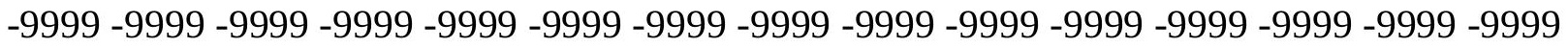

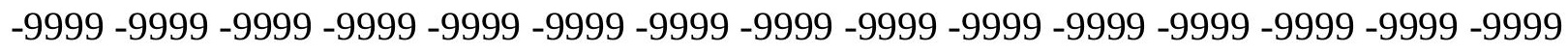

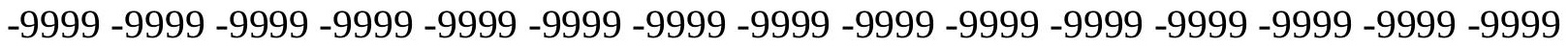

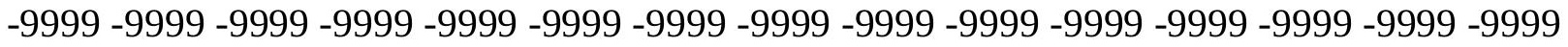
-9999 -9999 -9999 -9999 -9999 -9999 -9999 -9999 -9999 -9999 -9999 -9999 -9999 -9999 -9999 -

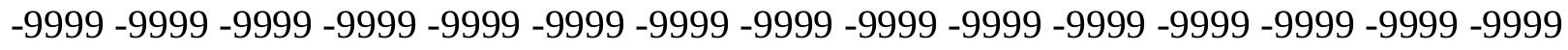

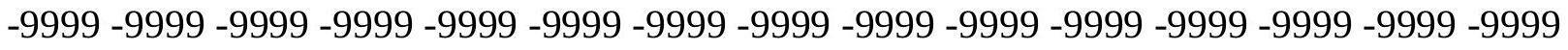
-9999 -9999 -9999 -9999 -9999 -9999 -9999 -9999 -9999 -9999 -9999 -9999 -9999 -9999 -9999 -9999 -9999 -9999 -9999 -9999 -9999 -9999 -9999 -9999-9999 -9999 -9999 -9999 -9999 -9999 -9999 -9999 -9999 -9999 -9999 -9999 -9999 -9999 -9999 -9999 -9999 -9999 -9999 -9999 -9999 -

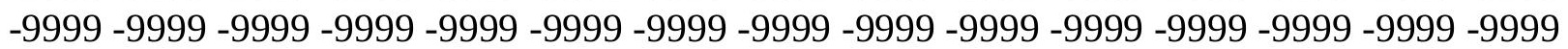


-9999 -9999 -9999 -9999 -9999 -9999 -9999 -9999 -9999 -9999 -9999 -9999 -9999 -9999 -9999 -9999 -9999 -9999 -9999 -9999 -9999 -9999 -9999 -9999 -9999 -9999 -9999 -9999 -9999 -9999 -

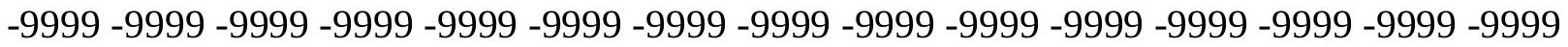
-9999 -9999 -9999 -9999 -9999 -9999 -9999 -9999 -9999 -9999 -9999 -9999 -9999 -9999 -9999 -9999 -9999 -9999 -9999 -9999 -9999 -9999 -9999 -9999-9999 -9999 -9999 -9999 -9999 -9999 -9999 -9999 -9999 -9999 -9999 -9999 -9999 -9999 -9999 -9999 -9999 -9999 -9999 -9999 -9999 -9999 -9999 -9999 -9999 -9999 -9999 -9999 -9999 -9999 -9999 -9999 -9999 -9999 -9999 -9999

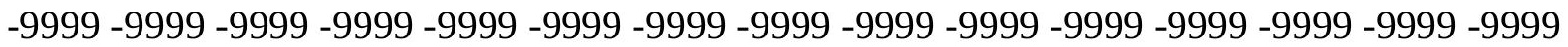

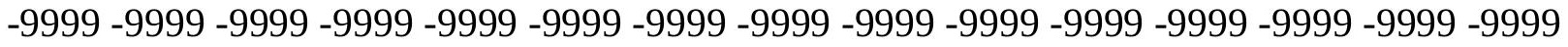
-9999 -9999 -9999 -9999 -9999 -9999 -9999 -9999 -9999 -9999 -9999 -9999 -9999 -9999 -9999 -9999 -9999 -9999 -9999 -9999 -9999 -9999 -9999 -9999 -9999 -9999 -9999 -9999 -9999 -9999 -9999 -9999 -9999 -9999 -9999 -9999 -9999 -9999 -9999 -9999 -9999 -9999 -9999 -9999 -9999 -9999 -9999 -9999 -9999 -9999 -9999 -9999 -9999 -9999 -9999 -9999 -9999 -9999 -9999 -9999 -9999 -9999 -9999 -9999 -9999 -9999 -9999 -9999 -9999 -9999 -9999 -9999 -9999 -9999 -9999 -9999 -9999 -9999 -9999 -9999 -9999 -9999 -9999 -9999 -9999 -9999 -9999 -9999 -9999 -

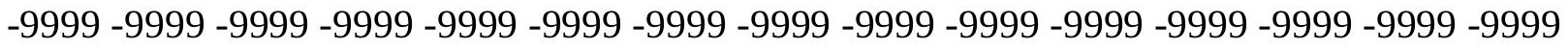
-9999 -9999 -9999 -9999 -9999 -9999 -9999 -9999 -9999 -9999 -9999 -9999 -9999 -9999 -9999 -9999 -9999 -9999 -9999 -9999 -9999 -9999 -9999 -9999 -9999 -9999 -9999 -9999 -9999 -9999 -9999 -9999 -9999 -9999 -9999 -9999 -9999 -9999 -9999 -9999 -9999 -9999 -9999 -9999 -9999 -

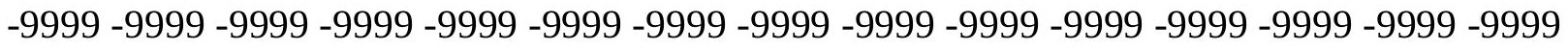
-9999 -9999 -9999 -9999 -9999 -9999 -9999 -9999 -9999 -9999 -9999 -9999 -9999 -9999 -9999

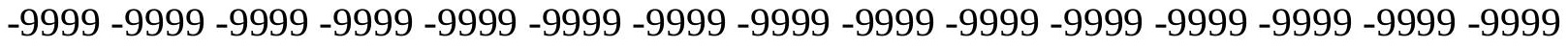
-9999 -9999 -9999 -9999 -9999 -9999 -9999 -9999 -9999 -9999 -9999 -9999 -9999 -9999 -9999 -9999 -9999 -9999 -9999 -9999 -9999 -9999 -9999 -9999 -9999 -9999 -9999 -9999 -9999 -9999 -

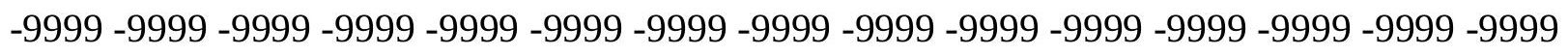
-9999 -9999 -9999 -9999 -9999 -9999 -9999 -9999 -9999 -9999 -9999 -9999 -9999 -9999 -9999 -9999 -9999 -9999 -9999 -9999 -9999 -9999 -9999 -9999 -9999 -9999 -9999 -9999 -9999 -9999 -

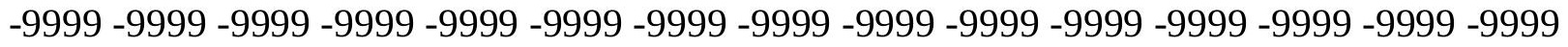
-9999 -9999 -9999 -9999 -9999 -9999 -9999 -9999 -9999 -9999 -9999 -9999 -9999 -9999 -9999 -9999 -9999 -9999 -9999 -9999 -9999 -9999 -9999 -9999 -9999 -9999 -9999 -9999 -9999 -999 -9999 -9999 -9999 -9999 -9999 -9999 -9999 -9999 -9999 -9999 -9999 -9999 -9999 -9999 -9999 -9999 -9999 -9999 -9999 -9999 -9999 -9999 -9999 -9999 -9999 -9999 -9999 -9999 -9999 -9999 -

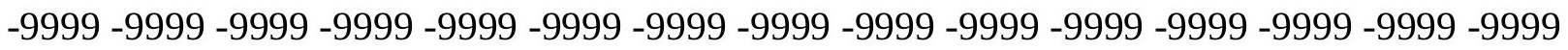

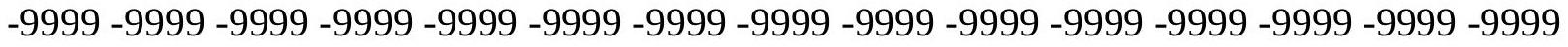

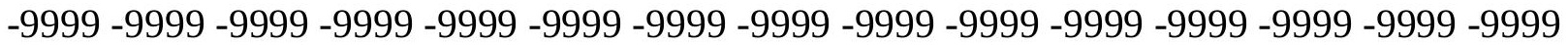
-9999 -9999 -9999 -9999 -9999 -9999 -9999 -9999 -9999 -9999 -9999 -9999 -9999 -9999 -9999 -

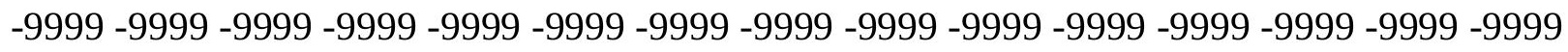

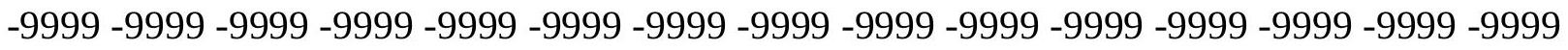
-9999 -9999 -9999 -9999 -9999 -9999 -9999 -9999 -9999 -9999 -9999 -9999 -9999 -9999 - -999 -9999 -9999 -9999 -9999 -9999 -9999 -9999 -9999 -9999 -9999 -9999 -9999 -9999 -9999 -9999 -

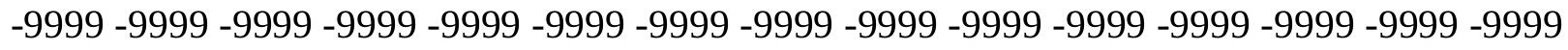

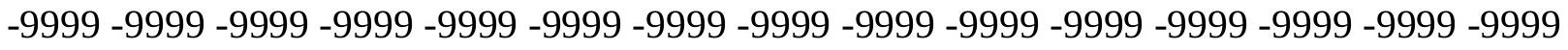
-9999 -9999 -9999 -9999 -9999 -9999 -9999 -9999 -9999 -9999 -9999 -9999 -9999 -9999 -9999 -9999 -9999 -9999 -9999 -9999 -9999 -9999 -9999 -9999-9999 -9999 -9999 -9999 -9999 -9999 -9999 -9999 -9999 -9999 -9999 -9999 -9999 -9999 -9999 -9999 -9999 -9999 -9999 -9999 -9999 -

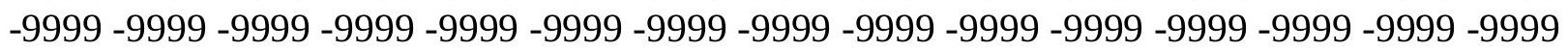


-9999 -9999 -9999 -9999 -9999 -9999 -9999 -9999 -9999 -9999 -9999 -9999 -9999 -9999 -9999 -9999 -9999 -9999 -9999 -9999 -9999 -9999 -9999 -9999 -9999 -9999 -9999 -9999 -9999 -9999 -

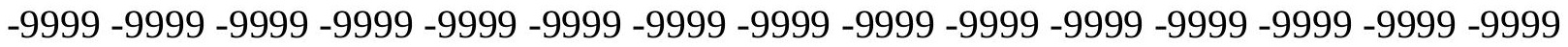
-9999 -9999 -9999 -9999 -9999 -9999 -9999 -9999 -9999 -9999 -9999 -9999 -9999 -9999 -9999 -9999 -9999 -9999 -9999 -9999 -9999 -9999 -9999 -9999-9999 -9999 -9999 -9999 -9999 -9999 -9999 -9999 -9999 -9999 -9999 -9999 -9999 -9999 -9999 -9999 -9999 -9999 -9999 -9999 -9999 -9999 -9999 -9999 -9999 -9999 -9999 -9999 -9999 -9999 -9999 -9999 -9999 -9999 -9999 -9999

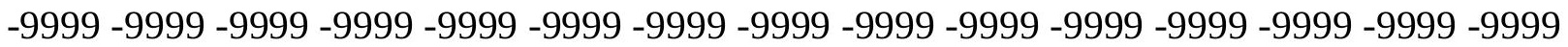

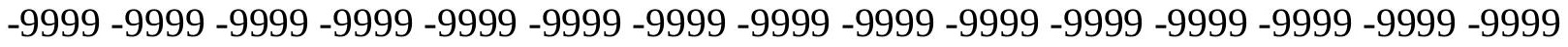
-9999 -9999 -9999 -9999 -9999 -9999 -9999 -9999 -9999 -9999 -9999 -9999 -9999 -9999 -9999 -9999 -9999 -9999 -9999 -9999 -9999 -9999 -9999 -9999 -9999 -9999 -9999 -9999 -9999 -9999 -9999 -9999 -9999 -9999 -9999 -9999 -9999 -9999 -9999 -9999 -9999 -9999 -9999 -9999 -9999 -9999 -9999 -9999 -9999 -9999 -9999 -9999 -9999 -9999 -9999 -9999 -9999 -9999 -9999 -9999 -

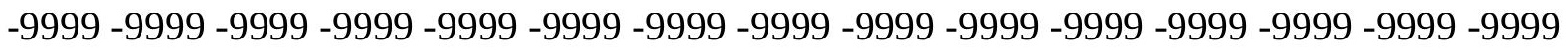
-9999 -9999 -9999 -9999 -9999 -9999 -9999 -9999 -9999 -9999 -9999 -9999 -9999 -9999 -9999 -

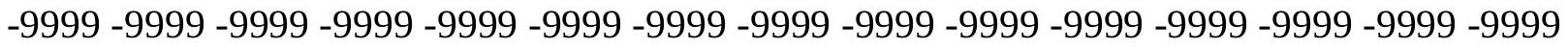
-9999 -9999 -9999 -9999 -9999 -9999 -9999 -9999 -9999 -9999 -9999 -9999 -9999 -9999 -9999 -9999 -9999 -9999 -9999 -9999 -9999 -9999 -9999 -9999 -9999 -9999 -9999 -9999 -9999 -9999 -9999 -9999 -9999 -9999 -9999 -9999 -9999 -9999 -9999 -9999 -9999 -9999 -9999 -9999 - -999 -

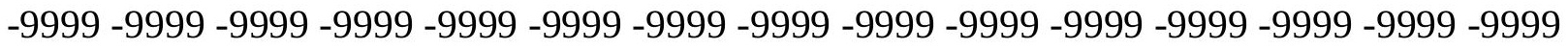

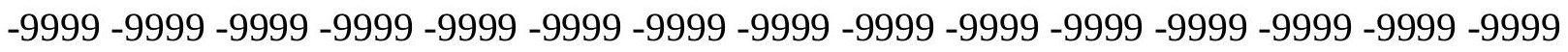
-9999 -9999 -9999 -9999 -9999 -9999 -9999 -9999 -9999 -9999 -9999 -9999 -9999 -9999 -9999 -9999 -9999 -9999 -9999 -9999 -9999 -9999 -9999 -9999 -9999 -9999 -9999 -9999 -9999 -9999 -9999 -9999 -9999 -9999 -9999 -9999 -9999 -9999 -9999 -9999 -9999 -9999 -9999 -9999 -9999 -

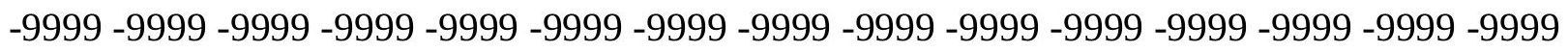
-9999 -9999 -9999 -9999 -9999 -9999 -9999 -9999 -9999 -9999 -9999 -9999 -9999 -9999 -9999 -9999 -9999 -9999 -9999 -9999 -9999 -9999 -9999 -9999 -9999 -9999 -9999 -9999 -9999 -9999 -

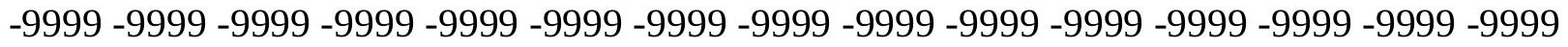
-9999 -9999 -9999 -9999 -9999 -9999 -9999 -9999 -9999 -9999 -9999 -9999 -9999 -9999 -9999 -9999 -9999 -9999 -9999 -9999 -9999 -9999 -9999 -9999 -9999 -9999 -9999 -9999 -9999 -999 -

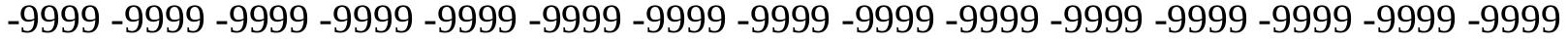
-9999 -9999 -9999 -9999 -9999 -9999 -9999 -9999 -9999 -9999 -9999 -9999 -9999 -9999 -9999 -

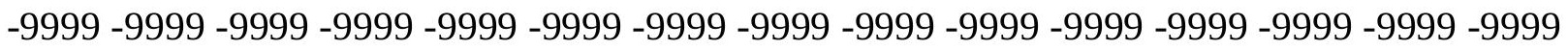

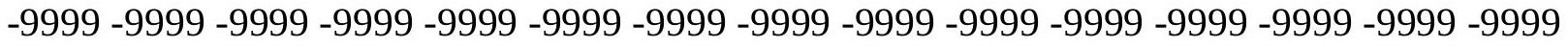

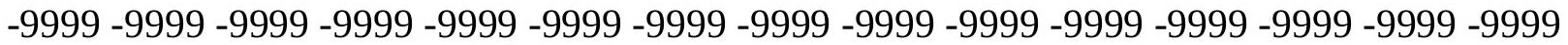

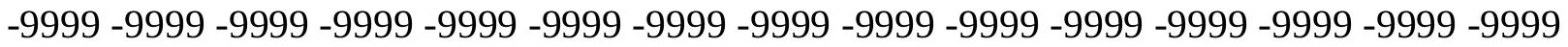

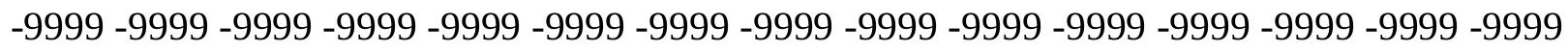

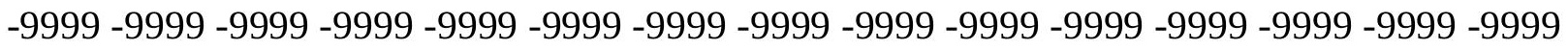

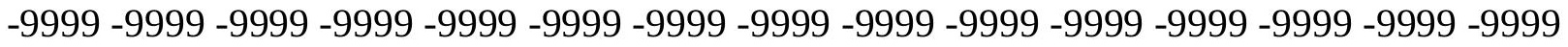
-9999 -9999 -9999 -9999 -9999 -9999 -9999 -9999 -9999 -9999 -9999 -9999 -9999 -9999 -9999 -

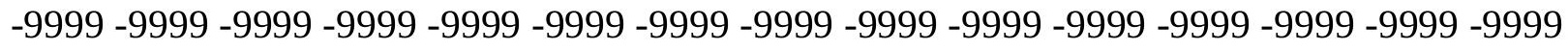

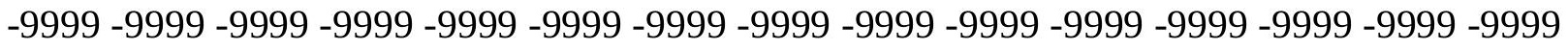
-9999 -9999 -9999 -9999 -9999 -9999 -9999 -9999 -9999 -9999 -9999 -9999 -9999 -9999 -9999 -9999 -9999 -9999 -9999 -9999 -9999 -9999 -9999 -9999 -9999 -9999 -9999 -9999 -9999 -9999 -9999 -9999 -9999 -9999 -9999 -9999 -9999 -9999 -9999 -9999 -9999 -9999 -9999 -9999 -

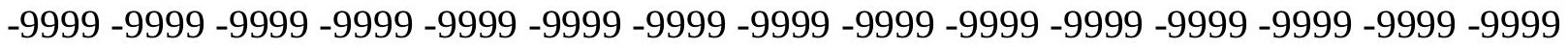


-9999 -9999 -9999 -9999 -9999 -9999 -9999 -9999 -9999 -9999 -9999 -9999 -9999 -9999 -9999 -9999 -9999 -9999 -9999 -9999 -9999 -9999 -9999 -9999 -9999 -9999 -9999 -9999 -9999 -9999 -

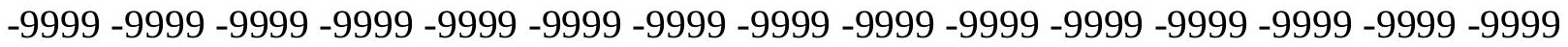
-9999 -9999 -9999 -9999 -9999 -9999 -9999 -9999 -9999 -9999 -9999 -9999 -9999 -9999 -9999 -9999 -9999 -9999 -9999 -9999 -9999 -9999 -9999 -9999-9999 -9999 -9999 -9999 -9999 -9999 -9999 -9999 -9999 -9999 -9999 -9999 -9999 -9999 -9999 -9999 -9999 -9999 -9999 -9999 -9999 -9999 -9999 -9999 -9999 -9999 -9999 -9999 -9999 -9999 -9999 -9999 -9999 -9999 -9999 -9999

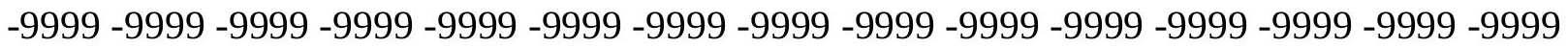

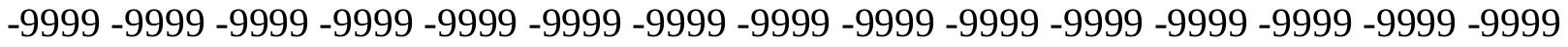
-9999 -9999 -9999 -9999 -9999 -9999 -9999 -9999 -9999 -9999 -9999 -9999 -9999 -9999 -9999 -9999 -9999 -9999 -9999 -9999 -9999 -9999 -9999 -9999 -9999 -9999 -9999 -9999 -9999 -9999 -9999 -9999 -9999 -9999 -9999 -9999 -9999 -9999 -9999 -9999 -9999 -9999 -9999 -9999 -9999 -9999 -9999 -9999 -9999 -9999 -9999 -9999 -9999 -9999 -9999 -9999 -9999 -9999 -9999 -9999 -

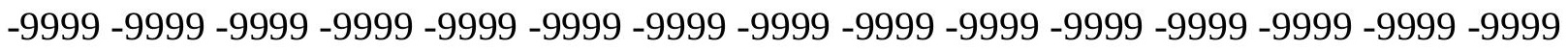
-9999 -9999 -9999 -9999 -9999 -9999 -9999 -9999 -9999 -9999 -9999 -9999 -9999 -9999 -9999 -

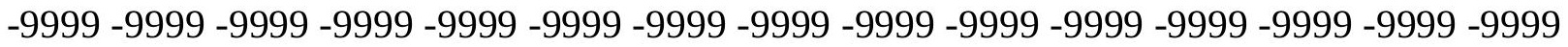
-9999 -9999 -9999 -9999 -9999 -9999 -9999 -9999 -9999 -9999 -9999 -9999 -9999 -9999 -9999 -9999 -9999 -9999 -9999 -9999 -9999 -9999 -9999 -9999 -9999 -9999 -9999 -9999 -9999 - 9999 -9999 -9999 -9999 -9999 -9999 -9999 -9999 -9999 -9999 -9999 -9999 -9999 -9999 -9999 -9999 -

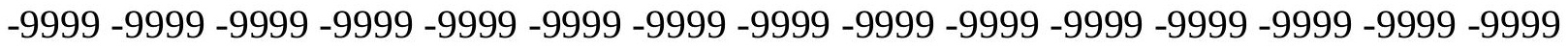

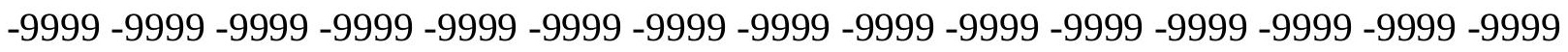
-9999 -9999 -9999 -9999 -9999 -9999 -9999 -9999 -9999 -9999 -9999 -9999 -9999 -9999 - 9999 -9999 -9999 -9999 -9999 -9999 -9999 -9999 -9999 -9999 -9999 -9999 -9999 -9999 -9999 -9999 -9999 -9999 -9999 -9999 -9999 -9999 -9999 -9999 -9999 -9999 -9999 -9999 -9999 -9999 -9999 -9999 -9999 -9999 -9999 -9999 -9999 -9999 -9999 -9999 -9999 -9999 -9999 -9999 -9999 -9999 -9999 -9999 -9999 -9999 -9999 -9999 -9999 -9999 -9999 -9999 -9999 -9999 -9999 -9999 -9999 -9999 -9999 -9999 -9999 -9999 -9999 -9999 -9999 -9999 -9999 -9999 -9999 -9999 -9999 -

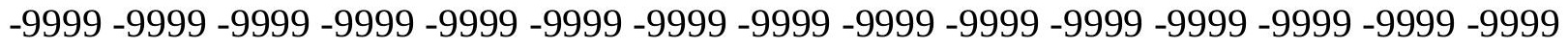
-9999 -9999 -9999 -9999 -9999 -9999 -9999 -9999 -9999 -9999 -9999 -9999 -9999 -9999 -9999 -9999 -9999 -9999 -9999 -9999 -9999 -9999 -9999 -9999 -9999 -9999 -9999 -9999 -9999 -999 -9999 -9999 -9999 -9999 -9999 -9999 -9999 -9999 -9999 -9999 -9999 -9999 -9999 -9999 -9999 -9999 -9999 -9999 -9999 -9999 -9999 -9999 -9999 -9999 -9999 -9999 -9999 -9999 -9999 -9999 -

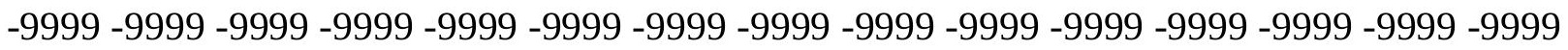

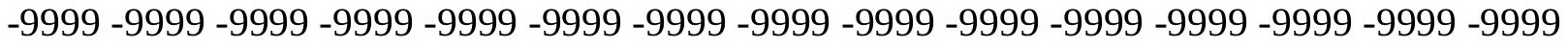

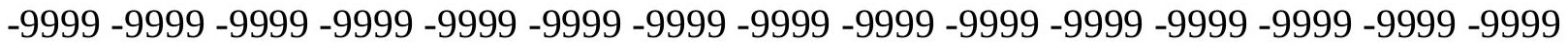

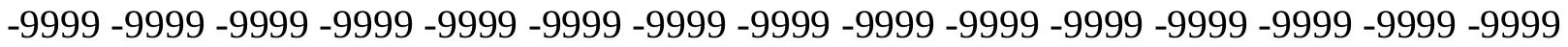

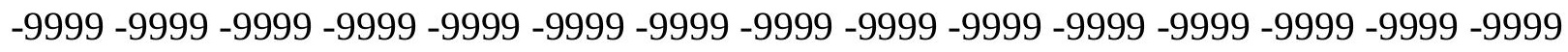

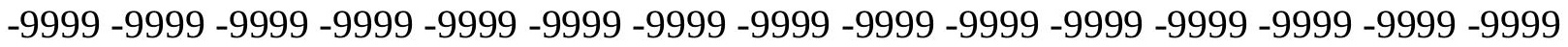

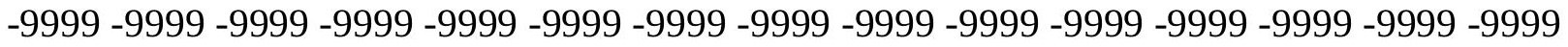
-9999 -9999 -9999 -9999 -9999 -9999 -9999 -9999 -9999 -9999 -9999 -9999 -9999 -9999 -9999 -

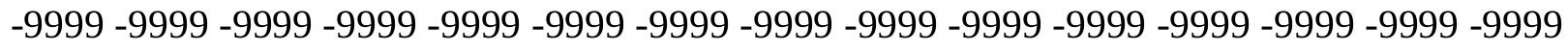

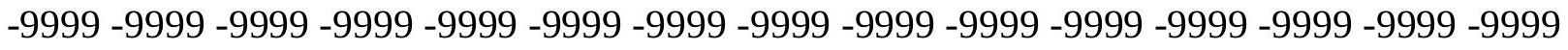
-9999 -9999 -9999 -9999 -9999 -9999 -9999 -9999 -9999 -9999 -9999 -9999 -9999 -9999 -9999 -9999 -9999 -9999 -9999 -9999 -9999 -9999 -9999 -9999-9999 -9999 -9999 -9999 -9999 -9999 -9999 -9999 -9999 -9999 -9999 -9999 -9999 -9999 -9999 -9999 -9999 -9999 -9999 -9999 -9999 -

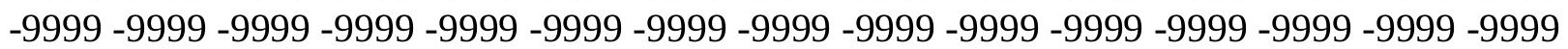


-9999 -9999 -9999 -9999 -9999 -9999 -9999 -9999 -9999 -9999 -9999 -9999 -9999 -9999 -9999 -9999 -9999 -9999 -9999 -9999 -9999 -9999 -9999 -9999 -9999 -9999 -9999 -9999 -9999 -9999 -9999 -9999 -9999 -9999 -9999 -9999 -9999 -9999 -9999 -9999 -9999 -9999 -9999 -9999 - 9999 -9999 -9999 -9999 -9999 -9999 -9999 -9999 -9999 -9999 -9999 -9999 -9999 -9999 -9999 -9999 -9999 -9999 -9999 -9999 -9999 -9999 -9999 -9999 -9999 -9999 -9999 -9999 -9999 -9999 -9999 -9999 -9999 -9999 -9999 -9999 -9999 -9999 -9999 -9999 -9999 -9999 -9999 -9999 -9999 -9999 -9999 -9999 -9999 -9999 -9999 -9999 -9999 -9999 -9999 -9999 -9999 -9999 -9999 -9999

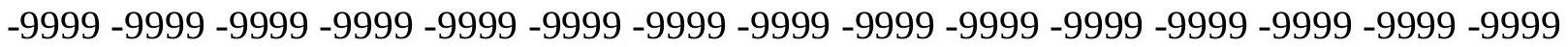

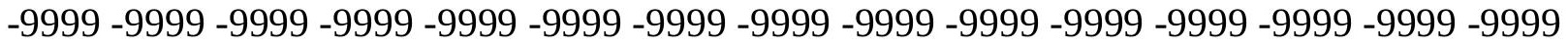
-9999 -9999 -9999 -9999 -9999 -9999 -9999 -9999 -9999 -9999 -9999 -9999 -9999 -9999 -9999 -9999 -9999 -9999 -9999 -9999 -9999 -9999 -9999 -9999 -9999 -9999 -9999 -9999 -9999 -9999 -9999 -9999 -9999 -9999 -9999 -9999 -9999 -9999 -9999 -9999 -9999 -9999 -9999 -9999 -9999 -9999 -9999 -9999 -9999 -9999 -9999 -9999 -9999 -9999 -9999 -9999 -9999 -9999 -9999 -9999 -9999 -9999 -9999 -9999 -9999 -9999 -9999 -9999 -9999 -9999 -9999 -9999 -9999 -9999 -9999 -9999 -9999 -9999 -9999 -9999 -9999 -9999 -9999 -9999 -9999 -9999 -9999 -9999 -9999 -9999 -

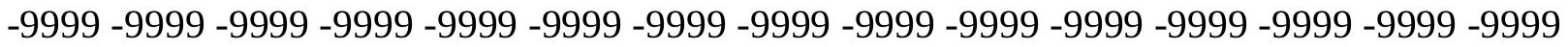
-9999 -9999 -9999 -9999 -9999 -9999 -9999 -9999 -9999 -9999 -9999 -9999 -9999 -9999 -9999 -9999 -9999 -9999 -9999 -9999 -9999 -9999 -9999 -9999 -9999 -9999 -9999 -9999 -9999 - 9999 -9999 -9999 -9999 -9999 -9999 -9999 -9999 -9999 -9999 -9999 -9999 -9999 -9999 -9999 -9999 -

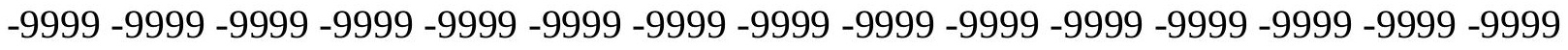

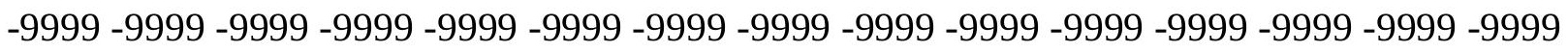

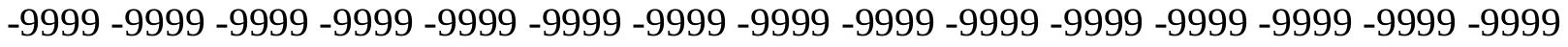
-9999 -9999 -9999 -9999 -9999 -9999 -9999 -9999 -9999 -9999 -9999 -9999 -9999 -9999 -9999 -9999 -9999 -9999 -9999 -9999 -9999 -9999 -9999 -9999 -9999 -9999 -9999 -9999 -9999 -9999 -

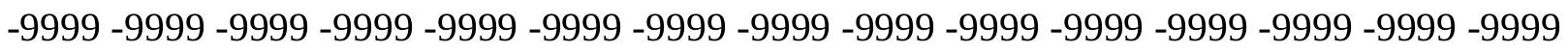
-9999 -9999 -9999 -9999 -9999 -9999 -9999 -9999 -9999 -9999 -9999 -9999 -9999 -9999 -9999 -9999 -9999 -9999 -9999 -9999 -9999 -9999 -9999 -9999 -9999 -9999 -9999 -9999 -9999 -9999 -

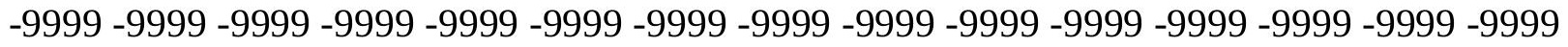
-9999 -9999 -9999 -9999 -9999 -9999 -9999 -9999 -9999 -9999 -9999 -9999 -9999 -9999 -9999 -9999 -9999 -9999 -9999 -9999 -9999 -9999 -9999 -9999 -9999 -9999 -9999 -9999 -9999 -999 -9999 -9999 -9999 -9999 -9999 -9999 -9999 -9999 -9999 -9999 -9999 -9999 -9999 -9999 -9999 -9999 -9999 -9999 -9999 -9999 -9999 -9999 -9999 -9999 -9999 -9999 -9999 -9999 -9999 -

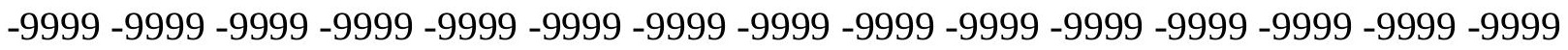

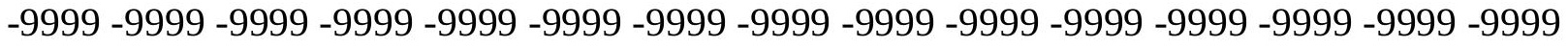

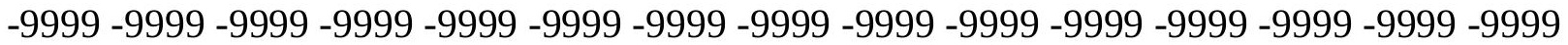

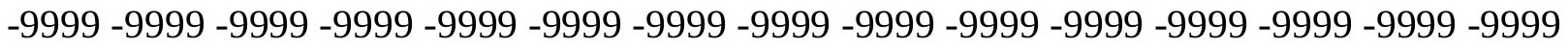

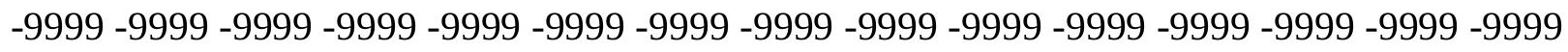

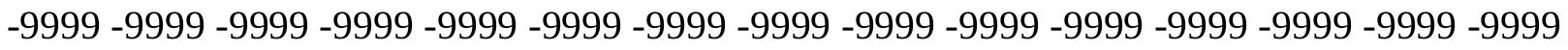

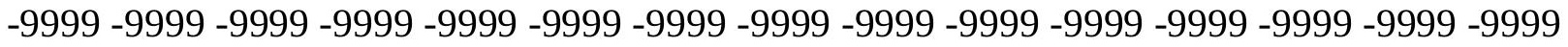
-9999 -9999 -9999 -9999 -9999 -9999 -9999 -9999 -9999 -9999 -9999 -9999 -9999 -9999 -9999 -

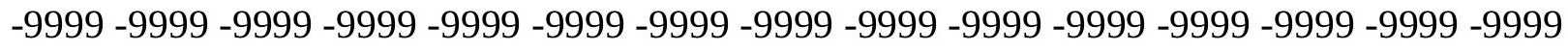

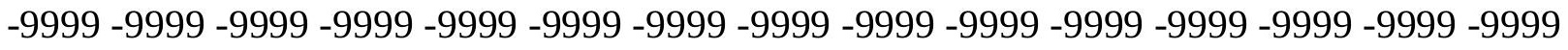
-9999 -9999 -9999 -9999 -9999 -9999 -9999 -9999 -9999 -9999 -9999 -9999 -9999 -9999 -9999 -9999 -9999 -9999 -9999 -9999 -9999 -9999 -9999 -9999-9999 -9999 -9999 -9999 -9999 -9999 -9999 -9999 -9999 -9999 -9999 -9999 -9999 -9999 -9999 -9999 -9999 -9999 -9999 -9999 -9999 -

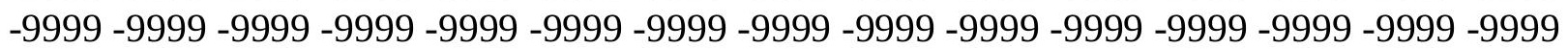


-9999 -9999 -9999 -9999 -9999 -9999 -9999 -9999 -9999 -9999 -9999 -9999 -9999 -9999 -9999 -9999 -9999 -9999 -9999 -9999 -9999 -9999 -9999 -9999 -9999 -9999 -9999 -9999 -9999 -9999 -

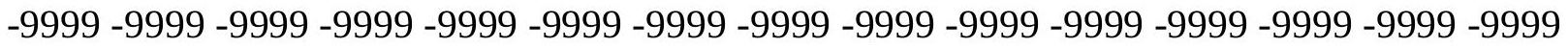
-9999 -9999 -9999 -9999 -9999 -9999 -9999 -9999 -9999 -9999 -9999 -9999 -9999 -9999 -9999 -9999 -9999 -9999 -9999 -9999 -9999 -9999 -9999 -9999-9999 -9999 -9999 -9999 -9999 -9999 -9999 -9999 -9999 -9999 -9999 -9999 -9999 -9999 -9999 -9999 -9999 -9999 -9999 -9999 -9999 -9999 -9999 -9999 -9999 -9999 -9999 -9999 -9999 -9999 -9999 -9999 -9999 -9999 -9999 -9999

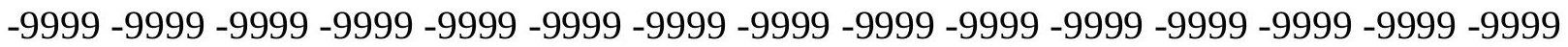

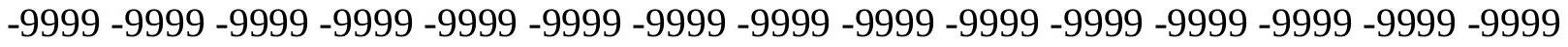

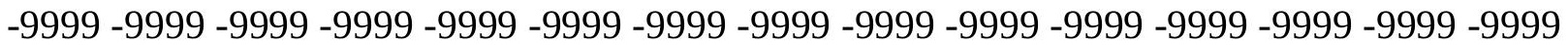
-9999 -9999 -9999 -9999 -9999 -9999 -9999 -9999 -9999 -9999 -9999 -9999 -9999 -9999 -9999 -9999 -9999 -9999 -9999 -9999 -9999 -9999 -9999 -9999 -9999 -9999 -9999 -9999 -9999 -9999 -9999 -9999 -9999 -9999 -9999 -9999 -9999 -9999 -9999 -9999 -9999 -9999 -9999 -9999 -

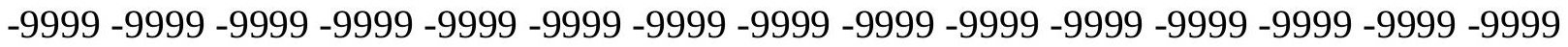
-9999 -9999 -9999 -9999 -9999 -9999 -9999 -9999 -9999 -9999 -9999 -9999 -9999 -9999 -9999 -

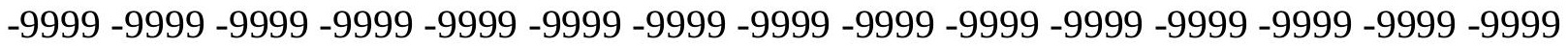
-9999 -9999 -9999 -9999 -9999 -9999 -9999 -9999 -9999 -9999 -9999 -9999 -9999 -9999 -9999 -9999 -9999 -9999 -9999 -9999 -9999 -9999 -9999 -9999 -9999 -9999 -9999 -9999 -9999 -9999 -9999 -9999 -9999 -9999 -9999 -9999 -9999 -9999 -9999 -9999 -9999 -9999 -9999 -9999 -9999 -

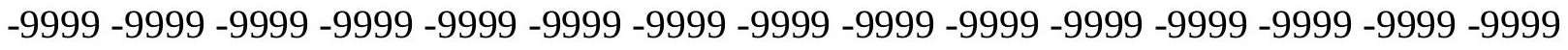

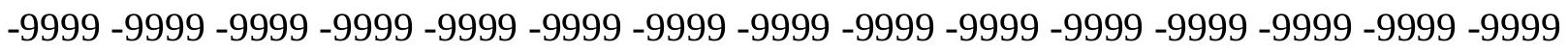
-9999 -9999 -9999 -9999 -9999 -9999 -9999 -9999 -9999 -9999 -9999 -9999 -9999 -9999 -9999 -9999 -9999 -9999 -9999 -9999 -9999 -9999 -9999 -9999 -9999 -9999 -9999 -9999 -9999 -9999 -9999 -9999 -9999 -9999 -9999 -9999 -9999 -9999 -9999 -9999 -9999 -9999 -9999 -9999 -9999 -

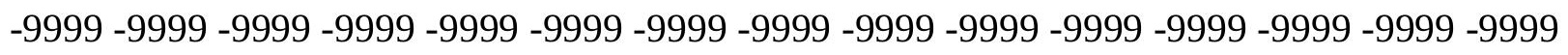
-9999 -9999 -9999 -9999 -9999 -9999 -9999 -9999 -9999 -9999 -9999 -9999 -9999 -9999 -9999 -9999 -9999 -9999 -9999 -9999 -9999 -9999 -9999 -9999 -9999 -9999 -9999 -9999 -9999 -9999 -

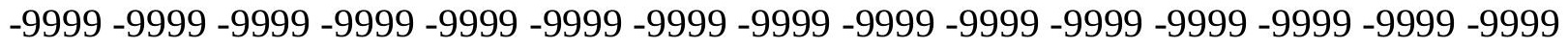
-9999 -9999 -9999 -9999 -9999 -9999 -9999 -9999 -9999 -9999 -9999 -9999 -9999 -9999 -9999 -9999 -9999 -9999 -9999 -9999 -9999 -9999 -9999 -9999 -9999 -9999 -9999 -9999 -9999 -999 -9999 -9999 -9999 -9999 -9999 -9999 -9999 -9999 -9999 -9999 -9999 -9999 -9999 -9999 -9999 -9999 -9999 -9999 -9999 -9999 -9999 -9999 -9999 -9999 -9999 -9999 -9999 -9999 -9999 -9999 -

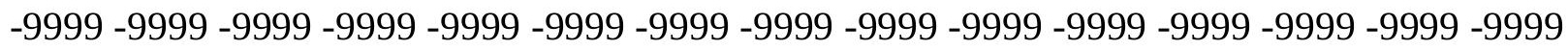

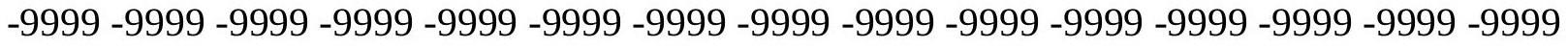

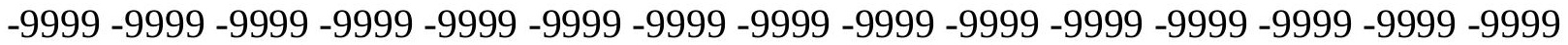
-9999 -9999 -9999 -9999 -9999 -9999 -9999 -9999 -9999 -9999 -9999 -9999 -9999 -9999 -9999 -

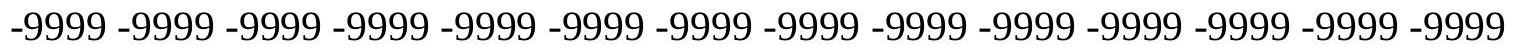

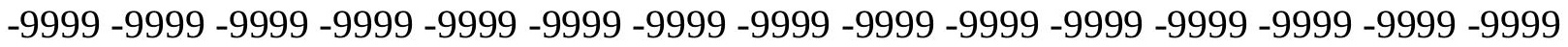
-9999 -9999 -9999 -9999 -9999 -9999 -9999 -9999 -9999 -9999 -9999 -9999 -9999 - 9999 - -999 -9999 -9999 -9999 -9999 -9999 -9999 -9999 -9999 -9999 -9999 -9999 -9999 -9999 -9999 -9999 -

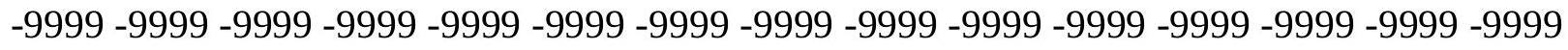

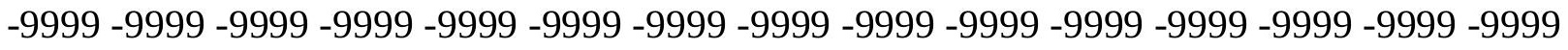
-9999 -9999 -9999 -9999 -9999 -9999 -9999 -9999 -9999 -9999 -9999 -9999 -9999 -9999 -9999 -9999 -9999 -9999 -9999 -9999 -9999 -9999 -9999 -9999-9999 -9999 -9999 -9999 -9999 -9999 -9999 -9999 -9999 -9999 -9999 -9999 -9999 -9999 -9999 -9999 -9999 -9999 -9999 -9999 -9999 -

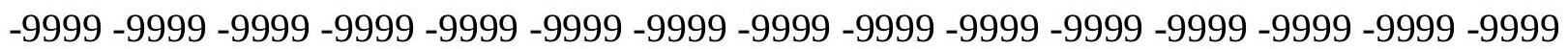


-9999 -9999 -9999 -9999 -9999 -9999 -9999 -9999 -9999 -9999 -9999 -9999 -9999 -9999 -9999 -9999 -9999 -9999 -9999 -9999 -9999 -9999 -9999 -9999 -9999 -9999 -9999 -9999 -9999 -9999 -

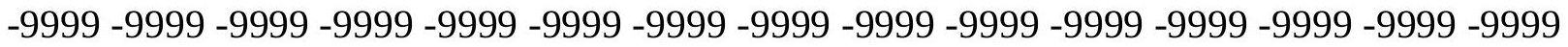
-9999 -9999 -9999 -9999 -9999 -9999 -9999 -9999 -9999 -9999 -9999 -9999 -9999 -9999 -9999 -9999 -9999 -9999 -9999 -9999 -9999 -9999 -9999 -9999-9999 -9999 -9999 -9999 -9999 -9999 -9999 -9999 -9999 -9999 -9999 -9999 -9999 -9999 -9999 -9999 -9999 -9999 -9999 -9999 -9999 -9999 -9999 -9999 -9999 -9999 -9999 -9999 -9999 -9999 -9999 -9999 -9999 -9999 -9999 -9999

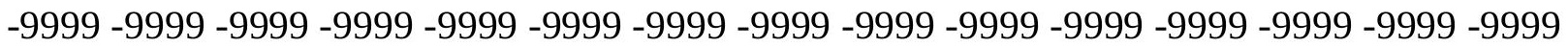

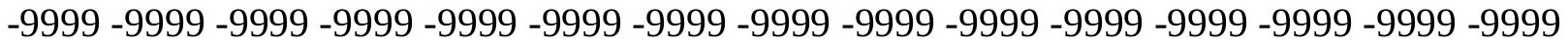
-9999 -9999 -9999 -9999 -9999 -9999 -9999 -9999 -9999 -9999 -9999 -9999 -9999 -9999 -9999 -9999 -9999 -9999 -9999 -9999 -9999 -9999 -9999 -9999 -9999 -9999 -9999 -9999 -9999 -9999 -9999 -9999 -9999 -9999 -9999 -9999 -9999 -9999 -9999 -9999 -9999 -9999 -9999 -9999 -9999 -9999 -9999 -9999 -9999 -9999 -9999 -9999 -9999 -9999 -9999 -9999 -9999 -9999 -9999 -9999 -9999 -9999 -9999 -9999 -9999 -9999 -9999 -9999 -9999 -9999 -9999 -9999 -9999 -9999 -9999 -9999 -9999 -9999 -9999 -9999 -9999 -9999 -9999 -9999 -9999 -9999 -9999 -9999 -9999 -9999 -

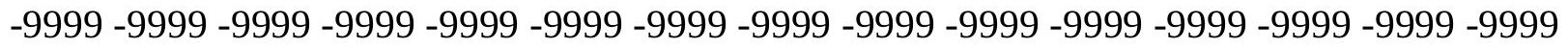
-9999 -9999 -9999 -9999 -9999 -9999 -9999 -9999 -9999 -9999 -9999 -9999 -9999 -9999 -9999 -9999 -9999 -9999 -9999 -9999 -9999 -9999 -9999 -9999 -9999 -9999 -9999 -9999 -9999 -9999 -9999 -9999 -9999 -9999 -9999 -9999 -9999 -9999 -9999 -9999 -9999 -9999 -9999 -9999 -

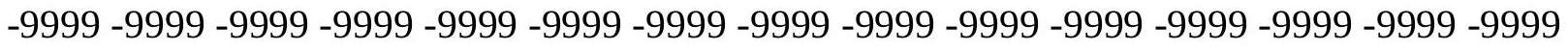
-9999 -9999 -9999 -9999 -9999 -9999 -9999 -9999 -9999 -9999 -9999 -9999 -9999 -9999 -9999 -999 -

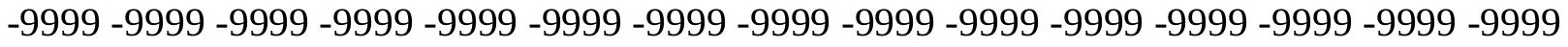
-9999 -9999 -9999 -9999 -9999 -9999 -9999 -9999 -9999 -9999 -9999 -9999 -9999 -9999 -9999 -9999 -9999 -9999 -9999 -9999 -9999 -9999 -9999 -9999 -9999 -9999 -9999 -9999 -9999 -9999 -9999 -9999 -9999 -9999 -9999 -9999 -9999 -9999 -9999 -9999 -9999 -9999 -9999 -9999 -9999 -9999 -9999 -9999 -9999 -9999 -9999 -9999 -9999 -9999 -9999 -9999 -9999 -9999 -9999 -9999 -9999 -9999 -9999 -9999 -9999 -9999 -9999 -9999 -9999 -9999 -9999 -9999 -9999 -9999 -9999 -

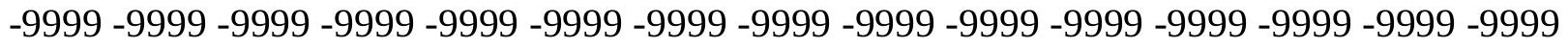
-9999 -9999 -9999 -9999 -9999 -9999 -9999 -9999 -9999 -9999 -9999 -9999 -9999 -9999 -9999 -9999 -9999 -9999 -9999 -9999 -9999 -9999 -9999 -9999 -9999 -9999 -9999 -9999 -9999 -999 -9999 -9999 -9999 -9999 -9999 -9999 -9999 -9999 -9999 -9999 -9999 -9999 -9999 -9999 -9999 -9999 -9999 -9999 -9999 -9999 -9999 -9999 -9999 -9999 -9999 -9999 -9999 -9999 -9999 -9999 -

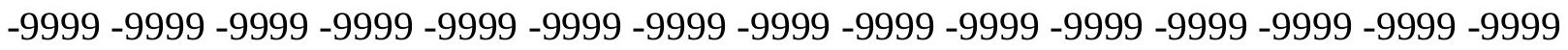

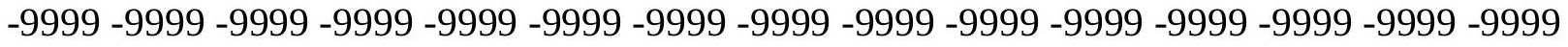

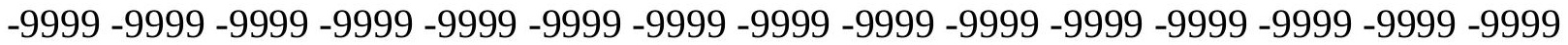
-9999 -9999 -9999 -9999 -9999 -9999 -9999 -9999 -9999 -9999 -9999 -9999 -9999 -9999 -9999

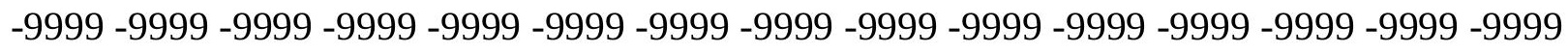

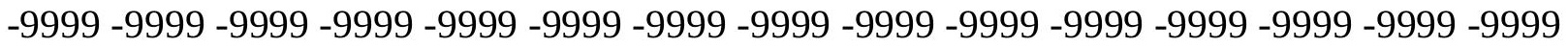
-9999 -9999 -9999 -9999 -9999 -9999 -9999 -9999 -9999 -9999 -9999 -9999 -9999 - 9999 - -999 -9999 -9999 -9999 -9999 -9999 -9999 -9999 -9999 -9999 -9999 -9999 -9999 -9999 -9999 -9999 -

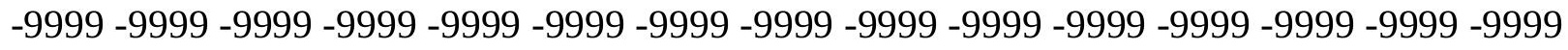

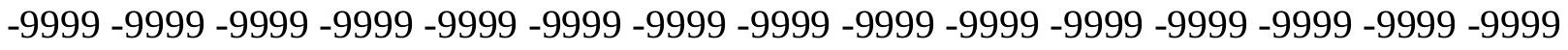
-9999 -9999 -9999 -9999 -9999 -9999 -9999 -9999 -9999 -9999 -9999 -9999 -9999 -9999 -9999 -9999 -9999 -9999 -9999 -9999 -9999 -9999 -9999 -9999 -9999 -9999 -9999 -9999 -9999 -9999 -9999 -9999 -9999 -9999 -9999 -9999 -9999 -9999 -9999 -9999 -9999 -9999 -9999 -9999 -

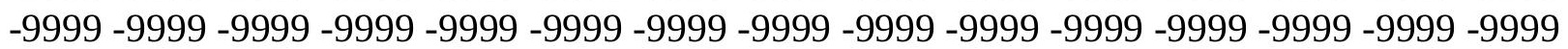


-9999 -9999 -9999 -9999 -9999 -9999 -9999 -9999 -9999 -9999 -9999 -9999 -9999 -9999 -9999 -9999 -9999 -9999 -9999 -9999 -9999 -9999 -9999 -9999 -9999 -9999 -9999 -9999 -9999 -9999 -9999 -9999 -9999 -9999 -9999 -9999 -9999 -9999 -9999 -9999 -9999 -9999 -9999 -9999 - 9999 -9999 -9999 -9999 -9999 -9999 -9999 -9999 -9999 -9999 -9999 -9999 -9999 -9999 -9999 -9999 -9999 -9999 -9999 -9999 -9999 -9999 -9999 -9999 -9999-9999 -9999 -9999 -9999 -9999 -9999 -9999 -9999 -9999 -9999 -9999 -9999 -9999 -9999 -9999 -9999 -9999 -9999 -9999 -9999 -9999 -9999 -9999 -9999 -9999 -9999 -9999 -9999 -9999 -9999 -9999 -9999 -9999 -9999 -9999 -9999

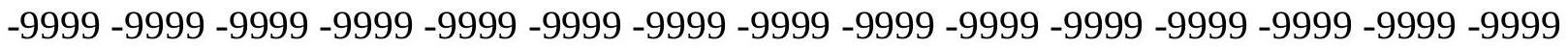

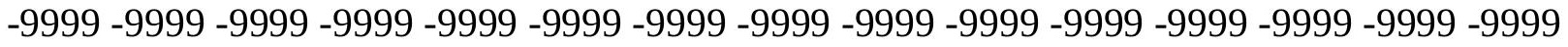
-9999 -9999 -9999 -9999 -9999 -9999 -9999 -9999 -9999 -9999 -9999 -9999 -9999 -9999 -9999 -9999 -9999 -9999 -9999 -9999 -9999 -9999 -9999 -9999 -9999 -9999 -9999 -9999 -9999 -9999 -9999 -9999 -9999 -9999 -9999 -9999 -9999 -9999 -9999 -9999 -9999 -9999 -9999 -9999 -9999 -9999 -9999 -9999 -9999 -9999 -9999 -9999 -9999 -9999 -9999 -9999 -9999 -9999 -9999 -9999 -

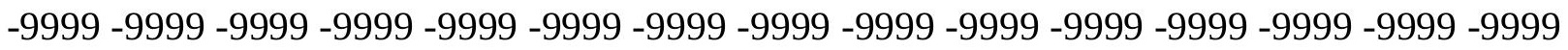
-9999 -9999 -9999 -9999 -9999 -9999 -9999 -9999 -9999 -9999 -9999 -9999 -9999 -9999 -9999 -

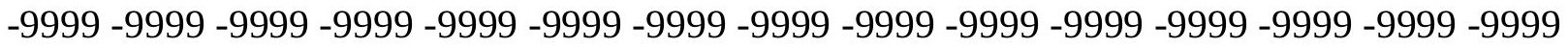
-9999 -9999 -9999 -9999 -9999 -9999 -9999 -9999 -9999 -9999 -9999 -9999 -9999 -9999 -9999 -9999 -9999 -9999 -9999 -9999 -9999 -9999 -9999 -9999 -9999 -9999 -9999 -9999 -9999 -9999 -9999 -9999 -9999 -9999 -9999 -9999 -9999 -9999 -9999 -9999 -9999 -9999 -9999 -9999 -9999 -

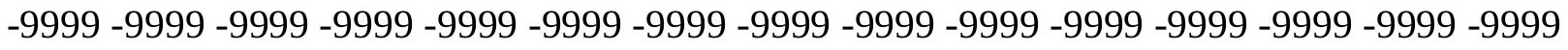
-9999 -9999 -9999 -9999 -9999 -9999 -9999 -9999 -9999 -9999 -9999 -9999 -9999 -9999 -9999 -999 -9999 -9999 -9999 -9999 -9999 -9999 -9999 -9999 -9999 -9999 -9999 -9999 -9999 -9999 - 9999 -9999 -9999 -9999 -9999 -9999 -9999 -9999 -9999 -9999 -9999 -9999 -9999 -9999 -9999 -

-9999 -9999 -9999 -9999 -9999 -9999 -9999 -9999 -9999 -9999 -9999 -9999 -9999 -9999 -9999 -

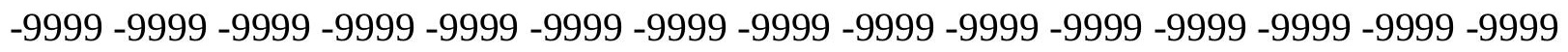
-9999 -9999 -9999 -9999 -9999 -9999 -9999 -9999 -9999 -9999 -9999 -9999 -9999 -9999 -9999 -9999 -9999 -9999 -9999 -9999 -9999 -9999 -9999 -9999 -9999 -9999 -9999 -9999 -9999 -9999 -

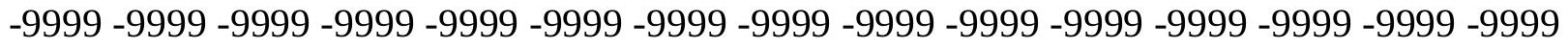
-9999 -9999 -9999 -9999 -9999 -9999 -9999 -9999 -9999 -9999 -9999 -9999 -9999 -9999 -9999 -9999 -9999 -9999 -9999 -9999 -9999 -9999 -9999 -9999 -9999 -9999 -9999 -9999 -9999 -999 -

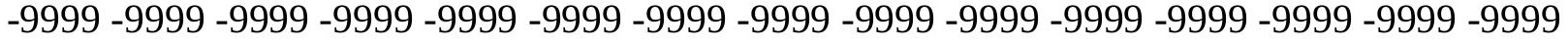
-9999 -9999 -9999 -9999 -9999 -9999 -9999 -9999 -9999 -9999 -9999 -9999 -9999 -9999 -9999 -

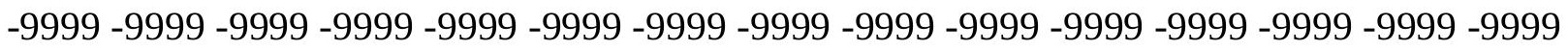

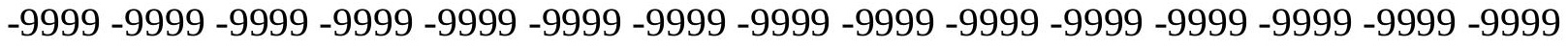

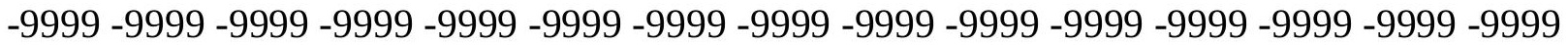

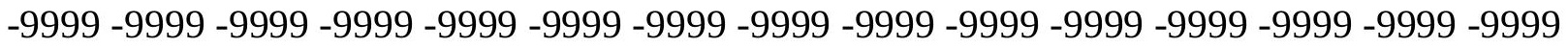

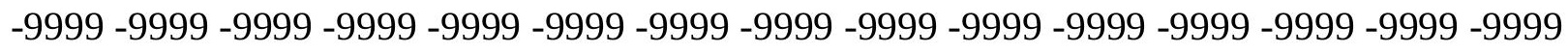

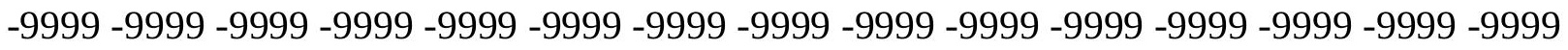

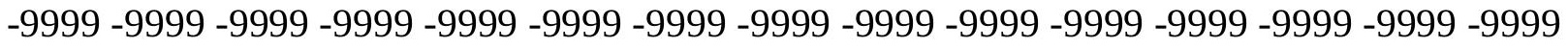
-9999 -9999 -9999 -9999 -9999 -9999 -9999 -9999 -9999 -9999 -9999 -9999 -9999 -9999 -9999 -

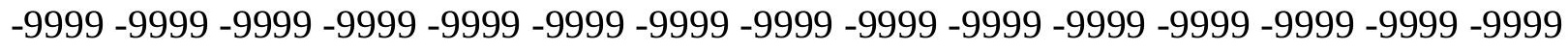

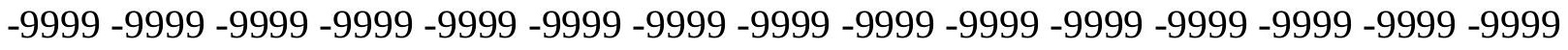
-9999 -9999 -9999 -9999 -9999 -9999 -9999 -9999 -9999 -9999 -9999 -9999 -9999 -9999 -9999 -9999 -9999 -9999 -9999 -9999 -9999 -9999 -9999 -9999-9999 -9999 -9999 -9999 -9999 -9999 -9999 -9999 -9999 -9999 -9999 -9999 -9999 -9999 -9999 -9999 -9999 -9999 -9999 -9999 -9999 -

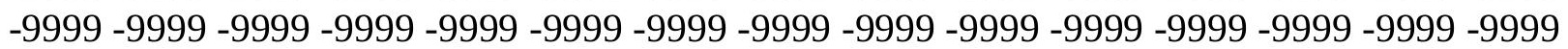


-9999 -9999 -9999 -9999 -9999 -9999 -9999 -9999 -9999 -9999 -9999 -9999 -9999 -9999 -9999 -9999 -9999 -9999 -9999 -9999 -9999 -9999 -9999 -9999 -9999 -9999 -9999 -9999 -9999 -9999 -9999 -9999 -9999 -9999 -9999 -9999 -9999 -9999 -9999 -9999 -9999 -9999 -9999 -9999 -9999 -9999 -9999 -9999 -9999 -9999 -9999 -9999 -9999 -9999 -9999 -9999 -9999 -9999 -9999 -9999 -9999 -9999 -9999 -9999 -9999 -9999 -9999 -9999-9999 -9999 -9999 -9999 -9999 -9999 -9999 -9999 -9999 -9999 -9999 -9999 -9999 -9999 -9999 -9999 -9999 -9999 -9999 -9999 -9999 -9999 -9999 -9999 -9999 -9999 -9999 -9999 -9999 -9999 -9999 -9999 -9999 -9999 -9999 -9999

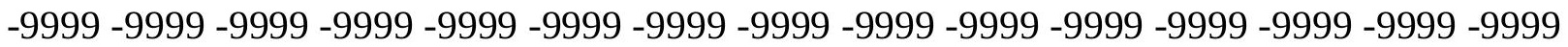

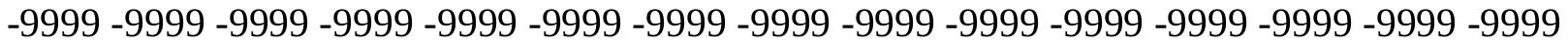
-9999 -9999 -9999 -9999 -9999 -9999 -9999 -9999 -9999 -9999 -9999 -9999 -9999 -9999 -9999 -9999 -9999 -9999 -9999 -9999 -9999 -9999 -9999 -9999 -9999 -9999 -9999 -9999 -9999 -9999 -9999 -9999 -9999 -9999 -9999 -9999 -9999 -9999 -9999 -9999 -9999 -9999 -9999 -9999 -9999 -9999 -9999 -9999 -9999 -9999 -9999 -9999 -9999 -9999 -9999 -9999 -9999 -9999 -9999 -9999 -

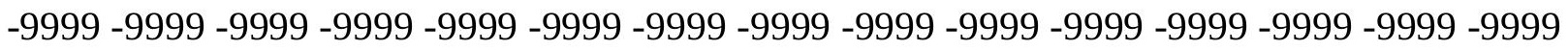
-9999 -9999 -9999 -9999 -9999 -9999 -9999 -9999 -9999 -9999 -9999 -9999 -9999 -9999 -9999 -

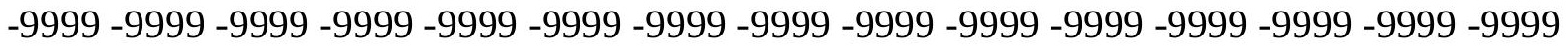
-9999 -9999 -9999 -9999 -9999 -9999 -9999 -9999 -9999 -9999 -9999 -9999 -9999 -9999 -9999 -9999 -9999 -9999 -9999 -9999 -9999 -9999 -9999 -9999 -9999 -9999 -9999 -9999 -9999 -9999 -9999 -9999 -9999 -9999 -9999 -9999 -9999 -9999 -9999 -9999 -9999 -9999 -9999 -9999 -9999 -

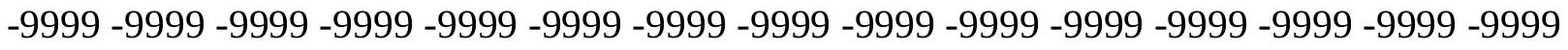

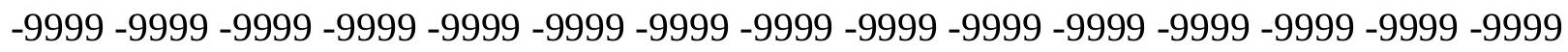
-9999 -9999 -9999 -9999 -9999 -9999 -9999 -9999 -9999 -9999 -9999 -9999 -9999 -9999 -9999 -9999 -9999 -9999 -9999 -9999 -9999 -9999 -9999 -9999 -9999 -9999 -9999 -9999 -9999 -9999 -9999 -9999 -9999 -9999 -9999 -9999 -9999 -9999 -9999 -9999 -9999 -9999 -9999 -9999 -9999 -

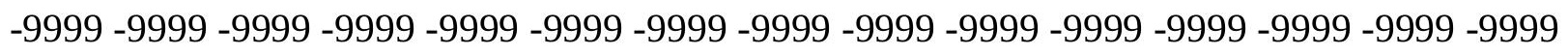
-9999 -9999 -9999 -9999 -9999 -9999 -9999 -9999 -9999 -9999 -9999 -9999 -9999 -9999 -9999 -9999 -9999 -9999 -9999 -9999 -9999 -9999 -9999 -9999 -9999 -9999 -9999 -9999 -9999 -9999 -

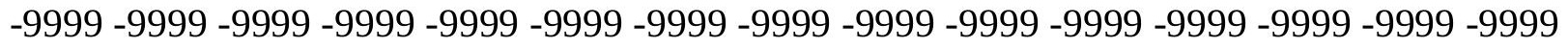
-9999 -9999 -9999 -9999 -9999 -9999 -9999 -9999 -9999 -9999 -9999 -9999 -9999 -9999 -9999 -9999 -9999 -9999 -9999 -9999 -9999 -9999 -9999 -9999 -9999 -9999 -9999 -9999 - -999 -

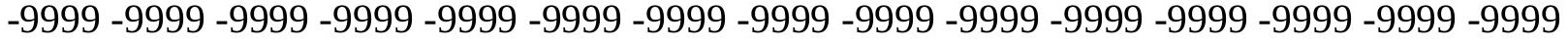
-9999 -9999 -9999 -9999 -9999 -9999 -9999 -9999 -9999 -9999 -9999 -9999 -9999 -9999 -9999 -

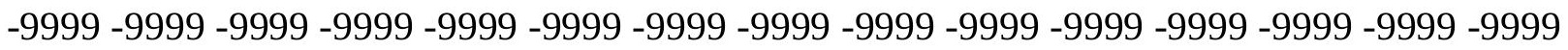

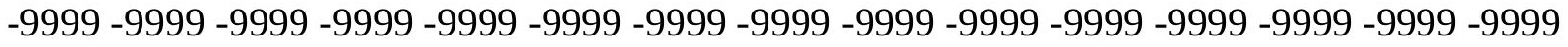

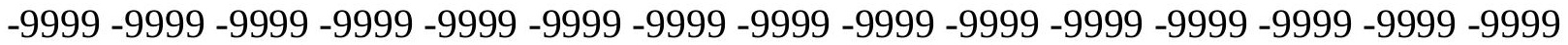

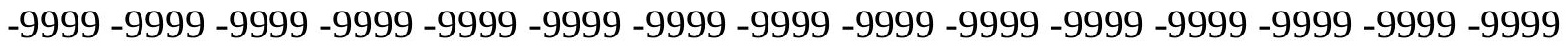

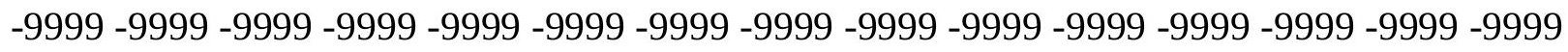

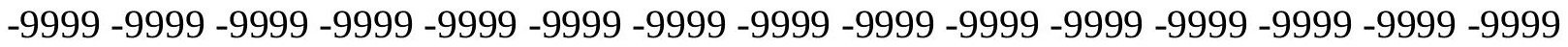

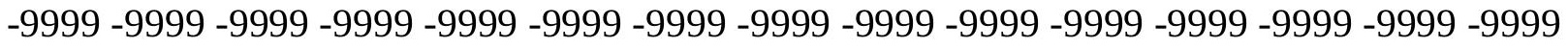
-9999 -9999 -9999 -9999 -9999 -9999 -9999 -9999 -9999 -9999 -9999 -9999 -9999 -9999 -9999 -

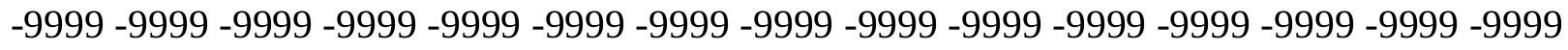

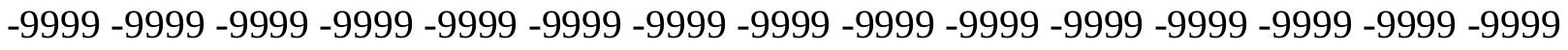
-9999 -9999 -9999 -9999 -9999 -9999 -9999 -9999 -9999 -9999 -9999 -9999 -9999 -9999 -9999 -9999 -9999 -9999 -9999 -9999 -9999 -9999 -9999 -9999-9999 -9999 -9999 -9999 -9999 -9999 -9999 -9999 -9999 -9999 -9999 -9999 -9999 -9999 -9999 -9999 -9999 -9999 -9999 -9999 -9999 -

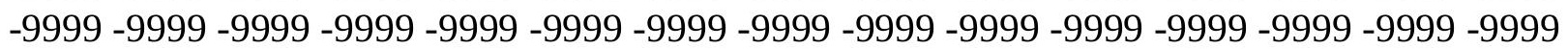


-9999 -9999 -9999 -9999 -9999 -9999 -9999 -9999 -9999 -9999 -9999 -9999 -9999 -9999 -9999 -9999 -9999 -9999 -9999 -9999 -9999 -9999 -9999 -9999 -9999 -9999 -9999 -9999 -9999 -9999 -

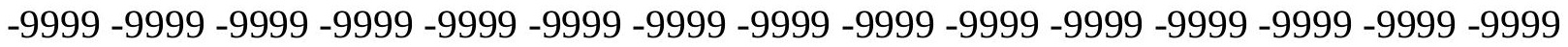
-9999 -9999 -9999 -9999 -9999 -9999 -9999 -9999 -9999 -9999 -9999 -9999 -9999 -9999 -9999 -9999 -9999 -9999 -9999 -9999 -9999 -9999 -9999 -9999-9999 -9999 -9999 -9999 -9999 -9999 -9999 -9999 -9999 -9999 -9999 -9999 -9999 -9999 -9999 -9999 -9999 -9999 -9999 -9999 -9999 -9999 -9999 -9999 -9999 -9999 -9999 -9999 -9999 -9999 -9999 -9999 -9999 -9999 -9999 -9999

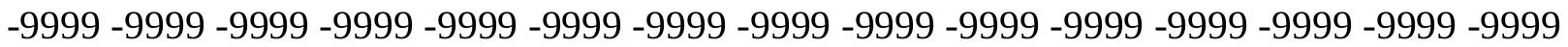
-9999 -9999 -9999 -9999 -9999 -9999 -9999 -9999 -9999 -9999 -9999 -9999 -9999 -9999 -9999 -9999 -9999 -9999 -9999 -9999 -9999 -9999 -9999 -9999 -9999 -9999 -9999 -9999 -9999

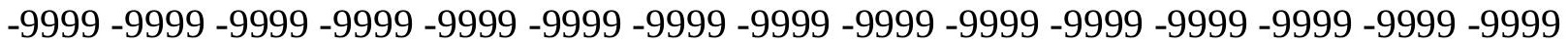
-9999 -9999 -9999 -9999 -9999 -9999 -9999 -9999 -9999 -9999 -9999 -9999 -9999 -9999 -9999 -9999 -9999 -9999 -9999 -9999 -9999 -9999 -9999 -9999 -9999 -9999 -9999 -9999 -9999 -9999 -9999 -9999 -9999 -9999 -9999 -9999 -9999 -9999 -9999 -9999 -9999 -9999 -9999 -9999 - 9999 -9999 -9999 -9999 -9999 -9999 -9999 -9999 -9999 -9999 -9999 -9999 -9999 -9999 -9999 -9999

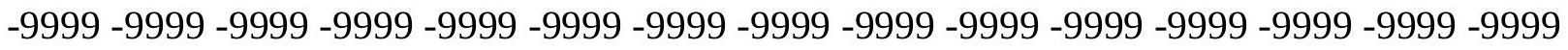
-9999 -9999 -9999 -9999 -9999 -9999 -9999 -9999 -9999 -9999 -9999 -9999 -9999 -9999 -9999 -9999 -9999 -9999 -9999 -9999 -9999 -9999 -9999 -9999 -9999 -9999 -9999 -9999 -9999 -9999 -9999 -9999 -9999 -9999 -9999 -9999 -9999 -9999 -9999 -9999 -9999 -9999 -9999 -9999 -9999 -

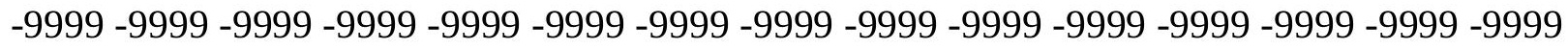

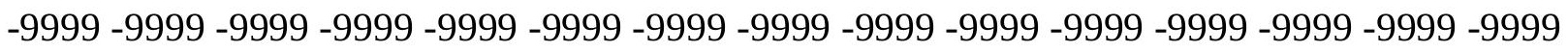
-9999 -9999 -9999 -9999 -9999 -9999 -9999 -9999 -9999 -9999 -9999 -9999 -9999 -9999 -9999 -9999 -9999 -9999 -9999 -9999 -9999 -9999 -9999 -9999 -9999 -9999 -9999 -9999 -9999 -9999 -9999 -9999 -9999 -9999 -9999 -9999 -9999 -9999 -9999 -9999 -9999 -9999 -9999 -9999 -9999 -

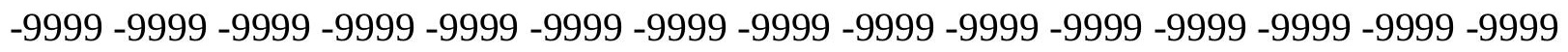
-9999 -9999 -9999 -9999 -9999 -9999 -9999 -9999 -9999 -9999 -9999 -9999 -9999 -9999 -9999 -9999 -9999 -9999 -9999 -9999 -9999 -9999 -9999 -9999 -9999 -9999 -9999 -9999 -9999 -9999 -

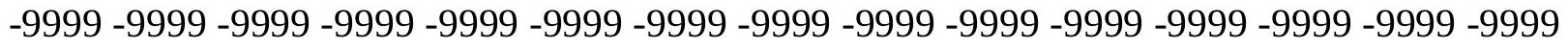
-9999 -9999 -9999 -9999 -9999 -9999 -9999 -9999 -9999 -9999 -9999 -9999 -9999 -9999 -9999 -9999 -9999 -9999 -9999 -9999 -9999 -9999 -9999 -9999 -9999 -9999 -9999 -9999 -9999 -999 -9999 -9999 -9999 -9999 -9999 -9999 -9999 -9999 -9999 -9999 -9999 -9999 -9999 -9999 -9999 -9999 -9999 -9999 -9999 -9999 -9999 -9999 -9999 -9999 -9999 -9999 -9999 -9999 -9999 -9999 -

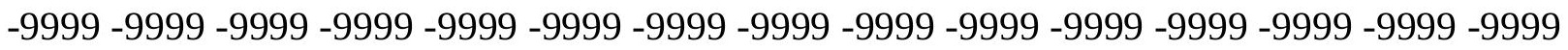

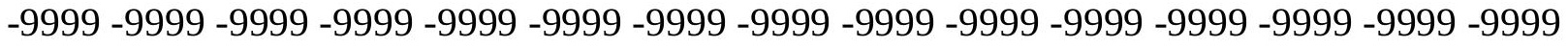
-9999 -9999 -9999 -9999 -9999 -9999 -9999 -9999 -9999 -9999 -9999 -9999 -9999 -9999 -

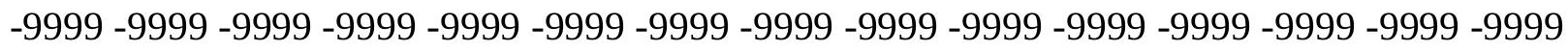

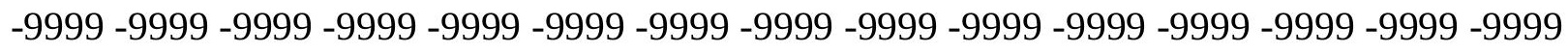

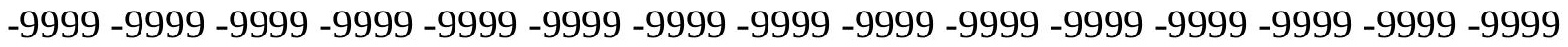
-9999 -9999 -9999 -9999 -9999 -9999 -9999 -9999 -9999 -9999 -9999 -9999 -9999 - 9999 - -999 -9999 -9999 -9999 -9999 -9999 -9999 -9999 -9999 -9999 -9999 -9999 -9999 -9999 -9999 -9999 -

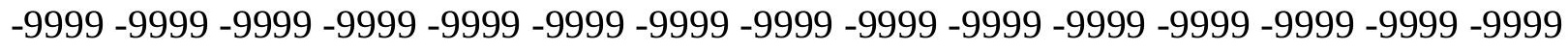

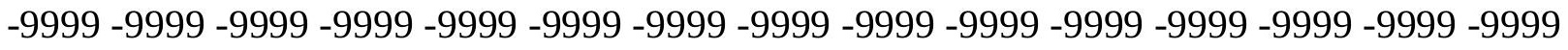
-9999 -9999 -9999 -9999 -9999 -9999 -9999 -9999 -9999 -9999 -9999 -9999 -9999 -9999 -9999 -9999 -9999 -9999 -9999 -9999 -9999 -9999 -9999 -9999-9999 -9999 -9999 -9999 -9999 -9999 -9999 -9999 -9999 -9999 -9999 -9999 -9999 -9999 -9999 -9999 -9999 -9999 -9999 -9999 -9999 -

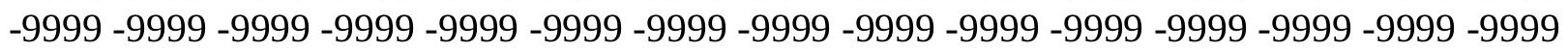


-9999 -9999 -9999 -9999 -9999 -9999 -9999 -9999 -9999 -9999 -9999 -9999 -9999 -9999 -9999 -9999 -9999 -9999 -9999 -9999 -9999 -9999 -9999 -9999 -9999 -9999 -9999 -9999 -9999 -9999 -

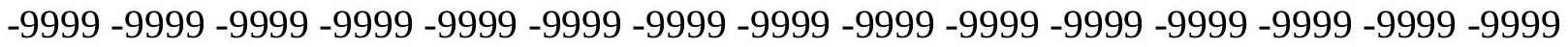
-9999 -9999 -9999 -9999 -9999 -9999 -9999 -9999 -9999 -9999 -9999 -9999 -9999 -9999 -9999 -9999 -9999 -9999 -9999 -9999 -9999 -9999 -9999 -9999-9999 -9999 -9999 -9999 -9999 -9999 -9999 -9999 -9999 -9999 -9999 -9999 -9999 -9999 -9999 -9999 -9999 -9999 -9999 -9999 -9999 -9999 -9999 -9999 -9999 -9999 -9999 -9999 -9999 -9999 -9999 -9999 -9999 -9999 -9999 -9999

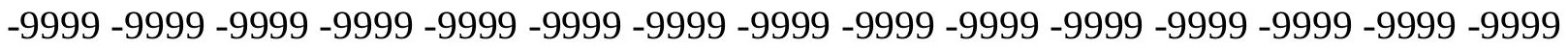

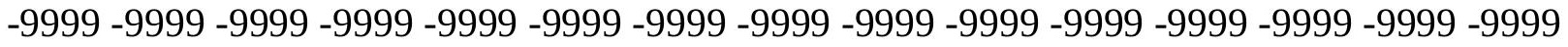
-9999 -9999 -9999 -9999 -9999 -9999 -9999 -9999 -9999 -9999 -9999 -9999 -9999 -9999 -9999 -9999 -9999 -9999 -9999 -9999 -9999 -9999 -9999 -9999 -9999 -9999 -9999 -9999 -9999 -9999 -9999 -9999 -9999 -9999 -9999 -9999 -9999 -9999 -9999 -9999 -9999 -9999 -9999 -9999 -9999 -9999 -9999 -9999 -9999 -9999 -9999 -9999 -9999 -9999 -9999 -9999 -9999 -9999 -9999 -9999 -9999 -9999 -9999 -9999 -9999 -9999 -9999 -9999 -9999 -9999 -9999 -9999 -9999 -9999 -9999 -9999 -9999 -9999 -9999 -9999 -9999 -9999 -9999 -9999 -9999 -9999 -9999 -9999 -9999 -9999 -9999 -9999 -9999 -9999 -9999 -9999 -9999 -9999 -9999 -9999 -9999 -9999 - 9999 - -999 -

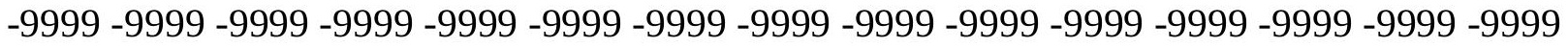
-9999 -9999 -9999 -9999 -9999 -9999 -9999 -9999 -9999 -9999 -9999 -9999 -9999 -9999 -9999 -9999 -9999 -9999 -9999 -9999 -9999 -9999 -9999 -9999 -9999 -9999 -9999 -9999 -9999 -9999 -

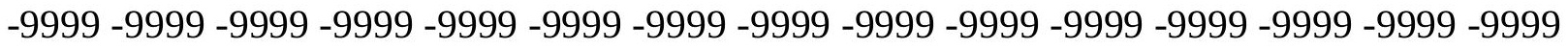
-9999 -9999 -9999 -9999 -9999 -9999 -9999 -9999 -9999 -9999 -9999 -9999 -9999 -9999 -9999

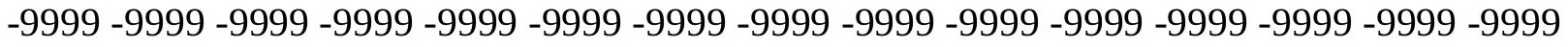
-9999 -9999 -9999 -9999 -9999 -9999 -9999 -9999 -9999 -9999 -9999 -9999 -9999 -9999 -9999 -9999 -9999 -9999 -9999 -9999 -9999 -9999 -9999 -9999 -9999 -9999 -9999 -9999 -9999 -9999 -

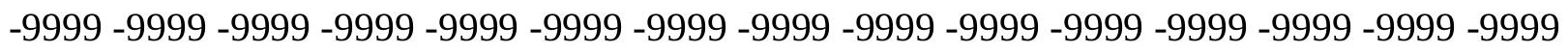
-9999 -9999 -9999 -9999 -9999 -9999 -9999 -9999 -9999 -9999 -9999 -9999 -9999 -9999 -9999 -9999 -9999 -9999 -9999 -9999 -9999 -9999 -9999 -9999 -9999 -9999 -9999 -9999 -9999 -9999 -

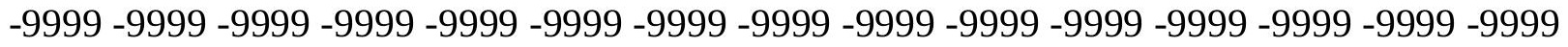
-9999 -9999 -9999 -9999 -9999 -9999 -9999 -9999 -9999 -9999 -9999 -9999 -9999 -9999 -9999 -9999 -9999 -9999 -9999 -9999 -9999 -9999 -9999 -9999 -9999 -9999 -9999 -9999 -9999 -999 -

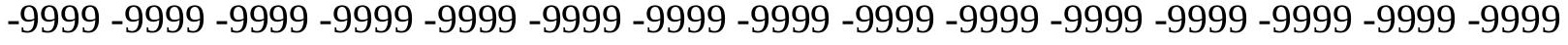
-9999 -9999 -9999 -9999 -9999 -9999 -9999 -9999 -9999 -9999 -9999 -9999 -9999 -9999 -9999 -

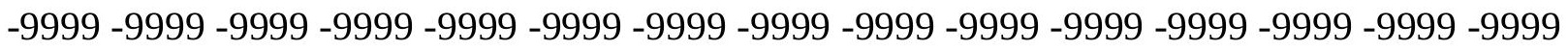

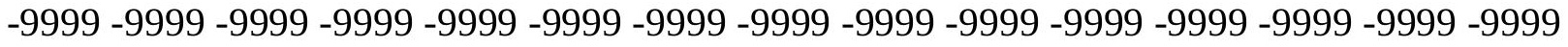

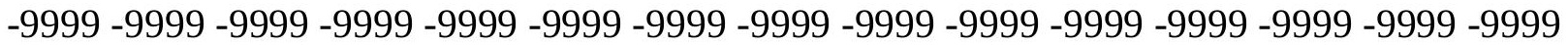
-9999 -9999 -9999 -9999 -9999 -9999 -9999 -9999 -9999 -9999 -9999 -9999 -9999 -9999 -9999 -

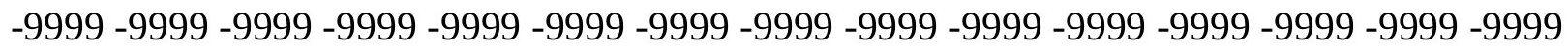

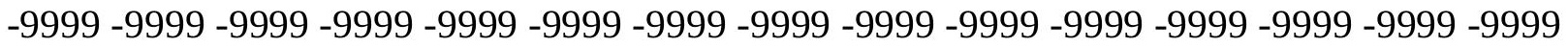
-9999 -9999 -9999 -9999 -9999 -9999 -9999 -9999 -9999 -9999 -9999 -9999 -9999 - 9999 - -999 -9999 -9999 -9999 -9999 -9999 -9999 -9999 -9999 -9999 -9999 -9999 -9999 -9999 -9999 -9999 -

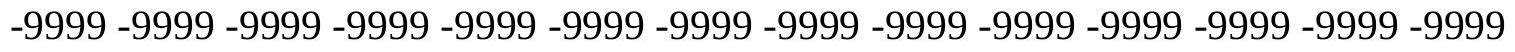

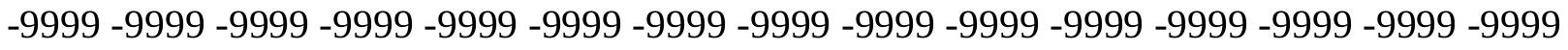
-9999 -9999 -9999 -9999 -9999 -9999 -9999 -9999 -9999 -9999 -9999 -9999 -9999 -9999 -9999 -9999 -9999 -9999 -9999 -9999 -9999 -9999 -9999 -9999-9999 -9999 -9999 -9999 -9999 -9999 -9999 -9999 -9999 -9999 -9999 -9999 -9999 -9999 -9999 -9999 -9999 -9999 -9999 -9999 -9999 -

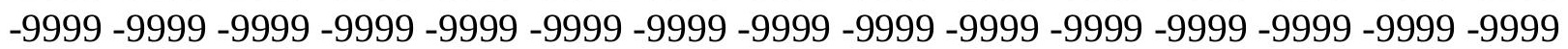


-9999 -9999 -9999 -9999 -9999 -9999 -9999 -9999 -9999 -9999 -9999 -9999 -9999 -9999 -9999 -9999 -9999 -9999 -9999 -9999 -9999 -9999 -9999 -9999 -9999 -9999 -9999 -9999 -9999 -9999 -9999 -9999 -9999 -9999 -9999 -9999 -9999 -9999 -9999 -9999 -9999 -9999 -9999 -9999 - 9999 -9999 -9999 -9999 -9999 -9999 -9999 -9999 -9999 -9999 -9999 -9999 -9999 -9999 -9999 -9999 -9999 -9999 -9999 -9999 -9999 -9999 -9999 -9999 -9999-9999 -9999 -9999 -9999 -9999 -9999 -9999 -9999 -9999 -9999 -9999 -9999 -9999 -9999 -9999 -9999 -9999 -9999 -9999 -9999 -9999 -9999 -9999 -9999 -9999 -9999 -9999 -9999 -9999 -9999 -9999 -9999 -9999 -9999 -9999 -9999

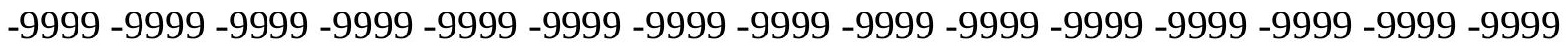
-9999 -9999 -9999 -9999 -9999 -9999 -9999 -9999 -9999 -9999 -9999 -9999 -9999 -9999 -9999 -9999 -9999 -9999 -9999 -9999 -9999 -9999 -9999 -9999 -9999 -9999 -9999 -9999 -9999 -9999

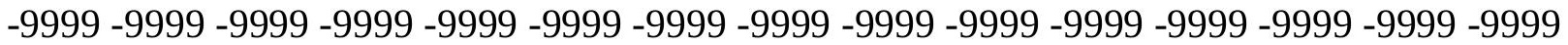
-9999 -9999 -9999 -9999 -9999 -9999 -9999 -9999 -9999 -9999 -9999 -9999 -9999 -9999 -9999 -9999 -9999 -9999 -9999 -9999 -9999 -9999 -9999 -9999 -9999 -9999 -9999 -9999 -9999 -9999 -

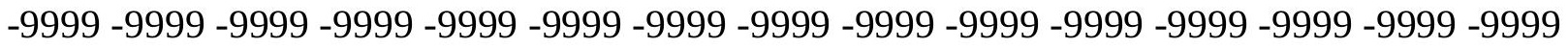
-9999 -9999 -9999 -9999 -9999 -9999 -9999 -9999 -9999 -9999 -9999 -9999 -9999 -9999 -9999

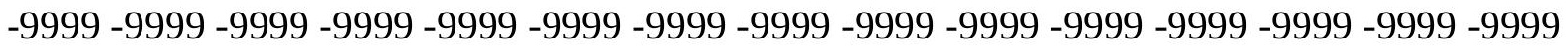
-9999 -9999 -9999 -9999 -9999 -9999 -9999 -9999 -9999 -9999 -9999 -9999 -9999 -9999 -9999 -9999 -9999 -9999 -9999 -9999 -9999 -9999 -9999 -9999 -9999 -9999 -9999 -9999 -9999 - 9999 -9999 -9999 -9999 -9999 -9999 -9999 -9999 -9999 -9999 -9999 -9999 -9999 -9999 -9999 -9999 -9999 -9999 -9999 -9999 -9999 -9999 -9999 -9999 -9999 -9999 -9999 -9999 -9999 -9999 -9999 -9999 -9999 -9999 -9999 -9999 -9999 -9999 -9999 -9999 -9999 -9999 -9999 -9999 -9999 -9999 -9999 -9999 -9999 -9999 -9999 -9999 -9999 -9999 -9999 -9999 -9999 -9999 -9999 -9999 -9999 -9999 -9999 -9999 -9999 -9999 -9999 -9999 -9999 -9999 -9999 -9999 -9999 -9999 -9999 -9999 -9999 -9999 -9999 -9999 -9999 -9999 -9999 -9999 -9999 -9999 -9999 -9999 -9999 -9999 -9999 -9999 -9999 -9999 -9999 -9999 -9999 -9999 -9999 -9999 -9999 -9999 -9999 -9999 -9999 -9999 -9999 -9999 -9999 -9999 -9999 -9999 -9999 -9999 -9999 -9999 -9999 -9999 -9999 -9999 -9999 -9999 -9999 -9999 -9999 -9999 -9999 -9999 -9999 -9999 -9999 -9999 -9999 -9999 -9999 -9999 -9999 -9999 -9999 -9999 -9999 -9999 -9999 -9999 -9999 -9999 -9999 -9999 -9999 -9999 -9999 -9999 -9999 -9999 -9999 -9999 -9999 -9999 -9999 -9999 -9999 -9999 -9999 -9999 -9999 -9999 -9999 -9999 -9999 -9999 -9999 -9999 -9999 -9999 -9999 -9999 -9999 -9999 -9999 -999 -9999 -9999 -9999 -9999 -9999 -9999 -9999 -9999 -9999 -9999 -9999 -9999 -9999 -9999 -9999 -9999 -9999 -9999 -9999 -9999 -9999 -9999 -9999 -9999 -9999 -9999 -9999 -9999 -9999 -9999 -

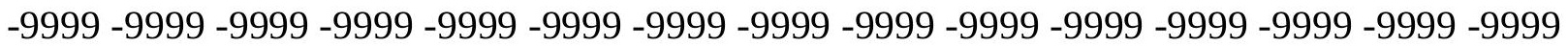

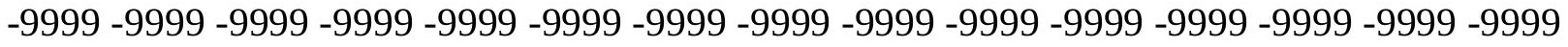

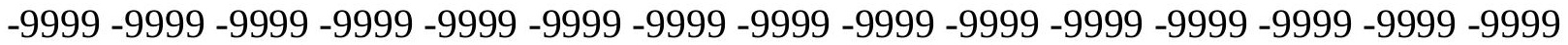
-9999 -9999 -9999 -9999 -9999 -9999 -9999 -9999 -9999 -9999 -9999 -9999 -9999 -9999 -9999

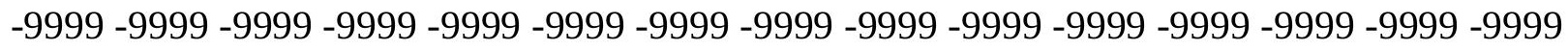

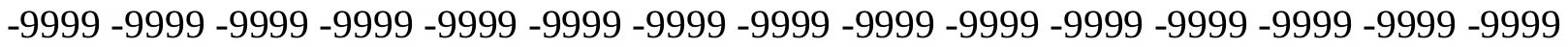

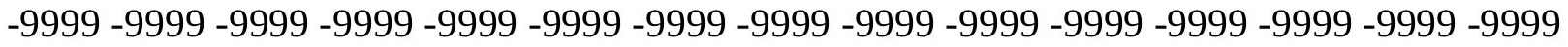
-9999 -9999 -9999 -9999 -9999 -9999 -9999 -9999 -9999 -9999 -9999 -9999 -9999 -9999 -9999 -

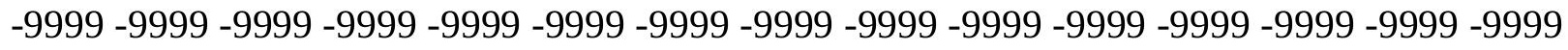

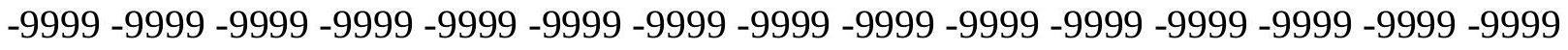
-9999 -9999 -9999 -9999 -9999 -9999 -9999 -9999 -9999 -9999 -9999 -9999 -9999 -9999 -9999 -9999 -9999 -9999 -9999 -9999 -9999 -9999 -9999 -9999-9999 -9999 -9999 -9999 -9999 -9999 -9999 -9999 -9999 -9999 -9999 -9999 -9999 -9999 -9999 -9999 -9999 -9999 -9999 -9999 -9999 -

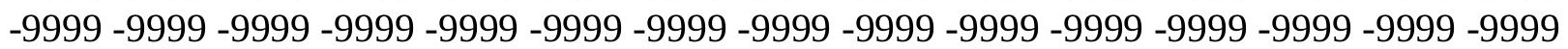


-9999 -9999 -9999 -9999 -9999 -9999 -9999 -9999 -9999 -9999 -9999 -9999 -9999 -9999 -9999 -9999 -9999 -9999 -9999 -9999 -9999 -9999 -9999 -9999 -9999 -9999 -9999 -9999 -9999 -9999 -9999 -9999 -9999 -9999 -9999 -9999 -9999 -9999 -9999 -9999 -9999 -9999 -9999 -9999 -9999 -9999 -9999 -9999 -9999 -9999 -9999 -9999 -9999 -9999 -9999 -9999 -9999 -9999 -9999 -9999 -9999 -9999 -9999 -9999 -9999 -9999 -9999 -9999 -9999 -9999 -9999 -9999 -9999 -9999 -9999 -9999 -9999 -9999 -9999 -9999 -9999 -9999 -9999 -9999 -9999 -9999 -9999 -9999 -9999 -9999 -9999 -9999 -9999 -9999 -9999 -9999 -9999 -9999 -9999 -9999 -9999 -9999 -9999 -9999 -

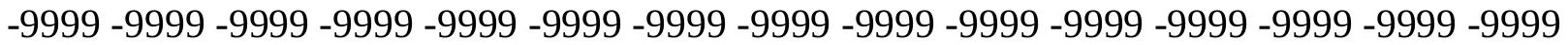
-9999 -9999 -9999 -9999 -9999 -9999 -9999 -9999 -9999 -9999 -9999 -9999 -9999 -9999 -9999 -9999 -9999 -9999 -9999 -9999 -9999 -9999 -9999 -9999 -9999 -9999 -9999 -9999 -9999 -9999 -

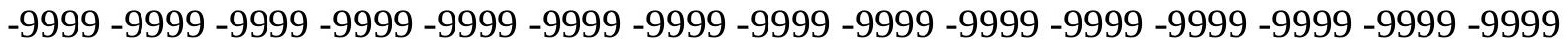
-9999 -9999 -9999 -9999 -9999 -9999 -9999 -9999 -9999 -9999 -9999 -9999 -9999 -9999 -9999 -9999 -9999 -9999 -9999 -9999 -9999 -9999 -9999 -9999 -9999 -9999 -9999 -9999 -9999 -9999 -9999 -9999 -9999 -9999 -9999 -9999 -9999 -9999 -9999 -9999 -9999 -9999 -9999 -9999 -9999 -9999 -9999 -9999 -9999 -9999 -9999 -9999 -9999 -9999 -9999 -9999 -9999 -9999 -9999 -9999 -9999 -9999 -9999 -9999 -9999 -9999 -9999 -9999 -9999 -9999 -9999 -9999 -9999 -9999 -9999 -9999 -9999 -9999 -9999 -9999 -9999 -9999 -9999 -9999 -9999 -9999 -9999 -9999 -9999 -9999 -9999 -9999 -9999 -9999 -9999 -9999 -9999 -9999 -9999 -9999 -9999 -9999 -9999 -9999 -9999 -9999 -9999 -9999 -9999 -9999 -9999 -9999 -9999 -9999 -9999 -9999 -9999 -9999 -9999 -9999 -9999 -9999 -9999 -9999 -9999 -9999 -9999 -9999 -9999 -9999 -9999 -9999 -9999 -9999 -9999

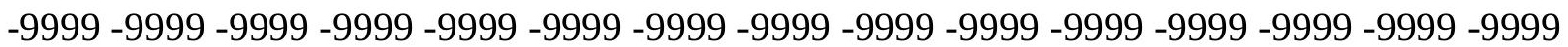
-9999 -9999 -9999 -9999 -9999 -9999 -9999 -9999 -9999 -9999 -9999 -9999 -9999 -9999 -9999 -9999 -9999 -9999 -9999 -9999 -9999 -9999 -9999 -9999 -9999 -9999 -9999 -9999 -9999 -9999 -9999 -9999 -9999 -9999 -9999 -9999 -9999 -9999 -9999 -9999 -9999 -9999 -9999 -9999 -9999

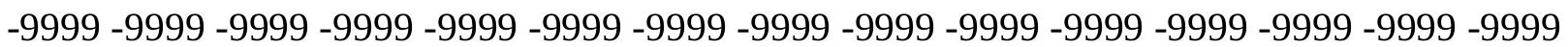
-9999 -9999 -9999 -9999 -9999 -9999 -9999 -9999 -9999 -9999 -9999 -9999 -9999 -9999 -9999 -9999 -9999 -9999 -9999 -9999 -9999 -9999 -9999 -9999 -9999 -9999 -9999 -9999 -9999 -9999 -9999 -9999 -9999 -9999 -9999 -9999 -9999 -9999 -9999 -9999 -9999 -9999 -9999 -9999

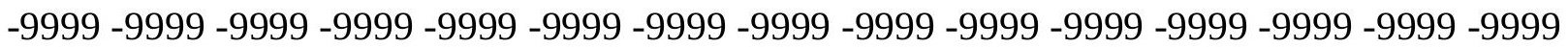
-9999 -9999 -9999 -9999 -9999 -9999 -9999 -9999 -9999 -9999 -9999 -9999 -9999 -9999 -9999 -9999 -9999 -9999 -9999 -9999 -9999 -9999 -9999 -9999 -9999 -9999 -9999 -9999 -9999 -9999 -

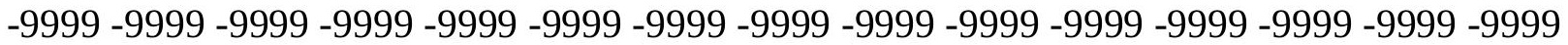
-9999 -9999 -9999 -9999 -9999 -9999 -9999 -9999 -9999 -9999 -9999 -9999 -9999 -9999 -9999 -9999 -9999 -9999 -9999 -9999 -9999 -9999 -9999 -9999 -9999 -9999 -9999 -9999 -9999 -9999 -9999 -9999 -9999 -9999 -9999 -9999 -9999 -9999 -9999 -9999 -9999 -9999 -9999 -9999 -9999 -9999 -9999 -9999 -9999 -9999 -9999 -9999 -9999 -9999 -9999 -9999 -9999 -9999 -9999 -9999 -9999 -9999 -9999 -9999 -9999 -9999 -9999 -9999 -9999 -9999 -9999 -9999 -9999 -9999 -9999

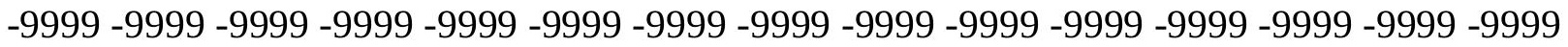
-9999 -9999 -9999 -9999 -9999 -9999 -9999 -9999 -9999 -9999 -9999 -9999 -9999 -9999 -9999 -9999 -9999 -9999 -9999 -9999 -9999 -9999 -9999 -9999 -9999 -9999 -9999 -9999 -9999 -9999 -

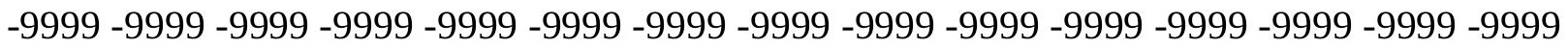
-9999 -9999 -9999 -9999 -9999 -9999 -9999 -9999 -9999 -9999 -9999 -9999 -9999 -9999 -9999 -9999 -9999 -9999 -9999 -9999 -9999 -9999 -9999 -9999 -9999 -9999 -9999 -9999 -9999 -9999 -9999 -9999 -9999 -9999 -9999 -9999 -9999 -9999 -9999 -9999 -9999 -9999 -9999 -9999 -9999 -9999 -9999 -9999 -9999 -9999 -9999 -9999 -9999 -9999 -9999 -9999 -9999 -9999 -9999 -9999

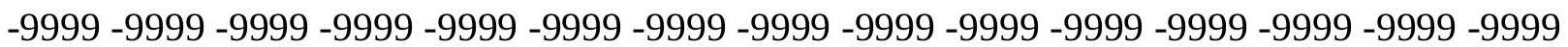


-9999 -9999 -9999 -9999 -9999 -9999 -9999 -9999 -9999 -9999 -9999 -9999 -9999 -9999 -9999 -9999 -9999 -9999 -9999 -9999 -9999 -9999 -9999 -9999 -9999 -9999 -9999 -9999 -9999 -9999 -

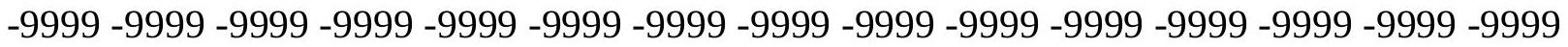
-9999 -9999 -9999 -9999 -9999 -9999 -9999 -9999 -9999 -9999 -9999 -9999 -9999 -9999 -9999 -9999 -9999 -9999 -9999 -9999 -9999 -9999 -9999 -9999-9999 -9999 -9999 -9999 -9999 -9999 -9999 -9999 -9999 -9999 -9999 -9999 -9999 -9999 -9999 -9999 -9999 -9999 -9999 -9999 -9999 -9999 -9999 -9999 -9999 -9999 -9999 -9999 -9999 -9999 -9999 -9999 -9999 -9999 -9999 -

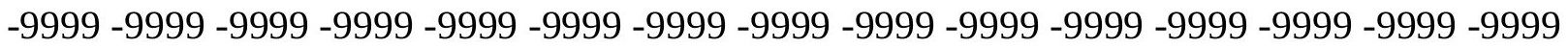

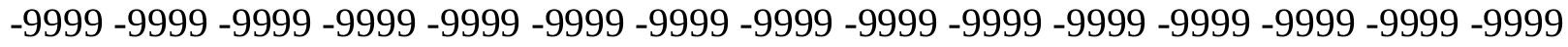
-9999 -9999 -9999 -9999 -9999 -9999 -9999 -9999 -9999 -9999 -9999 -9999 -9999 -9999 -9999 -9999 -9999 -9999 -9999 -9999 -9999 -9999 -9999 -9999 -9999 -9999 -9999 -9999 -9999 -9999 -9999 -9999 -9999 -9999 -9999 -9999 -9999 -9999 -9999 -9999 -9999 -9999 -9999 -9999 -9999 -9999 -9999 -9999 -9999 -9999 -9999 -9999 -9999 -9999 -9999 -9999 -9999 -9999 -9999 -9999 -9999 -9999 -9999 -9999 -9999 -9999 -9999 -9999 -9999 -9999 -9999 -9999 -9999 -9999 -9999 -9999 -9999 -9999 -9999 -9999 -9999 -9999 -9999 -9999 -9999 -9999 -9999 -9999 -9999 -9999 -

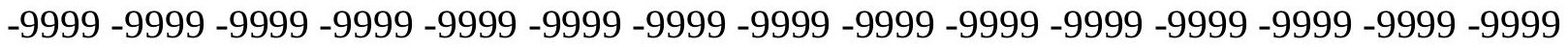
-9999 -9999 -9999 -9999 -9999 -9999 -9999 -9999 -9999 -9999 -9999 -9999 -9999 -9999 -9999 -9999 -9999 -9999 -9999 -9999 -9999 -9999 -9999 -9999 -9999 -9999 -9999 -9999 -9999 -9999 -9999 -9999 -9999 -9999 -9999 -9999 -9999 -9999 -9999 -9999 -9999 -9999 -9999 -9999 -9999 -

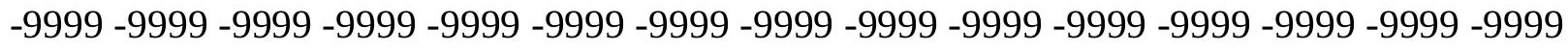

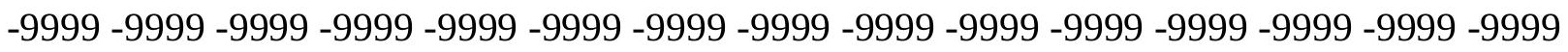

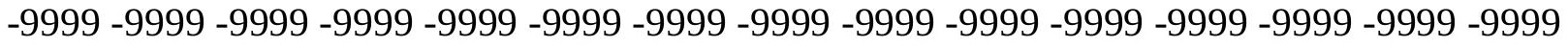
-9999 -9999 -9999 -9999 -9999 -9999 -9999 -9999 -9999 -9999 -9999 -9999 -9999 -9999 -9999 -9999 -9999 -9999 -9999 -9999 -9999 -9999 -9999 -9999 -9999 -9999 -9999 -9999 -9999 -9999 -

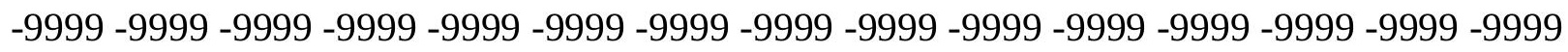
-9999 -9999 -9999 -9999 -9999 -9999 -9999 -9999 -9999 -9999 -9999 -9999 -9999 -9999 -9999 -9999 -9999 -9999 -9999 -9999 -9999 -9999 -9999 -9999 -9999 -9999 -9999 -9999 -9999 -9999 -

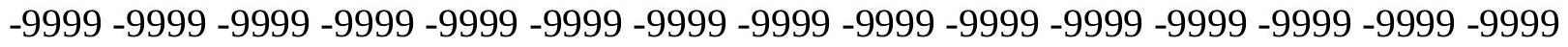
-9999 -9999 -9999 -9999 -9999 -9999 -9999 -9999 -9999 -9999 -9999 -9999 -9999 -9999 -9999 -9999 -9999 -9999 -9999 -9999 -9999 -9999 -9999 -9999 -9999 -9999 -9999 -9999 -9999 -999 -9999 -9999 -9999 -9999 -9999 -9999 -9999 -9999 -9999 -9999 -9999 -9999 -9999 -9999 -9999 -

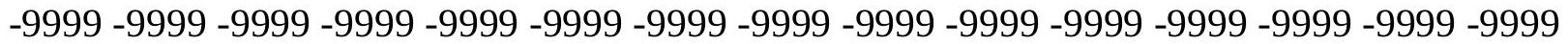

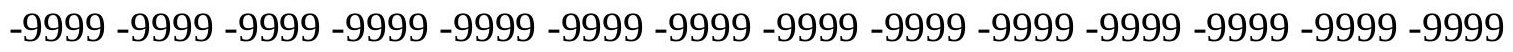

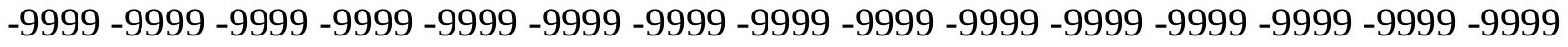

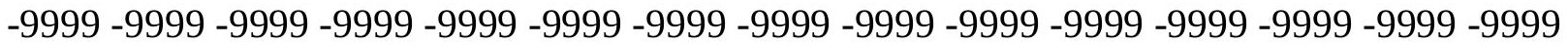

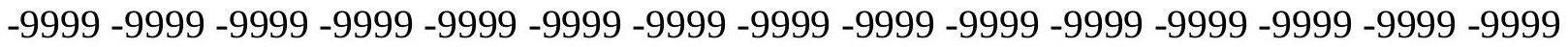

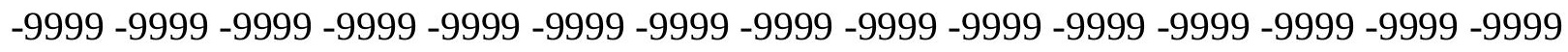

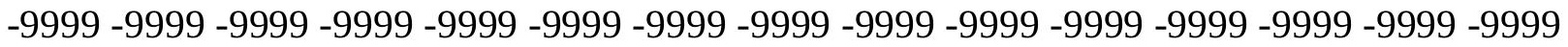

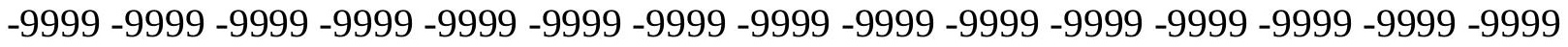
-9999 -9999 -9999 -9999 -9999 -9999 -9999 -9999 -9999 -9999 -9999 -9999 -9999 -9999 -9999 -

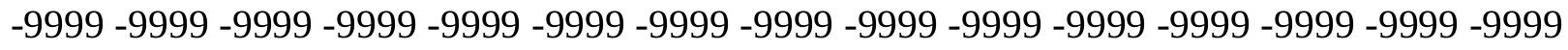

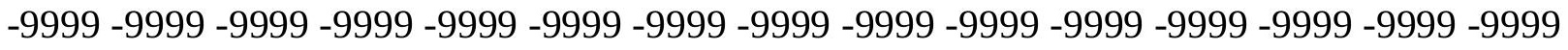
-9999 -9999 -9999 -9999 -9999 -9999 -9999 -9999 -9999 -9999 -9999 -9999 -9999 -9999 -9999 -9999 -9999 -9999 -9999 -9999 -9999 -9999 -9999 -9999-9999 -9999 -9999 -9999 -9999 -9999 -9999 -9999 -9999 -9999 -9999 -9999 -9999 -9999 -9999 -9999 -9999 -9999 -9999 -9999 -9999 -

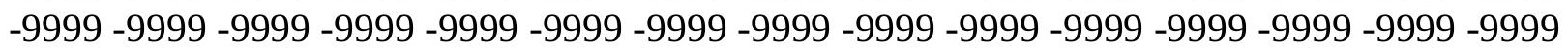


-9999 -9999 -9999 -9999 -9999 -9999 -9999 -9999 -9999 -9999 -9999 -9999 -9999 -9999 -9999 -9999 -9999 -9999 -9999 -9999 -9999 -9999 -9999 -9999 -9999 -9999 -9999 -9999 -9999 -9999 -

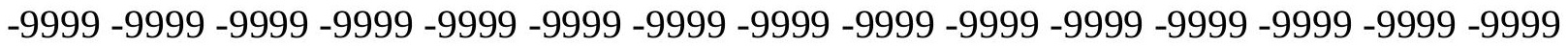
-9999 -9999 -9999 -9999 -9999 -9999 -9999 -9999 -9999 -9999 -9999 -9999 -9999 -9999 -9999 -9999 -9999 -9999 -9999 -9999 -9999 -9999 -9999 -9999-9999 -9999 -9999 -9999 -9999 -9999 -9999 -9999 -9999 -9999 -9999 -9999 -9999 -9999 -9999 -9999 -9999 -9999 -9999 -9999 -9999 -9999 -9999 -9999 -9999 -9999 -9999 -9999 -9999 -9999 -9999 -9999 -9999 -9999 -9999 -9999

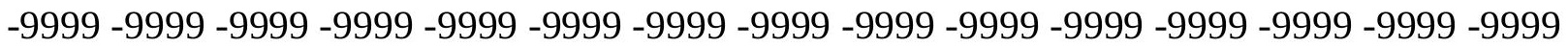

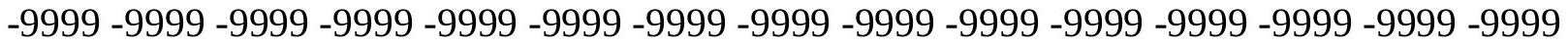
-9999 -9999 -9999 -9999 -9999 -9999 -9999 -9999 -9999 -9999 -9999 -9999 -9999 -9999 -9999 -9999 -9999 -9999 -9999 -9999 -9999 -9999 -9999 -9999 -9999 -9999 -9999 -9999 -9999 -9999 -9999 -9999 -9999 -9999 -9999 -9999 -9999 -9999 -9999 -9999 -9999 -9999 -9999 -9999 -9999 -9999 -9999 -9999 -9999 -9999 -9999 -9999 -9999 -9999 -9999 -9999 -9999 -9999 -9999 -9999 -9999 -9999 -9999 -9999 -9999 -9999 -9999 -9999 -9999 -9999 -9999 -9999 -9999 -9999 -9999 -9999 -9999 -9999 -9999 -9999 -9999 -9999 -9999 -9999 -9999 -9999 -9999 -9999 -9999 -

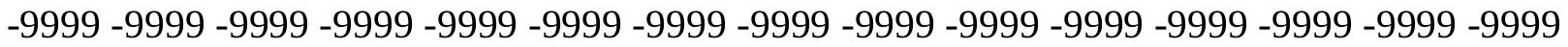
-9999 -9999 -9999 -9999 -9999 -9999 -9999 -9999 -9999 -9999 -9999 -9999 -9999 -9999 -9999 -9999 -9999 -9999 -9999 -9999 -9999 -9999 -9999 -9999 -9999 -9999 -9999 -9999 -9999 -9999 -9999 -9999 -9999 -9999 -9999 -9999 -9999 -9999 -9999 -9999 -9999 -9999 -9999 -9999 -9999 -

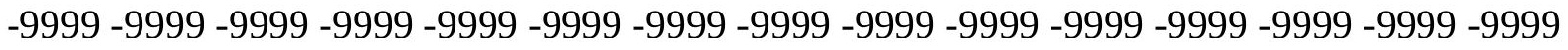
-9999 -9999 -9999 -9999 -9999 -9999 -9999 -9999 -9999 -9999 -9999 -9999 -9999 -9999 -9999

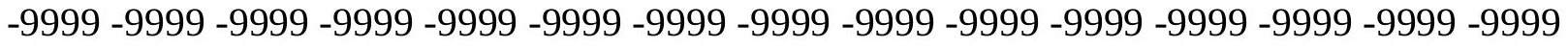
-9999 -9999 -9999 -9999 -9999 -9999 -9999 -9999 -9999 -9999 -9999 -9999 -9999 -9999 -9999 -9999 -9999 -9999 -9999 -9999 -9999 -9999 -9999 -9999 -9999 -9999 -9999 -9999 -9999 -9999 -

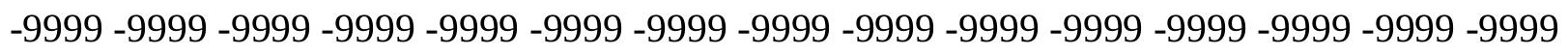
-9999 -9999 -9999 -9999 -9999 -9999 -9999 -9999 -9999 -9999 -9999 -9999 -9999 -9999 -9999 -9999 -9999 -9999 -9999 -9999 -9999 -9999 -9999 -9999 -9999 -9999 -9999 -9999 -9999 -9999 -

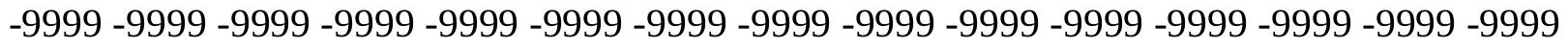
-9999 -9999 -9999 -9999 -9999 -9999 -9999 -9999 -9999 -9999 -9999 -9999 -9999 -9999 -9999 -9999 -9999 -9999 -9999 -9999 -9999 -9999 -9999 -9999 -9999 -9999 -9999 -9999 -9999 -999 -9999 -9999 -9999 -9999 -9999 -9999 -9999 -9999 -9999 -9999 -9999 -9999 -9999 -9999 -9999 -9999 -9999 -9999 -9999 -9999 -9999 -9999 -9999 -9999 -9999 -9999 -9999 -9999 -9999 -9999 -

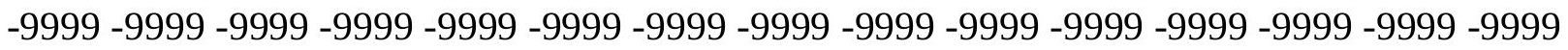

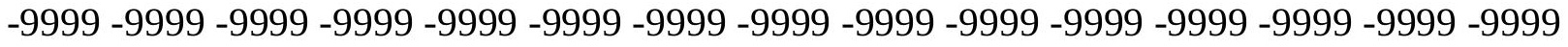

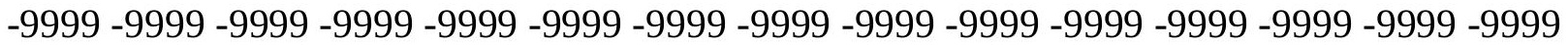
-9999 -9999 -9999 -9999 -9999 -9999 -9999 -9999 -9999 -9999 -9999 -9999 -9999 -9999 -9999 -

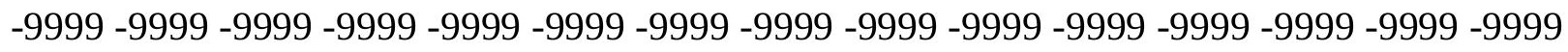

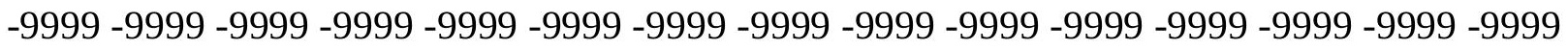
-9999 -9999 -9999 -9999 -9999 -9999 -9999 -9999 -9999 -9999 -9999 -9999 -9999 -9999 - -999 -9999 -9999 -9999 -9999 -9999 -9999 -9999 -9999 -9999 -9999 -9999 -9999 -9999 -9999 -9999 -

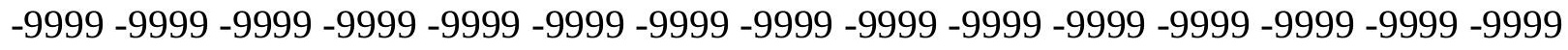

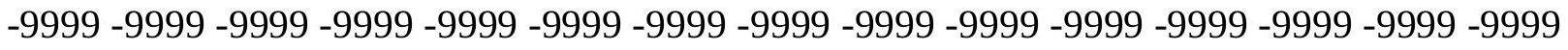
-9999 -9999 -9999 -9999 -9999 -9999 -9999 -9999 -9999 -9999 -9999 -9999 -9999 -9999 -9999 -9999 -9999 -9999 -9999 -9999 -9999 -9999 -9999 -9999-9999 -9999 -9999 -9999 -9999 -9999 -9999 -9999 -9999 -9999 -9999 -9999 -9999 -9999 -9999 -9999 -9999 -9999 -9999 -9999 -9999 -

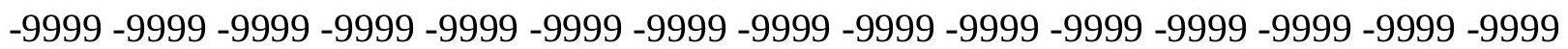


-9999 -9999 -9999 -9999 -9999 -9999 -9999 -9999 -9999 -9999 -9999 -9999 -9999 -9999 -9999 -9999 -9999 -9999 -9999 -9999 -9999 -9999 -9999 -9999 -9999 -9999 -9999 -9999 -9999 -9999 -

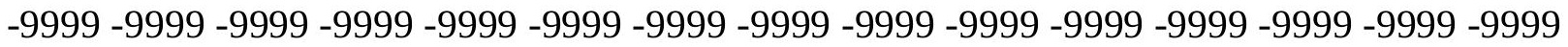
-9999 -9999 -9999 -9999 -9999 -9999 -9999 -9999 -9999 -9999 -9999 -9999 -9999 -9999 -9999 -9999 -9999 -9999 -9999 -9999 -9999 -9999 -9999 -9999-9999 -9999 -9999 -9999 -9999 -9999 -9999 -9999 -9999 -9999 -9999 -9999 -9999 -9999 -9999 -9999 -9999 -9999 -9999 -9999 -9999 -9999 -9999 -9999 -9999 -9999 -9999 -9999 -9999 -9999 -9999 -9999 -9999 -9999 -9999 -9999

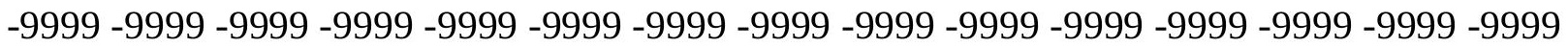

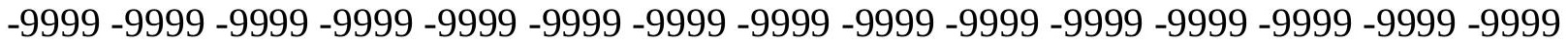
-9999 -9999 -9999 -9999 -9999 -9999 -9999 -9999 -9999 -9999 -9999 -9999 -9999 -9999 -9999 -9999 -9999 -9999 -9999 -9999 -9999 -9999 -9999 -9999 -9999 -9999 -9999 -9999 -9999 -9999 -9999 -9999 -9999 -9999 -9999 -9999 -9999 -9999 -9999 -9999 -9999 -9999 -9999 -9999 -9999 -9999 -9999 -9999 -9999 -9999 -9999 -9999 -9999 -9999 -9999 -9999 -9999 -9999 -9999 -9999 -

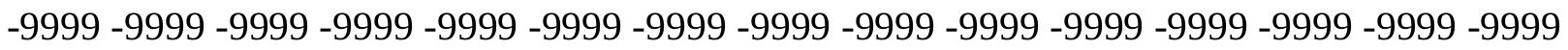
-9999 -9999 -9999 -9999 -9999 -9999 -9999 -9999 -9999 -9999 -9999 -9999 -9999 -9999 -9999 -

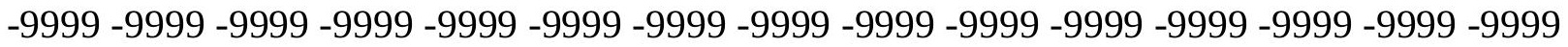
-9999 -9999 -9999 -9999 -9999 -9999 -9999 -9999 -9999 -9999 -9999 -9999 -9999 -9999 -9999 -9999 -9999 -9999 -9999 -9999 -9999 -9999 -9999 -9999 -9999 -9999 -9999 -9999 -9999 -9999 -9999 -9999 -9999 -9999 -9999 -9999 -9999 -9999 -9999 -9999 -9999 -9999 -9999 -9999 - -999 -

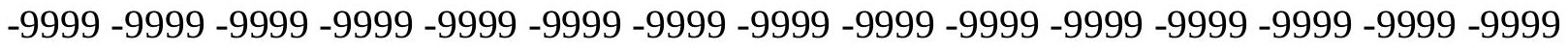

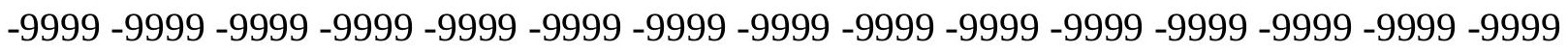
-9999 -9999 -9999 -9999 -9999 -9999 -9999 -9999 -9999 -9999 -9999 -9999 -9999 -9999 -9999 -9999 -9999 -9999 -9999 -9999 -9999 -9999 -9999 -9999 -9999 -9999 -9999 -9999 -9999 -9999 -9999 -9999 -9999 -9999 -9999 -9999 -9999 -9999 -9999 -9999 -9999 -9999 -9999 -9999 -9999 -

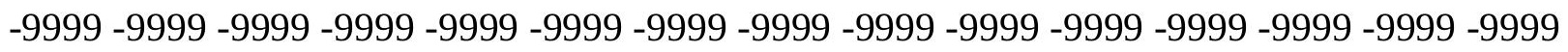
-9999 -9999 -9999 -9999 -9999 -9999 -9999 -9999 -9999 -9999 -9999 -9999 -9999 -9999 -9999 -9999 -9999 -9999 -9999 -9999 -9999 -9999 -9999 -9999 -9999 -9999 -9999 -9999 -9999 -9999 -

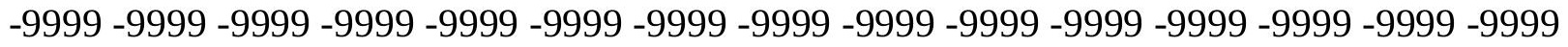
-9999 -9999 -9999 -9999 -9999 -9999 -9999 -9999 -9999 -9999 -9999 -9999 -9999 -9999 -9999 -9999 -9999 -9999 -9999 -9999 -9999 -9999 -9999 -9999 -9999 -9999 -9999 -9999 -9999 -999 -

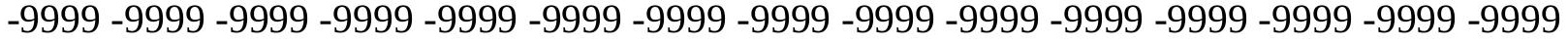
-9999 -9999 -9999 -9999 -9999 -9999 -9999 -9999 -9999 -9999 -9999 -9999 -9999 -9999 -9999 -

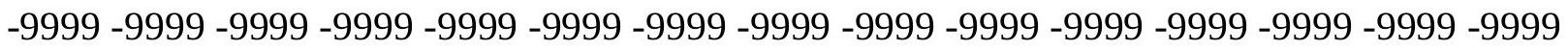

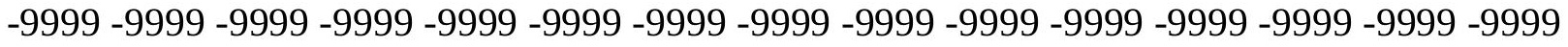

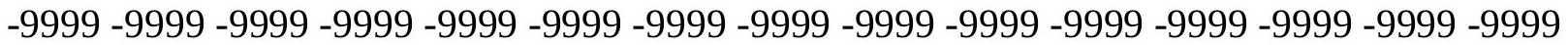

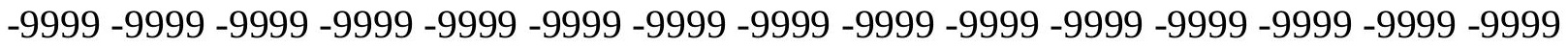

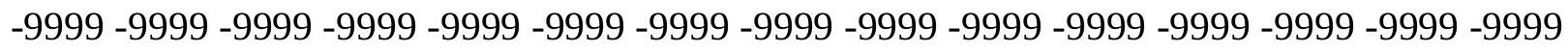

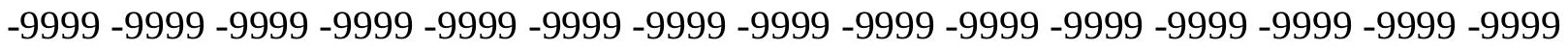

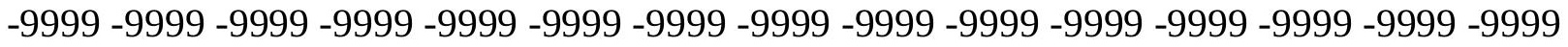
-9999 -9999 -9999 -9999 -9999 -9999 -9999 -9999 -9999 -9999 -9999 -9999 -9999 -9999 -9999 -

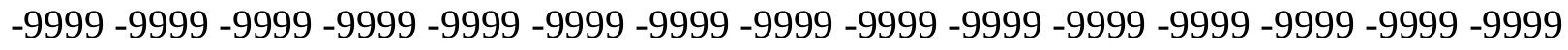

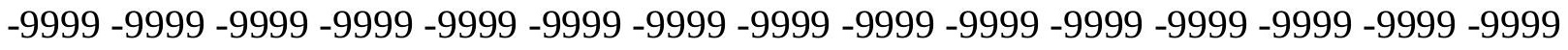
-9999 -9999 -9999 -9999 -9999 -9999 -9999 -9999 -9999 -9999 -9999 -9999 -9999 -9999 -9999 -9999 -9999 -9999 -9999 -9999 -9999 -9999 -9999 -9999 -9999 -9999 -9999 -9999 -9999 -9999 -9999 -9999 -9999 -9999 -9999 -9999 -9999 -9999 -9999 -9999 -9999 -9999 -9999 -9999 -

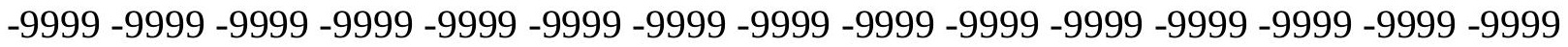


-9999 -9999 -9999 -9999 -9999 -9999 -9999 -9999 -9999 -9999 -9999 -9999 -9999 -9999 -9999 -9999 -9999 -9999 -9999 -9999 -9999 -9999 -9999 -9999 -9999 -9999 -9999 -9999 -9999 -9999 -

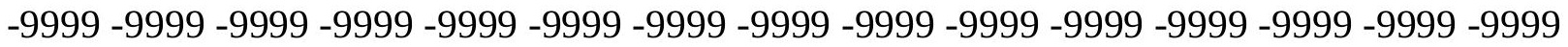
-9999 -9999 -9999 -9999 -9999 -9999 -9999 -9999 -9999 -9999 -9999 -9999 -9999 -9999 -9999 -9999 -9999 -9999 -9999 -9999 -9999 -9999 -9999 -9999-9999 -9999 -9999 -9999 -9999 -9999 -9999 -9999 -9999 -9999 -9999 -9999 -9999 -9999 -9999 -9999 -9999 -9999 -9999 -9999 -9999 -9999 -9999 -9999 -9999 -9999 -9999 -9999 -9999 -9999 -9999 -9999 -9999 -9999 -9999 -9999

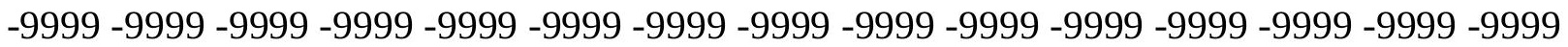

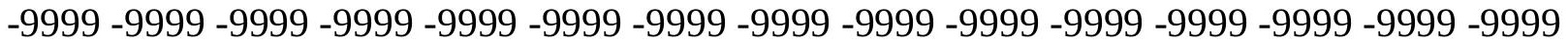
-9999 -9999 -9999 -9999 -9999 -9999 -9999 -9999 -9999 -9999 -9999 -9999 -9999 -9999 -9999 -9999 -9999 -9999 -9999 -9999 -9999 -9999 -9999 -9999 -9999 -9999 -9999 -9999 -9999 -9999 -9999 -9999 -9999 -9999 -9999 -9999 -9999 -9999 -9999 -9999 -9999 -9999 -9999 -9999 -9999 -9999 -9999 -9999 -9999 -9999 -9999 -9999 -9999 -9999 -9999 -9999 -9999 -9999 -9999 -9999 -

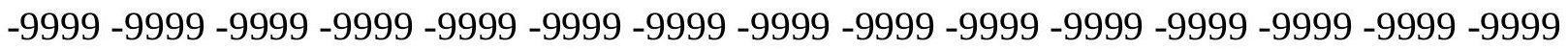
-9999 -9999 -9999 -9999 -9999 -9999 -9999 -9999 -9999 -9999 -9999 -9999 -9999 -9999 -9999 -

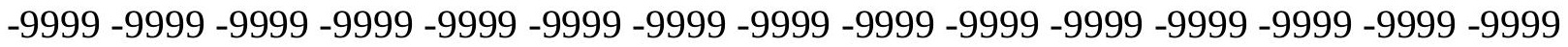
-9999 -9999 -9999 -9999 -9999 -9999 -9999 -9999 -9999 -9999 -9999 -9999 -9999 -9999 -9999 -9999 -9999 -9999 -9999 -9999 -9999 -9999 -9999 -9999 -9999 -9999 -9999 -9999 -9999 - 9999 -9999 -9999 -9999 -9999 -9999 -9999 -9999 -9999 -9999 -9999 -9999 -9999 -9999 -9999 -9999 -

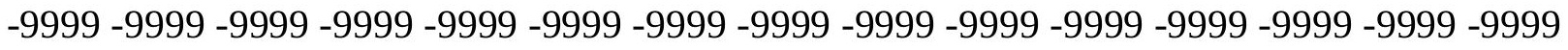

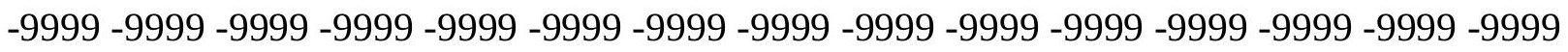
-9999 -9999 -9999 -9999 -9999 -9999 -9999 -9999 -9999 -9999 -9999 -9999 -9999 -9999 - 9999 -9999 -9999 -9999 -9999 -9999 -9999 -9999 -9999 -9999 -9999 -9999 -9999 -9999 -9999 -9999 -9999 -9999 -9999 -9999 -9999 -9999 -9999 -9999 -9999 -9999 -9999 -9999 -9999 -9999 -9999 -9999 -9999 -9999 -9999 -9999 -9999 -9999 -9999 -9999 -9999 -9999 -9999 -9999 -9999 -9999 -9999 -9999 -9999 -9999 -9999 -9999 -9999 -9999 -9999 -9999 -9999 -9999 -9999 -9999 -9999 -9999 -9999 -9999 -9999 -9999 -9999 -9999 -9999 -9999 -9999 -9999 -9999 -9999 -9999 -

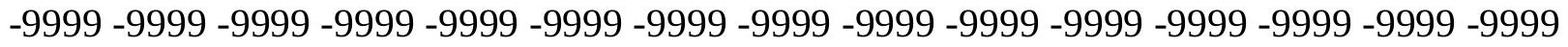
-9999 -9999 -9999 -9999 -9999 -9999 -9999 -9999 -9999 -9999 -9999 -9999 -9999 -9999 -9999 -9999 -9999 -9999 -9999 -9999 -9999 -9999 -9999 -9999 -9999 -9999 -9999 -9999 -9999 -999 -9999 -9999 -9999 -9999 -9999 -9999 -9999 -9999 -9999 -9999 -9999 -9999 -9999 -9999 -9999 -9999 -9999 -9999 -9999 -9999 -9999 -9999 -9999 -9999 -9999 -9999 -9999 -9999 -9999 -9999 -

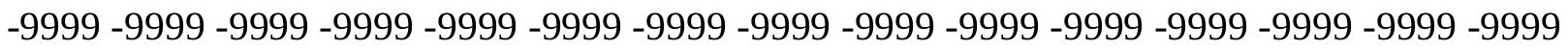

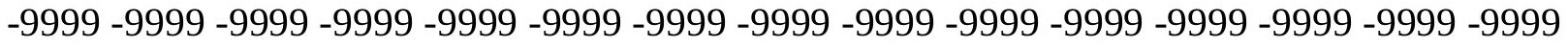

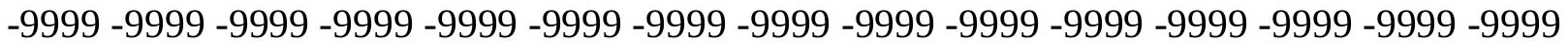

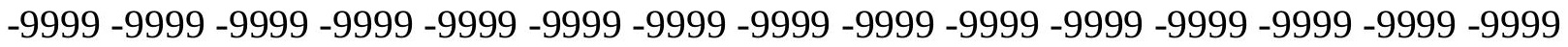

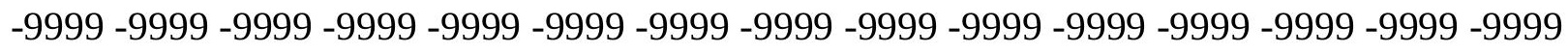

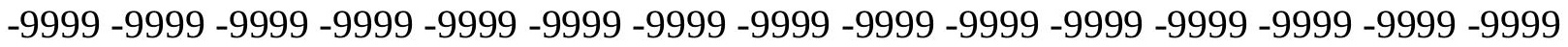

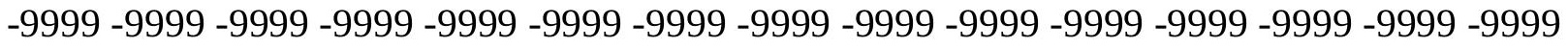
-9999 -9999 -9999 -9999 -9999 -9999 -9999 -9999 -9999 -9999 -9999 -9999 -9999 -9999 -9999 -

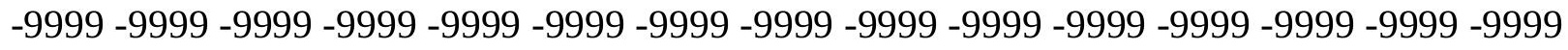

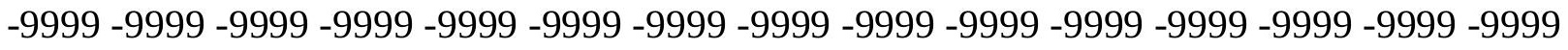
-9999 -9999 -9999 -9999 -9999 -9999 -9999 -9999 -9999 -9999 -9999 -9999 -9999 -9999 -9999 -9999 -9999 -9999 -9999 -9999 -9999 -9999 -9999 -9999-9999 -9999 -9999 -9999 -9999 -9999 -9999 -9999 -9999 -9999 -9999 -9999 -9999 -9999 -9999 -9999 -9999 -9999 -9999 -9999 -9999 -

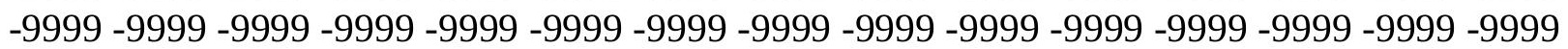


-9999 -9999 -9999 -9999 -9999 -9999 -9999 -9999 -9999 -9999 -9999 -9999 -9999 -9999 -9999 -9999 -9999 -9999 -9999 -9999 -9999 -9999 -9999 -9999 -9999 -9999 -9999 -9999 -9999 -9999 -9999 -9999 -9999 -9999 -9999 -9999 -9999 -9999 -9999 -9999 -9999 -9999 -9999 -9999 - 9999 -9999 -9999 -9999 -9999 -9999 -9999 -9999 -9999 -9999 -9999 -9999 -9999 -9999 -9999 -9999 -9999 -9999 -9999 -9999 -9999 -9999 -9999 -9999 -9999 -9999 -9999 -9999 -9999 -9999 -9999 -9999 -9999 -9999 -9999 -9999 -9999 -9999 -9999 -9999 -9999 -9999 -9999 -9999 -9999 -9999 -9999 -9999 -9999 -9999 -9999 -9999 -9999 -9999 -9999 -9999 -9999 -9999 -9999 -9999

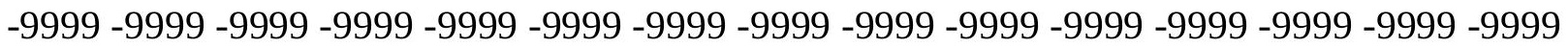

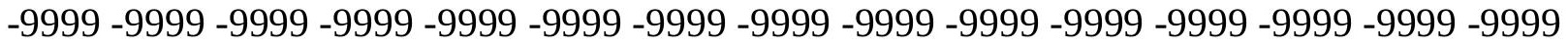
-9999 -9999 -9999 -9999 -9999 -9999 -9999 -9999 -9999 -9999 -9999 -9999 -9999 -9999 -9999 -9999 -9999 -9999 -9999 -9999 -9999 -9999 -9999 -9999 -9999 -9999 -9999 -9999 -9999 -9999 -9999 -9999 -9999 -9999 -9999 -9999 -9999 -9999 -9999 -9999 -9999 -9999 -9999 -9999 -9999 -9999 -9999 -9999 -9999 -9999 -9999 -9999 -9999 -9999 -9999 -9999 -9999 -9999 -9999 -9999 -9999 -9999 -9999 -9999 -9999 -9999 -9999 -9999 -9999 -9999 -9999 -9999 -9999 -9999 -9999 -9999 -9999 -9999 -9999 -9999 -9999 -9999 -9999 -9999 -9999 -9999 -9999 -9999 -9999 -9999 -

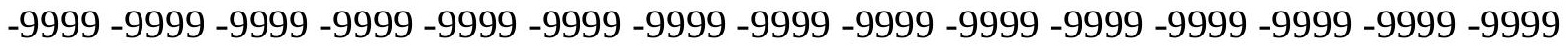
-9999 -9999 -9999 -9999 -9999 -9999 -9999 -9999 -9999 -9999 -9999 -9999 -9999 -9999 -9999 -9999 -9999 -9999 -9999 -9999 -9999 -9999 -9999 -9999 -9999 -9999 -9999 -9999 -9999 - 9999 -9999 -9999 -9999 -9999 -9999 -9999 -9999 -9999 -9999 -9999 -9999 -9999 -9999 -9999 -9999 -

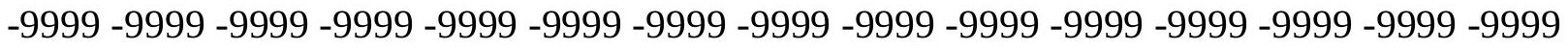

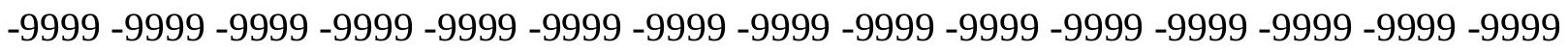

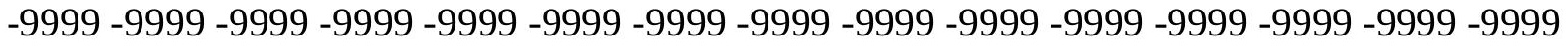
-9999 -9999 -9999 -9999 -9999 -9999 -9999 -9999 -9999 -9999 -9999 -9999 -9999 -9999 -9999 -9999 -9999 -9999 -9999 -9999 -9999 -9999 -9999 -9999 -9999 -9999 -9999 -9999 -9999 -9999 -

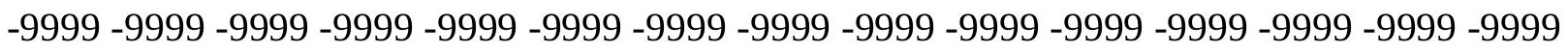
-9999 -9999 -9999 -9999 -9999 -9999 -9999 -9999 -9999 -9999 -9999 -9999 -9999 -9999 -9999 -9999 -9999 -9999 -9999 -9999 -9999 -9999 -9999 -9999 -9999 -9999 -9999 -9999 -9999 -9999 -

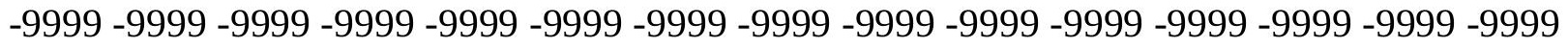
-9999 -9999 -9999 -9999 -9999 -9999 -9999 -9999 -9999 -9999 -9999 -9999 -9999 -9999 -9999 -9999 -9999 -9999 -9999 -9999 -9999 -9999 -9999 -9999 -9999 -9999 -9999 -9999 -9999 -999 -9999 -9999 -9999 -9999 -9999 -9999 -9999 -9999 -9999 -9999 -9999 -9999 -9999 -9999 -9999 -9999 -9999 -9999 -9999 -9999 -9999 -9999 -9999 -9999 -9999 -9999 -9999 -9999 -9999 -

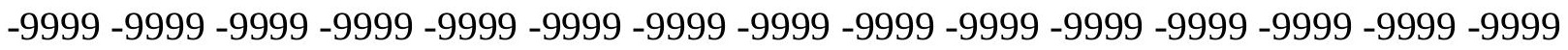

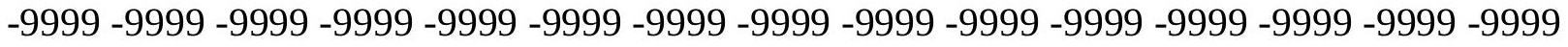

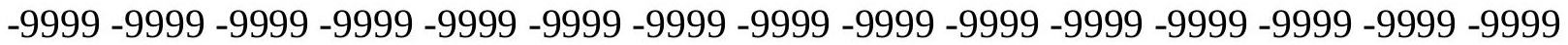

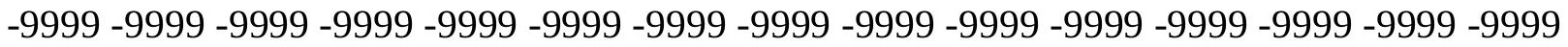

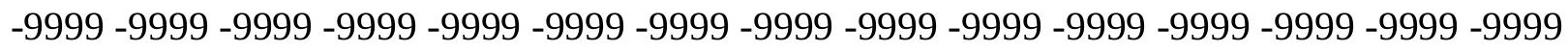

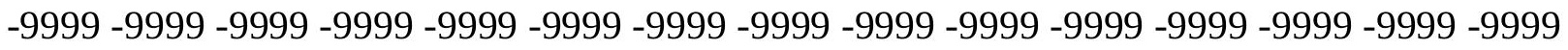

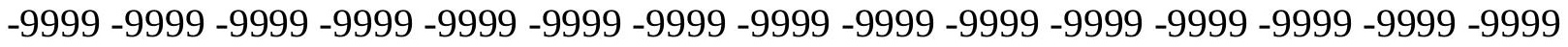
-9999 -9999 -9999 -9999 -9999 -9999 -9999 -9999 -9999 -9999 -9999 -9999 -9999 -9999 -9999 -

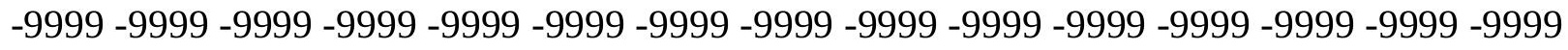

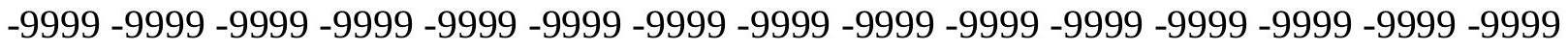
-9999 -9999 -9999 -9999 -9999 -9999 -9999 -9999 -9999 -9999 -9999 -9999 -9999 -9999 -9999 -9999 -9999 -9999 -9999 -9999 -9999 -9999 -9999 -9999-9999 -9999 -9999 -9999 -9999 -9999 -9999 -9999 -9999 -9999 -9999 -9999 -9999 -9999 -9999 -9999 -9999 -9999 -9999 -9999 -9999 -

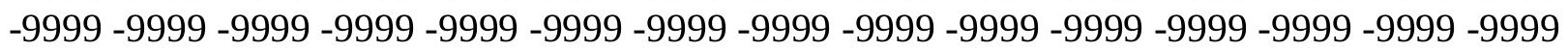


-9999 -9999 -9999 -9999 -9999 -9999 -9999 -9999 -9999 -9999 -9999 -9999 -9999 -9999 -9999 -9999 -9999 -9999 -9999 -9999 -9999 -9999 -9999 -9999 -9999 -9999 -9999 -9999 -9999 -9999 -

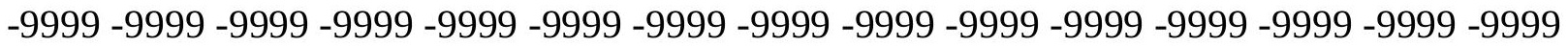
-9999 -9999 -9999 -9999 -9999 -9999 -9999 -9999 -9999 -9999 -9999 -9999 -9999 -9999 -9999 -9999 -9999 -9999 -9999 -9999 -9999 -9999 -9999 -9999-9999 -9999 -9999 -9999 -9999 -9999 -9999 -9999 -9999 -9999 -9999 -9999 -9999 -9999 -9999 -9999 -9999 -9999 -9999 -9999 -9999 -9999 -9999 -9999 -9999 -9999 -9999 -9999 -9999 -9999 -9999 -9999 -9999 -9999 -9999 -9999

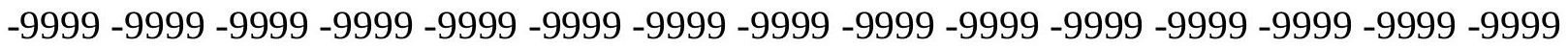

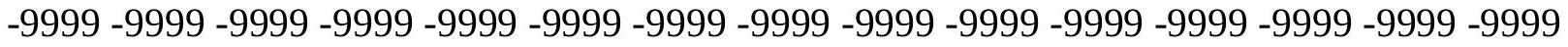

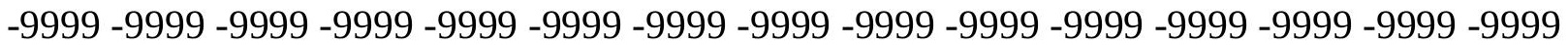
-9999 -9999 -9999 -9999 -9999 -9999 -9999 -9999 -9999 -9999 -9999 -9999 -9999 -9999 -9999 -9999 -9999 -9999 -9999 -9999 -9999 -9999 -9999 -9999 -9999 -9999 -9999 -9999 -9999 -9999 -9999 -9999 -9999 -9999 -9999 -9999 -9999 -9999 -9999 -9999 -9999 -9999 -9999 -9999 -

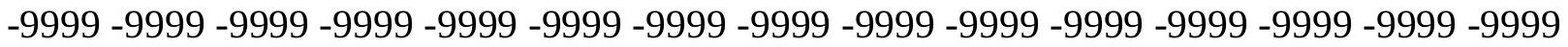
-9999 -9999 -9999 -9999 -9999 -9999 -9999 -9999 -9999 -9999 -9999 -9999 -9999 -9999 -9999 -

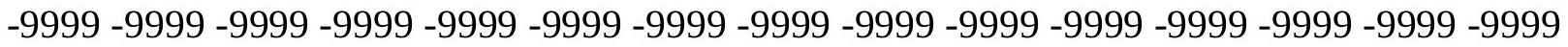
-9999 -9999 -9999 -9999 -9999 -9999 -9999 -9999 -9999 -9999 -9999 -9999 -9999 -9999 -9999 -9999 -9999 -9999 -9999 -9999 -9999 -9999 -9999 -9999 -9999 -9999 -9999 -9999 -9999 -9999 -9999 -9999 -9999 -9999 -9999 -9999 -9999 -9999 -9999 -9999 -9999 -9999 -9999 -9999 -9999 -

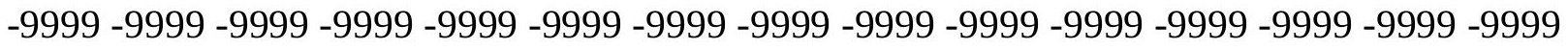

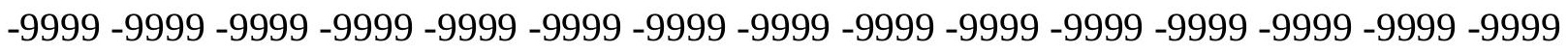
-9999 -9999 -9999 -9999 -9999 -9999 -9999 -9999 -9999 -9999 -9999 -9999 -9999 -9999 -9999 -9999 -9999 -9999 -9999 -9999 -9999 -9999 -9999 -9999 -9999 -9999 -9999 -9999 -9999 -9999 -9999 -9999 -9999 -9999 -9999 -9999 -9999 -9999 -9999 -9999 -9999 -9999 -9999 -9999 -9999 -

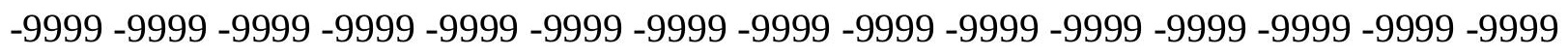
-9999 -9999 -9999 -9999 -9999 -9999 -9999 -9999 -9999 -9999 -9999 -9999 -9999 -9999 -9999 -9999 -9999 -9999 -9999 -9999 -9999 -9999 -9999 -9999 -9999 -9999 -9999 -9999 -9999 -9999 -

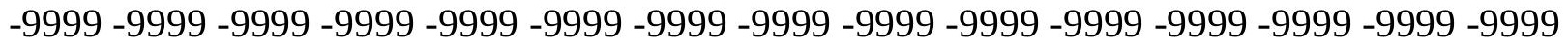
-9999 -9999 -9999 -9999 -9999 -9999 -9999 -9999 -9999 -9999 -9999 -9999 -9999 -9999 -9999 -9999 -9999 -9999 -9999 -9999 -9999 -9999 -9999 -9999 -9999 -9999 -9999 -9999 -9999 -999 -9999 -9999 -9999 -9999 -9999 -9999 -9999 -9999 -9999 -9999 -9999 -9999 -9999 -9999 -9999 -9999 -9999 -9999 -9999 -9999 -9999 -9999 -9999 -9999 -9999 -9999 -9999 -9999 -9999 -9999 -

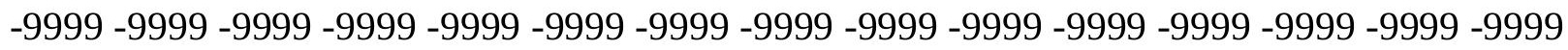

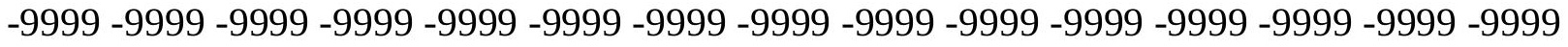

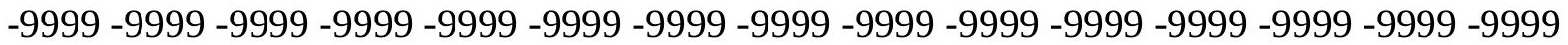
-9999 -9999 -9999 -9999 -9999 -9999 -9999 -9999 -9999 -9999 -9999 -9999 -9999 -9999 -9999 -

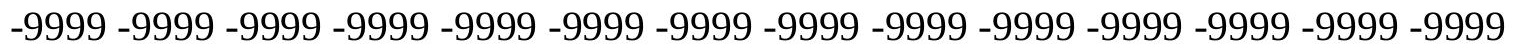

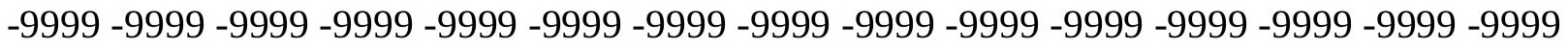
-9999 -9999 -9999 -9999 -9999 -9999 -9999 -9999 -9999 -9999 -9999 -9999 -9999 - 9999 - -999 -9999 -9999 -9999 -9999 -9999 -9999 -9999 -9999 -9999 -9999 -9999 -9999 -9999 -9999 -9999 -

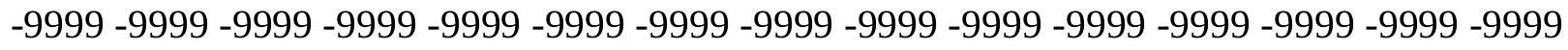

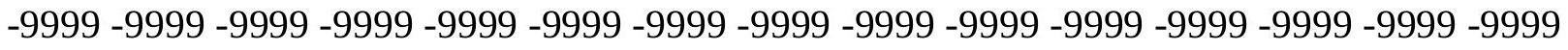
-9999 -9999 -9999 -9999 -9999 -9999 -9999 -9999 -9999 -9999 -9999 -9999 -9999 -9999 -9999 -9999 -9999 -9999 -9999 -9999 -9999 -9999 -9999 -9999-9999 -9999 -9999 -9999 -9999 -9999 -9999 -9999 -9999 -9999 -9999 -9999 -9999 -9999 -9999 -9999 -9999 -9999 -9999 -9999 -9999 -

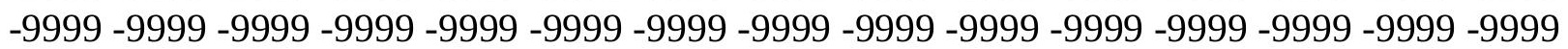


-9999 -9999 -9999 -9999 -9999 -9999 -9999 -9999 -9999 -9999 -9999 -9999 -9999 -9999 -9999 -9999 -9999 -9999 -9999 -9999 -9999 -9999 -9999 -9999 -9999 -9999 -9999 -9999 -9999 -9999 -

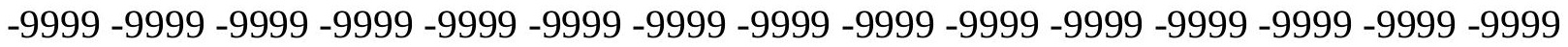
-9999 -9999 -9999 -9999 -9999 -9999 -9999 -9999 -9999 -9999 -9999 -9999 -9999 -9999 -9999 -9999 -9999 -9999 -9999 -9999 -9999 -9999 -9999 -9999-9999 -9999 -9999 -9999 -9999 -9999 -9999 -9999 -9999 -9999 -9999 -9999 -9999 -9999 -9999 -9999 -9999 -9999 -9999 -9999 -9999 -9999 -9999 -9999 -9999 -9999 -9999 -9999 -9999 -9999 -9999 -9999 -9999 -9999 -9999 -9999

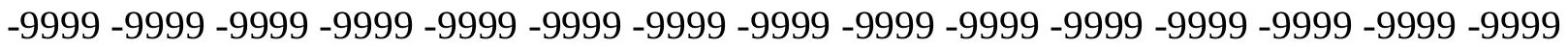

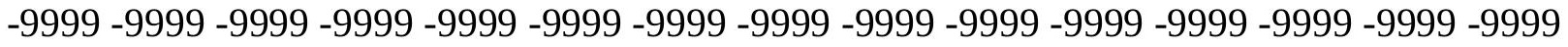
-9999 -9999 -9999 -9999 -9999 -9999 -9999 -9999 -9999 -9999 -9999 -9999 -9999 -9999 -9999 -9999 -9999 -9999 -9999 -9999 -9999 -9999 -9999 -9999 -9999 -9999 -9999 -9999 -9999 -9999 -9999 -9999 -9999 -9999 -9999 -9999 -9999 -9999 -9999 -9999 -9999 -9999 -9999 -9999 -9999 -9999 -9999 -9999 -9999 -9999 -9999 -9999 -9999 -9999 -9999 -9999 -9999 -9999 -9999 -9999 -9999 -9999 -9999 -9999 -9999 -9999 -9999 -9999 -9999 -9999 -9999 -9999 -9999 -9999 -9999 -9999 -9999 -9999 -9999 -9999 -9999 -9999 -9999 -9999 -9999 -9999 -9999 -9999 -9999 -9999 -

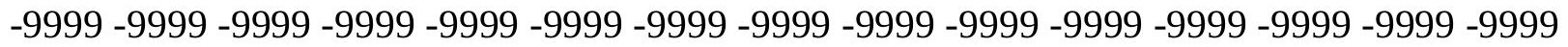
-9999 -9999 -9999 -9999 -9999 -9999 -9999 -9999 -9999 -9999 -9999 -9999 -9999 -9999 -9999 -9999 -9999 -9999 -9999 -9999 -9999 -9999 -9999 -9999 -9999 -9999 -9999 -9999 -9999 -9999 -9999 -9999 -9999 -9999 -9999 -9999 -9999 -9999 -9999 -9999 -9999 -9999 -9999 -9999 -

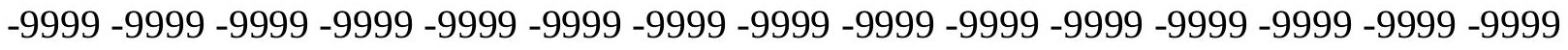
-9999 -9999 -9999 -9999 -9999 -9999 -9999 -9999 -9999 -9999 -9999 -9999 -9999 -9999 -9999 -999 -

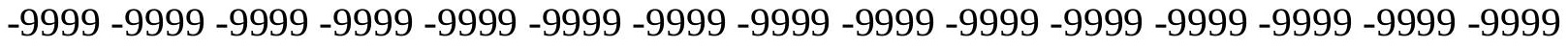
-9999 -9999 -9999 -9999 -9999 -9999 -9999 -9999 -9999 -9999 -9999 -9999 -9999 -9999 -9999 -9999 -9999 -9999 -9999 -9999 -9999 -9999 -9999 -9999 -9999 -9999 -9999 -9999 -9999 -9999 -9999 -9999 -9999 -9999 -9999 -9999 -9999 -9999 -9999 -9999 -9999 -9999 -9999 -9999 -9999 -9999 -9999 -9999 -9999 -9999 -9999 -9999 -9999 -9999 -9999 -9999 -9999 -9999 -9999 -9999 -9999 -9999 -9999 -9999 -9999 -9999 -9999 -9999 -9999 -9999 -9999 -9999 -9999 -9999 -9999 -

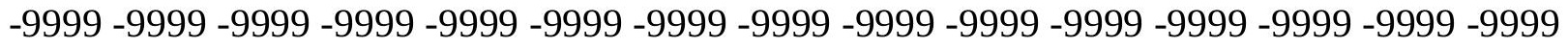
-9999 -9999 -9999 -9999 -9999 -9999 -9999 -9999 -9999 -9999 -9999 -9999 -9999 -9999 -9999 -9999 -9999 -9999 -9999 -9999 -9999 -9999 -9999 -9999 -9999 -9999 -9999 -9999 -9999 -999 -9999 -9999 -9999 -9999 -9999 -9999 -9999 -9999 -9999 -9999 -9999 -9999 -9999 -9999 -9999 -9999 -9999 -9999 -9999 -9999 -9999 -9999 -9999 -9999 -9999 -9999 -9999 -9999 -9999 -9999 -

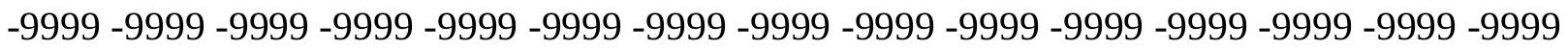

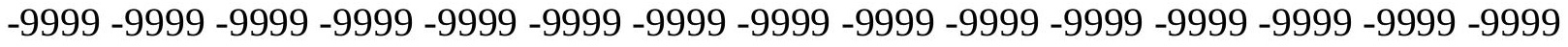

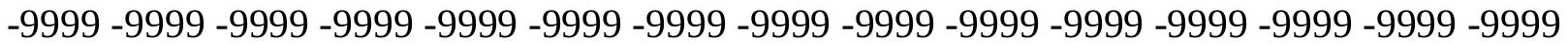
-9999 -9999 -9999 -9999 -9999 -9999 -9999 -9999 -9999 -9999 -9999 -9999 -9999 -9999 -9999

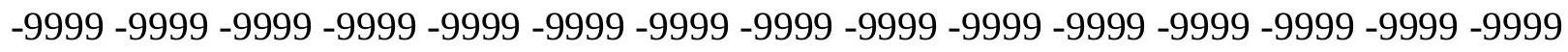

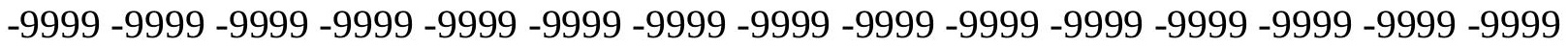
-9999 -9999 -9999 -9999 -9999 -9999 -9999 -9999 -9999 -9999 -9999 -9999 -9999 - 9999 - -999 -9999 -9999 -9999 -9999 -9999 -9999 -9999 -9999 -9999 -9999 -9999 -9999 -9999 -9999 -9999 -

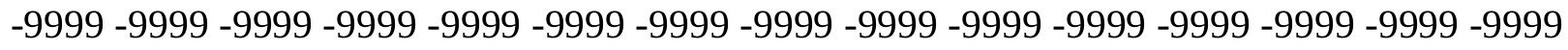

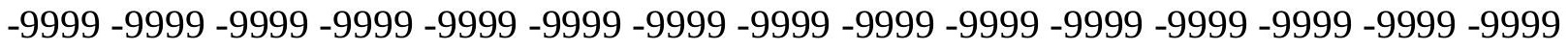
-9999 -9999 -9999 -9999 -9999 -9999 -9999 -9999 -9999 -9999 -9999 -9999 -9999 -9999 -9999 -9999 -9999 -9999 -9999 -9999 -9999 -9999 -9999 -9999 -9999 -9999 -9999 -9999 -9999 -9999 -9999 -9999 -9999 -9999 -9999 -9999 -9999 -9999 -9999 -9999 -9999 -9999 -9999 -9999 -

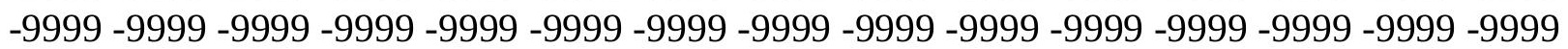


-9999 -9999 -9999 -9999 -9999 -9999 -9999 -9999 -9999 -9999 -9999 -9999 -9999 -9999 -9999 -9999 -9999 -9999 -9999 -9999 -9999 -9999 -9999 -9999 -9999 -9999 -9999 -9999 -9999 -9999 -9999 -9999 -9999 -9999 -9999 -9999 -9999 -9999 -9999 -9999 -9999 -9999 -9999 -9999 - 9999 -9999 -9999 -9999 -9999 -9999 -9999 -9999 -9999 -9999 -9999 -9999 -9999 -9999 -9999 -9999 -9999 -9999 -9999 -9999 -9999 -9999 -9999 -9999 -9999-9999 -9999 -9999 -9999 -9999 -9999 -9999 -9999 -9999 -9999 -9999 -9999 -9999 -9999 -9999 -9999 -9999 -9999 -9999 -9999 -9999 -9999 -9999 -9999 -9999 -9999 -9999 -9999 -9999 -9999 -9999 -9999 -9999 -9999 -9999 -9999

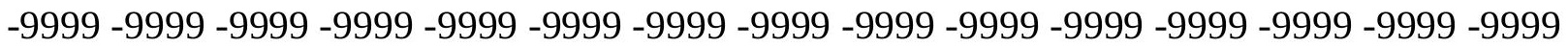

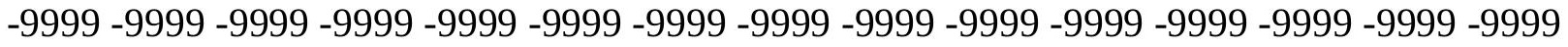
-9999 -9999 -9999 -9999 -9999 -9999 -9999 -9999 -9999 -9999 -9999 -9999 -9999 -9999 -9999 -9999 -9999 -9999 -9999 -9999 -9999 -9999 -9999 -9999 -9999 -9999 -9999 -9999 -9999 -9999 -9999 -9999 -9999 -9999 -9999 -9999 -9999 -9999 -9999 -9999 -9999 -9999 -9999 -9999 -9999 -9999 -9999 -9999 -9999 -9999 -9999 -9999 -9999 -9999 -9999 -9999 -9999 -9999 -9999 -9999 -

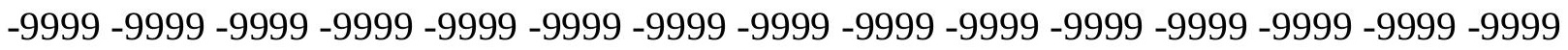
-9999 -9999 -9999 -9999 -9999 -9999 -9999 -9999 -9999 -9999 -9999 -9999 -9999 -9999 -9999 -

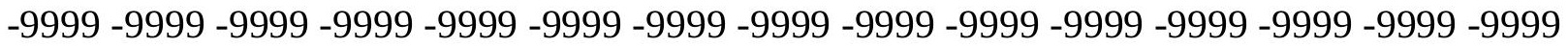
-9999 -9999 -9999 -9999 -9999 -9999 -9999 -9999 -9999 -9999 -9999 -9999 -9999 -9999 -9999 -9999 -9999 -9999 -9999 -9999 -9999 -9999 -9999 -9999 -9999 -9999 -9999 -9999 -9999 -9999 -9999 -9999 -9999 -9999 -9999 -9999 -9999 -9999 -9999 -9999 -9999 -9999 -9999 -9999 -9999 -

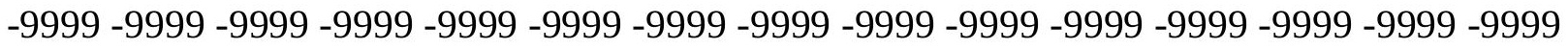
-9999 -9999 -9999 -9999 -9999 -9999 -9999 -9999 -9999 -9999 -9999 -9999 -9999 -9999 -9999 -999 -9999 -9999 -9999 -9999 -9999 -9999 -9999 -9999 -9999 -9999 -9999 -9999 -9999 -9999 - 9999 -9999 -9999 -9999 -9999 -9999 -9999 -9999 -9999 -9999 -9999 -9999 -9999 -9999 -9999 -

-9999 -9999 -9999 -9999 -9999 -9999 -9999 -9999 -9999 -9999 -9999 -9999 -9999 -9999 -9999 -

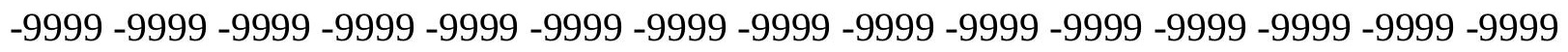
-9999 -9999 -9999 -9999 -9999 -9999 -9999 -9999 -9999 -9999 -9999 -9999 -9999 -9999 -9999 -9999 -9999 -9999 -9999 -9999 -9999 -9999 -9999 -9999 -9999 -9999 -9999 -9999 -9999 -9999 -

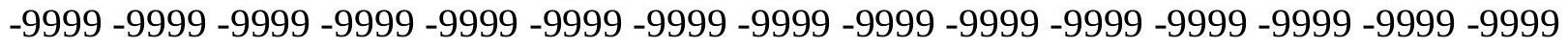
-9999 -9999 -9999 -9999 -9999 -9999 -9999 -9999 -9999 -9999 -9999 -9999 -9999 -9999 -9999 -9999 -9999 -9999 -9999 -9999 -9999 -9999 -9999 -9999 -9999 -9999 -9999 -9999 -9999 -999 -

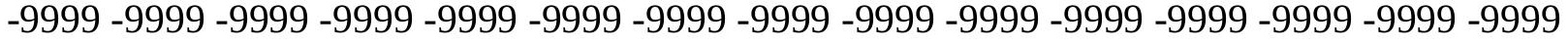
-9999 -9999 -9999 -9999 -9999 -9999 -9999 -9999 -9999 -9999 -9999 -9999 -9999 -9999 -9999 -

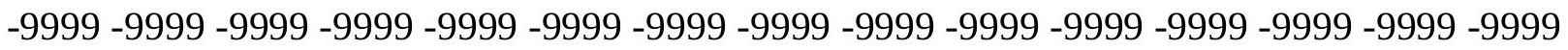

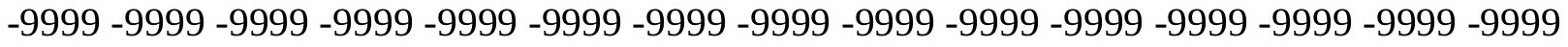

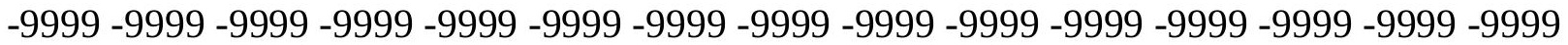

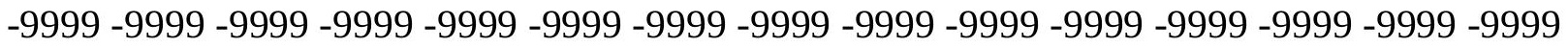

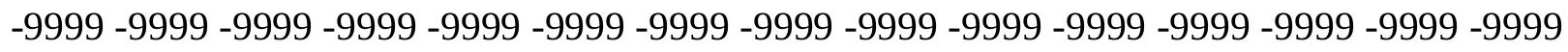

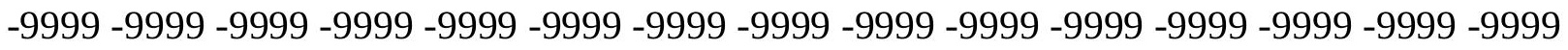

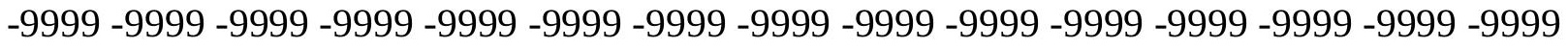
-9999 -9999 -9999 -9999 -9999 -9999 -9999 -9999 -9999 -9999 -9999 -9999 -9999 -9999 -9999 -

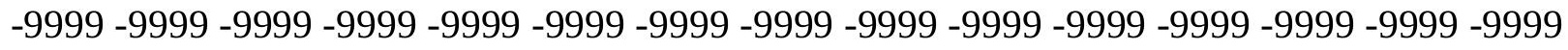

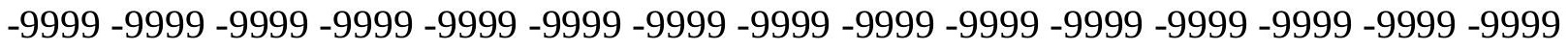
-9999 -9999 -9999 -9999 -9999 -9999 -9999 -9999 -9999 -9999 -9999 -9999 -9999 -9999 -9999 -9999 -9999 -9999 -9999 -9999 -9999 -9999 -9999 -9999-9999 -9999 -9999 -9999 -9999 -9999 -9999 -9999 -9999 -9999 -9999 -9999 -9999 -9999 -9999 -9999 -9999 -9999 -9999 -9999 -9999 -

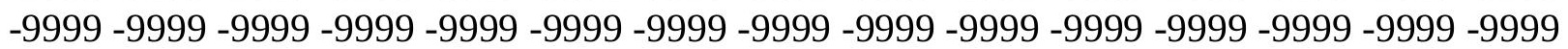


-9999 -9999 -9999 -9999 -9999 -9999 -9999 -9999 -9999 -9999 -9999 -9999 -9999 -9999 -9999 -9999 -9999 -9999 -9999 -9999 -9999 -9999 -9999 -9999 -9999 -9999 -9999 -9999 -9999 -9999 -9999 -9999 -9999 -9999 -9999 -9999 -9999 -9999 -9999 -9999 -9999 -9999 -9999 -9999 -9999 -9999 -9999 -9999 -9999 -9999 -9999 -9999 -9999 -9999 -9999 -9999 -9999 -9999 -9999 -9999 -9999 -9999 -9999 -9999 -9999 -9999 -9999 -9999-9999 -9999 -9999 -9999 -9999 -9999 -9999 -9999 -9999 -9999 -9999 -9999 -9999 -9999 -9999 -9999 -9999 -9999 -9999 -9999 -9999 -9999 -9999 -9999 -9999 -9999 -9999 -9999 -9999 -9999 -9999 -9999 -9999 -9999 -9999 -9999

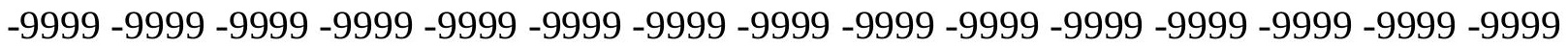

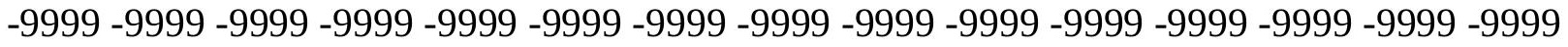
-9999 -9999 -9999 -9999 -9999 -9999 -9999 -9999 -9999 -9999 -9999 -9999 -9999 -9999 -9999 -9999 -9999 -9999 -9999 -9999 -9999 -9999 -9999 -9999 -9999 -9999 -9999 -9999 -9999 -9999 -9999 -9999 -9999 -9999 -9999 -9999 -9999 -9999 -9999 -9999 -9999 -9999 -9999 -9999 -9999 -9999 -9999 -9999 -9999 -9999 -9999 -9999 -9999 -9999 -9999 -9999 -9999 -9999 -9999 -9999 -

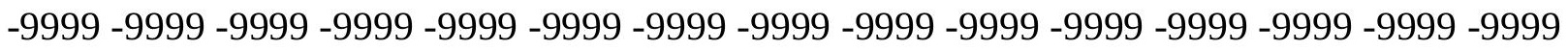
-9999 -9999 -9999 -9999 -9999 -9999 -9999 -9999 -9999 -9999 -9999 -9999 -9999 -9999 -9999 -

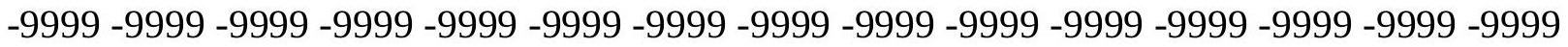
-9999 -9999 -9999 -9999 -9999 -9999 -9999 -9999 -9999 -9999 -9999 -9999 -9999 -9999 -9999 -9999 -9999 -9999 -9999 -9999 -9999 -9999 -9999 -9999 -9999 -9999 -9999 -9999 -9999 -9999 -9999 -9999 -9999 -9999 -9999 -9999 -9999 -9999 -9999 -9999 -9999 -9999 -9999 -9999 -9999 -

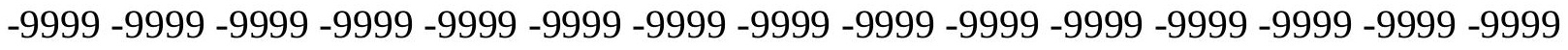

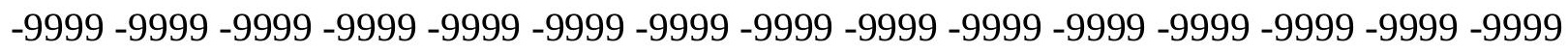
-9999 -9999 -9999 -9999 -9999 -9999 -9999 -9999 -9999 -9999 -9999 -9999 -9999 -9999 -9999 -9999 -9999 -9999 -9999 -9999 -9999 -9999 -9999 -9999 -9999 -9999 -9999 -9999 -9999 -9999 -9999 -9999 -9999 -9999 -9999 -9999 -9999 -9999 -9999 -9999 -9999 -9999 -9999 -9999 -9999 -

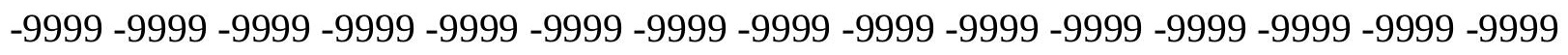
-9999 -9999 -9999 -9999 -9999 -9999 -9999 -9999 -9999 -9999 -9999 -9999 -9999 -9999 -9999 -9999 -9999 -9999 -9999 -9999 -9999 -9999 -9999 -9999 -9999 -9999 -9999 -9999 -9999 -9999 -

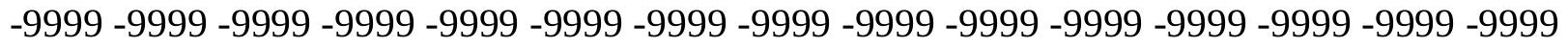
-9999 -9999 -9999 -9999 -9999 -9999 -9999 -9999 -9999 -9999 -9999 -9999 -9999 -9999 -9999 -9999 -9999 -9999 -9999 -9999 -9999 -9999 -9999 -9999 -9999 -9999 -9999 -9999 - -999 -

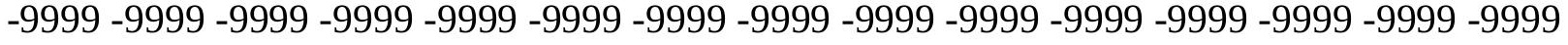
-9999 -9999 -9999 -9999 -9999 -9999 -9999 -9999 -9999 -9999 -9999 -9999 -9999 -9999 -9999 -

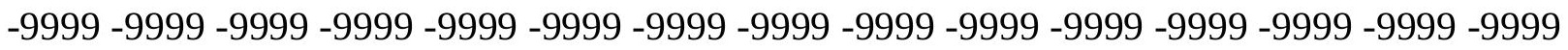

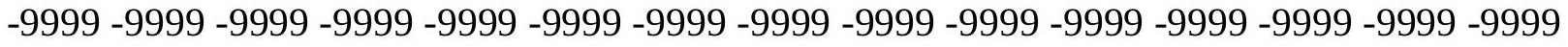

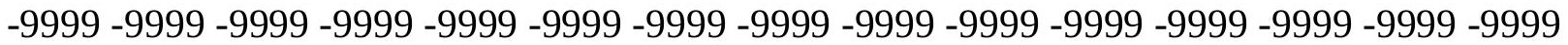

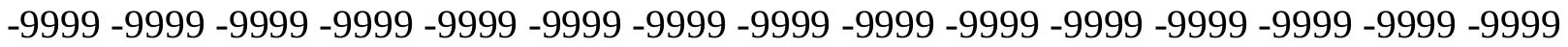

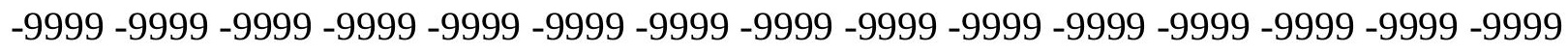

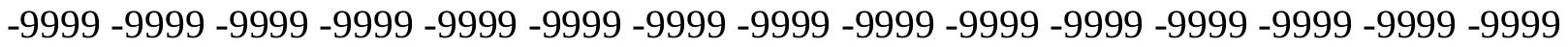

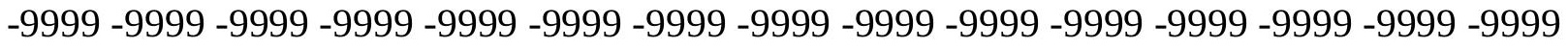
-9999 -9999 -9999 -9999 -9999 -9999 -9999 -9999 -9999 -9999 -9999 -9999 -9999 -9999 -9999 -

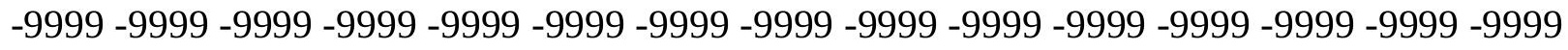

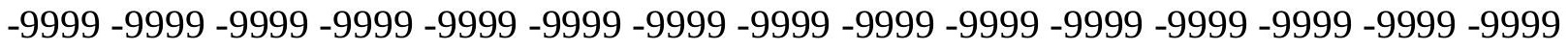
-9999 -9999 -9999 -9999 -9999 -9999 -9999 -9999 -9999 -9999 -9999 -9999 -9999 -9999 -9999 -9999 -9999 -9999 -9999 -9999 -9999 -9999 -9999 -9999-9999 -9999 -9999 -9999 -9999 -9999 -9999 -9999 -9999 -9999 -9999 -9999 -9999 -9999 -9999 -9999 -9999 -9999 -9999 -9999 -9999 -

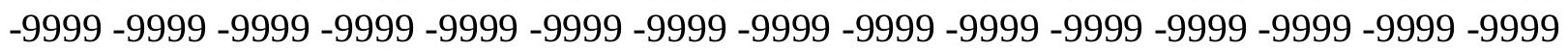


-9999 -9999 -9999 -9999 -9999 -9999 -9999 -9999 -9999 -9999 -9999 -9999 -9999 -9999 -9999 -9999 -9999 -9999 -9999 -9999 -9999 -9999 -9999 -9999 -9999 -9999 -9999 -9999 -9999 -9999 -

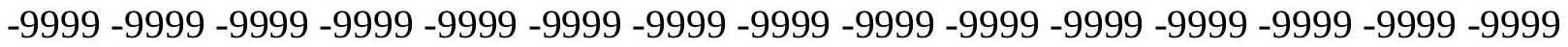
-9999 -9999 -9999 -9999 -9999 -9999 -9999 -9999 -9999 -9999 -9999 -9999 -9999 -9999 -9999 -9999 -9999 -9999 -9999 -9999 -9999 -9999 -9999 -9999-9999 -9999 -9999 -9999 -9999 -9999 -9999 -9999 -9999 -9999 -9999 -9999 -9999 -9999 -9999 -9999 -9999 -9999 -9999 -9999 -9999 -9999 -9999 -9999 -9999 -9999 -9999 -9999 -9999 -9999 -9999 -9999 -9999 -9999 -9999 -9999

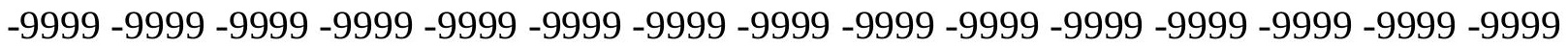
-9999 -9999 -9999 -9999 -9999 -9999 -9999 -9999 -9999 -9999 -9999 -9999 -9999 -9999 -9999 -9999 -9999 -9999 -9999 -9999 -9999 -9999 -9999 -9999 -9999 -9999 -9999 -9999 -9999

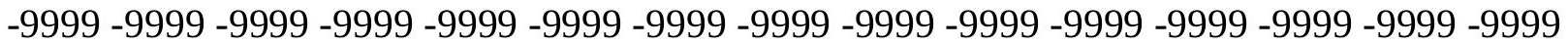
-9999 -9999 -9999 -9999 -9999 -9999 -9999 -9999 -9999 -9999 -9999 -9999 -9999 -9999 -9999 -9999 -9999 -9999 -9999 -9999 -9999 -9999 -9999 -9999 -9999 -9999 -9999 -9999 -9999 -9999 -9999 -9999 -9999 -9999 -9999 -9999 -9999 -9999 -9999 -9999 -9999 -9999 -9999 -9999 - 9999 -9999 -9999 -9999 -9999 -9999 -9999 -9999 -9999 -9999 -9999 -9999 -9999 -9999 -9999 -9999

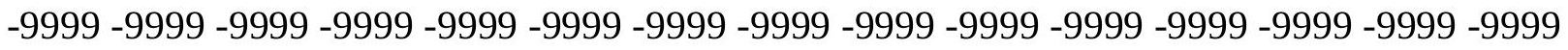
-9999 -9999 -9999 -9999 -9999 -9999 -9999 -9999 -9999 -9999 -9999 -9999 -9999 -9999 -9999 -9999 -9999 -9999 -9999 -9999 -9999 -9999 -9999 -9999 -9999 -9999 -9999 -9999 -9999 -9999 -9999 -9999 -9999 -9999 -9999 -9999 -9999 -9999 -9999 -9999 -9999 -9999 -9999 -9999 -9999 -

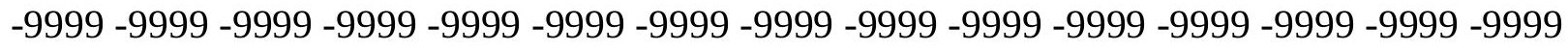

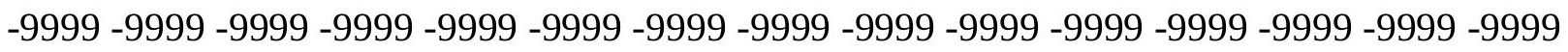
-9999 -9999 -9999 -9999 -9999 -9999 -9999 -9999 -9999 -9999 -9999 -9999 -9999 -9999 -9999 -9999 -9999 -9999 -9999 -9999 -9999 -9999 -9999 -9999 -9999 -9999 -9999 -9999 -9999 -9999 -9999 -9999 -9999 -9999 -9999 -9999 -9999 -9999 -9999 -9999 -9999 -9999 -9999 -9999 -9999 -

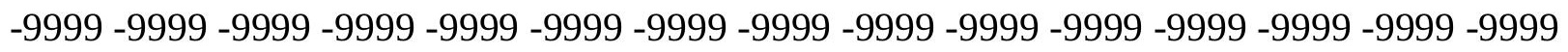
-9999 -9999 -9999 -9999 -9999 -9999 -9999 -9999 -9999 -9999 -9999 -9999 -9999 -9999 -9999 -9999 -9999 -9999 -9999 -9999 -9999 -9999 -9999 -9999 -9999 -9999 -9999 -9999 -9999 -9999 -

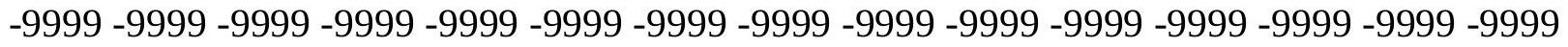
-9999 -9999 -9999 -9999 -9999 -9999 -9999 -9999 -9999 -9999 -9999 -9999 -9999 -9999 -9999 -9999 -9999 -9999 -9999 -9999 -9999 -9999 -9999 -9999 -9999 -9999 -9999 -9999 -9999 -999 -9999 -9999 -9999 -9999 -9999 -9999 -9999 -9999 -9999 -9999 -9999 -9999 -9999 -9999 -9999 -9999 -9999 -9999 -9999 -9999 -9999 -9999 -9999 -9999 -9999 -9999 -9999 -9999 -9999 -9999 -

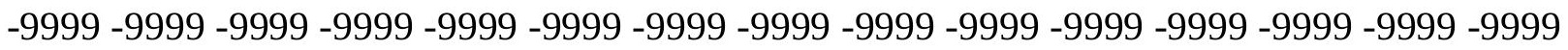

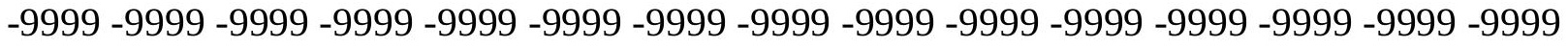
-9999 -9999 -9999 -9999 -9999 -9999 -9999 -9999 -9999 -9999 -9999 -9999 -9999 -9999 -

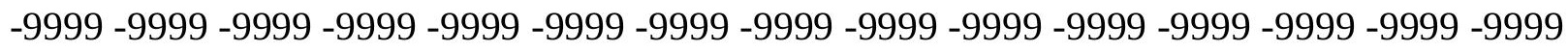

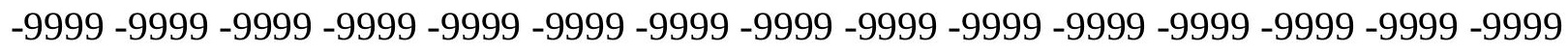

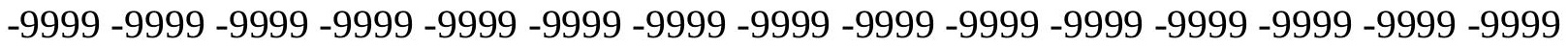
-9999 -9999 -9999 -9999 -9999 -9999 -9999 -9999 -9999 -9999 -9999 -9999 -9999 - 9999 - -999 -9999 -9999 -9999 -9999 -9999 -9999 -9999 -9999 -9999 -9999 -9999 -9999 -9999 -9999 -9999 -

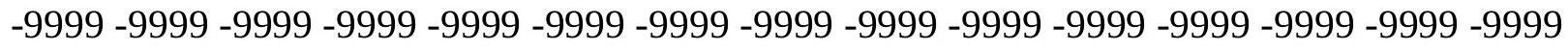

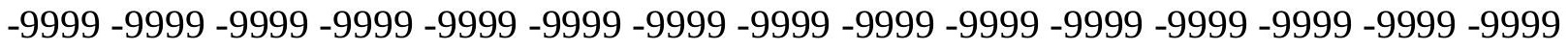
-9999 -9999 -9999 -9999 -9999 -9999 -9999 -9999 -9999 -9999 -9999 -9999 -9999 -9999 -9999 -9999 -9999 -9999 -9999 -9999 -9999 -9999 -9999 -9999-9999 -9999 -9999 -9999 -9999 -9999 -9999 -9999 -9999 -9999 -9999 -9999 -9999 -9999 -9999 -9999 -9999 -9999 -9999 -9999 -9999 -

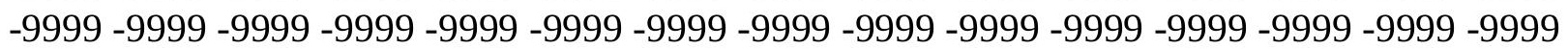


-9999 -9999 -9999 -9999 -9999 -9999 -9999 -9999 -9999 -9999 -9999 -9999 -9999 -9999 -9999 -9999 -9999 -9999 -9999 -9999 -9999 -9999 -9999 -9999 -9999 -9999 -9999 -9999 -9999 -9999 -

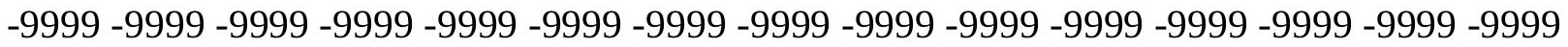
-9999 -9999 -9999 -9999 -9999 -9999 -9999 -9999 -9999 -9999 -9999 -9999 -9999 -9999 -9999 -9999 -9999 -9999 -9999 -9999 -9999 -9999 -9999 -9999-9999 -9999 -9999 -9999 -9999 -9999 -9999 -9999 -9999 -9999 -9999 -9999 -9999 -9999 -9999 -9999 -9999 -9999 -9999 -9999 -9999 -9999 -9999 -9999 -9999 -9999 -9999 -9999 -9999 -9999 -9999 -9999 -9999 -9999 -9999 -9999

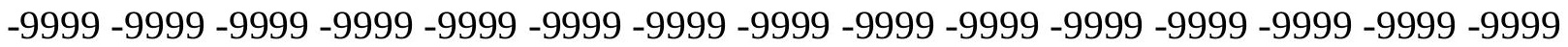

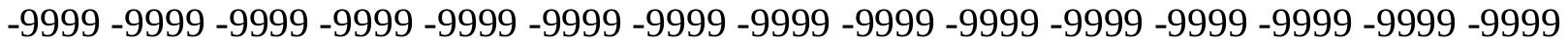
-9999 -9999 -9999 -9999 -9999 -9999 -9999 -9999 -9999 -9999 -9999 -9999 -9999 -9999 -9999 -9999 -9999 -9999 -9999 -9999 -9999 -9999 -9999 -9999 -9999 -9999 -9999 -9999 -9999 -9999 -9999 -9999 -9999 -9999 -9999 -9999 -9999 -9999 -9999 -9999 -9999 -9999 -9999 -9999 -9999 -9999 -9999 -9999 -9999 -9999 -9999 -9999 -9999 -9999 -9999 -9999 -9999 -9999 -9999 -9999 -9999 -9999 -9999 -9999 -9999 -9999 -9999 -9999 -9999 -9999 -9999 -9999 -9999 -9999 -9999 -9999 -9999 -9999 -9999 -9999 -9999 -9999 -9999 -9999 -9999 -9999 -9999 -9999 -9999 -9999 -9999 -9999 -9999 -9999 -9999 -9999 -9999 -9999 -9999 -9999 -9999 -9999 - 9999 - -999 -

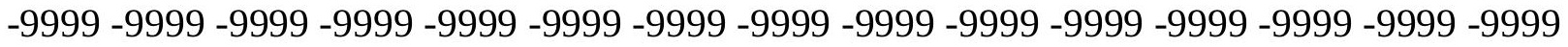
-9999 -9999 -9999 -9999 -9999 -9999 -9999 -9999 -9999 -9999 -9999 -9999 -9999 -9999 -9999 -9999 -9999 -9999 -9999 -9999 -9999 -9999 -9999 -9999 -9999 -9999 -9999 -9999 -9999 -9999 -

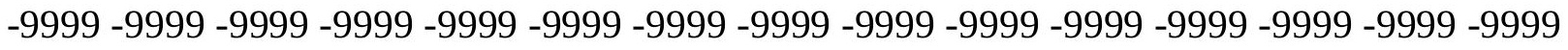
-9999 -9999 -9999 -9999 -9999 -9999 -9999 -9999 -9999 -9999 -9999 -9999 -9999 -9999 -9999

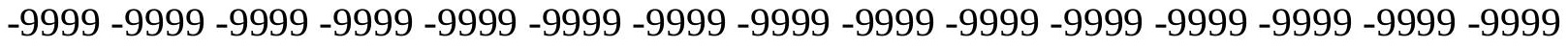
-9999 -9999 -9999 -9999 -9999 -9999 -9999 -9999 -9999 -9999 -9999 -9999 -9999 -9999 -9999 -9999 -9999 -9999 -9999 -9999 -9999 -9999 -9999 -9999 -9999 -9999 -9999 -9999 -9999 -9999 -

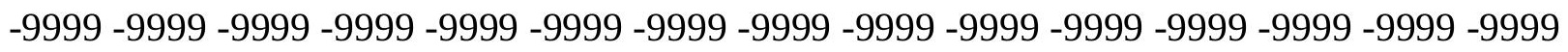
-9999 -9999 -9999 -9999 -9999 -9999 -9999 -9999 -9999 -9999 -9999 -9999 -9999 -9999 -9999 -9999 -9999 -9999 -9999 -9999 -9999 -9999 -9999 -9999 -9999 -9999 -9999 -9999 -9999 -9999 -

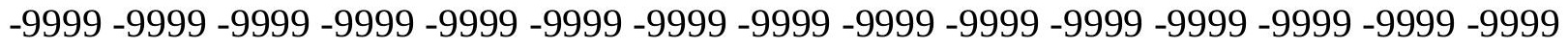
-9999 -9999 -9999 -9999 -9999 -9999 -9999 -9999 -9999 -9999 -9999 -9999 -9999 -9999 -9999 -9999 -9999 -9999 -9999 -9999 -9999 -9999 -9999 -9999 -9999 -9999 -9999 -9999 -9999 -999 -

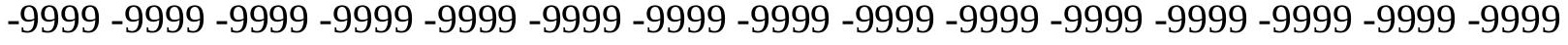
-9999 -9999 -9999 -9999 -9999 -9999 -9999 -9999 -9999 -9999 -9999 -9999 -9999 -9999 -9999 -

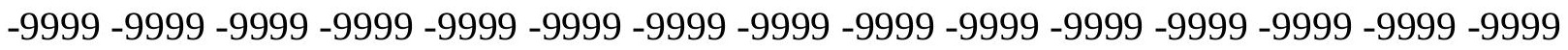

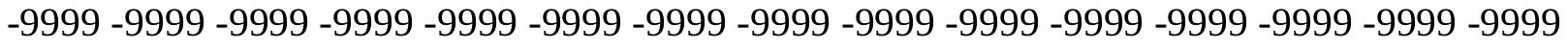

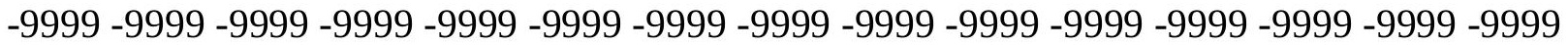
-9999 -9999 -9999 -9999 -9999 -9999 -9999 -9999 -9999 -9999 -9999 -9999 -9999 -9999 -9999 -

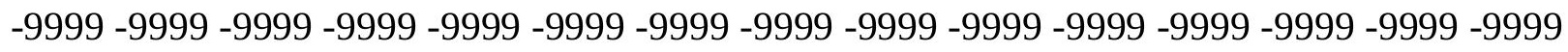

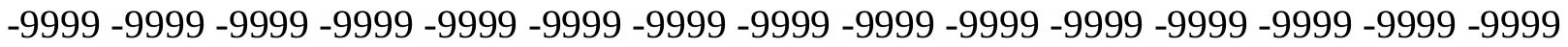
-9999 -9999 -9999 -9999 -9999 -9999 -9999 -9999 -9999 -9999 -9999 -9999 -9999 - 9999 - -999 -9999 -9999 -9999 -9999 -9999 -9999 -9999 -9999 -9999 -9999 -9999 -9999 -9999 -9999 -9999 -

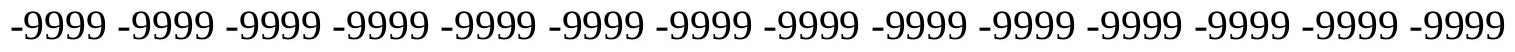

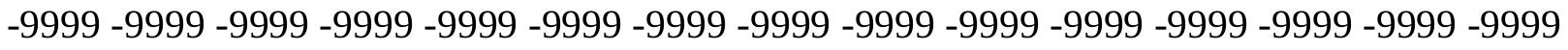
-9999 -9999 -9999 -9999 -9999 -9999 -9999 -9999 -9999 -9999 -9999 -9999 -9999 -9999 -9999 -9999 -9999 -9999 -9999 -9999 -9999 -9999 -9999 -9999-9999 -9999 -9999 -9999 -9999 -9999 -9999 -9999 -9999 -9999 -9999 -9999 -9999 -9999 -9999 -9999 -9999 -9999 -9999 -9999 -9999 -

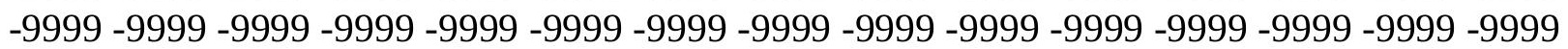


-9999 -9999 -9999 -9999 -9999 -9999 -9999 -9999 -9999 -9999 -9999 -9999 -9999 -9999 -9999 -9999 -9999 -9999 -9999 -9999 -9999 -9999 -9999 -9999 -9999 -9999 -9999 -9999 -9999 -9999 -9999 -9999 -9999 -9999 -9999 -9999 -9999 -9999 -9999 -9999 -9999 -9999 -9999 -9999 - 9999 -9999 -9999 -9999 -9999 -9999 -9999 -9999 -9999 -9999 -9999 -9999 -9999 -9999 -9999 -9999 -9999 -9999 -9999 -9999 -9999 -9999 -9999 -9999 -9999-9999 -9999 -9999 -9999 -9999 -9999 -9999 -9999 -9999 -9999 -9999 -9999 -9999 -9999 -9999 -9999 -9999 -9999 -9999 -9999 -9999 -9999 -9999 -9999 -9999 -9999 -9999 -9999 -9999 -9999 -9999 -9999 -9999 -9999 -9999 -9999

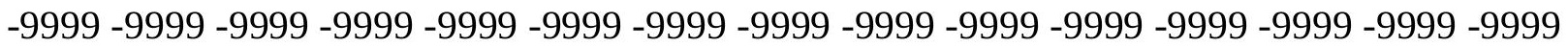
-9999 -9999 -9999 -9999 -9999 -9999 -9999 -9999 -9999 -9999 -9999 -9999 -9999 -9999 -9999 -9999 -9999 -9999 -9999 -9999 -9999 -9999 -9999 -9999 -9999 -9999 -9999 -9999 -9999 -9999

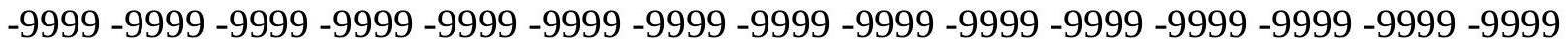
-9999 -9999 -9999 -9999 -9999 -9999 -9999 -9999 -9999 -9999 -9999 -9999 -9999 -9999 -9999 -9999 -9999 -9999 -9999 -9999 -9999 -9999 -9999 -9999 -9999 -9999 -9999 -9999 -9999 -9999 -

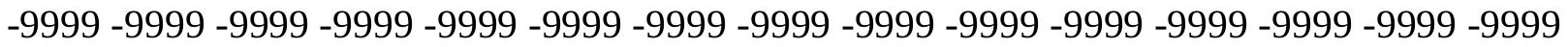
-9999 -9999 -9999 -9999 -9999 -9999 -9999 -9999 -9999 -9999 -9999 -9999 -9999 -9999 -9999

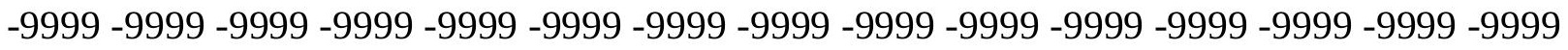
-9999 -9999 -9999 -9999 -9999 -9999 -9999 -9999 -9999 -9999 -9999 -9999 -9999 -9999 -9999 -9999 -9999 -9999 -9999 -9999 -9999 -9999 -9999 -9999 -9999 -9999 -9999 -9999 -9999 - 9999 -9999 -9999 -9999 -9999 -9999 -9999 -9999 -9999 -9999 -9999 -9999 -9999 -9999 -9999 -9999 -9999 -9999 -9999 -9999 -9999 -9999 -9999 -9999 -9999 -9999 -9999 -9999 -9999 -9999 -9999 -9999 -9999 -9999 -9999 -9999 -9999 -9999 -9999 -9999 -9999 -9999 -9999 -9999 -9999 -9999 -9999 -9999 -9999 -9999 -9999 -9999 -9999 -9999 -9999 -9999 -9999 -9999 -9999 -9999 -9999 -9999 -9999 -9999 -9999 -9999 -9999 -9999 -9999 -9999 -9999 -9999 -9999 -9999 -9999 -9999 -9999 -9999 -9999 -9999 -9999 -9999 -9999 -9999 -9999 -9999 -9999 -9999 -9999 -9999 -9999 -9999 -9999 -9999 -9999 -9999 -9999 -9999 -9999 -9999 -9999 -9999 -9999 -9999 -9999 -9999 -9999 -9999 -9999 -9999 -9999 -9999 -9999 -9999 -9999 -9999 -9999 -9999 -9999 -9999 -9999 -9999 -9999 -9999 -9999 -9999 -9999 -9999 -9999 -9999 -9999 -9999 -9999 -9999 -9999 -9999 -9999 -9999 -9999 -9999 -9999 -9999 -9999 -9999 -9999 -9999 -9999 -9999 -9999 -9999 -9999 -9999 -9999 -9999 -9999 -9999 -9999 -9999 -9999 -9999 -9999 -9999 -9999 -9999 -9999 -9999 -9999 -9999 -9999 -9999 -9999 -9999 -9999 -9999 -9999 -9999 -9999 -9999 -9999 -999 -9999 -9999 -9999 -9999 -9999 -9999 -9999 -9999 -9999 -9999 -9999 -9999 -9999 -9999 -9999 -9999 -9999 -9999 -9999 -9999 -9999 -9999 -9999 -9999 -9999 -9999 -9999 -9999 -9999 -9999 -

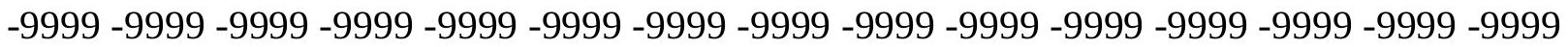

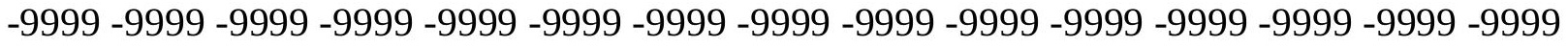

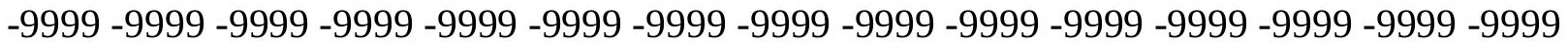
-9999 -9999 -9999 -9999 -9999 -9999 -9999 -9999 -9999 -9999 -9999 -9999 -9999 -9999 -9999

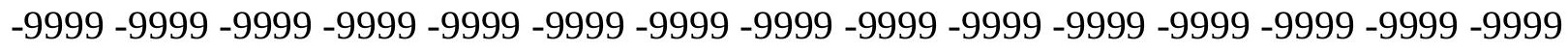

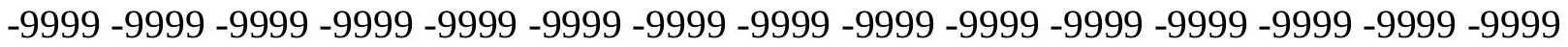

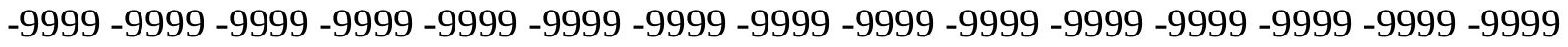
-9999 -9999 -9999 -9999 -9999 -9999 -9999 -9999 -9999 -9999 -9999 -9999 -9999 -9999 -9999 -

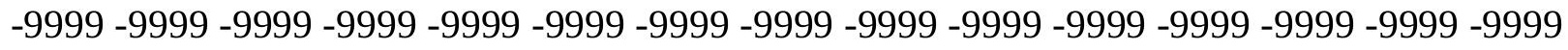

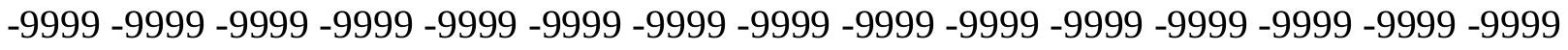
-9999 -9999 -9999 -9999 -9999 -9999 -9999 -9999 -9999 -9999 -9999 -9999 -9999 -9999 -9999 -9999 -9999 -9999 -9999 -9999 -9999 -9999 -9999 -9999-9999 -9999 -9999 -9999 -9999 -9999 -9999 -9999 -9999 -9999 -9999 -9999 -9999 -9999 -9999 -9999 -9999 -9999 -9999 -9999 -9999 -

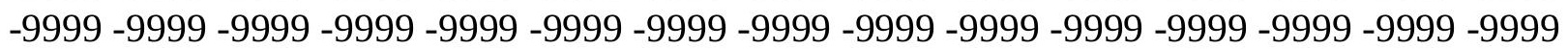


-9999 -9999 -9999 -9999 -9999 -9999 -9999 -9999 -9999 -9999 -9999 -9999 -9999 -9999 -9999 -9999 -9999 -9999 -9999 -9999 -9999 -9999 -9999 -9999 -9999 -9999 -9999 -9999 -9999 -9999 -9999 -9999 -9999 -9999 -9999 -9999 -9999 -9999 -9999 -9999 -9999 -9999 -9999 -9999 -9999 -9999 -9999 -9999 -9999 -9999 -9999 -9999 -9999 -9999 -9999 -9999 -9999 -9999 -9999 -9999 -9999 -9999 -9999 -9999 -9999 -9999 -9999 -9999 -9999 -9999 -9999 -9999 -9999 -9999 -9999 -9999 -9999 -9999 -9999 -9999 -9999 -9999 -9999 -9999 -9999 -9999 -9999 -9999 -9999 -9999 -9999 -9999 -9999 -9999 -9999 -9999 -9999 -9999 -9999 -9999 -9999 -9999 -9999 -9999 -

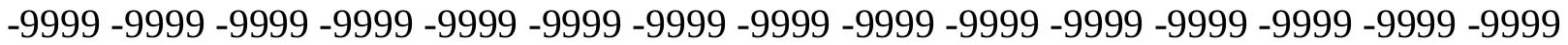
-9999 -9999 -9999 -9999 -9999 -9999 -9999 -9999 -9999 -9999 -9999 -9999 -9999 -9999 -9999 -9999 -9999 -9999 -9999 -9999 -9999 -9999 -9999 -9999 -9999 -9999 -9999 -9999 -9999 -9999 -

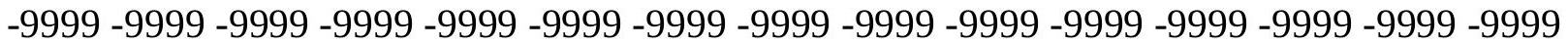
-9999 -9999 -9999 -9999 -9999 -9999 -9999 -9999 -9999 -9999 -9999 -9999 -9999 -9999 -9999 -9999 -9999 -9999 -9999 -9999 -9999 -9999 -9999 -9999 -9999 -9999 -9999 -9999 -9999 -9999 -9999 -9999 -9999 -9999 -9999 -9999 -9999 -9999 -9999 -9999 -9999 -9999 -9999 -9999 -9999 -9999 -9999 -9999 -9999 -9999 -9999 -9999 -9999 -9999 -9999 -9999 -9999 -9999 -9999 -9999 -9999 -9999 -9999 -9999 -9999 -9999 -9999 -9999 -9999 -9999 -9999 -9999 -9999 -9999 -9999 -9999 -9999 -9999 -9999 -9999 -9999 -9999 -9999 -9999 -9999 -9999 -9999 -9999 -9999 -9999 -9999 -9999 -9999 -9999 -9999 -9999 -9999 -9999 -9999 -9999 -9999 -9999 -9999 -9999 -9999 -9999 -9999 -9999 -9999 -9999 -9999 -9999 -9999 -9999 -9999 -9999 -9999 -9999 -9999 -9999 -9999 -9999 -9999 -9999 -9999 -9999 -9999 -9999 -9999 -9999 -9999 -9999 -9999 -9999 -9999

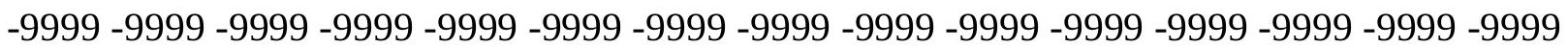
-9999 -9999 -9999 -9999 -9999 -9999 -9999 -9999 -9999 -9999 -9999 -9999 -9999 -9999 -9999 -9999 -9999 -9999 -9999 -9999 -9999 -9999 -9999 -9999 -9999 -9999 -9999 -9999 -9999 -9999 -9999 -9999 -9999 -9999 -9999 -9999 -9999 -9999 -9999 -9999 -9999 -9999 -9999 -9999 -9999

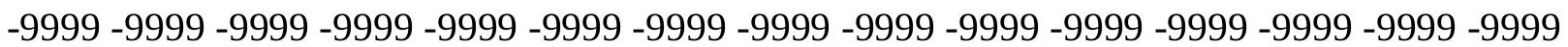
-9999 -9999 -9999 -9999 -9999 -9999 -9999 -9999 -9999 -9999 -9999 -9999 -9999 -9999 -9999 -9999 -9999 -9999 -9999 -9999 -9999 -9999 -9999 -9999 -9999 -9999 -9999 -9999 -9999 -9999 -9999 -9999 -9999 -9999 -9999 -9999 -9999 -9999 -9999 -9999 -9999 -9999 -9999 -9999

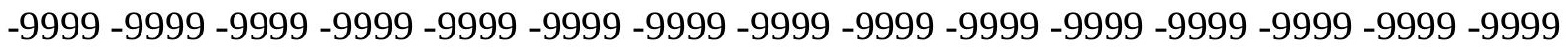
-9999 -9999 -9999 -9999 -9999 -9999 -9999 -9999 -9999 -9999 -9999 -9999 -9999 -9999 -9999 -9999 -9999 -9999 -9999 -9999 -9999 -9999 -9999 -9999 -9999 -9999 -9999 -9999 -9999 -9999 -

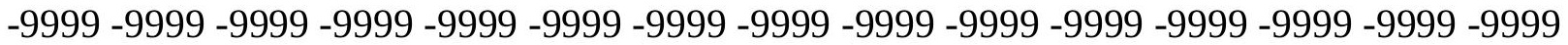
-9999 -9999 -9999 -9999 -9999 -9999 -9999 -9999 -9999 -9999 -9999 -9999 -9999 -9999 -9999 -9999 -9999 -9999 -9999 -9999 -9999 -9999 -9999 -9999 -9999 -9999 -9999 -9999 -9999 -9999 -9999 -9999 -9999 -9999 -9999 -9999 -9999 -9999 -9999 -9999 -9999 -9999 -9999 -9999 -9999 -9999 -9999 -9999 -9999 -9999 -9999 -9999 -9999 -9999 -9999 -9999 -9999 -9999 -9999 -9999 -9999 -9999 -9999 -9999 -9999 -9999 -9999 -9999 -9999 -9999 -9999 -9999 -9999 -9999 -9999

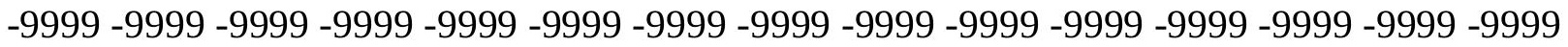
-9999 -9999 -9999 -9999 -9999 -9999 -9999 -9999 -9999 -9999 -9999 -9999 -9999 -9999 -9999 -9999 -9999 -9999 -9999 -9999 -9999 -9999 -9999 -9999 -9999 -9999 -9999 -9999 -9999 -9999 -

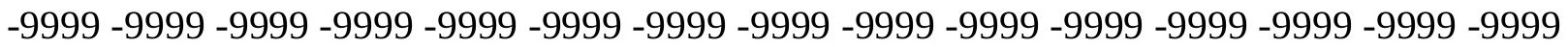
-9999 -9999 -9999 -9999 -9999 -9999 -9999 -9999 -9999 -9999 -9999 -9999 -9999 -9999 -9999 -9999 -9999 -9999 -9999 -9999 -9999 -9999 -9999 -9999 -9999 -9999 -9999 -9999 -9999 -9999 -9999 -9999 -9999 -9999 -9999 -9999 -9999 -9999 -9999 -9999 -9999 -9999 -9999 -9999 -9999 -9999 -9999 -9999 -9999 -9999 -9999 -9999 -9999 -9999 -9999 -9999 -9999 -9999 -9999 -9999

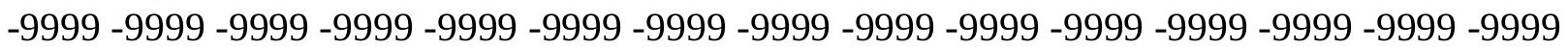


-9999 -9999 -9999 -9999 -9999 -9999 -9999 -9999 -9999 -9999 -9999 -9999 -9999 -9999 -9999 -9999 -9999 -9999 -9999 -9999 -9999 -9999 -9999 -9999 -9999 -9999 -9999 -9999 -9999 -9999 -

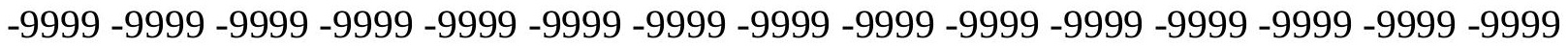
-9999 -9999 -9999 -9999 -9999 -9999 -9999 -9999 -9999 -9999 -9999 -9999 -9999 -9999 -9999 -9999 -9999 -9999 -9999 -9999 -9999 -9999 -9999 -9999-9999 -9999 -9999 -9999 -9999 -9999 -9999 -9999 -9999 -9999 -9999 -9999 -9999 -9999 -9999 -9999 -9999 -9999 -9999 -9999 -9999 -9999 -9999 -9999 -9999 -9999 -9999 -9999 -9999 -9999 -9999 -9999 -9999 -9999 -9999 -

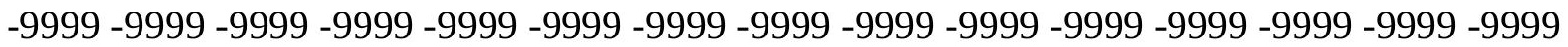

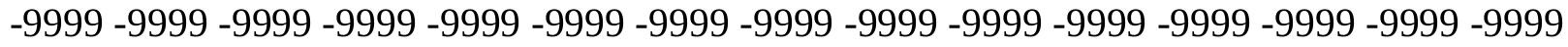
-9999 -9999 -9999 -9999 -9999 -9999 -9999 -9999 -9999 -9999 -9999 -9999 -9999 -9999 -9999 -9999 -9999 -9999 -9999 -9999 -9999 -9999 -9999 -9999 -9999 -9999 -9999 -9999 -9999 -9999 -9999 -9999 -9999 -9999 -9999 -9999 -9999 -9999 -9999 -9999 -9999 -9999 -9999 -9999 -9999 -9999 -9999 -9999 -9999 -9999 -9999 -9999 -9999 -9999 -9999 -9999 -9999 -9999 -9999 -9999 -9999 -9999 -9999 -9999 -9999 -9999 -9999 -9999 -9999 -9999 -9999 -9999 -9999 -9999 -9999 -9999 -9999 -9999 -9999 -9999 -9999 -9999 -9999 -9999 -9999 -9999 -9999 -9999 -9999 -9999 -

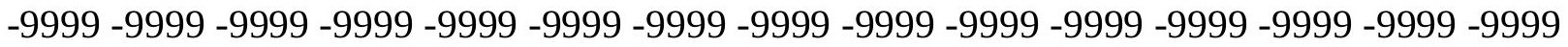
-9999 -9999 -9999 -9999 -9999 -9999 -9999 -9999 -9999 -9999 -9999 -9999 -9999 -9999 -9999 -9999 -9999 -9999 -9999 -9999 -9999 -9999 -9999 -9999 -9999 -9999 -9999 -9999 -9999 -9999 -9999 -9999 -9999 -9999 -9999 -9999 -9999 -9999 -9999 -9999 -9999 -9999 -9999 -9999 -9999 -

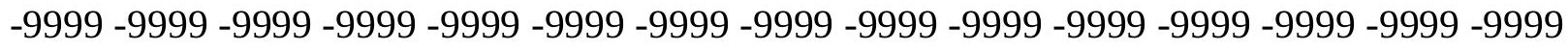

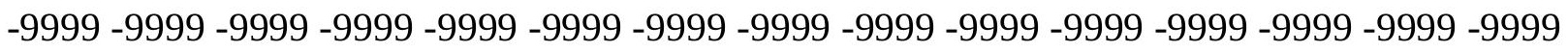

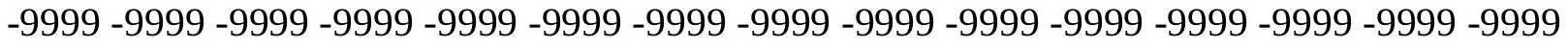
-9999 -9999 -9999 -9999 -9999 -9999 -9999 -9999 -9999 -9999 -9999 -9999 -9999 -9999 -9999 -9999 -9999 -9999 -9999 -9999 -9999 -9999 -9999 -9999 -9999 -9999 -9999 -9999 -9999 -9999 -

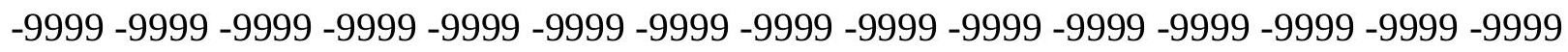
-9999 -9999 -9999 -9999 -9999 -9999 -9999 -9999 -9999 -9999 -9999 -9999 -9999 -9999 -9999 -9999 -9999 -9999 -9999 -9999 -9999 -9999 -9999 -9999 -9999 -9999 -9999 -9999 -9999 -9999 -

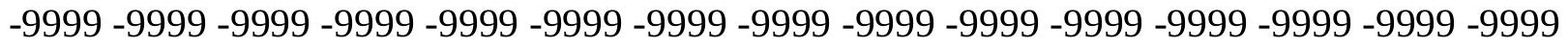
-9999 -9999 -9999 -9999 -9999 -9999 -9999 -9999 -9999 -9999 -9999 -9999 -9999 -9999 -9999 -9999 -9999 -9999 -9999 -9999 -9999 -9999 -9999 -9999 -9999 -9999 -9999 -9999 -9999 -999 -9999 -9999 -9999 -9999 -9999 -9999 -9999 -9999 -9999 -9999 -9999 -9999 -9999 -9999 -9999 -

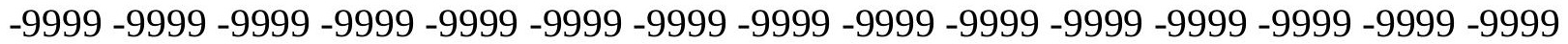

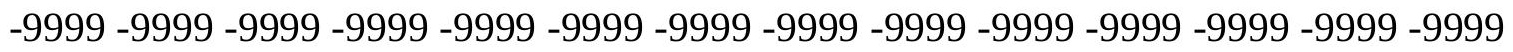

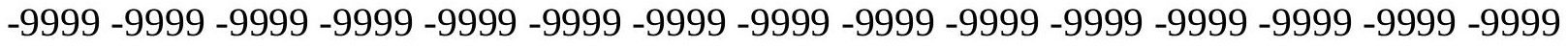

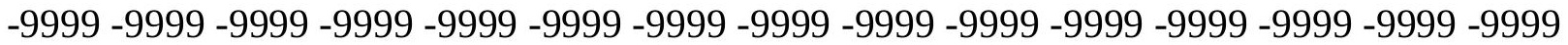

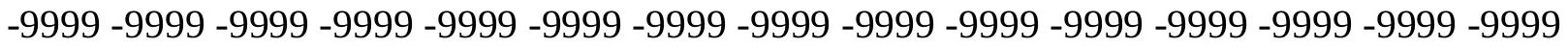

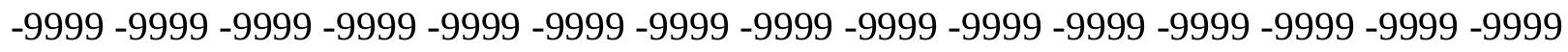

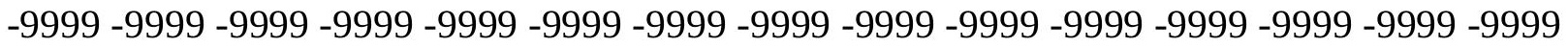

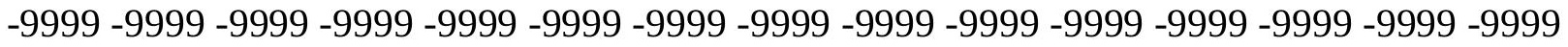
-9999 -9999 -9999 -9999 -9999 -9999 -9999 -9999 -9999 -9999 -9999 -9999 -9999 -9999 -9999 -

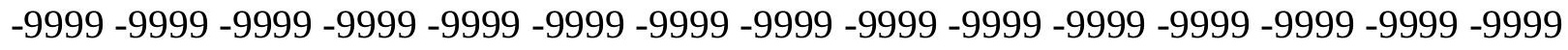

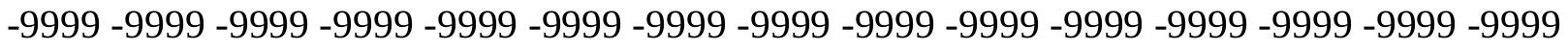
-9999 -9999 -9999 -9999 -9999 -9999 -9999 -9999 -9999 -9999 -9999 -9999 -9999 -9999 -9999 -9999 -9999 -9999 -9999 -9999 -9999 -9999 -9999 -9999-9999 -9999 -9999 -9999 -9999 -9999 -9999 -9999 -9999 -9999 -9999 -9999 -9999 -9999 -9999 -9999 -9999 -9999 -9999 -9999 -9999 -

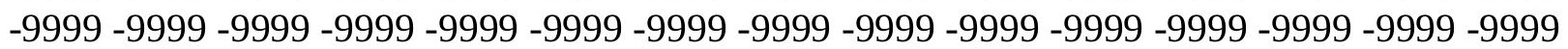


-9999 -9999 -9999 -9999 -9999 -9999 -9999 -9999 -9999 -9999 -9999 -9999 -9999 -9999 -9999 -9999 -9999 -9999 -9999 -9999 -9999 -9999 -9999 -9999 -9999 -9999 -9999 -9999 -9999 -9999 -

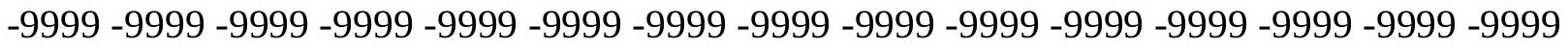
-9999 -9999 -9999 -9999 -9999 -9999 -9999 -9999 -9999 -9999 -9999 -9999 -9999 -9999 -9999 -9999 -9999 -9999 -9999 -9999 -9999 -9999 -9999 -9999-9999 -9999 -9999 -9999 -9999 -9999 -9999 -9999 -9999 -9999 -9999 -9999 -9999 -9999 -9999 -9999 -9999 -9999 -9999 -9999 -9999 -9999 -9999 -9999 -9999 -9999 -9999 -9999 -9999 -9999 -9999 -9999 -9999 -9999 -9999 -9999

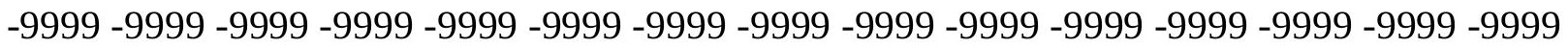

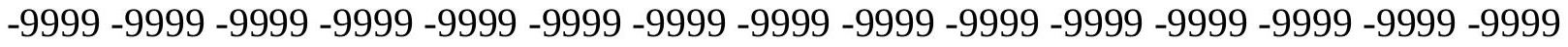
-9999 -9999 -9999 -9999 -9999 -9999 -9999 -9999 -9999 -9999 -9999 -9999 -9999 -9999 -9999 -9999 -9999 -9999 -9999 -9999 -9999 -9999 -9999 -9999 -9999 -9999 -9999 -9999 -9999 -9999 -9999 -9999 -9999 -9999 -9999 -9999 -9999 -9999 -9999 -9999 -9999 -9999 -9999 -9999 -9999 -9999 -9999 -9999 -9999 -9999 -9999 -9999 -9999 -9999 -9999 -9999 -9999 -9999 -9999 -9999 -9999 -9999 -9999 -9999 -9999 -9999 -9999 -9999 -9999 -9999 -9999 -9999 -9999 -9999 -9999 -9999 -9999 -9999 -9999 -9999 -9999 -9999 -9999 -9999 -9999 -9999 -9999 -9999 -9999 -

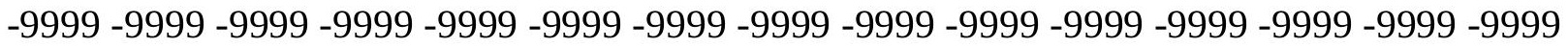
-9999 -9999 -9999 -9999 -9999 -9999 -9999 -9999 -9999 -9999 -9999 -9999 -9999 -9999 -9999 -9999 -9999 -9999 -9999 -9999 -9999 -9999 -9999 -9999 -9999 -9999 -9999 -9999 -9999 -9999 -9999 -9999 -9999 -9999 -9999 -9999 -9999 -9999 -9999 -9999 -9999 -9999 -9999 -9999 -9999 -

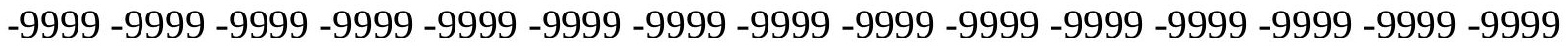
-9999 -9999 -9999 -9999 -9999 -9999 -9999 -9999 -9999 -9999 -9999 -9999 -9999 -9999 -9999

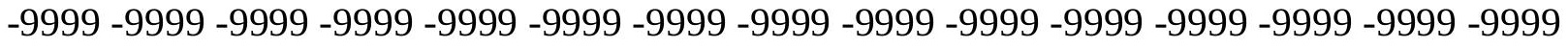
-9999 -9999 -9999 -9999 -9999 -9999 -9999 -9999 -9999 -9999 -9999 -9999 -9999 -9999 -9999 -9999 -9999 -9999 -9999 -9999 -9999 -9999 -9999 -9999 -9999 -9999 -9999 -9999 -9999 -9999 -

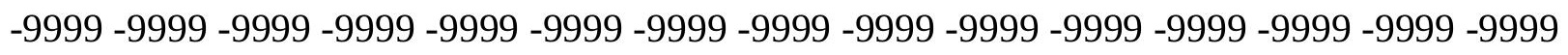
-9999 -9999 -9999 -9999 -9999 -9999 -9999 -9999 -9999 -9999 -9999 -9999 -9999 -9999 -9999 -9999 -9999 -9999 -9999 -9999 -9999 -9999 -9999 -9999 -9999 -9999 -9999 -9999 -9999 -9999 -

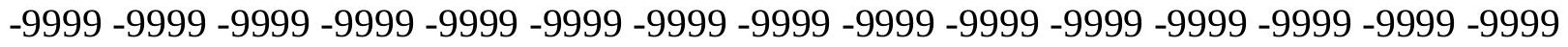
-9999 -9999 -9999 -9999 -9999 -9999 -9999 -9999 -9999 -9999 -9999 -9999 -9999 -9999 -9999 -9999 -9999 -9999 -9999 -9999 -9999 -9999 -9999 -9999 -9999 -9999 -9999 -9999 -9999 -999 -9999 -9999 -9999 -9999 -9999 -9999 -9999 -9999 -9999 -9999 -9999 -9999 -9999 -9999 -9999 -9999 -9999 -9999 -9999 -9999 -9999 -9999 -9999 -9999 -9999 -9999 -9999 -9999 -9999 -9999 -

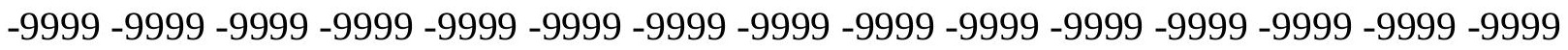

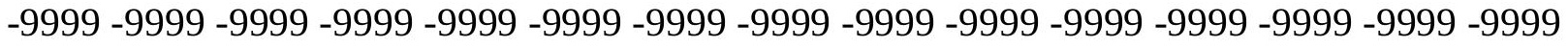

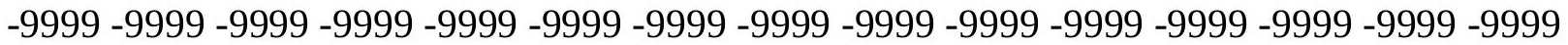
-9999 -9999 -9999 -9999 -9999 -9999 -9999 -9999 -9999 -9999 -9999 -9999 -9999 -9999 -9999 -

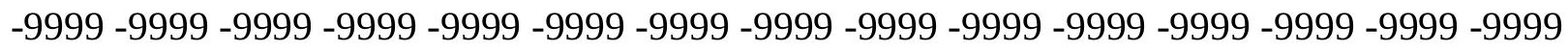

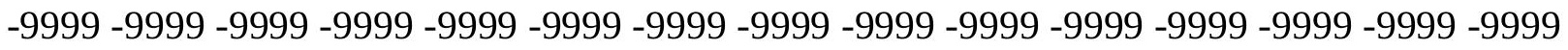
-9999 -9999 -9999 -9999 -9999 -9999 -9999 -9999 -9999 -9999 -9999 -9999 -9999 -9999 - -999 -9999 -9999 -9999 -9999 -9999 -9999 -9999 -9999 -9999 -9999 -9999 -9999 -9999 -9999 -9999 -

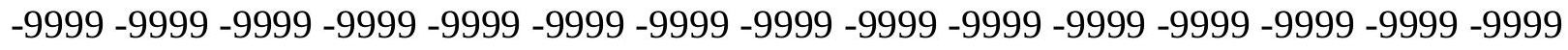

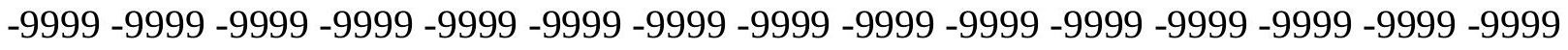
-9999 -9999 -9999 -9999 -9999 -9999 -9999 -9999 -9999 -9999 -9999 -9999 -9999 -9999 -9999 -9999 -9999 -9999 -9999 -9999 -9999 -9999 -9999 -9999-9999 -9999 -9999 -9999 -9999 -9999 -9999 -9999 -9999 -9999 -9999 -9999 -9999 -9999 -9999 -9999 -9999 -9999 -9999 -9999 -9999 -

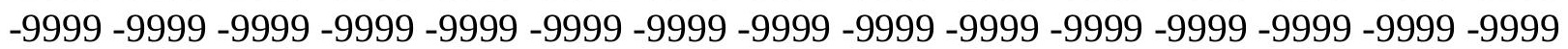


-9999 -9999 -9999 -9999 -9999 -9999 -9999 -9999 -9999 -9999 -9999 -9999 -9999 -9999 -9999 -9999 -9999 -9999 -9999 -9999 -9999 -9999 -9999 -9999 -9999 -9999 -9999 -9999 -9999 -9999 -

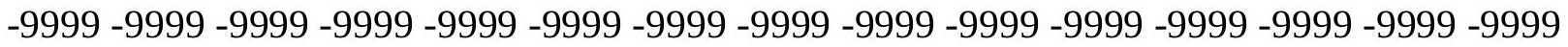
-9999 -9999 -9999 -9999 -9999 -9999 -9999 -9999 -9999 -9999 -9999 -9999 -9999 -9999 -9999 -9999 -9999 -9999 -9999 -9999 -9999 -9999 -9999 -9999-9999 -9999 -9999 -9999 -9999 -9999 -9999 -9999 -9999 -9999 -9999 -9999 -9999 -9999 -9999 -9999 -9999 -9999 -9999 -9999 -9999 -9999 -9999 -9999 -9999 -9999 -9999 -9999 -9999 -9999 -9999 -9999 -9999 -9999 -9999 -9999

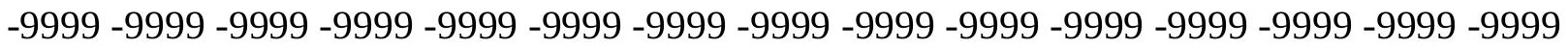

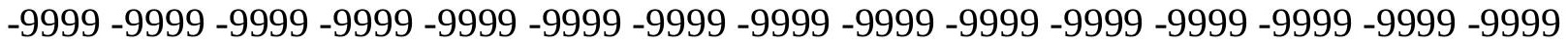
-9999 -9999 -9999 -9999 -9999 -9999 -9999 -9999 -9999 -9999 -9999 -9999 -9999 -9999 -9999 -9999 -9999 -9999 -9999 -9999 -9999 -9999 -9999 -9999 -9999 -9999 -9999 -9999 -9999 -9999 -9999 -9999 -9999 -9999 -9999 -9999 -9999 -9999 -9999 -9999 -9999 -9999 -9999 -9999 -9999 -9999 -9999 -9999 -9999 -9999 -9999 -9999 -9999 -9999 -9999 -9999 -9999 -9999 -9999 -9999 -

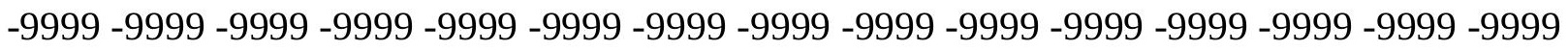
-9999 -9999 -9999 -9999 -9999 -9999 -9999 -9999 -9999 -9999 -9999 -9999 -9999 -9999 -9999 -

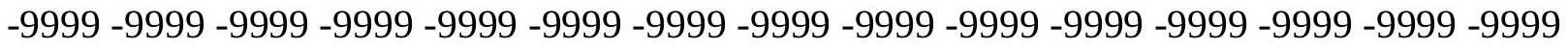
-9999 -9999 -9999 -9999 -9999 -9999 -9999 -9999 -9999 -9999 -9999 -9999 -9999 -9999 -9999 -9999 -9999 -9999 -9999 -9999 -9999 -9999 -9999 -9999 -9999 -9999 -9999 -9999 -9999 -9999 -9999 -9999 -9999 -9999 -9999 -9999 -9999 -9999 -9999 -9999 -9999 -9999 -9999 -9999 - -999 -

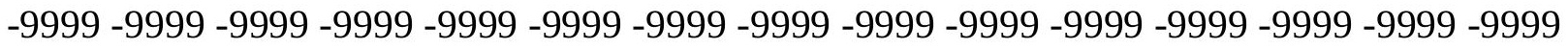

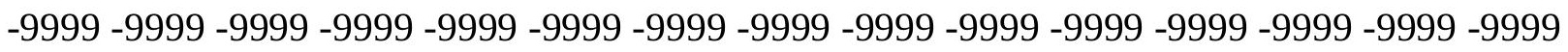
-9999 -9999 -9999 -9999 -9999 -9999 -9999 -9999 -9999 -9999 -9999 -9999 -9999 -9999 -9999 -9999 -9999 -9999 -9999 -9999 -9999 -9999 -9999 -9999 -9999 -9999 -9999 -9999 -9999 -9999 -9999 -9999 -9999 -9999 -9999 -9999 -9999 -9999 -9999 -9999 -9999 -9999 -9999 -9999 -9999 -

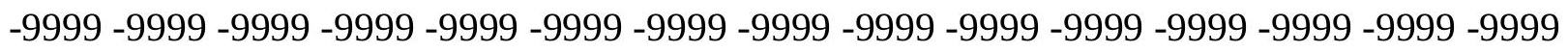
-9999 -9999 -9999 -9999 -9999 -9999 -9999 -9999 -9999 -9999 -9999 -9999 -9999 -9999 -9999 -9999 -9999 -9999 -9999 -9999 -9999 -9999 -9999 -9999 -9999 -9999 -9999 -9999 -9999 -9999 -

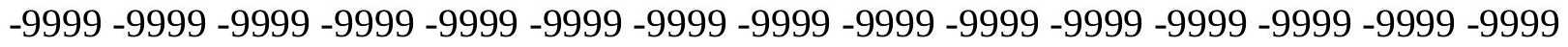
-9999 -9999 -9999 -9999 -9999 -9999 -9999 -9999 -9999 -9999 -9999 -9999 -9999 -9999 -9999 -9999 -9999 -9999 -9999 -9999 -9999 -9999 -9999 -9999 -9999 -9999 -9999 -9999 -9999 -999 -

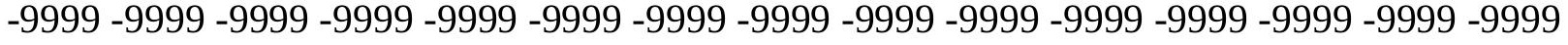
-9999 -9999 -9999 -9999 -9999 -9999 -9999 -9999 -9999 -9999 -9999 -9999 -9999 -9999 -9999 -

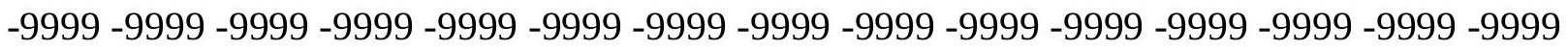

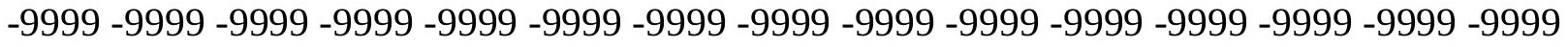

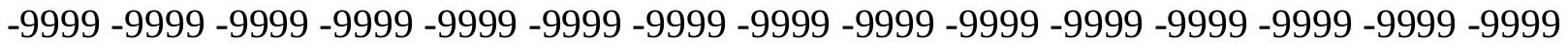

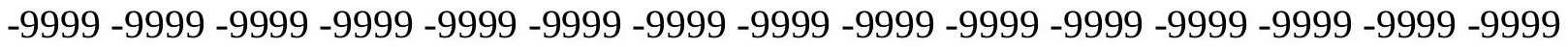

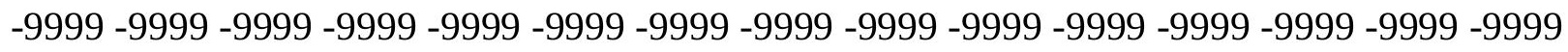

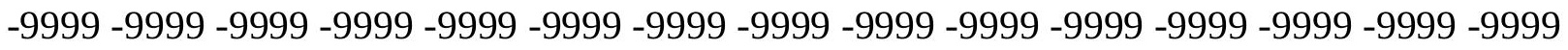

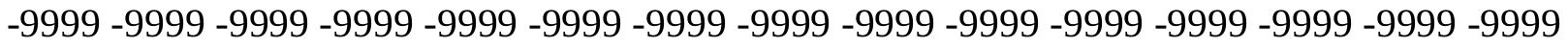
-9999 -9999 -9999 -9999 -9999 -9999 -9999 -9999 -9999 -9999 -9999 -9999 -9999 -9999 -9999 -

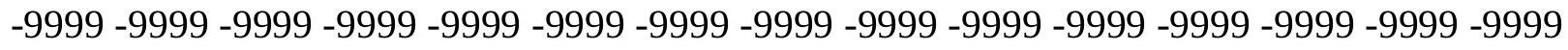

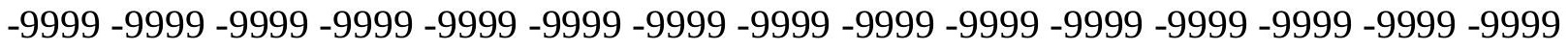
-9999 -9999 -9999 -9999 -9999 -9999 -9999 -9999 -9999 -9999 -9999 -9999 -9999 -9999 -9999 -9999 -9999 -9999 -9999 -9999 -9999 -9999 -9999 -9999 -9999 -9999 -9999 -9999 -9999 -9999 -9999 -9999 -9999 -9999 -9999 -9999 -9999 -9999 -9999 -9999 -9999 -9999 -9999 -9999 -

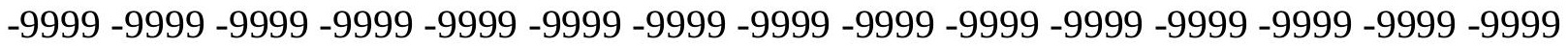


-9999 -9999 -9999 -9999 -9999 -9999 -9999 -9999 -9999 -9999 -9999 -9999 -9999 -9999 -9999 -9999 -9999 -9999 -9999 -9999 -9999 -9999 -9999 -9999 -9999 -9999 -9999 -9999 -9999 -9999 -

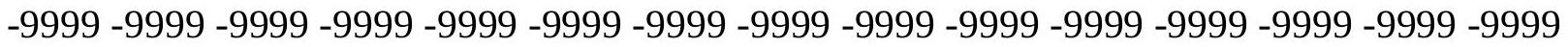
-9999 -9999 -9999 -9999 -9999 -9999 -9999 -9999 -9999 -9999 -9999 -9999 -9999 -9999 -9999 -9999 -9999 -9999 -9999 -9999 -9999 -9999 -9999 -9999-9999 -9999 -9999 -9999 -9999 -9999 -9999 -9999 -9999 -9999 -9999 -9999 -9999 -9999 -9999 -9999 -9999 -9999 -9999 -9999 -9999 -9999 -9999 -9999 -9999 -9999 -9999 -9999 -9999 -9999 -9999 -9999 -9999 -9999 -9999 -9999

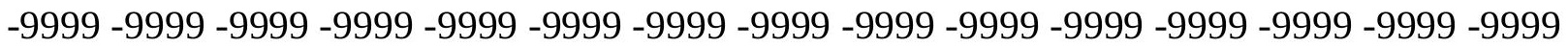

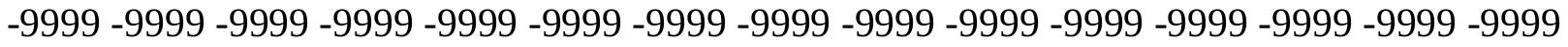
-9999 -9999 -9999 -9999 -9999 -9999 -9999 -9999 -9999 -9999 -9999 -9999 -9999 -9999 -9999 -9999 -9999 -9999 -9999 -9999 -9999 -9999 -9999 -9999 -9999 -9999 -9999 -9999 -9999 -9999 -9999 -9999 -9999 -9999 -9999 -9999 -9999 -9999 -9999 -9999 -9999 -9999 -9999 -9999 -9999 -9999 -9999 -9999 -9999 -9999 -9999 -9999 -9999 -9999 -9999 -9999 -9999 -9999 -9999 -9999 -

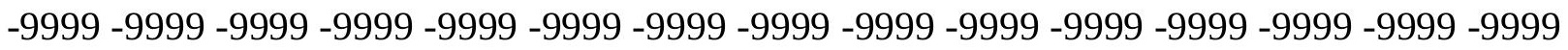
-9999 -9999 -9999 -9999 -9999 -9999 -9999 -9999 -9999 -9999 -9999 -9999 -9999 -9999 -9999 -

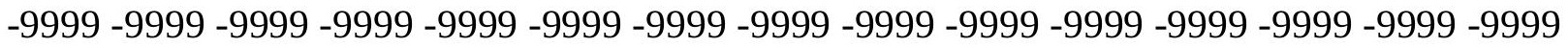
-9999 -9999 -9999 -9999 -9999 -9999 -9999 -9999 -9999 -9999 -9999 -9999 -9999 -9999 -9999 -9999 -9999 -9999 -9999 -9999 -9999 -9999 -9999 -9999 -9999 -9999 -9999 -9999 -9999 - 9999 -9999 -9999 -9999 -9999 -9999 -9999 -9999 -9999 -9999 -9999 -9999 -9999 -9999 -9999 -9999 -

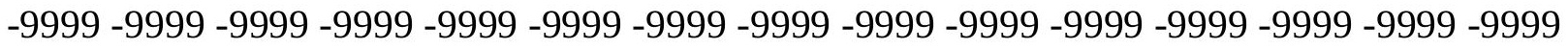

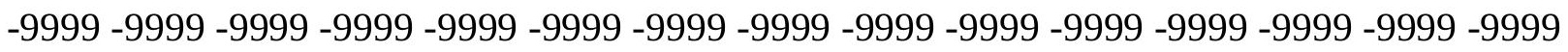
-9999 -9999 -9999 -9999 -9999 -9999 -9999 -9999 -9999 -9999 -9999 -9999 -9999 -9999 - 9999 -9999 -9999 -9999 -9999 -9999 -9999 -9999 -9999 -9999 -9999 -9999 -9999 -9999 -9999 -9999 -9999 -9999 -9999 -9999 -9999 -9999 -9999 -9999 -9999 -9999 -9999 -9999 -9999 -9999 -9999 -9999 -9999 -9999 -9999 -9999 -9999 -9999 -9999 -9999 -9999 -9999 -9999 -9999 -9999 -9999 -9999 -9999 -9999 -9999 -9999 -9999 -9999 -9999 -9999 -9999 -9999 -9999 -9999 -9999 -9999 -9999 -9999 -9999 -9999 -9999 -9999 -9999 -9999 -9999 -9999 -9999 -9999 -9999 -9999 -

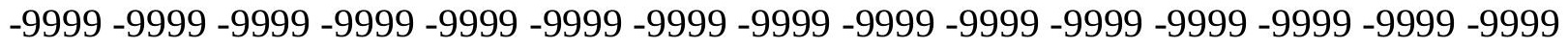
-9999 -9999 -9999 -9999 -9999 -9999 -9999 -9999 -9999 -9999 -9999 -9999 -9999 -9999 -9999 -9999 -9999 -9999 -9999 -9999 -9999 -9999 -9999 -9999 -9999 -9999 -9999 -9999 -9999 -999 -9999 -9999 -9999 -9999 -9999 -9999 -9999 -9999 -9999 -9999 -9999 -9999 -9999 -9999 -9999 -9999 -9999 -9999 -9999 -9999 -9999 -9999 -9999 -9999 -9999 -9999 -9999 -9999 -9999 -9999 -

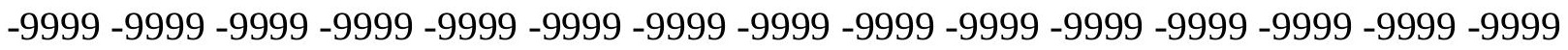

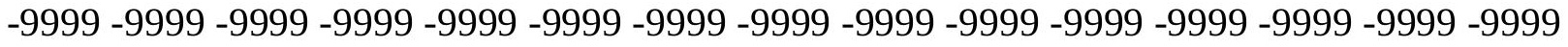

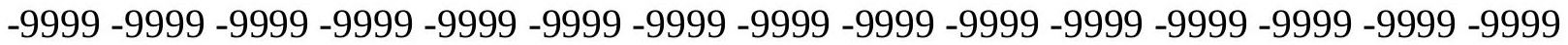

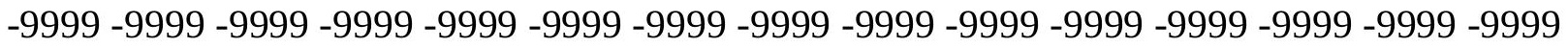

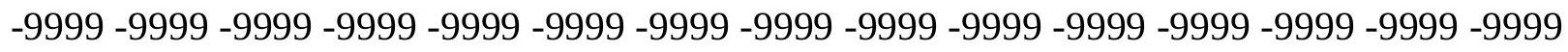

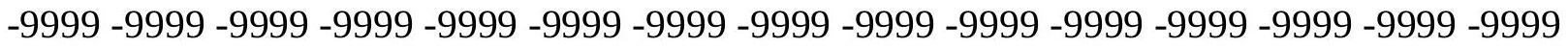

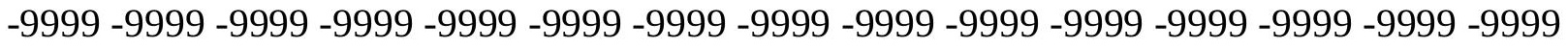
-9999 -9999 -9999 -9999 -9999 -9999 -9999 -9999 -9999 -9999 -9999 -9999 -9999 -9999 -9999 -

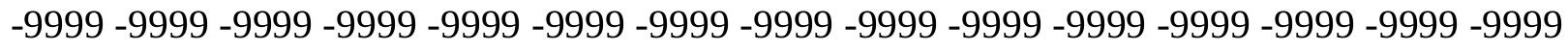

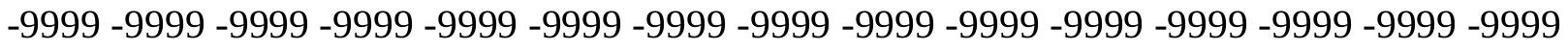
-9999 -9999 -9999 -9999 -9999 -9999 -9999 -9999 -9999 -9999 -9999 -9999 -9999 -9999 -9999 -9999 -9999 -9999 -9999 -9999 -9999 -9999 -9999 -9999-9999 -9999 -9999 -9999 -9999 -9999 -9999 -9999 -9999 -9999 -9999 -9999 -9999 -9999 -9999 -9999 -9999 -9999 -9999 -9999 -9999 -

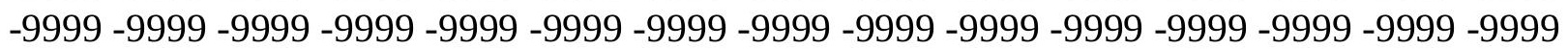


-9999 -9999 -9999 -9999 -9999 -9999 -9999 -9999 -9999 -9999 -9999 -9999 -9999 -9999 -9999 -9999 -9999 -9999 -9999 -9999 -9999 -9999 -9999 -9999 -9999 -9999 -9999 -9999 -9999 -9999 -9999 -9999 -9999 -9999 -9999 -9999 -9999 -9999 -9999 -9999 -9999 -9999 -9999 -9999 - 9999 -9999 -9999 -9999 -9999 -9999 -9999 -9999 -9999 -9999 -9999 -9999 -9999 -9999 -9999 -9999 -9999 -9999 -9999 -9999 -9999 -9999 -9999 -9999 -9999 -9999 -9999 -9999 -9999 -9999 -9999 -9999 -9999 -9999 -9999 -9999 -9999 -9999 -9999 -9999 -9999 -9999 -9999 -9999 -9999 -9999 -9999 -9999 -9999 -9999 -9999 -9999 -9999 -9999 -9999 -9999 -9999 -9999 -9999 -9999

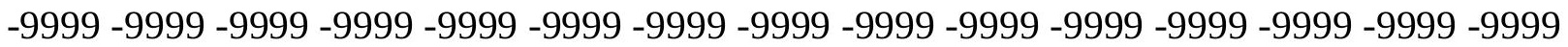

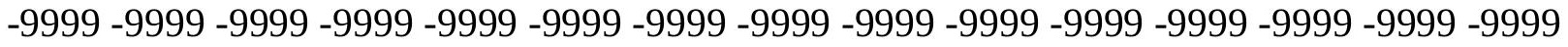
-9999 -9999 -9999 -9999 -9999 -9999 -9999 -9999 -9999 -9999 -9999 -9999 -9999 -9999 -9999 -9999 -9999 -9999 -9999 -9999 -9999 -9999 -9999 -9999 -9999 -9999 -9999 -9999 -9999 -9999 -9999 -9999 -9999 -9999 -9999 -9999 -9999 -9999 -9999 -9999 -9999 -9999 -9999 -9999 -9999 -9999 -9999 -9999 -9999 -9999 -9999 -9999 -9999 -9999 -9999 -9999 -9999 -9999 -9999 -9999 -9999 -9999 -9999 -9999 -9999 -9999 -9999 -9999 -9999 -9999 -9999 -9999 -9999 -9999 -9999 -9999 -9999 -9999 -9999 -9999 -9999 -9999 -9999 -9999 -9999 -9999 -9999 -9999 -9999 -9999 -

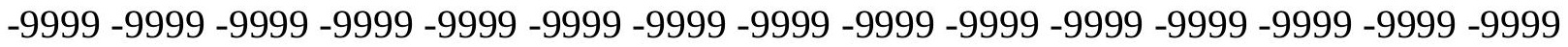
-9999 -9999 -9999 -9999 -9999 -9999 -9999 -9999 -9999 -9999 -9999 -9999 -9999 -9999 -9999 -9999 -9999 -9999 -9999 -9999 -9999 -9999 -9999 -9999 -9999 -9999 -9999 -9999 -9999 - 9999 -9999 -9999 -9999 -9999 -9999 -9999 -9999 -9999 -9999 -9999 -9999 -9999 -9999 -9999 -9999 -

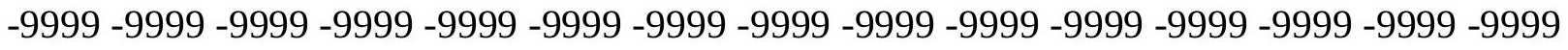

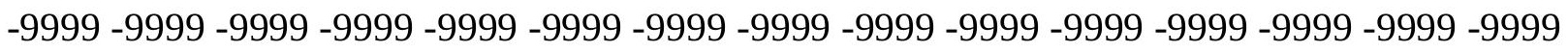

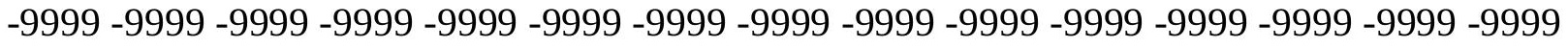
-9999 -9999 -9999 -9999 -9999 -9999 -9999 -9999 -9999 -9999 -9999 -9999 -9999 -9999 -9999 -9999 -9999 -9999 -9999 -9999 -9999 -9999 -9999 -9999 -9999 -9999 -9999 -9999 -9999 -9999 -

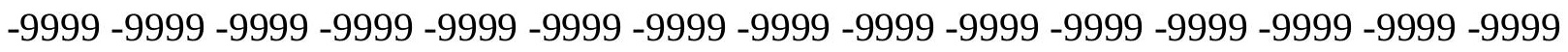
-9999 -9999 -9999 -9999 -9999 -9999 -9999 -9999 -9999 -9999 -9999 -9999 -9999 -9999 -9999 -9999 -9999 -9999 -9999 -9999 -9999 -9999 -9999 -9999 -9999 -9999 -9999 -9999 -9999 -9999 -

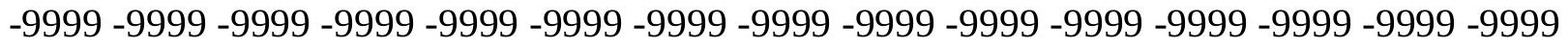
-9999 -9999 -9999 -9999 -9999 -9999 -9999 -9999 -9999 -9999 -9999 -9999 -9999 -9999 -9999 -9999 -9999 -9999 -9999 -9999 -9999 -9999 -9999 -9999 -9999 -9999 -9999 -9999 -9999 -999 -9999 -9999 -9999 -9999 -9999 -9999 -9999 -9999 -9999 -9999 -9999 -9999 -9999 -9999 -9999 -9999 -9999 -9999 -9999 -9999 -9999 -9999 -9999 -9999 -9999 -9999 -9999 -9999 -9999 -

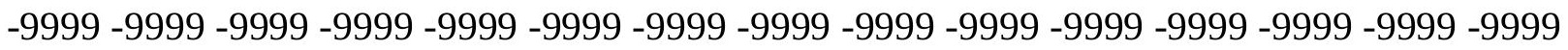

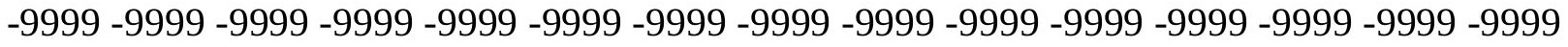

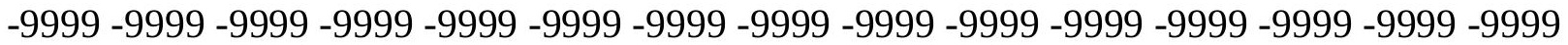

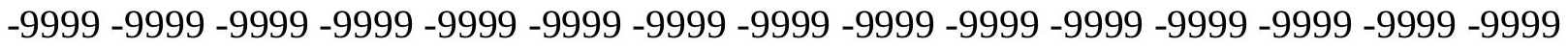

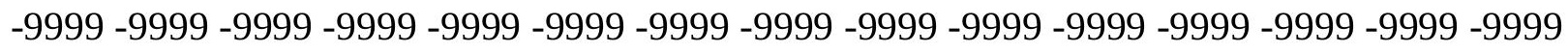

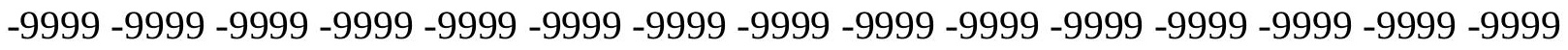

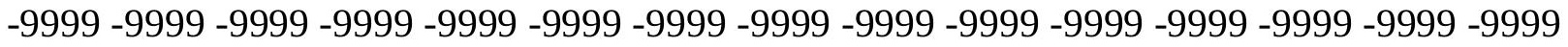
-9999 -9999 -9999 -9999 -9999 -9999 -9999 -9999 -9999 -9999 -9999 -9999 -9999 -9999 -9999 -

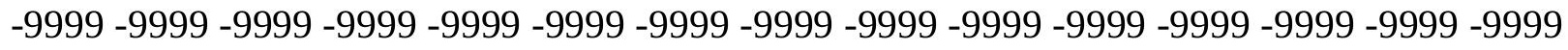

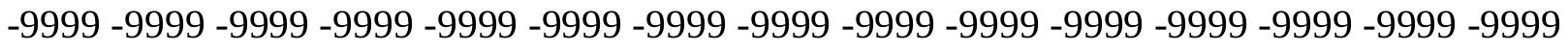
-9999 -9999 -9999 -9999 -9999 -9999 -9999 -9999 -9999 -9999 -9999 -9999 -9999 -9999 -9999 -9999 -9999 -9999 -9999 -9999 -9999 -9999 -9999 -9999-9999 -9999 -9999 -9999 -9999 -9999 -9999 -9999 -9999 -9999 -9999 -9999 -9999 -9999 -9999 -9999 -9999 -9999 -9999 -9999 -9999 -

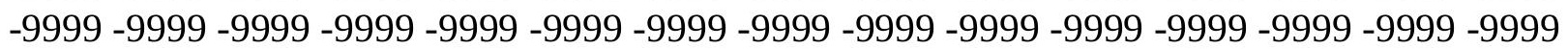


-9999 -9999 -9999 -9999 -9999 -9999 -9999 -9999 -9999 -9999 -9999 -9999 -9999 -9999 -9999 -9999 -9999 -9999 -9999 -9999 -9999 -9999 -9999 -9999 -9999 -9999 -9999 -9999 -9999 -9999 -

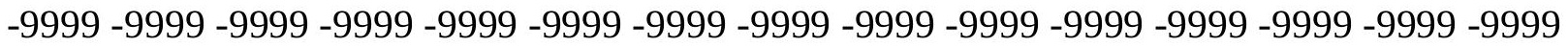
-9999 -9999 -9999 -9999 -9999 -9999 -9999 -9999 -9999 -9999 -9999 -9999 -9999 -9999 -9999 -9999 -9999 -9999 -9999 -9999 -9999 -9999 -9999 -9999-9999 -9999 -9999 -9999 -9999 -9999 -9999 -9999 -9999 -9999 -9999 -9999 -9999 -9999 -9999 -9999 -9999 -9999 -9999 -9999 -9999 -9999 -9999 -9999 -9999 -9999 -9999 -9999 -9999 -9999 -9999 -9999 -9999 -9999 -9999 -9999

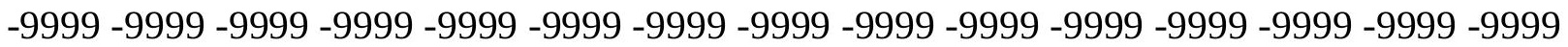

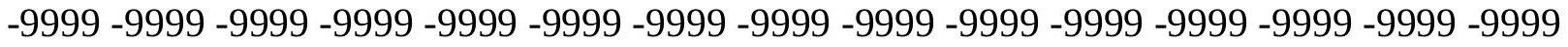

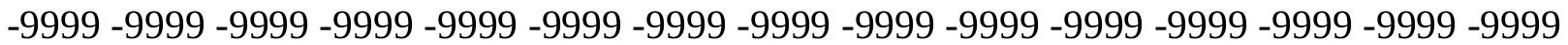
-9999 -9999 -9999 -9999 -9999 -9999 -9999 -9999 -9999 -9999 -9999 -9999 -9999 -9999 -9999 -9999 -9999 -9999 -9999 -9999 -9999 -9999 -9999 -9999 -9999 -9999 -9999 -9999 -9999 -9999 -9999 -9999 -9999 -9999 -9999 -9999 -9999 -9999 -9999 -9999 -9999 -9999 -9999 -9999 -

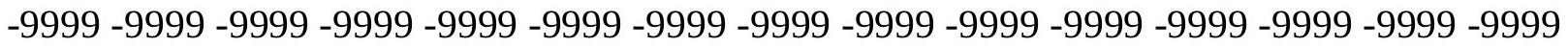
-9999 -9999 -9999 -9999 -9999 -9999 -9999 -9999 -9999 -9999 -9999 -9999 -9999 -9999 -9999 -

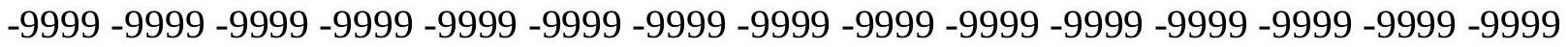
-9999 -9999 -9999 -9999 -9999 -9999 -9999 -9999 -9999 -9999 -9999 -9999 -9999 -9999 -9999 -9999 -9999 -9999 -9999 -9999 -9999 -9999 -9999 -9999 -9999 -9999 -9999 -9999 -9999 -9999 -9999 -9999 -9999 -9999 -9999 -9999 -9999 -9999 -9999 -9999 -9999 -9999 -9999 -9999 -9999 -

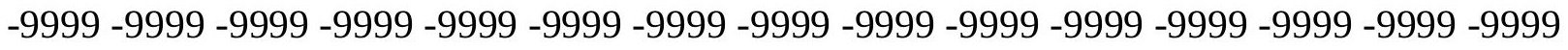

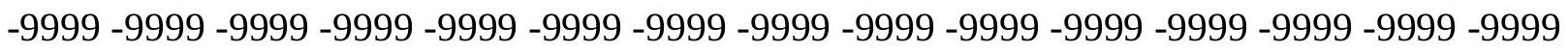
-9999 -9999 -9999 -9999 -9999 -9999 -9999 -9999 -9999 -9999 -9999 -9999 -9999 -9999 -9999 -9999 -9999 -9999 -9999 -9999 -9999 -9999 -9999 -9999 -9999 -9999 -9999 -9999 -9999 -9999 -9999 -9999 -9999 -9999 -9999 -9999 -9999 -9999 -9999 -9999 -9999 -9999 -9999 -9999 -9999 -

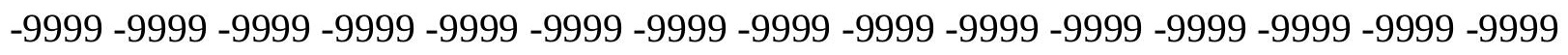
-9999 -9999 -9999 -9999 -9999 -9999 -9999 -9999 -9999 -9999 -9999 -9999 -9999 -9999 -9999 -9999 -9999 -9999 -9999 -9999 -9999 -9999 -9999 -9999 -9999 -9999 -9999 -9999 -9999 -9999 -

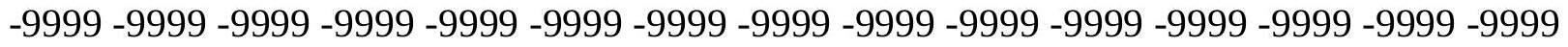
-9999 -9999 -9999 -9999 -9999 -9999 -9999 -9999 -9999 -9999 -9999 -9999 -9999 -9999 -9999 -9999 -9999 -9999 -9999 -9999 -9999 -9999 -9999 -9999 -9999 -9999 -9999 -9999 -9999 -999 -9999 -9999 -9999 -9999 -9999 -9999 -9999 -9999 -9999 -9999 -9999 -9999 -9999 -9999 -9999 -9999 -9999 -9999 -9999 -9999 -9999 -9999 -9999 -9999 -9999 -9999 -9999 -9999 -9999 -9999 -

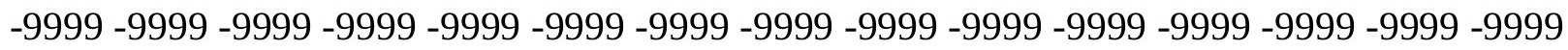

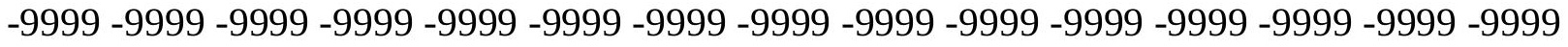

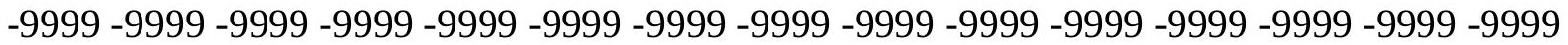
-9999 -9999 -9999 -9999 -9999 -9999 -9999 -9999 -9999 -9999 -9999 -9999 -9999 -9999 -9999 -

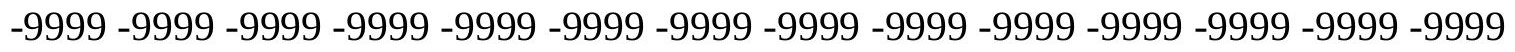

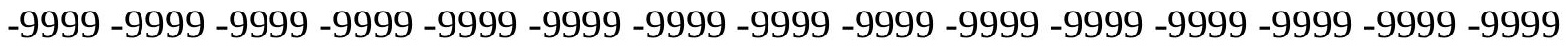
-9999 -9999 -9999 -9999 -9999 -9999 -9999 -9999 -9999 -9999 -9999 -9999 -9999 - 9999 - -999 -9999 -9999 -9999 -9999 -9999 -9999 -9999 -9999 -9999 -9999 -9999 -9999 -9999 -9999 -9999 -

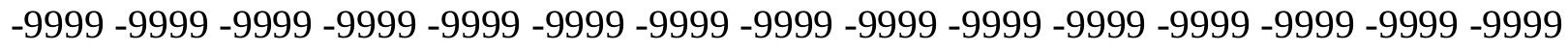

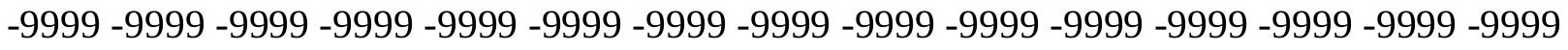
-9999 -9999 -9999 -9999 -9999 -9999 -9999 -9999 -9999 -9999 -9999 -9999 -9999 -9999 -9999 -9999 -9999 -9999 -9999 -9999 -9999 -9999 -9999 -9999-9999 -9999 -9999 -9999 -9999 -9999 -9999 -9999 -9999 -9999 -9999 -9999 -9999 -9999 -9999 -9999 -9999 -9999 -9999 -9999 -9999 -

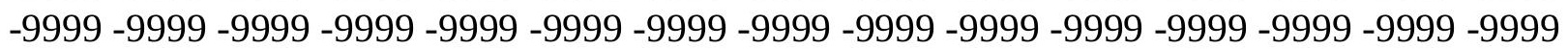


-9999 -9999 -9999 -9999 -9999 -9999 -9999 -9999 -9999 -9999 -9999 -9999 -9999 -9999 -9999 -9999 -9999 -9999 -9999 -9999 -9999 -9999 -9999 -9999 -9999 -9999 -9999 -9999 -9999 -9999 -

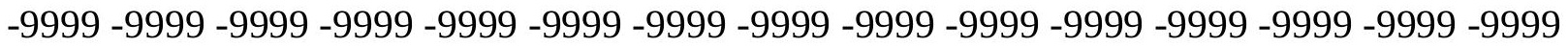
-9999 -9999 -9999 -9999 -9999 -9999 -9999 -9999 -9999 -9999 -9999 -9999 -9999 -9999 -9999 -9999 -9999 -9999 -9999 -9999 -9999 -9999 -9999 -9999-9999 -9999 -9999 -9999 -9999 -9999 -9999 -9999 -9999 -9999 -9999 -9999 -9999 -9999 -9999 -9999 -9999 -9999 -9999 -9999 -9999 -9999 -9999 -9999 -9999 -9999 -9999 -9999 -9999 -9999 -9999 -9999 -9999 -9999 -9999 -9999

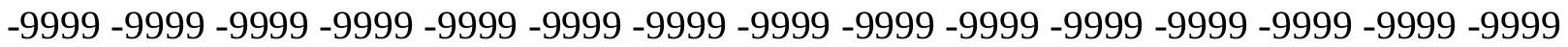

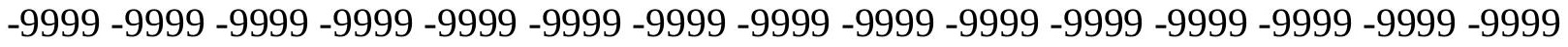
-9999 -9999 -9999 -9999 -9999 -9999 -9999 -9999 -9999 -9999 -9999 -9999 -9999 -9999 -9999 -9999 -9999 -9999 -9999 -9999 -9999 -9999 -9999 -9999 -9999 -9999 -9999 -9999 -9999 -9999 -9999 -9999 -9999 -9999 -9999 -9999 -9999 -9999 -9999 -9999 -9999 -9999 -9999 -9999 -9999 -9999 -9999 -9999 -9999 -9999 -9999 -9999 -9999 -9999 -9999 -9999 -9999 -9999 -9999 -9999 -9999 -9999 -9999 -9999 -9999 -9999 -9999 -9999 -9999 -9999 -9999 -9999 -9999 -9999 -9999 -9999 -9999 -9999 -9999 -9999 -9999 -9999 -9999 -9999 -9999 -9999 -9999 -9999 -9999 -9999 -

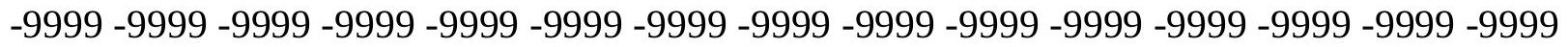
-9999 -9999 -9999 -9999 -9999 -9999 -9999 -9999 -9999 -9999 -9999 -9999 -9999 -9999 -9999 -9999 -9999 -9999 -9999 -9999 -9999 -9999 -9999 -9999 -9999 -9999 -9999 -9999 -9999 -9999 -9999 -9999 -9999 -9999 -9999 -9999 -9999 -9999 -9999 -9999 -9999 -9999 -9999 -9999 -

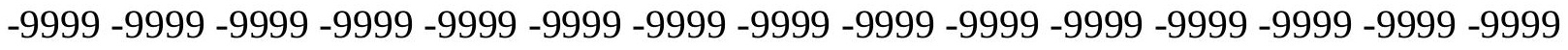
-9999 -9999 -9999 -9999 -9999 -9999 -9999 -9999 -9999 -9999 -9999 -9999 -9999 -9999 -9999 -999 -

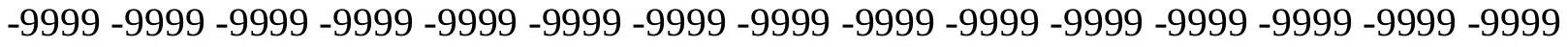
-9999 -9999 -9999 -9999 -9999 -9999 -9999 -9999 -9999 -9999 -9999 -9999 -9999 -9999 -9999 -9999 -9999 -9999 -9999 -9999 -9999 -9999 -9999 -9999 -9999 -9999 -9999 -9999 -9999 -9999 -9999 -9999 -9999 -9999 -9999 -9999 -9999 -9999 -9999 -9999 -9999 -9999 -9999 -9999 -9999 -9999 -9999 -9999 -9999 -9999 -9999 -9999 -9999 -9999 -9999 -9999 -9999 -9999 -9999 -9999 -9999 -9999 -9999 -9999 -9999 -9999 -9999 -9999 -9999 -9999 -9999 -9999 -9999 -9999 -9999 -

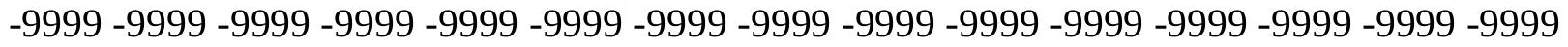
-9999 -9999 -9999 -9999 -9999 -9999 -9999 -9999 -9999 -9999 -9999 -9999 -9999 -9999 -9999 -9999 -9999 -9999 -9999 -9999 -9999 -9999 -9999 -9999 -9999 -9999 -9999 -9999 -9999 -999 -9999 -9999 -9999 -9999 -9999 -9999 -9999 -9999 -9999 -9999 -9999 -9999 -9999 -9999 -9999 -9999 -9999 -9999 -9999 -9999 -9999 -9999 -9999 -9999 -9999 -9999 -9999 -9999 -9999 -9999 -

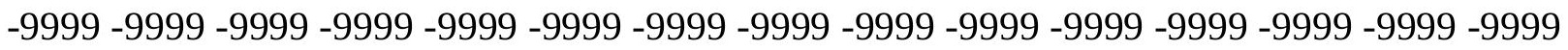

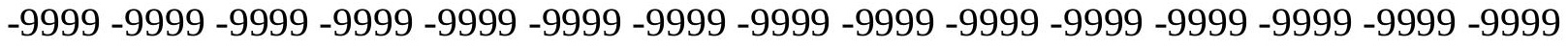

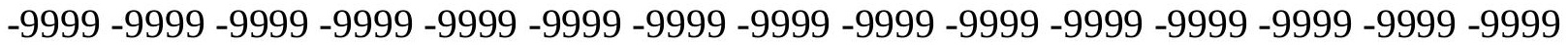
-9999 -9999 -9999 -9999 -9999 -9999 -9999 -9999 -9999 -9999 -9999 -9999 -9999 -9999 -9999

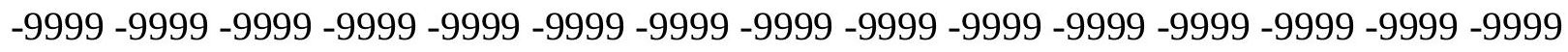

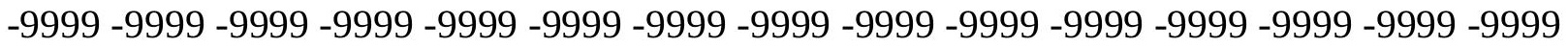
-9999 -9999 -9999 -9999 -9999 -9999 -9999 -9999 -9999 -9999 -9999 -9999 -9999 - 9999 - -999 -9999 -9999 -9999 -9999 -9999 -9999 -9999 -9999 -9999 -9999 -9999 -9999 -9999 -9999 -9999 -

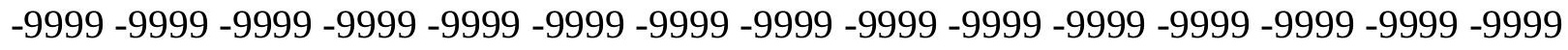

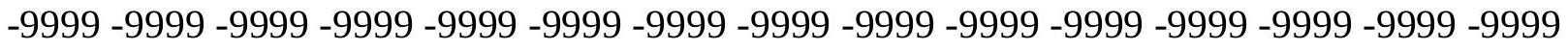
-9999 -9999 -9999 -9999 -9999 -9999 -9999 -9999 -9999 -9999 -9999 -9999 -9999 -9999 -9999 -9999 -9999 -9999 -9999 -9999 -9999 -9999 -9999 -9999 -9999 -9999 -9999 -9999 -9999 -9999 -9999 -9999 -9999 -9999 -9999 -9999 -9999 -9999 -9999 -9999 -9999 -9999 -9999 -9999 -

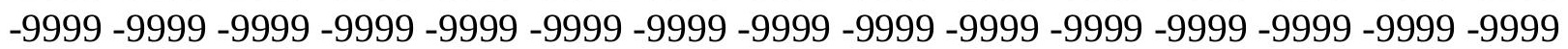


-9999 -9999 -9999 -9999 -9999 -9999 -9999 -9999 -9999 -9999 -9999 -9999 -9999 -9999 -9999 -9999 -9999 -9999 -9999 -9999 -9999 -9999 -9999 -9999 -9999 -9999 -9999 -9999 -9999 -9999 -9999 -9999 -9999 -9999 -9999 -9999 -9999 -9999 -9999 -9999 -9999 -9999 -9999 -9999 - 9999 -9999 -9999 -9999 -9999 -9999 -9999 -9999 -9999 -9999 -9999 -9999 -9999 -9999 -9999 -9999 -9999 -9999 -9999 -9999 -9999 -9999 -9999 -9999 -9999-9999 -9999 -9999 -9999 -9999 -9999 -9999 -9999 -9999 -9999 -9999 -9999 -9999 -9999 -9999 -9999 -9999 -9999 -9999 -9999 -9999 -9999 -9999 -9999 -9999 -9999 -9999 -9999 -9999 -9999 -9999 -9999 -9999 -9999 -9999 -9999

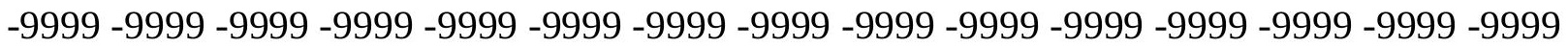

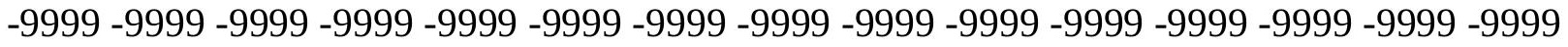
-9999 -9999 -9999 -9999 -9999 -9999 -9999 -9999 -9999 -9999 -9999 -9999 -9999 -9999 -9999 -9999 -9999 -9999 -9999 -9999 -9999 -9999 -9999 -9999 -9999 -9999 -9999 -9999 -9999 -9999 -9999 -9999 -9999 -9999 -9999 -9999 -9999 -9999 -9999 -9999 -9999 -9999 -9999 -9999 -9999 -9999 -9999 -9999 -9999 -9999 -9999 -9999 -9999 -9999 -9999 -9999 -9999 -9999 -9999 -9999 -

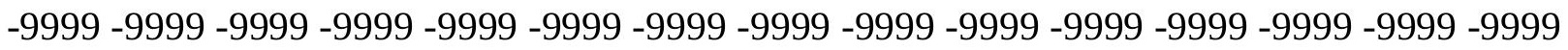
-9999 -9999 -9999 -9999 -9999 -9999 -9999 -9999 -9999 -9999 -9999 -9999 -9999 -9999 -9999 -

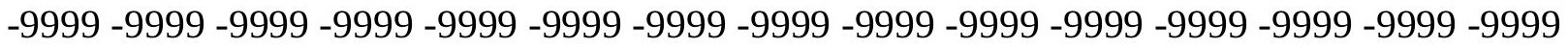
-9999 -9999 -9999 -9999 -9999 -9999 -9999 -9999 -9999 -9999 -9999 -9999 -9999 -9999 -9999 -9999 -9999 -9999 -9999 -9999 -9999 -9999 -9999 -9999 -9999 -9999 -9999 -9999 -9999 -9999 -9999 -9999 -9999 -9999 -9999 -9999 -9999 -9999 -9999 -9999 -9999 -9999 -9999 -9999 -9999 -

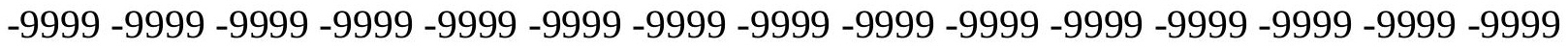
-9999 -9999 -9999 -9999 -9999 -9999 -9999 -9999 -9999 -9999 -9999 -9999 -9999 -9999 -9999 -999 -9999 -9999 -9999 -9999 -9999 -9999 -9999 -9999 -9999 -9999 -9999 -9999 -9999 -9999 - 9999 -9999 -9999 -9999 -9999 -9999 -9999 -9999 -9999 -9999 -9999 -9999 -9999 -9999 -9999 -

-9999 -9999 -9999 -9999 -9999 -9999 -9999 -9999 -9999 -9999 -9999 -9999 -9999 -9999 -9999 -

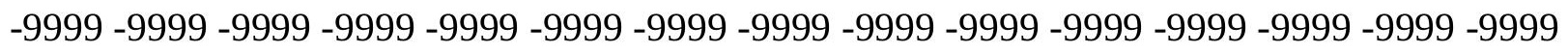
-9999 -9999 -9999 -9999 -9999 -9999 -9999 -9999 -9999 -9999 -9999 -9999 -9999 -9999 -9999 -9999 -9999 -9999 -9999 -9999 -9999 -9999 -9999 -9999 -9999 -9999 -9999 -9999 -9999 -9999 -

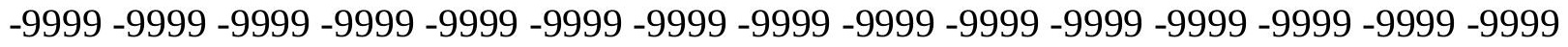
-9999 -9999 -9999 -9999 -9999 -9999 -9999 -9999 -9999 -9999 -9999 -9999 -9999 -9999 -9999 -9999 -9999 -9999 -9999 -9999 -9999 -9999 -9999 -9999 -9999 -9999 -9999 -9999 -9999 -999 -

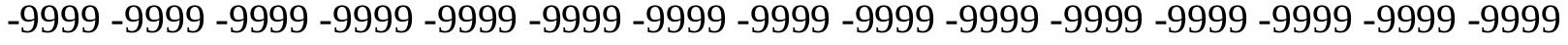
-9999 -9999 -9999 -9999 -9999 -9999 -9999 -9999 -9999 -9999 -9999 -9999 -9999 -9999 -9999 -

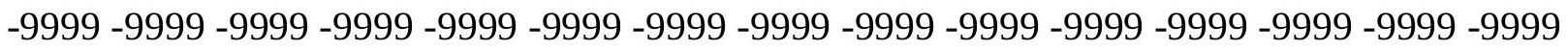

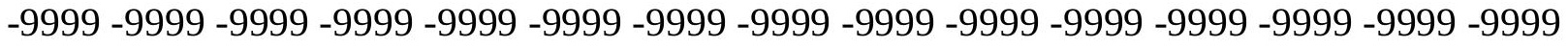

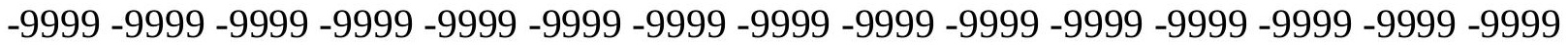

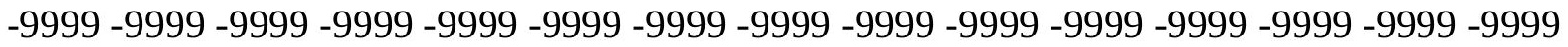

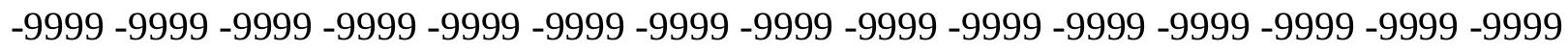

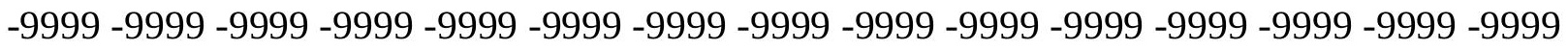

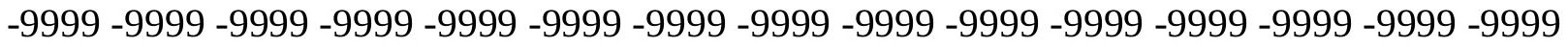
-9999 -9999 -9999 -9999 -9999 -9999 -9999 -9999 -9999 -9999 -9999 -9999 -9999 -9999 -9999 -

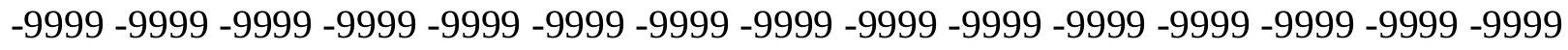

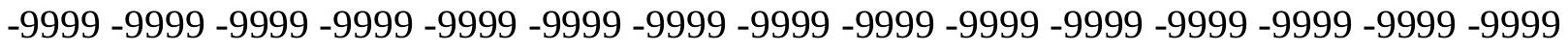
-9999 -9999 -9999 -9999 -9999 -9999 -9999 -9999 -9999 -9999 -9999 -9999 -9999 -9999 -9999 -9999 -9999 -9999 -9999 -9999 -9999 -9999 -9999 -9999-9999 -9999 -9999 -9999 -9999 -9999 -9999 -9999 -9999 -9999 -9999 -9999 -9999 -9999 -9999 -9999 -9999 -9999 -9999 -9999 -9999 -

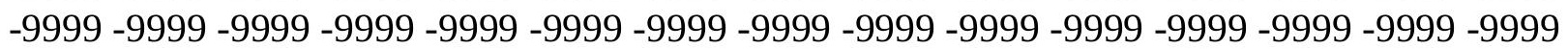


-9999 -9999 -9999 -9999 -9999 -9999 -9999 -9999 -9999 -9999 -9999 -9999 -9999 -9999 -9999 -9999 -9999 -9999 -9999 -9999 -9999 -9999 -9999 -9999 -9999 -9999 -9999 -9999 -9999 -9999 -9999 -9999 -9999 -9999 -9999 -9999 -9999 -9999 -9999 -9999 -9999 -9999 -9999 -9999 -9999 -9999 -9999 -9999 -9999 -9999 -9999 -9999 -9999 -9999 -9999 -9999 -9999 -9999 -9999 -9999 -9999 -9999 -9999 -9999 -9999 -9999 -9999 -9999-9999 -9999 -9999 -9999 -9999 -9999 -9999 -9999 -9999 -9999 -9999 -9999 -9999 -9999 -9999 -9999 -9999 -9999 -9999 -9999 -9999 -9999 -9999 -9999 -9999 -9999 -9999 -9999 -9999 -9999 -9999 -9999 -9999 -9999 -9999 -9999

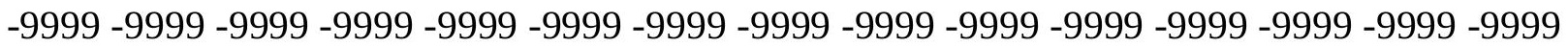

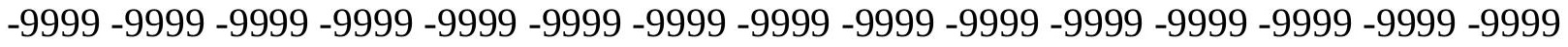
-9999 -9999 -9999 -9999 -9999 -9999 -9999 -9999 -9999 -9999 -9999 -9999 -9999 -9999 -9999 -9999 -9999 -9999 -9999 -9999 -9999 -9999 -9999 -9999 -9999 -9999 -9999 -9999 -9999 -9999 -9999 -9999 -9999 -9999 -9999 -9999 -9999 -9999 -9999 -9999 -9999 -9999 -9999 -9999 -9999 -9999 -9999 -9999 -9999 -9999 -9999 -9999 -9999 -9999 -9999 -9999 -9999 -9999 -9999 -9999 -

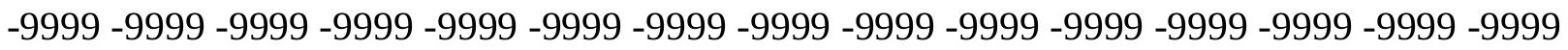
-9999 -9999 -9999 -9999 -9999 -9999 -9999 -9999 -9999 -9999 -9999 -9999 -9999 -9999 -9999 -

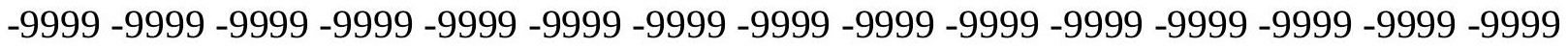
-9999 -9999 -9999 -9999 -9999 -9999 -9999 -9999 -9999 -9999 -9999 -9999 -9999 -9999 -9999 -9999 -9999 -9999 -9999 -9999 -9999 -9999 -9999 -9999 -9999 -9999 -9999 -9999 -9999 -9999 -9999 -9999 -9999 -9999 -9999 -9999 -9999 -9999 -9999 -9999 -9999 -9999 -9999 -9999 -9999 -

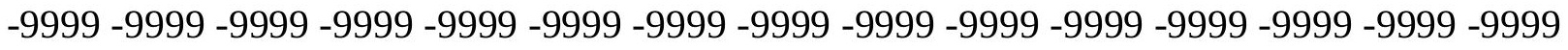

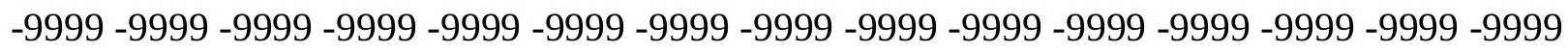
-9999 -9999 -9999 -9999 -9999 -9999 -9999 -9999 -9999 -9999 -9999 -9999 -9999 -9999 -9999 -9999 -9999 -9999 -9999 -9999 -9999 -9999 -9999 -9999 -9999 -9999 -9999 -9999 -9999 -9999 -9999 -9999 -9999 -9999 -9999 -9999 -9999 -9999 -9999 -9999 -9999 -9999 -9999 -9999 -9999 -

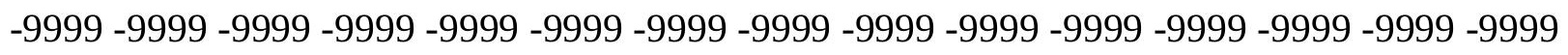
-9999 -9999 -9999 -9999 -9999 -9999 -9999 -9999 -9999 -9999 -9999 -9999 -9999 -9999 -9999 -9999 -9999 -9999 -9999 -9999 -9999 -9999 -9999 -9999 -9999 -9999 -9999 -9999 -9999 -9999 -

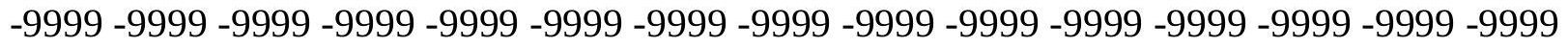
-9999 -9999 -9999 -9999 -9999 -9999 -9999 -9999 -9999 -9999 -9999 -9999 -9999 -9999 -9999 -9999 -9999 -9999 -9999 -9999 -9999 -9999 -9999 -9999 -9999 -9999 -9999 -9999 - -999 -

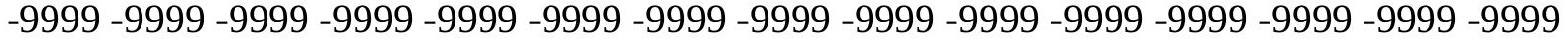
-9999 -9999 -9999 -9999 -9999 -9999 -9999 -9999 -9999 -9999 -9999 -9999 -9999 -9999 -9999 -

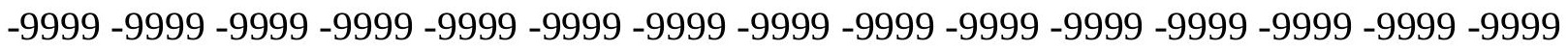

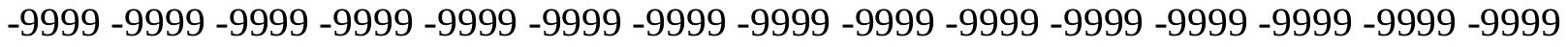

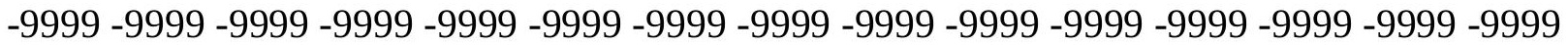

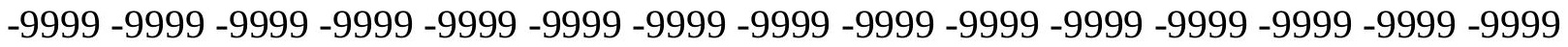

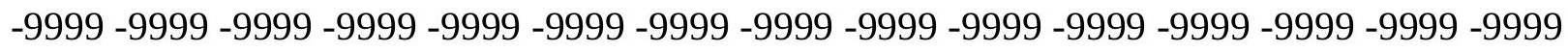

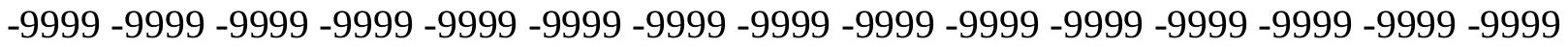

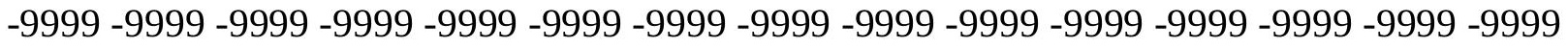
-9999 -9999 -9999 -9999 -9999 -9999 -9999 -9999 -9999 -9999 -9999 -9999 -9999 -9999 -9999 -

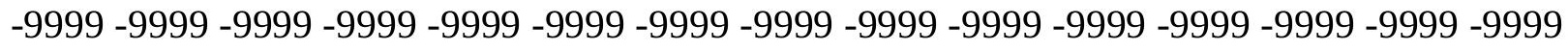

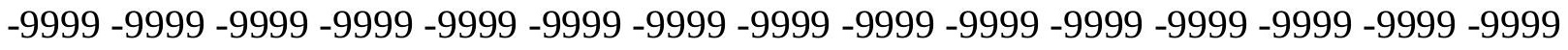
-9999 -9999 -9999 -9999 -9999 -9999 -9999 -9999 -9999 -9999 -9999 -9999 -9999 -9999 -9999 -9999 -9999 -9999 -9999 -9999 -9999 -9999 -9999 -9999-9999 -9999 -9999 -9999 -9999 -9999 -9999 -9999 -9999 -9999 -9999 -9999 -9999 -9999 -9999 -9999 -9999 -9999 -9999 -9999 -9999 -

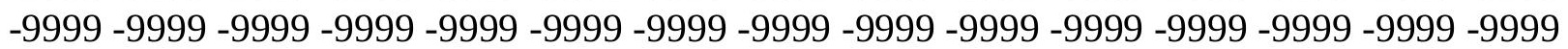


-9999 -9999 -9999 -9999 -9999 -9999 -9999 -9999 -9999 -9999 -9999 -9999 -9999 -9999 -9999 -9999 -9999 -9999 -9999 -9999 -9999 -9999 -9999 -9999 -9999 -9999 -9999 -9999 -9999 -9999 -

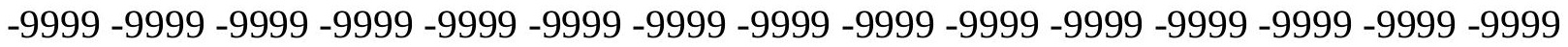
-9999 -9999 -9999 -9999 -9999 -9999 -9999 -9999 -9999 -9999 -9999 -9999 -9999 -9999 -9999 -9999 -9999 -9999 -9999 -9999 -9999 -9999 -9999 -9999-9999 -9999 -9999 -9999 -9999 -9999 -9999 -9999 -9999 -9999 -9999 -9999 -9999 -9999 -9999 -9999 -9999 -9999 -9999 -9999 -9999 -9999 -9999 -9999 -9999 -9999 -9999 -9999 -9999 -9999 -9999 -9999 -9999 -9999 -9999 -9999

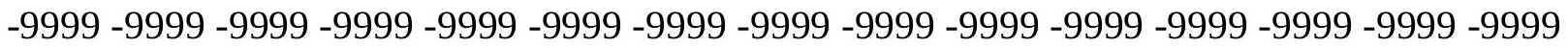
-9999 -9999 -9999 -9999 -9999 -9999 -9999 -9999 -9999 -9999 -9999 -9999 -9999 -9999 -9999 -9999 -9999 -9999 -9999 -9999 -9999 -9999 -9999 -9999 -9999 -9999 -9999 -9999 -9999

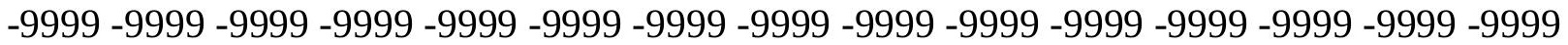
-9999 -9999 -9999 -9999 -9999 -9999 -9999 -9999 -9999 -9999 -9999 -9999 -9999 -9999 -9999 -9999 -9999 -9999 -9999 -9999 -9999 -9999 -9999 -9999 -9999 -9999 -9999 -9999 -9999 -9999 -9999 -9999 -9999 -9999 -9999 -9999 -9999 -9999 -9999 -9999 -9999 -9999 -9999 -9999 - 9999 -9999 -9999 -9999 -9999 -9999 -9999 -9999 -9999 -9999 -9999 -9999 -9999 -9999 -9999 -9999

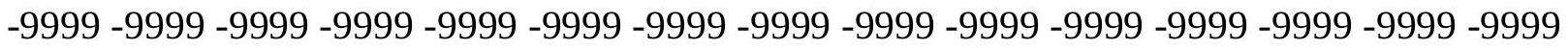
-9999 -9999 -9999 -9999 -9999 -9999 -9999 -9999 -9999 -9999 -9999 -9999 -9999 -9999 -9999 -9999 -9999 -9999 -9999 -9999 -9999 -9999 -9999 -9999 -9999 -9999 -9999 -9999 -9999 -9999 -9999 -9999 -9999 -9999 -9999 -9999 -9999 -9999 -9999 -9999 -9999 -9999 -9999 -9999 -9999 -

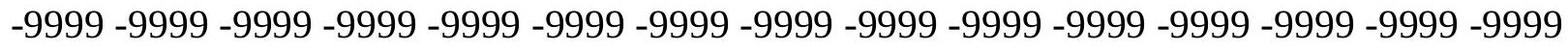

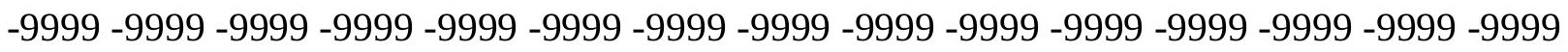
-9999 -9999 -9999 -9999 -9999 -9999 -9999 -9999 -9999 -9999 -9999 -9999 -9999 -9999 -9999 -9999 -9999 -9999 -9999 -9999 -9999 -9999 -9999 -9999 -9999 -9999 -9999 -9999 -9999 -9999 -9999 -9999 -9999 -9999 -9999 -9999 -9999 -9999 -9999 -9999 -9999 -9999 -9999 -9999 -9999 -

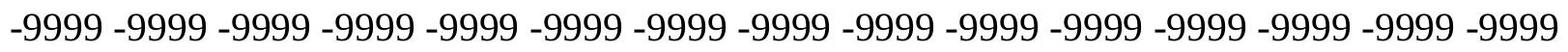
-9999 -9999 -9999 -9999 -9999 -9999 -9999 -9999 -9999 -9999 -9999 -9999 -9999 -9999 -9999 -9999 -9999 -9999 -9999 -9999 -9999 -9999 -9999 -9999 -9999 -9999 -9999 -9999 -9999 -9999 -

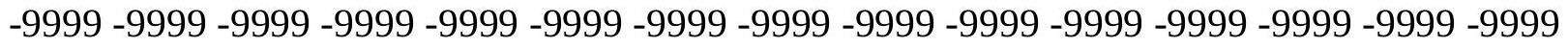
-9999 -9999 -9999 -9999 -9999 -9999 -9999 -9999 -9999 -9999 -9999 -9999 -9999 -9999 -9999 -9999 -9999 -9999 -9999 -9999 -9999 -9999 -9999 -9999 -9999 -9999 -9999 -9999 -9999 -999 -9999 -9999 -9999 -9999 -9999 -9999 -9999 -9999 -9999 -9999 -9999 -9999 -9999 -9999 -9999 -9999 -9999 -9999 -9999 -9999 -9999 -9999 -9999 -9999 -9999 -9999 -9999 -9999 -9999 -9999 -

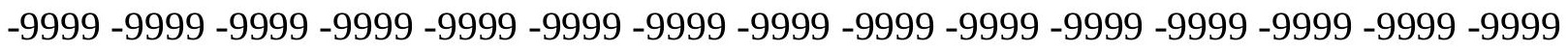

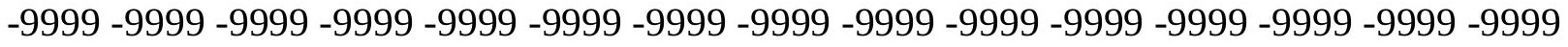
-9999 -9999 -9999 -9999 -9999 -9999 -9999 -9999 -9999 -9999 -9999 -9999 -9999 -9999 -

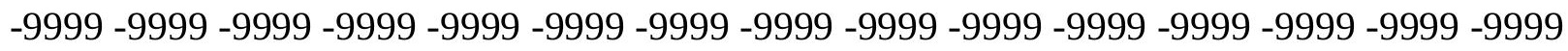

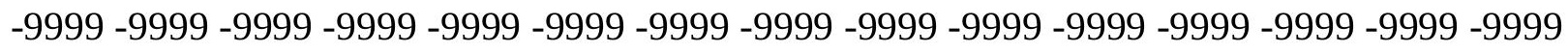

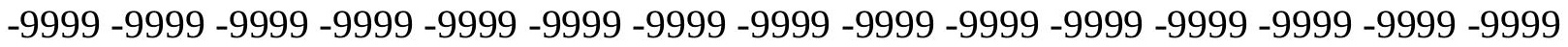
-9999 -9999 -9999 -9999 -9999 -9999 -9999 -9999 -9999 -9999 -9999 -9999 -9999 - 9999 - -999 -9999 -9999 -9999 -9999 -9999 -9999 -9999 -9999 -9999 -9999 -9999 -9999 -9999 -9999 -9999 -

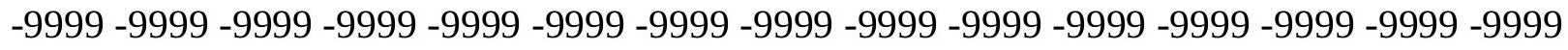

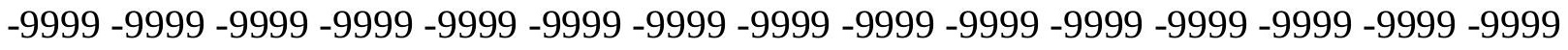
-9999 -9999 -9999 -9999 -9999 -9999 -9999 -9999 -9999 -9999 -9999 -9999 -9999 -9999 -9999 -9999 -9999 -9999 -9999 -9999 -9999 -9999 -9999 -9999-9999 -9999 -9999 -9999 -9999 -9999 -9999 -9999 -9999 -9999 -9999 -9999 -9999 -9999 -9999 -9999 -9999 -9999 -9999 -9999 -9999 -

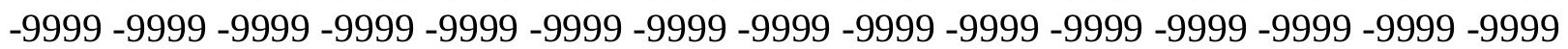


-9999 -9999 -9999 -9999 -9999 -9999 -9999 -9999 -9999 -9999 -9999 -9999 -9999 -9999 -9999 -9999 -9999 -9999 -9999 -9999 -9999 -9999 -9999 -9999 -9999 -9999 -9999 -9999 -9999 -9999 -

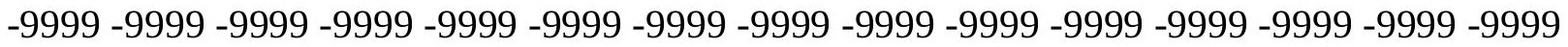
-9999 -9999 -9999 -9999 -9999 -9999 -9999 -9999 -9999 -9999 -9999 -9999 -9999 -9999 -9999 -9999 -9999 -9999 -9999 -9999 -9999 -9999 -9999 -9999-9999 -9999 -9999 -9999 -9999 -9999 -9999 -9999 -9999 -9999 -9999 -9999 -9999 -9999 -9999 -9999 -9999 -9999 -9999 -9999 -9999 -9999 -9999 -9999 -9999 -9999 -9999 -9999 -9999 -9999 -9999 -9999 -9999 -9999 -9999 -9999

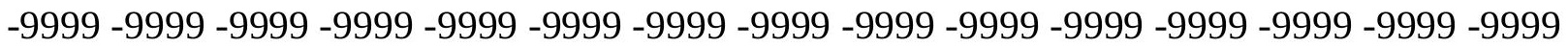

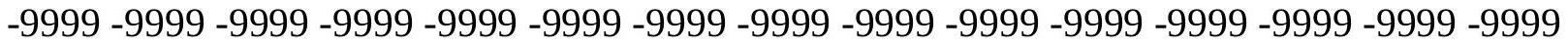
-9999 -9999 -9999 -9999 -9999 -9999 -9999 -9999 -9999 -9999 -9999 -9999 -9999 -9999 -9999 -9999 -9999 -9999 -9999 -9999 -9999 -9999 -9999 -9999 -9999 -9999 -9999 -9999 -9999 -9999 -9999 -9999 -9999 -9999 -9999 -9999 -9999 -9999 -9999 -9999 -9999 -9999 -9999 -9999 -9999 -9999 -9999 -9999 -9999 -9999 -9999 -9999 -9999 -9999 -9999 -9999 -9999 -9999 -9999 -9999 -9999 -9999 -9999 -9999 -9999 -9999 -9999 -9999 -9999 -9999 -9999 -9999 -9999 -9999 -9999 -9999 -9999 -9999 -9999 -9999 -9999 -9999 -9999 -9999 -9999 -9999 -9999 -9999 -9999 -9999 -9999 -9999 -9999 -9999 -9999 -9999 -9999 -9999 -9999 -9999 -9999 -9999 - 9999 - -999 -

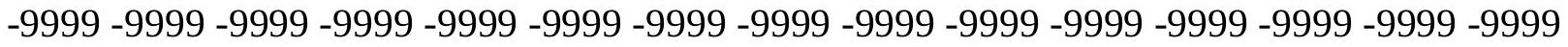
-9999 -9999 -9999 -9999 -9999 -9999 -9999 -9999 -9999 -9999 -9999 -9999 -9999 -9999 -9999 -9999 -9999 -9999 -9999 -9999 -9999 -9999 -9999 -9999 -9999 -9999 -9999 -9999 -9999 -9999 -

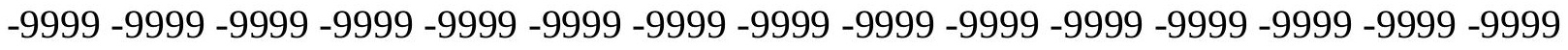
-9999 -9999 -9999 -9999 -9999 -9999 -9999 -9999 -9999 -9999 -9999 -9999 -9999 -9999 -9999

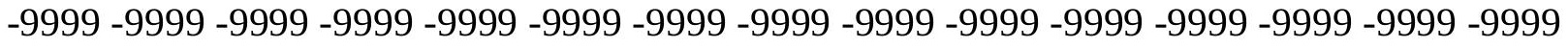
-9999 -9999 -9999 -9999 -9999 -9999 -9999 -9999 -9999 -9999 -9999 -9999 -9999 -9999 -9999 -9999 -9999 -9999 -9999 -9999 -9999 -9999 -9999 -9999 -9999 -9999 -9999 -9999 -9999 -9999 -

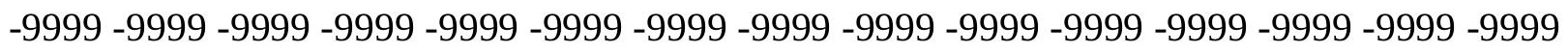
-9999 -9999 -9999 -9999 -9999 -9999 -9999 -9999 -9999 -9999 -9999 -9999 -9999 -9999 -9999 -9999 -9999 -9999 -9999 -9999 -9999 -9999 -9999 -9999 -9999 -9999 -9999 -9999 -9999 -9999 -

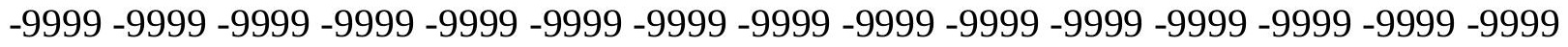
-9999 -9999 -9999 -9999 -9999 -9999 -9999 -9999 -9999 -9999 -9999 -9999 -9999 -9999 -9999 -9999 -9999 -9999 -9999 -9999 -9999 -9999 -9999 -9999 -9999 -9999 -9999 -9999 -9999 -999 -

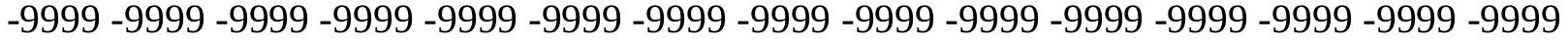
-9999 -9999 -9999 -9999 -9999 -9999 -9999 -9999 -9999 -9999 -9999 -9999 -9999 -9999 -9999 -

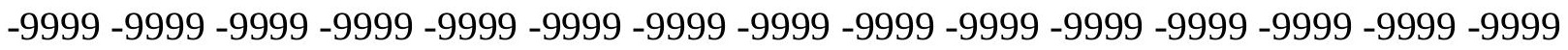

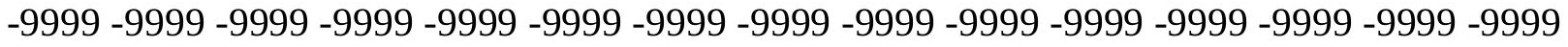

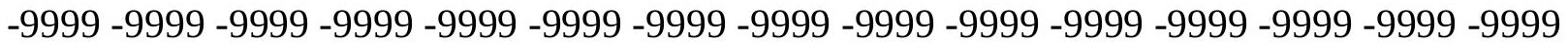
-9999 -9999 -9999 -9999 -9999 -9999 -9999 -9999 -9999 -9999 -9999 -9999 -9999 -9999 -9999 -

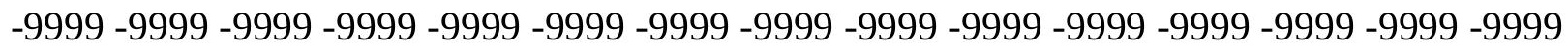

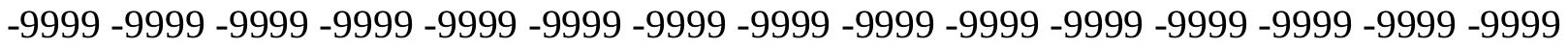
-9999 -9999 -9999 -9999 -9999 -9999 -9999 -9999 -9999 -9999 -9999 -9999 -9999 - 9999 - -999 -9999 -9999 -9999 -9999 -9999 -9999 -9999 -9999 -9999 -9999 -9999 -9999 -9999 -9999 -9999 -

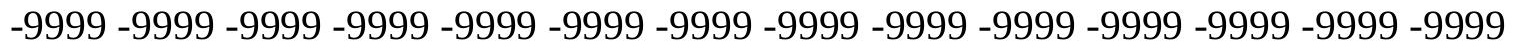

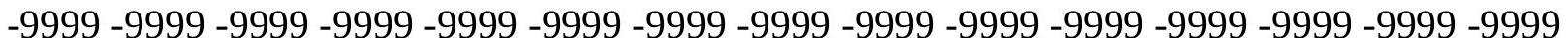
-9999 -9999 -9999 -9999 -9999 -9999 -9999 -9999 -9999 -9999 -9999 -9999 -9999 -9999 -9999 -9999 -9999 -9999 -9999 -9999 -9999 -9999 -9999 -9999-9999 -9999 -9999 -9999 -9999 -9999 -9999 -9999 -9999 -9999 -9999 -9999 -9999 -9999 -9999 -9999 -9999 -9999 -9999 -9999 -9999 -

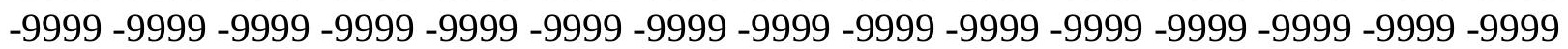


-9999 -9999 -9999 -9999 -9999 -9999 -9999 -9999 -9999 -9999 -9999 -9999 -9999 -9999 -9999 -9999 -9999 -9999 -9999 -9999 -9999 -9999 -9999 -9999 -9999 -9999 -9999 -9999 -9999 -9999 -9999 -9999 -9999 -9999 -9999 -9999 -9999 -9999 -9999 -9999 -9999 -9999 -9999 -9999 - 9999 -9999 -9999 -9999 -9999 -9999 -9999 -9999 -9999 -9999 -9999 -9999 -9999 -9999 -9999 -9999 -9999 -9999 -9999 -9999 -9999 -9999 -9999 -9999 -9999-9999 -9999 -9999 -9999 -9999 -9999 -9999 -9999 -9999 -9999 -9999 -9999 -9999 -9999 -9999 -9999 -9999 -9999 -9999 -9999 -9999 -9999 -9999 -9999 -9999 -9999 -9999 -9999 -9999 -9999 -9999 -9999 -9999 -9999 -9999 -9999

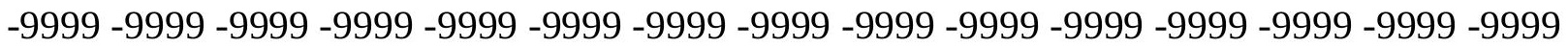
-9999 -9999 -9999 -9999 -9999 -9999 -9999 -9999 -9999 -9999 -9999 -9999 -9999 -9999 -9999 -9999 -9999 -9999 -9999 -9999 -9999 -9999 -9999 -9999 -9999 -9999 -9999 -9999 -9999 -9999

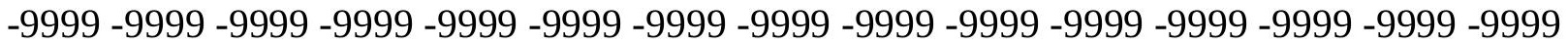
-9999 -9999 -9999 -9999 -9999 -9999 -9999 -9999 -9999 -9999 -9999 -9999 -9999 -9999 -9999 -9999 -9999 -9999 -9999 -9999 -9999 -9999 -9999 -9999 -9999 -9999 -9999 -9999 -9999 -9999 -

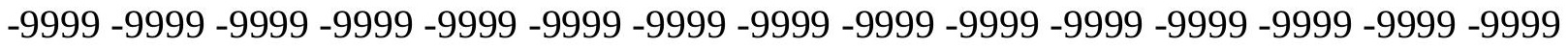
-9999 -9999 -9999 -9999 -9999 -9999 -9999 -9999 -9999 -9999 -9999 -9999 -9999 -9999 -9999

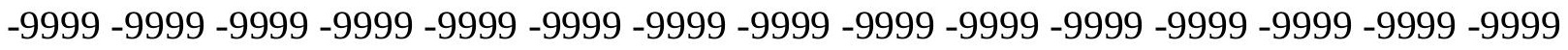
-9999 -9999 -9999 -9999 -9999 -9999 -9999 -9999 -9999 -9999 -9999 -9999 -9999 -9999 -9999 -9999 -9999 -9999 -9999 -9999 -9999 -9999 -9999 -9999 -9999 -9999 -9999 -9999 -9999 - 9999 -9999 -9999 -9999 -9999 -9999 -9999 -9999 -9999 -9999 -9999 -9999 -9999 -9999 -9999 -9999 -9999 -9999 -9999 -9999 -9999 -9999 -9999 -9999 -9999 -9999 -9999 -9999 -9999 -9999 -9999 -9999 -9999 -9999 -9999 -9999 -9999 -9999 -9999 -9999 -9999 -9999 -9999 -9999 -9999 -9999 -9999 -9999 -9999 -9999 -9999 -9999 -9999 -9999 -9999 -9999 -9999 -9999 -9999 -9999 -9999 -9999 -9999 -9999 -9999 -9999 -9999 -9999 -9999 -9999 -9999 -9999 -9999 -9999 -9999 -9999 -9999 -9999 -9999 -9999 -9999 -9999 -9999 -9999 -9999 -9999 -9999 -9999 -9999 -9999 -9999 -9999 -9999 -9999 -9999 -9999 -9999 -9999 -9999 -9999 -9999 -9999 -9999 -9999 -9999 -9999 -9999 -9999 -9999 -9999 -9999 -9999 -9999 -9999 -9999 -9999 -9999 -9999 -9999 -9999 -9999 -9999 -9999 -9999 -9999 -9999 -9999 -9999 -9999 -9999 -9999 -9999 -9999 -9999 -9999 -9999 -9999 -9999 -9999 -9999 -9999 -9999 -9999 -9999 -9999 -9999 -9999 -9999 -9999 -9999 -9999 -9999 -9999 -9999 -9999 -9999 -9999 -9999 -9999 -9999 -9999 -9999 -9999 -9999 -9999 -9999 -9999 -9999 -9999 -9999 -9999 -9999 -9999 -9999 -9999 -9999 -9999 -9999 -9999 -999 -9999 -9999 -9999 -9999 -9999 -9999 -9999 -9999 -9999 -9999 -9999 -9999 -9999 -9999 -9999 -9999 -9999 -9999 -9999 -9999 -9999 -9999 -9999 -9999 -9999 -9999 -9999 -9999 -9999 -9999 -

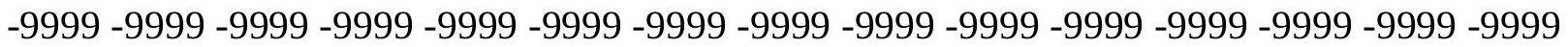

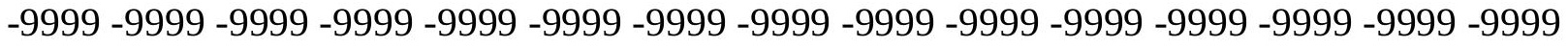

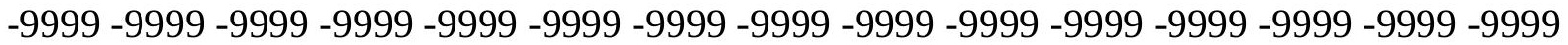
-9999 -9999 -9999 -9999 -9999 -9999 -9999 -9999 -9999 -9999 -9999 -9999 -9999 -9999 -9999

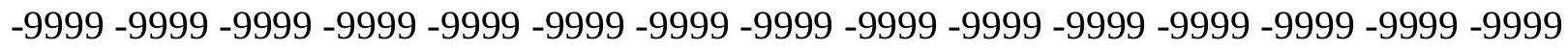

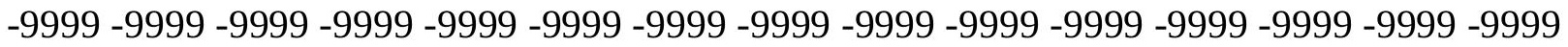

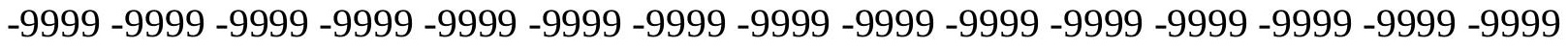
-9999 -9999 -9999 -9999 -9999 -9999 -9999 -9999 -9999 -9999 -9999 -9999 -9999 -9999 -9999 -

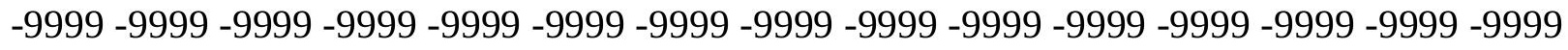

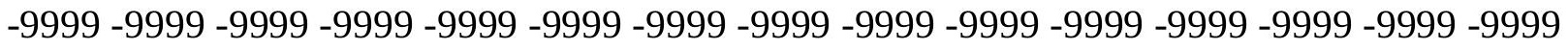
-9999 -9999 -9999 -9999 -9999 -9999 -9999 -9999 -9999 -9999 -9999 -9999 -9999 -9999 -9999 -9999 -9999 -9999 -9999 -9999 -9999 -9999 -9999 -9999-9999 -9999 -9999 -9999 -9999 -9999 -9999 -9999 -9999 -9999 -9999 -9999 -9999 -9999 -9999 -9999 -9999 -9999 -9999 -9999 -9999 -

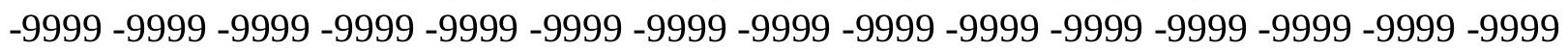


-9999 -9999 -9999 -9999 -9999 -9999 -9999 -9999 -9999 -9999 -9999 -9999 -9999 -9999 -9999 -9999 -9999 -9999 -9999 -9999 -9999 -9999 -9999 -9999 -9999 -9999 -9999 -9999 -9999 -9999 -9999 -9999 -9999 -9999 -9999 -9999 -9999 -9999 -9999 -9999 -9999 -9999 -9999 -9999 -9999 -9999 -9999 -9999 -9999 -9999 -9999 -9999 -9999 -9999 -9999 -9999 -9999 -9999 -9999 -9999 -9999 -9999 -9999 -9999 -9999 -9999 -9999 -9999 -9999 -9999 -9999 -9999 -9999 -9999 -9999 -9999 -9999 -9999 -9999 -9999 -9999 -9999 -9999 -9999 -9999 -9999 -9999 -9999 -9999 -9999 -9999 -9999 -9999 -9999 -9999 -9999 -9999 -9999 -9999 -9999 -9999 -9999 -9999 -9999 -

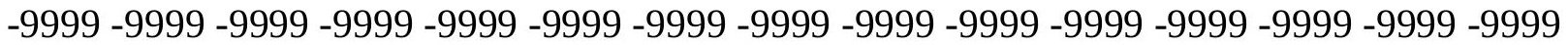
-9999 -9999 -9999 -9999 -9999 -9999 -9999 -9999 -9999 -9999 -9999 -9999 -9999 -9999 -9999 -9999 -9999 -9999 -9999 -9999 -9999 -9999 -9999 -9999 -9999 -9999 -9999 -9999 -9999 -9999 -

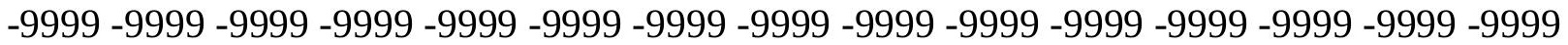
-9999 -9999 -9999 -9999 -9999 -9999 -9999 -9999 -9999 -9999 -9999 -9999 -9999 -9999 -9999 -9999 -9999 -9999 -9999 -9999 -9999 -9999 -9999 -9999 -9999 -9999 -9999 -9999 -9999 -9999 -9999 -9999 -9999 -9999 -9999 -9999 -9999 -9999 -9999 -9999 -9999 -9999 -9999 -9999 -9999 -9999 -9999 -9999 -9999 -9999 -9999 -9999 -9999 -9999 -9999 -9999 -9999 -9999 -9999 -9999 -9999 -9999 -9999 -9999 -9999 -9999 -9999 -9999 -9999 -9999 -9999 -9999 -9999 -9999 -9999 -9999 -9999 -9999 -9999 -9999 -9999 -9999 -9999 -9999 -9999 -9999 -9999 -9999 -9999 -9999 -9999 -9999 -9999 -9999 -9999 -9999 -9999 -9999 -9999 -9999 -9999 -9999 -9999 -9999 -9999 -9999 -9999 -9999 -9999 -9999 -9999 -9999 -9999 -9999 -9999 -9999 -9999 -9999 -9999 -9999 -9999 -9999 -9999 -9999 -9999 -9999 -9999 -9999 -9999 -9999 -9999 -9999 -9999 -9999 -9999

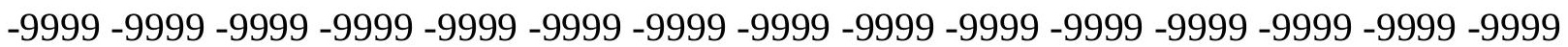
-9999 -9999 -9999 -9999 -9999 -9999 -9999 -9999 -9999 -9999 -9999 -9999 -9999 -9999 -9999 -9999 -9999 -9999 -9999 -9999 -9999 -9999 -9999 -9999 -9999 -9999 -9999 -9999 -9999 -9999 -9999 -9999 -9999 -9999 -9999 -9999 -9999 -9999 -9999 -9999 -9999 -9999 -9999 -9999 -9999

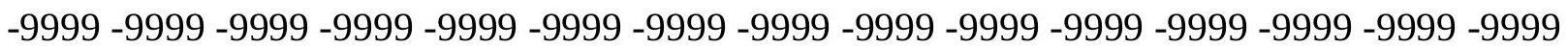
-9999 -9999 -9999 -9999 -9999 -9999 -9999 -9999 -9999 -9999 -9999 -9999 -9999 -9999 -9999 -9999 -9999 -9999 -9999 -9999 -9999 -9999 -9999 -9999 -9999 -9999 -9999 -9999 -9999 -9999 -9999 -9999 -9999 -9999 -9999 -9999 -9999 -9999 -9999 -9999 -9999 -9999 -9999 -9999

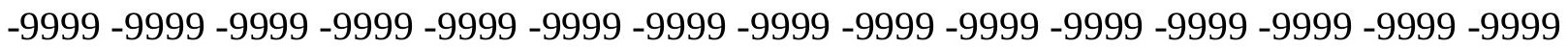
-9999 -9999 -9999 -9999 -9999 -9999 -9999 -9999 -9999 -9999 -9999 -9999 -9999 -9999 -9999 -9999 -9999 -9999 -9999 -9999 -9999 -9999 -9999 -9999 -9999 -9999 -9999 -9999 -9999 -9999 -

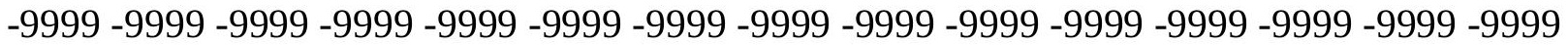
-9999 -9999 -9999 -9999 -9999 -9999 -9999 -9999 -9999 -9999 -9999 -9999 -9999 -9999 -9999 -9999 -9999 -9999 -9999 -9999 -9999 -9999 -9999 -9999 -9999 -9999 -9999 -9999 -9999 -9999 -9999 -9999 -9999 -9999 -9999 -9999 -9999 -9999 -9999 -9999 -9999 -9999 -9999 -9999 -9999 -9999 -9999 -9999 -9999 -9999 -9999 -9999 -9999 -9999 -9999 -9999 -9999 -9999 -9999 -9999 -9999 -9999 -9999 -9999 -9999 -9999 -9999 -9999 -9999 -9999 -9999 -9999 -9999 -9999 -9999

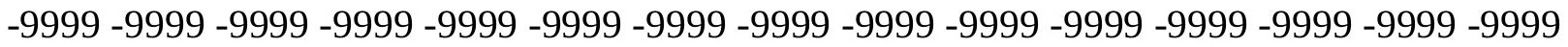
-9999 -9999 -9999 -9999 -9999 -9999 -9999 -9999 -9999 -9999 -9999 -9999 -9999 -9999 -9999 -9999 -9999 -9999 -9999 -9999 -9999 -9999 -9999 -9999 -9999 -9999 -9999 -9999 -9999 -9999 -

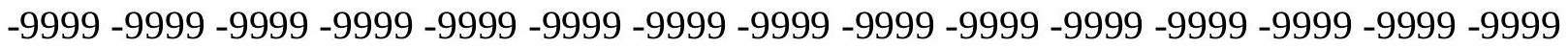
-9999 -9999 -9999 -9999 -9999 -9999 -9999 -9999 -9999 -9999 -9999 -9999 -9999 -9999 -9999 -9999 -9999 -9999 -9999 -9999 -9999 -9999 -9999 -9999 -9999 -9999 -9999 -9999 -9999 -9999 -9999 -9999 -9999 -9999 -9999 -9999 -9999 -9999 -9999 -9999 -9999 -9999 -9999 -9999 -9999 -9999 -9999 -9999 -9999 -9999 -9999 -9999 -9999 -9999 -9999 -9999 -9999 -9999 -9999 -9999

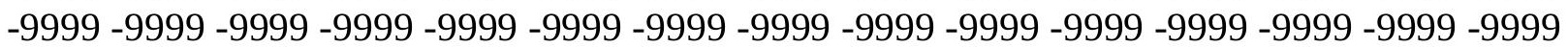


-9999 -9999 -9999 -9999 -9999 -9999 -9999 -9999 -9999 -9999 -9999 -9999 -9999 -9999 -9999 -9999 -9999 -9999 -9999 -9999 -9999 -9999 -9999 -9999 -9999 -9999 -9999 -9999 -9999 -9999 -

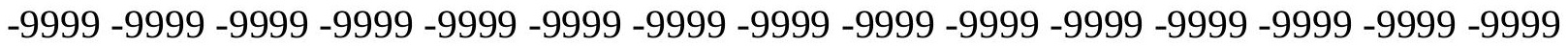
-9999 -9999 -9999 -9999 -9999 -9999 -9999 -9999 -9999 -9999 -9999 -9999 -9999 -9999 -9999 -9999 -9999 -9999 -9999 -9999 -9999 -9999 -9999 -9999-9999 -9999 -9999 -9999 -9999 -9999 -9999 -9999 -9999 -9999 -9999 -9999 -9999 -9999 -9999 -9999 -9999 -9999 -9999 -9999 -9999 -9999 -9999 -9999 -9999 -9999 -9999 -9999 -9999 -9999 -9999 -9999 -9999 -9999 -9999 -

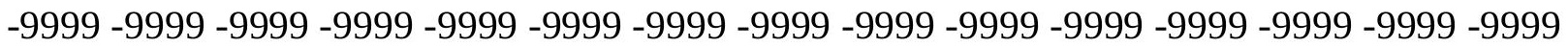

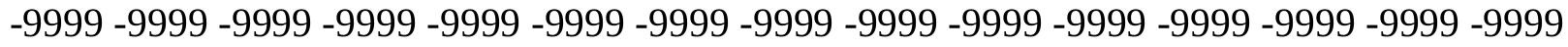
-9999 -9999 -9999 -9999 -9999 -9999 -9999 -9999 -9999 -9999 -9999 -9999 -9999 -9999 -9999 -9999 -9999 -9999 -9999 -9999 -9999 -9999 -9999 -9999 -9999 -9999 -9999 -9999 -9999 -9999 -9999 -9999 -9999 -9999 -9999 -9999 -9999 -9999 -9999 -9999 -9999 -9999 -9999 -9999 -9999 -9999 -9999 -9999 -9999 -9999 -9999 -9999 -9999 -9999 -9999 -9999 -9999 -9999 -9999 -9999 -9999 -9999 -9999 -9999 -9999 -9999 -9999 -9999 -9999 -9999 -9999 -9999 -9999 -9999 -9999 -9999 -9999 -9999 -9999 -9999 -9999 -9999 -9999 -9999 -9999 -9999 -9999 -9999 -9999 -9999 -

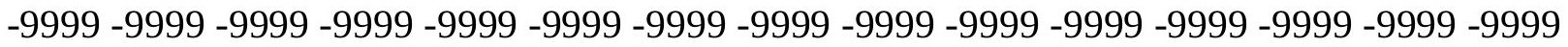
-9999 -9999 -9999 -9999 -9999 -9999 -9999 -9999 -9999 -9999 -9999 -9999 -9999 -9999 -9999 -9999 -9999 -9999 -9999 -9999 -9999 -9999 -9999 -9999 -9999 -9999 -9999 -9999 -9999 -9999 -9999 -9999 -9999 -9999 -9999 -9999 -9999 -9999 -9999 -9999 -9999 -9999 -9999 -9999 -9999 -

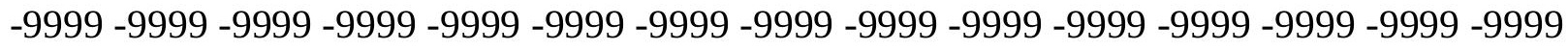

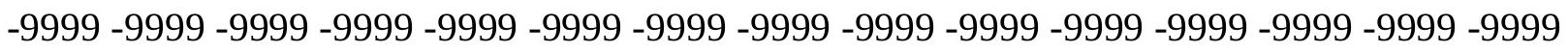

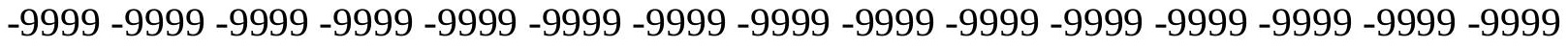
-9999 -9999 -9999 -9999 -9999 -9999 -9999 -9999 -9999 -9999 -9999 -9999 -9999 -9999 -9999 -9999 -9999 -9999 -9999 -9999 -9999 -9999 -9999 -9999 -9999 -9999 -9999 -9999 -9999 -9999 -

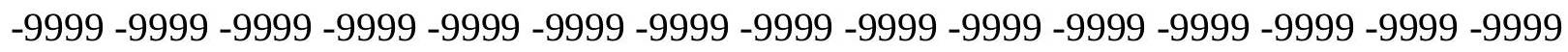
-9999 -9999 -9999 -9999 -9999 -9999 -9999 -9999 -9999 -9999 -9999 -9999 -9999 -9999 -9999 -9999 -9999 -9999 -9999 -9999 -9999 -9999 -9999 -9999 -9999 -9999 -9999 -9999 -9999 -9999 -

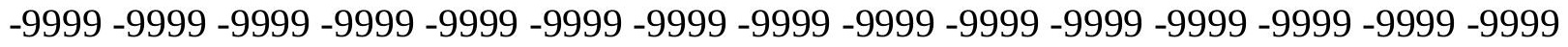
-9999 -9999 -9999 -9999 -9999 -9999 -9999 -9999 -9999 -9999 -9999 -9999 -9999 -9999 -9999 -9999 -9999 -9999 -9999 -9999 -9999 -9999 -9999 -9999 -9999 -9999 -9999 -9999 -9999 -999 -9999 -9999 -9999 -9999 -9999 -9999 -9999 -9999 -9999 -9999 -9999 -9999 -9999 -9999 -9999 -

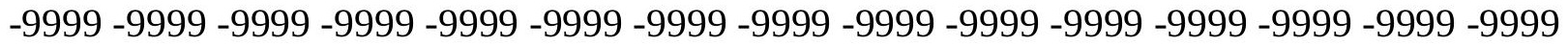

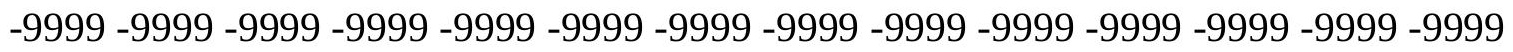

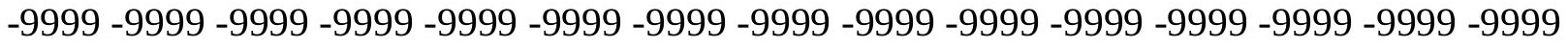

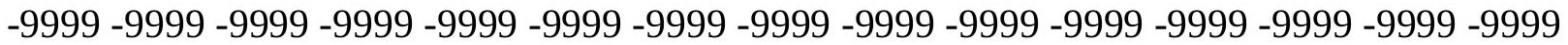

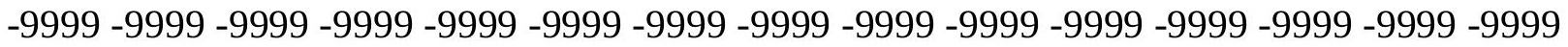

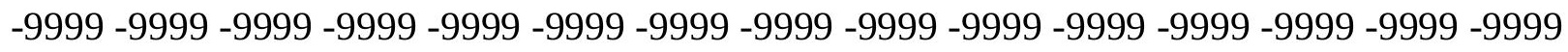

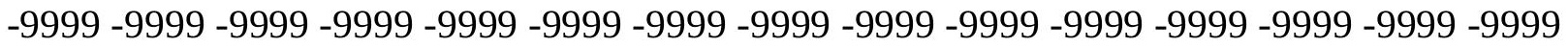

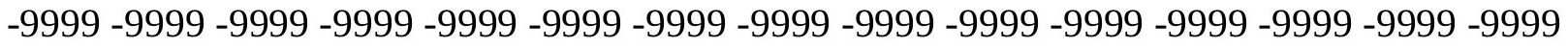
-9999 -9999 -9999 -9999 -9999 -9999 -9999 -9999 -9999 -9999 -9999 -9999 -9999 -9999 -9999 -

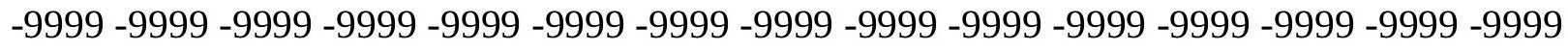

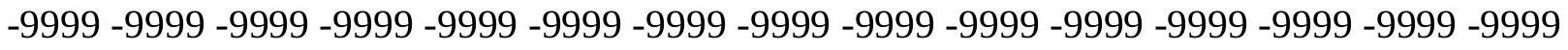
-9999 -9999 -9999 -9999 -9999 -9999 -9999 -9999 -9999 -9999 -9999 -9999 -9999 -9999 -9999 -9999 -9999 -9999 -9999 -9999 -9999 -9999 -9999 -9999-9999 -9999 -9999 -9999 -9999 -9999 -9999 -9999 -9999 -9999 -9999 -9999 -9999 -9999 -9999 -9999 -9999 -9999 -9999 -9999 -9999 -

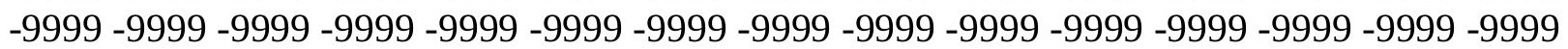


-9999 -9999 -9999 -9999 -9999 -9999 -9999 -9999 -9999 -9999 -9999 -9999 -9999 -9999 -9999 -9999 -9999 -9999 -9999 -9999 -9999 -9999 -9999 -9999 -9999 -9999 -9999 -9999 -9999 -9999 -

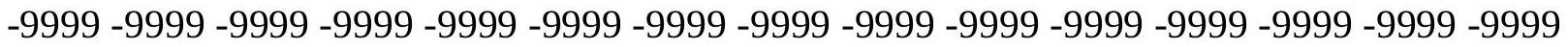
-9999 -9999 -9999 -9999 -9999 -9999 -9999 -9999 -9999 -9999 -9999 -9999 -9999 -9999 -9999 -9999 -9999 -9999 -9999 -9999 -9999 -9999 -9999 -9999-9999 -9999 -9999 -9999 -9999 -9999 -9999 -9999 -9999 -9999 -9999 -9999 -9999 -9999 -9999 -9999 -9999 -9999 -9999 -9999 -9999 -9999 -9999 -9999 -9999 -9999 -9999 -9999 -9999 -9999 -9999 -9999 -9999 -9999 -9999 -9999

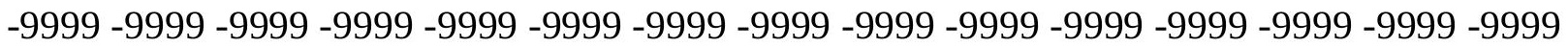

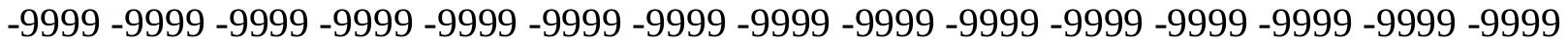
-9999 -9999 -9999 -9999 -9999 -9999 -9999 -9999 -9999 -9999 -9999 -9999 -9999 -9999 -9999 -9999 -9999 -9999 -9999 -9999 -9999 -9999 -9999 -9999 -9999 -9999 -9999 -9999 -9999 -9999 -9999 -9999 -9999 -9999 -9999 -9999 -9999 -9999 -9999 -9999 -9999 -9999 -9999 -9999 -9999 -9999 -9999 -9999 -9999 -9999 -9999 -9999 -9999 -9999 -9999 -9999 -9999 -9999 -9999 -9999 -9999 -9999 -9999 -9999 -9999 -9999 -9999 -9999 -9999 -9999 -9999 -9999 -9999 -9999 -9999 -9999 -9999 -9999 -9999 -9999 -9999 -9999 -9999 -9999 -9999 -9999 -9999 -9999 -9999 -

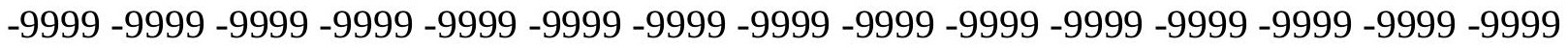
-9999 -9999 -9999 -9999 -9999 -9999 -9999 -9999 -9999 -9999 -9999 -9999 -9999 -9999 -9999 -9999 -9999 -9999 -9999 -9999 -9999 -9999 -9999 -9999 -9999 -9999 -9999 -9999 -9999 -9999 -9999 -9999 -9999 -9999 -9999 -9999 -9999 -9999 -9999 -9999 -9999 -9999 -9999 -9999 -9999 -

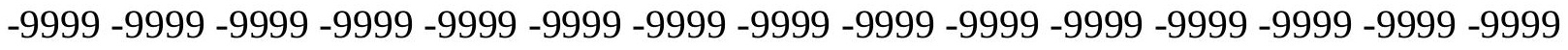
-9999 -9999 -9999 -9999 -9999 -9999 -9999 -9999 -9999 -9999 -9999 -9999 -9999 -9999 -9999

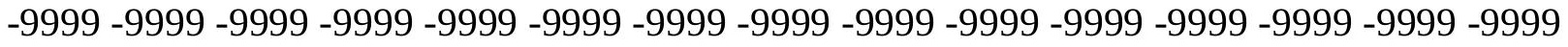
-9999 -9999 -9999 -9999 -9999 -9999 -9999 -9999 -9999 -9999 -9999 -9999 -9999 -9999 -9999 -9999 -9999 -9999 -9999 -9999 -9999 -9999 -9999 -9999 -9999 -9999 -9999 -9999 -9999 -9999 -

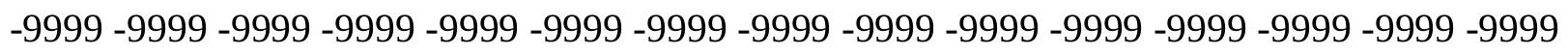
-9999 -9999 -9999 -9999 -9999 -9999 -9999 -9999 -9999 -9999 -9999 -9999 -9999 -9999 -9999 -9999 -9999 -9999 -9999 -9999 -9999 -9999 -9999 -9999 -9999 -9999 -9999 -9999 -9999 -9999 -

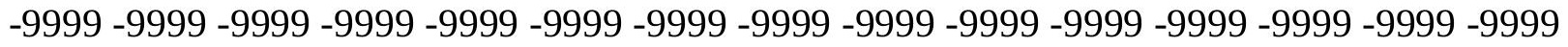
-9999 -9999 -9999 -9999 -9999 -9999 -9999 -9999 -9999 -9999 -9999 -9999 -9999 -9999 -9999 -9999 -9999 -9999 -9999 -9999 -9999 -9999 -9999 -9999 -9999 -9999 -9999 -9999 -9999 -999 -9999 -9999 -9999 -9999 -9999 -9999 -9999 -9999 -9999 -9999 -9999 -9999 -9999 -9999 -9999 -9999 -9999 -9999 -9999 -9999 -9999 -9999 -9999 -9999 -9999 -9999 -9999 -9999 -9999 -9999 -

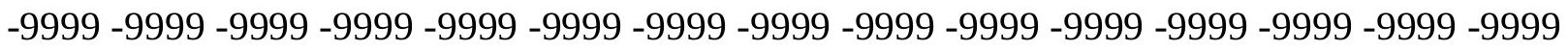

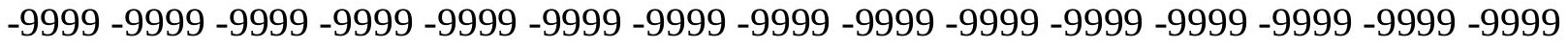

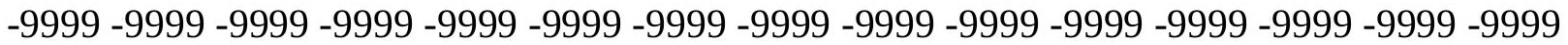
-9999 -9999 -9999 -9999 -9999 -9999 -9999 -9999 -9999 -9999 -9999 -9999 -9999 -9999 -9999 -

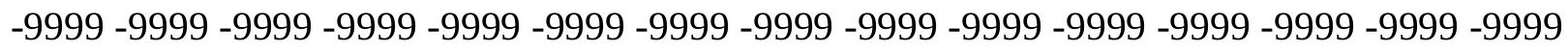

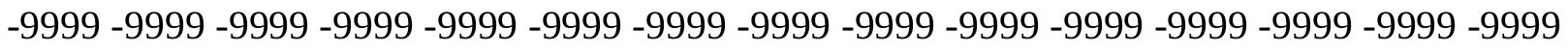
-9999 -9999 -9999 -9999 -9999 -9999 -9999 -9999 -9999 -9999 -9999 -9999 -9999 -9999 - -999 -9999 -9999 -9999 -9999 -9999 -9999 -9999 -9999 -9999 -9999 -9999 -9999 -9999 -9999 -9999 -

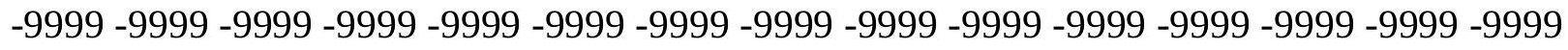

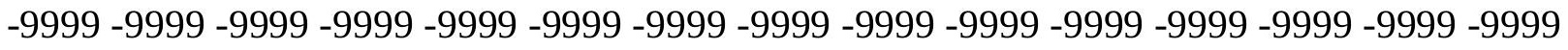
-9999 -9999 -9999 -9999 -9999 -9999 -9999 -9999 -9999 -9999 -9999 -9999 -9999 -9999 -9999 -9999 -9999 -9999 -9999 -9999 -9999 -9999 -9999 -9999-9999 -9999 -9999 -9999 -9999 -9999 -9999 -9999 -9999 -9999 -9999 -9999 -9999 -9999 -9999 -9999 -9999 -9999 -9999 -9999 -9999 -

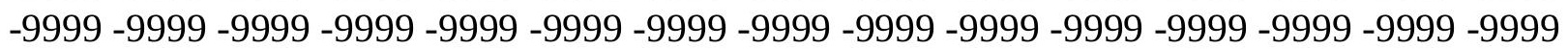


-9999 -9999 -9999 -9999 -9999 -9999 -9999 -9999 -9999 -9999 -9999 -9999 -9999 -9999 -9999 -9999 -9999 -9999 -9999 -9999 -9999 -9999 -9999 -9999 -9999 -9999 -9999 -9999 -9999 -9999 -

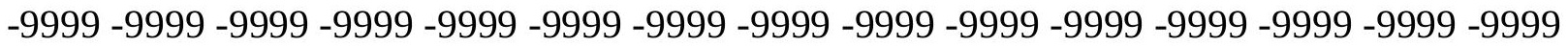
-9999 -9999 -9999 -9999 -9999 -9999 -9999 -9999 -9999 -9999 -9999 -9999 -9999 -9999 -9999 -9999 -9999 -9999 -9999 -9999 -9999 -9999 -9999 -9999-9999 -9999 -9999 -9999 -9999 -9999 -9999 -9999 -9999 -9999 -9999 -9999 -9999 -9999 -9999 -9999 -9999 -9999 -9999 -9999 -9999 -9999 -9999 -9999 -9999 -9999 -9999 -9999 -9999 -9999 -9999 -9999 -9999 -9999 -9999 -9999

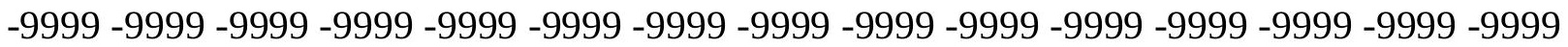

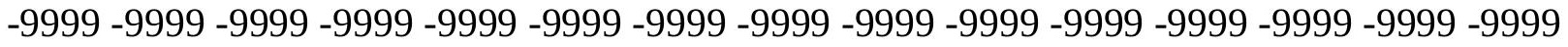
-9999 -9999 -9999 -9999 -9999 -9999 -9999 -9999 -9999 -9999 -9999 -9999 -9999 -9999 -9999 -9999 -9999 -9999 -9999 -9999 -9999 -9999 -9999 -9999 -9999 -9999 -9999 -9999 -9999 -9999 -9999 -9999 -9999 -9999 -9999 -9999 -9999 -9999 -9999 -9999 -9999 -9999 -9999 -9999 -9999 -9999 -9999 -9999 -9999 -9999 -9999 -9999 -9999 -9999 -9999 -9999 -9999 -9999 -9999 -9999 -

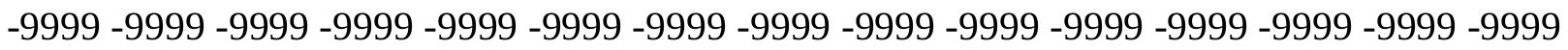
-9999 -9999 -9999 -9999 -9999 -9999 -9999 -9999 -9999 -9999 -9999 -9999 -9999 -9999 -9999 -

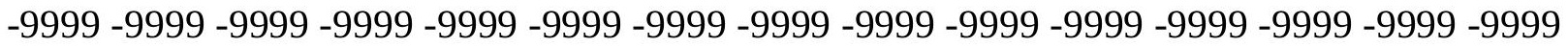
-9999 -9999 -9999 -9999 -9999 -9999 -9999 -9999 -9999 -9999 -9999 -9999 -9999 -9999 -9999 -9999 -9999 -9999 -9999 -9999 -9999 -9999 -9999 -9999 -9999 -9999 -9999 -9999 -9999 -9999 -9999 -9999 -9999 -9999 -9999 -9999 -9999 -9999 -9999 -9999 -9999 -9999 -9999 -9999 - -999 -

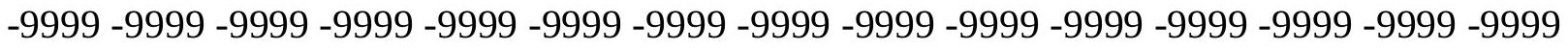

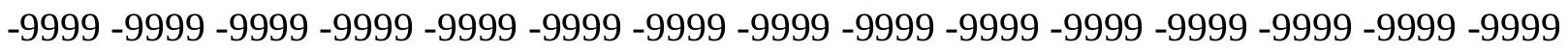
-9999 -9999 -9999 -9999 -9999 -9999 -9999 -9999 -9999 -9999 -9999 -9999 -9999 -9999 -9999 -9999 -9999 -9999 -9999 -9999 -9999 -9999 -9999 -9999 -9999 -9999 -9999 -9999 -9999 -9999 -9999 -9999 -9999 -9999 -9999 -9999 -9999 -9999 -9999 -9999 -9999 -9999 -9999 -9999 -9999 -

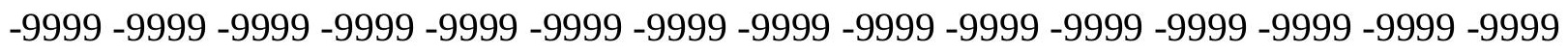
-9999 -9999 -9999 -9999 -9999 -9999 -9999 -9999 -9999 -9999 -9999 -9999 -9999 -9999 -9999 -9999 -9999 -9999 -9999 -9999 -9999 -9999 -9999 -9999 -9999 -9999 -9999 -9999 -9999 -9999 -

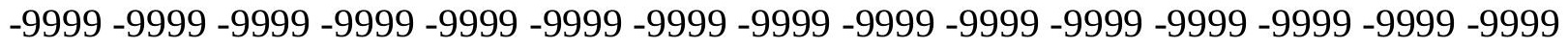
-9999 -9999 -9999 -9999 -9999 -9999 -9999 -9999 -9999 -9999 -9999 -9999 -9999 -9999 -9999 -9999 -9999 -9999 -9999 -9999 -9999 -9999 -9999 -9999 -9999 -9999 -9999 -9999 -9999 -999 -

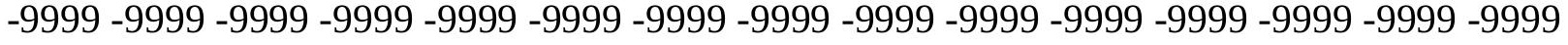
-9999 -9999 -9999 -9999 -9999 -9999 -9999 -9999 -9999 -9999 -9999 -9999 -9999 -9999 -9999 -

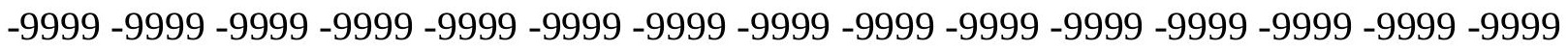

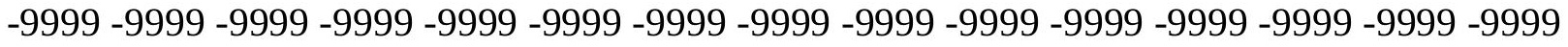

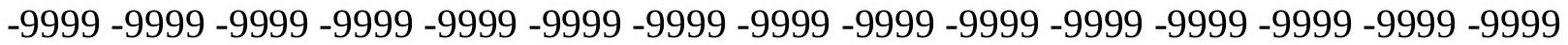

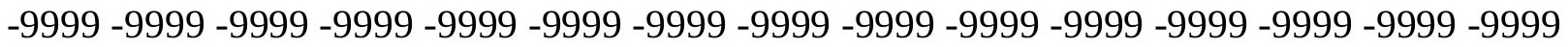

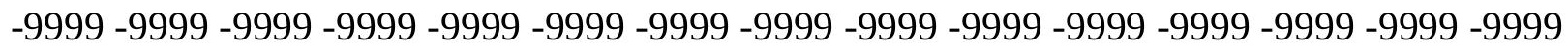

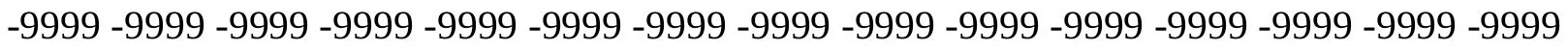

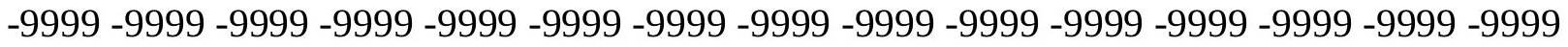
-9999 -9999 -9999 -9999 -9999 -9999 -9999 -9999 -9999 -9999 -9999 -9999 -9999 -9999 -9999 -

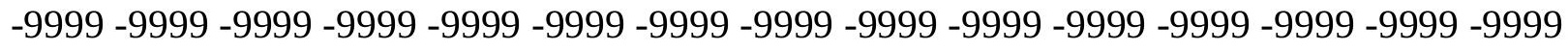

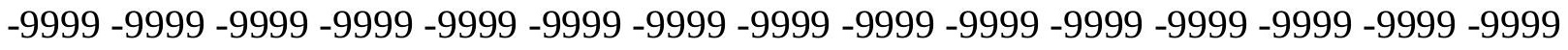
-9999 -9999 -9999 -9999 -9999 -9999 -9999 -9999 -9999 -9999 -9999 -9999 -9999 -9999 -9999 -9999 -9999 -9999 -9999 -9999 -9999 -9999 -9999 -9999 -9999 -9999 -9999 -9999 -9999 -9999 -9999 -9999 -9999 -9999 -9999 -9999 -9999 -9999 -9999 -9999 -9999 -9999 -9999 -9999 -

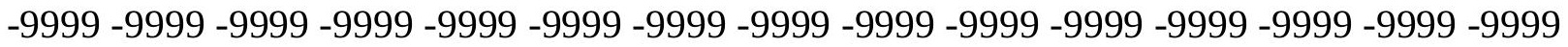




$$
\begin{aligned}
& \text {-9999 -9999 -9999 -9999 -9999 -9999 -9999 -9999 -9999 -9999 -9999 -9999 -9999 -9999 -9999 } \\
& \text {-9999 -9999 -9999 -9999 -9999 -9999 -9999 -9999 -9999 -9999 -9999 -9999 -9999 -9999 -9999 } \\
& \text {-9999 -9999 -9999 -9999 -9999 -9999 -9999 -9999 -9999 -9999 -9999 -9999 -9999 -9999 -9999 } \\
& \text {-9999 -9999 -9999 -9999 -9999 -9999 -9999 -9999 -9999 -9999 -9999 -9999 -9999 -9999 -9999 } \\
& \text {-9999 -9999 -9999 -9999 -9999 -9999 -9999 -9999 -9999 -9999 -9999 -9999 -9999 -9999 -9999 - } \\
& \text {-9999 -9999 -9999 -9999 -9999 -9999 -9999 -9999 -9999 -9999 -9999 -9999 -9999 -9999 -9999 - } \\
& \text {-9999 -9999 -9999 -9999 -9999 -9999 -9999 -9999 -9999 -9999 -9999 -9999 -9999 -9999 -9999 }
\end{aligned}
$$

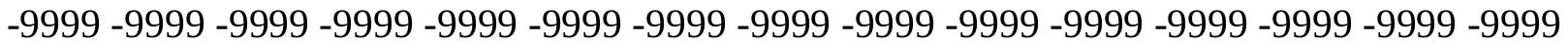

$$
\begin{aligned}
& \text {-9999 -9999 -9999 -9999 -9999 -9999 -9999 -9999 -9999 -9999 -9999 -9999 -9999 -9999 -9999 - } \\
& \text {-9999 -9999 -9999 -9999 -9999 -9999 -9999 -9999 -9999 -9999 -9999 -9999 -9999 -9999 -9999 - }
\end{aligned}
$$

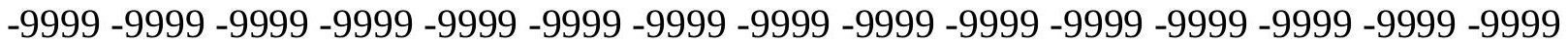

$$
\begin{aligned}
& \text {-9999 -9999 -9999 -9999 -9999 -9999 -9999 -9999 -9999 -9999 -9999 -9999 -9999 -9999 -9999 } \\
& \text {-9999 -9999 -9999 -9999 -9999 -9999 -9999 -9999 -9999 -9999 -9999 -9999 -9999 -9999 -9999 - } \\
& \text {-9999 -9999 -9999 -9999 -9999 -9999 -9999 -9999 -9999 -9999 -9999 -9999 -9999 -9999 -9999 - } \\
& \text {-9999 -9999 -9999 -9999 -9999 -9999 -9999 -9999 -9999 -9999 -9999 -9999 -9999 -9999 -9999 - }
\end{aligned}
$$

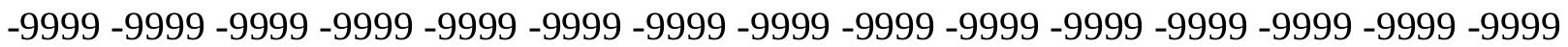

$$
\begin{aligned}
& \text {-9999 -9999 -9999 -9999 -9999 -9999 -9999 -9999 -9999 -9999 -9999 -9999 -9999 -9999 -9999 } \\
& \text {-9999 -9999 -9999 -9999 -9999 -9999 -9999 -9999 -9999 -9999 -9999 -9999 -9999 -9999 -9999 - } \\
& \text {-9999 -9999 -9999 -9999 -9999 -9999 -9999 -9999 -9999 -9999 -9999 -9999 -9999 -9999 -9999 - } \\
& \text {-9999 -9999 -9999 -9999 -9999 -9999 -9999 -9999 -9999 -9999 -9999 -9999 -9999 -9999 -9999 - } \\
& \text {-9999 -9999 -9999 -9999 -9999 -9999 -9999 -9999 -9999 -9999 -9999 -9999 -9999 -9999 -9999 } \\
& \text {-9999 -9999 -9999 -9999 -9999 -9999 -9999 -9999 -9999 -9999 -9999 -9999 -9999 -9999 -9999 - } \\
& \text {-9999 -9999 -9999 -9999 -9999 -9999 -9999 -9999 -9999 -9999 -9999 -9999 -9999 -9999 -9999 - } \\
& \text {-9999 -9999 -9999 -9999 -9999 -9999 -9999 -9999 -9999 -9999 -9999 -9999 -9999 -9999 -9999 - } \\
& \text {-9999 -9999 -9999 -9999 -9999 -9999 -9999 -9999 -9999 -9999 -9999 -9999 -9999 -9999 }
\end{aligned}
$$


u4top_elev 


$\begin{array}{ll}\text { ncols } & 389 \\ \text { nrows } & 437 \\ \text { xllcorner } & 545925 \\ \text { yllcorner } & 100925 \\ \text { cellsize } & 150\end{array}$

NODATA_value -9999

-9999 -9999 -9999 -9999 -9999 -9999 -9999 -9999 -9999 -9999 -9999 -9999 -9999 -9999 -9999 -9999 -9999 -9999 -9999 -9999 -9999 -9999 -9999 -9999 -9999 -9999 -9999 -9999 -9999 -9999 -999 -9999 -9999 -9999 -9999 -9999 -9999 -9999 -9999 -9999 -9999 -9999 -9999 -9999 -9999 -9999 -9999 -9999 -9999 -9999 -9999 -9999 -9999 -9999 -9999 -9999 -9999 -9999 -9999 -9999 -9999

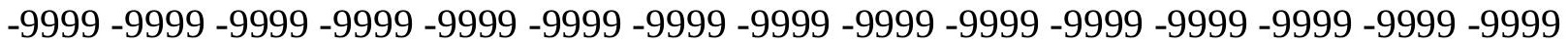
-9999 -9999 -9999 -9999 -9999 -9999 -9999 -9999 -9999 -9999 -9999 -9999 -9999 -9999 -9999 -9999 -9999 -9999 -9999 -9999 -9999 -9999 -9999 -9999 -9999 -9999 -9999 -9999 -9999 -9999 -9999 -9999 -9999 -9999 -9999 -9999 -9999 -9999 -9999 -9999 -9999 -9999 -9999 -9999 - 9999 -9999 -9999 -9999 -9999 -9999 -9999 -9999 -9999 -9999 -9999 -9999 -9999 -9999 -9999 -9999

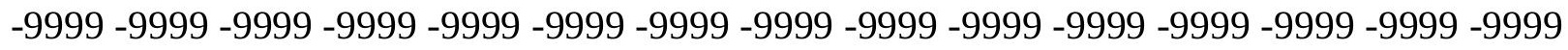
-9999 -9999 -9999 -9999 -9999 -9999 -9999 -9999 -9999 -9999 -9999 -9999 -9999 -9999 -9999 -9999 -9999 -9999 -9999 -9999 -9999 -9999 -9999 -9999 -9999 -9999 -9999 -9999 -9999 -9999 -999 -9999 -9999 -9999 -9999 -9999 -9999 -9999 -9999 -9999 -9999 -9999 -9999 -9999 -9999 -9999 -9999 -9999 -9999 -9999 -9999 -9999 -9999 -9999 -9999 -9999 -9999 -9999 -9999 -9999 -9999 -9999 -9999 -9999 -9999 -9999 -9999 -9999 -9999 -9999 -9999 -9999 -9999 -9999 -9999 -9999 -9999 -9999 -9999 -9999 -9999 -9999 -9999 -9999 -9999 -9999 -9999 -9999 -9999 -9999 -9999 -9999 -9999 -9999 -9999 -9999 -9999 -9999 -9999 -9999 -9999 -9999 -9999 -9999 -9999 -9999 -9999 -9999 -9999 -9999 -9999 -9999 -9999 -9999 -9999 -9999 -9999 -9999 -9999 -9999 -9999 -9999 -9999 -9999 -9999 -9999 -9999 -9999 -9999 -9999 -9999 -9999 -9999 -9999 -9999 -9999 -9999 -9999 -9999 -9999 -9999 -9999 -9999 -9999 -9999 -9999 -9999 -9999 -9999 -9999 -9999 -9999 -9999 -9999 -9999 -9999 -9999 -9999 -9999 -9999 -9999 -9999 -9999 -9999 -9999 -9999 -9999 -9999 -9999 -9999 -9999 -9999 -9999 -9999 -9999 -9999 -9999 -9999 -9999 -9999 -9999 -9999 -9999 -9999 -9999 -9999 -9999 -9999 -9999 -9999 -9999 -9999 -9999 -9999 -9999 -9999 -9999 -9999 -9999 -9999 -9999 -9999 -9999 -9999 -9999 -9999 -9999 -9999 -9999 -9999 -999 -9999 -9999 -9999 -9999 -9999 -9999 -9999 -9999 -9999 -9999 -9999 -9999 -9999 -9999 -9999 -9999 -9999 -9999 -9999 -9999 -9999 -9999 -9999 -9999 -9999 -9999 -9999 -9999 -9999 -

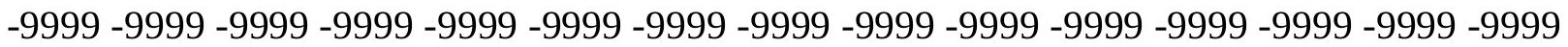
-9999 -9999 -9999 -9999 -9999 -9999 -9999 -9999 -9999 -9999 -9999 -9999 -9999 -9999 -9999 -9999 -9999 -9999 -9999 -9999 -9999 -9999 -9999 -9999 -9999 -9999 -9999 -9999 -9999 -9999 -

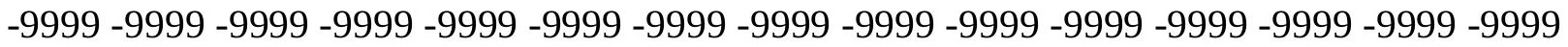

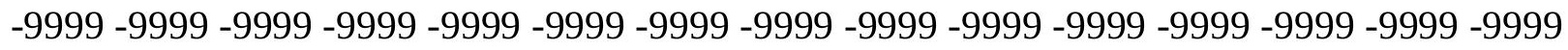
-9999 -9999 -9999 -9999 -9999 -9999 -9999 -9999 -9999 -9999 -9999 -9999 -9999 - 9999 - -9999 -9999 -9999 -9999 -9999 -9999 -9999 -9999 -9999 -9999 -9999 -9999 -9999 -9999 - 9999 - -999 -9999 -9999 -9999 -9999 -9999 -9999 -9999 -9999 -9999 -9999 -9999 -9999 -9999 -9999 -9999 -

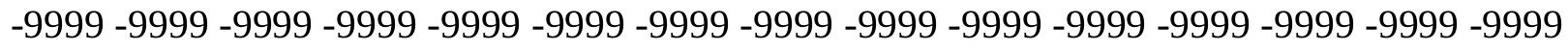

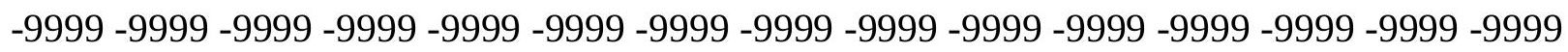
-9999 -9999 -9999 -9999 -9999 -9999 -9999 -9999 -9999 -9999 -9999 -9999 -9999 -9999 -9999 -9999 -9999 -9999 -9999 -9999 -9999 -9999 -9999 -9999-9999 -9999 -9999 -9999 -9999 -9999 -9999 -9999 -9999 -9999 -9999 -9999 -9999 -9999 -9999 -9999 -9999 -9999 -9999 -9999 -9999 -

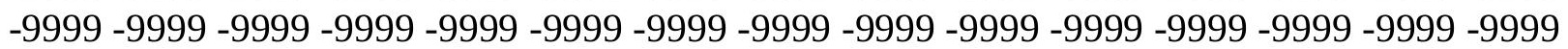


-9999 -9999 -9999 -9999 -9999 -9999 -9999 -9999 -9999 -9999 -9999 -9999 -9999 -9999 -9999 -9999 -9999 -9999 -9999 -9999 -9999 -9999 -9999 -9999 -9999 -9999 -9999 -9999 -9999 -9999 -

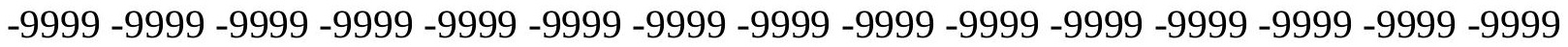
-9999 -9999 -9999 -9999 -9999 -9999 -9999 -9999 -9999 -9999 -9999 -9999 -9999 -9999 -9999 -9999 -9999 -9999 -9999 -9999 -9999 -9999 -9999 -9999-9999 -9999 -9999 -9999 -9999 -9999 -9999 -9999 -9999 -9999 -9999 -9999 -9999 -9999 -9999 -9999 -9999 -9999 -9999 -9999 -9999 -9999 -9999 -9999 -9999 -9999 -9999 -9999 -9999 -9999 -9999 -9999 -9999 -9999 -9999 -9999

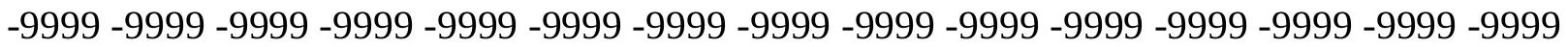

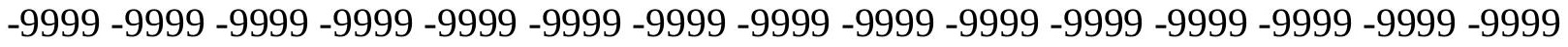
-9999 -9999 -9999 -9999 -9999 -9999 -9999 -9999 -9999 -9999 -9999 -9999 -9999 -9999 -9999 -9999 -9999 -9999 -9999 -9999 -9999 -9999 -9999 -9999 -9999 -9999 -9999 -9999 -9999 -9999 -9999 -9999 -9999 -9999 -9999 -9999 -9999 -9999 -9999 -9999 -9999 -9999 -9999 -9999 -9999 -9999 -9999 -9999 -9999 -9999 -9999 -9999 -9999 -9999 -9999 -9999 -9999 -9999 -9999 -9999 -9999 -9999 -9999 -9999 -9999 -9999 -9999 -9999 -9999 -9999 -9999 -9999 -9999 - 9999 -9999 -9999 -9999 -9999 -9999 -9999 -9999 -9999 -9999 -9999 -9999 -9999 -9999 -9999 -9999

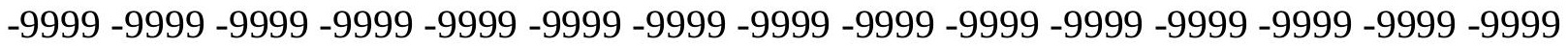
-9999 -9999 -9999 -9999 -9999 -9999 -9999 -9999 -9999 -9999 -9999 -9999 -9999 -9999 -9999 -9999 -9999 -9999 -9999 -9999 -9999 -9999 -9999 -9999 -9999 -9999 -9999 -9999 -9999 -9999 -9999 -9999 -9999 -9999 -9999 -9999 -9999 -9999 -9999 -9999 -9999 -9999 -9999 -9999 -9999 -

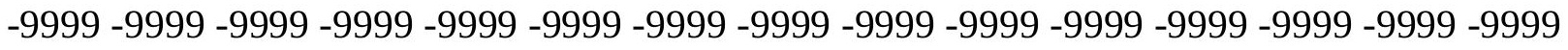

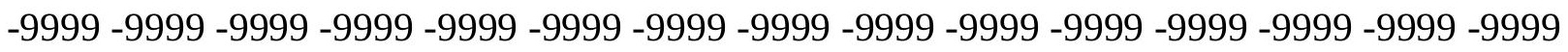
-9999 -9999 -9999 -9999 -9999 -9999 -9999 -9999 -9999 -9999 -9999 -9999 -9999 -9999 -9999 -9999 -9999 -9999 -9999 -9999 -9999 -9999 -9999 -9999 -9999 -9999 -9999 -9999 -9999 -9999 -9999 -9999 -9999 -9999 -9999 -9999 -9999 -9999 -9999 -9999 -9999 -9999 -9999 -9999 -9999 -

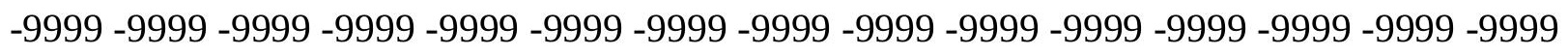
-9999 -9999 -9999 -9999 -9999 -9999 -9999 -9999 -9999 -9999 -9999 -9999 -9999 -9999 -9999 -9999 -9999 -9999 -9999 -9999 -9999 -9999 -9999 -9999 -9999 -9999 -9999 -9999 -9999 -9999 -

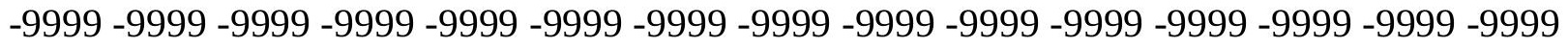
-9999 -9999 -9999 -9999 -9999 -9999 -9999 -9999 -9999 -9999 -9999 -9999 -9999 -9999 -9999 -9999 -9999 -9999 -9999 -9999 -9999 -9999 -9999 -9999 -9999 -9999 -9999 -9999 -9999 -999 -9999 -9999 -9999 -9999 -9999 -9999 -9999 -9999 -9999 -9999 -9999 -9999 -9999 -9999 -9999 -9999 -9999 -9999 -9999 -9999 -9999 -9999 -9999 -9999 -9999 -9999 -9999 -9999 -9999 -9999 -

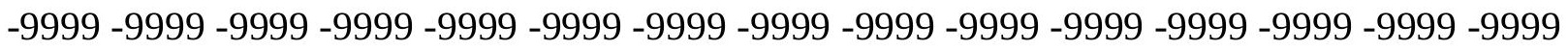

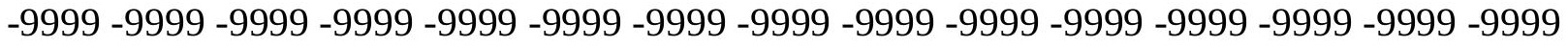

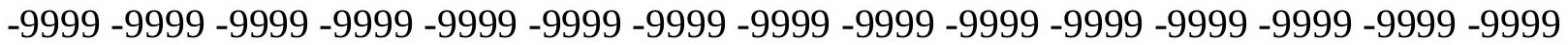

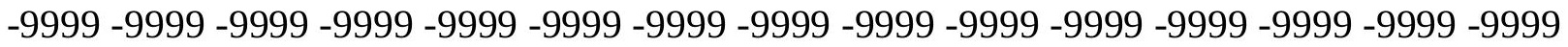

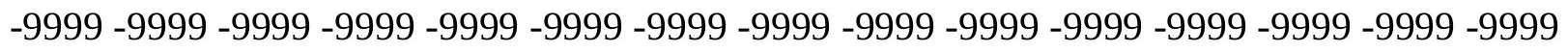

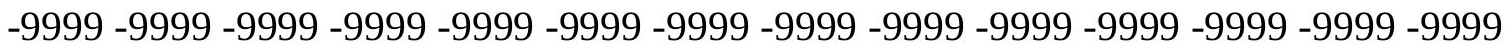
-9999 -9999 -9999 -9999 -9999 -9999 -9999 -9999 -9999 -9999 -9999 -9999 -9999 -9999 -9999 -9999 -9999 -9999 -9999 -9999 -9999 -9999 -9999 -9999 -9999 -9999 -9999 -9999 -9999 -9999 -

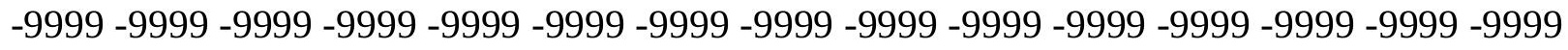

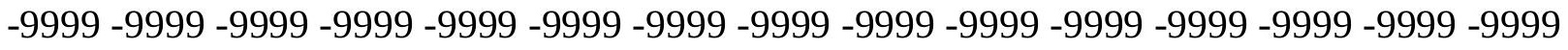
-9999 -9999 -9999 -9999 -9999 -9999 -9999 -9999 -9999 -9999 -9999 -9999 -9999 -9999 -9999 -9999 -9999 -9999 -9999 -9999 -9999 -9999 -9999 -9999-9999 -9999 -9999 -9999 -9999 -9999 -9999 -9999 -9999 -9999 -9999 -9999 -9999 -9999 -9999 -9999 -9999 -9999 -9999 -9999 -9999 -

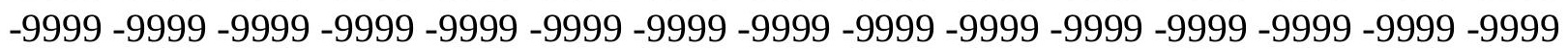


-9999 -9999 -9999 -9999 -9999 -9999 -9999 -9999 -9999 -9999 -9999 -9999 -9999 -9999 -9999 -9999 -9999 -9999 -9999 -9999 -9999 -9999 -9999 -9999 -9999 -9999 -9999 -9999 -9999 -9999 -9999 -9999 -9999 -9999 -9999 -9999 -9999 -9999 -9999 -9999 -9999 -9999 -9999 -9999 - 9999 -9999 -9999 -9999 -9999 -9999 -9999 -9999 -9999 -9999 -9999 -9999 -9999 -9999 -9999 -9999 -9999 -9999 -9999 -9999 -9999 -9999 -9999 -9999 -9999 -9999 -9999 -9999 -9999 -9999 -9999 -9999 -9999 -9999 -9999 -9999 -9999 -9999 -9999 -9999 -9999 -9999 -9999 -9999 -9999 -9999 -9999 -9999 -9999 -9999 -9999 -9999 -9999 -9999 -9999 -9999 -9999 -9999 -9999 -9999 -9999

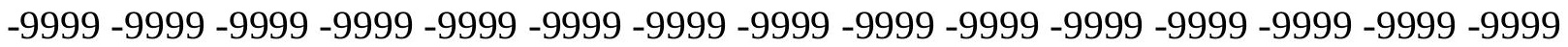
-9999 -9999 -9999 -9999 -9999 -9999 -9999 -9999 -9999 -9999 -9999 -9999 -9999 -9999 -9999 -9999 -9999 -9999 -9999 -9999 -9999 -9999 -9999 -9999 -9999 -9999 -9999 -9999 -9999 -9999

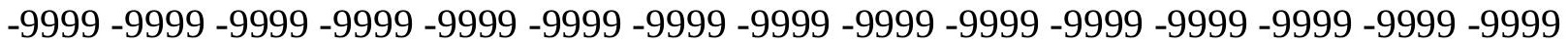
-9999 -9999 -9999 -9999 -9999 -9999 -9999 -9999 -9999 -9999 -9999 -9999 -9999 -9999 -9999 -9999 -9999 -9999 -9999 -9999 -9999 -9999 -9999 -9999 -9999 -9999 -9999 -9999 -9999 -9999 -

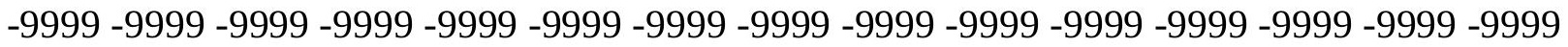
-9999 -9999 -9999 -9999 -9999 -9999 -9999 -9999 -9999 -9999 -9999 -9999 -9999 -9999 -9999

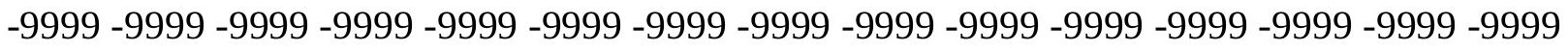
-9999 -9999 -9999 -9999 -9999 -9999 -9999 -9999 -9999 -9999 -9999 -9999 -9999 -9999 -9999 -9999 -9999 -9999 -9999 -9999 -9999 -9999 -9999 -9999 -9999 -9999 -9999 -9999 -9999 - -999 -9999 -9999 -9999 -9999 -9999 -9999 -9999 -9999 -9999 -9999 -9999 -9999 -9999 -9999 -9999 -9999 -9999 -9999 -9999 -9999 -9999 -9999 -9999 -9999 -9999 -9999 -9999 -9999 -9999 -9999 -9999 -9999 -9999 -9999 -9999 -9999 -9999 -9999 -9999 -9999 -9999 -9999 -9999 -9999 -9999 -999 -9999 -9999 -9999 -9999 -9999 -9999 -9999 -9999 -9999 -9999 -9999 -9999 -9999 -9999 -9999 -9999 -9999 -9999 -9999 -9999 -9999 -9999 -9999 -9999 -9999 -9999 -9999 -9999 -9999 -9999 -9999 -9999 -9999 -9999 -9999 -9999 -9999 -9999 -9999 -9999 -9999 -9999 -9999 -9999 -9999 -9999 -9999 -9999 -9999 -9999 -9999 -9999 -9999 -9999 -9999 -9999 -9999 -9999 -9999 -9999 -9999 -9999 -9999 -9999 -9999 -9999 -9999 -9999 -9999 -9999 -9999 -9999 -9999 -9999 -9999 -9999 -9999 -9999 -9999 -9999 -9999 -9999 -9999 -9999 -9999 -9999 -9999 -9999 -9999 -9999 -9999 -9999 -9999 -9999 -9999 -9999 -9999 -9999 -9999 -9999 -9999 -9999 -9999 -9999 -9999 -9999 -9999 -9999 -9999 -9999 -9999 -9999 -9999 -9999 -9999 -9999 -9999 -9999 -9999 -9999 -9999 -9999 -9999 -9999 -9999 -9999 -9999 -9999 -9999 -9999 -9999 -9999 -9999 -9999 -999 -9999 -9999 -9999 -9999 -9999 -9999 -9999 -9999 -9999 -9999 -9999 -9999 -9999 -9999 -9999 -9999 -9999 -9999 -9999 -9999 -9999 -9999 -9999 -9999 -9999 -9999 -9999 -9999 -9999 -9999 -

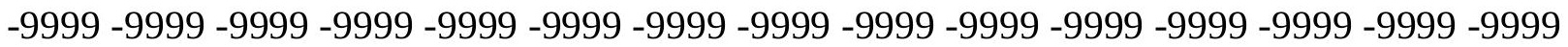

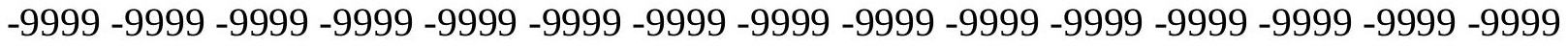

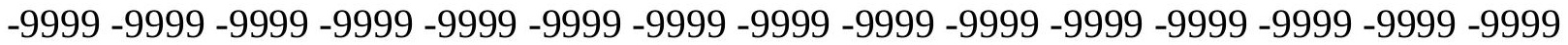
-9999 -9999 -9999 -9999 -9999 -9999 -9999 -9999 -9999 -9999 -9999 -9999 -9999 -9999 -9999

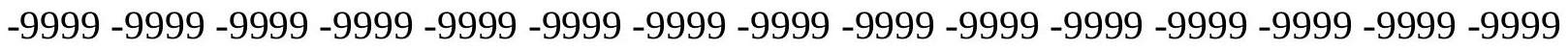

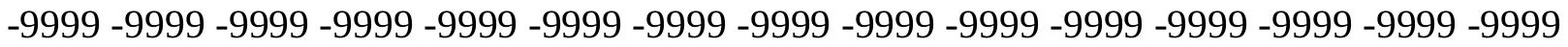

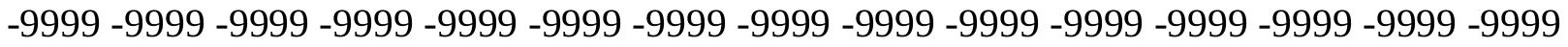
-9999 -9999 -9999 -9999 -9999 -9999 -9999 -9999 -9999 -9999 -9999 -9999 -9999 -9999 -9999 -

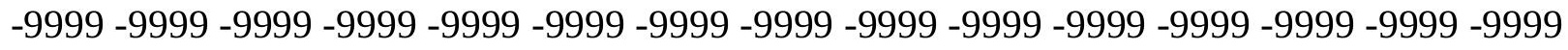

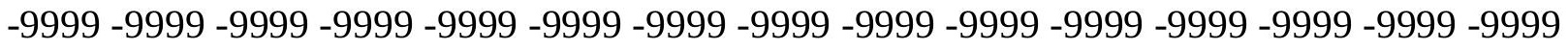
-9999 -9999 -9999 -9999 -9999 -9999 -9999 -9999 -9999 -9999 -9999 -9999 -9999 -9999 -9999 -9999 -9999 -9999 -9999 -9999 -9999 -9999 -9999 -9999 -9999 -9999 -9999 -9999 - -9999 -9999 -9999 -9999 -9999 -9999 -9999 -9999 -9999 -9999 -9999 -9999 -9999 -9999 -9999 -9999 -

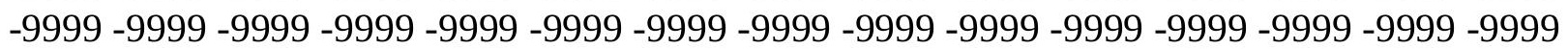


-9999 -9999 -9999 -9999 -9999 -9999 -9999 -9999 -9999 -9999 -9999 -9999 -9999 -9999 -9999 -9999 -9999 -9999 -9999 -9999 -9999 -9999 -9999 -9999 -9999 -9999 -9999 -9999 -9999 -9999 -9999 -9999 -9999 -9999 -9999 -9999 -9999 -9999 -9999 -9999 -9999 -9999 -9999 -9999 - 9999 -9999 -9999 -9999 -9999 -9999 -9999 -9999 -9999 -9999 -9999 -9999 -9999 -9999 -9999 -9999 -9999 -9999 -9999 -9999 -9999 -9999 -9999 -9999 -9999-9999 -9999 -9999 -9999 -9999 -9999 -9999 -9999 -9999 -9999 -9999 -9999 -9999 -9999 -9999 -9999 -9999 -9999 -9999 -9999 -9999 -9999 -9999 -9999 -9999 -9999 -9999 -9999 -9999 -9999 -9999 -9999 -9999 -9999 -9999 -9999

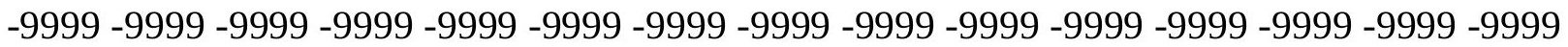

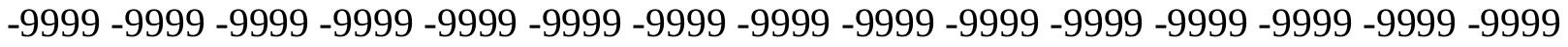
-9999 -9999 -9999 -9999 -9999 -9999 -9999 -9999 -9999 -9999 -9999 -9999 -9999 -9999 -9999

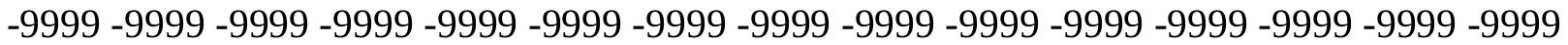
-9999 -9999 -9999 -9999 -9999 -9999 -9999 -9999 -9999 -9999 -9999 -9999 -9999 -9999 -9999 -9999 -9999 -9999 -9999 -9999 -9999 -9999 -9999 -9999 -9999 -9999 -9999 -9999 -9999 -9999 -

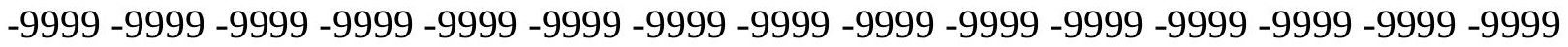
-9999 -9999 -9999 -9999 -9999 -9999 -9999 -9999 -9999 -9999 -9999 -9999 -9999 -9999 -9999

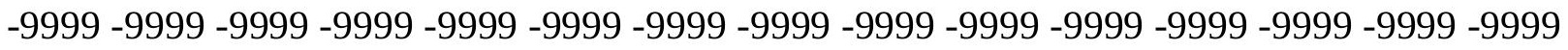
-9999 -9999 -9999 -9999 -9999 -9999 -9999 -9999 -9999 -9999 -9999 -9999 -9999 -9999 -9999 -9999 -9999 -9999 -9999 -9999 -9999 -9999 -9999 -9999 -9999 -9999 -9999 -9999 -9999 -9999 -9999 -9999 -9999 -9999 -9999 -9999 -9999 -9999 -9999 -9999 -9999 -9999 -9999 -9999 -9999 -9999 -9999 -9999 -9999 -9999 -9999 -9999 -9999 -9999 -9999 -9999 -9999 -9999 -9999 -9999 -9999 -9999 -9999 -9999 -9999 -9999 -9999 -9999 -9999 -9999 -9999 -9999 -9999 -9999 -9999 -999 -9999 -9999 -9999 -9999 -9999 -9999 -9999 -9999 -9999 -9999 -9999 -9999 -9999 -9999 -9999 -9999 -9999 -9999 -9999 -9999 -9999 -9999 -9999 -9999 -9999 -9999 -9999 -9999 -9999 -9999 -9999 -9999 -9999 -9999 -9999 -9999 -9999 -9999 -9999 -9999 -9999 -9999 -9999 -9999 -9999 -9999 -9999 -9999 -9999 -9999 -9999 -9999 -9999 -9999 -9999 -9999 -9999 -9999 -9999 -9999 -9999 -9999 -9999 -9999 -9999 -9999 -9999 -9999 -9999 -9999 -9999 -9999 -9999 -9999 -9999 -9999 -9999 -9999 -9999 -9999 -9999 -9999 -9999 -9999 -9999 -9999 -9999 -9999 -9999 -9999 -9999 -9999 -9999 -9999 -9999 -9999 -9999 -9999 -9999 -9999 -9999 -9999 -9999 -9999 -9999 -9999 -9999 -9999 -9999 -9999 -9999 -9999 -9999 -9999 -9999 -9999 -9999 -9999 -9999 -9999 -9999 -9999 -9999 -9999 -9999 -9999 -9999 -9999 -9999 -9999 -9999 -9999 -9999 -999 -9999 -9999 -9999 -9999 -9999 -9999 -9999 -9999 -9999 -9999 -9999 -9999 -9999 -9999 -9999 -9999 -9999 -9999 -9999 -9999 -9999 -9999 -9999 -9999 -9999 -9999 -9999 -9999 -9999 -9999 -

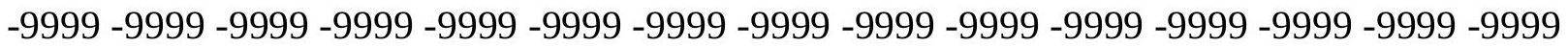

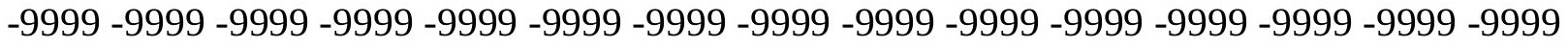

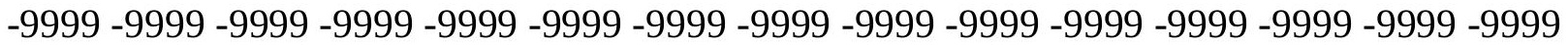
-9999 -9999 -9999 -9999 -9999 -9999 -9999 -9999 -9999 -9999 -9999 -9999 -9999 -9999 -9999

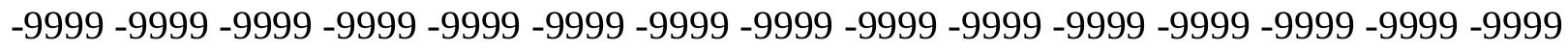

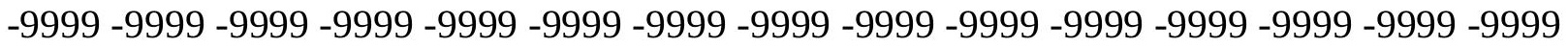
-9999 -9999 -9999 -9999 -9999 -9999 -9999 -9999 -9999 -9999 -9999 -9999 -9999 -9999 -9999 -9999 -9999 -9999 -9999 -9999 -9999 -9999 -9999 -9999 -9999 -9999 -9999 -9999 -9999 -9999 -

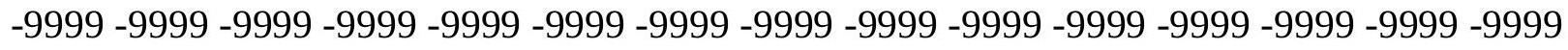

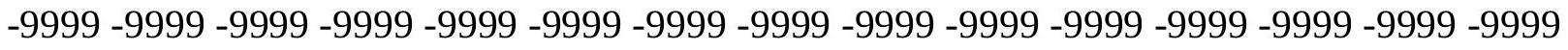
-9999 -9999 -9999 -9999 -9999 -9999 -9999 -9999 -9999 -9999 -9999 -9999 -9999 -9999 -9999 -9999 -9999 -9999 -9999 -9999 -9999 -9999 -9999 -9999-9999 -9999 -9999 -9999 -9999 -9999 -9999 -9999 -9999 -9999 -9999 -9999 -9999 -9999 -9999 -9999 -9999 -9999 -9999 -9999 -9999 -

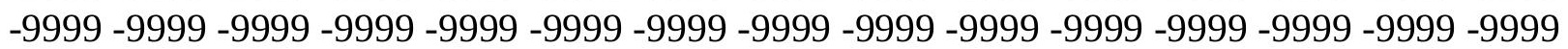


-9999 -9999 -9999 -9999 -9999 -9999 -9999 -9999 -9999 -9999 -9999 -9999 -9999 -9999 -9999 -9999 -9999 -9999 -9999 -9999 -9999 -9999 -9999 -9999 -9999 -9999 -9999 -9999 -9999 -9999 -9999 -9999 -9999 -9999 -9999 -9999 -9999 -9999 -9999 -9999 -9999 -9999 -9999 -9999 - 9999 -9999 -9999 -9999 -9999 -9999 -9999 -9999 -9999 -9999 -9999 -9999 -9999 -9999 -9999

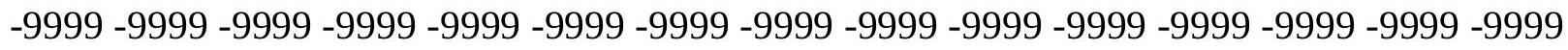
-9999 -9999 -9999 -9999 -9999 -9999 -9999 -9999 -9999 -9999 -9999 -9999 -9999 -9999 -9999 -9999 -9999 -9999 -9999 -9999 -9999 -9999 -9999 -9999 -9999 -9999 -9999 -9999 -9999 -9999

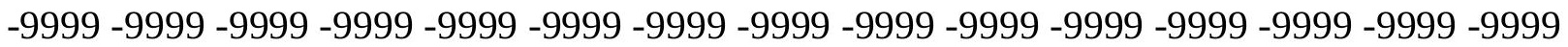

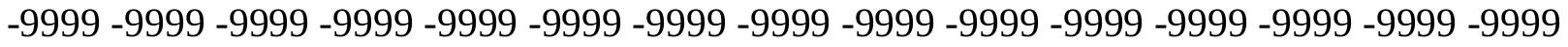
-9999 -9999 -9999 -9999 -9999 -9999 -9999 -9999 -9999 -9999 -9999 -9999 -9999 -9999 -9999 -9999 -9999 -9999 -9999 -9999 -9999 -9999 -9999 -9999 -9999 -9999 -9999 -9999 -9999 -9999 -9999 -9999 -9999 -9999 -9999 -9999 -9999 -9999 -9999 -9999 -9999 -9999 -9999 -9999 -9999 -9999 -9999 -9999 -9999 -9999 -9999 -9999 -9999 -9999 -9999 -9999 -9999 -9999 -9999 -9999 -

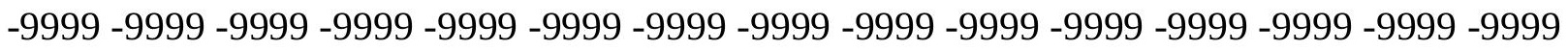
-9999 -9999 -9999 -9999 -9999 -9999 -9999 -9999 -9999 -9999 -9999 -9999 -9999 -9999 -9999 -

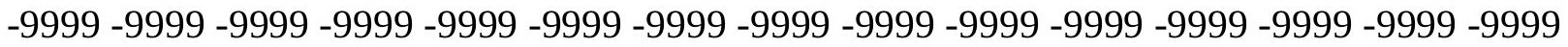
-9999 -9999 -9999 -9999 -9999 -9999 -9999 -9999 -9999 -9999 -9999 -9999 -9999 -9999 -9999 -9999 -9999 -9999 -9999 -9999 -9999 -9999 -9999 -9999 -9999 -9999 -9999 -9999 -9999 -9999 -9999 -9999 -9999 -9999 -9999 -9999 -9999 -9999 -9999 -9999 -9999 -9999 -9999 -9999 -9999 -

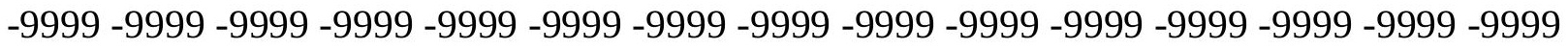
-9999 -9999 -9999 -9999 -9999 -9999 -9999 -9999 -9999 -9999 -9999 -9999 -9999 -9999 -9999

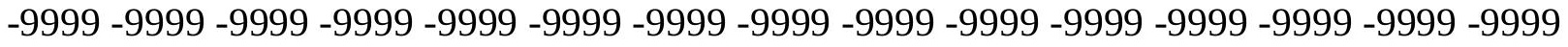
-9999 -9999 -9999 -9999 -9999 -9999 -9999 -9999 -9999 -9999 -9999 -9999 -9999 -9999 -9999 -9999 -9999 -9999 -9999 -9999 -9999 -9999 -9999 -9999 -9999 -9999 -9999 -9999 -9999 -9999 -9999 -9999 -9999 -9999 -9999 -9999 -9999 -9999 -9999 -9999 -9999 -9999 -9999 -9999 -9999 -9999 -9999 -9999 -9999 -9999 -9999 -9999 -9999 -9999 -9999 -9999 -9999 -9999 -9999 -9999 -9999 -9999 -9999 -9999 -9999 -9999 -9999 -9999 -9999 -9999 -9999 -9999 -9999 -9999 -9999 -9999 -9999 -9999 -9999 -9999 -9999 -9999 -9999 -9999 -9999 -9999 -9999 -9999 -9999 -9999 -9999 -9999 -9999 -9999 -9999 -9999 -9999 -9999 -9999 -9999 -9999 -9999 -9999 -9999 -9999 -9999 -9999 -9999 -9999 -9999 -9999 -9999 -9999 -9999 -9999 -9999 -9999 -9999 -9999 -9999 -9999 -9999 -9999 -9999 -9999 -9999 -9999 -9999 -9999 -9999 -9999 -9999 -9999 -9999 -9999 -9999 -9999 -9999 -9999 -9999 -9999 -9999 -9999 -9999 -9999 -9999 -9999 -9999 -9999 -

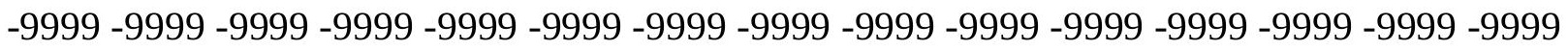

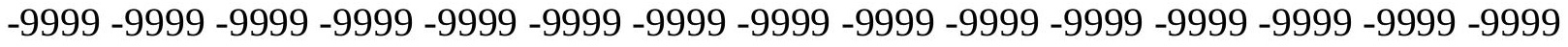
-9999 -9999 -9999 -9999 -9999 -9999 -9999 -9999 -9999 -9999 -9999 -9999 -9999 -9999 -9999 -

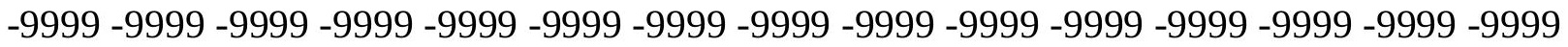

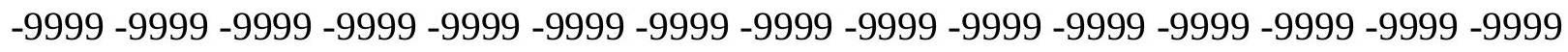

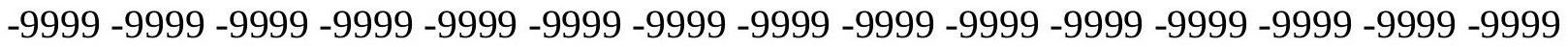

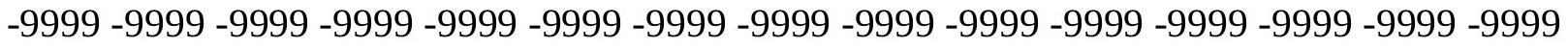
-9999 -9999 -9999 -9999 -9999 -9999 -9999 -9999 -9999 -9999 -9999 -9999 -9999 -9999 -9999 -

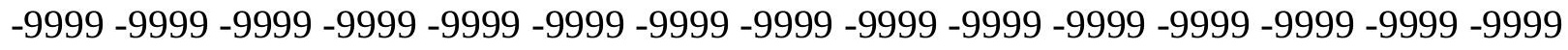

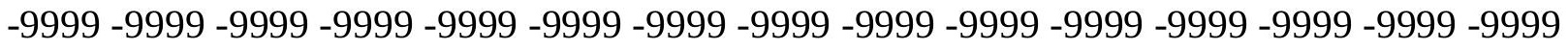
-9999 -9999 -9999 -9999 -9999 -9999 -9999 -9999 -9999 -9999 -9999 -9999 -9999 -9999 -9999 -9999 -9999 -9999 -9999 -9999 -9999 -9999 -9999 -9999-9999 -9999 -9999 -9999 -9999 -9999 -9999 -9999 -9999 -9999 -9999 -9999 -9999 -9999 -9999 -9999 -9999 -9999 -9999 -9999 -9999 -

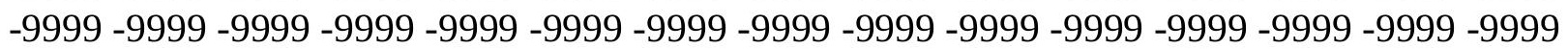


-9999 -9999 -9999 -9999 -9999 -9999 -9999 -9999 -9999 -9999 -9999 -9999 -9999 -9999 -9999 -9999 -9999 -9999 -9999 -9999 -9999 -9999 -9999 -9999 -9999 -9999 -9999 -9999 -9999 -9999 -9999 -9999 -9999 -9999 -9999 -9999 -9999 -9999 -9999 -9999 -9999 -9999 -9999 -9999 - 9999 -9999 -9999 -9999 -9999 -9999 -9999 -9999 -9999 -9999 -9999 -9999 -9999 -9999 -9999 -9999 -9999 -9999 -9999 -9999 -9999 -9999 -9999 -9999 -9999 -9999 -9999 -9999 -9999 -9999 -9999 -9999 -9999 -9999 -9999 -9999 -9999 -9999 -9999 -9999 -9999 -9999 -9999 -9999 -9999 -9999 -9999 -9999 -9999 -9999 -9999 -9999 -9999 -9999 -9999 -9999 -9999 -9999 -9999 -9999 -9999

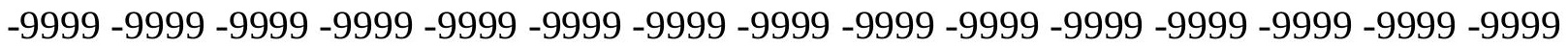

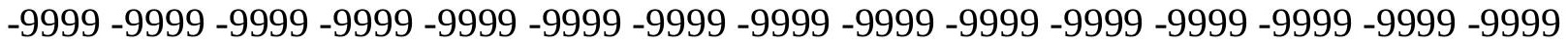
-9999 -9999 -9999 -9999 -9999 -9999 -9999 -9999 -9999 -9999 -9999 -9999 -9999 -9999 -9999 -9999 -9999 -9999 -9999 -9999 -9999 -9999 -9999 -9999 -9999 -9999 -9999 -9999 -9999 -9999 -9999 -9999 -9999 -9999 -9999 -9999 -9999 -9999 -9999 -9999 -9999 -9999 -9999 -9999 -9999 -9999 -9999 -9999 -9999 -9999 -9999 -9999 -9999 -9999 -9999 -9999 -9999 -9999 -9999 -9999 -9999 -9999 -9999 -9999 -9999 -9999 -9999 -9999 -9999 -9999 -9999 -9999 -9999 -9999 -9999 -9999 -9999 -9999 -9999 -9999 -9999 -9999 -9999 -9999 -9999 -9999 -9999 -9999 -9999 -

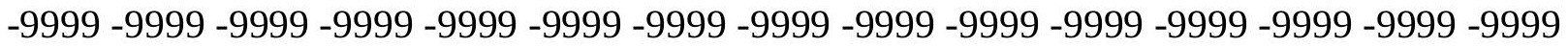
-9999 -9999 -9999 -9999 -9999 -9999 -9999 -9999 -9999 -9999 -9999 -9999 -9999 -9999 -9999 -9999 -9999 -9999 -9999 -9999 -9999 -9999 -9999 -9999 -9999 -9999 -9999 -9999 -9999 -9999 -9999 -9999 -9999 -9999 -9999 -9999 -9999 -9999 -9999 -9999 -9999 -9999 -9999 -9999 -9999 -9999 -9999 -9999 -9999 -9999 -9999 -9999 -9999 -9999 -9999 -9999 -9999 -9999 -9999 -9999 -9999 -9999 -9999 -9999 -9999 -9999 -9999 -9999 -9999 -9999 -9999 -9999 -9999 -9999 -9999 -999 -9999 -9999 -9999 -9999 -9999 -9999 -9999 -9999 -9999 -9999 -9999 -9999 -9999 -9999 -9999 -9999 -9999 -9999 -9999 -9999 -9999 -9999 -9999 -9999 -9999 -9999 -9999 -9999 -9999 -9999 -9999 -9999 -9999 -9999 -9999 -9999 -9999 -9999 -9999 -9999 -9999 -9999 -9999 -9999 -9999 -9999 -9999 -9999 -9999 -9999 -9999 -9999 -9999 -9999 -9999 -9999 -9999 -9999 -9999 -9999 -9999 -9999 -9999 -9999 -9999 -9999 -9999 -9999 -9999 -9999 -9999 -9999 -9999 -9999 -9999 -9999 -9999 -9999 -9999 -9999 -9999 -9999 -9999 -9999 -9999 -9999 -9999 -9999 -9999 -9999 -9999 -9999 -9999 -9999 -9999 -9999 -9999 -9999 -9999 -9999 -9999 -9999 -9999 -9999 -9999 -9999 -9999 -9999 -9999 -9999 -9999 -9999 -9999 -9999 -9999 -9999 -9999 -9999 -9999 -9999 -9999 -9999 -9999 -9999 -9999 -9999 -9999 -9999 -9999 -9999 -9999 -9999 -9999 -9999 -999 -9999 -9999 -9999 -9999 -9999 -9999 -9999 -9999 -9999 -9999 -9999 -9999 -9999 -9999 -9999 -9999 -9999 -9999 -9999 -9999 -9999 -9999 -9999 -9999 -9999 -9999 -9999 -9999 -9999 -9999 -

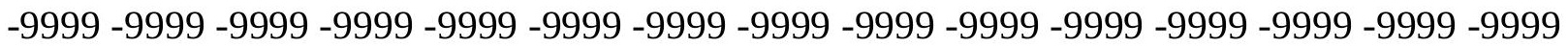

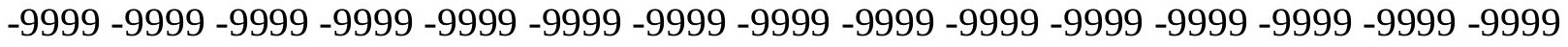

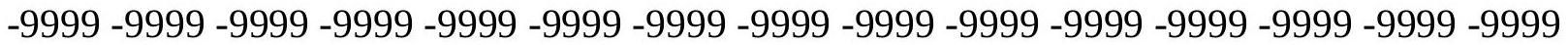
-9999 -9999 -9999 -9999 -9999 -9999 -9999 -9999 -9999 -9999 -9999 -9999 -9999 -9999 -9999 -9999 -9999 -9999 -9999 -9999 -9999 -9999 -9999 -9999 -9999 -9999 -9999 -9999 -9999 -

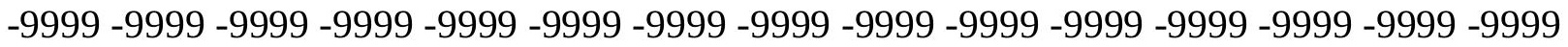
-9999 -9999 -9999 -9999 -9999 -9999 -9999 -9999 -9999 -9999 -9999 -9999 -9999 -9999 -9999 -9999 -9999 -9999 -9999 -9999 -9999 -9999 -9999 -9999 -9999 -9999 -9999 -9999 -9999 -9999 -

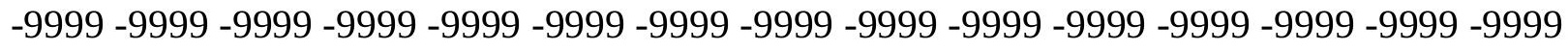

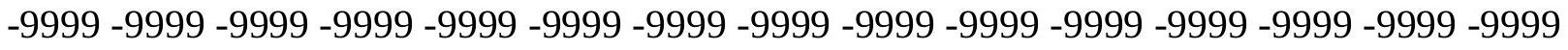
-9999 -9999 -9999 -9999 -9999 -9999 -9999 -9999 -9999 -9999 -9999 -9999 -9999 -9999 -9999 -9999 -9999 -9999 -9999 -9999 -9999 -9999 -9999 -9999-9999 -9999 -9999 -9999 -9999 -9999 -9999 -9999 -9999 -9999 -9999 -9999 -9999 -9999 -9999 -9999 -9999 -9999 -9999 -9999 -9999 -

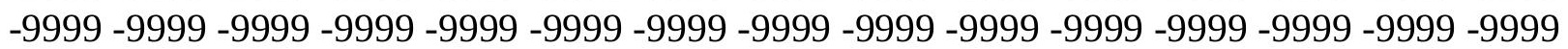


-9999 -9999 -9999 -9999 -9999 -9999 -9999 -9999 -9999 -9999 -9999 -9999 -9999 -9999 -9999 -9999 -9999 -9999 -9999 -9999 -9999 -9999 -9999 -9999 -9999 -9999 -9999 -9999 -9999 -9999 -

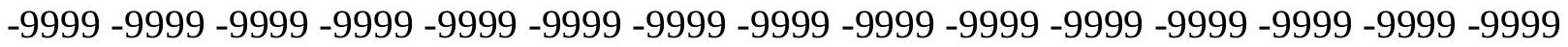
-9999 -9999 -9999 -9999 -9999 -9999 -9999 -9999 -9999 -9999 -9999 -9999 -9999 -9999 -9999 -9999 -9999 -9999 -9999 -9999 -9999 -9999 -9999 -9999-9999 -9999 -9999 -9999 -9999 -9999 -9999 -9999 -9999 -9999 -9999 -9999 -9999 -9999 -9999 -9999 -9999 -9999 -9999 -9999 -9999 -9999 -9999 -9999 -9999 -9999 -9999 -9999 -9999 -9999 -9999 -9999 -9999 -9999 -9999 -9999

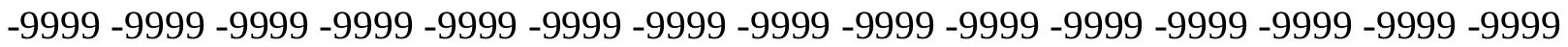

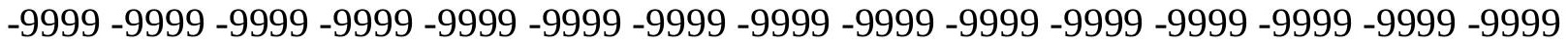
-9999 -9999 -9999 -9999 -9999 -9999 -9999 -9999 -9999 -9999 -9999 -9999 -9999 -9999 -9999 -9999 -9999 -9999 -9999 -9999 -9999 -9999 -9999 -9999 -9999 -9999 -9999 -9999 -9999 -9999 -9999 -9999 -9999 -9999 -9999 -9999 -9999 -9999 -9999 -9999 -9999 -9999 -9999 -9999 -9999 -9999 -9999 -9999 -9999 -9999 -9999 -9999 -9999 -9999 -9999 -9999 -9999 -9999 -9999 -9999 -9999 -9999 -9999 -9999 -9999 -9999 -9999 -9999 -9999 -9999 -9999 -9999 -9999 -9999 -9999 -9999 -9999 -9999 -9999 -9999 -9999 -9999 -9999 -9999 -9999 -9999 -9999 -9999 -9999 -9999 -

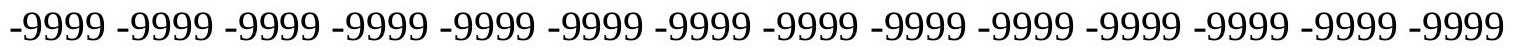
-9999 -9999 -9999 -9999 -9999 -9999 -9999 -9999 -9999 -9999 -9999 -9999 -9999 -9999 -9999 -9999 -9999 -9999 -9999 -9999 -9999 -9999 -9999 -9999 -9999 -9999 -9999 -9999 -9999 -9999 -9999 -9999 -9999 -9999 -9999 -9999 -9999 -9999 -9999 -9999 -9999 -9999 -9999 -9999 -9999 -

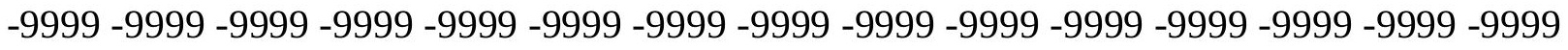

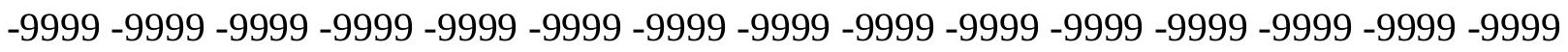
-9999 -9999 -9999 -9999 -9999 -9999 -9999 -9999 -9999 -9999 -9999 -9999 -9999 -9999 - 9999 -9999 -9999 -9999 -9999 -9999 -9999 -9999 -9999 -9999 -9999 -9999 -9999 -9999 -9999 -9999 -9999 -9999 -9999 -9999 -9999 -9999 -9999 -9999 -9999 -9999 -9999 -9999 -9999 -9999 -9999 -

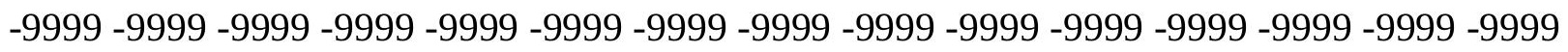
-9999 -9999 -9999 -9999 -9999 -9999 -9999 -9999 -9999 -9999 -9999 -9999 -9999 -9999 -9999 -9999 -9999 -9999 -9999 -9999 -9999 -9999 -9999 -9999 -9999 -9999 -9999 -9999 -9999 -9999 -

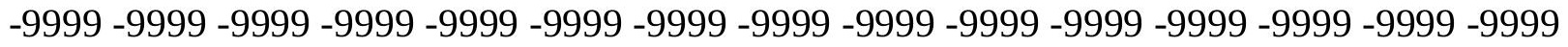
-9999 -9999 -9999 -9999 -9999 -9999 -9999 -9999 -9999 -9999 -9999 -9999 -9999 -9999 -9999 -9999 -9999 -9999 -9999 -9999 -9999 -9999 -9999 -9999 -9999 -9999 -9999 -9999 -9999 -999 -

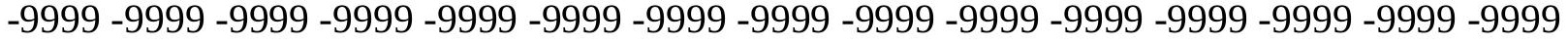
-9999 -9999 -9999 -9999 -9999 -9999 -9999 -9999 -9999 -9999 -9999 -9999 -9999 -9999 -9999 -

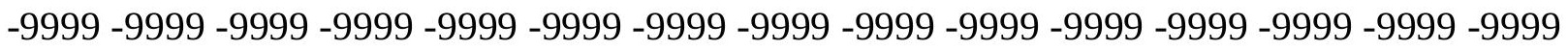

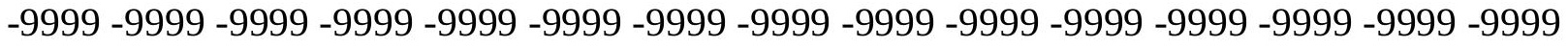

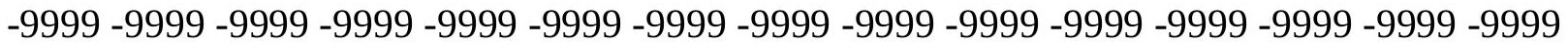
-9999 -9999 -9999 -9999 -9999 -9999 -9999 -9999 -9999 -9999 -9999 -9999 -9999 -9999 -9999 -

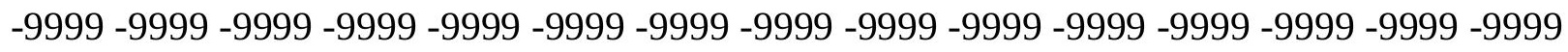

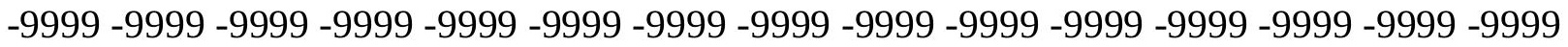
-9999 -9999 -9999 -9999 -9999 -9999 -9999 -9999 -9999 -9999 -9999 -9999 -9999 - 9999 - -999 -9999 -9999 -9999 -9999 -9999 -9999 -9999 -9999 -9999 -9999 -9999 -9999 -9999 -9999 -9999 -

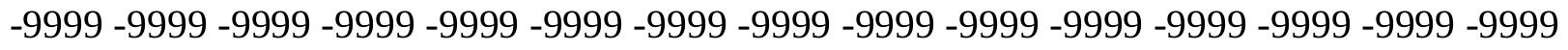

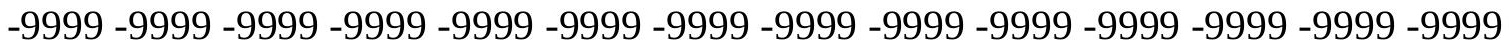
-9999 -9999 -9999 -9999 -9999 -9999 -9999 -9999 -9999 -9999 -9999 -9999 -9999 -9999 -9999 -9999 -9999 -9999 -9999 -9999 -9999 -9999 -9999 -9999-9999 -9999 -9999 -9999 -9999 -9999 -9999 -9999 -9999 -9999 -9999 -9999 -9999 -9999 -9999 -9999 -9999 -9999 -9999 -9999 -9999 -

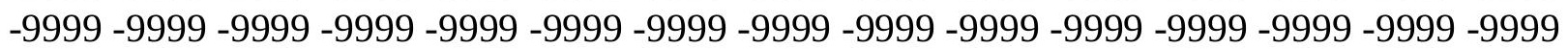


-9999 -9999 -9999 -9999 -9999 -9999 -9999 -9999 -9999 -9999 -9999 -9999 -9999 -9999 -9999 -9999 -9999 -9999 -9999 -9999 -9999 -9999 -9999 -9999 -9999 -9999 -9999 -9999 -9999 -9999 -

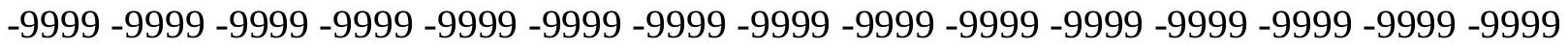
-9999 -9999 -9999 -9999 -9999 -9999 -9999 -9999 -9999 -9999 -9999 -9999 -9999 -9999 -9999 -9999 -9999 -9999 -9999 -9999 -9999 -9999 -9999 -9999-9999 -9999 -9999 -9999 -9999 -9999 -9999 -9999 -9999 -9999 -9999 -9999 -9999 -9999 -9999 -9999 -9999 -9999 -9999 -9999 -9999 -9999 -9999 -9999 -9999 -9999 -9999 -9999 -9999 -9999 -9999 -9999 -9999 -9999 -9999 -9999

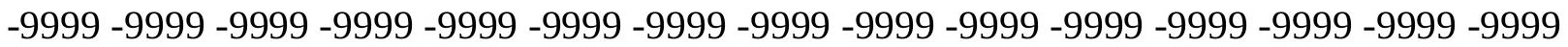

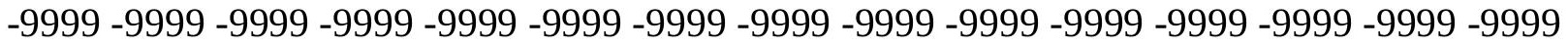
-9999 -9999 -9999 -9999 -9999 -9999 -9999 -9999 -9999 -9999 -9999 -9999 -9999 -9999 -9999 -9999 -9999 -9999 -9999 -9999 -9999 -9999 -9999 -9999 -9999 -9999 -9999 -9999 -9999 -9999 -9999 -9999 -9999 -9999 -9999 -9999 -9999 -9999 -9999 -9999 -9999 -9999 -9999 -9999 -9999 -9999 -9999 -9999 -9999 -9999 -9999 -9999 -9999 -9999 -9999 -9999 -9999 -9999 -9999 -9999 -

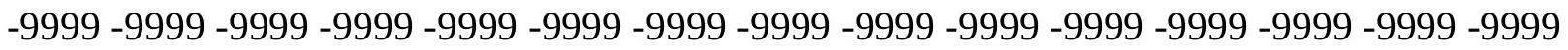
-9999 -9999 -9999 -9999 -9999 -9999 -9999 -9999 -9999 -9999 -9999 -9999 -9999 -9999 -9999 -

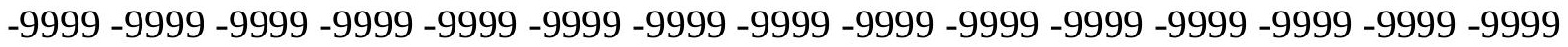
-9999 -9999 -9999 -9999 -9999 -9999 -9999 -9999 -9999 -9999 -9999 -9999 -9999 -9999 -9999 -9999 -9999 -9999 -9999 -9999 -9999 -9999 -9999 -9999 -9999 -9999 -9999 -9999 -9999 -9999 -9999 -9999 -9999 -9999 -9999 -9999 -9999 -9999 -9999 -9999 -9999 -9999 -9999 -9999 -9999 -

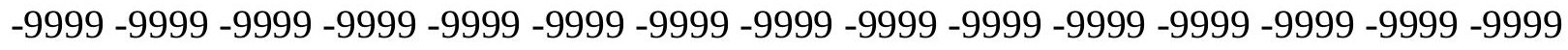

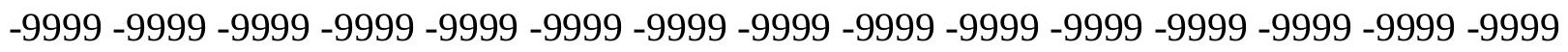
-9999 -9999 -9999 -9999 -9999 -9999 -9999 -9999 -9999 -9999 -9999 -9999 -9999 -9999 -9999 -9999 -9999 -9999 -9999 -9999 -9999 -9999 -9999 -9999 -9999 -9999 -9999 -9999 -9999 -9999 -9999 -9999 -9999 -9999 -9999 -9999 -9999 -9999 -9999 -9999 -9999 -9999 -9999 -9999 -

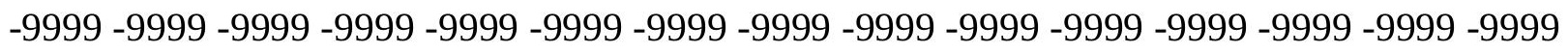
-9999 -9999 -9999 -9999 -9999 -9999 -9999 -9999 -9999 -9999 -9999 -9999 -9999 -9999 -9999 -9999 -9999 -9999 -9999 -9999 -9999 -9999 -9999 -9999 -9999 -9999 -9999 -9999 -9999 -9999 -

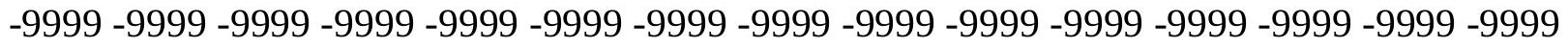
-9999 -9999 -9999 -9999 -9999 -9999 -9999 -9999 -9999 -9999 -9999 -9999 -9999 -9999 -9999 -9999 -9999 -9999 -9999 -9999 -9999 -9999 -9999 -9999 -9999 -9999 -9999 -9999 -9999 -999 -

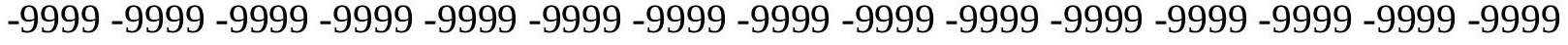
-9999 -9999 -9999 -9999 -9999 -9999 -9999 -9999 -9999 -9999 -9999 -9999 -9999 -9999 -9999 -

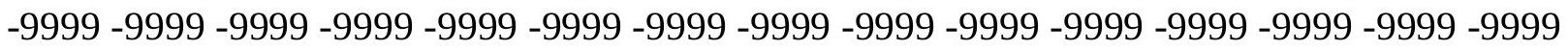

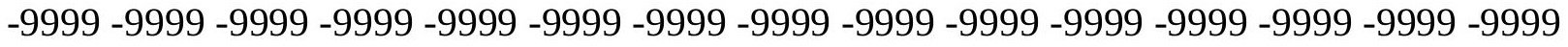

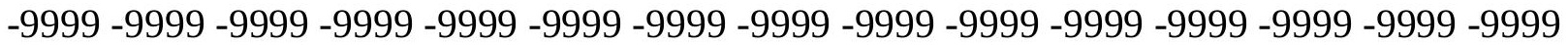

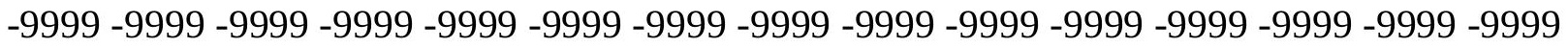

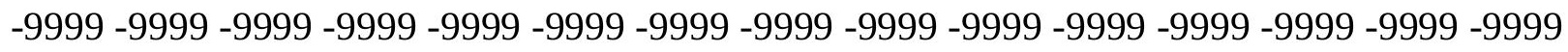

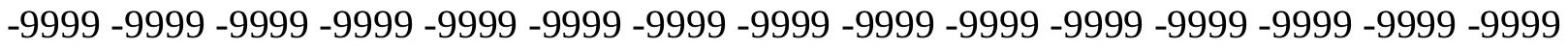

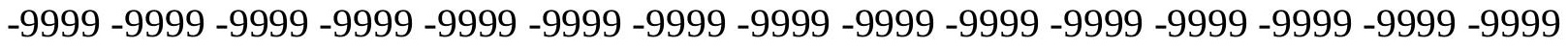
-9999 -9999 -9999 -9999 -9999 -9999 -9999 -9999 -9999 -9999 -9999 -9999 -9999 -9999 -9999 -

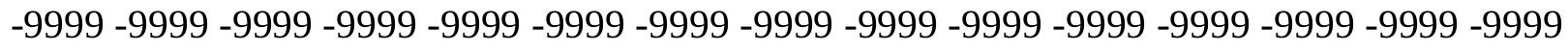

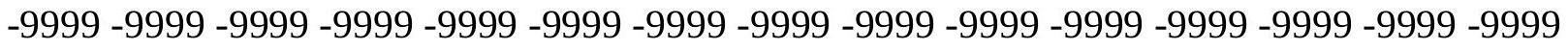
-9999 -9999 -9999 -9999 -9999 -9999 -9999 -9999 -9999 -9999 -9999 -9999 -9999 -9999 -9999 -9999 -9999 -9999 -9999 -9999 -9999 -9999 -9999 -9999-9999 -9999 -9999 -9999 -9999 -9999 -9999 -9999 -9999 -9999 -9999 -9999 -9999 -9999 -9999 -9999 -9999 -9999 -9999 -9999 -9999 -

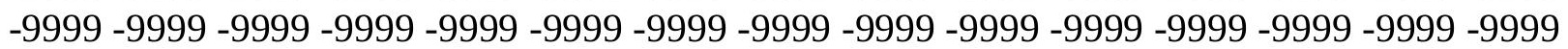


-9999 -9999 -9999 -9999 -9999 -9999 -9999 -9999 -9999 -9999 -9999 -9999 -9999 -9999 -9999 -9999 -9999 -9999 -9999 -9999 -9999 -9999 -9999 -9999 -9999 -9999 -9999 -9999 -9999 -

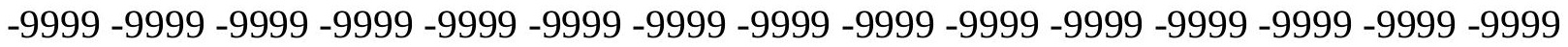
-9999 -9999 -9999 -9999 -9999 -9999 -9999 -9999 -9999 -9999 -9999 -9999 -9999 -9999 -9999 -9999 -9999 -9999 -9999 -9999 -9999 -9999 -9999 -9999 -9999 -9999 -9999 -9999 -9999 -9999 -9999 -9999 -9999 -9999 -9999 -9999 -9999 -9999 -9999 -9999 -9999 -9999 -9999 -9999 -9999 -9999 -9999 -9999 -9999 -9999 -9999 -9999 -9999 -9999 -9999 -9999 -9999 -9999 -9999 -9999

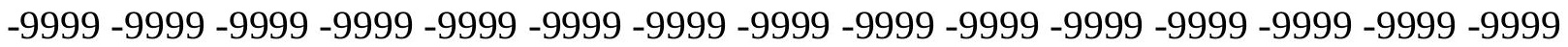

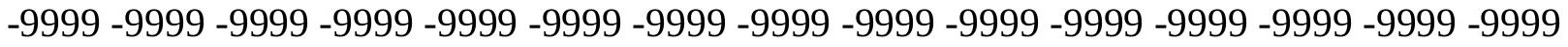
-9999 -9999 -9999 -9999 -9999 -9999 -9999 -9999 -9999 -9999 -9999 -9999 -9999 -9999 -9999 -9999 -9999 -9999 -9999 -9999 -9999 -9999 -9999 -9999 -9999 -9999 -9999 -9999 -9999 -9999 -9999 -9999 -9999 -9999 -9999 -9999 -9999 -9999 -9999 -9999 -9999 -9999 -9999 -9999 -9999 -9999 -9999 -9999 -9999 -9999 -9999 -9999 -9999 -9999 -9999 -9999 -9999 -9999 -9999 -9999 -9999 -9999 -9999 -9999 -9999 -9999 -9999 -9999 -9999 -9999 -9999 -9999 -9999 -9999 -9999 -9999 -9999 -9999 -9999 -9999 -9999 -9999 -9999 -9999 -9999 -9999 -9999 -9999 -9999 -9999 -

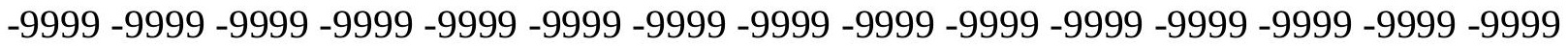
-9999 -9999 -9999 -9999 -9999 -9999 -9999 -9999 -9999 -9999 -9999 -9999 -9999 -9999 -9999 -9999 -9999 -9999 -9999 -9999 -9999 -9999 -9999 -9999 -9999 -9999 -9999 -9999 -9999 - 9999 -9999 -9999 -9999 -9999 -9999 -9999 -9999 -9999 -9999 -9999 -9999 -9999 -9999 -9999 -9999 -

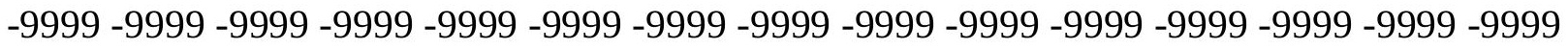

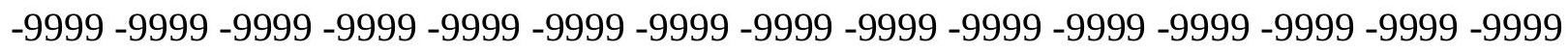

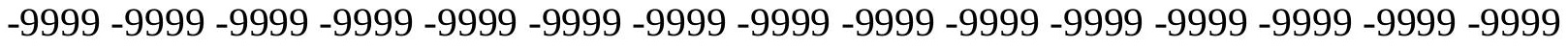
-9999 -9999 -9999 -9999 -9999 -9999 -9999 -9999 -9999 -9999 -9999 -9999 -9999 -9999 -9999 -9999 -9999 -9999 -9999 -9999 -9999 -9999 -9999 -9999 -9999 -9999 -9999 -9999 -9999 -9999 -

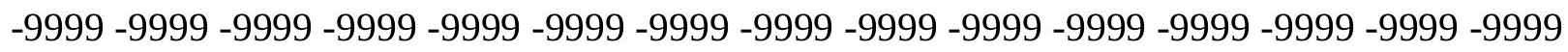
-9999 -9999 -9999 -9999 -9999 -9999 -9999 -9999 -9999 -9999 -9999 -9999 -9999 -9999 -9999 -9999 -9999 -9999 -9999 -9999 -9999 -9999 -9999 -9999 -9999 -9999 -9999 -9999 -9999 -9999 -9999 -9999 -9999 -9999 -9999 -9999 -9999 -9999 -9999 -9999 -9999 -9999 -9999 -9999 -9999 -9999 -9999 -9999 -9999 -9999 -9999 -9999 -9999 -9999 -9999 -9999 -9999 -9999 -9999 -9999 -9999 -9999 -9999 -9999 -9999 -9999 -9999 -9999 -9999 -9999 -9999 -9999 -9999 -999 -

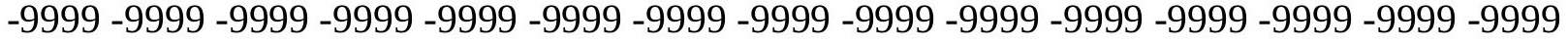
-9999 -9999 -9999 -9999 -9999 -9999 -9999 -9999 -9999 -9999 -9999 -9999 -9999 -9999 -9999 -

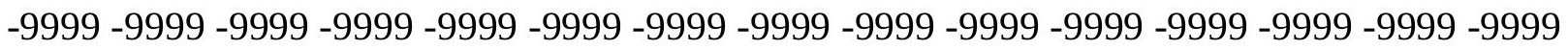

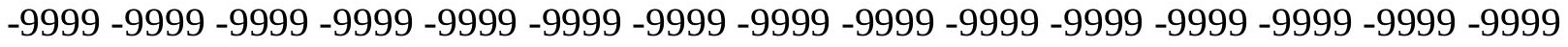

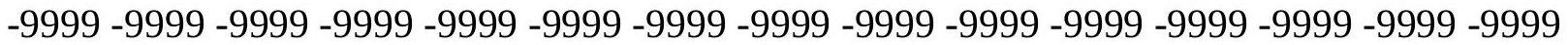

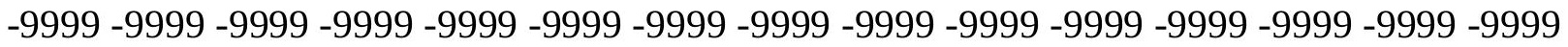

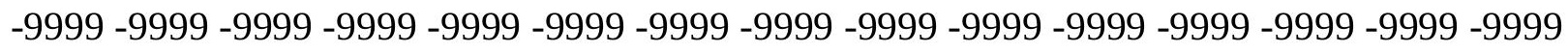

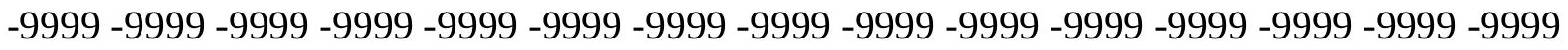

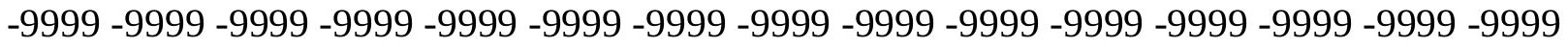
-9999 -9999 -9999 -9999 -9999 -9999 -9999 -9999 -9999 -9999 -9999 -9999 -9999 -9999 -9999 -

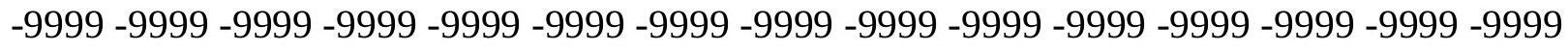

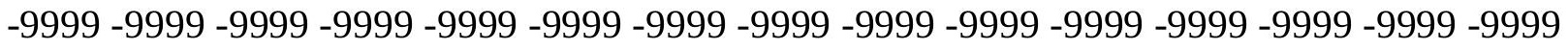
-9999 -9999 -9999 -9999 -9999 -9999 -9999 -9999 -9999 -9999 -9999 -9999 -9999 -9999 -9999 -9999 -9999 -9999 -9999 -9999 -9999 -9999 -9999 -9999-9999 -9999 -9999 -9999 -9999 -9999 -9999 -9999 -9999 -9999 -9999 -9999 -9999 -9999 -9999 -9999 -9999 -9999 -9999 -9999 -9999 -

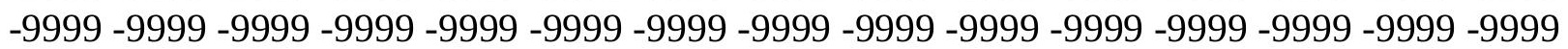


-9999 -9999 -9999 -9999 -9999 -9999 -9999 -9999 -9999 -9999 -9999 -9999 -9999 -9999 -9999 -9999 -9999 -9999 -9999 -9999 -9999 -9999 -9999 -9999 -9999 -9999 -9999 -9999 -9999 -9999 -

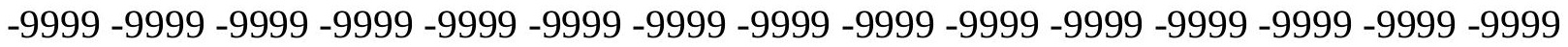
-9999 -9999 -9999 -9999 -9999 -9999 -9999 -9999 -9999 -9999 -9999 -9999 -9999 -9999 -9999 -9999 -9999 -9999 -9999 -9999 -9999 -9999 -9999 -9999-9999 -9999 -9999 -9999 -9999 -9999 -9999 -9999 -9999 -9999 -9999 -9999 -9999 -9999 -9999 -9999 -9999 -9999 -9999 -9999 -9999 -

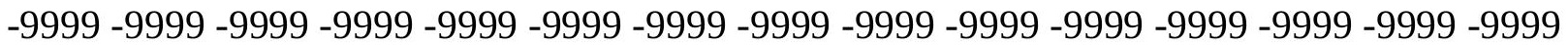
-9999 -9999 -9999 -9999 -9999 -9999 -9999 -9999 -9999 -9999 -9999 -9999 -9999 -9999 -9999 -9999 -9999 -9999 -9999 -9999 -9999 -9999 -9999 -9999 -9999 -9999 -9999 -9999 -9999 -9999 -9999 -9999 -9999 -9999 -9999 -9999 -9999 -9999 -9999 -9999 -9999 -9999 -9999 -9999 -9999 -9999 -9999 -9999 -9999 -9999 -9999 -9999 -9999 -9999 -9999 -9999 -9999 -9999 -9999 -9999 -9999 -9999 -9999 -9999 -9999 -9999 -9999 -9999 -9999 -9999 -9999 -9999 -9999 -9999 -9999 -9999 -9999 -9999 -9999 -9999 -9999 -9999 -9999 -9999 -9999 -9999 -9999 -9999 -9999 -9999 -9999 -9999 -9999 -9999 -9999 -9999 -9999 -9999 -9999 -9999 -9999 -9999 -9999 -9999 -9999 -9999 -9999 -9999 -9999 -9999 -9999 -9999 -9999 -9999 -9999 -9999 -9999 -9999 -9999 -

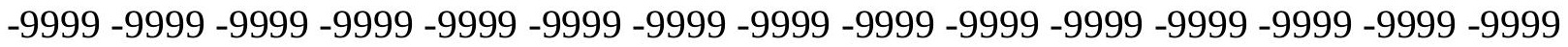
-9999 -9999 -9999 -9999 -9999 -9999 -9999 -9999 -9999 -9999 -9999 -9999 -9999 -9999 -9999 -9999 -9999 -9999 -9999 -9999 -9999 -9999 -9999 -9999 -9999 -9999 -9999 -9999 -9999 -9999 -9999 -9999 -9999 -9999 -9999 -9999 -9999 -9999 -9999 -9999 -9999 -9999 -9999 -9999 -9999 -

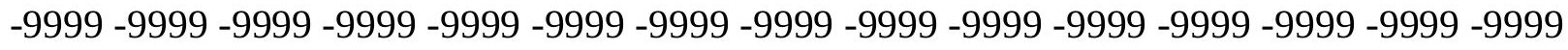

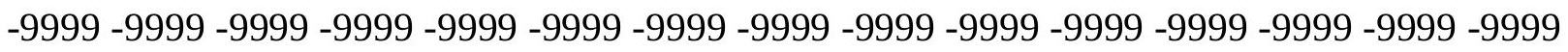
-9999 -9999 -9999 -9999 -9999 -9999 -9999 -9999 -9999 -9999 -9999 -9999 -9999 -9999 - 9999 -9999 -9999 -9999 -9999 -9999 -9999 -9999 -9999 -9999 -9999 -9999 -9999 -9999 -9999 -9999 -9999 -9999 -9999 -9999 -9999 -9999 -9999 -9999 -9999 -9999 -9999 -9999 -9999 -9999 -9999 -

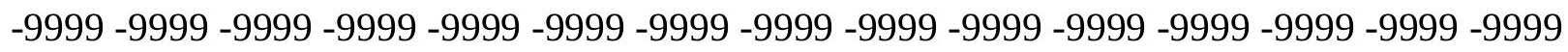
-9999 -9999 -9999 -9999 -9999 -9999 -9999 -9999 -9999 -9999 -9999 -9999 -9999 -9999 -9999 -9999 -9999 -9999 -9999 -9999 -9999 -9999 -9999 -9999 -9999 -9999 -9999 -9999 -9999 -9999 -

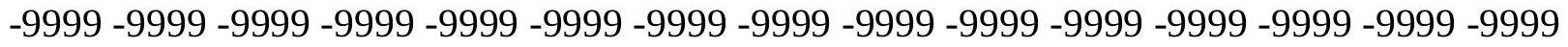
-9999 -9999 -9999 -9999 -9999 -9999 -9999 -9999 -9999 -9999 -9999 -9999 -9999 -9999 -9999 -9999 -9999 -9999 -9999 -9999 -9999 -9999 -9999 -9999 -9999 -9999 -9999 -9999 -9999 -999 -9999 -9999 -9999 -9999 -9999 -9999 -9999 -9999 -9999 -9999 -9999 -9999 -9999 -9999 -9999 -9999 -9999 -9999 -9999 -9999 -9999 -9999 -9999 -9999 -9999 -9999 -9999 -9999 -9999 -9999 -

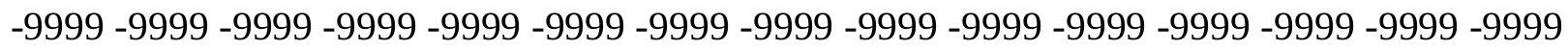

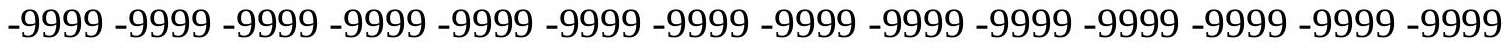
-9999 -9999 -9999 -9999 -9999 -9999 -9999 -9999 -9999 -9999 -9999 -9999 -9999 -9999 -9999

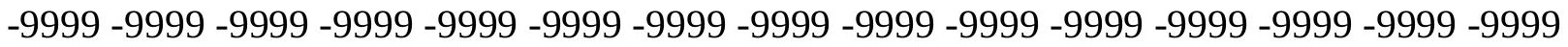

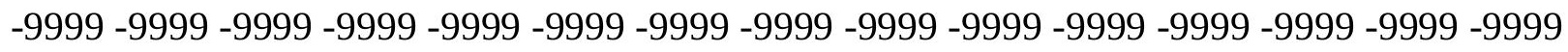

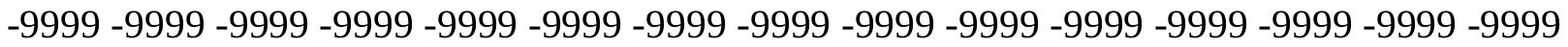

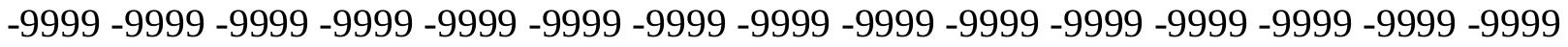
-9999 -9999 -9999 -9999 -9999 -9999 -9999 -9999 -9999 -9999 -9999 -9999 -9999 -9999 -9999 -

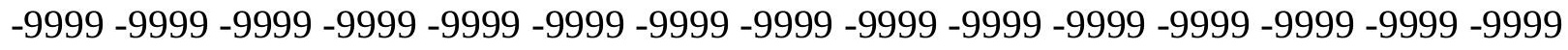

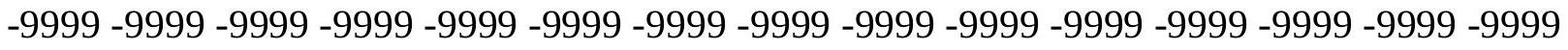
-9999 -9999 -9999 -9999 -9999 -9999 -9999 -9999 -9999 -9999 -9999 -9999 -9999 -9999 -9999 -9999 -9999 -9999 -9999 -9999 -9999 -9999 -9999 -9999-9999 -9999 -9999 -9999 -9999 -9999 -9999 -9999 -9999 -9999 -9999 -9999 -9999 -9999 -9999 -9999 -9999 -9999 -9999 -9999 -9999 -

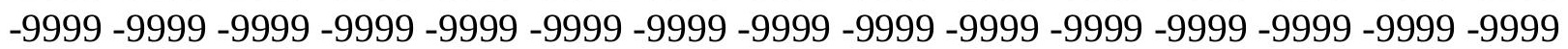


-9999 -9999 -9999 -9999 -9999 -9999 -9999 -9999 -9999 -9999 -9999 -9999 -9999 -9999 -9999 -9999 -9999 -9999 -9999 -9999 -9999 -9999 -9999 -9999 -9999 -9999 -9999 -9999 -9999 -9999 -

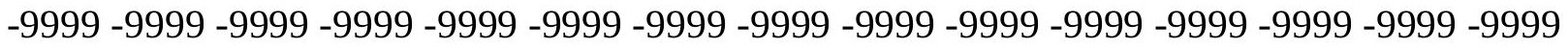
-9999 -9999 -9999 -9999 -9999 -9999 -9999 -9999 -9999 -9999 -9999 -9999 -9999 -9999 -9999 -9999 -9999 -9999 -9999 -9999 -9999 -9999 -9999 -9999-9999 -9999 -9999 -9999 -9999 -9999 -9999 -9999 -9999 -9999 -9999 -9999 -9999 -9999 -9999 -9999 -9999 -9999 -9999 -9999 -9999 -9999 -9999 -9999 -9999 -9999 -9999 -9999 -9999 -9999 -9999 -9999 -9999 -9999 -9999 -9999

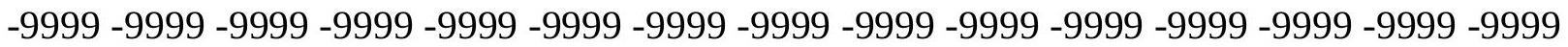

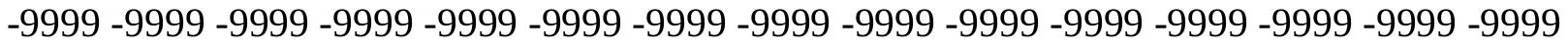
-9999 -9999 -9999 -9999 -9999 -9999 -9999 -9999 -9999 -9999 -9999 -9999 -9999 -9999 -9999 -9999 -9999 -9999 -9999 -9999 -9999 -9999 -9999 -9999 -9999 -9999 -9999 -9999 -9999 -9999 -9999 -9999 -9999 -9999 -9999 -9999 -9999 -9999 -9999 -9999 -9999 -9999 -9999 -9999 -9999 -9999 -9999 -9999 -9999 -9999 -9999 -9999 -9999 -9999 -9999 -9999 -9999 -9999 -9999 -9999 -9999 -9999 -9999 -9999 -9999 -9999 -9999 -9999 -9999 -9999 -9999 -9999 -9999 -9999 -9999 -9999 -9999 -9999 -9999 -9999 -9999 -9999 -9999 -9999 -9999 -9999 -9999 -9999 -9999

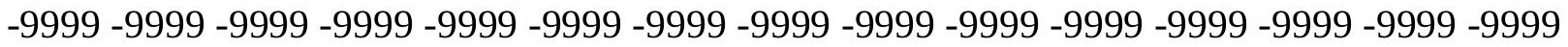
-9999 -9999 -9999 -9999 -9999 -9999 -9999 -9999 -9999 -9999 -9999 -9999 -9999 -9999 -9999 -9999 -9999 -9999 -9999 -9999 -9999 -9999 -9999 -9999 -9999 -9999 -9999 -9999 -9999 -9999 -9999 -9999 -9999 -9999 -9999 -9999 -9999 -9999 -9999 -9999 -9999 -9999 -9999 -9999 -9999 -

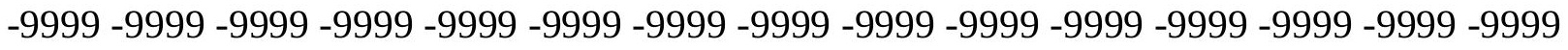

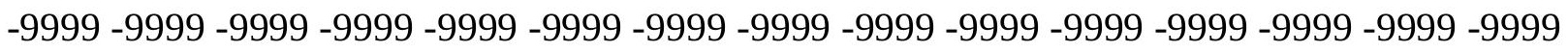
-9999 -9999 -9999 -9999 -9999 -9999 -9999 -9999 -9999 -9999 -9999 -9999 -9999 -9999 -9999 -9999 -9999 -9999 -9999 -9999 -9999 -9999 -9999 -9999 -9999 -9999 -9999 -9999 -9999 -9999 -9999 -9999 -9999 -9999 -9999 -9999 -9999 -9999 -9999 -9999 -9999 -9999 -9999 -9999 -9999 -

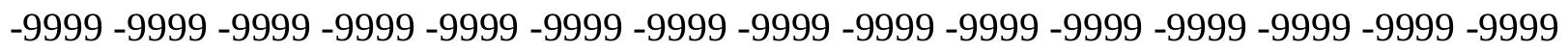
-9999 -9999 -9999 -9999 -9999 -9999 -9999 -9999 -9999 -9999 -9999 -9999 -9999 -9999 -9999 -9999 -9999 -9999 -9999 -9999 -9999 -9999 -9999 -9999 -9999 -9999 -9999 -9999 -9999 -9999 -

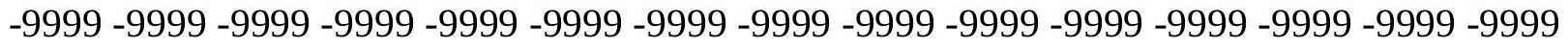
-9999 -9999 -9999 -9999 -9999 -9999 -9999 -9999 -9999 -9999 -9999 -9999 -9999 -9999 -9999 -9999 -9999 -9999 -9999 -9999 -9999 -9999 -9999 -9999 -9999 -9999 -9999 -9999 -9999 -999 -9999 -9999 -9999 -9999 -9999 -9999 -9999 -9999 -9999 -9999 -9999 -9999 -9999 -9999 -9999 -9999 -9999 -9999 -9999 -9999 -9999 -9999 -9999 -9999 -9999 -9999 -9999 -9999 -9999 -9999 -

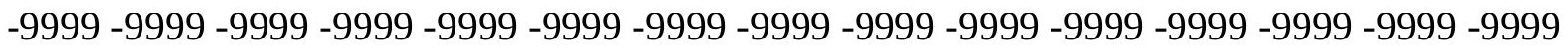

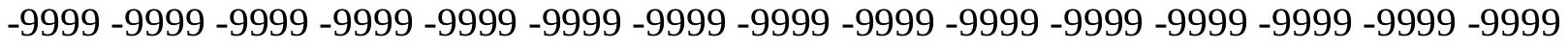

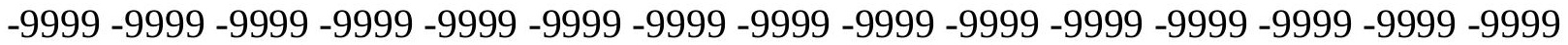

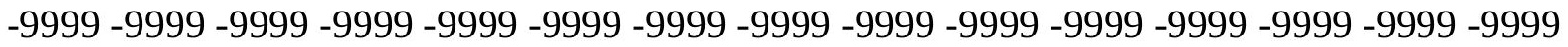

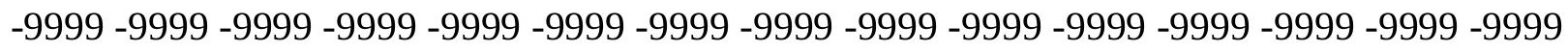

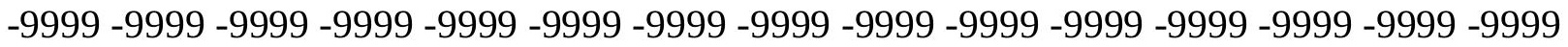
-9999 -9999 -9999 -9999 -9999 -9999 -9999 -9999 -9999 -9999 -9999 -9999 -9999 - 9999 - -999 -9999 -9999 -9999 -9999 -9999 -9999 -9999 -9999 -9999 -9999 -9999 -9999 -9999 -9999 - -999 -

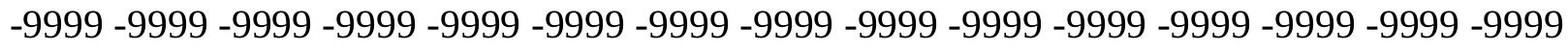

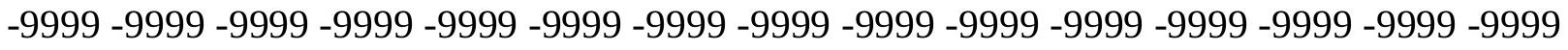
-9999 -9999 -9999 -9999 -9999 -9999 -9999 -9999 -9999 -9999 -9999 -9999 -9999 -9999 -9999 -9999 -9999 -9999 -9999 -9999 -9999 -9999 -9999 -9999-9999 -9999 -9999 -9999 -9999 -9999 -9999 -9999 -9999 -9999 -9999 -9999 -9999 -9999 -9999 -9999 -9999 -9999 -9999 -9999 -9999 -

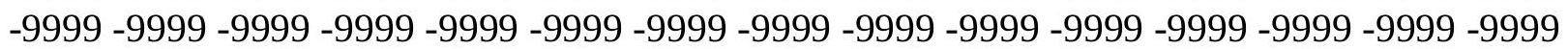


-9999 -9999 -9999 -9999 -9999 -9999 -9999 -9999 -9999 -9999 -9999 -9999 -9999 -9999 -9999 -9999 -9999 -9999 -9999 -9999 -9999 -9999 -9999 -9999 -9999 -9999 -9999 -9999 -9999 -9999 -9999 -9999 -9999 -9999 -9999 -9999 -9999 -9999 -9999 -9999 -9999 -9999 -9999 -9999 -9999 -9999 -9999 -9999 -9999 -9999 -9999 -9999 -9999 -9999 -9999 -9999 -9999 -9999 -9999 -9999 -9999 -9999 -9999 -9999 -9999 -9999 -9999 -9999 -9999 -9999 -9999 -9999 -9999 -9999 -9999 -9999 -9999 -9999 -9999 -9999 -9999 -9999 -9999 -9999 -9999 -9999 -9999 -9999 -9999 -9999 -9999 -9999 -9999 -9999 -9999 -9999 -9999 -9999 -9999 -9999 -9999 -9999 -9999 -9999 -9999 -

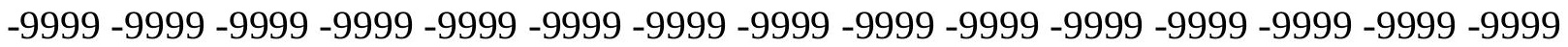
-9999 -9999 -9999 -9999 -9999 -9999 -9999 -9999 -9999 -9999 -9999 -9999 -9999 -9999 -9999 -9999 -9999 -9999 -9999 -9999 -9999 -9999 -9999 -9999 -9999 -9999 -9999 -9999 -9999 -9999 -

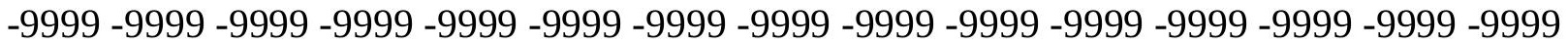
-9999 -9999 -9999 -9999 -9999 -9999 -9999 -9999 -9999 -9999 -9999 -9999 -9999 -9999 -9999 -9999 -9999 -9999 -9999 -9999 -9999 -9999 -9999 -9999 -9999 -9999 -9999 -9999 -9999 -9999 -9999 -9999 -9999 -9999 -9999 -9999 -9999 -9999 -9999 -9999 -9999 -9999 -9999 -9999 -9999 -9999 -9999 -9999 -9999 -9999 -9999 -9999 -9999 -9999 -9999 -9999 -9999 -9999 -9999 -9999

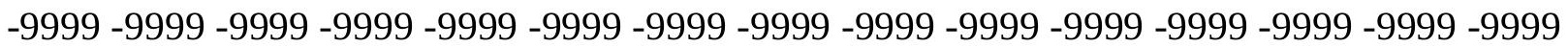
-9999 -9999 -9999 -9999 -9999 -9999 -9999 -9999 -9999 -9999 -9999 -9999 -9999 -9999 -9999 -9999 -9999 -9999 -9999 -9999 -9999 -9999 -9999 -9999 -9999 -9999 -9999 -9999 -9999 -9999 -9999 -9999 -9999 -9999 -9999 -9999 -9999 -9999 -9999 -9999 -9999 -9999 -9999 -9999 -9999 -9999 -9999 -9999 -9999 -9999 -9999 -9999 -9999 -9999 -9999 -9999 -9999 -9999 -9999 -9999 -9999 -9999 -9999 -9999 -9999 -9999 -9999 -9999 -9999 -9999 -9999 -9999 -9999 -9999 -9999 -9999 -9999 -9999 -9999 -9999 -9999 -9999 -9999 -9999 -9999 -9999 -9999 -9999 -9999 -9999 -9999 -9999 -9999 -9999 -9999 -9999 -9999 -9999 -9999 -9999 -9999 -9999 -9999 -9999 -9999 -9999 -9999 -9999 -9999 -9999 -9999 -9999 -9999 -9999 -9999 -9999 -9999 -9999 -9999 -9999 -9999 -9999 -9999 -9999 -9999 -9999 -9999 -9999 -9999 -9999 -9999 -9999 -9999 -9999 -9999 -9999 -9999 -9999 -9999 -9999 -9999 -9999 -9999 -9999 -9999 -9999 -9999 -9999 -9999 -9999 -9999 -9999 -9999 -9999 -9999 -9999 -9999 -9999 -9999 -9999 -9999 -9999 -9999 -9999 -9999 -9999 -9999 -9999 -9999 -9999 -9999 -9999 -9999 -9999 -9999 -9999 -9999 -9999 -9999

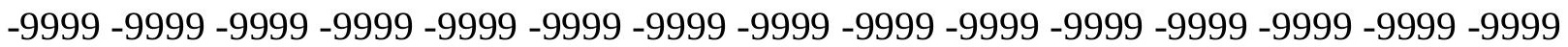
-9999 -9999 -9999 -9999 -9999 -9999 -9999 -9999 -9999 -9999 -9999 -9999 -9999 -9999 -9999 -9999 -9999 -9999 -9999 -9999 -9999 -9999 -9999 -9999 -9999 -9999 -9999 -9999 -9999 -9999 -

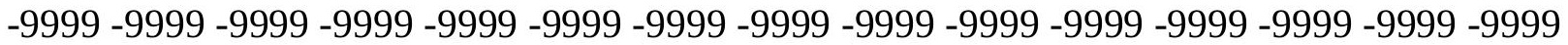
-9999 -9999 -9999 -9999 -9999 -9999 -9999 -9999 -9999 -9999 -9999 -9999 -9999 -9999 -9999 -9999 -9999 -9999 -9999 -9999 -9999 -9999 -9999 -9999 -9999 -9999 -9999 -9999 -9999 -9999 -9999 -9999 -9999 -9999 -9999 -9999 -9999 -9999 -9999 -9999 -9999 -9999 -9999 -9999 -9999 -9999 -9999 -9999 -9999 -9999 -9999 -9999 -9999 -9999 -9999 -9999 -9999 -9999 -9999 -9999 -9999 -9999 -9999 -9999 -9999 -9999 -9999 -9999 -9999 -9999 -9999 -9999 -9999 -9999 -9999

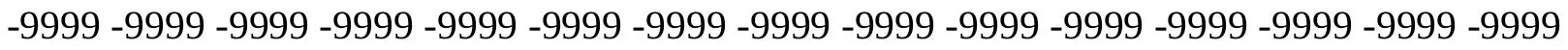
-9999 -9999 -9999 -9999 -9999 -9999 -9999 -9999 -9999 -9999 -9999 -9999 -9999 -9999 -9999 -9999 -9999 -9999 -9999 -9999 -9999 -9999 -9999 -9999 -9999 -9999 -9999 -9999 -9999 -9999 -9999 -9999 -9999 -9999 -9999 -9999 -9999 -9999 -9999 -9999 -9999 -9999 -9999 -9999 -9999 -999 -9999 -9999 -9999 -9999 -9999 -9999 -9999 -9999 -9999 -9999 -9999 -9999 -9999 -9999 -9999 -9999 -9999 -9999 -9999 -9999 -9999 -9999 -9999 -9999 -9999 -9999 -9999 -9999 -9999 -9999 -9999 -9999 -9999 -9999 -9999 -9999 -9999 -9999 -9999 -9999 -9999 -9999 -9999 -9999 -9999 -9999 -9999 -9999 -9999 -9999 -9999 -9999 -9999 -9999 -9999 -9999 -9999 -9999 -9999 -9999 -9999 -9999 -9999 -9999 -9999 -9999 -9999 -9999 -9999 -9999 -9999 -9999 -9999 -9999 
-9999 -9999 -9999 -9999 -9999 -9999 -9999 -9999 -9999 -9999 -9999 -9999 -9999 -9999 -9999 -9999 -9999 -9999 -9999 -9999 -9999 -9999 -9999 -9999 -9999 -9999 -9999 -9999 -9999 -9999 -

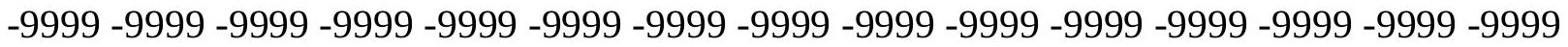
-9999 -9999 -9999 -9999 -9999 -9999 -9999 -9999 -9999 -9999 -9999 -9999 -9999 -9999 -9999 -9999 -9999 -9999 -9999 -9999 -9999 -9999 -9999 -9999-9999 -9999 -9999 -9999 -9999 -9999 -9999 -9999 -9999 -9999 -9999 -9999 -9999 -9999 -9999 -9999 -9999 -9999 -9999 -9999 -9999 -9999 -9999 -9999 -9999 -9999 -9999 -9999 -9999 -9999 -9999 -9999 -9999 -9999 -9999 -9999

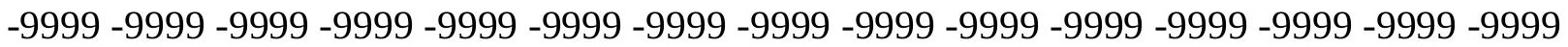

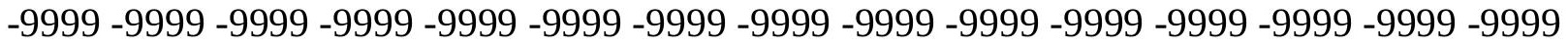
-9999 -9999 -9999 -9999 -9999 -9999 -9999 -9999 -9999 -9999 -9999 -9999 -9999 -9999 -9999 -9999 -9999 -9999 -9999 -9999 -9999 -9999 -9999 -9999 -9999 -9999 -9999 -9999 -9999 -9999 -9999 -9999 -9999 -9999 -9999 -9999 -9999 -9999 -9999 -9999 -9999 -9999 -9999 -9999 -9999 -9999 -9999 -9999 -9999 -9999 -9999 -9999 -9999 -9999 -9999 -9999 -9999 -9999 -9999 -9999 -

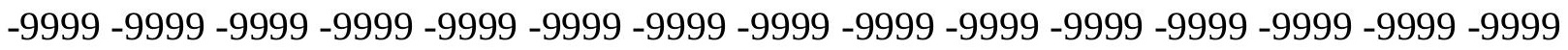
-9999 -9999 -9999 -9999 -9999 -9999 -9999 -9999 -9999 -9999 -9999 -9999 -9999 -9999 -9999 -

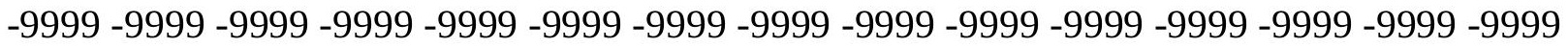
-9999 -9999 -9999 -9999 -9999 -9999 -9999 -9999 -9999 -9999 -9999 -9999 -9999 -9999 -9999 -9999 -9999 -9999 -9999 -9999 -9999 -9999 -9999 -9999 -9999 -9999 -9999 -9999 -9999 -9999 -9999 -9999 -9999 -9999 -9999 -9999 -9999 -9999 -9999 -9999 -9999 -9999 -9999 -9999 -9999 -

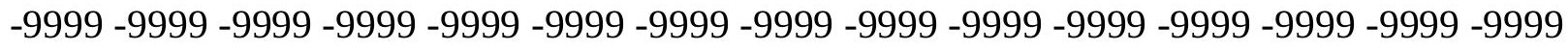

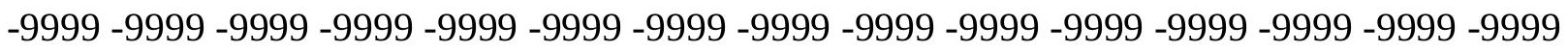

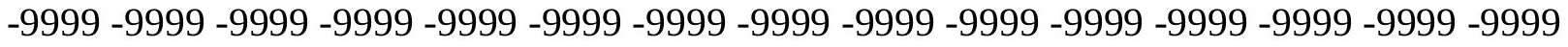
-9999 -9999 -9999 -9999 -9999 -9999 -9999 -9999 -9999 -9999 -9999 -9999 -9999 -9999 -9999 -9999 -9999 -9999 -9999 -9999 -9999 -9999 -9999 -9999 -9999 -9999 -9999 -9999 -9999 -9999 -

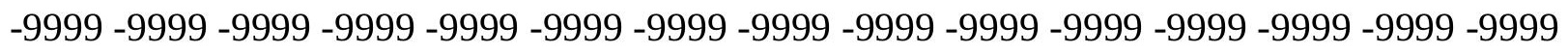
-9999 -9999 -9999 -9999 -9999 -9999 -9999 -9999 -9999 -9999 -9999 -9999 -9999 -9999 -9999 -9999 -9999 -9999 -9999 -9999 -9999 -9999 -9999 -9999 -9999 -9999 -9999 -9999 -9999 -

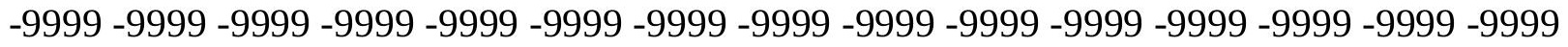
-9999 -9999 -9999 -9999 -9999 -9999 -9999 -9999 -9999 -9999 -9999 -9999 -9999 -9999 -9999 -9999 -9999 -9999 -9999 -9999 -9999 -9999 -9999 -9999 -9999 -9999 -9999 -9999 -9999 -999 -

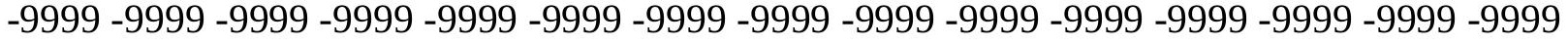
-9999 -9999 -9999 -9999 -9999 -9999 -9999 -9999 -9999 -9999 -9999 -9999 -9999 -9999 -9999 -

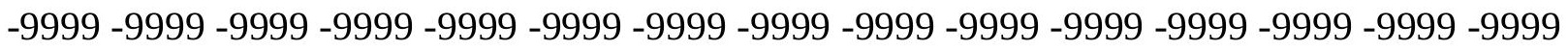

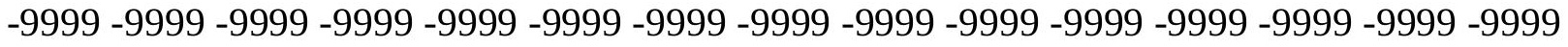

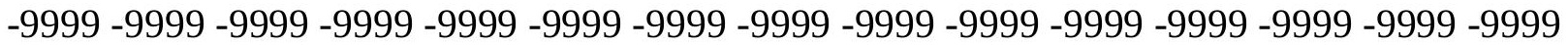
-9999 -9999 -9999 -9999 -9999 -9999 -9999 -9999 -9999 -9999 -9999 -9999 -9999 -9999 -9999

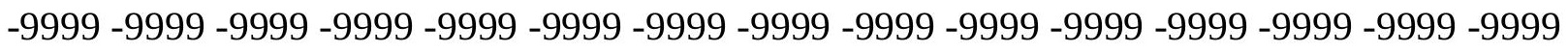

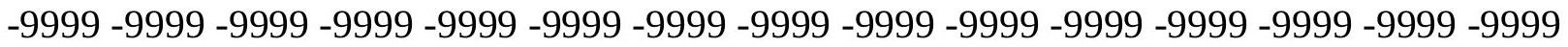
-9999 -9999 -9999 -9999 -9999 -9999 -9999 -9999 -9999 -9999 -9999 -9999 -9999 - 9999 - -999 -9999 -9999 -9999 -9999 -9999 -9999 -9999 -9999 -9999 -9999 -9999 -9999 -9999 -9999 -9999 -

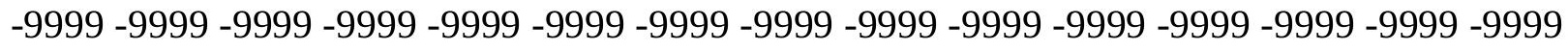

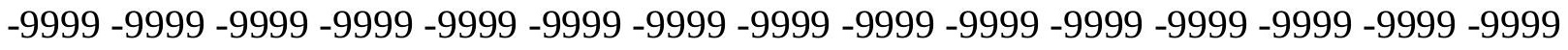
-9999 -9999 -9999 -9999 -9999 -9999 -9999 -9999 -9999 -9999 -9999 -9999 -9999 -9999 -9999 -9999 -9999 -9999 -9999 -9999 -9999 -9999 -9999 -9999-9999 -9999 -9999 -9999 -9999 -9999 -9999 -9999 -9999 -9999 -9999 -9999 -9999 -9999 -9999 -9999 -9999 -9999 -9999 -9999 -9999 -

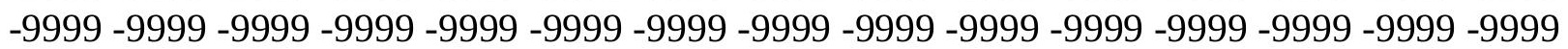


-9999 -9999 -9999 -9999 -9999 -9999 -9999 -9999 -9999 -9999 -9999 -9999 -9999 -9999 -9999 -9999 -9999 -9999 -9999 -9999 -9999 -9999 -9999 -9999 -9999 -9999 -9999 -9999 -9999 -9999 -9999 -9999 -9999 -9999 -9999 -9999 -9999 -9999 -9999 -9999 -9999 -9999 -9999 -9999 - 9999 -9999 -9999 -9999 -9999 -9999 -9999 -9999 -9999 -9999 -9999 -9999 -9999 -9999 -9999 -9999 -9999 -9999 -9999 -9999 -9999 -9999 -9999 -9999 -9999 -9999 -9999 -9999 -9999 -9999 - -9999 -9999 -9999 -9999 -9999 -9999 -9999 -9999 -9999 -9999 -9999 -9999 -9999 -9999 -9999 -9999 -9999 -9999 -9999 -9999 -9999 -9999 -9999 -9999 -9999 -9999 -9999 -9999 -9999 -9999

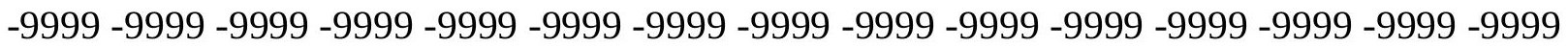

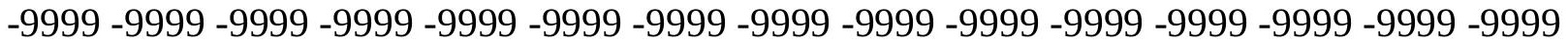
-9999 -9999 -9999 -9999 -9999 -9999 -9999 -9999 -9999 -9999 -9999 -9999 -9999 -9999 -9999

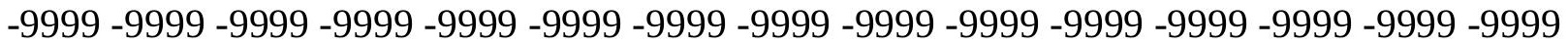
-9999 -9999 -9999 -9999 -9999 -9999 -9999 -9999 -9999 -9999 -9999 -9999 -9999 -9999 -9999 -9999 -9999 -9999 -9999 -9999 -9999 -9999 -9999 -9999 -9999 -9999 -9999 -9999 -9999 -9999 -9999 -9999 -9999 -9999 -9999 -9999 -9999 -9999 -9999 -9999 -9999 -9999 -9999 -9999 - -9999 -9999 -9999 -9999 -9999 -9999 -9999 -9999 -9999 -9999 -9999 -9999 -9999 -9999 -9999 -9999

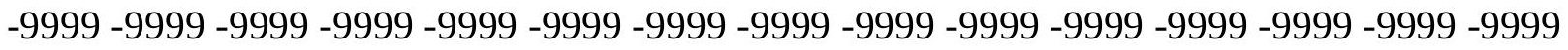
-9999 -9999 -9999 -9999 -9999 -9999 -9999 -9999 -9999 -9999 -9999 -9999 -9999 -9999 -9999 -9999 -9999 -9999 -9999 -9999 -9999 -9999 -9999 -9999 -9999 -9999 -9999 -9999 -9999 -9999 -9999 -9999 -9999 -9999 -9999 -9999 -9999 -9999 -9999 -9999 -9999 -9999 -9999 -9999 -9999 -

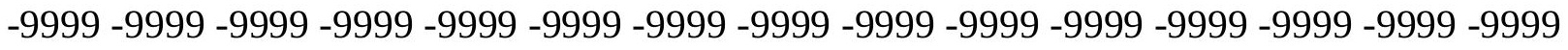
-9999 -9999 -9999 -9999 -9999 -9999 -9999 -9999 -9999 -9999 -9999 -9999 -9999 -9999 -9999 -999 -9999 -9999 -9999 -9999 -9999 -9999 -9999 -9999 -9999 -9999 -9999 -9999 -9999 -9999 -9999 -9999 -9999 -9999 -9999 -9999 -9999 -9999 -9999 -9999 -9999 -9999 -9999 -9999 -9999 -9999 -9999 -9999 -9999 -9999 -9999 -9999 -9999 -9999 -9999 -9999 -9999 -9999 -9999 -9999 -9999 -9999 -9999 -9999 -9999 -9999 -9999 -9999 -9999 -9999 -9999 -9999 -9999 -9999 -9999 -9999 -9999 -9999 -9999 -9999 -9999 -9999 -9999 -9999 -9999 -9999 -9999 -9999 -9999 -9999 -9999 -9999 -9999 -9999 -9999 -9999 -9999 -9999 -9999 -9999 -9999 -9999 -9999 -9999 -9999 -9999 -9999 -9999 -9999 -9999 -9999 -9999 -9999 -9999 -9999 -9999 -9999 -9999 -9999 -9999 -9999 -9999 -9999 -9999 -9999 -9999 -9999 -9999 -9999 -9999 -9999 -9999 -9999 -9999 -9999 -9999 -9999 -9999 -9999 -9999 -9999 -9999 -9999 -9999 -9999 -9999 -9999 -9999 -9999 -9999 -999 -9999 -9999 -9999 -9999 -9999 -9999 -9999 -9999 -9999 -9999 -9999 -9999 -9999 -9999 -9999 -9999 -9999 -9999 -9999 -9999 -9999 -9999 -9999 -9999 -9999 -9999 -9999 -9999 -9999 -

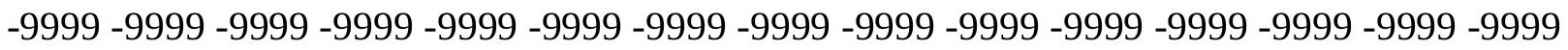

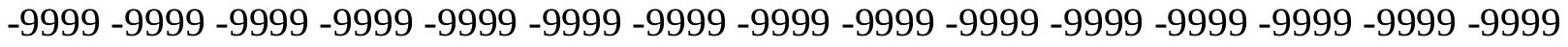

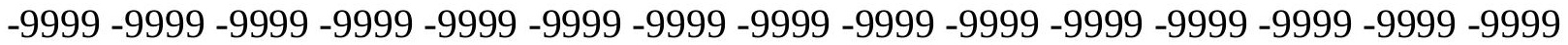
-9999 -9999 -9999 -9999 -9999 -9999 -9999 -9999 -9999 -9999 -9999 -9999 -9999 -9999 -9999 -

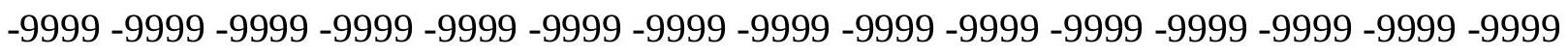

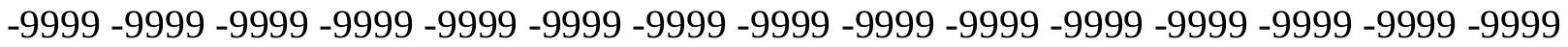

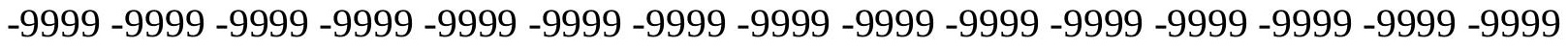
-9999 -9999 -9999 -9999 -9999 -9999 -9999 -9999 -9999 -9999 -9999 -9999 -9999 -9999 -9999 -

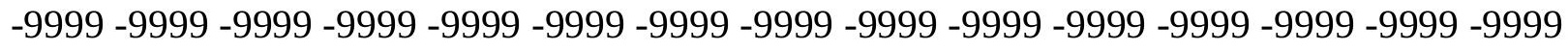

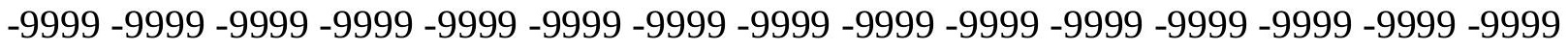
-9999 -9999 -9999 -9999 -9999 -9999 -9999 -9999 -9999 -9999 -9999 -9999 -9999 -9999 -9999 -9999 -9999 -9999 -9999 -9999 -9999 -9999 -9999 -9999-9999 -9999 -9999 -9999 -9999 -9999 -9999 -9999 -9999 -9999 -9999 -9999 -9999 -9999 -9999 -9999 -9999 -9999 -9999 -9999 -9999 -

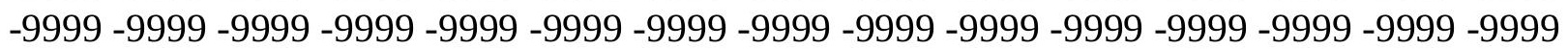


-9999 -9999 -9999 -9999 -9999 -9999 -9999 -9999 -9999 -9999 -9999 -9999 -9999 -9999 -9999 -9999 -9999 -9999 -9999 -9999 -9999 -9999 -9999 -9999 -9999 -9999 -9999 -9999 -9999 -9999 -

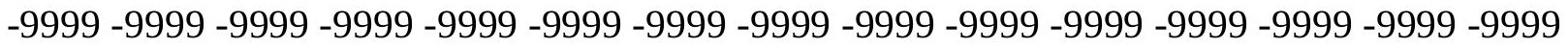
-9999 -9999 -9999 -9999 -9999 -9999 -9999 -9999 -9999 -9999 -9999 -9999 -9999 -9999 -9999 -9999 -9999 -9999 -9999 -9999 -9999 -9999 -9999 -9999-9999 -9999 -9999 -9999 -9999 -9999 -9999 -9999 -9999 -9999 -9999 -9999 -9999 -9999 -9999 -9999 -9999 -9999 -9999 -9999 -9999 -9999 -9999 -9999 -9999 -9999 -9999 -9999 -9999 -9999 -9999 -9999 -9999 -9999 -9999 -9999

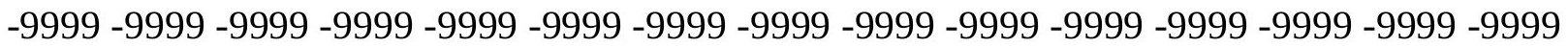

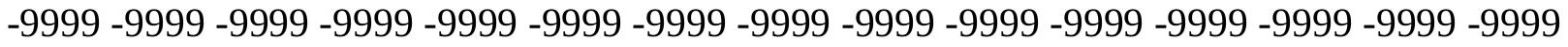
-9999 -9999 -9999 -9999 -9999 -9999 -9999 -9999 -9999 -9999 -9999 -9999 -9999 -9999 -9999 -9999 -9999 -9999 -9999 -9999 -9999 -9999 -9999 -9999 -9999 -9999 -9999 -9999 -9999 -9999 -9999 -9999 -9999 -9999 -9999 -9999 -9999 -9999 -9999 -9999 -9999 -9999 -9999 -9999 -9999 -9999 -9999 -9999 -9999 -9999 -9999 -9999 -9999 -9999 -9999 -9999 -9999 -9999 -9999 -9999 -9999 -9999 -9999 -9999 -9999 -9999 -9999 -9999 -9999 -9999 -9999 -9999 -9999 - 9999 -9999 -9999 -9999 -9999 -9999 -9999 -9999 -9999 -9999 -9999 -9999 -9999 -9999 -9999 -9999

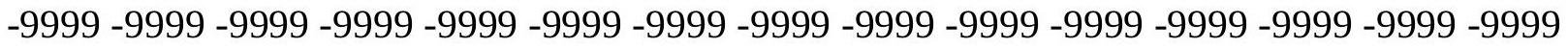
-9999 -9999 -9999 -9999 -9999 -9999 -9999 -9999 -9999 -9999 -9999 -9999 -9999 -9999 -9999 -9999 -9999 -9999 -9999 -9999 -9999 -9999 -9999 -9999 -9999 -9999 -9999 -9999 -9999 -9999 -9999 -9999 -9999 -9999 -9999 -9999 -9999 -9999 -9999 -9999 -9999 -9999 -9999 -9999 -9999 -

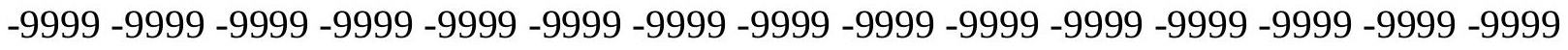

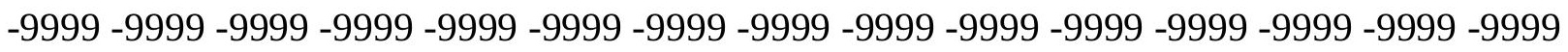
-9999 -9999 -9999 -9999 -9999 -9999 -9999 -9999 -9999 -9999 -9999 -9999 -9999 -9999 -9999 -9999 -9999 -9999 -9999 -9999 -9999 -9999 -9999 -9999 -9999 -9999 -9999 -9999 -9999 -9999 -9999 -9999 -9999 -9999 -9999 -9999 -9999 -9999 -9999 -9999 -9999 -9999 -9999 -9999 -9999 -

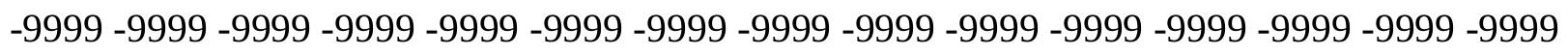
-9999 -9999 -9999 -9999 -9999 -9999 -9999 -9999 -9999 -9999 -9999 -9999 -9999 -9999 -9999 -9999 -9999 -9999 -9999 -9999 -9999 -9999 -9999 -9999 -9999 -9999 -9999 -9999 -9999 -9999 -

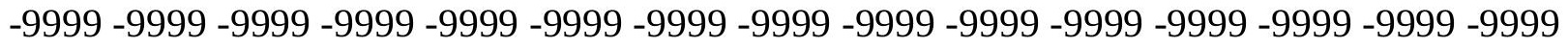
-9999 -9999 -9999 -9999 -9999 -9999 -9999 -9999 -9999 -9999 -9999 -9999 -9999 -9999 -9999 -9999 -9999 -9999 -9999 -9999 -9999 -9999 -9999 -9999 -9999 -9999 -9999 -9999 -9999 -999 -9999 -9999 -9999 -9999 -9999 -9999 -9999 -9999 -9999 -9999 -9999 -9999 -9999 -9999 -9999 -9999 -9999 -9999 -9999 -9999 -9999 -9999 -9999 -9999 -9999 -9999 -9999 -9999 -9999 -9999 -

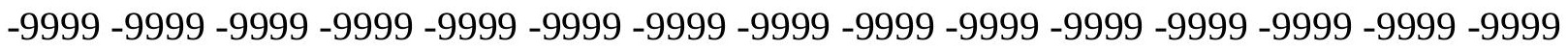

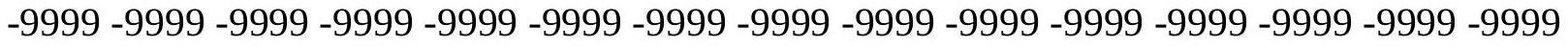

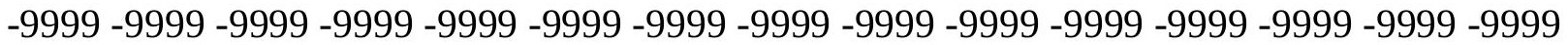

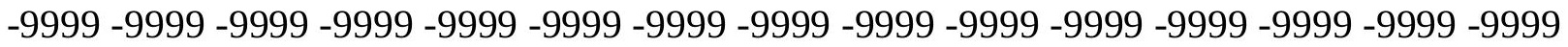

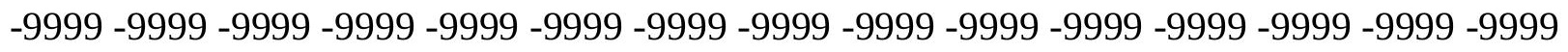

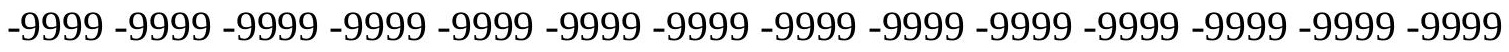
-9999 -9999 -9999 -9999 -9999 -9999 -9999 -9999 -9999 -9999 -9999 -9999 -9999 -9999 -9999 -9999 -9999 -9999 -9999 -9999 -9999 -9999 -9999 -9999 -9999 -9999 -9999 -9999 -9999 -9999 -

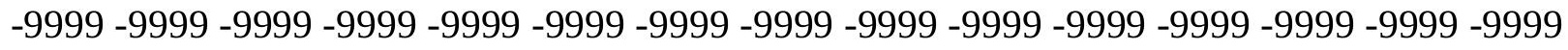

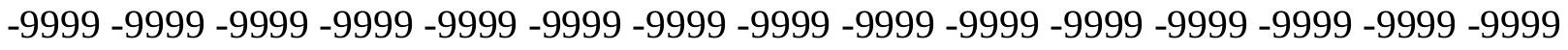
-9999 -9999 -9999 -9999 -9999 -9999 -9999 -9999 -9999 -9999 -9999 -9999 -9999 -9999 -9999 -9999 -9999 -9999 -9999 -9999 -9999 -9999 -9999 -9999-9999 -9999 -9999 -9999 -9999 -9999 -9999 -9999 -9999 -9999 -9999 -9999 -9999 -9999 -9999 -9999 -9999 -9999 -9999 -9999 -9999 -

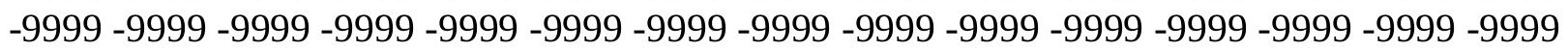


-9999 -9999 -9999 -9999 -9999 -9999 -9999 -9999 -9999 -9999 -9999 -9999 -9999 -9999 -9999 -9999 -9999 -9999 -9999 -9999 -9999 -9999 -9999 -9999 -9999 -9999 -9999 -9999 -9999 -9999 -9999 -9999 -9999 -9999 -9999 -9999 -9999 -9999 -9999 -9999 -9999 -9999 -9999 -9999 - 9999 -9999 -9999 -9999 -9999 -9999 -9999 -9999 -9999 -9999 -9999 -9999 -9999 -9999 -9999 -9999 -9999 -9999 -9999 -9999 -9999 -9999 -9999 -9999 -9999 -9999 -9999 -9999 -9999 -9999 -9999 -9999 -9999 -9999 -9999 -9999 -9999 -9999 -9999 -9999 -9999 -9999 -9999 -9999 -9999 -9999 -9999 -9999 -9999 -9999 -9999 -9999 -9999 -9999 -9999 -9999 -9999 -9999 -9999 -9999 -9999

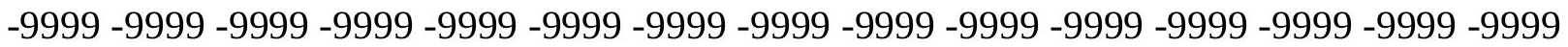
-9999 -9999 -9999 -9999 -9999 -9999 -9999 -9999 -9999 -9999 -9999 -9999 -9999 -9999 -9999 -9999 -9999 -9999 -9999 -9999 -9999 -9999 -9999 -9999 -9999 -9999 -9999 -9999 -9999 -9999

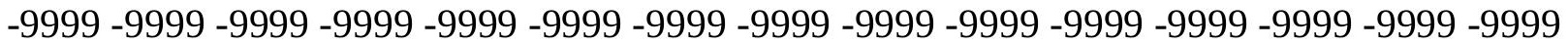
-9999 -9999 -9999 -9999 -9999 -9999 -9999 -9999 -9999 -9999 -9999 -9999 -9999 -9999 -9999 -9999 -9999 -9999 -9999 -9999 -9999 -9999 -9999 -9999 -9999 -9999 -9999 -9999 -9999 -9999 -

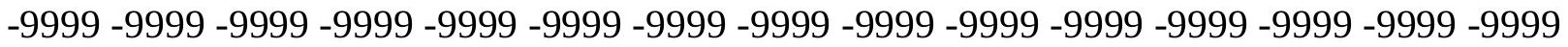
-9999 -9999 -9999 -9999 -9999 -9999 -9999 -9999 -9999 -9999 -9999 -9999 -9999 -9999 -9999

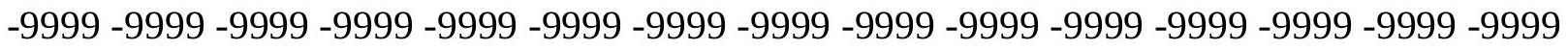
-9999 -9999 -9999 -9999 -9999 -9999 -9999 -9999 -9999 -9999 -9999 -9999 -9999 -9999 -9999 -9999 -9999 -9999 -9999 -9999 -9999 -9999 -9999 -9999 -9999 -9999 -9999 -9999 -9999 - -999 -9999 -9999 -9999 -9999 -9999 -9999 -9999 -9999 -9999 -9999 -9999 -9999 -9999 -9999 -9999 -9999 -9999 -9999 -9999 -9999 -9999 -9999 -9999 -9999 -9999 -9999 -9999 -9999 -9999 -9999 -9999 -9999 -9999 -9999 -9999 -9999 -9999 -9999 -9999 -9999 -9999 -9999 -9999 -9999 -9999 -999 -9999 -9999 -9999 -9999 -9999 -9999 -9999 -9999 -9999 -9999 -9999 -9999 -9999 -9999 -9999 -9999 -9999 -9999 -9999 -9999 -9999 -9999 -9999 -9999 -9999 -9999 -9999 -9999 -9999 -9999 -9999 -9999 -9999 -9999 -9999 -9999 -9999 -9999 -9999 -9999 -9999 -9999 -9999 -9999 -9999 -9999 -9999 -9999 -9999 -9999 -9999 -9999 -9999 -9999 -9999 -9999 -9999 -9999 -9999 -9999 -9999 -9999 -9999 -9999 -9999 -9999 -9999 -9999 -9999 -9999 -9999 -9999 -9999 -9999 -9999 -9999 -9999 -9999 -9999 -9999 -9999 -9999 -9999 -9999 -9999 -9999 -9999 -9999 -9999 -9999 -9999 -9999 -9999 -9999 -9999 -9999 -9999 -9999 -9999 -9999 -9999 -9999 -9999 -9999 -9999 -9999 -9999 -9999 -9999 -9999 -9999 -9999 -9999 -9999 -9999 -9999 -9999 -9999 -9999 -9999 -9999 -9999 -9999 -9999 -9999 -9999 -9999 -9999 -9999 -9999 -9999 -9999 -9999 -9999 -999 -9999 -9999 -9999 -9999 -9999 -9999 -9999 -9999 -9999 -9999 -9999 -9999 -9999 -9999 -9999 -9999 -9999 -9999 -9999 -9999 -9999 -9999 -9999 -9999 -9999 -9999 -9999 -9999 -9999 -9999 -

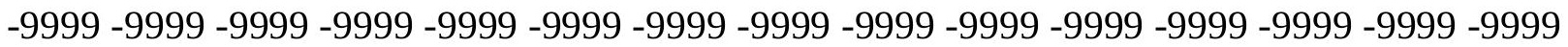

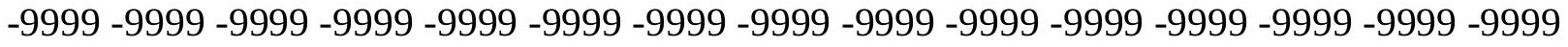

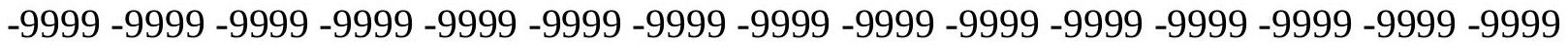
-9999 -9999 -9999 -9999 -9999 -9999 -9999 -9999 -9999 -9999 -9999 -9999 -9999 -9999 -9999

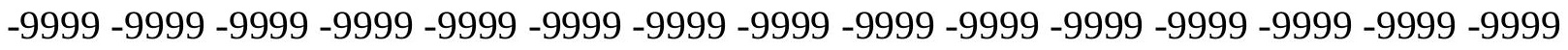

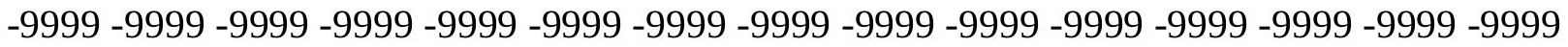

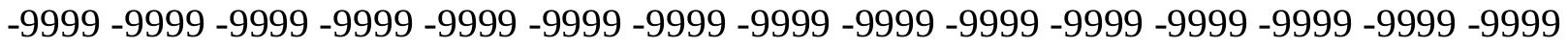
-9999 -9999 -9999 -9999 -9999 -9999 -9999 -9999 -9999 -9999 -9999 -9999 -9999 -9999 -9999 -

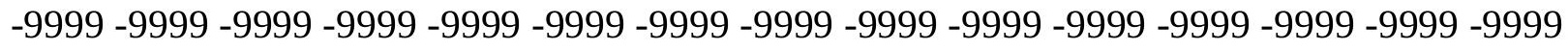

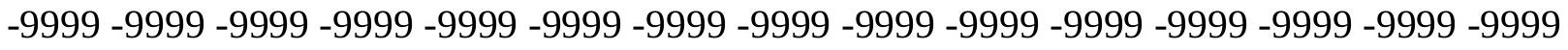
-9999 -9999 -9999 -9999 -9999 -9999 -9999 -9999 -9999 -9999 -9999 -9999 -9999 -9999 -9999 -9999 -9999 -9999 -9999 -9999 -9999 -9999 -9999 -9999 -9999 -9999 -9999 -9999 - -9999 -9999 -9999 -9999 -9999 -9999 -9999 -9999 -9999 -9999 -9999 -9999 -9999 -9999 -9999 -9999 -

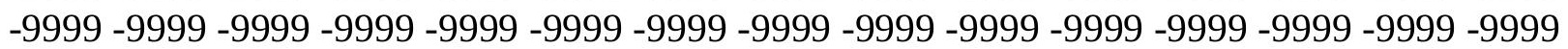


-9999 -9999 -9999 -9999 -9999 -9999 -9999 -9999 -9999 -9999 -9999 -9999 -9999 -9999 -9999 -9999 -9999 -9999 -9999 -9999 -9999 -9999 -9999 -9999 -9999 -9999 -9999 -9999 -9999 -9999 -9999 -9999 -9999 -9999 -9999 -9999 -9999 -9999 -9999 -9999 -9999 -9999 -9999 -9999 - 9999 -9999 -9999 -9999 -9999 -9999 -9999 -9999 -9999 -9999 -9999 -9999 -9999 -9999 -9999 -9999 -9999 -9999 -9999 -9999 -9999 -9999 -9999 -9999 -9999-9999 -9999 -9999 -9999 -9999 -9999 -9999 -9999 -9999 -9999 -9999 -9999 -9999 -9999 -9999 -9999 -9999 -9999 -9999 -9999 -9999 -9999 -9999 -9999 -9999 -9999 -9999 -9999 -9999 -9999 -9999 -9999 -9999 -9999 -9999 -9999

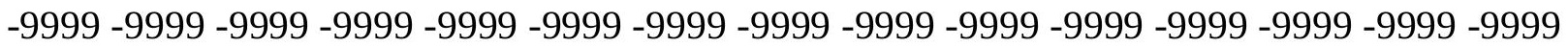

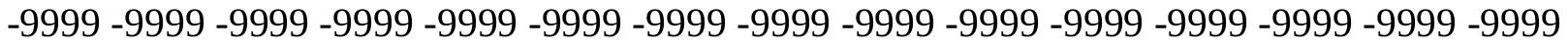
-9999 -9999 -9999 -9999 -9999 -9999 -9999 -9999 -9999 -9999 -9999 -9999 -9999 -9999 -9999

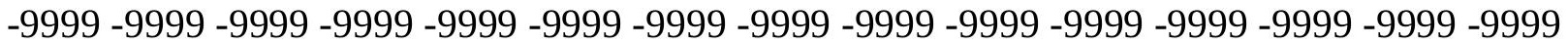
-9999 -9999 -9999 -9999 -9999 -9999 -9999 -9999 -9999 -9999 -9999 -9999 -9999 -9999 -9999 -9999 -9999 -9999 -9999 -9999 -9999 -9999 -9999 -9999 -9999 -9999 -9999 -9999 -9999 -9999 -

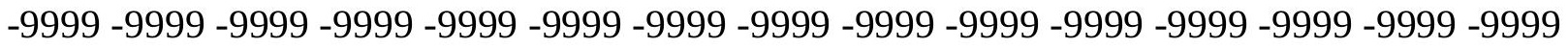
-9999 -9999 -9999 -9999 -9999 -9999 -9999 -9999 -9999 -9999 -9999 -9999 -9999 -9999 -9999

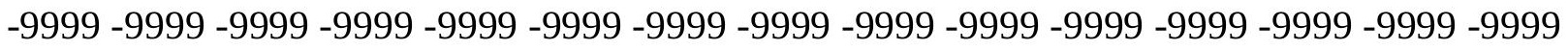
-9999 -9999 -9999 -9999 -9999 -9999 -9999 -9999 -9999 -9999 -9999 -9999 -9999 -9999 -9999 -9999 -9999 -9999 -9999 -9999 -9999 -9999 -9999 -9999 -9999 -9999 -9999 -9999 -9999 -9999 -9999 -9999 -9999 -9999 -9999 -9999 -9999 -9999 -9999 -9999 -9999 -9999 -9999 -9999 -9999 -9999 -9999 -9999 -9999 -9999 -9999 -9999 -9999 -9999 -9999 -9999 -9999 -9999 -9999 -9999 -9999 -9999 -9999 -9999 -9999 -9999 -9999 -9999 -9999 -9999 -9999 -9999 -9999 -9999 -9999 -999 -9999 -9999 -9999 -9999 -9999 -9999 -9999 -9999 -9999 -9999 -9999 -9999 -9999 -9999 -9999 -9999 -9999 -9999 -9999 -9999 -9999 -9999 -9999 -9999 -9999 -9999 -9999 -9999 -9999 -9999 -9999 -9999 -9999 -9999 -9999 -9999 -9999 -9999 -9999 -9999 -9999 -9999 -9999 -9999 -9999 -9999 -9999 -9999 -9999 -9999 -9999 -9999 -9999 -9999 -9999 -9999 -9999 -9999 -9999 -9999 -9999 -9999 -9999 -9999 -9999 -9999 -9999 -9999 -9999 -9999 -9999 -9999 -9999 -9999 -9999 -9999 -9999 -9999 -9999 -9999 -9999 -9999 -9999 -9999 -9999 -9999 -9999 -9999 -9999 -9999 -9999 -9999 -9999 -9999 -9999 -9999 -9999 -9999 -9999 -9999 -9999 -9999 -9999 -9999 -9999 -9999 -9999 -9999 -9999 -9999 -9999 -9999 -9999 -9999 -9999 -9999 -9999 -9999 -9999 -9999 -9999 -9999 -9999 -9999 -9999 -9999 -9999 -9999 -9999 -9999 -9999 -9999 -9999 -999 -9999 -9999 -9999 -9999 -9999 -9999 -9999 -9999 -9999 -9999 -9999 -9999 -9999 -9999 -9999 -9999 -9999 -9999 -9999 -9999 -9999 -9999 -9999 -9999 -9999 -9999 -9999 -9999 -9999 -9999 -

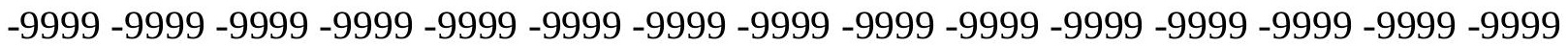

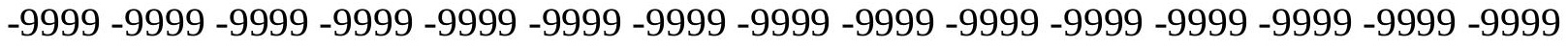

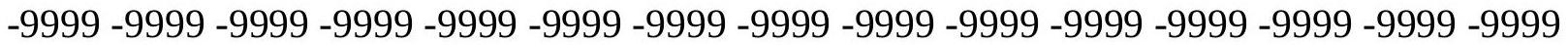
-9999 -9999 -9999 -9999 -9999 -9999 -9999 -9999 -9999 -9999 -9999 -9999 -9999 -9999 -9999

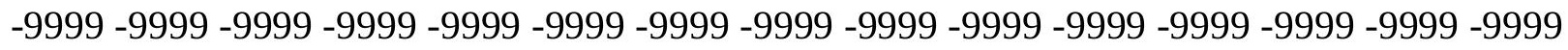

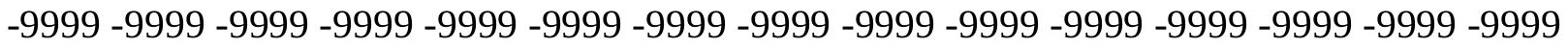
-9999 -9999 -9999 -9999 -9999 -9999 -9999 -9999 -9999 -9999 -9999 -9999 -9999 -9999 -9999 -9999 -9999 -9999 -9999 -9999 -9999 -9999 -9999 -9999 -9999 -9999 -9999 -9999 -9999 -9999 -

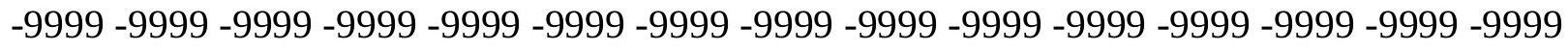

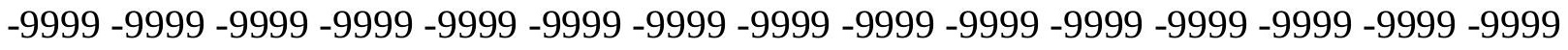
-9999 -9999 -9999 -9999 -9999 -9999 -9999 -9999 -9999 -9999 -9999 -9999 -9999 -9999 -9999 -9999 -9999 -9999 -9999 -9999 -9999 -9999 -9999 -9999-9999 -9999 -9999 -9999 -9999 -9999 -9999 -9999 -9999 -9999 -9999 -9999 -9999 -9999 -9999 -9999 -9999 -9999 -9999 -9999 -9999 -

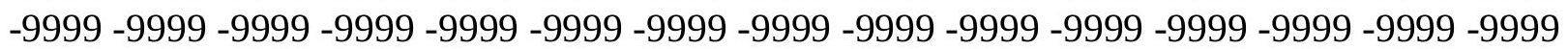


-9999 -9999 -9999 -9999 -9999 -9999 -9999 -9999 -9999 -9999 -9999 -9999 -9999 -9999 -9999 -9999 -9999 -9999 -9999 -9999 -9999 -9999 -9999 -9999 -9999 -9999 -9999 -9999 -9999 -9999 -9999 -9999 -9999 -9999 -9999 -9999 -9999 -9999 -9999 -9999 -9999 -9999 -9999 -9999 - 9999 -9999 -9999 -9999 -9999 -9999 -9999 -9999 -9999 -9999 -9999 -9999 -9999 -9999 -9999

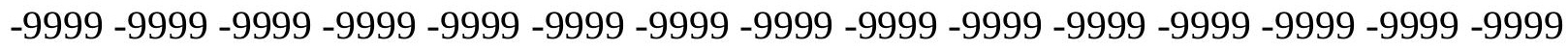
-9999 -9999 -9999 -9999 -9999 -9999 -9999 -9999 -9999 -9999 -9999 -9999 -9999 -9999 -9999 -9999 -9999 -9999 -9999 -9999 -9999 -9999 -9999 -9999 -9999 -9999 -9999 -9999 -9999 -9999

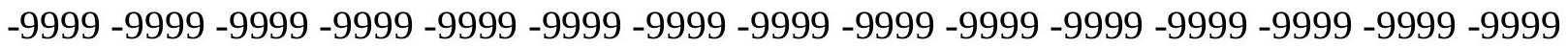

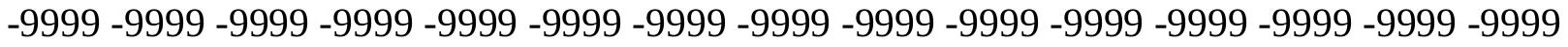
-9999 -9999 -9999 -9999 -9999 -9999 -9999 -9999 -9999 -9999 -9999 -9999 -9999 -9999 -9999 -9999 -9999 -9999 -9999 -9999 -9999 -9999 -9999 -9999 -9999 -9999 -9999 -9999 -9999 -9999 -9999 -9999 -9999 -9999 -9999 -9999 -9999 -9999 -9999 -9999 -9999 -9999 -9999 -9999 -9999 -9999 -9999 -9999 -9999 -9999 -9999 -9999 -9999 -9999 -9999 -9999 -9999 -9999 -9999 -9999 -

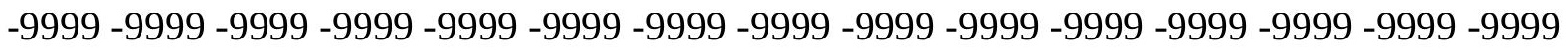
-9999 -9999 -9999 -9999 -9999 -9999 -9999 -9999 -9999 -9999 -9999 -9999 -9999 -9999 -9999 -

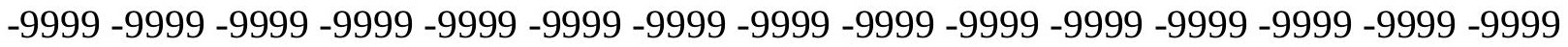
-9999 -9999 -9999 -9999 -9999 -9999 -9999 -9999 -9999 -9999 -9999 -9999 -9999 -9999 -9999 -9999 -9999 -9999 -9999 -9999 -9999 -9999 -9999 -9999 -9999 -9999 -9999 -9999 -9999 -9999 -9999 -9999 -9999 -9999 -9999 -9999 -9999 -9999 -9999 -9999 -9999 -9999 -9999 -9999 -9999 -

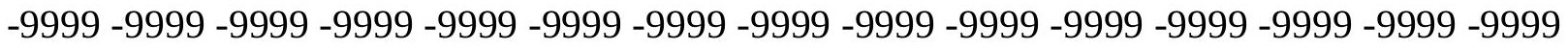
-9999 -9999 -9999 -9999 -9999 -9999 -9999 -9999 -9999 -9999 -9999 -9999 -9999 -9999 -9999

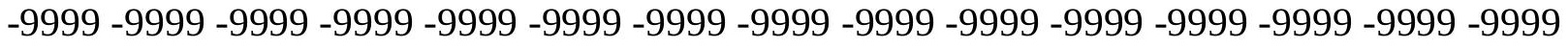
-9999 -9999 -9999 -9999 -9999 -9999 -9999 -9999 -9999 -9999 -9999 -9999 -9999 -9999 -9999 -9999 -9999 -9999 -9999 -9999 -9999 -9999 -9999 -9999 -9999 -9999 -9999 -9999 -9999 -9999 -9999 -9999 -9999 -9999 -9999 -9999 -9999 -9999 -9999 -9999 -9999 -9999 -9999 -9999 -9999 -9999 -9999 -9999 -9999 -9999 -9999 -9999 -9999 -9999 -9999 -9999 -9999 -9999 -9999 -9999 -9999 -9999 -9999 -9999 -9999 -9999 -9999 -9999 -9999 -9999 -9999 -9999 -9999 -9999 -9999 -9999 -9999 -9999 -9999 -9999 -9999 -9999 -9999 -9999 -9999 -9999 -9999 -9999 -9999 -9999 -9999 -9999 -9999 -9999 -9999 -9999 -9999 -9999 -9999 -9999 -9999 -9999 -9999 -9999 -9999 -9999 -9999 -9999 -9999 -9999 -9999 -9999 -9999 -9999 -9999 -9999 -9999 -9999 -9999 -9999 -9999 -9999 -9999 -9999 -9999 -9999 -9999 -9999 -9999 -9999 -9999 -9999 -9999 -9999 -9999 -9999 -9999 -9999 -9999 -9999 -9999 -9999 -9999 -9999 -9999 -9999 -9999 -9999 -9999 -

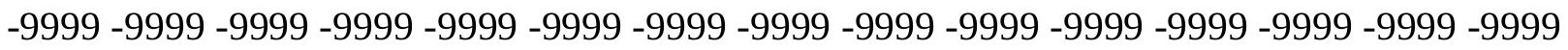

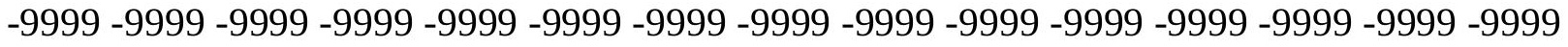
-9999 -9999 -9999 -9999 -9999 -9999 -9999 -9999 -9999 -9999 -9999 -9999 -9999 -9999 -9999 -

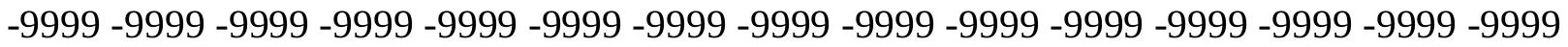

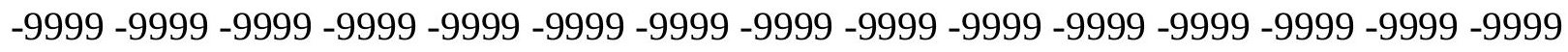

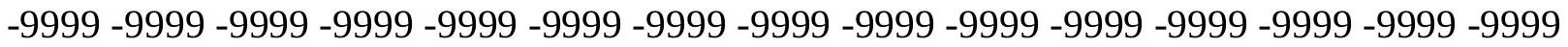

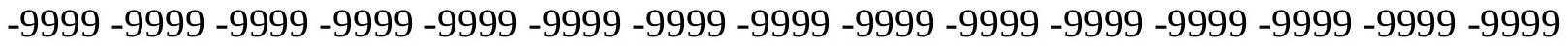
-9999 -9999 -9999 -9999 -9999 -9999 -9999 -9999 -9999 -9999 -9999 -9999 -9999 -9999 -9999 -

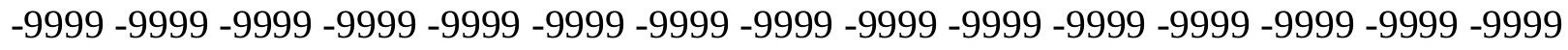

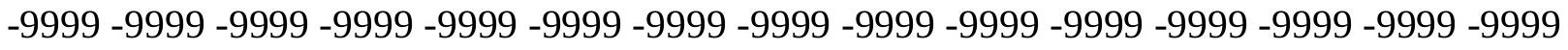
-9999 -9999 -9999 -9999 -9999 -9999 -9999 -9999 -9999 -9999 -9999 -9999 -9999 -9999 -9999 -9999 -9999 -9999 -9999 -9999 -9999 -9999 -9999 -9999-9999 -9999 -9999 -9999 -9999 -9999 -9999 -9999 -9999 -9999 -9999 -9999 -9999 -9999 -9999 -9999 -9999 -9999 -9999 -9999 -9999 -

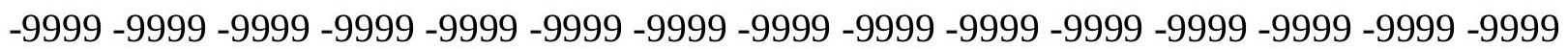


-9999 -9999 -9999 -9999 -9999 -9999 -9999 -9999 -9999 -9999 -9999 -9999 -9999 -9999 -9999 -9999 -9999 -9999 -9999 -9999 -9999 -9999 -9999 -9999 -9999 -9999 -9999 -9999 -9999 -9999 -9999 -9999 -9999 -9999 -9999 -9999 -9999 -9999 -9999 -9999 -9999 -9999 -9999 -9999 - 9999 -9999 -9999 -9999 -9999 -9999 -9999 -9999 -9999 -9999 -9999 -9999 -9999 -9999 -9999 -9999 -9999 -9999 -9999 -9999 -9999 -9999 -9999 -9999 -9999 -9999 -9999 -9999 -9999 -9999 -9999 -9999 -9999 -9999 -9999 -9999 -9999 -9999 -9999 -9999 -9999 -9999 -9999 -9999 -9999 -9999 -9999 -9999 -9999 -9999 -9999 -9999 -9999 -9999 -9999 -9999 -9999 -9999 -9999 -9999 -9999

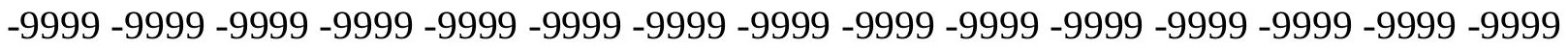

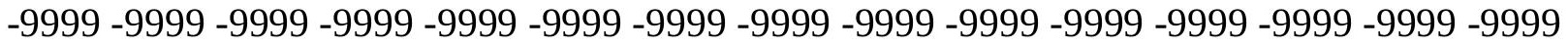
-9999 -9999 -9999 -9999 -9999 -9999 -9999 -9999 -9999 -9999 -9999 -9999 -9999 -9999 -9999 -9999 -9999 -9999 -9999 -9999 -9999 -9999 -9999 -9999 -9999 -9999 -9999 -9999 -9999 -9999 -9999 -9999 -9999 -9999 -9999 -9999 -9999 -9999 -9999 -9999 -9999 -9999 -9999 -9999 -9999 -9999 -9999 -9999 -9999 -9999 -9999 -9999 -9999 -9999 -9999 -9999 -9999 -9999 -9999 -9999 -9999 -9999 -9999 -9999 -9999 -9999 -9999 -9999 -9999 -9999 -9999 -9999 -9999 -9999 -9999 -9999 -9999 -9999 -9999 -9999 -9999 -9999 -9999 -9999 -9999 -9999 -9999 -9999 -9999 -

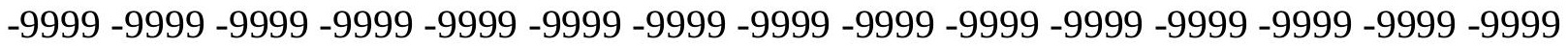
-9999 -9999 -9999 -9999 -9999 -9999 -9999 -9999 -9999 -9999 -9999 -9999 -9999 -9999 -9999 -9999 -9999 -9999 -9999 -9999 -9999 -9999 -9999 -9999 -9999 -9999 -9999 -9999 -9999 -9999 -9999 -9999 -9999 -9999 -9999 -9999 -9999 -9999 -9999 -9999 -9999 -9999 -9999 -9999 -9999 -9999 -9999 -9999 -9999 -9999 -9999 -9999 -9999 -9999 -9999 -9999 -9999 -9999 -9999 -9999 -9999 -9999 -9999 -9999 -9999 -9999 -9999 -9999 -9999 -9999 -9999 -9999 -9999 -9999 -9999 -999 -9999 -9999 -9999 -9999 -9999 -9999 -9999 -9999 -9999 -9999 -9999 -9999 -9999 -9999 -9999 -9999 -9999 -9999 -9999 -9999 -9999 -9999 -9999 -9999 -9999 -9999 -9999 -9999 -9999 -9999 -9999 -9999 -9999 -9999 -9999 -9999 -9999 -9999 -9999 -9999 -9999 -9999 -9999 -9999 -9999 -9999 -9999 -9999 -9999 -9999 -9999 -9999 -9999 -9999 -9999 -9999 -9999 -9999 -9999 -9999 -9999 -9999 -9999 -9999 -9999 -9999 -9999 -9999 -9999 -9999 -9999 -9999 -9999 -9999 -9999 -9999 -9999 -9999 -9999 -9999 -9999 -9999 -9999 -9999 -9999 -9999 -9999 -9999 -9999 -9999 -9999 -9999 -9999 -9999 -9999 -9999 -9999 -9999 -9999 -9999 -9999 -9999 -9999 -9999 -9999 -9999 -9999 -9999 -9999 -9999 -9999 -9999 -9999 -9999 -9999 -9999 -9999 -9999 -9999 -9999 -9999 -9999 -9999 -9999 -9999 -9999 -9999 -9999 -9999 -9999 -9999 -9999 -9999 -9999 -999 -9999 -9999 -9999 -9999 -9999 -9999 -9999 -9999 -9999 -9999 -9999 -9999 -9999 -9999 -9999 -9999 -9999 -9999 -9999 -9999 -9999 -9999 -9999 -9999 -9999 -9999 -9999 -9999 -9999 -9999 -

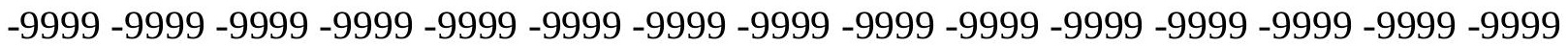

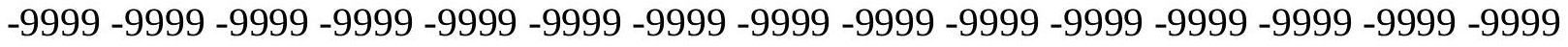

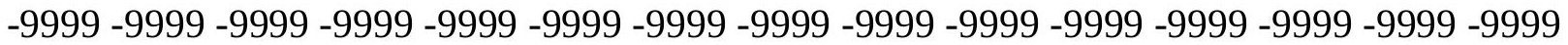
-9999 -9999 -9999 -9999 -9999 -9999 -9999 -9999 -9999 -9999 -9999 -9999 -9999 -9999 -9999 -9999 -9999 -9999 -9999 -9999 -9999 -9999 -9999 -9999 -9999 -9999 -9999 -9999 -9999 -

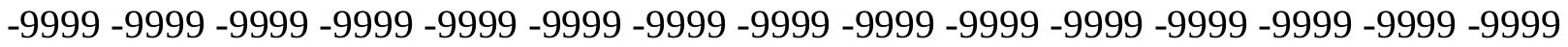
-9999 -9999 -9999 -9999 -9999 -9999 -9999 -9999 -9999 -9999 -9999 -9999 -9999 -9999 -9999 -9999 -9999 -9999 -9999 -9999 -9999 -9999 -9999 -9999 -9999 -9999 -9999 -9999 -9999 -9999 -

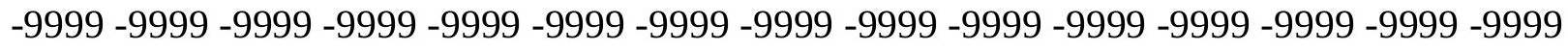

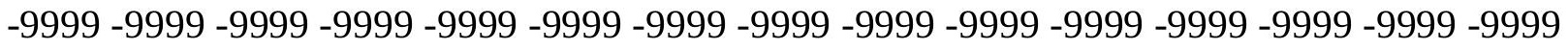
-9999 -9999 -9999 -9999 -9999 -9999 -9999 -9999 -9999 -9999 -9999 -9999 -9999 -9999 -9999 -9999 -9999 -9999 -9999 -9999 -9999 -9999 -9999 -9999-9999 -9999 -9999 -9999 -9999 -9999 -9999 -9999 -9999 -9999 -9999 -9999 -9999 -9999 -9999 -9999 -9999 -9999 -9999 -9999 -9999 -

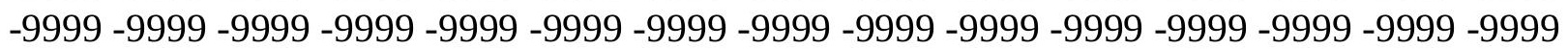


-9999 -9999 -9999 -9999 -9999 -9999 -9999 -9999 -9999 -9999 -9999 -9999 -9999 -9999 -9999 -9999 -9999 -9999 -9999 -9999 -9999 -9999 -9999 -9999 -9999 -9999 -9999 -9999 -9999 -9999 -

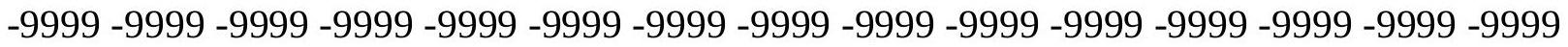
-9999 -9999 -9999 -9999 -9999 -9999 -9999 -9999 -9999 -9999 -9999 -9999 -9999 -9999 -9999 -9999 -9999 -9999 -9999 -9999 -9999 -9999 -9999 -9999-9999 -9999 -9999 -9999 -9999 -9999 -9999 -9999 -9999 -9999 -9999 -9999 -9999 -9999 -9999 -9999 -9999 -9999 -9999 -9999 -9999 -9999 -9999 -9999 -9999 -9999 -9999 -9999 -9999 -9999 -9999 -9999 -9999 -9999 -9999 -9999

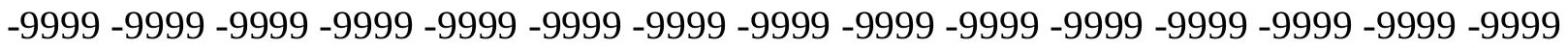

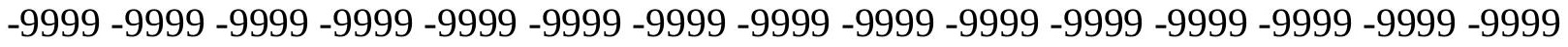
-9999 -9999 -9999 -9999 -9999 -9999 -9999 -9999 -9999 -9999 -9999 -9999 -9999 -9999 -9999 -9999 -9999 -9999 -9999 -9999 -9999 -9999 -9999 -9999 -9999 -9999 -9999 -9999 -9999 -9999 -9999 -9999 -9999 -9999 -9999 -9999 -9999 -9999 -9999 -9999 -9999 -9999 -9999 -9999 -9999 -9999 -9999 -9999 -9999 -9999 -9999 -9999 -9999 -9999 -9999 -9999 -9999 -9999 -9999 -9999 -9999 -9999 -9999 -9999 -9999 -9999 -9999 -9999 -9999 -9999 -9999 -9999 -9999 -9999 -9999 -9999 -9999 -9999 -9999 -9999 -9999 -9999 -9999 -9999 -9999 -9999 -9999 -9999 -9999 -9999 -

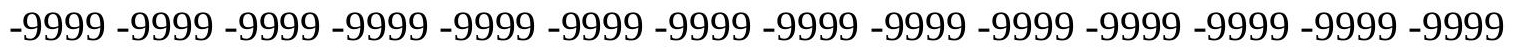
-9999 -9999 -9999 -9999 -9999 -9999 -9999 -9999 -9999 -9999 -9999 -9999 -9999 -9999 -9999 -9999 -9999 -9999 -9999 -9999 -9999 -9999 -9999 -9999 -9999 -9999 -9999 -9999 -9999 -9999 -9999 -9999 -9999 -9999 -9999 -9999 -9999 -9999 -9999 -9999 -9999 -9999 -9999 -9999 -9999 -

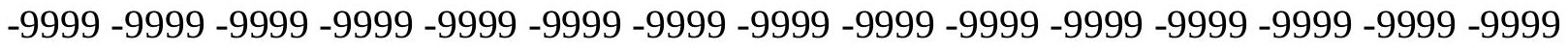

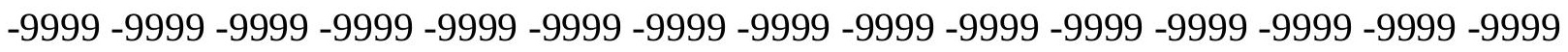
-9999 -9999 -9999 -9999 -9999 -9999 -9999 -9999 -9999 -9999 -9999 -9999 -9999 -9999 - 9999 -9999 -9999 -9999 -9999 -9999 -9999 -9999 -9999 -9999 -9999 -9999 -9999 -9999 -9999 -9999 -9999 -9999 -9999 -9999 -9999 -9999 -9999 -9999 -9999 -9999 -9999 -9999 -9999 -9999 -9999 -

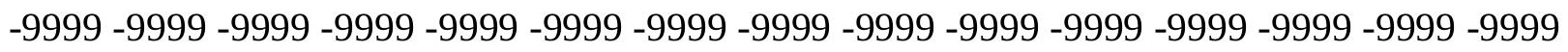
-9999 -9999 -9999 -9999 -9999 -9999 -9999 -9999 -9999 -9999 -9999 -9999 -9999 -9999 -9999 -9999 -9999 -9999 -9999 -9999 -9999 -9999 -9999 -9999 -9999 -9999 -9999 -9999 -9999 -9999 -

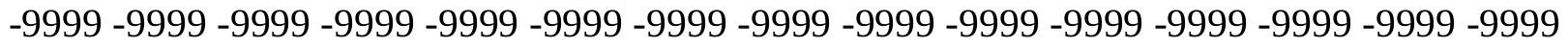
-9999 -9999 -9999 -9999 -9999 -9999 -9999 -9999 -9999 -9999 -9999 -9999 -9999 -9999 -9999 -9999 -9999 -9999 -9999 -9999 -9999 -9999 -9999 -9999 -9999 -9999 -9999 -9999 -9999 -999 -

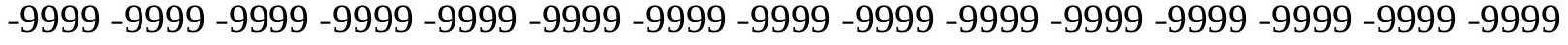
-9999 -9999 -9999 -9999 -9999 -9999 -9999 -9999 -9999 -9999 -9999 -9999 -9999 -9999 -9999 -

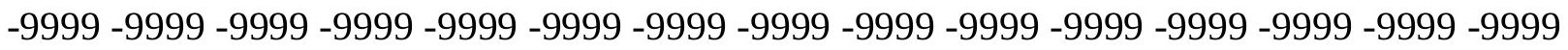

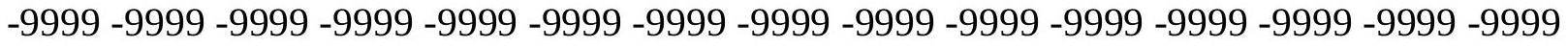

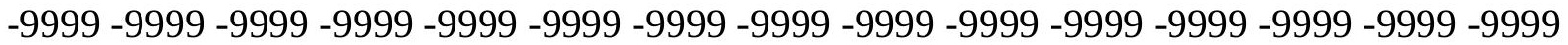
-9999 -9999 -9999 -9999 -9999 -9999 -9999 -9999 -9999 -9999 -9999 -9999 -9999 -9999 -9999 -

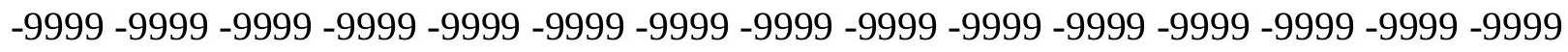

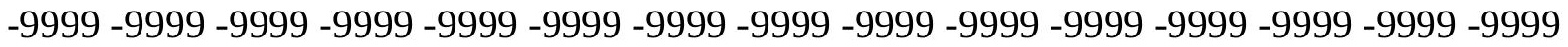
-9999 -9999 -9999 -9999 -9999 -9999 -9999 -9999 -9999 -9999 -9999 -9999 -9999 - 9999 - -999 -9999 -9999 -9999 -9999 -9999 -9999 -9999 -9999 -9999 -9999 -9999 -9999 -9999 -9999 -9999 -

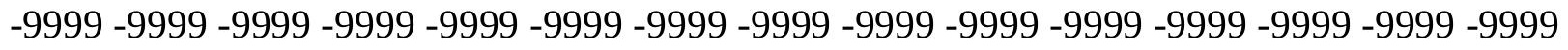

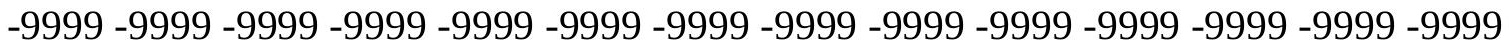
-9999 -9999 -9999 -9999 -9999 -9999 -9999 -9999 -9999 -9999 -9999 -9999 -9999 -9999 -9999 -9999 -9999 -9999 -9999 -9999 -9999 -9999 -9999 -9999-9999 -9999 -9999 -9999 -9999 -9999 -9999 -9999 -9999 -9999 -9999 -9999 -9999 -9999 -9999 -9999 -9999 -9999 -9999 -9999 -9999 -

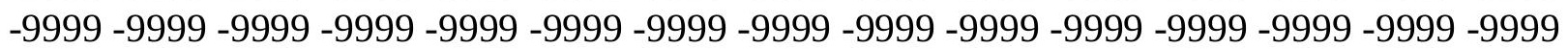


-9999 -9999 -9999 -9999 -9999 -9999 -9999 -9999 -9999 -9999 -9999 -9999 -9999 -9999 -9999 -9999 -9999 -9999 -9999 -9999 -9999 -9999 -9999 -9999 -9999 -9999 -9999 -9999 -9999 -9999 -

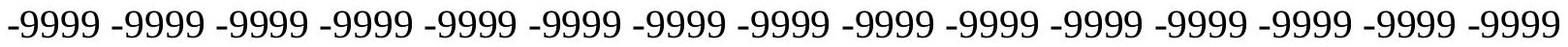
-9999 -9999 -9999 -9999 -9999 -9999 -9999 -9999 -9999 -9999 -9999 -9999 -9999 -9999 -9999 -9999 -9999 -9999 -9999 -9999 -9999 -9999 -9999 -9999-9999 -9999 -9999 -9999 -9999 -9999 -9999 -9999 -9999 -9999 -9999 -9999 -9999 -9999 -9999 -9999 -9999 -9999 -9999 -9999 -9999 -9999 -9999 -9999 -9999 -9999 -9999 -9999 -9999 -9999 -9999 -9999 -9999 -9999 -9999 -9999

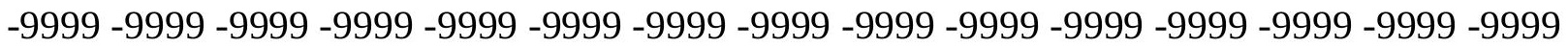

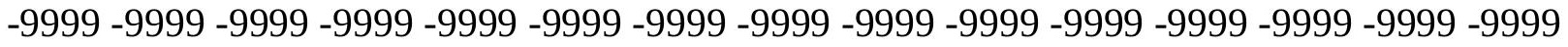
-9999 -9999 -9999 -9999 -9999 -9999 -9999 -9999 -9999 -9999 -9999 -9999 -9999 -9999 -9999 -9999 -9999 -9999 -9999 -9999 -9999 -9999 -9999 -9999 -9999 -9999 -9999 -9999 -9999 -9999 -9999 -9999 -9999 -9999 -9999 -9999 -9999 -9999 -9999 -9999 -9999 -9999 -9999 -9999 -9999 -9999 -9999 -9999 -9999 -9999 -9999 -9999 -9999 -9999 -9999 -9999 -9999 -9999 -9999 -9999 -

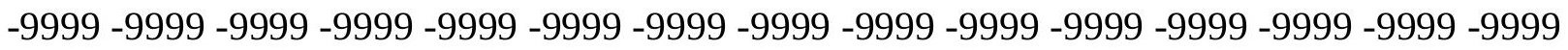
-9999 -9999 -9999 -9999 -9999 -9999 -9999 -9999 -9999 -9999 -9999 -9999 -9999 -9999 -9999 -

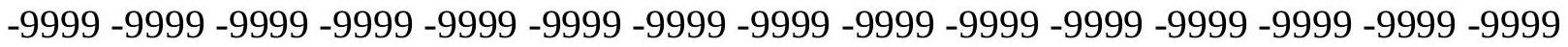
-9999 -9999 -9999 -9999 -9999 -9999 -9999 -9999 -9999 -9999 -9999 -9999 -9999 -9999 -9999 -9999 -9999 -9999 -9999 -9999 -9999 -9999 -9999 -9999 -9999 -9999 -9999 -9999 -9999 -9999 -9999 -9999 -9999 -9999 -9999 -9999 -9999 -9999 -9999 -9999 -9999 -9999 -9999 -9999 -9999 -

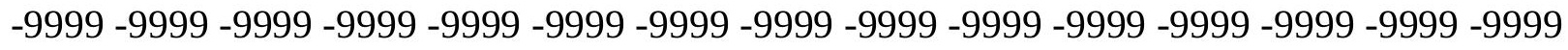

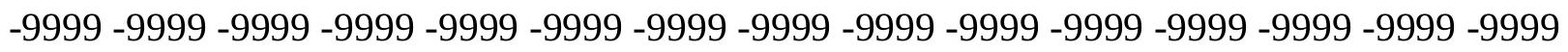
-9999 -9999 -9999 -9999 -9999 -9999 -9999 -9999 -9999 -9999 -9999 -9999 -9999 -9999 -9999 -9999 -9999 -9999 -9999 -9999 -9999 -9999 -9999 -9999 -9999 -9999 -9999 -9999 -9999 -9999 -9999 -9999 -9999 -9999 -9999 -9999 -9999 -9999 -9999 -9999 -9999 -9999 -9999 -9999 -

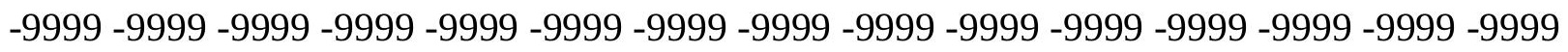
-9999 -9999 -9999 -9999 -9999 -9999 -9999 -9999 -9999 -9999 -9999 -9999 -9999 -9999 -9999 -9999 -9999 -9999 -9999 -9999 -9999 -9999 -9999 -9999 -9999 -9999 -9999 -9999 -9999 -9999 -

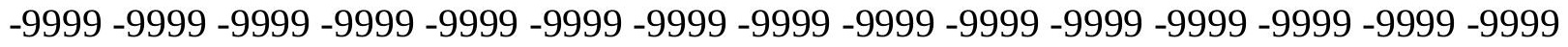
-9999 -9999 -9999 -9999 -9999 -9999 -9999 -9999 -9999 -9999 -9999 -9999 -9999 -9999 -9999 -9999 -9999 -9999 -9999 -9999 -9999 -9999 -9999 -9999 -9999 -9999 -9999 -9999 -9999 -999 -

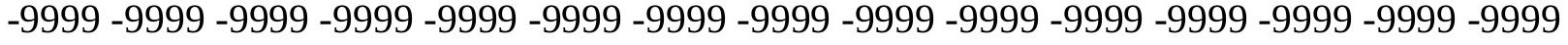
-9999 -9999 -9999 -9999 -9999 -9999 -9999 -9999 -9999 -9999 -9999 -9999 -9999 -9999 -9999 -

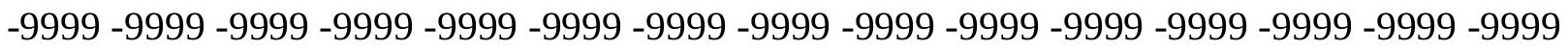

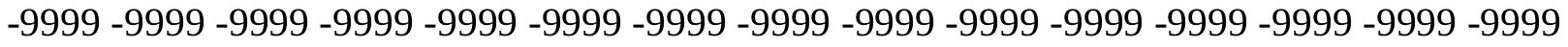

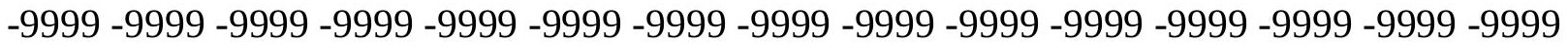

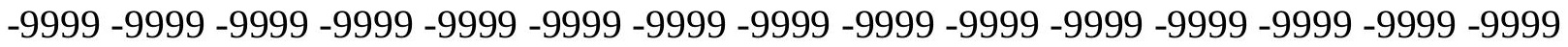

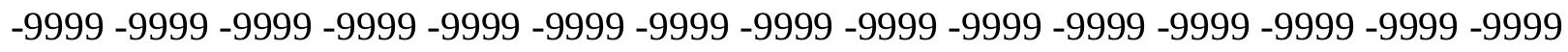

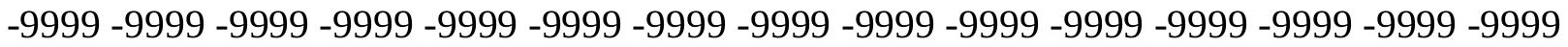

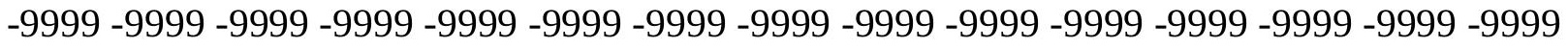
-9999 -9999 -9999 -9999 -9999 -9999 -9999 -9999 -9999 -9999 -9999 -9999 -9999 -9999 -9999 -

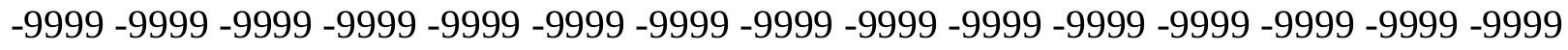

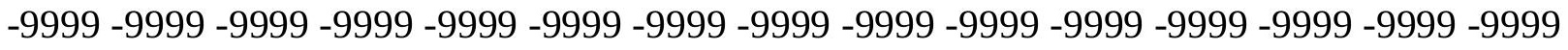
-9999 -9999 -9999 -9999 -9999 -9999 -9999 -9999 -9999 -9999 -9999 -9999 -9999 -9999 -9999 -9999 -9999 -9999 -9999 -9999 -9999 -9999 -9999 -9999-9999 -9999 -9999 -9999 -9999 -9999 -9999 -9999 -9999 -9999 -9999 -9999 -9999 -9999 -9999 -9999 -9999 -9999 -9999 -9999 -9999 -

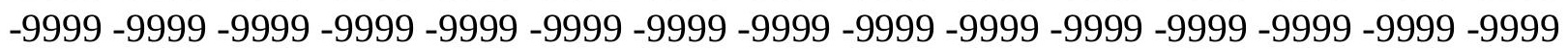


-9999 -9999 -9999 -9999 -9999 -9999 -9999 -9999 -9999 -9999 -9999 -9999 -9999 -9999 -9999 -9999 -9999 -9999 -9999 -9999 -9999 -9999 -9999 -9999 -9999 -9999 -9999 -9999 -9999 -

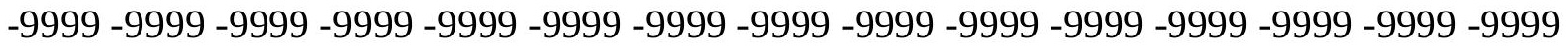
-9999 -9999 -9999 -9999 -9999 -9999 -9999 -9999 -9999 -9999 -9999 -9999 -9999 -9999 -9999 -9999 -9999 -9999 -9999 -9999 -9999 -9999 -9999 -9999 -9999 -9999 -9999 -9999 -9999 -9999 -9999 -9999 -9999 -9999 -9999 -9999 -9999 -9999 -9999 -9999 -9999 -9999 -9999 -9999 -9999 -9999 -9999 -9999 -9999 -9999 -9999 -9999 -9999 -9999 -9999 -9999 -9999 -9999 -9999 -9999

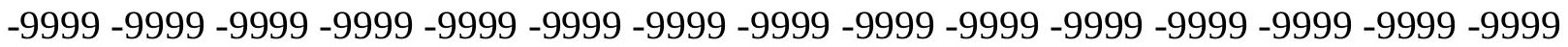

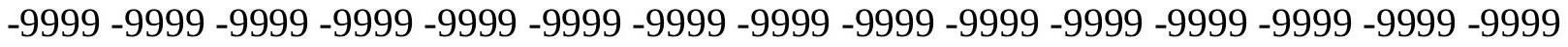
-9999 -9999 -9999 -9999 -9999 -9999 -9999 -9999 -9999 -9999 -9999 -9999 -9999 -9999 -9999 -9999 -9999 -9999 -9999 -9999 -9999 -9999 -9999 -9999 -9999 -9999 -9999 -9999 -9999 -9999 -9999 -9999 -9999 -9999 -9999 -9999 -9999 -9999 -9999 -9999 -9999 -9999 -9999 -9999 -9999 -9999 -9999 -9999 -9999 -9999 -9999 -9999 -9999 -9999 -9999 -9999 -9999 -9999 -9999 -9999 -9999 -9999 -9999 -9999 -9999 -9999 -9999 -9999 -9999 -9999 -9999 -9999 -9999 -9999 -9999 -9999 -9999 -9999 -9999 -9999 -9999 -9999 -9999 -9999 -9999 -9999 -9999 -9999 -9999 -9999 -

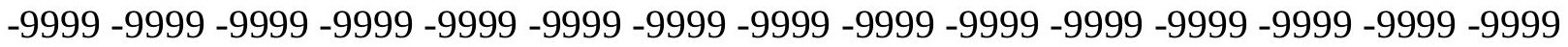
-9999 -9999 -9999 -9999 -9999 -9999 -9999 -9999 -9999 -9999 -9999 -9999 -9999 -9999 -9999 -9999 -9999 -9999 -9999 -9999 -9999 -9999 -9999 -9999 -9999 -9999 -9999 -9999 -9999 - 9999 -9999 -9999 -9999 -9999 -9999 -9999 -9999 -9999 -9999 -9999 -9999 -9999 -9999 -9999 -9999 -

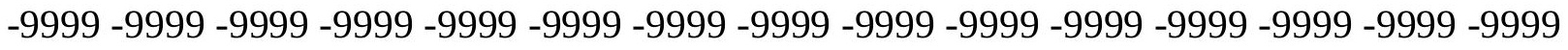

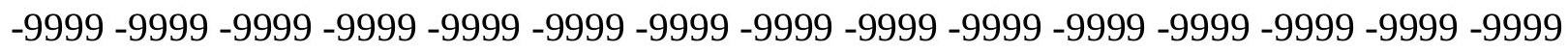

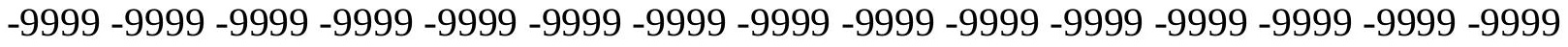
-9999 -9999 -9999 -9999 -9999 -9999 -9999 -9999 -9999 -9999 -9999 -9999 -9999 -9999 -9999 -9999 -9999 -9999 -9999 -9999 -9999 -9999 -9999 -9999 -9999 -9999 -9999 -9999 -9999 -9999 -

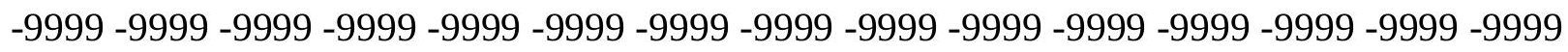
-9999 -9999 -9999 -9999 -9999 -9999 -9999 -9999 -9999 -9999 -9999 -9999 -9999 -9999 -9999 -9999 -9999 -9999 -9999 -9999 -9999 -9999 -9999 -9999 -9999 -9999 -9999 -9999 -9999 -9999 -9999 -9999 -9999 -9999 -9999 -9999 -9999 -9999 -9999 -9999 -9999 -9999 -9999 -9999 -9999 -9999 -9999 -9999 -9999 -9999 -9999 -9999 -9999 -9999 -9999 -9999 -9999 -9999 -9999 -9999 -9999 -9999 -9999 -9999 -9999 -9999 -9999 -9999 -9999 -9999 -9999 -9999 -9999 -999 -

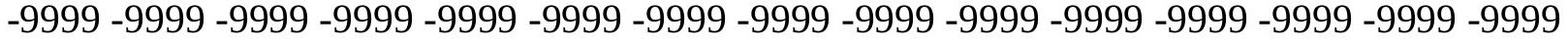
-9999 -9999 -9999 -9999 -9999 -9999 -9999 -9999 -9999 -9999 -9999 -9999 -9999 -9999 -9999 -

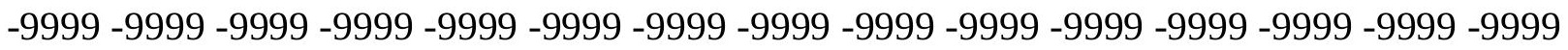

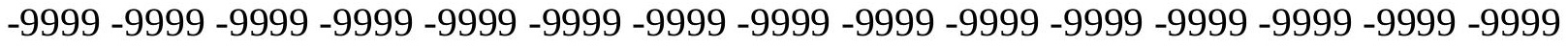

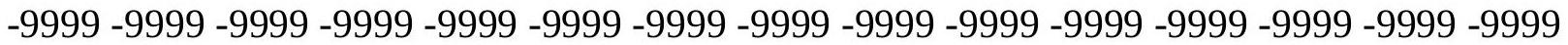

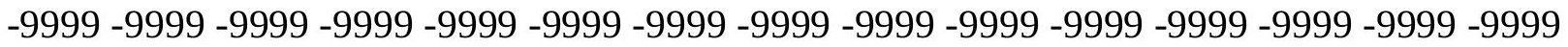

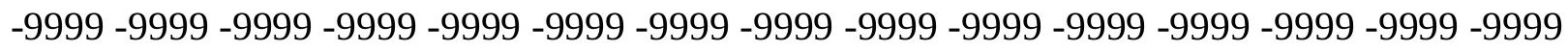

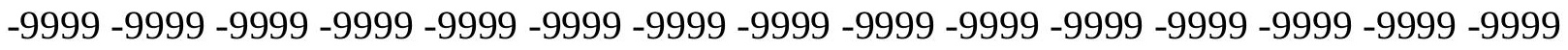

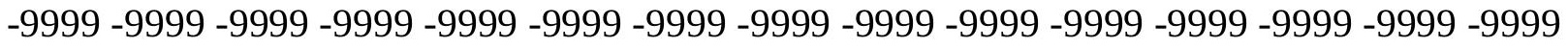
-9999 -9999 -9999 -9999 -9999 -9999 -9999 -9999 -9999 -9999 -9999 -9999 -9999 -9999 -9999 -

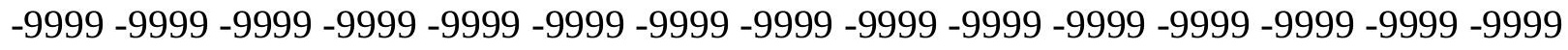

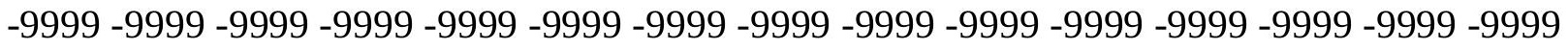
-9999 -9999 -9999 -9999 -9999 -9999 -9999 -9999 -9999 -9999 -9999 -9999 -9999 -9999 -9999 -9999 -9999 -9999 -9999 -9999 -9999 -9999 -9999 -9999-9999 -9999 -9999 -9999 -9999 -9999 -9999 -9999 -9999 -9999 -9999 -9999 -9999 -9999 -9999 -9999 -9999 -9999 -9999 -9999 -9999 -

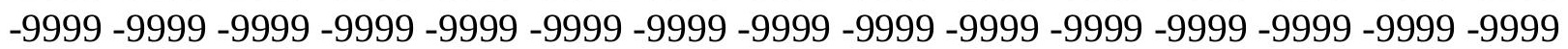


-9999 -9999 -9999 -9999 -9999 -9999 -9999 -9999 -9999 -9999 -9999 -9999 -9999 -9999 -9999 -9999 -9999 -9999 -9999 -9999 -9999 -9999 -9999 -9999 -9999 -9999 -9999 -9999 -9999 -9999 -

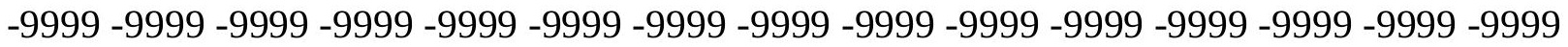
-9999 -9999 -9999 -9999 -9999 -9999 -9999 -9999 -9999 -9999 -9999 -9999 -9999 -9999 -9999 -9999 -9999 -9999 -9999 -9999 -9999 -9999 -9999 -9999-9999 -9999 -9999 -9999 -9999 -9999 -9999 -9999 -9999 -9999 -9999 -9999 -9999 -9999 -9999 -9999 -9999 -9999 -9999 -9999 -9999 -

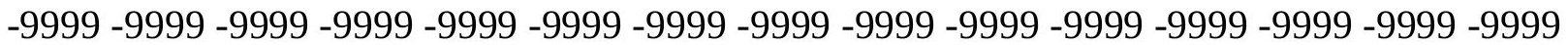
-9999 -9999 -9999 -9999 -9999 -9999 -9999 -9999 -9999 -9999 -9999 -9999 -9999 -9999 -9999 -9999 -9999 -9999 -9999 -9999 -9999 -9999 -9999 -9999 -9999 -9999 -9999 -9999 -9999 -9999 -9999 -9999 -9999 -9999 -9999 -9999 -9999 -9999 -9999 -9999 -9999 -9999 -9999 -9999 -9999 -9999 -9999 -9999 -9999 -9999 -9999 -9999 -9999 -9999 -9999 -9999 -9999 -9999 -9999 -9999 -9999 -9999 -9999 -9999 -9999 -9999 -9999 -9999 -9999 -9999 -9999 -9999 -9999 -9999 -9999 -9999 -9999 -9999 -9999 -9999 -9999 -9999 -9999 -9999 -9999 -9999 -9999 -9999 -9999 -9999 -9999 -9999 -9999 -9999 -9999 -9999 -9999 -9999 -9999 -9999 -9999 -9999 -9999 -9999 -9999 -9999 -9999 -9999 -9999 -9999 -9999 -9999 -9999 -9999 -9999 -9999 -9999 -9999 -9999 -

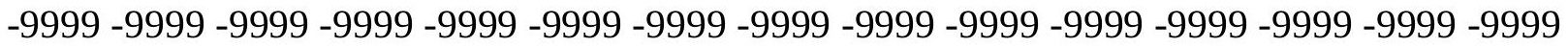
-9999 -9999 -9999 -9999 -9999 -9999 -9999 -9999 -9999 -9999 -9999 -9999 -9999 -9999 -9999 -9999 -9999 -9999 -9999 -9999 -9999 -9999 -9999 -9999 -9999 -9999 -9999 -9999 -9999 -9999 -9999 -9999 -9999 -9999 -9999 -9999 -9999 -9999 -9999 -9999 -9999 -9999 -9999 -9999 -9999 -

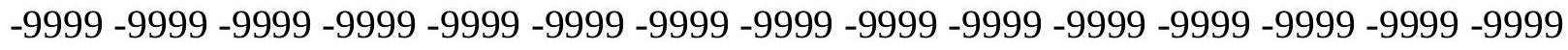

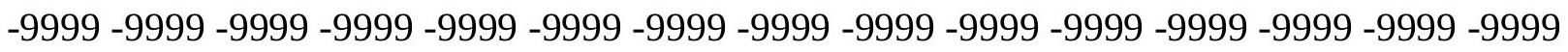
-9999 -9999 -9999 -9999 -9999 -9999 -9999 -9999 -9999 -9999 -9999 -9999 -9999 -9999 - 9999 -9999 -9999 -9999 -9999 -9999 -9999 -9999 -9999 -9999 -9999 -9999 -9999 -9999 -9999 -9999 -9999 -9999 -9999 -9999 -9999 -9999 -9999 -9999 -9999 -9999 -9999 -9999 -9999 -9999 -9999 -

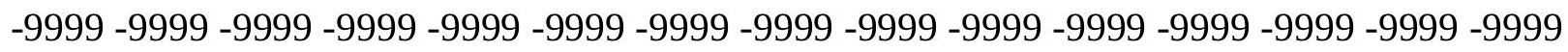
-9999 -9999 -9999 -9999 -9999 -9999 -9999 -9999 -9999 -9999 -9999 -9999 -9999 -9999 -9999 -9999 -9999 -9999 -9999 -9999 -9999 -9999 -9999 -9999 -9999 -9999 -9999 -9999 -9999 -9999 -

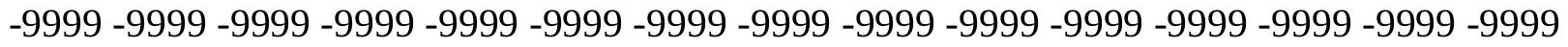
-9999 -9999 -9999 -9999 -9999 -9999 -9999 -9999 -9999 -9999 -9999 -9999 -9999 -9999 -9999 -9999 -9999 -9999 -9999 -9999 -9999 -9999 -9999 -9999 -9999 -9999 -9999 -9999 -9999 -999 -9999 -9999 -9999 -9999 -9999 -9999 -9999 -9999 -9999 -9999 -9999 -9999 -9999 -9999 -9999 -9999 -9999 -9999 -9999 -9999 -9999 -9999 -9999 -9999 -9999 -9999 -9999 -9999 -9999 -9999 -

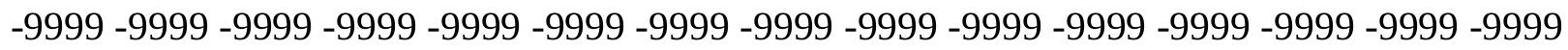

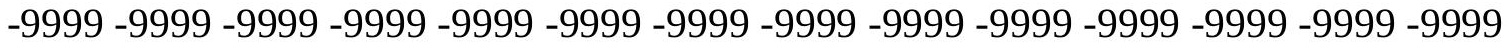
-9999 -9999 -9999 -9999 -9999 -9999 -9999 -9999 -9999 -9999 -9999 -9999 -9999 -9999 -9999

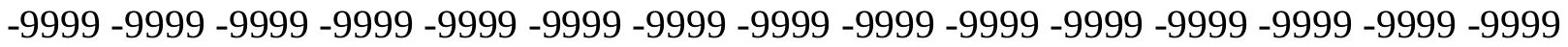

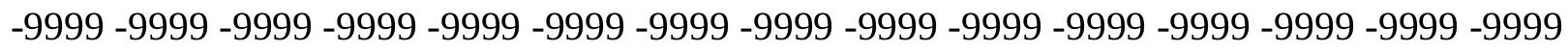

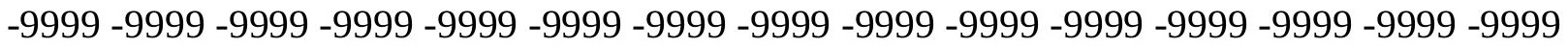

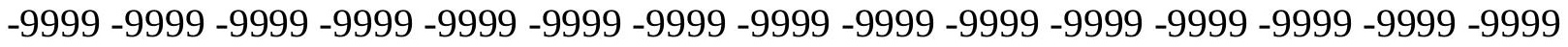
-9999 -9999 -9999 -9999 -9999 -9999 -9999 -9999 -9999 -9999 -9999 -9999 -9999 -9999 -9999 -

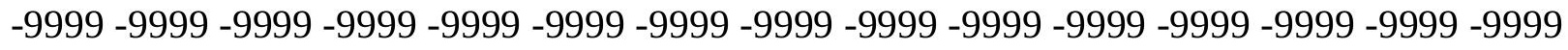

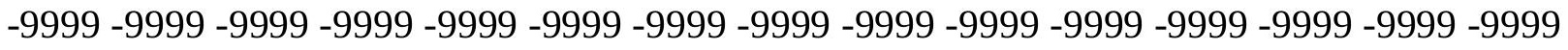
-9999 -9999 -9999 -9999 -9999 -9999 -9999 -9999 -9999 -9999 -9999 -9999 -9999 -9999 -9999 -9999 -9999 -9999 -9999 -9999 -9999 -9999 -9999 -9999-9999 -9999 -9999 -9999 -9999 -9999 -9999 -9999 -9999 -9999 -9999 -9999 -9999 -9999 -9999 -9999 -9999 -9999 -9999 -9999 -9999 -

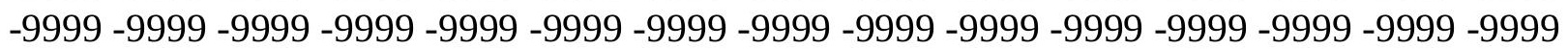


-9999 -9999 -9999 -9999 -9999 -9999 -9999 -9999 -9999 -9999 -9999 -9999 -9999 -9999 -9999 -9999 -9999 -9999 -9999 -9999 -9999 -9999 -9999 -9999 -9999 -9999 -9999 -9999 -9999 -9999 -

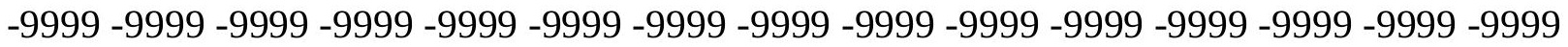
-9999 -9999 -9999 -9999 -9999 -9999 -9999 -9999 -9999 -9999 -9999 -9999 -9999 -9999 -9999 -9999 -9999 -9999 -9999 -9999 -9999 -9999 -9999 -9999-9999 -9999 -9999 -9999 -9999 -9999 -9999 -9999 -9999 -9999 -9999 -9999 -9999 -9999 -9999 -9999 -9999 -9999 -9999 -9999 -9999 -9999 -9999 -9999 -9999 -9999 -9999 -9999 -9999 -9999 -9999 -9999 -9999 -9999 -9999 -9999

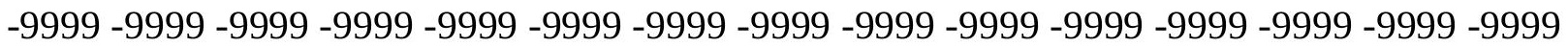

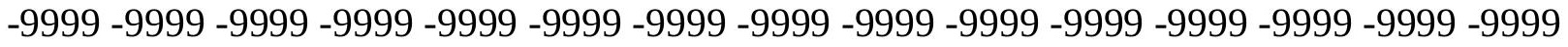
-9999 -9999 -9999 -9999 -9999 -9999 -9999 -9999 -9999 -9999 -9999 -9999 -9999 -9999 -9999 -9999 -9999 -9999 -9999 -9999 -9999 -9999 -9999 -9999 -9999 -9999 -9999 -9999 -9999 -9999 -9999 -9999 -9999 -9999 -9999 -9999 -9999 -9999 -9999 -9999 -9999 -9999 -9999 -9999 -9999 -9999 -9999 -9999 -9999 -9999 -9999 -9999 -9999 -9999 -9999 -9999 -9999 -9999 -9999 -9999 -9999 -9999 -9999 -9999 -9999 -9999 -9999 -9999 -9999 -9999 -9999 -9999 -9999 -9999 -9999 -9999 -9999 -9999 -9999 -9999 -9999 -9999 -9999 -9999 -9999 -9999 -9999 -9999 -9999

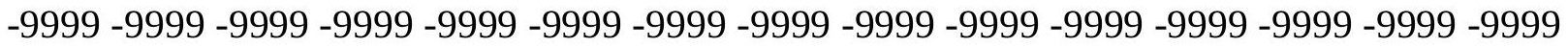
-9999 -9999 -9999 -9999 -9999 -9999 -9999 -9999 -9999 -9999 -9999 -9999 -9999 -9999 -9999 -9999 -9999 -9999 -9999 -9999 -9999 -9999 -9999 -9999 -9999 -9999 -9999 -9999 -9999 -9999 -9999 -9999 -9999 -9999 -9999 -9999 -9999 -9999 -9999 -9999 -9999 -9999 -9999 -9999 -9999 -

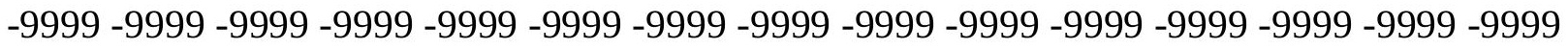

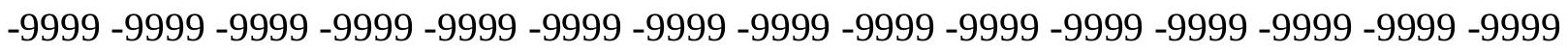
-9999 -9999 -9999 -9999 -9999 -9999 -9999 -9999 -9999 -9999 -9999 -9999 -9999 -9999 -9999 -9999 -9999 -9999 -9999 -9999 -9999 -9999 -9999 -9999 -9999 -9999 -9999 -9999 -9999 -9999 -9999 -9999 -9999 -9999 -9999 -9999 -9999 -9999 -9999 -9999 -9999 -9999 -9999 -9999 -9999 -

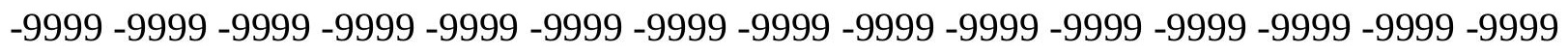
-9999 -9999 -9999 -9999 -9999 -9999 -9999 -9999 -9999 -9999 -9999 -9999 -9999 -9999 -9999 -9999 -9999 -9999 -9999 -9999 -9999 -9999 -9999 -9999 -9999 -9999 -9999 -9999 -9999 -9999 -

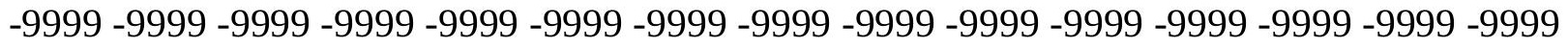
-9999 -9999 -9999 -9999 -9999 -9999 -9999 -9999 -9999 -9999 -9999 -9999 -9999 -9999 -9999 -9999 -9999 -9999 -9999 -9999 -9999 -9999 -9999 -9999 -9999 -9999 -9999 -9999 -9999 -999 -9999 -9999 -9999 -9999 -9999 -9999 -9999 -9999 -9999 -9999 -9999 -9999 -9999 -9999 -9999 -9999 -9999 -9999 -9999 -9999 -9999 -9999 -9999 -9999 -9999 -9999 -9999 -9999 -9999 -9999 -

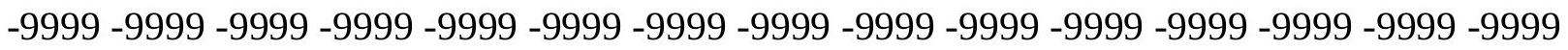

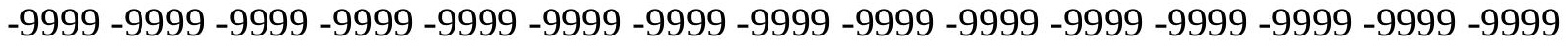

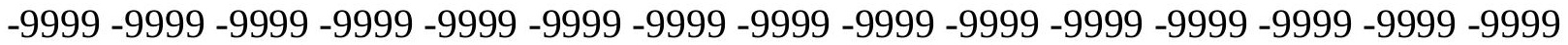

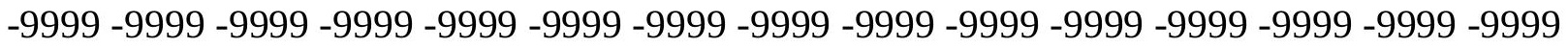

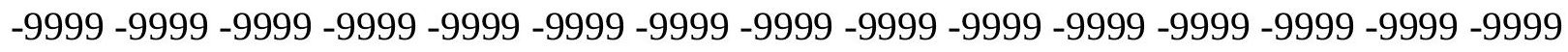

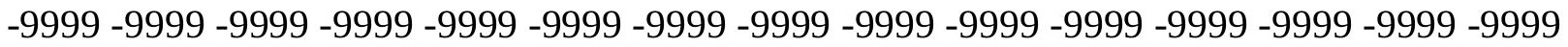
-9999 -9999 -9999 -9999 -9999 -9999 -9999 -9999 -9999 -9999 -9999 -9999 -9999 - 9999 - -999 -9999 -9999 -9999 -9999 -9999 -9999 -9999 -9999 -9999 -9999 -9999 -9999 -9999 -9999 - -999 -

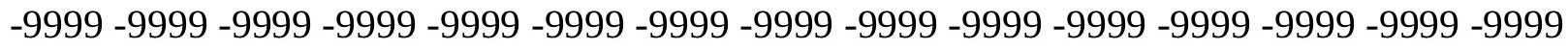

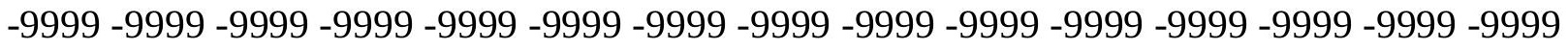
-9999 -9999 -9999 -9999 -9999 -9999 -9999 -9999 -9999 -9999 -9999 -9999 -9999 -9999 -9999 -9999 -9999 -9999 -9999 -9999 -9999 -9999 -9999 -9999-9999 -9999 -9999 -9999 -9999 -9999 -9999 -9999 -9999 -9999 -9999 -9999 -9999 -9999 -9999 -9999 -9999 -9999 -9999 -9999 -9999 -

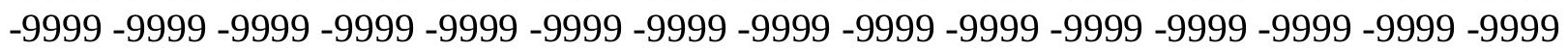


-9999 -9999 -9999 -9999 -9999 -9999 -9999 -9999 -9999 -9999 -9999 -9999 -9999 -9999 -9999 -9999 -9999 -9999 -9999 -9999 -9999 -9999 -9999 -9999 -9999 -9999 -9999 -9999 -9999 -9999 -9999 -9999 -9999 -9999 -9999 -9999 -9999 -9999 -9999 -9999 -9999 -9999 -9999 -9999 -9999 -9999 -9999 -9999 -9999 -9999 -9999 -9999 -9999 -9999 -9999 -9999 -9999 -9999 -9999 -9999 -9999 -9999 -9999 -9999 -9999 -9999 -9999 -9999 -9999 -9999 -9999 -9999 -9999 -9999 -9999 -9999 -9999 -9999 -9999 -9999 -9999 -9999 -9999 -9999 -9999 -9999 -9999 -9999 -9999 -9999 -9999 -9999 -9999 -9999 -9999 -9999 -9999 -9999 -9999 -9999 -9999 -9999 -9999 -9999 -9999 -

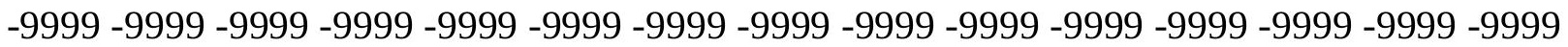
-9999 -9999 -9999 -9999 -9999 -9999 -9999 -9999 -9999 -9999 -9999 -9999 -9999 -9999 -9999 -9999 -9999 -9999 -9999 -9999 -9999 -9999 -9999 -9999 -9999 -9999 -9999 -9999 -9999 -9999 -

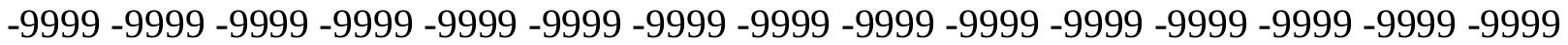
-9999 -9999 -9999 -9999 -9999 -9999 -9999 -9999 -9999 -9999 -9999 -9999 -9999 -9999 -9999 -9999 -9999 -9999 -9999 -9999 -9999 -9999 -9999 -9999 -9999 -9999 -9999 -9999 -9999 -9999 -9999 -9999 -9999 -9999 -9999 -9999 -9999 -9999 -9999 -9999 -9999 -9999 -9999 -9999 -9999 -9999 -9999 -9999 -9999 -9999 -9999 -9999 -9999 -9999 -9999 -9999 -9999 -9999 -9999 -9999

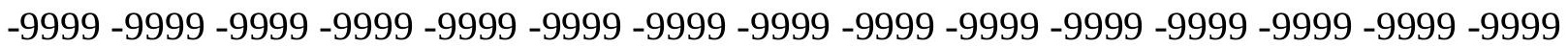
-9999 -9999 -9999 -9999 -9999 -9999 -9999 -9999 -9999 -9999 -9999 -9999 -9999 -9999 -9999 -9999 -9999 -9999 -9999 -9999 -9999 -9999 -9999 -9999 -9999 -9999 -9999 -9999 -9999 -9999 -9999 -9999 -9999 -9999 -9999 -9999 -9999 -9999 -9999 -9999 -9999 -9999 -9999 -9999 -9999 -9999 -9999 -9999 -9999 -9999 -9999 -9999 -9999 -9999 -9999 -9999 -9999 -9999 -9999 -9999 -9999 -9999 -9999 -9999 -9999 -9999 -9999 -9999 -9999 -9999 -9999 -9999 -9999 -9999 -9999 -9999 -9999 -9999 -9999 -9999 -9999 -9999 -9999 -9999 -9999 -9999 -9999 -9999 -9999 -9999 -9999 -9999 -9999 -9999 -9999 -9999 -9999 -9999 -9999 -9999 -9999 -9999 -9999 -9999 -9999 -9999 -9999 -9999 -9999 -9999 -9999 -9999 -9999 -9999 -9999 -9999 -9999 -9999 -9999 -9999 -9999 -9999 -9999 -9999 -9999 -9999 -9999 -9999 -9999 -9999 -9999 -9999 -9999 -9999 -9999 -9999 -9999 -9999 -9999 -9999 -9999 -9999 -9999 -9999 -9999 -9999 -9999 -9999 -9999 -9999 -9999 -9999 -9999 -9999 -9999 -9999 -9999 -9999 -9999 -9999 -9999 -9999 -9999 -9999 -9999 -9999 -9999 -9999 -9999 -9999 -9999 -9999 -9999 -9999 -9999 -9999 -9999 -9999 -9999

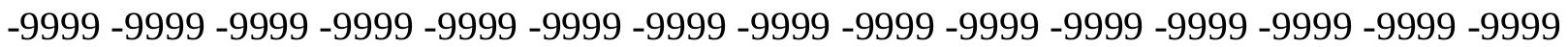
-9999 -9999 -9999 -9999 -9999 -9999 -9999 -9999 -9999 -9999 -9999 -9999 -9999 -9999 -9999 -9999 -9999 -9999 -9999 -9999 -9999 -9999 -9999 -9999 -9999 -9999 -9999 -9999 -9999 -9999 -

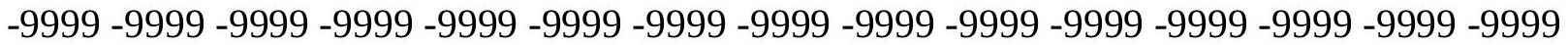
-9999 -9999 -9999 -9999 -9999 -9999 -9999 -9999 -9999 -9999 -9999 -9999 -9999 -9999 -9999 -9999 -9999 -9999 -9999 -9999 -9999 -9999 -9999 -9999 -9999 -9999 -9999 -9999 -9999 -9999 -9999 -9999 -9999 -9999 -9999 -9999 -9999 -9999 -9999 -9999 -9999 -9999 -9999 -9999 -9999 -9999 -9999 -9999 -9999 -9999 -9999 -9999 -9999 -9999 -9999 -9999 -9999 -9999 -9999 -9999 -9999 -9999 -9999 -9999 -9999 -9999 -9999 -9999 -9999 -9999 -9999 -9999 -9999 -9999 -9999

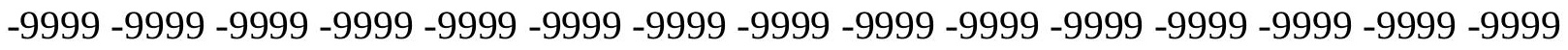
-9999 -9999 -9999 -9999 -9999 -9999 -9999 -9999 -9999 -9999 -9999 -9999 -9999 -9999 -9999 -9999 -9999 -9999 -9999 -9999 -9999 -9999 -9999 -9999 -9999 -9999 -9999 -9999 -9999 -9999 -9999 -9999 -9999 -9999 -9999 -9999 -9999 -9999 -9999 -9999 -9999 -9999 -9999 -9999 -9999 -999 -9999 -9999 -9999 -9999 -9999 -9999 -9999 -9999 -9999 -9999 -9999 -9999 -9999 -9999 -9999 -9999 -9999 -9999 -9999 -9999 -9999 -9999 -9999 -9999 -9999 -9999 -9999 -9999 -9999 -9999 -9999 -9999 -9999 -9999 -9999 -9999 -9999 -9999 -9999 -9999 -9999 -9999 -9999 -9999 -9999 -9999 -9999 -9999 -9999 -9999 -9999 -9999 -9999 -9999 -9999 -9999 -9999 -9999 -9999 -9999 -9999 -9999 -9999 -9999 -9999 -9999 -9999 -9999 -9999 -9999 -9999 -9999 -9999 -9999 
-9999 -9999 -9999 -9999 -9999 -9999 -9999 -9999 -9999 -9999 -9999 -9999 -9999 -9999 -9999 -9999 -9999 -9999 -9999 -9999 -9999 -9999 -9999 -9999 -9999 -9999 -9999 -9999 -9999 -9999 -

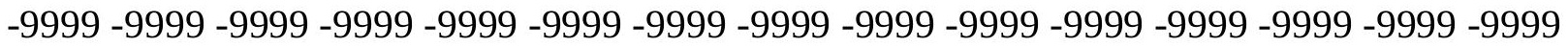
-9999 -9999 -9999 -9999 -9999 -9999 -9999 -9999 -9999 -9999 -9999 -9999 -9999 -9999 -9999 -9999 -9999 -9999 -9999 -9999 -9999 -9999 -9999 -9999-9999 -9999 -9999 -9999 -9999 -9999 -9999 -9999 -9999 -9999 -9999 -9999 -9999 -9999 -9999 -9999 -9999 -9999 -9999 -9999 -9999 -9999 -9999 -9999 -9999 -9999 -9999 -9999 -9999 -9999 -9999 -9999 -9999 -9999 -9999 -9999

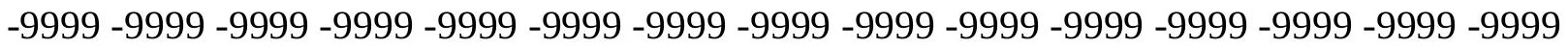

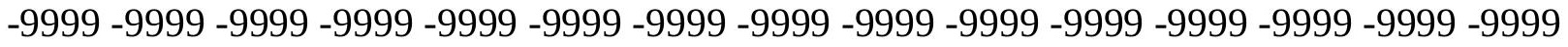
-9999 -9999 -9999 -9999 -9999 -9999 -9999 -9999 -9999 -9999 -9999 -9999 -9999 -9999 -9999 -9999 -9999 -9999 -9999 -9999 -9999 -9999 -9999 -9999 -9999 -9999 -9999 -9999 -9999 -9999 -9999 -9999 -9999 -9999 -9999 -9999 -9999 -9999 -9999 -9999 -9999 -9999 -9999 -9999 -9999 -9999 -9999 -9999 -9999 -9999 -9999 -9999 -9999 -9999 -9999 -9999 -9999 -9999 -9999 -9999 -

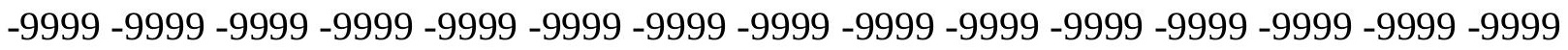
-9999 -9999 -9999 -9999 -9999 -9999 -9999 -9999 -9999 -9999 -9999 -9999 -9999 -9999 -9999 -

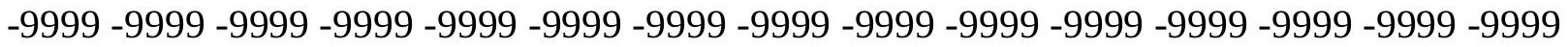
-9999 -9999 -9999 -9999 -9999 -9999 -9999 -9999 -9999 -9999 -9999 -9999 -9999 -9999 -9999 -9999 -9999 -9999 -9999 -9999 -9999 -9999 -9999 -9999 -9999 -9999 -9999 -9999 -9999 -9999 -9999 -9999 -9999 -9999 -9999 -9999 -9999 -9999 -9999 -9999 -9999 -9999 -9999 -9999 -9999 -

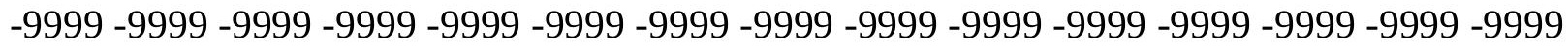

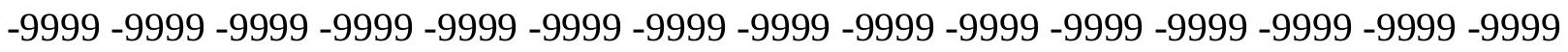

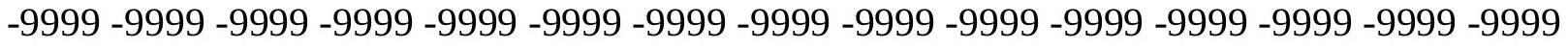
-9999 -9999 -9999 -9999 -9999 -9999 -9999 -9999 -9999 -9999 -9999 -9999 -9999 -9999 -9999 -9999 -9999 -9999 -9999 -9999 -9999 -9999 -9999 -9999 -9999 -9999 -9999 -9999 -9999 -9999 -

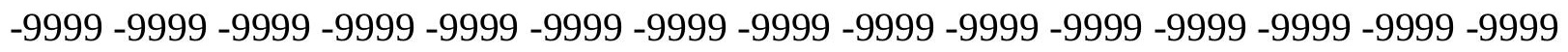
-9999 -9999 -9999 -9999 -9999 -9999 -9999 -9999 -9999 -9999 -9999 -9999 -9999 -9999 -9999 -9999 -9999 -9999 -9999 -9999 -9999 -9999 -9999 -9999 -9999 -9999 -9999 -9999 -9999 -

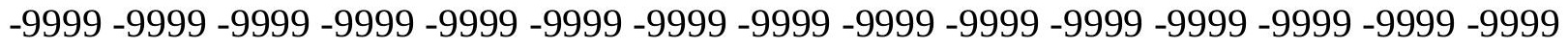
-9999 -9999 -9999 -9999 -9999 -9999 -9999 -9999 -9999 -9999 -9999 -9999 -9999 -9999 -9999 -9999 -9999 -9999 -9999 -9999 -9999 -9999 -9999 -9999 -9999 -9999 -9999 -9999 -9999 -999 -

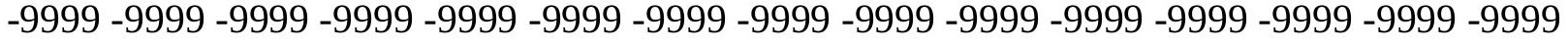
-9999 -9999 -9999 -9999 -9999 -9999 -9999 -9999 -9999 -9999 -9999 -9999 -9999 -9999 -9999 -

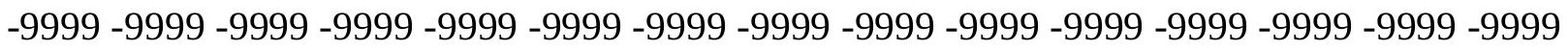

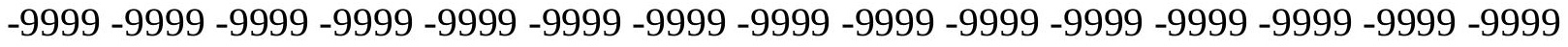

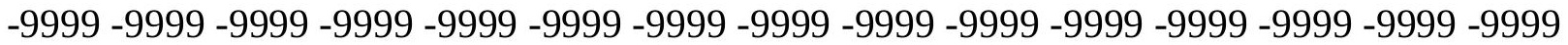
-9999 -9999 -9999 -9999 -9999 -9999 -9999 -9999 -9999 -9999 -9999 -9999 -9999 -9999 -9999

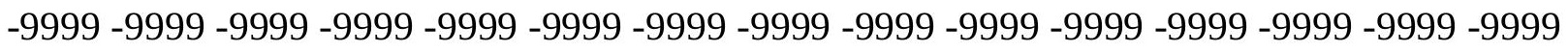

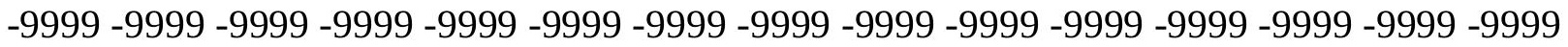
-9999 -9999 -9999 -9999 -9999 -9999 -9999 -9999 -9999 -9999 -9999 -9999 -9999 - 9999 - -999 -9999 -9999 -9999 -9999 -9999 -9999 -9999 -9999 -9999 -9999 -9999 -9999 -9999 -9999 -9999 -

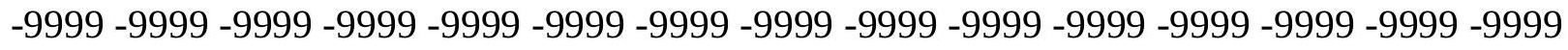

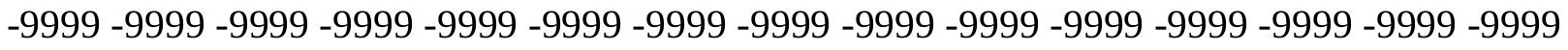
-9999 -9999 -9999 -9999 -9999 -9999 -9999 -9999 -9999 -9999 -9999 -9999 -9999 -9999 -9999 -9999 -9999 -9999 -9999 -9999 -9999 -9999 -9999 -9999-9999 -9999 -9999 -9999 -9999 -9999 -9999 -9999 -9999 -9999 -9999 -9999 -9999 -9999 -9999 -9999 -9999 -9999 -9999 -9999 -9999 -

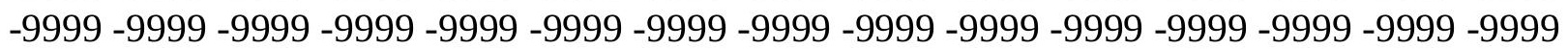


-9999 -9999 -9999 -9999 -9999 -9999 -9999 -9999 -9999 -9999 -9999 -9999 -9999 -9999 -9999 -9999 -9999 -9999 -9999 -9999 -9999 -9999 -9999 -9999 -9999 -9999 -9999 -9999 -9999 -9999 -9999 -9999 -9999 -9999 -9999 -9999 -9999 -9999 -9999 -9999 -9999 -9999 -9999 -9999 - 9999 -9999 -9999 -9999 -9999 -9999 -9999 -9999 -9999 -9999 -9999 -9999 -9999 -9999 -9999 -9999 -9999 -9999 -9999 -9999 -9999 -9999 -9999 -9999 -9999 -9999 -9999 -9999 -9999 -9999 - -9999 -9999 -9999 -9999 -9999 -9999 -9999 -9999 -9999 -9999 -9999 -9999 -9999 -9999 -9999 -9999 -9999 -9999 -9999 -9999 -9999 -9999 -9999 -9999 -9999 -9999 -9999 -9999 -9999 -9999

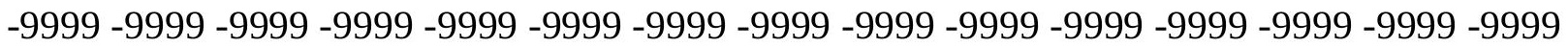

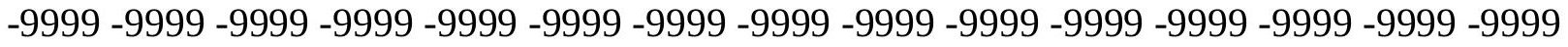
-9999 -9999 -9999 -9999 -9999 -9999 -9999 -9999 -9999 -9999 -9999 -9999 -9999 -9999 -9999

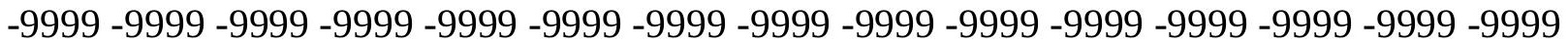
-9999 -9999 -9999 -9999 -9999 -9999 -9999 -9999 -9999 -9999 -9999 -9999 -9999 -9999 -9999 -9999 -9999 -9999 -9999 -9999 -9999 -9999 -9999 -9999 -9999 -9999 -9999 -9999 -9999 -9999 -9999 -9999 -9999 -9999 -9999 -9999 -9999 -9999 -9999 -9999 -9999 -9999 -9999 -9999 - -9999 -9999 -9999 -9999 -9999 -9999 -9999 -9999 -9999 -9999 -9999 -9999 -9999 -9999 -9999 -9999

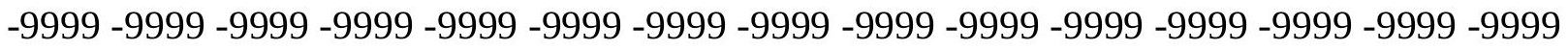
-9999 -9999 -9999 -9999 -9999 -9999 -9999 -9999 -9999 -9999 -9999 -9999 -9999 -9999 -9999 -9999 -9999 -9999 -9999 -9999 -9999 -9999 -9999 -9999 -9999 -9999 -9999 -9999 -9999 -9999 -9999 -9999 -9999 -9999 -9999 -9999 -9999 -9999 -9999 -9999 -9999 -9999 -9999 -9999 -9999 -

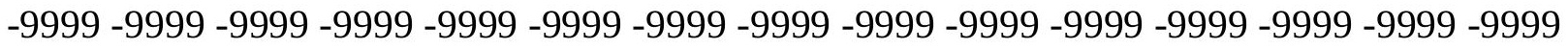
-9999 -9999 -9999 -9999 -9999 -9999 -9999 -9999 -9999 -9999 -9999 -9999 -9999 -9999 -9999 -999 -9999 -9999 -9999 -9999 -9999 -9999 -9999 -9999 -9999 -9999 -9999 -9999 -9999 -9999 -9999 -9999 -9999 -9999 -9999 -9999 -9999 -9999 -9999 -9999 -9999 -9999 -9999 -9999 -9999 -9999 -9999 -9999 -9999 -9999 -9999 -9999 -9999 -9999 -9999 -9999 -9999 -9999 -9999 -9999 -9999 -9999 -9999 -9999 -9999 -9999 -9999 -9999 -9999 -9999 -9999 -9999 -9999 -9999 -9999 -9999 -9999 -9999 -9999 -9999 -9999 -9999 -9999 -9999 -9999 -9999 -9999 -9999 -9999 -9999 -9999 -9999 -9999 -9999 -9999 -9999 -9999 -9999 -9999 -9999 -9999 -9999 -9999 -9999 -9999 -9999 -9999 -9999 -9999 -9999 -9999 -9999 -9999 -9999 -9999 -9999 -9999 -9999 -9999 -9999 -9999 -9999 -9999 -9999 -9999 -9999 -9999 -9999 -9999 -9999 -9999 -9999 -9999 -9999 -9999 -9999 -9999 -9999 -9999 -9999 -9999 -9999 -9999 -9999 -9999 -9999 -9999 -9999 -9999 -9999 -999 -9999 -9999 -9999 -9999 -9999 -9999 -9999 -9999 -9999 -9999 -9999 -9999 -9999 -9999 -9999 -9999 -9999 -9999 -9999 -9999 -9999 -9999 -9999 -9999 -9999 -9999 -9999 -9999 -9999 -

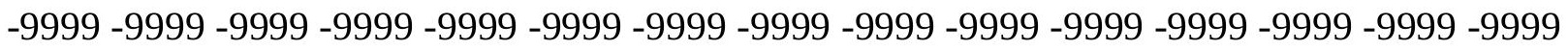

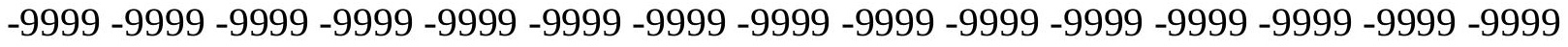

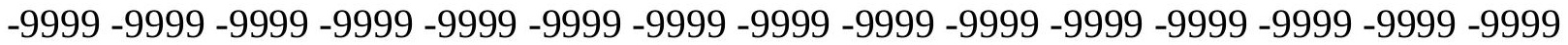
-9999 -9999 -9999 -9999 -9999 -9999 -9999 -9999 -9999 -9999 -9999 -9999 -9999 -9999 -9999 -

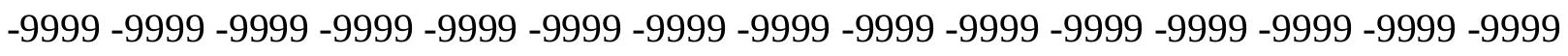

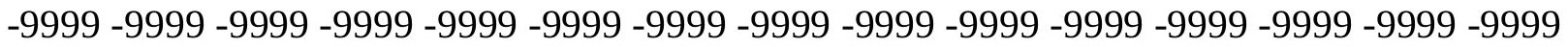

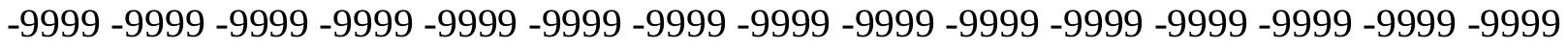
-9999 -9999 -9999 -9999 -9999 -9999 -9999 -9999 -9999 -9999 -9999 -9999 -9999 -9999 -9999 -

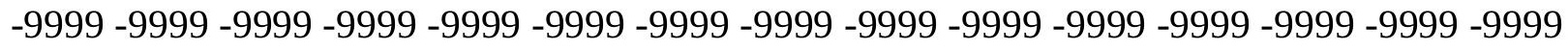

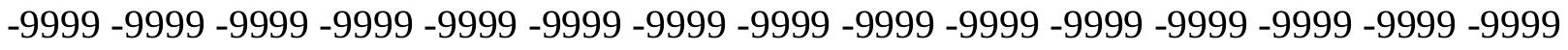
-9999 -9999 -9999 -9999 -9999 -9999 -9999 -9999 -9999 -9999 -9999 -9999 -9999 -9999 -9999 -9999 -9999 -9999 -9999 -9999 -9999 -9999 -9999 -9999-9999 -9999 -9999 -9999 -9999 -9999 -9999 -9999 -9999 -9999 -9999 -9999 -9999 -9999 -9999 -9999 -9999 -9999 -9999 -9999 -9999 -

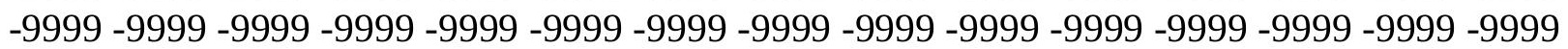


-9999 -9999 -9999 -9999 -9999 -9999 -9999 -9999 -9999 -9999 -9999 -9999 -9999 -9999 -9999 -9999 -9999 -9999 -9999 -9999 -9999 -9999 -9999 -9999 -9999 -9999 -9999 -9999 -9999 -9999 -

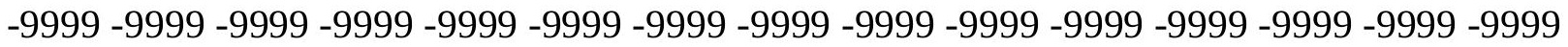
-9999 -9999 -9999 -9999 -9999 -9999 -9999 -9999 -9999 -9999 -9999 -9999 -9999 -9999 -9999 -9999 -9999 -9999 -9999 -9999 -9999 -9999 -9999 -9999-9999 -9999 -9999 -9999 -9999 -9999 -9999 -9999 -9999 -9999 -9999 -9999 -9999 -9999 -9999 -9999 -9999 -9999 -9999 -9999 -9999 -9999 -9999 -9999 -9999 -9999 -9999 -9999 -9999 -9999 -9999 -9999 -9999 -9999 -9999 -9999

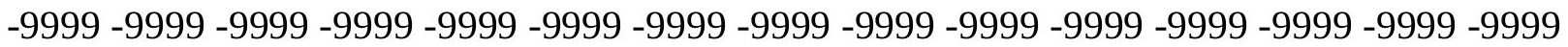

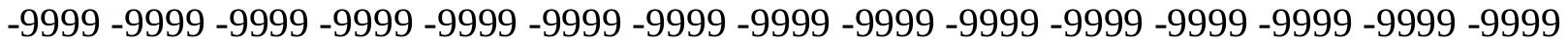
-9999 -9999 -9999 -9999 -9999 -9999 -9999 -9999 -9999 -9999 -9999 -9999 -9999 -9999 -9999 -9999 -9999 -9999 -9999 -9999 -9999 -9999 -9999 -9999 -9999 -9999 -9999 -9999 -9999 -9999 -9999 -9999 -9999 -9999 -9999 -9999 -9999 -9999 -9999 -9999 -9999 -9999 -9999 -9999 -9999 -9999 -9999 -9999 -9999 -9999 -9999 -9999 -9999 -9999 -9999 -9999 -9999 -9999 -9999 -9999 -9999 -9999 -9999 -9999 -9999 -9999 -9999 -9999 -9999 -9999 -9999 -9999 -9999 - 9999 -9999 -9999 -9999 -9999 -9999 -9999 -9999 -9999 -9999 -9999 -9999 -9999 -9999 -9999 -9999

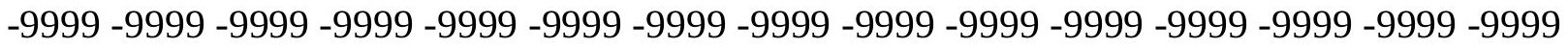
-9999 -9999 -9999 -9999 -9999 -9999 -9999 -9999 -9999 -9999 -9999 -9999 -9999 -9999 -9999 -9999 -9999 -9999 -9999 -9999 -9999 -9999 -9999 -9999 -9999 -9999 -9999 -9999 -9999 -9999 -9999 -9999 -9999 -9999 -9999 -9999 -9999 -9999 -9999 -9999 -9999 -9999 -9999 -9999 -9999 -

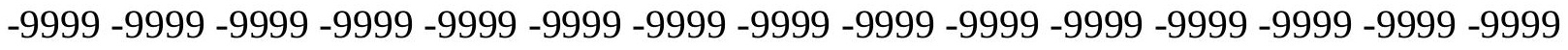

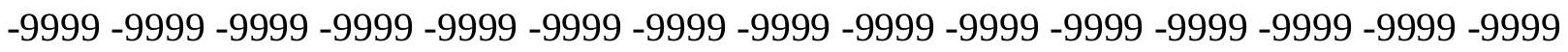
-9999 -9999 -9999 -9999 -9999 -9999 -9999 -9999 -9999 -9999 -9999 -9999 -9999 -9999 -9999 -9999 -9999 -9999 -9999 -9999 -9999 -9999 -9999 -9999 -9999 -9999 -9999 -9999 -9999 -9999 -9999 -9999 -9999 -9999 -9999 -9999 -9999 -9999 -9999 -9999 -9999 -9999 -9999 -9999 -9999 -

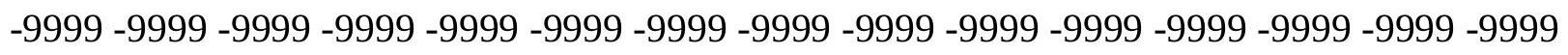
-9999 -9999 -9999 -9999 -9999 -9999 -9999 -9999 -9999 -9999 -9999 -9999 -9999 -9999 -9999 -9999 -9999 -9999 -9999 -9999 -9999 -9999 -9999 -9999 -9999 -9999 -9999 -9999 -9999 -9999 -

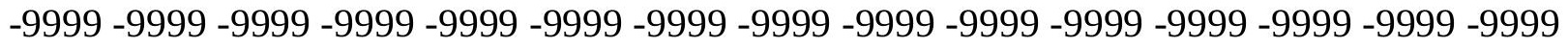
-9999 -9999 -9999 -9999 -9999 -9999 -9999 -9999 -9999 -9999 -9999 -9999 -9999 -9999 -9999 -9999 -9999 -9999 -9999 -9999 -9999 -9999 -9999 -9999 -9999 -9999 -9999 -9999 -9999 -999 -9999 -9999 -9999 -9999 -9999 -9999 -9999 -9999 -9999 -9999 -9999 -9999 -9999 -9999 -9999 -9999 -9999 -9999 -9999 -9999 -9999 -9999 -9999 -9999 -9999 -9999 -9999 -9999 -9999 -9999 -

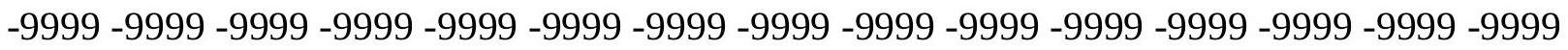

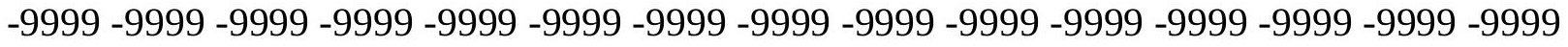

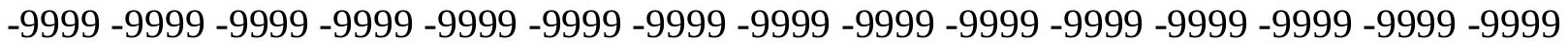

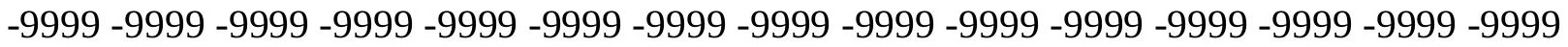

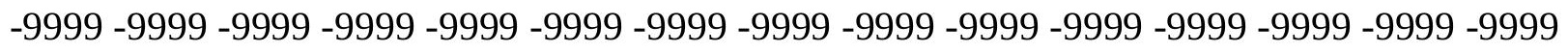

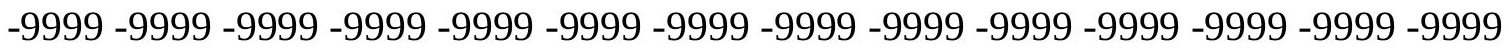
-9999 -9999 -9999 -9999 -9999 -9999 -9999 -9999 -9999 -9999 -9999 -9999 -9999 -9999 -9999 -9999 -9999 -9999 -9999 -9999 -9999 -9999 -9999 -9999 -9999 -9999 -9999 -9999 -9999 -9999 -

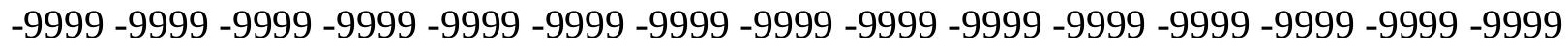

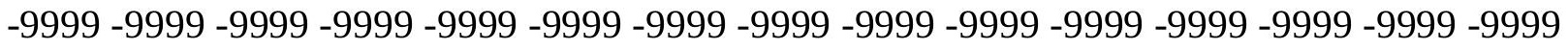
-9999 -9999 -9999 -9999 -9999 -9999 -9999 -9999 -9999 -9999 -9999 -9999 -9999 -9999 -9999 -9999 -9999 -9999 -9999 -9999 -9999 -9999 -9999 -9999-9999 -9999 -9999 -9999 -9999 -9999 -9999 -9999 -9999 -9999 -9999 -9999 -9999 -9999 -9999 -9999 -9999 -9999 -9999 -9999 -9999 -

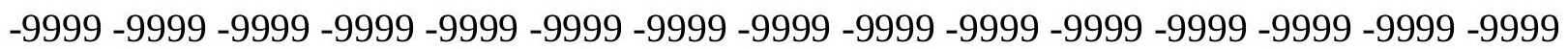


-9999 -9999 -9999 -9999 -9999 -9999 -9999 -9999 -9999 -9999 -9999 -9999 -9999 -9999 -9999 -9999 -9999 -9999 -9999 -9999 -9999 -9999 -9999 -9999 -9999 -9999 -9999 -9999 -9999 -9999 -9999 -9999 -9999 -9999 -9999 -9999 -9999 -9999 -9999 -9999 -9999 -9999 -9999 -9999 -9999 -9999 -9999 -9999 -9999 -9999 204.8155975342 204.2059936523203.596496582 202.9868927002202 .0724945068201 .4629974365200 .5485992432199 .9389953613 199.0247039795198 .4151000977197 .8054962158197 .500793457197 .1959991455 196.891204834196 .5863952637195 .9768066406195 .3672943115194 .7577056885 193.8433074951193 .233795166192 .3193969727191 .4051055908190 .4907073975 189.5764007568188 .3571929932187 .1381072998186 .2236938477185 .6141052246 185.3094024658184 .699798584184 .0901947021183 .7854003906183 .4806976318 183.1759033203182 .87109375182 .87109375182 .5662994385182 .5662994385 182.261505127181 .9566955566181 .6519012451181 .3471984863181 .0424041748 180.432800293180 .432800293181 .6519012451183 .4806976318184 .3950042725 185.3094024658185 .9188995361186 .2236938477186 .8332977295187 .1381072998 187.7476043701188 .6620025635189 .5764007568190 .4907073975190 .1858978271 190.4907073975191 .7097930908192 .9290008545193 .5386047363194 .1481018066 194.7577056885195 .3672943115195 .9768066406196 .891204834 -9999 -9999 -9999-9999 -9999 -9999 -9999 -9999 -9999 -9999 -9999 -9999 -9999 -9999 -9999 -9999 -9999 -9999 -9999 -9999 -9999 -9999 -9999 -9999 -9999 -9999 -9999 -9999 -9999 -9999 -9999 -9999 -9999 -9999 -9999 -9999 -9999 -9999 -9999 -9999 -9999 -9999 -9999 -9999 -9999 -9999 -9999 -9999 -9999

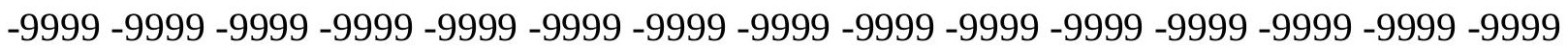
-9999 -9999 -9999 -9999 -9999 -9999 -9999 -9999 -9999 -9999 -9999 -9999 -9999 -9999 -9999 -9999 -9999 -9999 -9999 -9999 -9999 -9999 -9999 -9999 -9999 -9999 -9999 -9999 -9999 -9999 -9999 -9999 -9999 -9999 -9999 -9999 -9999 -9999 -9999 -9999 -9999 -9999 -9999 -9999 -9999

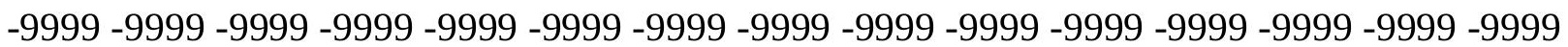
-9999 -9999 -9999 -9999 -9999 -9999 -9999 -9999 -9999 -9999 -9999 -9999 -9999 -9999 -9999 -9999 -9999 -9999 -9999 -9999 -9999 -9999 -9999 -9999 -9999 -9999 -9999 -9999 -9999 -9999 -9999 -9999 -9999 -9999 -9999 -9999 -9999 -9999 -9999 -9999 -9999 -9999 -9999 -9999 -9999 -9999 -9999 -9999 -9999 -9999 -9999 -9999 -9999 -9999 -9999 -9999 -9999 -9999

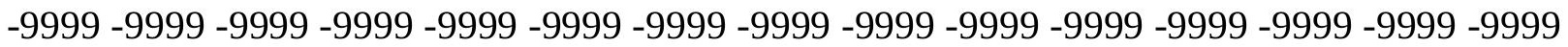
-9999 -9999 -9999 -9999 -9999 -9999 -9999 -9999 -9999 -9999 -9999 -9999 -9999 -9999 -9999 -9999 -9999 -9999 -9999 -9999 -9999 -9999 -9999 -9999 -9999 -9999 -9999 -9999 -9999 -9999 -9999 -9999 -9999 -9999 -9999 -9999 -9999 -9999 -9999 -9999 -9999 -9999 -9999 -9999 -9999 -9999 -9999 -9999 -9999 -9999 -9999 -9999 -9999 -9999 -9999 -9999 -9999 -9999 -9999 -9999 -9999 -9999 -9999 -9999 -9999 -9999 -9999 -9999 -9999 -9999 -9999 -9999 -9999 -9999 -9999 -9999 -9999 -9999 -9999 -9999 -9999 -9999 -9999 -9999 -9999 -9999 -9999 -9999 -9999 -9999 -9999 -9999 -9999 -9999 -9999 -9999 -9999 -9999 -9999 -9999 -9999 -9999 -9999 -9999 -9999 -9999 -9999 -9999 -9999 -9999 -9999 -9999 -9999 -9999 -9999 -9999 -9999 -9999 -9999 -9999 -9999 -9999-9999 202.9868927002 202.3773040771201.7678070068 201.158203125 200.5485992432200 .2438049316199 .6342926025198 .7198944092198 .1103057861 197.500793457196 .891204834196 .2816009521195 .9768066406195 .3672943115 195.3672943115195 .0625194 .7577056885194 .1481018066193 .8433074951192 .9290008545 192.3193969727191 .4051055908190 .4907073975189 .5764007568188 .6620025635 187.7476043701186 .8332977295185 .6141052246184 .699798584184 .0901947021 183.7854003906183 .1759033203182 .87109375182 .5662994385182 .261505127 181.9566955566181 .6519012451181 .6519012451181 .6519012451181 .6519012451 
181.3471984863181.0424041748 180.7375946045180 .1280059814179 .8231964111 179.8231964111179 .8231964111180 .7375946045181 .6519012451182 .87109375 183.7854003906184 .3950042725185 .3094024658186 .2236938477187 .1381072998 187.7476043701188 .3571929932188 .6620025635188 .966796875188 .6620025635 187.7476043701187 .4429016113189 .5764007568186 .2236938477185 .6141052246 185.9188995361186 .528503418187 .1381072998188 .0523986816189 .2716064453 190.4907073975192 .3193969727194 .1481018066196 .2816009521198 .4151000977 200.8533935547 202.9868927002 -9999 -9999 -9999 -9999 -9999 -9999 -9999 -9999 -9999 -9999 -9999 -9999 -9999 -9999 -9999 -9999 -9999 -9999 -9999 -9999 -9999 -9999 -9999 -9999 -9999 -9999 -9999 -9999 -9999 -9999 -9999 -9999 -9999 -9999 -9999 -9999 -9999 -9999 -9999

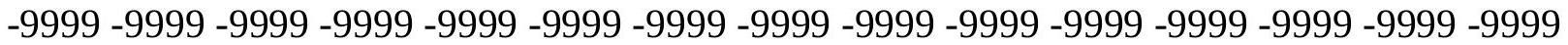
-9999 -9999 -9999 -9999 -9999 -9999 -9999 -9999 -9999 -9999 -9999 -9999 -9999 -9999 -9999 -9999 -9999 -9999 -9999 -9999 -9999 -9999 -9999 -9999 -9999 -9999 -9999 -9999 -9999 -9999 -9999 -9999 -9999 -9999 -9999 -9999 -9999 -9999 -9999 -9999 -9999 -9999 -9999 -9999 - 9999 -9999 -9999 -9999 -9999 -9999 -9999 -9999 -9999 -9999 -9999 -9999 -9999 -9999 -9999 -9999

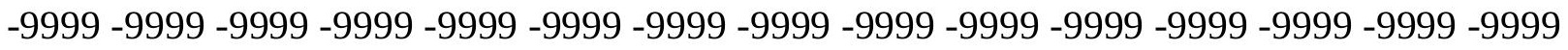
-9999 -9999 -9999 -9999 -9999 -9999 -9999 -9999 -9999 -9999 -9999 -9999 -9999 -9999 -9999 -9999 -9999 -9999 -9999 -9999 -9999 -9999 -9999 -9999 -9999 -9999 -9999 -9999 -9999 -9999 -9999 -9999 -9999 -9999 -9999 -9999 -9999 -9999 -9999 -9999 -9999 -9999 -9999 -9999 -9999 -

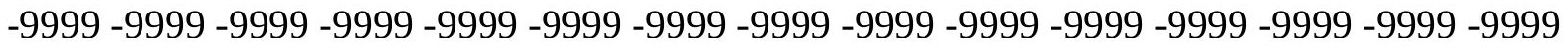

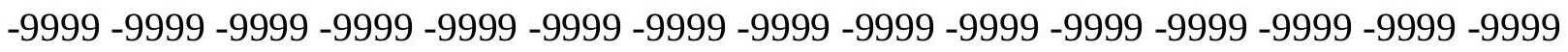
-9999 -9999 -9999 -9999 -9999 -9999 -9999 -9999 -9999 -9999 -9999 -9999 -9999 -9999 -9999 -9999 -9999 -9999 -9999 -9999 -9999 -9999 -9999 -9999 -9999 -9999 -9999 -9999 -9999 -9999 -

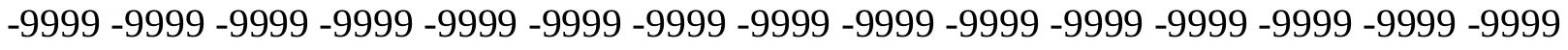

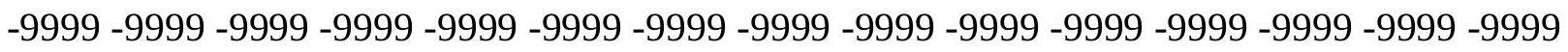
-9999 -9999 -9999 -9999 -9999 -9999 -9999 -9999 -9999 -9999 -9999 -9999 -9999 -9999 -9999 -9999 -9999 -9999 -9999 -9999 -9999 -9999 -9999 -9999 -9999 -9999 -9999 -9999 -9999 -9999 -

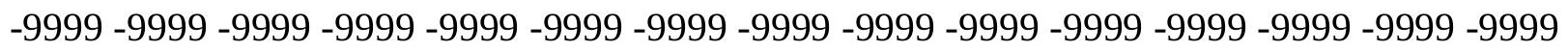
200.8533935547200 .8533935547200 .2438049316199 .9389953613199 .329498291 199.0247039795198 .7198944092198 .4151000977198 .1103057861197 .8054962158 197.1959991455196 .5863952637195 .9768066406195 .3672943115194 .7577056885 194.4528961182194 .1481018066193 .8433074951193 .5386047363193 .233795166 192.9290008545192 .3193969727191 .7097930908190 .795501709190 .1858978271 189.2716064453188 .3571929932187 .4429016113186 .528503418185 .3094024658 184.3950042725183 .7854003906183 .1759033203182 .5662994385181 .9566955566 181.6519012451181 .3471984863181 .3471984863181 .0424041748181 .0424041748 181.0424041748181 .0424041748181 .0424041748181 .0424041748180 .7375946045 180.432800293180 .1280059814180 .1280059814180 .1280059814180 .432800293 181.3471984863182 .261505127183 .1759033203184 .0901947021185 .3094024658 186.2236938477186 .8332977295187 .7476043701188 .3571929932188 .966796875 189.5764007568189 .5764007568189 .2716064453188 .6620025635188 .0523986816 187.4429016113186 .2236938477185 .0045928955183 .7854003906182 .87109375 182.261505127 182.261505127 182.261505127 182.5662994385 184.0901947021 185.9188995361188 .0523986816190 .1858978271192 .624206543194 .7577056885 196.891204834199 .0247039795200 .8533935547202 .9868927002205 .1204071045 206.9490966797 -9999 -9999 -9999 -9999 -9999 -9999 -9999 -9999 -9999 -9999 -9999 -9999 
-9999 -9999 -9999 -9999 -9999 -9999 -9999 -9999 -9999 -9999 -9999 -9999 -9999 -9999 -9999 -9999 -9999 -9999 -9999 -9999 -9999 -9999 -9999 -9999 -9999 -9999 -9999 -9999 -9999 -9999 -9999 -9999 -9999 -9999 -9999 -9999 -9999 -9999 -9999 -9999 -9999 -9999 -9999 -9999 -9999 -9999 -9999 -9999 -9999 -9999 -9999 -9999 -9999 -9999 -9999 -9999 -9999 -9999 -9999 -9999 -9999 -9999 -9999 -9999 -9999 -9999 -9999 -9999 -9999 -9999 -9999 -9999 -9999 -9999 -9999 -9999 -9999 -9999 -9999 -9999 -9999 -9999 -9999 -9999 -9999 -9999 -9999 -9999 -9999 -9999 -9999 -9999 -9999 -9999 -9999 -9999 -9999 -9999 -9999 -9999 -9999 -9999 -9999 -9999 -9999

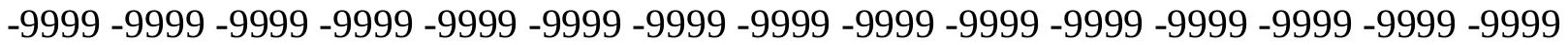
-9999 -9999 -9999-9999-9999-9999

-9999 -9999 -9999 -9999 -9999 -9999 -9999 -9999 -9999 -9999 -9999 -9999 -9999 -9999 -9999 -9999 -9999 -9999 -9999 -9999 -9999 -9999 -9999 -9999 -9999 -9999 -9999 -9999 -9999 -9999 -9999 -9999 -9999 -9999 -9999 -9999 -9999 -9999 -9999 -9999 -9999 -9999 -9999 -9999 -9999

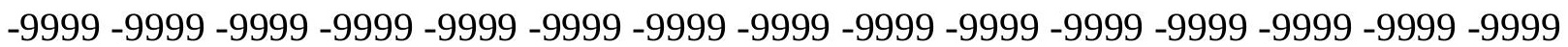
-9999 -9999 -9999 -9999 -9999 -9999 -9999 -9999 -9999 -9999 -9999 -9999 -9999 -9999 -9999 -9999 -9999 -9999 -9999 -9999 -9999 -9999 -9999 -9999 -9999 -9999 -9999 -9999 -9999 -9999

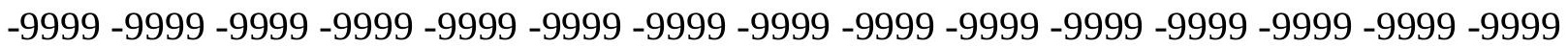

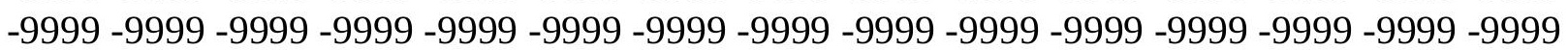
-9999 -9999 -9999 -9999 -9999 -9999 -9999 -9999 -9999 -9999 -9999 -9999 -9999 -9999 -9999 -9999 -9999 -9999 -9999 -9999 -9999 -9999 -9999 -9999 -9999 -9999 -9999 -9999 -9999 -9999 -9999 -9999 -9999 -9999 -9999 -9999 -9999 -9999 -9999 -9999 -9999 -9999 -9999 -9999 198.1103057861197 .8054962158197 .500793457197 .1959991455196 .891204834 196.891204834196 .891204834196 .5863952637196 .5863952637196 .2816009521 195.6721038818195 .3672943115194 .7577056885194 .1481018066193 .8433074951 193.5386047363192 .9290008545192 .624206543192 .3193969727192 .3193969727 192.0146026611191 .4051055908190 .795501709190 .1858978271189 .5764007568 188.6620025635188 .0523986816187 .1381072998186 .2236938477185 .0045928955 184.0901947021183 .4806976318182 .5662994385181 .9566955566181 .3471984863 181.0424041748180 .7375946045180 .432800293180 .432800293180 .432800293 180.432800293180 .432800293180 .432800293180 .432800293180 .7375946045 180.432800293180 .432800293180 .432800293180 .432800293180 .7375946045 181.3471984863181 .9566955566182 .87109375183 .7854003906185 .0045928955 185.9188995361186 .8332977295187 .7476043701188 .6620025635189 .2716064453 189.8811035156190 .1858978271190 .1858978271189 .8811035156189 .5764007568 188.966796875188 .3571929932187 .4429016113186 .2236938477185 .3094024658 184.3950042725183 .7854003906183 .7854003906183 .7854003906184 .0901947021 184.3950042725185 .3094024658186 .2236938477187 .4429016113188 .3571929932 189.5764007568190 .795501709191 .7097930908193 .233795166195 .0625197 .1959991455 199.329498291201 .7678070068204 .2059936523206 .9490966797209 .9969024658 -9999 -9999 -9999 -9999 -9999 -9999 -9999 -9999 -9999 -9999 -9999 -9999 -9999 -9999 -9999 -9999 -9999 -9999 -9999 -9999 -9999 -9999 -9999 -9999 -9999 -9999 -9999 -9999 -9999 -9999 -9999 -9999 -9999 -9999 -9999 -9999 -9999 -9999 -9999 -9999 -9999 -9999 -9999 -9999 -9999 -9999

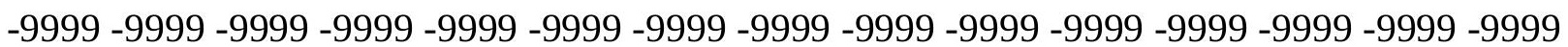
-9999 -9999 -9999 -9999 -9999 -9999 -9999 -9999 -9999 -9999 -9999 -9999 -9999 -9999 -9999 -999 -9999 -9999 -9999 -9999 -9999 -9999 -9999 -9999 -9999 -9999 -9999 -9999 -9999 -9999 -9999 -9999 -9999 -9999 -9999 -9999 -9999 -9999 -9999 -9999 -9999 -9999 -9999 -9999 -9999 -9999

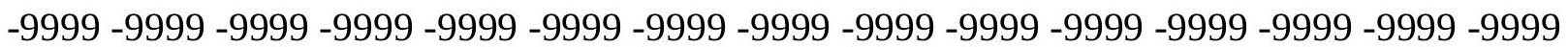


-9999 -9999 -9999 -9999 -9999 -9999 -9999 -9999 -9999 -9999 -9999 -9999 -9999

-9999 -9999 -9999 -9999 -9999 -9999 -9999 -9999 -9999 -9999 -9999 -9999 -9999 -9999 -9999

-9999 -9999 -9999 -9999 -9999 -9999 -9999 -9999 -9999 -9999 -9999 -9999 -9999 -9999 -9999

-9999 -9999 -9999 -9999 -9999 -9999 -9999 -9999 -9999 -9999 -9999 -9999 -9999 -9999 -9999

-9999 -9999 -9999 -9999 -9999 -9999 -9999 -9999 -9999 -9999 -9999 -9999 -9999 -9999 -9999 -

-9999 -9999 -9999 -9999 -9999 -9999 -9999 -9999 -9999 -9999 -9999 -9999 -9999 -9999 -9999 -

-9999 -9999 -9999 -9999 -9999 -9999 -9999 -9999 -9999 -9999 -9999 -9999 -9999 -9999 -9999 -

-9999 -9999 -9999 -9999 -9999 -9999 -9999 -9999 -9999 -9999 -9999 -9999 -9999 -9999 -9999

-9999 -9999 -9999 -9999 -9999 -9999 -9999 -9999 -9999 -9999 -9999 -9999 -9999 -9999 -9999

-9999 -9999 -9999 -9999 -9999 -9999 -9999 -9999 -9999 -9999 -9999 -9999 -9999 -9999 -9999 -

-9999 -9999 -9999 -9999 -9999 -9999 -9999 -9999 -9999 -9999 -9999 -9999 -9999 -9999 -9999 -

-9999 -9999 -9999 -9999 -9999 -9999 -9999 -9999 -9999 -9999 -9999 -9999 -9999

194.7577056885194 .7577056885194 .7577056885194 .7577056885194 .7577056885

194.7577056885194 .7577056885194 .4528961182194 .4528961182194 .4528961182

194.1481018066 193.8433074951 193.5386047363193 .233795166192 .624206543

192.3193969727192 .0146026611191 .7097930908191 .4051055908191 .1002960205

190.795501709190 .4907073975190 .1858978271189 .5764007568188 .966796875

188.3571929932187 .4429016113186 .528503418185 .6141052246184 .699798584

183.7854003906183 .1759033203182 .261505127181 .6519012451181 .0424041748 180.432800293180 .1280059814179 .8231964111179 .5184020996179 .5184020996 179.5184020996179 .5184020996179 .8231964111179 .8231964111180 .1280059814 180.432800293180 .432800293180 .432800293180 .7375946045181 .0424041748 181.3471984863 181.9566955566182.87109375 183.7854003906184 .699798584 185.9188995361186 .8332977295187 .7476043701188 .6620025635189 .5764007568 190.1858978271190 .4907073975190 .795501709191 .1002960205190 .795501709 190.4907073975189 .8811035156189 .2716064453188 .6620025635187 .7476043701 186.8332977295186 .2236938477185 .6141052246185 .6141052246185 .6141052246 185.9188995361186 .2236938477186 .8332977295187 .7476043701188 .966796875 189.8811035156191 .1002960205192 .0146026611193 .233795166194 .1481018066195 .0625 195.9768066406197 .500793457198 .7198944092197 .8054962158199 .9389953613 202.9868927002206 .0346984863209 .0825958252 -9999 -9999 -9999 -9999 -9999 -9999 -9999 -9999 -9999 -9999 -9999 -9999 -9999 -9999 -9999 -9999 -9999 -9999 -9999 -9999 -9999 -9999 -9999 -9999 -9999 -9999 -9999 -9999 -9999 -9999 -9999 -9999 -9999 -9999 -9999 -9999 -9999 -9999 -9999 -9999 -9999 -9999 -9999 -9999 -9999 -9999 -9999 -9999 -9999 -9999 -9999 -9999 -9999 -9999 -9999 -9999 -9999 -9999 -9999 -9999 -9999 -9999 -9999 -9999 -9999 -9999 -9999 -9999 -9999 -9999 -9999 -9999 -9999 -9999 -9999 -9999 -9999 -9999 -9999 -9999 -9999 -9999 -9999 -9999 -9999 -9999 -9999 -9999 -9999 -9999 -9999 -9999 -9999 -9999 -9999 -9999 -9999 -9999 -9999 -9999 -9999 -9999 -9999 -9999 -9999 -9999 -9999 -9999 -9999 -9999 -9999 -9999 -9999 -9999 -9999 -9999 -9999 -9999 -9999 -9999 -9999 -9999 -9999 -9999 -9999 -9999 -9999 -9999 -9999 -9999 -9999-9999 -9999 -9999 -9999 -9999 -9999 -9999 -9999 -9999 -9999 -9999 -9999 -9999 -9999 -9999 -9999 -9999 -9999 -9999 -9999 -9999 -9999 -9999 -9999 -9999 -9999 -9999 -9999-9999-9999-9999 -9999 -9999 -9999 -9999 -9999 -9999 -9999 -9999 -9999 -9999 -9999 -9999 -9999 -9999 -9999 -9999 -9999 -9999 -9999 -9999 -9999 -9999 -9999 -9999 -9999 -9999 -9999 -9999 -9999 -9999 -9999 -9999 -9999 -9999 -9999 -9999 -9999 -9999 -9999 -9999 -9999 -9999 -9999 -9999 -9999

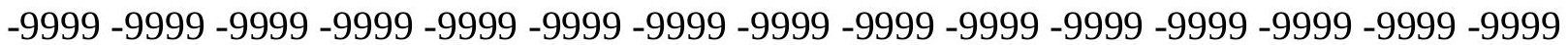


-9999 -9999 -9999 -9999 -9999 -9999 -9999 -9999 -9999 -9999 -9999 -9999 -9999 -9999 -9999 -9999 -9999 -9999 -9999 -9999 -9999 -9999 -9999 -9999 -9999 -9999 -9999 -9999 -9999 -9999

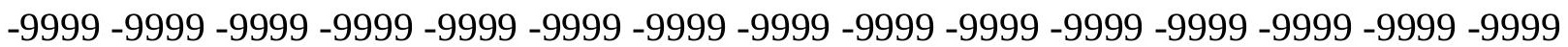
-9999 -9999 -9999 -9999 -9999 -9999 -9999 -9999 -9999 -9999 -9999 -9999 -9999 -9999 -9999 -9999 -9999 -9999 -9999 -9999 -9999 -9999 -9999 -9999 -9999 -9999 -9999 191.7097930908 191.7097930908191 .7097930908192 .0146026611192 .0146026611192 .0146026611 192.3193969727192 .3193969727192 .3193969727192 .3193969727192 .0146026611 192.0146026611192 .0146026611191 .7097930908191 .4051055908191 .1002960205 190.795501709190 .4907073975190 .4907073975190 .1858978271189 .8811035156 189.5764007568189 .2716064453188 .6620025635188 .3571929932187 .7476043701 186.8332977295186 .2236938477185 .3094024658184 .3950042725183 .7854003906 182.87109375181 .9566955566181 .3471984863180 .432800293179 .8231964111 179.5184020996179 .2136993408178 .9089050293178 .9089050293178 .604095459 178.9089050293178 .9089050293179 .2136993408179 .5184020996179 .8231964111 180.1280059814180 .432800293180 .7375946045181 .0424041748181 .6519012451 182.261505127182 .87109375183 .7854003906184 .699798584185 .9188995361 186.8332977295187 .7476043701188 .966796875189 .5764007568190 .4907073975 191.1002960205191 .7097930908191 .7097930908192 .0146026611192 .0146026611 191.7097930908191 .1002960205190 .4907073975189 .8811035156189 .2716064453 188.6620025635188 .0523986816187 .7476043701187 .4429016113187 .4429016113 187.7476043701188 .3571929932188 .966796875189 .5764007568190 .4907073975 191.7097930908192 .624206543193 .5386047363194 .7577056885195 .6721038818 196.5863952637 197.500793457 198.4151000977 199.0247039795 198.7198944092 197.8054962158196 .891204834199 .0247039795201 .7678070068204 .5108032227 207.25390625 -9999 -9999 -9999 -9999 -9999 -9999 -9999 -9999 -9999 -9999 -9999 -9999 -9999 -9999 -9999 -9999 -9999 -9999 -9999 -9999 -9999 -9999 -9999 -9999 -9999 -9999 -9999 -9999 -9999 -9999 -9999 -9999 -9999 -9999 -9999 -9999 -9999 -9999 -9999 -9999 -9999 -9999 -9999 -9999 -9999 -9999 -9999 -9999 -9999 -9999 -9999 -9999 -9999 -9999 -9999 -9999 -9999 -9999 -9999 -9999 -9999 -9999 -9999 -9999 -9999 -9999 -9999 -9999 -9999 -9999 -9999 -9999 -9999 -9999 -9999 -9999 -9999 -9999 -9999 -9999 -9999 -9999 -9999 -9999 -9999 -9999 -9999 -9999 -9999 -9999 -9999 -9999 -9999 -9999 -9999 -9999 -9999 -9999 -9999 -9999 -9999 -9999 -9999 -9999 -9999 -9999 -9999 -9999 -9999 -9999 -9999 -9999 -9999 -9999 -9999 -9999 -9999 -9999 -9999 -9999 -9999 -9999 -9999 -9999 -9999 -9999 -9999 -9999 -9999 -9999 -9999 -9999 -9999 -9999 -9999 -9999 -9999 -9999 -9999 -9999 -9999 -9999 -9999 -9999 -9999

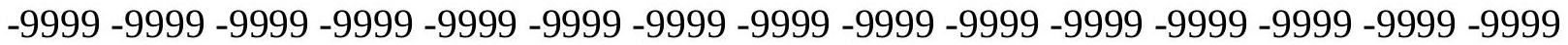
-9999 -9999 -9999 -9999 -9999 -9999 -9999 -9999 -9999 -9999 -9999 -9999 -9999 -9999 -9999

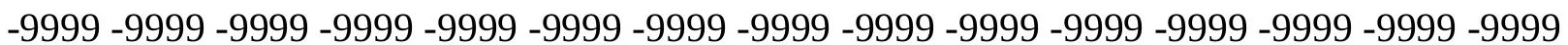

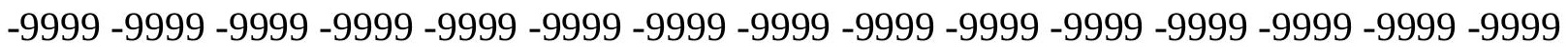
-9999 -9999 -9999 -9999 -9999 -9999 -9999 -9999 -9999 -9999 -9999 -9999 -9999 -9999 -9999 -9999 -9999 -9999 -9999 -9999 -9999 -9999 -9999 -9999 -9999 -9999 -9999 -9999 - -9999 -9999 -9999 -9999 -9999 -9999 -9999 -9999 -9999 -9999 -9999 -9999 -9999 -9999 -9999 -9999 -9999

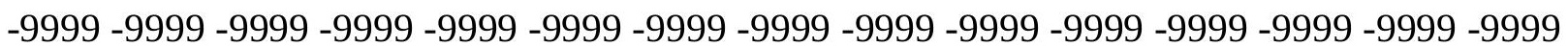
-9999 -9999 -9999 -9999 -9999 -9999 -9999 -9999 -9999 -9999 -9999 -9999 -9999 -9999 -9999 -9999 -9999 -9999 -9999 -9999 -9999 -9999 -9999 -9999 -9999 -9999 -9999 188.3571929932 188.3571929932188 .6620025635188 .966796875189 .2716064453189 .5764007568 189.5764007568189 .8811035156189 .8811035156189 .8811035156189 .8811035156 
189.8811035156189.8811035156189.8811035156189.5764007568189.5764007568 189.2716064453189 .2716064453188 .966796875188 .6620025635188 .6620025635 188.3571929932187 .7476043701187 .4429016113186 .8332977295186 .528503418 185.6141052246185 .0045928955184 .0901947021183 .4806976318182 .5662994385 181.6519012451181 .0424041748180 .1280059814179 .5184020996178 .9089050293 178.604095459178 .2993011475177 .9945068359177 .9945068359177 .9945068359 178.2993011475178 .2993011475178 .604095459179 .2136993408179 .5184020996 180.1280059814180 .432800293181 .0424041748181 .6519012451182 .261505127 183.1759033203184 .0901947021185 .0045928955185 .9188995361186 .8332977295 188.0523986816188 .966796875189 .8811035156190 .795501709191 .7097930908 192.3193969727192 .624206543192 .9290008545193 .233795166192 .9290008545 192.9290008545192 .624206543192 .0146026611191 .4051055908191 .1002960205 190.4907073975190 .1858978271189 .8811035156189 .5764007568189 .8811035156 189.8811035156190 .4907073975191 .1002960205191 .7097930908192 .624206543 193.5386047363194 .4528961182195 .3672943115196 .2816009521197 .1959991455 198.1103057861198 .7198944092199 .329498291199 .6342926025199 .329498291 198.7198944092197 .8054962158196 .891204834195 .9768066406197 .8054962158 200.5485992432203 .2917022705206 .3394927979 -9999 -9999 -9999 -9999 -9999 -9999 -9999 -9999 -9999 -9999 -9999 -9999 -9999 -9999 -9999 -9999 -9999 -9999 -9999 -9999 -9999 -9999

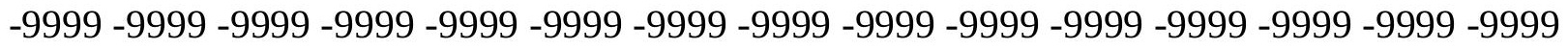
-9999 -9999 -9999 -9999 -9999 -9999 -9999 -9999 -9999 -9999 -9999 -9999 -9999 -9999 -9999 -9999 -9999 -9999 -9999 -9999 -9999 -9999 -9999 -9999 -9999 -9999 -9999 -9999 -9999 -9999 -9999 -9999 -9999 -9999 -9999 -9999 -9999 -9999 -9999 -9999 -9999 -9999-9999-9999-9999 -999 -9999 -9999 -9999 -9999 -9999 -9999 -9999 -9999 -9999 -9999 -9999 -9999 -9999 -9999 -9999 -9999 -9999 -9999 -9999 -9999 -9999 -9999 -9999 -9999 -9999 -9999 -9999 -9999 -9999 -9999 -9999 -9999 -9999 -9999 -9999 -9999 -9999 -9999 -9999 -9999 -9999 -9999 -9999 -9999 -9999 $-9999$

-9999 -9999 -9999 -9999 -9999 -9999 -9999 -9999 -9999 -9999 -9999 -9999 -9999 -9999 -9999 -9999 -9999 -9999 -9999 -9999 -9999 -9999 -9999 -9999 -9999 -9999 -9999 -9999 -9999 -9999 -9999 -9999 -9999 -9999 -9999 -9999 -9999 -9999 -9999 -9999 -9999 -9999 -9999 -9999 -9999 -9999 -9999 -9999 -9999 -9999 -9999 -9999 -9999 -9999 -9999 -9999 -9999 -9999 -9999 -9999

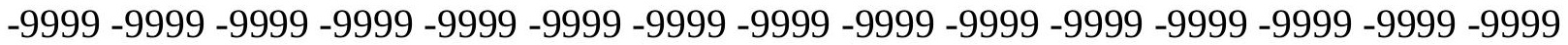

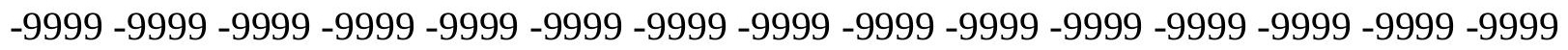

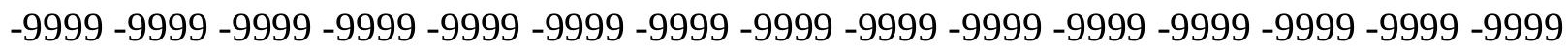
-9999 -9999 -9999 -9999 -9999 -9999 -9999 -9999 -9999 -9999 -9999 -9999 -9999 -9999 -9999 -9999 -9999 -9999 -9999 -9999 -9999 -9999 -9999 -9999 -9999 -9999 -9999 -9999 -9999 -9999

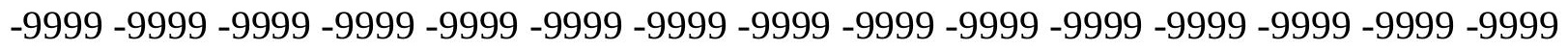
-9999 -9999-9999-9999 -9999-9999 -9999 -9999-9999-9999 -9999-9999 185.3094024658 185.3094024658185 .6141052246186 .2236938477186 .528503418186 .8332977295 186.8332977295187 .1381072998187 .4429016113187 .4429016113187 .7476043701 187.7476043701187 .7476043701188 .0523986816188 .0523986816187 .7476043701 187.7476043701187 .7476043701187 .4429016113187 .4429016113187 .1381072998 186.8332977295186 .528503418186 .2236938477185 .9188995361185 .3094024658 184.699798584183 .7854003906183 .1759033203182 .261505127181 .6519012451 180.7375946045180 .1280059814179 .5184020996178 .9089050293178 .2993011475 177.6896972656177 .3849029541177 .3849029541177 .3849029541177 .3849029541 
177.6896972656177 .9945068359178 .2993011475178 .9089050293179 .5184020996 180.1280059814180 .7375946045181 .3471984863182 .261505127183 .1759033203 184.0901947021185 .0045928955185 .9188995361187 .1381072998188 .0523986816 189.2716064453190 .1858978271191 .1002960205192 .0146026611192 .624206543 193.233795166193 .8433074951194 .1481018066194 .4528961182194 .4528961182 194.1481018066194 .1481018066193 .8433074951193 .233795166192 .9290008545 192.624206543192 .3193969727192 .0146026611192 .0146026611192 .0146026611 192.3193969727 192.624206543193.233795166193.8433074951 194.7577056885 195.6721038818196 .5863952637197 .1959991455198 .1103057861198 .7198944092 199.6342926025200 .2438049316200 .5485992432200 .5485992432200 .2438049316 199.6342926025199 .0247039795198 .1103057861196 .891204834195 .9768066406195 .0625 196.5863952637 199.329498291 202.3773040771 205.1204071045 -9999 -9999 -9999 -9999 -9999 -9999 -9999 -9999 -9999 -9999 -9999 -9999 -9999 -9999 -9999 -9999 -9999 -9999 -9999 -9999 -9999 -9999 -9999 -9999 -9999 -9999 -9999 -9999 -9999 -9999 -9999 -9999 -9999 - 9999 -9999 -9999 -9999 -9999 -9999 -9999 -9999 -9999 -9999 -9999 -9999 -9999 -9999 -9999 -9999

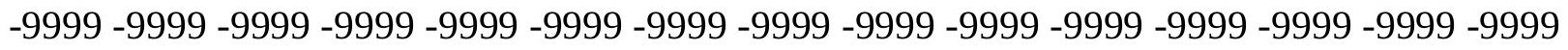
-9999 -9999 -9999 -9999 -9999 -9999 -9999 -9999 -9999 -9999 -9999 -9999 -9999 -9999 -9999 -9999 -9999 -9999 -9999 -9999 -9999 -9999 -9999 -9999 -9999 -9999 -9999 -9999 -9999 -9999 -9999 -9999 -9999 -9999 -9999 -9999 -9999 -9999 -9999 -9999 -9999 -9999 -9999 -9999 -9999 -

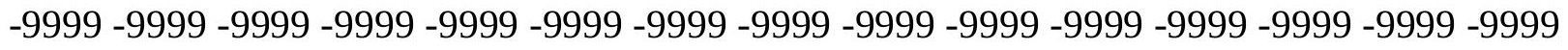
$-9999-9999$

-9999 -9999 -9999 -9999 -9999 -9999 -9999 -9999 -9999 -9999 -9999 -9999 -9999 -9999 -9999 -9999 -9999 -9999 -9999 -9999 -9999 -9999 -9999 -9999 -9999 -9999 -9999 -9999 -9999 -9999 -

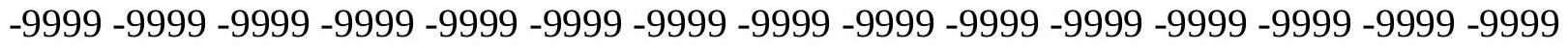

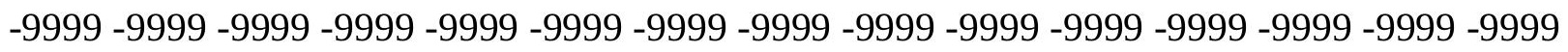
-9999 -9999 -9999 -9999 -9999 -9999 -9999 -9999 -9999 -9999 -9999 -9999 -9999 -9999 -9999 -9999 -9999 -9999 -9999 -9999 -9999 -9999 -9999 -9999 -9999 -9999 -9999 -9999 -9999 -9999

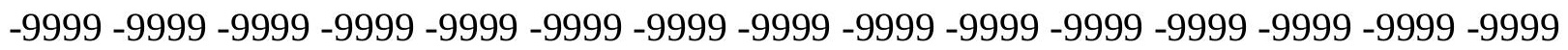
-9999 -9999 -9999 -9999 -9999 -9999 -9999 -9999 -9999 -9999 -9999 -9999 -9999 -9999 -9999 -9999 -9999 -9999 -9999 -9999 -9999 -9999 -9999 -9999 -9999 -9999 -9999 -9999 -9999 -9999 -9999 -9999 -9999 -9999 -9999 -9999 -9999 -9999 -9999 -9999 -9999 -9999 -9999 -9999 -9999 -9999 -9999 -9999 -9999 -9999 -9999 -9999 -9999 -9999 -9999 -9999 182.261505127 182.261505127182 .261505127182 .5662994385183 .1759033203183 .4806976318 183.7854003906184 .3950042725184 .699798584185 .0045928955185 .3094024658 185.3094024658185 .6141052246185 .9188995361185 .9188995361186 .2236938477 186.2236938477 186.2236938477 186.2236938477 186.2236938477 185.9188995361 185.9188995361185 .6141052246185 .3094024658185 .0045928955184 .699798584 184.0901947021183 .4806976318182 .87109375182 .261505127181 .6519012451 180.7375946045180 .1280059814179 .2136993408178 .604095459177 .9945068359 177.6896972656177 .0802001953176 .7754058838176 .7754058838176 .7754058838 176.7754058838177 .0802001953177 .3849029541177 .9945068359178 .604095459 179.2136993408 180.1280059814181.0424041748 181.9566955566182.87109375 183.7854003906185 .0045928955185 .9188995361187 .1381072998188 .3571929932 189.2716064453190.4907073975 191.4051055908 192.3193969727 193.233795166 194.1481018066194 .7577056885195 .0625195 .3672943115195 .6721038818195 .6721038818 195.6721038818195 .6721038818195 .3672943115195 .0625195 .0625194 .7577056885 
194.4528961182194 .4528961182194 .4528961182194 .4528961182194 .7577056885 195.3672943115195 .6721038818196 .2816009521197 .1959991455197 .8054962158 198.7198944092199 .329498291199 .9389953613200 .5485992432201 .158203125 201.4629974365201 .7678070068201 .7678070068201 .4629974365200 .8533935547 200.2438049316199 .329498291198 .4151000977197 .1959991455196 .2816009521 195.3672943115194 .1481018066195 .6721038818198 .7198944092201 .4629974365 204.2059936523 -9999 -9999 -9999 -9999 -9999 -9999 -9999 -9999 -9999 -9999 -9999 -9999 -9999 -9999 -9999 -9999 -9999 -9999 -9999 -9999 -9999 -9999 -9999 -9999 -9999 -9999 -9999 -999 -

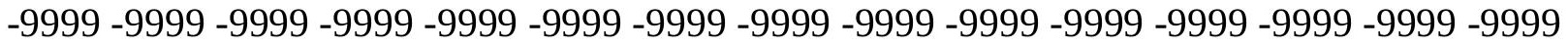
-9999 -9999 -9999 -9999 -9999 -9999 -9999 -9999 -9999 -9999 -9999 -9999 -9999 -9999 -9999

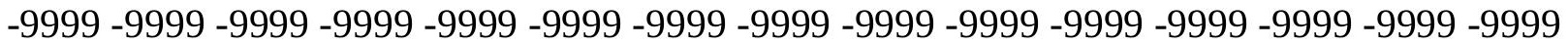
-9999 -9999 -9999 -9999 -9999 -9999 -9999 -9999 -9999 -9999 -9999 -9999 -9999 -9999 -9999 -9999 -9999 -9999 -9999 -9999 -9999 -9999 -9999 -9999 -9999 -9999 -9999 -9999 -9999 -9999 -9999 -9999 -9999 -9999 -9999 -9999 -9999 -9999 -9999 -9999 -9999 -9999 -9999 -9999 - -9999 -9999 -9999 -9999 -9999-9999 -9999-9999

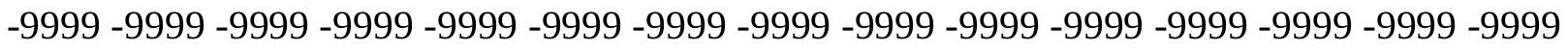
-9999 -9999 -9999 -9999 -9999 -9999 -9999 -9999 -9999 -9999 -9999 -9999 -9999 -9999 -9999 -9999 -9999 -9999 -9999 -9999 -9999 -9999 -9999 -9999 -9999 -9999 -9999 -9999 -9999 -9999 -9999 -9999 -9999 -9999 -9999 -9999 -9999 -9999 -9999 -9999 -9999 -9999 -9999 -9999 -9999 -

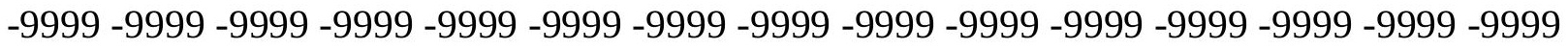

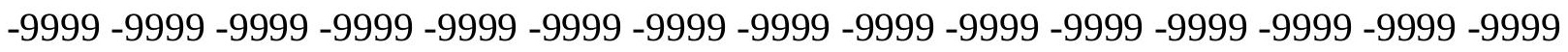
-9999 -9999 -9999 -9999 -9999 -9999 -9999 -9999 -9999 -9999 -9999 -9999 -9999 -9999 -9999 -9999 -9999 -9999 -9999 -9999 -9999 -9999 -9999 -9999 -9999 -9999 -9999 -9999 -9999 -9999 -

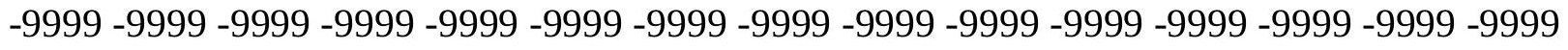

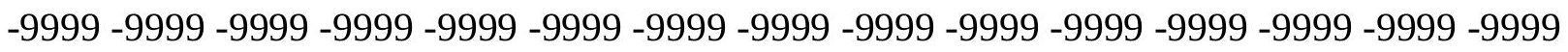
-9999-9999 -9999 -9999-9999 -9999 -9999-9999 -9999-9999 -9999 179.2136993408 179.2136993408179 .2136993408179 .8231964111180 .1280059814180 .7375946045 181.0424041748181 .6519012451181 .9566955566182 .261505127182 .87109375 183.1759033203183 .4806976318183 .7854003906184 .0901947021184 .0901947021 184.3950042725184 .3950042725184 .699798584184 .699798584184 .699798584 184.699798584184 .3950042725184 .0901947021184 .0901947021183 .4806976318 183.1759033203182 .5662994385181 .9566955566181 .3471984863180 .7375946045 180.1280059814179 .2136993408178 .604095459177 .9945068359177 .3849029541 177.0802001953176 .4705963135176 .165802002176 .165802002176 .165802002 176.165802002176 .4705963135177 .0802001953177 .3849029541178 .2993011475 179.2136993408180 .1280059814181 .0424041748182 .261505127183 .4806976318 184.699798584185 .9188995361187 .1381072998188 .3571929932189 .5764007568 190.4907073975191 .7097930908192 .624206543193 .8433074951194 .4528961182 195.3672943115195 .9768066406196 .5863952637196 .891204834197 .1959991455 197.500793457 197.500793457 197.500793457 197.1959991455 197.1959991455 197.1959991455196 .891204834196 .891204834196 .891204834196 .891204834 197.1959991455197 .500793457197 .8054962158198 .4151000977199 .0247039795 199.6342926025200 .2438049316200 .8533935547201 .4629974365202 .0724945068 202.6820983887202 .9868927002203 .2917022705203 .2917022705203 .2917022705 202.9868927002202 .3773040771201 .7678070068200 .8533935547199 .9389953613 199.0247039795197 .8054962158196 .891204834195 .6721038818194 .7577056885 
193.8433074951195 .0625198 .1103057861200 .8533935547203 .596496582 -9999 -9999 -9999 -9999 -9999 -9999 -9999 -9999 -9999 -9999 -9999 -9999 -9999 -9999 -9999 -9999 -9999

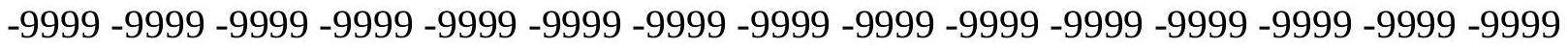
-9999 -9999 -9999 -9999 -9999 -9999 -9999 -9999 -9999 -9999 -9999 -9999 -9999 -9999 -9999 -9999 -9999 -9999 -9999 -9999 -9999 -9999 -9999 -9999-9999 -9999 -9999 -9999 -9999 -9999 -9999 -9999 -9999 -9999 -9999 -9999 -9999 -9999 -9999 -9999 -9999 -9999 -9999 -9999 -9999

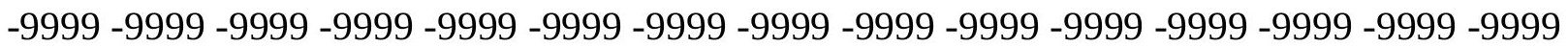

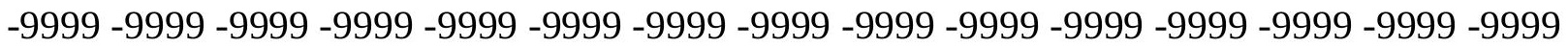

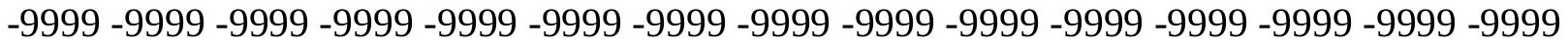
-9999 -9999 -9999 -9999 -9999 -9999 -9999 -9999 -9999 -9999 -9999 -9999 -9999 -9999 -9999

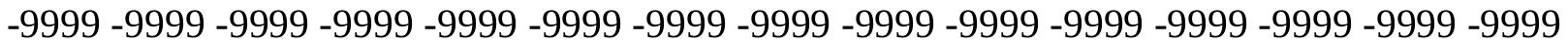
-9999 -9999 -9999 -9999 -9999 -9999 -9999 -9999 -9999 -9999 -9999 -9999 -9999 -9999 -9999 -9999 -9999 -9999 -9999 -9999 -9999 -9999 -9999 -9999 -9999 -9999 -9999 -9999 -9999 -9999 -

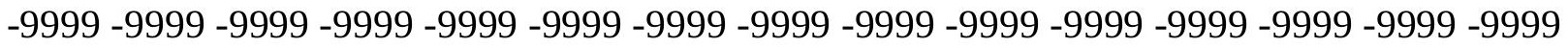
-9999 -9999 -9999 -9999 -9999 -9999 -9999 -9999 -9999 -9999 -9999 -9999 -9999 -9999 -9999

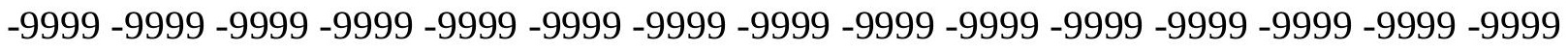
-9999 -9999 -9999 -9999 -9999 -9999 -9999 -9999 -9999 -9999 -9999 -9999 -9999 -9999 -9999 -9999 -9999 -9999 -9999 -9999 -9999 -9999 -9999 -9999 -9999 -9999 -9999 -9999 -9999 -9999 -9999 -9999 -9999 -9999 -9999 -9999 -9999 -9999 -9999 -9999 -9999 -9999 -9999 -9999 -9999 -9999 -9999 -9999-9999 -9999 -9999 -9999 -9999 -9999 -9999 -9999 176.165802002 176.165802002176 .4705963135176 .7754058838177 .0802001953177 .6896972656 178.2993011475178 .604095459179 .2136993408179 .8231964111180 .1280059814 180.7375946045181 .0424041748181 .6519012451181 .9566955566182 .261505127 182.5662994385182 .87109375182 .87109375183 .1759033203183 .1759033203 183.1759033203183 .1759033203183 .1759033203182 .87109375182 .5662994385 182.261505127181 .6519012451181 .3471984863180 .7375946045180 .1280059814 179.5184020996178 .9089050293177 .9945068359177 .3849029541177 .0802001953 176.4705963135175 .8609924316175 .5561981201175 .5561981201175 .5561981201 175.5561981201175 .8609924316176 .4705963135177 .0802001953177 .9945068359 178.9089050293180 .1280059814181 .3471984863182 .5662994385184 .0901947021 185.3094024658186 .528503418188 .0523986816189 .2716064453190 .4907073975 191.7097930908192 .9290008545194 .1481018066195 .0625195 .9768066406196 .5863952637 197.500793457 197.8054962158 198.4151000977 198.7198944092199.0247039795 199.0247039795199 .329498291199 .329498291199 .329498291199 .329498291 199.329498291199 .329498291199 .329498291199 .6342926025199 .6342926025 199.9389953613200 .5485992432200 .8533935547201 .4629974365202 .0724945068 202.6820983887 203.2917022705 203.9011993408 204.2059936523 204.8155975342 205.1204071045205 .1204071045205 .1204071045204 .8155975342204 .5108032227 204.2059936523 203.2917022705 202.6820983887 201.7678070068 200.8533935547 199.6342926025198 .7198944092197 .500793457196 .5863952637195 .6721038818 194.7577056885193 .8433074951194 .7577056885197 .8054962158200 .8533935547 204.2059936523 -9999 -9999 -9999 -9999 -9999 -9999 -9999 -9999 -9999 -9999 -9999 -9999 -9999 -9999 -9999 -9999 -9999 -9999 -9999 -9999 -9999 -9999 -9999 -9999 -9999 -9999 -9999 -9999 -9999 -9999 -9999 -9999 -9999 -9999 -9999 -9999-9999 -9999 -9999 -9999 -9999 -9999 -9999 -9999 -9999 -9999 -9999 -9999 -9999 -9999 -9999 -9999 -9999 -9999 -9999 -9999 -9999 -

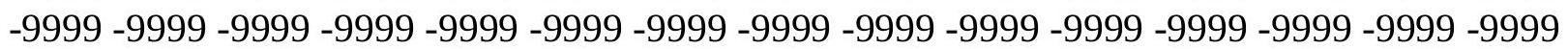


-9999 -9999 -9999 -9999 -9999 -9999 -9999 -9999 -9999 -9999 -9999 -9999 -9999 -9999 -9999 -9999 -9999 -9999 -9999 -9999 -9999 -9999 -9999 -9999 -9999 -9999 -9999 -9999 -9999 -9999 -9999 -9999 -9999 -9999 -9999 -9999 -9999 -9999 -9999 -9999 -9999 -9999 -9999 -9999 -9999 -9999 -9999-9999

-9999 -9999 -9999 -9999 -9999 -9999 -9999 -9999 -9999 -9999 -9999 -9999 -9999 -9999 -9999 -9999 -9999 -9999 -9999 -9999 -9999 -9999 -9999 -9999 -9999 -9999 -9999 -9999 -9999 -9999 -9999 -9999 -9999 -9999 -9999 -9999 -9999 -9999 -9999 -9999 -9999 -9999 -9999 -9999 -9999

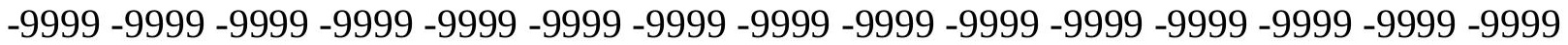

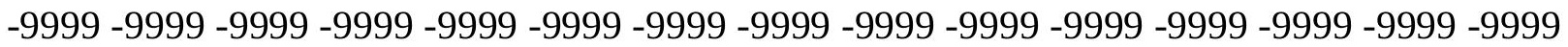
-9999 -9999 -9999 -9999 -9999 -9999 -9999 -9999 -9999 -9999 -9999 -9999 -9999 -9999 -9999 -

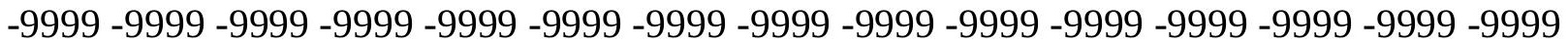
-9999 -9999 -9999 -9999 -9999 -9999 -9999 -9999 -9999 -9999 -9999 -9999 -9999 -9999 -9999

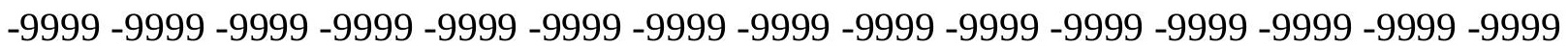
-9999 -9999 -9999 -9999 -9999 -9999 -9999 -9999 -9999 -9999 -9999 -9999 -9999 -9999 -9999 -9999 -9999 -9999 -9999 -9999 -9999 -9999 -9999 -9999 -9999 173.1179962158 173.1179962158173 .1179962158173 .4226989746173 .7274932861174 .337097168 174.6419067383175 .2514038086175 .8609924316176 .4705963135177 .0802001953 177.6896972656178 .2993011475178 .9089050293179 .2136993408179 .8231964111 180.1280059814180 .7375946045181 .0424041748181 .3471984863181 .3471984863 181.6519012451181 .6519012451181 .9566955566181 .9566955566181 .6519012451 181.6519012451181 .3471984863181 .0424041748180 .432800293180 .1280059814 179.5184020996178 .9089050293178 .2993011475177 .6896972656177 .0802001953 176.4705963135175 .8609924316175 .5561981201175 .2514038086174 .9467010498 174.9467010498174 .9467010498175 .5561981201175 .8609924316176 .7754058838 177.6896972656178 .9089050293180 .1280059814181 .6519012451182 .87109375 184.3950042725185 .9188995361187 .4429016113188 .966796875190 .4907073975 191.7097930908192 .9290008545194 .1481018066195 .3672943115196 .2816009521 197.1959991455198 .1103057861198 .7198944092199 .329498291199 .9389953613 200.2438049316200 .5485992432200 .8533935547201 .158203125201 .158203125 201.4629974365201 .4629974365201 .4629974365201 .7678070068202 .0724945068 202.0724945068202 .3773040771202 .6820983887203 .2917022705203 .596496582 204.2059936523204 .8155975342205 .425201416205 .7299957275206 .3394927979 206.6443023682 206.9490966797 207.25390625 207.25390625 207.25390625 206.9490966797 206.6443023682206 .0346984863205 .425201416204 .5108032227203 .596496582 202.6820983887 201.7678070068200.5485992432 199.6342926025 198.7198944092 197.500793457196 .5863952637195 .6721038818195 .0625194 .1481018066195 .3672943115 199.0247039795202 .9868927002207 .25390625 -9999 -9999 -9999 -9999 -9999 -9999 -9999 -9999 -9999 -9999 -9999 -9999 -9999 -9999 -9999 -9999 -9999 -9999 -9999 -9999 -9999 -9999 -9999 -9999 -9999 -9999 -9999 -9999 -9999 -9999 -9999 -9999 -9999 -9999 -9999 -9999 -9999 -9999 -9999 -9999 -9999 -9999 -9999 -9999 -9999 -9999 -9999 -9999 -9999 -9999 -9999 -9999 -9999 -9999 -9999 -9999 -9999 -9999 -9999 -9999 -9999 -9999 -9999 -9999 -9999 -9999 -9999 -9999 -9999 -9999 -9999 -9999 -9999 -9999 -9999 -9999 -9999 -9999 -9999 -9999 -9999 -9999 -9999 -9999 -9999 -9999 -9999 -9999 -9999 -9999 -9999 -9999 -9999 -9999 -9999 -9999 -9999 -9999 -9999 -9999 -9999 -9999 -9999 -9999 -9999 -9999 -9999 -9999 -9999 -9999 -9999 -9999 -9999 -9999 -9999 -9999-9999 -9999

-9999 -9999 -9999 -9999 -9999 -9999 -9999 -9999 -9999 -9999 -9999 -9999 -9999 -9999 -9999 
-9999 -9999 -9999 -9999 -9999 -9999 -9999 -9999 -9999 -9999 -9999 -9999 -9999 -9999 -9999 -9999 -9999 -9999 -9999 -9999 -9999 -9999 -9999 -9999 -9999 -9999 -9999 -9999 -9999 -9999 -9999 -9999 -9999 -9999 -9999 -9999 -9999 -9999 -9999 -9999 -9999 -9999 -9999 -9999 -9999 -9999 -9999 -9999 -9999 -9999 -9999 -9999 -9999 -9999 -9999 -9999 -9999 -9999 -9999 -9999 -9999 -9999 -9999 -9999 -9999 -9999 -9999 -9999 -9999 -9999 -9999 -9999 -9999 -9999 -9999 -9999 -9999 -9999 -9999 -9999 -9999 -9999 -9999 -9999 -9999 -9999 -9999 -9999 -9999 -9999 -9999 -9999 -9999 -9999 -9999 -9999 -9999 -9999 -9999 -9999 -9999 -9999 -9999 -9999 -9999

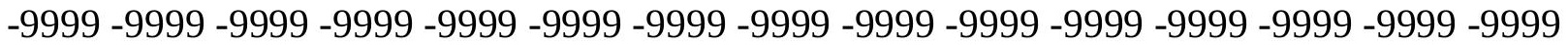
-9999 -9999 -9999 -9999 -9999 -9999 -9999 -9999 -9999 -9999 -9999 -9999 -9999 -9999 -9999 -9999 -9999 -9999 -9999 -9999-9999 -9999 -9999 -9999 170.3748931885170 .3748931885 170.070098877170 .070098877170 .3748931885170 .6797027588171 .2891998291 171.8988037109172 .5084075928173 .1179962158173 .7274932861174 .337097168 174.9467010498175 .8609924316176 .4705963135177 .0802001953177 .6896972656 177.9945068359178 .604095459178 .9089050293179 .5184020996179 .8231964111 180.1280059814180 .432800293180 .432800293180 .7375946045180 .7375946045 180.432800293180 .432800293180 .1280059814179 .8231964111179 .5184020996 178.9089050293178 .2993011475177 .6896972656177 .0802001953176 .4705963135 175.8609924316175 .5561981201174 .9467010498174 .6419067383174 .337097168 174.337097168174 .337097168174 .6419067383175 .2514038086176 .165802002 177.3849029541178 .604095459180 .1280059814181 .6519012451183 .1759033203 185.0045928955186 .528503418188 .3571929932189 .8811035156191 .4051055908 192.9290008545194 .1481018066195 .3672943115196 .5863952637197 .500793457 198.7198944092199 .329498291200 .2438049316200 .8533935547201 .4629974365 201.7678070068202 .3773040771202 .6820983887202 .9868927002203 .2917022705 203.596496582203 .596496582203 .9011993408204 .2059936523204 .5108032227 204.8155975342205 .1204071045205 .425201416206 .0346984863206 .3394927979 206.9490966797207 .5587005615207 .8634033203208 .4730072021208 .7778015137 208.7778015137208 .7778015137208 .7778015137208 .7778015137208 .7778015137 208.7778015137208 .7778015137208 .1681976318207 .5587005615206 .6443023682 206.0346984863204 .8155975342203 .9011993408202 .9868927002201 .7678070068 200.8533935547199 .6342926025198 .7198944092197 .8054962158197 .1959991455 196.2816009521195 .6721038818195 .0625197 .8054962158202 .3773040771206 .9490966797 211.2160949707 -9999 -9999 -9999 -9999 -9999 -9999 -9999 -9999 -9999 -9999 -9999 -9999 -9999 -9999 -9999 -9999 -9999 -9999 -9999 -9999 -9999 -9999 -9999 -9999 -9999 -9999 -9999

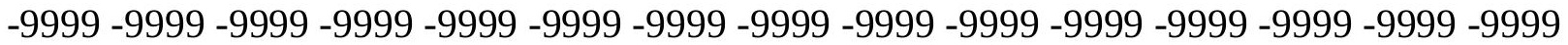
-9999 -9999 -9999 -9999 -9999 -9999 -9999 -9999 -9999 -9999 -9999 -9999 -9999 -9999 -9999

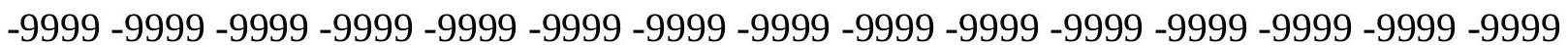

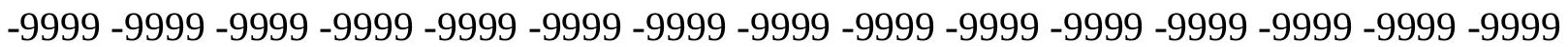

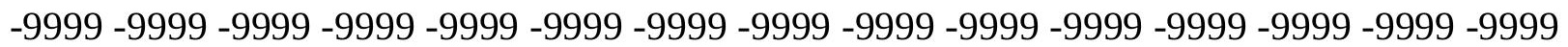
-9999 -9999 -9999 -9999 -9999 -9999 -9999 -9999 -9999 -9999 -9999 -9999 -9999 -9999 -9999 -9999 -9999 -9999 -9999 -9999 -9999 -9999 -9999 -9999 -9999 -9999 -9999 -9999 -9999

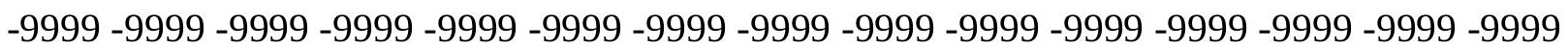
-9999 -9999 -9999 -9999 -9999 -9999 -9999 -9999 -9999 -9999 -9999 -9999 -9999 -9999 -9999 -9999 -9999 -9999 -9999 -9999 -9999 -9999 -9999 -9999 -9999 -9999 -9999 -9999 -9999 -9999 -9999 -9999 -9999 -9999 -9999 -9999 -9999 -9999 -9999 -9999 -9999 -9999 -9999 -9999 -9999

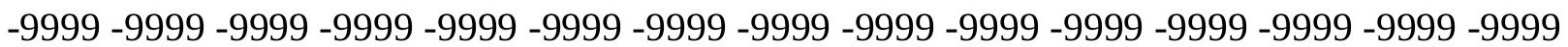


-9999 -9999 -9999 -9999 -9999 -9999 -9999 -9999 -9999 -9999 -9999 -9999 -9999 -9999 -9999 -9999 -9999 -9999 -9999 -9999 -9999 -9999 -9999 -9999 -9999 -9999 -9999 -9999 -9999 -9999 -9999 -9999 -9999 -9999 -9999 -9999 -9999 -9999 -9999 -9999 -9999 -9999 -9999 -9999 -9999 -9999 -9999 -9999 -9999 -9999 -9999 -9999 -9999 -9999 -9999 -9999 -9999 -9999 -9999 -9999 -9999 -9999 -9999 -9999 -9999 -9999 -9999 -9999 167.3269958496 167.3269958496 167.3269958496 167.3269958496167.0222015381 167.3269958496167.6318054199 168.241394043168 .8509979248169 .4604949951170 .070098877170 .9844970703 171.5939941406172 .5084075928173 .1179962158174 .0323028564174 .6419067383 175.2514038086175 .8609924316176 .4705963135177 .0802001953177 .3849029541 177.9945068359178 .2993011475178 .604095459178 .9089050293179 .2136993408 179.5184020996179 .5184020996179 .5184020996179 .5184020996179 .2136993408 178.604095459178 .2993011475177 .6896972656177 .0802001953176 .4705963135 175.8609924316175 .5561981201174 .9467010498174 .337097168174 .0323028564 173.7274932861173 .4226989746173 .4226989746173 .7274932861174 .6419067383 175.5561981201176 .7754058838178 .2993011475179 .8231964111181 .6519012451 183.4806976318185 .3094024658187 .1381072998188 .966796875190 .795501709 192.3193969727193 .8433074951195 .3672943115196 .5863952637197 .8054962158 198.7198944092199 .9389953613200 .8533935547201 .4629974365202 .3773040771 202.9868927002203 .596496582203 .9011993408204 .5108032227204 .8155975342 205.1204071045205 .7299957275206 .0346984863206 .3394927979206 .6443023682 206.9490966797207 .5587005615207 .8634033203208 .4730072021208 .7778015137 208.7778015137208 .7778015137208 .7778015137208 .7778015137208 .7778015137 208.7778015137208 .7778015137208 .7778015137208 .7778015137208 .7778015137 208.7778015137208 .7778015137208 .7778015137208 .7778015137208 .7778015137 208.7778015137208 .1681976318207 .25390625206 .3394927979205 .425201416 204.2059936523 203.2917022705 202.0724945068 201.158203125 200.2438049316 199.329498291 198.7198944092198.1103057861 197.500793457 197.1959991455 $197.1959991455202 .0724945068206 .6443023682209 .692199707212 .4351959229-9999$ -9999 -9999 -9999 -9999 -9999 -9999 -9999 -9999 -9999 -9999 -9999 -9999 -9999 -9999 -9999

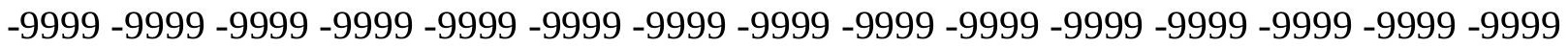
-9999 -9999 -9999 -9999 -9999 -9999 -9999 -9999 -9999 -9999 -9999 -9999 -9999 -9999 -9999 -

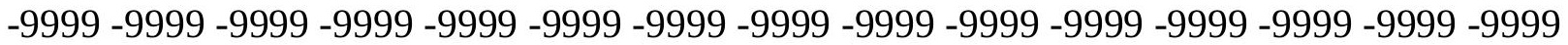
-9999 -9999 -9999 -9999 -9999 -9999 -9999 -9999 -9999 -9999 -9999 -9999 -9999 -9999 -9999 -9999 -9999 -9999 -9999 -9999 -9999 -9999 -9999 -9999 -9999 -9999 -9999 -9999 -9999 -9999 -

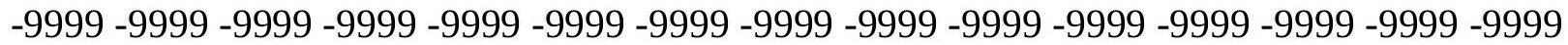
-9999 -9999 -9999 -9999 -9999 -9999-9999-9999

-9999 -9999 -9999 -9999 -9999 -9999 -9999 -9999 -9999 -9999 -9999 -9999 -9999 -9999 -9999

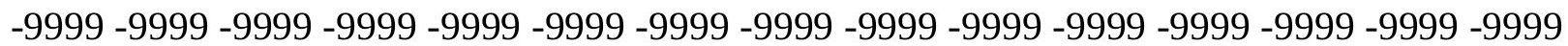
-9999 -9999 -9999 -9999 -9999 -9999 -9999 -9999 -9999 -9999 -9999 -9999 -9999 -9999 -9999 -9999 -9999 -9999 -9999 -9999 -9999 -9999 -9999 -9999 -9999 -9999 -9999 -9999 -9999 -9999 -

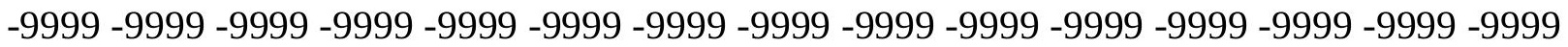
-9999 -9999 -9999 -9999 -9999 -9999 -9999 -9999 -9999 -9999 -9999 -9999 -9999 -9999 -9999 -9999 -9999 -9999 -9999 -9999 -9999 -9999 -9999 -9999 -9999 -9999 -9999 -9999 -9999 -9999 -9999 -9999 -9999 -9999 -9999 -9999 -9999 -9999 -9999 -9999 -9999 -9999 -9999 -9999 -9999 -999 -9999 -9999 -9999 -9999 -9999 -9999 -9999 -9999 -9999 -9999 -9999 -9999 -9999 -9999 -9999

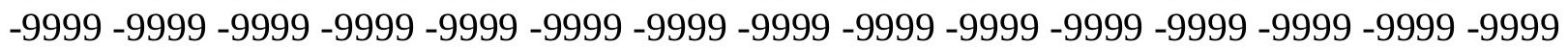


-9999 -9999 -9999 -9999 -9999 -9999-9999 164.5839996338164 .5839996338164 .5839996338 164.5839996338164 .5839996338164 .2792053223164 .2792053223164 .8887023926 165.1934967041165 .8031005859166 .7174987793167 .3269958496168 .241394043 168.8509979248169 .7653045654170 .6797027588171 .2891998291172 .2035980225 172.8132019043173 .4226989746174 .0323028564174 .6419067383175 .2514038086 175.8609924316176 .4705963135177 .0802001953177 .3849029541177 .6896972656 177.9945068359178 .2993011475178 .604095459178 .604095459178 .2993011475 177.9945068359177 .3849029541177 .0802001953176 .4705963135175 .8609924316 175.2514038086174 .9467010498174 .337097168173 .7274932861173 .1179962158 172.8132019043172 .5084075928172 .5084075928172 .8132019043173 .4226989746 174.337097168175 .8609924316177 .6896972656179 .5184020996181 .3471984863 183.4806976318185 .6141052246187 .7476043701189 .5764007568191 .4051055908 193.233795166194 .7577056885196 .2816009521197 .500793457198 .7198944092 199.9389953613200 .8533935547201 .7678070068202 .6820983887203 .596496582 204.2059936523204 .8155975342205 .7299957275206 .0346984863206 .6443023682 207.25390625207 .8634033203208 .1681976318208 .7778015137208 .7778015137 208.7778015137208 .7778015137208 .7778015137208 .7778015137208 .7778015137 208.7778015137208 .7778015137208 .7778015137208 .7778015137208 .7778015137 208.7778015137208 .7778015137208 .7778015137208 .7778015137208 .7778015137 208.7778015137208 .7778015137208 .7778015137208 .7778015137208 .7778015137 208.7778015137208 .7778015137208 .7778015137208 .7778015137207 .8634033203 206.9490966797205 .7299957275204 .8155975342203 .9011993408202 .9868927002 202.0724945068201 .158203125200 .5485992432199 .9389953613199 .6342926025 199.6342926025199 .6342926025200 .5485992432203 .9011993408206 .6443023682 209.3874053955 -9999 -9999 -9999 -9999 -9999 -9999 -9999 -9999 -9999 -9999 -9999 -9999 -9999 -9999 -9999 -9999 -9999 -9999 -9999 -9999 -9999 -9999 -9999 -9999 -9999 -9999 -9999 -9999 -9999 -9999 -9999 -9999 -9999 -9999 -9999 -9999 -9999 -9999 -9999 -9999 -9999 -9999

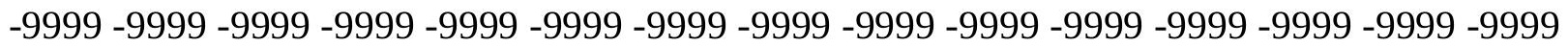
-9999 -9999 -9999 -9999 -9999 -9999 -9999 -9999 -9999 -9999 -9999 -9999 -9999 -9999 -9999 -9999 -9999 -9999 -9999 -9999 -9999 -9999 -9999 -9999 -9999 -9999 -9999 -9999 -9999 -9999 -9999 -9999 -9999 -9999 -9999 -9999 -9999 -9999 -9999 -9999 -9999 -9999 -9999 -9999 -9999 -9999 -9999 -9999 -9999 -9999 -9999 -9999 -9999 -9999 -9999 -9999

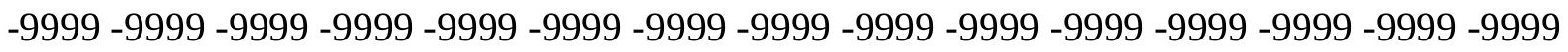
-9999 -9999 -9999 -9999 -9999 -9999 -9999 -9999 -9999 -9999 -9999 -9999 -9999 -9999 -9999 -9999 -9999 -9999 -9999 -9999 -9999 -9999 -9999 -9999 -9999 -9999 -9999 -9999 -9999 -9999

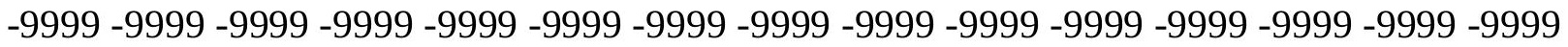

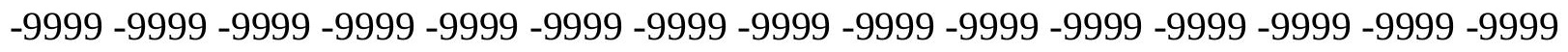

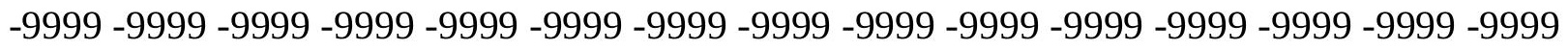
-9999 -9999 -9999 -9999 -9999 -9999 -9999 -9999 -9999 -9999 -9999 -9999 -9999 -9999 -9999 -9999 -9999 -9999 -9999 -9999 -9999 -9999 -9999 -9999 -9999 -9999 -9999 -9999 -9999 -9999 -

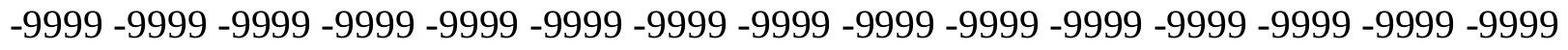

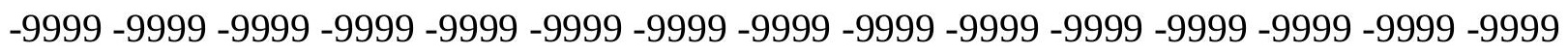
-9999 -9999 -9999 -9999 -9999 -9999 -9999 161.8408966064 161.8408966064161 .8408966064 161.8408966064161 .5361022949161 .5361022949161 .5361022949161 .8408966064 162.4505004883163 .0599975586163 .6696014404164 .5839996338165 .1934967041 166.1078948975167 .0222015381167 .9365997314168 .8509979248169 .4604949951 
170.3748931885170 .9844970703171 .5939941406172 .5084075928173 .1179962158 173.7274932861174 .337097168174 .9467010498175 .5561981201176 .165802002 176.7754058838177 .0802001953177 .3849029541177 .3849029541177 .3849029541 177.0802001953176 .4705963135175 .8609924316175 .2514038086174 .9467010498 174.337097168174 .0323028564173 .4226989746172 .8132019043172 .2035980225 171.5939941406170 .9844970703170 .9844970703170 .9844970703171 .8988037109 173.1179962158174 .6419067383176 .7754058838178 .9089050293181 .0424041748 183.4806976318185 .6141052246188 .0523986816189 .8811035156192 .0146026611 193.8433074951195 .3672943115196 .891204834198 .4151000977199 .6342926025 200.8533935547201 .7678070068202 .9868927002203 .9011993408204 .8155975342 205.7299957275206 .3394927979207 .25390625207 .8634033203208 .4730072021 208.7778015137208 .7778015137208 .7778015137208 .7778015137208 .7778015137 208.7778015137208 .7778015137208 .7778015137208 .7778015137208 .7778015137 208.7778015137208 .7778015137208 .7778015137208 .7778015137208 .7778015137 208.7778015137208 .7778015137208 .7778015137208 .7778015137208 .7778015137 208.7778015137 208.7778015137208.7778015137 208.7778015137 208.7778015137 208.7778015137208 .7778015137208 .7778015137208 .7778015137208 .7778015137 208.7778015137208 .4730072021207 .5587005615206 .6443023682205 .7299957275 204.8155975342203 .9011993408203 .2917022705202 .6820983887202 .3773040771 202.0724945068201 .7678070068201 .158203125200 .2438049316200 .8533935547 203.9011993408206 .6443023682209 .3874053955 -9999 -9999 -9999 -9999 -9999 -9999 -9999

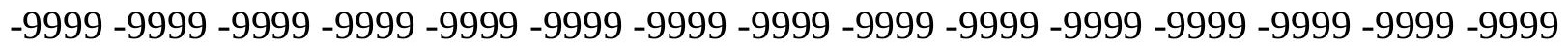
-9999 -9999 -9999 -9999 -9999 -9999 -9999 -9999 -9999 -9999 -9999 -9999 -9999 -9999 -9999 -9999 -9999 -9999 -9999 -9999 -9999 -9999 -9999 -9999 -9999 -9999 -9999 -9999 -9999 -9999 -9999 -9999 -9999 -9999 -9999 -9999 -9999 -9999 -9999 -9999 -9999 -9999 -9999 -9999 -9999 -9999 -9999 -9999 -9999 -9999 -9999 -9999 -9999 -9999 -9999 -9999 -9999 -9999 -9999 -9999

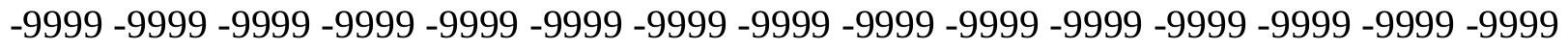
-9999 -9999 -9999 -9999 -9999 -9999 -9999 -9999 -9999 -9999 -9999 -9999 -9999 -9999 -999 -9999 -9999 -9999 -9999 -9999 -9999 -9999 -9999 -9999 -9999 -9999 -9999 -9999 -9999 -9999 -9999 -9999 -9999 -9999 -9999 -9999 -9999 -9999 -9999 -9999 -9999 -9999 -9999 -9999 -9999 -9999 -9999 -9999 -9999 -9999 -9999 -9999 -9999 -9999 -9999 -9999 -9999 -9999 -9999 -9999

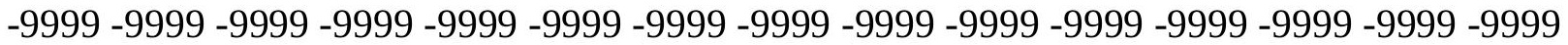
-9999 -9999 -9999 -9999 -9999 -9999 -9999 -9999 -9999 -9999 -9999 -9999 -9999 -9999 -9999 -9999 -9999 -9999 -9999 -9999 -9999 -9999 -9999 -9999 -9999 -9999 -9999 -9999 -9999 -9999 -9999 -9999 -9999 -9999 -9999 -9999 -9999 -9999 -9999 -9999 -9999 -9999 -9999 -9999 -9999 -9999 -9999 -9999 -9999 -9999 -9999 -9999 -9999 -9999 -9999 -9999 -9999 -9999 -9999 -9999

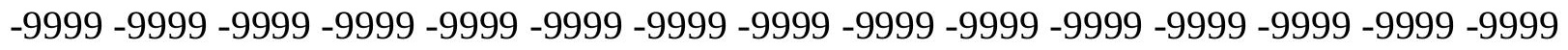

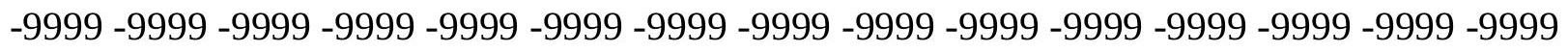
-9999 -9999-9999 -9999 -9999-9999 159.0977935791 159.0977935791 159.0977935791 159.0977935791159 .0977935791158 .7929992676158 .7929992676158 .4882965088 158.7929992676159 .4026031494160 .0122070312160 .6217956543161 .5361022949 162.4505004883163 .3648071289164 .2792053223165 .1934967041166 .1078948975 166.7174987793167 .6318054199168 .241394043169 .1557006836169 .7653045654 170.6797027588171 .2891998291171 .8988037109172 .8132019043173 .4226989746 174.337097168 174.9467010498175.5561981201 175.8609924316176 .165802002 176.165802002175 .5561981201175 .2514038086174 .337097168173 .7274932861 
173.4226989746173 .1179962158172 .8132019043172 .5084075928171 .8988037109 170.9844970703170 .070098877169 .1557006836168 .8509979248168 .8509979248 169.7653045654170 .9844970703173 .1179962158175 .5561981201177 .9945068359 180.432800293183 .1759033203185 .6141052246188 .0523986816190 .1858978271 192.3193969727194 .1481018066195 .9768066406197 .500793457199 .0247039795 200.2438049316201 .4629974365202 .6820983887203 .9011993408204 .8155975342 205.7299957275206 .6443023682207 .5587005615208 .4730072021208 .7778015137 208.7778015137208 .7778015137208 .7778015137208 .7778015137208 .7778015137 208.7778015137208 .7778015137208 .7778015137208 .7778015137208 .7778015137 208.7778015137208 .7778015137208 .7778015137208 .7778015137208 .7778015137 208.7778015137208 .7778015137208 .7778015137208 .7778015137208 .7778015137 208.7778015137208 .7778015137208 .7778015137208 .7778015137208 .7778015137 208.7778015137208 .7778015137208 .7778015137208 .7778015137208 .7778015137 208.7778015137208 .7778015137208 .7778015137208 .7778015137208 .7778015137 208.4730072021207 .5587005615206 .6443023682206 .0346984863205 .425201416 204.8155975342204 .2059936523203 .596496582202 .9868927002201 .7678070068 200.5485992432199 .329498291201 .158203125203 .596496582206 .0346984863 208.4730072021 -9999 -9999 -9999 -9999 -9999 -9999 -9999 -9999 -9999 -9999 -9999 -9999 -9999 -9999 -9999 -9999 -9999 -9999 -9999 -9999 -9999 -9999 -9999 -9999 -9999 -9999 -9999 -9999 -9999 -9999 -9999 -9999 -9999 -9999 -9999 -9999 -9999 -9999 -9999 -9999 -9999 -9999

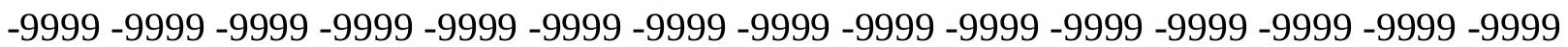
-9999 -9999 -9999 -9999 -9999 -9999 -9999 -9999 -9999 -9999 -9999 -9999 -9999 -9999 -9999 -9999 -9999 -9999 -9999 -9999 -9999 -9999 -9999 -9999 -9999 -9999 -9999 -9999 -9999 -9999 -9999 -9999 -9999 -9999 -9999 -9999 -9999 -9999 -9999 -9999 -9999 -9999 -9999 -9999 -9999 -9999 -9999 -9999 -9999 -9999 -9999 -9999

-9999 -9999 -9999 -9999 -9999 -9999 -9999 -9999 -9999 -9999 -9999 -9999 -9999 -9999 -9999 -9999 -9999 -9999 -9999 -9999 -9999 -9999 -9999 -9999 -9999 -9999 -9999 -9999 -9999 -9999 -9999 -9999 -9999 -9999 -9999 -9999 -9999 -9999 -9999 -9999 -9999 -9999 -9999 -9999 -9999 -9999 -9999 -9999 -9999 -9999 -9999 -9999 -9999 -9999 -9999 -9999 -9999 -9999 -9999 -9999 -9999 -9999 -9999 -9999 -9999 -9999 -9999 -9999 -9999 -9999 -9999 -9999 -9999 -9999 -9999 -9999 -9999 -9999 -9999 -9999 -9999 -9999 -9999 -9999 -9999 -9999 -9999 -9999 -9999 -9999 -9999 -9999 -9999 -9999 -9999 -9999 -9999 -9999 -9999 -9999 -9999 -9999 -9999 -9999 -9999 -9999 -9999 -9999 -9999 -9999 -9999 -9999 -9999 -9999 -9999 -9999 -9999 -9999 -9999 -9999 -9999 -9999 -9999 -9999 -9999 -9999 -9999 -9999 -9999 -9999 -9999 -9999 -9999 -9999 -9999 -9999 -9999 -9999 -9999 -9999 -9999 -9999 -9999 -9999 -9999 -9999 -9999 -9999 -9999 -9999 -9999 -9999 -9999 -9999 -9999 156.6596069336156.6596069336156.6596069336 156.6596069336156 .3547973633156 .3547973633156 .0500030518156 .0500030518 155.7451934814156 .0500030518156 .3547973633156 .9642944336157 .878692627 158.7929992676159 .7073974609160 .6217956543161 .5361022949162 .4505004883 163.3648071289163 .974395752164 .8887023926165 .4983062744166 .4127044678 167.0222015381167 .9365997314168 .5462036133169 .4604949951170 .070098877 170.9844970703171 .8988037109172 .8132019043173 .4226989746174 .0323028564 174.337097168174 .337097168174 .0323028564173 .1179962158172 .2035980225 171.5939941406170 .9844970703170 .9844970703170 .9844970703170 .9844970703 170.3748931885169 .4604949951167 .9365997314166 .7174987793165 .8031005859 165.8031005859166 .7174987793168 .5462036133170 .9844970703173 .7274932861 
176.7754058838179 .5184020996182 .5662994385185 .3094024658187 .7476043701 190.1858978271192 .3193969727194 .1481018066195 .9768066406197 .8054962158 199.329498291200 .5485992432202 .0724945068203 .2917022705204 .5108032227 205.425201416206 .6443023682207 .5587005615208 .7778015137208 .7778015137 208.7778015137208 .7778015137208 .7778015137208 .7778015137208 .7778015137 208.7778015137208 .7778015137208 .7778015137208 .7778015137208 .7778015137 208.7778015137208 .7778015137208 .7778015137208 .7778015137208 .7778015137 208.7778015137208 .7778015137208 .7778015137208 .7778015137208 .7778015137 208.7778015137208 .7778015137208 .7778015137208 .7778015137208 .7778015137 208.7778015137208 .7778015137208 .7778015137208 .7778015137208 .7778015137 208.7778015137208 .7778015137208 .7778015137208 .7778015137208 .7778015137 208.7778015137208.7778015137208.7778015137208.7778015137208.7778015137 207.8634033203207 .25390625206 .3394927979205 .7299957275204 .8155975342 203.596496582202 .3773040771201 .158203125199 .6342926025198 .1103057861 200.5485992432202 .9868927002205 .1204071045 -9999 -9999 -9999 -9999 -9999 -9999 -9999 -9999 -9999 -9999 -9999 -9999 -9999 -9999 -9999 -9999 -9999 -9999 -9999 -9999 -9999 -9999

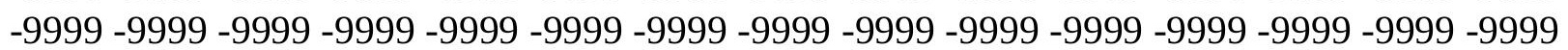
-9999 -9999 -9999 -9999 -9999 -9999 -9999 -9999 -9999 -9999 -9999 -9999 -9999 -9999 -9999 -999 -9999 -9999 -9999 -9999 -9999 -9999 -9999 -9999 -9999 -9999 -9999 -9999 -9999 -9999 -9999 -9999 -9999 -9999 -9999 -9999 -9999 -9999 -9999 -9999 -9999 -9999 -9999 -9999 -9999 -9999

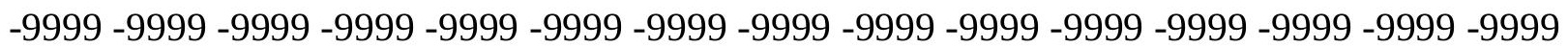
-9999 -9999 -9999 -9999 -9999 -9999 -9999 -9999 -9999 -9999 -9999 -9999 -9999 -9999 -9999 -9999 -9999 -9999 -9999 -9999 -9999 -9999 -9999 -9999 -9999 -9999 -9999 -9999 -9999 -9999 -9999 -9999 -9999 -9999 -9999 -9999 -9999 -9999 -9999 -9999 -9999

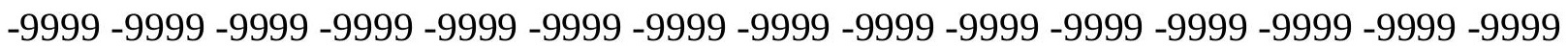
-9999 -9999 -9999 -9999 -9999 -9999 -9999 -9999 -9999 -9999 -9999 -9999 -9999 -9999 -9999 -9999 -9999 -9999 -9999 -9999 -9999 -9999 -9999 -9999 -9999 -9999 -9999 -9999 -9999 -9999 -9999 -9999 -9999 -9999 -9999 -9999 -9999 -9999 -9999 -9999 -9999 -9999 -9999 -9999 -9999

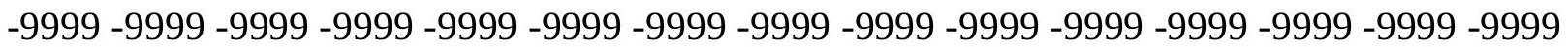

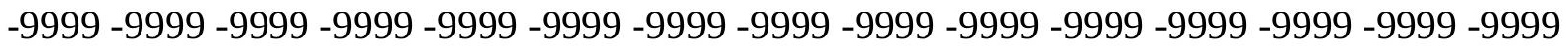
-9999 -9999 -9999 -9999 -9999 -9999 -9999 -9999 -9999 -9999 -9999 -9999 -9999 -9999 -9999 -9999 -9999 -9999 -9999 -9999 -9999 -9999 -9999 -9999 -9999 -9999 -9999 -9999 -9999 -9999 -9999 -9999 -9999 -9999 154.2212982178 154.2212982178154 .2212982178153 .9165039062 153.9165039062153 .9165039062153 .6116943359153 .6116943359153 .3069000244 153.0021057129153 .0021057129153 .3069000244154 .2212982178155 .1356048584 156.0500030518156 .9642944336157 .878692627158 .7929992676159 .7073974609 160.3170013428161 .2312927246161 .8408966064162 .7552947998163 .3648071289 163.974395752164 .8887023926165 .4983062744166 .4127044678167 .0222015381 168.241394043169 .1557006836170 .3748931885171 .2891998291172 .2035980225 172.5084075928172 .2035980225171 .5939941406170 .3748931885169 .1557006836 167.9365997314167 .6318054199167 .6318054199168 .241394043168 .8509979248 168.5462036133167 .3269958496165 .1934967041163 .3648071289161 .8408966064 161.8408966064162 .7552947998164 .8887023926167 .9365997314171 .2891998291 174.9467010498178 .2993011475181 .3471984863184 .3950042725187 .1381072998 189.5764007568192 .0146026611194 .1481018066195 .9768066406197 .8054962158 199.329498291200.8533935547202.0724945068203.596496582 204.8155975342 
206.0346984863207 .25390625208 .4730072021208 .7778015137208 .7778015137 208.7778015137208 .7778015137208 .7778015137208 .7778015137208 .7778015137 208.7778015137208 .7778015137208 .7778015137208 .7778015137208 .7778015137 208.7778015137208 .7778015137208 .7778015137208 .7778015137208 .7778015137 208.7778015137208 .7778015137208 .7778015137208 .7778015137208 .7778015137 208.7778015137208 .7778015137208 .7778015137208 .7778015137208 .7778015137 208.7778015137208 .7778015137208 .7778015137208 .7778015137208 .7778015137 208.7778015137208 .7778015137208 .7778015137208 .7778015137208 .7778015137 208.7778015137208 .7778015137208 .7778015137208 .7778015137208 .7778015137 208.7778015137208 .7778015137208 .7778015137207 .8634033203206 .6443023682 205.425201416204 .2059936523202 .6820983887201 .158203125199 .6342926025 198.1103057861197 .500793457199 .6342926025201 .7678070068203 .9011993408 -9999 -9999 -9999 -9999 -9999 -9999 -9999 -9999 -9999 -9999 -9999 -9999 -9999 -9999 -9999 -9999 -9999 -9999 -9999 -9999 -9999 -9999 -9999 -9999 -9999 -9999 -9999 -9999 -9999 -9999 -9999 -9999 -9999 -9999 -9999 -9999 -9999 -9999 -9999 -9999 -9999 -9999 -9999 -9999 -9999 -9999 -9999 -9999 -9999 -9999 -9999 -9999 -9999 -9999 -9999 -9999 -9999 -9999 -9999 -9999 -9999 -

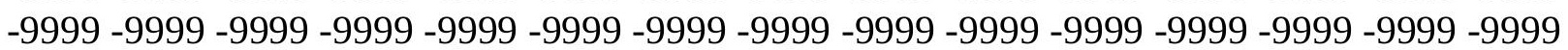
-9999 -9999 -9999 -9999 -9999 -9999 -9999 -9999 -9999 -9999 -9999 -9999 -9999 -9999 -9999 -9999 -9999 -9999 -9999 -9999 -9999 -9999 -9999 -9999 -9999 -9999 -9999 -9999 -9999 -9999 -9999 -9999 -9999 -9999 -9999 -9999 -9999 -9999 -9999 -9999 -9999 -9999 -9999 -9999 -9999

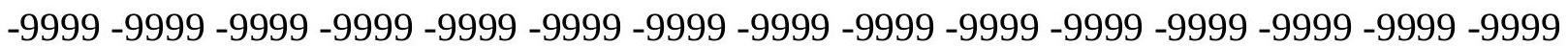
-9999 -9999 -9999 -9999 -9999 -9999 -9999 -9999 -9999 -9999 -9999 -9999 -9999 -9999 -9999 -9999 -9999 -9999 -9999 -9999 -9999 -9999 -9999 -9999 -9999 -9999 -9999 -9999 -9999 -9999 -9999 -9999 -9999 -9999 -9999 -9999 -9999 -9999 -9999 -9999 -9999 -9999 -9999 -9999 -9999

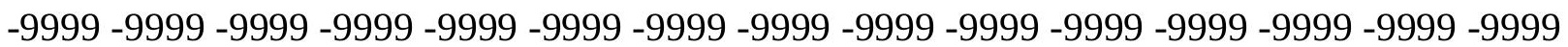
-9999 -9999 -9999 -9999 -9999 -9999 -9999 -9999 -9999 -9999 -9999 -9999 -9999 -9999 -9999 -9999 -9999 -9999 -9999 -9999 -9999 -9999 -9999 -9999 -9999 -9999 -9999 -9999 -9999 -9999 -9999 -9999 -9999 -9999 -9999 -9999 -9999 -9999 -9999 -9999 -9999 -9999 -9999 -9999 -9999 -9999 -9999 -9999 -9999 -9999 -9999 -9999 -9999 -9999 -9999 -9999 -9999 -9999 -9999 -9999 -9999 -9999 -9999 -9999 151.7830047607 151.4781951904151 .4781951904151 .4781951904 151.4781951904151 .1734008789151 .1734008789150 .8686065674150 .5639038086 150.2590942383150 .2590942383150 .5639038086151 .1734008789152 .3925933838 153.3069000244154 .2212982178155 .1356048584156 .0500030518156 .6596069336 157.5738983154158 .1835021973158 .7929992676159 .7073974609160 .3170013428 160.9264984131161 .5361022949162 .1457061768163 .0599975586163 .6696014404 164.8887023926166 .1078948975167 .3269958496168 .8509979248169 .7653045654 170.070098877169 .7653045654168 .5462036133166 .7174987793164 .8887023926 163.0599975586162 .4505004883162 .7552947998163 .974395752165 .4983062744 165.8031005859164 .2792053223161 .5361022949158 .4882965088156 .6596069336 156.3547973633157 .5738983154160 .6217956543164 .2792053223168 .5462036133 172.5084075928176 .4705963135179 .8231964111183 .1759033203186 .2236938477 188.6620025635191 .1002960205193 .5386047363195 .3672943115197 .1959991455 199.0247039795200 .5485992432201 .7678070068203 .2917022705204 .8155975342 206.0346984863207 .5587005615208 .7778015137208 .7778015137208 .7778015137 208.7778015137208 .7778015137208 .7778015137208 .7778015137208 .7778015137 208.7778015137208 .7778015137208 .7778015137208 .7778015137208 .7778015137 
208.7778015137208 .7778015137208 .7778015137208 .7778015137208 .7778015137 208.7778015137208 .7778015137208 .7778015137208 .7778015137208 .7778015137 208.7778015137208 .7778015137208 .7778015137208 .7778015137208 .7778015137 208.7778015137208 .7778015137208 .7778015137208 .7778015137208 .7778015137 208.7778015137208 .7778015137208 .7778015137208 .7778015137208 .7778015137 208.7778015137208 .7778015137208 .7778015137208 .7778015137208 .7778015137 208.7778015137208 .7778015137208 .7778015137208 .7778015137208 .7778015137 207.5587005615206 .0346984863204 .5108032227202 .9868927002201 .4629974365 199.6342926025198 .1103057861196 .5863952637197 .1959991455199 .329498291 202.0724945068 204.8155975342 -9999 -9999 -9999 -9999 -9999 -9999 -9999 -9999 -9999 -9999 -9999 -9999 -9999 -9999 -9999 -9999 -9999 -9999 -9999 -9999 -9999 -9999 -9999 -9999 -9999 -9999 -9999 -9999 -9999 -9999 -9999 -9999 -9999 -9999 -9999 -9999 -9999 -9999 -9999 -9999 -9999 -9999 -9999 -9999 -9999 -9999 -9999 -9999 -9999 -9999 -9999 -9999 -9999 -9999 -9999 -9999 -9999 -9999 -9999 -9999 -9999 -9999 -9999 -9999 -9999 -9999 -9999 -9999 -9999 -9999 -9999 -9999 -9999 -9999 -9999 -9999 -9999 -9999 -9999 -9999 -9999 -9999 -9999 -9999

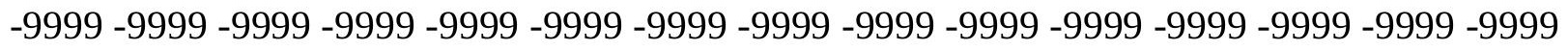
-9999 -9999-9999-9999-9999

-9999 -9999 -9999 -9999 -9999 -9999 -9999 -9999 -9999 -9999 -9999 -9999 -9999 -9999 -9999 -9999 -9999 -9999 -9999 -9999 -9999 -9999 -9999 -9999 -9999 -9999 -9999 -9999 -9999 -9999 -

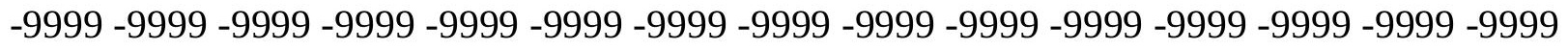
-9999 -9999 -9999 -9999 -9999 -9999 -9999 -9999 -9999 -9999 -9999 -9999 -9999 -9999 -9999 -9999 -9999 -9999 -9999 -9999 -9999 -9999 -9999 -9999 -9999 -9999 -9999 -9999 -9999 -9999 -9999 -9999 -9999 -9999 -9999 -9999 -9999 -9999 -9999 -9999 -9999 -9999 -9999 -9999 -9999 -9999 -9999 -9999 -9999 -9999 -9999 -9999 -9999 -9999 -9999 -9999 -9999 -9999 -9999 -9999 -9999 -9999 -9999 -9999 -9999 -9999 -9999 -9999 -9999 -9999 -9999 -9999 -9999 -9999 -9999 -9999 -9999 -9999 -9999 -9999 -9999 -9999 -9999 -9999 -9999 -9999 -9999 -9999 -9999 -9999 -9999 -9999 -9999 -9999 -9999 -9999 -9999 -9999 -9999 -9999 -9999 -9999 -9999 -9999 -9999 -9999 -9999-9999 149.6495056152149.6495056152149.3446960449 149.3446960449 149.3446960449149 .0399017334149 .0399017334148 .7351074219148 .4304046631 148.1255950928147 .8208007812147 .5160064697147 .8208007812148 .7351074219 149.6495056152150 .5639038086151 .4781951904152 .3925933838153 .0021057129 153.9165039062154 .5260925293155 .1356048584155 .7451934814156 .3547973633 156.9642944336157 .5738983154157 .878692627158 .4882965088159 .0977935791 160.0122070312160 .9264984131162 .4505004883163 .974395752165 .8031005859 167.0222015381167 .3269958496166 .7174987793164 .8887023926162 .1457061768 159.0977935791156 .3547973633155 .1356048584155 .1356048584157 .2691040039 160.3170013428162 .1457061768160 .0122070312155 .7451934814151 .7830047607 149.6495056152149 .3446960449151 .4781951904155 .1356048584160 .0122070312 165.1934967041169 .7653045654174 .0323028564177 .6896972656181 .3471984863 184.3950042725187 .1381072998189 .8811035156192 .3193969727194 .4528961182 196.2816009521198 .1103057861199 .6342926025201 .158203125202 .6820983887 204.2059936523 205.7299957275 207.25390625 208.7778015137208.7778015137 208.7778015137208 .7778015137208 .7778015137208 .7778015137208 .7778015137 208.7778015137208 .7778015137208 .7778015137208 .7778015137208 .7778015137 208.7778015137208 .7778015137208 .7778015137208 .7778015137208 .7778015137 208.7778015137 208.7778015137208.7778015137 208.7778015137 208.7778015137 
208.7778015137208 .7778015137208 .7778015137208 .7778015137208 .7778015137 208.7778015137208 .7778015137208 .7778015137208 .7778015137208 .7778015137 208.7778015137208 .7778015137208 .7778015137208 .7778015137208 .7778015137 208.7778015137208 .7778015137208 .7778015137208 .7778015137208 .7778015137 208.7778015137208 .7778015137208 .7778015137208 .7778015137208 .7778015137 208.7778015137208 .7778015137208 .1681976318206 .3394927979204 .8155975342 203.2917022705 201.4629974365 199.9389953613198.1103057861 196.891204834 195.9768066406197 .500793457200 .2438049316202 .6820983887 -9999 -9999 -9999 -9999 -9999 -9999 -9999 -9999 -9999 -9999 -9999 -9999 -9999 -9999 -9999 -9999 -9999 -9999 -9999 -9999 -9999 -9999 -9999 -9999 -9999 -9999 -9999 -9999 -9999 -9999 -9999 -9999 -9999 -9999 -

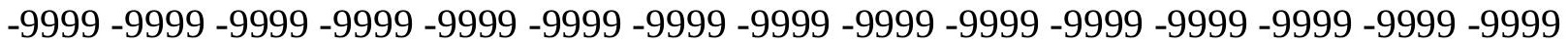
-9999 -9999 -9999 -9999 -9999 -9999 -9999 -9999 -9999 -9999 -9999 -9999 -9999 -9999 -9999 -999 -9999 -9999 -9999 -9999 -9999 -9999 -9999 -9999 -9999 -9999 -9999 -9999 -9999 -9999 -9999 -9999 -9999 -9999 -9999 -9999 -9999 -9999 -9999 -9999 -9999 -9999 -9999 -9999 -9999 -9999 -9999 -9999 -9999 -9999 -9999 -9999 -9999 -9999 -9999

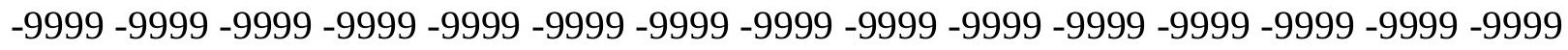

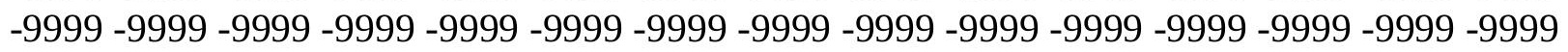

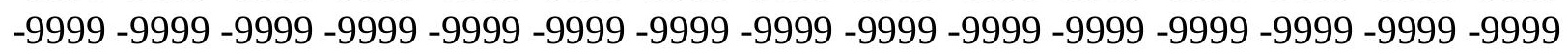
-9999 -9999 -9999 -9999 -9999 -9999 -9999 -9999 -9999 -9999 -9999 -9999 -9999 -9999 -9999 -999 -

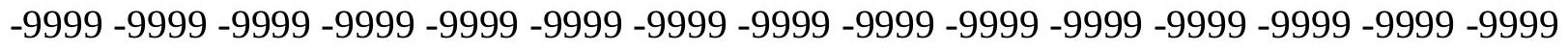

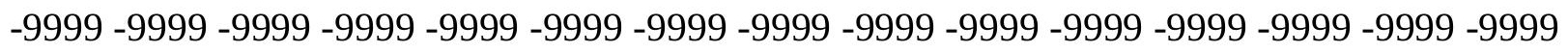

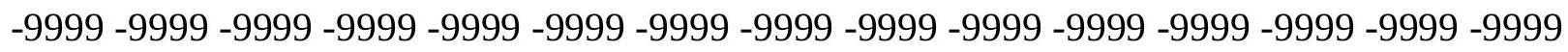
-9999 -9999 -9999 -9999 -9999 -9999 -9999 -9999 -9999 -9999 -9999 -9999 -9999 -9999 -9999 -

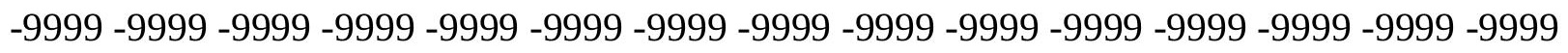

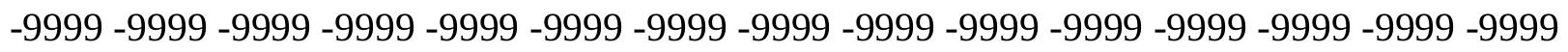
-9999-9999 148.4304046631 148.4304046631 148.4304046631 148.4304046631 148.4304046631148 .1255950928148 .1255950928147 .8208007812147 .5160064697 147.5160064697147 .2111968994146 .9064025879146 .2969055176145 .9920959473 146.6015930176147 .2111968994148 .1255950928149 .0399017334149 .6495056152 150.2590942383150 .8686065674151 .4781951904152 .0877990723152 .3925933838 153.0021057129153 .3069000244153 .9165039062154 .2212982178154 .5260925293 154.8307952881155 .4403991699156 .6596069336158 .1835021973160 .3170013428 162.1457061768163 .974395752164 .5839996338163 .3648071289160 .3170013428 156.0500030518151 .7830047607148 .1255950928145 .6873016357145 .0776977539 147.2111968994151 .4781951904156 .6596069336152 .0877990723147 .5160064697 143.5538024902141 .1154937744141 .1154937744143 .8585968018149 .3446960449 155.4403991699161 .2312927246166 .4127044678170 .9844970703174 .9467010498 178.604095459181 .9566955566185 .0045928955188 .0523986816190 .4907073975 192.624206543194 .7577056885196 .5863952637198 .4151000977199 .9389953613 201.7678070068203 .2917022705205 .1204071045206 .9490966797208 .7778015137 208.7778015137208 .7778015137208 .7778015137208 .7778015137208 .7778015137 208.7778015137208 .7778015137208 .7778015137208 .7778015137208 .7778015137 208.7778015137208 .7778015137208 .7778015137208 .7778015137208 .7778015137 208.7778015137208 .7778015137208 .7778015137208 .7778015137208 .7778015137 208.7778015137208 .7778015137208 .7778015137208 .7778015137208 .7778015137 208.7778015137 208.7778015137208.7778015137 208.7778015137 208.7778015137 
208.7778015137208 .7778015137208 .7778015137208 .7778015137208 .7778015137 208.7778015137208 .7778015137208 .7778015137208 .7778015137208 .7778015137 208.7778015137208 .7778015137208 .7778015137208 .7778015137208 .7778015137 208.7778015137208 .7778015137208 .7778015137208 .7778015137208 .4730072021 206.6443023682205 .1204071045203 .2917022705201 .4629974365199 .9389953613 198.7198944092197 .500793457195 .9768066406195 .6721038818198 .1103057861 200.8533935547 -9999 -9999 -9999 -9999 -9999 -9999 -9999 -9999 -9999 -9999 -9999 -9999 -9999 -9999 -9999 -9999 -9999 -9999 -9999 -9999 -9999 -9999 -9999 -9999 -9999 -9999 -9999 -9999 -9999 -9999 -9999 -9999 -9999 -9999 -9999 -9999 -9999 -9999 -9999 -9999 -9999 -9999 -9999 -9999 -9999 -9999 -9999 -9999 -9999 -9999 -9999 -9999 -9999 -9999 -9999 -9999 -9999 -9999 -9999 -9999 -9999 -9999 -9999 -9999 -9999 -9999 -9999 -9999 -9999 -9999 -9999 -9999 -9999 -9999 -9999 -9999 -9999 -9999 -9999 -9999 -9999 -9999 -9999 -9999 -9999 -9999 -9999 -9999 -9999 -9999 -9999 -9999 -9999 -9999 -9999 -9999 -9999 -9999 -9999 -9999 -9999 -9999 -9999 -9999 -9999 -9999 -9999 -9999 -9999 -9999 -9999 -9999 -9999 -9999 -9999 -9999 -9999 -9999 -9999 -9999 -9999 -9999 -9999 -9999 -9999 -9999 -9999 -9999 -9999 -9999 -9999 -9999

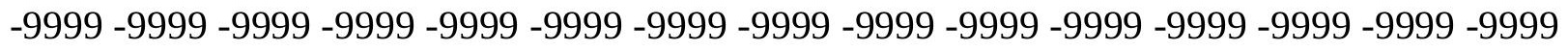

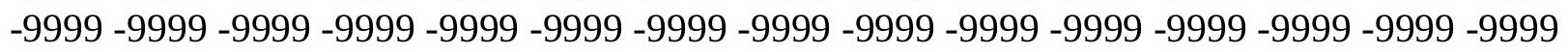

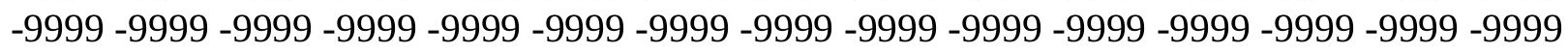

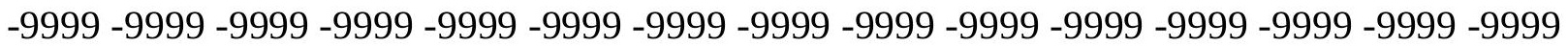

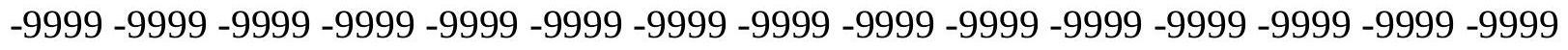

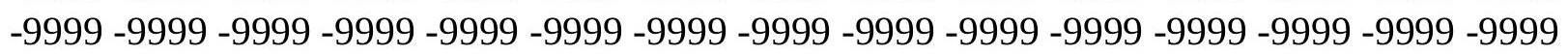

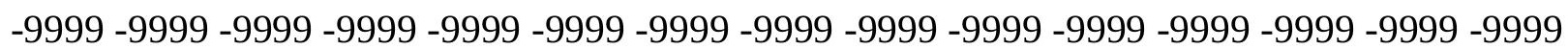
-9999 -9999 -9999 -9999 -9999 -9999 -9999 -9999 -9999 -9999 -9999 -9999 -9999 -9999 -9999 -9999 147.5160064697 147.5160064697 147.5160064697 147.5160064697 147.5160064697 147.2111968994147 .2111968994146 .9064025879146 .9064025879146 .6015930176 146.2969055176145 .9920959473145 .6873016357145 .3825073242144 .7729034424 144.4682006836145 .0776977539145 .6873016357146 .2969055176146 .9064025879 147.2111968994147 .8208007812148 .4304046631148 .7351074219149 .0399017334 149.6495056152149 .6495056152149 .9542999268149 .9542999268149 .9542999268 150.2590942383150 .5639038086151 .7830047607153 .3069000244155 .7451934814 158.1835021973160 .3170013428160 .9264984131159 .0977935791154 .8307952881 149.0399017334142 .9441986084138 .0677032471134 .4102020264132 .8863067627 134.1054992676137 .4580993652140 .2012023926139 .8963928223137 .4580993652 134.4102020264131 .9720001221131 .9720001221136 .2389984131143 .2489929199 150.5639038086157 .2691040039162 .7552947998167 .0222015381170 .9844970703 174.9467010498178 .604095459182 .261505127185 .6141052246188 .3571929932 190.4907073975192 .624206543194 .4528961182196 .2816009521198 .1103057861 199.9389953613201 .7678070068203 .9011993408206 .0346984863208 .1681976318 208.7778015137208 .7778015137208 .7778015137208 .7778015137208 .7778015137 208.7778015137208 .7778015137208 .7778015137208 .7778015137208 .7778015137 208.7778015137208 .7778015137208 .7778015137208 .7778015137208 .7778015137 208.7778015137208 .7778015137208 .7778015137208 .7778015137208 .7778015137 208.7778015137208 .7778015137208 .7778015137208 .7778015137208 .7778015137 208.7778015137208 .7778015137208 .7778015137208 .7778015137208 .7778015137 208.7778015137208 .7778015137208 .7778015137208 .7778015137208 .7778015137 208.7778015137 208.7778015137208.7778015137 208.7778015137 208.7778015137 
208.7778015137208 .7778015137208 .7778015137208 .7778015137208 .7778015137 208.7778015137208 .7778015137208 .7778015137208 .7778015137208 .7778015137 208.7778015137206 .9490966797205 .1204071045203 .596496582201 .7678070068 200.2438049316198 .7198944092197 .1959991455195 .3672943115193 .8433074951 196.5863952637 199.329498291 -9999 -9999 -9999 -9999 -9999 -9999 -9999 -9999 -9999 -9999 -9999 -9999 -9999 -9999 -9999 -9999 -9999 -9999 -9999 -9999 -9999 -9999 -9999 -9999 -9999 -9999 -9999 -9999 -9999 -9999 -9999 -9999 -9999 -9999 -9999 -9999 -9999 -9999 -9999

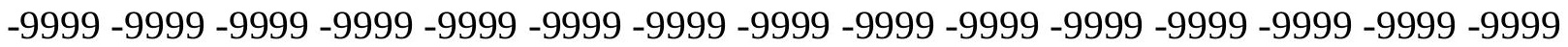

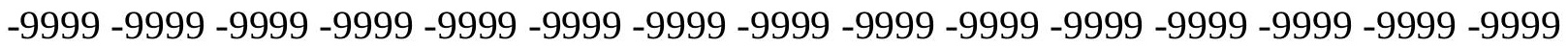
-9999 -9999 -9999 -9999 -9999 -9999 -9999 -9999 -9999 -9999 -9999 -9999 -9999 -9999 -9999

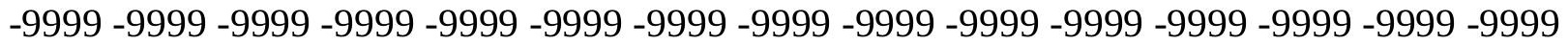
$-9999-9999$

-9999 -9999 -9999 -9999 -9999 -9999 -9999 -9999 -9999 -9999 -9999 -9999 -9999 -9999 -9999 -9999 -9999 -9999 -9999 -9999 -9999 -9999 -9999 -9999 -9999 -9999 -9999 -9999 -9999 -9999 -9999 -9999 -9999 -9999 -9999 -9999 -9999 -9999 -9999 -9999 -9999 -9999 -9999 -9999 -9999 -9999 -9999 -9999 -9999 -9999 -9999 -9999 -9999 -9999 -9999 -9999 -9999 -9999 - -9999 - -9999 -

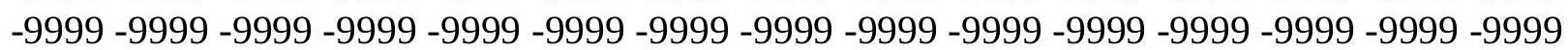
-9999 -9999 -9999 -9999 -9999 -9999 -9999 -9999 -9999 -9999 -9999 -9999 -9999 -9999 -9999 -999 -9999 -9999 -9999 -9999 -9999 -9999 -9999 -9999 -9999 -9999 -9999 -9999 -9999 -9999 -9999 -9999 -9999 -9999 -9999 -9999 -9999 -9999 -9999 -9999 -9999 -9999 -9999 -9999 -9999 -9999

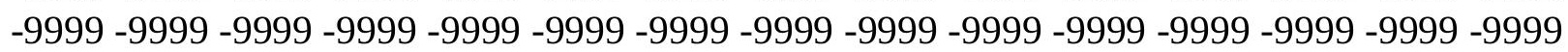

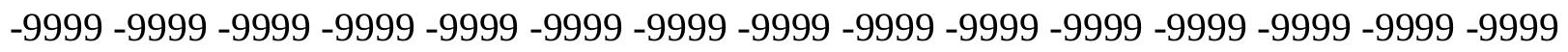
146.9064025879146 .6015930176146 .6015930176146 .6015930176146 .6015930176 146.2969055176146 .2969055176145 .9920959473145 .9920959473145 .6873016357 145.3825073242145 .0776977539144 .7729034424144 .4682006836144 .1634063721 143.5538024902143 .2489929199142 .9441986084143 .5538024902143 .8585968018 144.1634063721144 .4682006836144 .7729034424145 .0776977539145 .3825073242 145.6873016357145 .9920959473145 .9920959473145 .9920959473145 .6873016357 145.3825073242145 .0776977539145 .0776977539145 .9920959473147 .8208007812 150.5639038086153 .0021057129155 .4403991699156 .3547973633154 .5260925293 147.8208007812139 .8963928223132 .8863067627127 .7050018311123 .43800354 123.43800354123 .1332015991123 .1332015991124 .0475006104127 .0953979492 127.7050018311126 .4858016968124 .3523025513122 .5235977173129 .533706665 137.7628936768146 .2969055176153 .3069000244157 .878692627161 .8408966064 165.4983062744170 .070098877174 .337097168178 .604095459182 .261505127 185.3094024658187 .7476043701189 .8811035156191 .7097930908193 .8433074951 195.6721038818197 .8054962158199 .9389953613202 .0724945068204 .5108032227 206.9490966797 208.7778015137208.7778015137 208.7778015137208.7778015137 208.7778015137208 .7778015137208 .7778015137208 .7778015137208 .7778015137 208.7778015137208 .7778015137208 .7778015137208 .7778015137208 .7778015137 208.7778015137208 .7778015137208 .7778015137208 .7778015137208 .7778015137 208.7778015137 208.7778015137208.7778015137208.7778015137 208.7778015137 208.7778015137208 .7778015137208 .7778015137208 .7778015137208 .7778015137 208.7778015137208 .7778015137208 .7778015137208 .7778015137208 .7778015137 208.7778015137208 .7778015137208 .7778015137208 .7778015137208 .7778015137 208.7778015137208 .7778015137208 .7778015137208 .7778015137208 .7778015137 
208.7778015137208 .7778015137208 .7778015137208 .7778015137208 .7778015137 208.7778015137208 .7778015137208 .7778015137207 .25390625205 .425201416 203.596496582 202.0724945068 200.2438049316 198.4151000977 196.5863952637 194.7577056885192 .9290008545194 .7577056885197 .500793457200 .2438049316 -9999

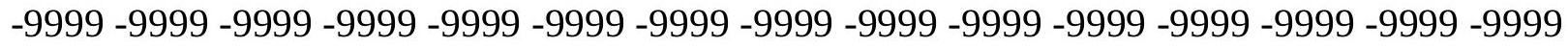

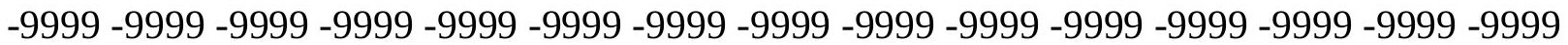

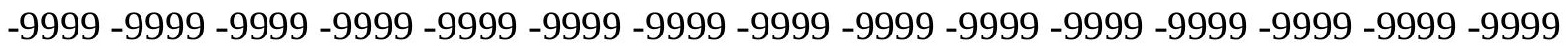

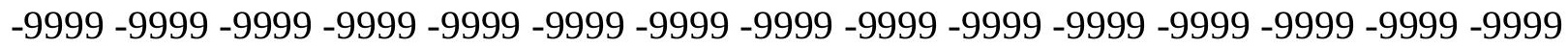
-9999 -9999 -999 -

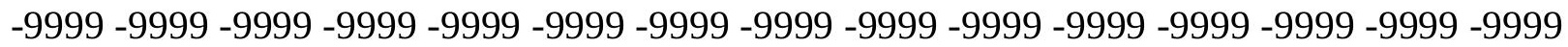
-9999 -9999 -9999 -9999 -9999 -9999 -9999 -9999

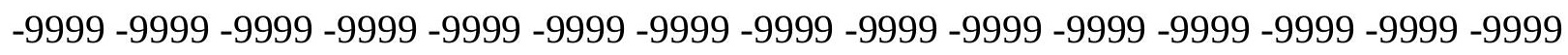

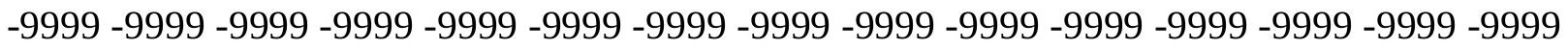

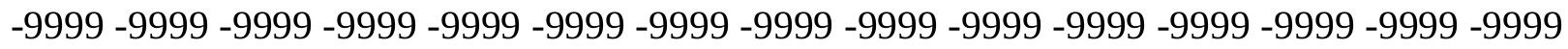

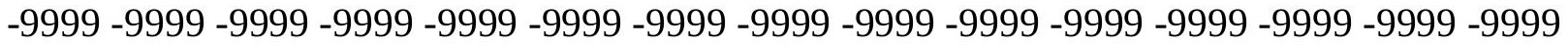

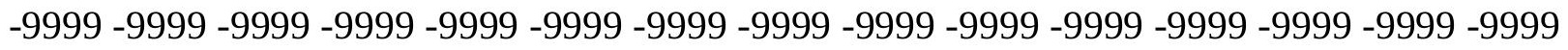

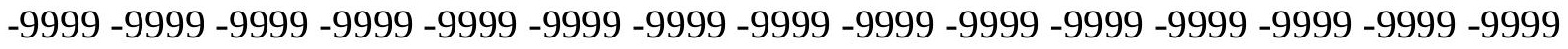

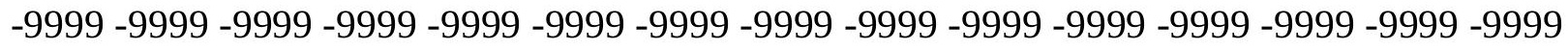

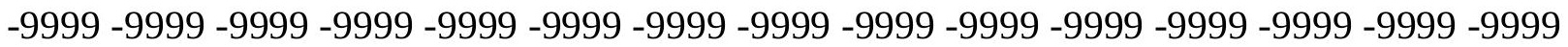
-9999 -9999-

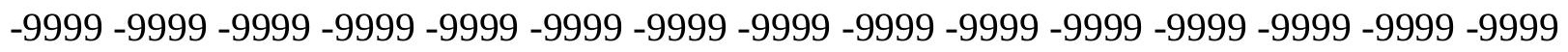
145.9920959473145 .6873016357145 .6873016357145 .6873016357145 .3825073242 145.3825073242145 .0776977539145 .0776977539144 .7729034424144 .4682006836 144.4682006836144 .1634063721143 .5538024902143 .2489929199142 .9441986084 142.3347015381142 .0299072266141 .4203033447141 .1154937744141 .1154937744 141.1154937744141 .4203033447141 .4203033447141 .7250976562142 .0299072266 142.3347015381142 .3347015381142 .3347015381142 .0299072266141 .4203033447 140.8106994629139 .8963928223139 .2868041992139 .5915985107141 .4203033447 144.7729034424147 .2111968994148 .4304046631148 .1255950928148 .1255950928 136.8484954834128 .0097961426121 .9140014648119 .4757995605119 .1709976196 118.8662033081118 .5614013672118 .5614013672118 .5614013672118 .8662033081 119.7806015015120 .3900985718120 .0852966309120 .9997024536125 .8762969971 133.1911010742141 .1154937744149 .0399017334151 .4781951904154 .5260925293 158.4882965088163 .6696014404169 .1557006836174 .337097168178 .2993011475 181.6519012451184 .3950042725186 .528503418188 .3571929932190 .1858978271 192.3193969727 194.4528961182 197.1959991455 199.93899553613202.6820983887 205.7299957275208 .4730072021208 .7778015137208 .7778015137208 .7778015137 208.7778015137208 .7778015137208 .7778015137208 .7778015137208 .7778015137 208.7778015137208 .7778015137208 .7778015137208 .7778015137208 .7778015137 208.7778015137208 .7778015137208 .7778015137208 .7778015137208 .7778015137 208.7778015137208 .7778015137208 .7778015137208 .7778015137208 .7778015137 208.7778015137208 .7778015137208 .7778015137208 .7778015137208 .7778015137 208.7778015137208 .7778015137208 .7778015137208 .7778015137208 .7778015137 208.7778015137208 .7778015137208 .7778015137208 .7778015137208 .7778015137 208.7778015137208 .7778015137208 .7778015137208 .7778015137208 .7778015137 208.7778015137208 .7778015137208 .7778015137208 .7778015137208 .7778015137 
208.7778015137208.7778015137208.7778015137208.7778015137207.25390625 205.425201416203 .596496582201 .7678070068199 .9389953613198 .1103057861 195.9768066406 194.1481018066192.3193969727 193.233795166195.6721038818 198.4151000977 -9999 -9999 -9999 -9999 -9999 -9999 -9999 -9999 -9999 -9999 -9999 -9999

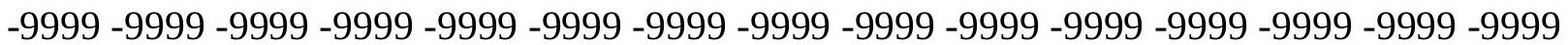

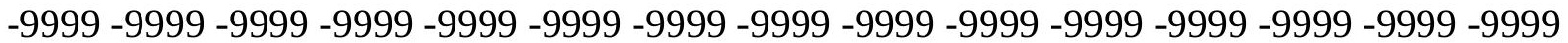

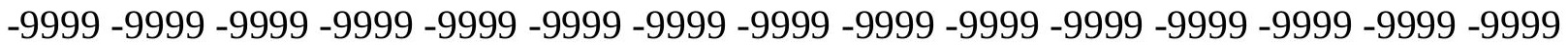

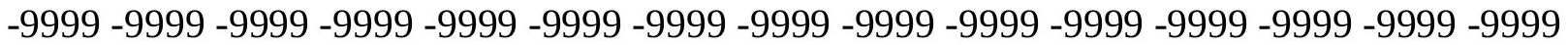

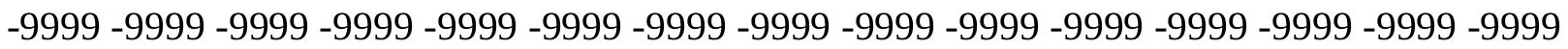

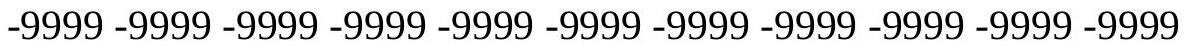

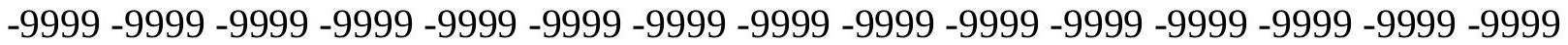

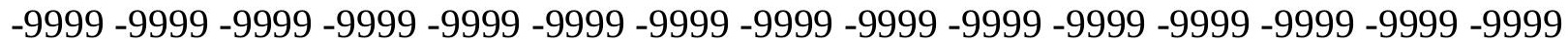

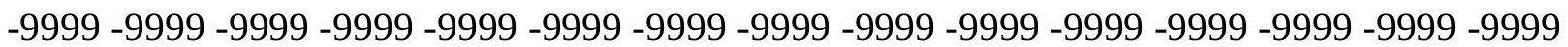

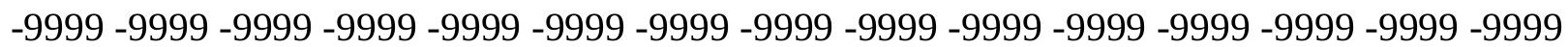

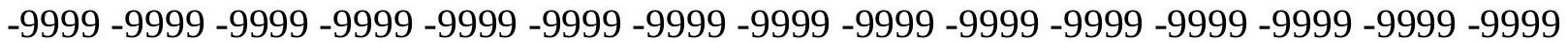

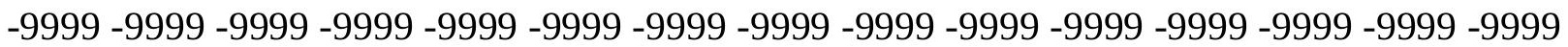
-9999 -

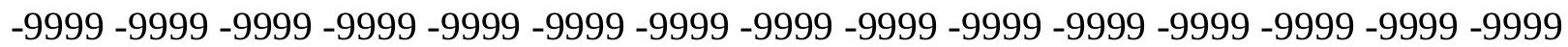

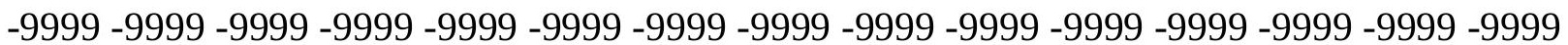
-9999 -9999 -9999 -9999 -9999 -9999 -9999 -9999 -9999 -9999 -9999 -9999 -9999 -9999 145.0776977539145 .0776977539144 .7729034424144 .7729034424144 .7729034424 144.4682006836144 .4682006836144 .1634063721143 .8585968018143 .8585968018 143.5538024902143 .2489929199142 .9441986084142 .6394042969142 .0299072266 141.7250976562141 .1154937744140 .8106994629140 .2012023926139 .5915985107 138.9819946289138 .3724975586138 .3724975586138 .3724975586138 .3724975586 138.6772003174138 .6772003174138 .6772003174138 .3724975586137 .7628936768 137.1533050537135 .9342041016134 .7149963379133 .8007049561132 .8863067627 133.8007049561137 .4580993652142 .6394042969140 .8106994629134 .4102020264 127.0953979492122 .2188034058118 .8662033081118 .2565994263117 .647102356 117.342300415117 .0374984741117 .0374984741117 .0374984741117 .0374984741 117.342300415 117.647102356 117.9517974854118.2565994263119.1709976196 122.8283996582128 .6192932129134 .7149963379139 .8963928223142 .3347015381 145.0776977539149 .6495056152156 .0500030518163 .3648071289168 .8509979248 173.7274932861177 .0802001953179 .8231964111181 .9566955566183 .7854003906 185.6141052246187 .7476043701190 .4907073975193 .5386047363196 .891204834 200.2438049316203 .596496582206 .9490966797208 .7778015137208 .7778015137 208.7778015137208 .7778015137208 .7778015137208 .7778015137208 .7778015137 208.7778015137208 .7778015137208 .7778015137208 .7778015137208 .7778015137 208.7778015137208 .7778015137208 .7778015137208 .7778015137208 .7778015137 208.7778015137208 .7778015137208 .7778015137208 .7778015137208 .7778015137 208.7778015137208 .7778015137208 .7778015137208 .7778015137208 .7778015137 208.7778015137208 .7778015137208 .7778015137208 .7778015137208 .7778015137 208.7778015137208 .7778015137208 .7778015137208 .7778015137208 .7778015137 208.7778015137208 .7778015137208 .7778015137208 .7778015137208 .7778015137 208.7778015137208 .7778015137208 .7778015137208 .7778015137208 .7778015137 208.7778015137208 .7778015137208 .7778015137208 .7778015137208 .7778015137 
208.7778015137207 .25390625205 .425201416203 .2917022705201 .4629974365 199.329498291 197.500793457 195.3672943115193.5386047363191.4051055908 191.1002960205 193.5386047363196 .2816009521 -9999 -9999 -9999 -9999 -9999 -9999 -9999 -9999 -9999 -9999 -9999 -9999 -9999 -9999 -9999 -9999 -9999 -9999 -9999 -9999 -9999 -9999 -9999 -9999 -9999 -9999 -9999 -9999 -9999 -9999 -9999-9999 -9999 -9999 -9999 -9999 -9999 -9999 -9999 -9999 -9999 -9999 -9999 -9999 -9999 -9999 -9999 -9999 -9999 -9999 -9999 -9999

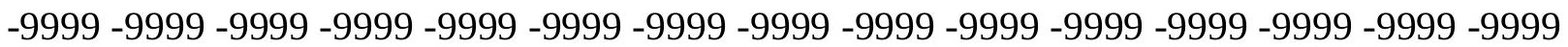

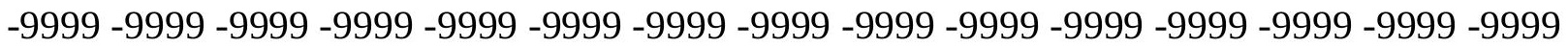

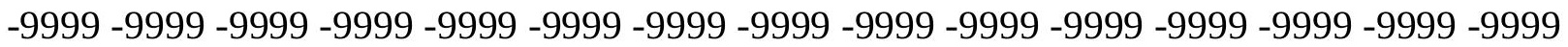
-9999 -9999 -9999 -9999 -9999 -9999 -9999 -9999 -9999 -9999 -9999 -9999 -9999 -9999 -9999 -

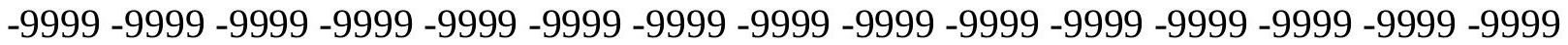
-9999 -9999 -9999 -9999 -9999 -9999 -9999 -9999 -9999 -9999 -9999 -9999 -9999 -9999 -9999 -9999 -9999 -9999 -9999 -9999 -9999 -9999 -9999 -9999 -9999 -9999 -9999 -9999 -9999 -9999 -9999 -9999 -9999 -9999 -9999 -9999 -9999 -9999 -9999 -9999 -9999 -9999 -9999 -9999 -9999 -9999 -9999 -9999 -9999 -9999 -9999 -9999 -9999 -9999 -9999 -9999 -9999 -9999 -9999 -9999

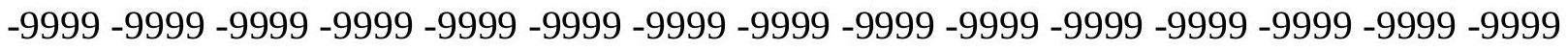

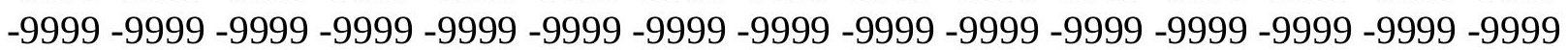

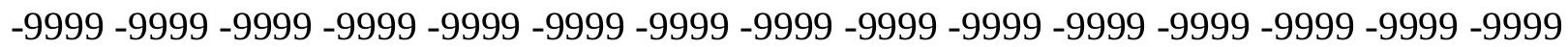
-9999 -9999 -9999 -9999 -9999 -9999 -9999 -9999 -9999 -9999 -9999 -9999 -9999 144.4682006836144 .4682006836144 .1634063721144 .1634063721143 .8585968018 143.8585968018143 .5538024902143 .2489929199143 .2489929199142 .9441986084 142.6394042969142 .3347015381142 .0299072266141 .7250976562141 .4203033447 141.1154937744140 .5059967041139 .8963928223139 .5915985107138 .9819946289 138.3724975586 137.4580993652 136.8484954834 136.2389984131 135.3246002197 135.0198059082135 .0198059082135 .0198059082135 .0198059082134 .7149963379 134.1054992676132 .8863067627131 .3623962402129 .8385009766128 .3144989014 127.0953979492126 .1809997559126 .4858016968142 .6394042969132 .5814971924 119.4757995605118 .5614013672117 .9517974854117 .0374984741116 .4279022217 115.818397522115 .5136032104115 .2088012695115 .2088012695115 .2088012695 115.5136032104115 .818397522116 .1231002808116 .4279022217117 .0374984741 117.342300415119 .1709976196123 .43800354128 .0097961426131 .0576019287 132.5814971924133 .8007049561138 .3724975586148 .4304046631156 .6596069336 162.4505004883167 .3269958496171 .5939941406174 .337097168175 .8609924316 177.6896972656179 .8231964111182 .261505127185 .6141052246189 .2716064453 193.233795166197 .1959991455201 .158203125205 .1204071045208 .7778015137 208.7778015137208 .7778015137208 .7778015137208 .7778015137208 .7778015137 208.7778015137208.7778015137208.7778015137 208.7778015137 208.7778015137 208.7778015137 208.7778015137208.7778015137208.7778015137 208.7778015137 208.7778015137208 .7778015137208 .7778015137208 .7778015137208 .7778015137 208.7778015137208 .7778015137208 .7778015137208 .7778015137208 .7778015137 208.7778015137208 .7778015137208 .7778015137208 .7778015137208 .7778015137 208.7778015137208 .7778015137208 .7778015137208 .7778015137208 .7778015137 208.7778015137208.7778015137208.7778015137208.7778015137208.7778015137 208.7778015137208 .7778015137208 .7778015137208 .7778015137208 .7778015137 208.7778015137208 .7778015137208 .7778015137208 .7778015137208 .7778015137 208.7778015137208 .7778015137208 .7778015137206 .9490966797205 .1204071045 
202.9868927002200 .8533935547198 .7198944092196 .5863952637194 .7577056885 192.624206543190 .4907073975189 .2716064453191 .7097930908194 .4528961182 -9999 -9999 -9999 -9999 -9999 -9999 -9999 -9999 -9999 -9999 -9999 -9999 -9999 -9999 -9999 -9999 -9999 -9999 -9999 -9999 -9999 -9999 -9999 -9999 -9999 -9999 -9999 -9999 -9999 -9999 -9999 -9999 -9999 -9999 -9999 -9999 -9999 -9999 -9999 -9999 -9999 -9999 -9999 -9999 -9999 -9999 -9999 -9999 -9999 -9999 -9999 -9999 -9999 -9999 -9999 -9999 -9999 -9999 -9999 -9999 -9999 -9999 -9999 -9999 -9999 -9999 -9999 -9999 -9999 -9999 -9999 -9999 -9999 -9999 -9999 -9999

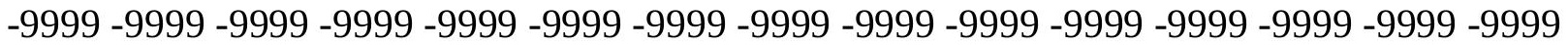
-9999 -9999-9999-9999-9999

-9999 -9999 -9999 -9999 -9999 -9999 -9999 -9999 -9999 -9999 -9999 -9999 -9999 -9999 -9999 -9999 -9999 -9999 -9999 -9999 -9999 -9999 -9999 -9999 -9999 -9999 -9999 -9999 -9999 -9999 -9999 -9999 -9999 -9999 -9999 -9999 -9999 -9999 -9999 -9999 -9999 -9999 -9999 -9999 -9999

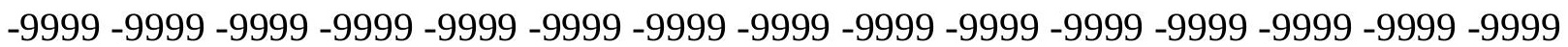
-9999 -9999 -9999 -9999 -9999 -9999 -9999 -9999 -9999 -9999 -9999 -9999 -9999 -9999 -9999 -9999 -9999 -9999 -9999 -9999 -9999 -9999 -9999 -9999 -9999 -9999 -9999 -9999 -9999 -9999

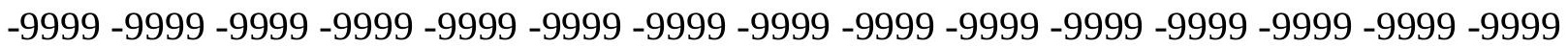

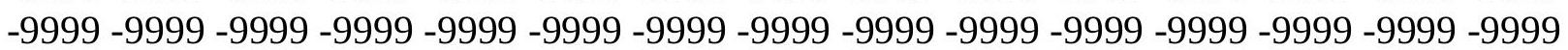
-9999 -9999 -9999 -9999 -9999 -9999 -9999 -9999 -9999 -9999 -9999 -9999 -9999 -9999 -9999 -9999 -9999 -9999 -9999 -9999 -9999 -9999 -9999 -9999 -9999 -9999 -9999 143.8585968018 143.5538024902143 .5538024902143 .2489929199143 .2489929199142 .9441986084 142.9441986084142 .6394042969142 .3347015381142 .3347015381142 .0299072266 141.7250976562141 .4203033447141 .1154937744140 .8106994629140 .2012023926 139.8963928223139 .2868041992138 .9819946289138 .3724975586137 .7628936768 137.1533050537136 .2389984131135 .6293945312134 .7149963379134 .1054992676 133.1911010742132 .2767028809131 .3623962402131 .3623962402131 .0576019287 130.1432037354128 .6192932129127 .0953979492125 .5715026855124 .0475006104 123.1332015991121 .9140014648120 .9997024536120 .0852966309118 .8662033081 117.9517974854117 .0374984741116 .1231002808115 .2088012695114 .5991973877 113.9896011353113 .6848983765113 .6848983765113 .3800964355113 .6848983765 113.9896011353114 .2944030762114 .5991973877115 .2088012695115 .818397522 116.4279022217117 .0374984741118 .2565994263121 .6092987061124 .0475006104 124.9618988037124 .0475006104123 .43800354142 .9441986084147 .8208007812 152.6972961426159 .0977935791164 .2792053223166 .7174987793168 .241394043 169.7653045654172 .2035980225175 .5561981201179 .5184020996184 .0901947021 188.966796875193 .5386047363198 .4151000977202 .6820983887207 .25390625 208.7778015137208 .7778015137208 .7778015137208 .7778015137208 .7778015137 208.7778015137208 .7778015137208 .7778015137208 .7778015137208 .7778015137 208.7778015137208 .7778015137208 .7778015137208 .7778015137208 .7778015137 208.7778015137208 .7778015137208 .7778015137208 .7778015137208 .7778015137 208.7778015137208 .7778015137208 .7778015137208 .7778015137208 .7778015137 208.7778015137208 .7778015137208 .7778015137208 .7778015137208 .7778015137 208.7778015137208 .7778015137208 .7778015137208 .7778015137208 .7778015137 208.7778015137208 .7778015137208 .7778015137208 .7778015137208 .7778015137 208.7778015137208 .7778015137208 .7778015137208 .7778015137208 .7778015137 208.7778015137208 .7778015137208 .7778015137208 .7778015137208 .7778015137 208.7778015137208.7778015137208.7778015137208.7778015137206.6443023682 
204.5108032227202 .3773040771200 .2438049316198 .1103057861195 .9768066406 193.8433074951191 .7097930908189 .5764007568187 .7476043701189 .8811035156 192.624206543195 .3672943115 -9999 -9999 -9999 -9999 -9999 -9999 -9999 -9999 -9999 -9999 -9999 -9999 -9999 -9999 -9999 -9999 -9999 -9999 -9999 -9999 -9999 -9999 -9999 -9999 -9999 -9999 -9999 -9999 -9999 -9999 -9999 -9999 -9999-9999 -9999 -9999 -9999 -9999 -9999 -9999 -9999 -9999 -9999 -9999 -9999 -9999 -9999 -9999 -9999 -9999 -9999 -9999 -9999 -9999 -9999 -9999 -9999 -9999 -9999 -9999 -9999 -9999 -9999 -9999 -9999 -9999 -9999 -9999 -9999

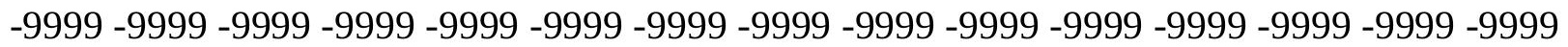
-9999 -9999 -9999 -9999 -9999-9999-9999 -9999 -9999-9999

-9999 -9999 -9999 -9999 -9999 -9999 -9999 -9999 -9999 -9999 -9999 -9999 -9999 -9999 -9999

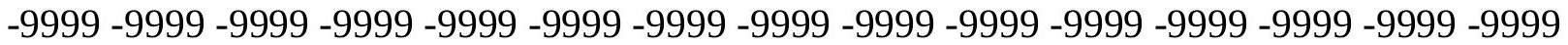
-9999 -9999 -9999 -9999 -9999 -9999 -9999 -9999 -9999 -9999 -9999 -9999 -9999 -9999 -9999 -9999 -9999 -9999 -9999 -9999 -9999 -9999 -9999 -9999 -9999 -9999 -9999 -9999 -9999 -9999 -9999 -9999 -9999 -9999 -9999 -9999 -9999 -9999 -9999 -9999 -9999 -9999 -9999 -9999 -9999 -9999 -9999 -9999 -9999 -9999 -9999 -9999 -9999 -9999 -9999 -9999 -9999 -9999 -9999 -9999

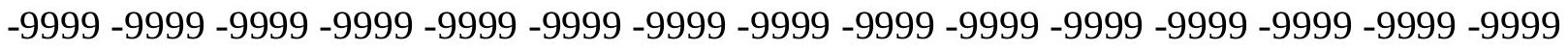
-9999 -9999 -9999 -9999 -9999 -9999 -9999 -9999 -9999 -9999 -9999 -9999 -9999 -9999 -9999 -9999 -9999 -9999 -9999 -9999 -9999 -9999 -9999 -9999 -9999 -9999 -9999 -9999 -9999 -9999 -9999 -9999 -9999 -9999 -9999 -9999 -9999 -9999 -9999 -9999 -9999 143.2489929199 142.9441986084142 .9441986084142 .6394042969142 .3347015381142 .3347015381 142.0299072266142 .0299072266141 .7250976562141 .4203033447141 .1154937744 140.8106994629140 .8106994629140 .2012023926139 .8963928223139 .5915985107 139.2868041992138 .6772003174138 .0677032471137 .7628936768137 .1533050537 136.5437011719135 .6293945312135 .0198059082134 .4102020264133 .4958953857 132.5814971924131 .6672058105130 .7528076172129 .8385009766128 .9241027832 128.0097961426127 .0953979492125 .8762969971124 .9618988037123 .7427978516 122.8283996582121 .6092987061120 .6949005127119 .4757995605118 .5614013672 117.342300415116 .4279022217115 .5136032104114 .5991973877113 .6848983765 113.075302124112 .4656982422111 .8561019897111 .8561019897111 .8561019897 111.8561019897112 .4656982422112 .7705001831113 .3800964355113 .9896011353 114.5991973877115 .2088012695116 .1231002808116 .7326965332117 .0374984741 118.5614013672120 .0852966309120 .0852966309121 .9140014648128 .3144989014 133.8007049561139 .8963928223147 .2111968994155 .4403991699156 .3547973633 157.5738983154159 .7073974609163 .0599975586167 .3269958496172 .5084075928 178.2993011475183 .7854003906189 .5764007568194 .7577056885199 .9389953613 204.8155975342208 .7778015137208 .7778015137208 .7778015137208 .7778015137 208.7778015137208 .7778015137208 .7778015137208 .7778015137208 .7778015137 208.7778015137 208.7778015137 208.7778015137 208.7778015137 208.7778015137 208.7778015137208 .7778015137208 .7778015137208 .7778015137208 .7778015137 208.7778015137208 .7778015137208 .7778015137208 .7778015137208 .7778015137 208.7778015137208 .7778015137208 .7778015137208 .7778015137208 .7778015137 208.7778015137208 .7778015137208 .7778015137208 .7778015137208 .7778015137 208.7778015137208 .7778015137208 .7778015137208 .7778015137208 .7778015137 208.7778015137208 .7778015137208 .7778015137208 .7778015137208 .7778015137 208.7778015137208 .7778015137208 .7778015137208 .7778015137208 .7778015137 208.7778015137 208.7778015137208.7778015137 208.7778015137 208.7778015137 
208.4730072021206 .0346984863203 .9011993408201 .7678070068199 .329498291 197.1959991455195 .0625192 .9290008545190 .795501709188 .6620025635186 .8332977295 188.0523986816 191.1002960205 194.1481018066 -9999 -9999 -9999 -9999 -9999 -9999 -9999 -9999 -9999 -9999 -9999 -9999 -9999 -9999 -9999 -9999 -9999 -9999 -9999 -9999 -9999 -9999 -9999 -9999 -9999 -9999 -9999 -9999 -9999 -9999 -9999 -9999 -9999 -9999 -9999 -9999 -9999 -9999 -9999 -9999 -9999 -9999 -9999 -9999 -9999 -9999 -9999 -9999 -9999 -9999 -9999 -9999 -9999 -9999 -9999 -9999 -9999 -9999 -9999 -9999 -9999 -9999 -9999 -9999 -9999 -9999 -9999

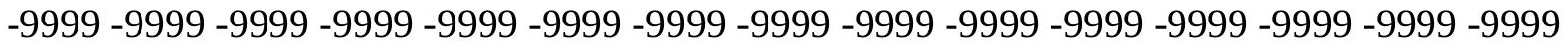
-9999 -9999 -9999 -9999 -9999 -9999-9999 -9999 -9999 -9999 -9999 -9999 -9999 -9999 -9999 -9999 -9999 -9999 -9999 -9999 -9999 -9999 -9999 -9999 -9999 -9999 -9999 -9999 -9999 -9999 -9999 -9999 -9999 -9999 -9999 -9999 -9999 -9999 -9999 -9999 -9999 -9999 -9999 -9999 -9999 -9999 -9999 -9999 -9999 -9999 -9999 -9999 -9999 -9999 -9999 -9999

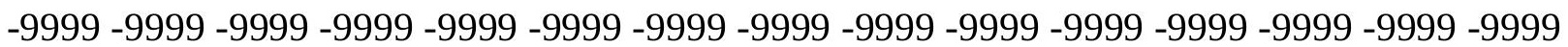
-9999 -9999 -9999 -9999 -9999 -9999 -9999 -9999 -9999 -9999 -9999 -9999 -9999 -9999 -9999 -9999 -9999 -9999 -9999 -9999 -9999 -9999 -9999 -9999 -9999 -9999 -9999 -9999 -9999 -9999 -9999 -9999 -9999 -9999 -9999 -9999 -9999 -9999 -9999 -9999 -9999 -9999 -9999 -9999 -9999 -

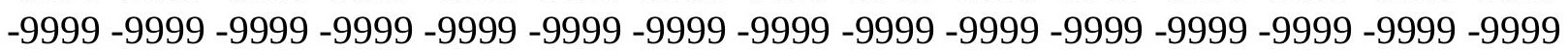
-9999 -9999 -9999 -9999 -9999 -9999 -9999 -9999 -9999 -9999 -9999 -9999 -9999 -9999 -9999 -9999 -9999 -9999 -9999 -9999 -9999 -9999 -9999 -9999 -9999 -9999 142.6394042969 142.3347015381142 .0299072266141 .7250976562141 .7250976562141 .4203033447 141.1154937744141 .1154937744140 .8106994629140 .5059967041140 .2012023926 139.8963928223139 .5915985107139 .2868041992138 .9819946289138 .6772003174 138.0677032471137 .7628936768137 .1533050537136 .5437011719135 .9342041016 135.3246002197134 .4102020264133 .8007049561133 .1911010742132 .2767028809 131.3623962402130 .4479980469129 .533706665128 .6192932129127 .7050018311 126.7906036377125 .5715026855124 .6570968628123 .7427978516122 .5235977173 121.6092987061120 .3900985718119 .1709976196118 .2565994263117 .0374984741 116.1231002808114 .9039993286113 .9896011353112 .7705001831112 .1608963013 111.24659729110 .6370010376110 .3321990967110 .0273971558110 .0273971558 110.3321990967110 .9418029785111 .24659729112 .1608963013112 .7705001831 113.6848983765114 .2944030762115 .2088012695115 .818397522116 .4279022217 117.0374984741117 .647102356117 .9517974854118 .2565994263118 .5614013672 118.8662033081124 .6570968628131 .9720001221138 .0677032471142 .3347015381 144.7729034424148 .1255950928152 .3925933838158 .4882965088164 .8887023926 171.5939941406178 .2993011475185 .0045928955191 .1002960205196 .5863952637 202.3773040771 207.5587005615 208.7778015137208.7778015137208.7778015137 208.7778015137208 .7778015137208 .7778015137208 .7778015137208 .7778015137 208.7778015137208 .7778015137208 .7778015137208 .7778015137208 .7778015137 208.7778015137208 .7778015137208 .7778015137208 .7778015137208 .7778015137 208.7778015137208 .7778015137208 .7778015137208 .7778015137208 .7778015137 208.7778015137208 .7778015137208 .7778015137208 .7778015137208 .7778015137 208.7778015137208 .7778015137208 .7778015137208 .7778015137208 .7778015137 208.7778015137208 .7778015137208 .7778015137208 .7778015137208 .7778015137 208.7778015137208 .7778015137208 .7778015137208 .7778015137208 .7778015137 208.7778015137208 .7778015137208 .7778015137208 .7778015137208 .7778015137 208.7778015137208.7778015137208.7778015137208.7778015137208.7778015137 
208.7778015137207.8634033203205.7299957275 203.2917022705 200.8533935547 198.7198944092196 .5863952637194 .1481018066192 .0146026611190 .1858978271 $188.3571929932186 .528503418187 .1381072998189 .8811035156192 .9290008545-9999$ -9999 -9999 -9999 -9999 -9999 -9999 -9999 -9999 -9999 -9999 -9999 -9999 -9999 -9999 -9999 -9999 -9999 -9999 -9999 -9999 -9999 -9999 -9999 -9999-9999 -9999 -9999 -9999 -9999 -9999 -9999 -9999 -9999 -9999 -9999 -9999 -9999 -9999 -9999 -9999 -9999 -9999 -9999 -9999 -9999

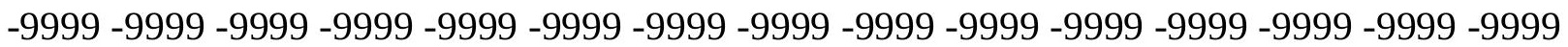
-9999 -9999 -9999 -9999 -9999 -9999 -9999 -9999 -9999 -9999 -9999 -9999 -9999 -9999 -9999 -9999 -9999 -9999 -9999 -9999 -9999 -9999 -9999 -9999 -9999 -9999 -9999 -9999 -9999 -999 $-9999$

-9999 -9999 -9999 -9999 -9999 -9999 -9999 -9999 -9999 -9999 -9999 -9999 -9999 -9999 -9999 -9999 -9999 -9999 -9999 -9999 -9999 -9999 -9999 -9999 -9999 -9999 -9999 -9999 -9999 -9999 -9999 -9999 -9999 -9999 -9999 -9999 -9999 -9999 -9999 -9999 -9999 -9999 -9999 -9999 -9999 -9999 -9999 -9999 -9999 -9999 -9999 -9999 -9999 -9999 -9999 -9999 -9999 -9999 -9999 -9999 -9999 -9999 -9999 -9999 -9999 -9999 -9999 -9999 -9999 -9999 -9999 -9999 -9999 -9999 -9999

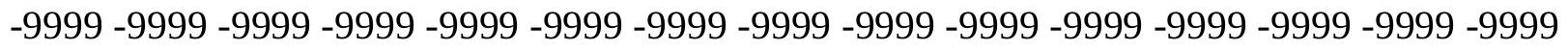

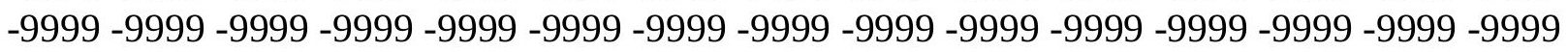

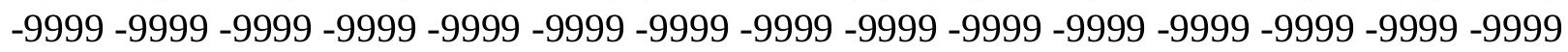
-9999 -9999 -9999 -9999 -9999 -9999 -9999 -9999 -9999 -9999 -9999 -9999 -9999-999 -999 -9999 -9999 -9999 -9999 -9999 -9999 -9999 -9999 -9999 -9999 142.0299072266 141.7250976562141 .4203033447141 .4203033447141 .1154937744140 .8106994629 140.5059967041140 .5059967041140 .2012023926139 .8963928223139 .5915985107 139.2868041992138 .9819946289138 .6772003174138 .3724975586138 .0677032471 137.4580993652137 .1533050537136 .5437011719135 .9342041016135 .3246002197 134.7149963379134 .1054992676133 .4958953857132 .5814971924131 .9720001221 131.0576019287130 .1432037354129 .2288970947128 .3144989014127 .4001998901 126.4858016968125 .5715026855124 .3523025513123 .43800354122 .5235977173 121.3044967651120 .3900985718119 .1709976196117 .9517974854117 .0374984741 115.818397522114 .5991973877113 .6848983765112 .4656982422111 .551399231 110.6370010376109 .7226028442109 .1130981445108 .5035018921108 .5035018921 108.5035018921108 .8082962036109 .4179000854110 .0273971558110 .9418029785 111.8561019897112 .4656982422113 .3800964355114 .2944030762115 .2088012695 115.818397522116 .4279022217117 .0374984741117 .342300415117 .9517974854 118.2565994263118 .2565994263118 .5614013672118 .5614013672121 .9140014648 127.4001998901131 .6672058105135 .6293945312141 .4203033447149 .0399017334 156.9642944336164 .8887023926172 .5084075928179 .8231964111186 .528503418 192.9290008545199 .0247039795204 .8155975342208 .7778015137208 .7778015137 208.7778015137208 .7778015137208 .7778015137208 .7778015137208 .7778015137 208.7778015137208 .7778015137208 .7778015137208 .7778015137208 .7778015137 208.7778015137208 .7778015137208 .7778015137208 .7778015137208 .7778015137 208.7778015137208 .7778015137208 .7778015137208 .7778015137208 .7778015137 208.7778015137 208.7778015137208.7778015137208.7778015137 208.7778015137 208.7778015137 208.7778015137208.7778015137208.7778015137 208.7778015137 208.7778015137208 .7778015137208 .7778015137208 .7778015137208 .7778015137 208.7778015137 208.7778015137208.7778015137208.7778015137208.7778015137 208.7778015137 208.7778015137208.7778015137208.7778015137208.7778015137 
208.7778015137208 .7778015137208 .7778015137208 .7778015137208 .7778015137 208.7778015137208 .7778015137208 .7778015137207 .25390625204 .8155975342 202.6820983887200 .2438049316198 .1103057861195 .6721038818193 .5386047363 191.7097930908189 .5764007568188 .0523986816186 .528503418186 .2236938477 189.2716064453 192.0146026611 -9999 -9999-9999 -9999 -9999 -9999 -9999 -9999 -9999 -9999 -9999 -9999 -9999 -9999 -9999 -9999 -9999 -9999 -9999 -9999 -9999 -9999 -9999 -9999 -9999 -9999 -9999 -9999 -9999 -9999 -9999 -9999 -9999 -9999 -9999 -9999 -9999 -9999 -9999

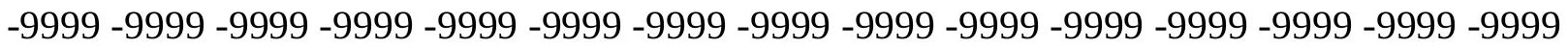
-9999 -9999 -9999 -9999 -9999 -9999 -9999 -9999 -9999 -9999 -9999 -9999 -9999 -9999 -9999 -9999 -9999 -9999 -9999 -9999 -9999 -9999 -9999 -9999 -9999 -9999 -9999 -9999 -9999 -9999 -999 -9999 -9999 -9999 -9999 -9999 -9999 -9999 -9999 -9999 -9999 -9999 -9999 -9999 -9999 -9999 -9999 -9999 -9999 -9999 -9999 -9999 -9999 -9999 -9999 -9999 -9999 -9999 -9999 -9999 -9999 -9999 -9999 -9999 -9999 -9999 -9999 -9999 -9999 -9999 -9999 -9999 -9999 -9999 -9999 -9999 -9999 -9999 -9999 -9999 -9999 -9999 -9999 -9999 -9999 -9999 -9999 -9999 -9999 -9999 -9999 -9999 -9999 -9999 -9999 -9999 -9999 -9999

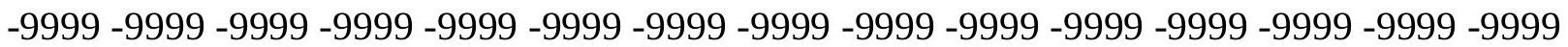

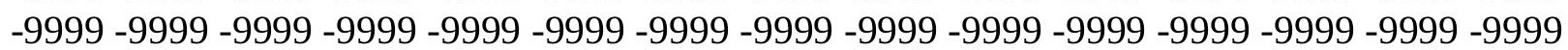
-9999 -9999 -9999 -9999 -9999 -9999 -9999 -9999 -9999 -9999 -9999 -9999 -9999 -9999 -9999 -999 -9999 -9999 -9999 -9999 -9999 -9999 -9999 -9999 -9999 -9999 -9999 -9999 -9999 -9999 -9999 -9999 -9999 -9999 -9999 -9999 -9999 -9999 -9999 -9999 -9999 -9999 -9999 -9999 -9999 -9999 -9999 -9999-9999 -9999 -9999 -9999 -9999-9999 -9999 141.4203033447 141.1154937744 141.1154937744140 .8106994629140 .5059967041140 .2012023926139 .8963928223 139.8963928223139 .5915985107139 .2868041992138 .9819946289138 .6772003174 138.3724975586138 .0677032471137 .7628936768137 .4580993652136 .8484954834 136.5437011719135 .9342041016135 .6293945312135 .0198059082134 .4102020264 133.8007049561132 .8863067627132 .2767028809131 .3623962402130 .7528076172 129.8385009766128 .9241027832128 .0097961426127 .0953979492126 .1809997559 125.2667007446124 .3523025513123 .43800354122 .2188034058121 .3044967651 120.0852966309119 .1709976196117 .9517974854117 .0374984741115 .818397522 114.5991973877113 .6848983765112 .4656982422111 .24659729110 .3321990967 109.1130981445108 .1986999512107 .5891036987106 .979598999106 .979598999 106.979598999107 .2844009399108 .1986999512108 .8082962036109 .7226028442 110.6370010376111 .8561019897112 .7705001831113 .6848983765114 .5991973877 115.2088012695115 .818397522116 .4279022217117 .0374984741117 .342300415 117.647102356117 .9517974854117 .9517974854117 .9517974854117 .9517974854 117.9517974854120 .6949005127122 .8283996582131 .3623962402140 .2012023926 149.3446960449158.1835021973 166.4127044678 174.337097168181.3471984863 188.3571929932195.0625 201.7678070068 207.8634033203 208.7778015137208.7778015137 208.7778015137208 .7778015137208 .7778015137208 .7778015137208 .7778015137 208.7778015137208 .7778015137208 .7778015137208 .7778015137208 .7778015137 208.7778015137 208.7778015137208.7778015137 208.7778015137 208.7778015137 208.7778015137208 .7778015137208 .7778015137208 .7778015137208 .7778015137 208.7778015137 208.7778015137 208.7778015137 208.7778015137 208.7778015137 208.7778015137208 .7778015137208 .7778015137208 .7778015137208 .7778015137 208.7778015137208 .7778015137208 .7778015137208 .7778015137208 .7778015137 208.7778015137208 .7778015137208 .7778015137208 .7778015137208 .7778015137 
208.7778015137208 .7778015137208 .7778015137208 .7778015137208 .7778015137 208.7778015137208 .7778015137208 .7778015137208 .7778015137208 .7778015137 208.7778015137208 .7778015137208 .7778015137206 .6443023682204 .2059936523 202.0724945068199 .6342926025197 .500793457195 .3672943115193 .233795166 191.4051055908189 .5764007568188 .0523986816186 .8332977295185 .6141052246 188.6620025635191 .4051055908 -9999 -9999 -9999 -9999 -9999 -9999 -9999 -9999 -9999 -9999 -9999 -9999 -9999 -9999 -9999 -9999 -9999 -9999 -9999 -9999 -9999 -9999 -9999 -9999 -9999 -9999 -9999 -9999 -9999 -9999 -9999 -9999 -9999 -9999 -9999 -9999 -9999 -9999 -9999 -999 -

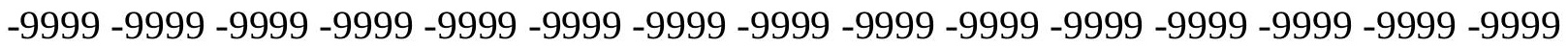
-9999 -9999 -9999 -9999 -9999 -9999 -9999 -9999 -9999 -9999 -9999 -9999 -9999 -9999 -9999

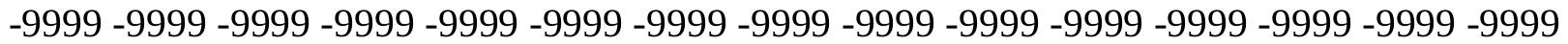
-9999 -9999 -9999-9999-9999-9999

-9999 -9999 -9999 -9999 -9999 -9999 -9999 -9999 -9999 -9999 -9999 -9999 -9999 -9999 -9999 -9999 -9999 -9999 -9999 -9999 -9999 -9999 -9999 -9999 -9999 -9999 -9999 -9999 -9999 -9999 -9999 -9999 -9999 -9999 -9999 -9999 -9999 -9999 -9999 -9999 -9999 -9999 -9999 -9999 -9999

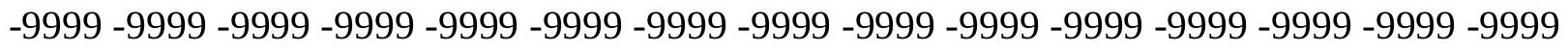

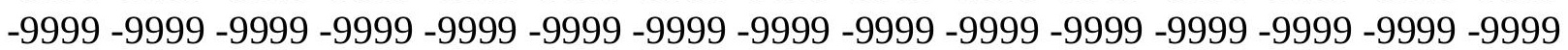
-9999 -9999 -9999 -9999 -9999 -9999 -9999 -9999 -9999 -9999 -9999 -9999 -9999 -9999 -9999 -999 -9999 -9999 -9999 -9999 -9999 -9999 -9999 -9999 -9999 -9999 -9999 -9999 -9999 -9999 -9999 -9999 -9999 -9999 -9999 -9999 -9999 -9999 -9999 -9999 -9999 -9999 -9999 -9999 -9999 -9999 -9999 -9999 -9999 -9999 -9999 -9999 -9999 -9999 -9999 -9999 -9999 -9999 -9999 -9999 -9999 -9999 -9999 -9999 -9999-9999 -9999-9999 -9999 141.1154937744140 .8106994629 140.5059967041140 .2012023926139 .8963928223139 .8963928223139 .5915985107 139.2868041992138 .9819946289138 .6772003174138 .3724975586138 .0677032471 137.7628936768137 .4580993652137 .1533050537136 .8484954834136 .5437011719 135.9342041016135 .6293945312135 .0198059082134 .4102020264133 .8007049561 133.1911010742132 .5814971924131 .9720001221131 .0576019287130 .4479980469 129.533706665128 .6192932129128 .0097961426127 .0953979492126 .1809997559 125.2667007446124 .3523025513123 .43800354122 .2188034058121 .3044967651 120.3900985718119 .1709976196118 .2565994263117 .0374984741116 .1231002808 114.9039993286113 .6848983765112 .7705001831111 .551399231110 .3321990967 109.1130981445108 .1986999512106 .979598999106 .0652008057105 .7603988647 105.4557037354105 .7603988647106 .0652008057106 .979598999107 .8938980103 108.8082962036110 .0273971558110 .9418029785112 .1608963013113 .075302124 113.9896011353114 .5991973877115 .5136032104116 .1231002808116 .4279022217 116.7326965332117 .0374984741117 .342300415117 .342300415117 .342300415 117.342300415117 .342300415117 .0374984741116 .7326965332123 .7427978516 132.5814971924142 .0299072266151 .4781951904160 .3170013428168 .241394043 175.5561981201182 .87109375190 .4907073975197 .8054962158204 .8155975342 208.7778015137208 .7778015137208 .7778015137208 .7778015137208 .7778015137 208.7778015137208 .7778015137208 .7778015137208 .7778015137208 .7778015137 208.7778015137208 .7778015137208 .7778015137208 .7778015137208 .7778015137 208.7778015137208 .7778015137208 .7778015137208 .7778015137208 .7778015137 208.7778015137208 .7778015137208 .7778015137208 .7778015137208 .7778015137 208.7778015137208 .7778015137208 .7778015137208 .7778015137208 .7778015137 208.7778015137208 .7778015137208 .7778015137208 .7778015137208 .7778015137 
208.7778015137208 .7778015137208 .7778015137208 .7778015137208 .7778015137 208.7778015137 208.7778015137208.7778015137208.7778015137 208.7778015137 208.7778015137208 .7778015137208 .7778015137208 .7778015137208 .7778015137 208.7778015137208 .7778015137208 .7778015137208 .7778015137208 .7778015137 208.4730072021206 .0346984863203 .596496582201 .4629974365199 .0247039795 196.891204834194 .7577056885192 .9290008545191 .1002960205189 .5764007568 $188.3571929932187 .1381072998186 .2236938477188 .0523986816190 .795501709-9999$ -9999 -9999 -9999 -9999 -9999 -9999 -9999 -9999 -9999 -9999 -9999 -9999 -9999 -9999 -9999 -9999 -9999 -9999 -9999 -9999 -9999 -9999 -9999 -9999 -9999 -9999 -9999 -9999 -9999 -9999 -9999 -9999 -9999 -9999 -9999 -9999 -9999 -9999 -9999 -9999 -9999 -9999 -9999 -9999 -9999 -

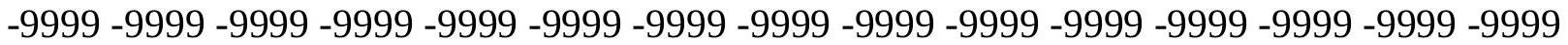
-9999 -9999 -9999 -9999 -9999 -9999 -9999 -9999 -9999 -9999 -9999 -9999 -9999 -9999 -9999 -999 -9999 -9999 -9999 -9999 -9999 -9999 -9999 -9999 -9999 -9999 -9999 -9999 -9999 -9999 -9999 -9999 -9999 -9999 -9999 -9999 -9999 -9999 -9999 -9999 -9999 -9999 -9999 -9999 -9999 -9999 -9999 -9999 -9999 -9999 -9999 -9999 -9999 -9999 -9999 -9999 -9999 -9999 -9999

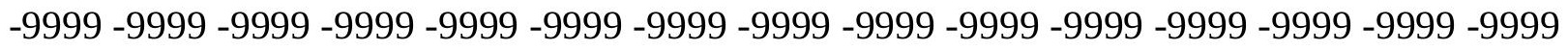
-9999 -9999 -9999 -9999 -9999 -9999 -9999 -9999 -9999 -9999 -9999 -9999 -9999 -9999 -9999 -9999 -9999 -9999 -9999 -9999 -9999 -9999 -9999 -9999 -9999 -9999 -9999 -9999 -9999 -9999 -

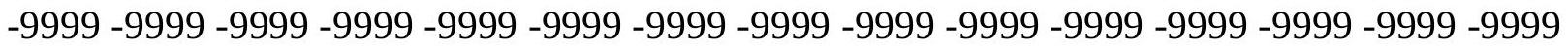

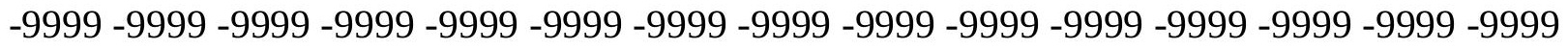

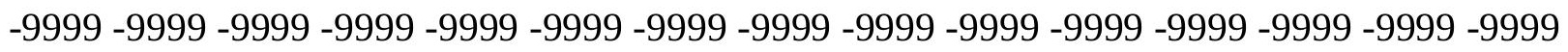
-9999 -9999 -9999 -9999 -9999 -9999 -9999 -9999 -9999 -9999 -9999 -9999 -9999 -9999 -9999 -9999 -9999 -9999 -9999-9999-9999 -9999 140.5059967041 140.2012023926139.8963928223 139.8963928223139 .5915985107139 .2868041992138 .9819946289138 .6772003174 138.3724975586138.3724975586138.0677032471 137.7628936768 137.4580993652 137.1533050537 136.5437011719 136.2389984131 135.9342041016135.6293945312 135.0198059082134 .4102020264134 .1054992676133 .4958953857132 .8863067627 132.2767028809 131.6672058105130.7528076172 130.1432037354 129.2288970947 128.6192932129127 .7050018311126 .7906036377125 .8762969971125 .2667007446 124.3523025513123 .43800354122 .5235977173121 .3044967651120 .3900985718 119.4757995605118 .2565994263117 .342300415116 .4279022217115 .2088012695 113.9896011353113 .075302124111 .8561019897110 .6370010376109 .4179000854 108.5035018921107 .2844009399106 .0652008057105 .1509017944104 .5412979126 104.5412979126104 .5412979126105 .1509017944106 .0652008057106 .979598999 108.1986999512109 .4179000854110 .3321990967111 .551399231112 .4656982422 113.3800964355114 .2944030762114 .9039993286115 .5136032104116 .1231002808 116.4279022217116 .7326965332116 .7326965332117 .0374984741117 .0374984741 116.7326965332116 .7326965332116 .4279022217115 .818397522117 .342300415 125.8762969971135 .3246002197144 .7729034424153 .9165039062161 .2312927246 168.5462036133176 .4705963135185 .0045928955193 .5386047363201 .4629974365 208.7778015137208 .7778015137208 .7778015137208 .7778015137208 .7778015137 208.7778015137208 .7778015137208 .7778015137208 .7778015137208 .7778015137 208.7778015137208 .7778015137208 .7778015137208 .7778015137208 .7778015137 208.7778015137208 .7778015137208 .7778015137208 .7778015137208 .7778015137 208.7778015137208 .7778015137208 .7778015137208 .7778015137208 .7778015137 208.7778015137 208.7778015137208.7778015137 208.7778015137 208.7778015137 
208.7778015137208 .7778015137208 .7778015137208 .7778015137208 .7778015137 208.7778015137 208.7778015137208.7778015137208.7778015137 208.7778015137 208.7778015137208 .7778015137208 .7778015137208 .7778015137208 .7778015137 208.7778015137208 .7778015137208 .7778015137208 .7778015137208 .7778015137 208.7778015137208 .7778015137208 .7778015137208 .7778015137208 .7778015137 208.7778015137207 .8634033203205 .425201416203 .2917022705200 .8533935547 198.7198944092196 .5863952637194 .7577056885192 .9290008545191 .4051055908 189.8811035156188 .6620025635187 .4429016113186 .528503418187 .7476043701 190.4907073975 -9999 -9999 -9999 -9999 -9999 -9999 -9999 -9999 -9999 -9999 -9999 -9999 -9999 -9999 -9999 -9999 -9999 -9999 -9999 -9999 -9999 -9999 -9999 -9999 -9999 -9999 -9999 -9999 -9999 -9999 -9999 -9999 -9999 -9999 -9999 -9999 -9999 -9999 -9999 -9999 -9999 -9999 -999 -9999 -9999 -9999 -9999 -9999 -9999 -9999 -9999 -9999 -9999 -9999 -9999 -9999 -9999 -9999 -9999 -9999 -9999 -9999 -9999 -9999 -9999 -9999 -9999 -9999 -9999 -9999 -9999 -9999 -9999 -9999 -9999 -9999 -9999 -9999 -9999 -9999 -9999 -9999 -9999 -9999 -9999 -9999 -9999 -9999 $-9999$

-9999 -9999 -9999 -9999 -9999 -9999 -9999 -9999 -9999 -9999 -9999 -9999 -9999 -9999 -9999

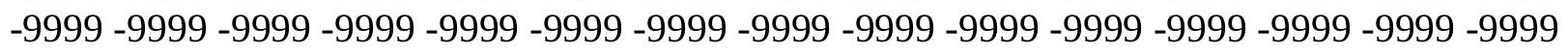

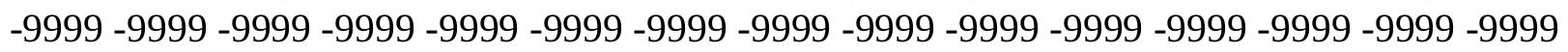

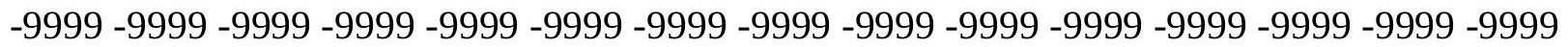

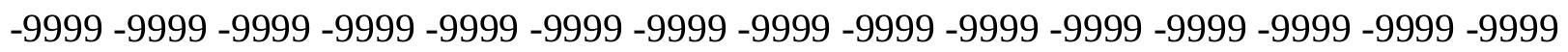

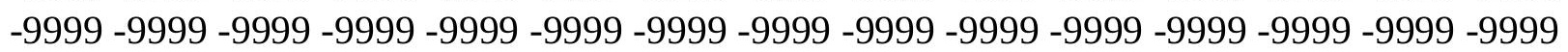

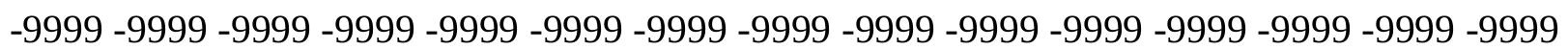
-9999 -9999 -9999 -9999 -9999 -9999 -9999 -9999 -9999 -9999 -9999 -9999 -9999 -9999 -9999 -9999 -9999 -9999 -9999 -9999 -9999 -9999 -9999 -9999 -9999 -9999 -9999 -9999 -9999 -9999 -9999 -9999-9999 -9999 -9999-9999-9999 139.8963928223139 .5915985107139 .2868041992 138.9819946289138 .6772003174138 .6772003174138 .3724975586138 .0677032471 137.7628936768137 .4580993652137 .1533050537136 .8484954834136 .5437011719 136.2389984131135 .9342041016135 .3246002197135 .0198059082134 .7149963379 134.1054992676133 .4958953857133 .1911010742132 .5814971924131 .9720001221 131.3623962402130 .4479980469129 .8385009766129 .2288970947128 .3144989014 127.4001998901126 .7906036377125 .8762969971124 .9618988037124 .3523025513 123.43800354122 .5235977173121 .6092987061120 .6949005127119 .7806015015 118.5614013672117 .647102356116 .7326965332115 .5136032104114 .5991973877 113.3800964355112 .4656982422111 .24659729110 .0273971558109 .1130981445 107.8938980103106 .6747970581105 .4557037354104 .5412979126104 .2365036011 104.2365036011104 .8460998535105 .4557037354106 .0652008057106 .979598999 107.8938980103108 .8082962036110 .0273971558110 .9418029785112 .1608963013 113.075302124113 .9896011353114 .5991973877115 .2088012695115 .5136032104 116.1231002808116 .1231002808116 .4279022217116 .4279022217116 .4279022217 116.1231002808116 .1231002808115 .5136032104115 .2088012695114 .9039993286 119.1709976196128 .3144989014137 .7628936768146 .9064025879152 .6972961426 159.7073974609168 .5462036133178 .604095459188 .6620025635197 .8054962158 206.0346984863208 .7778015137208 .7778015137208 .7778015137208 .7778015137 208.7778015137208 .7778015137208 .7778015137208 .7778015137208 .7778015137 208.7778015137208 .7778015137208 .7778015137208 .7778015137208 .7778015137 208.7778015137 208.7778015137208.7778015137 208.7778015137 208.7778015137 
208.7778015137208 .7778015137208 .7778015137208 .7778015137208 .7778015137 208.7778015137 208.7778015137208.7778015137208.7778015137 208.7778015137 208.7778015137208 .7778015137208 .7778015137208 .7778015137208 .7778015137 208.7778015137208 .7778015137208 .7778015137208 .7778015137208 .7778015137 208.7778015137208 .7778015137208 .7778015137208 .7778015137208 .7778015137 208.7778015137208 .7778015137208 .7778015137208 .7778015137208 .7778015137 208.7778015137 208.7778015137 208.7778015137 208.7778015137 208.7778015137 208.7778015137208 .7778015137207 .5587005615205 .1204071045202 .6820983887 200.5485992432198 .4151000977196 .2816009521194 .4528961182192 .9290008545 191.4051055908190 .1858978271188 .966796875188 .0523986816187 .1381072998 187.1381072998189 .8811035156 -9999 -9999 -9999 -9999 -9999 -9999 -9999 -9999 -9999 -9999 -9999 -9999 -9999 -9999 -9999 -9999 -9999 -9999 -9999 -9999 -9999 -9999 -9999 -9999 -9999 -9999 -9999 -9999 -9999 -9999 -9999 -9999 -9999 -9999 -9999 -9999 -9999 -9999 -9999 -9999 -9999 -9999 -9999 -9999 -9999 -9999 -9999 -9999 -9999 -9999 -9999 -9999 -9999 -9999 -9999 -9999 -9999 -9999 -9999 -9999 -9999 -9999 -9999 -9999 -9999 -9999 -9999 -9999 -9999

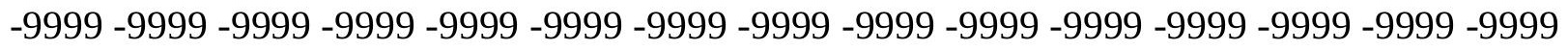
-9999 -9999-9999

-9999 -9999 -9999 -9999 -9999 -9999 -9999 -9999 -9999 -9999 -9999 -9999 -9999 -9999 -9999

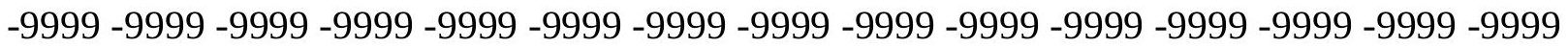

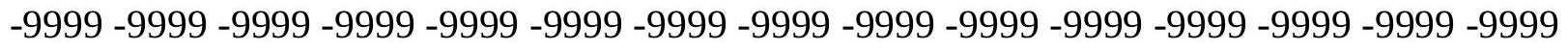

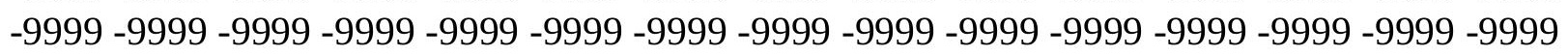

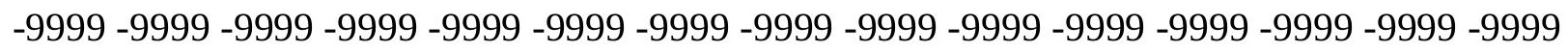
-9999 -9999 -9999 -9999 -9999 -9999 -9999 -9999 -9999 -9999 -9999 -9999 -9999 -9999 -9999 -

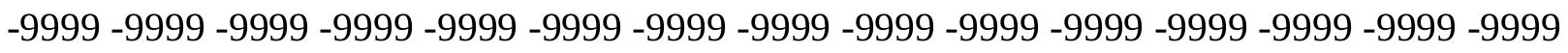

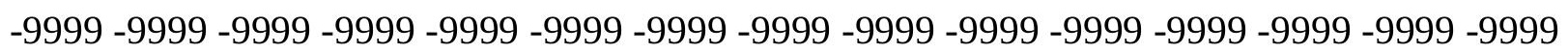

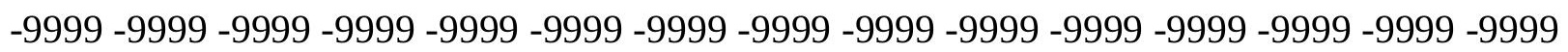
-9999 -9999 -9999 -9999-9999-9999 139.2868041992 138.9819946289 138.9819946289 138.6772003174138 .3724975586138 .0677032471137 .7628936768137 .4580993652 137.4580993652137 .1533050537136 .8484954834136 .5437011719136 .2389984131 135.6293945312135 .3246002197135 .0198059082134 .7149963379134 .1054992676 133.8007049561133 .1911010742132 .8863067627132 .2767028809131 .6672058105 131.0576019287130 .1432037354129 .533706665128 .9241027832128 .0097961426 127.4001998901126 .4858016968125 .8762969971124 .9618988037124 .3523025513 123.43800354122 .5235977173121 .9140014648120 .9997024536120 .0852966309 119.1709976196118 .2565994263117 .0374984741116 .1231002808115 .2088012695 113.9896011353113 .075302124111 .8561019897110 .9418029785109 .7226028442 108.8082962036107 .5891036987106 .3700027466105 .4557037354104 .8460998535 104.8460998535104 .8460998535105 .4557037354106 .0652008057106 .6747970581 107.5891036987108 .5035018921109 .1130981445110 .0273971558110 .9418029785 111.551399231112 .7705001831113 .6848983765114 .2944030762114 .9039993286 115.2088012695115 .5136032104115 .818397522115 .818397522115 .818397522 115.818397522115 .5136032104115 .5136032104114 .9039993286114 .5991973877 113.9896011353113 .6848983765121 .3044967651129 .533706665136 .2389984131 142.0299072266149 .3446960449159 .4026031494171 .5939941406183 .7854003906 194.1481018066 202.6820983887208.7778015137 208.7778015137 208.7778015137 208.7778015137 208.7778015137208.7778015137 208.7778015137 208.7778015137 
208.7778015137208 .7778015137208 .7778015137208 .7778015137208 .7778015137 208.7778015137208 .7778015137208 .7778015137208 .7778015137208 .7778015137 208.7778015137208 .7778015137208 .7778015137208 .7778015137208 .7778015137 208.7778015137208 .7778015137208 .7778015137208 .7778015137208 .7778015137 208.7778015137208 .7778015137208 .7778015137208 .7778015137208 .7778015137 208.7778015137208 .7778015137208 .7778015137208 .7778015137208 .7778015137 208.7778015137208 .7778015137208 .7778015137208 .7778015137208 .7778015137 208.7778015137 208.7778015137 208.7778015137 208.7778015137 208.7778015137 208.7778015137208 .7778015137208 .7778015137208 .7778015137208 .7778015137 208.7778015137208 .7778015137208 .7778015137208 .7778015137206 .9490966797 204.5108032227202 .3773040771200 .2438049316198 .1103057861196 .2816009521 194.4528961182192 .9290008545191 .4051055908190 .1858978271189 .2716064453 188.3571929932187 .7476043701186 .8332977295189 .5764007568 -9999 -9999-9999 -9999 -9999 -9999 -9999 -9999 -9999 -9999 -9999 -9999 -9999 -9999 -9999 -9999 -9999 -9999 -9999 -9999 -9999 -9999 -9999 -9999 -9999 -9999 -9999 -9999 -9999 -9999 -9999 -9999 -9999 -9999

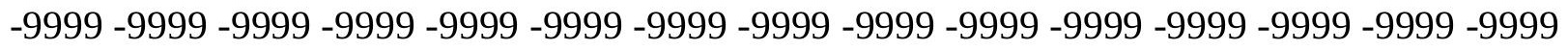

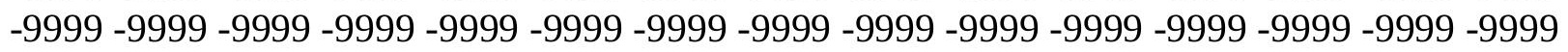

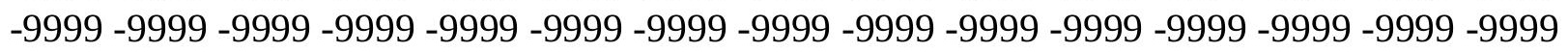
-9999 -9999 -9999 -9999-9999 -9999-9999

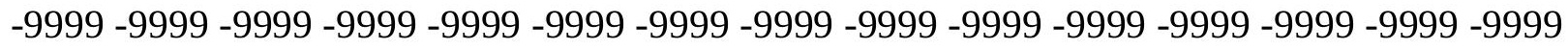

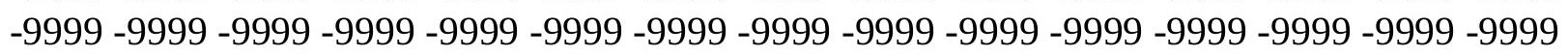

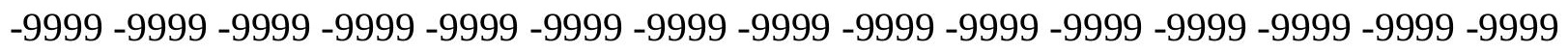
-9999 -9999 -9999 -9999 -9999 -9999 -9999 -9999 -9999 -9999 -9999 -9999 -9999 -9999 -9999 -9999 -9999 -9999 -9999 -9999 -9999 -9999 -9999 -9999 -9999 -9999 -9999 -9999 -9999 -9999 -

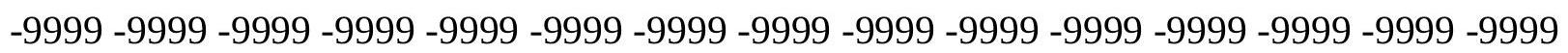

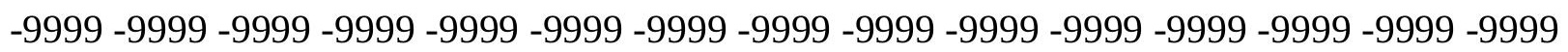

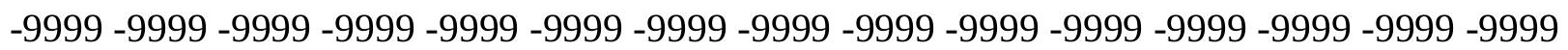

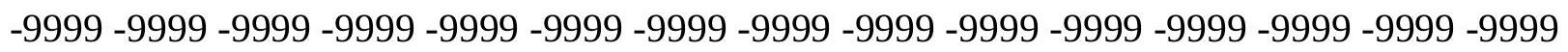
-9999 -9999-9999-9999-9999 138.9819946289 138.6772003174 138.3724975586 138.0677032471138 .0677032471137 .7628936768137 .4580993652137 .1533050537 136.8484954834136 .5437011719136 .2389984131135 .9342041016135 .6293945312 135.3246002197135 .0198059082134 .7149963379134 .1054992676133 .8007049561 133.4958953857132 .8863067627132 .2767028809131 .9720001221131 .3623962402 130.7528076172130 .1432037354129 .533706665128 .6192932129128 .0097961426 127.4001998901126 .4858016968125 .8762969971124 .9618988037124 .3523025513 123.43800354122 .8283996582121 .9140014648121 .3044967651120 .3900985718 119.4757995605118 .5614013672117 .647102356116 .7326965332115 .818397522 114.9039993286113 .6848983765112 .7705001831111 .551399231110 .6370010376 109.7226028442108 .5035018921107 .5891036987106 .3700027466105 .7603988647 105.4557037354105 .4557037354105 .7603988647106 .0652008057106 .6747970581 107.2844009399 108.1986999512108.8082962036109.7226028442110.6370010376 111.24659729112 .1608963013112 .4656982422113 .3800964355113 .9896011353 114.5991973877114 .9039993286115 .2088012695115 .5136032104115 .5136032104 115.5136032104115 .2088012695115 .2088012695114 .9039993286114 .2944030762 113.9896011353113 .3800964355113 .075302124115 .818397522121 .9140014648 126.4858016968130 .4479980469137 .1533050537149 .3446960449164 .5839996338 
179.2136993408190 .1858978271199 .0247039795206 .6443023682208 .7778015137 208.7778015137208 .7778015137208 .7778015137208 .7778015137208 .7778015137 208.7778015137208 .7778015137208 .7778015137208 .7778015137208 .7778015137 208.7778015137208 .7778015137208 .7778015137208 .7778015137208 .7778015137 208.7778015137208 .7778015137208 .7778015137208 .7778015137208 .7778015137 208.7778015137208 .7778015137208 .7778015137208 .7778015137208 .7778015137 208.7778015137208 .7778015137208 .7778015137208 .7778015137208 .7778015137 208.7778015137 208.7778015137 208.7778015137 208.7778015137 208.7778015137 208.7778015137208 .7778015137208 .7778015137208 .7778015137208 .7778015137 208.7778015137208 .7778015137208 .7778015137208 .7778015137208 .7778015137 208.7778015137 208.7778015137208.7778015137208.7778015137 208.7778015137 208.7778015137208.7778015137208.7778015137208.7778015137 208.7778015137 208.7778015137206 .6443023682204 .2059936523202 .0724945068199 .9389953613 197.8054962158196 .2816009521194 .4528961182192 .9290008545191 .7097930908 190.4907073975189 .5764007568188 .6620025635187 .4429016113186 .528503418 189.2716064453 -9999 -9999 -9999 -9999 -9999 -9999 -9999 -9999 -9999 -9999 -9999 -9999 -9999 -9999 -9999 -9999 -9999 -9999 -9999 -9999 -9999 -9999 -9999 -9999 -9999 -9999 -9999 -9999 -9999 -9999 -9999 -9999 -9999 -9999 -9999 -9999 -9999 -9999 -9999 -9999 -9999 -9999 -999 -9999 -9999 -9999 -9999 -9999 -9999 -9999 -9999 -9999 -9999 -9999 -9999 -9999 -9999 -9999 -999 -

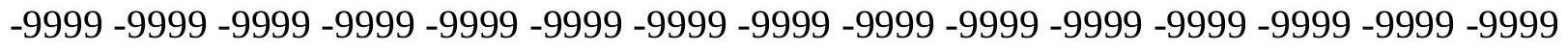
-9999 -9999 -9999 -9999 -9999 -9999 -9999 -9999 -9999 -9999 -9999 -9999- -9999 -

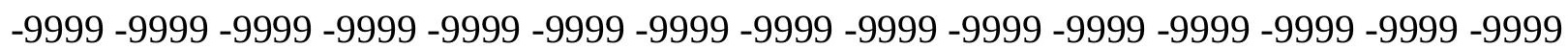
-9999 -9999 -9999 -9999 -9999 -9999 -9999 -9999 -9999 -9999 -9999 -9999 -9999 -9999 -9999 -9999 -9999 -9999 -9999 -9999 -9999 -9999 -9999 -9999 -9999 -9999 -9999 -9999 -9999 -9999 -

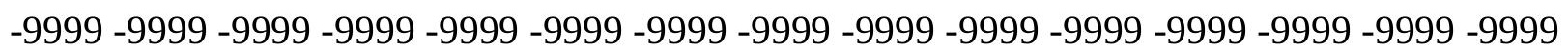
-9999 -9999 -9999 -9999 -9999 -9999 -9999 -9999 -9999 -9999 -9999 -9999 -9999 -9999 -9999 -9999 -9999 -9999 -9999 -9999 -9999 -9999 -9999 -9999 -9999 -9999 -9999 -9999 -9999 - -9999 -

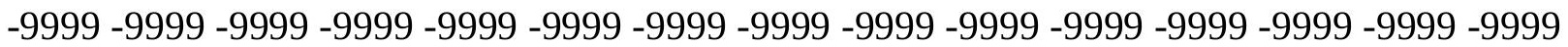

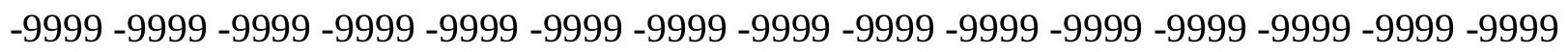

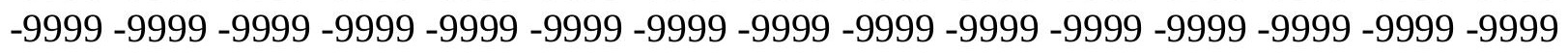
-9999 -9999-9999 -9999 138.3724975586138.0677032471 138.0677032471 137.7628936768 137.4580993652137 .1533050537137 .1533050537136 .8484954834136 .5437011719 136.2389984131135 .9342041016135 .6293945312135 .3246002197135 .0198059082 134.7149963379134 .4102020264133 .8007049561133 .4958953857133 .1911010742 132.5814971924132 .2767028809131 .6672058105131 .0576019287130 .4479980469 129.8385009766129 .2288970947128 .6192932129127 .7050018311127 .0953979492 126.4858016968125 .5715026855124 .9618988037124 .3523025513123 .7427978516 122.8283996582122 .2188034058121 .6092987061120 .6949005127120 .0852966309 119.1709976196118 .2565994263117 .342300415116 .4279022217115 .5136032104 114.5991973877113 .6848983765112 .4656982422111 .551399231110 .6370010376 109.4179000854 108.5035018921 107.5891036987 106.6747970581 106.3700027466 106.0652008057106 .0652008057106 .3700027466106 .6747970581107 .2844009399 107.8938980103108 .8082962036109 .4179000854110 .3321990967111 .24659729 111.8561019897112 .4656982422113 .075302124113 .3800964355113 .6848983765 114.2944030762114 .5991973877114 .9039993286114 .9039993286115 .2088012695 114.9039993286114 .9039993286114 .5991973877114 .2944030762113 .6848983765 
113.3800964355112 .7705001831112 .4656982422112 .1608963013116 .1231002808 119.4757995605121 .6092987061124 .6570968628140 .5059967041157 .878692627 175.2514038086185 .3094024658194 .1481018066202 .3773040771208 .7778015137 208.7778015137208 .7778015137208 .7778015137208 .7778015137208 .7778015137 208.7778015137208 .7778015137208 .7778015137208 .7778015137208 .7778015137 208.7778015137208 .7778015137208 .7778015137208 .7778015137208 .7778015137 208.7778015137208 .7778015137208 .7778015137208 .7778015137208 .7778015137 208.7778015137 208.7778015137 208.7778015137 208.7778015137 208.7778015137 208.7778015137208 .7778015137208 .7778015137208 .7778015137208 .7778015137 208.7778015137208 .7778015137208 .7778015137208 .7778015137208 .7778015137 208.7778015137208 .7778015137208 .7778015137208 .7778015137208 .7778015137 208.7778015137 208.7778015137 208.7778015137 208.7778015137 208.7778015137 208.7778015137 208.7778015137 208.7778015137 208.7778015137 208.7778015137 208.7778015137208 .7778015137208 .7778015137208 .7778015137208 .7778015137 208.7778015137208 .4730072021206 .0346984863203 .9011993408201 .7678070068 199.6342926025197 .8054962158195 .9768066406194 .4528961182192 .9290008545 191.7097930908190 .4907073975189 .2716064453187 .7476043701186 .528503418 186.2236938477 188.966796875 -9999 -9999 -9999 -9999 -9999 -9999 -9999 -9999 -9999 -9999 -9999 -9999 -9999 -9999 -9999 -9999 -9999 -9999 -9999 -9999 -9999 -9999 -9999 -9999

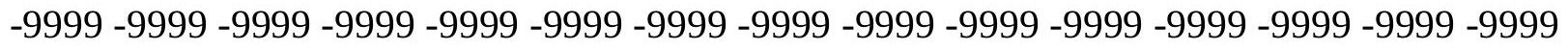

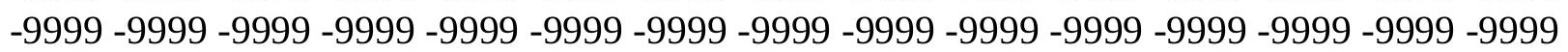

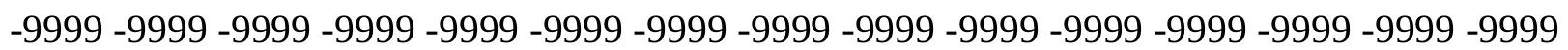
-9999 -9999 -9999 -9999 -9999 -9999 -9999 -9999 -9999 -9999 -9999 -9999 -9999 -9999 -9999 -9999 -9999 -9999 -9999 -9999 -9999 -9999 -9999 -9999 -9999 -9999 -9999 -9999 -9999 -9999 -9999 -9999 -9999 -9999 -9999 -9999 -9999 -9999 -9999 -9999 -9999 -9999 -9999 -9999 -9999 -9999 -9999 -9999 -9999 -9999 -9999 -9999 -9999 -9999 -9999 -9999 -9999 -9999 -9999 -9999 -9999 -9999 -9999 -9999 -9999 -9999 -9999 -9999 -9999 -9999 -9999 -9999 -9999 -9999 -9999

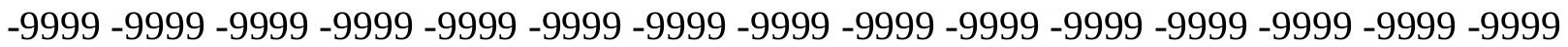
-9999 -9999 -9999 -9999 -9999 -9999 -9999 -9999 -9999 -9999 -9999 -9999 -9999 -9999 -9999

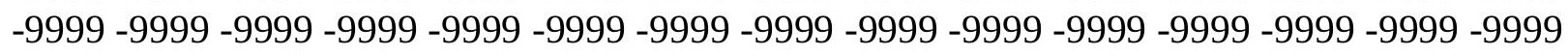
-9999 -9999 -9999 -9999 -9999 -9999 -9999 -9999 -9999 -9999 -9999 -9999 -9999 -9999 -9999 -9999 -9999 -9999 -9999 -9999 -9999 -9999 -9999 -9999 -9999 -9999 -9999 -9999 -9999 -9999 -9999-9999-9999 137.7628936768 137.7628936768 137.4580993652137.4580993652 137.1533050537136 .8484954834136 .5437011719136 .2389984131136 .2389984131 135.9342041016135 .6293945312135 .3246002197135 .0198059082134 .7149963379 134.4102020264134 .1054992676133 .4958953857133 .1911010742132 .8863067627 132.2767028809131 .9720001221131 .3623962402130 .7528076172130 .1432037354 129.8385009766128 .9241027832128 .3144989014127 .7050018311127 .0953979492 126.4858016968125 .5715026855124 .9618988037124 .3523025513123 .7427978516 123.1332015991122 .5235977173121 .6092987061120 .9997024536120 .3900985718 119.7806015015118 .8662033081118 .2565994263117 .342300415116 .4279022217 115.5136032104114 .5991973877113 .3800964355112 .4656982422111 .551399231 110.6370010376109 .7226028442108 .8082962036107 .8938980103107 .2844009399 106.979598999 106.979598999 106.979598999 107.2844009399107.5891036987 108.1986999512108 .8082962036109 .4179000854110 .0273971558110 .9418029785 111.8561019897112 .4656982422113 .075302124113 .3800964355113 .6848983765 
113.6848983765113 .6848983765114 .2944030762114 .2944030762114 .5991973877 114.5991973877114 .5991973877114 .2944030762113 .9896011353113 .6848983765 113.075302124112 .7705001831112 .4656982422111 .8561019897111 .551399231 112.1608963013115 .2088012695117 .9517974854123 .7427978516135 .3246002197 150.5639038086165 .4983062744177 .6896972656188 .0523986816196 .891204834 205.1204071045208 .7778015137208 .7778015137208 .7778015137208 .7778015137 208.7778015137208 .7778015137208 .7778015137208 .7778015137208 .7778015137 208.7778015137208 .7778015137208 .7778015137208 .7778015137208 .7778015137 208.7778015137208 .7778015137208 .7778015137208 .7778015137208 .7778015137 208.7778015137208 .7778015137208 .7778015137208 .7778015137208 .7778015137 208.7778015137 208.7778015137208.7778015137208.7778015137 208.7778015137 208.7778015137208 .7778015137208 .7778015137208 .7778015137208 .7778015137 208.7778015137 208.7778015137208.7778015137 208.7778015137 208.7778015137 208.7778015137208 .7778015137208 .7778015137208 .7778015137208 .7778015137 208.7778015137208 .7778015137208 .7778015137208 .7778015137208 .7778015137 208.7778015137 208.7778015137208.7778015137 208.7778015137 208.7778015137 208.7778015137208 .7778015137208 .7778015137208 .1681976318205 .7299957275 203.596496582201 .4629974365199 .329498291197 .500793457195 .9768066406 194.1481018066192 .624206543191 .1002960205189 .8811035156188 .3571929932 186.8332977295 185.3094024658 185.9188995361188 .6620025635 -9999 -9999 -9999 -9999 -9999 -9999 -9999 -9999 -9999 -9999 -9999 -9999 -9999 -9999 -9999 -9999 -9999 -9999 -9999 -

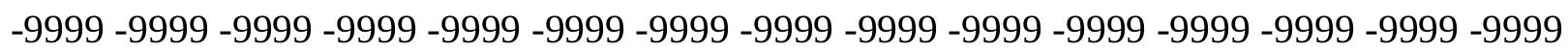
-9999 -9999 -9999 -9999 -9999 -9999 -9999 -9999 -9999 -9999 -9999 -9999 -9999 -9999 -9999 -

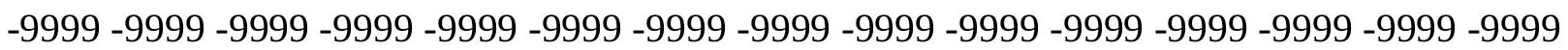

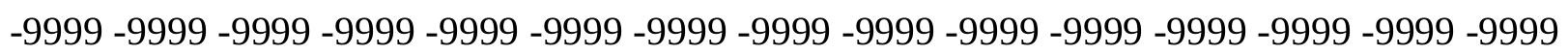
-9999 -9999 -9999-9999

-9999 -9999 -9999 -9999 -9999 -9999 -9999 -9999 -9999 -9999 -9999 -9999 -9999 -9999 -9999

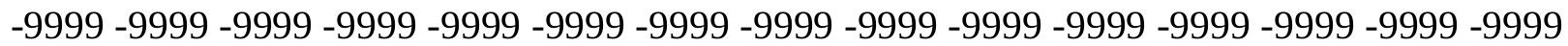

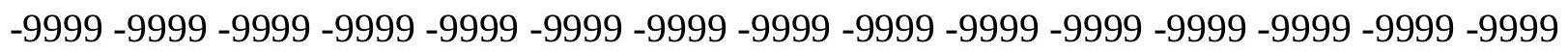

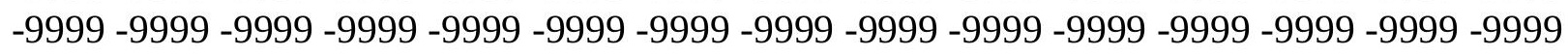
-9999 -9999 -9999 -9999 -9999 -9999 -9999 -9999 -9999 -9999 -9999 -9999 -9999 -9999 -9999 -9999 -9999 -9999 -9999 -9999 -9999 -9999 -9999 -9999 -9999 -9999 -9999 -9999 -9999 -9999 -

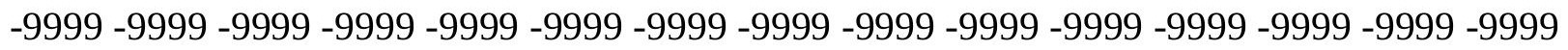

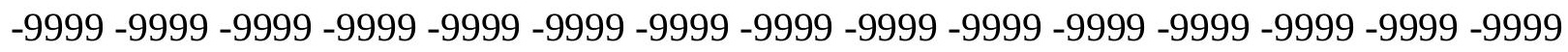

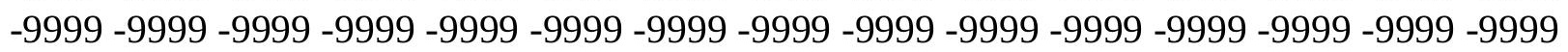
-9999 -9999-9999 137.1533050537137.1533050537 136.8484954834136.5437011719 136.5437011719136 .2389984131135 .9342041016135 .6293945312135 .6293945312 135.3246002197135 .0198059082134 .7149963379134 .4102020264134 .1054992676 133.8007049561133 .1911010742132 .8863067627132 .5814971924131 .9720001221 131.6672058105131 .0576019287130 .7528076172130 .1432037354129 .533706665 128.9241027832128 .3144989014127 .7050018311127 .0953979492126 .1809997559 125.5715026855124 .9618988037124 .3523025513123 .7427978516123 .1332015991 122.5235977173121 .9140014648121 .3044967651120 .6949005127120 .3900985718 119.7806015015118 .8662033081118 .2565994263117 .342300415116 .4279022217 115.5136032104114 .2944030762113 .3800964355112 .4656982422111 .551399231 110.6370010376109 .7226028442109 .1130981445108 .1986999512107 .8938980103 
107.5891036987107 .5891036987107 .8938980103107 .8938980103108 .1986999512 108.8082962036109 .4179000854110 .0273971558110 .6370010376111 .551399231 112.1608963013113 .075302124113 .6848983765113 .9896011353113 .9896011353 113.9896011353113 .9896011353113 .6848983765113 .9896011353114 .2944030762 114.2944030762113 .9896011353113 .6848983765113 .3800964355113 .075302124 112.4656982422112 .1608963013111 .8561019897111 .24659729110 .9418029785 110.6370010376112 .4656982422116 .1231002808122 .5235977173131 .6672058105 143.8585968018156 .3547973633169 .4604949951180 .7375946045191 .1002960205 199.9389953613208 .1681976318208 .7778015137208 .7778015137208 .7778015137 208.7778015137208 .7778015137208 .7778015137208 .7778015137208 .7778015137 208.7778015137208 .7778015137208 .7778015137208 .7778015137208 .7778015137 208.7778015137208 .7778015137208 .7778015137208 .7778015137208 .7778015137 208.7778015137208 .7778015137208 .7778015137208 .7778015137208 .7778015137 208.7778015137208 .7778015137208 .7778015137208 .7778015137208 .7778015137 208.7778015137208 .7778015137208 .7778015137208 .7778015137208 .7778015137 208.7778015137208 .7778015137208 .7778015137208 .7778015137208 .7778015137 208.7778015137208 .7778015137208 .7778015137208 .7778015137208 .7778015137 208.7778015137208 .7778015137208 .7778015137208 .7778015137208 .7778015137 208.7778015137208 .7778015137208 .7778015137208 .7778015137208 .7778015137 208.7778015137208 .7778015137208 .7778015137208 .7778015137207 .8634033203 205.425201416203 .2917022705201 .158203125199 .329498291197 .1959991455 195.3672943115193 .8433074951192 .0146026611190 .4907073975188 .966796875 $187.1381072998185 .6141052246184 .0901947021185 .9188995361188 .3571929932-9999$ -9999 -9999 -9999 -9999 -9999 -9999 -9999 -9999 -9999 -9999 -9999 -9999 -9999 -9999 -9999

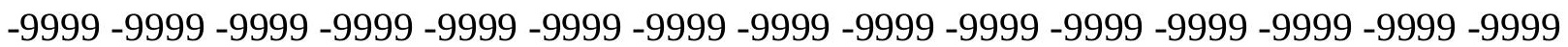
-9999 -9999 -9999 -9999 -9999 -9999 -9999 -9999 -9999 -9999 -9999 -9999 -9999 -9999 -9999 -9999 -9999 -9999 -9999 -9999 -9999 -9999 -9999 -9999 -9999 -9999 -9999 -9999 -9999 -9999

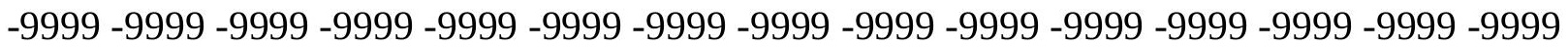
-9999 -9999 -9999 -9999 -9999-9999

-9999 -9999 -9999 -9999 -9999 -9999 -9999 -9999 -9999 -9999 -9999 -9999 -9999 -9999 -9999 -9999 -9999 -9999 -9999 -9999 -9999 -9999 -9999 -9999 -9999 -9999 -9999 -9999 -9999 -9999 -

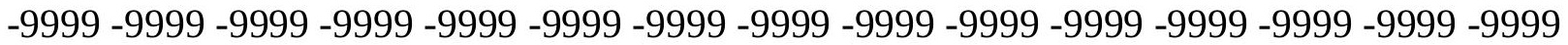
-9999 -9999 -9999 -9999 -9999 -9999 -9999 -9999 -9999 -9999 -9999 -9999 -9999 -9999 -9999 -9999 -9999 -9999 -9999 -9999 -9999 -9999 -9999 -9999 -9999 -9999 -9999 -9999 -9999 -9999 -9999 -9999 -9999 -9999 -9999 -9999 -9999 -9999 -9999 -9999 -9999 -9999 -9999 -9999 -9999 -9999 -9999 -9999 -9999 -9999 -9999 -9999 -9999 -9999 -9999 -9999 -9999 -9999 -9999 -9999 -9999 -9999 -9999 -9999 -9999 -9999 -9999 -9999 -9999 -9999 -9999 -9999 -9999 -9999 -9999

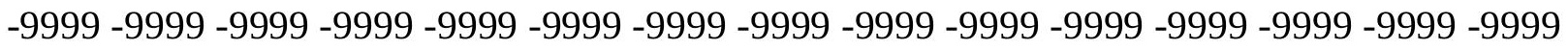
-9999 -9999 136.5437011719 136.5437011719 136.2389984131 136.2389984131 135.9342041016135 .9342041016135 .6293945312135 .3246002197135 .0198059082 135.0198059082134 .7149963379134 .4102020264134 .1054992676133 .8007049561 133.4958953857132 .8863067627132 .5814971924132 .2767028809131 .9720001221 131.3623962402131 .0576019287130 .4479980469129 .8385009766129 .533706665 128.9241027832128 .3144989014127 .7050018311127 .0953979492126 .1809997559 125.5715026855124 .9618988037124 .3523025513123 .7427978516123 .1332015991 122.5235977173121 .9140014648121 .6092987061120 .9997024536120 .6949005127 
120.0852966309119 .7806015015119 .1709976196118 .2565994263117 .647102356 116.7326965332115 .5136032104114 .5991973877113 .3800964355112 .4656982422 111.551399231110 .9418029785110 .0273971558109 .1130981445108 .8082962036 108.5035018921108 .5035018921108 .5035018921108 .5035018921108 .8082962036 109.1130981445109 .4179000854110 .0273971558110 .6370010376111 .24659729 111.8561019897112 .7705001831113 .3800964355113 .9896011353114 .2944030762 114.2944030762114 .2944030762113 .9896011353113 .6848983765113 .3800964355 113.6848983765113 .6848983765113 .3800964355113 .075302124112 .7705001831 112.4656982422111 .8561019897111 .551399231111 .24659729110 .6370010376 110.3321990967110 .0273971558109 .7226028442113 .9896011353119 .7806015015 127.4001998901137 .4580993652149 .0399017334161 .2312927246173 .4226989746 184.3950042725194 .1481018066202 .9868927002208 .7778015137208 .7778015137 208.7778015137208 .7778015137208 .7778015137208 .7778015137208 .7778015137 208.7778015137208 .7778015137208 .7778015137208 .7778015137208 .7778015137 208.7778015137208 .7778015137208 .7778015137208 .7778015137208 .7778015137 208.7778015137208 .7778015137208 .7778015137208 .7778015137208 .7778015137 208.7778015137208 .7778015137208 .7778015137208 .7778015137208 .7778015137 208.7778015137208 .7778015137208 .7778015137208 .7778015137208 .7778015137 208.7778015137208 .7778015137208 .7778015137208 .7778015137208 .7778015137 208.7778015137208 .7778015137208 .7778015137208 .7778015137208 .7778015137 208.7778015137208 .7778015137208 .7778015137208 .7778015137208 .7778015137 208.7778015137208 .7778015137208 .7778015137208 .7778015137208 .7778015137 208.7778015137208 .7778015137208 .7778015137208 .7778015137208 .7778015137 208.7778015137207 .25390625205 .1204071045202 .9868927002200 .8533935547 198.7198944092196 .891204834195 .0625193 .233795166191 .4051055908189 .5764007568 187.7476043701185 .9188995361184 .3950042725183 .1759033203185 .6141052246 188.0523986816 -9999 -9999 -9999 -9999 -9999 -9999 -9999 -9999 -9999 -9999 -9999 -9999 -9999 -9999 -9999 -9999 -9999 -9999 -9999 -9999 -9999 -9999 -9999 -9999 -9999 -9999 -9999

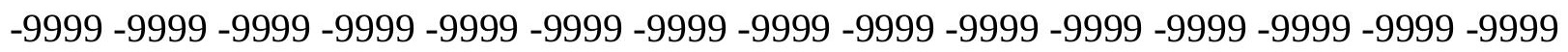

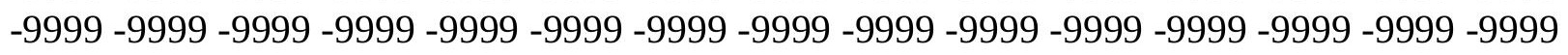

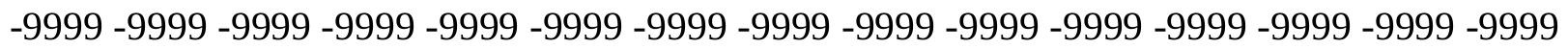
-9999 -9999 -9999 -9999 -9999 -9999 -9999 -9999 -9999

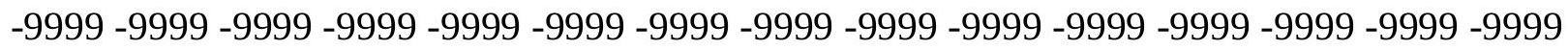
-9999 -9999 -9999 -9999 -9999 -9999 -9999 -9999 -9999 -9999 -9999 -9999 -9999 -9999 -9999 -9999 -9999 -9999 -9999 -9999 -9999 -9999 -9999 -9999 -9999 -9999 -9999 -9999 -9999 -9999

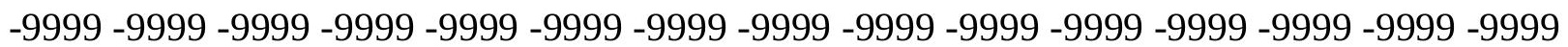

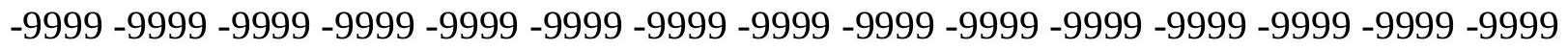

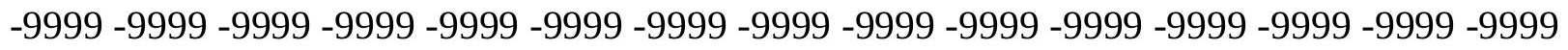

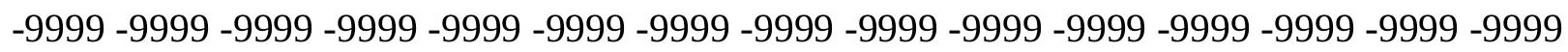
-9999 -9999 -9999 -9999 -9999 -9999 -9999 -9999 -9999 -9999 -9999 -9999 -9999 -9999 -9999 -

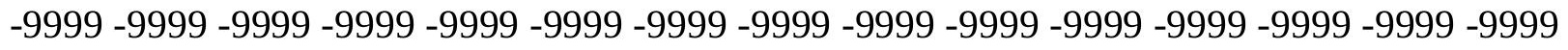
-9999 136.2389984131 135.9342041016 135.9342041016135.6293945312135.6293945312 135.3246002197135 .3246002197135 .0198059082134 .7149963379134 .7149963379 134.4102020264134 .1054992676133 .8007049561133 .4958953857133 .1911010742 132.8863067627132 .5814971924131 .9720001221131 .6672058105131 .3623962402 130.7528076172130 .4479980469129 .8385009766129 .2288970947128 .6192932129 
128.3144989014127 .7050018311127 .0953979492126 .1809997559125 .5715026855 124.9618988037124 .3523025513123 .7427978516123 .1332015991122 .5235977173 122.2188034058121 .6092987061121 .3044967651120 .9997024536120 .6949005127 120.0852966309119 .7806015015119 .4757995605118 .8662033081117 .9517974854 117.0374984741115 .818397522114 .5991973877113 .3800964355112 .4656982422 111.551399231110 .9418029785110 .3321990967109 .7226028442109 .4179000854 109.1130981445109 .1130981445109 .1130981445109 .1130981445109 .4179000854 109.7226028442110 .0273971558110 .6370010376110 .9418029785111 .551399231 112.1608963013113 .075302124113 .3800964355113 .9896011353114 .2944030762 114.2944030762114 .2944030762114 .2944030762113 .9896011353113 .3800964355 113.3800964355113 .3800964355113 .075302124112 .4656982422112 .1608963013 111.551399231111 .24659729110 .9418029785110 .6370010376110 .0273971558 109.7226028442109 .4179000854109 .1130981445110 .0273971558115 .2088012695 121.9140014648130 .7528076172141 .1154937744153 .0021057129165 .4983062744 177.3849029541187 .7476043701196 .891204834205 .425201416208 .7778015137 208.7778015137208.7778015137208.7778015137 208.7778015137 208.7778015137 208.7778015137208 .7778015137208 .7778015137208 .7778015137208 .7778015137 208.7778015137208 .7778015137208 .7778015137208 .7778015137208 .7778015137 208.7778015137208 .7778015137208 .7778015137208 .7778015137208 .7778015137 208.7778015137208 .7778015137208 .7778015137208 .7778015137208 .7778015137 208.7778015137208 .7778015137208 .7778015137208 .7778015137208 .7778015137 208.7778015137208 .7778015137208 .7778015137208 .7778015137208 .7778015137 208.7778015137208 .7778015137208 .7778015137208 .7778015137208 .7778015137 208.7778015137208 .7778015137208 .7778015137208 .7778015137208 .7778015137 208.7778015137208 .7778015137208 .7778015137208 .7778015137208 .7778015137 208.7778015137208 .7778015137208 .7778015137208 .7778015137208 .7778015137 208.7778015137208 .7778015137206 .9490966797204 .8155975342202 .6820983887 200.5485992432198 .4151000977196 .2816009521194 .4528961182192 .624206543 190.4907073975188 .6620025635186 .8332977295185 .0045928955183 .1759033203 182.87109375185 .6141052246188 .0523986816 -9999 -9999 -9999 -9999 -9999 -9999 -9999 -9999 -9999 -9999 -9999 -9999 -9999 -9999 -9999 -9999 -9999 -9999 -9999 -9999 -9999 -9999 -9999 -9999 -9999 -9999 -9999 -9999 -9999 -9999 -9999 -9999 -9999 -9999 -9999 -9999-9999 -

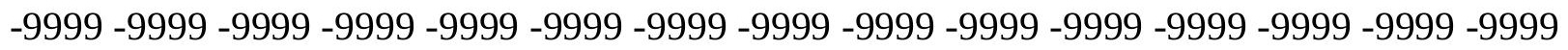

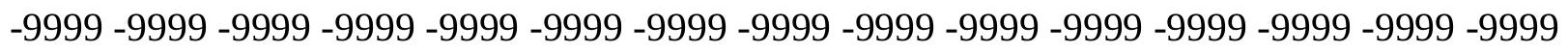
-9999 -9999 -9999 -9999 -9999 -9999 -9999 -9999 -9999 -9999 -9999 -9999 -9999 -9999 -9999 -9999 -9999 -9999 -9999 -9999 -9999 -9999 -9999 -9999 -9999 -9999 -9999 -9999

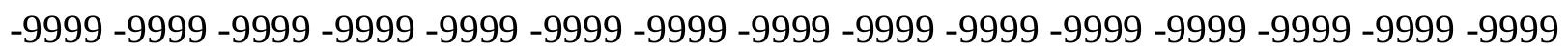

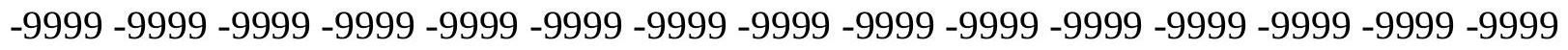

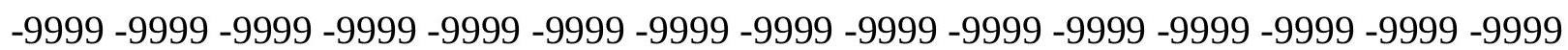
-9999 -9999 -9999 -9999 -9999 -9999 -9999 -9999 -9999 -9999 -9999 -9999 -9999 -9999 -9999 -

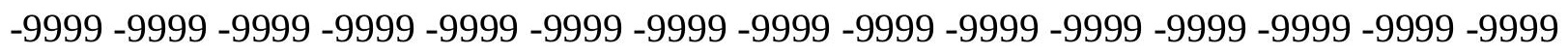

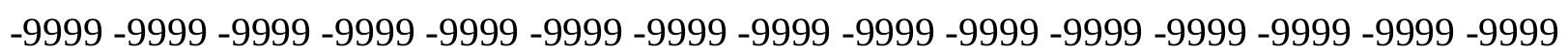

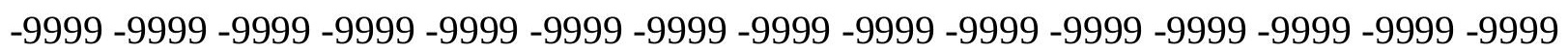
-9999 -9999 -9999 -9999 -9999 -9999 -9999 -9999 -9999 -9999 -9999 -9999 -9999 -9999 -9999 -999 135.6293945312 135.3246002197135.3246002197135.3246002197135.0198059082 135.0198059082134 .7149963379134 .7149963379134 .4102020264134 .1054992676 
134.1054992676133 .8007049561133 .4958953857133 .1911010742132 .8863067627 132.5814971924132 .2767028809131 .9720001221131 .3623962402131 .0576019287 130.7528076172130 .1432037354129 .8385009766129 .2288970947128 .6192932129 128.0097961426127 .7050018311127 .0953979492126 .1809997559125 .5715026855 124.9618988037124 .3523025513123 .7427978516123 .1332015991122 .5235977173 122.2188034058121 .6092987061121 .3044967651120 .9997024536120 .6949005127 120.3900985718120 .3900985718120 .0852966309119 .7806015015119 .1709976196 118.5614013672117 .647102356116 .1231002808114 .5991973877113 .3800964355 112.4656982422111 .8561019897111 .24659729110 .3321990967110 .0273971558 110.0273971558109 .7226028442109 .7226028442109 .7226028442109 .7226028442 110.0273971558110 .3321990967110 .6370010376110 .9418029785111 .551399231 111.8561019897112 .4656982422113 .075302124113 .3800964355113 .9896011353 113.9896011353114 .2944030762114 .2944030762114 .2944030762113 .9896011353 113.3800964355112 .7705001831112 .7705001831112 .1608963013111 .8561019897 111.24659729110 .9418029785110 .6370010376110 .3321990967110 .0273971558 109.4179000854109.1130981445108.8082962036108.5035018921 108.5035018921 108.8082962036114 .9039993286122 .8283996582132 .2767028809144 .1634063721 156.9642944336169 .4604949951180 .432800293189 .8811035156198 .7198944092 207.25390625208 .7778015137208 .7778015137208 .7778015137208 .7778015137 208.7778015137208 .7778015137208 .7778015137208 .7778015137208 .7778015137 208.7778015137208 .7778015137208 .7778015137208 .7778015137208 .7778015137 208.7778015137208 .7778015137208 .7778015137208 .7778015137208 .7778015137 208.7778015137208 .7778015137208 .7778015137208 .7778015137208 .7778015137 208.7778015137 208.7778015137208.7778015137 208.7778015137 208.7778015137 208.7778015137 208.7778015137208.7778015137 208.7778015137 208.7778015137 208.7778015137 208.7778015137208.7778015137 208.7778015137 208.7778015137 208.7778015137208 .7778015137208 .7778015137208 .7778015137208 .7778015137 208.7778015137208 .7778015137208 .7778015137208 .7778015137208 .7778015137 208.7778015137208 .7778015137208 .7778015137208 .7778015137208 .7778015137 208.7778015137208 .7778015137208 .7778015137208 .7778015137206 .6443023682 204.2059936523202 .0724945068199 .9389953613197 .8054962158195 .9768066406 193.8433074951192 .0146026611189 .8811035156188 .0523986816186 .2236938477 184.3950042725 183.1759033203 182.87109375185 .3094024658 -9999 -9999 -9999 -9999 -9999 -9999 -9999 -9999 -9999 -9999 -9999 -9999 -9999 -9999 -9999 -9999 -9999 -9999 -9999 -9999 -9999 -9999 -9999 -9999 -9999 -9999 -9999 -9999 -9999 -9999 -9999 -9999 -9999 -9999

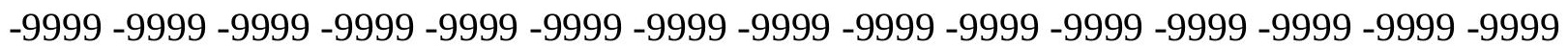

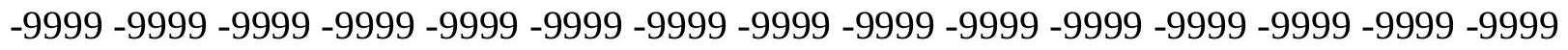

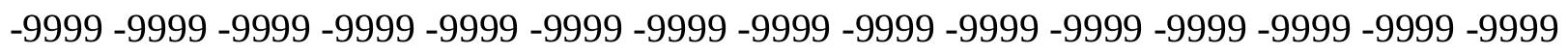
$-9999$

-9999 -9999 -9999 -9999 -9999 -9999 -9999 -9999 -9999 -9999 -9999 -9999 -9999 - -9999 -

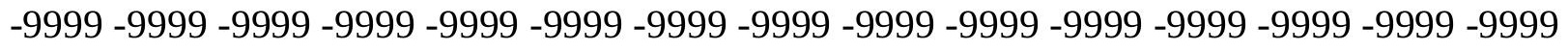

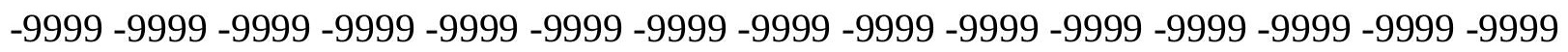

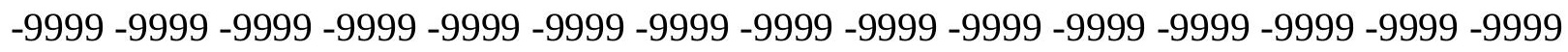
-9999 -9999 -9999 -9999 -9999 -9999 -9999 -9999 -9999 -9999 -9999 -9999 -9999 -9999 -9999 -

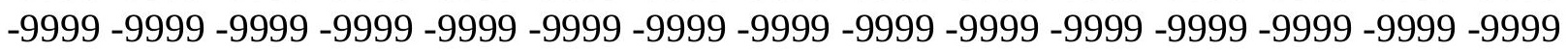

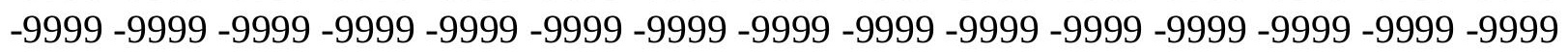


-9999 -9999 -9999 -9999 -9999 -9999 -9999 -9999 -9999 -9999 -9999 -9999 -9999 -9999 -9999 -9999 -9999 -9999 -9999 -9999 -9999 -9999 -9999 -9999 -9999 -9999 -9999 -9999 -9999 -9999 134.7149963379134 .7149963379134 .7149963379134 .7149963379134 .4102020264 134.4102020264134 .4102020264134 .1054992676133 .8007049561133 .8007049561 133.4958953857133 .1911010742132 .8863067627132 .5814971924132 .2767028809 131.9720001221131 .6672058105131 .3623962402131 .0576019287130 .4479980469 130.1432037354129 .533706665129 .2288970947128 .6192932129128 .0097961426 127.7050018311127 .0953979492126 .4858016968125 .8762969971124 .9618988037 124.3523025513123 .7427978516123 .1332015991122 .5235977173122 .2188034058 121.6092987061121 .3044967651120 .9997024536120 .6949005127120 .3900985718 120.3900985718120 .3900985718120 .3900985718120 .0852966309120 .0852966309 119.4757995605118 .5614013672117 .0374984741114 .9039993286113 .3800964355 112.1608963013111 .8561019897111 .24659729110 .9418029785110 .6370010376 110.6370010376110 .3321990967110 .3321990967110 .3321990967110 .3321990967 110.3321990967110 .6370010376110 .9418029785111 .24659729111 .8561019897 112.1608963013112 .7705001831113 .075302124113 .3800964355113 .6848983765 113.6848983765113 .9896011353113 .9896011353113 .9896011353113 .6848983765 113.075302124112 .7705001831113 .6848983765113 .9896011353110 .6370010376 110.3321990967110 .0273971558109 .7226028442109 .7226028442109 .4179000854 108.8082962036108 .5035018921108 .1986999512107 .8938980103108 .1986999512 108.1986999512108 .5035018921113 .9896011353121 .9140014648134 .4102020264 147.8208007812160 .9264984131171 .8988037109181 .6519012451191 .1002960205 200.2438049316208 .7778015137208 .7778015137208 .7778015137208 .7778015137 208.7778015137208 .7778015137208 .7778015137208 .7778015137208 .7778015137 208.7778015137208 .7778015137208 .7778015137208 .7778015137208 .7778015137 208.7778015137208 .7778015137208 .7778015137208 .7778015137208 .7778015137 208.7778015137208 .7778015137208 .7778015137208 .7778015137208 .7778015137 208.7778015137208 .7778015137208 .7778015137208 .7778015137208 .7778015137 208.7778015137208 .7778015137208 .7778015137208 .7778015137208 .7778015137 208.7778015137208 .7778015137208 .7778015137208 .7778015137208 .7778015137 208.7778015137208 .7778015137208 .7778015137208 .7778015137208 .7778015137 208.7778015137208 .7778015137208 .7778015137208 .7778015137208 .7778015137 208.7778015137208 .7778015137208 .7778015137208 .7778015137208 .7778015137 208.7778015137208 .7778015137208 .7778015137208 .7778015137208 .4730072021 206.3394927979203 .9011993408201 .7678070068199 .6342926025197 .500793457 195.3672943115193 .5386047363191 .4051055908189 .5764007568187 .7476043701 186.2236938477185 .3094024658184 .699798584182 .87109375185 .3094024658 -9999-9999 -9999 -9999 -9999 -9999 -9999 -9999 -9999 -9999 -9999 -9999 -9999 -9999 -9999 -9999 -9999 -9999 -9999 -9999 -9999 -9999 -9999 -9999 -9999 -9999 -9999 -9999 -9999 -9999 -9999 -9999 -9999 -9999 -9999 -9999 -9999 -9999 -9999 -9999 -9999 -9999 -9999 -9999 -9999 -9999 -9999 -9999 -9999 -9999 -9999 -9999 -9999 -9999 -9999 -9999 -9999 -9999 -9999 -9999 -9999 -9999

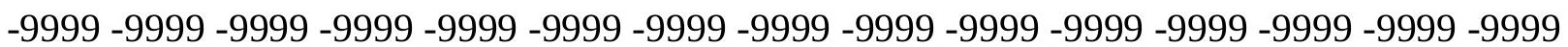
$-9999-9999$

-9999 -9999 -9999 -9999 -9999 -9999 -9999 -9999 -9999 -9999 -9999 -9999 -9999 -9999 -9999 -9999 -9999 -9999 -9999 -9999 -9999 -9999 -9999 -9999 -9999 -9999 -9999 -9999 -9999 -9999

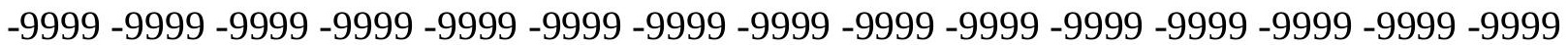


-9999 -9999 -9999 -9999 -9999 -9999 -9999 -9999 -9999 -9999 -9999 -9999 -9999 -9999 -9999 -9999 -9999 -9999 -9999 -9999 -9999 -9999 -9999 -9999 -9999 -9999 -9999 -9999 -9999 -9999

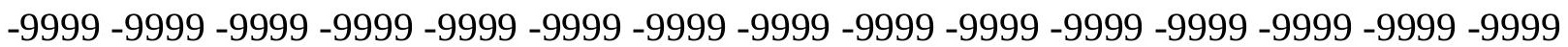
-9999 -9999 -9999 -9999 -9999 -9999 -9999 -9999 -9999 -9999 -9999 -9999 -9999 -9999 -9999 -9999 -9999 -9999 -9999 -9999 -9999 -9999 -9999 -9999 -9999 -9999 -9999 -9999 -9999 -9999 -9999 -9999 -9999 -9999 -9999 -9999 -9999 -9999 -9999 -9999 -9999 -9999 -9999 -9999 134.1054992676134 .1054992676134 .1054992676134 .1054992676134 .1054992676 134.1054992676133 .8007049561133 .8007049561133 .4958953857133 .4958953857 133.1911010742132 .8863067627132 .5814971924132 .2767028809132 .2767028809 131.9720001221131 .3623962402131 .0576019287130 .7528076172130 .4479980469 129.8385009766129 .533706665129 .2288970947128 .6192932129128 .0097961426 127.7050018311127 .0953979492126 .4858016968125 .8762969971125 .2667007446 124.6570968628124 .0475006104123 .43800354122 .8283996582122 .2188034058 121.6092987061121 .3044967651120 .9997024536120 .6949005127120 .3900985718 120.3900985718120 .3900985718120 .3900985718120 .3900985718120 .3900985718 120.6949005127120 .3900985718119 .7806015015118 .2565994263115 .5136032104 113.075302124113 .9896011353113 .3800964355111 .551399231111 .551399231 111.24659729110 .9418029785110 .9418029785110 .6370010376110 .6370010376 110.6370010376110 .9418029785110 .9418029785111 .24659729111 .551399231 112.1608963013112 .4656982422112 .7705001831113 .075302124113 .3800964355 113.3800964355113 .6848983765113 .6848983765113 .6848983765113 .6848983765 113.3800964355112 .7705001831112 .1608963013110 .9418029785110 .0273971558 109.7226028442109 .4179000854109 .4179000854109 .1130981445108 .8082962036 108.8082962036108 .5035018921108 .1986999512107 .5891036987107 .5891036987 107.8938980103107 .8938980103108 .1986999512108 .1986999512112 .7705001831 123.7427978516137 .1533050537151 .7830047607161 .5361022949171 .2891998291 181.9566955566192 .624206543202 .9868927002208 .7778015137208 .7778015137 208.7778015137208 .7778015137208 .7778015137208 .7778015137208 .7778015137 208.7778015137208 .7778015137208 .7778015137208 .7778015137208 .7778015137 208.7778015137208 .7778015137208 .7778015137208 .7778015137208 .7778015137 208.7778015137208 .7778015137208 .7778015137208 .7778015137208 .7778015137 208.7778015137208 .7778015137208 .7778015137208 .7778015137208 .7778015137 208.7778015137208 .7778015137208 .7778015137208 .7778015137208 .7778015137 208.7778015137208 .7778015137208 .7778015137208 .7778015137208 .7778015137 208.7778015137208 .7778015137208 .7778015137208 .7778015137208 .7778015137 208.7778015137208 .7778015137208 .7778015137208 .7778015137208 .7778015137 208.7778015137208 .7778015137208 .7778015137208 .7778015137208 .7778015137 208.7778015137208 .7778015137208 .7778015137208 .7778015137208 .7778015137 208.7778015137208 .1681976318206 .0346984863203 .596496582201 .4629974365 199.329498291197 .1959991455195 .3672943115193 .233795166191 .4051055908 189.8811035156188 .6620025635187 .4429016113186 .8332977295180 .432800293 182.87109375185 .3094024658 -9999 -9999 -9999 -9999 -9999 -9999 -9999 -9999 -9999 -9999 -9999 -9999 -9999 -9999 -9999 -9999 -9999 -9999 -9999 -9999 -9999 -9999 -9999 -9999 -9999 -9999 -9999 -9999 -9999 -9999 -9999 -9999 -9999 -9999 -9999 -9999 -9999 -9999 -9999 -9999 -999 -9999 -9999 -9999 -9999 -9999 -9999 -9999 -9999 -9999 -9999 -9999 -9999 -9999 -9999 -9999

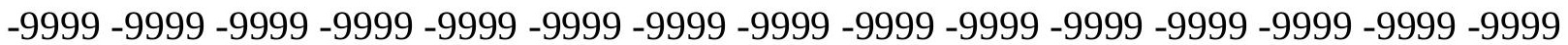


-9999 -9999 -9999 -9999 -9999 -9999 -9999 -9999

-9999 -9999 -9999 -9999 -9999 -9999 -9999 -9999 -9999 -9999 -9999 -9999 -9999 -9999 -9999

-9999 -9999 -9999 -9999 -9999 -9999 -9999 -9999 -9999 -9999 -9999 -9999 -9999 -9999 -9999

-9999 -9999 -9999 -9999 -9999 -9999 -9999 -9999 -9999 -9999 -9999 -9999 -9999 -9999 -9999

-9999 -9999 -9999 -9999 -9999 -9999 -9999 -9999 -9999 -9999 -9999 -9999 -9999 -9999 -9999

-9999 -9999 -9999 -9999 -9999 -9999 -9999 -9999 -9999 -9999 -9999 -9999 -9999 -9999 -9999 -

-9999 -9999 -9999 -9999 -9999 -9999 -9999 -9999 -9999 -9999 -9999 -9999 -9999 -9999 -9999

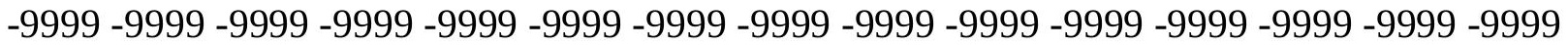

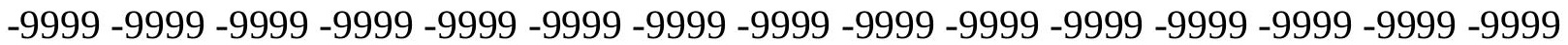

-9999 -9999 -9999 -9999 -9999 -9999 -9999 -9999 -9999 -9999 -9999 -9999 -9999

133.4958953857133 .4958953857133 .4958953857133 .4958953857133 .4958953857 133.4958953857133 .4958953857133 .1911010742133 .1911010742132 .8863067627 132.8863067627132 .5814971924132 .5814971924132 .2767028809131 .9720001221 131.6672058105131 .3623962402131 .0576019287130 .7528076172130 .4479980469 129.8385009766129 .533706665128 .9241027832128 .6192932129128 .0097961426 127.7050018311127 .0953979492126 .4858016968125 .8762969971125 .2667007446 124.6570968628124 .0475006104123 .43800354122 .8283996582122 .2188034058 121.6092987061121 .3044967651120 .6949005127120 .3900985718120 .0852966309 120.0852966309120 .0852966309120 .0852966309120 .0852966309120 .3900985718 120.6949005127120 .9997024536121 .3044967651121 .6092987061120 .3900985718 117.0374984741114 .9039993286114 .5991973877112 .4656982422112 .1608963013 111.8561019897111 .551399231111 .551399231111 .24659729111 .24659729111 .24659729 111.24659729111 .24659729111 .24659729111 .551399231111 .8561019897112 .1608963013 112.4656982422112 .7705001831113 .075302124113 .075302124113 .3800964355 113.3800964355113 .3800964355113 .3800964355113 .075302124112 .7705001831 112.1608963013111 .24659729110 .0273971558108 .8082962036108 .5035018921 108.5035018921108 .5035018921108 .5035018921108 .5035018921108 .1986999512 107.8938980103107 .5891036987107 .2844009399107 .2844009399107 .5891036987 107.5891036987107 .8938980103107 .8938980103107 .8938980103112 .4656982422 124.3523025513136 .8484954834148 .1255950928159 .4026031494171 .5939941406 184.0901947021196 .5863952637208 .1681976318208 .7778015137208 .7778015137 208.7778015137208 .7778015137208 .7778015137208 .7778015137208 .7778015137 208.7778015137208 .7778015137208 .7778015137208 .7778015137208 .7778015137 208.7778015137208 .7778015137208 .7778015137208 .7778015137208 .7778015137 208.7778015137208 .7778015137208 .7778015137208 .7778015137208 .7778015137 208.7778015137208 .7778015137208 .7778015137208 .7778015137208 .7778015137 208.7778015137208 .7778015137208 .7778015137208 .7778015137208 .7778015137 208.7778015137208 .7778015137208 .7778015137208 .7778015137208 .7778015137 208.7778015137208 .7778015137208 .7778015137208 .7778015137208 .7778015137 208.7778015137208 .7778015137208 .7778015137208 .7778015137208 .7778015137 208.7778015137208 .7778015137208 .7778015137208 .7778015137208 .7778015137 208.7778015137208 .7778015137208 .7778015137208 .7778015137208 .7778015137 208.7778015137208 .1681976318205 .7299957275203 .596496582201 .4629974365 199.329498291197 .1959991455195 .3672943115193 .8433074951192 .3193969727 191.1002960205189 .8811035156189 .2716064453188 .966796875180 .432800293 182.87109375185 .0045928955 -9999 -9999 -9999 -9999 -9999 -9999 -9999 -9999 -9999 -9999 
-9999 -9999 -9999 -9999 -9999 -9999 -9999 -9999 -9999 -9999 -9999 -9999 -9999 -9999 -9999 -9999 -9999 -9999 -9999 -9999 -9999 -9999 -9999 -9999 -9999 -9999 -9999 -9999 -9999 -9999

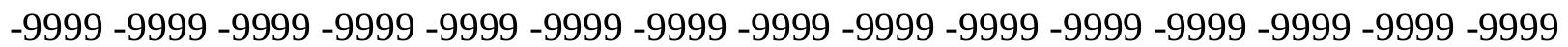
-9999 -9999 -9999 -9999 -9999 -9999 -9999 -9999 -9999 -9999 -9999 -9999 -9999 -9999 -9999 -9999 -9999 -9999 -9999-9999-9999-9999

-9999 -9999 -9999 -9999 -9999 -9999 -9999 -9999 -9999 -9999 -9999 -9999 -9999 -9999 -9999 -9999 -9999 -9999 -9999 -9999 -9999 -9999 -9999 -9999 -9999 -9999 -9999 -9999 -9999 -9999 -9999 -9999 -9999 -9999 -9999 -9999 -9999 -9999 -9999 -9999 -9999 -9999 -9999 -9999 -9999

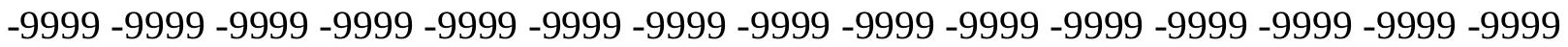
-9999 -9999 -9999 -9999 -9999 -9999 -9999 -9999 -9999 -9999 -9999 -9999 -9999 -9999 -9999 -

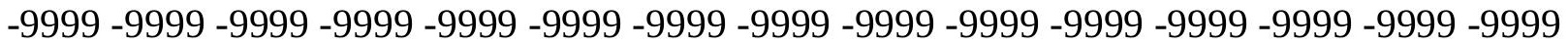
-9999 -9999 -9999 -9999 -9999 -9999 -9999 -9999 -9999 -9999 -9999 -9999 -9999 -9999 -9999 -9999 -9999 -9999 -9999 -9999 -9999 -9999 -9999 -9999 -9999 -9999 -9999 -9999 -9999 -9999 -9999 -9999 -9999 -9999 -9999 -9999 -9999 -9999 -9999 -9999 -9999 -9999 132.8863067627 132.8863067627132 .8863067627132 .8863067627132 .8863067627132 .8863067627 132.8863067627132 .8863067627132 .8863067627132 .5814971924132 .5814971924 132.2767028809132 .2767028809131 .9720001221131 .6672058105131 .3623962402 131.0576019287130 .7528076172130 .4479980469130 .1432037354129 .8385009766 129.533706665128 .9241027832128 .6192932129128 .0097961426127 .7050018311 127.0953979492126 .4858016968126 .1809997559125 .5715026855124 .9618988037 124.3523025513123 .7427978516123 .1332015991122 .5235977173121 .9140014648 121.3044967651120 .6949005127120 .3900985718120 .0852966309119 .7806015015 119.4757995605119 .4757995605119 .4757995605119 .7806015015120 .0852966309 120.3900985718120 .6949005127121 .6092987061122 .5235977173122 .8283996582 120.9997024536115 .5136032104113 .3800964355113 .075302124112 .7705001831 112.1608963013112 .1608963013111 .8561019897111 .551399231111 .551399231 111.551399231111 .551399231111 .551399231111 .551399231111 .8561019897 111.8561019897112 .1608963013112 .4656982422112 .7705001831112 .7705001831 113.075302124113 .075302124113 .075302124113 .075302124113 .075302124 112.7705001831112 .1608963013111 .551399231110 .6370010376109 .7226028442 108.8082962036107 .8938980103107 .8938980103107 .8938980103107 .8938980103 107.8938980103107 .5891036987107 .2844009399107 .2844009399106 .979598999 107.2844009399107 .2844009399107 .5891036987107 .5891036987107 .5891036987 107.2844009399 107.2844009399 111.24659729 122.2188034058 133.8007049561 146.2969055176160 .6217956543175 .8609924316190 .1858978271203 .596496582 208.7778015137208 .7778015137208 .7778015137208 .7778015137208 .7778015137 208.7778015137208 .7778015137208 .7778015137208 .7778015137208 .7778015137 208.7778015137208 .7778015137208 .7778015137208 .7778015137208 .7778015137 208.7778015137208 .7778015137208 .7778015137208 .7778015137208 .7778015137 208.7778015137208 .7778015137208 .7778015137208 .7778015137208 .7778015137 208.7778015137208 .7778015137208 .7778015137208 .7778015137208 .7778015137 208.7778015137208 .7778015137208 .7778015137208 .7778015137208 .7778015137 208.7778015137208 .7778015137208 .7778015137208 .7778015137208 .7778015137 208.7778015137208 .7778015137208 .7778015137208 .7778015137208 .7778015137 208.7778015137208 .7778015137208 .7778015137208 .7778015137208 .7778015137 208.7778015137208.7778015137208.7778015137208.7778015137208.7778015137 
208.7778015137208.7778015137208.7778015137208.7778015137207.8634033203 205.7299957275203 .596496582201 .4629974365199 .6342926025197 .8054962158 196.2816009521194 .7577056885193 .5386047363192 .624206543192 .0146026611 191.7097930908191 .4051055908180 .432800293182 .87109375185 .0045928955 -9999 -9999 -9999 -9999 -9999 -9999 -9999 -9999 -9999 -9999 -9999 -9999 -9999 -9999 -9999 -9999 -9999 -9999 -9999 -9999 -9999 -9999 -9999 -9999 -9999 -9999 -9999 -9999 -9999 -9999 -9999 -9999 -9999 -9999 -9999 -9999 -9999 -9999 -9999 -9999 -9999 -9999 -9999 -9999 -9999 -9999 -9999

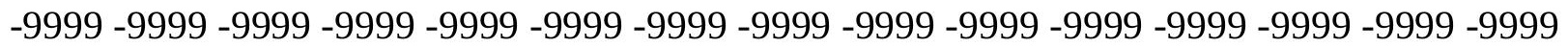
-9999 -9999 -9999 -9999 -9999 -9999 -9999 -9999 -9999 -9999 -9999 -9999 -9999 -9999 -9999 -9999 -9999 -9999 -9999 -9999 -9999 -9999 -9999 -9999 -9999 -9999 -9999 -9999 -9999

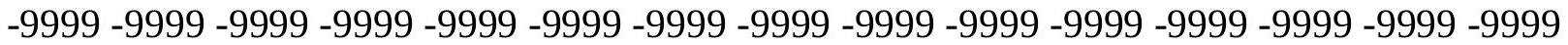
-9999 -9999 -9999 -9999 -9999 -9999 -9999 -9999 -9999 -9999 -9999 -9999 -9999 -9999 -9999 -9999 -9999 -9999 -9999 -9999 -9999 -9999 -9999 -9999 -9999 -9999 -9999 -9999 -9999 -9999 -9999 -9999 -9999 -9999 -9999 -9999 -9999 -9999 -9999 -9999 -9999 -9999 -9999 -9999 -9999 -9999 -9999 -9999 -9999 -9999 -9999 -9999 -9999 -9999 -9999 -9999 -9999 -9999 -9999 -9999

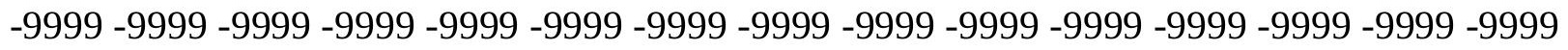

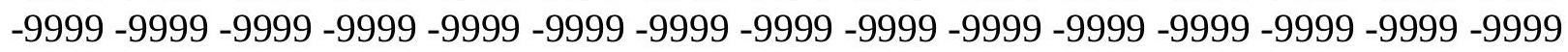
-9999 -9999 -9999 -9999-9999 -9999 -9999 -9999 -9999 -9999 -9999 131.9720001221 132.2767028809132 .2767028809132 .2767028809132 .2767028809132 .5814971924 132.5814971924132 .2767028809132 .2767028809132 .2767028809132 .2767028809 131.9720001221131 .9720001221131 .6672058105131 .3623962402131 .3623962402 131.0576019287130 .7528076172130 .4479980469130 .1432037354129 .8385009766 129.533706665128 .9241027832128 .6192932129128 .0097961426127 .7050018311 127.0953979492126 .7906036377126 .1809997559125 .5715026855124 .9618988037 124.3523025513123 .7427978516123 .1332015991122 .5235977173121 .9140014648 121.3044967651120 .9997024536120 .3900985718120 .0852966309119 .7806015015 119.4757995605119 .1709976196119 .1709976196119 .1709976196119 .1709976196 119.1709976196119 .4757995605119 .7806015015120 .3900985718121 .3044967651 122.8283996582125 .5715026855114 .2944030762113 .6848983765113 .3800964355 112.7705001831112 .4656982422112 .1608963013112 .1608963013111 .8561019897 111.8561019897111 .551399231111 .551399231111 .551399231111 .8561019897 111.8561019897112 .1608963013112 .1608963013112 .4656982422112 .4656982422 112.7705001831112 .7705001831112 .7705001831112 .7705001831112 .7705001831 112.4656982422112 .1608963013111 .8561019897111 .24659729110 .3321990967 109.7226028442108 .8082962036108 .1986999512107 .5891036987107 .2844009399 107.2844009399 107.5891036987 107.2844009399 106.979598999 106.979598999 106.979598999 107.2844009399 107.2844009399 107.2844009399 107.2844009399 107.2844009399 106.979598999 106.979598999 106.6747970581 109.4179000854 119.7806015015133 .4958953857150 .2590942383168 .241394043185 .0045928955 199.6342926025208 .7778015137208 .7778015137208 .7778015137208 .7778015137 208.7778015137208 .7778015137208 .7778015137208 .7778015137208 .7778015137 208.7778015137208 .7778015137208 .7778015137208 .7778015137208 .7778015137 208.7778015137208 .7778015137208 .7778015137208 .7778015137208 .7778015137 208.7778015137208 .7778015137208 .7778015137208 .7778015137208 .7778015137 208.7778015137208 .7778015137208 .7778015137208 .7778015137208 .7778015137 208.7778015137 208.7778015137208.7778015137 208.7778015137 208.7778015137 
208.7778015137208 .7778015137208 .7778015137208 .7778015137208 .7778015137 208.7778015137 208.7778015137208.7778015137208.7778015137 208.7778015137 208.7778015137208 .7778015137208 .7778015137208 .7778015137208 .7778015137 208.7778015137208 .7778015137208 .7778015137208 .7778015137208 .7778015137 208.7778015137208 .7778015137208 .7778015137208 .7778015137208 .7778015137 208.7778015137208 .1681976318206 .0346984863203 .9011993408202 .0724945068 200.2438049316198 .7198944092197 .500793457196 .2816009521195 .3672943115 194.7577056885194 .4528961182194 .1481018066194 .1481018066180 .432800293 182.87109375 -9999 -9999 -9999 -9999 -9999 -9999 -9999 -9999 -9999 -9999 -9999 -9999 -9999 -9999 -9999 -9999 -9999 -9999 -9999 -9999 -9999 -9999 -9999 -9999 -9999 -9999 -9999

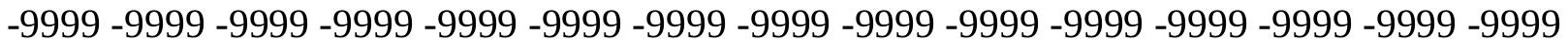
-9999 -9999 -9999 -9999 -9999 -9999 -9999 -9999 -9999 -9999 -9999 -9999 -9999 -9999 -9999

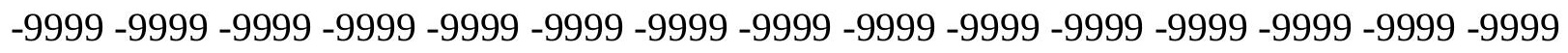
-9999 -9999 -9999-9999

-9999 -9999 -9999 -9999 -9999 -9999 -9999 -9999 -9999 -9999 -9999 -9999 -9999 -9999 -9999

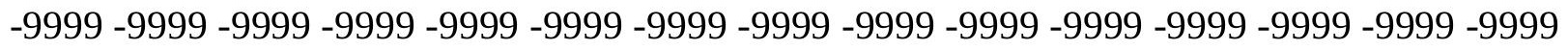
-9999 -9999 -9999 -9999 -9999 -9999 -9999 -9999 -9999 -9999 -9999 -9999 -9999 -9999 -9999 -9999 -9999 -9999 -9999 -9999 -9999 -9999 -9999 -9999 -9999 -9999 -9999 -9999 -9999 -9999 -

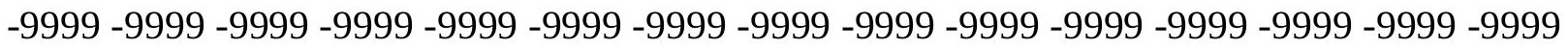

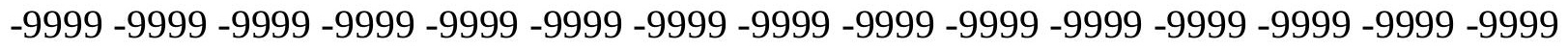

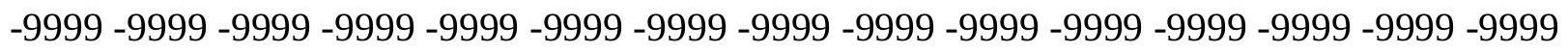

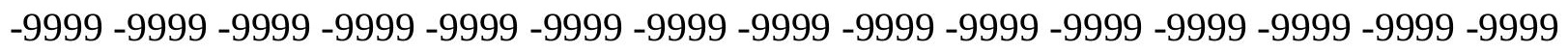
-9999 -9999 -9999 -9999-9999 -9999 -9999 -9999 -9999 -9999 -9999 131.3623962402 131.6672058105131 .6672058105131 .6672058105131 .9720001221131 .9720001221 131.9720001221131 .9720001221131 .9720001221131 .6672058105131 .6672058105 131.6672058105131 .3623962402131 .3623962402131 .0576019287130 .7528076172 130.4479980469130 .4479980469130 .1432037354129 .533706665129 .2288970947 128.9241027832128 .6192932129128 .3144989014127 .7050018311127 .4001998901 126.7906036377126 .4858016968125 .8762969971125 .2667007446124 .6570968628 124.0475006104123 .43800354122 .8283996582122 .2188034058121 .6092987061 120.9997024536120 .6949005127120 .0852966309119 .4757995605119 .1709976196 118.8662033081118 .5614013672118 .5614013672118 .2565994263118 .2565994263 118.2565994263118 .2565994263118 .2565994263118 .2565994263118 .2565994263 117.647102356114 .2944030762113 .9896011353113 .6848983765113 .3800964355 112.7705001831112 .7705001831112 .4656982422112 .1608963013112 .1608963013 111.8561019897111 .8561019897111 .551399231111 .8561019897111 .8561019897 111.8561019897112 .1608963013112 .1608963013112 .1608963013112 .4656982422 112.4656982422112 .4656982422112 .4656982422112 .4656982422112 .4656982422 112.1608963013111 .8561019897111 .551399231110 .9418029785110 .3321990967 109.7226028442108 .8082962036108 .5035018921107 .8938980103107 .5891036987 107.2844009399 107.2844009399 107.2844009399106.979598999 106.979598999 107.2844009399 107.2844009399 107.2844009399 107.2844009399106.979598999 106.979598999 106.979598999 106.6747970581 106.3700027466 106.3700027466 107.5891036987122 .5235977173141 .1154937744162 .1457061768181 .6519012451 196.891204834208 .7778015137208 .7778015137208 .7778015137208 .7778015137 208.7778015137 208.7778015137 208.7778015137 208.7778015137 208.7778015137 
208.7778015137208 .7778015137208 .7778015137208 .7778015137208 .7778015137 208.7778015137208 .7778015137208 .7778015137208 .7778015137208 .7778015137 208.7778015137208 .7778015137208 .7778015137208 .7778015137208 .7778015137 208.7778015137208 .7778015137208 .7778015137208 .7778015137208 .7778015137 208.7778015137208 .7778015137208 .7778015137208 .7778015137208 .7778015137 208.7778015137208 .7778015137208 .7778015137208 .7778015137208 .7778015137 208.7778015137 208.7778015137 208.7778015137 208.7778015137 208.7778015137 208.7778015137 208.7778015137 208.7778015137 208.7778015137 208.7778015137 208.7778015137208 .7778015137208 .7778015137208 .7778015137208 .7778015137 208.7778015137208 .7778015137208 .7778015137208 .7778015137208 .7778015137 208.7778015137208 .7778015137208 .4730072021206 .6443023682204 .8155975342 202.9868927002201 .4629974365200 .2438049316199 .0247039795198 .1103057861 197.500793457197 .1959991455196 .891204834196 .891204834196 .891204834 180.7375946045182 .87109375 -9999 -9999 -9999 -9999 -9999 -9999 -9999 -9999 -9999 -9999 -9999 -9999 -9999 -9999 -9999 -9999 -9999 -9999 -9999 -9999 -9999 -9999 -9999 -9999 -9999 -9999 -9999 -9999 -9999 -9999 -9999 -9999 -9999 -9999 -9999 -9999 -9999 -9999 - -9999 - -9999 -

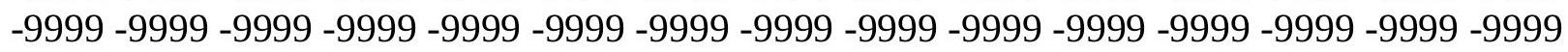

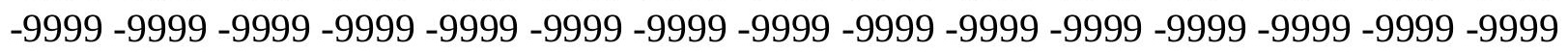
-9999 -9999 -9999 -9999-9999

-9999 -9999 -9999 -9999 -9999-9999 -9999 -9999 -9999 -9999 -9999 -9999 -9999 -9999 -9999 -

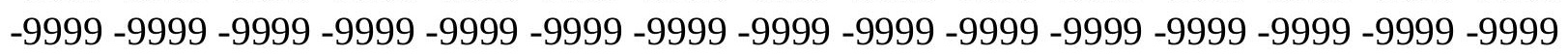

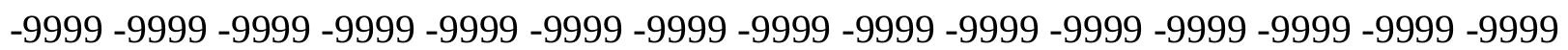
-9999 -9999 -9999 -9999 -9999 -9999 -9999 -9999 -9999 -9999 -9999 -9999 -9999 -9999 -9999 -

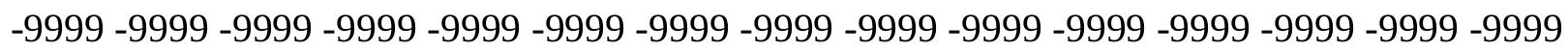

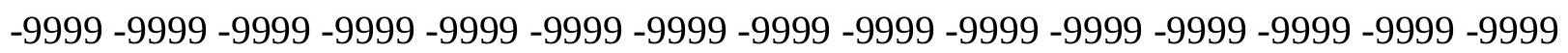

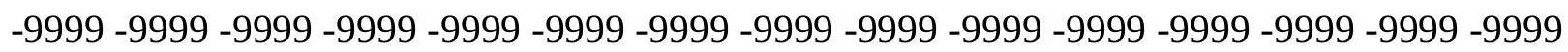
-9999 -9999 -9999 -9999 -9999 -9999 -9999 -9999 -9999 -9999 -9999 -9999 -9999 -9999 -9999 -9999 -9999 -9999 -9999 -9999 -9999 -9999 -9999 -9999 -9999 130.4479980469 130.7528076172131 .0576019287131 .0576019287131 .3623962402131 .3623962402 131.3623962402131 .3623962402131 .3623962402131 .3623962402131 .3623962402 131.3623962402131 .0576019287131 .0576019287130 .7528076172130 .7528076172 130.4479980469130 .1432037354129 .8385009766129 .533706665129 .2288970947 128.9241027832128 .6192932129128 .3144989014127 .7050018311127 .4001998901 126.7906036377126 .4858016968125 .8762969971125 .5715026855124 .9618988037 124.3523025513123 .7427978516123 .1332015991122 .5235977173121 .9140014648 121.3044967651120 .6949005127120 .0852966309119 .7806015015119 .1709976196 118.8662033081118 .5614013672118 .2565994263117 .9517974854117 .647102356 117.342300415117 .0374984741116 .7326965332116 .1231002808115 .5136032104 114.2944030762113 .6848983765113 .9896011353113 .6848983765113 .3800964355 113.075302124112 .7705001831112 .4656982422112 .4656982422112 .1608963013 112.1608963013112 .1608963013111 .8561019897111 .8561019897111 .8561019897 111.8561019897111 .8561019897111 .8561019897112 .1608963013112 .1608963013 112.1608963013112 .1608963013112 .1608963013112 .1608963013112 .1608963013 112.1608963013111 .8561019897111 .551399231111 .24659729110 .6370010376 110.0273971558109 .7226028442109 .1130981445108 .5035018921108 .1986999512 107.8938980103 107.5891036987 107.5891036987 107.2844009399 107.2844009399 
107.2844009399 107.2844009399 107.2844009399 106.979598999 106.979598999 106.979598999106 .979598999106 .6747970581106 .3700027466106 .3700027466 106.0652008057108 .8082962036114 .5991973877135 .3246002197157 .878692627 179.5184020996193 .8433074951206 .3394927979208 .7778015137208 .7778015137 208.7778015137208 .7778015137208 .7778015137208 .7778015137208 .7778015137 208.7778015137208 .7778015137208 .7778015137208 .7778015137208 .7778015137 208.7778015137208 .7778015137208 .7778015137208 .7778015137208 .7778015137 208.7778015137208 .7778015137208 .7778015137208 .7778015137208 .7778015137 208.7778015137208 .7778015137208 .7778015137208 .7778015137208 .7778015137 208.7778015137208 .7778015137208 .7778015137208 .7778015137208 .7778015137 208.7778015137208 .7778015137208 .7778015137208 .7778015137208 .7778015137 208.7778015137208 .7778015137208 .7778015137208 .7778015137208 .7778015137 208.7778015137208 .7778015137208 .7778015137208 .7778015137208 .7778015137 208.7778015137208 .7778015137208 .7778015137208 .7778015137208 .7778015137 208.7778015137208 .7778015137208 .7778015137208 .7778015137208 .7778015137 208.7778015137 208.7778015137208.7778015137 208.7778015137 208.7778015137 207.5587005615206 .0346984863204 .5108032227202 .9868927002202 .0724945068 201.158203125200 .5485992432199 .9389953613199 .6342926025199 .6342926025 199.6342926025 178.604095459180 .7375946045 -9999 -9999 -9999 -9999 -9999 -9999 -9999

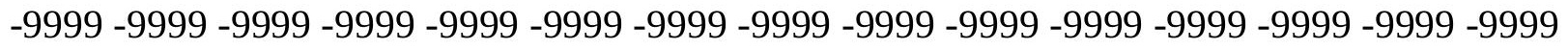
-9999 -9999 -9999 -9999 -9999 -9999 -9999 -9999 -9999 -9999 -9999 -9999 -9999 -9999 -9999 -999 -9999 -9999 -9999 -9999 -9999 -9999 -9999 -9999 -9999 -9999 -9999 -9999 -9999 -9999 -9999 -

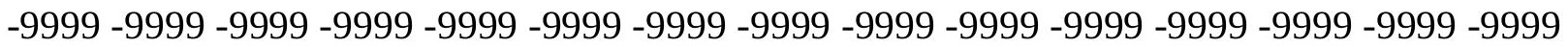
-9999 -9999 -9999 -9999-9999-9999-9999-9999

-9999 -9999 -9999 -9999 -9999 -9999 -9999 -9999 -9999 -9999 -9999 -9999 -9999 -9999 -9999 -9999 -9999 -9999 -9999 -9999 -9999 -9999 -9999 -9999 -9999 -9999 -9999 -9999 -9999 -9999 -9999 -9999 -9999 -9999 -9999 -9999 -9999 -9999 -9999 -9999 -9999 -9999 -9999 -9999 -9999

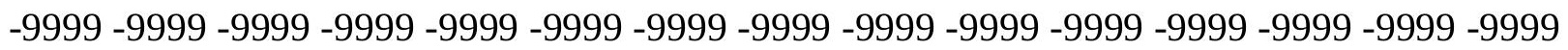
-9999 -9999 -9999 -9999 -9999 -9999 -9999 -9999 -9999 -9999 -9999 -9999 -9999 -9999 -9999 -9999 -9999 -9999 -9999 -9999 -9999 -9999 -9999 -9999 -9999 -9999 -9999 -9999 -9999 -9999 -9999 -9999 -9999 -9999 -9999 -9999 -9999 -9999 -9999 -9999 -9999 -9999 -9999 -9999 -9999 -9999 -9999 -9999 -9999 -9999 -9999 -9999 -9999 -9999 -9999 -9999 -9999 -9999 -9999 -9999 -9999 -9999 -9999 -9999-9999-9999-9999-9999-9999 129.533706665129 .8385009766 130.1432037354130 .4479980469130 .4479980469130 .7528076172130 .7528076172 130.7528076172131 .0576019287131 .0576019287131 .0576019287130 .7528076172 130.7528076172130 .7528076172130 .4479980469130 .4479980469130 .1432037354 130.1432037354129 .8385009766129 .533706665129 .2288970947128 .9241027832 128.6192932129128 .3144989014127 .7050018311127 .4001998901127 .0953979492 126.4858016968126 .1809997559125 .5715026855125 .2667007446124 .6570968628 124.0475006104123 .43800354122 .8283996582122 .2188034058121 .6092987061 120.9997024536120 .3900985718120 .0852966309119 .4757995605118 .8662033081 118.5614013672118 .2565994263117 .647102356117 .342300415117 .0374984741 116.4279022217115 .818397522115 .2088012695114 .2944030762113 .3800964355 113.075302124113 .3800964355113 .6848983765113 .3800964355113 .075302124 112.7705001831112 .4656982422112 .1608963013112 .1608963013112 .1608963013 112.1608963013112 .1608963013111 .8561019897111 .8561019897111 .8561019897 
111.8561019897111 .8561019897111 .8561019897111 .8561019897111 .8561019897 111.8561019897112 .1608963013112 .1608963013111 .8561019897111 .8561019897 111.8561019897111 .551399231111 .24659729110 .9418029785110 .6370010376 110.0273971558109 .7226028442109 .1130981445108 .8082962036108 .5035018921 108.1986999512107 .8938980103107 .5891036987107 .5891036987107 .5891036987 107.2844009399 107.2844009399 107.2844009399 106.979598999 106.979598999 106.979598999106 .6747970581106 .3700027466106 .3700027466106 .0652008057 105.7603988647105 .4557037354115 .5136032104133 .1911010742153 .6116943359 173.1179962158189 .2716064453202 .6820983887208 .7778015137208 .7778015137 208.7778015137208 .7778015137208 .7778015137208 .7778015137208 .7778015137 208.7778015137208 .7778015137208 .7778015137208 .7778015137208 .7778015137 208.7778015137208 .7778015137208 .7778015137208 .7778015137208 .7778015137 208.7778015137208 .7778015137208 .7778015137208 .7778015137208 .7778015137 208.7778015137208 .7778015137208 .7778015137208 .7778015137208 .7778015137 208.7778015137208 .7778015137208 .7778015137208 .7778015137208 .7778015137 208.7778015137208 .7778015137208 .7778015137208 .7778015137208 .7778015137 208.7778015137208 .7778015137208 .7778015137208 .7778015137208 .7778015137 208.7778015137208 .7778015137208 .7778015137208 .7778015137208 .7778015137 208.7778015137208 .7778015137208 .7778015137208 .7778015137208 .7778015137 208.7778015137208 .7778015137208 .7778015137208 .7778015137208 .7778015137 208.7778015137 208.7778015137 208.7778015137 208.7778015137 208.7778015137 208.7778015137208 .7778015137207 .5587005615206 .0346984863205 .1204071045 204.2059936523203 .596496582202 .9868927002202 .6820983887202 .6820983887 202.6820983887 202.6820983887178 .604095459180 .7375946045 -9999 -9999 -9999 -9999 -9999 -9999 -9999 -9999 -9999 -9999 -9999 -9999 -9999 -9999 -9999 -9999 -9999 -9999 -9999 -9999 -9999 -9999 -9999 -9999 -9999 -9999 -9999 -9999 -9999 -9999 -9999 -9999 -9999 -9999 -9999 -9999 -9999 -9999 -9999 -9999 -9999 -9999 -9999 -9999 -9999 -9999 -9999 -9999 -9999

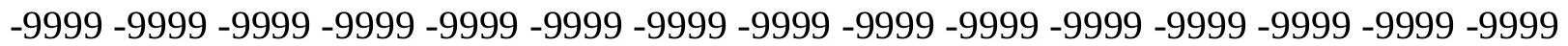
-9999 -9999-9999 -9999 -9999 -9999-9999 -9999 -9999-9999

-9999 -9999 -9999 -9999 -9999 -9999 -9999 -9999 -9999 -9999 -9999 -9999 -9999 -9999 -9999

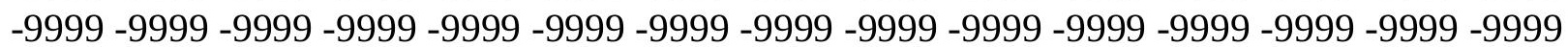
-9999 -9999 -9999 -9999 -9999 -9999 -9999 -9999 -9999 -9999 -9999 -9999 -9999 -9999-9999 -

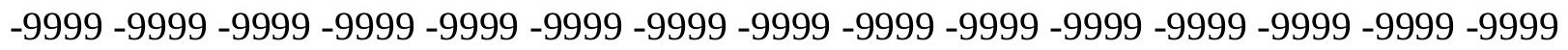
-9999 -9999 -9999 -9999 -9999 -9999 -9999 -9999 -9999 -9999 -9999 -9999 -9999 -9999 -9999

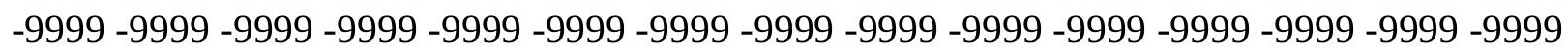

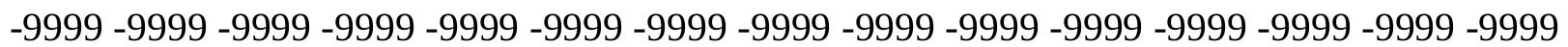

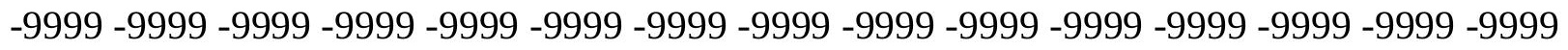
-9999 -9999 -9999 -9999-9999 -9999 -9999 -9999 128.6192932129128 .9241027832 129.2288970947129 .533706665129 .8385009766130 .1432037354130 .1432037354 130.1432037354130 .4479980469130 .4479980469130 .4479980469130 .4479980469 130.4479980469130 .4479980469130 .1432037354130 .1432037354130 .1432037354 129.8385009766129 .533706665129 .533706665129 .2288970947128 .9241027832 128.6192932129128 .3144989014128 .0097961426127 .4001998901127 .0953979492 126.7906036377126 .1809997559125 .8762969971125 .2667007446124 .9618988037 124.3523025513123 .7427978516123 .1332015991122 .5235977173121 .9140014648 121.3044967651120 .6949005127120 .3900985718119 .7806015015119 .1709976196 
118.8662033081118 .2565994263117 .9517974854117 .342300415116 .7326965332 116.1231002808115 .5136032104114 .5991973877113 .6848983765112 .7705001831 112.1608963013112 .4656982422113 .075302124113 .3800964355113 .3800964355 112.7705001831112 .1608963013111 .8561019897112 .1608963013112 .1608963013 112.1608963013112 .1608963013111 .8561019897111 .8561019897111 .8561019897 111.551399231111 .551399231111 .551399231111 .551399231111 .551399231 111.8561019897111 .8561019897111 .8561019897111 .8561019897111 .551399231 111.551399231111 .551399231111 .24659729110 .9418029785110 .6370010376 110.3321990967110 .0273971558109 .7226028442109 .4179000854108 .8082962036 108.5035018921108 .1986999512108 .1986999512107 .8938980103107 .5891036987 107.5891036987 107.5891036987 107.2844009399 107.2844009399 106.979598999 106.979598999106 .6747970581106 .6747970581106 .3700027466106 .0652008057 105.7603988647105 .4557037354105 .1509017944115 .5136032104131 .6672058105 149.9542999268168 .241394043184 .699798584198 .7198944092208 .7778015137 208.7778015137208 .7778015137208 .7778015137208 .7778015137208 .7778015137 208.7778015137208.7778015137208.7778015137 208.7778015137 208.7778015137 208.7778015137 208.7778015137208.7778015137 208.7778015137 208.7778015137 208.7778015137208 .7778015137208 .7778015137208 .7778015137208 .7778015137 208.7778015137208 .7778015137208 .7778015137208 .7778015137208 .7778015137 208.7778015137208 .7778015137208 .7778015137208 .7778015137208 .7778015137 208.7778015137208 .7778015137208 .7778015137208 .7778015137208 .7778015137 208.7778015137208 .7778015137208 .7778015137208 .7778015137208 .7778015137 208.7778015137208 .7778015137208 .7778015137208 .7778015137208 .7778015137 208.7778015137208.7778015137208.7778015137208.7778015137208.7778015137 208.7778015137208 .7778015137208 .7778015137208 .7778015137208 .7778015137 208.7778015137208.7778015137208.7778015137208.7778015137208.7778015137 208.7778015137208.7778015137208.7778015137208.7778015137208.7778015137 208.1681976318207 .25390625206 .6443023682206 .0346984863205 .7299957275 205.7299957275205 .7299957275205 .7299957275206 .0346984863178 .9089050293 181.0424041748 -9999 -9999 -9999 -9999 -9999 -9999 -9999 -9999 -9999 -9999 -9999 -9999 -9999 -9999 -9999 -9999 -9999 -9999 -9999 -9999 -9999 -9999 -9999 -9999 -9999 -9999 -9999

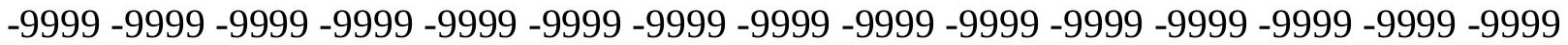

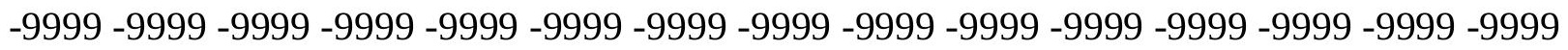

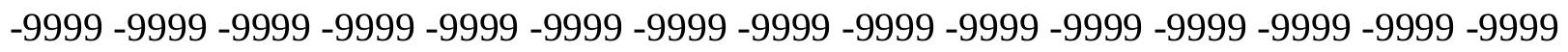
$-9999$

-9999 -9999 -9999 -9999 -9999 -9999 -9999 -9999 -9999 -9999 -9999 -9999 -9999 -9999 -9999

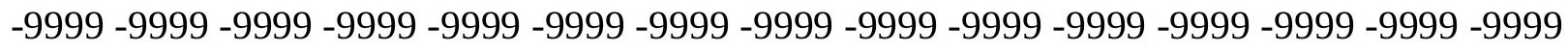

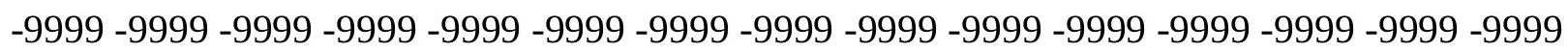

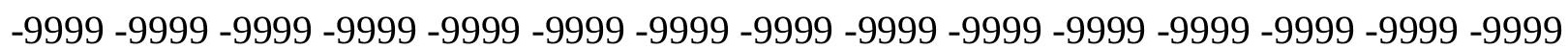
-9999 -9999 -9999 -9999 -9999 -9999 -9999 -9999 -9999 -9999 -9999 -9999 -9999 -9999 -9999 -

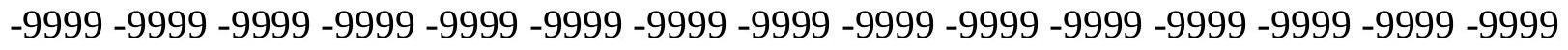

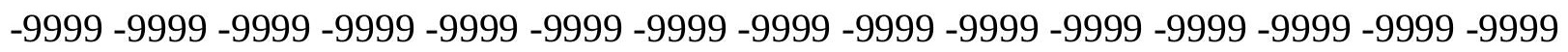
-9999 -9999 -9999 -9999 -9999 -9999 -9999 -9999 -9999 -9999 -9999 -9999 -9999 -9999 -9999 -9999 -9999 -9999 -9999 -9999-9999-9999 127.7050018311 128.0097961426128.3144989014 128.6192932129128 .9241027832129 .2288970947129 .533706665129 .533706665 129.8385009766129 .8385009766129 .8385009766130 .1432037354130 .1432037354 
130.1432037354129 .8385009766129 .8385009766129 .8385009766129 .533706665 129.533706665129 .2288970947128 .9241027832128 .9241027832128 .6192932129 128.3144989014128 .0097961426127 .7050018311127 .0953979492126 .7906036377 126.4858016968125 .8762969971125 .5715026855124 .9618988037124 .6570968628 124.0475006104123 .43800354122 .8283996582122 .2188034058121 .6092987061 121.3044967651120 .6949005127120 .0852966309119 .4757995605119 .1709976196 118.5614013672117 .9517974854117 .647102356117 .0374984741116 .4279022217 115.818397522114 .9039993286113 .9896011353112 .7705001831111 .551399231 111.24659729111 .8561019897112 .7705001831113 .3800964355113 .6848983765 113.075302124111 .8561019897111 .8561019897111 .8561019897111 .8561019897 111.8561019897111 .8561019897111 .8561019897111 .8561019897111 .551399231 111.551399231111 .551399231111 .551399231111 .551399231111 .551399231111 .551399231 111.551399231111 .551399231111 .551399231111 .551399231111 .24659729111 .24659729 110.9418029785110 .9418029785110 .6370010376110 .3321990967110 .0273971558 109.7226028442109 .4179000854109 .1130981445108 .8082962036108 .5035018921 108.1986999512108 .1986999512107 .8938980103107 .5891036987107 .5891036987 107.2844009399 107.2844009399 106.979598999 106.979598999 106.6747970581 106.3700027466106 .3700027466106 .0652008057105 .7603988647105 .4557037354 104.8460998535114 .2944030762129 .8385009766146 .9064025879163 .974395752 180.432800293195 .3672943115208 .4730072021208 .7778015137208 .7778015137 208.7778015137208 .7778015137208 .7778015137208 .7778015137208 .7778015137 208.7778015137208 .7778015137208 .7778015137208 .7778015137208 .7778015137 208.7778015137208 .7778015137208 .7778015137208 .7778015137208 .7778015137 208.7778015137208 .7778015137208 .7778015137208 .7778015137208 .7778015137 208.7778015137208 .7778015137208 .7778015137208 .7778015137208 .7778015137 208.7778015137 208.7778015137208.7778015137208.7778015137 208.7778015137 208.7778015137 208.7778015137208.7778015137208.7778015137 208.7778015137 208.7778015137208 .7778015137208 .7778015137208 .7778015137208 .7778015137 208.7778015137208 .7778015137208 .7778015137208 .7778015137208 .7778015137 208.7778015137208 .7778015137208 .7778015137208 .7778015137208 .7778015137 208.7778015137208 .7778015137208 .7778015137208 .7778015137208 .7778015137 208.7778015137208 .7778015137208 .7778015137208 .7778015137208 .7778015137 208.7778015137 208.7778015137208.7778015137 208.7778015137 208.7778015137 208.7778015137 208.7778015137208.7778015137 208.7778015137 208.7778015137 208.7778015137208 .7778015137176 .7754058838178 .9089050293 -9999 -9999 -9999 -9999 -9999 -9999 -9999 -9999 -9999 -9999 -9999 -9999 -9999 -9999 -9999 -9999 -9999 -9999 -9999

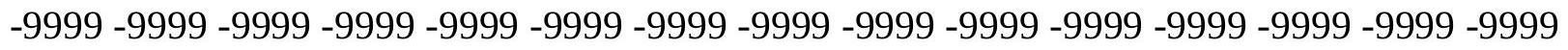

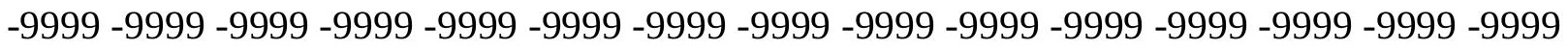
-9999 -9999 -9999 -9999 -9999 -9999 -9999 -9999 -9999 -9999 -9999 -9999 -9999 -9999 -9999 -9999 -9999 -9999 -9999 -9999 -9999 -9999 -9999 -9999

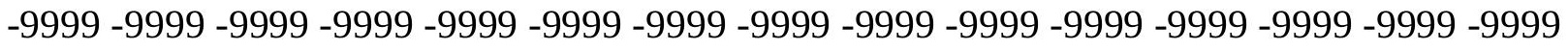

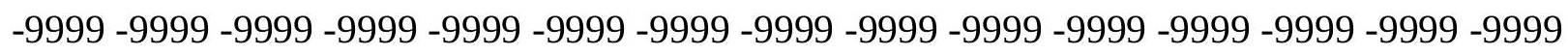
-9999 -9999 -9999 -9999 -9999 -9999 -9999 -9999 -9999 -9999 -9999 -9999 -9999 -9999 -9999 -9999 -9999 -9999 -9999 -9999 -9999 -9999 -9999 -9999 -9999 -9999 -9999 -9999 -9999 -9999 -9999 -9999 -9999 -9999 -9999 -9999 -9999 -9999 -9999 -9999 -9999 -9999 -9999 -9999 -9999 -

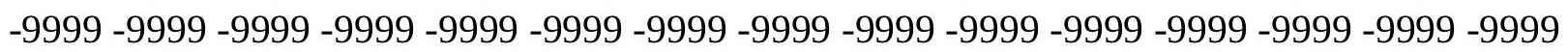


-9999 -9999 -9999 -9999 -9999 -9999 -9999 -9999 -9999 -9999 -9999 -9999 -9999 -9999 -9999 -9999 -9999 -9999 -9999 -9999 -9999 -9999 -9999 -9999 -9999 -9999 -9999 -9999 -9999 -9999 -9999 -9999 -9999 -9999 -9999 -9999 -9999 127.0953979492 127.4001998901 128.0097961426 128.3144989014128 .6192932129128 .6192932129128 .9241027832129 .2288970947 129.2288970947129 .533706665129 .533706665129 .533706665129 .533706665 129.533706665129 .533706665129 .533706665129 .533706665129 .2288970947 129.2288970947128 .9241027832128 .6192932129128 .3144989014128 .3144989014 128.0097961426127 .7050018311127 .4001998901126 .7906036377126 .4858016968 126.1809997559125 .8762969971125 .2667007446124 .9618988037124 .3523025513 123.7427978516123 .1332015991122 .8283996582122 .2188034058121 .6092987061 120.9997024536120 .3900985718119 .7806015015119 .4757995605118 .8662033081 118.5614013672117 .9517974854117 .647102356117 .0374984741116 .4279022217 115.5136032104114 .5991973877113 .6848983765112 .4656982422111 .24659729 110.6370010376111 .551399231112 .1608963013113 .075302124113 .6848983765 114.2944030762112 .7705001831112 .1608963013111 .8561019897111 .8561019897 111.8561019897111 .8561019897111 .551399231111 .551399231111 .551399231 111.24659729111 .24659729111 .24659729111 .24659729111 .24659729111 .24659729 111.24659729111 .24659729111 .24659729111 .24659729110 .9418029785110 .9418029785 110.9418029785110 .6370010376110 .3321990967110 .3321990967110 .0273971558 109.7226028442109 .4179000854109 .1130981445108 .8082962036108 .5035018921 108.5035018921108 .1986999512107 .8938980103107 .8938980103107 .5891036987 107.5891036987107 .2844009399107 .2844009399106 .979598999106 .6747970581 106.3700027466106 .0652008057105 .7603988647105 .4557037354105 .1509017944 104.8460998535112 .4656982422128 .0097961426144 .1634063721160 .9264984131 177.0802001953192 .3193969727206 .3394927979208 .7778015137208 .7778015137 208.7778015137208 .7778015137208 .7778015137208 .7778015137208 .7778015137 208.7778015137208 .7778015137208 .7778015137208 .7778015137208 .7778015137 208.7778015137208 .7778015137208 .7778015137208 .7778015137208 .7778015137 208.7778015137208 .7778015137208 .7778015137208 .7778015137208 .7778015137 208.7778015137208 .7778015137208 .7778015137208 .7778015137208 .7778015137 208.7778015137208 .7778015137208 .7778015137208 .7778015137208 .7778015137 208.7778015137208 .7778015137208 .7778015137208 .7778015137208 .7778015137 208.7778015137208 .7778015137208 .7778015137208 .7778015137208 .7778015137 208.7778015137208 .7778015137208 .7778015137208 .7778015137208 .7778015137 208.7778015137208 .7778015137208 .7778015137208 .7778015137208 .7778015137 208.7778015137208 .7778015137208 .7778015137208 .7778015137208 .7778015137 208.7778015137208 .7778015137208 .7778015137208 .7778015137208 .7778015137 208.7778015137208 .7778015137208 .7778015137208 .7778015137208 .7778015137 208.7778015137208 .7778015137208 .7778015137208 .7778015137208 .7778015137 208.7778015137208 .7778015137208 .7778015137177 .0802001953179 .2136993408 -9999 -9999 -9999 -9999 -9999 -9999 -9999 -9999 -9999 -9999 -9999 -9999 -9999 -9999 -9999 -9999 -9999 -9999 -9999 -9999 -9999 -9999 -9999 -9999 -9999 -9999 -9999 -9999 -9999 -9999 -9999 -9999 -9999 -9999 -9999 -9999 -9999 -9999 -9999 -9999 -9999 -9999 -9999 -9999 -9999 -9999 -9999 -9999 -9999 -9999 -9999 -9999 -9999 -9999 -9999 -9999 -9999 -9999 -9999 -9999 -9999 -9999 -9999 -9999 -9999 -9999 -9999 -9999 -9999 -9999 -9999 -9999

-9999 -9999 -9999 -9999 -9999 -9999 -9999 -9999 -9999 -9999 -9999 -9999 -9999 -9999 -9999 
-9999 -9999 -9999 -9999 -9999 -9999 -9999 -9999 -9999 -9999 -9999 -9999 -9999 -9999 -9999 -9999 -9999 -9999 -9999 -9999 -9999 -9999 -9999 -9999 -9999 -9999 -9999 -9999 -9999 -9999 -9999 -9999 -9999 -9999 -9999 -9999 -9999 -9999 -9999 -9999 -9999 -9999 -9999 -9999 -9999 -9999 -9999 -9999 -9999 -9999 -9999 -9999 -9999 -9999 -9999 -9999 -9999 -9999 -9999 -9999 -9999 -9999 -9999 -9999 -9999 -9999 -9999 -9999 -9999 -9999 -9999 -9999-9999 -9999 -9999 -9999 -9999 -9999 -9999 -9999 -9999 -9999 -9999 -9999 -9999 -9999 -9999 -9999 -9999 -9999

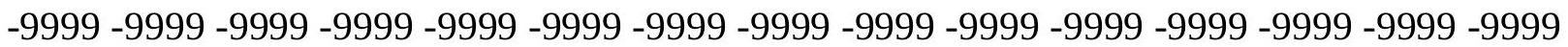
-9999 -9999-9999 -9999-9999-9999 126.1809997559 126.4858016968 126.7906036377 127.4001998901127 .7050018311128 .0097961426128 .3144989014128 .6192932129 128.6192932129128 .9241027832128 .9241027832129 .2288970947129 .2288970947 129.2288970947 129.2288970947 129.2288970947 129.2288970947 128.9241027832 128.9241027832128 .6192932129128 .6192932129128 .3144989014128 .0097961426 128.0097961426127 .7050018311127 .4001998901127 .0953979492126 .7906036377 126.1809997559125 .8762969971125 .5715026855124 .9618988037124 .6570968628 124.0475006104123 .43800354123 .1332015991122 .5235977173121 .9140014648 121.3044967651120 .6949005127120 .3900985718119 .7806015015119 .1709976196 118.8662033081118 .5614013672117 .9517974854117 .647102356117 .0374984741 116.4279022217115 .818397522114 .9039993286113 .9896011353112 .7705001831 111.24659729110 .3321990967110 .9418029785111 .8561019897112 .7705001831 113.3800964355113 .3800964355113 .075302124112 .4656982422111 .8561019897 111.8561019897111 .551399231111 .551399231111 .551399231111 .24659729111 .24659729 110.9418029785110 .9418029785110 .9418029785110 .9418029785110 .9418029785 110.9418029785110 .9418029785110 .9418029785110 .9418029785110 .9418029785 110.9418029785110 .6370010376110 .6370010376110 .6370010376110 .3321990967 110.0273971558110 .0273971558109 .7226028442109 .4179000854109 .1130981445 109.1130981445108 .8082962036108 .5035018921108 .5035018921108 .1986999512 107.8938980103107 .8938980103107 .5891036987107 .2844009399107 .2844009399 106.979598999106 .6747970581106 .3700027466106 .0652008057105 .7603988647 105.4557037354105 .1509017944104 .8460998535110 .6370010376125 .8762969971 141.7250976562158 .1835021973174 .6419067383190 .4907073975204 .8155975342 208.7778015137208 .7778015137208 .7778015137208 .7778015137208 .7778015137 208.7778015137208 .7778015137208 .7778015137208 .7778015137208 .7778015137 208.7778015137208 .7778015137208 .7778015137208 .7778015137208 .7778015137 208.7778015137208 .7778015137208 .7778015137208 .7778015137208 .7778015137 208.7778015137208.7778015137208.7778015137208.7778015137208.7778015137 208.7778015137 208.7778015137208.7778015137208.7778015137 208.7778015137 208.7778015137208.7778015137208.7778015137 208.7778015137 208.7778015137 208.7778015137 208.7778015137208.7778015137208.7778015137 208.7778015137 208.7778015137208 .7778015137208 .7778015137208 .7778015137208 .7778015137 208.7778015137208 .7778015137208 .7778015137208 .7778015137208 .7778015137 208.7778015137208 .7778015137208 .7778015137208 .7778015137208 .7778015137 208.7778015137208.7778015137208.7778015137208.7778015137 208.7778015137 208.7778015137208 .7778015137208 .7778015137208 .7778015137208 .7778015137 208.7778015137208.7778015137208.7778015137208.7778015137208.7778015137 208.7778015137208 .7778015137208 .7778015137208 .7778015137208 .7778015137 208.7778015137 177.0802001953 -9999 -9999 -9999 -9999 -9999 -9999 -9999 -9999 -9999 
-9999 -9999 -9999 -9999 -9999 -9999 -9999 -9999 -9999 -9999 -9999 -9999 -9999 -9999 -9999 -9999 -9999 -9999 -9999 -9999 -9999 -9999 -9999 -9999 -9999 -9999 -9999 -9999 -9999 -9999

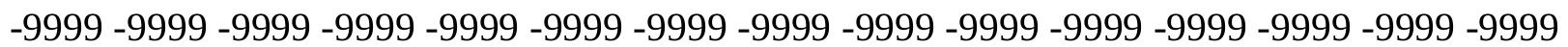
-9999 -9999 -9999 -9999 -9999 -9999 -9999 -9999 -9999 -9999 -9999 -9999 -9999 -9999 -9999 -9999 -9999-9999

-9999 -9999 -9999 -9999 -9999 -9999 -9999 -9999 -9999 -9999 -9999 -9999 -9999 -9999 -9999 -9999 -9999 -9999 -9999 -9999 -9999 -9999 -9999 -9999 -9999 -9999 -9999 -9999 -9999 -9999 -9999 -9999 -9999 -9999 -9999 -9999 -9999 -9999 -9999 -9999 -9999 -9999 -9999 -9999 -9999 -999 -9999 -9999 -9999 -9999 -9999 -9999 -9999 -9999 -9999 -9999 -9999 -9999 -9999 -9999 -9999 -9999 -9999 -9999 -9999 -9999 -9999 -9999 -9999 -9999 -9999 -9999 -9999 -9999 -9999 -9999

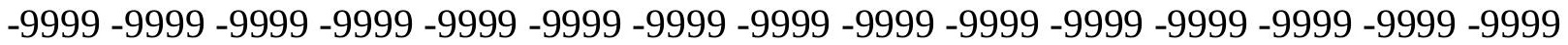
-9999 -9999 -9999 -9999 -9999 -9999 -9999 -9999 -9999 -9999 -9999 -9999 -9999 -9999 -9999 -9999 -9999 -9999 -9999 -9999 -9999 -9999 -9999 -9999 -9999 -9999 -9999 -9999 -9999 -9999 -9999 -9999 -9999 -9999 -9999 124.9618988037125 .5715026855125 .8762969971 126.4858016968126 .7906036377127 .0953979492127 .4001998901127 .7050018311 128.0097961426128 .3144989014128 .3144989014128 .6192932129128 .6192932129 128.9241027832128 .9241027832128 .9241027832128 .9241027832128 .9241027832 128.6192932129128 .6192932129128 .3144989014128 .3144989014128 .0097961426 128.0097961426127 .7050018311127 .4001998901127 .0953979492126 .7906036377 126.4858016968126 .1809997559125 .5715026855125 .2667007446124 .9618988037 124.3523025513124 .0475006104123 .43800354122 .8283996582122 .2188034058 121.6092987061121 .3044967651120 .6949005127120 .0852966309119 .7806015015 119.1709976196118 .8662033081118 .5614013672118 .2565994263117 .647102356 117.0374984741116 .7326965332116 .1231002808115 .5136032104114 .5991973877 113.3800964355112 .1608963013110 .6370010376110 .6370010376111 .24659729 111.8561019897112 .4656982422112 .7705001831112 .4656982422112 .1608963013 111.8561019897111 .551399231111 .551399231111 .24659729111 .24659729110 .9418029785 110.9418029785110 .6370010376110 .6370010376110 .6370010376110 .6370010376 110.6370010376110 .6370010376110 .6370010376110 .6370010376110 .6370010376 110.6370010376110 .6370010376110 .6370010376110 .3321990967110 .3321990967 110.3321990967110 .0273971558110 .0273971558109 .7226028442109 .4179000854 109.4179000854109 .1130981445108 .8082962036108 .8082962036108 .5035018921 108.1986999512108 .1986999512107 .8938980103107 .5891036987107 .5891036987 107.2844009399106 .979598999106 .6747970581106 .3700027466106 .0652008057 105.7603988647105 .4557037354105 .1509017944104 .5412979126109 .1130981445 124.0475006104139 .8963928223156 .3547973633173 .4226989746189 .5764007568 204.5108032227208 .7778015137208 .7778015137208 .7778015137208 .7778015137 208.7778015137 208.7778015137208.7778015137 208.7778015137 208.7778015137 208.7778015137208 .7778015137208 .7778015137208 .7778015137208 .7778015137 208.7778015137208 .7778015137208 .7778015137208 .7778015137208 .7778015137 208.7778015137208 .7778015137208 .7778015137208 .7778015137208 .7778015137 208.7778015137208 .7778015137208 .7778015137208 .7778015137208 .7778015137 208.7778015137208 .7778015137208 .7778015137208 .7778015137208 .7778015137 208.7778015137208 .7778015137208 .7778015137208 .7778015137208 .7778015137 208.7778015137208 .7778015137208 .7778015137208 .7778015137208 .7778015137 208.7778015137208 .7778015137208 .7778015137208 .7778015137208 .7778015137 
208.7778015137208 .7778015137208 .7778015137208 .7778015137208 .7778015137 208.7778015137 208.7778015137208.7778015137208.7778015137 208.7778015137 208.7778015137208 .7778015137208 .7778015137208 .7778015137208 .7778015137 208.7778015137208 .7778015137208 .7778015137208 .7778015137208 .7778015137 208.7778015137208 .7778015137208 .7778015137208 .7778015137208 .7778015137 208.7778015137208 .7778015137175 .2514038086177 .3849029541 -9999 -9999 -9999 -9999 -9999 -9999 -9999 -9999 -9999 -9999 -9999 -9999 -9999 -9999 -9999 -9999 -9999 -9999 -9999

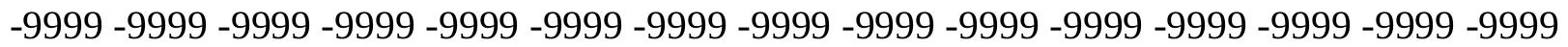
-9999 -9999 -9999 -9999 -9999 -9999 -9999 -9999 -9999 -9999 -9999 -9999 -9999 -9999 -9999 -9999 -9999 -9999 -9999 -9999 -9999 -9999 -9999 -9999 -9999 -9999 -9999 -9999 -9999 -9999 -999 -9999 -9999 -9999 -9999-9999-9999-9999

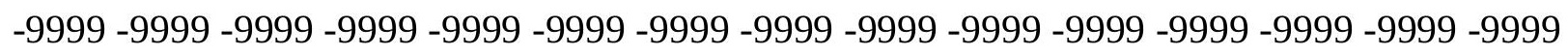
-9999 -9999 -9999 -9999 -9999 -9999 -9999 -9999 -9999 -9999 -9999 -9999 -9999 -9999 -9999 -9999 -9999 -9999 -9999 -9999 -9999 -9999 -9999 -9999 -9999 -9999 -9999 -9999 -9999 -9999 -9999 -9999 -9999 -9999 -9999 -9999 -9999 -9999 -9999 -9999 -9999 -9999 -9999 -9999 -9999

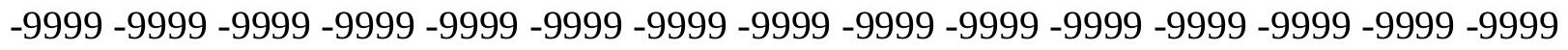
-9999 -9999 -9999 -9999 -9999 -9999 -9999 -9999 -9999 -9999 -9999 -9999 -9999 -9999 -9999 -

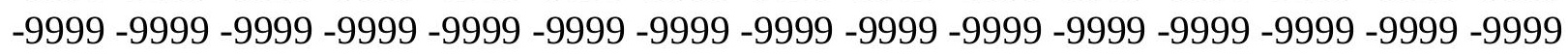
-9999 -9999 -9999 -9999 -9999 -9999 -9999 -9999 -9999 -9999 -9999 -9999 -9999 -9999 -9999 -9999 -9999 -9999-9999 123.7427978516 124.3523025513 124.9618988037 125.2667007446 125.8762969971126 .1809997559126 .4858016968127 .0953979492127 .4001998901 127.7050018311127 .7050018311128 .0097961426128 .3144989014128 .3144989014 128.3144989014128 .3144989014128 .6192932129128 .6192932129128 .3144989014 128.3144989014128 .3144989014128 .0097961426128 .0097961426127 .7050018311 127.7050018311127 .4001998901127 .0953979492126 .7906036377126 .4858016968 126.1809997559125 .8762969971125 .5715026855125 .2667007446124 .6570968628 124.3523025513123 .7427978516123 .1332015991122 .8283996582122 .2188034058 121.6092987061120 .9997024536120 .6949005127120 .0852966309119 .7806015015 119.1709976196119 .1709976196118 .8662033081118 .5614013672117 .9517974854 117.342300415117 .0374984741116 .7326965332116 .4279022217115 .818397522 114.9039993286113 .6848983765112 .1608963013110 .0273971558110 .6370010376 111.24659729111 .551399231111 .8561019897111 .8561019897111 .551399231 111.551399231111 .24659729111 .24659729110 .9418029785110 .9418029785 110.6370010376110 .6370010376110 .3321990967110 .3321990967110 .3321990967 110.3321990967110 .3321990967110 .3321990967110 .3321990967110 .3321990967 110.3321990967110 .3321990967110 .3321990967110 .3321990967110 .3321990967 110.3321990967110 .0273971558110 .0273971558110 .0273971558109 .7226028442 109.4179000854109 .4179000854109 .1130981445109 .1130981445108 .8082962036 108.5035018921108 .5035018921108 .1986999512107 .8938980103107 .8938980103 107.5891036987 107.2844009399 106.979598999 106.6747970581 106.3700027466 106.0652008057105 .7603988647105 .4557037354105 .1509017944104 .5412979126 107.5891036987123 .1332015991139 .2868041992155 .4403991699173 .4226989746 190.1858978271205 .1204071045208 .7778015137208 .7778015137208 .7778015137 208.7778015137208 .7778015137208 .7778015137208 .7778015137208 .7778015137 208.7778015137208 .7778015137208 .7778015137208 .7778015137208 .7778015137 208.7778015137 208.7778015137208.7778015137 208.7778015137 208.7778015137 
208.7778015137 208.7778015137208.7778015137208.7778015137 208.7778015137 208.7778015137208 .7778015137208 .7778015137208 .7778015137208 .7778015137 208.7778015137208 .7778015137208 .7778015137208 .7778015137208 .7778015137 208.7778015137208 .7778015137208 .7778015137208 .7778015137208 .7778015137 208.7778015137208 .7778015137208 .7778015137208 .7778015137208 .7778015137 208.7778015137208 .7778015137208 .7778015137208 .7778015137208 .7778015137 208.7778015137 208.7778015137 208.7778015137 208.7778015137 208.7778015137 208.7778015137 208.7778015137 208.7778015137 208.7778015137 208.7778015137 208.7778015137208 .7778015137208 .7778015137208 .7778015137208 .7778015137 208.7778015137208 .7778015137208 .7778015137208 .7778015137208 .7778015137 208.7778015137208 .7778015137208 .7778015137208 .7778015137208 .7778015137 208.7778015137208 .7778015137208 .7778015137208 .7778015137175 .2514038086 177.3849029541 -9999 -9999 -9999 -9999 -9999 -9999 -9999 -9999 -9999 -9999 -9999 -9999 -9999 -9999 -9999 -9999 -9999 -9999 -9999 -9999 -9999 -9999 -9999 -9999 -9999 -9999 -9999 -9999 -9999 -9999 -9999 -9999 -9999 -9999 -9999 -9999 -9999 -9999 -9999 -9999 -9999 -9999

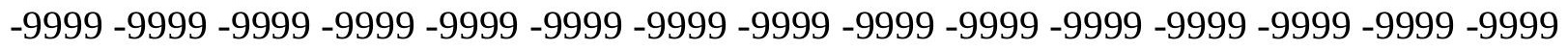
-9999 -9999 -9999 -9999 -9999 -9999 -9999 -9999 -9999 -9999 -9999 -9999 -9999 -

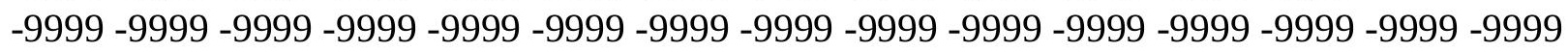

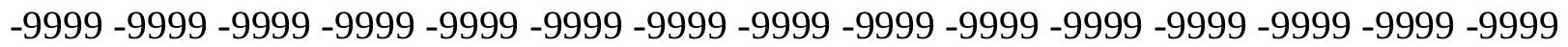

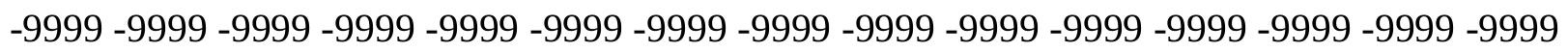

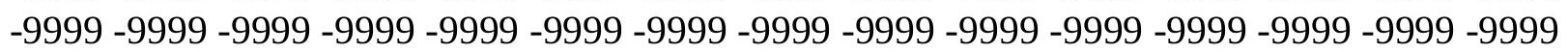

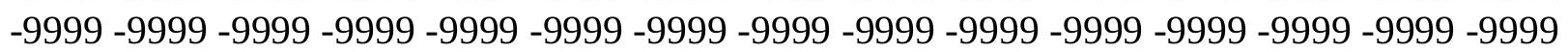
-9999 -9999 -9999 -9999 -9999 -9999 -9999 -9999 -9999 -9999 -9999 -9999 -9999 -9999 -9999 -9999 -9999 -9999 -9999 -9999 -9999 -9999 -9999 -9999 -9999 -9999 -9999 -9999 -9999 -9999 -9999 -9999 -9999 -9999 -9999 -9999 -9999 -9999 -9999 -9999 -9999 -9999 -9999 -9999 -9999 -9999 -9999-9999 122.5235977173 123.1332015991 123.7427978516124.3523025513 124.6570968628125 .2667007446125 .8762969971126 .1809997559126 .4858016968 126.7906036377127 .0953979492127 .4001998901127 .7050018311127 .7050018311 128.0097961426128 .0097961426128 .0097961426128 .0097961426128 .0097961426 128.0097961426128 .0097961426128 .0097961426127 .7050018311127 .7050018311 127.4001998901127 .4001998901127 .0953979492126 .7906036377126 .4858016968 126.1809997559125 .8762969971125 .5715026855125 .2667007446124 .9618988037 124.6570968628124 .0475006104123 .7427978516123 .1332015991122 .5235977173 121.9140014648121 .6092987061120 .9997024536120 .3900985718120 .0852966309 119.4757995605119 .4757995605119 .1709976196119 .1709976196118 .8662033081 118.5614013672117 .9517974854117 .647102356117 .647102356117 .647102356 117.647102356117 .0374984741115 .818397522113 .9896011353111 .8561019897 110.0273971558110 .6370010376110 .9418029785111 .24659729111 .24659729111 .24659729 110.9418029785110 .9418029785110 .6370010376110 .6370010376110 .3321990967 110.3321990967110 .3321990967110 .0273971558110 .0273971558110 .0273971558 110.0273971558110 .0273971558110 .0273971558110 .0273971558110 .0273971558 110.0273971558110 .0273971558110 .0273971558110 .0273971558110 .0273971558 110.0273971558110 .0273971558110 .0273971558109 .7226028442109 .7226028442 109.7226028442109 .4179000854109 .4179000854109 .1130981445108 .8082962036 108.8082962036108 .5035018921108 .1986999512108 .1986999512107 .8938980103 107.5891036987 107.2844009399 106.979598999 106.6747970581 106.3700027466 
106.0652008057 105.7603988647 105.4557037354105.1509017944 104.5412979126 106.0652008057122 .5235977173139 .8963928223157 .878692627175 .8609924316 192.624206543206 .9490966797208 .7778015137208 .7778015137208 .7778015137 208.7778015137208 .7778015137208 .7778015137208 .7778015137208 .7778015137 208.7778015137208 .7778015137208 .7778015137208 .7778015137208 .7778015137 208.7778015137208 .7778015137208 .7778015137208 .7778015137208 .7778015137 208.7778015137208 .7778015137208 .7778015137208 .7778015137208 .7778015137 208.7778015137 208.7778015137 208.7778015137 208.7778015137 208.7778015137 208.7778015137208 .7778015137208 .7778015137208 .7778015137208 .7778015137 208.7778015137208 .7778015137208 .7778015137208 .7778015137208 .7778015137 208.7778015137208 .7778015137208 .7778015137208 .7778015137208 .7778015137 208.7778015137208.7778015137208.7778015137208.7778015137 208.7778015137 208.7778015137208 .7778015137208 .7778015137208 .7778015137208 .7778015137 208.7778015137208 .7778015137208 .7778015137208 .7778015137208 .7778015137 208.7778015137208 .7778015137208 .7778015137208 .7778015137208 .7778015137 208.7778015137 208.7778015137208.7778015137 208.7778015137 208.7778015137 208.7778015137208 .7778015137208 .7778015137208 .7778015137208 .7778015137 208.7778015137208 .7778015137208 .7778015137208 .7778015137173 .4226989746 175.5561981201 -9999 -9999 -9999 -9999 -9999 -9999 -9999 -9999 -9999 -9999 -9999 -9999

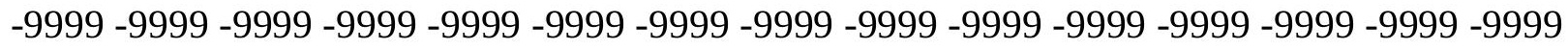
-9999 -9999 -9999 -9999 -9999 -9999 -9999 -9999 -9999 -9999 -9999 -9999 -9999 -9999 -9999

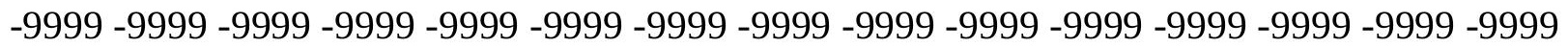
-9999 -9999 -9999 -9999 -9999 -9999 -9999 -9999 -9999 -9999 -9999 -9999 -9999 -

-9999 -9999 -9999 -9999 -9999 -9999 -9999 -9999 -9999 -9999 -9999 -9999 -9999 -9999 -9999 -

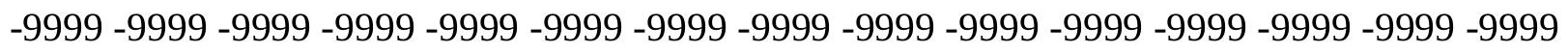
-9999 -9999 -9999 -9999 -9999 -9999 -9999 -9999 -9999 -9999 -9999 -9999 -9999 -9999 -9999 -9999 -9999 -9999 -9999 -9999 -9999 -9999 -9999 -9999 -9999 -9999 -9999 -9999 -9999 -9999

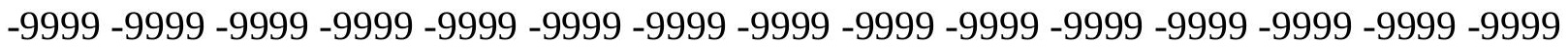
-9999 -9999 -9999 -9999 -9999 -9999 -9999 -9999 -9999 -9999 -9999 -9999 -9999 -9999 -9999

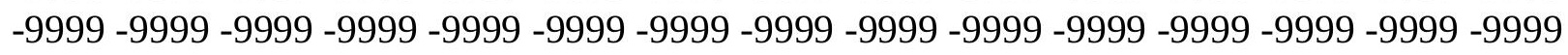
-9999 -9999 -9999 -9999 -9999 -9999 -9999 -9999 -9999 -9999 -9999 -9999 -9999 -9999 -9999 -9999 -9999-9999 121.9140014648122.5235977173123.1332015991 123.7427978516 124.3523025513124 .6570968628125 .2667007446125 .5715026855126 .1809997559 126.4858016968126 .7906036377127 .0953979492127 .0953979492127 .4001998901 127.7050018311127 .7050018311127 .7050018311127 .7050018311127 .7050018311 127.7050018311127 .7050018311127 .7050018311127 .7050018311127 .4001998901 127.4001998901127 .0953979492126 .7906036377126 .7906036377126 .4858016968 126.1809997559125 .8762969971125 .5715026855125 .2667007446124 .9618988037 124.3523025513124 .0475006104123 .43800354123 .1332015991122 .5235977173 121.9140014648121 .3044967651120 .9997024536120 .3900985718120 .0852966309 119.4757995605119 .4757995605119 .4757995605119 .4757995605119 .4757995605 119.4757995605118 .8662033081118 .5614013672119 .1709976196119 .7806015015 119.7806015015119 .4757995605118 .5614013672116 .7326965332113 .9896011353 110.9418029785110 .0273971558110 .3321990967110 .3321990967110 .6370010376 110.6370010376110 .6370010376110 .3321990967110 .3321990967110 .3321990967 110.0273971558110 .0273971558109 .7226028442109 .7226028442109 .7226028442 
109.7226028442109 .7226028442109 .7226028442109 .7226028442109 .7226028442 109.7226028442109 .7226028442110 .0273971558110 .0273971558110 .0273971558 110.0273971558110 .0273971558110 .0273971558110 .0273971558109 .7226028442 109.7226028442109 .7226028442109 .4179000854109 .4179000854109 .1130981445 109.1130981445108 .8082962036108 .8082962036108 .5035018921108 .1986999512 107.8938980103107 .5891036987107 .5891036987107 .2844009399106 .979598999 106.3700027466106 .0652008057105 .7603988647105 .4557037354105 .1509017944 104.5412979126104 .5412979126121 .6092987061140 .2012023926160 .0122070312 178.9089050293195 .3672943115208 .7778015137208 .7778015137208 .7778015137 208.7778015137208 .7778015137208 .7778015137208 .7778015137208 .7778015137 208.7778015137208 .7778015137208 .7778015137208 .7778015137208 .7778015137 208.7778015137208 .7778015137208 .7778015137208 .7778015137208 .7778015137 208.7778015137208 .7778015137208 .7778015137208 .7778015137208 .7778015137 208.7778015137208 .7778015137208 .7778015137208 .7778015137208 .7778015137 208.7778015137208 .7778015137208 .7778015137208 .7778015137208 .7778015137 208.7778015137208 .7778015137208 .7778015137208 .7778015137208 .7778015137 208.7778015137208 .7778015137208 .7778015137208 .7778015137208 .7778015137 208.7778015137208 .7778015137208 .7778015137208 .7778015137208 .7778015137 208.7778015137208 .7778015137208 .7778015137208 .7778015137208 .7778015137 208.7778015137208 .7778015137208 .7778015137208 .7778015137208 .7778015137 208.7778015137208 .7778015137208 .7778015137208 .7778015137208 .7778015137 208.7778015137208 .7778015137208 .7778015137208 .7778015137208 .7778015137 208.7778015137208 .7778015137208 .7778015137208 .7778015137208 .7778015137 208.7778015137208 .7778015137208 .7778015137208 .7778015137208 .7778015137 208.7778015137173 .7274932861175 .5561981201 -9999 -9999 -9999 -9999 -9999 -9999 -9999 -9999 -9999 -9999 -9999 -9999 -9999 -9999 -9999 -9999 -9999 -9999 -9999 -9999 -9999 -999 - 9999 - 9999 - 9999 -

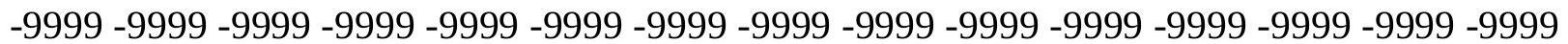

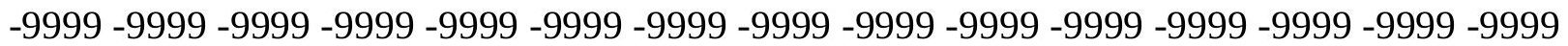

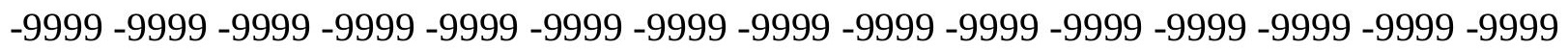
$-9999-9999$

-9999 -9999 -9999 -9999 -9999 -9999 -9999 -9999 -9999 -9999 -9999 -9999 -9999 -9999 -

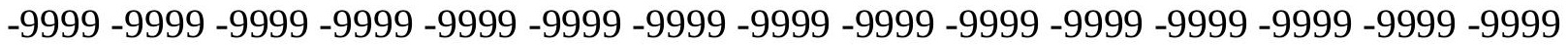

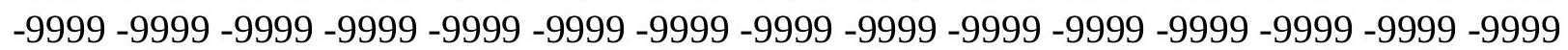

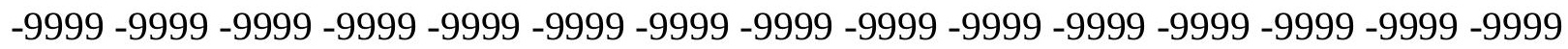
-9999 -

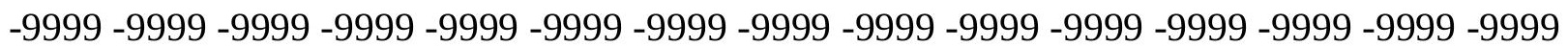

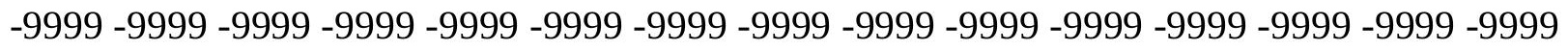

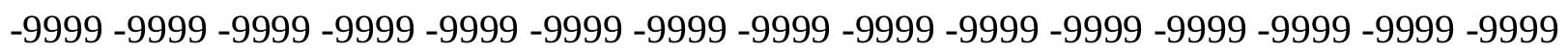
-9999-9999 120.3900985718 121.3044967651 121.9140014648 122.5235977173 123.1332015991123 .7427978516124 .3523025513124 .6570968628125 .2667007446 125.5715026855125 .8762969971126 .1809997559126 .4858016968126 .7906036377 127.0953979492127 .0953979492127 .4001998901127 .4001998901127 .4001998901 127.4001998901127 .4001998901127 .4001998901127 .4001998901127 .4001998901 127.0953979492127 .0953979492126 .7906036377126 .7906036377126 .4858016968 126.1809997559125 .8762969971125 .5715026855125 .2667007446124 .9618988037 124.6570968628124 .3523025513123 .7427978516123 .43800354122 .8283996582 
122.5235977173121 .9140014648121 .3044967651120 .9997024536120 .3900985718 120.0852966309119 .4757995605119 .4757995605119 .4757995605119 .7806015015 120.3900985718120 .3900985718120 .3900985718120 .6949005127120 .9997024536 121.9140014648122 .2188034058122 .5235977173121 .9140014648120 .0852966309 117.0374984741113 .075302124109 .4179000854109 .7226028442110 .0273971558 110.0273971558110 .0273971558110 .0273971558110 .0273971558110 .0273971558 109.7226028442109 .7226028442109 .4179000854109 .4179000854109 .4179000854 109.4179000854109 .4179000854109 .4179000854109 .4179000854109 .4179000854 109.4179000854109 .4179000854109 .7226028442109 .7226028442109 .7226028442 109.7226028442109 .7226028442110 .0273971558110 .0273971558109 .7226028442 109.7226028442109 .7226028442109 .7226028442109 .7226028442109 .4179000854 109.4179000854109 .1130981445109 .1130981445108 .8082962036108 .5035018921 108.1986999512108 .1986999512107 .8938980103107 .5891036987107 .2844009399 106.979598999106 .6747970581106 .3700027466105 .7603988647105 .4557037354 105.1509017944104 .8460998535104 .2365036011118 .5614013672138 .0677032471 160.0122070312181 .0424041748196 .891204834208 .7778015137208 .7778015137 208.7778015137208 .7778015137208 .7778015137208 .7778015137208 .7778015137 208.7778015137208 .7778015137208 .7778015137208 .7778015137208 .7778015137 208.7778015137208 .7778015137208 .7778015137208 .7778015137208 .7778015137 208.7778015137208 .7778015137208 .7778015137208 .7778015137208 .7778015137 208.7778015137208 .7778015137208 .7778015137208 .7778015137208 .7778015137 208.7778015137208 .7778015137208 .7778015137208 .7778015137208 .7778015137 208.7778015137208 .7778015137208 .7778015137208 .7778015137208 .7778015137 208.7778015137208 .7778015137208 .7778015137208 .7778015137208 .7778015137 208.7778015137208 .7778015137208 .7778015137208 .7778015137208 .7778015137 208.7778015137208 .7778015137208 .7778015137208 .7778015137208 .7778015137 208.7778015137208 .7778015137208 .7778015137208 .7778015137208 .7778015137 208.7778015137208 .7778015137208 .7778015137208 .7778015137208 .7778015137 208.7778015137208 .7778015137208 .7778015137208 .7778015137208 .7778015137 208.7778015137 208.7778015137208.7778015137 208.7778015137 208.7778015137 208.7778015137208 .7778015137208 .7778015137208 .7778015137208 .7778015137 208.7778015137208 .7778015137171 .8988037109173 .7274932861 -9999 -9999 -9999-9999 -9999 -9999 -9999 -9999 -9999 -9999 -9999 -9999 -9999 -9999 -9999 -9999 -9999 -9999 -9999 -9999 -9999 -9999 -9999 -9999 -9999 -9999 -9999 -9999 -9999 -9999 -9999 -9999 -9999 -9999

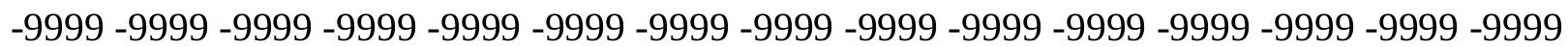

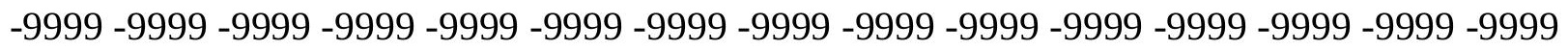
-9999 -9999-9999-9999-9999

-9999 -9999 -9999 -9999 -9999 -9999 -9999 -9999 -9999 -9999 -9999 -9999 -9999 -9999 -9999 -

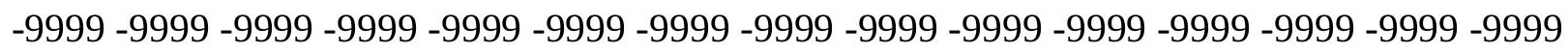
-9999 -9999 -9999 -9999 -9999 -9999 -9999 -9999 -9999 -9999 -9999 -9999 -9999 -9999 -9999 -

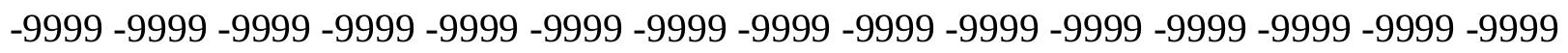

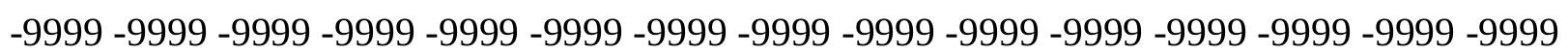

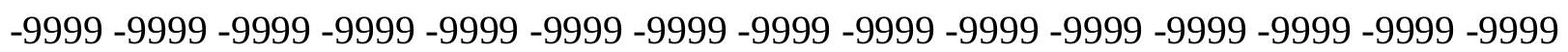
-9999 -9999 -9999 -9999 -9999 -9999 -9999 -9999 -9999 -9999 -9999 -9999 -9999 -9999 -9999 -

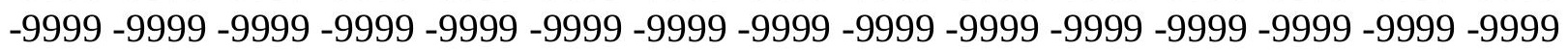
-9999 119.1709976196120.0852966309 120.6949005127 121.3044967651 121.9140014648 
122.5235977173123 .1332015991123 .7427978516124 .3523025513124 .6570968628 125.2667007446125 .5715026855125 .8762969971126 .1809997559126 .4858016968 126.7906036377126 .7906036377127 .0953979492127 .0953979492127 .0953979492 127.4001998901127 .4001998901127 .0953979492127 .0953979492127 .0953979492 127.0953979492126 .7906036377126 .7906036377126 .4858016968126 .1809997559 126.1809997559125 .8762969971125 .5715026855125 .2667007446124 .9618988037 124.6570968628124 .3523025513123 .7427978516123 .43800354122 .8283996582 122.5235977173121 .9140014648121 .3044967651120 .9997024536120 .3900985718 120.0852966309119 .7806015015119 .4757995605119 .4757995605119 .7806015015 120.3900985718120 .9997024536121 .9140014648122 .5235977173123 .1332015991 123.7427978516124 .6570968628124 .9618988037124 .9618988037123 .7427978516 120.3900985718115 .818397522111 .551399231109 .4179000854109 .4179000854 109.7226028442109 .7226028442109 .7226028442109 .7226028442109 .4179000854 109.4179000854109 .4179000854109 .1130981445109 .1130981445109 .1130981445 109.1130981445109 .1130981445109 .1130981445109 .1130981445109 .1130981445 109.1130981445109 .4179000854109 .4179000854109 .4179000854109 .7226028442 109.7226028442109 .7226028442109 .7226028442109 .7226028442109 .7226028442 109.7226028442109 .7226028442109 .7226028442109 .7226028442109 .4179000854 109.4179000854109 .4179000854109 .1130981445108 .8082962036108 .8082962036 108.5035018921108 .1986999512107 .8938980103107 .5891036987107 .2844009399 106.979598999106 .6747970581106 .3700027466106 .0652008057105 .4557037354 105.1509017944104 .8460998535104 .2365036011112 .4656982422131 .9720001221 154.8307952881181 .3471984863194 .4528961182205 .425201416208 .7778015137 208.7778015137208 .7778015137208 .7778015137208 .7778015137208 .7778015137 208.7778015137208 .7778015137208 .7778015137208 .7778015137208 .7778015137 208.7778015137208 .7778015137208 .7778015137208 .7778015137208 .7778015137 208.7778015137208 .7778015137208 .7778015137208 .7778015137208 .7778015137 208.7778015137208 .7778015137208 .7778015137208 .7778015137208 .7778015137 208.7778015137208 .7778015137208 .7778015137208 .7778015137208 .7778015137 208.7778015137208 .7778015137208 .7778015137208 .7778015137208 .7778015137 208.7778015137208 .7778015137208 .7778015137208 .7778015137208 .7778015137 208.7778015137 208.7778015137 208.7778015137 208.7778015137 208.7778015137 208.7778015137208 .7778015137208 .7778015137208 .7778015137208 .7778015137 208.7778015137208 .7778015137208 .7778015137208 .7778015137208 .7778015137 208.7778015137208 .7778015137208 .7778015137208 .7778015137208 .7778015137 208.7778015137208 .7778015137208 .7778015137208 .7778015137208 .7778015137 208.7778015137208 .7778015137208 .7778015137208 .7778015137208 .7778015137 208.7778015137 208.7778015137208.7778015137 208.7778015137 208.7778015137 208.7778015137208 .7778015137208 .7778015137171 .8988037109173 .7274932861 -9999 -9999 -9999 -9999 -9999 -9999 -9999 -9999 -9999 -9999 -9999 -9999 -9999 -9999 -9999 -9999

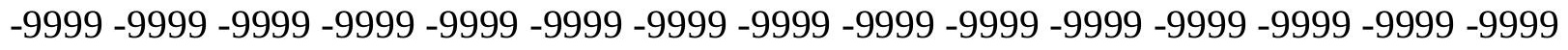

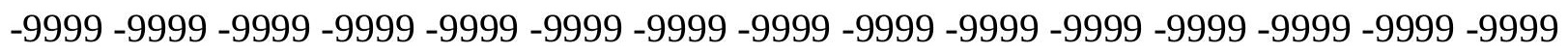

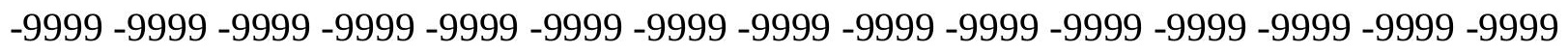
-9999 -9999 -9999 -9999-9999-9999-9999

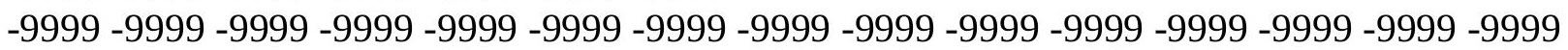

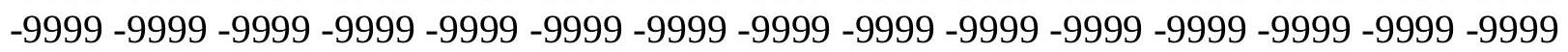


-9999 -9999 -9999 -9999 -9999 -9999 -9999 -9999 -9999 -9999 -9999 -9999 -9999 -9999 -9999 -9999 -9999 -9999 -9999 -9999 -9999 -9999 -9999 -9999 -9999 -9999 -9999 -9999 -9999 -9999

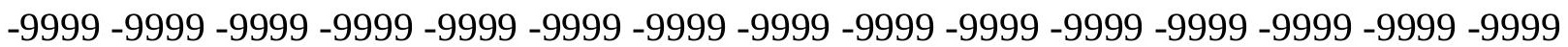
-9999 -9999 -9999 -9999 -9999 -9999 -9999 -9999 -9999 -9999 -9999 -9999 -9999 -9999 -9999

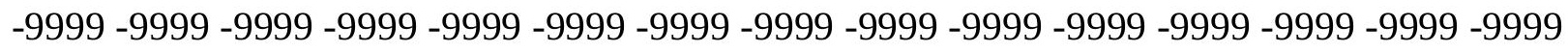
-9999 -9999 -9999 -9999 -9999 -9999 -9999 -9999 -9999 -9999 -9999 -9999 -9999 -9999 -9999 117.647102356118 .5614013672119 .4757995605120 .0852966309120 .6949005127 121.6092987061122 .2188034058122 .8283996582123 .43800354123 .7427978516 124.3523025513124 .6570968628125 .2667007446125 .5715026855125 .8762969971 126.1809997559126 .4858016968126 .4858016968126 .7906036377126 .7906036377 127.0953979492127 .0953979492127 .0953979492127 .0953979492127 .0953979492 126.7906036377126 .7906036377126 .4858016968126 .4858016968126 .1809997559 126.1809997559125 .8762969971125 .5715026855125 .2667007446125 .2667007446 124.9618988037124 .6570968628124 .0475006104123 .7427978516123 .43800354 122.8283996582122 .5235977173121 .9140014648121 .6092987061120 .9997024536 120.6949005127120 .0852966309119 .7806015015119 .7806015015119 .4757995605 119.7806015015120 .3900985718121 .6092987061122 .8283996582124 .0475006104 124.6570968628125 .2667007446125 .8762969971126 .7906036377127 .0953979492 127.0953979492122 .8283996582117 .9517974854113 .6848983765110 .0273971558 109.1130981445109 .4179000854109 .4179000854109 .4179000854109 .1130981445 109.1130981445109 .1130981445108 .8082962036108 .8082962036108 .8082962036 108.5035018921108 .5035018921108 .5035018921108 .8082962036108 .8082962036 108.8082962036109 .1130981445109 .1130981445109 .1130981445109 .4179000854 109.4179000854109 .7226028442109 .7226028442109 .7226028442109 .7226028442 109.7226028442109 .7226028442109 .7226028442109 .7226028442109 .7226028442 109.7226028442109 .4179000854109 .4179000854109 .1130981445109 .1130981445 108.8082962036108 .5035018921108 .5035018921108 .1986999512107 .8938980103 107.5891036987 107.2844009399 106.6747970581 106.3700027466 106.0652008057 105.7603988647105 .4557037354104 .8460998535104 .5412979126106 .0652008057 124.3523025513142 .3347015381167 .0222015381185 .3094024658198 .4151000977 208.7778015137208 .7778015137208 .7778015137208 .7778015137208 .7778015137 208.7778015137208 .7778015137208 .7778015137208 .7778015137208 .7778015137 208.7778015137208 .7778015137208 .7778015137208 .7778015137208 .7778015137 208.7778015137208 .7778015137208 .7778015137208 .7778015137208 .7778015137 208.7778015137208 .7778015137208 .7778015137208 .7778015137208 .7778015137 208.7778015137 208.7778015137208.7778015137208.7778015137 208.7778015137 208.7778015137208.7778015137208.7778015137 208.7778015137 208.7778015137 208.7778015137 208.7778015137208.7778015137208.7778015137 208.7778015137 208.7778015137208 .7778015137208 .7778015137208 .7778015137208 .7778015137 208.7778015137208 .7778015137208 .7778015137208 .7778015137208 .7778015137 208.7778015137 208.7778015137208.7778015137208.7778015137 208.7778015137 208.7778015137208.7778015137208.7778015137208.7778015137 208.7778015137 208.7778015137208 .7778015137208 .7778015137208 .7778015137208 .7778015137 208.7778015137208 .7778015137208 .7778015137208 .7778015137208 .7778015137 208.7778015137208 .7778015137208 .7778015137208 .7778015137208 .7778015137 208.7778015137 208.7778015137208.7778015137208.7778015137208.7778015137 
171.8988037109173 .7274932861 -9999 -9999 -9999 -9999 -9999 -9999 -9999 -9999 -9999 -9999 -9999 -9999 -9999 -9999 -9999 -9999 -9999 -9999 -9999 -9999 -9999 -9999 -9999 -9999

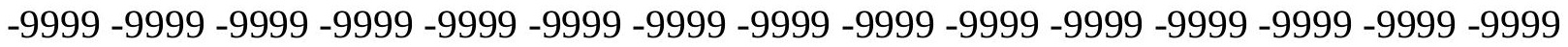
-9999 -9999 -9999 -9999 -9999 -9999 -9999 -9999 -9999 -9999 -9999 -9999 -9999 -9999 -9999 -9999 -9999 -9999 -9999 -9999 -9999 -9999 -9999 -9999 -9999 -9999 -9999 -9999 -9999 -9999 -9999 -9999 -9999 -9999 -9999 -9999 -9999 -9999 -9999 -9999 -9999 -9999 -9999

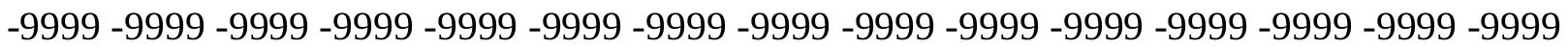

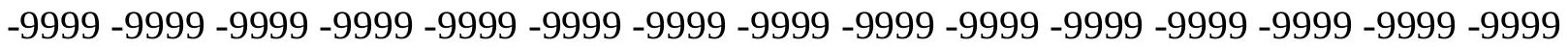
-9999 -9999 -9999 -9999 -9999 -9999 -9999 -9999 -9999 -9999 -9999 -9999 -9999 -9999 -9999 -9999 -9999 -9999 -9999 -9999 -9999 -9999 -9999 -9999 -9999 -9999 -9999 -9999 -9999 -9999 -

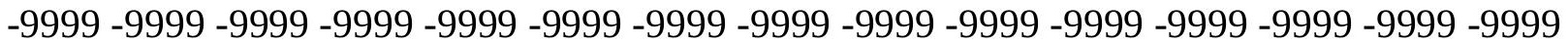

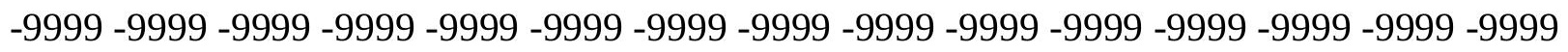
-9999 -9999 -9999 -9999 -9999 -9999 -9999 -9999 -9999 -9999 -9999 -9999 -9999 -9999 116.1231002808117 .0374984741117 .9517974854118 .8662033081119 .4757995605 120.3900985718120 .9997024536121 .6092987061122 .2188034058122 .8283996582 123.43800354124 .0475006104124 .3523025513124 .9618988037125 .2667007446 125.5715026855125 .8762969971126 .1809997559126 .1809997559126 .4858016968 126.4858016968126 .7906036377126 .7906036377126 .7906036377126 .7906036377 126.7906036377126 .7906036377126 .4858016968126 .4858016968126 .1809997559 126.1809997559125 .8762969971125 .8762969971125 .5715026855125 .2667007446 124.9618988037124 .6570968628124 .3523025513124 .0475006104123 .7427978516 123.43800354122 .8283996582122 .5235977173122 .2188034058121 .6092987061 121.3044967651120 .6949005127120 .3900985718120 .3900985718120 .0852966309 119.7806015015119 .4757995605120 .6949005127121 .9140014648123 .43800354 124.3523025513125 .2667007446125 .8762969971126 .4858016968127 .0953979492 127.4001998901126 .4858016968123 .43800354119 .4757995605115 .2088012695 111.551399231108 .8082962036109 .1130981445109 .1130981445109 .1130981445 108.8082962036108 .8082962036108 .8082962036108 .5035018921108 .5035018921 108.5035018921108 .1986999512108 .1986999512108 .1986999512108 .5035018921 108.5035018921108 .5035018921108 .8082962036108 .8082962036109 .1130981445 109.4179000854109 .4179000854109 .4179000854109 .7226028442109 .7226028442 109.7226028442109 .7226028442110 .0273971558110 .0273971558109 .7226028442 109.7226028442109 .7226028442109 .7226028442109 .4179000854109 .4179000854 109.1130981445109 .1130981445108 .8082962036108 .5035018921108 .1986999512 107.8938980103107 .5891036987107 .2844009399106 .979598999106 .6747970581 106.3700027466105 .7603988647105 .4557037354105 .1509017944104 .5412979126 104.2365036011 116.4279022217 134.7149963379 154.8307952881 173.1179962158 187.7476043701199 .9389953613208 .7778015137208 .7778015137208 .7778015137 208.7778015137208.7778015137208.7778015137208.7778015137208.7778015137 208.7778015137208 .7778015137208 .7778015137208 .7778015137208 .7778015137 208.7778015137208 .7778015137208 .7778015137208 .7778015137208 .7778015137 208.7778015137208.7778015137208.7778015137208.7778015137 208.7778015137 208.7778015137208 .7778015137208 .7778015137208 .7778015137208 .7778015137 208.7778015137208 .7778015137208 .7778015137208 .7778015137208 .7778015137 208.7778015137208 .7778015137208 .7778015137208 .7778015137208 .7778015137 208.7778015137208.7778015137208.7778015137208.7778015137208.7778015137 
208.7778015137208 .7778015137208 .7778015137208 .7778015137208 .7778015137 208.7778015137 208.7778015137208.7778015137208.7778015137 208.7778015137 208.7778015137208 .7778015137208 .7778015137208 .7778015137208 .7778015137 208.7778015137208 .7778015137208 .7778015137208 .7778015137208 .7778015137 208.7778015137208 .7778015137208 .7778015137208 .7778015137208 .7778015137 208.7778015137208 .7778015137208 .7778015137208 .7778015137208 .7778015137 208.7778015137208 .7778015137208 .7778015137208 .7778015137208 .7778015137 208.7778015137170 .070098877171 .8988037109 -9999 -9999 -9999 -9999 -9999 -9999 -9999 -9999 -9999 -9999 -9999 -9999 -9999 -9999 -9999 -9999 -9999 -9999 -9999 -9999 -9999 -9999 -9999 -9999 -9999 -9999 -9999 -9999 -9999 -9999 -9999 -9999 -9999 -9999 -9999 -9999 -9999 -

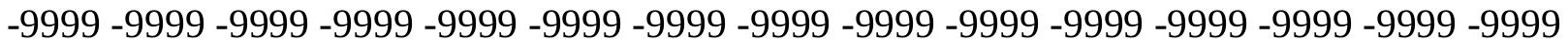
-9999 -9999 -9999 -9999 -9999 -9999 -9999 -9999 -9999 -9999 -9999 -9999 -9999 -9999 -9999 -9999 -9999 -9999 -9999 -9999 -9999 -9999 -9999 -9999 -9999 -9999 -9999 -9999 -9999 -9999 -9999 -9999 -9999 -9999 -9999 -9999 -9999 -9999 -9999 -9999 -9999 -9999 -9999 -9999 -9999 -9999 -9999 -9999 -9999 -9999 -9999 -9999 -9999 -9999 -9999 -9999 -9999 -9999 -9999 -9999

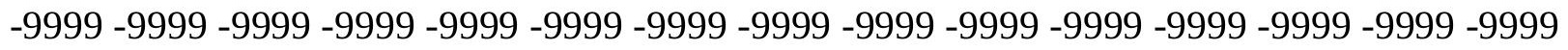

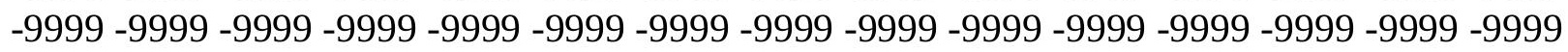

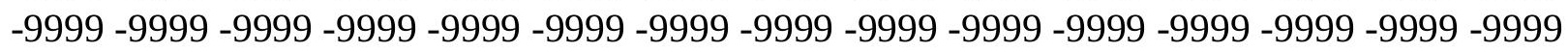

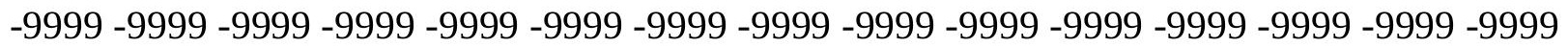
-9999 -9999 -9999 -9999 -9999 -9999 -9999 -9999 -9999 -9999 -9999 -9999 -9999 -9999 115.5136032104116 .4279022217117 .342300415118 .2565994263119 .1709976196 119.7806015015120 .3900985718121 .3044967651121 .9140014648122 .5235977173 123.1332015991123 .43800354124 .0475006104124 .3523025513124 .9618988037 125.2667007446125 .5715026855125 .8762969971125 .8762969971126 .1809997559 126.4858016968126 .4858016968126 .4858016968126 .4858016968126 .4858016968 126.4858016968126 .4858016968126 .4858016968126 .1809997559126 .1809997559 125.8762969971125 .8762969971125 .5715026855125 .2667007446125 .2667007446 124.9618988037124 .6570968628124 .3523025513124 .0475006104123 .7427978516 123.43800354123 .1332015991122 .5235977173122 .2188034058121 .9140014648 121.3044967651120 .9997024536120 .6949005127120 .6949005127120 .6949005127 120.9997024536120 .6949005127121 .3044967651122 .2188034058123 .43800354 124.3523025513125 .2667007446125 .5715026855126 .1809997559126 .1809997559 126.1809997559124 .9618988037123 .1332015991119 .7806015015116 .1231002808 112.7705001831110 .0273971558108 .8082962036108 .8082962036108 .8082962036 108.5035018921108 .5035018921108 .5035018921108 .1986999512108 .1986999512 107.8938980103107 .8938980103107 .8938980103108 .1986999512108 .1986999512 108.1986999512108 .5035018921108 .5035018921108 .8082962036109 .1130981445 109.1130981445109 .4179000854109 .4179000854109 .7226028442109 .7226028442 109.7226028442110 .0273971558110 .0273971558110 .0273971558110 .0273971558 110.0273971558109 .7226028442109 .7226028442109 .7226028442109 .4179000854 109.4179000854109 .1130981445108 .8082962036108 .8082962036108 .5035018921 108.1986999512107 .8938980103107 .5891036987106 .979598999106 .6747970581 106.3700027466 106.0652008057 105.4557037354105.1509017944104.8460998535 104.2365036011109 .1130981445126 .1809997559143 .5538024902160 .6217956543 175.8609924316188 .6620025635199 .9389953613208 .7778015137208 .7778015137 208.7778015137 208.7778015137208.7778015137 208.7778015137 208.7778015137 
208.7778015137 208.7778015137208.7778015137208.7778015137 208.7778015137 208.7778015137208 .7778015137208 .7778015137208 .7778015137208 .7778015137 208.7778015137208 .7778015137208 .7778015137208 .7778015137208 .7778015137 208.7778015137208 .7778015137208 .7778015137208 .7778015137208 .7778015137 208.7778015137208 .7778015137208 .7778015137208 .7778015137208 .7778015137 208.7778015137208 .7778015137208 .7778015137208 .7778015137208 .7778015137 208.7778015137208 .7778015137208 .7778015137208 .7778015137208 .7778015137 208.7778015137 208.7778015137 208.7778015137 208.7778015137 208.7778015137 208.7778015137208 .7778015137208 .7778015137208 .7778015137208 .7778015137 208.7778015137208 .7778015137208 .7778015137208 .7778015137208 .7778015137 208.7778015137 208.7778015137208.7778015137208.7778015137 208.7778015137 208.7778015137 208.7778015137 208.7778015137 208.7778015137 208.7778015137 208.7778015137208 .7778015137208 .7778015137208 .7778015137208 .7778015137 208.7778015137208 .7778015137208 .7778015137208 .7778015137208 .7778015137 208.7778015137 208.7778015137 170.070098877 171.8988037109 -9999 -9999 -9999 -9999 -9999 -9999 -9999 -9999 -9999 -9999 -9999 -9999 -9999 -9999 -9999 -9999 -9999 -9999 -9999 -

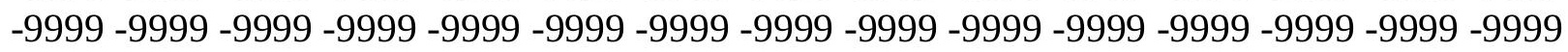

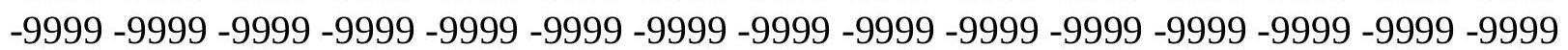

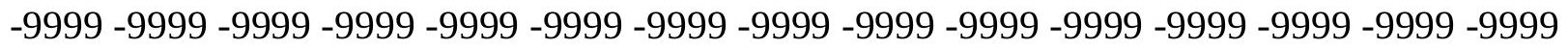
-9999-9999

-9999 -9999 -9999 -9999 -9999 -9999 -9999 -9999 -9999 -9999 -9999 -9999 -9999 -9999 -9999

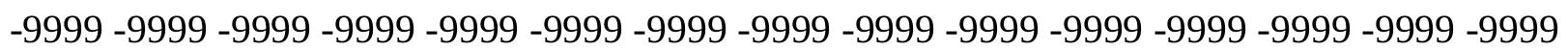
-9999 -9999 -9999 -9999 -9999 -9999 -9999 -9999 -9999 -9999 -9999 -9999 -9999 -9999 -9999 -9999 -9999 -9999 -9999 -9999 -9999 -9999 -9999 -9999 -9999 -9999 -9999 -9999 -9999 -9999 -9999 -9999 -9999 -9999 -9999 -9999 -9999 -9999 -9999 -9999 -9999 -9999 -9999 -9999 -9999 -9999 -9999 -9999 -9999 -9999 -9999 -9999 -9999 -9999 -9999 -9999 -9999 -9999 -9999 -9999

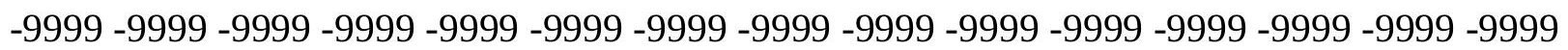
-9999 -9999 -9999 -9999 -9999 -9999 -9999 -9999 -9999 -9999 -9999 -9999 -9999 113.9896011353114 .9039993286115 .818397522116 .7326965332117 .647102356 118.5614013672119 .1709976196120 .0852966309120 .6949005127121 .3044967651 121.9140014648122 .5235977173123 .1332015991123 .7427978516124 .0475006104 124.6570968628124 .9618988037125 .2667007446125 .5715026855125 .8762969971 125.8762969971126 .1809997559126 .1809997559126 .1809997559126 .4858016968 126.4858016968126 .4858016968126 .1809997559126 .1809997559126 .1809997559 125.8762969971125 .8762969971125 .5715026855125 .5715026855125 .2667007446 124.9618988037124 .9618988037124 .6570968628124 .3523025513124 .0475006104 123.7427978516123 .43800354123 .1332015991122 .8283996582122 .5235977173 121.9140014648121 .6092987061121 .3044967651120 .9997024536120 .9997024536 120.9997024536121 .9140014648121 .3044967651121 .6092987061122 .5235977173 123.43800354124 .0475006104124 .6570968628124 .9618988037124 .9618988037 124.6570968628124 .3523025513123 .43800354121 .6092987061119 .1709976196 116.4279022217113 .3800964355110 .9418029785108 .8082962036108 .5035018921 108.5035018921108 .5035018921108 .1986999512108 .1986999512107 .8938980103 107.8938980103107 .8938980103107 .5891036987107 .5891036987107 .8938980103 107.8938980103108 .1986999512108 .1986999512108 .5035018921108 .8082962036 109.1130981445 109.1130981445 109.4179000854 109.4179000854109.7226028442 
109.7226028442110 .0273971558110 .0273971558110 .0273971558110 .0273971558 110.0273971558110 .0273971558110 .0273971558110 .0273971558109 .7226028442 109.7226028442109 .4179000854109 .4179000854109 .1130981445108 .8082962036 108.5035018921108 .1986999512107 .8938980103107 .5891036987107 .2844009399 106.979598999106 .6747970581106 .0652008057105 .7603988647105 .4557037354 104.8460998535104 .5412979126103 .9317016602116 .7326965332132 .5814971924 148.4304046631163 .0599975586176 .4705963135188 .3571929932199 .329498291 208.7778015137208 .7778015137208 .7778015137208 .7778015137208 .7778015137 208.7778015137208 .7778015137208 .7778015137208 .7778015137208 .7778015137 208.7778015137208 .7778015137208 .7778015137208 .7778015137208 .7778015137 208.7778015137208 .7778015137208 .7778015137208 .7778015137208 .7778015137 208.7778015137208 .7778015137208 .7778015137208 .7778015137208 .7778015137 208.7778015137208 .7778015137208 .7778015137208 .7778015137208 .7778015137 208.7778015137208 .7778015137208 .7778015137208 .7778015137208 .7778015137 208.7778015137208 .7778015137208 .7778015137208 .7778015137208 .7778015137 208.7778015137208 .7778015137208 .7778015137208 .7778015137208 .7778015137 208.7778015137208 .7778015137208 .7778015137208 .7778015137208 .7778015137 208.7778015137208 .7778015137208 .7778015137208 .7778015137208 .7778015137 208.7778015137208 .7778015137208 .7778015137208 .7778015137208 .7778015137 208.7778015137208 .7778015137208 .7778015137208 .7778015137208 .7778015137 208.7778015137208 .7778015137208 .7778015137208 .7778015137208 .7778015137 208.7778015137208 .7778015137208 .7778015137208 .7778015137208 .7778015137 208.7778015137208 .7778015137208 .7778015137168 .5462036133170 .070098877 -9999 -9999 -9999 -9999 -9999 -9999 -9999 -9999 -9999 -9999 -9999 -9999 -9999 -9999 -9999 -9999 -9999 -9999 -9999 -9999 -9999 -9999 -9999 -9999 -9999 -9999 -9999 -9999 -9999 -9999 -9999 -9999 -9999 -9999 -9999 -9999 -9999 -9999 -9999 -9999 -9999 -9999 -9999 -9999 -9999 -9999 -9999 -9999 -9999 -9999 -9999 -9999 -9999 -9999 -9999 -9999 -9999 -9999 -9999 -9999 -9999 -9999 -9999 -9999 -9999-9999

-9999 -9999 -9999 -9999 -9999 -9999 -9999 -9999 -9999 -9999 -9999 -9999 -9999 -9999 -9999 -9999 -9999 -9999 -9999 -9999 -9999 -9999 -9999 -9999 -9999 -9999 -9999 -9999 -9999 -9999 -9999 -9999 -9999 -9999 -9999 -9999 -9999 -9999 -9999 -9999 -9999 -9999 -9999 -9999 -9999 -9999 -9999 -9999 -9999 -9999 -9999 -9999 -9999 -9999 -9999 -9999 -9999 -9999 -9999 -9999 -

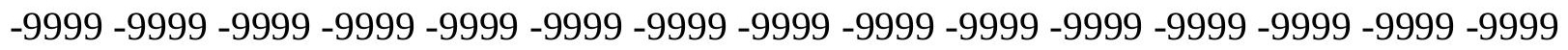

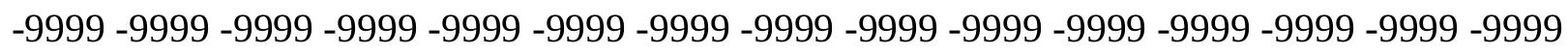

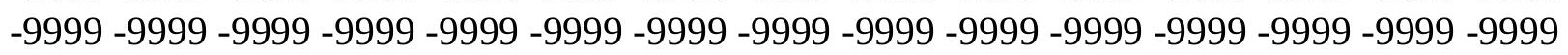
-9999 -9999 -9999-9999-9999 -9999 -9999 -9999 -9999-9999-9999 -9999 112.4656982422 113.3800964355114 .2944030762115 .5136032104116 .4279022217117 .0374984741 117.9517974854118 .8662033081119 .4757995605120 .3900985718120 .9997024536 121.6092987061122 .2188034058122 .8283996582123 .43800354123 .7427978516 124.3523025513124 .6570968628124 .9618988037125 .2667007446125 .5715026855 125.8762969971125 .8762969971126 .1809997559126 .1809997559126 .1809997559 126.1809997559126 .1809997559126 .1809997559126 .1809997559125 .8762969971 125.8762969971125 .5715026855125 .5715026855125 .2667007446125 .2667007446 124.9618988037124 .6570968628124 .6570968628124 .3523025513124 .0475006104 123.7427978516123 .43800354123 .1332015991122 .8283996582122 .5235977173 122.2188034058121 .9140014648121 .6092987061121 .3044967651120 .9997024536 
120.6949005127120 .0852966309120 .9997024536121 .9140014648122 .5235977173 123.1332015991123 .7427978516124 .0475006104124 .0475006104123 .7427978516 123.1332015991122 .2188034058121 .6092987061120 .3900985718118 .5614013672 116.4279022217113 .9896011353111 .551399231109 .7226028442108 .5035018921 108.1986999512108 .1986999512108 .1986999512107 .8938980103107 .8938980103 107.5891036987107 .5891036987107 .5891036987107 .5891036987107 .5891036987 107.8938980103107 .8938980103108 .1986999512108 .5035018921108 .8082962036 108.8082962036109 .1130981445109 .4179000854109 .7226028442109 .7226028442 110.0273971558110 .0273971558110 .0273971558110 .0273971558110 .3321990967 110.3321990967110 .3321990967110 .0273971558110 .0273971558110 .0273971558 109.7226028442109 .7226028442109 .4179000854109 .4179000854109 .1130981445 108.8082962036108 .5035018921108 .1986999512107 .8938980103107 .5891036987 106.979598999106 .6747970581106 .3700027466105 .7603988647105 .4557037354 105.1509017944104 .5412979126104 .2365036011106 .6747970581121 .9140014648 136.5437011719150 .2590942383163 .0599975586175 .8609924316188 .3571929932 199.329498291208.1681976318208.7778015137208.7778015137208.7778015137 208.7778015137208 .7778015137208 .7778015137208 .7778015137208 .7778015137 208.7778015137208 .7778015137208 .7778015137208 .7778015137208 .7778015137 208.7778015137208 .7778015137208 .7778015137208 .7778015137208 .7778015137 208.7778015137208 .7778015137208 .7778015137208 .7778015137208 .7778015137 208.7778015137208 .7778015137208 .7778015137208 .7778015137208 .7778015137 208.7778015137208 .7778015137208 .7778015137208 .7778015137208 .7778015137 208.7778015137208 .7778015137208 .7778015137208 .7778015137208 .7778015137 208.7778015137208 .7778015137208 .7778015137208 .7778015137208 .7778015137 208.7778015137 208.7778015137 208.7778015137 208.7778015137 208.7778015137 208.7778015137 208.7778015137208.7778015137 208.7778015137 208.7778015137 208.7778015137208 .7778015137208 .7778015137208 .7778015137208 .7778015137 208.7778015137208 .7778015137208 .7778015137208 .7778015137208 .7778015137 208.7778015137208 .7778015137208 .7778015137208 .7778015137208 .7778015137 208.7778015137208 .7778015137208 .7778015137208 .7778015137208 .7778015137 208.7778015137208 .7778015137208 .7778015137208 .7778015137168 .5462036133 170.070098877 -9999 -9999 -9999 -9999 -9999 -9999 -9999 -9999 -9999 -9999 -9999 -9999

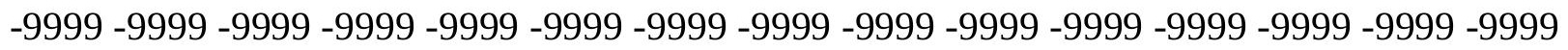
-9999 -9999 -9999 -9999 -9999 -9999 -9999 -9999 -9999 -9999 -9999 -9999 -9999 -9999 -9999

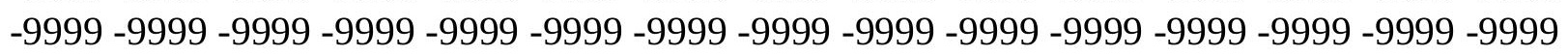
-9999 -9999 -9999 -9999 -9999 -9999 -9999 -9999

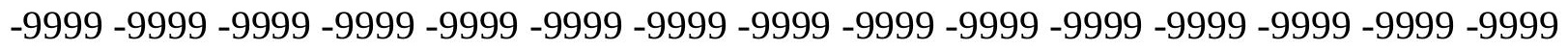

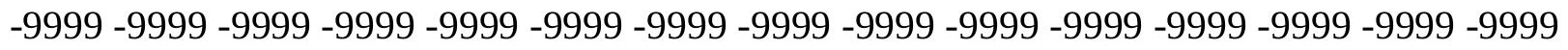

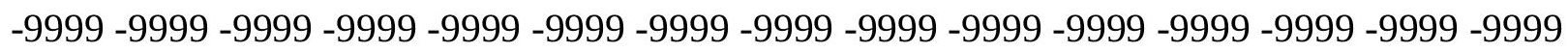
-9999 -9999 -9999 -9999 -9999 -9999 -9999 -9999 -9999 -9999 -9999 -9999 -9999 -9999 -9999 -

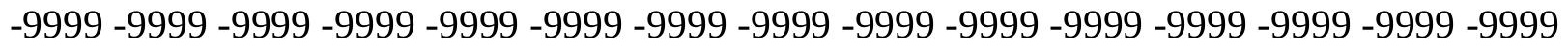

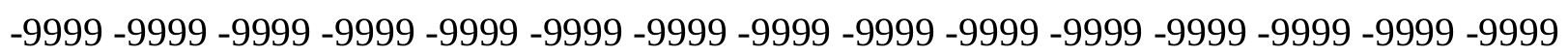

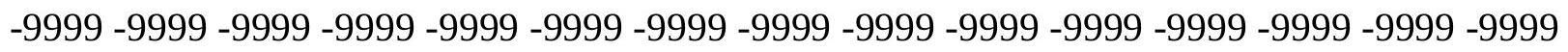
-9999 -9999 -9999 -9999 -9999 -9999-9999 -9999-9999-9999-9999 110.6370010376 111.8561019897112 .7705001831113 .9896011353114 .9039993286115 .818397522 116.7326965332117 .647102356118 .2565994263119 .1709976196119 .7806015015 
120.6949005127121 .3044967651121 .9140014648122 .5235977173123 .1332015991 123.43800354124 .0475006104124 .3523025513124 .6570968628124 .9618988037 125.2667007446125 .5715026855125 .5715026855125 .8762969971125 .8762969971 125.8762969971126 .1809997559125 .8762969971125 .8762969971125 .8762969971 125.8762969971125 .5715026855125 .5715026855125 .2667007446125 .2667007446 124.9618988037124 .9618988037124 .6570968628124 .6570968628124 .3523025513 124.0475006104123 .7427978516123 .7427978516123 .43800354123 .1332015991 122.8283996582122 .5235977173122 .2188034058121 .9140014648121 .6092987061 121.3044967651120 .9997024536120 .6949005127121 .3044967651121 .9140014648 122.5235977173123 .1332015991123 .1332015991123 .43800354123 .1332015991 122.8283996582122 .2188034058121 .3044967651120 .3900985718119 .4757995605 117.9517974854116 .1231002808113 .9896011353112 .1608963013110 .3321990967 108.8082962036108 .1986999512108 .1986999512107 .8938980103107 .8938980103 107.5891036987107 .5891036987107 .2844009399107 .2844009399107 .2844009399 107.2844009399 107.5891036987 107.8938980103108.1986999512108.5035018921 108.8082962036109 .1130981445109 .1130981445109 .4179000854109 .7226028442 110.0273971558110 .0273971558110 .0273971558110 .3321990967110 .3321990967 110.3321990967110 .3321990967110 .3321990967110 .3321990967110 .3321990967 110.0273971558110 .0273971558110 .0273971558109 .7226028442109 .7226028442 109.4179000854109 .1130981445108 .8082962036108 .1986999512107 .8938980103 107.5891036987107 .2844009399106 .979598999106 .3700027466106 .0652008057 105.7603988647105 .1509017944104 .8460998535104 .2365036011103 .9317016602 111.8561019897125 .2667007446137 .7628936768149 .0399017334161 .8408966064 176.4705963135190 .1858978271199 .329498291205 .425201416208 .7778015137 208.7778015137208 .7778015137208 .7778015137208 .7778015137208 .7778015137 208.7778015137208 .7778015137208 .7778015137208 .7778015137208 .7778015137 208.7778015137208 .7778015137208 .7778015137208 .7778015137208 .7778015137 208.7778015137208 .7778015137208 .7778015137208 .7778015137208 .7778015137 208.7778015137208 .7778015137208 .7778015137208 .7778015137208 .7778015137 208.7778015137208 .7778015137208 .7778015137208 .7778015137208 .7778015137 208.7778015137208 .7778015137208 .7778015137208 .7778015137208 .7778015137 208.7778015137208 .7778015137208 .7778015137208 .7778015137208 .7778015137 208.7778015137208 .7778015137208 .7778015137208 .7778015137208 .7778015137 208.7778015137208 .7778015137208 .7778015137208 .7778015137208 .7778015137 208.7778015137208 .7778015137208 .7778015137208 .7778015137208 .7778015137 208.7778015137208 .7778015137208 .7778015137208 .7778015137208 .7778015137 208.7778015137208 .7778015137208 .7778015137208 .7778015137208 .7778015137 208.7778015137208.7778015137208.7778015137208.7778015137208.7778015137 208.7778015137208 .7778015137208 .7778015137208 .7778015137208 .7778015137 166.7174987793168 .241394043170 .070098877 -9999 -9999 -9999 -9999 -9999 -9999 -9999 -9999 -9999 -9999 -9999 -9999 -9999 -9999 -9999 -9999 -9999 -9999 -9999 -9999 -9999 -9999

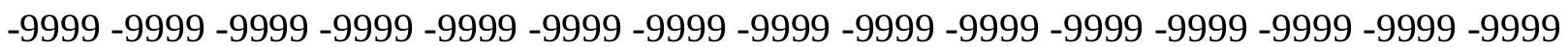

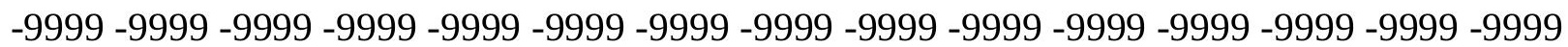
-9999 -9999 -9999 -9999 -9999 -9999 -9999 -9999 -9999 -9999 -9999 -9999 -9999 -9999 -9999 -9999 -9999 -9999 -9999 -9999 -9999 -9999 -9999 -9999 -9999 -9999 -9999

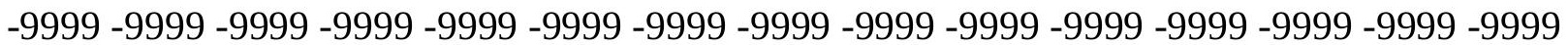


-9999 -9999 -9999 -9999 -9999 -9999 -9999 -9999 -9999 -9999 -9999 -9999 -9999 -9999 -9999 -9999 -9999 -9999 -9999 -9999 -9999 -9999 -9999 -9999 -9999 -9999 -9999 -9999 -9999 -9999 -9999 -9999 -9999 -9999 -9999 -9999 -9999 -9999 -9999 -9999 -9999 -9999 -9999 -9999 -9999 -9999 -9999 -9999 -9999 -9999 -9999 -9999 -9999 -9999 -9999 -9999 -9999 -9999 -9999 -9999 -9999 -9999 -9999 -9999 -9999 -9999 -9999 -9999 -9999 -9999 -9999 -9999 -9999 -9999 - -9999 -9999 -9999 -9999 -9999 -9999 -9999 -9999 -9999 -9999 -9999 109.1130981445 110.0273971558111 .24659729112 .4656982422113 .3800964355114 .2944030762 115.2088012695116 .1231002808117 .0374984741117 .9517974854118 .8662033081 119.4757995605120 .0852966309120 .9997024536121 .6092987061122 .2188034058 122.8283996582123 .1332015991123 .7427978516124 .0475006104124 .3523025513 124.9618988037124 .9618988037125 .2667007446125 .5715026855125 .5715026855 125.8762969971125 .8762969971125 .8762969971125 .8762969971125 .8762969971 125.8762969971125 .5715026855125 .5715026855125 .5715026855125 .2667007446 125.2667007446124 .9618988037124 .9618988037124 .6570968628124 .3523025513 124.3523025513124 .0475006104123 .7427978516123 .7427978516123 .43800354 123.1332015991123 .1332015991122 .8283996582122 .5235977173122 .5235977173 122.2188034058121 .6092987061121 .3044967651121 .3044967651121 .6092987061 121.9140014648122 .5235977173122 .8283996582122 .8283996582122 .5235977173 122.5235977173121 .9140014648121 .3044967651120 .6949005127119 .7806015015 118.5614013672117 .342300415115 .818397522114 .2944030762112 .4656982422 110.9418029785109 .4179000854108 .1986999512107 .8938980103107 .8938980103 107.5891036987107 .5891036987107 .2844009399107 .2844009399107 .2844009399 107.2844009399 107.2844009399 107.5891036987107.8938980103108.1986999512 108.5035018921108 .8082962036109 .1130981445109 .4179000854109 .7226028442 109.7226028442110 .0273971558110 .0273971558110 .3321990967110 .3321990967 110.3321990967110 .6370010376110 .6370010376110 .6370010376110 .3321990967 110.3321990967110 .3321990967110 .3321990967110 .0273971558110 .0273971558 109.7226028442109 .4179000854109 .1130981445108 .8082962036108 .5035018921 108.1986999512107 .8938980103107 .2844009399106 .979598999106 .6747970581 106.3700027466105 .7603988647105 .4557037354104 .8460998535104 .5412979126 103.9317016602103 .6268997192115 .5136032104126 .1809997559135 .6293945312 145.6873016357163 .6696014404181 .0424041748188 .6620025635194 .4528961182 200.2438049316205 .7299957275208 .7778015137208 .7778015137208 .7778015137 208.7778015137208 .7778015137208 .7778015137208 .7778015137208 .7778015137 208.7778015137208 .7778015137208 .7778015137208 .7778015137208 .7778015137 208.7778015137208 .7778015137208 .7778015137208 .7778015137208 .7778015137 208.7778015137208.7778015137208.7778015137 208.7778015137 208.7778015137 208.7778015137 208.7778015137208.7778015137208.7778015137 208.7778015137 208.7778015137208 .7778015137208 .7778015137208 .7778015137208 .7778015137 208.7778015137208 .7778015137208 .7778015137208 .7778015137208 .7778015137 208.7778015137208.7778015137208.7778015137208.7778015137 208.7778015137 208.7778015137208.7778015137208.7778015137208.7778015137 208.7778015137 208.7778015137208 .7778015137208 .7778015137208 .7778015137208 .7778015137 208.7778015137208 .7778015137208 .7778015137208 .7778015137208 .7778015137 208.7778015137208 .7778015137208 .7778015137208 .7778015137208 .7778015137 208.7778015137208.7778015137208.7778015137208.7778015137208.7778015137 
208.7778015137208 .7778015137208 .7778015137208 .7778015137208 .7778015137 208.7778015137208 .7778015137166 .7174987793168 .241394043 -9999 -9999 -9999 -9999 -9999 -9999 -9999 -9999 -9999 -9999 -9999 -9999 -9999 -9999 -9999 -9999 -9999 -9999 -9999 -9999 -9999 -9999 -9999 -9999 -9999 -9999 -9999 -9999 -9999 -9999 -9999 -9999 -9999 -9999 -9999 -9999 -9999 -9999 -9999 -9999 -9999 -9999 -9999-9999 -9999 -9999 -9999 -9999 -9999 -9999 -9999 -9999 -9999 -9999 -9999 -9999 -9999 -9999 -9999 -9999 -9999 -9999 -9999 -9999 -9999 -9999 -9999 -9999 -9999 -9999 -9999 -9999 -9999 -9999 -9999 -9999 -9999 -9999 -9999

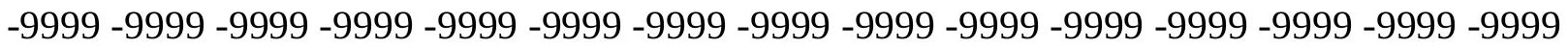

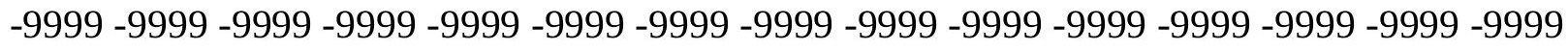
-9999 -9999 -9999 -9999 -9999 -9999 -9999 -9999 -9999 -9999 -9999 -9999 -9999 -9999 -9999

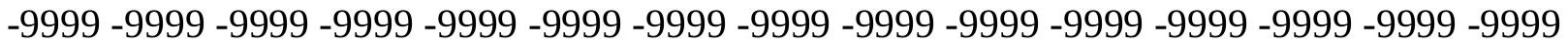
-9999 -9999 -9999 -9999 -9999 -9999 -9999 -9999 -9999 -9999 -9999 -9999 -9999 -9999 -9999 -

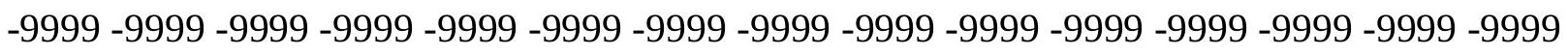
-9999 -9999 -9999 -9999 -9999 -9999 -9999 -9999 -9999 -9999 108.5035018921 109.7226028442110 .6370010376111 .8561019897112 .7705001831113 .9896011353 114.9039993286115 .818397522116 .7326965332117 .647102356118 .2565994263 119.1709976196119 .7806015015120 .6949005127121 .3044967651121 .9140014648 122.5235977173122 .8283996582123 .43800354123 .7427978516124 .3523025513 124.6570968628124 .9618988037125 .2667007446125 .2667007446125 .5715026855 125.5715026855125 .8762969971125 .8762969971125 .8762969971125 .8762969971 125.5715026855125 .5715026855125 .5715026855125 .2667007446125 .2667007446 124.9618988037124 .9618988037124 .6570968628124 .6570968628124 .3523025513 124.3523025513124 .0475006104124 .0475006104123 .7427978516123 .43800354 123.43800354123 .1332015991123 .1332015991122 .8283996582122 .8283996582 122.5235977173122 .2188034058121 .9140014648121 .9140014648121 .9140014648 122.2188034058122 .2188034058122 .5235977173122 .2188034058122 .2188034058 121.6092987061121 .3044967651120 .6949005127120 .0852966309119 .1709976196 118.2565994263117 .0374984741115 .5136032104114 .2944030762112 .7705001831 111.24659729110 .0273971558108 .8082962036107 .8938980103107 .8938980103 107.5891036987107 .5891036987107 .2844009399107 .2844009399106 .979598999 106.979598999107 .2844009399107 .5891036987107 .8938980103108 .1986999512 108.5035018921108 .8082962036109 .4179000854109 .4179000854109 .7226028442 110.0273971558110 .3321990967110 .3321990967110 .3321990967110 .6370010376 110.6370010376110 .6370010376110 .6370010376110 .6370010376110 .6370010376 110.6370010376110 .3321990967110 .3321990967110 .3321990967110 .0273971558 109.7226028442109 .7226028442109 .4179000854109 .1130981445108 .8082962036 108.5035018921107 .8938980103107 .5891036987107 .2844009399106 .979598999 106.3700027466106.0652008057 105.4557037354105.1509017944104.8460998535 104.2365036011 103.6268997192 107.2844009399115.5136032104124.0475006104 134.7149963379149 .6495056152163 .974395752174 .6419067383181 .9566955566 188.6620025635195 .0625201 .7678070068208 .7778015137208 .7778015137208 .7778015137 208.7778015137208 .7778015137208 .7778015137208 .7778015137208 .7778015137 208.7778015137208 .7778015137208 .7778015137208 .7778015137208 .7778015137 208.7778015137208 .7778015137208 .7778015137208 .7778015137208 .7778015137 208.7778015137208 .7778015137208 .7778015137208 .7778015137208 .7778015137 208.7778015137208.7778015137208.7778015137208.7778015137 208.7778015137 
208.7778015137208 .7778015137208 .7778015137208 .7778015137208 .7778015137 208.7778015137208 .7778015137208 .7778015137208 .7778015137208 .7778015137 208.7778015137208 .7778015137208 .7778015137208 .7778015137208 .7778015137 208.7778015137208 .7778015137208 .7778015137208 .7778015137208 .7778015137 208.7778015137208 .7778015137208 .7778015137208 .7778015137208 .7778015137 208.7778015137208 .7778015137208 .7778015137208 .7778015137208 .7778015137 208.7778015137208 .7778015137208 .7778015137208 .7778015137208 .7778015137 208.7778015137208 .7778015137208 .7778015137208 .7778015137208 .7778015137 208.7778015137208 .7778015137208 .7778015137208 .7778015137208 .7778015137 208.7778015137208 .7778015137166 .4127044678168 .241394043 -9999 -9999 -9999 -9999 -9999 -9999 -9999 -9999 -9999 -9999 -9999 -9999 -9999 -9999 -9999 -9999 -9999 -9999 -9999 -9999 -9999 -9999 -9999 -9999 -9999 -9999 -9999 -9999 -9999 -9999 -9999 -9999 -9999 -9999 -9999 -9999 -9999 -9999 -9999 -9999 -9999 -9999 -9999 -9999 -9999 -9999 -9999 -9999 -9999 -9999 -9999 -9999 -9999 -9999 -9999 -9999 -9999 -9999 -9999 -9999 -9999 -9999 -9999 -9999 -9999 -9999 -9999 -9999 -9999 -9999 -9999 -9999 -9999 -9999 -9999 -9999 -9999 -9999

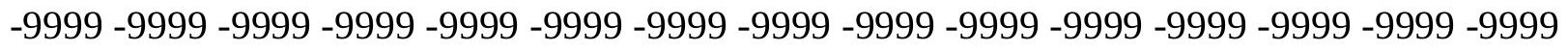

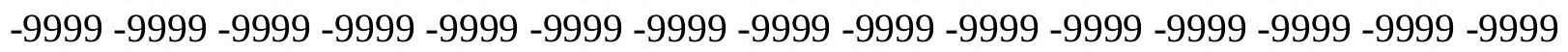

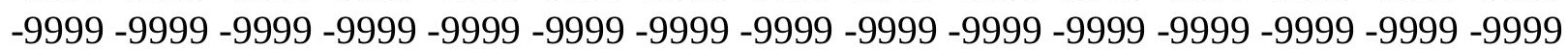
-9999 -9999 -9999 -9999 -9999 -9999 -9999 -9999 -9999 -9999 -9999 -9999 -9999 -9999 -9999 -999 -

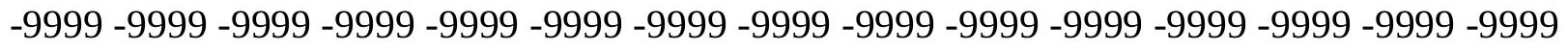

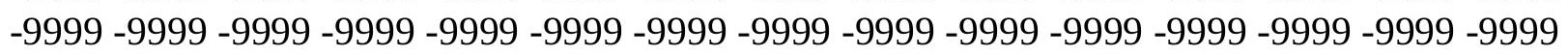
-9999 -9999-9999-9999-9999-9999-9999-9999-9999 106.6747970581 107.8938980103 109.1130981445110 .0273971558111 .24659729112 .4656982422113 .3800964355 114.2944030762115 .2088012695116 .1231002808117 .0374984741117 .9517974854 118.8662033081119 .4757995605120 .0852966309120 .9997024536121 .6092987061 122.2188034058122 .5235977173123 .1332015991123 .7427978516124 .0475006104 124.3523025513124 .6570968628124 .9618988037125 .2667007446125 .2667007446 125.5715026855125 .5715026855125 .5715026855125 .5715026855125 .5715026855 125.5715026855125 .5715026855125 .5715026855125 .2667007446125 .2667007446 124.9618988037124 .9618988037124 .6570968628124 .6570968628124 .3523025513 124.3523025513124 .0475006104124 .0475006104123 .7427978516123 .7427978516 123.43800354123 .43800354123 .1332015991123 .1332015991122 .8283996582 122.8283996582122 .5235977173122 .2188034058122 .2188034058122 .2188034058 122.2188034058122 .2188034058122 .2188034058121 .9140014648121 .6092987061 121.3044967651120 .9997024536120 .3900985718119 .4757995605118 .8662033081 117.647102356116 .7326965332115 .5136032104114 .2944030762112 .7705001831 111.551399231110 .3321990967109 .1130981445108 .1986999512107 .8938980103 107.5891036987 107.5891036987 107.2844009399 107.2844009399 107.2844009399 107.2844009399107 .2844009399107 .5891036987107 .8938980103108 .5035018921 108.8082962036109 .1130981445109 .4179000854109 .7226028442110 .0273971558 110.3321990967110 .3321990967110 .6370010376110 .6370010376110 .6370010376 110.9418029785110 .9418029785110 .9418029785110 .9418029785110 .9418029785 110.6370010376110 .6370010376110 .6370010376110 .3321990967110 .3321990967 110.0273971558109 .7226028442109 .4179000854109 .1130981445108 .8082962036 108.5035018921108 .1986999512107 .8938980103107 .2844009399106 .979598999 106.6747970581 106.3700027466105.7603988647 105.4557037354104.8460998535 
104.5412979126103 .9317016602103 .6268997192105 .4557037354113 .6848983765 122.5235977173135 .6293945312148 .4304046631159 .0977935791167 .9365997314 175.5561981201183 .1759033203191 .4051055908199 .329498291207 .25390625 208.7778015137208 .7778015137208 .7778015137208 .7778015137208 .7778015137 208.7778015137208 .7778015137208 .7778015137208 .7778015137208 .7778015137 208.7778015137208 .7778015137208 .7778015137208 .7778015137208 .7778015137 208.7778015137 208.7778015137 208.7778015137 208.7778015137 208.7778015137 208.7778015137208 .7778015137208 .7778015137208 .7778015137208 .7778015137 208.7778015137208 .7778015137208 .7778015137208 .7778015137208 .7778015137 208.7778015137208 .7778015137208 .7778015137208 .7778015137208 .7778015137 208.7778015137208 .7778015137208 .7778015137208 .7778015137208 .7778015137 208.7778015137208 .7778015137208 .7778015137208 .7778015137208 .7778015137 208.7778015137208 .7778015137208 .7778015137208 .7778015137208 .7778015137 208.7778015137208 .7778015137208 .7778015137208 .7778015137208 .7778015137 208.7778015137208 .7778015137208 .7778015137208 .7778015137208 .7778015137 208.7778015137208 .7778015137208 .7778015137208 .7778015137208 .7778015137 208.7778015137208 .7778015137208 .7778015137208 .7778015137208 .7778015137 208.7778015137 208.7778015137208.7778015137 164.8887023926 166.4127044678 -9999 -9999 -9999 -9999 -9999 -9999 -9999 -9999 -9999 -9999 -9999 -9999 -9999 -9999 -9999 -9999

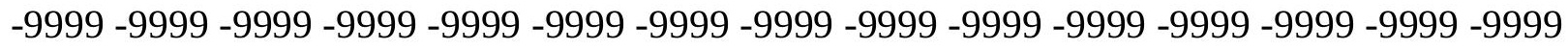

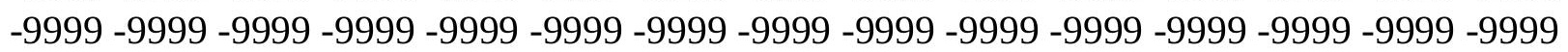

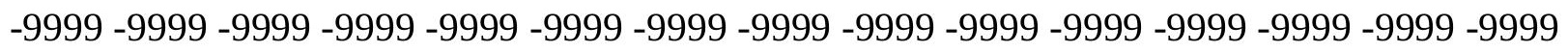
$-9999-9999$

-9999 -9999 -9999 -9999 -9999 -9999 -9999 -9999 -9999 -9999 -9999 -9999 -9999 -9999 -9999

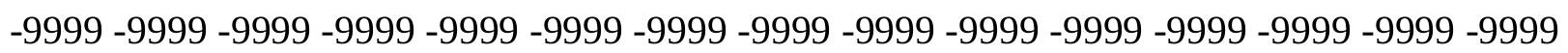

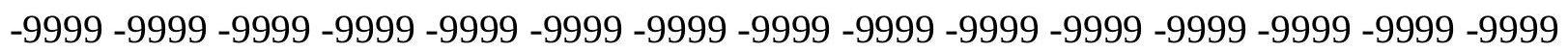
-9999 -9999 -9999 -9999 -9999 -9999 -9999 -9999 -9999 -9999 -9999 -9999 -9999 - -9999 - -9999 -

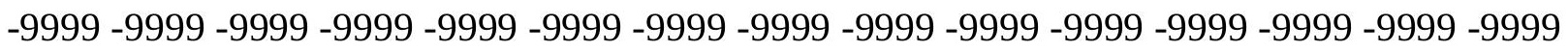

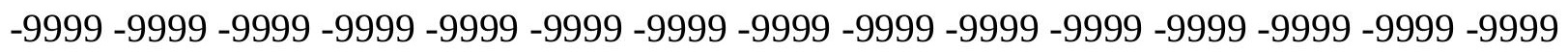

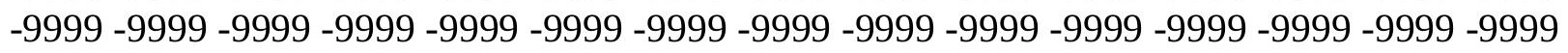
-9999 -9999 -9999 -9999-9999 -9999-9999-9999 104.8460998535106 .0652008057 107.2844009399 108.5035018921 109.7226028442110.6370010376111.8561019897 112.7705001831113 .9896011353114 .9039993286115 .818397522116 .7326965332 117.647102356118 .2565994263119 .1709976196119 .7806015015120 .6949005127 121.3044967651121 .9140014648122 .5235977173122 .8283996582123 .43800354 123.7427978516124 .3523025513124 .6570968628124 .9618988037124 .9618988037 125.2667007446125 .5715026855125 .5715026855125 .5715026855125 .5715026855 125.5715026855125 .5715026855125 .5715026855125 .5715026855125 .2667007446 125.2667007446124 .9618988037124 .9618988037124 .6570968628124 .6570968628 124.3523025513124 .3523025513124 .0475006104124 .0475006104123 .7427978516 123.7427978516123 .7427978516123 .43800354123 .43800354123 .1332015991 123.1332015991122 .8283996582122 .8283996582122 .5235977173122 .5235977173 122.2188034058122 .2188034058122 .2188034058121 .9140014648121 .6092987061 121.3044967651120 .9997024536120 .3900985718119 .7806015015119 .1709976196 118.5614013672117 .647102356116 .4279022217115 .2088012695114 .2944030762 113.075302124111 .8561019897110 .6370010376109 .4179000854108 .5035018921 
107.8938980103107 .8938980103107 .5891036987107 .5891036987107 .5891036987 107.2844009399107 .2844009399107 .5891036987107 .8938980103108 .1986999512 108.8082962036109 .1130981445109 .4179000854109 .7226028442110 .0273971558 110.3321990967110 .6370010376110 .6370010376110 .9418029785110 .9418029785 110.9418029785110 .9418029785110 .9418029785110 .9418029785110 .9418029785 110.9418029785110 .9418029785110 .9418029785110 .6370010376110 .6370010376 110.3321990967110 .0273971558110 .0273971558109 .7226028442109 .4179000854 109.1130981445108 .8082962036108 .1986999512107 .8938980103107 .5891036987 107.2844009399 106.6747970581 106.3700027466106.0652008057 105.4557037354 105.1509017944104 .5412979126104 .2365036011103 .6268997192103 .3221969604 104.2365036011112 .7705001831123 .43800354134 .4102020264144 .4682006836 153.6116943359161 .8408966064170 .3748931885179 .8231964111189 .2716064453 197.8054962158205 .7299957275208 .7778015137208 .7778015137208 .7778015137 208.7778015137208 .7778015137208 .7778015137208 .7778015137208 .7778015137 208.7778015137208 .7778015137208 .7778015137208 .7778015137208 .7778015137 208.7778015137208 .7778015137208 .7778015137208 .7778015137208 .7778015137 208.7778015137208 .7778015137208 .7778015137208 .7778015137208 .7778015137 208.7778015137208 .7778015137208 .7778015137208 .7778015137208 .7778015137 208.7778015137208 .7778015137208 .7778015137208 .7778015137208 .7778015137 208.7778015137208 .7778015137208 .7778015137208 .7778015137208 .7778015137 208.7778015137208 .7778015137208 .7778015137208 .7778015137208 .7778015137 208.7778015137208 .7778015137208 .7778015137208 .7778015137208 .7778015137 208.7778015137208 .7778015137208 .7778015137208 .7778015137208 .7778015137 208.7778015137 208.7778015137208.7778015137 208.7778015137 208.7778015137 208.7778015137 208.7778015137 208.7778015137 208.7778015137 208.7778015137 208.7778015137208 .7778015137208 .7778015137208 .7778015137208 .7778015137 208.7778015137208 .7778015137208 .7778015137208 .7778015137208 .7778015137 164.5839996338166 .4127044678 -9999 -9999 -9999 -9999 -9999 -9999 -9999 -9999 -9999 -9999 -9999 -9999 -9999 -9999 -9999 -9999 -9999 -9999 -9999 -9999 -9999 -9999 -9999 -9999 -

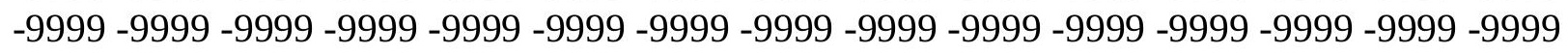

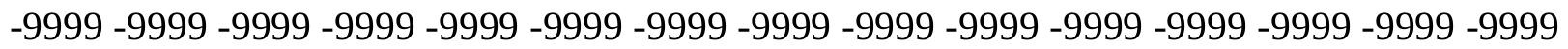
-9999 -9999-9999 -9999-9999-9999-9999-9999

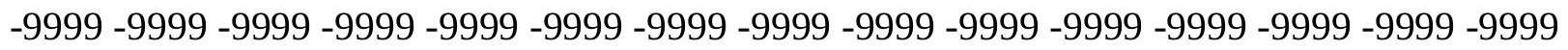

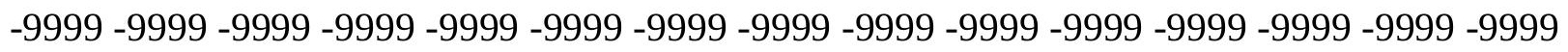

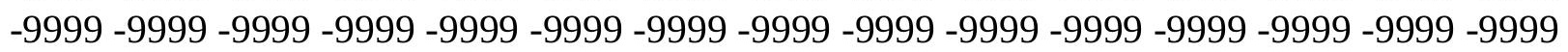

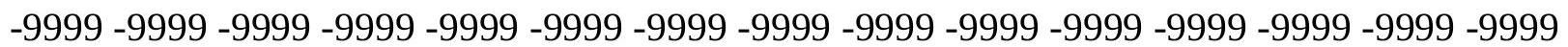

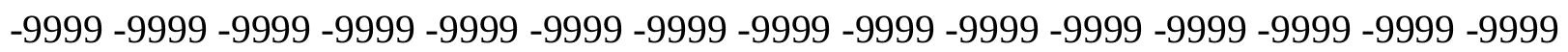

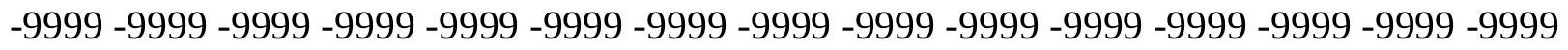

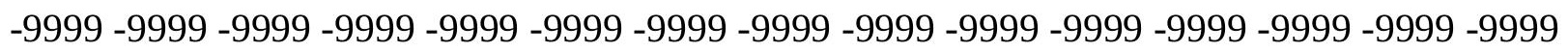
-9999 -9999 -9999 -9999-9999 -9999 -9999 103.0174026489104 .2365036011105 .4557037354 106.6747970581 107.8938980103109.1130981445 110.3321990967 111.24659729 112.4656982422113 .3800964355114 .5991973877115 .5136032104116 .4279022217 117.342300415117 .9517974854118 .8662033081119 .4757995605120 .3900985718 120.9997024536121 .6092987061122 .2188034058122 .8283996582123 .1332015991 123.7427978516124 .0475006104124 .3523025513124 .6570968628124 .9618988037 125.2667007446125 .5715026855125 .5715026855125 .5715026855125 .5715026855 
125.8762969971125 .5715026855125 .5715026855125 .5715026855125 .2667007446 125.2667007446124 .9618988037124 .9618988037124 .6570968628124 .6570968628 124.3523025513124 .0475006104124 .0475006104124 .0475006104123 .7427978516 123.7427978516123 .7427978516123 .43800354123 .43800354123 .43800354123 .1332015991 123.1332015991122 .8283996582122 .8283996582122 .5235977173122 .5235977173 122.2188034058121 .9140014648121 .9140014648121 .6092987061120 .9997024536 120.6949005127120 .0852966309119 .4757995605118 .8662033081118 .2565994263 117.342300415116 .4279022217115 .2088012695114 .2944030762113 .075302124 112.1608963013110 .9418029785110 .0273971558109 .1130981445108 .1986999512 107.8938980103107 .8938980103107 .8938980103107 .8938980103107 .8938980103 107.8938980103107 .8938980103108 .1986999512108 .5035018921109 .1130981445 109.4179000854109 .7226028442110 .0273971558110 .3321990967110 .6370010376 110.6370010376110 .9418029785110 .9418029785111 .24659729111 .24659729111 .24659729 111.24659729111 .24659729111 .24659729111 .24659729110 .9418029785110 .9418029785 110.9418029785110 .6370010376110 .6370010376110 .3321990967110 .0273971558 109.7226028442109 .4179000854109 .1130981445108 .8082962036108 .5035018921 108.1986999512107 .8938980103107 .2844009399106 .979598999106 .6747970581 106.0652008057105 .7603988647105 .4557037354104 .8460998535104 .5412979126 103.9317016602103 .6268997192103 .0174026489103 .0174026489112 .4656982422 121.9140014648131 .0576019287139 .5915985107148 .1255950928156 .6596069336 166.4127044678178 .2993011475186 .8332977295195 .9768066406205 .1204071045 208.7778015137208 .7778015137208 .7778015137208 .7778015137208 .7778015137 208.7778015137208 .7778015137208 .7778015137208 .7778015137208 .7778015137 208.7778015137208 .7778015137208 .7778015137208 .7778015137208 .7778015137 208.7778015137208 .7778015137208 .7778015137208 .7778015137208 .7778015137 208.7778015137 208.7778015137208.7778015137 208.7778015137 208.7778015137 208.7778015137208 .7778015137208 .7778015137208 .7778015137208 .7778015137 208.7778015137208 .7778015137208 .7778015137208 .7778015137208 .7778015137 208.7778015137208 .7778015137208 .7778015137208 .7778015137208 .7778015137 208.7778015137208 .7778015137208 .7778015137208 .7778015137208 .7778015137 208.7778015137208 .7778015137208 .7778015137208 .7778015137208 .7778015137 208.7778015137208 .7778015137208 .7778015137208 .7778015137208 .7778015137 208.7778015137 208.7778015137208.7778015137 208.7778015137 208.7778015137 208.7778015137208 .7778015137208 .7778015137208 .7778015137208 .7778015137 208.7778015137208 .7778015137208 .7778015137208 .7778015137208 .7778015137 208.7778015137208 .7778015137163 .0599975586164 .5839996338 -9999 -9999 -9999 -9999 -9999 -9999 -9999 -9999 -9999 -9999 -9999 -9999 -9999 -9999 -9999 -9999 -9999 -9999 - 9999 -

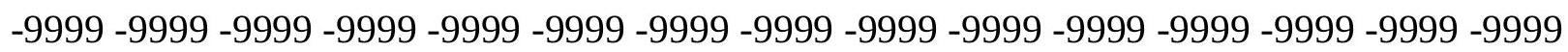

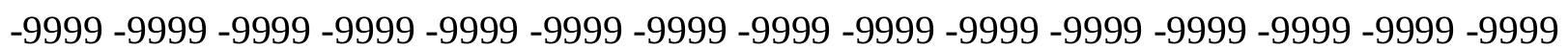
-9999 -9999 -9999 -9999 -9999 -9999 -9999 -9999 -9999 -9999 -9999 -9999 -9999 -9999 -9999 -9999 -9999 -9999 -9999 -9999 -9999 -9999 -9999 -9999 -9999 -9999 -9999 -999 -9999 -9999 -9999 -9999 -9999 -9999 -9999 -9999 -9999 -9999 -9999 -9999 -9999 -9999 -9999 -9999 -9999 -9999 -9999 -9999 -9999 -9999 -9999 -9999 -9999 -9999 -9999 -9999 -9999 -9999 -9999 -9999 -9999 -9999 -9999 -9999 -9999 -9999 -9999 -9999 -9999 -9999 -9999 -9999 -9999 -9999 -9999 -9999 -9999 -9999 -9999 -9999 -9999 -9999 -9999 -9999 -9999 -9999 -9999 -9999 -

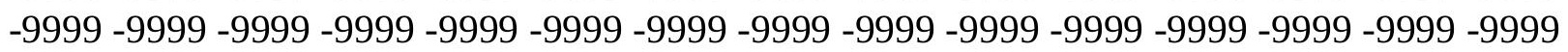


-9999 -9999 -9999 -9999 -9999 -9999 -9999 -9999 -9999 -9999 -9999 -9999 -9999 -9999 -9999 -9999 -9999 -9999 -9999 -9999 -9999-9999 102.4077987671103 .9317016602105 .1509017944 106.3700027466107 .5891036987108 .8082962036109 .7226028442110 .9418029785 112.1608963013113 .075302124113 .9896011353114 .9039993286115 .818397522 116.7326965332117 .647102356118 .5614013672119 .1709976196120 .0852966309 120.6949005127121 .3044967651121 .9140014648122 .5235977173123 .1332015991 123.43800354124 .0475006104124 .3523025513124 .6570968628124 .9618988037 125.2667007446125 .2667007446125 .5715026855125 .5715026855125 .8762969971 125.8762969971125 .8762969971125 .8762969971125 .5715026855125 .5715026855 125.2667007446125 .2667007446124 .9618988037124 .6570968628124 .3523025513 124.3523025513124 .0475006104124 .0475006104124 .0475006104123 .7427978516 123.7427978516123 .7427978516123 .7427978516123 .43800354123 .43800354123 .43800354 123.1332015991123 .1332015991122 .8283996582122 .5235977173122 .5235977173 122.2188034058121 .9140014648121 .6092987061121 .3044967651120 .9997024536 120.3900985718120 .0852966309119 .4757995605118 .5614013672117 .9517974854 117.0374984741116 .1231002808115 .2088012695114 .2944030762113 .3800964355 112.1608963013111 .24659729110 .3321990967109 .4179000854108 .5035018921 108.1986999512108 .1986999512108 .1986999512108 .1986999512108 .1986999512 108.1986999512108 .5035018921108 .8082962036109 .1130981445109 .4179000854 109.7226028442110 .0273971558110 .3321990967110 .6370010376110 .9418029785 110.9418029785111 .24659729111 .24659729111 .24659729111 .551399231111 .551399231 111.551399231111 .551399231111 .24659729111 .24659729111 .24659729111 .24659729 110.9418029785110 .9418029785110 .6370010376110 .3321990967110 .3321990967 110.0273971558109 .7226028442109 .4179000854109 .1130981445108 .8082962036 108.1986999512107 .8938980103107 .5891036987107 .2844009399106 .6747970581 106.3700027466106 .0652008057105 .4557037354105 .1509017944104 .5412979126 104.2365036011103 .6268997192103 .3221969604102 .712600708102 .4077987671 110.3321990967118 .5614013672126 .4858016968134 .7149963379142 .9441986084 151.4781951904163 .3648071289174 .337097168184 .699798584195 .0625205 .425201416 208.7778015137208 .7778015137208 .7778015137208 .7778015137208 .7778015137 208.7778015137208 .7778015137208 .7778015137208 .7778015137208 .7778015137 208.7778015137208 .7778015137208 .7778015137208 .7778015137208 .7778015137 208.7778015137208 .7778015137208 .7778015137208 .7778015137208 .7778015137 208.7778015137208 .7778015137208 .7778015137208 .7778015137208 .7778015137 208.7778015137208 .7778015137208 .7778015137208 .7778015137208 .7778015137 208.7778015137208 .7778015137208 .7778015137208 .7778015137208 .7778015137 208.7778015137 208.7778015137208.7778015137 208.7778015137 208.7778015137 208.7778015137 208.7778015137208.7778015137208.7778015137 208.7778015137 208.7778015137208 .7778015137208 .7778015137208 .7778015137208 .7778015137 208.7778015137208 .7778015137208 .7778015137208 .7778015137208 .7778015137 208.7778015137208 .7778015137208 .7778015137208 .7778015137208 .7778015137 208.7778015137208.7778015137208.7778015137208.7778015137 208.7778015137 208.7778015137208 .7778015137208 .7778015137208 .7778015137208 .7778015137 208.7778015137208 .7778015137162 .7552947998164 .5839996338 -9999 -9999 -9999-9999 -9999 -9999 -9999 -9999 -9999 -9999 -9999 -9999 -9999 -9999 -9999 -9999 -9999 -9999 -9999 -9999 -9999 -9999 -9999 -9999 -9999 -9999 -9999 -9999 -9999 -9999 -9999 -9999 -9999 -9999 
-9999 -9999 -9999 -9999 -9999 -9999 -9999 -9999 -9999 -9999 -9999 -9999 -9999 -9999 -9999 -9999 -9999 -9999 -9999 -9999 -9999 -9999 -9999 -9999 -9999 -9999 -9999

-9999 -9999 -9999 -9999 -9999 -9999 -9999 -9999 -9999 -9999 -9999 -9999 -9999 -9999 -9999 -9999 -9999 -9999 -9999 -9999 -9999 -9999 -9999 -9999 -9999 -9999 -9999 -9999 -9999 -9999 -9999 -9999 -9999 -9999 -9999 -9999 -9999 -9999 -9999 -9999 -9999 -9999 -9999 -9999 -9999 -9999 -9999 -9999 -9999 -9999 -9999 -9999 -9999 -9999 -9999 -9999 -9999 -9999 -9999 -9999 -9999 -9999 -9999 -9999 -9999 -9999 -9999 -9999 -9999 -9999 -9999 -9999 -9999 -9999 -9999 -9999 -9999 -9999 -9999 -9999 -9999 -9999 -9999 -9999 -9999 -9999 -9999 -9999 -9999 -9999 -999 -9999 -9999 -9999 -9999 -9999 -9999 -9999 -9999 -9999 -9999 -9999 -9999 -9999 -9999 -9999 -9999 -9999 -9999 -9999 -9999 -9999 100.5791015625 102.1029968262 103.3221969604 104.5412979126105 .7603988647106 .979598999108 .1986999512109 .4179000854 110.6370010376111 .551399231112 .7705001831113 .6848983765114 .5991973877 115.5136032104116 .4279022217117 .342300415118 .2565994263118 .8662033081 119.7806015015120 .3900985718120 .9997024536121 .6092987061122 .2188034058 122.8283996582123 .43800354123 .7427978516124 .3523025513124 .6570968628 124.9618988037125 .2667007446125 .2667007446125 .5715026855125 .8762969971 125.8762969971125 .8762969971125 .8762969971125 .8762969971125 .8762969971 125.5715026855125 .5715026855125 .2667007446124 .9618988037124 .6570968628 124.3523025513124 .3523025513124 .0475006104124 .0475006104123 .7427978516 123.7427978516123 .7427978516123 .7427978516123 .7427978516123 .43800354 123.43800354123 .43800354123 .43800354123 .1332015991122 .8283996582122 .5235977173 122.2188034058121 .9140014648121 .9140014648121 .6092987061120 .9997024536 120.6949005127120 .0852966309119 .7806015015119 .1709976196118 .5614013672 117.9517974854117 .0374984741116 .1231002808115 .2088012695114 .5991973877 113.3800964355112 .4656982422111 .551399231110 .6370010376110 .0273971558 109.1130981445108 .5035018921108 .5035018921108 .5035018921108 .5035018921 108.5035018921108 .8082962036108 .8082962036109 .1130981445109 .4179000854 109.7226028442110 .0273971558110 .3321990967110 .6370010376110 .9418029785 111.24659729111 .551399231111 .551399231111 .551399231111 .551399231111 .551399231 111.551399231111 .551399231111 .551399231111 .551399231111 .551399231111 .24659729 111.24659729111 .24659729110 .9418029785110 .6370010376110 .6370010376 110.3321990967110 .0273971558109 .7226028442109 .4179000854109 .1130981445 108.8082962036108 .5035018921108 .1986999512107 .8938980103107 .2844009399 106.979598999106 .6747970581106 .0652008057105 .7603988647105 .4557037354 104.8460998535104 .5412979126103 .9317016602103 .6268997192103 .0174026489 102.4077987671102 .1029968262106 .6747970581114 .2944030762121 .9140014648 130.1432037354138 .9819946289149 .3446960449160 .6217956543172 .2035980225 184.3950042725196 .5863952637207 .8634033203208 .7778015137208 .7778015137 208.7778015137208 .7778015137208 .7778015137208 .7778015137208 .7778015137 208.7778015137208 .7778015137208 .7778015137208 .7778015137208 .7778015137 208.7778015137208 .7778015137208 .7778015137208 .7778015137208 .7778015137 208.7778015137208 .7778015137208 .7778015137208 .7778015137208 .7778015137 208.7778015137208 .7778015137208 .7778015137208 .7778015137208 .7778015137 208.7778015137208 .7778015137208 .7778015137208 .7778015137208 .7778015137 208.7778015137208 .7778015137208 .7778015137208 .7778015137208 .7778015137 208.7778015137208 .7778015137208 .7778015137208 .7778015137208 .7778015137 
208.7778015137208 .7778015137208 .7778015137208 .7778015137208 .7778015137 208.7778015137 208.7778015137208.7778015137208.7778015137 208.7778015137 208.7778015137208 .7778015137208 .7778015137208 .7778015137208 .7778015137 208.7778015137208 .7778015137208 .7778015137208 .7778015137208 .7778015137 208.7778015137208 .7778015137208 .7778015137208 .7778015137208 .7778015137 208.7778015137208 .7778015137208 .7778015137208 .7778015137161 .2312927246 162.7552947998164 .2792053223 -9999 -9999 -9999 -9999 -9999 -9999 -9999 -9999 -9999 -9999 -9999 -9999 -9999 -9999 -9999 -9999 -9999 -9999 -9999 -9999 -9999 -9999 -9999 -9999 -9999 -9999 -9999 -9999 -9999 -9999 -9999 -9999 -9999 -9999 -9999 -9999 -9999 -9999 -9999 -9999 -9999 -9999 -9999 -9999 -9999 -9999 -9999 -9999 -9999 -9999 -9999 -9999 -9999 -9999 -9999 -9999 -9999-9999-9999-9999

-9999 -9999 -9999 -9999 -9999 -9999 -9999 -9999 -9999 -9999 -9999 -9999 -9999 -9999 -9999 -9999 -9999 -9999 -9999 -9999 -9999 -9999 -9999 -9999 -9999 -9999 -9999 -9999 -9999 -9999 -9999 -9999 -9999 -9999 -9999 -9999 -9999 -9999 -9999 -9999 -9999 -9999 -9999 -9999 -9999 -9999 -9999 -9999 -9999 -9999 -9999 -9999 -9999 -9999 -9999 -9999 -9999 -9999 -9999 -9999

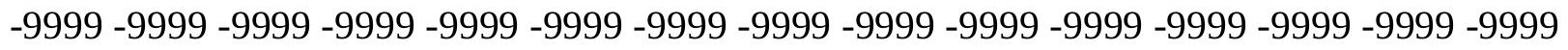

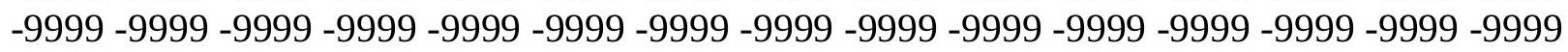

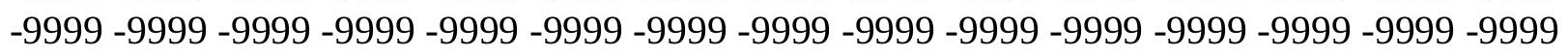
-9999 -9999 -9999 -9999 -9999 98.75038146973 100.2742996216101.4934005737 102.712600708104 .2365036011105 .4557037354106 .6747970581107 .8938980103 109.1130981445110 .0273971558111 .24659729112 .1608963013113 .3800964355 114.2944030762115 .2088012695116 .1231002808117 .0374984741117 .9517974854 118.8662033081119 .4757995605120 .0852966309120 .9997024536121 .6092987061 122.2188034058122 .8283996582123 .1332015991123 .7427978516124 .0475006104 124.3523025513124 .9618988037125 .2667007446125 .5715026855125 .5715026855 125.8762969971125 .8762969971126 .1809997559126 .1809997559126 .1809997559 125.8762969971125 .8762969971125 .5715026855125 .2667007446124 .9618988037 124.6570968628124 .3523025513124 .3523025513124 .0475006104124 .0475006104 123.7427978516123 .7427978516123 .7427978516123 .7427978516123 .43800354 123.43800354123 .43800354123 .43800354123 .1332015991122 .8283996582122 .5235977173 122.2188034058122 .2188034058121 .9140014648121 .6092987061121 .3044967651 120.9997024536120 .3900985718120 .0852966309119 .4757995605118 .8662033081 118.2565994263117 .647102356117 .0374984741116 .1231002808115 .5136032104 114.5991973877113 .6848983765112 .7705001831112 .1608963013111 .24659729 110.3321990967109 .7226028442108 .8082962036108 .8082962036108 .8082962036 108.8082962036109 .1130981445109 .1130981445109 .4179000854109 .7226028442 109.7226028442110 .3321990967110 .6370010376110 .9418029785111 .24659729 111.551399231111 .551399231111 .8561019897111 .8561019897111 .8561019897 111.8561019897111 .8561019897111 .8561019897111 .8561019897111 .8561019897 111.8561019897111 .551399231111 .551399231111 .551399231111 .24659729111 .24659729 110.9418029785110 .6370010376110 .3321990967110 .3321990967110 .0273971558 109.7226028442109 .4179000854109 .1130981445108 .8082962036108 .1986999512 107.8938980103 107.5891036987 107.2844009399 106.979598999 106.3700027466 106.0652008057105 .4557037354105 .1509017944104 .8460998535104 .2365036011 103.9317016602103 .3221969604102 .712600708102 .4077987671101 .7982025146 103.0174026489 110.3321990967 118.2565994263126.7906036377136.2389984131 
146.6015930176158 .4882965088172 .2035980225186 .8332977295200 .5485992432 208.7778015137208 .7778015137208 .7778015137208 .7778015137208 .7778015137 208.7778015137208 .7778015137208 .7778015137208 .7778015137208 .7778015137 208.7778015137208 .7778015137208 .7778015137208 .7778015137208 .7778015137 208.7778015137208 .7778015137208 .7778015137208 .7778015137208 .7778015137 208.7778015137208 .7778015137208 .7778015137208 .7778015137208 .7778015137 208.7778015137208 .7778015137208 .7778015137208 .7778015137208 .7778015137 208.7778015137208 .7778015137208 .7778015137208 .7778015137208 .7778015137 208.7778015137208 .7778015137208 .7778015137208 .7778015137208 .7778015137 208.7778015137208 .7778015137208 .7778015137208 .7778015137208 .7778015137 208.7778015137 208.7778015137208.7778015137208.7778015137 208.7778015137 208.7778015137208.7778015137208.7778015137208.7778015137 208.7778015137 208.7778015137 208.7778015137 208.7778015137 208.7778015137 208.7778015137 208.7778015137208 .7778015137208 .7778015137208 .7778015137208 .7778015137 208.7778015137208 .7778015137208 .7778015137208 .7778015137208 .7778015137 208.7778015137208 .7778015137160 .9264984131162 .7552947998 -9999 -9999 -9999 -9999 -9999 -9999 -9999 -9999 -9999 -9999 -9999 -9999 -9999 -9999 -9999 -9999 -9999 -9999-9999 -

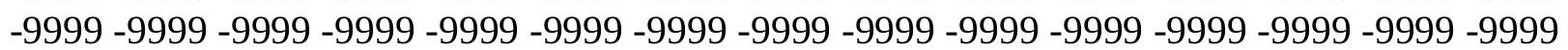

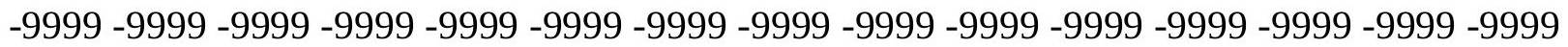
-9999 -9999 -9999 -9999 -9999 -9999 -9999 -9999 -9999 -9999 -9999

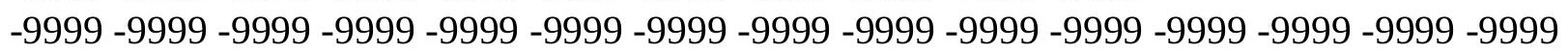

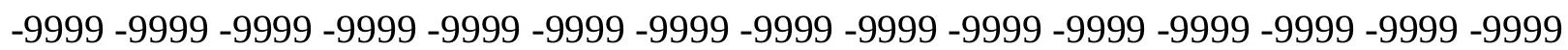
-9999 -9999 -9999 -9999 -9999 -9999 -9999 -9999 -9999 -9999 -9999 -9999 -9999 -9999 -9999 -

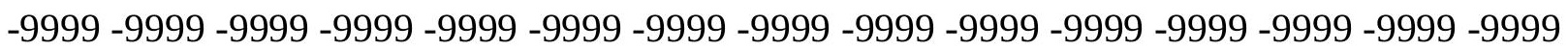

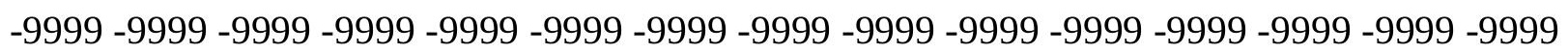

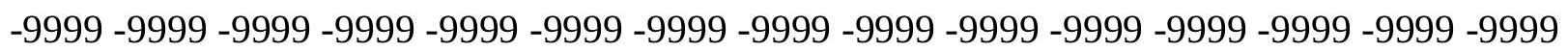

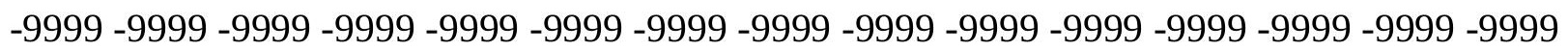
-9999 -9999-9999-9999 96.92166900635 98.445587158299.66472625732 101.1886978149 102.4077987671103 .6268997192104 .8460998535106 .0652008057107 .2844009399 108.5035018921109 .7226028442110 .9418029785111 .8561019897113 .075302124 113.9896011353114 .9039993286115 .818397522116 .7326965332117 .647102356 118.5614013672119 .1709976196120 .0852966309120 .6949005127121 .3044967651 121.9140014648122 .5235977173123 .1332015991123 .43800354124 .0475006104 124.3523025513124 .6570968628125 .2667007446125 .5715026855125 .8762969971 125.8762969971126 .1809997559126 .1809997559126 .4858016968126 .4858016968 126.1809997559126 .1809997559125 .8762969971125 .5715026855124 .9618988037 124.6570968628124 .3523025513124 .0475006104124 .0475006104123 .7427978516 123.7427978516123 .7427978516123 .7427978516123 .43800354123 .43800354123 .43800354 123.1332015991123 .1332015991122 .8283996582122 .8283996582122 .5235977173 122.2188034058121 .9140014648121 .6092987061121 .3044967651120 .9997024536 120.6949005127120 .3900985718119 .7806015015119 .4757995605118 .8662033081 118.2565994263117 .647102356117 .0374984741116 .4279022217115 .5136032104 114.9039993286113 .9896011353113 .3800964355112 .4656982422111 .551399231 110.9418029785110 .3321990967109 .4179000854109 .1130981445109 .1130981445 109.1130981445109 .4179000854109 .4179000854109 .7226028442110 .0273971558 110.3321990967110 .6370010376110 .9418029785111 .24659729111 .551399231 
111.8561019897111 .8561019897111 .8561019897112 .1608963013112 .1608963013 112.1608963013112 .1608963013112 .1608963013112 .1608963013111 .8561019897 111.8561019897111 .8561019897111 .8561019897111 .551399231111 .551399231 111.24659729110 .9418029785110 .9418029785110 .6370010376110 .3321990967 110.0273971558109 .7226028442109 .4179000854109 .1130981445108 .8082962036 108.5035018921108 .1986999512107 .8938980103107 .2844009399106 .979598999 106.6747970581106 .3700027466105 .7603988647105 .4557037354105 .1509017944 104.5412979126104 .2365036011103 .6268997192103 .0174026489102 .712600708 102.1029968262101 .4934005737101 .1886978149106 .979598999114 .9039993286 123.43800354132 .5814971924143 .8585968018158 .7929992676176 .165802002 193.233795166205 .425201416208 .7778015137208 .7778015137208 .7778015137 208.7778015137208 .7778015137208 .7778015137208 .7778015137208 .7778015137 208.7778015137208 .7778015137208 .7778015137208 .7778015137208 .7778015137 208.7778015137208 .7778015137208 .7778015137208 .7778015137208 .7778015137 208.7778015137208 .7778015137208 .7778015137208 .7778015137208 .7778015137 208.7778015137208 .7778015137208 .7778015137208 .7778015137208 .7778015137 208.7778015137208 .7778015137208 .7778015137208 .7778015137208 .7778015137 208.7778015137208 .7778015137208 .7778015137208 .7778015137208 .7778015137 208.7778015137208 .7778015137208 .7778015137208 .7778015137208 .7778015137 208.7778015137208 .7778015137208 .7778015137208 .7778015137208 .7778015137 208.7778015137208 .7778015137208 .7778015137208 .7778015137208 .7778015137 208.7778015137208 .7778015137208 .7778015137208 .7778015137208 .7778015137 208.7778015137208 .7778015137208 .7778015137208 .7778015137208 .7778015137 208.7778015137208 .7778015137208 .7778015137208 .7778015137208 .7778015137 208.7778015137 208.7778015137208.7778015137 208.7778015137 160.9264984131 162.4505004883 -9999 -9999 -9999 -9999 -9999 -9999 -9999 -9999 -9999 -9999 -9999 -9999 -9999 -9999 -9999 -9999 -9999 -9999 -9999 -9999 -9999 -9999 -9999 -9999 -9999 -9999 -9999

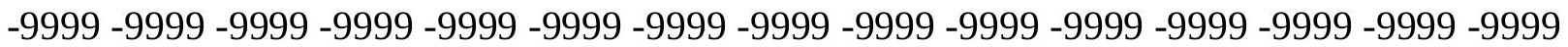

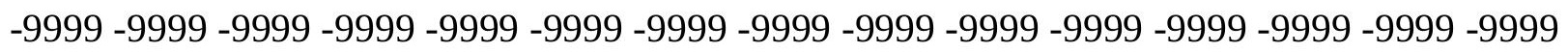
-9999-9999

-9999 -9999 -9999 -9999 -9999 -9999 -9999 -9999 -9999 -9999 -9999 -9999 -9999 -9999 -9999

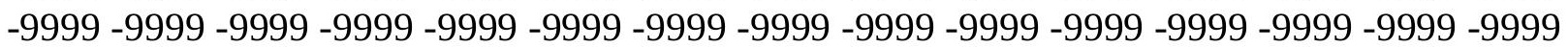

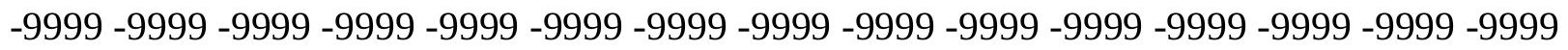
-9999 -9999 -9999 -9999 -9999 -9999 -9999 -9999 -9999 -9999 -9999 -9999 -9999 -9999 -9999

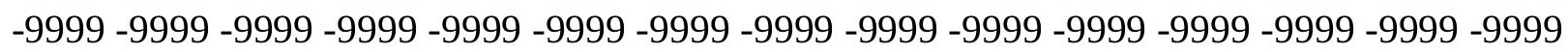

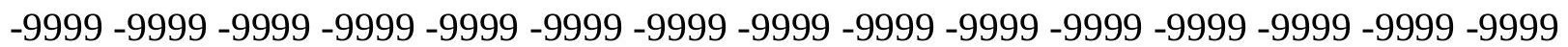

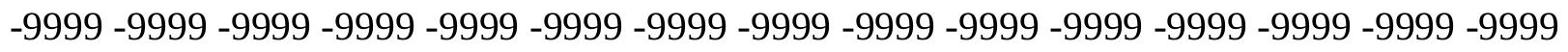

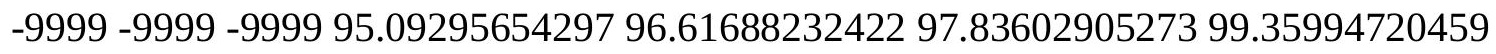
100.5791015625101 .7982025146103 .3221969604104 .5412979126105 .7603988647 106.979598999108 .1986999512109 .4179000854110 .6370010376111 .551399231 112.7705001831113 .6848983765114 .5991973877115 .5136032104116 .4279022217 117.342300415118 .2565994263118 .8662033081119 .7806015015120 .3900985718 120.9997024536121 .9140014648122 .2188034058122 .8283996582123 .43800354 124.0475006104124 .3523025513124 .6570968628125 .2667007446125 .5715026855 125.8762969971126 .1809997559126 .4858016968126 .4858016968126 .7906036377 126.7906036377126 .4858016968126 .4858016968125 .8762969971125 .5715026855 
124.9618988037124 .6570968628124 .0475006104124 .0475006104123 .7427978516 123.7427978516123 .7427978516123 .43800354123 .43800354123 .43800354123 .43800354 123.1332015991123 .1332015991122 .8283996582122 .8283996582122 .5235977173 122.2188034058121 .9140014648121 .6092987061121 .3044967651120 .9997024536 120.6949005127120 .3900985718120 .0852966309119 .7806015015119 .1709976196 118.8662033081118 .2565994263117 .647102356117 .0374984741116 .4279022217 115.818397522115 .2088012695114 .2944030762113 .6848983765112 .7705001831 112.1608963013111 .551399231110 .9418029785110 .0273971558109 .4179000854 109.4179000854109 .7226028442109 .7226028442110 .0273971558110 .0273971558 110.3321990967110 .6370010376110 .9418029785111 .24659729111 .551399231 111.8561019897111 .8561019897112 .1608963013112 .1608963013112 .1608963013 112.1608963013112 .1608963013112 .1608963013112 .1608963013112 .1608963013 112.1608963013112 .1608963013111 .8561019897111 .8561019897111 .8561019897 111.551399231111 .24659729111 .24659729110 .9418029785110 .6370010376 110.6370010376110 .3321990967110 .0273971558109 .7226028442109 .4179000854 109.1130981445108 .8082962036108 .5035018921107 .8938980103107 .5891036987 107.2844009399106 .979598999106 .3700027466106 .0652008057105 .7603988647 105.1509017944104 .8460998535104 .5412979126103 .9317016602103 .3221969604 103.0174026489102 .4077987671102 .1029968262101 .4934005737100 .8839035034 104.5412979126111 .8561019897119 .4757995605128 .3144989014142 .3347015381 164.2792053223186 .528503418197 .1959991455205 .7299957275208 .7778015137 208.7778015137208 .7778015137208 .7778015137208 .7778015137208 .7778015137 208.7778015137208 .7778015137208 .7778015137208 .7778015137208 .7778015137 208.7778015137208 .7778015137208 .7778015137208 .7778015137208 .7778015137 208.7778015137 208.7778015137208.7778015137 208.7778015137 208.7778015137 208.7778015137 208.7778015137208.7778015137208.7778015137 208.7778015137 208.7778015137208 .7778015137208 .7778015137208 .7778015137208 .7778015137 208.7778015137208 .7778015137208 .7778015137208 .7778015137208 .7778015137 208.7778015137208 .7778015137208 .7778015137208 .7778015137208 .7778015137 208.7778015137208 .7778015137208 .7778015137208 .7778015137208 .7778015137 208.7778015137208 .7778015137208 .7778015137208 .7778015137208 .7778015137 208.7778015137208 .7778015137208 .7778015137208 .7778015137208 .7778015137 208.7778015137 208.7778015137208.7778015137 208.7778015137 208.7778015137 208.7778015137208 .7778015137208 .7778015137208 .7778015137208 .7778015137 208.7778015137208 .7778015137208 .7778015137208 .7778015137208 .7778015137 159.4026031494 160.9264984131 -9999 -9999 -9999 -9999 -9999 -9999 -9999 -9999 -9999

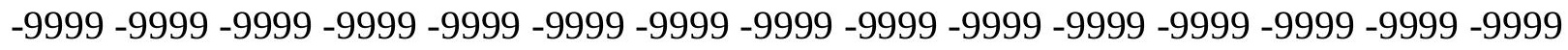

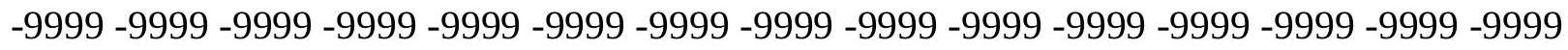

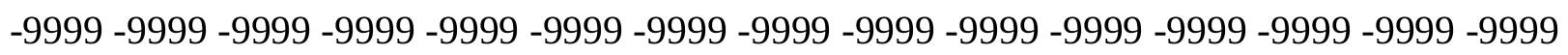
-9999 -9999 -9999 -9999 -9999

-9999 -9999 -9999 -9999 -9999-9999 -9999 -9999 -9999 -9999 -9999 -9999 -9999 -9999 - -999 -

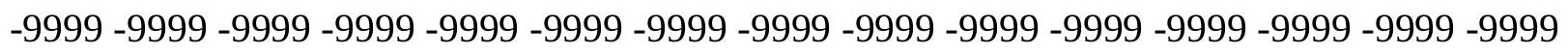
-9999 -9999 -9999 -9999 -9999 -9999 -9999 -9999 -9999 -9999 -9999 -9999 -9999 -9999 -9999 -9999 -9999 -9999 -9999 -9999 -9999 -9999 -9999 -9999 -9999 -9999 -9999 -9999 -9999 -9999 -9999 -9999 -9999 -9999 -9999 -9999 -9999 -9999 -9999 -9999 -9999 -9999 -9999 -9999 -9999 -

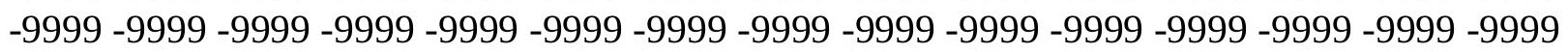


-9999 -9999 -9999 -9999 -9999 -9999 -9999 -9999 -9999 -9999 -9999 -9999 -9999 -9999 -9999 -9999 -9999-9999 94.4833908081196.0073165893697.5312423706198.75038146973 100.2742996216101 .4934005737102 .712600708104 .2365036011105 .4557037354 106.6747970581107 .8938980103109 .1130981445110 .0273971558111 .24659729 112.4656982422113 .3800964355114 .2944030762115 .2088012695116 .1231002808 117.0374984741117 .9517974854118 .8662033081119 .4757995605120 .3900985718 120.9997024536121 .6092987061122 .2188034058122 .8283996582123 .43800354 123.7427978516124 .3523025513124 .6570968628125 .2667007446125 .5715026855 125.8762969971126 .1809997559126 .4858016968126 .7906036377127 .0953979492 127.0953979492127 .0953979492126 .7906036377126 .1809997559125 .5715026855 124.9618988037124 .3523025513124 .0475006104123 .7427978516123 .7427978516 123.7427978516123 .43800354123 .43800354123 .43800354123 .43800354123 .1332015991 123.1332015991122 .8283996582122 .8283996582122 .5235977173122 .2188034058 121.9140014648121 .6092987061121 .3044967651120 .9997024536120 .9997024536 120.6949005127120 .3900985718119 .7806015015119 .4757995605119 .1709976196 118.5614013672118 .2565994263117 .647102356117 .0374984741116 .4279022217 115.818397522115 .2088012695114 .5991973877113 .9896011353113 .3800964355 112.7705001831112 .1608963013111 .24659729110 .6370010376110 .0273971558 109.7226028442110 .0273971558110 .0273971558110 .3321990967110 .3321990967 110.6370010376110 .9418029785111 .24659729111 .551399231111 .8561019897 111.8561019897112 .1608963013112 .1608963013112 .4656982422112 .4656982422 112.4656982422112 .4656982422112 .4656982422112 .4656982422112 .4656982422 112.1608963013112 .1608963013112 .1608963013111 .8561019897111 .8561019897 111.551399231111 .551399231111 .24659729111 .24659729110 .9418029785110 .6370010376 110.3321990967110 .0273971558109 .7226028442109 .4179000854109 .1130981445 108.8082962036108 .5035018921108 .1986999512107 .8938980103107 .5891036987 106.979598999106 .6747970581106 .3700027466106 .0652008057105 .4557037354 105.1509017944104 .5412979126104 .2365036011103 .9317016602103 .3221969604 102.712600708102 .4077987671101 .7982025146101 .1886978149100 .5791015625 102.4077987671108 .5035018921115 .2088012695123 .43800354152 .0877990723 171.8988037109185 .9188995361196 .2816009521204 .8155975342208 .7778015137 208.7778015137208 .7778015137208 .7778015137208 .7778015137208 .7778015137 208.7778015137 208.7778015137208.7778015137 208.7778015137 208.7778015137 208.7778015137208 .7778015137208 .7778015137208 .7778015137208 .7778015137 208.7778015137208 .7778015137208 .7778015137208 .7778015137208 .7778015137 208.7778015137208 .7778015137208 .7778015137208 .7778015137208 .7778015137 208.7778015137208.7778015137208.7778015137 208.7778015137 208.7778015137 208.7778015137 208.7778015137208.7778015137208.7778015137 208.7778015137 208.7778015137208 .7778015137208 .7778015137208 .7778015137208 .7778015137 208.7778015137208 .7778015137208 .7778015137208 .7778015137208 .7778015137 208.7778015137208 .7778015137208 .7778015137208 .7778015137208 .7778015137 208.7778015137208.7778015137208.7778015137208.7778015137 208.7778015137 208.7778015137208 .7778015137208 .7778015137208 .7778015137208 .7778015137 208.7778015137208 .7778015137208 .7778015137208 .7778015137208 .7778015137 208.7778015137208 .7778015137208 .7778015137208 .7778015137208 .7778015137 159.0977935791160 .6217956543 -9999 -9999 -9999 -9999 -9999 -9999 -9999 -9999 -9999 
-9999 -9999 -9999 -9999 -9999 -9999 -9999 -9999 -9999 -9999 -9999 -9999 -9999 -9999 -9999 -9999 -9999 -9999 -9999 -9999 -9999 -9999 -9999 -9999 -9999 -9999 -9999 -9999 -9999 -9999

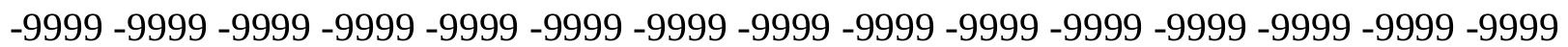
-9999 -9999 -9999-9999

-9999 -9999 -9999 -9999 -9999 -9999 -9999 -9999 -9999 -9999 -9999 -9999 -9999 -9999 -9999 -9999 -9999 -9999 -9999 -9999 -9999 -9999 -9999 -9999 -9999 -9999 -9999 -9999 -9999 -9999

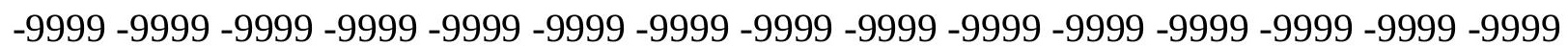
-9999 -9999 -9999 -9999 -9999 -9999 -9999 -9999 -9999 -9999 -9999 -9999 -9999 -9999 -9999 -9999 -9999 -9999 -9999 -9999 -9999 -9999 -9999 -9999 -9999 -9999 -9999 -9999 -9999 -9999

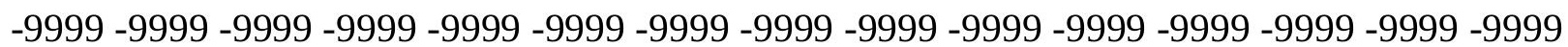

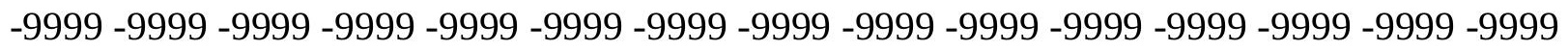
-9999 -9999 92.6546783447394.1785964965895.7025299072396.92166900635 98.445587158299 .66472625732101 .1886978149102 .4077987671103 .6268997192 104.8460998535106 .3700027466107 .5891036987108 .5035018921109 .7226028442 110.9418029785111 .8561019897113 .075302124113 .9896011353114 .9039993286 115.818397522116 .7326965332117 .647102356118 .5614013672119 .1709976196 120.0852966309120 .6949005127121 .3044967651121 .9140014648122 .5235977173 123.1332015991123 .7427978516124 .0475006104124 .6570968628125 .2667007446 125.5715026855125 .8762969971126 .4858016968126 .7906036377127 .0953979492 127.4001998901127 .4001998901127 .4001998901127 .0953979492126 .4858016968 125.8762969971124 .9618988037124 .3523025513123 .7427978516123 .7427978516 123.7427978516123 .43800354123 .43800354123 .43800354123 .43800354123 .1332015991 123.1332015991123 .1332015991122 .8283996582122 .5235977173122 .2188034058 121.9140014648121 .6092987061121 .3044967651120 .9997024536120 .9997024536 120.6949005127120 .3900985718120 .0852966309119 .7806015015119 .4757995605 119.1709976196118 .5614013672118 .2565994263117 .647102356117 .342300415 116.7326965332116 .1231002808115 .5136032104114 .9039993286114 .2944030762 113.6848983765113 .075302124112 .4656982422111 .8561019897111 .24659729 110.6370010376110 .0273971558110 .3321990967110 .3321990967110 .6370010376 110.6370010376110 .9418029785111 .24659729111 .551399231111 .551399231 111.8561019897112 .1608963013112 .1608963013112 .4656982422112 .4656982422 112.4656982422112 .7705001831112 .7705001831112 .7705001831112 .4656982422 112.4656982422112 .4656982422112 .4656982422112 .1608963013112 .1608963013 111.8561019897111 .8561019897111 .551399231111 .551399231111 .24659729 110.9418029785110 .9418029785110 .6370010376110 .3321990967110 .0273971558 109.7226028442109 .4179000854109 .1130981445108 .8082962036108 .5035018921 107.8938980103107 .5891036987107 .2844009399106 .979598999106 .6747970581 106.0652008057 105.7603988647 105.4557037354104.8460998535104.5412979126 104.2365036011103 .6268997192103 .3221969604102 .712600708102 .1029968262 101.4934005737101 .1886978149100 .5791015625100 .5791015625108 .1986999512 120.3900985718138 .9819946289157 .878692627173 .7274932861186 .2236938477 196.5863952637205 .7299957275208 .7778015137208 .7778015137208 .7778015137 208.7778015137208 .7778015137208 .7778015137208 .7778015137208 .7778015137 208.7778015137208 .7778015137208 .7778015137208 .7778015137208 .7778015137 208.7778015137208 .7778015137208 .7778015137208 .7778015137208 .7778015137 208.7778015137 208.7778015137208.7778015137 208.7778015137 208.7778015137 
208.7778015137208 .7778015137208 .7778015137208 .7778015137208 .7778015137 208.7778015137208 .7778015137208 .7778015137208 .7778015137208 .7778015137 208.7778015137208 .7778015137208 .7778015137208 .7778015137208 .7778015137 208.7778015137208 .7778015137208 .7778015137208 .7778015137208 .7778015137 208.7778015137208 .7778015137208 .7778015137208 .7778015137208 .7778015137 208.7778015137208 .7778015137208 .7778015137208 .7778015137208 .7778015137 208.7778015137208 .7778015137208 .7778015137208 .7778015137208 .7778015137 208.7778015137208 .7778015137208 .7778015137208 .7778015137208 .7778015137 208.7778015137208 .7778015137208 .7778015137208 .7778015137208 .7778015137 208.7778015137208 .7778015137157 .5738983154159 .0977935791 -9999 -9999 -9999 -9999 -9999 -9999 -9999 -9999 -9999 -9999 -9999 -9999 -9999 -9999 -9999 -9999 -9999 -9999 -9999 -9999 -9999 -9999 -9999 -9999 -9999 -9999 -9999 -9999 -9999 -9999 -9999 -9999 -9999 -9999

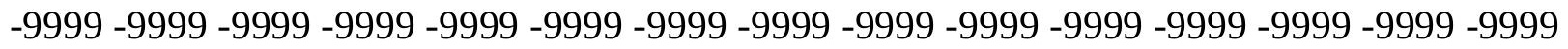
-9999 -9999 -9999 -9999 -9999 -9999 -9999 -9999 -9999

-9999 -9999 -9999 -9999 -9999 -9999 -9999 -9999 -9999 -9999 -9999 -9999 -9999 -9999 -9999

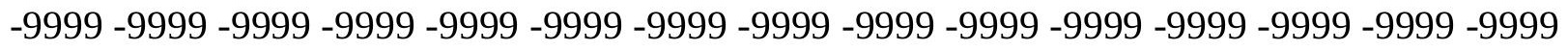

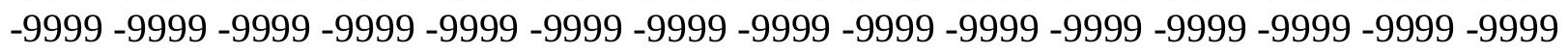

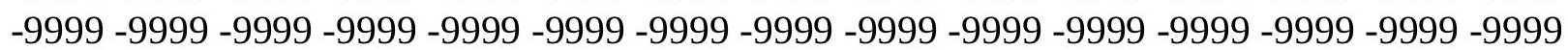
-9999 -9999 -9999 -9999 -9999 -9999 -9999 -9999 -9999 -9999 -9999 -9999 -9999 -9999 -9999 -999 -

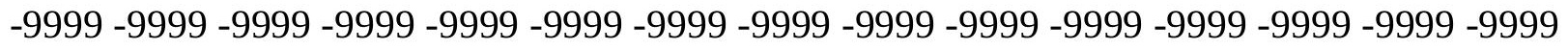

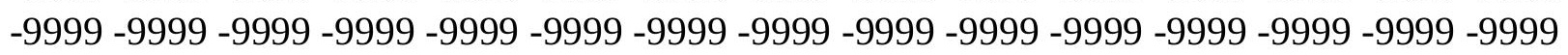
-9999 91.13075256348 92.349891662693.8738174438595.0929565429796.61688232422 97.8360290527399 .35994720459100 .5791015625102 .1029968262103 .3221969604 104.5412979126105 .7603988647106 .979598999108 .1986999512109 .4179000854 110.6370010376111 .551399231112 .7705001831113 .6848983765114 .5991973877 115.818397522116 .4279022217117 .342300415118 .2565994263119 .1709976196 119.7806015015120 .3900985718121 .3044967651121 .9140014648122 .5235977173 123.1332015991123 .43800354124 .0475006104124 .6570968628124 .9618988037 125.5715026855126 .1809997559126 .4858016968127 .0953979492127 .4001998901 127.7050018311128 .0097961426128 .0097961426127 .7050018311127 .0953979492 126.1809997559124 .9618988037124 .0475006104123 .7427978516123 .7427978516 123.7427978516123 .7427978516123 .43800354123 .43800354123 .43800354123 .1332015991 123.1332015991122 .8283996582122 .5235977173122 .2188034058122 .2188034058 121.6092987061121 .3044967651120 .9997024536120 .9997024536120 .6949005127 120.3900985718120 .0852966309119 .7806015015119 .4757995605119 .1709976196 118.8662033081118 .5614013672118 .2565994263117 .9517974854117 .342300415 117.0374984741116 .4279022217115 .818397522115 .5136032104114 .9039993286 114.2944030762113 .6848983765113 .075302124112 .4656982422111 .8561019897 111.24659729110 .6370010376110 .6370010376110 .6370010376110 .9418029785 110.9418029785111 .24659729111 .551399231111 .551399231111 .8561019897 112.1608963013112 .1608963013112 .4656982422112 .4656982422112 .7705001831 112.7705001831112 .7705001831112 .7705001831112 .7705001831112 .7705001831 112.7705001831112 .4656982422112 .4656982422112 .4656982422112 .1608963013 112.1608963013111 .8561019897111 .8561019897111 .551399231111 .24659729 111.24659729110 .9418029785110 .6370010376110 .3321990967110 .0273971558 109.7226028442109 .4179000854109 .1130981445108 .8082962036108 .5035018921 
108.1986999512107 .8938980103107 .5891036987107 .2844009399106 .6747970581 106.3700027466106 .0652008057105 .7603988647105 .1509017944104 .8460998535 104.5412979126103 .9317016602103 .6268997192103 .0174026489102 .4077987671 102.1029968262101 .4934005737100 .8839035034100 .2742996216104 .2365036011 115.818397522130 .4479980469147 .2111968994163 .0599975586177 .0802001953 188.966796875199 .6342926025208 .7778015137208 .7778015137208 .7778015137 208.7778015137208 .7778015137208 .7778015137208 .7778015137208 .7778015137 208.7778015137208 .7778015137208 .7778015137208 .7778015137208 .7778015137 208.7778015137208 .7778015137208 .7778015137208 .7778015137208 .7778015137 208.7778015137 208.7778015137208.7778015137 208.7778015137 208.7778015137 208.7778015137208 .7778015137208 .7778015137208 .7778015137208 .7778015137 208.7778015137 208.7778015137208.7778015137 208.7778015137 208.7778015137 208.7778015137208 .7778015137208 .7778015137208 .7778015137208 .7778015137 208.7778015137208.7778015137208.7778015137208.7778015137208.7778015137 208.7778015137208 .7778015137208 .7778015137208 .7778015137208 .7778015137 208.7778015137208.7778015137208.7778015137 208.7778015137 208.7778015137 208.7778015137208 .7778015137208 .7778015137208 .7778015137208 .7778015137 208.7778015137208 .7778015137208 .7778015137208 .7778015137208 .7778015137 208.7778015137208 .7778015137208 .7778015137208 .7778015137208 .7778015137 208.7778015137208 .7778015137208 .7778015137157 .2691040039158 .7929992676 -9999 -9999 -9999 -9999 -9999 -9999 -9999 -9999 -9999 -9999 -9999 -9999 -9999 -9999 -9999 -9999 -9999 -9999 -9999 -9999 -9999 -9999 -9999 -9999 -9999 -9999 -9999 -9999 -9999 -9999 -9999 -9999 -9999 -9999 -9999 -9999 -9999 -9999 -9999 -9999 -9999 -9999 -9999 -9999 -9999 -9999 -9999 -9999 -9999 -9999 -9999 -9999 -9999 -9999 -9999 -9999 -9999 -

-9999 -9999 -9999 -9999 -9999 -9999 -9999 -9999 -9999 -9999 -9999 -9999 -9999 -9999 -9999 -9999 -9999 -9999 -9999 -9999 -9999 -9999 -9999 -9999 -9999 -9999 -9999 -9999 -9999 -9999

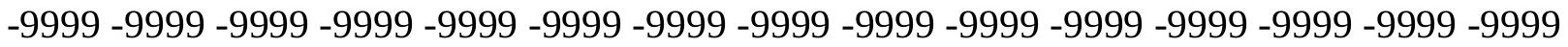

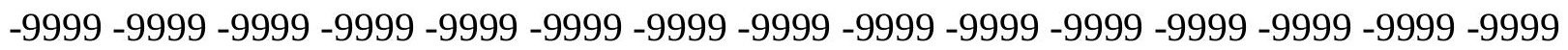
-9999 -9999 -9999 -9999 -9999 -9999 -9999 -9999 -9999 -9999 -9999 -9999 -9999 -9999 -9999 -9999 -9999 -9999 -9999 -9999 -9999 -9999 -9999 -9999 -9999 -9999 -9999 -9999 -9999 -9999 -9999 -9999 -9999 -9999 -9999 -9999 -9999 -9999 -9999 -9999 -9999 -9999 -9999 -9999 -9999 89.302040100190.5211791992292.0450973510793.5690307617294.78817749023 96.3121032714897 .5312423706199 .05516815186100 .2742996216101 .4934005737 103.0174026489104 .2365036011105 .4557037354106 .6747970581107 .8938980103 109.1130981445110 .3321990967111 .551399231112 .4656982422113 .3800964355 114.5991973877115 .5136032104116 .4279022217117 .342300415117 .9517974854 118.8662033081119 .4757995605120 .3900985718120 .9997024536121 .6092987061 122.2188034058122 .8283996582123 .43800354124 .0475006104124 .3523025513 124.9618988037125 .5715026855126 .1809997559126 .4858016968127 .0953979492 127.4001998901128 .0097961426128 .3144989014128 .3144989014128 .3144989014 127.7050018311127 .0953979492125 .8762969971124 .3523025513124 .3523025513 124.3523025513124 .0475006104123 .7427978516123 .7427978516123 .43800354 123.43800354123 .1332015991122 .8283996582122 .8283996582122 .5235977173 122.2188034058121 .9140014648121 .6092987061121 .3044967651120 .9997024536 120.6949005127120 .3900985718120 .0852966309119 .7806015015119 .4757995605 119.4757995605119 .1709976196118 .8662033081118 .5614013672118 .2565994263 
117.9517974854117 .647102356117 .0374984741116 .7326965332116 .1231002808 115.818397522115 .2088012695114 .9039993286114 .2944030762113 .6848983765 113.075302124112 .4656982422111 .8561019897111 .24659729110 .9418029785 110.9418029785110 .9418029785111 .24659729111 .24659729111 .551399231 111.8561019897112 .1608963013112 .1608963013112 .4656982422112 .4656982422 112.7705001831112 .7705001831112 .7705001831112 .7705001831112 .7705001831 112.7705001831112 .7705001831112 .7705001831112 .7705001831112 .7705001831 112.4656982422112 .4656982422112 .1608963013112 .1608963013111 .8561019897 111.551399231111 .551399231111 .24659729110 .9418029785110 .9418029785 110.6370010376110 .3321990967110 .0273971558109 .7226028442109 .4179000854 109.1130981445108 .8082962036108 .5035018921108 .1986999512107 .8938980103 107.2844009399106 .979598999106 .6747970581106 .3700027466106 .0652008057 105.4557037354105 .1509017944104 .8460998535104 .2365036011103 .9317016602 103.3221969604103 .0174026489102 .4077987671101 .7982025146101 .1886978149 100.579101562599 .96952056885109 .7226028442123 .43800354139 .2868041992 155.1356048584169 .7653045654183 .1759033203194 .7577056885205 .1204071045 208.7778015137208 .7778015137208 .7778015137208 .7778015137208 .7778015137 208.7778015137208 .7778015137208 .7778015137208 .7778015137208 .7778015137 208.7778015137208 .7778015137208 .7778015137208 .7778015137208 .7778015137 208.7778015137208 .7778015137208 .7778015137208 .7778015137208 .7778015137 208.7778015137208 .7778015137208 .7778015137208 .7778015137208 .7778015137 208.7778015137208 .7778015137208 .7778015137208 .7778015137208 .7778015137 208.7778015137208 .7778015137208 .7778015137208 .7778015137208 .7778015137 208.7778015137208 .7778015137208 .7778015137208 .7778015137208 .7778015137 208.7778015137208 .7778015137208 .7778015137208 .7778015137208 .7778015137 208.7778015137208.7778015137208.7778015137208.7778015137208.7778015137 208.7778015137208 .7778015137208 .7778015137208 .7778015137208 .7778015137 208.7778015137208 .7778015137208 .7778015137208 .7778015137208 .7778015137 208.7778015137208 .7778015137208 .7778015137208 .7778015137208 .7778015137 208.7778015137208 .7778015137208 .7778015137208 .7778015137208 .7778015137 155.7451934814157 .2691040039 -9999 -9999 -9999 -9999 -9999 -9999 -9999 -9999 -9999 -9999 -9999 -9999 -9999 -9999 -9999 -9999 -9999 -9999 -9999 -9999 -9999 -9999 -9999 -9999 -9999 -9999 -9999 -9999 -9999 -9999 -9999 -9999 -9999 -9999 -9999 -9999 -9999 -9999 -9999 -

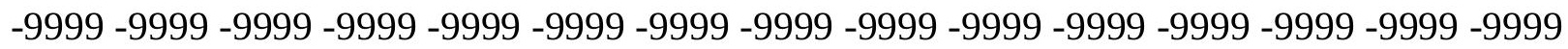
-9999-9999-9999

-9999 -9999 -9999 -9999 -9999 -9999 -9999 -9999 -9999 -9999 -9999 -9999 -9999 -9999 -9999 -9999 -9999 -9999 -9999 -9999 -9999 -9999 -9999 -9999 -9999 -9999 -9999 -9999 -9999 -9999

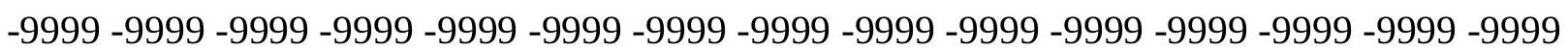
-9999 -9999 -9999 -9999 -9999 -9999 -9999 -9999 -9999 -9999 -9999 -9999 -9999 -9999 -9999 -9999 -9999 -9999 -9999 -9999 -9999 -9999 -9999 -9999 -9999 -9999 -9999 -9999 -9999 -9999 -9999 -9999 -9999 -9999 -9999 -9999 -9999 -9999 -9999 -9999 -9999 -9999 -9999 -9999 -9999 -9999 -9999 -9999 -9999 -9999 -9999 -9999 -9999 -9999 -9999 -9999 -9999 -9999 -9999 87.7781066894588 .9972534179790 .2164001464891 .7403335571392 .95947265625 94.4833908081195 .7025299072397 .2264633178798 .445587158299 .96952056885 101.1886978149102 .712600708103 .9317016602105 .1509017944106 .3700027466 107.5891036987108 .8082962036110 .0273971558111 .24659729112 .1608963013 
113.3800964355114 .2944030762115 .2088012695116 .1231002808117 .0374984741 117.9517974854118 .5614013672119 .4757995605120 .0852966309120 .6949005127 121.3044967651121 .9140014648122 .5235977173123 .1332015991123 .7427978516 124.3523025513124 .9618988037125 .5715026855125 .8762969971126 .4858016968 127.0953979492127 .7050018311128 .0097961426128 .6192932129128 .6192932129 128.9241027832128 .6192932129128 .0097961426127 .4001998901126 .4858016968 125.8762969971125 .2667007446124 .6570968628124 .3523025513123 .7427978516 123.43800354123 .43800354123 .1332015991122 .8283996582122 .5235977173 122.2188034058121 .9140014648121 .6092987061121 .3044967651120 .9997024536 120.6949005127120 .3900985718120 .0852966309119 .7806015015119 .4757995605 119.4757995605119 .1709976196118 .8662033081118 .8662033081118 .5614013672 118.2565994263117 .9517974854117 .647102356117 .342300415117 .0374984741 116.4279022217116 .1231002808115 .818397522115 .2088012695114 .9039993286 114.2944030762113 .6848983765113 .075302124112 .7705001831112 .1608963013 111.551399231112 .4656982422111 .24659729111 .24659729111 .551399231111 .8561019897 111.8561019897112 .1608963013112 .4656982422112 .4656982422112 .7705001831 112.7705001831112 .7705001831113 .075302124113 .075302124113 .075302124 113.075302124113 .075302124113 .075302124112 .7705001831112 .7705001831 112.7705001831112 .4656982422112 .4656982422112 .1608963013111 .8561019897 111.8561019897111 .551399231111 .551399231111 .24659729110 .9418029785 110.6370010376110 .3321990967110 .0273971558109 .7226028442109 .4179000854 109.1130981445108 .8082962036108 .5035018921108 .1986999512107 .8938980103 107.5891036987107 .2844009399106 .979598999106 .6747970581106 .3700027466 105.7603988647105 .4557037354105 .1509017944104 .5412979126104 .2365036011 103.9317016602103 .3221969604102 .712600708102 .4077987671101 .7982025146 101.1886978149100 .5791015625103 .3221969604117 .342300415133 .4958953857 149.6495056152165 .1934967041179 .2136993408191 .7097930908202 .6820983887 208.7778015137208 .7778015137208 .7778015137208 .7778015137208 .7778015137 208.7778015137208 .7778015137208 .7778015137208 .7778015137208 .7778015137 208.7778015137208 .7778015137208 .7778015137208 .7778015137208 .7778015137 208.7778015137208 .7778015137208 .7778015137208 .7778015137208 .7778015137 208.7778015137208 .7778015137208 .7778015137208 .7778015137208 .7778015137 208.7778015137208 .7778015137208 .7778015137208 .7778015137208 .7778015137 208.7778015137208 .7778015137208 .7778015137208 .7778015137208 .7778015137 208.7778015137208 .7778015137208 .7778015137208 .7778015137208 .7778015137 208.7778015137208 .7778015137208 .7778015137208 .7778015137208 .7778015137 208.7778015137208 .7778015137208 .7778015137208 .7778015137208 .7778015137 208.7778015137208.7778015137208.7778015137208.7778015137208.7778015137 208.7778015137208 .7778015137208 .7778015137208 .7778015137208 .7778015137 208.7778015137208 .7778015137208 .7778015137208 .7778015137208 .7778015137 208.7778015137208 .7778015137208 .7778015137208 .7778015137208 .7778015137 208.7778015137155 .7451934814157 .2691040039 -9999 -9999-9999 -9999-9999 -9999-9999 -9999 -9999 -9999 -9999 -9999 -9999 -9999 -9999 -9999 -9999 -9999 -9999 -9999 -9999 -9999 -9999 -9999 -9999 -9999 -9999 -9999 -9999 -9999 -9999 -9999 -9999 -9999 -9999 -9999 -9999

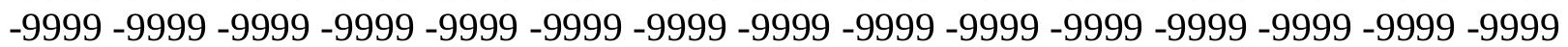
-9999 -9999 -9999-9999 
-9999 -9999 -9999 -9999 -9999 -9999 -9999 -9999 -9999 -9999 -9999 -9999 -9999 -9999 -9999 -9999 -9999 -9999 -9999 -9999 -9999 -9999 -9999 -9999 -9999 -9999 -9999 -9999 -9999 -9999 -9999 -9999 -9999 -9999 -9999 -9999 -9999 -9999 -9999 -9999 -9999 -9999 -9999 -9999 -9999 -9999 -9999 -9999 -9999 -9999 -9999 -9999 -9999 -9999 -9999 -9999 -9999 -9999 -9999 -9999 -9999 -9999 -9999 -9999 -9999 -9999 -9999 -9999 -9999 -9999 -9999 -9999-9999 -9999 -9999 -

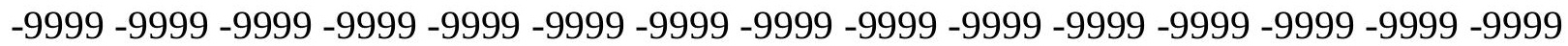
-9999 -9999 -9999 -9999 -9999 -9999 -9999 -9999 -9999 -9999 -9999 -9999 -9999 -9999 87.4733276367288 .6924667358490 .2164001464891 .4355392456192 .65467834473 94.1785964965895 .397743225196 .9216690063598 .445587158299 .66472625732 100.8839035034102 .4077987671103 .6268997192104 .8460998535106 .3700027466 107.5891036987108 .8082962036109 .7226028442110 .9418029785112 .1608963013 113.075302124113 .9896011353114 .9039993286115 .818397522116 .7326965332 117.647102356118 .2565994263119 .1709976196119 .7806015015120 .6949005127 121.3044967651121 .9140014648122 .5235977173123 .1332015991123 .43800354 124.0475006104124 .6570968628125 .2667007446125 .8762969971126 .4858016968 127.0953979492127 .7050018311128 .0097961426128 .6192932129128 .9241027832 129.2288970947129 .2288970947129 .2288970947128 .9241027832128 .6192932129 127.4001998901126 .4858016968125 .5715026855124 .6570968628124 .0475006104 123.7427978516123 .1332015991123 .1332015991122 .8283996582122 .5235977173 122.2188034058121 .6092987061121 .3044967651120 .9997024536120 .6949005127 120.3900985718120 .0852966309119 .7806015015119 .4757995605119 .4757995605 119.1709976196119 .1709976196118 .8662033081118 .5614013672118 .5614013672 118.2565994263117 .9517974854117 .9517974854117 .647102356117 .342300415 117.0374984741116 .4279022217116 .1231002808115 .818397522115 .2088012695 114.9039993286114 .2944030762113 .6848983765113 .3800964355112 .7705001831 112.1608963013111 .551399231111 .24659729111 .551399231111 .551399231 111.8561019897112 .1608963013112 .1608963013112 .4656982422112 .7705001831 112.7705001831112 .7705001831113 .075302124113 .075302124113 .075302124 113.075302124113 .075302124113 .075302124113 .075302124113 .075302124 112.7705001831112 .7705001831112 .7705001831112 .4656982422112 .1608963013 112.1608963013111 .8561019897111 .8561019897111 .551399231111 .24659729 111.24659729110 .9418029785110 .6370010376110 .3321990967110 .0273971558 109.7226028442109 .4179000854109 .1130981445108 .8082962036108 .5035018921 108.1986999512107 .8938980103107 .5891036987107 .2844009399106 .979598999 106.3700027466106 .0652008057105 .7603988647105 .4557037354105 .1509017944 104.5412979126104 .2365036011103 .6268997192103 .3221969604102 .712600708 102.1029968262101 .4934005737101 .1886978149100 .2742996216113 .075302124 130.1432037354146 .9064025879163 .3648071289177 .9945068359190 .795501709 201.7678070068208 .7778015137208 .7778015137208 .7778015137208 .7778015137 208.7778015137208 .7778015137208 .7778015137208 .7778015137208 .7778015137 208.7778015137208 .7778015137208 .7778015137208 .7778015137208 .7778015137 208.7778015137208.7778015137208.7778015137208.7778015137 208.7778015137 208.7778015137208 .7778015137208 .7778015137208 .7778015137208 .7778015137 208.7778015137208.7778015137208.7778015137208.7778015137208.7778015137 208.7778015137208 .7778015137208 .7778015137208 .7778015137208 .7778015137 208.7778015137 208.7778015137208.7778015137208.7778015137208.7778015137 
208.7778015137208 .7778015137208 .7778015137208 .7778015137208 .7778015137 208.7778015137208 .7778015137208 .7778015137208 .7778015137208 .7778015137 208.7778015137208 .7778015137208 .7778015137208 .7778015137208 .7778015137 208.7778015137208 .7778015137208 .7778015137208 .7778015137208 .7778015137 208.7778015137208 .7778015137208 .7778015137208 .7778015137208 .7778015137 208.7778015137 208.7778015137208.7778015137 208.7778015137 208.7778015137 208.7778015137208 .7778015137153 .9165039062155 .4403991699 -9999 -9999 -9999-9999 -9999 -9999 -9999 -9999 -9999 -9999 -9999 -9999 -9999 -9999 -9999 -9999 -9999 -9999 -9999 -9999 -9999 -9999 -9999 -9999 -9999 -9999 -9999 -9999 -9999 -9999 -9999 -9999 -9999 -9999

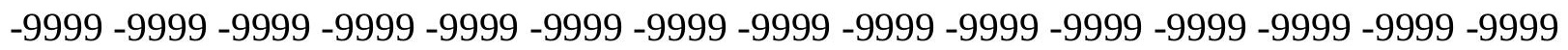
-9999 -9999 -9999 -9999-9999-9999-9999

-9999 -9999 -9999 -9999 -9999 -9999 -9999 -9999 -9999 -9999 -9999 -9999 -9999 -9999 -9999 -9999 -9999 -9999 -9999 -9999 -9999 -9999 -9999 -9999 -9999 -9999 -9999 -9999 -9999 -9999 -9999 -9999 -9999 -9999 -9999 -9999 -9999 -9999 -9999 -9999 -9999 -9999 -9999 -9999 -9999 -9999 -9999 -9999 -9999 -9999 -9999 -9999 -9999 -9999 -9999 -9999 -9999 -9999 -9999 -9999

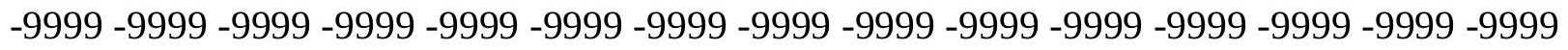

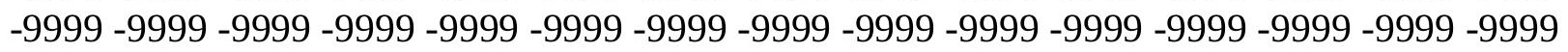
-9999 -9999 -9999 -9999 -9999 -9999 -9999 -9999 -9999 -9999 -9999 -9999 -9999 85.9494018554787 .4733276367288 .6924667358489 .9116134643691 .13075256348 92.6546783447393 .8738174438595 .397743225196 .6168823242298 .14080810547 99.35994720459100 .8839035034102 .1029968262103 .6268997192104 .8460998535 106.0652008057 107.2844009399 108.5035018921 109.7226028442110.9418029785 111.8561019897113 .075302124113 .9896011353114 .9039993286115 .818397522 116.7326965332117 .342300415118 .2565994263118 .8662033081119 .7806015015 120.3900985718120 .9997024536121 .6092987061122 .2188034058122 .8283996582 123.43800354123 .7427978516124 .3523025513124 .9618988037125 .5715026855 126.1809997559126 .7906036377127 .4001998901128 .0097961426128 .6192932129 128.9241027832129 .533706665129 .8385009766129 .8385009766130 .1432037354 130.1432037354128 .6192932129127 .0953979492125 .8762969971124 .9618988037 124.3523025513123 .7427978516123 .1332015991122 .8283996582122 .5235977173 122.2188034058121 .9140014648121 .3044967651120 .9997024536120 .6949005127 120.3900985718120 .0852966309119 .7806015015119 .4757995605119 .1709976196 119.1709976196118 .8662033081118 .8662033081118 .8662033081118 .5614013672 118.5614013672118 .2565994263118 .2565994263117 .9517974854117 .647102356 117.647102356117 .342300415117 .0374984741116 .7326965332116 .1231002808 115.818397522115 .5136032104114 .9039993286114 .2944030762113 .9896011353 113.3800964355112 .7705001831112 .4656982422111 .8561019897111 .551399231 111.8561019897111 .8561019897112 .1608963013112 .4656982422112 .4656982422 112.7705001831112 .7705001831113 .075302124113 .075302124113 .075302124 113.075302124113 .075302124113 .075302124113 .075302124113 .075302124113 .075302124 113.075302124112 .7705001831112 .7705001831112 .7705001831112 .4656982422 112.1608963013112 .1608963013111 .8561019897111 .8561019897111 .551399231 111.24659729110 .9418029785110 .6370010376110 .3321990967110 .0273971558 109.7226028442109 .4179000854109 .1130981445108 .8082962036108 .5035018921 108.1986999512107 .8938980103107 .5891036987107 .2844009399106 .979598999 106.6747970581 106.3700027466106.0652008057 105.7603988647 105.4557037354 
104.8460998535104 .5412979126104 .2365036011103 .6268997192103 .0174026489 102.712600708102 .1029968262101 .4934005737100 .8839035034111 .8561019897 128.9241027832146 .6015930176163 .3648071289178 .604095459191 .4051055908 202.0724945068208 .7778015137208 .7778015137208 .7778015137208 .7778015137 208.7778015137208 .7778015137208 .7778015137208 .7778015137208 .7778015137 208.7778015137208 .7778015137208 .7778015137208 .7778015137208 .7778015137 208.7778015137208 .7778015137208 .7778015137208 .7778015137208 .7778015137 208.7778015137208 .7778015137208 .7778015137208 .7778015137208 .7778015137 208.7778015137208 .7778015137208 .7778015137208 .7778015137208 .7778015137 208.7778015137208 .7778015137208 .7778015137208 .7778015137208 .7778015137 208.7778015137208 .7778015137208 .7778015137208 .7778015137208 .7778015137 208.7778015137208 .7778015137208 .7778015137208 .7778015137208 .7778015137 208.7778015137208.7778015137208.7778015137208.7778015137208.7778015137 208.7778015137208 .7778015137208 .7778015137208 .7778015137208 .7778015137 208.7778015137208 .7778015137208 .7778015137208 .7778015137208 .7778015137 208.7778015137 208.7778015137208.7778015137208.7778015137 208.7778015137 208.7778015137208 .7778015137208 .7778015137208 .7778015137208 .7778015137 208.7778015137208 .7778015137208 .7778015137153 .9165039062155 .4403991699 -9999 -9999 -9999 -9999 -9999 -9999 -9999 -9999 -9999 -9999 -9999 -9999 -9999 -9999 -9999 -9999 -9999 -9999 -9999 -9999 -9999 -9999 -9999 -9999 -9999 -9999 -9999 -9999 -9999 -9999 -9999 -9999 -9999 -9999 -9999 -9999 -9999 -9999 -9999 -9999 -9999 -9999 -9999 -9999 -9999 -9999 -9999 -9999 -9999 -9999 -9999 -9999 -9999 -9999 -9999 -9999 -9999 -9999 -9999 -9999 -9999 -9999 -9999 -9999 -9999 -9999 -9999 -9999 -9999 -9999 -9999 -9999 -9999 -9999 -9999 -9999 -9999 -9999 -9999 -9999 -9999 -9999 -9999 -9999 -9999 -9999 -9999 -9999 -9999 -9999 -9999 -9999 -9999 -9999 -9999 -9999 -9999 -9999 -9999 -9999 -9999 -9999 -9999 -9999 -9999 -9999 -9999 -9999 -9999 -9999 -9999 -9999 -9999 -9999 -9999 -9999 -9999 -9999 -9999 -9999 -9999 -9999 -9999 -9999 -9999 -9999 -9999 -9999 -9999 -9999 -9999 -9999 -9999 -9999 -9999 -9999 -9999 -9999 -9999 -9999 -9999 -9999 -9999 -9999 -9999 -9999 -9999 -9999 -9999 -9999 -9999 -9999 -9999 -9999 -9999 -9999 -9999 84.73026275635 85.9494018554787 .1685485839888 .3876876831189 .6068267822391 .13075256348 92.349891662693 .8738174438595 .0929565429796 .6168823242297 .83602905273 99.35994720459100 .5791015625102 .1029968262103 .3221969604104 .8460998535 106.0652008057107 .2844009399108 .5035018921109 .7226028442110 .6370010376 111.8561019897112 .7705001831113 .9896011353114 .9039993286115 .5136032104 116.4279022217117 .342300415117 .9517974854118 .8662033081119 .4757995605 120.0852966309120 .6949005127121 .3044967651121 .9140014648122 .5235977173 123.1332015991123 .43800354124 .0475006104124 .6570968628125 .2667007446 125.8762969971126 .4858016968127 .0953979492127 .7050018311128 .3144989014 128.9241027832129 .2288970947129 .533706665129 .8385009766130 .1432037354 129.8385009766128 .6192932129127 .4001998901126 .1809997559124 .9618988037 124.0475006104123 .43800354123 .1332015991122 .8283996582122 .5235977173 121.9140014648121 .6092987061120 .9997024536120 .6949005127120 .3900985718 119.7806015015119 .4757995605119 .4757995605119 .1709976196118 .8662033081 118.8662033081118 .8662033081118 .5614013672118 .5614013672118 .5614013672 118.5614013672118 .2565994263118 .2565994263118 .2565994263117 .9517974854 117.9517974854117 .647102356117 .342300415117 .0374984741116 .7326965332 
116.4279022217116 .1231002808115 .5136032104115 .2088012695114 .5991973877 113.9896011353113 .6848983765113 .075302124112 .4656982422111 .8561019897 111.8561019897111 .8561019897112 .1608963013112 .4656982422112 .4656982422 112.7705001831112 .7705001831113 .075302124113 .075302124113 .075302124 113.075302124113 .075302124113 .075302124113 .075302124113 .075302124113 .075302124 113.075302124113 .075302124112 .7705001831112 .7705001831112 .7705001831 112.4656982422112 .1608963013112 .1608963013111 .8561019897111 .551399231 111.551399231111 .24659729110 .9418029785110 .6370010376110 .3321990967 110.0273971558109 .7226028442109 .4179000854109 .1130981445108 .8082962036 108.5035018921108 .1986999512107 .8938980103107 .5891036987107 .2844009399 106.979598999106 .6747970581106 .3700027466106 .0652008057105 .7603988647 105.1509017944104 .8460998535104 .5412979126103 .9317016602103 .6268997192 103.0174026489102 .4077987671102 .1029968262101 .4934005737111 .551399231 128.9241027832147 .5160064697165 .4983062744181 .0424041748193 .8433074951 203.596496582208 .7778015137208 .7778015137208 .7778015137208 .7778015137 208.7778015137208 .7778015137208 .7778015137208 .7778015137208 .7778015137 208.7778015137208 .7778015137208 .7778015137208 .7778015137208 .7778015137 208.7778015137208 .7778015137208 .7778015137208 .7778015137208 .7778015137 208.7778015137208 .7778015137208 .7778015137208 .7778015137208 .7778015137 208.7778015137208 .7778015137208 .7778015137208 .7778015137208 .7778015137 208.7778015137208 .7778015137208 .7778015137208 .7778015137208 .7778015137 208.7778015137208 .7778015137208 .7778015137208 .7778015137208 .7778015137 208.7778015137208 .7778015137208 .7778015137208 .7778015137208 .7778015137 208.7778015137208 .7778015137208 .7778015137208 .7778015137208 .7778015137 208.7778015137208 .7778015137208 .7778015137208 .7778015137208 .7778015137 208.7778015137208 .7778015137208 .7778015137208 .7778015137208 .7778015137 208.7778015137208 .7778015137208 .7778015137208 .7778015137208 .7778015137 208.7778015137208 .7778015137208 .7778015137208 .7778015137208 .7778015137 208.7778015137208.7778015137208.7778015137208.7778015137 153.9165039062 -9999 -9999 -9999 -9999 -9999 -9999 -9999 -9999 -9999 -9999 -9999 -9999 -9999 -9999 -9999 -9999 -9999 -9999 -9999 -9999 -9999 -9999 -9999 -9999 -9999 -9999 -9999 -9999 -9999 -9999 -9999 -9999 -9999 -9999 -9999 -9999 -9999 -9999 -9999 -9999 -9999 -9999 -9999 -9999 -9999 -9999 -9999 -9999 -9999 -9999 -9999 -9999 -9999 -9999 -9999

-9999 -9999 -9999 -9999 -9999 -9999 -9999 -9999 -9999 -9999 -9999 -9999 -9999 -9999 -9999 -9999 -9999 -9999 -9999 -9999 -9999 -9999 -9999 -9999 -9999 -9999 -9999 -9999 -9999 -9999

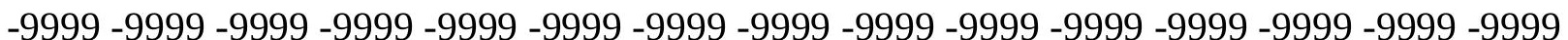

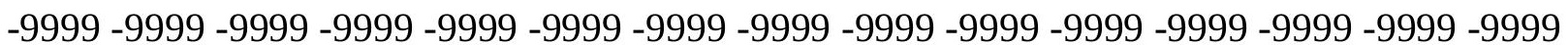

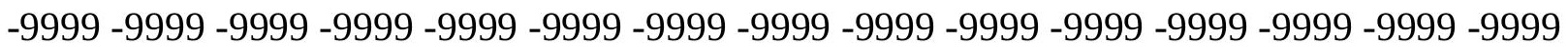
-9999 -9999 -9999 -9999 -9999 -9999 -9999 -9999 -9999 -9999 -9999 -9999 -9999 -9999 -9999 -9999 -9999 -9999 -9999 -9999 -9999 -9999 -9999 -9999 -9999 -9999 83.81591033936 85.0350494384886 .254188537687 .1685485839888 .3876876831189 .60682678223 90.8259735107492 .349891662693 .5690307617295 .0929565429796 .31210327148 97.8360290527399 .35994720459100 .5791015625102 .1029968262103 .3221969604 104.5412979126106 .0652008057107 .2844009399108 .5035018921109 .7226028442 110.6370010376111 .8561019897112 .7705001831113 .6848983765114 .5991973877 115.5136032104116 .4279022217117 .0374984741117 .9517974854118 .5614013672 
119.1709976196119 .7806015015120 .3900985718120 .9997024536121 .6092987061 122.2188034058122 .5235977173123 .1332015991123 .7427978516124 .0475006104 124.6570968628125 .2667007446125 .8762969971126 .4858016968127 .0953979492 127.7050018311128 .3144989014128 .6192932129128 .9241027832129 .2288970947 128.9241027832128 .6192932129128 .0097961426126 .7906036377125 .8762969971 124.6570968628124 .0475006104123 .43800354122 .8283996582122 .5235977173 121.9140014648121 .6092987061121 .3044967651120 .6949005127120 .3900985718 119.7806015015119 .4757995605119 .1709976196118 .8662033081118 .8662033081 118.5614013672118 .5614013672118 .5614013672118 .5614013672118 .5614013672 118.5614013672118 .5614013672118 .5614013672118 .2565994263118 .2565994263 118.2565994263118 .2565994263117 .9517974854117 .647102356117 .647102356 117.342300415117 .0374984741116 .4279022217116 .1231002808115 .818397522 115.2088012695114 .5991973877114 .2944030762113 .6848983765113 .075302124 112.7705001831112 .1608963013111 .8561019897112 .1608963013112 .4656982422 112.4656982422112 .7705001831112 .7705001831113 .075302124113 .075302124 113.075302124113 .075302124113 .075302124113 .075302124113 .3800964355 113.3800964355113 .075302124113 .075302124113 .075302124113 .075302124 112.7705001831112 .7705001831112 .7705001831112 .4656982422112 .1608963013 112.1608963013111 .8561019897111 .551399231111 .24659729110 .9418029785 110.9418029785110 .6370010376110 .0273971558109 .7226028442109 .4179000854 109.1130981445108 .8082962036108 .8082962036108 .5035018921108 .1986999512 107.8938980103107 .5891036987107 .2844009399106 .979598999106 .6747970581 106.3700027466106 .0652008057105 .7603988647105 .1509017944104 .8460998535 104.5412979126103 .9317016602103 .6268997192103 .0174026489102 .4077987671 101.7982025146110 .9418029785129 .2288970947149 .0399017334168 .241394043 184.699798584196 .5863952637205 .1204071045208 .7778015137208 .7778015137 208.7778015137208 .7778015137208 .7778015137208 .7778015137208 .7778015137 208.7778015137208 .7778015137208 .7778015137208 .7778015137208 .7778015137 208.7778015137208 .7778015137208 .7778015137208 .7778015137208 .7778015137 208.7778015137208 .7778015137208 .7778015137208 .7778015137208 .7778015137 208.7778015137208 .7778015137208 .7778015137208 .7778015137208 .7778015137 208.7778015137208 .7778015137208 .7778015137208 .7778015137208 .7778015137 208.7778015137208 .7778015137208 .7778015137208 .7778015137208 .7778015137 208.7778015137208 .7778015137208 .7778015137208 .7778015137208 .7778015137 208.7778015137208 .7778015137208 .7778015137208 .7778015137208 .7778015137 208.7778015137208 .7778015137208 .7778015137208 .7778015137208 .7778015137 208.7778015137208 .7778015137208 .7778015137208 .7778015137208 .7778015137 208.7778015137208 .7778015137208 .7778015137208 .7778015137208 .7778015137 208.7778015137208 .7778015137208 .7778015137208 .7778015137208 .7778015137 208.7778015137208 .7778015137208 .7778015137208 .7778015137208 .7778015137 208.7778015137152 .3925933838153 .6116943359 -9999 -9999 -9999 -9999 -9999 -9999 -9999

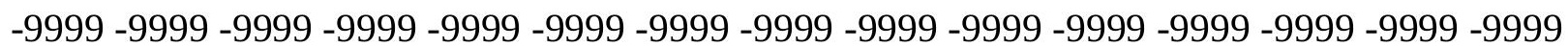

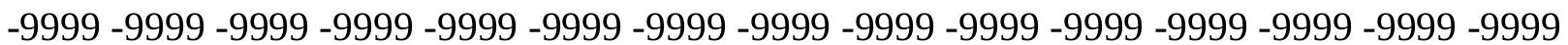
-9999$-9999-9999$

-9999 -9999 -9999 -9999 -9999 -9999 -9999 -9999 -9999 -9999 -9999 -9999 -9999 -9999 -9999 
-9999 -9999 -9999 -9999 -9999 -9999 -9999 -9999 -9999 -9999 -9999 -9999 -9999 -9999 -9999 -9999 -9999 -9999 -9999 -9999 -9999 -9999 -9999 -9999 -9999 -9999 -9999 -9999 -9999 -9999 -9999 -9999 -9999 -9999 -9999 -9999 -9999 -9999 -9999 -9999 -9999 -9999 -9999 -9999 -9999 -9999 -9999 -9999 -9999 -9999 -9999 -9999 -9999 -9999 -9999 -9999 -9999 -9999 -9999 -9999 -9999 -9999 -9999 -9999 -9999 -9999 -9999 -9999 -9999 -9999 -9999 -9999 -9999 -9999 - -9999 -9999 -9999 -9999 -9999 -9999 -9999 -9999 -9999 -9999 -9999 82.90155792236 84.1206970214885 .3398437586 .254188537687 .4733276367288 .38768768311 89.6068267822390 .8259735107492 .349891662693 .5690307617295 .09295654297 96.6168823242297 .8360290527399 .35994720459100 .8839035034102 .1029968262 103.3221969604104 .8460998535106 .0652008057107 .2844009399108 .5035018921 109.7226028442110 .9418029785111 .8561019897113 .075302124113 .9896011353 114.9039993286115 .5136032104116 .4279022217117 .0374984741117 .647102356 118.2565994263118 .8662033081119 .4757995605120 .0852966309120 .6949005127 121.3044967651121 .6092987061122 .2188034058122 .8283996582123 .1332015991 123.7427978516124 .0475006104124 .6570968628124 .9618988037125 .5715026855 126.1809997559126 .7906036377127 .4001998901127 .7050018311128 .0097961426 128.0097961426127 .7050018311127 .4001998901126 .7906036377126 .1809997559 125.2667007446124 .3523025513123 .43800354122 .8283996582122 .5235977173 121.9140014648121 .6092987061121 .3044967651120 .6949005127120 .3900985718 119.7806015015119 .4757995605119 .1709976196118 .8662033081118 .5614013672 118.2565994263 118.2565994263 118.2565994263 118.2565994263 118.2565994263 118.2565994263118 .2565994263118 .5614013672118 .5614013672118 .5614013672 118.5614013672118 .5614013672118 .2565994263118 .2565994263118 .2565994263 117.9517974854117 .647102356117 .342300415117 .0374984741116 .7326965332 116.1231002808115 .818397522115 .2088012695114 .9039993286114 .2944030762 113.9896011353113 .3800964355112 .7705001831112 .4656982422112 .1608963013 112.1608963013112 .4656982422112 .7705001831112 .7705001831112 .7705001831 112.7705001831113 .075302124113 .075302124113 .075302124113 .075302124 113.3800964355113 .3800964355113 .3800964355113 .3800964355113 .075302124 113.075302124113 .075302124113 .075302124112 .7705001831112 .7705001831 112.4656982422112 .1608963013112 .1608963013111 .8561019897111 .551399231 111.24659729110 .9418029785110 .6370010376110 .3321990967110 .0273971558 109.7226028442109 .4179000854109 .1130981445108 .8082962036108 .5035018921 108.1986999512107 .8938980103107 .8938980103107 .5891036987107 .2844009399 106.979598999106 .6747970581106 .3700027466106 .0652008057105 .7603988647 105.1509017944104 .8460998535104 .5412979126103 .9317016602103 .6268997192 103.0174026489102 .4077987671110 .3321990967128 .9241027832149 .0399017334 169.4604949951188 .0523986816197 .500793457205 .1204071045208 .7778015137 208.7778015137208 .7778015137208 .7778015137208 .7778015137208 .7778015137 208.7778015137208 .7778015137208 .7778015137208 .7778015137208 .7778015137 208.7778015137208 .7778015137208 .7778015137208 .7778015137208 .7778015137 208.7778015137208.7778015137208.7778015137208.7778015137 208.7778015137 208.7778015137208 .7778015137208 .7778015137208 .7778015137208 .7778015137 208.7778015137208.7778015137208.7778015137208.7778015137208.7778015137 208.7778015137208 .7778015137208 .7778015137208 .7778015137208 .7778015137 208.7778015137208.7778015137208.7778015137208.7778015137208.7778015137 
208.7778015137208 .7778015137208 .7778015137208 .7778015137208 .7778015137 208.7778015137 208.7778015137208.7778015137208.7778015137 208.7778015137 208.7778015137208 .7778015137208 .7778015137208 .7778015137208 .7778015137 208.7778015137208 .7778015137208 .7778015137208 .7778015137208 .7778015137 208.7778015137208 .7778015137208 .7778015137208 .7778015137208 .7778015137 208.7778015137 208.7778015137208.7778015137 208.7778015137 208.7778015137 208.7778015137208 .7778015137208 .7778015137152 .0877990723 -9999 -9999-9999-9999 -9999 -9999 -9999 -9999 -9999 -9999 -9999 -9999 -9999 -9999 -9999 -9999 -9999 -9999 -9999 -9999 -9999 -9999 -9999 -9999 -9999 -9999 -9999 -9999 -9999 -9999 -9999 -9999 -9999 -9999 -9999 -9999 -9999 -9999 -9999 -9999 -9999 -9999 -9999 -9999 -9999 -9999 -9999 -9999 -999 -9999 -9999-9999-9999-9999

-9999 -9999 -9999 -9999 -9999 -9999 -9999 -9999 -9999 -9999 -9999 -9999 -9999 -9999 -9999 -9999 -9999 -9999 -9999 -9999 -9999 -9999 -9999 -9999 -9999 -9999 -9999 -9999 -9999 -9999

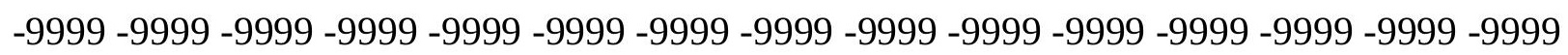
-9999 -9999 -9999 -9999 -9999 -9999 -9999 -9999 -9999 -9999 -9999 -9999 -9999 -9999 -9999

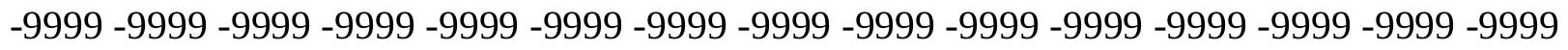

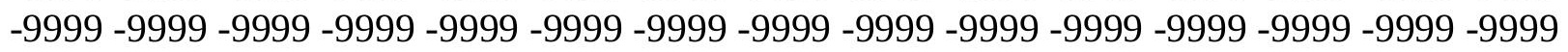
-9999 -9999-9999 -9999-9999 -9999-9999-9999-9999-9999 83.2063369751 84.4254837036185 .6446228027386 .5589828491287 .7781066894588 .69246673584 89.9116134643691.1307525634892.349891662693.8738174438595.09295654297 96.6168823242298 .1408081054799 .66472625732100 .8839035034102 .4077987671 103.6268997192104 .8460998535106 .3700027466107 .5891036987108 .8082962036 110.0273971558110 .9418029785112 .1608963013113 .075302124113 .9896011353 114.9039993286115 .818397522116 .4279022217117 .0374984741117 .647102356 118.2565994263118 .8662033081119 .1709976196119 .7806015015120 .3900985718 120.6949005127121 .3044967651121 .6092987061122 .2188034058122 .5235977173 123.1332015991123 .43800354123 .7427978516124 .3523025513124 .6570968628 125.2667007446125 .8762969971126 .1809997559126 .4858016968126 .7906036377 126.7906036377126 .4858016968126 .1809997559125 .5715026855124 .9618988037 124.3523025513123 .43800354122 .8283996582122 .2188034058121 .9140014648 121.3044967651120 .9997024536120 .6949005127120 .0852966309119 .7806015015 119.1709976196118 .8662033081118 .5614013672118 .2565994263117 .9517974854 117.9517974854117 .9517974854117 .9517974854117 .9517974854118 .2565994263 118.2565994263118 .2565994263118 .5614013672118 .5614013672118 .5614013672 118.5614013672118 .5614013672118 .5614013672118 .5614013672118 .5614013672 118.2565994263118 .2565994263117 .9517974854117 .647102356117 .342300415 116.7326965332116 .4279022217115 .818397522115 .5136032104114 .9039993286 114.5991973877113 .9896011353113 .6848983765113 .075302124112 .4656982422 112.1608963013112 .1608963013112 .4656982422112 .4656982422112 .7705001831 112.7705001831112 .7705001831113 .075302124113 .075302124113 .075302124 113.075302124113 .3800964355113 .3800964355113 .3800964355113 .3800964355 113.3800964355113 .075302124113 .075302124113 .075302124112 .7705001831 112.7705001831112 .4656982422112 .1608963013112 .1608963013111 .8561019897 111.551399231111 .24659729110 .9418029785110 .3321990967110 .0273971558 109.7226028442109 .4179000854109 .1130981445109 .1130981445108 .8082962036 108.5035018921108 .1986999512107 .8938980103107 .5891036987107 .5891036987 
107.2844009399 106.979598999106.6747970581 106.3700027466106.0652008057 105.4557037354105 .1509017944104 .8460998535104 .2365036011103 .9317016602 103.3221969604103 .0174026489108 .8082962036128 .0097961426147 .8208007812 167.0222015381183 .1759033203194 .4528961182203 .2917022705208 .7778015137 208.7778015137208 .7778015137208 .7778015137208 .7778015137208 .7778015137 208.7778015137208 .7778015137208 .7778015137208 .7778015137208 .7778015137 208.7778015137208 .7778015137208 .7778015137208 .7778015137208 .7778015137 208.7778015137208 .7778015137208 .7778015137208 .7778015137208 .7778015137 208.7778015137208 .7778015137208 .7778015137208 .7778015137208 .7778015137 208.7778015137208 .7778015137208 .7778015137208 .7778015137208 .7778015137 208.7778015137208 .7778015137208 .7778015137208 .7778015137208 .7778015137 208.7778015137208 .7778015137208 .7778015137208 .7778015137208 .7778015137 208.7778015137208 .7778015137208 .7778015137208 .7778015137208 .7778015137 208.7778015137208 .7778015137208 .7778015137208 .7778015137208 .7778015137 208.7778015137208 .7778015137208 .7778015137208 .7778015137208 .7778015137 208.7778015137208 .7778015137208 .7778015137208 .7778015137208 .7778015137 208.7778015137208 .7778015137208 .7778015137208 .7778015137208 .7778015137 208.7778015137208 .7778015137208 .7778015137208 .7778015137208 .7778015137 208.7778015137208.7778015137208.7778015137 150.5639038086152 .0877990723 -9999 -9999 -9999 -9999 -9999 -9999 -9999 -9999 -9999 -9999 -9999 -9999 -9999 -9999 -9999 -9999

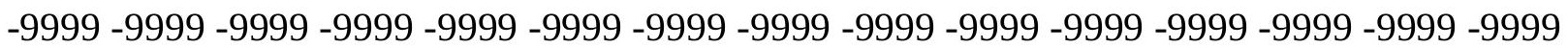
-9999 -9999 -9999 -9999 -9999 -9999 -9999 -9999 -9999 -9999 -9999 -9999 -9999 -9999 -9999 -9999 -9999 -9999 -9999 -9999 -9999 -9999

-9999 -9999 -9999 -9999 -9999 -9999 -9999 -9999 -9999 -9999 -9999 -9999 -9999 -9999 -9999 -9999 -9999 -9999 -9999 -9999 -9999 -9999 -9999 -9999 -9999 -9999 -9999 -9999 -9999 -9999 -9999 -9999 -9999 -9999 -9999 -9999 -9999 -9999 -9999 -9999 -9999 -9999 -9999 -9999 -9999 -9999 -9999 -9999 -9999 -9999 -9999 -9999 -9999 -9999 -9999 -9999 -9999 -9999 -9999 -9999 -9999 -9999 -9999 -9999 -9999 -9999 -9999 -9999 -9999 -9999 -9999 -9999 -9999 -9999 -9999 -9999 -9999 -9999 -9999 -9999 -9999 -9999 -9999 -9999 -9999 -9999 -9999 -9999 -9999 -9999 -999 -9999 -9999 -9999 -9999 -9999 -9999 -9999 -9999 -9999 82.59677124023 83.81591033936 85.0350494384886 .254188537687 .1685485839888 .0829010009888 .99725341797 89.9116134643691.1307525634892.6546783447394.1785964965895.3977432251 96.9216690063598 .445587158299 .96952056885101 .1886978149102 .712600708 103.9317016602105 .1509017944106 .6747970581107 .8938980103109 .1130981445 110.3321990967111 .24659729112 .4656982422113 .3800964355114 .2944030762 115.2088012695115 .818397522116 .4279022217117 .0374984741117 .647102356 118.2565994263118 .5614013672118 .8662033081119 .4757995605119 .7806015015 120.3900985718120 .6949005127121 .3044967651121 .6092987061121 .9140014648 122.2188034058122 .5235977173122 .8283996582123 .1332015991123 .7427978516 124.0475006104124 .6570968628124 .9618988037125 .2667007446125 .2667007446 125.2667007446124 .9618988037124 .6570968628124 .3523025513123 .7427978516 123.1332015991122 .5235977173121 .9140014648121 .6092987061120 .9997024536 120.6949005127120 .3900985718120 .0852966309119 .4757995605119 .1709976196 118.8662033081118 .5614013672117 .9517974854117 .647102356117 .647102356 117.647102356117 .647102356117 .647102356117 .9517974854117 .9517974854 118.2565994263118 .2565994263118 .5614013672118 .5614013672118 .5614013672 
118.8662033081118 .8662033081118 .8662033081118 .8662033081118 .8662033081 118.8662033081118 .5614013672118 .2565994263117 .9517974854117 .647102356 117.342300415116 .7326965332116 .4279022217116 .1231002808115 .5136032104 115.2088012695114 .5991973877114 .2944030762113 .6848983765113 .075302124 112.4656982422112 .1608963013112 .1608963013112 .1608963013112 .4656982422 112.4656982422112 .7705001831112 .7705001831113 .075302124113 .075302124 113.075302124113 .3800964355113 .3800964355113 .3800964355113 .3800964355 113.3800964355113 .3800964355113 .3800964355113 .075302124113 .075302124 112.7705001831112 .7705001831112 .4656982422112 .1608963013111 .8561019897 111.551399231111 .24659729110 .9418029785110 .6370010376110 .3321990967 110.0273971558109 .7226028442109 .4179000854109 .1130981445108 .8082962036 108.5035018921108 .5035018921108 .1986999512107 .8938980103107 .5891036987 107.2844009399 107.2844009399 106.979598999 106.6747970581 106.3700027466 106.0652008057105 .4557037354105 .1509017944104 .8460998535104 .2365036011 103.9317016602103 .3221969604109 .4179000854126 .4858016968145 .3825073242 162.1457061768177 .0802001953189 .5764007568199 .6342926025208 .1681976318 208.7778015137208 .7778015137208 .7778015137208 .7778015137208 .7778015137 208.7778015137208 .7778015137208 .7778015137208 .7778015137208 .7778015137 208.7778015137208 .7778015137208 .7778015137208 .7778015137208 .7778015137 208.7778015137208.7778015137208.7778015137208.7778015137208.7778015137 208.7778015137208 .7778015137208 .7778015137208 .7778015137208 .7778015137 208.7778015137208 .7778015137208 .7778015137208 .7778015137208 .7778015137 208.7778015137208 .7778015137208 .7778015137208 .7778015137208 .7778015137 208.7778015137208 .7778015137208 .7778015137208 .7778015137208 .7778015137 208.7778015137208 .7778015137208 .7778015137208 .7778015137208 .7778015137 208.7778015137208 .7778015137208 .7778015137208 .7778015137208 .7778015137 208.7778015137208 .7778015137208 .7778015137208 .7778015137208 .7778015137 208.7778015137208 .7778015137208 .7778015137208 .7778015137208 .7778015137 208.7778015137208 .7778015137208 .7778015137208 .7778015137208 .7778015137 208.7778015137208.7778015137208.7778015137208.7778015137208.7778015137 208.7778015137208 .7778015137208 .7778015137208 .7778015137150 .5639038086 -9999 -9999 -9999 -9999 -9999 -9999 -9999 -9999 -9999 -9999 -9999 -9999 -9999 -9999 -9999 -9999

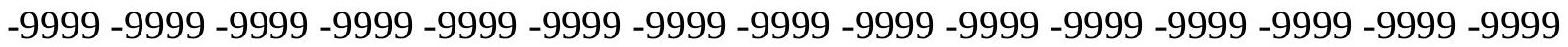

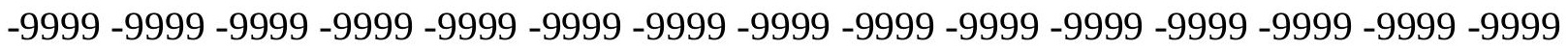
-9999 -9999 -9999 -9999 -9999 -9999 -9999

-9999 -9999 -9999 -9999 -9999 -9999 -9999 -9999 -9999 -9999 -9999 -9999 -9999 -9999 -9999

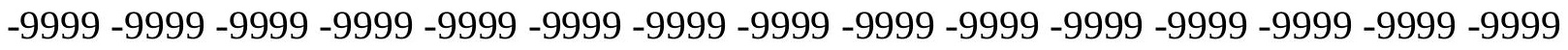

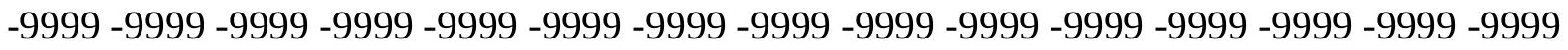
-9999 -9999 -9999 -9999 -9999 -9999 -9999 -9999 -9999 -9999 -9999 -9999 -9999 -9999 -9999 -9999 -9999 -9999 -9999 -9999 -9999 -9999 -9999 -9999 -9999 -9999 -9999 -9999 -9999 -9999 -

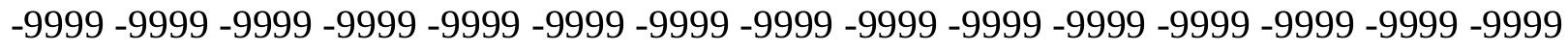
-9999 -9999 -9999 -9999-9999 -9999 -9999 -9999 81.9871978759883 .51112365723 84.7302627563585 .9494018554786 .8637619018687 .7781066894588 .69246673584 89.302040100190.5211791992291.4355392456192.9594726562594.48339080811 96.0073165893697 .5312423706199 .05516815186100 .2742996216101 .7982025146 103.0174026489104 .2365036011105 .7603988647106 .979598999108 .1986999512 
109.4179000854110 .6370010376111 .8561019897112 .7705001831113 .6848983765 114.5991973877115 .5136032104116 .1231002808116 .7326965332117 .342300415 117.647102356117 .9517974854118 .2565994263118 .5614013672118 .8662033081 119.4757995605119 .7806015015120 .3900985718120 .6949005127120 .9997024536 121.3044967651121 .6092987061121 .9140014648121 .9140014648122 .2188034058 122.5235977173123 .1332015991123 .1332015991123 .43800354123 .7427978516 123.7427978516123 .7427978516123 .43800354123 .1332015991122 .8283996582 122.5235977173121 .9140014648121 .6092987061120 .9997024536120 .6949005127 120.3900985718119 .7806015015119 .4757995605119 .1709976196118 .8662033081 118.5614013672118 .2565994263117 .9517974854117 .647102356117 .342300415 117.342300415117 .342300415117 .342300415117 .647102356117 .647102356 117.9517974854117 .9517974854118 .2565994263118 .2565994263118 .5614013672 118.8662033081118 .8662033081119 .1709976196119 .1709976196119 .1709976196 119.1709976196119 .1709976196118 .8662033081118 .5614013672118 .2565994263 117.9517974854117 .647102356117 .342300415117 .0374984741116 .4279022217 116.1231002808115 .818397522115 .2088012695114 .9039993286114 .2944030762 113.9896011353113 .3800964355113 .075302124112 .7705001831112 .7705001831 113.075302124113 .075302124113 .075302124113 .075302124113 .075302124113 .075302124 113.3800964355114 .9039993286113 .3800964355113 .3800964355113 .3800964355 113.3800964355113 .3800964355113 .3800964355113 .3800964355113 .3800964355 113.075302124113 .075302124112 .7705001831112 .4656982422112 .1608963013 111.8561019897111 .551399231111 .24659729110 .6370010376110 .3321990967 110.0273971558109 .7226028442109 .4179000854109 .1130981445109 .1130981445 108.8082962036108 .5035018921108 .1986999512108 .1986999512107 .8938980103 107.5891036987 107.2844009399 107.2844009399 106.979598999 106.6747970581 106.3700027466106 .0652008057105 .4557037354105 .1509017944104 .8460998535 104.2365036011103 .9317016602108 .8082962036124 .0475006104140 .2012023926 156.0500030518170 .6797027588183 .7854003906195 .0625205 .1204071045208 .7778015137 208.7778015137208 .7778015137208 .7778015137208 .7778015137208 .7778015137 208.7778015137 208.7778015137208.7778015137208.7778015137 208.7778015137 208.7778015137208 .7778015137208 .7778015137208 .7778015137208 .7778015137 208.7778015137208 .7778015137208 .7778015137208 .7778015137208 .7778015137 208.7778015137208 .7778015137208 .7778015137208 .7778015137208 .7778015137 208.7778015137208 .7778015137208 .7778015137208 .7778015137208 .7778015137 208.7778015137208 .7778015137208 .7778015137208 .7778015137208 .7778015137 208.7778015137208 .7778015137208 .7778015137208 .7778015137208 .7778015137 208.7778015137208 .7778015137208 .7778015137208 .7778015137208 .7778015137 208.7778015137208 .7778015137208 .7778015137208 .7778015137208 .7778015137 208.7778015137208 .7778015137208 .7778015137208 .7778015137208 .7778015137 208.7778015137208 .7778015137208 .7778015137208 .7778015137208 .7778015137 208.7778015137208 .7778015137208 .7778015137208 .7778015137208 .7778015137 208.7778015137 208.7778015137208.7778015137 208.7778015137 208.7778015137 208.7778015137208.7778015137208.7778015137 149.0399017334 150.5639038086-9999 -9999 -9999 -9999 -9999 -9999 -9999 -9999 -9999 -9999 -9999 -9999 -9999 -9999 -9999 -9999

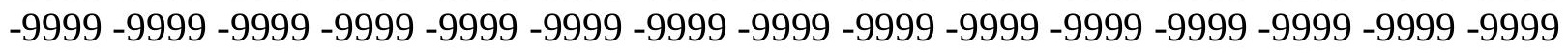

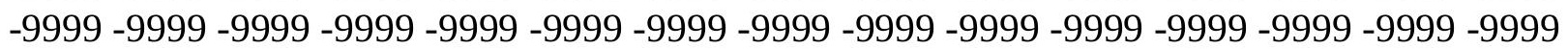


-9999 -9999 -9999 -9999-9999 -9999

-9999 -9999 -9999 -9999 -9999 -9999 -9999 -9999 -9999 -9999 -9999 -9999 -9999 -9999 -9999

-9999 -9999 -9999 -9999 -9999 -9999 -9999 -9999 -9999 -9999 -9999 -9999 -9999 -9999 -9999

-9999 -9999 -9999 -9999 -9999 -9999 -9999 -9999 -9999 -9999 -9999 -9999 -9999 -9999 -9999

-9999 -9999 -9999 -9999 -9999 -9999 -9999 -9999 -9999 -9999 -9999 -9999-9999 -9999 -9999 -

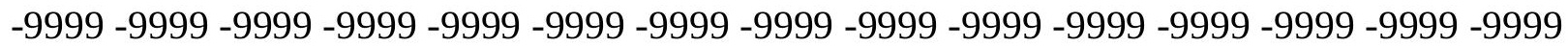

-9999 -9999 -9999 -9999 -9999 -9999 -9999 -9999 -9999 -9999 -9999 -9999 -9999 -9999 -9999

-9999 -9999-9999 -9999 -9999-9999-9999 81.07285308838 82.90155792236 84.12069702148

85.6446228027386 .8637619018688 .0829010009888 .9972534179789 .60682678223

90.2164001464890 .8259735107492 .0450973510793 .5690307617295 .3977432251

96.9216690063598 .1408081054799 .66472625732100 .8839035034102 .4077987671

103.6268997192104 .8460998535106 .0652008057107 .5891036987108 .8082962036

110.0273971558111 .24659729112 .1608963013113 .3800964355114 .2944030762

115.2088012695115 .818397522116 .4279022217117 .0374984741117 .647102356

117.9517974854117 .9517974854118 .2565994263118 .2565994263118 .5614013672

118.8662033081119 .1709976196119 .7806015015120 .0852966309120 .3900985718 120.6949005127120 .6949005127120 .9997024536121 .3044967651121 .6092987061 121.6092987061121 .6092987061121 .9140014648121 .9140014648121 .9140014648 121.9140014648121 .9140014648121 .9140014648121 .6092987061121 .3044967651 120.9997024536120 .6949005127120 .3900985718120 .0852966309119 .4757995605 119.1709976196119 .1709976196118 .8662033081118 .5614013672118 .2565994263 117.9517974854117 .647102356117 .647102356117 .342300415117 .342300415 117.0374984741117 .0374984741117 .342300415117 .342300415117 .647102356 117.647102356117 .9517974854118 .2565994263118 .2565994263118 .5614013672 118.8662033081118 .8662033081119 .1709976196119 .1709976196119 .4757995605 119.4757995605119 .4757995605119 .1709976196119 .1709976196118 .8662033081 118.5614013672117 .9517974854117 .647102356117 .342300415117 .0374984741 116.7326965332116 .4279022217115 .818397522115 .5136032104115 .2088012695 114.5991973877114 .2944030762113 .9896011353113 .9896011353113 .9896011353 113.9896011353113 .9896011353113 .9896011353114 .2944030762114 .2944030762 114.2944030762114 .2944030762114 .2944030762114 .2944030762114 .2944030762 114.2944030762113 .9896011353113 .9896011353113 .9896011353113 .6848983765 113.3800964355113 .3800964355113 .075302124113 .075302124112 .7705001831 112.4656982422111 .8561019897111 .551399231111 .24659729110 .9418029785 110.6370010376110 .3321990967110 .0273971558109 .7226028442109 .4179000854 109.1130981445108 .8082962036108 .8082962036108 .5035018921108 .1986999512 108.1986999512107 .8938980103107 .5891036987107 .2844009399107 .2844009399 106.979598999106 .6747970581106 .3700027466106 .0652008057105 .4557037354 105.1509017944104 .8460998535104 .2365036011108 .5035018921121 .3044967651 135.0198059082149 .6495056152164 .2792053223177 .9945068359190 .4907073975 201.7678070068208 .7778015137208 .7778015137208 .7778015137208 .7778015137 208.7778015137208 .7778015137208 .7778015137208 .7778015137208 .7778015137 208.7778015137208 .7778015137208 .7778015137208 .7778015137208 .7778015137 208.7778015137208 .7778015137208 .7778015137208 .7778015137208 .7778015137 208.7778015137208 .7778015137208 .7778015137208 .7778015137208 .7778015137 208.7778015137 208.7778015137208.7778015137 208.7778015137 208.7778015137 
208.7778015137208 .7778015137208 .7778015137208 .7778015137208 .7778015137 208.7778015137208 .7778015137208 .7778015137208 .7778015137208 .7778015137 208.7778015137208 .7778015137208 .7778015137208 .7778015137208 .7778015137 208.7778015137208 .7778015137208 .7778015137208 .7778015137208 .7778015137 208.7778015137208 .7778015137208 .7778015137208 .7778015137208 .7778015137 208.7778015137208 .7778015137208 .7778015137208 .7778015137208 .7778015137 208.7778015137208 .7778015137208 .7778015137208 .7778015137208 .7778015137 208.7778015137208 .7778015137208 .7778015137208 .7778015137208 .7778015137 208.7778015137208 .7778015137208 .7778015137208 .7778015137208 .7778015137 208.7778015137149 .0399017334 -9999 -9999 -9999 -9999 -9999 -9999 -9999 -9999 -9999 -9999 -9999 -9999 -9999 -9999 -9999 -9999 -9999 -9999 -9999 -9999 -9999 -9999 -9999 -9999

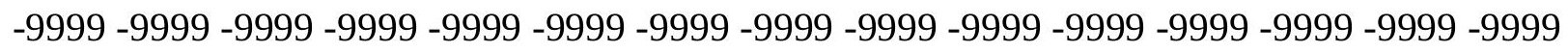
-9999 -9999 -9999 -9999 -9999 -9999 -9999 -9999 -9999 -9999 -9999 -9999 -9999 -9999 -9999 -9999 -9999 -9999 -9999 -9999 -9999 -9999 -9999 -9999 -9999 -9999 -9999 -9999 -9999 -9999 -9999 -9999 -9999 -9999 -9999 -9999 -9999 -9999 -9999 -9999 -9999 -9999 -9999

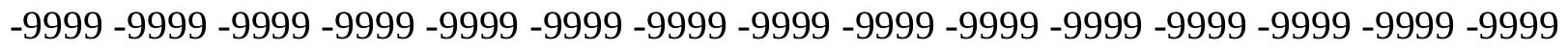
-9999 -9999 -9999 -9999 -9999 -9999 -9999 -9999 -9999 -9999 -9999 -9999 -9999 -9999 -9999 -9999 -9999 -9999 -9999 -9999 -9999 -9999 -9999 -9999 -9999 -9999 -9999 -9999 -9999 -9999 -9999 -9999 -9999 -9999 -9999 -9999 -9999 -9999 -9999 -9999 -9999 -9999 -9999 -9999 -9999 -9999 -9999 -9999 -9999-9999 -9999 80.15849304199 81.6824111938583 .51112365723 85.3398437586 .8637619018688 .3876876831189 .6068267822390 .52117919922 91.1307525634891 .4355392456191 .7403335571393 .2642517089894 .78817749023 96.3121032714897 .8360290527399 .05516815186100 .5791015625101 .7982025146 103.0174026489 104.2365036011 105.4557037354106.6747970581 107.8938980103 109.4179000854110 .6370010376111 .8561019897112 .7705001831113 .9896011353 114.9039993286115 .818397522116 .4279022217117 .0374984741117 .342300415 117.9517974854117 .9517974854118 .2565994263118 .2565994263117 .647102356 117.9517974854118 .5614013672118 .8662033081119 .1709976196119 .1709976196 119.4757995605119 .7806015015119 .7806015015120 .0852966309120 .3900985718 120.6949005127120 .3900985718120 .3900985718120 .3900985718120 .3900985718 120.3900985718120 .3900985718120 .0852966309120 .0852966309120 .0852966309 119.7806015015119 .4757995605119 .1709976196118 .8662033081118 .8662033081 118.5614013672118 .2565994263118 .2565994263117 .9517974854117 .647102356 117.647102356117 .342300415117 .342300415117 .0374984741117 .0374984741 117.0374984741117 .0374984741117 .0374984741117 .0374984741117 .342300415 117.342300415117 .647102356117 .9517974854118 .2565994263118 .2565994263 118.5614013672118 .8662033081118 .8662033081119 .1709976196119 .4757995605 119.4757995605119 .7806015015119 .7806015015119 .4757995605119 .1709976196 118.8662033081118 .5614013672118 .2565994263117 .9517974854117 .647102356 117.342300415117 .0374984741116 .7326965332116 .4279022217116 .1231002808 115.818397522115 .5136032104115 .2088012695115 .2088012695114 .9039993286 114.9039993286115 .2088012695115 .2088012695115 .2088012695115 .2088012695 115.2088012695115 .2088012695115 .2088012695115 .2088012695115 .2088012695 115.2088012695115 .2088012695115 .2088012695114 .9039993286114 .9039993286 114.5991973877114 .2944030762113 .9896011353113 .9896011353113 .6848983765 113.075302124112 .7705001831112 .4656982422111 .8561019897111 .551399231 
111.24659729110 .6370010376110 .3321990967110 .0273971558109 .7226028442 109.4179000854109 .4179000854109 .1130981445108 .8082962036108 .8082962036 108.5035018921108 .1986999512108 .1986999512107 .8938980103107 .5891036987 107.2844009399106 .979598999106 .979598999106 .6747970581106 .3700027466 106.0652008057105 .4557037354105 .1509017944104 .8460998535108 .5035018921 118.5614013672129 .8385009766143 .8585968018158 .7929992676173 .4226989746 186.8332977295199 .0247039795208 .7778015137208 .7778015137208 .7778015137 208.7778015137208 .7778015137208 .7778015137208 .7778015137208 .7778015137 208.7778015137208 .7778015137208 .7778015137208 .7778015137208 .7778015137 208.7778015137208 .7778015137208 .7778015137208 .7778015137208 .7778015137 208.7778015137208 .7778015137208 .7778015137208 .7778015137208 .7778015137 208.7778015137208 .7778015137208 .7778015137208 .7778015137208 .7778015137 208.7778015137208 .7778015137208 .7778015137208 .7778015137208 .7778015137 208.7778015137208.7778015137208.7778015137208.7778015137208.7778015137 208.7778015137208 .7778015137208 .7778015137208 .7778015137208 .7778015137 208.7778015137208.7778015137208.7778015137 208.7778015137 208.7778015137 208.7778015137208 .7778015137208 .7778015137208 .7778015137208 .7778015137 208.7778015137208 .7778015137208 .7778015137208 .7778015137208 .7778015137 208.7778015137208 .7778015137208 .7778015137208 .7778015137208 .7778015137 208.7778015137 208.7778015137208.7778015137208.7778015137 208.7778015137 208.7778015137 208.7778015137208.7778015137 208.7778015137 208.7778015137 208.7778015137 208.7778015137 147.5160064697149 .0399017334 -9999-9999 -9999 -9999 -9999 -9999 -9999 -9999 -9999 -9999 -9999 -9999 -9999 -9999 -9999 -9999 -9999 -9999 -9999 -9999 -9999 -9999 -9999 -9999 -9999 -9999 -9999 -9999 -9999 -9999 -9999 -9999 -9999 -9999 -

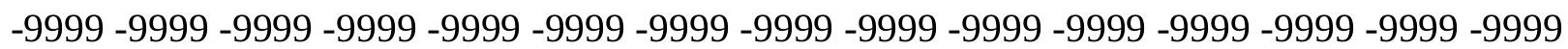
-9999-9999

-9999 -9999 -9999 -9999 -9999 -9999 -9999 -9999 -9999 -9999 -9999 -9999 -9999 -9999 -9999

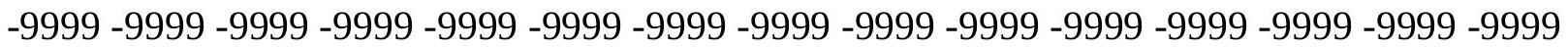
-9999 -9999 -9999 -9999 -9999 -9999 -9999 -9999 -9999 -9999 -9999 -9999 -9999 -9999 -9999

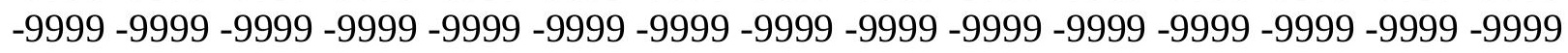
-9999 -9999 -9999 -9999 -9999 -9999 -9999 -9999 -9999 -9999 -9999 -9999 -9999 -9999 -9999 -9999 -9999 -9999 -9999 -9999 -9999 -9999 -9999 -9999 -9999 -9999 -9999 -9999 -9999 -9999 -9999 -9999 -9999 -9999-9999 -9999 80.76805877686 82.29197692871 84.12069702148 86.254188537688 .0829010009889 .9116134643691 .4355392456192 .3498916626 92.9594726562593 .2642517089893 .8738174438594 .7881774902396 .31210327148 97.5312423706198 .75038146973100 .2742996216101 .4934005737102 .4077987671 103.6268997192104 .8460998535106 .0652008057107 .2844009399108 .5035018921 109.7226028442111 .24659729112 .4656982422113 .3800964355114 .5991973877 115.5136032104116 .4279022217117 .0374984741117 .647102356117 .9517974854 118.2565994263118 .2565994263118 .2565994263117 .9517974854117 .9517974854 117.9517974854117 .9517974854118 .2565994263118 .5614013672118 .5614013672 118.5614013672118 .5614013672118 .8662033081118 .8662033081119 .1709976196 119.1709976196118 .8662033081118 .8662033081118 .5614013672118 .5614013672 118.5614013672118 .2565994263118 .2565994263118 .2565994263118 .2565994263 117.9517974854117 .9517974854117 .647102356117 .647102356117 .342300415 117.342300415117 .342300415117 .0374984741117 .0374984741117 .0374984741 
117.0374984741116 .7326965332116 .7326965332116 .7326965332116 .7326965332 116.7326965332116 .7326965332116 .7326965332117 .0374984741117 .0374984741 117.342300415117 .647102356117 .647102356117 .9517974854118 .2565994263 118.5614013672118 .8662033081118 .8662033081119 .1709976196119 .4757995605 119.7806015015119 .7806015015120 .0852966309119 .7806015015119 .4757995605 119.1709976196118 .8662033081118 .5614013672118 .2565994263117 .9517974854 117.647102356117 .647102356117 .342300415117 .0374984741117 .0374984741 116.7326965332116 .4279022217116 .4279022217116 .1231002808116 .1231002808 116.1231002808116 .1231002808116 .1231002808116 .4279022217116 .4279022217 116.4279022217116 .4279022217116 .4279022217116 .4279022217116 .4279022217 116.1231002808116 .1231002808116 .1231002808115 .818397522115 .818397522 115.5136032104115 .2088012695114 .9039993286114 .5991973877114 .2944030762 113.9896011353113 .3800964355113 .075302124112 .4656982422112 .1608963013 111.551399231111 .24659729110 .6370010376110 .3321990967110 .0273971558 109.7226028442109 .4179000854109 .1130981445109 .1130981445108 .8082962036 108.5035018921108 .5035018921108 .1986999512107 .8938980103107 .8938980103 107.5891036987 107.2844009399 106.979598999 106.979598999 106.6747970581 106.3700027466 106.0652008057 105.4557037354105.1509017944 108.1986999512 116.4279022217124 .9618988037139 .5915985107155 .1356048584169 .7653045654 183.7854003906196 .5863952637208 .1681976318208 .7778015137208 .7778015137 208.7778015137208 .7778015137208 .7778015137208 .7778015137208 .7778015137 208.7778015137208 .7778015137208 .7778015137208 .7778015137208 .7778015137 208.7778015137208 .7778015137208 .7778015137208 .7778015137208 .7778015137 208.7778015137208 .7778015137208 .7778015137208 .7778015137208 .7778015137 208.7778015137208 .7778015137208 .7778015137208 .7778015137208 .7778015137 208.7778015137208 .7778015137208 .7778015137208 .7778015137208 .7778015137 208.7778015137208 .7778015137208 .7778015137208 .7778015137208 .7778015137 208.7778015137208 .7778015137208 .7778015137208 .7778015137208 .7778015137 208.7778015137208 .7778015137208 .7778015137208 .7778015137208 .7778015137 208.7778015137208 .7778015137208 .7778015137208 .7778015137208 .7778015137 208.7778015137208 .7778015137208 .7778015137208 .7778015137208 .7778015137 208.7778015137208 .7778015137208 .7778015137208 .7778015137208 .7778015137 208.7778015137208 .7778015137208 .7778015137208 .7778015137208 .7778015137 208.7778015137 208.7778015137 208.7778015137 208.7778015137 208.7778015137 208.7778015137208 .7778015137208 .7778015137147 .5160064697 -9999 -9999 -9999 -9999 -9999 -9999 -9999 -9999 -9999 -9999 -9999 -9999 -9999 -9999 -9999 -9999 -9999 -9999 -9999

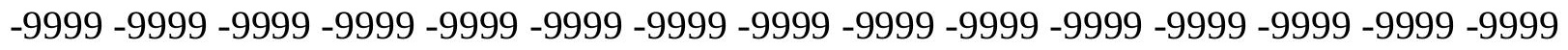

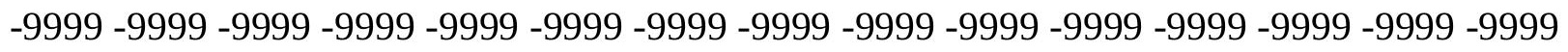
$-9999-9999$

-9999 -9999 -9999 -9999 -9999 -9999 -9999 -9999 -9999 -9999 -9999 -9999 -9999 -9999 -9999

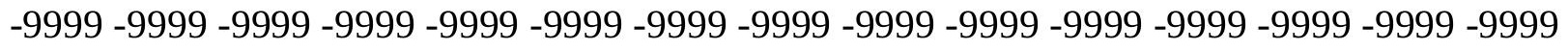

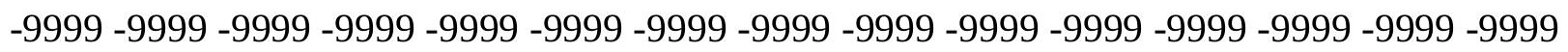

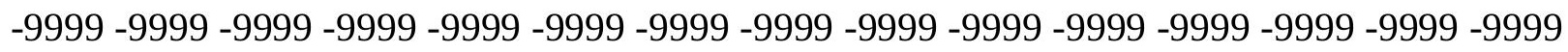
-9999 -9999 -9999 -9999 -9999 -9999 -9999 -9999 -9999 -9999 -9999 -9999 -9999 -9999 -9999 -9999 -9999 -9999 -9999 -9999 -9999 -9999 -9999 -9999 -9999 -9999 -9999 -9999 -9999 -9999 -9999 -9999 -9999 -9999 -9999 79.54891967773 81.0728530883882 .59677124023 
84.73026275635 87.16854858398 89.6068267822391.7403335571393.56903076172 94.7881774902395 .397743225195 .7025299072396 .3121032714896 .92166900635 97.8360290527399 .05516815186100 .2742996216101 .1886978149102 .4077987671 103.3221969604104 .2365036011105 .4557037354106 .6747970581107 .8938980103 109.1130981445110 .3321990967111 .8561019897113 .075302124114 .2944030762 115.2088012695116 .1231002808116 .7326965332117 .342300415117 .9517974854 118.5614013672118 .5614013672118 .5614013672118 .2565994263117 .9517974854 117.9517974854117 .647102356117 .647102356117 .9517974854117 .647102356 117.647102356117 .647102356117 .647102356117 .342300415117 .342300415117 .342300415 117.342300415117 .0374984741117 .0374984741116 .7326965332116 .4279022217 116.4279022217116 .4279022217116 .4279022217116 .4279022217116 .1231002808 116.1231002808116 .1231002808116 .1231002808116 .1231002808116 .1231002808 116.1231002808116 .1231002808116 .1231002808116 .1231002808116 .1231002808 116.1231002808116 .1231002808116 .4279022217116 .4279022217116 .4279022217 116.4279022217116 .4279022217116 .7326965332116 .7326965332117 .0374984741 117.342300415117 .342300415117 .647102356117 .9517974854118 .2565994263 118.2565994263118 .5614013672118 .8662033081119 .1709976196119 .4757995605 119.4757995605119 .7806015015119 .7806015015119 .4757995605119 .4757995605 119.1709976196118 .8662033081118 .5614013672118 .2565994263118 .2565994263 117.9517974854117 .9517974854117 .647102356117 .647102356117 .647102356 117.647102356 117.342300415 117.342300415 117.342300415 117.342300415 117.342300415 117.342300415117 .342300415117 .342300415117 .342300415117 .342300415117 .342300415 117.342300415117 .342300415117 .342300415117 .342300415117 .342300415 117.0374984741117 .0374984741116 .7326965332116 .4279022217116 .1231002808 115.818397522115 .5136032104115 .2088012695114 .5991973877114 .2944030762 113.6848983765113 .075302124112 .7705001831112 .1608963013111 .551399231 111.24659729110 .6370010376110 .3321990967110 .0273971558109 .7226028442 109.4179000854109 .1130981445108 .8082962036108 .8082962036108 .5035018921 108.1986999512108 .1986999512107 .8938980103107 .8938980103107 .5891036987 107.2844009399 106.979598999 106.979598999 106.6747970581 106.3700027466 106.0652008057105 .7603988647108 .1986999512116 .1231002808125 .5715026855 138.3724975586152 .6972961426167 .6318054199181 .9566955566195 .0625207 .25390625 208.7778015137 208.7778015137208.7778015137 208.7778015137 208.7778015137 208.7778015137208 .7778015137208 .7778015137208 .7778015137208 .7778015137 208.7778015137208 .7778015137208 .7778015137208 .7778015137208 .7778015137 208.7778015137 208.7778015137208.7778015137 208.7778015137208.7778015137 208.7778015137208.7778015137208.7778015137 208.7778015137 208.7778015137 208.7778015137208 .7778015137208 .7778015137208 .7778015137208 .7778015137 208.7778015137208 .7778015137208 .7778015137208 .7778015137208 .7778015137 208.7778015137208 .7778015137208 .7778015137208 .7778015137208 .7778015137 208.7778015137208 .7778015137208 .7778015137208 .7778015137208 .7778015137 208.7778015137208.7778015137208.7778015137208.7778015137 208.7778015137 208.7778015137208 .7778015137208 .7778015137208 .7778015137208 .7778015137 208.7778015137208 .7778015137208 .7778015137208 .7778015137208 .7778015137 208.7778015137208 .7778015137208 .7778015137208 .7778015137208 .7778015137 208.7778015137208.7778015137208.7778015137208.7778015137208.7778015137 
208.7778015137208.7778015137208.7778015137208.7778015137 208.7778015137 145.9920959473147 .2111968994 -9999 -9999 -9999 -9999 -9999 -9999 -9999 -9999 -9999 -9999 -9999 -9999 -9999 -9999 -9999 -9999 -9999 -9999 -9999 -9999 -9999 -9999 -9999 -9999 -9999 -9999 -9999 -9999 -9999 -9999 -9999 -9999 -9999 -9999 -9999 -9999 -9999 -9999 -9999 -9999 -9999 -9999 -9999 -9999 -9999 -9999 -9999 -9999 -9999 -9999 -9999 -9999 -9999 -9999 -9999 -9999 -9999 -9999 -9999 -9999 -9999 -9999 -9999 -9999 -9999 -9999 -9999 -9999 -9999 -9999 -9999 -9999 -9999 -9999 -9999 -9999 -9999 -9999 -9999 -9999 -9999 -9999 -9999 -9999 -9999 -9999 -9999 -9999 -9999 -9999 -9999 -9999 -9999 -9999 -9999

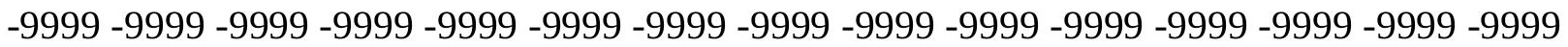
-9999 -9999 -9999 -9999 -9999 -9999 -9999 -9999 -9999 -9999 -9999 -9999 -9999 -9999 -9999 -9999 -9999 -9999 -9999 -9999 -9999 -9999 -9999 -9999 -9999 -9999 -9999 -9999 -9999 -9999 -9999 -9999 -9999 -9999 78.63455963135 79.8537063598681 .0728530883882 .90155792236 85.3398437588 .0829010009890 .8259735107493 .5690307617295 .70252990723 97.2264633178797 .8360290527398 .1408081054798 .445587158299 .05516815186 99.66472625732100 .5791015625101 .4934005737102 .4077987671103 .3221969604 103.9317016602104 .8460998535105 .7603988647106 .979598999108 .1986999512 109.7226028442110 .9418029785112 .4656982422113 .6848983765114 .9039993286 115.818397522116 .7326965332117 .342300415117 .9517974854118 .2565994263 118.8662033081118 .8662033081118 .8662033081118 .2565994263117 .9517974854 117.9517974854117 .647102356117 .647102356117 .342300415117 .0374984741 116.7326965332116 .4279022217116 .4279022217116 .1231002808115 .818397522 115.5136032104115 .5136032104115 .2088012695114 .9039993286114 .5991973877 114.5991973877114 .2944030762114 .2944030762114 .2944030762114 .2944030762 114.2944030762114 .2944030762114 .2944030762114 .5991973877114 .5991973877 114.5991973877114 .9039993286114 .9039993286115 .2088012695115 .2088012695 115.5136032104115 .5136032104115 .818397522115 .818397522115 .818397522 116.1231002808116 .1231002808116 .4279022217116 .4279022217116 .7326965332 116.7326965332117 .0374984741117 .342300415117 .647102356117 .647102356 117.9517974854118 .2565994263118 .5614013672118 .5614013672118 .8662033081 119.1709976196119 .1709976196119 .4757995605119 .4757995605119 .1709976196 119.1709976196118 .8662033081118 .5614013672118 .2565994263118 .2565994263 118.2565994263118 .2565994263117 .9517974854118 .2565994263118 .2565994263 118.2565994263118 .2565994263118 .2565994263118 .2565994263118 .2565994263 118.2565994263118 .2565994263118 .5614013672118 .5614013672118 .5614013672 118.5614013672118 .5614013672118 .5614013672118 .5614013672118 .5614013672 118.2565994263118 .2565994263118 .2565994263117 .9517974854117 .9517974854 117.647102356117 .342300415117 .0374984741116 .7326965332116 .4279022217 115.818397522115 .5136032104114 .9039993286114 .2944030762113 .6848983765 113.075302124112 .4656982422112 .1608963013111 .551399231110 .9418029785 110.6370010376110 .0273971558109 .7226028442109 .4179000854109 .1130981445 109.1130981445108 .8082962036108 .5035018921108 .5035018921108 .1986999512 108.1986999512107 .8938980103107 .5891036987107 .5891036987107 .2844009399 106.979598999106 .979598999106 .6747970581106 .3700027466106 .0652008057 108.1986999512116 .4279022217126 .1809997559138 .0677032471151 .7830047607 166.4127044678180 .7375946045194 .4528961182206 .9490966797208 .7778015137 208.7778015137208.7778015137208.7778015137208.7778015137208.7778015137 
208.7778015137 208.7778015137208.7778015137208.7778015137 208.7778015137 208.7778015137208 .7778015137208 .7778015137208 .7778015137208 .7778015137 208.7778015137208 .7778015137208 .7778015137208 .7778015137208 .7778015137 208.7778015137208 .7778015137208 .7778015137208 .7778015137208 .7778015137 208.7778015137208 .7778015137208 .7778015137208 .7778015137208 .7778015137 208.7778015137208 .7778015137208 .7778015137208 .7778015137208 .7778015137 208.7778015137208 .7778015137208 .7778015137208 .7778015137208 .7778015137 208.7778015137 208.7778015137 208.7778015137 208.7778015137 208.7778015137 208.7778015137208 .7778015137208 .7778015137208 .7778015137208 .7778015137 208.7778015137208 .7778015137208 .7778015137208 .7778015137208 .7778015137 208.7778015137 208.7778015137208.7778015137208.7778015137 208.7778015137 208.7778015137208.7778015137208.7778015137208.7778015137 208.7778015137 208.7778015137 208.7778015137 208.7778015137 208.7778015137 208.7778015137 208.7778015137208 .7778015137208 .7778015137208 .7778015137208 .7778015137 145.9920959473 -9999 -9999 -9999 -9999 -9999 -9999 -9999 -9999 -9999 -9999 -9999 -9999

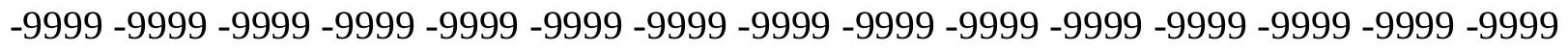

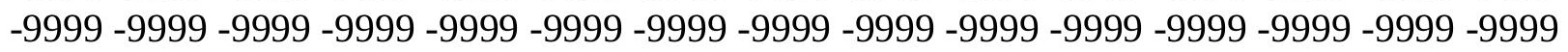
-9999 -9999 -9999 -9999 -9999 -9999 -9999 -9999

-9999 -9999 -9999 -9999 -9999 -9999 -9999 -9999 -9999 -9999 -9999 -9999 -9999 -9999 -9999

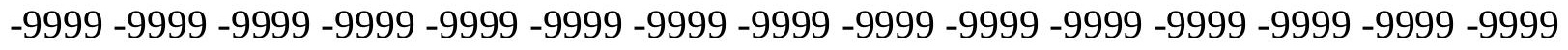

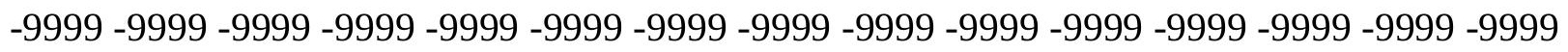

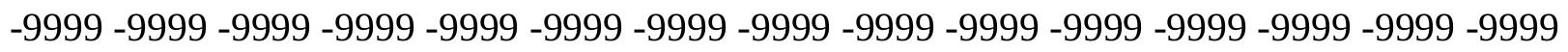
-9999 -9999 -9999 -9999 -9999 -9999 -9999 -9999 -9999 -9999 -9999 -9999 -9999 -9999 -9999 -

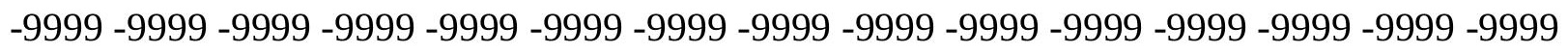
-9999 -9999-9999 78.63455963135 79.24413299561 79.85370635986 81.07285308838 82.5967712402385 .3398437588 .6924667358492 .349891662695 .70252990723 98.1408081054799 .66472625732100 .2742996216100 .5791015625100 .2742996216 100.5791015625101 .1886978149102 .1029968262103 .0174026489103 .6268997192 103.9317016602104 .5412979126105 .1509017944106 .0652008057107 .2844009399 108.8082962036110 .0273971558111 .551399231112 .7705001831114 .2944030762 115.2088012695116 .4279022217117 .0374984741117 .647102356117 .9517974854 118.2565994263118 .5614013672119 .1709976196118 .5614013672118 .2565994263 118.2565994263117 .9517974854117 .9517974854117 .342300415117 .0374984741 116.4279022217115 .818397522115 .5136032104114 .9039993286114 .5991973877 114.2944030762113 .6848983765113 .3800964355113 .075302124112 .7705001831 112.4656982422112 .4656982422112 .1608963013112 .1608963013112 .1608963013 112.1608963013112 .4656982422112 .4656982422112 .7705001831112 .7705001831 113.075302124113 .3800964355113 .6848983765113 .6848983765113 .9896011353 114.2944030762114 .5991973877114 .9039993286115 .2088012695115 .2088012695 115.5136032104115 .818397522115 .818397522116 .1231002808116 .4279022217 116.4279022217116 .7326965332117 .0374984741117 .0374984741117 .342300415 117.647102356117 .647102356117 .9517974854118 .2565994263118 .5614013672 118.5614013672118 .8662033081118 .8662033081119 .1709976196118 .8662033081 118.8662033081118 .5614013672118 .5614013672118 .2565994263118 .2565994263 117.9517974854117 .9517974854118 .2565994263118 .2565994263118 .2565994263 118.5614013672118 .8662033081118 .8662033081119 .1709976196119 .1709976196 
119.1709976196119 .4757995605119 .4757995605119 .4757995605119 .4757995605 119.4757995605119 .4757995605119 .4757995605119 .4757995605119 .4757995605 119.4757995605119 .4757995605119 .4757995605119 .1709976196119 .1709976196 118.8662033081118 .5614013672118 .2565994263117 .9517974854117 .647102356 117.0374984741116 .7326965332116 .1231002808115 .5136032104114 .9039993286 114.2944030762113 .6848983765113 .075302124112 .4656982422111 .8561019897 111.24659729110 .9418029785110 .3321990967110 .0273971558109 .7226028442 109.4179000854109 .1130981445108 .8082962036108 .5035018921108 .5035018921 108.1986999512108 .1986999512107 .8938980103107 .8938980103107 .5891036987 107.5891036987107 .2844009399106 .979598999106 .979598999106 .6747970581 106.3700027466108 .5035018921116 .7326965332126 .1809997559137 .4580993652 150.8686065674165 .1934967041180 .1280059814194 .1481018066206 .6443023682 208.7778015137208 .7778015137208 .7778015137208 .7778015137208 .7778015137 208.7778015137208 .7778015137208 .7778015137208 .7778015137208 .7778015137 208.7778015137208 .7778015137208 .7778015137208 .7778015137208 .7778015137 208.7778015137 208.7778015137208.7778015137 208.7778015137 208.7778015137 208.7778015137208 .7778015137208 .7778015137208 .7778015137208 .7778015137 208.7778015137208 .7778015137208 .7778015137208 .7778015137208 .7778015137 208.7778015137208 .7778015137208 .7778015137208 .7778015137208 .7778015137 208.7778015137208 .7778015137208 .7778015137208 .7778015137208 .7778015137 208.7778015137 208.7778015137 208.7778015137 208.7778015137 208.7778015137 208.7778015137208 .7778015137208 .7778015137208 .7778015137208 .7778015137 208.7778015137208 .7778015137208 .7778015137208 .7778015137208 .7778015137 208.7778015137208 .7778015137208 .7778015137208 .7778015137208 .7778015137 208.7778015137208 .7778015137208 .7778015137208 .7778015137208 .7778015137 208.7778015137208 .7778015137208 .7778015137208 .7778015137208 .7778015137 208.7778015137208 .7778015137208 .7778015137208 .7778015137208 .7778015137 208.7778015137144 .4682006836145 .6873016357 -9999 -9999 -9999 -9999 -9999 -9999 -9999 -9999 -9999 -9999 -9999 -9999 -9999 -9999 -9999 -9999 -9999 -9999 -9999 -9999 -9999 -9999 -9999 -9999 -9999 -9999 -9999 -9999 -9999 -9999 -9999 -9999 -9999 -9999 -9999 -9999 -9999 -9999 -9999 -9999 -9999 -9999 -9999 -9999 -9999 -9999 -9999 -9999 -9999 -9999 -9999 -9999 -9999 -9999 -9999 -9999 -9999 -9999 -9999 -9999 -9999 -9999 -9999 -9999

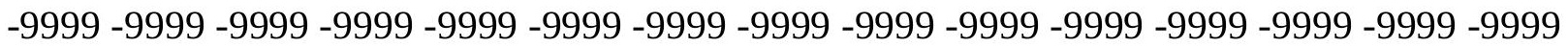
-9999 -9999 -9999 -9999 -9999 -9999 -9999 -9999 -9999 -9999 -9999 -9999 -9999 -9999 -9999 -9999 -9999 -9999 -9999 -9999 -9999 -9999 -9999 -9999 -9999 -9999 -9999 -9999 -9999 -9999 -9999 -9999 -9999 -9999 -9999 -9999 -9999 -9999 -9999 -9999 -9999 -9999 -9999 -9999 -9999

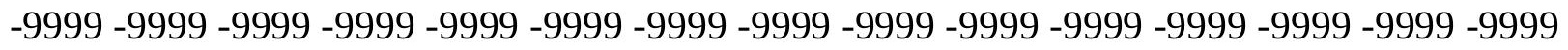
-9999 -9999-9999 79.54891967773 79.8537063598680 .1584930419980 .76805877686 82.29197692871 85.03504943848 88.9972534179793.56903076172 97.22646331787 100.2742996216101 .7982025146102 .4077987671102 .1029968262101 .4934005737 101.4934005737102 .4077987671103 .3221969604104 .2365036011104 .5412979126 104.5412979126104 .5412979126104 .8460998535105 .7603988647107 .2844009399 108.8082962036110 .3321990967111 .8561019897113 .3800964355114 .5991973877 115.818397522116 .7326965332117 .647102356117 .9517974854118 .2565994263 117.9517974854117 .647102356117 .342300415117 .647102356118 .2565994263 118.5614013672118 .5614013672118 .2565994263117 .342300415116 .7326965332 
115.818397522114 .9039993286113 .9896011353113 .3800964355112 .7705001831 112.4656982422111 .8561019897111 .551399231110 .9418029785110 .6370010376 110.3321990967110 .3321990967110 .0273971558110 .0273971558110 .0273971558 110.3321990967110 .3321990967110 .6370010376110 .9418029785111 .24659729 111.551399231111 .8561019897112 .1608963013112 .7705001831113 .075302124 113.3800964355113 .6848983765113 .9896011353114 .5991973877114 .9039993286 115.2088012695115 .2088012695115 .5136032104115 .818397522116 .1231002808 116.4279022217116 .4279022217116 .7326965332117 .0374984741117 .0374984741 117.342300415117 .647102356117 .647102356117 .9517974854118 .2565994263 118.2565994263118 .5614013672118 .5614013672118 .5614013672118 .5614013672 118.2565994263118 .2565994263117 .9517974854117 .9517974854117 .647102356 117.647102356117 .9517974854117 .9517974854118 .2565994263118 .5614013672 118.8662033081119 .1709976196119 .4757995605119 .7806015015120 .0852966309 120.0852966309120 .3900985718120 .3900985718120 .3900985718120 .6949005127 120.6949005127120 .6949005127120 .3900985718120 .3900985718120 .3900985718 120.3900985718120 .3900985718120 .3900985718120 .0852966309120 .0852966309 119.7806015015119 .4757995605119 .1709976196118 .8662033081118 .2565994263 117.9517974854117 .342300415116 .7326965332116 .1231002808115 .5136032104 114.9039993286114 .2944030762113 .3800964355112 .7705001831112 .1608963013 111.551399231110 .9418029785110 .6370010376110 .0273971558109 .7226028442 109.4179000854109 .1130981445108 .8082962036108 .5035018921108 .5035018921 108.1986999512108 .1986999512107 .8938980103107 .8938980103107 .8938980103 107.5891036987107 .5891036987107 .2844009399107 .2844009399106 .979598999 106.6747970581108 .5035018921116 .4279022217125 .5715026855136 .2389984131 148.7351074219163 .974395752179 .2136993408194 .1481018066206 .6443023682 208.7778015137208 .7778015137208 .7778015137208 .7778015137208 .7778015137 208.7778015137208 .7778015137208 .7778015137208 .7778015137208 .7778015137 208.7778015137208 .7778015137208 .7778015137208 .7778015137208 .7778015137 208.7778015137208 .7778015137208 .7778015137208 .7778015137208 .7778015137 208.7778015137208 .7778015137208 .7778015137208 .7778015137208 .7778015137 208.7778015137208 .7778015137208 .7778015137208 .7778015137208 .7778015137 208.7778015137208 .7778015137208 .7778015137208 .7778015137208 .7778015137 208.7778015137208 .7778015137208 .7778015137208 .7778015137208 .7778015137 208.7778015137208 .7778015137208 .7778015137208 .7778015137208 .7778015137 208.7778015137208 .7778015137208 .7778015137208 .7778015137208 .7778015137 208.7778015137208 .7778015137208 .7778015137208 .7778015137208 .7778015137 208.7778015137208 .7778015137208 .7778015137208 .7778015137208 .7778015137 208.7778015137208.7778015137208.7778015137208.7778015137208.7778015137 208.7778015137208 .7778015137208 .7778015137208 .7778015137208 .7778015137 208.7778015137208 .7778015137208 .7778015137208 .7778015137208 .7778015137 208.7778015137208 .7778015137144 .4682006836 -9999 -9999 -9999 -9999 -9999 -9999 -9999

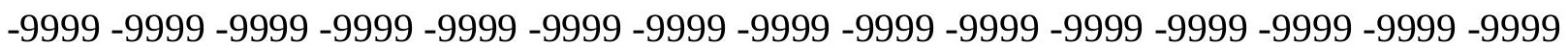

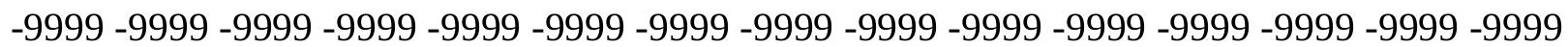
-9999 -9999 -9999 -9999 -9999 -9999 -9999 -9999 -9999 -9999 -9999 -9999 -9999 -9999 -9999 -9999 -9999 -9999 -9999 -9999 -9999 -9999 -9999 -9999 -9999 -9999 -9999

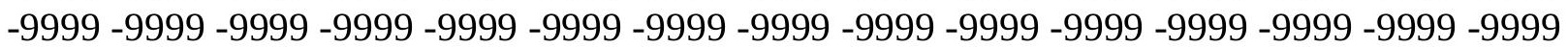


-9999 -9999 -9999 -9999 -9999 -9999 -9999 -9999 -9999 -9999 -9999 -9999 -9999 -9999 -9999 -9999 -9999 -9999 -9999 -9999 -9999 -9999 -9999 -9999 -9999 -9999 -9999 -9999 -9999 -9999

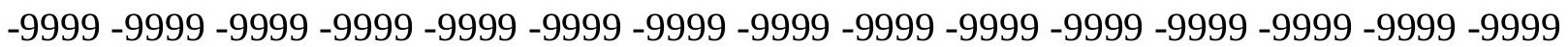
-9999 -9999 -9999 -9999 -9999 -9999 -9999 -9999 -9999 -9999 -9999 -9999 -9999 -9999 -9999 -9999 -9999 79.54891967773 80.4632720947380.7680587768681.07285308838 80.7680587768682 .2919769287184 .4254837036189 .302040100193 .87381744385 98.4455871582101 .1886978149102 .712600708103 .6268997192102 .4077987671 101.4934005737101 .4934005737102 .712600708104 .5412979126105 .1509017944 105.1509017944103 .9317016602103 .6268997192103 .9317016602105 .1509017944 106.6747970581108 .5035018921110 .6370010376112 .1608963013113 .6848983765 114.9039993286116 .1231002808117 .0374984741117 .647102356118 .2565994263 118.5614013672118 .2565994263117 .342300415115 .818397522117 .647102356 119.1709976196119 .4757995605119 .4757995605118 .5614013672117 .647102356 116.1231002808114 .9039993286113 .6848983765112 .7705001831111 .8561019897 111.24659729110 .6370010376110 .0273971558109 .4179000854109 .1130981445 108.5035018921108 .1986999512108 .1986999512107 .8938980103107 .8938980103 108.1986999512108 .1986999512108 .5035018921108 .8082962036109 .1130981445 109.7226028442110 .0273971558110 .6370010376110 .9418029785111 .551399231 112.1608963013112 .4656982422113 .075302124113 .3800964355113 .9896011353 114.2944030762114 .5991973877114 .9039993286115 .2088012695115 .5136032104 115.818397522116 .1231002808116 .4279022217116 .4279022217116 .7326965332 116.7326965332117 .0374984741117 .342300415117 .342300415117 .647102356 117.647102356117 .9517974854117 .9517974854117 .9517974854117 .9517974854 117.9517974854117 .647102356117 .647102356117 .342300415117 .342300415 117.342300415 117.342300415 117.342300415 117.647102356118.2565994263 118.5614013672119 .1709976196119 .4757995605120 .0852966309120 .3900985718 120.6949005127120 .9997024536120 .9997024536121 .3044967651121 .3044967651 121.6092987061121 .6092987061121 .6092987061121 .6092987061121 .3044967651 121.3044967651121 .3044967651121 .3044967651121 .3044967651120 .9997024536 120.6949005127120 .6949005127120 .3900985718120 .0852966309119 .4757995605 119.1709976196118 .5614013672117 .9517974854117 .342300415116 .7326965332 116.1231002808115 .2088012695114 .5991973877113 .6848983765113 .075302124 112.4656982422111 .8561019897111 .24659729110 .6370010376110 .0273971558 109.7226028442109 .1130981445108 .8082962036108 .8082962036108 .5035018921 108.1986999512108 .1986999512108 .1986999512107 .8938980103107 .8938980103 107.8938980103107 .5891036987107 .5891036987107 .5891036987107 .2844009399 107.2844009399106.979598999108.1986999512115.5136032104124.0475006104 133.8007049561145 .6873016357160 .9264984131178 .9089050293193 .8433074951 206.0346984863208 .7778015137208 .7778015137208 .7778015137208 .7778015137 208.7778015137208 .7778015137208 .7778015137208 .7778015137208 .7778015137 208.7778015137208 .7778015137208 .7778015137208 .7778015137208 .7778015137 208.7778015137 208.7778015137208.7778015137208.7778015137 208.7778015137 208.7778015137208 .7778015137208 .7778015137208 .7778015137208 .7778015137 208.7778015137208 .7778015137208 .7778015137208 .7778015137208 .7778015137 208.7778015137208 .7778015137208 .7778015137208 .7778015137208 .7778015137 208.7778015137208 .7778015137208 .7778015137208 .7778015137208 .7778015137 
208.7778015137208 .7778015137208 .7778015137208 .7778015137208 .7778015137 208.7778015137 208.7778015137208.7778015137208.7778015137 208.7778015137 208.7778015137208 .7778015137208 .7778015137208 .7778015137208 .7778015137 208.7778015137208 .7778015137208 .7778015137208 .7778015137208 .7778015137 208.7778015137208 .7778015137208 .7778015137208 .7778015137208 .7778015137 208.7778015137208 .7778015137208 .7778015137208 .7778015137208 .7778015137 208.7778015137208 .7778015137208 .7778015137208 .7778015137208 .7778015137 $208.7778015137208 .7778015137208 .7778015137142 .9441986084144 .1634063721-9999$ -9999 -9999 -9999 -9999 -9999 -9999 -9999 -9999 -9999 -9999 -9999 -9999 -9999 -9999 -9999 -9999 -9999 -9999 -9999 -9999 -9999 -9999 -9999 -9999 -9999 -9999 -9999 -9999 -9999 -9999 -

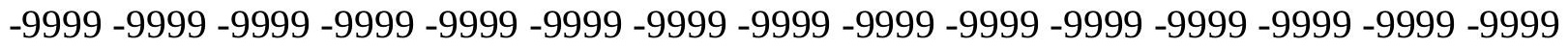
$-9999-9999$

-9999 -9999 -9999 -9999 -9999 -9999 -9999 -9999 -9999 -9999 -9999 -9999 -9999 -9999 -9999 -9999 -9999 -9999 -9999 -9999 -9999 -9999 -9999 -9999 -9999 -9999 -9999 -9999 -9999 -9999 -9999 -9999 -9999 -9999 -9999 -9999 -9999 -9999 -9999 -9999 -9999 -9999 -9999 -9999 -9999

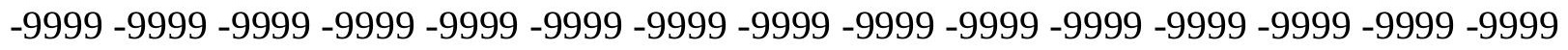

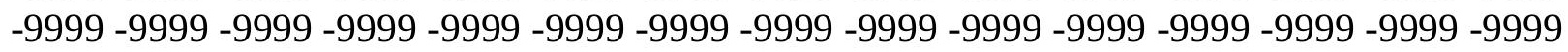

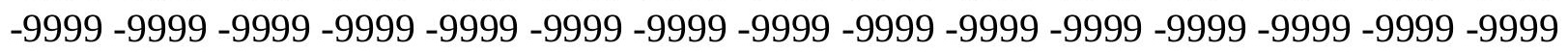
-9999 79.5489196777380 .1584930419981 .3776321411182 .5967712402383 .2063369751 82.9015579223681 .6824111938583 .8159103393690 .21640014648101 .4934005737 103.9317016602104 .2365036011105 .7603988647106 .979598999104 .5412979126 103.6268997192102 .712600708103 .0174026489106 .979598999106 .3700027466 104.8460998535102 .4077987671101 .4934005737102 .1029968262103 .6268997192 105.7603988647108 .1986999512110 .6370010376112 .4656982422113 .6848983765 114.9039993286115 .818397522116 .7326965332117 .647102356118 .5614013672 118.8662033081119 .1709976196118 .8662033081118 .8662033081119 .7806015015 120.3900985718120 .6949005127120 .3900985718119 .4757995605117 .647102356 115.818397522113 .9896011353112 .4656982422111 .24659729110 .3321990967 109.4179000854108 .8082962036108 .1986999512107 .5891036987106 .979598999 106.3700027466 106.0652008057 106.0652008057 105.7603988647 105.7603988647 106.0652008057106 .3700027466106 .6747970581106 .979598999107 .5891036987 108.1986999512108 .8082962036109 .1130981445109 .7226028442110 .3321990967 110.9418029785111 .551399231112 .1608963013112 .7705001831113 .075302124 113.6848983765114 .2944030762114 .5991973877114 .9039993286115 .2088012695 115.5136032104115 .818397522116 .1231002808116 .1231002808116 .4279022217 116.4279022217116 .7326965332116 .7326965332117 .0374984741117 .0374984741 117.342300415 117.342300415 117.342300415 117.342300415 117.342300415 117.342300415 117.0374984741117 .0374984741116 .7326965332116 .7326965332116 .7326965332 116.7326965332117 .0374984741117 .342300415117 .9517974854118 .5614013672 119.1709976196119 .7806015015120 .3900985718120 .9997024536121 .3044967651 121.6092987061121 .9140014648121 .9140014648122 .2188034058122 .2188034058 122.5235977173122 .5235977173122 .5235977173122 .2188034058122 .2188034058 122.2188034058122 .2188034058121 .9140014648121 .9140014648121 .6092987061 121.3044967651120 .9997024536120 .6949005127120 .3900985718119 .7806015015 119.1709976196118 .5614013672117 .9517974854117 .342300415116 .4279022217 115.818397522114 .9039993286113 .9896011353113 .3800964355112 .4656982422 
111.8561019897111 .24659729110 .6370010376110 .0273971558109 .4179000854 109.1130981445108 .8082962036108 .5035018921108 .1986999512108 .1986999512 107.8938980103107 .8938980103107 .8938980103107 .8938980103107 .8938980103 107.8938980103107 .5891036987107 .5891036987107 .5891036987107 .2844009399 107.2844009399 107.5891036987114.5991973877121.9140014648 130.7528076172 141.4203033447154 .5260925293179 .2136993408192 .0146026611203 .9011993408 208.7778015137208 .7778015137208 .7778015137208 .7778015137208 .7778015137 208.7778015137208 .7778015137208 .7778015137208 .7778015137208 .7778015137 208.7778015137208 .7778015137208 .7778015137208 .7778015137208 .7778015137 208.7778015137208 .7778015137208 .7778015137208 .7778015137208 .7778015137 208.7778015137208 .7778015137208 .7778015137208 .7778015137208 .7778015137 208.7778015137208 .7778015137208 .7778015137208 .7778015137208 .7778015137 208.7778015137208 .7778015137208 .7778015137208 .7778015137208 .7778015137 208.7778015137208 .7778015137208 .7778015137208 .7778015137208 .7778015137 208.7778015137208 .7778015137208 .7778015137208 .7778015137208 .7778015137 208.7778015137208 .7778015137208 .7778015137208 .7778015137208 .7778015137 208.7778015137208 .7778015137208 .7778015137208 .7778015137208 .7778015137 208.7778015137208 .7778015137208 .7778015137208 .7778015137208 .7778015137 208.7778015137208 .7778015137208 .7778015137208 .7778015137208 .7778015137 208.7778015137208 .7778015137208 .7778015137208 .7778015137208 .7778015137 208.7778015137 208.7778015137 208.7778015137 208.7778015137 208.7778015137 208.7778015137 208.7778015137208 .7778015137142 .9441986084 -9999 -9999 -9999 -9999 -9999 -9999 -9999 -9999 -9999 -9999 -9999 -9999 -9999 -9999 -9999 -9999 -9999 -9999 -9999

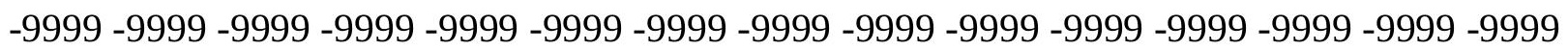
-9999 -9999 -9999 -9999 -9999 -9999 -9999 -9999 -9999 -9999 -9999 -9999 -9999 - -9999 -

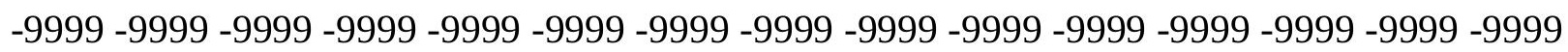
-9999 -9999 -9999 -9999 -9999 -9999 -9999 -9999 -9999 -9999 -9999 -9999 -9999 - -9999 - -9999 -

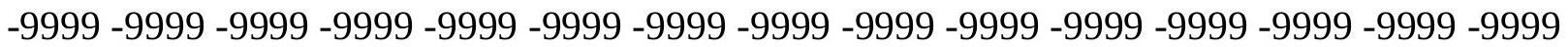

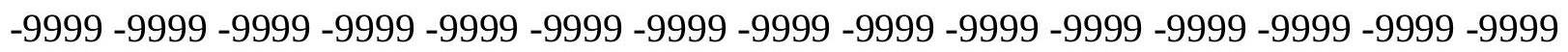

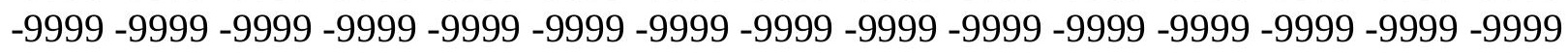
-9999 -9999 -9999 -9999 -9999 -9999 -9999 -9999 -9999 -9999 -9999 -9999 -9999 -9999 -9999 81.3776321411180 .4632720947380 .4632720947381 .9871978759884 .12069702148 85.0350494384884 .7302627563580 .7680587768681 .3776321411198 .75038146973 115.5136032104116 .1231002808113 .9896011353117 .9517974854121 .3044967651 119.7806015015117 .9517974854120 .6949005127120 .3900985718112 .7705001831 106.979598999 102.407798767199.0551681518698.445587158299.66472625732 101.4934005737104 .2365036011107 .5891036987110 .3321990967112 .1608963013 113.6848983765114 .5991973877115 .5136032104116 .4279022217117 .342300415 118.2565994263119 .1709976196120 .0852966309120 .9997024536121 .6092987061 122.5235977173121 .9140014648122 .2188034058121 .6092987061119 .7806015015 117.342300415114 .9039993286112 .7705001831111 .24659729109 .7226028442 108.5035018921107 .5891036987106 .979598999106 .0652008057105 .4557037354 104.8460998535104 .5412979126104 .2365036011103 .9317016602103 .9317016602 103.9317016602103 .9317016602104 .5412979126104 .8460998535105 .4557037354 106.0652008057 106.6747970581 107.2844009399 107.8938980103108.8082962036 109.4179000854110 .0273971558110 .6370010376111 .24659729112 .1608963013 
112.4656982422113 .075302124113 .6848983765114 .2944030762114 .5991973877 114.9039993286115 .2088012695115 .5136032104115 .818397522115 .818397522 116.1231002808116 .1231002808116 .4279022217116 .4279022217116 .7326965332 116.7326965332116 .7326965332117 .0374984741117 .0374984741117 .0374984741 117.0374984741116 .7326965332116 .4279022217116 .4279022217116 .1231002808 115.818397522115 .818397522115 .818397522116 .4279022217116 .7326965332 117.342300415118 .2565994263119 .1709976196119 .7806015015120 .6949005127 121.3044967651121 .6092987061122 .2188034058122 .5235977173122 .5235977173 122.8283996582123 .1332015991123 .1332015991123 .1332015991123 .1332015991 123.1332015991123 .1332015991123 .1332015991122 .8283996582122 .5235977173 122.5235977173122 .2188034058121 .9140014648121 .6092987061121 .3044967651 120.9997024536120 .3900985718119 .7806015015119 .1709976196118 .5614013672 117.647102356116 .7326965332116 .1231002808115 .2088012695114 .2944030762 113.3800964355112 .4656982422111 .8561019897110 .9418029785110 .3321990967 109.7226028442109 .4179000854108 .8082962036108 .5035018921108 .1986999512 107.8938980103107 .5891036987107 .5891036987107 .5891036987107 .5891036987 107.5891036987107 .5891036987107 .5891036987107 .5891036987107 .5891036987 107.5891036987107 .5891036987107 .2844009399107 .2844009399113 .3800964355 119.7806015015127 .7050018311138 .0677032471152 .3925933838170 .070098877 185.9188995361199 .329498291208 .7778015137208 .7778015137208 .7778015137 208.7778015137208 .7778015137208 .7778015137208 .7778015137208 .7778015137 208.7778015137208 .7778015137208 .7778015137208 .7778015137208 .7778015137 208.7778015137208 .7778015137208 .7778015137208 .7778015137208 .7778015137 208.7778015137208 .7778015137208 .7778015137208 .7778015137208 .7778015137 208.7778015137208 .7778015137208 .7778015137208 .7778015137208 .7778015137 208.7778015137208 .7778015137208 .7778015137208 .7778015137208 .7778015137 208.7778015137208 .7778015137208 .7778015137208 .7778015137208 .7778015137 208.7778015137208 .7778015137208 .7778015137208 .7778015137208 .7778015137 208.7778015137208 .7778015137208 .7778015137208 .7778015137208 .7778015137 208.7778015137208 .7778015137208 .7778015137208 .7778015137208 .7778015137 208.7778015137208 .7778015137208 .7778015137208 .7778015137208 .7778015137 208.7778015137208 .7778015137208 .7778015137208 .7778015137208 .7778015137 208.7778015137208 .7778015137208 .7778015137208 .7778015137208 .7778015137 208.7778015137208 .7778015137208 .7778015137208 .7778015137208 .7778015137 208.7778015137208 .7778015137208 .7778015137208 .7778015137208 .7778015137 141.4203033447142 .9441986084 -9999 -9999 -9999 -9999 -9999 -9999 -9999 -9999 -9999 -9999 -9999 -9999 -9999 -9999 -9999 -9999 -9999 -9999 -9999 -9999 -9999 -9999-9999-9999 -

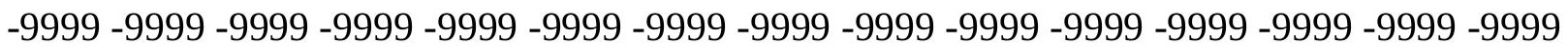
-9999 -9999 -9999 -9999 -9999 -9999 -9999 -9999

-9999 -9999 -9999 -9999 -9999 -9999 -9999 -9999 -9999 -9999 -9999 -9999 -9999 -9999 -9999 -9999 -9999 -9999 -9999 -9999 -9999 -9999 -9999 -9999 -9999 -9999 -9999 -9999 -9999 -9999

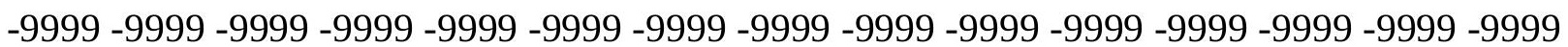
-9999 -9999 -9999 -9999 -9999 -9999 -9999 -9999 -9999 -9999 -9999 -9999 -9999 -9999 -9999 -9999 -9999 -9999 -9999 -9999 -9999 -9999 -9999 -9999 -9999 -9999 -9999 -9999 -9999 -9999 -999 -9999 -9999 -9999 -9999 -9999 -9999 -9999 -9999 -9999 -9999 -9999 -9999 -9999 -9999 79.5489196777379 .5489196777380 .1584930419981 .3776321411183 .51112365723 
86.2541885376 88.3876876831192.349891662696.00731658936101.7982025146 109.3966064453118 .0637664795121 .8013839722122 .669883728124 .5390090942 126.385055542126 .7121887207126 .4858016968128 .6192932129128 .3144989014 121.6092987061108 .198699951297 .5312423706194 .7881774902395 .3977432251 96.9216690063599 .05516815186102 .1029968262106 .0652008057109 .7226028442 111.551399231112 .7705001831113 .3800964355114 .2944030762115 .2088012695 116.4279022217117 .647102356119 .1709976196120 .6949005127122 .2188034058 122.8283996582123 .1332015991123 .1332015991122 .8283996582122 .2188034058 119.1709976196116 .1231002808113 .3800964355111 .24659729109 .4179000854 108.1986999512106 .979598999106 .0652008057105 .1509017944104 .5412979126 103.6268997192103 .0174026489102 .4077987671102 .1029968262101 .7982025146 101.7982025146101 .7982025146102 .1029968262102 .712600708103 .3221969604 103.9317016602104 .5412979126105 .4557037354106 .0652008057106 .979598999 107.5891036987108 .5035018921109 .1130981445110 .0273971558110 .6370010376 111.24659729111 .8561019897112 .7705001831113 .075302124113 .6848983765 114.2944030762114 .5991973877114 .9039993286115 .2088012695115 .5136032104 115.5136032104115 .818397522115 .818397522115 .818397522116 .1231002808 116.1231002808116 .4279022217116 .4279022217116 .4279022217116 .4279022217 116.4279022217116 .4279022217116 .1231002808116 .1231002808115 .818397522 115.2088012695115 .2088012695114 .9039993286115 .2088012695115 .5136032104 116.1231002808117 .0374984741117 .9517974854118 .8662033081119 .7806015015 120.6949005127121 .3044967651121 .9140014648122 .5235977173122 .8283996582 123.1332015991123 .43800354123 .43800354123 .7427978516123 .7427978516 124.0475006104124 .0475006104123 .7427978516123 .7427978516123 .43800354 123.1332015991122 .8283996582122 .5235977173122 .5235977173122 .2188034058 121.9140014648121 .6092987061120 .9997024536120 .3900985718119 .7806015015 118.8662033081117 .9517974854117 .0374984741116 .1231002808115 .2088012695 114.2944030762113 .3800964355112 .4656982422111 .551399231110 .9418029785 110.0273971558109 .4179000854108 .8082962036108 .5035018921108 .1986999512 107.8938980103107 .5891036987107 .2844009399107 .2844009399107 .2844009399 107.2844009399 107.2844009399 107.5891036987107.5891036987107.5891036987 107.5891036987107 .5891036987107 .5891036987107 .5891036987107 .2844009399 111.8561019897117 .342300415124 .0475006104133 .4958953857146 .6015930176 161.8408966064178 .2993011475193 .233795166207 .25390625208 .7778015137 208.7778015137208 .7778015137208 .7778015137208 .7778015137208 .7778015137 208.7778015137 208.7778015137 208.7778015137 208.7778015137 208.7778015137 208.7778015137208 .7778015137208 .7778015137208 .7778015137208 .7778015137 208.7778015137208 .7778015137208 .7778015137208 .7778015137208 .7778015137 208.7778015137208 .7778015137208 .7778015137208 .7778015137208 .7778015137 208.7778015137208 .7778015137208 .7778015137208 .7778015137208 .7778015137 208.7778015137208 .7778015137208 .7778015137208 .7778015137208 .7778015137 208.7778015137208.7778015137208.7778015137208.7778015137 208.7778015137 208.7778015137208 .7778015137208 .7778015137208 .7778015137208 .7778015137 208.7778015137208 .7778015137208 .7778015137208 .7778015137208 .7778015137 208.7778015137208 .7778015137208 .7778015137208 .7778015137208 .7778015137 208.7778015137208.7778015137208.7778015137208.7778015137208.7778015137 
208.7778015137208 .7778015137208 .7778015137208 .7778015137208 .7778015137 208.7778015137 208.7778015137208.7778015137208.7778015137 208.7778015137 208.7778015137208 .7778015137208 .7778015137208 .7778015137208 .7778015137 208.7778015137208 .7778015137141 .4203033447 -9999 -9999 -9999 -9999 -9999 -9999 -9999 -9999 -9999 -9999 -9999 -9999 -9999 -9999 -9999 -9999 -9999 -9999 -9999 -9999 -9999 -9999 -9999 -9999 -9999 -9999 -9999 -9999 -9999 -9999 -9999 -9999 -9999 -9999 -9999 -9999 -9999 -9999 -9999 -9999 -9999 -9999 -9999 -9999 -9999 -9999 -9999

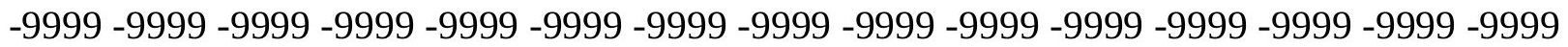
-9999 -9999 -9999 -9999 -9999 -9999 -9999 -9999 -9999 -9999 -9999 -9999 -9999 -9999 -9999 -9999 -9999 -9999 -9999 -9999 -9999 -9999 -9999 -9999 -9999 -9999 -9999 -9999 -9999 -9999 -9999 -9999 -9999 -9999 -9999 -9999 -9999 -9999 -9999 -9999 -9999 -9999 -9999 -9999 -9999 -999 -9999 -9999 -9999 -9999 -9999 -9999 -9999 -9999 -9999 -9999 -9999 -9999 -9999 -9999 -9999 -999 -9999 -9999 -9999 -9999 -9999 -9999 -9999 -9999 -9999 -9999 -9999 -9999 -9999 -9999 81.0728530883881 .0728530883881 .3776321411181 .9871978759885 .03504943848 89.302040100196.31210327148 104.2365036011 113.3800964355 115.2970504761 117.7787322998121 .2475204468124 .0457992554125 .5200576782126 .4706726074 127.2519302368 127.9568557739128.9241027832128.9241027832127.0953979492 120.6949005127110 .332199096796 .3121032714893 .5690307617293 .56903076172 94.4833908081196 .3121032714899 .05516815186103 .6268997192108 .8082962036 109.7226028442110 .6370010376111 .551399231112 .4656982422113 .3800964355 114.5991973877116 .1231002808117 .9517974854119 .7806015015121 .6092987061 122.2188034058122 .5235977173122 .8283996582121 .6092987061119 .7806015015 117.0374984741113 .9896011353111 .551399231109 .4179000854107 .8938980103 106.6747970581105 .4557037354104 .5412979126103 .6268997192103 .0174026489 102.1029968262101 .4934005737100 .8839035034100 .274299621699 .96952056885 99.96952056885100 .2742996216100 .5791015625101 .1886978149101 .7982025146 102.4077987671103 .3221969604104 .2365036011105 .1509017944105 .7603988647 106.6747970581 107.5891036987 108.1986999512109.1130981445 110.0273971558 110.6370010376111 .24659729112 .1608963013112 .7705001831113 .3800964355 113.6848983765114 .2944030762114 .5991973877114 .9039993286115 .2088012695 115.2088012695115 .2088012695115 .5136032104115 .5136032104115 .5136032104 115.818397522115 .818397522116 .1231002808116 .1231002808116 .1231002808 116.1231002808116 .1231002808115 .818397522115 .5136032104115 .2088012695 114.5991973877114 .2944030762114 .2944030762114 .2944030762114 .9039993286 115.5136032104116 .4279022217117 .342300415118 .2565994263119 .4757995605 120.3900985718121 .3044967651122 .2188034058122 .5235977173122 .8283996582 123.1332015991123 .43800354123 .7427978516124 .0475006104124 .3523025513 124.3523025513124 .3523025513124 .3523025513124 .3523025513123 .7427978516 123.43800354123 .1332015991122 .8283996582122 .8283996582122 .8283996582 122.5235977173122 .2188034058121 .6092987061120 .9997024536120 .0852966309 119.1709976196118 .2565994263117 .342300415116 .1231002808115 .2088012695 114.2944030762113 .075302124112 .1608963013111 .24659729110 .6370010376 109.7226028442109 .1130981445108 .5035018921107 .8938980103107 .5891036987 107.2844009399106.979598999 106.6747970581 106.6747970581 106.6747970581 106.6747970581106 .979598999107 .2844009399107 .2844009399107 .2844009399 107.2844009399 107.2844009399 107.2844009399 107.5891036987 107.5891036987 
110.6370010376114 .9039993286120 .0852966309127 .7050018311138 .9819946289 153.6116943359170 .3748931885186 .8332977295202 .3773040771208 .7778015137 208.7778015137208 .7778015137208 .7778015137208 .7778015137208 .7778015137 208.7778015137208 .7778015137208 .7778015137208 .7778015137208 .7778015137 208.7778015137208 .7778015137208 .7778015137208 .7778015137208 .7778015137 208.7778015137208 .7778015137208 .7778015137208 .7778015137208 .7778015137 208.7778015137208 .7778015137208 .7778015137208 .7778015137208 .7778015137 208.7778015137208 .7778015137208 .7778015137208 .7778015137208 .7778015137 208.7778015137208 .7778015137208 .7778015137208 .7778015137208 .7778015137 208.7778015137208 .7778015137208 .7778015137208 .7778015137208 .7778015137 208.7778015137208 .7778015137208 .7778015137208 .7778015137208 .7778015137 208.7778015137 208.7778015137 208.7778015137208.7778015137 208.7778015137 208.7778015137208 .7778015137208 .7778015137208 .7778015137208 .7778015137 208.7778015137208 .7778015137208 .7778015137208 .7778015137208 .7778015137 208.7778015137208 .7778015137208 .7778015137208 .7778015137208 .7778015137 208.7778015137208 .7778015137208 .7778015137208 .7778015137208 .7778015137 208.7778015137208 .7778015137208 .7778015137208 .7778015137208 .7778015137 208.7778015137208 .7778015137140 .2012023926141 .4203033447 -9999 -9999 -9999 -9999 -9999 -9999 -9999 -9999 -9999 -9999 -9999 -9999 -9999 -9999 -9999 -9999 -9999 -9999 -9999

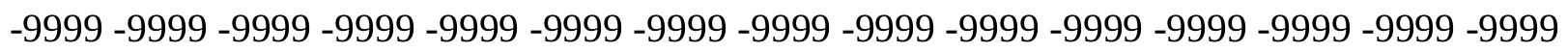
-9999 -9999 -9999 -9999 -9999 -9999 -9999 -9999 -9999 -9999 -9999 -9999 -

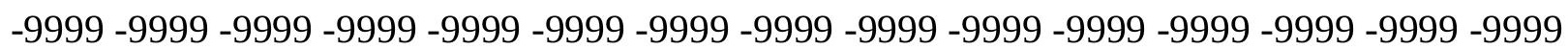
-9999 -9999 -9999 -9999 -9999 -9999 -9999 -9999 -9999 -9999 -9999 -9999 -9999 -9999 -9999 -

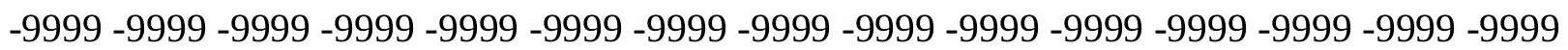

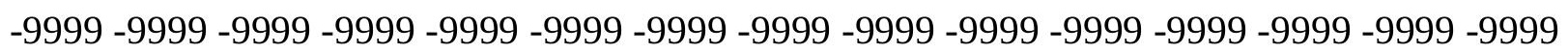

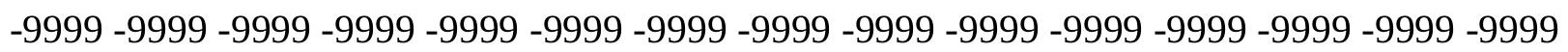
-9999 -9999 -9999 -9999 -9999 -9999 -9999 -9999 -9999 -9999 -9999 -9999 -9999 82.9015579223682 .9015579223682 .9015579223682 .9015579223684 .73026275635 87.1685485839892 .65467834473103 .3221969604114 .9039993286122 .2188034058 122.2600326538121 .9578704834122 .6919631958124 .1285705566125 .1628417969 125.1661987305124 .863067627124 .9010314941125 .2667007446124 .6570968628 122.8283996582118 .5614013672112 .4656982422103 .017402648995 .09295654297 94.7881774902394 .4833908081193 .8738174438595 .397743225199 .66472625732 103.3221969604106 .0652008057107 .8938980103109 .1130981445110 .3321990967 111.24659729112 .4656982422113 .9896011353115 .5136032104117 .0374984741 118.5614013672119 .1709976196120 .0852966309120 .6949005127118 .2565994263 115.818397522113 .3800964355110 .9418029785109 .1130981445107 .2844009399 106.3700027466105 .1509017944104 .2365036011103 .3221969604102 .712600708 101.7982025146100 .883903503499 .9695205688599 .3599472045998 .75038146973 98.445587158298 .445587158298 .7503814697399 .0551681518699 .66472625732 100.2742996216101 .1886978149102 .1029968262103 .0174026489104 .2365036011 105.1509017944105 .7603988647106 .6747970581107 .5891036987108 .1986999512 109.1130981445110 .0273971558110 .6370010376111 .551399231112 .1608963013 112.7705001831113 .3800964355113 .9896011353114 .2944030762114 .5991973877 114.5991973877114 .9039993286114 .9039993286114 .9039993286114 .9039993286 115.2088012695115 .2088012695115 .5136032104115 .5136032104115 .818397522 
116.1231002808116 .1231002808116 .1231002808115 .818397522115 .2088012695 114.5991973877113 .9896011353113 .6848983765113 .3800964355113 .3800964355 113.9896011353114 .5991973877115 .5136032104116 .7326965332117 .647102356 118.5614013672119 .7806015015120 .6949005127121 .9140014648122 .2188034058 122.5235977173122 .8283996582123 .43800354123 .7427978516124 .0475006104 124.3523025513124 .6570968628124 .6570968628124 .9618988037124 .6570968628 124.3523025513123 .7427978516123 .1332015991123 .1332015991123 .43800354 123.43800354123 .1332015991122 .5235977173121 .9140014648121 .3044967651 120.3900985718119 .4757995605118 .2565994263117 .342300415116 .1231002808 114.9039993286113 .9896011353113 .075302124111 .8561019897110 .9418029785 110.0273971558109 .4179000854108 .5035018921107 .8938980103107 .2844009399 106.979598999106 .6747970581106 .3700027466106 .0652008057105 .7603988647 105.7603988647106 .0652008057106 .3700027466106 .6747970581106 .979598999 106.979598999 106.979598999 107.2844009399 107.2844009399 107.2844009399 107.5891036987109 .7226028442112 .1608963013115 .818397522121 .3044967651 131.0576019287145 .9920959473163 .6696014404181 .3471984863198 .1103057861 208.7778015137208 .7778015137208 .7778015137208 .7778015137208 .7778015137 208.7778015137208 .7778015137208 .7778015137208 .7778015137208 .7778015137 208.7778015137208 .7778015137208 .7778015137208 .7778015137208 .7778015137 208.7778015137 208.7778015137208.7778015137208.7778015137 208.7778015137 208.7778015137208.7778015137208.7778015137208.7778015137 208.7778015137 208.7778015137208 .7778015137208 .7778015137208 .7778015137208 .7778015137 208.7778015137208 .7778015137208 .7778015137208 .7778015137208 .7778015137 208.7778015137208.7778015137208.7778015137208.7778015137208.7778015137 208.7778015137 208.7778015137208.7778015137208.7778015137 208.7778015137 208.7778015137208 .7778015137208 .7778015137208 .7778015137208 .7778015137 208.7778015137208 .7778015137208 .7778015137208 .7778015137208 .7778015137 208.7778015137208 .7778015137208 .7778015137208 .7778015137208 .7778015137 208.7778015137208 .7778015137208 .7778015137208 .7778015137208 .7778015137 208.7778015137208 .7778015137208 .7778015137208 .7778015137208 .7778015137 208.7778015137208 .7778015137208 .7778015137208 .7778015137208 .7778015137 208.7778015137208.7778015137208.7778015137 208.7778015137 139.8963928223 -9999 -9999 -9999 -9999 -9999 -9999 -9999 -9999 -9999 -9999 -9999 -9999 -9999 -9999 -9999 -9999 -9999 -9999 -9999 -9999 -9999 -9999 -9999 -9999 -9999 -9999 -9999 -9999 -9999 -9999 -9999 -9999 -9999 -9999 -9999 -9999 -9999 -9999 -9999 -9999 -9999 -9999 -9999 -9999 -9999 -9999 -

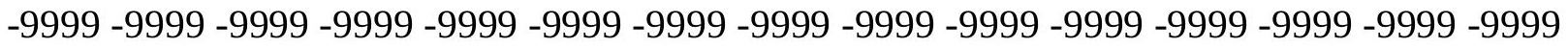

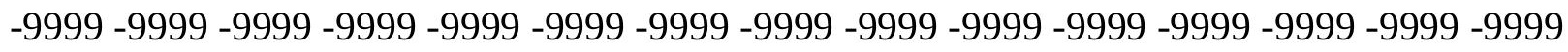

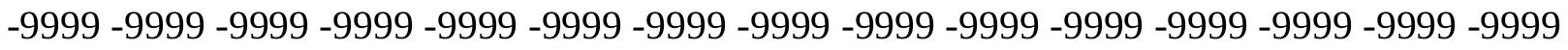

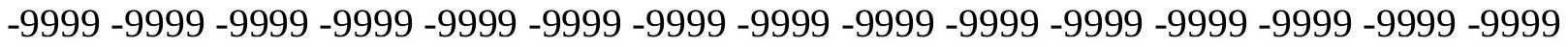
-9999 -9999 -9999 -9999 -9999 -9999 -9999 -9999 -9999 -9999 -9999 -9999 -9999 -9999 -9999 -9999 -9999 -9999-9999 -9999 -9999 -9999 -9999 -9999-9999 -9999-9999 84.12069702148 85.0350494384884 .7302627563585 .9494018554787 .1685485839888 .69246673584 90.5211791992295 .3977432251108 .8082962036121 .6092987061124 .3523025513 123.1332015991122 .5235977173121 .9140014648122 .8283996582123 .7427978516 122.2188034058120 .6949005127119 .7806015015119 .1709976196118 .2565994263 116.7326965332115 .2088012695112 .7705001831108 .1986999512101 .4934005737 
98.1408081054796.9216690063595.7025299072395.0929565429796.00731658936 98.4455871582102 .4077987671104 .5412979126106 .0652008057107 .5891036987 108.8082962036110 .0273971558111 .551399231112 .7705001831113 .9896011353 114.5991973877115 .2088012695115 .2088012695114 .9039993286113 .075302124 111.24659729109 .1130981445107 .5891036987106 .3700027466105 .4557037354 104.8460998535104 .2365036011103 .6268997192102 .712600708101 .7982025146 100.883903503499 .9695205688599 .0551681518698 .445587158297 .83602905273 97.5312423706197 .2264633178797 .5312423706197 .8360290527398 .4455871582 99.35994720459100 .2742996216101 .1886978149102 .4077987671103 .3221969604 104.2365036011105 .1509017944106 .0652008057106 .6747970581107 .5891036987 108.5035018921109 .1130981445110 .0273971558110 .9418029785111 .8561019897 112.4656982422113 .075302124113 .6848983765113 .9896011353114 .2944030762 114.5991973877114 .5991973877114 .5991973877114 .5991973877114 .5991973877 114.5991973877114 .5991973877114 .9039993286115 .2088012695115 .818397522 116.1231002808116 .4279022217116 .4279022217116 .1231002808115 .5136032104 114.5991973877113 .6848983765113 .075302124112 .4656982422112 .7705001831 113.3800964355113 .9896011353114 .9039993286115 .818397522116 .7326965332 117.9517974854118 .8662033081119 .7806015015120 .6949005127121 .3044967651 121.9140014648122 .2188034058122 .8283996582123 .1332015991123 .7427978516 124.0475006104124 .3523025513124 .6570968628124 .9618988037124 .9618988037 124.6570968628124 .0475006104123 .1332015991123 .43800354123 .7427978516 123.7427978516123 .7427978516123 .1332015991122 .5235977173121 .6092987061 120.6949005127119 .4757995605118 .2565994263117 .0374984741115 .818397522 114.5991973877113 .6848983765112 .4656982422111 .551399231110 .6370010376 109.7226028442108 .8082962036107 .8938980103107 .2844009399106 .6747970581 106.0652008057105 .7603988647105 .4557037354105 .4557037354105 .1509017944 104.8460998535105 .1509017944105 .7603988647106 .0652008057106 .3700027466 106.3700027466106 .6747970581106 .6747970581106 .979598999107 .2844009399 107.2844009399 108.5035018921 110.3321990967112.7705001831 116.4279022217 123.43800354140 .2012023926158 .7929992676177 .3849029541194 .7577056885 208.7778015137208 .7778015137208 .7778015137208 .7778015137208 .7778015137 208.7778015137 208.7778015137208.7778015137 208.7778015137208.7778015137 208.7778015137208 .7778015137208 .7778015137208 .7778015137208 .7778015137 208.7778015137208 .7778015137208 .7778015137208 .7778015137208 .7778015137 208.7778015137208.7778015137208.7778015137208.7778015137208.7778015137 208.7778015137208 .7778015137208 .7778015137208 .7778015137208 .7778015137 208.7778015137208.7778015137208.7778015137 208.7778015137 208.7778015137 208.7778015137 208.7778015137208.7778015137208.7778015137 208.7778015137 208.7778015137208 .7778015137208 .7778015137208 .7778015137208 .7778015137 208.7778015137208 .7778015137208 .7778015137208 .7778015137208 .7778015137 208.7778015137208 .7778015137208 .7778015137208 .7778015137208 .7778015137 208.7778015137208.7778015137208.7778015137208.7778015137 208.7778015137 208.7778015137208 .7778015137208 .7778015137208 .7778015137208 .7778015137 208.7778015137208.7778015137208.7778015137208.7778015137208.7778015137 208.7778015137208 .7778015137208 .7778015137208 .7778015137208 .7778015137 208.7778015137208.7778015137208.7778015137208.7778015137138.6772003174 
139.8963928223 -9999 -9999 -9999 -9999 -9999 -9999 -9999 -9999 -9999 -9999 -9999 -9999 -9999 -9999 -9999 -9999 -9999 -9999 -9999 -9999 -9999 -9999 -9999 -9999 -9999 -9999 -9999

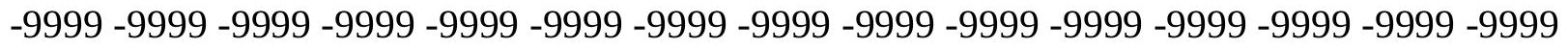
-9999 -9999-9999

-9999 -9999 -9999 -9999 -9999 -9999 -9999 -9999 -9999 -9999 -9999 -9999 -9999 -9999 -9999 -9999 -9999 -9999 -9999 -9999 -9999 -9999 -9999 -9999 -9999 -9999 -9999 -9999 -9999 -9999

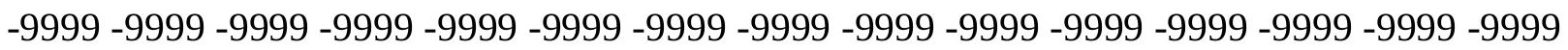
-9999 -9999 -9999 -9999 -9999 -9999 -9999 -9999 -9999 -9999 -9999 -9999 -9999 -9999 -9999

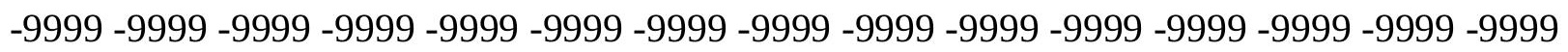
-9999 -9999 -9999 -9999-9999 -9999 -9999 -9999 -9999 -9999 -9999 84.42548370361 86.8637619018688 .0829010009889 .302040100190 .2164001464891 .13075256348 92.6546783447395 .09295654297100 .2742996216110 .6370010376120 .0852966309 122.5235977173122 .2188034058121 .9140014648121 .3044967651121 .6092987061 121.3044967651119 .4757995605117 .342300415115 .818397522114 .9039993286 113.6848983765113 .075302124112 .7705001831112 .7705001831111 .551399231 108.8082962036104 .541297912699 .6647262573297 .5312423706196 .31210327148 97.22646331787100 .2742996216103 .6268997192104 .8460998535105 .1509017944 104.8460998535106 .0652008057107 .2844009399109 .1130981445110 .3321990967 110.9418029785110 .9418029785110 .6370010376110 .0273971558109 .1130981445 107.8938980103106 .3700027466105 .1509017944104 .5412979126103 .9317016602 104.2365036011104 .2365036011103 .9317016602103 .3221969604102 .4077987671 101.7982025146100 .883903503499 .66472625732100 .274299621699 .66472625732 98.7503814697396 .9216690063596 .6168823242296 .6168823242296 .92166900635 97.5312423706198 .445587158299 .66472625732100 .5791015625101 .7982025146 103.0174026489103 .9317016602104 .5412979126105 .4557037354106 .0652008057 106.979598999107 .5891036987108 .5035018921109 .4179000854110 .3321990967 111.24659729112 .1608963013112 .7705001831113 .3800964355113 .6848983765 113.9896011353114 .2944030762114 .2944030762114 .5991973877114 .2944030762 114.2944030762114 .2944030762114 .2944030762114 .5991973877114 .9039993286 115.818397522116 .7326965332117 .0374984741117 .342300415117 .0374984741 116.1231002808114 .9039993286113 .6848983765112 .7705001831112 .1608963013 112.1608963013112 .7705001831113 .6848983765114 .2944030762115 .2088012695 115.818397522116 .7326965332117 .647102356118 .5614013672119 .1709976196 120.0852966309120 .6949005127121 .3044967651121 .6092987061122 .2188034058 122.8283996582123 .1332015991123 .43800354123 .7427978516124 .6570968628 124.9618988037124 .9618988037124 .6570968628123 .7427978516123 .7427978516 124.0475006104124 .3523025513124 .0475006104123 .43800354122 .8283996582 121.6092987061120 .3900985718119 .1709976196117 .647102356116 .4279022217 115.2088012695114 .2944030762113 .075302124112 .1608963013110 .9418029785 110.0273971558109 .1130981445108 .1986999512107 .2844009399106 .3700027466 105.7603988647105 .4557037354105 .1509017944104 .8460998535104 .5412979126 104.2365036011103 .9317016602103 .9317016602104 .5412979126105 .1509017944 105.4557037354105 .7603988647106 .0652008057106 .3700027466106 .6747970581 106.979598999107 .2844009399107 .5891036987109 .1130981445110 .6370010376 114.9039993286123 .43800354138 .3724975586156 .6596069336175 .2514038086 192.9290008545208 .4730072021208 .7778015137208 .7778015137208 .7778015137 
208.7778015137 208.7778015137208.7778015137208.7778015137 208.7778015137 208.7778015137208 .7778015137208 .7778015137208 .7778015137208 .7778015137 208.7778015137208 .7778015137208 .7778015137208 .7778015137208 .7778015137 208.7778015137208 .7778015137208 .7778015137208 .7778015137208 .7778015137 208.7778015137208 .7778015137208 .7778015137208 .7778015137208 .7778015137 208.7778015137208 .7778015137208 .7778015137208 .7778015137208 .7778015137 208.7778015137208 .7778015137208 .7778015137208 .7778015137208 .7778015137 208.7778015137 208.7778015137 208.7778015137 208.7778015137 208.7778015137 208.7778015137208 .7778015137208 .7778015137208 .7778015137208 .7778015137 208.7778015137208 .7778015137208 .7778015137208 .7778015137208 .7778015137 208.7778015137 208.7778015137208.7778015137208.7778015137 208.7778015137 208.7778015137208 .7778015137208 .7778015137208 .7778015137208 .7778015137 208.7778015137 208.7778015137 208.7778015137 208.7778015137 208.7778015137 208.7778015137208 .7778015137208 .7778015137208 .7778015137208 .7778015137 208.7778015137208 .7778015137208 .7778015137208 .7778015137208 .7778015137 208.7778015137 138.3724975586 139.5915985107 -9999 -9999 -9999 -9999 -9999 -9999 -9999 -9999 -9999 -9999 -9999 -9999 -9999 -9999 -9999 -9999 -9999 -9999 -9999 -9999 -9999 -9999 -9999 -9999 -9999 -9999 -9999 -9999 -9999 -9999 -9999 -9999 -9999 -9999 -9999 -9999 -9999 -9999 -9999 -9999 -9999-9999 -9999-9999

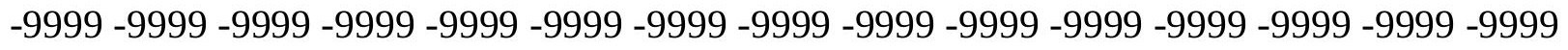

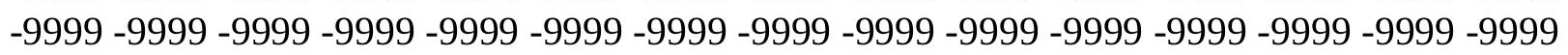

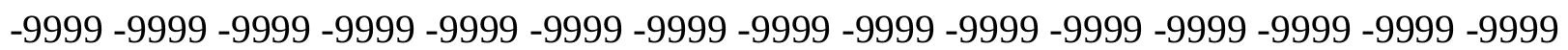
-9999 -9999 -9999 -9999 -9999 -9999 -9999 -9999 -9999 -9999 -9999 -9999 -9999 -9999 -9999 -9999 -9999 -9999 -9999 -9999 -9999 -9999 -9999 -9999 -9999 -9999 -9999 -9999 -9999 -9999 -9999 -9999 -9999 -9999 -9999 -9999 -9999 -9999 -9999 -9999 85.94940185547 90.2164001464891 .7403335571392 .349891662693 .5690307617294 .48339080811 95.397743225197 .22646331787100 .5791015625105 .1509017944110 .9418029785 116.4279022217119 .4757995605120 .9997024536121 .3044967651121 .3044967651 120.3900985718118 .8662033081116 .7326965332114 .5991973877112 .4656982422 110.6370010376109 .7226028442109 .4179000854110 .0273971558111 .24659729 112.4656982422113 .3800964355114 .2944030762114 .5991973877115 .5136032104 116.1231002808116 .1231002808117 .0374984741120 .9997024536123 .43800354 120.3900985718116 .1231002808113 .3800964355111 .24659729109 .7226028442 108.5035018921109 .1130981445108 .1986999512106 .979598999106 .3700027466 105.1509017944104 .2365036011102 .712600708102 .4077987671102 .1029968262 102.712600708103 .3221969604104 .2365036011103 .9317016602103 .3221969604 102.712600708102 .1029968262101 .188697814999 .96952056885100 .2742996216 99.3599472045997.2264633178796.6168823242296.3121032714896.00731658936 96.3121032714896 .9216690063597 .8360290527399 .05516815186100 .2742996216 101.4934005737102 .712600708103 .6268997192104 .2365036011104 .8460998535 105.4557037354106 .0652008057106 .6747970581107 .5891036987108 .5035018921 109.7226028442110 .6370010376111 .8561019897112 .4656982422113 .3800964355 113.6848983765113 .9896011353114 .2944030762114 .5991973877114 .5991973877 114.5991973877114 .2944030762113 .9896011353113 .9896011353113 .9896011353 114.9039993286115 .818397522117 .342300415118 .2565994263118 .8662033081 118.5614013672117 .647102356116 .1231002808114 .5991973877113 .075302124 
112.1608963013112 .1608963013112 .7705001831113 .3800964355113 .9896011353 114.2944030762114 .9039993286115 .5136032104116 .1231002808116 .7326965332 117.647102356118 .5614013672119 .1709976196119 .7806015015120 .0852966309 120.6949005127121 .3044967651121 .3044967651121 .6092987061122 .2188034058 123.1332015991124 .3523025513124 .9618988037124 .3523025513123 .7427978516 123.43800354124 .0475006104124 .3523025513124 .0475006104123 .43800354 122.5235977173121 .3044967651119 .7806015015118 .2565994263116 .7326965332 115.5136032104114 .5991973877113 .3800964355112 .4656982422111 .551399231 110.6370010376109 .4179000854108 .5035018921107 .2844009399106 .3700027466 105.4557037354104 .8460998535104 .5412979126104 .2365036011103 .9317016602 103.9317016602103 .6268997192103 .3221969604103 .0174026489103 .3221969604 103.6268997192104 .2365036011104 .8460998535105 .1509017944105 .4557037354 106.0652008057106 .3700027466106 .979598999107 .2844009399108 .1986999512 110.0273971558114 .2944030762123 .7427978516138 .0677032471156 .3547973633 174.6419067383192 .0146026611207 .25390625208 .7778015137208 .7778015137 208.7778015137208 .7778015137208 .7778015137208 .7778015137208 .7778015137 208.7778015137208 .7778015137208 .7778015137208 .7778015137208 .7778015137 208.7778015137208 .7778015137208 .7778015137208 .7778015137208 .7778015137 208.7778015137208 .7778015137208 .7778015137208 .7778015137208 .7778015137 208.7778015137208 .7778015137208 .7778015137208 .7778015137208 .7778015137 208.7778015137208 .7778015137208 .7778015137208 .7778015137208 .7778015137 208.7778015137208 .7778015137208 .7778015137208 .7778015137208 .7778015137 208.7778015137208 .7778015137208 .7778015137208 .7778015137208 .7778015137 208.7778015137208 .7778015137208 .7778015137208 .7778015137208 .7778015137 208.7778015137208 .7778015137208 .7778015137208 .7778015137208 .7778015137 208.7778015137 208.7778015137208.7778015137 208.7778015137 208.7778015137 208.7778015137208 .7778015137208 .7778015137208 .7778015137208 .7778015137 208.7778015137208 .7778015137208 .7778015137208 .7778015137208 .7778015137 208.7778015137208 .7778015137208 .7778015137208 .7778015137208 .7778015137 208.7778015137208 .7778015137208 .7778015137208 .7778015137208 .7778015137 208.7778015137 208.7778015137 137.1533050537 138.3724975586 -9999 -9999 -9999-9999 -9999 -9999 -9999 -9999 -9999 -9999 -9999 -9999 -9999 -9999 -9999 -9999 -9999 -9999 -9999

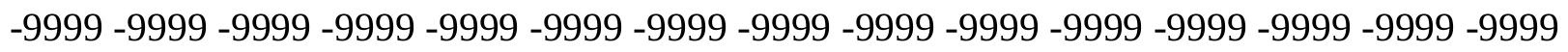
-9999 -9999 -9999 -9999 -9999 -9999 -9999 -9999 -9999 -9999

-9999 -9999 -9999 -9999 -9999 -9999 -9999 -9999 -9999 -9999 -9999 -9999 -9999 -9999 -9999

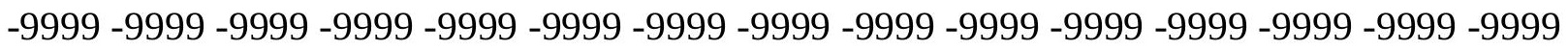

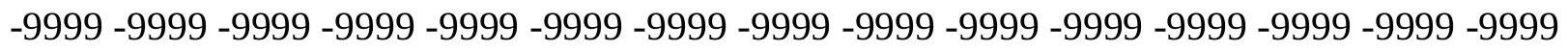

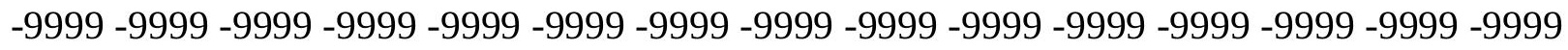

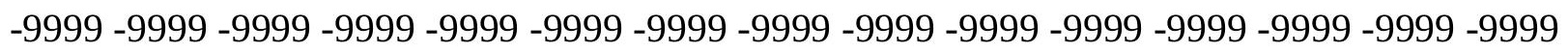
-9999 -9999 -9999 -9999 -9999 -9999 -9999 -9999-9999-9999 90.52117919922 92.95947265625 93.8738174438594.7881774902396.3121032714897.83602905273 99.35994720459101 .4934005737104 .5412979126107 .8938980103111 .8561019897 115.5136032104117 .9517974854120 .0852966309120 .9997024536120 .3900985718 119.1709976196117 .0374984741114 .5991973877111 .551399231108 .8082962036 106.0652008057 104.2365036011 103.9317016602106 .0652008057108 .8082962036 110.9418029785114 .9039993286123 .43800354131 .3623962402134 .1054992676 
134.4102020264 136.2389984131 138.9819946289143 .5538024902146 .9064025879 145.3825073242143 .2489929199143 .5538024902143 .5538024902141 .1154937744 137.4580993652135 .0198059082132 .8863067627131 .6672058105128 .9241027832 122.2188034058114 .9039993286110 .0273971558105 .4557037354105 .1509017944 104.8460998535104 .8460998535105 .7603988647106 .6747970581106 .0652008057 105.1509017944103 .3221969604102 .4077987671100 .579101562599 .05516815186 98.445587158297 .8360290527396 .9216690063596 .3121032714895 .70252990723 95.7025299072396 .3121032714897 .5312423706198 .75038146973100 .2742996216 101.4934005737102 .712600708103 .6268997192104 .2365036011104 .5412979126 104.8460998535105 .1509017944105 .7603988647106 .6747970581107 .8938980103 109.1130981445110 .3321990967111 .551399231112 .4656982422113 .3800964355 113.9896011353114 .2944030762114 .5991973877114 .9039993286117 .0374984741 117.0374984741114 .9039993286114 .2944030762113 .6848983765113 .6848983765 114.2944030762116 .1231002808118 .2565994263120 .0852966309120 .9997024536 120.6949005127119 .4757995605117 .647102356116 .1231002808114 .5991973877 112.7705001831113 .3800964355113 .6848983765113 .6848983765113 .6848983765 113.6848983765113 .6848983765113 .9896011353114 .5991973877115 .2088012695 115.818397522116 .7326965332117 .342300415117 .647102356117 .9517974854 118.2565994263118 .2565994263118 .2565994263118 .5614013672119 .1709976196 120.0852966309121 .6092987061123 .7427978516122 .2188034058121 .6092987061 121.9140014648123 .1332015991123 .7427978516123 .7427978516122 .5235977173 121.3044967651119 .7806015015118 .2565994263116 .7326965332115 .5136032104 114.5991973877113 .6848983765112 .7705001831111 .8561019897110 .9418029785 110.0273971558108 .8082962036107 .8938980103106 .6747970581105 .4557037354 104.5412979126103 .9317016602103 .6268997192103 .3221969604103 .3221969604 103.0174026489103 .0174026489102 .712600708102 .4077987671102 .1029968262 102.4077987671103 .0174026489103 .6268997192104 .2365036011104 .8460998535 105.4557037354106 .0652008057106 .3700027466106 .979598999107 .5891036987 109.4179000854113 .3800964355122 .2188034058137 .4580993652156 .9642944336 174.9467010498191 .7097930908206 .6443023682208 .7778015137208 .7778015137 208.7778015137208 .7778015137208 .7778015137208 .7778015137208 .7778015137 208.7778015137 208.7778015137208.7778015137 208.7778015137208.7778015137 208.7778015137208 .7778015137208 .7778015137208 .7778015137208 .7778015137 208.7778015137208 .7778015137208 .7778015137208 .7778015137208 .7778015137 208.7778015137208 .7778015137208 .7778015137208 .7778015137208 .7778015137 208.7778015137208 .7778015137208 .7778015137208 .7778015137208 .7778015137 208.7778015137208.7778015137208.7778015137 208.7778015137 208.7778015137 208.7778015137 208.7778015137208.7778015137208.7778015137 208.7778015137 208.7778015137208 .7778015137208 .7778015137208 .7778015137208 .7778015137 208.7778015137208 .7778015137208 .7778015137208 .7778015137208 .7778015137 208.7778015137208 .7778015137208 .7778015137208 .7778015137208 .7778015137 208.7778015137208.7778015137208.7778015137208.7778015137 208.7778015137 208.7778015137208 .7778015137208 .7778015137208 .7778015137208 .7778015137 208.7778015137208 .7778015137208 .7778015137208 .7778015137208 .7778015137 208.7778015137 208.7778015137208.7778015137 208.7778015137 208.7778015137 208.7778015137 208.7778015137208.7778015137 136.8484954834138.0677032471 -9999 
-9999 -9999 -9999 -9999 -9999 -9999 -9999 -9999 -9999 -9999 -9999 -9999 -9999 -9999 -9999 -9999 -9999 -9999 -9999 -9999 -9999 -9999 -9999 -9999 -9999 -9999 -9999 -9999 -9999 -9999 -9999 -9999 -9999 -9999 -9999 -9999 -9999 -9999 -9999 -9999 -9999 -9999 -

-9999 -9999 -9999 -9999 -9999 -9999 -9999 -9999 -9999 -9999 -9999 -9999 -9999 -9999 -9999 -9999 -9999 -9999 -9999 -9999 -9999 -9999 -9999 -9999 -9999 -9999 -9999-9999 -9999 -9999 -9999 -9999 -9999 -9999 -9999 -9999 -9999 -9999 -9999 -9999 -9999 -9999 -9999 -9999 -9999

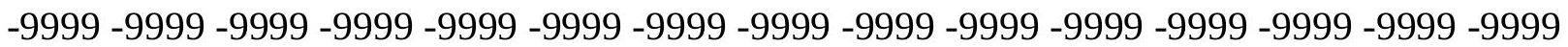
-9999 -9999 -9999 -9999 -9999 -9999 -9999 -9999 -9999 -9999 -9999 -9999 -9999 -9999 -9999 -9999 -9999 -9999 -9999 -9999 -9999 -9999 -9999 -9999 95.70252990723 95.09295654297 95.397743225196 .0073165893697 .2264633178799 .35994720459101 .4934005737 103.9317016602106 .0652008057108 .5035018921110 .9418029785113 .3800964355 116.1231002808118 .5614013672120 .0852966309120 .6949005127120 .0852966309 118.5614013672116 .1231002808112 .7705001831109 .1130981445105 .1509017944 101.798202514699 .3599472045998 .4455871582100 .5791015625104 .2365036011 107.2844009399113 .075302124127 .0953979492140 .8106994629145 .0776977539 146.6015930176151 .1734008789155 .4403991699160 .0122070312163 .3648071289 163.6696014404163 .974395752167 .3269958496170 .070098877166 .1078948975 161.2312927246157 .878692627156 .0500030518158 .4882965088159 .4026031494 154.8307952881148 .7351074219142 .9441986084137 .4580993652131 .0576019287 125.2667007446120 .9997024536116 .7326965332111 .551399231105 .7603988647 104.5412979126105 .7603988647103 .6268997192100 .883903503499 .05516815186 99.0551681518698 .7503814697397 .5312423706196 .3121032714895 .70252990723 95.7025299072396 .0073165893697 .2264633178798 .75038146973100 .5791015625 101.7982025146103 .0174026489103 .6268997192103 .9317016602104 .2365036011 104.2365036011104 .2365036011104 .8460998535105 .7603988647106 .6747970581 108.1986999512109 .7226028442111 .24659729112 .4656982422113 .3800964355 113.9896011353114 .5991973877115 .2088012695118 .2565994263119 .1709976196 118.8662033081117 .647102356114 .9039993286113 .6848983765113 .075302124 113.9896011353116 .1231002808119 .1709976196121 .9140014648123 .43800354 123.1332015991121 .3044967651119 .7806015015118 .5614013672117 .9517974854 117.0374984741116 .4279022217115 .5136032104114 .5991973877113 .6848983765 113.075302124112 .7705001831112 .4656982422112 .7705001831113 .3800964355 113.9896011353114 .9039993286115 .5136032104115 .5136032104115 .2088012695 114.9039993286114 .5991973877114 .5991973877114 .9039993286114 .9039993286 115.5136032104116 .4279022217117 .342300415117 .342300415117 .647102356 118.8662033081120 .6949005127122 .5235977173121 .9140014648120 .6949005127 119.4757995605117 .647102356116 .1231002808114 .9039993286113 .6848983765 113.075302124112 .4656982422111 .8561019897111 .24659729110 .3321990967 109.4179000854108.5035018921 107.2844009399105.7603988647104.5412979126 103.3221969604102 .712600708102 .4077987671102 .4077987671102 .4077987671 102.4077987671102 .4077987671102 .1029968262101 .7982025146101 .4934005737 101.4934005737101 .7982025146102 .712600708103 .3221969604103 .9317016602 104.5412979126105 .4557037354106 .0652008057106 .6747970581106 .979598999 108.8082962036112 .1608963013119 .1709976196136 .2389984131155 .7451934814 174.6419067383191 .4051055908206 .0346984863208 .7778015137208 .7778015137 208.7778015137 208.7778015137208.7778015137 208.7778015137 208.7778015137 
208.7778015137 208.7778015137208.7778015137208.7778015137 208.7778015137 208.7778015137208 .7778015137208 .7778015137208 .7778015137208 .7778015137 208.7778015137208 .7778015137208 .7778015137208 .7778015137208 .7778015137 208.7778015137208 .7778015137208 .7778015137208 .7778015137208 .7778015137 208.7778015137208 .7778015137208 .7778015137208 .7778015137208 .7778015137 208.7778015137208 .7778015137208 .7778015137208 .7778015137208 .7778015137 208.7778015137208 .7778015137208 .7778015137208 .7778015137208 .7778015137 208.7778015137 208.7778015137 208.7778015137 208.7778015137 208.7778015137 208.7778015137208 .7778015137208 .7778015137208 .7778015137208 .7778015137 208.7778015137208 .7778015137208 .7778015137208 .7778015137208 .7778015137 208.7778015137 208.7778015137208.7778015137208.7778015137 208.7778015137 208.7778015137208 .7778015137208 .7778015137208 .7778015137208 .7778015137 208.7778015137 208.7778015137 208.7778015137 208.7778015137 208.7778015137 208.7778015137208 .7778015137208 .7778015137208 .7778015137208 .7778015137 $208.7778015137208 .7778015137208 .7778015137135 .6293945312136 .8484954834-9999$ -9999 -9999 -9999 -9999 -9999 -9999 -9999 -9999 -9999 -9999 -9999 -9999 -9999 -9999 -9999

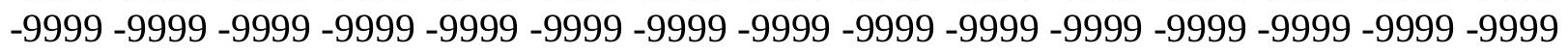

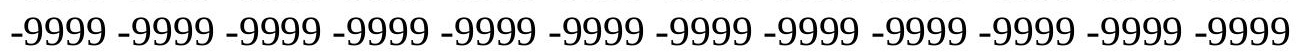
-9999 -9999 -9999 -9999 -9999 -9999 -9999 -9999 -9999 -9999 -9999 -9999 -9999 -9999 -9999 -9999 -9999 -9999 -9999 -9999 -9999 -9999 -9999 -9999 -9999 -9999 -9999 -9999 -9999 -9999 -

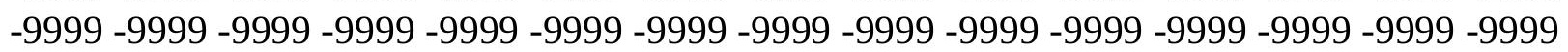

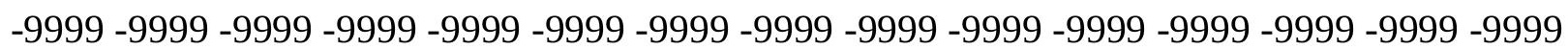
-9999 -9999 -9999 -9999 -9999 -9999 -9999 -9999 -9999 -9999 -9999 -9999 -9999 -9999 -9999 -9999 -9999 -9999 -9999 -9999 -9999 -9999 -9999 112.7705001831104 .2365036011 100.579101562599 .9695205688599 .66472625732100 .8839035034103 .3221969604 106.6747970581110 .3321990967112 .7705001831113 .6848983765114 .5991973877 116.4279022217118 .8662033081120 .3900985718121 .6092987061122 .2188034058 121.3044967651119 .1709976196115 .818397522111 .8561019897106 .979598999 102.4077987671 98.1408081054795.0929565429793.5690307617298.75038146973 105.7603988647105 .4557037354107 .2844009399117 .9517974854130 .1432037354 141.4203033447151 .4781951904159 .7073974609165 .8031005859169 .4604949951 171.8988037109174 .0323028564175 .8609924316178 .6497344971180 .2446289062 179.609375177 .1519165039174 .7788696289174 .053604126175 .3079986572175 .817779541 173.0176086426167 .0222015381164 .2792053223161 .8408966064158 .4882965088 154.8307952881151 .7830047607147 .8208007812141 .4203033447134 .4102020264 128.0097961426121 .3044967651113 .075302124104 .236503601198 .75038146973 99.66472625732100 .883903503496 .9216690063596 .3121032714896 .00731658936 95.7025299072396 .0073165893697 .2264633178799 .05516815186100 .8839035034 102.4077987671103 .3221969604103 .9317016602103 .9317016602103 .6268997192 103.3221969604103 .3221969604103 .6268997192104 .2365036011105 .7603988647 107.5891036987 109.7226028442 111.551399231 112.7705001831 113.6848983765 114.2944030762115 .2088012695117 .647102356120 .6949005127121 .6092987061 121.3044967651119 .7806015015116 .4279022217114 .2944030762112 .4656982422 113.075302124115 .818397522119 .7806015015123 .1332015991126 .1809997559 124.9618988037123 .43800354120 .9997024536121 .6092987061121 .9140014648 121.6092987061120 .0852966309117 .647102356115 .5136032104113 .6848983765 
112.7705001831111 .8561019897111 .24659729110 .9418029785111 .24659729 112.4656982422113 .3800964355113 .6848983765113 .3800964355112 .4656982422 111.551399231110 .9418029785110 .6370010376110 .6370010376110 .3321990967 110.3321990967110 .0273971558110 .0273971558110 .6370010376111 .8561019897 114.2944030762116 .7326965332118 .5614013672118 .8662033081117 .9517974854 116.7326965332114 .9039993286113 .6848983765112 .4656982422111 .551399231 111.24659729110 .9418029785110 .9418029785110 .6370010376110 .0273971558 109.1130981445107 .8938980103106 .6747970581105 .1509017944103 .6268997192 102.712600708101 .7982025146101 .4934005737101 .4934005737101 .4934005737 101.4934005737101 .7982025146101 .4934005737101 .1886978149100 .8839035034 100.8839035034101 .1886978149101 .4934005737102 .4077987671103 .0174026489 103.9317016602104 .5412979126105 .4557037354106 .0652008057106 .6747970581 110.3321990967111 .24659729120 .0852966309135 .0198059082153 .6116943359 173.4226989746190 .1858978271204 .8155975342208 .7778015137208 .7778015137 208.7778015137208 .7778015137208 .7778015137208 .7778015137208 .7778015137 208.7778015137208 .7778015137208 .7778015137208 .7778015137208 .7778015137 208.7778015137208 .7778015137208 .7778015137208 .7778015137208 .7778015137 208.7778015137208 .7778015137208 .7778015137208 .7778015137208 .7778015137 208.7778015137208 .7778015137208 .7778015137208 .7778015137208 .7778015137 208.7778015137208 .7778015137208 .7778015137208 .7778015137208 .7778015137 208.7778015137208 .7778015137208 .7778015137208 .7778015137208 .7778015137 208.7778015137208 .7778015137208 .7778015137208 .7778015137208 .7778015137 208.7778015137208 .7778015137208 .7778015137208 .7778015137208 .7778015137 208.7778015137208 .7778015137208 .7778015137208 .7778015137208 .7778015137 208.7778015137208 .7778015137208 .7778015137208 .7778015137208 .7778015137 208.7778015137208 .7778015137208 .7778015137208 .7778015137208 .7778015137 208.7778015137208 .7778015137208 .7778015137208 .7778015137208 .7778015137 208.7778015137208 .7778015137208 .7778015137208 .7778015137208 .7778015137 208.7778015137208 .7778015137208 .7778015137208 .7778015137208 .7778015137 208.7778015137208 .7778015137208 .7778015137208 .7778015137135 .6293945312 136.5437011719 -9999 -9999 -9999 -9999 -9999 -9999 -9999 -9999 -9999 -9999 -9999 -9999 -9999 -9999 -9999 -9999 -9999 -9999 -9999 -9999 -9999 -9999 -9999 -9999 -9999 -9999 -9999 -9999 -9999 -9999 -9999 -9999 -9999 -9999 -9999 -9999 -9999 -9999 -9999 -9999 -9999 -9999 -9999 -9999 -9999 -9999 -9999 -9999 -9999 -9999 -9999 -9999 -9999 -9999 -9999 -9999 -9999

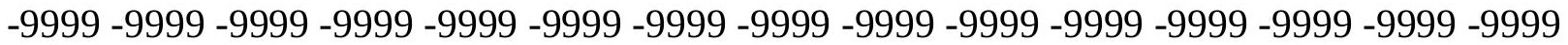
-9999 -9999 -9999 -9999 -9999 -9999 -9999 -9999 -9999 -9999 -9999 -9999 -9999 -9999 -9999

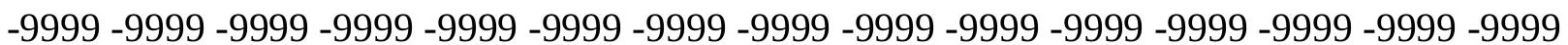
-9999 -9999 -9999 -9999 -9999 -9999 -9999 -9999 -9999 -9999 -9999 -9999 -9999 -9999 -9999 -9999 -9999 -9999 -9999 -9999 -9999-9999 148.7351074219131 .3623962402116 .4279022217 109.7226028442107 .2844009399105 .7603988647106 .979598999109 .1130981445 112.7705001831117 .342300415120 .9997024536122 .2188034058122 .2188034058 125.1707458496126 .8775558472126 .5200424194124 .6570968628124 .3523025513 123.1332015991120 .3900985718116 .4279022217111 .24659729105 .7603988647 99.9695205688595 .0929565429791 .7403335571389 .3020401001104 .5412979126 113.3800964355115 .818397522115 .2088012695109 .7226028442113 .3800964355 130.1432037354147 .2111968994158 .7929992676166 .7174987793170 .6797027588 
172.8132019043177 .3849029541181 .3471984863183 .4806976318184 .3950042725 187.2083587646186 .7998352051184 .8905029297184 .0390625184 .5274200439 184.9340667725184 .0146484375182 .0084991455180 .4791412354179 .2167816162 177.8835296631177 .2748565674178 .2993011475174 .337097168167 .6318054199 160.0122070312153 .3069000244146 .6015930176138 .6772003174131 .0576019287 124.6570968628117 .0374984741106 .370002746695 .397743225197 .53124237061 96.6168823242296 .0073165893696 .3121032714897 .8360290527399 .96952056885 101.7982025146103 .3221969604103 .9317016602103 .9317016602103 .6268997192 103.0174026489102 .1029968262101 .7982025146101 .7982025146102 .712600708 104.5412979126106 .6747970581109 .4179000854111 .8561019897113 .3800964355 114.2944030762114 .5991973877115 .5136032104119 .7806015015122 .8283996582 124.3523025513123 .7427978516122 .2188034058118 .5614013672115 .5136032104 114.2944030762112 .4656982422116 .4279022217121 .6092987061126 .7906036377 129.8385009766128 .9241027832125 .5715026855122 .8283996582124 .0475006104 127.0953979492127 .7050018311124 .6570968628119 .7806015015115 .5136032104 113.6848983765113 .3800964355112 .4656982422110 .9418029785109 .7226028442 109.7226028442111 .24659729112 .7705001831113 .6848983765112 .4656982422 110.3321990967108 .8082962036108 .1986999512107 .8938980103107 .2844009399 106.0652008057105 .4557037354104 .2365036011103 .6268997192104 .8460998535 106.0652008057109 .4179000854112 .4656982422114 .5991973877115 .2088012695 114.5991973877113 .3800964355111 .8561019897110 .6370010376109 .7226028442 109.4179000854109 .4179000854109 .7226028442110 .0273971558110 .0273971558 109.7226028442108 .8082962036107 .5891036987106 .0652008057104 .5412979126 103.0174026489101 .7982025146100 .8839035034100 .5791015625100 .2742996216 100.2742996216100 .2742996216100 .5791015625100 .5791015625100 .2742996216 100.2742996216100 .2742996216100 .5791015625100 .8839035034101 .4934005737 102.1029968262103 .0174026489103 .9317016602104 .5412979126105 .4557037354 106.0652008057106 .979598999109 .1130981445118 .5614013672132 .2767028809 149.6495056152168 .8509979248186 .8332977295202 .3773040771208 .7778015137 208.7778015137208 .7778015137208 .7778015137208 .7778015137208 .7778015137 208.7778015137208 .7778015137208 .7778015137208 .7778015137208 .7778015137 208.7778015137208 .7778015137208 .7778015137208 .7778015137208 .7778015137 208.7778015137208 .7778015137208 .7778015137208 .7778015137208 .7778015137 208.7778015137208 .7778015137208 .7778015137208 .7778015137208 .7778015137 208.7778015137208 .7778015137208 .7778015137208 .7778015137208 .7778015137 208.7778015137208 .7778015137208 .7778015137208 .7778015137208 .7778015137 208.7778015137 208.7778015137208.7778015137 208.7778015137 208.7778015137 208.7778015137208 .7778015137208 .7778015137208 .7778015137208 .7778015137 208.7778015137208 .7778015137208 .7778015137208 .7778015137208 .7778015137 208.7778015137208 .7778015137208 .7778015137208 .7778015137208 .7778015137 208.7778015137208 .7778015137208 .7778015137208 .7778015137208 .7778015137 208.7778015137208 .7778015137208 .7778015137208 .7778015137208 .7778015137 208.7778015137208 .7778015137208 .7778015137208 .7778015137208 .7778015137 208.7778015137208 .7778015137208 .7778015137208 .7778015137208 .7778015137 208.7778015137208 .7778015137208 .7778015137208 .7778015137208 .7778015137 134.1054992676 135.3246002197 -9999 -9999 -9999 -9999 -9999 -9999 -9999 -9999 -9999 
-9999 -9999 -9999 -9999 -9999 -9999 -9999 -9999 -9999 -9999 -9999 -9999 -9999 -9999 -9999 -9999 -9999 -9999 -9999 -9999 -9999 -9999 -9999 -9999 -9999 -9999 -9999 -9999 -9999 -9999 -9999 -9999-9999

-9999 -9999 -9999 -9999 -9999 -9999 -9999 -9999 -9999 -9999 -9999 -9999 -9999 -9999 -9999 -9999 -9999 -9999 -9999 -9999 -9999 -9999 -9999 -9999 -9999 -9999 -9999 -9999 - -9999 - -9999 -

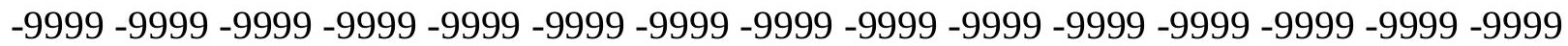

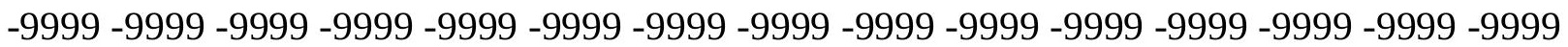

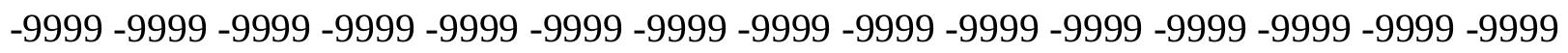
-9999 -9999 -9999 -9999 -9999-9999 177.3017425537 165.5822296143 150.9960174561 136.8484954834124 .3523025513116 .4279022217114 .2944030762115 .5136032104 117.0374984741120 .0852966309125 .5715026855129 .7922668457132 .7950897217 135.2880859375137 .4546203613137 .9901885986135 .7348022461131 .3623962402 128.3144989014125 .5715026855122 .5235977173117 .9517974854111 .8561019897 105.150901794499 .0551681518693 .8738174438589 .6068267822390 .21640014648 117.342300415120 .9997024536122 .2188034058122 .5235977173121 .9140014648 109.7226028442115 .2088012695129 .533706665142 .9441986084153 .6116943359 160.0122070312165 .8031005859174 .0323028564182 .261505127187 .1381072998 190.795501709192 .9290008545192 .9290008545188 .966796875187 .754776001 187.822479248188 .6540985107189 .6801757812190 .4853973389190 .6096954346 190.0813903809189 .3487548828189 .1309509277189 .0089874268187 .3151855469 184.5756530762182 .261505127173 .4226989746163 .974395752156 .9642944336 152.3925933838149 .9542999268145 .9920959473137 .4580993652126 .1809997559 113.3800964355101 .798202514697 .2264633178796 .9216690063599 .35994720459 101.7982025146103 .6268997192104 .5412979126104 .5412979126104 .2365036011 103.3221969604102 .1029968262100 .883903503499 .9695205688599 .66472625732 100.5791015625102 .712600708107 .2844009399109 .1130981445112 .4656982422 114.5991973877115 .2088012695114 .5991973877117 .0374984741120 .9997024536 123.7427978516125 .5715026855125 .8762969971124 .3523025513121 .3044967651 118.5614013672117 .647102356116 .4279022217119 .4757995605124 .6570968628 129.8385009766136 .8484954834133 .4958953857128 .9241027832122 .2188034058 126.7906036377133 .1911010742133 .4958953857129 .2288970947122 .5235977173 115.818397522115 .2088012695114 .9039993286114 .9039993286111 .8561019897 109.1130981445110 .0273971558111 .551399231113 .9896011353115 .818397522 113.3800964355110 .6370010376108 .1986999512108 .8082962036108 .5035018921 107.2844009399105 .7603988647104 .5412979126103 .0174026489101 .1886978149 101.1886978149103 .6268997192106 .979598999109 .4179000854110 .9418029785 111.551399231111 .24659729110 .0273971558108 .8082962036107 .5891036987 106.979598999 106.979598999 107.5891036987108.5035018921 109.4179000854 109.7226028442109 .4179000854108 .5035018921106 .979598999105 .4557037354 103.6268997192102 .1029968262100 .579101562599 .6647262573299 .05516815186 99.0551681518699 .0551681518699 .0551681518699 .0551681518699 .35994720459 99.3599472045999 .3599472045999 .3599472045999 .6647262573299 .96952056885 100.5791015625101 .1886978149102 .1029968262103 .0174026489103 .6268997192 104.5412979126105 .4557037354106 .3700027466106 .979598999114 .2944030762 127.4001998901143 .2489929199161 .2312927246180 .7375946045198 .7198944092 208.7778015137 208.7778015137208.7778015137208.7778015137 208.7778015137 
208.7778015137 208.7778015137208.7778015137208.7778015137 208.7778015137 208.7778015137208 .7778015137208 .7778015137208 .7778015137208 .7778015137 208.7778015137208 .7778015137208 .7778015137208 .7778015137208 .7778015137 208.7778015137208 .7778015137208 .7778015137208 .7778015137208 .7778015137 208.7778015137208 .7778015137208 .7778015137208 .7778015137208 .7778015137 208.7778015137208 .7778015137208 .7778015137208 .7778015137208 .7778015137 208.7778015137208 .7778015137208 .7778015137208 .7778015137208 .7778015137 208.7778015137 208.7778015137 208.7778015137 208.7778015137 208.7778015137 208.7778015137208 .7778015137208 .7778015137208 .7778015137208 .7778015137 208.7778015137208 .7778015137208 .7778015137208 .7778015137208 .7778015137 208.7778015137 208.7778015137208.7778015137208.7778015137 208.7778015137 208.7778015137208 .7778015137208 .7778015137208 .7778015137208 .7778015137 208.7778015137208.7778015137208.7778015137 208.7778015137 208.7778015137 208.7778015137208 .7778015137208 .7778015137208 .7778015137208 .7778015137 208.7778015137208 .7778015137208 .7778015137208 .7778015137208 .7778015137 208.7778015137 208.7778015137 134.1054992676 135.0198059082 -9999 -9999 -9999 -9999 -9999 -9999 -9999 -9999 -9999 -9999 -9999 -9999 -9999 -9999 -9999 -9999 -9999 -9999-9999 -

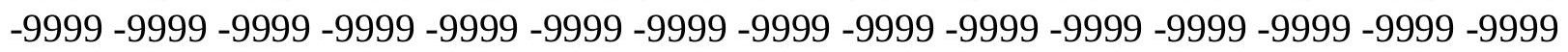
-9999 -9999 -9999 -9999 -9999-9999-9999

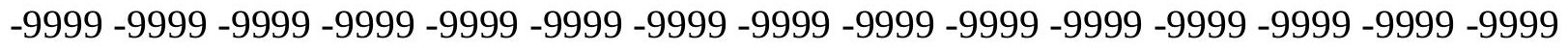

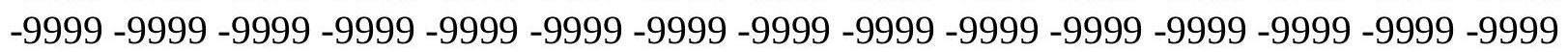

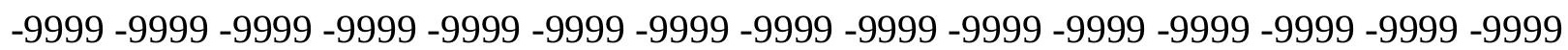
-9999 -9999 -9999 -9999 -9999 -9999 -9999 -9999 -9999 -9999 -9999 -9999 -9999 -9999 -9999 -9999 -9999 -9999 -9999 -9999 -9999 -9999 -9999 -9999 -9999 -9999 -9999 -9999 -9999 -9999 -9999 -9999 -9999 -9999-9999-9999 192.9441070557 181.6324310303 169.8169250488 157.4830322266144 .1634063721132 .2767028809129 .533706665130 .4479980469 129.2288970947131 .8849334717135 .4690551758139 .3460388184143 .3466339111 147.4234313965150 .0347290039148 .9571533203145 .3825073242137 .7628936768 132.5814971924128 .0097961426124 .0475006104119 .1709976196112 .1608963013 104.846099853598 .7503814697393 .2642517089888 .3876876831196 .31210327148 112.4656982422121 .6092987061124 .6570968628124 .6570968628121 .3044967651 113.6848983765100 .5791015625109 .1130981445121 .3044967651133 .8007049561 142.6394042969152 .0877990723165 .4983062744178 .2993011475188 .3571929932 194.7577056885197 .500793457196 .2816009521190 .1858978271187 .353515625 186.0915374756187 .0055389404189 .8366851807193 .0433349609194 .7555389404 194.2677612305 192.6242980957 191.3815765381 190.9150543213190.9647827148 190.511932373188 .6823883057183 .4960174561175 .8609924316170 .9844970703 168.241394043168 .8509979248168 .5462036133163 .6696014404154 .8307952881 139.5915985107124 .6570968628114 .5991973877107 .2844009399102 .712600708 104.5412979126105 .7603988647105 .7603988647105 .4557037354104 .5412979126 103.0174026489 101.188697814999.35994720459 97.83602905273 97.22646331787 101.1886978149104 .5412979126108 .1986999512110 .9418029785112 .7705001831 115.5136032104116 .4279022217114 .5991973877113 .9896011353114 .9039993286 116.4279022217118 .2565994263120 .6949005127123 .43800354128 .0097961426 137.7628936768146 .6015930176149 .0399017334149 .9542999268150 .8686065674 152.3925933838157 .2691040039159 .7073974609152 .3925933838146 .6015930176 
153.3069000244160 .9264984131161 .5361022949157 .5738983154148 .4304046631 139.8963928223138 .0677032471138 .0677032471137 .1533050537135 .6293945312 131.6672058105128 .3144989014128 .0097961426128 .3144989014128 .3144989014 127.4001998901125 .2667007446122 .5235977173119 .4757995605116 .1231002808 112.1608963013108 .1986999512105 .4557037354103 .0174026489100 .2742996216 98.75038146973103 .3221969604107 .8938980103110 .3321990967110 .9418029785 110.6370010376109 .4179000854107 .5891036987105 .7603988647104 .5412979126 104.2365036011104 .8460998535106 .0652008057107 .5891036987108 .8082962036 109.7226028442109 .4179000854108 .1986999512106 .6747970581104 .5412979126 102.4077987671100 .883903503499 .3599472045998 .445587158297 .83602905273 97.5312423706197 .2264633178797 .5312423706197 .5312423706197 .83602905273 98.1408081054798 .445587158298 .445587158298 .7503814697399 .35994720459 99.66472625732100 .2742996216100 .8839035034101 .7982025146102 .712600708 103.6268997192104 .5412979126105 .4557037354106 .3700027466107 .2844009399 122.2188034058134 .4102020264148 .1255950928169 .1557006836193 .233795166 201.4629974365207 .8634033203208 .7778015137208 .7778015137208 .7778015137 208.7778015137208 .7778015137208 .7778015137208 .7778015137208 .7778015137 208.7778015137208 .7778015137208 .7778015137208 .7778015137208 .7778015137 208.7778015137208 .7778015137208 .7778015137208 .7778015137208 .7778015137 208.7778015137208 .7778015137208 .7778015137208 .7778015137208 .7778015137 208.7778015137208 .7778015137208 .7778015137208 .7778015137208 .7778015137 208.7778015137208 .7778015137208 .7778015137208 .7778015137208 .7778015137 208.7778015137208 .7778015137208 .7778015137208 .7778015137208 .7778015137 208.7778015137208 .7778015137208 .7778015137208 .7778015137208 .7778015137 208.7778015137208 .7778015137208 .7778015137208 .7778015137208 .7778015137 208.7778015137208 .7778015137208 .7778015137208 .7778015137208 .7778015137 208.7778015137208 .7778015137208 .7778015137208 .7778015137208 .7778015137 208.7778015137208 .7778015137208 .7778015137208 .7778015137208 .7778015137 208.7778015137208 .7778015137208 .7778015137208 .7778015137208 .7778015137 208.7778015137208 .7778015137208 .7778015137208 .7778015137208 .7778015137 208.7778015137208 .7778015137208 .7778015137208 .7778015137208 .7778015137 208.7778015137208 .7778015137132 .5814971924133 .8007049561 -9999 -9999 -9999 -9999 -9999 -9999 -9999 -9999 -9999 -9999 -9999 -9999 -9999 -9999 -9999 -9999 -9999 -9999 -9999

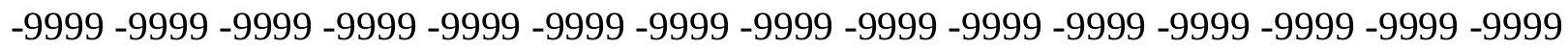
-9999 -9999 -9999 -9999 -9999 -9999 -9999

-9999 -9999 -9999 -9999 -9999 -9999 -9999 -9999 -9999 -9999 -9999 -9999 -9999 -9999 -9999 -9999 -9999 -9999 -9999 -9999 -9999 -9999 -9999 -9999 -9999 -9999 -9999 -9999 -9999 -9999

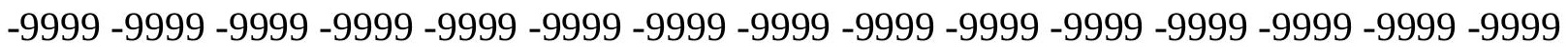
-9999 -9999 -9999 -9999 -9999 -9999 -9999 -9999 -9999 -9999 -9999 -9999 -9999 -9999 -9999 -9999 -9999 -9999 -9999 -9999 -9999 -9999 -9999 -9999 -9999 -9999 -9999 -9999 -9999 -9999 -9999 -9999 -9999 -9999 -9999 216.6606140137 206.3672485352 196.183380127 187.2660064697179 .5184020996168 .8509979248160 .9264984131154 .3262634277 150.4038085938147 .2237701416145 .5680389404145 .7176971436147 .6716461182 150.9607696533154 .9829406738159 .4026031494154 .8307952881147 .8208007812 140.5059967041134 .7149963379129 .8385009766124 .3523025513118 .5614013672 111.24659729104 .236503601198 .7503814697393 .2642517089887 .77810668945 
98.75038146973110 .3321990967118 .8662033081122 .8283996582122 .8283996582 119.4757995605113 .684898376589 .302040100195 .3977432251104 .2365036011 114.5991973877122 .5235977173133 .8007049561152 .6972961426172 .2035980225 185.9188995361194 .7577056885199 .0247039795197 .8054962158189 .8811035156 183.8907165527179 .6666870117179 .586227417184 .1745758057189 .9910583496 193.0617218018192 .2366485596188 .7661437988186 .0064086914186 .279510498 187.9465332031188 .8590087891188 .4722900391188 .0523986816183 .1759033203 181.0424041748178 .9089050293176 .165802002173 .7274932861175 .2514038086 173.4226989746161 .8408966064147 .8208007812138 .0677032471129 .533706665 118.5614013672110 .0273971558107 .8938980103107 .2844009399106 .0652008057 104.5412979126102 .712600708100 .579101562597 .8360290527395 .70252990723 94.4833908081197 .83602905273101 .4934005737105 .7603988647110 .0273971558 112.7705001831116 .1231002808117 .9517974854116 .7326965332114 .5991973877 114.2944030762115 .2088012695116 .7326965332119 .7806015015123 .7427978516 131.3623962402144 .1634063721157 .878692627168 .241394043176 .165802002 183.1759033203189 .2716064453194 .1481018066196 .891204834194 .1481018066 191.7097930908193 .8433074951196 .2816009521196 .2816009521192 .9290008545 185.3094024658177 .9945068359174 .6419067383174 .0323028564174 .0323028564 173.4226989746170 .3748931885166 .1078948975161 .2312927246157 .5738983154 154.5260925293151 .7830047607149 .3446960449146 .6015930176143 .5538024902 140.2012023926136 .2389984131132 .5814971924129 .8385009766127 .0953979492 124.0475006104120 .6949005127118 .2565994263115 .5136032104111 .551399231 111.24659729110 .3321990967108 .8082962036106 .3700027466103 .9317016602 102.712600708102 .4077987671103 .0174026489104 .8460998535106 .6747970581 108.5035018921109 .4179000854109 .1130981445107 .8938980103105 .7603988647 103.3221969604101 .188697814999 .0551681518697 .5312423706196 .61688232422 96.0073165893695 .7025299072395 .397743225195 .7025299072396 .00731658936 96.3121032714896 .9216690063597 .2264633178797 .5312423706197 .83602905273 98.1408081054798 .7503814697399 .3599472045999 .96952056885100 .5791015625 101.4934005737102 .4077987671103 .6268997192104 .5412979126105 .4557037354 106.3700027466119 .7806015015123 .7427978516129 .8385009766151 .7830047607 172.5084075928185 .9188995361194 .7577056885202 .3773040771208 .7778015137 208.7778015137208 .7778015137208 .7778015137208 .7778015137208 .7778015137 208.7778015137208 .7778015137208 .7778015137208 .7778015137208 .7778015137 208.7778015137208 .7778015137208 .7778015137208 .7778015137208 .7778015137 208.7778015137 208.7778015137 208.7778015137 208.7778015137 208.7778015137 208.7778015137208 .7778015137208 .7778015137208 .7778015137208 .7778015137 208.7778015137208 .7778015137208 .7778015137208 .7778015137208 .7778015137 208.7778015137208 .7778015137208 .7778015137208 .7778015137208 .7778015137 208.7778015137208 .7778015137208 .7778015137208 .7778015137208 .7778015137 208.7778015137208 .7778015137208 .7778015137208 .7778015137208 .7778015137 208.7778015137208 .7778015137208 .7778015137208 .7778015137208 .7778015137 208.7778015137208 .7778015137208 .7778015137208 .7778015137208 .7778015137 208.7778015137208 .7778015137208 .7778015137208 .7778015137208 .7778015137 208.7778015137208 .7778015137208 .7778015137208 .7778015137208 .7778015137 208.7778015137 208.7778015137208.7778015137 208.7778015137 208.7778015137 
208.7778015137208 .7778015137208 .7778015137208 .7778015137208 .7778015137 208.7778015137208.7778015137208.7778015137208.7778015137 132.5814971924 133.4958953857 -9999 -9999 -9999 -9999 -9999 -9999 -9999 -9999 -9999 -9999 -9999 -9999 -9999 -9999 -9999 -9999 -9999 -9999 -9999 -9999 -9999 -9999 -9999 -9999 -9999 -9999 -9999 -9999 -9999 -9999 -9999 -9999 -9999 -9999 -9999 -9999 -9999 -9999 -9999 -9999 -9999 -9999 -9999 -9999 -9999 -9999 -9999 -9999 -9999 -9999 -9999 -9999 -9999 -9999 -9999 -9999 -9999 -9999 -9999 -9999 -9999 -9999 -9999 -9999 -9999 -9999 -9999 -9999 -9999 -9999

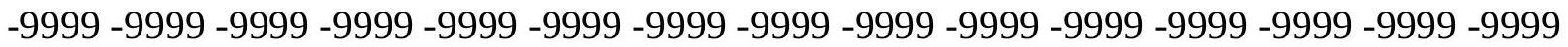

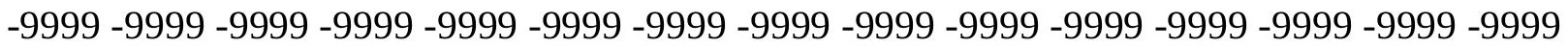
-9999 -9999 -9999 -9999 -9999 -9999 -9999 -9999 -9999 -9999 -9999 -9999 -9999 -9999 -9999 -9999 -9999 -9999 -9999 239.0496520996 229.1983947754 218.2261962891209.0825958252 202.3773040771 197.500793457191.8022613525 186.0280914307 179.485244751 172.2447814941164 .6019134521157 .8694000244153 .6446533203152 .5696411133 154.2212982178155 .4403991699154 .2212982178151 .1734008789146 .2969055176 140.5059967041135 .3246002197129 .8385009766123 .43800354116 .7326965332 110.0273971558103 .626899719299 .9695205688596 .0073165893695 .70252990723 102.712600708110 .3321990967116 .7326965332120 .0852966309120 .0852966309 117.647102356113 .075302124107 .284400939985 .0350494384890 .82597351074 97.53124237061103 .9317016602114 .5991973877135 .9342041016158 .4882965088 174.337097168185 .6141052246189 .0266571045189 .0303344727185 .3112030029 178.6058654785169 .7653045654166 .4127044678172 .2035980225180 .1280059814 184.0901947021184 .3950042725179 .2136993408174 .6419067383178 .2993011475 182.4715881348184 .7152252197184 .3950042725185 .3094024658186 .2236938477 186.6298828125186 .1038818359185 .0908355713185 .0419921875186 .4011993408 186.1387786865181 .9566955566170 .9844970703161 .8408966064151 .1734008789 136.2389984131121 .6092987061112 .4656982422108 .1986999512106 .0652008057 104.5412979126103 .017402648999 .9695205688596 .6168823242293 .56903076172 91.7403335571391 .7403335571396 .31210327148101 .1886978149106 .0652008057 109.4179000854113 .3800964355115 .818397522115 .2088012695113 .9896011353 113.075302124113 .3800964355114 .9039993286118 .2565994263122 .2188034058 129.2288970947141 .1154937744156 .0500030518173 .1179962158189 .8811035156 201.3201904297 211.2760620117218.5337677002 222.6458129883 223.7769012451 223.9475097656224 .5417633057224 .9037628174223 .7603607178220 .6035461426 217.0207366943216 .0926971436212 .4351959229210 .3016967773209 .692199707 209.3874053955 208.4730072021204.2059936523195.9768066406186.8332977295 179.2136993408174 .337097168171 .8988037109169 .7653045654168 .241394043 165.8031005859163 .0599975586160 .0122070312156 .3547973633152 .6972961426 149.6495056152146 .6015930176139 .8963928223133 .8007049561132 .5814971924 129.533706665121 .6092987061112 .7705001831105 .7603988647102 .1029968262 100.8839035034100 .8839035034101 .4934005737103 .9317016602106 .979598999 109.4179000854 110.3321990967 108.8082962036106.6747970581 104.2365036011 101.798202514699 .3599472045997 .2264633178795 .7025299072394 .78817749023 94.1785964965893 .5690307617293 .5690307617293 .8738174438594 .17859649658 94.7881774902395 .397743225195 .7025299072396 .0073165893696 .61688232422 96.9216690063597 .5312423706198 .1408081054798 .7503814697399 .66472625732 100.2742996216101 .1886978149102 .1029968262103 .3221969604104 .5412979126 
105.4557037354106 .0652008057112 .4656982422121 .9140014648136 .8484954834 153.6116943359167 .9365997314179 .2136993408188 .6620025635198 .1103057861 207.8634033203 208.7778015137208.7778015137208.7778015137208.7778015137 208.7778015137208 .7778015137208 .7778015137208 .7778015137208 .7778015137 208.7778015137208 .7778015137208 .7778015137208 .7778015137208 .7778015137 208.7778015137208 .7778015137208 .7778015137208 .7778015137208 .7778015137 208.7778015137208 .7778015137208 .7778015137208 .7778015137208 .7778015137 208.7778015137208 .7778015137208 .7778015137208 .7778015137208 .7778015137 208.7778015137208 .7778015137208 .7778015137208 .7778015137208 .7778015137 208.7778015137208 .7778015137208 .7778015137208 .7778015137208 .7778015137 208.7778015137208 .7778015137208 .7778015137208 .7778015137208 .7778015137 208.7778015137208 .7778015137208 .7778015137208 .7778015137208 .7778015137 208.7778015137208.7778015137208.7778015137208.7778015137208.7778015137 208.7778015137208 .7778015137208 .7778015137208 .7778015137208 .7778015137 208.7778015137208 .7778015137208 .7778015137208 .7778015137208 .7778015137 208.7778015137 208.7778015137208.7778015137208.7778015137 208.7778015137 208.7778015137208 .7778015137208 .7778015137208 .7778015137208 .7778015137 208.7778015137208 .7778015137208 .7778015137208 .7778015137131 .0576019287 132.2767028809 -9999 -9999 -9999 -9999 -9999 -9999 -9999 -9999 -9999 -9999 -9999 -9999 -9999 -9999 -9999 -9999 -9999 -9999 -9999 -9999 -9999 -9999 -9999 -9999 -9999 -9999 -9999 -9999 -9999 -9999 -9999 -9999 -9999 -9999 -9999 -9999 -9999 -9999 -9999 -9999 -9999 -9999 -9999 -9999 -9999 -9999 -9999 -9999 -9999 -9999 -9999 -9999 -9999 -9999 -9999 -9999 -9999 -9999 -9999 -9999 -9999 -9999 -9999 -9999 -9999 -9999 -9999 -9999 -9999 -9999 -9999 -9999 -9999 -9999 -9999 -9999 -9999 -9999 -9999 -9999 -9999 -9999 -9999 -9999 -9999 -9999 -9999 -9999 -9999 -9999 -9999 -9999 -9999 -9999 -9999 -9999 -9999 -9999 -9999 -9999 -9999 -9999 -9999 -9999 -9999 -9999 -9999 -9999 -9999 -9999 -9999 -9999 -9999 -9999 -9999 -9999 -9999-9999 259.7382202148250.5334014893239.8659057617 230.1127929688 222.1884002686216 .3973999023213 .0447998047210 .4746551514206 .247177124 199.8545684814189 .7593688965176 .9504547119164 .9949798584156 .9639129639 152.6972961426151 .1734008789150 .5639038086148 .4304046631145 .6873016357 141.7250976562136 .8484954834131 .9720001221126 .7906036377120 .6949005127 113.9896011353110 .3321990967106 .979598999103 .322196960499 .66472625732 102.4077987671107 .2844009399112 .1608963013116 .1231002808118 .2565994263 118.2565994263116 .1231002808112 .7705001831108 .503501892185 .64462280273 84.7302627563585 .3398437591 .1307525634899 .66472625732113 .3800964355 128.9241027832144 .7729034424159 .0977935791169 .7653045654173 .9404449463 175.5586547852172 .5084075928163 .3648071289154 .2212982178152 .0877990723 155.1356048584162 .1457061768167 .9365997314166 .7174987793165 .1934967041 170.6797027588177 .3849029541181 .6519012451184 .0901947021185 .3094024658 188.8072662354190 .908782959191 .9163360596192 .5866546631193 .8118286133 195.3637237549195 .9324188232194 .0444641113189 .6729125977184 .699798584 169.4604949951154 .2212982178139 .5915985107127 .7050018311117 .342300415 107.2844009399 105.1509017944 103.931701660299.6647262573295.70252990723 94.1785964965891 .7403335571391 .1307525634891 .4355392456195 .3977432251 100.2742996216105 .1509017944108 .1986999512109 .7226028442109 .7226028442 108.8082962036108 .1986999512108 .1986999512109 .1130981445111 .551399231 
115.5136032104121 .3044967651129 .8385009766143 .2489929199163 .3648071289 185.7033233643204 .8131408691219 .3344268799229 .6809997559236 .4176940918 240.2796173096242 .7842102051244 .1132354736244 .0585479736242 .2597961426 239.4160766602237 .0455627441235 .7496337891234 .7129364014234 .5896759033 235.8269500732237 .8985748291239 .5610961914237 .1228027344225 .2362060547 211.520904541201 .4629974365196 .5863952637198 .4151000977201 .4629974365 201.158203125199 .0247039795197 .1959991455193 .8433074951188 .0523986816 181.9566955566177 .3849029541173 .7274932861169 .1557006836165 .1934967041 162.7552947998157 .5738983154145 .3825073242131 .6672058105121 .3044967651 113.3800964355107 .2844009399101 .7982025146100 .5791015625104 .2365036011 107.5891036987111 .551399231111 .551399231109 .1130981445106 .0652008057 102.71260070899 .6647262573296 .9216690063594 .7881774902393 .26425170898 92.349891662692 .349891662693 .5690307617293 .5690307617296 .92166900635 92.349891662692 .9594726562593 .8738174438594 .1785964965894 .78817749023 95.0929565429795 .397743225196 .0073165893696 .6168823242297 .22646331787 98.1408081054799 .0551681518699 .96952056885100 .8839035034102 .1029968262 103.0174026489103 .9317016602104 .8460998535105 .4557037354112 .1608963013 123.7427978516137 .1533050537150 .8686065674163 .0599975586174 .337097168 185.3094024658196 .2816009521207 .8634033203208 .7778015137208 .7778015137 208.7778015137208 .7778015137208 .7778015137208 .7778015137208 .7778015137 208.7778015137208 .7778015137208 .7778015137208 .7778015137208 .7778015137 208.7778015137208 .7778015137208 .7778015137208 .7778015137208 .7778015137 208.7778015137208 .7778015137208 .7778015137208 .7778015137208 .7778015137 208.7778015137208 .7778015137208 .7778015137208 .7778015137208 .7778015137 208.7778015137208 .7778015137208 .7778015137208 .7778015137208 .7778015137 208.7778015137208 .7778015137208 .7778015137208 .7778015137208 .7778015137 208.7778015137208 .7778015137208 .7778015137208 .7778015137208 .7778015137 208.7778015137208 .7778015137208 .7778015137208 .7778015137208 .7778015137 208.7778015137208 .7778015137208 .7778015137208 .7778015137208 .7778015137 208.7778015137208 .7778015137208 .7778015137208 .7778015137208 .7778015137 208.7778015137208 .7778015137208 .7778015137208 .7778015137208 .7778015137 208.7778015137208 .7778015137208 .7778015137208 .7778015137208 .7778015137 208.7778015137208 .7778015137208 .7778015137208 .7778015137208 .7778015137 208.7778015137208.7778015137208.7778015137208.7778015137208.7778015137 208.7778015137131 .0576019287131 .9720001221 -9999 -9999 -9999 -9999 -9999 -9999-9999 -9999 -9999 -9999 -9999 -9999 -9999 -9999 -9999 -9999 -9999 -9999 -9999 -9999 -9999 -9999

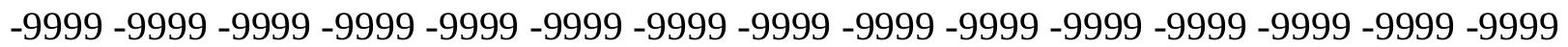
$-9999-9999$ -9999 -9999 -9999 -9999 -9999 -9999 -9999 -9999 -9999 -9999 -9999 -9999 -9999 -9999 -9999 -9999 -9999 -9999 -9999 -9999 -9999 -9999 -9999 -9999 -9999 -9999 -9999 -9999 -9999 -9999 -

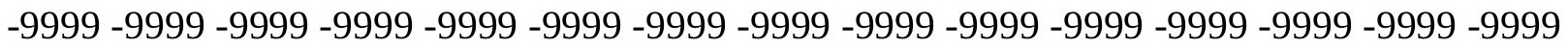
-9999 -9999 -9999 -9999 -9999 -9999 -9999 -9999 -9999 -9999 -9999 -9999 -9999 -9999 -9999 -9999 -9999 -9999 -9999 -9999 -9999 -9999 -9999 -9999 -9999 -9999 -9999 -9999 -9999 -9999 -9999 -9999 278.8783874512 268.2109069824259.0674133301250.5334014893 242.3041992188235 .2940979004229 .1983947754225 .2362060547223 .4075012207 217.5851898193209 .9969024658195 .9768066406178 .9089050293163 .3648071289 
154.8307952881149 .6495056152146 .6015930176144 .7729034424141 .7250976562 138.6772003174134 .7149963379130 .7528076172126 .7906036377122 .2188034058 119.4757995605116 .7326965332113 .3800964355110 .0273971558106 .3700027466 105.4557037354109 .1130981445112 .1608963013114 .9039993286117 .0374984741 117.9517974854117 .647102356116 .1231002808113 .3800964355110 .0273971558 106.674797058187 .7781066894586 .254188537684 .4254837036187 .77810668945 92.349891662699 .35994720459113 .6848983765129 .533706665143 .2489929199 153.9165039062161 .8408966064163 .0599975586153 .0021057129140 .5059967041 133.8007049561133 .1911010742141 .7250976562151 .7830047607155 .1356048584 158.1835021973165 .1934967041172 .8132019043180 .432800293185 .6141052246 189.0029907227192 .1015777588194 .4086608887195 .9276733398197 .2531738281 198.8628234863200 .5823669434201 .6945343018201 .2537689209198 .7764892578 192.8349304199182 .261505127168 .8509979248156 .3547973633142 .9441986084 130.4479980469119 .1709976196110 .9418029785106 .0652008057103 .0174026489 98.1408081054793 .8738174438591 .1307525634889 .9116134643690 .21640014648 92.0450973510796 .31210327148100 .5791015625102 .1029968262102 .4077987671 102.712600708102 .4077987671102 .1029968262102 .1029968262102 .712600708 104.2365036011 106.979598999 111.551399231116 .4279022217126 .1809997559 145.9920959473170 .070098877194 .7577056885212 .6218109131227 .4258422852 236.1638183594242 .296875247 .8569946289251 .3256835938252 .063293457249 .789855957 246.5669708252243 .9231414795242 .771270752243 .6253204346246 .2259063721 250.2593383789254 .7198791504258 .1430664062258 .4577941895245 .6567993164 230.4176025391220 .054901123214 .5686950684218 .8356933594225 .5410003662 226.7601013184226 .7601013184226 .7601013184224 .9313964844220 .054901123 213.6544036865209 .692199707205 .7299957275202 .9868927002199 .6342926025 194.7577056885186 .8332977295172 .2035980225155 .7451934814143 .2489929199 133.8007049561127 .4001998901122 .5235977173115 .2088012695110 .0273971558 112.1608963013114 .9039993286111 .24659729107 .8938980103104 .5412979126 101.188697814997 .8360290527394 .4833908081193 .5690307617290 .82597351074 90.2164001464891 .4355392456192 .0450973510792 .349891662692 .3498916626 92.6546783447393 .2642517089893 .5690307617294 .4833908081194 .78817749023 95.0929565429793 .8738174438594 .4833908081195 .0929565429795 .70252990723 96.6168823242297 .5312423706198 .445587158299 .66472625732100 .5791015625 101.7982025146102 .4077987671103 .3221969604103 .9317016602104 .2365036011 111.551399231123 .1332015991135 .3246002197147 .5160064697159 .7073974609 171.8988037109184 .3950042725197 .1959991455208 .7778015137208 .7778015137 208.7778015137 208.7778015137208.7778015137 208.7778015137 208.7778015137 208.7778015137 208.7778015137 208.7778015137 208.7778015137 208.7778015137 208.7778015137208 .7778015137208 .7778015137208 .7778015137208 .7778015137 208.7778015137208 .7778015137208 .7778015137208 .7778015137208 .7778015137 208.7778015137208 .7778015137208 .7778015137208 .7778015137208 .7778015137 208.7778015137208 .7778015137208 .7778015137208 .7778015137208 .7778015137 208.7778015137208 .7778015137208 .7778015137208 .7778015137208 .7778015137 208.7778015137208 .7778015137208 .7778015137208 .7778015137208 .7778015137 208.7778015137208 .7778015137208 .7778015137208 .7778015137208 .7778015137 208.7778015137 208.7778015137208.7778015137 208.7778015137 208.7778015137 
208.7778015137208 .7778015137208 .7778015137208 .7778015137208 .7778015137 208.7778015137 208.7778015137208.7778015137208.7778015137 208.7778015137 208.7778015137208 .7778015137208 .7778015137208 .7778015137208 .7778015137 208.7778015137208 .7778015137208 .7778015137208 .7778015137208 .7778015137 208.7778015137208 .7778015137208 .7778015137208 .7778015137208 .7778015137 208.7778015137129 .533706665130 .7528076172 -9999 -9999 -9999 -9999 -9999 -9999 -9999

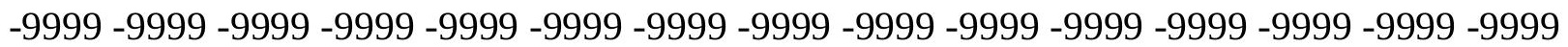

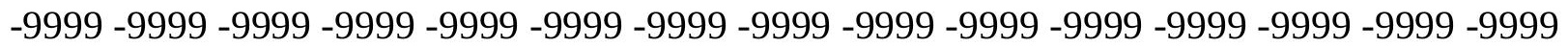
$-9999-9999$

-9999 -9999 -9999 -9999 -9999 -9999 -9999 -9999 -9999 -9999 -9999 -9999 -9999 -9999 -9999

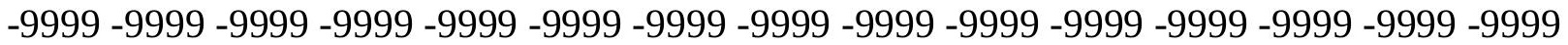
-9999 -9999 -9999 -9999 -9999 -9999 -9999 -9999 -9999 -9999 -9999 -9999 -9999 -9999 -9999 -9999 -9999 -9999 -9999 -9999 -9999 -9999 -9999 -9999 -9999 -9999 -9999 -9999 -9999 -9999 -9999 -9999 -9999 -9999 -9999 -9999 -9999 -9999 -9999 -9999 -9999 -9999 -9999 -9999 -9999 -9999 -9999 284.9740905762 272.4779052734264.2486877441257.5433959961 250.5334014893243 .8280944824237 .4275970459231 .6367034912227 .9792938232 218.8356933594197 .500793457174 .9467010498162 .4505004883155 .1356048584 149.3446960449 144.7729034424141.1154937744 137.7628936768 134.1054992676 130.4479980469126 .4858016968123 .1332015991121 .9140014648122 .2188034058 121.3044967651118 .8662033081115 .818397522112 .4656982422109 .1130981445 113.075302124116 .1231002808117 .9517974854118 .8662033081119 .4757995605 119.4757995605118 .5614013672117 .0374984741114 .9039993286112 .1608963013 109.4179000854106 .674797058189 .9116134643688 .0829010009885 .33984375 81.3776321411186 .5589828491298 .14080810547112 .1608963013124 .6570968628 135.3246002197142 .9441986084143 .8585968018135 .3246002197124 .3523025513 119.4757995605120 .0852966309126 .7906036377135 .9342041016142 .0299072266 148.4304046631157 .2691040039166 .7174987793177 .6896972656185 .8910827637 191.431854248194 .5461578369196 .2328033447197 .276184082198 .3613128662 199.8040618896201 .4576263428202 .7258758545202 .7553863525200 .6732330322 195.3325653076186 .8332977295175 .2514038086165 .1934967041154 .5260925293 142.9441986084129 .8385009766118 .8662033081112 .1608963013107 .8938980103 103.322196960499 .3599472045996 .0073165893693 .5690307617292 .3498916626 92.0450973510793 .5690307617295 .7025299072396 .9216690063597 .53124237061 97.8360290527397 .8360290527397 .5312423706196 .9216690063596 .92166900635 97.5312423706198 .75038146973101 .1886978149105 .1509017944112 .4656982422 123.7427978516140 .8106994629165 .1934967041190 .795501709212 .4351959229 219.3641815186227 .9046325684237 .5334777832245 .2932434082246 .9634399414 244.5390777588241 .0032958984237 .9862518311237 .4084625244240 .0135803223 245.4797058105252 .4909973145259 .3356323242263 .0969238281260 .4906921387 250.5334014893240 .4754943848230 .4176025391222 .4931030273220 .054901123 221.883605957228 .5888977051236 .2084960938240 .7801971436241 .4058074951 239.1167449951235 .4671173096232 .1872711182229 .6726531982228 .0695343018 227.1820526123226 .7601013184219 .1405029297208 .7778015137195 .0625175 .5561981201 157.5738983154146 .2969055176138 .0677032471128 .9241027832121 .9140014648 121.3044967651121 .3044967651115 .5136032104107 .8938980103102 .1029968262 99.6647262573295.397743225192.04509735107 89.60682678223 88.38768768311 
88.38768768311 88.99725341797 89.9116134643690.5211791992291.13075256348 92.0450973510792 .349891662692 .9594726562593 .2642517089893 .56903076172 93.5690307617293 .8738174438592 .6546783447393 .2642517089893 .87381744385 94.7881774902395 .7025299072396 .9216690063597 .8360290527399 .05516815186 99.96952056885101 .1886978149101 .7982025146102 .4077987671102 .712600708 102.712600708110 .6370010376121 .6092987061133 .1911010742145 .6873016357 158.7929992676172 .5084075928186 .528503418200 .2438049316208 .7778015137 208.7778015137208 .7778015137208 .7778015137208 .7778015137208 .7778015137 208.7778015137208 .7778015137208 .7778015137208 .7778015137208 .7778015137 208.7778015137208 .7778015137208 .7778015137208 .7778015137208 .7778015137 208.7778015137208 .7778015137208 .7778015137208 .7778015137208 .7778015137 208.7778015137208 .7778015137208 .7778015137208 .7778015137208 .7778015137 208.7778015137208 .7778015137208 .7778015137208 .7778015137208 .7778015137 208.7778015137208 .7778015137208 .7778015137208 .7778015137208 .7778015137 208.7778015137208 .7778015137208 .7778015137208 .7778015137208 .7778015137 208.7778015137208 .7778015137208 .7778015137208 .7778015137208 .7778015137 208.7778015137208 .7778015137208 .7778015137208 .7778015137208 .7778015137 208.7778015137208 .7778015137208 .7778015137208 .7778015137208 .7778015137 208.7778015137208 .7778015137208 .7778015137208 .7778015137208 .7778015137 208.7778015137 208.7778015137208.7778015137 208.7778015137 208.7778015137 208.7778015137 208.7778015137208.7778015137 208.7778015137 208.7778015137 208.7778015137208 .7778015137208 .7778015137208 .7778015137208 .7778015137 208.7778015137208 .7778015137129 .533706665130 .4479980469 -9999 -9999 -9999 -9999 -9999 -9999 -9999 -9999 -9999 -9999 -9999 -9999 -9999 -9999 -9999 -9999 -9999 -9999 -9999

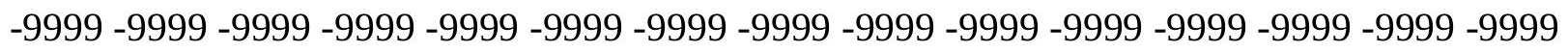
-9999 -9999 -9999-9999

-9999 -9999 -9999 -9999 -9999 -9999 -9999 -9999 -9999 -9999 -9999 -9999 -9999 -9999 -9999

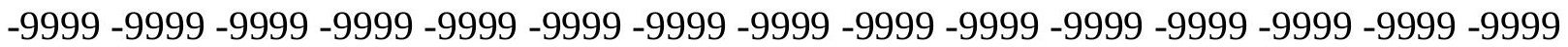
-9999 -9999 -9999 -9999 -9999 -9999 -9999 -9999 -9999 -9999 -9999 -9999 -9999 -9999 -9999

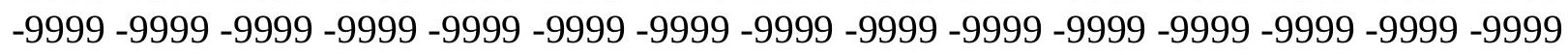
-9999 -9999 -9999 -9999 -9999 -9999 -9999 -9999 -9999 -9999 -9999 -9999 -9999 -9999 -9999 -9999 301.4324951172 289.2410888672 276.1353149414268.5156860352 262.7247924805 256.3243103027249 .6190032959241 .6945953369232 .8558044434224 .6266021729 210.3016967773179 .5184020996151 .1734008789144 .7729034424145 .0776977539 142.0299072266138 .6772003174134 .7149963379130 .7528076172126 .4858016968 122.5235977173118 .8662033081120 .9997024536122 .8283996582123 .1332015991 121.9140014648120 .0852966309117 .342300415118 .2565994263121 .6092987061 123.1332015991124 .0475006104124 .0475006104123 .43800354122 .8283996582 122.2188034058120 .9997024536119 .1709976196117 .342300415115 .2088012695 112.7705001831110 .637001037693 .5690307617292 .0450973510789 .91161346436 87.7781066894585 .9494018554789 .91161346436100 .8839035034110 .3321990967 118.2565994263122 .8283996582122 .8283996582116 .7326965332109 .7226028442 109.1130981445112 .1608963013116 .4279022217122 .8283996582129 .8385009766 137.7628936768146 .9064025879157 .878692627172 .2035980225184 .1231384277 191.3411712646194 .1678619385194 .780090332194 .8877563477195 .3116607666 196.2850189209 197.6458740234198.9019775391 199.1411895752 197.4196624756 
192.9873962402185 .8721618652177 .0802001953169 .7653045654162 .1457061768 152.6972961426138 .9819946289125 .8762969971117 .9517974854112 .7705001831 109.1130981445106 .3700027466102 .407798767198 .7503814697396 .00731658936 94.1785964965892 .9594726562592 .349891662692 .6546783447393 .26425170898 93.5690307617293 .5690307617293 .2642517089892 .9594726562592 .3498916626 92.349891662692 .349891662693 .2642517089896 .92166900635101 .4934005737 103.3221969604111 .24659729132 .5814971924156 .9642944336173 .7274932861 186.528503418197 .500793457208 .1681976318224 .0171051025225 .0565032959 225.1019439697221 .8986816406219 .4109954834219 .8924407959224 .1325073242 232.6065063477242 .9282073975252 .6458740234257 .6093139648255 .8937072754 247.1806945801242 .6089935303233 .1605987549224 .3218994141221 .2740020752 221.5787963867224 .0171051025236 .8667449951244 .6783447266247 .9431762695 248.2246398926246 .965423584245 .343963623244 .286819458244 .0161132812 244.2663116455243 .4983978271239 .3514251709232 .0779418945222 .3876342773 210.9113006592186 .528503418170 .070098877156 .9642944336144 .7729034424 135.9342041016131 .3623962402128 .6192932129124 .9618988037120 .6949005127 113.9896011353105 .760398864796 .0073165893689 .9116134643688 .99725341797 87.4733276367284 .7302627563589 .9116134643690 .2164001464888 .38768768311 89.6068267822390 .5211791992291 .4355392456192 .0450973510792 .3498916626 92.0450973510792 .0450973510792 .0450973510792 .349891662691 .13075256348 92.0450973510792 .9594726562593 .8738174438594 .7881774902396 .00731658936 97.2264633178798 .1408081054799 .3599472045999 .96952056885100 .5791015625 100.8839035034100 .8839035034100 .8839035034109 .1130981445120 .0852966309 132.2767028809145 .6873016357160 .3170013428175 .5561981201190 .4907073975 204.5108032227 208.7778015137208.7778015137 208.7778015137 208.7778015137 208.7778015137 208.7778015137208.7778015137 208.7778015137 208.7778015137 208.7778015137208 .7778015137208 .7778015137208 .7778015137208 .7778015137 208.7778015137208 .7778015137208 .7778015137208 .7778015137208 .7778015137 208.7778015137208 .7778015137208 .7778015137208 .7778015137208 .7778015137 208.7778015137208 .7778015137208 .7778015137208 .7778015137208 .7778015137 208.7778015137208 .7778015137208 .7778015137208 .7778015137208 .7778015137 208.7778015137208 .7778015137208 .7778015137208 .7778015137208 .7778015137 208.7778015137 208.7778015137208.7778015137 208.7778015137 208.7778015137 208.7778015137208 .7778015137208 .7778015137208 .7778015137208 .7778015137 208.7778015137208 .7778015137208 .7778015137208 .7778015137208 .7778015137 208.7778015137208 .7778015137208 .7778015137208 .7778015137208 .7778015137 208.7778015137 208.7778015137208.7778015137 208.7778015137 208.7778015137 208.7778015137208 .7778015137208 .7778015137208 .7778015137208 .7778015137 208.7778015137208 .7778015137208 .7778015137208 .7778015137208 .7778015137 208.7778015137208 .7778015137208 .7778015137128 .0097961426129 .2288970947 -9999 -9999 -9999 -9999 -9999 -9999 -9999 -9999 -9999 -9999-9999 -9999 -9999 -9999 -9999 -9999

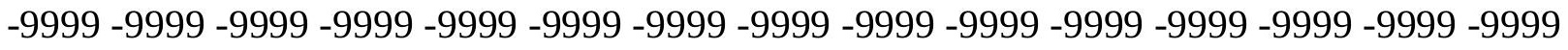
-9999 -9999-9999 -9999-9999-9999-9999 -9999 -9999 -9999 -9999 -9999 -9999 -9999 -9999 -9999 -9999 -9999 -9999 -9999 -9999 -9999 -9999 -9999 -9999 -9999 -9999 -9999 -9999 -9999 -9999 -9999 -9999 -9999 -9999 -9999 -9999 -

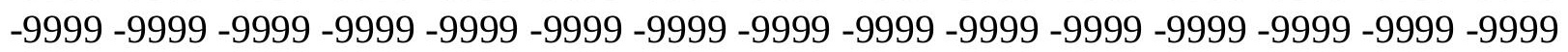


-9999 -9999 -9999 -9999 -9999 -9999 -9999 -9999 -9999 -9999 -9999 -9999 -9999 -9999 -9999 -9999 -9999 -9999 -9999 -9999 -9999 -9999 -9999 -9999 -9999 -9999 -9999 -9999 -9999 -9999 305.0899047852301 .7373046875292 .2889099121281 .3167114258273 .0874938965 265.7726135254258 .7626037598251 .1428985596242 .3041992188230 .4176025391 213.959197998192 .9290008545167 .0222015381145 .6873016357138 .6772003174 137.7628936768135 .3246002197132 .5814971924128 .3144989014123 .7427978516 119.4757995605124 .3523025513131 .9720001221134 .4102020264131 .9720001221 140.2012023926146 .9064025879125 .2667007446130 .7528076172136 .2389984131 136.8484954834134 .7149963379132 .5814971924130 .4479980469128 .6192932129 127.0953979492125 .5715026855124 .0475006104122 .2188034058120 .3900985718 118.5614013672116 .7326965332114 .9039993286113 .989601135396 .61688232422 95.7025299072394 .7881774902394 .1785964965892 .9594726562590 .52117919922 97.83602905273104 .2365036011107 .8938980103109 .1130981445105 .7603988647 102.712600708103 .3221969604105 .7603988647108 .8082962036113 .6848983765 119.4757995605126 .4858016968133 .4958953857143 .8585968018163 .0599975586 179.8231964111187 .3352966309189 .0545349121188 .5040740967187 .7809753418 187.6555480957188 .1300506592188 .978012085190 .1221008301190 .9019622803 189.810043335186 .4790802002181 .3483581543175 .5561981201170 .3748931885 164.8887023926157 .2691040039145 .3825073242132 .8863067627123 .43800354 116.7326965332113 .075302124110 .6370010376107 .5891036987104 .2365036011 100.579101562596 .9216690063594 .1785964965892 .0450973510790 .21640014648 89.302040100189 .302040100189 .9116134643690 .2164001464890 .21640014648 89.9116134643690 .2164001464890 .2164001464890 .8259735107492 .04509735107 92.0450973510789 .9116134643692 .95947265625109 .7226028442129 .8385009766 142.6394042969150 .8686065674152 .3925933838156 .0500030518169 .4604949951 183.7854003906192 .624206543188 .4542541504189 .1313171387192 .0885009766 196.564453125206 .7517547607222 .974899292235 .4206390381242 .6711883545 245.7461242676244 .4376983643236 .8179931641228 .2841033936221 .883605957 218.8356933594221 .2740020752230 .4176025391236 .4137420654242 .9836120605 247.4067382812249 .3863525391249 .8026275635249 .6426849365249 .6976470947 250.239074707250 .9643707275250 .7863922119248 .9207763672244 .7954101562 238.2741546631228 .6423797607216 .6507415771208 .4730072021188 .3571929932 174.0323028564163 .0599975586152 .6972961426143 .8585968018137 .4580993652 131.9720001221125 .5715026855118 .5614013672111 .24659729103 .9317016602 97.2264633178787 .7781066894580 .4632720947382 .2919769287189 .3020401001 86.5589828491288 .0829010009889 .302040100190 .2164001464890 .82597351074 91.1307525634891 .4355392456191 .1307525634890 .2164001464890 .21640014648 89.3020401001 89.9116134643690.8259735107491.7403335571392.65467834473 93.87381744385 95.0929565429796.31210327148 97.2264633178798.14080810547 99.0551681518699 .3599472045999 .3599472045999 .3599472045999 .05516815186 107.8938980103119 .1709976196132 .5814971924147 .8208007812163 .974395752 180.432800293195 .0625207 .5587005615208 .7778015137208 .7778015137208 .7778015137 208.7778015137208 .7778015137208 .7778015137208 .7778015137208 .7778015137 208.7778015137208 .7778015137208 .7778015137208 .7778015137208 .7778015137 208.7778015137208 .7778015137208 .7778015137208 .7778015137208 .7778015137 208.7778015137208.7778015137208.7778015137208.7778015137208.7778015137 
208.7778015137 208.7778015137208.7778015137208.7778015137 208.7778015137 208.7778015137208 .7778015137208 .7778015137208 .7778015137208 .7778015137 208.7778015137208 .7778015137208 .7778015137208 .7778015137208 .7778015137 208.7778015137208 .7778015137208 .7778015137208 .7778015137208 .7778015137 208.7778015137208 .7778015137208 .7778015137208 .7778015137208 .7778015137 208.7778015137208 .7778015137208 .7778015137208 .7778015137208 .7778015137 208.7778015137 208.7778015137 208.7778015137 208.7778015137 208.7778015137 208.7778015137 208.7778015137 208.7778015137 208.7778015137 208.7778015137 208.7778015137208 .7778015137208 .7778015137208 .7778015137208 .7778015137 208.7778015137208 .7778015137208 .7778015137208 .7778015137208 .7778015137 208.7778015137208 .7778015137208 .7778015137208 .7778015137128 .0097961426 128.9241027832 -9999 -9999 -9999 -9999 -9999 -9999 -9999 -9999 -9999 -9999 -9999 -9999 -9999 -9999 -9999 -9999 -9999 -9999 -9999 -9999 -9999 -9999 -9999 -9999 -9999 -9999 -9999 -9999 -9999 -9999 -9999 -9999 -9999 -9999 -9999 -9999 -9999 -9999 -9999 -9999 -9999 -9999 -9999 -9999 -9999 -9999 -9999 -9999 -9999 -9999 -9999 -9999

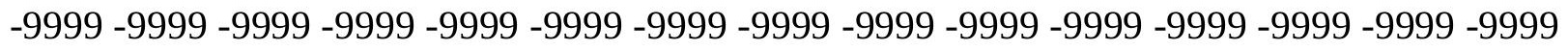

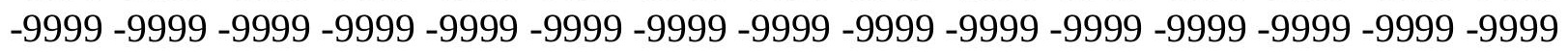

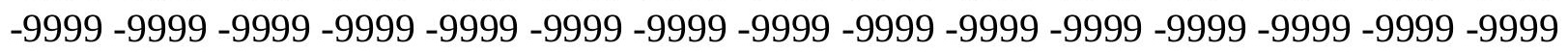
-9999 -9999 -9999 -9999 -9999 -9999 -9999 -9999 -9999 -9999 -9999 -9999 -9999 -9999 305.3947143555304 .4802856445300 .8229064941294 .4223937988285 .8884887695 277.0497131348267 .9060974121259 .0674133301249 .6190032959239 .2563018799 224.6266021729200 .8533935547175 .8609924316158 .1835021973145 .6873016357 136.8484954834131 .6672058105128 .9241027832125 .8762969971121 .6092987061 120.6949005127133 .1911010742154 .5260925293179 .5184020996167 .0222015381 159.0977935791157 .878692627155 .4403991699149 .0399017334149 .9542999268 156.0500030518150 .2590942383144 .7729034424140 .2012023926136 .5437011719 133.4958953857131 .0576019287129 .2288970947127 .4001998901125 .5715026855 124.0475006104122 .2188034058120 .6949005127119 .4757995605118 .8662033081 101.1886978149101 .4934005737102 .1029968262102 .1029968262101 .1886978149 97.8360290527392 .0450973510793 .2642517089896 .9216690063599 .35994720459 99.3599472045999 .0551681518699 .66472625732101 .1886978149103 .6268997192 107.2844009399111 .8561019897117 .342300415121 .3044967651129 .533706665 149.6495056152169 .1557006836176 .165802002177 .0802001953176 .4024047852 175.4957885742175 .4532775879175 .6301116943175 .4045257568175 .8753051758 177.9945068359177 .6896972656175 .8609924316173 .1179962158170 .3748931885 167.0222015381163 .6696014404158 .1835021973149 .0399017334138 .6772003174 128.9241027832120 .9997024536116 .7326965332114 .2944030762111 .8561019897 109.1130981445104 .8460998535100 .274299621696 .6168823242293 .26425170898 89.3020401001 86.2541885376 86.2541885376 87.16854858398 88.08290100098 88.99725341797 89.6068267822390.2164001464891.1307525634891.13075256348 89.60682678223 87.47332763672 83.51112365723 83.8159103393696.00731658936 110.3321990967118 .5614013672121 .6092987061113 .6848983765107 .5891036987 115.2088012695126 .7906036377135 .9342041016144 .4682006836152 .3925933838 158.7929992676159 .0977935791165 .1934967041194 .4528961182205 .8477630615 215.0297851562223 .2780456543231 .9414978027226 .4553985596221 .883605957 216.3973999023213 .959197998215 .787902832225 .2362060547231 .7031555176 
237.4547576904241 .6486816406244 .2167510986245 .4642028809246 .0992584229 246.7920227051247 .8118591309248 .9757385254249 .7465515137249 .5830993652 247.9865722656244 .6928863525239 .4527435303233 .323135376225 .1975860596 214.1843719482204 .8155975342191 .7097930908175 .2514038086160 .3170013428 149.6495056152141 .7250976562135 .6293945312130 .4479980469125 .2667007446 119.1709976196111 .24659729101 .188697814990 .2164001464880 .46327209473 84.1206970214885 .6446228027386 .5589828491287 .4733276367288 .38768768311 89.3020401001 89.9116134643690.2164001464890.21640014648 89.3020401001 88.38768768311 87.16854858398 87.77810668945 88.38768768311 89.60682678223 90.5211791992291 .7403335571392 .9594726562594 .1785964965895 .3977432251 96.3121032714896 .9216690063597 .5312423706197 .8360290527397 .83602905273 97.8360290527397 .53124237061106 .979598999119 .7806015015134 .7149963379 151.4781951904168 .8509979248185 .3094024658197 .1959991455206 .9490966797 208.7778015137208 .7778015137208 .7778015137208 .7778015137208 .7778015137 208.7778015137208 .7778015137208 .7778015137208 .7778015137208 .7778015137 208.7778015137208 .7778015137208 .7778015137208 .7778015137208 .7778015137 208.7778015137 208.7778015137208.7778015137 208.7778015137 208.7778015137 208.7778015137208 .7778015137208 .7778015137208 .7778015137208 .7778015137 208.7778015137208 .7778015137208 .7778015137208 .7778015137208 .7778015137 208.7778015137208.7778015137208.7778015137208.7778015137 208.7778015137 208.7778015137208 .7778015137208 .7778015137208 .7778015137208 .7778015137 208.7778015137208 .7778015137208 .7778015137208 .7778015137208 .7778015137 208.7778015137208 .7778015137208 .7778015137208 .7778015137208 .7778015137 208.7778015137208 .7778015137208 .7778015137208 .7778015137208 .7778015137 208.7778015137208 .7778015137208 .7778015137208 .7778015137208 .7778015137 208.7778015137208 .7778015137208 .7778015137208 .7778015137208 .7778015137 208.7778015137208 .7778015137208 .7778015137208 .7778015137208 .7778015137 208.7778015137208 .7778015137208 .7778015137208 .7778015137208 .7778015137 208.7778015137 126.4858016968 127.7050018311 -9999 -9999 -9999 -9999 -9999 -9999 -9999 -9999 -9999 -9999 -9999 -9999 -9999 -9999 -9999 -9999 -9999 -9999 -9999 -9999 -9999 -9999 -9999 -9999 -9999 -9999 -9999 -9999 -9999 -9999 -9999 -9999 -9999 -9999 -9999 -9999 -9999

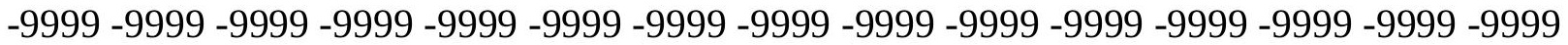

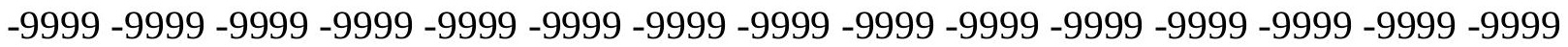
-9999 -9999 -9999 -9999 -9999 -9999 -9999 -9999 -9999 -9999 -9999 -9999 -9999 -9999 -9999 -9999 -9999 -9999 -9999 -9999 -9999 -9999 -9999 -9999 -9999 -9999 -9999 -9999 -9999 -9999 -9999 -9999 -9999 -9999 -9999 -9999 -9999 -9999 -9999 -9999 -9999 -9999 -9999 -9999 306.0043029785305 .0899047852301 .7373046875295 .9464111328288 .6315002441 279.7927856445269 .1253051758257 .8482055664245 .6567993164233 .7702026367 218.2261962891193 .5386047363169 .4604949951153 .0021057129141 .4203033447 132.8863067627127 .0953979492123 .1332015991120 .0852966309129 .533706665 142.3347015381157 .878692627174 .9467010498188 .3571929932186 .8332977295 179.2136993408172 .2035980225167 .0222015381164 .2792053223162 .4505004883 161.8408966064157 .2691040039151 .1734008789145 .6873016357141 .1154937744 137.7628936768135 .3246002197133 .1911010742131 .0576019287129 .533706665 127.7050018311126 .1809997559124 .6570968628123 .7427978516123 .43800354 123.7427978516106 .6747970581107 .8938980103109 .1130981445109 .4179000854 
106.065200805796 .3121032714885 .6446228027390 .2164001464893 .87381744385 95.0929565429795 .397743225196 .3121032714897 .5312423706199 .66472625732 103.0174026489106 .6747970581110 .9418029785114 .2944030762119 .7806015015 129.8385009766141 .4203033447151 .1734008789158 .1835021973159 .7073974609 158.7929992676159 .4026031494159 .4026031494157 .5738983154156 .3547973633 157.5738983154159 .7073974609160 .9264984131161 .5361022949161 .8408966064 161.2312927246160 .3170013428157 .2691040039150 .2590942383141 .4203033447 132.8863067627125 .2667007446120 .6949005127117 .647102356114 .9039993286 111.8561019897108 .1986999512103 .931701660298 .7503814697393 .26425170898 88.6924667358485 .6446228027385 .3398437586 .254188537688 .08290100098 89.9116134643691.7403335571392.9594726562593.8738174438593.56903076172 92.0450973510789 .6068267822386 .5589828491286 .5589828491292 .95947265625 100.5791015625104 .8460998535104 .846099853597 .2264633178790 .52117919922 93.2642517089899 .05516815186101 .7982025146105 .7603988647113 .9896011353 120.0852966309117 .9517974854120 .9997024536139 .5915985107161 .2312927246 172.5084075928181 .0424041748195 .9768066406206 .3394927979210 .3016967773 208.1681976318206 .6443023682208 .7778015137214 .5686950684222 .1884002686 227.5466003418231 .3868103027233 .8509063721235 .1669311523235 .9203033447 236.810760498238 .0925140381239 .7118682861241 .399810791242 .7647705078 243.4086303711242 .9957580566241 .383605957238 .5846405029233 .6983032227 227.2498321533218 .3928527832206 .0406036377190 .4907073975172 .2035980225 158.4882965088149 .3446960449144 .4682006836141 .7250976562137 .4580993652 131.6672058105123 .7427978516114 .9039993286106 .065200805795 .70252990723 85.9494018554785 .0350494384885 .3398437585 .9494018554786 .86376190186 87.7781066894588 .6924667358488 .9972534179788 .9972534179788 .38768768311 86.8637619018685 .0350494384885 .6446228027386 .254188537687 .16854858398 88.3876876831189 .6068267822390 .8259735107492 .0450973510793 .26425170898 94.1785964965895 .0929565429795 .7025299072396 .3121032714896 .31210327148 96.3121032714896 .3121032714896 .31210327148106 .979598999120 .9997024536 137.7628936768155 .7451934814172 .2035980225184 .3950042725194 .1481018066 202.9868927002208 .7778015137208 .7778015137208 .7778015137208 .7778015137 208.7778015137208 .7778015137208 .7778015137208 .7778015137208 .7778015137 208.7778015137208 .7778015137208 .7778015137208 .7778015137208 .7778015137 208.7778015137208 .7778015137208 .7778015137208 .7778015137208 .7778015137 208.7778015137208 .7778015137208 .7778015137208 .7778015137208 .7778015137 208.7778015137208 .7778015137208 .7778015137208 .7778015137208 .7778015137 208.7778015137208.7778015137208.7778015137 208.7778015137 208.7778015137 208.7778015137 208.7778015137208.7778015137208.7778015137 208.7778015137 208.7778015137208 .7778015137208 .7778015137208 .7778015137208 .7778015137 208.7778015137208 .7778015137208 .7778015137208 .7778015137208 .7778015137 208.7778015137208 .7778015137208 .7778015137208 .7778015137208 .7778015137 208.7778015137208.7778015137208.7778015137208.7778015137 208.7778015137 208.7778015137208.7778015137208.7778015137208.7778015137208.7778015137 208.7778015137208.7778015137208.7778015137208.7778015137208.7778015137 208.7778015137208 .7778015137208 .7778015137208 .7778015137208 .7778015137 208.7778015137208 .7778015137126 .1809997559127 .4001998901 -9999-9999-9999 -9999 
-9999 -9999 -9999 -9999 -9999 -9999 -9999 -9999 -9999 -9999 -9999 -9999-9999 -9999 -9999 -9999 -9999 -9999 -9999 -9999 -9999 -9999 -9999 -9999 -9999 -9999 -9999 -9999 -9999 -9999 -9999-9999

-9999 -9999 -9999 -9999 -9999 -9999 -9999 -9999 -9999 -9999 -9999 -9999 -9999 -9999 -9999 -9999 -9999 -9999 -9999 -9999 -9999 -9999 -9999 -9999 -9999 -9999 -9999-9999 -9999 -9999 -9999 -9999 -9999 -9999 -9999 -9999 -9999 -9999 -9999 -9999 -9999 -9999 -9999 -9999 -9999 -9999 -9999 -9999 -9999 -9999 -9999 -9999 -9999 -9999 -9999 -9999 -9999 -9999 -9999 -999 -9999 -9999 -9999 -9999 -9999 -9999 -9999 -9999 -9999 -9999 -9999 -9999 -9999 306.0043029785306 .9186096191305 .6994934082302 .6516113281296 .8606872559 289.2410888672 280.0975036621268.8204956055 255.7147064209241.0850067139 227.6744995117210 .6065063477187 .1381072998164 .2792053223147 .8208007812 136.5437011719128 .6192932129123 .1332015991126 .7906036377138 .0677032471 150.5639038086163 .0599975586176 .165802002188 .6620025635195 .9768066406 196.5863952637190 .4907073975181 .9566955566176 .7754058838172 .8132019043 169.1557006836165 .1934967041160 .3170013428154 .2212982178149 .0399017334 144.7729034424141 .4203033447138 .9819946289136 .8484954834135 .0198059082 133.1911010742131 .6672058105130 .1432037354128 .6192932129128 .0097961426 127.4001998901127 .7050018311128 .9241027832111 .8561019897113 .3800964355 114.2944030762113 .380096435599 .9695205688586 .254188537685 .64462280273 89.9116134643691.4355392456192.0450973510793.2642517089894.78817749023 97.22646331787100 .2742996216103 .6268997192106 .979598999110 .3321990967 113.3800964355112 .7705001831114 .5991973877125 .2667007446136 .5437011719 141.4203033447142 .9441986084140 .5059967041136 .8484954834135 .6293945312 135.9342041016138 .6772003174142 .3347015381145 .0776977539147 .5160064697 149.9542999268152 .0877990723153 .9165039062153 .6116943359148 .7351074219 142.0299072266135 .6293945312129 .2288970947124 .3523025513120 .3900985718 117.0374984741113 .9896011353110 .9418029785106 .674797058199 .66472625732 92.6546783447388 .3876876831185 .9494018554785 .6446228027386 .86376190186 89.6068267822392.95947265625 95.397743225197.2264633178797.83602905273 97.5312423706196 .3121032714894 .7881774902394 .4833908081194 .17859649658 96.0073165893697 .5312423706198 .1408081054797 .2264633178793 .26425170898 89.3020401001 88.6924667358488.38768768311 83.51112365723 80.76805877686 87.1685485839893.8738174438591.43553924561 89.9116134643692.3498916626 98.75038146973106 .6747970581120 .3900985718155 .4403991699177 .3849029541 189.2716064453191 .7097930908191 .4051055908196 .2816009521202 .9868927002 209.9969024658213 .3495941162217 .164352417219 .1054840088219 .8722839355 220.2542266846221 .052230835222 .4604644775224 .4680938721226 .9460449219 229.6571807861232 .2219238281234 .2146606445235 .3466339111235 .2761688232 233.5585479736229 .7460632324222 .7620697021212 .1296844482198 .0620269775 181.9566955566167 .6318054199158 .1835021973154 .2212982178152 .3925933838 147.8208007812141 .7250976562134 .4102020264126 .4858016968119 .7806015015 111.8561019897100 .579101562587 .1685485839883 .8159103393684 .12069702148 85.3398437586 .5589828491287 .4733276367287 .7781066894587 .77810668945 87.1685485839886 .254188537684 .7302627563583 .5111236572383 .81591033936 84.7302627563585 .9494018554787 .1685485839888 .6924667358489 .91161346436 91.1307525634892 .349891662693 .2642517089894 .1785964965894 .78817749023 
95.0929565429795 .0929565429795 .0929565429794 .7881774902394 .78817749023 107.2844009399122 .5235977173140 .2012023926158 .1835021973168 .8509979248 178.604095459188 .0523986816198 .1103057861208 .1681976318208 .7778015137 208.7778015137208 .7778015137208 .7778015137208 .7778015137208 .7778015137 208.7778015137208 .7778015137208 .7778015137208 .7778015137208 .7778015137 208.7778015137208 .7778015137208 .7778015137208 .7778015137208 .7778015137 208.7778015137208 .7778015137208 .7778015137208 .7778015137208 .7778015137 208.7778015137208 .7778015137208 .7778015137208 .7778015137208 .7778015137 208.7778015137208 .7778015137208 .7778015137208 .7778015137208 .7778015137 208.7778015137208 .7778015137208 .7778015137208 .7778015137208 .7778015137 208.7778015137208 .7778015137208 .7778015137208 .7778015137208 .7778015137 208.7778015137208 .7778015137208 .7778015137208 .7778015137208 .7778015137 208.7778015137208 .7778015137208 .7778015137208 .7778015137208 .7778015137 208.7778015137208 .7778015137208 .7778015137208 .7778015137208 .7778015137 208.7778015137208 .7778015137208 .7778015137208 .7778015137208 .7778015137 208.7778015137 208.7778015137208.7778015137 208.7778015137 208.7778015137 208.7778015137208 .7778015137208 .7778015137208 .7778015137208 .7778015137 208.7778015137 208.7778015137208.7778015137 124.9618988037125 .8762969971 -9999 -9999 -9999 -9999 -9999 -9999 -9999 -9999 -9999 -9999 -9999 -9999 -9999 -9999 -9999 -9999

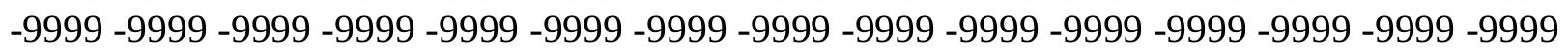
$-9999-9999-9999-9999-9999$

-9999 -9999 -9999 -9999 -9999 -9999 -9999 -9999 -9999 -9999 -9999 -9999 -9999 -9999 -9999 -9999 -9999 -9999 -9999 -9999 -9999 -9999 -9999 -9999 -9999 -9999 -9999 -9999 -9999 -9999 -9999 -9999 -9999 -9999 -9999 -9999 -9999 -9999 -9999 -9999 -9999 -9999 -9999 -9999 -9999 -

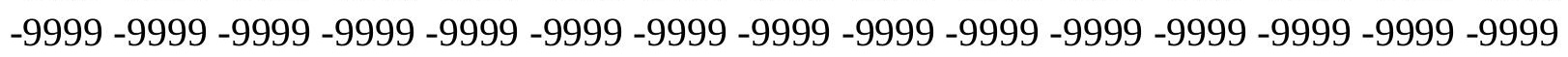
-9999 -9999-9999-9999-9999 -9999-9999-9999 -9999-9999-9999-9999 306.0043029785 307.5281982422307 .8330078125306 .6138000488303 .2611999512297 .1654968262 288.9363098145277 .9641113281266 .0773925781253 .8860015869240 .4754943848 223.7122955322202 .9868927002176 .7754058838152 .0877990723138 .6772003174 130.7528076172131 .6672058105138 .3724975586148 .7351074219161 .2312927246 171.5939941406180 .7375946045189 .8811035156197 .8054962158202 .3773040771 202.3773040771 197.8054962158 190.795501709 184.0901947021 177.9945068359 172.8132019043167 .3269958496161 .5361022949155 .1356048584150 .8686065674 147.5160064697144 .4682006836142 .0299072266140 .2012023926138 .3724975586 136.8484954834135 .3246002197133 .8007049561132 .5814971924131 .6672058105 131.3623962402131 .6672058105132 .2767028809133 .8007049561135 .6293945312 114.2944030762110 .027397155899 .9695205688587 .7781066894580 .46327209473 84.7302627563587 .1685485839888 .6924667358490 .8259735107492 .95947265625 95.7025299072398 .75038146973102 .1029968262105 .1509017944107 .8938980103 108.8082962036106 .979598999107 .2844009399114 .2944030762123 .1332015991 128.0097961426129 .533706665127 .4001998901124 .3523025513123 .1332015991 123.1332015991123 .43800354124 .9618988037128 .0097961426131 .6672058105 135.6293945312139 .2868041992143 .2489929199145 .9920959473144 .4682006836 140.8106994629136 .5437011719131 .3623962402126 .4858016968122 .2188034058 118.8662033081115 .818397522112 .1608963013106 .97959899998 .75038146973 91.1307525634888 .0829010009886 .8637619018686 .254188537687 .77810668945 
92.349891662697 .53124237061100 .8839035034102 .712600708102 .712600708 102.1029968262102 .4077987671102 .4077987671102 .4077987671101 .7982025146 101.4934005737100 .579101562599 .3599472045998 .7503814697396 .92166900635 94.7881774902394 .1785964965891 .1307525634883 .8159103393678 .32978057861 79.8537063598682 .9015579223681 .0728530883877 .7202072143675 .89148712158 77.110626220781 .0728530883892 .3498916626110 .0273971558133 .1911010742 155.1356048584167 .0222015381166 .4127044678175 .8609924316184 .699798584 193.8433074951197 .1959991455199 .329498291200 .3443908691200 .2803344727 200.1790466309200 .8707275391202 .3844604492204 .6271972656207 .5894317627 211.3128051758215 .4612731934219 .3014221191222 .330947876224 .4411773682 225.4278564453224 .311630249219 .9705352783212 .0109100342201 .3437347412 189.8811035156179 .5184020996172 .2035980225166 .7174987793162 .4505004883 156.9642944336150 .2590942383143 .5538024902136 .8484954834131 .3623962402 124.9618988037116 .7326965332105 .455703735491 .1307525634882 .59677124023 84.1206970214885 .6446228027386 .5589828491286 .8637619018686 .86376190186 86.5589828491285 .6446228027385 .0350494384883 .8159103393682 .90155792236 82.2919769287183 .5111236572385 .0350494384886 .5589828491288 .08290100098 89.302040100190 .5211791992291 .7403335571392 .6546783447393 .56903076172 93.8738174438594 .1785964965894 .1785964965893 .8738174438593 .56903076172 94.17859649658107 .2844009399121 .9140014648137 .4580993652149 .9542999268 160.6217956543171 .2891998291182 .5662994385194 .4528961182206 .3394927979 208.7778015137208.7778015137208.7778015137208.7778015137208.7778015137 208.7778015137208 .7778015137208 .7778015137208 .7778015137208 .7778015137 208.7778015137208.7778015137208.7778015137208.7778015137 208.7778015137 208.7778015137208.7778015137208.7778015137208.7778015137 208.7778015137 208.7778015137 208.7778015137208.7778015137208.7778015137 208.7778015137 208.7778015137208 .7778015137208 .7778015137208 .7778015137208 .7778015137 208.7778015137208.7778015137208.7778015137208.7778015137208.7778015137 208.7778015137208 .7778015137208 .7778015137208 .7778015137208 .7778015137 208.7778015137208 .7778015137208 .7778015137208 .7778015137208 .7778015137 208.7778015137208 .7778015137208 .7778015137208 .7778015137208 .7778015137 208.7778015137208 .7778015137208 .7778015137208 .7778015137208 .7778015137 208.7778015137 208.7778015137208.7778015137 208.7778015137 208.7778015137 208.7778015137208 .7778015137208 .7778015137208 .7778015137208 .7778015137 208.7778015137208 .7778015137208 .7778015137208 .7778015137208 .7778015137 208.7778015137208 .7778015137208 .7778015137208 .7778015137124 .6570968628 125.5715026855 -9999 -9999 -9999 -9999 -9999 -9999 -9999 -9999 -9999 -9999 -9999 -9999

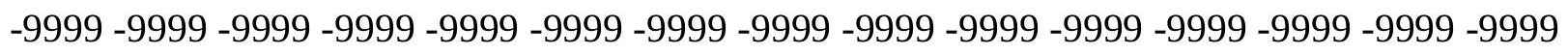
-9999 -9999 -9999 -9999 -9999 -9999 -9999 -9999

-9999 -9999 -9999 -9999 -9999 -9999 -9999 -9999 -9999 -9999 -9999 -9999 -9999 -9999 -999 -

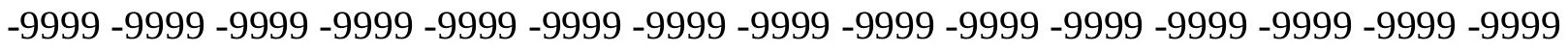

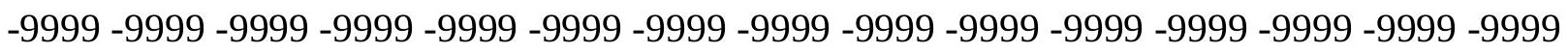
-9999 -9999 -9999 -9999 -9999 -9999 -9999 -9999 -9999 -9999 -9999 -9999 -9999 -9999 -9999 -9999 -9999 -9999 -9999 -9999 -9999 -9999 -9999 -9999 -9999 -9999 305.3947143555 307.2233886719308 .1377868652307 .8330078125306 .0043029785302 .0421142578 295.9464111328286 .4979858398274 .0018005371260 .2864990234249 .9237976074 
236.5133056641216 .3973999023192 .3193969727165 .8031005859146 .2969055176 140.5059967041140 .5059967041145 .6873016357154 .8307952881167 .6318054199 183.4806976318188 .0523986816193 .233795166199 .0247039795203 .9011993408 206.6443023682206 .3394927979202 .6820983887196 .2816009521188 .6620025635 180.7375946045174 .337097168168 .5462036133162 .7552947998157 .2691040039 153.0021057129149 .3556060791146 .9064025879145 .0776977539143 .2489929199 141.7250976562140 .5059967041138 .9819946289137 .4580993652136 .2389984131 135.3246002197135 .0198059082135 .0198059082135 .6293945312136 .5437011719 138.0677032471139 .6868591309141 .054306030397 .8360290527389 .60682678223 78.3297805786179 .5489196777382 .5967712402385 .3398437588 .38768768311 91.4355392456194 .7881774902398 .14080810547101 .4934005737104 .2365036011 106.3700027466 107.2844009399 107.2844009399107.8938980103110.6370010376 114.2944030762117 .0374984741118 .2565994263117 .9517974854116 .4279022217 115.818397522114 .9039993286112 .7705001831111 .8561019897114 .2944030762 118.2565994263122 .5235977173126 .7906036377132 .2767028809136 .8484954834 138.3724975586138 .0677032471136 .2389984131132 .5814971924128 .3144989014 123.43800354120 .3900985718117 .0374984741113 .075302124107 .2844009399 98.7503814697390 .8259735107488 .9972534179789 .302040100188 .69246673584 90.2164001464896 .31210327148103 .0174026489106 .6747970581108 .1986999512 107.5891036987106 .3700027466107 .2844009399107 .8938980103108 .1986999512 107.5891036987106 .6747970581105 .4557037354104 .5412979126104 .2365036011 103.9317016602104 .2365036011105 .1509017944101 .493400573792 .3498916626 86.2541885376 84.12069702148 83.2063369751 81.37763214111 78.93934631348 75.8914871215874 .6723632812576 .5010681152380 .7680587768681 .07285308838 85.0350494384898 .4455871582113 .3800964355130 .4479980469143 .2489929199 159.7073974609170 .3748931885172 .8132019043176 .4705963135178 .2993011475 177.0802001953177 .0802001953177 .8764648438179 .6173553467181 .8516387939 184.6218566895188 .6567993164194 .0604858398199 .1831359863202 .82472229 206.029800415209 .5790710449211 .6784973145210 .2008666992205 .3382415771 198.7924957275193 .233795166188 .966796875185 .0045928955178 .2993011475 170.3748931885163 .0599975586156 .3547973633150 .2590942383145 .0776977539 140.5059967041135 .3246002197129 .8385009766121 .6092987061107 .8938980103 92.6546783447383 .8159103393685 .3398437585 .9494018554786 .2541885376 86.254188537685 .9494018554785 .3398437585 .0350494384884 .42548370361 83.8159103393682 .9015579223681 .6824111938582 .9015579223684 .42548370361 86.254188537687 .7781066894589 .302040100190 .5211791992291 .43553924561 92.349891662692 .6546783447392 .9594726562592 .9594726562592 .95947265625 92.6546783447392 .349891662693 .56903076172106 .0652008057118 .5614013672 130.1432037354141 .4203033447153 .3069000244166 .4127044678180 .1280059814 193.8433074951206 .6443023682208 .7778015137208 .7778015137208 .7778015137 208.7778015137208 .7778015137208 .7778015137208 .7778015137208 .7778015137 208.7778015137208.7778015137208.7778015137208.7778015137 208.7778015137 208.7778015137208 .7778015137208 .7778015137208 .7778015137208 .7778015137 208.7778015137208 .7778015137208 .7778015137208 .7778015137208 .7778015137 208.7778015137208 .7778015137208 .7778015137208 .7778015137208 .7778015137 208.7778015137 208.7778015137208.7778015137208.7778015137208.7778015137 
208.7778015137208 .7778015137208 .7778015137208 .7778015137208 .7778015137 208.7778015137208 .7778015137208 .7778015137208 .7778015137208 .7778015137 208.7778015137208 .7778015137208 .7778015137208 .7778015137208 .7778015137 208.7778015137208 .7778015137208 .7778015137208 .7778015137208 .7778015137 208.7778015137208 .7778015137208 .7778015137208 .7778015137208 .7778015137 208.7778015137208 .7778015137208 .7778015137208 .7778015137208 .7778015137 208.7778015137208 .7778015137208 .7778015137208 .7778015137208 .7778015137 208.7778015137208 .7778015137208 .7778015137208 .7778015137208 .7778015137 123.43800354124 .3523025513 -9999 -9999 -9999 -9999 -9999 -9999 -9999 -9999 -9999 -9999 -9999 -9999 -9999 -9999 -9999 -9999 -9999 -9999 -9999 -9999 -9999 -9999 -9999 -9999 -9999 -9999 -9999 -9999 -9999 -9999 -9999 -9999 -9999 -9999 -9999

-9999 -9999 -9999 -9999 -9999 -9999 -9999 -9999 -9999 -9999 -9999 -9999 -9999 -9999 -9999 -9999 -9999 -9999 -9999 -9999 -9999 -9999 -9999 -9999 -9999 -9999 -9999 -9999 -9999 -9999 -9999 -9999 -9999 -9999 -9999 -9999 -9999 -9999 -9999 -9999 -9999 -9999 -9999 -9999 -9999 -9999 -9999 -9999 -9999 -9999 -9999 -9999 -9999 -9999 -9999 -9999 -9999 -9999 -9999 -9999 -9999 -9999 -9999 -9999 -9999-9999 -9999 -9999 -9999 -9999 302.3468017578 305.0899047852306 .6138000488306 .9186096191305 .6994934082302 .9563903809 298.6893920898293 .2033081055283 .7549133301268 .2109069824251 .7525024414 239.5610961914224 .6266021729200 .5485992432188 .6620025635174 .337097168 161.2312927246154 .2212982178153 .9165039062158 .7929992676167 .6318054199 178.9089050293189 .5764007568195 .9768066406200 .2438049316203 .596496582 206.3394927979 208.1681976318208.1681976318205.7299957275 199.9389953613 191.7097930908181 .9566955566175 .5561981201169 .4604949951163 .974395752 159.0977935791153 .6498718262151 .1955413818149 .0399017334147 .5160064697 145.9920959473145 .0776977539143 .8585968018142 .3347015381140 .8106994629 139.5915985107138 .6772003174138 .0677032471138 .0677032471138 .3724975586 139.2868041992140 .5059967041141 .7250976562142 .9441986084143 .8585968018 144.7729034424145 .1192779541145 .3825073242145 .0776977539144 .1634063721 142.9441986084141 .1154937744139 .2868041992137 .4580993652135 .6293945312 134.1054992676132 .8863067627108 .5035018921108 .1986999512107 .5891036987 108.1986999512109 .4179000854110 .6370010376111 .551399231111 .551399231 110.9418029785110 .6370010376110 .0273971558109 .4179000854109 .7226028442 110.6370010376112 .7705001831116 .1231002808120 .3900985718125 .2667007446 130.1432037354132 .8863067627134 .7149963379135 .3246002197134 .1054992676 130.1432037354125 .2667007446121 .6092987061118 .2565994263115 .5136032104 111.24659729103 .322196960496 .3121032714893 .5690307617293 .56903076172 93.8738174438596 .31210327148102 .1029968262107 .8938980103110 .9418029785 111.8561019897110 .3321990967108 .8082962036108 .1986999512107 .8938980103 108.8082962036109 .1130981445108 .5035018921107 .5891036987107 .2844009399 107.8938980103108 .1986999512108 .8082962036113 .9896011353121 .6092987061 117.647102356104 .2365036011111 .55139923194 .4833908081192 .3498916626 88.6924667358483 .206336975178 .3297805786177 .110626220776 .50106811523 74.3675689697376 .1962814331186 .8637619018699 .05516815186104 .8460998535 106.979598999106 .0652008057120 .6949005127142 .6394042969152 .6972961426 152.3925933838151 .1734008789153 .0021057129154 .5260925293156 .3547973633 158.1835021973159 .7073974609162 .7552947998168 .8509979248174 .6419067383 
176.7754058838179 .2136993408185 .3094024658191 .1002960205191 .7097930908 190.1858978271187 .7476043701186 .2236938477190 .1858978271191 .1002960205 184.0901947021174 .0323028564165 .1934967041158 .1835021973153 .6116943359 150.2590942383146 .9064025879143 .2489929199138 .9819946289132 .5814971924 122.8283996582110 .941802978597 .8360290527385 .3398437585 .3398437585 .64462280273 85.3398437585 .3398437585 .3398437585 .3398437585 .3398437585 .03504943848 84.7302627563583 .8159103393683 .206336975182 .9015579223685 .03504943848 86.8637619018688 .3876876831189 .6068267822390 .5211791992291 .43553924561 91.7403335571392 .0450973510792 .0450973510792 .0450973510791 .74033355713 91.4355392456191 .4355392456192 .95947265625101 .7982025146111 .551399231 122.8283996582135 .0198059082149 .6495056152165 .1934967041181 .0424041748 195.9768066406208 .7778015137208 .7778015137208 .7778015137208 .7778015137 208.7778015137 208.7778015137 208.7778015137 208.7778015137 208.7778015137 208.7778015137208 .7778015137208 .7778015137208 .7778015137208 .7778015137 208.7778015137208 .7778015137208 .7778015137208 .7778015137208 .7778015137 208.7778015137208 .7778015137208 .7778015137208 .7778015137208 .7778015137 208.7778015137208 .7778015137208 .7778015137208 .7778015137208 .7778015137 208.7778015137208 .7778015137208 .7778015137208 .7778015137208 .7778015137 208.7778015137208 .7778015137208 .7778015137208 .7778015137208 .7778015137 208.7778015137208 .7778015137208 .7778015137208 .7778015137208 .7778015137 208.7778015137208 .7778015137208 .7778015137208 .7778015137208 .7778015137 208.7778015137 208.7778015137 208.7778015137 208.7778015137 208.7778015137 208.7778015137208 .7778015137208 .7778015137208 .7778015137208 .7778015137 208.7778015137208 .7778015137208 .7778015137208 .7778015137208 .7778015137 208.7778015137208 .7778015137208 .7778015137208 .7778015137208 .7778015137 208.7778015137208 .7778015137208 .7778015137208 .7778015137208 .7778015137 123.1332015991124 .0475006104 -9999 -9999 -9999 -9999 -9999 -9999 -9999 -9999 -9999 -9999 -9999 -9999 -9999 -9999 -9999 -9999 -9999 -9999 -9999 -9999 -9999 -9999 -9999 -9999 -9999 -9999 -9999 -9999 -9999 -9999 -9999 -9999 -9999-9999

-9999 -9999 -9999 -9999 -9999 -9999 -9999 -9999 -9999 -9999 -9999 -9999 -9999 -9999 -9999

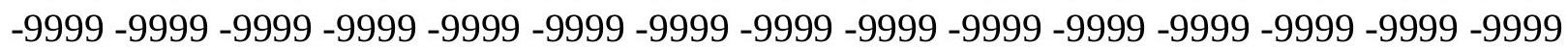
-9999 -9999 -9999 -9999 -9999 -9999 -9999 -9999 -9999 -9999 -9999 -9999 -9999 -9999 -9999 -

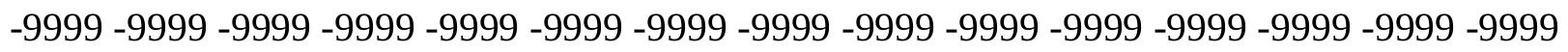
-9999 -9999 -9999-9999 -9999 -9999 -9999-9999-9999-9999 299.6037902832 302.0421142578303 .5660095215302 .9563903809300 .2132873535295 .9464111328 290.7650146484285 .5835876465277 .3544921875259 .9816894531239 .8659057617 224.6266021729208 .4730072021203 .2917022705193 .233795166181 .9566955566 172.5084075928166 .4127044678165 .4983062744169 .1557006836176 .165802002 184.3950042725192 .0146026611197 .8054962158201 .4629974365203 .596496582 205.425201416206 .6443023682207 .25390625206 .6443023682202 .6820983887 194.1481018066184 .3950042725176 .4705963135170 .3748931885165 .1934967041 158.3052978516155 .7496032715153 .0021057129150 .8686065674149 .3446960449 148.4304046631147 .8208007812146 .9064025879145 .3825073242143 .8585968018 142.6394042969141 .7250976562141 .1154937744140 .8106994629141 .1154937744 141.7250976562142 .6394042969143 .5538024902144 .1634063721145 .0776977539 145.6873016357145 .9920959473145 .6873016357145 .3825073242144 .4682006836 
143.2489929199141 .7250976562139 .8963928223137 .7628936768135 .6293945312 133.8007049561131 .9720001221130 .7528076172132 .8863067627130 .5131072998 130.4105377197107 .2844009399107 .5891036987107 .8938980103107 .5891036987 107.5891036987107 .2844009399107 .5891036987109 .1130981445110 .9418029785 110.9418029785111 .24659729113 .6848983765117 .0374984741120 .6949005127 124.6570968628127 .7050018311130 .4479980469133 .1911010742134 .1054992676 131.0576019287126 .4858016968122 .5235977173119 .1709976196117 .647102356 115.2088012695109 .1130981445103 .017402648999 .6647262573298 .75038146973 99.96952056885103 .0174026489107 .5891036987112 .1608963013113 .9896011353 114.5991973877112 .7705001831109 .7226028442106 .3700027466103 .6268997192 104.8460998535106 .979598999107 .8938980103108 .8082962036110 .3321990967 111.8561019897112 .1608963013111 .24659729115 .818397522118 .5614013672 113.075302124124 .9618988037115 .2088012695109 .1130981445123 .1332015991 101.798202514694 .1785964965886 .254188537681 .9871978759879 .85370635986 80.1584930419983 .206336975190 .2164001464895 .0929565429785 .03504943848 76.1962814331184 .4254837036197 .53124237061108 .8082962036118 .5614013672 124.6570968628128 .6192932129132 .8863067627135 .3246002197134 .7149963379 134.4102020264135 .6293945312138 .0677032471140 .5059967041142 .6394042969 143.8585968018146 .2969055176151 .7830047607157 .5738983154160 .6217956543 163.0599975586166 .7174987793171 .8988037109181 .3471984863187 .4429016113 181.9566955566172 .5084075928164 .8887023926158 .4882965088155 .1356048584 153.0021057129150 .8686065674148 .4304046631144 .7729034424139 .8963928223 134.4102020264126 .4858016968114 .2944030762100 .274299621686 .2541885376 85.0350494384884 .7302627563584 .7302627563585 .0350494384885 .64462280273 86.254188537686 .8637619018686 .5589828491286 .254188537685 .64462280273 85.03504943848 84.73026275635 85.94940185547 87.77810668945 88.99725341797 89.9116134643690.5211791992290.8259735107491.1307525634891.13075256348 90.8259735107490 .8259735107490 .5211791992290 .5211791992290 .21640014648 92.9594726562596 .61688232422105 .1509017944117 .647102356133 .4958953857 150.5639038086168 .241394043185 .0045928955199 .329498291208 .7778015137 208.7778015137208 .7778015137208 .7778015137208 .7778015137208 .7778015137 208.7778015137 208.7778015137 208.7778015137 208.7778015137 208.7778015137 208.7778015137208 .7778015137208 .7778015137208 .7778015137208 .7778015137 208.7778015137208 .7778015137208 .7778015137208 .7778015137208 .7778015137 208.7778015137208 .7778015137208 .7778015137208 .7778015137208 .7778015137 208.7778015137208 .7778015137208 .7778015137208 .7778015137208 .7778015137 208.7778015137 208.7778015137208.7778015137 208.7778015137 208.7778015137 208.7778015137 208.7778015137208.7778015137 208.7778015137 208.7778015137 208.7778015137208 .7778015137208 .7778015137208 .7778015137208 .7778015137 208.7778015137208 .7778015137208 .7778015137208 .7778015137208 .7778015137 208.7778015137 208.7778015137208.7778015137 208.7778015137 208.7778015137 208.7778015137 208.7778015137208.7778015137 208.7778015137 208.7778015137 208.7778015137208 .7778015137208 .7778015137208 .7778015137208 .7778015137 208.7778015137208 .7778015137208 .7778015137208 .7778015137208 .7778015137 208.7778015137208 .7778015137121 .9140014648122 .8283996582 -9999 -9999 -9999 -9999 -9999 -9999 -9999 -9999 -9999 -9999 -9999 -9999 -9999 -9999 -9999 -9999 -9999 -9999 -9999 
-9999 -9999 -9999 -9999 -9999 -9999 -9999 -9999 -9999 -9999 -9999 -9999 -9999 -9999 -9999 -9999 -9999 -9999 -9999 -9999 -9999 -9999 -9999 -9999 -9999 -9999 -9999 -9999 -9999 -9999

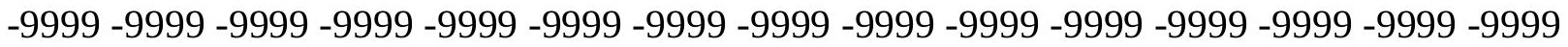
-9999 -9999 -9999 -9999 -9999 -9999 -9999 -9999 -9999 -9999 -9999 -9999 -9999 -9999 -9999 -9999 -9999 -9999 -9999 -9999 -9999 -9999 -9999 -9999 -9999 -9999 -9999 -9999 -9999 -9999 -9999 -9999 -9999 -9999 -9999 -9999 -9999 -9999 -9999 288.9363098145292 .8984985352 296.2510986328297 .7750854492295 .9464111328291 .3746032715283 .7549133301 275.8305053711269 .7348022461262 .1152038574247 .7902984619228 .8936004639 207.25390625 204.5108032227 201.4629974365 195.0625 187.1381072998 180.432800293 175.8609924316174 .6419067383176 .7754058838181 .3471984863187 .1381072998 192.3193969727196 .5863952637199 .0247039795200 .5485992432201 .4629974365 202.0724945068202.9868927002 203.9011993408203.9011993408 193.8433074951 184.0901947021176 .4705963135170 .6797027588162 .6549987793160 .485244751 157.878692627154 .8307952881152 .6972961426151 .1734008789150 .2590942383 149.9542999268149 .6495056152147 .8208007812146 .2969055176145 .0776977539 144.1634063721143 .5538024902143 .5538024902143 .5538024902143 .8585968018 144.4682006836145 .0776977539145 .6873016357146 .2969055176146 .6015930176 146.6015930176146 .6015930176145 .9920959473145 .0776977539143 .8585968018 142.3347015381140 .8106994629138 .9819946289136 .8484954834134 .7149963379 133.1911010742132 .2767028809133 .1911010742135 .0198059082134 .3419799805 138.3724975586139 .2868041992139 .8963928223106 .0652008057106 .0652008057 106.0652008057106 .6747970581108 .1986999512109 .7226028442110 .0273971558 110.3321990967112 .1608963013114 .5991973877117 .647102356120 .6949005127 123.1332015991125 .8762969971128 .9241027832130 .4479980469129 .2288970947 126.1809997559123 .1332015991120 .3900985718118 .5614013672116 .4279022217 112.1608963013107 .5891036987105 .1509017944103 .9317016602105 .1509017944 107.5891036987111 .24659729114 .2944030762116 .4279022217117 .0374984741 115.5136032104110 .6370010376102 .102996826295 .0929565429795 .70252990723 99.96952056885104 .5412979126109 .1130981445112 .7705001831115 .2088012695 116.4279022217115 .818397522113 .3800964355118 .2565994263113 .9896011353 121.6092987061124 .6570968628119 .1709976196133 .1911010742130 .1432037354 105.455703735496 .3121032714890 .8259735107488 .3876876831188 .99725341797 90.8259735107493 .5690307617293 .5690307617286 .8637619018681 .37763214111 84.7302627563592 .0450973510799 .66472625732106 .979598999111 .8561019897 115.818397522119 .1709976196121 .3044967651121 .3044967651121 .6092987061 124.0475006104126 .4858016968126 .4858016968125 .8762969971126 .7906036377 128.9241027832132 .2767028809136 .5437011719139 .5915985107142 .6394042969 145.3825073242149 .6495056152159 .4026031494167 .3269958496167 .9365997314 164.8887023926162 .4505004883159 .7073974609157 .2691040039155 .1356048584 152.6972961426150 .5639038086147 .8208007812144 .4682006836140 .8106994629 135.0198059082126 .1809997559114 .5991973877100 .883903503485 .64462280273 84.1206970214883 .8159103393684 .4254837036185 .9494018554787 .47332763672 88.6924667358488 .9972534179788 .6924667358488 .0829010009887 .47332763672 87.4733276367287 .7781066894587 .4733276367288 .6924667358489 .3020401001 89.9116134643689 .9116134643689 .9116134643689 .9116134643689 .91161346436 89.6068267822389 .6068267822389 .6068267822389 .6068267822389 .3020401001 
89.302040100192.04509735107 103.0174026489 118.5614013672135.6293945312 154.2212982178173 .4226989746189 .8811035156200 .2438049316206 .9490966797 208.7778015137208 .7778015137208 .7778015137208 .7778015137208 .7778015137 208.7778015137208 .7778015137208 .7778015137208 .7778015137208 .7778015137 208.7778015137208 .7778015137208 .7778015137208 .7778015137208 .7778015137 208.7778015137208 .7778015137208 .7778015137208 .7778015137208 .7778015137 208.7778015137208 .7778015137208 .7778015137208 .7778015137208 .7778015137 208.7778015137208 .7778015137208 .7778015137208 .7778015137208 .7778015137 208.7778015137208 .7778015137208 .7778015137208 .7778015137208 .7778015137 208.7778015137208 .7778015137208 .7778015137208 .7778015137208 .7778015137 208.7778015137208 .7778015137208 .7778015137208 .7778015137208 .7778015137 208.7778015137208 .7778015137208 .7778015137208 .7778015137208 .7778015137 208.7778015137208 .7778015137208 .7778015137208 .7778015137208 .7778015137 208.7778015137208 .7778015137208 .7778015137208 .7778015137208 .7778015137 208.7778015137208 .7778015137208 .7778015137208 .7778015137208 .7778015137 208.7778015137208 .7778015137208 .7778015137208 .7778015137208 .7778015137 208.7778015137208 .7778015137121 .6092987061102 .3380279541 -9999 -9999 -9999 -9999

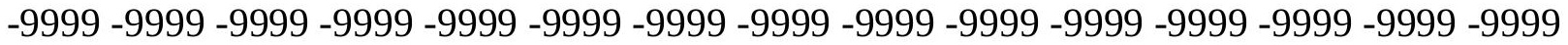

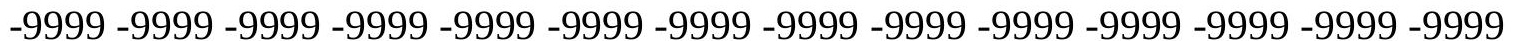

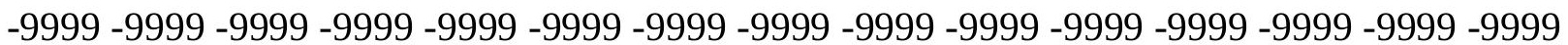

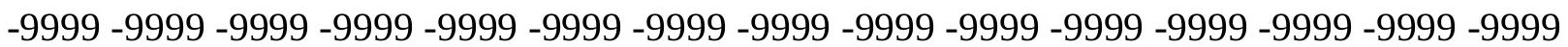

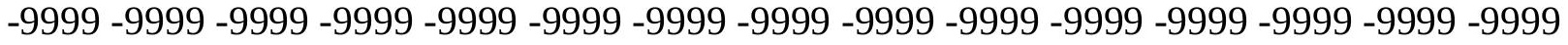

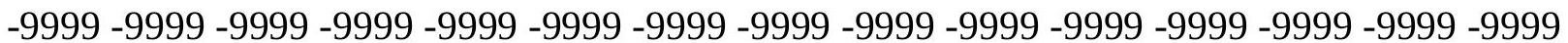
-9999 -9999 -9999 -9999 -9999 -9999 -9999 -9999 274.6113891602 277.6592102051 281.6214904785284 .3645019531285 .2789001465282 .2309875488276 .4400939941 267.2966003418257 .2385864258250 .2286071777241 .6945953369228 .8936004639 211.2160949707197 .500793457198 .1103057861197 .500793457194 .4528961182 189.5764007568185 .3094024658181 .9566955566180 .7375946045181 .9566955566 184.3950042725187 .7476043701191 .1002960205193 .5386047363194 .7577056885 195.3672943115195 .0625195 .0625195 .3672943115196 .2816009521195 .3672943115 189.2716064453181 .0424041748175 .5561981201170 .6797027588164 .5227355957 162.4505004883159 .0977935791156 .3547973633154 .2212982178152 .3925933838 151.4781951904150 .8686065674150 .5639038086149 .3446960449148 .1255950928 147.2111968994146 .2969055176145 .9920959473145 .6873016357145 .9920959473 146.2969055176146 .6015930176146 .9064025879147 .2111968994147 .5160064697 147.8208007812147 .8208007812147 .5160064697146 .9064025879145 .9920959473 145.0776977539143 .8585968018142 .3347015381140 .5059967041138 .6772003174 137.1533050537135 .6293945312135 .3246002197135 .6293945312136 .5437011719 136.8096618652138 .9819946289139 .8963928223140 .5059967041140 .8106994629 141.4203033447141 .7250976562106 .6747970581107 .5891036987108 .1986999512 109.1130981445110 .0273971558111 .551399231113 .6848983765115 .818397522 118.2565994263119 .7806015015121 .6092987061124 .3523025513126 .1809997559 126.1809997559124 .9618988037123 .1332015991121 .3044967651119 .1709976196 116.7326965332114 .2944030762111 .551399231109 .7226028442108 .8082962036 109.7226028442111 .24659729113 .3800964355115 .5136032104117 .647102356 117.9517974854115 .5136032104109 .417900085496 .6168823242286 .2541885376 
87.1685485839893 .26425170898101 .7982025146110 .3321990967115 .5136032104 118.5614013672120 .0852966309120 .3900985718119 .1709976196117 .9517974854 117.647102356119 .1709976196123 .1332015991121 .9140014648138 .6772003174 137.4580993652130 .4479980469122 .8283996582101 .798202514699 .35994720459 99.6647262573299 .9695205688598 .445587158296 .3121032714896 .31210327148 96.9216690063595 .7025299072396 .0073165893699 .05516815186103 .3221969604 106.3700027466108 .8082962036110 .9418029785112 .4656982422113 .9896011353 115.818397522118 .5614013672120 .9997024536119 .1709976196117 .0374984741 117.9517974854119 .4757995605120 .6949005127122 .5235977173124 .9618988037 127.0953979492126 .7906036377128 .0097961426135 .0198059082142 .6394042969 147.8208007812151 .4781951904154 .5260925293156 .3547973633155 .4403991699 153.6116943359151 .7830047607149 .6495056152148 .1255950928146 .2969055176 143.5538024902139 .2868041992133 .8007049561125 .5715026855113 .3800964355 98.7503814697383 .206336975182 .2919769287183 .5111236572385 .94940185547 88.9972534179790.82597351074 91.1307525634890.82597351074 90.21640014648 89.6068267822389 .6068267822389 .6068267822388 .9972534179788 .38768768311 88.9972534179788 .9972534179788 .9972534179788 .6924667358488 .69246673584 88.6924667358488 .6924667358488 .6924667358488 .6924667358488 .69246673584 88.9972534179788 .9972534179788 .6924667358494 .17859649658105 .1509017944 119.7806015015138 .0677032471158 .7929992676179 .5184020996186 .8332977295 192.9290008545199 .329498291206 .0346984863208 .7778015137208 .7778015137 208.7778015137208 .7778015137208 .7778015137208 .7778015137208 .7778015137 208.7778015137208 .7778015137208 .7778015137208 .7778015137208 .7778015137 208.7778015137208 .7778015137208 .7778015137208 .7778015137208 .7778015137 208.7778015137208 .7778015137208 .7778015137208 .7778015137208 .7778015137 208.7778015137208 .7778015137208 .7778015137208 .7778015137208 .7778015137 208.7778015137208 .7778015137208 .7778015137208 .7778015137208 .7778015137 208.7778015137208 .7778015137208 .7778015137208 .7778015137208 .7778015137 208.7778015137208 .7778015137208 .7778015137208 .7778015137208 .7778015137 208.7778015137208 .7778015137208 .7778015137208 .7778015137208 .7778015137 208.7778015137208 .7778015137208 .7778015137208 .7778015137208 .7778015137 208.7778015137208 .7778015137208 .7778015137208 .7778015137208 .7778015137 208.7778015137208 .7778015137208 .7778015137208 .7778015137208 .7778015137 208.7778015137 208.7778015137 208.7778015137 208.7778015137 208.7778015137 208.7778015137208 .7778015137208 .7778015137120 .3900985718120 .9997024536 -9999 -9999 -9999 -9999 -9999 -9999 -9999 -9999 -9999 -9999 -9999 -9999 -9999 -9999 -9999 -9999

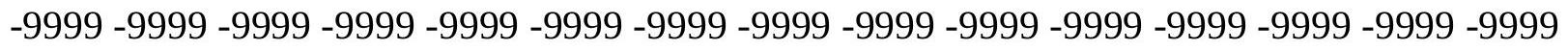
-9999-9999

-9999 -9999 -9999 -9999 -9999 -9999 -9999 -9999 -9999 -9999 -9999 -9999 -9999 -9999 -9999

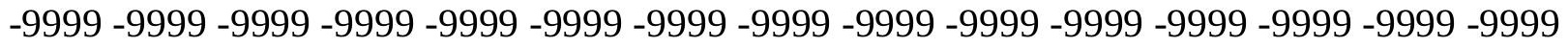

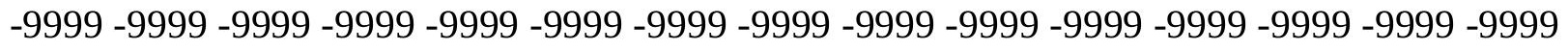

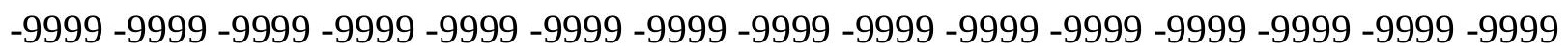
-9999-9999-9999-9999-9999-9999-9999 259.0674133301 257.5433959961 259.3721008301 261.5056152344261 .5056152344259 .3721008301256 .0195007324251 .1428985596 245.0471954346237 .7324066162229 .8079986572217 .9214019775198 .4151000977 183.1759033203189 .2716064453192 .624206543193 .5386047363192 .624206543 
190.1858978271187 .7476043701185 .6141052246184 .3950042725184 .699798584 185.9188995361187 .4429016113188 .966796875189 .8811035156189 .8811035156 189.2716064453 188.6620025635187.4429016113 185.9188995361 187.7476043701 187.1381072998183 .7854003906178 .9089050293174 .0323028564167 .5958862305 165.8386993408163 .3648071289160 .3170013428157 .5738983154155 .4403991699 153.6116943359152 .3925933838151 .4781951904151 .1734008789150 .2590942383 149.6495056152148 .7351074219148 .4304046631148 .1255950928147 .8208007812 148.1255950928148 .1255950928148 .4304046631148 .7351074219149 .0399017334 149.0399017334149 .0399017334149 .0399017334148 .7351074219148 .1255950928 147.5160064697146 .6015930176145 .6873016357144 .4682006836142 .9441986084 141.7250976562140 .2012023926139 .2868041992138 .6772003174138 .6772003174 138.9819946289139 .2488098145140 .5059967041140 .8106994629141 .4203033447 141.7250976562142 .0299072266142 .3347015381142 .6394042969142 .9441986084 143.2489929199143 .2489929199110 .0273971558111 .24659729112 .7705001831 114.5991973877116 .4279022217117 .9517974854119 .4757995605121 .6092987061 123.1332015991123 .43800354123 .1332015991122 .5235977173120 .9997024536 119.4757995605117 .647102356115 .818397522114 .2944030762113 .075302124 112.4656982422112 .7705001831113 .9896011353114 .9039993286115 .818397522 116.4279022217114 .5991973877109 .4179000854101 .493400573790 .21640014648 81.6824111938583 .5111236572391 .43553924561103 .0174026489114 .2944030762 119.7806015015121 .9140014648123 .43800354123 .43800354122 .8283996582 121.9140014648121 .9140014648121 .9140014648122 .5235977173122 .8283996582 138.0677032471135 .6293945312132 .5814971924129 .8385009766128 .6192932129 127.4001998901109 .4179000854107 .5891036987104 .5412979126103 .0174026489 103.3221969604104 .2365036011103 .9317016602102 .712600708102 .712600708 103.6268997192105 .1509017944106 .979598999108 .8082962036110 .6370010376 112.4656982422113 .6848983765114 .5991973877114 .9039993286113 .075302124 111.24659729111 .8561019897112 .4656982422113 .075302124113 .6848983765 114.9039993286116 .1231002808116 .1231002808116 .7326965332120 .6949005127 125.5715026855128 .0097961426131 .0576019287136 .2389984131140 .5059967041 143.5538024902145 .0776977539145 .6873016357145 .3825073242145 .3825073242 144.7729034424143 .5538024902141 .4203033447137 .7628936768131 .9720001221 123.1332015991111 .2465972996 .3121032714880 .7680587768681 .98719787598 85.9494018554791.1307525634892.349891662692.95947265625 92.95947265625 92.349891662691 .4355392456191 .1307525634890 .8259735107490 .52117919922 89.3020401001 88.08290100098 87.77810668945 87.47332763672 87.16854858398 87.16854858398 87.16854858398 87.16854858398 87.47332763672 87.77810668945 88.0829010009888 .3876876831188 .6924667358488 .6924667358488 .69246673584 92.65467834473103 .3221969604120 .0852966309139 .2868041992156 .3547973633 167.9365997314176 .4705963135184 .0901947021192 .3193969727200 .8533935547 208.7778015137208 .7778015137208 .7778015137208 .7778015137208 .7778015137 208.7778015137208 .7778015137208 .7778015137208 .7778015137208 .7778015137 208.7778015137208 .7778015137208 .7778015137208 .7778015137208 .7778015137 208.7778015137208 .7778015137208 .7778015137208 .7778015137208 .7778015137 208.7778015137208 .7778015137208 .7778015137208 .7778015137208 .7778015137 208.7778015137208 .7778015137208 .7778015137208 .7778015137208 .7778015137 
208.7778015137208 .7778015137208 .7778015137208 .7778015137208 .7778015137 208.7778015137208 .7778015137208 .7778015137208 .7778015137208 .7778015137 208.7778015137208 .7778015137208 .7778015137208 .7778015137208 .7778015137 208.7778015137208 .7778015137208 .7778015137208 .7778015137208 .7778015137 208.7778015137208 .7778015137208 .7778015137208 .7778015137208 .7778015137 208.7778015137208 .7778015137208 .7778015137208 .7778015137208 .7778015137 208.7778015137208 .7778015137208 .7778015137208 .7778015137208 .7778015137 208.7778015137208 .7778015137208 .7778015137208 .7778015137208 .7778015137 119.7806015015120 .6949005127 -9999 -9999-9999 -9999 -9999 -9999 -9999 -9999 -9999 -9999 -9999 -9999 -9999 -9999 -9999 -9999 -9999 -9999 -9999 -9999 -9999 -9999 -9999 -9999 -9999 -9999 -9999 -9999 -9999 -9999-9999 -9999

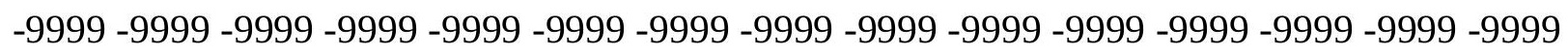
-9999 -9999 -9999 -9999 -9999 -9999 -9999 -9999 -9999 -9999 -9999 -9999 -9999 -9999 -9999 -9999 -9999 -9999 -9999 -9999 -9999 -9999 -9999 -9999 -9999 -9999 -9999 -9999 -9999 -9999 -

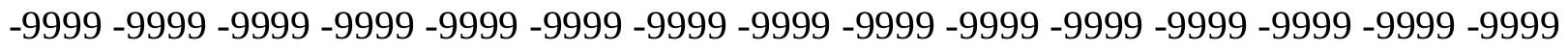
-9999 -9999 -9999 -9999-9999-9999 241.3898010254 239.8659057617 238.9515075684 239.2563018799238 .9515075684235 .5989074707231 .0270996094227 .3697052002 223.7122955322220 .9691925049216 .7021942139207 .8634033203193 .233795166 179.2136993408180 .432800293184 .0901947021187 .7476043701189 .8811035156 190.4907073975189 .8811035156188 .3571929932187 .1381072998186 .2236938477 185.6141052246185 .9188995361186 .2236938477186 .528503418186 .2236938477 185.3094024658183 .7854003906182 .87109375181 .9566955566181 .3471984863 181.3471984863181 .0424041748179 .2136993408176 .165802002169 .8166351318 168.6090698242166 .7174987793163 .974395752161 .2312927246158 .7929992676 156.3547973633154 .5260925293152 .6972961426152 .3925933838151 .7830047607 151.1734008789150 .8686065674150 .2590942383149 .9542999268149 .9542999268 149.9542999268149 .9542999268150 .2590942383150 .2590942383150 .5639038086 150.5639038086150 .5639038086150 .5639038086150 .2590942383149 .9542999268 149.6495056152149 .0399017334148 .4304046631147 .8208007812146 .9064025879 145.9920959473144 .7729034424143 .8585968018143 .2489929199142 .6394042969 142.3347015381142 .3347015381142 .2353057861141 .7840270996142 .6394042969 142.6394042969142 .6394042969142 .9441986084142 .9441986084142 .9441986084 142.9441986084142 .9441986084142 .9441986084142 .6394042969142 .0299072266 141.4203033447113 .6848983765115 .2088012695117 .0374984741118 .5614013672 119.7806015015120 .9997024536121 .3044967651121 .6092987061121 .3044967651 120.6949005127119 .4757995605118 .2565994263117 .342300415116 .1231002808 115.5136032104114 .9039993286115 .2088012695115 .5136032104116 .1231002808 115.818397522114 .2944030762110 .6370010376103 .322196960494 .48339080811 85.94940185547 81.3776321411184.4254837036193.56903076172 106.3700027466 118.2565994263122 .8283996582124 .3523025513125 .5715026855125 .5715026855 125.2667007446124 .9618988037124 .6570968628124 .6570968628124 .6570968628 123.7427978516119 .4757995605116 .1231002808133 .1911010742135 .0198059082 135.9342041016136 .2389984131134 .1054992676130 .7528076172128 .6192932129 110.3321990967109 .7226028442109 .4179000854110 .0273971558110 .0273971558 108.1986999512106 .6747970581106 .979598999108 .1986999512110 .0273971558 112.7705001831115 .818397522117 .9517974854117 .0374984741114 .2944030762 
111.551399231109 .4179000854108 .8082962036109 .4179000854109 .4179000854 109.1130981445109 .4179000854109 .7226028442110 .0273971558110 .9418029785 111.551399231112 .7705001831111 .24659729111 .24659729115 .818397522121 .6092987061 128.0097961426133 .1911010742136 .2389984131138 .0677032471139 .8963928223 140.8106994629141 .1154937744140 .5059967041138 .3724975586134 .7149963379 129.2288970947 120.9997024536108.198699951292.95947265625 81.07285308838 85.9494018554790 .8259735107493 .8738174438595 .0929565429795 .09295654297 94.1785964965893 .2642517089892 .0450973510791 .4355392456191 .13075256348 90.5211791992288 .6924667358486 .254188537685 .6446228027385 .3398437585 .33984375 85.6446228027385 .6446228027386 .254188537686 .5589828491287 .16854858398 87.7781066894588 .3876876831188 .6924667358488 .9972534179788 .99725341797 91.74033355713103 .6268997192119 .7806015015134 .4102020264147 .2111968994 158.1835021973168 .241394043177 .9945068359188 .3571929932198 .4151000977 208.1681976318208 .7778015137208 .7778015137208 .7778015137208 .7778015137 208.7778015137208 .7778015137208 .7778015137208 .7778015137208 .7778015137 208.7778015137 208.7778015137208.7778015137 208.7778015137 208.7778015137 208.7778015137208 .7778015137208 .7778015137208 .7778015137208 .7778015137 208.7778015137208 .7778015137208 .7778015137208 .7778015137208 .7778015137 208.7778015137208 .7778015137208 .7778015137208 .7778015137208 .7778015137 208.7778015137208 .7778015137208 .7778015137208 .7778015137208 .7778015137 208.7778015137 208.7778015137208.7778015137 208.7778015137 208.7778015137 208.7778015137208 .7778015137208 .7778015137208 .7778015137208 .7778015137 208.7778015137208 .7778015137208 .7778015137208 .7778015137208 .7778015137 208.7778015137 208.7778015137208.7778015137 208.7778015137 208.7778015137 208.7778015137 208.7778015137208.7778015137 208.7778015137 208.7778015137 208.7778015137 208.7778015137208.7778015137208.7778015137 208.7778015137 208.7778015137208 .7778015137208 .7778015137208 .7778015137118 .5614013672 119.4757995605 -9999 -9999 -9999 -9999 -9999 -9999 -9999 -9999 -9999 -9999 -9999 -9999 -9999 -9999 -9999 -9999 -9999 -9999 -9999 -9999 -9999 -9999 -9999 -9999 -9999 -9999 - -999 -9999 -9999-9999-9999-9999

-9999 -9999 -9999 -9999 -9999 -9999 -9999 -9999 -9999 -9999 -9999 -9999 -9999 -9999 -9999 -9999 -9999 -9999 -9999 -9999 -9999 -9999 -9999 -9999 -9999 -9999 -9999 -9999 -9999 -9999 -

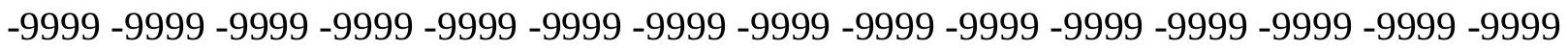
-9999 -9999 -9999 -9999 -9999 -9999 -9999 -9999 -9999 -9999 -9999 -9999 -9999 -9999 -9999 -9999 -9999 -9999 -9999 -9999 -9999 228.8936004639225.8457946777 223.4075012207 221.2740020752218 .8356933594214 .8735046387210 .6065063477206 .3394927979 202.3773040771 197.500793457 191.4051055908 183.4806976318 180.7375946045 179.5184020996180 .1280059814182 .261505127185 .3094024658187 .7476043701 188.6620025635188 .966796875188 .0523986816187 .1381072998186 .2236938477 185.6141052246185 .0045928955184 .699798584184 .0901947021183 .1759033203 181.6519012451180 .432800293179 .2136993408178 .2993011475177 .6896972656 177.3849029541176 .7754058838175 .5561981201171 .0030975342170 .3684082031 169.1557006836166 .7174987793164 .2792053223161 .8408966064159 .7073974609 157.5738983154155 .7451934814154 .2212982178153 .6116943359153 .0021057129 152.3925933838152 .0877990723151 .7830047607151 .7830047607151 .7830047607 151.7830047607151 .7830047607152 .0877990723152 .0877990723152 .0877990723 
152.0877990723152 .0877990723152 .0877990723151 .7830047607151 .4781951904 151.1734008789150 .8686065674150 .5639038086149 .9542999268149 .6495056152 149.0399017334148 .4304046631147 .8208007812147 .5160064697146 .9064025879 146.6015930176145 .9920959473145 .6873016357144 .982711792144 .4682006836 144.1634063721143 .8585968018143 .5538024902143 .5538024902143 .2489929199 143.2489929199142 .9441986084142 .6394042969142 .3347015381141 .7250976562 141.1154937744139 .8963928223138 .6772003174137 .1533050537117 .342300415 118.5614013672119 .4757995605120 .0852966309120 .3900985718120 .3900985718 120.0852966309119 .4757995605118 .8662033081118 .2565994263117 .647102356 117.0374984741116 .7326965332116 .7326965332116 .7326965332116 .4279022217 115.2088012695113 .3800964355109 .4179000854103 .322196960496 .61688232422 88.3876876831184.12069702148 89.302040100198.75038146973109.7226028442 119.1709976196123 .7427978516125 .8762969971127 .0953979492127 .4001998901 127.4001998901127 .4001998901127 .7050018311127 .7050018311127 .4001998901 126.1809997559123 .1332015991120 .9997024536120 .9997024536121 .9140014648 122.8283996582128 .0097961426130 .4479980469131 .6672058105131 .0576019287 128.0097961426114 .9039993286113 .6848983765114 .2944030762113 .6848983765 111.8561019897110 .0273971558109 .7226028442110 .9418029785112 .4656982422 116.1231002808125 .2667007446132 .5814971924132 .2767028809127 .4001998901 118.5614013672110 .9418029785109 .4179000854110 .0273971558109 .4179000854 108.5035018921107 .2844009399106 .6747970581106 .6747970581106 .0652008057 105.4557037354103 .9317016602101 .1886978149100 .2742996216103 .6268997192 109.1130981445115 .2088012695120 .9997024536125 .2667007446128 .3144989014 131.3623962402 134.1054992676 136.2389984131 137.1533050537136.8484954834 135.0198059082131 .9720001221126 .4858016968117 .9517974854106 .6747970581 93.26425170898 87.77810668945 92.0450973510795.397743225197.22646331787 97.5312423706196 .6168823242295 .0929565429793 .2642517089891 .74033355713 91.7403335571391 .7403335571391 .4355392456191 .4355392456187 .47332763672 86.2541885376 83.2063369751 83.51112365723 84.12069702148 84.73026275635 85.6446228027386 .5589828491287 .1685485839888 .0829010009888 .99725341797 89.302040100189 .6068267822389 .302040100193 .26425170898103 .0174026489 115.5136032104128 .3144989014140 .5059967041152 .3925933838164 .2792053223 175.8609924316187 .1381072998197 .8054962158207 .5587005615208 .7778015137 208.7778015137208 .7778015137208 .7778015137208 .7778015137208 .7778015137 208.7778015137208 .7778015137208 .7778015137208 .7778015137208 .7778015137 208.7778015137208 .7778015137208 .7778015137208 .7778015137208 .7778015137 208.7778015137208.7778015137208.7778015137 208.7778015137 208.7778015137 208.7778015137 208.7778015137208.7778015137208.7778015137 208.7778015137 208.7778015137208 .7778015137208 .7778015137208 .7778015137208 .7778015137 208.7778015137208 .7778015137208 .7778015137208 .7778015137208 .7778015137 208.7778015137208 .7778015137208 .7778015137208 .7778015137208 .7778015137 208.7778015137208.7778015137208.7778015137208.7778015137 208.7778015137 208.7778015137208 .7778015137208 .7778015137208 .7778015137208 .7778015137 208.7778015137208 .7778015137208 .7778015137208 .7778015137208 .7778015137 208.7778015137208 .7778015137208 .7778015137208 .7778015137208 .7778015137 208.7778015137208.7778015137208.7778015137208.7778015137208.7778015137 
208.7778015137 208.7778015137 118.2565994263119 .1709976196 -9999 -9999 -9999 -9999 -9999 -9999 -9999 -9999 -9999 -9999 -9999 -9999 -9999 -9999 -9999 -9999 -9999 -9999 -9999 -9999 -9999 -9999 -9999 -9999 -9999 -9999 -9999 -9999 -9999 -9999 -9999

-9999 -9999 -9999 -9999 -9999 -9999 -9999 -9999 -9999 -9999 -9999 -9999 -9999 -9999 -9999 -9999 -9999 -9999 -9999 -9999 -9999 -9999 -9999 -9999-9999 -9999 -9999 -9999 -9999 -9999 -9999 -9999 -9999 -9999 -9999 -9999 -9999 -9999 -9999 -9999 -9999 -9999 -9999 -9999 -9999

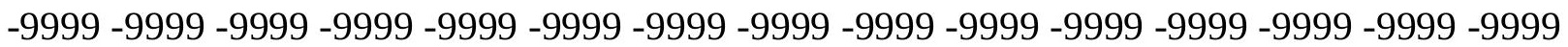
-9999 -9999 -9999 -9999 -9999 225.5410003662 220.3596038818 216.0926971436 211.8256988525206 .9490966797202 .0724945068198 .4151000977195 .0625191 .1002960205 185.9188995361177 .9945068359168 .8509979248171 .5939941406176 .4705963135 178.604095459180 .1280059814181 .9566955566184 .3950042725186 .2236938477 187.4429016113187 .7476043701187 .4429016113186 .528503418185 .6141052246 184.699798584183 .4806976318182 .5662994385181 .6519012451180 .432800293 178.9089050293177 .6896972656176 .7754058838175 .8609924316175 .2514038086 174.6419067383174 .0323028564171 .2981109619171 .0547332764170 .3748931885 168.5462036133166 .4127044678164 .5839996338162 .7552947998160 .6217956543 158.7929992676157 .2691040039155 .7451934814154 .8307952881154 .2212982178 153.9165039062153 .6116943359153 .3069000244153 .6116943359153 .6116943359 153.6116943359153 .9165039062153 .9165039062153 .9165039062153 .9165039062 153.9165039062153 .6116943359153 .6116943359153 .6116943359153 .3069000244 153.0021057129153 .0021057129152 .6972961426152 .6972961426152 .6972961426 152.3925933838152 .3925933838152 .0877990723151 .7830047607151 .4781951904 151.1734008789150 .2590942383149 .0399017334147 .8208007812146 .6015930176 145.6873016357145 .0776977539144 .4682006836144 .1634063721143 .5538024902 143.2489929199142 .9441986084142 .6394042969142 .0299072266141 .4203033447 140.8106994629139 .8963928223138 .3724975586137 .1533050537135 .3246002197 133.1911010742131 .0576019287118 .8662033081119 .4757995605119 .4757995605 119.4757995605119 .1709976196118 .8662033081118 .5614013672118 .2565994263 117.9517974854117 .647102356117 .647102356117 .0374984741116 .4279022217 114.9039993286112 .7705001831109 .7226028442106 .0652008057101 .7982025146 94.7881774902391 .1307525634896 .92166900635105 .7603988647113 .075302124 119.1709976196123 .43800354125 .8762969971127 .4001998901128 .0097961426 128.6192932129128 .9241027832129 .2288970947129 .533706665129 .8385009766 129.533706665128 .3144989014127 .4001998901125 .8762969971124 .9618988037 124.0475006104123 .1332015991123 .43800354129 .533706665131 .0576019287 129.533706665125 .2667007446118 .5614013672117 .0374984741116 .4279022217 114.9039993286113 .6848983765113 .075302124114 .2944030762115 .5136032104 120.6949005127135 .0198059082147 .8208007812149 .0399017334143 .5538024902 130.7528076172118 .2565994263114 .5991973877113 .9896011353111 .551399231 110.0273971558108 .1986999512106 .6747970581105 .1509017944103 .6268997192 101.493400573797.8360290527393.5690307617292.6546783447394.78817749023 98.75038146973103 .6268997192108 .8082962036112 .7705001831117 .0374984741 121.3044967651125 .5715026855128 .9241027832131 .3623962402132 .5814971924 132.5814971924131 .0576019287128 .0097961426123 .7427978516116 .7326965332 106.065200805794 .1785964965895 .0929565429798 .75038146973100 .8839035034 100.883903503499 .3599472045997 .2264633178794 .4833908081192 .3498916626 
92.9594726562593 .5690307617293 .8738174438593 .5690307617291 .43553924561 88.9972534179785 .6446228027381 .3776321411182 .2919769287183 .2063369751 84.4254837036185 .3398437586 .8637619018688 .0829010009888 .99725341797 89.9116134643690 .2164001464890 .2164001464892 .9594726562590 .52117919922 102.1029968262113 .6848983765125 .5715026855138 .3724975586151 .4781951904 164.2792053223 176.7754058838188.0523986816198.1103057861 206.6443023682 208.7778015137208 .7778015137208 .7778015137208 .7778015137208 .7778015137 208.7778015137208 .7778015137208 .7778015137208 .7778015137208 .7778015137 208.7778015137208 .7778015137208 .7778015137208 .7778015137208 .7778015137 208.7778015137208 .7778015137208 .7778015137208 .7778015137208 .7778015137 208.7778015137208 .7778015137208 .7778015137208 .7778015137208 .7778015137 208.7778015137 208.7778015137208.7778015137 208.7778015137 208.7778015137 208.7778015137208 .7778015137208 .7778015137208 .7778015137208 .7778015137 208.7778015137208 .7778015137208 .7778015137208 .7778015137208 .7778015137 208.7778015137208 .7778015137208 .7778015137208 .7778015137208 .7778015137 208.7778015137208.7778015137208.7778015137 208.7778015137 208.7778015137 208.7778015137208 .7778015137208 .7778015137208 .7778015137208 .7778015137 208.7778015137208 .7778015137208 .7778015137208 .7778015137208 .7778015137 208.7778015137208 .7778015137208 .7778015137208 .7778015137208 .7778015137 208.7778015137 208.7778015137 117.0374984741 117.9517974854 -9999 -9999-9999-9999 -9999 -9999 -9999 -9999 -9999 -9999 -9999 -9999 -9999 -9999 -9999 -9999 -9999 -9999 -9999 -9999 -9999 -9999 -9999 -9999 -9999 -9999 -9999 -9999 -9999 -9999 -9999 -9999 -9999 -9999 -9999 -9999 -9999 -9999 -9999 -9999 -9999 -9999 -9999 -9999 -9999 -9999

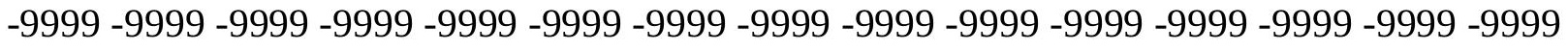
-9999 -9999 -9999 -9999 -9999 -9999 -9999 -9999 -9999 -9999 -9999 -9999 -9999 -9999 -9999 -9999 -9999 -9999 -9999 -9999 -9999 -9999 -9999 -9999 -9999 -9999 -9999 -9999 -9999 -9999 -9999 -9999 -9999 -9999 230.1127929688 222.1884002686214.2639007568209.9969024658 206.0346984863198 .7198944092191 .7097930908186 .8332977295183 .4806976318 179.8231964111174 .9467010498168 .241394043168 .241394043170 .6797027588 174.337097168177 .6896972656180 .1280059814182 .261505127184 .0901947021 185.3094024658186 .2236938477186 .528503418185 .9188995361185 .3094024658 184.0901947021182 .87109375181 .6519012451180 .432800293179 .2136993408 177.9945068359176 .7754058838175 .8609924316174 .9467010498174 .0323028564 173.4226989746172 .8132019043172 .2035980225170 .9891052246170 .6797027588 169.4604949951167 .9365997314166 .7174987793164 .8887023926163 .3648071289 161.5361022949160 .0122070312158 .4882965088157 .2691040039156 .3547973633 155.7451934814155 .4403991699155 .1356048584155 .1356048584155 .1356048584 155.1356048584155 .4403991699155 .4403991699155 .4403991699155 .4403991699 155.4403991699155 .4403991699155 .1356048584155 .1356048584155 .1356048584 155.1356048584155 .1356048584155 .1356048584155 .1356048584155 .4403991699 155.7451934814156 .0500030518156 .3547973633156 .3547973633156 .6596069336 156.6596069336156 .0500030518155 .1356048584153 .3069000244150 .5639038086 149.0399017334147 .8208007812146 .6015930176145 .3825073242144 .7729034424 143.8585968018143 .5538024902142 .9441986084142 .3347015381142 .0299072266 141.4203033447140 .5059967041139 .5915985107138 .3724975586136 .8484954834 135.3246002197133 .4958953857131 .6672058105129 .8385009766127 .7050018311 
118.8662033081118 .8662033081118 .8662033081118 .8662033081118 .8662033081 118.8662033081118 .5614013672118 .2565994263117 .9517974854117 .342300415 116.4279022217115 .2088012695113 .075302124110 .9418029785108 .5035018921 106.0652008057102 .712600708101 .7982025146107 .2844009399113 .6848983765 117.647102356120 .6949005127123 .43800354125 .5715026855126 .7906036377 127.7050018311128 .6192932129129 .2288970947129 .8385009766130 .7528076172 131.9720001221132 .5814971924131 .6672058105129 .8385009766128 .3144989014 126.4858016968125 .2667007446124 .9618988037124 .9618988037124 .6570968628 129.533706665131 .0576019287126 .1809997559121 .6092987061119 .7806015015 118.5614013672117 .342300415116 .4279022217116 .1231002808116 .4279022217 119.1709976196126 .1809997559141 .4203033447155 .1356048584158 .4882965088 154.8307952881146 .9064025879136 .8484954834127 .0953979492119 .4757995605 115.2088012695112 .4656982422110 .3321990967108 .1986999512106 .6747970581 104.5412979126100 .579101562595 .0929565429785 .3398437584 .12069702148 85.0350494384890 .2164001464893 .2642517089896 .61688232422100 .8839035034 105.7603988647110 .6370010376115 .5136032104119 .7806015015123 .43800354 125.8762969971127 .4001998901127 .7050018311126 .7906036377124 .3523025513 120.0852966309113 .075302124105 .455703735499 .96952056885103 .9317016602 105.4557037354104 .5412979126102 .407798767199 .6647262573297 .22646331787 95.397743225195 .0929565429795 .7025299072396 .0073165893696 .00731658936 95.0929565429793 .8738174438592 .9594726562592 .6546783447383 .81591033936 81.3776321411182 .9015579223684 .4254837036185 .9494018554787 .77810668945 89.302040100190 .2164001464890 .8259735107491 .1307525634890 .52117919922 90.2164001464895 .3977432251103 .3221969604113 .3800964355126 .4858016968 140.2012023926153 .9165039062166 .4127044678178 .2993011475188 .6620025635 196.891204834203 .9011993408208 .7778015137208 .7778015137208 .7778015137 208.7778015137208 .7778015137208 .7778015137208 .7778015137208 .7778015137 208.7778015137208 .7778015137208 .7778015137208 .7778015137208 .7778015137 208.7778015137208 .7778015137208 .7778015137208 .7778015137208 .7778015137 208.7778015137208 .7778015137208 .7778015137208 .7778015137208 .7778015137 208.7778015137208.7778015137208.7778015137208.7778015137208.7778015137 208.7778015137208 .7778015137208 .7778015137208 .7778015137208 .7778015137 208.7778015137 208.7778015137208.7778015137 208.7778015137 208.7778015137 208.7778015137208 .7778015137208 .7778015137208 .7778015137208 .7778015137 208.7778015137208 .7778015137208 .7778015137208 .7778015137208 .7778015137 208.7778015137208.7778015137208.7778015137208.7778015137208.7778015137 208.7778015137208.7778015137208.7778015137 208.7778015137 208.7778015137 208.7778015137 208.7778015137208.7778015137208.7778015137 208.7778015137 208.7778015137208 .7778015137208 .7778015137115 .818397522116 .7326965332 117.342300415 -9999 -9999 -9999 -9999 -9999 -9999 -9999 -9999 -9999 -9999 -9999 -9999 -9999 -9999 -9999 -9999 -9999 -9999 -9999 -9999 -9999 -9999 -9999 -9999 -9999 -9999 -999 $-9999-9999-9999$ -9999 -9999 -9999 -9999 -9999 -9999 -9999 -9999 -9999 -9999 -9999 -9999 -9999 -9999 -9999 -9999 -9999 -9999 -9999 -9999 -9999 -9999 -9999 -9999-9999 -9999 -9999 -9999 -9999 -9999 -9999 -9999 -9999 -9999 -9999 -9999 -9999 -9999 -9999 -9999 -9999 -9999 -9999 -9999 -9999 -

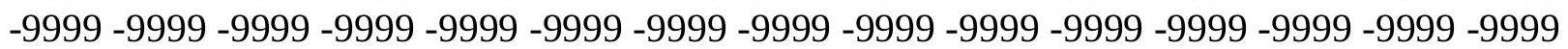


-9999 -9999 -9999 236.5133056641 232.246307373222.4931030273212.4351959229 208.7778015137205 .425201416196 .891204834188 .0523986816181 .9566955566 177.3849029541173 .4226989746170 .6797027588169 .7653045654170 .070098877 171.5939941406174 .337097168177 .3849029541180 .1280059814182 .5662994385 183.7854003906184 .699798584185 .0045928955185 .0045928955184 .699798584 183.4806976318182 .261505127181 .0424041748179 .5184020996178 .2993011475 177.0802001953175 .8609924316174 .9467010498174 .337097168173 .4226989746 173.1179962158172 .5084075928171 .8988037109170 .686630249170 .4466552734 169.7653045654168 .8509979248167 .9365997314166 .7174987793165 .1934967041 163.974395752162 .4505004883161 .2312927246160 .0122070312158 .7929992676 157.878692627157 .2691040039156 .6596069336156 .6596069336156 .6596069336 157.5738983154158 .4882965088159 .7073974609160 .3170013428159 .4026031494 158.4882965088156 .9642944336156 .6596069336156 .6596069336156 .6596069336 156.6596069336156 .6596069336156 .9642944336157 .2691040039157 .5738983154 158.1835021973158 .7929992676159 .4026031494160 .0122070312160 .6217956543 161.2312927246161 .5361022949161 .1127319336159 .8108673096157 .5738983154 154.5260925293151 .7830047607149 .6495056152147 .8208007812146 .2969055176 145.0776977539144 .1634063721143 .5538024902142 .9441986084142 .3347015381 141.7250976562141 .1154937744140 .2012023926139 .2868041992138 .3724975586 137.1533050537135 .6293945312134 .1054992676132 .2767028809130 .7528076172 128.9241027832127 .4001998901125 .5715026855118 .5614013672118 .5614013672 118.8662033081118 .8662033081118 .8662033081118 .5614013672118 .2565994263 117.647102356117 .0374984741115 .818397522114 .2944030762112 .4656982422 110.9418029785110 .0273971558110 .3321990967112 .1608963013116 .1231002808 120.0852966309121 .3044967651122 .2188034058123 .43800354124 .9618988037 125.5715026855126 .4858016968127 .0953979492128 .0097961426128 .9241027832 130.4479980469132 .8863067627134 .4102020264132 .5814971924130 .1432037354 128.6192932129127 .4001998901126 .7906036377126 .1809997559125 .8762969971 125.5715026855124 .9618988037124 .0475006104123 .1332015991122 .5235977173 121.6092987061120 .3900985718119 .4757995605118 .8662033081118 .8662033081 119.7806015015121 .9140014648129 .2288970947143 .2489929199154 .178817749 159.8009338379159 .906463623157 .3072814941153 .6116943359140 .2012023926 126.1809997559119 .7806015015116 .4279022217113 .075302124110 .9418029785 109.4179000854 107.2844009399 103.322196960497.8360290527392.04509735107 89.3020401001 89.9116134643692.0450973510793.2642517089893.56903076172 93.8738174438595 .7025299072399 .66472625732104 .5412979126109 .4179000854 113.3800964355116 .4279022217118 .8662033081120 .6949005127121 .6092987061 120.6949005127118 .5614013672115 .818397522113 .075302124110 .9418029785 110.6370010376110 .3321990967108 .5035018921105 .4557037354102 .712600708 100.274299621698 .7503814697398 .1408081054798 .445587158298 .75038146973 98.7503814697398 .7503814697398 .445587158297 .5312423706195 .3977432251 90.8259735107486 .254188537682 .2919769287183 .206336975185 .03504943848 87.1685485839888 .9972534179790 .5211791992291 .4355392456191 .43553924561 90.8259735107490 .5211791992292 .0450973510797 .22646331787106 .0652008057 117.9517974854130 .7528076172143 .8585968018156 .3547973633168 .241394043 178.9089050293185 .9188995361192 .3193969727198 .4151000977204 .5108032227 
208.7778015137 208.7778015137208.7778015137208.7778015137 208.7778015137 208.7778015137208 .7778015137208 .7778015137208 .7778015137208 .7778015137 208.7778015137208 .7778015137208 .7778015137208 .7778015137208 .7778015137 208.7778015137208 .7778015137208 .7778015137208 .7778015137208 .7778015137 208.7778015137208 .7778015137208 .7778015137208 .7778015137208 .7778015137 208.7778015137208 .7778015137208 .7778015137208 .7778015137208 .7778015137 208.7778015137208 .7778015137208 .7778015137208 .7778015137208 .7778015137 208.7778015137 208.7778015137 208.7778015137 208.7778015137 208.7778015137 208.7778015137208 .7778015137208 .7778015137208 .7778015137208 .7778015137 208.7778015137208 .7778015137208 .7778015137208 .7778015137208 .7778015137 208.7778015137 208.7778015137208.7778015137208.7778015137 208.7778015137 208.7778015137208 .7778015137208 .7778015137208 .7778015137208 .7778015137 208.7778015137 208.7778015137208.7778015137 208.7778015137 208.7778015137 115.5136032104116 .1231002808 -9999 -9999 -9999 -9999 -9999 -9999 -9999 -9999 -9999 -9999 -9999 -9999 -9999 -9999 -9999 -9999 -9999 -9999 -9999 -9999 -9999 -9999 -9999 -9999 -9999 -9999 -9999-9999-9999-9999

-9999 -9999 -9999 -9999 -9999 -9999 -9999 -9999 -9999 -9999 -9999 -9999 -9999 -9999 -9999 -9999 -9999 -9999 -9999 -9999 -9999 -9999 -9999 -9999 -9999 -9999 -9999 -9999 -9999 -9999 -999 -

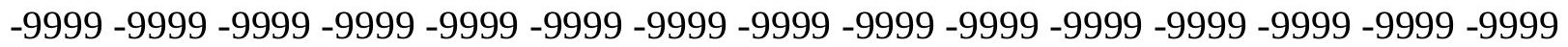

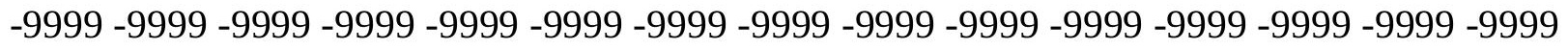
-9999 -9999 242.6089935303 239.8659057617 235.2940979004 227.9792938232 220.3596038818215 .1782989502210 .3016967773203 .596496582195 .9768066406 187.7476043701180 .1280059814174 .0323028564171 .5939941406171 .2891998291 171.5939941406173 .1179962158175 .2514038086177 .6896972656180 .1280059814 181.9566955566183 .4806976318184 .0901947021184 .0901947021183 .7854003906 183.1759033203181 .9566955566180 .432800293178 .9089050293177 .3849029541 175.8609924316174 .6419067383173 .7274932861173 .4226989746173 .1179962158 172.8132019043172 .2035980225171 .8988037109171 .2891998291170 .2313232422 170.070098877169 .4604949951168 .5462036133167 .9365997314166 .7174987793 165.8031005859164 .5839996338163 .3648071289162 .4505004883161 .8408966064 161.2312927246161 .2312927246161 .2312927246161 .5361022949162 .1457061768 163.3648071289164 .8887023926167 .0222015381169 .1557006836170 .9844970703 171.2891998291168 .8509979248164 .2792053223158 .7929992676157 .878692627 157.878692627158 .1835021973158 .1835021973158 .7929992676159 .4026031494 160.0122070312160 .9264984131161 .8408966064162 .7552947998163 .6696014404 164.5839996338165 .1934967041165 .8031005859165 .8031005859163 .9623565674 161.5465698242158 .1835021973154 .5260925293151 .4781951904149 .0399017334 147.2111968994145 .6873016357144 .7729034424143 .8585968018143 .2489929199 142.3347015381141 .7250976562141 .1154937744140 .2012023926139 .2868041992 138.3724975586137 .1533050537135 .9342041016134 .4102020264133 .1911010742 131.6672058105130 .1432037354128 .6192932129127 .0953979492125 .8762969971 118.2565994263118 .5614013672118 .5614013672118 .5614013672118 .5614013672 118.2565994263117 .9517974854117 .342300415116 .4279022217115 .2088012695 114.2944030762113 .3800964355113 .3800964355114 .9039993286117 .0374984741 120.0852966309121 .9140014648122 .2188034058122 .2188034058122 .5235977173 123.43800354123 .7427978516124 .3523025513124 .6570968628124 .9618988037 
126.4858016968128 .3144989014130 .4479980469131 .9720001221130 .4479980469 128.6192932129127 .7050018311127 .4001998901127 .0953979492126 .7906036377 126.1809997559125 .8762969971125 .2667007446124 .9618988037124 .0475006104 124.0475006104124 .9618988037121 .9140014648120 .9997024536120 .9997024536 121.3044967651121 .9140014648122 .8283996582125 .5715026855137 .4580993652 149.9542999268155 .3338470459157 .7109375158 .0595397949155 .4403991699 145.3825073242133 .4958953857125 .8762969971120 .6949005127117 .342300415 115.2088012695113 .3800964355110 .6370010376111 .8561019897102 .1029968262 97.8360290527395 .0929565429794 .7881774902395 .397743225196 .00731658936 97.2264633178797 .2264633178798 .4455871582100 .5791015625103 .0174026489 105.1509017944105 .7603988647106 .0652008057106 .3700027466108 .5035018921 110.3321990967112 .4656982422114 .2944030762115 .5136032104116 .7326965332 117.0374984741116 .1231002808117 .647102356110 .9418029785107 .5891036987 104.8460998535103 .0174026489101 .7982025146101 .4934005737101 .4934005737 101.7982025146101 .7982025146101 .7982025146101 .4934005737100 .5791015625 98.1408081054795 .397743225192 .349891662690 .2164001464885 .64462280273 84.1206970214886 .254188537688 .3876876831190 .2164001464891 .74033355713 91.4355392456190 .8259735107490 .2164001464890 .2164001464892 .65467834473 101.1886978149111 .8561019897123 .43800354135 .0198059082146 .6015930176 156.9642944336166 .1078948975173 .4226989746179 .5184020996185 .3094024658 191.4051055908197 .8054962158205 .1204071045208 .7778015137208 .7778015137 208.7778015137208 .7778015137208 .7778015137208 .7778015137208 .7778015137 208.7778015137208 .7778015137208 .7778015137208 .7778015137208 .7778015137 208.7778015137208 .7778015137208 .7778015137208 .7778015137208 .7778015137 208.7778015137208 .7778015137208 .7778015137208 .7778015137208 .7778015137 208.7778015137208 .7778015137208 .7778015137208 .7778015137208 .7778015137 208.7778015137208 .7778015137208 .7778015137208 .7778015137208 .7778015137 208.7778015137208 .7778015137208 .7778015137208 .7778015137208 .7778015137 208.7778015137208 .7778015137208 .7778015137208 .7778015137208 .7778015137 208.7778015137208 .7778015137208 .7778015137208 .7778015137208 .7778015137 208.7778015137208 .7778015137208 .7778015137208 .7778015137208 .7778015137 208.7778015137208 .7778015137208 .7778015137208 .7778015137208 .7778015137 208.7778015137 208.7778015137208.7778015137208.7778015137 208.7778015137 208.7778015137 113.9896011353114 .9039993286115 .818397522 -9999 -9999 -9999 -9999 -9999 -9999 -9999 -9999 -9999 -9999 -9999 -9999 -9999 -9999 -9999 -9999 -9999 -9999 -9999 -9999 -9999 -9999 -9999 -9999 -9999 -9999 -9999 -9999-9999

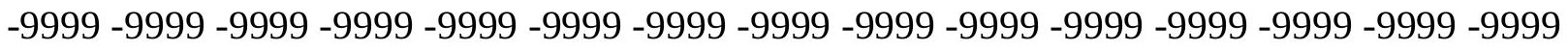

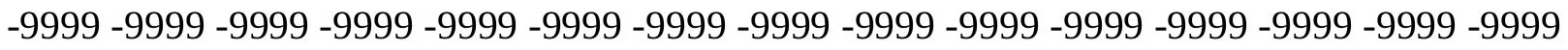
-9999 -9999 -9999 -9999 -9999 -9999 -9999 -9999 -9999 -9999 -9999 -9999 -9999 -9999 -9999 -9999 -9999 -9999 -9999 -9999 -9999 -9999 -9999 -9999 -9999 -9999 -9999 -9999 -9999 -9999 -9999 -9999 245.3520050049241.0850067139237.4275970459233.7702026367 229.5032043457223.4075012207217.0070037842 212.4351959229 206.6443023682 196.5863952637185 .9188995361177 .3849029541171 .8988037109172 .2035980225 173.1179962158174 .6419067383176 .4705963135178 .2993011475180 .432800293 181.9566955566182 .87109375183 .4806976318183 .1759033203182 .5662994385 181.6519012451180 .1280059814178 .604095459176 .7754058838175 .2514038086 
173.7274932861172 .5084075928172 .2035980225171 .8988037109171 .8988037109 172.2035980225171 .8988037109171 .5939941406170 .1763153076169 .9002685547 169.7653045654169 .1557006836168 .5462036133168 .241394043168 .241394043 167.9365997314167 .9365997314167 .3269958496167 .0222015381166 .4127044678 166.1078948975166 .1078948975166 .4127044678167 .0222015381167 .9365997314 169.4604949951171 .5939941406174 .6419067383178 .2993011475181 .9566955566 183.4806976318180 .1280059814174 .337097168168 .5462036133163 .974395752 160.3170013428159 .4026031494159 .7073974609160 .3170013428161 .2312927246 162.1457061768163 .3648071289164 .5839996338165 .8031005859167 .0222015381 168.241394043168 .8509979248169 .4604949951169 .1557006836167 .3227844238 164.6853790283160 .9264984131156 .9642944336153 .3069000244150 .2590942383 147.8208007812146 .2969055176145 .0776977539144 .1634063721143 .2489929199 142.6394042969141 .7250976562141 .1154937744140 .2012023926139 .2868041992 138.3724975586137 .4580993652136 .2389984131135 .0198059082133 .8007049561 132.5814971924131 .0576019287129 .8385009766128 .6192932129127 .0953979492 125.8762969971124 .3523025513118 .2565994263118 .2565994263118 .2565994263 118.2565994263117 .9517974854117 .647102356117 .0374984741116 .7326965332 116.1231002808115 .818397522116 .1231002808117 .342300415118 .5614013672 120.6949005127121 .9140014648122 .2188034058121 .9140014648121 .9140014648 121.9140014648121 .3044967651120 .9997024536119 .7806015015119 .7806015015 122.2188034058124 .9618988037126 .7906036377127 .7050018311126 .7906036377 126.1809997559126 .1809997559126 .7906036377126 .7906036377126 .7906036377 126.4858016968125 .8762969971125 .5715026855125 .2667007446124 .6570968628 123.7427978516122 .8283996582122 .5235977173122 .2188034058122 .2188034058 122.8283996582124 .0475006104125 .5715026855128 .6192932129131 .9720001221 140.2012023926145 .6873016357148 .7351074219149 .9542999268148 .4304046631 144.4682006836138 .0677032471131 .3623962402124 .9618988037122 .2188034058 120.0852966309117 .647102356114 .2944030762114 .5991973877106 .3700027466 102.712600708100 .274299621699 .0551681518698 .75038146973100 .2742996216 99.96952056885100 .2742996216101 .1886978149103 .0174026489105 .1509017944 106.979598999 107.8938980103107.8938980103 107.5891036987 107.2844009399 106.3700027466104 .5412979126106 .6747970581112 .7705001831117 .342300415 119.4757995605118 .2565994263114 .2944030762110 .9418029785108 .1986999512 106.3700027466105 .4557037354104 .8460998535104 .8460998535104 .8460998535 105.1509017944104 .8460998535104 .5412979126103 .9317016602102 .712600708 100.883903503498 .445587158296 .0073165893693 .5690307617290 .52117919922 88.3876876831186 .5589828491287 .1685485839888 .9972534179790 .21640014648 90.5211791992289 .9116134643689 .6068267822389 .9116134643692 .65467834473 99.05516815186107 .5891036987117 .342300415127 .4001998901137 .1533050537 145.9920959473153 .6116943359160 .0122070312165 .4983062744170 .6797027588 176.165802002183 .1759033203191 .4051055908199 .329498291204 .8155975342 208.7778015137208 .7778015137208 .7778015137208 .7778015137208 .7778015137 208.7778015137208 .7778015137208 .7778015137208 .7778015137208 .7778015137 208.7778015137208 .7778015137208 .7778015137208 .7778015137208 .7778015137 208.7778015137208 .7778015137208 .7778015137208 .7778015137208 .7778015137 208.7778015137208 .7778015137208 .7778015137208 .7778015137208 .7778015137 
208.7778015137208 .7778015137208 .7778015137208 .7778015137208 .7778015137 208.7778015137208 .7778015137208 .7778015137208 .7778015137208 .7778015137 208.7778015137208 .7778015137208 .7778015137208 .7778015137208 .7778015137 208.7778015137208 .7778015137208 .7778015137208 .7778015137208 .7778015137 208.7778015137208 .7778015137208 .7778015137208 .7778015137208 .7778015137 208.7778015137208 .7778015137208 .7778015137208 .7778015137208 .7778015137 208.7778015137 208.7778015137 208.7778015137 208.7778015137 208.7778015137 208.7778015137208 .7778015137113 .6848983765114 .5991973877 -9999 -9999 -9999 -9999 -9999 -9999 -9999 -9999 -9999 -9999 -9999 -9999 -9999 -9999 -9999 -9999 -9999 -9999 -9999 -9999 -9999 -9999 -9999 -9999 -9999 -9999 -9999 -9999 -9999

-9999 -9999 -9999 -9999 -9999 -9999 -9999 -9999 -9999 -9999 -9999 -9999 -9999 -9999 -9999 -9999 -9999 -9999 -9999 -9999 -9999 -9999 -9999 -9999 -9999 -9999 -9999 -9999 -9999 -9999 -9999 -9999 -9999 -9999 -9999 -9999 -9999 -9999 -9999 -9999 -9999 -9999 -9999 -9999 -9999

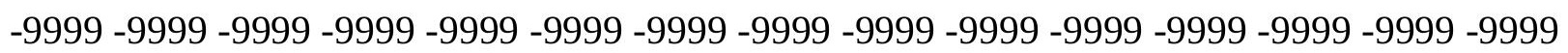
-9999 250.5334014893244.7424926758239.5610961914236.2084960938235.9037017822 234.6844940186228 .5888977051221 .883605957217 .9214019775213 .0447998047 201.7678070068189 .2716064453179 .8231964111172 .5084075928173 .4226989746 174.9467010498176 .165802002177 .6896972656179 .2136993408180 .7375946045 181.9566955566182 .87109375182 .87109375182 .5662994385181 .6519012451 180.432800293178 .9089050293177 .0802001953175 .2514038086173 .4226989746 171.8988037109170 .6797027588170 .6797027588170 .9844970703171 .2891998291 171.5939941406171 .8988037109171 .2891998291170 .420425415170 .070098877 169.7653045654170 .070098877171 .2891998291171 .8988037109172 .2035980225 172.5084075928172 .2035980225171 .8988037109171 .5939941406170 .9844970703 170.6797027588170 .6797027588170 .9844970703171 .8988037109173 .1179962158 174.6419067383177 .0802001953180 .432800293184 .3950042725189 .2716064453 194.1481018066188 .3571929932182 .261505127176 .7754058838172 .5084075928 169.1557006836166 .7174987793164 .5839996338163 .0599975586162 .7552947998 163.974395752165 .1934967041166 .7174987793168 .5462036133169 .7653045654 171.2891998291172 .2035980225172 .5084075928171 .8988037109170 .0542449951 167.3037872314163.3648071289 159.0977935791 154.8307952881 151.1734008789 148.4304046631146 .9064025879145 .6873016357144 .4682006836143 .5538024902 142.6394042969142 .0299072266141 .1154937744140 .2012023926139 .5915985107 138.6772003174137 .7628936768136 .8484954834135 .6293945312134 .7149963379 133.4958953857132 .2767028809131 .0576019287129 .8385009766128 .6192932129 127.4001998901125 .8762969971124 .3523025513117 .9517974854117 .9517974854 117.9517974854117 .9517974854117 .647102356117 .647102356117 .647102356 117.647102356117 .647102356117 .647102356118 .2565994263119 .1709976196 120.6949005127121 .9140014648122 .2188034058122 .2188034058122 .2188034058 120.9997024536117 .9517974854114 .5991973877111 .24659729110 .9418029785 116.7326965332122 .2188034058123 .43800354122 .8283996582122 .8283996582 123.7427978516124 .9618988037126 .1809997559126 .4858016968126 .4858016968 126.4858016968126 .1809997559125 .8762969971125 .5715026855124 .9618988037 124.3523025513123 .43800354122 .8283996582122 .8283996582123 .43800354 124.0475006104125 .5715026855127 .4001998901129 .8385009766132 .5814971924 133.4958953857132 .5814971924134 .7149963379135 .0198059082135 .3246002197 
136.8484954834136 .2389984131132 .5814971924127 .0953979492126 .4858016968 124.6570968628121 .6092987061117 .9517974854119 .1709976196110 .0273971558 106.6747970581104 .2365036011102 .712600708101 .7982025146103 .3221969604 102.712600708102 .712600708103 .3221969604104 .8460998535106 .3700027466 107.8938980103109 .1130981445109 .4179000854108 .5035018921107 .8938980103 106.979598999106 .0652008057106 .0652008057107 .8938980103116 .4279022217 118.5614013672116 .7326965332112 .7705001831109 .1130981445107 .8938980103 107.5891036987107 .5891036987108 .1986999512108 .5035018921108 .8082962036 108.5035018921107 .8938980103107 .2844009399106 .3700027466104 .8460998535 103.0174026489100 .883903503498 .445587158296 .0073165893693 .56903076172 92.0450973510791 .4355392456188 .6924667358487 .1685485839888 .08290100098 88.69246673584 88.69246673584 88.3876876831190.21640014648 93.26425170898 98.14080810547104 .8460998535112 .4656982422120 .6949005127128 .3144989014 135.3246002197141 .4203033447146 .6015930176150 .8686065674155 .4403991699 158.7929992676165 .1934967041174 .6419067383185 .9188995361190 .4907073975 194.7577056885198 .7198944092202 .9868927002207 .8634033203208 .7778015137 208.7778015137208 .7778015137208 .7778015137208 .7778015137208 .7778015137 208.7778015137208 .7778015137208 .7778015137208 .7778015137208 .7778015137 208.7778015137208 .7778015137208 .7778015137208 .7778015137208 .7778015137 208.7778015137208 .7778015137208 .7778015137208 .7778015137208 .7778015137 208.7778015137208 .7778015137208 .7778015137208 .7778015137208 .7778015137 208.7778015137208 .7778015137208 .7778015137208 .7778015137208 .7778015137 208.7778015137208 .7778015137208 .7778015137208 .7778015137208 .7778015137 208.7778015137208 .7778015137208 .7778015137208 .7778015137208 .7778015137 208.7778015137208 .7778015137208 .7778015137208 .7778015137208 .7778015137 208.7778015137208 .7778015137208 .7778015137208 .7778015137208 .7778015137 208.7778015137 208.7778015137208.7778015137 208.7778015137 208.7778015137 $208.7778015137208 .7778015137112 .4656982422113 .3800964355113 .9896011353-9999$ -9999 -9999 -9999 -9999 -9999 -9999 -9999 -9999 -9999 -9999 -9999 -9999 -9999 -9999 -9999 -9999 -9999 -9999 -9999 -9999 -9999 -9999 -9999 -9999 -9999 -9999 -9999 -9999 -9999 -9999 -9999 -9999 -9999 -9999 -9999 -9999 -9999 -9999 -9999 -9999 -9999 -9999 -9999 -9999 -9999 -9999 -9999 -9999 -9999 -9999 -9999 -9999 -9999 -9999 -9999 -9999-999 -999 -

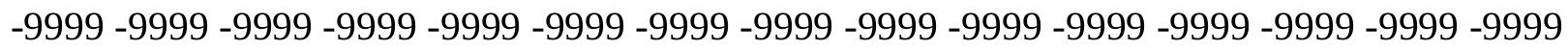

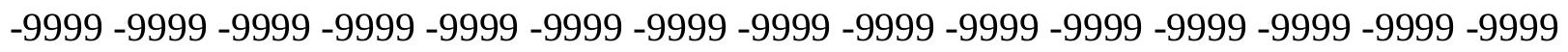
248.7046966553243 .2185058594238 .9515075684233 .7702026367230 .7223052979 232.8558044434234 .3798065186229 .1983947754222 .4931030273219 .4452972412 214.5686950684202 .6820983887189 .5764007568180 .432800293174 .6419067383 175.2514038086176 .4705963135177 .6896972656178 .9089050293180 .432800293 181.3471984863182 .261505127182 .87109375182 .5662994385181 .9566955566 180.7375946045179 .2136993408177 .6896972656175 .8609924316174 .0323028564 172.5084075928171 .2891998291170 .3748931885170 .070098877170 .3748931885 170.6797027588170 .9844970703171 .2891998291170 .9844970703170 .6797027588 171.2891998291172 .2035980225173 .4226989746174 .6419067383175 .8609924316 176.4705963135176 .7754058838176 .7754058838176 .4705963135175 .8609924316 175.2514038086174 .9467010498174 .9467010498175 .2514038086175 .8609924316 177.0802001953178 .604095459180 .7375946045183 .1759033203186 .528503418 
190.4907073975192 .624206543190 .795501709186 .8332977295183 .1759033203 179.8231964111177 .0802001953175 .5561981201174 .6419067383173 .7274932861 170.9844970703167 .6318054199167 .0222015381168 .8509979248170 .6797027588 172.5084075928173 .7274932861174 .9467010498175 .2514038086174 .337097168 172.5084075928169 .6750488281165 .8031005859161 .2312927246156 .6596069336 152.0877990723149 .6495056152147 .8208007812146 .2969055176145 .0776977539 143.8585968018142 .9441986084142 .0299072266141 .4203033447140 .5059967041 139.5915985107 138.9819946289 138.0677032471 137.1533050537 136.2389984131 135.3246002197134 .4102020264133 .1911010742132 .2767028809131 .0576019287 129.8385009766128 .6192932129127 .4001998901125 .8762969971124 .0475006104 117.342300415117 .342300415117 .647102356117 .9517974854117 .9517974854 118.2565994263118 .5614013672118 .5614013672118 .5614013672118 .8662033081 119.1709976196120 .3900985718121 .6092987061122 .5235977173122 .5235977173 122.2188034058120 .3900985718115 .2088012695108 .8082962036102 .712600708 100.5791015625107 .8938980103116 .7326965332117 .9517974854117 .9517974854 120.0852966309122 .5235977173124 .0475006104125 .2667007446126 .1809997559 126.1809997559126 .1809997559126 .1809997559125 .8762969971125 .5715026855 124.9618988037124 .3523025513123 .7427978516123 .43800354123 .1332015991 123.7427978516126 .1809997559126 .1809997559128 .0097961426129 .8385009766 131.3623962402131 .0576019287128 .6192932129124 .0475006104120 .6949005127 120.6949005127125 .2667007446129 .8385009766130 .1432037354128 .3144989014 129.8385009766128 .6192932129124 .9618988037120 .9997024536120 .9997024536 112.7705001831109 .7226028442106 .979598999105 .1509017944107 .2844009399 106.0652008057105 .1509017944104 .8460998535105 .1509017944109 .1130981445 110.3321990967108 .1986999512109 .1130981445109 .4179000854109 .4179000854 107.8938980103 107.2844009399 106.979598999 108.1986999512110.6370010376 112.7705001831112 .7705001831111 .24659729110 .0273971558107 .2844009399 106.979598999108 .1986999512110 .0273971558111 .551399231112 .4656982422 112.7705001831112 .1608963013110 .9418029785109 .7226028442108 .1986999512 106.3700027466104 .5412979126102 .102996826299 .6647262573297 .22646331787 95.0929565429793 .5690307617292 .349891662690 .5211791992289 .3020401001 88.9972534179789 .6068267822390 .5211791992288 .3876876831191 .13075256348 93.8738174438597 .83602905273103 .0174026489108 .8082962036115 .2088012695 120.9997024536126 .1809997559130 .4479980469133 .8007049561136 .2389984131 138.0677032471140 .2012023926144 .7729034424154 .5260925293165 .1934967041 173.1179962158178 .604095459183 .4806976318188 .3571929932193 .5386047363 199.9389953613 206.9490966797208.7778015137208.7778015137208.7778015137 208.7778015137 208.7778015137208.7778015137 208.7778015137 208.7778015137 208.7778015137208 .7778015137208 .7778015137208 .7778015137208 .7778015137 208.7778015137208 .7778015137208 .7778015137208 .7778015137208 .7778015137 208.7778015137 208.7778015137208.7778015137208.7778015137 208.7778015137 208.7778015137208.7778015137208.7778015137208.7778015137 208.7778015137 208.7778015137208 .7778015137208 .7778015137208 .7778015137208 .7778015137 208.7778015137208 .7778015137208 .7778015137208 .7778015137208 .7778015137 208.7778015137208 .7778015137208 .7778015137208 .7778015137208 .7778015137 208.7778015137208.7778015137208.7778015137208.7778015137208.7778015137 
208.7778015137208 .7778015137208 .7778015137208 .7778015137208 .7778015137 208.7778015137208.7778015137208.7778015137208.7778015137 112.1608963013 112.7705001831 -9999 -9999 -9999 -9999 -9999 -9999 -9999 -9999 -9999 -9999 -9999 -9999 -9999 -9999 -9999 -9999 -9999 -9999 -9999 -9999 -9999 -9999 -9999 -9999 -9999 -9999 -9999 $-9999$

-9999 -9999 -9999 -9999 -9999 -9999 -9999 -9999 -9999 -9999 -9999 -9999 -9999 -9999 -9999 -9999 -9999 -9999 -9999 -9999 -9999 -9999 -9999 -9999 -9999 -9999 -9999 -9999 -9999 -9999

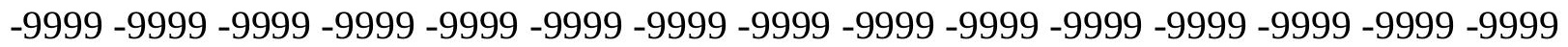
-9999 -9999 -9999 -9999 -9999 -9999 -9999 -9999 -9999 -9999 -9999 -9999 -9999 -9999 233.7702026367227 .6744995117224 .0171051025221 .5787963867220 .054901123 219.7501068115221 .883605957222 .7978973389221 .2740020752217 .6165924072 213.6544036865207 .25390625196 .5863952637185 .6141052246177 .3849029541 174.9467010498176 .4705963135177 .6896972656178 .9089050293180 .1280059814 181.3471984863181 .9566955566182 .5662994385182 .5662994385182 .261505127 181.3471984863180 .1280059814178 .604095459177 .0802001953175 .2514038086 173.4226989746171 .8988037109170 .9844970703170 .070098877170 .070098877 170.3748931885170 .9844970703171 .5939941406171 .8988037109172 .5084075928 173.1179962158174 .0323028564175 .2514038086176 .7754058838177 .9945068359 179.5184020996180 .432800293181 .0424041748181 .0424041748180 .432800293 179.8231964111179 .2136993408178 .604095459178 .2993011475178 .604095459 179.2136993408180 .1280059814181 .3471984863182 .5662994385183 .7854003906 185.3094024658187 .1381072998188 .966796875189 .2716064453188 .0523986816 186.2236938477185 .0045928955183 .1759033203182 .5662994385183 .1759033203 185.0045928955180 .7375946045177 .9945068359176 .4705963135174 .6419067383 172.8132019043174 .337097168176 .165802002177 .3849029541177 .6896972656 176.7754058838174 .9467010498172 .2035980225168 .241394043163 .974395752 159.0977935791154 .8307952881151 .7830047607149 .3446960449147 .5160064697 145.6873016357144 .4682006836143 .2489929199142 .3347015381141 .4203033447 140.8106994629139 .8963928223139 .2868041992138 .3724975586137 .7628936768 136.8484954834135 .9342041016135 .0198059082134 .1054992676133 .1911010742 132.2767028809 131.0576019287 130.1432037354128.9241027832 127.4001998901 125.8762969971123 .7427978516121 .3044967651117 .0374984741117 .647102356 117.9517974854118 .5614013672118 .8662033081119 .1709976196119 .4757995605 119.4757995605119 .7806015015120 .6949005127121 .6092987061122 .5235977173 122.5235977173121 .9140014648119 .4757995605114 .2944030762106 .0652008057 95.397743225188 .3876876831191 .4355392456199 .35994720459106 .979598999 113.9896011353118 .8662033081121 .9140014648124 .0475006104124 .9618988037 125.5715026855125 .8762969971126 .1809997559125 .8762969971125 .5715026855 125.2667007446124 .9618988037124 .3523025513123 .7427978516123 .43800354 123.1332015991123 .7427978516124 .9618988037126 .1809997559127 .7050018311 128.6192932129129 .2288970947128 .3144989014125 .8762969971124 .0475006104 118.8662033081116 .1231002808113 .9896011353115 .818397522123 .7427978516 130.4479980469134 .1054992676131 .0576019287127 .0953979492122 .5235977173 120.3900985718114 .5991973877111 .24659729108 .8082962036111 .551399231 109.7226028442108 .1986999512106 .979598999106 .3700027466106 .0652008057 110.0273971558110 .9418029785111 .8561019897112 .4656982422112 .4656982422 
111.8561019897108 .1986999512107 .2844009399107 .2844009399109 .1130981445 111.551399231112 .4656982422110 .6370010376104 .5412979126103 .9317016602 105.7603988647110 .3321990967109 .1130981445112 .4656982422115 .5136032104 116.7326965332116 .4279022217115 .2088012695113 .6848983765111 .8561019897 109.7226028442107 .5891036987105 .4557037354102 .71260070899 .96952056885 97.2264633178795.0929565429793.5690307617292.0450973510791.13075256348 90.2164001464890 .2164001464890 .5211791992290 .8259735107490 .52117919922 92.0450973510794 .4833908081197 .83602905273101 .7982025146106 .0652008057 110.6370010376114 .5991973877117 .9517974854120 .6949005127122 .2188034058 123.1332015991123 .1332015991123 .1332015991123 .7427978516135 .0198059082 145.9920959473154 .8307952881161 .8408966064167 .3269958496171 .8988037109 177.3849029541184 .3950042725192 .9290008545200 .5485992432204 .2059936523 206.0346984863207 .8634033203208 .7778015137208 .7778015137208 .7778015137 208.7778015137208 .7778015137208 .7778015137208 .7778015137208 .7778015137 208.7778015137208 .7778015137208 .7778015137208 .7778015137208 .7778015137 208.7778015137208 .7778015137208 .7778015137208 .7778015137208 .7778015137 208.7778015137208 .7778015137208 .7778015137208 .7778015137208 .7778015137 208.7778015137208 .7778015137208 .7778015137208 .7778015137208 .7778015137 208.7778015137208 .7778015137208 .7778015137208 .7778015137208 .7778015137 208.7778015137208 .7778015137208 .7778015137208 .7778015137208 .7778015137 208.7778015137208 .7778015137208 .7778015137208 .7778015137208 .7778015137 208.7778015137208 .7778015137208 .7778015137208 .7778015137208 .7778015137 208.7778015137208 .7778015137208 .7778015137208 .7778015137208 .7778015137 110.9418029785111 .551399231112 .4656982422 -9999 -9999 -9999 -9999 -9999 -9999 -9999 -9999 -9999 -9999 -9999 -9999 -9999 -9999 -9999 -9999 -9999 -9999 -9999 -9999 -9999 -9999 -9999 -9999-9999-9999-9999

-9999 -9999 -9999 -9999 -9999 -9999 -9999 -9999 -9999 -9999 -9999 -9999 -9999 -9999 -9999

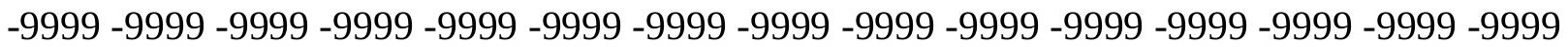
-9999 -9999 -9999 -9999 -9999 -9999 -9999 -9999 -9999 -9999 -9999 -9999 -9999 -9999 -9999

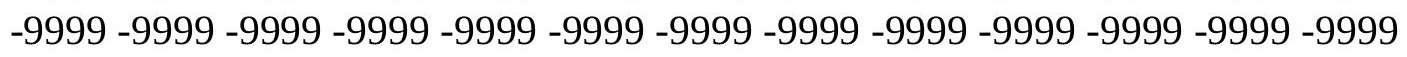
214.2639007568207 .25390625201 .7678070068199 .6342926025199 .9389953613 201.7678070068203 .9011993408204 .5108032227205 .1204071045206 .9490966797 206.6443023682202 .3773040771195 .0625186 .2236938477177 .6896972656171 .2891998291 173.1179962158176 .4705963135178 .604095459180 .1280059814181 .3471984863 181.9566955566182 .5662994385182 .87109375182 .5662994385181 .9566955566 181.0424041748179 .8231964111178 .2993011475179 .8231964111175 .2514038086 174.0323028564173 .1179962158172 .2035980225171 .8988037109171 .8988037109 172.2035980225172 .5084075928173 .1179962158174 .0323028564174 .6419067383 175.5561981201176 .4705963135177 .9945068359179 .5184020996181 .3471984863 183.1759033203184 .3950042725185 .0045928955185 .0045928955184 .0901947021 183.1759033203182 .261505127181 .3471984863181 .0424041748181 .0424041748 181.3471984863181 .9566955566182 .5662994385182 .87109375183 .1759033203 182.87109375182 .261505127185 .0045928955186 .528503418187 .1381072998 186.8332977295186 .2236938477185 .9188995361186 .2236938477187 .1381072998 187.4429016113186 .2236938477185 .0045928955185 .0045928955181 .0424041748 178.9089050293177 .9945068359178 .2993011475179 .2136993408179 .8231964111 
179.2136993408177 .6896972656174 .9467010498171 .2891998291166 .7174987793 162.1457061768157 .878692627154 .2212982178151 .1734008789148 .7351074219 146.6015930176145 .0776977539143 .8585968018142 .6394042969141 .7250976562 141.1154937744140 .2012023926139 .5915985107138 .9819946289138 .0677032471 137.4580993652136 .5437011719135 .9342041016135 .0198059082134 .1054992676 133.1911010742132 .2767028809131 .3623962402130 .1432037354128 .9241027832 127.4001998901125 .5715026855123 .1332015991120 .3900985718117 .0374984741 117.9517974854118 .2565994263118 .8662033081119 .4757995605119 .7806015015 120.0852966309120 .6949005127121 .3044967651121 .6092987061122 .2188034058 122.2188034058121 .3044967651118 .5614013672113 .6848983765106 .6747970581 94.1785964965883 .8159103393682 .2919769287186 .8637619018699 .05516815186 112.1608963013118 .2565994263121 .9140014648123 .7427978516124 .6570968628 125.2667007446125 .5715026855125 .5715026855125 .5715026855125 .2667007446 124.9618988037124 .6570968628124 .0475006104123 .7427978516123 .1332015991 123.1332015991123 .43800354124 .6570968628125 .8762969971126 .7906036377 127.4001998901127 .0953979492126 .1809997559123 .7427978516120 .9997024536 119.4757995605115 .2088012695111 .551399231107 .5891036987117 .342300415 131.3623962402133 .4958953857131 .3623962402126 .7906036377122 .5235977173 120.9997024536115 .2088012695111 .8561019897109 .4179000854113 .3800964355 111.551399231109 .7226028442108 .5035018921107 .2844009399106 .6747970581 110.6370010376111 .551399231112 .1608963013112 .4656982422112 .4656982422 112.1608963013111 .551399231107 .5891036987106 .979598999109 .7226028442 112.1608963013112 .7705001831110 .9418029785106 .979598999102 .4077987671 100.5791015625109 .7226028442113 .6848983765115 .818397522119 .7806015015 120.6949005127119 .4757995605117 .647102356115 .5136032104113 .3800964355 110.9418029785108 .5035018921105 .4557037354102 .407798767199 .35994720459 96.6168823242294 .4833908081192 .6546783447391 .1307525634890 .52117919922 90.2164001464890 .2164001464890 .8259735107491 .1307525634892 .04509735107 93.5690307617295 .397743225198 .14080810547101 .1886978149104 .2365036011 107.2844009399109 .7226028442111 .551399231112 .7705001831113 .075302124 112.7705001831111 .8561019897111 .551399231113 .9896011353120 .9997024536 129.8385009766138 .3724975586145 .3825073242151 .1734008789154 .8307952881 159.0977935791165 .1934967041174 .6419067383186 .528503418188 .0523986816 189.5764007568192 .0146026611195 .6721038818200 .2438049316205 .7299957275 208.7778015137208 .7778015137208 .7778015137208 .7778015137208 .7778015137 208.7778015137208 .7778015137208 .7778015137208 .7778015137208 .7778015137 208.7778015137208.7778015137208.7778015137 208.7778015137 208.7778015137 208.7778015137 208.7778015137208.7778015137208.7778015137 208.7778015137 208.7778015137208 .7778015137208 .7778015137208 .7778015137208 .7778015137 208.7778015137208 .7778015137208 .7778015137208 .7778015137208 .7778015137 208.7778015137208 .7778015137208 .7778015137208 .7778015137208 .7778015137 208.7778015137208.7778015137208.7778015137208.7778015137 208.7778015137 208.7778015137208.7778015137208.7778015137208.7778015137208.7778015137 208.7778015137208 .7778015137208 .7778015137208 .7778015137208 .7778015137 208.7778015137110 .3321990967111 .24659729 -9999 -9999 -9999 -9999 -9999 -9999 -9999 -9999 -9999 -9999 -9999 -9999 -9999 -9999 -9999 -9999 -9999 -9999 -9999 -9999 -9999 -9999 
-9999 -9999 -9999-9999 -9999

-9999 -9999 -9999 -9999 -9999 -9999 -9999 -9999 -9999 -9999 -9999 -9999 -9999 -9999 -9999

-9999 -9999 -9999 -9999 -9999 -9999 -9999 -9999 -9999 -9999 -9999 -9999 -9999 -9999 -9999

-9999 -9999 -9999 -9999 -9999 -9999 -9999 -9999 -9999 -9999 -9999 -9999 -9999 -9999 -9999

-9999 -9999 -9999 -9999 -9999 -9999 -9999 -9999 -9999-9999 -9999 -9999 194.1481018066 -

187.7476043701180 .1280059814174 .9467010498175 .2514038086177 .6896972656

178.9089050293179 .5184020996180 .432800293182 .5662994385186 .528503418

188.6620025635186 .2236938477180 .432800293173 .7274932861172 .8132019043

172.5084075928174 .337097168177 .3849029541179 .5184020996181 .0424041748

182.261505127182 .5662994385183 .1759033203183 .1759033203183 .1759033203

182.5662994385181 .9566955566180 .7375946045179 .5184020996178 .2993011475

177.0802001953175 .8609924316174 .6419067383174 .0323028564173 .7274932861

173.7274932861174 .0323028564174 .337097168174 .9467010498175 .8609924316

176.4705963135177 .6896972656178 .9089050293180 .432800293181 .9566955566

184.0901947021185 .9188995361187 .7476043701188 .6620025635188 .0523986816

186.8332977295185 .6141052246184 .3950042725183 .4806976318182 .87109375

182.5662994385182 .87109375182 .87109375183 .1759033203182 .87109375182 .261505127

181.3471984863181 .0424041748182 .261505127184 .0901947021185 .0045928955

185.6141052246185 .6141052246185 .9188995361186 .528503418187 .1381072998

187.4429016113187 .1381072998186 .528503418185 .6141052246183 .4806976318 182.261505127183 .4806976318186 .8332977295183 .1759033203181 .9566955566 181.3471984863180 .1280059814177 .3849029541174 .0323028564169 .7653045654 165.1934967041160 .6217956543156 .3547973633153 .0021057129149 .9542999268 147.5160064697145 .6873016357144 .1634063721142 .9441986084142 .0299072266 141.1154937744140 .5059967041139 .8963928223139 .2868041992138 .3724975586 137.7628936768137 .1533050537136 .5437011719135 .6293945312135 .0198059082 134.1054992676133 .1911010742132 .2767028809131 .3623962402130 .4479980469 129.2288970947127 .4001998901124 .6570968628121 .6092987061118 .8662033081 117.342300415118 .2565994263118 .8662033081119 .4757995605119 .7806015015 120.3900985718120 .9997024536121 .3044967651121 .9140014648122 .2188034058 121.9140014648121 .3044967651119 .4757995605115 .5136032104110 .9418029785 106.3700027466 102.102996826298.7503814697399.05516815186105.7603988647 114.5991973877119 .7806015015122 .5235977173123 .7427978516124 .3523025513 124.6570968628124 .9618988037124 .9618988037124 .9618988037124 .9618988037 124.6570968628124 .0475006104123 .7427978516123 .1332015991122 .5235977173 122.8283996582122 .8283996582123 .7427978516124 .9618988037125 .5715026855 125.8762969971125 .5715026855124 .3523025513122 .5235977173120 .0852966309 117.342300415115 .2088012695113 .075302124114 .5991973877120 .9997024536 128.9241027832132 .2767028809130 .1432037354124 .3523025513120 .3900985718 121.9140014648114 .9039993286111 .551399231115 .818397522114 .2944030762 112.4656982422110 .6370010376109 .1130981445107 .8938980103107 .2844009399 110.9418029785111 .551399231112 .1608963013112 .7705001831112 .7705001831 112.7705001831112 .4656982422112 .1608963013109 .7226028442111 .8561019897 113.6848983765114 .2944030762113 .075302124110 .3321990967106 .979598999 104.2365036011 103.0174026489116.1231002808 119.7806015015 122.2188034058 123.43800354120 .9997024536118 .2565994263116 .4279022217114 .2944030762 
111.551399231108 .5035018921105 .1509017944101 .798202514698 .4455871582 95.397743225192 .6546783447390 .8259735107489 .9116134643689 .3020401001 89.302040100189 .9116134643690 .8259735107492 .0450973510793 .26425170898 94.7881774902396 .6168823242298 .75038146973100 .8839035034103 .0174026489 104.8460998535106 .0652008057106 .6747970581106 .6747970581106 .3700027466 105.1509017944104 .2365036011104 .2365036011106 .6747970581111 .24659729 117.9517974854124 .3523025513130 .1432037354134 .4102020264137 .4580993652 140.2012023926143 .5538024902149 .9542999268159 .4026031494166 .4127044678 170.6797027588174 .6419067383178 .9089050293184 .699798584192 .0146026611 199.6342926025206 .9490966797208 .7778015137208 .7778015137208 .7778015137 208.7778015137 208.7778015137 208.7778015137 208.7778015137 208.7778015137 208.7778015137208 .7778015137208 .7778015137208 .7778015137208 .7778015137 208.7778015137208 .7778015137208 .7778015137208 .7778015137208 .7778015137 208.7778015137208 .7778015137208 .7778015137208 .7778015137208 .7778015137 208.7778015137208 .7778015137208 .7778015137208 .7778015137208 .7778015137 208.7778015137 208.7778015137208.7778015137 208.7778015137 208.7778015137 208.7778015137208 .7778015137208 .7778015137208 .7778015137208 .7778015137 208.7778015137208 .7778015137208 .7778015137208 .7778015137208 .7778015137 208.7778015137208 .7778015137208 .7778015137208 .7778015137208 .7778015137 208.7778015137 109.1130981445 110.0273971558110 .6370010376 -9999 -9999 -9999 -9999 -9999 -9999 -9999 -9999 -9999 -9999 -9999 -9999 -9999 -9999 -9999 -9999 -9999 -9999 -9999 -9999 -9999 -9999 -9999-9999 -9999-9999

-9999 -9999 -9999 -9999 -9999 -9999 -9999 -9999 -9999 -9999 -9999 -9999 -9999 -9999 -9999

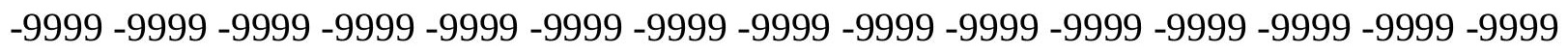

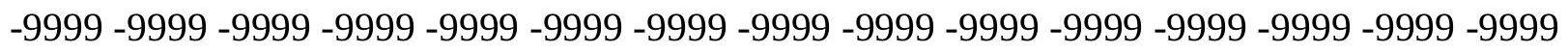
-9999 -9999 -9999 -9999 -9999 -9999 -9999 -9999 -9999 -9999 -9999 177.9945068359 170.9844970703165 .8031005859163 .3648071289160 .9264984131160 .6217956543 163.0599975586161 .5361022949159 .4026031494161 .8408966064160 .9264984131 164.2792053223169 .4604949951177 .6896972656176 .7754058838179 .8231964111 179.8231964111179 .8231964111180 .432800293181 .9566955566183 .7854003906 185.3094024658183 .1759033203183 .7854003906184 .3950042725184 .3950042725 184.3950042725184 .0901947021183 .1759033203182 .261505127181 .0424041748 179.8231964111178 .604095459177 .3849029541176 .4705963135175 .8609924316 175.5561981201175 .5561981201175 .8609924316176 .165802002176 .7754058838 177.3849029541 178.2993011475 179.5184020996180.7375946045 182.261505127 183.7854003906185 .6141052246187 .7476043701189 .5764007568191 .1002960205 189.8811035156188 .3571929932186 .8332977295185 .3094024658184 .3950042725 183.4806976318183 .1759033203182 .87109375182 .87109375182 .87109375181 .9566955566 181.0424041748180 .1280059814180 .1280059814180 .7375946045181 .6519012451 182.5662994385183 .4806976318183 .0897674561183 .6764984131184 .3280792236 185.0425567627185 .3094024658185 .0045928955184 .3950042725183 .4806976318 182.5662994385182 .5662994385184 .0901947021185 .6141052246185 .6141052246 185.0045928955184 .0901947021182 .5662994385180 .1280059814176 .7754058838 172.5084075928167 .9365997314163 .0599975586158 .4882965088154 .4498443604 150.8686065674148 .0606842041146 .2969055176144 .7729034424143 .5538024902 142.3347015381141 .4203033447140 .8106994629140 .2012023926139 .5915985107 
138.9819946289138 .3724975586137 .7628936768136 .8484954834136 .2389984131 135.6293945312134 .7149963379133 .8007049561132 .8863067627132 .2767028809 131.0576019287130 .1432037354128 .9241027832125 .8762969971122 .5235977173 119.4757995605117 .0374984741117 .647102356118 .2565994263118 .8662033081 119.7806015015120 .3900985718120 .6949005127121 .3044967651121 .6092987061 121.9140014648121 .6092987061121 .3044967651120 .3900985718117 .647102356 115.818397522119 .4757995605122 .5235977173119 .4757995605116 .1231002808 116.7326965332118 .8662033081120 .9997024536122 .5235977173123 .43800354 123.7427978516124 .0475006104124 .3523025513124 .3523025513124 .3523025513 124.3523025513124 .0475006104123 .7427978516123 .1332015991122 .5235977173 121.9140014648122 .2188034058122 .8283996582122 .8283996582124 .0475006104 124.3523025513124 .3523025513124 .0475006104123 .1332015991121 .9140014648 119.7806015015117 .9517974854116 .1231002808117 .0374984741118 .5614013672 124.0475006104128 .0097961426130 .1432037354128 .9241027832122 .8283996582 117.9517974854122 .8283996582128 .9241027832110 .3321990967116 .1231002808 114.2944030762112 .4656982422110 .6370010376109 .1130981445108 .1986999512 107.2844009399110 .6370010376111 .551399231112 .1608963013112 .7705001831 113.075302124113 .3800964355113 .6848983765114 .2944030762115 .5136032104 114.9039993286117 .342300415117 .0374984741116 .1231002808114 .2944030762 111.8561019897110 .6370010376110 .6370010376112 .1608963013120 .3900985718 126.7906036377128 .0097961426124 .3523025513118 .5614013672116 .7326965332 114.5991973877111 .8561019897108 .5035018921104 .5412979126100 .5791015625 96.9216690063593 .5690307617290 .8259735107488 .9972534179787 .77810668945 87.7781066894588 .3876876831189 .302040100190 .8259735107492 .65467834473 94.4833908081196 .3121032714898 .1408081054799 .66472625732101 .4934005737 102.712600708103 .3221969604103 .9317016602103 .6268997192103 .0174026489 101.7982025146100 .579101562599 .6647262573299 .66472625732101 .1886978149 104.2365036011108 .8082962036113 .3800964355117 .342300415120 .3900985718 122.2188034058123 .43800354123 .7427978516124 .0475006104135 .6293945312 144.7729034424151 .1734008789156 .0500030518161 .2312927246167 .9365997314 176.4705963135186 .528503418195 .3672943115201 .4629974365206 .0346984863 208.7778015137 208.7778015137208.7778015137 208.7778015137208.7778015137 208.7778015137208 .7778015137208 .7778015137208 .7778015137208 .7778015137 208.7778015137208 .7778015137208 .7778015137208 .7778015137208 .7778015137 208.7778015137208.7778015137208.7778015137208.7778015137208.7778015137 208.7778015137208 .7778015137208 .7778015137208 .7778015137208 .7778015137 208.7778015137208.7778015137208.7778015137 208.7778015137 208.7778015137 208.7778015137 208.7778015137208.7778015137208.7778015137 208.7778015137 208.7778015137208 .7778015137208 .7778015137208 .7778015137208 .7778015137 208.7778015137208 .7778015137208 .7778015137208 .7778015137208 .7778015137 $208.7778015137208 .7778015137208 .7778015137108 .8082962036109 .4179000854-9999$ -9999 -9999 -9999 -9999 -9999 -9999 -9999 -9999 -9999 -9999 -9999 -9999 -9999 -9999 -9999 -9999 -9999 -9999 -9999 -9999 -9999 -9999 -9999 -9999-9999 -9999 -9999 -9999 -9999 -9999 -9999 -9999 -9999 -9999 -9999 -9999 -9999 -9999 -9999 -9999 -9999 -9999 -9999 -9999 -9999 -9999 -9999 -9999 -9999 -9999 -9999 -9999 -9999 -9999 -9999 -

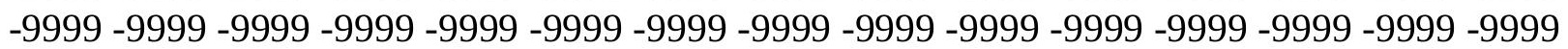


-9999 -9999 -9999 -9999 -9999 -9999 -9999 -9999 -9999 -9999 -9999 172.2035980225 162.1457061768162 .7552947998163 .3648071289163 .6696014404164 .5839996338 165.4983062744164 .8887023926163 .3648071289162 .4505004883163 .3648071289 166.7174987793170 .9844970703178 .604095459181 .3471984863182 .87109375 183.4806976318183 .4806976318183 .4806976318184 .0901947021185 .0045928955 182.87109375184 .0901947021185 .0045928955185 .6141052246185 .6141052246 185.6141052246185 .3094024658184 .699798584183 .7854003906182 .5662994385 181.3471984863180 .432800293179 .2136993408178 .2993011475177 .6896972656 177.3849029541177 .3849029541177 .3849029541177 .6896972656178 .2993011475 179.2136993408179 .8231964111181 .0424041748182 .261505127183 .4806976318 185.0045928955186 .528503418188 .0523986816189 .5764007568190 .1858978271 189.5764007568188 .3571929932186 .8332977295185 .3094024658184 .0901947021 183.1759033203182 .5662994385182 .261505127181 .9566955566181 .3471984863 180.7375946045179 .8231964111178 .9089050293178 .604095459178 .9089050293 179.5184020996180 .1280059814180 .7375946045181 .3471984863181 .9566955566 182.261505127182 .261505127182 .261505127181 .6519012451180 .7375946045 179.8231964111179 .5184020996180 .432800293181 .6519012451183 .1759033203 185.3094024658186 .528503418187 .1381072998186 .8332977295183 .4806976318 178.9089050293174 .9467010498170 .070098877165 .1934967041160 .3170013428 155.7451934814151 .7830047607148 .9084472656146 .9064025879145 .3825073242 143.8585968018142 .6394042969141 .7250976562141 .1154937744140 .5059967041 139.8963928223139 .2868041992138 .6772003174138 .0677032471137 .4580993652 136.8484954834135 .9342041016135 .3246002197134 .4102020264133 .4958953857 132.5814971924131 .3623962402130 .1432037354128 .3144989014125 .8762969971 122.8283996582120 .0852966309117 .647102356116 .7326965332117 .647102356 118.2565994263119 .1709976196119 .7806015015120 .3900985718120 .9997024536 121.3044967651121 .3044967651120 .9997024536120 .6949005127120 .0852966309 119.7806015015120 .0852966309120 .9997024536121 .6092987061122 .2188034058 121.9140014648121 .3044967651120 .9997024536121 .3044967651122 .2188034058 122.8283996582123 .1332015991123 .1332015991123 .43800354123 .43800354123 .43800354 123.43800354123 .1332015991123 .1332015991122 .8283996582122 .2188034058 121.9140014648121 .9140014648122 .2188034058122 .5235977173123 .1332015991 123.1332015991123 .43800354123 .1332015991122 .5235977173121 .6092987061 120.3900985718119 .1709976196118 .5614013672118 .8662033081120 .0852966309 126.1809997559130 .7528076172131 .3623962402131 .3623962402119 .7806015015 117.342300415121 .6092987061127 .0953979492108 .5035018921113 .9896011353 113.075302124111 .551399231110 .0273971558108 .8082962036107 .8938980103 107.2844009399110 .6370010376111 .24659729111 .8561019897112 .4656982422 113.075302124113 .6848983765114 .5991973877115 .818397522117 .647102356 118.2565994263123 .1332015991123 .43800354122 .2188034058120 .3900985718 118.8662033081117 .9517974854114 .5991973877113 .6848983765110 .6370010376 120.3900985718129 .2288970947132 .8863067627129 .8385009766122 .2188034058 114.5991973877111 .8561019897108 .1986999512103 .931701660299 .35994720459 95.0929565429791 .4355392456188 .3876876831186 .254188537685 .64462280273 85.6446228027386 .8637619018688 .6924667358490 .8259735107493 .26425170898 95.7025299072397 .8360290527399 .66472625732101 .1886978149102 .1029968262 
102.712600708103 .0174026489102 .712600708101 .7982025146100 .5791015625 99.3599472045997 .8360290527396 .9216690063596 .6168823242297 .53124237061 99.35994720459102 .1029968262105 .1509017944107 .8938980103109 .4179000854 110.3321990967110 .6370010376110 .9418029785113 .075302124119 .4757995605 127.0953979492133 .1911010742138 .0677032471142 .9441986084149 .9542999268 159.4026031494170 .9844970703183 .1759033203188 .0523986816192 .9290008545 198.7198944092204 .8155975342208 .7778015137208 .7778015137208 .7778015137 208.7778015137208 .7778015137208 .7778015137208 .7778015137208 .7778015137 208.7778015137208 .7778015137208 .7778015137208 .7778015137208 .7778015137 208.7778015137208 .7778015137208 .7778015137208 .7778015137208 .7778015137 208.7778015137208 .7778015137208 .7778015137208 .7778015137208 .7778015137 208.7778015137208 .7778015137208 .7778015137208 .7778015137208 .7778015137 208.7778015137208 .7778015137208 .7778015137208 .7778015137208 .7778015137 208.7778015137208 .7778015137208 .7778015137208 .7778015137208 .7778015137 208.7778015137208 .7778015137208 .7778015137208 .7778015137208 .7778015137 208.7778015137 208.7778015137208.7778015137 107.5891036987 108.1986999512-9999 -9999 -9999 -9999 -9999 -9999 -9999 -9999 -9999 -9999 -9999 -9999 -9999-9999-9999-9999 -9999 -9999 -9999 -9999 -9999 -9999 -9999 -9999 -9999 -9999 -9999 -9999 -9999 -9999 -9999 -9999 -9999 -9999 -9999 -9999 -9999 -9999 -9999 -9999 -9999 -9999 -9999 -9999 -9999 -9999 -9999 -9999 -9999 -9999 -9999 -9999 -9999 -9999 -9999 -9999 -9999 -9999 -9999 -9999 -9999 -9999 -9999 -9999 -9999 -9999 -9999 -9999 -9999 -9999 -9999 -9999 -9999 -9999 -9999 -9999 -9999 -9999 -9999 -9999 -9999 -9999 177.6896972656 163.0599975586162 .7552947998164 .8887023926167 .3269958496168 .8509979248 169.7653045654169 .1557006836167 .9365997314167 .0222015381167 .3269958496 169.4604949951172 .2035980225179 .2136993408182 .261505127184 .3950042725 186.2236938477185 .6141052246185 .3094024658185 .3094024658185 .6141052246 183.4806976318185 .0045928955185 .9188995361186 .528503418186 .8332977295 186.8332977295186 .528503418185 .9188995361185 .0045928955184 .0901947021 182.87109375181 .9566955566180 .7375946045180 .1280059814179 .5184020996 178.9089050293178 .9089050293178 .9089050293179 .2136993408179 .8231964111 180.432800293181 .0424041748181 .9566955566183 .1759033203184 .0901947021 185.3094024658186 .528503418187 .4429016113188 .3571929932188 .3571929932 187.7476043701186 .8332977295185 .6141052246184 .3950042725183 .1759033203 182.261505127181 .3471984863180 .5134124756179 .7512664795179 .1588287354 178.604095459177 .6896972656177 .0802001953176 .7754058838176 .7754058838 177.0802001953177 .6896972656178 .2993011475178 .604095459178 .9089050293 179.2136993408179 .2136993408178 .604095459177 .9945068359176 .7754058838 175.5561981201175 .8609924316177 .3849029541178 .9089050293181 .6519012451 184.3950042725186 .2236938477188 .3571929932190 .795501709190 .4907073975 185.0045928955179 .2136993408171 .5939941406166 .7174987793161 .8408966064 157.2691040039153 .3069000244149 .9399261475147 .1550292969145 .6873016357 144.1634063721142 .9441986084142 .0299072266141 .4203033447140 .5059967041 139.8963928223139 .5915985107138 .9819946289138 .3724975586137 .7628936768 137.1533050537136 .2389984131135 .3246002197134 .4102020264133 .4958953857 132.5814971924131 .0576019287129 .533706665127 .7050018311125 .2667007446 122.5235977173119 .7806015015117 .9517974854116 .4279022217116 .4279022217 
117.342300415117 .9517974854118 .8662033081119 .4757995605120 .0852966309 120.3900985718120 .3900985718120 .3900985718119 .7806015015119 .7806015015 121.6092987061122 .5235977173118 .2565994263114 .9039993286118 .8662033081 122.8283996582122 .8283996582121 .9140014648121 .9140014648122 .2188034058 122.2188034058122 .2188034058122 .2188034058122 .5235977173122 .5235977173 122.5235977173122 .5235977173122 .2188034058122 .2188034058121 .9140014648 121.9140014648121 .6092987061121 .6092987061121 .3044967651121 .6092987061 121.9140014648122 .5235977173122 .8283996582122 .5235977173122 .2188034058 121.6092987061120 .9997024536120 .6949005127120 .9997024536122 .5235977173 124.6570968628127 .4001998901131 .9720001221134 .4102020264131 .0576019287 114.2944030762115 .2088012695118 .8662033081122 .8283996582107 .2844009399 111.24659729110 .9418029785110 .0273971558108 .8082962036107 .8938980103 107.2844009399 106.6747970581 110.3321990967 110.9418029785111 .551399231 112.1608963013112 .7705001831113 .6848983765114 .9039993286116 .4279022217 115.818397522119 .4757995605124 .0475006104137 .7628936768132 .2767028809 122.5235977173120 .9997024536120 .0852966309118 .8662033081117 .0374984741 110.9418029785107 .5891036987121 .9140014648133 .1911010742134 .4102020264 129.533706665124 .3523025513116 .1231002808107 .5891036987103 .3221969604 98.7503814697393 .8738174438589 .302040100185 .9494018554783 .51112365723 82.9015579223683 .5111236572385 .0350494384887 .4733276367290 .52117919922 93.8738174438596 .9216690063599 .35994720459101 .4934005737102 .712600708 103.3221969604103 .6268997192103 .0174026489102 .1029968262100 .8839035034 99.6647262573298 .1408081054796 .9216690063595 .7025299072395 .3977432251 95.397743225196 .3121032714897 .8360290527399 .66472625732100 .8839035034 102.1029968262102 .4077987671102 .712600708103 .3221969604105 .7603988647 109.7226028442114 .5991973877118 .8662033081122 .5235977173125 .8762969971 131.6672058105141 .7250976562153 .3069000244164 .2792053223171 .8988037109 178.2993011475185 .6141052246193 .8433074951202 .0724945068208 .7778015137 208.7778015137208 .7778015137208 .7778015137208 .7778015137208 .7778015137 208.7778015137208 .7778015137208 .7778015137208 .7778015137208 .7778015137 208.7778015137208 .7778015137208 .7778015137208 .7778015137208 .7778015137 208.7778015137208 .7778015137208 .7778015137208 .7778015137208 .7778015137 208.7778015137208 .7778015137208 .7778015137208 .7778015137208 .7778015137 208.7778015137208 .7778015137208 .7778015137208 .7778015137208 .7778015137 208.7778015137208 .7778015137208 .7778015137208 .7778015137208 .7778015137 208.7778015137208 .7778015137208 .7778015137208 .7778015137208 .7778015137 208.7778015137208.7778015137208.7778015137208.7778015137 208.7778015137 106.979598999107 .8938980103 -9999 -9999 -9999 -9999 -9999 -9999 -9999 -9999 -9999 -9999 -9999 -9999 -9999 -9999 -9999 -9999 -9999 -9999 -9999 -9999 -9999 -9999 -9999 -9999 $-9999$

-9999 -9999 -9999 -9999 -9999 -9999 -9999 -9999 -9999 -9999 -9999 -9999 -9999 -9999 -9999 -

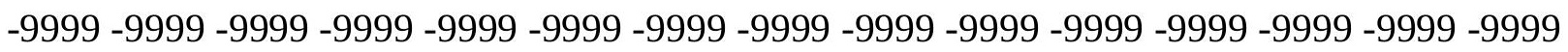
-9999 -9999 -9999 -9999 -9999 -9999 -9999 -9999 -9999 -9999 -9999 -9999 -9999 -9999 -9999 -9999 -9999 -9999 -9999 -9999 -9999 -9999 -9999 -9999 -9999 -9999 -9999 184.0901947021 173.4226989746168 .5462036133171 .8988037109174 .0323028564174 .9467010498 174.337097168172 .8132019043171 .2891998291170 .9844970703171 .8988037109 
173.7274932861179 .8231964111182 .5662994385184 .699798584185 .9188995361 186.2236938477186 .2236938477186 .2236938477186 .2236938477184 .3950042725 185.6141052246186 .8332977295187 .7476043701188 .0523986816188 .0523986816 187.7476043701187 .4429016113186 .528503418185 .6141052246184 .3950042725 183.4806976318182 .261505127181 .6519012451180 .7375946045180 .432800293 180.1280059814180 .1280059814180 .432800293181 .0424041748181 .3471984863 182.261505127182 .87109375183 .4806976318184 .3950042725185 .0045928955 185.6141052246186 .2236938477186 .2236938477185 .9188995361185 .6141052246 184.699798584183 .4806976318182 .5662994385181 .3471984863180 .1280059814 179.5184020996178 .604095459177 .9945068359177 .3849029541176 .4705963135 175.5561981201174 .9467010498174 .6419067383174 .337097168174 .6419067383 174.9467010498175 .5561981201175 .8609924316176 .165802002176 .165802002 175.8609924316175 .5561981201174 .9467010498174 .0323028564173 .4226989746 173.7274932861175 .5561981201178 .2993011475181 .6519012451183 .1759033203 184.3950042725186 .2236938477190 .795501709197 .1959991455187 .1381072998 179.2136993408175 .5561981201167 .6318054199162 .7552947998158 .1835021973 154.2212982178150 .8686065674147 .9318389893146 .2969055176144 .7729034424 143.2489929199142 .3347015381141 .4203033447140 .8106994629140 .2012023926 139.5915985107138 .9819946289138 .6772003174138 .0677032471137 .1533050537 136.5437011719135 .6293945312134 .7149963379133 .4958953857132 .2767028809 130.7528076172128 .9241027832126 .7906036377124 .3523025513121 .9140014648 119.4757995605117 .342300415115 .5136032104114 .9039993286115 .818397522 116.4279022217117 .342300415118 .2565994263118 .8662033081119 .1709976196 119.4757995605119 .4757995605119 .1709976196119 .4757995605120 .9997024536 121.3044967651118 .5614013672116 .4279022217118 .8662033081122 .2188034058 122.8283996582122 .2188034058121 .9140014648121 .9140014648121 .6092987061 121.6092987061121 .6092987061121 .6092987061121 .6092987061121 .6092987061 121.6092987061121 .3044967651120 .9997024536120 .6949005127120 .3900985718 120.0852966309120 .0852966309120 .0852966309120 .3900985718121 .3044967651 121.9140014648122 .2188034058122 .2188034058121 .9140014648121 .6092987061 121.6092987061121 .9140014648123 .1332015991124 .9618988037127 .4001998901 130.1432037354131 .6672058105128 .9241027832122 .8283996582106 .6747970581 109.4179000854115 .818397522120 .3900985718107 .5891036987109 .1130981445 108.8082962036108 .1986999512107 .5891036987106 .979598999106 .3700027466 109.4179000854110 .0273971558110 .6370010376110 .9418029785111 .551399231 112.1608963013113 .075302124114 .5991973877116 .1231002808116 .1231002808 120.3900985718125 .8762969971130 .1432037354127 .7050018311122 .2188034058 121.3044967651119 .7806015015117 .9517974854115 .818397522113 .3800964355 112.1608963013110 .9418029785122 .2188034058129 .533706665130 .4479980469 129.2288970947124 .6570968628116 .1231002808106 .065200805799 .05516815186 93.2642517089887 .4733276367283 .206336975180 .7680587768679 .85370635986 80.7680587768682 .9015579223686 .254188537689 .9116134643694 .17859649658 98.14080810547101 .1886978149103 .3221969604104 .2365036011104 .5412979126 104.2365036011103 .3221969604102 .1029968262100 .883903503499 .66472625732 98.445587158296 .9216690063596 .0073165893695 .0929565429794 .78817749023 94.7881774902395 .397743225196 .3121032714896 .9216690063597 .53124237061 
98.1408081054798 .445587158299 .35994720459100 .8839035034103 .3221969604 106.0652008057108 .5035018921110 .3321990967111 .8561019897114 .5991973877 125.2667007446136 .5437011719146 .9064025879155 .4403991699162 .7552947998 173.1179962158183 .1759033203192 .9290008545202 .0724945068208 .7778015137 208.7778015137208 .7778015137208 .7778015137208 .7778015137208 .7778015137 208.7778015137208 .7778015137208 .7778015137208 .7778015137208 .7778015137 208.7778015137208 .7778015137208 .7778015137208 .7778015137208 .7778015137 208.7778015137208 .7778015137208 .7778015137208 .7778015137208 .7778015137 208.7778015137208 .7778015137208 .7778015137208 .7778015137208 .7778015137 208.7778015137208 .7778015137208 .7778015137208 .7778015137208 .7778015137 208.7778015137208 .7778015137208 .7778015137208 .7778015137208 .7778015137 208.7778015137 208.7778015137 208.7778015137208.7778015137 208.7778015137 208.7778015137208 .7778015137208 .7778015137208 .7778015137105 .7603988647 106.6747970581 -9999 -9999 -9999 -9999 -9999 -9999 -9999 -9999 -9999 -9999 -9999 -9999 -9999 -9999 -9999 -9999 -9999 -9999 -9999 -9999 -9999 -9999 -9999 -9999 -9999

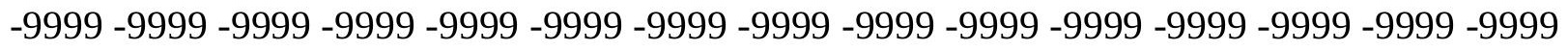

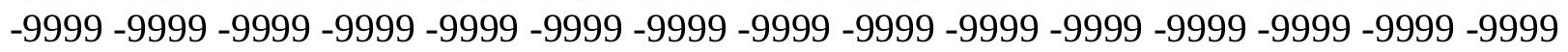

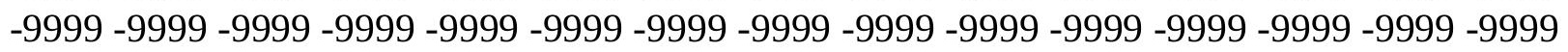
-9999 -9999 -9999 -9999 -9999 -9999 -9999 -9999 -9999 -9999 -9999 -9999 -9999 199.6342926025189 .5764007568180 .7375946045179 .5184020996180 .7375946045 179.5184020996177 .0802001953174 .9467010498173 .7274932861174 .337097168 175.5561981201180 .1280059814182 .261505127184 .0901947021185 .0045928955 185.9188995361185 .9188995361186 .2236938477183 .4806976318185 .0045928955 186.528503418187 .7476043701188 .966796875189 .2716064453189 .5764007568 189.2716064453188 .6620025635187 .7476043701186 .8332977295185 .6141052246 184.699798584183 .7854003906182 .87109375182 .261505127181 .6519012451 181.3471984863181 .3433227539181 .6519012451181 .9566955566182 .261505127 182.87109375183 .1759033203183 .7854003906184 .0901947021184 .3950042725 184.699798584184 .3950042725184 .0901947021183 .4806976318182 .87109375 182.261505127181 .3471984863180 .1280059814178 .9089050293177 .9945068359 177.0802001953176 .165802002175 .5561981201174 .9467010498174 .0323028564 173.4226989746172 .8132019043172 .2035980225172 .2035980225172 .2035980225 172.5084075928172 .8132019043173 .1179962158173 .4226989746173 .4226989746 173.1179962158172 .8132019043172 .2035980225171 .5939941406171 .5939941406 172.2035980225173 .7274932861176 .7754058838181 .6519012451181 .0424041748 181.0424041748185 .0045928955184 .699798584186 .2236938477183 .1759033203 177.9945068359172 .5084075928167 .6318054199163 .0599975586158 .7929992676 154.8307952881151 .4781951904148 .477355957145 .8990783691144 .7729034424 143.5538024902142 .3347015381141 .7250976562140 .8106994629140 .5059967041 139.8963928223139 .2868041992138 .6772003174138 .0677032471137 .4580993652 136.5437011719135 .6293945312134 .4102020264133 .1911010742131 .9720001221 130.1432037354128 .3144989014125 .8762969971123 .43800354120 .9997024536 118.5614013672116 .4279022217114 .2944030762112 .7705001831113 .6848983765 114.5991973877115 .5136032104116 .1231002808117 .0374984741117 .9517974854 117.9517974854118 .2565994263118 .5614013672118 .8662033081119 .1709976196 119.1709976196118 .5614013672118 .5614013672119 .1709976196120 .3900985718 
120.9997024536120 .9997024536121 .3044967651121 .3044967651120 .9997024536 120.9997024536120 .9997024536120 .6949005127120 .6949005127120 .3900985718 120.3900985718120 .0852966309119 .4757995605118 .8662033081118 .2565994263 117.647102356117 .9517974854118 .8662033081120 .0852966309121 .3044967651 121.9140014648121 .9140014648121 .9140014648121 .6092987061121 .6092987061 121.6092987061122 .2188034058123 .43800354125 .2667007446127 .4001998901 129.2288970947128 .9241027832125 .2667007446118 .2565994263118 .5614013672 112.4656982422112 .4656982422116 .1231002808110 .3321990967108 .5035018921 107.5891036987106 .979598999106 .3700027466105 .7603988647108 .8082962036 109.4179000854109 .7226028442110 .0273971558110 .3321990967110 .9418029785 111.551399231112 .1608963013113 .3800964355112 .4656982422115 .818397522 119.4757995605122 .8283996582122 .8283996582122 .5235977173121 .6092987061 120.3900985718118 .5614013672116 .1231002808113 .6848983765111 .24659729 110.0273971558111 .8561019897115 .5136032104112 .7705001831120 .3900985718 125.8762969971127 .0953979492123 .43800354116 .1231002808106 .3700027466 95.397743225185 .9494018554780 .4632720947377 .7202072143677 .1106262207 78.3297805786180 .7680587768684 .4254837036189 .302040100194 .48339080811 99.35994720459103 .0174026489104 .8460998535105 .1509017944104 .8460998535 104.2365036011103 .3221969604102 .1029968262101 .1886978149100 .2742996216 99.0551681518698 .1408081054796 .9216690063596 .0073165893695 .09295654297 94.7881774902394 .4833908081194 .7881774902395 .0929565429795 .3977432251 96.0073165893696 .6168823242297 .5312423706198 .445587158299 .66472625732 100.5791015625101 .4934005737102 .1029968262103 .0174026489106 .3700027466 113.6848983765122 .8283996582132 .5814971924142 .0299072266151 .4781951904 162.1457061768173 .4226989746184 .699798584195 .0625204 .5108032227208 .7778015137 208.7778015137208.7778015137208.7778015137 208.7778015137 208.7778015137 208.7778015137208 .7778015137208 .7778015137208 .7778015137208 .7778015137 208.7778015137208 .7778015137208 .7778015137208 .7778015137208 .7778015137 208.7778015137208 .7778015137208 .7778015137208 .7778015137208 .7778015137 208.7778015137208 .7778015137208 .7778015137208 .7778015137208 .7778015137 208.7778015137208 .7778015137208 .7778015137208 .7778015137208 .7778015137 208.7778015137 208.7778015137208.7778015137 208.7778015137208.7778015137 208.7778015137 208.7778015137208.7778015137 208.7778015137 208.7778015137 208.7778015137208.7778015137208.7778015137208.7778015137 105.4557037354 106.0652008057 -9999 -9999 -9999 -9999 -9999 -9999 -9999 -9999 -9999 -9999 -9999 -9999 -9999 -9999 -9999 -9999 -9999 -9999 -9999 -9999 -9999 -9999 -9999 -9999

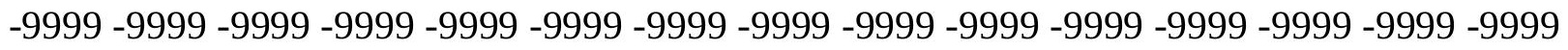

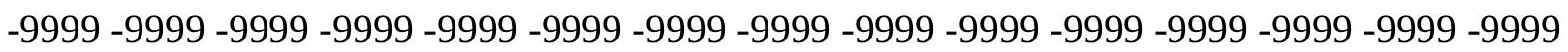

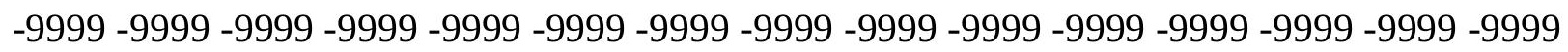
-9999 -9999 -9999 -9999 -9999 -9999 -9999 -9999 -9999 -9999 -9999 -9999 -9999 -9999 206.6443023682 198.4151000977 194.4528961182190.1858978271 183.4806976318 180.1280059814177 .3849029541175 .8609924316176 .165802002177 .0802001953 177.9945068359178 .9089050293182 .87109375183 .7854003906184 .699798584 185.3094024658185 .6141052246184 .0901947021185 .6141052246187 .4429016113 188.966796875190 .1858978271190 .795501709191 .1002960205190 .795501709 190.1858978271189 .2716064453188 .0523986816186 .8332977295185 .9188995361 
184.699798584183 .7854003906183 .1759033203182 .5662994385182 .0842132568 181.9566955566182 .261505127182 .5662994385182 .87109375183 .1759033203 183.4806976318183 .4806976318183 .4806976318183 .4806976318183 .1759033203 182.87109375182 .261505127181 .3471984863180 .432800293179 .8231964111 178.604095459177 .3849029541176 .4705963135175 .2514038086174 .337097168 173.7274932861172 .8132019043172 .2035980225171 .5939941406170 .9844970703 170.3748931885170 .070098877169 .7653045654169 .7653045654170 .070098877 170.3748931885170 .6797027588170 .9844970703170 .9844970703170 .6797027588 170.6797027588170 .070098877170 .070098877169 .7653045654170 .3748931885 171.2891998291172 .8132019043174 .337097168177 .0802001953177 .9945068359 182.261505127180 .1280059814180 .432800293179 .2136993408175 .5561981201 174.9467010498167 .6318054199163 .0599975586158 .7929992676154 .8307952881 151.4781951904148 .7351074219146 .3074951172144 .0461730957143 .5538024902 142.6394042969141 .7250976562141 .1154937744140 .5059967041139 .8963928223 139.5915985107138 .9819946289138 .3724975586137 .4580993652136 .5437011719 135.6293945312134 .4102020264133 .1911010742131 .3623962402129 .533706665 127.7050018311125 .2667007446122 .8283996582120 .6949005127118 .2565994263 116.1231002808113 .9896011353112 .1608963013111 .24659729112 .1608963013 113.075302124113 .9896011353117 .647102356119 .4757995605117 .647102356 116.1231002808116 .7326965332117 .0374984741117 .342300415117 .647102356 117.647102356117 .9517974854118 .2565994263118 .5614013672119 .1709976196 119.7806015015120 .0852966309120 .0852966309120 .0852966309120 .0852966309 119.7806015015119 .4757995605119 .4757995605120 .6949005127119 .1709976196 119.1709976196118 .5614013672117 .9517974854117 .0374984741117 .0374984741 117.9517974854119 .1709976196120 .6949005127121 .6092987061121 .9140014648 121.9140014648121 .3044967651120 .9997024536120 .6949005127120 .9997024536 121.6092987061122 .5235977173123 .7427978516124 .9618988037125 .5715026855 124.3523025513121 .9140014648118 .5614013672115 .5136032104113 .3800964355 111.551399231113 .3800964355110 .6370010376108 .5035018921106 .979598999 106.0652008057108 .5035018921108 .5035018921108 .8082962036109 .1130981445 109.4179000854109 .4179000854109 .7226028442110 .0273971558110 .3321990967 110.9418029785109 .4179000854111 .8561019897114 .5991973877117 .342300415 118.8662033081118 .2565994263120 .0852966309119 .7806015015118 .5614013672 116.4279022217113 .9896011353110 .6370010376107 .2844009399104 .8460998535 102.1029968262105 .4557037354106 .3700027466104 .8460998535108 .5035018921 121.9140014648126 .1809997559122 .8283996582113 .3800964355101 .4934005737 91.4355392456181 .9871978759875 .8914871215875 .2819290161175 .89148712158 78.3297805786182 .5967712402387 .7781066894593 .8738174438599 .96952056885 104.5412979126105 .7603988647105 .4557037354104 .5412979126103 .6268997192 102.712600708102 .1029968262101 .4934005737100 .8839035034100 .2742996216 99.6647262573298.75038146973 97.5312423706196.3121032714895.3977432251 94.7881774902394 .4833908081194 .7881774902395 .0929565429795 .70252990723 96.3121032714897 .5312423706197 .5312423706197 .8360290527397 .83602905273 97.5312423706197 .2264633178797 .83602905273100 .2742996216105 .4557037354 112.7705001831121 .3044967651130 .7528076172141 .4203033447153 .0021057129 165.1934967041177 .0802001953188 .6620025635199 .0247039795207 .8634033203 
208.7778015137 208.7778015137208.7778015137208.7778015137 208.7778015137 208.7778015137208 .7778015137208 .7778015137208 .7778015137208 .7778015137 208.7778015137208 .7778015137208 .7778015137208 .7778015137208 .7778015137 208.7778015137208 .7778015137208 .7778015137208 .7778015137208 .7778015137 208.7778015137208 .7778015137208 .7778015137208 .7778015137208 .7778015137 208.7778015137208 .7778015137208 .7778015137208 .7778015137208 .7778015137 208.7778015137208 .7778015137208 .7778015137208 .7778015137208 .7778015137 208.7778015137208 .7778015137208 .7778015137208 .7778015137208 .7778015137 208.7778015137208 .7778015137208 .7778015137208 .7778015137104 .2365036011 104.8460998535 -9999 -9999 -9999 -9999 -9999 -9999 -9999 -9999 -9999 -9999 -9999 -9999 -9999 -9999 -9999 -9999 -9999 -9999 -9999 -9999 -9999 -9999 -9999 -9999

-9999 -9999 -9999 -9999 -9999 -9999 -9999 -9999 -9999 -9999 -9999 -9999 -9999 -9999 -9999 -9999 -9999 -9999 -9999 -9999 -9999 -9999 -9999 -9999 -9999 -9999 -9999 -9999 -9999 -9999 -9999 -9999 -9999 -9999 -9999 -9999 -9999 -9999 -9999 -9999 -9999 -9999 -9999 -9999 -9999 -9999 -9999 -9999 -9999 -9999 -9999 -9999 -9999 -9999 -9999 -9999 -9999 -9999 -9999 -9999 -9999 212.4351959229 208.7778015137 198.7198944092 187.7476043701 179.8231964111 177.3849029541 178.2993011475179.2136993408179.5184020996179.8231964111 179.8231964111180 .1280059814180 .7375946045181 .3471984863182 .5662994385 184.0901947021185 .9188995361188 .0523986816189 .8811035156191 .4051055908 192.3193969727192 .624206543192 .3193969727191 .7097930908190 .4907073975 189.2716064453188 .0523986816186 .8332977295185 .6141052246184 .699798584 183.7854003906183 .1759033203182 .5826416016182 .5662994385182 .5662994385 182.5662994385182 .87109375183 .1759033203183 .1759033203182 .87109375 182.5662994385182 .261505127181 .6519012451181 .0424041748180 .432800293 179.2136993408178 .2993011475177 .3849029541176 .165802002174 .9467010498 173.7274932861172 .5084075928171 .5939941406170 .9844970703170 .3748931885 170.070098877169 .4604949951168 .8509979248168 .241394043167 .9365997314 167.6318054199167 .6318054199167 .6318054199167 .9365997314168 .241394043 168.5462036133168 .5462036133168 .5462036133168 .5462036133168 .241394043 168.241394043168 .241394043168 .8509979248170 .070098877171 .2891998291 172.5084075928174 .0323028564175 .2514038086176 .4705963135177 .0802001953 177.0802001953176 .165802002177 .0802001953170 .9844970703167 .0222015381 162.7552947998158 .4882965088154 .5260925293151 .1734008789148 .7351074219 146.6015930176144 .378616333143 .8585968018142 .6394042969141 .7250976562 141.1154937744140 .5059967041140 .2012023926139 .5915985107138 .9819946289 138.3724975586137 .4580993652136 .5437011719135 .6293945312134 .4102020264 132.8863067627131 .3623962402129 .2288970947127 .0953979492124 .9618988037 122.5235977173120 .3900985718118 .2565994263116 .1231002808114 .5991973877 113.9896011353114 .5991973877118 .2565994263121 .9140014648119 .7806015015 120.6949005127122 .8283996582119 .4757995605114 .9039993286114 .2944030762 114.9039993286115 .2088012695115 .5136032104115 .818397522116 .1231002808 116.4279022217116 .4279022217117 .0374984741117 .9517974854118 .2565994263 118.5614013672118 .5614013672118 .2565994263118 .2565994263117 .9517974854 119.1709976196118 .8662033081119 .4757995605119 .7806015015119 .1709976196 117.9517974854116 .7326965332116 .7326965332117 .9517974854120 .0852966309 121.9140014648122 .8283996582122 .2188034058121 .6092987061120 .6949005127 
119.7806015015119 .4757995605119 .4757995605119 .7806015015120 .0852966309 120.6949005127122 .5235977173122 .2188034058122 .2188034058120 .9997024536 118.5614013672115 .818397522113 .6848983765111 .551399231112 .4656982422 110.0273971558108 .1986999512106 .6747970581109 .1130981445108 .8082962036 109.1130981445 109.1130981445 109.1130981445 109.1130981445 109.1130981445 109.1130981445108 .8082962036106 .3700027466107 .2844009399109 .1130981445 111.24659729113 .3800964355115 .2088012695115 .818397522115 .818397522 114.9039993286117 .342300415116 .1231002808114 .2944030762111 .551399231 107.8938980103103 .931701660299 .6647262573293 .5690307617298 .14080810547 101.4934005737104 .5412979126109 .4179000854115 .818397522120 .3900985718 121.6092987061113 .3800964355101 .493400573792 .9594726562585 .64462280273 80.1584930419975 .2819290161174 .062782287676 .8058471679781 .07285308838 86.254188537692 .349891662699 .05516815186105 .4557037354104 .8460998535 103.9317016602103 .0174026489102 .4077987671101 .7982025146101 .7982025146 101.7982025146101 .7982025146101 .7982025146101 .4934005737100 .5791015625 99.3599472045998.1408081054796.9216690063596.0073165893695.3977432251 95.397743225195 .7025299072396 .3121032714897 .2264633178797 .83602905273 97.8360290527397 .2264633178796 .6168823242295 .397743225194 .48339080811 94.4833908081195 .7025299072399 .35994720459104 .8460998535112 .4656982422 121.6092987061132 .2767028809144 .4682006836157 .2691040039170 .3748931885 182.87109375194 .1481018066203 .596496582208 .7778015137208 .7778015137 208.7778015137208 .7778015137208 .7778015137208 .7778015137208 .7778015137 208.7778015137208 .7778015137208 .7778015137208 .7778015137208 .7778015137 208.7778015137208 .7778015137208 .7778015137208 .7778015137208 .7778015137 208.7778015137208 .7778015137208 .7778015137208 .7778015137208 .7778015137 208.7778015137208 .7778015137208 .7778015137208 .7778015137208 .7778015137 208.7778015137208 .7778015137208 .7778015137208 .7778015137208 .7778015137 208.7778015137208 .7778015137208 .7778015137208 .7778015137208 .7778015137 208.7778015137208 .7778015137208 .7778015137208 .7778015137208 .7778015137 208.7778015137208 .7778015137208 .7778015137103 .6268997192104 .5412979126 -9999 -9999 -9999 -9999 -9999 -9999 -9999 -9999 -9999 -9999 -9999 -9999 -9999 -9999 -9999 -999 -999 -9999 -9999 -9999 -9999 -9999 -9999 -9999

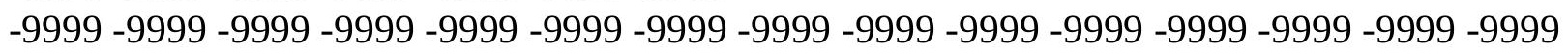

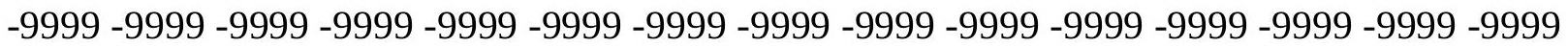

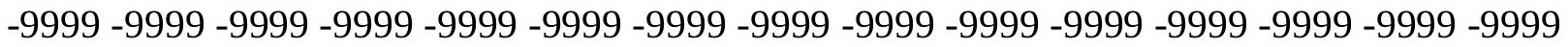

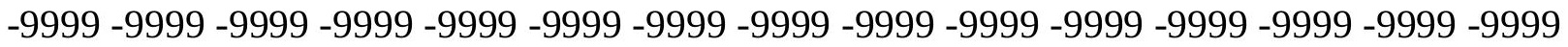
-9999 -9999-9999 209.3874053955 199.6342926025 192.3193969727 186.8332977295 183.1759033203181 .0424041748180 .7375946045180 .7375946045180 .432800293 180.1280059814180 .432800293181 .3471984863182 .5662994385184 .0901947021 186.2236938477188 .3571929932190 .795501709192 .624206543194 .1481018066 194.4528961182194 .1481018066193 .233795166191 .7097930908190 .4907073975 188.966796875187 .4429016113186 .2236938477185 .0045928955184 .0901947021 183.4806976318182 .7514648438182 .5662994385182 .5662994385182 .5662994385 182.5662994385182 .87109375182 .5662994385181 .9566955566181 .6519012451 181.0424041748180 .1280059814179 .5184020996178 .2993011475177 .3849029541 176.165802002174 .9467010498173 .7274932861172 .5084075928170 .9844970703 
170.070098877169 .1557006836168 .5462036133168 .241394043167 .9365997314 167.6318054199167 .0222015381166 .4127044678165 .8031005859165 .4983062744 165.4983062744165 .8031005859166 .1078948975166 .4127044678166 .4127044678 166.7174987793166 .7174987793166 .7174987793166 .7174987793166 .7174987793 167.3269958496168 .8509979248170 .3748931885171 .2891998291171 .8988037109 172.5084075928173 .4226989746174 .337097168174 .6419067383174 .6419067383 174.0323028564172 .8132019043170 .070098877166 .4127044678162 .1457061768 157.878692627153 .9165039062150 .8686065674148 .4304046631146 .6015930176 144.565032959143 .8585968018142 .6394042969142 .0299072266141 .4203033447 140.8106994629140 .2012023926139 .5915985107139 .2868041992138 .3724975586 137.7628936768136 .8484954834135 .6293945312134 .4102020264132 .8863067627 131.0576019287129 .2288970947127 .0953979492124 .9618988037122 .5235977173 120.3900985718118 .5614013672117 .0374984741116 .1231002808116 .1231002808 117.342300415 119.4757995605 121.9140014648 122.2188034058 122.2188034058 122.8283996582121 .3044967651118 .8662033081117 .647102356116 .1231002808 115.2088012695114 .9039993286114 .5991973877114 .5991973877114 .9039993286 114.9039993286115 .5136032104116 .1231002808117 .0374984741118 .8662033081 118.2565994263117 .647102356117 .342300415116 .7326965332117 .0374984741 119.1709976196120 .3900985718120 .6949005127120 .3900985718118 .8662033081 116.7326965332116 .1231002808121 .9140014648121 .9140014648124 .0475006104 124.0475006104122 .5235977173120 .9997024536119 .1709976196117 .9517974854 117.342300415116 .7326965332118 .5614013672119 .1709976196120 .0852966309 120.9997024536121 .6092987061121 .3044967651120 .3900985718118 .5614013672 116.4279022217114 .2944030762112 .1608963013113 .075302124110 .6370010376 108.1986999512110 .3321990967110 .0273971558109 .7226028442109 .4179000854 109.4179000854109 .1130981445108 .8082962036108 .5035018921108 .1986999512 105.1509017944106 .0652008057107 .2844009399108 .8082962036110 .3321990967 112.1608963013 113.3800964355 113.6848983765 113.6848983765113.075302124 114.9039993286113 .9896011353112 .1608963013109 .4179000854105 .7603988647 101.798202514697 .8360290527393 .5690307617295 .7025299072399 .35994720459 103.9317016602108 .8082962036113 .075302124114 .2944030762110 .6370010376 102.407798767194 .7881774902389 .302040100185 .0350494384882 .59677124023 81.0728530883879 .8537063598677 .4154205322380 .1584930419984 .42548370361 89.9116134643695.397743225199.66472625732 101.1886978149 100.8839035034 100.2742996216100 .2742996216100 .2742996216100 .8839035034101 .7982025146 102.4077987671103 .0174026489103 .3221969604103 .0174026489101 .4934005737 99.9695205688598 .445587158297 .2264633178796 .3121032714896 .31210327148 96.6168823242297 .2264633178798 .1408081054798 .7503814697398 .75038146973 97.8360290527396 .6168823242294 .7881774902393 .2642517089892 .3498916626 92.6546783447394 .4833908081198 .4455871582104 .8460998535113 .3800964355 124.0475006104136 .2389984131149 .6495056152163 .6696014404177 .3849029541 189.5764007568199 .0247039795206 .6443023682208 .7778015137208 .7778015137 208.7778015137208 .7778015137208 .7778015137208 .7778015137208 .7778015137 208.7778015137208 .7778015137208 .7778015137208 .7778015137208 .7778015137 208.7778015137208 .7778015137208 .7778015137208 .7778015137208 .7778015137 208.7778015137208 .7778015137208 .7778015137208 .7778015137208 .7778015137 
208.7778015137208 .7778015137208 .7778015137208 .7778015137208 .7778015137 208.7778015137208 .7778015137208 .7778015137208 .7778015137208 .7778015137 208.7778015137208 .7778015137208 .7778015137208 .7778015137208 .7778015137 208.7778015137208 .7778015137208 .7778015137208 .7778015137208 .7778015137 208.7778015137 208.7778015137 102.4077987671 103.3221969604 -9999 -9999 -9999-9999 -9999 -9999 -9999 -9999 -9999 -9999 -9999 -9999 -9999 -9999 -9999 -9999 -9999 -9999 -9999 -9999 -9999-9999-9999

-9999 -9999 -9999 -9999 -9999 -9999 -9999 -9999 -9999 -9999 -9999 -9999 -9999 -9999 -9999 -9999 -9999 -9999 -9999 -9999 -9999 -9999 -9999 -9999 -9999 -9999 -9999 -9999 -9999 -9999

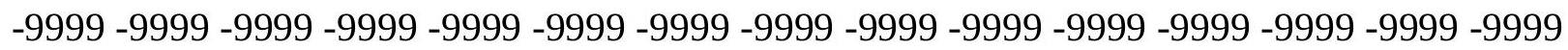
-9999 -9999 -9999 -9999 -9999 -9999 -9999 -9999 -9999 -9999 -9999 -9999 -9999 -9999 -9999 -9999 -9999 -9999 -9999 -9999 204.5108032227 199.329498291 194.7577056885 190.1858978271185 .6141052246181 .3471984863180 .7375946045180 .1280059814 180.1280059814180 .7375946045181 .9566955566183 .7854003906185 .9188995361 188.6620025635191 .4051055908193 .8433074951195 .6721038818196 .2816009521 195.6721038818194 .4528961182192 .9290008545191 .4051055908189 .5764007568 188.0523986816186 .528503418185 .3094024658184 .3950042725183 .4806976318 182.5662994385182 .261505127181 .9566955566181 .9566955566181 .9566955566 181.6519012451181 .3471984863180 .7375946045180 .1280059814179 .5184020996 178.604095459177 .6896972656176 .4705963135175 .5561981201174 .0323028564 172.8132019043171 .5939941406170 .070098877168 .8509979248167 .6318054199 166.7174987793166 .4127044678166 .4127044678166 .1078948975166 .1078948975 165.4983062744165 .1934967041164 .2792053223163 .6696014404163 .974395752 164.2792053223164 .2792053223164 .5839996338164 .8887023926164 .8887023926 164.8887023926165 .1934967041165 .1934967041165 .4983062744166 .7174987793 168.5462036133170 .3748931885171 .2891998291171 .2891998291171 .2891998291 171.5939941406172 .5084075928172 .8132019043172 .8132019043172 .5084075928 171.8988037109169 .4604949951166 .1078948975162 .1457061768157 .878692627 153.6116943359150 .8686065674148 .4304046631146 .6015930176144 .6701202393 143.8585968018142 .6394042969142 .0299072266141 .4203033447140 .8106994629 140.5059967041139 .8963928223139 .2868041992138 .6772003174137 .7628936768 136.8484954834135 .6293945312134 .4102020264132 .8863067627131 .0576019287 129.2288970947127 .0953979492124 .9618988037122 .8283996582120 .9997024536 119.1709976196117 .9517974854117 .647102356117 .9517974854119 .1709976196 120.6949005127121 .9140014648121 .9140014648122 .5235977173122 .5235977173 122.2188034058121 .6092987061121 .9140014648119 .7806015015118 .8662033081 119.1709976196118 .8662033081118 .5614013672118 .2565994263117 .647102356 117.9517974854118 .8662033081120 .0852966309122 .8283996582127 .4001998901 122.5235977173120 .3900985718119 .7806015015119 .4757995605119 .4757995605 120.9997024536121 .6092987061121 .6092987061120 .6949005127122 .2188034058 118.5614013672121 .6092987061125 .5715026855126 .7906036377124 .6570968628 122.2188034058119 .7806015015117 .647102356115 .818397522117 .342300415 120.6949005127121 .9140014648121 .9140014648121 .9140014648121 .9140014648 121.9140014648121 .3044967651120 .3900985718121 .9140014648119 .1709976196 116.7326965332115 .5136032104114 .9039993286111 .8561019897112 .4656982422 111.551399231110 .9418029785110 .6370010376110 .0273971558109 .7226028442 
109.4179000854108 .8082962036108 .1986999512107 .5891036987105 .1509017944 106.0652008057106 .979598999108 .1986999512109 .7226028442110 .6370010376 111.551399231112 .1608963013111 .8561019897111 .24659729110 .3321990967 111.8561019897110 .0273971558107 .8938980103104 .8460998535101 .4934005737 98.7503814697394 .7881774902396 .0073165893699 .05516815186103 .0174026489 106.979598999109 .4179000854109 .4179000854105 .150901794496 .92166900635 86.5589828491281 .3776321411180 .4632720947381 .6824111938583 .51112365723 87.4733276367288 .6924667358482 .2919769287187 .1685485839887 .77810668945 91.1307525634894 .1785964965896 .0073165893696 .6168823242296 .92166900635 97.2264633178798 .1408081054799 .66472625732101 .1886978149102 .712600708 103.9317016602104 .5412979126104 .8460998535103 .3221969604101 .4934005737 99.6647262573298 .445587158297 .5312423706197 .5312423706197 .83602905273 98.445587158299 .66472625732100 .5791015625100 .274299621699 .35994720459 97.2264633178795 .0929565429793 .2642517089891 .7403335571390 .82597351074 90.8259735107493 .5690307617298 .4455871582106 .0652008057116 .1231002808 128.3144989014142 .0299072266156 .6596069336170 .9844970703185 .0045928955 193.5386047363201 .158203125208 .4730072021208 .7778015137208 .7778015137 208.7778015137208 .7778015137208 .7778015137208 .7778015137208 .7778015137 208.7778015137208 .7778015137208 .7778015137208 .7778015137208 .7778015137 208.7778015137208 .7778015137208 .7778015137208 .7778015137208 .7778015137 208.7778015137208 .7778015137208 .7778015137208 .7778015137208 .7778015137 208.7778015137208 .7778015137208 .7778015137208 .7778015137208 .7778015137 208.7778015137208 .7778015137208 .7778015137208 .7778015137208 .7778015137 208.7778015137208 .7778015137208 .7778015137208 .7778015137208 .7778015137 208.7778015137 208.7778015137208.7778015137 208.7778015137 208.7778015137 208.7778015137 208.7778015137 102.1029968262 102.712600708 -9999 -9999 -9999 -9999 -9999 -9999 -9999 -9999 -9999 -9999 -9999 -9999 -9999 -9999 -9999 -9999 -9999 -9999 -9999 -9999 -9999-9999

-9999 -9999 -9999 -9999 -9999 -9999 -9999 -9999 -9999 -9999 -9999 -9999 -9999 -9999 -9999 -9999 -9999 -9999 -9999 -9999 -9999 -9999 -9999 -9999 -9999 -9999 -9999 -9999 -9999 -9999

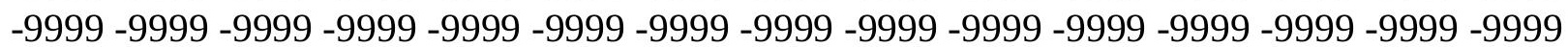

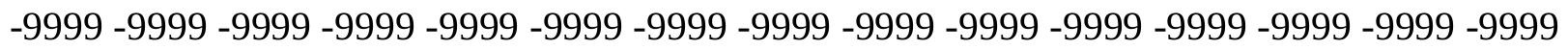
-9999 -9999 -9999 -9999-9999 -9999 -9999 -9999 201.4629974365197 .1959991455 192.624206543186 .528503418180 .1280059814180 .1280059814180 .432800293 181.6519012451183 .1759033203185 .3094024658188 .3571929932191 .4051055908 194.7577056885197 .1959991455197 .500793457196 .5863952637195 .3672943115 193.8433074951192 .0146026611190 .1858978271188 .3571929932186 .528503418 185.3094024658184 .0901947021182 .87109375181 .9566955566181 .3471984863 181.0424041748180 .7375946045180 .7375946045180 .432800293179 .8231964111 179.2136993408178 .604095459177 .6896972656176 .7754058838175 .8609924316 174.6419067383173 .4226989746172 .2035980225170 .9844970703169 .7653045654 168.241394043167 .0222015381165 .8031005859164 .5839996338164 .8887023926 164.8887023926164 .8887023926164 .8887023926164 .5839996338164 .2792053223 163.6696014404163 .3648071289163 .0599975586163 .0599975586163 .0599975586 163.0599975586163 .3648071289163 .3648071289163 .3648071289163 .3648071289 166.7174987793164 .5839996338165 .8031005859167 .3269958496170 .6797027588 
170.6797027588170 .070098877169 .7653045654170 .070098877170 .6797027588 170.9844970703170 .6797027588170 .6797027588170 .3748931885168 .5462036133 165.8031005859162 .1457061768158 .1835021973154 .2212982178151 .1734008789 148.7351074219146 .6015930176144 .805770874143 .0395812988142 .9441986084 142.0299072266141 .7250976562141 .1154937744140 .5059967041140 .2012023926 139.5915985107138 .6772003174138 .0677032471136 .8484954834135 .9342041016 134.4102020264132 .8863067627131 .0576019287129 .2288970947127 .4001998901 125.2667007446123 .1332015991121 .6092987061120 .0852966309119 .1709976196 118.8662033081119 .1709976196120 .0852966309121 .3044967651122 .2188034058 123.43800354124 .9618988037121 .3044967651121 .3044967651121 .3044967651 120.6949005127120 .0852966309120 .3900985718122 .2188034058121 .6092987061 121.9140014648120 .6949005127119 .7806015015119 .7806015015120 .3900985718 121.9140014648123 .1332015991122 .8283996582123 .1332015991121 .9140014648 121.3044967651121 .6092987061120 .9997024536120 .9997024536121 .6092987061 122.8283996582122 .8283996582122 .2188034058120 .9997024536123 .43800354 131.6672058105127 .7050018311124 .0475006104120 .9997024536117 .9517974854 115.2088012695118 .2565994263123 .43800354126 .4858016968126 .4858016968 125.2667007446124 .0475006104123 .1332015991122 .5235977173121 .9140014648 122.8283996582122 .8283996582121 .6092987061119 .4757995605117 .9517974854 117.0374984741113 .6848983765114 .2944030762113 .075302124112 .4656982422 111.551399231110 .9418029785110 .0273971558109 .4179000854108 .8082962036 107.8938980103107 .2844009399104 .8460998535105 .7603988647106 .6747970581 107.5891036987108 .8082962036109 .7226028442110 .3321990967110 .6370010376 110.3321990967109 .7226028442108 .8082962036107 .2844009399108 .5035018921 106.6747970581104 .2365036011101 .798202514699 .9695205688599 .35994720459 97.2264633178799.35994720459 102.1029968262104.8460998535106.0652008057 105.1509017944101 .188697814995 .0929565429788 .3876876831183 .2063369751 79.8537063598678 .9393463134882 .2919769287190 .5211791992295 .3977432251 92.6546783447388 .3876876831189 .302040100188 .3876876831190 .52117919922 92.0450973510792 .9594726562593 .2642517089894 .1785964965895 .70252990723 98.14080810547100 .5791015625102 .712600708104 .2365036011104 .8460998535 104.8460998535103 .9317016602102 .4077987671100 .883903503499 .66472625732 98.75038146973 98.1408081054798.445587158299.35994720459 100.5791015625 102.1029968262102 .4077987671100 .883903503498 .1408081054795 .70252990723 93.2642517089891 .7403335571390 .5211791992289 .6068267822390 .21640014648 92.6546783447399 .35994720459109 .1130981445120 .9997024536134 .4102020264 148.7351074219163 .0599975586175 .8609924316186 .2236938477195 .0625202 .9868927002 208.7778015137208.7778015137208.7778015137208.7778015137208.7778015137 208.7778015137208 .7778015137208 .7778015137208 .7778015137208 .7778015137 208.7778015137208 .7778015137208 .7778015137208 .7778015137208 .7778015137 208.7778015137 208.7778015137208.7778015137208.7778015137 208.7778015137 208.7778015137208.7778015137208.7778015137208.7778015137 208.7778015137 208.7778015137208 .7778015137208 .7778015137208 .7778015137208 .7778015137 208.7778015137208 .7778015137208 .7778015137208 .7778015137208 .7778015137 208.7778015137208 .7778015137208 .7778015137208 .7778015137208 .7778015137 208.7778015137208 .7778015137208 .7778015137208 .7778015137100 .8839035034 
101.4934005737 -9999 -9999 -9999 -9999 -9999 -9999 -9999 -9999 -9999 -9999 -9999 -9999 -9999 -9999 -9999 -9999 -9999 -9999 -9999 -9999 -9999 -9999

-9999 -9999 -9999 -9999 -9999 -9999 -9999 -9999 -9999 -9999 -9999 -9999 -9999 -9999 -9999 -9999 -9999 -9999 -9999 -9999 -9999 -9999 -9999 -9999 -9999 -9999 -9999 -9999 -9999 -9999 -9999 -9999 -9999 -9999 -9999 -9999 -9999 -9999 -9999 -9999 -9999 -9999-9999 -9999 -9999 -

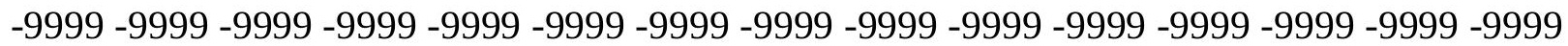
-9999 -9999 -9999 -9999 -9999 -9999 -9999 -9999 -9999 -9999 204.2059936523 199.329498291193 .8433074951187 .7476043701181 .0424041748181 .6519012451 182.87109375184 .699798584187 .7476043701191 .1002960205194 .7577056885 196.891204834197 .8054962158197 .1959991455195 .9768066406194 .4528961182 192.3193969727190 .1858978271188 .0523986816186 .2236938477184 .699798584 183.4806976318182 .261505127181 .0424041748180 .432800293179 .8231964111 179.5184020996179 .2136993408178 .9089050293178 .2993011475177 .6896972656 176.7754058838176 .165802002174 .9467010498174 .0323028564172 .8132019043 171.8988037109170 .6797027588169 .4604949951168 .241394043167 .0222015381 165.8031005859164 .5839996338163 .974395752163 .974395752164 .2792053223 164.2792053223164 .2792053223164 .2792053223163 .974395752163 .6696014404 163.3648071289163 .0599975586162 .7552947998162 .4505004883162 .1457061768 161.8408966064161 .8408966064161 .8408966064161 .8408966064162 .4505004883 163.6696014404164 .8887023926166 .4127044678168 .241394043168 .8509979248 168.5462036133167 .9365997314168 .5462036133168 .8509979248168 .8509979248 168.8509979248169 .4604949951169 .4604949951168 .241394043165 .8031005859 162.4505004883158 .7929992676155 .1356048584151 .7830047607149 .0399017334 146.9064025879145 .0776977539143 .3182373047142 .9441986084142 .3347015381 141.7250976562141 .4203033447140 .8106994629140 .2012023926139 .8963928223 138.9819946289138 .0677032471137 .1533050537135 .9342041016134 .7149963379 133.1911010742131 .3623962402129 .533706665127 .7050018311125 .5715026855 123.7427978516122 .2188034058120 .6949005127119 .7806015015119 .4757995605 119.7806015015120 .3900985718121 .3044967651122 .2188034058123 .1332015991 122.8283996582120 .3900985718119 .4757995605119 .1709976196118 .2565994263 117.342300415117 .647102356119 .1709976196120 .6949005127121 .3044967651 120.6949005127120 .3900985718120 .0852966309120 .3900985718120 .9997024536 121.6092987061121 .3044967651121 .3044967651120 .9997024536120 .9997024536 120.9997024536120 .9997024536120 .9997024536121 .6092987061122 .2188034058 122.2188034058129 .533706665126 .4858016968126 .4858016968127 .7050018311 124.0475006104122 .2188034058118 .8662033081115 .5136032104115 .5136032104 123.43800354131 .3623962402132 .8863067627130 .4479980469128 .0097961426 125.8762969971124 .3523025513123 .43800354122 .8283996582123 .43800354 123.1332015991122 .5235977173120 .9997024536119 .7806015015118 .8662033081 115.2088012695116 .1231002808114 .9039993286113 .6848983765112 .4656982422 111.551399231110 .6370010376109 .4179000854108 .5035018921107 .5891036987 103.9317016602104 .5412979126105 .4557037354106 .3700027466106 .979598999 107.8938980103108 .5035018921109 .1130981445109 .1130981445108 .8082962036 108.1986999512107 .2844009399106 .0652008057104 .5412979126105 .7603988647 103.9317016602102 .4077987671100 .883903503497 .5312423706198 .14080810547 99.66472625732101 .4934005737103 .3221969604103 .9317016602102 .712600708 
99.9695205688595 .7025299072391 .4355392456196 .6168823242285 .94940185547 86.2541885376 88.3876876831192.3498916626 95.397743225197.53124237061 95.397743225191 .1307525634892 .0450973510791 .1307525634890 .52117919922 90.2164001464890 .5211791992291 .1307525634892 .6546783447396 .00731658936 99.66472625732102 .1029968262103 .6268997192104 .5412979126104 .5412979126 104.2365036011103 .3221969604102 .1029968262100 .579101562599 .35994720459 98.7503814697398 .7503814697399 .35994720459100 .8839035034102 .4077987671 103.9317016602101 .188697814998 .445587158295 .7025299072393 .56903076172 92.0450973510791 .1307525634889 .6068267822388 .3876876831188 .08290100098 94.17859649658103 .0174026489114 .2944030762126 .7906036377140 .5059967041 154.2212982178166 .7174987793177 .9945068359188 .0523986816196 .891204834 205.1204071045208 .7778015137208 .7778015137208 .7778015137208 .7778015137 208.7778015137208 .7778015137208 .7778015137208 .7778015137208 .7778015137 208.7778015137208 .7778015137208 .7778015137208 .7778015137208 .7778015137 208.7778015137208 .7778015137208 .7778015137208 .7778015137208 .7778015137 208.7778015137208 .7778015137208 .7778015137208 .7778015137208 .7778015137 208.7778015137208 .7778015137208 .7778015137208 .7778015137208 .7778015137 208.7778015137208 .7778015137208 .7778015137208 .7778015137208 .7778015137 208.7778015137208 .7778015137208 .7778015137208 .7778015137208 .7778015137 208.7778015137208 .7778015137208 .7778015137208 .7778015137208 .7778015137 100.2742996216100 .8839035034 -9999 -9999 -9999 -9999 -9999 -9999 -9999 -9999 -9999 -9999 -9999 -9999 -9999 -9999 -9999 -9999 -9999 -9999 -9999-9999-999 -9999 -9999 -9999 -9999 -9999 -9999 -9999 -9999 -9999 -9999 -9999 -9999 -9999 -9999 -9999

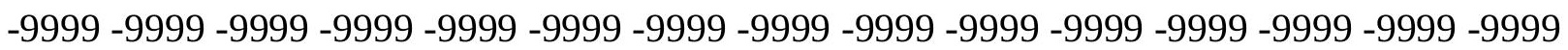

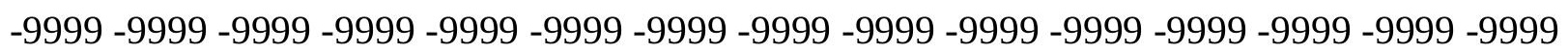

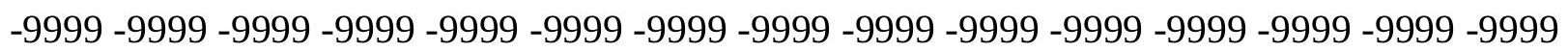
-9999 -9999 -9999 -9999 -9999 -9999 -9999 -9999 -9999-9999 -9999 -9999 207.8634033203 202.3773040771196 .2816009521190 .1858978271184 .0901947021183 .7854003906 187.4429016113191 .1002960205194 .4528961182196 .5863952637197 .8054962158 197.500793457196 .5863952637194 .7577056885192 .624206543190 .1858978271 187.7476043701185 .6141052246183 .7854003906182 .5662994385184 .3950042725 183.4806976318182 .261505127178 .2993011475177 .9945068359177 .3849029541 177.0802001953176 .4705963135175 .8609924316175 .2514038086174 .337097168 173.4226989746172 .2035980225171 .2891998291170 .070098877169 .1557006836 167.9365997314166 .7174987793165 .8031005859164 .8887023926164 .2792053223 163.6696014404163 .6696014404163 .974395752163 .974395752164 .2792053223 164.2792053223164 .2792053223163 .974395752163 .6696014404163 .0599975586 162.4505004883161 .8408966064161 .2312927246160 .9264984131160 .3170013428 160.3170013428160 .6217956543161 .2312927246162 .1457061768163 .3648071289 164.8887023926165 .8031005859166 .1078948975166 .4127044678166 .4127044678 167.0222015381167 .6318054199167 .6318054199168 .5462036133169 .1557006836 169.1557006836168 .241394043166 .1078948975163 .3648071289159 .7073974609 155.7451934814152 .3925933838149 .3446960449146 .9064025879145 .3825073242 143.5989990234143 .2489929199142 .6394042969142 .0299072266141 .7250976562 141.1154937744140 .5059967041139 .8963928223139 .2868041992138 .3724975586 137.4580993652136 .2389984131135 .0198059082133 .4958953857131 .6672058105 
129.8385009766128 .0097961426126 .1809997559124 .3523025513122 .5235977173 121.3044967651120 .3900985718120 .0852966309119 .7806015015120 .3900985718 120.6949005127121 .3044967651121 .6092987061120 .9997024536119 .7806015015 118.2565994263116 .4279022217115 .2088012695113 .9896011353112 .4656982422 115.5136032104117 .647102356118 .8662033081119 .1709976196119 .1709976196 118.8662033081118 .8662033081118 .8662033081118 .8662033081118 .8662033081 118.5614013672118 .5614013672118 .5614013672118 .5614013672118 .5614013672 118.8662033081119 .1709976196119 .4757995605119 .4757995605123 .1332015991 127.0953979492127 .7050018311126 .1809997559123 .43800354120 .0852966309 116.4279022217114 .9039993286114 .5991973877125 .8762969971139 .8963928223 135.6293945312131 .6672058105128 .9241027832126 .7906036377125 .5715026855 124.3523025513123 .7427978516123 .1332015991122 .2188034058121 .3044967651 121.6092987061120 .6949005127119 .7806015015116 .7326965332117 .9517974854 116.4279022217114 .9039993286113 .3800964355111 .8561019897110 .6370010376 109.4179000854108 .1986999512107 .2844009399103 .9317016602104 .5412979126 105.1509017944 105.7603988647 106.6747970581 106.979598999 107.5891036987 107.8938980103107 .8938980103107 .5891036987106 .979598999106 .0652008057 104.8460998535103 .6268997192102 .1029968262100 .579101562599 .66472625732 98.7503814697398 .7503814697399 .05516815186100 .2742996216101 .4934005737 102.4077987671102 .712600708101 .798202514699 .9695205688597 .53124237061 96.6168823242294 .4833908081192 .349891662693 .5690307617296 .61688232422 100.579101562599 .6647262573299 .3599472045999 .9695205688595 .3977432251 89.9116134643692 .0450973510792 .9594726562592 .6546783447390 .82597351074 88.3876876831189 .6068267822392 .9594726562598 .75038146973100 .8839035034 102.712600708103 .6268997192103 .9317016602103 .9317016602103 .9317016602 103.0174026489101 .493400573799 .9695205688598 .445587158297 .83602905273 98.445587158299 .66472625732100 .8839035034101 .4934005737100 .2742996216 97.8360290527395 .397743225193 .5690307617292 .0450973510790 .82597351074 89.9116134643688 .9972534179789 .302040100191 .4355392456198 .4455871582 108.5035018921120 .0852966309132 .5814971924145 .6873016357158 .1835021973 170.070098877181 .0424041748191 .1002960205200 .2438049316208 .7778015137 208.7778015137208 .7778015137208 .7778015137208 .7778015137208 .7778015137 208.7778015137208 .7778015137208 .7778015137208 .7778015137208 .7778015137 208.7778015137208 .7778015137208 .7778015137208 .7778015137208 .7778015137 208.7778015137208 .7778015137208 .7778015137208 .7778015137208 .7778015137 208.7778015137208 .7778015137208 .7778015137208 .7778015137208 .7778015137 208.7778015137208 .7778015137208 .7778015137208 .7778015137208 .7778015137 208.7778015137208 .7778015137208 .7778015137208 .7778015137208 .7778015137 208.7778015137208 .7778015137208 .7778015137208 .7778015137208 .7778015137 208.7778015137208 .7778015137208 .777801513799 .0551681518699 .96952056885 -9999 -9999 -9999 -9999 -9999 -9999 -9999 -9999 -9999 -9999 -9999 -9999 -9999 -9999 -9999 -9999 -9999 -9999 -9999 -9999-9999

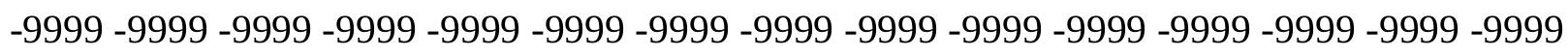

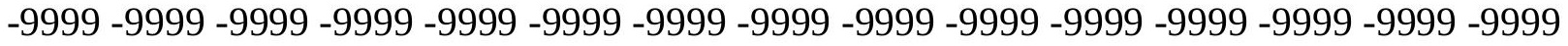

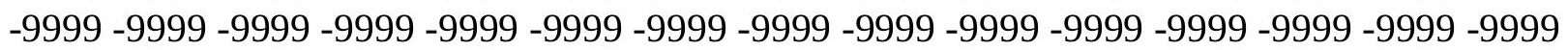

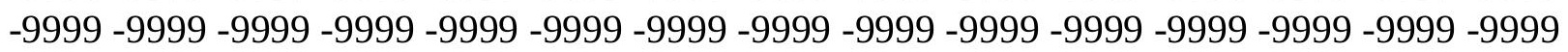


-9999 -9999 -9999 -9999 -9999 -9999 -9999 -9999 -9999 -9999 -9999 -9999 -9999 -9999 210.6065063477205 .425201416199 .9389953613194 .1481018066188 .3571929932 191.1002960205194 .4528961182196 .891204834197 .8054962158197 .8054962158 196.5863952637195 .0625192 .624206543190 .1858978271187 .4429016113184 .699798584 186.2236938477186 .2236938477185 .6141052246184 .699798584183 .4806976318 181.9566955566180 .1280059814175 .8609924316175 .2514038086174 .6419067383 174.0323028564173 .4226989746172 .5084075928171 .5939941406170 .6797027588 169.7653045654168 .5462036133167 .6318054199166 .7174987793165 .8031005859 164.8887023926164 .2792053223163 .974395752163 .6696014404163 .6696014404 163.974395752164 .2792053223164 .5839996338164 .5839996338164 .8887023926 164.5839996338164 .2792053223163 .6696014404162 .7552947998161 .8408966064 160.6217956543159 .7073974609159 .0977935791159 .0977935791159 .0977935791 159.7073974609160 .6217956543161 .5361022949162 .7552947998163 .3648071289 163.6696014404163 .974395752164 .5839996338165 .8031005859166 .7174987793 167.6318054199168 .5462036133169 .1557006836169 .1557006836168 .241394043 166.7174987793163 .974395752160 .6217956543156 .6596069336152 .6972961426 149.6495056152147 .2111968994145 .3825073242143 .8136749268143 .5538024902 142.9441986084142 .3347015381142 .0299072266141 .4203033447141 .1154937744 140.5059967041139 .5915985107138 .6772003174137 .7628936768136 .5437011719 135.3246002197133 .8007049561132 .2767028809130 .4479980469128 .6192932129 126.4858016968124 .9618988037123 .1332015991121 .9140014648120 .6949005127 120.0852966309119 .7806015015119 .7806015015120 .0852966309120 .3900985718 120.0852966309119 .7806015015118 .5614013672117 .342300415115 .5136032104 113.075302124111 .551399231111 .24659729112 .4656982422114 .5991973877 115.818397522116 .4279022217116 .4279022217116 .1231002808116 .1231002808 115.5136032104115 .2088012695114 .9039993286114 .9039993286114 .5991973877 114.5991973877114 .5991973877114 .9039993286114 .9039993286115 .2088012695 115.2088012695116 .7326965332123 .1332015991126 .1809997559126 .1809997559 124.6570968628122 .5235977173117 .647102356116 .1231002808116 .1231002808 119.1709976196126 .4858016968131 .9720001221132 .5814971924130 .4479980469 128.6192932129127 .0953979492125 .8762969971125 .2667007446124 .6570968628 124.0475006104123 .43800354122 .5235977173121 .6092987061120 .6949005127 119.7806015015118 .5614013672119 .4757995605117 .342300415115 .5136032104 113.6848983765112 .1608963013110 .6370010376109 .1130981445107 .8938980103 106.979598999103 .9317016602104 .5412979126104 .8460998535105 .4557037354 106.0652008057106 .3700027466106 .6747970581106 .6747970581106 .6747970581 106.3700027466105 .7603988647104 .8460998535103 .9317016602103 .0174026489 101.7982025146100 .883903503499 .9695205688599 .3599472045999 .35994720459 99.66472625732100 .5791015625101 .4934005737102 .1029968262102 .4077987671 102.1029968262101 .188697814999 .9695205688598 .445587158297 .83602905273 98.445587158299 .66472625732101 .7982025146103 .0174026489102 .1029968262 99.05516815186101 .7982025146100 .579101562592 .0450973510788 .08290100098 94.1785964965893 .2642517089892 .6546783447391 .4355392456188 .69246673584 88.3876876831194 .4833908081198 .75038146973101 .4934005737102 .4077987671 102.4077987671103 .0174026489103 .9317016602103 .9317016602102 .4077987671 99.35994720459 97.2264633178796.3121032714896.3121032714897.53124237061 
98.445587158298 .7503814697397 .8360290527396 .3121032714894 .48339080811 92.6546783447391 .4355392456190 .8259735107490 .5211791992291 .13075256348 89.302040100188 .6924667358495 .70252990723104 .2365036011114 .5991973877 125.8762969971138 .0677032471150 .5639038086163 .0599975586174 .6419067383 185.6141052246195 .6721038818204 .8155975342208 .7778015137208 .7778015137 208.7778015137208 .7778015137208 .7778015137208 .7778015137208 .7778015137 208.7778015137208 .7778015137208 .7778015137208 .7778015137208 .7778015137 208.7778015137 208.7778015137 208.7778015137 208.7778015137 208.7778015137 208.7778015137208 .7778015137208 .7778015137208 .7778015137208 .7778015137 208.7778015137208 .7778015137208 .7778015137208 .7778015137208 .7778015137 208.7778015137208 .7778015137208 .7778015137208 .7778015137208 .7778015137 208.7778015137 208.7778015137 208.7778015137 208.7778015137 208.7778015137 208.7778015137208 .7778015137208 .7778015137208 .7778015137208 .7778015137 208.7778015137208 .777801513798 .7503814697399 .35994720459 -9999 -9999 -9999 -9999 -9999 -9999 -9999 -9999 -9999 -9999 -9999 -9999 -9999 -9999 -9999 -9999 -9999 -9999 -9999 $-9999$

-9999 -9999 -9999 -9999 -9999 -9999 -9999 -9999 -9999 -9999 -9999 -9999 -9999 -9999 -9999 -9999 -9999 -9999 -9999 -9999 -9999 -9999 -9999 -9999 -9999 -9999 -9999 -9999 -9999 -9999 -999 -9999 -9999 -9999 -9999 -9999 -9999 -9999 -9999 -9999 -9999 -9999 -9999 -9999 -9999 -9999 -9999 -9999 -9999 -9999 -9999 -9999 -9999 -9999 -9999 -9999 -9999 -9999 -9999 -9999 -9999

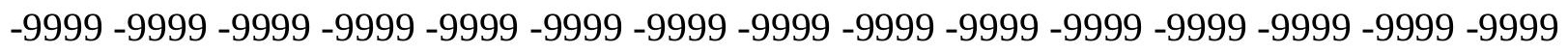
-9999 215.1782989502 209.9969024658204.5108032227 197.8054962158195.0625 197.500793457198 .4151000977198 .1103057861196 .891204834195 .0625192 .9290008545 190.4907073975187 .1381072998183 .7854003906187 .1381072998187 .1381072998 186.8332977295185 .9188995361184 .699798584182 .87109375181 .0424041748 178.604095459173 .7274932861173 .1179962158172 .5084075928171 .5939941406 170.6797027588170 .070098877169 .1557006836168 .241394043167 .3269958496 166.4127044678165 .4983062744164 .8887023926164 .2792053223163 .974395752 163.6696014404163 .6696014404163 .974395752164 .2792053223164 .5839996338 164.8887023926165 .1934967041165 .4983062744165 .4983062744165 .1934967041 164.2792053223163 .0599975586161 .8408966064160 .3170013428159 .0977935791 161.2312927246157 .878692627157 .5738983154157 .878692627158 .7929992676 159.7073974609160 .9264984131161 .2312927246160 .9264984131161 .2312927246 163.0599975586164 .5839996338165 .8031005859167 .0222015381168 .241394043 168.8509979248168 .8509979248168 .5462036133167 .0222015381164 .8887023926 161.5361022949157 .2691040039152 .6972961426149 .6495056152147 .5160064697 145.6873016357144 .0868530273143 .8585968018143 .2489929199142 .6394042969 142.3347015381142 .0299072266141 .4203033447140 .8106994629140 .2012023926 139.2868041992138 .0677032471136 .8484954834135 .6293945312134 .1054992676 132.5814971924130 .7528076172128 .9241027832127 .0953979492125 .2667007446 123.7427978516122 .2188034058120 .9997024536120 .0852966309119 .4757995605 119.1709976196119 .1709976196119 .1709976196118 .8662033081118 .5614013672 117.647102356116 .4279022217114 .9039993286112 .7705001831110 .6370010376 109.4179000854 110.3321990967 111.551399231112 .4656982422113 .075302124 113.075302124112 .7705001831112 .1608963013111 .551399231110 .9418029785 110.3321990967110 .0273971558109 .7226028442109 .7226028442109 .7226028442 
109.7226028442109 .7226028442109 .7226028442109 .4179000854125 .2667007446 123.43800354122 .2188034058122 .5235977173119 .7806015015116 .7326965332 115.818397522115 .818397522116 .4279022217121 .9140014648127 .4001998901 130.7528076172131 .6672058105130 .4479980469128 .6192932129126 .7906036377 125.5715026855125 .5715026855125 .2667007446124 .9618988037124 .0475006104 123.1332015991122 .5235977173121 .9140014648121 .3044967651119 .4757995605 120.3900985718117 .9517974854115 .818397522113 .6848983765111 .8561019897 110.3321990967108 .8082962036107 .2844009399103 .6268997192103 .9317016602 104.2365036011104 .5412979126105 .1509017944105 .4557037354105 .7603988647 105.7603988647105 .7603988647105 .7603988647105 .1509017944104 .8460998535 103.9317016602103 .3221969604102 .4077987671101 .4934005737100 .5791015625 100.274299621699 .9695205688599 .96952056885100 .2742996216100 .8839035034 101.7982025146102 .4077987671103 .0174026489103 .0174026489102 .712600708 102.4077987671101 .7982025146101 .7982025146102 .712600708103 .9317016602 104.5412979126104 .2365036011102 .712600708100 .579101562599 .96952056885 103.322196960496 .0073165893685 .6446228027387 .1685485839891 .43553924561 92.9594726562593 .2642517089892 .9594726562592 .0450973510792 .95947265625 96.61688232422100 .8839035034100 .274299621699 .96952056885100 .8839035034 102.712600708104 .8460998535102 .102996826297 .8360290527394 .78817749023 93.5690307617293 .8738174438594 .7881774902395 .7025299072396 .00731658936 95.397743225194 .4833908081192 .9594726562591 .7403335571390 .82597351074 90.2164001464889 .9116134643689 .9116134643689 .9116134643691 .74033355713 95.09295654297101 .7982025146110 .3321990967120 .0852966309131 .3623962402 144.1634063721156 .9642944336169 .4604949951180 .7375946045191 .4051055908 201.158203125208 .7778015137208 .7778015137208 .7778015137208 .7778015137 208.7778015137 208.7778015137 208.7778015137 208.7778015137 208.7778015137 208.7778015137208 .7778015137208 .7778015137208 .7778015137208 .7778015137 208.7778015137208 .7778015137208 .7778015137208 .7778015137208 .7778015137 208.7778015137208 .7778015137208 .7778015137208 .7778015137208 .7778015137 208.7778015137208 .7778015137208 .7778015137208 .7778015137208 .7778015137 208.7778015137208 .7778015137208 .7778015137208 .7778015137208 .7778015137 208.7778015137208 .7778015137208 .7778015137208 .7778015137208 .7778015137 208.7778015137208.7778015137208.7778015137 208.7778015137 208.7778015137 97.53124237061 98.14080810547 -9999 -9999 -9999 -9999 -9999 -9999 -9999 -9999 -9999 -9999 -9999 -9999 -9999 -9999 -9999 -9999 -9999 -9999 -9999 -9999 -9999 -9999 -9999 -9999 -9999 -9999 -9999 -9999 -9999 -9999 -9999 -9999 -9999 -9999 -9999

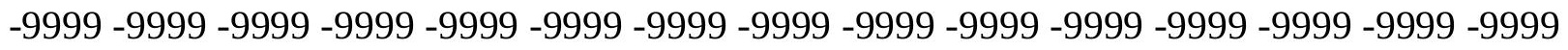

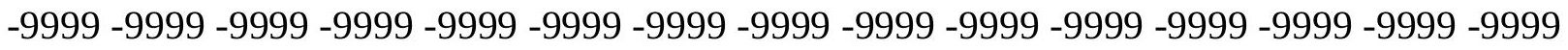
-9999 -9999 -9999 -9999 -9999 -9999 -9999 -9999 -9999 -9999 -9999 -9999 -9999 -9999 -9999 -9999 -9999 -9999 -9999 -9999 -9999 -9999 -9999 -9999 -9999 -9999 -9999 -9999 -9999 -9999 -999 -9999 -9999-9999220.3596038818214.8735046387 208.7778015137201.7678070068 199.0247039795198 .4151000977197 .1959991455195 .3672943115193 .8433074951 191.4051055908188 .0523986816184 .3950042725187 .7476043701188 .0523986816 187.7476043701186 .8332977295185 .6141052246183 .7854003906181 .6519012451 179.2136993408176 .7754058838171 .2891998291170 .6797027588170 .070098877 169.1557006836168 .5462036133167 .6318054199166 .7174987793166 .1078948975 
165.1934967041164 .5839996338163 .974395752163 .6696014404163 .3648071289 163.3648071289163 .6696014404163 .974395752164 .5839996338165 .1934967041 165.4983062744166 .1078948975166 .4127044678166 .4127044678166 .1078948975 165.4983062744163 .6696014404161 .8408966064160 .0122070312158 .4882965088 157.5738983154156 .6596069336156 .0500030518156 .3547973633156 .9642944336 157.878692627158 .7929992676160 .0122070312158 .1835021973160 .3170013428 161.8408966064163 .3648071289164 .8887023926166 .7174987793167 .6318054199 168.241394043168 .241394043167 .9365997314167 .0222015381165 .4983062744 162.7552947998158 .1835021973153 .6116943359149 .9542999268147 .5160064697 145.9920959473144 .375869751144 .1634063721143 .5538024902143 .2489929199 142.6394042969142 .3347015381142 .0299072266141 .4203033447140 .5059967041 139.5915985107138 .6772003174137 .1533050537135 .9342041016134 .4102020264 132.8863067627131 .3623962402129 .533706665127 .4001998901125 .5715026855 124.0475006104122 .5235977173120 .9997024536120 .0852966309119 .1709976196 118.5614013672118 .2565994263118 .2565994263117 .9517974854117 .647102356 117.0374984741116 .1231002808114 .9039993286113 .075302124111 .551399231 109.7226028442107 .8938980103108 .5035018921108 .8082962036109 .1130981445 109.1130981445108 .5035018921107 .8938980103106 .979598999105 .7603988647 105.1509017944104 .5412979126103 .9317016602103 .9317016602103 .6268997192 103.6268997192103 .6268997192103 .6268997192103 .9317016602112 .4656982422 115.5136032104114 .9039993286113 .6848983765111 .8561019897112 .4656982422 113.3800964355113 .6848983765118 .5614013672123 .1332015991126 .7906036377 128.9241027832129 .533706665128 .9241027832127 .7050018311126 .4858016968 125.5715026855125 .2667007446125 .2667007446125 .2667007446123 .43800354 122.5235977173121 .9140014648121 .9140014648121 .9140014648120 .0852966309 120.0852966309117 .647102356115 .2088012695113 .075302124111 .24659729 109.4179000854107 .8938980103103 .9317016602103 .9317016602103 .9317016602 104.2365036011104 .5412979126104 .8460998535105 .1509017944105 .1509017944 105.1509017944105 .1509017944104 .8460998535104 .5412979126103 .9317016602 103.3221969604102 .4077987671101 .7982025146101 .1886978149100 .5791015625 100.274299621699 .96952056885100 .2742996216100 .5791015625101 .1886978149 102.1029968262102 .712600708103 .6268997192104 .2365036011104 .5412979126 104.5412979126104 .5412979126104 .8460998535105 .1509017944105 .7603988647 105.7603988647104 .8460998535103 .3221969604100 .883903503498 .14080810547 103.0174026489101 .798202514688 .6924667358486 .254188537687 .47332763672 91.4355392456192 .9594726562593 .5690307617293 .8738174438595 .3977432251 101.1886978149 108.198699951299.3599472045996.61688232422 97.53124237061 97.53124237061105 .760398864798 .1408081054793 .5690307617291 .13075256348 90.2164001464890 .8259735107492 .349891662693 .2642517089893 .56903076172 93.2642517089892 .349891662691 .4355392456190 .5211791992289 .91161346436 89.3020401001 88.99725341797 88.99725341797 89.9116134643691.74033355713 94.78817749023100 .2742996216107 .2844009399116 .1231002808126 .1809997559 139.2868041992 152.3925933838165.1934967041 176.7754058838 187.7476043701 197.8054962158206 .9490966797208 .7778015137208 .7778015137208 .7778015137 208.7778015137208 .7778015137208 .7778015137208 .7778015137208 .7778015137 208.7778015137208.7778015137208.7778015137208.7778015137208.7778015137 
208.7778015137208 .7778015137208 .7778015137208 .7778015137208 .7778015137 208.7778015137 208.7778015137208.7778015137208.7778015137 208.7778015137 208.7778015137208 .7778015137208 .7778015137208 .7778015137208 .7778015137 208.7778015137208 .7778015137208 .7778015137208 .7778015137208 .7778015137 208.7778015137208 .7778015137208 .7778015137208 .7778015137208 .7778015137 208.7778015137208 .7778015137208 .7778015137208 .7778015137208 .7778015137 208.777801513796 .9216690063571 .660987854 -9999 -9999 -9999 -9999 -9999 -9999 -9999 -9999 -9999 -9999 -9999 -9999 -9999 -9999 -9999 -9999 -9999 -9999 -9999 -9999 -9999 -9999 -9999 -9999 -9999 -9999 -9999 -9999 -9999 -9999 -9999 -9999 -9999 -9999 -9999 -9999 -9999 -9999 -9999 -9999 -9999 -9999 -9999 -9999 -9999 -9999 -9999 -9999 -9999

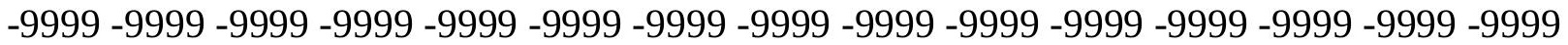
-9999 -9999 -9999 -9999 -9999 -9999 -9999 -9999 -9999 -9999 -9999 -9999 -9999 -9999 -9999 -999 -

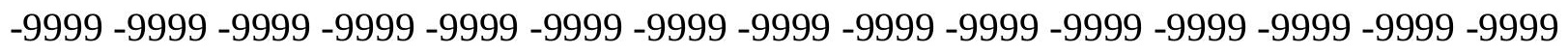
-9999 -9999 -9999 -9999 230.7223052979 225.2362060547 219.1405029297 211.520904541 201.4629974365196 .5863952637196 .2816009521195 .6721038818193 .233795166 189.5764007568185 .0045928955188 .3571929932188 .6620025635188 .6620025635 187.7476043701186 .528503418184 .3950042725182 .261505127179 .5184020996 177.0802001953174 .337097168169 .1557006836168 .5462036133167 .9365997314 167.0222015381166 .4127044678165 .4983062744164 .8887023926164 .2792053223 163.6696014404163 .3648071289163 .0599975586163 .0599975586163 .3648071289 163.6696014404164 .2792053223164 .8887023926165 .4983062744166 .1078948975 166.7174987793167 .0222015381167 .3269958496166 .7174987793165 .8031005859 163.974395752162 .1457061768160 .0122070312161 .2312927246156 .9642944336 155.7451934814154 .8307952881154 .5260925293155 .4403991699156 .3547973633 156.6596069336157 .878692627160 .3170013428160 .6217956543160 .3170013428 161.8408966064163 .974395752166 .1078948975166 .7174987793167 .3269958496 167.3269958496166 .7174987793166 .1078948975164 .8887023926163 .0599975586 157.878692627153 .3069000244149 .9542999268147 .5160064697145 .9920959473 144.5652618408144 .4682006836143 .8585968018143 .5538024902143 .2489929199 142.9441986084142 .3347015381141 .7250976562141 .1154937744140 .2012023926 138.9819946289137 .7628936768136 .2389984131134 .7149963379133 .1911010742 131.3623962402129 .533706665127 .7050018311125 .8762969971124 .3523025513 122.5235977173121 .3044967651120 .0852966309118 .8662033081118 .2565994263 117.647102356117 .342300415117 .0374984741117 .0374984741116 .7326965332 116.1231002808115 .2088012695113 .9896011353112 .4656982422110 .9418029785 109.1130981445106 .979598999105 .4557037354105 .4557037354104 .8460998535 103.9317016602103 .0174026489101 .7982025146100 .579101562599 .05516815186 98.4455871582 98.1408081054797.8360290527398.1408081054798.4455871582 98.445587158298 .75038146973100 .5791015625102 .4077987671104 .5412979126 104.2365036011104 .8460998535106 .0652008057108 .5035018921109 .7226028442 114.9039993286119 .7806015015123 .43800354125 .8762969971127 .0953979492 127.4001998901126 .4858016968125 .8762969971125 .2667007446124 .6570968628 124.6570968628124 .6570968628123 .7427978516121 .9140014648120 .0852966309 120.3900985718120 .3900985718120 .0852966309118 .8662033081116 .4279022217 113.6848983765114 .2944030762112 .1608963013110 .0273971558108 .5035018921 104.5412979126103 .9317016602103 .9317016602103 .9317016602103 .9317016602 
104.2365036011 104.5412979126104.5412979126104.8460998535104.8460998535 104.5412979126104 .2365036011103 .9317016602103 .3221969604102 .712600708 102.1029968262101 .4934005737100 .8839035034100 .5791015625100 .2742996216 100.2742996216100 .2742996216100 .5791015625101 .4934005737102 .1029968262 103.0174026489103 .9317016602104 .8460998535105 .7603988647106 .0652008057 106.0652008057106 .3700027466106 .6747970581106 .6747970581106 .3700027466 105.4557037354103 .6268997192100 .883903503498 .445587158297 .22646331787 109.113098144599 .6647262573293 .8738174438587 .4733276367288 .38768768311 90.5211791992293 .2642517089893 .8738174438595 .0929565429799 .96952056885 103.3221969604102 .1029968262100 .5791015625101 .188697814996 .00731658936 92.349891662690 .2164001464888 .9972534179791 .1307525634890 .52117919922 91.7403335571394 .1785964965891 .4355392456191 .4355392456191 .43553924561 90.8259735107490 .21640014648 89.60682678223 88.69246673584 88.38768768311 88.0829010009888 .3876876831189 .302040100191 .1307525634894 .17859649658 99.05516815186105 .4557037354113 .6848983765124 .0475006104136 .2389984131 149.0399017334161 .5361022949173 .4226989746184 .699798584194 .7577056885 204.2059936523 208.7778015137208.7778015137208.7778015137208.7778015137 208.7778015137208 .7778015137208 .7778015137208 .7778015137208 .7778015137 208.7778015137208 .7778015137208 .7778015137208 .7778015137208 .7778015137 208.7778015137208 .7778015137208 .7778015137208 .7778015137208 .7778015137 208.7778015137 208.7778015137 208.7778015137 208.7778015137 208.7778015137 208.7778015137208 .7778015137208 .7778015137208 .7778015137208 .7778015137 208.7778015137208 .7778015137208 .7778015137208 .7778015137208 .7778015137 208.7778015137 208.7778015137208.7778015137 208.7778015137 208.7778015137 208.7778015137 208.7778015137208.7778015137 208.7778015137 208.7778015137 96.00731658936 96.61688232422 -9999 -9999 -9999 -9999 -9999 -9999 -9999 -9999 -9999 -9999 -9999 -9999 -9999 -9999 -9999 -9999 -9999 -9999 -9999

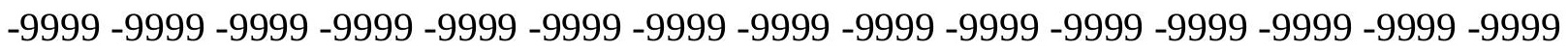
-9999 -9999 -9999 -9999 -9999 -9999 -9999 -9999 -9999 -9999 -9999 -9999 -9999 -9999 -9999

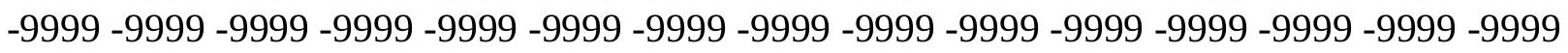
-9999 -9999 -9999 -9999 -9999 -9999 -9999 -9999 -9999 -9999 -9999 -9999 -9999 -9999 -9999 -9999 -9999 -9999 -9999 -9999 -9999 -9999 -9999 -9999 -9999 -9999 -9999 -9999 -9999 -9999 -9999 -9999-9999-9999-9999 239.8659057617 234.6844940186 228.2841033936 220.054901123208 .4730072021199 .0247039795199 .329498291196 .5863952637 191.7097930908186 .2236938477188 .0523986816188 .966796875189 .2716064453 188.3571929932187 .1381072998185 .0045928955182 .5662994385179 .8231964111 177.0802001953174 .337097168171 .2891998291167 .3269958496166 .4127044678 165.8031005859165 .1934967041164 .5839996338163 .974395752163 .3648071289 163.0599975586162 .7552947998162 .7552947998162 .7552947998163 .0599975586 163.6696014404164 .2792053223165 .1934967041165 .8031005859166 .7174987793 167.6318054199167 .9365997314168 .241394043167 .6318054199166 .4127044678 164.5839996338162 .4505004883160 .0122070312158 .4882965088156 .9642944336 155.4403991699154 .2212982178153 .3069000244154 .8307952881156 .0500030518 156.6596069336157 .5738983154163 .0599975586160 .9264984131158 .4882965088 160.6217956543162 .7552947998164 .2792053223165 .1934967041165 .4983062744 165.4983062744164 .8887023926164 .2792053223163 .0599975586159 .7073974609 
155.1356048584151 .7830047607149 .0399017334147 .2111968994145 .9920959473 144.703125144 .7729034424144 .1634063721143 .8585968018143 .5538024902 143.2489929199142 .9441986084142 .3347015381141 .7250976562140 .8106994629 139.5915985107138 .0677032471136 .5437011719135 .0198059082133 .4958953857 131.6672058105129 .8385009766128 .0097961426126 .1809997559124 .6570968628 122.8283996582121 .6092987061120 .0852966309118 .8662033081117 .9517974854 117.342300415116 .7326965332116 .7326965332116 .7326965332116 .7326965332 116.4279022217115 .818397522114 .9039993286113 .6848983765112 .4656982422 110.9418029785108 .8082962036106 .6747970581104 .2365036011101 .7982025146 100.883903503499 .6647262573298 .1408081054796 .9216690063595 .3977432251 94.4833908081193 .5690307617293 .8738174438594 .4833908081194 .17859649658 94.1785964965894 .4833908081195 .7025299072396 .3121032714897 .22646331787 99.66472625732104 .2365036011107 .5891036987110 .0273971558113 .075302124 117.0374984741120 .9997024536123 .43800354124 .9618988037125 .5715026855 125.2667007446124 .6570968628124 .0475006104123 .7427978516123 .7427978516 123.7427978516123 .43800354122 .2188034058120 .3900985718118 .8662033081 118.5614013672121 .3044967651117 .9517974854117 .0374984741115 .2088012695 112.7705001831110 .3321990967108 .5035018921106 .6747970581105 .4557037354 104.5412979126103 .9317016602103 .6268997192103 .6268997192103 .6268997192 103.9317016602103 .9317016602104 .2365036011104 .2365036011104 .2365036011 103.9317016602103 .6268997192103 .3221969604102 .712600708102 .1029968262 101.7982025146101 .1886978149100 .8839035034100 .2742996216100 .2742996216 100.2742996216100 .2742996216100 .8839035034101 .1886978149102 .1029968262 103.0174026489103 .9317016602105 .1509017944106 .0652008057106 .3700027466 106.6747970581 106.979598999 107.2844009399106.979598999106.6747970581 105.7603988647104 .2365036011101 .798202514699 .6647262573299 .66472625732 101.7982025146108 .503501892198 .7503814697390 .2164001464890 .21640014648 90.8259735107491 .1307525634891 .7403335571392 .9594726562595 .3977432251 98.1408081054799 .0551681518698 .445587158297 .2264633178794 .17859649658 91.1307525634888 .6924667358487 .1685485839885 .9494018554785 .03504943848 86.8637619018689 .6068267822390 .2164001464890 .2164001464890 .21640014648 89.9116134643689 .302040100188 .6924667358488 .0829010009887 .77810668945 87.4733276367287 .7781066894588 .6924667358490 .5211791992293 .56903076172 98.14080810547104 .2365036011112 .1608963013122 .2188034058133 .8007049561 146.6015930176158 .4882965088170 .3748931885181 .6519012451192 .3193969727 201.7678070068208 .7778015137208 .7778015137208 .7778015137208 .7778015137 208.7778015137208 .7778015137208 .7778015137208 .7778015137208 .7778015137 208.7778015137 208.7778015137208.7778015137208.7778015137 208.7778015137 208.7778015137208 .7778015137208 .7778015137208 .7778015137208 .7778015137 208.7778015137208 .7778015137208 .7778015137208 .7778015137208 .7778015137 208.7778015137208 .7778015137208 .7778015137208 .7778015137208 .7778015137 208.7778015137208.7778015137208.7778015137208.7778015137 208.7778015137 208.7778015137208 .7778015137208 .7778015137208 .7778015137208 .7778015137 208.7778015137208 .7778015137208 .7778015137208 .7778015137208 .7778015137 94.7881774902395 .3977432251 -9999 -9999 -9999 -9999 -9999 -9999 -9999 -9999 -9999 -9999 -9999 -9999 -9999 -9999 -9999 -9999 -9999 -9999 -9999 
-9999 -9999 -9999 -9999 -9999 -9999 -9999 -9999 -9999 -9999 -9999 -9999 -9999 -9999 -9999 -9999 -9999 -9999 -9999 -9999 -9999 -9999 -9999 -9999 -9999 -9999 -9999 -9999 -9999 -9999 -9999 -9999 -9999 -9999 -9999 -9999 -9999 -9999 -9999 -9999 -9999 -9999 -9999 -9999 -9999 -9999 -9999 -9999 -9999 -9999 -9999 -9999 -9999 -9999 -9999 -9999 -9999 -9999 -9999 -9999 -9999 -9999 -9999 -9999 -9999 -9999 -9999 -9999 -9999 -9999 -9999 -9999 -9999 -9999 -9999 -9999 -9999 -9999 -9999 -9999 -9999 246.8759002686240 .7801971436233 .7702026367 223.7122955322208 .1681976318203 .9011993408199 .9389953613194 .1481018066 187.4429016113187 .1381072998188 .6620025635189 .5764007568188 .966796875 187.4429016113185 .3094024658182 .87109375180 .1280059814177 .0802001953 174.337097168171 .2891998291166 .1078948975165 .4983062744164 .5839996338 163.974395752163 .3648071289163 .0599975586162 .4505004883162 .1457061768 162.1457061768162 .1457061768162 .4505004883162 .7552947998163 .3648071289 164.2792053223165 .1934967041166 .1078948975167 .3269958496168 .241394043 168.8509979248169 .1557006836168 .5462036133167 .3269958496165 .1934967041 163.0599975586160 .6217956543159 .0977935791157 .2691040039155 .7451934814 154.5260925293154 .2212982178155 .1356048584156 .6596069336158 .1835021973 156.9642944336158 .7929992676159 .4026031494156 .9642944336159 .0977935791 160.9264984131162 .4505004883163 .0599975586163 .3648071289163 .0599975586 162.4505004883161 .5361022949159 .7073974609156 .0500030518151 .4781951904 149.6495056152148 .1255950928146 .9064025879145 .9920959473144 .7507324219 144.7729034424144 .4682006836144 .4682006836144 .1634063721143 .8585968018 143.5538024902142 .9441986084142 .3347015381141 .4203033447139 .8963928223 138.3724975586136 .8484954834135 .3246002197133 .4958953857131 .6672058105 130.1432037354128 .3144989014126 .4858016968124 .9618988037123 .43800354 121.9140014648120 .6949005127119 .1709976196117 .9517974854117 .0374984741 116.7326965332116 .4279022217116 .7326965332117 .0374984741117 .0374984741 116.7326965332116 .1231002808115 .2088012695114 .2944030762112 .7705001831 111.24659729109 .1130981445106 .979598999104 .2365036011100 .8839035034 99.6647262573299 .05516815186101 .4934005737105 .1509017944109 .7226028442 111.8561019897108 .8082962036104 .5412979126101 .188697814998 .75038146973 97.2264633178796 .61688232422101 .1886978149109 .7226028442123 .7427978516 119.1709976196116 .4279022217117 .0374984741117 .647102356120 .0852966309 122.2188034058123 .43800354123 .7427978516123 .7427978516123 .1332015991 122.5235977173122 .5235977173122 .8283996582122 .8283996582122 .8283996582 122.2188034058120 .6949005127118 .8662033081117 .647102356116 .7326965332 116.4279022217115 .818397522114 .9039993286113 .3800964355111 .551399231 109.7226028442 107.8938980103 106.3700027466105.1509017944 104.2365036011 103.6268997192103 .3221969604103 .3221969604103 .3221969604103 .3221969604 103.6268997192103 .9317016602103 .9317016602103 .9317016602103 .6268997192 103.3221969604102 .712600708102 .4077987671101 .7982025146101 .4934005737 100.8839035034100 .5791015625100 .2742996216100 .274299621699 .96952056885 100.2742996216100 .5791015625101 .1886978149101 .7982025146102 .712600708 103.6268997192104 .8460998535105 .4557037354106 .3700027466106 .6747970581 106.979598999106 .979598999106 .979598999106 .979598999106 .3700027466 105.1509017944103 .3221969604101 .188697814999 .96952056885100 .8839035034 100.883903503496 .9216690063595 .7025299072393 .2642517089895 .09295654297 
93.5690307617292 .0450973510792 .6546783447393 .8738174438595 .3977432251 95.397743225194 .7881774902393 .2642517089891 .4355392456189 .60682678223 88.0829010009886 .8637619018685 .9494018554784 .7302627563586 .55898284912 88.9972534179790 .2164001464890 .2164001464889 .9116134643689 .3020401001 88.6924667358488 .3876876831187 .7781066894587 .4733276367287 .47332763672 87.7781066894588 .6924667358490 .2164001464893 .2642517089897 .53124237061 103.0174026489110 .6370010376120 .0852966309130 .7528076172142 .6394042969 154.8307952881166 .7174987793178 .604095459189 .5764007568199 .329498291 207.8634033203208 .7778015137208 .7778015137208 .7778015137208 .7778015137 208.7778015137208 .7778015137208 .7778015137208 .7778015137208 .7778015137 208.7778015137208 .7778015137208 .7778015137208 .7778015137208 .7778015137 208.7778015137208 .7778015137208 .7778015137208 .7778015137208 .7778015137 208.7778015137208 .7778015137208 .7778015137208 .7778015137208 .7778015137 208.7778015137208 .7778015137208 .7778015137208 .7778015137208 .7778015137 208.7778015137208 .7778015137208 .7778015137208 .7778015137208 .7778015137 208.7778015137208 .7778015137208 .7778015137208 .7778015137208 .7778015137 208.7778015137208 .7778015137208 .7778015137208 .7778015137208 .7778015137 94.17859649658 -9999 -9999 -9999 -9999 -9999 -9999 -9999 -9999 -9999 -9999 -9999 -9999 -9999 -9999 -9999 -9999 -9999 -9999 -9999 -9999 -9999 -9999 -9999 -9999 -9999 -9999 -9999 -9999 -9999 -9999 -9999 -9999 -9999 -9999

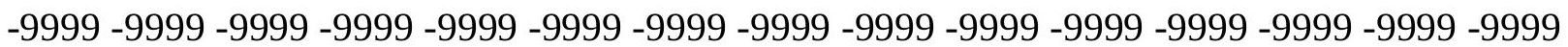
-9999 -9999 -9999 -9999 -9999 -9999 -9999 -9999 -9999 -9999 -9999 -9999 -9999 -9999 -9999 -9999 -9999 -9999 -9999 -9999 -9999 -9999 -9999 -9999 -9999 -9999 -9999 -9999 -9999 -9999 -9999 -9999 -9999 -9999 -9999 -9999 -9999 -9999 -9999 -9999 -9999 -9999 -9999 -9999 -9999 -9999 -9999 -9999 -9999 -9999 -9999 -9999 250.8381958008 244.7424926758236 .2084960938 223.7122955322208 .4730072021202 .6820983887195 .9768066406189 .2716064453 183.1759033203188 .0523986816189 .5764007568188 .966796875187 .4429016113 185.3094024658182 .87109375180 .1280059814177 .0802001953174 .337097168 171.2891998291168 .241394043164 .2792053223163 .6696014404163 .0599975586 162.4505004883162 .1457061768161 .8408966064161 .5361022949161 .5361022949 161.5361022949161 .8408966064162 .4505004883163 .0599975586163 .974395752 165.1934967041166 .4127044678167 .6318054199168 .8509979248169 .7653045654 170.070098877169 .7653045654168 .5462036133166 .4127044678163 .6696014404 161.5361022949159 .7073974609157 .878692627156 .3547973633155 .4403991699 155.4403991699156 .0500030518157 .2691040039158 .1835021973157 .878692627 156.6596069336156 .0500030518156 .6596069336157 .878692627159 .4026031494 160.3170013428160 .9264984131160 .9264984131160 .6217956543159 .7073974609 158.4882965088156 .3547973633153 .3069000244150 .2590942383148 .4304046631 147.2111968994146 .2969055176145 .6873016357144 .6556091309145 .0776977539 144.7729034424144 .7729034424144 .4682006836144 .4682006836144 .1634063721 143.8585968018142 .9441986084142 .0299072266140 .5059967041138 .9819946289 137.1533050537135 .6293945312133 .8007049561131 .9720001221130 .1432037354 128.6192932129127 .0953979492125 .5715026855124 .0475006104122 .8283996582 121.6092987061120 .0852966309118 .5614013672117 .342300415116 .7326965332 117.0374984741117 .342300415117 .9517974854118 .2565994263118 .2565994263 117.9517974854117 .0374984741116 .1231002808114 .9039993286113 .3800964355 
111.8561019897110 .0273971558107 .8938980103106 .3700027466106 .0652008057 107.5891036987110 .9418029785116 .4279022217123 .43800354130 .7528076172 122.8283996582115 .2088012695109 .7226028442106 .0652008057104 .2365036011 104.5412979126107 .8938980103115 .818397522122 .8283996582123 .43800354 121.6092987061120 .9997024536121 .9140014648124 .0475006104124 .3523025513 123.1332015991123 .1332015991122 .8283996582122 .2188034058121 .9140014648 121.6092987061121 .6092987061121 .6092987061121 .9140014648120 .6949005127 119.4757995605117 .9517974854116 .7326965332115 .5136032104114 .9039993286 113.9896011353112 .7705001831111 .551399231110 .0273971558108 .1986999512 106.6747970581105 .4557037354104 .5412979126103 .6268997192103 .0174026489 102.712600708102 .712600708102 .712600708103 .0174026489103 .0174026489 103.3221969604103 .3221969604103 .3221969604103 .0174026489102 .712600708 102.4077987671102 .1029968262101 .4934005737101 .1886978149100 .8839035034 100.5791015625100 .274299621699 .9695205688599 .9695205688599 .96952056885 100.2742996216100 .8839035034101 .4934005737102 .1029968262103 .0174026489 103.9317016602104 .8460998535105 .4557037354106 .0652008057106 .3700027466 106.3700027466106 .6747970581106 .6747970581106 .6747970581106 .6747970581 105.1509017944102 .407798767199 .0551681518699 .0551681518698 .14080810547 96.6168823242295 .397743225199 .9695205688597 .8360290527397 .83602905273 96.0073165893692 .0450973510795 .397743225196 .6168823242295 .70252990723 94.7881774902393 .2642517089891 .7403335571389 .6068267822388 .08290100098 86.8637619018686 .5589828491286 .8637619018688 .6924667358490 .52117919922 91.4355392456191 .1307525634890 .2164001464889 .6068267822388 .99725341797 88.38768768311 88.08290100098 87.77810668945 87.47332763672 87.77810668945 88.3876876831190.2164001464892.6546783447396.61688232422 101.7982025146 108.8082962036117 .0374984741127 .0953979492138 .0677032471150 .2590942383 162.7552947998175 .2514038086186 .528503418196 .5863952637205 .1204071045 208.7778015137208 .7778015137208 .7778015137208 .7778015137208 .7778015137 208.7778015137208 .7778015137208 .7778015137208 .7778015137208 .7778015137 208.7778015137208 .7778015137208 .7778015137208 .7778015137208 .7778015137 208.7778015137208.7778015137208.7778015137208.7778015137208.7778015137 208.7778015137208 .7778015137208 .7778015137208 .7778015137208 .7778015137 208.7778015137 208.7778015137208.7778015137 208.7778015137 208.7778015137 208.7778015137208.7778015137208.7778015137208.7778015137208.7778015137 208.7778015137208.7778015137208.7778015137208.7778015137208.7778015137 208.7778015137208 .7778015137208 .7778015137208 .777801513793 .26425170898 93.87381744385 -9999 -9999 -9999 -9999 -9999 -9999 -9999 -9999 -9999 -9999 -9999 -9999 -9999 -9999 -9999-9999-9999-9999 -9999 -9999 -9999 -9999 -9999 -9999 -9999 -9999 -9999 -9999 -9999 -9999 -9999 -9999 -9999 -9999 -9999 -9999 -9999 -9999 -9999 -9999 -9999 -9999 -9999 -9999 -9999 -9999 -9999 -9999 -

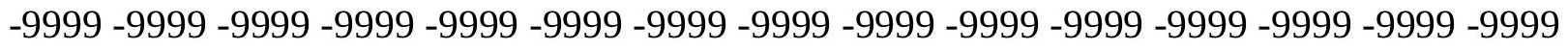

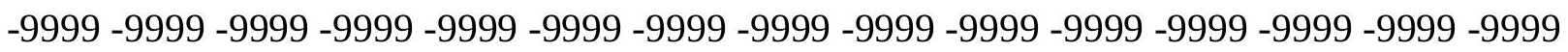
-9999 -9999 -9999 -9999 -9999 -9999 -9999 -9999 -9999 -9999 -9999 -9999 -9999 -9999 -9999 -9999 -9999 -9999 -9999 -9999 -9999 -9999 -9999 255.1051025391 247.1806945801 237.1228027344218 .5308990479202 .6820983887196 .5863952637190 .4907073975 185.0045928955 187.4429016113189.2716064453188.6620025635 187.1381072998 
185.0045928955182 .5662994385179 .8231964111177 .0802001953174 .337097168 171.2891998291168 .241394043163 .6696014404163 .0599975586162 .4505004883 161.8408966064161 .5361022949161 .2312927246160 .9264984131160 .9264984131 161.2312927246161 .5361022949162 .1457061768162 .7552947998163 .6696014404 164.8887023926166 .4127044678167 .6318054199169 .1557006836170 .3748931885 170.9844970703170 .9844970703169 .7653045654167 .3269958496164 .5839996338 162.1457061768160 .0122070312158 .1835021973156 .9642944336156 .3547973633 156.3547973633156 .6596069336157 .5738983154158 .4882965088158 .7929992676 157.5738983154156 .6596069336156 .6596069336157 .2691040039157 .878692627 158.4882965088159 .0977935791158 .7929992676157 .878692627156 .3547973633 155.4403991699153 .6116943359151 .1734008789149 .0399017334147 .5160064697 146.6015930176145 .9920959473145 .3080444336144 .4408721924143 .4114990234 144.7729034424144 .7729034424144 .7729034424144 .7729034424144 .4682006836 144.1634063721143 .5538024902142 .3347015381140 .8106994629139 .2868041992 137.4580993652135 .9342041016134 .1054992676132 .2767028809130 .4479980469 128.9241027832127 .7050018311126 .4858016968125 .2667007446124 .0475006104 122.8283996582121 .6092987061120 .0852966309118 .5614013672117 .342300415 117.9517974854118 .8662033081119 .4757995605119 .7806015015120 .0852966309 119.7806015015119 .1709976196118 .2565994263117 .0374984741115 .818397522 114.5991973877113 .3800964355112 .1608963013111 .8561019897112 .4656982422 114.5991973877118 .5614013672124 .0475006104129 .8385009766132 .5814971924 128.9241027832122 .2188034058116 .7326965332112 .7705001831111 .551399231 112.7705001831115 .5136032104118 .2565994263120 .3900985718120 .6949005127 120.3900985718121 .9140014648122 .2188034058121 .6092987061122 .2188034058 122.5235977173122 .5235977173124 .9618988037121 .6092987061120 .9997024536 120.6949005127120 .6949005127120 .6949005127120 .3900985718119 .4757995605 118.2565994263117 .0374984741115 .5136032104114 .2944030762113 .3800964355 112.1608963013110 .9418029785109 .7226028442108 .1986999512106 .6747970581 105.4557037354104 .2365036011103 .6268997192102 .712600708102 .4077987671 102.1029968262102 .1029968262102 .1029968262102 .1029968262102 .4077987671 102.712600708102 .712600708102 .712600708102 .4077987671102 .4077987671 102.1029968262101 .7982025146101 .4934005737101 .1886978149100 .5791015625 100.274299621699 .9695205688599 .6647262573299 .6647262573299 .66472625732 99.96952056885100 .2742996216100 .8839035034101 .4934005737102 .4077987671 103.3221969604103 .9317016602104 .5412979126104 .8460998535105 .1509017944 105.4557037354105 .4557037354106 .0652008057106 .3700027466106 .979598999 107.2844009399103 .9317016602100 .883903503499 .0551681518697 .83602905273 96.9216690063596 .6168823242299 .35994720459101 .7982025146102 .4077987671 97.53124237061100 .5791015625100 .579101562599 .0551681518697 .53124237061 96.3121032714895 .7025299072396 .6168823242299 .0551681518693 .56903076172 90.5211791992289 .9116134643690 .5211791992292 .0450973510793 .56903076172 94.1785964965892 .9594726562591 .1307525634890 .5211791992289 .91161346436 89.302040100188.6924667358488.08290100098 88.08290100098 88.08290100098 88.6924667358490 .2164001464892 .349891662695 .70252990723100 .5791015625 106.3700027466113 .6848983765122 .5235977173132 .8863067627144 .4682006836 157.2691040039170.6797027588183.1759033203192.9290008545 201.158203125 
208.4730072021 208.7778015137208.7778015137208.7778015137 208.7778015137 208.7778015137208 .7778015137208 .7778015137208 .7778015137208 .7778015137 208.7778015137208 .7778015137208 .7778015137208 .7778015137208 .7778015137 208.7778015137208 .7778015137208 .7778015137208 .7778015137208 .7778015137 208.7778015137208 .7778015137208 .7778015137208 .7778015137208 .7778015137 208.7778015137208 .7778015137208 .7778015137208 .7778015137208 .7778015137 208.7778015137208 .7778015137208 .7778015137208 .7778015137208 .7778015137 208.7778015137208 .7778015137208 .7778015137208 .7778015137208 .7778015137 208.7778015137208 .7778015137208 .7778015137208 .777801513792 .04509735107 92.65467834473 -9999 -9999 -9999 -9999 -9999 -9999 -9999 -9999 -9999 -9999 -9999 -9999 -9999 -9999 -9999 -9999-9999-9999

-9999 -9999 -9999 -9999 -9999 -9999 -9999 -9999 -9999 -9999 -9999 -9999 -9999 -9999 -9999 -9999 -9999 -9999 -9999 -9999 -9999 -9999 -9999 -9999 -9999 -9999 -9999 -9999 -9999 -9999 -9999 -9999 -9999 -9999 -9999 -9999 -9999 -9999 -9999 -9999 -9999 -9999 -9999 -9999 -9999 -9999 -9999 -9999 -9999 -9999 -9999 -9999 -9999 -9999 -9999 -9999 -9999 -9999 -9999 -9999

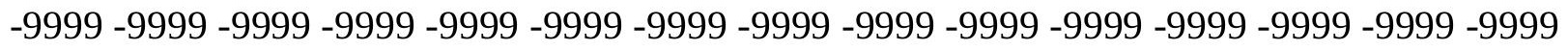
-9999 -9999 -9999 -9999-9999 -9999 -9999 -9999 -9999 256.3243103027248 .0950927734 231.6367034912204 .5108032227196 .5863952637191 .1002960205186 .2236938477 187.1381072998188 .0523986816187 .4429016113186 .2236938477184 .0901947021 181.9566955566179 .5184020996176 .7754058838174 .0323028564171 .2891998291 168.241394043163 .0599975586162 .1457061768161 .5361022949161 .2312927246 160.9264984131160 .6217956543160 .3170013428160 .3170013428160 .6217956543 160.9264984131161 .5361022949162 .4505004883163 .3648071289164 .5839996338 165.8031005859167 .3269958496169 .1557006836170 .3748931885171 .5939941406 172.2035980225171 .2891998291168 .5462036133165 .1934967041162 .4505004883 160.3170013428158 .4882965088157 .5738983154156 .9642944336156 .9642944336 157.2691040039157 .5738983154158 .1835021973158 .1835021973157 .5738983154 156.9642944336156 .6596069336156 .6596069336156 .6596069336156 .9642944336 156.9642944336156 .6596069336154 .8307952881153 .3069000244152 .0877990723 150.8686065674149 .3446960449147 .8208007812146 .6015930176145 .9920959473 145.6873016357144 .9960327148144 .1950683594143 .2827453613144 .7729034424 145.0776977539145 .0776977539145 .0776977539144 .7729034424144 .4682006836 143.8585968018142 .6394042969141 .4203033447139 .5915985107138 .0677032471 136.2389984131134 .4102020264132 .5814971924130 .7528076172129 .2288970947 128.3144989014127 .4001998901126 .4858016968125 .8762969971124 .6570968628 123.43800354121 .9140014648120 .6949005127119 .7806015015120 .0852966309 120.6949005127121 .3044967651121 .9140014648121 .9140014648121 .6092987061 120.9997024536120 .3900985718119 .4757995605118 .5614013672117 .647102356 116.7326965332116 .4279022217116 .4279022217117 .647102356120 .0852966309 123.43800354127 .7050018311131 .3623962402131 .9720001221129 .8385009766 125.2667007446120 .6949005127117 .647102356116 .7326965332118 .2565994263 124.9618988037122 .5235977173125 .2667007446125 .2667007446124 .9618988037 121.6092987061121 .6092987061124 .9618988037124 .9618988037121 .9140014648 121.9140014648121 .3044967651120 .9997024536120 .3900985718120 .0852966309 120.0852966309119 .7806015015119 .1709976196118 .2565994263117 .0374984741 115.818397522114 .2944030762113 .075302124111 .8561019897110 .6370010376 
109.1130981445107 .8938980103106 .3700027466105 .1509017944103 .9317016602 103.0174026489102 .4077987671101 .7982025146101 .4934005737101 .4934005737 101.1886978149101 .4934005737101 .4934005737101 .4934005737101 .7982025146 101.7982025146102 .1029968262101 .7982025146101 .7982025146101 .4934005737 101.4934005737101 .1886978149100 .8839035034100 .5791015625100 .2742996216 99.9695205688599 .6647262573299 .3599472045999 .3599472045999 .66472625732 99.96952056885100 .2742996216100 .5791015625101 .4934005737102 .4077987671 103.0174026489103 .6268997192103 .9317016602103 .9317016602103 .9317016602 104.2365036011104 .5412979126105 .4557037354106 .0652008057106 .0652008057 104.2365036011101 .798202514699 .9695205688598 .7503814697397 .83602905273 97.8360290527397 .8360290527398 .445587158298 .445587158298 .14080810547 102.4077987671103 .6268997192103 .3221969604102 .102996826298 .4455871582 98.4455871582 99.3599472045999.3599472045997.2264633178794.48339080811 93.5690307617293 .8738174438595 .397743225197 .2264633178797 .83602905273 96.0073165893693 .5690307617292 .0450973510791 .1307525634890 .52117919922 89.6068267822389 .302040100188 .6924667358488 .6924667358489 .3020401001 90.2164001464892 .349891662695 .0929565429798 .75038146973103 .9317016602 110.0273971558117 .647102356126 .7906036377137 .4580993652149 .9542999268 163.974395752178 .604095459187 .4429016113195 .9768066406203 .596496582 208.7778015137208 .7778015137208 .7778015137208 .7778015137208 .7778015137 208.7778015137208.7778015137208.7778015137208.7778015137 208.7778015137 208.7778015137208 .7778015137208 .7778015137208 .7778015137208 .7778015137 208.7778015137208 .7778015137208 .7778015137208 .7778015137208 .7778015137 208.7778015137 208.7778015137208.7778015137 208.7778015137 208.7778015137 208.7778015137 208.7778015137208.7778015137 208.7778015137 208.7778015137 208.7778015137208.7778015137208.7778015137208.7778015137 208.7778015137 208.7778015137208 .7778015137208 .7778015137208 .7778015137208 .7778015137 $208.7778015137208 .7778015137208 .7778015137208 .777801513791 .74033355713-9999$ -9999 -9999 -9999 -9999 -9999 -9999 -9999 -9999 -9999 -9999 -9999 -9999 -9999 -9999 -9999 -9999-9999

-9999 -9999 -9999 -9999 -9999 -9999 -9999 -9999 -9999 -9999 -9999 -9999 -9999 -9999 -9999 -9999 -9999 -9999 -9999 -9999 -9999 -9999 -9999 -9999 -9999 -9999 -9999 -9999 -9999 -9999 -

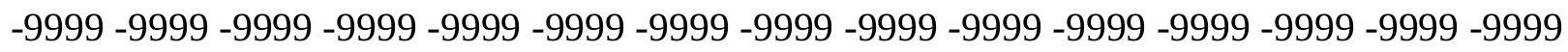
-9999 -9999 -9999 -9999 -9999 -9999 -9999 -9999 -9999 -9999 -9999 -9999 -9999 -9999 -9999 -9999 -9999 -9999 -9999 -9999 -9999 -9999 -9999 -9999 -9999 -9999 -9999 -9999 -9999 -9999 -999 -9999 -9999 -9999 -9999-9999 -9999 -9999 -9999 -9999 -9999 -9999 243.5233001709 219.1405029297195.9768066406191.4051055908 187.4429016113184.0901947021 184.699798584185 .3094024658184 .3950042725182 .87109375181 .0424041748 178.9089050293176 .4705963135174 .0323028564171 .2891998291168 .5462036133 165.4983062744161 .8408966064161 .2312927246160 .6217956543160 .3170013428 160.0122070312160 .0122070312160 .0122070312160 .0122070312160 .3170013428 160.9264984131161 .5361022949162 .7552947998163 .974395752165 .1934967041 166.7174987793168 .5462036133170 .070098877171 .5939941406172 .5084075928 172.5084075928168 .8509979248165 .1934967041162 .7552947998160 .3170013428 158.7929992676157 .878692627157 .2691040039157 .2691040039157 .2691040039 157.2691040039157 .5738983154157 .5738983154157 .2691040039156 .9642944336 
156.3547973633156 .0500030518155 .7451934814155 .1356048584155 .1356048584 154.5260925293151 .4781951904149 .6495056152149 .0399017334148 .1255950928 147.2111968994146 .2969055176145 .9920959473145 .3825073242145 .0776977539 144.6428375244143 .9497528076143 .125213623142 .243637085144 .7729034424 145.0776977539145 .0776977539144 .7729034424144 .4682006836143 .8585968018 142.9441986084141 .4203033447140 .2012023926138 .3724975586136 .5437011719 134.7149963379132 .8863067627131 .0576019287129 .8385009766129 .2288970947 128.6192932129128 .0097961426127 .7050018311126 .7906036377125 .5715026855 124.3523025513123 .1332015991122 .5235977173122 .5235977173122 .8283996582 123.43800354124 .0475006104124 .0475006104124 .0475006104123 .43800354 122.5235977173121 .6092987061120 .6949005127120 .0852966309119 .7806015015 119.4757995605120 .0852966309121 .3044967651123 .1332015991125 .5715026855 128.3144989014130 .4479980469130 .4479980469128 .6192932129125 .5715026855 122.2188034058120 .3900985718123 .1332015991121 .3044967651126 .1809997559 124.3523025513126 .4858016968126 .1809997559125 .8762969971125 .5715026855 125.2667007446124 .9618988037124 .9618988037121 .6092987061121 .3044967651 120.6949005127120 .3900985718119 .7806015015119 .4757995605118 .8662033081 118.5614013672117 .647102356116 .7326965332115 .818397522114 .2944030762 113.075302124111 .551399231110 .3321990967108 .8082962036107 .2844009399 106.0652008057104 .5412979126103 .3221969604102 .4077987671101 .4934005737 100.8839035034100 .5791015625100 .5791015625100 .2742996216100 .2742996216 100.5791015625100 .5791015625100 .8839035034100 .8839035034101 .1886978149 101.1886978149101 .1886978149101 .1886978149101 .1886978149101 .1886978149 100.8839035034100 .8839035034100 .5791015625100 .274299621699 .96952056885 99.3599472045999 .0551681518699 .0551681518699 .3599472045999 .66472625732 99.96952056885100 .5791015625101 .1886978149101 .7982025146102 .4077987671 102.712600708102 .712600708102 .712600708102 .712600708102 .4077987671 102.712600708103 .6268997192104 .2365036011104 .5412979126103 .6268997192 102.1029968262100 .883903503499 .6647262573299 .0551681518698 .75038146973 98.7503814697399 .0551681518699 .0551681518699 .0551681518699 .35994720459 103.0174026489103 .017402648999 .9695205688599 .96952056885100 .2742996216 101.1886978149100 .274299621698 .7503814697399 .9695205688596 .00731658936 96.0073165893697 .2264633178799 .35994720459101 .493400573798 .14080810547 96.0073165893694 .4833908081192 .9594726562592 .0450973510791 .13075256348 90.5211791992289 .9116134643689 .6068267822389 .9116134643690 .52117919922 92.0450973510794 .1785964965897 .22646331787101 .1886978149106 .3700027466 112.4656982422119 .7806015015129 .2288970947140 .8106994629154 .2212982178 167.9365997314179 .2136993408188 .966796875197 .8054962158206 .0346984863 208.7778015137208 .7778015137208 .7778015137208 .7778015137208 .7778015137 208.7778015137208 .7778015137208 .7778015137208 .7778015137208 .7778015137 208.7778015137208 .7778015137208 .7778015137208 .7778015137208 .7778015137 208.7778015137208 .7778015137208 .7778015137208 .7778015137208 .7778015137 208.7778015137208 .7778015137208 .7778015137208 .7778015137208 .7778015137 208.7778015137208 .7778015137208 .7778015137208 .7778015137208 .7778015137 208.7778015137208 .7778015137208 .7778015137208 .7778015137208 .7778015137 208.7778015137 208.7778015137208.7778015137 208.7778015137 208.7778015137 
208.7778015137208 .7778015137208 .777801513790 .5211791992291 .13075256348 -9999 -9999 -9999 -9999 -9999 -9999 -9999 -9999 -9999 -9999 -9999 -9999 -9999 -9999 -9999 -9999 $-9999$

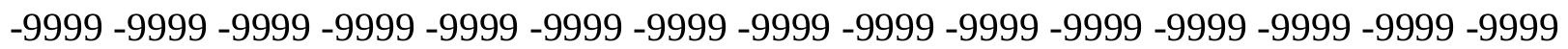

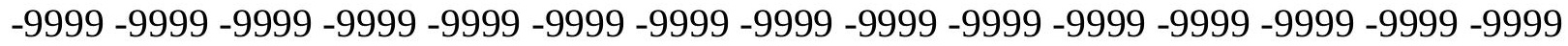

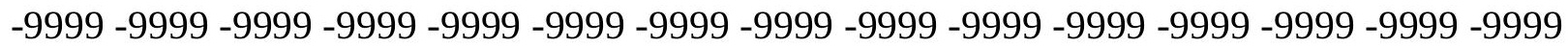

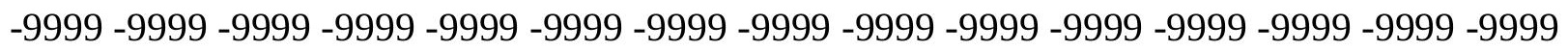

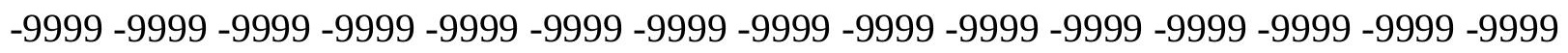
-9999 -9999 -9999 -9999 -9999 -9999 -9999 -9999 -9999 -9999 -9999 253.2763977051 235.2940979004 205.425201416191.7097930908 188.6620025635185.9188995361 182.5662994385182 .5662994385182 .5662994385181 .6519012451180 .1280059814 178.2993011475176 .165802002174 .0323028564171 .2891998291168 .8509979248 166.1078948975161 .5361022949160 .9264984131160 .3170013428160 .0122070312 159.7073974609159 .4026031494159 .4026031494159 .4026031494159 .7073974609 160.3170013428160 .9264984131161 .8408966064163 .0599975586164 .2792053223 165.8031005859167 .6318054199169 .1557006836170 .3748931885170 .9844970703 170.3748931885167 .9365997314164 .8887023926162 .7552947998160 .6217956543 159.0977935791158 .1835021973157 .5738983154157 .2691040039156 .9642944336 156.9642944336156 .6596069336156 .6596069336156 .6596069336156 .3547973633 156.3547973633155 .7451934814155 .1356048584154 .5260925293153 .3069000244 150.8686065674147 .5160064697146 .2969055176145 .6873016357145 .3825073242 145.0776977539145 .0776977539145 .0776977539144 .7729034424144 .7729034424 144.2894439697143 .6620330811142 .9398040771142 .1623077393144 .7729034424 144.7729034424145 .0776977539144 .7729034424144 .4682006836143 .8585968018 142.9441986084141 .7250976562140 .5059967041138 .9819946289137 .1533050537 135.3246002197133 .4958953857131 .6672058105130 .7528076172130 .1432037354 129.8385009766129 .533706665129 .2288970947128 .9241027832127 .7050018311 126.4858016968125 .2667007446124 .9618988037124 .9618988037125 .2667007446 125.8762969971126 .1809997559126 .4858016968126 .1809997559125 .2667007446 124.3523025513123 .7427978516122 .8283996582122 .2188034058121 .9140014648 121.9140014648122 .2188034058123 .1332015991124 .3523025513126 .1809997559 127.7050018311128 .6192932129128 .3144989014127 .0953979492124 .6570968628 122.2188034058121 .6092987061121 .6092987061123 .1332015991124 .6570968628 124.0475006104126 .7906036377126 .7906036377126 .4858016968125 .8762969971 125.5715026855124 .9618988037124 .3523025513120 .9997024536120 .3900985718 120.0852966309119 .4757995605118 .8662033081118 .5614013672117 .9517974854 117.0374984741116 .4279022217115 .5136032104114 .2944030762113 .075302124 111.551399231110 .0273971558108 .8082962036107 .2844009399105 .7603988647 104.2365036011 102.712600708 101.4934005737 100.274299621699.66472625732 99.3599472045999.3599472045999.3599472045999.3599472045999.35994720459 99.3599472045999 .6647262573299 .96952056885100 .2742996216100 .2742996216 100.5791015625100 .5791015625100 .8839035034100 .8839035034100 .8839035034 100.8839035034100 .8839035034100 .5791015625100 .274299621699 .96952056885 99.3599472045998 .7503814697399 .0551681518699 .3599472045999 .66472625732 99.96952056885100 .2742996216100 .8839035034101 .4934005737101 .7982025146 102.1029968262101 .7982025146101 .7982025146101 .4934005737100 .8839035034 
100.5791015625101 .7982025146102 .712600708103 .0174026489102 .712600708 102.1029968262101 .1886978149100 .5791015625100 .274299621699 .96952056885 99.6647262573299 .6647262573299 .6647262573299 .9695205688599 .96952056885 100.2742996216100 .5791015625100 .5791015625100 .8839035034101 .4934005737 101.4934005737101 .188697814999 .9695205688598 .7503814697397 .83602905273 97.8360290527398 .75038146973100 .2742996216101 .188697814999 .96952056885 98.1408081054796 .3121032714895 .0929565429793 .8738174438592 .65467834473 91.7403335571391 .1307525634890 .5211791992290 .5211791992290 .82597351074 92.0450973510793 .5690307617295 .7025299072398 .75038146973102 .712600708 107.2844009399 113.075302124 120.3900985718 130.1432037354143.2489929199 156.9642944336169 .7653045654181 .0424041748190 .795501709200 .2438049316 208.7778015137208 .7778015137208 .7778015137208 .7778015137208 .7778015137 208.7778015137208 .7778015137208 .7778015137208 .7778015137208 .7778015137 208.7778015137208 .7778015137208 .7778015137208 .7778015137208 .7778015137 208.7778015137208 .7778015137208 .7778015137208 .7778015137208 .7778015137 208.7778015137208 .7778015137208 .7778015137208 .7778015137208 .7778015137 208.7778015137208 .7778015137208 .7778015137208 .7778015137208 .7778015137 208.7778015137208 .7778015137208 .7778015137208 .7778015137208 .7778015137 208.7778015137208 .7778015137208 .7778015137208 .7778015137208 .7778015137 208.7778015137208 .7778015137208 .777801513789 .6068267822390 .21640014648 -9999 -9999 -9999 -9999 -9999 -9999 -9999 -9999 -9999 -9999 -9999 -9999 -9999 -9999 -9999 -9999 $-9999$

-9999 -9999 -9999 -9999 -9999 -9999 -9999 -9999 -9999 -9999 -9999 -9999 -9999 -9999 -999 -999 -999 -999 -999 -999 -999 -999 -

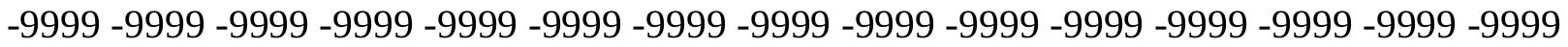

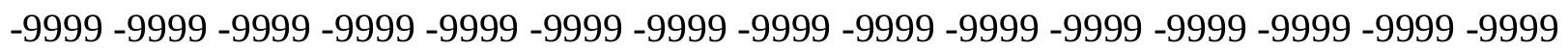

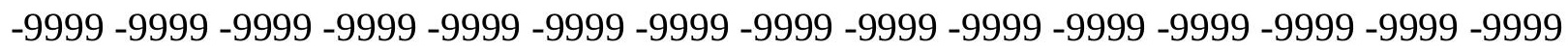

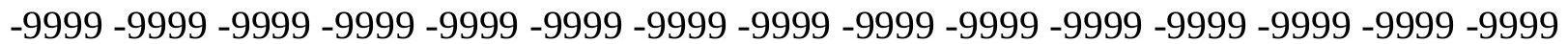
-9999 -9999 -9999 -9999 -9999 -9999 -9999 -9999 -9999 -9999 -9999 -9999 250.8381958008 227.3697052002 192.624206543191.1002960205 188.3571929932182.7688598633 180.1280059814180 .1280059814179 .8231964111178 .9089050293177 .6896972656 175.8609924316173 .7274932861171 .2891998291168 .8509979248166 .4127044678 161.2312927246160 .6217956543160 .3170013428159 .7073974609159 .4026031494 159.0977935791159 .0977935791159 .0977935791159 .0977935791159 .4026031494 160.0122070312160 .9264984131161 .8408966064163 .3648071289164 .5839996338 166.1078948975167 .6318054199168 .5462036133168 .8509979248168 .241394043 166.4127044678164 .2792053223162 .4505004883160 .6217956543159 .0977935791 158.1835021973157 .5738983154157 .2691040039156 .9642944336156 .3547973633 156.0500030518156 .0500030518156 .0500030518156 .0500030518156 .0500030518 155.7451934814154 .8307952881153 .6116943359151 .7830047607148 .4304046631 144.1634063721142 .6394042969142 .6394042969142 .6394042969142 .9441986084 144.1634063721144 .1634063721144 .1634063721144 .1634063721143 .8526763916 143.3497161865142 .7387542725142 .0704345703144 .7729034424144 .7729034424 144.7729034424144 .7729034424144 .4682006836143 .8585968018143 .2489929199 142.0299072266141 .1154937744139 .5915985107138 .0677032471136 .2389984131 134.7149963379133 .1911010742132 .2767028809131 .6672058105131 .0576019287 130.7528076172130 .7528076172130 .1432037354129 .2288970947128 .3144989014 
127.4001998901126 .7906036377126 .7906036377127 .0953979492127 .7050018311 128.3144989014128 .6192932129128 .0097961426127 .0953979492126 .1809997559 125.2667007446124 .3523025513124 .0475006104123 .43800354123 .43800354 123.7427978516124 .0475006104124 .6570968628125 .2667007446125 .8762969971 126.1809997559126 .1809997559125 .2667007446124 .0475006104122 .8283996582 122.5235977173122 .5235977173123 .1332015991123 .43800354126 .7906036377 126.7906036377126 .7906036377126 .4858016968125 .8762969971125 .2667007446 124.6570968628123 .7427978516120 .0852966309119 .7806015015119 .1709976196 118.5614013672117 .9517974854117 .342300415116 .7326965332115 .818397522 114.9039993286113 .9896011353112 .7705001831111 .551399231110 .0273971558 108.8082962036106 .979598999105 .4557037354103 .9317016602102 .1029968262 100.579101562599 .3599472045998 .445587158297 .8360290527397 .53124237061 97.8360290527398 .1408081054798 .1408081054798 .1408081054798 .4455871582 98.445587158299 .0551681518699 .3599472045999 .6647262573299 .96952056885 100.2742996216100 .2742996216100 .2742996216100 .5791015625100 .5791015625 100.8839035034100 .8839035034100 .579101562599 .9695205688599 .35994720459 99.0551681518699 .0551681518699 .0551681518699 .3599472045999 .96952056885 100.2742996216100 .5791015625101 .1886978149101 .1886978149101 .4934005737 101.1886978149100 .8839035034100 .5791015625100 .2742996216103 .6268997192 103.9317016602101 .4934005737101 .7982025146102 .1029968262101 .7982025146 101.4934005737101 .1886978149100 .8839035034100 .5791015625100 .5791015625 100.2742996216100 .5791015625100 .5791015625100 .5791015625100 .8839035034 100.8839035034101 .1886978149101 .4934005737101 .7982025146101 .7982025146 101.4934005737100 .579101562599 .9695205688599 .3599472045999 .35994720459 99.96952056885100 .8839035034101 .1886978149100 .883903503499 .66472625732 98.1408081054796 .6168823242295 .397743225194 .1785964965893 .26425170898 92.349891662691 .7403335571391 .4355392456191 .4355392456192 .04509735107 92.9594726562594 .4833908081196 .6168823242299 .66472625732103 .0174026489 107.5891036987113 .075302124119 .7806015015133 .4958953857147 .5160064697 160.6217956543172 .8132019043184 .0901947021194 .1481018066203 .596496582 208.7778015137208 .7778015137208 .7778015137208 .7778015137208 .7778015137 208.7778015137208 .7778015137208 .7778015137208 .7778015137208 .7778015137 208.7778015137208 .7778015137208 .7778015137208 .7778015137208 .7778015137 208.7778015137208 .7778015137208 .7778015137208 .7778015137208 .7778015137 208.7778015137208 .7778015137208 .7778015137208 .7778015137208 .7778015137 208.7778015137208 .7778015137208 .7778015137208 .7778015137208 .7778015137 208.7778015137208 .7778015137208 .7778015137208 .7778015137208 .7778015137 208.7778015137208 .7778015137208 .7778015137208 .7778015137208 .7778015137 208.7778015137208 .7778015137208 .777801513788 .99725341797 -9999 -9999 -9999 -9999 -9999 -9999 -9999 -9999 -9999 -9999 -9999 -9999 -9999 -9999 -9999 -9999 -9999 -

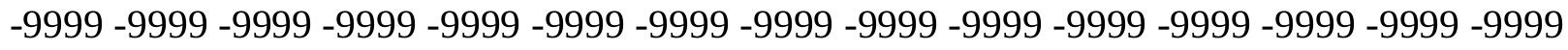

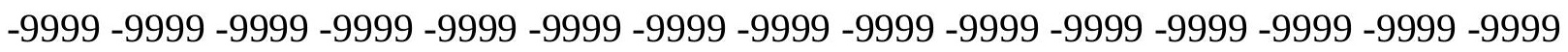

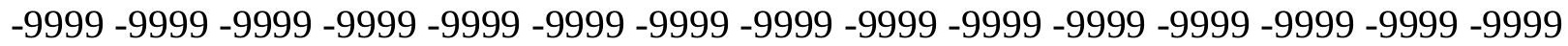
-9999 -

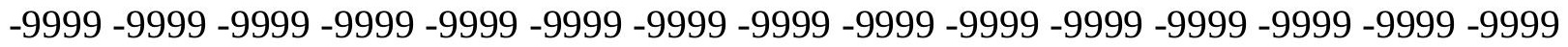
-9999 -9999 -9999 -9999 -9999 -9999 -9999 -9999 -9999 -9999 -9999 -9999 -9999 
246.8759002686217 .0070037842194 .7577056885190 .4907073975182 .4466400146 180.432800293176 .4705963135178 .604095459177 .9945068359177 .0802001953 175.2514038086173 .4226989746171 .2891998291169 .1557006836166 .7174987793 164.2792053223160 .6217956543160 .0122070312159 .7073974609159 .4026031494 159.0977935791158 .7929992676158 .4882965088158 .4882965088158 .4882965088 159.0977935791159 .7073974609160 .9264984131162 .1457061768163 .3648071289 164.5839996338165 .8031005859166 .4127044678166 .7174987793166 .1078948975 164.5839996338163 .0599975586161 .8408966064160 .3170013428159 .0977935791 158.1835021973157 .5738983154156 .9642944336156 .6596069336156 .0500030518 155.7451934814155 .1356048584155 .4403991699155 .7451934814155 .7451934814 155.4403991699154 .8307952881153 .0021057129150 .5639038086147 .2111968994 143.2489929199143 .2489929199140 .5059967041140 .5059967041141 .7250976562 142.6394042969143 .2489929199143 .5538024902143 .5538024902143 .3679046631 143.0132141113142 .5378265381141 .9846496582141 .3952178955144 .4682006836 144.7729034424144 .7729034424144 .4682006836144 .1634063721143 .5538024902 142.6394042969141 .7250976562140 .5059967041138 .9819946289137 .4580993652 136.2389984131134 .7149963379133 .8007049561133 .1911010742132 .5814971924 131.9720001221131 .6672058105131 .0576019287130 .4479980469129 .533706665 128.6192932129128 .3144989014128 .3144989014128 .6192932129129 .2288970947 129.8385009766130 .4479980469129 .533706665128 .6192932129127 .4001998901 126.4858016968125 .5715026855124 .9618988037124 .6570968628124 .3523025513 124.3523025513124 .0475006104124 .0475006104124 .0475006104123 .7427978516 124.0475006104124 .0475006104123 .7427978516123 .43800354122 .8283996582 122.5235977173125 .8762969971126 .1809997559126 .4858016968126 .7906036377 126.7906036377126 .4858016968126 .1809997559125 .5715026855124 .9618988037 124.0475006104123 .1332015991119 .4757995605118 .8662033081118 .2565994263 117.647102356117 .0374984741116 .4279022217115 .5136032104114 .5991973877 113.6848983765112 .4656982422111 .24659729110 .0273971558108 .8082962036 107.2844009399105 .4557037354103 .9317016602102 .1029968262100 .2742996216 98.7503814697397 .2264633178796 .0073165893695 .7025299072395 .70252990723 96.0073165893696 .3121032714896 .6168823242296 .9216690063597 .22646331787 97.5312423706198 .1408081054798 .445587158299 .0551681518699 .66472625732 99.9695205688599 .9695205688599 .9695205688599 .96952056885100 .2742996216 100.5791015625100 .8839035034100 .579101562599 .9695205688599 .35994720459 99.0551681518699 .0551681518699 .0551681518699 .3599472045999 .96952056885 100.2742996216100 .5791015625100 .8839035034100 .8839035034100 .8839035034 100.8839035034100 .579101562599 .9695205688599 .66472625732103 .6268997192 105.4557037354103 .6268997192100 .8839035034101 .1886978149101 .1886978149 101.1886978149101 .1886978149101 .4934005737101 .1886978149100 .8839035034 100.8839035034100 .8839035034100 .8839035034101 .1886978149101 .1886978149 101.4934005737101 .4934005737101 .7982025146101 .7982025146101 .7982025146 101.4934005737101 .1886978149100 .5791015625100 .5791015625100 .5791015625 100.8839035034101 .1886978149101 .4934005737101 .1886978149100 .5791015625 99.3599472045998.1408081054796.9216690063595.7025299072394.78817749023 93.8738174438592 .9594726562592 .349891662692 .0450973510792 .04509735107 92.6546783447393 .5690307617295 .0929565429797 .2264633178799 .96952056885 
103.6268997192108 .5035018921116 .1231002808127 .0953979492139 .8963928223 153.0021057129165 .4983062744177 .0802001953188 .3571929932198 .4151000977 208.1681976318208 .7778015137208 .7778015137208 .7778015137208 .7778015137 208.7778015137208 .7778015137208 .7778015137208 .7778015137208 .7778015137 208.7778015137208 .7778015137208 .7778015137208 .7778015137208 .7778015137 208.7778015137208 .7778015137208 .7778015137208 .7778015137208 .7778015137 208.7778015137208 .7778015137208 .7778015137208 .7778015137208 .7778015137 208.7778015137 208.7778015137 208.7778015137 208.7778015137 208.7778015137 208.7778015137208 .7778015137208 .7778015137208 .7778015137208 .7778015137 208.7778015137208 .7778015137208 .7778015137208 .7778015137208 .7778015137 $208.7778015137208 .7778015137208 .777801513788 .0829010009888 .69246673584-9999$ -9999 -9999 -9999 -9999 -9999 -9999 -9999 -9999 -9999 -9999 -9999 -9999 -9999 -9999 -9999 -9999 -9999 -9999 -9999 -9999 -9999 -9999 -9999 -9999 -9999 -9999 -9999 -9999 -9999 -9999 -9999 -9999 -9999 -9999 -9999 -9999 -9999 -9999 -9999 -9999 -9999 -9999 -9999 -9999 -9999 -9999 -9999 -9999 -9999 -9999 -9999 -9999 -9999 -9999 -9999 -9999 -9999 -9999 -9999 -9999

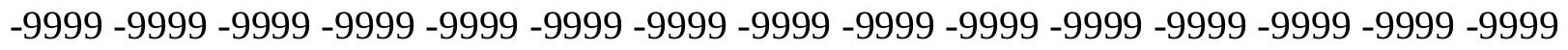

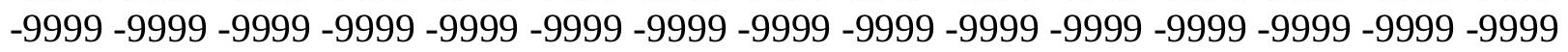
-9999 -9999 -9999 -9999 -9999 -9999 -9999 -9999 -9999 -9999 -9999 -9999 -9999 258.4577941895237 .4275970459202 .6820983887190 .795501709182 .2248687744 179.8231964111176 .165802002177 .3849029541177 .0802001953176 .4705963135 174.9467010498173 .1179962158170 .9844970703168 .8509979248166 .7174987793 161.2312927246160 .6217956543160 .3170013428159 .7073974609159 .4026031494 159.0977935791158 .7929992676158 .4882965088158 .1835021973157 .878692627 158.1835021973158 .7929992676159 .7073974609160 .9264984131162 .1457061768 163.0599975586163 .974395752164 .5839996338164 .5839996338163 .974395752 166.1078948975162 .1457061768160 .9264984131160 .0122070312159 .0977935791 158.1835021973157 .5738983154156 .9642944336156 .6596069336156 .0500030518 155.7451934814155 .4403991699155 .4403991699155 .7451934814155 .7451934814 155.4403991699154 .5260925293153 .0021057129150 .2590942383146 .9064025879 143.5538024902141 .1154937744139 .8963928223140 .2012023926140 .8106994629 141.7250976562142 .3347015381142 .6394042969142 .9441986084142 .942199707 142.7227478027142 .3706970215141 .9280700684141 .4373016357144 .4682006836 144.4682006836144 .4682006836144 .4682006836144 .1634063721143 .8585968018 142.9441986084142 .3347015381141 .4203033447140 .2012023926138 .9819946289 137.7628936768136 .5437011719135 .3246002197134 .4102020264133 .8007049561 133.1911010742132 .5814971924131 .9720001221131 .0576019287130 .4479980469 129.533706665129 .2288970947129 .2288970947129 .533706665129 .8385009766 130.4479980469130 .7528076172130 .1432037354129 .2288970947128 .3144989014 127.4001998901126 .4858016968125 .8762969971125 .2667007446124 .6570968628 124.3523025513123 .7427978516123 .43800354122 .5235977173121 .9140014648 122.2188034058122 .5235977173122 .8283996582125 .5715026855125 .5715026855 125.5715026855125 .8762969971126 .1809997559126 .4858016968126 .4858016968 126.4858016968126 .1809997559125 .5715026855124 .9618988037124 .0475006104 123.1332015991119 .1709976196118 .5614013672117 .9517974854117 .342300415 116.7326965332115 .818397522115 .2088012695114 .2944030762113 .3800964355 112.4656982422111 .24659729110 .0273971558108 .8082962036107 .2844009399 
105.7603988647104 .2365036011102 .4077987671100 .579101562598 .75038146973 96.9216690063595 .0929565429793 .8738174438593 .5690307617293 .87381744385 94.1785964965894 .7881774902395 .0929565429795 .397743225196 .00731658936 96.3121032714897 .2264633178797 .8360290527398 .7503814697399 .66472625732 99.9695205688599 .9695205688599 .6647262573299 .3599472045999 .35994720459 99.96952056885100 .5791015625100 .274299621699 .6647262573299 .05516815186 99.0551681518698 .7503814697399 .0551681518699 .3599472045999 .96952056885 100.2742996216100 .5791015625100 .8839035034100 .8839035034100 .5791015625 100.579101562599 .9695205688599 .6647262573299 .6647262573299 .66472625732 104.8460998535104 .5412979126100 .2742996216100 .5791015625100 .5791015625 100.8839035034101 .1886978149101 .1886978149101 .1886978149101 .1886978149 101.1886978149101 .1886978149101 .1886978149101 .4934005737101 .4934005737 101.7982025146101 .7982025146101 .7982025146102 .1029968262102 .1029968262 101.7982025146101 .4934005737101 .4934005737101 .1886978149101 .4934005737 101.4934005737101 .7982025146102 .1029968262101 .7982025146101 .1886978149 100.579101562599 .3599472045998 .445587158297 .2264633178796 .31210327148 95.0929565429794 .1785964965893 .5690307617292 .9594726562592 .3498916626 92.349891662692 .9594726562593 .8738174438595 .397743225197 .53124237061 100.8839035034105 .7603988647113 .075302124122 .5235977173133 .8007049561 146.2969055176158 .4882965088170 .6797027588182 .5662994385193 .5386047363 203.9011993408208 .7778015137208 .7778015137208 .7778015137208 .7778015137 208.7778015137208 .7778015137208 .7778015137208 .7778015137208 .7778015137 208.7778015137208 .7778015137208 .7778015137208 .7778015137208 .7778015137 208.7778015137208 .7778015137208 .7778015137208 .7778015137208 .7778015137 208.7778015137 208.7778015137208.7778015137208.7778015137 208.7778015137 208.7778015137 208.7778015137208.7778015137 208.7778015137 208.7778015137 208.7778015137208 .7778015137208 .7778015137208 .7778015137208 .7778015137 208.7778015137208 .7778015137208 .7778015137208 .7778015137208 .7778015137 208.7778015137 208.7778015137 208.7778015137 86.86376190186 87.77810668945 -9999 -9999 -9999 -9999 -9999 -9999 -9999 -9999 -9999 -9999 -9999 -9999 -9999 -9999 -9999 -9999 -9999 -9999 -9999 -9999 -9999 -9999 -9999 -9999 -9999 -9999 -9999 -9999 -9999 -9999 -9999

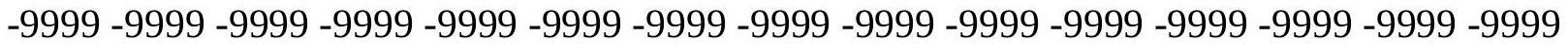

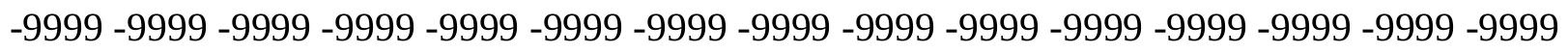

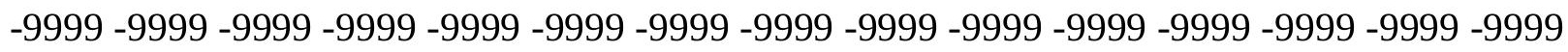
-9999 -9999 -9999 -9999 -9999 -9999 -9999 -9999 -9999 -9999 -9999 -9999 -9999 -9999 -9999 -9999 -9999 -9999 -9999 -9999 -9999 -9999 -9999 -9999 -9999 -9999 -9999 -9999 -9999 249.9237976074 222.7978973389 187.7476043701 182.3321990967178.9089050293 176.165802002173 .4226989746176 .4705963135175 .8609924316174 .6419067383 172.8132019043170 .6797027588168 .5462036133166 .4127044678161 .5361022949 160.9264984131160 .6217956543160 .0122070312159 .7073974609159 .0977935791 158.7929992676158 .1835021973157 .878692627157 .5738983154157 .2691040039 157.878692627158 .7929992676160 .0122070312160 .9264984131161 .8408966064 162.4505004883162 .7552947998162 .7552947998162 .4505004883164 .8887023926 160.9264984131160 .3170013428159 .4026031494158 .4882965088157 .878692627 157.2691040039156 .9642944336156 .6596069336156 .3547973633156 .0500030518 155.7451934814155 .7451934814155 .7451934814155 .7451934814155 .4403991699 
154.5260925293153 .3069000244150 .2590942383147 .2111968994144 .1634063721 142.0299072266140 .8106994629140 .5059967041140 .8106994629141 .4203033447 142.0299072266142 .3347015381142 .5843505859142 .6474151611142 .5278625488 142.275100708141 .9269104004141 .5171356201141 .0589447021144 .4682006836 144.4682006836144 .4682006836144 .4682006836144 .1634063721143 .5538024902 142.9441986084142 .3347015381141 .4203033447140 .2012023926139 .2868041992 138.0677032471136 .8484954834135 .9342041016135 .3246002197134 .4102020264 133.8007049561132 .8863067627131 .9720001221131 .0576019287130 .1432037354 129.533706665129 .533706665129 .8385009766130 .1432037354130 .4479980469 130.4479980469130 .1432037354129 .533706665128 .6192932129127 .7050018311 126.7906036377126 .1809997559125 .5715026855124 .9618988037124 .3523025513 123.43800354122 .8283996582121 .9140014648121 .3044967651121 .3044967651 121.6092987061121 .9140014648122 .2188034058125 .2667007446125 .5715026855 125.8762969971125 .8762969971126 .1809997559126 .1809997559125 .8762969971 125.5715026855124 .9618988037124 .0475006104123 .1332015991122 .2188034058 118.2565994263117 .647102356117 .0374984741116 .4279022217115 .5136032104 114.9039993286113 .9896011353113 .075302124112 .1608963013110 .9418029785 110.0273971558108 .8082962036107 .5891036987106 .0652008057104 .5412979126 103.0174026489101 .188697814999 .3599472045997 .5312423706195 .3977432251 93.5690307617292 .0450973510792 .0450973510792 .349891662692 .95947265625 93.2642517089893.8738174438594.1785964965894.7881774902395.3977432251 96.3121032714897 .2264633178798 .445587158299 .66472625732100 .5791015625 100.274299621699 .3599472045998 .1408081054797 .8360290527398 .14080810547 98.7503814697399 .0551681518698 .7503814697398 .445587158298 .4455871582 98.445587158298 .7503814697399 .3599472045999 .96952056885100 .2742996216 100.5791015625100 .8839035034100 .5791015625100 .5791015625100 .2742996216 99.9695205688599 .6647262573299 .3599472045999 .3599472045999 .35994720459 99.3599472045999 .6647262573299 .9695205688599 .96952056885100 .2742996216 100.5791015625100 .8839035034101 .1886978149101 .1886978149101 .1886978149 101.4934005737101 .4934005737101 .7982025146101 .7982025146101 .7982025146 102.1029968262102 .1029968262102 .1029968262102 .1029968262102 .1029968262 102.1029968262102 .1029968262102 .1029968262102 .1029968262102 .4077987671 102.4077987671102 .4077987671102 .4077987671102 .1029968262101 .4934005737 100.579101562599 .6647262573298 .7503814697397 .8360290527396 .61688232422 95.7025299072394 .7881774902393 .8738174438592 .9594726562592 .65467834473 92.349891662692 .9594726562594 .1785964965896 .0073165893699 .05516815186 103.6268997192110 .0273971558118 .5614013672128 .6192932129139 .8963928223 152.0877990723164 .5839996338176 .7754058838188 .6620025635199 .9389953613 208.7778015137208 .7778015137208 .7778015137208 .7778015137208 .7778015137 208.7778015137208 .7778015137208 .7778015137208 .7778015137208 .7778015137 208.7778015137 208.7778015137208.7778015137208.7778015137 208.7778015137 208.7778015137208.7778015137208.7778015137208.7778015137 208.7778015137 208.7778015137208 .7778015137208 .7778015137208 .7778015137208 .7778015137 208.7778015137208 .7778015137208 .7778015137208 .7778015137208 .7778015137 208.7778015137208 .7778015137208 .7778015137208 .7778015137208 .7778015137 208.7778015137208.7778015137208.7778015137208.7778015137208.7778015137 
208.7778015137 208.7778015137208 .777801513786 .55898284912 -9999 -9999 -9999 -9999 -9999 -9999 -9999 -9999 -9999 -9999 -9999 -9999 -9999 -9999 -9999 -9999

-9999 -9999 -9999 -9999 -9999 -9999 -9999 -9999 -9999 -9999 -9999 -9999 -9999 -9999 -9999 -9999 -9999 -9999 -9999 -9999 -9999 -9999 -9999 -9999 -9999 -9999 -9999 -9999 -9999 -9999 -9999 -9999 -9999 -9999 -9999 -9999 -9999 -9999 -9999 -9999 -9999 -9999 -9999 -9999 -9999 -9999 -9999 -9999 -9999 -9999 -9999 -9999 -9999 -9999 -9999 -9999 -9999 -9999 -9999 -9999 -9999 -9999 -9999 -9999 -9999 -9999 -9999 -9999 -9999 -9999 -9999 -9999 -9999 -9999 -9999 -9999 -9999 -9999 -9999 -9999 -9999 -9999 -9999 -9999 -9999 -9999 -9999 -9999 -9999 258.7626037598235 .9037017822199 .6342926025181 .3471984863179 .5184020996 177.3849029541174 .6419067383176 .165802002175 .5561981201174 .0323028564 172.2035980225170 .070098877167 .9365997314165 .8031005859161 .8408966064 161.2312927246160 .9264984131160 .3170013428160 .0122070312159 .4026031494 158.7929992676158 .4882965088157 .878692627157 .5738983154157 .5738983154 157.878692627158 .4882965088159 .0977935791160 .0122070312160 .6217956543 160.9264984131161 .2312927246161 .2312927246160 .9264984131160 .6217956543 160.0122070312159 .4026031494158 .7929992676158 .1835021973157 .5738983154 157.2691040039 156.9642944336156.6596069336156.3547973633156.3547973633 156.0500030518156 .0500030518156 .0500030518155 .7451934814155 .1356048584 154.2212982178152 .6972961426150 .2590942383147 .5160064697145 .0776977539 142.9441986084141 .7250976562141 .1154937744141 .1154937744141 .4203033447 141.7250976562142 .3347015381142 .4904632568142 .5363922119142 .4627685547 142.274017334141 .993850708141 .6442871094141 .2409515381144 .4682006836 144.4682006836144 .7729034424144 .7729034424144 .4682006836144 .1634063721 143.8585968018143 .2489929199142 .6394042969141 .7250976562140 .8106994629 139.5915985107138 .6772003174137 .4580993652136 .5437011719135 .6293945312 134.7149963379133 .8007049561132 .5814971924131 .6672058105130 .4479980469 129.8385009766129 .533706665129 .8385009766130 .1432037354130 .1432037354 130.1432037354129 .8385009766129 .2288970947128 .6192932129127 .7050018311 127.0953979492126 .1809997559125 .5715026855124 .6570968628124 .0475006104 123.1332015991122 .5235977173121 .6092987061120 .9997024536120 .9997024536 120.9997024536121 .3044967651121 .6092987061121 .9140014648125 .2667007446 125.2667007446125 .5715026855125 .5715026855125 .5715026855125 .2667007446 124.6570968628124 .0475006104123 .1332015991122 .2188034058117 .9517974854 117.342300415116 .7326965332116 .1231002808115 .2088012695114 .5991973877 113.6848983765112 .7705001831111 .8561019897110 .9418029785110 .0273971558 108.8082962036107 .5891036987106 .3700027466104 .8460998535103 .3221969604 101.7982025146100 .274299621698 .445587158296 .3121032714894 .48339080811 92.9594726562591 .7403335571391 .4355392456191 .4355392456191 .74033355713 92.349891662692 .6546783447393 .2642517089893 .5690307617294 .17859649658 95.0929565429796 .3121032714898 .1408081054799 .96952056885101 .4934005737 101.188697814999 .0551681518696 .6168823242295 .7025299072396 .31210327148 96.9216690063597 .5312423706197 .5312423706197 .5312423706197 .83602905273 98.1408081054798 .445587158299 .0551681518699 .66472625732100 .2742996216 100.5791015625100 .8839035034100 .5791015625100 .274299621699 .96952056885 99.6647262573299 .3599472045999 .0551681518699 .0551681518699 .05516815186 99.0551681518699 .0551681518699 .3599472045999 .3599472045999 .96952056885 
100.2742996216100 .5791015625100 .8839035034101 .1886978149101 .1886978149 101.4934005737101 .4934005737101 .7982025146102 .1029968262102 .1029968262 102.1029968262102 .4077987671102 .4077987671102 .4077987671102 .4077987671 102.4077987671102 .4077987671102 .712600708102 .712600708102 .712600708 103.0174026489103 .0174026489103 .0174026489102 .712600708102 .1029968262 101.4934005737100 .579101562599 .9695205688599 .0551681518698 .14080810547 97.2264633178796 .0073165893694 .7881774902393 .5690307617292 .65467834473 95.397743225192 .349891662692 .9594726562594 .4833908081197 .22646331787 101.4934005737106 .979598999114 .5991973877123 .43800354134 .1054992676 145.6873016357158 .1835021973171 .2891998291184 .0901947021195 .9768066406 206.6443023682208 .7778015137208 .7778015137208 .7778015137208 .7778015137 208.7778015137208 .7778015137208 .7778015137208 .7778015137208 .7778015137 208.7778015137208 .7778015137208 .7778015137208 .7778015137208 .7778015137 208.7778015137208 .7778015137208 .7778015137208 .7778015137208 .7778015137 208.7778015137208 .7778015137208 .7778015137208 .7778015137208 .7778015137 208.7778015137208 .7778015137208 .7778015137208 .7778015137208 .7778015137 208.7778015137208 .7778015137208 .7778015137208 .7778015137208 .7778015137 208.7778015137208 .7778015137208 .7778015137208 .7778015137208 .7778015137 208.7778015137208 .7778015137208 .777801513785 .6446228027386 .2541885376 -9999 -9999 -9999 -9999 -9999 -9999 -9999 -9999 -9999 -9999 -9999 -9999 -9999 -9999 -9999

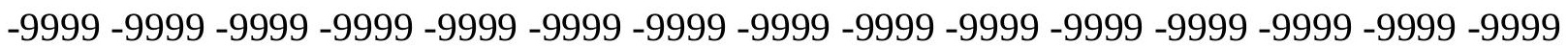
-9999 -9999 -9999 -9999 -9999 -9999 -9999 -9999 -9999 -9999 -9999 -9999 -9999 -9999 -9999 -9999 -9999 -9999 -9999 -9999 -9999 -9999 -9999 -9999 -9999 -9999 -9999 -9999 -9999 -9999 -999 -9999 -9999 -9999 -9999 -9999 -9999 -9999 -9999 -9999 -9999 -9999 -9999 -9999 -9999 -9999

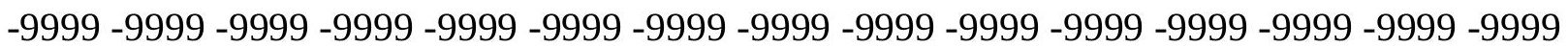
-9999 -9999 -9999 -9999 -9999 -9999 -9999 -9999 -9999 -9999 -9999 -9999 -9999 -9999 -9999 245.3520050049218 .2261962891183 .7854003906182 .87109375180 .7375946045 177.3849029541174 .0323028564175 .2514038086173 .7274932861171 .5939941406 169.4604949951167 .3269958496163 .0599975586162 .4505004883161 .8408966064 161.2312927246160 .6217956543160 .3170013428159 .7073974609159 .0977935791 158.7929992676158 .1835021973157 .878692627157 .878692627157 .878692627 158.1835021973158 .7929992676159 .0977935791159 .7073974609160 .0122070312 160.0122070312160 .0122070312159 .7073974609159 .4026031494159 .0977935791 158.7929992676158 .1835021973157 .878692627157 .2691040039156 .9642944336 156.6596069336156 .6596069336156 .3547973633156 .3547973633156 .3547973633 156.3547973633156 .0500030518155 .7451934814154 .8307952881153 .9165039062 152.3925933838150 .2590942383147 .8208007812145 .6873016357143 .8585968018 142.6394042969142 .0299072266141 .7250976562141 .7250976562142 .0299072266 142.3347015381142 .5356140137142 .5948028564142 .5367431641142 .3757324219 142.1305847168141 .8160247803141 .4423370361141 .0284576416144 .4682006836 144.7729034424144 .7729034424145 .0776977539144 .7729034424144 .7729034424 144.4682006836143 .8585968018143 .2489929199142 .3347015381141 .1154937744 139.8963928223138 .9819946289137 .7628936768136 .8484954834135 .6293945312 134.7149963379133 .4958953857132 .2767028809131 .0576019287129 .8385009766 129.8385009766129 .8385009766130 .1432037354130 .1432037354130 .1432037354 129.8385009766129 .2288970947128 .6192932129127 .7050018311127 .0953979492 
126.1809997559125 .2667007446124 .6570968628123 .7427978516122 .8283996582 122.2188034058121 .6092987061120 .9997024536120 .6949005127120 .6949005127 120.9997024536121 .6092987061121 .6092987061124 .6570968628124 .6570968628 124.9618988037124 .9618988037124 .6570968628124 .3523025513123 .7427978516 122.8283996582121 .9140014648120 .9997024536117 .342300415116 .4279022217 115.818397522115 .2088012695114 .2944030762113 .3800964355112 .7705001831 111.8561019897110 .6370010376109 .7226028442108 .8082962036107 .5891036987 106.3700027466 105.1509017944 103.9317016602102.4077987671 100.8839035034 99.3599472045997 .5312423706195 .7025299072394 .1785964965892 .65467834473 91.4355392456191 .1307525634891 .1307525634891 .1307525634891 .74033355713 92.0450973510792 .349891662692 .6546783447393 .2642517089893 .87381744385 95.0929565429796 .9216690063599 .35994720459102 .1029968262103 .0174026489 99.6647262573294 .1785964965894 .1785964965894 .7881774902395 .3977432251 96.0073165893696 .3121032714896 .6168823242296 .9216690063597 .22646331787 97.8360290527398 .445587158299 .3599472045999 .96952056885100 .5791015625 100.5791015625100 .5791015625100 .274299621699 .6647262573299 .35994720459 99.0551681518698 .7503814697398 .7503814697398 .7503814697398 .75038146973 98.7503814697398 .7503814697399 .0551681518699 .3599472045999 .96952056885 100.2742996216100 .5791015625100 .8839035034101 .1886978149101 .4934005737 101.4934005737101 .7982025146102 .1029968262102 .1029968262102 .4077987671 102.4077987671102 .712600708102 .712600708102 .712600708102 .712600708 103.0174026489103 .0174026489103 .3221969604103 .3221969604103 .3221969604 103.3221969604103 .3221969604103 .0174026489102 .712600708102 .1029968262 101.4934005737100 .8839035034100 .274299621699 .6647262573298 .4455871582 97.2264633178795 .7025299072394 .1785964965896 .3121032714896 .61688232422 96.3121032714896 .3121032714893 .2642517089895 .397743225198 .75038146973 103.9317016602110 .3321990967118 .2565994263127 .7050018311138 .6772003174 151.4781951904165 .1934967041179 .5184020996192 .3193969727203 .596496582 208.7778015137208 .7778015137208 .7778015137208 .7778015137208 .7778015137 208.7778015137208 .7778015137208 .7778015137208 .7778015137208 .7778015137 208.7778015137208 .7778015137208 .7778015137208 .7778015137208 .7778015137 208.7778015137208 .7778015137208 .7778015137208 .7778015137208 .7778015137 208.7778015137208 .7778015137208 .7778015137208 .7778015137208 .7778015137 208.7778015137208 .7778015137208 .7778015137208 .7778015137208 .7778015137 208.7778015137208 .7778015137208 .7778015137208 .7778015137208 .7778015137 208.7778015137208 .7778015137208 .7778015137208 .7778015137208 .7778015137 208.7778015137 208.777801513784 .7302627563585 .33984375 -9999-9999 -9999 -9999 -9999 -9999 -9999 -9999 -9999 -9999 -9999 -9999 -9999 -9999 -9999 -999 -999 -999 -

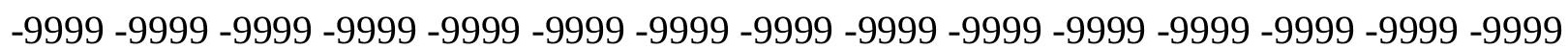
-9999 -9999 -9999 -9999 -9999 -9999 -9999 -9999 -9999 -9999 -9999 -9999 -9999 -9999 -9999 -

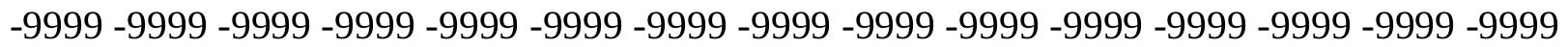
-9999 -9999 -9999 -9999 -9999 -9999 -9999 -9999 -9999 -9999 -9999 -9999 -9999 -9999 -9999 -9999 -9999 -9999 -9999 -9999 -9999 -9999 -9999 -9999 -9999 -9999 -9999 -9999 -9999 -9999 -9999 -9999 -9999 -9999 -9999 -9999 -9999 -9999 -9999 -9999 -9999 -9999 -9999 -9999 -9999 -9999 238.9515075684213.6544036865 190.6349029541 186.528503418 181.0424041748 176.4705963135173 .4226989746170 .6797027588168 .5462036133166 .4127044678 
164.8887023926163 .6696014404162 .7552947998162 .1457061768161 .5361022949 160.9264984131160 .6217956543160 .0122070312159 .7073974609159 .0977935791 158.7929992676158 .4882965088158 .1835021973158 .1835021973158 .1835021973 158.4882965088158 .7929992676158 .7929992676159 .0977935791159 .0977935791 158.7929992676161 .8408966064158 .4882965088158 .1835021973157 .878692627 157.5738983154157 .2691040039156 .9642944336156 .6596069336156 .6596069336 156.6596069336156 .3547973633156 .6596069336156 .6596069336156 .3547973633 156.3547973633155 .7451934814154 .8307952881153 .6116943359152 .0877990723 150.2590942383148 .1255950928146 .2969055176144 .7729034424143 .5538024902 142.9441986084142 .6394042969142 .6394042969142 .6394042969142 .6394042969 142.777557373142 .8079223633142 .7324981689142 .5666656494142 .323928833 142.0160217285141 .6600494385141 .2700500488144 .4682006836144 .7729034424 145.0776977539145 .3825073242145 .3825073242145 .6873016357145 .3825073242 145.0776977539144 .4682006836143 .8585968018142 .6394042969141 .4203033447 140.2012023926138 .9819946289137 .7628936768136 .5437011719135 .3246002197 134.1054992676132 .8863067627131 .6672058105130 .7528076172130 .4479980469 130.1432037354130 .1432037354130 .1432037354129 .8385009766129 .533706665 128.9241027832128 .3144989014127 .7050018311126 .7906036377125 .8762969971 125.2667007446124 .3523025513123 .43800354122 .8283996582121 .9140014648 121.3044967651120 .6949005127120 .3900985718120 .6949005127121 .3044967651 121.6092987061121 .6092987061121 .3044967651124 .0475006104124 .0475006104 124.0475006104123 .7427978516123 .1332015991122 .5235977173121 .6092987061 120.6949005127117 .0374984741116 .4279022217115 .818397522114 .9039993286 114.2944030762113 .3800964355112 .4656982422111 .551399231110 .6370010376 109.7226028442108 .8082962036107 .5891036987106 .6747970581105 .4557037354 104.2365036011103 .0174026489101 .7982025146100 .274299621698 .75038146973 97.2264633178795 .397743225193 .8738174438592 .6546783447391 .43553924561 91.1307525634890 .8259735107491 .1307525634891 .1307525634891 .43553924561 91.74033355571392 .0450973510792 .349891662692 .6546783447393 .26425170898 94.7881774902397 .22646331787100 .8839035034104 .846099853599 .66472625732 95.0929565429793.5690307617293.5690307617293.8738174438594.48339080811 95.0929565429795.397743225196.0073165893696.3121032714897.22646331787 97.8360290527398 .7503814697399 .66472625732100 .5791015625100 .5791015625 100.274299621699 .9695205688599 .3599472045999 .0551681518698 .75038146973 98.7503814697398 .445587158298 .445587158298 .445587158298 .4455871582 98.445587158298 .7503814697399 .0551681518699 .6647262573299 .96952056885 100.2742996216100 .5791015625100 .8839035034101 .1886978149101 .4934005737 101.7982025146102 .1029968262102 .4077987671102 .4077987671102 .712600708 102.712600708103 .0174026489103 .0174026489103 .3221969604103 .3221969604 103.3221969604103 .6268997192103 .6268997192103 .6268997192103 .6268997192 103.6268997192103 .3221969604103 .0174026489102 .712600708102 .4077987671 101.7982025146101 .4934005737100 .883903503499 .6647262573298 .14080810547 96.3121032714894 .4833908081197 .2264633178797 .5312423706197 .53124237061 97.5312423706197.5312423706196.9216690063596.31210327148 100.2742996216 105.7603988647112 .7705001831120 .9997024536131 .3623962402143 .8585968018 158.7929992676174 .337097168188 .966796875200 .2438049316208 .7778015137 
208.7778015137208 .7778015137208 .7778015137208 .7778015137208 .7778015137 208.7778015137208 .7778015137208 .7778015137208 .7778015137208 .7778015137 208.7778015137208 .7778015137208 .7778015137208 .7778015137208 .7778015137 208.7778015137208 .7778015137208 .7778015137208 .7778015137208 .7778015137 208.7778015137208 .7778015137208 .7778015137208 .7778015137208 .7778015137 208.7778015137208 .7778015137208 .7778015137208 .7778015137208 .7778015137 208.7778015137208 .7778015137208 .7778015137208 .7778015137208 .7778015137 208.7778015137208 .7778015137208 .7778015137208 .7778015137208 .7778015137 208.777801513783 .5111236572384 .12069702148 -9999 -9999 -9999 -9999 -9999 -9999 -9999 -9999 -9999 -9999 -9999 -9999 -9999-9999 -9999

-9999 -9999 -9999 -9999 -9999 -9999 -9999 -9999 -9999 -9999 -9999 -9999 -9999 -9999 -9999 -9999 -9999 -9999 -9999 -9999 -9999 -9999 -9999 -9999 -9999 -9999 -9999 -9999 -9999 -9999 -9999 -9999 -9999 -9999 -9999 -9999 -9999 -9999 -9999 -9999 -9999 -9999 -9999 -9999 -9999 -9999 -9999 -9999 -9999 -9999 -9999 -9999 -9999 -9999 -9999 -9999 -9999 -9999 -9999 -9999 -9999 -9999 -9999 -9999 -9999 -9999 -9999 -9999 -9999 -9999 -9999 -9999 -9999 -9999 -9999

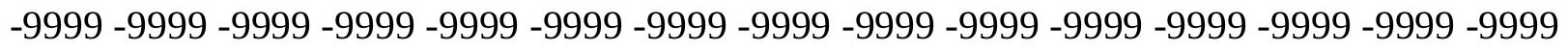
-9999 257.8482055664 240.1707000732 197.2564239502 194.7577056885 184.699798584 180.432800293176 .4705963135173 .1179962158170 .070098877167 .9365997314 165.8031005859164 .5839996338163 .3648071289162 .7552947998161 .8408966064 161.5361022949160 .9264984131160 .6217956543160 .0122070312159 .7073974609 159.4026031494159 .0977935791158 .7929992676158 .4882965088158 .4882965088 158.4882965088158 .4882965088158 .4882965088158 .4882965088158 .1835021973 157.878692627160 .6217956543157 .5738983154157 .2691040039157 .2691040039 156.9642944336156 .6596069336156 .6596069336156 .3547973633156 .3547973633 156.3547973633156 .3547973633156 .6596069336156 .6596069336156 .6596069336 156.3547973633155 .7451934814154 .5260925293153 .3069000244151 .7830047607 149.9542999268148 .4304046631146 .9064025879145 .6873016357144 .4682006836 143.8585968018143 .5538024902143 .2489929199143 .2489929199143 .2489929199 143.2129364014143 .1506652832143 .0217437744142 .819442749142 .5531005859 142.2366333008141 .8842773438141 .5093994141141 .1218719482144 .7729034424 145.3825073242145 .6873016357145 .9920959473146 .2969055176146 .2969055176 146.2969055176145 .9920959473145 .0776977539143 .8585968018142 .6394042969 141.4203033447140 .2012023926138 .9819946289137 .7628936768136 .2389984131 135.0198059082133 .8007049561132 .5814971924131 .6672058105131 .0576019287 130.7528076172130 .4479980469130 .1432037354129 .8385009766129 .533706665 128.9241027832128 .3144989014127 .4001998901126 .7906036377125 .8762969971 124.9618988037124 .0475006104123 .1332015991122 .5235977173121 .6092987061 120.9997024536120 .6949005127120 .3900985718120 .6949005127121 .3044967651 121.9140014648121 .6092987061121 .3044967651120 .6949005127120 .3900985718 123.1332015991122 .5235977173122 .2188034058121 .3044967651117 .647102356 117.0374984741116 .4279022217115 .5136032104114 .9039993286113 .9896011353 113.3800964355112 .4656982422111 .551399231110 .6370010376109 .7226028442 108.8082962036107 .5891036987106 .6747970581105 .4557037354104 .5412979126 103.3221969604102 .4077987671101 .188697814999 .6647262573298 .4455871582 96.9216690063595 .0929565429793 .8738174438592 .349891662691 .43553924561 91.1307525634890 .8259735107490 .8259735107491 .1307525634891 .13075256348 
91.4355392456191 .4355392456191 .4355392456191 .4355392456191 .43553924561 91.7403335571393 .2642517089895 .397743225197 .5312423706196 .61688232422 94.4833908081192 .9594726562592 .6546783447392 .9594726562593 .26425170898 93.8738174438594 .4833908081194 .7881774902395 .397743225196 .31210327148 97.2264633178798.1408081054799.0551681518699.6647262573299.96952056885 99.6647262573299 .3599472045999 .0551681518698 .7503814697398 .4455871582 98.445587158298 .1408081054798 .1408081054798 .1408081054798 .14080810547 98.1408081054798 .445587158298 .7503814697399 .3599472045999 .66472625732 100.2742996216100 .5791015625100 .8839035034101 .1886978149101 .4934005737 101.7982025146102 .1029968262102 .4077987671102 .712600708102 .712600708 103.0174026489103 .0174026489103 .3221969604103 .3221969604103 .6268997192 103.6268997192103 .9317016602103 .9317016602103 .9317016602103 .9317016602 103.9317016602103 .6268997192103 .3221969604103 .0174026489102 .712600708 102.4077987671102 .1029968262101 .4934005737100 .883903503499 .05516815186 96.9216690063594 .7881774902398 .1408081054798 .445587158298 .75038146973 98.7503814697398 .445587158298 .1408081054796 .9216690063596 .92166900635 101.4934005737107 .2844009399114 .5991973877123 .7427978516135 .6293945312 151.1734008789168 .241394043185 .3094024658195 .6721038818204 .8155975342 208.7778015137208 .7778015137208 .7778015137208 .7778015137208 .7778015137 208.7778015137208 .7778015137208 .7778015137208 .7778015137208 .7778015137 208.7778015137208 .7778015137208 .7778015137208 .7778015137208 .7778015137 208.7778015137208 .7778015137208 .7778015137208 .7778015137208 .7778015137 208.7778015137208 .7778015137208 .7778015137208 .7778015137208 .7778015137 208.7778015137208 .7778015137208 .7778015137208 .7778015137208 .7778015137 208.7778015137208 .7778015137208 .7778015137208 .7778015137208 .7778015137 208.7778015137208.7778015137208.7778015137208.7778015137208.7778015137 208.7778015137 208.777801513783 .206336975154 .96110534668 -9999 -9999 -9999 -9999 -9999 -9999 -9999 -9999 -9999 -9999 -9999 -9999 -9999 -9999

-9999 -9999 -9999 -9999 -9999 -9999 -9999 -9999 -9999 -9999 -9999 -9999 -9999 -9999 -9999

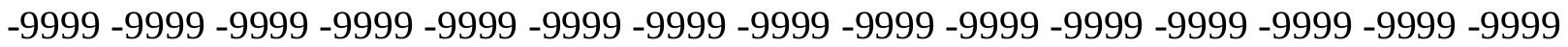
-9999 -9999 -9999 -9999 -9999 -9999 -9999 -9999 -9999 -9999 -9999 -9999 -9999 -9999 -9999

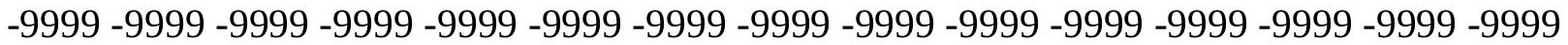

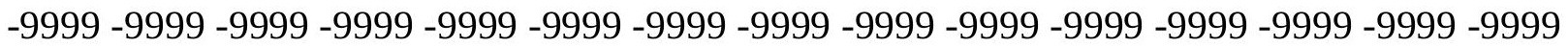
-9999 -9999 -9999 -9999 -9999 -9999 -9999 -9999 -9999 -9999 -9999 -9999 -9999 -9999 -9999 -9999 -9999 257.5433959961 202.1519470215 198.7956695557193 .233795166 185.6141052246180 .1280059814175 .8609924316172 .2035980225169 .1557006836 167.0222015381165 .1934967041163 .974395752163 .0599975586162 .4505004883 161.8408966064161 .2312927246160 .9264984131160 .6217956543160 .3170013428 159.7073974609159 .4026031494159 .0977935791158 .7929992676158 .7929992676 158.4882965088158 .1835021973158 .1835021973157 .878692627157 .5738983154 157.2691040039160 .0122070312156 .6596069336156 .6596069336156 .6596069336 156.3547973633156 .3547973633156 .0500030518156 .0500030518156 .0500030518 156.0500030518156 .3547973633156 .3547973633156 .6596069336156 .6596069336 156.3547973633155 .7451934814154 .2212982178153 .0021057129151 .4781951904 149.9542999268148 .7351074219147 .5160064697146 .2969055176145 .3825073242 144.7729034424144 .4682006836144 .1634063721143 .8585968018143 .8585968018 
143.7349700928143 .5538024902143 .3711090088143 .1086425781142 .7998962402 142.4593200684142 .1009063721141 .7359313965141 .3713989258144 .7729034424 145.3825073242145 .9920959473146 .2969055176146 .9064025879147 .2111968994 147.2111968994147 .2111968994145 .9920959473144 .7729034424143 .5538024902 142.3347015381141 .1154937744139 .8963928223138 .6772003174137 .1533050537 135.9342041016134 .7149963379133 .8007049561132 .8863067627131 .9720001221 131.3623962402131 .0576019287130 .4479980469129 .8385009766129 .533706665 128.9241027832128 .3144989014127 .4001998901126 .4858016968125 .5715026855 124.6570968628124 .0475006104123 .1332015991122 .2188034058121 .6092987061 120.9997024536120 .6949005127120 .6949005127120 .9997024536121 .3044967651 121.3044967651121 .3044967651120 .9997024536120 .3900985718120 .0852966309 119.4757995605118 .8662033081118 .2565994263117 .647102356117 .0374984741 116.4279022217115 .5136032104114 .9039993286113 .9896011353113 .3800964355 112.4656982422111 .551399231110 .6370010376109 .7226028442108 .8082962036 107.5891036987 106.6747970581 105.7603988647 104.5412979126103.6268997192 102.712600708101 .4934005737100 .579101562599 .3599472045998 .14080810547 96.6168823242295 .0929565429793 .5690307617292 .349891662691 .43553924561 91.1307525634890 .8259735107491 .1307525634891 .1307525634891 .13075256348 91.1307525634890 .8259735107490 .5211791992290 .2164001464889 .91161346436 89.3020401001 89.3020401001 88.6924667358491.4355392456192.65467834473 92.0450973510791 .7403335571391 .7403335571392 .0450973510792 .3498916626 92.95947265625 93.2642517089893.8738174438594.4833908081195.39774332251 96.3121032714897 .2264633178798 .1408081054798 .7503814697399 .05516815186 99.3599472045999 .0551681518698 .7503814697398 .7503814697398 .4455871582 98.1408081054798 .1408081054797 .8360290527397 .8360290527397 .83602905273 98.1408081054798 .1408081054798 .7503814697399 .0551681518699 .66472625732 99.96952056885100 .2742996216100 .8839035034101 .1886978149101 .4934005737 101.7982025146102 .1029968262102 .4077987671102 .712600708103 .0174026489 103.0174026489103 .3221969604103 .6268997192103 .6268997192103 .9317016602 103.9317016602103 .9317016602104 .2365036011104 .2365036011104 .2365036011 103.9317016602 103.9317016602 103.6268997192103.3221969604 103.0174026489 102.712600708102 .1029968262101 .4934005737100 .579101562599 .05516815186 96.9216690063598 .445587158298 .7503814697399 .3599472045999 .66472625732 99.6647262573299 .6647262573299 .0551681518698 .1408081054793 .87381744385 97.53124237061102 .712600708109 .1130981445117 .0374984741126 .7906036377 143.5538024902160 .6217956543176 .4705963135188 .966796875199 .0247039795 207.8634033203208 .7778015137208 .7778015137208 .7778015137208 .7778015137 208.7778015137208 .7778015137208 .7778015137208 .7778015137208 .7778015137 208.7778015137208 .7778015137208 .7778015137208 .7778015137208 .7778015137 208.7778015137208 .7778015137208 .7778015137208 .7778015137208 .7778015137 208.7778015137208 .7778015137208 .7778015137208 .7778015137208 .7778015137 208.7778015137208 .7778015137208 .7778015137208 .7778015137208 .7778015137 208.7778015137208 .7778015137208 .7778015137208 .7778015137208 .7778015137 208.7778015137208 .7778015137208 .7778015137208 .7778015137208 .7778015137 208.7778015137 208.777801513782 .2919769287182 .90155792236 -9999 -9999 -9999 -9999 -9999 -9999 -9999 -9999 -9999 -9999 -9999 -9999 -9999 -9999 
-9999 -9999 -9999 -9999 -9999 -9999 -9999 -9999 -9999 -9999 -9999 -9999 -9999 -9999 -9999 -9999 -9999 -9999 -9999 -9999 -9999 -9999 -9999 -9999 -9999 -9999 -9999 -9999 -9999 -9999 -9999 -9999 -9999 -9999 -9999 -9999 -9999 -9999 -9999 -9999 -9999 -9999 -9999 -9999 -9999 -9999 -9999 -9999 -9999 -9999 -9999 -9999 -9999 -9999 -9999 -9999 -9999 -9999 -9999 -9999 -9999 -9999 -9999 -9999 -9999 -9999 -9999 -9999 -9999 -9999 -9999 -9999-9999 -9999 -9999 -9999 -9999 -9999 -9999 -9999 -9999 -9999 -9999 -9999 -9999 -9999 -9999 -9999 -9999 -9999 -9999 -9999 269.7348022461249.3141937256202.7440490723 198.1103057861 190.4907073975184 .0901947021178 .2993011475173 .7274932861170 .3748931885 167.6318054199165 .8031005859164 .5839996338163 .3648071289162 .7552947998 162.1457061768161 .5361022949161 .2312927246160 .9264984131160 .6217956543 160.3170013428160 .0122070312159 .7073974609159 .4026031494159 .0977935791 158.4882965088158 .1835021973157 .878692627157 .5738983154156 .9642944336 156.6596069336159 .0977935791156 .0500030518156 .0500030518156 .0500030518 155.7451934814155 .7451934814155 .7451934814155 .7451934814155 .7451934814 155.7451934814155 .7451934814156 .0500030518156 .3547973633156 .3547973633 156.3547973633155 .4403991699153 .9165039062152 .3925933838151 .1734008789 149.9542999268149 .0399017334147 .8208007812146 .9064025879146 .2969055176 145.6873016357145 .0776977539144 .7729034424144 .7729034424144 .4682006836 144.1634063721144 .037612915143 .7415618896143 .4007263184143 .0335540771 142.6593017578142 .2906188965141 .9360809326141 .5980834961141 .2751617432 145.3825073242145 .9920959473146 .6015930176146 .9064025879147 .5160064697 147.5160064697147 .2111968994146 .6015930176145 .3825073242144 .1634063721 142.9441986084141 .7250976562140 .5059967041139 .2868041992138 .0677032471 136.8484954834135 .6293945312134 .7149963379133 .4958953857132 .8863067627 131.9720001221131 .3623962402130 .7528076172130 .1432037354129 .533706665 128.9241027832128 .0097961426127 .4001998901126 .4858016968125 .5715026855 124.6570968628123 .7427978516122 .8283996582121 .9140014648124 .3523025513 120.9997024536120 .9997024536120 .9997024536120 .9997024536121 .3044967651 120.9997024536120 .9997024536120 .6949005127120 .0852966309119 .4757995605 118.8662033081118 .2565994263117 .647102356117 .0374984741116 .4279022217 115.818397522114 .9039993286114 .2944030762113 .3800964355112 .4656982422 111.551399231110 .6370010376109 .7226028442108 .8082962036107 .8938980103 106.6747970581105 .7603988647104 .8460998535103 .6268997192102 .712600708 101.7982025146100 .883903503499 .9695205688599 .0551681518697 .83602905273 96.3121032714894 .7881774902393 .2642517089892 .0450973510791 .43553924561 91.1307525634890 .8259735107491 .1307525634891 .4355392456191 .13075256348 90.8259735107490 .5211791992290 .2164001464889 .6068267822388 .99725341797 88.0829010009887 .1685485839887 .1685485839888 .3876876831189 .60682678223 90.2164001464890 .5211791992290 .8259735107491 .1307525634891 .43553924561 92.0450973510792 .349891662692 .9594726562593 .5690307617294 .48339080811 95.397743225196 .6168823242297 .5312423706198 .1408081054798 .4455871582 98.7503814697398 .7503814697398 .7503814697398 .445587158298 .14080810547 98.1408081054797 .8360290527397 .8360290527397 .8360290527397 .83602905273 97.8360290527398 .1408081054798 .445587158299 .0551681518699 .35994720459 99.66472625732100 .2742996216100 .5791015625100 .8839035034101 .4934005737 101.7982025146102 .1029968262102 .4077987671102 .712600708103 .0174026489 
103.0174026489103 .3221969604103 .6268997192103 .9317016602103 .9317016602 104.2365036011 104.2365036011 104.2365036011 104.2365036011 104.2365036011 104.2365036011103 .9317016602103 .6268997192103 .3221969604103 .0174026489 102.4077987671102 .1029968262101 .188697814999 .9695205688598 .4455871582 96.6168823242299 .0551681518699 .66472625732100 .2742996216100 .5791015625 100.5791015625100 .579101562599 .9695205688599 .0551681518697 .53124237061 94.4833908081199 .05516815186105 .1509017944112 .7705001831123 .43800354 137.4580993652153 .0021057129167 .9365997314181 .0424041748192 .3193969727 202.3773040771208 .7778015137208 .7778015137208 .7778015137208 .7778015137 208.7778015137208 .7778015137208 .7778015137208 .7778015137208 .7778015137 208.7778015137208 .7778015137208 .7778015137208 .7778015137208 .7778015137 208.7778015137208 .7778015137208 .7778015137208 .7778015137208 .7778015137 208.7778015137 208.7778015137 208.7778015137 208.7778015137 208.7778015137 208.7778015137208 .7778015137208 .7778015137208 .7778015137208 .7778015137 208.7778015137208 .7778015137208 .7778015137208 .7778015137208 .7778015137 208.7778015137208.7778015137208.7778015137 208.7778015137 208.7778015137 208.7778015137 208.777801513781.37763214111 81.98719787598 -9999 -9999 -9999 -9999 -9999 -9999 -9999 -9999 -9999 -9999 -9999 -9999 -9999 -9999 -9999 -9999 -9999 -9999 -9999 -9999 -9999 -9999 -9999 -9999 -9999 -9999 -9999 -9999 -9999

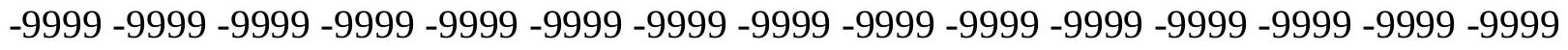

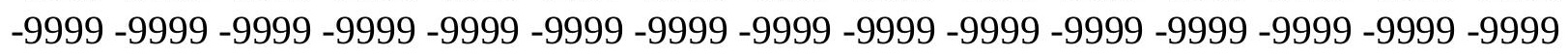

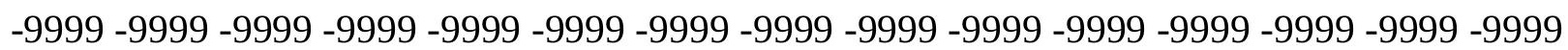
-9999 -9999 -9999 -9999 -9999 -9999 -9999 -9999 -9999 -9999 -9999 -9999 -9999 -9999 -9999 -

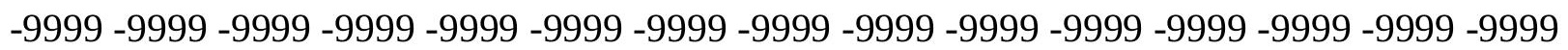
-9999 -9999-9999 259.9816894531205.817199707 200.9946594238194 .4528961182 187.4429016113180 .432800293175 .2514038086170 .9844970703168 .241394043 166.4127044678164 .8887023926163 .6696014404162 .7552947998162 .1457061768 161.8408966064161 .5361022949161 .2312927246160 .9264984131160 .6217956543 160.3170013428160 .0122070312159 .7073974609159 .4026031494158 .7929992676 158.4882965088157 .878692627157 .2691040039156 .6596069336156 .0500030518 158.4882965088155 .4403991699155 .4403991699155 .4403991699155 .4403991699 155.4403991699155 .4403991699155 .4403991699155 .4403991699155 .4403991699 155.4403991699155 .4403991699155 .7451934814155 .7451934814155 .4403991699 154.5260925293153 .3069000244152 .0877990723151 .1734008789149 .9542999268 149.0399017334148 .1255950928147 .5160064697146 .9064025879146 .2969055176 145.9920959473145 .6873016357145 .3825073242145 .0776977539144 .7729034424 144.4682006836144 .0813903809143 .6472320557143 .2152557373142 .8056335449 142.4306793213142 .0934295654141 .7916412354141 .5171661377145 .0776977539 145.6873016357146 .2969055176146 .9064025879147 .5160064697147 .5160064697 147.2111968994 146.6015930176145.9920959473144.7729034424143.5538024902 142.3347015381141 .4203033447140 .2012023926138 .9819946289137 .7628936768 136.5437011719135 .3246002197134 .4102020264133 .4958953857132 .5814971924 131.9720001221131 .3623962402130 .4479980469129 .8385009766128 .9241027832 128.3144989014127 .4001998901126 .4858016968125 .5715026855124 .6570968628 123.7427978516125 .8762969971122 .2188034058121 .6092987061121 .3044967651 121.3044967651121 .3044967651121 .3044967651120 .9997024536120 .9997024536 
120.6949005127120 .0852966309119 .7806015015119 .1709976196118 .5614013672 117.9517974854117 .342300415116 .4279022217115 .818397522115 .2088012695 114.2944030762113 .3800964355112 .4656982422111 .8561019897110 .9418029785 109.7226028442108 .8082962036107 .8938980103106 .979598999106 .0652008057 104.8460998535103 .9317016602103 .0174026489101 .7982025146100 .8839035034 99.9695205688599 .0551681518698 .445587158297 .2264633178795 .70252990723 93.8738174438592 .6546783447391 .4355392456191 .1307525634890 .82597351074 90.8259735107491 .1307525634891 .1307525634891 .1307525634890 .82597351074 90.8259735107490 .2164001464889 .6068267822388 .6924667358487 .77810668945 87.1685485839887 .1685485839887 .4733276367288 .3876876831188 .99725341797 89.6068267822389 .9116134643690 .5211791992290 .8259735107491 .43553924561 91.7403335571392 .0450973510792 .6546783447393 .5690307617294 .78817749023 96.0073165893696 .9216690063597 .5312423706198 .1408081054798 .4455871582 98.445587158298 .445587158298 .445587158298 .1408081054798 .14080810547 98.1408081054797 .8360290527397 .8360290527397 .5312423706197 .53124237061 98.1408081054798 .445587158298 .7503814697399 .3599472045999 .66472625732 100.2742996216100 .5791015625100 .8839035034101 .1886978149101 .7982025146 102.1029968262102 .4077987671102 .712600708103 .0174026489103 .3221969604 103.3221969604103 .6268997192103 .9317016602103 .9317016602104 .2365036011 104.2365036011 104.2365036011 104.2365036011 104.2365036011 104.2365036011 103.9317016602103 .6268997192103 .3221969604102 .712600708102 .4077987671 101.4934005737100 .579101562599 .3599472045997 .8360290527399 .35994720459 99.96952056885100 .5791015625100 .8839035034101 .1886978149101 .4934005737 101.1886978149 100.883903503499.9695205688598.7503814697396.92166900635 96.61688232422102 .4077987671110 .0273971558120 .3900985718132 .5814971924 146.6015930176160 .6217956543173 .7274932861185 .9188995361196 .891204834 206.9490966797208 .7778015137208 .7778015137208 .7778015137208 .7778015137 208.7778015137208 .7778015137208 .7778015137208 .7778015137208 .7778015137 208.7778015137208 .7778015137208 .7778015137208 .7778015137208 .7778015137 208.7778015137208 .7778015137208 .7778015137208 .7778015137208 .7778015137 208.7778015137208 .7778015137208 .7778015137208 .7778015137208 .7778015137 208.7778015137208 .7778015137208 .7778015137208 .7778015137208 .7778015137 208.7778015137208 .7778015137208 .7778015137208 .7778015137208 .7778015137 208.7778015137208 .7778015137208 .7778015137208 .7778015137208 .7778015137 208.7778015137208 .777801513781 .0728530883832 .06422805786 -9999 -9999 -9999 -9999 -9999 -9999 -9999 -9999 -9999 -9999-9999 -9999 -9999

-9999 -9999 -9999 -9999 -9999 -9999 -9999 -9999 -9999-9999 -9999 -9999 -9999 -9999 -9999 - -999 -

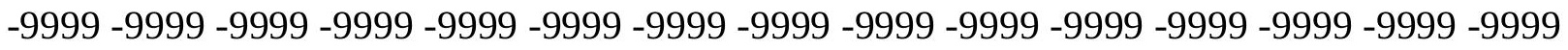
-9999 -9999 -9999 -9999 -9999 -9999 -9999 -9999 -9999 -9999 -9999 -9999 -9999 -9999 -9999 -9999 -9999 -9999 -9999 -9999 -9999 -9999 -9999 -9999 -9999 -9999 -9999 -9999 -9999 -9999 -

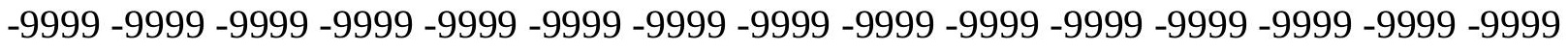

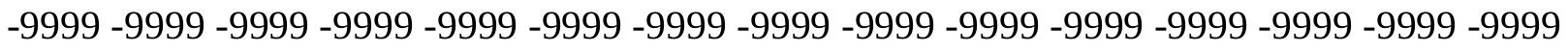
-9999 -9999 -9999 -9999 243.2185058594 203.4419555664 197.8054962158 189.5764007568 181.6519012451175 .5561981201171 .5939941406168 .5462036133166 .7174987793 164.8887023926163 .6696014404162 .7552947998162 .1457061768161 .8408966064 161.5361022949161 .5361022949161 .2312927246161 .2312927246160 .9264984131 
160.6217956543160 .3170013428159 .7073974609159 .0977935791158 .4882965088 157.878692627157 .2691040039156 .3547973633155 .7451934814158 .1835021973 155.1356048584155 .1356048584155 .1356048584155 .1356048584155 .1356048584 155.1356048584155 .1356048584154 .8307952881154 .8307952881154 .8307952881 154.8307952881154 .8307952881154 .5260925293154 .2212982178153 .6116943359 152.6972961426151 .7830047607150 .8686065674149 .9542999268149 .0399017334 148.4304046631147 .8208007812147 .2111968994146 .9064025879146 .6015930176 146.2969055176145 .9920959473145 .6873016357145 .3825073242144 .7729034424 144.1634063721143 .7923583984143 .2489929199142 .8646240234142 .4967193604 142.1932983398141 .943862915141 .7330932617141 .5453338623145 .3825073242 145.9920959473146 .6015930176147 .2111968994147 .2111968994147 .2111968994 146.6015930176145 .9920959473145 .0776977539144 .1634063721142 .9441986084 141.7250976562140 .8106994629139 .5915985107138 .3724975586137 .1533050537 136.2389984131135 .3246002197134 .1054992676133 .4958953857132 .5814971924 131.6672058105130 .7528076172130 .1432037354129 .2288970947128 .3144989014 127.4001998901126 .4858016968125 .5715026855124 .6570968628123 .7427978516 123.1332015991122 .5235977173121 .9140014648121 .9140014648121 .6092987061 121.6092987061121 .3044967651120 .9997024536120 .6949005127120 .0852966309 119.7806015015119 .1709976196118 .5614013672117 .9517974854117 .342300415 116.7326965332116 .1231002808115 .2088012695114 .5991973877113 .6848983765 112.7705001831111 .8561019897110 .9418029785110 .0273971558109 .1130981445 108.1986999512107 .2844009399106 .3700027466105 .1509017944104 .2365036011 103.0174026489102 .1029968262101 .188697814999 .9695205688599 .05516815186 98.1408081054797.2264633178796.3121032714894.4833908081192.65467834473 91.4355392456190 .5211791992290 .5211791992290 .5211791992290 .82597351074 91.1307525634891 .4355392456191 .4355392456191 .1307525634891 .43553924561 90.8259735107490 .2164001464889 .302040100188 .3876876831187 .77810668945 87.4733276367287 .4733276367288 .0829010009888 .6924667358488 .99725341797 89.6068267822389 .9116134643690 .5211791992290 .8259735107490 .82597351074 91.4355392456192 .0450973510793 .2642517089894 .4833908081195 .70252990723 96.6168823242297 .2264633178797 .8360290527398 .445587158298 .4455871582 98.445587158298 .445587158298 .445587158298 .445587158298 .14080810547 98.1408081054797 .8360290527397 .8360290527397 .8360290527398 .14080810547 98.445587158298 .7503814697399 .3599472045999 .6647262573299 .96952056885 100.5791015625100 .8839035034101 .1886978149101 .4934005737102 .1029968262 102.4077987671102 .712600708103 .0174026489103 .3221969604103 .3221969604 103.6268997192103 .9317016602103 .9317016602104 .2365036011104 .2365036011 104.2365036011 104.2365036011 104.2365036011 104.2365036011 103.9317016602 103.6268997192103 .0174026489102 .712600708102 .1029968262101 .1886978149 100.274299621699 .0551681518697 .53124237061100 .2742996216100 .8839035034 101.1886978149101 .7982025146102 .1029968262102 .1029968262102 .1029968262 101.4934005737100 .883903503499 .6647262573298 .1408081054795 .09295654297 100.5791015625107 .8938980103117 .342300415128 .6192932129140 .8106994629 154.2212982178167 .3269958496179 .8231964111191 .7097930908202 .6820983887 208.7778015137208 .7778015137208 .7778015137208 .7778015137208 .7778015137 208.7778015137 208.7778015137208.7778015137 208.7778015137 208.7778015137 
208.7778015137208 .7778015137208 .7778015137208 .7778015137208 .7778015137 208.7778015137 208.7778015137208.7778015137208.7778015137 208.7778015137 208.7778015137208 .7778015137208 .7778015137208 .7778015137208 .7778015137 208.7778015137208 .7778015137208 .7778015137208 .7778015137208 .7778015137 208.7778015137208 .7778015137208 .7778015137208 .7778015137208 .7778015137 208.7778015137208 .7778015137208 .7778015137208 .7778015137208 .7778015137 208.7778015137 80.1584930419941 .78936767578 -9999 -9999 -9999 -9999 -9999 -9999 -9999 -9999 -9999 -9999-9999-9999-9999

-9999 -9999 -9999 -9999 -9999 -9999 -9999 -9999 -9999 -9999 -9999 -9999 -9999 -9999 -9999 -9999 -9999 -9999 -9999 -9999 -9999 -9999 -9999 -9999 -9999 -9999 -9999 -9999 -9999 -9999 -9999 -9999 -9999 -9999 -9999 -9999 -9999 -9999 -9999 -9999 -9999 -9999 -9999 -9999 -9999 -999 -9999 -9999 -9999 -9999 -9999 -9999 -9999 -9999 -9999 -9999 -9999 -9999 -9999 -9999 -9999 -9999 -9999 -9999 -9999 -9999 -9999 -9999 -9999 -9999 -9999 -9999 -9999 -9999 -9999 -9999 -9999 -9999 -9999 -9999 -9999 -9999 -9999 -9999 -9999 -9999 -9999 -9999 -9999 -9999 -9999 -9999 -9999 -9999 -9999 256.3243103027 205.1857452393 198.214050293 190.1858978271 181.6519012451175 .5561981201171 .8988037109169 .1557006836166 .7174987793 164.8887023926163 .6696014404162 .7552947998162 .1457061768161 .8408966064 161.5361022949161 .5361022949161 .5361022949161 .5361022949161 .2312927246 161.2312927246160 .6217956543160 .3170013428159 .7073974609159 .0977935791 158.1835021973157 .2691040039156 .3547973633155 .7451934814158 .1835021973 155.1356048584155 .1356048584155 .1356048584155 .1356048584155 .1356048584 154.8307952881154 .8307952881154 .5260925293154 .5260925293154 .2212982178 154.2212982178153 .9165039062153 .6116943359153 .0021057129152 .6972961426 152.0877990723151 .1734008789150 .2590942383149 .6495056152149 .0399017334 148.4304046631147 .8208007812147 .5160064697147 .2111968994146 .9064025879 146.9064025879146 .6015930176146 .2969055176145 .6873016357145 .0754089355 144.1634063721143 .5538024902142 .9441986084142 .6394042969142 .4699859619 142.225692749142 .0516815186141 .9245452881141 .8219451904145 .0776977539 145.6873016357146 .2969055176146 .6015930176146 .9064025879146 .9064025879 146.6015930176145 .9920959473145 .0776977539144 .4682006836143 .2489929199 142.3347015381141 .1154937744140 .2012023926138 .9819946289138 .0677032471 136.8484954834135 .9342041016135 .0198059082134 .1054992676133 .1911010742 132.2767028809131 .3623962402133 .4958953857129 .533706665128 .6192932129 127.7050018311126 .7906036377125 .8762969971124 .9618988037124 .3523025513 123.43800354122 .8283996582122 .2188034058121 .9140014648121 .9140014648 121.6092987061121 .3044967651120 .6949005127120 .3900985718119 .7806015015 119.1709976196118 .8662033081118 .2565994263117 .647102356117 .0374984741 116.1231002808115 .5136032104114 .5991973877113 .9896011353113 .075302124 112.1608963013111 .24659729110 .3321990967109 .4179000854108 .5035018921 107.5891036987106 .6747970581105 .4557037354104 .5412979126103 .6268997192 102.4077987671101 .4934005737100 .274299621699 .0551681518697 .83602905273 96.6168823242295 .397743225193 .8738174438592 .0450973510790 .52117919922 89.6068267822389 .302040100189 .6068267822389 .9116134643690 .52117919922 91.1307525634891 .7403335571391 .7403335571392 .0450973510792 .65467834473 91.7403335571390 .8259735107490 .2164001464889 .6068267822388 .99725341797 88.38768768311 88.38768768311 88.38768768311 88.69246673584 88.99725341797 
89.6068267822389 .9116134643690 .2164001464890 .5211791992290 .82597351074 91.1307525634892 .0450973510793 .2642517089894 .4833908081195 .3977432251 96.6168823242297 .2264633178797 .8360290527398 .445587158298 .75038146973 98.7503814697398 .7503814697398 .7503814697398 .445587158298 .4455871582 98.1408081054798.1408081054798.1408081054798.1408081054798.4455871582 98.7503814697399 .0551681518699 .3599472045999 .66472625732100 .2742996216 100.5791015625100 .8839035034101 .1886978149101 .4934005737101 .7982025146 102.4077987671102 .712600708102 .712600708103 .0174026489103 .3221969604 103.6268997192103 .9317016602103 .9317016602104 .2365036011104 .2365036011 104.2365036011104 .2365036011104 .2365036011103 .9317016602103 .6268997192 103.3221969604103 .0174026489102 .4077987671101 .7982025146100 .8839035034 99.6647262573298 .4455871582100 .5791015625100 .8839035034101 .4934005737 102.1029968262102 .4077987671102 .712600708102 .712600708102 .712600708 102.4077987671101 .4934005737100 .579101562599 .0551681518694 .48339080811 99.66472625732106 .3700027466114 .9039993286124 .6570968628135 .9342041016 148.4304046631161 .5361022949174 .6419067383187 .4429016113199 .329498291 208.7778015137208 .7778015137208 .7778015137208 .7778015137208 .7778015137 208.7778015137208 .7778015137208 .7778015137208 .7778015137208 .7778015137 208.7778015137208 .7778015137208 .7778015137208 .7778015137208 .7778015137 208.7778015137208 .7778015137208 .7778015137208 .7778015137208 .7778015137 208.7778015137208.7778015137208.7778015137208.7778015137 208.7778015137 208.7778015137208 .7778015137208 .7778015137208 .7778015137208 .7778015137 208.7778015137208 .7778015137208 .7778015137208 .7778015137208 .7778015137 208.7778015137208.7778015137208.7778015137208.7778015137 208.7778015137 208.7778015137 79.2441329956179 .85370635986 -9999 -9999 -9999 -9999 -9999 -9999 -9999 -9999 -9999 -9999 -9999-9999-9999 -9999 -9999 -9999 -9999 -9999 -9999 -9999 -9999 -9999 -9999 -9999 -9999 -9999 -9999 -9999

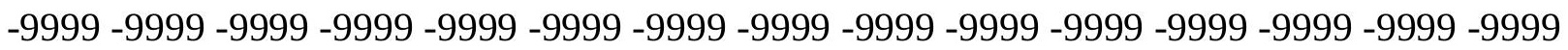
-9999 -9999 -9999 -9999 -9999 -9999 -9999 -9999 -9999 -9999 -9999 -9999 -9999 -9999 -9999 -9999 -9999 -9999 -9999 -9999 -9999 -9999 -9999 -9999 -9999 -9999 -9999 -9999 -9999 -9999 -9999 -9999 -9999 -9999 -9999 -9999 -9999 -9999 -9999 -9999 -9999 -9999-9999 -9999 -9999 -

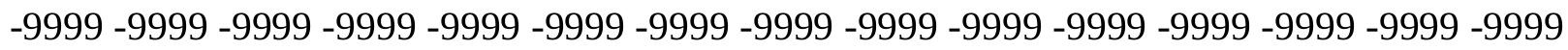
-9999 -9999-9999-9999-9999 246.2664031982 199.6233215332 189.2716064453 181.6519012451176 .7754058838173 .1179962158170 .070098877167 .0222015381 164.8887023926163 .3648071289162 .1457061768161 .8408966064161 .5361022949 161.5361022949161 .5361022949161 .8408966064161 .8408966064161 .8408966064 161.5361022949161 .2312927246160 .9264984131160 .3170013428159 .7073974609 158.7929992676157 .878692627156 .6596069336155 .7451934814155 .1356048584 155.1356048584155 .4403991699155 .4403991699155 .4403991699155 .1356048584 154.8307952881154 .5260925293154 .5260925293154 .2212982178153 .9165039062 153.6116943359153 .0021057129152 .3925933838152 .0877990723151 .4781951904 151.1734008789150 .5639038086149 .9542999268149 .3446960449148 .7351074219 148.1255950928147 .8208007812147 .2111968994147 .2111968994147 .2111968994 147.2111968994 147.2111968994146.9064025879 145.9920959473145 .0776977539 144.1634063721143 .2489929199142 .6394042969142 .3347015381142 .0299072266 142.1943817139142 .1266479492142 .1030426025142 .1029815674144 .4682006836 
145.0776977539145 .6873016357146 .2969055176146 .6015930176146 .6015930176 146.2969055176145 .9920959473145 .3825073242144 .4682006836143 .5538024902 142.6394042969141 .7250976562140 .8106994629139 .5915985107138 .6772003174 137.4580993652139 .5915985107138 .6772003174137 .7628936768136 .5437011719 135.6293945312131 .9720001221131 .0576019287130 .1432037354129 .2288970947 128.3144989014127 .4001998901126 .4858016968125 .5715026855124 .6570968628 123.7427978516123 .1332015991122 .5235977173122 .2188034058121 .9140014648 121.6092987061120 .9997024536120 .3900985718120 .0852966309119 .4757995605 118.8662033081118 .2565994263117 .647102356117 .0374984741116 .4279022217 115.818397522114 .9039993286114 .2944030762113 .3800964355112 .4656982422 111.551399231110 .6370010376109 .7226028442108 .8082962036107 .8938980103 106.979598999106 .0652008057105 .1509017944103 .9317016602103 .0174026489 101.7982025146100 .883903503499 .3599472045998 .1408081054796 .31210327148 94.7881774902392 .9594726562590 .8259735107488 .9972534179787 .77810668945 87.4733276367287 .7781066894588 .6924667358489 .6068267822390 .52117919922 91.4355392456192 .0450973510792 .6546783447392 .9594726562592 .95947265625 92.6546783447391 .7403335571391 .4355392456190 .8259735107490 .21640014648 89.60682678223 89.3020401001 89.302040100189.302040100189.60682678223 89.60682678223 89.9116134643690.2164001464890.5211791992290.82597351074 91.4355392456192 .349891662693 .2642517089894 .4833908081195 .70252990723 96.6168823242297 .5312423706198 .1408081054798 .7503814697399 .05516815186 99.0551681518699 .0551681518699 .0551681518699 .0551681518698 .75038146973 98.7503814697398 .445587158298 .445587158298 .445587158298 .75038146973 98.7503814697399 .0551681518699 .3599472045999 .96952056885100 .2742996216 100.5791015625100 .8839035034101 .1886978149101 .4934005737101 .7982025146 102.1029968262102 .4077987671102 .712600708103 .0174026489103 .3221969604 103.6268997192103 .6268997192103 .9317016602104 .2365036011104 .2365036011 104.2365036011104 .2365036011104 .2365036011103 .9317016602103 .6268997192 103.3221969604102 .712600708102 .1029968262101 .4934005737100 .5791015625 99.3599472045998 .4455871582101 .1886978149101 .4934005737102 .1029968262 102.712600708103 .0174026489103 .3221969604103 .3221969604103 .3221969604 103.0174026489102 .1029968262101 .188697814999 .9695205688598 .4455871582 99.05516815186105 .1509017944112 .4656982422121 .3044967651131 .6672058105 142.9441986084156 .0500030518170 .3748931885184 .3950042725196 .891204834 207.8634033203208 .7778015137208 .7778015137208 .7778015137208 .7778015137 208.7778015137208.7778015137208.7778015137208.7778015137208.7778015137 208.7778015137208.7778015137208.7778015137 208.7778015137 208.7778015137 208.7778015137 208.7778015137208.7778015137208.7778015137 208.7778015137 208.7778015137208 .7778015137208 .7778015137208 .7778015137208 .7778015137 208.7778015137208 .7778015137208 .7778015137208 .7778015137208 .7778015137 208.7778015137208 .7778015137208 .7778015137208 .7778015137208 .7778015137 208.7778015137208.7778015137208.7778015137208.7778015137208.7778015137 208.7778015137 208.7778015137 78.9393463134817 .90878677368 -9999 -9999 -9999 -9999 -9999 -9999 -9999 -9999 -9999 -9999 -9999 -9999 -9999 -9999 -9999 -9999 -9999 -9999 -9999 -9999 -9999 -9999 -9999 -9999 -9999 -9999 -9999 -9999 -9999 -9999 -9999 -9999 -9999 -9999 -9999 -9999 -9999 -9999 -9999 -9999 -9999 -9999 
-9999 -9999 -9999 -9999 -9999 -9999 -9999 -9999 -9999 -9999 -9999 -9999 -9999 -9999 -9999 -9999 -9999 -9999 -9999 -9999 -9999 -9999 -9999 -9999 -9999 -9999 -9999 -9999 -9999 -9999 -9999 -9999 -9999 -9999 -9999 -9999 -9999 -9999 -9999 -9999 -9999 -9999 -9999 -9999 -9999 -9999 -9999 -9999 -9999 -9999 -9999 -9999 -9999 -9999 -9999 -9999 -9999 -9999 -9999 -9999 -9999 -9999 -9999 -9999-9999260.8960876465 204.6727905273195 .2803649902 183.4806976318180 .432800293175 .8609924316170 .9844970703167 .0222015381 164.2792053223162 .4505004883161 .5361022949161 .2312927246161 .2312927246 161.2312927246161 .5361022949161 .8408966064162 .1457061768162 .1457061768 162.1457061768162 .1457061768161 .5361022949161 .2312927246160 .3170013428 159.4026031494158 .4882965088157 .5738983154156 .3547973633158 .4882965088 155.7451934814155 .7451934814156 .0500030518155 .7451934814155 .4403991699 155.1356048584154 .8307952881154 .2212982178153 .9165039062153 .6116943359 153.0021057129152 .3925933838151 .7830047607151 .1734008789150 .5639038086 150.2590942383149 .6495056152149 .3446960449149 .0399017334148 .4304046631 147.8208007812147 .5160064697147 .2111968994146 .9064025879146 .9064025879 146.9064025879147 .2111968994146 .9064025879145 .9920959473144 .7729034424 143.5538024902142 .6394042969142 .0299072266141 .7250976562141 .4203033447 141.7250976562142 .0299072266142 .2890625142 .4081573486142 .5123138428 144.7729034424145 .3825073242145 .9920959473146 .2969055176146 .2969055176 146.2969055176145 .9920959473145 .3825073242144 .7729034424143 .8585968018 142.9441986084142 .0299072266141 .1154937744140 .2012023926139 .2868041992 138.0677032471140 .2012023926139 .2868041992138 .0677032471134 .1054992676 133.1911010742132 .2767028809131 .3623962402130 .7528076172129 .8385009766 128.9241027832127 .7050018311126 .7906036377125 .8762969971124 .9618988037 124.0475006104123 .43800354122 .5235977173122 .2188034058121 .6092987061 121.3044967651120 .6949005127120 .0852966309119 .4757995605119 .1709976196 118.5614013672117 .9517974854117 .342300415116 .7326965332116 .1231002808 115.2088012695114 .5991973877113 .6848983765112 .7705001831112 .1608963013 111.24659729110 .0273971558109 .1130981445108 .1986999512107 .2844009399 106.3700027466105 .4557037354104 .5412979126103 .6268997192102 .712600708 101.4934005737100 .274299621698 .7503814697397 .2264633178795 .3977432251 92.9594726562590 .8259735107488 .0829010009885 .9494018554785 .03504943848 85.0350494384886 .254188537688 .0829010009889 .6068267822390 .82597351074 91.7403335571392 .6546783447392 .9594726562593 .2642517089893 .56903076172 93.2642517089892 .6546783447392 .349891662691 .7403335571391 .13075256348 90.8259735107490 .5211791992290 .2164001464899 .9116134643690 .21640014648 90.2164001464890 .5211791992290 .8259735107491 .1307525634891 .43553924561 92.0450973510792 .9594726562593 .8738174438595 .0929565429796 .00731658936 97.2264633178797 .8360290527398 .445587158299 .0551681518699 .35994720459 99.6647262573299 .6647262573299 .6647262573299 .3599472045999 .35994720459 99.0551681518699 .0551681518699 .0551681518699 .0551681518699 .05516815186 99.3599472045999 .3599472045999 .6647262573299 .96952056885100 .2742996216 100.5791015625100 .8839035034101 .1886978149101 .4934005737101 .7982025146 102.1029968262102 .4077987671102 .712600708103 .0174026489103 .3221969604 103.3221969604103 .6268997192103 .9317016602103 .9317016602104 .2365036011 104.2365036011 104.2365036011 103.9317016602 103.9317016602 103.6268997192 
103.0174026489102 .712600708102 .1029968262101 .1886978149100 .2742996216 99.3599472045998 .14080810547101 .4934005737102 .1029968262102 .712600708 103.0174026489103 .6268997192103 .6268997192103 .9317016602103 .6268997192 103.3221969604102 .712600708102 .1029968262100 .883903503499 .35994720459 98.75038146973103 .9317016602110 .6370010376118 .5614013672127 .7050018311 138.3724975586151 .1734008789166 .7174987793182 .261505127195 .6721038818 206.6443023682208 .7778015137208 .7778015137208 .7778015137208 .7778015137 208.7778015137208 .7778015137208 .7778015137208 .7778015137208 .7778015137 208.7778015137208 .7778015137208 .7778015137208 .7778015137208 .7778015137 208.7778015137208 .7778015137208 .7778015137208 .7778015137208 .7778015137 208.7778015137208 .7778015137208 .7778015137208 .7778015137208 .7778015137 208.7778015137208 .7778015137208 .7778015137208 .7778015137208 .7778015137 208.7778015137208 .7778015137208 .7778015137208 .7778015137208 .7778015137 208.7778015137208 .7778015137208 .7778015137208 .7778015137208 .7778015137 208.7778015137 208.7778015137 78.0249862670920 .10696411133 -9999 -9999 -9999 -9999 -9999 -9999 -9999-9999-9999 -9999-9999-9999

-9999 -9999 -9999 -9999 -9999 -9999 -9999 -9999 -9999 -9999 -9999 -9999 -9999 -9999 -9999 -9999 -9999 -9999 -9999 -9999 -9999 -9999 -9999 -9999 -9999 -9999 -9999 -9999 -9999 -9999 -999 -9999 -9999 -9999 -9999 -9999 -9999 -9999 -9999 -9999 -9999 -9999 -9999 -9999 -9999 -9999

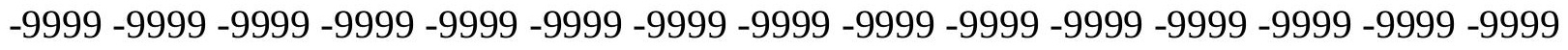
-9999 -9999 -9999 -9999 -9999 -9999 -9999 -9999 -9999 -9999 -9999 -9999 -9999 -9999 -9999

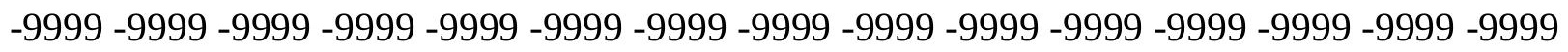
-9999 -9999 -9999 -9999 -9999-9999 246.2664031982 205.8844909668198 .7198944092 188.0523986816178 .604095459171 .5939941406166 .4127044678163 .3648071289 161.5361022949160 .6217956543160 .3170013428160 .6217956543160 .9264984131 161.5361022949161 .8408966064162 .4505004883162 .7552947998162 .7552947998 162.7552947998162 .4505004883162 .1457061768161 .5361022949160 .6217956543 159.7073974609158 .4882965088157 .5738983154156 .6596069336156 .6596069336 156.9642944336156 .9642944336156 .9642944336156 .3547973633155 .7451934814 155.1356048584154 .5260925293153 .9165039062153 .3069000244152 .6972961426 151.7830047607150 .8686065674150 .2590942383149 .6495056152149 .3446960449 149.3446960449149 .0399017334148 .7351074219148 .1255950928147 .5160064697 147.2111968994146 .6015930176146 .2969055176146 .2969055176146 .2969055176 146.6015930176146 .9064025879145 .3825073242143 .8585968018142 .6394042969 141.7250976562141 .1154937744140 .8106994629140 .8106994629141 .1154937744 141.4203033447142 .0299072266142 .763381958142 .9810943604144 .4682006836 145.0776977539145 .3825073242145 .9920959473145 .9920959473145 .9920959473 145.6873016357145 .3825073242145 .0776977539144 .4682006836143 .5538024902 142.6394042969141 .7250976562140 .8106994629139 .8963928223138 .6772003174 137.7628936768136 .8484954834135 .6293945312134 .7149963379133 .8007049561 132.8863067627131 .9720001221131 .3623962402130 .4479980469129 .533706665 128.3144989014127 .4001998901126 .4858016968125 .2667007446124 .3523025513 123.43800354122 .5235977173121 .9140014648121 .3044967651120 .6949005127 120.3900985718119 .7806015015119 .1709976196118 .5614013672117 .9517974854 117.647102356117 .0374984741116 .1231002808115 .5136032104114 .9039993286 113.9896011353113 .3800964355112 .4656982422111 .551399231110 .6370010376 
109.7226028442108 .8082962036107 .8938980103106 .6747970581105 .7603988647 104.8460998535104 .2365036011103 .3221969604102 .1029968262101 .1886978149 99.9695205688598 .445587158296 .6168823242294 .4833908081192 .04509735107 88.9972534179786 .254188537683 .5111236572382 .2919769287183 .51112365723 85.6446228027388 .0829010009889 .9116134643691 .4355392456192 .3498916626 93.2642517089893 .5690307617293 .8738174438593 .8738174438593 .87381744385 93.5690307617293 .2642517089892 .6546783447392 .0450973510791 .74033355713 91.4355392456191 .1307525634890 .8259735107490 .8259735107490 .82597351074 91.1307525634891 .4355392456191 .7403335571392 .0450973510792 .95947265625 93.5690307617294 .7881774902395 .7025299072396 .9216690063597 .83602905273 98.445587158299 .0551681518699 .6647262573299 .9695205688599 .96952056885 99.9695205688599 .9695205688599 .9695205688599 .6647262573299 .66472625732 99.6647262573299 .3599472045999 .3599472045999 .3599472045999 .66472625732 99.6647262573299 .96952056885100 .2742996216100 .5791015625100 .8839035034 101.1886978149101 .1886978149101 .4934005737101 .7982025146102 .1029968262 102.4077987671102 .712600708103 .0174026489103 .0174026489103 .3221969604 103.6268997192103 .6268997192103 .9317016602103 .9317016602103 .9317016602 103.9317016602103 .9317016602103 .6268997192103 .3221969604103 .0174026489 102.4077987671101 .7982025146101 .1886978149100 .274299621699 .35994720459 101.4934005737102 .1029968262102 .712600708103 .0174026489103 .6268997192 103.9317016602104 .2365036011104 .2365036011104 .2365036011103 .9317016602 103.3221969604102 .4077987671101 .493400573799 .9695205688598 .75038146973 103.3221969604109 .1130981445116 .4279022217124 .6570968628134 .4102020264 145.9920959473164 .5839996338181 .9566955566195 .0625205 .1204071045208 .7778015137 208.7778015137208 .7778015137208 .7778015137208 .7778015137208 .7778015137 208.7778015137208 .7778015137208 .7778015137208 .7778015137208 .7778015137 208.7778015137208 .7778015137208 .7778015137208 .7778015137208 .7778015137 208.7778015137208 .7778015137208 .7778015137208 .7778015137208 .7778015137 208.7778015137208 .7778015137208 .7778015137208 .7778015137208 .7778015137 208.7778015137208 .7778015137208 .7778015137208 .7778015137208 .7778015137 208.7778015137208 .7778015137208 .7778015137208 .7778015137208 .7778015137 208.7778015137208 .7778015137208 .7778015137208 .7778015137208 .7778015137 77.110626220742 .49723815918 -9999 -9999 -9999 -9999 -9999 -9999 -9999 -9999 -9999 -9999 -9999-9999

-9999 -9999 -9999 -9999 -9999 -9999 -9999 -9999 -9999 -9999 -9999 -9999 -9999 -9999 -9999 -9999 -9999 -9999 -9999 -9999 -9999 -9999 -9999 -9999 -9999 -9999 -9999 -9999 -9999 -9999

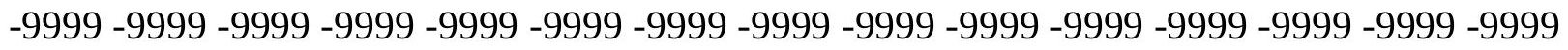

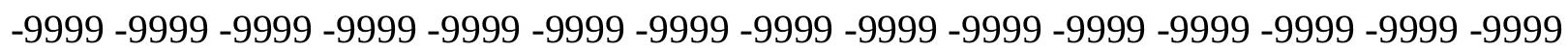

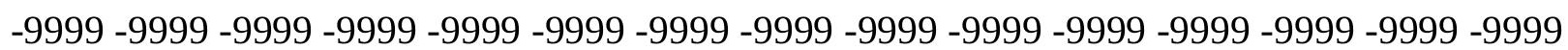
-9999 -9999 -9999 -9999 -9999 -9999 -9999 -9999 -9999 -9999 -9999 -9999 -9999 -9999 -9999 -999 -9999 -9999 -9999 -9999 -9999 -9999 -9999 215.001373291209 .9969024658191 .4051055908 178.9089050293170 .070098877164 .5839996338161 .5361022949160 .0122070312 159.7073974609159 .7073974609160 .0122070312160 .6217956543161 .5361022949 162.1457061768162 .7552947998163 .3648071289163 .6696014404163 .6696014404 163.6696014404163 .3648071289162 .7552947998161 .8408966064160 .9264984131 160.0122070312159 .0977935791158 .4882965088158 .1835021973158 .4882965088 
158.4882965088158 .1835021973157 .5738983154156 .6596069336155 .7451934814 154.8307952881153 .9165039062153 .0021057129152 .3925933838151 .1734008789 149.9542999268149 .3446960449149 .0399017334149 .0399017334149 .0399017334 148.7351074219148 .4304046631148 .1255950928147 .5160064697146 .6015930176 145.9920959473145 .3825073242145 .0776977539145 .0776977539144 .7729034424 144.4682006836143 .5538024902142 .3347015381141 .3566589355140 .5059967041 140.2012023926139 .8963928223140 .2012023926140 .5059967041141 .1154937744 141.7250976562142 .6394042969143 .2489929199143 .7943572998144 .7729034424 145.3825073242145 .6873016357145 .9920959473146 .2969055176146 .2969055176 145.9920959473145 .3825073242145 .0776977539144 .1634063721143 .2489929199 142.3347015381141 .4203033447140 .5059967041139 .2868041992138 .3724975586 137.4580993652136 .2389984131135 .3246002197134 .4102020264133 .4958953857 132.8863067627131 .9720001221131 .0576019287130 .1432037354128 .9241027832 128.0097961426126 .7906036377125 .5715026855124 .6570968628123 .43800354 122.5235977173121 .6092987061120 .9997024536120 .3900985718119 .7806015015 119.4757995605118 .8662033081118 .2565994263117 .647102356117 .0374984741 116.4279022217115 .818397522115 .2088012695114 .2944030762113 .6848983765 112.7705001831111 .8561019897111 .24659729110 .0273971558109 .1130981445 108.1986999512107 .2844009399106 .3700027466105 .4557037354104 .5412979126 103.6268997192102 .712600708102 .1029968262100 .883903503499 .96952056885 98.445587158296 .6168823242294 .1785964965891 .4355392456188 .38768768311 85.64462280273 82.59677124023 83.51112365723 83.206336975186.2541885376 88.9972534179791.1307525634892.349891662693.2642517089893.87381744385 94.1785964965894 .4833908081194 .4833908081194 .1785964965894 .17859649658 93.8738174438593 .2642517089892 .9594726562592 .349891662692 .04509735107 91.7403335571391 .7403335571391 .4355392456191 .7403335571391 .74033355713 92.0450973510792 .6546783447392 .9594726562593 .8738174438594 .48339080811 95.7025299072396 .6168823242297 .5312423706198 .445587158299 .35994720459 99.96952056885100 .2742996216100 .5791015625100 .5791015625100 .5791015625 100.5791015625100 .5791015625100 .2742996216100 .274299621699 .96952056885 99.9695205688599 .9695205688599 .9695205688599 .96952056885100 .2742996216 100.2742996216100 .5791015625100 .5791015625100 .8839035034101 .1886978149 101.4934005737101 .4934005737101 .7982025146102 .1029968262102 .4077987671 102.4077987671102 .712600708103 .0174026489103 .3221969604103 .3221969604 103.6268997192103 .6268997192103 .9317016602103 .9317016602103 .9317016602 103.9317016602 103.6268997192103.3221969604 103.0174026489 102.4077987671 101.7982025146101 .1886978149100 .274299621699 .35994720459101 .7982025146 102.4077987671103 .0174026489103 .3221969604103 .9317016602104 .2365036011 104.5412979126104 .5412979126104 .5412979126104 .2365036011103 .6268997192 103.0174026489101 .7982025146100 .579101562598 .75038146973103 .0174026489 108.1986999512114 .2944030762122 .2188034058132 .2767028809145 .3825073242 163.0599975586182 .261505127192 .9290008545202 .3773040771208 .7778015137 208.7778015137208 .7778015137208 .7778015137208 .7778015137208 .7778015137 208.7778015137208 .7778015137208 .7778015137208 .7778015137208 .7778015137 208.7778015137208 .7778015137208 .7778015137208 .7778015137208 .7778015137 208.7778015137208 .7778015137208 .7778015137208 .7778015137208 .7778015137 
208.7778015137208 .7778015137208 .7778015137208 .7778015137208 .7778015137 208.7778015137208 .7778015137208 .7778015137208 .7778015137208 .7778015137 208.7778015137208 .7778015137208 .7778015137208 .7778015137208 .7778015137 208.7778015137208 .7778015137208 .7778015137208 .7778015137208 .7778015137 208.7778015137 83.88812255859 -9999 -9999 -9999 -9999 -9999 -9999 -9999 -9999 -9999 -9999-9999-9999

-9999 -9999 -9999 -9999 -9999 -9999 -9999 -9999 -9999 -9999 -9999 -9999 -9999 -9999 -9999

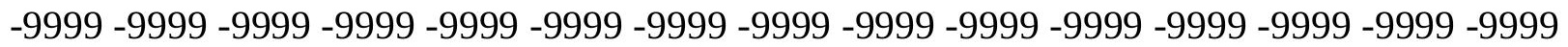

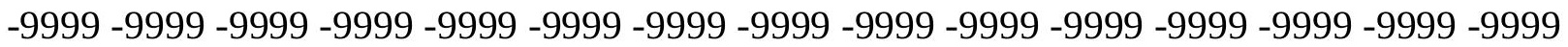
-9999 -9999 -9999 -9999 -9999 -9999 -9999 -9999 -9999 -9999 -9999 -9999 -9999 -9999 -9999 -9999 -9999 -9999 -9999 -9999 -9999 -9999 -9999 -9999 -9999 -9999 -9999 -9999 -9999 -9999 -999 -9999 -9999 -9999 -9999 -9999 -9999 -9999 -9999 -9999 -9999 -9999 -9999 -9999 -9999 -9999 -9999 -9999-9999 -9999-9999-9999-9999 219.0150299072 207.7985076904187 .4429016113 174.9467010498166 .4127044678161 .5361022949159 .4026031494158 .4882965088 158.4882965088159 .0977935791159 .7073974609160 .6217956543161 .5361022949 162.1457061768163 .0599975586163 .974395752164 .2792053223164 .8887023926 164.8887023926164 .5839996338163 .974395752163 .3648071289162 .4505004883 161.8408966064161 .2312927246160 .6217956543160 .3170013428160 .6217956543 160.6217956543160 .0122070312159 .0977935791157 .878692627156 .6596069336 155.4403991699153 .9165039062152 .6972961426151 .4781951904150 .2590942383 149.3446960449148 .7351074219148 .7351074219149 .0399017334149 .0399017334 149.0399017334148 .7351074219148 .1255950928147 .2111968994146 .2969055176 145.3825073242144 .4682006836143 .5538024902143 .2489929199142 .6394042969 142.0299072266141 .4203033447140 .5059967041139 .5915985107139 .2868041992 138.9819946289139 .2868041992139 .5915985107140 .2012023926140 .8106994629 141.4203033447142 .3347015381143 .2489929199144 .1634063721144 .7729034424 145.3825073242145 .9920959473146 .2969055176146 .6015930176146 .6015930176 146.2969055176145 .9920959473145 .3825073242144 .7729034424143 .8585968018 142.9441986084142 .0299072266140 .8106994629139 .8963928223138 .9819946289 137.7628936768136 .8484954834135 .9342041016135 .0198059082134 .1054992676 133.4958953857132 .5814971924131 .6672058105130 .7528076172129 .533706665 128.6192932129127 .4001998901126 .1809997559124 .6570968628123 .43800354 125.5715026855121 .6092987061120 .6949005127120 .0852966309119 .4757995605 118.8662033081118 .5614013672117 .9517974854117 .342300415116 .7326965332 116.1231002808115 .5136032104114 .9039993286113 .9896011353113 .3800964355 112.4656982422111 .551399231110 .6370010376109 .7226028442108 .8082962036 107.8938980103106 .6747970581105 .7603988647104 .8460998535103 .9317016602 103.3221969604102 .4077987671101 .7982025146100 .883903503499 .96952056885 98.7503814697396 .9216690063594 .4833908081191 .7403335571388 .99725341797 86.254188537684 .4254837036183 .8159103393685 .9494018554788 .69246673584 91.1307525634892 .6546783447393 .5690307617294 .1785964965894 .48339080811 94.7881774902394 .7881774902394 .7881774902394 .4833908081194 .48339080811 94.1785964965893 .8738174438593 .2642517089892 .9594726562592 .65467834473 92.349891662692 .349891662692 .349891662692 .349891662692 .65467834473 92.9594726562593 .2642517089893 .8738174438594 .7881774902395 .3977432251 96.6168823242297 .5312423706198 .445587158299 .3599472045999 .96952056885 
100.5791015625101 .1886978149101 .1886978149101 .4934005737101 .1886978149 101.1886978149101 .1886978149100 .8839035034100 .8839035034100 .5791015625 100.5791015625100 .2742996216100 .2742996216100 .5791015625100 .5791015625 100.5791015625100 .8839035034100 .8839035034101 .1886978149101 .1886978149 101.4934005737101 .4934005737101 .7982025146102 .1029968262102 .1029968262 102.4077987671102 .712600708102 .712600708103 .0174026489103 .3221969604 103.3221969604103 .6268997192103 .6268997192103 .9317016602103 .9317016602 103.9317016602103 .6268997192103 .3221969604103 .0174026489102 .4077987671 101.7982025146101 .1886978149100 .274299621699 .66472625732102 .1029968262 102.712600708103 .3221969604103 .6268997192104 .2365036011104 .5412979126 104.5412979126104 .8460998535104 .5412979126104 .5412979126103 .9317016602 103.3221969604102 .1029968262100 .883903503499 .35994720459102 .712600708 106.979598999112 .7705001831120 .0852966309129 .8385009766142 .9441986084 158.7929992676174 .6419067383187 .7476043701198 .4151000977207 .5587005615 208.7778015137208 .7778015137208 .7778015137208 .7778015137208 .7778015137 208.7778015137208 .7778015137208 .7778015137208 .7778015137208 .7778015137 208.7778015137208 .7778015137208 .7778015137208 .7778015137208 .7778015137 208.7778015137208 .7778015137208 .7778015137208 .7778015137208 .7778015137 208.7778015137208 .7778015137208 .7778015137208 .7778015137208 .7778015137 208.7778015137208 .7778015137208 .7778015137208 .7778015137208 .7778015137 208.7778015137208 .7778015137208 .7778015137208 .7778015137208 .7778015137 208.7778015137208 .7778015137208 .7778015137208 .7778015137208 .7778015137 208.777801513776 .19628143311 -9999 -9999 -9999 -9999 -9999 -9999 -9999 -9999 -9999 -9999 -9999-9999

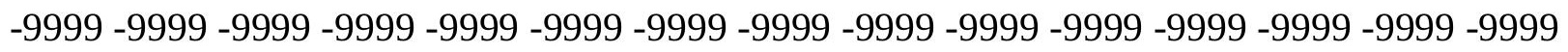

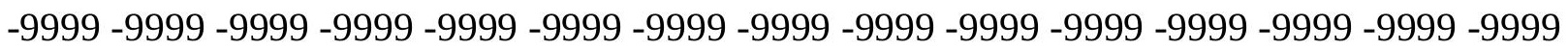

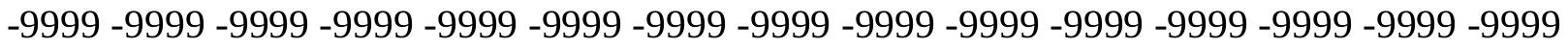

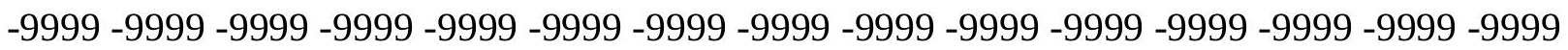

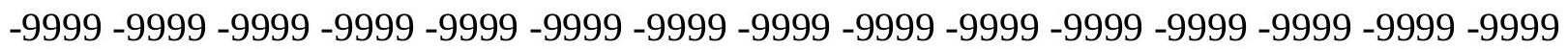

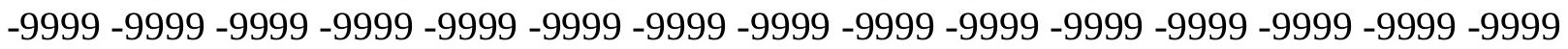
-9999 -9999 -9999 -9999 -9999 -9999 -9999 -9999 209.7355499268 193.8433074951 167.0222015381161 .5361022949158 .4882965088157 .2691040039157 .2691040039 157.878692627158 .4882965088159 .4026031494160 .3170013428161 .5361022949 162.4505004883163 .6696014404164 .5839996338165 .1934967041165 .8031005859 166.1078948975165 .8031005859165 .4983062744164 .5839996338163 .974395752 163.6696014404163 .3648071289163 .3648071289163 .3648071289163 .0599975586 163.0599975586162 .1457061768160 .9264984131159 .7073974609158 .4882965088 156.6596069336154 .8307952881152 .6972961426150 .8686065674149 .3446960449 148.7351074219148 .7351074219149 .3446960449149 .6495056152149 .9542999268 149.9542999268149 .3446960449148 .7351074219147 .5160064697146 .2969055176 144.7729034424143 .5538024902142 .3347015381141 .1154937744140 .2012023926 139.5915985107138 .9819946289138 .3724975586138 .0677032471138 .0677032471 138.0677032471138 .6772003174138 .9819946289139 .8963928223140 .5059967041 141.4203033447142 .3347015381143 .2489929199144 .1634063721145 .0776977539 148.7351074219145 .9920959473146 .6015930176146 .9064025879146 .9064025879 146.9064025879146 .2969055176145 .9920959473145 .0776977539144 .4682006836 
143.5538024902142 .3347015381141 .4203033447140 .5059967041139 .2868041992 138.3724975586137 .4580993652136 .5437011719135 .6293945312134 .7149963379 134.1054992676133 .1911010742132 .2767028809131 .3623962402130 .4479980469 129.2288970947128 .0097961426126 .4858016968124 .9618988037126 .7906036377 125.5715026855124 .6570968628123 .7427978516119 .7806015015119 .1709976196 118.5614013672117 .9517974854117 .647102356117 .0374984741116 .4279022217 115.818397522115 .2088012695114 .2944030762113 .6848983765113 .075302124 112.1608963013111 .24659729110 .3321990967109 .4179000854108 .5035018921 107.2844009399 106.3700027466105.4557037354104.5412979126103.3221969604 102.712600708102 .1029968262101 .4934005737101 .1886978149100 .2742996216 99.3599472045997 .8360290527395 .397743225192 .9594726562590 .52117919922 88.38768768311 87.47332763672 87.77810668945 89.9116134643692.3498916626 93.8738174438594 .7881774902395 .0929565429795 .397743225195 .3977432251 95.397743225195 .0929565429795 .0929565429794 .7881774902394 .48339080811 94.1785964965893 .8738174438593 .5690307617293 .2642517089892 .95947265625 92.9594726562592 .6546783447392 .9594726562592 .9594726562593 .26425170898 93.5690307617294 .1785964965894 .7881774902395 .397743225196 .31210327148 97.5312423706198 .445587158299 .35994720459100 .2742996216100 .8839035034 101.4934005737101 .7982025146102 .1029968262102 .1029968262101 .7982025146 101.7982025146101 .4934005737101 .4934005737101 .1886978149101 .1886978149 100.8839035034100 .8839035034100 .8839035034100 .8839035034100 .8839035034 100.8839035034101 .1886978149101 .1886978149101 .1886978149101 .4934005737 101.4934005737101 .7982025146101 .7982025146102 .1029968262102 .1029968262 102.4077987671102 .4077987671102 .712600708102 .712600708103 .0174026489 103.3221969604103 .3221969604103 .6268997192103 .6268997192103 .6268997192 103.6268997192103 .6268997192103 .3221969604102 .712600708102 .4077987671 101.7982025146101 .1886978149100 .579101562599 .96952056885102 .4077987671 103.0174026489103 .6268997192103 .9317016602104 .2365036011104 .5412979126 104.8460998535104 .8460998535104 .8460998535104 .5412979126103 .9317016602 103.3221969604102 .4077987671101 .188697814999 .96952056885102 .712600708 106.0652008057110 .9418029785117 .342300415126 .1809997559138 .0677032471 152.0877990723167 .0222015381180 .7375946045192 .9290008545203 .2917022705 208.7778015137208 .7778015137208 .7778015137208 .7778015137208 .7778015137 208.7778015137208 .7778015137208 .7778015137208 .7778015137208 .7778015137 208.7778015137208 .7778015137208 .7778015137208 .7778015137208 .7778015137 208.7778015137 208.7778015137208.7778015137 208.7778015137208.7778015137 208.7778015137208.7778015137208.7778015137 208.7778015137 208.7778015137 208.7778015137 208.7778015137208.7778015137 208.7778015137 208.7778015137 208.7778015137208 .7778015137208 .7778015137208 .7778015137208 .7778015137 208.7778015137208 .7778015137208 .7778015137208 .7778015137208 .7778015137 208.7778015137 75.28192901611 -9999 -9999 -9999 -9999 -9999 -9999 -9999 -9999 -9999 -9999-9999 -9999 -9999 -9999 -9999 -9999 -9999 -9999 -9999 -9999 -9999 -9999 -9999 -9999 -9999 -9999 -9999 -9999 -9999 -9999 -9999 -9999 -9999 -9999 -9999 -9999-9999 -9999 -9999 -9999 -9999 -9999 -9999 -9999 -9999 -9999 -9999 -9999 -9999 -9999 -9999 -9999 -9999 -9999 -9999 -9999 -9999 -

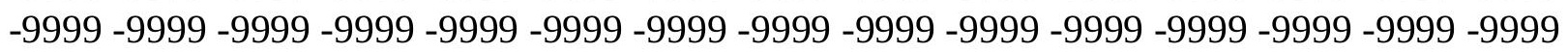


-9999 -9999 -9999 -9999 -9999 -9999 -9999 -9999 -9999 -9999 -9999 -9999 -9999 -9999 -9999

-9999 -9999 -9999 -9999 -9999 -9999 -9999 -9999 -9999 -9999 -9999 -9999 -9999 -9999 -9999 -9999 -9999 -9999 -9999 -9999 -9999 -9999 -9999 -9999 198.4151000977 173.4226989746 158.4882965088156 .3547973633156 .3547973633156 .9642944336157 .878692627 158.4882965088159 .4026031494160 .6217956543161 .5361022949162 .7552947998 163.974395752165 .1934967041166 .1078948975167 .0222015381167 .3269958496 167.3269958496166 .7174987793165 .8031005859165 .1934967041165 .1934967041 165.4983062744166 .1078948975166 .7174987793166 .4127044678165 .4983062744 164.2792053223163 .0599975586161 .8408966064160 .6217956543158 .7929992676 156.3547973633153 .6116943359150 .8686065674149 .3446960449149 .0399017334 149.9542999268150 .8686065674151 .7830047607152 .0877990723151 .7830047607 150.8686065674149 .6495056152148 .1255950928146 .2969055176144 .4682006836 142.6394042969141 .1154937744139 .5915985107138 .3724975586137 .4580993652 136.8484954834136 .8484954834136 .8484954834137 .1533050537137 .4580993652 138.0677032471138 .9819946289139 .8963928223140 .8106994629141 .7250976562 142.9441986084143 .8585968018144 .7729034424145 .6873016357146 .2969055176 149.6495056152146 .9064025879147 .2111968994147 .2111968994147 .2111968994 146.9064025879146 .2969055176145 .6873016357144 .7729034424143 .8585968018 142.9441986084142 .0299072266140 .8106994629139 .8963928223138 .9819946289 138.0677032471137 .1533050537136 .2389984131135 .3246002197134 .4102020264 133.8007049561132 .8863067627131 .9720001221131 .0576019287129 .8385009766 128.6192932129126 .7906036377125 .2667007446126 .7906036377125 .8762969971 124.9618988037123 .7427978516119 .7806015015119 .1709976196118 .5614013672 117.9517974854117 .342300415116 .7326965332116 .1231002808115 .5136032104 114.9039993286113 .9896011353113 .3800964355112 .4656982422111 .8561019897 110.9418029785110 .0273971558109 .1130981445107 .8938980103106 .979598999 106.0652008057104 .8460998535103 .9317016602103 .0174026489102 .1029968262 101.4934005737101 .1886978149101 .1886978149101 .1886978149100 .2742996216 99.0551681518696 .9216690063594 .4833908081192 .349891662690 .82597351074 90.2164001464891 .1307525634893 .2642517089896 .3121032714896 .31210327148 96.3121032714896 .3121032714896 .0073165893695 .7025299072395 .70252990723 95.397743225195 .0929565429794 .7881774902394 .4833908081194 .17859649658 93.8738174438593.8738174438593.5690307617293.2642517089893.26425170898 93.2642517089893 .2642517089893 .5690307617293 .8738174438594 .17859649658 94.7881774902395 .397743225196 .3121032714897 .2264633178798 .4455871582 99.35994720459100 .5791015625101 .1886978149102 .1029968262102 .4077987671 102.712600708102 .712600708102 .712600708102 .4077987671102 .4077987671 102.1029968262102 .1029968262101 .7982025146101 .4934005737101 .4934005737 101.4934005737101 .1886978149101 .1886978149101 .1886978149101 .1886978149 101.4934005737101 .4934005737101 .4934005737101 .4934005737101 .4934005737 101.7982025146101 .7982025146101 .7982025146102 .1029968262102 .1029968262 102.4077987671102 .4077987671102 .712600708102 .712600708103 .0174026489 103.3221969604103 .3221969604103 .6268997192103 .6268997192103 .6268997192 103.3221969604103 .0174026489102 .712600708102 .4077987671101 .7982025146 101.4934005737100 .8839035034100 .274299621699 .66472625732103 .3221969604 103.6268997192104 .2365036011104 .5412979126104 .8460998535104 .8460998535 
104.8460998535104 .8460998535104 .5412979126104 .2365036011103 .6268997192 102.71260070899 .66472625732100 .8839035034102 .712600708105 .4557037354 108.8082962036113 .9896011353121 .3044967651131 .6672058105144 .7729034424 159.4026031494174 .0323028564187 .1381072998198 .7198944092208 .7778015137 208.7778015137208 .7778015137208 .7778015137208 .7778015137208 .7778015137 208.7778015137208 .7778015137208 .7778015137208 .7778015137208 .7778015137 208.7778015137208 .7778015137208 .7778015137208 .7778015137208 .7778015137 208.7778015137208 .7778015137208 .7778015137208 .7778015137208 .7778015137 208.7778015137208 .7778015137208 .7778015137208 .7778015137208 .7778015137 208.7778015137208 .7778015137208 .7778015137208 .7778015137208 .7778015137 208.7778015137208 .7778015137208 .7778015137208 .7778015137208 .7778015137 208.7778015137208.7778015137208.7778015137208.7778015137 208.7778015137 74.67236328125 -9999 -9999 -9999 -9999 -9999 -9999 -9999 -9999 -9999 -9999 -9999 -9999 -9999 -9999 -9999 -9999 -9999 -9999 -9999 -9999 -9999 -9999 -9999 -9999 -9999 -9999 -9999 -9999 -9999 -9999 -9999 -9999 -9999 -9999 -9999 -9999 -9999 -9999 -9999 -9999 -9999 -9999

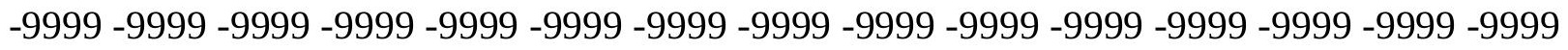
-9999 -9999 -9999 -9999 -9999 -9999 -9999 -9999 -9999 -9999 -9999 -9999 -9999 -9999 -9999 -9999 -9999 -9999 -9999 -9999 -9999 -9999 -9999 -9999 -9999 -9999 -9999 -9999 -9999 -9999 -9999 -9999 -9999 -9999 -9999 -9999 -9999 -9999 -9999 -9999 -9999 -9999 -9999-999 -999 -9999 -9999 -9999-9999 -9999-9999-9999 -9999 -9999-9999 181.9566955566 165.1934967041156 .0500030518156 .6596069336157 .5738983154158 .1835021973 158.7929992676159 .7073974609160 .6217956543161 .5361022949162 .7552947998 164.2792053223165 .8031005859167 .0222015381167 .9365997314168 .5462036133 168.5462036133167 .9365997314167 .0222015381166 .1078948975165 .8031005859 166.7174987793168 .241394043169 .7653045654170 .070098877167 .9365997314 166.1078948975164 .8887023926163 .974395752163 .3648071289162 .4505004883 159.7073974609155 .4403991699151 .7830047607150 .2590942383150 .8686065674 152.3925933838153 .9165039062154 .8307952881155 .1356048584154 .2212982178 153.0021057129151 .1734008789149 .0399017334146 .6015930176144 .4682006836 142.3347015381140 .2012023926138 .3724975586136 .8484954834135 .9342041016 135.3246002197135 .6293945312135 .9342041016136 .5437011719137 .4580993652 138.3724975586139 .2868041992140 .2012023926141 .4203033447142 .6394042969 143.5538024902144 .7729034424145 .6873016357146 .2969055176146 .9064025879 147.2111968994147 .5160064697147 .8208007812147 .8208007812147 .8208007812 147.2111968994146 .6015930176145 .9920959473145 .0776977539144 .1634063721 143.2489929199142 .3347015381141 .1154937744140 .2012023926139 .2868041992 138.3724975586137 .4580993652136 .5437011719135 .6293945312135 .0198059082 134.4102020264133 .4958953857132 .8863067627131 .6672058105130 .4479980469 128.9241027832127 .4001998901125 .5715026855127 .0953979492126 .1809997559 124.9618988037123 .7427978516122 .8283996582118 .8662033081118 .2565994263 117.647102356117 .0374984741116 .4279022217115 .818397522115 .2088012695 114.5991973877113 .6848983765113 .075302124112 .1608963013111 .551399231 110.6370010376109 .7226028442108 .8082962036107 .5891036987106 .6747970581 105.4557037354104 .5412979126103 .3221969604102 .4077987671101 .4934005737 100.8839035034100 .5791015625101 .1886978149102 .1029968262101 .7982025146 100.579101562598 .445587158296 .0073165893694 .1785964965892 .95947265625 
92.6546783447393 .5690307617295 .397743225196 .9216690063597 .22646331787 97.2264633178796.9216690063596.3121032714896.0073165893695.70252990723 95.397743225195 .0929565429794 .7881774902394 .4833908081194 .17859649658 93.8738174438593 .5690307617293 .5690307617293 .5690307617293 .56903076172 93.5690307617293 .5690307617293 .8738174438594 .4833908081194 .78817749023 95.397743225196 .3121032714897 .2264633178798 .1408081054799 .05516815186 100.2742996216101 .4934005737102 .4077987671102 .712600708103 .0174026489 103.3221969604103 .3221969604103 .3221969604103 .0174026489103 .0174026489 102.712600708102 .4077987671102 .4077987671102 .1029968262102 .1029968262 101.7982025146101 .7982025146101 .7982025146101 .7982025146101 .7982025146 101.7982025146101 .7982025146101 .7982025146101 .7982025146101 .7982025146 101.7982025146101 .7982025146101 .7982025146102 .1029968262102 .1029968262 102.1029968262102 .4077987671102 .4077987671102 .712600708102 .712600708 103.0174026489103 .0174026489103 .3221969604103 .3221969604103 .3221969604 103.3221969604103 .0174026489102 .712600708102 .4077987671102 .1029968262 101.4934005737101 .1886978149100 .8839035034100 .2742996216103 .3221969604 103.9317016602104 .2365036011104 .5412979126104 .8460998535104 .8460998535 104.8460998535104 .8460998535104 .5412979126104 .2365036011103 .6268997192 100.5791015625101 .1886978149102 .1029968262103 .3221969604104 .8460998535 107.2844009399 110.9418029785116.4279022217124.9618988037138.0677032471 153.0021057129168 .241394043182 .261505127194 .7577056885205 .7299957275 208.7778015137208 .7778015137208 .7778015137208 .7778015137208 .7778015137 208.7778015137208 .7778015137208 .7778015137208 .7778015137208 .7778015137 208.7778015137 208.7778015137208.7778015137 208.7778015137 208.7778015137 208.7778015137 208.7778015137208.7778015137 208.7778015137 208.7778015137 208.7778015137 208.7778015137208.7778015137208.7778015137 208.7778015137 208.7778015137208 .7778015137208 .7778015137208 .7778015137208 .7778015137 208.7778015137208 .7778015137208 .7778015137208 .7778015137208 .7778015137 208.7778015137208 .7778015137208 .7778015137208 .7778015137208 .7778015137 73.75800323486 -6.5458741188 -9999 -9999 -9999 -9999 -9999 -9999 -9999 -9999 -9999 -9999 $-9999$

-9999 -9999 -9999 -9999 -9999 -9999 -9999 -9999 -9999 -9999 -9999 -9999 -9999 -9999 -9999 -9999 -9999 -9999 -9999 -9999 -9999 -9999 -9999 -9999 -9999 -9999 -9999 -9999 -9999 -9999 -9999 -9999 -9999 -9999 -9999 -9999 -9999 -9999 -9999 -9999 -9999 -9999 -9999 -9999 -9999 -9999 -9999 -9999 -9999 -9999 -9999 -9999 -9999 -9999 -9999 -9999 -9999 -9999 -9999 -9999 -9999 -9999 -9999 -9999 -9999 -9999 -9999 -9999 -9999 -9999 -9999 -9999 -9999 -9999 -9999

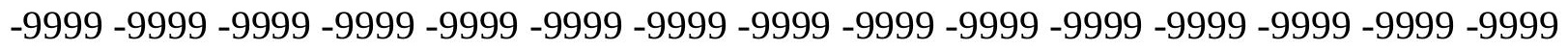
-9999 -9999 -9999 -9999 -9999 -9999 -9999 -9999-9999-9999-9999 171.5939941406 159.4026031494158 .7929992676158 .7929992676159 .0977935791159 .4026031494 160.0122070312160 .9264984131161 .8408966064163 .0599975586164 .2792053223 165.8031005859167 .6318054199168 .8509979248170 .070098877170 .3748931885 169.4604949951167 .9365997314166 .1078948975165 .8031005859167 .0222015381 169.1557006836171 .2891998291173 .1179962158169 .4604949951167 .3269958496 165.8031005859165 .4983062744166 .7174987793167 .6318054199165 .4983062744 159.4026031494153 .3069000244152 .3925933838154 .5260925293156 .9642944336 158.7929992676159 .7073974609159 .4026031494157 .878692627155 .7451934814 
153.0021057129150 .2590942383147 .5160064697144 .7729034424142 .6394042969 140.2012023926138 .0677032471136 .2389984131135 .0198059082135 .0198059082 135.3246002197136 .2389984131136 .8484954834137 .7628936768138 .6772003174 139.8963928223141 .1154937744142 .3347015381143 .5538024902144 .7729034424 145.9920959473146 .9064025879147 .5160064697148 .1255950928148 .4304046631 148.4304046631148 .4304046631148 .4304046631148 .1255950928147 .8208007812 147.2111968994146 .2969055176145 .3825073242144 .4682006836143 .5538024902 142.6394042969141 .4203033447140 .5059967041139 .5915985107138 .6772003174 137.7628936768136 .8484954834136 .2389984131135 .3246002197134 .7149963379 134.1054992676133 .1911010742132 .5814971924131 .0576019287129 .533706665 127.7050018311126 .1809997559124 .6570968628126 .1809997559125 .2667007446 124.0475006104122 .8283996582118 .8662033081118 .2565994263117 .647102356 116.7326965332116 .1231002808115 .5136032104114 .9039993286114 .2944030762 113.3800964355112 .7705001831111 .8561019897111 .24659729110 .3321990967 109.4179000854 108.5035018921 107.2844009399 106.3700027466105.1509017944 104.2365036011103 .0174026489102 .1029968262101 .1886978149100 .2742996216 99.96952056885101 .4934005737103 .0174026489103 .3221969604101 .7982025146 99.3599472045997 .2264633178795 .397743225194 .4833908081194 .17859649658 95.0929565429796 .0073165893696 .9216690063597 .2264633178797 .22646331787 96.9216690063596 .3121032714896 .0073165893695 .397743225195 .09295654297 94.7881774902394 .4833908081194 .1785964965893 .8738174438593 .56903076172 93.5690307617293 .5690307617293 .5690307617293 .5690307617293 .56903076172 93.8738174438594 .4833908081194 .7881774902395 .397743225196 .00731658936 96.9216690063597 .8360290527398 .7503814697399 .66472625732100 .8839035034 102.1029968262103 .0174026489103 .3221969604103 .6268997192103 .6268997192 103.6268997192103 .6268997192103 .6268997192103 .3221969604103 .0174026489 103.0174026489102 .712600708102 .4077987671102 .4077987671102 .4077987671 102.1029968262102 .1029968262102 .1029968262102 .1029968262102 .1029968262 102.1029968262101 .7982025146101 .7982025146101 .7982025146101 .7982025146 101.7982025146101 .7982025146102 .1029968262102 .1029968262102 .1029968262 102.1029968262102 .1029968262102 .4077987671102 .4077987671102 .712600708 102.712600708103 .0174026489103 .0174026489103 .0174026489103 .0174026489 102.712600708102 .712600708102 .4077987671102 .1029968262101 .7982025146 101.4934005737101 .1886978149100 .8839035034100 .8839035034103 .9317016602 104.2365036011104 .5412979126104 .8460998535105 .1509017944105 .1509017944 104.8460998535101 .7982025146102 .4077987671102 .712600708103 .0174026489 103.0174026489103 .3221969604103 .9317016602104 .8460998535106 .6747970581 109.4179000854113 .3800964355119 .1709976196133 .4958953857149 .0399017334 164.2792053223178 .9089050293191 .7097930908203 .2917022705208 .7778015137 208.7778015137208 .7778015137208 .7778015137208 .7778015137208 .7778015137 208.7778015137208 .7778015137208 .7778015137208 .7778015137208 .7778015137 208.7778015137208.7778015137208.7778015137208.7778015137 208.7778015137 208.7778015137208 .7778015137208 .7778015137208 .7778015137208 .7778015137 208.7778015137208 .7778015137208 .7778015137208 .7778015137208 .7778015137 208.7778015137208 .7778015137208 .7778015137208 .7778015137208 .7778015137 208.7778015137 208.7778015137208.7778015137208.7778015137 208.7778015137 
208.7778015137208.7778015137208.7778015137208.7778015137 73.14842987061 2.046618461609 -9999 -9999 -9999 -9999 -9999 -9999 -9999 -9999 -9999 -9999 -9999 -9999 -9999 -9999 -9999 -9999 -9999 -9999 -9999 -9999 -9999 -9999 -9999 -9999 -9999 -9999 -9999 -9999 -9999 -9999 -9999 -9999 -9999 -9999 -9999 -9999 -9999 -9999 -9999 -9999 -9999 -9999 -9999 -9999 -9999 -9999 -9999 -9999 -9999 -9999 -9999 -9999 -9999 -9999 -9999 -9999 -9999 -9999 -9999 -9999 -9999 -9999 -9999 -9999 -9999 -9999 -9999 -9999 -9999 -9999 -9999 -9999 -9999 -9999 -9999 -9999 -9999 -9999 -9999 -9999 -9999 -9999 -9999 -9999 -9999 -9999

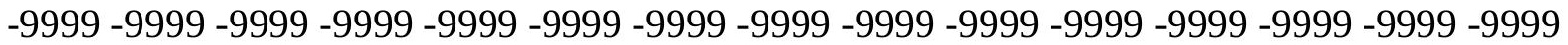
-9999 -9999 -9999 -9999 -9999 -9999 -9999 -9999 -9999 -9999 -9999 -9999 163.3648071289 161.8408966064160 .9264984131160 .0122070312159 .7073974609160 .3170013428 161.2312927246162 .1457061768163 .0599975586164 .5839996338166 .1078948975 167.9365997314169 .7653045654171 .2891998291172 .2035980225171 .5939941406 168.8509979248165 .8031005859164 .2792053223167 .0222015381170 .070098877 170.3748931885168 .5462036133168 .5462036133168 .241394043166 .4127044678 165.8031005859169 .4604949951173 .7274932861174 .6419067383165 .4983062744 154.8307952881158 .1835021973161 .5361022949163 .974395752165 .4983062744 165.4983062744164 .5839996338162 .1457061768158 .7929992676155 .4403991699 151.7830047607148 .7351074219145 .6873016357143 .5538024902141 .1154937744 139.2868041992137 .1533050537135 .3246002197135 .9342041016136 .5437011719 137.1533050537138 .0677032471138 .9819946289139 .8963928223141 .1154937744 142.3347015381143 .8585968018145 .0776977539146 .6015930176147 .8208007812 148.7351074219149 .3446960449149 .6495056152149 .6495056152149 .6495056152 149.3446960449149 .0399017334148 .7351074219148 .1255950928147 .5160064697 146.6015930176145 .6873016357144 .7729034424143 .8585968018142 .6394042969 141.7250976562140 .8106994629139 .8963928223138 .9819946289138 .0677032471 137.1533050537136 .2389984131135 .6293945312135 .0198059082134 .1054992676 133.4958953857132 .5814971924131 .3623962402129 .8385009766128 .3144989014 126.4858016968124 .9618988037123 .43800354125 .2667007446124 .0475006104 120.0852966309119 .1709976196118 .2565994263117 .342300415116 .7326965332 116.1231002808115 .5136032104114 .5991973877113 .9896011353113 .075302124 112.4656982422111 .551399231110 .9418029785110 .0273971558109 .1130981445 107.8938980103106 .979598999106 .0652008057104 .8460998535103 .9317016602 102.712600708101 .7982025146100 .8839035034100 .2742996216100 .5791015625 101.4934005737103 .3221969604104 .8460998535102 .102996826299 .66472625732 97.5312423706196 .0073165893695 .397743225195 .0929565429795 .70252990723 96.3121032714896 .6168823242296 .9216690063596 .9216690063596 .31210327148 96.0073165893695 .397743225195 .0929565429794 .7881774902394 .17859649658 93.8738174438593 .5690307617293 .2642517089893 .2642517089893 .26425170898 93.2642517089893 .2642517089893 .5690307617293 .8738174438594 .17859649658 94.4833908081195 .0929565429795 .7025299072396 .6168823242297 .22646331787 98.1408081054799 .05516815186100 .2742996216101 .1886978149102 .4077987671 103.3221969604103 .6268997192103 .9317016602103 .9317016602103 .9317016602 103.9317016602103 .9317016602103 .6268997192103 .3221969604103 .3221969604 103.0174026489103 .0174026489102 .712600708102 .712600708102 .712600708 102.4077987671102 .4077987671102 .4077987671102 .4077987671102 .4077987671 102.1029968262102 .1029968262102 .1029968262102 .1029968262102 .1029968262 
102.1029968262102 .1029968262102 .1029968262102 .1029968262102 .1029968262 102.1029968262102 .1029968262102 .1029968262102 .4077987671102 .4077987671 102.712600708102 .712600708102 .712600708102 .712600708102 .712600708 102.4077987671102 .4077987671102 .4077987671102 .1029968262102 .1029968262 101.7982025146101 .7982025146101 .4934005737101 .4934005737101 .4934005737 104.8460998535104 .8460998535102 .1029968262102 .712600708103 .3221969604 103.9317016602104 .8460998535105 .1509017944105 .1509017944104 .8460998535 104.5412979126104 .8460998535105 .4557037354106 .979598999109 .4179000854 113.6848983765121 .3044967651133 .1911010742147 .5160064697162 .7552947998 177.0802001953190 .1858978271201 .4629974365208 .7778015137208 .7778015137 208.7778015137208 .7778015137208 .7778015137208 .7778015137208 .7778015137 208.7778015137208 .7778015137208 .7778015137208 .7778015137208 .7778015137 208.7778015137208 .7778015137208 .7778015137208 .7778015137208 .7778015137 208.7778015137208 .7778015137208 .7778015137208 .7778015137208 .7778015137 208.7778015137208 .7778015137208 .7778015137208 .7778015137208 .7778015137 208.7778015137208 .7778015137208 .7778015137208 .7778015137208 .7778015137 208.7778015137208 .7778015137208 .7778015137208 .7778015137208 .7778015137 208.7778015137208 .7778015137208 .777801513772 .2340774536125 .39673423767 -9999 -9999 -9999 -9999 -9999 -9999 -9999 -9999 -9999 -9999 -9999

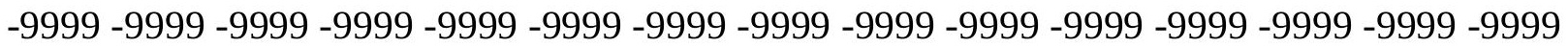

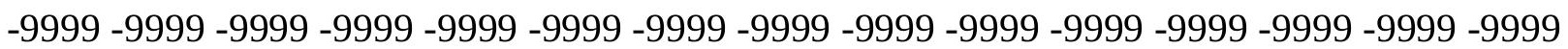

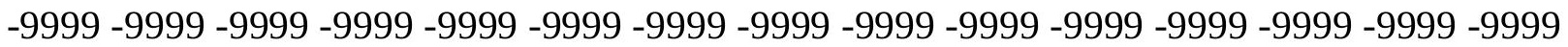

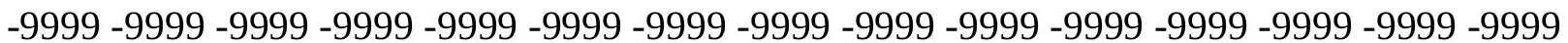

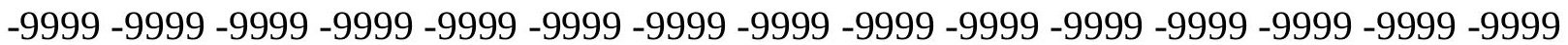
-9999-9999 -9999 -9999 -9999 -9999 -9999 -9999 -9999 -9999 -9999 -9999 -9999 -9999 -9999 162.7552947998162 .1457061768161 .5361022949161 .5361022949161 .5361022949 162.1457061768163 .0599975586164 .2792053223166 .1078948975167 .9365997314 170.3748931885172 .5084075928174 .337097168174 .337097168171 .2891998291 166.1078948975161 .2312927246167 .0222015381172 .2035980225170 .9844970703 170.3748931885169 .9862365723169 .4749755859169 .0083770752169 .8164672852 172.6474914551175 .5208129883175 .0778961182169 .985168457164 .8056488037 164.422668457166 .5897674561168 .6522521973169 .6343231201169 .2721099854 167.643157959164 .8341217041161 .2169647217157 .2922363281153 .3069000244 149.9542999268147 .2111968994145 .0776977539143 .2489929199141 .7250976562 140.2012023926138 .9819946289138 .6470336914138 .9819946289139 .5915985107 139.8963928223140 .5059967041141 .4203033447142 .3347015381143 .8585968018 145.3825073242147 .2111968994148 .7351074219149 .6495056152150 .5639038086 151.1734008789151 .4781951904151 .1734008789150 .8686065674150 .5639038086 149.9542999268149 .0399017334148 .4304046631147 .8208007812146 .9064025879 145.9920959473145 .0776977539143 .8585968018142 .9441986084142 .0299072266 140.8106994629139 .8963928223138 .9819946289138 .0677032471137 .4580993652 136.5437011719135 .6293945312135 .0198059082134 .4102020264133 .4958953857 132.5814971924131 .3623962402129 .8385009766128 .6192932129126 .7906036377 125.2667007446124 .0475006104122 .5235977173121 .3044967651123 .1332015991 119.1709976196118 .2565994263117 .342300415116 .7326965332115 .818397522 
115.2088012695114 .5991973877113 .6848983765113 .075302124112 .1608963013 111.24659729110 .3321990967109 .7226028442108 .8082962036107 .5891036987 106.6747970581105 .7603988647104 .8460998535103 .6268997192102 .712600708 101.7982025146100 .8839035034100 .5791015625100 .5791015625101 .1886978149 102.1029968262102 .1029968262100 .579101562598 .7503814697397 .22646331787 96.3121032714895 .7025299072395 .7025299072395 .7025299072396 .00731658936 96.3121032714896 .3121032714896 .0073165893695 .7025299072395 .09295654297 94.7881774902394 .4833908081193 .8738174438593 .5690307617293 .26425170898 92.9594726562592 .9594726562592 .6546783447392 .9594726562592 .95947265625 93.2642517089893 .5690307617293 .8738174438594 .1785964965894 .78817749023 95.397743225196 .0073165893696 .9216690063597 .5312423706198 .4455871582 99.35994720459100 .5791015625101 .4934005737102 .4077987671103 .0174026489 103.6268997192103 .9317016602104 .2365036011104 .2365036011104 .2365036011 103.9317016602103 .9317016602103 .6268997192103 .6268997192103 .3221969604 103.3221969604103 .0174026489103 .0174026489103 .0174026489103 .0174026489 102.712600708102 .712600708102 .712600708102 .712600708102 .4077987671 102.4077987671102 .4077987671102 .1029968262102 .1029968262102 .1029968262 102.1029968262101 .7982025146101 .7982025146101 .7982025146101 .7982025146 101.7982025146101 .7982025146102 .1029968262102 .1029968262102 .1029968262 102.4077987671102 .4077987671102 .4077987671102 .4077987671102 .4077987671 102.4077987671102 .4077987671102 .4077987671102 .4077987671102 .4077987671 102.4077987671102 .4077987671102 .4077987671102 .712600708103 .0174026489 103.3221969604103 .6268997192104 .2365036011104 .8460998535105 .7603988647 106.6747970581107 .2844009399106 .6747970581106 .0652008057105 .7603988647 105.7603988647106 .6747970581108 .1986999512111 .24659729116 .1231002808 124.0475006104135 .3246002197148 .4304046631162 .7552947998176 .7754058838 189.5764007568200 .8533935547208 .7778015137208 .7778015137208 .7778015137 208.7778015137208 .7778015137208 .7778015137208 .7778015137208 .7778015137 208.7778015137208 .7778015137208 .7778015137208 .7778015137208 .7778015137 208.7778015137208.7778015137208.7778015137208.7778015137208.7778015137 208.7778015137208 .7778015137208 .7778015137208 .7778015137208 .7778015137 208.7778015137208 .7778015137208 .7778015137208 .7778015137208 .7778015137 208.7778015137 208.7778015137208.7778015137 208.7778015137 208.7778015137 208.7778015137208 .7778015137208 .7778015137208 .7778015137208 .7778015137 208.7778015137208 .777801513771 .6244964599672 .23407745361 -9999 -9999 -9999 -9999 -9999 -9999 -9999 -9999 -9999 -9999 -9999 -9999 -9999 -9999 -9999 -9999 -9999 -9999 -9999 -9999 -9999 -9999 -9999 -9999 -9999 - 9999 -

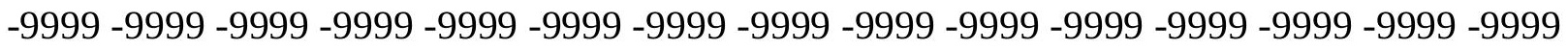
-9999 -9999 -9999 -9999 -9999 -9999 -9999 -9999 -9999 -9999 -9999 -9999 -9999 -9999 -9999 -9999 -9999 -9999 -9999 -9999 -9999 -9999 -9999 -9999 -9999 -9999 -9999 -9999 -9999 -9999 -

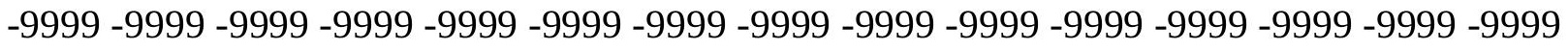

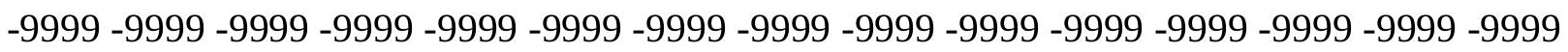
-9999 -9999 -9999 -9999 -9999 -9999 -9999 -9999 -9999 -9999 -9999 -9999 -9999 -9999 -9999 -9999 163.0599975586163.0599975586163.3648071289163.974395752 164.5839996338 165.4983062744166 .7174987793168 .5462036133170 .6797027588173 .4226989746 175.8609924316177 .6896972656177 .0802001953170 .070098877167 .0597991943 
169.0326843262172 .4729919434173 .8928985596173 .6783294678172 .921295166 172.2697296143172 .183303833173 .1512298584175 .014465332176 .6226043701 176.2840118408173 .9907684326171 .6216125488170 .6355133057171 .3750610352 172.341293335172 .5757598877171 .6975097656169 .6308441162166 .5845184326 162.885345459158 .9281158447155 .1356048584151 .4781951904149 .0399017334 147.3606872559 $145.8447723389144 .5696105957143 .4678344727142 .6632995605-9999$ -9999 -9999 -9999 -9999 -9999 -9999 -9999 -9999 -9999 -9999 -9999 -9999 -9999 -9999 -9999 -9999 -9999 150.8686065674149 .9542999268149 .0399017334148 .1255950928 149.9542999268145 .9920959473145 .0776977539144 .1634063721142 .9441986084 142.0299072266141 .1154937744139 .8963928223138 .9819946289138 .3724975586 137.4580993652136 .5437011719135 .9342041016135 .0198059082134 .1054992676 133.4958953857132 .2767028809131 .3623962402130 .1432037354128 .6192932129 127.0953979492125 .5715026855124 .3523025513122 .8283996582124 .6570968628 123.7427978516122 .5235977173118 .2565994263117 .342300415116 .7326965332 115.818397522114 .9039993286114 .2944030762113 .3800964355112 .7705001831 111.8561019897110 .9418029785110 .0273971558109 .1130981445108 .1986999512 107.2844009399 106.3700027466105.4557037354104.5412979126103.3221969604 102.4077987671101 .4934005737100 .8839035034100 .2742996216100 .2742996216 100.274299621699 .9695205688599 .3599472045998 .14080810547100 .2742996216 99.6647262573296 .0073165893695 .7025299072395 .7025299072395 .70252990723 96.0073165893696 .0073165893695 .7025299072395 .0929565429794 .78817749023 94.1785964965893 .5690307617293 .2642517089892 .6546783447392 .3498916626 92.349891662692 .349891662692 .0450973510792 .349891662692 .3498916626 92.65467834473 92.95947265625 93.2642517089893.8738174438594.17859649658 94.7881774902395 .7025299072396 .3121032714897 .2264633178797 .83602905273 98.7503814697399 .66472625732100 .5791015625101 .4934005737102 .4077987671 103.0174026489103 .6268997192103 .9317016602103 .9317016602104 .2365036011 104.2365036011104 .2365036011103 .9317016602103 .9317016602103 .9317016602 103.6268997192103 .6268997192103 .6268997192103 .3221969604103 .3221969604 103.3221969604103 .3221969604103 .0174026489103 .0174026489103 .0174026489 102.712600708102 .712600708102 .712600708102 .4077987671102 .4077987671 102.1029968262102 .1029968262101 .7982025146101 .7982025146101 .7982025146 101.7982025146101 .7982025146101 .7982025146101 .7982025146101 .7982025146 101.7982025146102 .1029968262102 .1029968262102 .1029968262102 .4077987671 102.4077987671102 .712600708102 .712600708102 .712600708103 .0174026489 103.0174026489103 .0174026489103 .3221969604103 .6268997192103 .6268997192 103.9317016602104 .5412979126104 .8460998535105 .4557037354106 .0652008057 106.979598999107 .5891036987107 .8938980103107 .5891036987106 .979598999 106.6747970581106 .6747970581107 .5891036987109 .7226028442113 .3800964355 118.8662033081127 .0953979492138 .0677032471150 .5639038086164 .2792053223 177.6896972656189 .8811035156200 .8533935547208 .7778015137208 .7778015137 208.7778015137208.7778015137208.7778015137208.7778015137208.7778015137 208.7778015137208 .7778015137208 .7778015137208 .7778015137208 .7778015137 208.7778015137208 .7778015137208 .7778015137208 .7778015137208 .7778015137 208.7778015137208 .7778015137208 .7778015137208 .7778015137208 .7778015137 208.7778015137208.7778015137208.7778015137208.7778015137 208.7778015137 
208.7778015137208 .7778015137208 .7778015137208 .7778015137208 .7778015137 208.7778015137208 .7778015137208 .7778015137208 .7778015137208 .7778015137 208.7778015137 208.7778015137 208.7778015137 70.71015167236 71.31971740723 -9999 -9999 -9999 -9999 -9999 -9999 -9999 -9999 -9999 -9999 -9999 -9999 -9999 -9999 -9999 -9999 -9999 -9999 -9999 -9999 -9999 -9999 -9999 -9999 -9999 - -9999 -9999 -9999 -9999 -9999 -9999 -9999 -9999 -9999 -9999 -9999 -9999 -9999 -9999 -9999 -9999 -9999 -9999 -9999 -9999 -9999 -9999 -9999 -9999 -9999 -9999 -9999 -9999 -9999 -9999 -9999

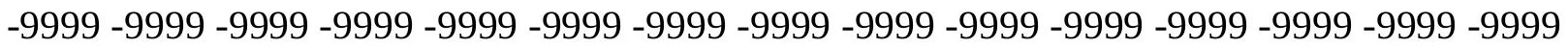

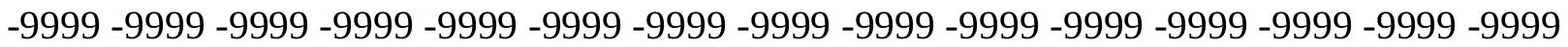
-9999 -9999 -9999 -9999 -9999 -9999 -9999 -9999 -9999 -9999 -9999 -9999 -9999 -9999 -9999 -9999 -9999 -9999 -9999 -9999 -9999 -9999 -9999 -9999 -9999 -9999 -9999 -9999 -9999 -9999 -9999 -9999 -9999 -9999-9999 166.4127044678 167.6318054199169 .1557006836 170.9844970703173 .4226989746176 .165802002178 .604095459179 .3710784912 177.4883270264173 .4899902344171 .2674865723 -9999 -9999 -9999 -9999 -9999 -9999 -9999 -9999 -9999 -9999 -9999 -9999 -9999 -9999 -9999 -9999 -9999 -9999 -9999 -9999 -9999 -9999 -9999 -9999 -9999 -9999 -9999 -9999 -9999 -9999 -9999 -9999 -9999 -9999 -9999 -9999 -9999 -9999 -9999 -9999 -9999 -9999 -9999 -9999 -9999 -9999 -9999 -9999 -9999 -9999 149.6495056152148 .4304046631147 .5160064697146 .2969055176145 .0776977539 144.1634063721142 .9441986084142 .0299072266141 .1154937744140 .2012023926 138.9819946289138 .3724975586137 .4580993652136 .5437011719135 .6293945312 135.0198059082134 .1054992676133 .1911010742132 .2767028809131 .3623962402 130.1432037354128 .9241027832127 .4001998901125 .8762969971124 .6570968628 126.1809997559124 .9618988037123 .7427978516119 .4757995605118 .5614013672 117.647102356116 .7326965332115 .818397522114 .9039993286113 .9896011353 113.075302124112 .1608963013111 .551399231110 .6370010376109 .7226028442 108.8082962036107 .8938980103106 .979598999106 .0652008057105 .1509017944 104.2365036011103 .3221969604102 .4077987671101 .4934005737100 .5791015625 99.9695205688599 .6647262573299 .0551681518698 .4455871582100 .8839035034 100.8839035034100 .579101562599 .9695205688599 .3599472045995 .70252990723 95.7025299072395 .7025299072395 .7025299072395 .397743225194 .78817749023 94.1785964965893 .5690307617292 .9594726562592 .349891662691 .74033355713 91.4355392456191 .4355392456191 .4355392456191 .4355392456191 .43553924561 91.7403335571391 .7403335571392 .349891662692 .6546783447393 .26425170898 93.5690307617294 .4833908081195 .0929565429795 .7025299072396 .61688232422 97.2264633178798 .1408081054798 .7503814697399 .66472625732100 .5791015625 101.4934005737102 .1029968262102 .712600708103 .3221969604103 .6268997192 103.9317016602103 .9317016602104 .2365036011104 .2365036011104 .2365036011 103.9317016602103 .9317016602103 .9317016602103 .9317016602103 .9317016602 103.6268997192103 .6268997192103 .6268997192103 .6268997192103 .6268997192 103.3221969604103 .3221969604103 .3221969604103 .0174026489103 .0174026489 102.712600708102 .4077987671102 .4077987671102 .1029968262101 .7982025146 101.7982025146101 .7982025146101 .4934005737101 .4934005737101 .4934005737 101.4934005737101 .4934005737101 .4934005737101 .7982025146101 .7982025146 102.1029968262102 .4077987671102 .4077987671102 .712600708103 .0174026489 103.3221969604103 .3221969604103 .6268997192103 .9317016602104 .2365036011 104.2365036011104 .8460998535105 .1509017944105 .4557037354106 .0652008057 
106.3700027466106 .979598999107 .5891036987107 .8938980103107 .8938980103 107.5891036987107 .2844009399106 .979598999107 .2844009399108 .5035018921 110.9418029785114 .9039993286121 .3044967651129 .533706665140 .5059967041 153.0021057129166 .1078948975178 .9089050293190 .795501709200 .8533935547 208.7778015137208 .7778015137208 .7778015137208 .7778015137208 .7778015137 208.7778015137208 .7778015137208 .7778015137208 .7778015137208 .7778015137 208.7778015137208 .7778015137208 .7778015137208 .7778015137208 .7778015137 208.7778015137208 .7778015137208 .7778015137208 .7778015137208 .7778015137 208.7778015137208 .7778015137208 .7778015137208 .7778015137208 .7778015137 208.7778015137 208.7778015137208.7778015137 208.7778015137 208.7778015137 208.7778015137208 .7778015137208 .7778015137208 .7778015137208 .7778015137 208.7778015137208.7778015137208.7778015137208.7778015137 208.7778015137 70.1005783081170 .71015167236 -9999 -9999 -9999 -9999 -9999 -9999 -9999 -9999 -9999 -9999 -9999

-9999 -9999 -9999 -9999 -9999 -9999 -9999 -9999 -9999 -9999 -9999 -9999 -9999 -9999 -9999

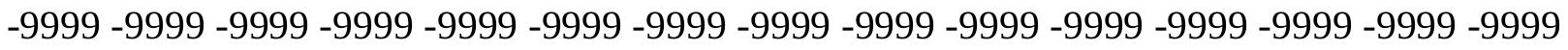
-9999 -9999 -9999 -9999 -9999 -9999 -9999 -9999 -9999 -9999 -9999 -9999 -9999 -9999 -9999 -9999 -9999 -9999 -9999 -9999 -9999 -9999 -9999 -9999 -9999 -9999 -9999 -9999 -9999 -9999 -

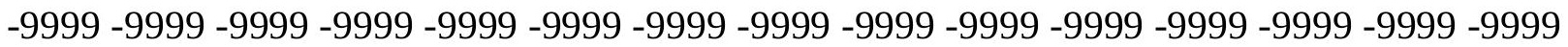

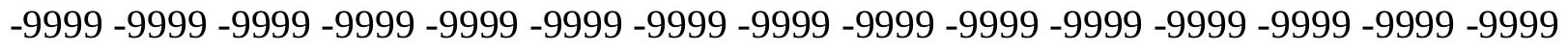

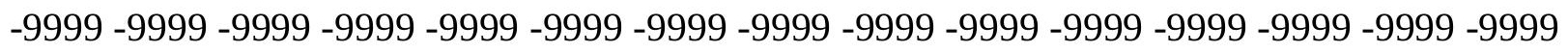

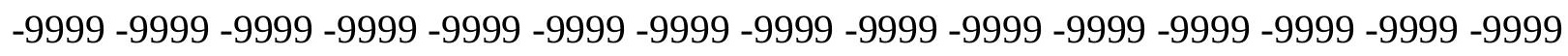
-9999 -9999 -9999 -9999 -9999 -9999 -9999 -9999 -9999 -9999 -9999 -9999 -9999 -9999 -9999 -

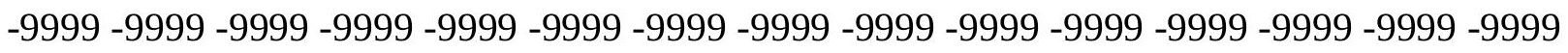

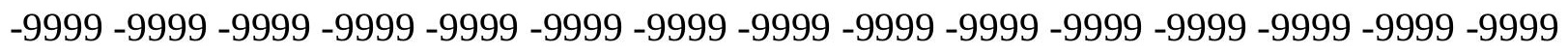
-9999 -9999 -9999 -9999-9999 -9999 -9999 -9999 147.8208007812146 .6015930176 145.3825073242144 .1634063721143 .2489929199142 .0299072266144 .1634063721 139.8963928223138 .9819946289138 .0677032471137 .4580993652136 .5437011719 135.6293945312135 .0198059082134 .1054992676133 .1911010742132 .2767028809 131.3623962402130 .1432037354128 .9241027832127 .7050018311126 .1809997559 124.6570968628126 .4858016968125 .2667007446124 .0475006104119 .7806015015 118.5614013672117 .647102356116 .7326965332115 .5136032104114 .5991973877 113.6848983765112 .7705001831111 .8561019897110 .9418029785110 .0273971558 109.1130981445108 .1986999512107 .5891036987106 .6747970581105 .7603988647 104.8460998535103 .9317016602103 .0174026489102 .1029968262101 .1886978149 100.274299621699 .6647262573299 .0551681518698 .14080810547100 .5791015625 100.5791015625100 .5791015625100 .274299621699 .9695205688599 .35994720459 98.7503814697396 .0073165893695 .7025299072395 .397743225195 .09295654297 94.1785964965893 .2642517089892 .6546783447391 .7403335571391 .13075256348 90.8259735107490 .5211791992290 .5211791992290 .5211791992290 .52117919922 90.8259735107491 .1307525634891 .4355392456191 .7403335571392 .3498916626 92.9594726562593 .5690307617294 .1785964965895 .0929565429795 .70252990723 96.6168823242297 .2264633178798 .1408081054799 .0551681518699 .66472625732 100.5791015625101 .1886978149101 .7982025146102 .4077987671103 .0174026489 103.3221969604103 .6268997192103 .9317016602103 .9317016602103 .9317016602 104.2365036011 104.2365036011 104.2365036011 104.2365036011 103.9317016602 
103.9317016602 103.9317016602 103.9317016602 103.9317016602 103.9317016602 103.9317016602103 .9317016602103 .6268997192103 .6268997192103 .3221969604 103.3221969604103 .0174026489102 .712600708102 .712600708102 .4077987671 102.1029968262101 .7982025146101 .7982025146101 .4934005737101 .4934005737 101.1886978149101 .1886978149101 .1886978149101 .1886978149101 .4934005737 101.7982025146102 .1029968262102 .4077987671102 .712600708103 .0174026489 103.3221969604103 .6268997192103 .9317016602104 .2365036011104 .5412979126 104.8460998535105 .1509017944105 .4557037354106 .0652008057106 .3700027466 106.6747970581 107.2844009399 107.5891036987 107.8938980103107.8938980103 107.8938980103 107.5891036987 107.2844009399 107.2844009399 107.5891036987 109.1130981445111 .551399231116 .1231002808122 .2188034058130 .7528076172 141.7250976562154 .2212982178167 .6318054199180 .1280059814191 .4051055908 200.8533935547208 .7778015137208 .7778015137208 .7778015137208 .7778015137 208.7778015137208 .7778015137208 .7778015137208 .7778015137208 .7778015137 208.7778015137208 .7778015137208 .7778015137208 .7778015137208 .7778015137 208.7778015137208 .7778015137208 .7778015137208 .7778015137208 .7778015137 208.7778015137208 .7778015137208 .7778015137208 .7778015137208 .7778015137 208.7778015137208 .7778015137208 .7778015137208 .7778015137208 .7778015137 208.7778015137208 .7778015137208 .7778015137208 .7778015137208 .7778015137 208.7778015137208 .7778015137208 .7778015137208 .7778015137208 .7778015137 208.777801513769 .4910125732470 .10057830811 -9999 -9999 -9999 -9999 -9999 -9999 -9999 -9999 -9999 -9999 -9999

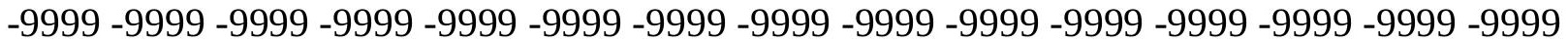

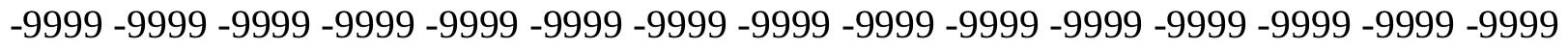

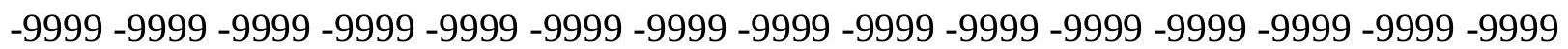

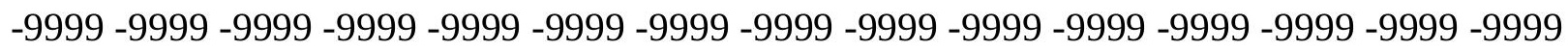

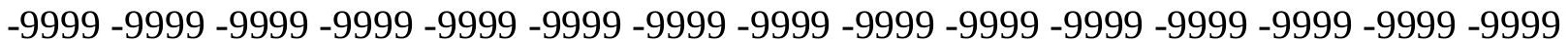

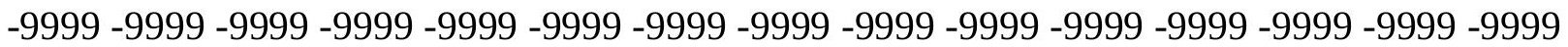

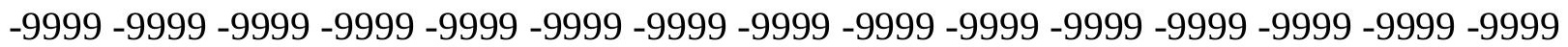

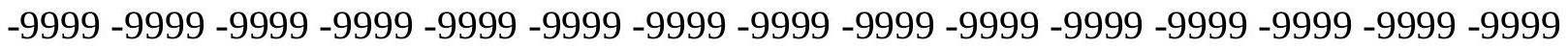

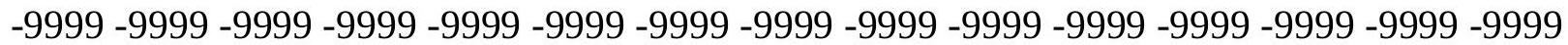

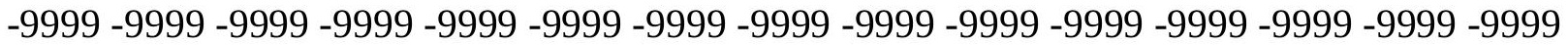

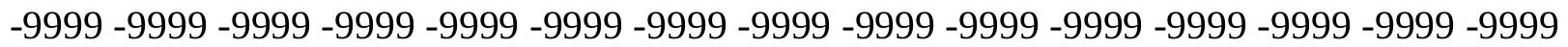
-9999 -9999 -9999 -9999 -9999 -9999 -9999 -9999 -9999 -9999 -9999 144.1634063721 143.2489929199142 .0299072266141 .1154937744139 .8963928223138 .9819946289 138.0677032471137 .1533050537136 .5437011719135 .6293945312134 .7149963379 133.8007049561133 .1911010742132 .2767028809131 .3623962402130 .1432037354 128.9241027832127 .7050018311126 .4858016968128 .3144989014127 .0953979492 125.5715026855124 .0475006104119 .7806015015118 .8662033081117 .647102356 116.7326965332115 .5136032104114 .5991973877113 .3800964355112 .4656982422 111.551399231110 .6370010376109 .7226028442108 .8082962036107 .8938980103 106.979598999 106.0652008057 105.1509017944 104.2365036011 103.3221969604 102.712600708101 .7982025146100 .8839035034100 .274299621699 .35994720459 98.445587158297 .83602905273100 .2742996216100 .2742996216100 .2742996216 99.9695205688599 .6647262573299 .0551681518696 .0073165893696 .00731658936 95.7025299072395 .397743225194 .7881774902393 .8738174438592 .65467834473 
91.4355392456190 .8259735107490 .2164001464889 .6068267822389 .3020401001 89.302040100189 .6068267822389 .9116134643690 .2164001464890 .52117919922 90.8259735107491 .4355392456192 .0450973510792 .6546783447393 .56903076172 94.1785964965895 .0929565429795 .7025299072396 .6168823242297 .22646331787 98.1408081054798 .7503814697399 .66472625732100 .2742996216100 .8839035034 101.4934005737102 .1029968262102 .712600708103 .0174026489103 .3221969604 103.6268997192103 .9317016602103 .9317016602103 .9317016602104 .2365036011 104.2365036011 104.2365036011 104.2365036011 104.2365036011 104.2365036011 104.2365036011104 .2365036011104 .2365036011104 .2365036011104 .2365036011 104.2365036011103 .9317016602103 .9317016602103 .6268997192103 .3221969604 103.3221969604103 .0174026489102 .712600708102 .4077987671102 .1029968262 101.7982025146101 .4934005737101 .1886978149101 .1886978149101 .1886978149 101.1886978149101 .1886978149101 .4934005737101 .4934005737102 .1029968262 102.4077987671102 .712600708103 .3221969604103 .6268997192103 .9317016602 104.5412979126104 .8460998535105 .1509017944105 .4557037354106 .0652008057 106.3700027466106 .6747970581107 .2844009399107 .5891036987107 .8938980103 107.8938980103107 .8938980103107 .8938980103107 .5891036987107 .2844009399 106.979598999106 .979598999107 .5891036987108 .8082962036111 .551399231 115.818397522122 .2188034058130 .4479980469141 .4203033447153 .9165039062 167.6318054199180 .7375946045191 .1002960205199 .329498291206 .9490966797 208.7778015137208 .7778015137208 .7778015137208 .7778015137208 .7778015137 208.7778015137208 .7778015137208 .7778015137208 .7778015137208 .7778015137 208.7778015137208 .7778015137208 .7778015137208 .7778015137208 .7778015137 208.7778015137208 .7778015137208 .7778015137208 .7778015137208 .7778015137 208.7778015137208 .7778015137208 .7778015137208 .7778015137208 .7778015137 208.7778015137208 .7778015137208 .7778015137208 .7778015137208 .7778015137 208.7778015137208 .7778015137208 .7778015137208 .7778015137208 .7778015137 208.7778015137208 .7778015137208 .7778015137208 .777801513768 .88143920898 69.49101257324 -9999 -9999 -9999 -9999 -9999 -9999 -9999 -9999 -9999 -9999 -9999 -9999 -9999 -9999 -9999 -9999 -9999 -9999 -9999 -9999 -9999 -9999 -9999 -9999 -9999 -9999 -9999 -9999 -9999 -9999 -9999 -9999 -9999 -9999 -9999 -9999 -9999 -9999 -9999 -9999 -9999 -9999 -9999 -9999 -9999 -9999 -9999 -9999 -9999 -9999 -9999 -9999 -9999 -9999 -9999 -9999 -9999 -9999 -9999 -9999 -9999 -9999 -9999 -9999 -9999 -9999 -9999 -9999 -9999 -9999 -9999 -9999 -9999 -9999 -9999 -9999 -9999 -9999 -9999 -9999 -9999 -9999 -9999 -9999 -9999 -9999

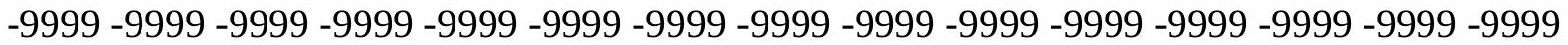
-9999 -9999 -9999 -9999 -9999 -9999 -9999 -9999 -9999 -9999 -9999 -9999 -9999 -9999 -9999 -9999 -9999 -9999 -9999 -9999 -9999 -9999 -9999 -9999 -9999 -9999 -9999 -9999 -9999 -9999

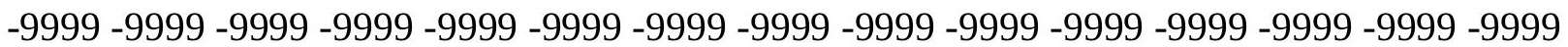
-9999 -9999 -9999 -9999 -9999 -9999 -9999 -9999 -9999 -9999 -9999 -9999 -9999 -9999 -9999 -9999 -9999 -9999 -9999 -9999 -9999 -9999 -9999 -9999 -9999 -9999 -9999 -9999 - -9999 -9999 -9999 -9999 -9999 -9999 -9999 -9999 -9999 -9999 -9999 -9999 -9999 -9999 -9999 -9999 141.1154937744139 .8963928223138 .9819946289138 .0677032471137 .1533050537 139.2868041992135 .3246002197134 .7149963379133 .8007049561132 .8863067627 132.2767028809131 .0576019287130 .1432037354129 .2288970947128 .0097961426 126.7906036377128 .6192932129127 .4001998901125 .8762969971121 .3044967651 120.0852966309118 .8662033081117 .647102356116 .7326965332115 .5136032104 
114.2944030762113 .075302124112 .1608963013110 .9418029785110 .0273971558 109.1130981445108 .1986999512107 .2844009399106 .3700027466105 .4557037354 104.5412979126103 .6268997192103 .0174026489102 .1029968262101 .4934005737 100.579101562599 .9695205688599 .0551681518698 .1408081054797 .53124237061 99.9695205688599 .9695205688599 .6647262573299 .3599472045998 .75038146973 95.7025299072396 .0073165893696 .0073165893695 .7025299072395 .3977432251 94.4833908081193 .2642517089892 .0450973510790 .8259735107489 .91161346436 88.99725341797 88.69246673584 88.38768768311 88.38768768311 88.69246673584 88.9972534179789 .6068267822390 .2164001464890 .5211791992291 .13075256348 92.0450973510792 .6546783447393 .5690307617294 .1785964965895 .09295654297 95.7025299072396 .6168823242297 .2264633178798 .1408081054798 .75038146973 99.3599472045999 .96952056885100 .5791015625101 .1886978149101 .7982025146 102.1029968262102 .712600708103 .0174026489103 .3221969604103 .6268997192 103.6268997192103 .9317016602103 .9317016602104 .2365036011104 .2365036011 104.5412979126104 .5412979126104 .5412979126104 .5412979126104 .8460998535 104.8460998535104 .8460998535104 .8460998535104 .5412979126104 .5412979126 104.2365036011104 .2365036011103 .9317016602103 .6268997192103 .3221969604 103.0174026489102 .712600708102 .4077987671102 .1029968262101 .7982025146 101.4934005737101 .1886978149100 .8839035034100 .8839035034101 .1886978149 101.1886978149101 .4934005737102 .1029968262102 .712600708103 .0174026489 103.6268997192104 .2365036011104 .5412979126105 .1509017944105 .4557037354 105.7603988647106 .3700027466106 .6747970581106 .979598999107 .5891036987 107.8938980103108 .1986999512108 .1986999512108 .1986999512108 .1986999512 107.5891036987 107.2844009399 106.6747970581 106.3700027466 106.3700027466 106.6747970581108 .1986999512110 .6370010376114 .5991973877120 .3900985718 128.6192932129138 .6772003174150 .8686065674164 .8887023926179 .5184020996 188.0523986816195 .9768066406203 .596496582208 .7778015137208 .7778015137 208.7778015137208 .7778015137208 .7778015137208 .7778015137208 .7778015137 208.7778015137208 .7778015137208 .7778015137208 .7778015137208 .7778015137 208.7778015137208 .7778015137208 .7778015137208 .7778015137208 .7778015137 208.7778015137208 .7778015137208 .7778015137208 .7778015137208 .7778015137 208.7778015137208 .7778015137208 .7778015137208 .7778015137208 .7778015137 208.7778015137208 .7778015137208 .7778015137208 .7778015137208 .7778015137 208.7778015137 208.7778015137208.7778015137 208.7778015137 208.7778015137 208.7778015137 208.777801513768 .2718734741268 .88143920898 -9999 -9999 -9999 -9999 -9999 -9999 -9999 -9999 -9999 -9999 -9999 -9999 -9999 -9999 -9999 -9999 -9999 -9999 -9999 -9999 -9999 -9999 -9999 -9999 -9999 - 9999 -

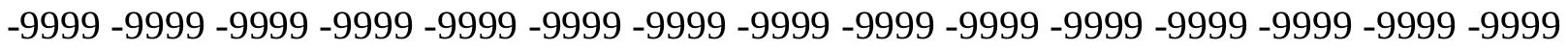
-9999 -9999 -9999 -9999 -9999 -9999 -9999 -9999 -9999 -9999 -9999 -9999 -9999 -9999 -9999

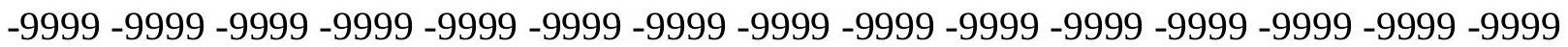

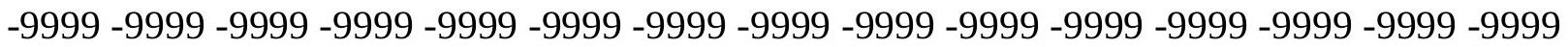
-9999 -9999 -9999 -9999 -9999 -9999 -9999 -9999 -9999 -9999 -9999 -9999 -9999 -9999 -9999 -9999 -9999 -9999 -9999 -9999 -9999 -9999 -9999 -9999 -9999 -9999 -9999 -9999 -9999 -9999 -9999 -9999 -9999 -9999 -9999 -9999 -9999 -9999 -9999 -9999 -9999 -9999 -9999 -9999 -9999 -9999 -9999 -9999 -9999 -9999 -9999 -9999 -9999 -9999 -9999 -9999 -9999 -9999 -9999 -9999 -9999 -9999 -9999 -9999 -9999 -9999 -9999 -9999 -9999 -9999 -9999 -9999 -9999 -9999 -9999 
-9999 -9999 -9999 -9999 -9999 -9999 -9999 -9999 -9999 -9999 -9999 -9999 -9999 -9999 -9999 -9999 -9999 -9999 -9999 -9999 -9999 -9999 -9999 -9999 -9999 -9999 -9999 -9999 -9999 -9999 -9999 138.9819946289138.0677032471 137.1533050537136.2389984131 135.3246002197 134.7149963379133 .8007049561132 .8863067627131 .9720001221131 .0576019287 130.1432037354129 .2288970947128 .3144989014127 .0953979492128 .9241027832 127.7050018311126 .1809997559121 .6092987061120 .3900985718119 .1709976196 117.9517974854116 .4279022217115 .2088012695113 .9896011353112 .7705001831 111.551399231110 .3321990967109 .4179000854108 .1986999512107 .2844009399 106.3700027466105 .4557037354104 .8460998535103 .9317016602103 .0174026489 102.4077987671101 .7982025146100 .8839035034100 .274299621699 .66472625732 98.7503814697398 .1408081054797 .2264633178796 .6168823242299 .35994720459 95.7025299072395 .7025299072395 .7025299072396 .0073165893696 .00731658936 96.0073165893695 .7025299072395 .0929565429794 .1785964965892 .95947265625 91.4355392456189 .9116134643688 .6924667358487 .7781066894587 .47332763672 87.47332763672 87.47332763672 88.08290100098 88.69246673584 89.3020401001 89.9116134643690 .5211791992291 .1307525634891 .7403335571392 .65467834473 93.5690307617294 .1785964965895 .0929565429796 .0073165893696 .61688232422 97.2264633178797 .8360290527398 .445587158299 .0551681518699 .66472625732 100.2742996216100 .8839035034101 .1886978149101 .7982025146102 .1029968262 102.712600708103 .0174026489103 .3221969604103 .6268997192103 .6268997192 103.9317016602104 .2365036011104 .5412979126104 .5412979126104 .8460998535 104.8460998535105 .1509017944105 .1509017944105 .1509017944105 .1509017944 105.1509017944105 .1509017944105 .1509017944104 .8460998535104 .8460998535 104.5412979126104 .2365036011103 .9317016602103 .6268997192103 .0174026489 102.712600708102 .4077987671101 .7982025146101 .4934005737101 .1886978149 101.1886978149100 .8839035034101 .1886978149101 .1886978149101 .7982025146 102.4077987671103 .0174026489103 .3221969604103 .9317016602104 .5412979126 105.1509017944105 .7603988647106 .0652008057106 .6747970581106 .979598999 107.2844009399107 .5891036987108 .1986999512108 .1986999512108 .5035018921 108.5035018921108 .5035018921108 .1986999512107 .5891036987106 .979598999 106.0652008057105 .7603988647105 .4557037354105 .7603988647106 .979598999 109.1130981445112 .4656982422117 .647102356124 .6570968628133 .8007049561 145.0776977539157 .878692627170 .6797027588181 .0424041748190 .4907073975 198.7198944092206 .6443023682208 .7778015137208 .7778015137208 .7778015137 208.7778015137208 .7778015137208 .7778015137208 .7778015137208 .7778015137 208.7778015137208 .7778015137208 .7778015137208 .7778015137208 .7778015137 208.7778015137208 .7778015137208 .7778015137208 .7778015137208 .7778015137 208.7778015137208 .7778015137208 .7778015137208 .7778015137208 .7778015137 208.7778015137208 .7778015137208 .7778015137208 .7778015137208 .7778015137 208.7778015137208 .7778015137208 .7778015137208 .7778015137208 .7778015137 208.7778015137208 .7778015137208 .7778015137208 .7778015137208 .7778015137 208.7778015137 68.27187347412 -9999 -9999 -9999 -9999 -9999 -9999 -9999 -9999 -9999 -9999-9999 -9999 -9999 -9999 -9999 -9999 -9999 -9999 -9999 -9999 -9999 -9999 -9999 -9999 -9999 -9999 -9999 -9999 -9999 -9999 -9999 -9999 -9999 -9999 -9999 -9999 -9999 -9999 -9999 -9999 -9999

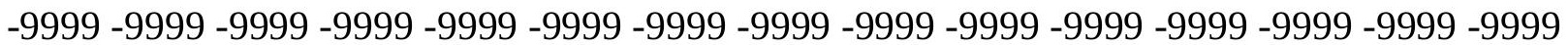


-9999 -9999 -9999 -9999 -9999 -9999 -9999 -9999 -9999 -9999 -9999 -9999 -9999 -9999 -9999 -9999 -9999 -9999 -9999 -9999 -9999 -9999 -9999 -9999 -9999 -9999 -9999 -9999 -9999 -9999

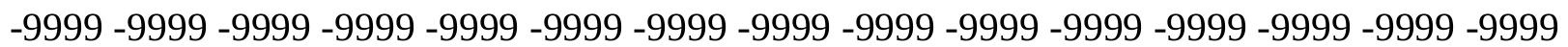
-9999 -9999 -9999 -9999 -9999 -9999 -9999 -9999 -9999 -9999 -9999 -9999 -9999 -9999 -9999 -9999 -9999 -9999 -9999 -9999 -9999 -9999 -9999 -9999 -9999 -9999 -9999 -9999 -9999 -9999 -9999 -9999 -9999 -9999 -9999 -9999 -9999 -9999 -9999 -9999 -9999 -9999 -9999 -9999 -9999 -9999 -9999 -9999 -9999 -9999 -9999 -9999 -9999 -9999 -9999 -9999 -9999 -9999 -9999 -9999

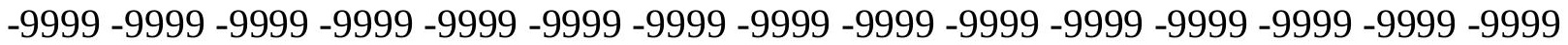
-9999 -9999 -9999 -9999 -9999 -9999 -9999 -9999 -9999 -9999 -9999 -9999 -9999 -9999 -9999 -9999 -9999 -9999 -9999136.5437011719 135.6293945312134.7149963379133.8007049561 132.8863067627131 .9720001221131 .0576019287130 .4479980469129 .2288970947 128.3144989014127 .4001998901129 .2288970947128 .0097961426123 .43800354 122.2188034058120 .6949005127119 .4757995605117 .9517974854116 .4279022217 114.9039993286113 .6848983765112 .1608963013110 .9418029785109 .7226028442 108.5035018921107 .5891036987106 .3700027466105 .4557037354104 .8460998535 103.9317016602103 .0174026489102 .4077987671101 .7982025146101 .1886978149 100.579101562599 .6647262573299 .0551681518698 .445587158297 .83602905273 97.2264633178796 .6168823242296 .3121032714896 .0073165893695 .70252990723 96.0073165893696 .0073165893696 .0073165893696 .0073165893695 .70252990723 94.4833908081193 .2642517089892 .0450973510790 .8259735107488 .69246673584 87.1685485839886 .5589828491286 .254188537686 .5589828491286 .86376190186 87.7781066894588 .3876876831188 .9972534179789 .9116134643690 .52117919922 91.1307525634891 .7403335571392 .6546783447393 .5690307617294 .17859649658 95.0929565429796 .0073165893696 .6168823242297 .2264633178797 .83602905273 98.1408081054798 .7503814697399 .3599472045999 .66472625732100 .2742996216 100.8839035034101 .1886978149101 .7982025146102 .1029968262102 .4077987671 103.0174026489103 .3221969604103 .6268997192103 .9317016602104 .2365036011 104.5412979126104 .8460998535104 .8460998535105 .1509017944105 .4557037354 105.4557037354105 .7603988647105 .7603988647105 .7603988647105 .7603988647 105.7603988647105 .4557037354105 .4557037354105 .1509017944104 .8460998535 104.5412979126103 .9317016602103 .6268997192103 .3221969604102 .712600708 102.4077987671101 .7982025146101 .4934005737101 .1886978149101 .1886978149 101.1886978149101 .4934005737102 .1029968262102 .712600708103 .3221969604 103.9317016602104 .5412979126105 .1509017944105 .7603988647106 .3700027466 106.6747970581107 .2844009399107 .5891036987107 .8938980103108 .1986999512 108.5035018921108 .8082962036108 .8082962036108 .8082962036108 .5035018921 107.8938980103107 .2844009399106 .3700027466105 .4557037354104 .8460998535 104.5412979126104 .5412979126105 .1509017944106 .979598999109 .7226028442 113.9896011353119 .7806015015127 .4001998901137 .1533050537148 .4304046631 160.3170013428172 .2035980225183 .1759033203193 .233795166202 .3773040771 208.7778015137208 .7778015137208 .7778015137208 .7778015137208 .7778015137 208.7778015137208 .7778015137208 .7778015137208 .7778015137208 .7778015137 208.7778015137208 .7778015137208 .7778015137208 .7778015137208 .7778015137 208.7778015137208 .7778015137208 .7778015137208 .7778015137208 .7778015137 208.7778015137208 .7778015137208 .7778015137208 .7778015137208 .7778015137 208.7778015137208.7778015137208.7778015137208.7778015137208.7778015137 
208.7778015137208 .7778015137208 .7778015137208 .7778015137208 .7778015137 208.7778015137208 .7778015137208 .7778015137208 .777801513767 .66230010986 -9999 -9999 -9999 -9999 -9999 -9999 -9999 -9999 -9999 -9999 -9999

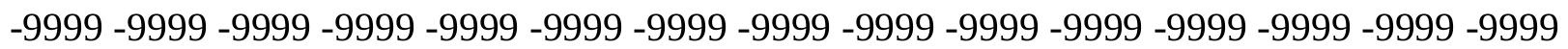

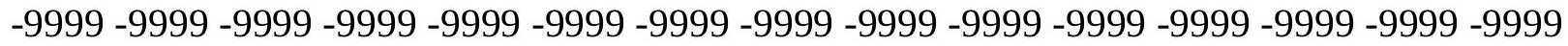

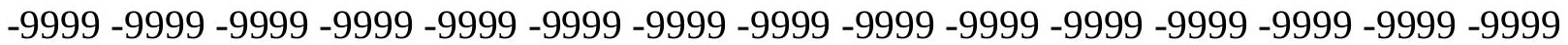

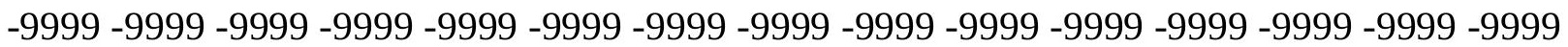

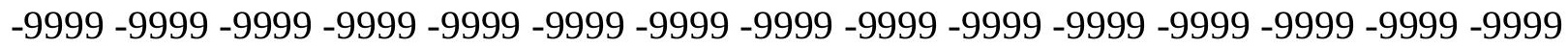

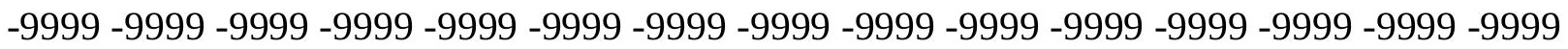

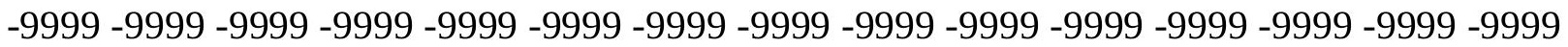

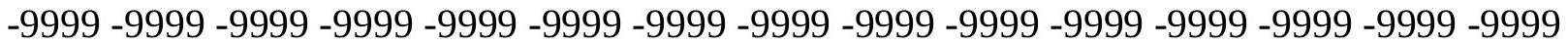

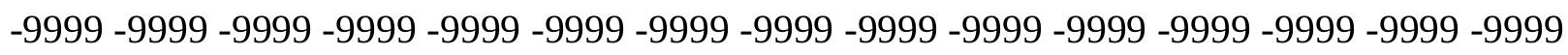

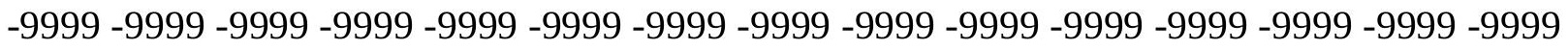

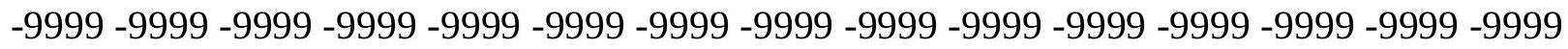

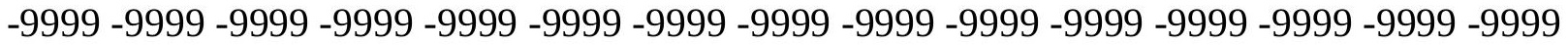
-9999 -9999 -9999 -9999 -9999 -9999 134.7149963379 134.1054992676 133.1911010742 132.2767028809131 .3623962402130 .4479980469129 .533706665128 .6192932129 127.4001998901126 .4858016968125 .2667007446124 .0475006104122 .5235977173 120.9997024536119 .4757995605117 .9517974854116 .1231002808114 .5991973877 113.075302124111 .551399231110 .0273971558108 .8082962036107 .5891036987 106.3700027466105 .4557037354104 .5412979126103 .6268997192103 .0174026489 102.4077987671101 .4934005737100 .8839035034100 .579101562599 .96952056885 99.3599472045998.7503814697398.1408081054797.5312423706197.22646331787 96.6168823242296 .3121032714896 .0073165893695 .7025299072395 .70252990723 95.7025299072395 .7025299072395 .397743225194 .7881774902393 .56903076172 92.0450973510790 .5211791992288 .3876876831186 .5589828491285 .33984375 85.03504943848 85.33984375 85.9494018554786.86376190186 87.77810668945 88.3876876831189 .302040100189 .9116134643690 .8259735107491 .43553924561 92.0450973510792 .6546783447393 .5690307617294 .1785964965895 .09295654297 96.0073165893696 .6168823242297 .2264633178797 .5312423706197 .83602905273 98.445587158298 .7503814697399 .3599472045999 .66472625732100 .2742996216 100.5791015625101 .1886978149101 .7982025146102 .1029968262102 .4077987671 103.0174026489103 .3221969604103 .6268997192104 .2365036011104 .5412979126 104.8460998535105 .1509017944105 .4557037354105 .7603988647106 .0652008057 106.0652008057 106.3700027466 106.3700027466 106.3700027466 106.3700027466 106.3700027466106 .0652008057105 .7603988647105 .4557037354105 .1509017944 104.5412979126104 .2365036011103 .6268997192103 .3221969604103 .0174026489 102.4077987671102 .1029968262101 .7982025146101 .4934005737101 .4934005737 101.7982025146102 .4077987671103 .3221969604103 .9317016602104 .5412979126 105.1509017944106 .0652008057106 .3700027466106 .979598999107 .5891036987 107.8938980103108 .1986999512108 .5035018921108 .8082962036109 .1130981445 109.1130981445 109.1130981445 109.1130981445 108.8082962036107.8938980103 106.979598999105 .7603988647104 .8460998535103 .9317016602103 .3221969604 103.0174026489103 .3221969604104 .5412979126106 .6747970581109 .7226028442 114.2944030762120 .0852966309128 .0097961426138 .0677032471150 .2590942383 163.3648071289175 .8609924316187 .7476043701198 .1103057861207 .25390625 
208.7778015137208 .7778015137208 .7778015137208 .7778015137208 .7778015137 208.7778015137 208.7778015137208.7778015137208.7778015137 208.7778015137 208.7778015137208 .7778015137208 .7778015137208 .7778015137208 .7778015137 208.7778015137208 .7778015137208 .7778015137208 .7778015137208 .7778015137 208.7778015137208 .7778015137208 .7778015137208 .7778015137208 .7778015137 208.7778015137208 .7778015137208 .7778015137208 .7778015137208 .7778015137 208.7778015137208 .7778015137208 .7778015137208 .7778015137208 .7778015137 208.7778015137208 .7778015137208 .777801513767 .05272674561 -9999 -9999 -9999 -9999 -9999 -9999 -9999 -9999 -9999 -9999 -9999

-9999 -9999 -9999 -9999 -9999 -9999 -9999 -9999 -9999 -9999 -9999 -9999 -9999 -9999 -9999

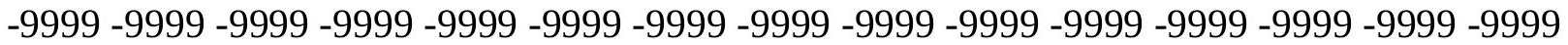
-9999 -9999 -9999 -9999 -9999 -9999 -9999 -9999 -9999 -9999 -9999 -9999 -9999 -9999 -9999 -9999 -9999 -9999 -9999 -9999 -9999 -9999 -9999 -9999 -9999 -9999 -9999 -9999 -9999 -9999 -9999 -9999 -9999 -9999 -9999 -9999 -9999 -9999 -9999 -9999 -9999 -9999 -9999 -9999 -9999 -9999 -9999 -9999 -9999 -9999 -9999 -9999 -9999 -9999 -9999 -9999 -9999 -9999 -9999 -9999

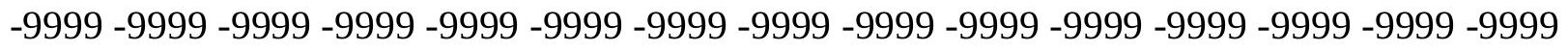

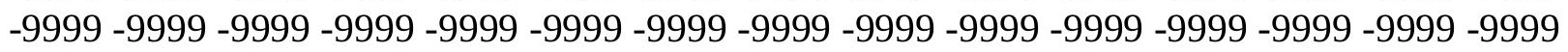

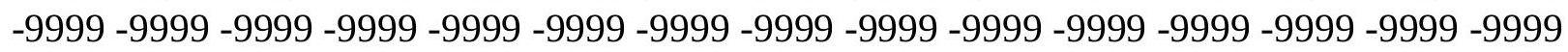

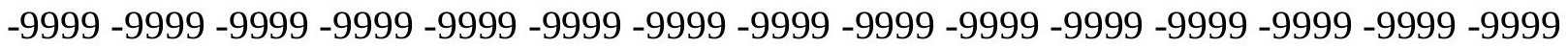

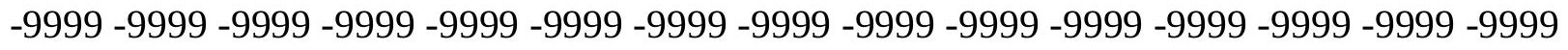

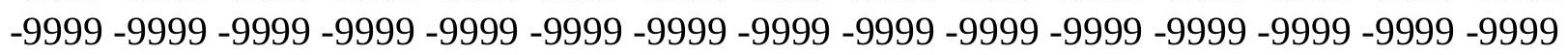
-9999 -9999-9999-9999-9999-9999-9999-9999-9999 132.2767028809 131.3623962402 130.4479980469129 .533706665128 .6192932129127 .4001998901126 .4858016968 125.2667007446124 .0475006104122 .8283996582121 .3044967651119 .4757995605 117.647102356115 .818397522113 .9896011353112 .4656982422110 .9418029785 109.4179000854107.8938980103 106.6747970581 105.4557037354104.2365036011 103.3221969604102 .712600708101 .7982025146101 .1886978149100 .5791015625 100.274299621699 .6647262573299 .3599472045998 .7503814697398 .14080810547 97.8360290527397 .2264633178796 .9216690063596 .3121032714896 .00731658936 95.7025299072395 .397743225195 .397743225195 .0929565429795 .09295654297 94.4833908081193 .8738174438592 .349891662690 .5211791992288 .38768768311 85.9494018554784 .1206970214883 .206336975183 .5111236572384 .73026275635 85.94940185547 87.16854858398 88.08290100098 88.99725341797 89.91161346436 90.5211791992291 .1307525634891 .7403335571392 .0450973510792 .65467834473 93.2642517089894 .1785964965895 .0929565429795 .7025299072396 .61688232422 96.9216690063597 .2264633178797 .5312423706197 .8360290527398 .14080810547 98.7503814697399 .0551681518699 .66472625732100 .2742996216100 .5791015625 101.1886978149101 .7982025146102 .1029968262102 .712600708103 .0174026489 103.6268997192103 .9317016602104 .5412979126104 .8460998535105 .4557037354 105.7603988647106 .0652008057106 .3700027466106 .6747970581106 .6747970581 106.979598999 106.979598999 106.979598999 106.979598999106.6747970581 106.3700027466106 .0652008057105 .7603988647105 .4557037354104 .8460998535 104.5412979126103 .9317016602103 .6268997192103 .0174026489102 .712600708 102.4077987671102 .1029968262102 .1029968262102 .4077987671103 .3221969604 103.9317016602104 .5412979126105 .4557037354106 .0652008057106 .6747970581 107.2844009399 107.8938980103108.1986999512108.8082962036109.1130981445 
109.1130981445109 .4179000854109 .4179000854109 .4179000854109 .4179000854 109.1130981445108 .8082962036107 .5891036987106 .3700027466105 .1509017944 103.9317016602102 .712600708102 .1029968262101 .4934005737101 .4934005737 102.1029968262103 .6268997192105 .7603988647109 .1130981445113 .3800964355 119.4757995605128 .3144989014141 .1154937744155 .7451934814170 .070098877 183.1759033203194 .7577056885204 .8155975342208 .7778015137208 .7778015137 208.7778015137208 .7778015137208 .7778015137208 .7778015137208 .7778015137 208.7778015137208 .7778015137208 .7778015137208 .7778015137208 .7778015137 208.7778015137208 .7778015137208 .7778015137208 .7778015137208 .7778015137 208.7778015137208 .7778015137208 .7778015137208 .7778015137208 .7778015137 208.7778015137208 .7778015137208 .7778015137208 .7778015137208 .7778015137 208.7778015137208 .7778015137208 .7778015137208 .7778015137208 .7778015137 208.7778015137208.7778015137208.7778015137 208.7778015137 208.7778015137 208.777801513766 .44316101074 -9999 -9999 -9999 -9999 -9999 -9999 -9999 -9999 -9999 $-9999-9999$

-9999 -9999 -9999 -9999 -9999 -9999 -9999 -9999 -9999-9999 -9999 -9999 -9999 -9999 -9999 -

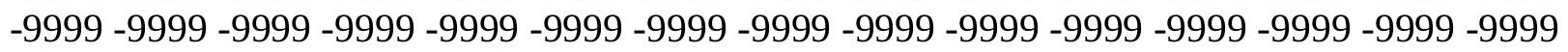

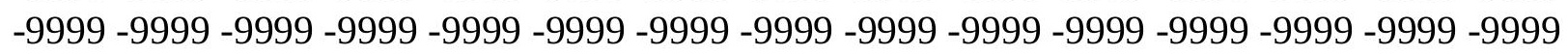

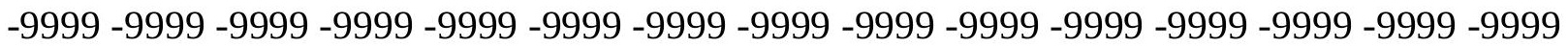

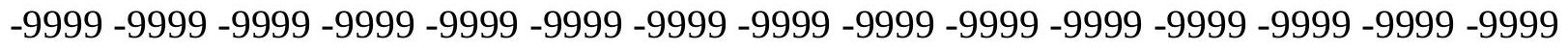

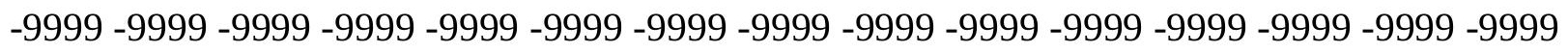

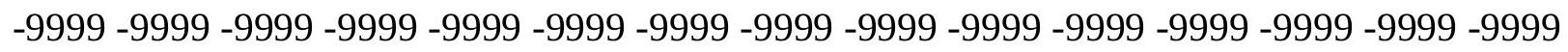
-9999 -9999 -9999 -9999 -9999 -9999 -9999 -9999 -9999 -9999 -9999 -9999 -9999 -9999 -9999 -

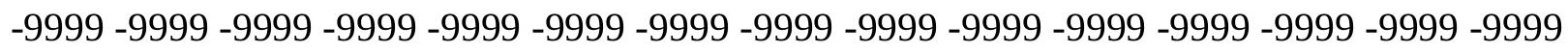

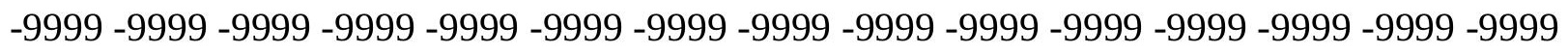
-9999 -9999 -9999 -9999 -9999 -9999 -9999 -9999 -9999 -9999 -9999 -9999 -9999 -9999 -9999

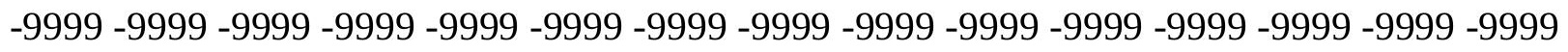
-9999 -9999-9999 -9999-9999-9999-9999 -9999 -9999-9999-9999-9999 129.533706665 128.6192932129127 .7050018311126 .4858016968125 .2667007446124 .0475006104 122.8283996582121 .3044967651119 .4757995605117 .342300415115 .2088012695 113.3800964355111 .551399231110 .0273971558108 .1986999512106 .6747970581 105.4557037354104 .2365036011103 .0174026489102 .1029968262101 .4934005737 100.579101562599 .9695205688599 .6647262573299 .0551681518698 .75038146973 98.445587158298 .1408081054797 .8360290527397 .5312423706196 .92166900635 96.6168823242296 .0073165893695 .7025299072395 .0929565429794 .78817749023 94.4833908081194 .4833908081193 .8738174438593 .2642517089892 .3498916626 91.1307525634888 .9972534179786 .5589828491284 .1206970214881 .68241119385 81.07285308838 82.59677124023 85.03504943848 87.16854858398 88.38768768311 89.302040100189 .9116134643690 .5211791992291 .1307525634891 .43553924561 92.0450973510792 .349891662692 .6546783447393 .2642517089893 .87381744385 94.7881774902395 .7025299072396 .3121032714896 .6168823242296 .92166900635 97.22646331787 97.2264633178797.8360290527398.1408081054798.4455871582 99.0551681518699 .3599472045999 .96952056885100 .5791015625101 .1886978149 101.7982025146102 .4077987671103 .0174026489103 .3221969604103 .9317016602 104.5412979126105 .1509017944105 .4557037354106 .0652008057106 .3700027466 106.6747970581 106.979598999 107.2844009399 107.5891036987 107.5891036987 
107.8938980103107 .5891036987107 .5891036987107 .2844009399106 .979598999 106.6747970581106 .0652008057105 .7603988647105 .1509017944104 .8460998535 104.2365036011103 .9317016602103 .6268997192103 .3221969604103 .0174026489 103.0174026489103 .6268997192104 .2365036011104 .8460998535105 .7603988647 106.3700027466106 .979598999107 .5891036987108 .1986999512108 .5035018921 109.1130981445109 .4179000854109 .7226028442109 .7226028442109 .7226028442 109.7226028442109 .7226028442109 .4179000854108 .8082962036108 .1986999512 106.979598999 105.7603988647 104.2365036011 103.0174026489 105.4557037354 105.1509017944104 .2365036011103 .322196960499 .96952056885101 .1886978149 102.712600708105 .1509017944108 .8082962036113 .6848983765120 .3900985718 135.3246002197151 .4781951904166 .7174987793180 .7375946045192 .9290008545 203.596496582208 .7778015137208 .7778015137208 .7778015137208 .7778015137 208.7778015137208 .7778015137208 .7778015137208 .7778015137208 .7778015137 208.7778015137208 .7778015137208 .7778015137208 .7778015137208 .7778015137 208.7778015137208 .7778015137208 .7778015137208 .7778015137208 .7778015137 208.7778015137 208.7778015137208.7778015137 208.7778015137 208.7778015137 208.7778015137208 .7778015137208 .7778015137208 .7778015137208 .7778015137 208.7778015137208 .7778015137208 .7778015137208 .7778015137208 .7778015137 208.7778015137208 .7778015137208 .7778015137208 .777801513765 .83358764648 -9999 -9999 -9999 -9999-9999-9999-9999-9999 -9999 -9999-9999

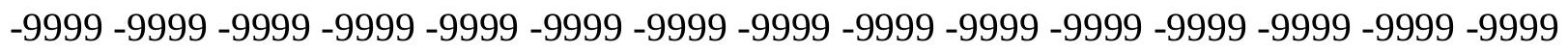
-9999 -9999 -9999 -9999 -9999 -9999 -9999 -9999 -9999 -9999 -9999 -9999 -9999 -9999 -9999 -9999 -9999 -9999 -9999 -9999 -9999 -9999 -9999 -9999 -9999 -9999 -9999 -9999 -9999 -9999 -

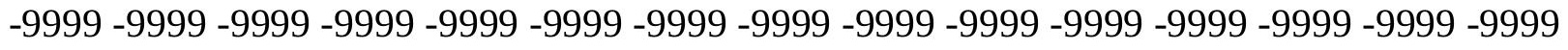

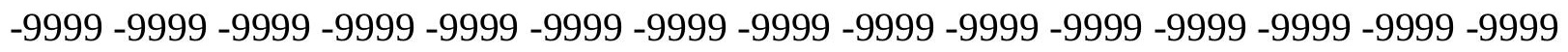
-9999 -9999 -9999 -9999 -9999 -9999 -9999 -9999 -9999 -9999 -9999 -9999 -9999 -9999 -9999

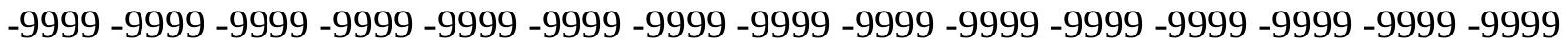

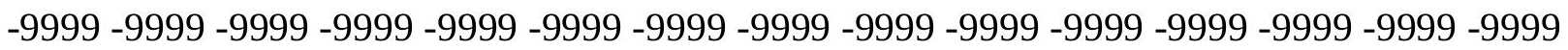
-9999 -9999 -9999 -9999 -9999 -9999 -9999 -9999 -9999 -9999 -9999 -9999 -9999 -9999 -9999 -9999 -9999 -9999 -9999 -9999 -9999 -9999 -9999 -9999 -9999 -9999 -9999 -9999 -9999 -9999 -9999 -9999 -9999 -9999 -9999 -9999 -9999 -9999 -9999-9999 -9999 -9999 -9999 -9999 -9999 -9999 -9999 -9999 -9999 -9999 -9999 -9999 -9999 -9999 -9999 -9999 -9999 -9999 -9999 -9999 -9999 -9999 -9999 -9999-9999 -9999 -9999 -9999 -9999 -9999 -9999 -9999 -9999 -9999 127.7050018311126 .4858016968125 .2667007446124 .0475006104122 .8283996582 120.9997024536118 .8662033081116 .7326965332114 .5991973877112 .4656982422 110.6370010376108 .8082962036106 .979598999105 .4557037354104 .2365036011 102.712600708101 .7982025146100 .883903503499 .9695205688599 .35994720459 98.75038146973 98.445587158298.1408081054797.8360290527397.53124237061 97.5312423706197 .2264633178796 .9216690063596 .6168823242296 .31210327148 95.7025299072395 .0929565429794 .4833908081193 .8738174438593 .56903076172 93.2642517089892 .6546783447391 .7403335571390 .5211791992289 .3020401001 87.47332763672 85.33984375 83.2063369751 81.07285308838 79.24413299561 83.5111236572387 .1685485839889 .302040100189 .9116134643690 .52117919922 91.1307525634891 .4355392456192 .0450973510792 .0450973510792 .3498916626 92.349891662692 .6546783447392 .9594726562593 .5690307617294 .17859649658 95.0929565429795 .397743225196 .0073165893696 .0073165893696 .31210327148 
96.6168823242296 .9216690063597 .2264633178797 .8360290527398 .14080810547 98.7503814697399 .3599472045999 .96952056885100 .5791015625101 .4934005737 102.1029968262102 .712600708103 .3221969604103 .9317016602104 .5412979126 105.1509017944105 .7603988647106 .0652008057106 .6747970581107 .2844009399 107.5891036987107 .8938980103108 .1986999512108 .5035018921108 .5035018921 108.5035018921108 .5035018921108 .1986999512107 .8938980103107 .2844009399 106.979598999106 .3700027466106 .0652008057105 .7603988647105 .1509017944 104.8460998535104 .5412979126104 .5412979126104 .2365036011104 .5412979126 104.8460998535105 .4557037354106 .0652008057106 .6747970581107 .2844009399 107.8938980103108 .5035018921109 .1130981445109 .4179000854110 .0273971558 110.0273971558110 .3321990967110 .3321990967110 .3321990967110 .0273971558 109.7226028442109 .4179000854108 .5035018921107 .5891036987106 .6747970581 105.1509017944103 .6268997192106 .0652008057105 .7603988647105 .4557037354 104.8460998535103 .9317016602102 .407798767199 .05516815186100 .5791015625 103.0174026489106 .6747970581112 .4656982422121 .3044967651134 .7149963379 150.2590942383165 .8031005859180 .1280059814192 .624206543203 .2917022705 208.7778015137208 .7778015137208 .7778015137208 .7778015137208 .7778015137 208.7778015137208 .7778015137208 .7778015137208 .7778015137208 .7778015137 208.7778015137208 .7778015137208 .7778015137208 .7778015137208 .7778015137 208.7778015137208 .7778015137208 .7778015137208 .7778015137208 .7778015137 208.7778015137208 .7778015137208 .7778015137208 .7778015137208 .7778015137 208.7778015137208 .7778015137208 .7778015137208 .7778015137208 .7778015137 208.7778015137208 .7778015137208 .7778015137208 .7778015137208 .7778015137 208.7778015137208 .7778015137208 .777801513765 .22400665283 -3.009516716 -9999-9999 -9999 -9999 -9999 -9999 -9999-9999 -9999 -9999

-9999 -9999 -9999 -9999 -9999 -9999 -9999 -9999 -9999 -9999 -9999 -9999 -9999 -9999 -9999 -9999 -9999 -9999 -9999 -9999 -9999 -9999 -9999 -9999 -9999 -9999 -9999 -9999 -9999 -9999 -

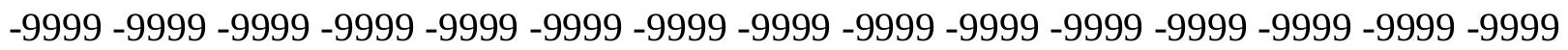
-9999 -9999 -9999 -9999 -9999 -9999 -9999 -9999 -9999 -9999 -9999 -9999 -9999 -9999 -9999 -9999 -9999 -9999 -9999 -9999 -9999 -9999 -9999 -9999 -9999 -9999 -9999 -9999 -9999 -9999 -9999 -9999 -9999 -9999 -9999 -9999 -9999 -9999 -9999-9999 -9999 -9999 -9999 -9999 -9999 -9999 -9999 -9999 -9999 -9999 -9999 -9999 -9999 -9999 -9999 -9999 -9999 -9999 -9999 -9999 -

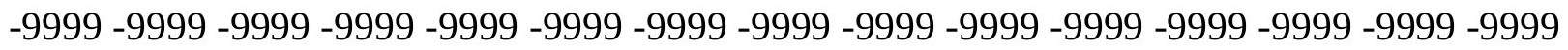
-9999 -9999 -9999 -9999 -9999 -9999 -9999 -9999 -9999 -9999 -9999 -9999 -9999 -9999 -9999 -9999 -9999 -9999 -9999 -9999 -9999 -9999 -9999 -9999 -9999 -9999 -9999 -9999 -9999 -9999 -

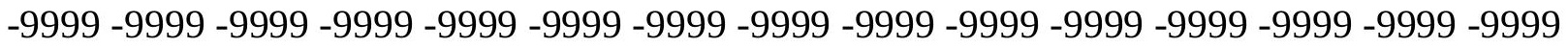

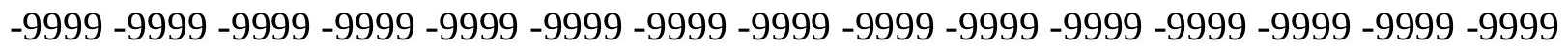

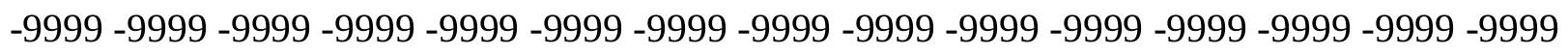
-9999 -9999 123.7427978516122.5235977173 120.6949005127118 .5614013672 116.1231002808113 .6848983765111 .551399231109 .4179000854107 .5891036987 105.7603988647104 .2365036011102 .712600708101 .1886978149100 .2742996216 99.0551681518698 .445587158297 .8360290527397 .5312423706197 .22646331787 96.9216690063596 .9216690063596 .6168823242296 .6168823242296 .61688232422 96.3121032714896 .3121032714895 .7025299072395 .397743225194 .48339080811 93.8738174438592 .9594726562592 .349891662691 .7403335571391 .13075256348 89.60682678223 88.38768768311 87.16854858398 85.9494018554784.73026275635 
83.81591033936 82.90155792236 83.81591033936 87.1685485839891.13075256348 91.7403335571391 .7403335571392 .0450973510792 .349891662692 .65467834473 92.6546783447392 .6546783447392 .6546783447392 .349891662692 .65467834473 92.6546783447393 .2642517089893 .5690307617294 .1785964965894 .48339080811 94.7881774902395 .0929565429795 .397743225195 .7025299072396 .00731658936 96.6168823242296 .9216690063597 .5312423706198 .1408081054798 .75038146973 99.35994720459100 .2742996216100 .8839035034101 .7982025146102 .4077987671 103.0174026489103 .9317016602104 .5412979126105 .1509017944105 .7603988647 106.3700027466106 .979598999107 .5891036987107 .8938980103108 .5035018921 108.8082962036109 .1130981445109 .4179000854109 .4179000854109 .1130981445 108.8082962036108 .5035018921108 .1986999512107 .8938980103107 .2844009399 106.979598999 106.6747970581 106.3700027466106.0652008057 105.7603988647 105.7603988647105 .7603988647105 .7603988647106 .0652008057106 .6747970581 107.2844009399 107.8938980103108.5035018921 109.1130981445 109.4179000854 110.0273971558110 .3321990967110 .6370010376110 .9418029785110 .9418029785 110.9418029785110 .6370010376110 .3321990967110 .0273971558109 .4179000854 108.5035018921107 .2844009399106 .0652008057104 .5412979126106 .6747970581 106.3700027466 106.3700027466105.7603988647105.1509017944 104.5412979126 103.3221969604101 .493400573799 .66472625732102 .4077987671106 .979598999 113.9896011353124 .0475006104137 .4580993652152 .3925933838167 .6318054199 181.6519012451193 .8433074951203 .9011993408208 .7778015137208 .7778015137 208.7778015137208 .7778015137208 .7778015137208 .7778015137208 .7778015137 208.7778015137208 .7778015137208 .7778015137208 .7778015137208 .7778015137 208.7778015137 208.7778015137208.7778015137 208.7778015137 208.7778015137 208.7778015137208.7778015137208.7778015137208.7778015137 208.7778015137 208.7778015137208.7778015137208.7778015137208.7778015137 208.7778015137 208.7778015137208.7778015137208.7778015137208.7778015137208.7778015137 208.7778015137208 .7778015137208 .7778015137208 .7778015137208 .7778015137 208.777801513764 .91924285889 -2.66501426697 -9999 -9999 -9999 -9999 -9999 -9999 -9999 -9999 -9999-9999

-9999 -9999 -9999 -9999 -9999 -9999 -9999 -9999 -9999 -9999 -9999 -9999 -9999 -9999 -9999 -9999 -9999 -9999 -9999 -9999 -9999 -9999 -9999 -9999 -9999 -9999 -9999 -9999 -9999 -9999 -

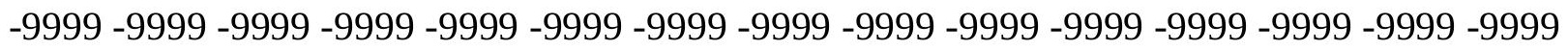
-9999 -9999 -9999 -9999 -9999 -9999 -9999 -9999 -9999 -9999 -9999 -9999 -9999 -9999 -9999 -9999 -9999 -9999 -9999 -9999 -9999 -9999 -9999 -9999 -9999 -9999 -9999 -9999 -9999 -9999 -9999 -9999 -9999 -9999 -9999 -9999 -9999 -9999 -9999 -9999 -9999 -9999 -9999 -9999 - -9999 -

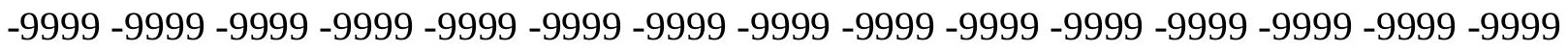

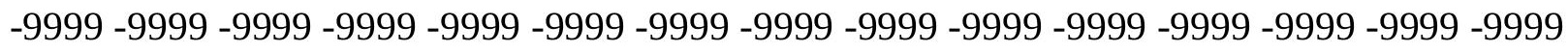
-9999 -9999 -9999 -9999 -9999 -9999 -9999 -9999 -9999 -9999 -9999 -9999 -9999 -9999 -9999 -9999 -9999 -9999 -9999 -9999 -9999 -9999 -9999 -9999 -9999 -9999 -9999 -9999 -9999 - -999 -

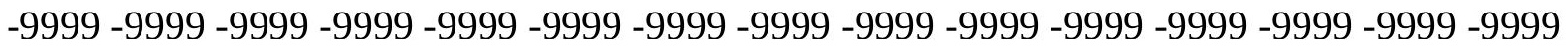

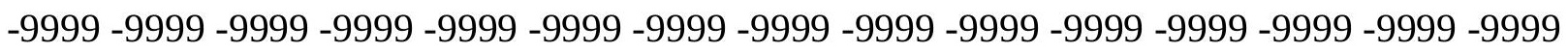
-9999 -9999 -9999 -9999 -9999 -9999 -9999 -9999 -9999 -9999 -9999 -9999 -9999 -9999 -9999 -9999 -9999 -9999 -9999-9999 118.8662033081116 .7326965332113 .9896011353 111.24659729108 .1986999512106 .3700027466104 .5412979126102 .712600708 101.188697814999 .6647262573298 .445587158297 .5312423706196 .92166900635 
96.3121032714896 .0073165893695 .7025299072395 .7025299072395 .70252990723 96.0073165893696 .0073165893696 .0073165893696 .0073165893695 .70252990723 95.397743225195 .0929565429794 .1785964965893 .2642517089891 .74033355713 90.8259735107489 .6068267822388 .0829010009886 .5589828491285 .64462280273 84.7302627563584 .7302627563584 .7302627563585 .0350494384885 .94940185547 88.0829010009890 .8259735107493 .2642517089893 .8738174438593 .56903076172 93.5690307617293 .5690307617293 .5690307617293 .2642517089892 .95947265625 92.6546783447392 .349891662692 .349891662692 .349891662692 .65467834473 92.9594726562593 .2642517089893 .5690307617293 .8738174438594 .17859649658 94.4833908081194 .7881774902395 .0929565429795 .397743225196 .00731658936 96.61688232422 97.2264633178798.1408081054798.7503814697399.66472625732 100.5791015625101 .4934005737102 .1029968262103 .0174026489103 .6268997192 104.5412979126105 .1509017944106 .0652008057106 .6747970581107 .2844009399 107.8938980103108 .5035018921108 .8082962036109 .4179000854109 .7226028442 110.0273971558110 .0273971558110 .0273971558109 .7226028442109 .4179000854 109.1130981445108 .5035018921108 .1986999512107 .8938980103107 .5891036987 107.2844009399 106.979598999 106.979598999 106.979598999 106.979598999 106.979598999107 .5891036987107 .8938980103108 .5035018921109 .1130981445 109.4179000854110.0273971558110.6370010376110.9418029785111.24659729 111.551399231111 .8561019897111 .8561019897111 .551399231111 .24659729 110.9418029785110 .0273971558109 .4179000854108 .1986999512106 .979598999 105.7603988647103 .9317016602106 .979598999106 .6747970581106 .3700027466 106.0652008057105 .7603988647104 .8460998535103 .9317016602102 .4077987671 99.05516815186102 .4077987671107 .8938980103116 .1231002808127 .0953979492 141.1154937744156 .3547973633170 .9844970703184 .3950042725195 .6721038818 205.1204071045208 .7778015137208 .7778015137208 .7778015137208 .7778015137 208.7778015137208 .7778015137208 .7778015137208 .7778015137208 .7778015137 208.7778015137208 .7778015137208 .7778015137208 .7778015137208 .7778015137 208.7778015137208 .7778015137208 .7778015137208 .7778015137208 .7778015137 208.7778015137208 .7778015137208 .7778015137208 .7778015137208 .7778015137 208.7778015137208 .7778015137208 .7778015137208 .7778015137208 .7778015137 208.7778015137 208.7778015137208.7778015137 208.7778015137 208.7778015137 208.7778015137208 .7778015137208 .7778015137208 .777801513764 .30966186523 -2.52150440216 -9999 -9999 -9999 -9999 -9999 -9999 -9999 -9999 -9999 -9999 -9999 -9999 -9999 -9999 -9999 -9999 -9999 -9999 -9999 -9999 -9999 -9999 -9999 -9999 -9999

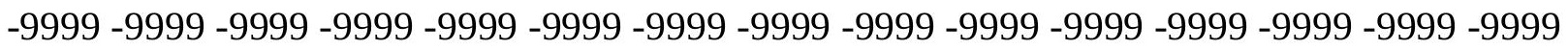

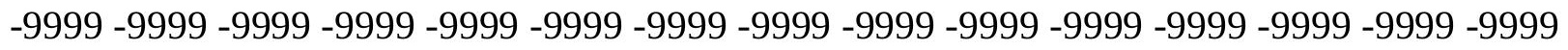

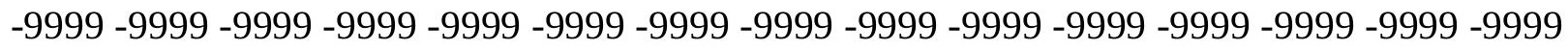
-9999 -9999 -9999 -9999 -9999 -9999 -9999 -9999 -9999 -9999 -9999 -9999 -9999 -9999 -9999 -9999 -9999 -9999 -9999 -9999 -9999 -9999 -9999 -9999 -9999 -9999 -9999 -9999 -9999 -9999 -

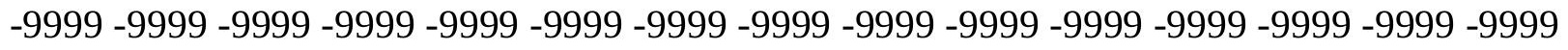

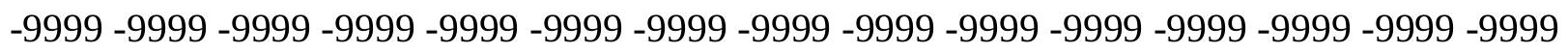

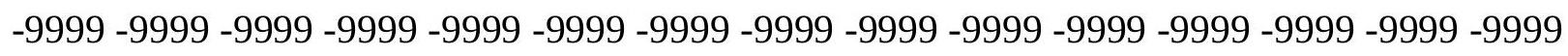
-9999 -9999 -9999 -9999 -9999 -9999 -9999 -9999 -9999 -9999 -9999 -9999 -9999 -9999 -9999 -

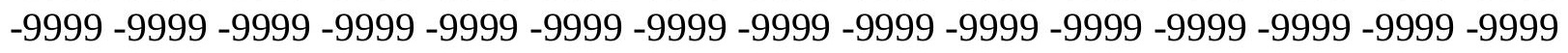

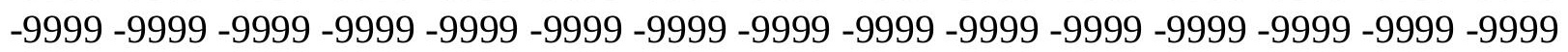


-9999 -9999 -9999 -9999 -9999 -9999 -9999 -9999 -9999 -9999 -9999 -9999 -9999 -9999 -9999 -9999 -9999 -9999 -9999 -9999 -9999-9999 115.2088012695 112.4656982422109 .4179000854 106.3700027466106 .0652008057101 .188697814999 .3599472045997 .83602905273 96.6168823242296 .0073165893695 .0929565429794 .7881774902394 .78817749023 94.7881774902394 .7881774902395 .0929565429795 .0929565429795 .3977432251 95.397743225195 .397743225195 .397743225195 .397743225195 .09295654297 94.1785964965893 .2642517089891 .4355392456189 .6068267822387 .16854858398 85.0350494384883 .206336975182 .2919769287182 .2919769287183 .2063369751 84.7302627563586 .5589828491288 .6924667358491 .4355392456193 .56903076172 95.7025299072395 .397743225194 .7881774902394 .4833908081194 .48339080811 94.1785964965893 .8738174438593 .5690307617292 .9594726562592 .65467834473 92.0450973510792 .0450973510792 .0450973510792 .0450973510792 .3498916626 92.349891662692 .6546783447392 .9594726562593 .2642517089893 .56903076172 93.8738174438594 .4833908081195 .0929565429795 .7025299072396 .61688232422 97.5312423706198 .445587158299 .05516815186100 .2742996216101 .1886978149 101.7982025146102 .712600708103 .6268997192104 .5412979126105 .4557037354 106.0652008057106 .979598999107 .5891036987108 .1986999512108 .8082962036 109.4179000854109 .7226028442110 .3321990967110 .6370010376110 .9418029785 110.6370010376110 .3321990967110 .0273971558109 .7226028442109 .4179000854 109.1130981445108 .8082962036108 .5035018921108 .1986999512108 .1986999512 107.8938980103108 .1986999512108 .1986999512108 .5035018921108 .8082962036 109.1130981445109 .7226028442110 .0273971558110 .6370010376111 .24659729 111.551399231112 .1608963013112 .4656982422112 .4656982422112 .4656982422 112.4656982422112 .1608963013111 .8561019897111 .24659729110 .3321990967 109.4179000854 108.1986999512 106.979598999 105.4557037354107.2844009399 106.979598999 106.979598999 106.6747970581 106.3700027466106.0652008057 105.1509017944104 .2365036011103 .017402648999 .05516815186102 .712600708 108.8082962036117 .647102356129 .533706665144 .1634063721160 .3170013428 174.9467010498187 .7476043701197 .500793457205 .7299957275208 .7778015137 208.7778015137208 .7778015137208 .7778015137208 .7778015137208 .7778015137 208.7778015137208 .7778015137208 .7778015137208 .7778015137208 .7778015137 208.7778015137208 .7778015137208 .7778015137208 .7778015137208 .7778015137 208.7778015137208 .7778015137208 .7778015137208 .7778015137208 .7778015137 208.7778015137208 .7778015137208 .7778015137208 .7778015137208 .7778015137 208.7778015137208.7778015137208.7778015137208.7778015137208.7778015137 208.7778015137208.7778015137208.7778015137208.7778015137208.7778015137 208.7778015137 208.777801513763 .70008850098 -2.49856805801 -9999 -9999 -9999 -9999 -9999 -9999 -9999 -9999-9999 -9999

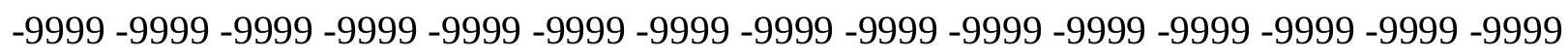
-9999 -9999 -9999 -9999 -9999 -9999 -9999 -9999 -9999 -9999 -9999 -9999 -9999 -9999 -9999 -999 -

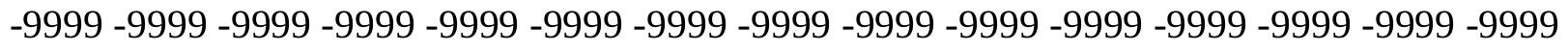

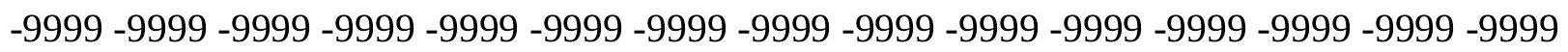

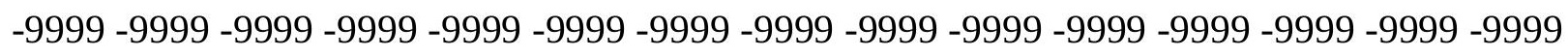
-9999 -9999 -9999 -9999 -9999 -9999 -9999 -9999 -9999 -9999 -9999 -9999 -9999 -9999 -9999 -

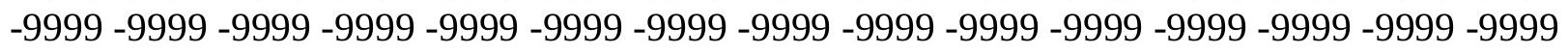

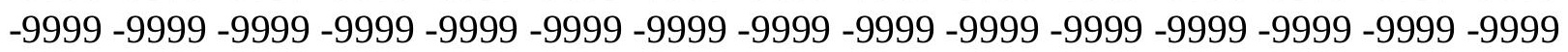


-9999 -9999 -9999 -9999 -9999 -9999 -9999 -9999 -9999 -9999 -9999 -9999 -9999 -9999 -9999 -9999 -9999 -9999 -9999 -9999 -9999 -9999 -9999 -9999 -9999 -9999 -9999 -9999 -9999 -9999

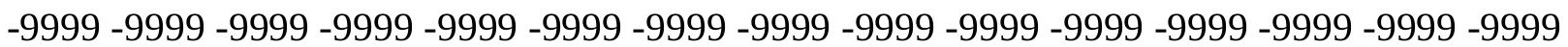
-9999 -9999 -9999 -9999 -9999 -9999 -9999 -9999 -9999 -9999 -9999 -9999 -9999 -9999 -9999 -9999 -9999 -9999 -9999 -9999 -9999 -9999 -9999 -9999 -9999 -9999 -9999 -9999 -9999 -9999 -9999 -9999 -9999 -9999 -9999 -9999 -9999 -9999 113.9896011353110 .9418029785 107.8938980103104 .5412979126101 .493400573798 .1408081054796 .00731658936 95.0929565429794 .1785964965893 .5690307617293 .5690307617293 .56903076172 93.8738174438594 .1785964965894 .4833908081194 .7881774902395 .09295654297 95.0929565429795 .0929565429795 .397743225195 .0929565429795 .09295654297 94.4833908081193 .5690307617291 .7403335571388 .9972534179785 .33984375 81.6824111938579 .5489196777378 .6345596313579 .8537063598681 .98719787598 84.4254837036187 .1685485839889 .9116134643692 .6546783447394 .48339080811 96.0073165893696 .0073165893695 .7025299072395 .397743225195 .09295654297 95.0929565429794 .4833908081194 .1785964965893 .2642517089892 .65467834473 92.0450973510791 .7403335571391 .4355392456191 .4355392456191 .43553924561 91.4355392456191 .4355392456191 .7403335571392 .0450973510792 .3498916626 92.9594726562593 .5690307617294 .1785964965894 .7881774902395 .70252990723 96.6168823242297 .8360290527398 .7503814697399 .66472625732100 .8839035034 101.7982025146102 .712600708103 .6268997192104 .5412979126105 .4557037354 106.3700027466106 .979598999107 .8938980103108 .5035018921109 .1130981445 109.7226028442110 .3321990967110 .6370010376111 .24659729111 .24659729111 .24659729 110.9418029785110 .9418029785110 .6370010376110 .3321990967110 .0273971558 109.7226028442109 .4179000854109 .1130981445109 .1130981445109 .1130981445 109.1130981445109 .4179000854109 .7226028442110 .0273971558110 .3321990967 110.9418029785111 .24659729111 .8561019897112 .1608963013112 .7705001831 113.075302124113 .3800964355113 .3800964355113 .3800964355113 .3800964355 113.075302124112 .4656982422111 .8561019897110 .9418029785109 .7226028442 108.5035018921106 .979598999105 .4557037354107 .2844009399106 .979598999 106.979598999106 .6747970581106 .6747970581106 .0652008057105 .4557037354 104.5412979126103 .322196960499 .05516815186103 .0174026489109 .1130981445 118.2565994263130 .1432037354145 .3825073242162 .4505004883178 .604095459 189.2716064453197 .500793457205 .1204071045208 .7778015137208 .7778015137 208.7778015137208 .7778015137208 .7778015137208 .7778015137208 .7778015137 208.7778015137208 .7778015137208 .7778015137208 .7778015137208 .7778015137 208.7778015137208 .7778015137208 .7778015137208 .7778015137208 .7778015137 208.7778015137208 .7778015137208 .7778015137208 .7778015137208 .7778015137 208.7778015137208 .7778015137208 .7778015137208 .7778015137208 .7778015137 208.7778015137208 .7778015137208 .7778015137208 .7778015137208 .7778015137 208.7778015137208 .7778015137208 .7778015137208 .7778015137208 .7778015137 208.7778015137 63.39530944824 -2.3211877346 -9999 -9999 -9999 -9999 -9999 -9999 -9999 -9999-9999-9999 -9999 -9999 -9999 -9999 -9999 -9999 -9999 -9999 -9999 -9999 -9999 -9999 -9999 -9999 -9999 -9999 -9999 -9999 -9999 -9999 -9999 -9999 -9999 -9999 -9999 -9999 -9999 -9999 -9999 -9999 -9999 -9999 -9999 -9999 -9999 -9999 -9999 -9999 -9999 -9999 -9999 -9999 -9999 -9999 -9999

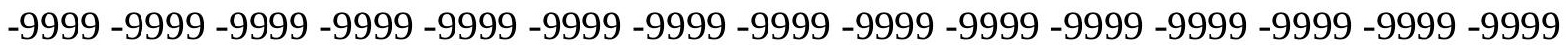


-9999 -9999 -9999 -9999 -9999 -9999 -9999 -9999 -9999 -9999 -9999 -9999 -9999 -9999 -9999 -9999 -9999 -9999 -9999 -9999 -9999 -9999 -9999 -9999 -9999 -9999 -9999 -9999 -9999 -9999

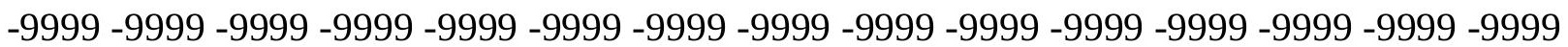
-9999 -9999 -9999 -9999 -9999 -9999 -9999 -9999 -9999 -9999 -9999 -9999 -9999 -9999 -9999 -9999 -9999 -9999 -9999 -9999 -9999 -9999 -9999 -9999 -9999 -9999 -9999 -9999 -9999 -9999 -9999 -9999 -9999 -9999 -9999 -9999 -9999 -9999 -9999 -9999 -9999 -9999 -9999 -9999 -9999 -9999 -9999 -9999 -9999 -9999 -9999 -9999 -9999 -9999 -9999 -9999 -9999 -9999 -9999 -9999

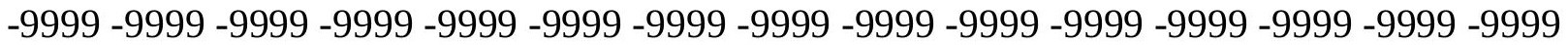
-9999 -9999 -9999 -9999 -9999 -9999 -9999 -9999 -9999 -9999 -9999 -9999 -9999 -9999 -9999 -9999 -9999 -9999 -9999 -9999 -9999 -9999 -9999 -9999 -9999 109.7226028442 106.3700027466103 .017402648999 .3599472045996 .0073165893693 .87381744385 92.9594726562592 .349891662692 .0450973510792 .6546783447393 .26425170898 93.8738174438594 .4833908081194 .7881774902395 .0929565429795 .09295654297 95.0929565429795 .0929565429795 .0929565429795 .0929565429794 .78817749023 93.8738174438592 .349891662689 .302040100184 .4254837036179 .24413299561 75.5867080688575 .5867080688577 .7202072143680 .7680587768684 .12069702148 87.4733276367290 .5211791992292 .349891662693 .8738174438594 .78817749023 95.397743225195 .397743225195 .397743225195 .7025299072395 .3977432251 95.0929565429794 .4833908081193 .5690307617292 .6546783447391 .74033355713 91.1307525634890 .8259735107490 .5211791992290 .2164001464890 .21640014648 90.2164001464890 .5211791992290 .8259735107491 .4355392456191 .74033355713 92.349891662693 .2642517089894 .1785964965895 .0929565429796 .00731658936 97.2264633178798 .445587158299 .35994720459100 .5791015625101 .4934005737 102.712600708103 .6268997192104 .5412979126105 .4557037354106 .3700027466 107.2844009399107 .8938980103108 .8082962036109 .4179000854110 .0273971558 110.6370010376111 .24659729111 .551399231111 .551399231111 .551399231111 .551399231 111.24659729111 .24659729110 .9418029785110 .6370010376110 .3321990967 110.3321990967110 .0273971558110 .0273971558110 .0273971558110 .3321990967 110.3321990967110 .6370010376110 .9418029785111 .551399231111 .8561019897 112.4656982422112 .7705001831113 .3800964355113 .6848983765113 .9896011353 114.2944030762114 .2944030762114 .2944030762113 .9896011353113 .6848983765 113.075302124112 .1608963013111 .24659729110 .0273971558108 .8082962036 107.2844009399105 .7603988647107 .2844009399106 .979598999106 .979598999 106.979598999106 .6747970581106 .3700027466105 .7603988647104 .8460998535 103.6268997192101 .7982025146102 .712600708108 .8082962036117 .342300415 128.6192932129142 .6394042969159 .4026031494179 .2136993408185 .6141052246 193.8433074951202 .3773040771208 .7778015137208 .7778015137208 .7778015137 208.7778015137208 .7778015137208 .7778015137208 .7778015137208 .7778015137 208.7778015137208 .7778015137208 .7778015137208 .7778015137208 .7778015137 208.7778015137208 .7778015137208 .7778015137208 .7778015137208 .7778015137 208.7778015137208 .7778015137208 .7778015137208 .7778015137208 .7778015137 208.7778015137208 .7778015137208 .7778015137208 .7778015137208 .7778015137 208.7778015137208 .7778015137208 .7778015137208 .7778015137208 .7778015137 208.7778015137208 .7778015137208 .7778015137208 .7778015137208 .7778015137 62.78573989868 -1.5371222496 -9999 -9999 -9999 -9999 -9999 -9999 -9999 -9999 -9999 -9999 -9999 -9999 -9999 -9999 -9999 -9999 -9999 -9999 -9999 -9999 -9999 -9999 -9999 -9999 -9999 
-9999 -9999 -9999 -9999 -9999 -9999 -9999 -9999 -9999 -9999 -9999 -9999 -9999 -9999 -9999 -9999 -9999 -9999 -9999 -9999 -9999 -9999 -9999 -9999 -9999 -9999 -9999 -9999 -9999 -9999

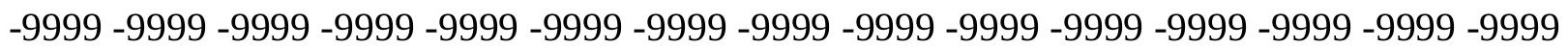
-9999 -9999 -9999 -9999 -9999 -9999 -9999 -9999 -9999 -9999 -9999 -9999 -9999 -9999 -9999 -9999 -9999 -9999 -9999 -9999 -9999 -9999 -9999 -9999 -9999 -9999 -9999 -9999 -9999 -9999 -9999 -9999 -9999 -9999 -9999 -9999 -9999 -9999 -9999 -9999 -9999 -9999 -9999 -9999 -9999 -9999 -9999 -9999 -9999 -9999 -9999 -9999 -9999 -9999 -9999 -9999 -9999 -9999 -9999 -9999

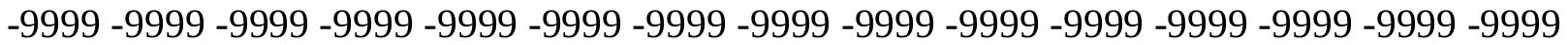

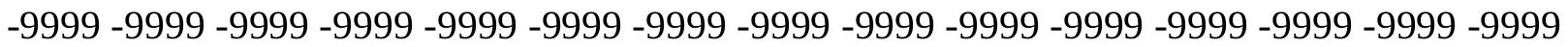
-9999 -9999 -9999 -9999 -9999 -9999 -9999 -9999 -9999 -9999 -9999 -9999 -9999 -9999 -9999 -9999 -9999 -9999 -9999 -9999 -9999 -9999 -9999 -9999 -9999 -9999 -9999 -9999 -9999 -9999 -9999 -9999 -9999 -9999 -9999 -9999 -9999 -9999 -9999 -9999 -9999 -9999 -9999 -9999 -9999 -9999 -9999 -9999 -9999 -9999 -9999 -9999 -9999 -9999 -9999 -9999 108.1986999512 104.5412979126100 .883903503496 .9216690063593 .5690307617291 .43553924561 90.8259735107491 .1307525634892 .0450973510793 .2642517089894 .78817749023 95.397743225195 .7025299072395 .397743225195 .0929565429795 .09295654297 95.0929565429795 .0929565429795 .397743225195 .0929565429794 .48339080811 93.2642517089890 .8259735107484 .7302627563578 .3297805786173 .45321655273 74.3675689697377 .4154205322380 .4632720947383 .8159103393686 .86376190186 89.302040100190 .8259735107492 .0450973510793 .2642517089894 .17859649658 94.7881774902395 .397743225195 .7025299072395 .7025299072395 .3977432251 94.7881774902393 .5690307617292 .6546783447391 .4355392456190 .82597351074 90.2164001464889 .6068267822389 .302040100188 .9972534179789 .3020401001 89.302040100189 .6068267822390 .2164001464890 .8259735107491 .43553924561 92.349891662693 .2642517089894 .4833908081195 .7025299072396 .61688232422 97.8360290527399 .05516815186100 .2742996216101 .4934005737102 .4077987671 103.6268997192104 .5412979126105 .4557037354106 .3700027466107 .2844009399 108.1986999512109 .1130981445109 .7226028442110 .3321990967110 .9418029785 111.551399231111 .8561019897111 .8561019897112 .1608963013112 .1608963013 111.8561019897111 .8561019897111 .551399231111 .24659729111 .24659729 110.9418029785110 .9418029785110 .9418029785110 .9418029785111 .24659729 111.551399231111 .8561019897112 .1608963013112 .4656982422113 .075302124 113.3800964355113 .9896011353114 .2944030762114 .5991973877114 .9039993286 115.2088012695115 .2088012695115 .2088012695114 .9039993286114 .2944030762 113.6848983765112 .7705001831111 .8561019897110 .6370010376109 .1130981445 107.5891036987106 .0652008057104 .2365036011106 .979598999106 .979598999 106.6747970581106 .6747970581106 .0652008057105 .4557037354104 .8460998535 103.3221969604101 .7982025146101 .7982025146107 .2844009399114 .9039993286 124.9618988037137 .1533050537149 .9542999268159 .7073974609176 .165802002 188.0523986816198 .1103057861206 .6443023682208 .7778015137208 .7778015137 208.7778015137208 .7778015137208 .7778015137208 .7778015137208 .7778015137 208.7778015137208 .7778015137208 .7778015137208 .7778015137208 .7778015137 208.7778015137208 .7778015137208 .7778015137208 .7778015137208 .7778015137 208.7778015137208 .7778015137208 .7778015137208 .7778015137208 .7778015137 208.7778015137208 .7778015137208 .7778015137208 .7778015137208 .7778015137 208.7778015137208.7778015137208.7778015137208.7778015137208.7778015137 
208.7778015137208 .7778015137208 .7778015137208 .7778015137208 .7778015137 62.480949401861 .507671236992 -9999 -9999 -9999 -9999 -9999 -9999 -9999 -9999 -9999 $-9999$

-9999 -9999 -9999 -9999 -9999 -9999 -9999 -9999 -9999 -9999 -9999 -9999 -9999 -9999 -999

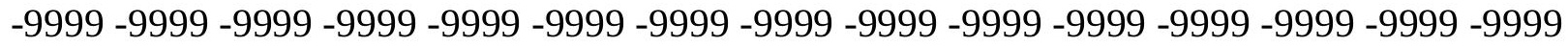

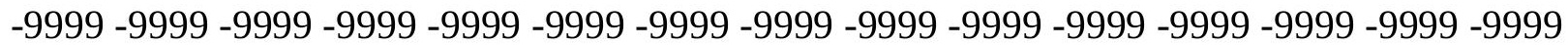

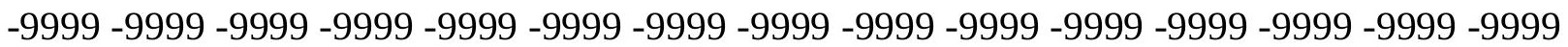

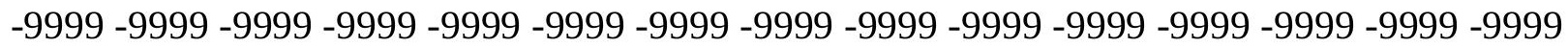
-9999 -9999 -9999 -9999 -9999 -9999 -

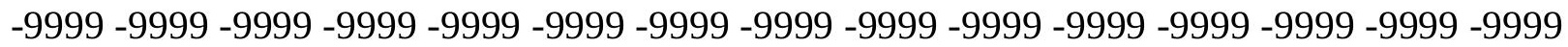

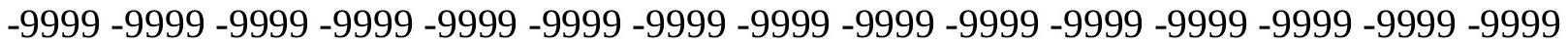

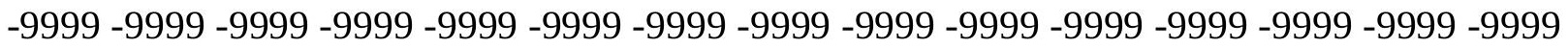

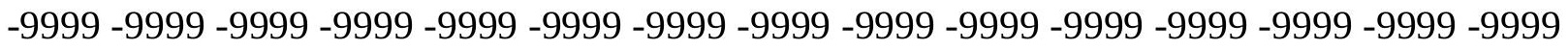

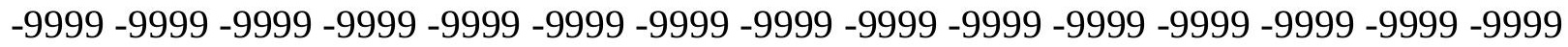

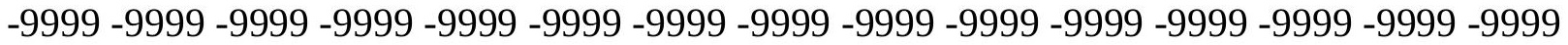

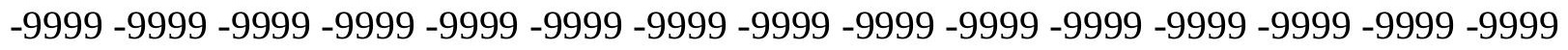
-9999 -9999 -9999 -9999 -9999 -9999 -9999 -9999 -9999 -9999 -9999 -9999 106.3700027466 102.102996826298.1408081054794.4833908081191.13075256348 89.3020401001 89.9116134643691.4355392456193.8738174438596.0073165893697.22646331787 97.2264633178796.3121032714895.397743225195.0929565429795.09295654297 95.0929565429795.397743225195.397743225195.0929565429793.87381744385 90.8259735107486 .254188537680 .7680587768676 .8058471679776 .50106811523 78.3297805786181 .0728530883884 .1206970214886 .5589828491288 .38768768311 89.6068267822390.2164001464891.7403335571392.95947265625 93.87381744385 94.7881774902395 .0929565429795 .7025299072395 .7025299072394 .78817749023 93.5690307617292 .349891662691 .1307525634890 .2164001464889 .3020401001 88.6924667358488 .3876876831188 .0829010009888 .0829010009888 .08290100098 88.3876876831188 .9972534179789 .9116134643690 .5211791992291 .74033355713 92.6546783447393 .8738174438595 .0929565429796 .3121032714897 .53124237061 98.7503814697399 .96952056885101 .1886978149102 .4077987671103 .6268997192 104.5412979126105 .7603988647106 .6747970581107 .5891036987108 .5035018921 109.1130981445110 .0273971558110 .6370010376111 .24659729111 .8561019897 112.1608963013112 .1608963013112 .4656982422112 .4656982422112 .4656982422 112.1608963013112 .1608963013111 .8561019897111 .8561019897111 .8561019897 111.8561019897111 .8561019897111 .8561019897112 .1608963013112 .4656982422 112.7705001831113 .075302124113 .3800964355113 .9896011353114 .2944030762 114.5991973877115 .2088012695115 .5136032104115 .818397522115 .818397522 116.1231002808115 .818397522115 .5136032104114 .9039993286114 .2944030762 113.3800964355112 .4656982422111 .24659729109 .7226028442108 .1986999512 106.3700027466104 .5412979126106 .979598999106 .6747970581106 .6747970581 106.3700027466106 .0652008057105 .4557037354104 .5412979126103 .3221969604 101.4934005737100 .8839035034105 .4557037354111 .8561019897120 .3900985718 130.4479980469141 .4203033447153 .0021057129167 .3269958496180 .7375946045 192.624206543202 .6820983887208 .7778015137208 .7778015137208 .7778015137 208.7778015137208 .7778015137208 .7778015137208 .7778015137208 .7778015137 208.7778015137208 .7778015137208 .7778015137208 .7778015137208 .7778015137 
208.7778015137208 .7778015137208 .7778015137208 .7778015137208 .7778015137 208.7778015137 208.7778015137208.7778015137208.7778015137 208.7778015137 208.7778015137208 .7778015137208 .7778015137208 .7778015137208 .7778015137 208.7778015137208 .7778015137208 .7778015137208 .7778015137208 .7778015137 208.7778015137208 .7778015137208 .7778015137208 .777801513762 .48094940186 12.06027603149 -9999 -9999 -9999 -9999 -9999 -9999 -9999 -9999 -9999 -9999 -9999 -9999 -9999 -9999 -9999 -9999 -9999 -9999 -9999 -9999 -9999 -9999 -9999 -9999 -9999

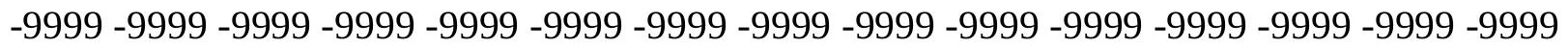
-9999 -9999 -9999 -9999 -9999 -9999 -9999 -9999 -9999 -9999 -9999 -9999 -9999 -9999 -9999 -9999 -9999 -9999 -9999 -9999 -9999 -9999 -9999 -9999 -9999 -9999 -9999 -9999 -9999 -9999 -

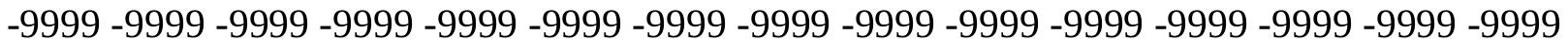

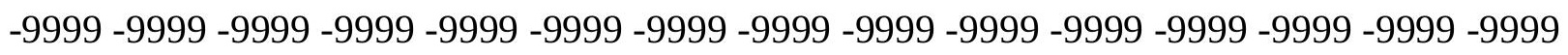
-9999 -9999 -9999 -9999 -9999 -9999 -9999 -9999 -9999 -9999 -9999 -9999 -9999 -9999 -9999 -9999 -9999 -9999 -9999 -9999 -9999 -9999 -9999 -9999 -9999 -9999 -9999 -9999 -9999 -9999 -9999 -9999 -9999 -9999 -9999 -9999 -9999 -9999 -9999 -9999 -9999 -9999 -9999 -9999 -9999

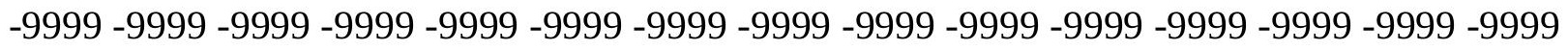
-9999 -9999 -9999 -9999 -9999 -9999 -9999 -9999 -9999 -9999 -9999 -9999 -9999 -9999 -9999 -9999 -9999 -9999 -9999 -9999 -9999 -9999 -9999 -9999 -9999 -9999 -9999 -9999 -9999 -9999 -9999 -9999 -9999 -9999 -9999 -9999 -9999 -9999 -9999 -9999 -9999 -9999 -9999 -999 -999 -

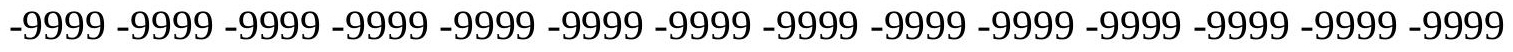
99.6647262573295 .7025299072391 .7403335571389 .9116134643688 .38768768311 90.5211791992294 .7881774902398 .1408081054799 .9695205688599 .05516815186 97.2264633178795 .7025299072394 .7881774902394 .7881774902395 .09295654297 95.7025299072395 .7025299072395 .397743225194 .4833908081192 .04509735107 88.69246673584 84.42548370361 81.37763214111 80.46327209473 81.07285308838 82.9015579223684 .7302627563586 .5589828491288 .0829010009888 .99725341797 89.9116134643690.8259735107492.0450973510792.95947265625 93.87381744385 94.4833908081194 .7881774902394 .7881774902393 .8738174438592 .95947265625 91.7403335571390 .5211791992289 .302040100188 .3876876831187 .77810668945 87.16854858398 86.86376190186 86.86376190186 87.16854858398 87.47332763672 88.0829010009888 .9972534179789 .9116134643690 .8259735107492 .04509735107 93.2642517089894 .7881774902396 .0073165893697 .2264633178798 .75038146973 99.96952056885101 .1886978149102 .4077987671103 .6268997192104 .8460998535 105.7603988647106 .6747970581107 .8938980103108 .5035018921109 .4179000854 110.3321990967110 .9418029785111 .551399231111 .8561019897112 .4656982422 112.4656982422112 .7705001831112 .7705001831112 .7705001831112 .7705001831 112.4656982422112 .4656982422112 .4656982422112 .4656982422112 .4656982422 112.4656982422112 .7705001831112 .7705001831113 .075302124113 .3800964355 113.9896011353114 .2944030762114 .5991973877115 .2088012695115 .5136032104 115.818397522116 .1231002808116 .4279022217116 .7326965332116 .7326965332 116.4279022217116 .1231002808115 .818397522114 .9039993286113 .9896011353 112.7705001831111 .551399231110 .0273971558108 .5035018921106 .979598999 105.1509017944106 .6747970581106 .6747970581106 .3700027466106 .0652008057 105.7603988647104 .8460998535103 .9317016602102 .712600708100 .8839035034 99.66472625732103 .3221969604108 .5035018921115 .5136032104124 .6570968628 135.3246002197147 .8208007812161 .2312927246174 .9467010498187 .4429016113 
198.4151000977207 .8634033203208 .7778015137208 .7778015137208 .7778015137 208.7778015137208 .7778015137208 .7778015137208 .7778015137208 .7778015137 208.7778015137208 .7778015137208 .7778015137208 .7778015137208 .7778015137 208.7778015137208 .7778015137208 .7778015137208 .7778015137208 .7778015137 208.7778015137208 .7778015137208 .7778015137208 .7778015137208 .7778015137 208.7778015137208 .7778015137208 .7778015137208 .7778015137208 .7778015137 208.7778015137208 .7778015137208 .7778015137208 .7778015137208 .7778015137 208.7778015137 208.7778015137208.7778015137 62.17617034912 40.73601150513 -9999 -9999 -9999 -9999 -9999 -9999 -9999 -9999 -9999 -9999 -9999 -9999 -9999 -9999 -9999 -9999 -9999 -9999 -9999 -9999 -9999 -9999 -9999 -9999 -9999 -9999 -9999 -9999 -9999 -9999 -9999 -9999 -9999 -9999 -9999 -9999 -9999 -9999 -9999 -9999 -999 -9999 -9999 -9999 -9999 -9999 -9999 -9999 -9999 -9999 -9999 -9999 -9999 -9999 -9999 -9999 -9999 -9999 -9999 -9999 -9999 -9999 -9999 -9999 -9999 -9999 -9999 -9999 -9999 -9999 -9999 -9999 -9999 -9999 -9999 -9999 -9999 -9999 -9999 -9999 -9999 -9999 -9999 -9999 -9999 -9999 -9999 -9999 -9999 -9999 -9999 -9999 -9999 -9999 -9999 -9999 -9999 -9999 -9999 -9999 -9999

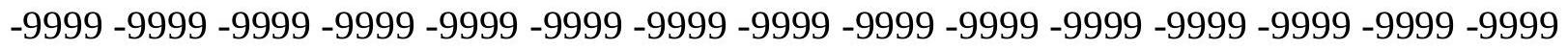

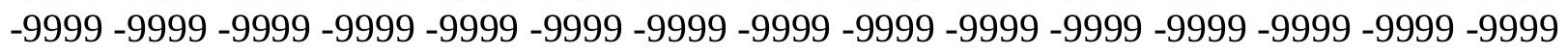

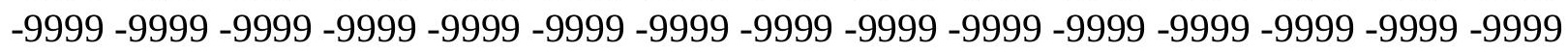

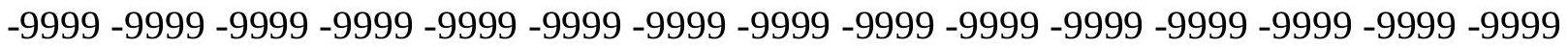

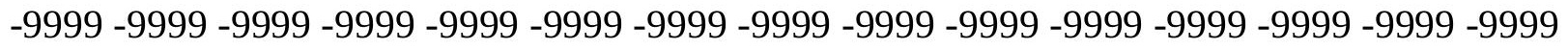

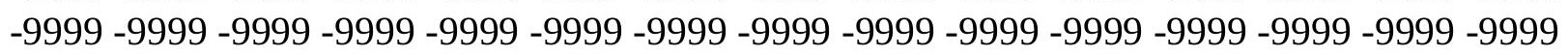

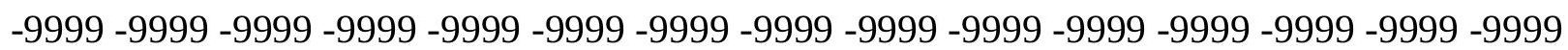
-9999 -9999 -9999 -9999 -9999 -9999 -9999 -9999 -9999 -9999 -9999 -9999 -9999 -9999 -9999 97.8360290527394 .1785964965891 .4355392456189 .6068267822388 .08290100098 93.87381744385101 .4934005737102 .407798767199 .6647262573296 .92166900635 95.397743225194 .4833908081194 .4833908081195 .0929565429795 .70252990723 96.0073165893696 .0073165893695 .0929565429793 .8738174438591 .74033355713 88.3876876831185 .6446228027384 .4254837036184 .4254837036185 .33984375 86.2541885376 87.47332763672 88.38768768311 88.9972534179789.91161346436 90.8259735107491 .4355392456192 .6546783447393 .2642517089893 .87381744385 93.8738174438593 .5690307617292 .9594726562592 .0450973510790 .82597351074 89.9116134643688 .6924667358487 .7781066894586 .8637619018686 .2541885376 85.9494018554785 .6446228027385 .9494018554786 .5589828491287 .16854858398 88.0829010009889 .302040100190 .5211791992291 .7403335571392 .95947265625 94.4833908081195 .7025299072397 .2264633178798 .445587158299 .96952056885 101.1886978149102 .4077987671103 .6268997192104 .8460998535106 .0652008057 106.979598999107 .8938980103108 .8082962036109 .7226028442110 .6370010376 111.24659729111 .8561019897112 .1608963013112 .4656982422112 .7705001831 113.075302124113 .075302124113 .075302124113 .075302124113 .075302124 112.7705001831112 .7705001831112 .7705001831113 .075302124113 .075302124 113.3800964355113 .6848983765113 .9896011353114 .2944030762114 .5991973877 114.9039993286115 .2088012695115 .818397522116 .1231002808116 .4279022217 116.7326965332117 .0374984741117 .342300415117 .342300415117 .0374984741 116.7326965332116 .1231002808115 .5136032104114 .5991973877113 .3800964355 112.1608963013110 .6370010376109 .1130981445107 .2844009399105 .7603988647 103.9317016602106 .6747970581106 .3700027466105 .7603988647105 .1509017944 
104.5412979126103 .3221969604102 .1029968262100 .274299621699 .05516815186 101.7982025146106 .0652008057111 .8561019897119 .7806015015130 .7528076172 143.5538024902156 .9642944336170 .6797027588183 .1759033203194 .7577056885 204.5108032227208 .7778015137208 .7778015137208 .7778015137208 .7778015137 208.7778015137208 .7778015137208 .7778015137208 .7778015137208 .7778015137 208.7778015137208 .7778015137208 .7778015137208 .7778015137208 .7778015137 208.7778015137 208.7778015137 208.7778015137 208.7778015137 208.7778015137 208.7778015137 208.7778015137 208.7778015137 208.7778015137 208.7778015137 208.7778015137208 .7778015137208 .7778015137208 .7778015137208 .7778015137 208.7778015137208 .7778015137208 .7778015137208 .7778015137208 .7778015137 208.7778015137 208.7778015137208 .777801513772 .37086486816 -9999 -9999 -9999-9999 -9999 -9999 -9999-9999-9999-9999

-9999 -9999 -9999 -9999 -9999 -9999 -9999 -9999 -9999 -9999 -9999 -9999 -9999 -9999 -9999 -9999 -9999 -9999 -9999 -9999 -9999 -9999 -9999 -9999 -9999 -9999 -9999 -9999 -9999 -9999 -9999 -9999 -9999 -9999 -9999 -9999 -9999 -9999 -9999 -9999 -9999 -9999 -9999 -9999 -9999

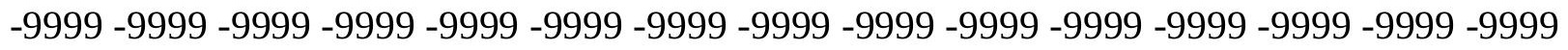

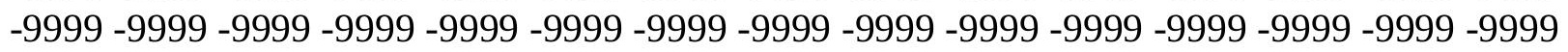

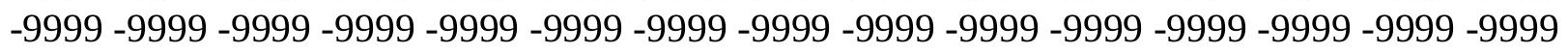

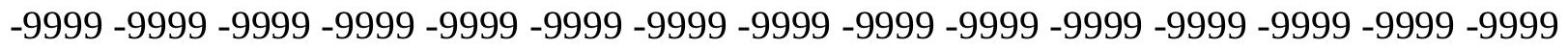

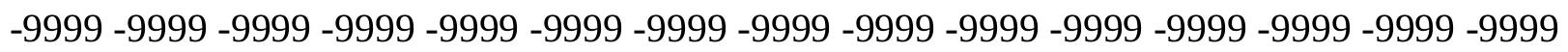

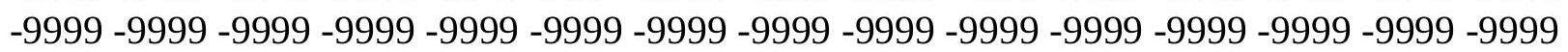

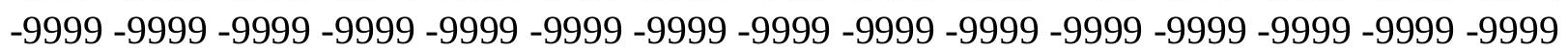

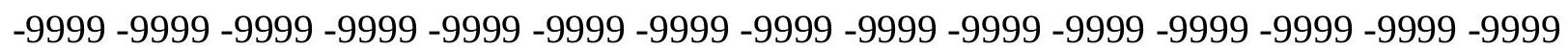
-9999 -9999 -9999 -9999 -9999 -9999 -9999 -9999 -9999 -9999 -9999 -9999 -9999 -9999 -9999 -

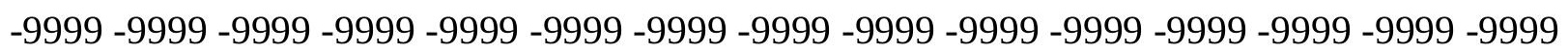

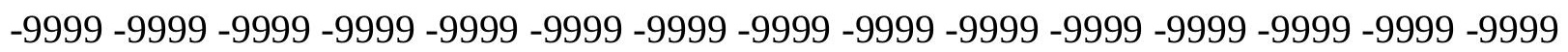
-9999-9999 93.8738174438591.43553924561 89.3020401001 87.47332763672 106.0652008057101 .188697814997 .5312423706195 .397743225194 .17859649658 93.8738174438594 .1785964965894 .7881774902395 .7025299072396 .31210327148 96.3121032714896 .0073165893695 .0929565429793 .5690307617291 .43553924561 89.6068267822388 .3876876831187 .7781066894587 .7781066894588 .08290100098 88.38768768311 88.99725341797 89.6068267822390.21640014648 91.13075256348 91.7403335571392 .349891662692 .6546783447392 .9594726562592 .95947265625 92.6546783447392 .0450973510791 .1307525634890 .2164001464888 .99725341797 88.0829010009886 .8637619018685 .9494018554785 .3398437585 .03504943848 84.7302627563585 .0350494384885 .6446228027386 .5589828491287 .47332763672 88.69246673584 89.91161346436 91.4355392456192.9594726562594.17859649658 95.7025299072397 .2264633178798 .445587158299 .96952056885101 .1886978149 102.4077987671103 .9317016602104 .8460998535106 .0652008057107 .2844009399 108.1986999512 109.1130981445110.0273971558 110.6370010376111 .551399231 111.8561019897112 .4656982422112 .7705001831113 .075302124113 .3800964355 113.3800964355113 .3800964355113 .3800964355113 .3800964355113 .3800964355 113.3800964355113 .3800964355113 .3800964355113 .6848983765113 .6848983765 113.9896011353114 .2944030762114 .9039993286115 .2088012695115 .5136032104 115.818397522116 .1231002808116 .4279022217117 .0374984741117 .342300415 117.647102356117 .647102356117 .647102356117 .647102356117 .0374984741 
116.7326965332115 .818397522114 .9039993286113 .6848983765112 .4656982422 110.9418029785109 .4179000854107 .8938980103106 .3700027466104 .5412979126 106.3700027466106 .0652008057105 .4557037354104 .8460998535103 .9317016602 102.712600708101 .188697814997 .2264633178798 .4455871582100 .8839035034 104.5412979126109 .4179000854116 .1231002808127 .7050018311140 .5059967041 153.9165039062167 .3269958496180 .1280059814191 .7097930908202 .0724945068 208.7778015137208 .7778015137208 .7778015137208 .7778015137208 .7778015137 208.7778015137208 .7778015137208 .7778015137208 .7778015137208 .7778015137 208.7778015137208 .7778015137208 .7778015137208 .7778015137208 .7778015137 208.7778015137208 .7778015137208 .7778015137208 .7778015137208 .7778015137 208.7778015137208.7778015137208.7778015137208.7778015137208.7778015137 208.7778015137208 .7778015137208 .7778015137208 .7778015137208 .7778015137 208.7778015137208 .7778015137208 .7778015137208 .7778015137208 .7778015137 208.777801513761 .8713798522940 .4072303772 -9999 -9999 -9999 -9999 -9999 -9999 -9999 -9999 -9999-9999

-9999 -9999 -9999 -9999 -9999 -9999 -9999 -9999 -9999 -9999 -9999 -9999 -9999 -9999 -9999 -9999 -9999 -9999 -9999 -9999 -9999 -9999 -9999 -9999 -9999 -9999 -9999 -9999 -9999 -9999 -9999 -9999 -9999 -9999 -9999 -9999 -9999 -9999 -9999 -9999 -9999 -9999 -9999 -9999 -9999 -9999 -9999 -9999 -9999 -9999 -9999 -9999 -9999 -9999 -9999 -9999 -9999 -9999 -9999 -9999 -

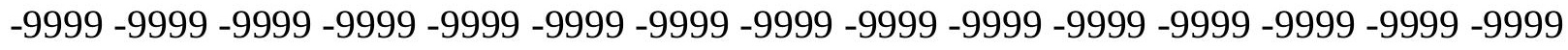

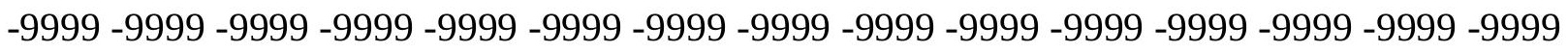
-9999 -9999 -9999 -9999 -9999 -9999 -9999 -9999 -9999 -9999 -9999 -9999 -9999 -9999 -9999 -9999 -9999 -9999 -9999 -9999 -9999 -9999 -9999 -9999 -9999 -9999 -9999 -9999 -9999 -9999 -

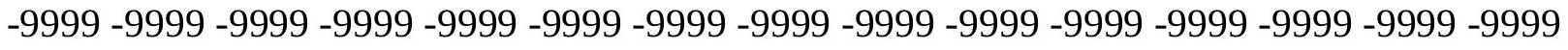

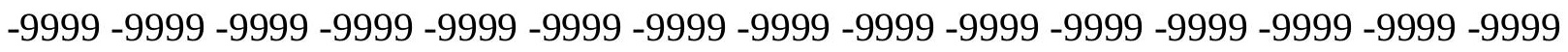
-9999 -9999 -9999 -9999 -9999 -9999 -9999 -9999 -9999 -9999 -9999 -9999 -9999 -9999 -9999 -9999 -9999 -9999 -9999 -9999 -9999 -9999 -9999 -9999 -9999 -9999 -9999 -9999 -9999 -9999 -

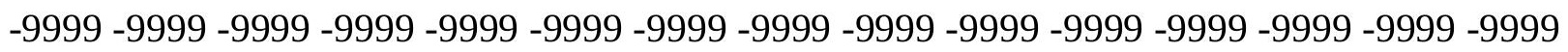

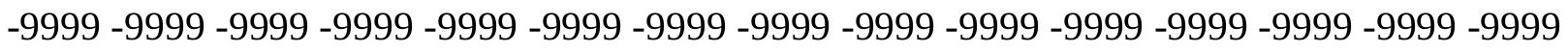
-9999 -9999 -9999 93.8738174438591.13075256348 88.99725341797 87.77810668945 92.9594726562593 .5690307617292 .6546783447392 .349891662692 .65467834473 93.5690307617294 .4833908081195 .7025299072396 .6168823242296 .92166900635 96.9216690063596 .3121032714895 .0929565429793 .5690307617292 .3498916626 91.4355392456191 .1307525634890 .2164001464889 .9116134643689 .60682678223 89.9116134643690 .5211791992291 .1307525634891 .4355392456192 .04509735107 92.349891662692 .349891662692 .6546783447392 .349891662692 .04509735107 91.4355392456190 .5211791992289 .6068267822388 .3876876831187 .47332763672 86.2541885376 85.33984375 84.73026275635 84.12069702148 84.12069702148 84.4254837036185 .0350494384885 .9494018554787 .1685485839888 .38768768311 89.9116134643691.4355392456192.6546783447394.1785964965895.70252990723 97.2264633178798.7503814697399.96952056885101.4934005737102.712600708 103.9317016602105 .1509017944106 .3700027466107 .2844009399108 .5035018921 109.4179000854110 .3321990967110 .9418029785111 .551399231112 .1608963013 112.7705001831113 .075302124113 .3800964355113 .6848983765113 .6848983765 113.6848983765113 .6848983765113 .6848983765113 .6848983765113 .3800964355 113.6848983765113 .9896011353113 .9896011353114 .2944030762114 .5991973877 
114.9039993286115 .2088012695115 .5136032104115 .818397522116 .1231002808 116.4279022217116 .7326965332117 .0374984741117 .342300415117 .647102356 117.9517974854117 .9517974854117 .647102356117 .342300415116 .7326965332 116.1231002808115 .2088012695113 .9896011353112 .7705001831111 .24659729 109.7226028442108 .1986999512106 .6747970581105 .1509017944103 .6268997192 105.7603988647105 .1509017944104 .2365036011103 .3221969604102 .1029968262 100.579101562597 .2264633178798 .4455871582100 .5791015625103 .9317016602 109.1130981445116 .4279022217126 .7906036377139 .2868041992152 .3925933838 165.4983062744177 .9945068359189 .5764007568199 .9389953613208 .7778015137 208.7778015137208 .7778015137208 .7778015137208 .7778015137208 .7778015137 208.7778015137208 .7778015137208 .7778015137208 .7778015137208 .7778015137 208.7778015137208 .7778015137208 .7778015137208 .7778015137208 .7778015137 208.7778015137208 .7778015137208 .7778015137208 .7778015137208 .7778015137 208.7778015137208 .7778015137208 .7778015137208 .7778015137208 .7778015137 208.7778015137208 .7778015137208 .7778015137208 .7778015137208 .7778015137 208.7778015137208 .7778015137208 .7778015137208 .7778015137208 .7778015137 61.8713798522911 .44708824158 -9999 -9999 -9999 -9999 -9999 -9999 -9999 -9999 -9999 $-9999$

-9999 -9999 -9999 -9999 -9999 -9999 -9999 -9999 -9999 -9999 -9999 -9999 -9999 -9999 -9999 -9999 -9999 -9999 -9999 -9999 -9999 -9999 -9999 -9999 -9999 -9999 -9999 -9999 -9999 -9999 -9999 -9999 -9999 -9999 -9999 -9999 -9999 -9999 -9999 -9999 -9999 -9999 -9999 -9999 -9999 -9999 -9999 -9999 -9999 -9999 -9999 -9999 -9999 -9999 -9999 -9999 -9999 -9999 -9999 -9999 -9999 -9999 -9999 -9999 -9999 -9999 -9999 -9999 -9999 -9999 -9999 -9999 -9999 -9999 -9999 -9999 -9999 -9999 -9999 -9999 -9999 -9999 -9999 -9999 -9999 -9999 -9999 -9999 -9999 -9999 -9999 -9999 -9999 -9999 -9999 -9999 -9999 -9999 -9999 -9999 -9999 -9999 -9999 -9999 -9999 -9999 -9999 -9999 -9999 -9999 -9999 -9999 -9999 -9999 -9999 -9999 -9999 -9999 -9999 -9999 -9999 -9999 -9999 -9999 -9999 -9999 -9999 -9999 -9999 -9999 -9999 -9999 -9999 -9999 -9999 -9999 -9999 -9999 -9999 -9999 -9999 -9999 -9999 -9999 -9999 -9999 -9999 -9999 -9999 -9999 -9999 -9999 -9999 -9999 -9999 -9999 -9999 -9999 -9999 -9999 -9999 -9999 -9999 -9999 -9999 -9999 -9999 -9999 -9999 -9999 -9999 -9999 -9999 -9999 -9999 -9999 -9999 -9999 -9999 -9999 -999 -9999 -9999 -9999 -9999 -9999 -9999 -9999 -9999 -9999 -9999 -9999 -9999 -9999 -9999 -9999 -9999 -9999 -9999 -9999 -9999 -9999 -9999 -9999 -9999 -9999 -9999 -9999 -9999 -9999 -9999 -9999 -9999-9999-9999 93.56903076172 90.52117919922 88.08290100098 86.2541885376 88.38768768311 89.9116134643690.8259735107491.7403335571393.26425170898 94.4833908081195 .7025299072396 .9216690063597 .5312423706197 .53124237061 97.2264633178796 .3121032714895 .397743225194 .4833908081193 .56903076172 92.9594726562592 .349891662691 .4355392456191 .1307525634891 .13075256348 91.1307525634892 .6546783447392 .6546783447392 .6546783447392 .65467834473 92.349891662692 .349891662691 .7403335571391 .4355392456190 .52117919922 89.9116134643688 .9972534179788 .0829010009886 .8637619018685 .94940185547 85.0350494384884 .1206970214883 .5111236572383 .5111236572383 .81591033936 84.7302627563585 .9494018554787 .1685485839888 .3876876831189 .91161346436 91.4355392456192 .9594726562594 .4833908081196 .0073165893697 .22646331787 98.75038146973100 .2742996216101 .4934005737103 .0174026489104 .2365036011 105.4557037354106 .6747970581107 .5891036987108 .8082962036109 .7226028442 110.6370010376111 .24659729111 .8561019897112 .4656982422113 .075302124 
113.3800964355113 .6848983765113 .9896011353113 .9896011353113 .9896011353 113.9896011353113 .9896011353113 .9896011353113 .9896011353114 .2944030762 114.5991973877114 .5991973877114 .9039993286115 .2088012695115 .2088012695 115.5136032104115 .818397522116 .1231002808116 .4279022217116 .7326965332 116.7326965332117 .0374984741117 .342300415117 .647102356117 .9517974854 117.9517974854117 .647102356117 .342300415116 .7326965332116 .1231002808 114.9039993286113 .9896011353112 .4656982422111 .24659729109 .7226028442 108.5035018921106 .979598999105 .4557037354103 .9317016602102 .712600708 104.5412979126103 .6268997192102 .712600708101 .188697814997 .53124237061 97.5312423706198 .75038146973100 .5791015625104 .2365036011109 .7226028442 117.342300415127 .4001998901139 .2868041992152 .0877990723164 .8887023926 177.0802001953188 .6620025635199 .0247039795208 .1681976318208 .7778015137 208.7778015137208 .7778015137208 .7778015137208 .7778015137208 .7778015137 208.7778015137208 .7778015137208 .7778015137208 .7778015137208 .7778015137 208.7778015137208 .7778015137208 .7778015137208 .7778015137208 .7778015137 208.7778015137 208.7778015137208.7778015137 208.7778015137 208.7778015137 208.7778015137208 .7778015137208 .7778015137208 .7778015137208 .7778015137 208.7778015137208 .7778015137208 .7778015137208 .7778015137208 .7778015137 208.7778015137208 .7778015137208 .7778015137208 .777801513761 .87137985229 6250468492508 -9999 -9999 -9999 -9999 -9999 -9999 -9999 -9999 -9999 -9999 -9999 -9999 -9999 -9999 -9999 -9999 -9999 -9999 -9999 -9999 -9999 -9999 -9999 -9999 -9999 -9999 -9999 -9999 -9999 -9999 -9999 -9999 -9999 -9999 -9999 -9999 -9999 -9999 -9999 -9999 -9999 -9999 -9999 -9999 -9999 -9999 -9999 -9999 -9999 -9999 -9999 -9999-9999-9999-9999 -999 -9999 -9999 -9999 -9999 -9999 -9999 -9999 -9999 -9999 -9999 -9999 -9999 -9999 -9999 -9999 -9999 -9999 -9999 -9999 -9999 -9999 -9999 -9999 -9999 -9999 -9999 -9999 -9999 -9999 -9999 -9999 -9999 -9999 -9999 -9999 -9999 -9999 -9999 -9999 -9999 -9999 -9999 -9999 -9999 -9999 -9999 -9999 -9999 -9999 -9999 -9999 -9999 -9999 -9999 -9999 -9999 -9999 -9999 -9999 -9999

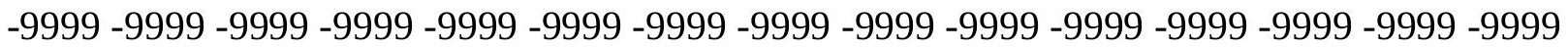
-9999 -9999 -9999 -9999 -9999 -9999 -9999 -9999 -9999 -9999 -9999 -9999 -9999 -9999 -9999 -9999 -9999 -9999 -9999 -9999 -9999 -9999 -9999 -9999 -9999 -9999 -9999 -9999 -9999 -9999 -9999 -9999 -9999 -9999 -9999 -9999 -9999 -9999 -9999 -9999 -9999 -9999 -9999 -9999 -9999

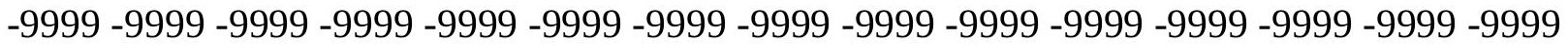

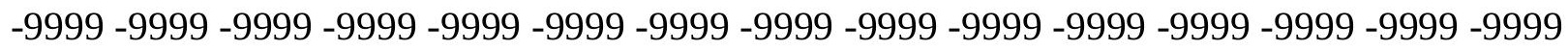

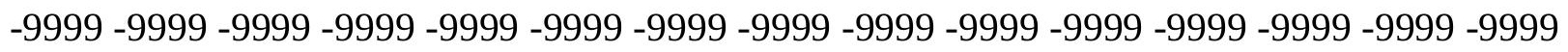
-9999 -9999 -9999 -9999-9999-9999 89.60682678223 86.86376190186 85.94940185547 87.7781066894589 .6068267822391 .1307525634892 .9594726562594 .48339080811 96.00731658936 97.2264633178797.83602905273 98.1408081054798.14080810547 97.5312423706196 .9216690063596 .0073165893695 .397743225194 .48339080811 93.8738174438593 .2642517089892 .6546783447392 .349891662692 .65467834473 93.2642517089893 .2642517089893 .2642517089892 .9594726562592 .65467834473 92.0450973510791 .4355392456190 .8259735107490 .2164001464889 .60682678223 88.69246673584 87.77810668945 86.86376190186 85.9494018554785.03504943848 84.1206970214883 .5111236572383 .206336975183 .8159103393684 .73026275635 85.9494018554787 .4733276367288 .6924667358490 .2164001464891 .74033355713 93.2642517089894 .7881774902396 .3121032714897 .5312423706199 .05516815186 100.5791015625101 .7982025146103 .3221969604104 .5412979126105 .7603988647 
106.979598999107 .8938980103109 .1130981445110 .0273971558110 .6370010376 111.551399231112 .1608963013112 .7705001831113 .3800964355113 .6848983765 113.9896011353113 .9896011353114 .2944030762114 .2944030762114 .2944030762 114.2944030762114 .2944030762114 .5991973877114 .9039993286114 .9039993286 114.9039993286115 .2088012695115 .2088012695115 .5136032104115 .818397522 116.1231002808116 .4279022217116 .7326965332117 .0374984741117 .342300415 117.342300415117 .647102356117 .342300415117 .647102356117 .647102356117 .342300415 117.0374984741116 .4279022217115 .818397522114 .5991973877113 .3800964355 112.1608963013110 .9418029785109 .7226028442108 .1986999512106 .979598999 105.7603988647104 .2365036011103 .0174026489101 .7982025146100 .5791015625 99.3599472045998.445587158297.8360290527398.1408081054799.05516815186 101.1886978149104 .8460998535110 .6370010376118 .5614013672128 .6192932129 140.2012023926152 .6972961426165 .1934967041177 .3849029541188 .6620025635 198.7198944092207 .8634033203208 .7778015137208 .7778015137208 .7778015137 208.7778015137208 .7778015137208 .7778015137208 .7778015137208 .7778015137 208.7778015137208.7778015137208.7778015137 208.7778015137 208.7778015137 208.7778015137208 .7778015137208 .7778015137208 .7778015137208 .7778015137 208.7778015137208 .7778015137208 .7778015137208 .7778015137208 .7778015137 208.7778015137208 .7778015137208 .7778015137208 .7778015137208 .7778015137 208.7778015137208 .7778015137208 .7778015137208 .7778015137208 .7778015137 208.7778015137208 .777801513761 .56660079956 -2.84570670128 -9999 -9999 -9999 -9999 -9999 -9999 -9999 -9999-9999-9999 -9999 -9999 -9999 -9999 -9999 -9999 -9999 -9999 -9999 -9999 -9999 -9999 -9999 -9999 -9999 -9999 -9999 -9999 -9999 -9999 -9999 -9999 -9999 -9999 -9999 -9999 -9999 -9999 -9999 -9999 -9999 -9999 -9999 -9999 -9999 -9999 -9999 -9999 -9999 -9999 -9999 -9999 -9999 -9999 -9999 -9999 -9999 -9999 -9999 -9999 -9999 -9999 -9999 -9999 -9999 -9999 -9999 -9999 -9999 -9999 -9999 -9999 -9999 -9999 -9999 -9999 -9999 -9999 -9999 -9999 -9999 -9999 -9999 -9999 -9999

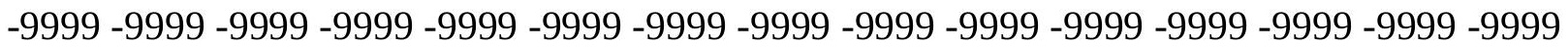
-9999 -9999 -9999 -9999 -9999 -9999 -9999 -9999 -9999 -9999 -9999 -9999 -9999 -9999 -9999 -9999 -9999 -9999 -9999 -9999 -9999 -9999 -9999 -9999 -9999 -9999 -9999 -9999 -9999 -9999 -999 -9999 -9999 -9999 -9999 -9999 -9999 -9999 -9999 -9999 -9999 -9999 -9999 -9999 -9999 -9999

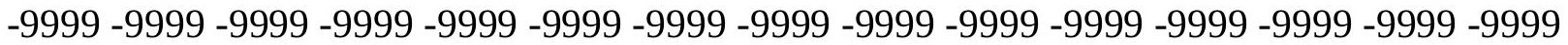

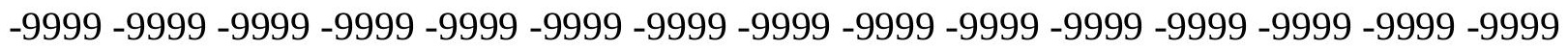
-9999 -9999 -9999 -9999 -9999 -9999 -9999 -9999 -9999 -9999 -9999 -9999 -9999 -9999 -9999 -9999 -9999 -9999 -9999 -9999 -9999 -9999 -9999 -9999 -9999 -9999 -9999 -9999 -9999 -9999 -9999 -9999 -9999 -9999 -9999 -9999 -9999 -9999 -9999 -9999 -9999 -9999 -9999 -9999 -9999 -9999 -9999-9999 -9999 -9999-9999-9999 88.69246673584 87.16854858398 87.16854858398 89.302040100191.1307525634893.2642517089894.7881774902396.31210327148 97.5312423706198 .445587158298 .7503814697398 .7503814697398 .4455871582 97.83602905273 97.2264633178796.61688232422 95.70252990723 95.09295654297 94.4833908081194 .1785964965893 .8738174438593 .8738174438594 .17859649658 94.1785964965893 .8738174438593 .2642517089892 .6546783447392 .04509735107 91.4355392456190 .8259735107490 .2164001464889 .302040100188 .69246673584 87.7781066894587 .1685485839886 .254188537685 .3398437584 .42548370361 83.8159103393683 .5111236572384 .1206970214885 .3398437586 .55898284912 87.7781066894589 .302040100190 .8259735107492 .349891662693 .56903076172 
95.0929565429796 .6168823242298 .1408081054799 .35994720459100 .8839035034 102.4077987671103 .6268997192104 .8460998535106 .0652008057107 .2844009399 108.1986999512109 .4179000854110 .3321990967111 .24659729111 .8561019897 112.4656982422113 .075302124113 .6848983765113 .9896011353114 .2944030762 114.2944030762114 .5991973877114 .5991973877114 .5991973877114 .5991973877 114.9039993286115 .2088012695115 .2088012695115 .2088012695115 .2088012695 115.2088012695115 .2088012695115 .5136032104115 .818397522116 .1231002808 116.4279022217117 .0374984741117 .342300415117 .647102356117 .9517974854 117.9517974854117 .9517974854117 .9517974854117 .342300415116 .7326965332 116.4279022217115 .818397522114 .9039993286113 .9896011353112 .7705001831 111.24659729110 .0273971558108 .8082962036107 .5891036987106 .3700027466 105.4557037354104 .2365036011103 .0174026489102 .1029968262100 .8839035034 99.6647262573298.75038146973 98.1408081054798.1408081054799.05516815186 101.1886978149105 .1509017944111 .24659729119 .7806015015130 .1432037354 142.0299072266154 .2212982178166 .7174987793178 .604095459189 .2716064453 199.329498291208.1681976318208.7778015137208.7778015137208.7778015137 208.7778015137208 .7778015137208 .7778015137208 .7778015137208 .7778015137 208.7778015137208 .7778015137208 .7778015137208 .7778015137208 .7778015137 208.7778015137208 .7778015137208 .7778015137208 .7778015137208 .7778015137 208.7778015137208 .7778015137208 .7778015137208 .7778015137208 .7778015137 208.7778015137208 .7778015137208 .7778015137208 .7778015137208 .7778015137 208.7778015137208 .7778015137208 .7778015137208 .7778015137208 .7778015137 $208.7778015137208 .777801513761 .56660079956-4.10879659653$-9999 -9999 -9999 -9999 -9999 -9999 -9999-9999-9999-9999

-9999 -9999 -9999 -9999 -9999 -9999 -9999 -9999 -9999 -9999 -9999 -9999 -9999 -9999 -9999 -9999 -9999 -9999 -9999 -9999 -9999 -9999 -9999 -9999 -9999 -9999 -9999 -9999 -9999 -9999 -9999 -9999 -9999 -9999 -9999 -9999 -9999 -9999 -9999 -9999 -9999 -9999 -9999 -9999 - -9999 -

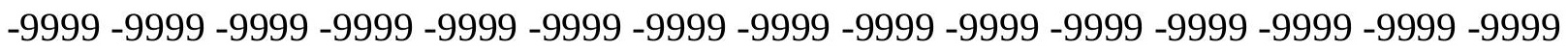

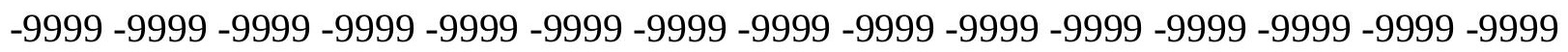

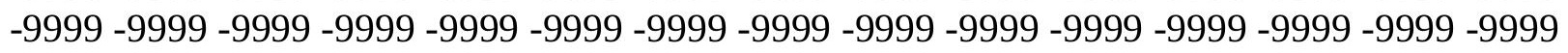
-9999 -9999 -9999 -9999 -9999 -9999 -9999 -9999 -9999 -9999 -9999 -9999 -9999 -9999 -9999

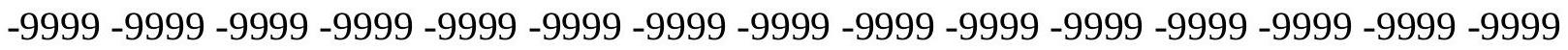

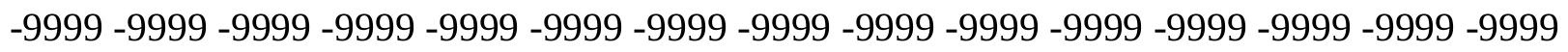

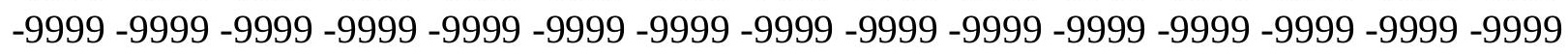

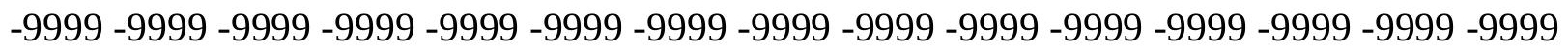

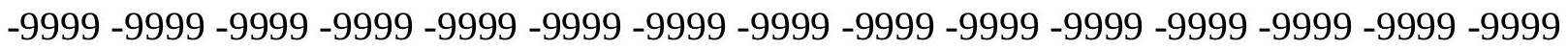

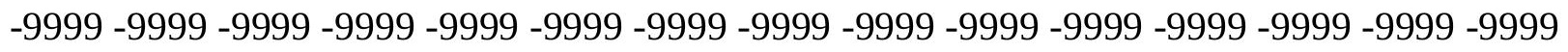

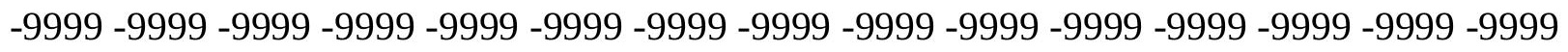
-9999 -9999 -9999 -9999 -9999 -9999 -9999 -9999 90.52117919922 89.91161346436 89.9116134643691 .7403335571393 .8738174438595 .397743225196 .92166900635 98.1408081054798 .7503814697399 .3599472045999 .3599472045999 .05516815186 98.445587158298 .1408081054797 .5312423706196 .9216690063596 .31210327148 95.7025299072395 .397743225195 .0929565429795 .0929565429795 .09295654297 94.7881774902394 .4833908081193 .8738174438593 .2642517089892 .65467834473 91.7403335571391 .1307525634890 .21640014648 89.60682678223 88.99725341797 88.38768768311 87.77810668945 86.86376190186 86.2541885376 85.33984375 
85.0350494384884 .7302627563585 .3398437586 .254188537687 .47332763672 88.9972534179790 .2164001464891 .4355392456192 .9594726562594 .48339080811 95.7025299072397 .2264633178798 .7503814697399 .96952056885101 .4934005737 102.712600708103 .9317016602105 .1509017944106 .3700027466107 .5891036987 108.8082962036109 .7226028442110 .6370010376111 .551399231112 .1608963013 112.7705001831113 .3800964355113 .6848983765114 .2944030762114 .2944030762 114.5991973877114 .5991973877114 .5991973877114 .5991973877114 .9039993286 115.2088012695115 .2088012695115 .2088012695115 .2088012695115 .2088012695 115.2088012695115 .2088012695115 .5136032104115 .5136032104116 .1231002808 116.4279022217117 .0374984741117 .342300415117 .9517974854118 .2565994263 118.5614013672118 .5614013672118 .5614013672117 .9517974854117 .342300415 116.1231002808114 .9039993286113 .9896011353112 .7705001831111 .24659729 110.0273971558108 .8082962036107 .5891036987106 .3700027466105 .4557037354 104.5412979126103 .6268997192102 .712600708101 .4934005737100 .5791015625 99.3599472045998 .445587158298 .1408081054797 .8360290527398 .4455871582 100.5791015625104 .8460998535111 .24659729120 .3900985718131 .6672058105 143.8585968018156 .6596069336168 .8509979248180 .432800293191 .1002960205 200.5485992432208 .7778015137208 .7778015137208 .7778015137208 .7778015137 208.7778015137208.7778015137208.7778015137208.7778015137208.7778015137 208.7778015137 208.7778015137208.7778015137208.7778015137 208.7778015137 208.7778015137 208.7778015137208.7778015137208.7778015137 208.7778015137 208.7778015137208 .7778015137208 .7778015137208 .7778015137208 .7778015137 208.7778015137208 .7778015137208 .7778015137208 .7778015137208 .7778015137 208.7778015137208 .7778015137208 .7778015137208 .7778015137208 .7778015137 208.7778015137208 .777801513761 .26181030273 -4.69056034088 -9999 -9999 -9999 -9999 -9999 -9999 -9999-9999-9999-9999 -9999 -9999 -9999 -9999 -9999 -9999 -9999 -9999 -9999 -9999 -9999 -9999 -9999 -9999 -9999

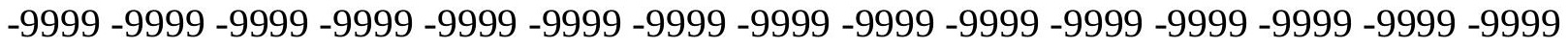
-9999 -9999 -9999 -9999 -9999 -9999 -9999 -9999 -9999 -9999 -9999 -9999 -9999 -9999 -9999 -9999 -9999 -9999 -9999 -9999 -9999 -9999 -9999 -9999 -9999 -9999 -9999 -9999 -9999 -9999 -9999 -9999 -9999 -9999 -9999 -9999 -9999 -9999 -9999 -9999 -9999 -9999 -9999 -9999 -9999 -9999 -9999 -9999 -9999 -9999 -9999 -9999 -9999 -9999 -9999 -9999 -9999 -9999 -9999 -9999 -

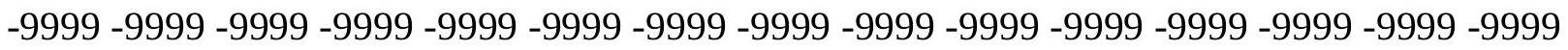
-9999 -9999 -9999 -9999 -9999 -9999 -9999 -9999 -9999 -9999 -9999 -9999 -9999 -9999 -9999 -9999 -9999 -9999 -9999 -9999 -9999 -9999 -9999 -9999 -9999 -9999 -9999 -9999 -9999 -9999 -

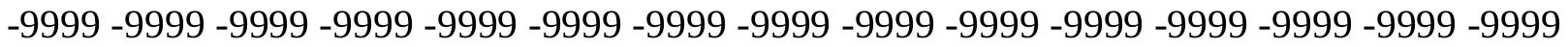

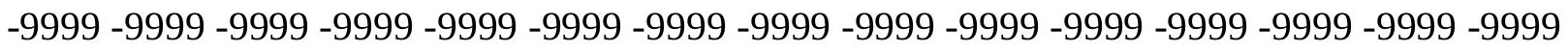

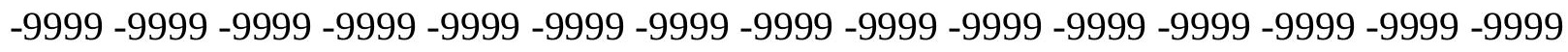
-9999 -9999 -9999 -9999 -9999 -9999 -9999 -9999 -9999 -9999 -9999 -9999 -9999 -9999 -9999 -9999 -9999 -9999 -9999 -9999 -9999 -9999 -9999 -9999 -9999 -9999 -9999 -9999 -9999 -9999 -9999 -9999-9999 -9999 -9999 -9999-9999-9999-9999 94.4833908081193.56903076172 92.9594726562594 .7881774902396 .3121032714897 .8360290527398 .75038146973 99.3599472045999 .6647262573299 .6647262573299 .6647262573299 .05516815186 98.7503814697398 .1408081054797 .5312423706197 .2264633178796 .92166900635 96.6168823242296 .3121032714896 .3121032714896 .0073165893695 .70252990723 95.397743225194.7881774902393.8738174438593.2642517089892.3498916626 
91.4355392456190 .8259735107490 .2164001464889 .6068267822389 .3020401001 88.6924667358488 .0829010009887 .4733276367286 .8637619018686 .55898284912 86.5589828491287 .1685485839887 .7781066894588 .9972534179790 .21640014648 91.4355392456192 .6546783447393 .8738174438595 .0929565429796 .61688232422 97.8360290527399 .35994720459100 .5791015625101 .7982025146103 .3221969604 104.5412979126105 .7603988647106 .979598999107 .8938980103109 .1130981445 110.0273971558110 .9418029785111 .8561019897112 .4656982422113 .075302124 113.6848983765114 .2944030762114 .5991973877114 .5991973877114 .9039993286 114.9039993286114 .9039993286114 .9039993286114 .9039993286115 .2088012695 115.5136032104115 .2088012695115 .2088012695114 .9039993286114 .9039993286 114.9039993286115 .2088012695115 .2088012695115 .818397522116 .1231002808 116.7326965332117 .647102356117 .9517974854118 .5614013672118 .8662033081 118.8662033081118 .8662033081118 .5614013672117 .9517974854116 .7326965332 115.2088012695113 .6848983765112 .1608963013110 .6370010376109 .1130981445 107.5891036987106 .3700027466105 .1509017944103 .9317016602103 .0174026489 102.1029968262101 .4934005737100 .274299621699 .3599472045998 .4455871582 97.5312423706196 .9216690063596 .6168823242296 .9216690063598 .75038146973 103.0174026489110 .0273971558120 .3900985718132 .8863067627146 .2969055176 159.4026031494171 .5939941406182 .87109375192 .9290008545202 .3773040771 208.7778015137208.7778015137208.7778015137208.7778015137208.7778015137 208.7778015137 208.7778015137208.7778015137208.7778015137 208.7778015137 208.7778015137208 .7778015137208 .7778015137208 .7778015137208 .7778015137 208.7778015137208 .7778015137208 .7778015137208 .7778015137208 .7778015137 208.7778015137208 .7778015137208 .7778015137208 .7778015137208 .7778015137 208.7778015137208 .7778015137208 .7778015137208 .7778015137208 .7778015137 208.7778015137208 .7778015137208 .7778015137208 .7778015137208 .7778015137 208.777801513761 .26181030273 -4.98864793777 -9999 -9999 -9999 -9999 -9999 -9999 -9999 -9999 -9999-9999

-9999 -9999 -9999 -9999 -9999 -9999 -9999 -9999 -9999 -9999 -9999 -9999 -9999 -9999 -9999

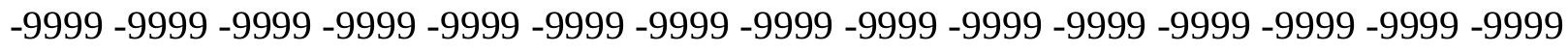
-9999 -9999 -9999 -9999 -9999 -9999 -9999 -9999 -9999 -9999 -9999 -9999 -9999 -9999 -9999

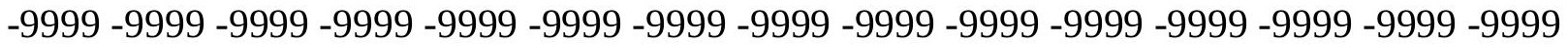

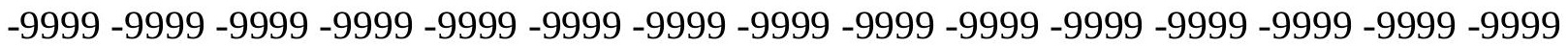
-9999 -9999 -9999 -9999 -9999 -9999 -9999 -9999 -9999 -9999 -9999 -9999 -9999 -9999 -9999 -9999 -9999 -9999 -9999 -9999 -9999 -9999 -9999 -9999 -9999 -9999 -9999 -9999 -9999 -9999 -9999 -9999 -9999 -9999 -9999 -9999 -9999 -9999 -9999 -9999 -9999 -9999 -9999 -9999 -9999

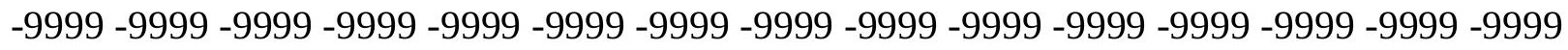

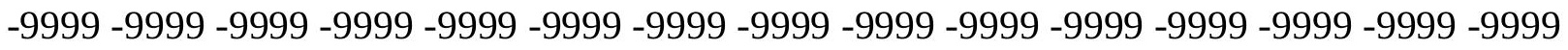
-9999 -9999 -9999 -9999 -9999 -9999 -9999 -9999 -9999 -9999 -9999 -9999 -9999 -9999 -9999 -9999 -9999 -9999 -9999 -9999 -9999 -9999 -9999 -9999 -9999 -9999 -9999 -9999 -9999 -9999 -

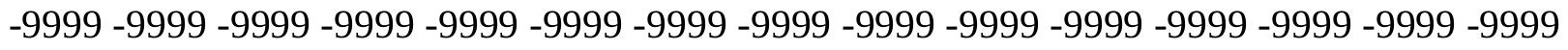
-9999 -9999 -9999 -9999 -9999 -9999 -9999 -9999 -9999 -9999 -9999 -9999 -9999 -9999 -9999 - -999 -9999 -9999 -9999 -9999 -9999 -9999 -9999 -9999 -9999 -9999 98.75038146973 97.5312423706196 .0073165893697 .2264633178798 .445587158299 .35994720459 99.96952056885100 .2742996216100 .274299621699 .9695205688599 .66472625732 99.0551681518698 .7503814697398 .445587158298 .1408081054797 .83602905273 
97.5312423706197 .2264633178797 .2264633178796 .9216690063596 .61688232422 96.3121032714895 .7025299072395 .0929565429794 .1785964965892 .95947265625 92.349891662691 .7403335571391 .1307525634890 .8259735107490 .52117919922 89.9116134643689 .6068267822388 .9972534179788 .6924667358488 .69246673584 88.6924667358488 .9972534179789 .6068267822390 .5211791992291 .74033355713 92.6546783447393 .8738174438595 .0929565429796 .3121032714897 .53124237061 98.7503814697399 .96952056885101 .1886978149102 .4077987671103 .6268997192 105.1509017944 106.0652008057 107.2844009399 108.5035018921 109.4179000854 110.6370010376111 .551399231112 .1608963013113 .075302124113 .6848983765 113.9896011353114 .5991973877114 .9039993286114 .9039993286114 .9039993286 114.9039993286114 .9039993286114 .9039993286115 .2088012695115 .2088012695 115.2088012695115 .2088012695114 .9039993286114 .9039993286114 .5991973877 114.5991973877114 .5991973877114 .9039993286115 .2088012695115 .818397522 116.7326965332117 .342300415118 .2565994263118 .8662033081119 .1709976196 119.1709976196119 .1709976196118 .8662033081118 .2565994263117 .0374984741 115.5136032104113 .9896011353112 .4656982422110 .6370010376109 .1130981445 107.5891036987106 .0652008057104 .5412979126103 .6268997192102 .4077987671 101.4934005737100 .274299621699 .3599472045998 .1408081054796 .92166900635 95.397743225194 .1785964965893 .8738174438593 .5690307617295 .09295654297 99.35994720459106 .979598999118 .8662033081133 .8007049561149 .0399017334 162.4505004883174 .337097168185 .3094024658195 .3672943115204 .2059936523 208.7778015137208 .7778015137208 .7778015137208 .7778015137208 .7778015137 208.7778015137208 .7778015137208 .7778015137208 .7778015137208 .7778015137 208.7778015137208 .7778015137208 .7778015137208 .7778015137208 .7778015137 208.7778015137208 .7778015137208 .7778015137208 .7778015137208 .7778015137 208.7778015137208 .7778015137208 .7778015137208 .7778015137208 .7778015137 208.7778015137208 .7778015137208 .7778015137208 .7778015137208 .7778015137 208.7778015137208 .7778015137208 .7778015137208 .7778015137208 .7778015137 208.777801513760 .95701980591 -5.2219209671 -9999 -9999 -9999 -9999 -9999 -9999 -9999 -9999-9999-9999

-9999 -9999 -9999 -9999 -9999 -9999 -9999 -9999 -9999 -9999 -9999 -9999 -9999 -9999 -9999 -9999 -9999 -9999 -9999 -9999 -9999 -9999 -9999 -9999 -9999 -9999 -9999 -9999 -9999 -9999 -9999 -9999 -9999 -9999 -9999 -9999 -9999 -9999 -9999-9999 -9999 -9999 -9999-9999-999 - -999 -9999 -9999 -9999 -9999 -9999 -9999 -9999 -9999 -9999 -9999 -9999 -9999 -9999 -9999 -9999

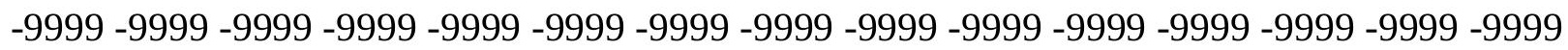
-9999 -9999 -9999 -9999 -9999 -9999 -9999 -9999 -9999 -9999 -9999 -9999 -9999 -9999 -9999

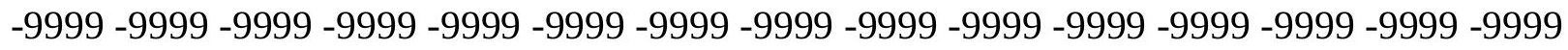

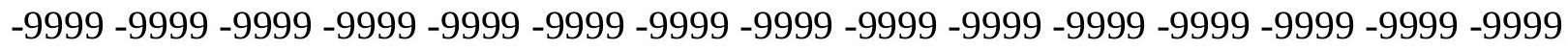
-9999 -9999 -9999 -9999 -9999 -9999 -9999 -9999 -9999 -9999 -9999 -9999 -9999 -9999 -9999 -9999 -9999 -9999 -9999 -9999 -9999 -9999 -9999 -9999 -9999 -9999 -9999 -9999 -9999 -9999 -

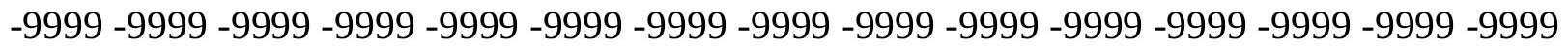
-9999 -9999 -9999 -9999 -9999 -9999 -9999 -9999 -9999 -9999 -9999 -9999 -9999 -9999 -9999 -9999 -9999 -9999 -9999 -9999 -9999 -9999 -9999 -9999 -9999 -9999 -9999 -9999 -9999 -9999 -9999 -9999 -9999 -9999 -9999 -9999 -9999 -9999 -9999 -9999 -9999 -9999 -9999 -9999 -9999 -9999 -9999 -9999 -9999 -9999 -9999 -9999 -9999 -9999 -9999 -9999 102.4077987671 100.883903503499 .3599472045999 .35994720459100 .2742996216100 .5791015625 
100.8839035034100 .8839035034100 .579101562599 .9695205688599 .35994720459 99.0551681518698 .7503814697398 .7503814697398 .445587158298 .14080810547 98.1408081054798 .1408081054797 .8360290527397 .8360290527397 .53124237061 96.9216690063596 .3121032714895 .397743225194 .1785964965893 .26425170898 92.9594726562592 .6546783447392 .349891662692 .0450973510791 .74033355713 91.1307525634890 .8259735107490 .8259735107490 .8259735107490 .82597351074 91.1307525634891 .7403335571392 .349891662693 .2642517089894 .17859649658 95.0929565429796 .3121032714897 .2264633178798 .445587158299 .66472625732 100.8839035034102 .1029968262103 .3221969604104 .2365036011105 .4557037354 106.6747970581107 .8938980103108 .8082962036110 .0273971558110 .9418029785 111.8561019897112 .7705001831113 .3800964355113 .9896011353114 .5991973877 114.9039993286115 .2088012695115 .2088012695115 .2088012695115 .2088012695 115.2088012695114 .9039993286115 .2088012695115 .2088012695115 .2088012695 114.9039993286114 .9039993286114 .5991973877114 .2944030762113 .9896011353 113.9896011353114 .2944030762114 .5991973877115 .5136032104116 .4279022217 117.342300415118 .2565994263118 .8662033081119 .1709976196119 .1709976196 119.1709976196118 .8662033081117 .9517974854116 .7326965332115 .5136032104 113.9896011353112 .1608963013110 .6370010376108 .8082962036107 .2844009399 105.4557037354104 .5412979126103 .3221969604102 .1029968262101 .1886978149 99.9695205688599 .0551681518697 .8360290527396 .3121032714895 .09295654297 93.2642517089891 .7403335571389 .9116134643688 .6924667358492 .65467834473 101.1886978149116 .4279022217133 .8007049561151 .7830047607164 .8887023926 176.7754058838187 .7476043701197 .500793457206 .0346984863208 .7778015137 208.7778015137208 .7778015137208 .7778015137208 .7778015137208 .7778015137 208.7778015137208 .7778015137208 .7778015137208 .7778015137208 .7778015137 208.7778015137208 .7778015137208 .7778015137208 .7778015137208 .7778015137 208.7778015137208 .7778015137208 .7778015137208 .7778015137208 .7778015137 208.7778015137208 .7778015137208 .7778015137208 .7778015137208 .7778015137 208.7778015137208 .7778015137208 .7778015137208 .7778015137208 .7778015137 208.7778015137208 .7778015137208 .7778015137208 .7778015137208 .7778015137 60.95701980591 -5.39519071579 -9999 -9999 -9999 -9999 -9999 -9999 -9999 -9999 -9999 $-9999$

-9999 -9999 -9999 -9999 -9999 -9999 -9999 -9999 -9999 -9999 -9999 -9999 -9999 -9999 -9999 -9999 -9999 -9999 -9999 -9999 -9999 -9999 -9999 -9999 -9999 -9999 -9999 -9999 -9999 -9999

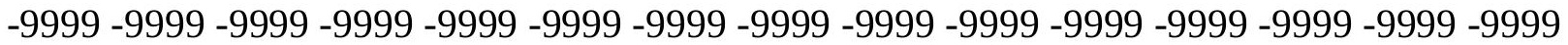
-9999 -9999 -9999 -9999 -9999 -9999 -9999 -9999 -9999 -9999 -9999 -9999 -9999 -9999 -9999

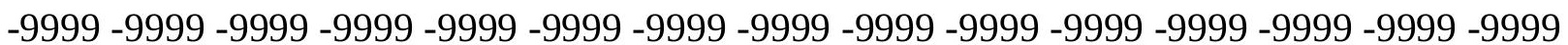

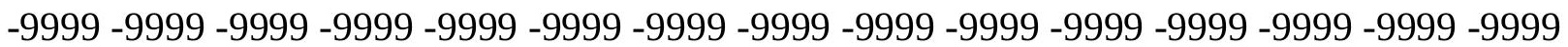
-9999 -9999 -9999 -9999 -9999 -9999 -9999 -9999 -9999 -9999 -9999 -9999 -9999 -9999 -9999 -9999 -9999 -9999 -9999 -9999 -9999 -9999 -9999 -9999 -9999 -9999 -9999 -9999 - -9999 -9999 -9999 -9999 -9999 -9999 -9999 -9999 -9999 -9999 -9999 -9999 -9999 -9999 -9999 -9999 -9999

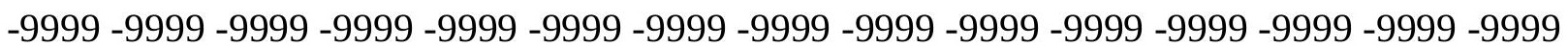
-9999 -9999 -9999 -9999 -9999 -9999 -9999 -9999 -9999 -9999 -9999 -9999 -9999 -9999 -9999 -9999 -9999 -9999 -9999 -9999 -9999 -9999 -9999 -9999 -9999 -9999 -9999 -9999 -9999 -9999 -999 -9999 -9999 -9999 -9999 -9999 -9999 -9999 -9999 -9999 -9999 -9999 -9999 -9999 -9999 -9999

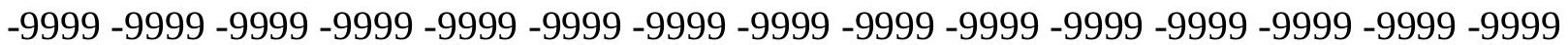


-9999 -9999 -9999 -9999 -9999 -9999 -9999 -9999 -9999 -9999 -9999 -9999 105.7603988647 104.2365036011102 .4077987671100 .8839035034101 .4934005737101 .4934005737 101.4934005737100 .8839035034100 .579101562599 .6647262573299 .66472625732 99.3599472045999 .0551681518699 .0551681518699 .0551681518699 .05516815186 99.0551681518699 .0551681518699 .0551681518698 .7503814697398 .4455871582 97.8360290527396 .9216690063596 .0073165893695 .0929565429794 .78817749023 94.4833908081194 .1785964965893 .8738174438593 .5690307617293 .26425170898 92.9594726562592 .9594726562592 .9594726562592 .9594726562593 .26425170898 93.8738174438594 .4833908081195 .0929565429795 .7025299072396 .61688232422 97.5312423706198 .445587158299 .35994720459100 .5791015625101 .4934005737 102.712600708103 .9317016602105 .1509017944106 .0652008057107 .2844009399 108.5035018921109 .4179000854110 .3321990967111 .551399231112 .1608963013 113.075302124113 .6848983765114 .2944030762114 .9039993286115 .2088012695 115.5136032104115 .5136032104115 .5136032104115 .5136032104115 .2088012695 114.9039993286115 .2088012695115 .2088012695115 .2088012695114 .9039993286 114.5991973877114 .2944030762113 .6848983765113 .3800964355113 .3800964355 113.6848983765113 .9896011353114 .9039993286116 .1231002808117 .342300415 118.2565994263118 .8662033081119 .1709976196119 .1709976196118 .8662033081 118.5614013672117 .647102356116 .4279022217115 .2088012695113 .6848983765 112.1608963013110 .3321990967108 .8082962036107 .2844009399105 .4557037354 104.2365036011103 .0174026489102 .1029968262100 .883903503499 .66472625732 98.7503814697397 .5312423706196 .0073165893694 .7881774902393 .26425170898 91.4355392456189 .6068267822387 .4733276367285 .3398437595 .09295654297 114.2944030762133 .4958953857151 .1734008789166 .1078948975178 .604095459 189.5764007568199 .0247039795207 .5587005615208 .7778015137208 .7778015137 208.7778015137208 .7778015137208 .7778015137208 .7778015137208 .7778015137 208.7778015137208 .7778015137208 .7778015137208 .7778015137208 .7778015137 208.7778015137208 .7778015137208 .7778015137208 .7778015137208 .7778015137 208.7778015137208 .7778015137208 .7778015137208 .7778015137208 .7778015137 208.7778015137208 .7778015137208 .7778015137208 .7778015137208 .7778015137 208.7778015137 208.7778015137208.7778015137208.7778015137 208.7778015137 208.7778015137208 .7778015137208 .7778015137208 .777801513760 .95701980591 -5.594602108 -9999 -9999-9999 -9999 -9999 -9999 -9999 -9999 -9999 -9999 -9999 -9999 -9999 -9999 -9999 -9999 -9999 -9999 -9999 -9999 -9999 -9999 -9999 -9999 -9999 -9999 -9999 -9999 -9999 -9999 -9999 -9999 -9999 -9999 -9999 -9999 -9999 -9999 -9999 -9999

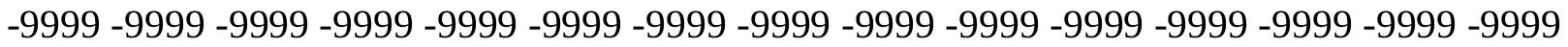

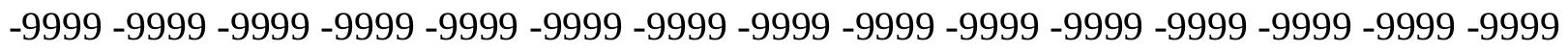

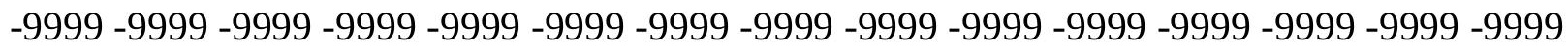

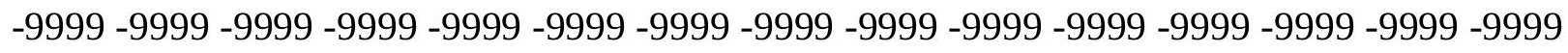
-9999 -9999 -9999 -9999 -9999 -9999 -9999 -9999 -9999 -9999 -9999 -9999 -9999 -9999 -9999 -

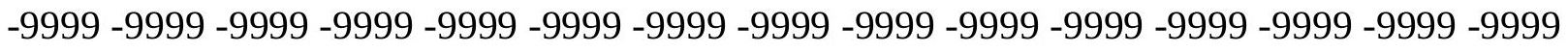

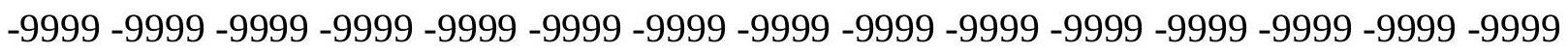
-9999 -9999 -9999 -9999 -9999 -9999 -9999 -9999 -9999 -9999 -9999 -9999 -9999 -9999 -9999 -9999 -9999 -9999 -9999 -9999 -9999 -9999 -9999 -9999-9999 -9999 -9999 -9999 -9999 -9999 -9999 -9999 -9999 -9999 -9999 -9999 -9999 -9999 -9999 -9999 -9999 -9999 -9999 -9999 -9999 -

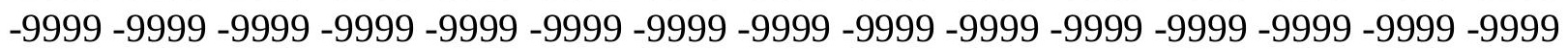


-9999 -9999 -9999 -9999 -9999 -9999 -9999 -9999 -9999 -9999 -9999 -9999 -9999 -9999 -9999 -9999 -9999 -9999 -9999 -9999 -9999 -9999 -9999 -9999 -9999 -9999 -9999 -9999 108.8082962036106 .979598999105 .1509017944102 .4077987671102 .1029968262 102.1029968262101 .4934005737101 .1886978149100 .5791015625100 .2742996216 99.9695205688599 .6647262573299 .3599472045999 .3599472045999 .66472625732 99.6647262573299 .9695205688599 .96952056885100 .274299621699 .96952056885 99.6647262573298 .7503814697398 .1408081054797 .5312423706196 .92166900635 96.3121032714896 .0073165893695 .7025299072395 .7025299072395 .3977432251 95.0929565429795 .0929565429795 .0929565429795 .397743225195 .70252990723 96.0073165893696 .6168823242296 .9216690063597 .5312423706198 .14080810547 98.7503814697399 .66472625732100 .5791015625101 .4934005737102 .4077987671 103.6268997192104 .5412979126105 .7603988647106 .6747970581107 .8938980103 108.8082962036110 .0273971558110 .9418029785111 .8561019897112 .7705001831 113.6848983765114 .2944030762114 .9039993286115 .2088012695115 .5136032104 115.818397522115 .818397522115 .818397522115 .818397522115 .5136032104 115.2088012695115 .5136032104115 .2088012695115 .2088012695114 .9039993286 114.2944030762113 .9896011353113 .3800964355113 .075302124112 .7705001831 112.7705001831113 .3800964355114 .5991973877115 .818397522117 .0374984741 117.9517974854118 .5614013672118 .8662033081118 .8662033081118 .5614013672 117.9517974854117 .0374984741116 .1231002808114 .9039993286113 .3800964355 111.8561019897110 .3321990967108 .8082962036106 .979598999105 .7603988647 104.2365036011103 .0174026489101 .7982025146100 .883903503499 .66472625732 98.445587158297 .2264633178796 .0073165893694 .4833908081192 .95947265625 91.1307525634889 .302040100187 .4733276367285 .3398437593 .87381744385 113.9896011353134 .1054992676151 .4781951904166 .4127044678179 .5184020996 190.4907073975200 .2438049316208 .7778015137208 .7778015137208 .7778015137 208.7778015137208 .7778015137208 .7778015137208 .7778015137208 .7778015137 208.7778015137208 .7778015137208 .7778015137208 .7778015137208 .7778015137 208.7778015137208 .7778015137208 .7778015137208 .7778015137208 .7778015137 208.7778015137208 .7778015137208 .7778015137208 .7778015137208 .7778015137 208.7778015137208 .7778015137208 .7778015137208 .7778015137208 .7778015137 208.7778015137208 .7778015137208 .7778015137208 .7778015137208 .7778015137 208.7778015137208 .7778015137208 .7778015137208 .777801513760 .65224075317 -5.87391519547 -9999 -9999 -9999 -9999 -9999 -9999 -9999 -9999 -9999 -9999 -9999 -9999 -9999 -9999 -9999 -9999 -9999 -9999 -9999 -9999 -9999 -9999 -9999 -9999 -9999 -9999 -9999 -9999 -9999 -9999 -9999 -9999 -9999 -9999 -9999 -9999 -9999 -9999 -9999 -9999 -9999 -9999 -9999 -9999 -9999 -9999 -9999 -9999 -9999 -9999 -9999 -9999 -9999 -9999 -9999

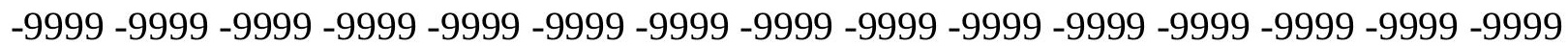
-9999 -9999 -9999 -9999 -9999 -9999 -9999 -9999 -9999 -9999 -9999 -9999 -9999 -9999 -9999 -9999 -9999 -9999 -9999 -9999 -9999 -9999 -9999 -9999 -9999 -9999 -9999 -9999 -9999 -9999 -

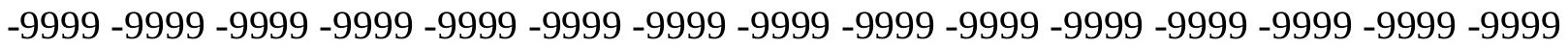

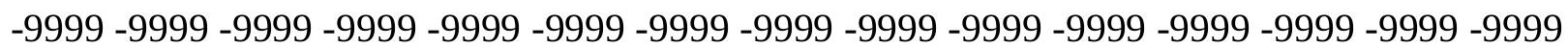
-9999 -9999 -9999 -9999 -9999 -9999 -9999 -9999 -9999 -9999 -9999 -9999 -9999 -9999 -9999 -9999 -9999 -9999 -9999 -9999 -9999 -9999 -9999 -9999 -9999 -9999 -9999 -9999 -9999 -9999 -999 -9999 -9999 -9999 -9999 -9999 -9999 -9999 -9999 -9999 -9999 -9999 -9999 -9999 -9999 -9999

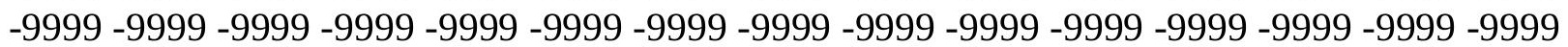


-9999 -9999 -9999 -9999 -9999 -9999 -9999 -9999 -9999 -9999 -9999 -9999 -9999 -9999 -9999 -9999 -9999 -9999 -9999 -9999 -9999 -9999 -9999 -9999 -9999 -9999 -9999 -9999 -9999 -9999 -9999 -9999 -9999 -9999 -9999 -9999 -9999 -9999 -9999 -9999 -9999 -9999 -9999 -9999 -9999 110.0273971558107 .8938980103104 .5412979126102 .712600708102 .4077987671 101.7982025146101 .1886978149100 .5791015625100 .274299621699 .96952056885 99.9695205688599 .9695205688599 .96952056885100 .2742996216100 .8839035034 101.1886978149101 .4934005737101 .7982025146101 .4934005737100 .8839035034 100.274299621699 .6647262573299 .0551681518698 .7503814697398 .14080810547 98.1408081054797 .8360290527397 .5312423706197 .5312423706197 .53124237061 97.5312423706197 .8360290527397 .8360290527398 .1408081054798 .4455871582 98.7503814697399 .3599472045999 .66472625732100 .2742996216100 .8839035034 101.7982025146102 .4077987671103 .3221969604104 .2365036011105 .4557037354 106.3700027466107 .2844009399108 .5035018921109 .4179000854110 .3321990967 111.551399231112 .4656982422113 .075302124113 .9896011353114 .5991973877 115.2088012695115 .818397522116 .1231002808116 .1231002808116 .4279022217 116.1231002808115 .818397522115 .5136032104115 .5136032104115 .5136032104 115.5136032104115 .2088012695114 .9039993286114 .2944030762113 .9896011353 113.3800964355112 .7705001831112 .1608963013112 .1608963013113 .075302124 114.2944030762115 .5136032104116 .4279022217117 .647102356117 .9517974854 118.2565994263118 .2565994263117 .9517974854117 .342300415116 .4279022217 115.5136032104114 .2944030762113 .075302124111 .551399231110 .0273971558 108.5035018921106 .979598999105 .4557037354104 .2365036011103 .0174026489 101.7982025146100 .579101562599 .3599472045998 .445587158296 .92166900635 95.7025299072394 .1785964965892 .6546783447391 .1307525634889 .3020401001 87.4733276367285 .3398437596 .31210327148117 .0374984741135 .9342041016 152.0877990723166 .7174987793179 .8231964111191 .1002960205200 .8533935547 208.7778015137208 .7778015137208 .7778015137208 .7778015137208 .7778015137 208.7778015137208 .7778015137208 .7778015137208 .7778015137208 .7778015137 208.7778015137208 .7778015137208 .7778015137208 .7778015137208 .7778015137 208.7778015137208 .7778015137208 .7778015137208 .7778015137208 .7778015137 208.7778015137208 .7778015137208 .7778015137208 .7778015137208 .7778015137 208.7778015137208 .7778015137208 .7778015137208 .7778015137208 .7778015137 208.7778015137208.7778015137208.7778015137208.7778015137208.7778015137 208.7778015137208 .777801513760 .65224075317 -6.12805891037 -9999 -9999 -9999 -9999 -9999 -9999 -9999 -9999-9999 -9999

-9999 -9999 -9999 -9999 -9999 -9999 -9999 -9999 -9999 -9999 -9999 -9999 -9999 -9999 -9999 -9999 -9999 -9999 -9999 -9999 -9999 -9999 -9999 -9999 -9999 -9999 -9999 -9999 -9999 -9999

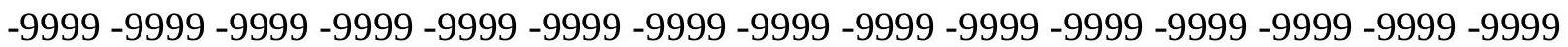
-9999 -9999 -9999 -9999 -9999 -9999 -9999 -9999 -9999 -9999 -9999 -9999 -9999 -9999 -9999 -9999 -9999 -9999 -9999 -9999 -9999 -9999 -9999 -9999 -9999 -9999 -9999 -9999 - -9999 -9999 -9999 -9999 -9999 -9999 -9999 -9999 -9999 -9999 -9999 -9999 -9999 -9999 -9999 -9999 -9999

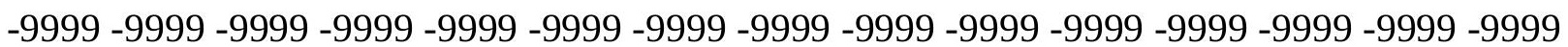
-9999 -9999 -9999 -9999 -9999 -9999 -9999 -9999 -9999 -9999 -9999 -9999 -9999 -9999 -9999 -9999 -9999 -9999 -9999 -9999 -9999 -9999 -9999 -9999 -9999 -9999 -9999 -9999 -9999 -9999 -999 -9999 -9999 -9999 -9999 -9999 -9999 -9999 -9999 -9999 -9999 -9999 -9999 -9999 -9999 -9999

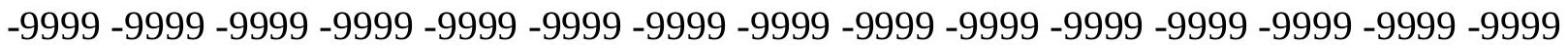


-9999 -9999 -9999 -9999 -9999 -9999 -9999 -9999 -9999 -9999 -9999 -9999 -9999 -9999 -9999 -9999 -9999 -9999 -9999 -9999 -9999 -9999 -9999 -9999 -9999 -9999 -9999 -9999 -9999 -9999

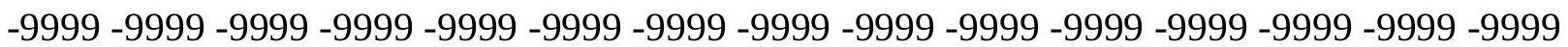
-9999 -9999 -9999 -9999 -9999 -9999 -9999 -9999 -9999 -9999 -9999 -9999 -9999 -9999 -9999 -9999 113.3800964355 111.24659729 107.8938980103102.712600708 102.4077987671 101.7982025146101 .1886978149100 .5791015625100 .274299621699 .96952056885 99.96952056885100 .2742996216100 .8839035034101 .4934005737102 .1029968262 103.0174026489103 .3221969604103 .3221969604102 .712600708102 .1029968262 101.7982025146101 .1886978149100 .8839035034100 .5791015625100 .2742996216 99.9695205688599 .9695205688599 .6647262573299 .6647262573299 .66472625732 99.96952056885100 .2742996216100 .5791015625100 .5791015625100 .5791015625 100.8839035034101 .1886978149101 .7982025146102 .1029968262102 .712600708 103.6268997192104 .2365036011105 .1509017944106 .0652008057106 .979598999 107.8938980103109 .1130981445110 .0273971558110 .9418029785111 .8561019897 112.7705001831113 .6848983765114 .2944030762115 .2088012695115 .5136032104 116.1231002808116 .4279022217116 .7326965332116 .7326965332116 .4279022217 116.1231002808115 .818397522115 .818397522115 .818397522115 .818397522 115.5136032104114 .9039993286114 .5991973877113 .9896011353113 .3800964355 112.7705001831112 .4656982422112 .4656982422113 .075302124113 .9896011353 115.2088012695116 .1231002808117 .0374984741117 .342300415117 .647102356 117.647102356117 .342300415116 .7326965332115 .818397522114 .9039993286 113.9896011353112 .4656982422111 .24659729109 .7226028442108 .5035018921 106.979598999105 .4557037354104 .2365036011103 .0174026489101 .7982025146 100.579101562599 .3599472045998 .1408081054796 .9216690063595 .70252990723 94.1785964965892 .6546783447391 .1307525634889 .302040100187 .47332763672 85.6446228027398 .4455871582121 .6092987061137 .4580993652152 .3925933838 166.7174987793179 .5184020996191 .1002960205201 .158203125208 .7778015137 208.7778015137208 .7778015137208 .7778015137208 .7778015137208 .7778015137 208.7778015137208 .7778015137208 .7778015137208 .7778015137208 .7778015137 208.7778015137208 .7778015137208 .7778015137208 .7778015137208 .7778015137 208.7778015137208 .7778015137208 .7778015137208 .7778015137208 .7778015137 208.7778015137208 .7778015137208 .7778015137208 .7778015137208 .7778015137 208.7778015137208 .7778015137208 .7778015137208 .7778015137208 .7778015137 208.7778015137208 .7778015137208 .7778015137208 .7778015137208 .7778015137 208.777801513760 .65224075317 -6.40553379059 -9999 -9999 -9999 -9999 -9999 -9999 -9999 -9999 -9999-9999 -9999 -9999 -9999 -9999 -9999 -9999 -9999 -9999 -9999 -9999 -9999 -9999 -9999 -9999 -9999

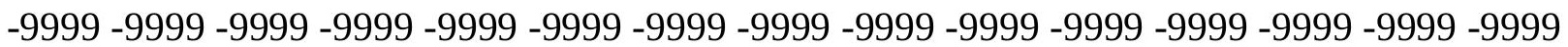

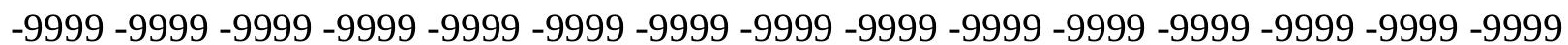
-9999 -9999 -9999 -9999 -9999 -9999 -9999 -9999 -9999 -9999 -9999 -9999 -9999 - -9999 -9999 -9999 -9999 -9999 -9999 -9999 -9999 -9999 -9999 -9999 -9999 -9999 -9999 -9999 -9999 -9999

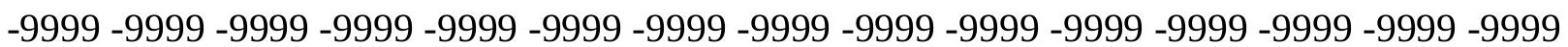
-9999 -9999 -9999 -9999 -9999 -9999 -9999 -9999 -9999 -9999 -9999 -9999 -9999 -9999 -9999 -9999 -9999 -9999 -9999 -9999 -9999 -9999 -9999 -9999 -9999 -9999 -9999 -9999 -9999 -9999 -999 -9999 -9999 -9999 -9999 -9999 -9999 -9999 -9999 -9999 -9999 -9999 -9999 -9999 -9999 -9999

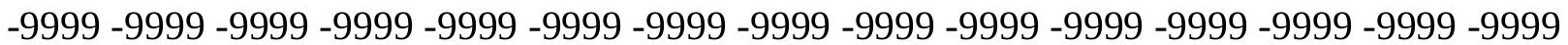


-9999 -9999 -9999 -9999 -9999 -9999 -9999 -9999 -9999 -9999 -9999 -9999 -9999 -9999 -9999 -9999 -9999 -9999 -9999 -9999 -9999 -9999 -9999 -9999 -9999 -9999 -9999 -9999 -9999 -9999

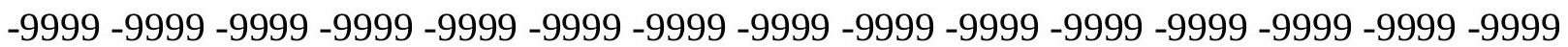
-9999 -9999 -9999 -9999 -9999 -9999 -9999 -9999 -9999 -9999 -9999 -9999 -9999 -9999 -9999 -9999 -9999 -9999 -9999 -9999 -9999 -9999 -9999 -9999 -9999 -9999 -9999 -9999 -9999 -9999 -9999 -9999 117.342300415116.7326965332110.6370010376 105.4557037354 102.1029968262101 .4934005737100 .8839035034100 .2742996216100 .2742996216 100.2742996216100 .5791015625101 .1886978149101 .7982025146103 .0174026489 103.9317016602104 .8460998535104 .8460998535104 .5412979126103 .9317016602 103.6268997192103 .3221969604103 .0174026489102 .712600708102 .4077987671 102.4077987671102 .1029968262102 .1029968262102 .1029968262102 .1029968262 102.1029968262102 .4077987671102 .4077987671102 .4077987671102 .4077987671 102.4077987671102 .712600708103 .0174026489103 .3221969604103 .9317016602 104.5412979126105 .1509017944105 .7603988647106 .6747970581107 .5891036987 108.5035018921109 .4179000854110 .6370010376111 .551399231112 .4656982422 113.3800964355113 .9896011353114 .9039993286115 .5136032104116 .1231002808 116.4279022217116 .7326965332117 .0374984741117 .0374984741116 .7326965332 116.4279022217116 .1231002808116 .4279022217116 .1231002808116 .1231002808 115.5136032104115 .2088012695114 .5991973877113 .9896011353113 .6848983765 113.075302124112 .7705001831112 .7705001831113 .3800964355113 .9896011353 114.9039993286115 .818397522116 .4279022217116 .7326965332117 .0374984741 117.0374984741116 .4279022217116 .1231002808115 .2088012695114 .2944030762 113.3800964355112 .1608963013110 .9418029785109 .4179000854108 .1986999512 106.6747970581105 .4557037354104 .2365036011103 .0174026489101 .7982025146 100.579101562599 .3599472045998 .1408081054796 .9216690063595 .3977432251 94.1785964965892 .6546783447390 .8259735107489 .302040100187 .47332763672 85.6446228027398 .75038146973118 .8662033081136 .2389984131151 .7830047607 166.1078948975179 .2136993408190 .795501709201 .158203125208 .7778015137 208.7778015137208 .7778015137208 .7778015137208 .7778015137208 .7778015137 208.7778015137208 .7778015137208 .7778015137208 .7778015137208 .7778015137 208.7778015137208 .7778015137208 .7778015137208 .7778015137208 .7778015137 208.7778015137208 .7778015137208 .7778015137208 .7778015137208 .7778015137 208.7778015137208 .7778015137208 .7778015137208 .7778015137208 .7778015137 208.7778015137208 .7778015137208 .7778015137208 .7778015137208 .7778015137 208.7778015137208 .7778015137208 .7778015137208 .7778015137208 .7778015137 208.777801513760 .34745025635 -6.76695251465 -9999 -9999 -9999 -9999 -9999 -9999 -9999 -9999 -9999-9999

-9999 -9999 -9999 -9999 -9999 -9999 -9999 -9999 -9999 -9999 -9999 -9999 -9999 -9999 -9999 -9999 -9999 -9999 -9999 -9999 -9999 -9999 -9999 -9999 -9999 -9999 -9999 -9999 -9999 -9999 -9999 -9999 -9999 -9999 -9999 -9999 -9999 -9999 -9999 -9999 -9999 -9999 -9999 - -9999 -9999 -9999 -9999 -9999 -9999 -9999 -9999 -9999 -9999 -9999 -9999 -9999 -9999 -9999 -9999 -9999

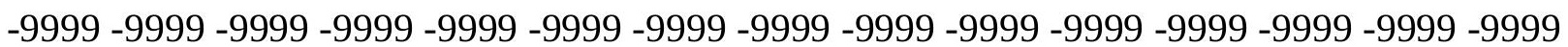
-9999 -9999 -9999 -9999 -9999 -9999 -9999 -9999 -9999 -9999 -9999 -9999 -9999 -9999 -9999 -9999 -9999 -9999 -9999 -9999 -9999 -9999 -9999 -9999 -9999 -9999 -9999 -9999 -9999 -9999 -999 -

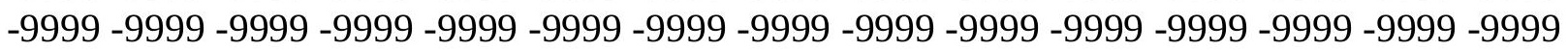

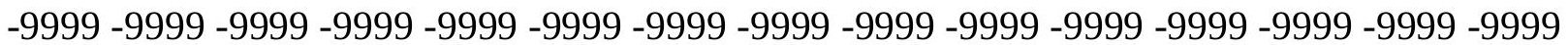


-9999 -9999 -9999 -9999 -9999 -9999 -9999 -9999 -9999 -9999 -9999 -9999 -9999 -9999 -9999 -9999 -9999 -9999 -9999 -9999 -9999 -9999 -9999 -9999 -9999 -9999 -9999 -9999 -9999 -9999

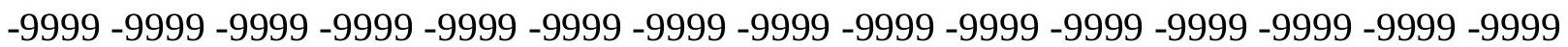
-9999 -9999 -9999 -9999 -9999 -9999 -9999 -9999 -9999 -9999 -9999 -9999 -9999 -9999 -9999 -9999 -9999 -9999 -9999 -9999 -9999 -9999 -9999 -9999 -9999 -9999 -9999 -9999 -9999 -9999 -9999 -9999 -9999 -9999 -9999 -9999 -9999 -9999 -9999 -9999 -9999 -9999 -9999 -9999 -9999 -9999 -9999 -9999 -9999 114.9039993286110.3321990967 106.3700027466103.0174026489 100.8839035034100 .5791015625100 .2742996216100 .2742996216100 .5791015625 101.1886978149102 .1029968262103 .3221969604104 .5412979126105 .4557037354 105.7603988647105 .7603988647105 .4557037354105 .4557037354105 .1509017944 105.1509017944104 .8460998535104 .8460998535104 .5412979126104 .5412979126 104.2365036011104 .2365036011104 .2365036011104 .2365036011104 .2365036011 104.2365036011104 .2365036011104 .2365036011103 .9317016602104 .2365036011 104.2365036011104 .5412979126104 .8460998535105 .4557037354105 .7603988647 106.6747970581107 .2844009399108 .1986999512109 .1130981445110 .0273971558 110.9418029785111 .8561019897112 .7705001831113 .6848983765114 .5991973877 115.2088012695115 .818397522116 .4279022217116 .7326965332117 .0374984741 117.0374984741117 .0374984741117 .0374984741116 .4279022217116 .7326965332 116.7326965332116 .7326965332116 .4279022217115 .818397522115 .5136032104 114.9039993286114 .2944030762113 .9896011353113 .3800964355113 .075302124 113.3800964355113 .6848983765113 .9896011353114 .5991973877115 .2088012695 115.818397522116 .1231002808116 .1231002808116 .1231002808115 .818397522 115.2088012695114 .5991973877113 .6848983765112 .7705001831111 .551399231 110.3321990967109 .1130981445107 .8938980103106 .6747970581105 .4557037354 103.9317016602102 .712600708101 .4934005737100 .579101562599 .35994720459 98.1408081054796 .6168823242295 .397743225193 .8738174438592 .3498916626 90.8259735107489 .302040100187 .4733276367285 .6446228027398 .75038146973 116.7326965332134 .4102020264150 .5639038086165 .1934967041178 .604095459 190.1858978271200 .8533935547208 .7778015137208 .7778015137208 .7778015137 208.7778015137208 .7778015137208 .7778015137208 .7778015137208 .7778015137 208.7778015137208 .7778015137208 .7778015137208 .7778015137208 .7778015137 208.7778015137208 .7778015137208 .7778015137208 .7778015137208 .7778015137 208.7778015137208 .7778015137208 .7778015137208 .7778015137208 .7778015137 208.7778015137208 .7778015137208 .7778015137208 .7778015137208 .7778015137 208.7778015137208 .7778015137208 .7778015137208 .7778015137208 .7778015137 208.7778015137208 .7778015137208 .7778015137208 .777801513760 .34745025635 -7.13927030563 -9999 -9999 -9999 -9999 -9999 -9999 -9999 -9999 -9999 -9999 -9999 -9999 -9999 -9999 -9999 -9999 -9999 -9999 -9999 -9999 -9999 -9999 -9999 -9999 -9999 -9999 -9999 -9999 -9999 -9999 -9999 -9999 -9999 -9999 -9999 -9999 -9999 -9999 -9999 -9999 -9999 -9999 -9999 -9999 -9999 -9999 -9999 -9999 -9999 -9999 -9999 -9999 -9999 - -9999 -9999 -9999 -9999 -9999 -9999 -9999 -9999 -9999 -9999 -9999 -9999 -9999 -9999 -9999 -9999 -9999

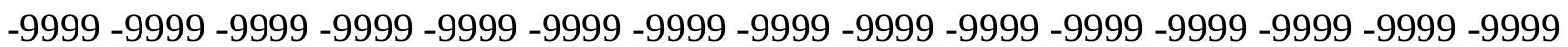
-9999 -9999 -9999 -9999 -9999 -9999 -9999 -9999 -9999 -9999 -9999 -9999 -9999 -9999 -9999 -9999 -9999 -9999 -9999 -9999 -9999 -9999 -9999 -9999 -9999 -9999 -9999 -9999 -9999 -9999 -9999 -9999 -9999 -9999 -9999 -9999 -9999 -9999 -9999 -9999 -9999 -9999 -9999 -9999 -9999

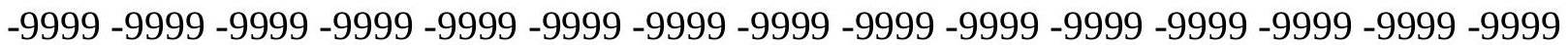


-9999 -9999 -9999 -9999 -9999 -9999 -9999 -9999 -9999 -9999 -9999 -9999 -9999 -9999 -9999 -9999 -9999 -9999 -9999 -9999 -9999 -9999 -9999 -9999 -9999 -9999 -9999 -9999 -9999 -9999

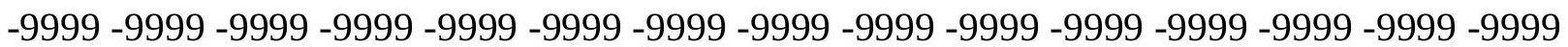
-9999 -9999 -9999 -9999 -9999 -9999 -9999 -9999 -9999 -9999 -9999 -9999 -9999 -9999 -9999 -9999 -9999 -9999 -9999 -9999 -9999 -9999 -9999 -9999 -9999 -9999 -9999 -9999 -9999 -9999 -9999 -9999 -9999 -9999 -9999 -9999 -9999 -9999 -9999 -9999 -9999 -9999 -9999 -9999 -9999 -9999 -9999 -9999 -9999 -9999 -9999 110.0273971558106 .6747970581103 .9317016602 101.4934005737100 .2742996216100 .2742996216100 .5791015625101 .1886978149 102.1029968262103 .3221969604104 .5412979126105 .4557037354106 .0652008057 106.6747970581106 .979598999106 .979598999106 .979598999106 .979598999 106.979598999106 .979598999106 .979598999106 .6747970581106 .6747970581 106.3700027466106 .3700027466106 .3700027466106 .0652008057106 .0652008057 105.7603988647105 .7603988647105 .4557037354105 .4557037354105 .4557037354 105.4557037354105 .7603988647106 .0652008057106 .6747970581107 .2844009399 107.8938980103108 .8082962036109 .4179000854110 .3321990967111 .551399231 112.4656982422113 .3800964355114 .2944030762114 .9039993286115 .818397522 116.1231002808116 .7326965332117 .0374984741117 .342300415117 .342300415 117.342300415117 .0374984741116 .7326965332117 .0374984741117 .0374984741 117.0374984741116 .7326965332116 .4279022217115 .818397522115 .2088012695 114.5991973877114 .2944030762113 .6848983765113 .6848983765113 .6848983765 113.6848983765113 .9896011353114 .5991973877114 .9039993286115 .2088012695 115.5136032104115 .5136032104115 .2088012695114 .9039993286114 .5991973877 113.6848983765113 .075302124112 .1608963013110 .9418029785110 .0273971558 108.8082962036107 .5891036987106 .3700027466105 .1509017944103 .9317016602 102.712600708101 .4934005737100 .274299621699 .0551681518697 .83602905273 96.6168823242295 .397743225193 .8738174438592 .349891662690 .82597351074 89.302040100187 .4733276367285 .6446228027398 .75038146973115 .818397522 133.1911010742149 .6495056152164 .5839996338177 .9945068359189 .8811035156 200.5485992432208 .7778015137208 .7778015137208 .7778015137208 .7778015137 208.7778015137208 .7778015137208 .7778015137208 .7778015137208 .7778015137 208.7778015137208 .7778015137208 .7778015137208 .7778015137208 .7778015137 208.7778015137208 .7778015137208 .7778015137208 .7778015137208 .7778015137 208.7778015137208.7778015137208.7778015137208.7778015137208.7778015137 208.7778015137208 .7778015137208 .7778015137208 .7778015137208 .7778015137 208.7778015137208 .7778015137208 .7778015137208 .7778015137208 .7778015137 208.7778015137208 .7778015137208 .777801513760 .04267120361 -7.55305433273 -9999 -9999 -9999 -9999 -9999 -9999 -9999 -9999 -9999 -9999

-9999 -9999 -9999 -9999 -9999 -9999 -9999 -9999 -9999 -9999 -9999 -9999 -9999 -9999 -9999 -9999 -9999 -9999 -9999 -9999 -9999 -9999 -9999 -9999 -9999 -9999 -9999 -9999 -9999 -9999 -9999 -9999 -9999 -9999 -9999 -9999 -9999 -9999 -9999 -9999 -9999 -9999 -9999 - -9999 -9999 -9999 -9999 -9999 -9999 -9999 -9999 -9999 -9999 -9999 -9999 -9999 -9999 -9999 -9999 -9999

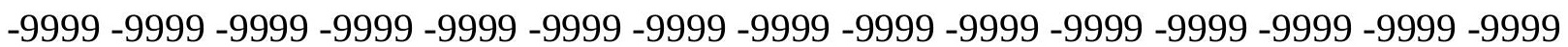
-9999 -9999 -9999 -9999 -9999 -9999 -9999 -9999 -9999 -9999 -9999 -9999 -9999 -9999 -9999 -9999 -9999 -9999 -9999 -9999 -9999 -9999 -9999 -9999 -9999 -9999 -9999 -9999 -9999 -9999 -9999 -9999 -9999 -9999 -9999 -9999 -9999 -9999 -9999 -9999 -9999 -9999 -9999 -9999 -9999

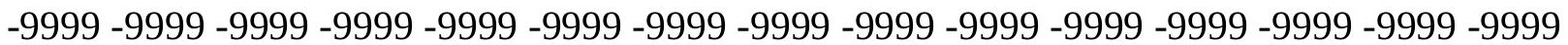


-9999 -9999 -9999 -9999 -9999 -9999 -9999 -9999 -9999 -9999 -9999 -9999 -9999 -9999 -9999 -9999 -9999 -9999 -9999 -9999 -9999 -9999 -9999 -9999 -9999 -9999 -9999 -9999 -9999 -9999

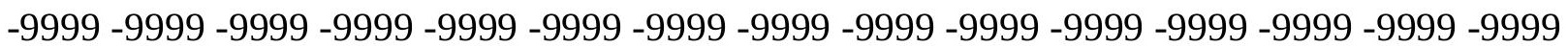
-9999 -9999 -9999 -9999 -9999 -9999 -9999 -9999 -9999 -9999 -9999 -9999 -9999 -9999 -9999 -9999 -9999 -9999 -9999 -9999 -9999 -9999 -9999 -9999 -9999 -9999 -9999 -9999 -9999 -9999 -9999 -9999 -9999 -9999 -9999 -9999 -9999 -9999 -9999 -9999 -9999 -9999 -9999 -9999 -9999 -9999 -9999 -9999 -9999 -9999 -9999 -9999 -9999 107.8938980103105 .4557037354 103.3221969604101 .1886978149100 .5791015625101 .4934005737102 .4077987671 103.3221969604104 .5412979126105 .7603988647106 .6747970581107 .5891036987 108.1986999512108 .5035018921108 .8082962036109 .1130981445109 .1130981445 109.1130981445109 .1130981445108 .8082962036108 .8082962036108 .5035018921 108.5035018921108 .1986999512107 .8938980103107 .5891036987107 .2844009399 107.2844009399106.979598999 106.6747970581 106.6747970581 106.6747970581 106.6747970581106 .979598999107 .2844009399107 .8938980103108 .5035018921 109.1130981445110 .0273971558110 .9418029785111 .8561019897112 .7705001831 113.6848983765114 .5991973877115 .2088012695116 .1231002808116 .4279022217 117.0374984741117 .342300415117 .342300415117 .342300415117 .0374984741 116.7326965332117 .342300415117 .647102356117 .647102356117 .342300415 117.0374984741116 .7326965332116 .1231002808115 .5136032104114 .9039993286 114.5991973877113 .9896011353113 .9896011353113 .6848983765113 .9896011353 113.9896011353114 .2944030762114 .5991973877114 .5991973877114 .9039993286 114.9039993286114 .5991973877114 .2944030762113 .6848983765113 .075302124 112.4656982422111 .551399231110 .3321990967109 .4179000854108 .5035018921 107.2844009399106 .0652008057104 .8460998535103 .6268997192102 .712600708 101.4934005737100 .274299621699 .0551681518697 .8360290527396 .61688232422 95.0929565429793 .8738174438592 .349891662690 .8259735107488 .99725341797 87.4733276367285 .6446228027399 .66472625732116 .1231002808133 .1911010742 149.3446960449164 .2792053223177 .6896972656189 .5764007568200 .2438049316 208.7778015137208 .7778015137208 .7778015137208 .7778015137208 .7778015137 208.7778015137208 .7778015137208 .7778015137208 .7778015137208 .7778015137 208.7778015137208 .7778015137208 .7778015137208 .7778015137208 .7778015137 208.7778015137208 .7778015137208 .7778015137208 .7778015137208 .7778015137 208.7778015137208 .7778015137208 .7778015137208 .7778015137208 .7778015137 208.7778015137208 .7778015137208 .7778015137208 .7778015137208 .7778015137 208.7778015137208 .7778015137208 .7778015137208 .7778015137208 .7778015137 208.7778015137208 .777801513760 .04267120361 -7.94606971741 -9999 -9999 -9999 -9999 -9999 -9999 -9999 -9999-9999 -9999

-9999 -9999 -9999 -9999 -9999 -9999 -9999 -9999 -9999 -9999 -9999 -9999 -9999 -9999 -9999 -9999 -9999 -9999 -9999 -9999 -9999 -9999 -9999 -9999 -9999 -9999 -9999 -9999 -9999 -9999 -9999 -9999 -9999 -9999 -9999 -9999 -9999 -9999 -9999 -9999 -9999 -9999 -9999 - -9999 -9999 -9999 -9999 -9999 -9999 -9999 -9999 -9999 -9999 -9999 -9999 -9999 -9999 -9999 -9999 -9999

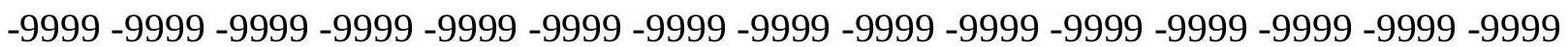
-9999 -9999 -9999 -9999 -9999 -9999 -9999 -9999 -9999 -9999 -9999 -9999 -9999 -9999 -9999 -9999 -9999 -9999 -9999 -9999 -9999 -9999 -9999 -9999 -9999 -9999 -9999 -9999 -9999 -9999 -9999 -9999 -9999 -9999 -9999 -9999 -9999 -9999 -9999 -9999 -9999 -9999 -9999 -9999 -9999

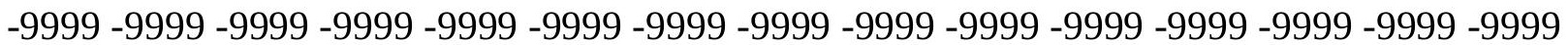


-9999 -9999 -9999 -9999 -9999 -9999 -9999 -9999 -9999 -9999 -9999 -9999 -9999 -9999 -9999 -9999 -9999 -9999 -9999 -9999 -9999 -9999 -9999 -9999 -9999 -9999 -9999 -9999 -9999 -9999

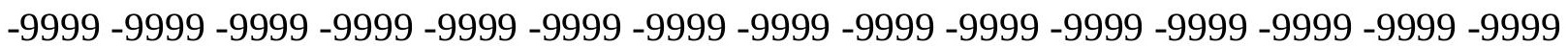
-9999 -9999 -9999 -9999 -9999 -9999 -9999 -9999 -9999 -9999 -9999 -9999 -9999 -9999 -9999 -9999 -9999 -9999 -9999 -9999 -9999 -9999 -9999 -9999 -9999 -9999 -9999 -9999 -9999 -9999 -9999 -9999 -9999 -9999 -9999 -9999 -9999 -9999 -9999 -9999 -9999 -9999 -9999 -9999 -9999 -9999 -9999 -9999 -9999 -9999 -9999 -9999 -9999 -9999 109.7226028442107 .5891036987 105.4557037354103 .6268997192102 .1029968262102 .712600708103 .6268997192 104.8460998535106 .0652008057107 .2844009399108 .5035018921109 .4179000854 110.0273971558110 .6370010376110 .9418029785111 .24659729111 .24659729111 .24659729 110.9418029785110 .9418029785110 .6370010376110 .3321990967110 .0273971558 109.7226028442109 .4179000854108 .8082962036108 .5035018921108 .1986999512 107.8938980103107 .5891036987107 .5891036987107 .5891036987107 .5891036987 107.8938980103108 .1986999512108 .8082962036109 .4179000854110 .3321990967 111.24659729112 .1608963013113 .075302124113 .9896011353114 .9039993286 115.5136032104116 .4279022217116 .7326965332117 .0374984741117 .342300415 117.342300415 117.342300415 117.0374984741 117.342300415 117.647102356 117.9517974854117 .9517974854117 .9517974854117 .342300415117 .0374984741 116.4279022217115 .818397522115 .2088012695114 .5991973877114 .2944030762 113.9896011353113 .9896011353113 .9896011353113 .9896011353113 .9896011353 114.2944030762114 .2944030762114 .2944030762113 .9896011353113 .9896011353 113.3800964355113 .075302124112 .4656982422111 .551399231110 .6370010376 110.0273971558108 .8082962036107 .8938980103106 .6747970581105 .7603988647 104.5412979126103 .6268997192102 .4077987671101 .188697814999 .96952056885 99.0551681518697 .8360290527396 .3121032714895 .0929565429793 .87381744385 92.349891662690 .8259735107488 .9972534179787 .4733276367286 .55898284912 100.8839035034117 .0374984741133 .8007049561149 .6495056152164 .5839996338 177.6896972656189 .5764007568199 .9389953613208 .7778015137208 .7778015137 208.7778015137208 .7778015137208 .7778015137208 .7778015137208 .7778015137 208.7778015137208 .7778015137208 .7778015137208 .7778015137208 .7778015137 208.7778015137208 .7778015137208 .7778015137208 .7778015137208 .7778015137 208.7778015137208 .7778015137208 .7778015137208 .7778015137208 .7778015137 208.7778015137208 .7778015137208 .7778015137208 .7778015137208 .7778015137 208.7778015137208 .7778015137208 .7778015137208 .7778015137208 .7778015137 208.7778015137208 .7778015137208 .7778015137208 .7778015137208 .7778015137 60.04267120361 -8.40184116364 -9999 -9999 -9999 -9999 -9999 -9999 -9999 -9999 -9999 $-9999$

-9999 -9999 -9999 -9999 -9999 -9999 -9999 -9999 -9999 -9999 -9999 -9999 -9999 -9999 -9999 -9999 -9999 -9999 -9999 -9999 -9999 -9999 -9999 -9999 -9999 -9999 -9999 -9999 -9999 -9999 -9999 -9999 -9999 -9999 -9999 -9999 -9999 -9999 -9999 -9999 -9999 -9999 -9999 -9999 -9999 -9999 -9999 -9999 -9999 -9999 -9999 -9999 -9999 -9999 -9999 -9999 -9999 -9999 -9999 -9999

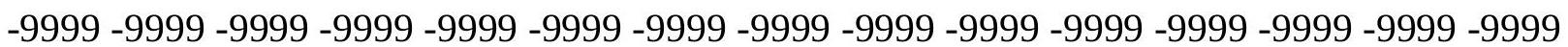
-9999 -9999 -9999 -9999 -9999 -9999 -9999 -9999 -9999 -9999 -9999 -9999 -9999 -9999 -9999 -9999 -9999 -9999 -9999 -9999 -9999 -9999 -9999 -9999 -9999 -9999 -9999 -9999 -9999 -9999 -9999 -9999 -9999 -9999 -9999 -9999 -9999 -9999 -9999 -9999 -9999 -9999 -9999 -9999 -9999

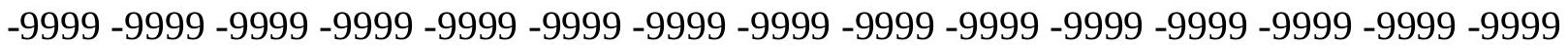


-9999 -9999 -9999 -9999 -9999 -9999 -9999 -9999 -9999 -9999 -9999 -9999 -9999 -9999 -9999 -9999 -9999 -9999 -9999 -9999 -9999 -9999 -9999 -9999 -9999 -9999 -9999 -9999 -9999 -9999

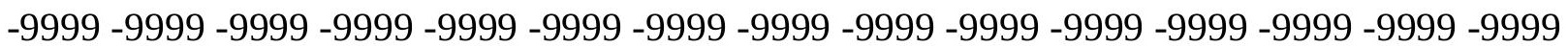
-9999 -9999 -9999 -9999 -9999 -9999 -9999 -9999 -9999 -9999 -9999 -9999 -9999 -9999 -9999 -9999 -9999 -9999 -9999 -9999 -9999 -9999 -9999 -9999 -9999 -9999 -9999 -9999 -9999 -9999 -9999 -9999 -9999 -9999 -9999 -9999 -9999 -9999 -9999 -9999 -9999 -9999 -9999 -9999 -9999 -9999 -9999 -9999 -9999 -9999 -9999 -9999 -9999 -9999 -9999 -9999 109.7226028442 107.8938980103106 .3700027466105 .1509017944104 .2365036011105 .4557037354 106.6747970581108 .1986999512109 .4179000854110 .6370010376111 .551399231 112.4656982422113 .075302124113 .3800964355113 .3800964355113 .075302124 113.075302124112 .7705001831112 .4656982422112 .1608963013111 .8561019897 111.24659729110 .9418029785110 .3321990967110 .0273971558109 .4179000854 108.8082962036108 .5035018921108 .5035018921108 .1986999512108 .1986999512 108.5035018921108 .8082962036109 .1130981445109 .7226028442110 .6370010376 111.551399231112 .4656982422113 .3800964355114 .2944030762115 .2088012695 115.818397522116 .4279022217117 .0374984741117 .342300415117 .342300415 117.342300415117 .0374984741117 .0374984741117 .647102356117 .9517974854 117.9517974854118 .2565994263117 .9517974854117 .647102356117 .0374984741 116.4279022217115 .818397522115 .5136032104114 .9039993286114 .5991973877 114.2944030762113 .9896011353113 .9896011353113 .9896011353113 .9896011353 113.9896011353113 .6848983765113 .6848983765113 .3800964355113 .075302124 112.7705001831112 .1608963013111 .551399231110 .9418029785110 .0273971558 109.4179000854108 .1986999512107 .2844009399106 .3700027466105 .4557037354 104.2365036011103 .3221969604102 .1029968262101 .188697814999 .96952056885 98.7503814697397 .5312423706196 .3121032714895 .0929565429793 .56903076172 92.349891662690 .8259735107489 .302040100187 .4733276367287 .16854858398 102.1029968262118 .2565994263134 .7149963379150 .5639038086165 .1934967041 177.9945068359189 .2716064453199 .6342926025208 .4730072021208 .7778015137 208.7778015137208 .7778015137208 .7778015137208 .7778015137208 .7778015137 208.7778015137208 .7778015137208 .7778015137208 .7778015137208 .7778015137 208.7778015137208 .7778015137208 .7778015137208 .7778015137208 .7778015137 208.7778015137208 .7778015137208 .7778015137208 .7778015137208 .7778015137 208.7778015137208 .7778015137208 .7778015137208 .7778015137208 .7778015137 208.7778015137208 .7778015137208 .7778015137208 .7778015137208 .7778015137 208.7778015137208 .7778015137208 .7778015137208 .7778015137208 .7778015137 59.73788070679 -9999 -9999 -9999 -9999 -9999 -9999 -9999 -9999 -9999 -9999 -9999

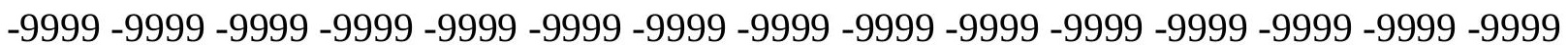

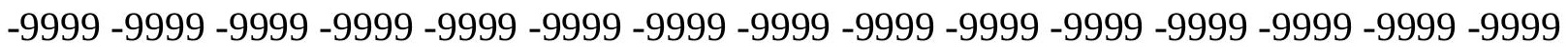
-9999 -9999 -9999 -9999 -9999 -9999 -9999 -9999 -9999 -9999 -9999 -9999 -9999 -9999 -9999 -9999 -9999 -9999 -9999 -9999 -9999 -9999 -9999 -9999 -9999 -9999 -9999 -9999 - -9999 -9999 -9999 -9999 -9999 -9999 -9999 -9999 -9999 -9999 -9999 -9999 -9999 -9999 -9999 -9999 -9999

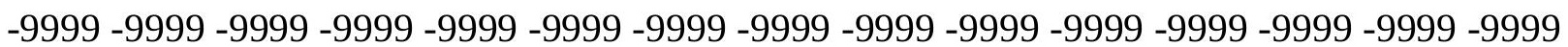
-9999 -9999 -9999 -9999 -9999 -9999 -9999 -9999 -9999 -9999 -9999 -9999 -9999 -9999 -9999 -9999 -9999 -9999 -9999 -9999 -9999 -9999 -9999 -9999 -9999 -9999 -9999 -9999 -9999 -9999 -9999 -9999 -9999 -9999 -9999 -9999 -9999 -9999 -9999 -9999 -9999 -9999 -9999 -9999 -9999

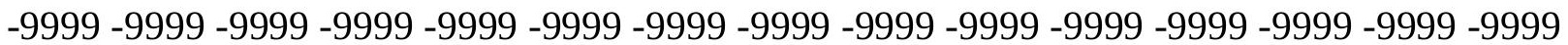


-9999 -9999 -9999 -9999 -9999 -9999 -9999 -9999 -9999 -9999 -9999 -9999 -9999 -9999 -9999 -9999 -9999 -9999 -9999 -9999 -9999 -9999 -9999 -9999 -9999 -9999 -9999 -9999 -9999 -9999

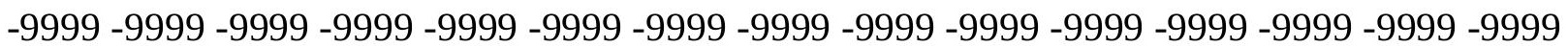
-9999 -9999 -9999 -9999 -9999 -9999 -9999 -9999 -9999 -9999 -9999 -9999 -9999 -9999 -9999 -9999 -9999 -9999 -9999 -9999 -9999 -9999 -9999 -9999 -9999 -9999 -9999 -9999 -9999 -9999 -9999 -9999 -9999 -9999 -9999 -9999 -9999 -9999 -9999 -9999 -9999 -9999 -9999 110.6370010376109 .4179000854108 .5035018921107 .5891036987107 .5891036987 109.1130981445110 .6370010376112 .1608963013113 .3800964355114 .2944030762 114.9039993286115 .2088012695115 .2088012695115 .2088012695114 .9039993286 114.5991973877114 .2944030762113 .9896011353113 .6848983765113 .075302124 112.4656982422111 .8561019897111 .24659729110 .6370010376110 .0273971558 109.4179000854109 .1130981445108 .8082962036108 .8082962036108 .8082962036 109.1130981445109 .4179000854110 .0273971558110 .9418029785111 .551399231 112.4656982422113 .3800964355114 .5991973877115 .2088012695116 .1231002808 116.7326965332117 .0374984741117 .342300415117 .0374984741117 .0374984741 117.0374984741117 .342300415117 .647102356117 .9517974854117 .9517974854 117.9517974854117 .9517974854117 .647102356117 .0374984741116 .4279022217 115.818397522115 .5136032104114 .9039993286114 .5991973877114 .2944030762 113.9896011353113 .9896011353113 .6848983765113 .6848983765113 .3800964355 113.3800964355113 .075302124112 .7705001831112 .4656982422112 .1608963013 111.551399231110 .9418029785110 .3321990967109 .4179000854108 .5035018921 107.8938980103106 .979598999105 .7603988647104 .8460998535103 .9317016602 103.0174026489101 .7982025146100 .883903503499 .6647262573298 .75038146973 97.5312423706196 .3121032714895 .0929565429793 .5690307617292 .3498916626 90.8259735107489 .302040100187 .4733276367287 .77810668945102 .1029968262 118.2565994263135 .3246002197151 .4781951904165 .4983062744177 .6896972656 188.966796875199 .0247039795207 .8634033203208 .7778015137208 .7778015137 208.7778015137208 .7778015137208 .7778015137208 .7778015137208 .7778015137 208.7778015137208 .7778015137208 .7778015137208 .7778015137208 .7778015137 208.7778015137208 .7778015137208 .7778015137208 .7778015137208 .7778015137 208.7778015137208 .7778015137208 .7778015137208 .7778015137208 .7778015137 208.7778015137208 .7778015137208 .7778015137208 .7778015137208 .7778015137 208.7778015137208 .7778015137208 .7778015137208 .7778015137208 .7778015137 208.7778015137 208.7778015137208.7778015137 208.7778015137 59.73788070679-9999 -9999 -9999 -9999 -9999 -9999 -9999 -9999 -9999 -9999 -9999 -9999 -9999 -9999 -9999 -9999 -9999 -9999 -9999 -9999 -9999 -9999 -9999 -9999 -9999 -9999 -9999 -9999 -9999 -9999 -9999 -9999 -9999 -9999 -9999 -9999 -9999 -9999 -9999 -9999 -9999

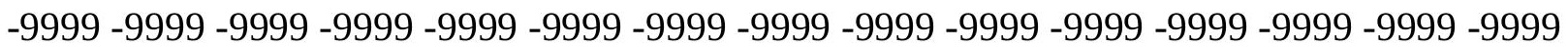
-9999 -9999 -9999 -9999 -9999 -9999 -9999 -9999 -9999 -9999 -9999 -9999 -9999 -9999 -9999 -9999 -9999 -9999 -9999 -9999 -9999 -9999 -9999 -9999 -9999 -9999 -9999 -9999 - -9999 -9999 -9999 -9999 -9999 -9999 -9999 -9999 -9999 -9999 -9999 -9999 -9999 -9999 -9999 -9999 -9999

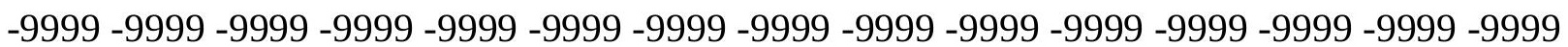
-9999 -9999 -9999 -9999 -9999 -9999 -9999 -9999 -9999 -9999 -9999 -9999 -9999 -9999 -9999 -9999 -9999 -9999 -9999 -9999 -9999 -9999 -9999 -9999 -9999 -9999 -9999 -9999 -9999 -9999 -999 -9999 -9999 -9999 -9999 -9999 -9999 -9999 -9999 -9999 -9999 -9999 -9999 -9999 -9999 -9999

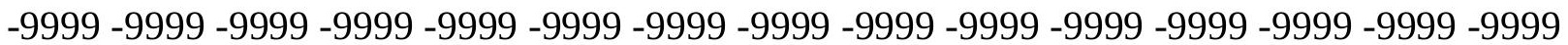


-9999 -9999 -9999 -9999 -9999 -9999 -9999 -9999 -9999 -9999 -9999 -9999 -9999 -9999 -9999 -9999 -9999 -9999 -9999 -9999 -9999 -9999 -9999 -9999 -9999 -9999 -9999 -9999 -9999 -9999

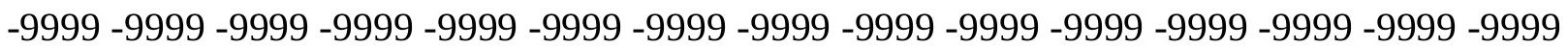
-9999 -9999 -9999 -9999 -9999 -9999 -9999 -9999 -9999 -9999 -9999 -9999 -9999 -9999 -9999 -9999 -9999 -9999 -9999 -9999 -9999 -9999 -9999 -9999 -9999 -9999 -9999 -9999 -9999 -9999 112.7705001831112 .1608963013111 .551399231111 .24659729111 .8561019897 113.6848983765115 .2088012695116 .4279022217117 .0374984741117 .0374984741 117.0374984741117 .0374984741116 .7326965332116 .4279022217116 .1231002808 115.818397522115 .2088012695114 .5991973877113 .9896011353113 .075302124 112.1608963013111 .551399231110 .9418029785110 .3321990967109 .7226028442 109.4179000854109 .1130981445109 .1130981445109 .4179000854109 .7226028442 110.3321990967110 .9418029785111 .8561019897112 .7705001831113 .6848983765 114.5991973877115 .5136032104116 .1231002808116 .7326965332117 .0374984741 117.342300415117 .0374984741117 .0374984741117 .342300415117 .647102356 117.647102356117 .9517974854117 .9517974854117 .9517974854117 .647102356 117.342300415117 .0374984741116 .4279022217115 .818397522115 .5136032104 115.2088012695114 .5991973877114 .2944030762113 .9896011353113 .6848983765 113.6848983765113 .3800964355113 .075302124112 .7705001831112 .4656982422 112.1608963013111 .8561019897111 .24659729110 .9418029785110 .3321990967 109.4179000854108 .8082962036107 .8938980103107 .2844009399106 .3700027466 105.4557037354104 .5412979126103 .6268997192102 .4077987671101 .4934005737 100.579101562599 .3599472045998 .445587158297 .2264633178796 .00731658936 94.7881774902393 .5690307617292 .349891662690 .8259735107489 .3020401001 87.4733276367285 .9494018554799 .35994720459117 .342300415135 .0198059082 151.7830047607164 .8887023926176 .7754058838187 .7476043701197 .8054962158 206.6443023682208 .7778015137208 .7778015137208 .7778015137208 .7778015137 208.7778015137208 .7778015137208 .7778015137208 .7778015137208 .7778015137 208.7778015137208 .7778015137208 .7778015137208 .7778015137208 .7778015137 208.7778015137208 .7778015137208 .7778015137208 .7778015137208 .7778015137 208.7778015137208 .7778015137208 .7778015137208 .7778015137208 .7778015137 208.7778015137208 .7778015137208 .7778015137208 .7778015137208 .7778015137 208.7778015137208 .7778015137208 .7778015137208 .7778015137208 .7778015137 208.7778015137 208.777801513759 .73788070679 -9999 -9999 -9999 -9999 -9999 -9999 -9999 -9999 -9999 -9999-9999 -9999 -9999 -9999 -9999 -9999 -9999 -9999 -9999 -9999 -9999 -9999 -9999 -9999 -9999 -9999 -9999 -9999 -9999 -9999 -9999 -9999 -9999 -9999 -9999 -9999 -9999 -9999 -9999 -9999 -9999

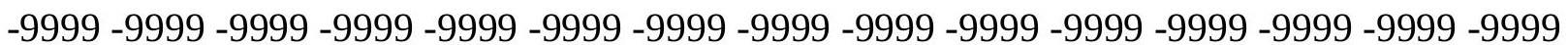

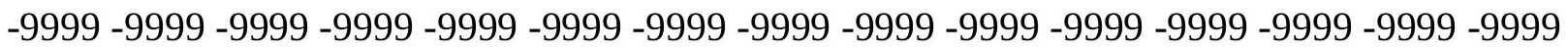
-9999 -9999 -9999 -9999 -9999 -9999 -9999 -9999 -9999 -9999 -9999 -9999 -9999 -9999 -9999 -9999 -9999 -9999 -9999 -9999 -9999 -9999 -9999 -9999 -9999 -9999 -9999 -9999 - -9999 -9999 -9999 -9999 -9999 -9999 -9999 -9999 -9999 -9999 -9999 -9999 -9999 -9999 -9999 -9999 -9999

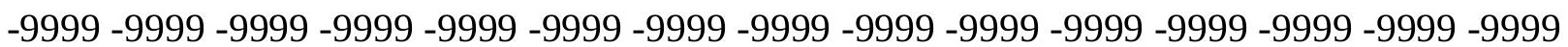
-9999 -9999 -9999 -9999 -9999 -9999 -9999 -9999 -9999 -9999 -9999 -9999 -9999 -9999 -9999 -9999 -9999 -9999 -9999 -9999 -9999 -9999 -9999 -9999 -9999 -9999 -9999 -9999 -9999 -9999 -9999 -9999 -9999 -9999 -9999 -9999 -9999 -9999 -9999 -9999 -9999 -9999 -9999 -9999 -9999

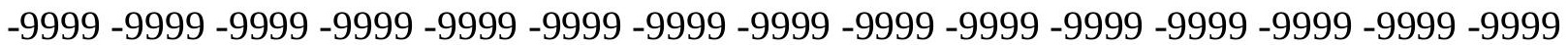


-9999 -9999 -9999 -9999 -9999 -9999 -9999 -9999 -9999 -9999 -9999 -9999 -9999 -9999 -9999 -9999 -9999 -9999 -9999 -9999 -9999 -9999 -9999 -9999 -9999 -9999 -9999 -9999 -9999 -9999

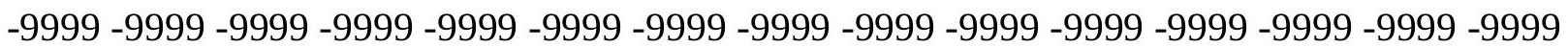
-9999 -9999 -9999 -9999 -9999 -9999 -9999 -9999 -9999 -9999 -9999 -9999 -9999 -9999 -9999 -9999 -9999 116.1231002808115.818397522115.818397522 115.818397522117 .0374984741 118.5614013672118 .8662033081118 .8662033081118 .8662033081118 .5614013672 118.2565994263118 .2565994263117 .9517974854117 .342300415116 .7326965332 116.1231002808115 .2088012695114 .2944030762113 .3800964355112 .4656982422 111.551399231110 .9418029785110 .3321990967110 .0273971558109 .7226028442 109.4179000854109 .4179000854109 .7226028442110 .3321990967110 .9418029785 111.8561019897112 .7705001831113 .6848983765114 .5991973877115 .5136032104 116.1231002808116 .7326965332117 .0374984741117 .0374984741117 .0374984741 117.342300415117 .647102356117 .647102356117 .647102356117 .647102356117 .647102356 117.647102356117 .342300415117 .0374984741116 .7326965332116 .4279022217 115.818397522115 .5136032104114 .9039993286114 .5991973877114 .2944030762 113.9896011353113 .6848983765113 .3800964355113 .075302124112 .7705001831 112.4656982422112 .1608963013111 .551399231111 .24659729110 .6370010376 110.0273971558109 .4179000854108 .8082962036108 .1986999512107 .2844009399 106.6747970581105 .7603988647104 .8460998535103 .9317016602103 .0174026489 102.1029968262101 .1886978149100 .274299621699 .3599472045998 .14080810547 97.2264633178796 .0073165893694 .7881774902393 .5690307617292 .3498916626 90.8259735107489 .302040100187 .7781066894585 .9494018554795 .09295654297 114.9039993286132 .8863067627148 .4304046631162 .1457061768174 .6419067383 185.6141052246195 .9768066406205 .1204071045208 .7778015137208 .7778015137 208.7778015137208 .7778015137208 .7778015137208 .7778015137208 .7778015137 208.7778015137208 .7778015137208 .7778015137208 .7778015137208 .7778015137 208.7778015137208 .7778015137208 .7778015137208 .7778015137208 .7778015137 208.7778015137208 .7778015137208 .7778015137208 .7778015137208 .7778015137 208.7778015137208 .7778015137208 .7778015137208 .7778015137208 .7778015137 208.7778015137208 .7778015137208 .7778015137208 .7778015137208 .7778015137 208.7778015137 208.7778015137 208.7778015137 208.777801513759.73788070679 -9999 -9999 -9999 -9999 -9999 -9999 -9999 -9999 -9999 -9999 -9999 -9999 -9999 -9999 -9999 -9999 -9999 -9999 -9999 -9999 -9999 -9999 -9999 -9999 -9999 -9999 -9999 -9999 -9999 -9999 -9999 -9999 -9999 -9999 -9999 -9999 -9999 -9999 -9999 -9999 -9999

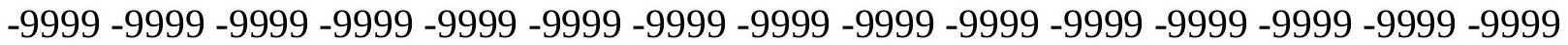
-9999 -9999 -9999 -9999 -9999 -9999 -9999 -9999 -9999 -9999 -9999 -9999 -9999 -9999 -9999 -9999 -9999 -9999 -9999 -9999 -9999 -9999 -9999 -9999 -9999 -9999 -9999 -9999 -9999 -9999 -

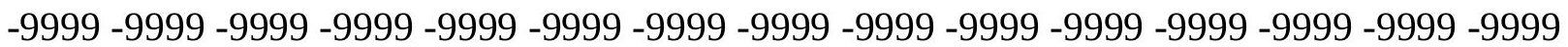
-9999 -9999 -9999 -9999 -9999 -9999 -9999 -9999 -9999 -9999 -9999 -9999 -9999 -9999 -9999 -9999 -9999 -9999 -9999 -9999 -9999 -9999 -9999 -9999 -9999 -9999 -9999 -9999 - -9999 -9999 -9999 -9999 -9999 -9999 -9999 -9999 -9999 -9999 -9999 -9999 -9999 -9999 -9999 -9999 -9999

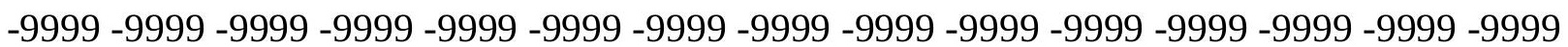
-9999 -9999 -9999 -9999 -9999 -9999 -9999 -9999 -9999 -9999 -9999 -9999 -9999 -9999 -9999 -9999 -9999 -9999 -9999 -9999 -9999 -9999 -9999 -9999 -9999 -9999 -9999 -9999 -9999 -9999 -999 -9999 -9999 -9999 -9999 -9999 -9999 -9999 -9999 -9999 -9999 -9999 -9999 -9999 -9999 -9999

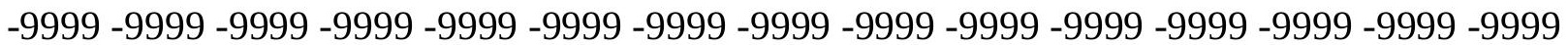


-9999 -9999 -9999 -9999 -9999 -9999 -9999 -9999 -9999 -9999 -9999 -9999 -9999 -9999 -9999 -9999 -9999 -9999 -9999 -9999 -9999 -9999 -9999 -9999 -9999 -9999 -9999 -9999 -9999 -9999 -9999 -9999 -9999 -9999 120.3900985718 120.6949005127120 .6949005127120 .9997024536 120.3900985718120 .3900985718120 .0852966309120 .0852966309119 .7806015015 119.7806015015119 .4757995605118 .8662033081118 .2565994263117 .342300415 116.4279022217115 .5136032104114 .2944030762113 .3800964355112 .4656982422 111.551399231110 .9418029785110 .3321990967110 .0273971558109 .7226028442 109.7226028442110 .0273971558110 .3321990967110 .9418029785111 .8561019897 112.7705001831113 .6848983765114 .5991973877115 .2088012695116 .1231002808 116.4279022217116 .7326965332117 .342300415117 .342300415117 .647102356 117.647102356117 .647102356117 .647102356117 .342300415117 .342300415117 .342300415 117.0374984741116 .7326965332116 .4279022217116 .1231002808115 .818397522 115.2088012695114 .9039993286114 .5991973877113 .9896011353113 .6848983765 113.3800964355113 .075302124112 .7705001831112 .1608963013111 .8561019897 111.551399231110 .9418029785110 .6370010376110 .0273971558109 .4179000854 108.8082962036108 .1986999512107 .5891036987106 .6747970581106 .0652008057 105.1509017944104 .2365036011103 .6268997192102 .712600708101 .7982025146 100.883903503499 .9695205688599 .0551681518698 .1408081054796 .92166900635 96.0073165893694 .7881774902393 .5690307617292 .349891662690 .82597351074 89.302040100187 .7781066894586 .254188537687 .77810668945111 .8561019897 128.3144989014143 .5538024902158 .1835021973171 .2891998291183 .1759033203 193.8433074951203 .596496582208 .7778015137208 .7778015137208 .7778015137 208.7778015137208 .7778015137208 .7778015137208 .7778015137208 .7778015137 208.7778015137208 .7778015137208 .7778015137208 .7778015137208 .7778015137 208.7778015137208 .7778015137208 .7778015137208 .7778015137208 .7778015137 208.7778015137208 .7778015137208 .7778015137208 .7778015137208 .7778015137 208.7778015137208 .7778015137208 .7778015137208 .7778015137208 .7778015137 208.7778015137208 .7778015137208 .7778015137208 .7778015137208 .7778015137 208.7778015137 208.7778015137 208.777801513759 .43310165405 -9999 -9999 -9999 -9999 -9999 -9999 -9999 -9999 -9999 -9999 -9999 -9999 -9999 -9999 -9999 -9999 -9999 -9999 -9999 -9999 -9999 -9999 -9999 -9999 -9999 -9999

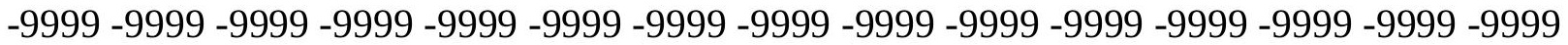
-9999 -9999 -9999 -9999 -9999 -9999 -9999 -9999 -9999 -9999 -9999 -9999 -9999 -9999 -9999 -9999 -9999 -9999 -9999 -9999 -9999 -9999 -9999 -9999 -9999 -9999 -9999 -9999 -9999 -9999 -9999 -9999 -9999 -9999 -9999 -9999 -9999 -9999 -9999 -9999 -9999 -9999 -9999 -9999 -9999 -9999 -9999 -9999 -9999 -9999 -9999 -9999 -9999 -9999 -9999 -9999 -9999 -9999 -9999 -9999 -9999 -9999 -9999 -9999 -9999 -9999 -9999 -9999 -9999 -9999 -9999 -9999 -9999 -9999 -9999

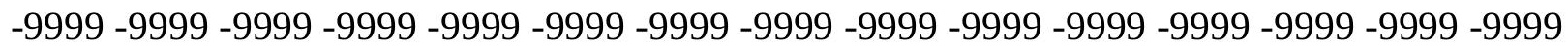
-9999 -9999 -9999 -9999 -9999 -9999 -9999 -9999 -9999 -9999 -9999 -9999 -9999 -9999 -9999 -9999 -9999 -9999 -9999 -9999 -9999 -9999 -9999 -9999 -9999 -9999 -9999 -9999 -9999 -9999 -

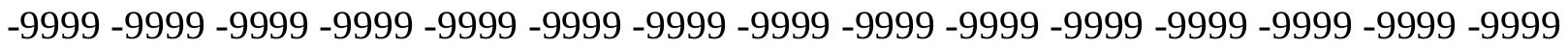
-9999 -9999 -9999 -9999 -9999 -9999 -9999 -9999 -9999 -9999 -9999 -9999 -9999 -9999 -9999 -9999 -9999 -9999 -9999 -9999 -9999 -9999 -9999 -9999 -9999 -9999 -9999 -9999 -9999 -9999 -9999 -9999 -9999 -9999 -9999 -9999 -9999 -9999 -9999 -9999 -9999 -9999 -9999 -9999 -9999 -999 -9999 -9999 -9999 -9999 -9999 -9999 -9999 -9999 -9999 -9999 -9999 -9999 -9999 -9999 -9999

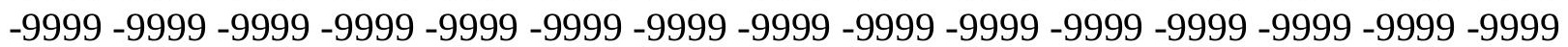


-9999 -9999 -9999 -9999 -9999 -9999 124.6570968628124 .3523025513123 .1332015991 121.9140014648120 .9997024536120 .9997024536121 .3044967651120 .9997024536 120.6949005127120 .3900985718119 .7806015015118 .8662033081117 .647102356 116.4279022217115 .2088012695113 .9896011353113 .075302124112 .1608963013 111.24659729110 .6370010376110 .3321990967110 .0273971558110 .0273971558 110.0273971558110 .3321990967110 .9418029785111 .551399231112 .4656982422 113.3800964355114 .2944030762115 .2088012695115 .818397522116 .7326965332 117.342300415 117.647102356 117.647102356117.647102356 117.647102356117.342300415 117.342300415117 .0374984741117 .0374984741116 .7326965332116 .7326965332 116.4279022217116 .1231002808115 .818397522115 .5136032104115 .2088012695 114.5991973877114 .2944030762113 .9896011353113 .3800964355113 .075302124 112.7705001831112 .1608963013111 .8561019897111 .551399231110 .9418029785 110.6370010376110 .0273971558109 .4179000854108 .8082962036108 .1986999512 107.5891036987106 .979598999106 .0652008057105 .4557037354104 .5412979126 103.9317016602103 .0174026489102 .1029968262101 .1886978149100 .5791015625 99.6647262573298 .7503814697397 .8360290527396 .9216690063596 .00731658936 94.7881774902393 .5690307617292 .349891662691 .1307525634889 .60682678223 88.0829010009886 .254188537684 .42548370361101 .4934005737120 .3900985718 137.7628936768153 .6116943359167 .6318054199180 .432800293191 .7097930908 201.7678070068208 .7778015137208 .7778015137208 .7778015137208 .7778015137 208.7778015137 208.7778015137208.7778015137 208.7778015137 208.7778015137 208.7778015137208 .7778015137208 .7778015137208 .7778015137208 .7778015137 208.7778015137208 .7778015137208 .7778015137208 .7778015137208 .7778015137 208.7778015137 208.7778015137208.7778015137 208.7778015137 208.7778015137 208.7778015137 208.7778015137208.7778015137 208.7778015137 208.7778015137 208.7778015137 208.7778015137208.7778015137 208.7778015137 208.7778015137 208.7778015137 208.777801513759 .43310165405 -9999 -9999-9999 -9999 -9999-9999 -9999 -9999 -9999-9999-9999

-9999 -9999 -9999 -9999 -9999 -9999 -9999 -9999 -9999 -9999 -9999 -9999 -9999 -9999 -9999 -9999 -9999 -9999 -9999 -9999 -9999 -9999 -9999 -9999 -9999 -9999 -9999 -9999 -9999 -9999 -9999 -9999 -9999 -9999 -9999 -9999 -9999 -9999 -9999 -9999 -9999 -9999 -9999 -9999 -9999 -9999 -9999 -9999 -9999 -9999 -9999 -9999 -9999 -9999 -9999 -9999 -9999 -9999 -9999 -9999 -

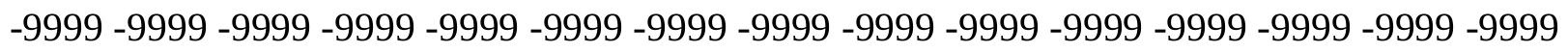
-9999 -9999 -9999 -9999 -9999 -9999 -9999 -9999 -9999 -9999 -9999 -9999 -9999 -9999 -9999 -9999 -9999 -9999 -9999 -9999 -9999 -9999 -9999 -9999 -9999 -9999 -9999 -9999 -9999 -9999

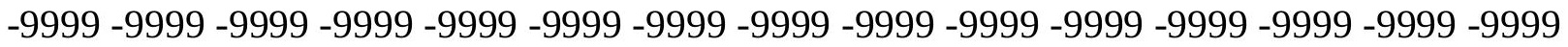

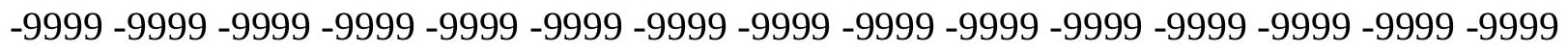

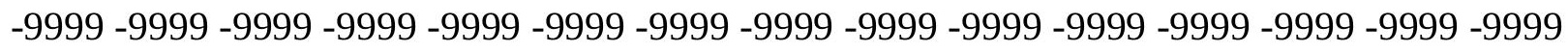
-9999 -9999 -9999 -9999 -9999 -9999 -9999 -9999 -9999 -9999 -9999 -9999 -9999 -9999 -9999 -9999 -9999 -9999 -9999 -9999 -9999 -9999 -9999 -9999 -9999 -9999 -9999 -9999 -9999 -9999 -

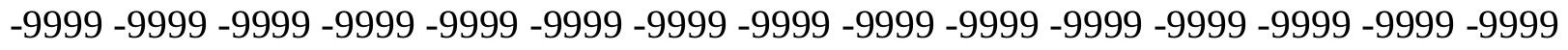

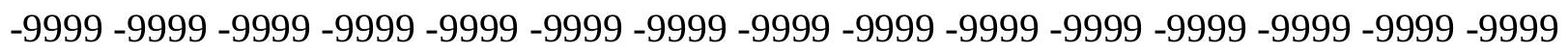
-9999 -9999 -9999 -9999 -9999 -9999 -9999 -9999 -9999 -9999 -9999 -9999 -9999 -9999 -9999 -9999 -9999 -9999 -9999 -9999 -9999 -9999 -9999 -9999 -9999 -9999 -9999 -9999 -9999 -9999 -9999 -9999 -9999 -9999 -9999 -9999 -9999 -9999 126.1809997559124 .9618988037 123.7427978516122 .8283996582122 .5235977173122 .2188034058121 .9140014648 
121.9140014648120 .9997024536120 .0852966309118 .5614013672117 .0374984741 115.818397522114 .9039993286113 .6848983765112 .7705001831111 .8561019897 111.24659729110 .6370010376110 .3321990967113 .3800964355110 .3321990967 110.6370010376110 .9418029785111 .551399231112 .4656982422113 .3800964355 114.2944030762115 .5136032104116 .4279022217117 .0374984741117 .647102356 117.9517974854117 .9517974854117 .647102356117 .342300415117 .0374984741 117.0374984741116 .7326965332116 .7326965332116 .4279022217116 .4279022217 116.1231002808115 .818397522115 .5136032104115 .2088012695114 .9039993286 114.2944030762113 .9896011353113 .6848983765113 .075302124112 .7705001831 112.4656982422111 .8561019897111 .551399231110 .9418029785110 .3321990967 110.0273971558109 .4179000854108 .8082962036108 .1986999512107 .5891036987 106.979598999106 .0652008057105 .4557037354104 .8460998535103 .9317016602 103.3221969604102 .4077987671101 .7982025146100 .883903503499 .96952056885 99.3599472045998.445587158297.8360290527396.9216690063596.00731658936 94.7881774902393 .5690307617292 .349891662691 .1307525634899 .60682678223 88.0829010009886 .5589828491284 .7302627563592 .65467834473112 .7705001831 131.9720001221149 .3446960449164 .5839996338177 .9945068359189 .5764007568 199.9389953613208 .7778015137208 .7778015137208 .7778015137208 .7778015137 208.7778015137208 .7778015137208 .7778015137208 .7778015137208 .7778015137 208.7778015137208 .7778015137208 .7778015137208 .7778015137208 .7778015137 208.7778015137208 .7778015137208 .7778015137208 .7778015137208 .7778015137 208.7778015137208 .7778015137208 .7778015137208 .7778015137208 .7778015137 208.7778015137208 .7778015137208 .7778015137208 .7778015137208 .7778015137 208.7778015137208 .7778015137208 .7778015137208 .7778015137208 .7778015137 208.7778015137 208.777801513759 .43310165405 -9999 -9999 -9999 -9999 -9999 -9999 -9999 -9999 -9999 -9999-9999 -9999 -9999 -9999 -9999 -9999 -9999 -9999 -9999 -9999 -9999 -9999 -9999 -9999 -9999 -9999 -9999 -9999 -9999 -9999 -9999 -9999 -9999 -9999 -9999 -9999 -9999 -9999 -9999 -9999 -9999 -9999 -9999 -9999 -9999 -9999 -9999 -9999 -9999 -9999 -9999 -9999 -9999 -9999 -9999 -9999 -9999 -9999 -9999 -9999 -9999 -9999 -9999 -9999 -9999 -9999 -9999 -9999 -9999 -9999 -9999 -9999 -9999 -9999 -9999 -9999 -9999 -9999 -9999 -9999 -9999 -9999 -9999 -9999 -9999 -9999 -9999 -9999 -9999 -9999 -9999 -9999 -9999 -9999 -9999 -9999 -9999 -9999 -9999 -9999 -9999 -9999 -9999 -9999 -9999 -9999 -9999 -9999 -9999 -9999 -9999 -9999 -9999 -9999 -9999 -9999 -9999 -9999 -9999 -9999 -9999 -9999 -9999 -9999 -9999 -9999 -9999 -9999 -9999 -9999 -9999

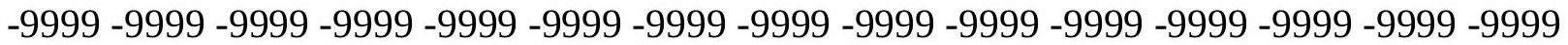
-9999 -9999 -9999 -9999 -9999 -9999 -9999 -9999 -9999 -9999 -9999 -9999 -9999 -9999 -9999

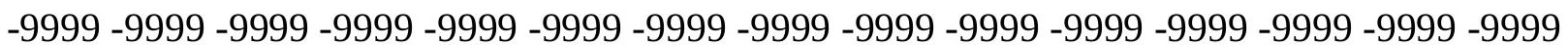

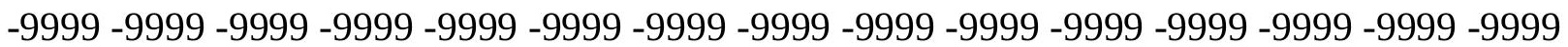
-9999 -9999 -9999 -9999 -9999 -9999 -9999 -9999 -9999 -9999 -9999 -9999 -9999 -9999 -9999 -9999 -9999 -9999 -9999 -9999 -9999 -9999 -9999 -9999 -9999 -9999 -9999 -9999 - -9999 -9999 -9999 -9999 -9999 -9999 -9999 -9999 -9999 -9999 -9999 -9999 -9999 -9999 -9999 -9999 -9999

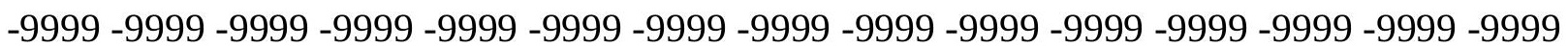
-9999 -9999 -9999 -9999 -9999 -9999 -9999 -9999 -9999 -9999 126.4858016968 125.5715026855124 .6570968628124 .3523025513123 .7427978516123 .43800354 123.1332015991121 .9140014648120 .3900985718119 .1709976196117 .9517974854 116.7326965332115 .5136032104114 .5991973877113 .6848983765112 .7705001831 
112.1608963013111 .551399231111 .24659729111 .24659729111 .551399231111 .551399231 112.1608963013112 .7705001831113 .6848983765114 .5991973877115 .5136032104 116.4279022217117 .342300415117 .9517974854117 .9517974854117 .647102356 117.342300415117 .0374984741116 .7326965332116 .4279022217116 .4279022217 116.1231002808116 .1231002808116 .1231002808115 .818397522115 .5136032104 115.2088012695114 .9039993286114 .5991973877114 .2944030762113 .6848983765 113.3800964355112 .7705001831112 .4656982422111 .8561019897111 .551399231 110.9418029785110 .6370010376110 .0273971558109 .4179000854108 .8082962036 108.1986999512107 .5891036987106 .979598999106 .3700027466105 .4557037354 104.8460998535104 .2365036011103 .3221969604102 .712600708102 .1029968262 101.1886978149100 .579101562599 .6647262573299 .0551681518698 .4455871582 97.5312423706196 .6168823242296 .0073165893694 .7881774902393 .87381744385 92.6546783447391 .1307525634889 .9116134643688 .3876876831186 .55898284912 84.7302627563586 .2541885376107 .2844009399128 .0097961426146 .6015930176 162.4505004883176 .165802002188 .0523986816198 .4151000977207 .25390625 208.7778015137208.7778015137208.7778015137 208.7778015137 208.7778015137 208.7778015137208 .7778015137208 .7778015137208 .7778015137208 .7778015137 208.7778015137208 .7778015137208 .7778015137208 .7778015137208 .7778015137 208.7778015137208 .7778015137208 .7778015137208 .7778015137208 .7778015137 208.7778015137 208.7778015137208.7778015137 208.7778015137 208.7778015137 208.7778015137208 .7778015137208 .7778015137208 .7778015137208 .7778015137 208.7778015137208 .7778015137208 .7778015137208 .7778015137208 .7778015137 59.43310165405 -9999 -9999 -9999 -9999 -9999 -9999 -9999 -9999 -9999 -9999 -9999 -9999 -9999 -9999 -9999 -9999 -9999 -9999 -9999 -9999 -9999 -9999 -9999 -9999 -9999 -9999 -9999 -9999 -9999 -9999 -9999 -9999 -9999 -9999 -9999 -9999 -9999 -9999 -9999 -9999 -9999 -9999 -9999 -9999 -9999 -9999 -9999 -9999 -9999 -9999 -9999 -9999 -9999 -9999 -9999 -9999 -9999 -9999 -9999 -9999 -9999 -9999 -9999 -9999 -9999 -9999 -9999 -9999 -9999 -9999 -9999

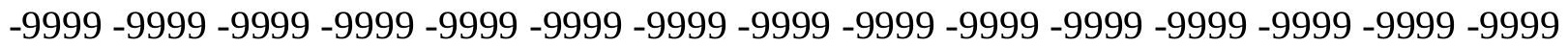
-9999 -9999 -9999 -9999 -9999 -9999 -9999 -9999 -9999 -9999 -9999 -9999 -9999 -9999 -9999 -9999 -9999 -9999 -9999 -9999 -9999 -9999 -9999 -9999 -9999 -9999 -9999 -9999 -9999 -9999 -9999 -9999 -9999 -9999 -9999 -9999 -9999 -9999 -9999 -9999 -9999 -9999 -9999 -9999 -9999

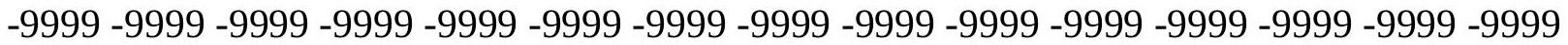

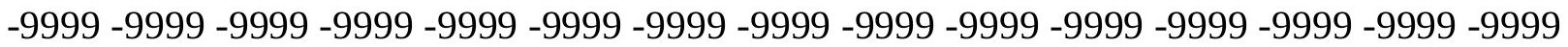
-9999 -9999 -9999 -9999 -9999 -9999 -9999 -9999 -9999 -9999 -9999 -9999 -9999 -9999 -9999 -9999 -9999 -9999 -9999 -9999 -9999 -9999 -9999 -9999 -9999 -9999 -9999 -9999 -9999 -9999 -9999 -9999 -9999 -9999 -9999 -9999 -9999 -9999 -9999 -9999 -9999 -9999 -9999 -9999 -9999

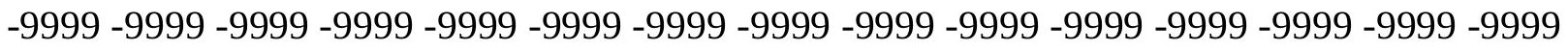

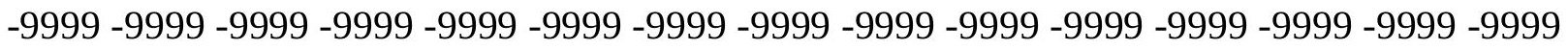
-9999 -9999 -9999 -9999 -9999 -9999 -9999 -9999 -9999 -9999 -9999 -9999 -9999 -9999 -9999 -9999 -9999 -9999 -9999 -9999 -9999 -9999 -9999 -9999 -9999 -9999 127.7050018311 127.0953979492126 .4858016968126 .1809997559125 .8762969971124 .9618988037 124.0475006104122 .8283996582121 .6092987061120 .3900985718118 .8662033081 117.647102356116 .4279022217115 .2088012695114 .2944030762113 .3800964355 112.7705001831112 .4656982422112 .1608963013112 .1608963013112 .1608963013 112.4656982422112 .7705001831113 .3800964355114 .2944030762115 .2088012695 116.1231002808117 .0374984741117 .647102356117 .647102356117 .342300415 
117.0374984741116 .7326965332116 .4279022217116 .1231002808116 .1231002808 115.818397522115 .818397522115 .818397522115 .5136032104115 .2088012695 114.9039993286114 .5991973877114 .2944030762113 .9896011353113 .3800964355 113.075302124112 .4656982422112 .1608963013111 .551399231110 .9418029785 110.6370010376110 .0273971558109 .4179000854108 .8082962036108 .1986999512 107.5891036987106 .979598999106 .3700027466105 .7603988647104 .8460998535 104.2365036011103 .6268997192103 .0174026489102 .1029968262101 .4934005737 100.8839035034100 .274299621699 .3599472045998 .7503814697398 .14080810547 97.5312423706196 .6168823242296 .0073165893695 .0929565429793 .87381744385 92.6546783447391 .4355392456189 .9116134643688 .3876876831186 .86376190186 85.0350494384882 .90155792236104 .5412979126126 .4858016968145 .3825073242 161.5361022949175 .2514038086186 .8332977295197 .1959991455206 .0346984863 208.7778015137208 .7778015137208 .7778015137208 .7778015137208 .7778015137 208.7778015137208 .7778015137208 .7778015137208 .7778015137208 .7778015137 208.7778015137208 .7778015137208 .7778015137208 .7778015137208 .7778015137 208.7778015137 208.7778015137208.7778015137 208.7778015137 208.7778015137 208.7778015137208 .7778015137208 .7778015137208 .7778015137208 .7778015137 208.7778015137208 .7778015137208 .7778015137208 .7778015137208 .7778015137 208.7778015137208 .7778015137208 .7778015137208 .7778015137208 .7778015137 59.12831115723 -9999 -9999 -9999 -9999 -9999 -9999 -9999 -9999 -9999 -9999 -9999 -9999 -9999 -9999 -9999 -9999 -9999 -9999 -9999 -9999 -9999 -9999 -9999 -9999 -9999 -9999 -9999 -9999 -9999 -9999 -9999 -9999 -9999 -9999 -9999 -9999 -9999 -9999 -9999 -9999 -9999 -9999 -9999 -9999 -9999 -9999 -9999 -9999 -9999 -9999 -9999 -9999 -9999-9999-9999-9999 -999 -9999 -9999 -9999 -9999 -9999 -9999 -9999 -9999 -9999 -9999 -9999 -9999 -9999 -9999 -9999 -9999 -9999 -9999 -9999 -9999 -9999 -9999 -9999 -9999 -9999 -9999 -9999 -9999 -9999 -9999 -9999 -9999 -9999 -9999 -9999 -9999 -9999 -9999 -9999 -9999 -9999 -9999 -9999 -9999 -9999 -9999 -9999 -9999 -9999 -9999 -9999 -9999 -9999 -9999 -9999 -9999 -9999 -9999 -9999 -9999

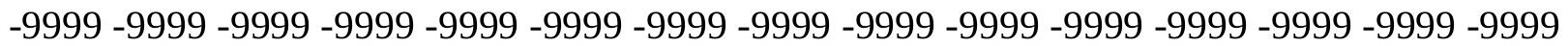
-9999 -9999 -9999 -9999 -9999 -9999 -9999 -9999 -9999 -9999 -9999 -9999 -9999 -9999 -9999 -9999 -9999 -9999 -9999 -9999 -9999 -9999 -9999 -9999 -9999 -9999 -9999 -9999 -9999 -9999 -9999 -9999 -9999 -9999 -9999 -9999 -9999 -9999 -9999 -9999 -9999 -9999 -9999 -9999 -9999

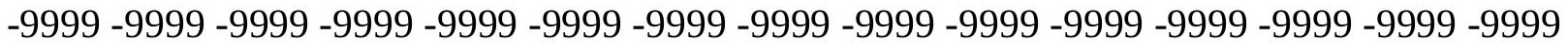

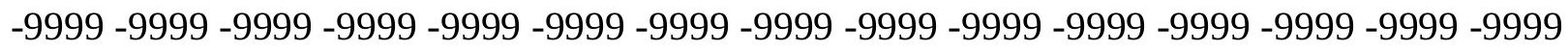
-9999 -9999 -9999 -9999 -9999 -9999 -9999 -9999 -9999 -9999 -9999 -9999 -9999 -9999 -9999 -

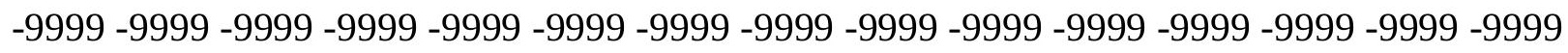

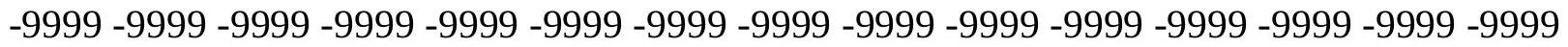
-9999 -9999 -9999 -9999 -9999 -9999 -9999 -9999 -9999 -9999 -9999 -9999 -9999 128.3144989014127 .7050018311127 .4001998901126 .4858016968125 .5715026855 124.6570968628123 .43800354122 .2188034058120 .6949005127119 .1709976196 117.647102356116 .4279022217115 .5136032104114 .5991973877113 .6848983765 113.075302124112 .7705001831112 .4656982422112 .4656982422112 .4656982422 112.7705001831113 .3800964355113 .6848983765114 .2944030762115 .2088012695 115.818397522116 .4279022217116 .7326965332116 .7326965332116 .4279022217 116.1231002808116 .1231002808115 .818397522115 .818397522115 .5136032104 115.5136032104115 .5136032104115 .2088012695114 .9039993286114 .5991973877 114.2944030762113 .9896011353113 .6848983765113 .075302124112 .7705001831 
112.1608963013111 .8561019897111 .24659729110 .6370010376110 .0273971558 109.7226028442109 .1130981445108 .5035018921107 .8938980103106 .979598999 106.3700027466105 .7603988647105 .1509017944104 .5412979126103 .6268997192 103.0174026489102 .4077987671101 .7982025146100 .8839035034100 .2742996216 99.6647262573299 .0551681518698 .445587158298 .1408081054797 .53124237061 96.6168823242296 .0073165893695 .0929565429794 .1785964965892 .95947265625 91.7403335571390 .2164001464888 .6924667358486 .8637619018685 .03504943848 83.2063369751105 .4557037354126 .1809997559145 .0776977539161 .5361022949 174.9467010498186 .2236938477195 .9768066406204 .5108032227208 .7778015137 208.7778015137208 .7778015137208 .7778015137208 .7778015137208 .7778015137 208.7778015137208 .7778015137208 .7778015137208 .7778015137208 .7778015137 208.7778015137208 .7778015137208 .7778015137208 .7778015137208 .7778015137 208.7778015137 208.7778015137 208.7778015137 208.7778015137 208.7778015137 208.7778015137208 .7778015137208 .7778015137208 .7778015137208 .7778015137 208.7778015137 208.7778015137 208.7778015137 208.7778015137 208.7778015137 208.7778015137 208.7778015137 208.7778015137 208.7778015137 59.12831115723 -9999 -9999 -9999 -9999 -9999 -9999 -9999 -9999 -9999 -9999 -9999 -9999 -9999 -9999 -9999 -9999 -9999 -9999 -9999 -9999 -9999 -9999 -9999 -9999 -9999 -9999 -9999 -9999 -9999 -9999 -9999 -9999 -9999 -9999 -9999 -9999 -9999 -9999 -9999 -9999 -9999 -999 -

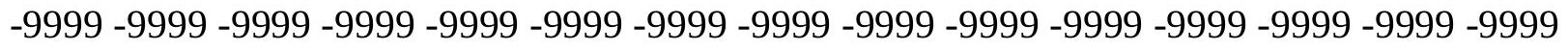

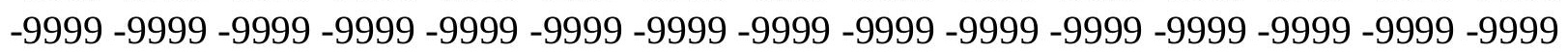

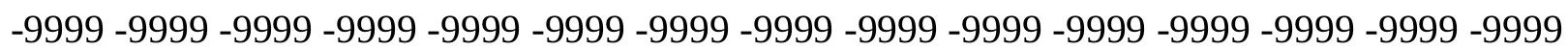
-9999 -9999 -9999 -9999 -9999 -9999 -9999 -9999 -9999 -9999 -9999 -9999 -9999 -9999 -9999 -9999 -9999 -9999 -9999 -9999 -9999 -9999 -9999 -9999 -9999 -9999 -9999 -9999 -9999 -9999 -9999 -9999 -9999 -9999 -9999 -9999 -9999 -9999 -9999 -9999 -9999 -9999 -9999 -9999 -9999 -9999 -9999 -9999 -9999 -9999 -9999 -9999 -9999 -9999 -9999 -9999 -9999 -9999 -9999 -9999 -9999 -9999 -9999 -9999 -9999 -9999 -9999 -9999 -9999 -9999 -9999 -9999 -9999 -9999 -9999

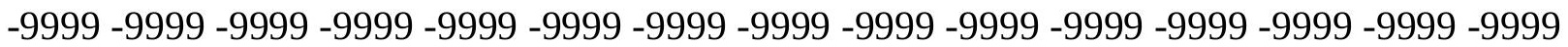
-9999 -9999 -9999 -9999 -9999 -9999 -9999 -9999 -9999 -9999 -9999 -9999 -9999 -9999 -9999

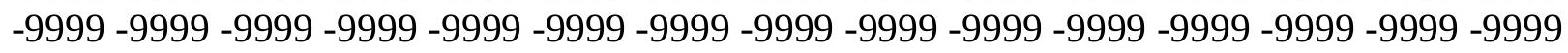
-9999 -9999 -9999 -9999 -9999 -9999 -9999 -9999 -9999 -9999 -9999 -9999 -9999 -9999 -9999

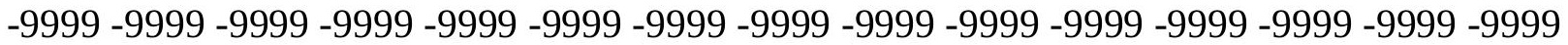

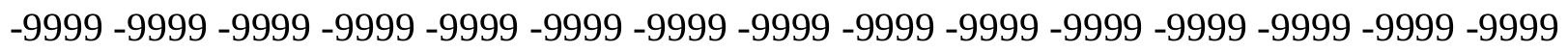
-9999 -9999 -9999 -9999 -9999 -9999 -9999 -9999 -9999 -9999 -9999 -9999 -9999 -9999 128.9241027832128 .3144989014127 .7050018311126 .7906036377125 .5715026855 124.3523025513123 .1332015991121 .6092987061120 .3900985718118 .8662033081 117.647102356116 .4279022217115 .5136032104114 .5991973877113 .9896011353 113.3800964355113 .075302124112 .7705001831112 .7705001831112 .7705001831 112.7705001831113 .075302124113 .3800964355113 .9896011353114 .5991973877 115.2088012695115 .5136032104115 .818397522115 .818397522115 .818397522 115.5136032104115 .5136032104115 .5136032104115 .5136032104115 .2088012695 115.2088012695114 .9039993286114 .5991973877114 .2944030762113 .9896011353 113.6848983765113 .3800964355112 .7705001831112 .4656982422111 .8561019897 111.24659729110 .9418029785110 .3321990967109 .7226028442109 .1130981445 108.5035018921107 .8938980103107 .2844009399106 .6747970581106 .0652008057 105.1509017944104 .5412979126103 .9317016602103 .0174026489102 .4077987671 
101.7982025146101 .1886978149100 .579101562599 .9695205688599 .35994720459 99.0551681518698 .445587158297 .8360290527397 .5312423706196 .92166900635 96.0073165893695 .397743225194 .1785964965893 .2642517089892 .04509735107 90.5211791992288 .9972534179787 .1685485839885 .3398437583 .2063369751 100.2742996216124 .9618988037145 .6873016357161 .8408966064174 .6419067383 185.6141052246194 .7577056885203 .2917022705208 .7778015137208 .7778015137 208.7778015137208 .7778015137208 .7778015137208 .7778015137208 .7778015137 208.7778015137208 .7778015137208 .7778015137208 .7778015137208 .7778015137 208.7778015137208 .7778015137208 .7778015137208 .7778015137208 .7778015137 208.7778015137208 .7778015137208 .7778015137208 .7778015137208 .7778015137 208.7778015137208 .7778015137208 .7778015137208 .7778015137208 .7778015137 208.7778015137208 .7778015137208 .7778015137208 .7778015137208 .7778015137 208.7778015137 208.777801513758 .8235282897959 .12831115723 -9999 -9999 -9999 -9999 -9999 -9999 -9999 -9999-9999 -9999 -9999 -9999 -9999 -9999 -9999 -9999 -9999 -9999 -9999 -9999 -9999 -9999 -9999 -9999 -9999 -9999 -9999 -9999 -9999 -9999 -9999 -9999 -9999 -9999 -9999 -9999 -9999 -9999 -9999 -9999 -9999

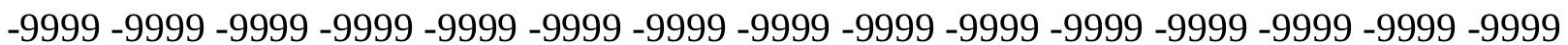
-9999 -9999 -9999 -9999 -9999 -9999 -9999 -9999 -9999 -9999 -9999 -9999 -9999 -9999 -9999 -9999 -9999 -9999 -9999 -9999 -9999 -9999 -9999 -9999 -9999 -9999 -9999 -9999 -9999 -9999 -9999 -9999 -9999 -9999 -9999 -9999 -9999 -9999 -9999 -9999 -9999 -9999 -9999 -9999 -9999

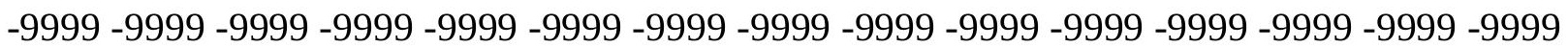
-9999 -9999 -9999 -9999 -9999 -9999 -9999 -9999 -9999 -9999 -9999 -9999 -9999 -9999 -9999 -9999 -9999 -9999 -9999 -9999 -9999 -9999 -9999 -9999 -9999 -9999 -9999 -9999 -9999 -9999 -9999 -9999 -9999 -9999 -9999 -9999 -9999 -9999 -9999 -9999 -9999 -9999 -9999 -9999 -9999

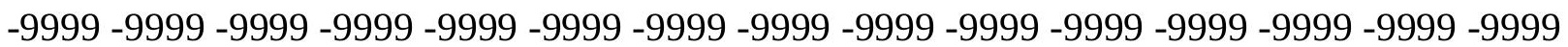
-9999 -9999 -9999 -9999 -9999 -9999 -9999 -9999 -9999 -9999 -9999 -9999 -9999 -9999 -9999 -9999 -9999 -9999 -9999 -9999 -9999 -9999 -9999 -9999 -9999 -9999 -9999 -9999 -9999 -9999 -9999 -9999 -9999 -9999 -9999 -9999 -9999 -9999 -9999 -9999 -9999 -9999 -9999 -9999 -9999 -9999 -9999 -9999 -9999 -9999 -9999 -9999 -9999 -9999 -9999 -9999 -9999 -9999 -9999 -9999 -9999 -9999 -9999 -9999 -9999 -9999 -9999 -9999 -9999 -9999 -9999 -9999 -9999 -9999 -9999 -9999 -9999 -9999 -9999 -9999 -9999 -9999 -9999 -9999 -9999 -9999 -9999 -9999 -9999 -9999 -9999 128.0097961426127.0953979492126.1809997559124.9618988037123.7427978516 122.2188034058120 .9997024536119 .4757995605118 .2565994263117 .0374984741 116.1231002808115 .2088012695114 .2944030762113 .6848983765113 .3800964355 112.7705001831112 .4656982422112 .4656982422112 .4656982422112 .4656982422 112.4656982422112 .7705001831113 .3800964355113 .9896011353114 .2944030762 114.9039993286114 .9039993286115 .2088012695115 .2088012695115 .2088012695 115.2088012695115 .2088012695114 .9039993286114 .9039993286114 .5991973877 114.2944030762113 .9896011353113 .6848983765113 .3800964355113 .075302124 112.4656982422112 .1608963013111 .551399231110 .9418029785110 .3321990967 110.0273971558109 .4179000854108 .8082962036108 .1986999512107 .5891036987 106.6747970581106 .0652008057105 .4557037354104 .8460998535103 .9317016602 103.3221969604102 .712600708102 .1029968262101 .1886978149100 .5791015625 99.9695205688599 .6647262573299 .0551681518698 .7503814697398 .14080810547 97.8360290527397 .5312423706196 .9216690063596 .3121032714895 .3977432251 94.4833908081193 .5690307617292 .349891662690 .8259735107489 .3020401001 
87.4733276367285 .6446228027383 .5111236572398 .4455871582123 .7427978516 146.9064025879161 .8408966064174 .0323028564184 .3950042725193 .5386047363 201.4629974365208 .4730072021208 .7778015137208 .7778015137208 .7778015137 208.7778015137208 .7778015137208 .7778015137208 .7778015137208 .7778015137 208.7778015137208 .7778015137208 .7778015137208 .7778015137208 .7778015137 208.7778015137208 .7778015137208 .7778015137208 .7778015137208 .7778015137 208.7778015137208 .7778015137208 .7778015137208 .7778015137208 .7778015137 208.7778015137208 .7778015137208 .7778015137208 .7778015137208 .7778015137 208.7778015137208 .7778015137208 .7778015137208 .7778015137208 .7778015137 58.8235282897916 .92799568176 -9999 -9999 -9999 -9999 -9999 -9999 -9999 -9999 -9999 -9999-9999

-9999 -9999 -9999 -9999 -9999 -9999 -9999 -9999 -9999 -9999 -9999 -9999 -9999 -9999 -9999 -9999 -9999 -9999 -9999 -9999 -9999 -9999 -9999 -9999 -9999 -9999 -9999 -9999 -9999 -9999 -9999 -9999 -9999 -9999 -9999 -9999 -9999 -9999 -9999 -9999 -9999 -9999 -9999 -9999 -9999 -9999 -9999 -9999 -9999 -9999 -9999 -9999 -9999 -9999 -9999 -9999 -9999 -9999 -9999 -9999

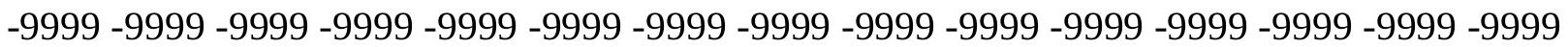

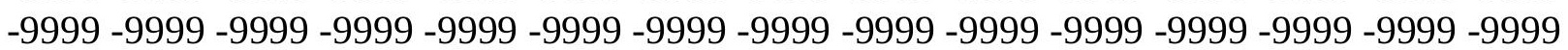
-9999 -9999 -9999 -9999 -9999 -9999 -9999 -9999 -9999 -9999 -9999 -9999 -9999 -9999 -9999 -999 -9999 -9999 -9999 -9999 -9999 -9999 -9999 -9999 -9999 -9999 -9999 -9999 -9999 -9999 -9999 -9999 -9999 -9999 -9999 -9999 -9999 -9999 -9999 -9999 -9999 -9999 -9999 -9999 -9999 -9999

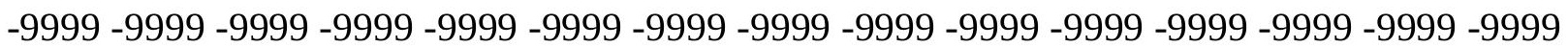
-9999 -9999 -9999 -9999 -9999 -9999 -9999 -9999 -9999 -9999 -9999 -9999 -9999 -9999 -9999 -9999 -9999 -9999 -9999 -9999 -9999 -9999 -9999 -9999 -9999 -9999 -9999 -9999 -9999 -9999 -9999 -9999 -9999 -9999 -9999 -9999 -9999 -9999 -9999 -9999 -9999 -9999 -9999 -9999 -9999

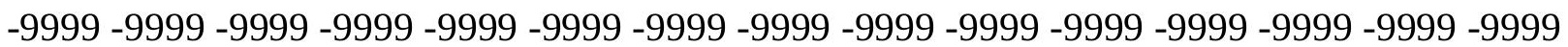
-9999 -9999 -9999 -9999 -9999 -9999 -9999 -9999 -9999 -9999 -9999 -9999 -9999 -9999 -9999 -9999 -9999 -9999 -9999 -9999 -9999 -9999 -9999 -9999 -9999 -9999 -9999 -9999 -9999 -9999

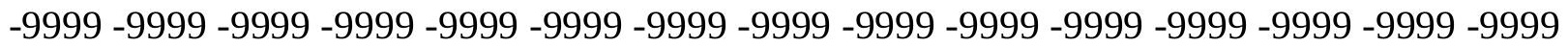
-9999-9999 127.4001998901 126.1809997559 125.2667007446124.0475006104 122.5235977173121 .3044967651120 .0852966309118 .8662033081117 .647102356 116.7326965332115 .5136032104114 .9039993286113 .9896011353113 .3800964355 113.075302124112 .4656982422112 .1608963013111 .8561019897111 .8561019897 111.551399231111 .551399231112 .1608963013112 .7705001831113 .3800964355 113.9896011353114 .2944030762114 .5991973877114 .9039993286114 .9039993286 114.9039993286114 .9039993286114 .5991973877114 .5991973877114 .2944030762 113.9896011353113 .6848983765113 .3800964355113 .075302124112 .7705001831 112.1608963013111 .8561019897111 .24659729110 .6370010376110 .0273971558 109.4179000854 108.8082962036108.1986999512 107.5891036987106.979598999 106.3700027466105 .7603988647104 .8460998535104 .2365036011103 .6268997192 103.0174026489102 .1029968262101 .4934005737100 .8839035034100 .2742996216 99.6647262573299 .0551681518698 .7503814697398 .445587158298 .14080810547 97.8360290527397 .5312423706197 .2264633178796 .6168823242295 .70252990723 94.7881774902393 .8738174438592 .6546783447391 .1307525634889 .3020401001 87.4733276367285 .6446228027383 .5111236572398 .75038146973122 .5235977173 143.8585968018160 .0122070312172 .5084075928182 .87109375191 .7097930908 199.329498291206.3394927979 208.7778015137208.7778015137208.7778015137 
208.7778015137208 .7778015137208 .7778015137208 .7778015137208 .7778015137 208.7778015137 208.7778015137208.7778015137208.7778015137 208.7778015137 208.7778015137208 .7778015137208 .7778015137208 .7778015137208 .7778015137 208.7778015137208 .7778015137208 .7778015137208 .7778015137208 .7778015137 208.7778015137208 .7778015137208 .7778015137208 .7778015137208 .7778015137 208.7778015137208 .7778015137208 .7778015137208 .7778015137208 .7778015137 58.823528289796 .425911903381 -9999 -9999 -9999 -9999 -9999 -9999 -9999 -9999 -9999 $-9999-9999$

-9999 -9999 -9999 -9999 -9999 -9999 -9999 -9999 -9999 -9999 -9999 -9999 -9999 -9999 -9999 -9999 -9999 -9999 -9999 -9999 -9999 -9999 -9999 -9999 -9999 -9999 -9999 -9999 -9999 -9999

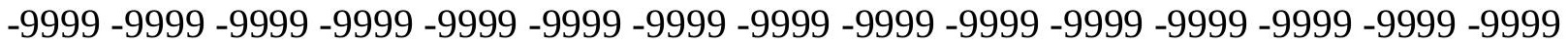
-9999 -9999 -9999 -9999 -9999 -9999 -9999 -9999 -9999 -9999 -9999 -9999 -9999 -9999 -9999 -9999 -9999 -9999 -9999 -9999 -9999 -9999 -9999 -9999 -9999 -9999 -9999 -9999 -9999 -9999 -9999 -9999 -9999 -9999 -9999 -9999 -9999 -9999 -9999 -9999 -9999 -9999 -9999 -9999 -9999 -9999 -9999 -9999 -9999 -9999 -9999 -9999 -9999 -9999 -9999 -9999 -9999 -9999 -9999 -9999

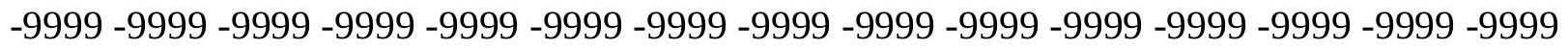
-9999 -9999 -9999 -9999 -9999 -9999 -9999 -9999 -9999 -9999 -9999 -9999 -9999 -9999 -9999 -9999 -9999 -9999 -9999 -9999 -9999 -9999 -9999 -9999 -9999 -9999 -9999 -9999 -9999 -9999 -

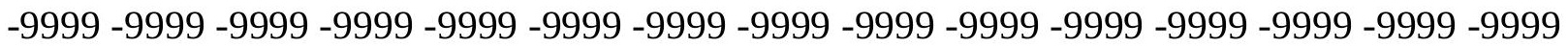

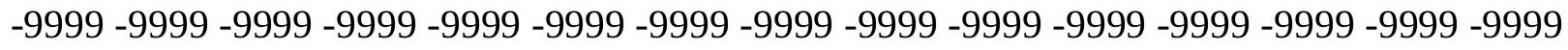
-9999 -9999 -9999 -9999 -9999 -9999 -9999 -9999 -9999 -9999 -9999 -9999 -9999 -9999 -9999 -9999 -9999 -9999 -9999 -9999 -9999 -9999 -9999 -9999 -9999 -9999 -9999 -9999 -9999 -9999 -9999 -9999 -9999 -9999 -9999 -9999 -9999 -9999 -9999 -9999 -9999 -9999 -9999 -9999 -9999 -

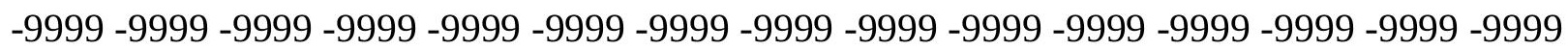

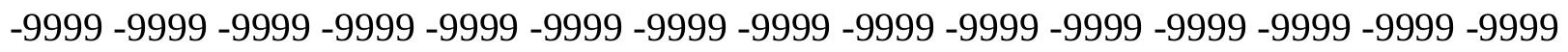
-9999 -9999 -9999 -9999 124.9618988037 123.7427978516122 .5235977173121 .3044967651 120.0852966309119 .1709976196117 .9517974854117 .0374984741116 .1231002808 115.2088012695114 .2944030762113 .6848983765113 .075302124112 .4656982422 112.1608963013111 .8561019897111 .551399231111 .24659729111 .24659729111 .551399231 112.1608963013112 .7705001831113 .3800964355113 .9896011353114 .2944030762 114.2944030762114 .5991973877114 .5991973877114 .5991973877114 .5991973877 114.2944030762114 .2944030762113 .9896011353113 .6848983765113 .3800964355 112.7705001831112 .4656982422111 .8561019897111 .551399231110 .9418029785 110.3321990967109 .7226028442109 .1130981445108 .5035018921107 .8938980103 107.2844009399106 .6747970581106 .0652008057105 .1509017944104 .5412979126 103.9317016602103 .3221969604102 .4077987671101 .7982025146101 .1886978149 100.579101562599 .6647262573299 .3599472045998 .7503814697398 .4455871582 98.1408081054798.1408081054797.83602905273 97.5312423706197.22646331787 96.9216690063596 .3121032714895 .397743225194 .1785964965892 .95947265625 91.4355392456189 .6068267822387 .7781066894585 .9494018554783 .81591033936 99.96952056885122 .5235977173142 .6394042969158 .4882965088170 .6797027588 180.7375946045189 .2716064453196 .891204834203 .9011993408208 .7778015137 208.7778015137208 .7778015137208 .7778015137208 .7778015137208 .7778015137 208.7778015137208 .7778015137208 .7778015137208 .7778015137208 .7778015137 208.7778015137208 .7778015137208 .7778015137208 .7778015137208 .7778015137 208.7778015137 208.7778015137208.7778015137 208.7778015137 208.7778015137 
208.7778015137208 .7778015137208 .7778015137208 .7778015137208 .7778015137 208.7778015137208 .7778015137208 .7778015137208 .7778015137208 .7778015137 208.7778015137 58.82352828979 58.82352828979 -9999 -9999 -9999 -9999 -9999 -9999 -9999 -9999 -9999 -9999 -9999-9999

-9999 -9999 -9999 -9999 -9999 -9999 -9999 -9999 -9999 -9999 -9999 -9999 -9999 -9999 -9999 -9999 -9999 -9999 -9999 -9999 -9999 -9999 -9999 -9999 -9999 -9999 -9999 -9999 -9999 -9999 -9999 -9999 -9999 -9999 -9999 -9999 -9999 -9999 -9999 -9999 -9999 -9999 -9999 -9999 -9999

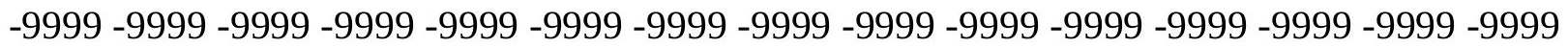
-9999 -9999 -9999 -9999 -9999 -9999 -9999 -9999 -9999 -9999 -9999 -9999 -9999 -9999 -9999 -9999 -9999 -9999 -9999 -9999 -9999 -9999 -9999 -9999 -9999 -9999 -9999 -9999 -9999 -9999

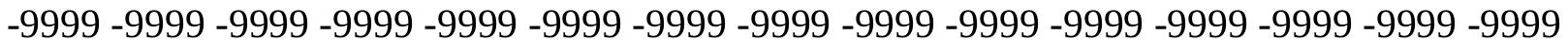
-9999 -9999 -9999 -9999 -9999 -9999 -9999 -9999 -9999 -9999 -9999 -9999 -9999 -9999 -9999 -9999 -9999 -9999 -9999 -9999 -9999 -9999 -9999 -9999 -9999 -9999 -9999 -9999 -9999 -9999 -9999 -9999 -9999 -9999 -9999 -9999 -9999 -9999 -9999 -9999 -9999 -9999 -9999 -9999 -9999 -9999 -9999 -9999 -9999 -9999 -9999 -9999 -9999 -9999 -9999 -9999 -9999 -9999 -9999 -9999 -9999 -9999 -9999 -9999 -9999 -9999 -9999 -9999 -9999 -9999 -9999 -9999 -9999 -9999 -9999 -999 -

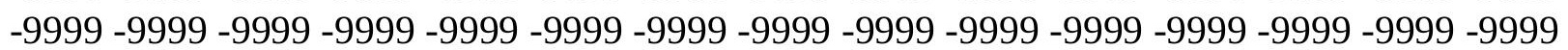
-9999 -9999 -9999 -9999 -9999 -9999 -9999 -9999 -9999 -9999 -9999 -9999 -9999 -9999 -9999 -999 -9999 -9999 -9999 -9999 -9999 -9999 -9999 -9999 -9999 -9999 -9999 -9999 -9999 -9999 -9999 -9999 -9999 -9999 -9999 -9999 -9999 -9999 -9999 -9999 -9999 -9999 -9999 -9999 -9999 -9999 -9999 -9999 -9999 -9999 -9999 -9999 -9999 -9999 -9999 -9999 -9999 -9999 -9999 -9999 -9999 -9999 -9999 -9999 -9999-9999 123.7427978516122 .5235977173121 .3044967651 120.3900985718119 .1709976196118 .2565994263117 .342300415116 .4279022217 115.5136032104114 .5991973877113 .9896011353113 .3800964355112 .7705001831 112.1608963013111 .551399231111 .24659729111 .24659729111 .24659729111 .551399231 111.8561019897112 .4656982422113 .075302124113 .3800964355113 .9896011353 113.9896011353114 .2944030762114 .2944030762114 .2944030762114 .2944030762 114.2944030762113 .9896011353113 .6848983765113 .3800964355113 .075302124 112.4656982422112 .1608963013111 .551399231111 .24659729110 .6370010376 110.0273971558109 .4179000854108 .8082962036108 .1986999512107 .5891036987 106.979598999106 .3700027466105 .7603988647104 .8460998535104 .2365036011 103.6268997192102 .712600708102 .1029968262101 .4934005737100 .8839035034 99.9695205688599 .3599472045998 .7503814697398 .445587158298 .14080810547 98.1408081054798 .1408081054797 .8360290527397 .8360290527397 .53124237061 97.2264633178796 .6168823242295 .7025299072394 .7881774902393 .26425170898 91.7403335571389 .9116134643688 .0829010009885 .9494018554783 .81591033936 103.3221969604125 .5715026855143 .2489929199157 .5738983154168 .8509979248 178.604095459186 .8332977295194 .4528961182201 .158203125207 .25390625 208.7778015137208 .7778015137208 .7778015137208 .7778015137208 .7778015137 208.7778015137208 .7778015137208 .7778015137208 .7778015137208 .7778015137 208.7778015137 208.7778015137208.7778015137 208.7778015137 208.7778015137 208.7778015137208 .7778015137208 .7778015137208 .7778015137208 .7778015137 208.7778015137208 .7778015137208 .7778015137208 .7778015137208 .7778015137 208.7778015137208 .7778015137208 .7778015137208 .7778015137208 .7778015137 208.7778015137 58.82352828979 58.82352828979 -9999 -9999 -9999 -9999 -9999 -9999 -9999 -9999 -9999 -9999 -9999-9999 
-9999 -9999 -9999 -9999 -9999 -9999 -9999 -9999 -9999 -9999 -9999 -9999 -9999 -9999 -9999 -9999 -9999 -9999 -9999 -9999 -9999 -9999 -9999 -9999 -9999 -9999 -9999 -9999 -9999 -9999

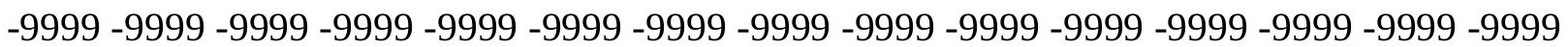
-9999 -9999 -9999 -9999 -9999 -9999 -9999 -9999 -9999 -9999 -9999 -9999 -9999 -9999 -9999 -9999 -9999 -9999 -9999 -9999 -9999 -9999 -9999 -9999 -9999 -9999 -9999 -9999 -9999 -9999 -9999 -9999 -9999 -9999 -9999 -9999 -9999 -9999 -9999 -9999 -9999 -9999 -9999 -9999 -9999 -9999 -9999 -9999 -9999 -9999 -9999 -9999 -9999 -9999 -9999 -9999 -9999 -9999 -9999 -9999

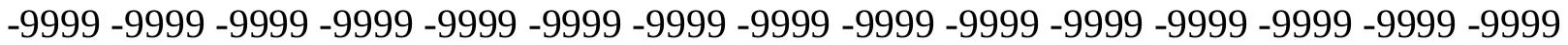
-9999 -9999 -9999 -9999 -9999 -9999 -9999 -9999 -9999 -9999 -9999 -9999 -9999 -9999 -9999 -9999 -9999 -9999 -9999 -9999 -9999 -9999 -9999 -9999 -9999 -9999 -9999 -9999 -9999 -9999 -9999 -9999 -9999 -9999 -9999 -9999 -9999 -9999 -9999 -9999 -9999 -9999 -9999 -9999 -9999 -9999 -9999 -9999 -9999 -9999 -9999 -9999 -9999 -9999 -9999 -9999 -9999 -9999 -9999 -9999

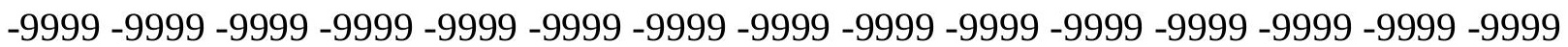
-9999 -9999 -9999 -9999 -9999 -9999 -9999 -9999 -9999 -9999 -9999 -9999 -9999 -9999 -9999 -9999 -9999 -9999 -9999 -9999 -9999 -9999 -9999 -9999 -9999 -9999 -9999 -9999 -9999 -9999 -9999 -9999 -9999 -9999 -9999 -9999 -9999 -9999 -9999 -9999 -9999 -9999 -9999 -9999 -9999 -9999 -9999 -9999 -9999 -9999 -9999 -9999 -9999 -9999 -9999 -9999 -9999 -9999 -9999 -9999 -9999 -9999 -9999 -9999 -9999 -9999 -9999 121.3044967651120 .0852966309119 .1709976196 118.2565994263117 .342300415116 .4279022217115 .818397522114 .9039993286 114.2944030762113 .3800964355112 .7705001831112 .4656982422111 .8561019897 111.551399231111 .24659729111 .24659729111 .551399231111 .8561019897112 .4656982422 112.7705001831113 .3800964355113 .6848983765113 .9896011353113 .9896011353 114.2944030762114 .2944030762113 .9896011353113 .9896011353113 .6848983765 113.6848983765113 .075302124112 .7705001831112 .4656982422111 .8561019897 111.551399231110 .9418029785110 .3321990967109 .7226028442109 .1130981445 108.5035018921107 .8938980103107 .2844009399106 .6747970581106 .0652008057 105.4557037354104 .5412979126103 .9317016602103 .3221969604102 .712600708 101.7982025146101 .1886978149100 .579101562599 .6647262573299 .05516815186 98.445587158298 .1408081054797 .8360290527397 .8360290527398 .14080810547 98.1408081054798 .1408081054798 .1408081054797 .8360290527397 .22646331787 96.3121032714895 .0929565429793 .5690307617292 .0450973510790 .21640014648 88.0829010009885 .9494018554786 .86376190186111 .24659729131 .0576019287 145.6873016357157 .2691040039167 .3269958496176 .165802002184 .0901947021 191.4051055908198 .1103057861204 .2059936523208 .7778015137208 .7778015137 208.7778015137208 .7778015137208 .7778015137208 .7778015137208 .7778015137 208.7778015137208 .7778015137208 .7778015137208 .7778015137208 .7778015137 208.7778015137208 .7778015137208 .7778015137208 .7778015137208 .7778015137 208.7778015137208 .7778015137208 .7778015137208 .7778015137208 .7778015137 208.7778015137208 .7778015137208 .7778015137208 .7778015137208 .7778015137 208.7778015137208 .7778015137208 .7778015137208 .777801513758 .82352828979 58.82352828979 -9999 -9999 -9999 -9999 -9999 -9999 -9999 -9999 -9999 -9999 -9999 -9999 -9999 -9999 -9999 -9999 -9999 -9999 -9999 -9999 -9999 -9999 -9999 -9999 -9999 -9999-9999 -9999 -9999 -9999 -9999 -9999 -9999 -9999 -9999 -9999 -9999 -9999 -9999 -9999 -9999 -9999 -9999 -9999 -9999 -9999 -9999 -9999 -9999 -9999 -9999 -9999 -9999 -9999 -9999 -9999 -9999 -999 -9999 -9999 -9999 -9999 -9999 -9999 -9999 -9999 -9999 -9999 -9999 -9999 -9999 -9999 -9999

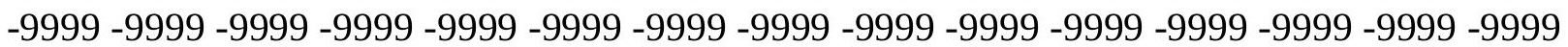


-9999 -9999 -9999 -9999 -9999 -9999 -9999 -9999 -9999 -9999 -9999 -9999 -9999 -9999 -9999 -9999 -9999 -9999 -9999 -9999 -9999 -9999 -9999 -9999 -9999 -9999 -9999 -9999 -9999 -9999 -9999 -9999 -9999 -9999 -9999 -9999 -9999 -9999 -9999 -9999 -9999 -9999 -9999 -9999 -9999 -9999 -9999 -9999 -9999 -9999 -9999 -9999 -9999 -9999 -9999 -9999 -9999 -9999 -9999 -9999 -9999 -9999 -9999 -9999 -9999 -9999 -9999 -9999 -9999 -9999 -9999 -9999 -9999 -9999 -9999 -9999 -9999 -9999 -9999 -9999 -9999 -9999 -9999 -9999 -9999 -9999 -9999 -9999 -9999 -9999 -9999 -9999 -9999 -9999 -9999 -9999 -9999 -9999 -9999 -9999 -9999 -9999 -9999 -9999 -9999

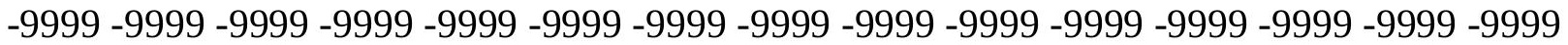

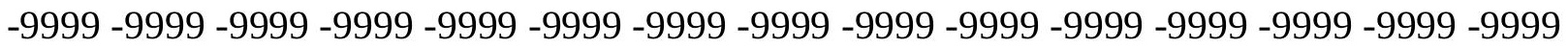
-9999 -9999 -9999 -9999 -9999 -9999 -9999 -9999 -9999 -9999 -9999 -9999 -9999 -9999 -9999 -9999 -9999 -9999 -9999 -9999 -9999 -9999 -9999 -9999 -9999 -9999 -9999 -9999 -9999 -9999 -9999 -9999 -9999 -9999 -9999 -9999 -9999 -9999 -9999 -9999 -9999 -9999 -9999 -9999 -9999 -9999 -9999 -9999 -9999 -9999 -9999 -9999 -9999 120.0852966309119 .1709976196 118.2565994263117 .647102356116 .7326965332115 .818397522115 .2088012695 114.5991973877113 .6848983765113 .075302124112 .7705001831112 .1608963013 111.8561019897111 .8561019897111 .8561019897111 .8561019897112 .1608963013 112.4656982422113 .075302124113 .3800964355113 .6848983765113 .9896011353 113.9896011353113 .9896011353113 .9896011353113 .9896011353113 .9896011353 113.6848983765113 .3800964355113 .075302124112 .7705001831112 .1608963013 111.8561019897111 .24659729110 .6370010376110 .0273971558109 .4179000854 108.8082962036108 .1986999512107 .5891036987106 .979598999106 .3700027466 105.7603988647105 .1509017944104 .2365036011103 .6268997192103 .0174026489 102.4077987671101 .7982025146101 .1886978149100 .274299621699 .66472625732 98.7503814697398 .1408081054797 .8360290527397 .8360290527398 .14080810547 98.445587158298 .445587158298 .7503814697398 .7503814697398 .4455871582 97.8360290527396 .9216690063595 .7025299072394 .1785964965892 .3498916626 90.5211791992288 .3876876831185 .9494018554791 .74033355713122 .8283996582 135.9342041016146 .9064025879156 .6596069336165 .8031005859174 .0323028564 181.6519012451188 .6620025635195 .0625201 .158203125206 .3394927979208 .7778015137 208.7778015137208 .7778015137208 .7778015137208 .7778015137208 .7778015137 208.7778015137208 .7778015137208 .7778015137208 .7778015137208 .7778015137 208.7778015137208 .7778015137208 .7778015137208 .7778015137208 .7778015137 208.7778015137208 .7778015137208 .7778015137208 .7778015137208 .7778015137 208.7778015137208 .7778015137208 .7778015137208 .7778015137208 .7778015137 208.7778015137208 .7778015137208 .7778015137208 .777801513758 .51874923706 58.82352828979 -9999 -9999 -9999 -9999 -9999 -9999 -9999 -9999 -9999 -9999 -9999 -9999 -9999 -9999 -9999 -9999 -9999 -9999 -9999 -9999 -9999 -9999 -9999 -9999 -9999 -9999 -9999

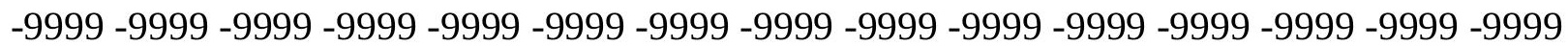
-9999 -9999 -9999 -9999 -9999 -9999 -9999 -9999 -9999 -9999 -9999 -9999 -9999 -9999 -9999 -9999 -9999 -9999 -9999 -9999 -9999 -9999 -9999 -9999 -9999 -9999 -9999 -9999 -9999 -9999 -9999 -9999 -9999 -9999 -9999 -9999 -9999 -9999 -9999 -9999 -9999 -9999 -9999 -9999 -9999

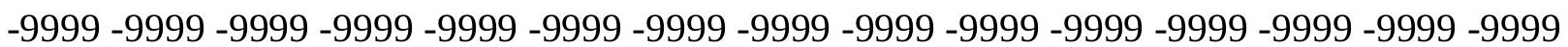
-9999 -9999 -9999 -9999 -9999 -9999 -9999 -9999 -9999 -9999 -9999 -9999 -9999 -9999 -9999 -9999 -9999 -9999 -9999 -9999 -9999 -9999 -9999 -9999 -9999 -9999 -9999 -9999 -9999 -9999 -999 -9999 -9999 -9999 -9999 -9999 -9999 -9999 -9999 -9999 -9999 -9999 -9999 -9999 -9999 -9999

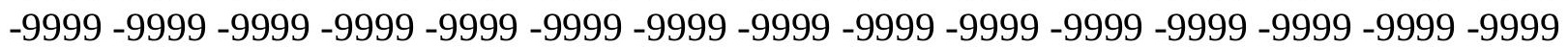


-9999 -9999 -9999 -9999 -9999 -9999 -9999 -9999 -9999 -9999 -9999 -9999 -9999 -9999 -9999 -9999 -9999 -9999 -9999 -9999 -9999 -9999 -9999 -9999 -9999 -9999 -9999 -9999 -9999 -9999 -9999 -9999 -9999 -9999 -9999 -9999 -9999 -9999 -9999 -9999 -9999 -9999 -9999 -9999 -9999 -9999 -9999 -9999 -9999 -9999 -9999 -9999 -9999 -9999 -9999 -9999 -9999 -9999 -9999 -9999 -9999 -9999 -9999 -9999 -9999 -9999 -9999 -9999 -9999 -9999 -9999 -9999 -9999 -9999 -9999 -9999 -9999 -9999 -9999 -9999 -9999 -9999 -9999 -9999 -9999 -9999 -9999 -9999 -9999 -9999 -9999 -9999 -9999 -9999 -9999 -9999 -9999 -9999 -9999 -9999 -9999 -9999 -9999 -9999 -9999 -9999 -9999 -9999 -9999 -9999 -9999 -9999 -9999 -9999 -9999 118.5614013672

117.647102356117 .0374984741116 .1231002808115 .5136032104114 .9039993286 114.2944030762113 .6848983765113 .075302124112 .7705001831112 .4656982422 112.1608963013112 .1608963013112 .1608963013112 .4656982422112 .7705001831 113.075302124113 .3800964355113 .6848983765113 .9896011353113 .9896011353 113.9896011353113 .9896011353113 .9896011353113 .6848983765113 .6848983765 113.3800964355113 .075302124112 .4656982422112 .1608963013111 .551399231 110.9418029785110 .6370010376110 .0273971558109 .4179000854108 .8082962036 108.1986999512107 .5891036987106 .6747970581106 .0652008057105 .4557037354 104.8460998535104 .2365036011103 .6268997192103 .0174026489102 .1029968262 101.4934005737100 .8839035034100 .274299621699 .6647262573299 .05516815186 98.1408081054797 .8360290527398 .1408081054798 .445587158298 .75038146973 99.0551681518699 .3599472045999 .3599472045999 .0551681518698 .4455871582 97.5312423706196 .3121032714894 .4833908081192 .6546783447390 .52117919922 88.3876876831185 .9494018554797 .53124237061119 .7806015015135 .6293945312 146.6015930176155 .4403991699163 .6696014404171 .5939941406178 .9089050293 185.6141052246192 .0146026611197 .8054962158202 .9868927002207 .5587005615 208.7778015137208 .7778015137208 .7778015137208 .7778015137208 .7778015137 208.7778015137208 .7778015137208 .7778015137208 .7778015137208 .7778015137 208.7778015137208 .7778015137208 .7778015137208 .7778015137208 .7778015137 208.7778015137208 .7778015137208 .7778015137208 .7778015137208 .7778015137 208.7778015137208 .7778015137208 .7778015137208 .7778015137208 .7778015137 208.7778015137208.7778015137208.777801513758.51874923706 58.82352828979 -9999 -9999 -9999 -9999 -9999 -9999 -9999 -9999 -9999 -9999 -9999 -9999 -9999 -9999 -9999 -9999 -9999 -9999 -9999 -9999 -9999 -9999 -9999 -9999 -9999 -9999 -9999 -9999 -9999 -9999 -9999 -9999 -9999 -9999 -9999 -9999 -9999 -9999 -9999 -9999 -9999 -9999 -9999 -9999 -9999 -9999 -9999 -9999 -9999 -9999 -9999 -9999 -9999 -9999 -9999 -9999 -9999 -9999 -9999 -9999 -9999 -9999 -9999 -9999 -9999 -9999 -9999 -9999 -9999 -9999 -9999 -9999 -9999 -9999 -9999 -9999 -9999 -9999 -9999 -9999 -9999 -9999 -9999 -9999 -9999 -9999 -9999 -9999 -

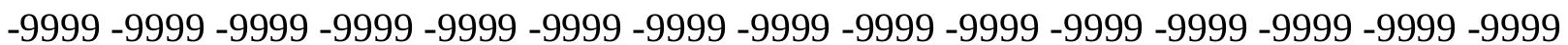
-9999 -9999 -9999 -9999 -9999 -9999 -9999 -9999 -9999 -9999 -9999 -9999 -9999 -9999 -9999 -9999 -9999 -9999 -9999 -9999 -9999 -9999 -9999 -9999 -9999 -9999 -9999 -9999 -9999 -9999 -9999 -9999 -9999 -9999 -9999 -9999 -9999 -9999 -9999 -9999 -9999 -9999 -9999 -9999 -9999 -9999 -9999 -9999 -9999 -9999 -9999 -9999 -9999 -9999 -9999 -9999 -9999 -9999 -9999 -9999

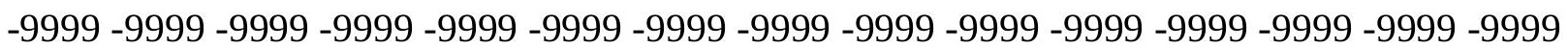
-9999 -9999 -9999 -9999 -9999 -9999 -9999 -9999 -9999 -9999 -9999 -9999 -9999 -9999 -9999 -9999 -9999 -9999 -9999 -9999 -9999 -9999 -9999 -9999 -9999 -9999 -9999 -9999 -9999 -9999 -9999 -9999 -9999 -9999 -9999 -9999 -9999 -9999 -9999 -9999 -9999 -9999 -9999 -9999 -9999

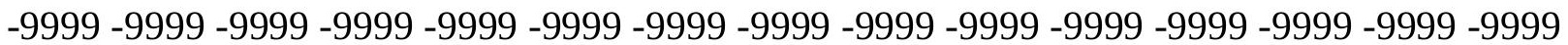


-9999 -9999 -9999 -9999 -9999 -9999 -9999 -9999 -9999 -9999 -9999 -9999 -9999 -9999 -9999 -9999 -9999 -9999 -9999 -9999 -9999 -9999 -9999 -9999 -9999 -9999 -9999 -9999 -9999 -9999 -9999 -9999 -9999 -9999 -9999 -9999 -9999 -9999 -9999 -9999 -9999 117.647102356 117.0374984741116 .4279022217115 .818397522115 .2088012695114 .5991973877 113.9896011353113 .6848983765113 .075302124113 .075302124112 .7705001831 112.7705001831112 .7705001831112 .7705001831113 .075302124113 .3800964355 113.6848983765113 .6848983765113 .9896011353113 .9896011353113 .9896011353 113.9896011353113 .9896011353113 .6848983765113 .6848983765113 .3800964355 112.7705001831112 .4656982422111 .8561019897111 .551399231110 .9418029785 110.3321990967109 .7226028442109 .1130981445108 .5035018921107 .8938980103 107.2844009399 106.6747970581 106.0652008057 105.1509017944 104.5412979126 103.9317016602103 .3221969604102 .712600708102 .1029968262101 .4934005737 100.8839035034100 .579101562599 .9695205688599 .3599472045998 .75038146973 98.445587158298 .7503814697399 .0551681518699 .6647262573299 .96952056885 99.9695205688599 .9695205688599 .6647262573299 .0551681518698 .14080810547 96.6168823242294 .7881774902392 .9594726562590 .5211791992288 .38768768311 85.94940185547100 .8839035034118 .8662033081133 .8007049561144 .4682006836 153.0021057129161 .2312927246169 .1557006836176 .4705963135182 .87109375 188.966796875194 .7577056885199 .6342926025204 .2059936523208 .1681976318 208.7778015137208 .7778015137208 .7778015137208 .7778015137208 .7778015137 208.7778015137208 .7778015137208 .7778015137208 .7778015137208 .7778015137 208.7778015137208 .7778015137208 .7778015137208 .7778015137208 .7778015137 208.7778015137208 .7778015137208 .7778015137208 .7778015137208 .7778015137 208.7778015137208 .7778015137208 .7778015137208 .7778015137208 .7778015137 208.7778015137 208.777801513758.51874923706 58.82352828979 -9999 -9999 -9999 -9999 -9999 -9999 -9999 -9999 -9999 -9999 -9999 -9999 -9999 -9999 -9999 -9999 -9999 -9999 -9999 -9999 -9999 -9999 -9999 -9999 -9999 -9999 -9999 -9999 -9999 -9999 -9999 -9999 -9999 -9999 -9999 -9999 -9999 -9999 -9999 -9999 -9999 -9999 -9999 -9999 -9999 -9999 -9999 -9999 -9999 -9999 -9999 -9999 -9999 -9999 -9999 -9999 -9999 -9999 -9999 -9999 -9999 -9999 -9999 -9999 -9999 -9999 -9999 -9999 -9999 -9999 -9999 -9999 -9999 -9999 -9999 -9999 -9999 -9999 -9999 -9999 -9999 -9999 -9999 -9999 -9999 -9999 -9999 -9999 -

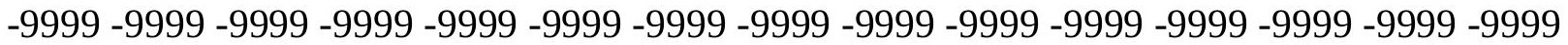
-9999 -9999 -9999 -9999 -9999 -9999 -9999 -9999 -9999 -9999 -9999 -9999 -9999 -9999 -9999 -9999 -9999 -9999 -9999 -9999 -9999 -9999 -9999 -9999 -9999 -9999 -9999 -9999 -9999 -9999 -9999 -9999 -9999 -9999 -9999 -9999 -9999 -9999 -9999 -9999 -9999 -9999 -9999 -9999 -9999 -9999 -9999 -9999 -9999 -9999 -9999 -9999 -9999 -9999 -9999 -9999 -9999 -9999 -9999 -9999

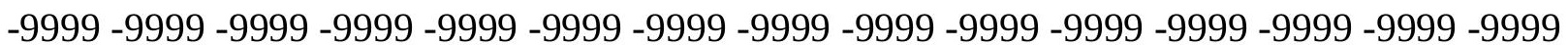

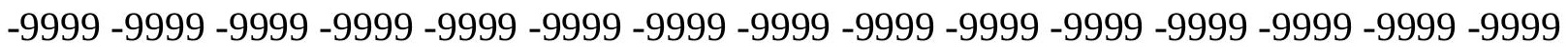
-9999 -9999 -9999 -9999 -9999 -9999 -9999 -9999 -9999 -9999 -9999 -9999 -9999 -9999 -9999 -9999 -9999 -9999 -9999 -9999 -9999 -9999 -9999 -9999 -9999 -9999 -9999 -9999 - -9999 -9999 -9999 -9999 -9999 -9999 -9999 -9999 -9999 -9999 -9999 -9999 -9999 -9999 -9999 -9999 -9999

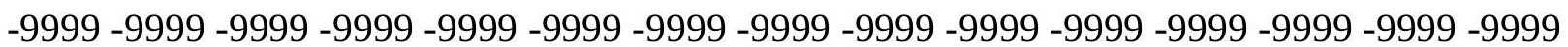
-9999 -9999 -9999 -9999 -9999 -9999 -9999 -9999 -9999 -9999 -9999 -9999 -9999 -9999 -9999 -9999 -9999 -9999 -9999 -9999 -9999 -9999 -9999 -9999 -9999 -9999 -9999 -9999 116.7326965332116 .1231002808115 .5136032104114 .9039993286114 .5991973877 113.9896011353113 .6848983765113 .3800964355113 .3800964355113 .3800964355 
113.3800964355113 .3800964355113 .3800964355113 .6848983765113 .9896011353 113.9896011353113 .9896011353114 .2944030762114 .2944030762113 .9896011353 113.9896011353113 .6848983765113 .6848983765113 .075302124112 .7705001831 112.4656982422111 .8561019897111 .24659729110 .6370010376110 .3321990967 109.7226028442109 .1130981445108 .1986999512107 .5891036987106 .979598999 106.3700027466105 .7603988647105 .1509017944104 .5412979126103 .9317016602 103.3221969604102 .712600708102 .1029968262101 .4934005737101 .1886978149 100.5791015625100 .274299621699 .6647262573299 .3599472045999 .35994720459 99.6647262573299 .96952056885100 .2742996216100 .5791015625100 .8839035034 100.5791015625100 .274299621699 .3599472045998 .445587158296 .92166900635 95.0929565429792 .9594726562590 .5211791992288 .0829010009886 .86376190186 103.9317016602119 .7806015015133 .1911010742143 .2489929199150 .8686065674 159.4026031494167 .0222015381174 .0323028564180 .432800293186 .2236938477 191.4051055908196 .2816009521200 .8533935547204 .8155975342208 .4730072021 208.7778015137208 .7778015137208 .7778015137208 .7778015137208 .7778015137 208.7778015137208.7778015137208.7778015137 208.7778015137 208.7778015137 208.7778015137208 .7778015137208 .7778015137208 .7778015137208 .7778015137 208.7778015137208 .7778015137208 .7778015137208 .7778015137208 .7778015137 208.7778015137208 .7778015137208 .7778015137208 .7778015137208 .7778015137 208.7778015137 58.51874923706 58.82352828979 -9999 -9999 -9999 -9999 -9999 -9999 -9999 -9999 -9999 -9999 -9999-9999 -9999

-9999 -9999 -9999 -9999 -9999 -9999 -9999 -9999 -9999 -9999 -9999 -9999 -9999 -9999 -9999 -9999 -9999 -9999 -9999 -9999 -9999 -9999 -9999 -9999 -9999 -9999 -9999 -9999 -9999 -9999 -

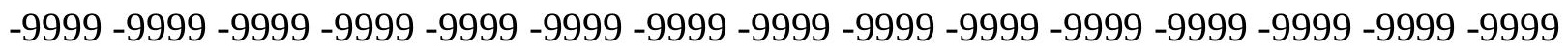

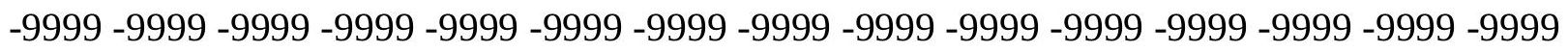
-9999 -9999 -9999 -9999 -9999 -9999 -9999 -9999 -9999 -9999 -9999 -9999 -9999 -9999 -9999

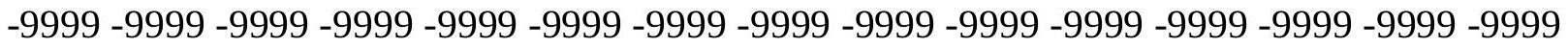

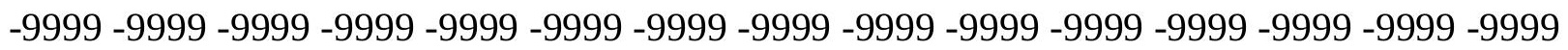
-9999 -9999 -9999 -9999 -9999 -9999 -9999 -9999 -9999 -9999 -9999 -9999 -9999 -9999 -9999 -9999 -9999 -9999 -9999 -9999 -9999 -9999 -9999 -9999 -9999 -9999 -9999 -9999 -9999 -9999 -9999 -9999 -9999 -9999 -9999 -9999 -9999 -9999 -9999 -9999 -9999 -9999-9999 -9999 -9999 -9999 -9999 -9999 -9999 -9999 -9999 -9999 -9999 -9999 -9999 -9999 -9999 -9999 -9999 -9999 -

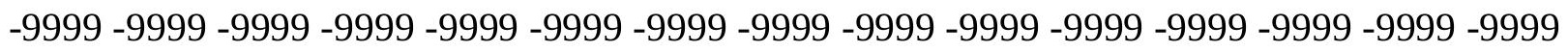
-9999 -9999 -9999 -9999 -9999 -9999 -9999 -9999 -9999 -9999 -9999 -9999 -9999 -9999 -9999 -9999 -9999 -9999 -9999 -9999 -9999 -9999 -9999 -9999 -9999 -9999 -9999 -9999 -9999 -9999

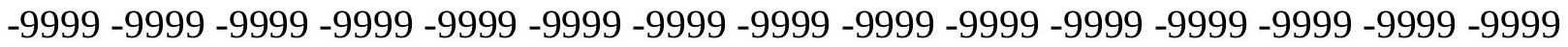

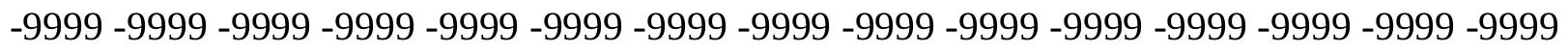

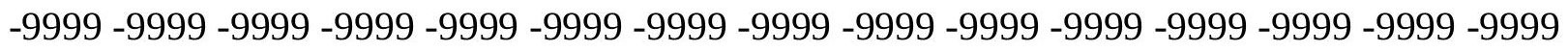
-9999 -9999 -9999 -9999 -9999 -9999 -9999 -9999 -9999 -9999 -9999 -9999 -9999 -9999 116.4279022217115 .818397522115 .5136032104114 .9039993286114 .5991973877 114.2944030762113 .9896011353113 .9896011353113 .9896011353113 .9896011353 113.9896011353113 .9896011353113 .9896011353114 .2944030762114 .2944030762 114.2944030762114 .2944030762114 .2944030762114 .2944030762113 .9896011353 113.9896011353113 .6848983765113 .3800964355112 .7705001831112 .4656982422 111.8561019897111 .24659729110 .6370010376110 .0273971558109 .4179000854 108.8082962036108 .1986999512107 .5891036987106 .979598999106 .3700027466 
105.4557037354104 .8460998535104 .2365036011103 .6268997192103 .3221969604 102.712600708102 .1029968262101 .7982025146101 .1886978149100 .8839035034 100.5791015625100 .2742996216100 .2742996216100 .2742996216100 .5791015625 100.8839035034101 .1886978149101 .4934005737101 .4934005737101 .4934005737 100.883903503499 .6647262573298 .445587158296 .9216690063594 .78817749023 92.6546783447390 .2164001464887 .7781066894591 .43553924561107 .8938980103 122.5235977173134 .7149963379143 .8585968018151 .7830047607159 .0977935791 165.8031005859172 .2035980225177 .9945068359183 .4806976318188 .3571929932 192.9290008545197 .1959991455201 .158203125204 .8155975342208 .1681976318 208.7778015137208 .7778015137208 .7778015137208 .7778015137208 .7778015137 208.7778015137208 .7778015137208 .7778015137208 .7778015137208 .7778015137 208.7778015137208 .7778015137208 .7778015137208 .7778015137208 .7778015137 208.7778015137208 .7778015137208 .7778015137208 .7778015137208 .7778015137 208.7778015137208 .7778015137208 .7778015137208 .7778015137208 .7778015137 58.5187492370658 .82352828979 -9999 -9999 -9999 -9999 -9999 -9999 -9999 -9999 -9999 -9999-9999-9999-9999

-9999 -9999 -9999 -9999 -9999 -9999 -9999 -9999 -9999 -9999 -9999 -9999 -9999 -9999 -9999 -9999 -9999 -9999 -9999 -9999 -9999 -9999 -9999 -9999 -9999 -9999 -9999 -9999 -9999 -9999 -

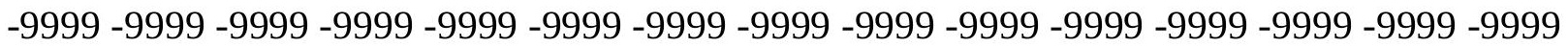

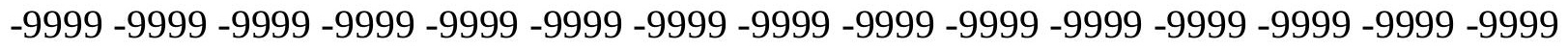
-9999 -9999 -9999 -9999 -9999 -9999 -9999 -9999 -9999 -9999 -9999 -9999 -9999 -9999 -9999

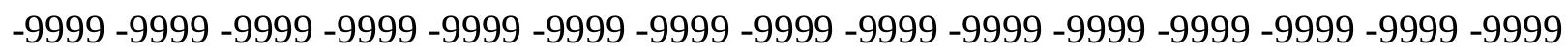
-9999 -9999 -9999 -9999 -9999 -9999 -9999 -9999 -9999 -9999 -9999 -9999 -9999 -9999 -9999 -

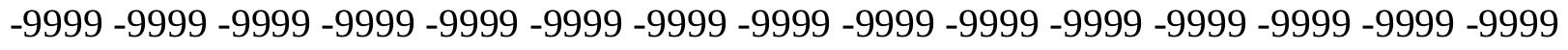

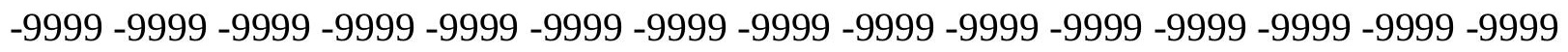
-9999 -9999 -9999 -9999 -9999 -9999 -9999 -9999 -9999 -9999 -9999 -9999 -9999 -9999 -9999 -9999 -9999 -9999 -9999 -9999 -9999 -9999 -9999 -9999 -9999 -9999 -9999 -9999 -9999 - -9999 -

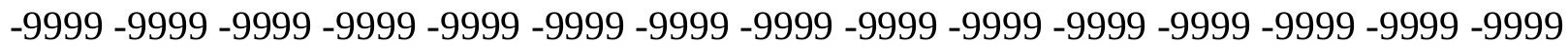
-9999 -9999 -9999 -9999 -9999 -9999 -9999 -9999 -9999 -9999 -9999 -9999 -9999 -9999 -9999

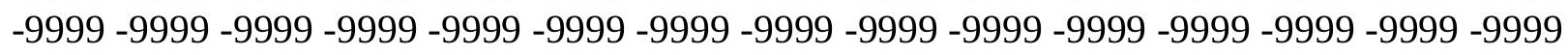
-9999 -9999 -9999 -9999 -9999 -9999 -9999 -9999 -9999 -9999 -9999 -9999 -9999 -9999 -9999 -9999 -9999 -9999 -9999 -9999 -9999 -9999 -9999 -9999 -9999 -9999 -9999 -9999 -9999 -9999 -

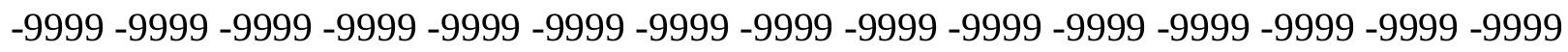

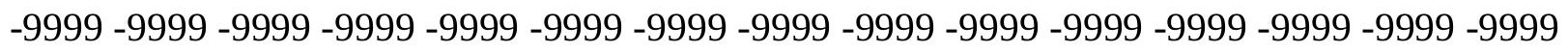
-9999 115.818397522 115.5136032104 115.2088012695114.9039993286114.5991973877 114.5991973877114 .5991973877114 .2944030762114 .2944030762114 .5991973877 114.5991973877114 .5991973877114 .5991973877114 .5991973877114 .5991973877 114.5991973877114 .2944030762114 .2944030762113 .9896011353113 .6848983765 113.3800964355112 .7705001831112 .4656982422111 .8561019897111 .24659729 110.6370010376110 .0273971558109 .4179000854108 .8082962036107 .8938980103 107.2844009399106 .6747970581106 .0652008057105 .4557037354104 .8460998535 104.2365036011103 .6268997192103 .0174026489102 .712600708102 .1029968262 101.7982025146101 .4934005737101 .1886978149100 .8839035034100 .8839035034 100.8839035034100 .8839035034101 .1886978149101 .7982025146102 .1029968262 102.4077987671102 .4077987671101 .7982025146101 .188697814999 .96952056885 98.445587158296 .6168823242294 .4833908081192 .349891662689 .91161346436 
87.4733276367296 .61688232422113 .3800964355127 .4001998901138 .0677032471 146.2969055176153 .0021057129159 .4026031494165 .1934967041170 .6797027588 175.8609924316180 .7375946045185 .3094024658189 .5764007568193 .8433074951 197.500793457201 .158203125204 .2059936523207 .5587005615208 .7778015137 208.7778015137208 .7778015137208 .7778015137208 .7778015137208 .7778015137 208.7778015137208 .7778015137208 .7778015137208 .7778015137208 .7778015137 208.7778015137208 .7778015137208 .7778015137208 .7778015137208 .7778015137 208.7778015137208 .7778015137208 .7778015137208 .7778015137208 .7778015137 208.7778015137 208.777801513758 .5187492370658 .51874923706 -9999 -9999 -9999 -9999 -9999 -9999 -9999 -9999 -9999 -9999 -9999 -9999 -9999 -9999

-9999 -9999 -9999 -9999 -9999 -9999 -9999 -9999 -9999 -9999 -9999 -9999 -9999 -9999 -9999 -9999 -9999 -9999 -9999 -9999 -9999 -9999 -9999 -9999 -9999 -9999 -9999 -9999 -9999 -9999 -9999 -9999 -9999 -9999 -9999 -9999 -9999 -9999 -9999 -9999 -9999 -9999 -9999 -9999 -9999 -

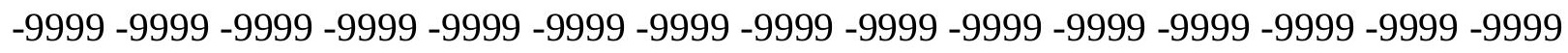
-9999 -9999 -9999 -9999 -9999 -9999 -9999 -9999 -9999 -9999 -9999 -9999 -9999 -9999 -9999

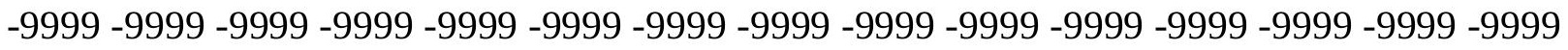
-9999 -9999 -9999 -9999 -9999 -9999 -9999 -9999 -9999 -9999 -9999 -9999 -9999 -9999 -9999 -9999 -9999 -9999 -9999 -9999 -9999 -9999 -9999 -9999 -9999 -9999 -9999 -9999 -9999 -9999 -999 -9999 -9999 -9999 -9999 -9999 -9999 -9999 -9999 -9999 -9999 -9999 -9999 -9999 -9999 -9999 -

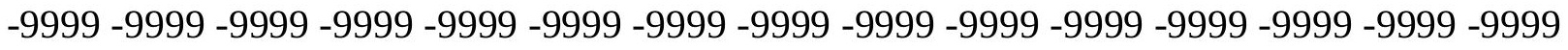
-9999 -9999 -9999 -9999 -9999 -9999 -9999 -9999 -9999 -9999 -9999 -9999 -9999 -9999 -9999 -999 -9999 -9999 -9999 -9999 -9999 -9999 -9999 -9999 -9999 -9999 -9999 -9999 -9999 -9999 -9999 -9999 -9999 -9999 -9999 -9999 -9999 -9999 -9999 -9999 -9999 -9999 -9999 -9999 -9999 -9999 -9999 -9999 -9999 -9999 -9999 -9999 -9999 -9999 -9999 -9999 -9999 -9999 -9999 -9999 -9999 -9999 -9999 -9999 -9999 -9999 -9999 -9999 -9999 -9999 -9999 -9999 -9999 -9999 -9999 -9999 -9999 -9999 -9999 -9999 -9999 -9999 -9999 -9999 -9999 -9999 -9999 -9999 -9999 -9999 -9999 -9999 -9999 -9999 -9999 -9999 -9999 -9999 -9999 -9999 -9999 -9999 -9999 -9999 -9999 -9999 -

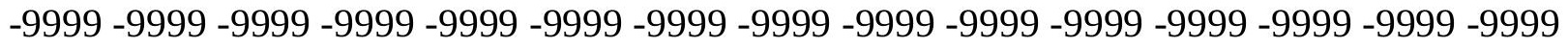
-9999 -9999 116.1231002808115.818397522115.5136032104 115.2088012695 115.2088012695114 .9039993286114 .9039993286114 .9039993286114 .9039993286 114.9039993286114 .9039993286114 .9039993286114 .9039993286114 .9039993286 114.9039993286114 .5991973877114 .2944030762113 .9896011353113 .6848983765 113.3800964355112 .7705001831112 .4656982422111 .8561019897111 .24659729 110.6370010376110 .0273971558109 .4179000854108 .5035018921107 .8938980103 107.2844009399106 .6747970581106 .0652008057105 .4557037354104 .8460998535 104.2365036011103 .6268997192103 .0174026489102 .712600708102 .1029968262 101.7982025146101 .4934005737101 .1886978149101 .1886978149101 .1886978149 101.1886978149101 .4934005737101 .7982025146102 .1029968262102 .712600708 103.0174026489102 .712600708102 .4077987671101 .188697814999 .96952056885 98.1408081054796 .3121032714894 .1785964965891 .7403335571389 .60682678223 86.86376190186103 .6268997192120 .9997024536133 .4958953857142 .3347015381 149.3446960449154 .8307952881159 .7073974609164 .5839996338169 .1557006836 173.7274932861177 .9945068359182 .261505127186 .2236938477190 .1858978271 193.8433074951197 .1959991455200 .5485992432203 .596496582206 .6443023682 208.7778015137208 .7778015137208 .7778015137208 .7778015137208 .7778015137 208.7778015137 208.7778015137208.7778015137 208.7778015137 208.7778015137 
208.7778015137208 .7778015137208 .7778015137208 .7778015137208 .7778015137 208.7778015137208 .7778015137208 .7778015137208 .7778015137208 .7778015137 208.7778015137208 .777801513758 .5187492370658 .51874923706 -9999 -9999 -9999 -9999 -9999 -9999 -9999 -9999 -9999 -9999 -9999 -9999 -9999 -9999

-9999 -9999 -9999 -9999 -9999 -9999 -9999 -9999 -9999 -9999 -9999 -9999 -9999 -9999 -9999 -9999 -9999 -9999 -9999 -9999 -9999 -9999 -9999 -9999 -9999 -9999 -9999 -9999 -9999 -9999 -9999 -9999 -9999 -9999 -9999 -9999 -9999 -9999 -9999 -9999 -9999 -9999 -9999 - -9999 - -9999 -

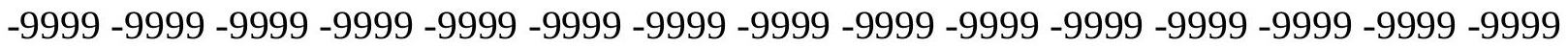

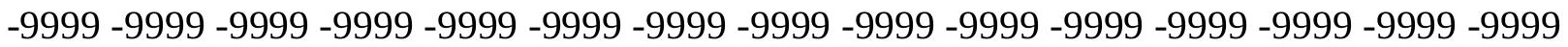
-9999 -9999 -9999 -9999 -9999 -9999 -9999 -9999 -9999 -9999 -9999 -9999 -9999 -9999 -9999 -

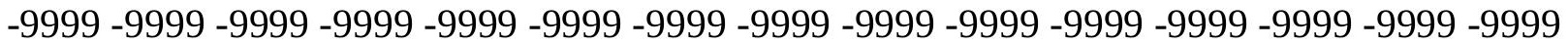
-9999 -9999 -9999 -9999 -9999 -9999 -9999 -9999 -9999 -9999 -9999 -9999 -9999 -9999 -9999 -9999 -9999 -9999 -9999 -9999 -9999 -9999 -9999 -9999 -9999 -9999 -9999 -9999 -9999 -9999 -9999 -9999 -9999 -9999 -9999 -9999 -9999 -9999 -9999 -9999 -9999 -9999 -9999 -9999 -9999 -9999 -9999 -9999 -9999 -9999 -9999 -9999 -9999 -9999 -9999 -9999 -9999 -9999 -9999 -9999

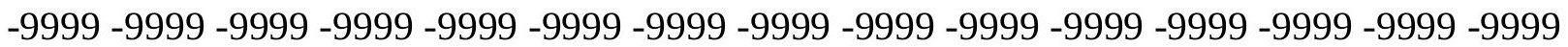

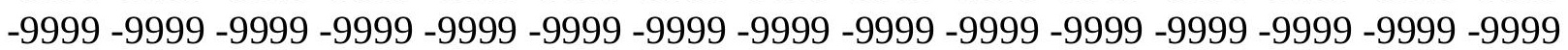
-9999 -9999 -9999 -9999 -9999 -9999 -9999 -9999 -9999 -9999 -9999 -9999 -9999 -9999 -9999 -999 -9999 -9999 -9999 -9999 -9999 -9999 -9999 -9999 -9999 -9999 -9999 -9999 -9999 -9999 -9999 -9999 -9999 -9999 -9999 -9999 -9999 -9999 -9999 -9999 -9999 -9999 -9999 -9999 -9999 -9999 -9999 -9999 -9999 -9999 -9999 -9999 -9999 -9999 -9999 -9999 -9999 -9999 -9999 -9999 -9999 -999 -9999 -9999 -9999 -9999 -9999 -9999 -9999 -9999 -9999 -9999 -9999 -9999 -9999 -9999 -9999 -9999 -9999 -9999 -9999 116.1231002808 115.818397522115 .818397522115 .5136032104 115.5136032104115 .5136032104115 .5136032104115 .5136032104115 .5136032104 115.5136032104115 .2088012695115 .2088012695115 .2088012695114 .9039993286 114.5991973877114 .2944030762113 .9896011353113 .3800964355113 .075302124 112.4656982422111 .8561019897111 .24659729110 .6370010376110 .0273971558 109.1130981445108 .5035018921107 .8938980103107 .2844009399106 .3700027466 105.7603988647105 .1509017944104 .5412979126103 .9317016602103 .6268997192 103.0174026489102 .4077987671102 .1029968262101 .7982025146101 .4934005737 101.1886978149101 .1886978149101 .1886978149101 .1886978149101 .4934005737 102.1029968262102 .4077987671102 .712600708103 .3221969604103 .0174026489 102.4077987671101 .188697814999 .3599472045997 .8360290527395 .70252990723 93.5690307617291 .1307525634888 .6924667358488 .99725341797113 .6848983765 130.4479980469140 .2012023926146 .9064025879152 .0877990723156 .3547973633 160.0122070312163 .974395752167 .6318054199171 .5939941406175 .2514038086 179.2136993408182 .87109375186 .528503418190 .1858978271193 .5386047363 196.891204834199 .9389953613202 .9868927002205 .425201416208 .1681976318 208.7778015137208 .7778015137208 .7778015137208 .7778015137208 .7778015137 208.7778015137208 .7778015137208 .7778015137208 .7778015137208 .7778015137 208.7778015137208 .7778015137208 .7778015137208 .7778015137208 .7778015137 208.7778015137208 .7778015137208 .7778015137208 .7778015137208 .7778015137 58.5187492370658 .82352828979 -9999 -9999 -9999 -9999 -9999 -9999 -9999 -9999 -9999 -9999 -9999 -9999-9999-9999 -9999 -9999 -9999 -9999 -9999 -9999 -9999 -9999 -9999 -9999 -9999 -9999 -9999 -9999 -9999

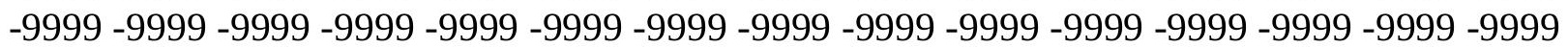


-9999 -9999 -9999 -9999 -9999 -9999 -9999 -9999 -9999 -9999 -9999 -9999 -9999 -9999 -9999 -9999 -9999 -9999 -9999 -9999 -9999 -9999 -9999 -9999 -9999 -9999 -9999 -9999 -9999 -9999 -9999 -9999 -9999 -9999 -9999 -9999 -9999 -9999 -9999 -9999 -9999 -9999 -9999 -9999 -9999 -9999 -9999 -9999 -9999 -9999 -9999 -9999 -9999 -9999 -9999 -9999 -9999 -9999 -9999 -9999 -9999 -9999 -9999 -9999 -9999 -9999 -9999 -9999 -9999 -9999 -9999 -9999 -9999 -9999 -9999 -9999 -9999 -9999 -9999 -9999 -9999 -9999 -9999 -9999 -9999 -9999 -9999 -9999 -9999 -9999 -9999 -9999 -9999 -9999 -9999 -9999 -9999 -9999 -9999 -9999 -9999 -9999 -9999 -9999 -9999

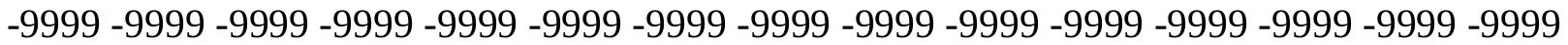
-9999 -9999 -9999 -9999 -9999 -9999 -9999 -9999 -9999 -9999 -9999 -9999 -9999 -9999 -9999 -9999 -9999 -9999 -9999 -9999 -9999 -9999 -9999 -9999 -9999 -9999 -9999 -9999 -9999 -9999 -9999 -9999 -9999 -9999 -9999 -9999 -9999 -9999 -9999 -9999 -9999 -9999 -9999 -9999 -9999 -9999 -9999 -9999 -9999 -9999 -9999 -9999 -9999 -9999 -9999 -9999 -9999 -9999 -9999 -9999

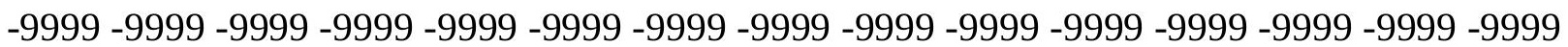
-9999 -9999 -9999 -9999 -9999 -9999 -9999 -9999 -9999 -9999 -9999 -9999 -9999 -9999 -9999 -9999 -9999 -9999 -9999 -9999 -9999 -9999 -9999 -9999 -9999 -9999 -9999 -9999 -9999 -9999 -9999 -9999 -9999 -9999 -9999 -9999 -9999 -9999 -9999 -9999 -9999 -9999 -9999 -9999 -9999 -9999 -9999 -9999 -9999 -9999 116.4279022217116 .4279022217116 .1231002808 116.1231002808116 .1231002808116 .1231002808115 .818397522115 .818397522 115.818397522115 .818397522115 .5136032104115 .5136032104115 .2088012695 114.9039993286114 .5991973877113 .9896011353113 .6848983765113 .075302124 112.4656982422111 .8561019897111 .24659729110 .6370010376110 .0273971558 109.1130981445108 .5035018921107 .8938980103106 .979598999106 .3700027466 105.7603988647105 .1509017944104 .5412979126103 .9317016602103 .3221969604 103.0174026489102 .4077987671102 .1029968262101 .7982025146101 .4934005737 101.1886978149101 .1886978149101 .1886978149101 .1886978149101 .4934005737 101.7982025146102 .1029968262102 .712600708103 .0174026489103 .0174026489 102.1029968262100 .579101562598 .7503814697396 .9216690063595 .09295654297 92.6546783447390 .5211791992288 .0829010009894 .78817749023127 .7050018311 137.7628936768144 .7729034424149 .9542999268153 .9165039062156 .9642944336 160.0122070312162 .7552947998165 .8031005859168 .8509979248172 .2035980225 175.8609924316179 .5184020996182 .87109375186 .528503418189 .8811035156 193.233795166196 .2816009521199 .0247039795201 .7678070068204 .5108032227 206.9490966797208 .7778015137208 .7778015137208 .7778015137208 .7778015137 208.7778015137208 .7778015137208 .7778015137208 .7778015137208 .7778015137 208.7778015137208 .7778015137208 .7778015137208 .7778015137208 .7778015137 208.7778015137208 .7778015137208 .7778015137208 .777801513758 .51874923706 58.51874923706 -9999 -9999 -9999 -9999 -9999 -9999 -9999 -9999 -9999 -9999 -9999 -9999 -9999-9999-9999 -9999 -9999 -9999 -9999 -9999 -9999 -9999 -9999 -9999 -9999 -9999 -9999 -9999 -9999 -9999 -9999 -9999 -9999 -9999 -9999 -9999 -9999 -9999 -9999 -9999 -9999 -9999 -9999 -9999 -9999 -9999 -9999 -9999 -9999 -9999 -9999 -9999 -9999 -9999 -9999 -9999 -9999 -9999 -9999 -9999

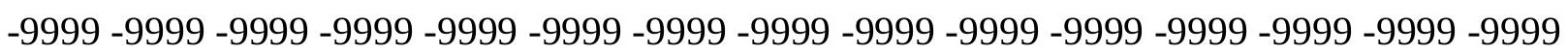
-9999 -9999 -9999 -9999 -9999 -9999 -9999 -9999 -9999 -9999 -9999 -9999 -9999 -9999 -9999 -9999 -9999 -9999 -9999 -9999 -9999 -9999 -9999 -9999 -9999 -9999 -9999 -9999 -9999 -9999 -999 -9999 -9999 -9999 -9999 -9999 -9999 -9999 -9999 -9999 -9999 -9999 -9999 -9999 -9999 -9999

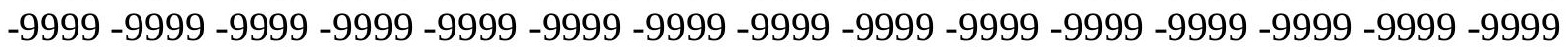


-9999 -9999 -9999 -9999 -9999 -9999 -9999 -9999 -9999 -9999 -9999 -9999 -9999 -9999 -9999 -9999 -9999 -9999 -9999 -9999 -9999 -9999 -9999 -9999 -9999 -9999 -9999 -9999 -9999 -9999 -9999 -9999 -9999 -9999 -9999 -9999 -9999 -9999 -9999 -9999 -9999 -9999 -9999 -9999 -9999 -9999 -9999 -9999 -9999 -9999 -9999 -9999 -9999 -9999 -9999 -9999 -9999 -9999 -9999 -9999 -9999 -9999 -9999 -9999 -9999 -9999 -9999 -9999 -9999 -9999 -9999 -9999 -9999 -9999 -9999 -9999 -9999 -9999 -9999 -9999 -9999 -9999 -9999 -9999 -9999 -9999 -9999 -9999 -9999 -9999 -9999 -9999 -9999 -9999 -9999 -9999 -9999 -9999 -9999 -9999 -9999 -9999 -9999 -9999 -9999 -9999 -9999 -9999 -9999 -9999 -9999 -9999 -9999 -9999 -9999 -9999 -9999 -9999 -9999 -9999 -9999 -9999 -9999 -9999 -9999 -9999 -9999 -9999 -9999 -9999 -9999 -9999 -9999 -9999 -9999 -9999 -9999 -9999 -9999 -9999 -9999 -9999 -9999 -9999 -9999 -9999 -9999 -9999 -9999 -9999 -9999 -9999 -9999 -9999 -9999 -9999-9999 116.7326965332116 .7326965332116 .4279022217 116.4279022217116 .4279022217116 .4279022217116 .1231002808116 .1231002808 115.818397522115 .818397522115 .5136032104115 .2088012695114 .9039993286 114.2944030762113 .9896011353113 .3800964355112 .7705001831112 .1608963013 111.551399231110 .6370010376110 .0273971558109 .4179000854108 .5035018921 107.8938980103106 .979598999106 .3700027466105 .7603988647105 .1509017944 104.5412979126103 .9317016602103 .3221969604102 .712600708102 .4077987671 101.7982025146101 .4934005737101 .1886978149101 .1886978149100 .8839035034 100.8839035034100 .8839035034101 .1886978149101 .4934005737101 .7982025146 102.1029968262102 .1029968262101 .7982025146100 .883903503499 .66472625732 97.8360290527396 .0073165893693 .8738174438591 .7403335571389 .60682678223 87.16854858398100 .5791015625123 .1332015991138 .0677032471145 .9920959473 151.1734008789154 .5260925293156 .9642944336158 .7929992676160 .9264984131 163.3648071289166 .1078948975169 .1557006836172 .5084075928175 .8609924316 179.2136993408182 .87109375186 .2236938477189 .2716064453192 .624206543 195.3672943115198 .1103057861200 .8533935547203 .2917022705205 .7299957275 207.8634033203208 .7778015137208 .7778015137208 .7778015137208 .7778015137 208.7778015137208 .7778015137208 .7778015137208 .7778015137208 .7778015137 208.7778015137208 .7778015137208 .7778015137208 .7778015137208 .7778015137 208.7778015137208 .777801513758 .5187492370658 .82352828979 -9999 -9999 -9999 -9999 -9999 -9999 -9999 -9999 -9999 -9999 -9999 -9999 -9999 -9999 -9999

-9999 -9999 -9999 -9999 -9999 -9999 -9999 -9999 -9999 -9999 -9999 -9999 -9999 -9999 -9999 -9999 -9999 -9999 -9999 -9999 -9999 -9999 -9999 -9999 -9999 -9999 -9999 -9999 -9999 -9999 -9999 -9999 -9999 -9999 -9999 -9999 -9999 -9999 -9999 -9999 -9999 -9999 -9999 -9999 -9999 -

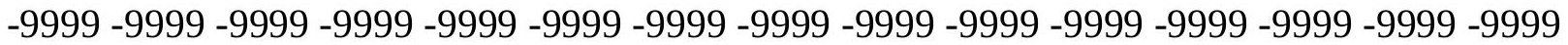
-9999 -9999 -9999 -9999 -9999 -9999 -9999 -9999 -9999 -9999 -9999 -9999 -9999 -9999 -9999 -9999 -9999 -9999 -9999 -9999 -9999 -9999 -9999 -9999 -9999 -9999 -9999 -9999 -9999 -9999

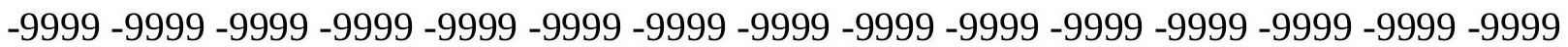
-9999 -9999 -9999 -9999 -9999 -9999 -9999 -9999 -9999 -9999 -9999 -9999 -9999 -9999 -9999 -9999 -9999 -9999 -9999 -9999 -9999 -9999 -9999 -9999 -9999 -9999 -9999 -9999 -9999 -9999 -9999 -9999 -9999 -9999 -9999 -9999 -9999 -9999 -9999 -9999 -9999 -9999 -9999 -9999 -9999

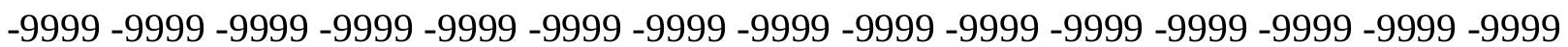
-9999 -9999 -9999 -9999 -9999 -9999 -9999 -9999 -9999 -9999 -9999 -9999 -9999 -9999 -9999 -9999 -9999 -9999 -9999 -9999 -9999 -9999 -9999 -9999 -9999 -9999 -9999 -9999 -9999 -9999 -999 -9999 -9999 -9999 -9999 -9999 -9999 -9999 -9999 -9999 -9999 -9999 -9999 -9999 -9999 -9999

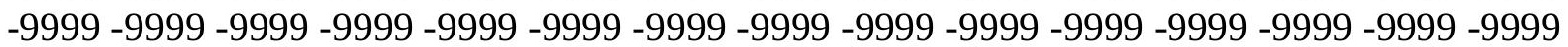


-9999 -9999 -9999 -9999 -9999 -9999 -9999 -9999 -9999 -9999 -9999 -9999 -9999 -9999 -9999 -9999 -9999 -9999 -9999 -9999 -9999 -9999 -9999 -9999 -9999 -9999 -9999 -9999 -9999 -9999 -9999 -9999 -9999 -9999 -9999 -9999 -9999 -9999 -9999 -9999 -9999 -9999 -9999 -9999 -9999 -9999 -9999 -9999 -9999 -9999 -9999 -9999 -9999 117.0374984741117 .0374984741 117.0374984741117 .0374984741116 .7326965332116 .7326965332116 .4279022217 116.4279022217116 .1231002808115 .818397522115 .5136032104114 .9039993286 114.5991973877113 .9896011353113 .3800964355112 .7705001831112 .1608963013 111.551399231110 .9418029785110 .0273971558109 .4179000854108 .5035018921 107.8938980103106 .979598999106 .3700027466105 .7603988647105 .1509017944 104.5412979126103 .9317016602103 .3221969604102 .712600708102 .1029968262 101.7982025146101 .4934005737101 .1886978149100 .8839035034100 .5791015625 100.5791015625100 .5791015625100 .5791015625100 .5791015625100 .8839035034 100.8839035034100 .8839035034100 .274299621699 .6647262573298 .4455871582 96.6168823242294 .7881774902392 .9594726562590 .8259735107488 .69246673584 86.2541885376102 .1029968262120 .3900985718135 .3246002197144 .7729034424 150.2590942383153 .6116943359155 .7451934814157 .2691040039158 .7929992676 160.6217956543162 .7552947998165 .8031005859168 .8509979248172 .2035980225 175.8609924316179 .2136993408182 .5662994385185 .6141052246188 .966796875 191.7097930908194 .7577056885197 .1959991455199 .6342926025202 .0724945068 204.5108032227206 .3394927979208 .4730072021208 .7778015137208 .7778015137 208.7778015137208 .7778015137208 .7778015137208 .7778015137208 .7778015137 208.7778015137208 .7778015137208 .7778015137208 .7778015137208 .7778015137 208.7778015137208 .777801513758 .5187492370658 .82352828979 -9999 -9999 -9999 -9999 -9999 -9999 -9999 -9999 -9999 -9999 -9999 -9999 -9999 -9999 -9999

-9999 -9999 -9999 -9999 -9999 -9999 -9999 -9999 -9999 -9999 -9999 -9999 -9999 -9999 -9999 -9999 -9999 -9999 -9999 -9999 -9999 -9999 -9999 -9999 -9999 -9999 -9999 -9999 -9999 -9999 -9999 -9999 -9999 -9999 -9999 -9999 -9999 -9999 -9999 -9999 -9999 -9999 -9999 -9999 -9999 -9999 -9999 -9999 -9999 -9999 -9999 -9999 -9999 -9999 -9999 -9999 -9999 -9999 -9999 -9999 -9999 -9999 -9999 -9999 -9999 -9999 -9999 -9999 -9999 -9999 -9999 -9999 -9999 -9999 -9999 -9999 -9999 -9999 -9999 -9999 -9999 -9999 -9999 -9999 -9999 -9999 -9999 -9999 -9999 -9999 -9999 -9999 -9999 -9999 -9999 -9999 -9999 -9999 -9999 -9999 -9999 -9999 -9999 -9999 -9999 -9999 -9999 -9999 -9999 -9999 -9999 -9999 -9999 -9999 -9999 -9999 -9999 -9999 -9999 -9999 -9999 -9999 -9999 -9999 -9999 -9999 -9999 -9999 -9999 -9999 -9999 -9999 -9999 -9999 -9999 -9999 -9999 -9999 -9999 -9999 -9999 -9999 -9999 -9999 -9999 -9999 -9999 -9999 -9999 -9999

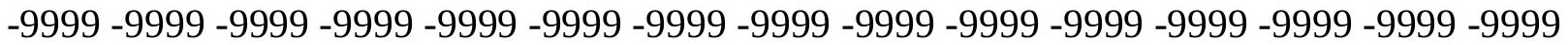
-9999 -9999 -9999 -9999 -9999 -9999 -9999 -9999 -9999 -9999 -9999 -9999 -9999 -9999 -9999

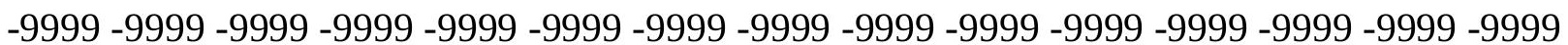

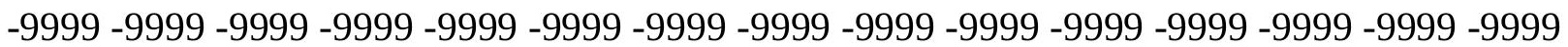
-9999 -9999 -9999 -9999 -9999 -9999 -9999 -9999 -9999 -9999 -9999 -9999 -9999 -9999 -9999 -9999 -9999 -9999 -9999 -9999 -9999 -9999 -9999 -9999 -9999 -9999 -9999 -9999 - -9999 -9999 -9999 -9999 -9999 -9999 -9999 -9999 -9999 -9999 -9999 -9999 -9999 -9999 -9999 -9999 -9999 -9999 -9999 -9999 -9999 -9999 -9999 -9999 -9999 -9999 -9999 -9999 -9999 -9999 -9999 -9999 -9999 -9999 -9999 -9999 -9999 -9999 -9999 -9999 -9999-9999 117.342300415 117.342300415 117.342300415117 .0374984741117 .0374984741116 .7326965332116 .4279022217 116.1231002808115 .818397522115 .2088012695114 .9039993286114 .2944030762 113.6848983765113 .075302124112 .4656982422111 .8561019897110 .9418029785 
110.3321990967109 .4179000854108 .8082962036107 .8938980103107 .2844009399 106.3700027466105 .7603988647104 .8460998535104 .2365036011103 .6268997192 103.0174026489102 .4077987671102 .1029968262101 .4934005737101 .1886978149 100.8839035034100 .2742996216100 .274299621699 .9695205688599 .96952056885 99.9695205688599 .6647262573299 .6647262573299 .6647262573299 .35994720459 99.0551681518698 .1408081054796 .9216690063595 .397743225193 .56903076172 91.7403335571389 .9116134643687 .4733276367286 .2541885376103 .0174026489 119.1709976196132 .8863067627142 .6394042969148 .7351074219152 .3925933838 154.2212982178155 .4403991699156 .0500030518157 .2691040039159 .4026031494 162.1457061768165 .4983062744168 .8509979248172 .2035980225175 .5561981201 178.9089050293182 .261505127185 .3094024658188 .3571929932191 .1002960205 193.8433074951196 .2816009521198 .7198944092200 .8533935547202 .9868927002 205.1204071045 206.9490966797 208.7778015137 208.7778015137 208.7778015137 208.7778015137208 .7778015137208 .7778015137208 .7778015137208 .7778015137 208.7778015137208 .7778015137208 .7778015137208 .7778015137208 .7778015137 58.8235282897958 .82352828979 -9999 -9999 -9999 -9999 -9999 -9999 -9999 -9999 -9999 -9999 -9999 -9999-9999-9999-9999 -9999 -9999 -9999 -9999 -9999 -9999 -9999 -9999 -9999 -9999 -9999 -9999 -9999 -9999 -9999 -9999 -9999 -9999 -9999 -9999 -9999 -9999 -9999 -9999 -9999 -9999 -9999 -9999 -9999 -9999 -9999 -9999 -9999 -9999 -9999 -9999 -9999 -9999 -9999 -9999 -9999 -9999 -9999 -9999 -9999 -9999 -9999 -9999 -9999 -9999 -9999 -9999 -9999 -9999 -9999 -9999 -9999 -9999 -9999 -9999 -9999 -9999 -9999 -9999 -9999 -9999 -9999 -9999 -9999 -9999 -9999 -9999 -9999 -9999 -9999 -9999 -9999 -9999 -9999 -9999 -9999 -9999 -9999 -9999 -9999 -9999 -9999-9999-9999-9999 -999 -9999 -9999 -9999 -9999 -9999 -9999 -9999 -9999 -9999 -9999 -9999 -9999 -9999 -9999 -9999 -9999 -9999 -9999 -9999 -9999 -9999 -9999 -9999 -9999 -9999 -9999 -9999 -9999 -9999 -9999 -9999 -9999 -9999 -9999 -9999 -9999 -9999 -9999 -9999 -9999 -9999 -9999 -9999 -9999 -9999 -9999 -9999 -9999 -9999 -9999 -9999 -9999 -9999 -9999 -9999 -9999 -9999 -9999 -9999 -9999

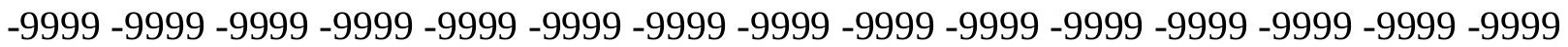
-9999 -9999 -9999 -9999 -9999 -9999 -9999 -9999 -9999 -9999 -9999 -9999 -9999 -9999 -9999

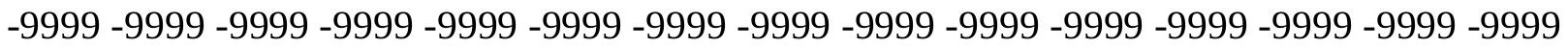
-9999 -9999 -9999 -9999 -9999 -9999 -9999 -9999 -9999 -9999 -9999 -9999 -9999 -9999 -9999

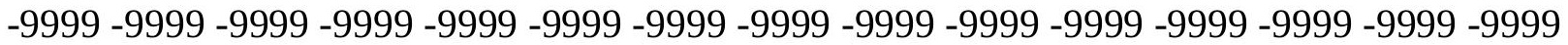

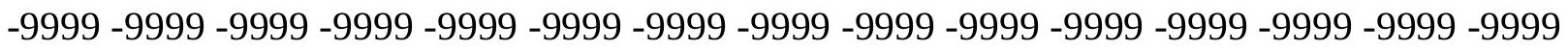
-9999 -9999 -9999 -9999 -9999 -9999 -9999 -9999 -9999 -9999 -9999 -9999 -9999 -9999 -9999 -9999 -9999 -9999 -9999 -9999 -9999 -9999 -9999 -9999 -9999 -9999 -9999 -9999 -9999 -9999 -9999 -9999 -9999 -9999 -9999 -9999 -9999 -9999 -9999 -9999 -9999 117.647102356 117.647102356117 .647102356117 .342300415117 .0374984741116 .7326965332 116.4279022217116 .1231002808115 .818397522115 .2088012695114 .5991973877 113.9896011353113 .3800964355112 .7705001831111 .8561019897111 .24659729 110.3321990967109 .4179000854108 .8082962036107 .8938980103107 .2844009399 106.3700027466105 .7603988647104 .8460998535104 .2365036011103 .6268997192 103.0174026489102 .4077987671101 .7982025146101 .1886978149100 .8839035034 100.274299621699 .9695205688599 .6647262573299 .3599472045999 .05516815186 99.0551681518698 .7503814697398 .445587158298 .445587158297 .83602905273 97.5312423706196 .6168823242295 .397743225194 .1785964965892 .3498916626 90.5211791992288 .6924667358486 .5589828491288 .69246673584103 .9317016602 
118.8662033081131 .6672058105141 .1154937744147 .2111968994150 .8686065674 152.6972961426153 .3069000244153 .3069000244153 .9165039062156 .0500030518 159.0977935791162 .4505004883165 .8031005859169 .1557006836172 .5084075928 175.5561981201178 .604095459181 .6519012451184 .699798584187 .4429016113 190.1858978271192 .624206543195 .0625197 .500793457199 .6342926025201 .7678070068 203.596496582205 .425201416207 .25390625208 .7778015137208 .7778015137 208.7778015137208 .7778015137208 .7778015137208 .7778015137208 .7778015137 208.7778015137208 .7778015137208 .7778015137208 .777801513758 .82352828979 -9999 -9999 -9999 -9999 -9999 -9999 -9999 -9999 -9999 -9999 -9999 -9999 -9999 -9999 -9999 -9999 -9999 -9999 -9999 -9999 -9999 -9999 -9999 -9999 -9999 -9999 -9999 -9999 -9999 -9999 -9999 -

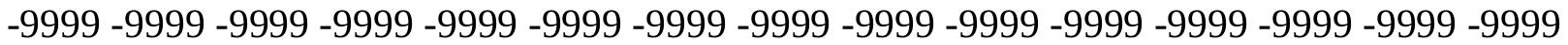
-9999 -9999 -9999 -9999 -9999 -9999 -9999 -9999 -9999 -9999 -9999 -9999 -9999 -9999 -9999 -999 -9999 -9999 -9999 -9999 -9999 -9999 -9999 -9999 -9999 -9999 -9999 -9999 -9999 -9999 -9999 -9999 -9999 -9999 -9999 -9999 -9999 -9999 -9999 -9999 -9999 -9999 -9999 -9999 -9999 -9999 -9999 -9999 -9999 -9999 -9999 -9999 -9999 -9999 -9999 -9999 -9999 -9999 -9999 -9999 -9999

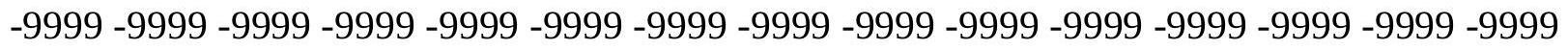

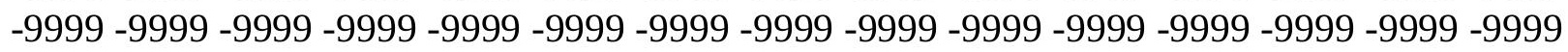

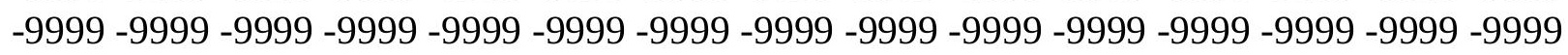

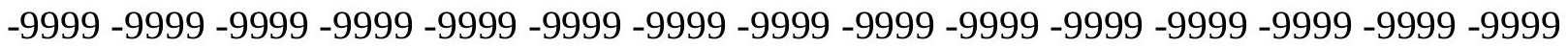

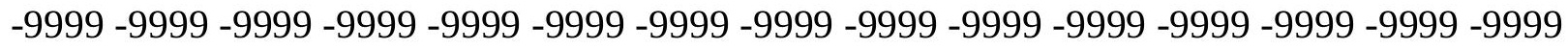

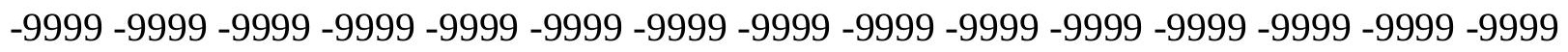

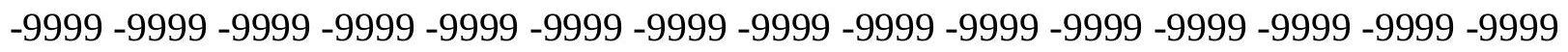
-9999 -9999 -9999 -9999 -9999 -9999 -9999 -9999 -9999 -9999 -9999 -9999 -9999 -9999 -9999 -

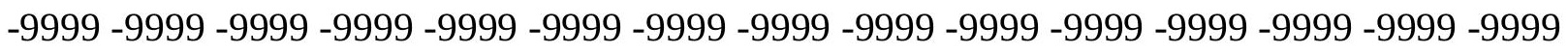

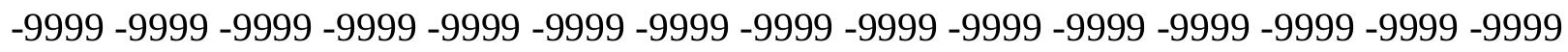
-9999 -9999 -9999 -9999 -9999 -9999 -9999 -9999 -9999 -9999 -9999 -9999 -9999 -9999 -9999

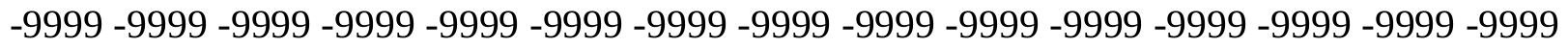
-9999 -9999 -9999 -9999 -9999 -9999 -9999 -9999 -9999 -9999 -9999 -9999 -9999 117.9517974854117 .647102356117 .647102356117 .342300415117 .0374984741 116.4279022217116 .1231002808115 .5136032104114 .9039993286114 .2944030762 113.6848983765112 .7705001831112 .1608963013111 .24659729110 .3321990967 109.7226028442108 .8082962036108 .1986999512107 .2844009399106 .3700027466 105.7603988647104 .8460998535104 .2365036011103 .6268997192102 .712600708 102.1029968262101 .4934005737100 .8839035034100 .579101562599 .96952056885 99.3599472045999 .0551681518698 .445587158298 .1408081054797 .83602905273 97.5312423706197 .2264633178796 .9216690063596 .6168823242296 .00731658936 95.0929565429793.8738174438592.6546783447391.13075256348 89.3020401001 87.4733276367285 .3398437590 .82597351074105 .7603988647119 .7806015015 131.6672058105140 .5059967041146 .2969055176149 .9542999268151 .4781951904 151.7830047607151 .4781951904150 .8686065674153 .6116943359156 .6596069336 159.7073974609162 .7552947998166 .1078948975169 .1557006836172 .5084075928 175.5561981201178 .2993011475181 .3471984863184 .0901947021186 .8332977295 189.2716064453191 .7097930908194 .1481018066196 .2816009521198 .4151000977 200.2438049316202 .3773040771204 .2059936523206 .0346984863207 .5587005615 208.7778015137208 .7778015137208 .7778015137208 .7778015137208 .7778015137 208.7778015137 208.7778015137 208.7778015137 58.82352828979 59.12831115723 -9999 
-9999 -9999 -9999 -9999 -9999 -9999 -9999 -9999 -9999 -9999 -9999 -9999 -9999 -9999 -9999 -9999 -9999 -9999 -9999 -9999 -9999 -9999 -9999 -9999 -9999 -9999 -9999 -9999 -9999 -9999 -9999 -9999 -9999 -9999 -9999 -9999 -9999 -9999 -9999 -9999 -9999 -9999 -9999 -9999 -9999 -9999 -9999 -9999 -9999 -9999 -9999 -9999 -9999 -9999 -9999 -9999 -9999 -9999 -9999 -9999 -9999 -9999 -9999 -9999 -9999 -9999 -9999 -9999 -9999 -9999 -9999 -9999 -9999 -9999 -9999 -9999 -9999 -9999 -9999 -9999 -9999 -9999 -9999 -9999 -9999 -9999 -9999 -9999 -9999 -9999 -9999 -9999 -9999 -9999 -9999 -9999 -9999 -9999 -9999 -9999 -9999 -9999 -9999 -9999 -9999

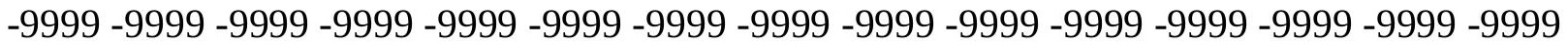
-9999 -9999 -9999 -9999 -9999 -9999 -9999 -9999 -9999 -9999 -9999 -9999 -9999 -9999 -9999 -9999 -9999 -9999 -9999 -9999 -9999 -9999 -9999 -9999 -9999 -9999 -9999 -9999 -9999 -9999 -9999 -9999 -9999 -9999 -9999 -9999 -9999 -9999 -9999 -9999 -9999 -9999 -9999 -9999 -9999 -9999 -9999 -9999 -9999 -9999 -9999 -9999 -9999 -9999 -9999 -9999 -9999 -9999 -9999 -9999

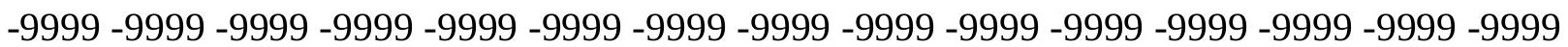
-9999 -9999 -9999 -9999 -9999 -9999 -9999 -9999 -9999 -9999 -9999 -9999 -9999 -9999 -9999 -9999 -9999 -9999 -9999 -9999 -9999 -9999 -9999 -9999 -9999 -9999 -9999 -9999 -9999 -9999 -9999 -9999 -9999 -9999 -9999 -9999 -9999 -9999 -9999 -9999 -9999 -9999 -9999 -9999 -9999 -

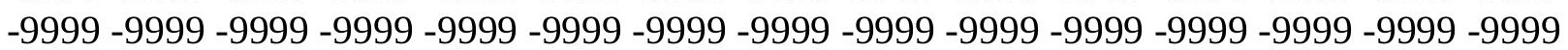
-9999 -9999 -9999 -9999 -9999 -9999 -9999 -9999 -9999 -9999 -9999 -9999 -9999 -9999 -9999 -9999 -9999 -9999 -9999 -9999 -9999 -9999 -9999 -9999 -9999 -9999 -9999 -9999 -9999 -9999 -9999 -9999 -9999 -9999 -9999 -9999 -9999 -9999 -9999 -9999 -9999 -9999 -9999 -9999 118.2565994263117 .9517974854117 .647102356117 .342300415117 .0374984741 116.4279022217115 .818397522115 .2088012695114 .5991973877113 .6848983765 113.075302124112 .1608963013111 .551399231110 .6370010376109 .7226028442 108.8082962036108 .1986999512107 .2844009399106 .3700027466105 .7603988647 104.8460998535104 .2365036011103 .3221969604102 .712600708102 .1029968262 101.4934005737100 .579101562599 .9695205688599 .3599472045999 .05516815186 98.445587158297 .8360290527397 .2264633178796 .9216690063596 .31210327148 96.0073165893695 .7025299072395 .0929565429794 .4833908081193 .87381744385 92.6546783447391 .4355392456189 .9116134643688 .3876876831186 .55898284912 84.4254837036193 .26425170898107 .8938980103121 .6092987061132 .5814971924 140.8106994629146 .2969055176149 .3446960449150 .8686065674151 .1734008789 150.8686065674150 .8686065674152 .3925933838154 .8307952881157 .5738983154 160.6217956543163 .3648071289166 .4127044678169 .4604949951172 .2035980225 175.2514038086177 .9945068359180 .7375946045183 .4806976318185 .9188995361 188.3571929932190 .795501709192 .9290008545195 .0625197 .1959991455199 .0247039795 200.8533935547202 .6820983887204 .5108032227206 .3394927979208 .1681976318 208.7778015137208.7778015137208.7778015137208.7778015137208.7778015137 208.7778015137 59.12831115723 59.12831115723 -9999 -9999 -9999 -9999 -9999 -9999 -9999 -9999 -9999 -9999 -9999 -9999 -9999 -9999 -9999 -9999 -9999 -9999 -9999 -9999 -9999 -9999 -9999 -9999 -9999 -9999 -9999 -9999 -9999 -9999 -9999 -9999 -9999 -9999 -9999 -9999 -9999 -9999 -9999 -9999 -9999 -9999 -9999 -9999 -9999 -9999

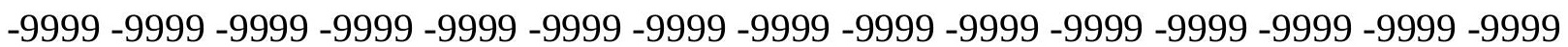
-9999 -9999 -9999 -9999 -9999 -9999 -9999 -9999 -9999 -9999 -9999 -9999 -9999 -9999 -9999 -9999 -9999 -9999 -9999 -9999 -9999 -9999 -9999 -9999 -9999 -9999 -9999 -9999 -9999 -9999 -9999 -9999 -9999 -9999 -9999 -9999 -9999 -9999 -9999 -9999 -9999 -9999 -9999 -9999 -9999

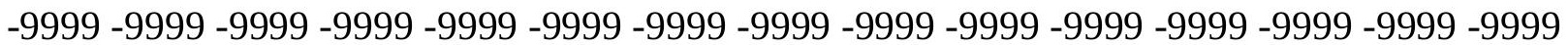


-9999 -9999 -9999 -9999 -9999 -9999 -9999 -9999 -9999 -9999 -9999 -9999 -9999 -9999 -9999 -9999 -9999 -9999 -9999 -9999 -9999 -9999 -9999 -9999 -9999 -9999 -9999 -9999 -9999 -9999 -9999 -9999 -9999 -9999 -9999 -9999 -9999 -9999 -9999 -9999 -9999 -9999 -9999 -9999 -9999 -9999 -9999 -9999 -9999 -9999 -9999 -9999 -9999 -9999 -9999 -9999 -9999 -9999 -9999 -9999 -9999 -9999 -9999 -9999 -9999 -9999 -9999 -9999 -9999 -9999 -9999 -9999 -9999 -9999 -9999 -9999 -9999 -9999 -9999 -9999 -9999 -9999 -9999 -9999 -9999 -9999 -9999 -9999 -9999 -9999 -9999 -9999 -9999 -9999 -9999 -9999 -9999 -9999 -9999 -9999 -9999 -9999 -9999 -9999 -9999

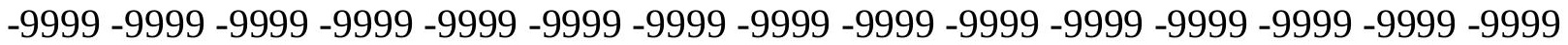
-9999 -9999 -9999 -9999 -9999 -9999 -9999 -9999 -9999 -9999 -9999 -9999 -9999 -9999 -9999 -9999 -9999 -9999 -9999 -9999 -9999 -9999 -9999 -9999 -9999 -9999 -9999 -9999 -9999 -9999 -9999 -9999 -9999 -9999 -9999 -9999 -9999 -9999 -9999 -9999 -9999 -9999 -9999 -9999 -9999 -9999 -9999 -9999 -9999 -9999 -9999 -9999 -9999 -9999 -9999 -9999 -9999 -9999 -9999 -9999 -9999 118.2565994263 117.647102356 117.342300415 116.7326965332116.1231002808 115.5136032104114 .9039993286113 .9896011353113 .3800964355112 .4656982422 111.551399231110 .6370010376110 .0273971558109 .1130981445108 .1986999512 107.2844009399106 .6747970581105 .7603988647104 .8460998535104 .2365036011 103.3221969604102 .712600708101 .7982025146101 .1886978149100 .5791015625 99.6647262573299 .0551681518698 .445587158297 .5312423706196 .92166900635 96.3121032714895 .7025299072395 .0929565429794 .7881774902394 .48339080811 93.8738174438593 .2642517089892 .6546783447391 .4355392456190 .21640014648 88.9972534179787 .1685485839885 .3398437583 .5111236572395 .3977432251 110.9418029785124 .0475006104134 .1054992676141 .4203033447146 .2969055176 149.3446960449150 .5639038086150 .8686065674150 .8686065674151 .1734008789 152.0877990723153 .9165039062156 .0500030518158 .4882965088161 .2312927246 163.6696014404166 .4127044678169 .4604949951172 .2035980225174 .9467010498 177.6896972656180 .1280059814182 .5662994385185 .0045928955187 .4429016113 189.5764007568191 .7097930908193 .8433074951195 .6721038818197 .500793457 199.329498291201 .158203125202 .9868927002204 .8155975342206 .6443023682 208.4730072021 208.7778015137208.7778015137208.7778015137208.7778015137 59.1283111572359 .12831115723 -9999 -9999 -9999 -9999 -9999 -9999 -9999 -9999 -9999 -9999 -9999 -9999 -9999 -9999 -9999 -9999

-9999 -9999 -9999 -9999 -9999 -9999 -9999 -9999 -9999 -9999 -9999 -9999 -9999 -9999 -9999 -9999 -9999 -9999 -9999 -9999 -9999 -9999 -9999 -9999 -9999 -9999 -9999 -9999 -9999 -9999 -9999 -9999 -9999 -9999 -9999 -9999 -9999 -9999 -9999 -9999 -9999 -9999 -9999 -9999 -9999 -

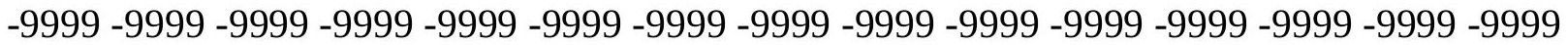
-9999 -9999 -9999 -9999 -9999 -9999 -9999 -9999 -9999 -9999 -9999 -9999 -9999 -9999 -9999 -9999 -9999 -9999 -9999 -9999 -9999 -9999 -9999 -9999 -9999 -9999 -9999 -9999 -9999 -9999

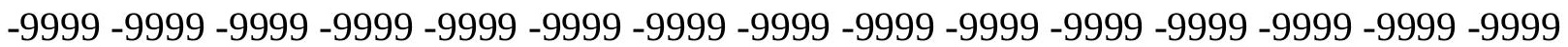
-9999 -9999 -9999 -9999 -9999 -9999 -9999 -9999 -9999 -9999 -9999 -9999 -9999 -9999 -9999 -9999 -9999 -9999 -9999 -9999 -9999 -9999 -9999 -9999 -9999 -9999 -9999 -9999 -9999 -9999 -9999 -9999 -9999 -9999 -9999 -9999 -9999 -9999 -9999 -9999 -9999 -9999 -9999 -9999 -9999 -999 -9999 -9999 -9999 -9999 -9999 -9999 -9999 -9999 -9999 -9999 -9999 -9999 -9999 -9999 -9999 -9999 -9999 -9999 -9999 -9999 -9999 -9999 -9999 -9999 -9999 -9999 -9999 -9999 -9999 -9999 -9999 -9999 -9999 -9999 -9999 -9999 -9999 -9999 -9999 -9999 -9999 -9999 -9999 -9999 -9999 -999 -9999 -9999 -9999 -9999 -9999 -9999 -9999 -9999 -9999 -9999 -9999 -9999 -9999 -9999 -9999

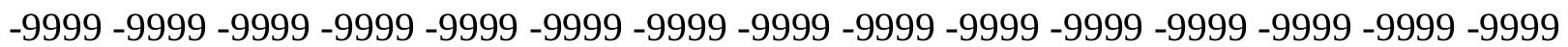


-9999 -9999 -9999 -9999 -9999 -9999 -9999 -9999 -9999 -9999 -9999 -9999 -9999 -9999 -9999 -9999 -9999 -9999 -9999 -9999 -9999 -9999 -9999 -9999 -9999 -9999 -9999 -9999 -9999 -9999

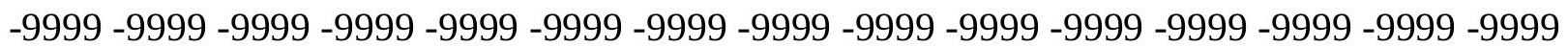
-9999 -9999 -9999 -9999 -9999 -9999 -9999 -9999 -9999 -9999 -9999 -9999 -9999 -9999 -9999 -9999 -9999 118.2565994263117.647102356117.342300415 116.7326965332115 .818397522 115.2088012695114 .2944030762113 .3800964355112 .7705001831111 .8561019897 110.9418029785110 .0273971558109 .1130981445108 .1986999512107 .2844009399 106.6747970581105 .7603988647104 .8460998535103 .9317016602103 .3221969604 102.4077987671101 .7982025146100 .8839035034100 .274299621699 .35994720459 98.7503814697397 .8360290527397 .2264633178796 .3121032714895 .3977432251 94.4833908081194 .1785964965893 .8738174438593 .2642517089892 .95947265625 92.349891662691 .4355392456190 .5211791992289 .302040100188 .08290100098 86.254188537684 .4254837036182 .5967712402397 .22646331787114 .2944030762 127.0953979492135 .9342041016142 .0299072266146 .2969055176149 .0399017334 150.5639038086150 .8686065674151 .1734008789151 .4781951904152 .0877990723 153.3069000244154 .8307952881156 .9642944336159 .0977935791161 .5361022949 163.974395752166 .4127044678169 .1557006836171 .8988037109174 .337097168 177.0802001953179 .5184020996181 .9566955566184 .0901947021186 .2236938477 188.3571929932190 .4907073975192 .3193969727194 .4528961182196 .2816009521 198.1103057861199 .9389953613201 .7678070068203 .2917022705205 .1204071045 206.9490966797208 .7778015137208 .7778015137208 .777801513759 .43310165405 59.43310165405 -9999 -9999 -9999 -9999 -9999 -9999 -9999 -9999 -9999 -9999 -9999 -9999 -9999 -9999-9999 -9999

-9999 -9999 -9999 -9999 -9999 -9999 -9999 -9999 -9999 -9999 -9999 -9999 -9999 -9999 -9999

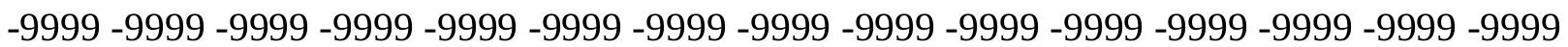
-9999 -9999 -9999 -9999 -9999 -9999 -9999 -9999 -9999 -9999 -9999 -9999 -9999 -9999 -9999 -9999 -9999 -9999 -9999 -9999 -9999 -9999 -9999 -9999 -9999 -9999 -9999 -9999 -9999 -9999 -9999 -9999 -9999 -9999 -9999 -9999 -9999 -9999 -9999 -9999 -9999 -9999 -9999 -9999 -9999 -9999 -9999 -9999 -9999 -9999 -9999 -9999 -9999 -9999 -9999 -9999 -9999 -9999 -9999 -9999

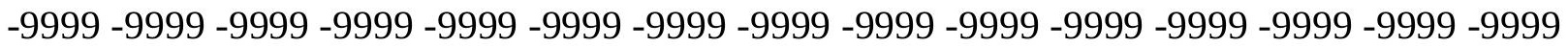
-9999 -9999 -9999 -9999 -9999 -9999 -9999 -9999 -9999 -9999 -9999 -9999 -9999 -9999 -9999 -9999 -9999 -9999 -9999 -9999 -9999 -9999 -9999 -9999 -9999 -9999 -9999 -9999 -9999 -9999 -9999 -9999 -9999 -9999 -9999 -9999 -9999 -9999 -9999 -9999 -9999 -9999 -9999 -9999 -9999 -9999 -9999 -9999 -9999 -9999 -9999 -9999 -9999 -9999 -9999 -9999 -9999 -9999 -9999 -9999 -

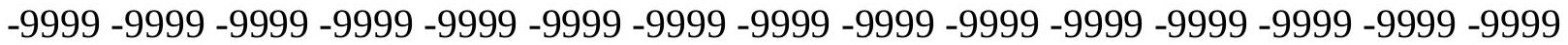
-9999 -9999 -9999 -9999 -9999 -9999 -9999 -9999 -9999 -9999 -9999 -9999 -9999 -9999 -9999 -9999 -9999 -9999 -9999 -9999 -9999 -9999 -9999 -9999 -9999 -9999 -9999 -9999 -9999 -9999

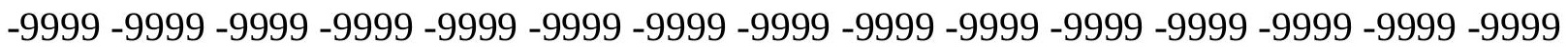
-9999 -9999 -9999 -9999 -9999 -9999 -9999 -9999 -9999 -9999 -9999 -9999 -9999 -9999 -9999 -9999 -9999 -9999 -9999 -9999 -9999 -9999 -9999 -9999 -9999 -9999 -9999 -9999 -9999 -9999 -9999 -9999 -9999 -9999 -9999 -9999 -9999 -9999 -9999 -9999 -9999 -9999 -9999 -9999 -9999 -9999 -9999 -9999 -9999 -9999 -9999 -9999 -9999 -9999 -9999 -9999 -9999 -9999 -9999 -9999 -9999 -9999 -9999 -9999 117.647102356 117.0374984741 116.1231002808 115.5136032104 114.5991973877113 .6848983765112 .7705001831111 .8561019897110 .9418029785 110.0273971558109 .1130981445108 .5035018921107 .5891036987106 .6747970581 105.7603988647104 .8460998535103 .9317016602103 .3221969604102 .4077987671 
101.4934005737100 .883903503499 .9695205688599 .3599472045998 .4455871582 97.5312423706196 .6168823242295 .7025299072394 .7881774902393 .56903076172 93.2642517089892 .9594726562592 .6546783447392 .0450973510791 .43553924561 90.5211791992289 .6068267822388 .3876876831187 .1685485839885 .64462280273 83.81591033936 81.9871978759898.4455871582 118.5614013672128 .6192932129 136.2389984131142 .0299072266145 .9920959473148 .7351074219149 .9542999268 150.5639038086150 .8686065674151 .1734008789151 .7830047607152 .3925933838 153.6116943359155 .1356048584156 .9642944336159 .0977935791161 .5361022949 163.6696014404166 .4127044678168 .8509979248171 .5939941406174 .0323028564 176.4705963135178 .604095459181 .0424041748183 .1759033203185 .3094024658 187.1381072998189 .2716064453191 .1002960205192 .9290008545194 .7577056885 196.5863952637 198.4151000977 200.2438049316202.0724945068 203.9011993408 205.7299957275207 .5587005615208 .777801513759 .4331016540515 .02973079681 -9999 -9999 -9999 -9999 -9999 -9999 -9999 -9999 -9999 -9999 -9999 -9999 -9999 -9999 -9999 -9999 -9999 -9999 -9999 -9999 -9999 -9999 -9999 -9999 -9999 -9999 -9999 -9999 -9999 -9999 -9999

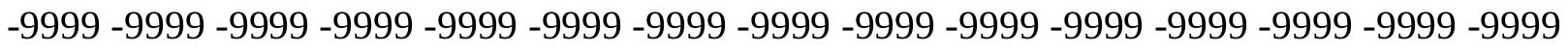
-9999 -9999 -9999 -9999 -9999 -9999 -9999 -9999 -9999 -9999 -9999 -9999 -9999 -9999 -9999 -9999 -9999 -9999 -9999 -9999 -9999 -9999 -9999 -9999 -9999 -9999 -9999 -9999 -9999 -9999 -9999 -9999 -9999 -9999 -9999 -9999 -9999 -9999 -9999 -9999 -9999 -9999 -9999 -9999 -9999

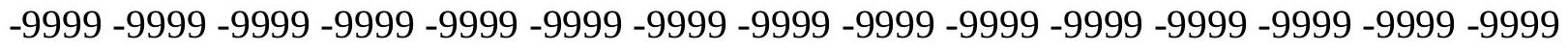

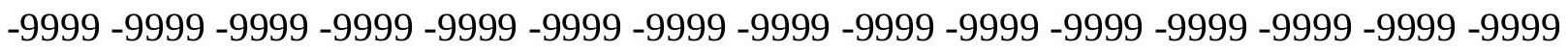
-9999 -9999 -9999 -9999 -9999 -9999 -9999 -9999 -9999 -9999 -9999 -9999 -9999 -9999 -9999 -9999 -9999 -9999 -9999 -9999 -9999 -9999 -9999 -9999 -9999 -9999 -9999 -9999 -9999 -9999 -

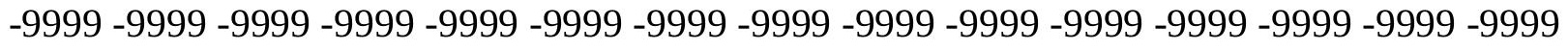

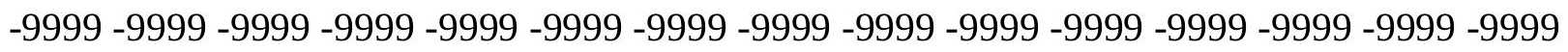
-9999 -9999 -9999 -9999 -9999 -9999 -9999 -9999 -9999 -9999 -9999 -9999 -9999 -9999 -9999

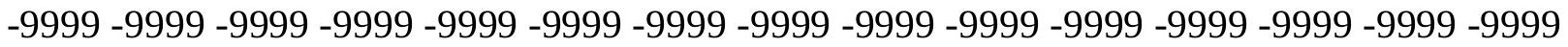

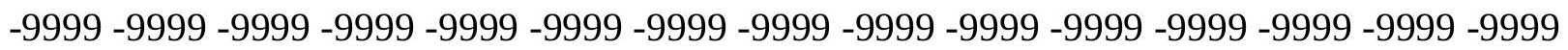
-9999 -9999 -9999 -9999 -9999 -9999 -9999 -9999 -9999 -9999 -9999 -9999 -9999 -9999 -9999 -9999 -9999 -9999 -9999 -9999 -9999 -9999 -9999 -9999 -9999 -9999 -9999 -9999 -9999 -9999 -9999 -9999 -9999 -9999 -9999 -9999 -9999 -9999 -9999-9999 -9999 -9999 -9999 -9999 -9999 -9999 -9999 -9999 -9999 -9999 -9999 -9999 -9999 -9999 -9999 -9999 -9999 -9999 -9999 -9999 -

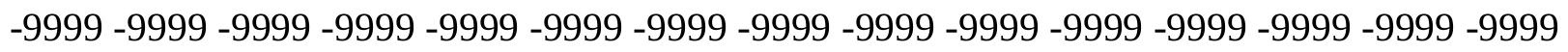
-9999 -9999 -9999 -9999 -9999 117.342300415 116.4279022217115 .5136032104 114.5991973877113 .9896011353113 .075302124112 .1608963013111 .24659729 110.3321990967109 .4179000854108 .5035018921107 .5891036987106 .6747970581 105.7603988647104 .8460998535103 .9317016602103 .3221969604102 .4077987671 101.4934005737100 .579101562599 .9695205688599 .0551681518698 .14080810547 97.2264633178796.3121032714895.397743225194.4833908081193.56903076172 92.9594726562592 .349891662692 .0450973510791 .4355392456190 .82597351074 89.9116134643688 .9972534179787 .7781066894586 .5589828491285 .03504943848 83.2063369751 81.3776321411197.83602905273 114.2944030762 126.7906036377 135.0198059082141 .1154937744145 .0776977539147 .8208007812149 .3446960449 150.2590942383150 .5639038086150 .8686065674151 .1734008789151 .7830047607 152.3925933838153 .6116943359155 .1356048584156 .9642944336159 .0977935791 161.2312927246163 .6696014404166 .1078948975168 .5462036133170 .9844970703 
173.4226989746175 .5561981201177 .9945068359180 .1280059814181 .9566955566 184.0901947021185 .9188995361188 .0523986816189 .8811035156191 .7097930908 193.5386047363195 .3672943115197 .1959991455199 .0247039795200 .8533935547 202.6820983887204 .5108032227206 .339492797959 .73788070679 -9999 -9999 -9999 -9999 -9999 -9999 -9999 -9999 -9999 -9999 -9999 -9999 -9999 -9999 -9999 -9999 -9999 -9999 -9999 -9999 -9999 -9999 -9999 -9999 -9999 -9999 -9999 -9999 -9999 -9999 -9999 -9999 -9999 -9999 -9999 -9999 -9999 -9999 -9999 -9999 -9999 -9999 -9999 -9999 -9999 -9999 -9999 -9999 -9999 -9999 -9999 -9999 -9999 -9999 -9999 -9999 -9999 -9999 -9999 -9999 -9999 -9999 -9999 -9999 -9999 -9999 -9999 -9999 -9999 -9999 -9999 -9999 -9999 -9999 -9999 -9999 -9999 -9999 -9999 -9999 -9999 -9999 -9999 -9999 -9999 -9999 -9999 -9999 -9999 -9999 -9999 -9999 -

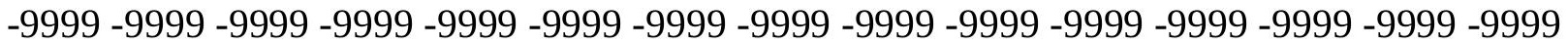
-9999 -9999 -9999 -9999 -9999 -9999 -9999 -9999 -9999 -9999 -9999 -9999 -9999 -9999 -9999 -9999 -9999 -9999 -9999 -9999 -9999 -9999 -9999 -9999 -9999 -9999 -9999 -9999 -9999 -9999 -9999 -9999 -9999 -9999 -9999 -9999 -9999 -9999 -9999 -9999 -9999 -9999 -9999 -9999 -9999 -9999 -9999 -9999 -9999 -9999 -9999 -9999 -9999 -9999 -9999 -9999 -9999 -9999 -9999 -9999

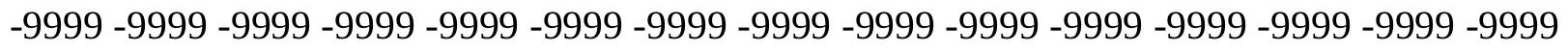
-9999 -9999 -9999 -9999 -9999 -9999 -9999 -9999 -9999 -9999 -9999 -9999 -9999 -9999 -9999 -

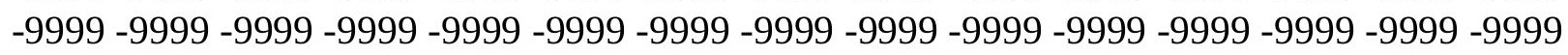

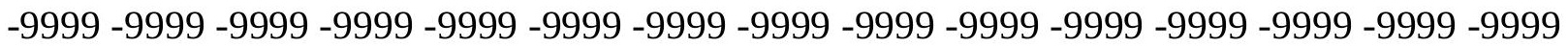

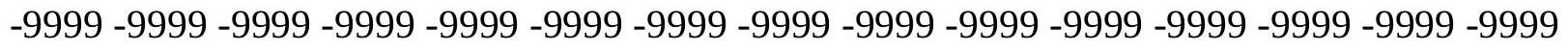

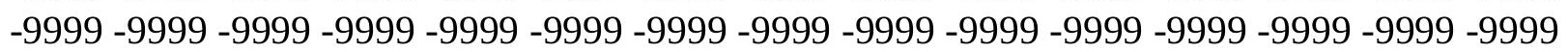

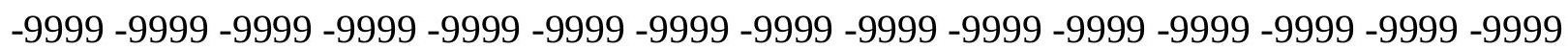
-9999 -9999 -9999 -9999 -9999 -9999 -9999 -9999 -9999 -9999 -9999 -9999-9999-9999-9999 -999 -9999 -9999 -9999 -9999 -9999 -9999 -9999 -9999 -9999 -9999 -9999 -9999 -9999 -9999 -9999 -9999 -9999 -9999 -9999-9999 -9999-9999 115.818397522114 .9039993286113 .9896011353 113.075302124112 .1608963013111 .24659729110 .3321990967109 .4179000854 108.5035018921107 .5891036987106 .6747970581105 .7603988647104 .8460998535 103.9317016602103 .3221969604102 .4077987671101 .4934005737100 .5791015625 99.66472625732 99.0551681518698.1408081054797.2264633178796.31210327148 95.397743225194 .4833908081193 .5690307617292 .9594726562592 .3498916626 91.7403335571391 .1307525634890 .2164001464889 .302040100188 .38768768311 87.1685485839885 .9494018554784 .4254837036182 .5967712402380 .76805877686 96.00731658936110 .9418029785123 .43800354132 .5814971924139 .2868041992 143.5538024902146 .2969055176148 .1255950928149 .0399017334149 .6495056152 149.9542999268150 .2590942383150 .5639038086151 .1734008789152 .0877990723 153.3069000244154 .8307952881156 .9642944336159 .0977935791161 .2312927246 163.6696014404165 .8031005859168 .241394043170 .3748931885172 .5084075928 174.9467010498176 .7754058838178 .9089050293181 .0424041748182 .87109375 184.699798584186 .528503418188 .3571929932190 .1858978271192 .0146026611 193.8433074951195 .6721038818197 .500793457199 .329498291201 .158203125 202.9868927002 59.73788070679 -9999 -9999 -9999 -9999 -9999 -9999 -9999 -9999 -9999 -9999 -9999 -9999 -9999-9999 -9999 -9999 -9999

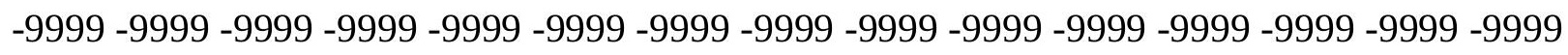
-9999 -9999 -9999 -9999 -9999 -9999 -9999 -9999 -9999 -9999 -9999 -9999 -9999 -9999 -9999 -9999 -9999 -9999 -9999 -9999 -9999 -9999 -9999 -9999 -9999 -9999 -9999 -9999 -9999 -9999 -

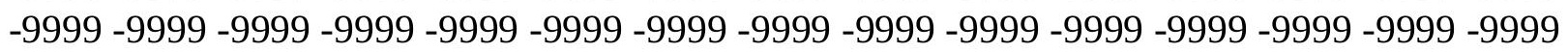


-9999 -9999 -9999 -9999 -9999 -9999 -9999 -9999 -9999 -9999 -9999 -9999 -9999 -9999 -9999 -9999 -9999 -9999 -9999 -9999 -9999 -9999 -9999 -9999 -9999 -9999 -9999 -9999 -9999 -9999 -9999 -9999 -9999 -9999 -9999 -9999 -9999 -9999 -9999 -9999 -9999 -9999 -9999 -9999 -9999 -9999 -9999 -9999 -9999 -9999 -9999 -9999 -9999 -9999 -9999 -9999 -9999 -9999 -9999 -9999 -9999 -9999 -9999 -9999 -9999 -9999 -9999 -9999 -9999 -9999 -9999 -9999 -9999 -9999 -9999 -9999 -9999 -9999 -9999 -9999 -9999 -9999 -9999 -9999 -9999 -9999 -9999 -9999 -9999 -9999 -9999 -9999 -9999 -9999 -9999 -9999 -9999 -9999 -9999 -9999 -9999 -9999 -9999 -9999 -9999

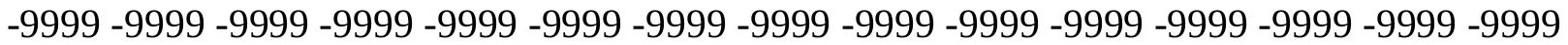
-9999 -9999 -9999 -9999 -9999 -9999 -9999 -9999 -9999 -9999 -9999 -9999 -9999 -9999 -9999 -9999 -9999 -9999 -9999 -9999 -9999 -9999 -9999 -9999 -9999 -9999 -9999 -9999 -9999 -9999 -

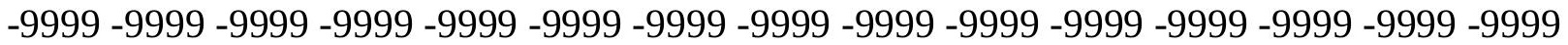
-9999 -9999 -9999 -9999 -9999 -9999 -9999 -9999 -9999 -9999 -9999 -9999 -9999 -9999 -9999

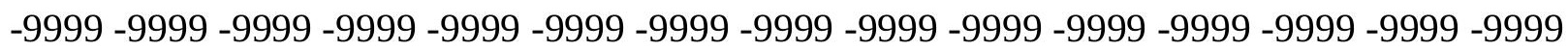
-9999 -9999 -9999 -9999 -9999 -9999 -9999 -9999 -9999 -9999 -9999 -9999 -9999 -9999 -9999 -9999 -9999 -9999 -9999 -9999 -9999 -9999 -9999 -9999 -9999 -9999 -9999 -9999 -9999 -9999 -9999 -9999 -9999 -9999 -9999 -9999 -9999 -9999 114.9039993286113 .9896011353 113.075302124112 .1608963013111 .24659729110 .3321990967109 .4179000854 108.5035018921107 .5891036987106 .6747970581105 .7603988647104 .8460998535 104.2365036011103 .3221969604102 .4077987671101 .4934005737100 .5791015625 99.6647262573299 .0551681518698 .1408081054797 .2264633178796 .31210327148 95.397743225194 .4833908081193 .5690307617292 .9594726562592 .3498916626 91.4355392456190 .8259735107489 .9116134643689 .302040100188 .08290100098 86.8637619018685 .6446228027384 .1206970214882 .2919769287181 .68241119385 94.78817749023108 .5035018921120 .3900985718130 .1432037354136 .8484954834 141.4203033447144 .4682006836146 .2969055176147 .5160064697148 .1255950928 148.7351074219149 .0399017334149 .3446960449149 .9542999268150 .5639038086 151.4781951904153 .0021057129154 .8307952881156 .6596069336158 .7929992676 160.9264984131163 .3648071289165 .4983062744167 .6318054199169 .7653045654 171.8988037109173 .7274932861175 .8609924316177 .6896972656179 .8231964111 181.6519012451183 .4806976318185 .3094024658187 .1381072998188 .966796875 190.795501709192 .624206543194 .4528961182196 .2816009521198 .1103057861 60.0426712036118 .03849411011 -9999 -9999 -9999 -9999 -9999 -9999 -9999 -9999 -9999 -9999 -9999 -9999 -9999 -9999 -9999-9999 -9999

-9999 -9999 -9999 -9999 -9999 -9999 -9999 -9999 -9999 -9999 -9999 -9999 -9999 -9999 -9999

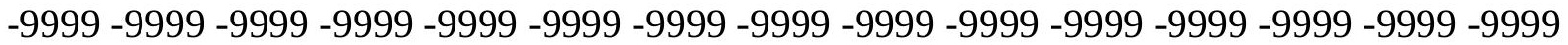
-9999 -9999 -9999 -9999 -9999 -9999 -9999 -9999 -9999 -9999 -9999 -9999 -9999 -9999 -9999 -9999 -9999 -9999 -9999 -9999 -9999 -9999 -9999 -9999 -9999 -9999 -9999 -9999 -9999 -9999

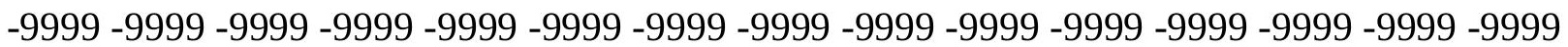
-9999 -9999 -9999 -9999 -9999 -9999 -9999 -9999 -9999 -9999 -9999 -9999 -9999 -9999 -9999 -9999 -9999 -9999 -9999 -9999 -9999 -9999 -9999 -9999 -9999 -9999 -9999 -9999 -9999 -9999 -9999 -9999 -9999 -9999 -9999 -9999 -9999 -9999 -9999 -9999 -9999 -9999 -9999 -9999 -9999

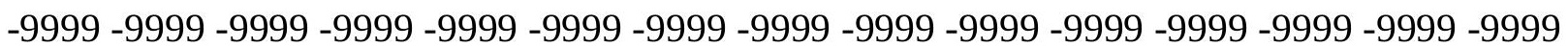
-9999 -9999 -9999 -9999 -9999 -9999 -9999 -9999 -9999 -9999 -9999 -9999 -9999 -9999 -9999 -9999 -9999 -9999 -9999 -9999 -9999 -9999 -9999 -9999 -9999 -9999 -9999 -9999 -9999 -9999 -9999 -9999 -9999 -9999 -9999 -9999 -9999 -9999 -9999 -9999 -9999 -9999 -9999 -9999 -9999

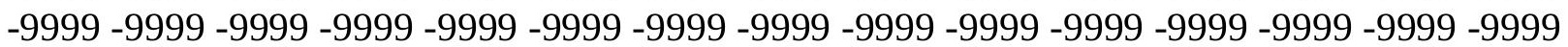


-9999 -9999 -9999 -9999 -9999 -9999 -9999 -9999 -9999 -9999 -9999 -9999 -9999 -9999 -9999 -9999 -9999 -9999 -9999 -9999 -9999 -9999 -9999 -9999 -9999 -9999 -9999 -9999 -9999 -9999 -9999 -9999 -9999 -9999 -9999 -9999 -9999 -9999 -9999 -9999 -9999 -9999 -9999 -9999 -9999 -9999 -9999 -9999 -9999 -9999 -9999 -9999 -9999 -9999 -9999 -9999 -9999 -9999 -9999 -9999 -9999 -9999 -9999 -9999 -9999 -9999 -9999 -9999 -9999 -9999 -9999 -9999 -9999 -9999 -9999 -9999 -9999 -9999 -9999 -9999 -9999 -9999 -9999 -9999 -9999 -9999 -9999 -9999 -9999 -9999 -9999 -9999 -9999 -9999 -9999 -9999 -9999 -9999 -9999 -9999 113.075302124 112.1608963013111 .24659729110 .3321990967109 .4179000854108 .5035018921 107.5891036987 106.6747970581 106.0652008057 105.1509017944104.2365036011 103.3221969604102 .4077987671101 .4934005737100 .579101562599 .96952056885 99.0551681518698 .1408081054797 .2264633178796 .3121032714895 .3977432251 94.7881774902393 .8738174438593 .2642517089892 .349891662691 .74033355713 90.8259735107489 .9116134643688 .9972534179788 .0829010009886 .86376190186 85.3398437583 .8159103393682 .2919769287181 .9871978759894 .17859649658 106.6747970581118 .2565994263127 .7050018311134 .7149963379139 .2868041992 142.3347015381144 .4682006836145 .6873016357146 .6015930176147 .2111968994 147.5160064697148 .1255950928148 .4304046631149 .0399017334149 .9542999268 151.4781951904153 .0021057129154 .8307952881156 .6596069336158 .7929992676 160.6217956543162 .7552947998164 .8887023926167 .0222015381168 .8509979248 170.9844970703172 .8132019043174 .6419067383176 .4705963135178 .2993011475 180.1280059814181 .9566955566183 .7854003906185 .6141052246187 .4429016113 189.2716064453 191.1002960205 192.9290008545194.757705688560.34745025635 -7.81425857544 -9999 -9999 -9999 -9999 -9999 -9999 -9999 -9999 -9999 -9999 -9999 -9999 -9999 -9999 -9999 -9999 -9999

-9999 -9999 -9999 -9999 -9999 -9999 -9999 -9999 -9999 -9999 -9999 -9999 -9999 -9999 -9999 -9999 -9999 -9999 -9999 -9999 -9999 -9999 -9999 -9999 -9999 -9999 -9999 -9999 -9999 -9999 -9999 -9999 -9999 -9999 -9999 -9999 -9999 -9999 -9999 -9999 -9999 -9999 -9999 -9999 -9999 -9999 -9999 -9999 -9999 -9999 -9999 -9999 -9999 -9999 -9999 -9999 -9999 -9999 -9999 -9999 -9999 -9999 -9999 -9999 -9999 -9999 -9999 -9999 -9999 -9999 -9999 -9999 -9999 -9999 -9999 -9999 -9999 -9999 -9999 -9999 -9999 -9999 -9999 -9999 -9999 -9999 -9999 -9999 -9999 -9999 -9999 -9999 -9999 -9999 -9999 -9999 -9999 -9999 -9999 -9999 -9999 -9999 -9999 -9999 -9999 -9999 -9999 -9999 -9999 -9999 -9999 -9999 -9999 -9999 -9999 -9999 -9999 -9999 -9999 -9999 -9999 -9999 -9999 -9999 -9999 -9999 -9999 -9999 -9999 -9999 -9999 -9999 -9999 -9999 -9999 -9999 -9999 -9999 -9999 -9999 -9999 -9999 -9999 -9999 -9999 -9999 -9999 -9999 -9999 -9999 -9999 -9999 -9999 -9999 -9999 -9999 -9999 -9999 -9999 -9999 -9999 -9999 -9999 -9999 -9999 -9999 -9999 -9999 -9999 -9999 -9999 -9999 -9999 -9999 -9999 -9999 -9999 -9999 -9999 -9999

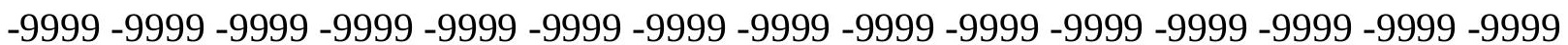

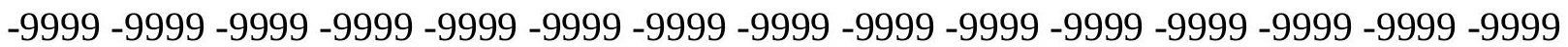
-9999 -9999 -9999 -9999 -9999 -9999 -9999 -9999 -9999 -9999 -9999 -9999 -9999 -9999 -9999 -9999 -9999 -9999 -9999 -9999 -9999 -9999 -9999 -9999 -9999 -9999 -9999 -9999 -9999 -9999 -9999 -9999 -9999 -9999 -9999 -9999 -9999 -9999 -9999 -9999 -9999 -9999 -9999 -9999 -9999

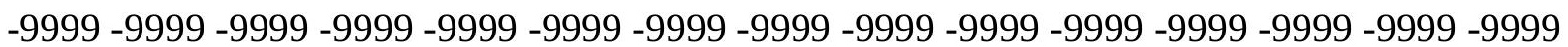
-9999 -9999 -9999 -9999 -9999 -9999 -9999 -9999 -9999 -9999 -9999 -9999 -9999 -9999 -9999 -9999 -9999 -9999 -9999 -9999 -9999 -9999 -9999 -9999 -9999 -9999 112.1608963013 111.24659729110 .3321990967109 .4179000854108 .5035018921107 .8938980103 106.979598999106 .0652008057105 .1509017944104 .2365036011103 .3221969604 
102.4077987671101 .7982025146100 .883903503499 .9695205688599 .05516815186 98.445587158297 .5312423706196 .6168823242295 .7025299072395 .09295654297 94.1785964965893 .2642517089892 .6546783447391 .7403335571390 .82597351074 89.9116134643688 .9972534179788 .0829010009886 .8637619018685 .33984375 83.8159103393682 .2919769287182 .5967712402393 .56903076172105 .1509017944 116.1231002808125 .8762969971131 .9720001221136 .5437011719139 .5915985107 142.0299072266143 .5538024902144 .4682006836145 .3825073242145 .9920959473 146.2969055176146 .9064025879147 .5160064697148 .4304046631149 .6495056152 151.1734008789152 .6972961426154 .5260925293156 .3547973633158 .1835021973 160.3170013428162 .1457061768163 .974395752166 .1078948975167 .9365997314 169.7653045654171 .5939941406173 .4226989746175 .2514038086177 .0802001953 178.9089050293180 .7375946045182 .5662994385184 .3950042725186 .2236938477 188.0523986816189 .8811035156191 .709793090860 .65224075317 -12.1321134567 -9999 -9999 -9999 -9999 -9999 -9999 -9999 -9999 -9999 -9999 -9999 -9999 -9999 -9999 -9999 -9999 $-9999$

-9999 -9999 -9999 -9999 -9999 -9999 -9999 -9999 -9999 -9999 -9999 -9999 -9999 -9999 -9999

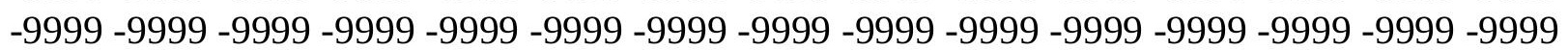
-9999 -9999 -9999 -9999 -9999 -9999 -9999 -9999 -9999 -9999 -9999 -9999 -9999 -9999 -9999 -9999 -9999 -9999 -9999 -9999 -9999 -9999 -9999 -9999 -9999 -9999 -9999 -9999 -9999 -9999 -9999 -9999 -9999 -9999 -9999 -9999 -9999 -9999 -9999 -9999 -9999 -9999 -9999 -9999 -9999 -9999 -9999 -9999 -9999 -9999 -9999 -9999 -9999 -9999 -9999 -9999 -9999 -9999 -9999 -9999 -9999 -9999 -9999 -9999 -9999 -9999 -9999 -9999 -9999 -9999 -9999 -9999 -9999 -9999 -9999 -9999 -9999 -9999 -9999 -9999 -9999 -9999 -9999 -9999 -9999 -9999 -9999-9999-9999-9999 -999 -9999 -9999 -9999 -9999 -9999 -9999 -9999 -9999 -9999 -9999 -9999 -9999 -9999 -9999 -9999 -9999 -9999 -9999 -9999 -9999 -9999 -9999 -9999 -9999 -9999 -9999 -9999 -9999 -9999 -9999 -9999 -9999 -9999 -9999 -9999 -9999 -9999 -9999 -9999 -9999 -9999 -9999 -9999 -9999 -9999 -9999 -9999 -9999 -9999 -9999 -9999 -9999 -9999 -9999 -9999 -9999 -9999 -9999 -9999 -9999

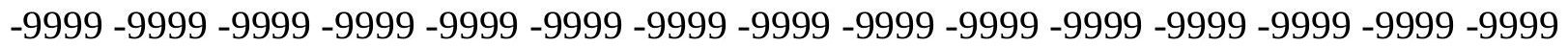
-9999 -9999 -9999 -9999 -9999 -9999 -9999 -9999 -9999 -9999 -9999 -9999 -9999 -9999 -9999 -9999 -9999 -9999 -9999 -9999 -9999 -9999 -9999 -9999 -9999 -9999 -9999 -9999 -9999 -9999 -999 -9999 -9999 -9999 -9999 -9999 -9999 -9999 -9999 -9999 -9999 -9999 -9999 -9999 -9999 -9999

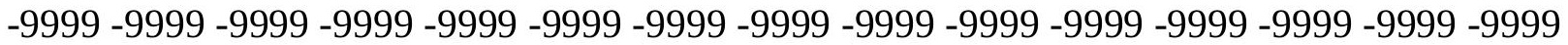

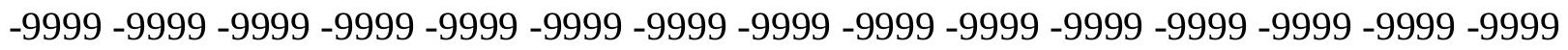
-9999 -9999 -9999 -9999 -9999 -9999 -9999 -9999 -9999 -9999 -9999 -9999 -9999 -9999 -9999 -999 -9999 -9999 -9999 -9999 -9999 -9999 -9999 -9999 -9999 -9999 -9999 -9999 -9999 110.3321990967109 .4179000854108 .5035018921107 .8938980103106 .979598999 106.0652008057105 .1509017944104 .2365036011103 .6268997192102 .712600708 101.7982025146100 .8839035034100 .274299621699 .3599472045998 .4455871582 97.8360290527396 .9216690063596 .0073165893695 .397743225194 .48339080811 93.5690307617292 .9594726562592 .0450973510791 .1307525634890 .21640014648 89.302040100188 .0829010009890 .5211791992287 .1685485839884 .12069702148 82.5967712402383 .5111236572393 .56903076172103 .9317016602113 .9896011353 122.5235977173128 .9241027832133 .4958953857136 .8484954834139 .2868041992 140.8106994629142 .3347015381143 .2489929199143 .8585968018144 .4682006836 145.3825073242145 .9920959473146 .9064025879148 .1255950928149 .3446960449 150.8686065674152 .3925933838154 .2212982178156 .0500030518157 .5738983154 
159.4026031494161 .2312927246163 .0599975586164 .8887023926166 .7174987793 168.5462036133170 .3748931885172 .2035980225174 .0323028564175 .8609924316 177.6896972656179 .5184020996181 .0424041748182 .87109375184 .699798584

186.528503418188 .357192993260 .65224075317 -9999 -9999 -9999 -9999 -9999 -9999 -9999 -9999 -9999 -9999 -9999 -9999 -9999 -9999 -9999 -9999 -9999 -9999

-9999 -9999 -9999 -9999 -9999 -9999 -9999 -9999 -9999 -9999 -9999 -9999 -9999 -9999 -9999

-9999 -9999 -9999 -9999 -9999 -9999 -9999 -9999 -9999 -9999 -9999 -9999 -9999 -9999 -9999 -9999 -9999 -9999 -9999 -9999 -9999 -9999 -9999 -9999 -9999 -9999 -9999 -9999 -9999 -9999

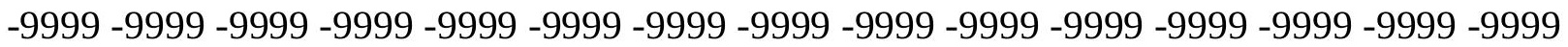
-9999 -9999 -9999 -9999 -9999 -9999 -9999 -9999 -9999 -9999 -9999 -9999 -9999 -9999 -9999

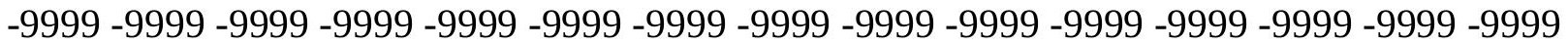
-9999 -9999 -9999 -9999 -9999 -9999 -9999 -9999 -9999 -9999 -9999 -9999 -9999 -9999 -9999 -9999 -9999 -9999 -9999 -9999 -9999 -9999 -9999 -9999 -9999 -9999 -9999 -9999 -9999 -9999 -9999 -9999 -9999 -9999 -9999 -9999 -9999 -9999 -9999 -9999 -9999 -9999 -9999 -9999 -9999 -9999 -9999 -9999 -9999 -9999 -9999 -9999 -9999 -9999 -9999 -9999 -9999 -9999 -9999 -9999

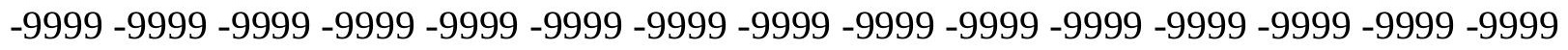

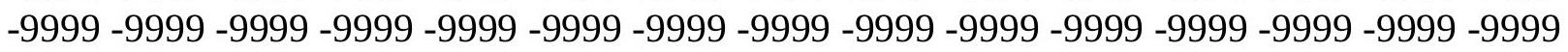

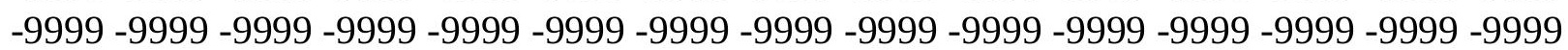

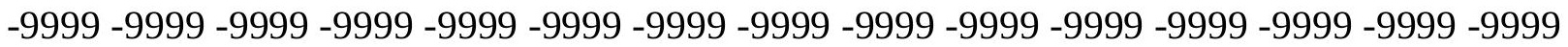
-9999 -9999 -9999 -9999 -9999 -9999 -9999 -9999 -9999 -9999 -9999 -9999 -9999 -9999 -9999 -

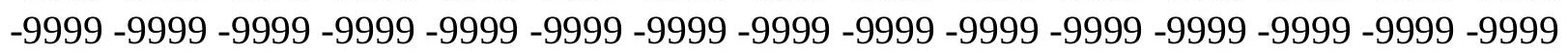

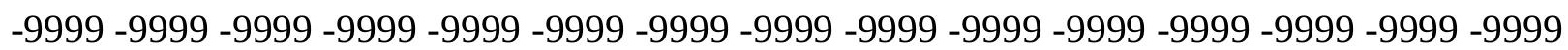
-9999 -9999 -9999 -9999 -9999 -9999 -9999 -9999 -9999 -9999 -9999 -9999-9999-9999-9999 -999 -9999 -9999 -9999 -9999 -9999 -9999 -9999 -9999 -9999 -9999 -9999 -9999 -9999 -9999 -9999 -9999 -9999 -9999 -9999 -9999 -9999 -9999 -9999 -9999 -9999 -9999 -9999 -9999 -9999 109.4179000854108 .5035018921107 .8938980103106 .979598999106 .0652008057 105.1509017944104 .5412979126103 .6268997192102 .712600708102 .1029968262 101.1886978149100 .274299621699 .6647262573298 .7503814697398 .14080810547 97.2264633178796 .6168823242295 .7025299072394 .7881774902394 .17859649658 93.2642517089892 .349891662691 .4355392456190 .5211791992289 .60682678223 88.3876876831187 .1685485839895 .0929565429784 .4254837036182 .59677124023 84.1206970214893 .26425170898102 .4077987671111 .551399231119 .1709976196 125.5715026855130 .1432037354133 .8007049561136 .2389984131138 .3724975586 139.5915985107140 .8106994629141 .7250976562142 .6394042969143 .5538024902 144.1634063721145 .0776977539146 .2969055176147 .5160064697148 .7351074219 150.2590942383151 .7830047607153 .6116943359155 .1356048584156 .9642944336 158.7929992676160 .3170013428162 .1457061768163 .974395752165 .4983062744 167.3269958496169 .1557006836170 .9844970703172 .8132019043174 .6419067383 176.165802002177 .9945068359179 .8231964111181 .6519012451183 .4806976318 60.9570198059124 .3300151825 -9999 -9999 -9999 -9999 -9999 -9999 -9999 -9999 -9999 -9999 -9999 -9999 -9999 -9999 -9999 -9999 -9999 -9999

-9999 -9999 -9999 -9999 -9999 -9999 -9999 -9999 -9999 -9999 -9999 -9999 -9999 -9999 -9999 -9999 -9999 -9999 -9999 -9999 -9999 -9999 -9999 -9999 -9999 -9999 -9999 -9999 -9999 -9999 -9999 -9999 -9999 -9999 -9999 -9999 -9999 -9999 -9999 -9999 -9999 -9999 -9999 -9999 -9999 -

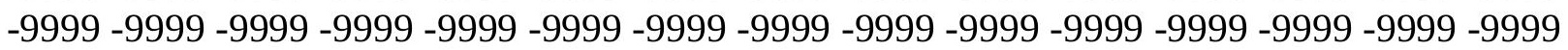

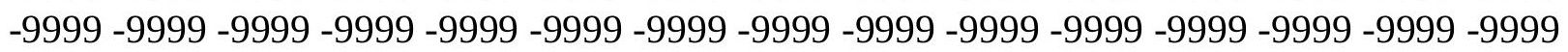


-9999 -9999 -9999 -9999 -9999 -9999 -9999 -9999 -9999 -9999 -9999 -9999 -9999 -9999 -9999 -9999 -9999 -9999 -9999 -9999 -9999 -9999 -9999 -9999 -9999 -9999 -9999 -9999 -9999 -9999 -9999 -9999 -9999 -9999 -9999 -9999 -9999 -9999 -9999 -9999 -9999 -9999 -9999 -9999 -9999 -9999 -9999 -9999 -9999 -9999 -9999 -9999 -9999 -9999 -9999 -9999 -9999 -9999 -9999 -9999 -9999 -9999 -9999 -9999 -9999 -9999 -9999 -9999 -9999 -9999 -9999 -9999 -9999 -9999 -9999 -9999 -9999 -9999 -9999 -9999 -9999 -9999 -9999 -9999 -9999 -9999 -9999 -9999 -9999 -9999 -9999 -9999 -9999 -9999 -9999 -9999 -9999 -9999 -9999 -9999 -9999 -9999 -9999 -9999 -9999

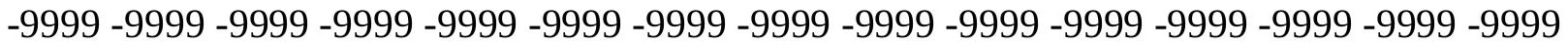
-9999 -9999 -9999 -9999 -9999 -9999 -9999 -9999 -9999 -9999 -9999 -9999 -9999 -9999 -9999 -9999 -9999 -9999 -9999 -9999 -9999 -9999 -9999 -9999 -9999 -9999 -9999 -9999 -9999 -9999 -

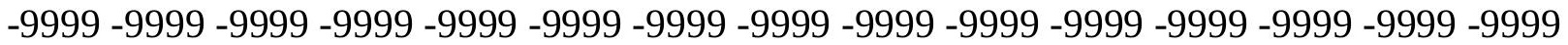
-9999 -9999 -9999 -9999 -9999 -9999 -9999 -9999 -9999 -9999 -9999 -9999 -9999 -9999 -9999

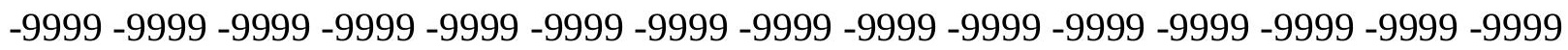
-9999 -9999 -9999 -9999 -9999 -9999 -9999 -9999 -9999 -9999 -9999 -9999 -9999 -9999 -9999 -9999 -9999 -9999 -9999 -9999 -9999 -9999 -9999 -9999 -9999 -9999 -9999 -9999 -9999 -9999 -9999 107.8938980103106.979598999 106.0652008057 105.4557037354104.5412979126 103.6268997192103 .0174026489102 .1029968262101 .4934005737100 .5791015625 99.9695205688599 .0551681518698 .445587158297 .8360290527396 .92166900635 96.3121032714895 .397743225194 .4833908081193 .8738174438592 .95947265625 92.0450973510791 .1307525634889 .9116134643688 .6924667358487 .47332763672 86.254188537684 .7302627563583 .206336975184 .7302627563592 .95947265625 101.1886978149109 .1130981445116 .4279022217122 .2188034058127 .0953979492 130.4479980469133 .1911010742135 .3246002197137 .1533050537138 .3724975586 139.5915985107140 .5059967041141 .4203033447142 .3347015381143 .2489929199 144.4682006836145 .6873016357146 .9064025879148 .1255950928149 .6495056152 151.1734008789152 .6972961426154 .5260925293156 .0500030518157 .5738983154 159.4026031494160 .9264984131162 .7552947998164 .2792053223166 .1078948975 167.9365997314169 .7653045654171 .2891998291173 .1179962158174 .9467010498 176.7754058838178 .604095459180 .128005981461 .261810302732 .903485298157 -9999 -9999 -9999 -9999 -9999 -9999 -9999 -9999 -9999 -9999 -9999 -9999 -9999 -9999 -9999 -9999 $-9999-9999$

-9999 -9999 -9999 -9999 -9999 -9999 -9999 -9999 -9999 -9999 -9999 -9999 -9999 -9999 -9999 -9999 -9999 -9999 -9999 -9999 -9999 -9999 -9999 -9999 -9999 -9999 -9999 -9999 -9999 -9999 -9999 -9999 -9999 -9999 -9999 -9999 -9999 -9999 -9999 -9999 -9999 -9999 -9999 -9999 -9999 -

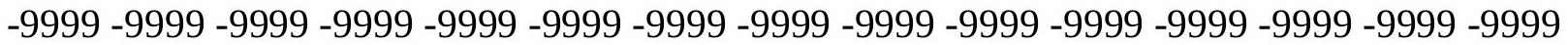
-9999 -9999 -9999 -9999 -9999 -9999 -9999 -9999 -9999 -9999 -9999 -9999 -9999 -9999 -9999 -9999 -9999 -9999 -9999 -9999 -9999 -9999 -9999 -9999 -9999 -9999 -9999 -9999 -9999 -9999

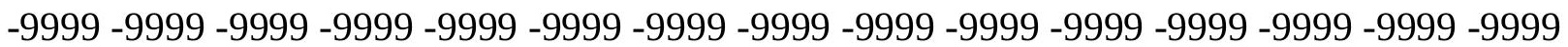
-9999 -9999 -9999 -9999 -9999 -9999 -9999 -9999 -9999 -9999 -9999 -9999 -9999 -9999 -9999 -9999 -9999 -9999 -9999 -9999 -9999 -9999 -9999 -9999 -9999 -9999 -9999 -9999 -9999 -9999 -9999 -9999 -9999 -9999 -9999 -9999 -9999 -9999 -9999 -9999 -9999 -9999 -9999 -9999 -9999 -999 -9999 -9999 -9999 -9999 -9999 -9999 -9999 -9999 -9999 -9999 -9999 -9999 -9999 -9999 -9999 -9999 -9999 -9999 -9999 -9999 -9999 -9999 -9999 -9999 -9999 -9999 -9999 -9999 -9999 -9999 -9999 -9999 -9999 -9999 -9999 -9999 -9999 -9999 -9999 -9999 -9999 -9999 -9999 -9999 -9999 -999 -9999 -9999 -9999 -9999 -9999 -9999 -9999 -9999 -9999 -9999 -9999 -9999 -9999 -9999 -9999

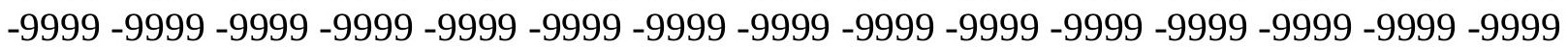


-9999 -9999 -9999 -9999 -9999 -9999 -9999 -9999 -9999 -9999 -9999 -9999 -9999 -9999 -9999 -9999 -9999 -9999 -9999 -9999 -9999 -9999 -9999 -9999 -9999 -9999 -9999 -9999 -9999 -9999

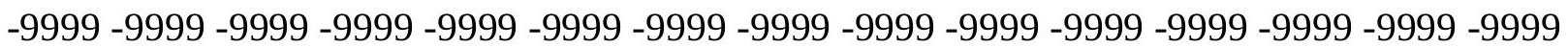
-9999 -9999 -9999 -9999 -9999 -9999 -9999 -9999 -9999 -9999 -9999 -9999 -9999 -9999 -9999 -9999 -9999 -9999 -9999 -9999 -9999 -9999 -9999 -9999 -9999 -9999 -9999 -9999 -9999 -9999 -9999 -9999 106.979598999 106.0652008057 105.4557037354104.5412979126 103.9317016602103 .3221969604102 .4077987671101 .7982025146100 .8839035034 100.274299621699 .6647262573298 .7503814697398 .1408081054797 .53124237061 96.6168823242296 .0073165893695 .0929565429794 .4833908081193 .56903076172 92.6546783447391 .4355392456190 .5211791992289 .302040100188 .08290100098 86.5589828491285 .3398437583 .8159103393685 .0350494384892 .65467834473 99.96952056885107 .2844009399113 .6848983765119 .1709976196123 .7427978516 127.4001998901130 .4479980469132 .5814971924134 .4102020264135 .9342041016 137.1533050537138 .0677032471139 .2868041992140 .2012023926141 .4203033447 142.3347015381143 .5538024902144 .7729034424145 .9920959473147 .5160064697 149.0399017334150 .2590942383151 .7830047607153 .3069000244154 .8307952881 156.6596069336158 .1835021973159 .7073974609161 .5361022949163 .0599975586 164.8887023926166 .7174987793168 .241394043170 .070098877171 .8988037109 173.7274932861175 .2514038086177 .080200195361 .56660079956 -9999 -9999 -9999 -9999 -9999 -9999 -9999 -9999 -9999 -9999 -9999 -9999 -9999 -9999 -9999 -9999 -9999 -9999 -9999 -9999 -9999 -9999 -9999 -9999 -9999 -9999 -9999 -9999 -9999 -9999 -9999 -9999 -9999 -9999 -999 -9999 -9999 -9999 -9999 -9999 -9999 -9999 -9999 -9999 -9999 -9999 -9999 -9999 -9999 -9999 -9999 -9999 -9999 -9999 -9999 -9999 -9999 -9999 -9999 -9999 -9999 -9999 -9999 -9999 -9999 -9999 -9999 -9999 -9999 -9999 -9999 -9999 -9999 -9999 -9999 -9999 -9999 -9999 -9999 -9999 -9999 -9999 -9999 -9999 -9999 -9999 -9999 -9999 -9999 -9999 -9999 -9999 -9999 -9999 -9999 -9999 -9999 -9999 -9999 -9999 -9999 -9999 -9999 -9999 -9999 -9999 -9999 -9999 -9999 -9999 -9999 -9999 -9999 -9999 -9999 -9999 -9999 -9999 -9999 -9999 -9999 -9999 -9999 -9999 -9999 -9999 -9999 -9999 -9999 -9999 -9999 -9999 -9999 -9999 -9999 -9999 -9999 -9999 -9999 -9999 -9999 -9999 -9999 -9999 -9999 -9999 -9999 -9999 -9999 -9999 -9999 -9999 -9999-999 -999 -9999 -9999 -9999 -9999 -9999 -9999 -9999 -9999 -9999 -9999 -9999 -9999 -9999 -9999 -9999 -9999 -9999 -9999 -9999 -9999 -9999 -9999 -9999 -9999 -9999 -9999 -9999 -9999 -9999 -9999 -9999 -9999 -9999 -9999 -9999 -9999 -9999 -9999 -9999 -9999 -9999 -9999 -9999 -9999 -9999 -9999 -9999 -9999 -9999 -9999 -9999 -9999 -9999 -9999 -9999 -9999 -9999 -9999 -9999 -9999 -9999 -9999 -9999 -9999 -9999 -9999 -9999 -9999 -9999 -9999 -9999 -9999 -9999 -9999 -9999 -9999 -9999 -9999 -9999 -9999 -9999 -9999 -9999 -9999 -9999 -9999 -9999 -9999 -9999 -9999 -9999 -9999 -9999 -9999 -9999 -9999 -9999 -9999 -9999 -9999 -9999 -9999 -9999 -9999 -9999 -

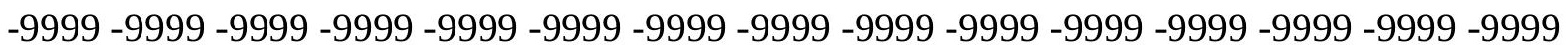
-9999 -9999 -9999 -9999 -9999 -9999 -9999 -9999 -9999 -9999 -9999 -9999 -9999 -9999 -9999 -9999 -9999 -9999 -9999 -9999 -9999 -9999 -9999 -9999 -9999 -9999 -9999 -9999 -9999 -9999 -9999 -9999 -9999 -9999 -9999 -9999 -9999 -9999 -9999 -9999 -9999 -9999 -9999 -9999 -9999 -9999 -9999 -9999 -9999 105.4557037354 104.8460998535104.2365036011 103.3221969604 102.712600708102 .1029968262101 .1886978149100 .579101562599 .96952056885 99.3599472045998 .7503814697397 .8360290527397 .2264633178796 .61688232422 95.7025299072395 .0929565429794 .1785964965893 .2642517089892 .04509735107 91.1307525634889 .9116134643688 .6924667358487 .1685485839885 .94940185547 84.4254837036185 .6446228027392 .349891662699 .05516815186105 .7603988647 
111.551399231116 .7326965332120 .9997024536124 .6570968628127 .4001998901 129.8385009766131 .6672058105133 .1911010742134 .7149963379135 .9342041016 137.1533050537138 .0677032471139 .2868041992140 .2012023926141 .4203033447 142.6394042969143 .8585968018145 .3825073242146 .6015930176148 .1255950928 149.3446960449150 .8686065674152 .3925933838153 .9165039062155 .1356048584 156.9642944336158 .4882965088160 .0122070312161 .8408966064163 .6696014404 165.4983062744167 .0222015381168 .8509979248170 .3748931885172 .2035980225 61.8713798522929 .69860649109 -9999 -9999 -9999 -9999 -9999 -9999 -9999 -9999 -9999 -9999 -9999 -9999 -9999 -9999 -9999 -9999 -9999 -9999 -9999 -9999 -9999 -9999 -9999 -9999 -9999 -9999 -9999 -9999 -9999 -9999 -9999 -9999 -9999 -9999 -9999 -9999 -9999 -9999 -9999 -9999 -9999 -9999 -9999 -9999 -9999 -9999 -9999 -9999 -9999 -9999 -9999 -9999 -9999 -9999 -9999 -9999 -9999 -9999 -9999 -9999 -9999 -9999 -9999 -9999 -9999 -9999 -9999 -9999 -9999 -9999 -9999 -9999 -9999 -9999 -9999 -9999 -9999 -9999 -9999 -9999 -9999 -9999 -9999 -9999 -9999 -9999 -9999 -9999 -9999 -9999 -9999 -9999 -9999 -9999 -9999 -9999 -9999 -9999 -9999 -9999 -9999 -9999 -9999 -9999 -9999 -9999 -9999 -9999 -9999 -9999 -9999 -9999 -9999 -9999 -9999 -9999 -9999 -9999 -9999 -9999 -9999 -9999 -9999 -9999

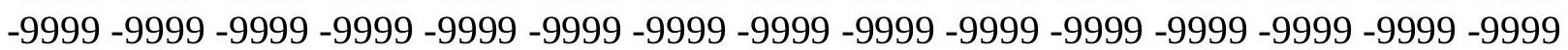
-9999 -9999 -9999 -9999 -9999 -9999 -9999 -9999 -9999 -9999 -9999 -9999 -9999 -9999 -9999 -9999 -9999 -9999 -9999 -9999 -9999 -9999 -9999 -9999 -9999 -9999 -9999 -9999 -9999 -9999 -9999 -9999 -9999 -9999 -9999 -9999 -9999 -9999 -9999 -9999 -9999 -9999 -9999 -9999 -9999

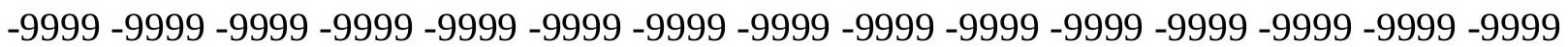
-9999 -9999 -9999 -9999 -9999 -9999 -9999 -9999 -9999 -9999 -9999 -9999 -9999 -9999 -9999 -9999 -9999 -9999 -9999 -9999 -9999 -9999 -9999 -9999 -9999 -9999 -9999 -9999 -9999 -9999 -9999 -9999 -9999 -9999 -9999 -9999 -9999 -9999 -9999 -9999 -9999 -9999 -9999 -9999 -9999

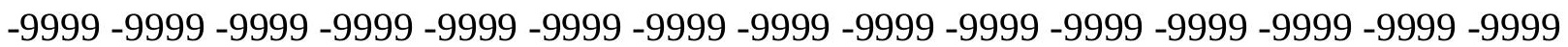
-9999 -9999 -9999 -9999 -9999 -9999 -9999 -9999 -9999 -9999 -9999 -9999 -9999 -9999 -9999 -9999 -9999 -9999 -9999 -9999 -9999 -9999 -9999 -9999 -9999 -9999 -9999 -9999 -9999 -9999 -9999 -9999 -9999 -9999 -9999 -9999 -9999 -9999 -9999 -9999 -9999 -9999 -9999 -9999 -9999

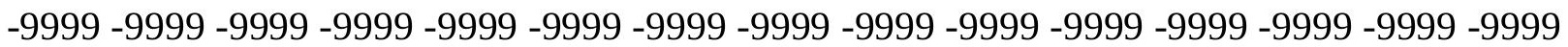
-9999 -9999 -9999 -9999 -9999 104.8460998535104.2365036011 103.6268997192 103.0174026489102 .4077987671101 .7982025146101 .1886978149100 .2742996216 99.6647262573299 .0551681518698 .445587158297 .8360290527397 .22646331787 96.3121032714895 .7025299072394 .7881774902393 .8738174438592 .95947265625 91.7403335571390 .5211791992289 .302040100188 .0829010009886 .55898284912 85.0350494384886 .254188537692 .349891662698 .4455871582104 .2365036011 109.7226028442114 .2944030762118 .5614013672121 .9140014648124 .6570968628 127.0953979492128 .9241027832130 .7528076172132 .2767028809133 .4958953857 134.7149963379135 .9342041016137 .1533050537138 .0677032471139 .2868041992 140.5059967041141 .7250976562142 .9441986084144 .1634063721145 .6873016357 146.9064025879148 .4304046631149 .6495056152151 .1734008789152 .3925933838 153.9165039062155 .4403991699157 .2691040039159 .0977935791160 .6217956543 162.4505004883163 .974395752165 .8031005859167 .3269958496169 .1557006836 62.4809494018612 .95928668976 -9999 -9999 -9999 -9999 -9999 -9999 -9999 -9999 -9999 -9999 -9999 -9999 -9999 -9999 -9999 -9999 -9999 -9999 -9999 -9999 -9999 -9999 -9999 -9999 -9999 -9999 -9999 -9999 -9999 -9999 -9999 -9999 -9999 -9999 -9999 -9999 -9999 -9999 -9999 -9999 -9999 -9999 -9999 -9999 -9999 -9999 -9999 -9999 -9999 
-9999 -9999 -9999 -9999 -9999 -9999 -9999 -9999 -9999 -9999 -9999 -9999 -9999 -9999 -9999 -9999 -9999 -9999 -9999 -9999 -9999 -9999 -9999 -9999 -9999 -9999 -9999 -9999 -9999 -9999 -9999 -9999 -9999 -9999 -9999 -9999 -9999 -9999 -9999 -9999 -9999 -9999 -9999 -9999 -9999 -9999 -9999 -9999 -9999 -9999 -9999 -9999 -9999 -9999 -9999 -9999 -9999 -9999 -9999 -9999 -9999 -9999 -9999 -9999 -9999 -9999 -9999 -9999 -9999 -9999 -9999 -9999 -9999 -9999 -9999 -9999 -9999 -9999 -9999 -9999 -9999 -9999 -9999 -9999 -9999 -9999 -9999 -9999 -9999 -9999 -9999 -9999 -9999 -9999 -9999 -9999 -9999 -9999 -9999 -9999 -9999 -9999 -9999 -9999 -9999

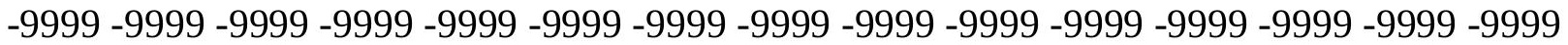
-9999 -9999 -9999 -9999 -9999 -9999 -9999 -9999 -9999 -9999 -9999 -9999 -9999 -9999 -9999 -9999 -9999 -9999 -9999 -9999 -9999 -9999 -9999 -9999 -9999 -9999 -9999 -9999 -9999 -9999 -

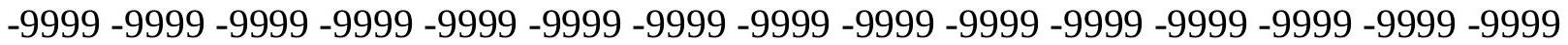
-9999 -9999 -9999 -9999 -9999 -9999 -9999 -9999 -9999 -9999 -9999 -9999 -9999 -9999 -9999

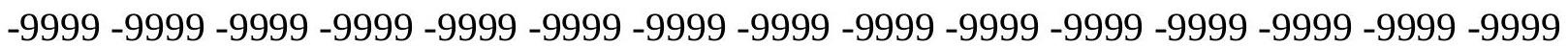
-9999 -9999 -9999 -9999 -9999 -9999 -9999 -9999 -9999 -9999 -9999 -9999 -9999 -9999 -9999 -9999 -9999 -9999 -9999 -9999 -9999 -9999 -9999 -9999 -9999 -9999 -9999 -9999 -9999 -9999 -9999 -9999 -9999 -9999 -9999 -9999 -9999 -9999 -9999 -9999 -9999 -9999 -9999 -9999 -9999 -

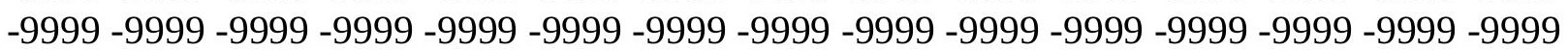
-9999 -9999 -9999 -9999 -9999 -9999 -9999 -9999 -9999 -9999 -9999 -9999 -9999 -9999 -9999 -9999 -9999 -9999 -9999 -9999 -9999 -9999 103.9317016602103 .3221969604102 .712600708 102.1029968262101 .4934005737100 .8839035034100 .274299621699 .66472625732 99.0551681518698 .445587158297 .8360290527397 .2264633178796 .31210327148 95.397743225194 .4833908081193 .5690307617292 .6546783447391 .43553924561 89.9116134643688 .6924667358487 .1685485839885 .6446228027386 .86376190186 92.349891662697 .83602905273103 .0174026489107 .8938980103112 .4656982422 116.1231002808119 .4757995605122 .2188034058124 .3523025513126 .4858016968 128.3144989014129 .8385009766131 .0576019287132 .2767028809133 .8007049561 134.7149963379135 .9342041016137 .1533050537138 .3724975586139 .5915985107 140.8106994629142 .0299072266143 .2489929199144 .4682006836145 .6873016357 147.2111968994148 .4304046631149 .6495056152151 .1734008789152 .6972961426 154.2212982178156 .0500030518157 .878692627159 .4026031494161 .2312927246 162.7552947998164 .5839996338166 .107894897562 .78573989868 -9999 -9999 -9999 -9999 -9999 -9999 -9999 -9999 -9999 -9999 -9999 -9999 -9999 -9999 -9999 -9999 -9999 -9999 -9999 $-9999$

-9999 -9999 -9999 -9999 -9999 -9999 -9999 -9999 -9999 -9999 -9999 -9999 -9999 -9999 -9999 -9999 -9999 -9999 -9999 -9999 -9999 -9999 -9999 -9999 -9999 -9999 -9999 -9999 -9999 -9999 -9999 -9999 -9999 -9999 -9999 -9999 -9999 -9999 -9999 -9999 -9999 -9999 -9999 -9999 -9999 -9999 -9999 -9999 -9999 -9999 -9999 -9999 -9999 -9999 -9999 -9999 -9999 -9999 -9999 -9999

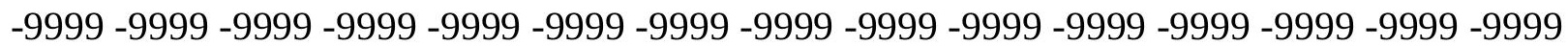
-9999 -9999 -9999 -9999 -9999 -9999 -9999 -9999 -9999 -9999 -9999 -9999 -9999 -9999 -9999 -9999 -9999 -9999 -9999 -9999 -9999 -9999 -9999 -9999 -9999 -9999 -9999 -9999 -9999 -9999 -9999 -9999 -9999 -9999 -9999 -9999 -9999 -9999 -9999 -9999 -9999 -9999 -9999 -9999 -9999 -999 -9999 -9999 -9999 -9999 -9999 -9999 -9999 -9999 -9999 -9999 -9999 -9999 -9999 -9999 -9999 -9999 -9999 -9999 -9999 -9999 -9999 -9999 -9999 -9999 -9999 -9999 -9999 -9999 -9999 -9999 -9999 -9999 -9999 -9999 -9999 -9999 -9999 -9999 -9999 -9999 -9999 -9999 -9999 -9999 -9999 -9999 -9999 -9999 -9999 -9999 -9999 -9999 -9999 -9999 -9999 -9999 -9999 -9999 -9999 -9999

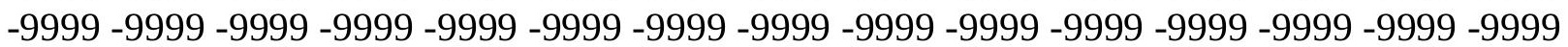


-9999 -9999 -9999 -9999 -9999 -9999 -9999 -9999 -9999 -9999 -9999 -9999 -9999 -9999 -9999 -9999 -9999 -9999 -9999 -9999 -9999 -9999 -9999 -9999 -9999 -9999 -9999 -9999 -9999 -9999 -9999 -9999 -9999 -9999 -9999 -9999 -9999 -9999 -9999 -9999 -9999 -9999 -9999 -9999 -9999 -9999 -9999 -9999 -9999 -9999 -9999 -9999 -9999 -9999 -9999 -9999 -9999 -9999 -9999 -9999 -9999 -9999 -9999 -9999 -9999 -9999 -9999 -9999 -9999 -9999 -9999 -9999 -9999 -9999 -9999 -9999 -9999 -9999 -9999 -9999 -9999 -9999 -9999 -9999 -9999 -9999 -9999 -9999 -9999 -9999 -9999 -9999 -9999 -9999 -9999 -9999 -9999 -9999 -9999 -9999 -9999 -9999 -9999 -9999 -9999 -9999 -9999 -9999 -9999 -9999 -9999 -9999 -9999 103.3221969604103 .0174026489 102.4077987671101 .7982025146101 .1886978149100 .8839035034100 .2742996216 99.6647262573299 .0551681518698 .445587158297 .8360290527397 .22646331787 96.3121032714895 .397743225194 .4833908081193 .2642517089892 .04509735107 90.8259735107489 .6068267822388 .0829010009886 .5589828491287 .77810668945 92.6546783447397 .53124237061102 .4077987671106 .6747970581110 .6370010376 113.9896011353117 .0374984741119 .7806015015121 .9140014648124 .0475006104 125.5715026855127 .4001998901128 .6192932129130 .1432037354131 .3623962402 132.5814971924133 .8007049561135 .0198059082136 .2389984131137 .4580993652 138.3724975586139 .5915985107140 .8106994629142 .0299072266143 .2489929199 144.4682006836145 .6873016357147 .2111968994148 .4304046631149 .9542999268 151.4781951904153 .3069000244154 .8307952881156 .6596069336158 .1835021973 159.7073974609161 .536102294963 .0905189514263 .09051895142 -9999 -9999 -9999 -9999 -9999 -9999 -9999 -9999 -9999 -9999 -9999 -9999 -9999 -9999 -9999 -9999 -9999 -9999 -9999 $-9999$

-9999 -9999 -9999 -9999 -9999 -9999 -9999 -9999 -9999 -9999 -9999 -9999 -9999 -9999 -9999 -9999 -9999 -9999 -9999 -9999 -9999 -9999 -9999 -9999 -9999 -9999 -9999 -9999 -9999 -9999

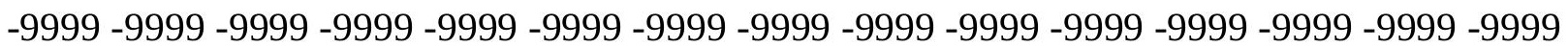
-9999 -9999 -9999 -9999 -9999 -9999 -9999 -9999 -9999 -9999 -9999 -9999 -9999 -9999 -9999 -9999 -9999 -9999 -9999 -9999 -9999 -9999 -9999 -9999 -9999 -9999 -9999 -9999 -9999 -9999 -9999 -9999 -9999 -9999 -9999 -9999 -9999 -9999 -9999 -9999 -9999 -9999 -9999 -9999 -9999 -9999 -9999 -9999 -9999 -9999 -9999 -9999 -9999 -9999 -9999 -9999 -9999 -9999 -9999 -9999 -9999 -9999 -9999 -9999 -9999 -9999 -9999 -9999 -9999 -9999 -9999 -9999 -9999 -9999 -9999 -9999 -9999 -9999 -9999 -9999 -9999 -9999 -9999 -9999 -9999 -9999 -9999 -9999 -9999 -9999 -

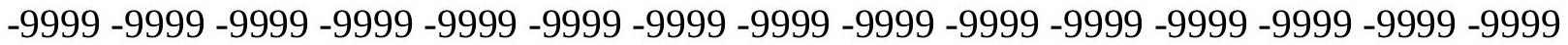
-9999 -9999 -9999 -9999 -9999 -9999 -9999 -9999 -9999 -9999 -9999 -9999 -9999 -9999 -9999 -9999 -9999 -9999 -9999 -9999 -9999 -9999 -9999 -9999 -9999 -9999 -9999 -9999 -9999 -9999 -9999 -9999 -9999 -9999 -9999 -9999 -9999 -9999 -9999 -9999 -9999 -9999 -9999 -9999 -9999 -9999 -9999 -9999 -9999 -9999 -9999 -9999 -9999 -9999 -9999 -9999 -9999 -9999 -9999 -9999 -9999 -9999 -9999 -9999 -9999 -9999 -9999 -9999 -9999 -9999 -9999 -9999 -9999 -9999 -9999

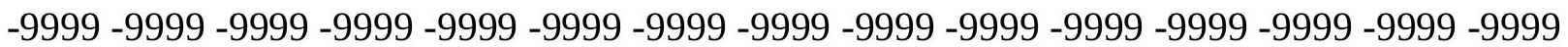
-9999 -9999 -9999 -9999 -9999 -9999 -9999 -9999 -9999 -9999 -9999 -9999 -9999 -9999 -9999 -9999 -9999 -9999 -9999 -9999 -9999 -9999 -9999 -9999 -9999 -9999 -9999 -9999 -9999 -9999 -9999 -9999 -9999 -9999 -9999 -9999 -9999 -9999 -9999 -9999 -9999 -9999 -9999 -9999 -9999 -9999 -9999 -9999 -9999 -9999 -9999 -9999 -9999 -9999 -9999 -9999 -9999 -9999 -9999 -9999 -9999 -9999 -9999 -9999 -9999 -9999 -9999 -9999 -9999 -9999 102.712600708 102.1029968262101 .7982025146101 .1886978149100 .8839035034100 .2742996216 99.9695205688599 .3599472045998 .7503814697397 .8360290527397 .22646331787 96.3121032714895 .397743225194 .1785964965892 .9594726562591 .74033355713 
90.2164001464888 .9972534179787 .4733276367289 .302040100193 .56903076172 97.53124237061101 .7982025146105 .4557037354109 .1130981445112 .1608963013 115.2088012695117 .647102356119 .7806015015121 .6092987061123 .1332015991 124.9618988037126 .4858016968128 .0097961426129 .2288970947130 .4479980469 131.6672058105132 .8863067627133 .8007049561135 .0198059082136 .2389984131 137.4580993652138 .3724975586139 .5915985107140 .8106994629142 .0299072266 143.2489929199144 .4682006836145 .9920959473147 .2111968994148 .7351074219 150.5639038086152 .0877990723153 .6116943359155 .4403991699156 .9642944336 158.488296508863 .7000885009834 .04568862915 -9999 -9999 -9999 -9999 -9999 -9999 -9999 -9999 -9999 -9999 -9999 -9999 -9999 -9999 -9999 -9999 -9999 -9999 -9999 -9999 -9999 -9999 -9999 -9999 -9999 -9999 -9999 -9999 -9999 -9999 -9999 -9999 -9999 -9999 -9999 -9999 -9999 -9999 -9999 -9999 -9999 -9999 -9999 -9999 -9999 -9999 -9999 -9999 -9999 -9999 -9999 -9999 -9999 -9999 -9999 -9999 -9999 -9999 -9999 -9999 -9999 -9999 -9999 -9999 -9999 -9999 -9999 -9999 -9999 -9999 -9999 -9999 -9999 -9999 -9999 -9999 -9999 -9999 -9999 -9999 -9999 -9999 -9999 -9999 -9999 -9999 -9999 -9999 -9999 -9999 -9999 -9999 -9999 -9999 -9999

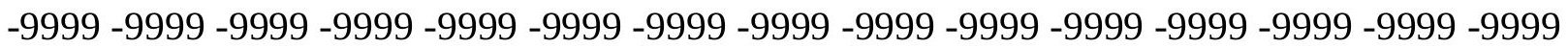

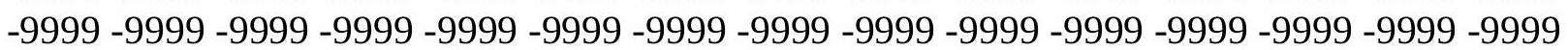
-9999 -9999 -9999 -9999 -9999 -9999 -9999 -9999 -9999 -9999 -9999 -9999 -9999 -9999 -9999 -999 -9999 -9999 -9999 -9999 -9999 -9999 -9999 -9999 -9999 -9999 -9999 -9999 -9999 -9999 -9999 -9999 -9999 -9999 -9999 -9999 -9999 -9999 -9999 -9999 -9999 -9999 -9999 -9999 -9999 -9999

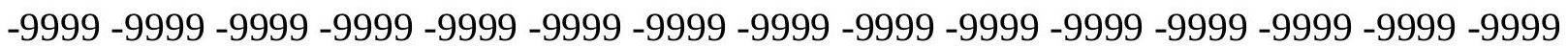
-9999 -9999 -9999 -9999 -9999 -9999 -9999 -9999 -9999 -9999 -9999 -9999 -9999 -9999 -9999 -9999 -9999 -9999 -9999 -9999 -9999 -9999 -9999 -9999 -9999 -9999 -9999 -9999 -9999 -9999 -9999 -9999 -9999 -9999 -9999 -9999 -9999 -9999 -9999 -9999 -9999 -9999 -9999 -9999 -9999

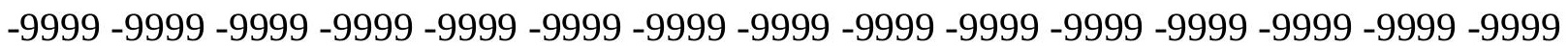
-9999 -9999 -9999 -9999 -9999 -9999 -9999 -9999 -9999 -9999 -9999 -9999 -9999 -9999 -9999 -9999 -9999 -9999 -9999 -9999 -9999 -9999 -9999 -9999 -9999 -9999 -9999 -9999 -9999 -9999 -9999 -9999 -9999 -9999 -9999 -9999 -9999 -9999 -9999 -9999 -9999 -9999 -9999 -9999 -9999 -9999 -9999 -9999 -9999 -9999 -9999 -9999 -9999 -9999 -9999 -9999 -9999 -9999 -9999 -9999

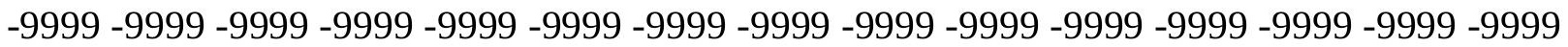
-9999 -9999 -9999 -9999 -9999 -9999 -9999 -9999 -9999 -9999 -9999 102.712600708 102.1029968262101 .7982025146101 .4934005737100 .8839035034100 .5791015625 99.9695205688599 .3599472045998 .7503814697398 .1408081054797 .22646331787 96.3121032714895 .0929565429793 .8738174438592 .6546783447391 .13075256348 89.60682678223 88.0829010009890.8259735107494.1785964965897.83602905273 101.1886978149104 .5412979126107 .5891036987110 .6370010376113 .075302124 115.5136032104117 .647102356119 .4757995605120 .9997024536122 .8283996582 124.3523025513125 .5715026855127 .0953979492128 .3144989014129 .533706665 130.7528076172131 .6672058105132 .8863067627133 .8007049561135 .0198059082 136.2389984131137 .1533050537138 .3724975586139 .5915985107140 .8106994629 142.0299072266143 .2489929199144 .7729034424146 .2969055176147 .8208007812 149.3446960449150 .8686065674152 .3925933838153 .9165039062155 .4403991699 64.0048828125 -9999 -9999 -9999 -9999 -9999 -9999 -9999 -9999 -9999 -9999 -9999 -9999 -9999 -9999 -9999 -9999 -9999 -9999 -9999 -9999 -9999 -9999 -9999 -9999 -9999 -9999 -9999 -9999 -9999 -9999 -9999 -9999 -9999 -9999 -9999 -9999

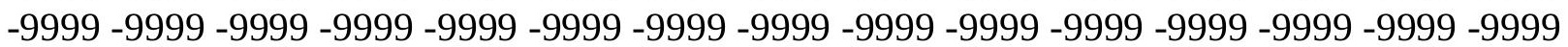


-9999 -9999 -9999 -9999 -9999 -9999 -9999 -9999 -9999 -9999 -9999 -9999 -9999 -9999 -9999 -9999 -9999 -9999 -9999 -9999 -9999 -9999 -9999 -9999 -9999 -9999 -9999 -9999 -9999 -9999 -9999 -9999 -9999 -9999 -9999 -9999 -9999 -9999 -9999 -9999 -9999 -9999 -9999 -9999 -9999 -9999 -9999 -9999 -9999 -9999 -9999 -9999 -9999 -9999 -9999 -9999 -9999 -9999 -9999 -9999 -9999 -9999 -9999 -9999 -9999 -9999 -9999 -9999 -9999 -9999 -9999 -9999 -9999 -9999 -9999 -9999 -9999 -9999 -9999 -9999 -9999 -9999 -9999 -9999 -9999 -9999 -9999 -9999 -9999 -9999 -9999 -9999 -9999 -9999 -9999 -9999 -9999 -9999 -9999 -9999 -9999 -9999 -9999 -9999 -9999

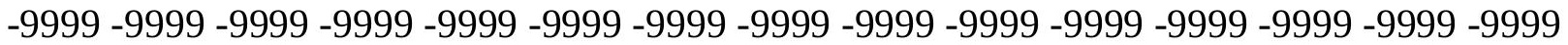
-9999 -9999 -9999 -9999 -9999 -9999 -9999 -9999 -9999 -9999 -9999 -9999 -9999 -9999 -9999 -9999 -9999 -9999 -9999 -9999 -9999 -9999 -9999 -9999 -9999 -9999 -9999 -9999 -9999 -9999 -

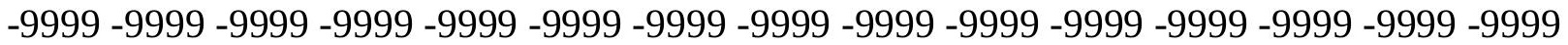
-9999 -9999 -9999 -9999 -9999 -9999 -9999 -9999 -9999 -9999 -9999 -9999 -9999 -9999 -9999

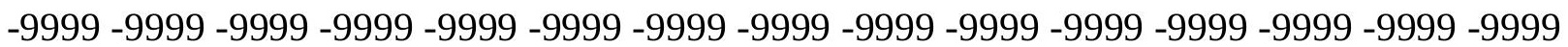
-9999 -9999 -9999 -9999 -9999 -9999 -9999 -9999 -9999 -9999 -9999 -9999 -9999 -9999 -9999 -9999 -9999 -9999 -9999 -9999 -9999 -9999 -9999 -9999 -9999 -9999 -9999 -9999 -9999 -9999 -9999 -9999 -9999 -9999 -9999 -9999 -9999 -9999 -9999 -9999 -9999 -9999 -9999 -9999 -9999 -

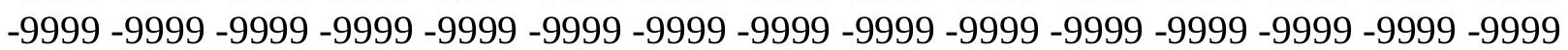
-9999 -9999 -9999 -9999 -9999 -9999 -9999 -9999 -9999 -9999 -9999 -9999 -9999 -9999 -9999 -9999 -9999 -9999 -9999 -9999 -9999 -9999 -9999 -9999 -9999 -9999 -9999 -9999 102.4077987671101 .7982025146101 .4934005737101 .1886978149100 .8839035034 100.274299621699 .6647262573299 .0551681518698 .1408081054797 .22646331787 96.0073165893694 .7881774902393 .5690307617292 .0450973510790 .52117919922 88.9972534179791 .7403335571394 .4833908081197 .53124237061100 .5791015625 103.6268997192106 .3700027466109 .1130981445111 .551399231113 .6848983765 115.5136032104117 .342300415119 .1709976196120 .6949005127122 .2188034058 123.43800354124 .9618988037126 .1809997559127 .4001998901128 .3144989014 129.533706665130 .4479980469131 .6672058105132 .8863067627133 .8007049561 134.7149963379135 .9342041016137 .1533050537138 .0677032471139 .2868041992 140.8106994629142 .0299072266143 .2489929199144 .7729034424146 .2969055176 147.8208007812149 .3446960449150 .868606567464 .6144485473664 .61444854736 -9999 -9999 -9999 -9999 -9999 -9999 -9999 -9999 -9999 -9999 -9999 -9999 -9999 -9999 -9999 -9999 -9999 -9999 -9999 -9999 -9999

-9999 -9999 -9999 -9999 -9999 -9999 -9999 -9999 -9999 -9999 -9999 -9999 -9999 -9999 -9999 -9999 -9999 -9999 -9999 -9999 -9999 -9999 -9999 -9999 -9999 -9999 -9999 -9999 -9999 -9999 -

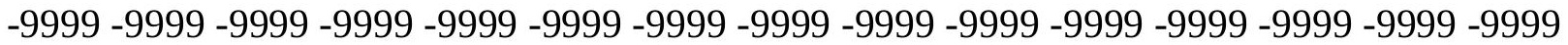
-9999 -9999 -9999 -9999 -9999 -9999 -9999 -9999 -9999 -9999 -9999 -9999 -9999 -9999 -9999 -9999 -9999 -9999 -9999 -9999 -9999 -9999 -9999 -9999 -9999 -9999 -9999 -9999 -9999 -9999

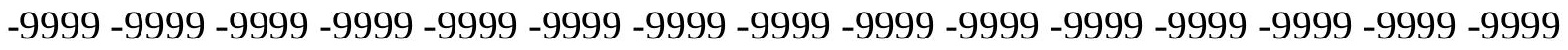
-9999 -9999 -9999 -9999 -9999 -9999 -9999 -9999 -9999 -9999 -9999 -9999 -9999 -9999 -9999 -9999 -9999 -9999 -9999 -9999 -9999 -9999 -9999 -9999 -9999 -9999 -9999 -9999 -9999 -9999 -9999 -9999 -9999 -9999 -9999 -9999 -9999 -9999 -9999 -9999 -9999 -9999 -9999 -9999 -9999 -999 -9999 -9999 -9999 -9999 -9999 -9999 -9999 -9999 -9999 -9999 -9999 -9999 -9999 -9999 -9999 -9999 -9999 -9999 -9999 -9999 -9999 -9999 -9999 -9999 -9999 -9999 -9999 -9999 -9999 -9999 -9999 -9999 -9999 -9999 -9999 -9999 -9999 -9999 -9999 -9999 -9999 -9999 -9999 -9999 -9999 -9999 -9999 -9999 -9999 -9999 -9999 -9999 -9999 -9999 -9999 -9999 -9999 -9999 -9999 -9999

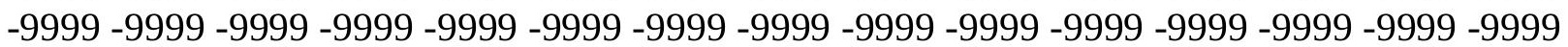


-9999 -9999 -9999 -9999 -9999 -9999 -9999 -9999 -9999 -9999 -9999 -9999 -9999 -9999 -9999 -9999 -9999 -9999 -9999 -9999 -9999 -9999 -9999 -9999 -9999 -9999 -9999 -9999 -9999 -9999 -9999 -9999 -9999 -9999 -9999 -9999 -9999 -9999 -9999 -9999 -9999 -9999 -9999 -9999 -9999 -9999 -9999 -9999 -9999 -9999 -9999 -9999 -9999 -9999 -9999 -9999 -9999 -9999 -9999 -9999 -9999 -9999 -9999 -9999 -9999 -9999 -9999 -9999 -9999 -9999 -9999 -9999 -9999 -9999 -9999 -9999 -9999 -9999 -9999 -9999 -9999 -9999 -9999 -9999 -9999 -9999 -9999 -9999 -9999 -9999 -9999 -9999 -9999 -9999 -9999 -9999 -9999 -9999 -9999 -9999 -9999 -9999 -9999 -9999 102.4077987671102 .1029968262101 .7982025146101 .4934005737101 .1886978149 100.579101562599 .9695205688599 .0551681518698 .1408081054796 .92166900635 95.7025299072394 .1785964965892 .9594726562591 .4355392456189 .91161346436 91.7403335571394 .4833908081197 .2264633178799 .96952056885102 .4077987671 105.1509017944107 .5891036987109 .7226028442111 .8561019897113 .6848983765 115.5136032104117 .0374984741118 .5614013672120 .0852966309121 .6092987061 122.8283996582124 .0475006104124 .9618988037126 .1809997559127 .4001998901 128.3144989014129 .533706665130 .4479980469131 .3623962402132 .5814971924 133.4958953857134 .4102020264135 .6293945312136 .8484954834138 .0677032471 139.2868041992140 .5059967041142 .0299072266143 .5538024902144 .7729034424 146.2969055176147 .820800781265 .2240066528339 .91730499268 -9999 -9999 -9999 -9999 -9999 -9999 -9999 -9999 -9999 -9999 -9999 -9999 -9999 -9999 -9999 -9999 -9999 -9999 -9999 $-9999-9999$

-9999 -9999 -9999 -9999 -9999 -9999 -9999 -9999 -9999 -9999 -9999 -9999 -9999 -9999 -9999 -9999 -9999 -9999 -9999 -9999 -9999 -9999 -9999 -9999 -9999 -9999 -9999 -9999 -9999 -9999 -9999 -9999 -9999 -9999 -9999 -9999 -9999 -9999 -9999 -9999 -9999 -9999 -9999 -9999 -9999 -9999 -9999 -9999 -9999 -9999 -9999 -9999 -9999 -9999 -9999 -9999 -9999 -9999 -9999 -9999

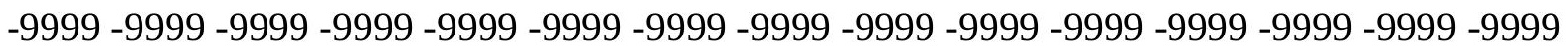
-9999 -9999 -9999 -9999 -9999 -9999 -9999 -9999 -9999 -9999 -9999 -9999 -9999 -9999 -9999 -9999 -9999 -9999 -9999 -9999 -9999 -9999 -9999 -9999 -9999 -9999 -9999 -9999 -9999 -9999 -9999 -9999 -9999 -9999 -9999 -9999 -9999 -9999 -9999 -9999 -9999 -9999 -9999 -9999 -9999 -9999 -9999 -9999 -9999 -9999 -9999 -9999 -9999 -9999 -9999 -9999 -9999 -9999 -9999 -9999 -9999 -9999 -9999 -9999 -9999 -9999 -9999 -9999 -9999 -9999 -9999 -9999 -9999 -9999 -9999 -9999 -9999 -9999 -9999 -9999 -9999 -9999 -9999 -9999 -9999 -9999 -9999 -9999 -9999 -9999 -9999 -9999 -9999 -9999 -9999 -9999 -9999 -9999 -9999 -9999 -9999 -9999 -9999 -9999 -9999 -9999 -9999 -9999 -9999 -9999 -9999 -9999 -9999 -9999 -9999 -9999 -9999 -9999 -9999 -9999 -9999 -9999 -9999 -9999 -9999 -9999 -9999 -9999 -9999 -9999 -9999 -9999 -9999 -9999 -9999 -9999 -9999 -9999 -9999 -9999 -9999 -9999 -9999 -9999 -9999 -9999 -9999 -9999 -9999 -9999 -9999 -9999 -9999 -9999 -9999 -9999 -9999 -9999 -9999 -9999 -9999 -9999 -9999 -9999 -9999 -9999 -9999 -9999 -9999 -9999 -9999 -9999 -9999 -9999 -9999 -9999 -9999 -9999 -9999 -9999

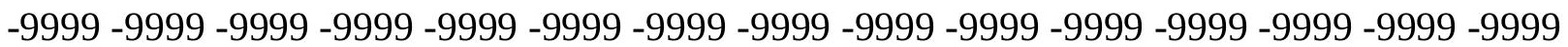
-9999 -9999 -9999 -9999 -9999 -9999 -9999 -9999 -9999 -9999 -9999 -9999 -9999 -9999 -9999 -9999 -9999 -9999 -9999 -9999 -9999 -9999 -9999 -9999 -9999 -9999 -9999 -9999 -9999 -9999 -9999 -9999 -9999 -9999 -9999 -9999 -9999 -9999 -9999 -9999 -9999 -9999 -9999 -9999 -9999 -9999 102.4077987671 102.1029968262 101.7982025146101.4934005737100.8839035034 99.9695205688599 .0551681518697 .8360290527396 .6168823242295 .09295654297 93.5690307617292 .0450973510790 .8259735107491 .1307525634893 .87381744385 96.6168823242299 .05516815186101 .4934005737103 .9317016602106 .0652008057 108.1986999512110 .3321990967112 .1608963013113 .6848983765115 .2088012695 
116.7326965332118 .2565994263119 .4757995605120 .6949005127121 .9140014648 122.8283996582124 .0475006104124 .9618988037126 .1809997559127 .0953979492 128.0097961426128 .9241027832130 .1432037354131 .0576019287131 .9720001221 133.1911010742134 .1054992676135 .3246002197136 .5437011719137 .7628936768 138.9819946289140 .5059967041141 .7250976562143 .2489929199144 .7729034424 65.52880096436 -9999 -9999 -9999 -9999 -9999 -9999 -9999 -9999 -9999 -9999 -9999 -9999 -9999 -9999 -9999 -9999 -9999 -9999 -9999 -9999 -9999 -9999

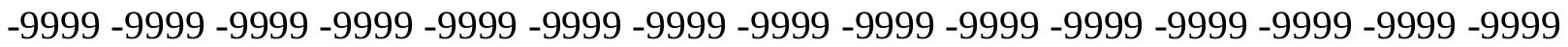

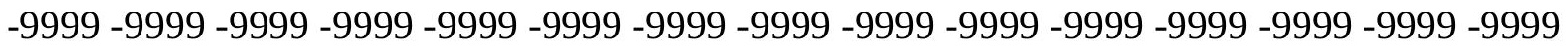
-9999 -9999 -9999 -9999 -9999 -9999 -9999 -9999 -9999 -9999 -9999 -9999 -9999 -9999 -9999 -

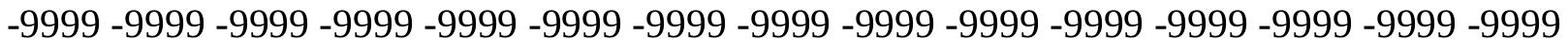
-9999 -9999 -9999 -9999 -9999 -9999 -9999 -9999 -9999 -9999 -9999 -9999 -9999 -9999 -9999 -9999 -9999 -9999 -9999 -9999 -9999 -9999 -9999 -9999 -9999 -9999 -9999 -9999 -9999 -9999 -9999 -9999 -9999 -9999 -9999 -9999 -9999 -9999 -9999 -9999 -9999 -9999 -9999 -9999 -9999 -9999 -9999 -9999 -9999 -9999 -9999 -9999 -9999 -9999 -9999 -9999 -9999 -9999 -9999 -9999

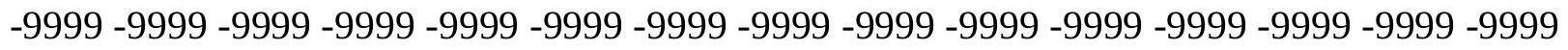

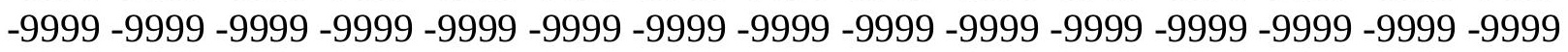

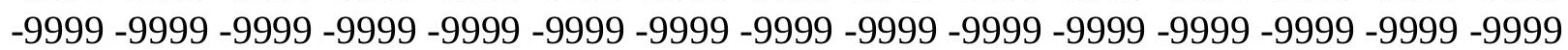
-9999 -9999 -9999 -9999 -9999 -9999 -9999 -9999 -9999 -9999 -9999 -9999 -9999 -9999 -9999 -9999 -9999 -9999 -9999 -9999 -9999 -9999 -9999 -9999 -9999 -9999 -9999 -9999 -9999 -9999 -9999 -9999 -9999 -9999 -9999 -9999 -9999 -9999 -9999 -9999 -9999 -9999 -9999 -9999 -9999

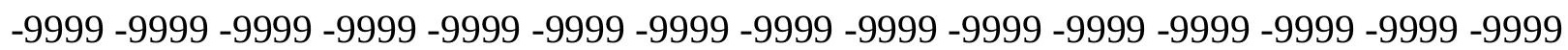
-9999 -9999 -9999 -9999 -9999 -9999 -9999 -9999 -9999 -9999 -9999 -9999 -9999 -9999 -9999 -9999 -9999 -9999 -9999 -9999 -9999 -9999 -9999 -9999 -9999 -9999 -9999 -9999 -9999 -9999 -9999 -9999 -9999 -9999 -9999 -9999 -9999 -9999 -9999 -9999 -9999 -9999 -9999 -9999 -9999 -9999 -9999 -9999 -9999 -9999 -9999 -9999 -9999 -9999 -9999 -9999 -9999 -9999 -9999 -9999 -9999 -9999 -9999 -9999 -9999 -9999 -9999 -9999 -9999 -9999 -9999 -9999 -9999 -9999 -9999

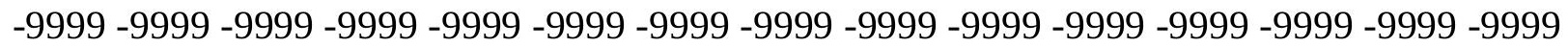
-9999-9999 102.4077987671 102.4077987671 102.4077987671 101.7982025146 101.188697814999 .9695205688598 .7503814697397 .2264633178796 .00731658936 94.4833908081192 .9594726562591 .4355392456190 .5211791992293 .26425170898 95.7025299072398 .14080810547100 .5791015625102 .712600708104 .8460998535 106.6747970581 108.5035018921 110.3321990967 111.8561019897113.3800964355 114.9039993286116 .1231002808117 .342300415118 .5614013672119 .7806015015 120.6949005127121 .9140014648122 .8283996582123 .7427978516124 .6570968628 125.8762969971126 .7906036377127 .7050018311128 .6192932129129 .533706665 130.4479980469131 .6672058105132 .5814971924133 .8007049561135 .0198059082 136.2389984131137 .4580993652138 .6772003174140 .201202392666 .13836669922 66.13836669922 -9999 -9999 -9999 -9999 -9999 -9999 -9999 -9999 -9999 -9999 -9999 -9999 -9999 -9999 -9999 -9999 -9999 -9999 -9999 -9999 -9999 -9999

-9999 -9999 -9999 -9999 -9999 -9999 -9999 -9999 -9999 -9999 -9999 -9999 -9999 -9999 -9999 -9999 -9999 -9999 -9999 -9999 -9999 -9999 -9999 -9999 -9999 -9999 -9999 -9999 -9999 -9999 -9999 -9999 -9999 -9999 -9999 -9999 -9999 -9999 -9999 -9999 -9999 -9999 -9999 -9999 -9999 -9999 -9999 -9999 -9999 -9999 -9999 -9999 -9999 -9999 -9999 -9999 -9999 -9999 -9999 -9999 -

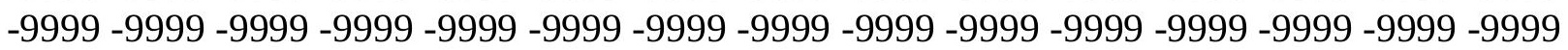

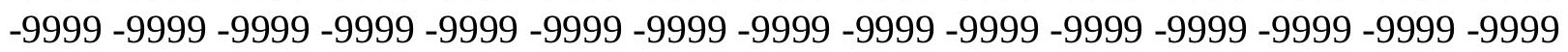


-9999 -9999 -9999 -9999 -9999 -9999 -9999 -9999 -9999 -9999 -9999 -9999 -9999 -9999 -9999 -9999 -9999 -9999 -9999 -9999 -9999 -9999 -9999 -9999 -9999 -9999 -9999 -9999 -9999 -9999 -9999 -9999 -9999 -9999 -9999 -9999 -9999 -9999 -9999 -9999 -9999 -9999 -9999 -9999 - 9999 -9999 -9999 -9999 -9999 -9999 -9999 -9999 -9999 -9999 -9999 -9999 -9999 -9999 -9999 -9999 -9999 -9999 -9999 -9999 -9999 -9999 -9999 -9999 -9999-9999 -9999 -9999 -9999 -9999 -9999 -9999 -9999 -9999 -9999 -9999 -9999 -9999 -9999 -9999 -9999 -9999 -9999 -9999 -9999 -9999 -9999 -9999 -9999 -9999 -9999 -9999 -9999 -9999 -9999 -9999 -9999 -9999 -9999 -9999 -9999 -999 -

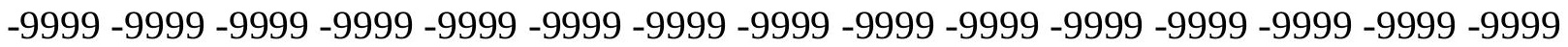
-9999 -9999 -9999 -9999 -9999 -9999 -9999 -9999 -9999 -9999 -9999 -9999 -9999 -9999 -9999 -9999 -9999 -9999 -9999 -9999 -9999 -9999 -9999 -9999 -9999 -9999 -9999 -9999 -9999 -9999

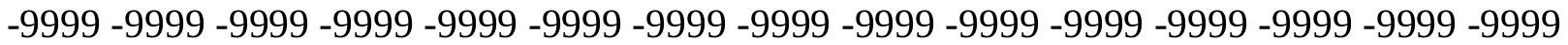
-9999 -9999 -9999 -9999 -9999 -9999 -9999 -9999 -9999 -9999 -9999 -9999 -9999 -9999 -9999 -9999 -9999 -9999 -9999 -9999 -9999 -9999 -9999 -9999 -9999 -9999 -9999 -9999 -9999 -9999 -

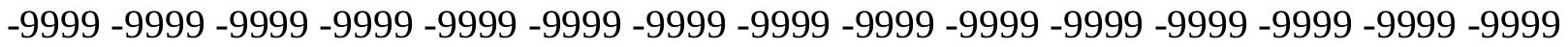
-9999 -9999 -9999 -9999 -9999 -9999 -9999 -9999 -9999 -9999 -9999 -9999 -9999 -9999 -9999 -9999 -9999-9999-9999 102.712600708 102.712600708 102.4077987671 101.1886978149 99.9695205688598 .1408081054796 .6168823242295 .0929565429793 .56903076172 92.0450973510790 .5211791992292 .6546783447394 .7881774902397 .22646331787 99.35994720459101 .4934005737103 .6268997192105 .4557037354106 .979598999 108.8082962036110 .3321990967111 .551399231113 .075302124114 .2944030762 115.2088012695116 .4279022217117 .647102356118 .5614013672119 .4757995605 120.6949005127121 .6092987061122 .5235977173123 .43800354124 .3523025513 125.2667007446126 .1809997559127 .0953979492128 .0097961426128 .9241027832 129.8385009766131 .0576019287131 .9720001221133 .1911010742134 .4102020264 135.6293945312136 .848495483466 .7479400634866 .44316101074 -9999 -9999 -9999 -9999 -9999 -9999 -9999 -9999 -9999 -9999 -9999 -9999 -9999 -9999 -9999 -9999 -9999 -9999 -9999 $-9999-9999-9999$

-9999 -9999 -9999 -9999 -9999 -9999 -9999 -9999 -9999 -9999 -9999 -9999 -9999 -9999 -9999 -9999 -9999 -9999 -9999 -9999 -9999 -9999 -9999 -9999 -9999 -9999 -9999 -9999 -9999 -9999 -9999 -9999 -9999 -9999 -9999 -9999 -9999 -9999 -9999 -9999 -9999 -9999 -9999 -9999 -999 -9999 -9999 -9999 -9999 -9999 -9999 -9999 -9999 -9999 -9999 -9999 -9999 -9999 -9999 -9999 -9999 -9999 -9999 -9999 -9999 -9999 -9999 -9999 -9999 -9999 -9999 -9999 -9999 -9999 -9999

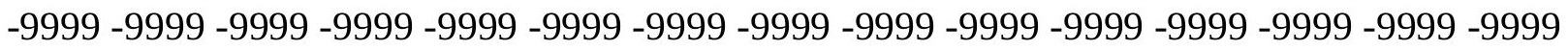

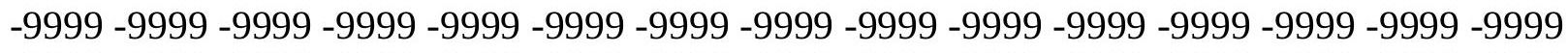
-9999 -9999 -9999 -9999 -9999 -9999 -9999 -9999 -9999 -9999 -9999 -9999 -9999 -9999 -9999 -9999 -9999 -9999 -9999 -9999 -9999 -9999 -9999 -9999 -9999 -9999 -9999 -9999 -9999 -9999

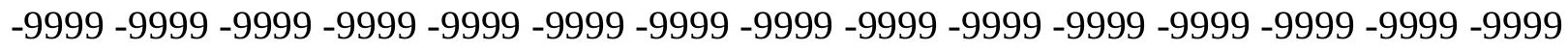

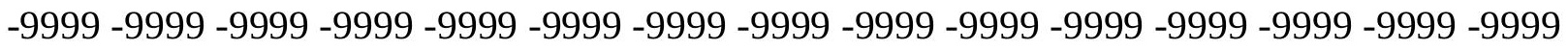
-9999 -9999 -9999 -9999 -9999 -9999 -9999 -9999 -9999 -9999 -9999 -9999 -9999 - 9999 - -999 -9999 -9999 -9999 -9999 -9999 -9999 -9999 -9999 -9999 -9999 -9999 -9999 -9999 -9999 -9999 -

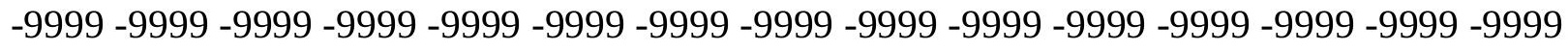

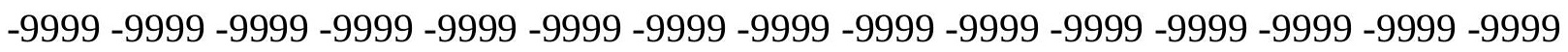
-9999 -9999 -9999 -9999 -9999 -9999 -9999 -9999 -9999 -9999 -9999 -9999 -9999 -9999 -9999 -9999 -9999 -9999 -9999 -9999 -9999 -9999 -9999 -9999-9999 -9999 -9999 -9999 -9999 -9999 -9999 -9999 -9999 -9999 -9999 -9999 -9999 -9999 -9999 -9999 -9999 -9999 -9999 -9999 -9999 -9999 -9999 -9999 -9999 -9999 -9999 -9999 -9999 -9999 -9999 -9999 -9999 -9999 -9999 -9999 
-9999 -9999 -9999 -9999 -9999 -9999 -9999 -9999 -9999 -9999 -9999 -9999 -9999 -9999 -9999 -9999 -9999 -9999 -9999 -9999 -9999 -9999 -9999 -9999 -9999 -9999 -9999 -9999 -9999 -9999 -9999 -9999 -9999 -9999-9999 103.9317016602 103.6268997192102 .712600708 101.188697814999 .0551681518697 .2264633178795 .7025299072394 .17859649658 92.6546783447391 .1307525634892 .0450973510794 .1785964965896 .31210327148 98.4455871582100 .2742996216102 .1029968262103 .9317016602105 .4557037354 106.979598999108 .5035018921109 .7226028442110 .9418029785112 .1608963013 113.3800964355114 .2944030762115 .5136032104116 .4279022217117 .342300415 118.2565994263119 .1709976196120 .0852966309120 .9997024536121 .9140014648 122.8283996582123 .7427978516124 .3523025513125 .2667007446126 .1809997559 127.0953979492128 .0097961426129 .2288970947130 .1432037354131 .3623962402 132.581497192467 .3575134277367 .05272674561 -9999 -9999 -9999 -9999 -9999 -9999 -9999 -9999 -9999 -9999 -9999 -9999 -9999 -9999 -9999 -9999 -9999 -9999 -9999 -9999 -9999-9999 $-9999$

-9999 -9999 -9999 -9999 -9999 -9999 -9999 -9999 -9999 -9999 -9999 -9999 -9999 -9999 -9999 -9999 -9999 -9999 -9999 -9999 -9999 -9999 -9999 -9999 -9999 -9999 -9999 -9999 -9999 -9999 -9999 -9999 -9999 -9999 -9999 -9999 -9999 -9999 -9999 -9999 -9999 -9999 -9999 -9999 -9999 -9999 -9999 -9999 -9999 -9999 -9999 -9999 -9999 -9999 -9999 -9999 -9999 -9999 -9999 -9999 -9999 -9999 -9999 -9999 -9999 -9999 -9999 -9999 -9999 -9999 -9999 -9999 -9999 -9999 -9999 -9999 -9999 -9999 -9999 -9999 -9999 -9999 -9999 -9999 -9999 -9999 -9999 -9999 -9999 -9999

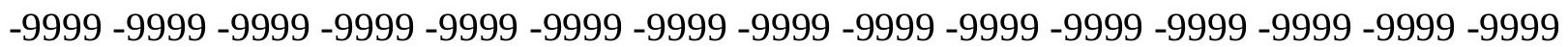
-9999 -9999 -9999 -9999 -9999 -9999 -9999 -9999 -9999 -9999 -9999 -9999 -9999 -9999 -9999 -9999 -9999 -9999 -9999 -9999 -9999 -9999 -9999 -9999 -9999 -9999 -9999 -9999 -9999 -9999 -9999 -9999 -9999 -9999 -9999 -9999 -9999 -9999 -9999 -9999 -9999 -9999 -9999 -9999 -9999

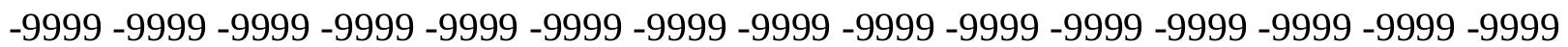
-9999 -9999 -9999 -9999 -9999 -9999 -9999 -9999 -9999 -9999 -9999 -9999 -9999 -9999 -9999 -9999 -9999 -9999 -9999 -9999 -9999 -9999 -9999 -9999 -9999 -9999 -9999 -9999 -9999 -9999 -9999 -9999 -9999 -9999 -9999 -9999 -9999 -9999 -9999 -9999 -9999 -9999 -9999 -9999 -9999 -9999 -9999 -9999 -9999 -9999 -9999 -9999 -9999 -9999 -9999 -9999 -9999 -9999 -9999 -9999 -9999 -9999 -9999 -9999 -9999 -9999 -9999 -9999 -9999 -9999 -9999 -9999 -9999 -9999 -9999 -9999 -9999 -9999 -9999 -9999 -9999 -9999 -9999 -9999 -9999 -9999 -9999 -9999 -9999 -9999 -

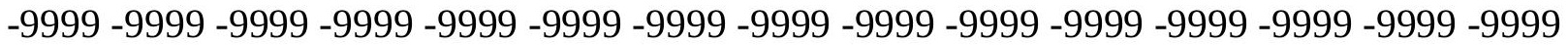
-9999 -9999 -9999 -9999 -9999 -9999 -9999 -9999 -9999 -9999 -9999 -9999 -9999 -9999 -9999 -9999 -9999 -9999 -9999 -9999 -9999 -9999 -9999 -9999 -9999 -9999 -9999 -9999 -9999 -9999 -9999 -9999 -9999 -9999 -9999 -9999 -9999 -9999 -9999 -9999 -9999 -9999 -9999 -9999 -9999 -9999 -9999 -9999 -9999 -9999 -9999-9999 104.5412979126102 .407798767199 .96952056885 97.8360290527396 .0073165893694 .4833908081193 .2642517089891 .74033355713 91.4355392456193 .5690307617295 .397743225197 .5312423706199 .35994720459 101.1886978149102 .712600708104 .2365036011105 .4557037354106 .6747970581 107.8938980103109 .1130981445110 .3321990967111 .24659729112 .1608963013 113.3800964355114 .2944030762115 .2088012695116 .1231002808117 .0374984741 117.647102356118 .5614013672119 .4757995605120 .3900985718120 .9997024536 121.9140014648122 .8283996582123 .43800354124 .3523025513125 .2667007446 126.1809997559127 .4001998901128 .3144989014129 .53370666567 .96708679199 67.66230010986 -9999 -9999 -9999 -9999 -9999 -9999 -9999 -9999 -9999 -9999 -9999 -9999 -9999 -9999 -9999 -9999 -9999 -9999 -9999 -9999 -9999 -9999 -9999 
-9999 -9999 -9999 -9999 -9999 -9999 -9999 -9999 -9999 -9999 -9999 -9999 -9999 -9999 -9999 -9999 -9999 -9999 -9999 -9999 -9999 -9999 -9999 -9999 -9999 -9999 -9999 -9999 -9999 -9999 -9999 -9999 -9999 -9999 -9999 -9999 -9999 -9999 -9999 -9999 -9999 -9999 -9999 -9999 -9999 -9999 -9999 -9999 -9999 -9999 -9999 -9999 -9999 -9999 -9999 -9999 -9999 -9999 -9999 -9999 -9999 -9999 -9999 -9999 -9999 -9999 -9999 -9999 -9999 -9999 -9999 -9999 -9999 -9999 -9999 -9999 -9999 -9999 -9999 -9999 -9999 -9999 -9999 -9999 -9999 -9999 -9999 -9999 -9999 -9999 -9999 -9999 -9999 -9999 -9999 -9999 -9999 -9999 -9999 -9999 -9999 -9999 -9999 -9999 -9999

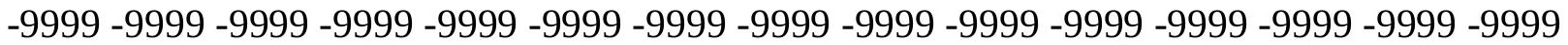
-9999 -9999 -9999 -9999 -9999 -9999 -9999 -9999 -9999 -9999 -9999 -9999 -9999 -9999 -9999 -9999 -9999 -9999 -9999 -9999 -9999 -9999 -9999 -9999 -9999 -9999 -9999 -9999 -9999 -9999 -

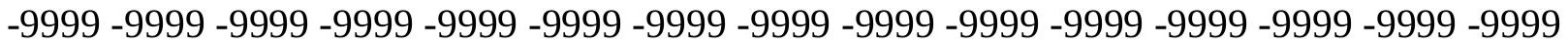
-9999 -9999 -9999 -9999 -9999 -9999 -9999 -9999 -9999 -9999 -9999 -9999 -9999 -9999 -9999

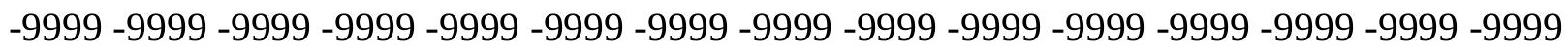
-9999 -9999 -9999 -9999 -9999 -9999 -9999 -9999 -9999 -9999 -9999 -9999 -9999 -9999 -9999 -9999 -9999 -9999 -9999 -9999 -9999 -9999 -9999 -9999 -9999 -9999 -9999 -9999 -9999 -9999 -9999 -9999 -9999 -9999 -9999 -9999 -9999 -9999 -9999 -9999 -9999 -9999 -9999 -9999 -9999 -9999 -9999 -9999 -9999 -9999 -9999 -9999 -9999 -9999 -9999 -9999 -9999 -9999 -9999 -9999 -9999 -9999 -9999 -9999 -9999 -9999 -9999 -9999 -9999 -9999 -9999 -9999 -9999 -9999 -9999 -9999 -9999 -9999 -9999 -9999 -9999 -9999 -9999 -9999 -9999 -9999 -9999 -9999 -9999 -9999 -9999 -9999 -9999 -9999 -9999 -9999 -9999 -9999 -9999 -9999 -9999 -9999 -9999 -9999 -9999

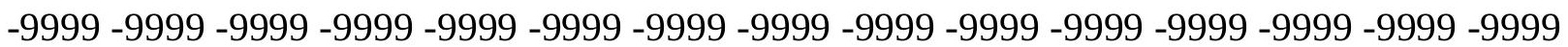
-9999 -9999 -9999 -9999 -9999 -9999 -9999 -9999 103.017402648999 .96952056885 97.8360290527396 .0073165893694 .7881774902393 .5690307617292 .3498916626 91.1307525634892 .9594726562594 .7881774902396 .6168823242298 .4455871582 99.96952056885101 .4934005737102 .712600708103 .9317016602105 .1509017944 106.3700027466107 .2844009399108 .1986999512109 .1130981445110 .3321990967 111.24659729111 .8561019897112 .7705001831113 .6848983765114 .5991973877 115.5136032104116 .1231002808117 .0374984741117 .647102356118 .5614013672 119.1709976196120 .0852966309120 .9997024536121 .6092987061122 .5235977173 123.43800354124 .3523025513125 .2667007446126 .485801696868 .27187347412 67.96708679199 -9999 -9999 -9999 -9999 -9999 -9999 -9999 -9999 -9999 -9999 -9999 -9999 -9999 -9999 -9999 -9999 -9999 -9999 -9999 -9999 -9999 -9999 -9999 -9999 -9999 -9999 -9999 -9999 -9999 -9999 -9999 -9999 -9999 -9999 -9999 -9999 -9999 -9999 -9999 -9999 -9999 -9999 -9999 -9999 -9999 -9999 -9999 -9999 -9999 -9999 -9999 -9999 -9999 -9999 -9999 -9999 -9999 -9999 -9999 -9999 -9999 -9999 -9999 -9999 -9999 -9999 -9999 -9999 -9999 -9999 -9999 -9999 -9999 -9999 -9999 -9999 -9999 -9999 -9999 -9999 -9999 -9999 -9999 -9999 -9999 -9999 -9999 -9999 -9999 -9999 -9999 -9999 -9999 -9999 -9999 -9999 -9999 -9999

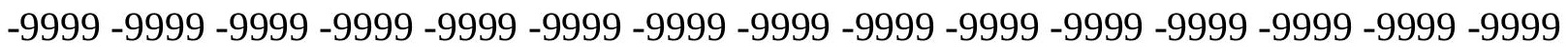
-9999 -9999 -9999 -9999 -9999 -9999 -9999 -9999 -9999 -9999 -9999 -9999 -9999 -9999 -9999 -9999 -9999 -9999 -9999 -9999 -9999 -9999 -9999 -9999 -9999 -9999 -9999 -9999 -9999 -9999 -9999 -9999 -9999 -9999 -9999 -9999 -9999 -9999 -9999 -9999 -9999 -9999 -9999 -9999 -9999 -9999 -9999 -9999 -9999 -9999 -9999 -9999 -9999 -9999 -9999 -9999 -9999 -9999 -9999 -9999 -9999 -9999 -9999 -9999 -9999 -9999 -9999 -9999 -9999 -9999 -9999 -9999 -9999 -9999 -9999 -9999 -9999 -9999 -9999 -9999 -9999 -9999 -9999 -9999 -9999 -9999 -9999 -9999 -9999 -9999 -9999 -9999 -9999 -9999 -9999 -9999 -9999 -9999 -9999 -9999 -9999 -9999 -9999 -9999 -9999

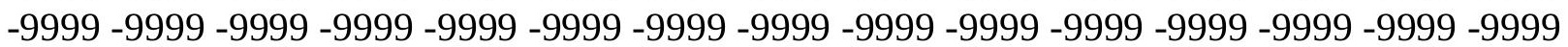


-9999 -9999 -9999 -9999 -9999 -9999 -9999 -9999 -9999 -9999 -9999 -9999 -9999 -9999 -9999 -9999 -9999 -9999 -9999 -9999 -9999 -9999 -9999 -9999 -9999 -9999 -9999 -9999 -9999 -9999 -9999 -9999 -9999 -9999 -9999 -9999 -9999 -9999 -9999 -9999 -9999 -9999 -9999 -9999 -9999 -9999 -9999 -9999 -9999 -9999 -9999 -9999 -9999 -9999 -9999 -9999 -9999 -9999 -9999 -9999 -9999 -9999 -9999 -9999 -9999 -9999 -9999 -9999 -9999 -9999 -9999 -9999 -9999 -9999 -9999 -9999 -9999 -9999 -9999 -9999 -9999 -9999 -9999 -9999 -9999 -9999 -9999 -9999 -9999 -9999 -9999 -9999 -9999 -9999 -9999 -9999 -9999 -9999 -9999 -9999 -9999 -9999 -9999 -9999 -9999 -9999 -9999 -9999 -9999 -9999 -9999 -9999 -9999 -9999 -9999 97.53124237061 96.0073165893695 .0929565429793 .8738174438592 .6546783447391 .43553924561 92.349891662694 .1785964965895 .7025299072397 .2264633178798 .75038146973 99.96952056885101 .1886978149102 .4077987671103 .3221969604104 .5412979126 105.4557037354106 .3700027466107 .2844009399108 .1986999512108 .8082962036 109.7226028442110 .6370010376111 .551399231112 .1608963013113 .075302124 113.6848983765114 .5991973877115 .2088012695116 .1231002808116 .7326965332 117.342300415118 .2565994263119 .1709976196119 .7806015015120 .6949005127 121.6092987061122 .523597717369 .1862335205168 .88143920898 -9999 -9999 -9999 -9999 -9999 -9999 -9999 -9999 -9999 -9999 -9999 -9999 -9999 -9999 -9999 -9999-9999-9999-9999 -9999 -9999 -9999-9999-9999

-9999 -9999 -9999 -9999 -9999 -9999 -9999 -9999 -9999 -9999 -9999 -9999 -9999 -9999 -9999 -9999 -9999 -9999 -9999 -9999 -9999 -9999 -9999 -9999 -9999 -9999 -9999 -9999 -9999 -9999

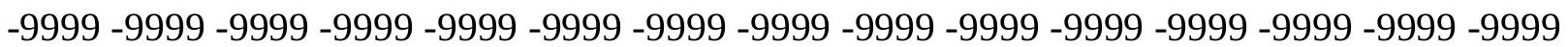
-9999 -9999 -9999 -9999 -9999 -9999 -9999 -9999 -9999 -9999 -9999 -9999 -9999 -9999 -9999 -9999 -9999 -9999 -9999 -9999 -9999 -9999 -9999 -9999 -9999 -9999 -9999 -9999 -9999 -9999 -9999 -9999 -9999 -9999 -9999 -9999 -9999 -9999 -9999 -9999 -9999 -9999 -9999 -9999 -9999

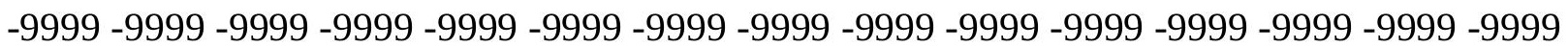
-9999 -9999 -9999 -9999 -9999 -9999 -9999 -9999 -9999 -9999 -9999 -9999 -9999 -9999 -9999 -9999 -9999 -9999 -9999 -9999 -9999 -9999 -9999 -9999 -9999 -9999 -9999 -9999 -9999 -9999 -9999 -9999 -9999 -9999 -9999 -9999 -9999 -9999 -9999 -9999 -9999 -9999 -9999 -9999 -9999 -9999 -9999 -9999 -9999 -9999 -9999 -9999 -9999 -9999 -9999 -9999 -9999 -9999 -9999 -9999 -9999 -9999 -9999 -9999 -9999 -9999 -9999 -9999 -9999 -9999 -9999 -9999 -9999 -9999 -9999 -9999 -9999 -9999 -9999 -9999 -9999 -9999 -9999 -9999 -9999 -9999 -9999 -9999 -9999 -9999 -9999 -9999 -9999 -9999 -9999 -9999 -9999 -9999 -9999 -9999 -9999 -9999 -9999 -9999 -9999 -9999 -9999 -9999 -9999 -9999 -9999 -9999 -9999 -9999 -9999 -9999 -9999 -9999 -9999 -9999 -9999 -9999 -9999 -9999 -9999 -9999 -9999 -9999 -9999 -9999 -9999 -9999 -9999 -9999 -9999

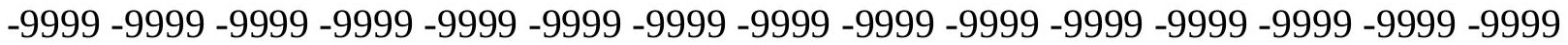
-9999 -9999 -9999 -9999 -9999 -9999 -9999 -9999 -9999 -9999 -9999 -9999 -9999 -9999 -9999 -9999 -9999 -9999 -9999 -9999 -9999 -9999 -9999 -9999 -9999 -9999 -9999 -9999 -9999 -9999

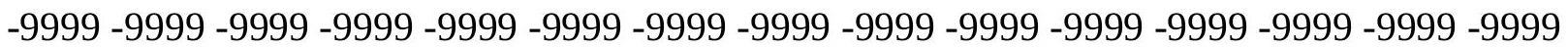
-9999 -9999 -9999 -9999 -9999 -9999 -9999 -9999 -9999 -9999 -9999 -9999 -9999 -9999 -9999 -9999 -9999 -9999 -9999 -9999 -9999 -9999 -9999 -9999 -9999 -9999 96.00731658936 95.397743225194 .1785964965893 .2642517089892 .0450973510792 .04509735107 93.5690307617295 .0929565429796 .3121032714897 .5312423706198 .75038146973 99.96952056885100 .8839035034101 .7982025146102 .712600708103 .3221969604 104.2365036011105 .1509017944106 .0652008057106 .6747970581107 .5891036987 108.1986999512109 .1130981445109 .7226028442110 .6370010376111 .24659729 112.1608963013112 .7705001831113 .3800964355114 .2944030762114 .9039993286 
115.5136032104116 .4279022217117 .0374984741117 .9517974854118 .8662033081 119.780601501569 .7957916259869 .18623352051 -9999 -9999 -9999 -9999 -9999 -9999 -9999 -9999 -9999 -9999 -9999 -9999 -9999 -9999 -9999 -9999 -9999 -9999 -9999 -9999 -9999 -9999 $-9999-9999$

-9999 -9999 -9999 -9999 -9999 -9999 -9999 -9999 -9999 -9999 -9999 -9999 -9999 -9999 -9999 -9999 -9999 -9999 -9999 -9999 -9999 -9999 -9999 -9999 -9999 -9999 -9999 -9999 -9999 -9999 -9999 -9999 -9999 -9999 -9999 -9999 -9999 -9999 -9999 -9999 -9999 -9999 -9999 -9999 -9999 -

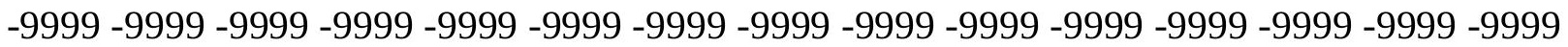

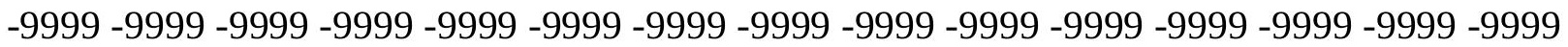
-9999 -9999 -9999 -9999 -9999 -9999 -9999 -9999 -9999 -9999 -9999 -9999 -9999 -9999 -9999

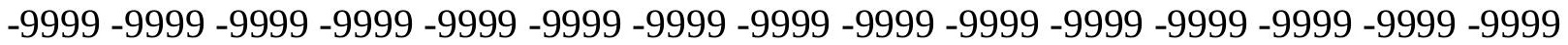
-9999 -9999 -9999 -9999 -9999 -9999 -9999 -9999 -9999 -9999 -9999 -9999 -9999 -9999 -9999 -9999 -9999 -9999 -9999 -9999 -9999 -9999 -9999 -9999 -9999 -9999 -9999 -9999 -9999 -9999 -9999 -9999 -9999 -9999 -9999 -9999 -9999 -9999 -9999 -9999 -9999 -9999 -9999 -9999 - 9999 -9999 -9999 -9999 -9999 -9999 -9999 -9999 -9999 -9999 -9999 -9999 -9999 -9999 -9999 -9999

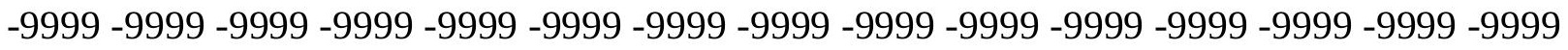

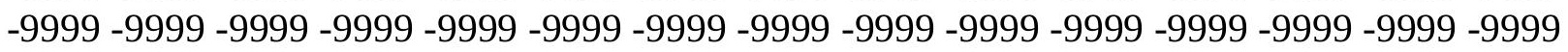
-9999 -9999 -9999 -9999 -9999 -9999 -9999 -9999 -9999 -9999 -9999 -9999 -9999 -9999 -9999 -999 -9999 -9999 -9999 -9999 -9999 -9999 -9999 -9999 -9999 -9999 -9999 -9999 -9999 -9999 -9999 -9999 -9999 -9999 -9999 -9999 -9999 -9999 -9999 -9999 -9999 -9999 -9999 -9999 -9999 -9999 -9999 -9999 -9999 -9999 -9999 -9999 -9999 -9999 -9999 -9999 -9999 -9999 -9999 -9999 -9999 -9999 -9999 -9999 -9999 -9999 -9999 -9999 -9999 -9999 -9999 -9999 -9999 -9999 -9999 -9999 -9999 -9999 -9999 -9999 -9999 -9999 -9999 -9999 -9999 -9999 -9999 -9999 -9999 -9999 -9999 -9999 -9999 -9999 -9999 -9999 -9999 -9999 -9999 -9999 -9999 -9999 -9999 -9999 -9999 -9999 -9999 -9999 -9999 -9999 -9999 -9999 -9999 -9999 -9999 -9999 -9999 -9999 -9999 -9999 -9999 -9999 -9999 -9999 -9999 -9999 -9999 -9999 -9999 -9999 -9999 -9999 -9999 -9999 94.7881774902393 .8738174438592 .6546783447391 .4355392456192 .95947265625 94.4833908081195 .397743225196 .6168823242297 .5312423706198 .4455871582 99.0551681518699 .96952056885100 .5791015625101 .4934005737102 .1029968262 103.0174026489103 .6268997192104 .5412979126105 .1509017944106 .0652008057 106.6747970581 107.5891036987 108.1986999512108.8082962036109.4179000854 110.3321990967110 .9418029785111 .551399231112 .1608963013113 .075302124 113.6848983765114 .5991973877115 .2088012695116 .1231002808117 .0374984741 70.1005783081169 .79579162598 -9999 -9999 -9999 -9999 -9999 -9999 -9999 -9999 -9999 -9999 -9999 -9999 -9999 -9999 -9999 -9999 -9999 -9999 -9999 -9999 -9999 -9999 -9999 -9999 -9999 -9999 -9999 -9999 -9999 -9999 -9999 -9999 -9999 -9999 -9999 -9999 -9999 -9999 -9999 -

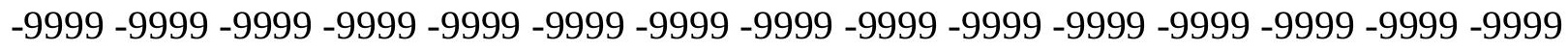

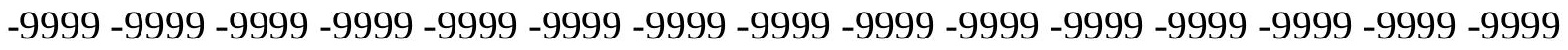

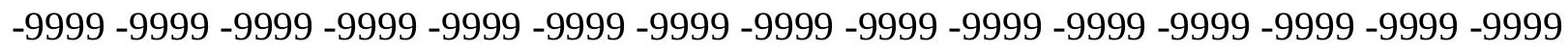
-9999 -9999 -9999 -9999 -9999 -9999 -9999 -9999 -9999 -9999 -9999 -9999 -9999 -9999 -9999 -

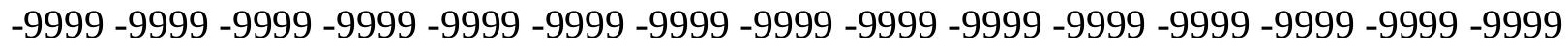

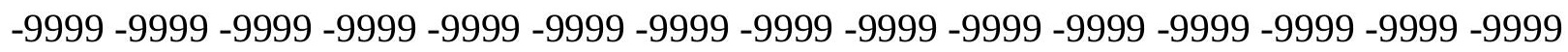
-9999 -9999 -9999 -9999 -9999 -9999 -9999 -9999 -9999 -9999 -9999 -9999 -9999 -9999 -9999 -9999 -9999 -9999 -9999 -9999 -9999 -9999 -9999 -9999 -9999 -9999 -9999 -9999 -9999 -9999 -9999 -9999 -9999 -9999 -9999 -9999 -9999 -9999 -9999 -9999 -9999 -9999 -9999 -9999 -9999 -

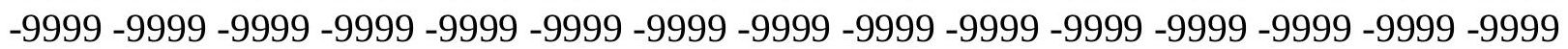


-9999 -9999 -9999 -9999 -9999 -9999 -9999 -9999 -9999 -9999 -9999 -9999 -9999 -9999 -9999 -9999 -9999 -9999 -9999 -9999 -9999 -9999 -9999 -9999 -9999 -9999 -9999 -9999 -9999 -9999 -

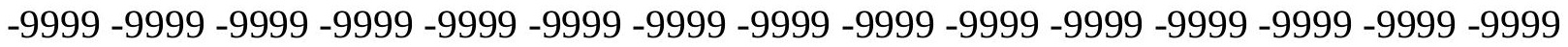
-9999 -9999 -9999 -9999 -9999 -9999 -9999 -9999 -9999 -9999 -9999 -9999 -9999 -9999 -9999 -9999 -9999 -9999 -9999 -9999 -9999 -9999 -9999 -9999-9999 -9999 -9999 -9999 -9999 -9999 -9999 -9999 -9999 -9999 -9999 -9999 -9999 -9999 -9999 -9999 -9999 -9999 -9999 -9999 -9999 -

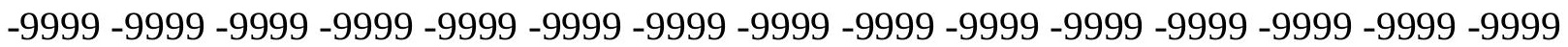

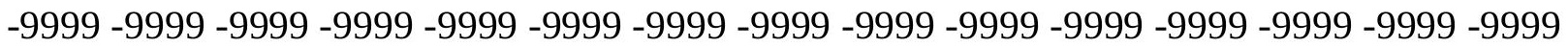

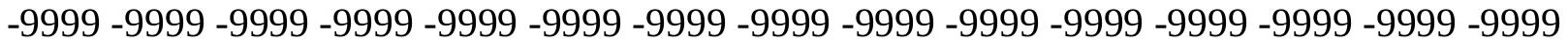

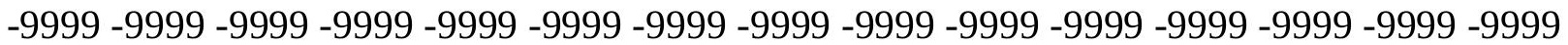
-9999 -9999 -9999 -9999 -9999 -9999 -9999 -9999 -9999 -9999 -9999 -9999 -9999 -9999 94.4833908081193 .2642517089892 .0450973510792 .349891662693 .56903076172 94.4833908081195 .397743225196 .3121032714896 .9216690063597 .53124237061 98.1408081054798 .7503814697399 .35994720459100 .2742996216100 .8839035034 101.4934005737102 .4077987671103 .0174026489103 .6268997192104 .5412979126 105.1509017944105 .7603988647106 .3700027466106 .979598999107 .5891036987 108.5035018921109 .1130981445109 .7226028442110 .3321990967111 .24659729 $111.8561019897112 .7705001831113 .684898376571 .014930725170 .71015167236-9999$ -9999 -9999 -9999 -9999 -9999 -9999 -9999 -9999 -9999 -9999 -9999 -9999 -9999 -9999 -9999 -9999 -9999 -9999 -9999 -9999 -9999 -9999 -9999 -9999

-9999 -9999 -9999 -9999 -9999 -9999 -9999 -9999 -9999 -9999 -9999 -9999 -9999 -9999 -9999 -9999 -9999 -9999 -9999 -9999 -9999 -9999 -9999 -9999 -9999 -9999 -9999 -9999 -9999 -9999 -9999 -9999 -9999 -9999 -9999 -9999 -9999 -9999 -9999 -9999 -9999 -9999 -9999 -9999 -9999 -

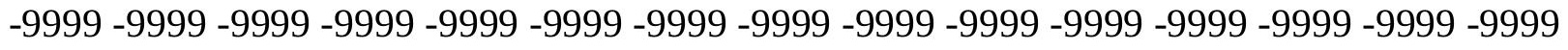

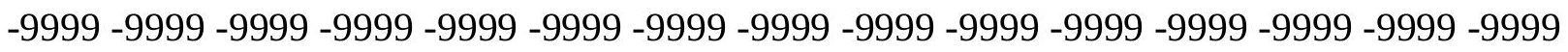
-9999 -9999 -9999 -9999 -9999 -9999 -9999 -9999 -9999 -9999 -9999 -9999 -9999 -9999 -9999 -9999 -9999 -9999 -9999 -9999 -9999 -9999 -9999 -9999 -9999 -9999 -9999 -9999 -9999 -9999 -

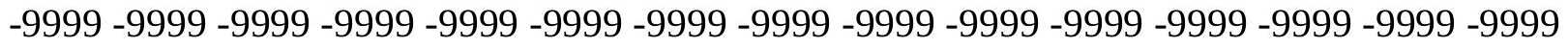
-9999 -9999 -9999 -9999 -9999 -9999 -9999 -9999 -9999 -9999 -9999 -9999 -9999 -9999 -9999 -9999 -9999 -9999 -9999 -9999 -9999 -9999 -9999 -9999 -9999 -9999 -9999 -9999 -9999 -999 -9999 -9999 -9999 -9999 -9999 -9999 -9999 -9999 -9999 -9999 -9999 -9999 -9999 -9999 -9999 -9999 -9999 -9999 -9999 -9999 -9999 -9999 -9999 -9999 -9999 -9999 -9999 -9999 -9999 -9999 -

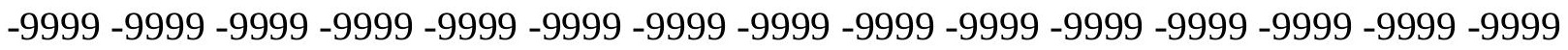

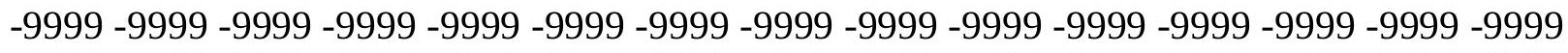
-9999 -9999 -9999 -9999 -9999 -9999 -9999 -9999 -9999 -9999 -9999 -9999 -9999 -9999 -9999 -

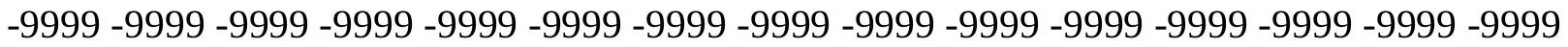

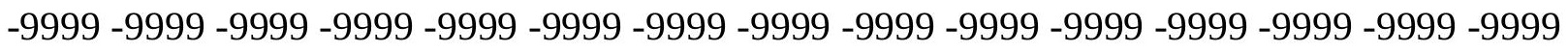

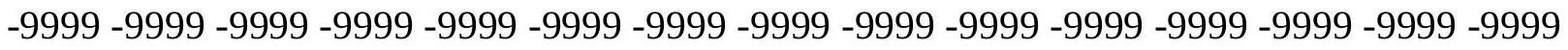

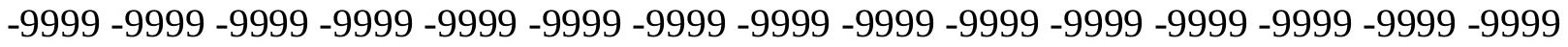
-9999 -9999 -9999 -9999 -9999 -9999 -9999 -9999 -9999 -9999 -9999 -9999 -9999 -9999 -9999 -

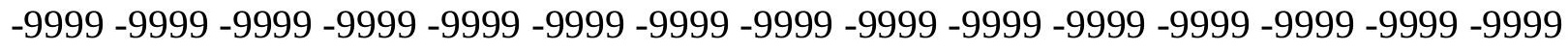

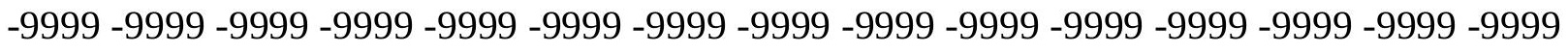
93.5690307617292 .349891662691 .7403335571392 .6546783447393 .56903076172 94.1785964965894 .7881774902395 .397743225195 .7025299072396 .31210327148 96.9216690063597 .5312423706198 .1408081054798 .7503814697399 .35994720459 99.96952056885100 .8839035034101 .4934005737102 .1029968262102 .712600708 
103.3221969604103 .9317016602104 .5412979126105 .1509017944105 .7603988647 106.6747970581 107.2844009399 107.8938980103108.5035018921 109.4179000854 110.3321990967 110.9418029785 71.3197174072371 .0149307251 -9999 -9999 -9999 -9999 -9999 -9999 -9999 -9999 -9999 -9999 -9999 -9999 -9999 -9999 -9999 -9999 -9999 -9999 -9999 -9999 -9999 -9999-9999-9999-9999

-9999 -9999 -9999 -9999 -9999 -9999 -9999 -9999 -9999 -9999 -9999 -9999 -9999 -9999 -9999

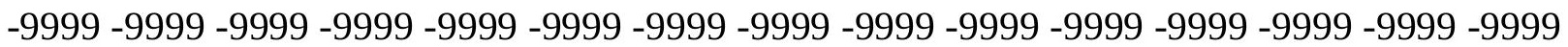
-9999 -9999 -9999 -9999 -9999 -9999 -9999 -9999 -9999 -9999 -9999 -9999 -9999 -9999 -9999 -9999 -9999 -9999 -9999 -9999 -9999 -9999 -9999 -9999 -9999 -9999 -9999 -9999 -9999 -9999 -9999 -9999 -9999 -9999 -9999 -9999 -9999 -9999 -9999 -9999 -9999 -9999 -9999 -9999 -9999 -9999 -9999 -9999 -9999 -9999 -9999 -9999 -9999 -9999 -9999 -9999 -9999 -9999 -9999 -9999 -999 -9999 -9999 -9999 -9999 -9999 -9999 -9999 -9999 -9999 -9999 -9999 -9999 -9999 -9999 -9999 -9999 -9999 -9999 -9999 -9999 -9999 -9999 -9999 -9999 -9999 -9999 -9999 -9999 -9999 -9999 -9999 -9999 -9999 -9999 -9999 -9999 -9999 -9999 -9999 -9999 -9999 -9999 -9999 -9999 -9999 -9999 -9999 -9999 -9999 -9999 -9999 -9999 -9999 -9999 -9999 -9999 -9999 -9999 -9999 -9999 -

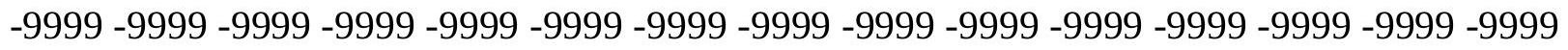
-9999 -9999 -9999 -9999 -9999 -9999 -9999 -9999 -9999 -9999 -9999 -9999 -9999 -9999 -9999 -9999 -9999 -9999 -9999 -9999 -9999 -9999 -9999 -9999 -9999 -9999 -9999 -9999 -9999 -9999 -

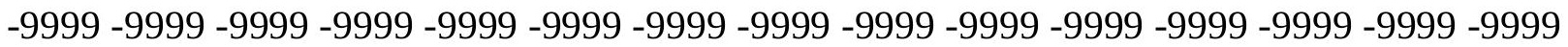

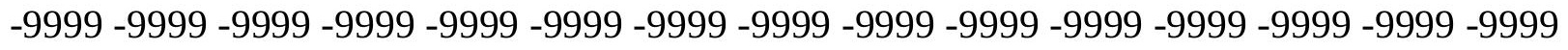

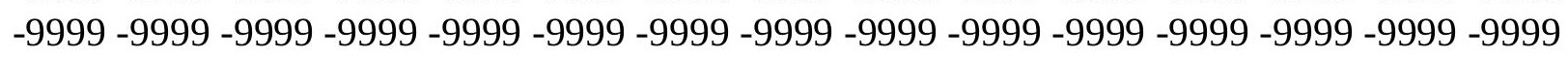

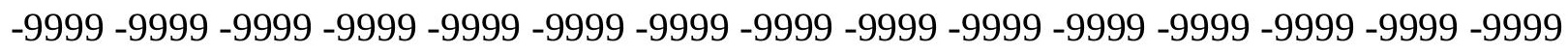
-9999 -9999 -9999 -9999 -9999 -9999 -9999 -9999 -9999 -9999 -9999 -9999 -9999 -9999 -9999 -9999 -9999 -9999 -9999 -9999 -9999 -9999 -9999 -9999 -9999 -9999 -9999 -9999 -9999 -9999 -

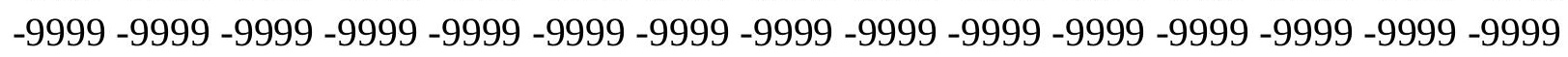
-9999 -9999 -9999 -9999 -9999 -9999 -9999 -9999 -9999 -9999 -9999 -9999 -9999 -9999 -9999 -9999 -9999 -9999 -9999 -9999-9999 -9999 -9999 -9999 -9999 -9999 -9999 -9999 -9999 -9999 -9999 92.95947265625 91.4355392456191.7403335571392.349891662692.95947265625 93.2642517089893 .5690307617293 .8738174438594 .1785964965894 .78817749023 95.397743225196 .0073165893696 .6168823242297 .2264633178797 .83602905273 98.445587158299 .0551681518699 .66472625732100 .2742996216100 .8839035034 101.4934005737102 .1029968262102 .712600708103 .3221969604103 .9317016602 104.8460998535105 .4557037354106 .0652008057106 .979598999107 .5891036987 108.503501892171 .9292907714871 .31971740723 -9999 -9999 -9999 -9999 -9999 -9999 -9999 -9999 -9999 -9999 -9999 -9999 -9999 -9999 -9999 -9999 -9999 -9999 -9999 -9999 -9999 -9999 -9999 -9999-9999

-9999 -9999 -9999 -9999 -9999 -9999 -9999 -9999 -9999 -9999 -9999 -9999 -9999 -9999 - 9999-

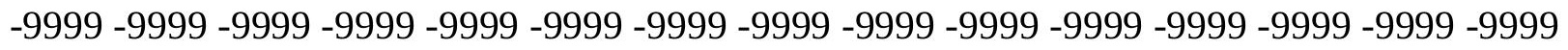
-9999 -9999 -9999 -9999 -9999 -9999 -9999 -9999 -9999 -9999 -9999 -9999 -9999 -9999 -9999 -9999 -9999 -9999 -9999 -9999 -9999 -9999 -9999 -9999 -9999 -9999 -9999 -9999 -9999 -9999 -

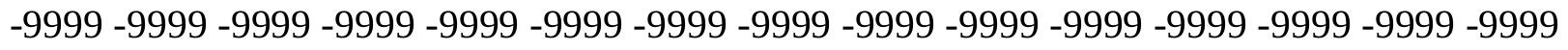

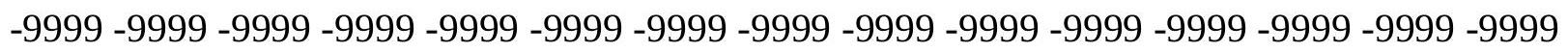

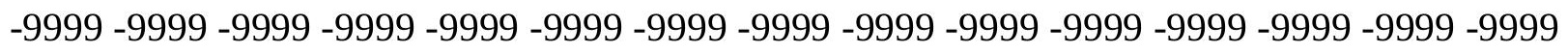
-9999 -9999 -9999 -9999 -9999 -9999 -9999 -9999 -9999 -9999 -9999 -9999 -9999 -9999 -9999

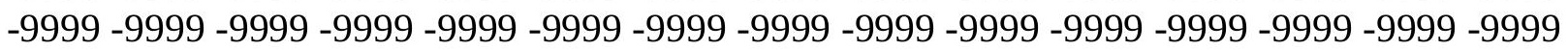

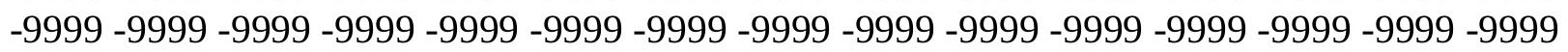


-9999 -9999 -9999 -9999 -9999 -9999 -9999 -9999 -9999 -9999 -9999 -9999 -9999 -9999 -9999 -9999 -9999 -9999 -9999 -9999 -9999 -9999 -9999 -9999 -9999 -9999 -9999 -9999 -9999 -9999 -9999 -9999 -9999 -9999 -9999 -9999 -9999 -9999 -9999 -9999 -9999 -9999 -9999 -9999 -9999 -9999 -9999 -9999 -9999 -9999 -9999 -9999 -9999 -9999 -9999 -9999 -9999 -9999 -9999 -9999 -9999 -9999 -9999 -9999 -9999 -9999 -9999 -9999 -9999 -9999 -9999 -9999 -9999 -9999 -9999 -9999 -9999 -9999 -9999 -9999 -9999 -9999 -9999 -9999 -9999 -9999 -9999 -9999 -9999 -9999 -9999 -9999 -9999 -9999 -9999 -9999 -9999 -9999 -9999 -9999 -9999 -9999 -9999 -9999 -9999

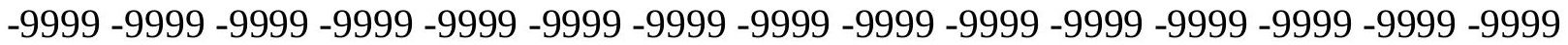
-9999 -9999 -9999 -9999 -9999 -9999 -9999 -9999 -9999 -9999 -9999 -9999 -9999 -9999 -9999 -9999 -9999 -9999 -9999 -9999 -9999 -9999 -9999 -9999 -9999 -9999 -9999 -9999 -9999 -9999 -

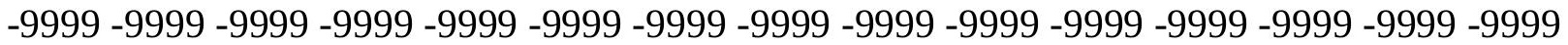
-9999 -9999 -9999 -9999 -9999 -9999 -9999 -9999 -9999 -9999 -9999 -9999 -9999 -9999 -9999 -9999 93.2642517089891.7403335571390.8259735107491.4355392456191.74033355713 91.7403335571391 .7403335571392 .0450973510792 .349891662692 .65467834473 93.2642517089893 .8738174438594 .4833908081195 .0929565429795 .70252990723 96.3121032714896 .9216690063597 .5312423706198 .1408081054798 .4455871582 99.0551681518699 .66472625732100 .2742996216100 .8839035034101 .4934005737 102.1029968262103 .0174026489103 .6268997192104 .2365036011105 .1509017944 72.5388565063572 .23407745361 -9999 -9999 -9999 -9999 -9999 -9999 -9999 -9999 -9999 -9999 -9999 -9999 -9999 -9999 -9999 -9999 -9999 -9999 -9999 -9999 -9999 -9999 -9999 -9999 $-9999-9999$

-9999 -9999 -9999 -9999 -9999 -9999 -9999 -9999 -9999 -9999 -9999 -9999 -9999 -9999 -9999 -9999 -9999 -9999 -9999 -9999 -9999 -9999 -9999 -9999 -9999 -9999 -9999 -9999 -9999 -9999 -9999 -9999 -9999 -9999 -9999 -9999 -9999 -9999 -9999 -9999 -9999 -9999 -9999 -9999 -9999

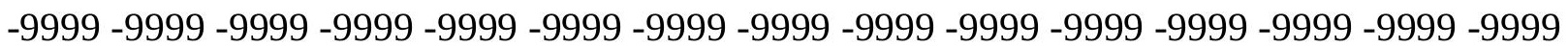
-9999 -9999 -9999 -9999 -9999 -9999 -9999 -9999 -9999 -9999 -9999 -9999 -9999 -9999 -9999 -9999 -9999 -9999 -9999 -9999 -9999 -9999 -9999 -9999 -9999 -9999 -9999 -9999 -9999 -9999 -9999 -9999 -9999 -9999 -9999 -9999 -9999 -9999 -9999 -9999 -9999 -9999 -9999 -9999 -9999 -9999 -9999 -9999 -9999 -9999 -9999 -9999 -9999 -9999 -9999 -9999 -9999 -9999 -9999 -9999

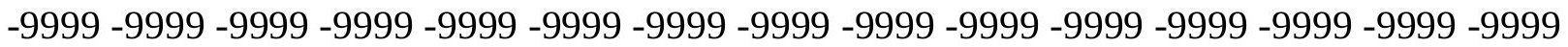
-9999 -9999 -9999 -9999 -9999 -9999 -9999 -9999 -9999 -9999 -9999 -9999 -9999 -9999 -9999 -

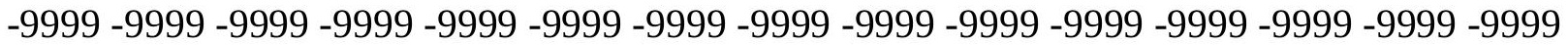
-9999 -9999 -9999 -9999 -9999 -9999 -9999 -9999 -9999 -9999 -9999 -9999 -9999 -9999 -9999 -9999 -9999 -9999 -9999 -9999 -9999 -9999 -9999 -9999 -9999 -9999 -9999 -9999 -9999 -9999 -

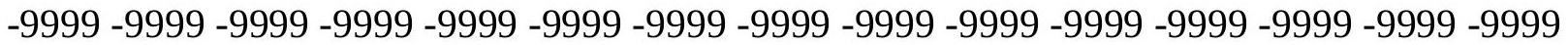
-9999 -9999 -9999 -9999 -9999 -9999 -9999 -9999 -9999 -9999 -9999 -9999 -9999 -9999 -9999 -9999 -9999 -9999 -9999 -9999 -9999 -9999 -9999 -9999 -9999 -9999 -9999 -9999 -9999 -9999

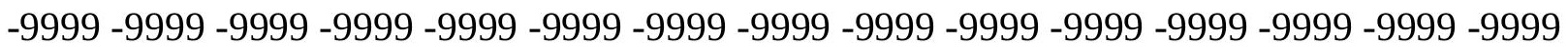
-9999 -9999 -9999 -9999 -9999 -9999 -9999 -9999 -9999 -9999 -9999 -9999 -9999 -9999 -9999 -9999 -9999 -9999 -9999 -9999 -9999 -9999 -9999 -9999 -9999 -9999 -9999 -9999 -9999 -9999 -9999 -9999 -9999 -9999 -9999 -9999 -9999 -9999 -9999 -9999 -9999 -9999 -9999 -9999 -9999 -999 -9999 -9999 -9999 -9999 -9999 -9999 -9999 -9999 -9999 -9999 -9999 -9999 -9999 -9999 -9999 -9999 -9999 -9999 -9999 -9999 -9999 -9999 -9999 -9999 -9999 -9999 -9999 -9999 -9999 -9999 -999 -999 -999 -999 -9999 -9999 92.0450973510790.5211791992290.2164001464890.21640014648 89.9116134643689 .9116134643689 .9116134643690 .2164001464890 .52117919922 91.1307525634891 .7403335571392 .349891662692 .9594726562593 .56903076172 
94.1785964965894 .7881774902395 .0929565429795 .7025299072396 .31210327148 96.9216690063597 .2264633178797 .8360290527398 .445587158299 .05516815186 99.66472625732100 .5791015625101 .1886978149101 .798202514673 .45321655273 73.1484298706172 .53885650635 -9999 -9999 -9999 -9999 -9999 -9999 -9999 -9999 -9999 -9999 -9999 -9999 -9999 -9999 -9999 -9999 -9999 -9999 -9999 -9999 -9999 -9999 -9999 -9999 $-9999-9999$

-9999 -9999 -9999 -9999 -9999 -9999 -9999 -9999 -9999 -9999 -9999 -9999 -9999 -9999 -9999 -9999 -9999 -9999 -9999 -9999 -9999 -9999 -9999 -9999 -9999 -9999 -9999 -9999 -9999 -9999

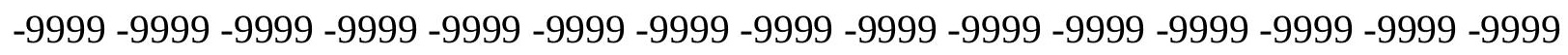
-9999 -9999 -9999 -9999 -9999 -9999 -9999 -9999 -9999 -9999 -9999 -9999 -9999 -9999 -9999 -9999 -9999 -9999 -9999 -9999 -9999 -9999 -9999 -9999 -9999 -9999 -9999 -9999 -9999 -9999 -9999 -9999 -9999 -9999 -9999 -9999 -9999 -9999 -9999 -9999 -9999 -9999 -9999 -9999 -9999

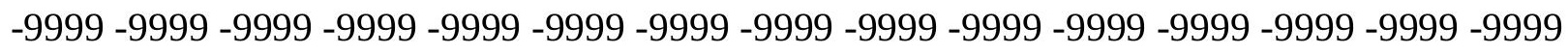
-9999 -9999 -9999 -9999 -9999 -9999 -9999 -9999 -9999 -9999 -9999 -9999 -9999 -9999 -9999 -9999 -9999 -9999 -9999 -9999 -9999 -9999 -9999 -9999 -9999 -9999 -9999 -9999 -9999 -9999

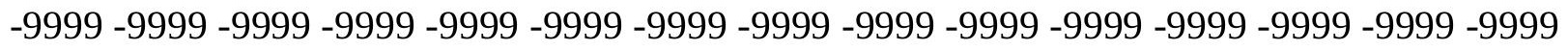
-9999 -9999 -9999 -9999 -9999 -9999 -9999 -9999 -9999 -9999 -9999 -9999 -9999 -9999 -9999 -

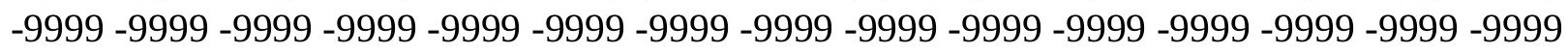

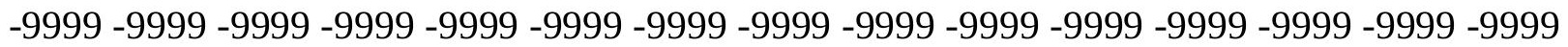

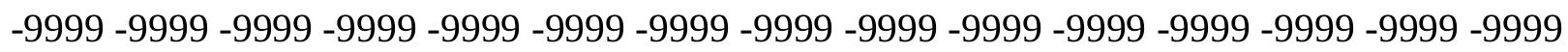

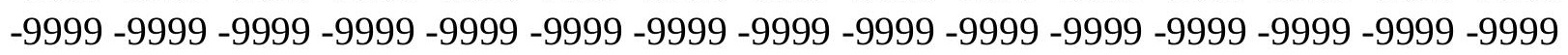

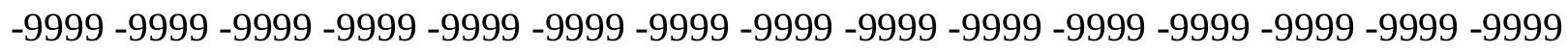
-9999 -9999 -9999 -9999 -9999 -9999 -9999 -9999 -9999 -9999 -9999 -9999 -9999 -9999 -9999 -9999 -9999 -9999 -9999 -9999 -9999 -9999 -9999 -9999 -9999 -9999 -9999 -9999 -9999 -9999 -

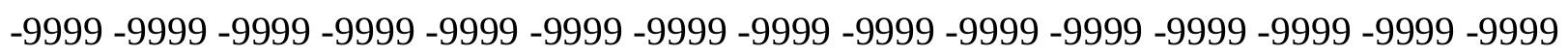
-9999 -9999 -9999 -9999 -9999 -9999 -9999 -9999 -9999 -9999 -9999 -9999 -9999 -9999 -9999 -9999 -9999 -9999 -9999 -9999 -9999 -9999 -9999 -9999 -9999 -9999 -9999 -9999 -9999 - -9999 -

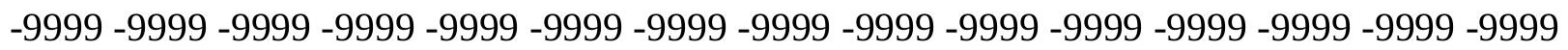
-9999-9999-9999 90.82597351074 89.3020401001 88.3876876831188.08290100098 87.77810668945 87.77810668945 87.77810668945 88.38768768311 88.99725341797 89.6068267822390 .2164001464890 .8259735107491 .4355392456192 .04509735107 92.6546783447392 .9594726562593 .5690307617293 .8738174438594 .48339080811 95.0929565429795.397743225196.0073165893696.61688232422 97.22646331787 $98.1408081054798 .7503814697399 .3599472045973 .7580032348673 .45321655273-9999$ -9999 -9999 -9999 -9999 -9999 -9999 -9999 -9999 -9999 -9999 -9999 -9999 -9999 -9999 -9999 -9999 -9999 -9999 -9999 -9999 -9999 -9999 -9999 -9999 -9999 -9999

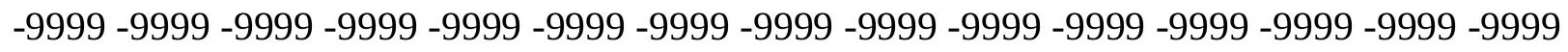

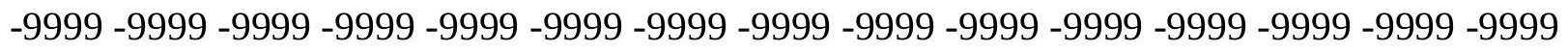

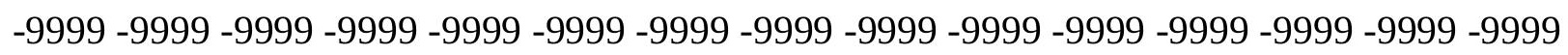
-9999 -9999 -9999 -9999 -9999 -9999 -9999 -9999 -9999 -9999 -9999 -9999 -9999 -9999 -9999 -

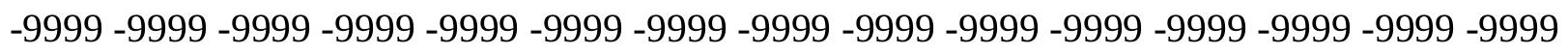

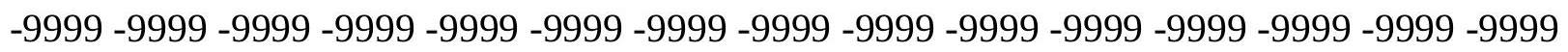

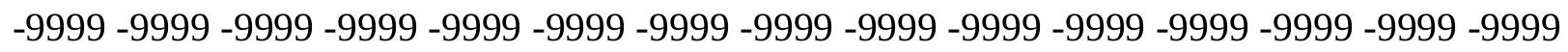
-9999 -9999 -9999 -9999 -9999 -9999 -9999 -9999 -9999 -9999 -9999 -9999 -9999 -9999 -9999 -

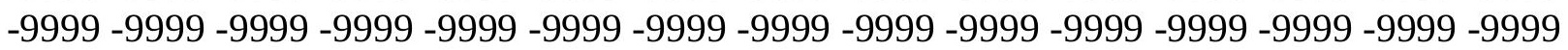

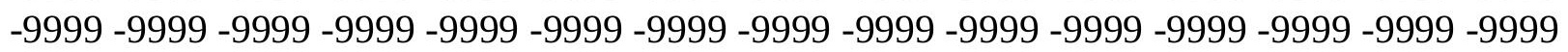


-9999 -9999 -9999 -9999 -9999 -9999 -9999 -9999 -9999 -9999 -9999 -9999 -9999 -9999 -9999 -9999 -9999 -9999 -9999 -9999 -9999 -9999 -9999 -9999 -9999 -9999 -9999 -9999 -9999 -9999 -9999 -9999 -9999 -9999 -9999 -9999 -9999 -9999 -9999 -9999 -9999 -9999 -9999 -9999 - 9999 -9999 -9999 -9999 -9999 -9999 -9999 -9999 -9999 -9999 -9999 -9999 -9999 -9999 -9999 -9999 -9999 -9999 -9999 -9999 -9999 -9999 -9999 -9999 -9999-9999 -9999 -9999 -9999 -9999 -9999 -9999 -9999 -9999 -9999 -9999 -9999 -9999 -9999 -9999 -9999 -9999 -9999 -9999 -9999 -9999 -9999 -9999 -9999 -9999 -9999 -9999 -9999 -9999 -9999 -9999 -9999 -9999 -9999 -9999 -9999 -999 -

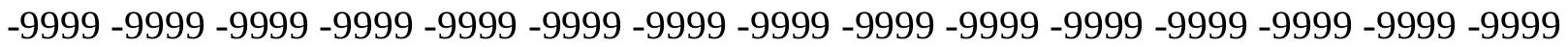
-9999 -9999 -9999 -9999 -9999 -9999 -9999 -9999 -9999 -9999 -9999 -9999 -9999 -9999 -9999 -9999 -9999 -9999 -9999 -9999 -9999 -9999 -9999 -9999 -9999 -9999 -9999 -9999 -9999 -9999 -9999 -9999 -9999 -9999 -9999 -9999 -9999 -9999 -9999 -9999 -9999 -9999 -9999 -9999 -9999 -9999 -9999 -9999 -9999 -9999 -9999 -9999 -9999 -9999 -9999 -9999 -9999 -9999 -9999 -9999 -9999 -9999 -9999 -9999 89.60682678223 87.77810668945 86.2541885376 85.64462280273 85.3398437585 .6446228027386 .254188537686 .8637619018687 .77810668945 88.3876876831188 .9972534179789 .6068267822390 .2164001464890 .52117919922 90.8259735107491 .4355392456191 .7403335571392 .0450973510792 .65467834473 93.2642517089893 .5690307617294 .1785964965895 .0929565429795 .70252990723 96.3121032714874 .6723632812574 .0627822876 -9999 -9999 -9999 -9999 -9999 -9999 -9999 -9999 -9999 -9999 -9999 -9999 -9999 -9999 -9999 -9999 -9999 -9999 -9999 -9999 -9999 -9999 -9999 -9999 -9999 -9999-9999-9999

-9999 -9999 -9999 -9999 -9999 -9999 -9999 -9999 -9999 -9999 -9999 -9999 -9999 -9999 -9999 -9999 -9999 -9999 -9999 -9999 -9999 -9999 -9999 -9999 -9999 -9999 -9999 -9999 -9999 -9999 -9999 -9999 -9999 -9999 -9999 -9999 -9999 -9999 -9999 -9999 -9999 -9999 -9999 -9999 -9999 -9999 -9999 -9999 -9999 -9999 -9999 -9999 -9999 -9999 -9999 -9999 -9999 -9999 -9999 -9999 -9999 -9999 -9999 -9999 -9999 -9999 -9999 -9999 -9999 -9999 -9999 -9999 -9999 -9999 -9999 -9999 -9999 -9999 -9999 -9999 -9999 -9999 -9999 -9999 -9999 -9999 -9999 -9999 -9999 -9999 -9999 -9999 -9999 -9999 -9999 -9999 -9999 -9999 -9999 -9999 -9999 -9999 -9999 -9999 -9999 -

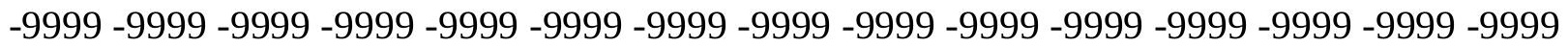

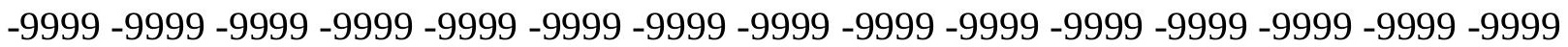
-9999 -9999 -9999 -9999 -9999 -9999 -9999 -9999 -9999 -9999 -9999 -9999 -9999 -9999 -999 -9999 -9999 -9999 -9999 -9999 -9999 -9999 -9999 -9999 -9999 -9999 -9999 -9999 -9999 -9999

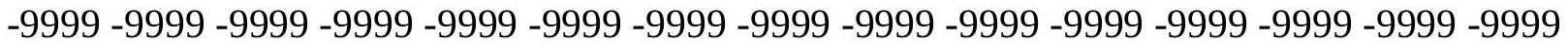

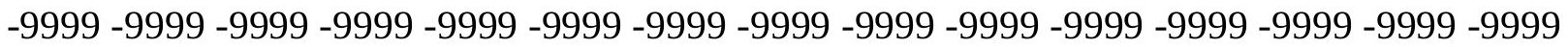
-9999 -9999 -9999 -9999 -9999 -9999 -9999 -9999 -9999 -9999 -9999 -9999 -9999 -9999 -9999 -9999 -9999 -9999 -9999 -9999 -9999 -9999 -9999 -9999 -9999 -9999 -9999 -9999 -9999 -9999 -9999 -9999 -9999 -9999 -9999 -9999 -9999 -9999 -9999 -9999 -9999 -9999 -9999 -9999 -9999

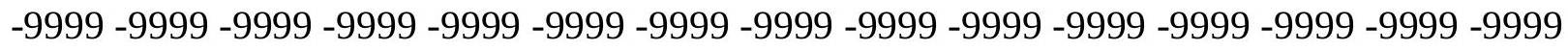

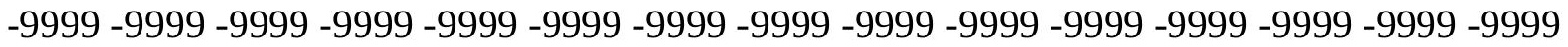
-9999 -9999 -9999 -9999 -9999 -9999 -9999 -9999 -9999 -9999 -9999 -9999 -9999 - 9999 - -999 -9999 -9999 -9999 -9999 -9999 -9999 -9999 -9999 -9999 -9999 -9999 -9999 -9999 -9999 -9999 -

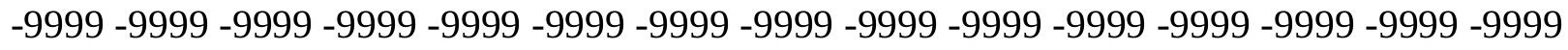

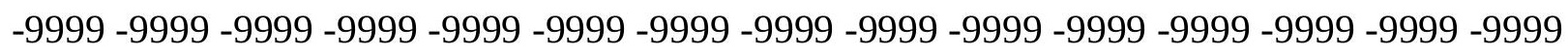
-9999 -9999-9999-9999-9999 88.08290100098 86.2541885376 84.73026275635 83.206336975183 .8159103393684 .4254837036185 .0350494384885 .94940185547 86.5589828491287 .1685485839887 .7781066894588 .0829010009888 .69246673584 88.9972534179789 .302040100189 .6068267822389 .9116134643690 .21640014648 
90.8259735107491 .4355392456192 .0450973510792 .6546783447393 .26425170898 75.2819290161174 .9771423339874 .36756896973 -9999 -9999 -9999 -9999 -9999 -9999 -9999 -9999 -9999 -9999 -9999 -9999 -9999 -9999 -9999 -9999 -9999 -9999 -9999 -9999 -9999 -9999 -9999 -9999 -9999 -9999-9999-9999

-9999 -9999 -9999 -9999 -9999 -9999 -9999 -9999 -9999 -9999 -9999 -9999 -9999 -9999 -9999 -9999 -9999 -9999 -9999 -9999 -9999 -9999 -9999 -9999 -9999 -9999 -9999 -9999 -9999 -9999 -9999 -9999 -9999 -9999 -9999 -9999 -9999 -9999 -9999 -9999 -9999 -9999 -9999 -9999 -9999 -

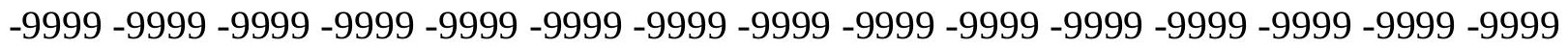
-9999 -9999 -9999 -9999 -9999 -9999 -9999 -9999 -9999 -9999 -9999 -9999 -9999 -9999 -9999 -9999 -9999 -9999 -9999 -9999 -9999 -9999 -9999 -9999 -9999 -9999 -9999 -9999 -9999 -9999

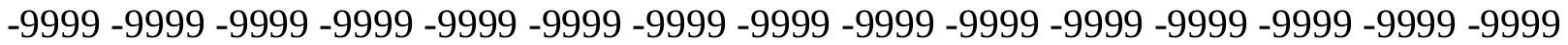
-9999 -9999 -9999 -9999 -9999 -9999 -9999 -9999 -9999 -9999 -9999 -9999 -9999 -9999 -9999 -9999 -9999 -9999 -9999 -9999 -9999 -9999 -9999 -9999 -9999 -9999 -9999 -9999 -9999 -9999 -9999 -9999 -9999 -9999 -9999 -9999 -9999 -9999 -9999 -9999 -9999 -9999 -9999 -9999 - 9999 -9999 -9999 -9999 -9999 -9999 -9999 -9999 -9999 -9999 -9999 -9999 -9999 -9999 -9999 -9999

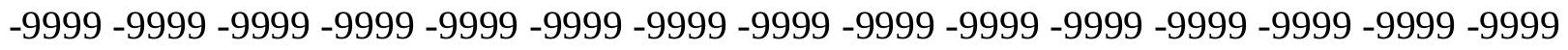
-9999 -9999 -9999 -9999 -9999 -9999 -9999 -9999 -9999 -9999 -9999 -9999 -9999 -9999 -9999 -9999 -9999 -9999 -9999 -9999 -9999 -9999 -9999 -9999 -9999 -9999 -9999 -9999 -9999 -9999 -999 -9999 -9999 -9999 -9999 -9999 -9999 -9999 -9999 -9999 -9999 -9999 -9999 -9999 -9999 -9999 -9999 -9999 -9999 -9999 -9999 -9999 -9999 -9999 -9999 -9999 -9999 -9999 -9999 -9999 -9999 -9999 -9999 -9999 -9999 -9999 -9999 -9999 -9999 -9999 -9999 -9999 -9999 -9999 -9999 -9999 -9999 -9999 -9999 -9999 -9999 -9999 -9999 -9999 -9999 -9999 -9999 -9999 -9999 -9999 -9999 -9999 -9999 -9999 -9999 -9999 -9999 -9999 -9999 -9999 -9999 -9999 -9999 -9999 -9999 -9999 -9999 -9999 -9999 -9999 -9999 -9999 -9999 -9999 -9999 -9999 -9999 -9999 -9999 -9999 -9999 -9999 -9999 -9999 -9999 -9999 -9999 -9999 -9999 -9999 -9999 -9999 -9999 -9999 -9999 -9999 -9999 -9999 -9999 -9999 -9999 -9999 -9999 -9999 -9999 -9999 -9999 -9999 -9999 -9999 -9999 -9999 -9999 -9999 -9999 -9999 -9999 -9999 84.73026275635 83.206336975182 .90155792236 82.9015579223683 .5111236572384 .1206970214885 .0350494384885 .64462280273 85.9494018554786 .5589828491286 .8637619018686 .8637619018687 .16854858398 87.4733276367287 .7781066894588 .0829010009888 .6924667358488 .99725341797 89.60682678223 90.21640014648 91.13075256348 75.58670806885 75.28192901611 -9999 -9999 -9999 -9999 -9999 -9999 -9999 -9999 -9999 -9999 -9999 -9999 -9999 -9999 -9999 -9999 -9999 -9999 -9999 -9999 -9999 -9999 -9999 -9999 -9999 -9999 -9999 -9999 -9999 -

-9999 -9999 -9999 -9999 -9999 -9999 -9999 -9999 -9999 -9999 -9999 -9999 -9999 -9999 -9999 -9999 -9999 -9999 -9999 -9999 -9999 -9999 -9999 -9999 -9999 -9999 -9999 -9999 -9999 -9999 -9999 -9999 -9999 -9999 -9999 -9999 -9999 -9999 -9999 -9999 -9999 -9999 -9999 -9999 -9999 -

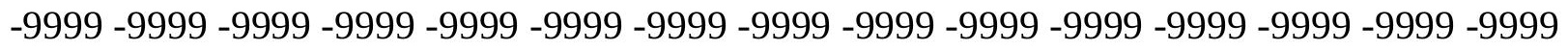

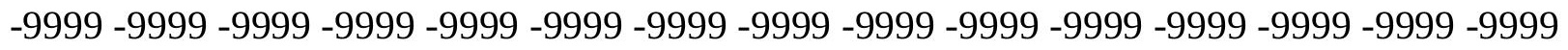
-9999 -9999 -9999 -9999 -9999 -9999 -9999 -9999 -9999 -9999 -9999 -9999 -9999 - 9999 - -999 -9999 -9999 -9999 -9999 -9999 -9999 -9999 -9999 -9999 -9999 -9999 -9999 -9999 -9999 -9999 -

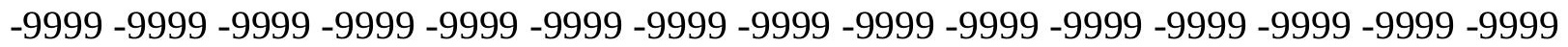

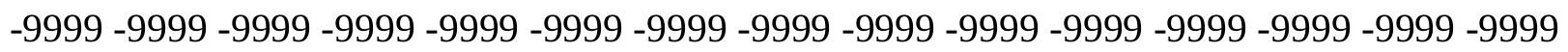
-9999 -9999 -9999 -9999 -9999 -9999 -9999 -9999 -9999 -9999 -9999 -9999 -9999 -9999 -9999 -9999 -9999 -9999 -9999 -9999 -9999 -9999 -9999 -9999 -9999 -9999 -9999 -9999 -9999 -9999 -9999 -9999 -9999 -9999 -9999 -9999 -9999 -9999 -9999 -9999 -9999 -9999 -9999 -9999 -9999 -

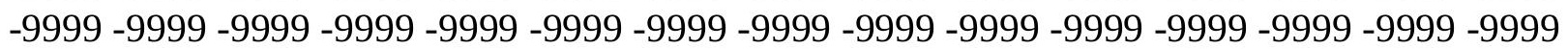


-9999 -9999 -9999 -9999 -9999 -9999 -9999 -9999 -9999 -9999 -9999 -9999 -9999 -9999 -9999 -9999 -9999 -9999 -9999 -9999 -9999 -9999 -9999 -9999 -9999 -9999 -9999 -9999 -9999 -9999 -9999 -9999 -9999 -9999 -9999 -9999 -9999 -9999 -9999 -9999 -9999 -9999 -9999 -9999 -9999 -9999 -9999 -9999 -9999 -9999 -9999 -9999 -9999 -9999 -9999 -9999 -9999 -9999 -9999 -9999 -9999 -9999 -9999 -9999 -9999 -9999 -9999 -9999 -9999 -9999 -9999 -9999 -9999 -9999 -9999 -9999 -9999 -9999 -9999 -9999 -9999 -9999 -9999 -9999 -9999 -9999 -9999 -9999 -9999 -9999 -9999 -9999 -9999 -9999 -9999 -9999 -9999 -9999 -9999 -9999 -9999 -9999 -9999 -9999 -9999

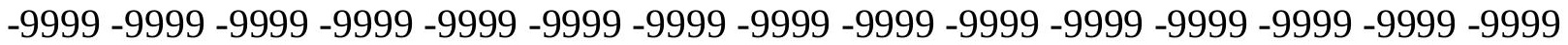
-9999 -9999 -9999 -9999 -9999 -9999 -9999 -9999 -9999 -9999 -9999 -9999 -9999 -9999 -9999 -9999 -9999 -9999 -9999 -9999 -9999 -9999 -9999 83.206336975183 .2063369751 82.9015579223682 .5967712402382 .5967712402383 .5111236572383 .81591033936 84.4254837036184 .7302627563585 .0350494384885 .3398437585 .3398437585 .33984375 85.6446228027385 .9494018554786 .254188537686 .8637619018687 .47332763672 88.0829010009876 .5010681152375 .89148712158 -9999 -9999 -9999 -9999 -9999 -9999 -9999 -9999 -9999 -9999 -9999 -9999 -9999 -9999 -9999 -9999 -9999 -9999 -9999 -9999 -9999 -9999 -9999 -9999 -9999 -9999 -9999 -9999 -9999 -9999

-9999 -9999 -9999 -9999 -9999 -9999 -9999 -9999 -9999 -9999 -9999 -9999 -9999 -9999 -9999 -9999 -9999 -9999 -9999 -9999 -9999 -9999 -9999 -9999 -9999 -9999 -9999 -9999 -9999 -9999 -9999 -9999 -9999 -9999 -9999 -9999 -9999 -9999 -9999 -9999 -9999 -9999 -9999 -9999 -9999 -9999 -9999 -9999 -9999 -9999 -9999 -9999 -9999 -9999 -9999 -9999 -9999 -9999 -9999 -9999

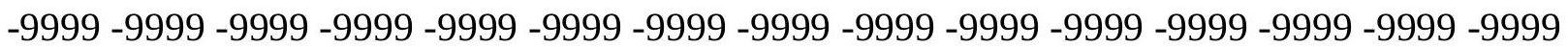
-9999 -9999 -9999 -9999 -9999 -9999 -9999 -9999 -9999 -9999 -9999 -9999 -9999 -9999 -9999 -9999 -9999 -9999 -9999 -9999 -9999 -9999 -9999 -9999 -9999 -9999 -9999 -9999 -9999 -9999 -9999 -9999 -9999 -9999 -9999 -9999 -9999 -9999 -9999 -9999 -9999 -9999 -9999 -9999 -9999

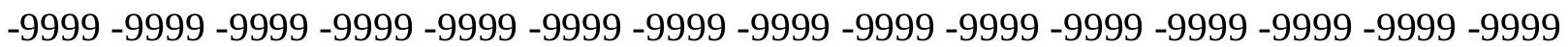
-9999 -9999 -9999 -9999 -9999 -9999 -9999 -9999 -9999 -9999 -9999 -9999 -9999 -9999 -9999 -9999 -9999 -9999 -9999 -9999 -9999 -9999 -9999 -9999 -9999 -9999 -9999 -9999 -9999 -9999 -9999 -9999 -9999 -9999 -9999 -9999 -9999 -9999 -9999 -9999 -9999 -9999 -9999 -9999 -9999 -9999 -9999 -9999 -9999 -9999 -9999 -9999 -9999 -9999 -9999 -9999 -9999 -9999 -9999 -9999 -9999 -9999 -9999 -9999 -9999 -9999 -9999 -9999 -9999 -9999 -9999 -9999 -9999 -9999 -9999 -9999 -9999 -9999 -9999 -9999 -9999 -9999 -9999 -9999 -9999 -9999 -9999 -9999 -9999 -9999 -

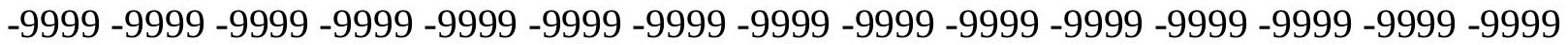
-9999 -9999 -9999 -9999 -9999 -9999 -9999 -9999 -9999 -9999 -9999 -9999 -9999 -9999 -9999 -9999 -9999 -9999 -9999 -9999 -9999 -9999 -9999 -9999 -9999 -9999 -9999 -9999 -9999 -9999 -

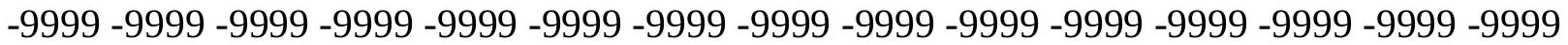
-9999 -9999 -9999 -9999 -9999 -9999 -9999 -9999 -9999 -9999 -9999 -9999 -9999 -9999 -9999 -9999 -9999 -9999 -9999 -9999 -9999 -9999 -9999 -9999 -9999 -9999 -9999 -9999 -9999 -9999

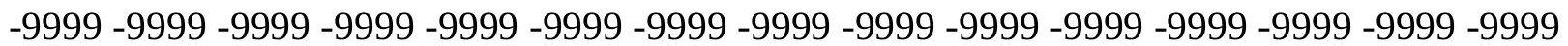
-9999 -9999 -9999 -9999 -9999 -9999 -9999 -9999 -9999 -9999 82.90155792236 82.5967712402382 .5967712402382 .2919769287182 .5967712402382 .90155792236 83.206336975183 .5111236572383 .5111236572383 .5111236572383 .51112365723 83.5111236572383 .8159103393684 .1206970214884 .7302627563585 .33984375 77.110626220776 .50106811523 -9999 -9999 -9999 -9999 -9999 -9999 -9999 -9999 -9999 -9999 -9999 -9999 -9999 -9999 -9999 -9999 -9999 -9999 -9999 -9999 -9999 -9999 -9999 -9999 -9999 -9999 -9999 -9999 -9999 -9999 -9999

-9999 -9999 -9999 -9999 -9999 -9999 -9999 -9999 -9999 -9999 -9999 -9999 -9999 -9999 -9999 
-9999 -9999 -9999 -9999 -9999 -9999 -9999 -9999 -9999 -9999 -9999 -9999 -9999 -9999 -9999 -9999 -9999 -9999 -9999 -9999 -9999 -9999 -9999 -9999 -9999 -9999 -9999 -9999 -9999 -9999 -9999 -9999 -9999 -9999 -9999 -9999 -9999 -9999 -9999 -9999 -9999 -9999 -9999 -9999 -9999 -9999 -9999 -9999 -9999 -9999 -9999 -9999 -9999 -9999 -9999 -9999 -9999 -9999 -9999 -9999 -9999 -9999 -9999 -9999 -9999 -9999 -9999 -9999 -9999-9999 -9999 -9999 -9999 -9999 -9999 -9999 -9999 -9999 -9999 -9999 -9999 -9999 -9999 -9999 -9999 -9999 -9999 -9999 -9999 -9999 -9999 -9999 -9999 -9999 -9999 -9999 -9999 -9999 -9999 -9999 -9999 -9999 -9999 -9999 -9999 -

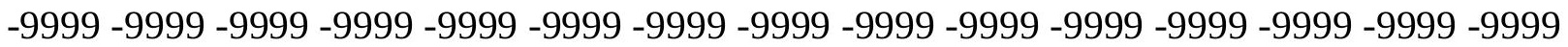
-9999 -9999 -9999 -9999 -9999 -9999 -9999 -9999 -9999 -9999 -9999 -9999 -9999 -9999 -9999 -9999 -9999 -9999 -9999 -9999 -9999 -9999 -9999 -9999 -9999 -9999 -9999 -9999 -9999 -9999 -

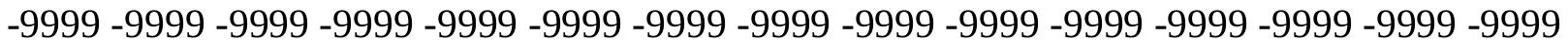
-9999 -9999 -9999 -9999 -9999 -9999 -9999 -9999 -9999 -9999 -9999 -9999 -9999 -9999 -9999 -9999 -9999 -9999 -9999 -9999 -9999 -9999 -9999 -9999 -9999 -9999 -9999 -9999 -9999 -9999 -9999 -9999 -9999 -9999 -9999 -9999 -9999 -9999 -9999 -9999 -9999 -9999 -9999 -9999 -9999 -9999 -9999 -9999 -9999 -9999 -9999 -9999 -9999 -9999 -9999 -9999 -9999 -9999 -9999 -9999

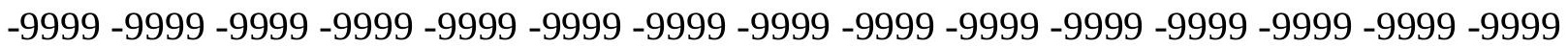
-9999 -9999 -9999 -9999 -9999 -9999 -9999 -9999 -9999 -9999 -9999 -9999 -9999 -9999 -9999 -9999 -9999 -9999 -9999 -9999 -9999 -9999 -9999 -9999 -9999 -9999 -9999 -9999 -9999 -9999 -9999 -9999 -9999 -9999 -9999 -9999 -9999 -9999 -9999 -9999 -9999 -9999 -9999 -9999 -9999 -9999 -9999 -9999 -9999 -9999 -9999 -9999 -9999 -9999 -9999 -9999 -9999 -9999 -9999 -9999 -9999 -9999 -9999 -9999 -9999 -9999 -9999 -9999 -9999 -9999 -9999 -9999 -9999 -9999 -9999 -9999 -9999 -9999 -9999 -9999 -9999 -9999 -9999 -9999 -9999 -9999 -9999 82.59677124023 82.2919769287181 .9871978759881 .6824111938581 .6824111938581 .98719787598 82.2919769287181 .9871978759881 .6824111938581 .6824111938579 .24413299561 78.6345596313578 .3297805786177 .7202072143677 .41542053223 -9999 -9999 -9999 -9999 -9999 -9999 -9999 -9999 -9999 -9999 -9999 -9999 -9999 -9999 -9999 -9999 -9999 -9999 -9999 -9999 -9999 -9999 -9999 -9999 -9999 -9999 -9999 -9999 -9999 -9999 -9999 -9999 -

-9999 -9999 -9999 -9999 -9999 -9999 -9999 -9999 -9999 -9999 -9999 -9999 -9999 -9999 -9999

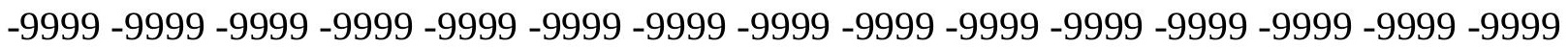

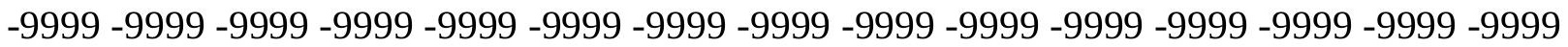
-9999 -9999 -9999 -9999 -9999 -9999 -9999 -9999 -9999 -9999 -9999 -9999 -9999 -9999 -9999

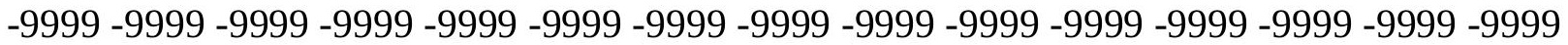
-9999 -9999 -9999 -9999 -9999 -9999 -9999 -9999 -9999 -9999 -9999 -9999 -9999 -9999 -9999 -9999 -9999 -9999 -9999 -9999 -9999 -9999 -9999 -9999 -9999 -9999 -9999 -9999 -9999 -9999 -

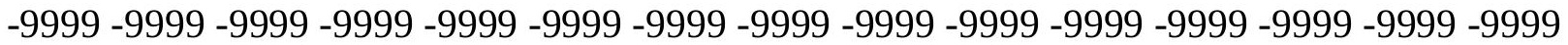
-9999 -9999 -9999 -9999 -9999 -9999 -9999 -9999 -9999 -9999 -9999 -9999 -9999 -9999 -9999 -9999 -9999 -9999 -9999 -9999 -9999 -9999 -9999 -9999 -9999 -9999 -9999 -9999 -9999 -9999

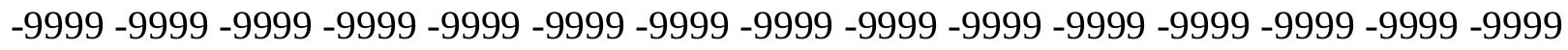
-9999 -9999 -9999 -9999 -9999 -9999 -9999 -9999 -9999 -9999 -9999 -9999 -9999 -9999 -9999 -9999 -9999 -9999 -9999 -9999 -9999 -9999 -9999 -9999 -9999 -9999 -9999 -9999 -9999 -9999 -9999 -9999 -9999 -9999 -9999 -9999 -9999 -9999 -9999 -9999 -9999 -9999 -9999 -9999 -9999 -999 -9999 -9999 -9999 -9999 -9999 -9999 -9999 -9999 -9999 -9999 -9999 -9999 -9999 -9999 -9999 -9999 -9999 -9999 -9999 -9999 -9999 -9999 -9999 -9999 -9999 -9999 -9999 -9999 -9999 -9999 -9999 -9999 -9999 -9999 -9999 -9999 -9999 -9999 -9999 -9999 -9999 -9999 -9999 -9999 -9999 -9999 -9999 -9999 -9999 -9999 -9999 -9999 -9999 -9999 -9999 -9999 -9999 -9999 -9999 -9999

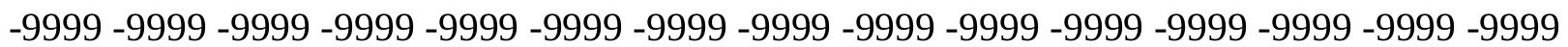


-9999 -9999 -9999 -9999 -9999 -9999 -9999 -9999 -9999 -9999 -9999 -9999 -9999 -9999 -9999 -9999 -9999 -9999 -9999 -9999 -9999 -9999 -9999 -9999 -9999 -9999 -9999 -9999 -9999 -9999 -9999 -9999 -9999 -9999 -9999 -9999 -9999 -9999 -9999 -9999 -9999 -9999 -9999 -9999 - -9999 -9999 -9999 -9999 -9999 -9999 -9999 -9999 -9999 -9999 -9999 -9999 -9999 -9999 -9999

82.2919769287181 .9871978759881 .6824111938581 .3776321411181 .07285308838 80.4632720947380 .1584930419979 .8537063598679 .2441329956178 .93934631348 78.32978057861 -9999 -9999 -9999 -9999 -9999 -9999 -9999 -9999 -9999 -9999 -9999 -9999

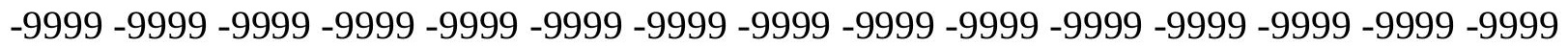
-9999 -9999 -9999 -9999-9999-9999 -9999

-9999 -9999 -9999 -9999 -9999 -9999 -9999 -9999 -9999 -9999 -9999 -9999 -9999 -9999 -9999 -9999 -9999 -9999 -9999 -9999 -9999 -9999 -9999 -9999 -9999 -9999 -9999 -9999 -9999 -9999 -999 -9999 -9999 -9999 -9999 -9999 -9999 -9999 -9999 -9999 -9999 -9999 -9999 -9999 -9999 -9999 -999 -9999 -9999 -9999 -9999 -9999 -9999 -9999 -9999 -9999 -9999 -9999 -9999 -9999 -9999 -9999 -9999 -9999 -9999 -9999 -9999 -9999 -9999 -9999 -9999 -9999 -9999 -9999 -9999 -9999 - 9999 -9999 -9999 -9999 -9999 -9999 -9999 -9999 -9999 -9999 -9999 -9999 -9999 -9999 -9999 -9999

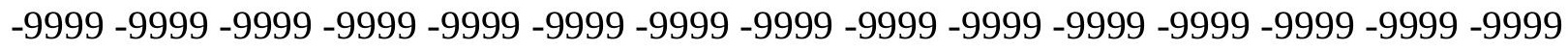
-9999 -9999 -9999 -9999 -9999 -9999 -9999 -9999 -9999 -9999 -9999 -9999 -9999 -9999 -9999 -9999 -9999 -9999 -9999 -9999 -9999 -9999 -9999 -9999 -9999 -9999 -9999 -9999 -9999 -9999 -9999 -9999 -9999 -9999 -9999 -9999 -9999 -9999 -9999 -9999 -9999 -9999 -9999 -9999 -9999 -

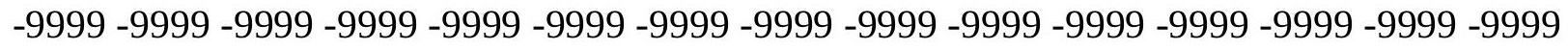

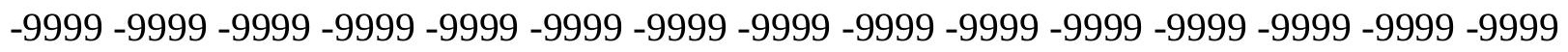
-9999 -9999 -9999 -9999 -9999 -9999 -9999 -9999 -9999 -9999 -9999 -9999 -9999 -9999 -9999 -9999 -9999 -9999 -9999 -9999 -9999 -9999 -9999 -9999 -9999 -9999 -9999 -9999 -9999 -9999 -9999 -9999 -9999 -9999 -9999 -9999 -9999 -9999 -9999 -9999 -9999 -9999 -9999 -9999 -9999 -

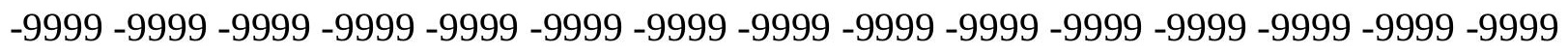
-9999 -9999 -9999 -9999 -9999 -9999 -9999 -9999 -9999 -9999 -9999 -9999 -9999 -9999 -9999 -

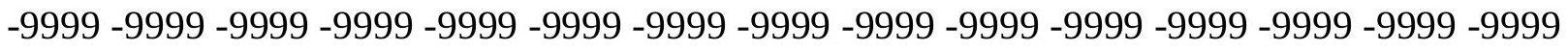

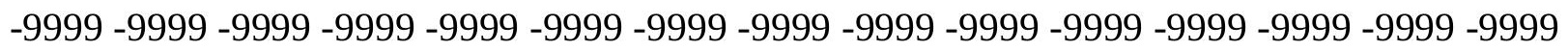
-9999 -9999 -9999 -9999 -9999 -9999 -9999 -9999 -9999 -9999 -9999 -9999 -9999 -9999 -9999 -9999 -9999 -9999 -9999 -9999 -9999 -9999 -9999 -9999 -9999 -9999 -9999 -9999 -9999 -9999 -9999 -9999 -9999 -9999 -9999 -9999 -9999 -9999 -9999-9999 -9999 -9999 -9999 -9999 -9999 -9999 -9999 -9999 -9999 -9999 -9999 -9999 -9999 -9999 -9999 -9999 -9999 -9999 -9999 -9999 -

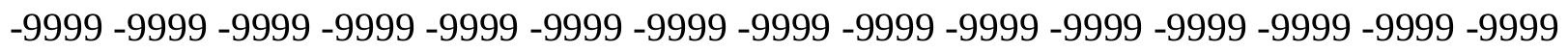
-9999 -9999 -9999 -9999 -9999 -9999 -9999 -9999 -9999 -9999 -9999 -9999 -9999 -9999 -9999 -9999 -9999 -9999 -9999 -9999 -9999 -9999 -9999 -9999 -9999 -9999 -9999 -9999 -9999 -9999 -9999 -9999 -9999 -9999 -9999 -9999 -9999 -9999 -9999 -9999 -9999 -9999 -9999 - -9999 -

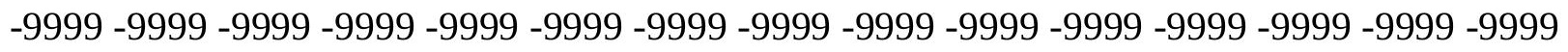

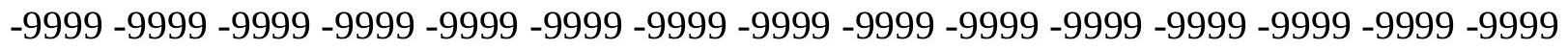
-9999 -9999 -9999 -9999 -9999 -9999 -9999 -9999 -9999 -9999 -9999 -9999 -9999 -9999 -9999 -9999 -9999 -9999 -9999 -9999 -9999 -9999 -9999 -9999 -9999 -9999 -9999 -9999 -9999 -9999 -

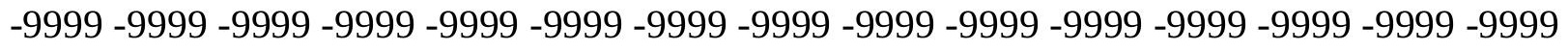

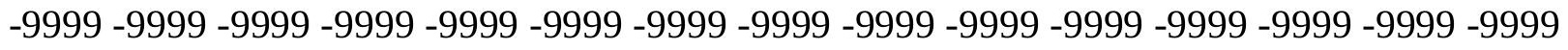
-9999 -9999 -9999 -9999 -9999 -9999 -9999 -9999 -9999 -9999 -9999 -9999 -9999 -9999 -9999 -9999 -9999 -9999 -9999 -9999 -9999 -9999 -9999 -9999-9999 -9999 -9999 -9999 -9999 -9999 -9999 -9999 -9999 -9999 -9999 -9999 -9999 -9999 -9999 -9999 -9999 -9999 -9999 -9999 -9999 -9999 -9999 -9999 -9999 -9999 -9999 -9999 -9999 -9999 -9999 -9999 -9999 -9999 -9999 -9999 
-9999 -9999 -9999 -9999 -9999 -9999 -9999 -9999 -9999 -9999 -9999 -9999 -9999 -9999 -9999 -9999 -9999 -9999 -9999 -9999 -9999 -9999 -9999 -9999 -9999 -9999 -9999 -9999 -9999 -9999 -

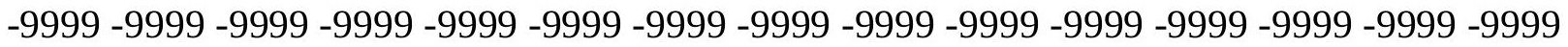
-9999 -9999 -9999 -9999 -9999 -9999 -9999 -9999 -9999 -9999 -9999 -9999 -9999 -9999 -9999 -9999 -9999 -9999 -9999 -9999 -9999 -9999 -9999 -9999-9999 -9999 -9999 -9999 -9999 -9999 -9999 -9999 -9999 -9999 -9999 -9999 -9999 -9999 -9999 -9999 -9999 -9999 -9999 -9999 -9999 -9999 -9999 -9999 -9999 -9999 -9999 -9999 -9999 -9999 -9999 -9999 -9999 -9999 -9999 -9999

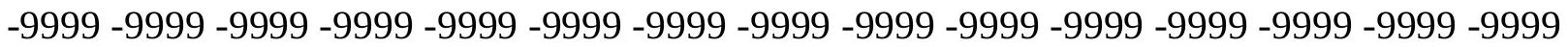

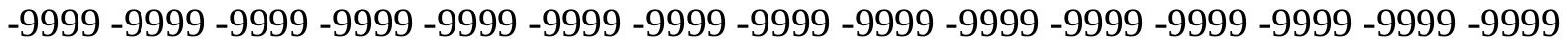
-9999 -9999 -9999 -9999 -9999 -9999 -9999 -9999 -9999 -9999 -9999 -9999 -9999 -9999 -9999 -9999 -9999 -9999 -9999 -9999 -9999 -9999 -9999 -9999 -9999 -9999 -9999 -9999 -9999 -9999 -9999 -9999 -9999 -9999 -9999 -9999 -9999 -9999 -9999 -9999 -9999 -9999 -9999 -9999 -9999 -9999 -9999 -9999 -9999 -9999 -9999 -9999 -9999 -9999 -9999 -9999 -9999 -9999 -9999 -9999 -9999 -9999 -9999 -9999 -9999 -9999 -9999 -9999 -9999 -9999 -9999 -9999 -9999 -9999 -9999 -9999 -9999 -9999 -9999 -9999 -9999 -9999 -9999 -9999 -9999 -9999 -9999 -9999 -9999 -9999 -9999 -9999 -9999 -9999 -9999 -9999 -9999 -9999 -9999 -9999 -9999 -9999 - 9999 - -999 -

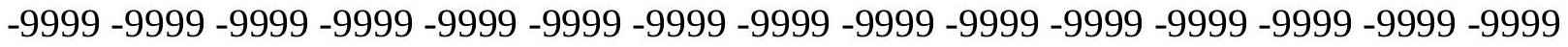
-9999 -9999 -9999 -9999 -9999 -9999 -9999 -9999 -9999 -9999 -9999 -9999 -9999 -9999 -9999 -9999 -9999 -9999 -9999 -9999 -9999 -9999 -9999 -9999 -9999 -9999 -9999 -9999 -9999 -9999 -

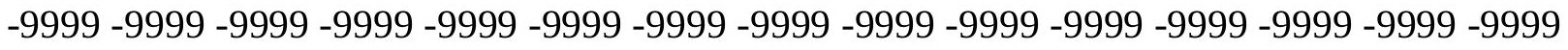
-9999 -9999 -9999 -9999 -9999 -9999 -9999 -9999 -9999 -9999 -9999 -9999 -9999 -9999 -9999

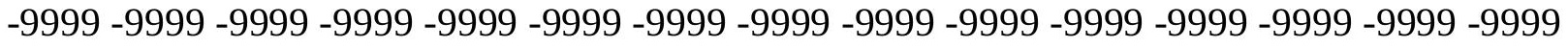
-9999 -9999 -9999 -9999 -9999 -9999 -9999 -9999 -9999 -9999 -9999 -9999 -9999 -9999 -9999 -9999 -9999 -9999 -9999 -9999 -9999 -9999 -9999 -9999 -9999 -9999 -9999 -9999 -9999 -9999 -

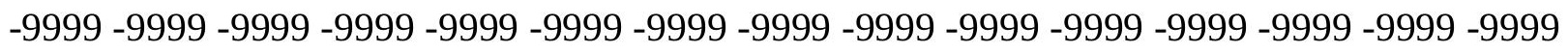
-9999 -9999 -9999 -9999 -9999 -9999 -9999 -9999 -9999 -9999 -9999 -9999 -9999 -9999 -9999 -9999 -9999 -9999 -9999 -9999 -9999 -9999 -9999 -9999 -9999 -9999 -9999 -9999 -9999 -9999 -

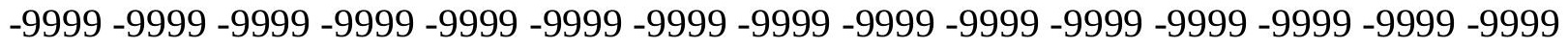
-9999 -9999 -9999 -9999 -9999 -9999 -9999 -9999 -9999 -9999 -9999 -9999 -9999 -9999 -9999 -9999 -9999 -9999 -9999 -9999 -9999 -9999 -9999 -9999 -9999 -9999 -9999 -9999 -9999 -999 -

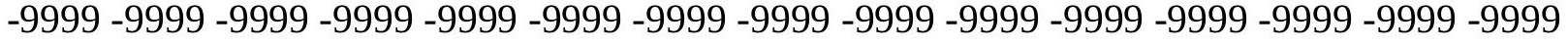
-9999 -9999 -9999 -9999 -9999 -9999 -9999 -9999 -9999 -9999 -9999 -9999 -9999 -9999 -9999 -

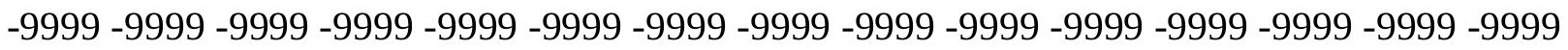

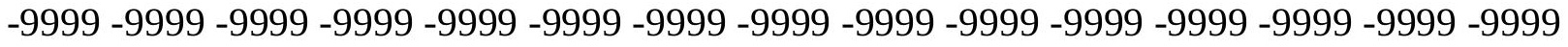

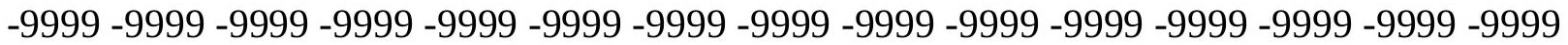
-9999 -9999 -9999 -9999 -9999 -9999 -9999 -9999 -9999 -9999 -9999 -9999 -9999 -9999 -9999 -

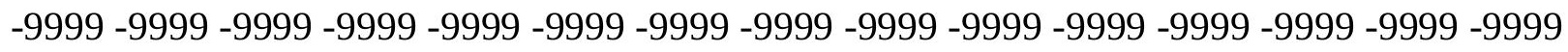

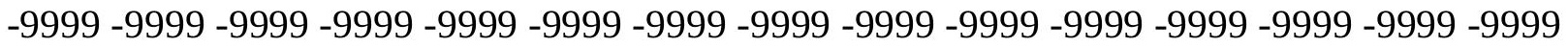
-9999 -9999 -9999 -9999 -9999 -9999 -9999 -9999 -9999 -9999 -9999 -9999 -9999 - 9999 - -999 -9999 -9999 -9999 -9999 -9999 -9999 -9999 -9999 -9999 -9999 -9999 -9999 -9999 -9999 -9999 -

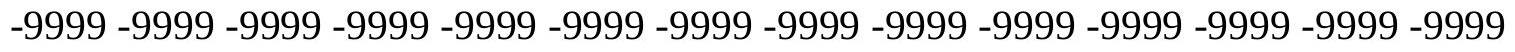

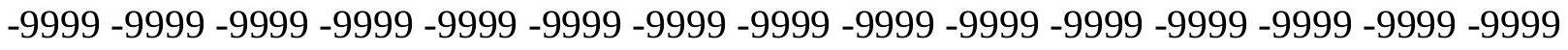
-9999 -9999 -9999 -9999 -9999 -9999 -9999 -9999 -9999 -9999 -9999 -9999 -9999 -9999 -9999 -9999 -9999 -9999 -9999 -9999 -9999 -9999 -9999 -9999-9999 -9999 -9999 -9999 -9999 -9999 -9999 -9999 -9999 -9999 -9999 -9999 -9999 -9999 -9999 -9999 -9999 -9999 -9999 -9999 -9999 -

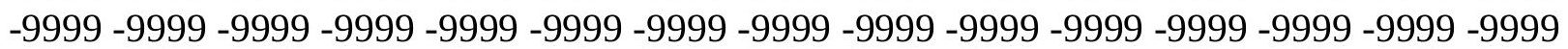


-9999 -9999 -9999 -9999 -9999 -9999 -9999 -9999 -9999 -9999 -9999 -9999 -9999 -9999 -9999 -9999 -9999 -9999 -9999 -9999 -9999 -9999 -9999 -9999 -9999 -9999 -9999 -9999 -9999 -9999 -9999 -9999 -9999 -9999 -9999 -9999 -9999 -9999 -9999 -9999 -9999 -9999 -9999 -9999 - 9999 -9999 -9999 -9999 -9999 -9999 -9999 -9999 -9999 -9999 -9999 -9999 -9999 -9999 -9999 -9999 -9999 -9999 -9999 -9999 -9999 -9999 -9999 -9999 -9999-9999 -9999 -9999 -9999 -9999 -9999 -9999 -9999 -9999 -9999 -9999 -9999 -9999 -9999 -9999 -9999 -9999 -9999 -9999 -9999 -9999 -9999 -9999 -9999 -9999 -9999 -9999 -9999 -9999 -9999 -9999 -9999 -9999 -9999 -9999 -9999

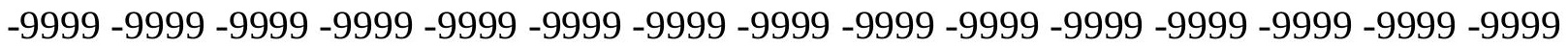
-9999 -9999 -9999 -9999 -9999 -9999 -9999 -9999 -9999 -9999 -9999 -9999 -9999 -9999 -9999 -9999 -9999 -9999 -9999 -9999 -9999 -9999 -9999 -9999 -9999 -9999 -9999 -9999 -9999 -9999

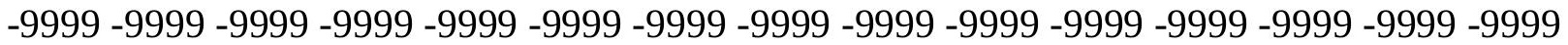
-9999 -9999 -9999 -9999 -9999 -9999 -9999 -9999 -9999 -9999 -9999 -9999 -9999 -9999 -9999 -9999 -9999 -9999 -9999 -9999 -9999 -9999 -9999 -9999 -9999 -9999 -9999 -9999 -9999 -9999 -

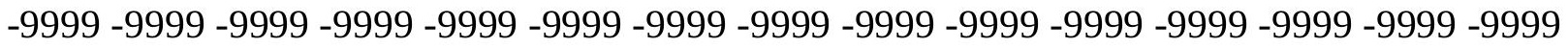
-9999 -9999 -9999 -9999 -9999 -9999 -9999 -9999 -9999 -9999 -9999 -9999 -9999 -9999 -9999

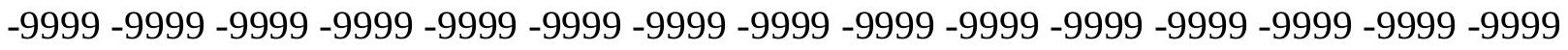
-9999 -9999 -9999 -9999 -9999 -9999 -9999 -9999 -9999 -9999 -9999 -9999 -9999 -9999 -9999 -9999 -9999 -9999 -9999 -9999 -9999 -9999 -9999 -9999 -9999 -9999 -9999 -9999 -9999 - 9999 -9999 -9999 -9999 -9999 -9999 -9999 -9999 -9999 -9999 -9999 -9999 -9999 -9999 -9999 -9999 -9999 -9999 -9999 -9999 -9999 -9999 -9999 -9999 -9999 -9999 -9999 -9999 -9999 -9999 -9999 -9999 -9999 -9999 -9999 -9999 -9999 -9999 -9999 -9999 -9999 -9999 -9999 -9999 -9999 -9999 -9999 -9999 -9999 -9999 -9999 -9999 -9999 -9999 -9999 -9999 -9999 -9999 -9999 -9999 -9999 -9999 -9999 -9999 -9999 -9999 -9999 -9999 -9999 -9999 -9999 -9999 -9999 -9999 -9999 -9999 -9999 -9999 -9999 -9999 -9999 -9999 -9999 -9999 -9999 -9999 -9999 -9999 -9999 -9999 -9999 -9999 -9999 -9999 -9999 -9999 -9999 -9999 -9999 -9999 -9999 -9999 -9999 -9999 -9999 -9999 -9999 -9999 -9999 -9999 -9999 -9999 -9999 -9999 -9999 -9999 -9999 -9999 -9999 -9999 -9999 -9999 -9999 -9999 -9999 -9999 -9999 -9999 -9999 -9999 -9999 -9999 -9999 -9999 -9999 -9999 -9999 -9999 -9999 -9999 -9999 -9999 -9999 -9999 -9999 -9999 -9999 -9999 -9999 -9999 -9999 -9999 -9999 -9999 -9999 -9999 -9999 -9999 -9999 -9999 -9999 -9999 -9999 -9999 -9999 -9999 -9999 -9999 -9999 -9999 -9999 -9999 -9999 -9999 -9999 -9999 -9999 -9999 -9999 -999 -9999 -9999 -9999 -9999 -9999 -9999 -9999 -9999 -9999 -9999 -9999 -9999 -9999 -9999 -9999 -9999 -9999 -9999 -9999 -9999 -9999 -9999 -9999 -9999 -9999 -9999 -9999 -9999 -9999 -9999 -

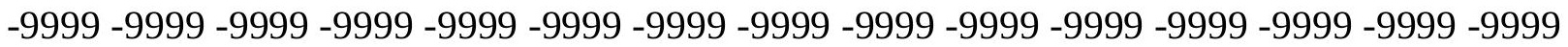

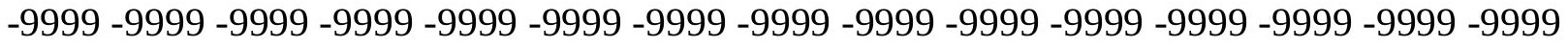

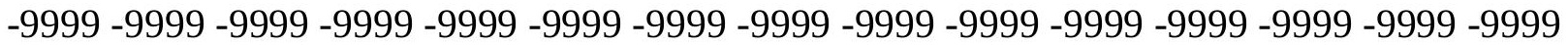
-9999 -9999 -9999 -9999 -9999 -9999 -9999 -9999 -9999 -9999 -9999 -9999 -9999 -9999 -9999

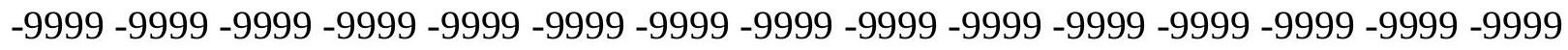

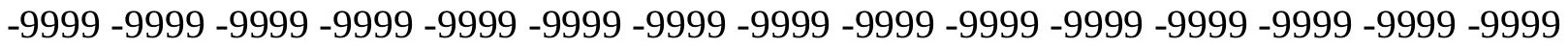

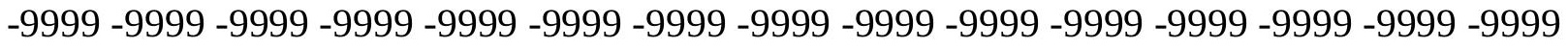
-9999 -9999 -9999 -9999 -9999 -9999 -9999 -9999 -9999 -9999 -9999 -9999 -9999 -9999 -9999 -

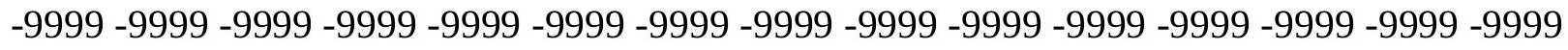

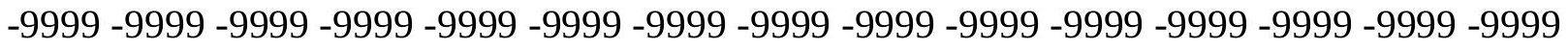
-9999 -9999 -9999 -9999 -9999 -9999 -9999 -9999 -9999 -9999 -9999 -9999 -9999 -9999 -9999 -9999 -9999 -9999 -9999 -9999 -9999 -9999 -9999 -9999-9999 -9999 -9999 -9999 -9999 -9999 -9999 -9999 -9999 -9999 -9999 -9999 -9999 -9999 -9999 -9999 -9999 -9999 -9999 -9999 -9999 -

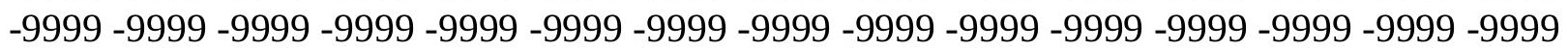


-9999 -9999 -9999 -9999 -9999 -9999 -9999 -9999 -9999 -9999 -9999 -9999 -9999 -9999 -9999 -9999 -9999 -9999 -9999 -9999 -9999 -9999 -9999 -9999 -9999 -9999 -9999 -9999 -9999 -9999 -9999 -9999 -9999 -9999 -9999 -9999 -9999 -9999 -9999 -9999 -9999 -9999 -9999 -9999 -9999 -9999 -9999 -9999 -9999 -9999 -9999 -9999 -9999 -9999 -9999 -9999 -9999 -9999 -9999 -9999 -9999 -9999 -9999 -9999 -9999 -9999 -9999 -9999 -9999 -9999 -9999 -9999 -9999 -9999 -9999 -9999 -9999 -9999 -9999 -9999 -9999 -9999 -9999 -9999 -9999 -9999 -9999 -9999 -9999 -9999 -9999 -9999 -9999 -9999 -9999 -9999 -9999 -9999 -9999 -9999 -9999 -9999 -9999 -9999 -

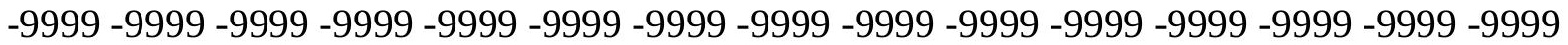
-9999 -9999 -9999 -9999 -9999 -9999 -9999 -9999 -9999 -9999 -9999 -9999 -9999 -9999 -9999 -9999 -9999 -9999 -9999 -9999 -9999 -9999 -9999 -9999 -9999 -9999 -9999 -9999 -9999 -9999 -

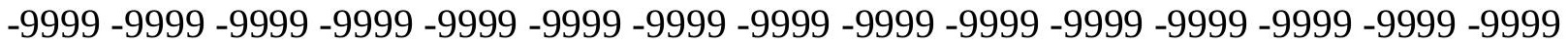
-9999 -9999 -9999 -9999 -9999 -9999 -9999 -9999 -9999 -9999 -9999 -9999 -9999 -9999 -9999 -9999 -9999 -9999 -9999 -9999 -9999 -9999 -9999 -9999 -9999 -9999 -9999 -9999 -9999 -9999 -9999 -9999 -9999 -9999 -9999 -9999 -9999 -9999 -9999 -9999 -9999 -9999 -9999 -9999 -9999 -9999 -9999 -9999 -9999 -9999 -9999 -9999 -9999 -9999 -9999 -9999 -9999 -9999 -9999 -9999 -9999 -9999 -9999 -9999 -9999 -9999 -9999 -9999 -9999 -9999 -9999 -9999 -9999 -9999 -9999 -9999 -9999 -9999 -9999 -9999 -9999 -9999 -9999 -9999 -9999 -9999 -9999 -9999 -9999 -9999 -9999 -9999 -9999 -9999 -9999 -9999 -9999 -9999 -9999 -9999 -9999 -9999 -9999 -9999 -9999 -9999 -9999 -9999 -9999 -9999 -9999 -9999 -9999 -9999 -9999 -9999 -9999 -9999 -9999 -9999 -9999 -9999 -9999 -9999 -9999 -9999 -9999 -9999 -9999 -9999 -9999 -9999 -9999 -9999 -9999

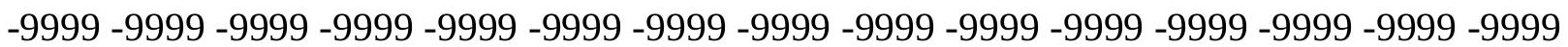
-9999 -9999 -9999 -9999 -9999 -9999 -9999 -9999 -9999 -9999 -9999 -9999 -9999 -9999 -9999 -9999 -9999 -9999 -9999 -9999 -9999 -9999 -9999 -9999 -9999 -9999 -9999 -9999 -9999 -9999 -9999 -9999 -9999 -9999 -9999 -9999 -9999 -9999 -9999 -9999 -9999 -9999 -9999 -9999 -9999

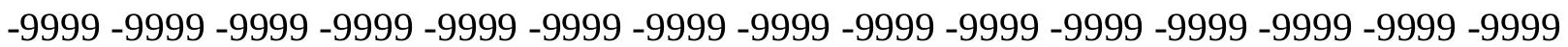
-9999 -9999 -9999 -9999 -9999 -9999 -9999 -9999 -9999 -9999 -9999 -9999 -9999 -9999 -9999 -9999 -9999 -9999 -9999 -9999 -9999 -9999 -9999 -9999 -9999 -9999 -9999 -9999 -9999 -9999 -9999 -9999 -9999 -9999 -9999 -9999 -9999 -9999 -9999 -9999 -9999 -9999 -9999 -9999

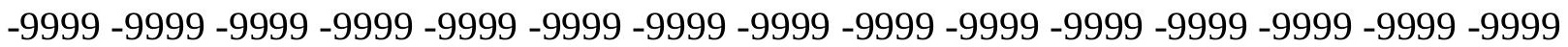
-9999 -9999 -9999 -9999 -9999 -9999 -9999 -9999 -9999 -9999 -9999 -9999 -9999 -9999 -9999 -9999 -9999 -9999 -9999 -9999 -9999 -9999 -9999 -9999 -9999 -9999 -9999 -9999 -9999 -9999 -

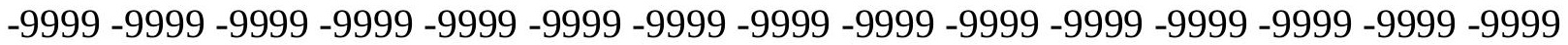
-9999 -9999 -9999 -9999 -9999 -9999 -9999 -9999 -9999 -9999 -9999 -9999 -9999 -9999 -9999 -9999 -9999 -9999 -9999 -9999 -9999 -9999 -9999 -9999 -9999 -9999 -9999 -9999 -9999 -9999 -9999 -9999 -9999 -9999 -9999 -9999 -9999 -9999 -9999 -9999 -9999 -9999 -9999 -9999 -9999 -9999 -9999 -9999 -9999 -9999 -9999 -9999 -9999 -9999 -9999 -9999 -9999 -9999 -9999 -9999 -9999 -9999 -9999 -9999 -9999 -9999 -9999 -9999 -9999 -9999 -9999 -9999 -9999 -9999 -9999

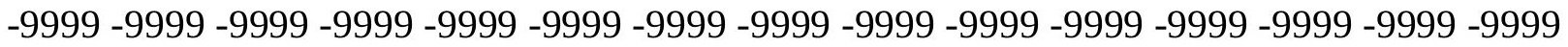
-9999 -9999 -9999 -9999 -9999 -9999 -9999 -9999 -9999 -9999 -9999 -9999 -9999 -9999 -9999 -9999 -9999 -9999 -9999 -9999 -9999 -9999 -9999 -9999 -9999 -9999 -9999 -9999 -9999 -9999 -

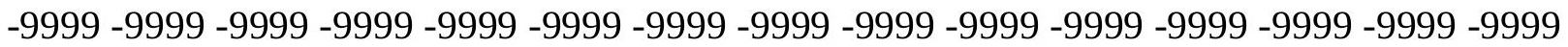
-9999 -9999 -9999 -9999 -9999 -9999 -9999 -9999 -9999 -9999 -9999 -9999 -9999 -9999 -9999 -9999 -9999 -9999 -9999 -9999 -9999 -9999 -9999 -9999 -9999 -9999 -9999 -9999 -9999 -9999 -9999 -9999 -9999 -9999 -9999 -9999 -9999 -9999 -9999 -9999 -9999 -9999 -9999 -9999 -9999 -9999 -9999 -9999 -9999 -9999 -9999 -9999 -9999 -9999 -9999 -9999 -9999 -9999 -9999 -9999

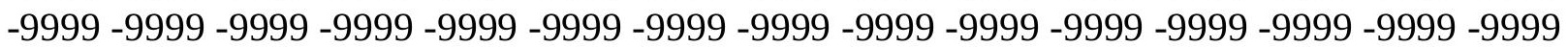


-9999 -9999 -9999 -9999 -9999 -9999 -9999 -9999 -9999 -9999 -9999 -9999 -9999 -9999 -9999 -9999 -9999 -9999 -9999 -9999 -9999 -9999 -9999 -9999 -9999 -9999 -9999 -9999 -9999 -9999 -

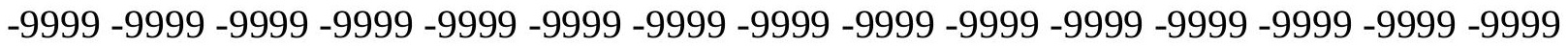
-9999 -9999 -9999 -9999 -9999 -9999 -9999 -9999 -9999 -9999 -9999 -9999 -9999 -9999 -9999 -9999 -9999 -9999 -9999 -9999 -9999 -9999 -9999 -9999-9999 -9999 -9999 -9999 -9999 -9999 -9999 -9999 -9999 -9999 -9999 -9999 -9999 -9999 -9999 -9999 -9999 -9999 -9999 -9999 -9999 -9999 -9999 -9999 -9999 -9999 -9999 -9999 -9999 -9999 -9999 -9999 -9999 -9999 -9999 -

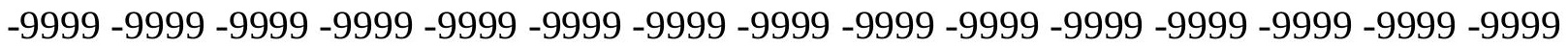

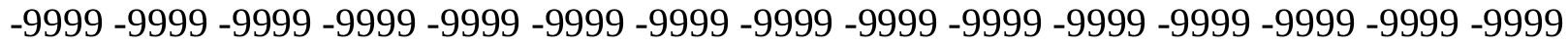
-9999 -9999 -9999 -9999 -9999 -9999 -9999 -9999 -9999 -9999 -9999 -9999 -9999 -9999 -9999 -9999 -9999 -9999 -9999 -9999 -9999 -9999 -9999 -9999 -9999 -9999 -9999 -9999 -9999 -9999 -9999 -9999 -9999 -9999 -9999 -9999 -9999 -9999 -9999 -9999 -9999 -9999 -9999 -9999 -9999 -9999 -9999 -9999 -9999 -9999 -9999 -9999 -9999 -9999 -9999 -9999 -9999 -9999 -9999 -9999 -9999 -9999 -9999 -9999 -9999 -9999 -9999 -9999 -9999 -9999 -9999 -9999 -9999 -9999 -9999 -9999 -9999 -9999 -9999 -9999 -9999 -9999 -9999 -9999 -9999 -9999 -9999 -9999 -9999 -9999 -

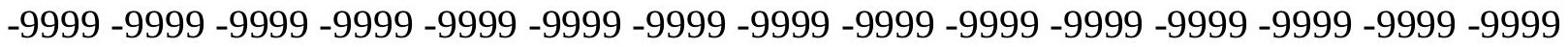
-9999 -9999 -9999 -9999 -9999 -9999 -9999 -9999 -9999 -9999 -9999 -9999 -9999 -9999 -9999 -9999 -9999 -9999 -9999 -9999 -9999 -9999 -9999 -9999 -9999 -9999 -9999 -9999 -9999 -9999 -9999 -9999 -9999 -9999 -9999 -9999 -9999 -9999 -9999 -9999 -9999 -9999 -9999 -9999 -9999 -

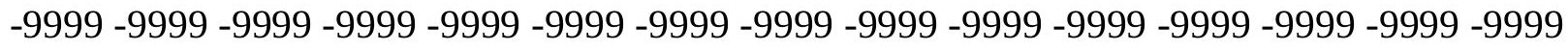

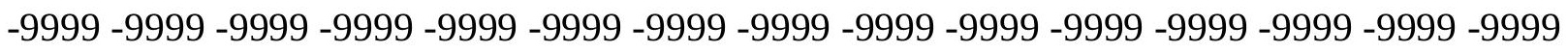

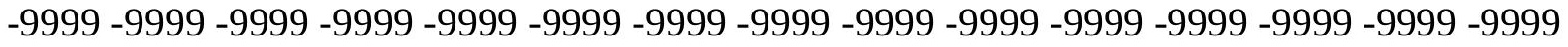
-9999 -9999 -9999 -9999 -9999 -9999 -9999 -9999 -9999 -9999 -9999 -9999 -9999 -9999 -9999 -9999 -9999 -9999 -9999 -9999 -9999 -9999 -9999 -9999 -9999 -9999 -9999 -9999 -9999 -9999 -

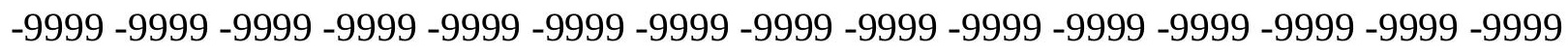
-9999 -9999 -9999 -9999 -9999 -9999 -9999 -9999 -9999 -9999 -9999 -9999 -9999 -9999 -9999 -9999 -9999 -9999 -9999 -9999 -9999 -9999 -9999 -9999 -9999 -9999 -9999 -9999 -9999 -9999 -

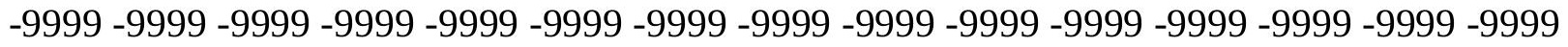
-9999 -9999 -9999 -9999 -9999 -9999 -9999 -9999 -9999 -9999 -9999 -9999 -9999 -9999 -9999 -9999 -9999 -9999 -9999 -9999 -9999 -9999 -9999 -9999 -9999 -9999 -9999 -9999 -9999 -999 -9999 -9999 -9999 -9999 -9999 -9999 -9999 -9999 -9999 -9999 -9999 -9999 -9999 -9999 -9999 -

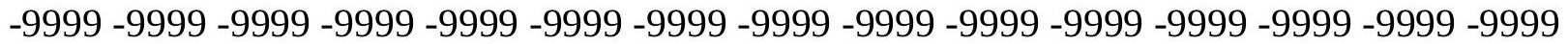

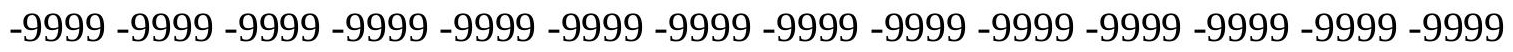

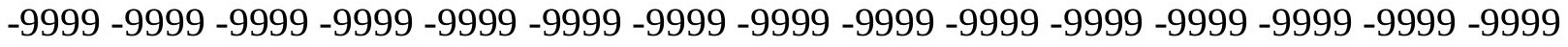

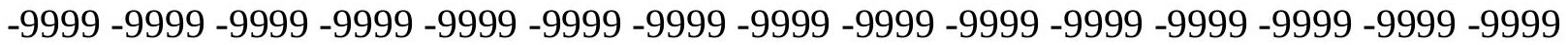

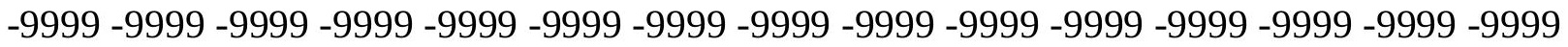

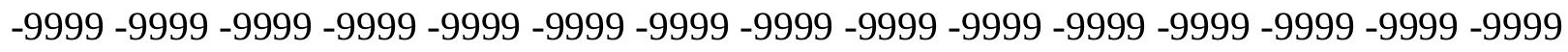

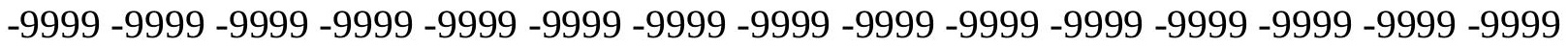

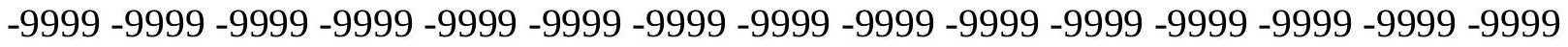
-9999 -9999 -9999 -9999 -9999 -9999 -9999 -9999 -9999 -9999 -9999 -9999 -9999 -9999 -9999 -

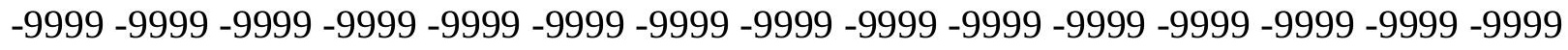

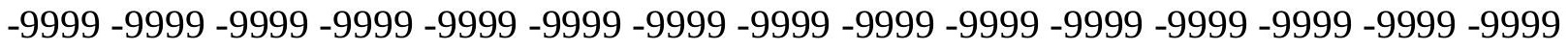
-9999 -9999 -9999 -9999 -9999 -9999 -9999 -9999 -9999 -9999 -9999 -9999 -9999 -9999 -9999 -9999 -9999 -9999 -9999 -9999 -9999 -9999 -9999 -9999-9999 -9999 -9999 -9999 -9999 -9999 -9999 -9999 -9999 -9999 -9999 -9999 -9999 -9999 -9999 -9999 -9999 -9999 -9999 -9999 -9999 -

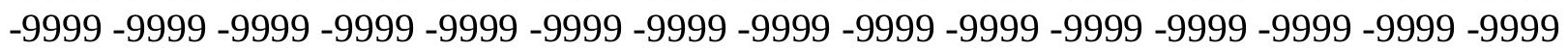


-9999 -9999 -9999 -9999 -9999 -9999 -9999 -9999 -9999 -9999 -9999 -9999 -9999 -9999 -9999 -9999 -9999 -9999 -9999 -9999 -9999 -9999 -9999 -9999 -9999 -9999 -9999 -9999 -9999 -9999 -

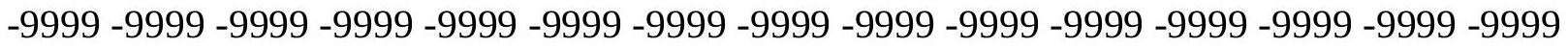
-9999 -9999 -9999 -9999 -9999 -9999 -9999 -9999 -9999 -9999 -9999 -9999 -9999 -9999 -9999 -9999 -9999 -9999 -9999 -9999 -9999 -9999 -9999 -9999-9999 -9999 -9999 -9999 -9999 -9999 -9999 -9999 -9999 -9999 -9999 -9999 -9999 -9999 -9999 -9999 -9999 -9999 -9999 -9999 -9999 -9999 -9999 -9999 -9999 -9999 -9999 -9999 -9999 -9999 -9999 -9999 -9999 -9999 -9999 -9999

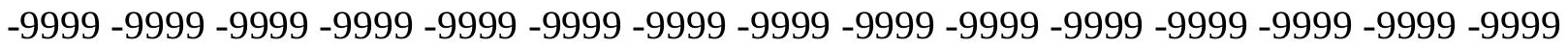

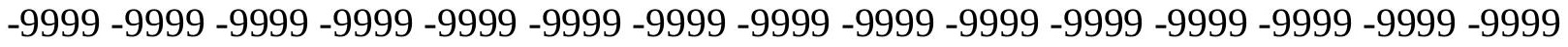
-9999 -9999 -9999 -9999 -9999 -9999 -9999 -9999 -9999 -9999 -9999 -9999 -9999 -9999 -9999 -9999 -9999 -9999 -9999 -9999 -9999 -9999 -9999 -9999 -9999 -9999 -9999 -9999 -9999 -9999 -9999 -9999 -9999 -9999 -9999 -9999 -9999 -9999 -9999 -9999 -9999 -9999 -9999 -9999 -9999 -9999 -9999 -9999 -9999 -9999 -9999 -9999 -9999 -9999 -9999 -9999 -9999 -9999 -9999 -9999 -9999 -9999 -9999 -9999 -9999 -9999 -9999 -9999 -9999 -9999 -9999 -9999 -9999 -9999 -9999 -9999 -9999 -9999 -9999 -9999 -9999 -9999 -9999 -9999 -9999 -9999 -9999 -9999 -9999 -

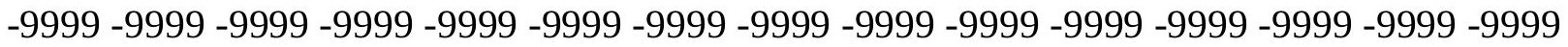
-9999 -9999 -9999 -9999 -9999 -9999 -9999 -9999 -9999 -9999 -9999 -9999 -9999 -9999 -9999 -9999 -9999 -9999 -9999 -9999 -9999 -9999 -9999 -9999 -9999 -9999 -9999 -9999 -9999 -9999 -9999 -9999 -9999 -9999 -9999 -9999 -9999 -9999 -9999 -9999 -9999 -9999 -9999 -9999 -9999 -

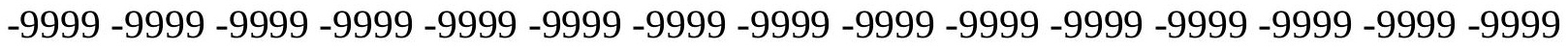
-9999 -9999 -9999 -9999 -9999 -9999 -9999 -9999 -9999 -9999 -9999 -9999 -9999 -9999 -9999

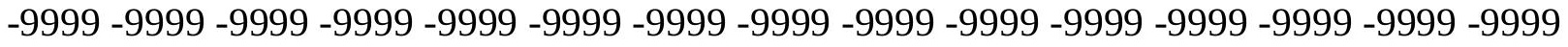
-9999 -9999 -9999 -9999 -9999 -9999 -9999 -9999 -9999 -9999 -9999 -9999 -9999 -9999 -9999 -9999 -9999 -9999 -9999 -9999 -9999 -9999 -9999 -9999 -9999 -9999 -9999 -9999 -9999 -9999 -

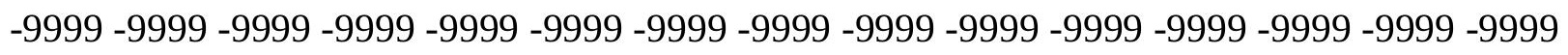
-9999 -9999 -9999 -9999 -9999 -9999 -9999 -9999 -9999 -9999 -9999 -9999 -9999 -9999 -9999 -9999 -9999 -9999 -9999 -9999 -9999 -9999 -9999 -9999 -9999 -9999 -9999 -9999 -9999 -9999 -

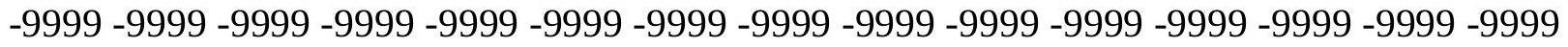
-9999 -9999 -9999 -9999 -9999 -9999 -9999 -9999 -9999 -9999 -9999 -9999 -9999 -9999 -9999 -9999 -9999 -9999 -9999 -9999 -9999 -9999 -9999 -9999 -9999 -9999 -9999 -9999 -9999 -999 -9999 -9999 -9999 -9999 -9999 -9999 -9999 -9999 -9999 -9999 -9999 -9999 -9999 -9999 -9999 -9999 -9999 -9999 -9999 -9999 -9999 -9999 -9999 -9999 -9999 -9999 -9999 -9999 -9999 -9999 -

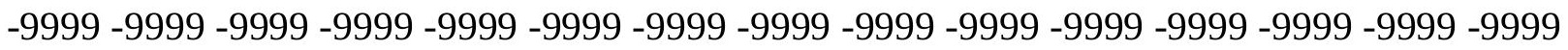

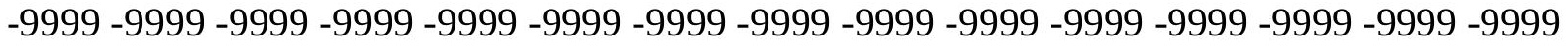

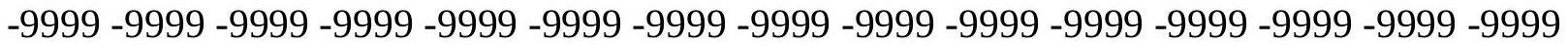
-9999 -9999 -9999 -9999 -9999 -9999 -9999 -9999 -9999 -9999 -9999 -9999 -9999 -9999 -9999 -

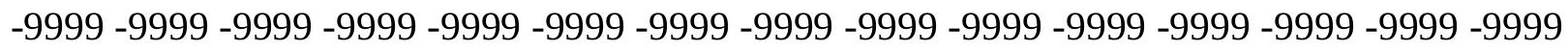

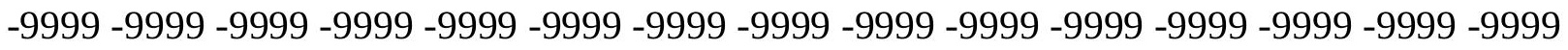
-9999 -9999 -9999 -9999 -9999 -9999 -9999 -9999 -9999 -9999 -9999 -9999 -9999 -9999 - -999 -9999 -9999 -9999 -9999 -9999 -9999 -9999 -9999 -9999 -9999 -9999 -9999 -9999 -9999 -9999 -

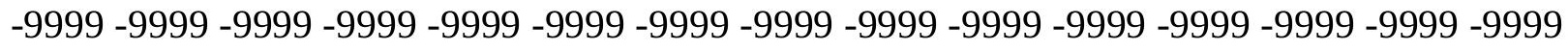

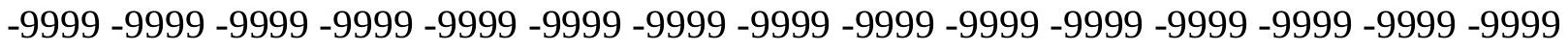
-9999 -9999 -9999 -9999 -9999 -9999 -9999 -9999 -9999 -9999 -9999 -9999 -9999 -9999 -9999 -9999 -9999 -9999 -9999 -9999 -9999 -9999 -9999 -9999-9999 -9999 -9999 -9999 -9999 -9999 -9999 -9999 -9999 -9999 -9999 -9999 -9999 -9999 -9999 -9999 -9999 -9999 -9999 -9999 -9999 -

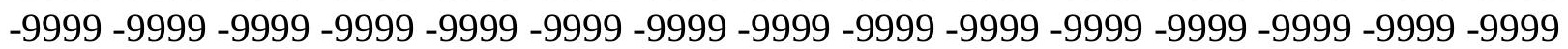


-9999 -9999 -9999 -9999 -9999 -9999 -9999 -9999 -9999 -9999 -9999 -9999 -9999 -9999 -9999 -9999 -9999 -9999 -9999 -9999 -9999 -9999 -9999 -9999 -9999 -9999 -9999 -9999 -9999 -9999 -

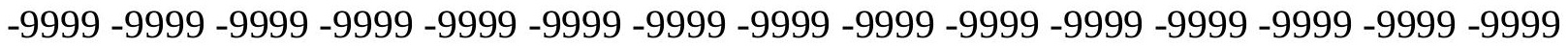
-9999 -9999 -9999 -9999 -9999 -9999 -9999 -9999 -9999 -9999 -9999 -9999 -9999 -9999 -9999 -9999 -9999 -9999 -9999 -9999 -9999 -9999 -9999 -9999-9999 -9999 -9999 -9999 -9999 -9999 -9999 -9999 -9999 -9999 -9999 -9999 -9999 -9999 -9999 -9999 -9999 -9999 -9999 -9999 -9999 -9999 -9999 -9999 -9999 -9999 -9999 -9999 -9999 -9999 -9999 -9999 -9999 -9999 -9999 -9999

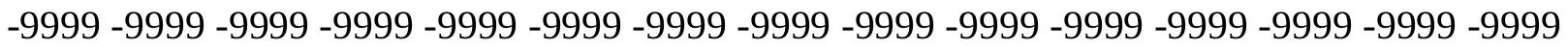

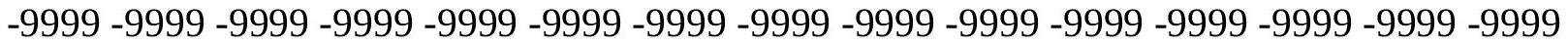
-9999 -9999 -9999 -9999 -9999 -9999 -9999 -9999 -9999 -9999 -9999 -9999 -9999 -9999 -9999 -9999 -9999 -9999 -9999 -9999 -9999 -9999 -9999 -9999 -9999 -9999 -9999 -9999 -9999 -9999 -9999 -9999 -9999 -9999 -9999 -9999 -9999 -9999 -9999 -9999 -9999 -9999 -9999 -9999 -9999 -9999 -9999 -9999 -9999 -9999 -9999 -9999 -9999 -9999 -9999 -9999 -9999 -9999 -9999 -9999 -

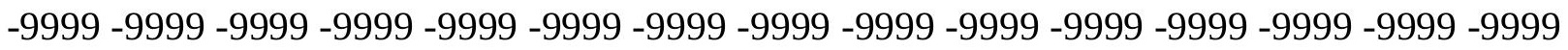
-9999 -9999 -9999 -9999 -9999 -9999 -9999 -9999 -9999 -9999 -9999 -9999 -9999 -9999 -9999 -

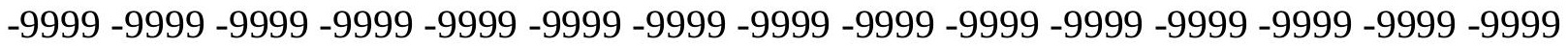
-9999 -9999 -9999 -9999 -9999 -9999 -9999 -9999 -9999 -9999 -9999 -9999 -9999 -9999 -9999 -9999 -9999 -9999 -9999 -9999 -9999 -9999 -9999 -9999 -9999 -9999 -9999 -9999 -9999 -9999 -9999 -9999 -9999 -9999 -9999 -9999 -9999 -9999 -9999 -9999 -9999 -9999 -9999 -9999 - -999 -

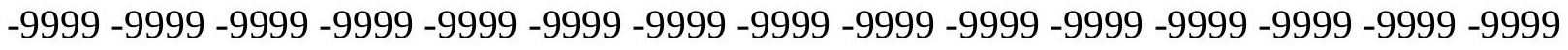

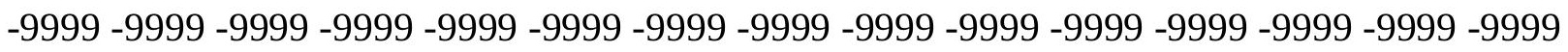
-9999 -9999 -9999 -9999 -9999 -9999 -9999 -9999 -9999 -9999 -9999 -9999 -9999 -9999 -9999 -9999 -9999 -9999 -9999 -9999 -9999 -9999 -9999 -9999 -9999 -9999 -9999 -9999 -9999 -9999 -9999 -9999 -9999 -9999 -9999 -9999 -9999 -9999 -9999 -9999 -9999 -9999 -9999 -9999 -9999 -

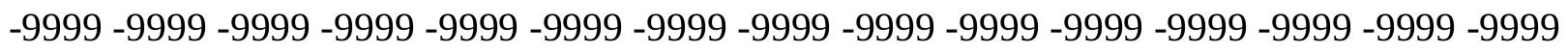
-9999 -9999 -9999 -9999 -9999 -9999 -9999 -9999 -9999 -9999 -9999 -9999 -9999 -9999 -9999 -9999 -9999 -9999 -9999 -9999 -9999 -9999 -9999 -9999 -9999 -9999 -9999 -9999 -9999 -9999 -

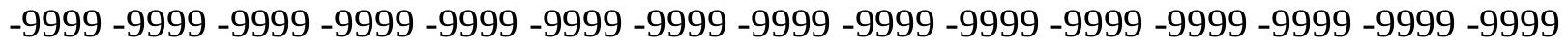
-9999 -9999 -9999 -9999 -9999 -9999 -9999 -9999 -9999 -9999 -9999 -9999 -9999 -9999 -9999 -9999 -9999 -9999 -9999 -9999 -9999 -9999 -9999 -9999 -9999 -9999 -9999 -9999 -9999 -999 -

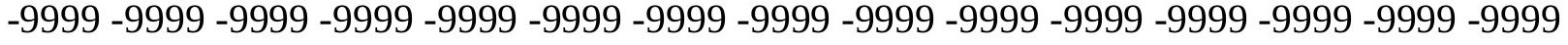
-9999 -9999 -9999 -9999 -9999 -9999 -9999 -9999 -9999 -9999 -9999 -9999 -9999 -9999 -9999 -

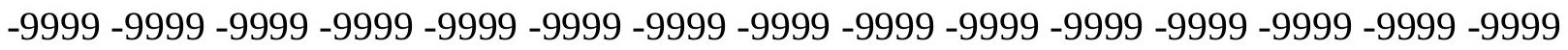

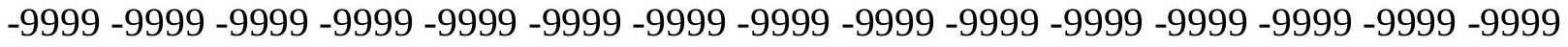

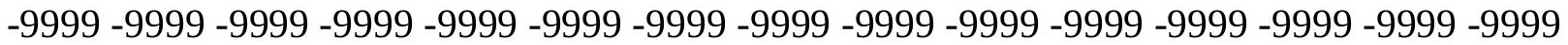

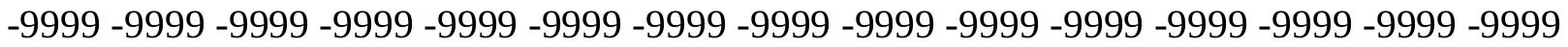

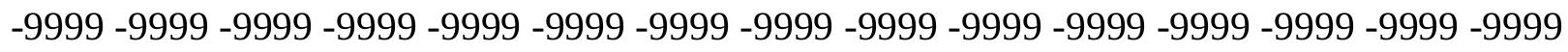

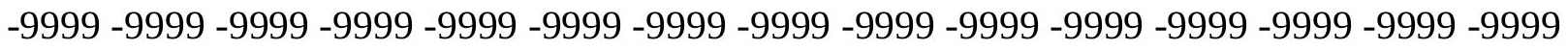

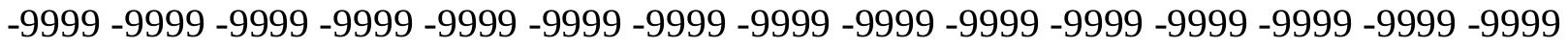
-9999 -9999 -9999 -9999 -9999 -9999 -9999 -9999 -9999 -9999 -9999 -9999 -9999 -9999 -9999 -

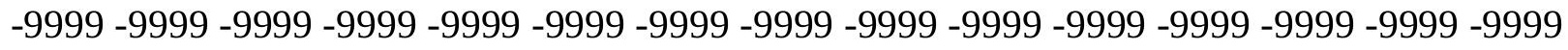

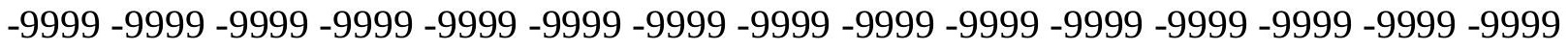
-9999 -9999 -9999 -9999 -9999 -9999 -9999 -9999 -9999 -9999 -9999 -9999 -9999 -9999 -9999 -9999 -9999 -9999 -9999 -9999 -9999 -9999 -9999 -9999 -9999 -9999 -9999 -9999 -9999 -9999 -9999 -9999 -9999 -9999 -9999 -9999 -9999 -9999 -9999 -9999 -9999 -9999 -9999 -9999 -

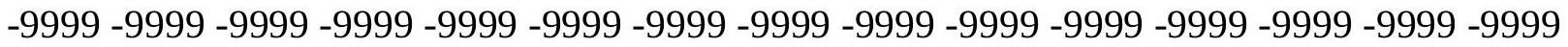


-9999 -9999 -9999 -9999 -9999 -9999 -9999 -9999 -9999 -9999 -9999 -9999 -9999 -9999 -9999 -9999 -9999 -9999 -9999 -9999 -9999 -9999 -9999 -9999 -9999 -9999 -9999 -9999 -9999 -9999 -

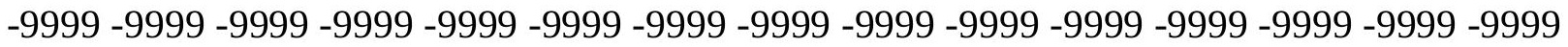
-9999 -9999 -9999 -9999 -9999 -9999 -9999 -9999 -9999 -9999 -9999 -9999 -9999 -9999 -9999 -9999 -9999 -9999 -9999 -9999 -9999 -9999 -9999 -9999-9999 -9999 -9999 -9999 -9999 -9999 -9999 -9999 -9999 -9999 -9999 -9999 -9999 -9999 -9999 -9999 -9999 -9999 -9999 -9999 -9999 -9999 -9999 -9999 -9999 -9999 -9999 -9999 -9999 -9999 -9999 -9999 -9999 -9999 -9999 -9999

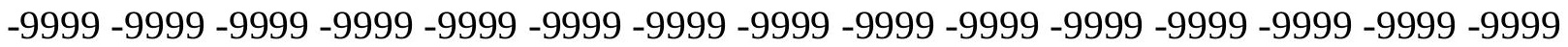

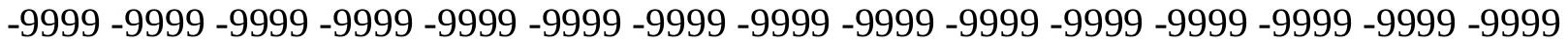
-9999 -9999 -9999 -9999 -9999 -9999 -9999 -9999 -9999 -9999 -9999 -9999 -9999 -9999 -9999 -9999 -9999 -9999 -9999 -9999 -9999 -9999 -9999 -9999 -9999 -9999 -9999 -9999 -9999 -9999 -9999 -9999 -9999 -9999 -9999 -9999 -9999 -9999 -9999 -9999 -9999 -9999 -9999 -9999 -9999 -9999 -9999 -9999 -9999 -9999 -9999 -9999 -9999 -9999 -9999 -9999 -9999 -9999 -9999 -9999 -

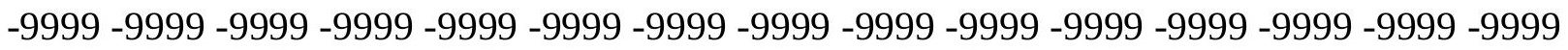
-9999 -9999 -9999 -9999 -9999 -9999 -9999 -9999 -9999 -9999 -9999 -9999 -9999 -9999 -9999 -

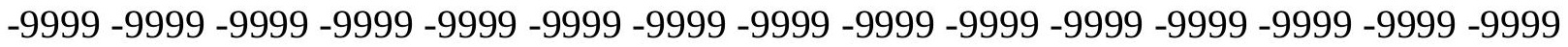
-9999 -9999 -9999 -9999 -9999 -9999 -9999 -9999 -9999 -9999 -9999 -9999 -9999 -9999 -9999 -9999 -9999 -9999 -9999 -9999 -9999 -9999 -9999 -9999 -9999 -9999 -9999 -9999 -9999 - 9999 -9999 -9999 -9999 -9999 -9999 -9999 -9999 -9999 -9999 -9999 -9999 -9999 -9999 -9999 -9999 -

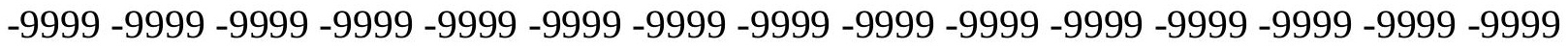

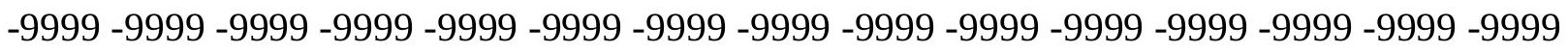
-9999 -9999 -9999 -9999 -9999 -9999 -9999 -9999 -9999 -9999 -9999 -9999 -9999 -9999 - 9999 -9999 -9999 -9999 -9999 -9999 -9999 -9999 -9999 -9999 -9999 -9999 -9999 -9999 -9999 -9999 -9999 -9999 -9999 -9999 -9999 -9999 -9999 -9999 -9999 -9999 -9999 -9999 -9999 -9999 -9999 -9999 -9999 -9999 -9999 -9999 -9999 -9999 -9999 -9999 -9999 -9999 -9999 -9999 -9999 -9999 -9999 -9999 -9999 -9999 -9999 -9999 -9999 -9999 -9999 -9999 -9999 -9999 -9999 -9999 -9999 -9999 -9999 -9999 -9999 -9999 -9999 -9999 -9999 -9999 -9999 -9999 -9999 -9999 -9999 -

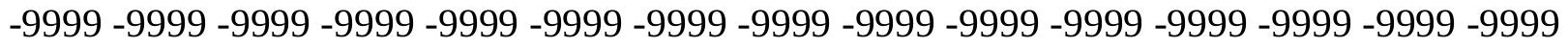
-9999 -9999 -9999 -9999 -9999 -9999 -9999 -9999 -9999 -9999 -9999 -9999 -9999 -9999 -9999 -9999 -9999 -9999 -9999 -9999 -9999 -9999 -9999 -9999 -9999 -9999 -9999 -9999 -9999 -999 -9999 -9999 -9999 -9999 -9999 -9999 -9999 -9999 -9999 -9999 -9999 -9999 -9999 -9999 -9999 -9999 -9999 -9999 -9999 -9999 -9999 -9999 -9999 -9999 -9999 -9999 -9999 -9999 -9999 -9999 -

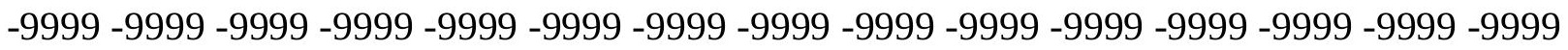

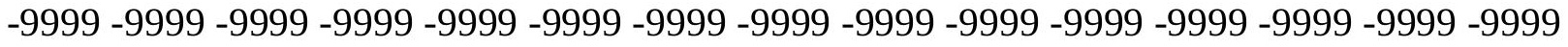

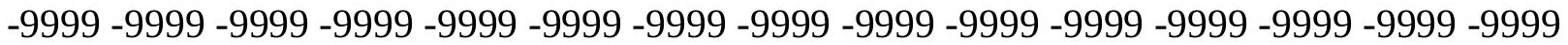

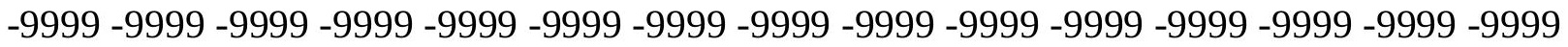

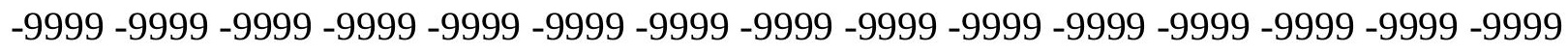

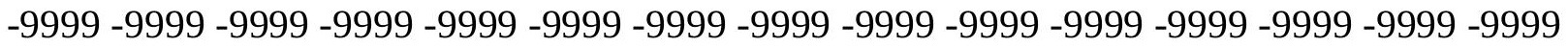

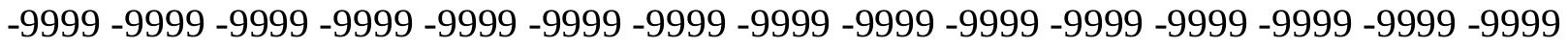
-9999 -9999 -9999 -9999 -9999 -9999 -9999 -9999 -9999 -9999 -9999 -9999 -9999 -9999 -9999 -

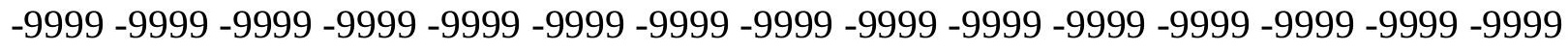

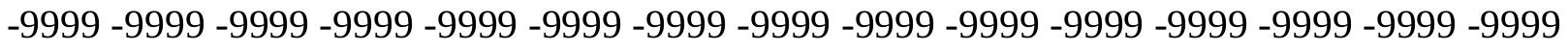
-9999 -9999 -9999 -9999 -9999 -9999 -9999 -9999 -9999 -9999 -9999 -9999 -9999 -9999 -9999 -9999 -9999 -9999 -9999 -9999 -9999 -9999 -9999 -9999-9999 -9999 -9999 -9999 -9999 -9999 -9999 -9999 -9999 -9999 -9999 -9999 -9999 -9999 -9999 -9999 -9999 -9999 -9999 -9999 -9999 -

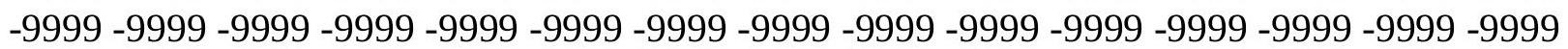


-9999 -9999 -9999 -9999 -9999 -9999 -9999 -9999 -9999 -9999 -9999 -9999 -9999 -9999 -9999 -9999 -9999 -9999 -9999 -9999 -9999 -9999 -9999 -9999 -9999 -9999 -9999 -9999 -9999 -9999 -9999 -9999 -9999 -9999 -9999 -9999 -9999 -9999 -9999 -9999 -9999 -9999 -9999 -9999 - 9999 -9999 -9999 -9999 -9999 -9999 -9999 -9999 -9999 -9999 -9999 -9999 -9999 -9999 -9999 -9999 -9999 -9999 -9999 -9999 -9999 -9999 -9999 -9999 -9999 -9999 -9999 -9999 -9999 -9999 -9999 -9999 -9999 -9999 -9999 -9999 -9999 -9999 -9999 -9999 -9999 -9999 -9999 -9999 -9999 -9999 -9999 -9999 -9999 -9999 -9999 -9999 -9999 -9999 -9999 -9999 -9999 -9999 -9999 -9999

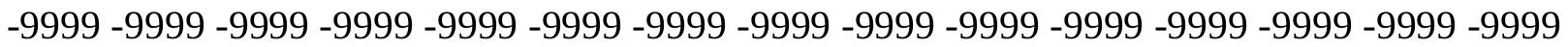

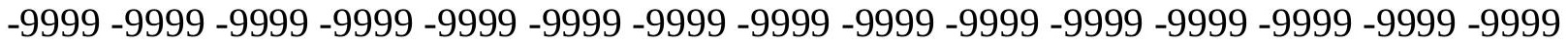
-9999 -9999 -9999 -9999 -9999 -9999 -9999 -9999 -9999 -9999 -9999 -9999 -9999 -9999 -9999 -9999 -9999 -9999 -9999 -9999 -9999 -9999 -9999 -9999 -9999 -9999 -9999 -9999 -9999 -9999 -9999 -9999 -9999 -9999 -9999 -9999 -9999 -9999 -9999 -9999 -9999 -9999 -9999 -9999 -9999 -9999 -9999 -9999 -9999 -9999 -9999 -9999 -9999 -9999 -9999 -9999 -9999 -9999 -9999 -9999 -9999 -9999 -9999 -9999 -9999 -9999 -9999 -9999 -9999 -9999 -9999 -9999 -9999 -9999 -9999 -9999 -9999 -9999 -9999 -9999 -9999 -9999 -9999 -9999 -9999 -9999 -9999 -9999 -9999 -9999 -

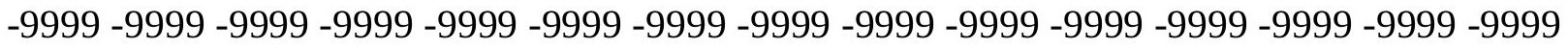
-9999 -9999 -9999 -9999 -9999 -9999 -9999 -9999 -9999 -9999 -9999 -9999 -9999 -9999 -9999 -9999 -9999 -9999 -9999 -9999 -9999 -9999 -9999 -9999 -9999 -9999 -9999 -9999 -9999 - 9999 -9999 -9999 -9999 -9999 -9999 -9999 -9999 -9999 -9999 -9999 -9999 -9999 -9999 -9999 -9999 -

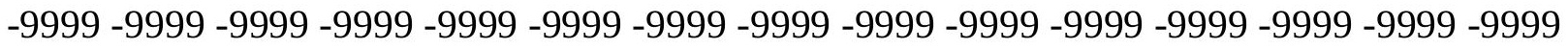

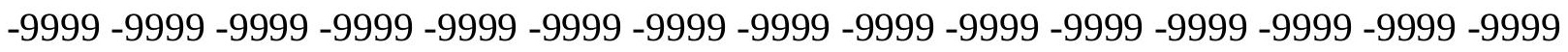

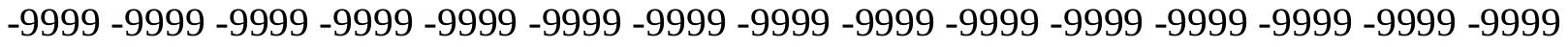
-9999 -9999 -9999 -9999 -9999 -9999 -9999 -9999 -9999 -9999 -9999 -9999 -9999 -9999 -9999 -9999 -9999 -9999 -9999 -9999 -9999 -9999 -9999 -9999 -9999 -9999 -9999 -9999 -9999 -9999 -

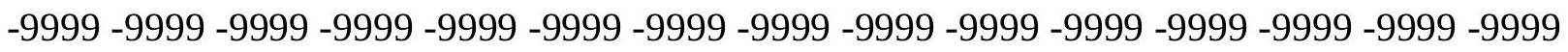
-9999 -9999 -9999 -9999 -9999 -9999 -9999 -9999 -9999 -9999 -9999 -9999 -9999 -9999 -9999 -9999 -9999 -9999 -9999 -9999 -9999 -9999 -9999 -9999 -9999 -9999 -9999 -9999 -9999 -9999 -

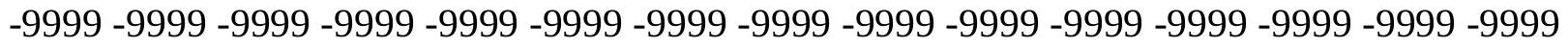
-9999 -9999 -9999 -9999 -9999 -9999 -9999 -9999 -9999 -9999 -9999 -9999 -9999 -9999 -9999 -9999 -9999 -9999 -9999 -9999 -9999 -9999 -9999 -9999 -9999 -9999 -9999 -9999 -9999 -999 -9999 -9999 -9999 -9999 -9999 -9999 -9999 -9999 -9999 -9999 -9999 -9999 -9999 -9999 -9999 -9999 -9999 -9999 -9999 -9999 -9999 -9999 -9999 -9999 -9999 -9999 -9999 -9999 -9999 -

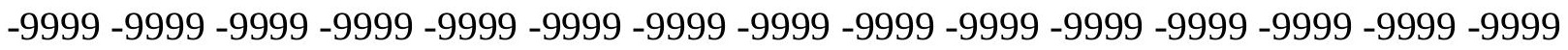

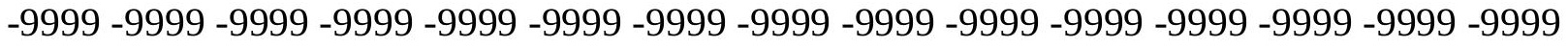

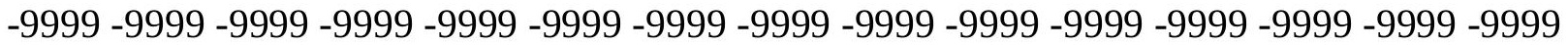

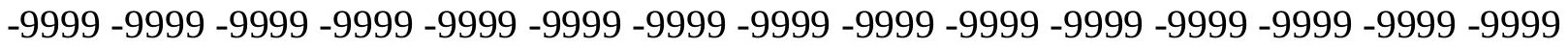

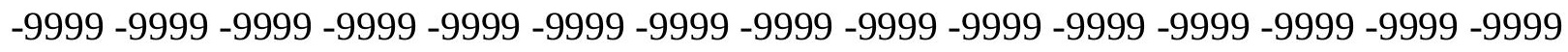

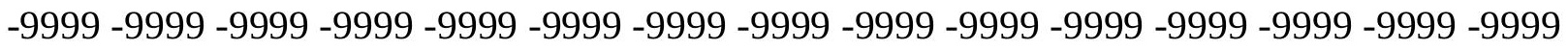

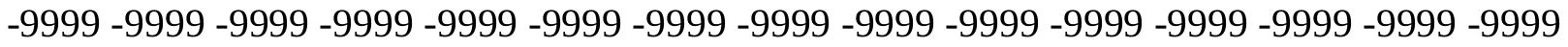
-9999 -9999 -9999 -9999 -9999 -9999 -9999 -9999 -9999 -9999 -9999 -9999 -9999 -9999 -9999 -

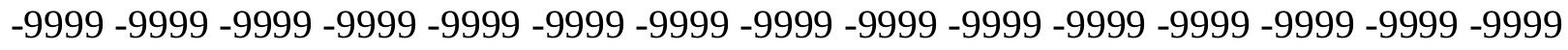

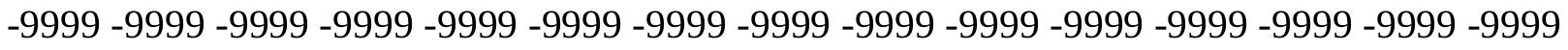
-9999 -9999 -9999 -9999 -9999 -9999 -9999 -9999 -9999 -9999 -9999 -9999 -9999 -9999 -9999 -9999 -9999 -9999 -9999 -9999 -9999 -9999 -9999 -9999-9999 -9999 -9999 -9999 -9999 -9999 -9999 -9999 -9999 -9999 -9999 -9999 -9999 -9999 -9999 -9999 -9999 -9999 -9999 -9999 -9999 -

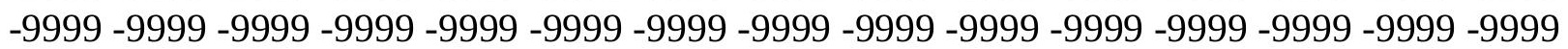


-9999 -9999 -9999 -9999 -9999 -9999 -9999 -9999 -9999 -9999 -9999 -9999 -9999 -9999 -9999 -9999 -9999 -9999 -9999 -9999 -9999 -9999 -9999 -9999 -9999 -9999 -9999 -9999 -9999 -9999 -

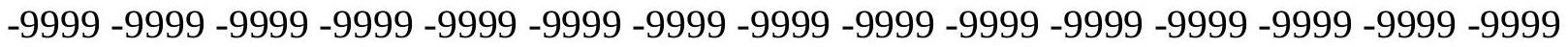
-9999 -9999 -9999 -9999 -9999 -9999 -9999 -9999 -9999 -9999 -9999 -9999 -9999 -9999 -9999 -9999 -9999 -9999 -9999 -9999 -9999 -9999 -9999 -9999-9999 -9999 -9999 -9999 -9999 -9999 -9999 -9999 -9999 -9999 -9999 -9999 -9999 -9999 -9999 -9999 -9999 -9999 -9999 -9999 -9999 -9999 -9999 -9999 -9999 -9999 -9999 -9999 -9999 -9999 -9999 -9999 -9999 -9999 -9999 -9999

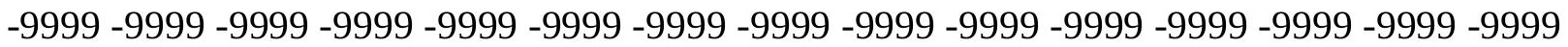

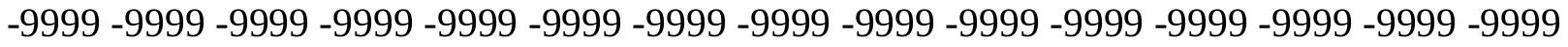

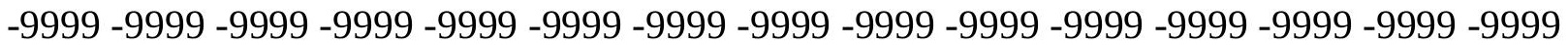
-9999 -9999 -9999 -9999 -9999 -9999 -9999 -9999 -9999 -9999 -9999 -9999 -9999 -9999 -9999 -9999 -9999 -9999 -9999 -9999 -9999 -9999 -9999 -9999 -9999 -9999 -9999 -9999 -9999 -9999 -9999 -9999 -9999 -9999 -9999 -9999 -9999 -9999 -9999 -9999 -9999 -9999 -9999 -9999 -

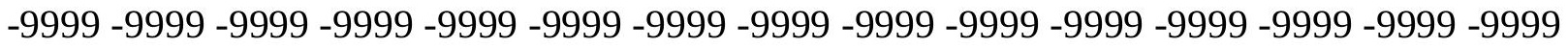
-9999 -9999 -9999 -9999 -9999 -9999 -9999 -9999 -9999 -9999 -9999 -9999 -9999 -9999 -9999 -

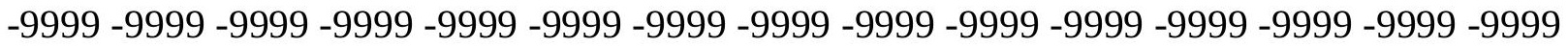
-9999 -9999 -9999 -9999 -9999 -9999 -9999 -9999 -9999 -9999 -9999 -9999 -9999 -9999 -9999 -9999 -9999 -9999 -9999 -9999 -9999 -9999 -9999 -9999 -9999 -9999 -9999 -9999 -9999 -9999 -9999 -9999 -9999 -9999 -9999 -9999 -9999 -9999 -9999 -9999 -9999 -9999 -9999 -9999 -9999 -

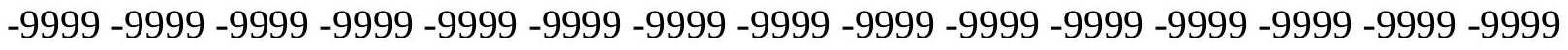

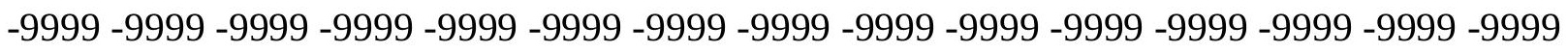
-9999 -9999 -9999 -9999 -9999 -9999 -9999 -9999 -9999 -9999 -9999 -9999 -9999 -9999 -9999 -9999 -9999 -9999 -9999 -9999 -9999 -9999 -9999 -9999 -9999 -9999 -9999 -9999 -9999 -9999 -9999 -9999 -9999 -9999 -9999 -9999 -9999 -9999 -9999 -9999 -9999 -9999 -9999 -9999 -9999 -

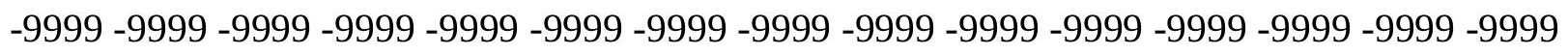
-9999 -9999 -9999 -9999 -9999 -9999 -9999 -9999 -9999 -9999 -9999 -9999 -9999 -9999 -9999 -9999 -9999 -9999 -9999 -9999 -9999 -9999 -9999 -9999 -9999 -9999 -9999 -9999 -9999 -9999 -

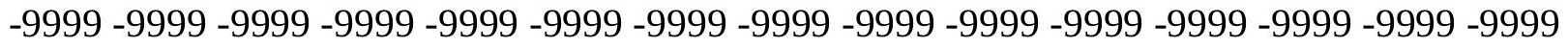
-9999 -9999 -9999 -9999 -9999 -9999 -9999 -9999 -9999 -9999 -9999 -9999 -9999 -9999 -9999 -9999 -9999 -9999 -9999 -9999 -9999 -9999 -9999 -9999 -9999 -9999 -9999 -9999 -9999 -999 -9999 -9999 -9999 -9999 -9999 -9999 -9999 -9999 -9999 -9999 -9999 -9999 -9999 -9999 -9999 -9999 -9999 -9999 -9999 -9999 -9999 -9999 -9999 -9999 -9999 -9999 -9999 -9999 -9999 -9999 -

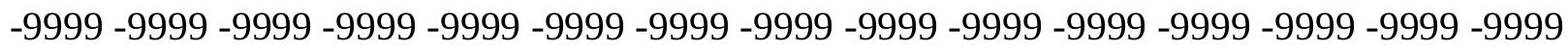

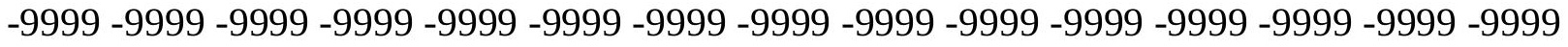

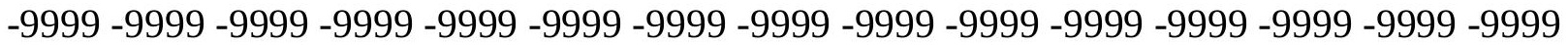
-9999 -9999 -9999 -9999 -9999 -9999 -9999 -9999 -9999 -9999 -9999 -9999 -9999 -9999 -9999 -

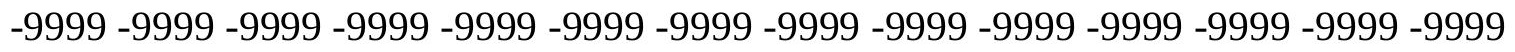

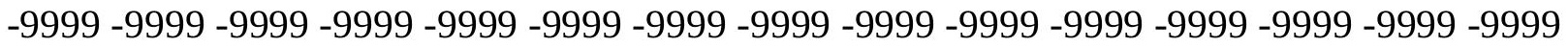
-9999 -9999 -9999 -9999 -9999 -9999 -9999 -9999 -9999 -9999 -9999 -9999 -9999 - 9999 - -999 -9999 -9999 -9999 -9999 -9999 -9999 -9999 -9999 -9999 -9999 -9999 -9999 -9999 -9999 -9999 -

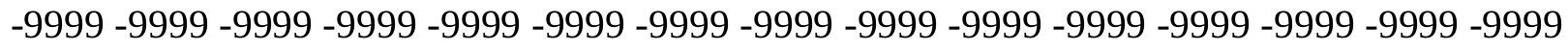

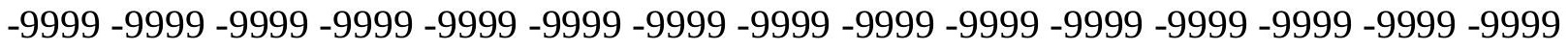
-9999 -9999 -9999 -9999 -9999 -9999 -9999 -9999 -9999 -9999 -9999 -9999 -9999 -9999 -9999 -9999 -9999 -9999 -9999 -9999 -9999 -9999 -9999 -9999-9999 -9999 -9999 -9999 -9999 -9999 -9999 -9999 -9999 -9999 -9999 -9999 -9999 -9999 -9999 -9999 -9999 -9999 -9999 -9999 -9999 -

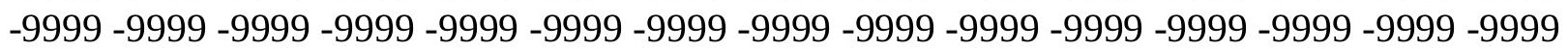


-9999 -9999 -9999 -9999 -9999 -9999 -9999 -9999 -9999 -9999 -9999 -9999 -9999 -9999 -9999 -9999 -9999 -9999 -9999 -9999 -9999 -9999 -9999 -9999 -9999 -9999 -9999 -9999 -9999 -9999 -

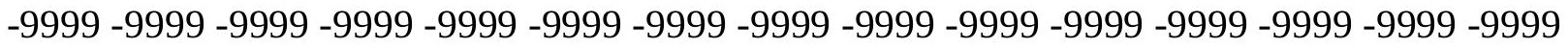
-9999 -9999 -9999 -9999 -9999 -9999 -9999 -9999 -9999 -9999 -9999 -9999 -9999 -9999 -9999 -9999 -9999 -9999 -9999 -9999 -9999 -9999 -9999 -9999-9999 -9999 -9999 -9999 -9999 -9999 -9999 -9999 -9999 -9999 -9999 -9999 -9999 -9999 -9999 -9999 -9999 -9999 -9999 -9999 -9999 -9999 -9999 -9999 -9999 -9999 -9999 -9999 -9999 -9999 -9999 -9999 -9999 -9999 -9999 -9999

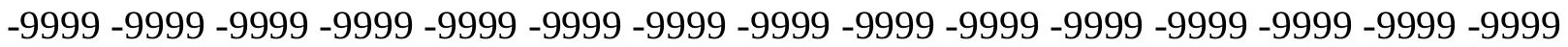

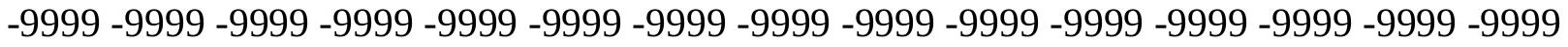
-9999 -9999 -9999 -9999 -9999 -9999 -9999 -9999 -9999 -9999 -9999 -9999 -9999 -9999 -9999 -9999 -9999 -9999 -9999 -9999 -9999 -9999 -9999 -9999 -9999 -9999 -9999 -9999 -9999 -9999 -9999 -9999 -9999 -9999 -9999 -9999 -9999 -9999 -9999 -9999 -9999 -9999 -9999 -9999 -9999 -9999 -9999 -9999 -9999 -9999 -9999 -9999 -9999 -9999 -9999 -9999 -9999 -9999 -9999 -9999 -9999 -9999 -9999 -9999 -9999 -9999 -9999 -9999 -9999 -9999 -9999 -9999 -9999 -9999 -9999 -9999 -9999 -9999 -9999 -9999 -9999 -9999 -9999 -9999 -9999 -9999 -9999 -9999 -9999 -9999 -

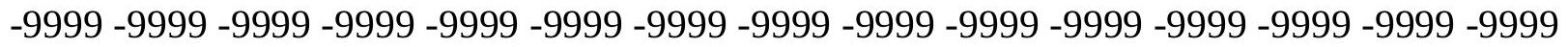
-9999 -9999 -9999 -9999 -9999 -9999 -9999 -9999 -9999 -9999 -9999 -9999 -9999 -9999 -9999 -9999 -9999 -9999 -9999 -9999 -9999 -9999 -9999 -9999 -9999 -9999 -9999 -9999 -9999 -9999 -9999 -9999 -9999 -9999 -9999 -9999 -9999 -9999 -9999 -9999 -9999 -9999 -9999 -9999 -

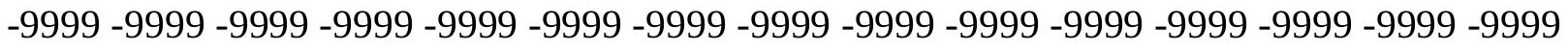
-9999 -9999 -9999 -9999 -9999 -9999 -9999 -9999 -9999 -9999 -9999 -9999 -9999 -9999 -9999 -999 -

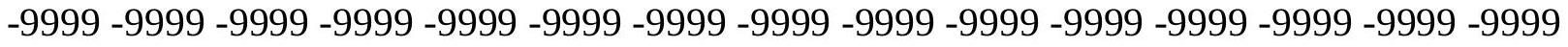
-9999 -9999 -9999 -9999 -9999 -9999 -9999 -9999 -9999 -9999 -9999 -9999 -9999 -9999 -9999 -9999 -9999 -9999 -9999 -9999 -9999 -9999 -9999 -9999 -9999 -9999 -9999 -9999 -9999 -9999 -9999 -9999 -9999 -9999 -9999 -9999 -9999 -9999 -9999 -9999 -9999 -9999 -9999 -9999 -9999 -9999 -9999 -9999 -9999 -9999 -9999 -9999 -9999 -9999 -9999 -9999 -9999 -9999 -9999 -9999 -9999 -9999 -9999 -9999 -9999 -9999 -9999 -9999 -9999 -9999 -9999 -9999 -9999 -9999 -9999 -

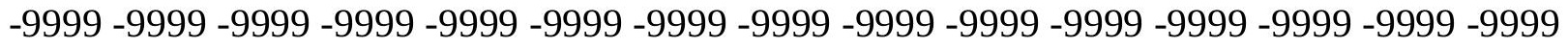
-9999 -9999 -9999 -9999 -9999 -9999 -9999 -9999 -9999 -9999 -9999 -9999 -9999 -9999 -9999 -9999 -9999 -9999 -9999 -9999 -9999 -9999 -9999 -9999 -9999 -9999 -9999 -9999 -9999 -999 -9999 -9999 -9999 -9999 -9999 -9999 -9999 -9999 -9999 -9999 -9999 -9999 -9999 -9999 -9999 -9999 -9999 -9999 -9999 -9999 -9999 -9999 -9999 -9999 -9999 -9999 -9999 -9999 -9999 -9999 -

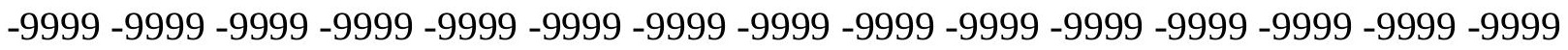

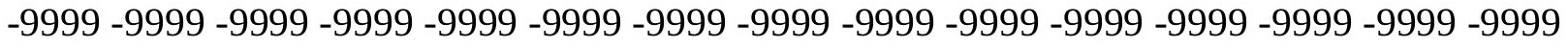

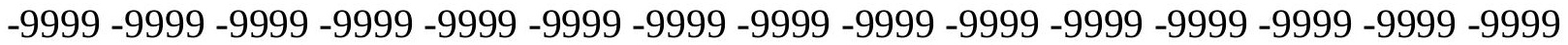
-9999 -9999 -9999 -9999 -9999 -9999 -9999 -9999 -9999 -9999 -9999 -9999 -9999 -9999 -9999

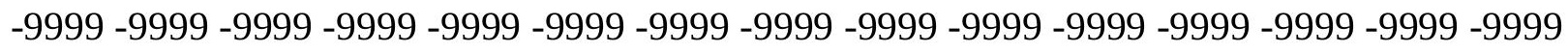

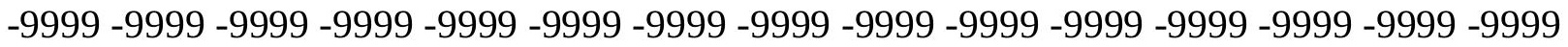
-9999 -9999 -9999 -9999 -9999 -9999 -9999 -9999 -9999 -9999 -9999 -9999 -9999 - 9999 - -999 -9999 -9999 -9999 -9999 -9999 -9999 -9999 -9999 -9999 -9999 -9999 -9999 -9999 -9999 -9999 -

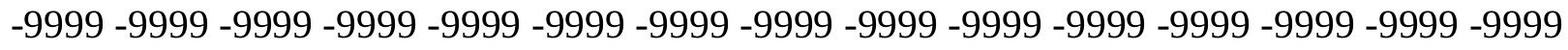

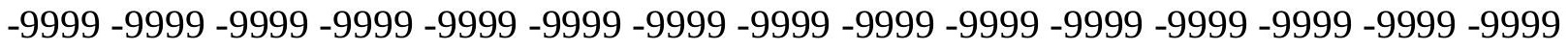
-9999 -9999 -9999 -9999 -9999 -9999 -9999 -9999 -9999 -9999 -9999 -9999 -9999 -9999 -9999 -9999 -9999 -9999 -9999 -9999 -9999 -9999 -9999 -9999 -9999 -9999 -9999 -9999 -9999 -9999 -9999 -9999 -9999 -9999 -9999 -9999 -9999 -9999 -9999 -9999 -9999 -9999 -9999 -9999 -

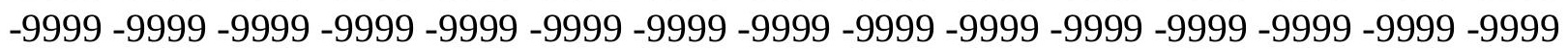


-9999 -9999 -9999 -9999 -9999 -9999 -9999 -9999 -9999 -9999 -9999 -9999 -9999 -9999 -9999 -9999 -9999 -9999 -9999 -9999 -9999 -9999 -9999 -9999 -9999 -9999 -9999 -9999 -9999 -9999 -9999 -9999 -9999 -9999 -9999 -9999 -9999 -9999 -9999 -9999 -9999 -9999 -9999 -9999 - 9999 -9999 -9999 -9999 -9999 -9999 -9999 -9999 -9999 -9999 -9999 -9999 -9999 -9999 -9999 -9999 -9999 -9999 -9999 -9999 -9999 -9999 -9999 -9999 -9999-9999 -9999 -9999 -9999 -9999 -9999 -9999 -9999 -9999 -9999 -9999 -9999 -9999 -9999 -9999 -9999 -9999 -9999 -9999 -9999 -9999 -9999 -9999 -9999 -9999 -9999 -9999 -9999 -9999 -9999 -9999 -9999 -9999 -9999 -9999 -9999

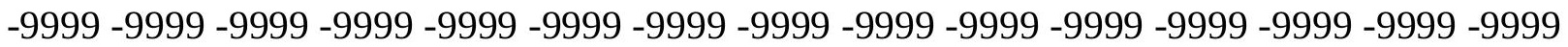

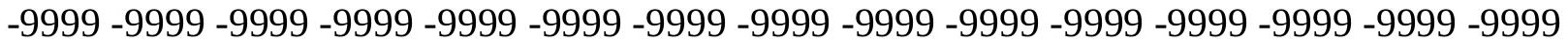
-9999 -9999 -9999 -9999 -9999 -9999 -9999 -9999 -9999 -9999 -9999 -9999 -9999 -9999 -9999 -9999 -9999 -9999 -9999 -9999 -9999 -9999 -9999 -9999 -9999 -9999 -9999 -9999 -9999 -9999 -9999 -9999 -9999 -9999 -9999 -9999 -9999 -9999 -9999 -9999 -9999 -9999 -9999 -9999 -9999 -9999 -9999 -9999 -9999 -9999 -9999 -9999 -9999 -9999 -9999 -9999 -9999 -9999 -9999 -9999 -

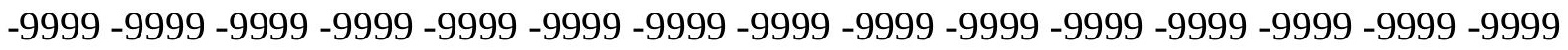
-9999 -9999 -9999 -9999 -9999 -9999 -9999 -9999 -9999 -9999 -9999 -9999 -9999 -9999 -9999 -

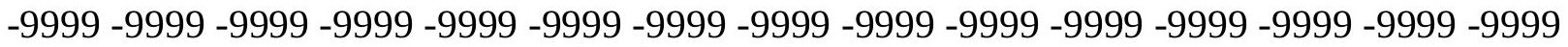
-9999 -9999 -9999 -9999 -9999 -9999 -9999 -9999 -9999 -9999 -9999 -9999 -9999 -9999 -9999 -9999 -9999 -9999 -9999 -9999 -9999 -9999 -9999 -9999 -9999 -9999 -9999 -9999 -9999 -9999 -9999 -9999 -9999 -9999 -9999 -9999 -9999 -9999 -9999 -9999 -9999 -9999 -9999 -9999 -9999 -

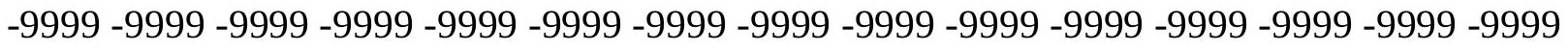
-9999 -9999 -9999 -9999 -9999 -9999 -9999 -9999 -9999 -9999 -9999 -9999 -9999 -9999 -9999 -999 -9999 -9999 -9999 -9999 -9999 -9999 -9999 -9999 -9999 -9999 -9999 -9999 -9999 -9999 - 9999 -9999 -9999 -9999 -9999 -9999 -9999 -9999 -9999 -9999 -9999 -9999 -9999 -9999 -9999 -

-9999 -9999 -9999 -9999 -9999 -9999 -9999 -9999 -9999 -9999 -9999 -9999 -9999 -9999 -9999 -

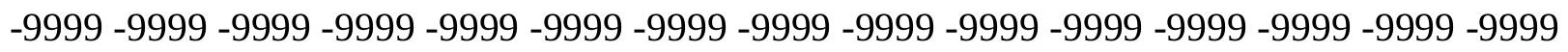
-9999 -9999 -9999 -9999 -9999 -9999 -9999 -9999 -9999 -9999 -9999 -9999 -9999 -9999 -9999 -9999 -9999 -9999 -9999 -9999 -9999 -9999 -9999 -9999 -9999 -9999 -9999 -9999 -9999 -9999 -

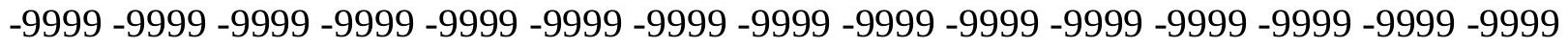
-9999 -9999 -9999 -9999 -9999 -9999 -9999 -9999 -9999 -9999 -9999 -9999 -9999 -9999 -9999 -9999 -9999 -9999 -9999 -9999 -9999 -9999 -9999 -9999 -9999 -9999 -9999 -9999 -9999 -999 -

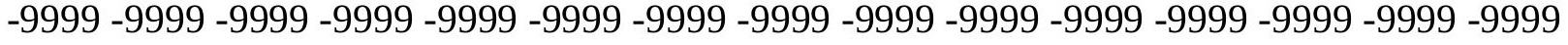
-9999 -9999 -9999 -9999 -9999 -9999 -9999 -9999 -9999 -9999 -9999 -9999 -9999 -9999 -9999 -

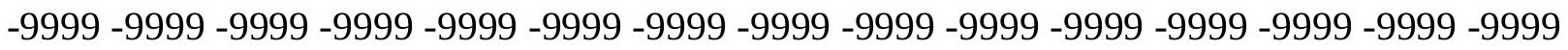

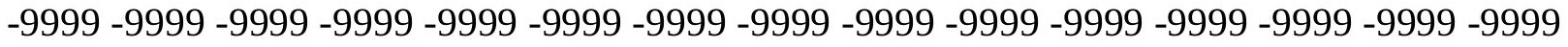

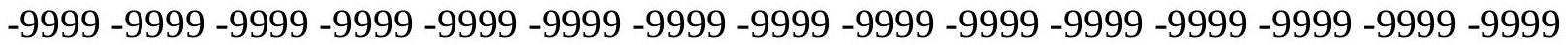

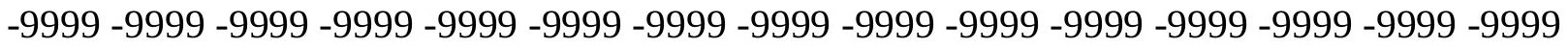

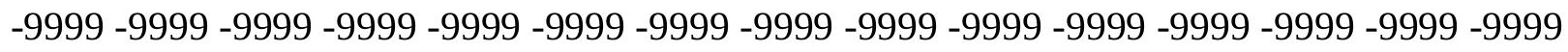

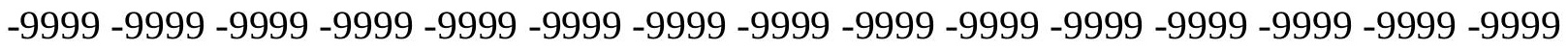

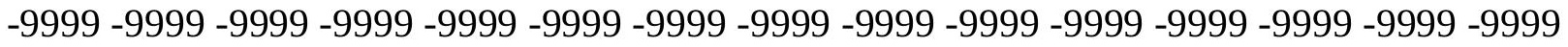
-9999 -9999 -9999 -9999 -9999 -9999 -9999 -9999 -9999 -9999 -9999 -9999 -9999 -9999 -9999 -

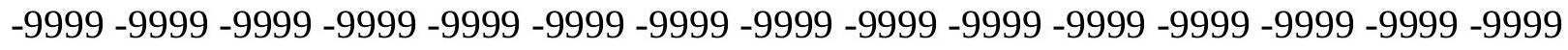

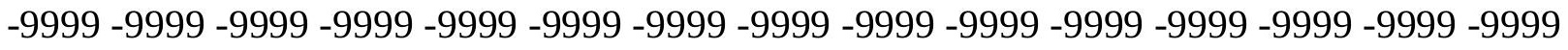
-9999 -9999 -9999 -9999 -9999 -9999 -9999 -9999 -9999 -9999 -9999 -9999 -9999 -9999 -9999 -9999 -9999 -9999 -9999 -9999 -9999 -9999 -9999 -9999-9999 -9999 -9999 -9999 -9999 -9999 -9999 -9999 -9999 -9999 -9999 -9999 -9999 -9999 -9999 -9999 -9999 -9999 -9999 -9999 -9999 -

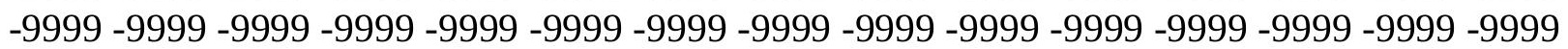


-9999 -9999 -9999 -9999 -9999 -9999 -9999 -9999 -9999 -9999 -9999 -9999 -9999 -9999 -9999 -9999 -9999 -9999 -9999 -9999 -9999 -9999 -9999 -9999 -9999 -9999 -9999 -9999 -9999 -9999 -9999 -9999 -9999 -9999 -9999 -9999 -9999 -9999 -9999 -9999 -9999 -9999 -9999 -9999 -9999 -9999 -9999 -9999 -9999 -9999 -9999 -9999 -9999 -9999 -9999 -9999 -9999 -9999 -9999 -9999 -9999 -9999 -9999 -9999 -9999 -9999 -9999 -9999-9999 -9999 -9999 -9999 -9999 -9999 -9999 -9999 -9999 -9999 -9999 -9999 -9999 -9999 -9999 -9999 -9999 -9999 -9999 -9999 -9999 -9999 -9999 -9999 -9999 -9999 -9999 -9999 -9999 -9999 -9999 -9999 -9999 -9999 -9999 -9999

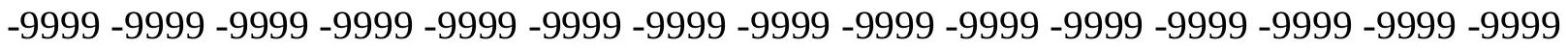

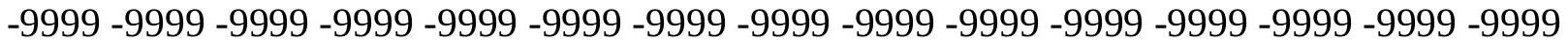
-9999 -9999 -9999 -9999 -9999 -9999 -9999 -9999 -9999 -9999 -9999 -9999 -9999 -9999 -9999 -9999 -9999 -9999 -9999 -9999 -9999 -9999 -9999 -9999 -9999 -9999 -9999 -9999 -9999 -9999 -9999 -9999 -9999 -9999 -9999 -9999 -9999 -9999 -9999 -9999 -9999 -9999 -9999 -9999 -9999 -9999 -9999 -9999 -9999 -9999 -9999 -9999 -9999 -9999 -9999 -9999 -9999 -9999 -9999 -9999 -

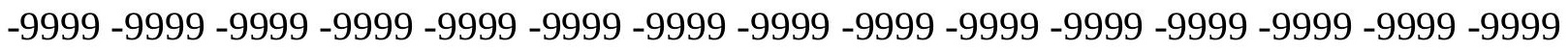
-9999 -9999 -9999 -9999 -9999 -9999 -9999 -9999 -9999 -9999 -9999 -9999 -9999 -9999 -9999 -

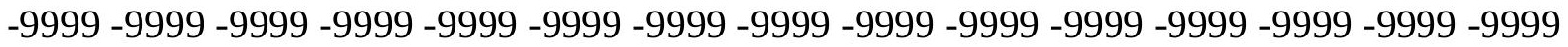
-9999 -9999 -9999 -9999 -9999 -9999 -9999 -9999 -9999 -9999 -9999 -9999 -9999 -9999 -9999 -9999 -9999 -9999 -9999 -9999 -9999 -9999 -9999 -9999 -9999 -9999 -9999 -9999 -9999 -9999 -9999 -9999 -9999 -9999 -9999 -9999 -9999 -9999 -9999 -9999 -9999 -9999 -9999 -9999 -9999 -

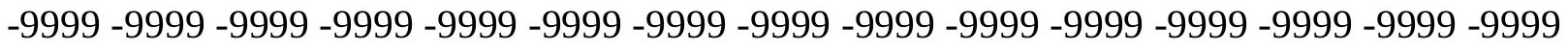

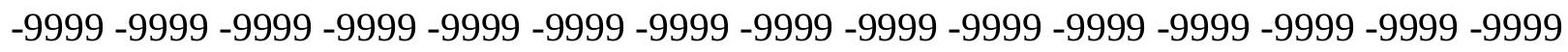
-9999 -9999 -9999 -9999 -9999 -9999 -9999 -9999 -9999 -9999 -9999 -9999 -9999 -9999 -9999 -9999 -9999 -9999 -9999 -9999 -9999 -9999 -9999 -9999 -9999 -9999 -9999 -9999 -9999 -9999 -9999 -9999 -9999 -9999 -9999 -9999 -9999 -9999 -9999 -9999 -9999 -9999 -9999 -9999 -9999 -

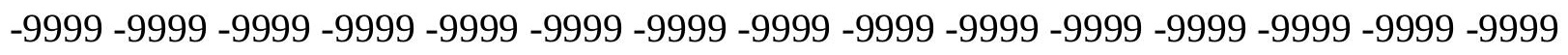
-9999 -9999 -9999 -9999 -9999 -9999 -9999 -9999 -9999 -9999 -9999 -9999 -9999 -9999 -9999 -9999 -9999 -9999 -9999 -9999 -9999 -9999 -9999 -9999 -9999 -9999 -9999 -9999 -9999 -9999 -

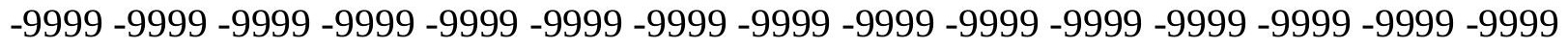
-9999 -9999 -9999 -9999 -9999 -9999 -9999 -9999 -9999 -9999 -9999 -9999 -9999 -9999 -9999 -9999 -9999 -9999 -9999 -9999 -9999 -9999 -9999 -9999 -9999 -9999 -9999 -9999 - -999 -

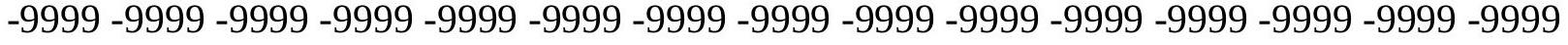
-9999 -9999 -9999 -9999 -9999 -9999 -9999 -9999 -9999 -9999 -9999 -9999 -9999 -9999 -9999 -

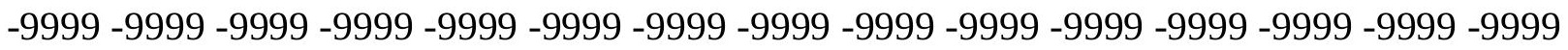

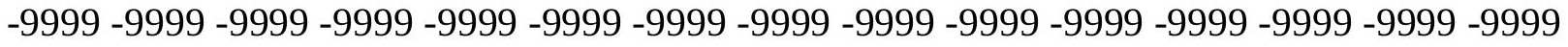

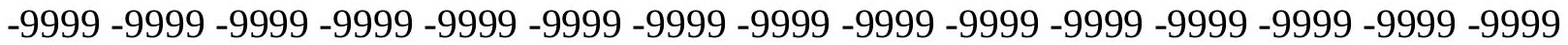

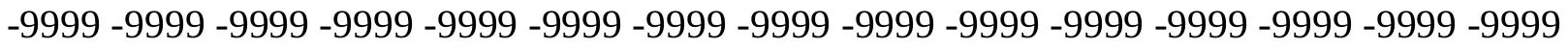

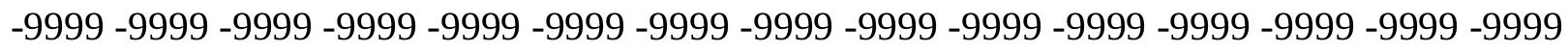

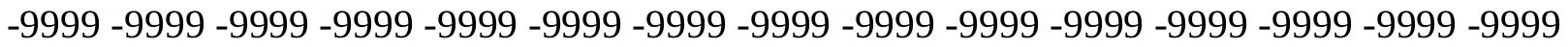

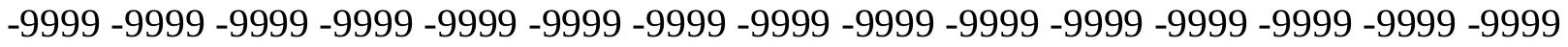
-9999 -9999 -9999 -9999 -9999 -9999 -9999 -9999 -9999 -9999 -9999 -9999 -9999 -9999 -9999 -

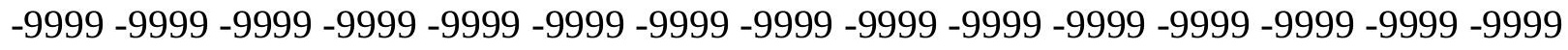

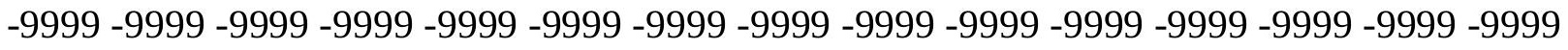
-9999 -9999 -9999 -9999 -9999 -9999 -9999 -9999 -9999 -9999 -9999 -9999 -9999 -9999 -9999 -9999 -9999 -9999 -9999 -9999 -9999 -9999 -9999 -9999-9999 -9999 -9999 -9999 -9999 -9999 -9999 -9999 -9999 -9999 -9999 -9999 -9999 -9999 -9999 -9999 -9999 -9999 -9999 -9999 -9999 -

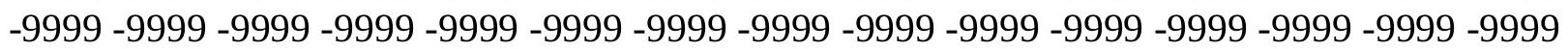


-9999 -9999 -9999 -9999 -9999 -9999 -9999 -9999 -9999 -9999 -9999 -9999 -9999 -9999 -9999 -9999 -9999 -9999 -9999 -9999 -9999 -9999 -9999 -9999 -9999 -9999 -9999 -9999 -9999 -9999 -

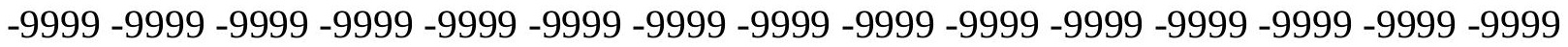
-9999 -9999 -9999 -9999 -9999 -9999 -9999 -9999 -9999 -9999 -9999 -9999 -9999 -9999 -9999 -9999 -9999 -9999 -9999 -9999 -9999 -9999 -9999 -9999-9999 -9999 -9999 -9999 -9999 -9999 -9999 -9999 -9999 -9999 -9999 -9999 -9999 -9999 -9999 -9999 -9999 -9999 -9999 -9999 -9999 -9999 -9999 -9999 -9999 -9999 -9999 -9999 -9999 -9999 -9999 -9999 -9999 -9999 -9999 -9999

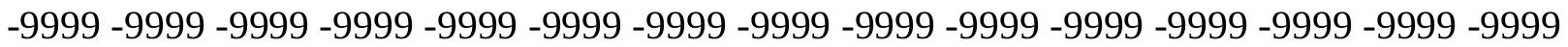
-9999 -9999 -9999 -9999 -9999 -9999 -9999 -9999 -9999 -9999 -9999 -9999 -9999 -9999 -9999 -9999 -9999 -9999 -9999 -9999 -9999 -9999 -9999 -9999 -9999 -9999 -9999 -9999 -9999

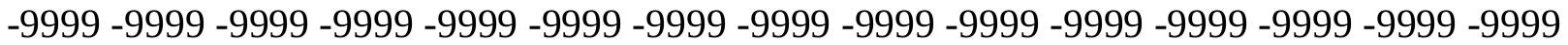
-9999 -9999 -9999 -9999 -9999 -9999 -9999 -9999 -9999 -9999 -9999 -9999 -9999 -9999 -9999 -9999 -9999 -9999 -9999 -9999 -9999 -9999 -9999 -9999 -9999 -9999 -9999 -9999 -9999 -9999 -9999 -9999 -9999 -9999 -9999 -9999 -9999 -9999 -9999 -9999 -9999 -9999 -9999 -9999 - 9999 -9999 -9999 -9999 -9999 -9999 -9999 -9999 -9999 -9999 -9999 -9999 -9999 -9999 -9999 -9999

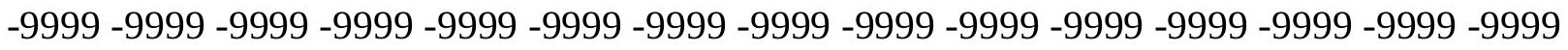
-9999 -9999 -9999 -9999 -9999 -9999 -9999 -9999 -9999 -9999 -9999 -9999 -9999 -9999 -9999 -9999 -9999 -9999 -9999 -9999 -9999 -9999 -9999 -9999 -9999 -9999 -9999 -9999 -9999 -9999 -9999 -9999 -9999 -9999 -9999 -9999 -9999 -9999 -9999 -9999 -9999 -9999 -9999 -9999 -9999 -

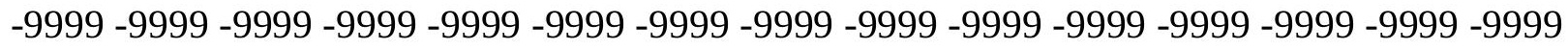

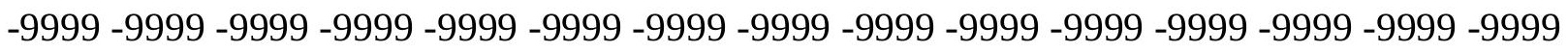
-9999 -9999 -9999 -9999 -9999 -9999 -9999 -9999 -9999 -9999 -9999 -9999 -9999 -9999 -9999 -9999 -9999 -9999 -9999 -9999 -9999 -9999 -9999 -9999 -9999 -9999 -9999 -9999 -9999 -9999 -9999 -9999 -9999 -9999 -9999 -9999 -9999 -9999 -9999 -9999 -9999 -9999 -9999 -9999 -9999 -

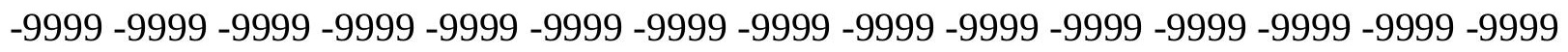
-9999 -9999 -9999 -9999 -9999 -9999 -9999 -9999 -9999 -9999 -9999 -9999 -9999 -9999 -9999 -9999 -9999 -9999 -9999 -9999 -9999 -9999 -9999 -9999 -9999 -9999 -9999 -9999 -9999 -9999 -

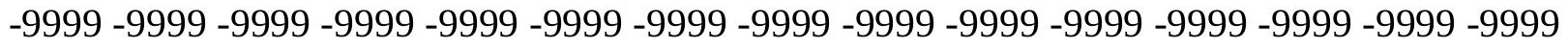
-9999 -9999 -9999 -9999 -9999 -9999 -9999 -9999 -9999 -9999 -9999 -9999 -9999 -9999 -9999 -9999 -9999 -9999 -9999 -9999 -9999 -9999 -9999 -9999 -9999 -9999 -9999 -9999 -9999 -999 -9999 -9999 -9999 -9999 -9999 -9999 -9999 -9999 -9999 -9999 -9999 -9999 -9999 -9999 -9999 -9999 -9999 -9999 -9999 -9999 -9999 -9999 -9999 -9999 -9999 -9999 -9999 -9999 -9999 -9999 -

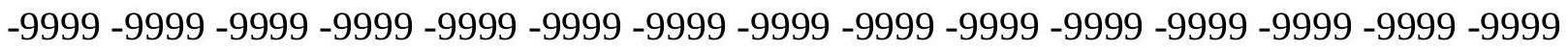

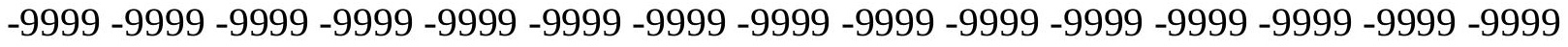
-9999 -9999 -9999 -9999 -9999 -9999 -9999 -9999 -9999 -9999 -9999 -9999 -9999 -9999 -

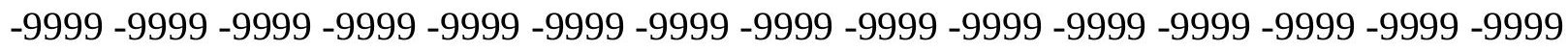

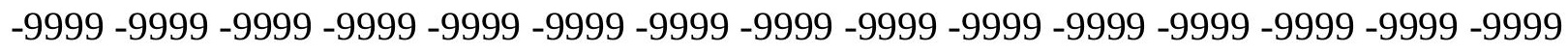

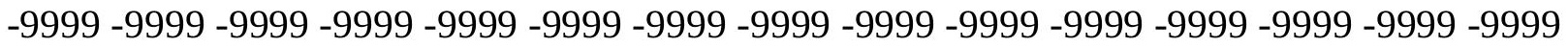
-9999 -9999 -9999 -9999 -9999 -9999 -9999 -9999 -9999 -9999 -9999 -9999 -9999 - 9999 - -999 -9999 -9999 -9999 -9999 -9999 -9999 -9999 -9999 -9999 -9999 -9999 -9999 -9999 -9999 -9999 -

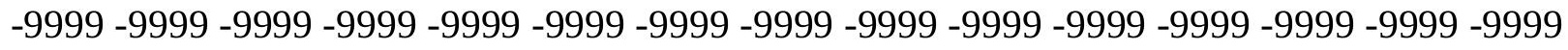

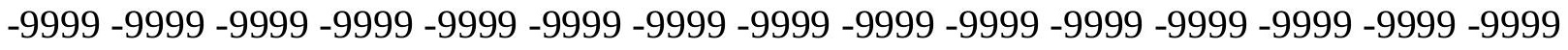
-9999 -9999 -9999 -9999 -9999 -9999 -9999 -9999 -9999 -9999 -9999 -9999 -9999 -9999 -9999 -9999 -9999 -9999 -9999 -9999 -9999 -9999 -9999 -9999-9999 -9999 -9999 -9999 -9999 -9999 -9999 -9999 -9999 -9999 -9999 -9999 -9999 -9999 -9999 -9999 -9999 -9999 -9999 -9999 -9999 -

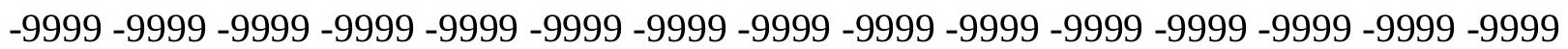


-9999 -9999 -9999 -9999 -9999 -9999 -9999 -9999 -9999 -9999 -9999 -9999 -9999 -9999 -9999 -9999 -9999 -9999 -9999 -9999 -9999 -9999 -9999 -9999 -9999 -9999 -9999 -9999 -9999 -9999 -

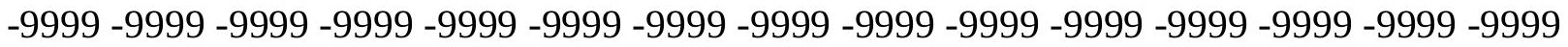
-9999 -9999 -9999 -9999 -9999 -9999 -9999 -9999 -9999 -9999 -9999 -9999 -9999 -9999 -9999 -9999 -9999 -9999 -9999 -9999 -9999 -9999 -9999 -9999-9999 -9999 -9999 -9999 -9999 -9999 -9999 -9999 -9999 -9999 -9999 -9999 -9999 -9999 -9999 -9999 -9999 -9999 -9999 -9999 -9999 -9999 -9999 -9999 -9999 -9999 -9999 -9999 -9999 -9999 -9999 -9999 -9999 -9999 -9999 -9999

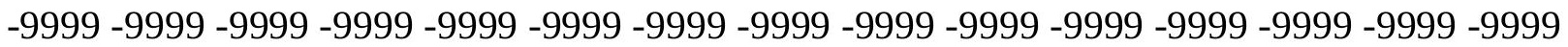

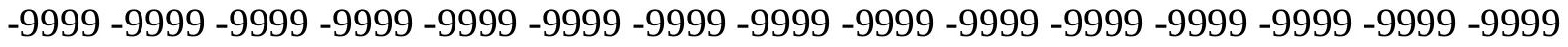
-9999 -9999 -9999 -9999 -9999 -9999 -9999 -9999 -9999 -9999 -9999 -9999 -9999 -9999 -9999 -9999 -9999 -9999 -9999 -9999 -9999 -9999 -9999 -9999 -9999 -9999 -9999 -9999 -9999 -9999 -9999 -9999 -9999 -9999 -9999 -9999 -9999 -9999 -9999 -9999 -9999 -9999 -9999 -9999 -9999 -9999 -9999 -9999 -9999 -9999 -9999 -9999 -9999 -9999 -9999 -9999 -9999 -9999 -9999 -9999 -9999 -9999 -9999 -9999 -9999 -9999 -9999 -9999 -9999 -9999 -9999 -9999 -9999 -9999 -9999 -9999 -9999 -9999 -9999 -9999 -9999 -9999 -9999 -9999 -9999 -9999 -9999 -9999 -9999 -9999 -9999 -9999 -9999 -9999 -9999 -9999 -9999 -9999 -9999 -9999 -9999 -9999 - 9999 - -999 -

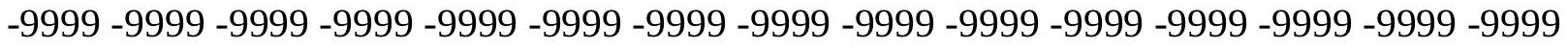
-9999 -9999 -9999 -9999 -9999 -9999 -9999 -9999 -9999 -9999 -9999 -9999 -9999 -9999 -9999 -9999 -9999 -9999 -9999 -9999 -9999 -9999 -9999 -9999 -9999 -9999 -9999 -9999 -9999 -9999 -

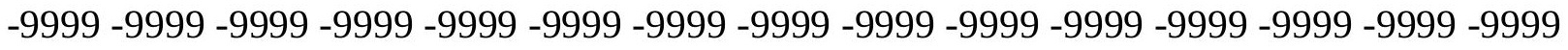
-9999 -9999 -9999 -9999 -9999 -9999 -9999 -9999 -9999 -9999 -9999 -9999 -9999 -9999 -9999

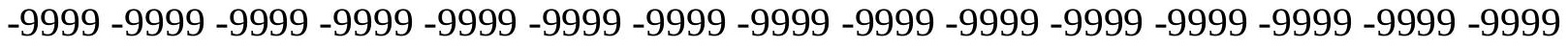
-9999 -9999 -9999 -9999 -9999 -9999 -9999 -9999 -9999 -9999 -9999 -9999 -9999 -9999 -9999 -9999 -9999 -9999 -9999 -9999 -9999 -9999 -9999 -9999 -9999 -9999 -9999 -9999 -9999 -9999 -

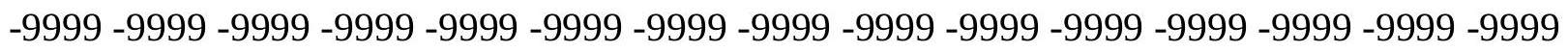
-9999 -9999 -9999 -9999 -9999 -9999 -9999 -9999 -9999 -9999 -9999 -9999 -9999 -9999 -9999 -9999 -9999 -9999 -9999 -9999 -9999 -9999 -9999 -9999 -9999 -9999 -9999 -9999 -9999 -9999 -

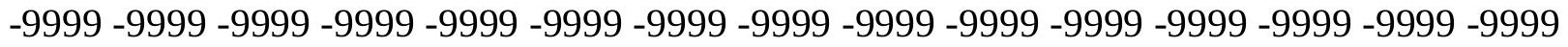
-9999 -9999 -9999 -9999 -9999 -9999 -9999 -9999 -9999 -9999 -9999 -9999 -9999 -9999 -9999 -9999 -9999 -9999 -9999 -9999 -9999 -9999 -9999 -9999 -9999 -9999 -9999 -9999 -9999 -999 -

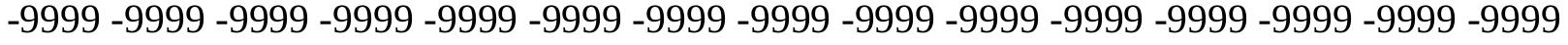
-9999 -9999 -9999 -9999 -9999 -9999 -9999 -9999 -9999 -9999 -9999 -9999 -9999 -9999 -9999 -

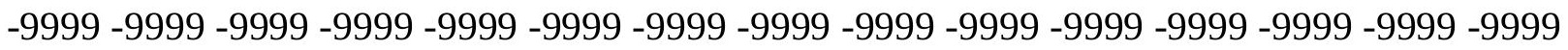

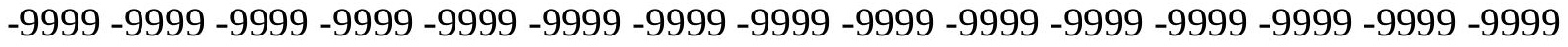

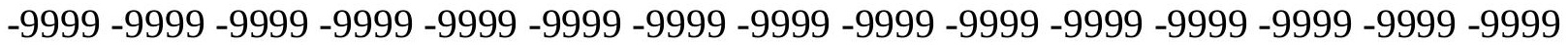
-9999 -9999 -9999 -9999 -9999 -9999 -9999 -9999 -9999 -9999 -9999 -9999 -9999 -9999 -9999 -

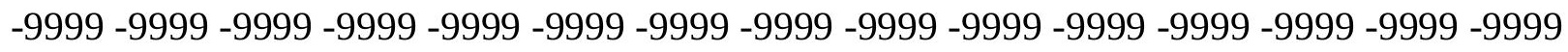

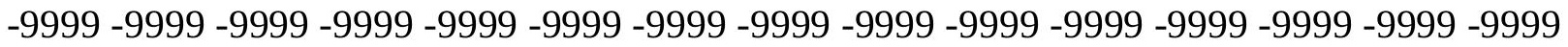
-9999 -9999 -9999 -9999 -9999 -9999 -9999 -9999 -9999 -9999 -9999 -9999 -9999 - 9999 - -999 -9999 -9999 -9999 -9999 -9999 -9999 -9999 -9999 -9999 -9999 -9999 -9999 -9999 -9999 -9999 -

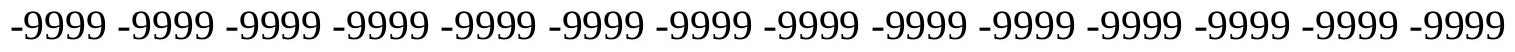

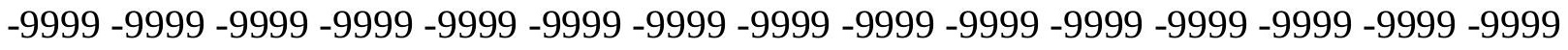
-9999 -9999 -9999 -9999 -9999 -9999 -9999 -9999 -9999 -9999 -9999 -9999 -9999 -9999 -9999 -9999 -9999 -9999 -9999 -9999 -9999 -9999 -9999 -9999-9999 -9999 -9999 -9999 -9999 -9999 -9999 -9999 -9999 -9999 -9999 -9999 -9999 -9999 -9999 -9999 -9999 -9999 -9999 -9999 -9999 -

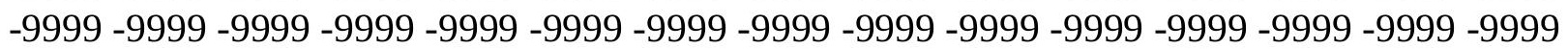


-9999 -9999 -9999 -9999 -9999 -9999 -9999 -9999 -9999 -9999 -9999 -9999 -9999 -9999 -9999 -9999 -9999 -9999 -9999 -9999 -9999 -9999 -9999 -9999 -9999 -9999 -9999 -9999 -9999 -9999 -9999 -9999 -9999 -9999 -9999 -9999 -9999 -9999 -9999 -9999 -9999 -9999 -9999 -9999 - 9999 -9999 -9999 -9999 -9999 -9999 -9999 -9999 -9999 -9999 -9999 -9999 -9999 -9999 -9999 -9999 -9999 -9999 -9999 -9999 -9999 -9999 -9999 -9999 -9999-9999 -9999 -9999 -9999 -9999 -9999 -9999 -9999 -9999 -9999 -9999 -9999 -9999 -9999 -9999 -9999 -9999 -9999 -9999 -9999 -9999 -9999 -9999 -9999 -9999 -9999 -9999 -9999 -9999 -9999 -9999 -9999 -9999 -9999 -9999 -9999

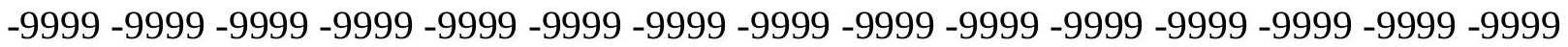
-9999 -9999 -9999 -9999 -9999 -9999 -9999 -9999 -9999 -9999 -9999 -9999 -9999 -9999 -9999 -9999 -9999 -9999 -9999 -9999 -9999 -9999 -9999 -9999 -9999 -9999 -9999 -9999 -9999 -9999

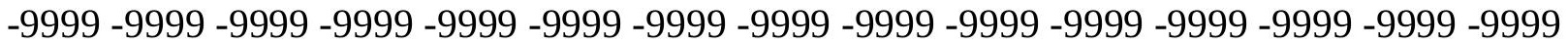
-9999 -9999 -9999 -9999 -9999 -9999 -9999 -9999 -9999 -9999 -9999 -9999 -9999 -9999 -9999 -9999 -9999 -9999 -9999 -9999 -9999 -9999 -9999 -9999 -9999 -9999 -9999 -9999 -9999 -9999 -

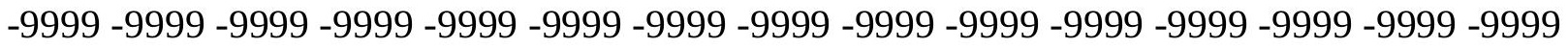
-9999 -9999 -9999 -9999 -9999 -9999 -9999 -9999 -9999 -9999 -9999 -9999 -9999 -9999 -9999

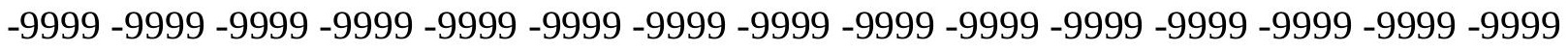
-9999 -9999 -9999 -9999 -9999 -9999 -9999 -9999 -9999 -9999 -9999 -9999 -9999 -9999 -9999 -9999 -9999 -9999 -9999 -9999 -9999 -9999 -9999 -9999 -9999 -9999 -9999 -9999 -9999 - 9999 -9999 -9999 -9999 -9999 -9999 -9999 -9999 -9999 -9999 -9999 -9999 -9999 -9999 -9999 -9999 -9999 -9999 -9999 -9999 -9999 -9999 -9999 -9999 -9999 -9999 -9999 -9999 -9999 -9999 -9999 -9999 -9999 -9999 -9999 -9999 -9999 -9999 -9999 -9999 -9999 -9999 -9999 -9999 -9999 -9999 -9999 -9999 -9999 -9999 -9999 -9999 -9999 -9999 -9999 -9999 -9999 -9999 -9999 -9999 -9999 -9999 -9999 -9999 -9999 -9999 -9999 -9999 -9999 -9999 -9999 -9999 -9999 -9999 -9999 -9999 -9999 -9999 -9999 -9999 -9999 -9999 -9999 -9999 -9999 -9999 -9999 -9999 -9999 -9999 -9999 -9999 -9999 -9999 -9999 -9999 -9999 -9999 -9999 -9999 -9999 -9999 -9999 -9999 -9999 -9999 -9999 -9999 -9999 -9999 -9999 -9999 -9999 -9999 -9999 -9999 -9999 -9999 -9999 -9999 -9999 -9999 -9999 -9999 -9999 -9999 -9999 -9999 -9999 -9999 -9999 -9999 -9999 -9999 -9999 -9999 -9999 -9999 -9999 -9999 -9999 -9999 -9999 -9999 -9999 -9999 -9999 -9999 -9999 -9999 -9999 -9999 -9999 -9999 -9999 -9999 -9999 -9999 -9999 -9999 -9999 -9999 -9999 -9999 -9999 -9999 -9999 -9999 -9999 -9999 -9999 -9999 -9999 -9999 -9999 -9999 -9999 -9999 -9999 -999 -9999 -9999 -9999 -9999 -9999 -9999 -9999 -9999 -9999 -9999 -9999 -9999 -9999 -9999 -9999 -9999 -9999 -9999 -9999 -9999 -9999 -9999 -9999 -9999 -9999 -9999 -9999 -9999 -9999 -9999 -

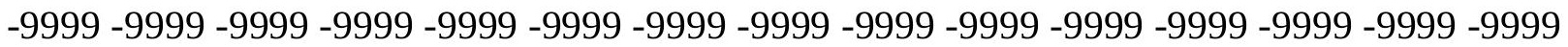

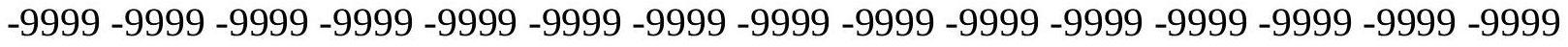

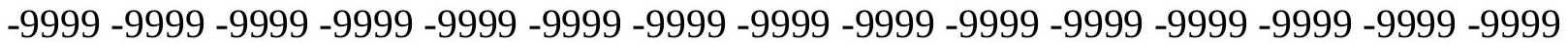
-9999 -9999 -9999 -9999 -9999 -9999 -9999 -9999 -9999 -9999 -9999 -9999 -9999 -9999 -9999

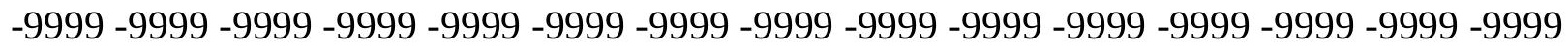

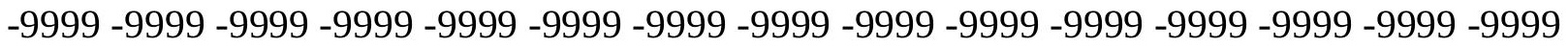

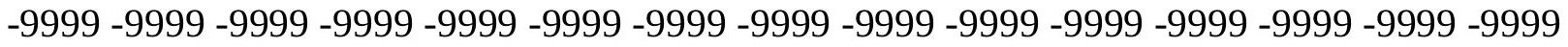
-9999 -9999 -9999 -9999 -9999 -9999 -9999 -9999 -9999 -9999 -9999 -9999 -9999 -9999 -9999 -

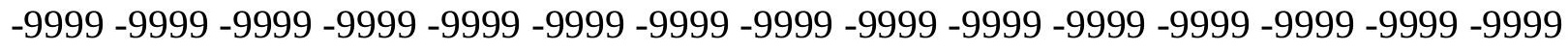

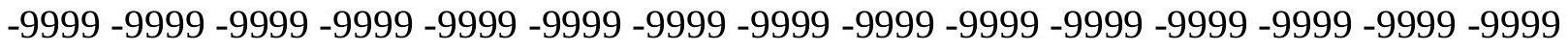
-9999 -9999 -9999 -9999 -9999 -9999 -9999 -9999 -9999 -9999 -9999 -9999 -9999 -9999 -9999 -9999 -9999 -9999 -9999 -9999 -9999 -9999 -9999 -9999-9999 -9999 -9999 -9999 -9999 -9999 -9999 -9999 -9999 -9999 -9999 -9999 -9999 -9999 -9999 -9999 -9999 -9999 -9999 -9999 -9999 -

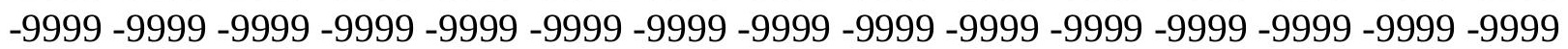


-9999 -9999 -9999 -9999 -9999 -9999 -9999 -9999 -9999 -9999 -9999 -9999 -9999 -9999 -9999 -9999 -9999 -9999 -9999 -9999 -9999 -9999 -9999 -9999 -9999 -9999 -9999 -9999 -9999 -9999 -9999 -9999 -9999 -9999 -9999 -9999 -9999 -9999 -9999 -9999 -9999 -9999 -9999 -9999 -9999 -9999 -9999 -9999 -9999 -9999 -9999 -9999 -9999 -9999 -9999 -9999 -9999 -9999 -9999 -9999 -9999 -9999 -9999 -9999 -9999 -9999 -9999 -9999 -9999 -9999 -9999 -9999 -9999 -9999 -9999 -9999 -9999 -9999 -9999 -9999 -9999 -9999 -9999 -9999 -9999 -9999 -9999 -9999 -9999 -9999 -9999 -9999 -9999 -9999 -9999 -9999 -9999 -9999 -9999 -9999 -9999 -9999 -9999 -9999 -

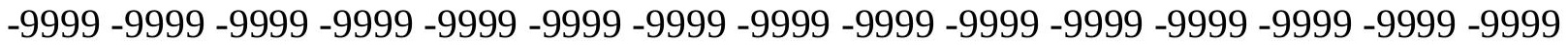
-9999 -9999 -9999 -9999 -9999 -9999 -9999 -9999 -9999 -9999 -9999 -9999 -9999 -9999 -9999 -9999 -9999 -9999 -9999 -9999 -9999 -9999 -9999 -9999 -9999 -9999 -9999 -9999 -9999 -9999 -

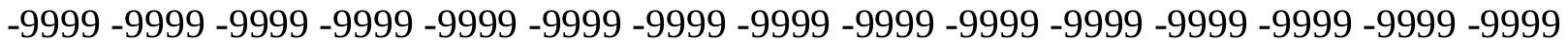
-9999 -9999 -9999 -9999 -9999 -9999 -9999 -9999 -9999 -9999 -9999 -9999 -9999 -9999 -9999 -9999 -9999 -9999 -9999 -9999 -9999 -9999 -9999 -9999 -9999 -9999 -9999 -9999 -9999 -9999 -9999 -9999 -9999 -9999 -9999 -9999 -9999 -9999 -9999 -9999 -9999 -9999 -9999 -9999 -9999 -9999 -9999 -9999 -9999 -9999 -9999 -9999 -9999 -9999 -9999 -9999 -9999 -9999 -9999 -9999 -9999 -9999 -9999 -9999 -9999 -9999 -9999 -9999 -9999 -9999 -9999 -9999 -9999 -9999 -9999 -9999 -9999 -9999 -9999 -9999 -9999 -9999 -9999 -9999 -9999 -9999 -9999 -9999 -9999 -9999 -9999 -9999 -9999 -9999 -9999 -9999 -9999 -9999 -9999 -9999 -9999 -9999 -9999 -9999 -9999 -9999 -9999 -9999 -9999 -9999 -9999 -9999 -9999 -9999 -9999 -9999 -9999 -9999 -9999 -9999 -9999 -9999 -9999 -9999 -9999 -9999 -9999 -9999 -9999 -9999 -9999 -9999 -9999 -9999 -9999

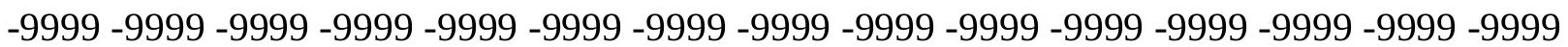
-9999 -9999 -9999 -9999 -9999 -9999 -9999 -9999 -9999 -9999 -9999 -9999 -9999 -9999 -9999 -9999 -9999 -9999 -9999 -9999 -9999 -9999 -9999 -9999 -9999 -9999 -9999 -9999 -9999 -9999 -9999 -9999 -9999 -9999 -9999 -9999 -9999 -9999 -9999 -9999 -9999 -9999 -9999 -9999 -9999

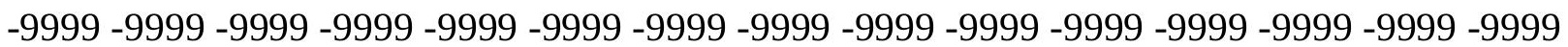
-9999 -9999 -9999 -9999 -9999 -9999 -9999 -9999 -9999 -9999 -9999 -9999 -9999 -9999 -9999 -9999 -9999 -9999 -9999 -9999 -9999 -9999 -9999 -9999 -9999 -9999 -9999 -9999 -9999 -9999 -9999 -9999 -9999 -9999 -9999 -9999 -9999 -9999 -9999 -9999 -9999 -9999 -9999 -9999

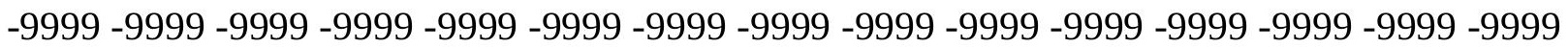
-9999 -9999 -9999 -9999 -9999 -9999 -9999 -9999 -9999 -9999 -9999 -9999 -9999 -9999 -9999 -9999 -9999 -9999 -9999 -9999 -9999 -9999 -9999 -9999 -9999 -9999 -9999 -9999 -9999 -9999 -

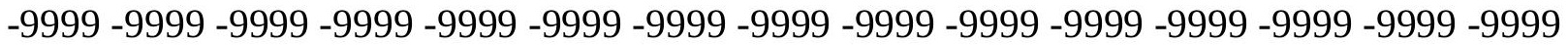
-9999 -9999 -9999 -9999 -9999 -9999 -9999 -9999 -9999 -9999 -9999 -9999 -9999 -9999 -9999 -9999 -9999 -9999 -9999 -9999 -9999 -9999 -9999 -9999 -9999 -9999 -9999 -9999 -9999 -9999 -9999 -9999 -9999 -9999 -9999 -9999 -9999 -9999 -9999 -9999 -9999 -9999 -9999 -9999 -9999 -9999 -9999 -9999 -9999 -9999 -9999 -9999 -9999 -9999 -9999 -9999 -9999 -9999 -9999 -9999 -9999 -9999 -9999 -9999 -9999 -9999 -9999 -9999 -9999 -9999 -9999 -9999 -9999 -9999 -9999

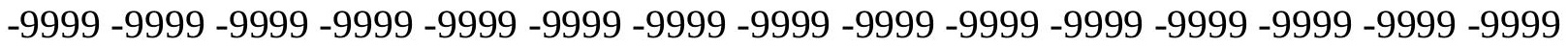
-9999 -9999 -9999 -9999 -9999 -9999 -9999 -9999 -9999 -9999 -9999 -9999 -9999 -9999 -9999 -9999 -9999 -9999 -9999 -9999 -9999 -9999 -9999 -9999 -9999 -9999 -9999 -9999 -9999 -9999 -

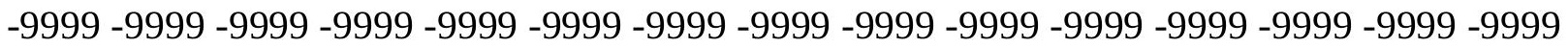
-9999 -9999 -9999 -9999 -9999 -9999 -9999 -9999 -9999 -9999 -9999 -9999 -9999 -9999 -9999 -9999 -9999 -9999 -9999 -9999 -9999 -9999 -9999 -9999 -9999 -9999 -9999 -9999 -9999 -9999 -9999 -9999 -9999 -9999 -9999 -9999 -9999 -9999 -9999 -9999 -9999 -9999 -9999 -9999 -9999 -9999 -9999 -9999 -9999 -9999 -9999 -9999 -9999 -9999 -9999 -9999 -9999 -9999 -9999 -9999

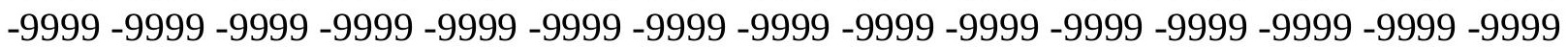


-9999 -9999 -9999 -9999 -9999 -9999 -9999 -9999 -9999 -9999 -9999 -9999 -9999 -9999 -9999 -9999 -9999 -9999 -9999 -9999 -9999 -9999 -9999 -9999 -9999 -9999 -9999 -9999 -9999 -9999 -

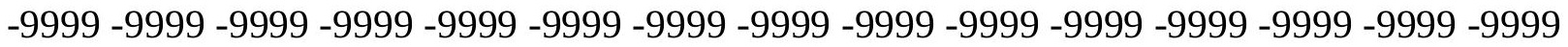
-9999 -9999 -9999 -9999 -9999 -9999 -9999 -9999 -9999 -9999 -9999 -9999 -9999 -9999 -9999 -9999 -9999 -9999 -9999 -9999 -9999 -9999 -9999 -9999-9999 -9999 -9999 -9999 -9999 -9999 -9999 -9999 -9999 -9999 -9999 -9999 -9999 -9999 -9999 -9999 -9999 -9999 -9999 -9999 -9999 -9999 -9999 -9999 -9999 -9999 -9999 -9999 -9999 -9999 -9999 -9999 -9999 -9999 -9999 -

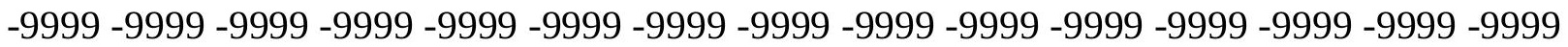

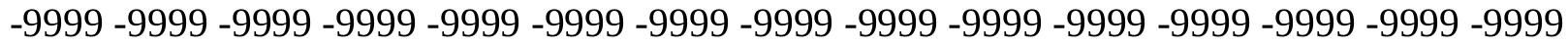
-9999 -9999 -9999 -9999 -9999 -9999 -9999 -9999 -9999 -9999 -9999 -9999 -9999 -9999 -9999 -9999 -9999 -9999 -9999 -9999 -9999 -9999 -9999 -9999 -9999 -9999 -9999 -9999 -9999 -9999 -9999 -9999 -9999 -9999 -9999 -9999 -9999 -9999 -9999 -9999 -9999 -9999 -9999 -9999 -9999 -9999 -9999 -9999 -9999 -9999 -9999 -9999 -9999 -9999 -9999 -9999 -9999 -9999 -9999 -9999 -9999 -9999 -9999 -9999 -9999 -9999 -9999 -9999 -9999 -9999 -9999 -9999 -9999 -9999 -9999 -9999 -9999 -9999 -9999 -9999 -9999 -9999 -9999 -9999 -9999 -9999 -9999 -9999 -9999 -9999 -

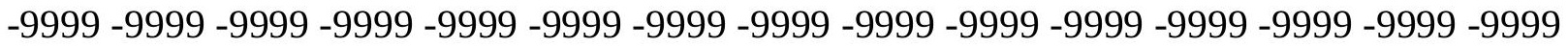
-9999 -9999 -9999 -9999 -9999 -9999 -9999 -9999 -9999 -9999 -9999 -9999 -9999 -9999 -9999 -9999 -9999 -9999 -9999 -9999 -9999 -9999 -9999 -9999 -9999 -9999 -9999 -9999 -9999 -9999 -9999 -9999 -9999 -9999 -9999 -9999 -9999 -9999 -9999 -9999 -9999 -9999 -9999 -9999 -9999 -

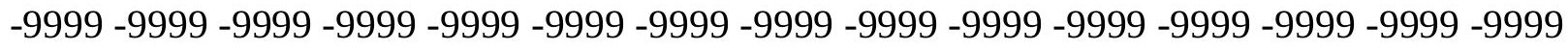

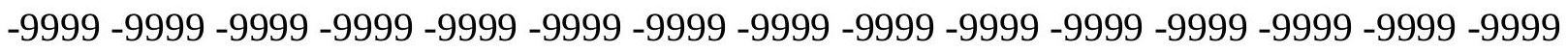

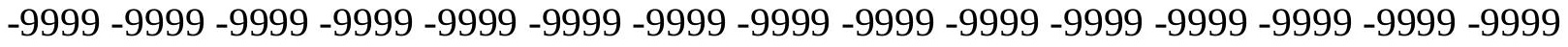
-9999 -9999 -9999 -9999 -9999 -9999 -9999 -9999 -9999 -9999 -9999 -9999 -9999 -9999 -9999 -9999 -9999 -9999 -9999 -9999 -9999 -9999 -9999 -9999 -9999 -9999 -9999 -9999 -9999 -9999 -

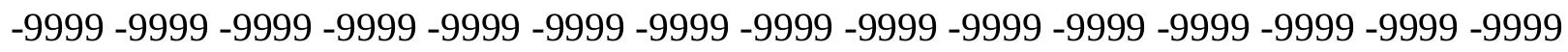
-9999 -9999 -9999 -9999 -9999 -9999 -9999 -9999 -9999 -9999 -9999 -9999 -9999 -9999 -9999 -9999 -9999 -9999 -9999 -9999 -9999 -9999 -9999 -9999 -9999 -9999 -9999 -9999 -9999 -9999 -

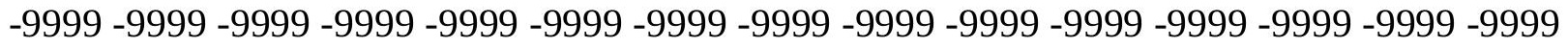
-9999 -9999 -9999 -9999 -9999 -9999 -9999 -9999 -9999 -9999 -9999 -9999 -9999 -9999 -9999 -9999 -9999 -9999 -9999 -9999 -9999 -9999 -9999 -9999 -9999 -9999 -9999 -9999 -9999 -999 -9999 -9999 -9999 -9999 -9999 -9999 -9999 -9999 -9999 -9999 -9999 -9999 -9999 -9999 -9999 -

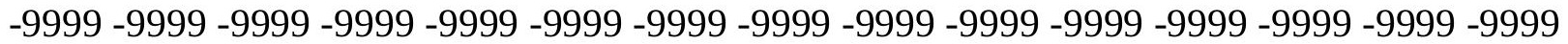

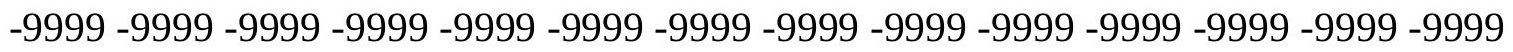

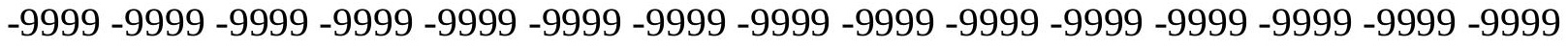

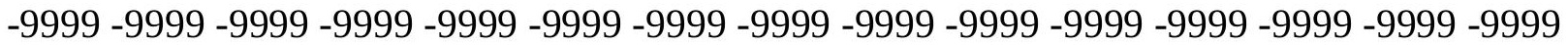

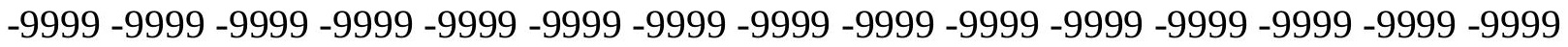

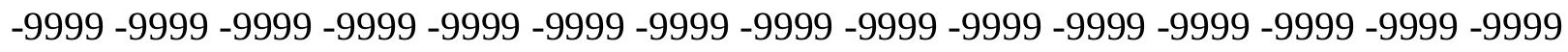

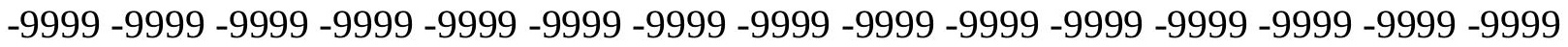

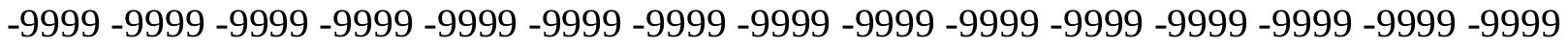
-9999 -9999 -9999 -9999 -9999 -9999 -9999 -9999 -9999 -9999 -9999 -9999 -9999 -9999 -9999 -

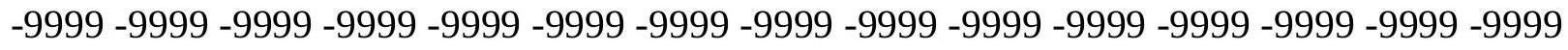

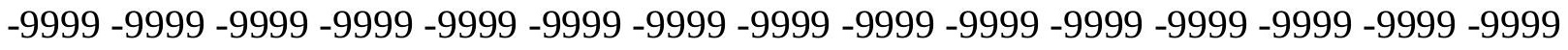
-9999 -9999 -9999 -9999 -9999 -9999 -9999 -9999 -9999 -9999 -9999 -9999 -9999 -9999 -9999 -9999 -9999 -9999 -9999 -9999 -9999 -9999 -9999 -9999-9999 -9999 -9999 -9999 -9999 -9999 -9999 -9999 -9999 -9999 -9999 -9999 -9999 -9999 -9999 -9999 -9999 -9999 -9999 -9999 -9999 -

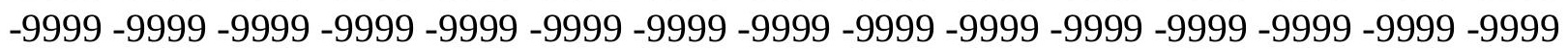


-9999 -9999 -9999 -9999 -9999 -9999 -9999 -9999 -9999 -9999 -9999 -9999 -9999 -9999 -9999 -9999 -9999 -9999 -9999 -9999 -9999 -9999 -9999 -9999 -9999 -9999 -9999 -9999 -9999 -9999 -

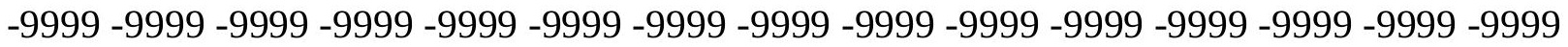
-9999 -9999 -9999 -9999 -9999 -9999 -9999 -9999 -9999 -9999 -9999 -9999 -9999 -9999 -9999 -9999 -9999 -9999 -9999 -9999 -9999 -9999 -9999 -9999-9999 -9999 -9999 -9999 -9999 -9999 -9999 -9999 -9999 -9999 -9999 -9999 -9999 -9999 -9999 -9999 -9999 -9999 -9999 -9999 -9999 -9999 -9999 -9999 -9999 -9999 -9999 -9999 -9999 -9999 -9999 -9999 -9999 -9999 -9999 -9999

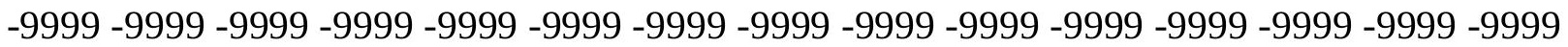

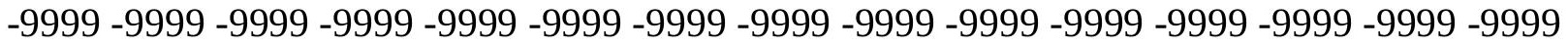
-9999 -9999 -9999 -9999 -9999 -9999 -9999 -9999 -9999 -9999 -9999 -9999 -9999 -9999 -9999 -9999 -9999 -9999 -9999 -9999 -9999 -9999 -9999 -9999 -9999 -9999 -9999 -9999 -9999 -9999 -9999 -9999 -9999 -9999 -9999 -9999 -9999 -9999 -9999 -9999 -9999 -9999 -9999 -9999 -9999 -9999 -9999 -9999 -9999 -9999 -9999 -9999 -9999 -9999 -9999 -9999 -9999 -9999 -9999 -9999 -9999 -9999 -9999 -9999 -9999 -9999 -9999 -9999 -9999 -9999 -9999 -9999 -9999 -9999 -9999 -9999 -9999 -9999 -9999 -9999 -9999 -9999 -9999 -9999 -9999 -9999 -9999 -9999 -9999 -

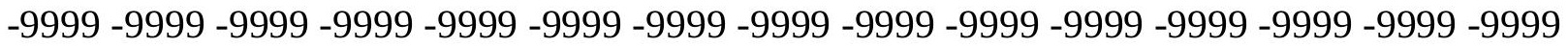
-9999 -9999 -9999 -9999 -9999 -9999 -9999 -9999 -9999 -9999 -9999 -9999 -9999 -9999 -9999 -9999 -9999 -9999 -9999 -9999 -9999 -9999 -9999 -9999 -9999 -9999 -9999 -9999 -9999 -9999 -9999 -9999 -9999 -9999 -9999 -9999 -9999 -9999 -9999 -9999 -9999 -9999 -9999 -9999 -9999 -

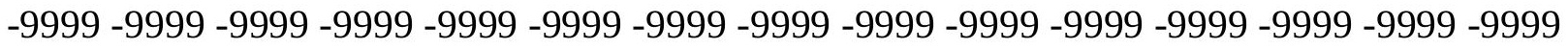
-9999 -9999 -9999 -9999 -9999 -9999 -9999 -9999 -9999 -9999 -9999 -9999 -9999 -9999 -9999

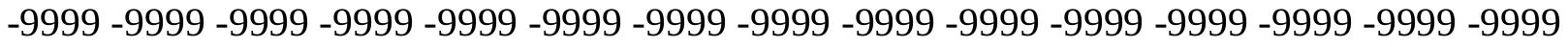
-9999 -9999 -9999 -9999 -9999 -9999 -9999 -9999 -9999 -9999 -9999 -9999 -9999 -9999 -9999 -9999 -9999 -9999 -9999 -9999 -9999 -9999 -9999 -9999 -9999 -9999 -9999 -9999 -9999 -9999 -

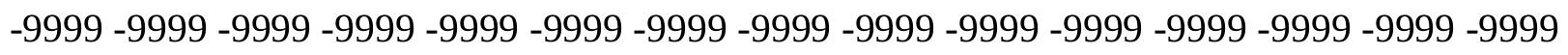
-9999 -9999 -9999 -9999 -9999 -9999 -9999 -9999 -9999 -9999 -9999 -9999 -9999 -9999 -9999 -9999 -9999 -9999 -9999 -9999 -9999 -9999 -9999 -9999 -9999 -9999 -9999 -9999 -9999 -9999 -

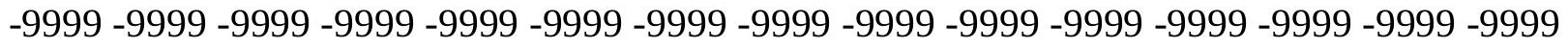
-9999 -9999 -9999 -9999 -9999 -9999 -9999 -9999 -9999 -9999 -9999 -9999 -9999 -9999 -9999 -9999 -9999 -9999 -9999 -9999 -9999 -9999 -9999 -9999 -9999 -9999 -9999 -9999 -9999 -999 -9999 -9999 -9999 -9999 -9999 -9999 -9999 -9999 -9999 -9999 -9999 -9999 -9999 -9999 -9999 -9999 -9999 -9999 -9999 -9999 -9999 -9999 -9999 -9999 -9999 -9999 -9999 -9999 -9999 -9999 -

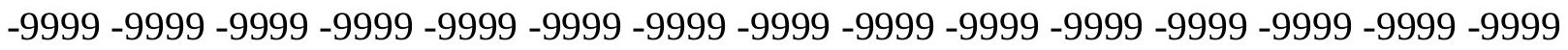

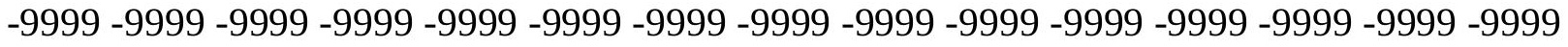

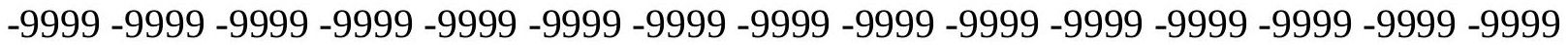
-9999 -9999 -9999 -9999 -9999 -9999 -9999 -9999 -9999 -9999 -9999 -9999 -9999 -9999 -9999 -

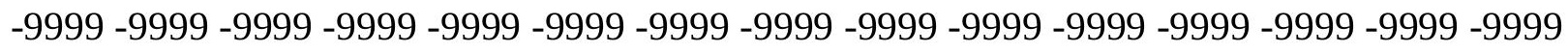

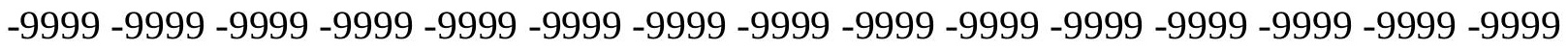
-9999 -9999 -9999 -9999 -9999 -9999 -9999 -9999 -9999 -9999 -9999 -9999 -9999 -9999 - -999 -9999 -9999 -9999 -9999 -9999 -9999 -9999 -9999 -9999 -9999 -9999 -9999 -9999 -9999 -9999 -

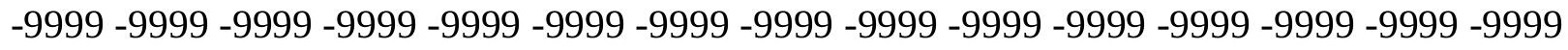

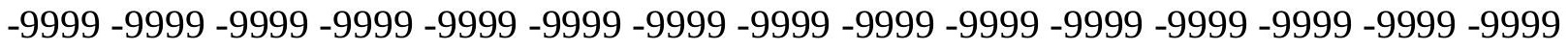
-9999 -9999 -9999 -9999 -9999 -9999 -9999 -9999 -9999 -9999 -9999 -9999 -9999 -9999 -9999 -9999 -9999 -9999 -9999 -9999 -9999 -9999 -9999 -9999-9999 -9999 -9999 -9999 -9999 -9999 -9999 -9999 -9999 -9999 -9999 -9999 -9999 -9999 -9999 -9999 -9999 -9999 -9999 -9999 -9999 -

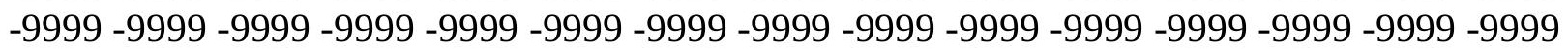


-9999 -9999 -9999 -9999 -9999 -9999 -9999 -9999 -9999 -9999 -9999 -9999 -9999 -9999 -9999 -9999 -9999 -9999 -9999 -9999 -9999 -9999 -9999 -9999 -9999 -9999 -9999 -9999 -9999 -9999 -

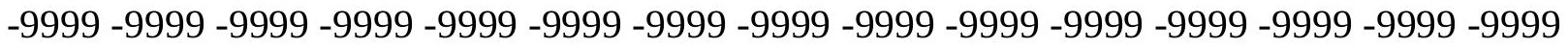
-9999 -9999 -9999 -9999 -9999 -9999 -9999 -9999 -9999 -9999 -9999 -9999 -9999 -9999 -9999 -9999 -9999 -9999 -9999 -9999 -9999 -9999 -9999 -9999-9999 -9999 -9999 -9999 -9999 -9999 -9999 -9999 -9999 -9999 -9999 -9999 -9999 -9999 -9999 -9999 -9999 -9999 -9999 -9999 -9999 -9999 -9999 -9999 -9999 -9999 -9999 -9999 -9999 -9999 -9999 -9999 -9999 -9999 -9999 -9999

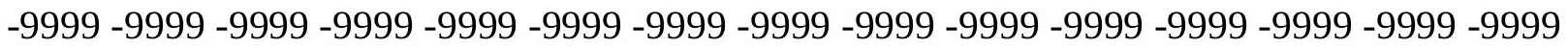

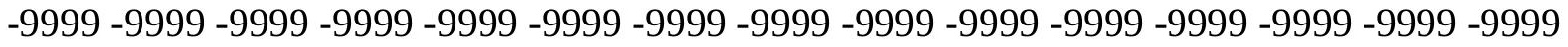
-9999 -9999 -9999 -9999 -9999 -9999 -9999 -9999 -9999 -9999 -9999 -9999 -9999 -9999 -9999 -9999 -9999 -9999 -9999 -9999 -9999 -9999 -9999 -9999 -9999 -9999 -9999 -9999 -9999 -9999 -9999 -9999 -9999 -9999 -9999 -9999 -9999 -9999 -9999 -9999 -9999 -9999 -9999 -9999 -9999 -9999 -9999 -9999 -9999 -9999 -9999 -9999 -9999 -9999 -9999 -9999 -9999 -9999 -9999 -9999 -

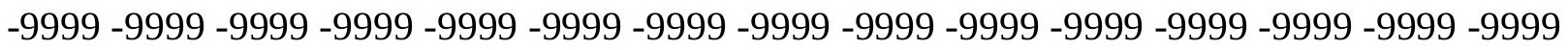
-9999 -9999 -9999 -9999 -9999 -9999 -9999 -9999 -9999 -9999 -9999 -9999 -9999 -9999 -9999 -

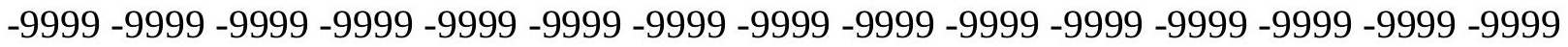
-9999 -9999 -9999 -9999 -9999 -9999 -9999 -9999 -9999 -9999 -9999 -9999 -9999 -9999 -9999 -9999 -9999 -9999 -9999 -9999 -9999 -9999 -9999 -9999 -9999 -9999 -9999 -9999 -9999 -9999 -9999 -9999 -9999 -9999 -9999 -9999 -9999 -9999 -9999 -9999 -9999 -9999 -9999 -9999 - -999 -

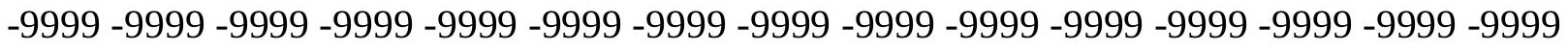

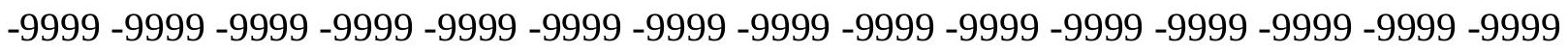
-9999 -9999 -9999 -9999 -9999 -9999 -9999 -9999 -9999 -9999 -9999 -9999 -9999 -9999 -9999 -9999 -9999 -9999 -9999 -9999 -9999 -9999 -9999 -9999 -9999 -9999 -9999 -9999 -9999 -9999 -9999 -9999 -9999 -9999 -9999 -9999 -9999 -9999 -9999 -9999 -9999 -9999 -9999 -9999 -9999 -

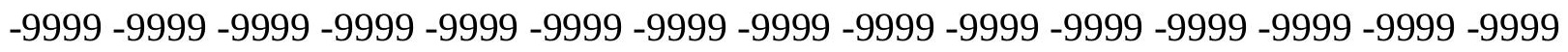
-9999 -9999 -9999 -9999 -9999 -9999 -9999 -9999 -9999 -9999 -9999 -9999 -9999 -9999 -9999 -9999 -9999 -9999 -9999 -9999 -9999 -9999 -9999 -9999 -9999 -9999 -9999 -9999 -9999 -9999 -

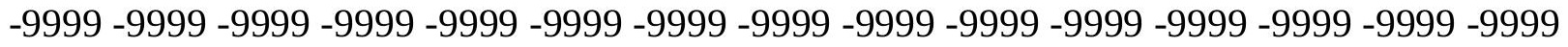
-9999 -9999 -9999 -9999 -9999 -9999 -9999 -9999 -9999 -9999 -9999 -9999 -9999 -9999 -9999 -9999 -9999 -9999 -9999 -9999 -9999 -9999 -9999 -9999 -9999 -9999 -9999 -9999 -9999 -999 -

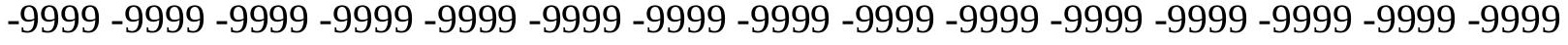
-9999 -9999 -9999 -9999 -9999 -9999 -9999 -9999 -9999 -9999 -9999 -9999 -9999 -9999 -9999 -

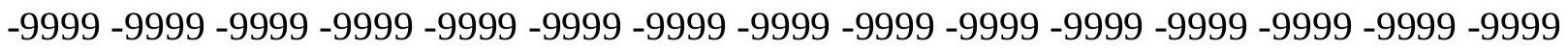

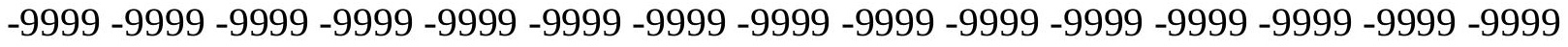

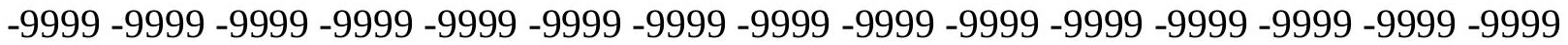

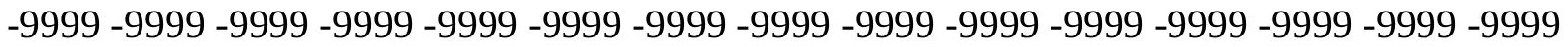

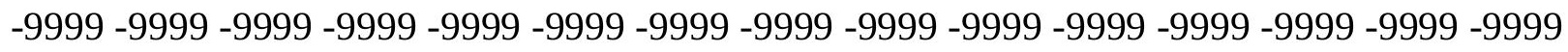

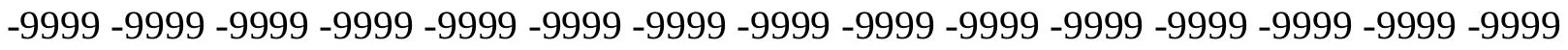

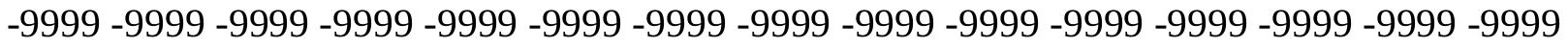
-9999 -9999 -9999 -9999 -9999 -9999 -9999 -9999 -9999 -9999 -9999 -9999 -9999 -9999 -9999 -

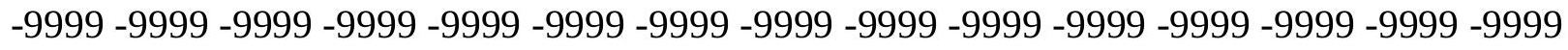

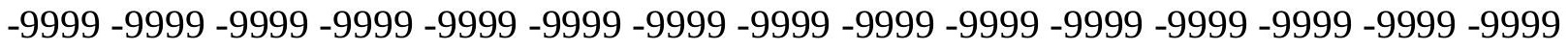
-9999 -9999 -9999 -9999 -9999 -9999 -9999 -9999 -9999 -9999 -9999 -9999 -9999 -9999 -9999 -9999 -9999 -9999 -9999 -9999 -9999 -9999 -9999 -9999 -9999 -9999 -9999 -9999 -9999 -9999 -9999 -9999 -9999 -9999 -9999 -9999 -9999 -9999 -9999 -9999 -9999 -9999 -9999 -9999 -

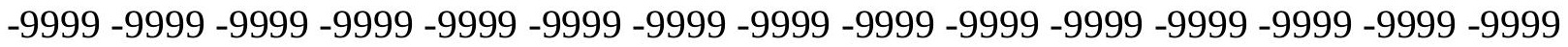


-9999 -9999 -9999 -9999 -9999 -9999 -9999 -9999 -9999 -9999 -9999 -9999 -9999 -9999 -9999 -9999 -9999 -9999 -9999 -9999 -9999 -9999 -9999 -9999 -9999 -9999 -9999 -9999 -9999 -9999 -

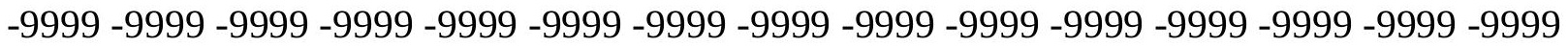
-9999 -9999 -9999 -9999 -9999 -9999 -9999 -9999 -9999 -9999 -9999 -9999 -9999 -9999 -9999 -9999 -9999 -9999 -9999 -9999 -9999 -9999 -9999 -9999-9999 -9999 -9999 -9999 -9999 -9999 -9999 -9999 -9999 -9999 -9999 -9999 -9999 -9999 -9999 -9999 -9999 -9999 -9999 -9999 -9999 -9999 -9999 -9999 -9999 -9999 -9999 -9999 -9999 -9999 -9999 -9999 -9999 -9999 -9999 -9999

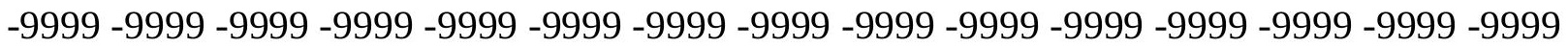

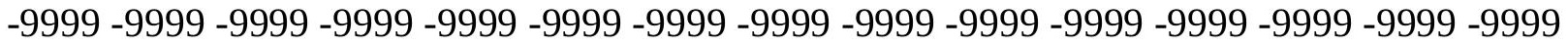
-9999 -9999 -9999 -9999 -9999 -9999 -9999 -9999 -9999 -9999 -9999 -9999 -9999 -9999 -9999 -9999 -9999 -9999 -9999 -9999 -9999 -9999 -9999 -9999 -9999 -9999 -9999 -9999 -9999 -9999 -9999 -9999 -9999 -9999 -9999 -9999 -9999 -9999 -9999 -9999 -9999 -9999 -9999 -9999 -9999 -9999 -9999 -9999 -9999 -9999 -9999 -9999 -9999 -9999 -9999 -9999 -9999 -9999 -9999 -9999 -

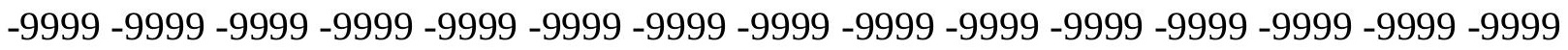
-9999 -9999 -9999 -9999 -9999 -9999 -9999 -9999 -9999 -9999 -9999 -9999 -9999 -9999 -9999 -

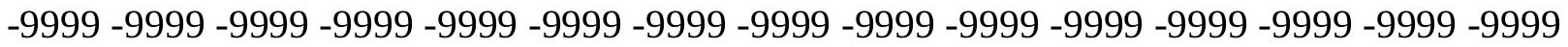
-9999 -9999 -9999 -9999 -9999 -9999 -9999 -9999 -9999 -9999 -9999 -9999 -9999 -9999 -9999 -9999 -9999 -9999 -9999 -9999 -9999 -9999 -9999 -9999 -9999 -9999 -9999 -9999 -9999 - 9999 -9999 -9999 -9999 -9999 -9999 -9999 -9999 -9999 -9999 -9999 -9999 -9999 -9999 -9999 -9999 -

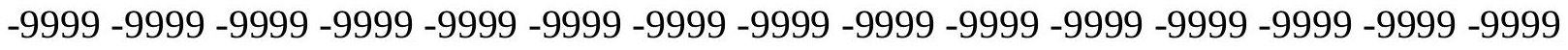

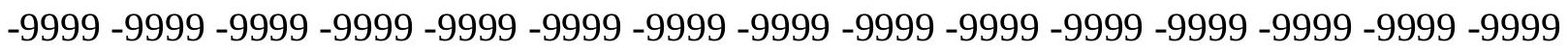
-9999 -9999 -9999 -9999 -9999 -9999 -9999 -9999 -9999 -9999 -9999 -9999 -9999 -9999 - 9999 -9999 -9999 -9999 -9999 -9999 -9999 -9999 -9999 -9999 -9999 -9999 -9999 -9999 -9999 -9999 -9999 -9999 -9999 -9999 -9999 -9999 -9999 -9999 -9999 -9999 -9999 -9999 -9999 -9999 -9999 -9999 -9999 -9999 -9999 -9999 -9999 -9999 -9999 -9999 -9999 -9999 -9999 -9999 -9999 -9999 -9999 -9999 -9999 -9999 -9999 -9999 -9999 -9999 -9999 -9999 -9999 -9999 -9999 -9999 -9999 -9999 -9999 -9999 -9999 -9999 -9999 -9999 -9999 -9999 -9999 -9999 -9999 -9999 -9999 -

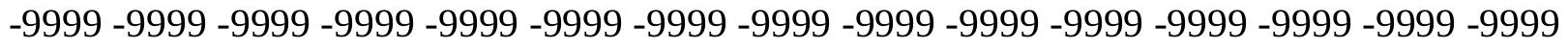
-9999 -9999 -9999 -9999 -9999 -9999 -9999 -9999 -9999 -9999 -9999 -9999 -9999 -9999 -9999 -9999 -9999 -9999 -9999 -9999 -9999 -9999 -9999 -9999 -9999 -9999 -9999 -9999 -9999 -999 -9999 -9999 -9999 -9999 -9999 -9999 -9999 -9999 -9999 -9999 -9999 -9999 -9999 -9999 -9999 -9999 -9999 -9999 -9999 -9999 -9999 -9999 -9999 -9999 -9999 -9999 -9999 -9999 -9999 -9999 -

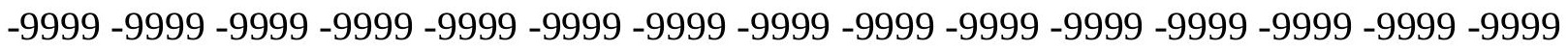

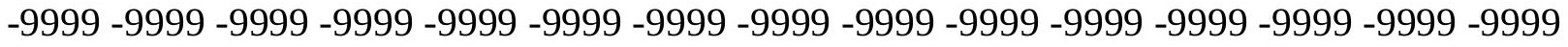

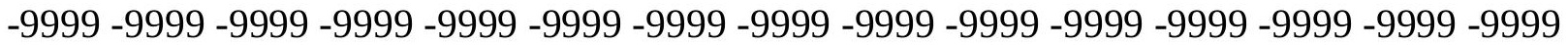

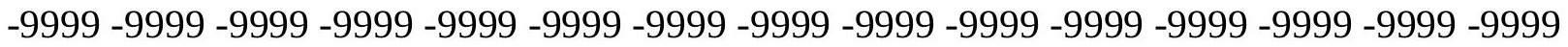

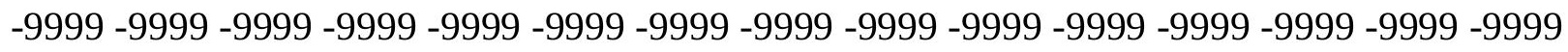

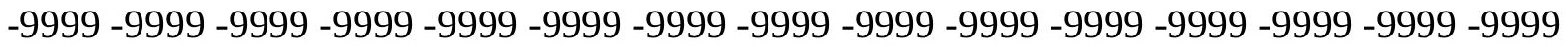

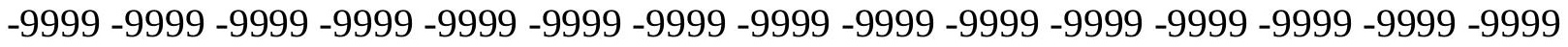
-9999 -9999 -9999 -9999 -9999 -9999 -9999 -9999 -9999 -9999 -9999 -9999 -9999 -9999 -9999 -

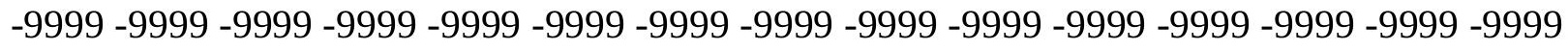

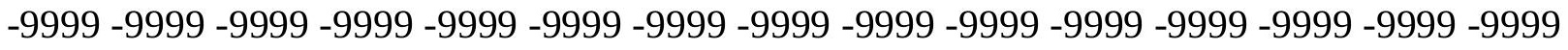
-9999 -9999 -9999 -9999 -9999 -9999 -9999 -9999 -9999 -9999 -9999 -9999 -9999 -9999 -9999 -9999 -9999 -9999 -9999 -9999 -9999 -9999 -9999 -9999-9999 -9999 -9999 -9999 -9999 -9999 -9999 -9999 -9999 -9999 -9999 -9999 -9999 -9999 -9999 -9999 -9999 -9999 -9999 -9999 -9999 -

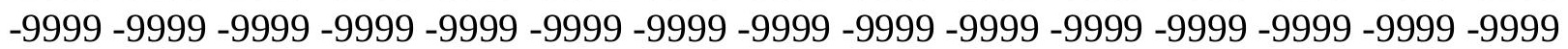


-9999 -9999 -9999 -9999 -9999 -9999 -9999 -9999 -9999 -9999 -9999 -9999 -9999 -9999 -9999 -9999 -9999 -9999 -9999 -9999 -9999 -9999 -9999 -9999 -9999 -9999 -9999 -9999 -9999 -9999 -9999 -9999 -9999 -9999 -9999 -9999 -9999 -9999 -9999 -9999 -9999 -9999 -9999 -9999 - 9999 -9999 -9999 -9999 -9999 -9999 -9999 -9999 -9999 -9999 -9999 -9999 -9999 -9999 -9999 -9999 -9999 -9999 -9999 -9999 -9999 -9999 -9999 -9999 -9999 -9999 -9999 -9999 -9999 -9999 -9999 -9999 -9999 -9999 -9999 -9999 -9999 -9999 -9999 -9999 -9999 -9999 -9999 -9999 -9999 -9999 -9999 -9999 -9999 -9999 -9999 -9999 -9999 -9999 -9999 -9999 -9999 -9999 -9999 -9999

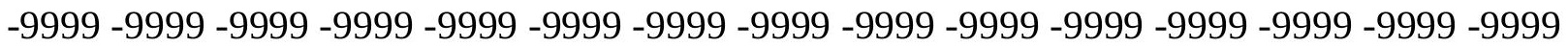

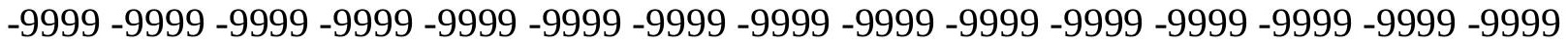
-9999 -9999 -9999 -9999 -9999 -9999 -9999 -9999 -9999 -9999 -9999 -9999 -9999 -9999 -9999 -9999 -9999 -9999 -9999 -9999 -9999 -9999 -9999 -9999 -9999 -9999 -9999 -9999 -9999 -9999 -9999 -9999 -9999 -9999 -9999 -9999 -9999 -9999 -9999 -9999 -9999 -9999 -9999 -9999 -9999 -9999 -9999 -9999 -9999 -9999 -9999 -9999 -9999 -9999 -9999 -9999 -9999 -9999 -9999 -9999 -9999 -9999 -9999 -9999 -9999 -9999 -9999 -9999 -9999 -9999 -9999 -9999 -9999 -9999 -9999 -9999 -9999 -9999 -9999 -9999 -9999 -9999 -9999 -9999 -9999 -9999 -9999 -9999 -9999 -9999 -

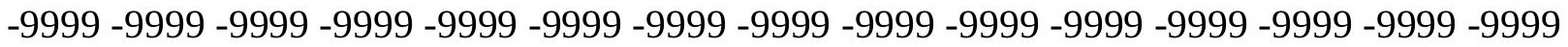
-9999 -9999 -9999 -9999 -9999 -9999 -9999 -9999 -9999 -9999 -9999 -9999 -9999 -9999 -9999 -9999 -9999 -9999 -9999 -9999 -9999 -9999 -9999 -9999 -9999 -9999 -9999 -9999 -9999 - 9999 -9999 -9999 -9999 -9999 -9999 -9999 -9999 -9999 -9999 -9999 -9999 -9999 -9999 -9999 -9999 -

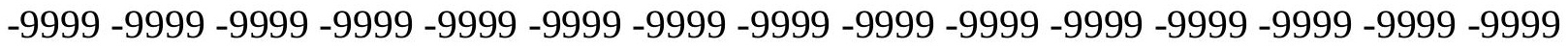

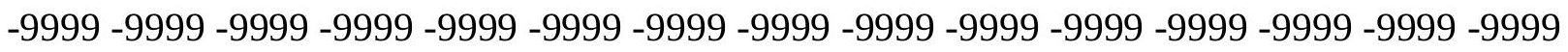

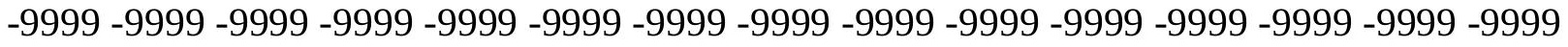
-9999 -9999 -9999 -9999 -9999 -9999 -9999 -9999 -9999 -9999 -9999 -9999 -9999 -9999 -9999 -9999 -9999 -9999 -9999 -9999 -9999 -9999 -9999 -9999 -9999 -9999 -9999 -9999 -9999 -9999 -

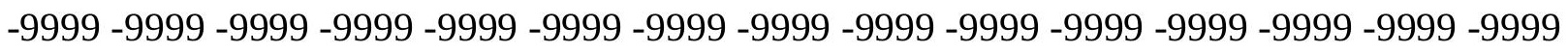
-9999 -9999 -9999 -9999 -9999 -9999 -9999 -9999 -9999 -9999 -9999 -9999 -9999 -9999 -9999 -9999 -9999 -9999 -9999 -9999 -9999 -9999 -9999 -9999 -9999 -9999 -9999 -9999 -9999 -9999 -

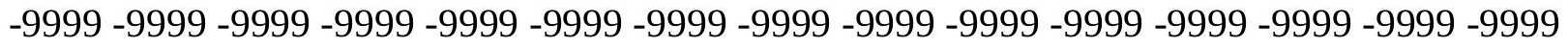
-9999 -9999 -9999 -9999 -9999 -9999 -9999 -9999 -9999 -9999 -9999 -9999 -9999 -9999 -9999 -9999 -9999 -9999 -9999 -9999 -9999 -9999 -9999 -9999 -9999 -9999 -9999 -9999 -9999 -999 -9999 -9999 -9999 -9999 -9999 -9999 -9999 -9999 -9999 -9999 -9999 -9999 -9999 -9999 -9999 -9999 -9999 -9999 -9999 -9999 -9999 -9999 -9999 -9999 -9999 -9999 -9999 -9999 -9999 -

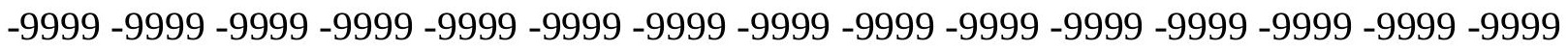

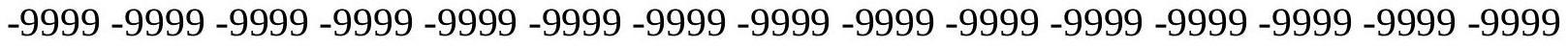

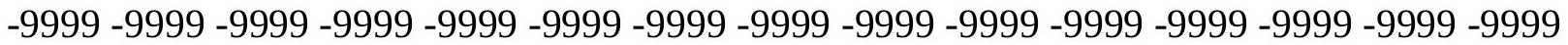

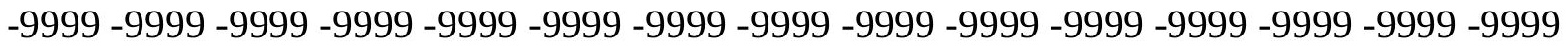

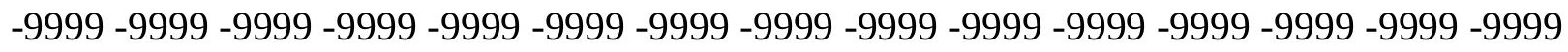

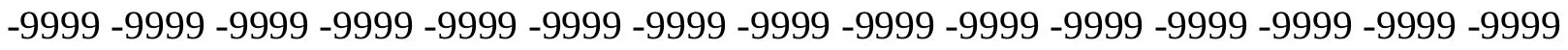

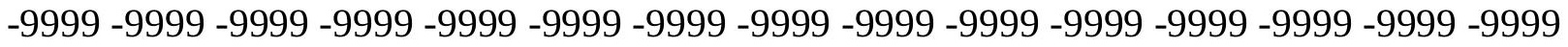
-9999 -9999 -9999 -9999 -9999 -9999 -9999 -9999 -9999 -9999 -9999 -9999 -9999 -9999 -9999 -

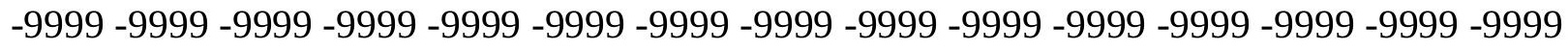

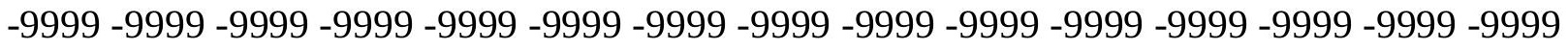
-9999 -9999 -9999 -9999 -9999 -9999 -9999 -9999 -9999 -9999 -9999 -9999 -9999 -9999 -9999 -9999 -9999 -9999 -9999 -9999 -9999 -9999 -9999 -9999-9999 -9999 -9999 -9999 -9999 -9999 -9999 -9999 -9999 -9999 -9999 -9999 -9999 -9999 -9999 -9999 -9999 -9999 -9999 -9999 -9999 -

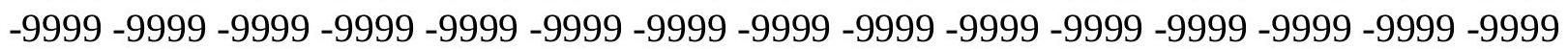


-9999 -9999 -9999 -9999 -9999 -9999 -9999 -9999 -9999 -9999 -9999 -9999 -9999 -9999 -9999 -9999 -9999 -9999 -9999 -9999 -9999 -9999 -9999 -9999 -9999 -9999 -9999 -9999 -9999 -9999 -

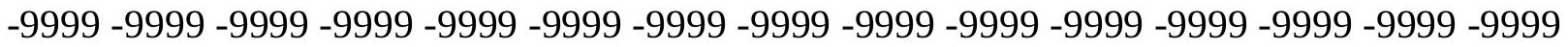
-9999 -9999 -9999 -9999 -9999 -9999 -9999 -9999 -9999 -9999 -9999 -9999 -9999 -9999 -9999 -9999 -9999 -9999 -9999 -9999 -9999 -9999 -9999 -9999-9999 -9999 -9999 -9999 -9999 -9999 -9999 -9999 -9999 -9999 -9999 -9999 -9999 -9999 -9999 -9999 -9999 -9999 -9999 -9999 -9999 -9999 -9999 -9999 -9999 -9999 -9999 -9999 -9999 -9999 -9999 -9999 -9999 -9999 -9999 -9999

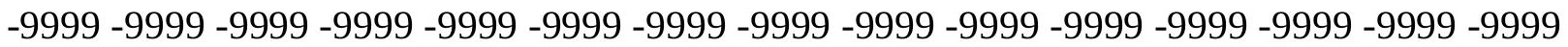

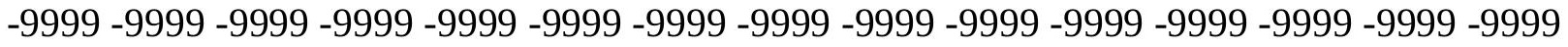

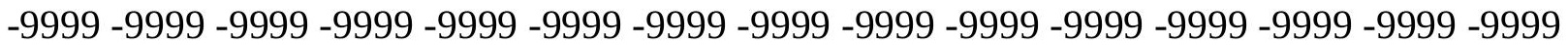
-9999 -9999 -9999 -9999 -9999 -9999 -9999 -9999 -9999 -9999 -9999 -9999 -9999 -9999 -9999 -9999 -9999 -9999 -9999 -9999 -9999 -9999 -9999 -9999 -9999 -9999 -9999 -9999 -9999 -9999 -9999 -9999 -9999 -9999 -9999 -9999 -9999 -9999 -9999 -9999 -9999 -9999 -9999 -9999 -

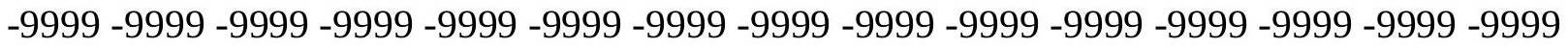
-9999 -9999 -9999 -9999 -9999 -9999 -9999 -9999 -9999 -9999 -9999 -9999 -9999 -9999 -9999 -

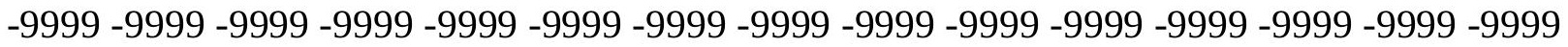
-9999 -9999 -9999 -9999 -9999 -9999 -9999 -9999 -9999 -9999 -9999 -9999 -9999 -9999 -9999 -9999 -9999 -9999 -9999 -9999 -9999 -9999 -9999 -9999 -9999 -9999 -9999 -9999 -9999 -9999 -9999 -9999 -9999 -9999 -9999 -9999 -9999 -9999 -9999 -9999 -9999 -9999 -9999 -9999 -9999 -

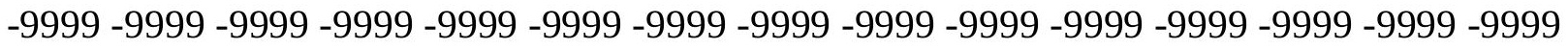

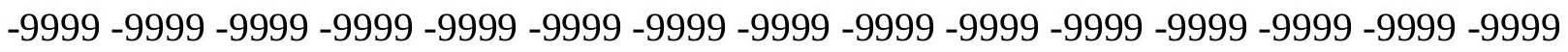
-9999 -9999 -9999 -9999 -9999 -9999 -9999 -9999 -9999 -9999 -9999 -9999 -9999 -9999 -9999 -9999 -9999 -9999 -9999 -9999 -9999 -9999 -9999 -9999 -9999 -9999 -9999 -9999 -9999 -9999 -9999 -9999 -9999 -9999 -9999 -9999 -9999 -9999 -9999 -9999 -9999 -9999 -9999 -9999 -9999 -

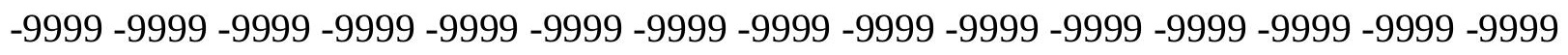
-9999 -9999 -9999 -9999 -9999 -9999 -9999 -9999 -9999 -9999 -9999 -9999 -9999 -9999 -9999 -9999 -9999 -9999 -9999 -9999 -9999 -9999 -9999 -9999 -9999 -9999 -9999 -9999 -9999 -9999 -

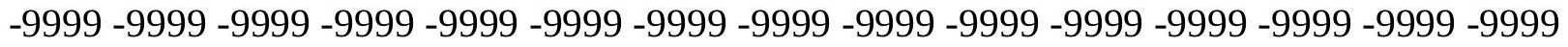
-9999 -9999 -9999 -9999 -9999 -9999 -9999 -9999 -9999 -9999 -9999 -9999 -9999 -9999 -9999 -9999 -9999 -9999 -9999 -9999 -9999 -9999 -9999 -9999 -9999 -9999 -9999 -9999 -9999 -999 -9999 -9999 -9999 -9999 -9999 -9999 -9999 -9999 -9999 -9999 -9999 -9999 -9999 -9999 -9999 -9999 -9999 -9999 -9999 -9999 -9999 -9999 -9999 -9999 -9999 -9999 -9999 -9999 -9999 -9999 -

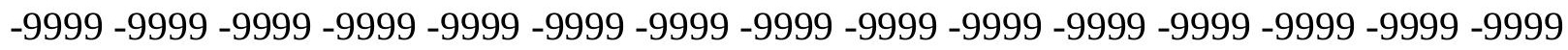

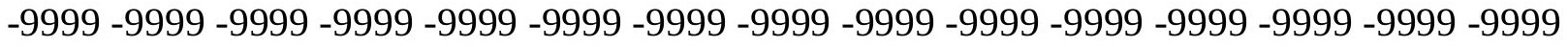

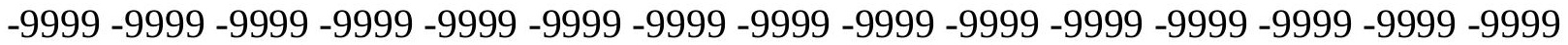
-9999 -9999 -9999 -9999 -9999 -9999 -9999 -9999 -9999 -9999 -9999 -9999 -9999 -9999 -9999 -

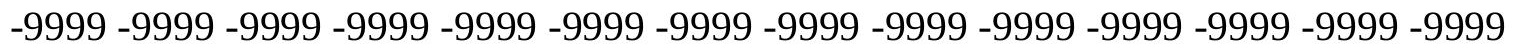

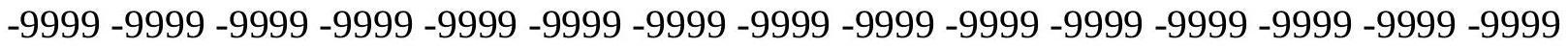
-9999 -9999 -9999 -9999 -9999 -9999 -9999 -9999 -9999 -9999 -9999 -9999 -9999 - 9999 - -999 -9999 -9999 -9999 -9999 -9999 -9999 -9999 -9999 -9999 -9999 -9999 -9999 -9999 -9999 -9999 -

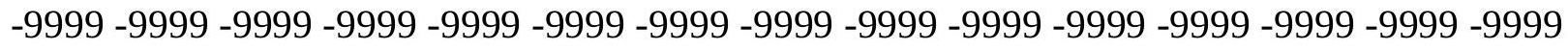

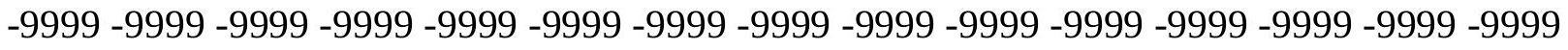
-9999 -9999 -9999 -9999 -9999 -9999 -9999 -9999 -9999 -9999 -9999 -9999 -9999 -9999 -9999 -9999 -9999 -9999 -9999 -9999 -9999 -9999 -9999 -9999-9999 -9999 -9999 -9999 -9999 -9999 -9999 -9999 -9999 -9999 -9999 -9999 -9999 -9999 -9999 -9999 -9999 -9999 -9999 -9999 -9999 -

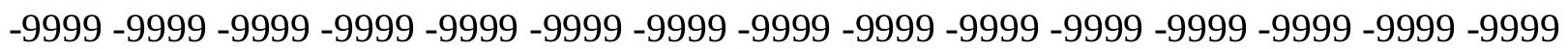


-9999 -9999 -9999 -9999 -9999 -9999 -9999 -9999 -9999 -9999 -9999 -9999 -9999 -9999 -9999 -9999 -9999 -9999 -9999 -9999 -9999 -9999 -9999 -9999 -9999 -9999 -9999 -9999 -9999 -9999 -

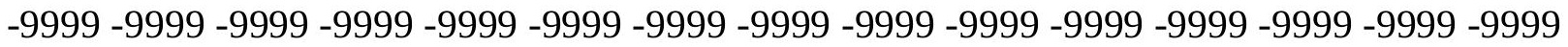
-9999 -9999 -9999 -9999 -9999 -9999 -9999 -9999 -9999 -9999 -9999 -9999 -9999 -9999 -9999 -9999 -9999 -9999 -9999 -9999 -9999 -9999 -9999 -9999-9999 -9999 -9999 -9999 -9999 -9999 -9999 -9999 -9999 -9999 -9999 -9999 -9999 -9999 -9999 -9999 -9999 -9999 -9999 -9999 -9999 -9999 -9999 -9999 -9999 -9999 -9999 -9999 -9999 -9999 -9999 -9999 -9999 -9999 -9999 -9999

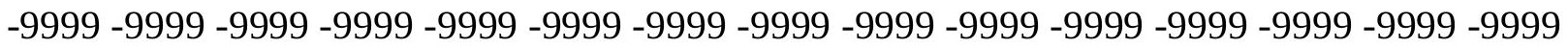

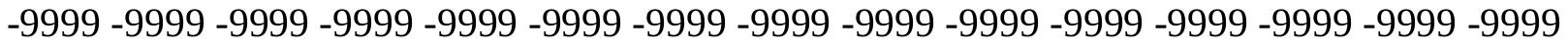
-9999 -9999 -9999 -9999 -9999 -9999 -9999 -9999 -9999 -9999 -9999 -9999 -9999 -9999 -9999 -9999 -9999 -9999 -9999 -9999 -9999 -9999 -9999 -9999 -9999 -9999 -9999 -9999 -9999 -9999 -9999 -9999 -9999 -9999 -9999 -9999 -9999 -9999 -9999 -9999 -9999 -9999 -9999 -9999 -9999 -9999 -9999 -9999 -9999 -9999 -9999 -9999 -9999 -9999 -9999 -9999 -9999 -9999 -9999 -9999 -9999 -9999 -9999 -9999 -9999 -9999 -9999 -9999 -9999 -9999 -9999 -9999 -9999 -9999 -9999 -9999 -9999 -9999 -9999 -9999 -9999 -9999 -9999 -9999 -9999 -9999 -9999 -9999 -9999 -9999 -

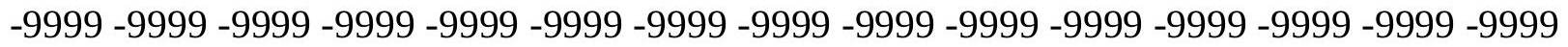
-9999 -9999 -9999 -9999 -9999 -9999 -9999 -9999 -9999 -9999 -9999 -9999 -9999 -9999 -9999 -9999 -9999 -9999 -9999 -9999 -9999 -9999 -9999 -9999 -9999 -9999 -9999 -9999 -9999 -9999 -9999 -9999 -9999 -9999 -9999 -9999 -9999 -9999 -9999 -9999 -9999 -9999 -9999 -9999 -

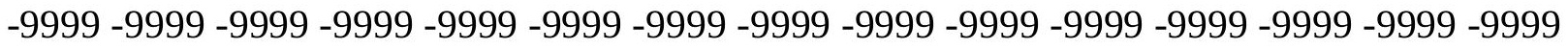
-9999 -9999 -9999 -9999 -9999 -9999 -9999 -9999 -9999 -9999 -9999 -9999 -9999 -9999 -9999 -999 -

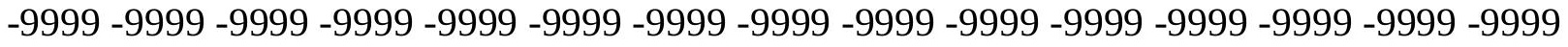
-9999 -9999 -9999 -9999 -9999 -9999 -9999 -9999 -9999 -9999 -9999 -9999 -9999 -9999 -9999 -9999 -9999 -9999 -9999 -9999 -9999 -9999 -9999 -9999 -9999 -9999 -9999 -9999 -9999 -9999 -9999 -9999 -9999 -9999 -9999 -9999 -9999 -9999 -9999 -9999 -9999 -9999 -9999 -9999 -9999 -9999 -9999 -9999 -9999 -9999 -9999 -9999 -9999 -9999 -9999 -9999 -9999 -9999 -9999 -9999 -9999 -9999 -9999 -9999 -9999 -9999 -9999 -9999 -9999 -9999 -9999 -9999 -9999 -9999 -9999 -

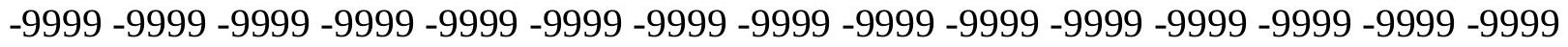
-9999 -9999 -9999 -9999 -9999 -9999 -9999 -9999 -9999 -9999 -9999 -9999 -9999 -9999 -9999 -9999 -9999 -9999 -9999 -9999 -9999 -9999 -9999 -9999 -9999 -9999 -9999 -9999 -9999 -999 -9999 -9999 -9999 -9999 -9999 -9999 -9999 -9999 -9999 -9999 -9999 -9999 -9999 -9999 -9999 -9999 -9999 -9999 -9999 -9999 -9999 -9999 -9999 -9999 -9999 -9999 -9999 -9999 -9999 -9999 -

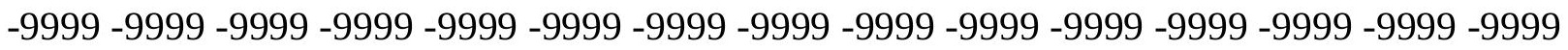

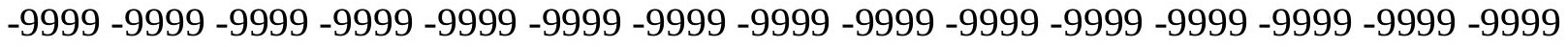

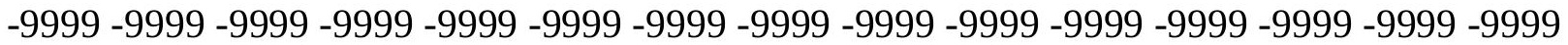
-9999 -9999 -9999 -9999 -9999 -9999 -9999 -9999 -9999 -9999 -9999 -9999 -9999 -9999 -9999

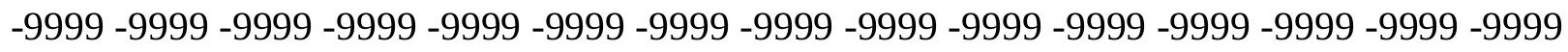

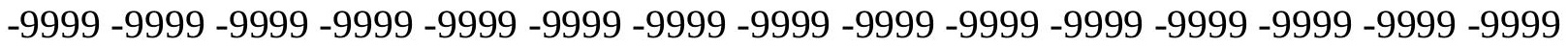
-9999 -9999 -9999 -9999 -9999 -9999 -9999 -9999 -9999 -9999 -9999 -9999 -9999 - 9999 - -999 -9999 -9999 -9999 -9999 -9999 -9999 -9999 -9999 -9999 -9999 -9999 -9999 -9999 -9999 -9999 -

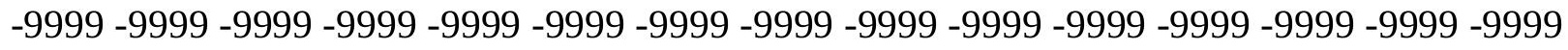

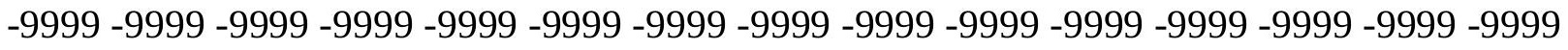
-9999 -9999 -9999 -9999 -9999 -9999 -9999 -9999 -9999 -9999 -9999 -9999 -9999 -9999 -9999 -9999 -9999 -9999 -9999 -9999 -9999 -9999 -9999 -9999 -9999 -9999 -9999 -9999 -9999 -9999 -9999 -9999 -9999 -9999 -9999 -9999 -9999 -9999 -9999 -9999 -9999 -9999 -9999 -9999 -

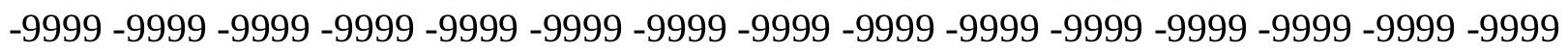


-9999 -9999 -9999 -9999 -9999 -9999 -9999 -9999 -9999 -9999 -9999 -9999 -9999 -9999 -9999 -9999 -9999 -9999 -9999 -9999 -9999 -9999 -9999 -9999 -9999 -9999 -9999 -9999 -9999 -9999 -9999 -9999 -9999 -9999 -9999 -9999 -9999 -9999 -9999 -9999 -9999 -9999 -9999 -9999 - 9999 -9999 -9999 -9999 -9999 -9999 -9999 -9999 -9999 -9999 -9999 -9999 -9999 -9999 -9999 -9999 -9999 -9999 -9999 -9999 -9999 -9999 -9999 -9999 -9999-9999 -9999 -9999 -9999 -9999 -9999 -9999 -9999 -9999 -9999 -9999 -9999 -9999 -9999 -9999 -9999 -9999 -9999 -9999 -9999 -9999 -9999 -9999 -9999 -9999 -9999 -9999 -9999 -9999 -9999 -9999 -9999 -9999 -9999 -9999 -9999

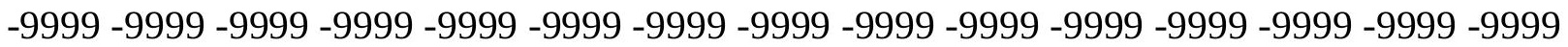

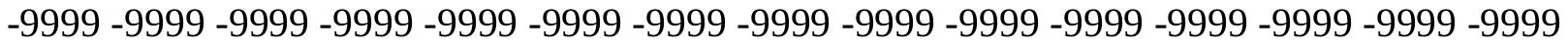
-9999 -9999 -9999 -9999 -9999 -9999 -9999 -9999 -9999 -9999 -9999 -9999 -9999 -9999 -9999 -9999 -9999 -9999 -9999 -9999 -9999 -9999 -9999 -9999 -9999 -9999 -9999 -9999 -9999 -9999 -9999 -9999 -9999 -9999 -9999 -9999 -9999 -9999 -9999 -9999 -9999 -9999 -9999 -9999 -9999 -9999 -9999 -9999 -9999 -9999 -9999 -9999 -9999 -9999 -9999 -9999 -9999 -9999 -9999 -9999 -

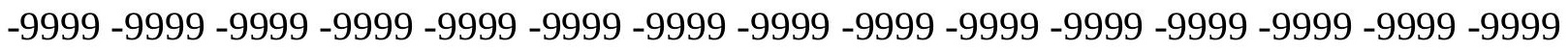
-9999 -9999 -9999 -9999 -9999 -9999 -9999 -9999 -9999 -9999 -9999 -9999 -9999 -9999 -9999 -

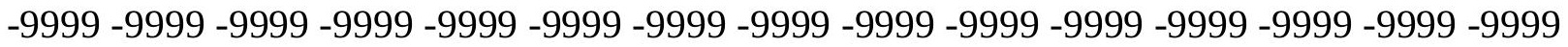
-9999 -9999 -9999 -9999 -9999 -9999 -9999 -9999 -9999 -9999 -9999 -9999 -9999 -9999 -9999 -9999 -9999 -9999 -9999 -9999 -9999 -9999 -9999 -9999 -9999 -9999 -9999 -9999 -9999 -9999 -9999 -9999 -9999 -9999 -9999 -9999 -9999 -9999 -9999 -9999 -9999 -9999 -9999 -9999 -9999 -

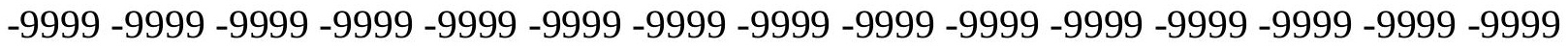
-9999 -9999 -9999 -9999 -9999 -9999 -9999 -9999 -9999 -9999 -9999 -9999 -9999 -9999 -9999 -999 -9999 -9999 -9999 -9999 -9999 -9999 -9999 -9999 -9999 -9999 -9999 -9999 -9999 -9999 - 9999 -9999 -9999 -9999 -9999 -9999 -9999 -9999 -9999 -9999 -9999 -9999 -9999 -9999 -9999 -

-9999 -9999 -9999 -9999 -9999 -9999 -9999 -9999 -9999 -9999 -9999 -9999 -9999 -9999 -9999 -

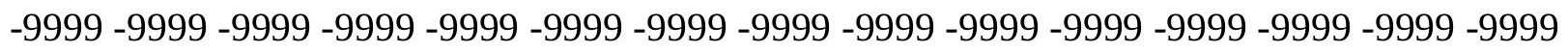
-9999 -9999 -9999 -9999 -9999 -9999 -9999 -9999 -9999 -9999 -9999 -9999 -9999 -9999 -9999 -9999 -9999 -9999 -9999 -9999 -9999 -9999 -9999 -9999 -9999 -9999 -9999 -9999 -9999 -9999 -

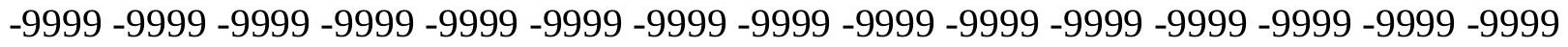
-9999 -9999 -9999 -9999 -9999 -9999 -9999 -9999 -9999 -9999 -9999 -9999 -9999 -9999 -9999 -9999 -9999 -9999 -9999 -9999 -9999 -9999 -9999 -9999 -9999 -9999 -9999 -9999 -9999 -999 -

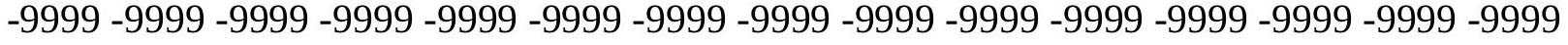
-9999 -9999 -9999 -9999 -9999 -9999 -9999 -9999 -9999 -9999 -9999 -9999 -9999 -9999 -9999 -

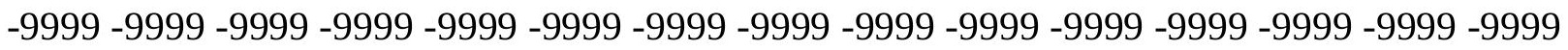

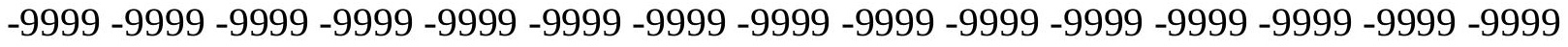

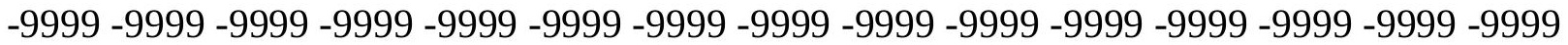

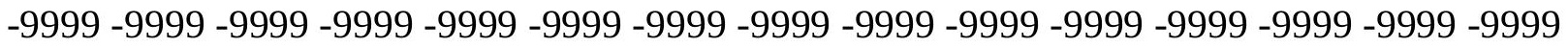

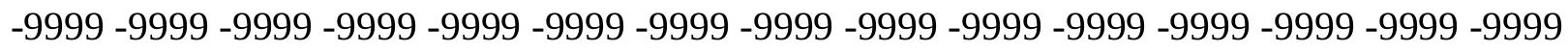

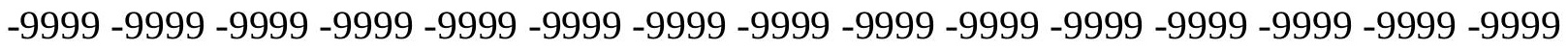

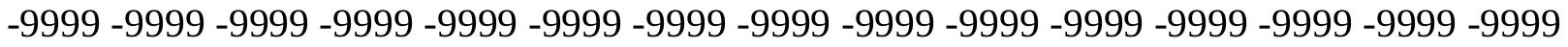
-9999 -9999 -9999 -9999 -9999 -9999 -9999 -9999 -9999 -9999 -9999 -9999 -9999 -9999 -9999 -

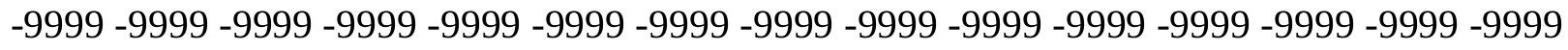

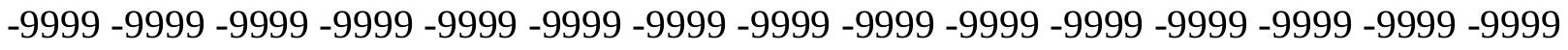
-9999 -9999 -9999 -9999 -9999 -9999 -9999 -9999 -9999 -9999 -9999 -9999 -9999 -9999 -9999 -9999 -9999 -9999 -9999 -9999 -9999 -9999 -9999 -9999-9999 -9999 -9999 -9999 -9999 -9999 -9999 -9999 -9999 -9999 -9999 -9999 -9999 -9999 -9999 -9999 -9999 -9999 -9999 -9999 -9999 -

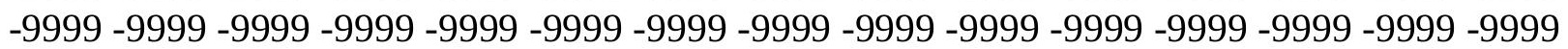


-9999 -9999 -9999 -9999 -9999 -9999 -9999 -9999 -9999 -9999 -9999 -9999 -9999 -9999 -9999 -9999 -9999 -9999 -9999 -9999 -9999 -9999 -9999 -9999 -9999 -9999 -9999 -9999 -9999 -9999 -9999 -9999 -9999 -9999 -9999 -9999 -9999 -9999 -9999 -9999 -9999 -9999 -9999 -9999 -9999 -9999 -9999 -9999 -9999 -9999 -9999 -9999 -9999 -9999 -9999 -9999 -9999 -9999 -9999 -9999 -9999 -9999 -9999 -9999 -9999 -9999 -9999 -9999-9999 -9999 -9999 -9999 -9999 -9999 -9999 -9999 -9999 -9999 -9999 -9999 -9999 -9999 -9999 -9999 -9999 -9999 -9999 -9999 -9999 -9999 -9999 -9999 -9999 -9999 -9999 -9999 -9999 -9999 -9999 -9999 -9999 -9999 -9999 -9999

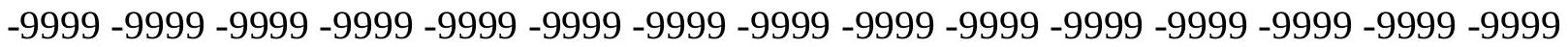

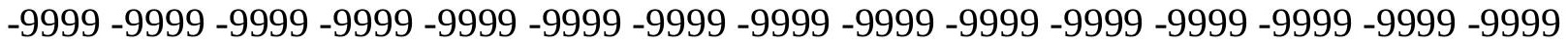
-9999 -9999 -9999 -9999 -9999 -9999 -9999 -9999 -9999 -9999 -9999 -9999 -9999 -9999 -9999 -9999 -9999 -9999 -9999 -9999 -9999 -9999 -9999 -9999 -9999 -9999 -9999 -9999 -9999 -9999 -9999 -9999 -9999 -9999 -9999 -9999 -9999 -9999 -9999 -9999 -9999 -9999 -9999 -9999 -9999 -9999 -9999 -9999 -9999 -9999 -9999 -9999 -9999 -9999 -9999 -9999 -9999 -9999 -9999 -9999 -

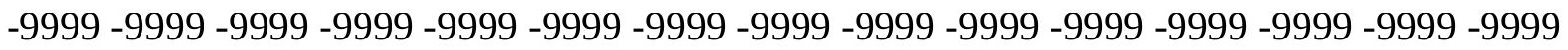
-9999 -9999 -9999 -9999 -9999 -9999 -9999 -9999 -9999 -9999 -9999 -9999 -9999 -9999 -9999 -

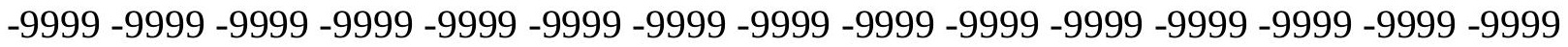
-9999 -9999 -9999 -9999 -9999 -9999 -9999 -9999 -9999 -9999 -9999 -9999 -9999 -9999 -9999 -9999 -9999 -9999 -9999 -9999 -9999 -9999 -9999 -9999 -9999 -9999 -9999 -9999 -9999 -9999 -9999 -9999 -9999 -9999 -9999 -9999 -9999 -9999 -9999 -9999 -9999 -9999 -9999 -9999 -9999 -

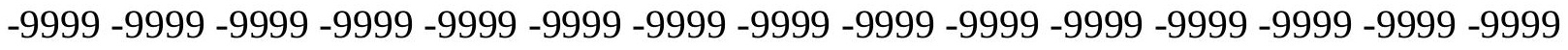

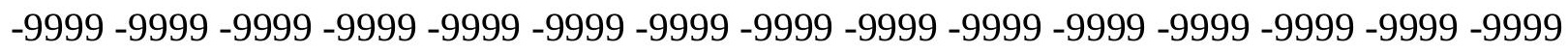
-9999 -9999 -9999 -9999 -9999 -9999 -9999 -9999 -9999 -9999 -9999 -9999 -9999 -9999 -9999 -9999 -9999 -9999 -9999 -9999 -9999 -9999 -9999 -9999 -9999 -9999 -9999 -9999 -9999 -9999 -9999 -9999 -9999 -9999 -9999 -9999 -9999 -9999 -9999 -9999 -9999 -9999 -9999 -9999 -9999 -

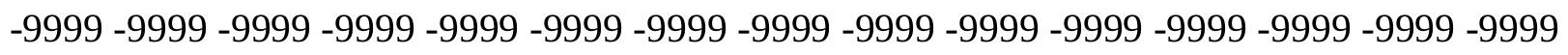
-9999 -9999 -9999 -9999 -9999 -9999 -9999 -9999 -9999 -9999 -9999 -9999 -9999 -9999 -9999 -9999 -9999 -9999 -9999 -9999 -9999 -9999 -9999 -9999 -9999 -9999 -9999 -9999 -9999 -9999 -

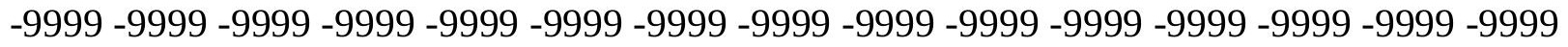
-9999 -9999 -9999 -9999 -9999 -9999 -9999 -9999 -9999 -9999 -9999 -9999 -9999 -9999 -9999 -9999 -9999 -9999 -9999 -9999 -9999 -9999 -9999 -9999 -9999 -9999 -9999 -9999 - -999 -

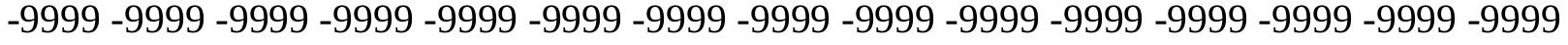
-9999 -9999 -9999 -9999 -9999 -9999 -9999 -9999 -9999 -9999 -9999 -9999 -9999 -9999 -9999 -

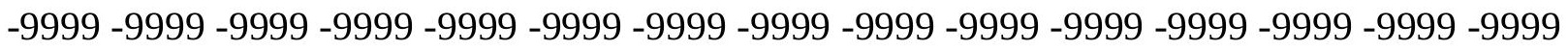

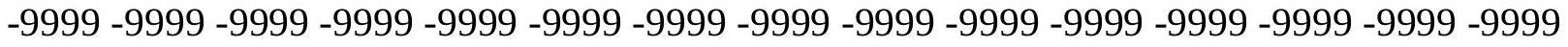

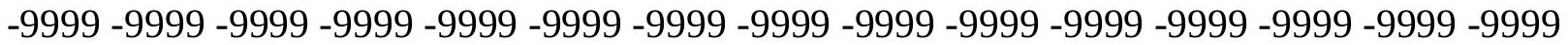

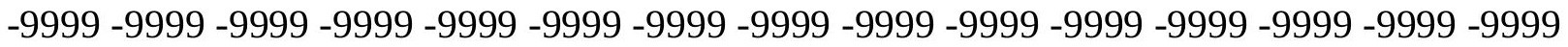

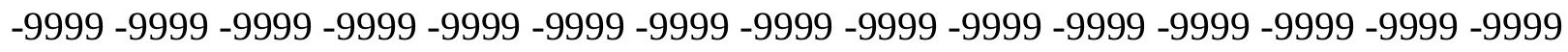

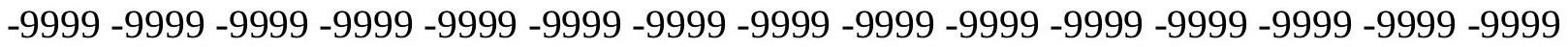

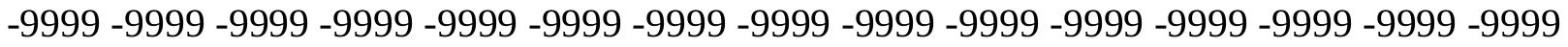
-9999 -9999 -9999 -9999 -9999 -9999 -9999 -9999 -9999 -9999 -9999 -9999 -9999 -9999 -9999 -

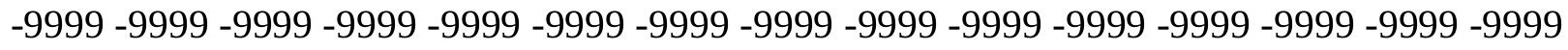

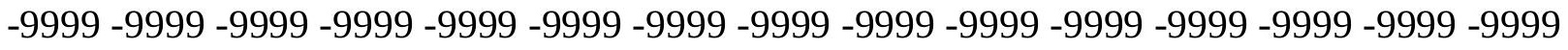
-9999 -9999 -9999 -9999 -9999 -9999 -9999 -9999 -9999 -9999 -9999 -9999 -9999 -9999 -9999 -9999 -9999 -9999 -9999 -9999 -9999 -9999 -9999 -9999-9999 -9999 -9999 -9999 -9999 -9999 -9999 -9999 -9999 -9999 -9999 -9999 -9999 -9999 -9999 -9999 -9999 -9999 -9999 -9999 -9999 -

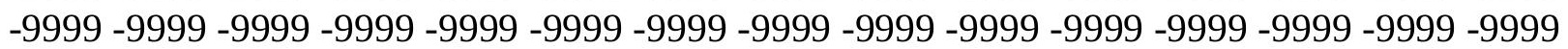


-9999 -9999 -9999 -9999 -9999 -9999 -9999 -9999 -9999 -9999 -9999 -9999 -9999 -9999 -9999 -9999 -9999 -9999 -9999 -9999 -9999 -9999 -9999 -9999 -9999 -9999 -9999 -9999 -9999 -9999 -

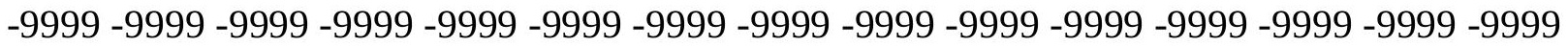
-9999 -9999 -9999 -9999 -9999 -9999 -9999 -9999 -9999 -9999 -9999 -9999 -9999 -9999 -9999 -9999 -9999 -9999 -9999 -9999 -9999 -9999 -9999 -9999-9999 -9999 -9999 -9999 -9999 -9999 -9999 -9999 -9999 -9999 -9999 -9999 -9999 -9999 -9999 -9999 -9999 -9999 -9999 -9999 -9999 -9999 -9999 -9999 -9999 -9999 -9999 -9999 -9999 -9999 -9999 -9999 -9999 -9999 -9999 -9999

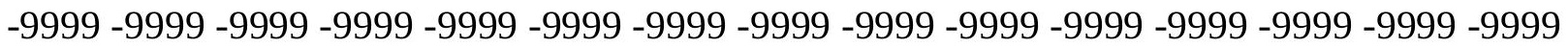
-9999 -9999 -9999 -9999 -9999 -9999 -9999 -9999 -9999 -9999 -9999 -9999 -9999 -9999 -9999 -9999 -9999 -9999 -9999 -9999 -9999 -9999 -9999 -9999 -9999 -9999 -9999 -9999 -9999

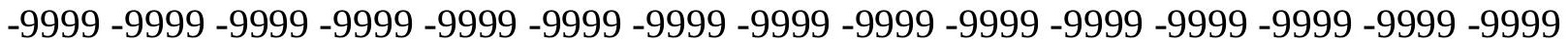
-9999 -9999 -9999 -9999 -9999 -9999 -9999 -9999 -9999 -9999 -9999 -9999 -9999 -9999 -9999 -9999 -9999 -9999 -9999 -9999 -9999 -9999 -9999 -9999 -9999 -9999 -9999 -9999 -9999 -9999 -9999 -9999 -9999 -9999 -9999 -9999 -9999 -9999 -9999 -9999 -9999 -9999 -9999 -9999 - 9999 -9999 -9999 -9999 -9999 -9999 -9999 -9999 -9999 -9999 -9999 -9999 -9999 -9999 -9999 -9999

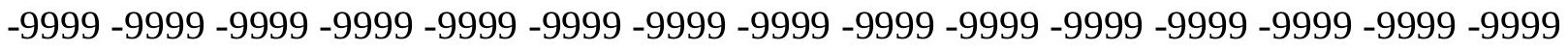
-9999 -9999 -9999 -9999 -9999 -9999 -9999 -9999 -9999 -9999 -9999 -9999 -9999 -9999 -9999 -9999 -9999 -9999 -9999 -9999 -9999 -9999 -9999 -9999 -9999 -9999 -9999 -9999 -9999 -9999 -9999 -9999 -9999 -9999 -9999 -9999 -9999 -9999 -9999 -9999 -9999 -9999 -9999 -9999 -9999 -

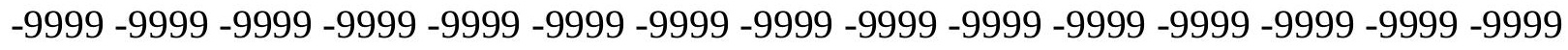

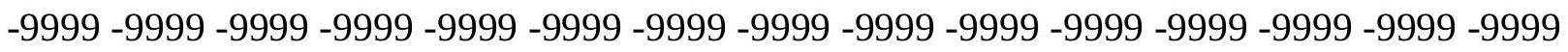
-9999 -9999 -9999 -9999 -9999 -9999 -9999 -9999 -9999 -9999 -9999 -9999 -9999 -9999 -9999 -9999 -9999 -9999 -9999 -9999 -9999 -9999 -9999 -9999 -9999 -9999 -9999 -9999 -9999 -9999 -9999 -9999 -9999 -9999 -9999 -9999 -9999 -9999 -9999 -9999 -9999 -9999 -9999 -9999 -9999 -

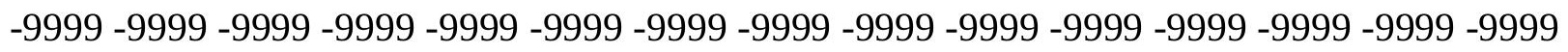
-9999 -9999 -9999 -9999 -9999 -9999 -9999 -9999 -9999 -9999 -9999 -9999 -9999 -9999 -9999 -9999 -9999 -9999 -9999 -9999 -9999 -9999 -9999 -9999 -9999 -9999 -9999 -9999 -9999 -9999 -

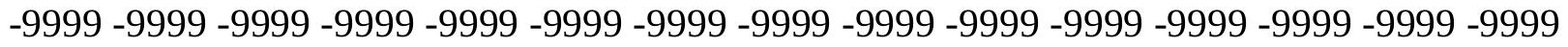
-9999 -9999 -9999 -9999 -9999 -9999 -9999 -9999 -9999 -9999 -9999 -9999 -9999 -9999 -9999 -9999 -9999 -9999 -9999 -9999 -9999 -9999 -9999 -9999 -9999 -9999 -9999 -9999 -9999 -999 -9999 -9999 -9999 -9999 -9999 -9999 -9999 -9999 -9999 -9999 -9999 -9999 -9999 -9999 -9999 -9999 -9999 -9999 -9999 -9999 -9999 -9999 -9999 -9999 -9999 -9999 -9999 -9999 -9999 -9999 -

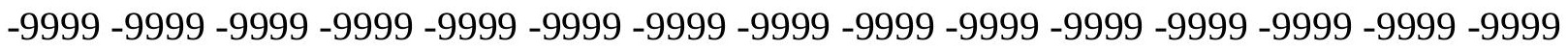

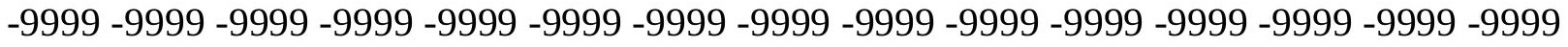
-9999 -9999 -9999 -9999 -9999 -9999 -9999 -9999 -9999 -9999 -9999 -9999 -9999 -9999 -

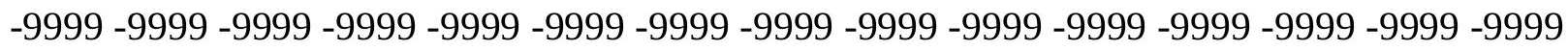

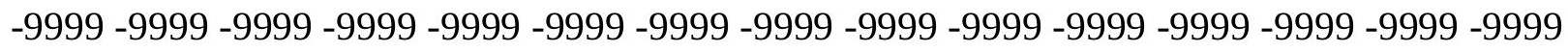

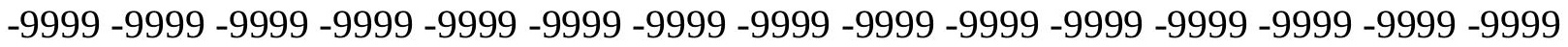
-9999 -9999 -9999 -9999 -9999 -9999 -9999 -9999 -9999 -9999 -9999 -9999 -9999 - 9999 - -999 -9999 -9999 -9999 -9999 -9999 -9999 -9999 -9999 -9999 -9999 -9999 -9999 -9999 -9999 -9999 -

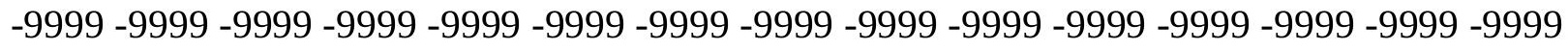

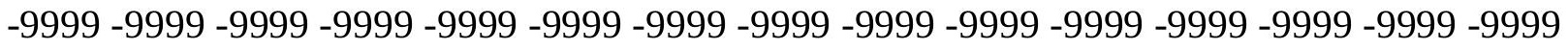
-9999 -9999 -9999 -9999 -9999 -9999 -9999 -9999 -9999 -9999 -9999 -9999 -9999 -9999 -9999 -9999 -9999 -9999 -9999 -9999 -9999 -9999 -9999 -9999-9999 -9999 -9999 -9999 -9999 -9999 -9999 -9999 -9999 -9999 -9999 -9999 -9999 -9999 -9999 -9999 -9999 -9999 -9999 -9999 -9999 -

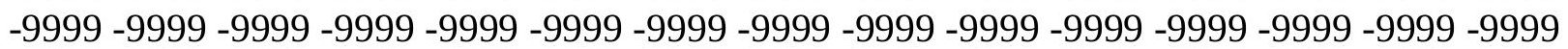


-9999 -9999 -9999 -9999 -9999 -9999 -9999 -9999 -9999 -9999 -9999 -9999 -9999 -9999 -9999 -9999 -9999 -9999 -9999 -9999 -9999 -9999 -9999 -9999 -9999 -9999 -9999 -9999 -9999 -9999 -

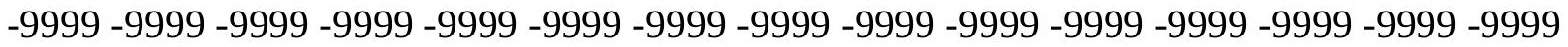
-9999 -9999 -9999 -9999 -9999 -9999 -9999 -9999 -9999 -9999 -9999 -9999 -9999 -9999 -9999 -9999 -9999 -9999 -9999 -9999 -9999 -9999 -9999 -9999-9999 -9999 -9999 -9999 -9999 -9999 -9999 -9999 -9999 -9999 -9999 -9999 -9999 -9999 -9999 -9999 -9999 -9999 -9999 -9999 -9999 -9999 -9999 -9999 -9999 -9999 -9999 -9999 -9999 -9999 -9999 -9999 -9999 -9999 -9999 -9999

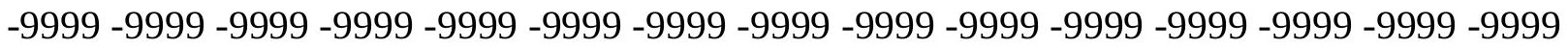

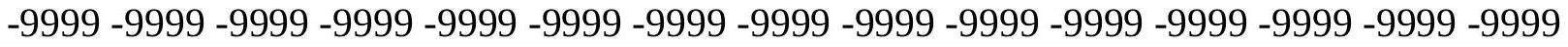
-9999 -9999 -9999 -9999 -9999 -9999 -9999 -9999 -9999 -9999 -9999 -9999 -9999 -9999 -9999 -9999 -9999 -9999 -9999 -9999 -9999 -9999 -9999 -9999 -9999 -9999 -9999 -9999 -9999 -9999 -9999 -9999 -9999 -9999 -9999 -9999 -9999 -9999 -9999 -9999 -9999 -9999 -9999 -9999 -9999 -9999 -9999 -9999 -9999 -9999 -9999 -9999 -9999 -9999 -9999 -9999 -9999 -9999 -9999 -9999 -9999 -9999 -9999 -9999 -9999 -9999 -9999 -9999 -9999 -9999 -9999 -9999 -9999 -9999 -9999 -9999 -9999 -9999 -9999 -9999 -9999 -9999 -9999 -9999 -9999 -9999 -9999 -9999 -9999 -9999 -9999 -9999 -9999 -9999 -9999 -9999 -9999 -9999 -9999 -9999 -9999 -9999 - 9999 - -999 -

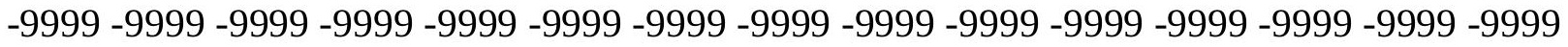
-9999 -9999 -9999 -9999 -9999 -9999 -9999 -9999 -9999 -9999 -9999 -9999 -9999 -9999 -9999 -9999 -9999 -9999 -9999 -9999 -9999 -9999 -9999 -9999 -9999 -9999 -9999 -9999 -9999 -9999 -

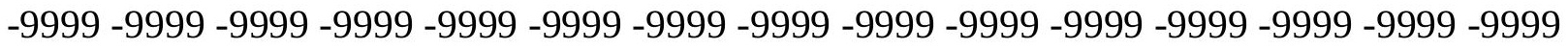
-9999 -9999 -9999 -9999 -9999 -9999 -9999 -9999 -9999 -9999 -9999 -9999 -9999 -9999 -9999

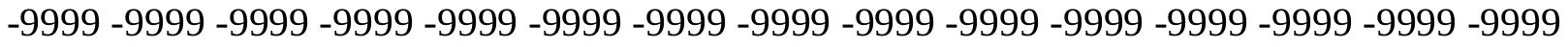
-9999 -9999 -9999 -9999 -9999 -9999 -9999 -9999 -9999 -9999 -9999 -9999 -9999 -9999 -9999 -9999 -9999 -9999 -9999 -9999 -9999 -9999 -9999 -9999 -9999 -9999 -9999 -9999 -9999 -9999 -

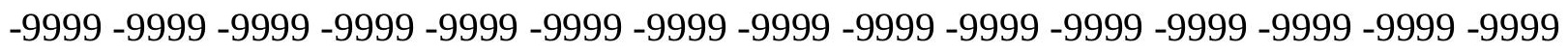
-9999 -9999 -9999 -9999 -9999 -9999 -9999 -9999 -9999 -9999 -9999 -9999 -9999 -9999 -9999 -9999 -9999 -9999 -9999 -9999 -9999 -9999 -9999 -9999 -9999 -9999 -9999 -9999 -9999 -9999 -

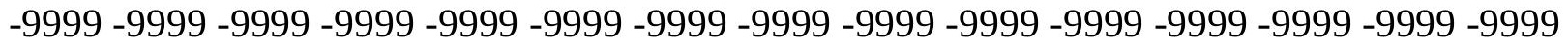
-9999 -9999 -9999 -9999 -9999 -9999 -9999 -9999 -9999 -9999 -9999 -9999 -9999 -9999 -9999 -9999 -9999 -9999 -9999 -9999 -9999 -9999 -9999 -9999 -9999 -9999 -9999 -9999 -9999 -999 -

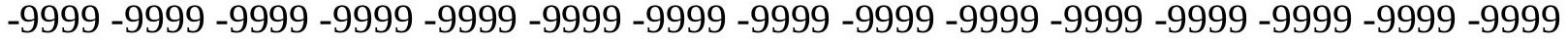
-9999 -9999 -9999 -9999 -9999 -9999 -9999 -9999 -9999 -9999 -9999 -9999 -9999 -9999 -9999 -

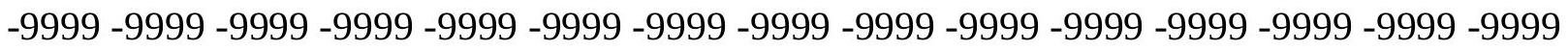

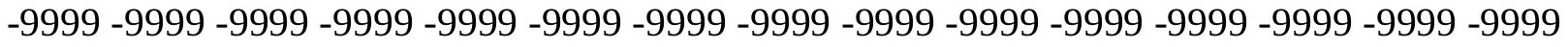

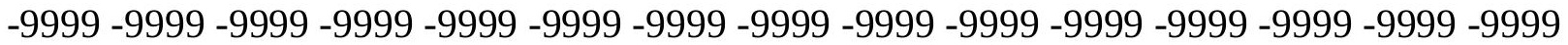
-9999 -9999 -9999 -9999 -9999 -9999 -9999 -9999 -9999 -9999 -9999 -9999 -9999 -9999 -9999 -

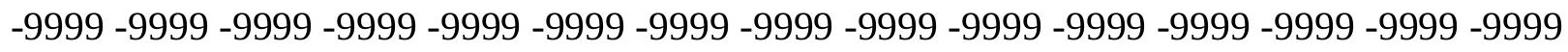

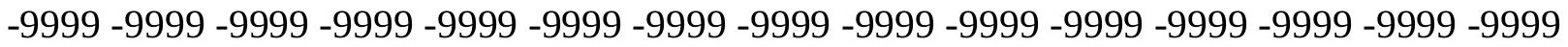
-9999 -9999 -9999 -9999 -9999 -9999 -9999 -9999 -9999 -9999 -9999 -9999 -9999 - 9999 - -999 -9999 -9999 -9999 -9999 -9999 -9999 -9999 -9999 -9999 -9999 -9999 -9999 -9999 -9999 -9999 -

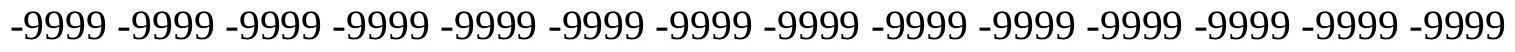

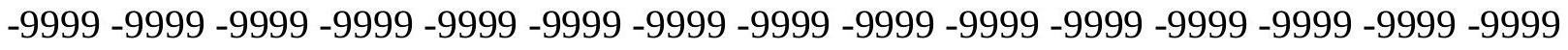
-9999 -9999 -9999 -9999 -9999 -9999 -9999 -9999 -9999 -9999 -9999 -9999 -9999 -9999 -9999 -9999 -9999 -9999 -9999 -9999 -9999 -9999 -9999 -9999-9999 -9999 -9999 -9999 -9999 -9999 -9999 -9999 -9999 -9999 -9999 -9999 -9999 -9999 -9999 -9999 -9999 -9999 -9999 -9999 -9999 -

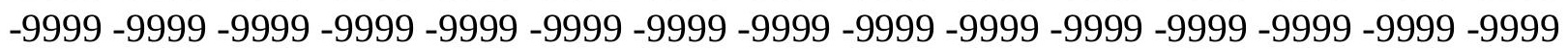


-9999 -9999 -9999 -9999 -9999 -9999 -9999 -9999 -9999 -9999 -9999 -9999 -9999 -9999 -9999 -9999 -9999 -9999 -9999 -9999 -9999 -9999 -9999 -9999 -9999 -9999 -9999 -9999 -9999 -9999 -9999 -9999 -9999 -9999 -9999 -9999 -9999 -9999 -9999 -9999 -9999 -9999 -9999 -9999 - 9999 -9999 -9999 -9999 -9999 -9999 -9999 -9999 -9999 -9999 -9999 -9999 -9999 -9999 -9999 -9999 -9999 -9999 -9999 -9999 -9999 -9999 -9999 -9999 -9999-9999 -9999 -9999 -9999 -9999 -9999 -9999 -9999 -9999 -9999 -9999 -9999 -9999 -9999 -9999 -9999 -9999 -9999 -9999 -9999 -9999 -9999 -9999 -9999 -9999 -9999 -9999 -9999 -9999 -9999 -9999 -9999 -9999 -9999 -9999 -9999

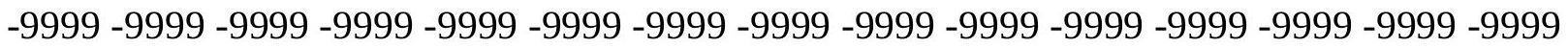
-9999 -9999 -9999 -9999 -9999 -9999 -9999 -9999 -9999 -9999 -9999 -9999 -9999 -9999 -9999 -9999 -9999 -9999 -9999 -9999 -9999 -9999 -9999 -9999 -9999 -9999 -9999 -9999 -9999 -9999

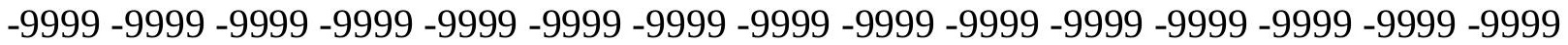
-9999 -9999 -9999 -9999 -9999 -9999 -9999 -9999 -9999 -9999 -9999 -9999 -9999 -9999 -9999 -9999 -9999 -9999 -9999 -9999 -9999 -9999 -9999 -9999 -9999 -9999 -9999 -9999 -9999 -9999 -

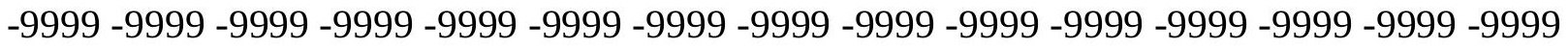
-9999 -9999 -9999 -9999 -9999 -9999 -9999 -9999 -9999 -9999 -9999 -9999 -9999 -9999 -9999

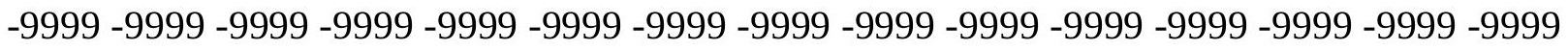
-9999 -9999 -9999 -9999 -9999 -9999 -9999 -9999 -9999 -9999 -9999 -9999 -9999 -9999 -9999 -9999 -9999 -9999 -9999 -9999 -9999 -9999 -9999 -9999 -9999 -9999 -9999 -9999 -9999 - 9999 -9999 -9999 -9999 -9999 -9999 -9999 -9999 -9999 -9999 -9999 -9999 -9999 -9999 -9999 -9999 -9999 -9999 -9999 -9999 -9999 -9999 -9999 -9999 -9999 -9999 -9999 -9999 -9999 -9999 -9999 -9999 -9999 -9999 -9999 -9999 -9999 -9999 -9999 -9999 -9999 -9999 -9999 -9999 -9999 -9999 -9999 -9999 -9999 -9999 -9999 -9999 -9999 -9999 -9999 -9999 -9999 -9999 -9999 -9999 -9999 -9999 -9999 -9999 -9999 -9999 -9999 -9999 -9999 -9999 -9999 -9999 -9999 -9999 -9999 -9999 -9999 -9999 -9999 -9999 -9999 -9999 -9999 -9999 -9999 -9999 -9999 -9999 -9999 -9999 -9999 -9999 -9999 -9999 -9999 -9999 -9999 -9999 -9999 -9999 -9999 -9999 -9999 -9999 -9999 -9999 -9999 -9999 -9999 -9999 -9999 -9999 -9999 -9999 -9999 -9999 -9999 -9999 -9999 -9999 -9999 -9999 -9999 -9999 -9999 -9999 -9999 -9999 -9999 -9999 -9999 -9999 -9999 -9999 -9999 -9999 -9999 -9999 -9999 -9999 -9999 -9999 -9999 -9999 -9999 -9999 -9999 -9999 -9999 -9999 -9999 -9999 -9999 -9999 -9999 -9999 -9999 -9999 -9999 -9999 -9999 -9999 -9999 -9999 -9999 -9999 -9999 -9999 -9999 -9999 -9999 -9999 -9999 -9999 -9999 -9999 -9999 -9999 -9999 -999 -9999 -9999 -9999 -9999 -9999 -9999 -9999 -9999 -9999 -9999 -9999 -9999 -9999 -9999 -9999 -9999 -9999 -9999 -9999 -9999 -9999 -9999 -9999 -9999 -9999 -9999 -9999 -9999 -9999 -9999 -

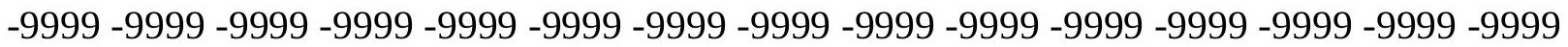

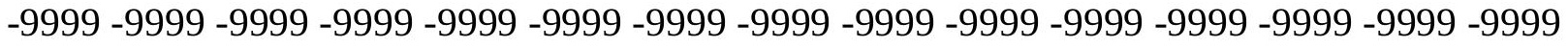

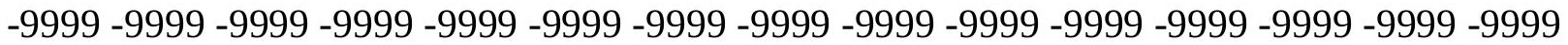
-9999 -9999 -9999 -9999 -9999 -9999 -9999 -9999 -9999 -9999 -9999 -9999 -9999 -9999 -9999

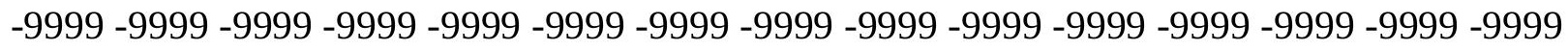

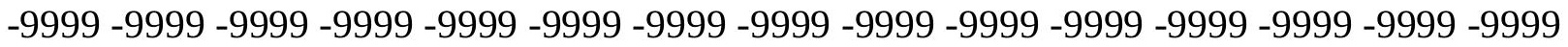

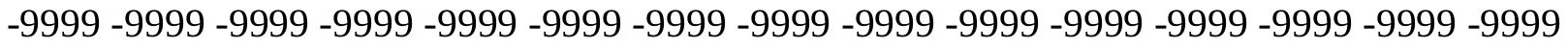
-9999 -9999 -9999 -9999 -9999 -9999 -9999 -9999 -9999 -9999 -9999 -9999 -9999 -9999 -9999 -

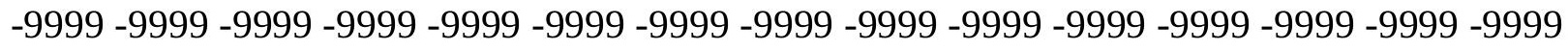

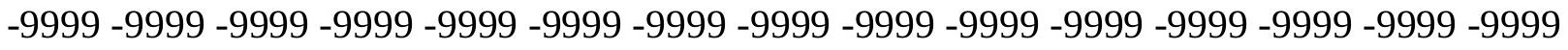
-9999 -9999 -9999 -9999 -9999 -9999 -9999 -9999 -9999 -9999 -9999 -9999 -9999 -9999 -9999 -9999 -9999 -9999 -9999 -9999 -9999 -9999 -9999 -9999-9999 -9999 -9999 -9999 -9999 -9999 -9999 -9999 -9999 -9999 -9999 -9999 -9999 -9999 -9999 -9999 -9999 -9999 -9999 -9999 -9999 -

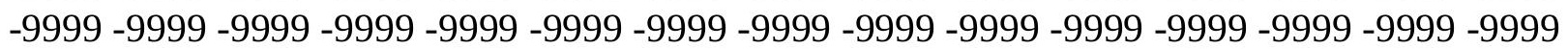


-9999 -9999 -9999 -9999 -9999 -9999 -9999 -9999 -9999 -9999 -9999 -9999 -9999 -9999 -9999 -9999 -9999 -9999 -9999 -9999 -9999 -9999 -9999 -9999 -9999 -9999 -9999 -9999 -9999 -9999 -9999 -9999 -9999 -9999 -9999 -9999 -9999 -9999 -9999 -9999 -9999 -9999 -9999 -9999 -9999 -9999 -9999 -9999 -9999 -9999 -9999 -9999 -9999 -9999 -9999 -9999 -9999 -9999 -9999 -9999 -9999 -9999 -9999 -9999 -9999 -9999 -9999 -9999 -9999 -9999 -9999 -9999 -9999 -9999 -9999 -9999 -9999 -9999 -9999 -9999 -9999 -9999 -9999 -9999 -9999 -9999 -9999 -9999 -9999 -9999 -9999 -9999 -9999 -9999 -9999 -9999 -9999 -9999 -9999 -9999 -9999 -9999 -9999 -9999 -

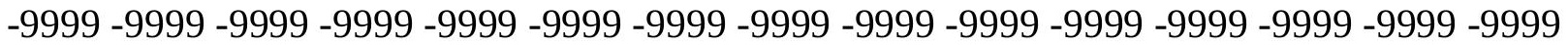
-9999 -9999 -9999 -9999 -9999 -9999 -9999 -9999 -9999 -9999 -9999 -9999 -9999 -9999 -9999 -9999 -9999 -9999 -9999 -9999 -9999 -9999 -9999 -9999 -9999 -9999 -9999 -9999 -9999 -9999 -

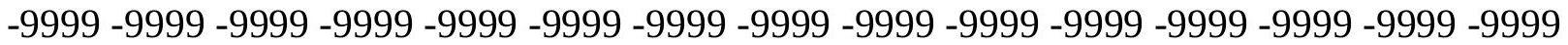
-9999 -9999 -9999 -9999 -9999 -9999 -9999 -9999 -9999 -9999 -9999 -9999 -9999 -9999 -9999 -9999 -9999 -9999 -9999 -9999 -9999 -9999 -9999 -9999 -9999 -9999 -9999 -9999 -9999 -9999 -9999 -9999 -9999 -9999 -9999 -9999 -9999 -9999 -9999 -9999 -9999 -9999 -9999 -9999 -9999 -9999 -9999 -9999 -9999 -9999 -9999 -9999 -9999 -9999 -9999 -9999 -9999 -9999 -9999 -9999 -9999 -9999 -9999 -9999 -9999 -9999 -9999 -9999 -9999 -9999 -9999 -9999 -9999 -9999 -9999 -9999 -9999 -9999 -9999 -9999 -9999 -9999 -9999 -9999 -9999 -9999 -9999 -9999 -9999 -9999 -9999 -9999 -9999 -9999 -9999 -9999 -9999 -9999 -9999 -9999 -9999 -9999 -9999 -9999 -9999 -9999 -9999 -9999 -9999 -9999 -9999 -9999 -9999 -9999 -9999 -9999 -9999 -9999 -9999 -9999 -9999 -9999 -9999 -9999 -9999 -9999 -9999 -9999 -9999 -9999 -9999 -9999 -9999 -9999 -9999

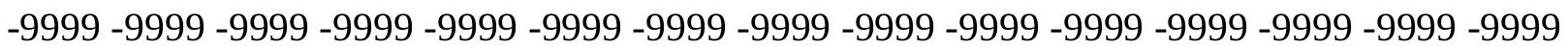
-9999 -9999 -9999 -9999 -9999 -9999 -9999 -9999 -9999 -9999 -9999 -9999 -9999 -9999 -9999 -9999 -9999 -9999 -9999 -9999 -9999 -9999 -9999 -9999 -9999 -9999 -9999 -9999 -9999 -9999 -9999 -9999 -9999 -9999 -9999 -9999 -9999 -9999 -9999 -9999 -9999 -9999 -9999 -9999 -9999

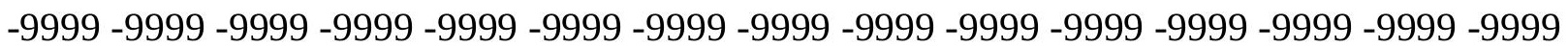
-9999 -9999 -9999 -9999 -9999 -9999 -9999 -9999 -9999 -9999 -9999 -9999 -9999 -9999 -9999 -9999 -9999 -9999 -9999 -9999 -9999 -9999 -9999 -9999 -9999 -9999 -9999 -9999 -9999 -9999 -9999 -9999 -9999 -9999 -9999 -9999 -9999 -9999 -9999 -9999 -9999 -9999 -9999 -9999

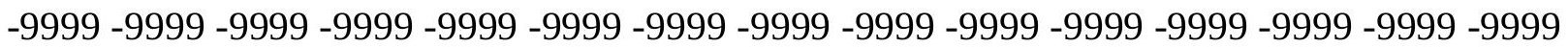
-9999 -9999 -9999 -9999 -9999 -9999 -9999 -9999 -9999 -9999 -9999 -9999 -9999 -9999 -9999 -9999 -9999 -9999 -9999 -9999 -9999 -9999 -9999 -9999 -9999 -9999 -9999 -9999 -9999 -9999 -

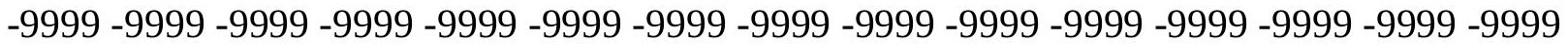
-9999 -9999 -9999 -9999 -9999 -9999 -9999 -9999 -9999 -9999 -9999 -9999 -9999 -9999 -9999 -9999 -9999 -9999 -9999 -9999 -9999 -9999 -9999 -9999 -9999 -9999 -9999 -9999 -9999 -9999 -9999 -9999 -9999 -9999 -9999 -9999 -9999 -9999 -9999 -9999 -9999 -9999 -9999 -9999 -9999 -9999 -9999 -9999 -9999 -9999 -9999 -9999 -9999 -9999 -9999 -9999 -9999 -9999 -9999 -9999 -9999 -9999 -9999 -9999 -9999 -9999 -9999 -9999 -9999 -9999 -9999 -9999 -9999 -9999 -9999

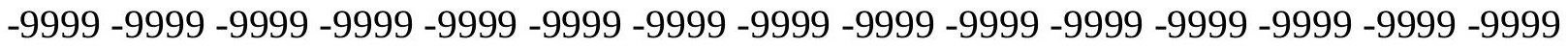
-9999 -9999 -9999 -9999 -9999 -9999 -9999 -9999 -9999 -9999 -9999 -9999 -9999 -9999 -9999 -9999 -9999 -9999 -9999 -9999 -9999 -9999 -9999 -9999 -9999 -9999 -9999 -9999 -9999 -9999 -

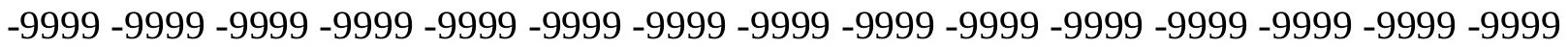
-9999 -9999 -9999 -9999 -9999 -9999 -9999 -9999 -9999 -9999 -9999 -9999 -9999 -9999 -9999 -9999 -9999 -9999 -9999 -9999 -9999 -9999 -9999 -9999 -9999 -9999 -9999 -9999 -9999 -9999 -9999 -9999 -9999 -9999 -9999 -9999 -9999 -9999 -9999 -9999 -9999 -9999 -9999 -9999 -9999 -9999 -9999 -9999 -9999 -9999 -9999 -9999 -9999 -9999 -9999 -9999 -9999 -9999 -9999 -9999

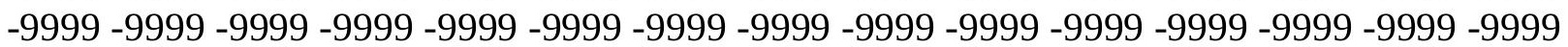


-9999 -9999 -9999 -9999 -9999 -9999 -9999 -9999 -9999 -9999 -9999 -9999 -9999 -9999 -9999 -9999 -9999 -9999 -9999 -9999 -9999 -9999 -9999 -9999 -9999 -9999 -9999 -9999 -9999 -9999 -

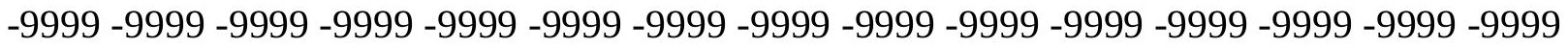
-9999 -9999 -9999 -9999 -9999 -9999 -9999 -9999 -9999 -9999 -9999 -9999 -9999 -9999 -9999 -9999 -9999 -9999 -9999 -9999 -9999 -9999 -9999 -9999-9999 -9999 -9999 -9999 -9999 -9999 -9999 -9999 -9999 -9999 -9999 -9999 -9999 -9999 -9999 -9999 -9999 -9999 -9999 -9999 -9999 -9999 -9999 -9999 -9999 -9999 -9999 -9999 -9999 -9999 -9999 -9999 -9999 -9999 -9999 -

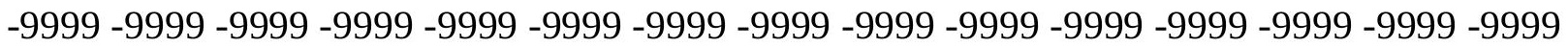

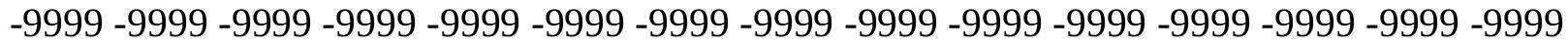
-9999 -9999 -9999 -9999 -9999 -9999 -9999 -9999 -9999 -9999 -9999 -9999 -9999 -9999 -9999 -9999 -9999 -9999 -9999 -9999 -9999 -9999 -9999 -9999 -9999 -9999 -9999 -9999 -9999 -9999 -9999 -9999 -9999 -9999 -9999 -9999 -9999 -9999 -9999 -9999 -9999 -9999 -9999 -9999 -9999 -9999 -9999 -9999 -9999 -9999 -9999 -9999 -9999 -9999 -9999 -9999 -9999 -9999 -9999 -9999 -9999 -9999 -9999 -9999 -9999 -9999 -9999 -9999 -9999 -9999 -9999 -9999 -9999 -9999 -9999 -9999 -9999 -9999 -9999 -9999 -9999 -9999 -9999 -9999 -9999 -9999 -9999 -9999 -9999 -9999 -

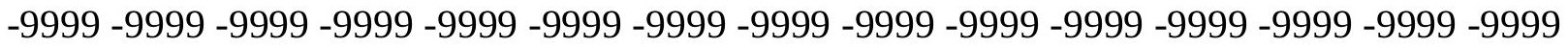
-9999 -9999 -9999 -9999 -9999 -9999 -9999 -9999 -9999 -9999 -9999 -9999 -9999 -9999 -9999 -9999 -9999 -9999 -9999 -9999 -9999 -9999 -9999 -9999 -9999 -9999 -9999 -9999 -9999 -9999 -9999 -9999 -9999 -9999 -9999 -9999 -9999 -9999 -9999 -9999 -9999 -9999 -9999 -9999 -9999 -

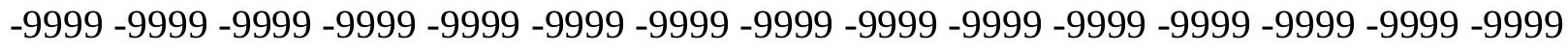

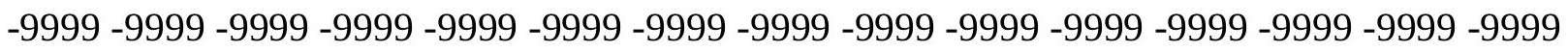

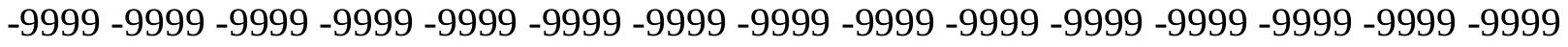
-9999 -9999 -9999 -9999 -9999 -9999 -9999 -9999 -9999 -9999 -9999 -9999 -9999 -9999 -9999 -9999 -9999 -9999 -9999 -9999 -9999 -9999 -9999 -9999 -9999 -9999 -9999 -9999 -9999 -9999 -

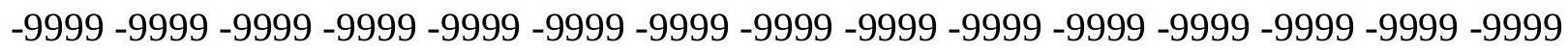
-9999 -9999 -9999 -9999 -9999 -9999 -9999 -9999 -9999 -9999 -9999 -9999 -9999 -9999 -9999 -9999 -9999 -9999 -9999 -9999 -9999 -9999 -9999 -9999 -9999 -9999 -9999 -9999 -9999 -9999 -

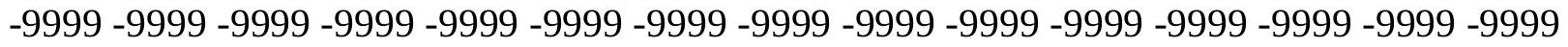
-9999 -9999 -9999 -9999 -9999 -9999 -9999 -9999 -9999 -9999 -9999 -9999 -9999 -9999 -9999 -9999 -9999 -9999 -9999 -9999 -9999 -9999 -9999 -9999 -9999 -9999 -9999 -9999 -9999 -999 -9999 -9999 -9999 -9999 -9999 -9999 -9999 -9999 -9999 -9999 -9999 -9999 -9999 -9999 -9999 -

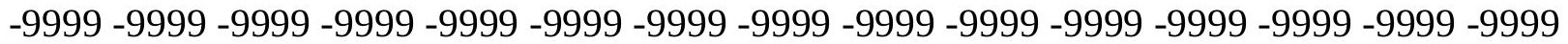

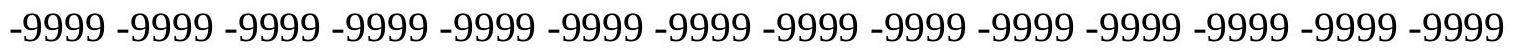

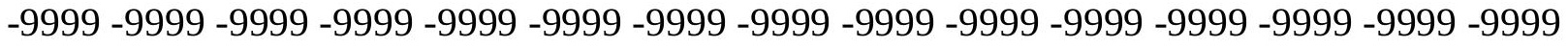

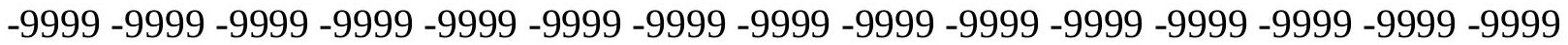

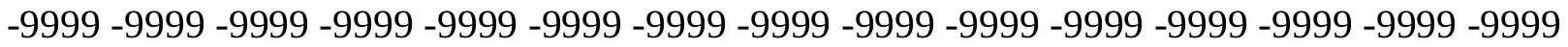

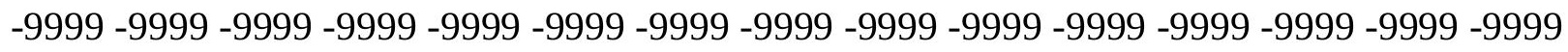

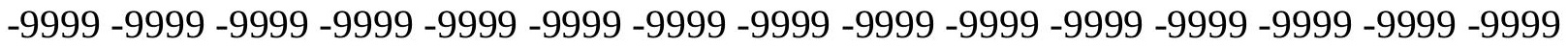

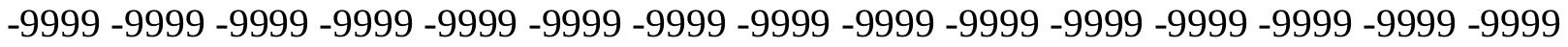
-9999 -9999 -9999 -9999 -9999 -9999 -9999 -9999 -9999 -9999 -9999 -9999 -9999 -9999 -9999 -

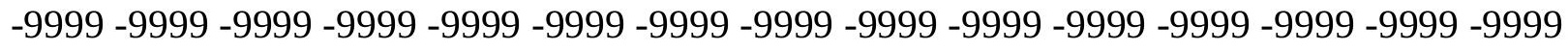

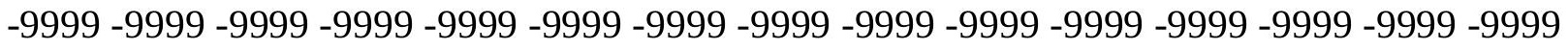
-9999 -9999 -9999 -9999 -9999 -9999 -9999 -9999 -9999 -9999 -9999 -9999 -9999 -9999 -9999 -9999 -9999 -9999 -9999 -9999 -9999 -9999 -9999 -9999-9999 -9999 -9999 -9999 -9999 -9999 -9999 -9999 -9999 -9999 -9999 -9999 -9999 -9999 -9999 -9999 -9999 -9999 -9999 -9999 -9999 -

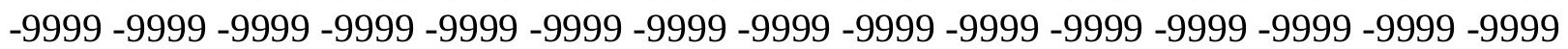


-9999 -9999 -9999 -9999 -9999 -9999 -9999 -9999 -9999 -9999 -9999 -9999 -9999 -9999 -9999 -9999 -9999 -9999 -9999 -9999 -9999 -9999 -9999 -9999 -9999 -9999 -9999 -9999 -9999 -9999 -

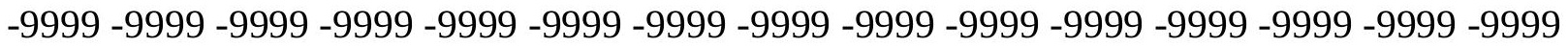
-9999 -9999 -9999 -9999 -9999 -9999 -9999 -9999 -9999 -9999 -9999 -9999 -9999 -9999 -9999 -9999 -9999 -9999 -9999 -9999 -9999 -9999 -9999 -9999-9999 -9999 -9999 -9999 -9999 -9999 -9999 -9999 -9999 -9999 -9999 -9999 -9999 -9999 -9999 -9999 -9999 -9999 -9999 -9999 -9999 -9999 -9999 -9999 -9999 -9999 -9999 -9999 -9999 -9999 -9999 -9999 -9999 -9999 -9999 -9999

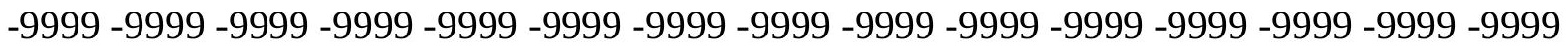

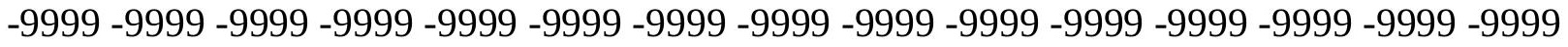
-9999 -9999 -9999 -9999 -9999 -9999 -9999 -9999 -9999 -9999 -9999 -9999 -9999 -9999 -9999 -9999 -9999 -9999 -9999 -9999 -9999 -9999 -9999 -9999 -9999 -9999 -9999 -9999 -9999 -9999 -9999 -9999 -9999 -9999 -9999 -9999 -9999 -9999 -9999 -9999 -9999 -9999 -9999 -9999 -9999 -9999 -9999 -9999 -9999 -9999 -9999 -9999 -9999 -9999 -9999 -9999 -9999 -9999 -9999 -9999 -9999 -9999 -9999 -9999 -9999 -9999 -9999 -9999 -9999 -9999 -9999 -9999 -9999 -9999 -9999 -9999 -9999 -9999 -9999 -9999 -9999 -9999 -9999 -9999 -9999 -9999 -9999 -9999 -9999 -

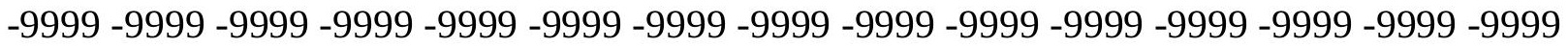
-9999 -9999 -9999 -9999 -9999 -9999 -9999 -9999 -9999 -9999 -9999 -9999 -9999 -9999 -9999 -9999 -9999 -9999 -9999 -9999 -9999 -9999 -9999 -9999 -9999 -9999 -9999 -9999 -9999 -9999 -9999 -9999 -9999 -9999 -9999 -9999 -9999 -9999 -9999 -9999 -9999 -9999 -9999 -9999 -9999 -

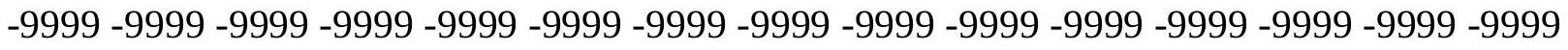
-9999 -9999 -9999 -9999 -9999 -9999 -9999 -9999 -9999 -9999 -9999 -9999 -9999 -9999 -9999

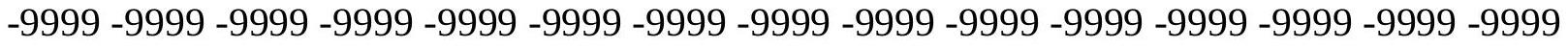
-9999 -9999 -9999 -9999 -9999 -9999 -9999 -9999 -9999 -9999 -9999 -9999 -9999 -9999 -9999 -9999 -9999 -9999 -9999 -9999 -9999 -9999 -9999 -9999 -9999 -9999 -9999 -9999 -9999 -9999 -

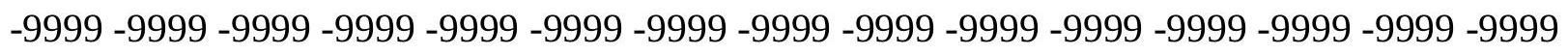
-9999 -9999 -9999 -9999 -9999 -9999 -9999 -9999 -9999 -9999 -9999 -9999 -9999 -9999 -9999 -9999 -9999 -9999 -9999 -9999 -9999 -9999 -9999 -9999 -9999 -9999 -9999 -9999 -9999 -9999 -

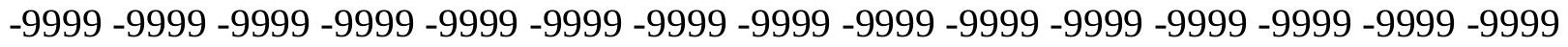
-9999 -9999 -9999 -9999 -9999 -9999 -9999 -9999 -9999 -9999 -9999 -9999 -9999 -9999 -9999 -9999 -9999 -9999 -9999 -9999 -9999 -9999 -9999 -9999 -9999 -9999 -9999 -9999 -9999 -999 -9999 -9999 -9999 -9999 -9999 -9999 -9999 -9999 -9999 -9999 -9999 -9999 -9999 -9999 -9999 -9999 -9999 -9999 -9999 -9999 -9999 -9999 -9999 -9999 -9999 -9999 -9999 -9999 -9999 -9999 -

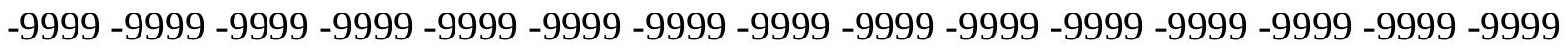

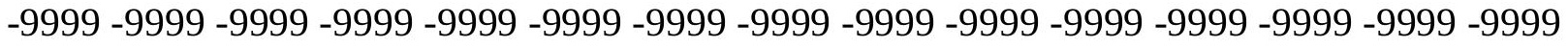

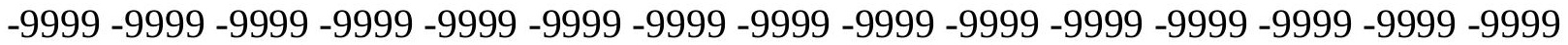
-9999 -9999 -9999 -9999 -9999 -9999 -9999 -9999 -9999 -9999 -9999 -9999 -9999 -9999 -9999 -

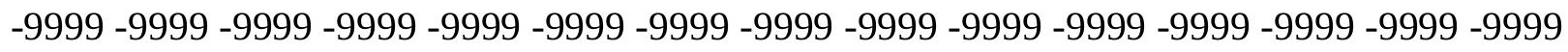

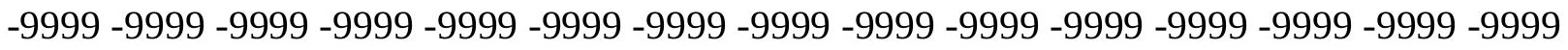
-9999 -9999 -9999 -9999 -9999 -9999 -9999 -9999 -9999 -9999 -9999 -9999 -9999 -9999 - -999 -9999 -9999 -9999 -9999 -9999 -9999 -9999 -9999 -9999 -9999 -9999 -9999 -9999 -9999 -9999 -

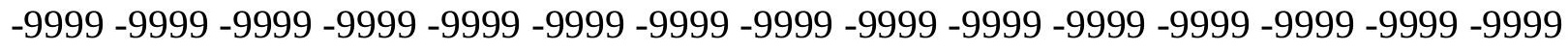

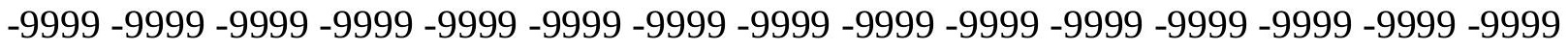
-9999 -9999 -9999 -9999 -9999 -9999 -9999 -9999 -9999 -9999 -9999 -9999 -9999 -9999 -9999 -9999 -9999 -9999 -9999 -9999 -9999 -9999 -9999 -9999-9999 -9999 -9999 -9999 -9999 -9999 -9999 -9999 -9999 -9999 -9999 -9999 -9999 -9999 -9999 -9999 -9999 -9999 -9999 -9999 -9999 -

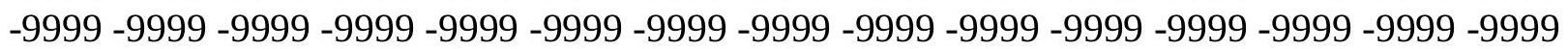


-9999 -9999 -9999 -9999 -9999 -9999 -9999 -9999 -9999 -9999 -9999 -9999 -9999 -9999 -9999 -9999 -9999 -9999 -9999 -9999 -9999 -9999 -9999 -9999 -9999 -9999 -9999 -9999 -9999 -9999 -

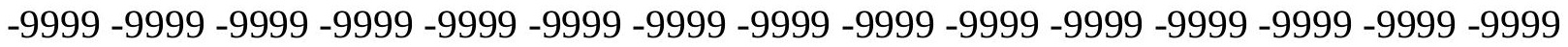
-9999 -9999 -9999 -9999 -9999 -9999 -9999 -9999 -9999 -9999 -9999 -9999 -9999 -9999 -9999 -9999 -9999 -9999 -9999 -9999 -9999 -9999 -9999 -9999-9999 -9999 -9999 -9999 -9999 -9999 -9999 -9999 -9999 -9999 -9999 -9999 -9999 -9999 -9999 -9999 -9999 -9999 -9999 -9999 -9999 -9999 -9999 -9999 -9999 -9999 -9999 -9999 -9999 -9999 -9999 -9999 -9999 -9999 -9999 -9999

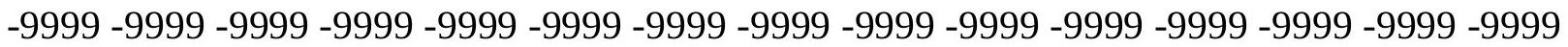

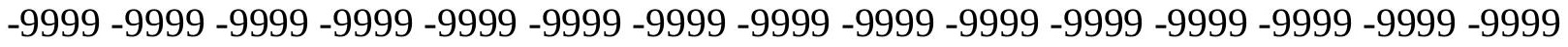
-9999 -9999 -9999 -9999 -9999 -9999 -9999 -9999 -9999 -9999 -9999 -9999 -9999 -9999 -9999 -9999 -9999 -9999 -9999 -9999 -9999 -9999 -9999 -9999 -9999 -9999 -9999 -9999 -9999 -9999 -9999 -9999 -9999 -9999 -9999 -9999 -9999 -9999 -9999 -9999 -9999 -9999 -9999 -9999 -9999 -9999 -9999 -9999 -9999 -9999 -9999 -9999 -9999 -9999 -9999 -9999 -9999 -9999 -9999 -9999 -

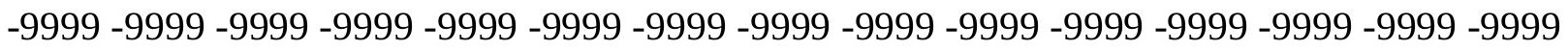
-9999 -9999 -9999 -9999 -9999 -9999 -9999 -9999 -9999 -9999 -9999 -9999 -9999 -9999 -9999 -

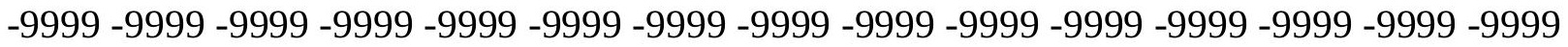
-9999 -9999 -9999 -9999 -9999 -9999 -9999 -9999 -9999 -9999 -9999 -9999 -9999 -9999 -9999 -9999 -9999 -9999 -9999 -9999 -9999 -9999 -9999 -9999 -9999 -9999 -9999 -9999 -9999 -9999 -9999 -9999 -9999 -9999 -9999 -9999 -9999 -9999 -9999 -9999 -9999 -9999 -9999 -9999 - -999 -

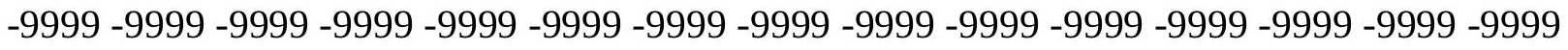

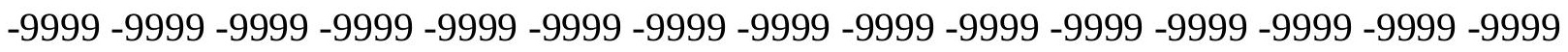
-9999 -9999 -9999 -9999 -9999 -9999 -9999 -9999 -9999 -9999 -9999 -9999 -9999 -9999 -9999 -9999 -9999 -9999 -9999 -9999 -9999 -9999 -9999 -9999 -9999 -9999 -9999 -9999 -9999 -9999 -9999 -9999 -9999 -9999 -9999 -9999 -9999 -9999 -9999 -9999 -9999 -9999 -9999 -9999 -9999 -

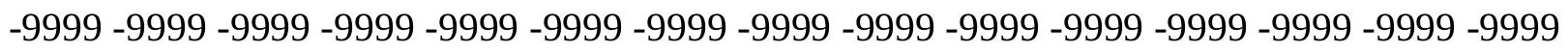
-9999 -9999 -9999 -9999 -9999 -9999 -9999 -9999 -9999 -9999 -9999 -9999 -9999 -9999 -9999 -9999 -9999 -9999 -9999 -9999 -9999 -9999 -9999 -9999 -9999 -9999 -9999 -9999 -9999 -9999 -

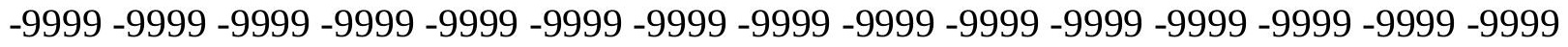
-9999 -9999 -9999 -9999 -9999 -9999 -9999 -9999 -9999 -9999 -9999 -9999 -9999 -9999 -9999 -9999 -9999 -9999 -9999 -9999 -9999 -9999 -9999 -9999 -9999 -9999 -9999 -9999 -9999 -999 -

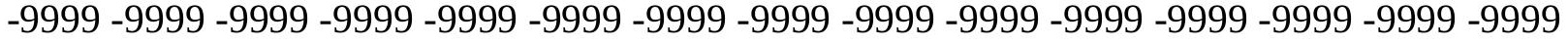
-9999 -9999 -9999 -9999 -9999 -9999 -9999 -9999 -9999 -9999 -9999 -9999 -9999 -9999 -9999 -

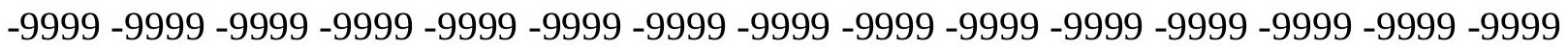

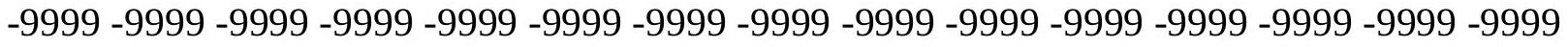

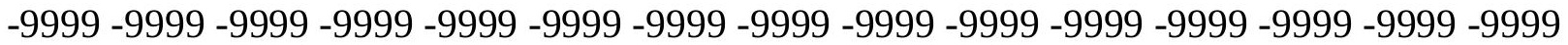

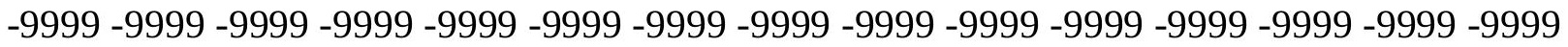

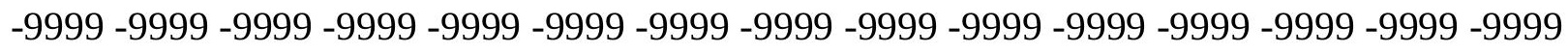

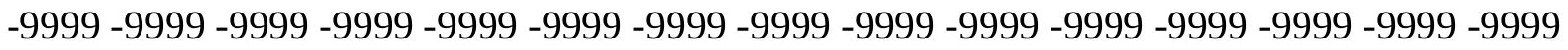

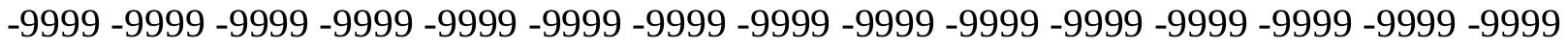
-9999 -9999 -9999 -9999 -9999 -9999 -9999 -9999 -9999 -9999 -9999 -9999 -9999 -9999 -9999 -

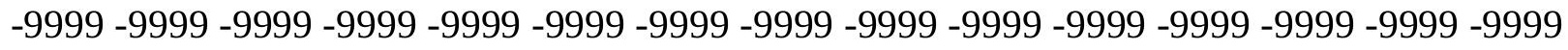

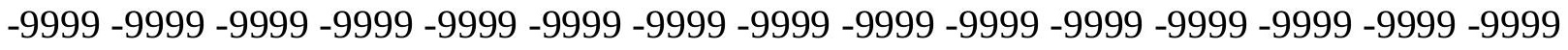
-9999 -9999 -9999 -9999 -9999 -9999 -9999 -9999 -9999 -9999 -9999 -9999 -9999 -9999 -9999 -9999 -9999 -9999 -9999 -9999 -9999 -9999 -9999 -9999 -9999 -9999 -9999 -9999 -9999 -9999 -9999 -9999 -9999 -9999 -9999 -9999 -9999 -9999 -9999 -9999 -9999 -9999 -9999 -9999 -

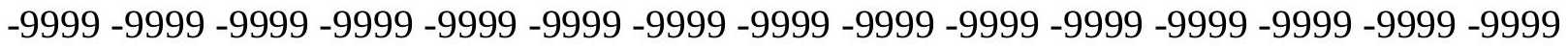


-9999 -9999 -9999 -9999 -9999 -9999 -9999 -9999 -9999 -9999 -9999 -9999 -9999 -9999 -9999 -9999 -9999 -9999 -9999 -9999 -9999 -9999 -9999 -9999 -9999 -9999 -9999 -9999 -9999 -9999 -

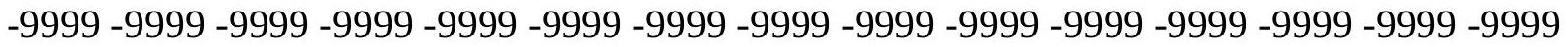
-9999 -9999 -9999 -9999 -9999 -9999 -9999 -9999 -9999 -9999 -9999 -9999 -9999 -9999 -9999 -9999 -9999 -9999 -9999 -9999 -9999 -9999 -9999 -9999-9999 -9999 -9999 -9999 -9999 -9999 -9999 -9999 -9999 -9999 -9999 -9999 -9999 -9999 -9999 -9999 -9999 -9999 -9999 -9999 -9999 -9999 -9999 -9999 -9999 -9999 -9999 -9999 -9999 -9999 -9999 -9999 -9999 -9999 -9999 -9999

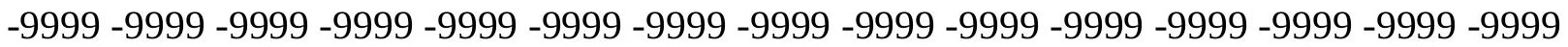

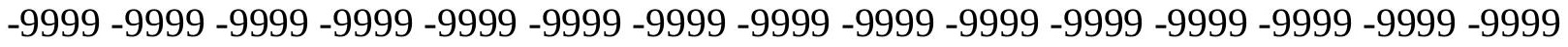
-9999 -9999 -9999 -9999 -9999 -9999 -9999 -9999 -9999 -9999 -9999 -9999 -9999 -9999 -9999 -9999 -9999 -9999 -9999 -9999 -9999 -9999 -9999 -9999 -9999 -9999 -9999 -9999 -9999 -9999 -9999 -9999 -9999 -9999 -9999 -9999 -9999 -9999 -9999 -9999 -9999 -9999 -9999 -9999 -9999 -9999 -9999 -9999 -9999 -9999 -9999 -9999 -9999 -9999 -9999 -9999 -9999 -9999 -9999 -9999 -

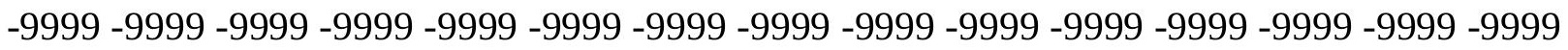
-9999 -9999 -9999 -9999 -9999 -9999 -9999 -9999 -9999 -9999 -9999 -9999 -9999 -9999 -9999 -

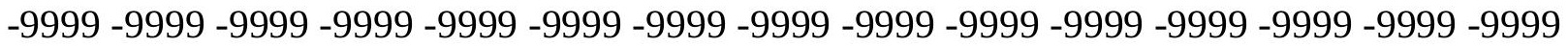
-9999 -9999 -9999 -9999 -9999 -9999 -9999 -9999 -9999 -9999 -9999 -9999 -9999 -9999 -9999 -9999 -9999 -9999 -9999 -9999 -9999 -9999 -9999 -9999 -9999 -9999 -9999 -9999 -9999 - 9999 -9999 -9999 -9999 -9999 -9999 -9999 -9999 -9999 -9999 -9999 -9999 -9999 -9999 -9999 -9999 -

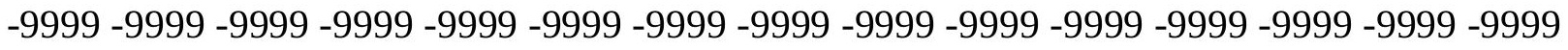

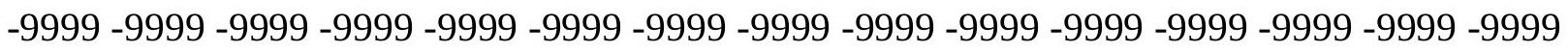
-9999 -9999 -9999 -9999 -9999 -9999 -9999 -9999 -9999 -9999 -9999 -9999 -9999 -9999 - 9999 -9999 -9999 -9999 -9999 -9999 -9999 -9999 -9999 -9999 -9999 -9999 -9999 -9999 -9999 -9999 -9999 -9999 -9999 -9999 -9999 -9999 -9999 -9999 -9999 -9999 -9999 -9999 -9999 -9999 -9999 -9999 -9999 -9999 -9999 -9999 -9999 -9999 -9999 -9999 -9999 -9999 -9999 -9999 -9999 -9999 -9999 -9999 -9999 -9999 -9999 -9999 -9999 -9999 -9999 -9999 -9999 -9999 -9999 -9999 -9999 -9999 -9999 -9999 -9999 -9999 -9999 -9999 -9999 -9999 -9999 -9999 -9999 -9999 -9999 -

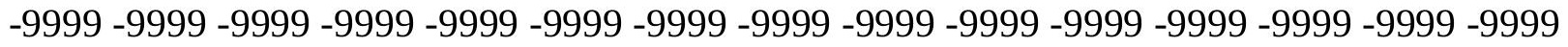
-9999 -9999 -9999 -9999 -9999 -9999 -9999 -9999 -9999 -9999 -9999 -9999 -9999 -9999 -9999 -9999 -9999 -9999 -9999 -9999 -9999 -9999 -9999 -9999 -9999 -9999 -9999 -9999 -9999 -999 -9999 -9999 -9999 -9999 -9999 -9999 -9999 -9999 -9999 -9999 -9999 -9999 -9999 -9999 -9999 -9999 -9999 -9999 -9999 -9999 -9999 -9999 -9999 -9999 -9999 -9999 -9999 -9999 -9999 -9999 -

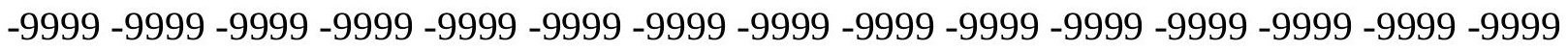

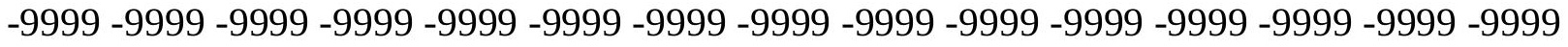

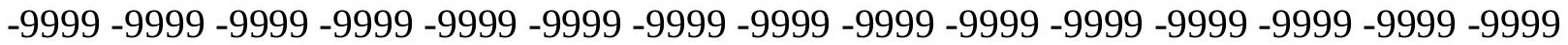

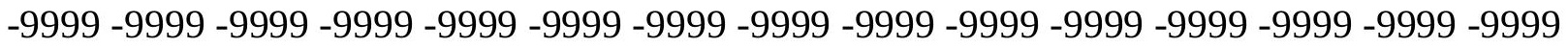

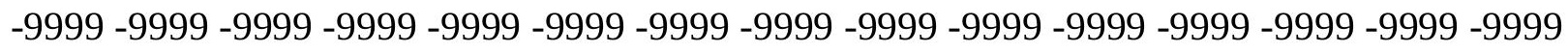

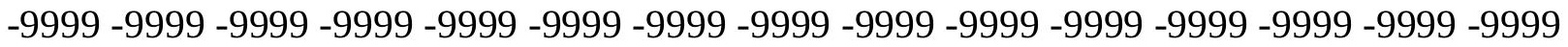

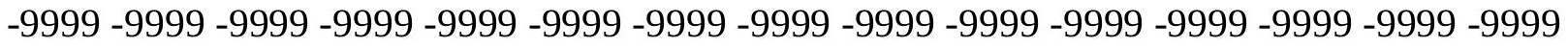
-9999 -9999 -9999 -9999 -9999 -9999 -9999 -9999 -9999 -9999 -9999 -9999 -9999 -9999 -9999 -

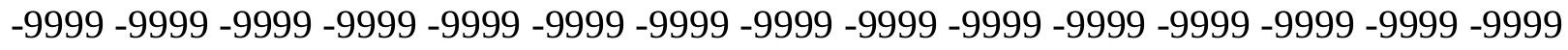

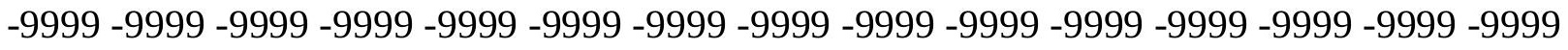
-9999 -9999 -9999 -9999 -9999 -9999 -9999 -9999 -9999 -9999 -9999 -9999 -9999 -9999 -9999 -9999 -9999 -9999 -9999 -9999 -9999 -9999 -9999 -9999-9999 -9999 -9999 -9999 -9999 -9999 -9999 -9999 -9999 -9999 -9999 -9999 -9999 -9999 -9999 -9999 -9999 -9999 -9999 -9999 -9999 -

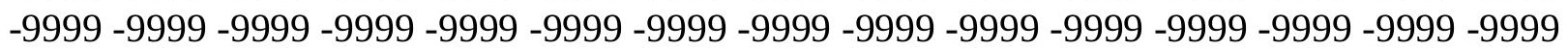


-9999 -9999 -9999 -9999 -9999 -9999 -9999 -9999 -9999 -9999 -9999 -9999 -9999 -9999 -9999 -9999 -9999 -9999 -9999 -9999 -9999 -9999 -9999 -9999 -9999 -9999 -9999 -9999 -9999 -9999 -9999 -9999 -9999 -9999 -9999 -9999 -9999 -9999 -9999 -9999 -9999 -9999 -9999 -9999 - 9999 -9999 -9999 -9999 -9999 -9999 -9999 -9999 -9999 -9999 -9999 -9999 -9999 -9999 -9999 -9999 -9999 -9999 -9999 -9999 -9999 -9999 -9999 -9999 -9999 -9999 -9999 -9999 -9999 -9999 -9999 -9999 -9999 -9999 -9999 -9999 -9999 -9999 -9999 -9999 -9999 -9999 -9999 -9999 -9999 -9999 -9999 -9999 -9999 -9999 -9999 -9999 -9999 -9999 -9999 -9999 -9999 -9999 -9999 -9999

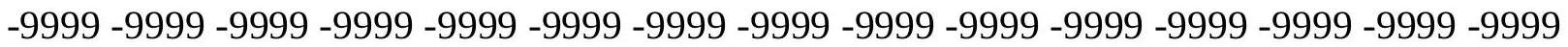

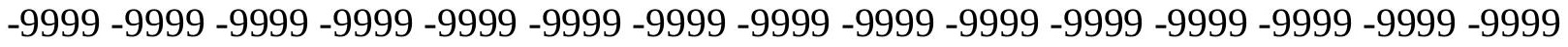
-9999 -9999 -9999 -9999 -9999 -9999 -9999 -9999 -9999 -9999 -9999 -9999 -9999 -9999 -9999 -9999 -9999 -9999 -9999 -9999 -9999 -9999 -9999 -9999 -9999 -9999 -9999 -9999 -9999 -9999 -9999 -9999 -9999 -9999 -9999 -9999 -9999 -9999 -9999 -9999 -9999 -9999 -9999 -9999 -9999 -9999 -9999 -9999 -9999 -9999 -9999 -9999 -9999 -9999 -9999 -9999 -9999 -9999 -9999 -9999 -9999 -9999 -9999 -9999 -9999 -9999 -9999 -9999 -9999 -9999 -9999 -9999 -9999 -9999 -9999 -9999 -9999 -9999 -9999 -9999 -9999 -9999 -9999 -9999 -9999 -9999 -9999 -9999 -9999 -9999 -

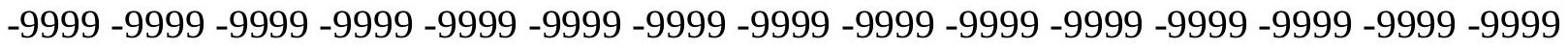
-9999 -9999 -9999 -9999 -9999 -9999 -9999 -9999 -9999 -9999 -9999 -9999 -9999 -9999 -9999 -9999 -9999 -9999 -9999 -9999 -9999 -9999 -9999 -9999 -9999 -9999 -9999 -9999 -9999 - 9999 -9999 -9999 -9999 -9999 -9999 -9999 -9999 -9999 -9999 -9999 -9999 -9999 -9999 -9999 -9999 -

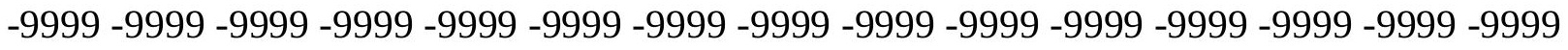

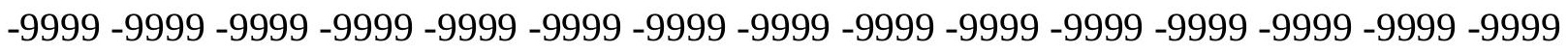

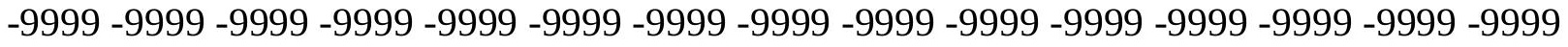
-9999 -9999 -9999 -9999 -9999 -9999 -9999 -9999 -9999 -9999 -9999 -9999 -9999 -9999 -9999 -9999 -9999 -9999 -9999 -9999 -9999 -9999 -9999 -9999 -9999 -9999 -9999 -9999 -9999 -9999 -

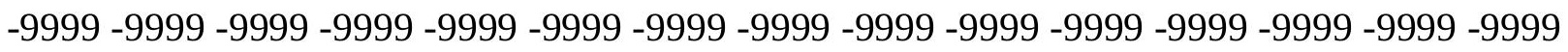
-9999 -9999 -9999 -9999 -9999 -9999 -9999 -9999 -9999 -9999 -9999 -9999 -9999 -9999 -9999 -9999 -9999 -9999 -9999 -9999 -9999 -9999 -9999 -9999 -9999 -9999 -9999 -9999 -9999 -9999 -

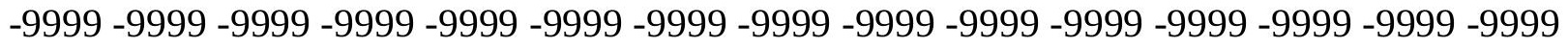
-9999 -9999 -9999 -9999 -9999 -9999 -9999 -9999 -9999 -9999 -9999 -9999 -9999 -9999 -9999 -9999 -9999 -9999 -9999 -9999 -9999 -9999 -9999 -9999 -9999 -9999 -9999 -9999 -9999 -999 -9999 -9999 -9999 -9999 -9999 -9999 -9999 -9999 -9999 -9999 -9999 -9999 -9999 -9999 -9999 -9999 -9999 -9999 -9999 -9999 -9999 -9999 -9999 -9999 -9999 -9999 -9999 -9999 -9999 -

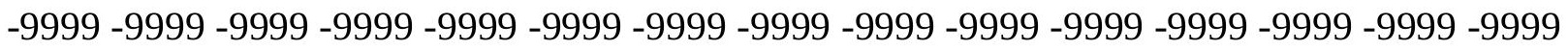

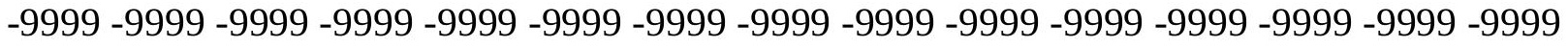

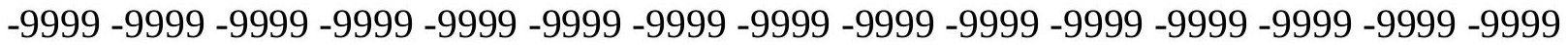

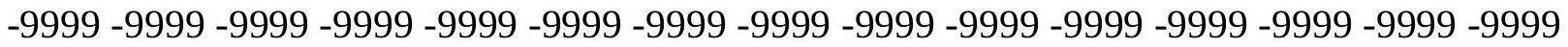

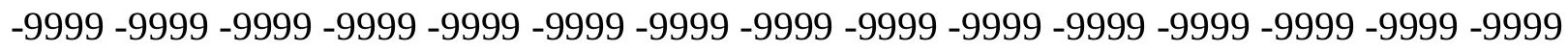

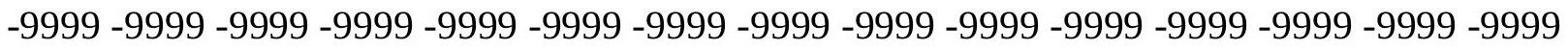

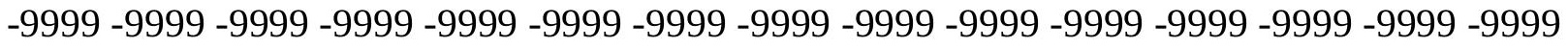
-9999 -9999 -9999 -9999 -9999 -9999 -9999 -9999 -9999 -9999 -9999 -9999 -9999 -9999 -9999 -

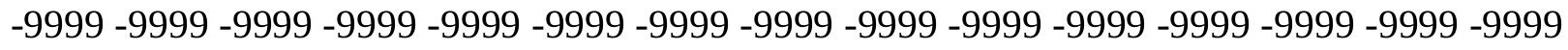

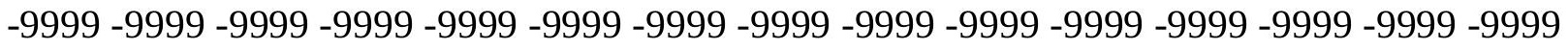
-9999 -9999 -9999 -9999 -9999 -9999 -9999 -9999 -9999 -9999 -9999 -9999 -9999 -9999 -9999 -9999 -9999 -9999 -9999 -9999 -9999 -9999 -9999 -9999-9999 -9999 -9999 -9999 -9999 -9999 -9999 -9999 -9999 -9999 -9999 -9999 -9999 -9999 -9999 -9999 -9999 -9999 -9999 -9999 -9999 -

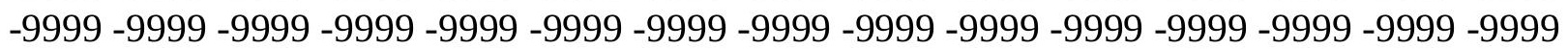


-9999 -9999 -9999 -9999 -9999 -9999 -9999 -9999 -9999 -9999 -9999 -9999 -9999 -9999 -9999 -9999 -9999 -9999 -9999 -9999 -9999 -9999 -9999 -9999 -9999 -9999 -9999 -9999 -9999 -9999 -

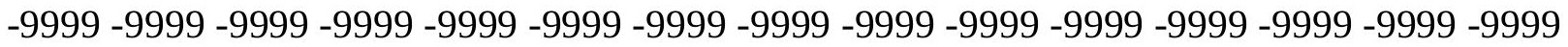
-9999 -9999 -9999 -9999 -9999 -9999 -9999 -9999 -9999 -9999 -9999 -9999 -9999 -9999 -9999 -9999 -9999 -9999 -9999 -9999 -9999 -9999 -9999 -9999-9999 -9999 -9999 -9999 -9999 -9999 -9999 -9999 -9999 -9999 -9999 -9999 -9999 -9999 -9999 -9999 -9999 -9999 -9999 -9999 -9999 -9999 -9999 -9999 -9999 -9999 -9999 -9999 -9999 -9999 -9999 -9999 -9999 -9999 -9999 -9999

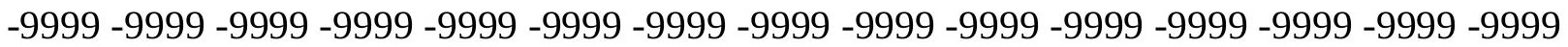

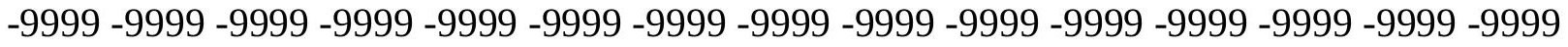

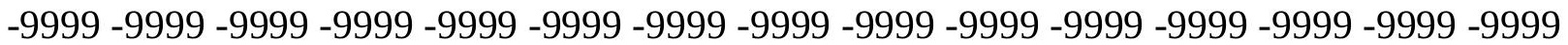
-9999 -9999 -9999 -9999 -9999 -9999 -9999 -9999 -9999 -9999 -9999 -9999 -9999 -9999 -9999 -9999 -9999 -9999 -9999 -9999 -9999 -9999 -9999 -9999 -9999 -9999 -9999 -9999 -9999 -9999 -9999 -9999 -9999 -9999 -9999 -9999 -9999 -9999 -9999 -9999 -9999 -9999 -9999 -9999 -

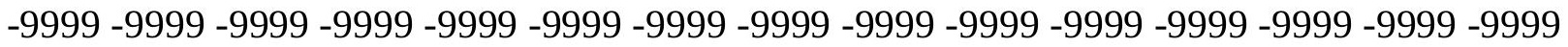
-9999 -9999 -9999 -9999 -9999 -9999 -9999 -9999 -9999 -9999 -9999 -9999 -9999 -9999 -9999 -

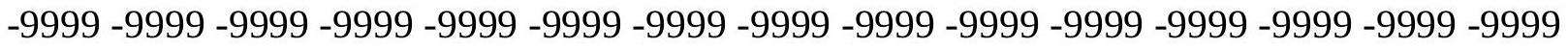
-9999 -9999 -9999 -9999 -9999 -9999 -9999 -9999 -9999 -9999 -9999 -9999 -9999 -9999 -9999 -9999 -9999 -9999 -9999 -9999 -9999 -9999 -9999 -9999 -9999 -9999 -9999 -9999 -9999 -9999 -9999 -9999 -9999 -9999 -9999 -9999 -9999 -9999 -9999 -9999 -9999 -9999 -9999 -9999 -9999 -

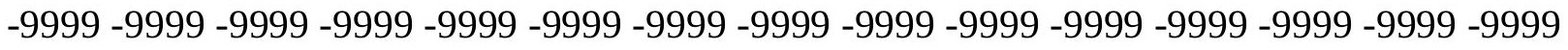

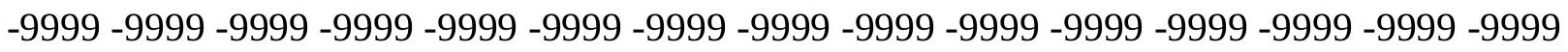
-9999 -9999 -9999 -9999 -9999 -9999 -9999 -9999 -9999 -9999 -9999 -9999 -9999 -9999 -9999 -9999 -9999 -9999 -9999 -9999 -9999 -9999 -9999 -9999 -9999 -9999 -9999 -9999 -9999 -9999 -9999 -9999 -9999 -9999 -9999 -9999 -9999 -9999 -9999 -9999 -9999 -9999 -9999 -9999 -9999 -

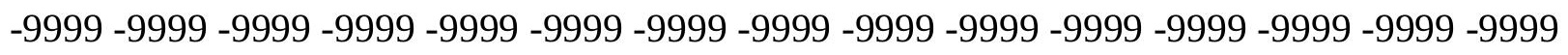
-9999 -9999 -9999 -9999 -9999 -9999 -9999 -9999 -9999 -9999 -9999 -9999 -9999 -9999 -9999 -9999 -9999 -9999 -9999 -9999 -9999 -9999 -9999 -9999 -9999 -9999 -9999 -9999 -9999 -9999 -

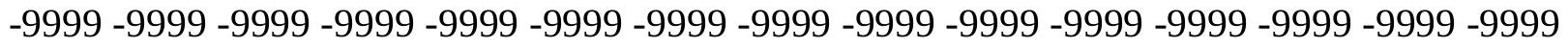
-9999 -9999 -9999 -9999 -9999 -9999 -9999 -9999 -9999 -9999 -9999 -9999 -9999 -9999 -9999 -9999 -9999 -9999 -9999 -9999 -9999 -9999 -9999 -9999 -9999 -9999 -9999 -9999 -9999 -999 -9999 -9999 -9999 -9999 -9999 -9999 -9999 -9999 -9999 -9999 -9999 -9999 -9999 -9999 -9999 -9999 -9999 -9999 -9999 -9999 -9999 -9999 -9999 -9999 -9999 -9999 -9999 -9999 -9999 -9999 -

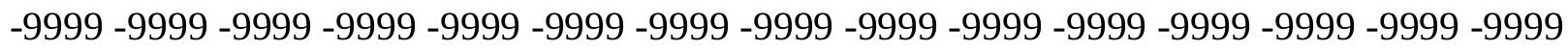

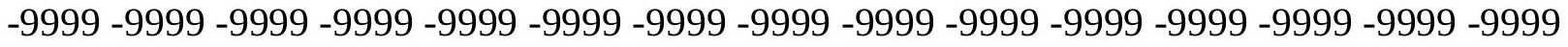

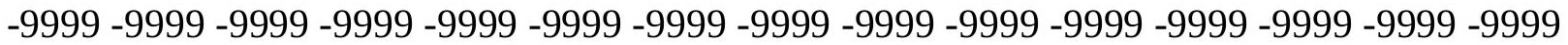
-9999 -9999 -9999 -9999 -9999 -9999 -9999 -9999 -9999 -9999 -9999 -9999 -9999 -9999 -9999 -

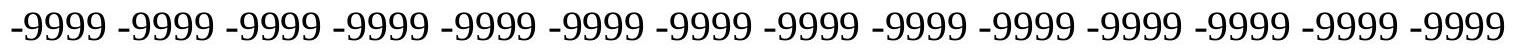

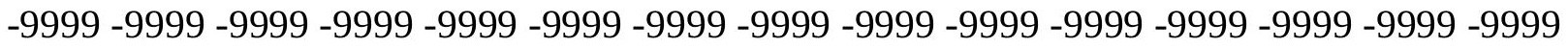
-9999 -9999 -9999 -9999 -9999 -9999 -9999 -9999 -9999 -9999 -9999 -9999 -9999 - 9999 - -999 -9999 -9999 -9999 -9999 -9999 -9999 -9999 -9999 -9999 -9999 -9999 -9999 -9999 -9999 -9999 -

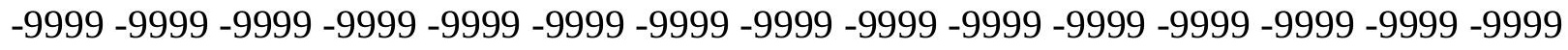

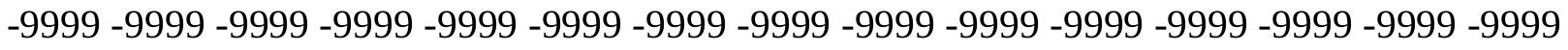
-9999 -9999 -9999 -9999 -9999 -9999 -9999 -9999 -9999 -9999 -9999 -9999 -9999 -9999 -9999 -9999 -9999 -9999 -9999 -9999 -9999 -9999 -9999 -9999-9999 -9999 -9999 -9999 -9999 -9999 -9999 -9999 -9999 -9999 -9999 -9999 -9999 -9999 -9999 -9999 -9999 -9999 -9999 -9999 -9999 -

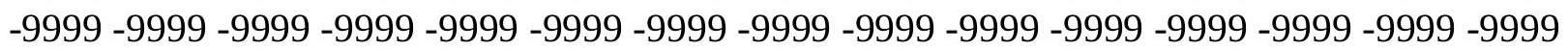


-9999 -9999 -9999 -9999 -9999 -9999 -9999 -9999 -9999 -9999 -9999 -9999 -9999 -9999 -9999 -9999 -9999 -9999 -9999 -9999 -9999 -9999 -9999 -9999 -9999 -9999 -9999 -9999 -9999 -9999 -

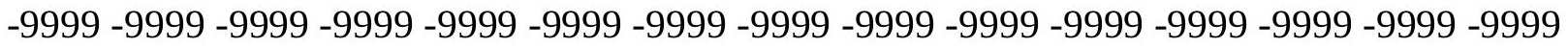
-9999 -9999 -9999 -9999 -9999 -9999 -9999 -9999 -9999 -9999 -9999 -9999 -9999 -9999 -9999 -9999 -9999 -9999 -9999 -9999 -9999 -9999 -9999 -9999-9999 -9999 -9999 -9999 -9999 -9999 -9999 -9999 -9999 -9999 -9999 -9999 -9999 -9999 -9999 -9999 -9999 -9999 -9999 -9999 -9999 -9999 -9999 -9999 -9999 -9999 -9999 -9999 -9999 -9999 -9999 -9999 -9999 -9999 -9999 -9999

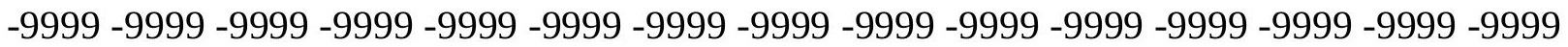

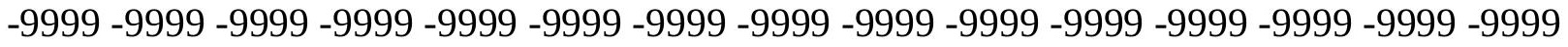
-9999 -9999 -9999 -9999 -9999 -9999 -9999 -9999 -9999 -9999 -9999 -9999 -9999 -9999 -9999 -9999 -9999 -9999 -9999 -9999 -9999 -9999 -9999 -9999 -9999 -9999 -9999 -9999 -9999 -9999 -9999 -9999 -9999 -9999 -9999 -9999 -9999 -9999 -9999 -9999 -9999 -9999 -9999 -9999 -9999 -9999 -9999 -9999 -9999 -9999 -9999 -9999 -9999 -9999 -9999 -9999 -9999 -9999 -9999 -9999 -9999 -9999 -9999 -9999 -9999 -9999 -9999 -9999 -9999 -9999 -9999 -9999 -9999 -9999 -9999 -9999 -9999 -9999 -9999 -9999 -9999 -9999 -9999 -9999 -9999 -9999 -9999 -9999 -9999 -9999 -

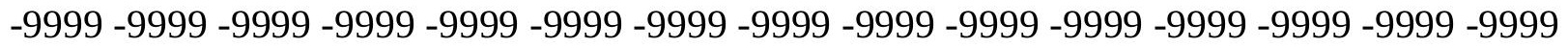
-9999 -9999 -9999 -9999 -9999 -9999 -9999 -9999 -9999 -9999 -9999 -9999 -9999 -9999 -9999 -9999 -9999 -9999 -9999 -9999 -9999 -9999 -9999 -9999 -9999 -9999 -9999 -9999 -9999 -9999 -9999 -9999 -9999 -9999 -9999 -9999 -9999 -9999 -9999 -9999 -9999 -9999 -9999 -9999 -

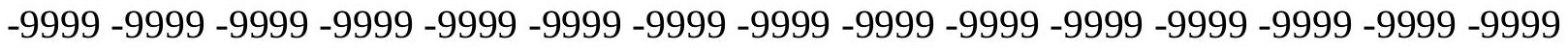
-9999 -9999 -9999 -9999 -9999 -9999 -9999 -9999 -9999 -9999 -9999 -9999 -9999 -9999 -9999 -999 -

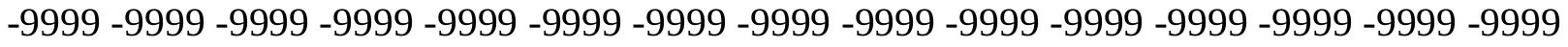
-9999 -9999 -9999 -9999 -9999 -9999 -9999 -9999 -9999 -9999 -9999 -9999 -9999 -9999 -9999 -9999 -9999 -9999 -9999 -9999 -9999 -9999 -9999 -9999 -9999 -9999 -9999 -9999 -9999 -9999 -9999 -9999 -9999 -9999 -9999 -9999 -9999 -9999 -9999 -9999 -9999 -9999 -9999 -9999 -9999 -9999 -9999 -9999 -9999 -9999 -9999 -9999 -9999 -9999 -9999 -9999 -9999 -9999 -9999 -9999 -9999 -9999 -9999 -9999 -9999 -9999 -9999 -9999 -9999 -9999 -9999 -9999 -9999 -9999 -9999 -

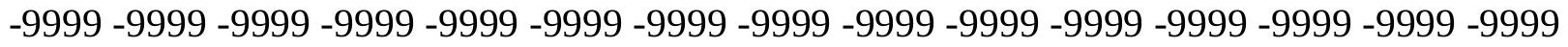
-9999 -9999 -9999 -9999 -9999 -9999 -9999 -9999 -9999 -9999 -9999 -9999 -9999 -9999 -9999 -9999 -9999 -9999 -9999 -9999 -9999 -9999 -9999 -9999 -9999 -9999 -9999 -9999 -9999 -999 -9999 -9999 -9999 -9999 -9999 -9999 -9999 -9999 -9999 -9999 -9999 -9999 -9999 -9999 -9999 -9999 -9999 -9999 -9999 -9999 -9999 -9999 -9999 -9999 -9999 -9999 -9999 -9999 -9999 -9999 -

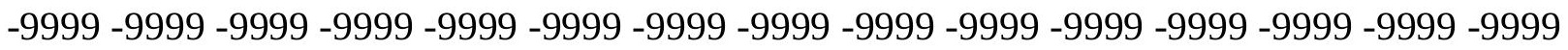

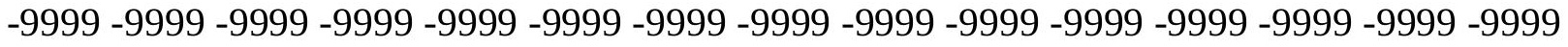

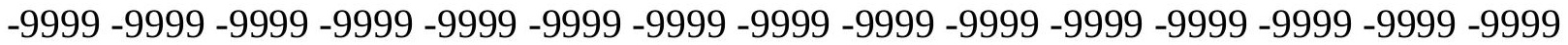
-9999 -9999 -9999 -9999 -9999 -9999 -9999 -9999 -9999 -9999 -9999 -9999 -9999 -9999 -9999

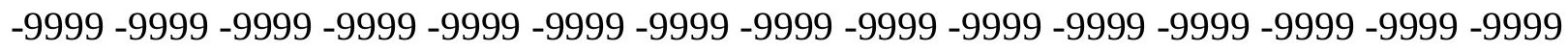

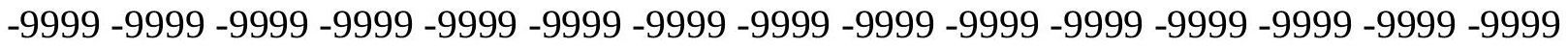
-9999 -9999 -9999 -9999 -9999 -9999 -9999 -9999 -9999 -9999 -9999 -9999 -9999 - 9999 - -999 -9999 -9999 -9999 -9999 -9999 -9999 -9999 -9999 -9999 -9999 -9999 -9999 -9999 -9999 -9999 -

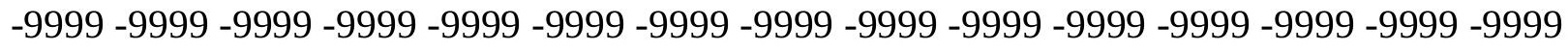

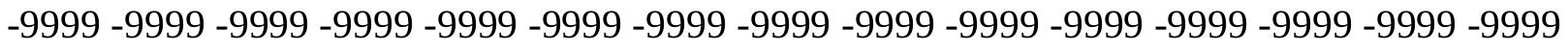
-9999 -9999 -9999 -9999 -9999 -9999 -9999 -9999 -9999 -9999 -9999 -9999 -9999 -9999 -9999 -9999 -9999 -9999 -9999 -9999 -9999 -9999 -9999 -9999 -9999 -9999 -9999 -9999 -9999 -9999 -9999 -9999 -9999 -9999 -9999 -9999 -9999 -9999 -9999 -9999 -9999 -9999 -9999 -9999 -

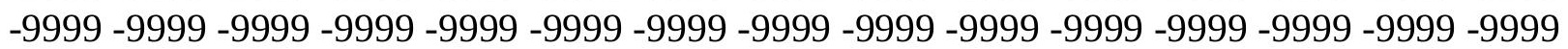


-9999 -9999 -9999 -9999 -9999 -9999 -9999 -9999 -9999 -9999 -9999 -9999 -9999 -9999 -9999 -9999 -9999 -9999 -9999 -9999 -9999 -9999 -9999 -9999 -9999 -9999 -9999 -9999 -9999 -9999 -9999 -9999 -9999 -9999 -9999 -9999 -9999 -9999 -9999 -9999 -9999 -9999 -9999 -9999 - 9999 -9999 -9999 -9999 -9999 -9999 -9999 -9999 -9999 -9999 -9999 -9999 -9999 -9999 -9999 -9999 -9999 -9999 -9999 -9999 -9999 -9999 -9999 -9999 -9999-9999 -9999 -9999 -9999 -9999 -9999 -9999 -9999 -9999 -9999 -9999 -9999 -9999 -9999 -9999 -9999 -9999 -9999 -9999 -9999 -9999 -9999 -9999 -9999 -9999 -9999 -9999 -9999 -9999 -9999 -9999 -9999 -9999 -9999 -9999 -9999

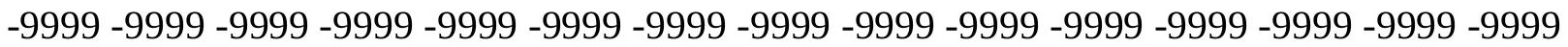

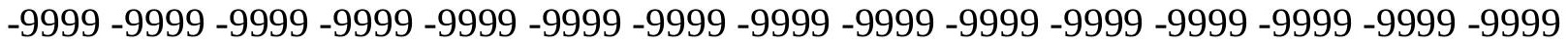
-9999 -9999 -9999 -9999 -9999 -9999 -9999 -9999 -9999 -9999 -9999 -9999 -9999 -9999 -9999 -9999 -9999 -9999 -9999 -9999 -9999 -9999 -9999 -9999 -9999 -9999 -9999 -9999 -9999 -9999 -9999 -9999 -9999 -9999 -9999 -9999 -9999 -9999 -9999 -9999 -9999 -9999 -9999 -9999 -9999 -9999 -9999 -9999 -9999 -9999 -9999 -9999 -9999 -9999 -9999 -9999 -9999 -9999 -9999 -9999 -

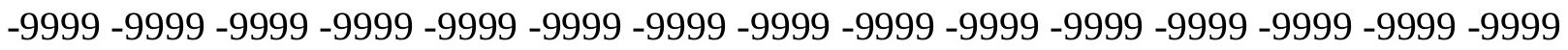
-9999 -9999 -9999 -9999 -9999 -9999 -9999 -9999 -9999 -9999 -9999 -9999 -9999 -9999 -9999 -

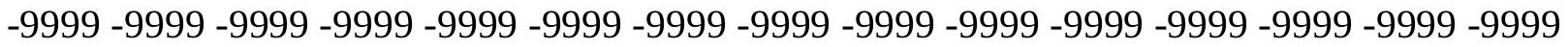
-9999 -9999 -9999 -9999 -9999 -9999 -9999 -9999 -9999 -9999 -9999 -9999 -9999 -9999 -9999 -9999 -9999 -9999 -9999 -9999 -9999 -9999 -9999 -9999 -9999 -9999 -9999 -9999 -9999 -9999 -9999 -9999 -9999 -9999 -9999 -9999 -9999 -9999 -9999 -9999 -9999 -9999 -9999 -9999 -9999 -

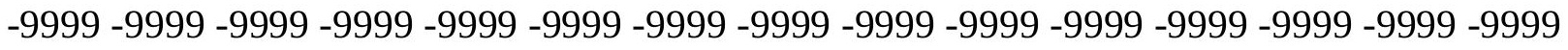
-9999 -9999 -9999 -9999 -9999 -9999 -9999 -9999 -9999 -9999 -9999 -9999 -9999 -9999 -9999 -999 -9999 -9999 -9999 -9999 -9999 -9999 -9999 -9999 -9999 -9999 -9999 -9999 -9999 -9999 - 9999 -9999 -9999 -9999 -9999 -9999 -9999 -9999 -9999 -9999 -9999 -9999 -9999 -9999 -9999 -

-9999 -9999 -9999 -9999 -9999 -9999 -9999 -9999 -9999 -9999 -9999 -9999 -9999 -9999 -9999 -

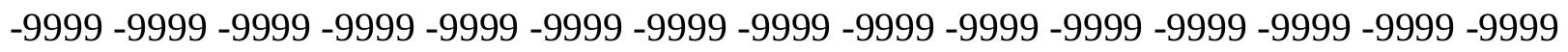
-9999 -9999 -9999 -9999 -9999 -9999 -9999 -9999 -9999 -9999 -9999 -9999 -9999 -9999 -9999 -9999 -9999 -9999 -9999 -9999 -9999 -9999 -9999 -9999 -9999 -9999 -9999 -9999 -9999 -9999 -

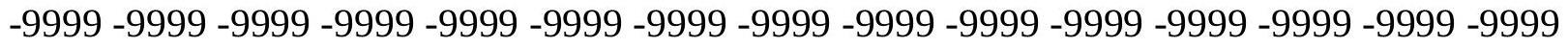
-9999 -9999 -9999 -9999 -9999 -9999 -9999 -9999 -9999 -9999 -9999 -9999 -9999 -9999 -9999 -9999 -9999 -9999 -9999 -9999 -9999 -9999 -9999 -9999 -9999 -9999 -9999 -9999 -9999 -999 -

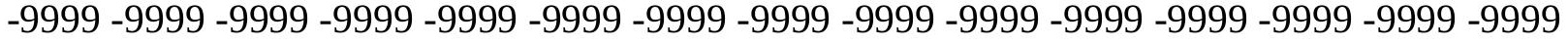
-9999 -9999 -9999 -9999 -9999 -9999 -9999 -9999 -9999 -9999 -9999 -9999 -9999 -9999 -9999 -

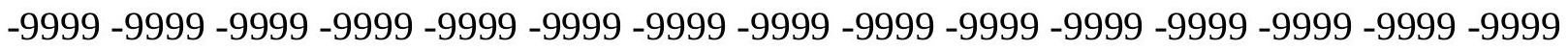

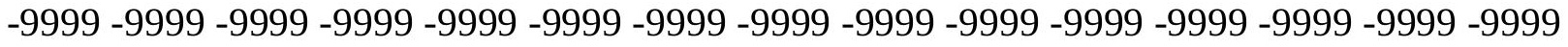

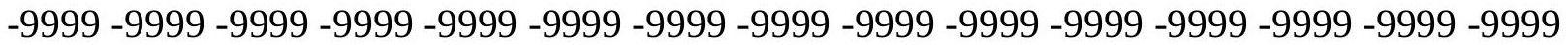

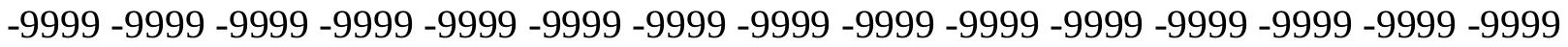

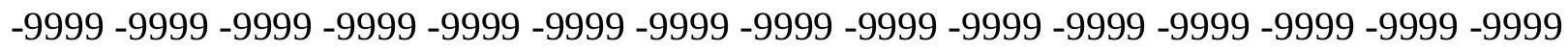

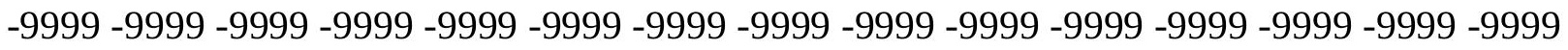

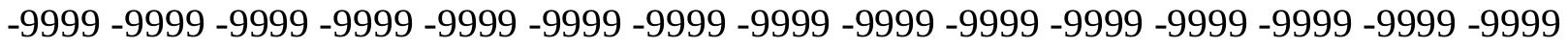
-9999 -9999 -9999 -9999 -9999 -9999 -9999 -9999 -9999 -9999 -9999 -9999 -9999 -9999 -9999 -

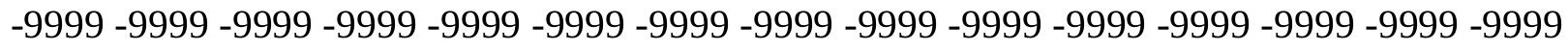

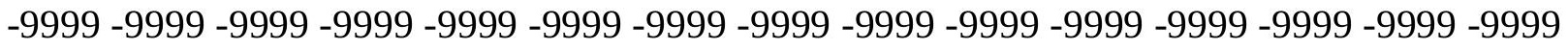
-9999 -9999 -9999 -9999 -9999 -9999 -9999 -9999 -9999 -9999 -9999 -9999 -9999 -9999 -9999 -9999 -9999 -9999 -9999 -9999 -9999 -9999 -9999 -9999-9999 -9999 -9999 -9999 -9999 -9999 -9999 -9999 -9999 -9999 -9999 -9999 -9999 -9999 -9999 -9999 -9999 -9999 -9999 -9999 -9999 -

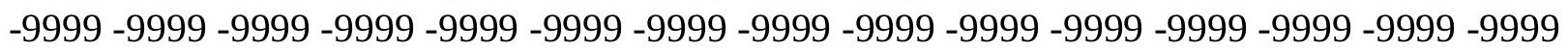


-9999 -9999 -9999 -9999 -9999 -9999 -9999 -9999 -9999 -9999 -9999 -9999 -9999 -9999 -9999 -9999 -9999 -9999 -9999 -9999 -9999 -9999 -9999 -9999 -9999 -9999 -9999 -9999 -9999 -9999 -9999 -9999 -9999 -9999 -9999 -9999 -9999 -9999 -9999 -9999 -9999 -9999 -9999 -9999 -9999 -9999 -9999 -9999 -9999 -9999 -9999 -9999 -9999 -9999 -9999 -9999 -9999 -9999 -9999 -9999 -9999 -9999 -9999 -9999 -9999 -9999 -9999 -9999-9999 -9999 -9999 -9999 -9999 -9999 -9999 -9999 -9999 -9999 -9999 -9999 -9999 -9999 -9999 -9999 -9999 -9999 -9999 -9999 -9999 -9999 -9999 -9999 -9999 -9999 -9999 -9999 -9999 -9999 -9999 -9999 -9999 -9999 -9999 -9999

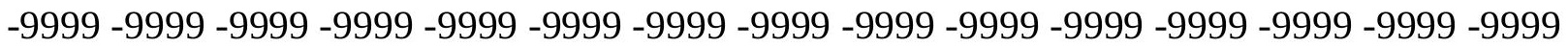

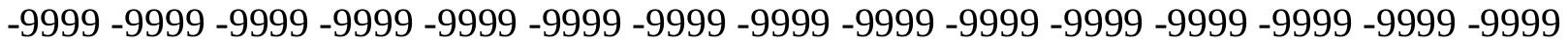
-9999 -9999 -9999 -9999 -9999 -9999 -9999 -9999 -9999 -9999 -9999 -9999 -9999 -9999 -9999 -9999 -9999 -9999 -9999 -9999 -9999 -9999 -9999 -9999 -9999 -9999 -9999 -9999 -9999 -9999 -9999 -9999 -9999 -9999 -9999 -9999 -9999 -9999 -9999 -9999 -9999 -9999 -9999 -9999 -9999 -9999 -9999 -9999 -9999 -9999 -9999 -9999 -9999 -9999 -9999 -9999 -9999 -9999 -9999 -9999 -

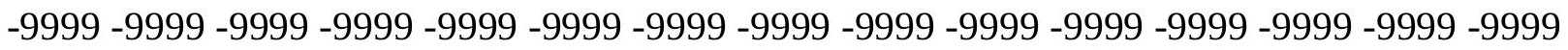
-9999 -9999 -9999 -9999 -9999 -9999 -9999 -9999 -9999 -9999 -9999 -9999 -9999 -9999 -9999 -

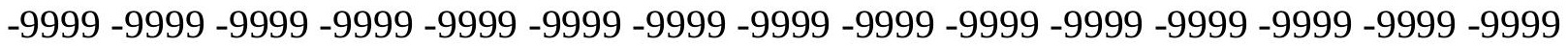
-9999 -9999 -9999 -9999 -9999 -9999 -9999 -9999 -9999 -9999 -9999 -9999 -9999 -9999 -9999 -9999 -9999 -9999 -9999 -9999 -9999 -9999 -9999 -9999 -9999 -9999 -9999 -9999 -9999 -9999 -9999 -9999 -9999 -9999 -9999 -9999 -9999 -9999 -9999 -9999 -9999 -9999 -9999 -9999 -9999 -

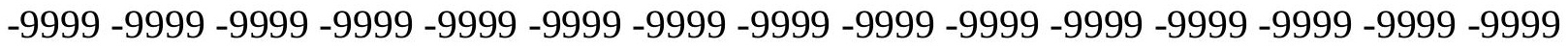

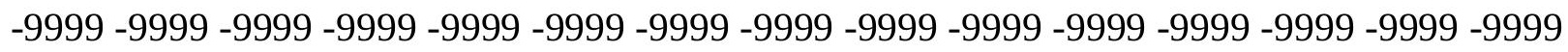
-9999 -9999 -9999 -9999 -9999 -9999 -9999 -9999 -9999 -9999 -9999 -9999 -9999 -9999 -9999 -9999 -9999 -9999 -9999 -9999 -9999 -9999 -9999 -9999 -9999 -9999 -9999 -9999 -9999 -9999 -9999 -9999 -9999 -9999 -9999 -9999 -9999 -9999 -9999 -9999 -9999 -9999 -9999 -9999 -9999 -

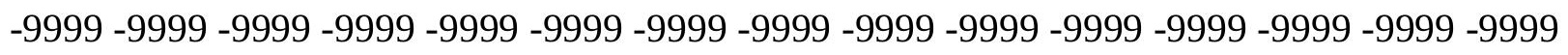
-9999 -9999 -9999 -9999 -9999 -9999 -9999 -9999 -9999 -9999 -9999 -9999 -9999 -9999 -9999 -9999 -9999 -9999 -9999 -9999 -9999 -9999 -9999 -9999 -9999 -9999 -9999 -9999 -9999 -9999 -

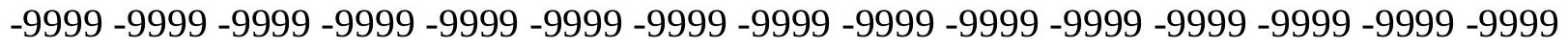
-9999 -9999 -9999 -9999 -9999 -9999 -9999 -9999 -9999 -9999 -9999 -9999 -9999 -9999 -9999 -9999 -9999 -9999 -9999 -9999 -9999 -9999 -9999 -9999 -9999 -9999 -9999 -9999 - -999 -

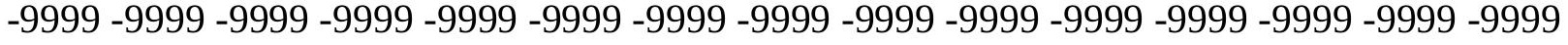
-9999 -9999 -9999 -9999 -9999 -9999 -9999 -9999 -9999 -9999 -9999 -9999 -9999 -9999 -9999 -

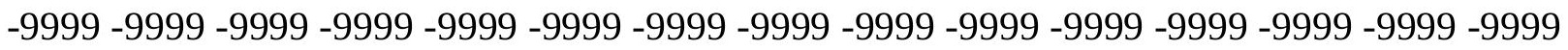

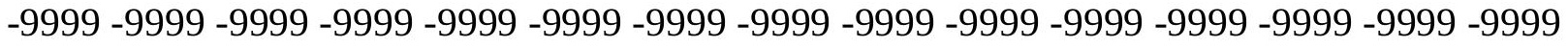

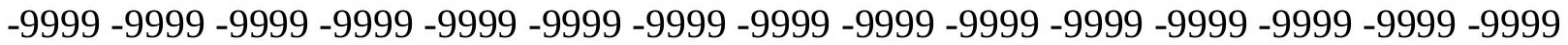

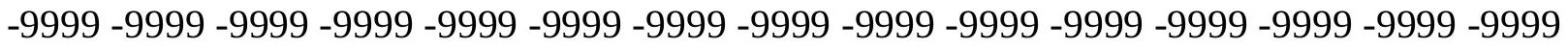

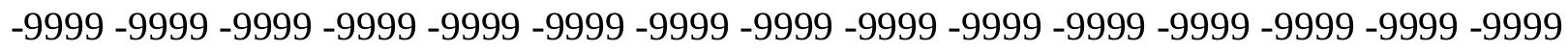

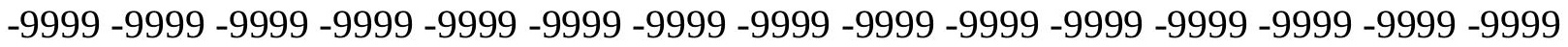

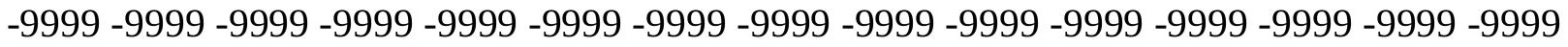
-9999 -9999 -9999 -9999 -9999 -9999 -9999 -9999 -9999 -9999 -9999 -9999 -9999 -9999 -9999 -

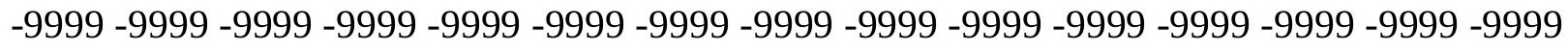

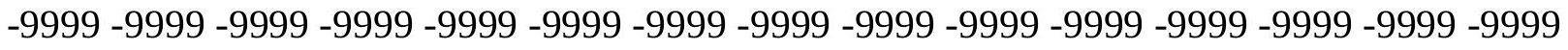
-9999 -9999 -9999 -9999 -9999 -9999 -9999 -9999 -9999 -9999 -9999 -9999 -9999 -9999 -9999 -9999 -9999 -9999 -9999 -9999 -9999 -9999 -9999 -9999-9999 -9999 -9999 -9999 -9999 -9999 -9999 -9999 -9999 -9999 -9999 -9999 -9999 -9999 -9999 -9999 -9999 -9999 -9999 -9999 -9999 -

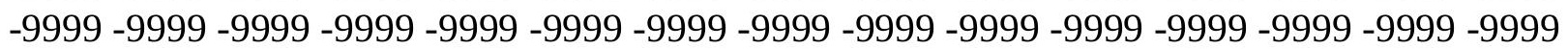


-9999 -9999 -9999 -9999 -9999 -9999 -9999 -9999 -9999 -9999 -9999 -9999 -9999 -9999 -9999 -9999 -9999 -9999 -9999 -9999 -9999 -9999 -9999 -9999 -9999 -9999 -9999 -9999 -9999 -9999 -

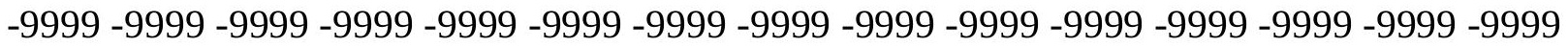
-9999 -9999 -9999 -9999 -9999 -9999 -9999 -9999 -9999 -9999 -9999 -9999 -9999 -9999 -9999 -9999 -9999 -9999 -9999 -9999 -9999 -9999 -9999 -9999-9999 -9999 -9999 -9999 -9999 -9999 -9999 -9999 -9999 -9999 -9999 -9999 -9999 -9999 -9999 -9999 -9999 -9999 -9999 -9999 -9999 -9999 -9999 -9999 -9999 -9999 -9999 -9999 -9999 -9999 -9999 -9999 -9999 -9999 -9999 -9999

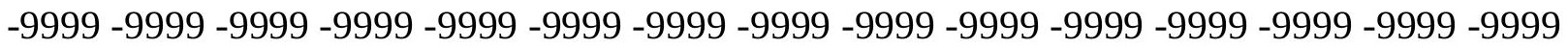
-9999 -9999 -9999 -9999 -9999 -9999 -9999 -9999 -9999 -9999 -9999 -9999 -9999 -9999 -9999 -9999 -9999 -9999 -9999 -9999 -9999 -9999 -9999 -9999 -9999 -9999 -9999 -9999 -9999

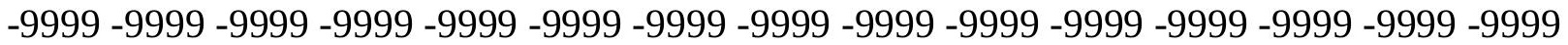
-9999 -9999 -9999 -9999 -9999 -9999 -9999 -9999 -9999 -9999 -9999 -9999 -9999 -9999 -9999 -9999 -9999 -9999 -9999 -9999 -9999 -9999 -9999 -9999 -9999 -9999 -9999 -9999 -9999 -9999 -9999 -9999 -9999 -9999 -9999 -9999 -9999 -9999 -9999 -9999 -9999 -9999 -9999 -9999 - 9999 -9999 -9999 -9999 -9999 -9999 -9999 -9999 -9999 -9999 -9999 -9999 -9999 -9999 -9999 -9999

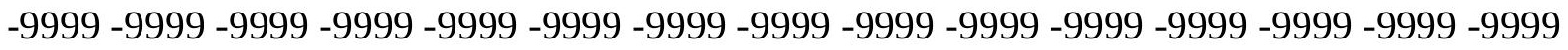
-9999 -9999 -9999 -9999 -9999 -9999 -9999 -9999 -9999 -9999 -9999 -9999 -9999 -9999 -9999 -9999 -9999 -9999 -9999 -9999 -9999 -9999 -9999 -9999 -9999 -9999 -9999 -9999 -9999 -9999 -9999 -9999 -9999 -9999 -9999 -9999 -9999 -9999 -9999 -9999 -9999 -9999 -9999 -9999 -9999 -

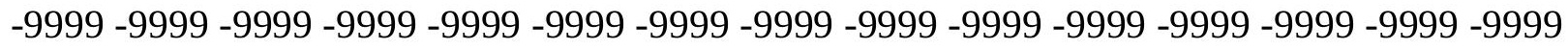

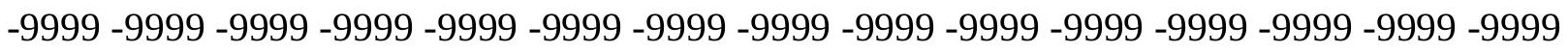
-9999 -9999 -9999 -9999 -9999 -9999 -9999 -9999 -9999 -9999 -9999 -9999 -9999 -9999 -9999 -9999 -9999 -9999 -9999 -9999 -9999 -9999 -9999 -9999 -9999 -9999 -9999 -9999 -9999 -9999 -9999 -9999 -9999 -9999 -9999 -9999 -9999 -9999 -9999 -9999 -9999 -9999 -9999 -9999 -9999 -

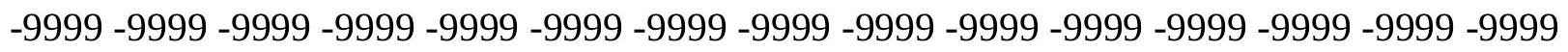
-9999 -9999 -9999 -9999 -9999 -9999 -9999 -9999 -9999 -9999 -9999 -9999 -9999 -9999 -9999 -9999 -9999 -9999 -9999 -9999 -9999 -9999 -9999 -9999 -9999 -9999 -9999 -9999 -9999 -9999 -

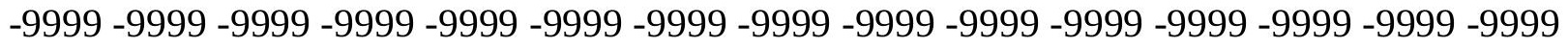
-9999 -9999 -9999 -9999 -9999 -9999 -9999 -9999 -9999 -9999 -9999 -9999 -9999 -9999 -9999 -9999 -9999 -9999 -9999 -9999 -9999 -9999 -9999 -9999 -9999 -9999 -9999 -9999 -9999 -999 -9999 -9999 -9999 -9999 -9999 -9999 -9999 -9999 -9999 -9999 -9999 -9999 -9999 -9999 -9999 -9999 -9999 -9999 -9999 -9999 -9999 -9999 -9999 -9999 -9999 -9999 -9999 -9999 -9999 -9999 -

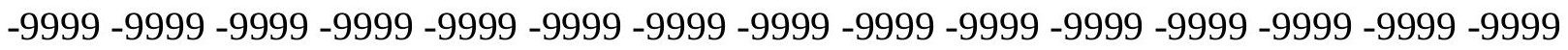

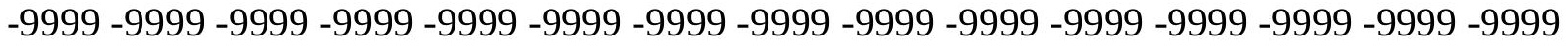
-9999 -9999 -9999 -9999 -9999 -9999 -9999 -9999 -9999 -9999 -9999 -9999 -9999 -9999 -

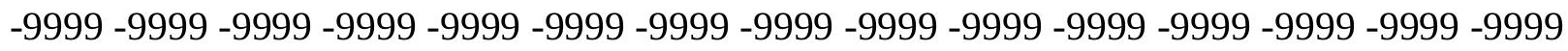

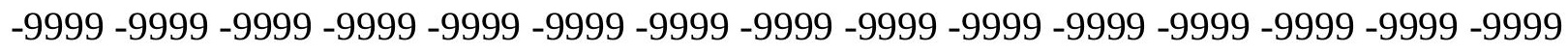

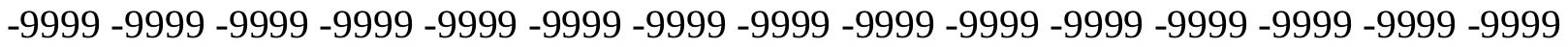
-9999 -9999 -9999 -9999 -9999 -9999 -9999 -9999 -9999 -9999 -9999 -9999 -9999 - 9999 - -999 -9999 -9999 -9999 -9999 -9999 -9999 -9999 -9999 -9999 -9999 -9999 -9999 -9999 -9999 -9999 -

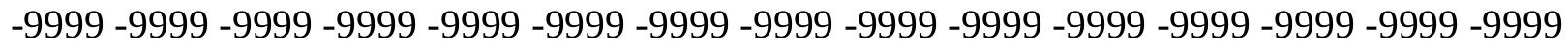

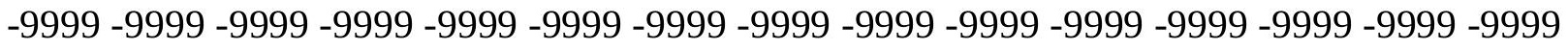
-9999 -9999 -9999 -9999 -9999 -9999 -9999 -9999 -9999 -9999 -9999 -9999 -9999 -9999 -9999 -9999 -9999 -9999 -9999 -9999 -9999 -9999 -9999 -9999-9999 -9999 -9999 -9999 -9999 -9999 -9999 -9999 -9999 -9999 -9999 -9999 -9999 -9999 -9999 -9999 -9999 -9999 -9999 -9999 -9999 -

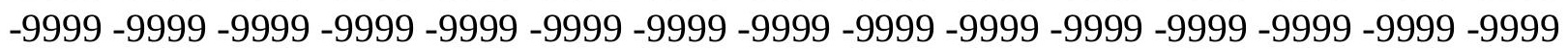


-9999 -9999 -9999 -9999 -9999 -9999 -9999 -9999 -9999 -9999 -9999 -9999 -9999 -9999 -9999 -9999 -9999 -9999 -9999 -9999 -9999 -9999 -9999 -9999 -9999 -9999 -9999 -9999 -9999 -9999 -

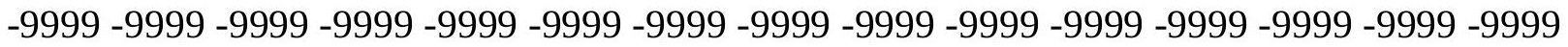
-9999 -9999 -9999 -9999 -9999 -9999 -9999 -9999 -9999 -9999 -9999 -9999 -9999 -9999 -9999 -9999 -9999 -9999 -9999 -9999 -9999 -9999 -9999 -9999-9999 -9999 -9999 -9999 -9999 -9999 -9999 -9999 -9999 -9999 -9999 -9999 -9999 -9999 -9999 -9999 -9999 -9999 -9999 -9999 -9999 -9999 -9999 -9999 -9999 -9999 -9999 -9999 -9999 -9999 -9999 -9999 -9999 -9999 -9999 -9999

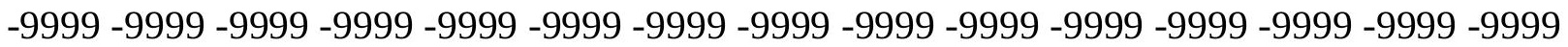

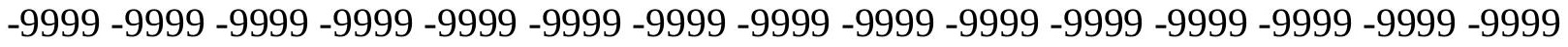
-9999 -9999 -9999 -9999 -9999 -9999 -9999 -9999 -9999 -9999 -9999 -9999 -9999 -9999 -9999 -9999 -9999 -9999 -9999 -9999 -9999 -9999 -9999 -9999 -9999 -9999 -9999 -9999 -9999 -9999 -9999 -9999 -9999 -9999 -9999 -9999 -9999 -9999 -9999 -9999 -9999 -9999 -9999 -9999 -9999 -9999 -9999 -9999 -9999 -9999 -9999 -9999 -9999 -9999 -9999 -9999 -9999 -9999 -9999 -9999 -9999 -9999 -9999 -9999 -9999 -9999 -9999 -9999 -9999 -9999 -9999 -9999 -9999 -9999 -9999 -9999 -9999 -9999 -9999 -9999 -9999 -9999 -9999 -9999 -9999 -9999 -9999 -9999 -9999 -9999 -9999 -9999 -9999 -9999 -9999 -9999 -9999 -9999 -9999 -9999 -9999 -9999 - 9999 - -999 -

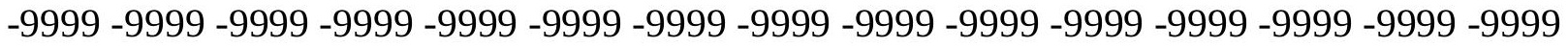
-9999 -9999 -9999 -9999 -9999 -9999 -9999 -9999 -9999 -9999 -9999 -9999 -9999 -9999 -9999 -9999 -9999 -9999 -9999 -9999 -9999 -9999 -9999 -9999 -9999 -9999 -9999 -9999 -9999 -9999 -

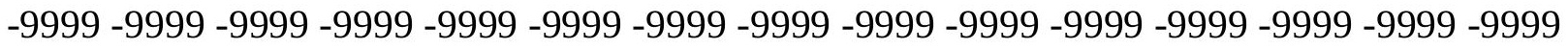
-9999 -9999 -9999 -9999 -9999 -9999 -9999 -9999 -9999 -9999 -9999 -9999 -9999 -9999 -9999

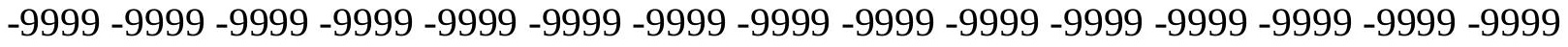
-9999 -9999 -9999 -9999 -9999 -9999 -9999 -9999 -9999 -9999 -9999 -9999 -9999 -9999 -9999 -9999 -9999 -9999 -9999 -9999 -9999 -9999 -9999 -9999 -9999 -9999 -9999 -9999 -9999 -9999 -

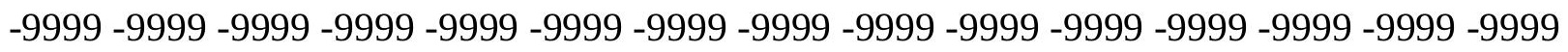
-9999 -9999 -9999 -9999 -9999 -9999 -9999 -9999 -9999 -9999 -9999 -9999 -9999 -9999 -9999 -9999 -9999 -9999 -9999 -9999 -9999 -9999 -9999 -9999 -9999 -9999 -9999 -9999 -9999 -9999 -

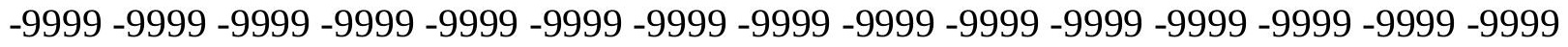
-9999 -9999 -9999 -9999 -9999 -9999 -9999 -9999 -9999 -9999 -9999 -9999 -9999 -9999 -9999 -9999 -9999 -9999 -9999 -9999 -9999 -9999 -9999 -9999 -9999 -9999 -9999 -9999 -9999 -999 -

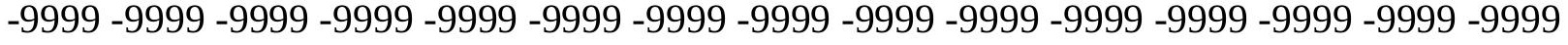
-9999 -9999 -9999 -9999 -9999 -9999 -9999 -9999 -9999 -9999 -9999 -9999 -9999 -9999 -9999 -

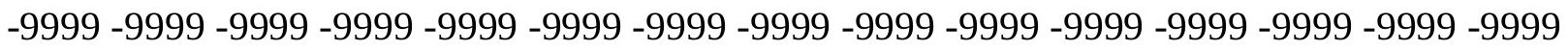

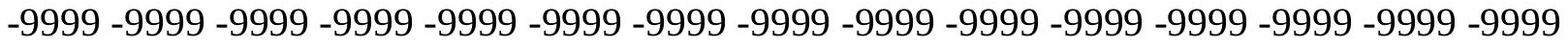

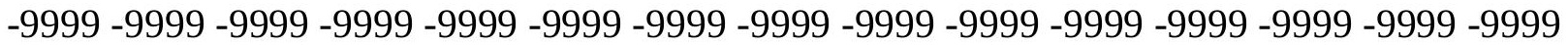
-9999 -9999 -9999 -9999 -9999 -9999 -9999 -9999 -9999 -9999 -9999 -9999 -9999 -9999 -9999 -

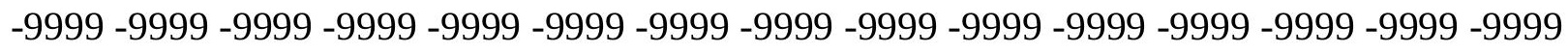

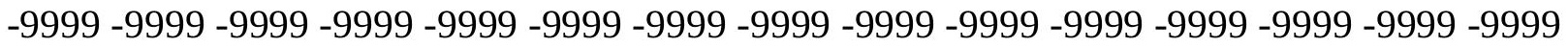
-9999 -9999 -9999 -9999 -9999 -9999 -9999 -9999 -9999 -9999 -9999 -9999 -9999 - 9999 - -999 -9999 -9999 -9999 -9999 -9999 -9999 -9999 -9999 -9999 -9999 -9999 -9999 -9999 -9999 -9999 -

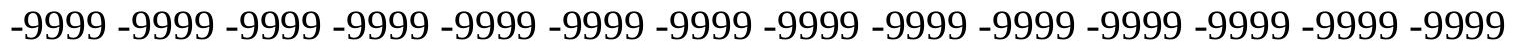

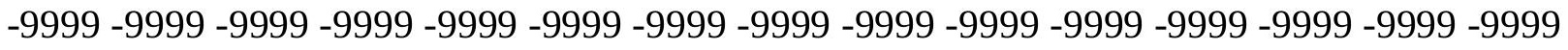
-9999 -9999 -9999 -9999 -9999 -9999 -9999 -9999 -9999 -9999 -9999 -9999 -9999 -9999 -9999 -9999 -9999 -9999 -9999 -9999 -9999 -9999 -9999 -9999-9999 -9999 -9999 -9999 -9999 -9999 -9999 -9999 -9999 -9999 -9999 -9999 -9999 -9999 -9999 -9999 -9999 -9999 -9999 -9999 -9999 -

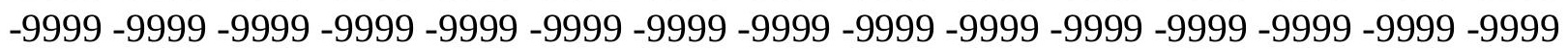


-9999 -9999 -9999 -9999 -9999 -9999 -9999 -9999 -9999 -9999 -9999 -9999 -9999 -9999 -9999 -9999 -9999 -9999 -9999 -9999 -9999 -9999 -9999 -9999 -9999 -9999 -9999 -9999 -9999 -9999 -9999 -9999 -9999 -9999 -9999 -9999 -9999 -9999 -9999 -9999 -9999 -9999 -9999 -9999 - 9999 -9999 -9999 -9999 -9999 -9999 -9999 -9999 -9999 -9999 -9999 -9999 -9999 -9999 -9999 -9999 -9999 -9999 -9999 -9999 -9999 -9999 -9999 -9999 -9999-9999 -9999 -9999 -9999 -9999 -9999 -9999 -9999 -9999 -9999 -9999 -9999 -9999 -9999 -9999 -9999 -9999 -9999 -9999 -9999 -9999 -9999 -9999 -9999 -9999 -9999 -9999 -9999 -9999 -9999 -9999 -9999 -9999 -9999 -9999 -9999

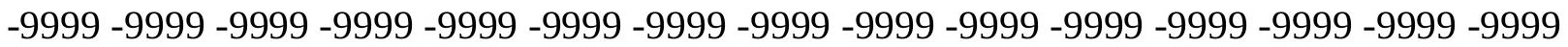
-9999 -9999 -9999 -9999 -9999 -9999 -9999 -9999 -9999 -9999 -9999 -9999 -9999 -9999 -9999 -9999 -9999 -9999 -9999 -9999 -9999 -9999 -9999 -9999 -9999 -9999 -9999 -9999 -9999 -9999

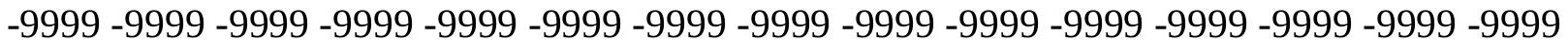
-9999 -9999 -9999 -9999 -9999 -9999 -9999 -9999 -9999 -9999 -9999 -9999 -9999 -9999 -9999 -9999 -9999 -9999 -9999 -9999 -9999 -9999 -9999 -9999 -9999 -9999 -9999 -9999 -9999 -9999 -

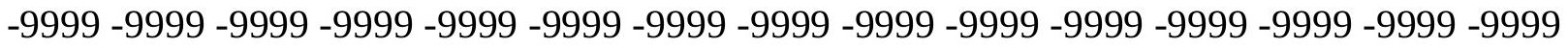
-9999 -9999 -9999 -9999 -9999 -9999 -9999 -9999 -9999 -9999 -9999 -9999 -9999 -9999 -9999

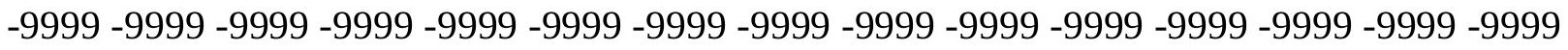
-9999 -9999 -9999 -9999 -9999 -9999 -9999 -9999 -9999 -9999 -9999 -9999 -9999 -9999 -9999 -9999 -9999 -9999 -9999 -9999 -9999 -9999 -9999 -9999 -9999 -9999 -9999 -9999 -9999 - 9999 -9999 -9999 -9999 -9999 -9999 -9999 -9999 -9999 -9999 -9999 -9999 -9999 -9999 -9999 -9999 -9999 -9999 -9999 -9999 -9999 -9999 -9999 -9999 -9999 -9999 -9999 -9999 -9999 -9999 -9999 -9999 -9999 -9999 -9999 -9999 -9999 -9999 -9999 -9999 -9999 -9999 -9999 -9999 -9999 -9999 -9999 -9999 -9999 -9999 -9999 -9999 -9999 -9999 -9999 -9999 -9999 -9999 -9999 -9999 -9999 -9999 -9999 -9999 -9999 -9999 -9999 -9999 -9999 -9999 -9999 -9999 -9999 -9999 -9999 -9999 -9999 -9999 -9999 -9999 -9999 -9999 -9999 -9999 -9999 -9999 -9999 -9999 -9999 -9999 -9999 -9999 -9999 -9999 -9999 -9999 -9999 -9999 -9999 -9999 -9999 -9999 -9999 -9999 -9999 -9999 -9999 -9999 -9999 -9999 -9999 -9999 -9999 -9999 -9999 -9999 -9999 -9999 -9999 -9999 -9999 -9999 -9999 -9999 -9999 -9999 -9999 -9999 -9999 -9999 -9999 -9999 -9999 -9999 -9999 -9999 -9999 -9999 -9999 -9999 -9999 -9999 -9999 -9999 -9999 -9999 -9999 -9999 -9999 -9999 -9999 -9999 -9999 -9999 -9999 -9999 -9999 -9999 -9999 -9999 -9999 -9999 -9999 -9999 -9999 -9999 -9999 -9999 -9999 -9999 -9999 -9999 -9999 -9999 -9999 -9999 -9999 -9999 -9999 -999 -9999 -9999 -9999 -9999 -9999 -9999 -9999 -9999 -9999 -9999 -9999 -9999 -9999 -9999 -9999 -9999 -9999 -9999 -9999 -9999 -9999 -9999 -9999 -9999 -9999 -9999 -9999 -9999 -9999 -9999 -

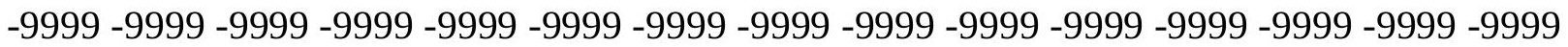

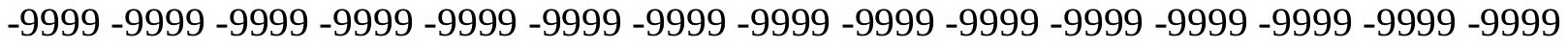

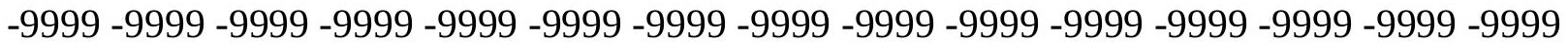
-9999 -9999 -9999 -9999 -9999 -9999 -9999 -9999 -9999 -9999 -9999 -9999 -9999 -9999 -9999

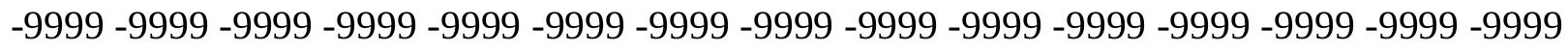

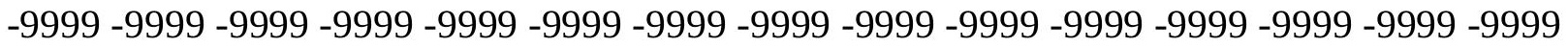

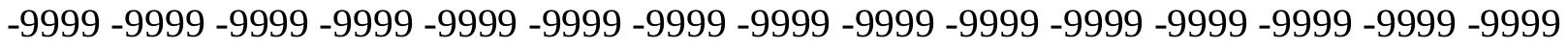
-9999 -9999 -9999 -9999 -9999 -9999 -9999 -9999 -9999 -9999 -9999 -9999 -9999 -9999 -9999 -

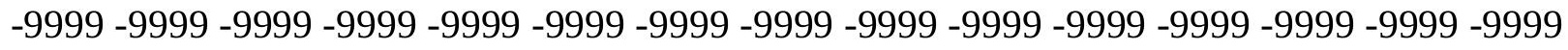

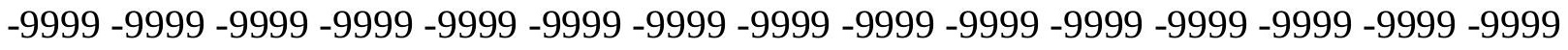
-9999 -9999 -9999 -9999 -9999 -9999 -9999 -9999 -9999 -9999 -9999 -9999 -9999 -9999 -9999 -9999 -9999 -9999 -9999 -9999 -9999 -9999 -9999 -9999-9999 -9999 -9999 -9999 -9999 -9999 -9999 -9999 -9999 -9999 -9999 -9999 -9999 -9999 -9999 -9999 -9999 -9999 -9999 -9999 -9999 -

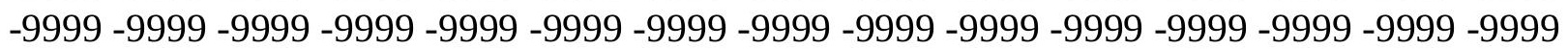


-9999 -9999 -9999 -9999 -9999 -9999 -9999 -9999 -9999 -9999 -9999 -9999 -9999 -9999 -9999 -9999 -9999 -9999 -9999 -9999 -9999 -9999 -9999 -9999 -9999 -9999 -9999 -9999 -9999 -9999 -9999 -9999 -9999 -9999 -9999 -9999 -9999 -9999 -9999 -9999 -9999 -9999 -9999 -9999 -9999 -9999 -9999 -9999 -9999 -9999 -9999 -9999 -9999 -9999 -9999 -9999 -9999 -9999 -9999 -9999 -9999 -9999 -9999 -9999 -9999 -9999 -9999 -9999 -9999 -9999 -9999 -9999 -9999 -9999 -9999 -9999 -9999 -9999 -9999 -9999 -9999 -9999 -9999 -9999 -9999 -9999 -9999 -9999 -9999 -9999 -9999 -9999 -9999 -9999 -9999 -9999 -9999 -9999 -9999 -9999 -9999 -9999 -9999 -9999 -

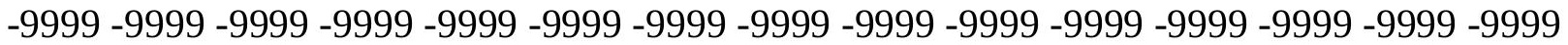
-9999 -9999 -9999 -9999 -9999 -9999 -9999 -9999 -9999 -9999 -9999 -9999 -9999 -9999 -9999 -9999 -9999 -9999 -9999 -9999 -9999 -9999 -9999 -9999 -9999 -9999 -9999 -9999 -9999 -9999 -

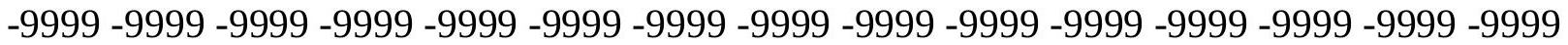
-9999 -9999 -9999 -9999 -9999 -9999 -9999 -9999 -9999 -9999 -9999 -9999 -9999 -9999 -9999 -9999 -9999 -9999 -9999 -9999 -9999 -9999 -9999 -9999 -9999 -9999 -9999 -9999 -9999 -9999 -9999 -9999 -9999 -9999 -9999 -9999 -9999 -9999 -9999 -9999 -9999 -9999 -9999 -9999 -9999 -9999 -9999 -9999 -9999 -9999 -9999 -9999 -9999 -9999 -9999 -9999 -9999 -9999 -9999 -9999 -9999 -9999 -9999 -9999 -9999 -9999 -9999 -9999 -9999 -9999 -9999 -9999 -9999 -9999 -9999 -9999 -9999 -9999 -9999 -9999 -9999 -9999 -9999 -9999 -9999 -9999 -9999 -9999 -9999 -9999 -9999 -9999 -9999 -9999 -9999 -9999 -9999 -9999 -9999 -9999 -9999 -9999 -9999 -9999 -9999 -9999 -9999 -9999 -9999 -9999 -9999 -9999 -9999 -9999 -9999 -9999 -9999 -9999 -9999 -9999 -9999 -9999 -9999 -9999 -9999 -9999 -9999 -9999 -9999 -9999 -9999 -9999 -9999 -9999 -9999

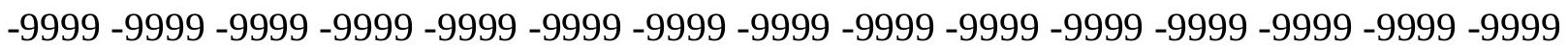
-9999 -9999 -9999 -9999 -9999 -9999 -9999 -9999 -9999 -9999 -9999 -9999 -9999 -9999 -9999 -9999 -9999 -9999 -9999 -9999 -9999 -9999 -9999 -9999 -9999 -9999 -9999 -9999 -9999 -9999 -9999 -9999 -9999 -9999 -9999 -9999 -9999 -9999 -9999 -9999 -9999 -9999 -9999 -9999 -9999

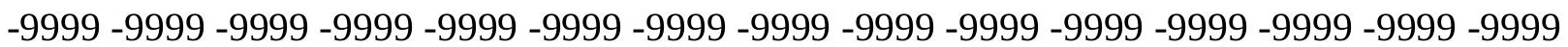
-9999 -9999 -9999 -9999 -9999 -9999 -9999 -9999 -9999 -9999 -9999 -9999 -9999 -9999 -9999 -9999 -9999 -9999 -9999 -9999 -9999 -9999 -9999 -9999 -9999 -9999 -9999 -9999 -9999 -9999 -9999 -9999 -9999 -9999 -9999 -9999 -9999 -9999 -9999 -9999 -9999 -9999 -9999 -9999

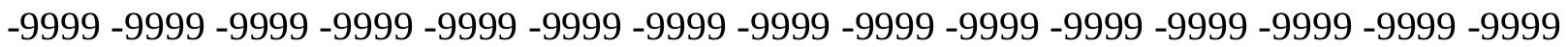
-9999 -9999 -9999 -9999 -9999 -9999 -9999 -9999 -9999 -9999 -9999 -9999 -9999 -9999 -9999 -9999 -9999 -9999 -9999 -9999 -9999 -9999 -9999 -9999 -9999 -9999 -9999 -9999 -9999 -9999 -

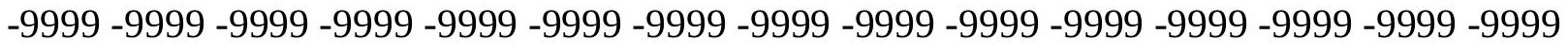
-9999 -9999 -9999 -9999 -9999 -9999 -9999 -9999 -9999 -9999 -9999 -9999 -9999 -9999 -9999 -9999 -9999 -9999 -9999 -9999 -9999 -9999 -9999 -9999 -9999 -9999 -9999 -9999 -9999 -9999 -9999 -9999 -9999 -9999 -9999 -9999 -9999 -9999 -9999 -9999 -9999 -9999 -9999 -9999 -9999 -9999 -9999 -9999 -9999 -9999 -9999 -9999 -9999 -9999 -9999 -9999 -9999 -9999 -9999 -9999 -9999 -9999 -9999 -9999 -9999 -9999 -9999 -9999 -9999 -9999 -9999 -9999 -9999 -9999 -9999

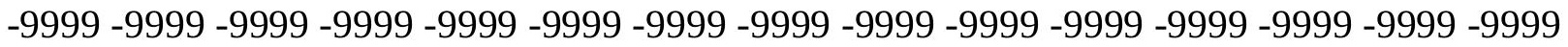
-9999 -9999 -9999 -9999 -9999 -9999 -9999 -9999 -9999 -9999 -9999 -9999 -9999 -9999 -9999 -9999 -9999 -9999 -9999 -9999 -9999 -9999 -9999 -9999 -9999 -9999 -9999 -9999 -9999 -9999 -

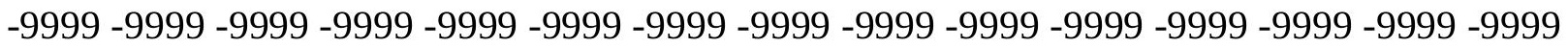
-9999 -9999 -9999 -9999 -9999 -9999 -9999 -9999 -9999 -9999 -9999 -9999 -9999 -9999 -9999 -9999 -9999 -9999 -9999 -9999 -9999 -9999 -9999 -9999 -9999 -9999 -9999 -9999 -9999 -9999 -9999 -9999 -9999 -9999 -9999 -9999 -9999 -9999 -9999 -9999 -9999 -9999 -9999 -9999 -9999 -9999 -9999 -9999 -9999 -9999 -9999 -9999 -9999 -9999 -9999 -9999 -9999 -9999 -9999 -9999

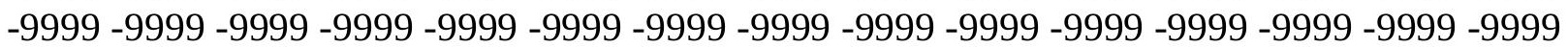


-9999 -9999 -9999 -9999 -9999 -9999 -9999 -9999 -9999 -9999 -9999 -9999 -9999 -9999 -9999 -9999 -9999 -9999 -9999 -9999 -9999 -9999 -9999 -9999 -9999 -9999 -9999 -9999 -9999 -9999 -

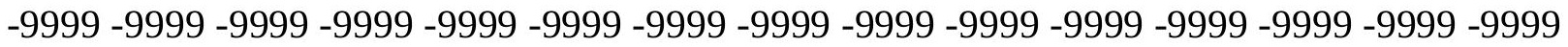
-9999 -9999 -9999 -9999 -9999 -9999 -9999 -9999 -9999 -9999 -9999 -9999 -9999 -9999 -9999 -9999 -9999 -9999 -9999 -9999 -9999 -9999 -9999 -9999-9999 -9999 -9999 -9999 -9999 -9999 -9999 -9999 -9999 -9999 -9999 -9999 -9999 -9999 -9999 -9999 -9999 -9999 -9999 -9999 -9999 -9999 -9999 -9999 -9999 -9999 -9999 -9999 -9999 -9999 -9999 -9999 -9999 -9999 -9999 -

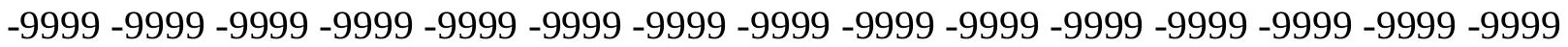

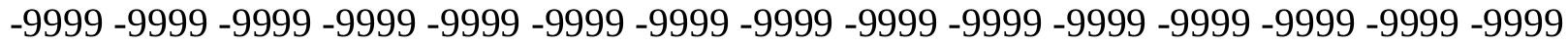
-9999 -9999 -9999 -9999 -9999 -9999 -9999 -9999 -9999 -9999 -9999 -9999 -9999 -9999 -9999 -9999 -9999 -9999 -9999 -9999 -9999 -9999 -9999 -9999 -9999 -9999 -9999 -9999 -9999 -9999 -9999 -9999 -9999 -9999 -9999 -9999 -9999 -9999 -9999 -9999 -9999 -9999 -9999 -9999 -9999 -9999 -9999 -9999 -9999 -9999 -9999 -9999 -9999 -9999 -9999 -9999 -9999 -9999 -9999 -9999 -9999 -9999 -9999 -9999 -9999 -9999 -9999 -9999 -9999 -9999 -9999 -9999 -9999 -9999 -9999 -9999 -9999 -9999 -9999 -9999 -9999 -9999 -9999 -9999 -9999 -9999 -9999 -9999 -9999 -9999 -

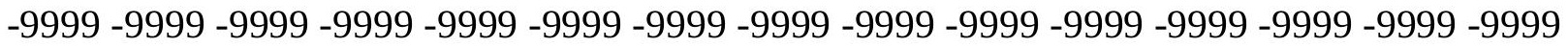
-9999 -9999 -9999 -9999 -9999 -9999 -9999 -9999 -9999 -9999 -9999 -9999 -9999 -9999 -9999 -9999 -9999 -9999 -9999 -9999 -9999 -9999 -9999 -9999 -9999 -9999 -9999 -9999 -9999 -9999 -9999 -9999 -9999 -9999 -9999 -9999 -9999 -9999 -9999 -9999 -9999 -9999 -9999 -9999 -9999 -

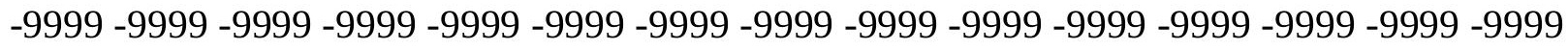

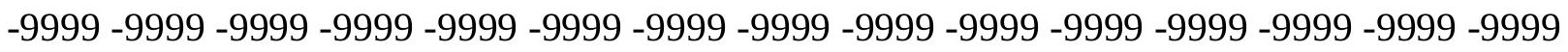

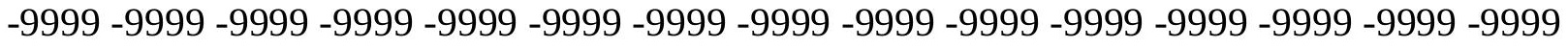
-9999 -9999 -9999 -9999 -9999 -9999 -9999 -9999 -9999 -9999 -9999 -9999 -9999 -9999 -9999 -9999 -9999 -9999 -9999 -9999 -9999 -9999 -9999 -9999 -9999 -9999 -9999 -9999 -9999 -9999 -

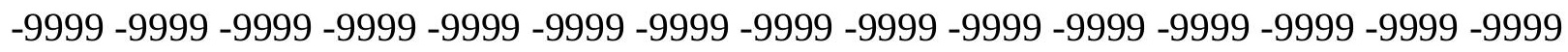
-9999 -9999 -9999 -9999 -9999 -9999 -9999 -9999 -9999 -9999 -9999 -9999 -9999 -9999 -9999 -9999 -9999 -9999 -9999 -9999 -9999 -9999 -9999 -9999 -9999 -9999 -9999 -9999 -9999 -9999 -

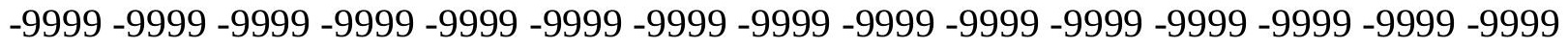
-9999 -9999 -9999 -9999 -9999 -9999 -9999 -9999 -9999 -9999 -9999 -9999 -9999 -9999 -9999 -9999 -9999 -9999 -9999 -9999 -9999 -9999 -9999 -9999 -9999 -9999 -9999 -9999 -9999 -999 -9999 -9999 -9999 -9999 -9999 -9999 -9999 -9999 -9999 -9999 -9999 -9999 -9999 -9999 -9999 -

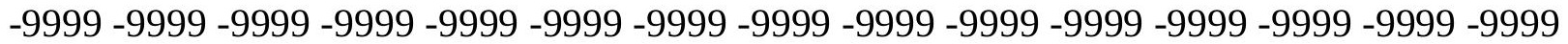

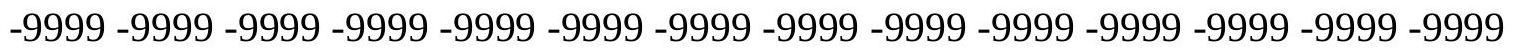

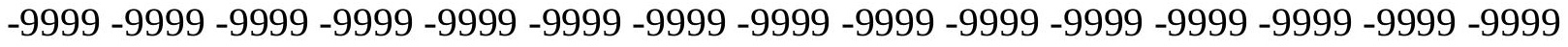

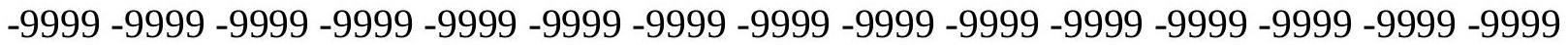

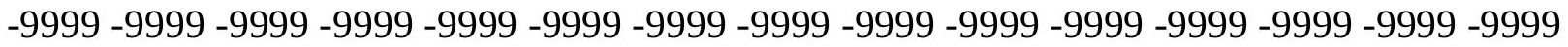

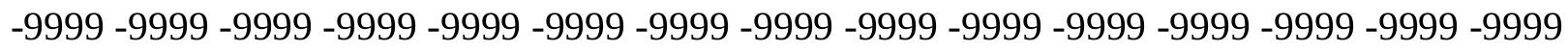

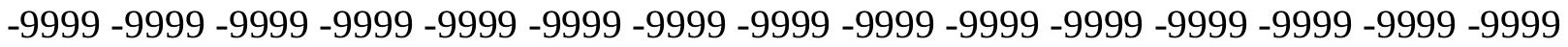

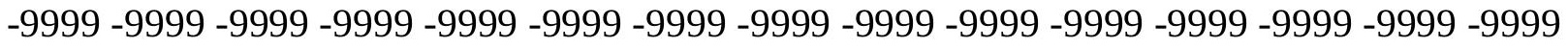
-9999 -9999 -9999 -9999 -9999 -9999 -9999 -9999 -9999 -9999 -9999 -9999 -9999 -9999 -9999 -

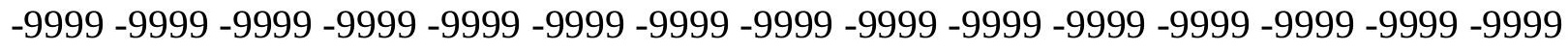

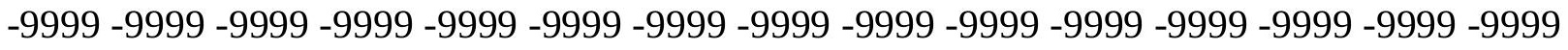
-9999 -9999 -9999 -9999 -9999 -9999 -9999 -9999 -9999 -9999 -9999 -9999 -9999 -9999 -9999 -9999 -9999 -9999 -9999 -9999 -9999 -9999 -9999 -9999-9999 -9999 -9999 -9999 -9999 -9999 -9999 -9999 -9999 -9999 -9999 -9999 -9999 -9999 -9999 -9999 -9999 -9999 -9999 -9999 -9999 -

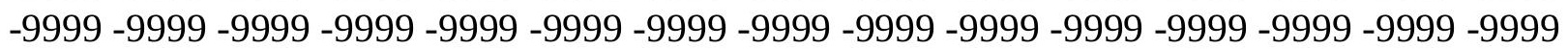


-9999 -9999 -9999 -9999 -9999 -9999 -9999 -9999 -9999 -9999 -9999 -9999 -9999 -9999 -9999 -9999 -9999 -9999 -9999 -9999 -9999 -9999 -9999 -9999 -9999 -9999 -9999 -9999 -9999 -9999 -

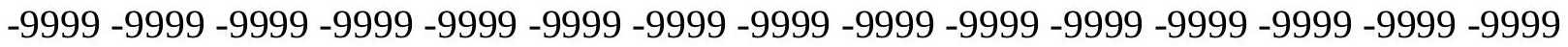
-9999 -9999 -9999 -9999 -9999 -9999 -9999 -9999 -9999 -9999 -9999 -9999 -9999 -9999 -9999 -9999 -9999 -9999 -9999 -9999 -9999 -9999 -9999 -9999-9999 -9999 -9999 -9999 -9999 -9999 -9999 -9999 -9999 -9999 -9999 -9999 -9999 -9999 -9999 -9999 -9999 -9999 -9999 -9999 -9999 -9999 -9999 -9999 -9999 -9999 -9999 -9999 -9999 -9999 -9999 -9999 -9999 -9999 -9999 -9999

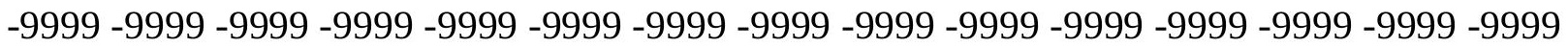

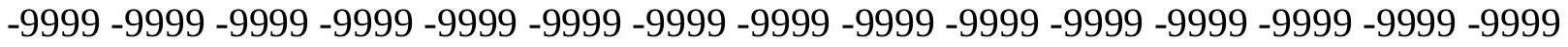
-9999 -9999 -9999 -9999 -9999 -9999 -9999 -9999 -9999 -9999 -9999 -9999 -9999 -9999 -9999 -9999 -9999 -9999 -9999 -9999 -9999 -9999 -9999 -9999 -9999 -9999 -9999 -9999 -9999 -9999 -9999 -9999 -9999 -9999 -9999 -9999 -9999 -9999 -9999 -9999 -9999 -9999 -9999 -9999 -9999 -9999 -9999 -9999 -9999 -9999 -9999 -9999 -9999 -9999 -9999 -9999 -9999 -9999 -9999 -9999 -9999 -9999 -9999 -9999 -9999 -9999 -9999 -9999 -9999 -9999 -9999 -9999 -9999 -9999 -9999 -9999 -9999 -9999 -9999 -9999 -9999 -9999 -9999 -9999 -9999 -9999 -9999 -9999 -9999 -

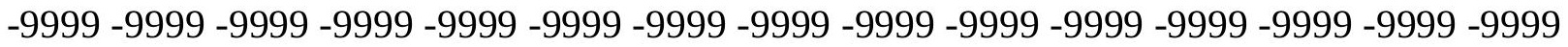
-9999 -9999 -9999 -9999 -9999 -9999 -9999 -9999 -9999 -9999 -9999 -9999 -9999 -9999 -9999 -9999 -9999 -9999 -9999 -9999 -9999 -9999 -9999 -9999 -9999 -9999 -9999 -9999 -9999 -9999 -9999 -9999 -9999 -9999 -9999 -9999 -9999 -9999 -9999 -9999 -9999 -9999 -9999 -9999 -9999 -

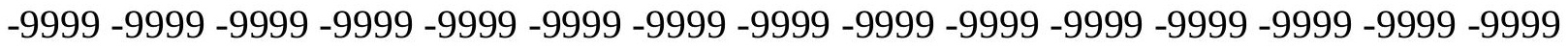
-9999 -9999 -9999 -9999 -9999 -9999 -9999 -9999 -9999 -9999 -9999 -9999 -9999 -9999 -9999

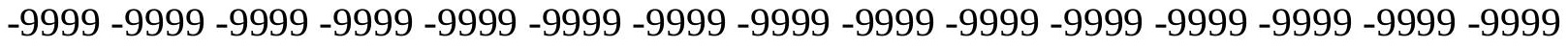
-9999 -9999 -9999 -9999 -9999 -9999 -9999 -9999 -9999 -9999 -9999 -9999 -9999 -9999 -9999 -9999 -9999 -9999 -9999 -9999 -9999 -9999 -9999 -9999 -9999 -9999 -9999 -9999 -9999 -9999 -

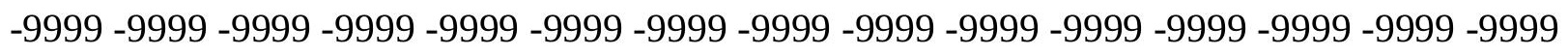
-9999 -9999 -9999 -9999 -9999 -9999 -9999 -9999 -9999 -9999 -9999 -9999 -9999 -9999 -9999 -9999 -9999 -9999 -9999 -9999 -9999 -9999 -9999 -9999 -9999 -9999 -9999 -9999 -9999 -9999 -

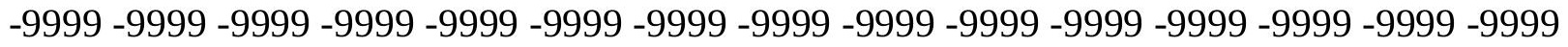
-9999 -9999 -9999 -9999 -9999 -9999 -9999 -9999 -9999 -9999 -9999 -9999 -9999 -9999 -9999 -9999 -9999 -9999 -9999 -9999 -9999 -9999 -9999 -9999 -9999 -9999 -9999 -9999 -9999 -999 -9999 -9999 -9999 -9999 -9999 -9999 -9999 -9999 -9999 -9999 -9999 -9999 -9999 -9999 -9999 -9999 -9999 -9999 -9999 -9999 -9999 -9999 -9999 -9999 -9999 -9999 -9999 -9999 -9999 -9999 -

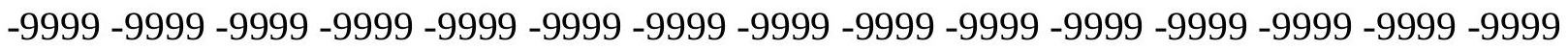

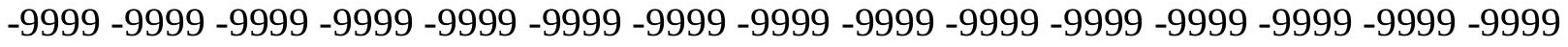

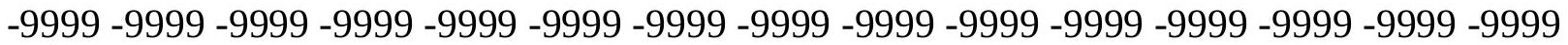
-9999 -9999 -9999 -9999 -9999 -9999 -9999 -9999 -9999 -9999 -9999 -9999 -9999 -9999 -9999 -

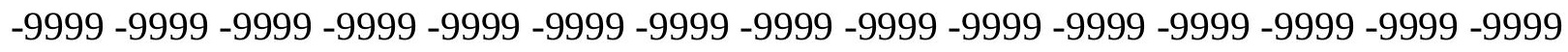

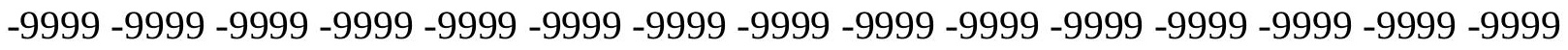
-9999 -9999 -9999 -9999 -9999 -9999 -9999 -9999 -9999 -9999 -9999 -9999 -9999 -9999 - -999 -9999 -9999 -9999 -9999 -9999 -9999 -9999 -9999 -9999 -9999 -9999 -9999 -9999 -9999 -9999 -

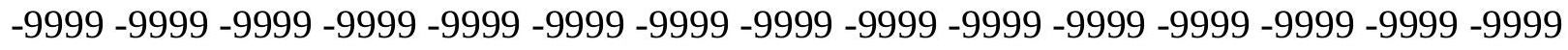

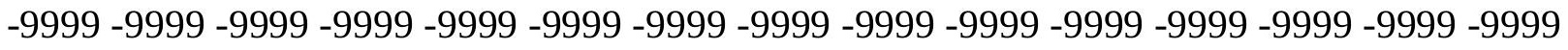
-9999 -9999 -9999 -9999 -9999 -9999 -9999 -9999 -9999 -9999 -9999 -9999 -9999 -9999 -9999 -9999 -9999 -9999 -9999 -9999 -9999 -9999 -9999 -9999-9999 -9999 -9999 -9999 -9999 -9999 -9999 -9999 -9999 -9999 -9999 -9999 -9999 -9999 -9999 -9999 -9999 -9999 -9999 -9999 -9999 -

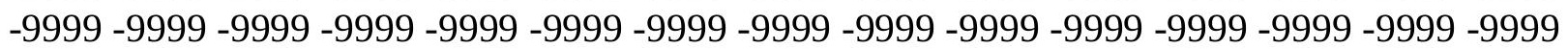


-9999 -9999 -9999 -9999 -9999 -9999 -9999 -9999 -9999 -9999 -9999 -9999 -9999 -9999 -9999 -9999 -9999 -9999 -9999 -9999 -9999 -9999 -9999 -9999 -9999 -9999 -9999 -9999 -9999 -9999 -

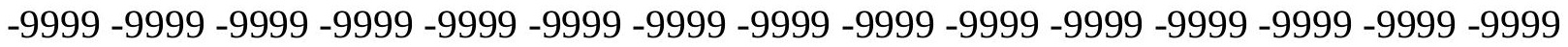
-9999 -9999 -9999 -9999 -9999 -9999 -9999 -9999 -9999 -9999 -9999 -9999 -9999 -9999 -9999 -9999 -9999 -9999 -9999 -9999 -9999 -9999 -9999 -9999-9999 -9999 -9999 -9999 -9999 -9999 -9999 -9999 -9999 -9999 -9999 -9999 -9999 -9999 -9999 -9999 -9999 -9999 -9999 -9999 -9999 -9999 -9999 -9999 -9999 -9999 -9999 -9999 -9999 -9999 -9999 -9999 -9999 -9999 -9999 -9999

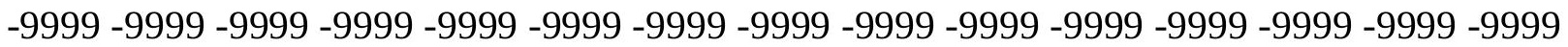

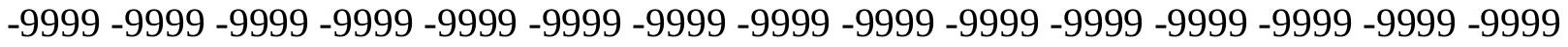
-9999 -9999 -9999 -9999 -9999 -9999 -9999 -9999 -9999 -9999 -9999 -9999 -9999 -9999 -9999 -9999 -9999 -9999 -9999 -9999 -9999 -9999 -9999 -9999 -9999 -9999 -9999 -9999 -9999 -9999 -9999 -9999 -9999 -9999 -9999 -9999 -9999 -9999 -9999 -9999 -9999 -9999 -9999 -9999 -9999 -9999 -9999 -9999 -9999 -9999 -9999 -9999 -9999 -9999 -9999 -9999 -9999 -9999 -9999 -9999 -

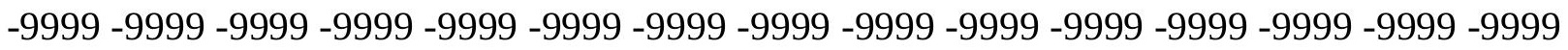
-9999 -9999 -9999 -9999 -9999 -9999 -9999 -9999 -9999 -9999 -9999 -9999 -9999 -9999 -9999 -

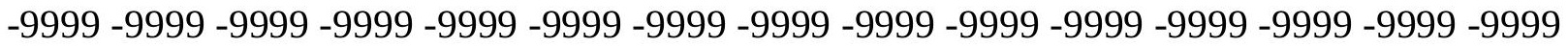
-9999 -9999 -9999 -9999 -9999 -9999 -9999 -9999 -9999 -9999 -9999 -9999 -9999 -9999 -9999 -9999 -9999 -9999 -9999 -9999 -9999 -9999 -9999 -9999 -9999 -9999 -9999 -9999 -9999 -9999 -9999 -9999 -9999 -9999 -9999 -9999 -9999 -9999 -9999 -9999 -9999 -9999 -9999 -9999 - -999 -

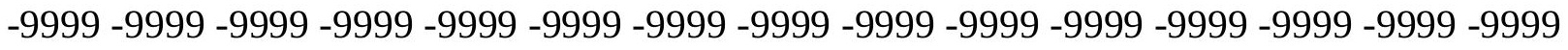

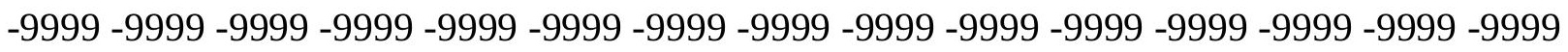
-9999 -9999 -9999 -9999 -9999 -9999 -9999 -9999 -9999 -9999 -9999 -9999 -9999 -9999 -9999 -9999 -9999 -9999 -9999 -9999 -9999 -9999 -9999 -9999 -9999 -9999 -9999 -9999 -9999 -9999 -9999 -9999 -9999 -9999 -9999 -9999 -9999 -9999 -9999 -9999 -9999 -9999 -9999 -9999 -9999 -

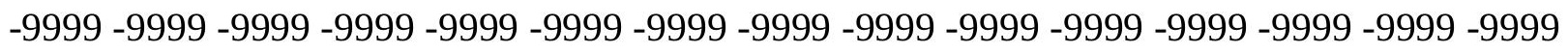
-9999 -9999 -9999 -9999 -9999 -9999 -9999 -9999 -9999 -9999 -9999 -9999 -9999 -9999 -9999 -9999 -9999 -9999 -9999 -9999 -9999 -9999 -9999 -9999 -9999 -9999 -9999 -9999 -9999 -9999 -

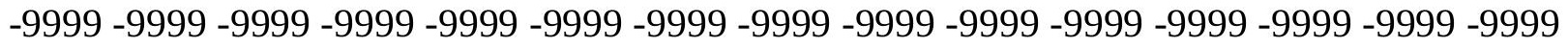
-9999 -9999 -9999 -9999 -9999 -9999 -9999 -9999 -9999 -9999 -9999 -9999 -9999 -9999 -9999 -9999 -9999 -9999 -9999 -9999 -9999 -9999 -9999 -9999 -9999 -9999 -9999 -9999 -9999 -999 -

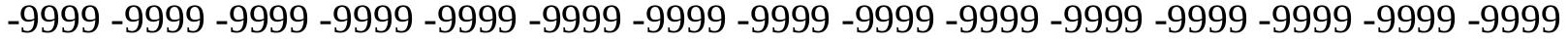
-9999 -9999 -9999 -9999 -9999 -9999 -9999 -9999 -9999 -9999 -9999 -9999 -9999 -9999 -9999 -

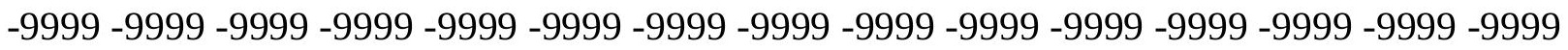

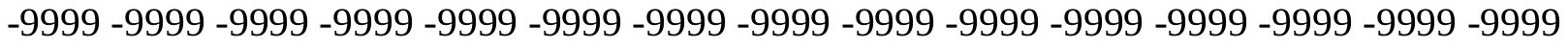

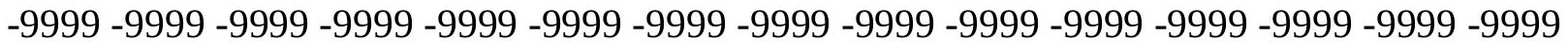

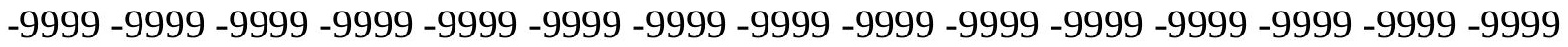

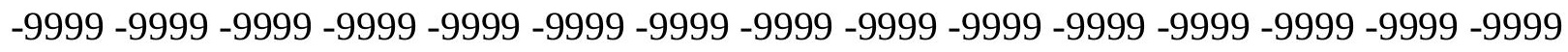

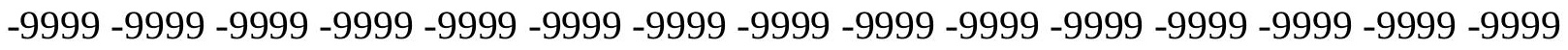

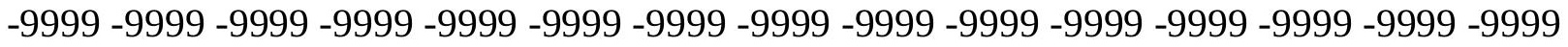
-9999 -9999 -9999 -9999 -9999 -9999 -9999 -9999 -9999 -9999 -9999 -9999 -9999 -9999 -9999 -

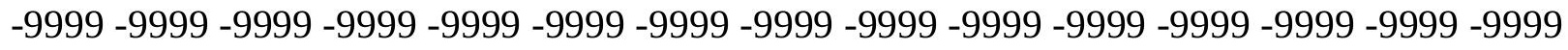

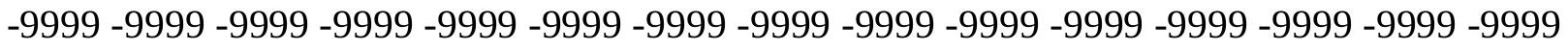
-9999 -9999 -9999 -9999 -9999 -9999 -9999 -9999 -9999 -9999 -9999 -9999 -9999 -9999 -9999 -9999 -9999 -9999 -9999 -9999 -9999 -9999 -9999 -9999 -9999 -9999 -9999 -9999 -9999 -9999 -9999 -9999 -9999 -9999 -9999 -9999 -9999 -9999 -9999 -9999 -9999 -9999 -9999 -9999 -

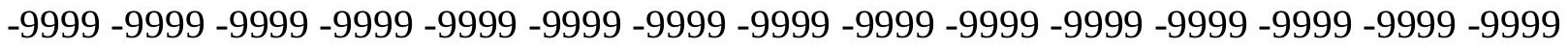


-9999 -9999 -9999 -9999 -9999 -9999 -9999 -9999 -9999 -9999 -9999 -9999 -9999 -9999 -9999 -9999 -9999 -9999 -9999 -9999 -9999 -9999 -9999 -9999 -9999 -9999 -9999 -9999 -9999 -9999 -

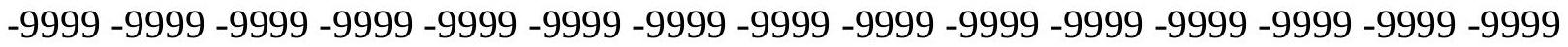
-9999 -9999 -9999 -9999 -9999 -9999 -9999 -9999 -9999 -9999 -9999 -9999 -9999 -9999 -9999 -9999 -9999 -9999 -9999 -9999 -9999 -9999 -9999 -9999-9999 -9999 -9999 -9999 -9999 -9999 -9999 -9999 -9999 -9999 -9999 -9999 -9999 -9999 -9999 -9999 -9999 -9999 -9999 -9999 -9999 -9999 -9999 -9999 -9999 -9999 -9999 -9999 -9999 -9999 -9999 -9999 -9999 -9999 -9999 -9999

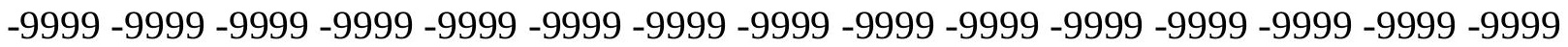

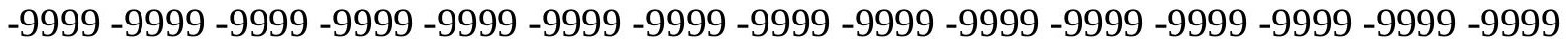
-9999 -9999 -9999 -9999 -9999 -9999 -9999 -9999 -9999 -9999 -9999 -9999 -9999 -9999 -9999 -9999 -9999 -9999 -9999 -9999 -9999 -9999 -9999 -9999 -9999 -9999 -9999 -9999 -9999 -9999 -9999 -9999 -9999 -9999 -9999 -9999 -9999 -9999 -9999 -9999 -9999 -9999 -9999 -9999 -9999 -9999 -9999 -9999 -9999 -9999 -9999 -9999 -9999 -9999 -9999 -9999 -9999 -9999 -9999 -9999 -

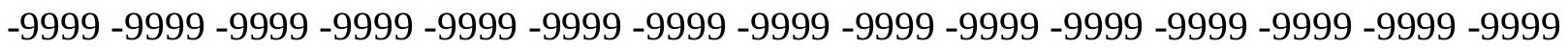
-9999 -9999 -9999 -9999 -9999 -9999 -9999 -9999 -9999 -9999 -9999 -9999 -9999 -9999 -9999 -

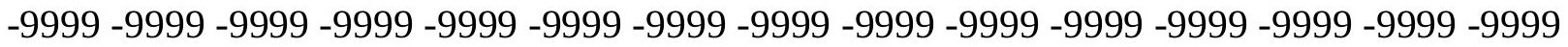
-9999 -9999 -9999 -9999 -9999 -9999 -9999 -9999 -9999 -9999 -9999 -9999 -9999 -9999 -9999 -9999 -9999 -9999 -9999 -9999 -9999 -9999 -9999 -9999 -9999 -9999 -9999 -9999 -9999 - 9999 -9999 -9999 -9999 -9999 -9999 -9999 -9999 -9999 -9999 -9999 -9999 -9999 -9999 -9999 -9999 -

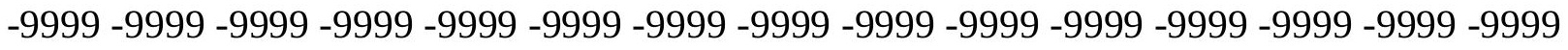

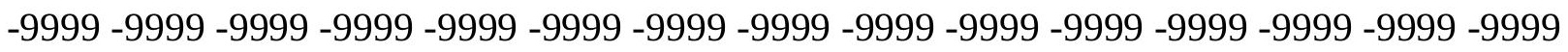
-9999 -9999 -9999 -9999 -9999 -9999 -9999 -9999 -9999 -9999 -9999 -9999 -9999 -9999 - 9999 -9999 -9999 -9999 -9999 -9999 -9999 -9999 -9999 -9999 -9999 -9999 -9999 -9999 -9999 -9999 -9999 -9999 -9999 -9999 -9999 -9999 -9999 -9999 -9999 -9999 -9999 -9999 -9999 -9999 -9999 -9999 -9999 -9999 -9999 -9999 -9999 -9999 -9999 -9999 -9999 -9999 -9999 -9999 -9999 -9999 -9999 -9999 -9999 -9999 -9999 -9999 -9999 -9999 -9999 -9999 -9999 -9999 -9999 -9999 -9999 -9999 -9999 -9999 -9999 -9999 -9999 -9999 -9999 -9999 -9999 -9999 -9999 -9999 -9999 -

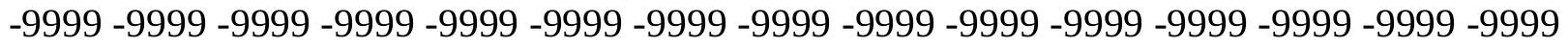
-9999 -9999 -9999 -9999 -9999 -9999 -9999 -9999 -9999 -9999 -9999 -9999 -9999 -9999 -9999 -9999 -9999 -9999 -9999 -9999 -9999 -9999 -9999 -9999 -9999 -9999 -9999 -9999 -9999 -999 -9999 -9999 -9999 -9999 -9999 -9999 -9999 -9999 -9999 -9999 -9999 -9999 -9999 -9999 -9999 -9999 -9999 -9999 -9999 -9999 -9999 -9999 -9999 -9999 -9999 -9999 -9999 -9999 -9999 -9999 -

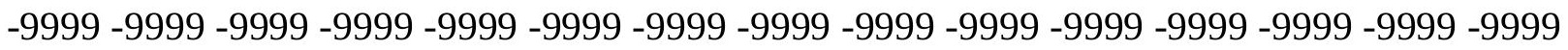

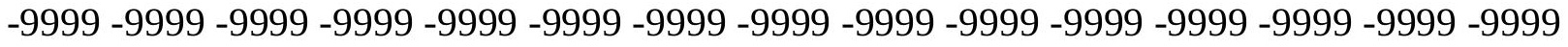

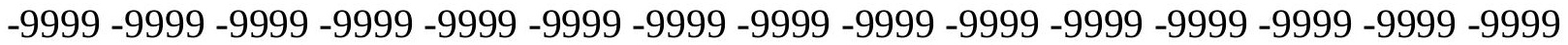

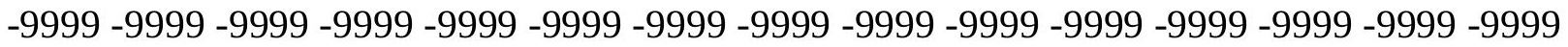

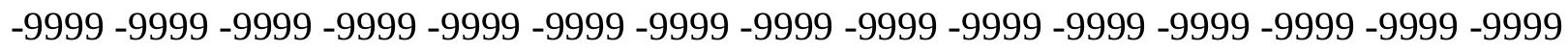

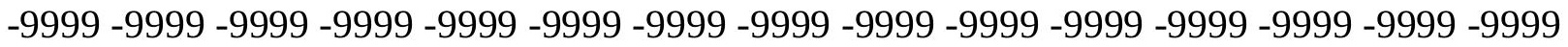

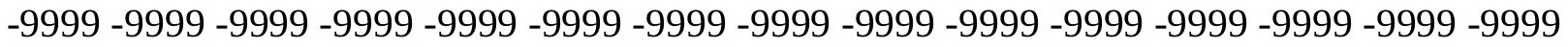
-9999 -9999 -9999 -9999 -9999 -9999 -9999 -9999 -9999 -9999 -9999 -9999 -9999 -9999 -9999 -

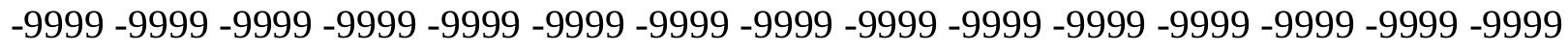

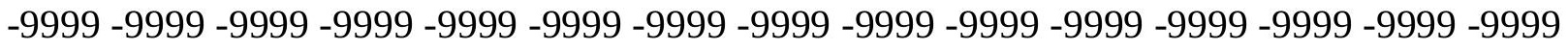
-9999 -9999 -9999 -9999 -9999 -9999 -9999 -9999 -9999 -9999 -9999 -9999 -9999 -9999 -9999 -9999 -9999 -9999 -9999 -9999 -9999 -9999 -9999 -9999-9999 -9999 -9999 -9999 -9999 -9999 -9999 -9999 -9999 -9999 -9999 -9999 -9999 -9999 -9999 -9999 -9999 -9999 -9999 -9999 -9999 -

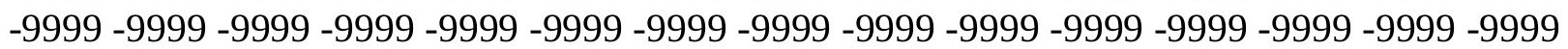


-9999 -9999 -9999 -9999 -9999 -9999 -9999 -9999 -9999 -9999 -9999 -9999 -9999 -9999 -9999 -9999 -9999 -9999 -9999 -9999 -9999 -9999 -9999 -9999 -9999 -9999 -9999 -9999 -9999 -9999 -9999 -9999 -9999 -9999 -9999 -9999 -9999 -9999 -9999 -9999 -9999 -9999 -9999 -9999 - 9999 -9999 -9999 -9999 -9999 -9999 -9999 -9999 -9999 -9999 -9999 -9999 -9999 -9999 -9999 -9999 -9999 -9999 -9999 -9999 -9999 -9999 -9999 -9999 -9999 -9999 -9999 -9999 -9999 -9999 -9999 -9999 -9999 -9999 -9999 -9999 -9999 -9999 -9999 -9999 -9999 -9999 -9999 -9999 -9999 -9999 -9999 -9999 -9999 -9999 -9999 -9999 -9999 -9999 -9999 -9999 -9999 -9999 -9999 -9999

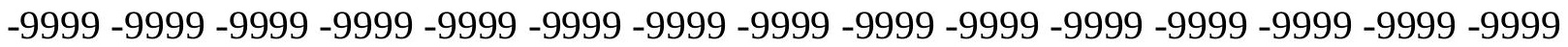

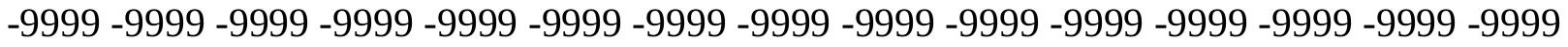
-9999 -9999 -9999 -9999 -9999 -9999 -9999 -9999 -9999 -9999 -9999 -9999 -9999 -9999 -9999 -9999 -9999 -9999 -9999 -9999 -9999 -9999 -9999 -9999 -9999 -9999 -9999 -9999 -9999 -9999 -9999 -9999 -9999 -9999 -9999 -9999 -9999 -9999 -9999 -9999 -9999 -9999 -9999 -9999 -9999 -9999 -9999 -9999 -9999 -9999 -9999 -9999 -9999 -9999 -9999 -9999 -9999 -9999 -9999 -9999 -9999 -9999 -9999 -9999 -9999 -9999 -9999 -9999 -9999 -9999 -9999 -9999 -9999 -9999 -9999 -9999 -9999 -9999 -9999 -9999 -9999 -9999 -9999 -9999 -9999 -9999 -9999 -9999 -9999 -9999 -

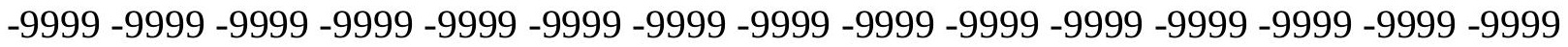
-9999 -9999 -9999 -9999 -9999 -9999 -9999 -9999 -9999 -9999 -9999 -9999 -9999 -9999 -9999 -9999 -9999 -9999 -9999 -9999 -9999 -9999 -9999 -9999 -9999 -9999 -9999 -9999 -9999 - 9999 -9999 -9999 -9999 -9999 -9999 -9999 -9999 -9999 -9999 -9999 -9999 -9999 -9999 -9999 -9999 -

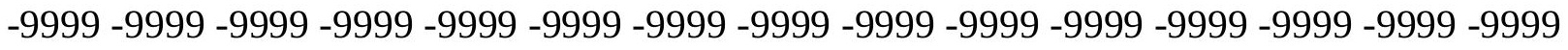

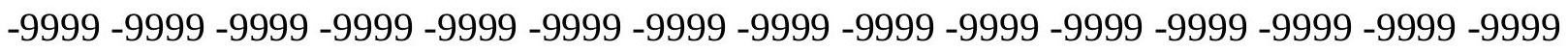

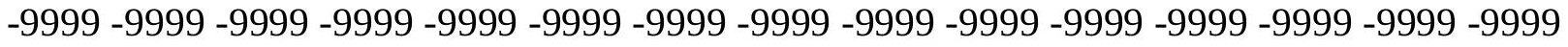
-9999 -9999 -9999 -9999 -9999 -9999 -9999 -9999 -9999 -9999 -9999 -9999 -9999 -9999 -9999 -9999 -9999 -9999 -9999 -9999 -9999 -9999 -9999 -9999 -9999 -9999 -9999 -9999 -9999 -9999 -

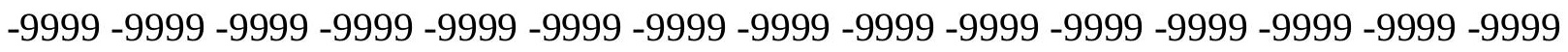
-9999 -9999 -9999 -9999 -9999 -9999 -9999 -9999 -9999 -9999 -9999 -9999 -9999 -9999 -9999 -9999 -9999 -9999 -9999 -9999 -9999 -9999 -9999 -9999 -9999 -9999 -9999 -9999 -9999 -9999 -

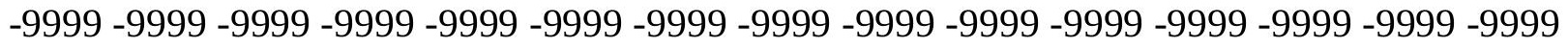
-9999 -9999 -9999 -9999 -9999 -9999 -9999 -9999 -9999 -9999 -9999 -9999 -9999 -9999 -9999 -9999 -9999 -9999 -9999 -9999 -9999 -9999 -9999 -9999 -9999 -9999 -9999 -9999 -9999 -999 -9999 -9999 -9999 -9999 -9999 -9999 -9999 -9999 -9999 -9999 -9999 -9999 -9999 -9999 -9999 -9999 -9999 -9999 -9999 -9999 -9999 -9999 -9999 -9999 -9999 -9999 -9999 -9999 -9999 -

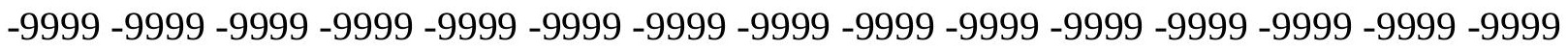

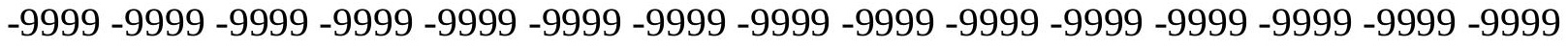

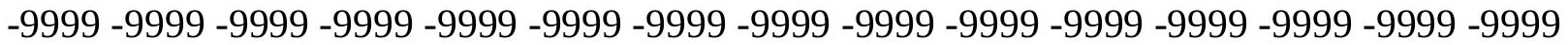

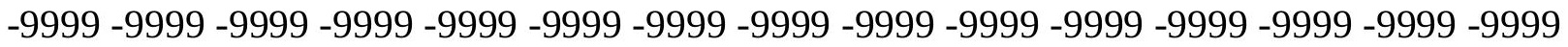

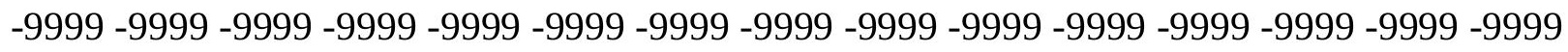

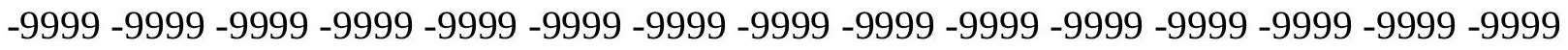

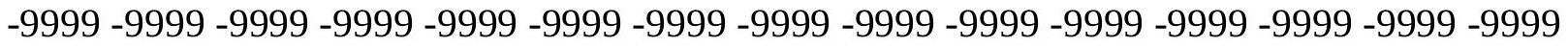
-9999 -9999 -9999 -9999 -9999 -9999 -9999 -9999 -9999 -9999 -9999 -9999 -9999 -9999 -9999 -

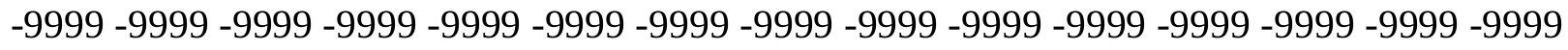

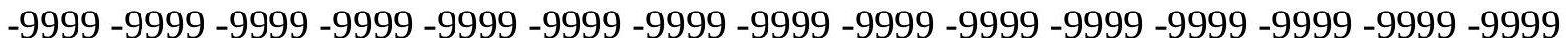
-9999 -9999 -9999 -9999 -9999 -9999 -9999 -9999 -9999 -9999 -9999 -9999 -9999 -9999 -9999 -9999 -9999 -9999 -9999 -9999 -9999 -9999 -9999 -9999-9999 -9999 -9999 -9999 -9999 -9999 -9999 -9999 -9999 -9999 -9999 -9999 -9999 -9999 -9999 -9999 -9999 -9999 -9999 -9999 -9999 -

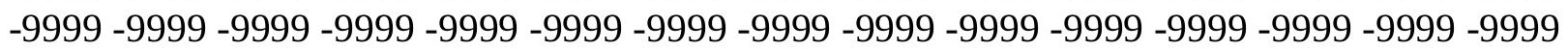


-9999 -9999 -9999 -9999 -9999 -9999 -9999 -9999 -9999 -9999 -9999 -9999 -9999 -9999 -9999 -9999 -9999 -9999 -9999 -9999 -9999 -9999 -9999 -9999 -9999 -9999 -9999 -9999 -9999 -9999 -

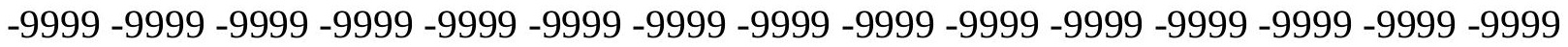
-9999 -9999 -9999 -9999 -9999 -9999 -9999 -9999 -9999 -9999 -9999 -9999 -9999 -9999 -9999 -9999 -9999 -9999 -9999 -9999 -9999 -9999 -9999 -9999-9999 -9999 -9999 -9999 -9999 -9999 -9999 -9999 -9999 -9999 -9999 -9999 -9999 -9999 -9999 -9999 -9999 -9999 -9999 -9999 -9999 -9999 -9999 -9999 -9999 -9999 -9999 -9999 -9999 -9999 -9999 -9999 -9999 -9999 -9999 -9999

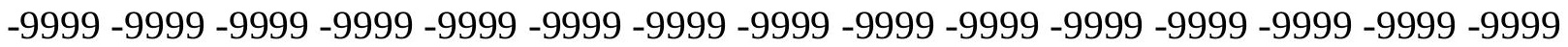

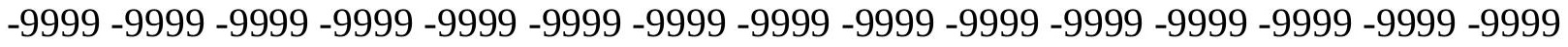

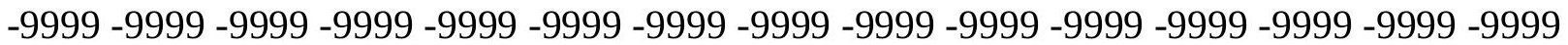
-9999 -9999 -9999 -9999 -9999 -9999 -9999 -9999 -9999 -9999 -9999 -9999 -9999 -9999 -9999 -9999 -9999 -9999 -9999 -9999 -9999 -9999 -9999 -9999 -9999 -9999 -9999 -9999 -9999 -9999 -9999 -9999 -9999 -9999 -9999 -9999 -9999 -9999 -9999 -9999 -9999 -9999 -9999 -9999 -

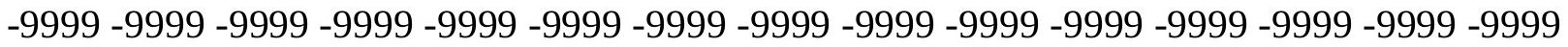
-9999 -9999 -9999 -9999 -9999 -9999 -9999 -9999 -9999 -9999 -9999 -9999 -9999 -9999 -9999 -

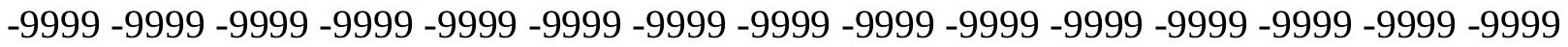
-9999 -9999 -9999 -9999 -9999 -9999 -9999 -9999 -9999 -9999 -9999 -9999 -9999 -9999 -9999 -9999 -9999 -9999 -9999 -9999 -9999 -9999 -9999 -9999 -9999 -9999 -9999 -9999 -9999 -9999 -9999 -9999 -9999 -9999 -9999 -9999 -9999 -9999 -9999 -9999 -9999 -9999 -9999 -9999 -9999 -

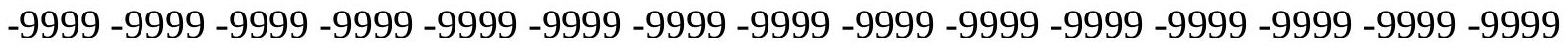

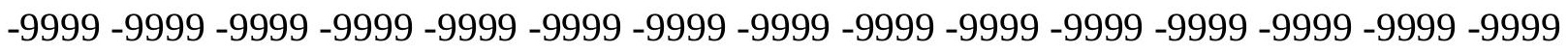
-9999 -9999 -9999 -9999 -9999 -9999 -9999 -9999 -9999 -9999 -9999 -9999 -9999 -9999 -9999 -9999 -9999 -9999 -9999 -9999 -9999 -9999 -9999 -9999 -9999 -9999 -9999 -9999 -9999 -9999 -9999 -9999 -9999 -9999 -9999 -9999 -9999 -9999 -9999 -9999 -9999 -9999 -9999 -9999 -9999 -

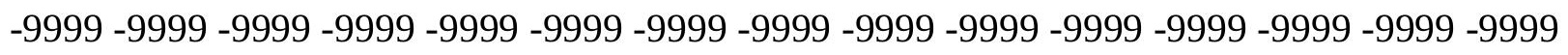
-9999 -9999 -9999 -9999 -9999 -9999 -9999 -9999 -9999 -9999 -9999 -9999 -9999 -9999 -9999 -9999 -9999 -9999 -9999 -9999 -9999 -9999 -9999 -9999 -9999 -9999 -9999 -9999 -9999 -9999 -

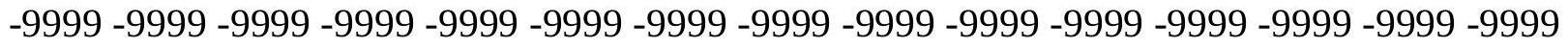
-9999 -9999 -9999 -9999 -9999 -9999 -9999 -9999 -9999 -9999 -9999 -9999 -9999 -9999 -9999 -9999 -9999 -9999 -9999 -9999 -9999 -9999 -9999 -9999 -9999 -9999 -9999 -9999 -9999 -999 -9999 -9999 -9999 -9999 -9999 -9999 -9999 -9999 -9999 -9999 -9999 -9999 -9999 -9999 -9999 -9999 -9999 -9999 -9999 -9999 -9999 -9999 -9999 -9999 -9999 -9999 -9999 -9999 -9999 -9999 -

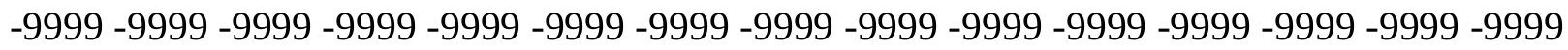

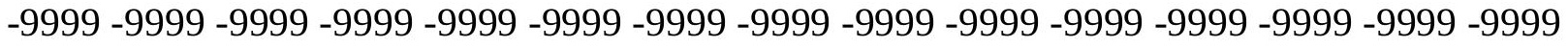

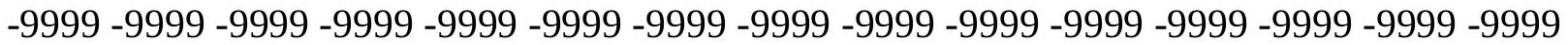
-9999 -9999 -9999 -9999 -9999 -9999 -9999 -9999 -9999 -9999 -9999 -9999 -9999 -9999 -9999 -

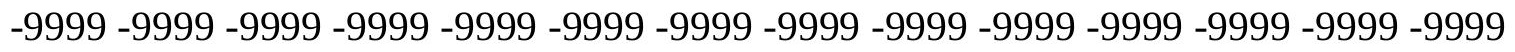

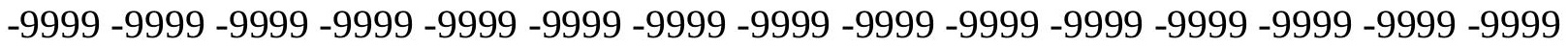
-9999 -9999 -9999 -9999 -9999 -9999 -9999 -9999 -9999 -9999 -9999 -9999 -9999 - 9999 - -999 -9999 -9999 -9999 -9999 -9999 -9999 -9999 -9999 -9999 -9999 -9999 -9999 -9999 -9999 -9999 -

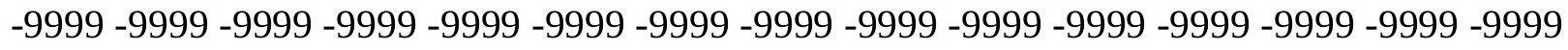

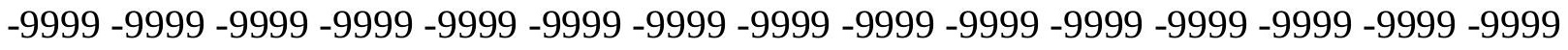
-9999 -9999 -9999 -9999 -9999 -9999 -9999 -9999 -9999 -9999 -9999 -9999 -9999 -9999 -9999 -9999 -9999 -9999 -9999 -9999 -9999 -9999 -9999 -9999-9999 -9999 -9999 -9999 -9999 -9999 -9999 -9999 -9999 -9999 -9999 -9999 -9999 -9999 -9999 -9999 -9999 -9999 -9999 -9999 -9999 -

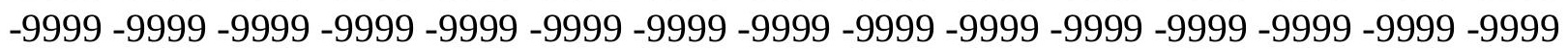


-9999 -9999 -9999 -9999 -9999 -9999 -9999 -9999 -9999 -9999 -9999 -9999 -9999 -9999 -9999 -9999 -9999 -9999 -9999 -9999 -9999 -9999 -9999 -9999 -9999 -9999 -9999 -9999 -9999 -9999 -

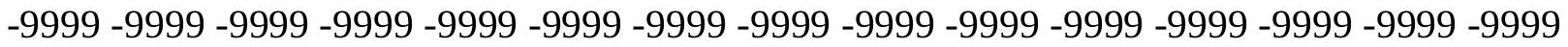
-9999 -9999 -9999 -9999 -9999 -9999 -9999 -9999 -9999 -9999 -9999 -9999 -9999 -9999 -9999 -9999 -9999 -9999 -9999 -9999 -9999 -9999 -9999 -9999-9999 -9999 -9999 -9999 -9999 -9999 -9999 -9999 -9999 -9999 -9999 -9999 -9999 -9999 -9999 -9999 -9999 -9999 -9999 -9999 -9999 -9999 -9999 -9999 -9999 -9999 -9999 -9999 -9999 -9999 -9999 -9999 -9999 -9999 -9999 -9999

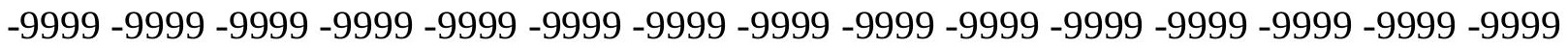

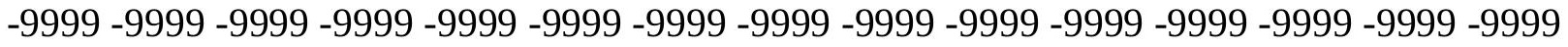
-9999 -9999 -9999 -9999 -9999 -9999 -9999 -9999 -9999 -9999 -9999 -9999 -9999 -9999 -9999 -9999 -9999 -9999 -9999 -9999 -9999 -9999 -9999 -9999 -9999 -9999 -9999 -9999 -9999 -9999 -9999 -9999 -9999 -9999 -9999 -9999 -9999 -9999 -9999 -9999 -9999 -9999 -9999 -9999 -9999 -9999 -9999 -9999 -9999 -9999 -9999 -9999 -9999 -9999 -9999 -9999 -9999 -9999 -9999 -9999 -9999 -9999 -9999 -9999 -9999 -9999 -9999 -9999 -9999 -9999 -9999 -9999 -9999 -9999 -9999 -9999 -9999 -9999 -9999 -9999 -9999 -9999 -9999 -9999 -9999 -9999 -9999 -9999 -9999 -9999 -

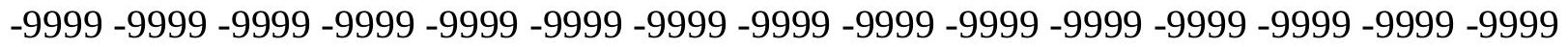
-9999 -9999 -9999 -9999 -9999 -9999 -9999 -9999 -9999 -9999 -9999 -9999 -9999 -9999 -9999 -9999 -9999 -9999 -9999 -9999 -9999 -9999 -9999 -9999 -9999 -9999 -9999 -9999 -9999 -9999 -9999 -9999 -9999 -9999 -9999 -9999 -9999 -9999 -9999 -9999 -9999 -9999 -9999 -9999 -

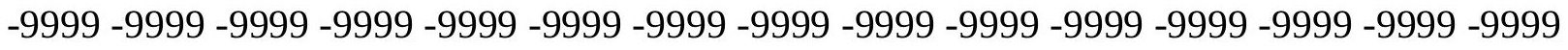
-9999 -9999 -9999 -9999 -9999 -9999 -9999 -9999 -9999 -9999 -9999 -9999 -9999 -9999 -9999 -999 -

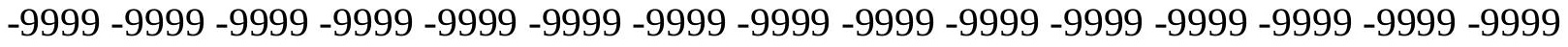
-9999 -9999 -9999 -9999 -9999 -9999 -9999 -9999 -9999 -9999 -9999 -9999 -9999 -9999 -9999 -9999 -9999 -9999 -9999 -9999 -9999 -9999 -9999 -9999 -9999 -9999 -9999 -9999 -9999 -9999 -9999 -9999 -9999 -9999 -9999 -9999 -9999 -9999 -9999 -9999 -9999 -9999 -9999 -9999 -9999 -9999 -9999 -9999 -9999 -9999 -9999 -9999 -9999 -9999 -9999 -9999 -9999 -9999 -9999 -9999 -9999 -9999 -9999 -9999 -9999 -9999 -9999 -9999 -9999 -9999 -9999 -9999 -9999 -9999 -9999 -

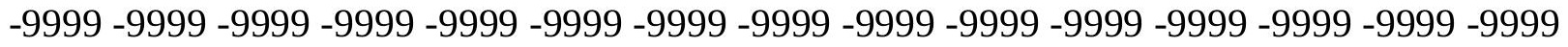
-9999 -9999 -9999 -9999 -9999 -9999 -9999 -9999 -9999 -9999 -9999 -9999 -9999 -9999 -9999 -9999 -9999 -9999 -9999 -9999 -9999 -9999 -9999 -9999 -9999 -9999 -9999 -9999 -9999 -999 -9999 -9999 -9999 -9999 -9999 -9999 -9999 -9999 -9999 -9999 -9999 -9999 -9999 -9999 -9999 -9999 -9999 -9999 -9999 -9999 -9999 -9999 -9999 -9999 -9999 -9999 -9999 -9999 -9999 -9999 -

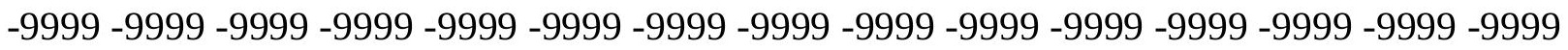

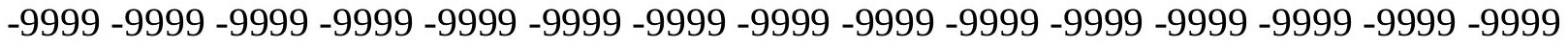

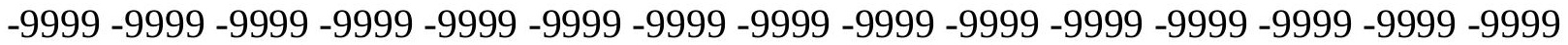
-9999 -9999 -9999 -9999 -9999 -9999 -9999 -9999 -9999 -9999 -9999 -9999 -9999 -9999 -9999

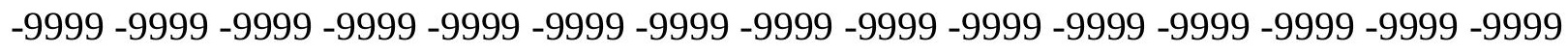

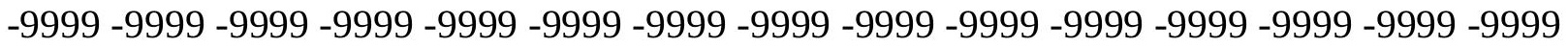
-9999 -9999 -9999 -9999 -9999 -9999 -9999 -9999 -9999 -9999 -9999 -9999 -9999 - 9999 - -999 -9999 -9999 -9999 -9999 -9999 -9999 -9999 -9999 -9999 -9999 -9999 -9999 -9999 -9999 -9999 -

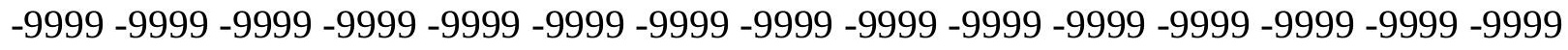

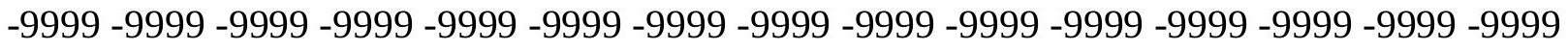
-9999 -9999 -9999 -9999 -9999 -9999 -9999 -9999 -9999 -9999 -9999 -9999 -9999 -9999 -9999 -9999 -9999 -9999 -9999 -9999 -9999 -9999 -9999 -9999 -9999 -9999 -9999 -9999 -9999 -9999 -9999 -9999 -9999 -9999 -9999 -9999 -9999 -9999 -9999 -9999 -9999 -9999 -9999 -9999 -

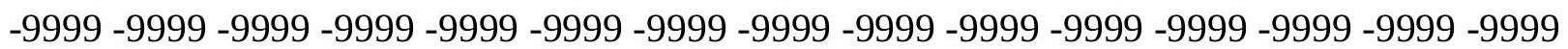




$$
\begin{aligned}
& \text {-9999 -9999 -9999 -9999 -9999 -9999 -9999 -9999 -9999 -9999 -9999 -9999 -9999 -9999 -9999 } \\
& \text {-9999 -9999 -9999 -9999 -9999 -9999 -9999 -9999 -9999 -9999 -9999 -9999 -9999 -9999 -9999 - }
\end{aligned}
$$

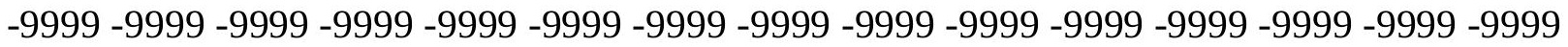

$$
\begin{aligned}
& \text {-9999 -9999 -9999 -9999 -9999 -9999 -9999 -9999 -9999 -9999 -9999 -9999 -9999 -9999 -9999 } \\
& \text {-9999 -9999 -9999 -9999 -9999 -9999 -9999 -9999 -9999 -9999 -9999 -9999 -9999 -9999 -9999 - } \\
& \text {-9999 -9999 -9999 -9999 -9999 -9999 -9999 -9999 -9999 -9999 -9999 -9999 -9999 -9999 -9999 - } \\
& \text {-9999 -9999 -9999 -9999 -9999 -9999 -9999 -9999 -9999 -9999 -9999 -9999 -9999 -9999 -9999 }
\end{aligned}
$$

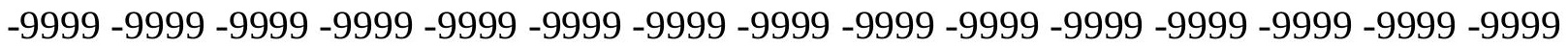

$$
\begin{aligned}
& \text {-9999 -9999 -9999 -9999 -9999 -9999 -9999 -9999 -9999 -9999 -9999 -9999 -9999 -9999 -9999 - } \\
& \text {-9999 -9999 -9999 -9999 -9999 -9999 -9999 -9999 -9999 -9999 -9999 -9999 -9999 -9999 -9999 - } \\
& \text {-9999 -9999 -9999 -9999 -9999 -9999 -9999 -9999 -9999 -9999 -9999 -9999 -9999 -9999 -9999 - } \\
& \text {-9999 -9999 -9999 -9999 -9999 -9999 -9999 -9999 -9999 -9999 -9999 -9999 -9999 -9999 -9999 } \\
& \text {-9999 -9999 -9999 -9999 -9999 -9999 -9999 -9999 -9999 -9999 -9999 -9999 -9999 -9999 -9999 - } \\
& \text {-9999 -9999 -9999 -9999 -9999 -9999 -9999 -9999 -9999 -9999 -9999 -9999 -9999 -9999 -9999 - } \\
& \text {-9999 -9999 -9999 -9999 -9999 -9999 -9999 -9999 -9999 -9999 -9999 -9999 -9999 -9999 -9999 - }
\end{aligned}
$$

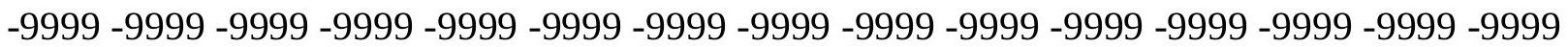

$$
\begin{aligned}
& \text {-9999 -9999 -9999 -9999 -9999 -9999 -9999 -9999 -9999 -9999 -9999 -9999 -9999 -9999 -9999 } \\
& \text {-9999 -9999 -9999 -9999 -9999 -9999 -9999 -9999 -9999 -9999 -9999 -9999 -9999 -9999 -9999 - } \\
& \text {-9999 -9999 -9999 -9999 -9999 -9999 -9999 -9999 -9999 -9999 -9999 -9999 -9999 -9999 -9999 } \\
& \text {-9999 -9999 -9999 -9999 -9999 -9999 -9999 -9999 -9999 -9999 -9999 -9999 -9999 -9999 -9999 - } \\
& \text {-9999 -9999 -9999 -9999 -9999 -9999 -9999 -9999 -9999 -9999 -9999 -9999 -9999 -9999 -9999 } \\
& \text {-9999 -9999 -9999 -9999 -9999 -9999 -9999 -9999 -9999 -9999 -9999 -9999 -9999 -9999 -9999 - } \\
& \text {-9999 -9999 -9999 -9999 -9999 -9999 -9999 -9999 -9999 -9999 -9999 -9999 -9999 -9999 - }
\end{aligned}
$$


u5top_elev 


$\begin{array}{ll}\text { ncols } & 389 \\ \text { nrows } & 437 \\ \text { xllcorner } & 545925 \\ \text { yllcorner } & 100925 \\ \text { cellsize } & 150\end{array}$

NODATA_value -9999

-9999 -9999 -9999 -9999 -9999 -9999 -9999 -9999 -9999 -9999 -9999 -9999 -9999 -9999 -9999 -9999 -9999 -9999 -9999 -9999 -9999 -9999 -9999 -9999 -9999 -9999 -9999 -9999 -9999 -9999 -999 -9999 -9999 -9999 -9999 -9999 -9999 -9999 -9999 -9999 -9999 -9999 -9999 -9999 -9999 -9999 -9999 -9999 -9999 -9999 -9999 -9999 -9999 -9999 -9999 -9999 -9999 -9999 -9999 -9999 -9999

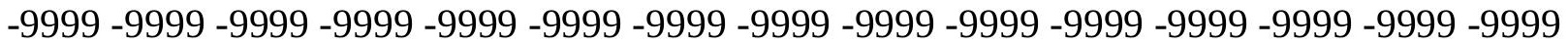
-9999 -9999 -9999 -9999 -9999 -9999 -9999 -9999 -9999 -9999 -9999 -9999 -9999 -9999 -9999 -9999 -9999 -9999 -9999 -9999 -9999 -9999 -9999 -9999 -9999 -9999 -9999 -9999 -9999 -9999 -9999 -9999 -9999 -9999 -9999 -9999 -9999 -9999 -9999 -9999 -9999 -9999 -9999 -9999 - 9999 -9999 -9999 -9999 -9999 -9999 -9999 -9999 -9999 -9999 -9999 -9999 -9999 -9999 -9999 -9999

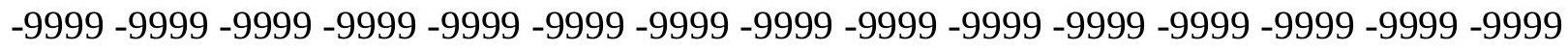
-9999 -9999 -9999 -9999 -9999 -9999 -9999 -9999 -9999 -9999 -9999 -9999 -9999 -9999 -9999 -9999 -9999 -9999 -9999 -9999 -9999 -9999 -9999 -9999 -9999 -9999 -9999 -9999 -9999 -9999 -999 -9999 -9999 -9999 -9999 -9999 -9999 -9999 -9999 -9999 -9999 -9999 -9999 -9999 -9999 -9999 -9999 -9999 -9999 -9999 -9999 -9999 -9999 -9999 -9999 -9999 -9999 -9999 -9999 -9999 -9999 -9999 -9999 -9999 -9999 -9999 -9999 -9999 -9999 -9999 -9999 -9999 -9999 -9999 -9999 -9999 -9999 -9999 -9999 -9999 -9999 -9999 -9999 -9999 -9999 -9999 -9999 -9999 -9999 -9999 -9999 -9999 -9999 -9999 -9999 -9999 -9999 -9999 -9999 -9999 -9999 -9999 -9999 -9999 -9999 -9999 -9999 -9999 -9999 -9999 -9999 -9999 -9999 -9999 -9999 -9999 -9999 -9999 -9999 -9999 -9999 -9999 -9999 -9999 -9999 -9999 -9999 -9999 -9999 -9999 -9999 -9999 -9999 -9999 -9999 -9999 -9999 -9999 -9999 -9999 -9999 -9999 -9999 -9999 -9999 -9999 -9999 -9999 -9999 -9999 -9999 -9999 -9999 -9999 -9999 -9999 -9999 -9999 -9999 -9999 -9999 -9999 -9999 -9999 -9999 -9999 -9999 -9999 -9999 -9999 -9999 -9999 -9999 -9999 -9999 -9999 -9999 -9999 -9999 -9999 -9999 -9999 -9999 -9999 -9999 -9999 -9999 -9999 -9999 -9999 -9999 -9999 -9999 -9999 -9999 -9999 -9999 -9999 -9999 -9999 -9999 -9999 -9999 -9999 -9999 -9999 -9999 -9999 -9999 -9999 -999 -9999 -9999 -9999 -9999 -9999 -9999 -9999 -9999 -9999 -9999 -9999 -9999 -9999 -9999 -9999 -9999 -9999 -9999 -9999 -9999 -9999 -9999 -9999 -9999 -9999 -9999 -9999 -9999 -9999 -

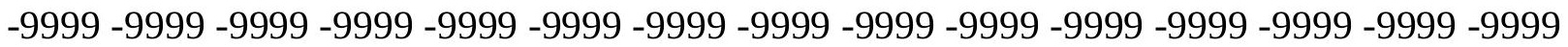
-9999 -9999 -9999 -9999 -9999 -9999 -9999 -9999 -9999 -9999 -9999 -9999 -9999 -9999 -9999 -9999 -9999 -9999 -9999 -9999 -9999 -9999 -9999 -9999 -9999 -9999 -9999 -9999 -9999 -9999 -

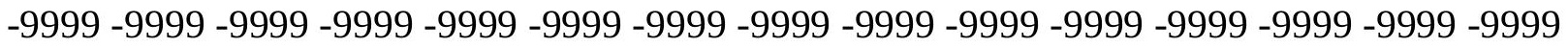

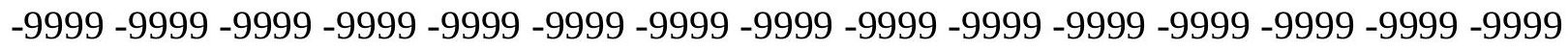
-9999 -9999 -9999 -9999 -9999 -9999 -9999 -9999 -9999 -9999 -9999 -9999 -9999 - 9999 - -9999 -9999 -9999 -9999 -9999 -9999 -9999 -9999 -9999 -9999 -9999 -9999 -9999 -9999 - 9999 - -999 -9999 -9999 -9999 -9999 -9999 -9999 -9999 -9999 -9999 -9999 -9999 -9999 -9999 -9999 -9999 -

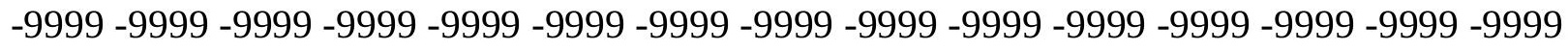

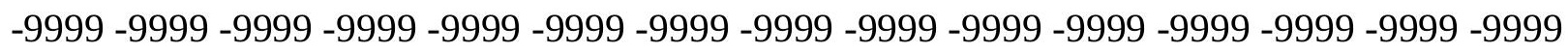
-9999 -9999 -9999 -9999 -9999 -9999 -9999 -9999 -9999 -9999 -9999 -9999 -9999 -9999 -9999 -9999 -9999 -9999 -9999 -9999 -9999 -9999 -9999 -9999-9999 -9999 -9999 -9999 -9999 -9999 -9999 -9999 -9999 -9999 -9999 -9999 -9999 -9999 -9999 -9999 -9999 -9999 -9999 -9999 -9999 -

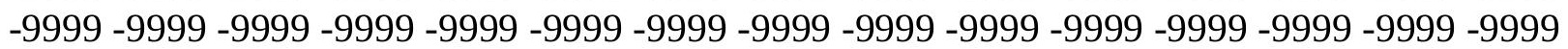


-9999 -9999 -9999 -9999 -9999 -9999 -9999 -9999 -9999 -9999 -9999 -9999 -9999 -9999 -9999 -9999 -9999 -9999 -9999 -9999 -9999 -9999 -9999 -9999 -9999 -9999 -9999 -9999 -9999 -9999 -

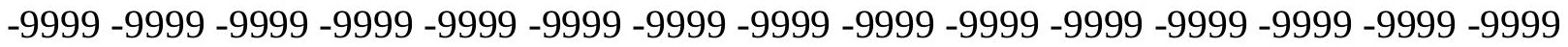
-9999 -9999 -9999 -9999 -9999 -9999 -9999 -9999 -9999 -9999 -9999 -9999 -9999 -9999 -9999 -9999 -9999 -9999 -9999 -9999 -9999 -9999 -9999 -9999-9999 -9999 -9999 -9999 -9999 -9999 -9999 -9999 -9999 -9999 -9999 -9999 -9999 -9999 -9999 -9999 -9999 -9999 -9999 -9999 -9999 -9999 -9999 -9999 -9999 -9999 -9999 -9999 -9999 -9999 -9999 -9999 -9999 -9999 -9999 -9999

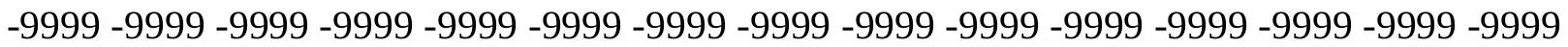

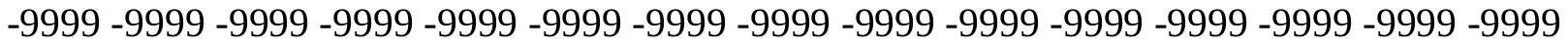
-9999 -9999 -9999 -9999 -9999 -9999 -9999 -9999 -9999 -9999 -9999 -9999 -9999 -9999 -9999 -9999 -9999 -9999 -9999 -9999 -9999 -9999 -9999 -9999 -9999 -9999 -9999 -9999 -9999 -9999 -9999 -9999 -9999 -9999 -9999 -9999 -9999 -9999 -9999 -9999 -9999 -9999 -9999 -9999 -9999 -9999 -9999 -9999 -9999 -9999 -9999 -9999 -9999 -9999 -9999 -9999 -9999 -9999 -9999 -9999 -9999 -9999 -9999 -9999 -9999 -9999 -9999 -9999 -9999 -9999 -9999 -9999 -9999 - 9999 -9999 -9999 -9999 -9999 -9999 -9999 -9999 -9999 -9999 -9999 -9999 -9999 -9999 -9999 -9999

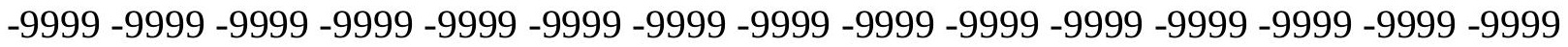
-9999 -9999 -9999 -9999 -9999 -9999 -9999 -9999 -9999 -9999 -9999 -9999 -9999 -9999 -9999 -9999 -9999 -9999 -9999 -9999 -9999 -9999 -9999 -9999 -9999 -9999 -9999 -9999 -9999 -9999 -9999 -9999 -9999 -9999 -9999 -9999 -9999 -9999 -9999 -9999 -9999 -9999 -9999 -9999 -9999 -

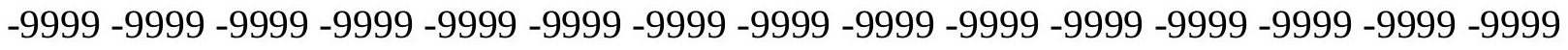

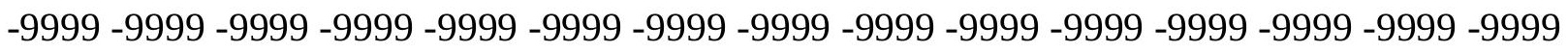
-9999 -9999 -9999 -9999 -9999 -9999 -9999 -9999 -9999 -9999 -9999 -9999 -9999 -9999 -9999 -9999 -9999 -9999 -9999 -9999 -9999 -9999 -9999 -9999 -9999 -9999 -9999 -9999 -9999 -9999 -9999 -9999 -9999 -9999 -9999 -9999 -9999 -9999 -9999 -9999 -9999 -9999 -9999 -9999 -9999 -

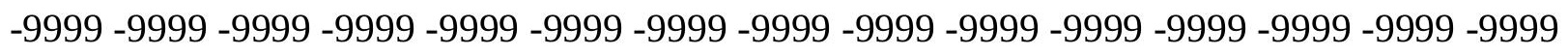
-9999 -9999 -9999 -9999 -9999 -9999 -9999 -9999 -9999 -9999 -9999 -9999 -9999 -9999 -9999 -9999 -9999 -9999 -9999 -9999 -9999 -9999 -9999 -9999 -9999 -9999 -9999 -9999 -9999 -9999 -

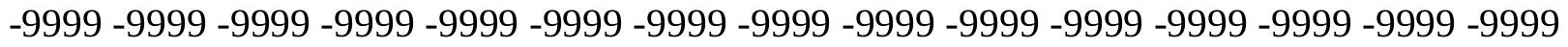
-9999 -9999 -9999 -9999 -9999 -9999 -9999 -9999 -9999 -9999 -9999 -9999 -9999 -9999 -9999 -9999 -9999 -9999 -9999 -9999 -9999 -9999 -9999 -9999 -9999 -9999 -9999 -9999 -9999 -999 -9999 -9999 -9999 -9999 -9999 -9999 -9999 -9999 -9999 -9999 -9999 -9999 -9999 -9999 -9999 -9999 -9999 -9999 -9999 -9999 -9999 -9999 -9999 -9999 -9999 -9999 -9999 -9999 -9999 -9999 -

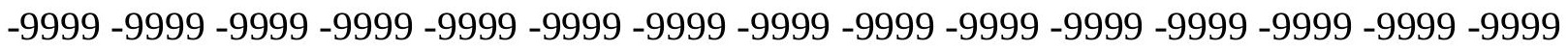

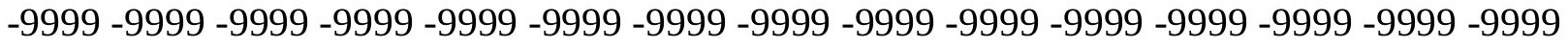

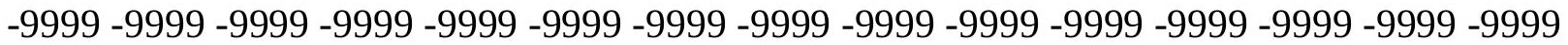

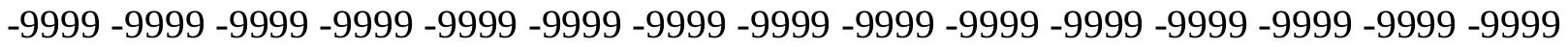

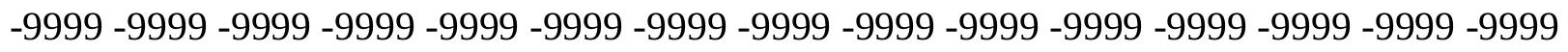

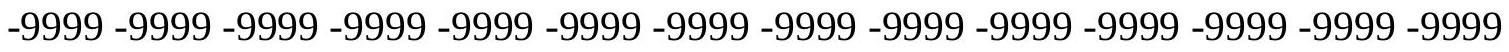
-9999 -9999 -9999 -9999 -9999 -9999 -9999 -9999 -9999 -9999 -9999 -9999 -9999 -9999 -9999 -9999 -9999 -9999 -9999 -9999 -9999 -9999 -9999 -9999 -9999 -9999 -9999 -9999 -9999 -9999 -

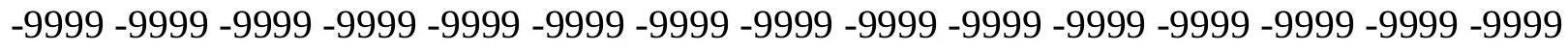

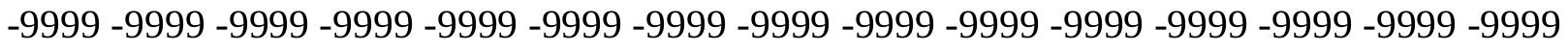
-9999 -9999 -9999 -9999 -9999 -9999 -9999 -9999 -9999 -9999 -9999 -9999 -9999 -9999 -9999 -9999 -9999 -9999 -9999 -9999 -9999 -9999 -9999 -9999-9999 -9999 -9999 -9999 -9999 -9999 -9999 -9999 -9999 -9999 -9999 -9999 -9999 -9999 -9999 -9999 -9999 -9999 -9999 -9999 -9999 -

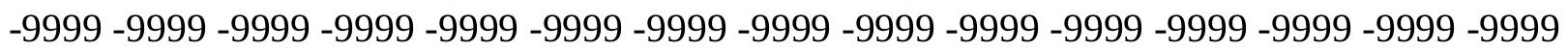


-9999 -9999 -9999 -9999 -9999 -9999 -9999 -9999 -9999 -9999 -9999 -9999 -9999 -9999 -9999 -9999 -9999 -9999 -9999 -9999 -9999 -9999 -9999 -9999 -9999 -9999 -9999 -9999 -9999 -9999 -9999 -9999 -9999 -9999 -9999 -9999 -9999 -9999 -9999 -9999 -9999 -9999 -9999 -9999 - 9999 -9999 -9999 -9999 -9999 -9999 -9999 -9999 -9999 -9999 -9999 -9999 -9999 -9999 -9999 -9999 -9999 -9999 -9999 -9999 -9999 -9999 -9999 -9999 -9999 -9999 -9999 -9999 -9999 -9999 -9999 -9999 -9999 -9999 -9999 -9999 -9999 -9999 -9999 -9999 -9999 -9999 -9999 -9999 -9999 -9999 -9999 -9999 -9999 -9999 -9999 -9999 -9999 -9999 -9999 -9999 -9999 -9999 -9999 -9999 -9999

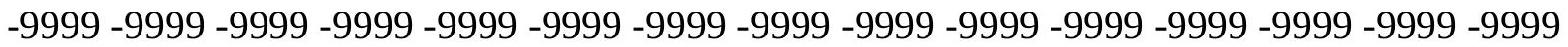
-9999 -9999 -9999 -9999 -9999 -9999 -9999 -9999 -9999 -9999 -9999 -9999 -9999 -9999 -9999 -9999 -9999 -9999 -9999 -9999 -9999 -9999 -9999 -9999 -9999 -9999 -9999 -9999 -9999 -9999

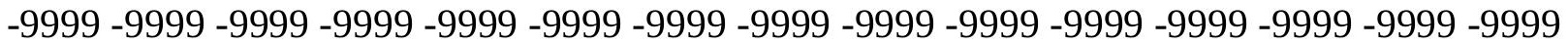
-9999 -9999 -9999 -9999 -9999 -9999 -9999 -9999 -9999 -9999 -9999 -9999 -9999 -9999 -9999 -9999 -9999 -9999 -9999 -9999 -9999 -9999 -9999 -9999 -9999 -9999 -9999 -9999 -9999 -9999 -

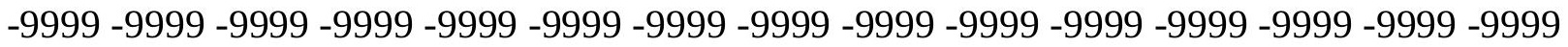
-9999 -9999 -9999 -9999 -9999 -9999 -9999 -9999 -9999 -9999 -9999 -9999 -9999 -9999 -9999

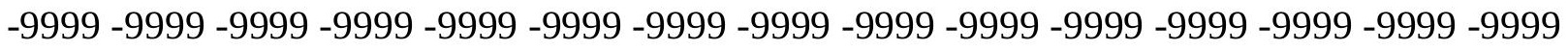
-9999 -9999 -9999 -9999 -9999 -9999 -9999 -9999 -9999 -9999 -9999 -9999 -9999 -9999 -9999 -9999 -9999 -9999 -9999 -9999 -9999 -9999 -9999 -9999 -9999 -9999 -9999 -9999 -9999 - -999 -9999 -9999 -9999 -9999 -9999 -9999 -9999 -9999 -9999 -9999 -9999 -9999 -9999 -9999 -9999 -9999 -9999 -9999 -9999 -9999 -9999 -9999 -9999 -9999 -9999 -9999 -9999 -9999 -9999 -9999 -9999 -9999 -9999 -9999 -9999 -9999 -9999 -9999 -9999 -9999 -9999 -9999 -9999 -9999 -9999 -999 -9999 -9999 -9999 -9999 -9999 -9999 -9999 -9999 -9999 -9999 -9999 -9999 -9999 -9999 -9999 -9999 -9999 -9999 -9999 -9999 -9999 -9999 -9999 -9999 -9999 -9999 -9999 -9999 -9999 -9999 -9999 -9999 -9999 -9999 -9999 -9999 -9999 -9999 -9999 -9999 -9999 -9999 -9999 -9999 -9999 -9999 -9999 -9999 -9999 -9999 -9999 -9999 -9999 -9999 -9999 -9999 -9999 -9999 -9999 -9999 -9999 -9999 -9999 -9999 -9999 -9999 -9999 -9999 -9999 -9999 -9999 -9999 -9999 -9999 -9999 -9999 -9999 -9999 -9999 -9999 -9999 -9999 -9999 -9999 -9999 -9999 -9999 -9999 -9999 -9999 -9999 -9999 -9999 -9999 -9999 -9999 -9999 -9999 -9999 -9999 -9999 -9999 -9999 -9999 -9999 -9999 -9999 -9999 -9999 -9999 -9999 -9999 -9999 -9999 -9999 -9999 -9999 -9999 -9999 -9999 -9999 -9999 -9999 -9999 -9999 -9999 -9999 -9999 -9999 -9999 -9999 -9999 -9999 -9999 -999 -9999 -9999 -9999 -9999 -9999 -9999 -9999 -9999 -9999 -9999 -9999 -9999 -9999 -9999 -9999 -9999 -9999 -9999 -9999 -9999 -9999 -9999 -9999 -9999 -9999 -9999 -9999 -9999 -9999 -9999 -

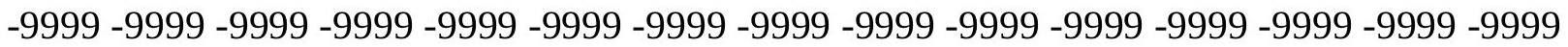

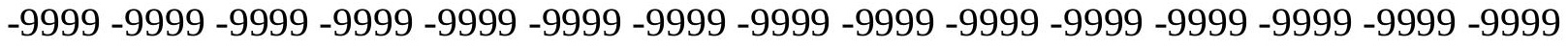

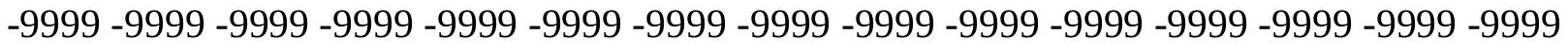
-9999 -9999 -9999 -9999 -9999 -9999 -9999 -9999 -9999 -9999 -9999 -9999 -9999 -9999 -9999

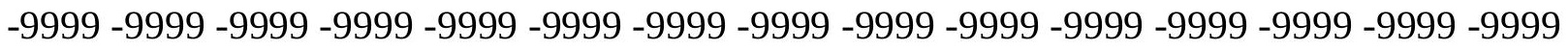

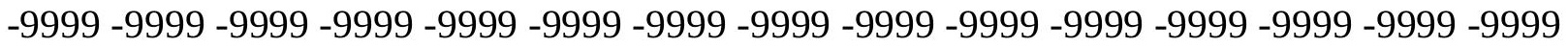

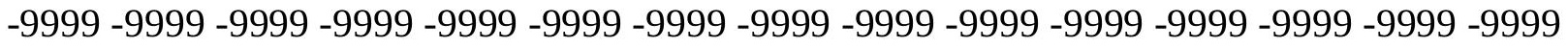
-9999 -9999 -9999 -9999 -9999 -9999 -9999 -9999 -9999 -9999 -9999 -9999 -9999 -9999 -9999 -

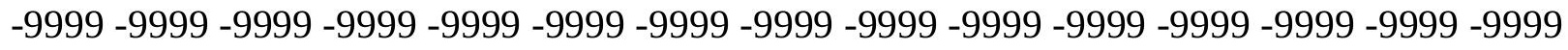

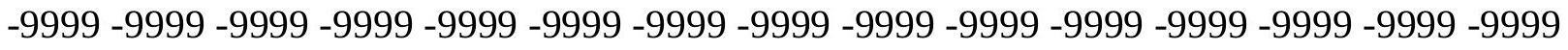
-9999 -9999 -9999 -9999 -9999 -9999 -9999 -9999 -9999 -9999 -9999 -9999 -9999 -9999 -9999 -9999 -9999 -9999 -9999 -9999 -9999 -9999 -9999 -9999 -9999 -9999 -9999 -9999 - -9999 -9999 -9999 -9999 -9999 -9999 -9999 -9999 -9999 -9999 -9999 -9999 -9999 -9999 -9999 -9999 -

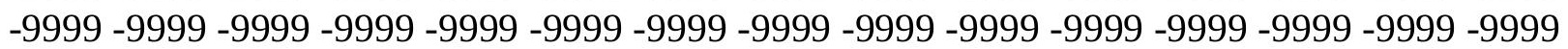


-9999 -9999 -9999 -9999 -9999 -9999 -9999 -9999 -9999 -9999 -9999 -9999 -9999 -9999 -9999 -9999 -9999 -9999 -9999 -9999 -9999 -9999 -9999 -9999 -9999 -9999 -9999 -9999 -9999 -9999 -9999 -9999 -9999 -9999 -9999 -9999 -9999 -9999 -9999 -9999 -9999 -9999 -9999 -9999 - 9999 -9999 -9999 -9999 -9999 -9999 -9999 -9999 -9999 -9999 -9999 -9999 -9999 -9999 -9999 -9999 -9999 -9999 -9999 -9999 -9999 -9999 -9999 -9999 -9999-9999 -9999 -9999 -9999 -9999 -9999 -9999 -9999 -9999 -9999 -9999 -9999 -9999 -9999 -9999 -9999 -9999 -9999 -9999 -9999 -9999 -9999 -9999 -9999 -9999 -9999 -9999 -9999 -9999 -9999 -9999 -9999 -9999 -9999 -9999 -9999

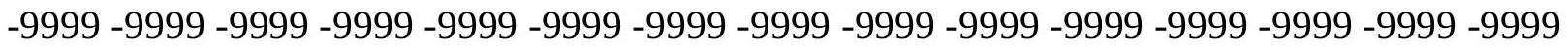

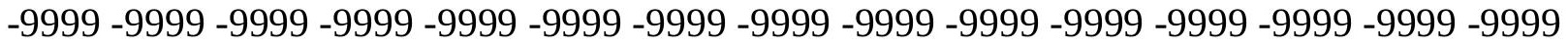
-9999 -9999 -9999 -9999 -9999 -9999 -9999 -9999 -9999 -9999 -9999 -9999 -9999 -9999 -9999

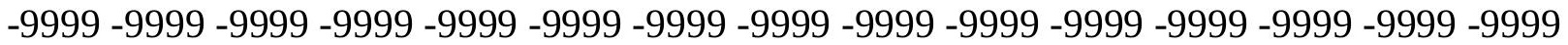
-9999 -9999 -9999 -9999 -9999 -9999 -9999 -9999 -9999 -9999 -9999 -9999 -9999 -9999 -9999 -9999 -9999 -9999 -9999 -9999 -9999 -9999 -9999 -9999 -9999 -9999 -9999 -9999 -9999 -9999 -

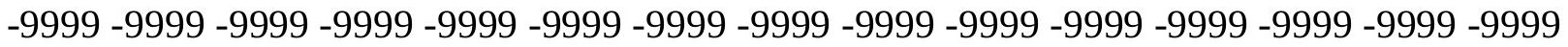
-9999 -9999 -9999 -9999 -9999 -9999 -9999 -9999 -9999 -9999 -9999 -9999 -9999 -9999 -9999

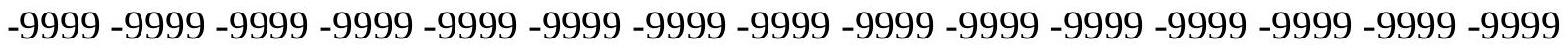
-9999 -9999 -9999 -9999 -9999 -9999 -9999 -9999 -9999 -9999 -9999 -9999 -9999 -9999 -9999 -9999 -9999 -9999 -9999 -9999 -9999 -9999 -9999 -9999 -9999 -9999 -9999 -9999 -9999 -9999 -9999 -9999 -9999 -9999 -9999 -9999 -9999 -9999 -9999 -9999 -9999 -9999 -9999 -9999 -9999 -9999 -9999 -9999 -9999 -9999 -9999 -9999 -9999 -9999 -9999 -9999 -9999 -9999 -9999 -9999 -9999 -9999 -9999 -9999 -9999 -9999 -9999 -9999 -9999 -9999 -9999 -9999 -9999 -9999 -9999 -999 -9999 -9999 -9999 -9999 -9999 -9999 -9999 -9999 -9999 -9999 -9999 -9999 -9999 -9999 -9999 -9999 -9999 -9999 -9999 -9999 -9999 -9999 -9999 -9999 -9999 -9999 -9999 -9999 -9999 -9999 -9999 -9999 -9999 -9999 -9999 -9999 -9999 -9999 -9999 -9999 -9999 -9999 -9999 -9999 -9999 -9999 -9999 -9999 -9999 -9999 -9999 -9999 -9999 -9999 -9999 -9999 -9999 -9999 -9999 -9999 -9999 -9999 -9999 -9999 -9999 -9999 -9999 -9999 -9999 -9999 -9999 -9999 -9999 -9999 -9999 -9999 -9999 -9999 -9999 -9999 -9999 -9999 -9999 -9999 -9999 -9999 -9999 -9999 -9999 -9999 -9999 -9999 -9999 -9999 -9999 -9999 -9999 -9999 -9999 -9999 -9999 -9999 -9999 -9999 -9999 -9999 -9999 -9999 -9999 -9999 -9999 -9999 -9999 -9999 -9999 -9999 -9999 -9999 -9999 -9999 -9999 -9999 -9999 -9999 -9999 -9999 -9999 -9999 -9999 -9999 -9999 -9999 -9999 -999 -9999 -9999 -9999 -9999 -9999 -9999 -9999 -9999 -9999 -9999 -9999 -9999 -9999 -9999 -9999 -9999 -9999 -9999 -9999 -9999 -9999 -9999 -9999 -9999 -9999 -9999 -9999 -9999 -9999 -9999 -

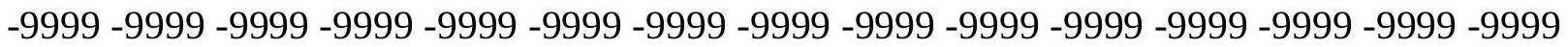

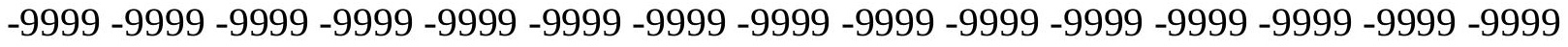

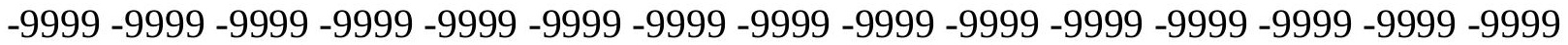
-9999 -9999 -9999 -9999 -9999 -9999 -9999 -9999 -9999 -9999 -9999 -9999 -9999 -9999 -9999

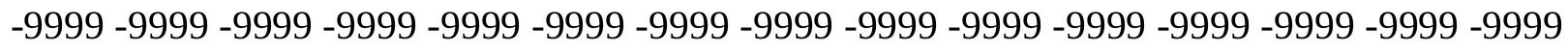

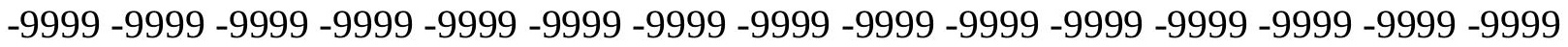
-9999 -9999 -9999 -9999 -9999 -9999 -9999 -9999 -9999 -9999 -9999 -9999 -9999 -9999 -9999 -9999 -9999 -9999 -9999 -9999 -9999 -9999 -9999 -9999 -9999 -9999 -9999 -9999 -9999 -9999 -

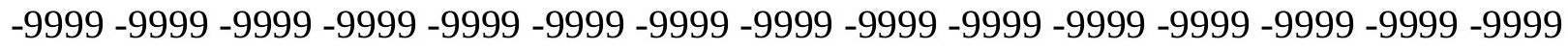

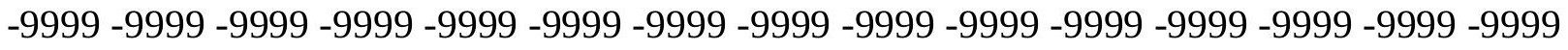
-9999 -9999 -9999 -9999 -9999 -9999 -9999 -9999 -9999 -9999 -9999 -9999 -9999 -9999 -9999 -9999 -9999 -9999 -9999 -9999 -9999 -9999 -9999 -9999-9999 -9999 -9999 -9999 -9999 -9999 -9999 -9999 -9999 -9999 -9999 -9999 -9999 -9999 -9999 -9999 -9999 -9999 -9999 -9999 -9999 -

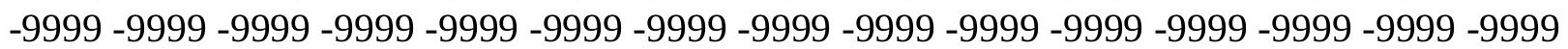


-9999 -9999 -9999 -9999 -9999 -9999 -9999 -9999 -9999 -9999 -9999 -9999 -9999 -9999 -9999 -9999 -9999 -9999 -9999 -9999 -9999 -9999 -9999 -9999 -9999 -9999 -9999 -9999 -9999 -9999 -9999 -9999 -9999 -9999 -9999 -9999 -9999 -9999 -9999 -9999 -9999 -9999 -9999 -9999 - 9999 -9999 -9999 -9999 -9999 -9999 -9999 -9999 -9999 -9999 -9999 -9999 -9999 -9999 -9999

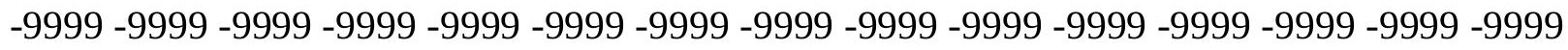
-9999 -9999 -9999 -9999 -9999 -9999 -9999 -9999 -9999 -9999 -9999 -9999 -9999 -9999 -9999 -9999 -9999 -9999 -9999 -9999 -9999 -9999 -9999 -9999 -9999 -9999 -9999 -9999 -9999 -9999

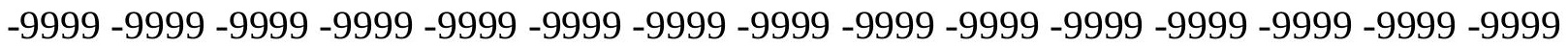

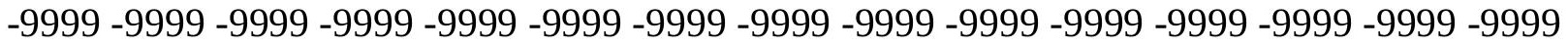
-9999 -9999 -9999 -9999 -9999 -9999 -9999 -9999 -9999 -9999 -9999 -9999 -9999 -9999 -9999 -9999 -9999 -9999 -9999 -9999 -9999 -9999 -9999 -9999 -9999 -9999 -9999 -9999 -9999 -9999 -9999 -9999 -9999 -9999 -9999 -9999 -9999 -9999 -9999 -9999 -9999 -9999 -9999 -9999 -9999 -9999 -9999 -9999 -9999 -9999 -9999 -9999 -9999 -9999 -9999 -9999 -9999 -9999 -9999 -9999 -

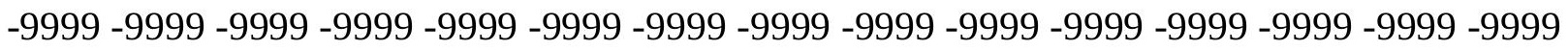
-9999 -9999 -9999 -9999 -9999 -9999 -9999 -9999 -9999 -9999 -9999 -9999 -9999 -9999 -9999 -

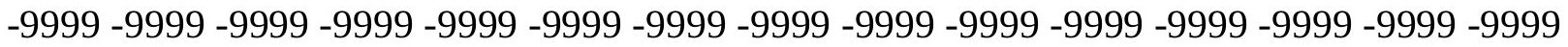
-9999 -9999 -9999 -9999 -9999 -9999 -9999 -9999 -9999 -9999 -9999 -9999 -9999 -9999 -9999 -9999 -9999 -9999 -9999 -9999 -9999 -9999 -9999 -9999 -9999 -9999 -9999 -9999 -9999 -9999 -9999 -9999 -9999 -9999 -9999 -9999 -9999 -9999 -9999 -9999 -9999 -9999 -9999 -9999 -9999 -

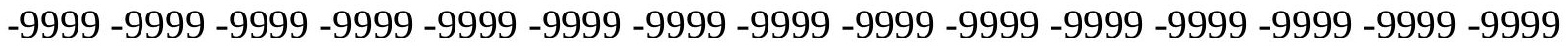
-9999 -9999 -9999 -9999 -9999 -9999 -9999 -9999 -9999 -9999 -9999 -9999 -9999 -9999 -9999

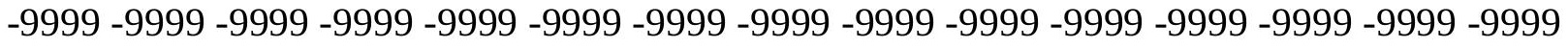
-9999 -9999 -9999 -9999 -9999 -9999 -9999 -9999 -9999 -9999 -9999 -9999 -9999 -9999 -9999 -9999 -9999 -9999 -9999 -9999 -9999 -9999 -9999 -9999 -9999 -9999 -9999 -9999 -9999 -9999 -9999 -9999 -9999 -9999 -9999 -9999 -9999 -9999 -9999 -9999 -9999 -9999 -9999 -9999 -9999 -9999 -9999 -9999 -9999 -9999 -9999 -9999 -9999 -9999 -9999 -9999 -9999 -9999 -9999 -9999 -9999 -9999 -9999 -9999 -9999 -9999 -9999 -9999 -9999 -9999 -9999 -9999 -9999 -9999 -9999 -9999 -9999 -9999 -9999 -9999 -9999 -9999 -9999 -9999 -9999 -9999 -9999 -9999 -9999 -9999 -9999 -9999 -9999 -9999 -9999 -9999 -9999 -9999 -9999 -9999 -9999 -9999 -9999 -9999 -9999 -9999 -9999 -9999 -9999 -9999 -9999 -9999 -9999 -9999 -9999 -9999 -9999 -9999 -9999 -9999 -9999 -9999 -9999 -9999 -9999 -9999 -9999 -9999 -9999 -9999 -9999 -9999 -9999 -9999 -9999 -9999 -9999 -9999 -9999 -9999 -9999 -9999 -9999 -9999 -9999 -9999 -9999 -9999 -9999 -

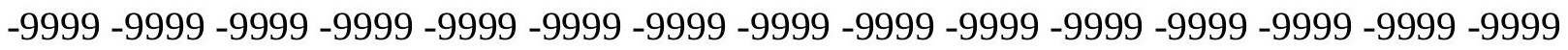

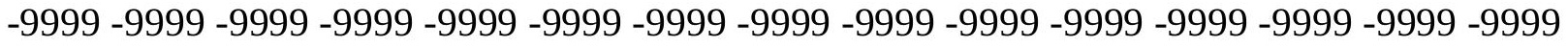
-9999 -9999 -9999 -9999 -9999 -9999 -9999 -9999 -9999 -9999 -9999 -9999 -9999 -9999 -9999 -

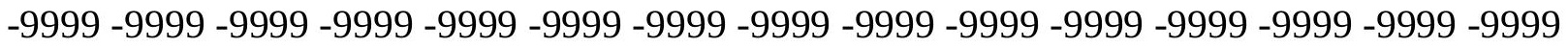

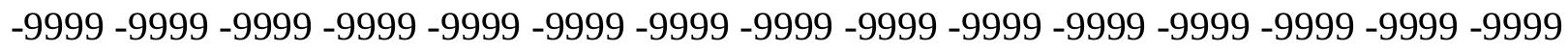

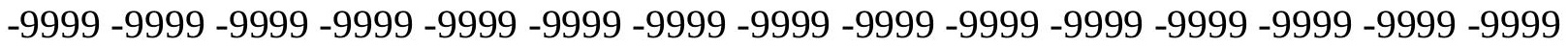

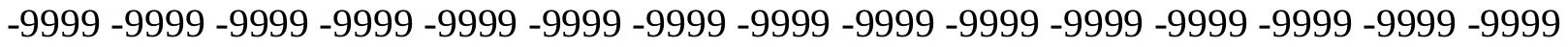
-9999 -9999 -9999 -9999 -9999 -9999 -9999 -9999 -9999 -9999 -9999 -9999 -9999 -9999 -9999 -

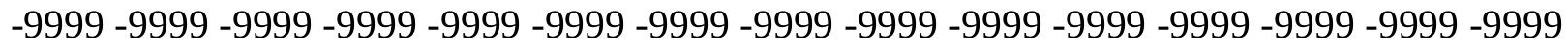

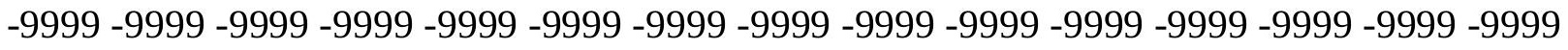
-9999 -9999 -9999 -9999 -9999 -9999 -9999 -9999 -9999 -9999 -9999 -9999 -9999 -9999 -9999 -9999 -9999 -9999 -9999 -9999 -9999 -9999 -9999 -9999-9999 -9999 -9999 -9999 -9999 -9999 -9999 -9999 -9999 -9999 -9999 -9999 -9999 -9999 -9999 -9999 -9999 -9999 -9999 -9999 -9999 -

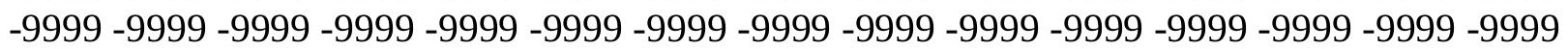


-9999 -9999 -9999 -9999 -9999 -9999 -9999 -9999 -9999 -9999 -9999 -9999 -9999 -9999 -9999 -9999 -9999 -9999 -9999 -9999 -9999 -9999 -9999 -9999 -9999 -9999 -9999 -9999 -9999 -9999 -9999 -9999 -9999 -9999 -9999 -9999 -9999 -9999 -9999 -9999 -9999 -9999 -9999 -9999 - 9999 -9999 -9999 -9999 -9999 -9999 -9999 -9999 -9999 -9999 -9999 -9999 -9999 -9999 -9999 -9999 -9999 -9999 -9999 -9999 -9999 -9999 -9999 -9999 -9999 -9999 -9999 -9999 -9999 -9999 -9999 -9999 -9999 -9999 -9999 -9999 -9999 -9999 -9999 -9999 -9999 -9999 -9999 -9999 -9999 -9999 -9999 -9999 -9999 -9999 -9999 -9999 -9999 -9999 -9999 -9999 -9999 -9999 -9999 -9999 -9999

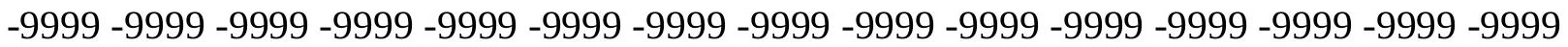

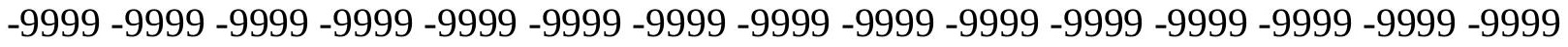
-9999 -9999 -9999 -9999 -9999 -9999 -9999 -9999 -9999 -9999 -9999 -9999 -9999 -9999 -9999 -9999 -9999 -9999 -9999 -9999 -9999 -9999 -9999 -9999 -9999 -9999 -9999 -9999 -9999 -9999 -9999 -9999 -9999 -9999 -9999 -9999 -9999 -9999 -9999 -9999 -9999 -9999 -9999 -9999 -9999 -9999 -9999 -9999 -9999 -9999 -9999 -9999 -9999 -9999 -9999 -9999 -9999 -9999 -9999 -9999 -9999 -9999 -9999 -9999 -9999 -9999 -9999 -9999 -9999 -9999 -9999 -9999 -9999 -9999 -9999 -9999 -9999 -9999 -9999 -9999 -9999 -9999 -9999 -9999 -9999 -9999 -9999 -9999 -9999 -

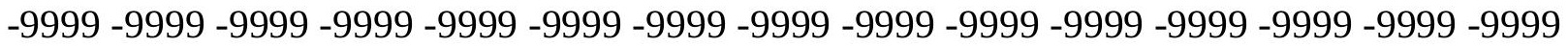
-9999 -9999 -9999 -9999 -9999 -9999 -9999 -9999 -9999 -9999 -9999 -9999 -9999 -9999 -9999 -9999 -9999 -9999 -9999 -9999 -9999 -9999 -9999 -9999 -9999 -9999 -9999 -9999 -9999 -9999 -9999 -9999 -9999 -9999 -9999 -9999 -9999 -9999 -9999 -9999 -9999 -9999 -9999 -9999 -9999 -9999 -9999 -9999 -9999 -9999 -9999 -9999 -9999 -9999 -9999 -9999 -9999 -9999 -9999 -9999 -9999 -9999 -9999 -9999 -9999 -9999 -9999 -9999 -9999 -9999 -9999 -9999 -9999 -9999 -9999 -999 -9999 -9999 -9999 -9999 -9999 -9999 -9999 -9999 -9999 -9999 -9999 -9999 -9999 -9999 -9999 -9999 -9999 -9999 -9999 -9999 -9999 -9999 -9999 -9999 -9999 -9999 -9999 -9999 -9999 -9999 -9999 -9999 -9999 -9999 -9999 -9999 -9999 -9999 -9999 -9999 -9999 -9999 -9999 -9999 -9999 -9999 -9999 -9999 -9999 -9999 -9999 -9999 -9999 -9999 -9999 -9999 -9999 -9999 -9999 -9999 -9999 -9999 -9999 -9999 -9999 -9999 -9999 -9999 -9999 -9999 -9999 -9999 -9999 -9999 -9999 -9999 -9999 -9999 -9999 -9999 -9999 -9999 -9999 -9999 -9999 -9999 -9999 -9999 -9999 -9999 -9999 -9999 -9999 -9999 -9999 -9999 -9999 -9999 -9999 -9999 -9999 -9999 -9999 -9999 -9999 -9999 -9999 -9999 -9999 -9999 -9999 -9999 -9999 -9999 -9999 -9999 -9999 -9999 -9999 -9999 -9999 -9999 -9999 -9999 -9999 -9999 -9999 -9999 -9999 -9999 -9999 -9999 -9999 -9999 -999 -9999 -9999 -9999 -9999 -9999 -9999 -9999 -9999 -9999 -9999 -9999 -9999 -9999 -9999 -9999 -9999 -9999 -9999 -9999 -9999 -9999 -9999 -9999 -9999 -9999 -9999 -9999 -9999 -9999 -9999 -

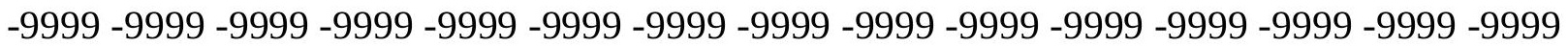

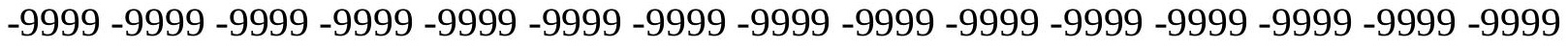

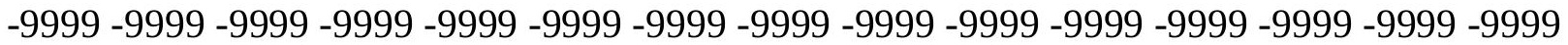
-9999 -9999 -9999 -9999 -9999 -9999 -9999 -9999 -9999 -9999 -9999 -9999 -9999 -9999 -9999 -9999 -9999 -9999 -9999 -9999 -9999 -9999 -9999 -9999 -9999 -9999 -9999 -9999 -9999 -

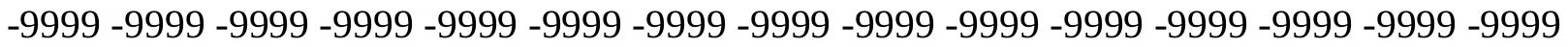
-9999 -9999 -9999 -9999 -9999 -9999 -9999 -9999 -9999 -9999 -9999 -9999 -9999 -9999 -9999 -9999 -9999 -9999 -9999 -9999 -9999 -9999 -9999 -9999 -9999 -9999 -9999 -9999 -9999 -9999 -

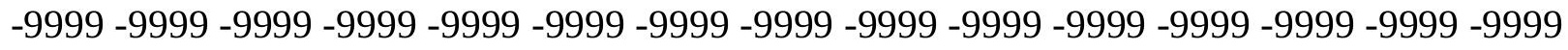

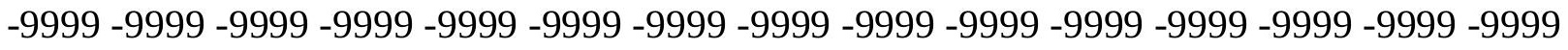
-9999 -9999 -9999 -9999 -9999 -9999 -9999 -9999 -9999 -9999 -9999 -9999 -9999 -9999 -9999 -9999 -9999 -9999 -9999 -9999 -9999 -9999 -9999 -9999-9999 -9999 -9999 -9999 -9999 -9999 -9999 -9999 -9999 -9999 -9999 -9999 -9999 -9999 -9999 -9999 -9999 -9999 -9999 -9999 -9999 -

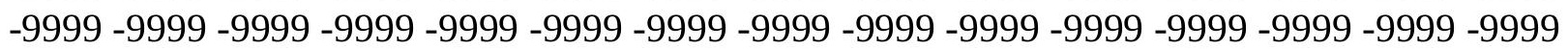


-9999 -9999 -9999 -9999 -9999 -9999 -9999 -9999 -9999 -9999 -9999 -9999 -9999 -9999 -9999 -9999 -9999 -9999 -9999 -9999 -9999 -9999 -9999 -9999 -9999 -9999 -9999 -9999 -9999 -9999 -

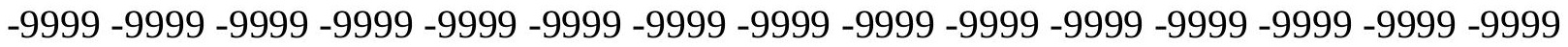
-9999 -9999 -9999 -9999 -9999 -9999 -9999 -9999 -9999 -9999 -9999 -9999 -9999 -9999 -9999 -9999 -9999 -9999 -9999 -9999 -9999 -9999 -9999 -9999-9999 -9999 -9999 -9999 -9999 -9999 -9999 -9999 -9999 -9999 -9999 -9999 -9999 -9999 -9999 -9999 -9999 -9999 -9999 -9999 -9999 -9999 -9999 -9999 -9999 -9999 -9999 -9999 -9999 -9999 -9999 -9999 -9999 -9999 -9999 -9999

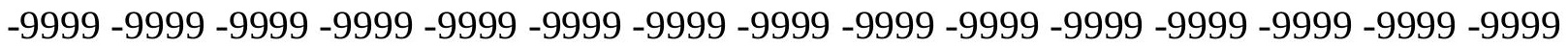

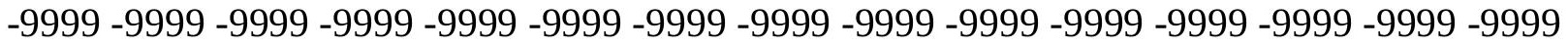
-9999 -9999 -9999 -9999 -9999 -9999 -9999 -9999 -9999 -9999 -9999 -9999 -9999 -9999 -9999 -9999 -9999 -9999 -9999 -9999 -9999 -9999 -9999 -9999 -9999 -9999 -9999 -9999 -9999 -9999 -9999 -9999 -9999 -9999 -9999 -9999 -9999 -9999 -9999 -9999 -9999 -9999 -9999 -9999 -9999 -9999 -9999 -9999 -9999 -9999 -9999 -9999 -9999 -9999 -9999 -9999 -9999 -9999 -9999 -9999 -9999 -9999 -9999 -9999 -9999 -9999 -9999 -9999 -9999 -9999 -9999 -9999 -9999 -9999 -9999 -9999 -9999 -9999 -9999 -9999 -9999 -9999 -9999 -9999 -9999 -9999 -9999 -9999 -9999 -9999 -

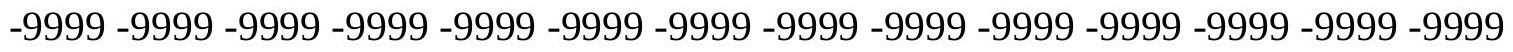
-9999 -9999 -9999 -9999 -9999 -9999 -9999 -9999 -9999 -9999 -9999 -9999 -9999 -9999 -9999 -9999 -9999 -9999 -9999 -9999 -9999 -9999 -9999 -9999 -9999 -9999 -9999 -9999 -9999 -9999 -9999 -9999 -9999 -9999 -9999 -9999 -9999 -9999 -9999 -9999 -9999 -9999 -9999 -9999 -9999 -

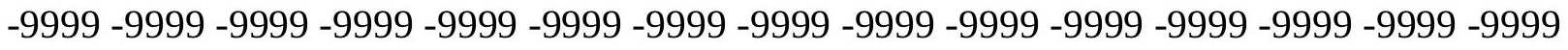

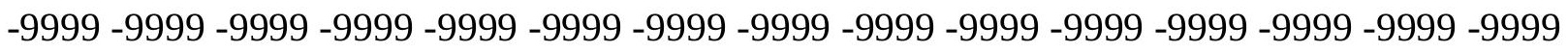
-9999 -9999 -9999 -9999 -9999 -9999 -9999 -9999 -9999 -9999 -9999 -9999 -9999 -9999 - 9999 -9999 -9999 -9999 -9999 -9999 -9999 -9999 -9999 -9999 -9999 -9999 -9999 -9999 -9999 -9999 -9999 -9999 -9999 -9999 -9999 -9999 -9999 -9999 -9999 -9999 -9999 -9999 -9999 -9999 -9999 -

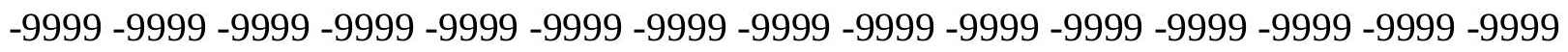
-9999 -9999 -9999 -9999 -9999 -9999 -9999 -9999 -9999 -9999 -9999 -9999 -9999 -9999 -9999 -9999 -9999 -9999 -9999 -9999 -9999 -9999 -9999 -9999 -9999 -9999 -9999 -9999 -9999 -9999 -

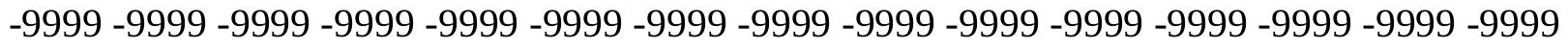
-9999 -9999 -9999 -9999 -9999 -9999 -9999 -9999 -9999 -9999 -9999 -9999 -9999 -9999 -9999 -9999 -9999 -9999 -9999 -9999 -9999 -9999 -9999 -9999 -9999 -9999 -9999 -9999 -9999 -999 -

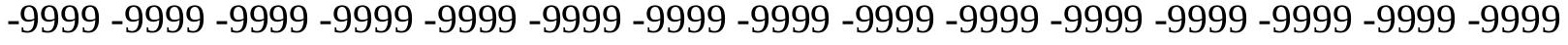
-9999 -9999 -9999 -9999 -9999 -9999 -9999 -9999 -9999 -9999 -9999 -9999 -9999 -9999 -9999 -

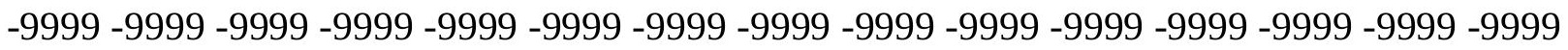

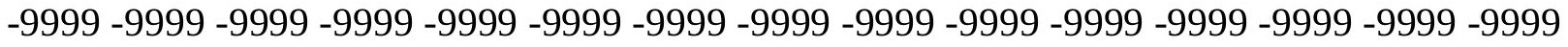

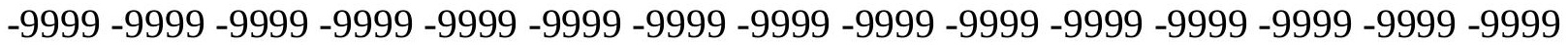
-9999 -9999 -9999 -9999 -9999 -9999 -9999 -9999 -9999 -9999 -9999 -9999 -9999 -9999 -9999 -

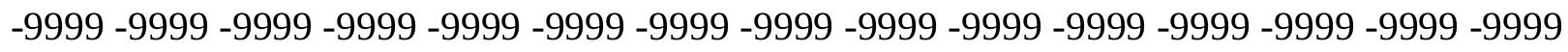

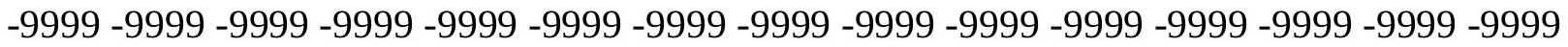
-9999 -9999 -9999 -9999 -9999 -9999 -9999 -9999 -9999 -9999 -9999 -9999 -9999 - 9999 - -999 -9999 -9999 -9999 -9999 -9999 -9999 -9999 -9999 -9999 -9999 -9999 -9999 -9999 -9999 -9999 -

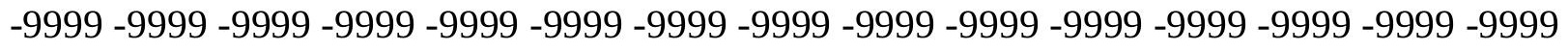

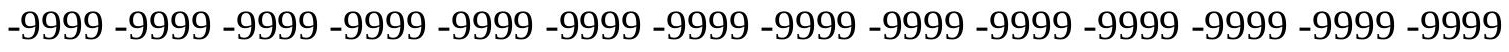
-9999 -9999 -9999 -9999 -9999 -9999 -9999 -9999 -9999 -9999 -9999 -9999 -9999 -9999 -9999 -9999 -9999 -9999 -9999 -9999 -9999 -9999 -9999 -9999-9999 -9999 -9999 -9999 -9999 -9999 -9999 -9999 -9999 -9999 -9999 -9999 -9999 -9999 -9999 -9999 -9999 -9999 -9999 -9999 -9999 -

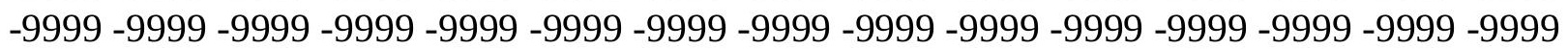


-9999 -9999 -9999 -9999 -9999 -9999 -9999 -9999 -9999 -9999 -9999 -9999 -9999 -9999 -9999 -9999 -9999 -9999 -9999 -9999 -9999 -9999 -9999 -9999 -9999 -9999 -9999 -9999 -9999 -9999 -

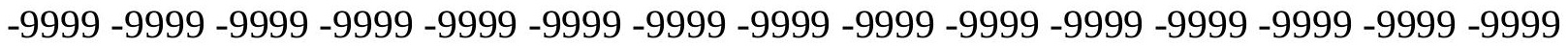
-9999 -9999 -9999 -9999 -9999 -9999 -9999 -9999 -9999 -9999 -9999 -9999 -9999 -9999 -9999 -9999 -9999 -9999 -9999 -9999 -9999 -9999 -9999 -9999-9999 -9999 -9999 -9999 -9999 -9999 -9999 -9999 -9999 -9999 -9999 -9999 -9999 -9999 -9999 -9999 -9999 -9999 -9999 -9999 -9999 -9999 -9999 -9999 -9999 -9999 -9999 -9999 -9999 -9999 -9999 -9999 -9999 -9999 -9999 -9999

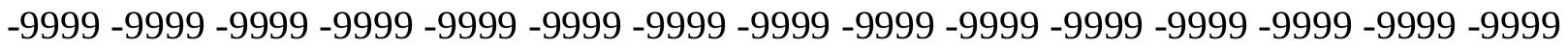

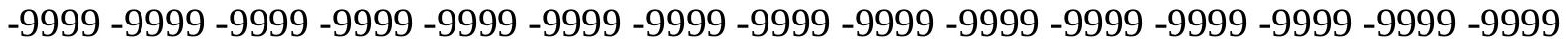
-9999 -9999 -9999 -9999 -9999 -9999 -9999 -9999 -9999 -9999 -9999 -9999 -9999 -9999 -9999 -9999 -9999 -9999 -9999 -9999 -9999 -9999 -9999 -9999 -9999 -9999 -9999 -9999 -9999 -9999 -9999 -9999 -9999 -9999 -9999 -9999 -9999 -9999 -9999 -9999 -9999 -9999 -9999 -9999 -9999 -9999 -9999 -9999 -9999 -9999 -9999 -9999 -9999 -9999 -9999 -9999 -9999 -9999 -9999 -9999 -

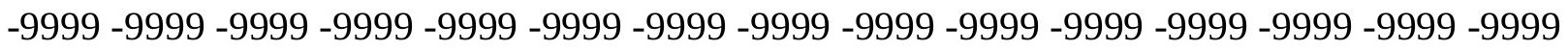
-9999 -9999 -9999 -9999 -9999 -9999 -9999 -9999 -9999 -9999 -9999 -9999 -9999 -9999 -9999 -

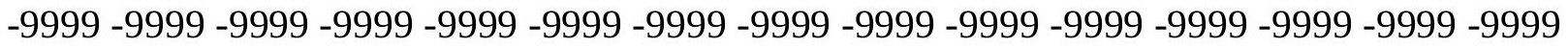
-9999 -9999 -9999 -9999 -9999 -9999 -9999 -9999 -9999 -9999 -9999 -9999 -9999 -9999 -9999 -9999 -9999 -9999 -9999 -9999 -9999 -9999 -9999 -9999 -9999 -9999 -9999 -9999 -9999 -9999 -9999 -9999 -9999 -9999 -9999 -9999 -9999 -9999 -9999 -9999 -9999 -9999 -9999 -9999 -9999 -

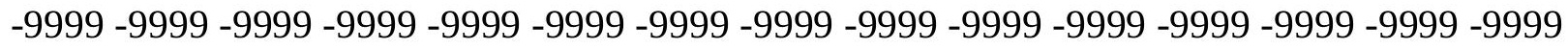

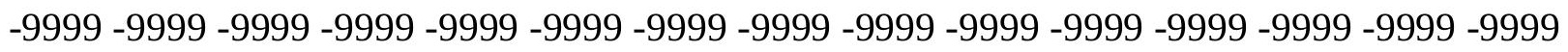
-9999 -9999 -9999 -9999 -9999 -9999 -9999 -9999 -9999 -9999 -9999 -9999 -9999 -9999 -9999 -9999 -9999 -9999 -9999 -9999 -9999 -9999 -9999 -9999 -9999 -9999 -9999 -9999 -9999 -9999 -9999 -9999 -9999 -9999 -9999 -9999 -9999 -9999 -9999 -9999 -9999 -9999 -9999 -9999 -

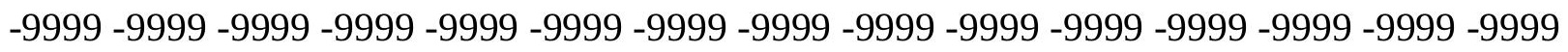
-9999 -9999 -9999 -9999 -9999 -9999 -9999 -9999 -9999 -9999 -9999 -9999 -9999 -9999 -9999 -9999 -9999 -9999 -9999 -9999 -9999 -9999 -9999 -9999 -9999 -9999 -9999 -9999 -9999 -9999 -

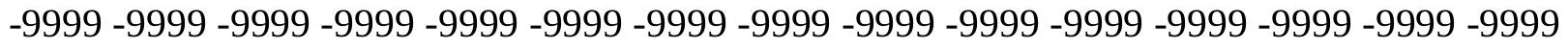
-9999 -9999 -9999 -9999 -9999 -9999 -9999 -9999 -9999 -9999 -9999 -9999 -9999 -9999 -9999 -9999 -9999 -9999 -9999 -9999 -9999 -9999 -9999 -9999 -9999 -9999 -9999 -9999 -9999 -999 -

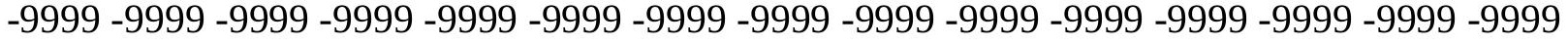
-9999 -9999 -9999 -9999 -9999 -9999 -9999 -9999 -9999 -9999 -9999 -9999 -9999 -9999 -9999 -

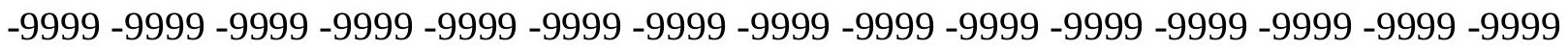

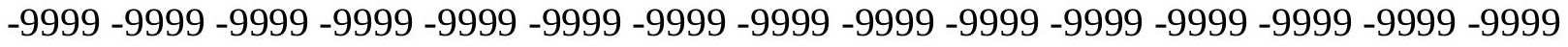

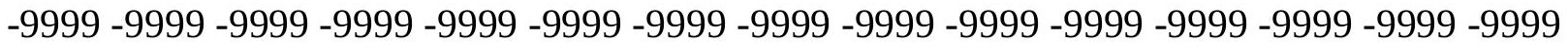

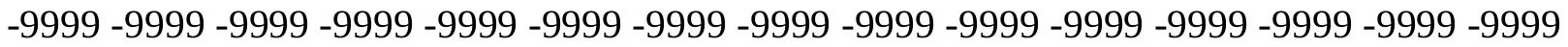

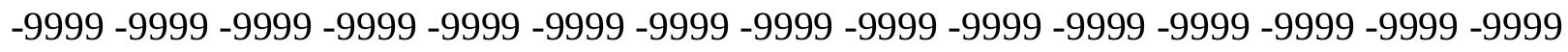

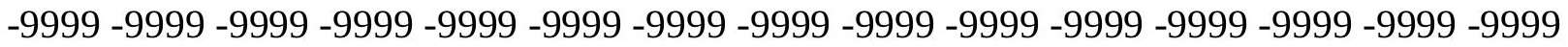

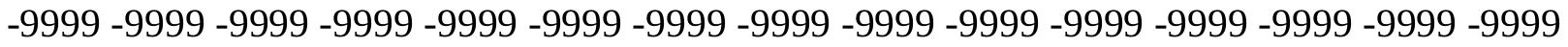
-9999 -9999 -9999 -9999 -9999 -9999 -9999 -9999 -9999 -9999 -9999 -9999 -9999 -9999 -9999 -

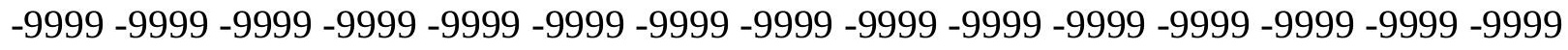

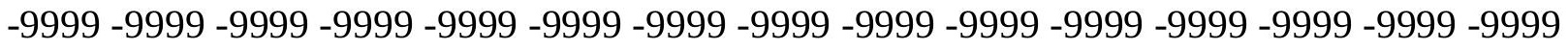
-9999 -9999 -9999 -9999 -9999 -9999 -9999 -9999 -9999 -9999 -9999 -9999 -9999 -9999 -9999 -9999 -9999 -9999 -9999 -9999 -9999 -9999 -9999 -9999-9999 -9999 -9999 -9999 -9999 -9999 -9999 -9999 -9999 -9999 -9999 -9999 -9999 -9999 -9999 -9999 -9999 -9999 -9999 -9999 -9999 -

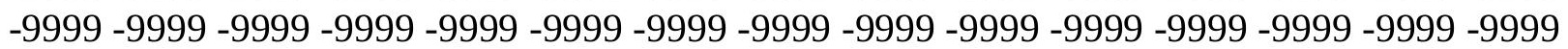


-9999 -9999 -9999 -9999 -9999 -9999 -9999 -9999 -9999 -9999 -9999 -9999 -9999 -9999 -9999 -9999 -9999 -9999 -9999 -9999 -9999 -9999 -9999 -9999 -9999 -9999 -9999 -9999 -9999 -

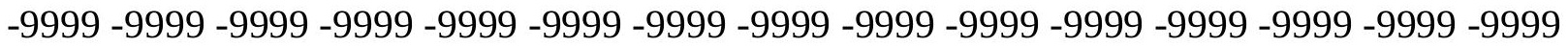
-9999 -9999 -9999 -9999 -9999 -9999 -9999 -9999 -9999 -9999 -9999 -9999 -9999 -9999 -9999 -9999 -9999 -9999 -9999 -9999 -9999 -9999 -9999 -9999 -9999 -9999 -9999 -9999 -9999 -9999 -9999 -9999 -9999 -9999 -9999 -9999 -9999 -9999 -9999 -9999 -9999 -9999 -9999 -9999 -9999 -9999 -9999 -9999 -9999 -9999 -9999 -9999 -9999 -9999 -9999 -9999 -9999 -9999 -9999 -9999

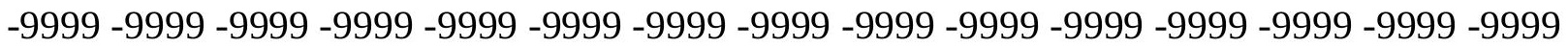

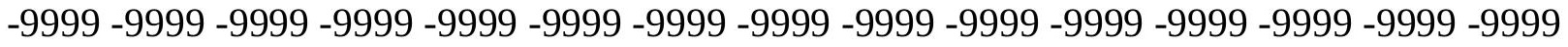
-9999 -9999 -9999 -9999 -9999 -9999 -9999 -9999 -9999 -9999 -9999 -9999 -9999 -9999 -9999 -9999 -9999 -9999 -9999 -9999 -9999 -9999 -9999 -9999 -9999 -9999 -9999 -9999 -9999 -9999 -9999 -9999 -9999 -9999 -9999 -9999 -9999 -9999 -9999 -9999 -9999 -9999 -9999 -9999 -9999 -9999 -9999 -9999 -9999 -9999 -9999 -9999 -9999 -9999 -9999 -9999 -9999 -9999 -9999 -9999 -9999 -9999 -9999 -9999 -9999 -9999 -9999 -9999 -9999 -9999 -9999 -9999 -9999 -9999 -9999 -9999 -9999 -9999 -9999 -9999 -9999 -9999 -9999 -9999 -9999 -9999 -9999 -9999 -9999 -9999 -

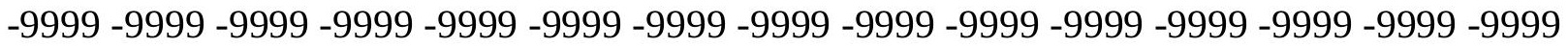
-9999 -9999 -9999 -9999 -9999 -9999 -9999 -9999 -9999 -9999 -9999 -9999 -9999 -9999 -9999 -9999 -9999 -9999 -9999 -9999 -9999 -9999 -9999 -9999 -9999 -9999 -9999 -9999 -9999 - 9999 -9999 -9999 -9999 -9999 -9999 -9999 -9999 -9999 -9999 -9999 -9999 -9999 -9999 -9999 -9999 -

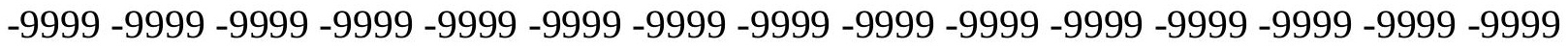

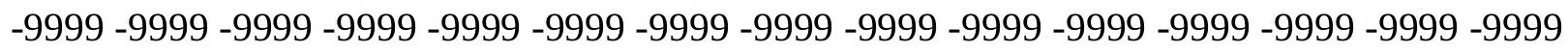

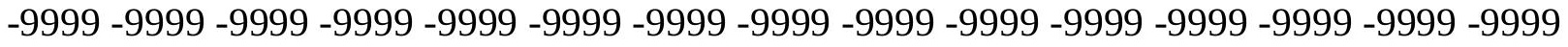
-9999 -9999 -9999 -9999 -9999 -9999 -9999 -9999 -9999 -9999 -9999 -9999 -9999 -9999 -9999 -9999 -9999 -9999 -9999 -9999 -9999 -9999 -9999 -9999 -9999 -9999 -9999 -9999 -9999 -9999 -

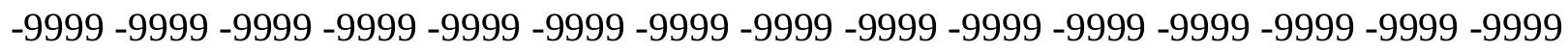
-9999 -9999 -9999 -9999 -9999 -9999 -9999 -9999 -9999 -9999 -9999 -9999 -9999 -9999 -9999 -9999 -9999 -9999 -9999 -9999 -9999 -9999 -9999 -9999 -9999 -9999 -9999 -9999 -9999 -9999 -9999 -9999 -9999 -9999 -9999 -9999 -9999 -9999 -9999 -9999 -9999 -9999 -9999 -9999 -9999 -9999 -9999 -9999 -9999 -9999 -9999 -9999 -9999 -9999 -9999 -9999 -9999 -9999 -9999 -9999 -9999 -9999 -9999 -9999 -9999 -9999 -9999 -9999 -9999 -9999 -9999 -9999 -9999 -999 -

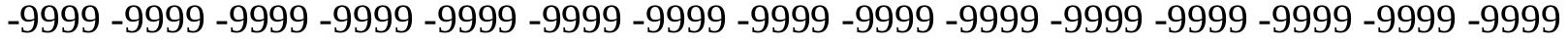
-9999 -9999 -9999 -9999 -9999 -9999 -9999 -9999 -9999 -9999 -9999 -9999 -9999 -9999 -9999 -

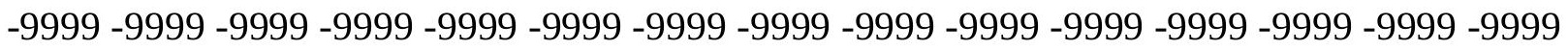

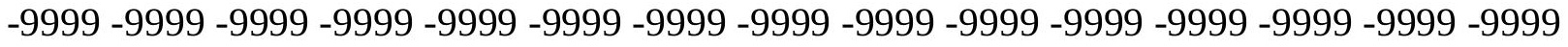

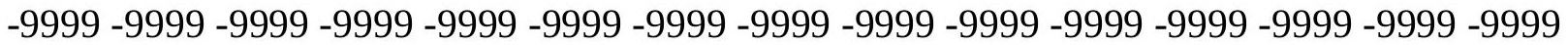

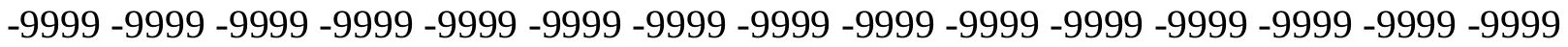

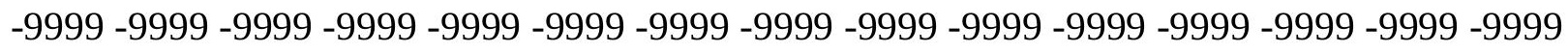

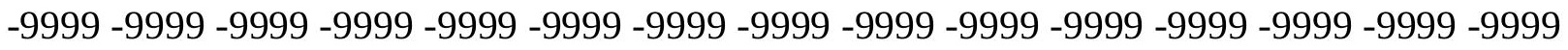

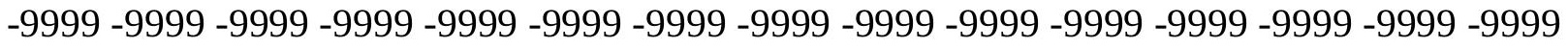
-9999 -9999 -9999 -9999 -9999 -9999 -9999 -9999 -9999 -9999 -9999 -9999 -9999 -9999 -9999 -

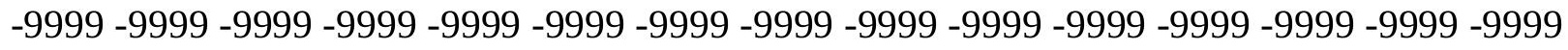

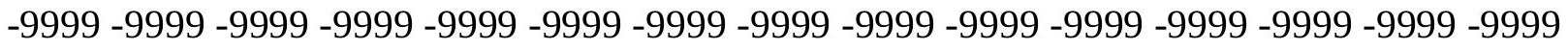
-9999 -9999 -9999 -9999 -9999 -9999 -9999 -9999 -9999 -9999 -9999 -9999 -9999 -9999 -9999 -9999 -9999 -9999 -9999 -9999 -9999 -9999 -9999 -9999-9999 -9999 -9999 -9999 -9999 -9999 -9999 -9999 -9999 -9999 -9999 -9999 -9999 -9999 -9999 -9999 -9999 -9999 -9999 -9999 -9999 -

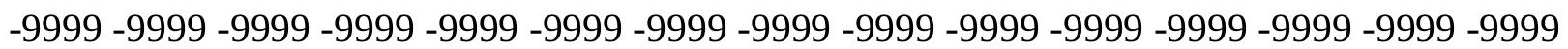


-9999 -9999 -9999 -9999 -9999 -9999 -9999 -9999 -9999 -9999 -9999 -9999 -9999 -9999 -9999 -9999 -9999 -9999 -9999 -9999 -9999 -9999 -9999 -9999 -9999 -9999 -9999 -9999 -9999 -9999 -

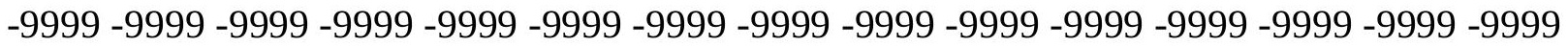
-9999 -9999 -9999 -9999 -9999 -9999 -9999 -9999 -9999 -9999 -9999 -9999 -9999 -9999 -9999 -9999 -9999 -9999 -9999 -9999 -9999 -9999 -9999 -9999-9999 -9999 -9999 -9999 -9999 -9999 -9999 -9999 -9999 -9999 -9999 -9999 -9999 -9999 -9999 -9999 -9999 -9999 -9999 -9999 -9999 -

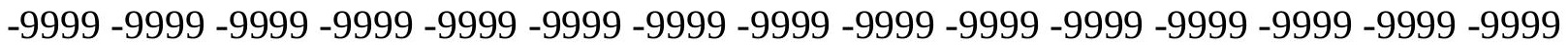
-9999 -9999 -9999 -9999 -9999 -9999 -9999 -9999 -9999 -9999 -9999 -9999 -9999 -9999 -9999 -9999 -9999 -9999 -9999 -9999 -9999 -9999 -9999 -9999 -9999 -9999 -9999 -9999 -9999 -9999 -9999 -9999 -9999 -9999 -9999 -9999 -9999 -9999 -9999 -9999 -9999 -9999 -9999 -9999 -9999 -9999 -9999 -9999 -9999 -9999 -9999 -9999 -9999 -9999 -9999 -9999 -9999 -9999 -9999 -9999 -9999 -9999 -9999 -9999 -9999 -9999 -9999 -9999 -9999 -9999 -9999 -9999 -9999 -9999 -9999 -9999 -9999 -9999 -9999 -9999 -9999 -9999 -9999 -9999 -9999 -9999 -9999 -9999 -9999 -9999 -9999 -9999 -9999 -9999 -9999 -9999 -9999 -9999 -9999 -9999 -9999 -9999 -9999 -9999 -9999 -9999 -9999 -9999 -9999 -9999 -9999 -9999 -9999 -9999 -9999 -9999 -9999 -9999 -9999 -

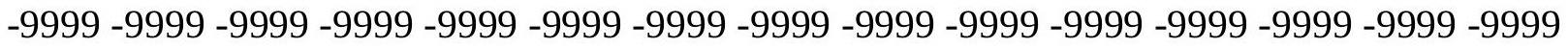
-9999 -9999 -9999 -9999 -9999 -9999 -9999 -9999 -9999 -9999 -9999 -9999 -9999 -9999 -9999 -9999 -9999 -9999 -9999 -9999 -9999 -9999 -9999 -9999 -9999 -9999 -9999 -9999 -9999 -9999 -9999 -9999 -9999 -9999 -9999 -9999 -9999 -9999 -9999 -9999 -9999 -9999 -9999 -9999 -9999 -

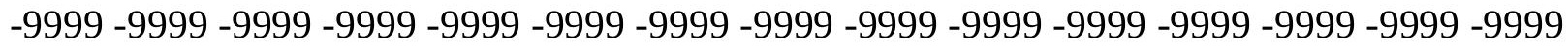

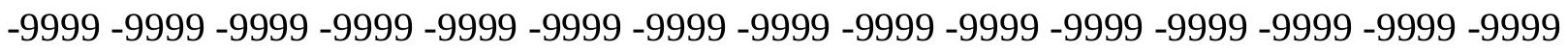
-9999 -9999 -9999 -9999 -9999 -9999 -9999 -9999 -9999 -9999 -9999 -9999 -9999 -9999 - 9999 -9999 -9999 -9999 -9999 -9999 -9999 -9999 -9999 -9999 -9999 -9999 -9999 -9999 -9999 -9999 -9999 -9999 -9999 -9999 -9999 -9999 -9999 -9999 -9999 -9999 -9999 -9999 -9999 -9999 -9999 -

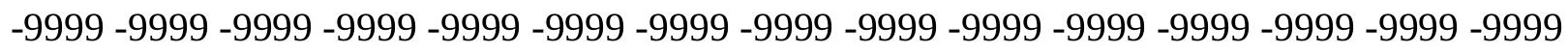
-9999 -9999 -9999 -9999 -9999 -9999 -9999 -9999 -9999 -9999 -9999 -9999 -9999 -9999 -9999 -9999 -9999 -9999 -9999 -9999 -9999 -9999 -9999 -9999 -9999 -9999 -9999 -9999 -9999 -9999 -

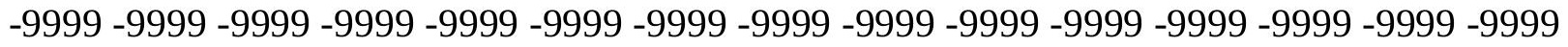
-9999 -9999 -9999 -9999 -9999 -9999 -9999 -9999 -9999 -9999 -9999 -9999 -9999 -9999 -9999 -9999 -9999 -9999 -9999 -9999 -9999 -9999 -9999 -9999 -9999 -9999 -9999 -9999 -9999 -999 -9999 -9999 -9999 -9999 -9999 -9999 -9999 -9999 -9999 -9999 -9999 -9999 -9999 -9999 -9999 -9999 -9999 -9999 -9999 -9999 -9999 -9999 -9999 -9999 -9999 -9999 -9999 -9999 -9999 -9999 -

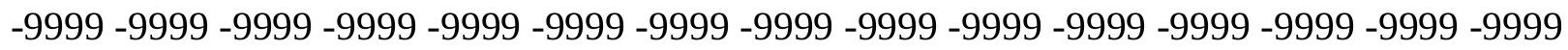

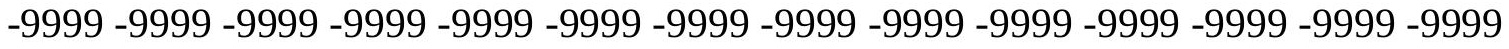
-9999 -9999 -9999 -9999 -9999 -9999 -9999 -9999 -9999 -9999 -9999 -9999 -9999 -9999 -9999

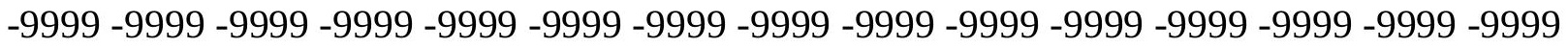

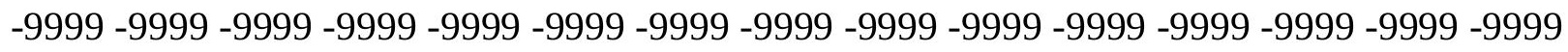

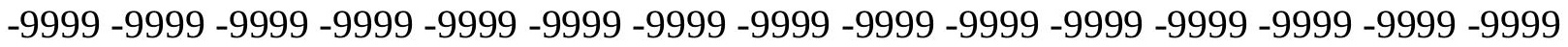

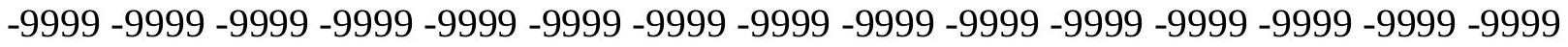
-9999 -9999 -9999 -9999 -9999 -9999 -9999 -9999 -9999 -9999 -9999 -9999 -9999 -9999 -9999 -

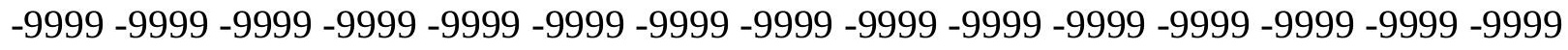

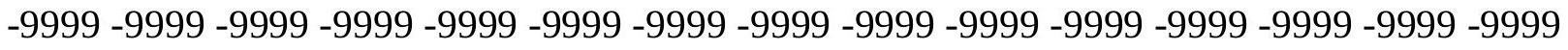
-9999 -9999 -9999 -9999 -9999 -9999 -9999 -9999 -9999 -9999 -9999 -9999 -9999 -9999 -9999 -9999 -9999 -9999 -9999 -9999 -9999 -9999 -9999 -9999-9999 -9999 -9999 -9999 -9999 -9999 -9999 -9999 -9999 -9999 -9999 -9999 -9999 -9999 -9999 -9999 -9999 -9999 -9999 -9999 -9999 -

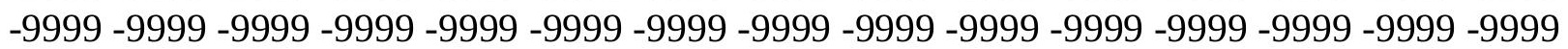


-9999 -9999 -9999 -9999 -9999 -9999 -9999 -9999 -9999 -9999 -9999 -9999 -9999 -9999 -9999 -9999 -9999 -9999 -9999 -9999 -9999 -9999 -9999 -9999 -9999 -9999 -9999 -9999 -9999 -9999 -

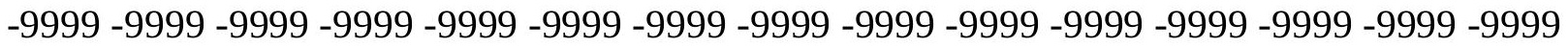
-9999 -9999 -9999 -9999 -9999 -9999 -9999 -9999 -9999 -9999 -9999 -9999 -9999 -9999 -9999 -9999 -9999 -9999 -9999 -9999 -9999 -9999 -9999 -9999-9999 -9999 -9999 -9999 -9999 -9999 -9999 -9999 -9999 -9999 -9999 -9999 -9999 -9999 -9999 -9999 -9999 -9999 -9999 -9999 -9999 -9999 -9999 -9999 -9999 -9999 -9999 -9999 -9999 -9999 -9999 -9999 -9999 -9999 -9999 -9999

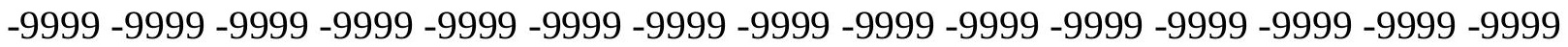

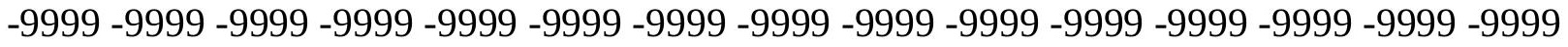
-9999 -9999 -9999 -9999 -9999 -9999 -9999 -9999 -9999 -9999 -9999 -9999 -9999 -9999 -9999 -9999 -9999 -9999 -9999 -9999 -9999 -9999 -9999 -9999 -9999 -9999 -9999 -9999 -9999 -9999 -9999 -9999 -9999 -9999 -9999 -9999 -9999 -9999 -9999 -9999 -9999 -9999 -9999 -9999 -9999 -9999 -9999 -9999 -9999 -9999 -9999 -9999 -9999 -9999 -9999 -9999 -9999 -9999 -9999 -9999 -9999 -9999 -9999 -9999 -9999 -9999 -9999 -9999 -9999 -9999 -9999 -9999 -9999 -9999 -9999 -9999 -9999 -9999 -9999 -9999 -9999 -9999 -9999 -9999 -9999 -9999 -9999 -9999 -9999

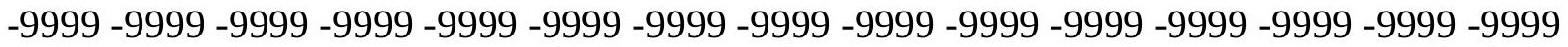
-9999 -9999 -9999 -9999 -9999 -9999 -9999 -9999 -9999 -9999 -9999 -9999 -9999 -9999 -9999 -9999 -9999 -9999 -9999 -9999 -9999 -9999 -9999 -9999 -9999 -9999 -9999 -9999 -9999 -9999 -9999 -9999 -9999 -9999 -9999 -9999 -9999 -9999 -9999 -9999 -9999 -9999 -9999 -9999 -9999 -

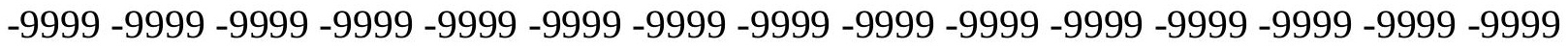

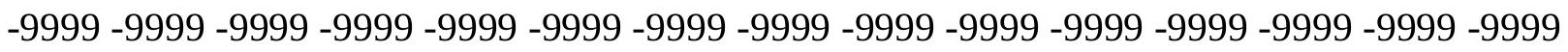
-9999 -9999 -9999 -9999 -9999 -9999 -9999 -9999 -9999 -9999 -9999 -9999 -9999 -9999 -9999 -9999 -9999 -9999 -9999 -9999 -9999 -9999 -9999 -9999 -9999 -9999 -9999 -9999 -9999 -9999 -9999 -9999 -9999 -9999 -9999 -9999 -9999 -9999 -9999 -9999 -9999 -9999 -9999 -9999 -9999 -

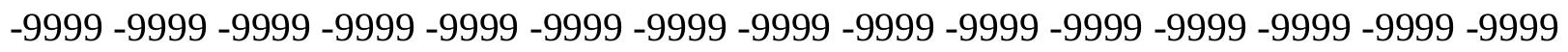
-9999 -9999 -9999 -9999 -9999 -9999 -9999 -9999 -9999 -9999 -9999 -9999 -9999 -9999 -9999 -9999 -9999 -9999 -9999 -9999 -9999 -9999 -9999 -9999 -9999 -9999 -9999 -9999 -9999 -9999 -

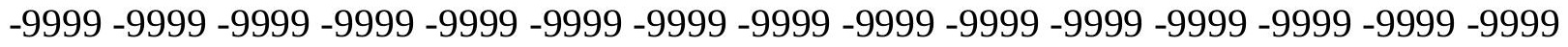
-9999 -9999 -9999 -9999 -9999 -9999 -9999 -9999 -9999 -9999 -9999 -9999 -9999 -9999 -9999 -9999 -9999 -9999 -9999 -9999 -9999 -9999 -9999 -9999 -9999 -9999 -9999 -9999 -9999 -999 -9999 -9999 -9999 -9999 -9999 -9999 -9999 -9999 -9999 -9999 -9999 -9999 -9999 -9999 -9999 -9999 -9999 -9999 -9999 -9999 -9999 -9999 -9999 -9999 -9999 -9999 -9999 -9999 -9999 -9999 -

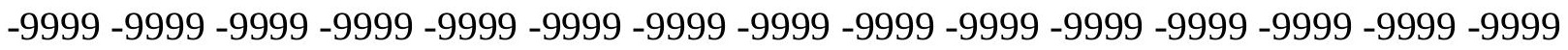

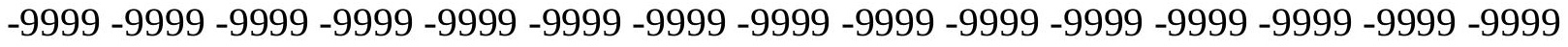

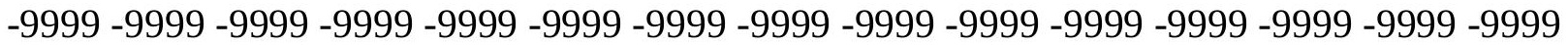

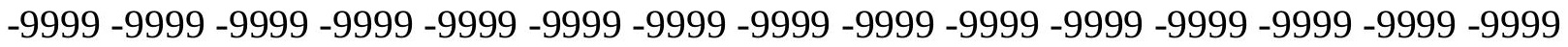

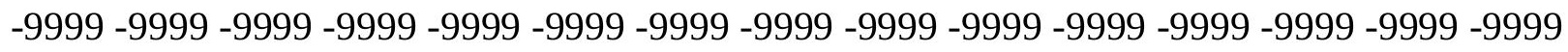

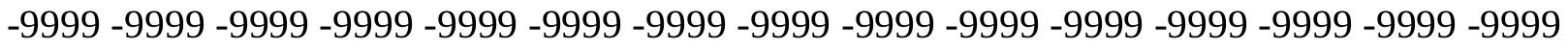
-9999 -9999 -9999 -9999 -9999 -9999 -9999 -9999 -9999 -9999 -9999 -9999 -9999 - 9999 - -999 -9999 -9999 -9999 -9999 -9999 -9999 -9999 -9999 -9999 -9999 -9999 -9999 -9999 -9999 - -999 -

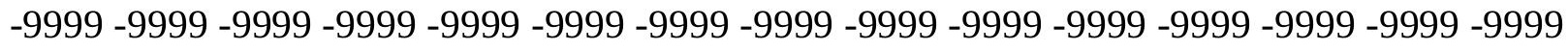

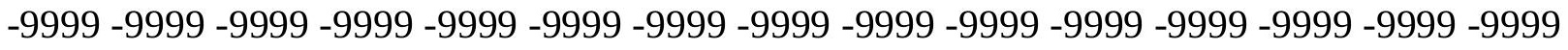
-9999 -9999 -9999 -9999 -9999 -9999 -9999 -9999 -9999 -9999 -9999 -9999 -9999 -9999 -9999 -9999 -9999 -9999 -9999 -9999 -9999 -9999 -9999 -9999-9999 -9999 -9999 -9999 -9999 -9999 -9999 -9999 -9999 -9999 -9999 -9999 -9999 -9999 -9999 -9999 -9999 -9999 -9999 -9999 -9999 -

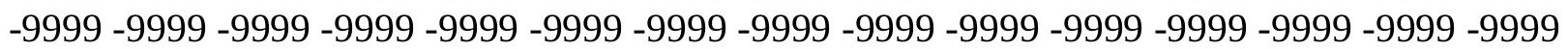


-9999 -9999 -9999 -9999 -9999 -9999 -9999 -9999 -9999 -9999 -9999 -9999 -9999 -9999 -9999 -9999 -9999 -9999 -9999 -9999 -9999 -9999 -9999 -9999 -9999 -9999 -9999 -9999 -9999 -9999 -9999 -9999 -9999 -9999 -9999 -9999 -9999 -9999 -9999 -9999 -9999 -9999 -9999 -9999 -9999 -9999 -9999 -9999 -9999 -9999 -9999 -9999 -9999 -9999 -9999 -9999 -9999 -9999 -9999 -9999 -9999 -9999 -9999 -9999 -9999 -9999 -9999 -9999 -9999 -9999 -9999 -9999 -9999 -9999 -9999 -9999 -9999 -9999 -9999 -9999 -9999 -9999 -9999 -9999 -9999 -9999 -9999 -9999 -9999 -9999 -9999 -9999 -9999 -9999 -9999 -9999 -9999 -9999 -9999 -9999 -9999 -9999 -9999 -9999 -9999 -

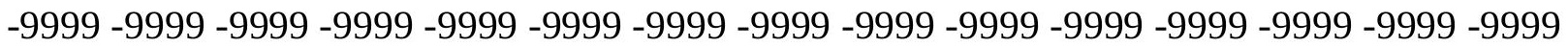
-9999 -9999 -9999 -9999 -9999 -9999 -9999 -9999 -9999 -9999 -9999 -9999 -9999 -9999 -9999 -9999 -9999 -9999 -9999 -9999 -9999 -9999 -9999 -9999 -9999 -9999 -9999 -9999 -9999 -9999 -

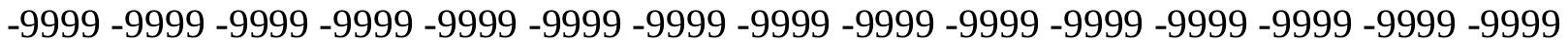
-9999 -9999 -9999 -9999 -9999 -9999 -9999 -9999 -9999 -9999 -9999 -9999 -9999 -9999 -9999 -9999 -9999 -9999 -9999 -9999 -9999 -9999 -9999 -9999 -9999 -9999 -9999 -9999 -9999 -9999 -9999 -9999 -9999 -9999 -9999 -9999 -9999 -9999 -9999 -9999 -9999 -9999 -9999 -9999 -9999 -9999 -9999 -9999 -9999 -9999 -9999 -9999 -9999 -9999 -9999 -9999 -9999 -9999 -9999 -9999

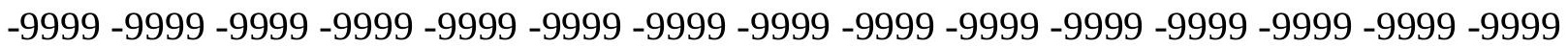
-9999 -9999 -9999 -9999 -9999 -9999 -9999 -9999 -9999 -9999 -9999 -9999 -9999 -9999 -9999 -9999 -9999 -9999 -9999 -9999 -9999 -9999 -9999 -9999 -9999 -9999 -9999 -9999 -9999 -9999 -9999 -9999 -9999 -9999 -9999 -9999 -9999 -9999 -9999 -9999 -9999 -9999 -9999 -9999 -9999 -9999 -9999 -9999 -9999 -9999 -9999 -9999 -9999 -9999 -9999 -9999 -9999 -9999 -9999 -9999 -9999 -9999 -9999 -9999 -9999 -9999 -9999 -9999 -9999 -9999 -9999 -9999 -9999 -9999 -9999 -9999 -9999 -9999 -9999 -9999 -9999 -9999 -9999 -9999 -9999 -9999 -9999 -9999 -9999 -9999 -9999 -9999 -9999 -9999 -9999 -9999 -9999 -9999 -9999 -9999 -9999 -9999 -9999 -9999 -9999 -9999 -9999 -9999 -9999 -9999 -9999 -9999 -9999 -9999 -9999 -9999 -9999 -9999 -9999 -9999 -9999 -9999 -9999 -9999 -9999 -9999 -9999 -9999 -9999 -9999 -9999 -9999 -9999 -9999 -9999 -9999 -9999 -9999 -9999 -9999 -9999 -9999 -9999 -9999 -9999 -9999 -9999 -9999 -9999 -9999 -9999 -9999 -9999 -9999 -9999 -9999 -9999 -9999 -9999 -9999 -9999 -9999 -9999 -9999 -9999 -9999 -9999 -9999 -9999 -9999 -9999 -9999 -9999 -9999 -9999 -9999 -9999 -9999 -9999

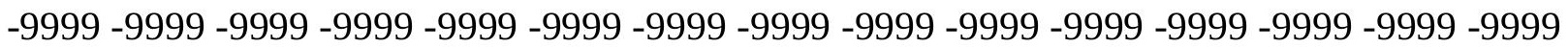
-9999 -9999 -9999 -9999 -9999 -9999 -9999 -9999 -9999 -9999 -9999 -9999 -9999 -9999 -9999 -9999 -9999 -9999 -9999 -9999 -9999 -9999 -9999 -9999 -9999 -9999 -9999 -9999 -9999 -9999 -

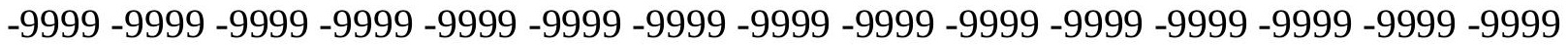
-9999 -9999 -9999 -9999 -9999 -9999 -9999 -9999 -9999 -9999 -9999 -9999 -9999 -9999 -9999 -9999 -9999 -9999 -9999 -9999 -9999 -9999 -9999 -9999 -9999 -9999 -9999 -9999 -9999 -9999 -9999 -9999 -9999 -9999 -9999 -9999 -9999 -9999 -9999 -9999 -9999 -9999 -9999 -9999 -9999 -9999 -9999 -9999 -9999 -9999 -9999 -9999 -9999 -9999 -9999 -9999 -9999 -9999 -9999 -9999 -9999 -9999 -9999 -9999 -9999 -9999 -9999 -9999 -9999 -9999 -9999 -9999 -9999 -9999 -9999

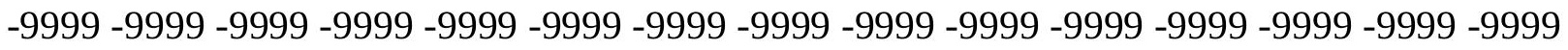
-9999 -9999 -9999 -9999 -9999 -9999 -9999 -9999 -9999 -9999 -9999 -9999 -9999 -9999 -9999 -9999 -9999 -9999 -9999 -9999 -9999 -9999 -9999 -9999 -9999 -9999 -9999 -9999 -9999 -9999 -9999 -9999 -9999 -9999 -9999 -9999 -9999 -9999 -9999 -9999 -9999 -9999 -9999 -9999 -9999 -999 -9999 -9999 -9999 -9999 -9999 -9999 -9999 -9999 -9999 -9999 -9999 -9999 -9999 -9999 -9999 -9999 -9999 -9999 -9999 -9999 -9999 -9999 -9999 -9999 -9999 -9999 -9999 -9999 -9999 -9999 -9999 -9999 -9999 -9999 -9999 -9999 -9999 -9999 -9999 -9999 -9999 -9999 -9999 -9999 -9999 -9999 -9999 -9999 -9999 -9999 -9999 -9999 -9999 -9999 -9999 -9999 -9999 -9999 -9999 -9999 -9999 -9999 -9999 -9999 -9999 -9999 -9999 -9999 -9999 -9999 -9999 -9999 -9999 -9999 
-9999 -9999 -9999 -9999 -9999 -9999 -9999 -9999 -9999 -9999 -9999 -9999 -9999 -9999 -9999 -9999 -9999 -9999 -9999 -9999 -9999 -9999 -9999 -9999 -9999 -9999 -9999 -9999 -9999 -9999 -

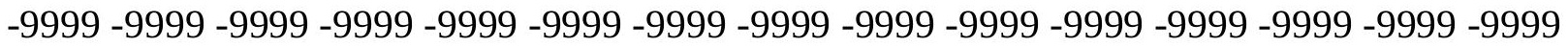
-9999 -9999 -9999 -9999 -9999 -9999 -9999 -9999 -9999 -9999 -9999 -9999 -9999 -9999 -9999 -9999 -9999 -9999 -9999 -9999 -9999 -9999 -9999 -9999-9999 -9999 -9999 -9999 -9999 -9999 -9999 -9999 -9999 -9999 -9999 -9999 -9999 -9999 -9999 -9999 -9999 -9999 -9999 -9999 -9999 -9999 -9999 -9999 -9999 -9999 -9999 -9999 -9999 -9999 -9999 -9999 -9999 -9999 -9999 -9999

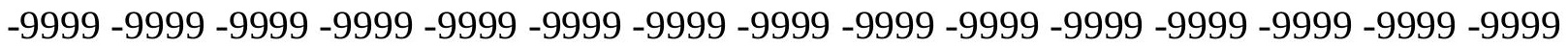

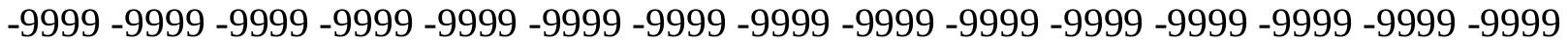
-9999 -9999 -9999 -9999 -9999 -9999 -9999 -9999 -9999 -9999 -9999 -9999 -9999 -9999 -9999 -9999 -9999 -9999 -9999 -9999 -9999 -9999 -9999 -9999 -9999 -9999 -9999 -9999 -9999 -9999 -9999 -9999 -9999 -9999 -9999 -9999 -9999 -9999 -9999 -9999 -9999 -9999 -9999 -9999 -9999 -9999 -9999 -9999 -9999 -9999 -9999 -9999 -9999 -9999 -9999 -9999 -9999 -9999 -9999 -9999 -

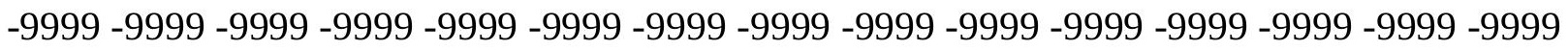
-9999 -9999 -9999 -9999 -9999 -9999 -9999 -9999 -9999 -9999 -9999 -9999 -9999 -9999 -9999 -

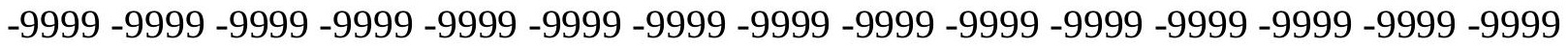
-9999 -9999 -9999 -9999 -9999 -9999 -9999 -9999 -9999 -9999 -9999 -9999 -9999 -9999 -9999 -9999 -9999 -9999 -9999 -9999 -9999 -9999 -9999 -9999 -9999 -9999 -9999 -9999 -9999 -9999 -9999 -9999 -9999 -9999 -9999 -9999 -9999 -9999 -9999 -9999 -9999 -9999 -9999 -9999 -9999 -

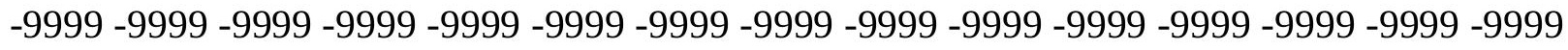

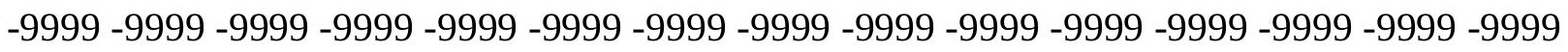

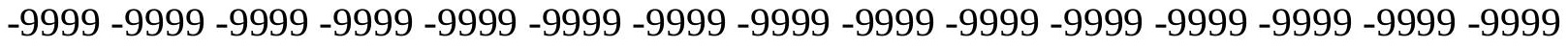
-9999 -9999 -9999 -9999 -9999 -9999 -9999 -9999 -9999 -9999 -9999 -9999 -9999 -9999 -9999 -9999 -9999 -9999 -9999 -9999 -9999 -9999 -9999 -9999 -9999 -9999 -9999 -9999 -9999 -9999 -

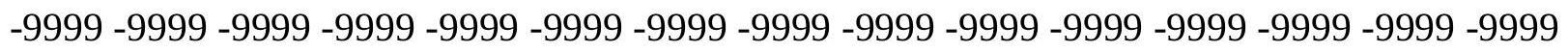
-9999 -9999 -9999 -9999 -9999 -9999 -9999 -9999 -9999 -9999 -9999 -9999 -9999 -9999 -9999 -9999 -9999 -9999 -9999 -9999 -9999 -9999 -9999 -9999 -9999 -9999 -9999 -9999 -9999 -

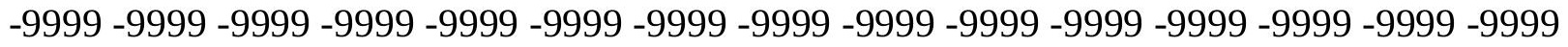
-9999 -9999 -9999 -9999 -9999 -9999 -9999 -9999 -9999 -9999 -9999 -9999 -9999 -9999 -9999 -9999 -9999 -9999 -9999 -9999 -9999 -9999 -9999 -9999 -9999 -9999 -9999 -9999 -9999 -999 -

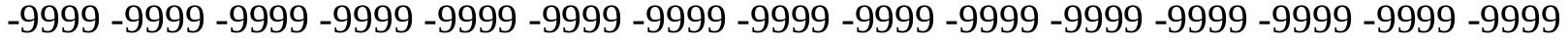
-9999 -9999 -9999 -9999 -9999 -9999 -9999 -9999 -9999 -9999 -9999 -9999 -9999 -9999 -9999 -

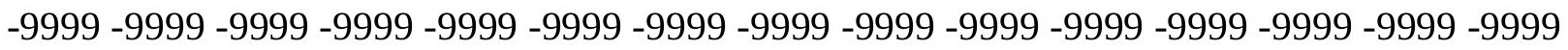

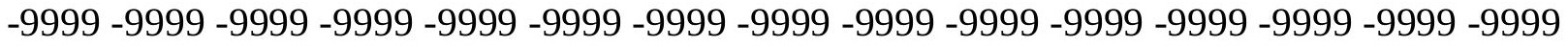

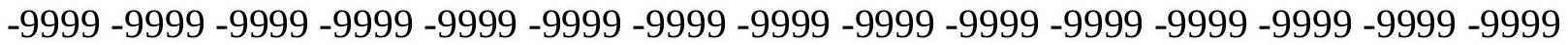
-9999 -9999 -9999 -9999 -9999 -9999 -9999 -9999 -9999 -9999 -9999 -9999 -9999 -9999 -9999

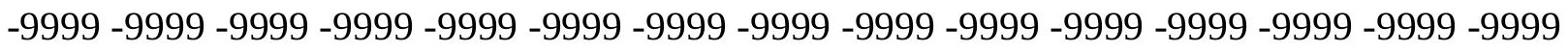

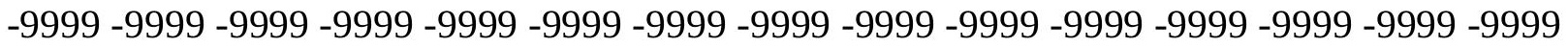
-9999 -9999 -9999 -9999 -9999 -9999 -9999 -9999 -9999 -9999 -9999 -9999 -9999 - 9999 - -999 -9999 -9999 -9999 -9999 -9999 -9999 -9999 -9999 -9999 -9999 -9999 -9999 -9999 -9999 -9999 -

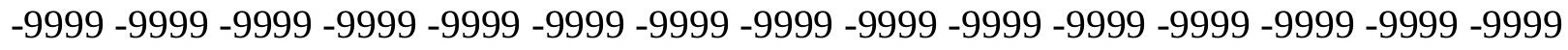

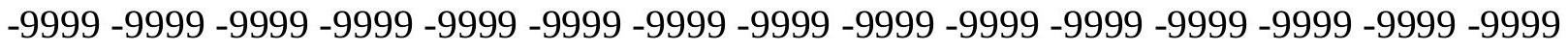
-9999 -9999 -9999 -9999 -9999 -9999 -9999 -9999 -9999 -9999 -9999 -9999 -9999 -9999 -9999 -9999 -9999 -9999 -9999 -9999 -9999 -9999 -9999 -9999-9999 -9999 -9999 -9999 -9999 -9999 -9999 -9999 -9999 -9999 -9999 -9999 -9999 -9999 -9999 -9999 -9999 -9999 -9999 -9999 -9999 -

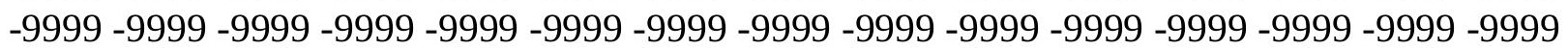


-9999 -9999 -9999 -9999 -9999 -9999 -9999 -9999 -9999 -9999 -9999 -9999 -9999 -9999 -9999 -9999 -9999 -9999 -9999 -9999 -9999 -9999 -9999 -9999 -9999 -9999 -9999 -9999 -9999 -9999 -9999 -9999 -9999 -9999 -9999 -9999 -9999 -9999 -9999 -9999 -9999 -9999 -9999 -9999 - 9999 -9999 -9999 -9999 -9999 -9999 -9999 -9999 -9999 -9999 -9999 -9999 -9999 -9999 -9999 -9999 -9999 -9999 -9999 -9999 -9999 -9999 -9999 -9999 -9999 -9999 -9999 -9999 -9999 -9999 - -9999 -9999 -9999 -9999 -9999 -9999 -9999 -9999 -9999 -9999 -9999 -9999 -9999 -9999 -9999 -9999 -9999 -9999 -9999 -9999 -9999 -9999 -9999 -9999 -9999 -9999 -9999 -9999 -9999 -9999

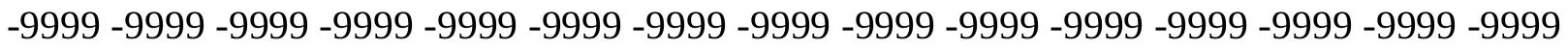

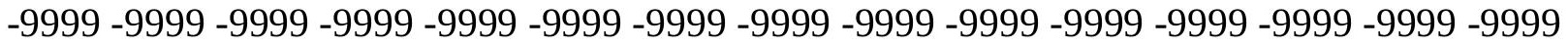
-9999 -9999 -9999 -9999 -9999 -9999 -9999 -9999 -9999 -9999 -9999 -9999 -9999 -9999 -9999

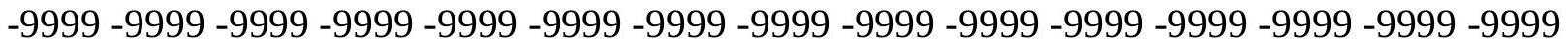
-9999 -9999 -9999 -9999 -9999 -9999 -9999 -9999 -9999 -9999 -9999 -9999 -9999 -9999 -9999 -9999 -9999 -9999 -9999 -9999 -9999 -9999 -9999 -9999 -9999 -9999 -9999 -9999 -9999 -9999 -9999 -9999 -9999 -9999 -9999 -9999 -9999 -9999 -9999 -9999 -9999 -9999 -9999 -9999 - -9999 -9999 -9999 -9999 -9999 -9999 -9999 -9999 -9999 -9999 -9999 -9999 -9999 -9999 -9999 -9999

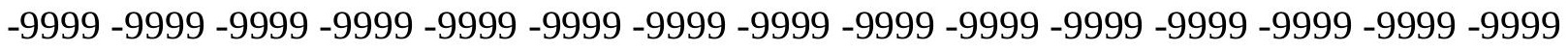
-9999 -9999 -9999 -9999 -9999 -9999 -9999 -9999 -9999 -9999 -9999 -9999 -9999 -9999 -9999 -9999 -9999 -9999 -9999 -9999 -9999 -9999 -9999 -9999 -9999 -9999 -9999 -9999 -9999 -9999 -9999 -9999 -9999 -9999 -9999 -9999 -9999 -9999 -9999 -9999 -9999 -9999 -9999 -9999 -9999 -

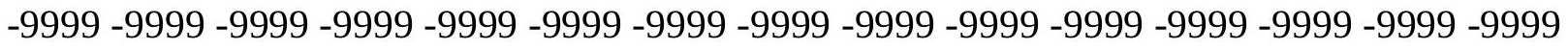
-9999 -9999 -9999 -9999 -9999 -9999 -9999 -9999 -9999 -9999 -9999 -9999 -9999 -9999 -9999 -999 -9999 -9999 -9999 -9999 -9999 -9999 -9999 -9999 -9999 -9999 -9999 -9999 -9999 -9999 -9999 -9999 -9999 -9999 -9999 -9999 -9999 -9999 -9999 -9999 -9999 -9999 -9999 -9999 -9999 -9999 -9999 -9999 -9999 -9999 -9999 -9999 -9999 -9999 -9999 -9999 -9999 -9999 -9999 -9999 -9999 -9999 -9999 -9999 -9999 -9999 -9999 -9999 -9999 -9999 -9999 -9999 -9999 -9999 -9999 -9999 -9999 -9999 -9999 -9999 -9999 -9999 -9999 -9999 -9999 -9999 -9999 -9999 -9999 -9999 -9999 -9999 -9999 -9999 -9999 -9999 -9999 -9999 -9999 -9999 -9999 -9999 -9999 -9999 -9999 -9999 -9999 -9999 -9999 -9999 -9999 -9999 -9999 -9999 -9999 -9999 -9999 -9999 -9999 -9999 -9999 -9999 -9999 -9999 -9999 -9999 -9999 -9999 -9999 -9999 -9999 -9999 -9999 -9999 -9999 -9999 -9999 -9999 -9999 -9999 -9999 -9999 -9999 -9999 -9999 -9999 -9999 -9999 -9999 -9999 -999 -9999 -9999 -9999 -9999 -9999 -9999 -9999 -9999 -9999 -9999 -9999 -9999 -9999 -9999 -9999 -9999 -9999 -9999 -9999 -9999 -9999 -9999 -9999 -9999 -9999 -9999 -9999 -9999 -9999 -

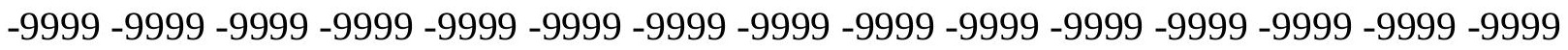

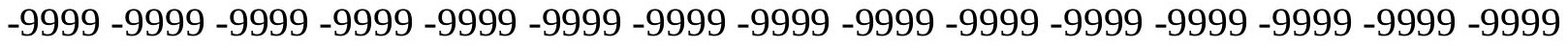

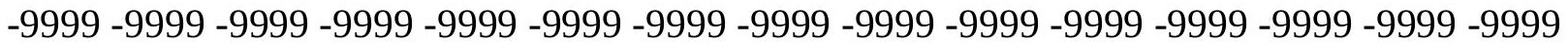
-9999 -9999 -9999 -9999 -9999 -9999 -9999 -9999 -9999 -9999 -9999 -9999 -9999 -9999 -9999 -

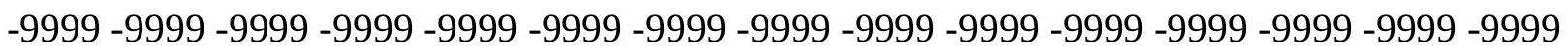

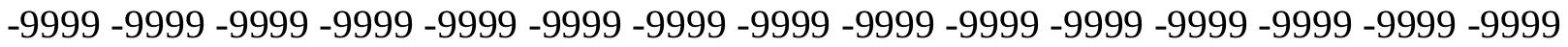

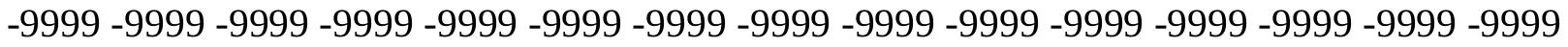
-9999 -9999 -9999 -9999 -9999 -9999 -9999 -9999 -9999 -9999 -9999 -9999 -9999 -9999 -9999 -

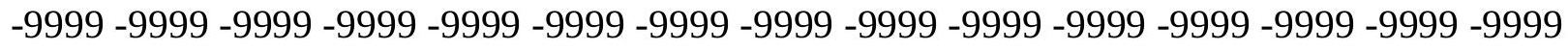

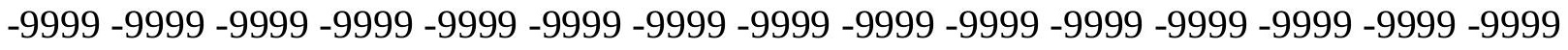
-9999 -9999 -9999 -9999 -9999 -9999 -9999 -9999 -9999 -9999 -9999 -9999 -9999 -9999 -9999 -9999 -9999 -9999 -9999 -9999 -9999 -9999 -9999 -9999-9999 -9999 -9999 -9999 -9999 -9999 -9999 -9999 -9999 -9999 -9999 -9999 -9999 -9999 -9999 -9999 -9999 -9999 -9999 -9999 -9999 -

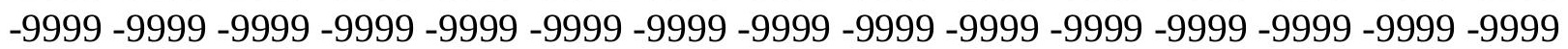


-9999 -9999 -9999 -9999 -9999 -9999 -9999 -9999 -9999 -9999 -9999 -9999 -9999 -9999 -9999 -9999 -9999 -9999 -9999 -9999 -9999 -9999 -9999 -9999 -9999 -9999 -9999 -9999 -9999 -9999 -

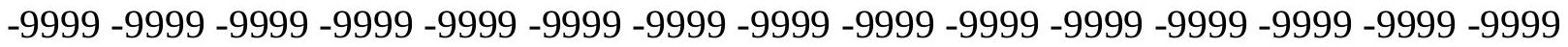
-9999 -9999 -9999 -9999 -9999 -9999 -9999 -9999 -9999 -9999 -9999 -9999 -9999 -9999 -9999 -9999 -9999 -9999 -9999 -9999 -9999 -9999 -9999 -9999-9999 -9999 -9999 -9999 -9999 -9999 -9999 -9999 -9999 -9999 -9999 -9999 -9999 -9999 -9999 -9999 -9999 -9999 -9999 -9999 -9999 -9999 -9999 -9999 -9999 -9999 -9999 -9999 -9999 -9999 -9999 -9999 -9999 -9999 -9999 -9999

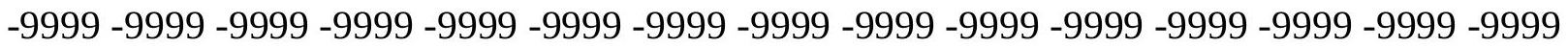

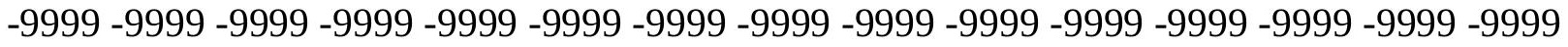
-9999 -9999 -9999 -9999 -9999 -9999 -9999 -9999 -9999 -9999 -9999 -9999 -9999 -9999 -9999 -9999 -9999 -9999 -9999 -9999 -9999 -9999 -9999 -9999 -9999 -9999 -9999 -9999 -9999 -9999 -9999 -9999 -9999 -9999 -9999 -9999 -9999 -9999 -9999 -9999 -9999 -9999 -9999 -9999 -9999 -9999 -9999 -9999 -9999 -9999 -9999 -9999 -9999 -9999 -9999 -9999 -9999 -9999 -9999 -9999 -9999 -9999 -9999 -9999 -9999 -9999 -9999 -9999 -9999 -9999 -9999 -9999 -9999 - 9999 -9999 -9999 -9999 -9999 -9999 -9999 -9999 -9999 -9999 -9999 -9999 -9999 -9999 -9999 -9999

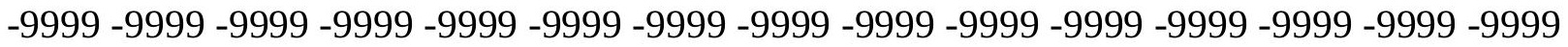
-9999 -9999 -9999 -9999 -9999 -9999 -9999 -9999 -9999 -9999 -9999 -9999 -9999 -9999 -9999 -9999 -9999 -9999 -9999 -9999 -9999 -9999 -9999 -9999 -9999 -9999 -9999 -9999 -9999 -9999 -9999 -9999 -9999 -9999 -9999 -9999 -9999 -9999 -9999 -9999 -9999 -9999 -9999 -9999 -9999 -

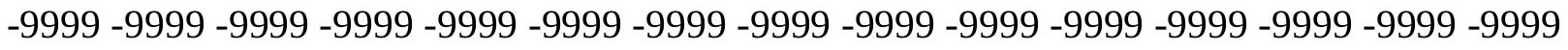

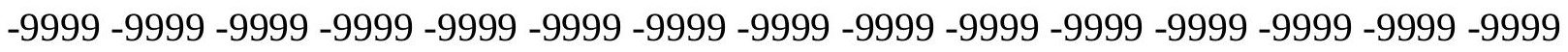
-9999 -9999 -9999 -9999 -9999 -9999 -9999 -9999 -9999 -9999 -9999 -9999 -9999 -9999 -9999 -9999 -9999 -9999 -9999 -9999 -9999 -9999 -9999 -9999 -9999 -9999 -9999 -9999 -9999 -9999 -9999 -9999 -9999 -9999 -9999 -9999 -9999 -9999 -9999 -9999 -9999 -9999 -9999 -9999 -9999 -

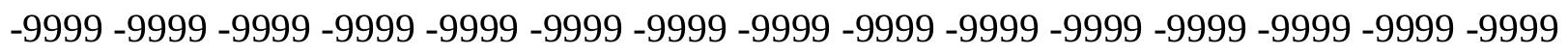
-9999 -9999 -9999 -9999 -9999 -9999 -9999 -9999 -9999 -9999 -9999 -9999 -9999 -9999 -9999 -9999 -9999 -9999 -9999 -9999 -9999 -9999 -9999 -9999 -9999 -9999 -9999 -9999 -9999 -9999 -

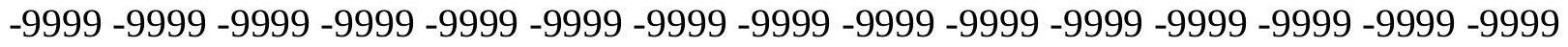
-9999 -9999 -9999 -9999 -9999 -9999 -9999 -9999 -9999 -9999 -9999 -9999 -9999 -9999 -9999 -9999 -9999 -9999 -9999 -9999 -9999 -9999 -9999 -9999 -9999 -9999 -9999 -9999 -9999 -999 -9999 -9999 -9999 -9999 -9999 -9999 -9999 -9999 -9999 -9999 -9999 -9999 -9999 -9999 -9999 -9999 -9999 -9999 -9999 -9999 -9999 -9999 -9999 -9999 -9999 -9999 -9999 -9999 -9999 -9999 -

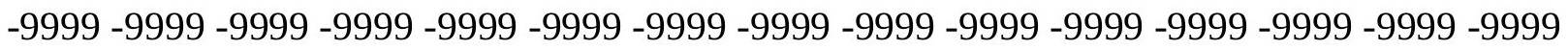

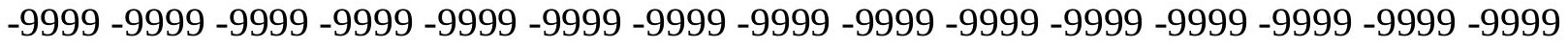

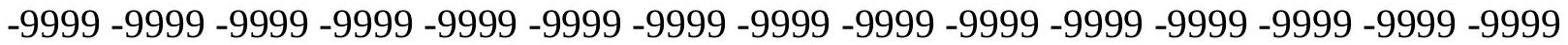

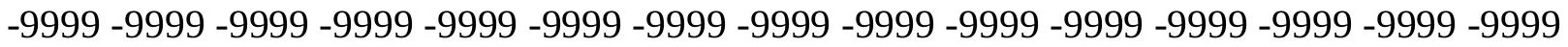

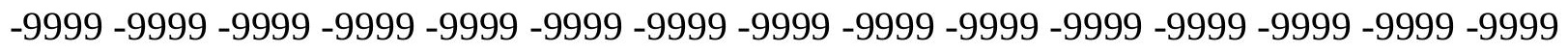

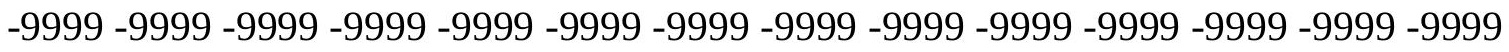
-9999 -9999 -9999 -9999 -9999 -9999 -9999 -9999 -9999 -9999 -9999 -9999 -9999 -9999 -9999 -9999 -9999 -9999 -9999 -9999 -9999 -9999 -9999 -9999 -9999 -9999 -9999 -9999 -9999 -9999 -

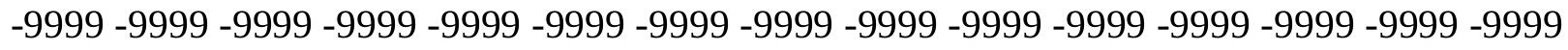

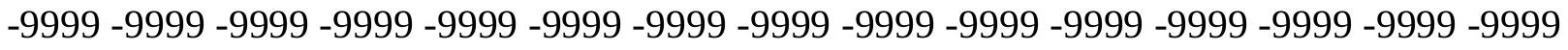
-9999 -9999 -9999 -9999 -9999 -9999 -9999 -9999 -9999 -9999 -9999 -9999 -9999 -9999 -9999 -9999 -9999 -9999 -9999 -9999 -9999 -9999 -9999 -9999-9999 -9999 -9999 -9999 -9999 -9999 -9999 -9999 -9999 -9999 -9999 -9999 -9999 -9999 -9999 -9999 -9999 -9999 -9999 -9999 -9999 -

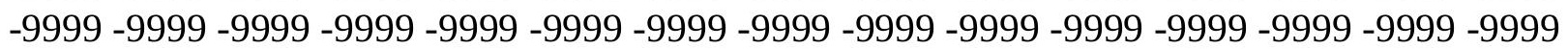


-9999 -9999 -9999 -9999 -9999 -9999 -9999 -9999 -9999 -9999 -9999 -9999 -9999 -9999 -9999 -9999 -9999 -9999 -9999 -9999 -9999 -9999 -9999 -9999 -9999 -9999 -9999 -9999 -9999 -9999 -9999 -9999 -9999 -9999 -9999 -9999 -9999 -9999 -9999 -9999 -9999 -9999 -9999 -9999 - 9999 -9999 -9999 -9999 -9999 -9999 -9999 -9999 -9999 -9999 -9999 -9999 -9999 -9999 -9999 -9999 -9999 -9999 -9999 -9999 -9999 -9999 -9999 -9999 -9999 -9999 -9999 -9999 -9999 -9999 -9999 -9999 -9999 -9999 -9999 -9999 -9999 -9999 -9999 -9999 -9999 -9999 -9999 -9999 -9999 -9999 -9999 -9999 -9999 -9999 -9999 -9999 -9999 -9999 -9999 -9999 -9999 -9999 -9999 -9999 -9999

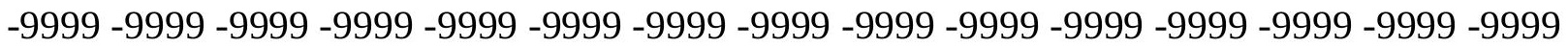
-9999 -9999 -9999 -9999 -9999 -9999 -9999 -9999 -9999 -9999 -9999 -9999 -9999 -9999 -9999 -9999 -9999 -9999 -9999 -9999 -9999 -9999 -9999 -9999 -9999 -9999 -9999 -9999 -9999 -9999

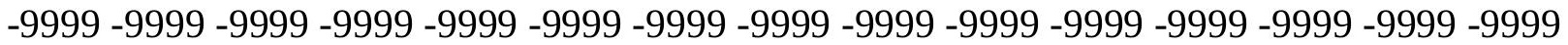
-9999 -9999 -9999 -9999 -9999 -9999 -9999 -9999 -9999 -9999 -9999 -9999 -9999 -9999 -9999 -9999 -9999 -9999 -9999 -9999 -9999 -9999 -9999 -9999 -9999 -9999 -9999 -9999 -9999 -9999 -

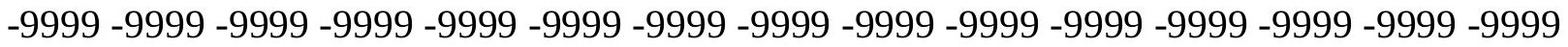
-9999 -9999 -9999 -9999 -9999 -9999 -9999 -9999 -9999 -9999 -9999 -9999 -9999 -9999 -9999

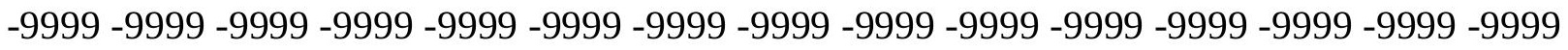
-9999 -9999 -9999 -9999 -9999 -9999 -9999 -9999 -9999 -9999 -9999 -9999 -9999 -9999 -9999 -9999 -9999 -9999 -9999 -9999 -9999 -9999 -9999 -9999 -9999 -9999 -9999 -9999 -9999 - -999 -9999 -9999 -9999 -9999 -9999 -9999 -9999 -9999 -9999 -9999 -9999 -9999 -9999 -9999 -9999 -9999 -9999 -9999 -9999 -9999 -9999 -9999 -9999 -9999 -9999 -9999 -9999 -9999 -9999 -9999 -9999 -9999 -9999 -9999 -9999 -9999 -9999 -9999 -9999 -9999 -9999 -9999 -9999 -9999 -9999 -999 -9999 -9999 -9999 -9999 -9999 -9999 -9999 -9999 -9999 -9999 -9999 -9999 -9999 -9999 -9999 -9999 -9999 -9999 -9999 -9999 -9999 -9999 -9999 -9999 -9999 -9999 -9999 -9999 -9999 -9999 -9999 -9999 -9999 -9999 -9999 -9999 -9999 -9999 -9999 -9999 -9999 -9999 -9999 -9999 -9999 -9999 -9999 -9999 -9999 -9999 -9999 -9999 -9999 -9999 -9999 -9999 -9999 -9999 -9999 -9999 -9999 -9999 -9999 -9999 -9999 -9999 -9999 -9999 -9999 -9999 -9999 -9999 -9999 -9999 -9999 -9999 -9999 -9999 -9999 -9999 -9999 -9999 -9999 -9999 -9999 -9999 -9999 -9999 -9999 -9999 -9999 -9999 -9999 -9999 -9999 -9999 -9999 -9999 -9999 -9999 -9999 -9999 -9999 -9999 -9999 -9999 -9999 -9999 -9999 -9999 -9999 -9999 -9999 -9999 -9999 -9999 -9999 -9999 -9999 -9999 -9999 -9999 -9999 -9999 -9999 -9999 -9999 -9999 -9999 -9999 -9999 -9999 -9999 -9999 -999 -9999 -9999 -9999 -9999 -9999 -9999 -9999 -9999 -9999 -9999 -9999 -9999 -9999 -9999 -9999 -9999 -9999 -9999 -9999 -9999 -9999 -9999 -9999 -9999 -9999 -9999 -9999 -9999 -9999 -9999 -

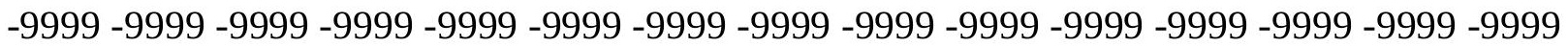

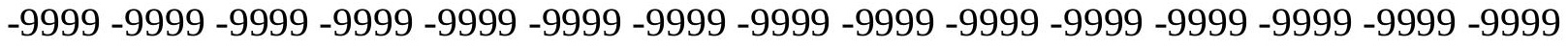

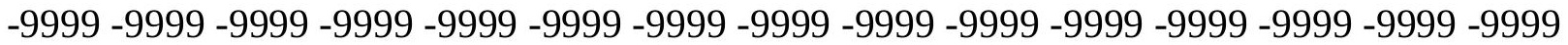
-9999 -9999 -9999 -9999 -9999 -9999 -9999 -9999 -9999 -9999 -9999 -9999 -9999 -9999 -9999

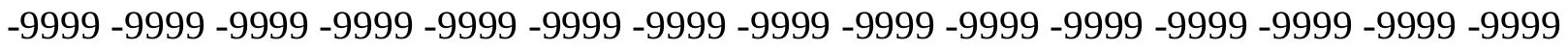

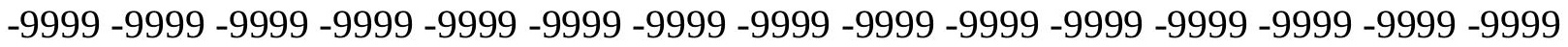

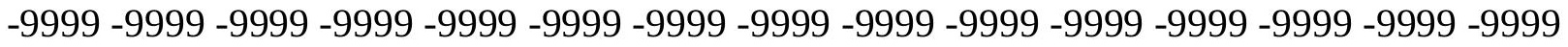
-9999 -9999 -9999 -9999 -9999 -9999 -9999 -9999 -9999 -9999 -9999 -9999 -9999 -9999 -9999 -

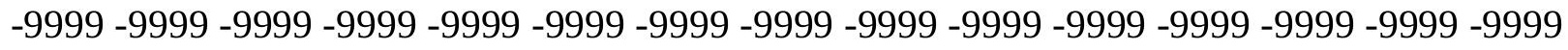

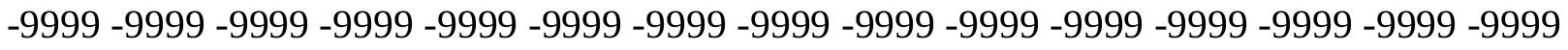
-9999 -9999 -9999 -9999 -9999 -9999 -9999 -9999 -9999 -9999 -9999 -9999 -9999 -9999 -9999 -9999 -9999 -9999 -9999 -9999 -9999 -9999 -9999 -9999 -9999 -9999 -9999 -9999 - -9999 -9999 -9999 -9999 -9999 -9999 -9999 -9999 -9999 -9999 -9999 -9999 -9999 -9999 -9999 -9999 -

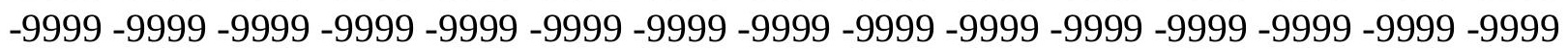


-9999 -9999 -9999 -9999 -9999 -9999 -9999 -9999 -9999 -9999 -9999 -9999 -9999 -9999 -9999 -9999 -9999 -9999 -9999 -9999 -9999 -9999 -9999 -9999 -9999 -9999 -9999 -9999 -9999 -9999 -9999 -9999 -9999 -9999 -9999 -9999 -9999 -9999 -9999 -9999 -9999 -9999 -9999 -9999 - 9999 -9999 -9999 -9999 -9999 -9999 -9999 -9999 -9999 -9999 -9999 -9999 -9999 -9999 -9999 -9999 -9999 -9999 -9999 -9999 -9999 -9999 -9999 -9999 -9999-9999 -9999 -9999 -9999 -9999 -9999 -9999 -9999 -9999 -9999 -9999 -9999 -9999 -9999 -9999 -9999 -9999 -9999 -9999 -9999 -9999 -9999 -9999 -9999 -9999 -9999 -9999 -9999 -9999 -9999 -9999 -9999 -9999 -9999 -9999 -9999

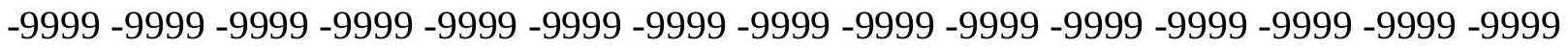

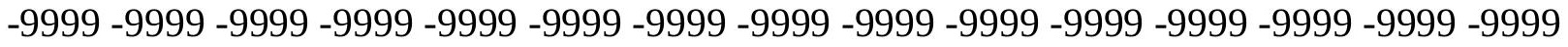
-9999 -9999 -9999 -9999 -9999 -9999 -9999 -9999 -9999 -9999 -9999 -9999 -9999 -9999 -9999

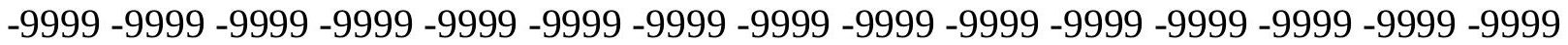
-9999 -9999 -9999 -9999 -9999 -9999 -9999 -9999 -9999 -9999 -9999 -9999 -9999 -9999 -9999 -9999 -9999 -9999 -9999 -9999 -9999 -9999 -9999 -9999 -9999 -9999 -9999 -9999 -9999 -9999 -

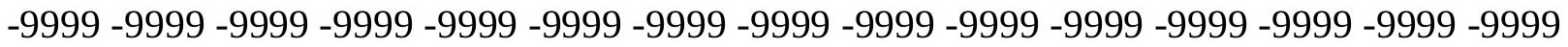
-9999 -9999 -9999 -9999 -9999 -9999 -9999 -9999 -9999 -9999 -9999 -9999 -9999 -9999 -9999

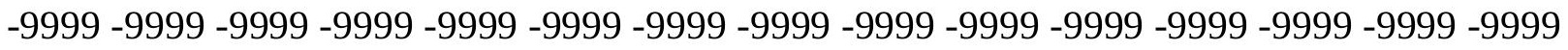
-9999 -9999 -9999 -9999 -9999 -9999 -9999 -9999 -9999 -9999 -9999 -9999 -9999 -9999 -9999 -9999 -9999 -9999 -9999 -9999 -9999 -9999 -9999 -9999 -9999 -9999 -9999 -9999 -9999 -9999 -9999 -9999 -9999 -9999 -9999 -9999 -9999 -9999 -9999 -9999 -9999 -9999 -9999 -9999 -9999 -9999 -9999 -9999 -9999 -9999 -9999 -9999 -9999 -9999 -9999 -9999 -9999 -9999 -9999 -9999 -9999 -9999 -9999 -9999 -9999 -9999 -9999 -9999 -9999 -9999 -9999 -9999 -9999 -9999 -9999 -999 -9999 -9999 -9999 -9999 -9999 -9999 -9999 -9999 -9999 -9999 -9999 -9999 -9999 -9999 -9999 -9999 -9999 -9999 -9999 -9999 -9999 -9999 -9999 -9999 -9999 -9999 -9999 -9999 -9999 -9999 -9999 -9999 -9999 -9999 -9999 -9999 -9999 -9999 -9999 -9999 -9999 -9999 -9999 -9999 -9999 -9999 -9999 -9999 -9999 -9999 -9999 -9999 -9999 -9999 -9999 -9999 -9999 -9999 -9999 -9999 -9999 -9999 -9999 -9999 -9999 -9999 -9999 -9999 -9999 -9999 -9999 -9999 -9999 -9999 -9999 -9999 -9999 -9999 -9999 -9999 -9999 -9999 -9999 -9999 -9999 -9999 -9999 -9999 -9999 -9999 -9999 -9999 -9999 -9999 -9999 -9999 -9999 -9999 -9999 -9999 -9999 -9999 -9999 -9999 -9999 -9999 -9999 -9999 -9999 -9999 -9999 -9999 -9999 -9999 -9999 -9999 -9999 -9999 -9999 -9999 -9999 -9999 -9999 -9999 -9999 -9999 -9999 -9999 -9999 -9999 -9999 -9999 -9999 -999 -9999 -9999 -9999 -9999 -9999 -9999 -9999 -9999 -9999 -9999 -9999 -9999 -9999 -9999 -9999 -9999 -9999 -9999 -9999 -9999 -9999 -9999 -9999 -9999 -9999 -9999 -9999 -9999 -9999 -9999 -

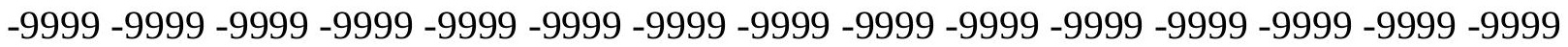

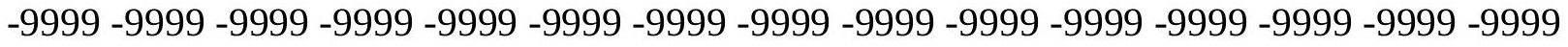

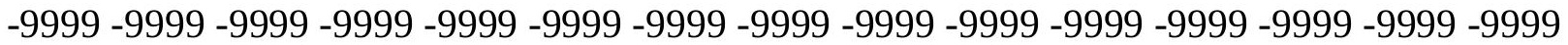
-9999 -9999 -9999 -9999 -9999 -9999 -9999 -9999 -9999 -9999 -9999 -9999 -9999 -9999 -9999

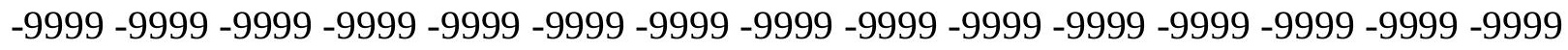

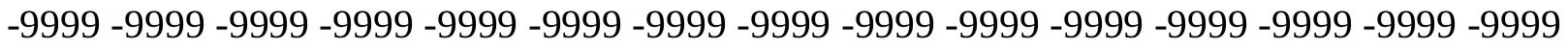
-9999 -9999 -9999 -9999 -9999 -9999 -9999 -9999 -9999 -9999 -9999 -9999 -9999 -9999 -9999 -9999 -9999 -9999 -9999 -9999 -9999 -9999 -9999 -9999 -9999 -9999 -9999 -9999 -9999 -9999 -

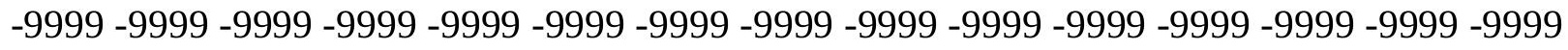

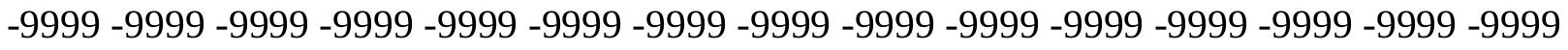
-9999 -9999 -9999 -9999 -9999 -9999 -9999 -9999 -9999 -9999 -9999 -9999 -9999 -9999 -9999 -9999 -9999 -9999 -9999 -9999 -9999 -9999 -9999 -9999-9999 -9999 -9999 -9999 -9999 -9999 -9999 -9999 -9999 -9999 -9999 -9999 -9999 -9999 -9999 -9999 -9999 -9999 -9999 -9999 -9999 -

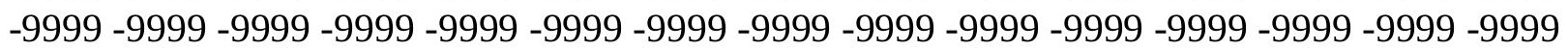


-9999 -9999 -9999 -9999 -9999 -9999 -9999 -9999 -9999 -9999 -9999 -9999 -9999 -9999 -9999 -9999 -9999 -9999 -9999 -9999 -9999 -9999 -9999 -9999 -9999 -9999 -9999 -9999 -9999 -9999 -9999 -9999 -9999 -9999 -9999 -9999 -9999 -9999 -9999 -9999 -9999 -9999 -9999 -9999 - 9999 -9999 -9999 -9999 -9999 -9999 -9999 -9999 -9999 -9999 -9999 -9999 -9999 -9999 -9999

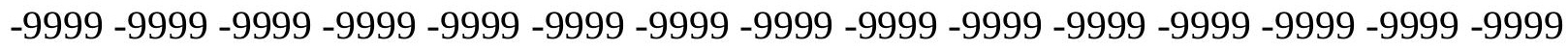
-9999 -9999 -9999 -9999 -9999 -9999 -9999 -9999 -9999 -9999 -9999 -9999 -9999 -9999 -9999 -9999 -9999 -9999 -9999 -9999 -9999 -9999 -9999 -9999 -9999 -9999 -9999 -9999 -9999 -9999

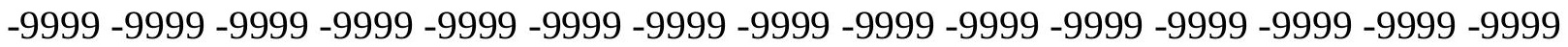

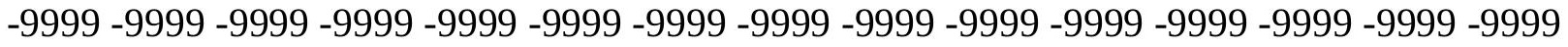
-9999 -9999 -9999 -9999 -9999 -9999 -9999 -9999 -9999 -9999 -9999 -9999 -9999 -9999 -9999 -9999 -9999 -9999 -9999 -9999 -9999 -9999 -9999 -9999 -9999 -9999 -9999 -9999 -9999 -9999 -9999 -9999 -9999 -9999 -9999 -9999 -9999 -9999 -9999 -9999 -9999 -9999 -9999 -9999 -9999 -9999 -9999 -9999 -9999 -9999 -9999 -9999 -9999 -9999 -9999 -9999 -9999 -9999 -9999 -9999 -

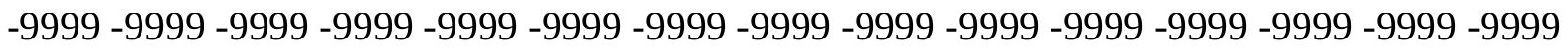
-9999 -9999 -9999 -9999 -9999 -9999 -9999 -9999 -9999 -9999 -9999 -9999 -9999 -9999 -9999 -

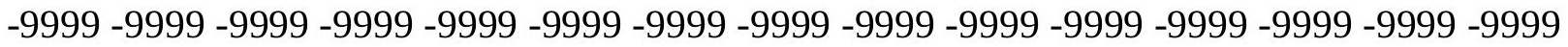
-9999 -9999 -9999 -9999 -9999 -9999 -9999 -9999 -9999 -9999 -9999 -9999 -9999 -9999 -9999 -9999 -9999 -9999 -9999 -9999 -9999 -9999 -9999 -9999 -9999 -9999 -9999 -9999 -9999 -9999 -9999 -9999 -9999 -9999 -9999 -9999 -9999 -9999 -9999 -9999 -9999 -9999 -9999 -9999 -9999 -

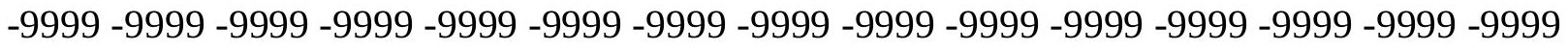
-9999 -9999 -9999 -9999 -9999 -9999 -9999 -9999 -9999 -9999 -9999 -9999 -9999 -9999 -9999

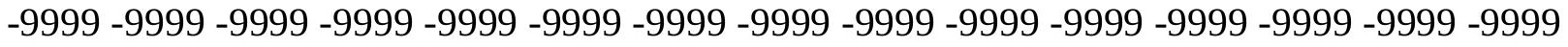
-9999 -9999 -9999 -9999 -9999 -9999 -9999 -9999 -9999 -9999 -9999 -9999 -9999 -9999 -9999 -9999 -9999 -9999 -9999 -9999 -9999 -9999 -9999 -9999 -9999 -9999 -9999 -9999 -9999 -9999 -9999 -9999 -9999 -9999 -9999 -9999 -9999 -9999 -9999 -9999 -9999 -9999 -9999 -9999 -9999 -9999 -9999 -9999 -9999 -9999 -9999 -9999 -9999 -9999 -9999 -9999 -9999 -9999 -9999 -9999 -9999 -9999 -9999 -9999 -9999 -9999 -9999 -9999 -9999 -9999 -9999 -9999 -9999 -9999 -9999 -9999 -9999 -9999 -9999 -9999 -9999 -9999 -9999 -9999 -9999 -9999 -9999 -9999 -9999 -9999 -9999 -9999 -9999 -9999 -9999 -9999 -9999 -9999 -9999 -9999 -9999 -9999 -9999 -9999 -9999 -9999 -9999 -9999 -9999 -9999 -9999 -9999 -9999 -9999 -9999 -9999 -9999 -9999 -9999 -9999 -9999 -9999 -9999 -9999 -9999 -9999 -9999 -9999 -9999 -9999 -9999 -9999 -9999 -9999 -9999 -9999 -9999 -9999 -9999 -9999 -9999 -9999 -9999 -9999 -9999 -9999 -9999 -9999 -9999 -

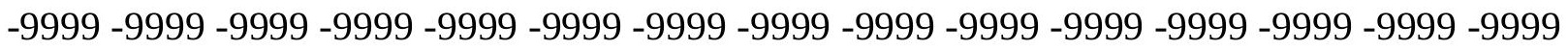

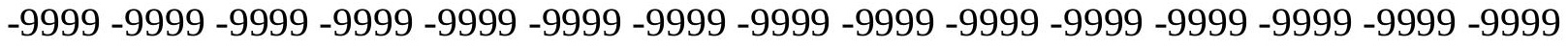
-9999 -9999 -9999 -9999 -9999 -9999 -9999 -9999 -9999 -9999 -9999 -9999 -9999 -9999 -9999 -

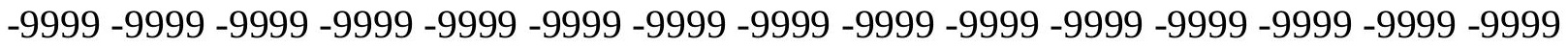

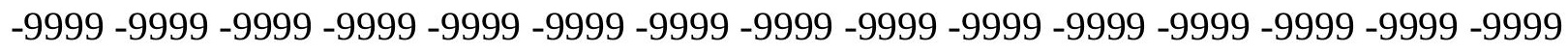

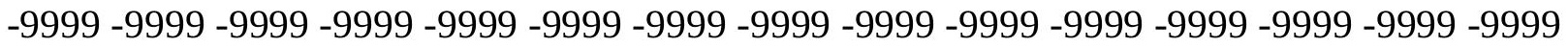

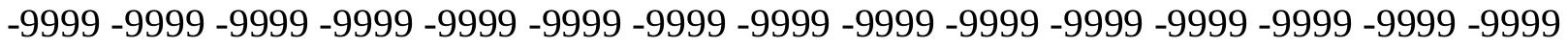
-9999 -9999 -9999 -9999 -9999 -9999 -9999 -9999 -9999 -9999 -9999 -9999 -9999 -9999 -9999 -

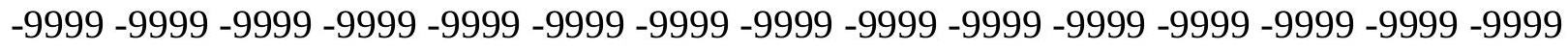

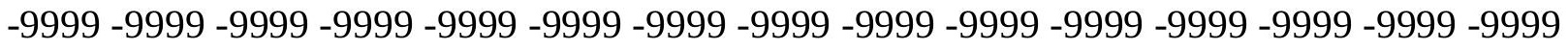
-9999 -9999 -9999 -9999 -9999 -9999 -9999 -9999 -9999 -9999 -9999 -9999 -9999 -9999 -9999 -9999 -9999 -9999 -9999 -9999 -9999 -9999 -9999 -9999-9999 -9999 -9999 -9999 -9999 -9999 -9999 -9999 -9999 -9999 -9999 -9999 -9999 -9999 -9999 -9999 -9999 -9999 -9999 -9999 -9999 -

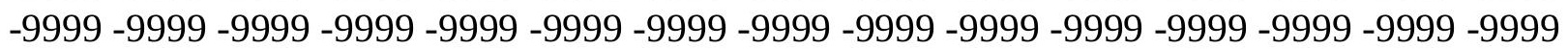


-9999 -9999 -9999 -9999 -9999 -9999 -9999 -9999 -9999 -9999 -9999 -9999 -9999 -9999 -9999 -9999 -9999 -9999 -9999 -9999 -9999 -9999 -9999 -9999 -9999 -9999 -9999 -9999 -9999 -9999 -9999 -9999 -9999 -9999 -9999 -9999 -9999 -9999 -9999 -9999 -9999 -9999 -9999 -9999 - 9999 -9999 -9999 -9999 -9999 -9999 -9999 -9999 -9999 -9999 -9999 -9999 -9999 -9999 -9999 -9999 -9999 -9999 -9999 -9999 -9999 -9999 -9999 -9999 -9999 -9999 -9999 -9999 -9999 -9999 -9999 -9999 -9999 -9999 -9999 -9999 -9999 -9999 -9999 -9999 -9999 -9999 -9999 -9999 -9999 -9999 -9999 -9999 -9999 -9999 -9999 -9999 -9999 -9999 -9999 -9999 -9999 -9999 -9999 -9999 -9999

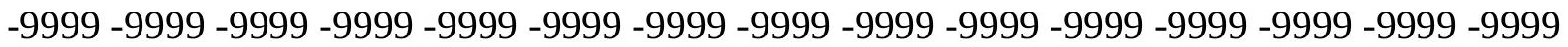

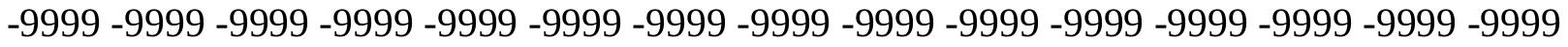
-9999 -9999 -9999 -9999 -9999 -9999 -9999 -9999 -9999 -9999 -9999 -9999 -9999 -9999 -9999 -9999 -9999 -9999 -9999 -9999 -9999 -9999 -9999 -9999 -9999 -9999 -9999 -9999 -9999 -9999 -9999 -9999 -9999 -9999 -9999 -9999 -9999 -9999 -9999 -9999 -9999 -9999 -9999 -9999 -9999 -9999 -9999 -9999 -9999 -9999 -9999 -9999 -9999 -9999 -9999 -9999 -9999 -9999 -9999 -9999 -9999 -9999 -9999 -9999 -9999 -9999 -9999 -9999 -9999 -9999 -9999 -9999 -9999 -9999 -9999 -9999 -9999 -9999 -9999 -9999 -9999 -9999 -9999 -9999 -9999 -9999 -9999 -9999 -9999 -

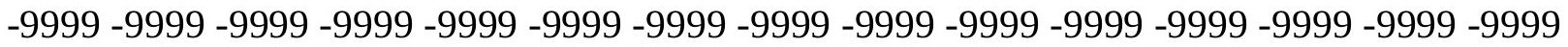
-9999 -9999 -9999 -9999 -9999 -9999 -9999 -9999 -9999 -9999 -9999 -9999 -9999 -9999 -9999 -9999 -9999 -9999 -9999 -9999 -9999 -9999 -9999 -9999 -9999 -9999 -9999 -9999 -9999 -9999 -9999 -9999 -9999 -9999 -9999 -9999 -9999 -9999 -9999 -9999 -9999 -9999 -9999 -9999 -9999 -9999 -9999 -9999 -9999 -9999 -9999 -9999 -9999 -9999 -9999 -9999 -9999 -9999 -9999 -9999 -9999 -9999 -9999 -9999 -9999 -9999 -9999 -9999 -9999 -9999 -9999 -9999 -9999 -9999 -9999 -999 -9999 -9999 -9999 -9999 -9999 -9999 -9999 -9999 -9999 -9999 -9999 -9999 -9999 -9999 -9999 -9999 -9999 -9999 -9999 -9999 -9999 -9999 -9999 -9999 -9999 -9999 -9999 -9999 -9999 -9999 -9999 -9999 -9999 -9999 -9999 -9999 -9999 -9999 -9999 -9999 -9999 -9999 -9999 -9999 -9999 -9999 -9999 -9999 -9999 -9999 -9999 -9999 -9999 -9999 -9999 -9999 -9999 -9999 -9999 -9999 -9999 -9999 -9999 -9999 -9999 -9999 -9999 -9999 -9999 -9999 -9999 -9999 -9999 -9999 -9999 -9999 -9999 -9999 -9999 -9999 -9999 -9999 -9999 -9999 -9999 -9999 -9999 -9999 -9999 -9999 -9999 -9999 -9999 -9999 -9999 -9999 -9999 -9999 -9999 -9999 -9999 -9999 -9999 -9999 -9999 -9999 -9999 -9999 -9999 -9999 -9999 -9999 -9999 -9999 -9999 -9999 -9999 -9999 -9999 -9999 -9999 -9999 -9999 -9999 -9999 -9999 -9999 -9999 -9999 -9999 -9999 -9999 -9999 -9999 -999 -9999 -9999 -9999 -9999 -9999 -9999 -9999 -9999 -9999 -9999 -9999 -9999 -9999 -9999 -9999 -9999 -9999 -9999 -9999 -9999 -9999 -9999 -9999 -9999 -9999 -9999 -9999 -9999 -9999 -9999 -

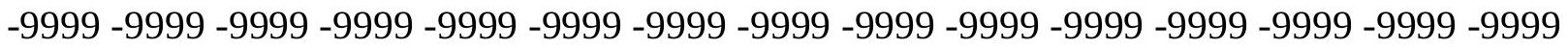

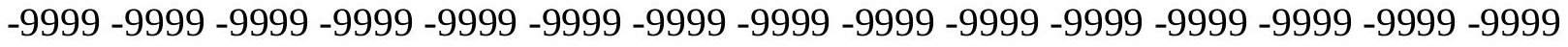

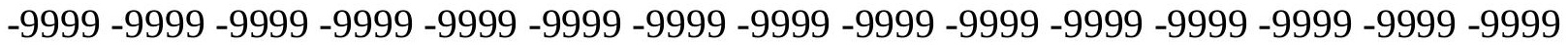
-9999 -9999 -9999 -9999 -9999 -9999 -9999 -9999 -9999 -9999 -9999 -9999 -9999 -9999 -9999 -9999 -9999 -9999 -9999 -9999 -9999 -9999 -9999 -9999 -9999 -9999 -9999 -9999 -9999 -

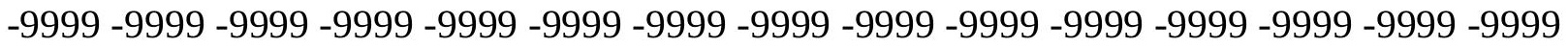
-9999 -9999 -9999 -9999 -9999 -9999 -9999 -9999 -9999 -9999 -9999 -9999 -9999 -9999 -9999 -9999 -9999 -9999 -9999 -9999 -9999 -9999 -9999 -9999 -9999 -9999 -9999 -9999 -9999 -9999 -

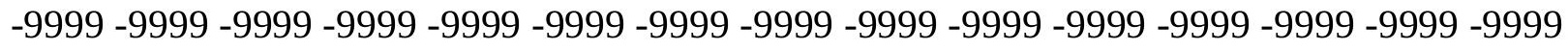

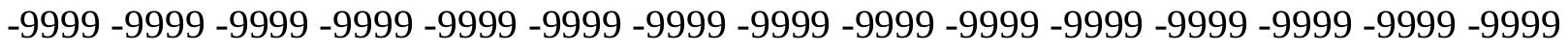
-9999 -9999 -9999 -9999 -9999 -9999 -9999 -9999 -9999 -9999 -9999 -9999 -9999 -9999 -9999 -9999 -9999 -9999 -9999 -9999 -9999 -9999 -9999 -9999-9999 -9999 -9999 -9999 -9999 -9999 -9999 -9999 -9999 -9999 -9999 -9999 -9999 -9999 -9999 -9999 -9999 -9999 -9999 -9999 -9999 -

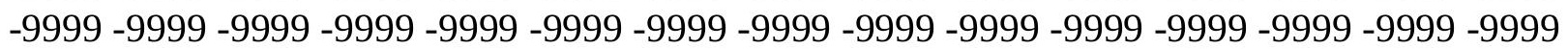


-9999 -9999 -9999 -9999 -9999 -9999 -9999 -9999 -9999 -9999 -9999 -9999 -9999 -9999 -9999 -9999 -9999 -9999 -9999 -9999 -9999 -9999 -9999 -9999 -9999 -9999 -9999 -9999 -9999 -9999 -

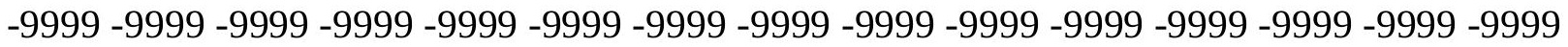
-9999 -9999 -9999 -9999 -9999 -9999 -9999 -9999 -9999 -9999 -9999 -9999 -9999 -9999 -9999 -9999 -9999 -9999 -9999 -9999 -9999 -9999 -9999 -9999-9999 -9999 -9999 -9999 -9999 -9999 -9999 -9999 -9999 -9999 -9999 -9999 -9999 -9999 -9999 -9999 -9999 -9999 -9999 -9999 -9999 -9999 -9999 -9999 -9999 -9999 -9999 -9999 -9999 -9999 -9999 -9999 -9999 -9999 -9999 -9999

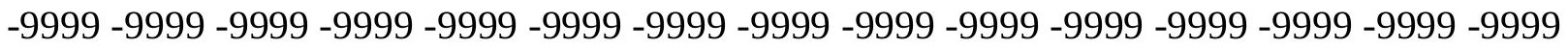

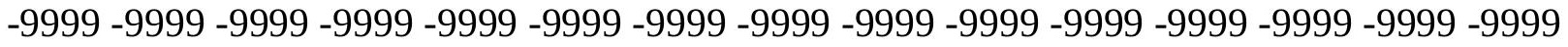
-9999 -9999 -9999 -9999 -9999 -9999 -9999 -9999 -9999 -9999 -9999 -9999 -9999 -9999 -9999 -9999 -9999 -9999 -9999 -9999 -9999 -9999 -9999 -9999 -9999 -9999 -9999 -9999 -9999 -9999 -9999 -9999 -9999 -9999 -9999 -9999 -9999 -9999 -9999 -9999 -9999 -9999 -9999 -9999 -9999 -9999 -9999 -9999 -9999 -9999 -9999 -9999 -9999 -9999 -9999 -9999 -9999 -9999 -9999 -9999 -9999 -9999 -9999 -9999 -9999 -9999 -9999 -9999 -9999 -9999 -9999 -9999 -9999 -9999 -9999 -9999 -9999 -9999 -9999 -9999 -9999 -9999 -9999 -9999 -9999 -9999 -9999 -9999 -9999 -9999 -

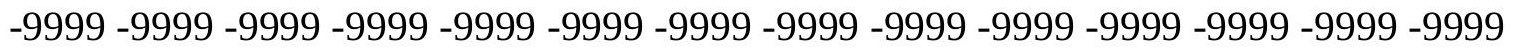
-9999 -9999 -9999 -9999 -9999 -9999 -9999 -9999 -9999 -9999 -9999 -9999 -9999 -9999 -9999 -9999 -9999 -9999 -9999 -9999 -9999 -9999 -9999 -9999 -9999 -9999 -9999 -9999 -9999 -9999 -9999 -9999 -9999 -9999 -9999 -9999 -9999 -9999 -9999 -9999 -9999 -9999 -9999 -9999 -9999 -

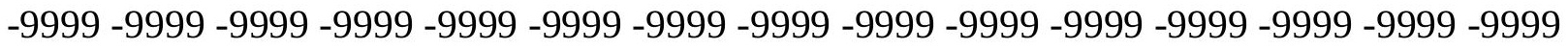

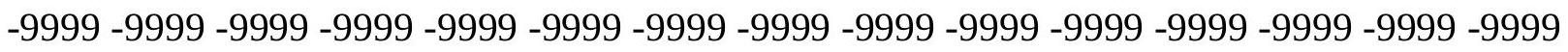
-9999 -9999 -9999 -9999 -9999 -9999 -9999 -9999 -9999 -9999 -9999 -9999 -9999 -9999 - 9999 -9999 -9999 -9999 -9999 -9999 -9999 -9999 -9999 -9999 -9999 -9999 -9999 -9999 -9999 -9999 -9999 -9999 -9999 -9999 -9999 -9999 -9999 -9999 -9999 -9999 -9999 -9999 -9999 -9999 -9999 -

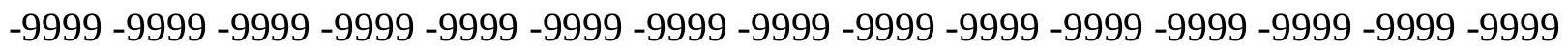
-9999 -9999 -9999 -9999 -9999 -9999 -9999 -9999 -9999 -9999 -9999 -9999 -9999 -9999 -9999 -9999 -9999 -9999 -9999 -9999 -9999 -9999 -9999 -9999 -9999 -9999 -9999 -9999 -9999 -9999 -

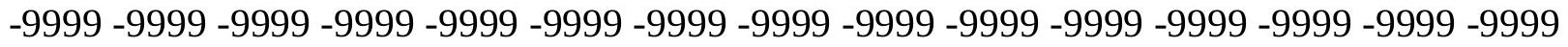
-9999 -9999 -9999 -9999 -9999 -9999 -9999 -9999 -9999 -9999 -9999 -9999 -9999 -9999 -9999 -9999 -9999 -9999 -9999 -9999 -9999 -9999 -9999 -9999 -9999 -9999 -9999 -9999 -9999 -999 -

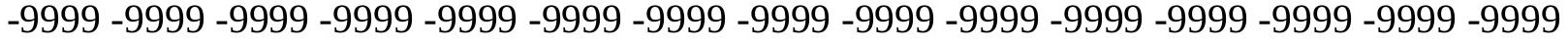
-9999 -9999 -9999 -9999 -9999 -9999 -9999 -9999 -9999 -9999 -9999 -9999 -9999 -9999 -9999 -

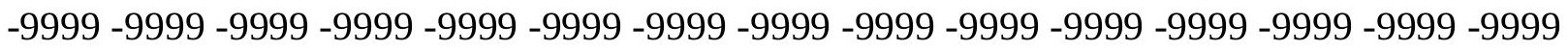

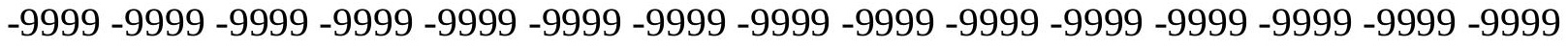

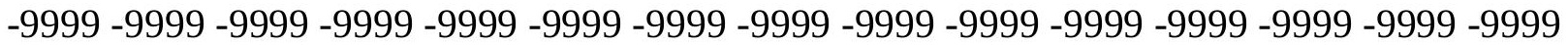
-9999 -9999 -9999 -9999 -9999 -9999 -9999 -9999 -9999 -9999 -9999 -9999 -9999 -9999 -9999 -

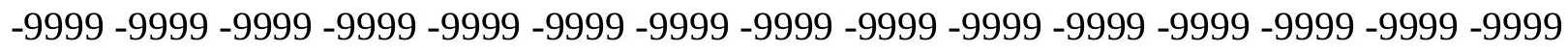

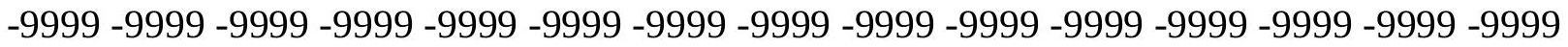
-9999 -9999 -9999 -9999 -9999 -9999 -9999 -9999 -9999 -9999 -9999 -9999 -9999 - 9999 - -999 -9999 -9999 -9999 -9999 -9999 -9999 -9999 -9999 -9999 -9999 -9999 -9999 -9999 -9999 -9999 -

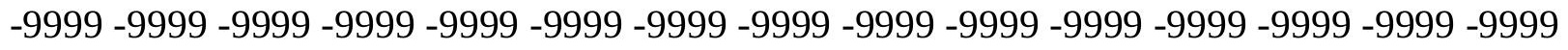

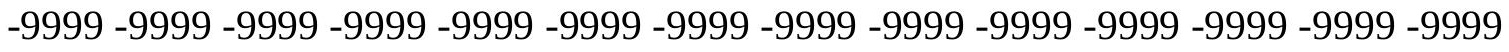
-9999 -9999 -9999 -9999 -9999 -9999 -9999 -9999 -9999 -9999 -9999 -9999 -9999 -9999 -9999 -9999 -9999 -9999 -9999 -9999 -9999 -9999 -9999 -9999-9999 -9999 -9999 -9999 -9999 -9999 -9999 -9999 -9999 -9999 -9999 -9999 -9999 -9999 -9999 -9999 -9999 -9999 -9999 -9999 -9999 -

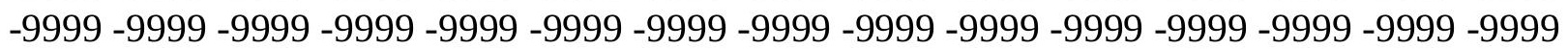


-9999 -9999 -9999 -9999 -9999 -9999 -9999 -9999 -9999 -9999 -9999 -9999 -9999 -9999 -9999 -9999 -9999 -9999 -9999 -9999 -9999 -9999 -9999 -9999 -9999 -9999 -9999 -9999 -9999 -9999 -

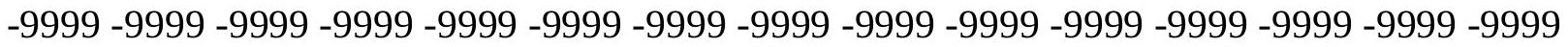
-9999 -9999 -9999 -9999 -9999 -9999 -9999 -9999 -9999 -9999 -9999 -9999 -9999 -9999 -9999 -9999 -9999 -9999 -9999 -9999 -9999 -9999 -9999 -9999-9999 -9999 -9999 -9999 -9999 -9999 -9999 -9999 -9999 -9999 -9999 -9999 -9999 -9999 -9999 -9999 -9999 -9999 -9999 -9999 -9999 -9999 -9999 -9999 -9999 -9999 -9999 -9999 -9999 -9999 -9999 -9999 -9999 -9999 -9999 -9999

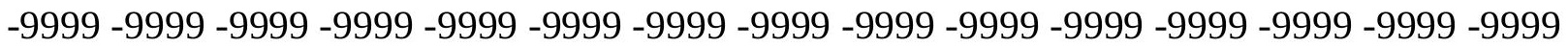

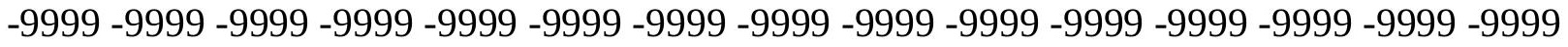
-9999 -9999 -9999 -9999 -9999 -9999 -9999 -9999 -9999 -9999 -9999 -9999 -9999 -9999 -9999 -9999 -9999 -9999 -9999 -9999 -9999 -9999 -9999 -9999 -9999 -9999 -9999 -9999 -9999 -9999 -9999 -9999 -9999 -9999 -9999 -9999 -9999 -9999 -9999 -9999 -9999 -9999 -9999 -9999 -9999 -9999 -9999 -9999 -9999 -9999 -9999 -9999 -9999 -9999 -9999 -9999 -9999 -9999 -9999 -9999 -

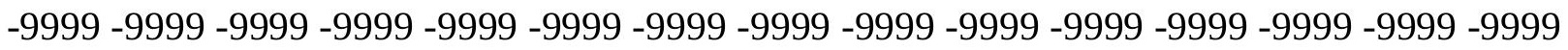
-9999 -9999 -9999 -9999 -9999 -9999 -9999 -9999 -9999 -9999 -9999 -9999 -9999 -9999 -9999 -

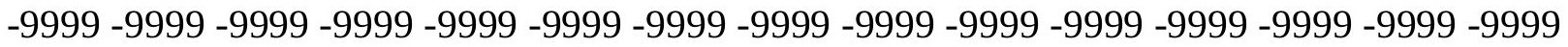
-9999 -9999 -9999 -9999 -9999 -9999 -9999 -9999 -9999 -9999 -9999 -9999 -9999 -9999 -9999 -9999 -9999 -9999 -9999 -9999 -9999 -9999 -9999 -9999 -9999 -9999 -9999 -9999 -9999 -9999 -9999 -9999 -9999 -9999 -9999 -9999 -9999 -9999 -9999 -9999 -9999 -9999 -9999 -9999 -9999 -

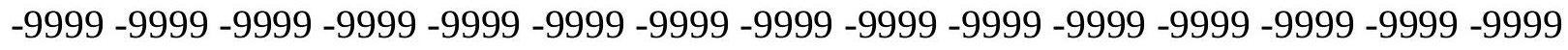

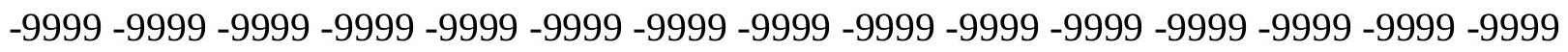
-9999 -9999 -9999 -9999 -9999 -9999 -9999 -9999 -9999 -9999 -9999 -9999 -9999 -9999 -9999 -9999 -9999 -9999 -9999 -9999 -9999 -9999 -9999 -9999 -9999 -9999 -9999 -9999 -9999 -9999 -9999 -9999 -9999 -9999 -9999 -9999 -9999 -9999 -9999 -9999 -9999 -9999 -9999 -9999 -

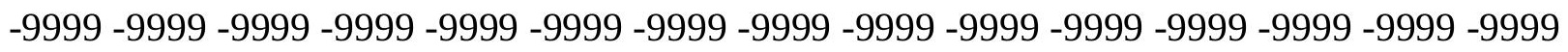
-9999 -9999 -9999 -9999 -9999 -9999 -9999 -9999 -9999 -9999 -9999 -9999 -9999 -9999 -9999 -9999 -9999 -9999 -9999 -9999 -9999 -9999 -9999 -9999 -9999 -9999 -9999 -9999 -9999 -9999 -

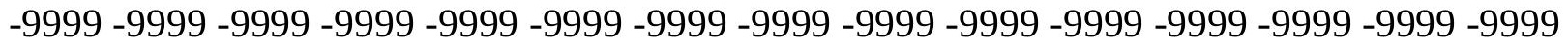
-9999 -9999 -9999 -9999 -9999 -9999 -9999 -9999 -9999 -9999 -9999 -9999 -9999 -9999 -9999 -9999 -9999 -9999 -9999 -9999 -9999 -9999 -9999 -9999 -9999 -9999 -9999 -9999 -9999 -999 -

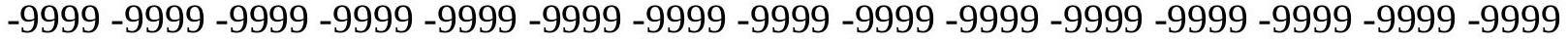
-9999 -9999 -9999 -9999 -9999 -9999 -9999 -9999 -9999 -9999 -9999 -9999 -9999 -9999 -9999 -

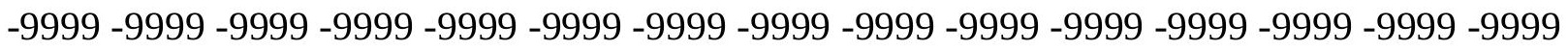

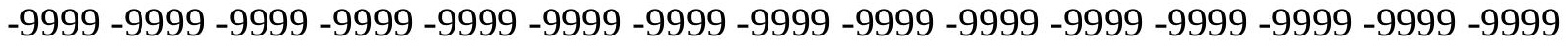

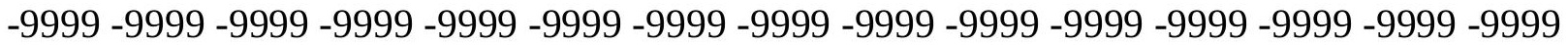

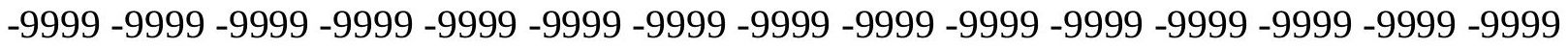

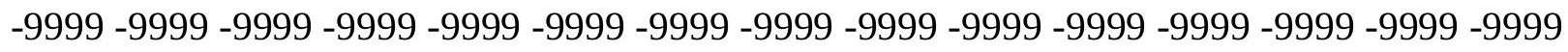

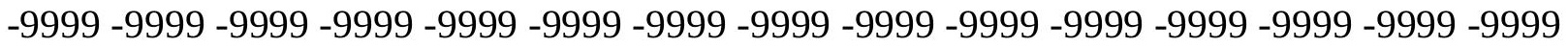

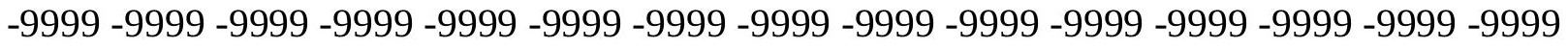
-9999 -9999 -9999 -9999 -9999 -9999 -9999 -9999 -9999 -9999 -9999 -9999 -9999 -9999 -9999 -

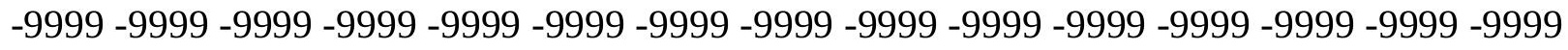

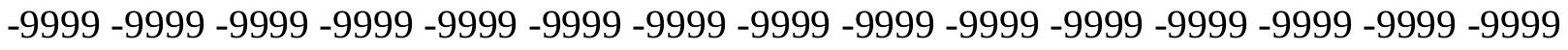
-9999 -9999 -9999 -9999 -9999 -9999 -9999 -9999 -9999 -9999 -9999 -9999 -9999 -9999 -9999 -9999 -9999 -9999 -9999 -9999 -9999 -9999 -9999 -9999-9999 -9999 -9999 -9999 -9999 -9999 -9999 -9999 -9999 -9999 -9999 -9999 -9999 -9999 -9999 -9999 -9999 -9999 -9999 -9999 -9999 -

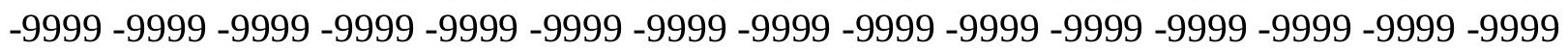


-9999 -9999 -9999 -9999 -9999 -9999 -9999 -9999 -9999 -9999 -9999 -9999 -9999 -9999 -9999 -9999 -9999 -9999 -9999 -9999 -9999 -9999 -9999 -9999 -9999 -9999 -9999 -9999 -9999 -

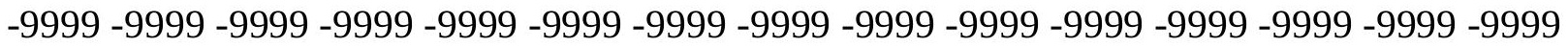
-9999 -9999 -9999 -9999 -9999 -9999 -9999 -9999 -9999 -9999 -9999 -9999 -9999 -9999 -9999 -9999 -9999 -9999 -9999 -9999 -9999 -9999 -9999 -9999 -9999 -9999 -9999 -9999 -9999 -9999 -9999 -9999 -9999 -9999 -9999 -9999 -9999 -9999 -9999 -9999 -9999 -9999 -9999 -9999 -9999 -9999 -9999 -9999 -9999 -9999 -9999 -9999 -9999 -9999 -9999 -9999 -9999 -9999 -9999 -9999

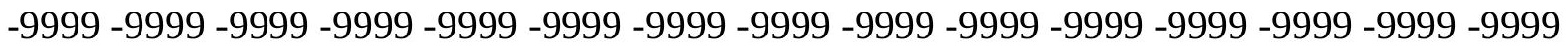

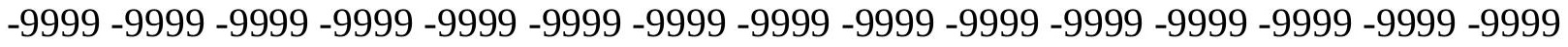
-9999 -9999 -9999 -9999 -9999 -9999 -9999 -9999 -9999 -9999 -9999 -9999 -9999 -9999 -9999 -9999 -9999 -9999 -9999 -9999 -9999 -9999 -9999 -9999 -9999 -9999 -9999 -9999 -9999 -9999 -9999 -9999 -9999 -9999 -9999 -9999 -9999 -9999 -9999 -9999 -9999 -9999 -9999 -9999 -9999 -9999 -9999 -9999 -9999 -9999 -9999 -9999 -9999 -9999 -9999 -9999 -9999 -9999 -9999 -9999 -9999 -9999 -9999 -9999 -9999 -9999 -9999 -9999 -9999 -9999 -9999 -9999 -9999 -9999 -9999 -9999 -9999 -9999 -9999 -9999 -9999 -9999 -9999 -9999 -9999 -9999 -9999 -9999 -9999 -9999 -

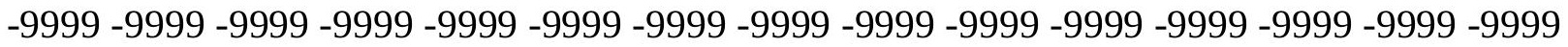
-9999 -9999 -9999 -9999 -9999 -9999 -9999 -9999 -9999 -9999 -9999 -9999 -9999 -9999 -9999 -9999 -9999 -9999 -9999 -9999 -9999 -9999 -9999 -9999 -9999 -9999 -9999 -9999 -9999 - 9999 -9999 -9999 -9999 -9999 -9999 -9999 -9999 -9999 -9999 -9999 -9999 -9999 -9999 -9999 -9999 -

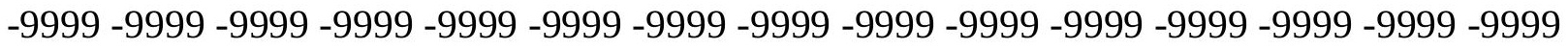

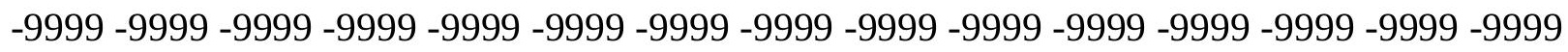

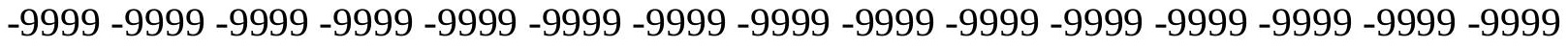
-9999 -9999 -9999 -9999 -9999 -9999 -9999 -9999 -9999 -9999 -9999 -9999 -9999 -9999 -9999 -9999 -9999 -9999 -9999 -9999 -9999 -9999 -9999 -9999 -9999 -9999 -9999 -9999 -9999 -9999 -

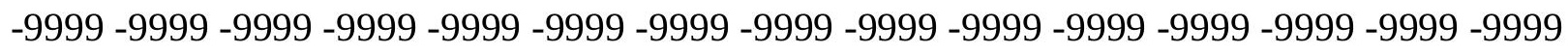
-9999 -9999 -9999 -9999 -9999 -9999 -9999 -9999 -9999 -9999 -9999 -9999 -9999 -9999 -9999 -9999 -9999 -9999 -9999 -9999 -9999 -9999 -9999 -9999 -9999 -9999 -9999 -9999 -9999 -9999 -9999 -9999 -9999 -9999 -9999 -9999 -9999 -9999 -9999 -9999 -9999 -9999 -9999 -9999 -9999 -9999 -9999 -9999 -9999 -9999 -9999 -9999 -9999 -9999 -9999 -9999 -9999 -9999 -9999 -9999 -9999 -9999 -9999 -9999 -9999 -9999 -9999 -9999 -9999 -9999 -9999 -9999 -9999 -999 -

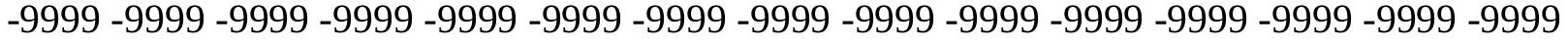
-9999 -9999 -9999 -9999 -9999 -9999 -9999 -9999 -9999 -9999 -9999 -9999 -9999 -9999 -9999 -

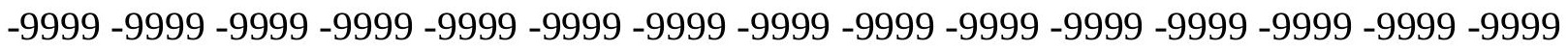

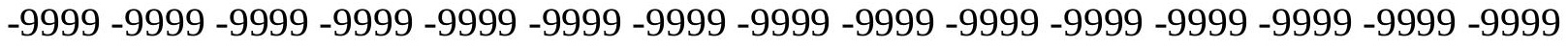

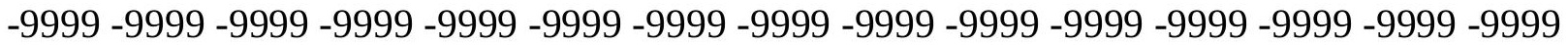

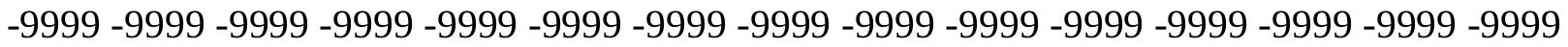

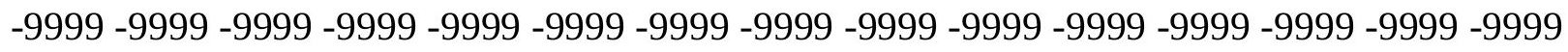

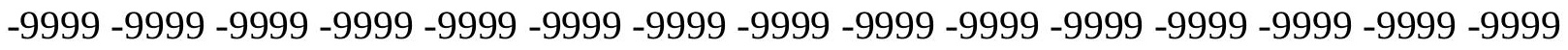

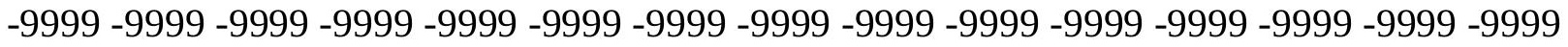
-9999 -9999 -9999 -9999 -9999 -9999 -9999 -9999 -9999 -9999 -9999 -9999 -9999 -9999 -9999 -

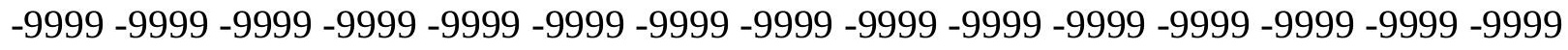

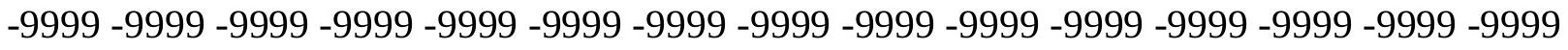
-9999 -9999 -9999 -9999 -9999 -9999 -9999 -9999 -9999 -9999 -9999 -9999 -9999 -9999 -9999 -9999 -9999 -9999 -9999 -9999 -9999 -9999 -9999 -9999-9999 -9999 -9999 -9999 -9999 -9999 -9999 -9999 -9999 -9999 -9999 -9999 -9999 -9999 -9999 -9999 -9999 -9999 -9999 -9999 -9999 -

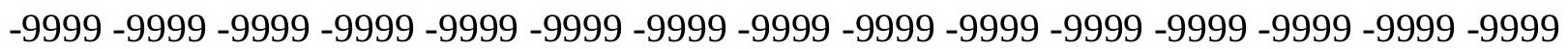


-9999 -9999 -9999 -9999 -9999 -9999 -9999 -9999 -9999 -9999 -9999 -9999 -9999 -9999 -9999 -9999 -9999 -9999 -9999 -9999 -9999 -9999 -9999 -9999 -9999 -9999 -9999 -9999 -9999 -9999 -

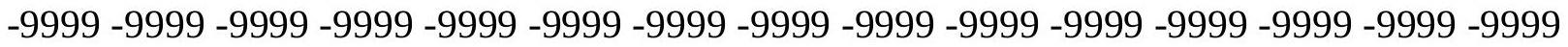
-9999 -9999 -9999 -9999 -9999 -9999 -9999 -9999 -9999 -9999 -9999 -9999 -9999 -9999 -9999 -9999 -9999 -9999 -9999 -9999 -9999 -9999 -9999 -9999-9999 -9999 -9999 -9999 -9999 -9999 -9999 -9999 -9999 -9999 -9999 -9999 -9999 -9999 -9999 -9999 -9999 -9999 -9999 -9999 -9999 -

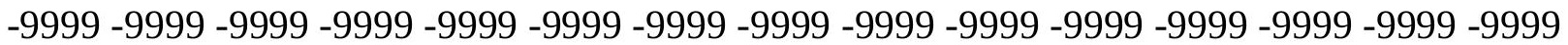
-9999 -9999 -9999 -9999 -9999 -9999 -9999 -9999 -9999 -9999 -9999 -9999 -9999 -9999 -9999 -9999 -9999 -9999 -9999 -9999 -9999 -9999 -9999 -9999 -9999 -9999 -9999 -9999 -9999 -9999 -9999 -9999 -9999 -9999 -9999 -9999 -9999 -9999 -9999 -9999 -9999 -9999 -9999 -9999 -9999 -9999 -9999 -9999 -9999 -9999 -9999 -9999 -9999 -9999 -9999 -9999 -9999 -9999 -9999 -9999 -9999 -9999 -9999 -9999 -9999 -9999 -9999 -9999 -9999 -9999 -9999 -9999 -9999 -9999 -9999 -9999 -9999 -9999 -9999 -9999 -9999 -9999 -9999 -9999 -9999 -9999 -9999 -9999 -9999 -9999 -9999 -9999 -9999 -9999 -9999 -9999 -9999 -9999 -9999 -9999 -9999 -9999 -9999 -9999 -9999 -9999 -9999 -9999 -9999 -9999 -9999 -9999 -9999 -9999 -9999 -9999 -9999 -9999 -9999 -

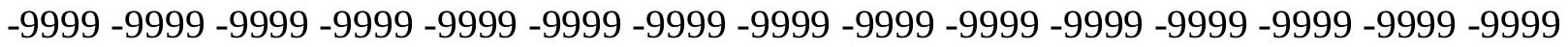
-9999 -9999 -9999 -9999 -9999 -9999 -9999 -9999 -9999 -9999 -9999 -9999 -9999 -9999 -9999 -9999 -9999 -9999 -9999 -9999 -9999 -9999 -9999 -9999 -9999 -9999 -9999 -9999 -9999 -9999 -9999 -9999 -9999 -9999 -9999 -9999 -9999 -9999 -9999 -9999 -9999 -9999 -9999 -9999 -9999 -

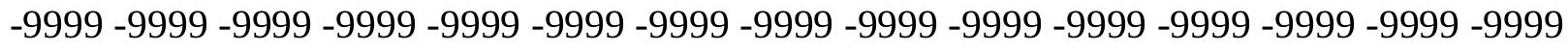

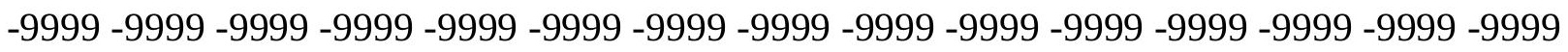
-9999 -9999 -9999 -9999 -9999 -9999 -9999 -9999 -9999 -9999 -9999 -9999 -9999 -9999 - 9999 -9999 -9999 -9999 -9999 -9999 -9999 -9999 -9999 -9999 -9999 -9999 -9999 -9999 -9999 -9999 -9999 -9999 -9999 -9999 -9999 -9999 -9999 -9999 -9999 -9999 -9999 -9999 -9999 -9999 -9999 -

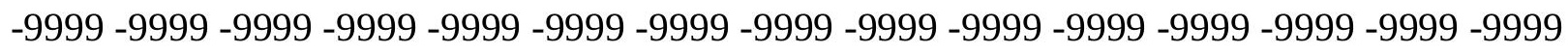
-9999 -9999 -9999 -9999 -9999 -9999 -9999 -9999 -9999 -9999 -9999 -9999 -9999 -9999 -9999 -9999 -9999 -9999 -9999 -9999 -9999 -9999 -9999 -9999 -9999 -9999 -9999 -9999 -9999 -9999 -

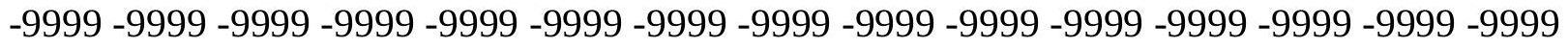
-9999 -9999 -9999 -9999 -9999 -9999 -9999 -9999 -9999 -9999 -9999 -9999 -9999 -9999 -9999 -9999 -9999 -9999 -9999 -9999 -9999 -9999 -9999 -9999 -9999 -9999 -9999 -9999 -9999 -999 -9999 -9999 -9999 -9999 -9999 -9999 -9999 -9999 -9999 -9999 -9999 -9999 -9999 -9999 -9999 -9999 -9999 -9999 -9999 -9999 -9999 -9999 -9999 -9999 -9999 -9999 -9999 -9999 -9999 -9999 -

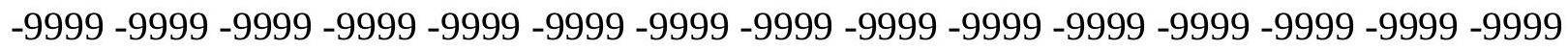

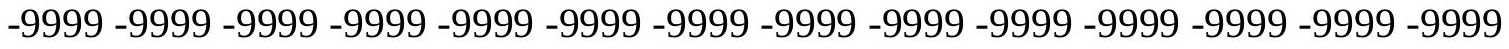
-9999 -9999 -9999 -9999 -9999 -9999 -9999 -9999 -9999 -9999 -9999 -9999 -9999 -9999 -9999

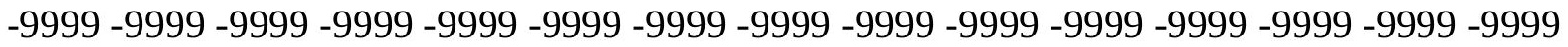

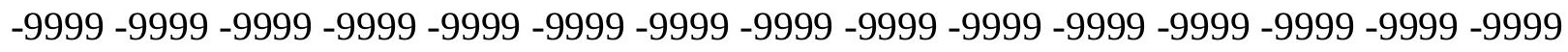

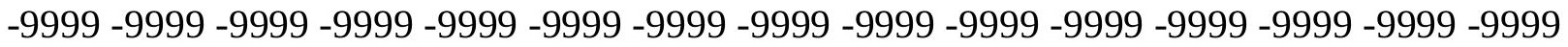

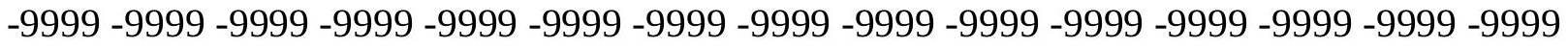
-9999 -9999 -9999 -9999 -9999 -9999 -9999 -9999 -9999 -9999 -9999 -9999 -9999 -9999 -9999 -

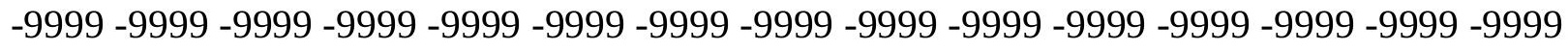

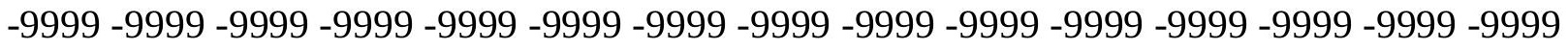
-9999 -9999 -9999 -9999 -9999 -9999 -9999 -9999 -9999 -9999 -9999 -9999 -9999 -9999 -9999 -9999 -9999 -9999 -9999 -9999 -9999 -9999 -9999 -9999-9999 -9999 -9999 -9999 -9999 -9999 -9999 -9999 -9999 -9999 -9999 -9999 -9999 -9999 -9999 -9999 -9999 -9999 -9999 -9999 -9999 -

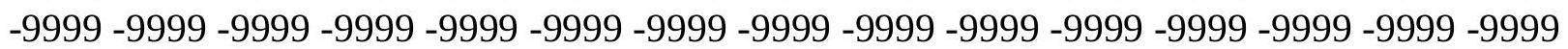


-9999 -9999 -9999 -9999 -9999 -9999 -9999 -9999 -9999 -9999 -9999 -9999 -9999 -9999 -9999 -9999 -9999 -9999 -9999 -9999 -9999 -9999 -9999 -9999 -9999 -9999 -9999 -9999 -9999 -9999 -

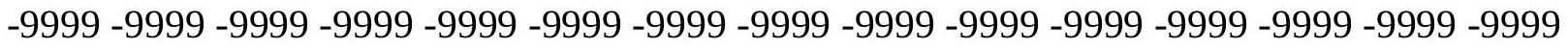
-9999 -9999 -9999 -9999 -9999 -9999 -9999 -9999 -9999 -9999 -9999 -9999 -9999 -9999 -9999 -9999 -9999 -9999 -9999 -9999 -9999 -9999 -9999 -9999-9999 -9999 -9999 -9999 -9999 -9999 -9999 -9999 -9999 -9999 -9999 -9999 -9999 -9999 -9999 -9999 -9999 -9999 -9999 -9999 -9999 -9999 -9999 -9999 -9999 -9999 -9999 -9999 -9999 -9999 -9999 -9999 -9999 -9999 -9999 -9999

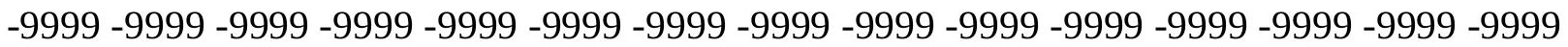

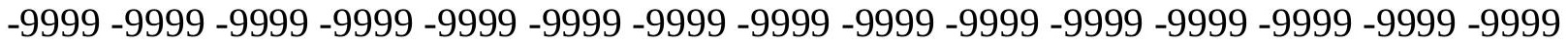
-9999 -9999 -9999 -9999 -9999 -9999 -9999 -9999 -9999 -9999 -9999 -9999 -9999 -9999 -9999 -9999 -9999 -9999 -9999 -9999 -9999 -9999 -9999 -9999 -9999 -9999 -9999 -9999 -9999 -9999 -9999 -9999 -9999 -9999 -9999 -9999 -9999 -9999 -9999 -9999 -9999 -9999 -9999 -9999 -9999 -9999 -9999 -9999 -9999 -9999 -9999 -9999 -9999 -9999 -9999 -9999 -9999 -9999 -9999 -9999 -9999 -9999 -9999 -9999 -9999 -9999 -9999 -9999 -9999 -9999 -9999 -9999 -9999 -9999 -9999 -9999 -9999 -9999 -9999 -9999 -9999 -9999 -9999 -9999 -9999 -9999 -9999 -9999 -9999

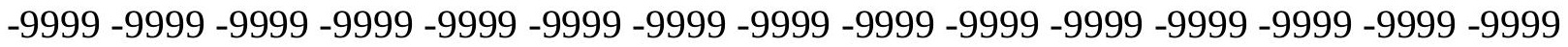
-9999 -9999 -9999 -9999 -9999 -9999 -9999 -9999 -9999 -9999 -9999 -9999 -9999 -9999 -9999 -9999 -9999 -9999 -9999 -9999 -9999 -9999 -9999 -9999 -9999 -9999 -9999 -9999 -9999 -9999 -9999 -9999 -9999 -9999 -9999 -9999 -9999 -9999 -9999 -9999 -9999 -9999 -9999 -9999 -9999 -

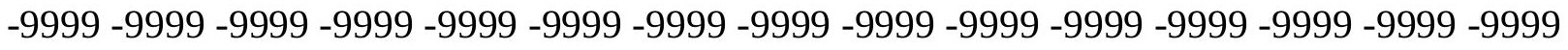

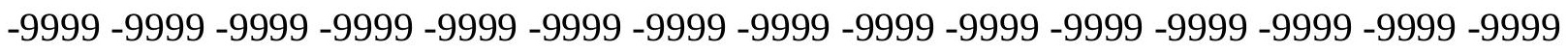
-9999 -9999 -9999 -9999 -9999 -9999 -9999 -9999 -9999 -9999 -9999 -9999 -9999 -9999 -9999 -9999 -9999 -9999 -9999 -9999 -9999 -9999 -9999 -9999 -9999 -9999 -9999 -9999 -9999 -9999 -9999 -9999 -9999 -9999 -9999 -9999 -9999 -9999 -9999 -9999 -9999 -9999 -9999 -9999 -9999 -

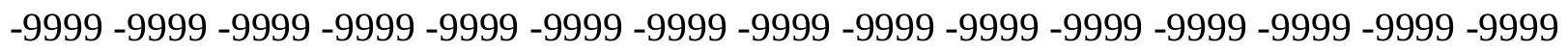
-9999 -9999 -9999 -9999 -9999 -9999 -9999 -9999 -9999 -9999 -9999 -9999 -9999 -9999 -9999 -9999 -9999 -9999 -9999 -9999 -9999 -9999 -9999 -9999 -9999 -9999 -9999 -9999 -9999 -9999 -

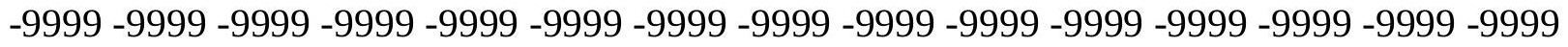
-9999 -9999 -9999 -9999 -9999 -9999 -9999 -9999 -9999 -9999 -9999 -9999 -9999 -9999 -9999 -9999 -9999 -9999 -9999 -9999 -9999 -9999 -9999 -9999 -9999 -9999 -9999 -9999 -9999 -999 -9999 -9999 -9999 -9999 -9999 -9999 -9999 -9999 -9999 -9999 -9999 -9999 -9999 -9999 -9999 -9999 -9999 -9999 -9999 -9999 -9999 -9999 -9999 -9999 -9999 -9999 -9999 -9999 -9999 -9999 -

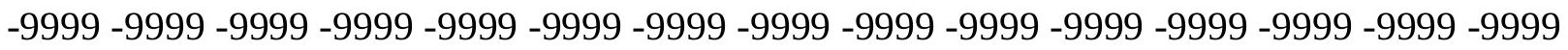

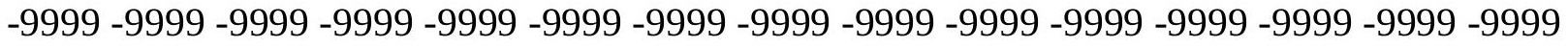

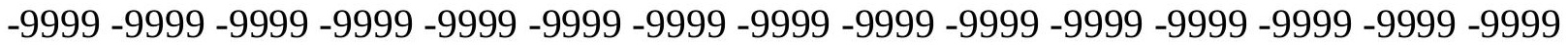

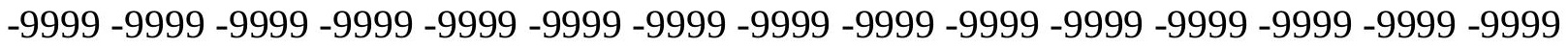

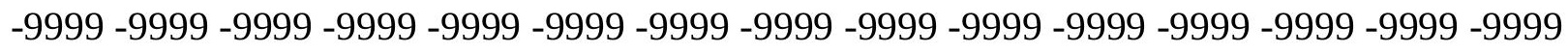

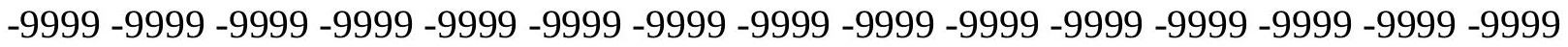
-9999 -9999 -9999 -9999 -9999 -9999 -9999 -9999 -9999 -9999 -9999 -9999 -9999 - 9999 - -999 -9999 -9999 -9999 -9999 -9999 -9999 -9999 -9999 -9999 -9999 -9999 -9999 -9999 -9999 - -999 -

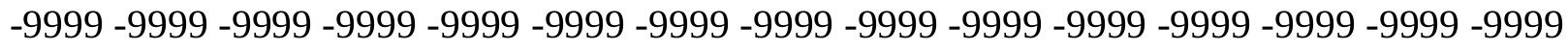

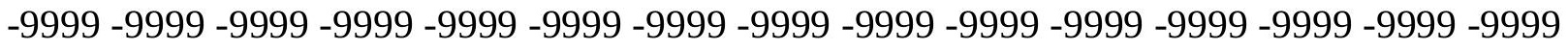
-9999 -9999 -9999 -9999 -9999 -9999 -9999 -9999 -9999 -9999 -9999 -9999 -9999 -9999 -9999 -9999 -9999 -9999 -9999 -9999 -9999 -9999 -9999 -9999-9999 -9999 -9999 -9999 -9999 -9999 -9999 -9999 -9999 -9999 -9999 -9999 -9999 -9999 -9999 -9999 -9999 -9999 -9999 -9999 -9999 -

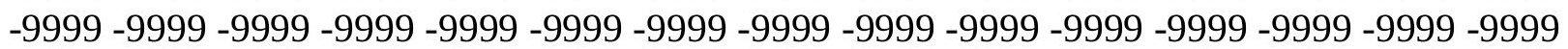


-9999 -9999 -9999 -9999 -9999 -9999 -9999 -9999 -9999 -9999 -9999 -9999 -9999 -9999 -9999 -9999 -9999 -9999 -9999 -9999 -9999 -9999 -9999 -9999 -9999 -9999 -9999 -9999 -9999 -9999 -9999 -9999 -9999 -9999 -9999 -9999 -9999 -9999 -9999 -9999 -9999 -9999 -9999 -9999 -9999 -9999 -9999 -9999 -9999 -9999 -9999 -9999 -9999 -9999 -9999 -9999 -9999 -9999 -9999 -9999 -9999 -9999 -9999 -9999 -9999 -9999 -9999 -9999 -9999 -9999 -9999 -9999 -9999 -9999 -9999 -9999 -9999 -9999 -9999 -9999 -9999 -9999 -9999 -9999 -9999 -9999 -9999 -9999 -9999 -9999 -9999 -9999 -9999 -9999 -9999 -9999 -9999 -9999 -9999 -9999 -9999 -9999 -9999 -9999 -9999 -

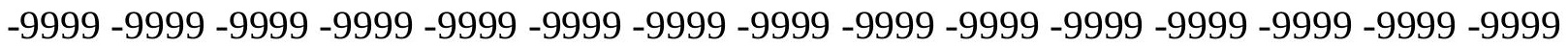
-9999 -9999 -9999 -9999 -9999 -9999 -9999 -9999 -9999 -9999 -9999 -9999 -9999 -9999 -9999 -9999 -9999 -9999 -9999 -9999 -9999 -9999 -9999 -9999 -9999 -9999 -9999 -9999 -9999 -9999 -

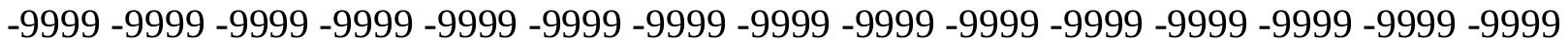
-9999 -9999 -9999 -9999 -9999 -9999 -9999 -9999 -9999 -9999 -9999 -9999 -9999 -9999 -9999 -9999 -9999 -9999 -9999 -9999 -9999 -9999 -9999 -9999 -9999 -9999 -9999 -9999 -9999 -9999 -9999 -9999 -9999 -9999 -9999 -9999 -9999 -9999 -9999 -9999 -9999 -9999 -9999 -9999 -9999 -9999 -9999 -9999 -9999 -9999 -9999 -9999 -9999 -9999 -9999 -9999 -9999 -9999 -9999 -9999

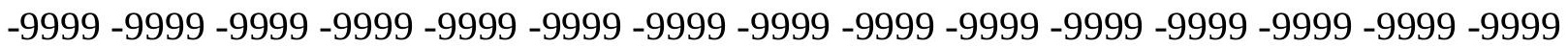
-9999 -9999 -9999 -9999 -9999 -9999 -9999 -9999 -9999 -9999 -9999 -9999 -9999 -9999 -9999 -9999 -9999 -9999 -9999 -9999 -9999 -9999 -9999 -9999 -9999 -9999 -9999 -9999 -9999 -9999 -9999 -9999 -9999 -9999 -9999 -9999 -9999 -9999 -9999 -9999 -9999 -9999 -9999 -9999 -9999 -9999 -9999 -9999 -9999 -9999 -9999 -9999 -9999 -9999 -9999 -9999 -9999 -9999 -9999 -9999 -9999 -9999 -9999 -9999 -9999 -9999 -9999 -9999 -9999 -9999 -9999 -9999 -9999 -9999 -9999 -9999 -9999 -9999 -9999 -9999 -9999 -9999 -9999 -9999 -9999 -9999 -9999 -9999 -9999 -9999 -9999 -9999 -9999 -9999 -9999 -9999 -9999 -9999 -9999 -9999 -9999 -9999 -9999 -9999 -9999 -9999 -9999 -9999 -9999 -9999 -9999 -9999 -9999 -9999 -9999 -9999 -9999 -9999 -9999 -9999 -9999 -9999 -9999 -9999 -9999 -9999 -9999 -9999 -9999 -9999 -9999 -9999 -9999 -9999 -9999 -9999 -9999 -9999 -9999 -9999 -9999 -9999 -9999 -9999 -9999 -9999 -9999 -9999 -9999 -9999 -9999 -9999 -9999 -9999 -9999 -9999 -9999 -9999 -9999 -9999 -9999 -9999 -9999 -9999 -9999 -9999 -9999 -9999 -9999 -9999 -9999 -9999 -9999 -9999 -9999 -9999 -9999 -9999 -9999

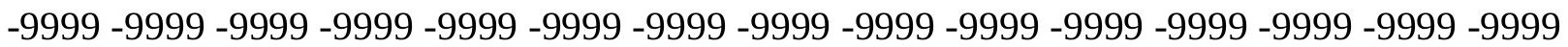
-9999 -9999 -9999 -9999 -9999 -9999 -9999 -9999 -9999 -9999 -9999 -9999 -9999 -9999 -9999 -9999 -9999 -9999 -9999 -9999 -9999 -9999 -9999 -9999 -9999 -9999 -9999 -9999 -9999 -9999 -

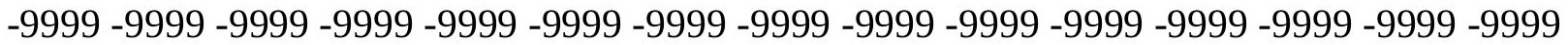
-9999 -9999 -9999 -9999 -9999 -9999 -9999 -9999 -9999 -9999 -9999 -9999 -9999 -9999 -9999 -9999 -9999 -9999 -9999 -9999 -9999 -9999 -9999 -9999 -9999 -9999 -9999 -9999 -9999 -9999 -9999 -9999 -9999 -9999 -9999 -9999 -9999 -9999 -9999 -9999 -9999 -9999 -9999 -9999 -9999 -9999 -9999 -9999 -9999 -9999 -9999 -9999 -9999 -9999 -9999 -9999 -9999 -9999 -9999 -9999 -9999 -9999 -9999 -9999 -9999 -9999 -9999 -9999 -9999 -9999 -9999 -9999 -9999 -9999 -9999

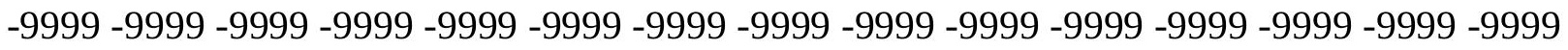
-9999 -9999 -9999 -9999 -9999 -9999 -9999 -9999 -9999 -9999 -9999 -9999 -9999 -9999 -9999 -9999 -9999 -9999 -9999 -9999 -9999 -9999 -9999 -9999 -9999 -9999 -9999 -9999 -9999 -9999 -9999 -9999 -9999 -9999 -9999 -9999 -9999 -9999 -9999 -9999 -9999 -9999 -9999 -9999 -9999 -999 -9999 -9999 -9999 -9999 -9999 -9999 -9999 -9999 -9999 -9999 -9999 -9999 -9999 -9999 -9999 -9999 -9999 -9999 -9999 -9999 -9999 -9999 -9999 -9999 -9999 -9999 -9999 -9999 -9999 -9999 -9999 -9999 -9999 -9999 -9999 -9999 -9999 -9999 -9999 -9999 -9999 -9999 -9999 -9999 -9999 -9999 -9999 -9999 -9999 -9999 -9999 -9999 -9999 -9999 -9999 -9999 -9999 -9999 -9999 -9999 -9999 -9999 -9999 -9999 -9999 -9999 -9999 -9999 -9999 -9999 -9999 -9999 -9999 -9999 
-9999 -9999 -9999 -9999 -9999 -9999 -9999 -9999 -9999 -9999 -9999 -9999 -9999 -9999 -9999 -9999 -9999 -9999 -9999 -9999 -9999 -9999 -9999 -9999 -9999 -9999 -9999 -9999 -9999 -9999 -

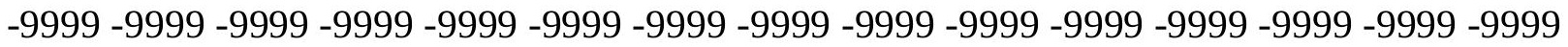
-9999 -9999 -9999 -9999 -9999 -9999 -9999 -9999 -9999 -9999 -9999 -9999 -9999 -9999 -9999 -9999 -9999 -9999 -9999 -9999 -9999 -9999 -9999 -9999-9999 -9999 -9999 -9999 -9999 -9999 -9999 -9999 -9999 -9999 -9999 -9999 -9999 -9999 -9999 -9999 -9999 -9999 -9999 -9999 -9999 -9999 -9999 -9999 -9999 -9999 -9999 -9999 -9999 -9999 -9999 -9999 -9999 -9999 -9999 -9999

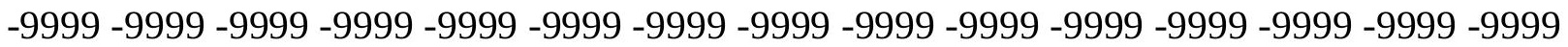

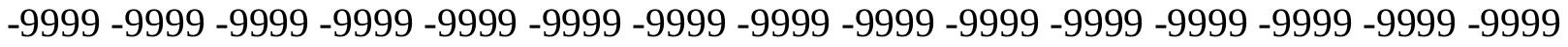
-9999 -9999 -9999 -9999 -9999 -9999 -9999 -9999 -9999 -9999 -9999 -9999 -9999 -9999 -9999 -9999 -9999 -9999 -9999 -9999 -9999 -9999 -9999 -9999 -9999 -9999 -9999 -9999 -9999 -9999 -9999 -9999 -9999 -9999 -9999 -9999 -9999 -9999 -9999 -9999 -9999 -9999 -9999 -9999 -9999 -9999 -9999 -9999 -9999 -9999 -9999 -9999 -9999 -9999 -9999 -9999 -9999 -9999 -9999 -9999 -

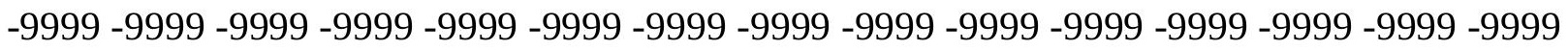
-9999 -9999 -9999 -9999 -9999 -9999 -9999 -9999 -9999 -9999 -9999 -9999 -9999 -9999 -9999 -

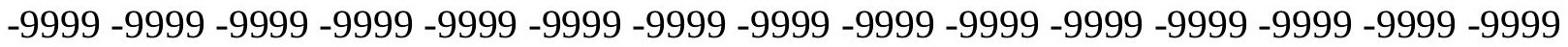
-9999 -9999 -9999 -9999 -9999 -9999 -9999 -9999 -9999 -9999 -9999 -9999 -9999 -9999 -9999 -9999 -9999 -9999 -9999 -9999 -9999 -9999 -9999 -9999 -9999 -9999 -9999 -9999 -9999 -9999 -9999 -9999 -9999 -9999 -9999 -9999 -9999 -9999 -9999 -9999 -9999 -9999 -9999 -9999 -9999 -

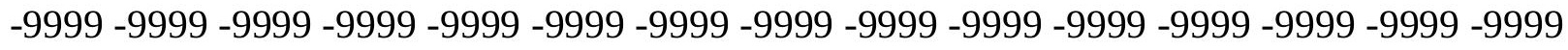

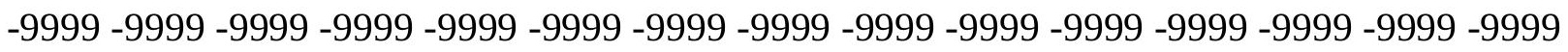

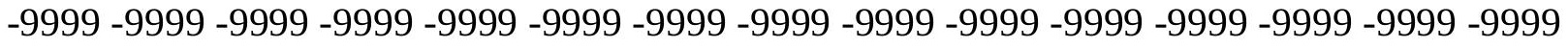
-9999 -9999 -9999 -9999 -9999 -9999 -9999 -9999 -9999 -9999 -9999 -9999 -9999 -9999 -9999 -9999 -9999 -9999 -9999 -9999 -9999 -9999 -9999 -9999 -9999 -9999 -9999 -9999 -9999 -9999 -

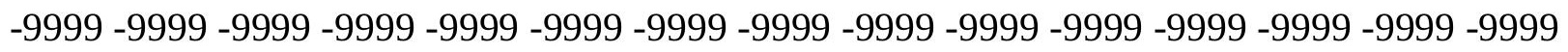
-9999 -9999 -9999 -9999 -9999 -9999 -9999 -9999 -9999 -9999 -9999 -9999 -9999 -9999 -9999 -9999 -9999 -9999 -9999 -9999 -9999 -9999 -9999 -9999 -9999 -9999 -9999 -9999 -9999 -

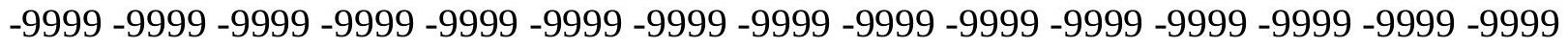
-9999 -9999 -9999 -9999 -9999 -9999 -9999 -9999 -9999 -9999 -9999 -9999 -9999 -9999 -9999 -9999 -9999 -9999 -9999 -9999 -9999 -9999 -9999 -9999 -9999 -9999 -9999 -9999 -9999 -999 -

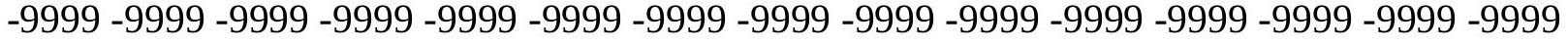
-9999 -9999 -9999 -9999 -9999 -9999 -9999 -9999 -9999 -9999 -9999 -9999 -9999 -9999 -9999 -

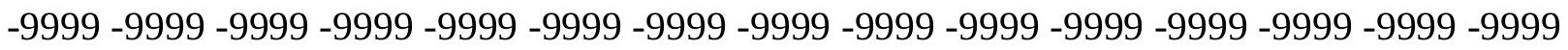

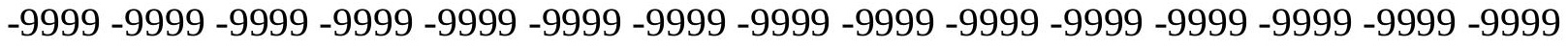

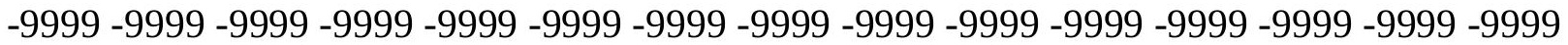
-9999 -9999 -9999 -9999 -9999 -9999 -9999 -9999 -9999 -9999 -9999 -9999 -9999 -9999 -9999

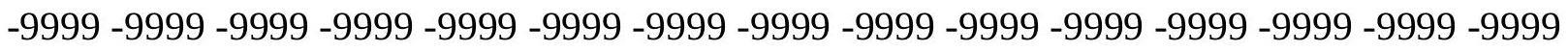

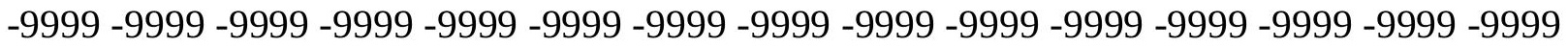
-9999 -9999 -9999 -9999 -9999 -9999 -9999 -9999 -9999 -9999 -9999 -9999 -9999 - 9999 - -999 -9999 -9999 -9999 -9999 -9999 -9999 -9999 -9999 -9999 -9999 -9999 -9999 -9999 -9999 -9999 -

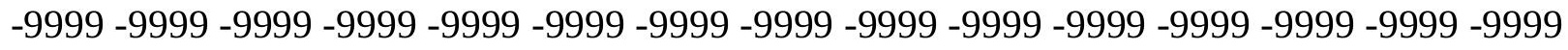

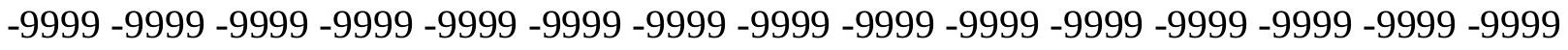
-9999 -9999 -9999 -9999 -9999 -9999 -9999 -9999 -9999 -9999 -9999 -9999 -9999 -9999 -9999 -9999 -9999 -9999 -9999 -9999 -9999 -9999 -9999 -9999-9999 -9999 -9999 -9999 -9999 -9999 -9999 -9999 -9999 -9999 -9999 -9999 -9999 -9999 -9999 -9999 -9999 -9999 -9999 -9999 -9999 -

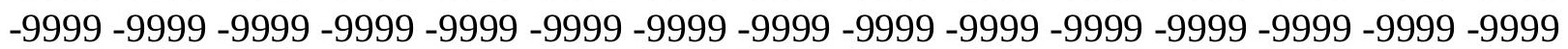


-9999 -9999 -9999 -9999 -9999 -9999 -9999 -9999 -9999 -9999 -9999 -9999 -9999 -9999 -9999 -9999 -9999 -9999 -9999 -9999 -9999 -9999 -9999 -9999 -9999 -9999 -9999 -9999 -9999 -9999 -9999 -9999 -9999 -9999 -9999 -9999 -9999 -9999 -9999 -9999 -9999 -9999 -9999 -9999 - 9999 -9999 -9999 -9999 -9999 -9999 -9999 -9999 -9999 -9999 -9999 -9999 -9999 -9999 -9999 -9999 -9999 -9999 -9999 -9999 -9999 -9999 -9999 -9999 -9999 -9999 -9999 -9999 -9999 -9999 - -9999 -9999 -9999 -9999 -9999 -9999 -9999 -9999 -9999 -9999 -9999 -9999 -9999 -9999 -9999 -9999 -9999 -9999 -9999 -9999 -9999 -9999 -9999 -9999 -9999 -9999 -9999 -9999 -9999 -9999

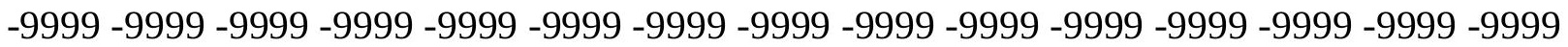

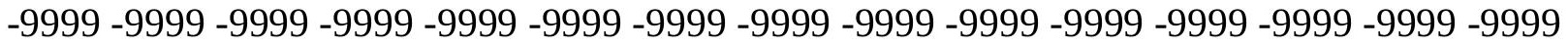
-9999 -9999 -9999 -9999 -9999 -9999 -9999 -9999 -9999 -9999 -9999 -9999 -9999 -9999 -9999

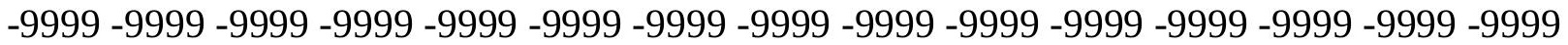
-9999 -9999 -9999 -9999 -9999 -9999 -9999 -9999 -9999 -9999 -9999 -9999 -9999 -9999 -9999 -9999 -9999 -9999 -9999 -9999 -9999 -9999 -9999 -9999 -9999 -9999 -9999 -9999 -9999 -9999 -9999 -9999 -9999 -9999 -9999 -9999 -9999 -9999 -9999 -9999 -9999 -9999 -9999 -9999 - -9999 -9999 -9999 -9999 -9999 -9999 -9999 -9999 -9999 -9999 -9999 -9999 -9999 -9999 -9999 -9999

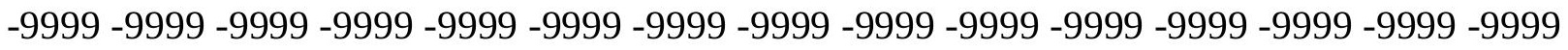
-9999 -9999 -9999 -9999 -9999 -9999 -9999 -9999 -9999 -9999 -9999 -9999 -9999 -9999 -9999 -9999 -9999 -9999 -9999 -9999 -9999 -9999 -9999 -9999 -9999 -9999 -9999 -9999 -9999 -9999 -9999 -9999 -9999 -9999 -9999 -9999 -9999 -9999 -9999 -9999 -9999 -9999 -9999 -9999 -9999 -

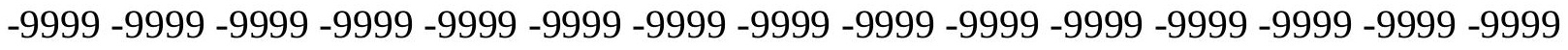
-9999 -9999 -9999 -9999 -9999 -9999 -9999 -9999 -9999 -9999 -9999 -9999 -9999 -9999 -9999 -999 -9999 -9999 -9999 -9999 -9999 -9999 -9999 -9999 -9999 -9999 -9999 -9999 -9999 -9999 -9999 -9999 -9999 -9999 -9999 -9999 -9999 -9999 -9999 -9999 -9999 -9999 -9999 -9999 -9999 -9999 -9999 -9999 -9999 -9999 -9999 -9999 -9999 -9999 -9999 -9999 -9999 -9999 -9999 -9999 -9999 -9999 -9999 -9999 -9999 -9999 -9999 -9999 -9999 -9999 -9999 -9999 -9999 -9999 -9999 -9999 -9999 -9999 -9999 -9999 -9999 -9999 -9999 -9999 -9999 -9999 -9999 -9999 -9999 -9999 -9999 -9999 -9999 -9999 -9999 -9999 -9999 -9999 -9999 -9999 -9999 -9999 -9999 -9999 -9999 -9999 -9999 -9999 -9999 -9999 -9999 -9999 -9999 -9999 -9999 -9999 -9999 -9999 -9999 -9999 -9999 -9999 -9999 -9999 -9999 -9999 -9999 -9999 -9999 -9999 -9999 -9999 -9999 -9999 -9999 -9999 -9999 -9999 -9999 -9999 -9999 -9999 -9999 -9999 -9999 -9999 -9999 -9999 -9999 -9999 -999 -9999 -9999 -9999 -9999 -9999 -9999 -9999 -9999 -9999 -9999 -9999 -9999 -9999 -9999 -9999 -9999 -9999 -9999 -9999 -9999 -9999 -9999 -9999 -9999 -9999 -9999 -9999 -9999 -9999 -

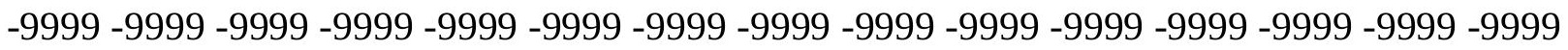

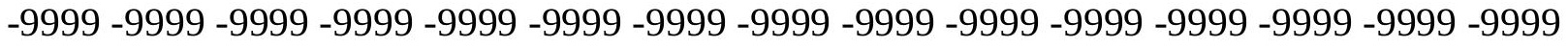

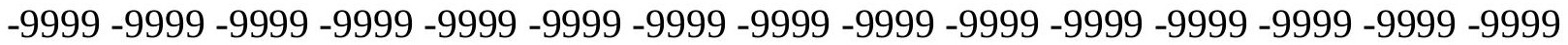
-9999 -9999 -9999 -9999 -9999 -9999 -9999 -9999 -9999 -9999 -9999 -9999 -9999 -9999 -9999 -

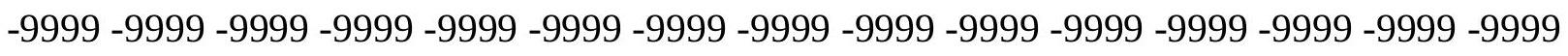

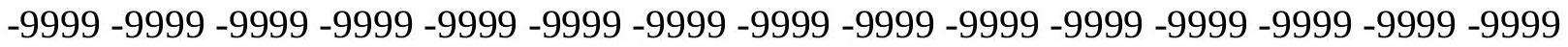

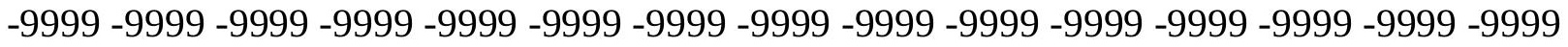
-9999 -9999 -9999 -9999 -9999 -9999 -9999 -9999 -9999 -9999 -9999 -9999 -9999 -9999 -9999 -

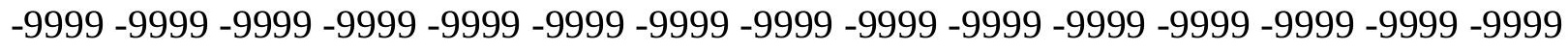

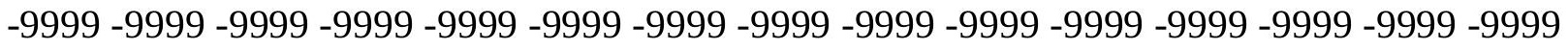
-9999 -9999 -9999 -9999 -9999 -9999 -9999 -9999 -9999 -9999 -9999 -9999 -9999 -9999 -9999 -9999 -9999 -9999 -9999 -9999 -9999 -9999 -9999 -9999-9999 -9999 -9999 -9999 -9999 -9999 -9999 -9999 -9999 -9999 -9999 -9999 -9999 -9999 -9999 -9999 -9999 -9999 -9999 -9999 -9999 -

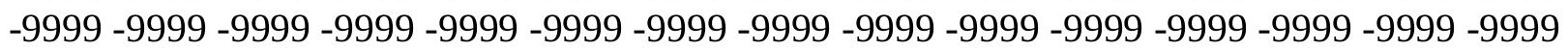


-9999 -9999 -9999 -9999 -9999 -9999 -9999 -9999 -9999 -9999 -9999 -9999 -9999 -9999 -9999 -9999 -9999 -9999 -9999 -9999 -9999 -9999 -9999 -9999 -9999 -9999 -9999 -9999 -9999 -9999 -

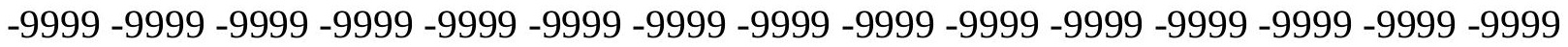
-9999 -9999 -9999 -9999 -9999 -9999 -9999 -9999 -9999 -9999 -9999 -9999 -9999 -9999 -9999 -9999 -9999 -9999 -9999 -9999 -9999 -9999 -9999 -9999-9999 -9999 -9999 -9999 -9999 -9999 -9999 -9999 -9999 -9999 -9999 -9999 -9999 -9999 -9999 -9999 -9999 -9999 -9999 -9999 -9999 -9999 -9999 -9999 -9999 -9999 -9999 -9999 -9999 -9999 -9999 -9999 -9999 -9999 -9999 -9999

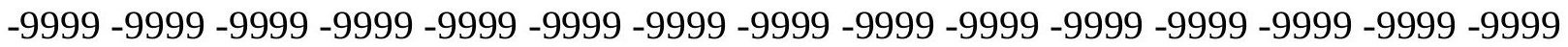

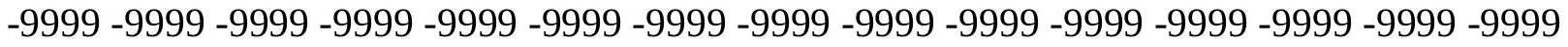
-9999 -9999 -9999 -9999 -9999 -9999 -9999 -9999 -9999 -9999 -9999 -9999 -9999 -9999 -9999 -9999 -9999 -9999 -9999 -9999 -9999 -9999 -9999 -9999 -9999 -9999 -9999 -9999 -9999 -9999 -9999 -9999 -9999 -9999 -9999 -9999 -9999 -9999 -9999 -9999 -9999 -9999 -9999 -9999 -9999 -9999 -9999 -9999 -9999 -9999 -9999 -9999 -9999 -9999 -9999 -9999 -9999 -9999 -9999 -9999 -9999 -9999 -9999 -9999 -9999 -9999 -9999 -9999 -9999 -9999 -9999 -9999 -9999 - 9999 -9999 -9999 -9999 -9999 -9999 -9999 -9999 -9999 -9999 -9999 -9999 -9999 -9999 -9999 -9999

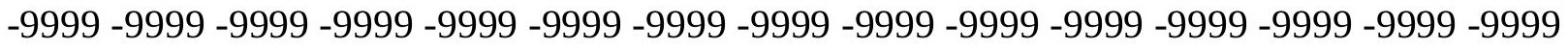
-9999 -9999 -9999 -9999 -9999 -9999 -9999 -9999 -9999 -9999 -9999 -9999 -9999 -9999 -9999 -9999 -9999 -9999 -9999 -9999 -9999 -9999 -9999 -9999 -9999 -9999 -9999 -9999 -9999 -9999 -9999 -9999 -9999 -9999 -9999 -9999 -9999 -9999 -9999 -9999 -9999 -9999 -9999 -9999 -9999 -

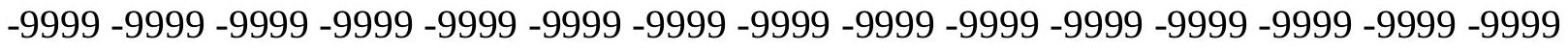

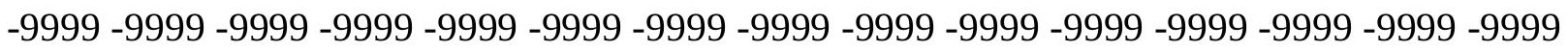
-9999 -9999 -9999 -9999 -9999 -9999 -9999 -9999 -9999 -9999 -9999 -9999 -9999 -9999 -9999 -9999 -9999 -9999 -9999 -9999 -9999 -9999 -9999 -9999 -9999 -9999 -9999 -9999 -9999 -9999 -9999 -9999 -9999 -9999 -9999 -9999 -9999 -9999 -9999 -9999 -9999 -9999 -9999 -9999 -9999 -

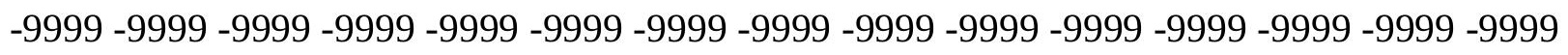
-9999 -9999 -9999 -9999 -9999 -9999 -9999 -9999 -9999 -9999 -9999 -9999 -9999 -9999 -9999 -9999 -9999 -9999 -9999 -9999 -9999 -9999 -9999 -9999 -9999 -9999 -9999 -9999 -9999 -9999 -

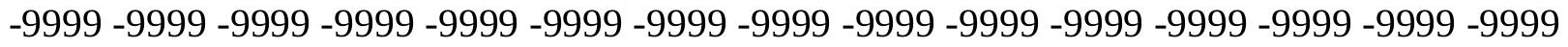
-9999 -9999 -9999 -9999 -9999 -9999 -9999 -9999 -9999 -9999 -9999 -9999 -9999 -9999 -9999 -9999 -9999 -9999 -9999 -9999 -9999 -9999 -9999 -9999 -9999 -9999 -9999 -9999 -9999 -999 -9999 -9999 -9999 -9999 -9999 -9999 -9999 -9999 -9999 -9999 -9999 -9999 -9999 -9999 -9999 -9999 -9999 -9999 -9999 -9999 -9999 -9999 -9999 -9999 -9999 -9999 -9999 -9999 -9999 -9999 -

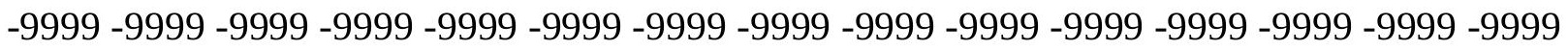

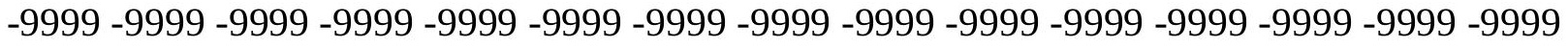

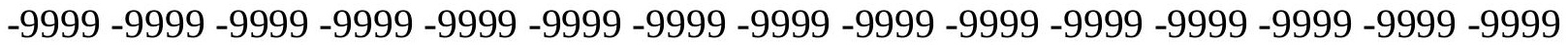

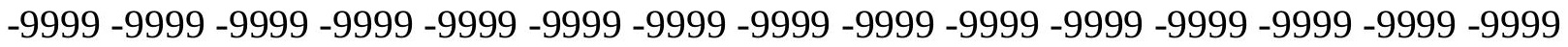

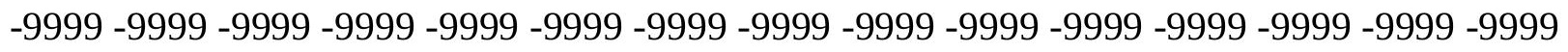

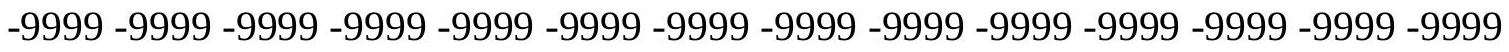
-9999 -9999 -9999 -9999 -9999 -9999 -9999 -9999 -9999 -9999 -9999 -9999 -9999 -9999 -9999 -9999 -9999 -9999 -9999 -9999 -9999 -9999 -9999 -9999 -9999 -9999 -9999 -9999 -9999 -9999 -

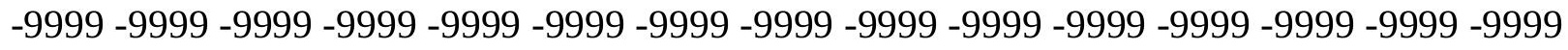

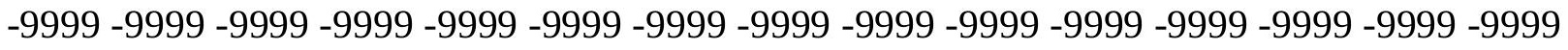
-9999 -9999 -9999 -9999 -9999 -9999 -9999 -9999 -9999 -9999 -9999 -9999 -9999 -9999 -9999 -9999 -9999 -9999 -9999 -9999 -9999 -9999 -9999 -9999-9999 -9999 -9999 -9999 -9999 -9999 -9999 -9999 -9999 -9999 -9999 -9999 -9999 -9999 -9999 -9999 -9999 -9999 -9999 -9999 -9999 -

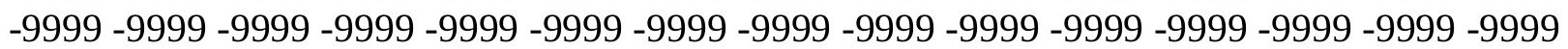


-9999 -9999 -9999 -9999 -9999 -9999 -9999 -9999 -9999 -9999 -9999 -9999 -9999 -9999 -9999 -9999 -9999 -9999 -9999 -9999 -9999 -9999 -9999 -9999 -9999 -9999 -9999 -9999 -9999 -9999 -9999 -9999 -9999 -9999 -9999 -9999 -9999 -9999 -9999 -9999 -9999 -9999 -9999 -9999 - 9999 -9999 -9999 -9999 -9999 -9999 -9999 -9999 -9999 -9999 -9999 -9999 -9999 -9999 -9999 -9999 -9999 -9999 -9999 -9999 -9999 -9999 -9999 -9999 -9999 -9999 -9999 -9999 -9999 -9999 -9999 -9999 -9999 -9999 -9999 -9999 -9999 -9999 -9999 -9999 -9999 -9999 -9999 -9999 -9999 -9999 -9999 -9999 -9999 -9999 -9999 -9999 -9999 -9999 -9999 -9999 -9999 -9999 -9999 -9999 -9999

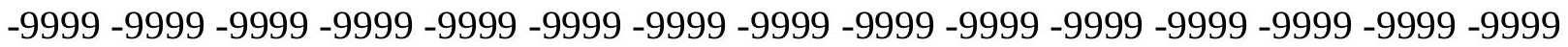
-9999 -9999 -9999 -9999 -9999 -9999 -9999 -9999 -9999 -9999 -9999 -9999 -9999 -9999 -9999 -9999 -9999 -9999 -9999 -9999 -9999 -9999 -9999 -9999 -9999 -9999 -9999 -9999 -9999 -9999

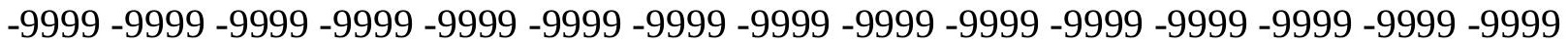
-9999 -9999 -9999 -9999 -9999 -9999 -9999 -9999 -9999 -9999 -9999 -9999 -9999 -9999 -9999 -9999 -9999 -9999 -9999 -9999 -9999 -9999 -9999 -9999 -9999 -9999 -9999 -9999 -9999 -9999 -

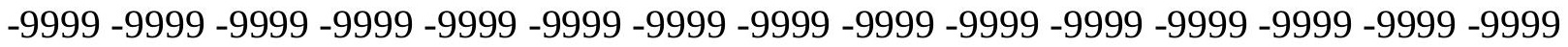
-9999 -9999 -9999 -9999 -9999 -9999 -9999 -9999 -9999 -9999 -9999 -9999 -9999 -9999 -9999

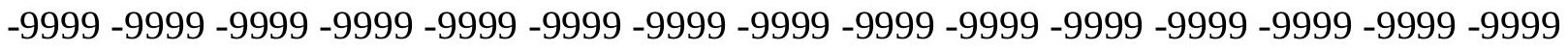
-9999 -9999 -9999 -9999 -9999 -9999 -9999 -9999 -9999 -9999 -9999 -9999 -9999 -9999 -9999 -9999 -9999 -9999 -9999 -9999 -9999 -9999 -9999 -9999 -9999 -9999 -9999 -9999 -9999 - -999 -9999 -9999 -9999 -9999 -9999 -9999 -9999 -9999 -9999 -9999 -9999 -9999 -9999 -9999 -9999 -9999 -9999 -9999 -9999 -9999 -9999 -9999 -9999 -9999 -9999 -9999 -9999 -9999 -9999 -9999 -9999 -9999 -9999 -9999 -9999 -9999 -9999 -9999 -9999 -9999 -9999 -9999 -9999 -9999 -9999 -999 -9999 -9999 -9999 -9999 -9999 -9999 -9999 -9999 -9999 -9999 -9999 -9999 -9999 -9999 -9999 -9999 -9999 -9999 -9999 -9999 -9999 -9999 -9999 -9999 -9999 -9999 -9999 -9999 -9999 -9999 -9999 -9999 -9999 -9999 -9999 -9999 -9999 -9999 -9999 -9999 -9999 -9999 -9999 -9999 -9999 -9999 -9999 -9999 -9999 -9999 -9999 -9999 -9999 -9999 -9999 -9999 -9999 -9999 -9999 -9999 -9999 -9999 -9999 -9999 -9999 -9999 -9999 -9999 -9999 -9999 -9999 -9999 -9999 -9999 -9999 -9999 -9999 -9999 -9999 -9999 -9999 -9999 -9999 -9999 -9999 -9999 -9999 -9999 -9999 -9999 -9999 -9999 -9999 -9999 -9999 -9999 -9999 -9999 -9999 -9999 -9999 -9999 -9999 -9999 -9999 -9999 -9999 -9999 -9999 -9999 -9999 -9999 -9999 -9999 -9999 -9999 -9999 -9999 -9999 -9999 -9999 -9999 -9999 -9999 -9999 -9999 -9999 -9999 -9999 -9999 -9999 -9999 -9999 -9999 -999 -9999 -9999 -9999 -9999 -9999 -9999 -9999 -9999 -9999 -9999 -9999 -9999 -9999 -9999 -9999 -9999 -9999 -9999 -9999 -9999 -9999 -9999 -9999 -9999 -9999 -9999 -9999 -9999 -9999 -9999 -

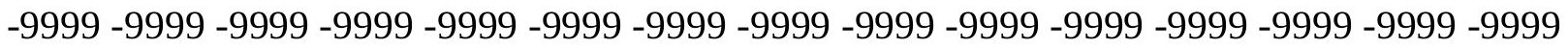

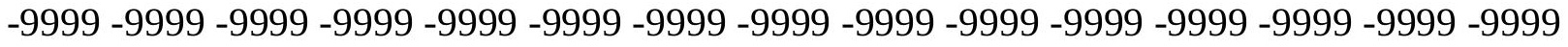

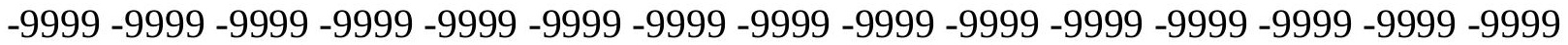
-9999 -9999 -9999 -9999 -9999 -9999 -9999 -9999 -9999 -9999 -9999 -9999 -9999 -9999 -9999

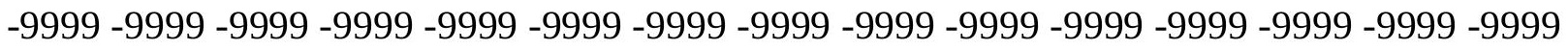

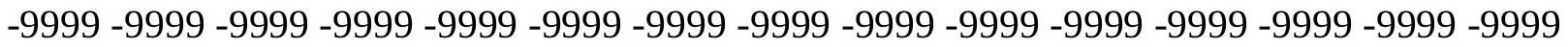

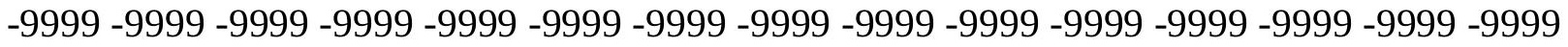
-9999 -9999 -9999 -9999 -9999 -9999 -9999 -9999 -9999 -9999 -9999 -9999 -9999 -9999 -9999 -

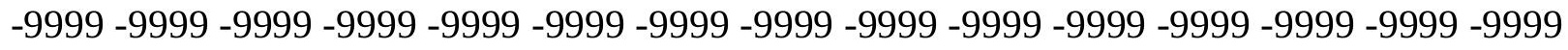

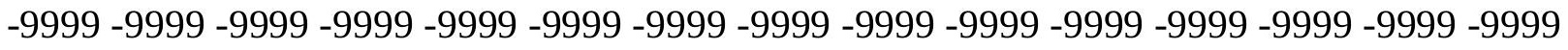
-9999 -9999 -9999 -9999 -9999 -9999 -9999 -9999 -9999 -9999 -9999 -9999 -9999 -9999 -9999 -9999 -9999 -9999 -9999 -9999 -9999 -9999 -9999 -9999 -9999 -9999 -9999 -9999 - -9999 -9999 -9999 -9999 -9999 -9999 -9999 -9999 -9999 -9999 -9999 -9999 -9999 -9999 -9999 -9999 -

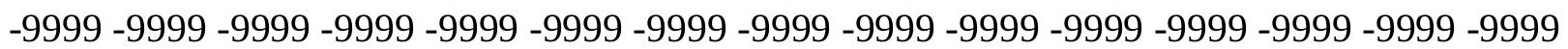


-9999 -9999 -9999 -9999 -9999 -9999 -9999 -9999 -9999 -9999 -9999 -9999 -9999 -9999 -9999 -9999 -9999 -9999 -9999 -9999 -9999 -9999 -9999 -9999 -9999 -9999 -9999 -9999 -9999 -9999 -9999 -9999 -9999 -9999 -9999 -9999 -9999 -9999 -9999 -9999 -9999 -9999 -9999 -9999 - 9999 -9999 -9999 -9999 -9999 -9999 -9999 -9999 -9999 -9999 -9999 -9999 -9999 -9999 -9999 -9999 -9999 -9999 -9999 -9999 -9999 -9999 -9999 -9999 -9999-9999 -9999 -9999 -9999 -9999 -9999 -9999 -9999 -9999 -9999 -9999 -9999 -9999 -9999 -9999 -9999 -9999 -9999 -9999 -9999 -9999 -9999 -9999 -9999 -9999 -9999 -9999 -9999 -9999 -9999 -9999 -9999 -9999 -9999 -9999 -9999

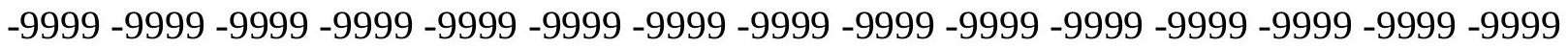

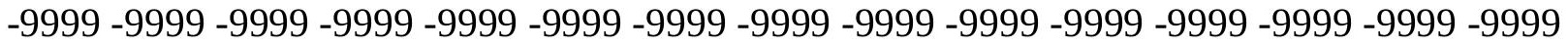
-9999 -9999 -9999 -9999 -9999 -9999 -9999 -9999 -9999 -9999 -9999 -9999 -9999 -9999 -9999

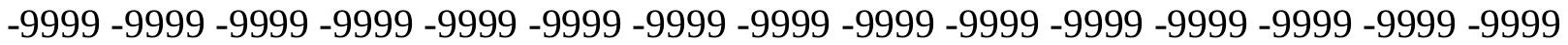
-9999 -9999 -9999 -9999 -9999 -9999 -9999 -9999 -9999 -9999 -9999 -9999 -9999 -9999 -9999 -9999 -9999 -9999 -9999 -9999 -9999 -9999 -9999 -9999 -9999 -9999 -9999 -9999 -9999 -9999 -

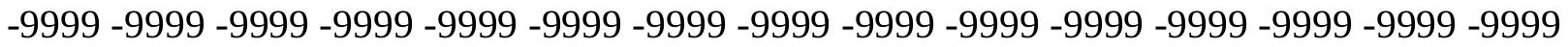
-9999 -9999 -9999 -9999 -9999 -9999 -9999 -9999 -9999 -9999 -9999 -9999 -9999 -9999 -9999

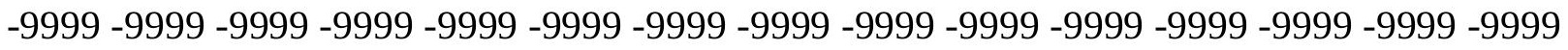
-9999 -9999 -9999 -9999 -9999 -9999 -9999 -9999 -9999 -9999 -9999 -9999 -9999 -9999 -9999 -9999 -9999 -9999 -9999 -9999 -9999 -9999 -9999 -9999 -9999 -9999 -9999 -9999 -9999 -9999 -9999 -9999 -9999 -9999 -9999 -9999 -9999 -9999 -9999 -9999 -9999 -9999 -9999 -9999 -9999 -9999 -9999 -9999 -9999 -9999 -9999 -9999 -9999 -9999 -9999 -9999 -9999 -9999 -9999 -9999 -9999 -9999 -9999 -9999 -9999 -9999 -9999 -9999 -9999 -9999 -9999 -9999 -9999 -9999 -9999 -999 -9999 -9999 -9999 -9999 -9999 -9999 -9999 -9999 -9999 -9999 -9999 -9999 -9999 -9999 -9999 -9999 -9999 -9999 -9999 -9999 -9999 -9999 -9999 -9999 -9999 -9999 -9999 -9999 -9999 -9999 -9999 -9999 -9999 -9999 -9999 -9999 -9999 -9999 -9999 -9999 -9999 -9999 -9999 -9999 -9999 -9999 -9999 -9999 -9999 -9999 -9999 -9999 -9999 -9999 -9999 -9999 -9999 -9999 -9999 -9999 -9999 -9999 -9999 -9999 -9999 -9999 -9999 -9999 -9999 -9999 -9999 -9999 -9999 -9999 -9999 -9999 -9999 -9999 -9999 -9999 -9999 -9999 -9999 -9999 -9999 -9999 -9999 -9999 -9999 -9999 -9999 -9999 -9999 -9999 -9999 -9999 -9999 -9999 -9999 -9999 -9999 -9999 -9999 -9999 -9999 -9999 -9999 -9999 -9999 -9999 -9999 -9999 -9999 -9999 -9999 -9999 -9999 -9999 -9999 -9999 -9999 -9999 -9999 -9999 -9999 -9999 -9999 -9999 -9999 -9999 -9999 -9999 -9999 -999 -9999 -9999 -9999 -9999 -9999 -9999 -9999 -9999 -9999 -9999 -9999 -9999 -9999 -9999 -9999 -9999 -9999 -9999 -9999 -9999 -9999 -9999 -9999 -9999 -9999 -9999 -9999 -9999 -9999 -9999 -

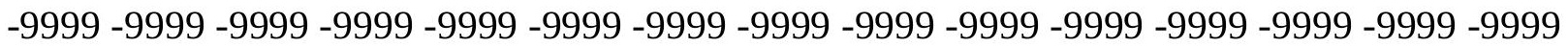

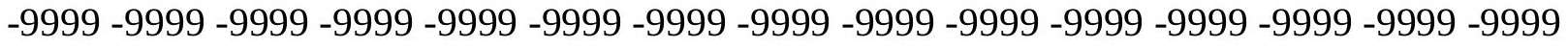

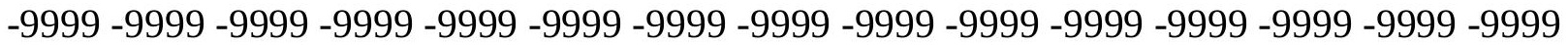
-9999 -9999 -9999 -9999 -9999 -9999 -9999 -9999 -9999 -9999 -9999 -9999 -9999 -9999 -9999

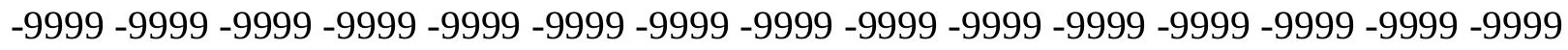

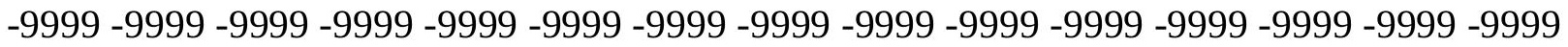
-9999 -9999 -9999 -9999 -9999 -9999 -9999 -9999 -9999 -9999 -9999 -9999 -9999 -9999 -9999 -9999 -9999 -9999 -9999 -9999 -9999 -9999 -9999 -9999 -9999 -9999 -9999 -9999 -9999 -9999 -

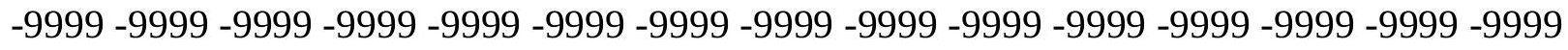

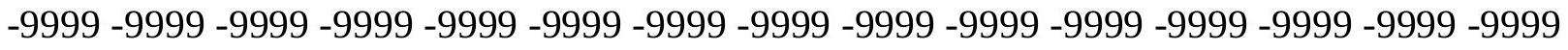
-9999 -9999 -9999 -9999 -9999 -9999 -9999 -9999 -9999 -9999 -9999 -9999 -9999 -9999 -9999 -9999 -9999 -9999 -9999 -9999 -9999 -9999 -9999 -9999-9999 -9999 -9999 -9999 -9999 -9999 -9999 -9999 -9999 -9999 -9999 -9999 -9999 -9999 -9999 -9999 -9999 -9999 -9999 -9999 -9999 -

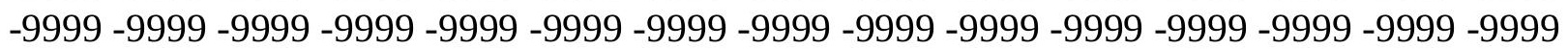


-9999 -9999 -9999 -9999 -9999 -9999 -9999 -9999 -9999 -9999 -9999 -9999 -9999 -9999 -9999 -9999 -9999 -9999 -9999 -9999 -9999 -9999 -9999 -9999 -9999 -9999 -9999 -9999 -9999 -9999 -9999 -9999 -9999 -9999 -9999 -9999 -9999 -9999 -9999 -9999 -9999 -9999 -9999 -9999 - 9999 -9999 -9999 -9999 -9999 -9999 -9999 -9999 -9999 -9999 -9999 -9999 -9999 -9999 -9999

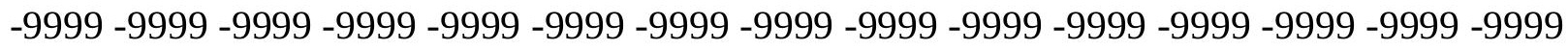
-9999 -9999 -9999 -9999 -9999 -9999 -9999 -9999 -9999 -9999 -9999 -9999 -9999 -9999 -9999 -9999 -9999 -9999 -9999 -9999 -9999 -9999 -9999 -9999 -9999 -9999 -9999 -9999 -9999 -9999

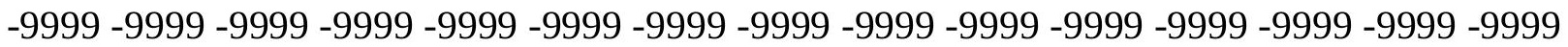

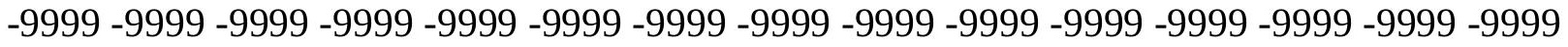
-9999 -9999 -9999 -9999 -9999 -9999 -9999 -9999 -9999 -9999 -9999 -9999 -9999 -9999 -9999 -9999 -9999 -9999 -9999 -9999 -9999 -9999 -9999 -9999 -9999 -9999 -9999 -9999 -9999 -9999 -9999 -9999 -9999 -9999 -9999 -9999 -9999 -9999 -9999 -9999 -9999 -9999 -9999 -9999 -9999 -9999 -9999 -9999 -9999 -9999 -9999 -9999 -9999 -9999 -9999 -9999 -9999 -9999 -9999 -9999 -

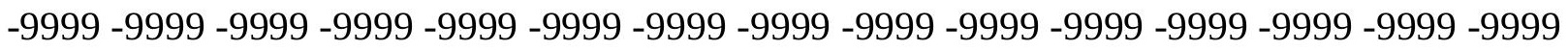
-9999 -9999 -9999 -9999 -9999 -9999 -9999 -9999 -9999 -9999 -9999 -9999 -9999 -9999 -9999 -

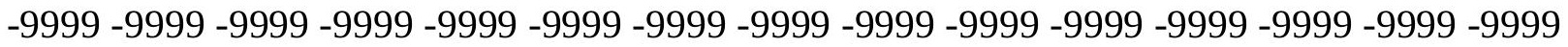
-9999 -9999 -9999 -9999 -9999 -9999 -9999 -9999 -9999 -9999 -9999 -9999 -9999 -9999 -9999 -9999 -9999 -9999 -9999 -9999 -9999 -9999 -9999 -9999 -9999 -9999 -9999 -9999 -9999 -9999 -9999 -9999 -9999 -9999 -9999 -9999 -9999 -9999 -9999 -9999 -9999 -9999 -9999 -9999 -9999 -

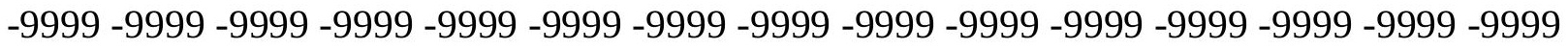
-9999 -9999 -9999 -9999 -9999 -9999 -9999 -9999 -9999 -9999 -9999 -9999 -9999 -9999 -9999

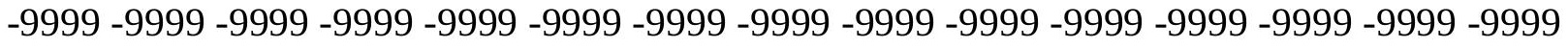
-9999 -9999 -9999 -9999 -9999 -9999 -9999 -9999 -9999 -9999 -9999 -9999 -9999 -9999 -9999 -9999 -9999 -9999 -9999 -9999 -9999 -9999 -9999 -9999 -9999 -9999 -9999 -9999 -9999 -9999 -9999 -9999 -9999 -9999 -9999 -9999 -9999 -9999 -9999 -9999 -9999 -9999 -9999 -9999 -9999 -9999 -9999 -9999 -9999 -9999 -9999 -9999 -9999 -9999 -9999 -9999 -9999 -9999 -9999 -9999 -9999 -9999 -9999 -9999 -9999 -9999 -9999 -9999 -9999 -9999 -9999 -9999 -9999 -9999 -9999 -9999 -9999 -9999 -9999 -9999 -9999 -9999 -9999 -9999 -9999 -9999 -9999 -9999 -9999 -9999 -9999 -9999 -9999 -9999 -9999 -9999 -9999 -9999 -9999 -9999 -9999 -9999 -9999 -9999 -9999 -9999 -9999 -9999 -9999 -9999 -9999 -9999 -9999 -9999 -9999 -9999 -9999 -9999 -9999 -9999 -9999 -9999 -9999 -9999 -9999 -9999 -9999 -9999 -9999 -9999 -9999 -9999 -9999 -9999 -9999 -9999 -9999 -9999 -9999 -9999 -9999 -9999 -9999 -9999 -9999 -9999 -9999 -9999 -9999 -

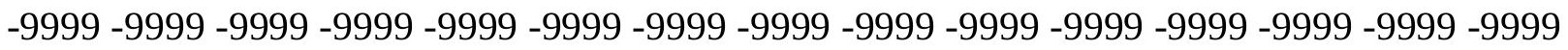

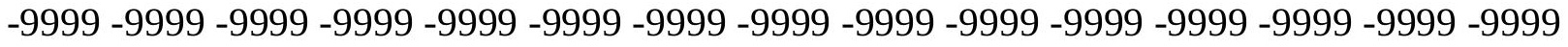
-9999 -9999 -9999 -9999 -9999 -9999 -9999 -9999 -9999 -9999 -9999 -9999 -9999 -9999 -9999 -

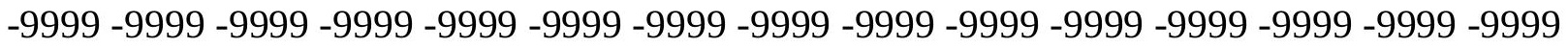

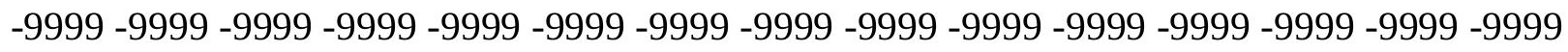

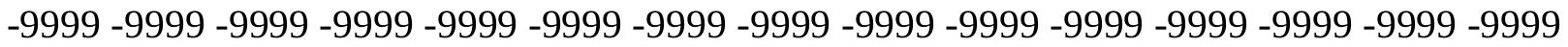

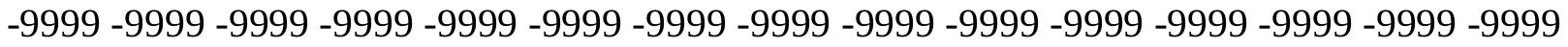
-9999 -9999 -9999 -9999 -9999 -9999 -9999 -9999 -9999 -9999 -9999 -9999 -9999 -9999 -9999 -

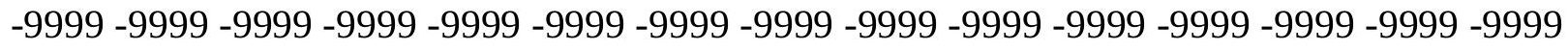

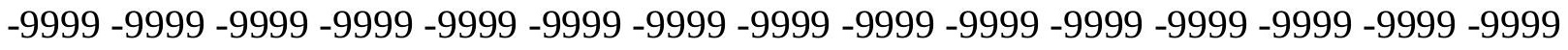
-9999 -9999 -9999 -9999 -9999 -9999 -9999 -9999 -9999 -9999 -9999 -9999 -9999 -9999 -9999 -9999 -9999 -9999 -9999 -9999 -9999 -9999 -9999 -9999-9999 -9999 -9999 -9999 -9999 -9999 -9999 -9999 -9999 -9999 -9999 -9999 -9999 -9999 -9999 -9999 -9999 -9999 -9999 -9999 -9999 -

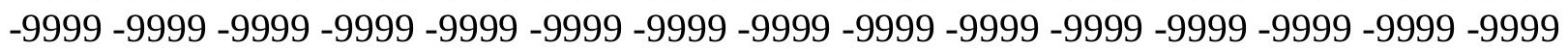


-9999 -9999 -9999 -9999 -9999 -9999 -9999 -9999 -9999 -9999 -9999 -9999 -9999 -9999 -9999 -9999 -9999 -9999 -9999 -9999 -9999 -9999 -9999 -9999 -9999 -9999 -9999 -9999 -9999 -9999 -9999 -9999 -9999 -9999 -9999 -9999 -9999 -9999 -9999 -9999 -9999 -9999 -9999 -9999 - 9999 -9999 -9999 -9999 -9999 -9999 -9999 -9999 -9999 -9999 -9999 -9999 -9999 -9999 -9999 -9999 -9999 -9999 -9999 -9999 -9999 -9999 -9999 -9999 -9999 -9999 -9999 -9999 -9999 -9999 -9999 -9999 -9999 -9999 -9999 -9999 -9999 -9999 -9999 -9999 -9999 -9999 -9999 -9999 -9999 -9999 -9999 -9999 -9999 -9999 -9999 -9999 -9999 -9999 -9999 -9999 -9999 -9999 -9999 -9999 -9999

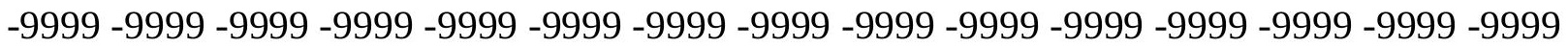

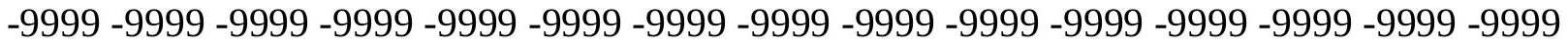
-9999 -9999 -9999 -9999 -9999 -9999 -9999 -9999 -9999 -9999 -9999 -9999 -9999 -9999 -9999 -9999 -9999 -9999 -9999 -9999 -9999 -9999 -9999 -9999 -9999 -9999 -9999 -9999 -9999 -9999 -9999 -9999 -9999 -9999 -9999 -9999 -9999 -9999 -9999 -9999 -9999 -9999 -9999 -9999 -9999 -9999 -9999 -9999 -9999 -9999 -9999 -9999 -9999 -9999 -9999 -9999 -9999 -9999 -9999 -9999 -9999 -9999 -9999 -9999 -9999 -9999 -9999 -9999 -9999 -9999 -9999 -9999 -9999 -9999 -9999 -9999 -9999 -9999 -9999 -9999 -9999 -9999 -9999 -9999 -9999 -9999 -9999 -9999 -9999 -

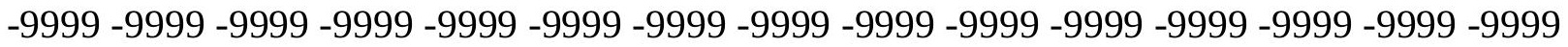
-9999 -9999 -9999 -9999 -9999 -9999 -9999 -9999 -9999 -9999 -9999 -9999 -9999 -9999 -9999 -9999 -9999 -9999 -9999 -9999 -9999 -9999 -9999 -9999 -9999 -9999 -9999 -9999 -9999 -9999 -9999 -9999 -9999 -9999 -9999 -9999 -9999 -9999 -9999 -9999 -9999 -9999 -9999 -9999 -9999 -9999 -9999 -9999 -9999 -9999 -9999 -9999 -9999 -9999 -9999 -9999 -9999 -9999 -9999 -9999 -9999 -9999 -9999 -9999 -9999 -9999 -9999 -9999 -9999 -9999 -9999 -9999 -9999 -9999 -9999 -999 -9999 -9999 -9999 -9999 -9999 -9999 -9999 -9999 -9999 -9999 -9999 -9999 -9999 -9999 -9999 -9999 -9999 -9999 -9999 -9999 -9999 -9999 -9999 -9999 -9999 -9999 -9999 -9999 -9999 -9999 -9999 -9999 -9999 -9999 -9999 -9999 -9999 -9999 -9999 -9999 -9999 -9999 -9999 -9999 -9999 -9999 -9999 -9999 -9999 -9999 -9999 -9999 -9999 -9999 -9999 -9999 -9999 -9999 -9999 -9999 -9999 -9999 -9999 -9999 -9999 -9999 -9999 -9999 -9999 -9999 -9999 -9999 -9999 -9999 -9999 -9999 -9999 -9999 -9999 -9999 -9999 -9999 -9999 -9999 -9999 -9999 -9999 -9999 -9999 -9999 -9999 -9999 -9999 -9999 -9999 -9999 -9999 -9999 -9999 -9999 -9999 -9999 -9999 -9999 -9999 -9999 -9999 -9999 -9999 -9999 -9999 -9999 -9999 -9999 -9999 -9999 -9999 -9999 -9999 -9999 -9999 -9999 -9999 -9999 -9999 -9999 -9999 -9999 -9999 -9999 -9999 -9999 -9999 -9999 -999 -9999 -9999 -9999 -9999 -9999 -9999 -9999 -9999 -9999 -9999 -9999 -9999 -9999 -9999 -9999 -9999 -9999 -9999 -9999 -9999 -9999 -9999 -9999 -9999 -9999 -9999 -9999 -9999 -9999 -9999 -

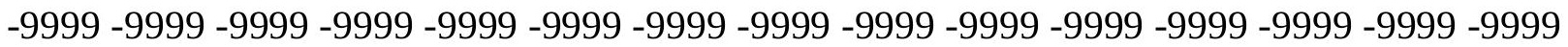

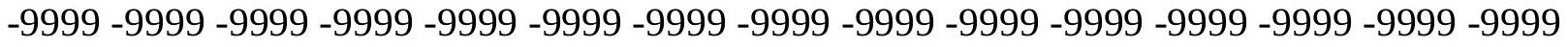

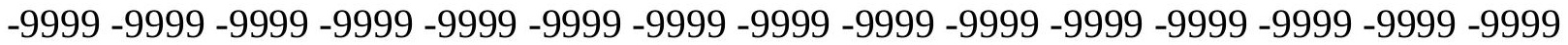
-9999 -9999 -9999 -9999 -9999 -9999 -9999 -9999 -9999 -9999 -9999 -9999 -9999 -9999 -9999 -9999 -9999 -9999 -9999 -9999 -9999 -9999 -9999 -9999 -9999 -9999 -9999 -9999 -9999 -

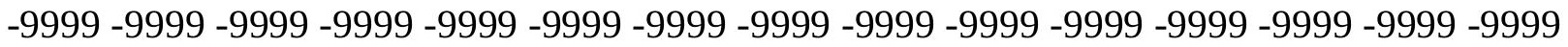
-9999 -9999 -9999 -9999 -9999 -9999 -9999 -9999 -9999 -9999 -9999 -9999 -9999 -9999 -9999 -9999 -9999 -9999 -9999 -9999 -9999 -9999 -9999 -9999 -9999 -9999 -9999 -9999 -9999 -9999 -

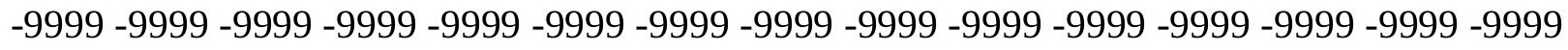

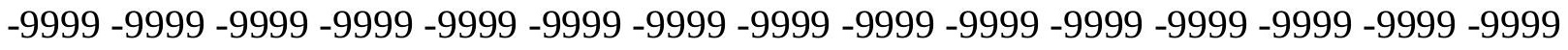
-9999 -9999 -9999 -9999 -9999 -9999 -9999 -9999 -9999 -9999 -9999 -9999 -9999 -9999 -9999 -9999 -9999 -9999 -9999 -9999 -9999 -9999 -9999 -9999-9999 -9999 -9999 -9999 -9999 -9999 -9999 -9999 -9999 -9999 -9999 -9999 -9999 -9999 -9999 -9999 -9999 -9999 -9999 -9999 -9999 -

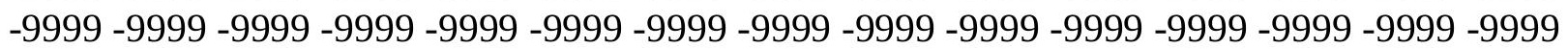


-9999 -9999 -9999 -9999 -9999 -9999 -9999 -9999 -9999 -9999 -9999 -9999 -9999 -9999 -9999 -9999 -9999 -9999 -9999 -9999 -9999 -9999 -9999 -9999 -9999 -9999 -9999 -9999 -9999 -9999 -

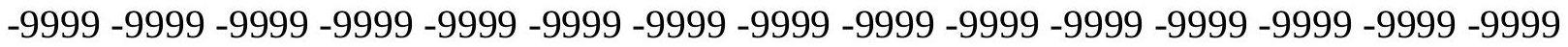
-9999 -9999 -9999 -9999 -9999 -9999 -9999 -9999 -9999 -9999 -9999 -9999 -9999 -9999 -9999 -9999 -9999 -9999 -9999 -9999 -9999 -9999 -9999 -9999-9999 -9999 -9999 -9999 -9999 -9999 -9999 -9999 -9999 -9999 -9999 -9999 -9999 -9999 -9999 -9999 -9999 -9999 -9999 -9999 -9999 -9999 -9999 -9999 -9999 -9999 -9999 -9999 -9999 -9999 -9999 -9999 -9999 -9999 -9999 -9999

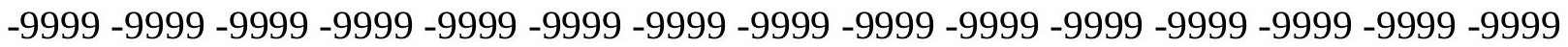

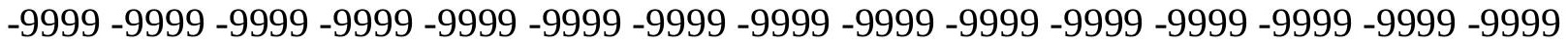
-9999 -9999 -9999 -9999 -9999 -9999 -9999 -9999 -9999 -9999 -9999 -9999 -9999 -9999 -9999 -9999 -9999 -9999 -9999 -9999 -9999 -9999 -9999 -9999 -9999 -9999 -9999 -9999 -9999 -9999 -9999 -9999 -9999 -9999 -9999 -9999 -9999 -9999 -9999 -9999 -9999 -9999 -9999 -9999 -9999 -9999 -9999 -9999 -9999 -9999 -9999 -9999 -9999 -9999 -9999 -9999 -9999 -9999 -9999 -9999 -9999 -9999 -9999 -9999 -9999 -9999 -9999 -9999 -9999 -9999 -9999 -9999 -9999 -9999 -9999 -9999 -9999 -9999 -9999 -9999 -9999 -9999 -9999 -9999 -9999 -9999 -9999 -9999 -9999 -9999 -

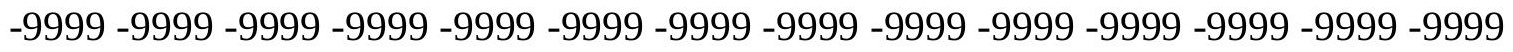
-9999 -9999 -9999 -9999 -9999 -9999 -9999 -9999 -9999 -9999 -9999 -9999 -9999 -9999 -9999 -9999 -9999 -9999 -9999 -9999 -9999 -9999 -9999 -9999 -9999 -9999 -9999 -9999 -9999 -9999 -9999 -9999 -9999 -9999 -9999 -9999 -9999 -9999 -9999 -9999 -9999 -9999 -9999 -9999 -9999 -

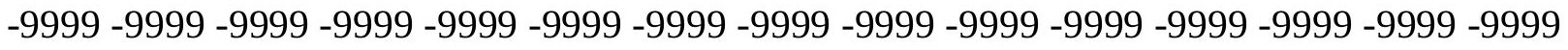

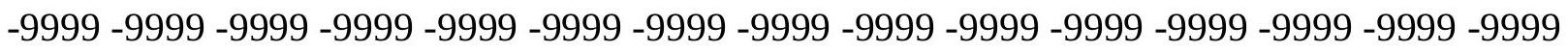
-9999 -9999 -9999 -9999 -9999 -9999 -9999 -9999 -9999 -9999 -9999 -9999 -9999 -9999 - 9999 -9999 -9999 -9999 -9999 -9999 -9999 -9999 -9999 -9999 -9999 -9999 -9999 -9999 -9999 -9999 -9999 -9999 -9999 -9999 -9999 -9999 -9999 -9999 -9999 -9999 -9999 -9999 -9999 -9999 -9999 -

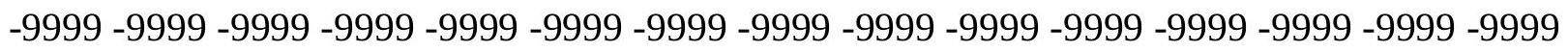
-9999 -9999 -9999 -9999 -9999 -9999 -9999 -9999 -9999 -9999 -9999 -9999 -9999 -9999 -9999 -9999 -9999 -9999 -9999 -9999 -9999 -9999 -9999 -9999 -9999 -9999 -9999 -9999 -9999 -9999 -

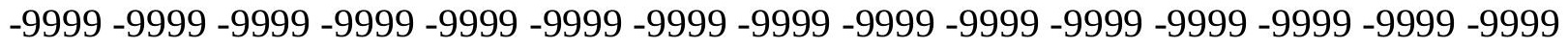
-9999 -9999 -9999 -9999 -9999 -9999 -9999 -9999 -9999 -9999 -9999 -9999 -9999 -9999 -9999 -9999 -9999 -9999 -9999 -9999 -9999 -9999 -9999 -9999 -9999 -9999 -9999 -9999 -9999 -999 -

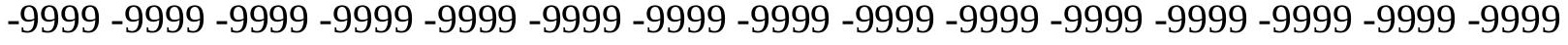
-9999 -9999 -9999 -9999 -9999 -9999 -9999 -9999 -9999 -9999 -9999 -9999 -9999 -9999 -9999 -

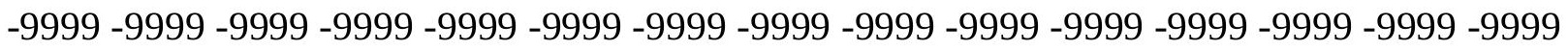

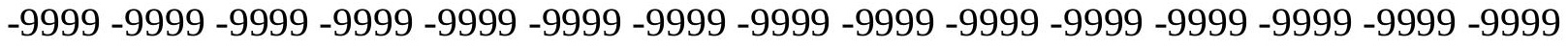

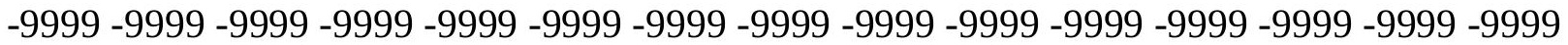
-9999 -9999 -9999 -9999 -9999 -9999 -9999 -9999 -9999 -9999 -9999 -9999 -9999 -9999 -9999 -

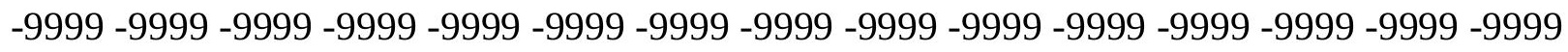

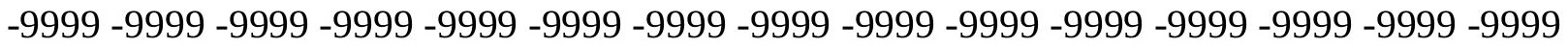
-9999 -9999 -9999 -9999 -9999 -9999 -9999 -9999 -9999 -9999 -9999 -9999 -9999 - 9999 - -999 -9999 -9999 -9999 -9999 -9999 -9999 -9999 -9999 -9999 -9999 -9999 -9999 -9999 -9999 -9999 -

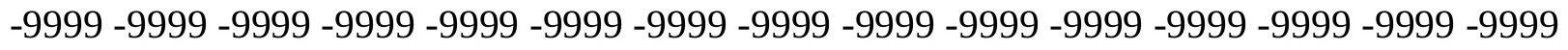

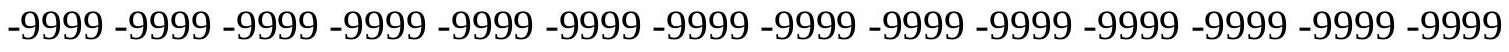
-9999 -9999 -9999 -9999 -9999 -9999 -9999 -9999 -9999 -9999 -9999 -9999 -9999 -9999 -9999 -9999 -9999 -9999 -9999 -9999 -9999 -9999 -9999 -9999-9999 -9999 -9999 -9999 -9999 -9999 -9999 -9999 -9999 -9999 -9999 -9999 -9999 -9999 -9999 -9999 -9999 -9999 -9999 -9999 -9999 -

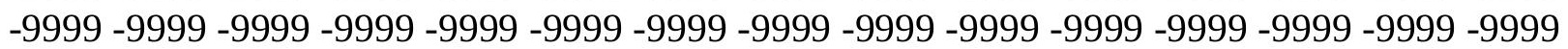


-9999 -9999 -9999 -9999 -9999 -9999 -9999 -9999 -9999 -9999 -9999 -9999 -9999 -9999 -9999 -9999 -9999 -9999 -9999 -9999 -9999 -9999 -9999 -9999 -9999 -9999 -9999 -9999 -9999 -9999 -

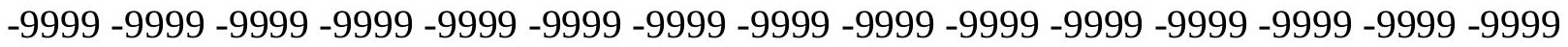
-9999 -9999 -9999 -9999 -9999 -9999 -9999 -9999 -9999 -9999 -9999 -9999 -9999 -9999 -9999 -9999 -9999 -9999 -9999 -9999 -9999 -9999 -9999 -9999-9999 -9999 -9999 -9999 -9999 -9999 -9999 -9999 -9999 -9999 -9999 -9999 -9999 -9999 -9999 -9999 -9999 -9999 -9999 -9999 -9999 -9999 -9999 -9999 -9999 -9999 -9999 -9999 -9999 -9999 -9999 -9999 -9999 -9999 -9999 -9999

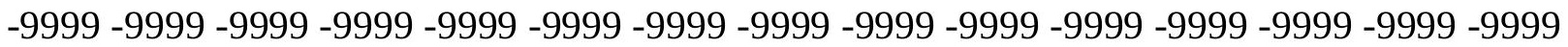

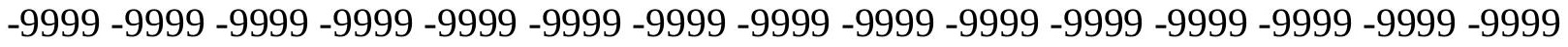
-9999 -9999 -9999 -9999 -9999 -9999 -9999 -9999 -9999 -9999 -9999 -9999 -9999 -9999 -9999 -9999 -9999 -9999 -9999 -9999 -9999 -9999 -9999 -9999 -9999 -9999 -9999 -9999 -9999 -9999 -9999 -9999 -9999 -9999 -9999 -9999 -9999 -9999 -9999 -9999 -9999 -9999 -9999 -9999 -9999 -9999 -9999 -9999 -9999 -9999 -9999 -9999 -9999 -9999 -9999 -9999 -9999 -9999 -9999 -9999 -

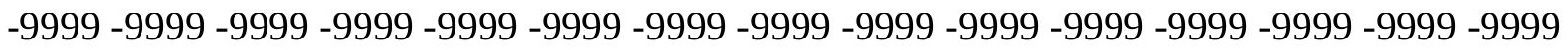
-9999 -9999 -9999 -9999 -9999 -9999 -9999 -9999 -9999 -9999 -9999 -9999 -9999 -9999 -9999 -

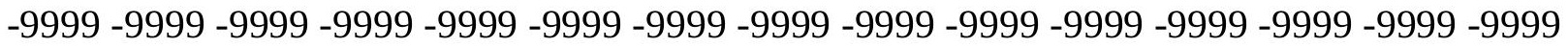
-9999 -9999 -9999 -9999 -9999 -9999 -9999 -9999 -9999 -9999 -9999 -9999 -9999 -9999 -9999 -9999 -9999 -9999 -9999 -9999 -9999 -9999 -9999 -9999 -9999 -9999 -9999 -9999 -9999 -9999 -9999 -9999 -9999 -9999 -9999 -9999 -9999 -9999 -9999 -9999 -9999 -9999 -9999 -9999 -9999 -

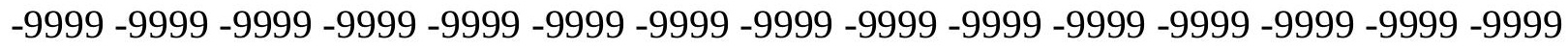

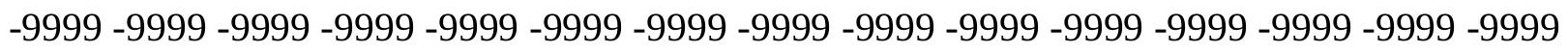
-9999 -9999 -9999 -9999 -9999 -9999 -9999 -9999 -9999 -9999 -9999 -9999 -9999 -9999 -9999 -9999 -9999 -9999 -9999 -9999 -9999 -9999 -9999 -9999 -9999 -9999 -9999 -9999 -9999 -9999 -9999 -9999 -9999 -9999 -9999 -9999 -9999 -9999 -9999 -9999 -9999 -9999 -9999 -9999 -

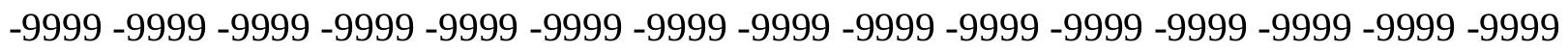
-9999 -9999 -9999 -9999 -9999 -9999 -9999 -9999 -9999 -9999 -9999 -9999 -9999 -9999 -9999 -9999 -9999 -9999 -9999 -9999 -9999 -9999 -9999 -9999 -9999 -9999 -9999 -9999 -9999 -9999 -

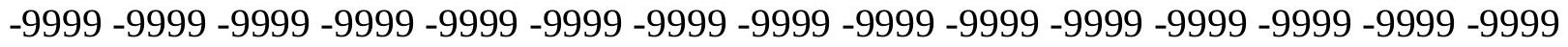
-9999 -9999 -9999 -9999 -9999 -9999 -9999 -9999 -9999 -9999 -9999 -9999 -9999 -9999 -9999 -9999 -9999 -9999 -9999 -9999 -9999 -9999 -9999 -9999 -9999 -9999 -9999 -9999 -9999 -999 -

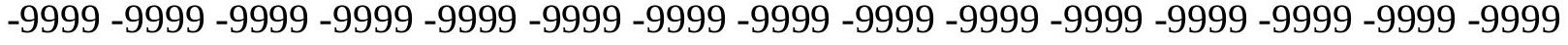
-9999 -9999 -9999 -9999 -9999 -9999 -9999 -9999 -9999 -9999 -9999 -9999 -9999 -9999 -9999 -

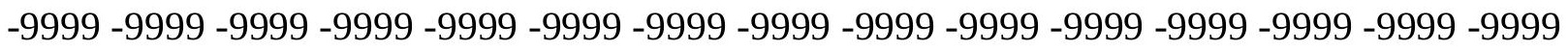

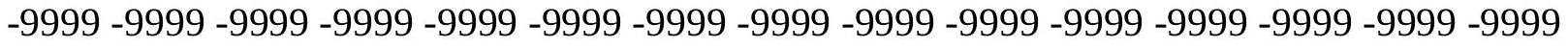

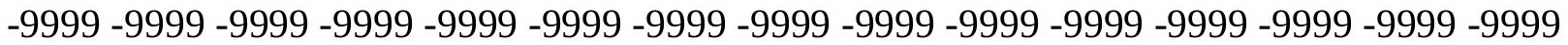

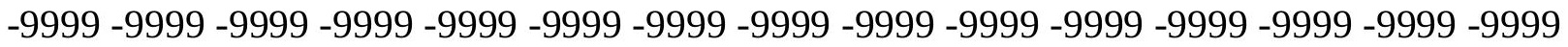

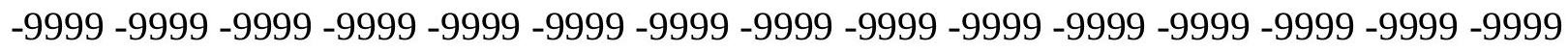

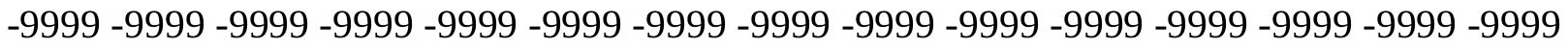

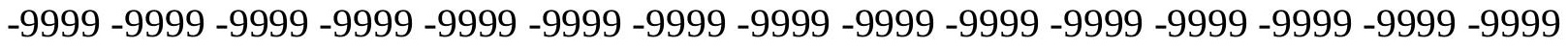
-9999 -9999 -9999 -9999 -9999 -9999 -9999 -9999 -9999 -9999 -9999 -9999 -9999 -9999 -9999 -

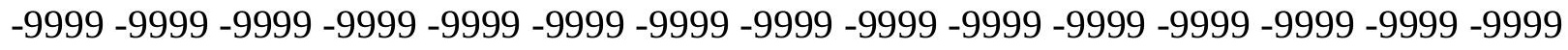

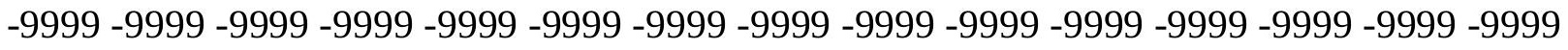
-9999 -9999 -9999 -9999 -9999 -9999 -9999 -9999 -9999 -9999 -9999 -9999 -9999 -9999 -9999 -9999 -9999 -9999 -9999 -9999 -9999 -9999 -9999 -9999-9999 -9999 -9999 -9999 -9999 -9999 -9999 -9999 -9999 -9999 -9999 -9999 -9999 -9999 -9999 -9999 -9999 -9999 -9999 -9999 -9999 -

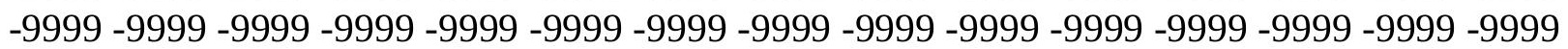


-9999 -9999 -9999 -9999 -9999 -9999 -9999 -9999 -9999 -9999 -9999 -9999 -9999 -9999 -9999 -9999 -9999 -9999 -9999 -9999 -9999 -9999 -9999 -9999 -9999 -9999 -9999 -9999 -9999 -

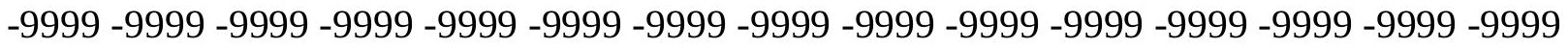
-9999 -9999 -9999 -9999 -9999 -9999 -9999 -9999 -9999 -9999 -9999 -9999 -9999 -9999 -9999 -9999 -9999 -9999 -9999 -9999 -9999 -9999 -9999 -9999 -9999 -9999 -9999 -9999 -9999 -9999 -9999 -9999 -9999 -9999 -9999 -9999 -9999 -9999 -9999 -9999 -9999 -9999 -9999 -9999 -9999 -9999 -9999 -9999 -9999 -9999 -9999 -9999 -9999 -9999 -9999 -9999 -9999 -9999 -9999 -9999

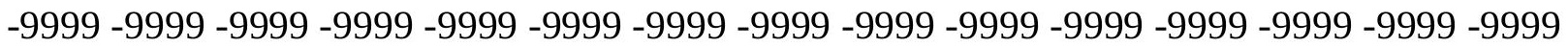

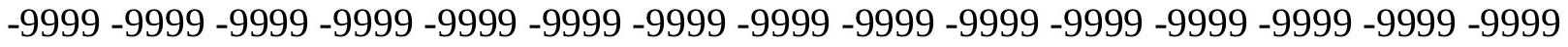
-9999 -9999 -9999 -9999 -9999 -9999 -9999 -9999 -9999 -9999 -9999 -9999 -9999 -9999 -9999 -9999 -9999 -9999 -9999 -9999 -9999 -9999 -9999 -9999 -9999 -9999 -9999 -9999 -9999 -9999 -9999 -9999 -9999 -9999 -9999 -9999 -9999 -9999 -9999 -9999 -9999 -9999 -9999 -9999 -9999 -9999 -9999 -9999 -9999 -9999 -9999 -9999 -9999 -9999 -9999 -9999 -9999 -9999 -9999 -9999 -9999 -9999 -9999 -9999 -9999 -9999 -9999 -9999 -9999 -9999 -9999 -9999 -9999 -9999 -9999 -9999 -9999 -9999 -9999 -9999 -9999 -9999 -9999 -9999 -9999 -9999 -9999 -9999 -9999 -9999 -

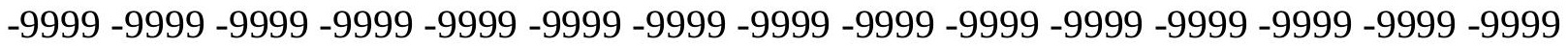
-9999 -9999 -9999 -9999 -9999 -9999 -9999 -9999 -9999 -9999 -9999 -9999 -9999 -9999 -9999 -9999 -9999 -9999 -9999 -9999 -9999 -9999 -9999 -9999 -9999 -9999 -9999 -9999 -9999 - 9999 -9999 -9999 -9999 -9999 -9999 -9999 -9999 -9999 -9999 -9999 -9999 -9999 -9999 -9999 -9999 -

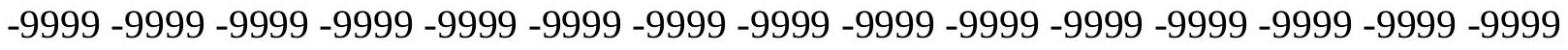

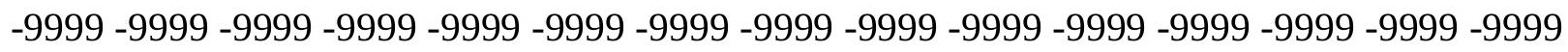

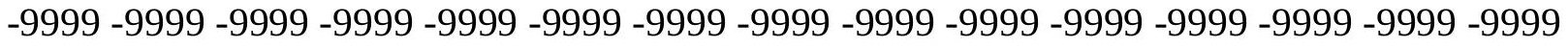
-9999 -9999 -9999 -9999 -9999 -9999 -9999 -9999 -9999 -9999 -9999 -9999 -9999 -9999 -9999 -9999 -9999 -9999 -9999 -9999 -9999 -9999 -9999 -9999 -9999 -9999 -9999 -9999 -9999 -9999 -

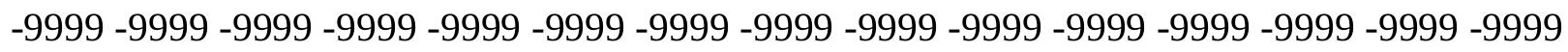
-9999 -9999 -9999 -9999 -9999 -9999 -9999 -9999 -9999 -9999 -9999 -9999 -9999 -9999 -9999 -9999 -9999 -9999 -9999 -9999 -9999 -9999 -9999 -9999 -9999 -9999 -9999 -9999 -9999 -9999 -9999 -9999 -9999 -9999 -9999 -9999 -9999 -9999 -9999 -9999 -9999 -9999 -9999 -9999 -9999 -9999 -9999 -9999 -9999 -9999 -9999 -9999 -9999 -9999 -9999 -9999 -9999 -9999 -9999 -9999 -9999 -9999 -9999 -9999 -9999 -9999 -9999 -9999 -9999 -9999 -9999 -9999 -9999 -999 -

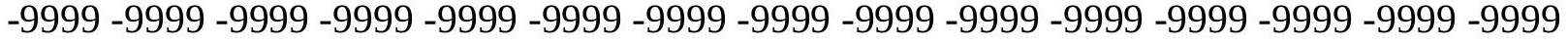
-9999 -9999 -9999 -9999 -9999 -9999 -9999 -9999 -9999 -9999 -9999 -9999 -9999 -9999 -9999 -

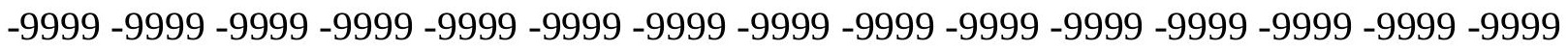

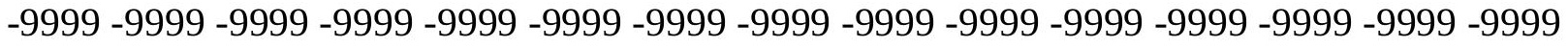

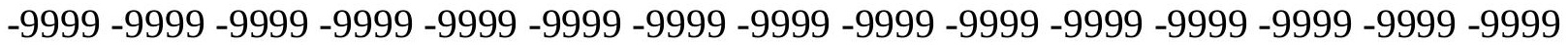

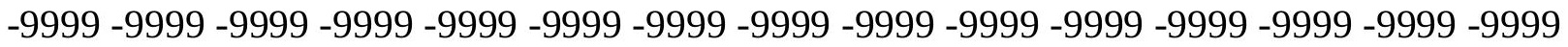

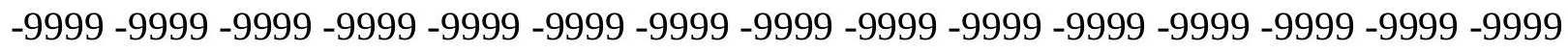

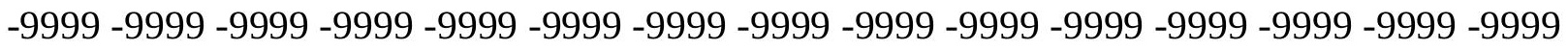

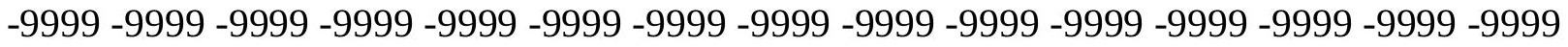
-9999 -9999 -9999 -9999 -9999 -9999 -9999 -9999 -9999 -9999 -9999 -9999 -9999 -9999 -9999 -

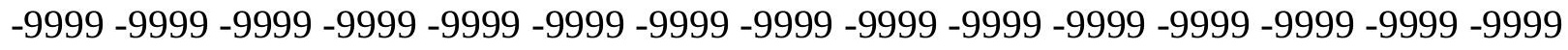

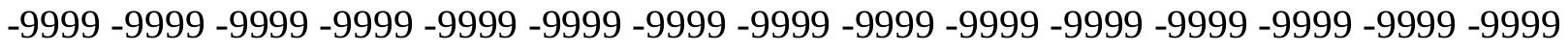
-9999 -9999 -9999 -9999 -9999 -9999 -9999 -9999 -9999 -9999 -9999 -9999 -9999 -9999 -9999 -9999 -9999 -9999 -9999 -9999 -9999 -9999 -9999 -9999-9999 -9999 -9999 -9999 -9999 -9999 -9999 -9999 -9999 -9999 -9999 -9999 -9999 -9999 -9999 -9999 -9999 -9999 -9999 -9999 -9999 -

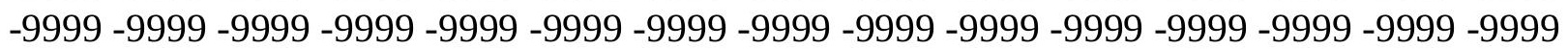


-9999 -9999 -9999 -9999 -9999 -9999 -9999 -9999 -9999 -9999 -9999 -9999 -9999 -9999 -9999 -9999 -9999 -9999 -9999 -9999 -9999 -9999 -9999 -9999 -9999 -9999 -9999 -9999 -9999 -9999 -

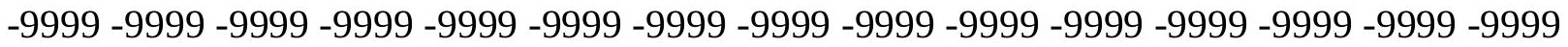
-9999 -9999 -9999 -9999 -9999 -9999 -9999 -9999 -9999 -9999 -9999 -9999 -9999 -9999 -9999 -9999 -9999 -9999 -9999 -9999 -9999 -9999 -9999 -9999-9999 -9999 -9999 -9999 -9999 -9999 -9999 -9999 -9999 -9999 -9999 -9999 -9999 -9999 -9999 -9999 -9999 -9999 -9999 -9999 -9999 -

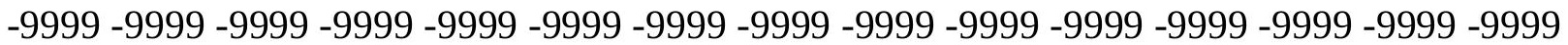
-9999 -9999 -9999 -9999 -9999 -9999 -9999 -9999 -9999 -9999 -9999 -9999 -9999 -9999 -9999 -9999 -9999 -9999 -9999 -9999 -9999 -9999 -9999 -9999 -9999 -9999 -9999 -9999 -9999 -9999 -9999 -9999 -9999 -9999 -9999 -9999 -9999 -9999 -9999 -9999 -9999 -9999 -9999 -9999 -9999 -9999 -9999 -9999 -9999 -9999 -9999 -9999 -9999 -9999 -9999 -9999 -9999 -9999 -9999 -9999 -9999 -9999 -9999 -9999 -9999 -9999 -9999 -9999 -9999 -9999 -9999 -9999 -9999 -9999 -9999 -9999 -9999 -9999 -9999 -9999 -9999 -9999 -9999 -9999 -9999 -9999 -9999 -9999 -9999 -9999 -9999 -9999 -9999 -9999 -9999 -9999 -9999 -9999 -9999 -9999 -9999 -9999 -9999 -9999 -9999 -9999 -9999 -9999 -9999 -9999 -9999 -9999 -9999 -9999 -9999 -9999 -9999 -9999 -9999 -

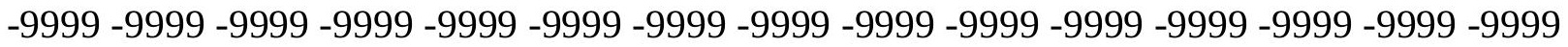
-9999 -9999 -9999 -9999 -9999 -9999 -9999 -9999 -9999 -9999 -9999 -9999 -9999 -9999 -9999 -9999 -9999 -9999 -9999 -9999 -9999 -9999 -9999 -9999 -9999 -9999 -9999 -9999 -9999 -9999 -9999 -9999 -9999 -9999 -9999 -9999 -9999 -9999 -9999 -9999 -9999 -9999 -9999 -9999 -9999 -

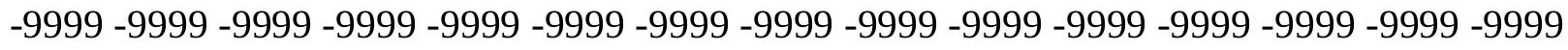

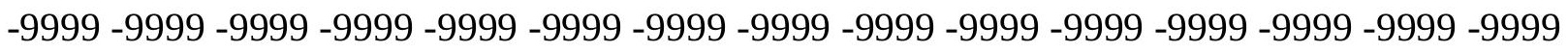
-9999 -9999 -9999 -9999 -9999 -9999 -9999 -9999 -9999 -9999 -9999 -9999 -9999 -9999 - 9999 -9999 -9999 -9999 -9999 -9999 -9999 -9999 -9999 -9999 -9999 -9999 -9999 -9999 -9999 -9999 -9999 -9999 -9999 -9999 -9999 -9999 -9999 -9999 -9999 -9999 -9999 -9999 -9999 -9999 -9999 -

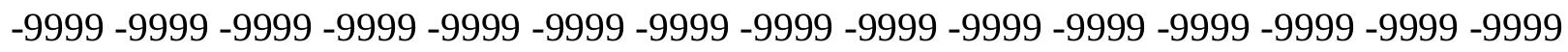
-9999 -9999 -9999 -9999 -9999 -9999 -9999 -9999 -9999 -9999 -9999 -9999 -9999 -9999 -9999 -9999 -9999 -9999 -9999 -9999 -9999 -9999 -9999 -9999 -9999 -9999 -9999 -9999 -9999 -9999 -

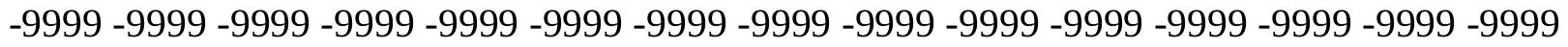
-9999 -9999 -9999 -9999 -9999 -9999 -9999 -9999 -9999 -9999 -9999 -9999 -9999 -9999 -9999 -9999 -9999 -9999 -9999 -9999 -9999 -9999 -9999 -9999 -9999 -9999 -9999 -9999 -9999 -999 -9999 -9999 -9999 -9999 -9999 -9999 -9999 -9999 -9999 -9999 -9999 -9999 -9999 -9999 -9999 -9999 -9999 -9999 -9999 -9999 -9999 -9999 -9999 -9999 -9999 -9999 -9999 -9999 -9999 -9999 -

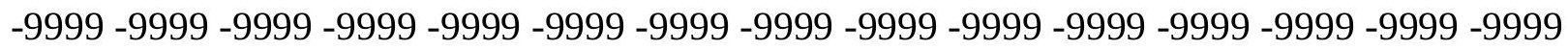

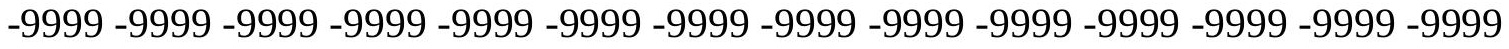
-9999 -9999 -9999 -9999 -9999 -9999 -9999 -9999 -9999 -9999 -9999 -9999 -9999 -9999 -9999

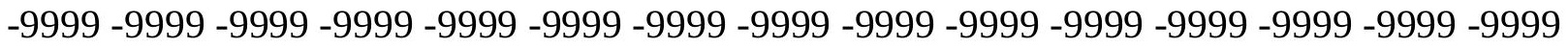

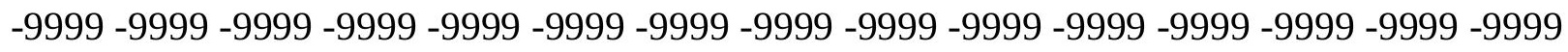

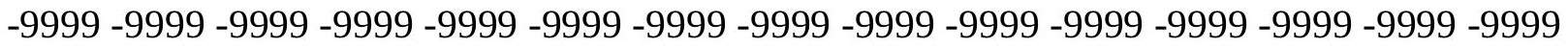

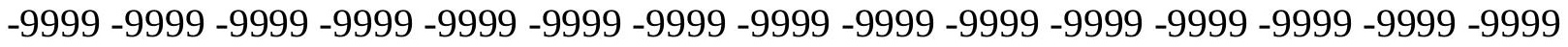
-9999 -9999 -9999 -9999 -9999 -9999 -9999 -9999 -9999 -9999 -9999 -9999 -9999 -9999 -9999 -

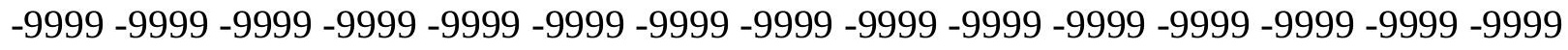

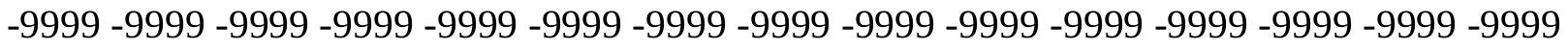
-9999 -9999 -9999 -9999 -9999 -9999 -9999 -9999 -9999 -9999 -9999 -9999 -9999 -9999 -9999 -9999 -9999 -9999 -9999 -9999 -9999 -9999 -9999 -9999-9999 -9999 -9999 -9999 -9999 -9999 -9999 -9999 -9999 -9999 -9999 -9999 -9999 -9999 -9999 -9999 -9999 -9999 -9999 -9999 -9999 -

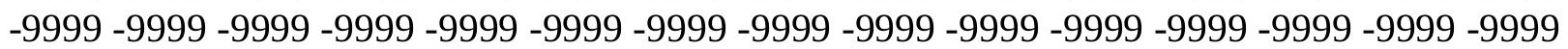


-9999 -9999 -9999 -9999 -9999 -9999 -9999 -9999 -9999 -9999 -9999 -9999 -9999 -9999 -9999 -9999 -9999 -9999 -9999 -9999 -9999 -9999 -9999 -9999 -9999 -9999 -9999 -9999 -9999 -9999 -

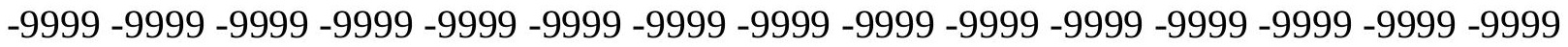
-9999 -9999 -9999 -9999 -9999 -9999 -9999 -9999 -9999 -9999 -9999 -9999 -9999 -9999 -9999 -9999 -9999 -9999 -9999 -9999 -9999 -9999 -9999 -9999-9999 -9999 -9999 -9999 -9999 -9999 -9999 -9999 -9999 -9999 -9999 -9999 -9999 -9999 -9999 -9999 -9999 -9999 -9999 -9999 -9999 -9999 -9999 -9999 -9999 -9999 -9999 -9999 -9999 -9999 -9999 -9999 -9999 -9999 -9999 -9999

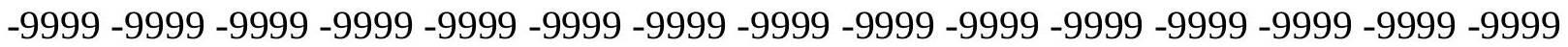

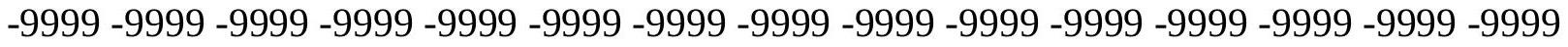
-9999 -9999 -9999 -9999 -9999 -9999 -9999 -9999 -9999 -9999 -9999 -9999 -9999 -9999 -9999 -9999 -9999 -9999 -9999 -9999 -9999 -9999 -9999 -9999 -9999 -9999 -9999 -9999 -9999 -9999 -9999 -9999 -9999 -9999 -9999 -9999 -9999 -9999 -9999 -9999 -9999 -9999 -9999 -9999 -9999 -9999 -9999 -9999 -9999 -9999 -9999 -9999 -9999 -9999 -9999 -9999 -9999 -9999 -9999 -9999 -9999 -9999 -9999 -9999 -9999 -9999 -9999 -9999 -9999 -9999 -9999 -9999 -9999 -9999 -9999 -9999 -9999 -9999 -9999 -9999 -9999 -9999 -9999 -9999 -9999 -9999 -9999 -9999 -9999

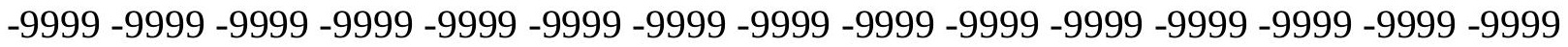
-9999 -9999 -9999 -9999 -9999 -9999 -9999 -9999 -9999 -9999 -9999 -9999 -9999 -9999 -9999 -9999 -9999 -9999 -9999 -9999 -9999 -9999 -9999 -9999 -9999 -9999 -9999 -9999 -9999 -9999 -9999 -9999 -9999 -9999 -9999 -9999 -9999 -9999 -9999 -9999 -9999 -9999 -9999 -9999 -9999 -

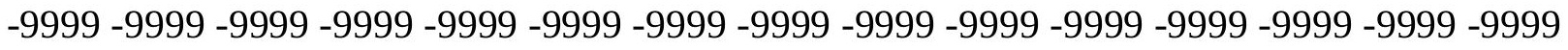

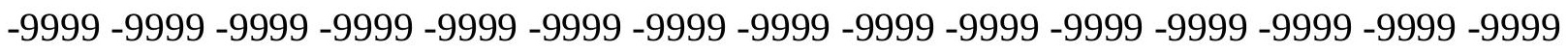
-9999 -9999 -9999 -9999 -9999 -9999 -9999 -9999 -9999 -9999 -9999 -9999 -9999 -9999 -9999 -9999 -9999 -9999 -9999 -9999 -9999 -9999 -9999 -9999 -9999 -9999 -9999 -9999 -9999 -9999 -9999 -9999 -9999 -9999 -9999 -9999 -9999 -9999 -9999 -9999 -9999 -9999 -9999 -9999 -9999 -

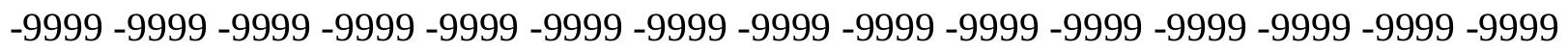
-9999 -9999 -9999 -9999 -9999 -9999 -9999 -9999 -9999 -9999 -9999 -9999 -9999 -9999 -9999 -9999 -9999 -9999 -9999 -9999 -9999 -9999 -9999 -9999 -9999 -9999 -9999 -9999 -9999 -9999 -

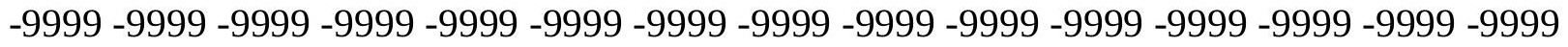
-9999 -9999 -9999 -9999 -9999 -9999 -9999 -9999 -9999 -9999 -9999 -9999 -9999 -9999 -9999 -9999 -9999 -9999 -9999 -9999 -9999 -9999 -9999 -9999 -9999 -9999 -9999 -9999 -9999 -999 -9999 -9999 -9999 -9999 -9999 -9999 -9999 -9999 -9999 -9999 -9999 -9999 -9999 -9999 -9999 -9999 -9999 -9999 -9999 -9999 -9999 -9999 -9999 -9999 -9999 -9999 -9999 -9999 -9999 -9999 -

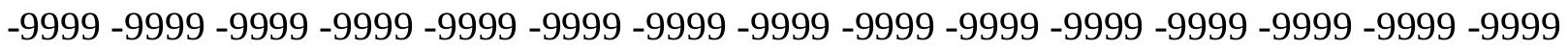

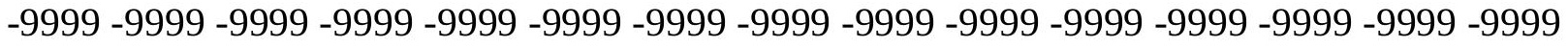

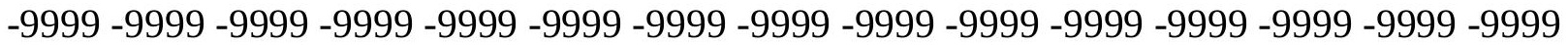

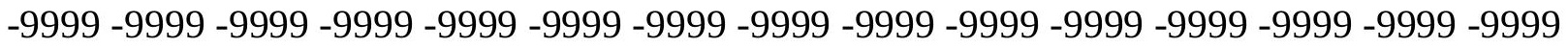

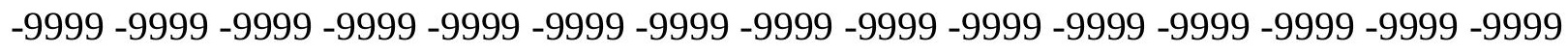

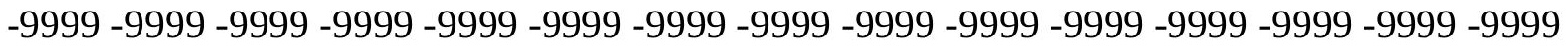
-9999 -9999 -9999 -9999 -9999 -9999 -9999 -9999 -9999 -9999 -9999 -9999 -9999 - 9999 - -999 -9999 -9999 -9999 -9999 -9999 -9999 -9999 -9999 -9999 -9999 -9999 -9999 -9999 -9999 - -999 -

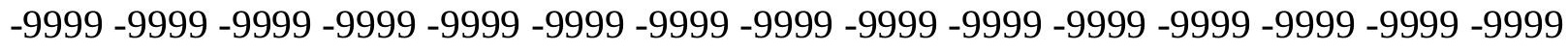

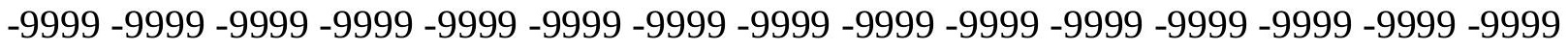
-9999 -9999 -9999 -9999 -9999 -9999 -9999 -9999 -9999 -9999 -9999 -9999 -9999 -9999 -9999 -9999 -9999 -9999 -9999 -9999 -9999 -9999 -9999 -9999-9999 -9999 -9999 -9999 -9999 -9999 -9999 -9999 -9999 -9999 -9999 -9999 -9999 -9999 -9999 -9999 -9999 -9999 -9999 -9999 -9999 -

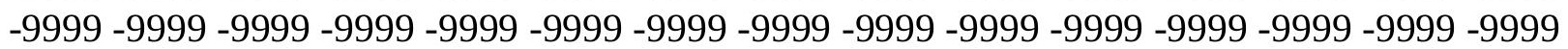


-9999 -9999 -9999 -9999 -9999 -9999 -9999 -9999 -9999 -9999 -9999 -9999 -9999 -9999 -9999 -9999 -9999 -9999 -9999 -9999 -9999 -9999 -9999 -9999 -9999 -9999 -9999 -9999 165.1934967041164 .8887023926164 .5839996338164 .2792053223164 .2792053223 163.974395752163 .6696014404163 .0599975586162 .7552947998162 .4505004883 162.1457061768161 .8408966064161 .5361022949161 .2312927246160 .9264984131 160.6217956543 -9999 -9999 -9999 -9999 -9999 -9999 -9999 -9999 -9999 -9999 -9999 -9999 -9999 -9999 -9999 -9999 -9999 -9999 -9999 -9999 -9999 -9999 -9999 -9999 -9999 -9999 -9999

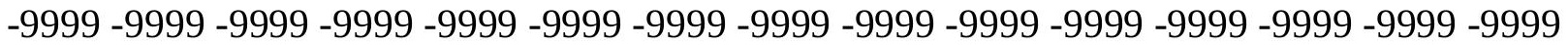
-9999 -9999 -9999 -9999 -9999 -9999 -9999 -9999 -9999 -9999 -9999 -9999 -9999 -9999 -9999 -9999 -9999 -9999 -9999 -9999 -9999 -9999 -9999 -9999 -9999 -9999 -9999 -9999 -9999 -9999 -

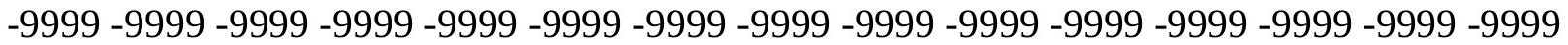
-9999 -9999 -9999 -9999 -9999 -9999 -9999 -9999 -9999 -9999 -9999 -9999 -9999 -9999 -9999

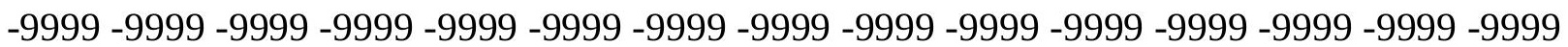
-9999 -9999 -9999 -9999 -9999 -9999 -9999 -9999 -9999 -9999 -9999 -9999 -9999 -9999 -9999 -9999 -9999 -9999 -9999 -9999 -9999 -9999 -9999 -9999 -9999 -9999 -9999 -9999 -9999 -9999 -9999 -9999 -9999 -9999 -9999 -9999 -9999 -9999 -9999 -9999 -9999 -9999 -9999 -9999 -9999 -9999 -9999 -9999 -9999 -9999 -9999 -9999 -9999 -9999 -9999 -9999 -9999 -9999 -9999 -9999 -9999 -9999 -9999 -9999 -9999 -9999 -9999 -9999 -9999 -9999 -9999 -9999 -9999 -9999 -9999 -9999 -9999 -9999 -9999 -9999 -9999 -9999 -9999 -9999 -9999 -9999 -9999 -9999 -9999 -9999 -9999 -9999 -9999 -9999 -9999 -9999 -9999 -9999 -9999 -9999 -9999 -9999 -9999 -9999 -9999

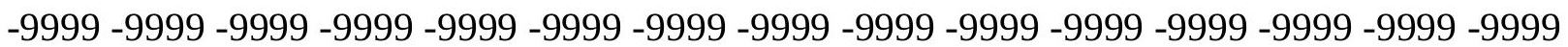

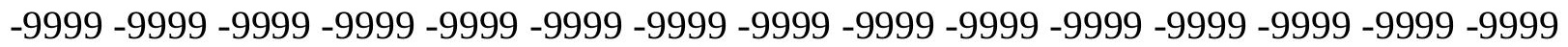
$-9999-9999-9999$

-9999 -9999 -9999 -9999 -9999 -9999 -9999 -9999 -9999 -9999 -9999 -9999 -9999 -9999 -9999

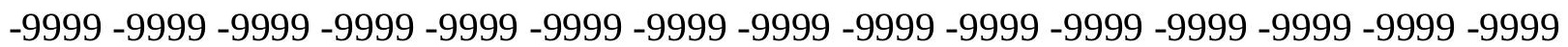
-9999 -9999 -9999 -9999 -9999 -9999 -9999 -9999 -9999 -9999 -9999 -9999 -9999 -9999 -9999 -9999 -9999 -9999 -9999 -9999 -9999 -9999 -9999 -9999 -9999 -9999 -9999 -9999 -9999 -9999 -9999 -9999 -9999 -9999 -9999 -9999 -9999 -9999 -9999 -9999 -9999 -9999 -9999 -9999 -9999 -9999 -9999 -9999 -9999 -9999 -9999 -9999 -9999 -9999 -9999 -9999 -9999 -9999 -9999 -9999

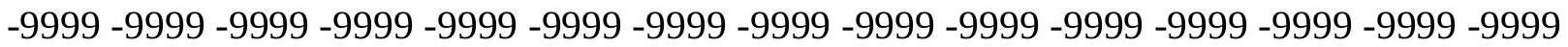
-9999 -9999 -9999 -9999 -9999 -9999-9999 163.0599975586163 .3648071289163 .3648071289 163.3648071289163 .0599975586163 .0599975586162 .7552947998162 .7552947998 162.4505004883162 .1457061768161 .8408966064161 .5361022949161 .2312927246 160.9264984131160 .6217956543160 .3170013428160 .0122070312159 .7073974609 159.4026031494159 .0977935791158 .7929992676158 .4882965088158 .1835021973 157.878692627157 .5738983154157 .2691040039156 .9642944336156 .9642944336 156.6596069336156 .6596069336156 .3547973633156 .3547973633156 .3547973633 156.3547973633 -9999 -9999 -9999 -9999 -9999 -9999 -9999 -9999 -9999 -9999 -9999 -9999 -9999 -9999 -9999 -9999 -9999 -9999 -9999 -9999 -9999 -9999 -9999 -9999 -9999 -9999 -9999 -9999 -9999 -9999 -9999 -9999 -9999 -9999 -9999 -9999 -9999 -9999 -9999 -9999 -9999 -9999 -9999 -9999 -9999 -9999 -9999 -9999 -9999 -9999 -9999 -9999 -9999 -9999 -9999 -9999 -9999

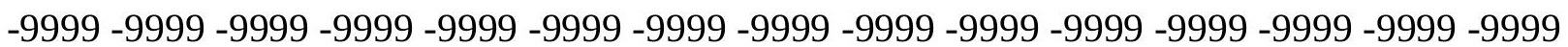
-9999 -9999 -9999 -9999 -9999 -9999 -9999 -9999 -9999 -9999 -9999 -9999 -9999 -9999 -9999 -9999 -9999 -9999 -9999 -9999 -9999 -9999 -9999 -9999 -9999 -9999 -9999 -9999 -9999 -9999 -9999 -9999 -9999 -9999 -9999 -9999 -9999 -9999 -9999 -9999 -9999 -9999 -9999 -9999 -9999

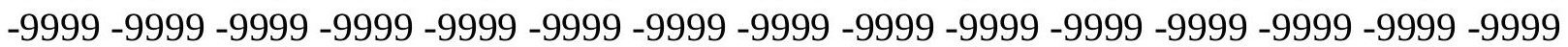


-9999 -9999 -9999 -9999 -9999 -9999 -9999 -9999 -9999 -9999 -9999 -9999 -9999 -9999 -9999 -9999 -9999 -9999 -9999 -9999 -9999 -9999 -9999 -9999 -9999 -9999 -9999 -9999 -9999 -9999 -

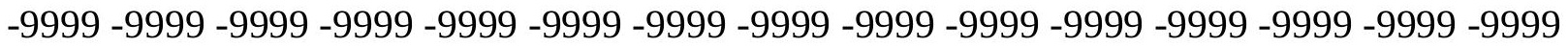
-9999 -9999 -9999 -9999 -9999 -9999 -9999 -9999 -9999 -9999 -9999 -9999 -9999 -9999 -9999 -9999 -9999 -9999 -9999 -9999 -9999 -9999 -9999 -9999-9999 -9999 -9999 -9999 -9999 -9999 -9999 -9999 -9999 -9999 -9999 -9999 -9999 -9999 -9999 -9999 -9999 -9999 -9999 -9999 -9999 -

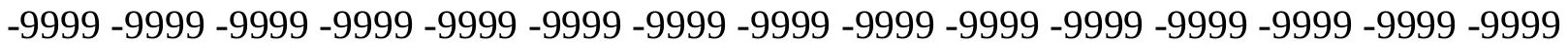
-9999 -9999 -9999-9999-9999-9999

-9999 -9999 -9999 -9999 -9999 -9999 -9999 -9999 -9999 -9999 -9999 -9999 -9999 -9999 -9999 -9999 -9999 -9999 -9999 -9999 -9999 -9999 -9999 -9999 -9999 -9999 -9999 -9999 -9999 -9999 -9999 -9999 -9999 -9999 -9999 -9999 -9999 -9999 -9999 -9999 -9999 -9999 -9999 -9999 -9999 -9999 -9999 -9999 -9999 -9999 -9999 -9999 -9999 -9999 -9999 -9999 -9999 -9999 -9999 -9999 -9999 -9999 -9999 -9999 -9999 -9999 -9999 -9999 -9999 -9999 -9999 -9999 -9999 -9999 -9999 -

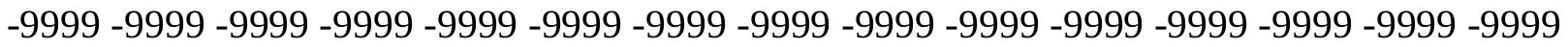
-9999 -9999 -9999 -9999 -9999 -9999 -9999 -9999 -9999 -9999 -9999 -9999 -9999 -9999 -9999 -9999 -9999 160.0122070312160.3170013428 160.6217956543160.6217956543 160.9264984131160 .9264984131160 .9264984131160 .9264984131160 .9264984131 160.9264984131160 .9264984131160 .9264984131160 .9264984131160 .9264984131 160.6217956543160 .6217956543160 .3170013428160 .0122070312159 .7073974609 159.4026031494159 .0977935791158 .7929992676158 .1835021973157 .878692627 157.2691040039156 .9642944336156 .6596069336156 .0500030518155 .7451934814 155.1356048584155 .1356048584154 .8307952881154 .5260925293154 .5260925293 154.2212982178154 .2212982178154 .2212982178153 .9165039062153 .9165039062 153.9165039062153 .9165039062153 .9165039062153 .9165039062153 .9165039062 153.9165039062154 .2212982178154 .2212982178154 .2212982178154 .2212982178 154.2212982178 153.9165039062153 .9165039062 -9999 -9999 -9999 -9999 -9999 -9999 -9999 -9999 -9999 -9999 -9999 -9999 -9999 -9999 -9999 -9999 -9999 -9999 -9999 -9999 -9999 -9999

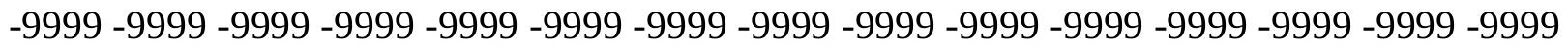
-9999 -9999 -9999 -9999 -9999 -9999 -9999 -9999 -9999 -9999 -9999 -9999 -9999 -9999 -9999 -9999 -9999 -9999 -9999 -9999 -9999 -9999 -9999 -9999 -9999 -9999 -9999 -9999 -9999 -999 -9999 -9999 -9999 -9999 -9999 -9999 -9999 -9999 -9999 -9999 -9999 -9999 -9999 -9999 -9999

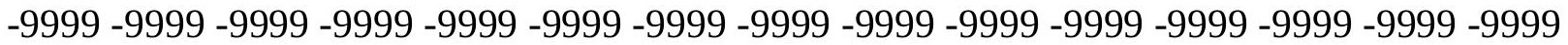
-9999 -9999 -9999 -9999 -9999 -9999 -9999 -9999 -9999-9999 -9999 -9999 -9999-9999-999 - -999 -

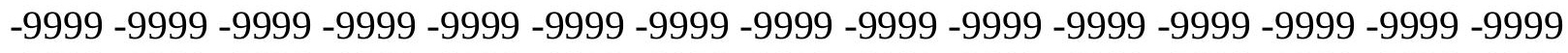
-9999 -9999 -9999 -9999 -9999 -9999 -9999 -9999 -9999 -9999 -9999 -9999 -9999 -9999 -9999 -9999 -9999 -9999 -9999 -9999 -9999 -9999 -9999 -9999 -9999 -9999 -9999 -9999 -9999 -9999

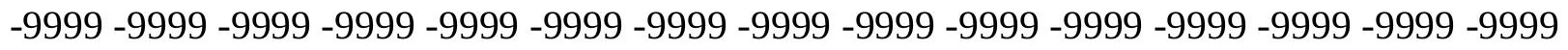

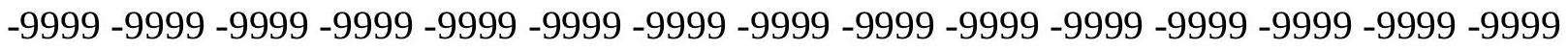
-9999 -9999 -9999 -9999 -9999 -9999 -9999 -9999 -9999 -9999 -9999 -9999 -9999 - 9999 - -999 -9999 -9999 -9999 -9999 -9999 -9999 -9999 -9999 -9999 -9999 -9999 -9999 -9999 -9999 -9999 -

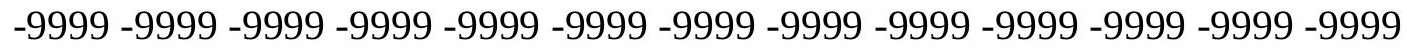

-9999 -9999 -9999 -9999 -9999 -9999 -9999 -9999 -9999 -9999 -9999 -9999 -9999 - -9999 -9999 -9999 -9999 -9999 -9999 -9999 -9999 -9999 -9999 -9999 -9999 -9999 -9999 -9999 -9999 -9999 -9999 -9999 -9999 -9999 -9999 -9999 -9999 -9999 -9999 -9999 -9999 -9999 -9999 -9999 -9999 -9999 -9999 -9999 -9999 -9999 -9999 -9999 -9999 -9999 -9999 -9999 -9999 -9999 -9999 -9999 -

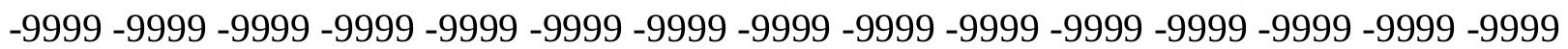


-9999 -9999 -9999 -9999 -9999 -9999 -9999 -9999 -9999 -9999 -9999 -9999 -9999 -9999 -9999 -9999 -9999 -9999 -9999 -9999 -9999 -9999 -9999 -9999 -9999 -9999 -9999 155.7451934814 156.0500030518156 .6596069336156 .9642944336157 .5738983154157 .878692627 158.1835021973158 .4882965088158 .4882965088158 .7929992676158 .7929992676 159.0977935791159 .4026031494159 .7073974609159 .7073974609159 .7073974609 159.7073974609159 .7073974609159 .7073974609159 .4026031494159 .4026031494 159.0977935791159 .0977935791158 .7929992676158 .4882965088157 .878692627 157.5738983154157 .2691040039156 .6596069336156 .3547973633156 .0500030518 155.4403991699155 .1356048584154 .5260925293154 .2212982178153 .6116943359 153.3069000244153 .0021057129152 .3925933838152 .0877990723151 .7830047607 151.7830047607151 .7830047607151 .7830047607151 .4781951904151 .4781951904 151.4781951904151 .4781951904151 .4781951904151 .7830047607151 .7830047607 151.7830047607151 .7830047607151 .4781951904151 .4781951904151 .4781951904 151.4781951904151 .1734008789151 .1734008789150 .8686065674150 .5639038086 150.2590942383149 .9542999268149 .6495056152149 .3446960449148 .7351074219 148.1255950928147 .8208007812147 .2111968994146 .6015930176145 .6873016357 145.0776977539144 .1634063721143 .5538024902142 .6394042969141 .7250976562 140.8106994629140 .2012023926139 .2868041992138 .3724975586137 .4580993652 136.5437011719135 .6293945312134 .7149963379133 .8007049561132 .8863067627 131.9720001221131 .3623962402130 .7528076172130 .1432037354 -9999 -9999 -9999-9999 -9999 -9999 -9999 -9999 -9999 -9999 -9999 -9999 -9999 -9999 -9999 -9999 -9999 -9999 -9999 -9999 -9999 -9999 -9999 -9999 -9999 -9999 -9999 -9999 -9999 -9999 -9999 -9999 -9999 -9999 -9999 -9999 -9999 -9999 -9999 -9999 -9999 -9999 -9999 -9999 -9999 -9999 -9999 -9999 -9999 -9999 -9999 -9999 -9999 -9999 -9999 -9999 -9999 -9999 -9999 -9999 -9999 -9999 -9999 -9999 -9999 -9999 -9999 -9999 -9999 -9999 -9999 -9999 -9999 -9999 -9999 -9999 -9999 -9999 -9999 -9999 -9999 -9999 -9999 -9999 -9999 -9999 -9999 -9999 -9999 -9999 -9999 -9999 -9999 -9999 -9999 -9999 -9999 -9999 -9999 -9999 -9999 -9999 -9999 -9999 -9999 -9999 -9999 -9999 -9999 -9999 -9999 -9999 -9999 -9999 -9999 -9999 -9999 -9999 -9999 -9999 -9999 -9999 -9999 -9999 -9999 -9999 -9999 -9999 -9999 -9999 -9999 -9999 -9999 -9999 -9999 -9999 -9999 -9999 -9999 -9999 -9999 -9999 -9999 -9999 -9999 -9999 -9999 -9999 -9999 -9999 -9999 -9999 -9999 -9999 -9999 -9999 -9999 -9999 -9999 -9999 -9999 -9999 -9999 -9999 -9999 -9999 -9999 -9999 -9999 -9999 -9999 -9999 -9999 -9999 -9999 -9999 -9999 -9999 -9999 -9999 -9999 -9999 -9999 -9999 -9999 -9999 -9999 -9999 -9999 -9999 -9999 -9999 -9999 -9999 -9999 -9999 -9999 -9999 -9999 -9999 -9999 -9999 -9999 -9999 -9999 -9999 -9999 -9999 -9999 -9999 -9999 -9999 -9999 -9999 -9999 -9999 -9999 -9999 -9999 -9999 -9999 -9999 -9999 -9999 -9999 -9999 -9999 -9999 -9999 -9999 -9999 -9999 -9999 -9999 -9999 -9999 -9999 -9999 -9999 -9999 -9999 -9999

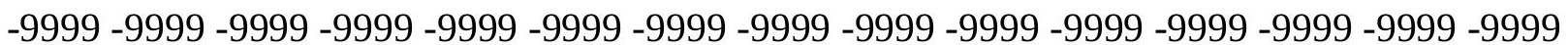

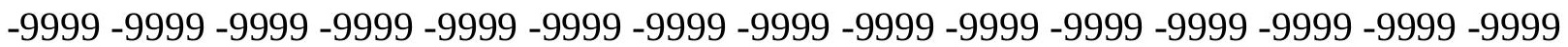
-9999 -9999 -9999 -9999 -9999 -9999 -9999 -9999 -9999 -9999 -9999 -9999 -9999 -9999 -9999 -9999 -9999 -9999 -9999 -9999 -9999 -9999 150.2590942383 150.8686065674151 .7830047607 152.3925933838153 .0021057129153 .6116943359154 .2212982178154 .5260925293 154.8307952881155 .4403991699155 .7451934814156 .0500030518156 .6596069336 156.9642944336157 .2691040039157 .5738983154157 .878692627158 .1835021973 158.4882965088158 .4882965088158 .7929992676158 .4882965088158 .4882965088 158.4882965088158 .4882965088158 .1835021973157 .878692627157 .878692627 157.5738983154157 .2691040039156 .9642944336156 .6596069336156 .0500030518 
155.7451934814155 .1356048584154 .8307952881154 .5260925293153 .9165039062 153.6116943359153 .0021057129152 .6972961426152 .3925933838151 .7830047607 151.4781951904151 .1734008789150 .8686065674150 .5639038086150 .2590942383 149.9542999268149 .6495056152149 .6495056152149 .6495056152149 .6495056152 149.6495056152149 .6495056152149 .6495056152149 .6495056152149 .6495056152 149.3446960449149 .3446960449149 .3446960449149 .0399017334149 .0399017334 148.7351074219148 .4304046631148 .1255950928147 .8208007812147 .5160064697 147.2111968994146 .6015930176147 .8208007812145 .6873016357145 .0776977539 144.4682006836143 .8585968018143 .2489929199142 .6394042969141 .7250976562 140.8106994629140 .2012023926139 .2868041992138 .3724975586137 .4580993652 136.5437011719135 .6293945312134 .7149963379133 .8007049561132 .8863067627 131.9720001221131 .0576019287130 .1432037354129 .533706665128 .6192932129 128.0097961426127 .4001998901126 .7906036377126 .1809997559125 .8762969971 125.5715026855125 .5715026855125 .2667007446125 .2667007446125 .5715026855 125.8762969971 126.1809997559 -9999 -9999 -9999 -9999 -9999 -9999 -9999 -9999 -9999 -9999 -9999 -9999 -9999 -9999 -9999 -9999 -9999 -9999-9999 -9999 -9999 -9999 -9999 -9999 -9999 -9999 -9999 -9999 -9999 -9999 -9999 -9999 -9999 -9999 -9999 -9999 -9999 -9999 -9999 -9999 -9999 -9999 -9999 -9999 -9999 -9999 -9999 -9999 -9999 -9999 -9999 -9999 -9999 -9999 -

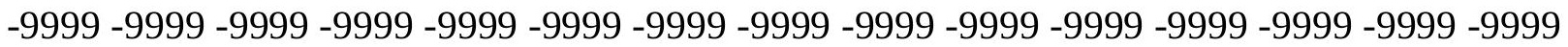

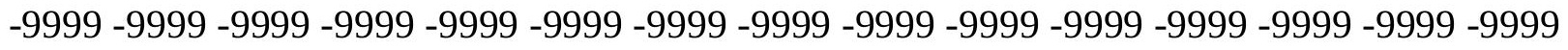

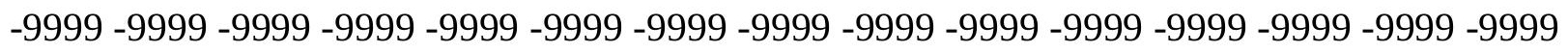

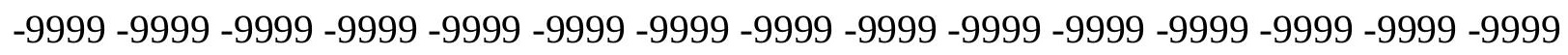
-9999 -9999 -9999 -9999 -9999 -9999 -9999 -9999 -9999 -9999 -9999 -9999 -9999 -9999 -9999 -

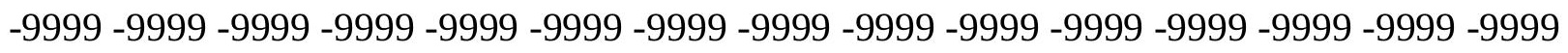

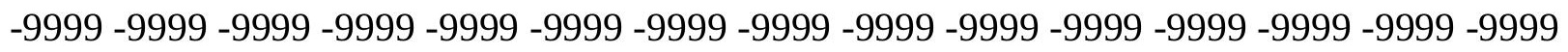

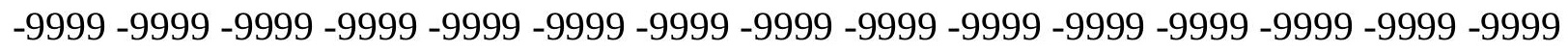
-9999 -9999 -9999 -9999 -9999 -9999 -9999 -9999 -9999 -9999 -9999 -9999 - 9999 -

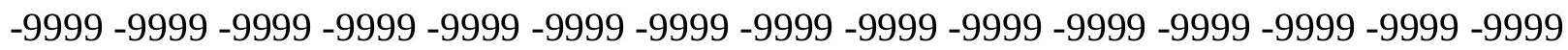

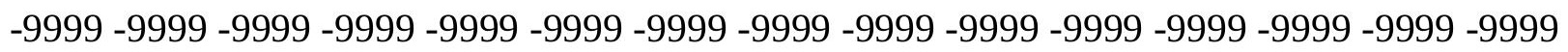

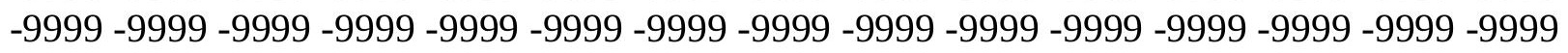
-9999 -9999 -9999 -9999 -9999 -9999 -9999 -9999 -9999 -9999 -9999 -9999 -9999 -9999 -9999

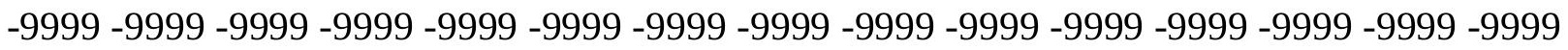

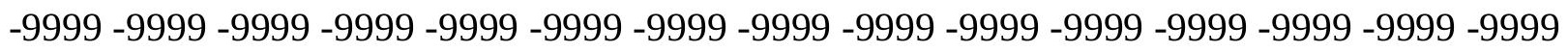
-9999 142.6394042969 143.5538024902 144.7729034424145.6873016357 146.6015930176 147.5160064697148 .1255950928149 .0399017334149 .6495056152150 .2590942383 150.8686065674151 .4781951904152 .0877990723152 .6972961426153 .3069000244 153.9165039062154 .5260925293154 .8307952881155 .4403991699155 .7451934814 156.0500030518156 .3547973633156 .6596069336156 .9642944336157 .2691040039 157.2691040039 157.2691040039157.5738983154 157.2691040039 157.2691040039 157.2691040039156 .9642944336156 .9642944336156 .6596069336156 .3547973633 156.0500030518155 .7451934814155 .4403991699155 .1356048584154 .5260925293 154.2212982178153 .9165039062153 .3069000244153 .0021057129152 .3925933838 152.0877990723151 .7830047607151 .1734008789150 .8686065674150 .5639038086 150.2590942383149 .9542999268149 .6495056152149 .3446960449149 .0399017334 149.0399017334148 .7351074219148 .7351074219148 .7351074219148 .7351074219 148.7351074219148 .4304046631148 .4304046631148 .4304046631148 .4304046631 
148.4304046631148 .1255950928148 .1255950928147 .8208007812147 .5160064697 147.5160064697147 .2111968994146 .7146453857146 .1815032959145 .8120880127 145.6873016357145 .0776977539144 .4682006836143 .8585968018143 .2489929199 142.6394042969142 .0299072266141 .1154937744140 .2012023926139 .5915985107 138.6772003174137 .7628936768136 .8484954834135 .9342041016135 .0198059082 134.1054992676132 .8863067627131 .9720001221131 .0576019287130 .1432037354 129.2288970947128 .3144989014127 .7050018311126 .7906036377126 .1809997559 125.5715026855124 .9618988037124 .3523025513124 .0475006104123 .43800354 123.1332015991123 .1332015991123 .1332015991123 .1332015991123 .43800354 123.7427978516124 .0475006104124 .6570968628125 .2667007446 -9999 -9999-9999 -9999 -9999 -9999 -9999 -9999 -9999 -9999 -9999 -9999 -9999 -9999 -9999 -9999 -9999 -9999 -9999 -9999 -9999 -9999 -9999 -9999 -9999 -9999 -9999 -9999 -9999 -9999 -9999 -9999 -9999 -9999 -9999 -9999 -9999 -9999 -9999 -9999 -9999 -9999 -9999 -9999 -9999 -9999 -9999 -9999 -9999 -9999 -9999 -9999 -9999 -9999 -9999 -9999 -9999 -9999 -9999 -9999 -9999 -9999 -9999 -9999 -9999 -9999 -9999 -9999 -9999 -9999 -9999 -9999 -9999 -9999 -9999 -9999 -9999 -9999 -9999

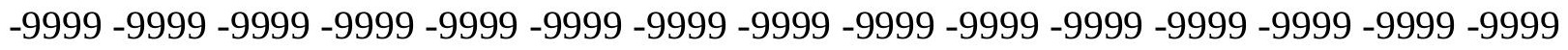
-9999 -9999 -9999 -9999 -9999 -9999 -9999 -9999 -9999 -9999 -9999 -9999 -9999 -9999 -9999 -9999 -9999 -9999 -9999 -9999 -9999 -9999 -9999 -9999 -9999 -9999 -9999 -9999 -9999 -9999 -

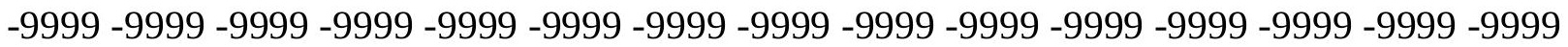

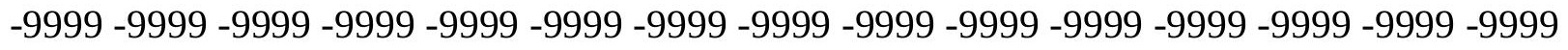
-9999 -9999 -9999 -9999 -9999 -9999 -9999 -9999 -9999 -9999 -9999 -9999 -9999 -9999 -9999

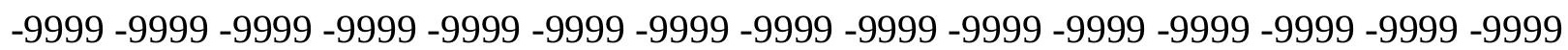
-9999 -9999 -9999 -9999 -9999 -9999 -9999 -9999 -9999 -9999 -9999 -9999 -9999 -9999 -9999 -9999 -9999 -9999 -9999 -9999 -9999 -9999 -9999 -9999 -9999 -9999 -9999 -9999 -9999 -9999 -9999 -9999 -9999 -9999 -9999 -9999 -9999 -9999 -9999 -9999 -9999 -9999 -9999 -9999 -9999 -9999 -9999 -9999 -9999 -9999 -9999 -9999 -9999 -9999 -9999 -9999 -9999 -9999 -9999 -9999 -9999 -9999 -9999 -9999 -9999 -9999 -9999 -9999 -9999 -9999 -9999 -9999 -9999 -9999 - 9999 -9999 -9999-9999 -9999-9999 -9999 -9999 -9999 -9999-9999 -9999-9999 136.2389984131 137.4580993652138 .6772003174139 .5915985107140 .8106994629141 .7250976562 142.9441986084143 .8585968018144 .7729034424145 .3825073242146 .2969055176 147.2111968994148 .1255950928148 .7351074219149 .3446960449150 .2590942383 150.8686065674151 .4781951904152 .0877990723152 .6972961426153 .0021057129 153.6116943359153 .9165039062154 .5260925293154 .8307952881155 .1356048584 155.4403991699155 .7451934814156 .0500030518156 .0500030518156 .0500030518 156.3547973633156 .0500030518156 .0500030518156 .0500030518155 .7451934814 155.7451934814155 .4403991699155 .1356048584154 .8307952881154 .5260925293 154.2212982178153 .9165039062153 .6116943359153 .3069000244152 .6972961426 152.3925933838152 .0877990723151 .4781951904151 .1734008789150 .8686065674 150.2590942383149 .9542999268149 .6495056152149 .3446960449149 .0399017334 148.7351074219148 .4304046631148 .4304046631148 .1255950928147 .8208007812 147.8208007812147 .8208007812147 .8208007812147 .5160064697147 .5160064697 147.5160064697147 .5160064697147 .5160064697147 .2111968994147 .2111968994 146.9064025879146 .9064025879146 .6015930176146 .2969055176145 .8193206787 145.244934082144 .8262329102144 .5823059082144 .4682006836143 .8585968018 143.2489929199142 .6394042969142 .0299072266141 .4203033447140 .5059967041 139.8963928223138 .9819946289138 .0677032471137 .1533050537136 .2389984131 
135.3246002197134 .4102020264133 .4958953857132 .5814971924131 .6672058105 130.4479980469129 .533706665128 .6192932129127 .7050018311126 .7906036377 126.1809997559125 .2667007446124 .6570968628124 .0475006104123 .43800354 122.8283996582122 .5235977173121 .9140014648121 .9140014648121 .6092987061 121.6092987061121 .6092987061121 .9140014648121 .9140014648121 .9140014648 122.5235977173123 .1332015991123 .7427978516124 .3523025513 -9999 -9999 -9999-9999 -9999 -9999 -9999 -9999 -9999 -9999 -9999 -9999 -9999 -9999 -9999 -9999 -9999 -9999 -9999

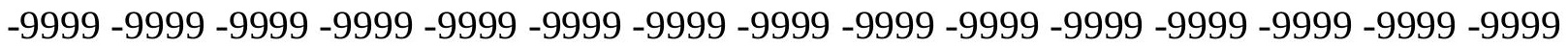

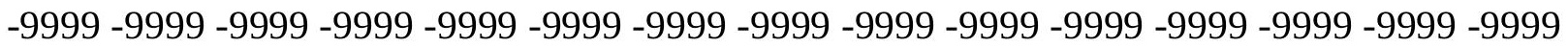
-9999 -9999 -9999 -9999 -9999 -9999 -9999 -9999 -9999 -9999 -9999 -9999 -9999 -9999 -9999 -

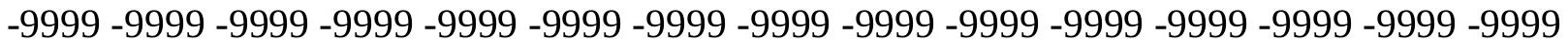
-9999 -9999 -9999 -9999 -9999 -9999 -9999 -9999 -9999 -9999 -9999 -9999 -9999 -9999 -9999 -9999 -9999 -9999 -9999 -9999 -9999 -9999 -9999 -9999 -9999 -9999 -9999 -9999 -9999 -9999 -9999 -9999 -9999 -9999 -9999 -9999 -9999 -9999 -9999 -9999 -9999 -9999 -9999 -9999 -9999 -9999 -9999 -9999 -9999 -9999 -9999 -9999 -9999 -9999 -9999 -9999 -9999 -9999 -9999 -9999 -9999 -9999 -9999 -9999 -9999 -9999 -9999 -9999 -9999 -9999 -9999 -9999 -9999 -9999 -9999

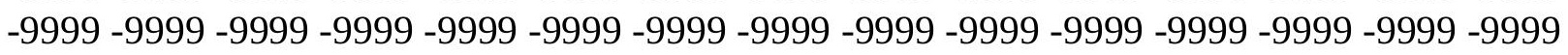
-9999 -9999 -9999 -9999 -9999 -9999 -9999 -9999 -9999 -9999 -9999 -9999 -9999 -9999 -9999 -9999 -9999 -9999 -9999 -9999 -9999 -9999 -9999 -9999 -9999 -9999 -9999 -9999 -9999 -9999 -9999 -9999 -9999 -9999 -9999 -9999 -9999 -9999 -9999 -9999 -9999 -9999 -9999 -9999 -9999 -9999 -9999 -9999 -9999 -9999 -9999 -9999 -9999 -9999 -9999 -9999 -9999 -9999 -9999 -9999 -9999 -9999 -9999 -9999 -9999 -9999 -9999 -9999 -9999 -9999 -9999 -9999 -9999 -9999 -9999 -9999 -9999 -9999 -9999 -9999 -9999 -9999 -9999 -9999 -9999 -9999 -9999 -9999 -9999 -9999 -9999 -9999 -9999 -9999 -9999 -9999 129.533706665130 .7528076172 131.9720001221133 .4958953857134 .7149963379135 .6293945312136 .8484954834 138.0677032471138 .9819946289140 .2012023926141 .1154937744142 .3347015381 143.2489929199144 .1634063721145 .0776977539145 .6873016357146 .6015930176 147.5160064697148 .1255950928148 .7351074219149 .3446960449150 .2590942383 150.5639038086151 .1734008789151 .7830047607152 .3925933838152 .6972961426 153.3069000244153 .6116943359153 .9165039062154 .2212982178154 .5260925293 154.5260925293154 .8307952881154 .8307952881154 .8307952881154 .8307952881 154.8307952881154 .8307952881154 .8307952881154 .5260925293154 .2212982178 154.2212982178153 .9165039062153 .6116943359153 .3069000244153 .0021057129 152.6972961426152 .0877990723151 .7830047607151 .4781951904151 .1734008789 150.5639038086150 .2590942383149 .9542999268149 .6495056152149 .0399017334 148.7351074219148 .4304046631148 .1255950928147 .8208007812147 .8208007812 147.5160064697147 .2111968994147 .2111968994146 .9064025879146 .9064025879 146.9064025879146 .6015930176146 .6015930176146 .6015930176146 .6015930176 146.2969055176146 .2969055176145 .9920959473145 .9920959473145 .6873016357 145.3825073242145 .0776977539144 .4481964111143 .9285888672143 .556854248 143.3076324463143 .0462493896142 .6394042969142 .0299072266141 .4203033447 140.8106994629140 .2012023926139 .2868041992138 .3724975586137 .7628936768 136.8484954834135 .9342041016135 .0198059082134 .1054992676132 .8863067627 131.9720001221131 .0576019287130 .1432037354128 .9241027832128 .0097961426 127.0953979492126 .1809997559125 .2667007446124 .3523025513123 .7427978516 122.8283996582122 .2188034058121 .6092987061121 .3044967651120 .6949005127 
120.3900985718120 .0852966309120 .0852966309120 .0852966309120 .3900985718 120.3900985718120 .6949005127120 .6949005127120 .9997024536122 .5235977173 121.6092987061122 .5235977173123 .1332015991123 .7427978516 -9999-9999 -9999 -9999 -9999 -9999 -9999 -9999 -9999 -9999 -9999 -9999 -9999 -9999 -9999 -9999 -9999 -9999 -9999 -

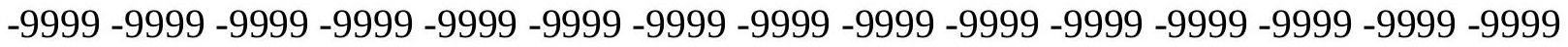

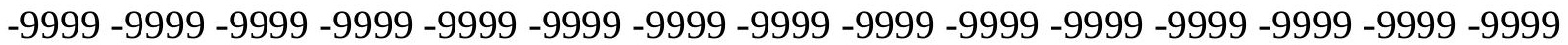

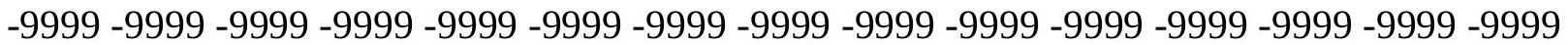

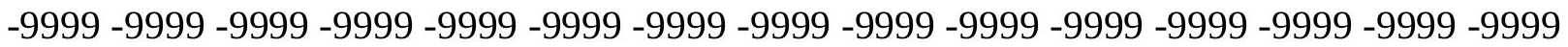

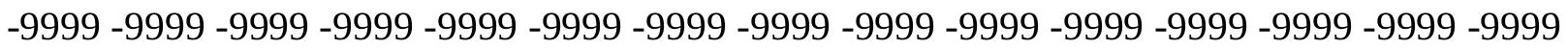

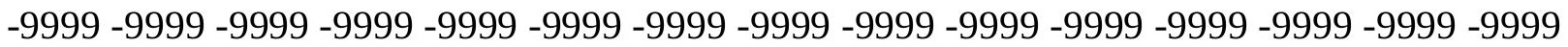

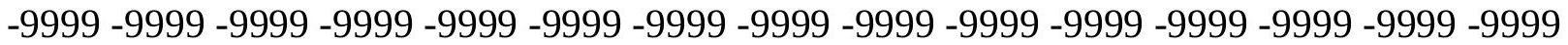

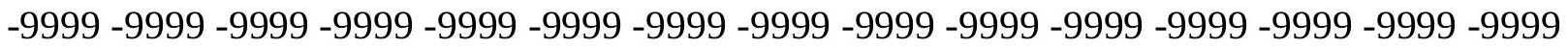

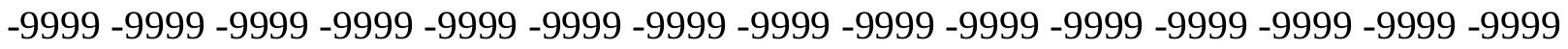

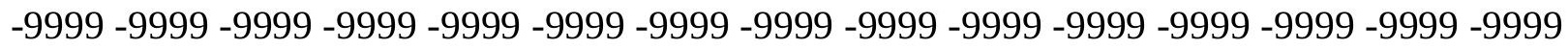

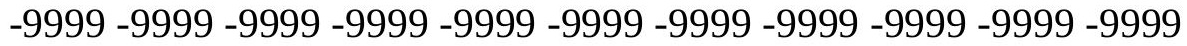

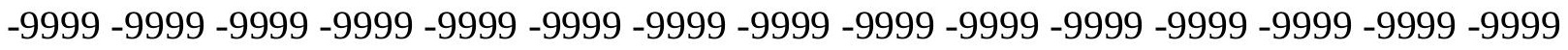

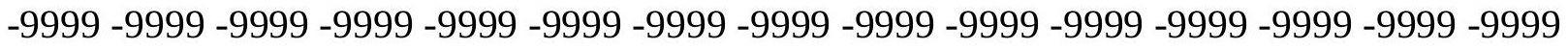

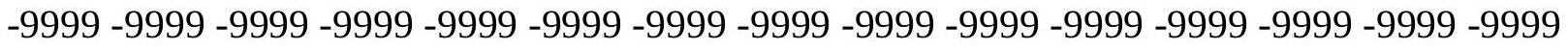

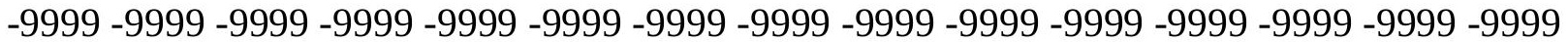

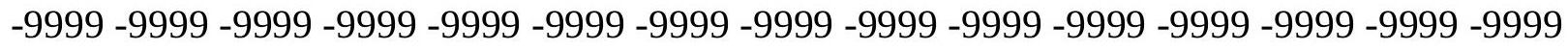
-9999 -9999 -9999 -9999 122.5235977173 123.7427978516125 .2667007446126 .4858016968 128.0097961426129 .2288970947130 .4479980469131 .6672058105132 .8863067627 134.1054992676135 .3246002197136 .5437011719137 .7628936768138 .6772003174 139.8963928223140 .8106994629141 .7250976562142 .6394042969143 .5538024902 144.4682006836145 .0776977539145 .9920959473146 .6015930176147 .5160064697 148.1255950928148 .7351074219149 .3446960449149 .9542999268150 .5639038086 150.8686065674151 .4781951904151 .7830047607152 .3925933838152 .6972961426 153.0021057129153 .3069000244153 .3069000244153 .6116943359153 .6116943359 153.6116943359153 .6116943359153 .6116943359153 .6116943359153 .6116943359 153.3069000244153 .3069000244153 .0021057129152 .6972961426152 .3925933838 152.0877990723151 .7830047607151 .4781951904151 .1734008789150 .8686065674 150.5639038086150 .2590942383149 .6495056152149 .3446960449149 .0399017334 148.7351074219148 .4304046631148 .1255950928147 .8208007812147 .5160064697 147.2111968994146 .9064025879146 .6015930176146 .6015930176146 .2969055176 145.9920959473145 .9920959473145 .9920959473145 .6873016357145 .6873016357 145.6873016357145 .3825073242145 .3825073242145 .0776977539145 .0776977539 144.7729034424144 .4682006836144 .4682006836143 .8022003174143 .1836547852 142.6857910156142 .3024139404141 .9989318848141 .67918396141 .2947845459 140.8106994629140 .2012023926139 .5915985107138 .6772003174138 .0677032471 137.1533050537136 .2389984131135 .3246002197134 .4102020264133 .4958953857 132.5814971924131 .6672058105130 .4479980469129 .533706665128 .6192932129 127.4001998901126 .4858016968125 .5715026855124 .6570968628123 .7427978516 122.8283996582121 .9140014648121 .3044967651120 .6949005127120 .0852966309 119.4757995605119 .1709976196118 .8662033081118 .5614013672118 .5614013672 118.5614013672118 .8250808716118 .8662033081119 .1709976196119 .4757995605 119.7806015015120 .0852966309120 .3900985718120 .6949005127121 .3044967651 
122.2188034058122 .8283996582123 .43800354 -9999 -9999 -9999 -9999 -9999 -9999 -9999 -9999 -9999 -9999 -9999 -9999 -9999 -9999 -9999 -9999 -9999 -9999 -9999 -9999 -9999 -9999

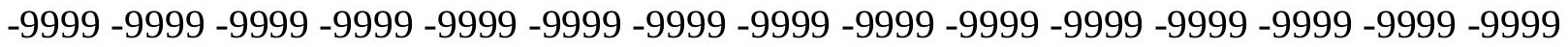
-9999 -9999 -9999 -9999 -9999 -9999 -9999 -9999 -9999 -9999 -9999 -9999 -9999 -9999 -9999 -9999 -9999 -9999 -9999 -9999 -9999 -9999 -9999 -9999-9999 -9999 -9999 -9999 -9999 -9999 -9999 -9999 -9999 -9999 -9999 -9999 -9999 -9999 -9999 -9999 -9999 -9999 -9999 -9999 -9999

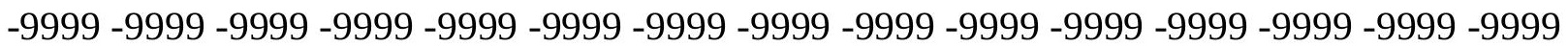

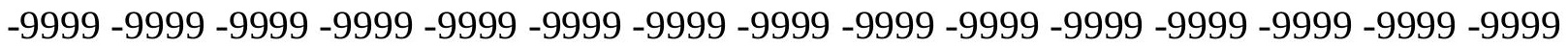

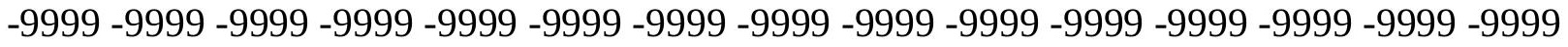
-9999 -9999 -9999 -9999 -9999 -9999 -9999 -9999 -9999 -9999 -9999 -9999 -9999 -9999 -9999 -9999 -9999 -9999 -9999 -9999 -9999 -9999 -9999 -9999 -9999 -9999 -9999 -9999 -9999 -9999 -9999 -9999 -9999 -9999 -9999 -9999 -9999 -9999 -9999 -9999 -9999 -9999 -9999 -9999 -9999 -999 -9999 -9999 -9999-9999-9999-9999

-9999 -9999 -9999 -9999 -9999 -9999 -9999 -9999 -9999 -9999 -9999 -9999 -9999 -9999 -9999 -9999 -9999 -9999 -9999 -9999 -9999 -9999 -9999 -9999 -9999 -9999 -9999 -9999 -9999 -9999

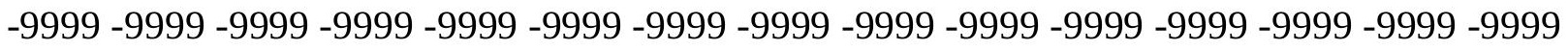
-9999 -9999 -9999 -9999 -9999 -9999 -9999 -9999 -9999 -9999 -9999 -9999 -9999 -9999 -9999 -9999 -9999 -9999 -9999 -9999 -9999 -9999 -9999 -9999 -9999 -9999 -9999 -9999 -9999 -9999 114.9039993286116 .4279022217117 .9517974854119 .4757995605120 .9997024536 122.2188034058 123.7427978516124.9618988037126.4858016968 127.7050018311 128.9241027832130 .1432037354131 .3623962402132 .5814971924133 .8007049561 135.0198059082136 .2389984131137 .1533050537138 .3724975586139 .2868041992 140.2012023926141 .1154937744142 .0299072266142 .9441986084143 .8585968018 144.4682006836145 .3825073242145 .9920959473146 .6015930176147 .2111968994 147.8208007812148 .4304046631149 .0399017334149 .6495056152149 .9542999268 150.5639038086150 .8686065674151 .1734008789151 .4781951904151 .7830047607 152.0877990723152 .3925933838152 .3925933838152 .3925933838152 .3925933838 152.3925933838152 .3925933838152 .3925933838152 .3925933838152 .0877990723 151.7830047607151 .7830047607151 .4781951904151 .1734008789150 .8686065674 150.5639038086150 .2590942383149 .9542999268149 .6495056152149 .3446960449 148.7351074219148 .4304046631148 .1255950928147 .8208007812147 .5160064697 147.2111968994146 .9064025879146 .6015930176146 .2969055176145 .9920959473 145.9920959473145 .6873016357145 .3825073242145 .3825073242145 .0776977539 145.0776977539144 .7729034424144 .7729034424144 .7729034424144 .4682006836 144.4682006836144 .1634063721143 .8585968018143 .8585968018143 .5538024902 143.2489929199142 .5837097168141 .9832458496141 .4828643799141 .0656433105 140.7046661377140 .3398590088139 .9267730713139 .428527832138 .8056945801 138.0677032471137 .4580993652136 .5437011719135 .9342041016135 .0198059082 134.1054992676133 .1911010742132 .2767028809131 .0576019287130 .1432037354 129.2288970947128 .0097961426127 .0953979492126 .1809997559124 .9618988037 124.0475006104123 .1332015991122 .2188034058121 .3044967651120 .3900985718 119.4757995605118 .8662033081118 .2565994263117 .647102356117 .342300415 117.0374984741117 .0374984741117 .0374984741117 .0374984741117 .342300415 117.6090240479117 .8636322021118 .1997909546118 .5614013672118 .8662033081 119.1709976196119 .4757995605120 .0852966309120 .3900985718120 .9997024536 121.9140014648 122.5235977173 123.1332015991 -9999 -9999 -9999 -9999 -9999 -9999 -9999 
-9999 -9999 -9999 -9999 -9999 -9999 -9999 -9999 -9999 -9999 -9999 -9999 -9999 -9999 -9999 -9999 -9999 -9999 -9999 -9999 -9999 -9999 -9999 -9999 -9999 -9999 -9999 -9999 -9999 -9999

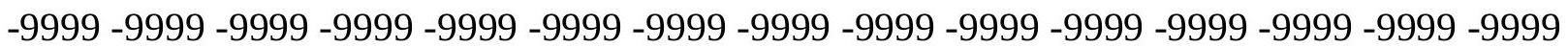
-9999 -9999 -9999 -9999 -9999 -9999 -9999 -9999 -9999 -9999 -9999 -9999 -9999 -9999 -9999 -9999 -9999 -9999 -9999 -9999 -9999 -9999 -9999 -9999 -9999 -9999 -9999 -9999 -9999 -9999 -9999 -9999 -9999 -9999 -9999 -9999 -9999 -9999 -9999 -9999 -9999 -9999 -9999 -9999 -9999 -9999 -9999 -9999 -9999 -9999 -9999 -9999 -9999 -9999 -9999 -9999 -9999 -9999 -9999 -9999

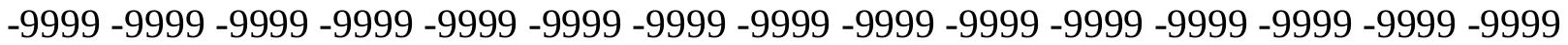
-9999 -9999 -9999 -9999 -9999 -9999 -9999 -9999 -9999 -9999 -9999 -9999 -9999 -9999 -9999 -9999 -9999 -9999 -9999 -9999 -9999 -9999 -9999 -9999 -9999 -9999 -9999 -9999 -9999 -9999 -

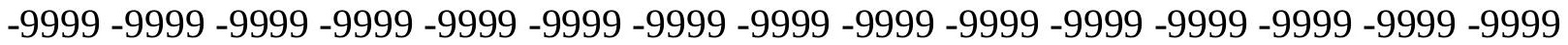
-9999 -9999-9999-9999

-9999 -9999 -9999 -9999 -9999 -9999 -9999 -9999 -9999 -9999 -9999 -9999 -9999 -9999 -9999 -9999 -9999 -9999 -9999 -9999 -9999 -9999 -9999 -9999 -9999 -9999 -9999 -9999 -9999 -9999 -9999 -9999 -9999 -9999 -9999 -9999 -9999 -9999 -9999 -9999 -9999 -9999 -9999 -9999 -9999 -9999 -9999 -9999 -9999 -9999 -9999 -9999 -9999 -9999 -9999 -9999 -9999 -9999 -9999 -9999 -9999 -9999 -9999 -9999 -9999 -9999-9999 -9999 -9999-9999 -9999 107.2844009399 109.1130981445110 .6370010376112 .1608963013113 .6848983765115 .2088012695 116.7326965332118 .2565994263119 .4757995605120 .9997024536123 .7427978516 124.9618988037126 .4858016968126 .1809997559127 .4001998901128 .6192932129 129.8385009766131 .0576019287132 .2767028809133 .4958953857134 .7149963379 135.6293945312136 .8484954834137 .7628936768138 .6772003174139 .5915985107 140.5059967041141 .4203033447142 .3347015381142 .9441986084143 .8585968018 144.4682006836145 .3825073242145 .9920959473146 .6015930176147 .2111968994 147.8208007812148 .1255950928148 .7351074219149 .0399017334149 .6495056152 149.9542999268150 .2590942383150 .5639038086150 .8686065674150 .8686065674 151.1734008789151 .1734008789151 .1734008789151 .1734008789151 .1734008789 151.1734008789151 .1734008789150 .8686065674150 .8686065674150 .5639038086 150.2590942383150 .2590942383149 .9542999268149 .6495056152149 .3446960449 149.0399017334148 .7351074219148 .4304046631147 .8208007812147 .5160064697 147.2111968994146 .9064025879146 .6015930176146 .2969055176145 .9920959473 145.6873016357145 .3825073242145 .3825073242145 .0776977539144 .7729034424 144.7729034424144 .4682006836144 .4682006836144 .1634063721144 .1634063721 143.8585968018143 .8585968018143 .5538024902143 .2489929199143 .2489929199 142.9441986084142 .6394042969142 .3347015381142 .0299072266141 .4166259766 140.8249664307140 .3077697754139 .8534851074139 .4354095459139 .0175018311 138.5595703125138 .0288848877137 .4107971191136 .7232666016136 .0176391602 135.2252655029134 .4102020264133 .4958953857132 .5814971924131 .6672058105 130.7528076172129 .8385009766128 .6192932129127 .7050018311126 .4858016968 125.5715026855124 .6570968628123 .43800354122 .5235977173121 .6092987061 120.3900985718119 .4757995605118 .5614013672117 .9517974854117 .0374984741 116.4279022217115 .818397522115 .5136032104115 .2088012695115 .2088012695 115.2088012695115 .5136032104115 .818397522116 .1231002808116 .4279022217 117.0374984741117 .342300415117 .9517974854118 .2565994263118 .8662033081 119.1709976196119 .4757995605119 .7806015015120 .3900985718120 .9997024536 121.6092987061122 .2188034058 -9999 -9999 -9999 -9999 -9999 -9999 -9999 -9999 -9999 
-9999 -9999 -9999 -9999 -9999 -9999 -9999 -9999 -9999 -9999 -9999 -9999 -9999 -9999 -9999 -9999 -9999 -9999 -9999 -9999 -9999 -9999 -9999 -9999 -9999 -9999 -9999 -9999 -9999 -9999

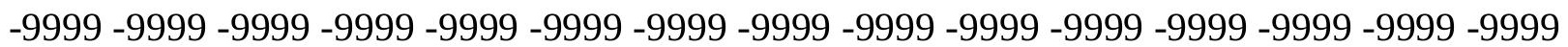
-9999 -9999 -9999 -9999 -9999 -9999 -9999 -9999 -9999 -9999 -9999 -9999 -9999 -9999 -9999 -9999 -9999 -9999 -9999 -9999 -9999 -9999 -9999 -9999 -9999 -9999 -9999 -9999 -9999 -9999 -9999 -9999 -9999 -9999 -9999 -9999 -9999 -9999 -9999 -9999 -9999 -9999 -9999 -9999 -9999 -9999 -9999 -9999 -9999 -9999 -9999 -9999 -9999 -9999 -9999 -9999 -9999 -9999 -9999 -9999

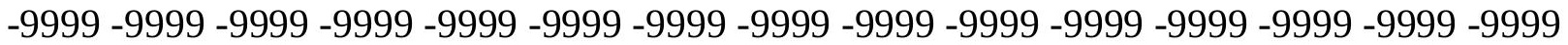
-9999 -9999 -9999 -9999 -9999 -9999 -9999 -9999 -9999 -9999 -9999 -9999 -9999 -9999 -9999 -9999 -9999 -9999 -9999 -9999 -9999 -9999 -9999 -9999 -9999 -9999 -9999 -9999 -9999 -9999 -

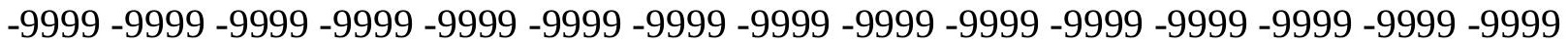
$-9999$

-9999 -9999 -9999 -9999 -9999 -9999 -9999 -9999 -9999 -9999 -9999 -9999 -9999 -9999 -9999 -9999 -9999 -9999 -9999 -9999 -9999 -9999 -9999 -9999 -9999 -9999 -9999 -9999 -9999 -9999 -9999 -9999 -9999 -9999 -9999 -9999 -9999 -9999 -9999 -9999 -9999 -9999 -9999 -9999 -9999 -9999 -9999 -9999 -9999 -9999 -9999 -9999 -9999 -9999 -9999 -9999 -9999 -9999 -9999 -9999 -999 -9999 -9999 -9999-9999-9999-9999-9999 99.35994720459 101.1886978149 103.0174026489 104.5412979126106 .3700027466107 .8938980103109 .4179000854112 .4656982422 113.9896011353115 .5136032104117 .0374984741118 .2565994263119 .7806015015 120.9997024536122 .2188034058123 .7427978516124 .9618988037124 .6570968628 125.8762969971127 .0953979492128 .3144989014129 .533706665130 .7528076172 131.9720001221132 .8863067627134 .1054992676135 .0198059082136 .2389984131 137.1533050537138 .0677032471138 .9819946289139 .8963928223140 .8106994629 141.7250976562142 .3347015381143 .2489929199143 .8585968018144 .4682006836 145.0776977539145 .6873016357146 .2969055176146 .9064025879147 .2111968994 147.8208007812148 .1255950928148 .7351074219149 .0399017334149 .3446960449 149.3446960449149 .6495056152149 .9542999268149 .9542999268149 .9542999268 149.9542999268149 .9542999268149 .9542999268149 .9542999268149 .9542999268 149.6495056152149 .6495056152149 .3446960449149 .0399017334148 .7351074219 148.7351074219148 .4304046631148 .1255950928147 .8208007812147 .5160064697 147.2111968994146 .9064025879146 .6015930176146 .2969055176145 .9920959473 145.6873016357145 .3825073242145 .0776977539144 .7729034424144 .4682006836 144.1634063721144 .1634063721143 .8585968018143 .5538024902143 .5538024902 143.2489929199143 .2489929199142 .9441986084142 .9441986084142 .6394042969 142.3347015381142 .3347015381142 .0299072266141 .7250976562141 .4203033447 140.9298858643140 .2808227539139 .6898956299139 .1544342041138 .661819458 138.1917266846137 .7188873291137 .2160491943136 .657989502136 .035736084 135.3576049805134 .6230010986133 .84815979133 .0093994141132 .1675872803 131.3623962402130 .4479980469129 .2288970947128 .3144989014127 .4001998901 126.1809997559125 .2667007446124 .0475006104123 .1332015991121 .9140014648 120.9997024536120 .0852966309118 .8662033081117 .9517974854117 .0374984741 116.1231002808115 .2088012695114 .5991973877113 .9896011353113 .6848983765 113.6848983765113 .3800964355113 .6848983765113 .9896011353114 .2944030762 114.5991973877115 .2088012695115 .818397522116 .4279022217116 .9163894653 117.342300415117 .9517974854118 .5614013672118 .8662033081119 .1709976196 119.4757995605119 .7806015015120 .0852966309120 .6949005127121 .3044967651 
121.9140014648 -9999 -9999 -9999 -9999 -9999 -9999 -9999 -9999 -9999 -9999 -9999 -9999 -9999 -9999 -9999 -9999 -9999 -9999 -9999 -9999 -9999 -9999 -9999 -9999 -9999 -9999 -9999 -9999 -9999 -9999 -9999 -9999 -9999 -9999 -9999 -9999 -9999 -9999 -9999 -9999 -9999 -9999 -9999 -9999 -9999 -9999 -9999 -9999 -9999 -9999 -9999 -9999 -9999 -9999 -9999 -9999 -9999 -9999 -9999 -9999 -9999 -9999 -9999 -9999 -9999 -9999 -9999 -9999 -9999-9999 -9999 -9999 -9999 -9999 -9999 -9999 -9999 -9999 -9999 -9999 -9999 -9999 -9999 -9999 -9999 -9999 -9999

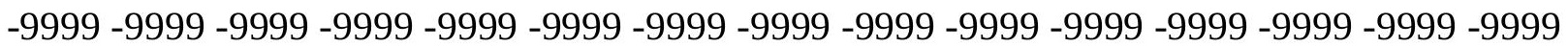
-9999 -9999 -9999 -9999 -9999 -9999 -9999 -9999 -9999 -9999 -9999 -9999 -9999 -9999 -9999 -999 -9999 -9999 -9999 -9999 -9999 -9999 -9999 -9999 -9999 -9999 -9999 -9999 -9999 -9999 -9999 -9999 -9999 -9999 -9999 -9999 -9999 -9999 -9999 -9999 -9999 -9999 -9999 -9999 -9999 -9999 -9999 -9999 -9999 -9999 -9999 -9999 -9999 -9999 -9999 -9999 -9999 -9999 -9999 -9999 -9999 -

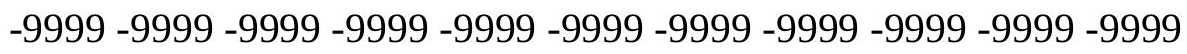

-9999 -9999 -9999 -9999 -9999 -9999 -9999 -9999 -9999 -9999 -9999 -9999 -9999 -9999 -9999 -9999 -9999 -9999 -9999 -9999 -9999 -9999 -9999 -9999 -9999 -9999 -9999 -9999 -9999 -9999 -9999 -9999 -9999 -9999 -9999 -9999 -9999 -9999 -9999 -9999 -9999 -9999 -9999 -9999 -9999

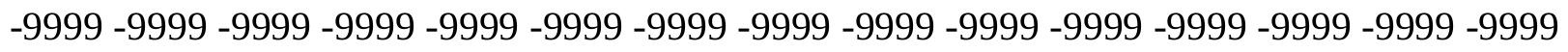
-9999 -9999 -9999 90.8259735107492.95947265625 94.7881774902396.92166900635 98.75038146973100 .2742996216102 .1029968262105 .1509017944106 .979598999 108.5035018921110 .0273971558111 .551399231112 .7705001831114 .2944030762 115.818397522117 .0374984741118 .2565994263119 .7806015015120 .9997024536 122.2188034058123 .43800354122 .8283996582124 .3523025513125 .5715026855 126.7906036377128 .0097961426129 .2288970947130 .1432037354131 .3623962402 132.5814971924133 .4958953857134 .7149963379135 .6293945312136 .5437011719 137.4580993652138 .3724975586139 .2868041992140 .2012023926140 .8106994629 141.7250976562142 .3347015381142 .9441986084143 .8585968018144 .4682006836 144.7729034424145 .3825073242145 .9920959473146 .2969055176146 .9064025879 147.2111968994147 .5160064697147 .8208007812148 .1255950928148 .4304046631 148.7351074219148 .7351074219148 .7351074219149 .0399017334149 .0399017334 149.0399017334148 .7351074219148 .7351074219148 .7351074219148 .4304046631 148.4304046631148 .1255950928147 .8208007812147 .5160064697147 .5160064697 147.2111968994146 .9064025879146 .6015930176146 .2969055176145 .9920959473 145.6873016357145 .3825073242145 .0776977539144 .7729034424144 .4682006836 144.1634063721143 .8585968018143 .8585968018143 .5538024902143 .2489929199 142.9441986084142 .9441986084142 .6394042969142 .3347015381142 .3347015381 142.0299072266142 .0299072266141 .7250976562141 .4203033447141 .1154937744 140.8106994629140 .8106994629140 .2012023926139 .8050384521139 .1601409912 138.5611877441138 .0036621094137 .4759368896136 .9616699219136 .4417419434 135.8972625732135 .3126525879134 .6788024902133 .995300293133 .261428833 132.4858703613131 .6672058105130 .7528076172129 .8385009766128 .9241027832 127.9825286865126 .9790344238125 .8762969971124 .9252624512123 .7427978516 122.8283996582121 .6092987061120 .6949005127119 .4757995605118 .5614013672 117.342300415116 .4279022217115 .5136032104114 .5991973877113 .6848983765 113.075302124112 .4656982422111 .8561019897111 .8561019897111 .8561019897 111.8561019897112 .4656982422112 .7705001831113 .3800964355113 .9896011353 114.5991973877115 .2088012695115 .9779586792116 .5140380859117 .0374984741 117.647102356118 .2565994263118 .5614013672118 .8662033081119 .1709976196 
119.4757995605 119.4757995605 119.7806015015120.3900985718120.6949005127 121.3044967651 -9999 -9999 -9999 -9999 -9999 -9999 -9999 -9999 -9999 -9999 -9999 -9999 -9999 -9999 -9999 -9999 -9999 -9999 -9999 -9999 -9999 -9999 -9999 -9999 -9999 -9999 -9999 -9999 -9999 -9999 -9999 -9999 -9999 -9999 -9999 -9999 -9999 -9999 -9999 -9999 -9999 -9999 -9999 -9999 -9999 -9999 -9999 -9999 -9999 -9999 -9999 -9999 -9999 -9999 -9999 -9999 -9999 -9999 -9999 -9999 -9999 -9999 -9999 -9999 -9999 -9999 -9999 -9999 -9999 -9999 -9999 -9999 -9999 -9999 -9999 -9999 -9999 -9999 -9999 -9999 -9999 -9999 -9999 -9999 -9999 -9999 -9999

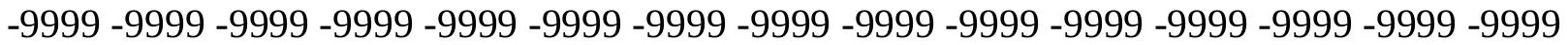

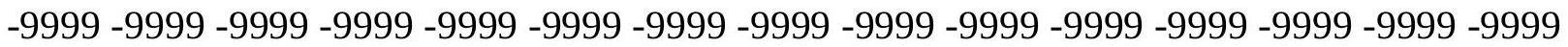
-9999 -9999 -9999 -9999 -9999 -9999 -9999 -9999 -9999 -9999 -9999 -9999 -9999 -9999 -9999 -9999 -9999 -9999 -9999 -9999 -9999 -9999 -9999 -9999 -9999 -9999 -9999 -9999 -9999 -9999 -9999 -9999 -9999 -9999 -9999 -9999 -9999 -9999 -9999 -9999 -9999 -9999 -9999 -9999 -9999 -9999 -9999 -9999 -9999 -9999 -9999 -9999 -9999 -9999

-9999 -9999 -9999 -9999 -9999 -9999 -9999 -9999 -9999 -9999 -9999 -9999 -9999 -9999 -9999 -9999 -9999 -9999 -9999 -9999 -9999 -9999 -9999 -9999 -9999 -9999 -9999 -9999 -9999 -9999

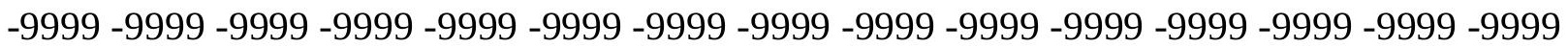
-9999 -9999 -9999 -9999 -9999 -9999 -9999 -9999 -9999 -9999 -9999 -9999 -9999 -9999 -9999 83.5111236572385 .9494018554788 .0829010009890 .2164001464892 .3498916626 94.4833908081196 .3121032714899 .66472625732101 .1886978149103 .0174026489 104.5412979126106 .0652008057107 .5891036987108 .8082962036110 .3321990967 111.8561019897113 .075302124114 .5991973877115 .818397522117 .0374984741 118.2565994263119 .4757995605120 .6949005127121 .9140014648122 .8283996582 122.5235977173123 .7427978516125 .2667007446126 .4858016968127 .4001998901 128.6192932129129 .8385009766131 .0576019287131 .9720001221133 .1911010742 134.1054992676135 .0198059082135 .9342041016136 .8484954834137 .7628936768 138.6772003174139 .2868041992140 .2012023926140 .8106994629141 .7250976562 142.3347015381142 .9441986084143 .5538024902144 .1634063721144 .4682006836 145.0776977539145 .3825073242145 .9920959473146 .2969055176146 .6015930176 146.9064025879147 .2111968994147 .2111968994147 .5160064697147 .5160064697 147.8208007812147 .8208007812147 .8208007812147 .8208007812147 .5160064697 147.5160064697147 .5160064697147 .2111968994147 .2111968994146 .9064025879 146.6015930176146 .6015930176146 .2969055176145 .9920959473145 .6873016357 145.3825073242145 .0776977539144 .7729034424144 .4682006836144 .1634063721 143.8585968018143 .8585968018143 .5538024902143 .2489929199142 .9441986084 142.6394042969142 .6394042969142 .3347015381142 .0299072266141 .7250976562 141.7250976562141 .4203033447141 .1154937744141 .1154937744140 .8106994629 140.5059967041140 .2012023926139 .8963928223139 .5915985107139 .2868041992 138.7011871338138 .0537872314137 .4420318604136 .8609466553136 .3006896973 135.7481994629135 .1890106201134 .6096038818133 .9993286133133 .3508300781 132.6601409912131 .9272155762131 .1538848877130 .3468780518129 .5086517334 128.6192932129127 .6829986572126 .7048187256125 .5715026855124 .6570968628 123.6697463989122 .5235977173121 .5995559692120 .3900985718119 .1709976196 118.2565994263117 .0374984741116 .1231002808114 .9039993286113 .9896011353 112.7705001831112 .1608963013111 .24659729110 .6370010376110 .3321990967 110.0273971558110 .0273971558110 .3321990967110 .9418029785111 .24659729 112.1608963013112 .7705001831113 .6848983765114 .2944030762115 .0892181396 
115.6519622803116 .2322387695116 .8145675659117 .3580551147117 .7706069946 118.1011047363118 .3868942261118 .631477356118 .8662033081119 .1709976196 119.1709976196119 .1709976196119 .7806015015120 .0852966309 -9999 -9999 -9999 -9999 -9999 -9999 -9999 -9999 -9999 -9999 -9999 -9999 -9999 -9999 -9999 -9999 -9999 -9999 -9999 -9999 -9999 -9999 -9999 -9999 -9999 -9999 -9999 -9999-9999 -9999 -9999 -9999 -9999 -9999 -9999 -9999 -9999 -9999 -9999 -9999 -9999 -9999 -9999 -9999 -9999 -9999 -9999 -9999 -9999 -9999 -9999 -9999 -9999 -9999 -9999 -9999 -9999 -9999 -9999 -9999 -9999 -9999 -9999 -9999

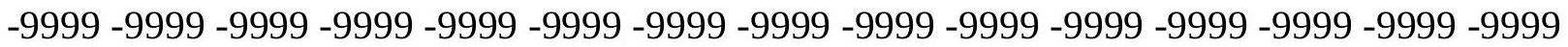
-9999 -9999 -9999 -9999 -9999 -9999 -9999 -9999 -9999 -9999 -9999 -9999 -9999 -9999 -9999 -9999 -9999 -9999 -9999 -9999 -9999 -9999 -9999 -9999 -9999 -9999 -9999 -9999 -9999 -9999 -

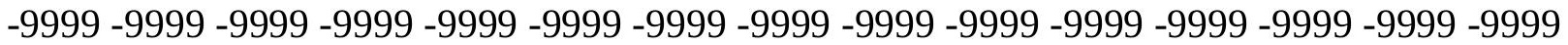
-9999 -9999 -9999 -9999 -9999 -9999 -9999 -9999 -9999 -9999 -9999 -9999 -9999 -9999 -9999 -9999 -9999 -9999 -9999 -9999 -9999 -9999 -9999 -9999 -9999 -9999 -9999 -9999 -9999 -9999 -9999 -9999 -9999 -9999 -9999 -9999 -9999 -9999 -9999 -9999 -9999 -9999 -9999 -9999 -9999 $-9999$

-9999 -9999 -9999 -9999 -9999 -9999 -9999 -9999 -9999 -9999 -9999 -9999 -9999 -9999 -9999

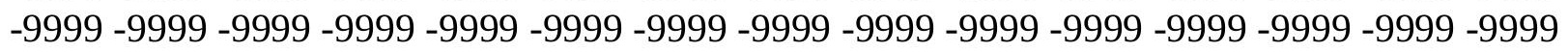

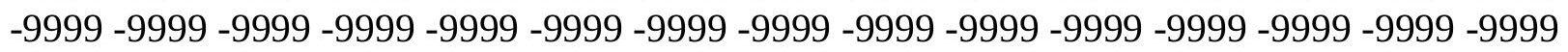
-9999 -9999 -9999 -9999 -9999 -9999 -9999 -9999 -9999 -9999 -9999 -9999 -9999 77.4154205322380 .1584930419982 .9015579223685 .3398437587 .77810668945 91.4355392456193 .5690307617295 .397743225197 .2264633178799 .05516815186 100.5791015625102 .1029968262103 .6268997192105 .1509017944106 .6747970581 107.8938980103109 .4179000854110 .6370010376111 .8561019897113 .3800964355 114.5991973877115 .818397522117 .0374984741117 .9517974854119 .1709976196 120.3900985718121 .3044967651120 .9997024536122 .2188034058123 .43800354 124.6570968628125 .8762969971127 .0953979492128 .3144989014129 .2288970947 130.4479980469131 .3623962402132 .5814971924133 .4958953857134 .4102020264 135.3246002197136 .2389984131137 .1533050537137 .7628936768138 .6772003174 139.5915985107140 .2012023926140 .8106994629141 .4203033447142 .0299072266 142.6394042969143 .2489929199143 .5538024902144 .1634063721144 .4682006836 145.0776977539145 .3825073242145 .6873016357145 .9920959473145 .9920959473 146.2969055176146 .2969055176146 .6015930176146 .6015930176146 .6015930176 146.6015930176146 .6015930176146 .6015930176146 .2969055176146 .2969055176 145.9920959473145 .9920959473145 .6873016357145 .3825073242145 .3825073242 145.0776977539144 .7729034424144 .4682006836144 .1634063721144 .1634063721 143.8585968018143 .5538024902143 .2489929199142 .9441986084142 .6394042969 142.3347015381142 .3347015381142 .0299072266141 .7250976562141 .4203033447 141.4203033447141 .1154937744140 .8106994629140 .5059967041140 .5059967041 140.2012023926139 .8963928223139 .5915985107139 .2868041992138 .9819946289 138.6772003174 138.2994842529 137.6170501709 136.9633178711 136.3367919922 135.7329101562135 .1436004639134 .5586242676133 .9669036865133 .3584442139 132.7255249023132 .0621185303131 .3640594482130 .6291351318129 .8572235107 129.0500946045128 .2087554932127 .3261871338126 .403503418125 .4496383667 124.3523025513123 .43800354122 .4606552124121 .3044967651120 .3900985718 119.1709976196117 .9517974854117 .0374984741115 .818397522114 .5991973877 113.6848983765112 .4656982422111 .551399231110 .6370010376109 .7226028442 
109.1130981445108.5035018921 108.5035018921 108.5035018921 108.8082962036 109.4179000854110 .0273971558110 .9418029785111 .8561019897112 .4656982422 113.3800964355114 .2042236328114 .7649383545115 .3412094116115 .9086685181 116.4212265015116 .8596572876117 .2162399292117 .521194458117 .7941055298 118.0704345703118 .3312835693118 .5614013672118 .5614013672118 .5614013672 118.5614013672118 .8662033081 -9999 -9999 -9999 -9999 -9999 -9999 -9999 -9999 -9999 -9999 -9999 -9999 -9999 -9999 -9999 -9999 -9999 -9999 -9999 -9999 -9999 -9999 -9999 -9999

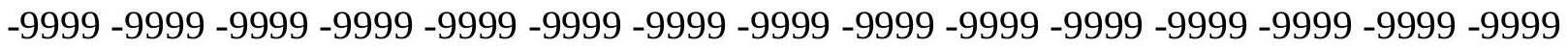

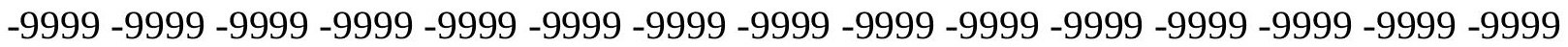
-9999 -9999 -9999 -9999 -9999 -9999 -9999 -9999 -9999 -9999 -9999 -9999 -9999 -9999 -9999

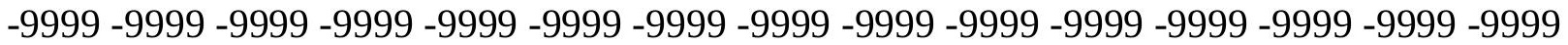
-9999 -9999 -9999 -9999 -9999 -9999 -9999 -9999 -9999 -9999 -9999 -9999 -9999 -9999 -9999 -9999 -9999 -9999 -9999 -9999 -9999 -9999 -9999 -9999 -9999 -9999 -9999 -9999 -9999 -9999 -9999 -9999 -9999 -9999 -9999 -9999 -9999 -9999 -9999 -9999 -9999 -9999 -9999 -9999 -9999 -9999 -9999 -9999 -9999 -9999 -9999 -9999 -9999 -9999 -9999 -9999 -9999 -9999 -9999 -9999

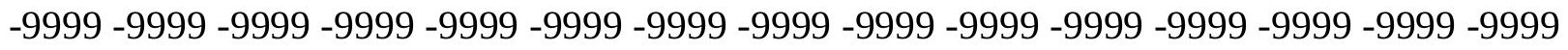
-9999 -9999 -9999 -9999-9999 -9999 -9999 -9999 -9999 -9999

-9999 -9999 -9999 -9999 -9999 -9999 -9999 -9999 -9999 -9999 -9999 -9999 -9999 -9999 -9999 -9999 -9999 -9999 -9999 -9999 -9999 -9999 -9999 -9999 -9999 -9999 -9999 -9999 -9999 -9999 -9999 -9999 -9999 -9999 -9999 -9999 -9999 -9999 -9999 -9999 -9999 -9999 -9999 -9999 -9999 -9999 -9999 -9999 -9999 -9999 -9999 -9999 -9999 -9999 -9999 71.62449645996 73.1484298706174 .6723632812576 .8058471679779 .8537063598682 .59677124023 86.8637619018689 .302040100191 .4355392456193 .5690307617295 .3977432251 96.9216690063598 .75038146973100 .2742996216101 .4934005737103 .0174026489 104.5412979126105 .7603988647106 .979598999108 .1986999512109 .4179000854 110.9418029785112 .1608963013113 .3800964355114 .2944030762115 .5136032104 116.7326965332117 .647102356118 .8662033081120 .0852966309120 .9997024536 120.6949005127121 .9140014648123 .1332015991124 .3523025513125 .5715026855 126.4858016968127 .7050018311128 .9241027832129 .8385009766131 .0576019287 131.9720001221132 .8863067627133 .8007049561134 .7149963379135 .6293945312 136.5437011719137 .1533050537138 .0677032471138 .6772003174139 .2868041992 140.2012023926140 .8106994629141 .1154937744141 .7250976562142 .3347015381 142.9441986084143 .2489929199143 .5538024902143 .8585968018144 .1634063721 144.4682006836144 .7729034424145 .0776977539145 .0776977539145 .3825073242 145.3825073242145 .3825073242145 .3825073242145 .3825073242145 .3825073242 145.3825073242145 .3825073242145 .0776977539145 .0776977539144 .7729034424 144.7729034424144 .4682006836144 .1634063721143 .8585968018143 .8585968018 143.5538024902143 .2489929199142 .9441986084142 .6394042969142 .3347015381 142.3347015381142 .0299072266141 .7250976562141 .4203033447141 .1154937744 141.1154937744140 .8106994629140 .5059967041140 .2012023926139 .8963928223 139.8963928223139 .5915985107139 .2868041992138 .9819946289138 .6772003174 138.3724975586 138.0677032471 137.7628936768137 .2382965088136 .5540008545 135.8921203613135 .2507629395134 .6260528564134 .0115661621133 .3993835449 132.7810211182132 .1487426758131 .4965820312130 .8195800781130 .1136627197 129.3755340576128 .6039733887127 .7986297607126 .9587478638126 .0857162476 125.1793060303124 .2438964844123 .284576416122 .2188034058121 .3044967651 
120.0852966309119 .1709976196117 .9517974854117 .0374984741115 .818397522 114.5991973877113 .6848983765112 .4656982422111 .24659729110 .3321990967 109.1130981445108 .1986999512107 .5891036987106 .979598999106 .979598999 106.979598999107 .2844009399108 .1986999512108 .8082962036109 .7226028442 110.6370010376111 .8561019897112 .7705001831113 .313949585113 .8586654663 114.4120941162114 .9523239136115 .4495010376115 .8886795044116 .2626037598 116.5876235962116 .8857955933117 .1681900024117 .4219436646117 .629234314 117.7805328369117 .9517974854117 .647102356117 .342300415117 .9517974854 -9999 -9999 -9999 -9999 -9999 -9999 -9999 -9999 -9999 -9999 -9999 -9999 -9999 -9999 -9999 -9999 -9999 -9999 -9999 -9999 -9999 -9999 -9999 -9999 -9999 -9999 -9999 -9999 -9999 -9999 -9999 -9999 -9999 -9999 -9999 -9999 -9999 -9999 -9999 -9999 -9999 -9999 -9999 -9999 -9999 -9999 -9999 -9999 -9999 -9999 -9999 -9999 -9999 -9999 -9999 -9999 -9999 -9999 -9999 -9999 -9999 -9999 -999 -9999 -9999 -9999 -9999 -9999 -9999 -9999 -9999 -9999 -9999 -9999 -9999 -9999 -9999 -9999 -9999 -9999 -9999 -9999 -9999 -9999 -9999 -9999 -9999 -9999 -9999 -9999 -9999 -9999 -9999 -9999 -9999 -9999 -9999 -9999 -9999 -9999 -9999 -9999 -9999 -9999 -9999 -9999 -9999 -9999

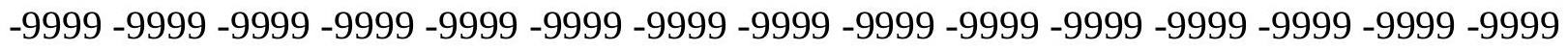
-9999 -9999 -9999 -9999 -9999 -9999 -9999 -9999 -9999 -9999 -9999 -9999 -9999 -9999 -9999 -9999 -9999 -9999 -9999 -9999 -9999 -9999 -9999 -9999 -9999 -9999 -9999 -9999 -9999 -9999 -

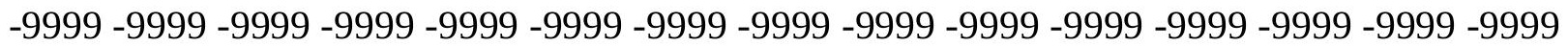
$-9999$

-9999 -9999 -9999 -9999 -9999 -9999 -9999 -9999 -9999 -9999 -9999 -9999 -9999 -9999 -9999 -9999 -9999 -9999 -9999 -9999 -9999 -9999 -9999 -9999 -9999 -9999 -9999 -9999 -9999 -9999 -9999 -9999 -9999 -9999 -9999 -9999 -9999 -9999 -9999 -9999 -9999 -9999 -9999 -9999 -9999 -9999 -9999-9999 -9999 -9999 -9999-9999 65.52880096436 67.35751342773 68.88143920898 70.4053573608471 .9292907714873 .4532165527376 .8058471679781 .37763214111 84.12069702148 86.8637619018689.302040100191.4355392456193.56903076172 95.397743225196 .9216690063598 .445587158299 .66472625732101 .1886978149 102.4077987671103 .6268997192104 .8460998535106 .0652008057107 .2844009399 108.5035018921109 .7226028442110 .9418029785111 .8561019897113 .075302124 114.2944030762115 .2088012695116 .4279022217117 .342300415118 .5614013672 119.4757995605118 .8662033081120 .3900985718121 .6092987061122 .5235977173 123.7427978516124 .9618988037126 .1809997559127 .0953979492128 .3144989014 129.2288970947130 .4479980469131 .3623962402132 .2767028809133 .1911010742 134.1054992676135 .0198059082135 .6293945312136 .5437011719137 .1533050537 138.0677032471138 .6772003174139 .2868041992139 .8963928223140 .5059967041 140.8106994629141 .4203033447142 .0299072266142 .3347015381142 .6394042969 142.9441986084143 .2489929199143 .5538024902143 .8585968018143 .8585968018 144.1634063721144 .1634063721144 .4682006836144 .4682006836144 .4682006836 144.4682006836144 .4682006836144 .1634063721144 .1634063721144 .1634063721 143.8585968018143 .8585968018143 .5538024902143 .2489929199143 .2489929199 142.9441986084142 .6394042969142 .3347015381142 .3347015381142 .0299072266 141.7250976562141 .4203033447141 .1154937744141 .1154937744140 .8106994629 140.5059967041140 .2012023926139 .8963928223139 .8963928223139 .5915985107 139.2868041992138 .9819946289138 .6772003174138 .3724975586138 .0677032471 137.7628936768137 .4580993652137 .1533050537136 .8484954834136 .2037811279 135.5156707764134 .8451538086134 .1900787354133 .5471496582132 .9113769531 
132.2767486572131 .63671875130 .9851379395130 .316986084129 .6278991699 128.9141693115128 .1723937988127 .4007797241126 .5983657837125 .7652435303 124.9019699097124 .0104522705123 .0931091309122 .1544723511121 .2004165649 120.23828125119 .1709976196118 .2565994263117 .0374984741116 .1231002808 114.9039993286113 .6848983765112 .7705001831111 .551399231110 .3321990967 109.1130981445108 .1986999512106 .979598999106 .0652008057105 .7603988647 105.4557037354105 .7603988647106 .0652008057106 .979598999107 .8938980103 108.8082962036110 .0273971558110 .9418029785111 .9336166382112 .4220123291 112.9378738403113 .4623336792113 .9725418091114 .4518508911114 .8830108643 115.2654266357115 .6038131714115 .9083023071116 .1795578003116 .4184417725 116.6180114746116 .7646713257116 .7731781006116 .5207366943116 .1231002808 116.4279022217 116.7326965332 -9999 -9999 -9999 -9999 -9999 -9999 -9999 -9999 -9999 -9999 -9999 -9999 -9999 -9999 -9999 -9999 -9999 -9999 -9999 -9999 -9999 -9999 -9999 -9999 -9999 -9999 -9999 -9999 -9999 -9999 -9999 -9999 -9999 -9999 -9999 -9999 -9999 -9999 -9999 -9999 -9999 -9999 -9999 -9999 -9999 -9999 -9999 -9999 -9999 -9999 -9999 -9999 -9999 -9999

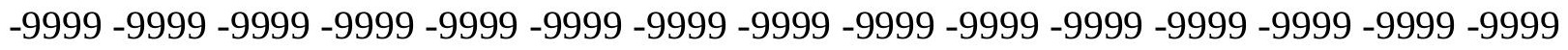
-9999 -9999 -9999 -9999 -9999 -9999 -9999 -9999 -9999 -9999 -9999 -9999 -9999 -9999 -9999 -9999 -9999 -9999 -9999 -9999 -9999 -9999 -9999 -9999 -9999 -9999 -9999 -9999 -9999 -9999 -

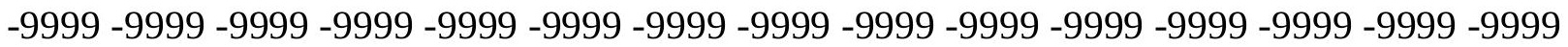

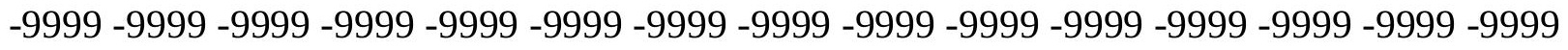

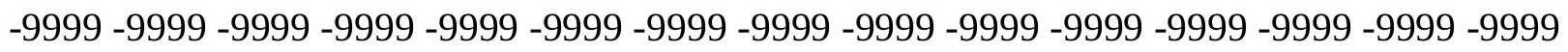

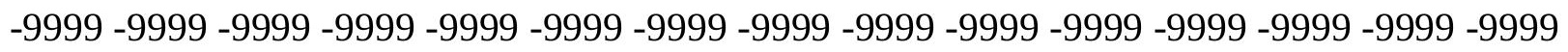
-9999 -9999-9999 -9999-9999-9999-9999-9999

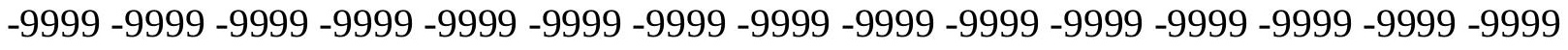

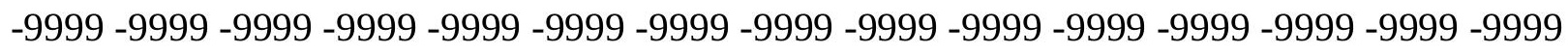

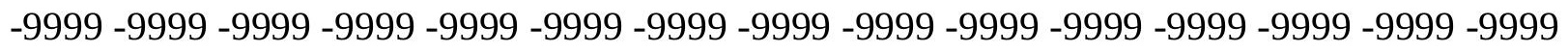
-9999 -9999 -9999 -9999 -9999 61.2618103027362.78573989868 64.30966186523 66.1383666992267 .6623001098669 .1862335205170 .7101516723674 .36756896973 78.0249862670981 .3776321411184 .4254837036187 .1685485839889 .60682678223 91.7403335571393 .5690307617295 .397743225196 .9216690063598 .14080810547 99.35994720459100 .5791015625101 .7982025146103 .0174026489104 .2365036011 105.1509017944106 .3700027466107 .2844009399108 .5035018921109 .7226028442 110.6370010376111 .8561019897112 .7705001831113 .9896011353114 .9039993286 115.818397522117 .0374984741117 .9517974854117 .342300415118 .5614013672 119.7806015015120 .9997024536122 .2188034058123 .43800354124 .6570968628 125.5715026855126 .7906036377127 .7050018311128 .6192932129129 .8385009766 130.7528076172131 .6672058105132 .5814971924133 .4958953857134 .1054992676 135.0198059082135 .6293945312136 .5437011719137 .1533050537137 .7628936768 138.3724975586138 .9819946289139 .5915985107140 .2012023926140 .5059967041 141.1154937744141 .4203033447141 .7250976562142 .0299072266142 .3347015381 142.6394042969142 .9441986084142 .9441986084143 .2489929199143 .2489929199 143.2489929199143 .2489929199143 .2489929199143 .2489929199143 .2489929199 143.2489929199142 .9441986084142 .9441986084142 .9441986084142 .6394042969 142.6394042969142 .3347015381142 .0299072266142 .0299072266141 .7250976562 141.4203033447141 .1154937744141 .1154937744140 .8106994629140 .5059967041 140.2012023926139 .8963928223139 .8963928223139 .5915985107139 .2868041992 
138.9819946289138 .6772003174138 .3724975586138 .3724975586138 .0677032471 137.7628936768137 .4580993652137 .1533050537136 .5437011719136 .2389984131 135.9082489014135 .2003326416134 .50730896133 .8282318115133 .1609191895 132.502456665131 .8489685059131 .19581604130 .5379638672129 .8704223633 129.1888122559128 .489151001127 .7680587769127 .0225372314126 .2508087158 125.4518814087124 .6259002686123 .773475647122 .8962783813121 .9969100952 121.0798187256120 .1508178711119 .2169570923118 .2565994263117 .342300415 116.4279022217115 .2088012695113 .9896011353113 .075302124111 .8561019897 110.6370010376109 .4179000854108 .5035018921107 .2844009399106 .0652008057 105.1509017944104 .5412979126104 .5412979126104 .5412979126105 .1509017944 106.0652008057106 .979598999108 .1986999512109 .4179000854110 .3321990967 111.0810470581111 .5378112793112 .0193328857112 .508644104112 .9887008667 113.4445037842113 .8647918701114 .2449493408114 .5844955444114 .8840408325 115.1376419067115 .350227356115 .519569397115 .6188735962115 .6111755371 115.5395812988115 .5136032104114 .9039993286115 .5136032104115 .818397522 -9999 -9999 -9999 -9999 -9999 -9999 -9999 -9999 -9999 -9999 -9999 -9999 -9999 -9999 -9999 -9999 -9999 -9999 -9999 -9999 -9999 -9999 -9999 -9999 -9999 -9999 -9999 -9999 -9999 -9999 -9999 -9999 -9999 -9999 -9999 -9999 -9999 -9999 -9999 -9999 -9999 -9999 -9999 -9999 -9999 -9999 -

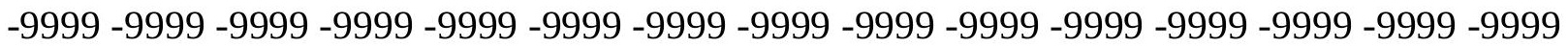

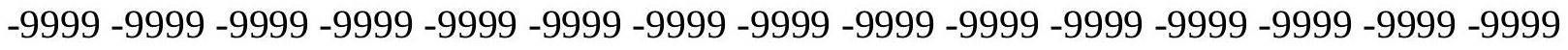

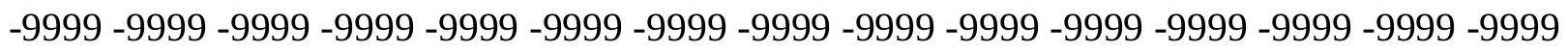
-9999 -9999 -9999 -9999 -9999 -9999 -9999 -9999 -9999 -9999 -9999 -9999 -9999 -9999 -9999 -9999 -9999 -9999 -9999 -9999 -9999 -9999 -9999 -9999 -9999 -9999 -9999 -9999 -9999 -9999 -

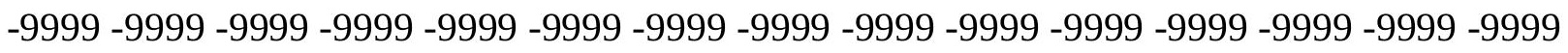

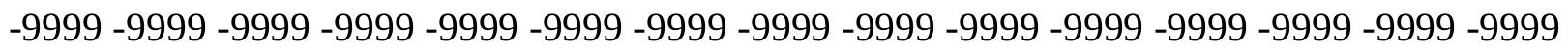
-9999 -9999 -9999 -9999 -9999 -9999 -9999 -9999 -9999 -9999 -9999 -9999 -9999 -9999 -9999

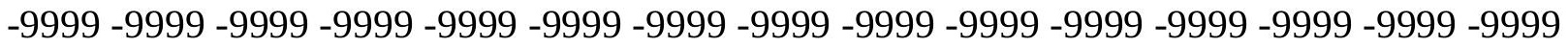

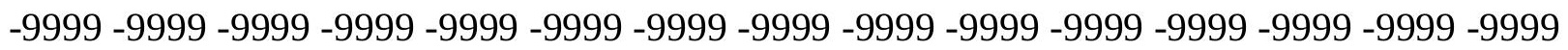

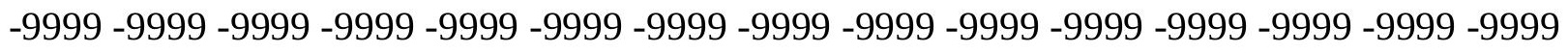
-9999 -9999 54.8613204956156.6900291442958.2139587402360.04267120361 61.5666007995663 .0905189514264 .9192428588966 .4431610107469 .49101257324 69.4910125732474 .062782287678 .0249862670981 .6824111938585 .03504943848 87.77810668945 90.2164001464892.349891662694.1785964965895.70252990723 96.9216690063598 .1408081054799 .35994720459100 .2742996216101 .1886978149 102.4077987671103 .3221969604104 .2365036011105 .4557037354106 .3700027466 107.2844009399108 .5035018921109 .4179000854110 .6370010376111 .551399231 112.4656982422113 .3800964355114 .5991973877115 .5136032104116 .4279022217 117.342300415117 .0374984741118 .2565994263119 .4757995605120 .6949005127 121.6092987061122 .8283996582124 .0475006104124 .9618988037126 .1809997559 127.0953979492128 .3144989014129 .2288970947130 .1432037354131 .0576019287 131.9720001221132 .5814971924133 .4958953857134 .4102020264135 .0198059082 135.6293945312136 .5437011719137 .1533050537137 .7628936768138 .3724975586 138.6772003174139 .2868041992139 .5915985107140 .2012023926140 .5059967041 140.8106994629141 .1154937744141 .4203033447141 .7250976562141 .7250976562 142.0299072266142 .0299072266142 .3347015381142 .3347015381142 .3347015381 142.3347015381142 .3347015381142 .3347015381142 .0299072266142 .0299072266 
142.0299072266141 .7250976562141 .7250976562141 .4203033447141 .4203033447 141.1154937744140 .8106994629140 .8106994629140 .5059967041140 .2012023926 139.8963928223139 .8963928223139 .5915985107139 .2868041992138 .9819946289 138.6772003174138 .6772003174138 .3724975586138 .0677032471137 .7628936768 137.4580993652137 .1533050537136 .8484954834136 .5437011719136 .2389984131 135.9342041016135 .3246002197134 .9434204102134 .2328338623133 .5344390869 132.8471984863132 .1690673828131 .4974822998130 .8292999268130 .1608428955 129.4880828857128 .8069000244128 .1135864258127 .4045791626126 .6768951416 125.9279556274125 .1562271118124 .3608474731123 .5419998169122 .7003707886 121.8377304077120 .9567565918120 .0616836548119 .1579589844118 .2520980835 117.3511505127 116.4624786377 115.5136032104 114.5991973877113.3800964355 112.4656982422111 .24659729110 .0273971558109 .1130981445107 .8938980103 106.6747970581105 .4557037354104 .5412979126104 .2365036011104 .2365036011 104.8460998535105 .4557037354106 .0652008057106 .979598999107 .8938980103 108.8082962036109 .8661346436110 .2514572144110 .6732711792111 .1180725098 111.5714035034112 .0193023682112 .4494628906112 .8522567749113 .2213897705 113.5519180298113 .8387374878114 .0746002197114 .2601318359114 .4001464844 114.4859008789114 .5090713501114 .4824829102114 .4088439941114 .2944030762 113.9896011353114 .5991973877 -9999 -9999 -9999 -9999 -9999 -9999 -9999 -9999 -9999

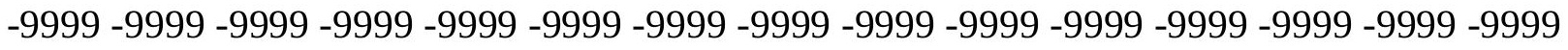
-9999 -9999 -9999 -9999 -9999 -9999 -9999 -9999 -9999 -9999 -9999 -9999 -9999 -9999 -9999 -9999 -9999 -9999 -9999 -9999 -9999 -9999 -9999 -9999 -9999 -9999 -9999 -9999 -9999 -9999 -9999 -9999 -9999 -9999 -9999 -9999 -9999 -9999 -9999 -9999 -9999 -9999-9999-9999-9999 -999 -9999 -9999 -9999 -9999 -9999 -9999 -9999 -9999 -9999 -9999 -9999 -9999 -9999 -9999 -9999 -9999 -9999 -9999 -9999 -9999 -9999 -9999 -9999 -9999 -9999 -9999 -9999 -9999 -9999 -9999 -9999 -9999 -9999 -9999 -9999 -9999 -9999 -9999 -9999 -9999 -9999 -9999 -9999 -9999 -9999 -9999 -9999 -9999 -9999 -9999 -9999 -9999 -9999 -9999 -9999 -9999 -9999 -9999 -9999 -9999

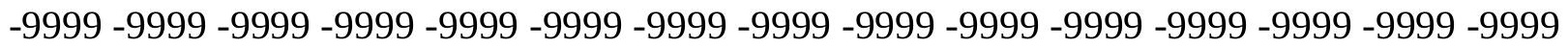
-9999 -9999 -9999 -9999 -9999 -9999 -9999 -9999 -9999 -9999 -9999 -9999 -9999 -9999 -9999 -9999 -9999 -9999 -9999-9999-9999-9999

-9999 -9999 -9999 -9999 -9999 -9999 -9999 -9999 -9999 -9999 -9999 -9999 -9999 -9999 -9999 -9999 -9999 -9999 -9999 -9999 -9999 -9999 -9999 -9999 -9999 -9999 -9999 -9999 -9999 -9999 -9999 -9999 -9999 -9999 -9999 -9999 -9999 -9999 -9999-9999 -9999 -9999 -9999 -9999 48.4608306884850 .2895507812552 .1182594299353 .6421813964855 .47089004517 57.2995986938558 .8235282897961 .8713798522963 .7000885009865 .22400665283 66.7479400634868 .2718734741269 .4910125732473 .7580032348678 .32978057861 82.29197692871 85.94940185547 88.6924667358491.13075256348 92.95947265625 94.4833908081196 .0073165893696 .9216690063598 .1408081054799 .05516815186 99.96952056885100 .8839035034101 .7982025146102 .4077987671103 .3221969604 104.2365036011105 .4557037354106 .3700027466107 .2844009399108 .1986999512 109.1130981445110 .3321990967111 .24659729112 .1608963013113 .075302124 113.9896011353114 .9039993286115 .818397522115 .2088012695116 .4279022217 117.647102356118 .8662033081120 .0852966309121 .3044967651122 .5235977173 123.43800354124 .6570968628125 .5715026855126 .4858016968127 .7050018311 128.6192932129129 .533706665130 .4479980469131 .3623962402131 .9720001221 132.8863067627133 .4958953857134 .4102020264135 .0198059082135 .6293945312 
136.2389984131136 .8484954834137 .4580993652138 .0677032471138 .3724975586 138.9819946289139 .2868041992139 .5915985107139 .8963928223140 .2012023926 140.5059967041140 .8106994629140 .8106994629141 .1154937744141 .1154937744 141.1154937744141 .4203033447141 .4203033447141 .4203033447141 .4203033447 141.1154937744141 .1154937744141 .1154937744141 .1154937744140 .8106994629 140.8106994629140 .5059967041140 .5059967041140 .2012023926139 .8963928223 139.8963928223139 .5915985107139 .2868041992138 .9819946289138 .9819946289 138.6772003174 138.3724975586138.0677032471 137.7628936768 137.4580993652 137.4580993652137 .1533050537136 .8484954834136 .5437011719136 .2389984131 135.6293945312135 .3246002197135 .0198059082134 .7149963379134 .0180969238 133.3042449951132 .6004333496131 .9055938721131 .2179107666130 .5351257324 129.854598999129 .1733093262128 .4879455566127 .7950363159127 .091468811 126.3742599487125 .6408843994124 .8891525269124 .1177978516123 .3261413574 122.5144882202121 .6836624146120 .8355712891119 .9729385376119 .0997085571 118.2208404541117 .3422241211116 .4702529907115 .6115264893114 .7729797363 113.9614028931113 .075302124111 .8561019897110 .9418029785109 .7226028442 108.8082962036107 .5891036987106 .3700027466105 .4557037354104 .8460998535 104.8460998535104 .8460998535105 .4557037354106 .0652008057106 .6747970581 107.5891036987108 .5035018921108 .7947540283109 .1006164551109 .4521560669 109.8377151489110 .2453079224110 .6625671387111 .0777053833111 .4800262451 111.8604049683112 .211517334112 .5263214111112 .7977523804113 .0182113647 113.1871566772113 .3134841919113 .3941574097113 .4340438843113 .4386978149 $113.3791427612113 .2661056519113 .075302124113 .3800964355113 .6848983765-9999$ -9999 -9999 -9999 -9999 -9999 -9999 -9999 -9999 -9999 -9999 -9999 -9999 -9999 -9999 -9999

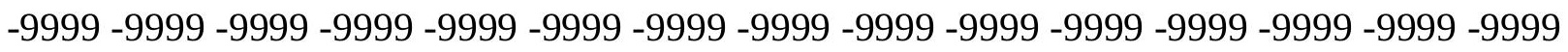
-9999 -9999 -9999 -9999 -9999 -9999 -9999 -9999 -9999 -9999 -9999 -9999 -9999 -9999 -9999

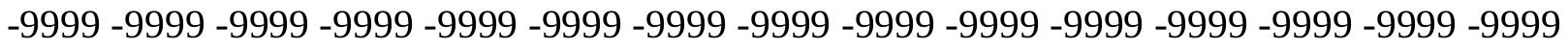

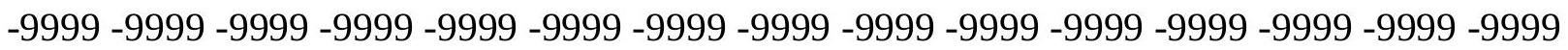
-9999 -9999 -9999 -9999 -9999 -9999 -9999 -9999 -9999 -9999 -9999 -9999 -9999 -9999 -9999 -9999 -9999 -9999 -9999 -9999 -9999 -9999 -9999 -9999 -9999 -9999 -9999 -9999 -9999 -9999 -9999 -9999 -9999 -9999 -9999 -9999 -9999 -9999 -9999 -9999 -9999 -9999 -9999 -9999 -9999 -9999 -9999 -9999 -9999 -9999 -9999 -9999 -9999 -9999 -9999 -9999 -9999 -9999 -9999 -9999 -

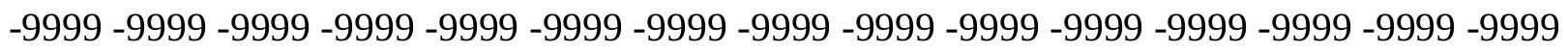
-9999 -9999 -9999 -9999 -9999 -9999 -9999 -9999 -9999 -9999 -9999 -9999 -9999 -9999 -9999 -9999 -9999 -9999 -9999 -9999 -9999 -9999 -9999 -9999 -9999 -9999 -9999 -9999 -9999 -

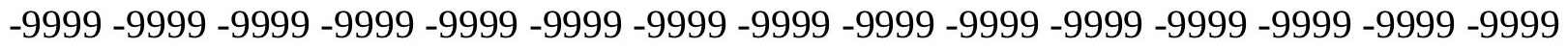
-9999 -9999 -9999 -9999 -9999-9999 -9999 -9999 -9999 -9999 -9999-9999 43.88906097412 45.717769622847 .5464782714849 .0704002380450 .8991203308154 .25175094604 55.7756805419957 .6043891906759 .1283111572360 .9570198059162 .48094940186 64.004882812565 .5288009643667 .0527267456168 .8814392089874 .36756896973 79.2441329956183 .5111236572387 .1685485839889 .9116134643692 .04509735107 93.87381744385 95.0929565429796.3121032714897.2264633178798.14080810547 98.7503814697399 .66472625732100 .2742996216100 .8839035034101 .7982025146 102.712600708103 .3221969604104 .2365036011105 .1509017944106 .0652008057 106.979598999107 .8938980103108 .8082962036109 .7226028442110 .6370010376 111.551399231112 .4656982422113 .3800964355114 .2944030762113 .6848983765 
114.9039993286116 .1231002808117 .342300415118 .5614013672119 .7806015015 120.6949005127121 .9140014648122 .8283996582124 .0475006104124 .9618988037 126.1809997559127 .0953979492128 .0097961426128 .9241027832129 .8385009766 130.4479980469131 .3623962402132 .2767028809132 .8863067627133 .4958953857 134.4102020264135 .0198059082135 .6293945312136 .2389984131136 .5437011719 137.1533050537137 .4580993652138 .0677032471138 .3724975586138 .6772003174 138.9819946289139 .2868041992139 .5915985107139 .8963928223139 .8963928223 140.2012023926140 .2012023926140 .2012023926140 .5059967041140 .5059967041 140.5059967041140 .5059967041140 .2012023926140 .2012023926140 .2012023926 140.2012023926139 .8963928223139 .8963928223139 .5915985107139 .5915985107 139.2868041992138 .9819946289138 .9819946289138 .6772003174138 .3724975586 138.0677032471138 .0677032471137 .7628936768137 .4580993652137 .1533050537 136.8484954834136 .5437011719136 .2389984131135 .9342041016135 .6293945312 135.3246002197135 .0198059082134 .7149963379134 .1054992676133 .8007049561 133.1337127686132 .4163970947131 .7073822021131 .0056304932130 .3095245361 129.6170959473128 .9260559082128 .2338867188127 .5378036499126 .8349456787 126.1226730347125 .3985519409124 .6605377197123 .9068527222123 .1364898682 122.3489761353121 .5447540283120 .7248153687119 .8911514282119 .0464553833 118.1944122314117 .3395080566116 .4870223999115 .6427307129114 .8125457764 114.0027236938113 .2194366455112 .468963623111 .551399231110 .6370010376 109.7226028442108 .5035018921107 .5891036987106 .3700027466105 .7603988647 105.4557037354105 .4557037354105 .7603988647106 .0652008057106 .6747970581 107.2844009399 107.7161865234107.877456665 108.0992965698108.3732833862 108.6901321411109 .0392684937109 .4100799561109 .7917022705110 .1738510132 110.5469741821110 .9023132324111 .2321395874111 .5289077759111 .7855987549 111.9956817627112 .1569595337112 .2770233154112 .3647384644112 .4210586548 112.4511871338112 .4549255371112 .451423645112 .4656982422112 .1608963013 112.4656982422113 .075302124 -9999 -9999 -9999 -9999 -9999 -9999 -9999 -9999 -9999 -9999 -9999 -9999 -9999 -9999 -9999 -9999 -9999 -9999 -9999 -9999 -9999 -9999 -9999 -9999 -9999 -9999 -9999 -9999 -9999 -9999 -9999 -9999 -9999 -9999 -9999 -9999 -9999 -9999 -9999 -9999 -9999 -9999 -9999 -9999 -9999 -9999 -9999 -9999-9999 -9999 -9999 -9999 -9999 -9999 -9999 -9999 -9999 -9999 -9999 -9999 -9999 -9999 -9999 -9999 -9999 -9999 -9999 -9999 -9999 -

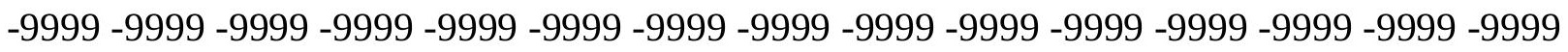
-9999 -9999 -9999 -9999 -9999 -9999 -9999 -9999 -9999 -9999 -9999 -9999 -9999 -9999 -9999 -9999 -9999 -9999 -9999 -9999 -9999 -9999 -9999 -9999 -9999 -9999 -9999 -9999 -9999 -9999

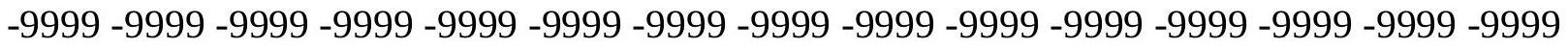

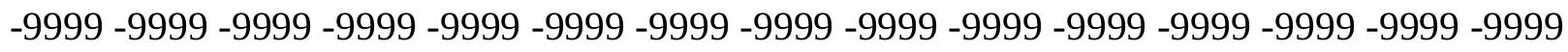

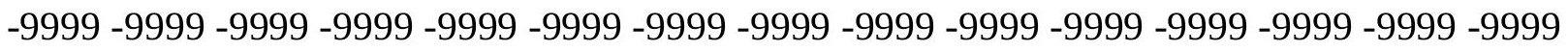
-9999 -9999-9999-9999-9999

-9999 -9999 -9999 -9999 -9999 -9999 -9999 -9999 -9999 -9999 -9999 -9999 -9999 -9999 -9999

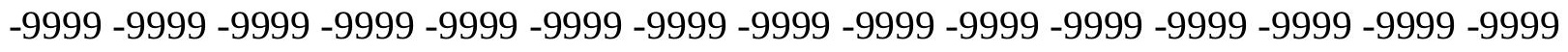
-9999 -9999 -9999 -9999 -9999 -9999 -9999 -9999 -9999 -9999 39.01250076294 40.8412094116242 .66992187544 .4986305236847 .8512611389249 .67998123169 51.5086898803753 .0326118469254 .8613204956156 .3852500915558 .21395874023 59.7378807067961 .2618103027362 .7857398986864 .3096618652365 .83358764648 70.1005783081175 .8914871215881 .0728530883885 .3398437588 .99725341797 
91.4355392456193 .2642517089894 .7881774902395 .7025299072396 .61688232422 97.5312423706198 .1408081054798 .7503814697399 .0551681518699 .66472625732 100.2742996216100 .8839035034101 .7982025146102 .4077987671103 .3221969604 103.9317016602104 .8460998535105 .7603988647106 .6747970581107 .5891036987 108.5035018921109 .4179000854110 .0273971558110 .9418029785111 .8561019897 112.7705001831111 .8561019897113 .3800964355114 .5991973877115 .818397522 116.7326965332117 .9517974854119 .1709976196120 .3900985718121 .3044967651 122.5235977173123 .43800354124 .3523025513125 .5715026855126 .4858016968 127.4001998901128 .3144989014129 .2288970947129 .8385009766130 .7528076172 131.3623962402132 .2767028809132 .8863067627133 .4958953857134 .1054992676 134.7149963379135 .3246002197135 .9342041016136 .2389984131136 .8484954834 137.1533050537137 .4580993652137 .7628936768138 .0677032471138 .3724975586 138.6772003174138 .9819946289138 .9819946289139 .2868041992139 .2868041992 139.2868041992139 .5915985107139 .5915985107139 .5915985107139 .5915985107 139.2868041992139 .2868041992139 .2868041992139 .2868041992138 .9819946289 138.9819946289138 .6772003174138 .6772003174138 .3724975586138 .0677032471 138.0677032471137 .7628936768137 .4580993652137 .1533050537137 .1533050537 136.8484954834136 .5437011719136 .2389984131135 .9342041016135 .6293945312 135.3246002197135 .0198059082134 .7149963379134 .4102020264133 .8007049561 133.4958953857133 .0187835693132 .2904205322131 .5696411133130 .855758667 130.1477813721129 .4442749023128 .7435150146128 .0435028076127 .3421020508 126.637008667125 .9258728027125 .2065200806124 .4769363403123 .7355117798 122.9808807373122 .212310791121 .4295272827120 .6331100464119 .824180603 119.0047302246118 .1774139404117 .345664978116 .5135726929115 .685874939 114.8677749634114 .0646057129113 .2820281982112 .5256271362111 .8011627197 111.1136550903110 .4681243896109 .4179000854108 .5035018921107 .5891036987 106.6747970581106 .3700027466106 .0652008057106 .0652008057106 .3700027466 106.6747970581 107.0378265381 107.0450057983 107.1184005737 107.2540817261 107.446762085107 .6885681152107 .9709091187108 .2842025757108 .6190795898 108.9658889771109 .3154602051109 .6591262817109 .9887008667110 .2966308594 110.5756607056110 .8196029663111 .0233688354111 .1848449707111 .3098297119 111.4050674438111 .4856948853111 .5526580811111 .6294326782111 .7075119019 $111.7943344116111 .8561019897111 .551399231111 .8561019897112 .4656982422-9999$ -9999 -9999 -9999 -9999 -9999 -9999 -9999 -9999 -9999 -9999 -9999 -9999 -9999 -9999 -9999 -9999 -9999 -9999 -9999 -9999 -9999 -9999 -9999 -9999 -9999 -9999 -9999 -9999 -9999 -9999 -999 -9999 -9999 -9999 -9999 -9999 -9999 -9999 -9999 -9999 -9999 -9999 -9999 -9999 -9999 -9999

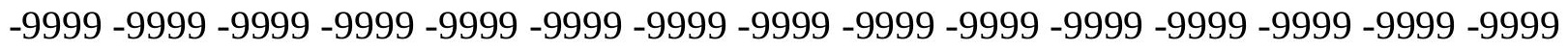

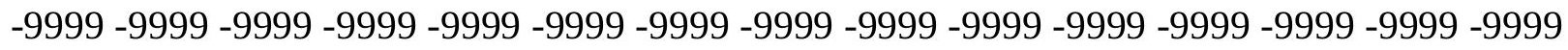
-9999 -9999 -9999 -9999 -9999 -9999 -9999 -9999 -9999 -9999 -9999 -9999 -9999 -9999 -9999 -

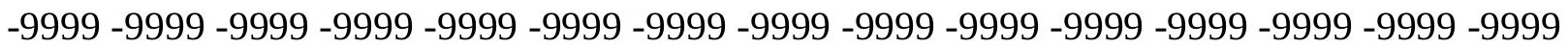

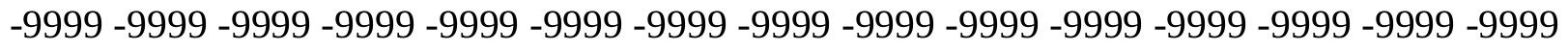

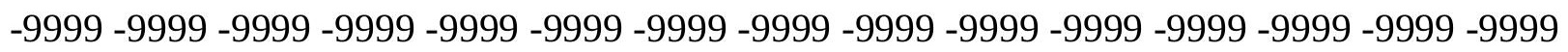

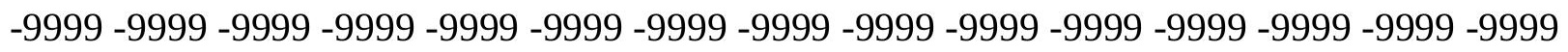
-9999 -9999 -9999 -9999 -9999 -9999 -9999 -9999 -9999 -9999 -9999 -9999 -

-9999 -9999 -9999 -9999 -9999 -9999 -9999 -9999 -9999 -9999 -9999 -9999 -9999 -9999 -9999

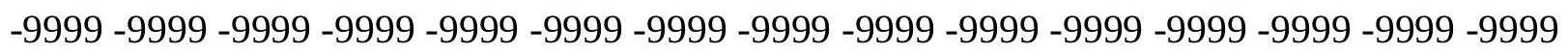


-9999 -9999 -9999 -9999 -9999 -9999 -9999 -9999 -9999 36.26942825317 38.09814071655 39.9268493652341 .7555618286145 .1082000732446 .9369087219248 .7656211853 50.2895507812552 .1182594299353 .9469718933155 .4708900451756 .99481964111 58.8235282897960 .3474502563561 .8713798522963 .3953094482464 .91924285889 71.6244964599678 .3297805786183 .8159103393688 .0829010009891 .13075256348 93.2642517089894 .4833908081195 .7025299072396 .3121032714896 .92166900635 97.5312423706197 .8360290527398 .445587158298 .7503814697399 .05516815186 99.66472625732100 .2742996216100 .5791015625101 .4934005737102 .1029968262 103.0174026489103 .6268997192104 .5412979126105 .4557037354106 .0652008057 106.979598999107 .8938980103108 .8082962036109 .4179000854110 .3321990967 111.24659729111 .8561019897111 .551399231112 .7705001831113 .9896011353 115.2088012695116 .4279022217117 .647102356118 .5614013672119 .7806015015 120.9997024536121 .9140014648122 .8283996582124 .0475006104124 .9618988037 125.8762969971126 .7906036377127 .7050018311128 .6192932129129 .2288970947 130.1432037354130 .7528076172131 .6672058105132 .2767028809132 .8863067627 133.4958953857134 .1054992676134 .7149963379135 .0198059082135 .6293945312 135.9342041016136 .5437011719136 .8484954834137 .1533050537137 .4580993652 137.7628936768137 .7628936768138 .0677032471138 .3724975586138 .3724975586 138.3724975586138 .6772003174138 .6772003174138 .6772003174138 .6772003174 138.6772003174138 .6772003174138 .3724975586138 .3724975586138 .3724975586 138.0677032471138 .0677032471137 .7628936768137 .7628936768137 .4580993652 137.4580993652137 .1533050537136 .8484954834136 .5437011719136 .2389984131 136.2389984131135 .9342041016135 .6293945312135 .3246002197135 .0198059082 134.7149963379134 .4102020264134 .1054992676133 .4958953857133 .1911010742 132.8863067627132 .2190704346131 .4885559082130 .764465332130 .0461273193 129.332611084128 .6226348877127 .9147186279127 .2071380615126 .4980545044 125.7855834961125 .0678100586124 .3429641724123 .6094284058122 .8659439087 122.1114959717121 .3456268311120 .5682678223119 .780090332118 .9822998047 118.1768569946117 .3663101196116 .5538864136115 .7433700562114 .9390106201 114.1455459595113 .3677978516112 .6109237671111 .8799514771111 .1801528931 110.5161132812109 .8924407959109 .3129425049108 .7815093994107 .8938980103 107.2844009399106 .979598999106 .979598999106 .9293060303106 .7320709229 106.596244812106 .5235137939106 .5136947632106 .5657196045106 .6760635376 106.8399505615107 .050201416107 .2990036011107 .5776748657107 .8778762817 108.1910629272108 .5090560913108 .824005127109 .1284255981109 .4153518677 109.6782073975109 .9117355347110 .1121444702110 .278503418110 .4133453369 110.5255279541110 .6269226074110 .7318725586110 .8531036377110 .9990310669 111.1495361328111 .24659729110 .9418029785110 .9418029785111 .551399231 -9999 -9999 -9999 -9999 -9999 -9999 -9999 -9999 -9999 -9999 -9999 -9999 -9999 -9999 -9999 -9999 -9999 -9999 -9999 -9999 -9999 -9999 -9999 -9999 -9999 -9999 -9999 -9999 -9999 -9999 -9999 -9999 -

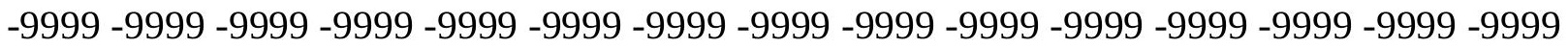
-9999 -9999 -9999 -9999 -9999 -9999 -9999 -9999 -9999 -9999 -9999 -9999 -9999 -9999 -9999 -9999 -9999 -9999 -9999 -9999 -9999 -9999 -9999 -9999 -9999 -9999 -9999 -9999 -9999 -9999 -9999 -9999 -9999 -9999 -9999 -9999 -9999 -9999 -9999 -9999 -9999 -9999 -9999 -9999 -9999 -9999 -9999 -9999 -9999 -9999 -9999 -9999 -9999 -9999 -9999 -9999 -9999 -9999 -9999 -9999 -9999 -9999 -9999 -9999 -9999 -9999 -9999 -9999 -9999 -9999 -9999 -9999 -9999 -9999 -9999 
-9999 -9999 -9999 -9999 -9999 -9999 -9999 -9999 -9999 -9999 -9999 -9999 -9999 -9999 -9999 -9999 -9999 -9999 -9999 -9999 -9999 -9999 -9999 -9999 -9999 -9999 -9999 -9999 -9999 -9999 -9999 -9999 -9999 -9999 -9999 -9999 -9999 -9999 -9999 -9999 -9999

-9999 -9999 -9999 -9999 -9999 -9999 -9999 -9999 -9999 -9999 -9999 -9999 -9999 -9999 -9999 -9999 -9999 -9999 -9999 -9999 -9999 -9999 -9999 -9999 -9999 -9999 -9999 -9999 -9999 -9999 -9999 -9999 -9999 -9999 -9999 -9999 -9999 31.39286994934 33.2215805053735 .05028915405 37.1837806701740 .5364189147942 .3651313781744 .1938400268646 .02254867554 47.8512611389249 .3751907348651 .2038993835452 .7278289794954 .55654144287 56.0804595947357 .6043891906759 .1283111572360 .6522407531762 .17617034912 65.8335876464874 .062782287681 .6824111938587 .1685485839891 .13075256348 93.5690307617294 .7881774902395 .7025299072396 .3121032714896 .92166900635 97.2264633178797 .5312423706197 .8360290527397 .8360290527398 .14080810547 98.445587158298 .7503814697399 .3599472045999 .66472625732100 .2742996216 100.8839035034101 .7982025146102 .4077987671103 .3221969604103 .9317016602 104.8460998535105 .7603988647106 .3700027466107 .2844009399108 .1986999512 108.8082962036109 .7226028442110 .3321990967110 .0273971558111 .24659729 112.4656982422113 .6848983765114 .9039993286116 .1231002808117 .0374984741 118.2565994263119 .4757995605120 .3900985718121 .3044967651122 .5235977173 123.43800354124 .3523025513125 .2667007446126 .1809997559127 .0953979492 128.0097961426128 .6192932129129 .533706665130 .1432037354130 .7528076172 131.6672058105132 .2767028809132 .8863067627133 .4958953857133 .8007049561 134.4102020264134 .7149963379135 .3246002197135 .6293945312135 .9342041016 136.2389984131136 .5437011719136 .8484954834137 .1533050537137 .1533050537 137.4580993652137 .4580993652137 .7628936768137 .7628936768137 .7628936768 137.7628936768137 .7628936768137 .7628936768137 .7628936768137 .7628936768 137.4580993652137 .4580993652137 .4580993652137 .1533050537137 .1533050537 136.8484954834136 .5437011719136 .5437011719136 .2389984131135 .9342041016 135.6293945312135 .6293945312135 .3246002197135 .0198059082134 .7149963379 134.4102020264134 .1054992676133 .8007049561133 .1911010742132 .8863067627 132.5814971924131 .9720001221131 .460647583130 .7280883789130 .0009613037 129.2786254883128 .5602722168127 .8447418213127 .1307678223126 .4168930054 125.7015762329124 .983253479124 .260383606123 .5315628052122 .7955093384 122.0512771606121 .2981491089120 .5358886719119 .7646255493118 .9851074219 118.1985855103117 .4069519043116 .6126403809115 .8186645508115 .0285568237 114.2461853027113 .4758605957112 .7219848633111 .9892730713111 .2822647095 110.60572052109 .9638519287109 .3608856201108 .80027771108 .2855911255 107.8193740845107 .4041290283107 .0412216187106 .7321395874106 .4775161743 106.2786636353106 .1364822388106 .052406311106 .0264587402106 .0579910278 106.1439743042106 .2801513672106 .4600601196106 .6767425537106 .9224472046 107.1897201538107 .4709396362107 .7588882446108 .0465393066108 .3271865845 108.594581604108 .8430099487109 .0680847168109 .2669525146109 .4393386841 109.587272644109 .717338562109 .8392944336109 .9700546265110 .1138458252 110.2788085938110 .4321136475110 .5396118164110 .6370010376110 .3321990967 110.6370010376110 .9418029785 -9999 -9999 -9999 -9999 -9999 -9999 -9999 -9999 -9999 -9999 -9999 -9999 -9999 -9999 -9999 -9999 -9999 -9999 -9999 -9999 -9999 -9999 -9999 -9999

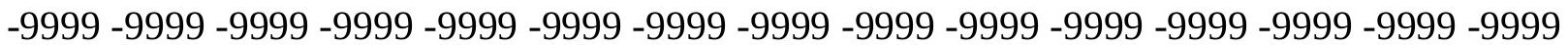


-9999 -9999 -9999 -9999 -9999 -9999 -9999 -9999 -9999 -9999 -9999 -9999 -9999 -9999 -9999 -9999 -9999 -9999 -9999 -9999 -9999 -9999 -9999 -9999 -9999 -9999 -9999 -9999 -9999 -9999

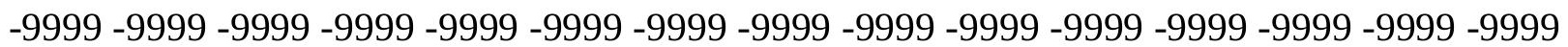
-9999 -9999 -9999 -9999 -9999 -9999 -9999 -9999 -9999 -9999 -9999 -9999 -9999 -9999 -9999

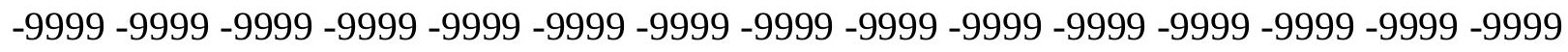
-9999 -9999 -9999 -9999 -9999 -9999 -9999 -9999 -9999 -9999 -9999 -9999 -9999 -9999 -9999 -9999 -9999 -9999 -9999 -9999 -9999 -9999 -9999 -9999 -9999 -9999 -9999 -9999 -9999 -9999

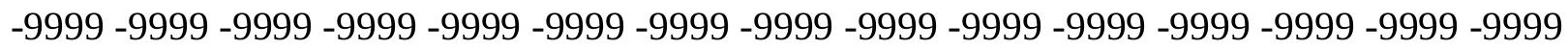
-9999-9999-9999

-9999 -9999 -9999 -9999 -9999 -9999 -9999 -9999 -9999 -9999 -9999 -9999 -9999 -9999 -9999 -9999 -9999 -9999 -9999 -9999 -9999 -9999 -9999 -9999 -9999 -9999 -9999 -9999 -9999 -9999 -9999 -9999 -9999 -9999 -9999 -9999 28.3450202941930 .4785099029532 .30722045898 35.6598587036137 .7933502197339 .622070312541 .4507789611843 .27949142456 45.1082000732446 .9369087219248 .4608306884850 .2895507812551 .81346893311 53.6421813964855 .1661109924356 .6900291442958 .2139587402359 .73788070679 61.2618103027368 .2718734741277 .7202072143685 .9494018554791 .43553924561 94.1785964965895 .7025299072396 .3121032714896 .6168823242296 .92166900635 97.22646331787 97.2264633178797.2264633178797.5312423706197.53124237061 97.5312423706197 .8360290527398 .1408081054798 .445587158298 .75038146973 99.3599472045999 .96952056885100 .5791015625101 .1886978149102 .1029968262 102.712600708103 .6268997192104 .2365036011105 .1509017944105 .7603988647 106.6747970581 107.2844009399108.1986999512108.8082962036108.1986999512 109.4179000854110.9418029785112.1608963013113.075302124114.2944030762 115.5136032104116 .7326965332117 .647102356118 .8662033081119 .7806015015 120.9997024536121 .9140014648122 .8283996582123 .7427978516124 .6570968628 125.5715026855126 .4858016968127 .4001998901128 .0097961426128 .9241027832 129.533706665130 .1432037354131 .0576019287131 .6672058105132 .2767028809 132.5814971924133 .1911010742133 .8007049561134 .1054992676134 .4102020264 135.0198059082135 .3246002197135 .6293945312135 .9342041016136 .2389984131 136.2389984131136 .5437011719136 .5437011719136 .8484954834136 .8484954834 136.8484954834136 .8484954834137 .1533050537136 .8484954834136 .8484954834 136.8484954834136 .8484954834136 .8484954834136 .5437011719136 .5437011719 136.2389984131136 .2389984131135 .9342041016135 .9342041016135 .6293945312 135.3246002197135 .0198059082135 .0198059082134 .7149963379134 .4102020264 134.1054992676133 .8007049561133 .4958953857132 .8863067627132 .5814971924 132.2767028809131 .9720001221131 .3623962402130 .7438354492130 .0094299316 129.2796478271 128.5538787842 127.831413269 127.1112442017 126.3922958374 125.6733474731124 .953125124 .2303771973123 .5038452148122 .7724533081 122.0352096558121 .2914352417120 .5406723022119 .7828674316119 .0183029175 118.2478103638117 .4726486206116 .6946411133115 .9160919189115 .1398086548 114.3690719604113 .607460022112 .8589096069112 .1274490356111 .4173812866 110.7328262329110 .0780944824109 .456993103108 .8734283447108 .3305435181 107.8315582275107 .3787994385106 .9745788574106 .6201248169106 .3167037964 106.0646286011105 .864692688105 .7171936035105 .6231460571105 .5825653076 105.5951004028105 .6582489014105 .7683181763105 .9195861816106 .1059188843 106.3205490112 106.5569458008 106.8083114624 107.0682296753 107.3304519653 
107.5890808105 107.8386383057 108.0742111206 108.2921676636108.490272522 108.6685180664108 .8287277222108 .9748458862109 .1149597168109 .2559356689 109.4109420776109 .5651473999109 .7131347656109 .7979049683109 .7226028442 109.7226028442110 .0273971558110 .0273971558 -9999 -9999 -9999 -9999 -9999 -9999 -9999 -9999 -9999 -9999 -9999 -9999 -9999 -9999 -9999 -9999 -9999 -9999 -9999 -9999 -9999 -9999 -9999 -9999 -9999 -9999 -9999 -9999 -9999 -9999 -9999 -9999 -9999 -9999 -9999 -9999 -9999

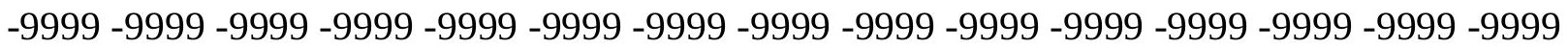

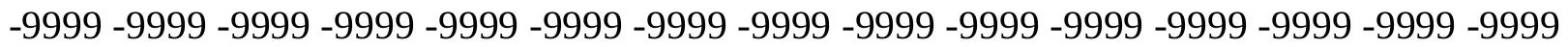
-9999 -9999 -9999 -9999 -9999 -9999 -9999 -9999 -9999 -9999 -9999 -9999 -9999 -9999 -9999 -9999 -9999 -9999 -9999 -9999 -9999 -9999 -9999 -9999 -9999 -9999 -9999 -9999 -9999 -9999 -

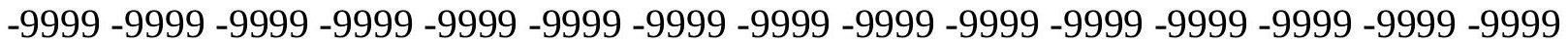
-9999 -9999 -9999 -9999 -9999 -9999 -9999 -9999 -9999 -9999 -9999 -9999 -9999 -9999 -9999 -999 -9999 -9999 -9999 -9999 -9999 -9999 -9999 -9999 -9999 -9999 -9999 -9999 -9999 -9999 -9999 -9999 -9999 -9999 -9999 -9999 -9999 -9999 -9999 -9999 -9999 -9999 -9999 -9999 -9999 -9999 -9999 -9999-9999-9999-9999

-9999 -9999 -9999 -9999 -9999-9999 -9999 -9999 -9999 -9999 -9999 -9999 -9999 -9999 -9999 -

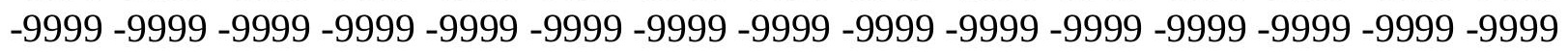
-9999 -9999 -9999 -9999 23.46845054626 25.60194969177 27.4306602478 29.56415939331 32.9167900085435 .0502891540536 .8790016174338 .7077102661140 .53641891479 42.3651313781744 .1938400268646 .0225486755447 .5464782714849 .37519073486 50.8991203308152 .7278289794954 .2517509460455 .7756805419957 .29959869385 58.8235282897960 .3474502563570 .4053573608481 .6824111938590 .82597351074 95.3977432251 96.92166900635 97.22646331787 97.2264633178797.22646331787 96.9216690063596 .9216690063596 .9216690063596 .9216690063596 .92166900635 96.9216690063596 .9216690063596 .9216690063596 .9216690063597 .22646331787 97.5312423706198.1408081054798.7503814697399.3599472045999.96952056885 100.5791015625101 .4934005737102 .1029968262103 .0174026489103 .6268997192 104.5412979126105 .1509017944105 .7603988647106 .6747970581107 .2844009399 106.6747970581 107.8938980103109.1130981445 110.3321990967 111.551399231 112.7705001831113 .9896011353115 .2088012695116 .1231002808117 .342300415 118.2565994263119 .4757995605120 .3900985718121 .3044967651122 .5235977173 123.43800354124 .3523025513124 .9618988037125 .8762969971126 .7906036377 127.4001998901128 .3144989014128 .9241027832129 .533706665130 .4479980469 131.0576019287131 .3623962402131 .9720001221132 .5814971924132 .8863067627 133.4958953857133 .8007049561134 .1054992676134 .4102020264134 .7149963379 135.0198059082135 .3246002197135 .6293945312135 .6293945312135 .9342041016 135.9342041016136 .2389984131136 .2389984131136 .2389984131136 .2389984131 136.2389984131136 .2389984131136 .2389984131136 .2389984131135 .9342041016 135.9342041016135 .6293945312135 .6293945312135 .3246002197135 .3246002197 135.0198059082134 .7149963379134 .7149963379134 .4102020264134 .1054992676 133.8007049561133 .4958953857133 .1911010742132 .8863067627132 .5814971924 131.9720001221131 .6672058105131 .3623962402130 .7528076172130 .0683746338 129.3324432373128 .6004486084127 .8718490601127 .1460113525126 .4221038818 125.69921875124 .9763412476124 .252456665123 .526550293122 .7976608276 122.0649414062121 .3276824951120 .5854263306119 .837928772119 .0853042603 118.3279571533117 .5667648315116 .8029937744116 .0383987427115 .2751617432 
114.5158996582113 .7636489868113 .0216751099112 .2936401367111 .5832214355 110.8943634033110 .2307662964109 .5963745117108 .9946365356108 .4291305542 107.9026947021107 .418258667106 .977935791106 .5838317871106 .2370452881 105.9387054443105 .688949585105 .4882125854105 .3363113403105 .2337265015 105.1802978516105 .1757583618105 .2180328369105 .3040313721105 .4287643433 105.5868988037105 .772567749105 .9802398682106 .203994751106 .4381027222 106.6769561768106 .9154434204107 .1488265991107 .3729095459107 .5845336914 107.7818145752107 .9646911621108 .1345443726108 .2941436768108 .4472198486 108.5986251831108 .7506637573108 .8977279663109 .020942688109 .0932388306 109.092124939109 .1130981445109 .4179000854109 .4179000854109 .7226028442 -9999 -9999 -9999 -9999 -9999 -9999 -9999 -9999 -9999 -9999 -9999 -9999 -9999 -9999 -9999 -9999 -9999 -9999 -9999 -9999 -9999 -9999 -9999 -9999 -9999 -9999 -9999 -9999 -9999 -9999 -9999 -9999 -9999 -9999 -9999 -9999 -9999 -9999 -9999 -9999 -9999 -9999 -9999 -9999 -9999 -9999 -9999 -9999 -9999 -9999 -9999 -9999 -9999 -9999 -9999 -9999 -9999 -9999 -9999 -9999 - 9999 -9999 -9999 -9999 -9999 -9999 -9999 -9999 -9999 -9999 -9999 -9999 -9999 -9999 -9999 -9999

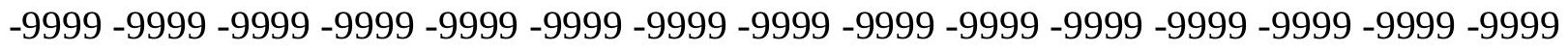
-9999 -9999 -9999 -9999 -9999 -9999 -9999 -9999 -9999 -9999 -9999 -9999 -9999 -9999 -9999 -9999 -9999 -9999 -9999 -9999 -9999 -9999 -9999 -9999 -9999 -9999 -9999 -9999 -9999 -9999 -9999 -9999 -9999 -9999 -9999 -9999 -9999 -9999 -9999 -9999 -9999 -9999 -9999 -9999 -9999 -

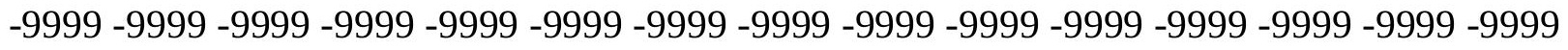
-9999 -9999 -9999 -9999 -9999 -9999 -9999 -9999 -9999-9999

-9999 -9999 -9999 -9999 -9999 -9999 -9999 -9999 -9999 -9999 -9999 -9999 -9999 -9999 -999 -9999 -9999 -9999 -9999 -9999 -9999 -9999 -9999 -9999 -9999 -9999 -9999 -9999 -9999 -9999 -9999 -9999-9999 20.7253894805922.55410003662 24.68759918213 28.34502029419 30.1737308502232 .0024414062534 .1359291076735 .9646492004437 .79335021973 39.622070312541 .4507789611843 .2794914245645 .1082000732446 .63212966919 48.4608306884849 .9847602844251 .8134689331153 .3373985290554 .86132049561 56.3852500915557 .909179687560 .9570198059171 .9292907714883 .81591033936 95.0929565429797 .2264633178797 .8360290527397 .5312423706197 .22646331787 96.9216690063596 .6168823242296 .6168823242296 .6168823242296 .61688232422 96.3121032714896 .3121032714896 .0073165893696 .0073165893696 .00731658936 96.3121032714896 .6168823242296 .9216690063597 .5312423706198 .14080810547 98.7503814697399 .35994720459100 .2742996216100 .8839035034101 .4934005737 102.1029968262103 .0174026489103 .6268997192104 .5412979126105 .1509017944 105.7603988647105 .1509017944106 .3700027466107 .5891036987108 .8082962036 110.0273971558111 .24659729112 .4656982422113 .6848983765114 .5991973877 115.818397522117 .0374984741117 .9517974854118 .8662033081120 .0852966309 120.9997024536121 .9140014648122 .8283996582123 .7427978516124 .6570968628 125.5715026855126 .1809997559127 .0953979492127 .7050018311128 .3144989014 129.2288970947 129.8385009766130.4479980469 130.7528076172 131.3623962402 131.9720001221132 .2767028809132 .8863067627133 .1911010742133 .4958953857 133.8007049561134 .1054992676134 .4102020264134 .7149963379135 .0198059082 135.0198059082135 .3246002197135 .3246002197135 .3246002197135 .6293945312 135.6293945312135 .6293945312135 .6293945312135 .6293945312135 .3246002197 135.3246002197135 .3246002197135 .0198059082135 .0198059082134 .7149963379 134.7149963379134 .4102020264134 .1054992676134 .1054992676133 .8007049561 
133.4958953857133 .1911010742132 .8863067627132 .5814971924132 .2767028809 131.9720001221131 .3623962402131 .0576019287130 .7528076172130 .1432037354 129.4344177246128 .6973571777127 .9636535645127 .2328491211126 .50440979 125.7776489258125 .0518112183124 .3260955811123 .5996856689122 .8717956543 122.1416931152121 .4087677002120 .6725234985119 .9327087402119 .1892471313 118.4423980713117 .6926651001116 .9409561157116 .1885528564115 .4371185303 114.6887283325113 .94581604113 .2111816406112 .4878234863111 .7791061401 111.0884094238110 .419342041109 .7752761841109 .1597824097108 .5759887695 108.0271835327107 .5159301758107 .0448913574106 .6159591675106 .2310714722 105.8911972046105 .5973587036105 .349609375105 .1481628418104 .992515564 104.8826904297104 .8181991577104 .7986831665104 .8223648071104 .8866577148 104.9873275757105 .1198043823105 .2789993286105 .4602661133105 .6586608887 105.8691940308106 .086807251106 .3070068359106 .5257720947106 .7394790649 106.9452056885107 .1410903931107 .3268280029107 .5031967163107 .6718673706 107.8344192505107 .9915542603108 .1431274414108 .2852172852108 .4050445557 108.4896087646108 .5035018921108 .5035018921108 .7373580933108 .8082962036 109.1130981445 -9999 -9999 -9999 -9999 -9999 -9999 -9999 -9999 -9999 -9999 -9999 -9999 -9999 -9999 -9999 -9999 -9999 -9999 -9999 -9999 -9999 -9999 -9999 -9999 -9999 -9999 -9999 -9999 -9999 -9999 -9999 -9999 -9999 -9999 -9999 -9999 -9999 -9999 -9999 -9999 -9999 -9999 -

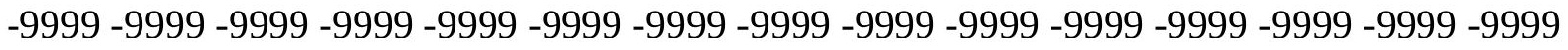

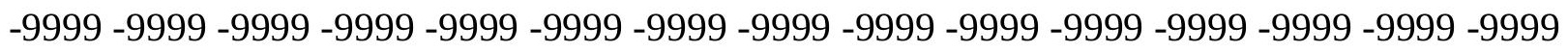
-9999 -9999 -9999 -9999 -9999 -9999 -9999 -9999 -9999 -9999 -9999 -9999 -9999 -9999 -9999 -9999 -9999 -9999 -9999 -9999 -9999 -9999 -9999 -9999 -9999 -9999 -9999 -9999 -9999 -9999 -

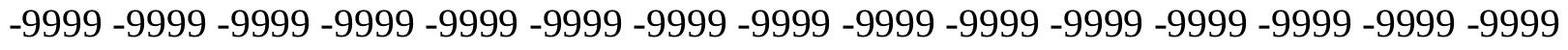

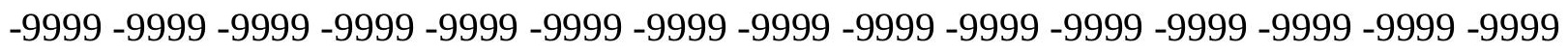

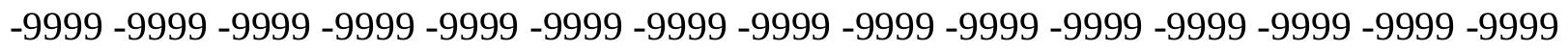
-9999 -9999 -9999 -9999 -9999 -9999 -9999 -9999 -9999 -9999 -9999 -9999 -9999 -9999 -9999 -9999 -9999 -9999 -9999 -9999 -9999 -9999 -9999 -9999 -9999 -9999 -9999 -9999 -9999 -9999 -9999 -9999 -9999 -9999 -9999 -9999 -9999 -9999 -9999 -9999 -9999 -9999 -9999 -9999 -9999 -9999 17.67753982544 19.8110294342 21.94453048706 25.29715919495 27.4306602478 29.2593708038331 .3928699493433 .2215805053735 .0502891540537 .18378067017 39.0125007629440 .8412094116242 .3651313781744 .1938400268646 .02254867554 47.5464782714849 .3751907348650 .8991203308152 .4230384826753 .94697189331 55.4708900451756 .9948196411162 .4809494018672 .5388565063582 .90155792236 91.1307525634895 .397743225196 .3121032714896 .6168823242296 .31210327148 96.0073165893696 .0073165893695 .7025299072395 .7025299072395 .70252990723 95.7025299072395 .397743225195 .0929565429795 .0929565429795 .09295654297 95.0929565429795 .397743225195 .7025299072396 .3121032714896 .92166900635 97.5312423706198 .1408081054798 .7503814697399 .66472625732100 .2742996216 100.8839035034101 .4934005737102 .1029968262103 .0174026489103 .6268997192 104.2365036011104 .8460998535104 .8460998535106 .0652008057107 .2844009399 108.5035018921109 .7226028442110 .9418029785112 .1608963013113 .075302124 114.2944030762115 .5136032104116 .4279022217117 .647102356118 .5614013672 119.4757995605120 .3900985718121 .6092987061122 .5235977173123 .1332015991 124.0475006104124 .9618988037125 .5715026855126 .4858016968127 .0953979492 128.0097961426128 .6192932129129 .2288970947129 .8385009766130 .4479980469 
130.7528076172131 .3623962402131 .6672058105132 .2767028809132 .5814971924 132.8863067627133 .1911010742133 .4958953857133 .8007049561134 .1054992676 134.1054992676134 .4102020264134 .4102020264134 .7149963379134 .7149963379 134.7149963379134 .7149963379134 .7149963379134 .7149963379134 .7149963379 134.7149963379134 .7149963379134 .4102020264134 .4102020264134 .4102020264 134.1054992676133 .8007049561133 .8007049561133 .4958953857133 .1911010742 132.8863067627132 .5814971924132 .2767028809131 .9720001221131 .6672058105 131.3623962402131 .0576019287130 .4479980469130 .1432037354129 .533706665 128.8416595459128 .1038818359127 .3689956665126 .6366271973125 .9063339233 125.1775665283124 .44972229123 .7221679688122 .9942703247122 .2654418945 121.5351486206120 .802986145120 .0686569214119 .3320617676118 .5932846069 117.8526763916117 .1108551025116 .3687438965115 .6275939941114 .8890151978 114.1549682617113 .4277114868112 .7098388672112 .0040969849111 .3135681152 110.6413269043109 .9907150269109 .3647994995108 .7668304443108 .1996383667 107.666229248 107.1689453125 106.7101974487 106.2916717529 105.915145874 105.581489563105 .2916183472105 .0455322266104 .8433532715104 .6844100952 104.5683746338104 .4944229126104 .4619827271104 .4693984985104 .5145339966 104.5938186646104 .7033996582104 .8388900757104 .9963684082105 .1717605591 105.3609161377 105.5593261719 105.7629928589 105.9684448242 106.1725616455 106.3725280762 106.5663070679 106.7531661987 106.9333190918 107.1074905396 107.2761001587 107.4387893677 107.5938034058 107.7378768921 107.8659973145 107.9750671387 107.8938980103108.1683502197 108.1986999512 108.3867340088 108.5035018921 108.5035018921 -9999 -9999 -9999 -9999 -9999 -9999 -9999 -9999 -9999

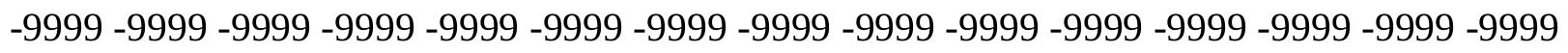

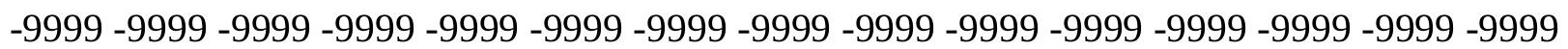

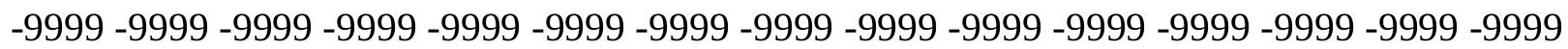

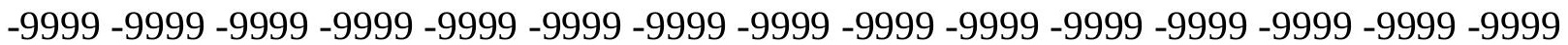

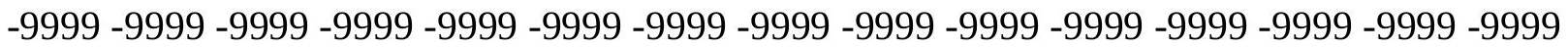

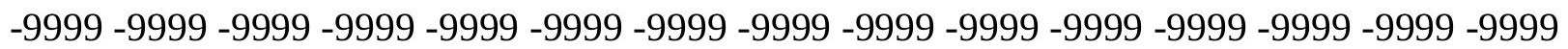

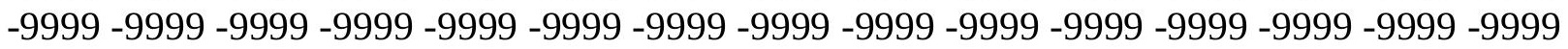

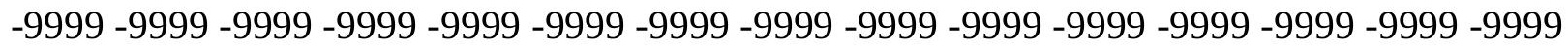

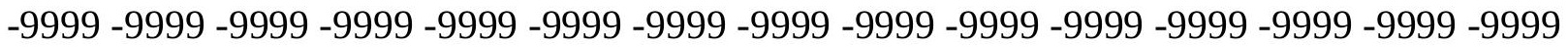

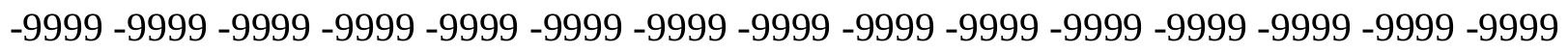
$-9999$

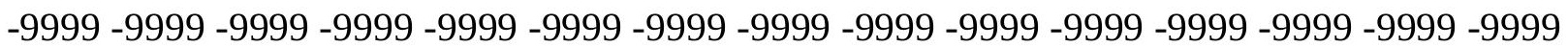

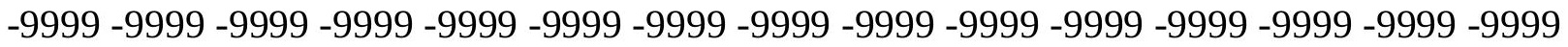
-9999 14.9344701767 16.76317977905 20.4206008911122.55410003662 24.68759918213 26.5163097381628 .6497993469230 .4785099029532 .6120109558134 .44071960449 36.2694282531738 .0981407165539 .9268493652341 .7555618286143 .58427047729 45.1082000732446 .9369087219248 .4608306884850 .2895507812551 .81346893311 53.3373985290554 .8613204956156 .3852500915562 .7857398986871 .31971740723 79.8537063598686 .8637619018691 .1307525634893 .2642517089894 .17859649658 94.4833908081194 .4833908081194 .7881774902394 .7881774902394 .78817749023 94.7881774902394 .7881774902394 .4833908081194 .1785964965893 .87381744385 93.8738174438593.8738174438594.17859649658 94.4833908081195.09295654297 95.7025299072396 .3121032714896 .9216690063597 .5312423706198 .14080810547 
98.7503814697399 .3599472045999 .96952056885100 .8839035034101 .4934005737 102.1029968262102 .712600708103 .3221969604103 .0174026489104 .5412979126 105.7603988647106 .979598999108 .1986999512109 .4179000854110 .6370010376 111.551399231112 .7705001831113 .9896011353114 .9039993286116 .1231002808 117.0374984741118 .2565994263119 .1709976196120 .0852966309120 .9997024536 121.9140014648122 .8283996582123 .7427978516124 .3523025513125 .2667007446 125.8762969971126 .7906036377127 .4001998901128 .0097961426128 .6192932129 129.2288970947129 .8385009766130 .1432037354130 .7528076172131 .0576019287 131.6672058105131 .9720001221132 .2767028809132 .5814971924132 .8863067627 133.1911010742133 .4958953857133 .4958953857133 .8007049561133 .8007049561 134.1054992676134 .1054992676134 .1054992676134 .1054992676134 .1054992676 134.1054992676134 .1054992676134 .1054992676134 .1054992676133 .8007049561 133.8007049561133 .4958953857133 .4958953857133 .1911010742132 .8863067627 132.5814971924132 .2767028809132 .2767028809131 .9720001221131 .3623962402 131.0576019287130 .7528076172130 .4479980469129 .8385009766129 .533706665 129.0308532715128 .2901306152127 .5520935059126 .8165740967126 .0832901001 125.3518829346124 .621925354123 .8929443359123 .1644668579122 .4360275269 121.7072067261120 .977645874120 .2471084595119 .5154571533118 .7827453613 118.0491714478117 .3151931763116 .581489563115 .848991394115 .1189498901 114.3928833008113 .6726455688112 .9603271484112 .2583389282111 .5691986084 110.8957519531110 .240776062109 .6073379517108 .9982528687108 .4164962769 107.8646240234107 .3453826904106 .8609008789106 .4133911133106 .0043563843 105.6353988647105 .3072967529105 .0208969116104 .7761611938104 .5731658936 104.4112014771104 .2897491455104 .2076873779104 .1642150879104 .1576843262 104.1862716675 104.2469787598 104.3366012573104.4513549805104.587928772 104.7429351807104 .9129714966105 .0941314697105 .2828598022105 .4761047363 105.6711196899105 .8651733398106 .0560379028106 .2425460815106 .424369812 106.6015396118106 .773765564106 .9401855469107 .0992584229107 .2491836548 107.388420105 107.5162887573 107.5891036987 107.749458313 107.8590545654 107.9755859375108 .076171875108 .1986999512 -9999 -9999 -9999 -9999 -9999 -9999 -9999 -9999 -9999 -9999 -9999 -9999 -9999 -9999 -9999 -9999 -9999 -9999 -9999 -9999 -9999 -9999 -9999 -9999 -9999 -9999 -9999 -9999 -9999 -9999 -9999 -9999 -9999 -9999 -9999 -9999 -9999 -

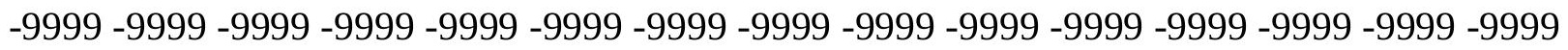
-9999 -9999 -9999 -9999 -9999 -9999 -9999 -9999 -9999 -9999 -9999 -9999 -9999 -9999 -9999 -9999 -9999 -9999 -9999 -9999 -9999 -9999 -9999 -9999 -9999 -9999 -9999 -9999 -9999 -9999 -

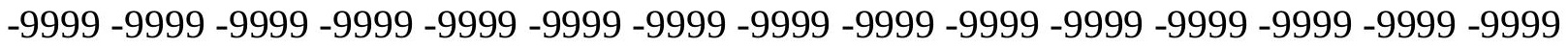

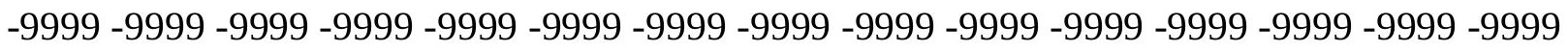

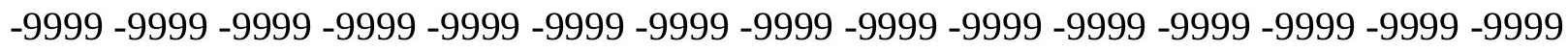
-9999 -9999 -9999 -9999 -9999 -9999 -9999 -9999 -9999 -9999 -9999 -9999 -9999 -9999 -9999 -

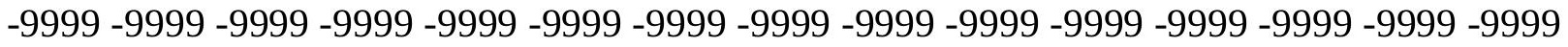
-9999 -9999-9999

-9999 -9999 -9999 -9999 -9999 -9999 -9999 -9999 -9999 -9999 -9999 -9999 -9999 -9999 -9999 -9999 -9999 -9999 -9999 -9999 -9999 -9999 -9999 -9999 -9999 -9999 -9999 -9999 -9999 -9999 11.8866195678714 .0201196670517 .6775398254419 .811029434221 .63973999023 23.7732391357425 .906740188627 .7354507446329 .8689403533931 .69765090942 33.5263595581135 .6598587036137 .4885711669939 .3172798156740 .84120941162 
42.66992187544 .4986305236846 .0225486755447 .8512611389249 .37519073486 50.8991203308152 .4230384826753 .9469718933155 .4708900451761 .87137985229 69.1862335205176 .5010681152382 .2919769287186 .8637619018689 .60682678223 91.1307525634892 .0450973510792 .6546783447392 .9594726562593 .56903076172 93.5690307617293 .5690307617293 .5690307617293 .5690307617293 .26425170898 92.9594726562592 .6546783447392 .6546783447392 .9594726562593 .56903076172 94.1785964965894 .4833908081195 .0929565429795 .7025299072396 .31210327148 96.9216690063597 .5312423706198 .1408081054798 .7503814697399 .35994720459 99.96952056885100 .5791015625101 .1886978149101 .7982025146101 .4934005737 102.712600708104 .2365036011105 .4557037354106 .6747970581107 .8938980103 109.1130981445110 .0273971558111 .24659729112 .4656982422113 .6848983765 114.5991973877115 .818397522116 .7326965332117 .647102356118 .8662033081 119.7806015015120 .6949005127121 .6092987061122 .5235977173123 .1332015991 124.0475006104124 .6570968628125 .5715026855126 .1809997559126 .7906036377 127.4001998901128 .0097961426128 .6192932129129 .2288970947129 .8385009766 130.1432037354130 .7528076172131 .0576019287131 .3623962402131 .6672058105 131.9720001221132 .2767028809132 .5814971924132 .8863067627133 .1911010742 133.1911010742133 .4958953857133 .4958953857133 .4958953857133 .4958953857 133.4958953857133 .4958953857133 .4958953857133 .4958953857133 .4958953857 133.1911010742133 .1911010742132 .8863067627132 .8863067627132 .5814971924 132.5814971924132 .2767028809131 .9720001221131 .6672058105131 .3623962402 131.0576019287130 .7528076172130 .4479980469129 .8385009766129 .533706665 128.9241027832128 .5194396973127 .7792816162127 .0414581299126 .3058547974 125.572265625124 .8404388428124 .1100387573123 .3807296753122 .6521682739 121.9240264893121 .1960449219120 .4680175781119 .7398376465119 .0115280151 118.283241272117 .5553131104116 .8282470703116 .1027908325115 .3798751831 114.6607284546113 .9468002319113 .2398376465112 .5417556763111 .8548126221 111.181312561110 .5238723755109 .8850250244109 .2675704956108 .674079895 108.1072998047 107.5695419312 107.0633163452 106.5905532837106.1533050537 105.7528991699105 .3907699585105 .0676193237104 .7842330933104 .5405502319 104.3366394043 104.1717910767 104.0454483032103.9563522339103.9034881592 103.8852157593103 .8998260498103 .9447860718104 .0174179077104 .1144866943 104.2331390381104 .3704833984104 .5237197876104 .6895370483104 .8648071289 105.0467605591105 .2329559326105 .420753479105 .6078491211105 .792755127 105.9747009277 106.1531600952106.3274078369 106.4964904785106.6593017578 106.8150482178106 .9638519287107 .1050338745107 .2394943237107 .3668746948 107.4890213013107 .6031188965107 .6955184937107 .7207183838107 .5891036987 -9999 -9999 -9999 -9999 -9999 -9999 -9999 -9999 -9999 -9999 -9999 -9999 -9999 -9999 -9999 -9999

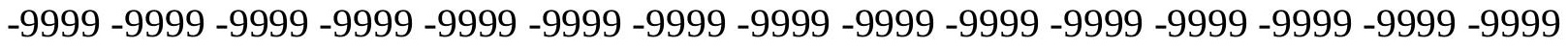
-9999 -9999 -9999 -9999 -9999 -9999 -9999 -9999 -9999 -9999 -9999 -9999 -9999 -9999 -9999 -

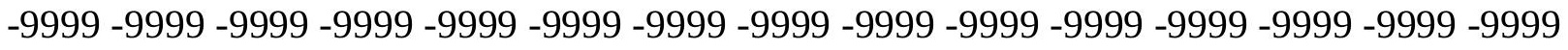

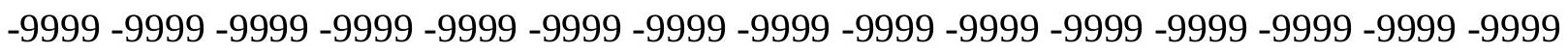
-9999 -9999 -9999 -9999 -9999 -9999 -9999 -9999 -9999 -9999 -9999 -9999 -9999 -9999 -9999 -9999 -9999 -9999 -9999 -9999 -9999 -9999 -9999 -9999 -9999 -9999 -9999 -9999 -9999 -9999 -9999 -9999 -9999 -9999 -9999 -9999 -9999 -9999 -9999 -9999 -9999 -9999 -9999 -9999 -9999 -

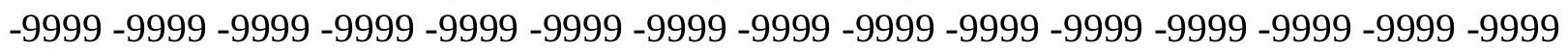


-9999 -9999 -9999 -9999 -9999 -9999 -9999 -9999 -9999 -9999 -9999 -9999 -9999 -9999 -9999 -9999 -9999 -9999 -9999 -9999 -9999 -9999 -9999

-9999 -9999 -9999 -9999 -9999 -9999 -9999 -9999 -9999 -9999 -9999 -9999 -9999 -9999 -9999 -9999 -9999 -9999 -9999 -9999 -9999 -9999 -9999 -9999 -9999 -9999 -9999 -9999 -9999 8.83876895904510 .9722604751613 .1057596206716 .7631797790518 .89668083191 21.0301704406723 .1636695861824 .9923801422127 .1258792877228 .95458984375 31.0880794525132 .9167900085434 .7455101013236 .5742111206138 .40293121338 40.2316398620642 .0603485107443 .8890609741245 .4129791259847 .24169921875 48.765621185350 .2895507812551 .8134689331153 .3373985290554 .86132049561 60.6522407531767 .0527267456173 .1484298706178 .6345596313582 .59677124023 85.9494018554788 .0829010009889 .6068267822390 .5211791992291 .43553924561 92.0450973510792 .349891662692 .349891662692 .349891662692 .3498916626 92.349891662692 .0450973510791 .7403335571391 .7403335571392 .04509735107 92.6546783447392 .9594726562593 .5690307617294 .1785964965894 .48339080811 95.0929565429795 .7025299072396 .3121032714896 .6168823242297 .22646331787 97.8360290527398 .445587158299 .0551681518699 .66472625732100 .2742996216 99.96952056885101 .1886978149102 .4077987671103 .9317016602105 .1509017944 106.3700027466107 .5891036987108 .8082962036109 .7226028442110 .9418029785 112.1608963013113 .3800964355114 .2944030762115 .5136032104116 .4279022217 117.342300415118 .2565994263119 .4757995605120 .3900985718120 .9997024536 121.9140014648122 .8283996582123 .7427978516124 .3523025513125 .2667007446 125.8762969971126 .4858016968127 .0953979492127 .7050018311128 .3144989014 128.9241027832129 .2288970947129 .8385009766130 .1432037354130 .4479980469 131.0576019287131 .3623962402131 .6672058105131 .9720001221132 .2767028809 132.2767028809132 .5814971924132 .5814971924132 .8863067627132 .8863067627 132.8863067627132 .8863067627132 .8863067627132 .8863067627132 .8863067627 132.8863067627132 .8863067627132 .5814971924132 .5814971924132 .2767028809 132.2767028809131 .9720001221131 .6672058105131 .3623962402131 .0576019287 130.7528076172130 .4479980469130 .1432037354129 .8385009766129 .533706665 128.9241027832128 .6192932129128 .0097961426127 .3089294434126 .5718002319 125.8366622925125 .1033706665124 .3717651367123 .6416244507122 .912727356 122.1848297119121 .4577484131120 .7313461304120 .0055465698119 .2803649902 118.5559539795117 .8325576782117 .1106033325116 .390663147115 .6735153198 114.9600982666114 .2516098022113 .5494232178112 .8551864624112 .1706695557 111.4979629517110 .8391799927110 .196723938109 .5729141235108 .9703063965 108.391242981107 .8382644653107 .3134841919106 .8191757202106 .3571243286 105.9291992188105 .5365905762105 .1806030273104 .8618469238104 .5810546875 104.3381500244104 .1332015991103 .9655532837103 .8346633911103 .7392959595 103.6783752441103 .6502304077103 .6532592773103 .6851501465103 .7436294556 103.8259429932103 .9296188354104 .0520477295104 .1908416748104 .3432312012 104.5065002441104 .6780929565104 .8557128906105 .0369338989105 .2194900513 105.4017486572105 .5825805664105 .7610473633105 .9361114502106 .1068191528 106.2723846436106 .4324951172106 .587020874106 .7359008789106 .8785552979 107.0137863159 107.1391220093 107.2466278076 107.3209152222 107.2844009399 107.2844009399 -9999 -9999 -9999 -9999 -9999 -9999 -9999 -9999 -9999 -9999 -9999 -9999 -9999 -9999 -9999 -9999 -9999 -9999 -9999 -9999 -9999 -9999 -9999 -9999 -9999 -9999 -9999 
-9999 -9999 -9999 -9999 -9999 -9999 -9999 -9999 -9999 -9999 -9999 -9999 -9999 -9999 -9999 -9999 -9999 -9999 -9999 -9999 -9999 -9999 -9999 -9999 -9999 -9999 -9999 -9999 -9999 -9999 -9999 -9999 -9999 -9999 -9999 -9999 -9999 -9999 -9999 -9999 -9999 -9999 -9999 -9999 -9999 -9999 -9999 -9999 -9999 -9999 -9999 -9999 -9999 -9999 -9999 -9999 -9999 -9999 -9999 -9999 -9999 -9999 -9999 -9999 -9999 -9999 -9999 -9999 -9999 -9999 -9999 -9999-9999 -9999 -9999 -9999 -9999 -9999 -9999 -9999 -9999 -9999 -9999 -9999 -9999 -9999 -9999 -9999 -9999 -9999

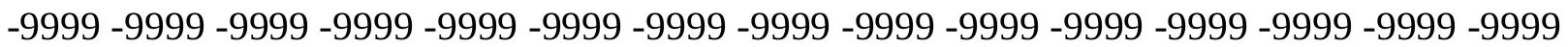
-9999 -9999 -9999 -9999 -9999 -9999 -9999 -9999 -9999 -9999 -9999 -9999 -9999 -9999 -9999 -9999 -9999 -9999 -9999 -9999 -9999 -9999 -9999 -9999 -9999 -9999 -9999 -9999 -9999 -9999 -9999 -9999 -9999 -9999 -9999 -9999 -9999 -9999 -9999 -9999 -9999 -9999 -9999 -9999 -9999 -9999 -9999 -9999 -9999 -9999 -9999 -9999 -9999 -9999 -9999 -9999 8.22919845581110 .3626899719214 .0201196670516 .1536102294918 .287109375 20.4206008911122 .2493095397924 .3828105926526 .5163097381628 .34502029419 30.4785099029532 .3072204589834 .1359291076735 .9646492004437 .79335021973 39.622070312541 .4507789611843 .2794914245644 .8034095764246 .32733917236 48.1560516357449 .6799812316951 .2038993835452 .7278289794953 .94697189331 59.4331016540564 .9192428588970 .4053573608475 .2819290161179 .24413299561 82.5967712402385 .0350494384886 .8637619018688 .3876876831189 .60682678223 90.2164001464890 .8259735107491 .1307525634891 .1307525634891 .13075256348 91.1307525634891 .1307525634891 .1307525634891 .1307525634891 .43553924561 91.7403335571392 .0450973510792 .349891662692 .9594726562593 .26425170898 93.8738174438594 .4833908081194 .7881774902395 .397743225196 .00731658936 96.3121032714896 .9216690063597 .5312423706198 .1408081054798 .75038146973 98.445587158299 .66472625732100 .8839035034102 .4077987671103 .6268997192 104.8460998535106 .0652008057107 .2844009399108 .5035018921109 .7226028442 110.6370010376111 .8561019897113 .075302124113 .9896011353115 .2088012695 116.1231002808117 .0374984741117 .9517974854118 .8662033081119 .7806015015 120.6949005127121 .6092987061122 .5235977173123 .1332015991124 .0475006104 124.6570968628125 .5715026855126 .1809997559126 .7906036377127 .4001998901 127.7050018311128 .3144989014128 .9241027832129 .2288970947129 .8385009766 130.1432037354130 .4479980469130 .7528076172131 .0576019287131 .3623962402 131.6672058105131 .9720001221131 .9720001221132 .2767028809132 .2767028809 132.2767028809132 .2767028809132 .5814971924132 .5814971924132 .2767028809 132.2767028809132 .2767028809132 .2767028809131 .9720001221131 .9720001221 131.6672058105131 .3623962402131 .3623962402131 .0576019287130 .7528076172 130.4479980469130 .1432037354129 .8385009766129 .533706665128 .9241027832 128.6192932129128 .0097961426127 .6161575317126 .8784332275126 .1424865723 125.4083328247124 .6759109497123 .9451370239123 .2158966064122 .4880599976 121.761505127121 .0361480713120 .3119659424119 .5889968872118 .8673553467 118.1472930908117 .4291534424116 .7134399414116 .0007629395115 .2919311523 114.5878829956113 .8897857666113 .198928833112 .5168762207111 .8452606201 111.1860122681110 .5410614014109 .9126358032109 .3028259277108 .7139968872 108.1482772827 107.6080093384107.095123291 106.6117248535106.1594161987 105.7399368286105 .3543548584105 .0038528442104 .6889801025104 .4103927612 104.1680221558103 .9619293213103 .791519165103 .6563339233103 .5551986694 103.4870910645103 .4504165649103 .4436569214103 .4646682739103 .5114059448 
103.5814666748103 .6726989746103 .7827301025103 .9093780518104 .0502319336 104.2029647827104 .365196228104 .5347518921104 .7093505859104 .8869094849 105.0657348633105 .2444992065105 .4219436646105 .5967941284105 .7680282593 105.9349746704106 .0974578857106 .2552261353106 .407585144106 .5531158447 106.6897277832106 .8131103516106 .9158401489106 .9869537354106 .979598999 106.979598999 106.6747970581 -9999 -9999 -9999 -9999 -9999 -9999 -9999 -9999 -9999 -9999 -9999 -9999 -9999 -9999 -9999 -9999 -9999 -9999 -9999 -9999 -9999 -9999 -9999 -9999

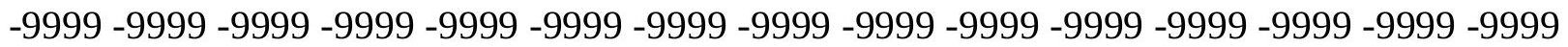

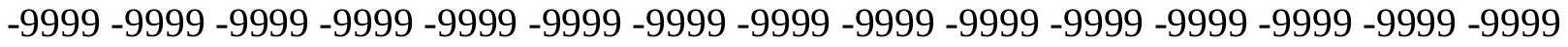
-9999 -9999 -9999 -9999 -9999 -9999 -9999 -9999 -9999 -9999 -9999 -9999 -9999 -9999 -9999 -9999 -9999 -9999 -9999 -9999 -9999 -9999 -9999 -9999 -9999 -9999 -9999 -9999 -9999 -9999 -9999 -9999 -9999 -9999 -9999 -9999 -9999 -9999 -9999 -9999 -9999 -9999 -9999 -9999 -9999 -999 -9999 -9999 -9999 -9999 -9999 -9999 -9999 -9999 -9999 -9999 -9999 -9999 -9999 -9999 -9999 -9999 -9999 -9999 -9999 -9999 -9999 -9999 -9999 -9999 -9999 -9999 -9999 -9999 -9999 -9999 -9999 -9999 -9999 -9999 -9999 -9999 -9999 -9999 -9999 -9999 -9999 -9999 -9999 -9999 -9999

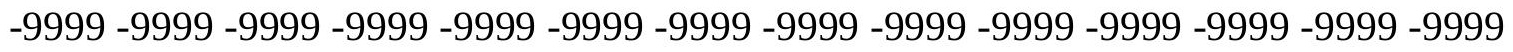

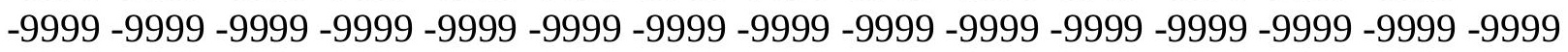
-9999 -9999 -9999 -9999 -9999 -9999 -9999 -9999 -9999 -9999 -9999 -9999 -9999 5.1813468933117 .31484317779510 .9722604751613 .1057596206715 .23925971985 17.37274932861 19.5062503814721.6397399902323.7732391357425.9067401886 27.7354507446329 .8689403533931 .6976509094233 .5263595581135 .35507965088 37.1837806701739 .0125007629440 .8412094116242 .66992187544 .19384002686 45.717769622847 .5464782714849 .0704002380450 .5943298339852 .11825942993 53.6421813964858 .5187492370663 .3953094482468 .2718734741272 .53885650635 76.5010681152379 .8537063598682 .5967712402384 .7302627563586 .2541885376 87.7781066894588 .6924667358489 .302040100189 .6068267822389 .91161346436 90.2164001464890 .2164001464890 .2164001464890 .2164001464890 .21640014648 90.5211791992290 .8259735107491 .1307525634891 .4355392456191 .74033355713 92.349891662692 .6546783447393 .2642517089893 .5690307617293 .87381744385 94.4833908081195 .0929565429795 .397743225196 .0073165893696 .61688232422 97.2264633178796 .9216690063598 .1408081054799 .35994720459100 .8839035034 102.1029968262103 .3221969604104 .5412979126105 .7603988647106 .979598999 108.1986999512109 .4179000854110 .6370010376111 .551399231112 .7705001831 113.6848983765114 .9039993286115 .818397522116 .7326965332117 .647102356 118.8662033081119 .4757995605120 .3900985718121 .3044967651122 .2188034058 122.8283996582123 .7427978516124 .3523025513124 .9618988037125 .5715026855 126.4858016968126 .7906036377127 .4001998901128 .0097961426128 .6192932129 128.9241027832129 .2288970947129 .8385009766130 .1432037354130 .4479980469 130.7528076172131 .0576019287131 .0576019287131 .3623962402131 .6672058105 131.6672058105131 .6672058105131 .9720001221131 .9720001221131 .9720001221 131.9720001221131 .9720001221131 .6672058105131 .6672058105131 .6672058105 131.3623962402131 .3623962402131 .0576019287130 .7528076172130 .4479980469 130.4479980469130 .1432037354129 .533706665129 .2288970947128 .9241027832 128.6192932129128 .3144989014127 .7050018311127 .2233581543126 .4875259399 125.7532501221125 .0206069946124 .2895965576123 .5602340698122 .8324813843 122.1063079834121 .3816833496120 .6586380005119 .9372329712119 .2176055908 
118.499961853117 .7846374512117 .0720443726116 .3627471924115 .657409668 114.9568481445114 .2620010376113 .5739898682112 .8940429688112 .2236251831 111.5642471313110 .9176940918110 .2857284546109 .6704025269109 .0736160278 108.497543335107 .9441375732107 .4155578613106 .91355896106 .4400939941 105.9966278076105 .5847625732105 .2054672241104 .8598327637104 .5483398438 104.2715911865104 .0295181274103 .8221893311103 .6490631104103 .5097427368 103.4031829834103 .3284606934103 .2840881348103 .268699646103 .2803115845 103.3170700073103 .3767776489103 .4575271606103 .5571365356103 .6735839844 103.8046417236103 .9482192993104 .1021194458104 .2642822266104 .4325714111 104.6050491333104 .7800216675104 .9560470581105 .1316680908105 .3054275513 105.4761428833105 .643081665105 .8059616089105 .9642944336106 .1170043945 106.2620773315106 .3966445923106 .5160446167106 .6136322021106 .6805953979 106.7077484131106 .6747970581106 .3700027466 -9999 -9999 -9999 -9999 -9999 -9999 -9999 -9999 -9999 -9999 -9999 -9999 -9999 -9999 -9999 -9999 -9999 -9999 -9999 -9999 -9999 -9999 -9999 -9999 -9999 -9999 -9999 -9999 -9999 -9999 -9999 -9999 -9999 -9999 -9999 -9999 -9999

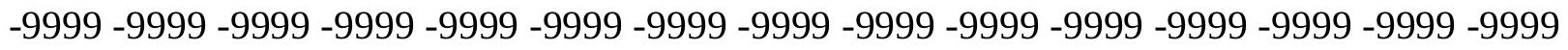

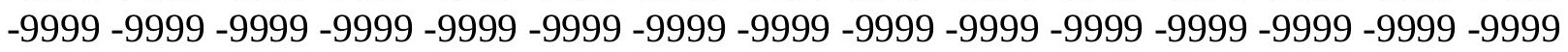
-9999 -9999 -9999 -9999 -9999 -9999 -9999 -9999 -9999 -9999 -9999 -9999 -9999 -9999 -9999 -999 -9999 -9999 -9999 -9999 -9999 -9999 -9999 -9999 -9999 -9999 -9999 -9999 -9999 -9999 -9999 -9999 -9999 -9999 -9999 -9999 -9999 -9999 -9999 -9999 -9999 -9999 -9999 -9999 -9999 -9999 -9999 -9999 -9999 -9999 -9999 -9999 -9999 -9999 -9999 -9999 -9999 -9999 -9999 -9999 -9999 -9999 -9999 -9999 -9999 -9999 -9999 -9999 -9999 -9999 -9999 -9999 -9999 -9999 -9999 -9999 -

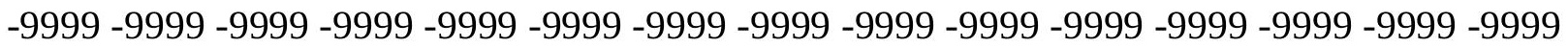
$-9999$

-9999 -9999 -9999 -9999 -9999 -9999 -9999 -9999 -9999 -9999 -9999 -9999 -9999 -9999 -9999 -9999 -9999 -9999 -9999 -9999 -9999 -9999 -9999 -9999 -9999 -9999 -9999 -9999 4.2669920921336 .40048694610610 .3626899719212 .4961900711114 .62969017029 16.7631797790518 .8966808319121 .0301704406723 .1636695861824 .99238014221 27.1258792877229 .2593708038331 .0880794525132 .9167900085434 .74551010132 36.5742111206138 .4029312133840 .2316398620642 .0603485107443 .58427047729 45.4129791259846 .9369087219248 .4608306884849 .9847602844251 .50868988037 53.3373985290557 .6043891906762 .1761703491266 .4431610107470 .40535736084 74.3675689697377 .4154205322380 .1584930419982 .5967712402384 .42548370361 85.9494018554786 .8637619018687 .7781066894588 .3876876831188 .69246673584 88.9972534179788 .9972534179788 .9972534179789 .302040100189 .3020401001 89.6068267822389 .9116134643690 .2164001464890 .5211791992290 .82597351074 91.1307525634891 .4355392456191 .7403335571392 .349891662692 .65467834473 92.9594726562593 .5690307617293 .8738174438594 .4833908081195 .09295654297 95.7025299072395 .397743225196 .6168823242297 .8360290527399 .35994720459 100.5791015625101 .7982025146103 .0174026489104 .2365036011105 .4557037354 106.6747970581107 .8938980103109 .1130981445110 .3321990967111 .24659729 112.4656982422113 .6848983765114 .5991973877115 .5136032104116 .7326965332 117.647102356118 .5614013672119 .4757995605120 .0852966309120 .9997024536 121.9140014648122 .5235977173123 .43800354124 .0475006104124 .6570968628 125.2667007446125 .8762969971126 .4858016968127 .0953979492127 .7050018311 128.0097961426128 .6192932129128 .9241027832129 .2288970947129 .8385009766 
130.1432037354130 .4479980469130 .4479980469130 .7528076172131 .0576019287 131.0576019287131 .3623962402131 .3623962402131 .3623962402131 .3623962402 131.3623962402131 .3623962402131 .3623962402131 .3623962402131 .0576019287 131.0576019287130 .7528076172130 .7528076172130 .4479980469130 .1432037354 129.8385009766129 .533706665129 .2288970947128 .9241027832128 .6192932129 128.3144989014127 .7050018311127 .4001998901126 .7906036377126 .135383606 125.4032516479124 .6726150513123 .9435424805123 .2161178589122 .4903869629 121.7664108276121 .0442504883120 .3240280151119 .6058731079118 .8900222778 118.1767425537117 .4664535522116 .7596206665116 .0568618774115 .35887146 114.6664962769113 .9806289673113 .3023834229112 .6329040527111 .9735717773 111.3257827759110 .6911773682110 .0713882446109 .4682769775108 .8835906982 108.3193283081 107.7772750854 107.2594146729 106.767364502 106.3029327393 105.8674621582105 .4624404907105 .0887451172104 .7473831177104 .4387969971 104.1635360718103 .9215393066103 .7128829956103 .537071228103 .3937683105 103.2820358276103 .2010650635103 .1495132446103 .1261749268103 .1292495728 103.1570663452 103.207611084103.2791213989103.3695755005 103.4770965576 103.5995635986103 .7350463867103 .8814544678104 .036857605104 .1992416382 104.3667907715 104.5378036499104.7107467651 104.8840408325105.0560684204 105.225479126105 .3913421631105 .5531234741105 .7100753784105 .8608093262 106.0030059814 106.1334075928 106.2472076416106.3380203247 106.3975448608 106.4159011841 106.3700027466 106.2564544678 106.0489807129 -9999 -9999 -9999-9999 -9999 -9999 -9999 -9999 -9999 -9999 -9999 -9999 -9999 -9999 -9999 -9999 -9999 -9999 -9999 -9999 -9999 -9999 -9999 -9999 -9999 -9999 -9999 -9999 -9999 -9999 -9999 -9999 -9999 -9999 -

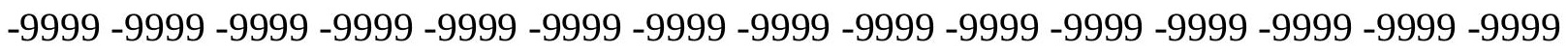

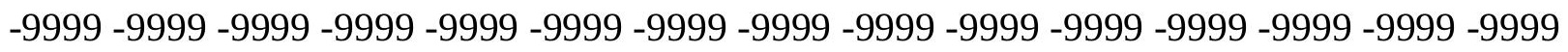
-9999 -9999 -9999 -9999 -9999 -9999 -9999 -9999 -9999 -9999 -9999 -9999 -9999 -9999 -9999

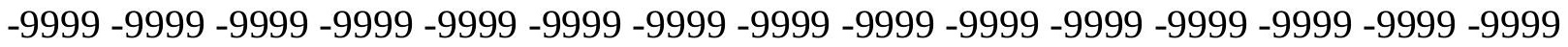

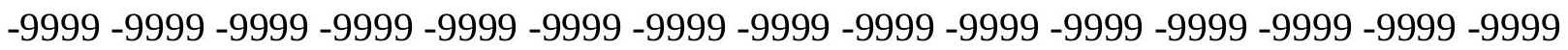
-9999 -9999 -9999 -9999 -9999 -9999 -9999 -9999 -9999 -9999 -9999 -9999 -9999 -9999 -9999 -9999 -9999 -9999 -9999 -9999 -9999 -9999 -9999 -9999 -9999 -9999 -9999 -9999 -9999 -9999

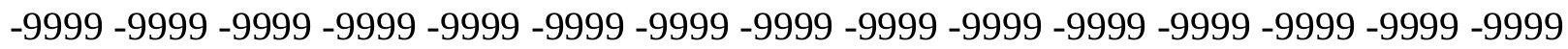
-9999 -9999-9999

-9999 -9999-9999 -9999 -9999 -9999 -9999 -9999 -9999 -9999 -9999 -9999 -9999 -9999 -9999 -9999 -9999 -9999 -9999 -9999 -9999 -9999 -9999 -9999 -9999 -9999 -9999 1.21914100647 3.6574220657357 .3148431777959 .4483394622811 .8866195678714 .02011966705 16.1536102294918 .28710937520 .4206008911122 .5541000366224 .68759918213 26.5163097381628 .6497993469230 .4785099029532 .3072204589834 .44071960449 36.2694282531738 .0981407165539 .622070312541 .4507789611843 .27949142456 44.8034095764246 .3273391723647 .8512611389249 .3751907348650 .89912033081 52.7278289794956 .9948196411160 .9570198059164 .9192428588968 .88143920898 72.2340774536175 .5867080688578 .3297805786180 .4632720947382 .59677124023 84.12069702148 85.33984375 86.2541885376 86.86376190186 87.47332763672 87.7781066894587 .7781066894588 .0829010009888 .3876876831188 .38768768311 88.69246673584 88.9972534179788.99725341797 89.302040100189.60682678223 89.9116134643690.2164001464890.8259735107491.1307525634891.43553924561 91.7403335571392 .0450973510792 .6546783447392 .9594726562593 .56903076172 
94.1785964965893 .8738174438595 .0929565429796 .6168823242297 .83602905273 99.05516815186100 .2742996216101 .7982025146103 .0174026489104 .2365036011 105.4557037354106 .6747970581107 .8938980103108 .8082962036110 .0273971558 111.24659729112 .1608963013113 .3800964355114 .2944030762115 .5136032104 116.4279022217117 .342300415118 .2565994263119 .1709976196120 .0852966309 120.6949005127121 .6092987061122 .5235977173123 .1332015991123 .7427978516 124.3523025513125 .2667007446125 .8762969971126 .1809997559126 .7906036377 127.4001998901127 .7050018311128 .3144989014128 .6192932129128 .9241027832 129.2288970947129 .533706665129 .8385009766130 .1432037354130 .4479980469 130.4479980469130 .7528076172130 .7528076172130 .7528076172131 .0576019287 131.0576019287131 .0576019287130 .7528076172130 .7528076172130 .7528076172 130.4479980469130 .4479980469130 .1432037354130 .1432037354129 .8385009766 129.533706665129 .2288970947128 .9241027832128 .6192932129128 .3144989014 127.7050018311127 .4001998901127 .0953979492126 .4858016968125 .8215713501 125.0920333862124 .3638763428123 .6372375488122 .9122467041122 .1890411377 121.4677505493120 .7485275269120 .0315628052119 .3170700073118 .6053466797 117.8967437744117 .1917190552116 .4907989502115 .7946395874115 .1039505005 114.4196090698113 .742477417113 .073638916112 .4141616821111 .7653503418 111.1284942627110 .5051193237109 .8967056274109 .3049697876108 .7315063477 108.1781539917107 .6465301514107 .1384887695106 .6555099487106 .1992645264 105.7709960938105 .3720779419105 .0033340454104 .6656951904104 .3595581055 104.0854568481103 .8433151245103 .6332244873103 .4547348022103 .3075637817 103.190864563103 .1039352417103 .0455780029103 .0147247314103 .0097579956 103.0291976929103 .0711975098103 .1341400146103 .2161026001103 .3153457642 103.4298782349103 .5578613281103 .6973114014103 .8464050293104 .0032196045 104.1660079956104.3330688477 104.502784729 104.6734695435104.8433914185 105.0109863281105 .1750488281105 .3347930908105 .4891662598105 .6365127563 105.7742767334105 .899055481106 .0060119629106 .0888900757106 .1394882202 106.1484527588106 .0999298096105 .9783096313105 .7603988647 -9999 -9999 -9999 -9999 -9999 -9999 -9999 -9999 -9999 -9999 -9999 -9999 -9999 -9999 -9999 -9999 -9999 -9999 -9999 -9999 -9999 -9999 -9999 -9999 -9999 -9999 -9999 -9999-9999 -9999 -9999 -9999 -9999 -9999 -9999 -9999 -9999 -9999 -9999 -9999 -9999 -9999 -9999 -9999 -9999 -9999 -9999 -9999 -9999 -

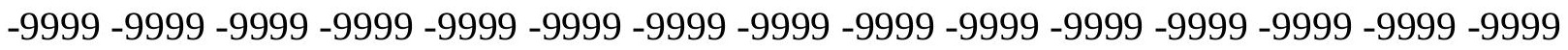
-9999 -9999 -9999 -9999 -9999 -9999 -9999 -9999 -9999 -9999 -9999 -9999 -9999 -9999 -9999 -9999 -9999 -9999 -9999 -9999 -9999 -9999 -9999 -9999 -9999 -9999 -9999 -9999 -9999 -9999 -

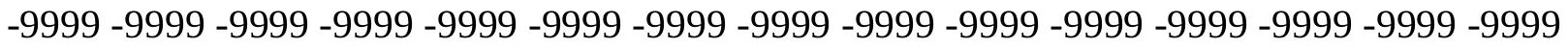

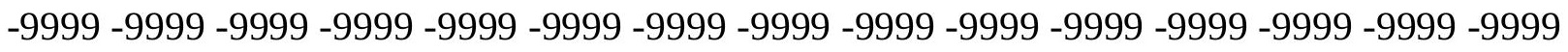

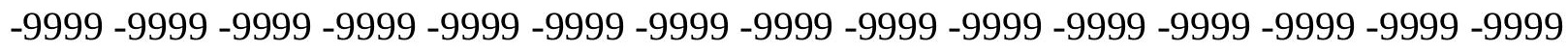
-9999 -9999 -9999 -9999 -9999 -9999 -9999 -9999 -9999 -9999 -9999 -9999 -9999 -9999 -9999 -9999 -9999-9999

-9999 -9999 -9999 -9999 -9999 -9999 -9999 -9999 -9999 -9999 -9999 -9999 -9999 -9999 -9999 - 6999 -

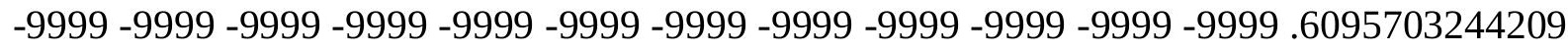
2.7430660724646 .7052731513988 .83876895904510 .9722604751613 .41055011749 15.5440397262617 .6775398254419 .811029434221 .9445304870624 .07802963257 26.2115192413328 .0402297973630 .1737308502232 .0024414062533 .83115005493 35.6598587036137 .4885711669939 .3172798156741 .1459884643642 .669921875 
44.1938400268646 .0225486755447 .5464782714849 .0704002380450 .28955078125 52.4230384826756 .0804595947360 .0426712036163 .7000885009867 .35751342773 70.7101516723673 .7580032348676 .5010681152378 .6345596313580 .76805877686 82.2919769287183 .5111236572384 .7302627563585 .3398437585 .94940185547 86.5589828491286 .8637619018687 .1685485839887 .1685485839887 .47332763672 87.7781066894587 .7781066894588 .0829010009888 .3876876831188 .69246673584 88.9972534179789 .302040100189 .6068267822389 .9116134643690 .21640014648 90.5211791992290 .8259735107491 .1307525634891 .7403335571392 .3498916626 92.9594726562592 .349891662693 .5690307617295 .0929565429796 .31210327148 97.8360290527399 .05516815186100 .2742996216101 .4934005737102 .712600708 103.9317016602105 .1509017944106 .3700027466107 .5891036987108 .8082962036 110.0273971558110 .9418029785112 .1608963013113 .075302124114 .2944030762 115.2088012695116 .1231002808117 .0374984741117 .9517974854118 .8662033081 119.7806015015120 .6949005127121 .3044967651122 .2188034058122 .8283996582 123.7427978516124 .3523025513124 .9618988037125 .5715026855126 .1809997559 126.4858016968127 .0953979492127 .4001998901128 .0097961426128 .3144989014 128.6192932129128 .9241027832129 .2288970947129 .533706665129 .8385009766 130.1432037354130 .1432037354130 .1432037354130 .4479980469130 .4479980469 130.4479980469130 .4479980469130 .4479980469130 .4479980469130 .1432037354 130.1432037354130 .1432037354129 .8385009766129 .533706665129 .533706665 129.2288970947128 .9241027832128 .6192932129128 .3144989014128 .0097961426 127.4001998901127 .0953979492126 .7906036377126 .1809997559125 .5452346802 124.8187255859124 .09349823123 .3697433472122 .6476516724121 .9274215698 121.2092590332120 .4933853149119 .7800674438119 .0695800781118 .3622894287 117.6585922241116 .9590072632116 .2640838623115 .5745239258114 .8910522461 114.2145462036113 .5458602905112 .8860244751112 .2360687256111 .5972213745 110.9706573486110 .3578033447109 .7599945068109 .1788253784108 .6157455444 108.0724411011107 .5503997803107 .0513305664106 .5765991211106 .1277542114 105.705947876105 .3124694824104 .9480667114104 .6136245728104 .3095092773 104.0362319946103 .7937316895103 .5820846558103 .4009017944103 .2499465942 103.1284484863103 .0358123779102 .970954895102 .9329299927102 .9202957153 102.9317245483102 .9655532837103 .0202941895103 .0941314697103 .1854476929 103.2923660278103 .4131622314103 .5459442139103 .6889572144103 .8403625488 103.9984512329104 .1614990234104 .327835083104 .4956817627104 .6632003784 104.8286132812104 .9904403687105 .1475830078105 .2987213135105 .4419708252 105.5745239258105 .6928787231105 .7922821045105 .8667068481105 .9082641602 $105.9078140259105 .8532791138105 .7276535034105 .4557037354105 .1509017944-9999$ -9999 -9999 -9999 -9999 -9999 -9999 -9999 -9999 -9999 -9999 -9999 -9999 -9999 -9999 -9999 -9999 -9999 -9999 -9999 -9999 -9999 -9999 -9999 -9999 -9999 -9999 -9999 -9999 -9999 -9999 -9999 -9999 -9999 -9999 -9999 -9999 -9999 -9999 -9999 -9999 -9999 -9999 -9999 - -9999 -9999 -9999 -9999 -9999 -9999 -9999 -9999 -9999 -9999 -9999 -9999 -9999 -9999 -9999 -9999 -9999

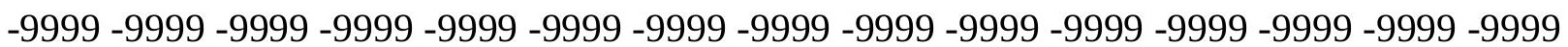
-9999 -9999 -9999 -9999 -9999 -9999 -9999 -9999 -9999 -9999 -9999 -9999 -9999 -9999 -9999 -9999 -9999 -9999 -9999 -9999 -9999 -9999 -9999 -9999 -9999 -9999 -9999 -9999 -9999 -9999 -999 -9999 -9999 -9999 -9999 -9999 -9999 -9999 -9999 -9999 -9999 -9999 -9999 -9999 -9999 -9999

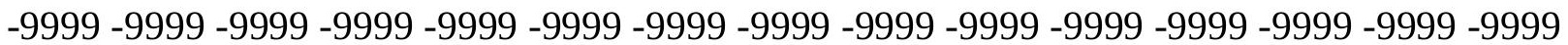


-9999 -9999 -9999 -9999 -9999 -9999 -9999 -9999 -9999 -9999 -9999 -9999 -9999 -9999 -9999 -9999 -9999 -9999 -9999 -9999

-9999 -9999 -9999 -9999 -9999 -9999 -9999 -9999 -9999 -9999 -9999 -9999 -9999 -9999 -9999 -9999 -9999 -9999 -9999 -9999 -9999 -9999 -9999 -9999 -9999 -9999-2.43828105927 -9999 3.6574220657355 .7909169197088 .22919845581110 .3626899719212 .80097007751 14.934470176717 .0679702758819 .2014598846421 .334960937523 .46845054626 25.6019496917727 .7354507446329 .5641593933131 .3928699493433 .52635955811 35.3550796508837 .1837806701739 .0125007629440 .5364189147942 .36513137817 43.8890609741245 .4129791259846 .9369087219248 .4608306884849 .98476028442 52.1182594299355 .4708900451759 .1283111572362 .7857398986866 .13836669922 69.1862335205172 .2340774536174 .6723632812577 .110626220778 .93934631348 80.7680587768681 .9871978759883 .206336975183 .8159103393684 .73026275635 85.0350494384885 .6446228027385 .9494018554786 .254188537686 .55898284912 86.5589828491286 .8637619018687 .1685485839887 .1685485839887 .47332763672 87.7781066894588 .0829010009888 .3876876831188 .6924667358488 .99725341797 89.302040100189 .6068267822389 .9116134643690 .2164001464890 .82597351074 91.4355392456190 .8259735107492 .349891662693 .5690307617295 .09295654297 96.3121032714897 .5312423706199 .05516815186100 .2742996216101 .4934005737 102.712600708103 .9317016602105 .1509017944106 .3700027466107 .5891036987 108.8082962036109 .7226028442110 .9418029785112 .1608963013113 .075302124 113.9896011353115 .2088012695116 .1231002808117 .0374984741117 .9517974854 118.8662033081119 .7806015015120 .3900985718121 .3044967651121 .9140014648 122.8283996582123 .43800354124 .0475006104124 .6570968628125 .2667007446 125.8762969971126 .4858016968126 .7906036377127 .4001998901127 .7050018311 128.0097961426128 .3144989014128 .6192932129128 .9241027832129 .2288970947 129.533706665129 .533706665129 .8385009766129 .8385009766129 .8385009766 130.1432037354130 .1432037354130 .1432037354129 .8385009766129 .8385009766 129.8385009766129 .533706665129 .533706665129 .2288970947128 .9241027832 128.9241027832128 .6192932129128 .3144989014128 .0097961426127 .7050018311 127.0953979492126 .7906036377126 .4858016968125 .8762969971125 .3059310913 124.5828475952123 .8609695435123 .1405334473122 .4217758179121 .7049407959 120.9903106689120 .2781600952119 .5688171387118 .8626327515118 .1600112915 117.4614028931116 .7673721313116 .0784912109115 .3954849243114 .7190856934 114.0501785278113 .3896026611112 .7383575439112 .0974197388111 .4679412842 110.851020813110 .2479629517109 .6600112915109 .0886154175108 .5351028442 108.0010223389107 .4877471924106 .9968490601106 .529586792106 .0874099731 105.67137146105 .2826919556104 .9220657349104 .5903320312104 .2878341675 104.0150604248103 .7719497681103 .5586166382103 .3746948242103 .2200088501 103.0938568115102 .9957199097102 .924621582102 .8797454834102 .8597717285 102.86353302102 .889503479102 .9363174438103 .0023117065103 .0859451294 103.1854629517103 .2992553711103 .4254989624103 .5625152588103 .7085189819 103.8618240356104 .0206832886104 .1833877563104 .3480987549104 .5128707886 104.6757659912104 .8350296021104 .9892196655105 .1367645264105 .2755889893 105.4027252197105 .5145568848105 .6063842773105 .6725082397105 .7055587769 105.6970062256105 .6351089478105 .5048141479105 .293006897104 .8460998535 -9999 -9999 -9999 -9999 -9999 -9999 -9999 -9999 -9999 -9999 -9999 -9999 -9999 -9999 -9999 -9999 
-9999 -9999 -9999 -9999 -9999 -9999 -9999 -9999 -9999 -9999 -9999 -9999 -9999 -9999 -9999 -9999 -9999 -9999 -9999 -9999 -9999 -9999 -9999 -9999 -9999 -9999 -9999 -9999 -9999 -9999

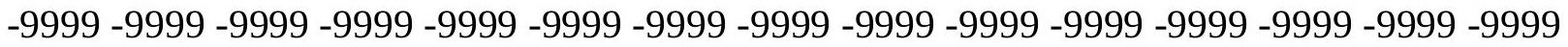
-9999 -9999 -9999 -9999 -9999 -9999 -9999 -9999 -9999 -9999 -9999 -9999 -9999 -9999 -9999 -9999 -9999 -9999 -9999 -9999 -9999 -9999 -9999 -9999 -9999 -9999 -9999-9999 -9999 -9999 -9999 -9999 -9999 -9999 -9999 -9999 -9999 -9999 -9999 -9999 -9999 -9999 -9999 -9999 -9999

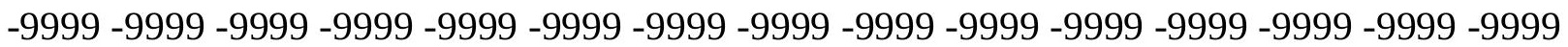

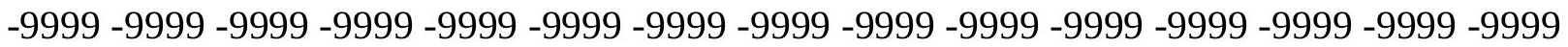

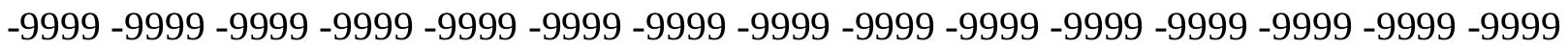
-9999 -9999 -9999-9999-9999

-9999 -9999 -9999 -9999 -9999 -9999 -9999 -9999 -9999 -9999 -9999 -9999 -9999 -9999 -9999

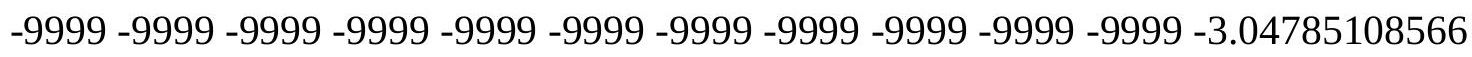
-.609570324421 3.0478510856635 .1813468933117 .6196279525769 .753124237061 12.191410064714 .3248996734616 .7631797790518 .8966808319121 .03017044067 23.1636695861825 .2971591949527 .1258792877229 .2593708038331 .08807945251 33.2215805053735 .0502891540536 .8790016174338 .4029312133840 .23163986206 42.0603485107443 .5842704772945 .1082000732446 .6321296691948 .15605163574 49.6799812316951 .8134689331154 .8613204956158 .2139587402361 .56660079956 64.9192428588967 .9670867919970 .7101516723673 .1484298706175 .58670806885 77.4154205322378 .9393463134880 .4632720947381 .6824111938582 .59677124023 83.206336975183 .8159103393684 .4254837036184 .7302627563585 .03504943848 85.3398437585 .6446228027385 .9494018554785 .9494018554786 .2541885376 86.5589828491286 .5589828491286 .8637619018687 .1685485839887 .47332763672 87.7781066894588 .0829010009888 .3876876831188 .6924667358488 .99725341797 89.60682678223 90.21640014648 89.302040100190.8259735107492.04509735107 93.5690307617294 .7881774902396 .3121032714897 .5312423706198 .75038146973 100.2742996216101 .4934005737102 .712600708103 .9317016602105 .1509017944 106.3700027466107 .5891036987108 .8082962036109 .7226028442110 .9418029785 111.8561019897113 .075302124113 .9896011353114 .9039993286116 .1231002808 117.0374984741117 .9517974854118 .8662033081119 .4757995605120 .3900985718 121.3044967651121 .9140014648122 .5235977173123 .43800354124 .0475006104 124.6570968628125 .2667007446125 .5715026855126 .1809997559126 .7906036377 127.0953979492127 .4001998901128 .0097961426128 .3144989014128 .6192932129 128.6192932129128 .9241027832129 .2288970947129 .2288970947129 .533706665 129.533706665129 .533706665129 .533706665129 .533706665129 .533706665129 .533706665 129.533706665129 .2288970947129 .2288970947128 .9241027832128 .6192932129 128.3144989014128 .3144989014128 .0097961426127 .7050018311127 .4001998901 126.7906036377126 .4858016968126 .1809997559125 .8228607178125 .1027145386 124.383430481123 .6652908325122 .9485473633122 .2335128784121 .5204544067 120.809715271120 .1016159058119 .3965454102118 .6949005127117 .9971389771 117.3037567139116 .6153411865115 .9324951172115 .2559509277114 .5864562988 113.9248809814113 .2720565796112 .6289520264111 .9965057373111 .3758087158 110.767868042110 .1739044189109 .5950546265109 .0326690674108 .4879379272 107.9623031616107 .4570159912106 .9735336304106 .5130157471106 .0768051147 105.6659011841105 .2814331055104 .9240646362104 .594581604104 .2933044434 104.0207214355103 .7767715454103 .5615921021103 .3748703003103 .2164535522 
103.0857315063 102.9822540283102.9051437378 102.8536605835102 .8266372681 102.8230133057102 .8414077759102 .8805618286102 .9389266968103 .0150756836 103.1073608398 103.2142562866 103.334022522 103.4650344849 103.6055374146 103.7538757324103 .9082946777104 .0670471191104 .2282409668104 .3898849487 104.549911499104 .7063140869104 .8573303223105 .0010910034105 .1353759766 105.2571868896105 .3629226685105 .4478759766105 .5065689087105 .5320663452 105.516418457105 .4481048584105 .3115844727105 .0951461792104 .8178634644 104.5412979126 -9999 -9999 -9999 -9999 -9999 -9999 -9999 -9999 -9999 -9999 -9999 -9999

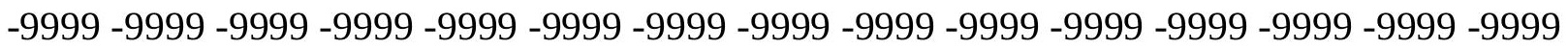

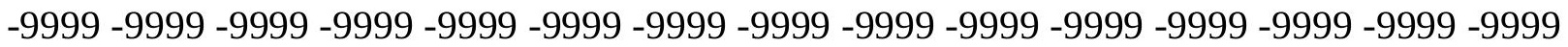

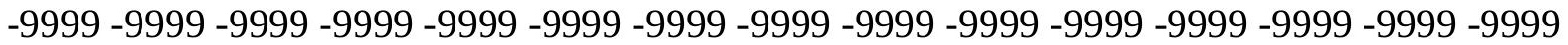

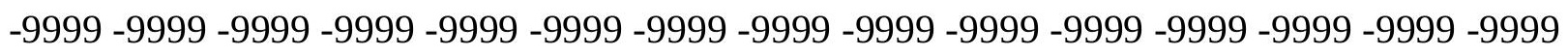

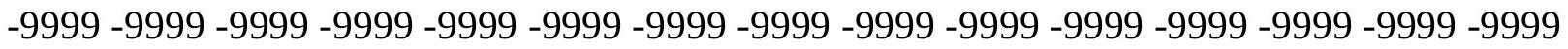

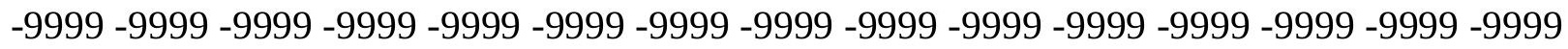

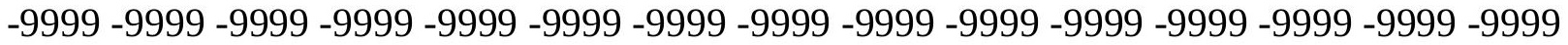

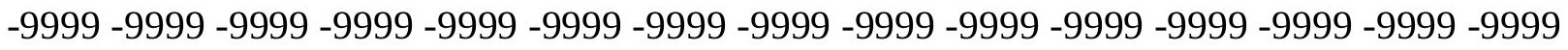

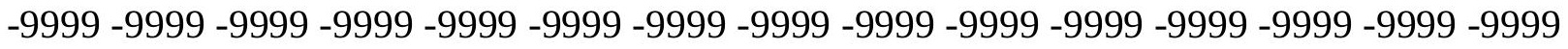
-9999 -9999 -9999 -9999 -9999 -9999 -9999 -9999

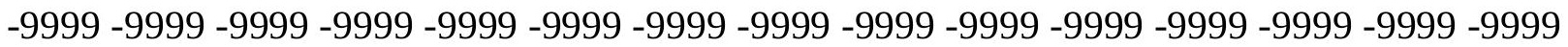
-9999 -9999 -9999 -9999 -9999 -9999 -9999 -9999 -9999 -9999 -9999 -3.65742206573 -1.21914100647 2.133496046066 4.571776866913 7.0100579261789.44833946228 11.5818300247214 .0201196670516 .1536102294918 .28710937520 .42060089111 22.5541000366224 .6875991821326 .8210906982428 .9545898437530 .78330039978 32.6120109558134 .7455101013236 .5742111206138 .0981407165539 .92684936523 41.7555618286143 .2794914245644 .8034095764246 .3273391723647 .85126113892 49.3751907348651 .2038993835454 .2517509460457 .6043891906760 .65224075317 63.7000885009866 .7479400634869 .4910125732471 .9292907714874 .0627822876 75.8914871215877 .4154205322378 .9393463134880 .1584930419981 .07285308838 81.9871978759882 .5967712402383 .206336975183 .5111236572383 .81591033936 84.1206970214884 .4254837036184 .7302627563585 .0350494384885 .03504943848 85.3398437585 .6446228027385 .6446228027385 .9494018554786 .2541885376 86.5589828491286 .5589828491287 .1685485839887 .4733276367287 .77810668945 88.3876876831188 .6924667358488 .0829010009889 .302040100190 .82597351074 92.0450973510793.5690307617294.7881774902396.3121032714897.53124237061 98.75038146973100 .2742996216101 .4934005737102 .712600708103 .9317016602 105.1509017944 106.3700027466 107.5891036987 108.8082962036109.7226028442 110.9418029785111 .8561019897113 .075302124113 .9896011353114 .9039993286 116.1231002808117 .0374984741117 .9517974854118 .5614013672119 .4757995605 120.3900985718120 .9997024536121 .9140014648122 .5235977173123 .1332015991 123.7427978516124 .3523025513124 .9618988037125 .5715026855126 .1809997559 126.4858016968126 .7906036377127 .4001998901127 .7050018311128 .0097961426 128.3144989014128 .6192932129128 .6192932129128 .9241027832128 .9241027832 129.2288970947 129.2288970947 129.2288970947 129.2288970947 129.2288970947 129.2288970947128 .9241027832128 .9241027832128 .6192932129128 .6192932129 128.3144989014128 .0097961426128 .0097961426127 .7050018311127 .4001998901 127.0953979492126 .7906036377126 .1809997559125 .8762969971125 .5715026855 
124.9350357056124 .2198867798123 .505821228122 .7931365967122 .0821609497 121.3732223511120 .6666870117119 .962928772119 .2623825073118 .5654830933 117.8727340698117 .1846618652116 .5018768311115 .825012207115 .1548080444 114.4919967651113 .8374633789113 .1920089722112 .5565872192111 .9320831299 111.3195495605110 .7199249268110 .1343460083109 .5638580322109 .0097198486 108.4730072021107 .9550552368107 .4570083618106 .9802246094106 .5257568359 106.0948638916105 .6884841919105 .3076782227104 .9530563354104 .6253890991 104.3249664307 104.0522689819103.8072509766103.5900650024103.4004440308 103.23828125103 .1030349731102 .9943161011102 .9113311768102 .8534545898 102.8195953369102 .8088226318102 .8198547363102 .8515548706102 .9024734497 102.9712905884103 .0564422607103 .15650177103 .2697753906103 .3947067261 103.5295639038103.6727218628 103.8223953247 103.9768295288 104.1341094971 104.2922134399 104.4489822388 104.6022338867104.7498931885104.8898086548 105.0196304321105 .1364135742105 .2367019653105 .31590271105 .3686218262 105.388168335105 .3669204712105 .2942504883105 .1574935913104 .946647644 104.6465454102 104.2365036011 -9999 -9999 -9999 -9999 -9999 -9999 -9999 -9999 -9999 -9999 -9999 -9999 -9999 -9999 -9999 -9999 -9999 -9999 -9999 -9999 -9999 -9999 -9999 -9999 -9999 -9999 -9999 -9999 -9999 -9999 -9999 -9999 -9999 -9999 -9999 -9999 -9999 -9999 -9999 -

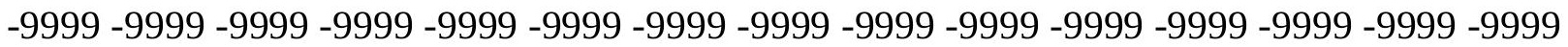

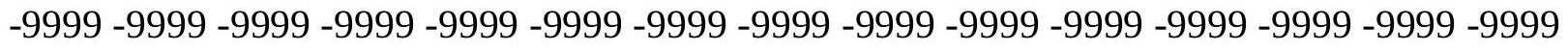

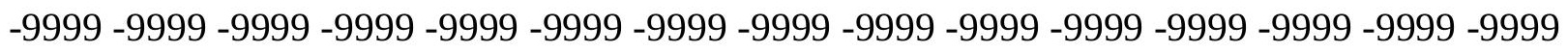

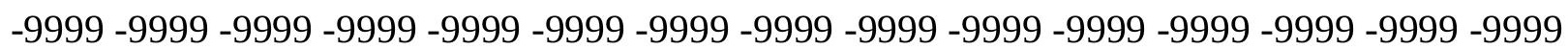
-9999 -9999 -9999 -9999 -9999 -9999 -9999 -9999 -9999 -9999 -9999 -9999 -9999 -9999 -9999 -

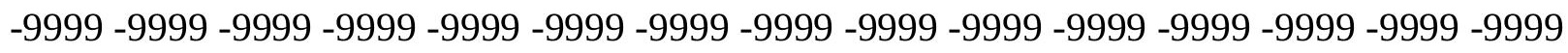

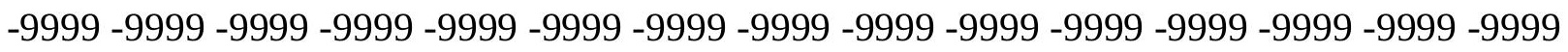
-9999 -9999 -9999 -9999 -9999 -9999 -9999 -9999 -9999 -9999 -9999

-9999 -9999 -9999 -9999 -9999 -9999 -9999 -9999 -9999 -9999 -9999 -9999 -9999 -9999 -9999 -9999 -9999-9999 -9999-9999 -9999-9999-9999 -9999 -9999 -7.01005792618 $-4.57177686691-.6095703244211 .5239260196693 .9622070789346 .400486946106$ 8.83876895904511 .2770500183113 .4105501174915 .8488302230817 .98232078552 20.1158199310322 .2493095397924 .3828105926526 .5163097381628 .64979934692 30.4785099029532 .6120109558134 .4407196044936 .2694282531738 .09814071655 39.622070312541 .4507789611842 .9747009277344 .4986305236846 .02254867554 47.5464782714849 .0704002380450 .5943298339853 .6421813964856 .99481964111 60.0426712036162 .7857398986865 .5288009643668 .2718734741270 .40535736084 72.5388565063574 .3675689697376 .1962814331177 .7202072143678 .93934631348 79.8537063598680 .7680587768681 .3776321411181 .9871978759882 .29197692871 82.9015579223683 .206336975183 .5111236572383 .5111236572383 .81591033936 84.1206970214884 .1206970214884 .4254837036184 .7302627563584 .73026275635 85.0350494384885 .3398437585 .6446228027385 .9494018554786 .2541885376 86.5589828491286 .8637619018687 .4733276367286 .5589828491288 .08290100098 89.302040100190.8259735107492.0450973510793.5690307617294.78817749023 96.3121032714897 .5312423706198 .75038146973100 .2742996216101 .4934005737 102.712600708103 .9317016602105 .1509017944106 .3700027466107 .5891036987 108.8082962036109 .7226028442110 .9418029785111 .8561019897113 .075302124 113.9896011353114 .9039993286116 .1231002808117 .0374984741117 .647102356 
118.5614013672119 .4757995605120 .3900985718120 .9997024536121 .9140014648 122.5235977173123 .1332015991123 .7427978516124 .3523025513124 .9618988037 125.5715026855125 .8762969971126 .4858016968126 .7906036377127 .0953979492 127.4001998901127 .7050018311128 .0097961426128 .3144989014128 .3144989014 128.6192932129128 .6192932129128 .9241027832128 .9241027832128 .9241027832 128.9241027832128 .9241027832128 .6192932129128 .6192932129128 .3144989014 128.3144989014128 .0097961426128 .0097961426127 .7050018311127 .4001998901 127.0953979492126 .7906036377126 .4858016968126 .1809997559125 .5715026855 125.2667007446124 .8019943237124 .0912780762123 .3815917969122 .6732635498 121.9666519165121 .2621154785120 .5600509644119 .8608779907119 .1650619507 118.4730606079117 .7854309082117 .1027069092116 .4255447388115 .7545700073 115.0905380249114 .4341812134113 .7863693237113 .1478805542112 .5196609497 111.902557373111 .2975769043110 .7056045532110 .1277084351109 .5648574829 109.0182189941 108.48878479 107.9777832031 107.4862594604 107.0154724121 106.5663986206106 .1402206421105 .7377929688105 .3601226807105 .0077896118 104.6815185547104 .3816070557104 .108505249103 .8621902466103 .642829895 103.4501953125103 .2842330933103 .1444625854103 .0305557251102 .9418029785 102.8776550293102 .8371200562102 .8193588257102 .8231811523102 .8475646973 102.8911514282102 .9527206421103 .0307846069103 .1239929199103 .2307281494 103.3494567871103 .4784927368103 .6162109375103 .7608337402103 .9105987549 104.0635757446104.2177200317 104.3708267212104.5205993652104.6647491455 104.8008651733104 .9264984131105 .038734436105 .1342773438105 .2088012695 105.2571334839105 .272857666105 .2488861084105 .1756668091105 .0403442383 104.832572937104 .5412979126104 .2365036011103 .9317016602 -9999 -9999 -9999 -9999 -9999 -9999 -9999 -9999 -9999 -9999 -9999 -9999 -9999 -9999 -9999 -9999 -9999 -9999 -9999 -9999 -9999 -9999 -9999 -9999 -9999 -9999 -9999 -9999 -9999 -9999 -9999 -9999 -9999 -9999 -

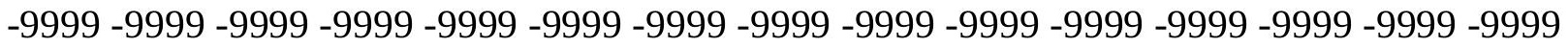

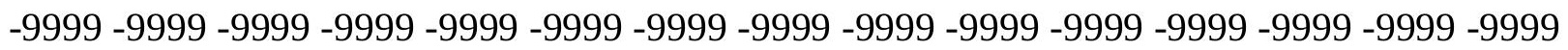
-9999 -9999 -9999 -9999 -9999 -9999 -9999 -9999 -9999 -9999 -9999 -9999 -9999 -9999 -9999 -9999 -9999 -9999 -9999 -9999 -9999 -9999 -9999 -9999 -9999 -9999 -9999 -9999 -9999 -9999 -9999 -9999 -9999 -9999 -9999 -9999 -9999 -9999 -9999-9999 -9999 -9999 -9999 -9999 -9999 -9999 -9999 -9999 -9999 -9999 -9999 -9999 -9999 -9999 -9999 -9999 -9999 -9999 -9999 -9999 -

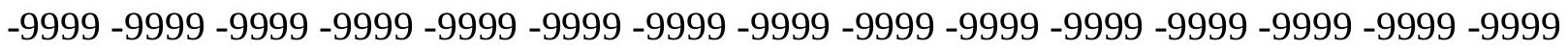
-9999 -9999 -9999 -9999 -9999 -9999 -9999 -9999 -9999 -9999 -9999 -9999 -9999 -9999 -9999 -9999 -9999 -9999 -9999 -9999 -9999 -9999 -9999 -9999 -9999 -9999 -9999 -9999 -9999 -9999 -999 -9999 -9999 -9999 -9999 -9999 -9999 -9999 -9999 -9999 -9999 -7.61962795258 $-5.18134689331-1.219141006471 .219141006473 .6574220657356 .095703125$ 8.53398323059110 .6674804687513 .1057596206715 .5440397262617 .67753982544 19.811029434222 .2493095397924 .3828105926526 .2115192413328 .34502029419 30.4785099029532 .3072204589834 .1359291076735 .9646492004437 .79335021973 39.622070312541 .1459884643642 .9747009277344 .4986305236846 .02254867554 47.5464782714848 .765621185350 .8991203308153 .6421813964856 .38525009155 59.4331016540562 .1761703491264 .6144485473667 .0527267456169 .49101257324 71.3197174072373 .1484298706174 .9771423339876 .1962814331177 .41542053223 78.6345596313579 .5489196777380 .1584930419980 .7680587768681 .37763214111 81.6824111938581 .9871978759882 .2919769287182 .5967712402382 .59677124023 
82.90155792236 83.2063369751 83.2063369751 83.51112365723 83.51112365723 83.8159103393684 .1206970214884 .4254837036184 .7302627563585 .03504943848 85.3398437585 .6446228027385 .9494018554785 .3398437586 .5589828491288 .08290100098 89.6068267822390 .8259735107492 .349891662693 .5690307617295 .09295654297 96.3121032714897 .5312423706199 .05516815186100 .2742996216101 .4934005737 102.712600708103 .9317016602105 .1509017944106 .3700027466107 .5891036987 108.8082962036110 .0273971558110 .9418029785112 .1608963013113 .075302124 113.9896011353115 .2088012695116 .1231002808117 .0374984741117 .9517974854 118.5614013672119 .4757995605120 .3900985718120 .9997024536121 .9140014648 122.5235977173123 .1332015991123 .7427978516124 .3523025513124 .9618988037 125.2667007446125 .8762969971126 .1809997559126 .4858016968127 .0953979492 127.4001998901127 .7050018311127 .7050018311128 .0097961426128 .3144989014 128.3144989014128 .3144989014128 .3144989014128 .6192932129128 .6192932129 128.3144989014128 .3144989014128 .3144989014128 .0097961426128 .0097961426 127.7050018311127 .7050018311127 .4001998901127 .0953979492126 .7906036377 126.4858016968126 .1809997559125 .8762969971125 .5715026855125 .2667007446 124.6570968628123 .9970703125123 .2920227051122 .5883026123121 .8862991333 121.1863937378120 .4890289307119 .794631958119 .1036911011118 .4167098999 117.7342529297117 .056892395116 .3852920532115 .720085144115 .0620346069 114.4118652344113 .7704315186113 .1385040283112 .516998291111 .9067459106 111.3087081909110 .7237243652110 .1528244019109 .5968856812109 .0570144653 108.5341262817108 .0293502808107 .5436477661107 .0782012939106 .633895874 106.2118377686105 .8128128052105 .4377822876105 .0872955322104 .7620315552 104.4622802734104 .1884918213103 .9406585693103 .7189559937103 .5231933594 103.3533554077 103.209022522 103.0899429321 102.9954681396 102.9251251221 102.8780059814102 .8533477783102 .8500595093102 .8672027588102 .9035110474 102.9578475952103 .0288162231103 .1151123047103 .2151870728103 .3275527954 103.450553894103 .582572937103 .7218399048103 .8665924072104 .0148773193 104.1646575928 104.3137054443104.4596710205104.6001205444104.7325210571 104.8543014526104 .9625701904105 .054145813105 .1249923706105 .1703872681 105.184425354105 .1606521606105 .090675354104 .9641418457104 .7718200684 104.521774292104 .2365036011103 .9317016602 -9999 -9999 -9999 -9999 -9999 -9999 -9999

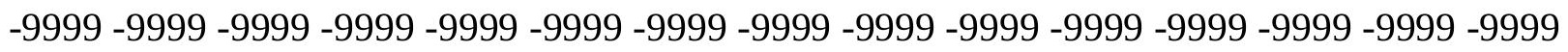
-9999 -9999 -9999 -9999 -9999 -9999 -9999 -9999 -9999 -9999 -9999 -9999 -9999 -9999 -9999 -9999 -9999 -9999 -9999 -9999 -9999 -9999 -9999 -9999 -9999 -9999 -9999 -9999 -9999 -9999 -

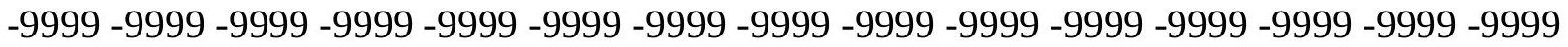

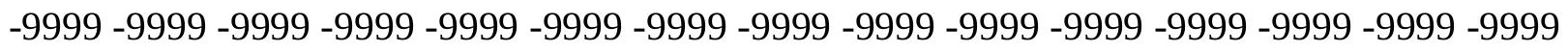

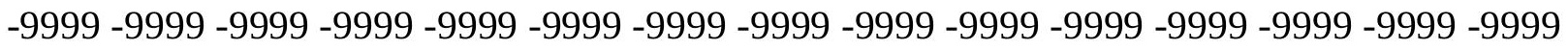
-9999 -9999 -9999 -9999 -9999 -9999 -9999 -9999 -9999 -9999 -9999 -9999 -9999 -9999 -9999 -9999 -9999 -9999 -9999 -9999 -9999 -9999 -9999 -9999 -9999 -9999 -9999 -9999 -9999 -9999 -

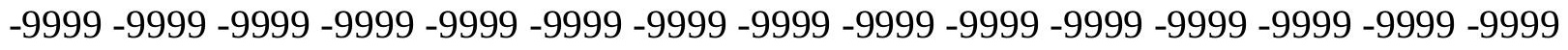
-9999 -9999 -9999 -9999 -9999 -9999 -9999 -9999 -9999 -9999 -9999 -9999 -9999 -9999 -9999 -9999 -9999 -9999 -9999 -9999 -9999 -9999 -9999 -9999 -9999 -9999 -9999 -9999 -9999 -9999 -9999 -9999 -9999 -9999 -9999 -9999 -9999 -8.22919845581 -4.26699209213 -1.52392601967.6095703244209 3.0478510856635 .486132144928 7.92441320419310 .3626899719212 .8009700775115 .2392597198517 .37274932861 
19.811029434221 .9445304870624 .0780296325726 .2115192413328 .34502029419 30.1737308502232 .3072204589834 .1359291076735 .9646492004437 .79335021973 39.3172798156741 .1459884643642 .66992187544 .1938400268645 .7177696228 47.2416992187548 .765621185350 .8991203308153 .6421813964856 .08045959473 58.8235282897961 .5666007995664 .004882812566 .1383666992268 .27187347412 70.4053573608471 .9292907714873 .7580032348674 .9771423339876 .19628143311 77.4154205322378 .0249862670978 .9393463134879 .5489196777380 .15849304199 80.4632720947380 .7680587768681 .0728530883881 .3776321411181 .68241119385 81.6824111938581 .9871978759882 .2919769287182 .2919769287182 .59677124023 82.5967712402382 .9015579223683 .206336975183 .5111236572383 .51112365723 83.8159103393684 .4254837036184 .7302627563583 .8159103393685 .33984375 86.8637619018688 .0829010009889 .6068267822390 .8259735107492 .3498916626 93.8738174438595 .0929565429796 .3121032714897 .8360290527399 .05516815186 100.2742996216101 .7982025146103 .0174026489104 .2365036011105 .4557037354 106.6747970581107 .8938980103108 .8082962036110 .0273971558111 .24659729 112.1608963013113 .075302124114 .2944030762115 .2088012695116 .1231002808 117.0374984741117 .9517974854118 .8662033081119 .4757995605120 .3900985718 120.9997024536121 .9140014648122 .5235977173123 .1332015991123 .7427978516 124.3523025513124 .6570968628125 .2667007446125 .8762969971126 .1809997559 126.4858016968126 .7906036377127 .0953979492127 .4001998901127 .7050018311 127.7050018311128 .0097961426128 .0097961426128 .0097961426128 .0097961426 128.0097961426128 .0097961426128 .0097961426128 .0097961426127 .7050018311 127.7050018311127 .4001998901127 .4001998901127 .0953979492126 .7906036377 126.4858016968126 .1809997559125 .8762969971125 .5715026855125 .2667007446 124.9618988037124 .6374282837123 .9362869263123 .2360687256122 .5371627808 121.8399581909121 .1448745728120 .4523544312119 .7628555298119 .0769042969 118.3949966431117 .7177352905117 .0457000732116 .3795700073115 .7199783325 115.0676879883114 .4234237671113 .7880172729113 .1622314453112 .5469665527 111.9430236816111 .3513412476110 .7727203369110 .2081375122109 .6584243774 109.1246109009108 .6075592041108 .1083145142107 .6277618408107 .1669998169 106.7268600464106 .3083572388105 .9122238159105 .5393600464105 .190284729 104.8656616211104 .5657577515104 .2910079956104 .0414352417103 .8172225952 103.6182022095103 .4444046021103 .295463562103 .1711807251103 .0709991455 102.9944839478102 .9408187866102 .9093093872102 .8989486694102 .9088745117 102.9378967285102 .9849700928103 .0487518311103 .1280212402103 .221282959 103.3270950317103 .4438095093103 .5698547363103 .7034606934103 .8428573608 103.9860916138104 .1311340332104 .2757644653104 .4176025391104 .5541687012 104.6828460693104 .8010177612104 .9057922363104 .994102478105 .0621948242 105.1058731079105 .1199035645105 .0986175537105 .0348205566104 .9194717407 $104.7447433472104 .5120239258104 .2365036011103 .9317016602103 .3221969604-9999$ -9999 -9999 -9999 -9999 -9999 -9999 -9999 -9999 -9999 -9999 -9999 -9999 -9999 -9999 -9999

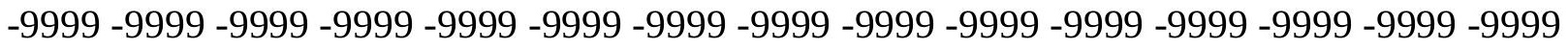
-9999 -9999 -9999 -9999 -9999 -9999 -9999 -9999 -9999 -9999 -9999 -9999 -9999 -9999 -9999 -9999 -9999 -9999 -9999 -9999 -9999 -9999 -9999 -9999 -9999 -9999 -9999 -9999 -9999 -9999 -

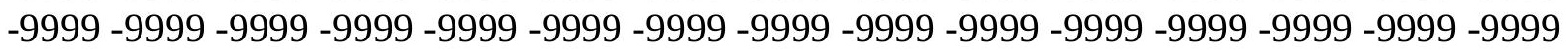

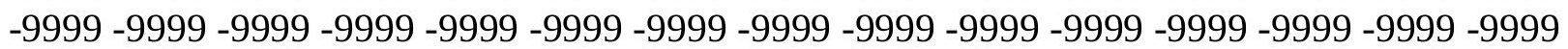


-9999 -9999 -9999 -9999 -9999 -9999 -9999 -9999 -9999 -9999 -9999 -9999 -9999 -9999 -9999 -9999 -9999 -9999 -9999 -9999 -9999 -9999 -9999 -9999 -9999 -9999 -9999 -9999 -9999 -9999

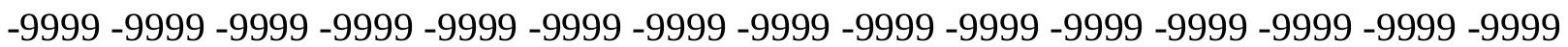
-9999 -9999 -9999 -9999 -9999 -9999 -9999 -9999 -9999 -9999 -9999 -9999 -9999 -9999 -9999 -9999 -9999

-9999 -9999 -9999 -9999 -9999 -9999 -9999 -9999 -9999 -9999 -9999 -9999 -9999 -9999 -9999 -9999 -9999 -9999 -9999 -9999 -9999 -9999 -9999 -9999 -11.5818300247 -8.83876895905 -4.57177686691 -2.13349604607.3047851026058 2.743066072464 5.181346893311 7.61962795257610 .0579099655212 .4961900711114 .934470176717 .37274932861 19.5062503814721 .6397399902324 .0780296325726 .2115192413328 .04022979736 30.1737308502232 .0024414062534 .1359291076735 .9646492004437 .79335021973 39.3172798156741 .1459884643642 .66992187544 .1938400268645 .7177696228 47.2416992187548 .765621185351 .2038993835453 .6421813964856 .08045959473 58.5187492370660 .9570198059163 .0905189514265 .2240066528367 .35751342773 69.1862335205171 .014930725172 .5388565063573 .7580032348674 .97714233398 76.1962814331177 .110626220777 .7202072143678 .3297805786178 .93934631348 79.2441329956179 .8537063598680 .1584930419980 .4632720947380 .46327209473 80.7680587768680 .7680587768681 .0728530883881 .0728530883881 .37763214111 81.3776321411181 .6824111938581 .9871978759881 .9871978759882 .29197692871 82.5967712402382 .9015579223683 .206336975182 .5967712402384 .12069702148 85.3398437586 .8637619018688 .3876876831189 .6068267822391 .13075256348 92.6546783447393 .8738174438595 .397743225196 .6168823242297 .83602905273 99.35994720459100 .5791015625101 .7982025146103 .0174026489104 .2365036011 105.4557037354106 .6747970581107 .8938980103109 .1130981445110 .3321990967 111.24659729112 .4656982422113 .3800964355114 .2944030762115 .2088012695 116.1231002808117 .0374984741117 .9517974854118 .8662033081119 .7806015015 120.3900985718121 .3044967651121 .9140014648122 .5235977173123 .1332015991 123.7427978516124 .3523025513124 .6570968628125 .2667007446125 .5715026855 126.1809997559126 .4858016968126 .7906036377127 .0953979492127 .0953979492 127.4001998901127 .7050018311127 .7050018311127 .7050018311127 .7050018311 127.7050018311127 .7050018311127 .7050018311127 .7050018311127 .7050018311 127.4001998901127 .4001998901127 .0953979492126 .7906036377126 .7906036377 126.4858016968126 .1809997559125 .8762969971125 .5715026855125 .2667007446 124.9618988037124 .3523025513123 .9083175659123 .213104248122 .5191497803 121.8268890381121 .1367340088120 .4491653442119 .7646484375119 .0837173462 118.4068984985117 .7348022461117 .0680160522116 .4072113037115 .7530517578 115.1062774658114 .4676055908113 .8378677368113 .2178115845112 .6083145142 112.0101547241111 .4242553711110 .8513793945110 .29246521109 .7483062744 109.219871521 108.7079620361 108.2135696411 107.7375183105 107.2808227539 106.8442459106106 .4287414551106 .0349884033105 .6638336182105 .3157653809 104.9914169312104 .6910400391104 .4150695801104 .1635360718103 .9366378784 103.7342224121103 .5563735962103 .4027557373103 .2732315063103 .1673049927 103.0846176147 103.0243988037 102.9860458374102.9686050415102.971282959 102.9929733276103 .0326919556103 .0891723633103 .1612548828103 .2474975586 103.3465118408103 .4566802979103 .5764465332103 .7040634155103 .8377609253 103.9755935669 104.1155471802 104.2554244995 104.3928527832104.5253372192 
104.6502304077104 .7648849487104 .8664398193104 .9519729614105 .0180358887 105.0609054565105 .0760040283105 .0582504272105 .0010681152104 .8970489502 $104.7365112305104 .5161819458104 .2365036011103 .9317016602103 .3221969604-9999$ -9999 -9999 -9999 -9999 -9999 -9999 -9999 -9999 -9999 -9999 -9999 -9999 -9999 -9999 -9999 -9999 -9999 -9999 -9999 -9999 -9999 -9999 -9999 -9999 -9999 -9999 -9999-9999 -9999 -9999 -9999 -9999 -9999 -9999 -9999 -9999 -9999 -9999 -9999 -9999 -9999 -9999 -9999 -9999 -9999

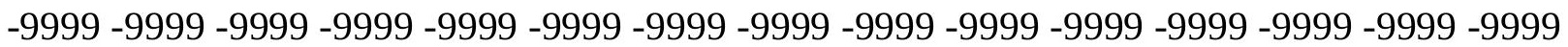

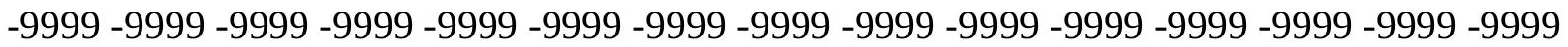
-9999 -9999 -9999 -9999 -9999 -9999 -9999 -9999 -9999 -9999 -9999 -9999 -9999 -9999 -9999 -9999 -9999 -9999 -9999 -9999 -9999 -9999 -9999 -9999 -9999 -9999 -9999 -9999 -9999 -9999

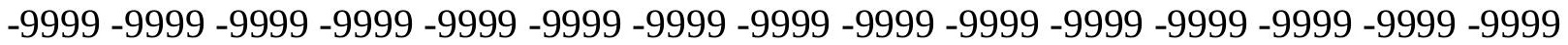
-9999 -9999 -9999 -9999 -9999 -9999 -9999 -9999 -9999 -9999 -9999 -9999 -9999 -9999 -9999 -

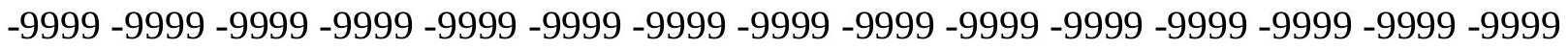
$-9999-9999$

-9999 -9999 -9999 -9999 -9999 -9999 -9999 -9999 -9999 -9999 -9999 -9999 -9999 -9999 -9999 -9999 -9999 -9999 -9999-9999 -9999 -9999-9999-9999-11.8866195679-9.44833946228 -5.18134689331 -2.43828105927 -9999 2.438281059265 4.87656211853 7.314843177795 10.0579099655212 .4961900711114 .934470176717 .0679702758819 .50625038147 21.6397399902324 .0780296325726 .2115192413328 .0402297973630 .17373085022 32.3072204589834 .1359291076735 .9646492004437 .7933502197339 .31727981567 41.1459884643642 .66992187544 .1938400268645 .717769622847 .24169921875 48.765621185351 .2038993835453 .3373985290555 .7756805419958 .21395874023 60.3474502563562 .4809494018664 .6144485473666 .4431610107468 .27187347412 70.1005783081171 .3197174072372 .8436431884874 .062782287674 .97714233398 75.8914871215876 .5010681152377 .4154205322377 .7202072143678 .32978057861 78.6345596313578 .9393463134879 .2441329956179 .5489196777379 .54891967773 79.8537063598679 .8537063598680 .1584930419980 .1584930419980 .46327209473 80.4632720947380 .7680587768680 .7680587768681 .0728530883881 .37763214111 81.6824111938581 .9871978759881 .3776321411182 .5967712402384 .12069702148 85.6446228027387 .1685485839888 .3876876831189 .9116134643691 .43553924561 92.6546783447394 .1785964965895 .397743225196 .9216690063598 .14080810547 99.35994720459100 .8839035034102 .1029968262103 .3221969604104 .5412979126 105.7603988647106 .979598999108 .1986999512109 .4179000854110 .3321990967 111.551399231112 .4656982422113 .6848983765114 .5991973877115 .5136032104 116.4279022217117 .342300415118 .2565994263118 .8662033081119 .7806015015 120.3900985718121 .3044967651121 .9140014648122 .5235977173123 .1332015991 123.7427978516124 .3523025513124 .6570968628125 .2667007446125 .5715026855 125.8762969971126 .1809997559126 .4858016968126 .7906036377127 .0953979492 127.0953979492127 .4001998901127 .4001998901127 .4001998901127 .4001998901 127.4001998901127 .4001998901127 .4001998901127 .4001998901127 .0953979492 127.0953979492126 .7906036377126 .7906036377126 .4858016968126 .1809997559 125.8762969971125 .5715026855125 .2667007446124 .9618988037124 .6570968628 124.3523025513123 .7427978516123 .2221755981122 .5332794189121 .8460388184 121.1608886719120 .4783172607119 .7987976074119 .1228866577118 .4511108398 117.7840957642117 .122428894116 .4667892456115 .8178329468115 .1763076782 114.5429153442113 .9184799194113 .3037338257112 .6995391846112 .1066589355 
111.5259857178110 .9582595825110 .4043960571109 .8651428223109 .3414382935 108.8340148926108 .3438339233107 .8716430664107 .4183959961106 .9848022461 106.5717544556106 .1798858643105 .8099822998105 .4625091553105 .1380691528 104.8369140625104 .559463501104 .3057479858104 .0759811401103 .8700485229 103.688041687103 .5296707153103 .3948440552103 .2831268311103 .1942138672 103.1274185181103 .0821685791103 .0576019287103 .0529785156103 .0672531128 103.0994949341103 .1485137939103 .213218689103 .2922134399103 .3841552734 103.4874725342103 .6006469727103 .7219314575103 .8495788574103 .9816741943 104.1162109375 104.2510070801 104.3837280273104.5119018555 104.6328735352 104.7439956665104 .8424453735104 .9254379272104 .9898223877105 .0322875977 105.0487670898105 .034614563104 .9835739136104 .8880767822104 .7389831543 104.5316848755104 .2365036011103 .9317016602103 .3221969604103 .0174026489 -9999 -9999 -9999 -9999 -9999 -9999 -9999 -9999 -9999 -9999 -9999 -9999 -9999 -9999 -9999 -9999 -9999 -9999 -9999 -9999 -9999 -9999 -9999 -9999 -9999 -9999 -9999 -9999 -9999 -9999 -9999 -9999 -9999 -9999 -9999 -9999 -9999 -9999 -9999 -9999 -9999 -9999 -9999 -9999 -9999 -9999

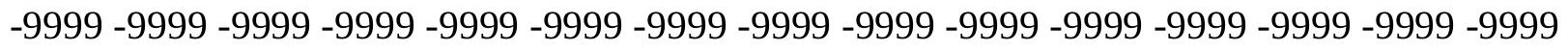
-9999 -9999 -9999 -9999 -9999 -9999 -9999 -9999 -9999 -9999 -9999 -9999 -9999 -9999 -9999 -9999 -9999 -9999 -9999 -9999 -9999 -9999 -9999 -9999 -9999 -9999 -9999 -9999 -9999 -9999 -

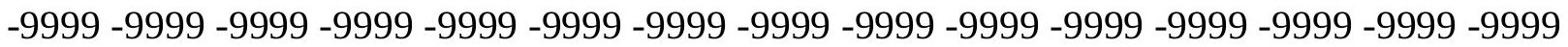

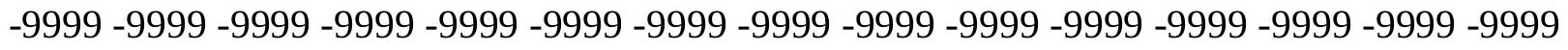

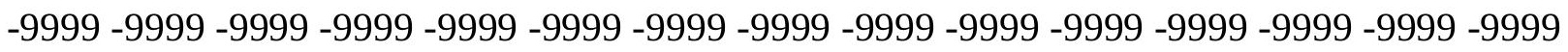

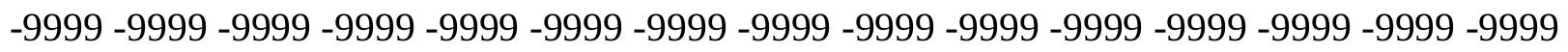
$-9999$

-9999 -9999 -9999 -9999 -9999 -9999 -9999 -9999 -9999 -9999 -9999 -9999 -9999 -9999 -9999 -9999 -9999 -9999 -9999-9999-9999 -9999-9999-9999-12.4961900711-8.22919845581 $-5.48613214493-2.74306607246-.3047851026062 .1334960460664 .87656211853$ 7.3148431777959 .75312423706112 .191410064714 .6296901702917 .06797027588 19.5062503814721 .6397399902324 .0780296325726 .2115192413328 .34502029419 30.1737308502232 .3072204589834 .1359291076735 .9646492004437 .79335021973 39.622070312541 .1459884643642 .66992187544 .1938400268645 .7177696228 47.24169921875 48.765621185351.2038993835453.33739852905 55.47089004517 57.909179687560 .0426712036161 .8713798522964 .004882812565 .83358764648 67.3575134277369 .1862335205170 .4053573608471 .9292907714872 .84364318848 74.062782287674 .9771423339875 .5867080688576 .1962814331176 .80584716797 77.110626220777 .7202072143678 .0249862670978 .0249862670978 .32978057861 78.6345596313578 .6345596313578 .9393463134878 .9393463134878 .93934631348 79.2441329956179 .2441329956179 .5489196777379 .5489196777379 .85370635986 80.1584930419980 .1584930419980 .4632720947380 .1584930419981 .37763214111 82.9015579223684 .4254837036185 .9494018554787 .1685485839888 .69246673584 90.2164001464891 .4355392456192 .9594726562594 .4833908081195 .70252990723 97.2264633178798.445587158299.66472625732 101.1886978149 102.4077987671 103.6268997192104 .8460998535106 .0652008057107 .2844009399108 .5035018921 109.4179000854110 .6370010376111 .8561019897112 .7705001831113 .6848983765 114.9039993286115 .818397522116 .7326965332117 .647102356118 .2565994263 119.1709976196120 .0852966309120 .6949005127121 .3044967651121 .9140014648 122.5235977173123 .1332015991123 .7427978516124 .3523025513124 .6570968628 
125.2667007446125 .5715026855125 .8762969971126 .1809997559126 .4858016968 126.7906036377126 .7906036377127 .0953979492127 .0953979492127 .0953979492 127.4001998901127 .4001998901127 .0953979492127 .0953979492127 .0953979492 127.0953979492126 .7906036377126 .7906036377126 .4858016968126 .1809997559 126.1809997559125 .8762969971125 .5715026855125 .2667007446124 .9618988037 124.6570968628124 .3523025513123 .7427978516123 .2627716064122 .5789871216 121.8968048096121 .2166748047120 .5390853882119 .8645401001119 .1935806274 118.5267562866117 .864692688117 .2079849243116 .5573043823115 .9133071899 115.2767333984114 .6482925415114 .0287857056113 .4189300537112 .8195800781 112.2314682007111 .6554794312111 .092338562110 .5429153442110 .0079574585 109.4883346558108 .9847640991108 .4981460571108 .0291824341107 .5787811279 107.1475906372106 .7364578247106 .3459625244105 .976852417105 .6295623779 105.3046569824105 .0024032593104 .7231903076104 .4670639038104 .2342453003 104.0246429443103 .8383560181103 .6751480103103 .5349502563103 .4173736572 103.3221817017 103.2487411499103.1965408325 103.1647720337 103.1527557373 103.1594924927103 .1841201782103 .2255020142103 .2826004028103 .3540802002 103.438659668103 .5348052979103 .6410369873103 .7556304932103 .8768768311 104.0028762817104 .1316452026104 .2610397339104 .3887557983104 .5123519897 104.6292037964104 .736656189104 .8319396973104 .9124069214104 .9751281738 105.0171279907105 .0347213745105 .0236740112104 .9781341553104 .8909606934 104.7522125244104 .5471191406104 .2365036011103 .9317016602103 .6268997192 103.0174026489 -9999 -9999 -9999 -9999 -9999 -9999 -9999 -9999 -9999 -9999 -9999 -9999 -9999 -9999 -9999 -9999 -9999 -9999 -9999 -9999 -9999 -9999 -9999 -9999 -9999 -9999 -9999

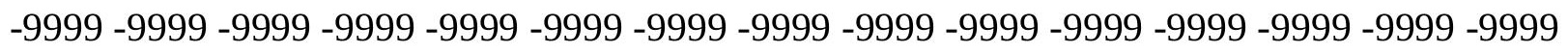

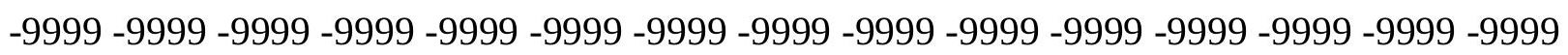
-9999 -9999 -9999 -9999 -9999 -9999 -9999 -9999 -9999 -9999 -9999 -9999 -9999 -9999 -9999 -9999 -9999 -9999 -9999 -9999 -9999 -9999 -9999 -9999 -9999 -9999 -9999 -9999 -9999 - -9999 -

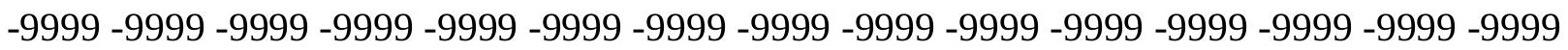

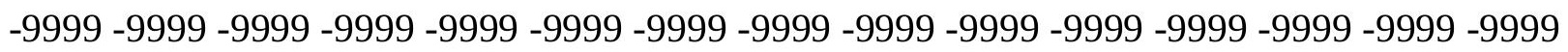

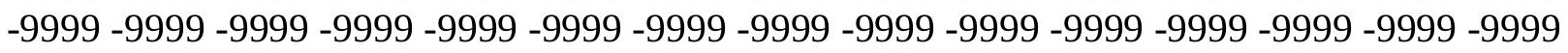
-9999 -9999 -9999 -9999 -9999 -9999 -9999 -9999 -9999 -9999 -9999 -9999 -9999 -9999 -9999 -9999 -9999-9999-9999-9999

-9999 -9999-9999 -9999 -9999 -9999 -9999 -9999 -9999 -9999 -9999 -9999 -9999 -9999 -9999 -9999 -9999 -9999 -9999 -9999 -9999 -9999 -9999 -9999-12.8009700775 -8.53398323059 -5.79091691971 -3.04785108566 -.304785102606 1.8287110328674 .571776866913 7.314843177795 9.753124237061 12.49619007111 14.9344701767 17.37274932861 19.5062503814721 .9445304870624 .0780296325726 .2115192413328 .34502029419 30.4785099029532 .6120109558134 .4407196044936 .2694282531738 .09814071655 39.622070312541 .4507789611842 .9747009277344 .4986305236846 .02254867554 47.24169921875 49.07040023804 51.20389938354 53.33739852905 56.99481964111 59.1283111572359 .4331016540561 .5666007995663 .3953094482465 .22400665283 66.7479400634868 .2718734741269 .7957916259871 .014930725171 .92929077148 73.1484298706173 .7580032348674 .6723632812575 .2819290161175 .89148712158 76.1962814331176 .5010681152376 .8058471679777 .110626220777 .41542053223 77.4154205322377 .7202072143677 .7202072143677 .7202072143678 .02498626709 78.0249862670978 .3297805786178 .3297805786178 .3297805786178 .63455963135 
78.6345596313578 .9393463134878 .9393463134878 .9393463134880 .15849304199 81.6824111938583 .206336975184 .7302627563586 .254188537687 .47332763672 88.9972534179790 .5211791992291 .7403335571393 .2642517089894 .78817749023 96.0073165893697 .5312423706198 .7503814697399 .96952056885101 .4934005737 102.712600708103 .9317016602105 .1509017944106 .3700027466107 .5891036987 108.8082962036109 .7226028442110 .9418029785111 .8561019897113 .075302124 113.9896011353114 .9039993286115 .818397522116 .7326965332117 .647102356 118.5614013672119 .4757995605120 .0852966309120 .6949005127121 .6092987061 122.2188034058122 .8283996582123 .43800354123 .7427978516124 .3523025513 124.6570968628125 .2667007446125 .5715026855125 .8762969971126 .1809997559 126.4858016968126 .4858016968126 .7906036377126 .7906036377127 .0953979492 127.0953979492127 .0953979492127 .0953979492127 .0953979492126 .7906036377 126.7906036377126 .4858016968126 .4858016968126 .1809997559126 .1809997559 125.8762969971125 .5715026855125 .2667007446125 .2667007446124 .9618988037 124.6570968628124 .0475006104123 .7427978516123 .3339767456122 .6553268433 121.9782028198121 .303062439120 .6304168701119 .9607620239119 .2946624756 118.6326675415117 .9753952026117 .3234405518116 .6774902344116 .0381774902 115.4062576294114 .7824172974114 .1674499512113 .5620651245112 .9670944214 112.3832702637111 .8114395142111 .2523193359110 .7067718506110 .175491333 109.6593399048 109.1590042114108.6753234863108.2089767456107.7608108521 107.331451416106 .9216766357106 .5320358276106 .1632461548105 .8156967163 105.4899520874105 .1862487793104 .9049835205104 .6462020874104 .4101257324 104.1966781616104 .0059890747103 .8378295898103 .6921691895103 .5686645508 103.4671173096103 .3869552612103 .3277206421103 .2886505127103 .2691192627 103.2681884766 103.2850418091 103.3185958862 103.3678665161 103.4315719604 103.5084838867103 .5971298218103 .6960678101103 .8036193848103 .9180984497 104.0376358032104 .1602859497104 .2839355469104 .4063262939104 .5250396729 104.6374816895104 .741027832104 .8329467773104 .9106750488104 .9714889526 105.0126953125105 .0309295654105 .0223770142104 .9817581177104 .9022445679 104.772567749104 .5766143799104 .2961044312103 .9317016602103 .6268997192 103.0174026489102 .712600708 -9999 -9999 -9999 -9999 -9999 -9999 -9999 -9999 -9999 -9999 -9999 -9999 -9999 -9999 -9999 -9999 -9999 -9999 -9999 -9999 -9999 -9999 -9999 -9999

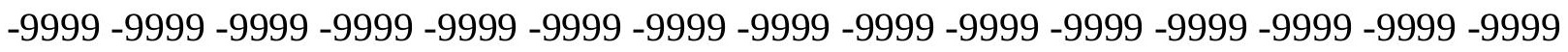
-9999 -9999 -9999 -9999 -9999 -9999 -9999 -9999 -9999 -9999 -9999 -9999 -9999 -9999 -9999 -9999 -9999 -9999 -9999 -9999 -9999 -9999 -9999 -9999 -9999 -9999 -9999 -9999 -9999 -9999 -

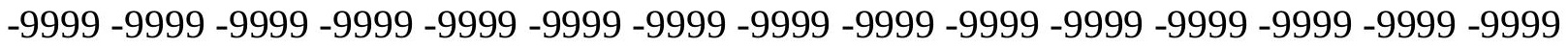

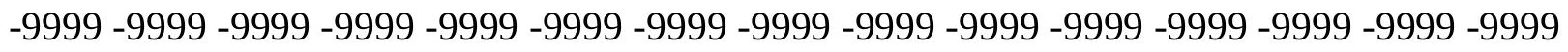

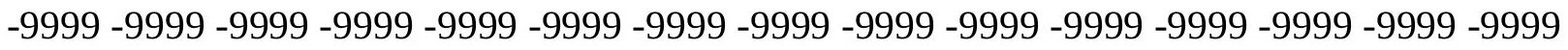
-9999 -9999 -9999 -9999 -9999 -9999 -9999 -9999 -9999 -9999 -9999 -9999 -9999 -9999 -9999 -9999 -9999 -9999 -9999 -9999 -9999 -9999 -9999 -9999 -9999 -9999 -9999 -9999 -9999 -9999 -9999 -9999 -9999 -9999-9999-9999-9999

-9999 -9999 -9999 -9999 -9999 -9999 -9999 -9999 -9999-9999 -9999 -9999 -9999 -9999 -9999 -9999 -9999 -9999 -9999 -9999 -9999 -9999 -9999 -9999-13.1057596207-8.83876895905 $-6.095703125-3.35263609886-.6095703244211 .8287110328674 .571776866913$ 7.31484317779510 .0579099655212 .4961900711114 .934470176717 .37274932861 19.811029434222 .2493095397924 .3828105926526 .5163097381628 .64979934692 
30.7833003997832 .9167900085434 .7455101013236 .5742111206138 .40293121338 39.9268493652341 .7555618286143 .2794914245644 .8034095764246 .02254867554 47.5464782714849 .0704002380451 .2038993835453 .3373985290557 .60438919067 59.4331016540561 .5666007995663 .0905189514264 .6144485473664 .61444854736 66.1383666992267 .6623001098668 .8814392089870 .1005783081171 .31971740723 72.2340774536172 .8436431884873 .7580032348674 .3675689697374 .67236328125 75.2819290161175 .5867080688575 .8914871215876 .1962814331176 .19628143311 76.5010681152376 .5010681152376 .8058471679776 .8058471679776 .80584716797 76.8058471679777 .110626220777 .110626220777 .110626220777 .41542053223 77.4154205322377 .4154205322376 .1962814331177 .7202072143679 .24413299561 80.4632720947381 .9871978759883 .5111236572385 .0350494384886 .55898284912 88.0829010009889 .302040100190 .8259735107492 .349891662693 .56903076172 95.0929565429796 .3121032714897 .8360290527399 .05516815186100 .5791015625 101.7982025146103 .0174026489104 .2365036011105 .4557037354106 .6747970581 107.8938980103109 .1130981445110 .0273971558111 .24659729112 .1608963013 113.3800964355114 .2944030762115 .2088012695116 .1231002808117 .0374984741 117.9517974854118 .8662033081119 .4757995605120 .3900985718120 .9997024536 121.6092987061122 .2188034058122 .8283996582123 .43800354124 .0475006104 124.3523025513124 .9618988037125 .2667007446125 .5715026855125 .8762969971 126.1809997559126 .1809997559126 .4858016968126 .4858016968126 .7906036377 126.7906036377126 .7906036377126 .7906036377126 .7906036377126 .7906036377 126.4858016968126 .4858016968126 .1809997559126 .1809997559125 .8762969971 125.8762969971125 .5715026855125 .2667007446124 .9618988037124 .6570968628 124.3523025513124 .0475006104123 .7427978516123 .4352722168122 .7617340088 122.0896453857121 .4194488525120 .751663208120 .0867996216119 .4254226685 118.7680892944118 .1154098511117 .4679870605116 .8265075684116 .1915969849 115.5640029907114 .9444046021114 .3335800171113 .7322387695113 .1411895752 112.5611495972111 .9929656982111 .4373245239110 .8950653076110 .3668746948 109.8535919189109 .3558578491108 .87449646108 .4101486206107 .9636154175 107.5354766846107 .1264953613106 .7371749878106 .3682022095106 .0199432373 105.6929397583105 .3874130249105 .103767395104 .842048645104 .6024780273 104.3850021362104 .189743042104 .0165100098103 .8652801514103 .7357559204 103.6277618408103 .5407791138103 .4744033813103 .4279174805103 .4007415771 103.391998291103 .4009017944103 .4264297485103 .4676361084103 .5233078003 103.5922622681103 .6730804443103 .7643814087103 .8645248413103 .9718704224 104.0845794678104 .2007522583104 .3182983398104 .435005188104 .5484924316 104.6562042236104 .7555389404104 .8437957764104 .9184646606104 .9769897461 105.0169372559105 .0352706909105 .0285644531104 .992149353104 .9198989868 104.8022155762104 .6248474121104 .3775100708104 .0531845093103 .6268997192 103.3221969604102 .712600708 -9999 -9999 -9999 -9999 -9999 -9999 -9999 -9999 -9999

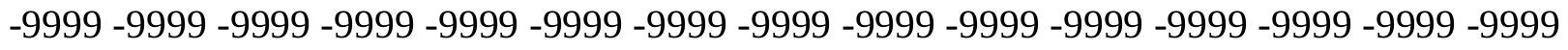

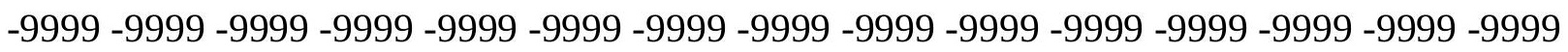
-9999 -9999 -9999 -9999 -9999 -9999 -9999 -9999 -9999 -9999 -9999 -9999 -9999 -9999 -9999 -9999 -9999 -9999 -9999 -9999 -9999 -9999 -9999 -9999 -9999 -9999 -9999 -9999 -9999 -9999 -

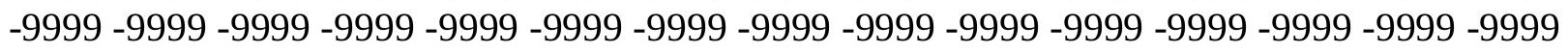

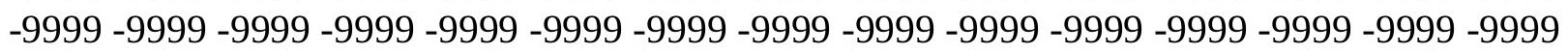


-9999 -9999 -9999 -9999 -9999 -9999 -9999 -9999 -9999 -9999 -9999 -9999 -9999 -9999 -9999 -9999 -9999 -9999 -9999 -9999 -9999 -9999 -9999 -9999 -9999 -9999 -9999 -9999 -9999 -9999 -9999 -9999 -9999 -9999 -9999 -9999 -9999 -9999 -9999 -9999 -9999 -9999 -9999 -9999 -9999 -9999 -9999 -9999 -9999 -9999 -9999 -9999

-9999 -9999 -9999 -9999 -9999 -9999 -9999 -9999 -9999 -9999 -9999 -9999 -9999 -9999 -9999 -9999 -9999 -9999 -9999 -9999 -9999 -9999 -9999 -9999-13.4105501175 -9.14355373383 $-6.095703125-3.35263609886-.6095703244211 .8287110328674 .87656211853$ 7.31484317779510 .0579099655212 .8009700775115 .2392597198517 .67753982544 20.1158199310322 .5541000366224 .6875991821327 .1258792877229 .25937080383 31.0880794525133 .2215805053735 .0502891540536 .8790016174338 .70771026611 40.5364189147942 .0603485107443 .5842704772945 .1082000732446 .32733917236 47.8512611389249 .3751907348651 .2038993835453 .3373985290557 .9091796875 60.3474502563562 .1761703491263 .7000885009865 .2240066528366 .44316101074 67.3575134277367 .0527267456168 .2718734741269 .4910125732470 .40535736084 71.3197174072372 .2340774536172 .8436431884873 .4532165527374 .0627822876 74.3675689697374 .6723632812574 .9771423339875 .2819290161175 .28192901611 75.5867080688575 .5867080688575 .5867080688575 .5867080688575 .89148712158 75.8914871215875 .8914871215875 .8914871215875 .8914871215875 .89148712158 76.1962814331176 .1962814331174 .9771423339876 .5010681152378 .02498626709 79.5489196777381 .0728530883882 .5967712402383 .8159103393685 .33984375 86.8637619018688 .3876876831189 .9116134643691 .1307525634892 .65467834473 94.1785964965895 .397743225196 .9216690063598 .1408081054799 .66472625732 100.8839035034102 .1029968262103 .3221969604104 .8460998535106 .0652008057 106.979598999108 .1986999512109 .4179000854110 .6370010376111 .551399231 112.7705001831113 .6848983765114 .5991973877115 .5136032104116 .4279022217 117.342300415118 .2565994263119 .1709976196119 .7806015015120 .3900985718 121.3044967651121 .9140014648122 .5235977173123 .1332015991123 .43800354 124.0475006104124 .3523025513124 .9618988037125 .2667007446125 .5715026855 125.8762969971125 .8762969971126 .1809997559126 .4858016968126 .4858016968 126.4858016968126 .4858016968126 .4858016968126 .4858016968126 .4858016968 126.4858016968126 .1809997559126 .1809997559125 .8762969971125 .8762969971 125.5715026855125 .2667007446125 .2667007446124 .9618988037124 .6570968628 124.3523025513124 .0475006104123 .7427978516123 .43800354122 .8974151611 122.2302932739121 .5649642944120 .9019393921120 .2417373657119 .5849304199 118.9320678711118 .2837677002117 .6406326294117 .0033416748116 .3725280762 115.7489242554115 .1332015991114 .5261230469113 .9283905029113 .3407974243 112.7640609741112 .1989974976111 .6462860107111 .1067581177110 .5810699463 110.0700531006109 .5743103027109 .0946502686108 .6316757202108 .1861572266 107.7586517334107 .3498840332106 .9603347778106 .5906524658106 .2411956787 105.9124832153105 .6047363281105 .3183441162105 .0533599854104 .8100204468 104.5882720947104 .3882522583104 .2097702026104 .0528411865103 .9171676636 103.8026123047103 .708694458103 .635055542103 .5810241699103 .5460739136 103.5293502808103 .530128479103 .5474319458103 .5803604126103 .627746582 103.6884689331103 .7611618042103 .8444900513103 .9368896484104 .0367431641 104.1422653198104 .2515945435104 .3626785278104 .4733505249104 .5812683105 104.6839065552104 .7787017822104 .8629837036104 .9342956543104 .9901885986 
105.0283889771105 .0462188721105 .0406265259105 .0074462891104 .9415283203 104.83543396104 .6809082031104 .4716873169104 .2236785889103 .9317016602 103.3221969604103 .0174026489102 .4077987671 -9999 -9999 -9999 -9999 -9999 -9999 -9999 -9999 -9999 -9999 -9999 -9999 -9999 -9999 -9999 -9999 -9999 -9999 -9999 -9999 -9999 -9999 -9999 -9999 -9999 -9999 -9999 -9999 -9999 -9999 -9999 -9999 -9999 -9999-9999 -9999 -9999 -9999 -9999 -9999 -9999 -9999 -9999 -9999 -9999 -9999 -9999 -9999 -9999 -9999 -9999 -9999 -9999 -9999 -9999 -9999 -9999 -9999 -9999 -9999 -9999 -9999 -9999 -9999 -9999 -9999 -9999 -

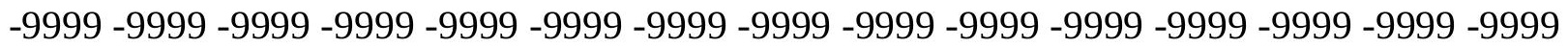

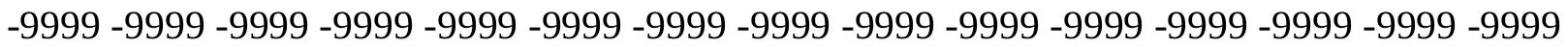
-9999 -9999 -9999 -9999 -9999 -9999 -9999 -9999 -9999 -9999 -9999 -9999 -9999 -9999 -9999 -

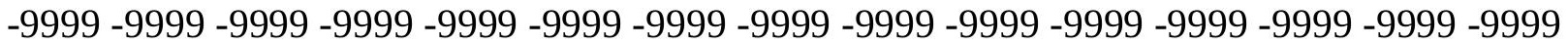
-9999 -9999 -9999 -9999 -9999 -9999 -9999 -9999 -9999 -9999 -9999 -9999 -9999 -9999 -9999 -9999 -9999 -9999 -9999-9999-9999-9999-9999

-9999 -9999 -9999 -9999 -9999 -9999 -9999 -9999 -9999 -9999 -9999 -9999 -9999 -9999 -9999 -9999 -9999 -9999 -9999 -9999 -9999 -9999 -9999 -9999-13.7153301239 -9.14355373383 $-6.095703125-3.35263609886-.3047851026062 .1334960460664 .87656211853$ 7.61962795257610 .3626899719213 .1057596206715 .5440397262618 .287109375 20.7253894805923 .1636695861825 .2971591949527 .430660247829 .56415939331 31.6976509094233 .8311500549335 .6598587036137 .4885711669939 .31727981567 40.8412094116242 .3651313781743 .8890609741245 .4129791259846 .93690872192 48.1560516357449 .3751907348651 .5086898803753 .3373985290558 .51874923706 60.9570198059162 .7857398986864 .6144485473666 .1383666992267 .35751342773 68.2718734741269 .1862335205169 .4910125732468 .8814392089869 .79579162598 70.7101516723671 .3197174072371 .9292907714872 .5388565063573 .14842987061 73.4532165527373 .7580032348674 .062782287674 .3675689697374 .36756896973 74.3675689697374 .6723632812574 .6723632812574 .6723632812574 .67236328125 74.6723632812574 .6723632812574 .6723632812574 .6723632812574 .67236328125 74.6723632812574 .9771423339874 .062782287675 .2819290161176 .80584716797 78.3297805786179 .8537063598681 .3776321411182 .9015579223684 .42548370361 85.9494018554787 .4733276367288 .6924667358490 .2164001464891 .74033355713 93.2642517089894 .4833908081196 .0073165893697 .2264633178798 .75038146973 99.96952056885101 .1886978149102 .712600708103 .9317016602105 .1509017944 106.3700027466 107.5891036987108.8082962036109.7226028442110.9418029785 111.8561019897113 .075302124113 .9896011353114 .9039993286115 .818397522 116.7326965332117 .647102356118 .5614013672119 .1709976196120 .0852966309 120.6949005127121 .3044967651121 .9140014648122 .5235977173123 .1332015991 123.7427978516124 .0475006104124 .6570968628124 .9618988037125 .2667007446 125.5715026855125 .8762969971125 .8762969971126 .1809997559126 .1809997559 126.1809997559126 .4858016968126 .4858016968126 .4858016968126 .1809997559 126.1809997559126 .1809997559125 .8762969971125 .8762969971125 .5715026855 125.5715026855125 .2667007446124 .9618988037124 .9618988037124 .6570968628 124.3523025513124 .0475006104123 .7427978516123 .43800354123 .0619125366 122.3996810913121 .739112854121 .0807266235120 .4250411987119 .7726211548 119.1240234375118 .4798736572117 .8407669067117 .2073745728116 .580329895 115.960357666115 .3481216431114 .7443847656114 .1498260498113 .5652236938 112.9912872314112 .4288253784111 .8785095215111 .3411331177110 .8173675537 
110.3080062866109 .8136444092109 .3350601196108 .872833252108 .4277114868 108.0002288818107 .5910720825107 .2007064819106 .8297729492106 .4785919189 106.1476821899105 .8372650146105 .5477218628105 .2791061401105 .0316696167 104.8053588867104 .6003189087104 .4163818359104 .2535552979104 .1115646362 103.9903030396103 .8893127441103 .808265686103 .7465438843103 .7036514282 103.6787872314103 .6712646484103 .6801452637103 .7045822144103 .7434463501 103.7956848145103 .8599777222103 .935043335104 .0193710327104 .1114044189 104.2093963623 104.3115310669 104.4158096313104.5200958252104.6220932007 104.719329834104 .8092651367104 .8892822266104 .9569854736105 .0099639893 105.0460510254105 .0627670288105 .0574188232105 .0262832642104 .9650192261 104.8681640625104 .7312927246104 .5489273071104 .3119659424103 .9317016602 103.6268997192103 .0174026489102 .4077987671 -9999 -9999 -9999 -9999 -9999 -9999 -9999 -9999 -9999 -9999 -9999 -9999 -9999 -9999 -9999 -9999 -9999 -9999 -9999 -9999 -9999 -9999 -9999 -9999 -9999 -9999 -9999 -9999 -9999 -9999 -9999 -9999 -9999 -9999 -9999 -9999 -9999 -9999 -9999 -9999 -9999 -9999 -9999 -9999 -9999 -9999 -9999 -9999 -9999 -9999 -9999 -9999

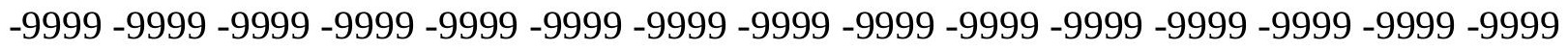

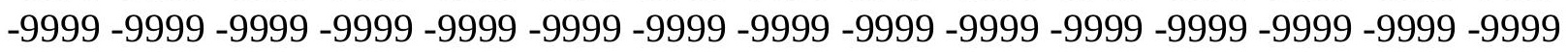
-9999 -9999 -9999 -9999 -9999 -9999 -9999 -9999 -9999 -9999 -9999 -9999 -9999 -9999 -9999 -999 -9999 -9999 -9999 -9999 -9999 -9999 -9999 -9999 -9999 -9999 -9999 -9999 -9999 -9999 -9999 -9999 -9999 -9999 -9999 -9999 -9999 -9999 -9999 -9999 -9999 -9999 -9999 -9999 -9999 -9999 -9999 -9999 -9999 -9999 -9999 -9999 -9999 -9999 -9999 -9999 -9999 -9999 -9999 -9999 -9999 -9999 -9999 -9999 -9999 -9999 -9999 -9999 -9999

-9999 -9999 -9999 -9999 -9999 -9999 -9999 -9999 -9999 -9999 -9999 -9999 -9999 -9999 -9999 -9999 -9999 -9999 -9999 -9999 -9999 -9999 -9999 -9999-13.7153301239 -9.14355373383 $-6.095703125-3.04785108566-99992.4382810592655 .1813468933118 .229198455811$ 10.9722604751613 .4105501174916 .1536102294918 .5918903350821 .3349609375 23.4684505462625 .906740188628 .0402297973630 .1737308502232 .30722045898 34.4407196044936 .2694282531738 .0981407165539 .9268493652341 .45077896118 42.9747009277344 .4986305236846 .0225486755447 .2416992187548 .46083068848 49.6799812316951 .5086898803756 .6900291442959 .4331016540561 .56660079956 63.7000885009865 .5288009643667 .0527267456168 .2718734741269 .18623352051 70.1005783081170 .4053573608470 .7101516723669 .1862335205170 .10057830811 70.7101516723671 .3197174072371 .9292907714872 .2340774536172 .53885650635 72.8436431884873 .1484298706173 .4532165527373 .4532165527373 .45321655273 73.7580032348673 .7580032348673 .7580032348673 .7580032348673 .75800323486 73.7580032348673 .4532165527373 .4532165527373 .4532165527373 .45321655273 73.4532165527372 .8436431884874 .3675689697375 .8914871215877 .41542053223 78.9393463134880 .4632720947381 .9871978759883 .5111236572384 .73026275635 86.2541885376 87.77810668945 89.302040100190.8259735107492.3498916626 93.5690307617295 .0929565429796 .3121032714897 .8360290527399 .05516815186 100.5791015625101 .7982025146103 .0174026489104 .2365036011105 .7603988647 106.979598999107 .8938980103109 .1130981445110 .3321990967111 .24659729 112.4656982422113 .3800964355114 .2944030762115 .5136032104116 .4279022217 117.0374984741117 .9517974854118 .8662033081119 .4757995605120 .3900985718 120.9997024536121 .6092987061122 .2188034058122 .8283996582123 .43800354 123.7427978516124 .3523025513124 .6570968628124 .9618988037125 .2667007446 
125.5715026855125 .8762969971125 .8762969971126 .1809997559126 .1809997559 126.1809997559126 .1809997559126 .1809997559126 .1809997559126 .1809997559 125.8762969971125 .8762969971125 .5715026855125 .5715026855125 .2667007446 125.2667007446124 .9618988037124 .6570968628124 .6570968628124 .3523025513 124.0475006104123 .7427978516123 .43800354123 .1332015991122 .5969924927 121.9410705566121 .2871780396120 .6358337402119 .9876174927119 .3430709839 118.7028198242118 .0674591064117 .4376602173116 .8140563965116 .1973571777 115.5882263184114 .9874038696114 .3955688477113 .8134994507113 .2418746948 112.6814956665112 .133026123111 .5972518921111 .0748214722110 .5665130615 110.0729217529109 .5947875977109 .1326904297108 .6873474121108 .259262085 107.8491134644107 .4573516846107 .0845870972106 .7311477661106 .3975219727 106.083946228105 .7907943726105 .5181427002105 .2662200928105 .0350036621 104.8246307373104 .6349563599104 .4659881592104 .3174667358104 .1893005371 104.0810470581103 .9924163818103 .9228286743103 .8718185425103 .8386383057 103.8226318359103 .8228988647103 .8386459351103 .8687896729103 .9123077393 103.967956543104 .0345077515104 .1104812622104 .1943969727104 .2845535278 104.3791885376104 .4763336182104 .5739135742104 .6696853638104 .76121521 104.8460159302104 .9215087891104 .9853286743105 .0351333618105 .0688095093 105.0839309692105 .0779800415105 .0476608276104 .9892349243104 .8979644775 104.7689743042104 .5957336426104 .3607635498104 .0345458984103 .6268997192 103.3221969604102 .712600708102 .1029968262 -9999 -9999 -9999 -9999 -9999 -9999 -9999

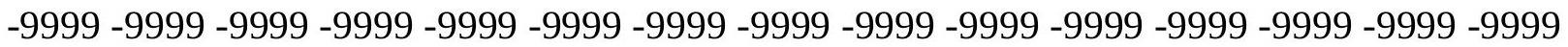
-9999 -9999 -9999 -9999 -9999 -9999 -9999 -9999 -9999 -9999 -9999 -9999 -9999 -9999 -9999 -9999 -9999 -9999 -9999 -9999 -9999 -9999 -9999 -9999 -9999 -9999 -9999 -9999 -9999 -9999 -9999 -9999 -9999 -9999 -9999 -9999 -9999 -9999 -9999 -9999 -9999 -9999 -9999 -9999 -9999 -9999 -9999 -9999 -9999 -9999 -9999 -9999 -9999 -9999 -9999 -9999 -9999 -9999 -9999 -9999 -9999 -9999 -9999 -9999 -9999 -9999 -9999 -9999 -9999 -9999 -9999 -9999 -9999 -9999 -9999

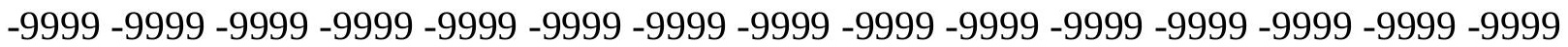
-9999 -9999 -9999 -9999 -9999 -9999 -9999 -9999 -9999 -9999 -9999 -9999 -9999 -9999 -9999 -9999 -9999 -9999 -9999 -9999 -9999 -9999 -9999 -9999 -9999 -9999 -9999 -9999 -9999 -9999 -9999 -9999 -9999 -9999 -9999 -9999 -9999

-9999 -9999 -9999 -9999 -9999 -9999 -9999 -9999 -9999 -9999 -9999 -9999 -9999 -9999 -9999 -9999 -9999-9999 -9999-9999-9999-9999-9999-9999-13.4105501175-8.83876895905 -5.79091691971 -2.74306607246 -9999 2.743066072464 5.790916919708 8.533983230591 11.5818300247214 .0201196670516 .7631797790519 .5062503814721 .94453048706 24.3828105926526 .5163097381628 .9545898437531 .0880794525133 .22158050537 35.0502891540536 .8790016174338 .7077102661140 .5364189147942 .06034851074 43.5842704772945 .1082000732446 .6321296691947 .8512611389249 .07040023804 50.2895507812551 .8134689331157 .2995986938560 .0426712036162 .48094940186 64.6144485473666 .4431610107467 .9670867919969 .1862335205170 .40535736084 71.014930725171 .3197174072371 .6244964599671 .6244964599671 .0149307251 70.1005783081170 .7101516723671 .3197174072371 .6244964599671 .92929077148 72.2340774536172 .2340774536172 .5388565063572 .5388565063572 .53885650635 72.5388565063572 .5388565063572 .5388565063572 .5388565063572 .53885650635 72.5388565063572 .5388565063572 .5388565063572 .2340774536172 .23407745361 72.2340774536171 .9292907714873 .4532165527374 .9771423339876 .50106811523 
78.0249862670979 .5489196777381 .0728530883882 .2919769287183 .81591033936 85.3398437586 .8637619018688 .3876876831189 .9116134643691 .43553924561 92.6546783447394 .1785964965895 .7025299072396 .9216690063598 .4455871582 99.66472625732101 .1886978149102 .4077987671103 .6268997192104 .8460998535 106.0652008057 107.2844009399 108.5035018921 109.7226028442110.6370010376 111.8561019897112 .7705001831113 .9896011353114 .9039993286115 .818397522 116.7326965332117 .647102356118 .2565994263119 .1709976196119 .7806015015 120.6949005127121 .3044967651121 .9140014648122 .5235977173123 .1332015991 123.43800354124 .0475006104124 .3523025513124 .6570968628124 .9618988037 125.2667007446125 .5715026855125 .5715026855125 .8762969971125 .8762969971 125.8762969971126 .1809997559125 .8762969971125 .8762969971125 .8762969971 125.8762969971125 .5715026855125 .5715026855125 .2667007446125 .2667007446 124.9618988037124 .9618988037124 .6570968628124 .6570968628124 .3523025513 124.0475006104123 .7427978516123 .7427978516123 .43800354122 .8217315674 122.1703262329121 .5207672119120 .873588562120 .2293624878119 .5886306763 118.9520111084118 .3201065063117 .6935882568117 .0730819702116 .4592895508 115.8528594971115 .2545318604114 .6649780273114 .0849609375113 .5151519775 112.9563369751112 .4091720581111 .8744354248111 .3527603149110 .8449172974 110.3514785767109 .8731765747109 .4105758667108 .9643783569108 .5350723267 108.1233215332107 .7295532227107 .3543701172106 .9981002808106 .6612243652 106.343963623 106.0467071533105.76953125105.5126876831 105.2761535645 105.0600738525104 .8643112183104 .6888885498104 .5335540771104 .3982162476 104.2824630737104 .1860275269104 .1083602905104 .0490341187104 .0073394775 103.9826583862103 .9741287231103 .9809951782104 .0022125244104 .0368270874 104.0836181641104 .141418457104 .2088088989104 .2843551636104 .3664169312 104.4532699585104 .543006897104 .6335983276104 .7228546143104 .8084106445 104.887840271104 .9585876465105 .0182952881105 .0646591187105 .0956115723 105.1087722778105 .1016159058105 .0710449219105 .0136642456104 .9249191284 104.7993087769104 .6282272339104 .3970031738104 .096534729103 .7310256958 103.3221969604 103.0174026489 102.4077987671 -9999 -9999 -9999 -9999 -9999 -9999 -9999 -9999 -9999 -9999 -9999 -9999 -9999 -9999 -9999 -9999 -9999 -9999 -9999 -9999 -9999 -9999

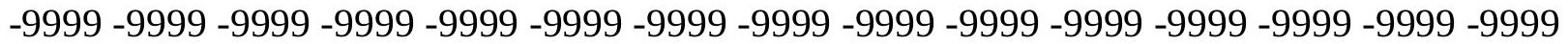

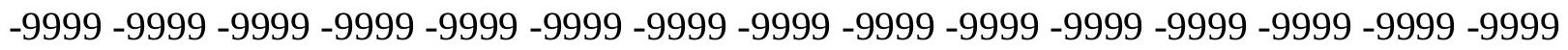
-9999 -9999 -9999 -9999 -9999 -9999 -9999 -9999 -9999 -9999 -9999 -9999 -9999 -9999 -9999 -9999 -9999 -9999 -9999 -9999 -9999 -9999 -9999 -9999 -9999 -9999 -9999 -9999 -9999 -9999 -9999 -9999 -9999 -9999 -9999 -9999 -9999 -9999 -9999 -9999 -9999 -9999 -9999 -9999 -9999 -

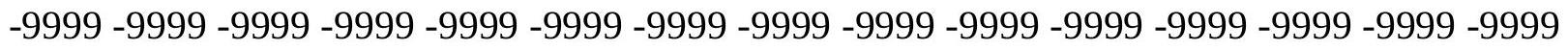

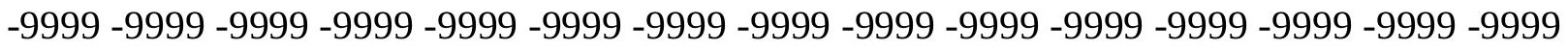

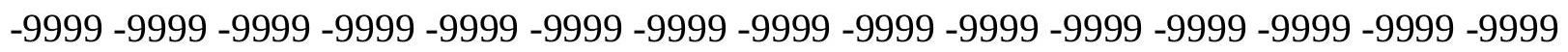
-9999 -9999 -9999 -9999 -9999-9999 -9999

-9999 -9999-9999 -9999 -9999 -9999 -9999 -9999 -9999-9999 -9999 -9999 -9999 -9999 -9999 -9999 -9999-9999 -9999-9999-9999 -9999-9999-9999-13.1057596207-8.53398323059 $-5.48613214493-2.13349604607$.6095703244209 3.3526360988626 .400486946106 9.4483394622812 .191410064714 .934470176717 .6775398254420 .11581993103 22.8588790893625 .2971591949527 .430660247829 .8689403533932 .00244140625 33.8311500549335 .9646492004437 .7933502197339 .622070312541 .14598846436 
42.9747009277344 .4986305236845 .717769622847 .2416992187548 .46083068848 49.6799812316950 .8991203308152 .1182594299357 .909179687560 .65224075317 63.3953094482465 .5288009643667 .3575134277368 .8814392089870 .40535736084 71.3197174072371 .9292907714872 .5388565063572 .5388565063572 .53885650635 71.9292907714871 .3197174072370 .1005783081170 .7101516723671 .0149307251 71.3197174072371 .3197174072371 .6244964599671 .6244964599671 .62449645996 71.6244964599671 .6244964599671 .6244964599671 .6244964599671 .62449645996 71.6244964599671 .3197174072371 .3197174072371 .3197174072371 .0149307251 71.014930725171 .014930725171 .014930725172 .5388565063573 .75800323486 75.2819290161176 .8058471679778 .3297805786179 .8537063598681 .37763214111 82.9015579223684 .4254837036185 .9494018554787 .4733276367288 .99725341797 90.5211791992292 .0450973510793 .2642517089894 .7881774902396 .31210327148 97.5312423706199 .05516815186100 .2742996216101 .7982025146103 .0174026489 104.2365036011105 .4557037354106 .6747970581107 .8938980103109 .1130981445 110.0273971558111 .24659729112 .4656982422113 .3800964355114 .2944030762 115.2088012695116 .1231002808117 .0374984741117 .9517974854118 .8662033081 119.4757995605120 .0852966309120 .9997024536121 .6092987061122 .2188034058 122.8283996582123 .1332015991123 .7427978516124 .0475006104124 .3523025513 124.9618988037124 .9618988037125 .2667007446125 .5715026855125 .5715026855 125.8762969971125 .8762969971125 .8762969971125 .8762969971125 .8762969971 125.8762969971125 .5715026855125 .5715026855125 .5715026855125 .2667007446 125.2667007446124 .9618988037124 .9618988037124 .6570968628124 .3523025513 124.3523025513124 .0475006104123 .7427978516123 .7427978516123 .43800354 123.0731658936122 .4261245728121 .7807388306121 .1375274658120 .4970626831 119.8598937988119 .2266387939118 .5979003906117 .9743347168117 .3565673828 116.745300293116 .141166687115 .5449142456114 .9571914673114 .3787460327 113.810256958113 .252494812112 .7061004639112 .1718444824111 .650352478 111.1423797607110 .6484909058110 .1694107056109 .7056884766109 .2580108643 108.8268661499108 .4128952026108 .0165176392107 .6383209229107 .2786254883 106.9379196167106 .6164245605106 .3145294189106 .0323257446105 .770072937 105.5277557373105 .3055343628105 .1032791138104 .9210205078104 .7585144043 104.6156845093104 .4921417236104 .3876266479104 .3016281128104 .233757019 104.1833267212104 .1497573853104 .1322250366104 .1300201416104 .1421356201 104.1676483154104 .2053985596104 .2542648315104 .3128662109104 .3798294067 104.4535598755104 .5324020386104 .6144866943104 .697845459104 .7803497314 104.8597183228104 .9335784912104 .9994125366105 .0548553467105 .0975952148 105.1255722046105 .1364593506105 .1277236938105 .0962905884105 .0389404297 104.9513397217104 .8281555176104 .6623306274104 .4438247681104 .1709747314 103.8514404297103 .4724502563103 .0174026489102 .712600708102 .1029968262 -9999 -9999 -9999 -9999 -9999 -9999 -9999 -9999 -9999 -9999 -9999 -9999 -9999 -9999 -9999 -9999

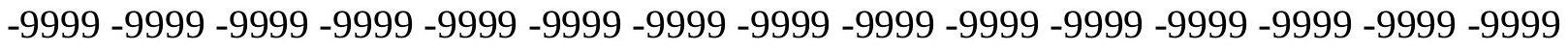

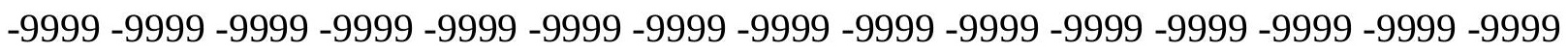
-9999 -9999 -9999 -9999 -9999 -9999 -9999 -9999 -9999 -9999 -9999 -9999 -9999 -9999 -9999 -9999 -9999 -9999 -9999 -9999 -9999 -9999 -9999 -9999 -9999 -9999 -9999 -9999 -9999 -9999 -

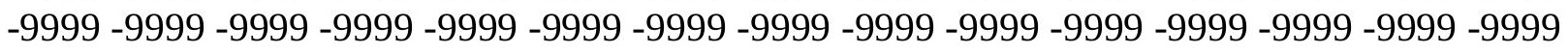

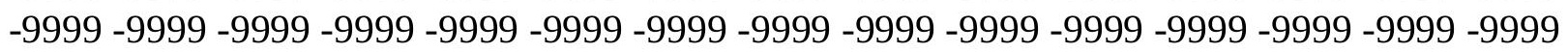


-9999 -9999 -9999 -9999 -9999 -9999 -9999 -9999 -9999 -9999 -9999 -9999 -9999 -9999 -9999

-9999 -9999 -9999 -9999 -9999 -9999 -9999 -9999 -9999 -9999 -9999 -9999 -9999 -9999 -9999 -

-9999 -9999 -9999 -9999 -9999 -9999 -9999 -9999 -9999 -9999 -9999 -9999

-9999 -9999 -9999 -9999 -9999 -9999 -9999 -9999 -9999 -9999 -9999 -9999 -9999 -9999 -9999

-9999 -9999 -9999 -9999 -9999 -9999 -9999 -9999 -9999-12.8009700775 -7.92441320419

$-4.87656211853-1.523926019671 .219141006474 .2669920921337 .314843177795$

10.0579099655213 .1057596206715 .8488302230818 .5918903350821 .03017044067

23.7732391357426 .2115192413328 .6497993469230 .7833003997832 .91679000854

35.0502891540536 .8790016174338 .7077102661140 .5364189147942 .06034851074

43.5842704772945 .1082000732446 .6321296691947 .8512611389249 .07040023804

50.2895507812551 .5086898803753 .9469718933158 .8235282897961 .56660079956

64.004882812566 .4431610107468 .2718734741270 .1005783081171 .31971740723

72.2340774536173 .1484298706173 .4532165527373 .4532165527373 .45321655273

73.1484298706172 .2340774536171 .3197174072370 .1005783081170 .40535736084 70.4053573608470 .7101516723670 .7101516723671 .014930725171 .0149307251 71.014930725171 .014930725170 .7101516723670 .7101516723670 .71015167236 70.4053573608470 .4053573608470 .4053573608470 .1005783081170 .10057830811 69.7957916259868 .5766525268670 .1005783081171 .6244964599673 .14842987061 74.6723632812576 .1962814331177 .7202072143679 .2441329956180 .76805877686 82.29197692871 83.81591033936 85.33984375 86.8637619018688.08290100098 89.6068267822391.1307525634892.6546783447394.1785964965895.3977432251 96.9216690063598 .1408081054799 .66472625732100 .8839035034102 .4077987671 103.6268997192104 .8460998535106 .0652008057107 .2844009399108 .5035018921 109.7226028442110 .6370010376111 .8561019897112 .7705001831113 .9896011353 114.9039993286115 .818397522116 .7326965332117 .647102356118 .2565994263 119.1709976196119 .7806015015120 .6949005127121 .3044967651121 .9140014648 122.5235977173122 .8283996582123 .43800354123 .7427978516124 .3523025513 124.6570968628124 .9618988037125 .2667007446125 .2667007446125 .5715026855 125.5715026855125 .8762969971125 .8762969971125 .8762969971125 .8762969971 125.5715026855125 .5715026855125 .5715026855125 .2667007446125 .2667007446 124.9618988037124 .9618988037124 .6570968628124 .6570968628124 .3523025513 124.3523025513124 .0475006104124 .0475006104123 .7427978516123 .43800354 123.3508605957122 .7080307007122 .0666275024121 .4271774292120 .7902374268 120.1563796997119 .5262069702118 .9003143311118 .2793655396117 .6639785767 117.0548400879116 .4525985718115 .8579788208115 .2716293335114 .6942901611 114.1266174316113 .5693893433113 .0232315063112 .4888916016111 .967010498 111.4583129883110 .9633789062110 .4829101562110 .0174484253109 .5676727295 109.1340637207 108.7172470093 108.3176422119107.8938980103 107.5721054077 107.2269821167 106.900680542 106.5935897827 106.305809021 106.037612915 105.7890090942105 .5601577759105 .3509368896105 .1613922119104 .9913024902 104.8405990601104 .7089004517104 .5959854126104 .5013504028104 .4246520996 104.3652267456104 .3225326538104 .2957839966104 .2842941284104 .287109375 104.3033370972 104.3318557739 104.37159729 104.4212341309 104.4794311523 104.544631958104 .6152572632104 .6894836426104 .765411377104 .8409805298 104.9139709473104 .9820861816105 .0428771973105 .0939559937105 .1329879761 105.1578903198105 .1663208008105 .1558227539105 .1233825684105 .0658874512 
104.9794158936104 .8594818115104 .7006988525104 .4983596802104 .2507553101 103.9652252197103 .6268997192103 .3221969604102 .712600708102 .4077987671 -9999 -9999 -9999 -9999 -9999 -9999 -9999 -9999 -9999 -9999 -9999 -9999 -9999 -9999 -9999 -9999 -9999 -9999 -9999 -9999 -9999 -9999 -9999 -9999 -9999 -9999 -9999 -9999 -9999 -9999 -9999 -9999 -9999 -9999 -9999 -9999 -9999 -9999 -9999 -9999-9999 -9999 -9999 -9999 -9999 -9999 -9999 -9999 -9999 -9999 -9999 -9999 -9999 -9999 -9999 -9999 -9999 -9999 -9999 -9999 -9999 -9999 -9999 -9999 -9999 -9999 -9999 -9999 -9999 -9999 -9999 -9999 -9999 -9999 -9999 -9999

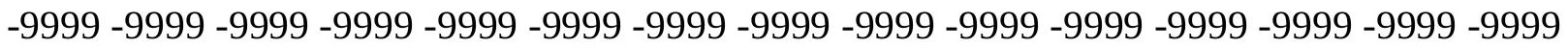

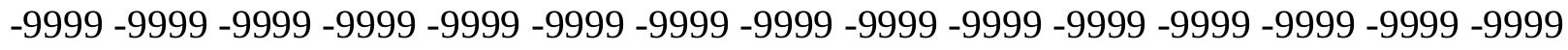
-9999 -9999 -9999 -9999 -9999 -9999 -9999 -9999 -9999 -9999 -9999 -9999 -9999 -9999 -9999 -9999 -9999 -9999 -9999 -9999 -9999 -9999 -9999 -9999 -9999 -9999 -9999 -9999 -9999 -9999 -9999 -9999 -9999 -9999 -9999 -9999 -9999 -9999 -9999 -9999 -9999 -9999

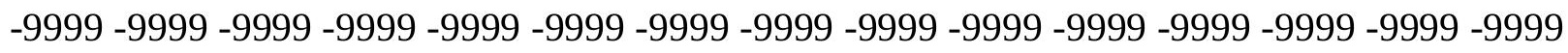
-9999 -9999 -9999 -9999 -9999 -9999 -9999 -9999 -9999-12.1914100647-8.83876895905 -3.96220707893 -.914355397224 2.133496046066 5.181346893311 8.229198455811 11.2770500183114 .0201196670516 .7631797790519 .5062503814722 .24930953979 24.6875991821327 .430660247829 .5641593933132 .0024414062534 .13592910767 35.9646492004438 .0981407165539 .9268493652341 .4507789611843 .27949142456 44.8034095764246 .0225486755447 .5464782714848 .765621185349 .98476028442 51.2038993835452 .1182594299354 .5565414428759 .4331016540562 .17617034912 64.9192428588967 .3575134277369 .1862335205171 .014930725172 .23407745361 73.4532165527374 .062782287674 .3675689697374 .6723632812574 .36756896973 74.062782287673 .1484298706172 .2340774536171 .014930725169 .79579162598 69.7957916259870 .1005783081170 .1005783081170 .1005783081170 .10057830811 70.1005783081170 .1005783081170 .1005783081169 .7957916259869 .79579162598 69.4910125732469 .4910125732469 .1862335205169 .1862335205168 .88143920898 68.5766525268667 .6623001098669 .1862335205170 .7101516723672 .23407745361 73.7580032348675 .2819290161176 .8058471679778 .3297805786179 .85370635986 81.3776321411182 .9015579223684 .4254837036185 .9494018554787 .47332763672 88.9972534179790.5211791992292.0450973510793.2642517089894.78817749023 96.3121032714897 .5312423706199 .05516815186100 .2742996216101 .4934005737 103.0174026489104 .2365036011105 .4557037354106 .6747970581107 .8938980103 109.1130981445110 .0273971558111 .24659729112 .4656982422113 .3800964355 114.2944030762115 .2088012695116 .1231002808117 .0374984741117 .9517974854 118.8662033081119 .4757995605120 .0852966309120 .9997024536121 .6092987061 122.2188034058122 .5235977173123 .1332015991123 .7427978516124 .0475006104 124.3523025513124 .6570968628124 .9618988037125 .2667007446125 .2667007446 125.5715026855125 .5715026855125 .5715026855125 .5715026855125 .5715026855 125.5715026855125 .5715026855125 .5715026855125 .2667007446125 .2667007446 124.9618988037124 .9618988037124 .6570968628124 .6570968628124 .3523025513 124.3523025513124 .0475006104124 .0475006104123 .7427978516123 .7427978516 123.43800354123 .0152893066122 .3776779175121 .7417602539121 .1081085205 120.4772872925119 .849899292119 .2265396118118 .6078643799117 .9944839478 117.3870925903116 .7863235474116 .1929016113115 .6074676514115 .03074646 114.4634017944113 .9061889648113 .3597259521112 .8247680664112 .3019256592 111.7919311523111 .2953567505110 .8128967285110 .3450927734109 .8926086426 
109.4559173584109.0356369019108.6321868896108.1986999512107.8778076172 107.527671814107 .1959762573106 .8831176758106 .5892028809106 .3145217896 106.0590820312105 .8230743408105 .6063919067105 .4090805054105 .2309494019 105.0719299316104 .931678772104 .8099746704104 .7063674927104 .6205062866 104.5517883301104 .4996948242104 .4634628296104 .4424591064104 .4357528687 104.442489624104 .4615859985104 .4920196533104 .5325088501104 .5817489624 104.6382522583104 .7004776001104 .7666702271104 .8349914551104 .9034423828 104.9699020386105 .0321426392105 .0877761841105 .134437561105 .1697692871 105.1916275024105 .1976623535105 .1854934692105 .1522293091105 .0949707031 105.0102005005104 .8942871094104 .7431945801104 .5543441772104 .3277435303 104.0685577393103 .7778778076103 .441368103103 .0174026489102 .4077987671 102.1029968262 -9999 -9999 -9999 -9999 -9999 -9999 -9999 -9999 -9999 -9999 -9999 -9999 -9999 -9999 -9999 -9999 -9999 -9999 -9999 -9999 -9999 -9999 -9999 -9999 -9999 -9999 -9999 -9999 -9999 -9999 -9999 -9999 -9999 -9999 -9999 -9999 -9999 -9999 -9999 -9999 -9999 -9999 -9999 -9999 -9999 -9999 -9999 -9999 -9999 -9999 -9999 -9999 -9999 -9999 -9999 -9999 -9999

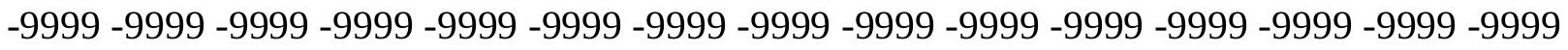
-9999 -9999 -9999 -9999 -9999 -9999 -9999 -9999 -9999 -9999 -9999 -9999 -9999 -9999 -9999 -9999 -9999 -9999 -9999 -9999 -9999 -9999 -9999 -9999 -9999 -9999 -9999 -9999 -9999 -9999 -

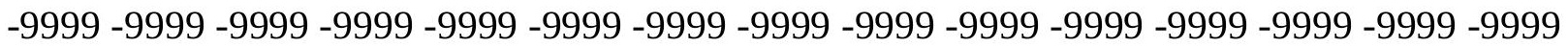

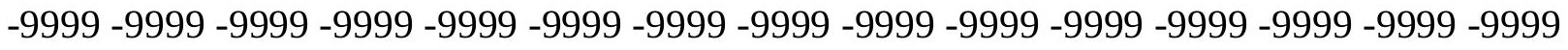

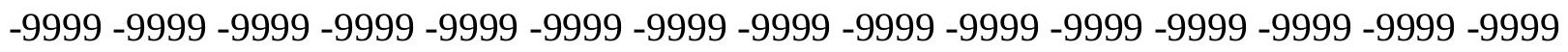

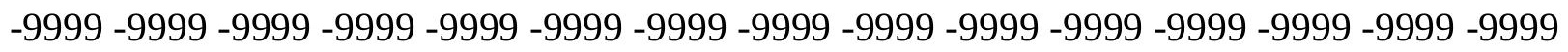
-9999 -9999 -9999 -9999 -9999 -9999 -9999 -9999 -9999 -11.2770500183 -7.92441320419 -3.04785108566 -9999 3.047851085663 6.095703125 9.143553733826 12.1914100647 15.2392597198517 .9823207855220 .7253894805923 .4684505462626 .21151924133 28.64979934692 30.78330039978 33.2215805053735.35507965088 37.18378067017 39.3172798156740 .8412094116242 .66992187544 .1938400268645 .7177696228 47.2416992187548 .4608306884849 .6799812316950 .8991203308151 .81346893311 52.7278289794955 .1661109924360 .0426712036163 .0905189514265 .83358764648 68.2718734741270 .4053573608471 .9292907714873 .1484298706174 .36756896973 74.9771423339875 .2819290161175 .5867080688575 .2819290161174 .97714233398 74.3675689697373 .1484298706171 .9292907714869 .1862335205169 .49101257324 69.4910125732469 .4910125732469 .4910125732469 .4910125732469 .49101257324 69.1862335205169 .1862335205168 .8814392089868 .8814392089868 .57665252686 68.5766525268668 .2718734741267 .9670867919967 .6623001098667 .66230010986 66.7479400634868 .2718734741269 .7957916259871 .3197174072372 .84364318848 74.3675689697375 .8914871215877 .4154205322379 .2441329956180 .76805877686 82.2919769287183 .8159103393685 .3398437586 .8637619018688 .08290100098 89.6068267822391.1307525634892.6546783447394.1785964965895.3977432251 96.9216690063598 .445587158299 .66472625732100 .8839035034102 .4077987671 103.6268997192104 .8460998535106 .0652008057107 .2844009399108 .5035018921 109.7226028442110 .6370010376111 .8561019897112 .7705001831113 .9896011353 114.9039993286115 .818397522116 .7326965332117 .647102356118 .2565994263 119.1709976196119 .7806015015120 .6949005127121 .3044967651121 .9140014648 122.5235977173122 .8283996582123 .43800354123 .7427978516124 .3523025513 124.6570968628124 .9618988037124 .9618988037125 .2667007446125 .5715026855 
125.5715026855125 .5715026855125 .5715026855125 .5715026855125 .5715026855 125.5715026855125 .5715026855125 .2667007446125 .2667007446124 .9618988037 124.9618988037124 .6570968628124 .6570968628124 .3523025513124 .3523025513 124.0475006104124 .0475006104123 .7427978516123 .7427978516123 .7427978516 123.3474349976122 .7134017944122 .0807876587121 .4501724243120 .8221054077 120.1971969604119 .5760421753118 .9592819214118 .3475418091117 .7414932251 117.1417770386116 .5491104126115 .9641189575115 .3875427246114 .820022583 114.2623062134113 .7150115967113 .1788787842112 .6545181274112 .1426544189 111.6438522339111 .1588134766110 .6880493164110 .2322463989109 .7918624878 109.367515564108 .9596099854108 .5035018921107 .8938980103107 .8394241333 107.5017471313107 .1825332642106 .8819046021106 .6001663208106 .3373413086 106.0936355591105 .8689498901105 .6633682251105 .4766921997105 .3088912964 105.1596298218105 .028717041104 .915725708104 .8203430176104 .741973877 104.6801528931104 .6341552734104 .6033554077104 .5868606567104 .5838699341 104.5933303833104 .6142501831104 .6453781128104 .6854782104104 .7330932617 104.7867355347104 .8447265625104 .9052810669104 .9664764404105 .0262756348 105.08253479105 .1329345703105 .175163269105 .2068557739105 .2258377075 105.2297592163105 .2162704468105 .1826400757105 .1262130737105 .0438537598 104.9325332642104 .7891387939104 .6117248535104 .3991851807104 .1520996094 $103.8709640503103 .5387649536103 .1596221924102 .712600708102 .1029968262-9999$ -9999 -9999 -9999 -9999 -9999 -9999 -9999 -9999 -9999 -9999 -9999 -9999 -9999 -9999 -9999 -9999 -9999 -9999 -9999 -9999 -9999 -9999 -9999 -9999 -9999 -9999 -9999 -9999 -9999 -9999 -9999 -9999 -9999 -9999 -9999 -9999 -9999 -9999 -9999 -9999 -9999 -9999 -9999 -9999 -9999 -999 -9999 -9999 -9999 -9999 -9999 -9999 -9999 -9999 -9999 -9999 -9999 -9999 -9999 -9999 -9999

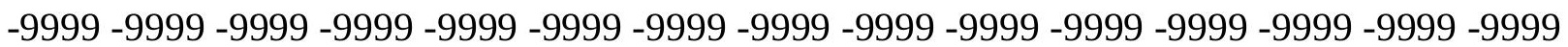
-9999 -9999 -9999 -9999 -9999 -9999 -9999 -9999 -9999 -9999 -9999 -9999 -9999 -9999 -9999 -9999 -9999 -9999 -9999 -9999 -9999 -9999 -9999 -9999 -9999 -9999 -9999 -9999 -9999 -9999 -9999 -9999 -9999 -9999 -9999 -9999 -9999 -9999 -9999 -9999 -9999 -9999 -9999 -9999 -9999

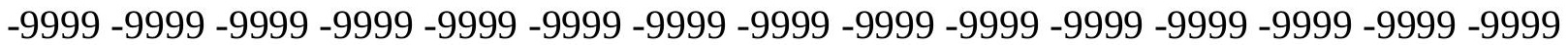
-9999 -9999 -9999 -9999 -9999 -9999 -9999 -9999 -9999 -9999 -9999 -9999 -9999 -9999 -9999 -9999 -9999 -9999 -9999 -9999 -9999 -9999 -9999 -9999 -9999 -9999 -9999 -9999 -9999 -9999 -9999 -9999 -9999 -9999 -9999-10.3626899719-6.7052731514 -2.13349604607 .9143553972244 4.2669920921337.314843177795 10.66748046875 13.715330123916 .4584007263219 .5062503814722 .2493095397924 .99238014221 27.430660247829 .8689403533932 .3072204589834 .4407196044936 .57421112061 38.7077102661140 .5364189147942 .3651313781743 .8890609741245 .41297912598 46.9369087219248 .1560516357449 .3751907348650 .5943298339851 .81346893311 52.7278289794953 .6421813964854 .5565414428760 .3474502563563 .70008850098 66.4431610107469 .1862335205171 .014930725172 .8436431884874 .0627822876 75.2819290161175 .8914871215876 .1962814331176 .5010681152376 .19628143311 75.8914871215875 .2819290161174 .062782287672 .8436431884871 .31971740723 68.8814392089868 .8814392089868 .8814392089868 .8814392089868 .88143920898 68.5766525268668 .5766525268668 .2718734741268 .2718734741267 .96708679199 67.6623001098667 .6623001098667 .3575134277367 .0527267456166 .74794006348 66.4431610107466 .1383666992267 .6623001098669 .1862335205170 .71015167236 72.2340774536173 .7580032348675 .2819290161176 .8058471679778 .32978057861 
79.8537063598681 .3776321411182 .9015579223684 .4254837036185 .94940185547 87.47332763672 88.9972534179790.5211791992292.0450973510793.56903076172 94.7881774902396 .3121032714897 .8360290527399 .05516815186100 .5791015625 101.7982025146103 .0174026489104 .2365036011105 .4557037354106 .6747970581 107.8938980103109 .1130981445110 .3321990967111 .24659729112 .4656982422 113.3800964355114 .5991973877115 .5136032104116 .4279022217117 .342300415 117.9517974854118 .8662033081119 .4757995605120 .3900985718120 .9997024536 121.6092987061122 .2188034058122 .8283996582123 .1332015991123 .7427978516 124.0475006104124 .3523025513124 .6570968628124 .9618988037125 .2667007446 125.5715026855125 .5715026855125 .5715026855125 .5715026855125 .8762969971 125.5715026855125 .5715026855125 .5715026855125 .2667007446125 .2667007446 124.9618988037124 .9618988037124 .6570968628124 .6570968628124 .3523025513 124.0475006104124 .0475006104124 .0475006104123 .7427978516123 .7427978516 123.7427978516123 .43800354123 .073097229122 .4435577393121 .8157119751 121.1901092529120 .5673675537119 .9480743408119 .3328857422118 .7223968506 118.1172943115117 .5182037354116 .9258422852116 .3408432007115 .763923645 115.1957321167114 .6369934082114 .0883331299113 .5504837036113 .024055481 112.5097579956112 .0081634521111 .5199432373111 .0456390381110 .5859146118 110.1412353516109 .7122039795109 .2992401123108 .9029083252108 .1986999512 107.8938980103107 .8173370361107 .4911880493107 .1832733154106 .8939056396 106.6231384277106 .3711776733106 .1379547119105 .9235610962105 .7278289795 105.550743103105 .3919906616105 .251411438105 .1286087036105 .0232849121 104.9348831177104 .8629684448104 .8068466187104 .7659301758104 .7393569946 104.7263565063104 .7259216309104 .7370758057104 .7586212158104 .7893600464 104.8278884888104 .8727722168104 .9223937988104 .9750366211105 .0288543701 105.0818939209105 .1321029663105 .1772537231105 .21509552105 .2433013916 105.2596740723105 .2618789673105 .2475967407105 .214225769105 .1592941284 105.0799865723104 .9736633301104 .837600708104 .6698913574104 .4686508179 104.2326126099 103.9595184326103.6454696655 103.2820129395 102.8661575317 102.4077987671 102.1029968262 -9999 -9999 -9999 -9999 -9999 -9999 -9999 -9999 -9999 -9999 -9999 -9999 -9999 -9999 -9999 -9999 -9999 -9999 -9999 -9999 -9999 -9999 -9999 -9999

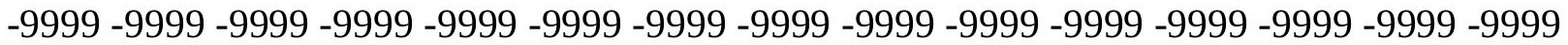

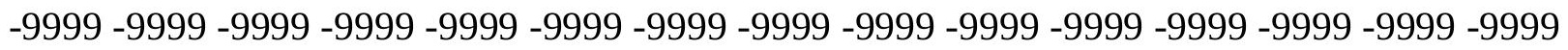
-9999 -9999 -9999 -9999 -9999 -9999 -9999 -9999 -9999 -9999 -9999 -9999 -9999 -9999 -9999 -9999 -9999 -9999 -9999 -9999 -9999 -9999 -9999 -9999 -9999 -9999 -9999 -9999 -9999 -9999

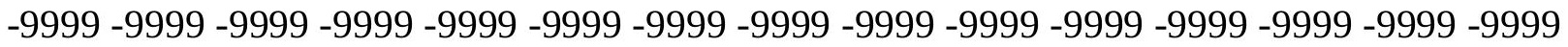

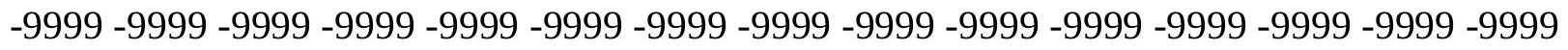

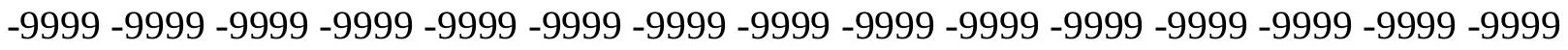
-9999 -9999 -9999 -9999 -9999 -9999 -9999 -9999 -9999 -9999 -9999 -9999 -9999 -9999 -9999 $-9999-9999$

-9999 -9999-9999 -9999 -9999 -9999 -9999 -9999 -9999-9999 -9999 -9999 -9999 -9999 -9999 -9999 -9999 -9999 -9999 -9999 -9999 -9999 -9999 -9999 -9999 -5.48613214493 -2.13349604607 2.438281059265 5.790916919708 8.838768959045 12.1914100647 15.2392597198518 .28710937521 .0301704406723 .7732391357426 .51630973816 28.95458984375 31.3928699493433 .8311500549335 .9646492004438 .09814071655 40.2316398620642 .0603485107443 .5842704772945 .4129791259846 .93690872192 
48.1560516357449 .3751907348650 .5943298339851 .8134689331152 .72782897949 53.6421813964854 .5565414428755 .4708900451760 .9570198059164 .30966186523 67.3575134277369 .7957916259871 .9292907714873 .4532165527374 .97714233398 75.8914871215876 .5010681152377 .110626220777 .110626220777 .1106262207 76.8058471679776 .1962814331175 .2819290161173 .7580032348672 .23407745361 70.4053573608468 .2718734741268 .2718734741268 .2718734741267 .96708679199 67.9670867919967 .6623001098667 .6623001098667 .3575134277367 .05272674561 66.7479400634866 .7479400634866 .4431610107466 .1383666992265 .83358764648 65.5288009643665 .2240066528366 .7479400634868 .5766525268670 .10057830811 71.6244964599673 .1484298706174 .6723632812576 .1962814331177 .72020721436 79.2441329956180 .7680587768682 .2919769287183 .8159103393685 .33984375 86.8637619018688 .3876876831189 .9116134643691 .4355392456192 .95947265625 94.1785964965895 .7025299072397 .2264633178798 .445587158299 .96952056885 101.1886978149102 .4077987671103 .9317016602105 .1509017944106 .3700027466 107.5891036987108 .8082962036109 .7226028442110 .9418029785112 .1608963013 113.075302124113 .9896011353114 .9039993286115 .818397522116 .7326965332 117.647102356118 .5614013672119 .1709976196120 .0852966309120 .6949005127 121.3044967651121 .9140014648122 .5235977173123 .1332015991123 .43800354 124.0475006104124 .3523025513124 .6570968628124 .9618988037125 .2667007446 125.2667007446125 .5715026855125 .5715026855125 .8762969971125 .8762969971 125.8762969971125 .8762969971125 .5715026855125 .5715026855125 .2667007446 125.2667007446124 .9618988037124 .6570968628124 .3523025513124 .3523025513 124.0475006104124 .0475006104124 .0475006104123 .7427978516123 .7427978516 123.7427978516123 .7427978516123 .43800354122 .8296432495122 .2042922974 121.5808639526120 .9599609375120 .3421936035119 .7281951904119 .1185684204 118.513999939117 .9151077271117 .3226089478116 .7371292114116 .1593856812 115.5900115967115 .0297470093114 .4791946411113 .9390869141113 .4100265503 112.8927307129112 .3877563477111 .8957824707111 .417350769110 .9531097412 110.5035324097110 .0692214966109 .6505966187109 .2482147217108 .5035018921 108.1986999512108 .1422576904107 .8085861206107 .492805481107 .1952362061 106.9159469604106 .6551742554106 .4128570557106 .1891098022105 .9837875366 105.7968902588105 .6281509399105 .4774246216105 .344329834105 .2286148071 105.1297531128105 .0473327637104 .9806976318104 .9292984009104 .8923034668 104.8689727783104 .8583221436104 .8594284058104 .871131897104 .8922729492 104.9214935303104 .9574279785104 .9985046387105 .0431060791105 .0894470215 105.1356658936105 .1797943115105 .2197189331105 .2532730103105 .2781906128 105.2922897339105 .2932434082105 .2787780762105 .2463607788105 .193649292 105.1180114746105 .0170822144104 .8883209229104 .7298355103104 .5395736694 104.315788269104 .0567550659103 .761100769103 .4281158447103 .0622024536 102.6919326782102 .2889175415 -9999 -9999 -9999 -9999 -9999 -9999 -9999 -9999 -9999

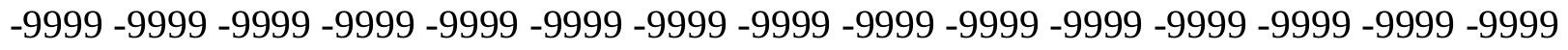

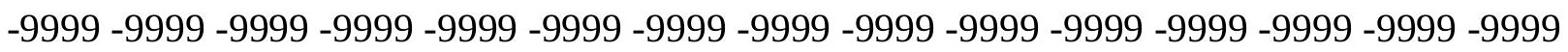
-9999 -9999 -9999 -9999 -9999 -9999 -9999 -9999 -9999 -9999 -9999 -9999 -9999 -9999 -9999 -9999 -9999 -9999 -9999 -9999 -9999 -9999 -9999 -9999 -9999 -9999 -9999 -9999 -9999 -9999 -

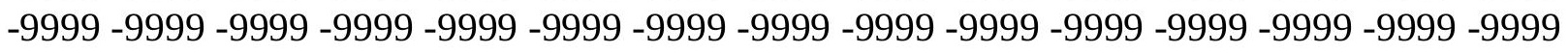

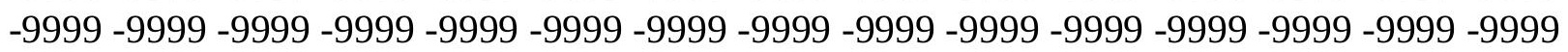


-9999 -9999 -9999 -9999 -9999 -9999 -9999 -9999 -9999 -9999 -9999 -9999 -9999 -9999 -9999 -9999 -9999 -9999 -9999 -9999 -9999 -9999 -9999 -9999 -9999 -9999 -9999 -9999 -9999 -9999

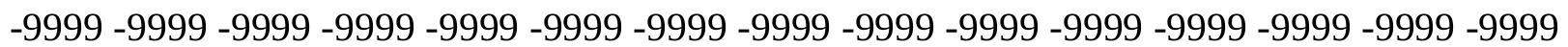
-9999-9999

-9999 -9999 -9999 -9999 -9999 -9999 -9999 -9999 -9999 -9999 -9999 -9999 -9999 -9999 -9999 -9999 -9999 -9999 -9999 -9999 -9999 -9999 -9999 -9999 -9999 -3.96220707893 -.609570324421 3.9622070789347 .31484317779510 .6674804687513 .7153301239 16.7631797790519 .811029434222 .8588790893625 .6019496917728 .34502029419 30.7833003997833 .2215805053735 .6598587036137 .7933502197339 .92684936523 41.7555618286143 .5842704772945 .1082000732446 .6321296691948 .15605163574 49.6799812316950 .8991203308151 .8134689331153 .0326118469253 .94697189331 54.8613204956155 .4708900451756 .3852500915556 .9948196411164 .61444854736 67.6623001098670 .4053573608472 .2340774536174 .062782287675 .28192901611 76.1962814331177 .110626220777 .4154205322377 .7202072143677 .72020721436 77.4154205322376 .8058471679776 .1962814331174 .9771423339873 .45321655273 71.6244964599667 .9670867919967 .6623001098667 .6623001098667 .35751342773 67.3575134277367 .0527267456166 .7479400634866 .7479400634866 .44316101074 66.1383666992265 .8335876464865 .5288009643665 .2240066528364 .91924285889 63.0905189514264 .6144485473666 .1383666992267 .9670867919969 .49101257324 71.014930725172 .5388565063574 .062782287675 .5867080688577 .1106262207 78.6345596313580 .1584930419981 .6824111938583 .206336975184 .73026275635 86.2541885376 87.77810668945 89.302040100190.8259735107492.3498916626 93.8738174438595 .0929565429796 .6168823242297 .8360290527399 .35994720459 100.5791015625102 .1029968262103 .3221969604104 .5412979126105 .7603988647 106.979598999108 .1986999512109 .4179000854110 .6370010376111 .551399231 112.7705001831113 .6848983765114 .5991973877115 .5136032104116 .4279022217 117.342300415118 .2565994263118 .8662033081119 .7806015015120 .3900985718 120.9997024536121 .6092987061122 .2188034058122 .8283996582123 .43800354 123.7427978516124 .3523025513124 .6570968628124 .9618988037125 .2667007446 125.2667007446125 .5715026855125 .8762969971125 .8762969971125 .8762969971 125.8762969971125 .8762969971125 .8762969971125 .5715026855125 .5715026855 125.2667007446124 .9618988037124 .6570968628124 .3523025513124 .3523025513 124.0475006104124 .0475006104123 .7427978516123 .7427978516123 .7427978516 123.7427978516123 .7427978516123 .43800354123 .2383422852122 .615196228 121.993637085121 .3742599487120 .7576599121120 .1444854736119 .5353317261 118.9308853149118 .3317642212117 .7386779785117 .1522445679116 .5731887817 116.0021438599115 .4398269653114 .8868637085114 .3439559937113 .8117218018 113.2908706665112 .7819519043112 .2856521606111 .8025054932111 .3331680298 110.8780975342110 .4379196167110 .0130386353109 .604019165109 .1130981445 108.5035018921108 .4759063721108 .1341323853107 .8099060059107 .5035629272 107.2151947021 106.9450378418 106.6930770874 106.4594268799 106.2439727783 106.0467453003105 .8674926758105 .7061157227105 .56224823105 .4356689453 105.3258895874105 .2325210571105 .1549530029105 .0926589966105 .0448608398 105.0108337402104 .9896316528104 .9803771973104 .9819488525104 .9932250977 105.0129089355105 .039680481105 .0720596313105 .1084976196105 .1472930908 105.186668396105 .2247390747105 .2595062256105 .2888946533105 .3107299805 
105.3228607178105 .3230056763105 .308921814105 .2781448364105 .2284011841 105.1571807861105 .06224823104 .9412612915104 .7924575806104 .6139907837 104.4045791626104 .1634063721103 .8901977539103 .5872650146103 .2580490112 102.9054031372102 .4077987671102 .0326385498 -9999 -9999 -9999 -9999 -9999 -9999 -9999 -9999 -9999 -9999 -9999 -9999 -9999 -9999 -9999 -9999 -9999 -9999 -9999 -9999 -9999 -9999 -9999 -9999 -9999 -9999 -9999 -9999 -9999 -9999 -9999 -9999 -9999 -9999 -9999 -9999 -9999 -9999 -9999 -9999 -9999 -9999 -9999 -9999 -9999 -9999 -9999 -9999 -9999 -9999 -9999 -9999

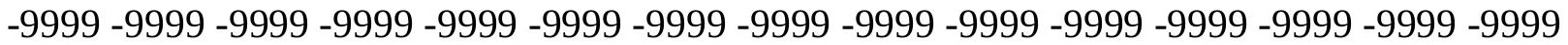
-9999 -9999 -9999 -9999 -9999 -9999 -9999 -9999 -9999 -9999 -9999 -9999 -9999 -9999 -9999 -9999 -9999 -9999 -9999 -9999 -9999 -9999 -9999 -9999 -9999 -9999 -9999 -9999 -9999 -9999 -9999 -9999 -9999 -9999 -9999 -9999 -9999 -9999 -9999 -9999 -9999 -9999 -9999 -9999 -9999 -9999 -9999 -9999 -9999 -9999 -9999 -9999 -9999 -9999 -9999 -9999 -9999 -9999 -9999 -9999

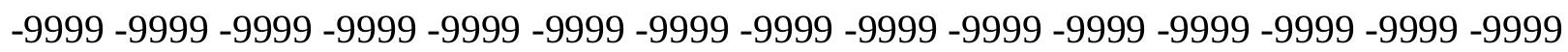
-9999 -9999-9999

-9999 -9999 -9999 -9999 -9999 -9999 -9999 -9999 -9999 -9999 -9999 -9999 -9999 -9999 -9999 -9999 -9999 -9999 -9999 -9999 -9999 -9999 -9999 -9999 -9999 -2.43828105927 .60957032442095.7909169197089.143553733826 12.1914100647 15.54403972626 18.5918903350821 .6397399902324 .6875991821327 .430660247830 .17373085022 32.6120109558135 .0502891540537 .4885711669939 .622070312541 .45077896118 43.5842704772945 .1082000732446 .9369087219248 .4608306884849 .67998123169 50.8991203308152 .1182594299353 .3373985290554 .2517509460455 .16611099243 55.7756805419956 .6900291442957 .2995986938559 .4331016540564 .91924285889 68.2718734741270 .7101516723672 .5388565063574 .062782287675 .28192901611 76.5010681152377 .4154205322378 .0249862670978 .3297805786178 .32978057861 78.3297805786177 .7202072143676 .8058471679775 .8914871215874 .36756896973 72.5388565063570 .4053573608467 .3575134277367 .0527267456167 .05272674561 66.7479400634866 .4431610107466 .1383666992265 .8335876464865 .52880096436 65.2240066528364 .9192428588964 .6144485473666 .1383666992265 .83358764648 65.5288009643664 .3096618652365 .8335876464867 .3575134277368 .88143920898 70.4053573608471 .9292907714873 .4532165527374 .9771423339876 .80584716797 78.3297805786179 .8537063598681 .3776321411182 .9015579223684 .42548370361 85.9494018554787 .4733276367288 .6924667358490 .2164001464891 .74033355713 93.2642517089894 .7881774902396 .0073165893697 .5312423706198 .75038146973 100.2742996216101 .4934005737102 .712600708104 .2365036011105 .4557037354 106.6747970581107 .8938980103109 .1130981445110 .0273971558111 .24659729 112.1608963013113 .3800964355114 .2944030762115 .2088012695116 .1231002808 117.0374984741117 .9517974854118 .8662033081119 .4757995605120 .0852966309 120.9997024536121 .6092987061122 .2188034058122 .8283996582123 .1332015991 123.7427978516124 .0475006104124 .3523025513124 .9618988037125 .2667007446 125.5715026855125 .5715026855125 .8762969971125 .8762969971126 .1809997559 126.1809997559126 .1809997559125 .8762969971125 .8762969971125 .5715026855 125.2667007446124 .9618988037124 .6570968628124 .3523025513124 .3523025513 124.0475006104124 .0475006104123 .7427978516123 .7427978516123 .7427978516 123.7427978516123 .43800354123 .43800354123 .43800354123 .0479736328122 .4279708862 121.8097763062121 .1940002441120 .5812683105119 .9721984863119 .3674545288 118.7676696777118 .173538208117 .5856933594117 .0048370361116 .4316101074 
115.8667297363115 .3108215332114 .7645874023114 .2286300659113 .7036590576 113.1902389526112 .6890411377112 .2006072998111 .7255859375111 .2644500732 110.8178024292110 .3860702515109 .9698257446109 .5694046021108 .8082962036 108.8082962036108 .467338562108 .1340866089107 .818397522107 .5203781128 107.2402801514 106.9781036377 106.7340011597 106.5078735352 106.2997741699 106.1094818115105 .9369277954105 .7817764282105 .6438446045105 .5226593018 105.4178848267105 .3289260864105 .2553100586105 .1962814331105 .1511535645 105.1190338135105 .099067688105 .0901794434105 .0913085938105 .1011962891 105.1186141968105 .1421356201105 .1703109741105 .2015151978105 .2340621948 105.2661514282105 .2958831787105 .3212738037105 .3402404785105 .3507003784 105.3504257202105 .3372268677105 .3087234497105 .2626800537105 .1966781616 105.1085662842104 .9961547852104 .8578872681104 .6922073364104 .498260498 104.2754516602104 .0241928101103 .7447738647103 .4367828369103 .0940093994 102.7029037476102 .2560806274 -9999 -9999 -9999 -9999 -9999 -9999 -9999 -9999 -9999 -9999 -9999 -9999 -9999 -9999 -9999 -9999 -9999 -9999 -9999 -9999 -9999 -9999 -9999 -9999

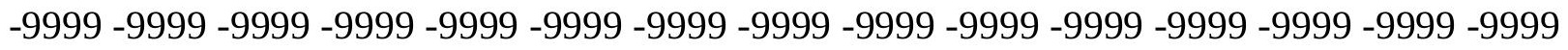
-9999 -9999 -9999 -9999 -9999 -9999 -9999 -9999 -9999 -9999 -9999 -9999 -9999 -9999 -9999 -9999 -9999 -9999 -9999 -9999 -9999 -9999 -9999 -9999 -9999 -9999 -9999 -9999 -9999 -9999 -

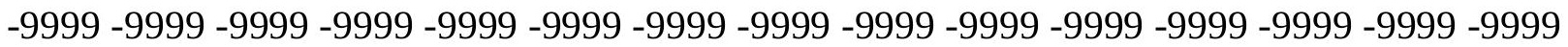

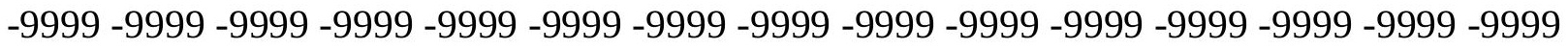

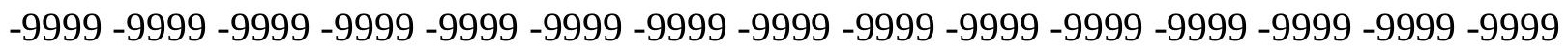
-9999 -9999 -9999 -9999 -9999 -9999 -9999 -9999 -9999 -9999 -9999 -9999 -9999 -9999 -9999 -

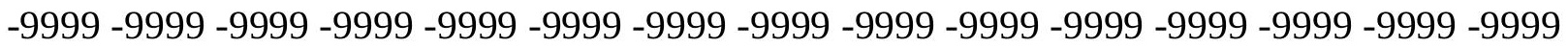
$-9999$

-9999 -9999 -9999 -9999 -9999 -9999 -9999 -9999 -9999 -9999 -9999 -9999 -9999 -9999 -9999 -9999 -9999 -9999 -9999 -9999 -9999 -9999 -9999 -9999 -9999 -9999 2.743066072464 6.09570312510 .9722604751614 .3248996734617 .6775398254420 .72538948059 23.7732391357426 .8210906982429 .5641593933132 .3072204589834 .74551010132 37.1837806701739 .3172798156741 .4507789611843 .5842704772945 .41297912598 46.9369087219248 .4608306884849 .9847602844251 .5086898803752 .42303848267 53.6421813964854 .5565414428755 .4708900451756 .3852500915556 .99481964111 57.6043891906758 .2139587402358 .8235282897964 .3096618652367 .96708679199 70.4053573608471 .9292907714873 .4532165527374 .9771423339876 .19628143311 77.4154205322378 .0249862670978 .6345596313578 .9393463134878 .93934631348 78.6345596313577 .7202072143676 .8058471679775 .2819290161173 .45321655273 71.3197174072368 .8814392089866 .4431610107466 .4431610107466 .13836669922 65.8335876464865 .5288009643665 .2240066528364 .9192428588966 .13836669922 66.1383666992266 .1383666992266 .1383666992265 .8335876464865 .52880096436 63.7000885009865 .2240066528366 .7479400634868 .2718734741270 .10057830811 71.6244964599673 .1484298706174 .6723632812576 .1962814331177 .72020721436 79.2441329956180 .7680587768682 .2919769287183 .8159103393685 .33984375 86.8637619018688 .3876876831189 .9116134643691 .1307525634892 .65467834473 94.1785964965895 .7025299072396 .9216690063598 .445587158299 .66472625732 101.1886978149102 .4077987671103 .6268997192104 .8460998535106 .0652008057 107.2844009399 108.5035018921 109.7226028442110.9418029785111.8561019897 113.075302124113 .9896011353114 .9039993286115 .818397522116 .7326965332 
117.647102356118 .5614013672119 .1709976196120 .0852966309120 .6949005127 121.3044967651121 .9140014648122 .5235977173123 .1332015991123 .43800354 124.0475006104124 .3523025513124 .6570968628125 .2667007446125 .5715026855 125.8762969971125 .8762969971126 .1809997559126 .1809997559126 .4858016968 126.4858016968126 .1809997559126 .1809997559125 .8762969971125 .5715026855 124.9618988037124 .6570968628124 .3523025513124 .0475006104124 .0475006104 123.7427978516123 .7427978516123 .7427978516123 .7427978516123 .43800354 123.43800354123 .43800354123 .1332015991123 .1332015991122 .8283996582 122.2658691406121 .6505508423121 .0378875732120 .4284973145119 .8230438232 119.22215271118 .6265258789118 .0367965698117 .4536590576116 .8777618408 116.3098144531115 .7504348755115 .2003326416114 .6601104736114 .1304779053 113.6119995117113 .1053390503112 .6110458374112 .1297683716111 .6619796753 111.2082901001110 .7691268921110 .3450698853109 .9364547729109 .4179000854 109.1130981445108 .8076553345108 .4648132324108 .1392059326107 .8309631348 107.5403594971107 .2674179077107 .0123062134106 .7749557495106 .5554428101 106.3535766602106 .1693191528106 .0023651123105 .8525619507105 .7194824219 105.6028137207105 .5019989014105 .4166030884105 .3459014893105 .2892608643 105.2458114624105 .2147598267105 .1950759888105 .1857452393105 .185585022 105.1934432983105 .2079696655105 .2277908325105 .2513885498105 .2771606445 105.3033905029105 .3282623291105 .3498840332105 .3662567139105 .3753662109 105.3750534058105 .3632125854105 .3375320435105 .2958526611105 .235824585 105.1553497314105 .0523605347104 .9254074097104 .7731704712104 .5949020386 104.3898468018104 .1576309204103 .8969421387103 .6049423218103 .2751693726 102.9017868042102 .4791641235102 .0102233887 -9999 -9999 -9999 -9999 -9999 -9999 -9999 -9999 -9999 -9999 -9999 -9999 -9999 -9999 -9999 -9999 -9999 -9999 -9999 -9999 -9999 -9999 -9999 -9999 -9999 -9999 -9999 -9999 -9999 -9999 -9999 -9999 -9999 -9999 -9999 -9999 -9999 -9999 -9999 -9999 -9999 -9999 -9999 -9999 -9999 -9999 -9999 -9999 -9999 -9999 -9999 -9999

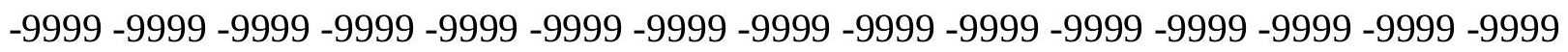
-9999 -9999 -9999 -9999 -9999 -9999 -9999 -9999 -9999 -9999 -9999 -9999 -9999 -9999 -9999 -9999 -9999 -9999 -9999 -9999 -9999 -9999 -9999 -9999 -9999 -9999 -9999 -9999 -9999 -9999 -9999 -9999 -9999 -9999 -9999 -9999 -9999 -9999 -9999 -9999 -9999 -9999 -9999 -9999 -9999 -9999 -9999 -9999 -9999 -9999 -9999 -9999 -9999 -9999 -9999 -9999 -9999 -9999 -9999 -9999 -9999 -9999 -9999 -9999 -9999 -9999 -9999 -9999 -9999 -9999 -9999 -9999 -999 -999 - -9999 $-9999-9999$

-9999 -9999 -9999 -9999 -9999 -9999 -9999 -9999 -9999 -9999 -9999 -9999 -9999 -9999 -9999 -9999 -9999 -9999 -9999 -9999 -9999 -9999 -9999 -9999 -9999 -9999 4.87656211853 8.22919845581113 .1057596206716 .4584007263219 .811029434222 .85887908936 25.906740188628 .9545898437531 .6976509094234 .4407196044936 .87900161743 39.3172798156741 .4507789611843 .5842704772945 .4129791259847 .24169921875 49.0704002380450 .5943298339851 .8134689331153 .0326118469254 .25175094604 55.1661109924356 .0804595947356 .9948196411157 .6043891906758 .21395874023 58.8235282897959 .4331016540559 .7378807067960 .3474502563566 .13836669922 68.5766525268670 .7101516723672 .5388565063574 .062782287675 .58670806885 77.110626220778 .0249862670978 .9393463134879 .2441329956179 .24413299561 79.2441329956178 .6345596313577 .7202072143676 .1962814331174 .67236328125 72.5388565063570 .1005783081166 .1383666992265 .8335876464865 .52880096436 
65.2240066528364 .9192428588964 .6144485473666 .1383666992266 .13836669922 66.1383666992266 .1383666992266 .1383666992265 .8335876464865 .52880096436 65.2240066528364 .9192428588966 .4431610107467 .9670867919969 .49101257324 71.014930725172 .8436431884874 .3675689697375 .8914871215877 .41542053223 78.9393463134880 .4632720947381 .9871978759883 .5111236572385 .03504943848 86.5589828491287 .7781066894589 .302040100190 .8259735107492 .3498916626 93.5690307617295 .0929565429796 .6168823242297 .8360290527399 .35994720459 100.5791015625101 .7982025146103 .3221969604104 .5412979126105 .7603988647 106.979598999108 .1986999512109 .4179000854110 .6370010376111 .551399231 112.7705001831113 .6848983765114 .5991973877115 .5136032104116 .4279022217 117.342300415118 .2565994263118 .8662033081119 .7806015015120 .3900985718 120.9997024536121 .9140014648122 .2188034058122 .8283996582123 .43800354 124.0475006104124 .3523025513124 .6570968628125 .2667007446125 .5715026855 125.8762969971126 .1809997559126 .4858016968126 .4858016968126 .7906036377 126.7906036377126 .4858016968126 .4858016968125 .8762969971125 .5715026855 124.9618988037124 .6570968628124 .0475006104124 .0475006104123 .7427978516 123.7427978516123 .7427978516123 .43800354123 .43800354123 .43800354123 .43800354 123.1332015991123 .1332015991122 .8283996582122 .8283996582122 .5235977173 122.1269073486121 .5139312744120 .9038085938120 .2972183228119 .6947860718 119.0972061157118 .5051116943117 .9192123413117 .3401412964116 .7686157227 116.2052459717115 .6507492065115 .10572052114 .5708770752114 .0467758179 113.5340957642113 .0333709717112 .5452651978112 .0702514648111 .6089324951 111.1617660522110 .729309082110 .3119277954109 .9101333618109 .4179000854 109.1546478271108 .8016357422108 .4655380249108 .1465072632107 .844833374 107.5605621338107 .2938766479107 .0447463989106 .8132705688106 .5992889404 106.4027862549106 .2234954834106 .0613098145105 .9158172607105 .7867431641 105.6735839844105 .5759277344105 .4930953979105 .4244918823105 .3693008423 105.3267669678105 .2959213257105 .2758255005105 .2653579712105 .2634506226 105.2688446045105 .2802581787105 .2962493896105 .315322876105 .3358459473 105.356086731105 .3742141724105 .3883132935105 .3964385986105 .3965148926 105.3864898682105 .3641662598105 .3274459839105 .2740478516105 .2019348145 105.1090927124104 .9940872192104 .8556137085104 .6928482056104 .5046615601 104.2899017334104 .046295166103 .7705383301103 .4580993652103 .1056060791 102.711555481 102.2819442749 -9999 -9999 -9999 -9999 -9999 -9999 -9999 -9999 -9999 -9999 -9999 -9999 -9999 -9999 -9999 -9999 -9999 -9999 -9999 -9999 -9999 -9999 -9999 -9999 -9999 -9999 -9999 -9999 -9999 -9999 -9999 -9999 -9999 -9999 -9999 -9999 -9999 -9999 -9999

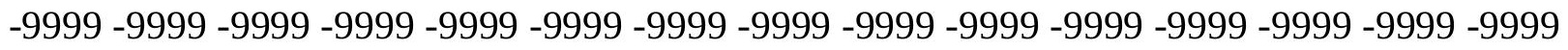

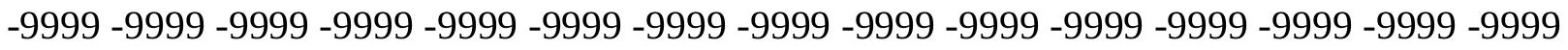

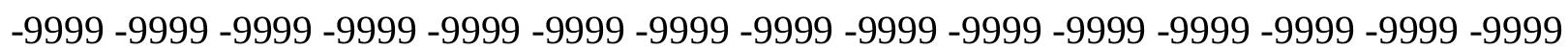

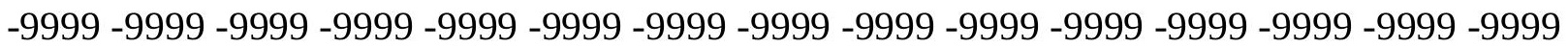

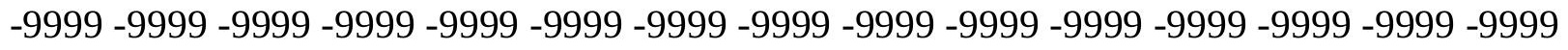

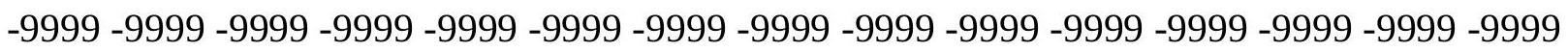
-9999 -9999 -9999 -9999 -9999 -9999 -9999 -9999 -9999 -9999 -9999 -9999 -9999 -9999 -9999 -9999 -9999 -9999 -9999 -9999 -9999 -9999 -9999 -9999 -9999 -9999 -9999 -9999 -9999 -9999 -9999 -9999 -9999 -9999 -9999 -9999 -9999 -9999 -9999-9999 -9999 7.314843177795 10.6674804687515 .5440397262618 .8966808319122 .2493095397925 .29715919495 
28.3450202941931 .3928699493434 .1359291076736 .8790016174339 .31727981567 41.7555618286143 .8890609741245 .717769622847 .8512611389249 .37519073486 50.8991203308152 .4230384826753 .6421813964854 .8613204956156 .08045959473 56.9948196411157 .6043891906758 .5187492370659 .1283111572359 .73788070679 60.0426712036160 .3474502563560 .6522407531760 .9570198059161 .26181030273 66.1383666992268 .8814392089871 .014930725172 .8436431884874 .67236328125 76.1962814331177 .7202072143678 .6345596313579 .2441329956179 .54891967773 79.5489196777379 .2441329956178 .3297805786177 .110626220775 .58670806885 73.4532165527371 .014930725168 .5766525268665 .2240066528365 .22400665283 64.9192428588964 .6144485473666 .1383666992266 .1383666992266 .13836669922 66.1383666992266 .1383666992266 .1383666992265 .8335876464865 .52880096436 65.2240066528364 .6144485473666 .1383666992267 .6623001098669 .18623352051 70.7101516723672 .5388565063574 .062782287675 .5867080688577 .1106262207 78.6345596313580 .1584930419981 .6824111938583 .206336975184 .42548370361 85.94940185547 87.47332763672 88.9972534179790.5211791992291.74033355713 93.2642517089894 .4833908081196 .0073165893697 .5312423706198 .75038146973 100.2742996216101 .4934005737102 .712600708104 .2365036011105 .4557037354 106.6747970581107 .8938980103109 .1130981445110 .0273971558111 .24659729 112.4656982422113 .3800964355114 .2944030762115 .2088012695116 .1231002808 117.0374984741117 .9517974854118 .8662033081119 .4757995605120 .3900985718 120.9997024536121 .6092987061122 .2188034058122 .8283996582123 .43800354 123.7427978516124 .3523025513124 .6570968628125 .2667007446125 .5715026855 125.8762969971126 .1809997559126 .4858016968126 .7906036377127 .0953979492 127.0953979492127 .0953979492126 .7906036377126 .1809997559125 .5715026855 124.9618988037124 .3523025513124 .0475006104123 .7427978516123 .7427978516 123.7427978516123 .43800354123 .43800354123 .43800354123 .43800354123 .1332015991 123.1332015991122 .8283996582122 .8283996582122 .5235977173122 .2188034058 121.9140014648121 .6092987061121 .3044967651120 .7893218994120 .1849060059 119.5849227905118 .9900054932118 .4008560181117 .8181152344117 .2425003052 116.6746292114116 .1152114868115 .5648422241115 .0242462158114 .4939804077 113.9747161865113 .467010498112 .9715118408112 .4887008667112 .0191955566 111.5634460449111 .1220169067110 .6952972412110 .2837905884109 .8878173828 109.5078277588109 .1440734863108 .796913147108 .4665222168108 .1532211304 107.8570556641107 .5782470703107 .3167800903107 .0727920532106 .8461456299 106.6368560791106 .4447021484106 .2695922852106 .1111602783105 .9691772461 105.843170166105 .7327651978105 .6373214722105 .5562973022105 .4889221191 105.4345092773105 .3921432495105 .3609619141105 .3399353027105 .3280792236 105.3242111206105 .3271560669105 .3355712891105 .3480453491105 .36302948 105.378868103 105.3937911987 105.4059677124105.4135055542 105.4143981934 105.4066696167105 .3881988525105 .3569717407105 .3107833862105 .2476577759 105.1655731201105 .0630493164104 .9386520386104 .7913284302104 .6196670532 104.4220581055104 .1958999634103 .9383392334103 .646270752103 .3180084229 102.9535980225 102.5579223633 102.1354751587 -9999 -9999 -9999 -9999 -9999 -9999 -9999

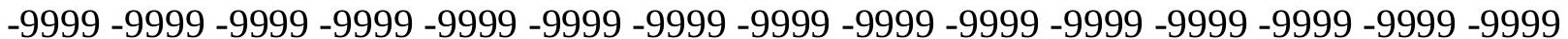

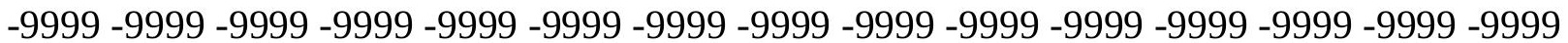
-9999- 
-9999 -9999 -9999 -9999 -9999 -9999 -9999 -9999 -9999 -9999 -9999 -9999 -9999 -9999 -9999 -9999 -9999 -9999 -9999 -9999 -9999 -9999 -9999 -9999 -9999 -9999 -9999 -9999 -9999 -9999 -9999 -9999 -9999 -9999 -9999 -9999 -9999 -9999 -9999 -9999 -9999 -9999 -9999 -9999 -9999 -9999 -9999 -9999 -9999 -9999 -9999 -9999 -9999 -9999 -9999 -9999 -9999 -9999 -9999 -9999 -9999 -9999 -9999 -9999 -9999 -9999 -9999 -9999 -9999 -9999 -9999 -9999-9999 -9999 -9999 -

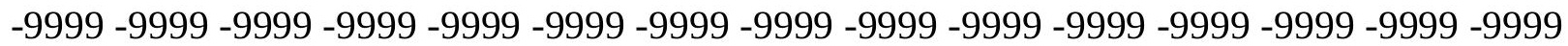
$-9999$

-9999 -9999 -9999 -9999 -9999 -9999 -9999 -9999 -9999 -9999 -9999 -9999 -9999 -9999 -9999 -9999 -9999 -9999 -9999 -9999 -9999 -9999 -9999 -9999 -9999 -9999 -9999 13.10575962067 16.7631797790521 .6397399902324 .9923801422128 .0402297973631 .08807945251 34.1359291076736 .8790016174339 .3172798156741 .7555618286144 .19384002686 46.3273391723648 .1560516357449 .9847602844251 .5086898803753 .03261184692 54.5565414428755 .7756805419956 .6900291442957 .909179687558 .51874923706 59.4331016540560 .0426712036160 .6522407531760 .9570198059161 .26181030273 61.5666007995661 .8713798522962 .1761703491262 .1761703491262 .78573989868 63.7000885009868 .8814392089871 .014930725173 .1484298706175 .28192901611 76.8058471679778 .3297805786179 .2441329956179 .8537063598679 .85370635986 79.5489196777378 .9393463134878 .0249862670976 .5010681152374 .36756896973 72.2340774536169 .4910125732464 .9192428588964 .6144485473664 .30966186523 65.8335876464865 .8335876464866 .1383666992266 .1383666992266 .13836669922 66.1383666992266 .1383666992265 .8335876464865 .5288009643665 .22400665283 64.3096618652365 .8335876464867 .3575134277369 .1862335205170 .71015167236 72.2340774536173 .7580032348675 .2819290161176 .8058471679778 .32978057861 79.8537063598681 .3776321411182 .9015579223684 .1206970214885 .64462280273 87.16854858398 88.69246673584 89.9116134643691.4355392456192.65467834473 94.1785964965895 .7025299072396 .9216690063598 .445587158299 .66472625732 101.1886978149102 .4077987671103 .6268997192104 .8460998535106 .3700027466 107.5891036987108 .5035018921109 .7226028442110 .9418029785111 .8561019897 113.075302124113 .9896011353114 .9039993286115 .818397522116 .7326965332 117.647102356118 .5614013672119 .1709976196120 .0852966309120 .6949005127 121.3044967651121 .9140014648122 .5235977173123 .1332015991123 .7427978516 124.0475006104124 .6570968628125 .2667007446125 .5715026855125 .8762969971 126.4858016968126 .7906036377127 .0953979492127 .4001998901127 .4001998901 127.4001998901127 .0953979492126 .4858016968125 .8762969971124 .9618988037 124.3523025513123 .7427978516123 .7427978516123 .7427978516123 .43800354 123.43800354123 .43800354123 .43800354123 .1332015991123 .1332015991123 .1332015991 122.8283996582122 .5235977173122 .2188034058121 .9140014648121 .6092987061 121.3044967651120 .9997024536120 .9997024536120 .6920700073120 .089225769 119.4910125732118 .8981323242118 .3112335205117 .7310256958117 .1581344604 116.5932617188116 .0370330811115 .4901428223114 .953163147114 .4267730713 113.9115219116113 .4080734253112 .9169082642112 .4386444092111 .9737472534 111.5227890015111 .086151123110 .6643600464110 .2577514648109 .8667831421 109.4917144775 109.1329269409108.7906188965 108.4651107788 108.1564941406 107.8649978638107 .590637207107 .3335800171107 .0937194824106 .87109375 106.6655197144106 .4769439697106 .3050460815106 .1496276855106 .0102539062 105.8865890503105 .7780380249105 .6841201782105 .6041183472105 .5374145508 
105.4831619263105 .4405899048105 .4087524414105 .386756897105 .3735198975 105.3679580688105 .368812561105 .374786377105 .3843917847105 .3960571289 105.4080657959105 .4186630249105 .425994873105 .4281311035105 .4231491089 105.4090270996105 .3837966919105 .3453521729105 .2917480469105 .2209701538 105.131439209105 .0215301514104 .8899307251104 .7350006104104 .555015564 104.3474807739104 .1100006104103 .8402709961103 .5373306274103 .200958252 102.8320236206102 .4320602417 -9999 -9999 -9999 -9999 -9999 -9999 -9999 -9999 -9999 -9999 -9999 -9999 -9999 -9999 -9999 -9999 -9999 -9999 -9999 -9999 -9999 -9999 -9999 -9999

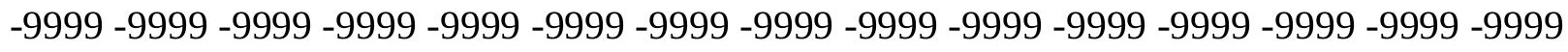
-9999 -9999 -9999 -9999 -9999 -9999 -9999 -9999 -9999 -9999 -9999 -9999 -9999 -9999 -9999

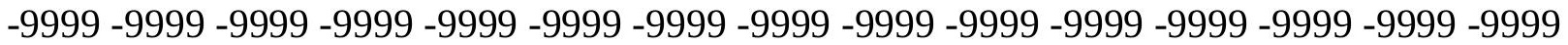
-9999 -9999 -9999 -9999 -9999 -9999 -9999 -9999 -9999 -9999 -9999 -9999 -9999 -9999 -9999 -999 -9999 -9999 -9999 -9999 -9999 -9999 -9999 -9999 -9999 -9999 -9999 -9999 -9999 -9999 -9999 -9999 -9999 -9999 -9999 -9999 -9999 -9999 -9999 -9999 -9999 -9999 -9999 -9999 -9999 -9999 -9999 -9999 -9999 -9999 -9999 -9999 -9999 -9999 -9999 -9999 -9999 -9999 -9999 -9999 -9999

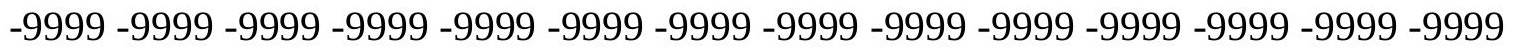
-9999 -9999 -9999 -9999 -9999 -9999 -9999 -9999 -9999 -9999 -9999 -9999 -9999 - -9999 -9999 -9999 -9999 -9999 -9999 -9999 -9999 -9999 -9999 -9999 -9999 -9999 -9999 16.15361022949 19.5062503814722 .8588790893627 .7354507446330 .7833003997833 .83115005493 36.8790016174339 .622070312542 .0603485107444 .4986305236846 .63212966919 48.765621185350 .5943298339852 .4230384826753 .9469718933155 .47089004517 56.6900291442957 .909179687558 .8235282897959 .7378807067960 .34745025635 60.9570198059161 .5666007995662 .1761703491262 .4809494018662 .78573989868 62.7857398986863 .0905189514263 .0905189514263 .0905189514263 .39530944824 64.004882812564 .9192428588968 .8814392089871 .3197174072373 .75800323486 75.8914871215877 .4154205322378 .6345596313579 .5489196777380 .15849304199 79.8537063598679 .5489196777378 .6345596313577 .110626220775 .28192901611 73.1484298706170 .7101516723664 .6144485473664 .3096618652365 .52880096436 65.8335876464865 .8335876464866 .1383666992266 .1383666992266 .13836669922 66.1383666992266 .1383666992265 .8335876464865 .5288009643665 .22400665283 64.3096618652365 .8335876464867 .3575134277368 .8814392089870 .40535736084 71.9292907714873 .4532165527375 .2819290161176 .5010681152378 .02498626709 79.5489196777381 .0728530883882 .5967712402384 .1206970214885 .33984375 86.8637619018688 .0829010009889 .6068267822391 .1307525634892 .3498916626 93.8738174438595 .0929565429796 .6168823242297 .8360290527399 .35994720459 100.5791015625102 .1029968262103 .3221969604104 .5412979126105 .7603988647 106.979598999 108.1986999512109.4179000854110.6370010376111.551399231 112.7705001831113 .6848983765114 .5991973877115 .818397522116 .4279022217 117.342300415118 .2565994263119 .1709976196119 .7806015015120 .3900985718 121.3044967651121 .9140014648122 .5235977173123 .1332015991123 .43800354 124.0475006104124 .6570968628124 .9618988037125 .5715026855126 .1809997559 126.4858016968127 .0953979492127 .4001998901127 .7050018311128 .0097961426 128.0097961426127 .7050018311127 .0953979492126 .1809997559124 .9618988037 124.0475006104123 .7427978516123 .7427978516123 .7427978516123 .7427978516 123.43800354123 .43800354123 .43800354123 .1332015991123 .1332015991122 .8283996582 122.5235977173122 .2188034058122 .2188034058121 .6092987061121 .3044967651 
120.9997024536120 .9997024536120 .6949005127120 .3900985718120 .0852966309 119.7806015015119 .4104537964118 .818901062118 .2336044312117 .6551818848 117.0843505859116 .5217285156115 .9680099487115 .4237823486114 .8897247314 114.366394043113 .8544387817113 .3543701172112 .8667984009112 .3921966553 111.9311447144111 .4840316772111 .051399231110 .6335906982110 .231086731 109.8441390991109 .4731674194109 .1183700562108 .7800979614108 .4584655762 108.153717041107 .8659133911107 .5952301025107 .3415985107107 .1050872803 106.8855514526106 .6829681396106 .4970626831106 .3276672363106 .1743850708 106.0369415283105 .9147949219105 .8075027466105 .7144241333105 .635017395 105.5685119629105 .5142440796105 .4713439941105 .4390335083105 .416305542 105.4021911621105 .3955154419105 .395072937105 .3994369507105 .4071273804 105.4164810181105 .4257888794105 .433265686105 .4370346069105 .4352264404 105.4258956909105 .4071350098105 .3769073486105 .3333053589105 .2743225098 105.1982650757105 .1033401489104 .9880065918104 .8504257202104 .6888809204 104.501121521104 .2851028442104 .03881073103 .7613143921103 .4517822266 103.1093444824102 .7326049805102 .3190765381 -9999 -9999 -9999 -9999 -9999 -9999-9999 -9999 -9999 -9999 -9999 -9999 -9999 -9999 -9999 -9999 -9999 -9999 -9999 -9999 -9999 -9999 -9999 -9999 -9999 -9999 -9999 -9999 -9999 -9999 -9999 -9999 -9999 -9999 -9999 -9999 -9999 -9999 -9999 -9999 -9999 -9999 -9999 -9999 -9999 -9999 -9999 -9999 -9999 -9999 -9999 -9999 -

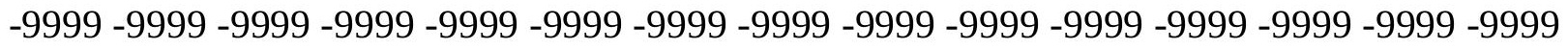
-9999 -9999 -9999 -9999 -9999 -9999 -9999 -9999 -9999 -9999 -9999 -9999 -9999 -9999 -9999 -9999 -9999 -9999 -9999 -9999 -9999 -9999 -9999 -9999 -9999 -9999 -9999 -9999 -9999 -9999 -9999 -9999 -9999 -9999 -9999 -9999 -9999 -9999 -9999 -9999 -9999 -9999 -9999 -9999 -9999 -9999 -9999 -9999 -9999 -9999 -9999 -9999 -9999 -9999 -9999 -9999 -9999 -9999 -9999 -9999 -9999 -9999 -9999 -9999 -9999 -9999 -9999 -9999 -9999 -9999 -9999 -9999 -9999 -9999 -9999 -9999 -9999 -9999 -9999 -9999 -9999 -9999 -9999 -9999 -9999 -9999 -9999 -9999 -9999 -9999 -9999 -9999 -9999 -9999 -9999 -9999 -9999 -9999 -9999 -9999 -9999 -9999 -9999 22.5541000366225 .906740188630 .7833003997833 .8311500549336 .87900161743 39.9268493652342 .3651313781745 .1082000732447 .2416992187549 .37519073486 51.5086898803753 .3373985290554 .8613204956156 .3852500915557 .60438919067 58.8235282897960 .0426712036160 .9570198059161 .5666007995662 .48094940186 62.7857398986863 .3953094482463 .7000885009864 .004882812564 .0048828125 64.3096618652364 .3096618652364 .004882812564 .004882812564 .0048828125 64.3096618652364 .9192428588965 .5288009643669 .1862335205171 .92929077148 74.3675689697376 .1962814331178 .0249862670979 .2441329956179 .85370635986 79.8537063598679 .8537063598678 .9393463134877 .7202072143676 .19628143311 74.062782287671 .6244964599668 .8814392089863 .7000885009865 .52880096436 65.5288009643665 .8335876464865 .8335876464866 .1383666992266 .13836669922 66.1383666992266 .1383666992265 .8335876464865 .5288009643665 .22400665283 64.004882812565 .8335876464867 .3575134277368 .8814392089870 .40535736084 71.9292907714873 .4532165527374 .9771423339876 .5010681152378 .02498626709 79.5489196777381 .0728530883882 .2919769287183 .8159103393685 .03504943848 86.5589828491287 .7781066894589 .302040100190 .5211791992292 .04509735107 93.5690307617294 .7881774902396 .3121032714897 .5312423706199 .05516815186 100.2742996216101 .4934005737103 .0174026489104 .2365036011105 .4557037354 106.6747970581 107.8938980103109.1130981445110.3321990967111.551399231 
112.4656982422113 .3800964355114 .5991973877115 .5136032104116 .4279022217 117.342300415117 .9517974854118 .8662033081119 .4757995605120 .3900985718 120.9997024536121 .6092987061122 .2188034058122 .8283996582123 .43800354 124.0475006104124 .3523025513124 .9618988037125 .5715026855126 .1809997559 126.4858016968127 .0953979492127 .4001998901128 .0097961426128 .3144989014 128.3144989014128 .3144989014127 .7050018311127 .0953979492125 .8762969971 124.3523025513124 .3523025513124 .3523025513124 .0475006104123 .7427978516 123.7427978516123 .43800354123 .43800354123 .1332015991122 .8283996582 122.8283996582122 .5235977173122 .2188034058121 .9140014648121 .6092987061 121.3044967651120 .9997024536120 .6949005127120 .3900985718120 .0852966309 119.7806015015119 .4757995605119 .4757995605119 .1709976196118 .7498321533 118.1653747559117 .5880661011117 .0185317993116 .4574584961115 .905456543 115.3631896973114 .8312301636114 .3102416992113 .8007202148113 .3032913208 112.8184280396112 .3467330933111 .8885955811111 .4445648193111 .0149917603 110.6003799438110 .2010040283109 .8172836304109 .4494400024109 .0978469849 108.7626342773108 .4440841675108 .1422653198107 .8573913574107 .5894241333 107.338470459107 .1044158936106 .8872680664106 .6867904663106 .5028686523 106.335144043106 .1833877563106 .0471191406105 .9259643555105 .8193435669 105.72681427105 .6476974487105 .5814208984105 .5272140503105 .4843978882 105.4520645142105 .4293441772105 .4151382446105 .4083328247105 .4075698853 105.4114303589105 .4183273315105 .4266052246105 .4345169067105 .4402542114 105.4420013428105 .4378509521105 .4259719849105 .4043960571105 .3712234497 105.3244628906105 .262336731105 .1829147339105 .0844726562104 .9650497437 104.822883606104 .6558914185104 .4622497559104 .2400131226103 .9879760742 103.7047424316103 .3890075684103 .0386581421102 .6524353027 -9999 -9999 -9999-9999 -9999 -9999 -9999 -9999 -9999 -9999 -9999 -9999 -9999 -9999 -9999 -9999 -9999 -9999 -9999 -9999 -9999 -9999 -9999 -9999 -9999 -9999 -9999 -9999 -9999 -9999 -9999 -9999 -9999 - 9999 - -999 -

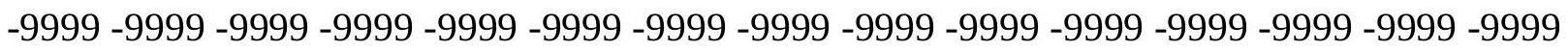
-9999 -9999 -9999 -9999 -9999 -9999 -9999 -9999 -9999 -9999 -9999 -9999 -9999 -9999 -9999 -9999 -9999 -9999 -9999 -9999 -9999 -9999 -9999 -9999 -9999 -9999 -9999 -9999 -9999 -9999 -9999 -9999 -9999 -9999 -9999 -9999 -9999 -9999 -9999-9999 -9999 -9999 -9999 -9999 -9999 -9999 -9999 -9999 -9999 -9999 -9999 -9999 -9999 -9999 -9999 -9999 -9999 -9999 -9999 -9999 -

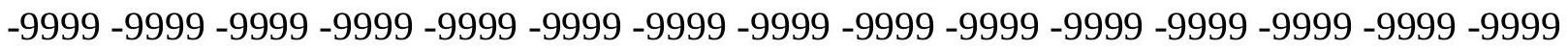

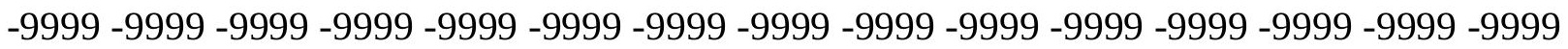
-9999-9999-9999

-9999 -9999 -9999 -9999 -9999 -9999 -9999 -9999 -9999 -9999 -9999 -9999 -9999 -9999 -9999 -9999 -9999 -9999 -9999 -9999 -9999 -9999 -9999 -9999 -9999 -9999 -9999 -9999 -9999 29.2593708038332 .3072204589837 .1837806701740 .2316398620642 .97470092773 45.717769622848 .1560516357450 .2895507812552 .4230384826754 .25175094604 55.7756805419957 .6043891906758 .8235282897960 .0426712036161 .26181030273 62.1761703491263 .0905189514263 .7000885009864 .3096618652364 .61444854736 65.2240066528365 .2240066528365 .5288009643665 .5288009643665 .52880096436 65.5288009643665 .2240066528364 .9192428588964 .9192428588966 .13836669922 65.2240066528365 .8335876464866 .1383666992269 .1862335205172 .23407745361 74.6723632812576 .8058471679778 .0249862670979 .2441329956179 .54891967773 79.5489196777379 .2441329956178 .0249862670976 .8058471679774 .67236328125 
72.5388565063569 .7957916259865 .2240066528365 .5288009643665 .52880096436 65.8335876464865 .8335876464866 .1383666992266 .1383666992266 .13836669922 66.1383666992266 .1383666992265 .8335876464865 .5288009643664 .0048828125 65.8335876464867 .3575134277368 .8814392089870 .4053573608471 .92929077148 73.4532165527374 .9771423339876 .5010681152378 .0249862670979 .54891967773 80.7680587768682 .2919769287183 .5111236572385 .0350494384886 .2541885376 87.7781066894588 .9972534179790 .2164001464891 .7403335571392 .95947265625 94.4833908081195 .7025299072397 .2264633178798 .445587158299 .96952056885 101.1886978149102 .712600708103 .9317016602105 .1509017944106 .3700027466 107.5891036987108 .8082962036110 .0273971558111 .24659729112 .1608963013 113.3800964355114 .2944030762115 .2088012695116 .1231002808117 .0374984741 117.9517974854118 .5614013672119 .4757995605120 .0852966309120 .6949005127 121.3044967651121 .9140014648122 .5235977173123 .1332015991123 .7427978516 124.3523025513124 .9618988037125 .5715026855125 .8762969971126 .4858016968 127.0953979492127 .7050018311128 .0097961426128 .6192932129128 .6192932129 128.9241027832128 .6192932129128 .0097961426127 .4001998901126 .4858016968 125.8762969971125 .2667007446124 .6570968628124 .3523025513123 .7427978516 123.43800354123 .43800354123 .1332015991122 .8283996582122 .5235977173 122.2188034058121 .9140014648121 .6092987061121 .3044967651120 .9997024536 120.6949005127120 .3900985718120 .0852966309119 .7806015015119 .4757995605 119.4757995605119 .1709976196118 .8662033081118 .8662033081118 .5614013672 118.1038589478117 .5268936157116 .9579620361116 .3976593018115 .8466644287 115.3055496216114 .7749862671114 .2554779053113 .7476577759113 .2519989014 112.7691192627112 .2994155884111 .8434371948111 .4015655518110 .9743041992 110.5619430542110 .1649169922109 .7834777832109 .418006897109 .0686645508 108.7357559204108 .4193649292108 .1197433472107 .8368911743107 .570930481 107.3217849731107 .089515686106 .8739089966106 .6748962402106 .4921722412 106.3255691528106 .1746520996106 .0391311646105 .9185180664105 .8124465942 105.7203445435105 .6417388916105 .5759735107105 .5224609375105 .4803924561 105.4489822388105 .4272155762105 .4140548706105 .4082183838105 .4083557129 105.4129257202105 .4203491211105 .4289245605105 .4368972778105 .442489624 105.443862915105 .4392166138105 .4266433716105 .4042739868105 .3701095581 105.3223114014105 .2588577271105 .1778869629105 .0773544312104 .9554214478 104.8100357056104 .6394271851104 .441619873104 .2151184082103 .958114624 103.6689682007103 .3454818726102 .9860534668102 .5890655518 -9999 -9999 -9999-9999 -9999 -9999 -9999 -9999 -9999 -9999 -9999 -9999 -9999 -9999 -9999 -9999 -9999 -9999 -9999

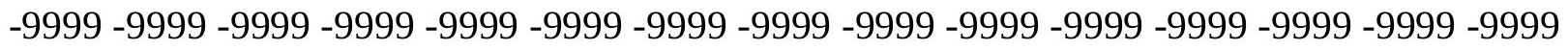

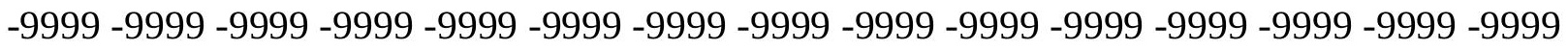
-9999 -9999 -9999 -9999 -9999 -9999 -9999 -9999 -9999 -9999 -9999 -9999 -9999 -9999 -9999 -9999 -9999 -9999 -9999 -9999 -9999 -9999 -9999 -9999 -9999 -9999 -9999 -9999 -9999 -9999 -

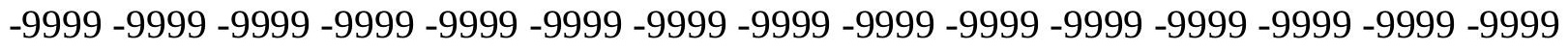

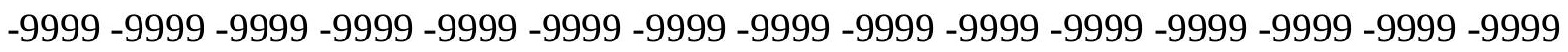
-9999 -9999 -9999 -9999 -9999 -9999 -9999 -9999 -9999 -9999 -9999 -9999 -9999 -9999 -9999 -

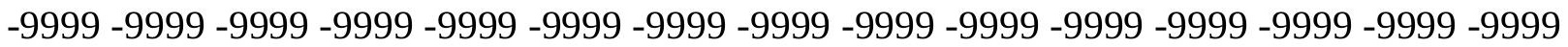
$-9999-9999$

-9999 -9999 -9999 -9999 -9999 -9999 -9999 -9999 -9999 -9999 -9999 -9999 -9999 -9999 -9999 
-9999 -9999 -9999 -9999 -9999 -9999 -9999 -9999 -9999 -9999 -9999 -9999 -9999 -9999 32.6120109558135 .9646492004440 .5364189147943 .5842704772946 .32733917236 48.765621185351 .2038993835453 .3373985290555 .1661109924356 .99481964111 58.5187492370660 .0426712036161 .2618103027362 .4809494018663 .39530944824 64.3096618652365 .2240066528365 .8335876464866 .1383666992266 .74794006348 66.7479400634867 .0527267456167 .0527267456167 .0527267456166 .74794006348 66.7479400634866 .4431610107466 .1383666992265 .8335876464865 .22400665283 65.2240066528365 .8335876464866 .1383666992266 .4431610107469 .79579162598 72.8436431884874 .9771423339876 .5010681152378 .0249862670978 .93934631348 79.2441329956178 .9393463134878 .3297805786177 .110626220775 .28192901611 72.8436431884870 .4053573608465 .2240066528365 .2240066528365 .52880096436 65.8335876464865 .8335876464866 .1383666992266 .1383666992266 .13836669922 66.1383666992266 .1383666992265 .8335876464865 .5288009643664 .30966186523 65.8335876464867 .3575134277368 .8814392089870 .7101516723672 .23407745361 73.7580032348675 .2819290161176 .5010681152378 .0249862670979 .54891967773 80.7680587768682 .2919769287183 .5111236572384 .7302627563586 .2541885376 87.4733276367288 .6924667358490 .2164001464891 .4355392456192 .65467834473 94.1785964965895 .397743225196 .9216690063598 .445587158299 .66472625732 100.8839035034102 .4077987671103 .6268997192104 .8460998535106 .3700027466 107.5891036987108 .8082962036109 .7226028442110 .9418029785112 .1608963013 113.075302124113 .9896011353114 .9039993286115 .818397522116 .7326965332 117.647102356118 .2565994263119 .1709976196119 .7806015015120 .6949005127 121.3044967651121 .9140014648122 .5235977173123 .1332015991123 .43800354 124.0475006104124 .6570968628125 .2667007446125 .8762969971126 .4858016968 127.0953979492127 .7050018311128 .0097961426128 .6192932129128 .9241027832 129.2288970947 129.2288970947 129.2288970947128.9241027832128.6192932129 127.4001998901126 .4858016968125 .5715026855124 .6570968628124 .0475006104 123.7427978516123 .1332015991123 .1332015991122 .8283996582122 .5235977173 122.2188034058121 .6092987061121 .3044967651120 .9997024536120 .6949005127 120.3900985718120 .0852966309119 .7806015015119 .4757995605119 .4757995605 119.1709976196119 .1709976196118 .8662033081118 .5614013672118 .5614013672 118.2565994263117 .9517974854117 .4691238403116 .9000091553116 .3397674561 115.7889785767115 .2483139038114 .7182922363114 .199546814113 .692565918 113.1979598999112 .7161560059112 .2477035522111 .7929992676111 .3525466919 110.9266586304110 .5157928467110 .1202163696109 .7403182983109 .3762893677 109.0284576416108 .696937561108 .3820114136108 .0837020874107 .8021697998 107.5373764038 107.2894134521 107.0581054688106.8434295654 106.6451416016 106.4631195068106 .2970199585106 .1466293335106 .0115509033105 .8915100098 105.7860412598105 .6947860718105 .6171798706105 .5527496338105 .5007781982 105.4605560303105 .4311523438105 .4115982056105 .400680542105 .3971176147 105.3994369507105 .4061126709105 .4154891968105 .4258804321105 .4355392456 105.4426956177105 .4455718994105 .4422988892105 .4310302734105 .4097824097 105.3766479492105 .3295516968105 .2665328979105 .1854705811105 .0844421387 104.9613342285104 .8142929077104 .6412353516104 .4404220581104 .2097549438 103.9473648071103 .6508102417103 .3178482056102 .9454803467102 .5304031372 -9999 -9999 -9999 -9999 -9999 -9999 -9999 -9999 -9999 -9999 -9999 -9999 -9999 -9999 -9999 -9999 
-9999 -9999 -9999 -9999 -9999 -9999 -9999 -9999 -9999 -9999 -9999 -9999 -9999 -9999 -9999 -9999 -9999 -9999 -9999 -9999 -9999 -9999 -9999 -9999 -9999 -9999 -9999 -9999 -9999 -9999

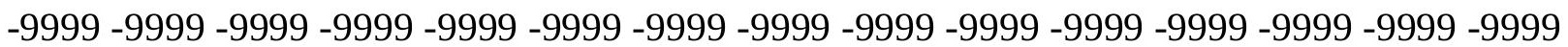
-9999 -9999 -9999 -9999 -9999 -9999 -9999 -9999 -9999 -9999 -9999 -9999 -9999 -9999 -9999 -9999 -9999 -9999 -9999 -9999 -9999 -9999 -9999 -9999 -9999 -9999 -9999-9999 -9999 -9999 -9999 -9999 -9999 -9999 -9999 -9999 -9999 -9999 -9999 -9999 -9999 -9999 -9999 -9999 -9999 -9999 -9999 -9999 -9999 -9999 -9999 -9999 -9999 -9999 -9999 -9999 -9999 -9999 -9999 -9999

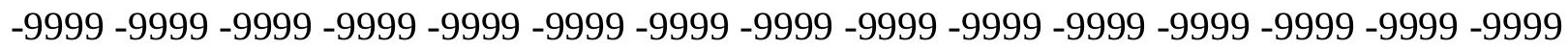
-9999 -9999-9999-9999

-9999 -9999 -9999 -9999 -9999 -9999 -9999 -9999 -9999 -9999 -9999 -9999 -9999 -9999 -9999 -9999 -9999 -9999 -9999 -9999 -9999 -9999 -9999 -9999 -9999 -9999 -9999 -9999 -9999 -9999 39.622070312542 .66992187546 .9369087219249 .6799812316952 .11825942993 54.2517509460456 .3852500915558 .2139587402360 .0426712036161 .26181030273 62.7857398986864 .004882812564 .9192428588965 .8335876464866 .74794006348 67.3575134277367 .9670867919968 .2718734741268 .5766525268668 .57665252686 68.8814392089868 .5766525268668 .5766525268668 .2718734741267 .96708679199 67.6623001098667 .0527267456166 .7479400634866 .1383666992265 .52880096436 65.8335876464866 .1383666992266 .1383666992266 .1383666992269 .79579162598 72.5388565063574 .3675689697376 .1962814331177 .4154205322378 .32978057861 78.3297805786178 .0249862670977 .110626220775 .2819290161173 .14842987061 70.7101516723664 .9192428588965 .2240066528365 .5288009643665 .83358764648 66.1383666992266 .1383666992266 .1383666992266 .4431610107466 .44316101074 66.1383666992266 .1383666992265 .8335876464864 .3096618652366 .13836669922 67.6623001098669 .1862335205170 .7101516723672 .2340774536173 .75800323486 75.2819290161176 .8058471679778 .0249862670979 .5489196777380 .76805877686 82.29197692871 83.51112365723 84.73026275635 85.94940185547 87.47332763672 88.6924667358489 .9116134643691 .1307525634892 .6546783447393 .87381744385 95.397743225196 .6168823242298 .1408081054799 .35994720459100 .8839035034 102.1029968262103 .6268997192104 .8460998535106 .0652008057107 .2844009399 108.5035018921109 .7226028442110 .9418029785111 .8561019897113 .075302124 113.9896011353114 .9039993286115 .818397522116 .7326965332117 .342300415 118.2565994263118 .8662033081119 .7806015015120 .3900985718120 .9997024536 121.6092987061122 .2188034058122 .8283996582123 .43800354123 .7427978516 124.3523025513124 .9618988037125 .5715026855126 .1809997559126 .7906036377 127.4001998901128 .0097961426128 .6192932129128 .9241027832129 .533706665 129.8385009766129 .8385009766130 .1432037354130 .1432037354128 .6192932129 127.0953979492125 .8762969971124 .9618988037124 .3523025513123 .7427978516 123.1332015991122 .8283996582122 .5235977173122 .2188034058121 .9140014648 121.3044967651120 .9997024536120 .6949005127120 .3900985718120 .0852966309 119.7806015015119 .4757995605119 .1709976196119 .1709976196118 .8662033081 118.8662033081118 .8662033081118 .5614013672118 .5614013672118 .2565994263 118.2565994263117 .9517974854117 .4120178223116 .8420257568116 .2810592651 115.7297897339115 .1887435913114 .6585617065114 .1397399902113 .6328964233 113.1384735107112 .6570281982112 .1889572144111 .7347869873111 .2948532104 110.8696136475110 .4593582153110 .0644989014109 .6852416992109 .3219451904 108.9747467041108 .6439590454108 .3296279907108 .0319671631107 .7509536743 
107.4867248535 107.2391433716107.0082244873106.7937927246106.5958023071 106.4139709473106 .2481918335106 .09815979105 .9637145996105 .8444824219 105.7402267456105 .6504821777105 .5748825073105 .5127868652105 .4635848999 105.426399231105 .4003448486105 .3842697144105 .3769683838105 .3770141602 105.3829574585105 .393196106105 .4061050415105 .4199752808105 .43309021 105.443687439105 .4499435425105 .450012207105 .4419250488105 .4237213135 105.3932876587105 .3486022949105 .2874450684105 .2078094482105 .1074752808 104.9844512939104 .836479187104 .6615982056104 .4575271606104 .2221908569 103.9529037476103 .6469726562103 .3008041382102 .9108428955 -9999 -9999 -9999-9999 -9999 -9999 -9999 -9999 -9999 -9999 -9999 -9999 -9999 -9999 -9999 -9999 -9999 -9999 -9999

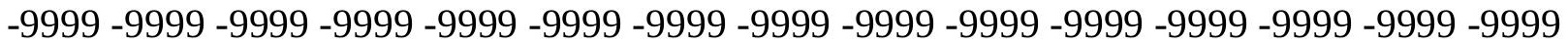
-9999 -9999 -9999 -9999 -9999 -9999 -9999 -9999 -9999 -9999 -9999 -9999 -9999 -9999 -9999 -9999 -9999 -9999 -9999 -9999 -9999 -9999 -9999 -9999 -9999 -9999 -9999 -9999 -9999 -9999 -

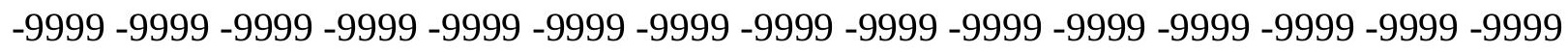
-9999 -9999 -9999 -9999 -9999 -9999 -9999 -9999 -9999 -9999 -9999 -9999 -9999 -9999 -9999

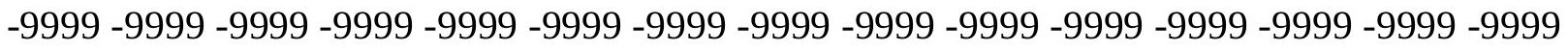
-9999 -9999 -9999 -9999 -9999 -9999 -9999 -9999 -9999 -9999 -9999 -9999 -9999 -9999 -9999 -9999 -9999 -9999 -9999 -9999 -9999 -9999 -9999 -9999 -9999 -9999 -9999 -9999 -9999 -9999 $-9999$

-9999 -9999 -9999 -9999 -9999 -9999 -9999 -9999 -9999 -9999 -9999 -9999 -9999 -9999 -9999

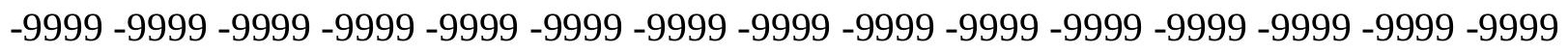
43.2794914245646 .3273391723649 .0704002380453 .3373985290555 .47089004517 57.6043891906759 .4331016540561 .2618103027362 .7857398986864 .30966186523 65.5288009643666 .4431610107467 .3575134277368 .2718734741268 .88143920898 69.4910125732470 .1005783081170 .4053573608470 .4053573608470 .71015167236 70.4053573608470 .4053573608470 .1005783081169 .7957916259869 .18623352051 68.8814392089868 .2718734741267 .6623001098667 .0527267456166 .44316101074 66.1383666992266 .1383666992266 .1383666992265 .8335876464865 .83358764648 68.5766525268671 .014930725173 .4532165527375 .2819290161176 .80584716797 77.4154205322377 .110626220776 .5010681152374 .9771423339872 .84364318848 70.7101516723668 .2718734741265 .2240066528365 .5288009643665 .83358764648 66.1383666992266 .1383666992266 .4431610107466 .4431610107466 .44316101074 66.4431610107466 .4431610107466 .1383666992264 .6144485473666 .44316101074 67.9670867919969 .4910125732471 .014930725172 .5388565063574 .0627822876 75.5867080688576 .8058471679778 .3297805786179 .8537063598681 .07285308838 82.2919769287183 .5111236572384 .7302627563585 .9494018554787 .16854858398 88.38768768311 89.6068267822391.1307525634892.349891662693.87381744385 95.0929565429796 .6168823242297 .8360290527399 .35994720459100 .5791015625 102.1029968262103 .3221969604104 .8460998535106 .0652008057107 .2844009399 108.5035018921109 .7226028442110 .6370010376111 .8561019897112 .7705001831 113.9896011353114 .9039993286115 .5136032104116 .4279022217117 .342300415 117.9517974854118 .8662033081119 .4757995605120 .0852966309120 .6949005127 121.3044967651 121.9140014648 122.5235977173123 .1332015991123 .43800354 124.0475006104124 .6570968628125 .2667007446125 .8762969971126 .4858016968 127.0953979492127 .7050018311128 .3144989014128 .9241027832129 .2288970947 129.533706665129 .8385009766130 .1432037354129 .8385009766128 .6192932129 
127.4001998901126 .1809997559124 .9618988037124 .0475006104123 .43800354 123.1332015991122 .8283996582122 .5235977173121 .9140014648121 .6092987061 120.9997024536120 .6949005127120 .3900985718119 .7806015015119 .4757995605 119.4757995605119 .1709976196118 .8662033081118 .8662033081118 .8662033081 118.5614013672118 .5614013672118 .5614013672118 .5614013672118 .2565994263 118.2565994263118 .2565994263117 .9333343506117 .3530960083116 .7814483643 116.2190704346115 .6665039062115 .124382019114 .5932235718114 .073638916 113.5660858154113 .0711288452112 .5891876221112 .1207885742111 .6662826538 111.2261505127110 .8006896973110 .390335083109 .9953155518109 .6160049438 109.2525863647108 .905380249108 .5744781494108 .2601165771107 .962310791 107.6812362671107 .4167938232107 .169052124106 .9378890991106 .7233505249 106.5252380371106 .3435440063106 .1780548096106 .0287322998105 .8953170776 105.7776794434105 .6754608154105 .588394165105 .5159072876105 .4574813843 105.4123001099105 .3795623779105 .3581695557105 .3469848633105 .3446502686 105.3498001099105 .3608703613105 .3763122559105 .3944473267105 .4136047363 105.4320526123105 .4479827881105 .4595565796105 .4647979736105 .461730957 105.4482040405105 .4221191406105 .3811950684105 .3233184814105 .246131897 105.1474838257105 .0249481201104 .876373291104 .6993026733104 .4915084839 $104.2501220703103 .9722518921103 .6542129517103 .2926864624102 .8842086792-9999$ -9999 -9999 -9999 -9999 -9999 -9999 -9999 -9999 -9999 -9999 -9999 -9999 -9999 -9999 -9999 -9999 -9999 -9999 -9999 -9999 -9999 -9999 -9999 -9999 -9999 -9999 -9999 -9999 -9999 -9999 -9999 -9999 -9999 -9999 -9999 -9999 -9999 -9999 -9999 -9999 -9999 -9999 -9999 -9999 -9999 -9999 -9999 -9999 -9999 -9999 -9999 -9999 -9999 -9999 -9999 -9999 -9999 -9999 -9999 -9999 -999 -9999 -9999 -9999 -9999 -9999 -9999 -9999 -9999 -9999 -9999 -9999 -9999 -9999 -9999 -9999 -9999 -9999 -9999 -9999 -9999 -9999 -9999 -9999 -9999 -9999 -9999 -9999 -9999 -9999 -9999 -9999 -9999 -9999 -9999 -9999 -9999 -9999 -9999 -9999 -9999 -9999 -9999 -9999 -9999 -9999 -9999 -9999 -9999 -9999 -9999 -9999 -9999 -9999 -9999 -9999 -9999 -9999 -9999 -9999 -9999

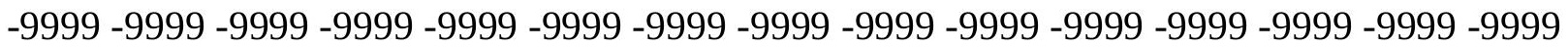
-9999-9999-9999

-9999 -9999 -9999 -9999 -9999 -9999 -9999 -9999 -9999 -9999 -9999 -9999 -9999 -9999 -9999 -9999 -9999 -9999 -9999 -9999 -9999 -9999 -9999 -9999 -9999 -9999 -9999 -9999 -9999 -9999 -999950.28955078125 53.0326118469256.9948196411159.1283111572360.95701980591 62.7857398986864 .3096618652365 .5288009643667 .0527267456167 .96708679199 68.8814392089869 .7957916259870 .7101516723671 .3197174072371 .62449645996 72.2340774536172 .2340774536172 .5388565063572 .5388565063572 .23407745361 71.9292907714871 .6244964599671 .3197174072370 .7101516723670 .10057830811 69.1862335205168 .5766525268667 .9670867919967 .0527267456166 .44316101074 65.8335876464865 .8335876464865 .5288009643665 .2240066528364 .91924285889 64.6144485473669 .7957916259872 .5388565063574 .6723632812575 .89148712158 75.8914871215875 .2819290161173 .7580032348672 .2340774536170 .10057830811 64.9192428588965 .2240066528365 .5288009643665 .8335876464866 .13836669922 66.4431610107466 .4431610107466 .7479400634866 .7479400634866 .74794006348 66.7479400634866 .4431610107464 .9192428588966 .7479400634868 .27187347412 69.7957916259871 .3197174072372 .8436431884874 .3675689697375 .89148712158 77.110626220778 .6345596313579 .8537063598681 .3776321411182 .59677124023 83.8159103393685 .0350494384886 .254188537687 .1685485839888 .38768768311 
89.6068267822390 .8259735107492 .349891662693 .5690307617295 .09295654297 96.3121032714897 .8360290527399 .35994720459100 .5791015625102 .1029968262 103.3221969604104 .5412979126106 .0652008057107 .2844009399108 .5035018921 109.7226028442110 .6370010376111 .8561019897112 .7705001831113 .6848983765 114.5991973877115 .5136032104116 .4279022217117 .0374984741117 .9517974854 118.5614013672119 .1709976196119 .7806015015120 .3900985718120 .9997024536 121.6092987061122 .2188034058122 .5235977173123 .1332015991123 .7427978516 124.0475006104124 .6570968628125 .2667007446125 .8762969971126 .4858016968 127.0953979492127 .7050018311128 .3144989014128 .6192932129128 .9241027832 129.2288970947 128.9241027832128.6192932129 128.0097961426126 .7906036377 125.8762969971124 .6570968628124 .0475006104123 .43800354122 .8283996582 122.5235977173121 .9140014648121 .6092987061121 .3044967651120 .6949005127 120.3900985718119 .7806015015119 .4757995605119 .1709976196118 .8662033081 118.8662033081118 .5614013672118 .5614013672118 .5614013672118 .5614013672 118.5614013672118 .5614013672118 .5614013672118 .5614013672118 .2565994263 118.2565994263118 .2565994263117 .8725204468117 .2897186279116 .7157516479 116.1511764526115 .5966339111115 .0526428223114 .5198364258113 .998664856 113.4897155762112 .9934082031112 .5102844238112 .0407028198111 .5851669312 111.143989563110 .717628479110 .3063201904109 .9104766846109 .5302886963 109.1661224365108 .8180999756108 .4864883423108 .1713256836107 .8728256226 107.5909423828107 .3257980347107 .077331543106 .845664978106 .6307067871 106.4325485229106 .2510910034106 .0864105225105 .9383621216105 .8069229126 105.6918411255105 .5929336548105 .5097198486105 .4417572021105 .3882904053 105.3485946655105 .3216323853105 .3063430786105 .3014373779105 .3056259155 105.3174057007105 .3352890015105 .3576431274105 .3828430176105 .4091720581 105.4348449707105 .4580078125105 .4766921997105 .488899231105 .49243927 105.4851608276105 .4647064209105 .4288406372105 .3750991821105 .3011627197 105.2044372559105 .0826034546104 .9330749512104 .7534713745104 .5407943726 104.2920837402104 .0038223267103 .6731185913103 .2965164185 -9999 -9999 -9999 -9999 -9999 -9999 -9999 -9999 -9999 -9999 -9999 -9999 -9999 -9999 -9999 -9999 -9999 -9999 -9999 -9999 -9999 -9999 -9999 -9999 -9999 -9999 -9999 -9999 -9999 -9999 -9999 -9999 -9999 -9999 -9999 -9999 -9999 -9999 -9999 -9999 -9999 -9999 -9999 -9999 -9999 -9999 -9999 -9999 -9999 -

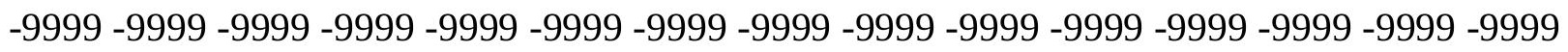
-9999 -9999 -9999 -9999 -9999 -9999 -9999 -9999 -9999 -9999 -9999 -9999 -9999 -9999 -9999 -9999 -9999 -9999 -9999 -9999 -9999 -9999 -9999 -9999 -9999 -9999 -9999 -9999 -9999 -9999

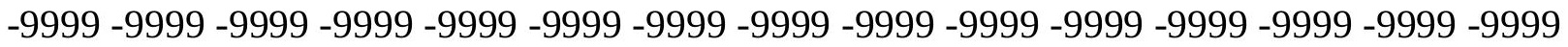

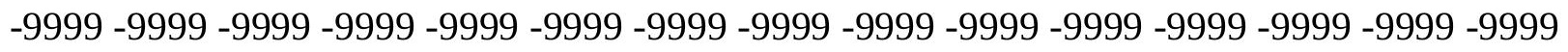

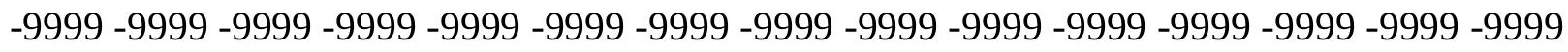
-9999 -9999 -9999 -9999 -9999 -9999 -9999 -9999 -9999 -9999 -9999 -9999 -9999 -9999 -9999 -9999 -9999 -9999 -9999 -9999 -9999 -9999 -9999 -9999 -9999 -9999 -9999 -9999 -9999 -9999 -9999 -9999 56.69002914429 59.12831115723 62.48094940186 64.30966186523 65.8335876464867 .3575134277368 .5766525268669 .4910125732470 .40535736084 71.3197174072372 .2340774536172 .8436431884873 .4532165527373 .75800323486 74.062782287674 .3675689697374 .3675689697374 .3675689697374 .0627822876 73.7580032348673 .4532165527372 .8436431884871 .9292907714871 .31971740723 70.4053573608469 .4910125732468 .5766525268667 .6623001098666 .74794006348 
66.1383666992265 .2240066528364 .9192428588964 .9192428588964 .61444854736 64.3096618652364 .004882812568 .8814392089871 .9292907714874 .0627822876 74.062782287673 .1484298706171 .9292907714870 .4053573608468 .88143920898 64.9192428588965 .2240066528365 .5288009643665 .8335876464866 .13836669922 66.4431610107466 .7479400634866 .7479400634867 .0527267456167 .05272674561 67.0527267456166 .7479400634865 .5288009643667 .0527267456168 .57665252686 70.1005783081171 .6244964599673 .1484298706174 .6723632812576 .19628143311 77.7202072143678 .9393463134880 .4632720947381 .6824111938582 .90155792236 84.1206970214885 .3398437586 .254188537687 .4733276367288 .38768768311 89.6068267822390 .8259735107492 .349891662693 .5690307617295 .09295654297 96.6168823242297 .8360290527399 .35994720459100 .8839035034102 .1029968262 103.3221969604104 .8460998535106 .0652008057107 .2844009399108 .5035018921 109.7226028442110 .9418029785111 .8561019897113 .075302124113 .9896011353 114.9039993286115 .5136032104116 .4279022217117 .0374984741117 .647102356 118.2565994263118 .8662033081119 .4757995605120 .0852966309120 .6949005127 121.3044967651121 .6092987061122 .2188034058122 .8283996582123 .1332015991 123.7427978516124 .0475006104124 .6570968628124 .9618988037125 .5715026855 126.1809997559126 .7906036377127 .4001998901127 .7050018311128 .0097961426 128.0097961426127 .7050018311127 .4001998901126 .7906036377126 .1809997559 125.2667007446124 .3523025513123 .43800354122 .8283996582122 .5235977173 121.9140014648121 .6092987061121 .3044967651120 .6949005127120 .3900985718 119.7806015015119 .4757995605119 .1709976196118 .8662033081118 .5614013672 118.2565994263118 .2565994263118 .2565994263118 .2565994263118 .2565994263 118.2565994263118 .2565994263118 .5614013672118 .5614013672118 .5614013672 118.5614013672118 .5614013672118 .2565994263117 .8055114746117 .2194900513 116.6424407959116 .075012207115 .5177307129114 .9712219238114 .4359664917 113.9125442505113 .4013900757112 .9030609131112 .417930603111 .9465026855 111.4891052246111 .0462188721110 .6181182861110 .2052154541109 .8077392578 109.4260787964109 .0603866577108 .7109603882108 .3778839111108 .0613861084 107.7614898682107 .4783630371107 .2120132446106 .9626541138106 .7302780151 106.5150909424106 .3171234131106 .1365737915105 .9733963013105 .8276824951 105.6992797852105 .588104248105 .4937362671105 .4158248901105 .3536834717 105.3066635132105 .2737731934105 .2540588379105 .2462844849105 .2492446899 105.261505127105 .2816390991105 .3080596924105 .3392028809105 .3733444214 105.4087295532105 .4434967041105 .4756774902105 .5032272339105 .52394104 105.5355987549105 .5357818604105 .5221405029105 .4920959473105 .4431762695 105.3726577759105 .2780609131105 .1566772461105 .0059967041104 .8229370117 $104.6044921875104 .3472595215104 .0485687256103 .7043838501103 .3089599609-9999$ -9999 -9999 -9999 -9999 -9999 -9999 -9999 -9999 -9999 -9999 -9999 -9999 -9999 -9999 -9999 -9999 -9999 -9999 -9999 -9999 -9999 -9999 -9999 -9999 -9999 -9999 -9999 -9999 -9999 -9999 -

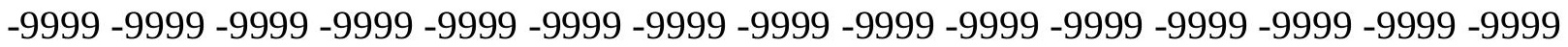
-9999 -9999 -9999 -9999 -9999 -9999 -9999 -9999 -9999 -9999 -9999 -9999 -9999 -9999 -9999 -9999 -9999 -9999 -9999 -9999 -9999 -9999 -9999 -9999 -9999 -9999 -9999 -9999 -9999 -9999 -9999 -9999 -9999 -9999 -9999 -9999 -9999 -9999 -9999 -9999 -9999 -9999 -9999 -9999 -9999 -9999 -9999 -9999 -9999 -9999 -9999 -9999 -9999 -9999 -9999 -9999 -9999 -9999 -9999 -9999 -

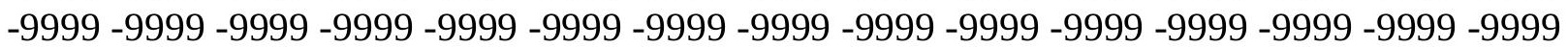


-9999 -9999 -9999 -9999 -9999 -9999 -9999 -9999 -9999 -9999 -9999 -9999 -9999 -9999 -9999 $-9999-9999$

-9999 -9999 -9999 -9999 -9999 -9999 -9999 -9999 -9999 -9999 -9999 -9999 -9999 -9999 -9999 -9999 -9999 -9999 -9999 -9999 -9999 -9999 -9999 -9999 -9999 -9999 -9999 -9999 -9999 -9999 -9999 -9999-9999 62.78573989868 64.61444854736 67.66230010986 68.88143920898 70.1005783081171 .3197174072372 .2340774536173 .1484298706173 .75800323486 74.3675689697374 .9771423339875 .5867080688575 .8914871215876 .19628143311 76.5010681152376 .5010681152376 .1962814331175 .8914871215875 .58670806885 74.9771423339874 .3675689697373 .4532165527372 .5388565063571 .62449645996 70.7101516723669 .4910125732468 .5766525268667 .3575134277366 .44316101074 65.5288009643664 .6144485473664 .3096618652364 .004882812563 .70008850098 63.3953094482463 .0905189514267 .9670867919971 .014930725171 .0149307251 70.1005783081169 .1862335205168 .2718734741264 .6144485473664 .91924285889 65.2240066528365 .5288009643665 .8335876464866 .4431610107466 .74794006348 67.0527267456167 .0527267456167 .3575134277367 .3575134277367 .35751342773 67.3575134277365 .8335876464867 .6623001098669 .1862335205170 .71015167236 72.2340774536173 .7580032348675 .2819290161176 .5010681152378 .02498626709 79.5489196777380 .7680587768681 .9871978759883 .206336975184 .42548370361 85.6446228027386 .5589828491287 .7781066894588 .6924667358489 .91161346436 91.1307525634892 .349891662693 .8738174438595 .0929565429796 .61688232422 98.1408081054799 .66472625732100 .8839035034102 .4077987671103 .6268997192 104.8460998535106 .3700027466107 .5891036987108 .8082962036110 .0273971558 110.9418029785112 .1608963013113 .075302124113 .9896011353114 .9039993286 115.818397522116 .4279022217117 .0374984741117 .647102356118 .2565994263 118.8662033081119 .1709976196119 .7806015015120 .3900985718120 .6949005127 121.3044967651121 .6092987061122 .2188034058122 .5235977173123 .1332015991 123.43800354123 .7427978516124 .3523025513124 .6570968628125 .2667007446 125.8762969971126 .1809997559126 .4858016968126 .7906036377126 .7906036377 126.4858016968126 .1809997559125 .5715026855124 .9618988037124 .3523025513 123.43800354122 .8283996582122 .2188034058121 .9140014648121 .3044967651 120.9997024536120 .6949005127120 .0852966309119 .7806015015119 .1709976196 118.8662033081118 .5614013672118 .2565994263117 .9517974854117 .9517974854 117.9517974854117 .9517974854117 .9517974854118 .2565994263118 .2565994263 118.2565994263118 .5614013672118 .5614013672118 .5614013672118 .5614013672 118.5614013672118 .5614013672118 .3284225464117 .7298965454117 .1399307251 116.5591659546115 .9881439209115 .4274902344114 .8777008057114 .3393554688 113.8129043579113 .2989120483112 .7977600098112 .309967041111 .8358764648 111.3759841919110 .9305877686110 .5001296997110 .084854126109 .6851806641 109.3012924194 108.9335098267 108.5819625854 108.246925354 107.9284439087 107.6267623901107 .3419570923107 .0743255615106 .82396698106 .5912017822 106.3761672974 106.1791992188106.0003585815105.83984375 105.697593689 105.5736160278105 .467590332105 .3792266846105 .3079147339105 .2530822754 105.2138214111105 .1892471313105 .1781921387105 .1795578003105 .1919555664 105.2140426636105 .2442855835105 .2811584473105 .3229522705105 .3679428101 105.4142379761105 .4598770142105 .502784729105 .5407180786105 .5713882446 105.5923233032105 .6010742188105 .5949478149105 .5713424683105 .5274047852 
105.4605331421105 .3678970337105 .2468795776105 .0943145752104 .9071273804 104.6817932129104 .4153594971104 .1024627686103 .7349777222 -9999 -9999 -9999 -9999 -9999 -9999 -9999 -9999 -9999 -9999 -9999 -9999 -9999 -9999 -9999 -9999 -9999 -9999 -9999 -9999 -9999 -9999 -9999 -9999 -9999 -9999 -9999 -9999 -9999 -9999 -9999 -9999 -9999 -9999 -9999 -9999 -9999 -9999 -9999 -9999 -9999 -9999 -9999-9999 -9999 -9999 -9999 -9999 -9999 -9999 -9999 -9999 -9999 -9999 -9999 -9999 -9999 -9999 -9999 -9999 -9999 -9999 -9999 -9999

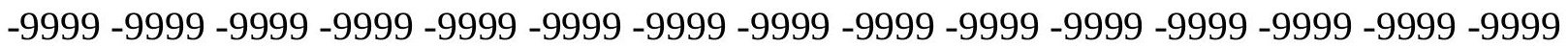

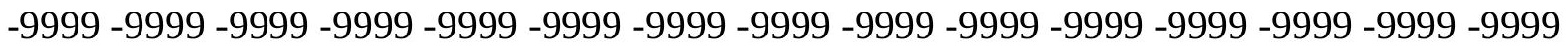
-9999 -9999 -9999 -9999 -9999 -9999 -9999 -9999 -9999 -9999 -9999 -9999 -9999 -9999 -9999 -9999 -9999 -9999 -9999 -9999 -9999 -9999 -9999 -9999 -9999 -9999 -9999 -9999 -9999 -9999 -9999 -9999 -9999 -9999 -9999 -9999 -9999 -9999 -9999 -9999 -9999 -9999 -9999 -9999 -9999 -9999 -9999 -9999 -9999 -9999 -9999 -9999 -9999 -9999 -9999 -9999 -9999 -9999 -9999 -

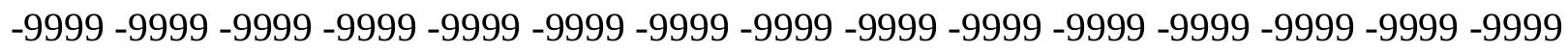
-9999 -9999 -9999 -9999 67.96708679199 69.18623352051 71.9292907714872 .84364318848 73.7580032348674 .6723632812575 .2819290161175 .8914871215876 .50106811523 77.110626220777 .7202072143678 .0249862670978 .3297805786178 .32978057861 78.3297805786178 .3297805786178 .0249862670977 .4154205322376 .80584716797 75.8914871215874 .9771423339874 .062782287672 .8436431884871 .62449645996 70.4053573608469 .1862335205167 .9670867919966 .7479400634865 .83358764648 64.9192428588964 .004882812563 .3953094482463 .3953094482463 .09051895142 62.7857398986862 .4809494018662 .4809494018662 .1761703491262 .17617034912 63.7000885009864 .004882812564 .3096618652364 .9192428588965 .22400665283 65.5288009643666 .1383666992266 .4431610107466 .7479400634867 .05272674561 67.3575134277367 .6623001098667 .9670867919967 .9670867919967 .96708679199 66.4431610107468 .2718734741269 .7957916259871 .3197174072372 .84364318848 74.062782287675 .5867080688577 .110626220778 .6345596313579 .85370635986 81.3776321411182 .5967712402383 .8159103393685 .0350494384886 .2541885376 87.1685485839888 .0829010009888 .9972534179789 .9116134643691 .13075256348 92.6546783447394 .1785964965895 .397743225196 .9216690063598 .4455871582 99.96952056885101 .1886978149102 .712600708103 .9317016602105 .1509017944 106.6747970581107 .8938980103109 .1130981445110 .3321990967111 .24659729 112.4656982422113 .3800964355114 .2944030762115 .2088012695115 .818397522 116.4279022217117 .0374984741117 .647102356118 .2565994263118 .5614013672 118.8662033081119 .4757995605119 .7806015015120 .3900985718120 .6949005127 121.3044967651121 .6092987061121 .9140014648122 .2188034058122 .5235977173 122.8283996582123 .1332015991123 .7427978516124 .0475006104124 .6570968628 124.9618988037125 .2667007446125 .2667007446125 .2667007446124 .9618988037 124.6570968628124 .3523025513123 .7427978516123 .1332015991122 .5235977173 121.9140014648121 .6092987061120 .9997024536120 .6949005127120 .3900985718 120.0852966309119 .4757995605119 .1709976196118 .8662033081118 .5614013672 117.9517974854117 .647102356117 .647102356117 .647102356117 .647102356 117.647102356117 .9517974854117 .9517974854118 .2565994263118 .2565994263 118.5614013672118 .5614013672118 .5614013672118 .8662033081118 .8662033081 118.8662033081118 .8581237793118 .246673584117 .6433563232117 .048828125 116.4636383057115 .8884124756115 .3236541748114 .7699508667114 .2277679443 113.6976699829113 .1800537109112 .6754379272112 .1841964722111 .7068328857 
111.2436676025110 .7951660156110 .3615951538109 .9434051514109 .540802002 109.1541366577108 .7835769653108 .4294433594108 .0918273926107 .7710266113 107.4672012329107 .1807250977106 .9118118286106 .6608886719106 .4282226562 106.2142562866106 .0191574097105 .84324646105 .6865463257105 .5491638184 105.430847168105 .331413269105 .2503128052105 .1870727539105 .1408538818 105.1108627319105 .0960083008105 .0952835083105 .1073684692105 .1310043335 105.1647033691105 .206993103105 .256187439105 .3105697632105 .3682403564 105.4272384644105 .4854354858105 .5405731201105 .5902862549105 .6320495605 105.6633148193105 .6812973022105 .683265686105 .666267395105 .627571106 105.5642471313105 .4735717773105 .3522949219105 .1971740723105 .0043334961 104.7700195312104 .4882125854104 .1547546387103 .7614822388 -9999 -9999 -9999 -9999 -9999 -9999 -9999 -9999 -9999 -9999 -9999 -9999 -9999 -9999 -9999 -9999 -9999 -9999 - -9999 -9999 -9999 -9999 -9999 -9999 -9999 -9999 -9999 -9999 -9999 -9999 -9999 -9999 -9999 -9999 -9999 -9999 -9999 -9999 -9999 -9999 -9999 -9999 -9999 -9999 -9999 -9999 -9999 -9999 -9999 -9999 -9999 -9999 -9999 -9999 -9999 -9999 -9999 -9999 -9999 -9999 -9999 -9999 -9999 -9999

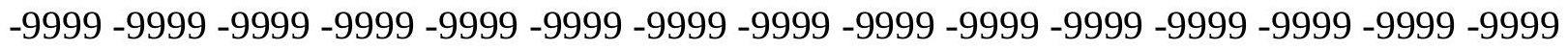
-9999 -9999 -9999 -9999 -9999 -9999 -9999 -9999 -9999 -9999 -9999 -9999 -9999 -9999 -9999 -9999 -9999 -9999 -9999 -9999 -9999 -9999 -9999 -9999 -9999 -9999 -9999 -9999 -9999 -9999 -

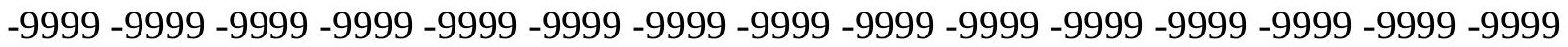

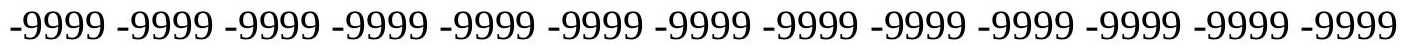

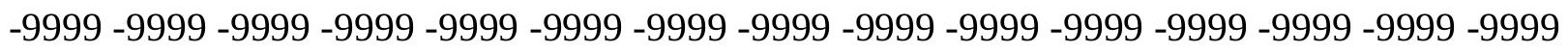

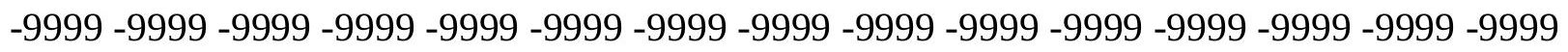
-9999-9999-9999-9999-9999 72.23407745361 73.14842987061 75.58670806885 76.1962814331176 .8058471679777 .4154205322378 .0249862670978 .63455963135 79.2441329956179 .5489196777380 .1584930419980 .1584930419980 .46327209473 80.4632720947380 .1584930419979 .8537063598679 .2441329956178 .63455963135 77.7202072143676 .5010681152375 .2819290161174 .062782287672 .84364318848 71.3197174072370 .1005783081168 .5766525268667 .3575134277366 .13836669922 64.9192428588964 .004882812563 .3953094482462 .7857398986862 .48094940186 62.1761703491262 .1761703491261 .8713798522961 .8713798522963 .39530944824 63.7000885009864 .004882812564 .3096618652364 .9192428588965 .22400665283 65.8335876464866 .1383666992266 .7479400634867 .0527267456167 .66230010986 67.9670867919968 .2718734741268 .2718734741268 .5766525268668 .57665252686 67.0527267456168 .8814392089870 .4053573608471 .9292907714873 .14842987061 74.6723632812576 .1962814331177 .7202072143678 .9393463134880 .46327209473 81.9871978759883 .5111236572384 .7302627563585 .9494018554786 .86376190186 87.7781066894588 .6924667358489 .302040100190 .5211791992291 .43553924561 92.9594726562594 .4833908081196 .0073165893697 .5312423706199 .05516815186 100.2742996216101 .7982025146103 .0174026489104 .2365036011105 .7603988647 106.979598999108 .1986999512109 .4179000854110 .6370010376111 .8561019897 112.7705001831113 .6848983765114 .5991973877115 .5136032104116 .1231002808 116.7326965332117 .342300415117 .647102356117 .9517974854118 .2565994263 118.5614013672118 .8662033081119 .4757995605119 .7806015015120 .3900985718 120.6949005127120 .9997024536121 .3044967651121 .6092987061121 .9140014648 121.9140014648122 .2188034058122 .5235977173123 .1332015991123 .1332015991 123.43800354123 .7427978516123 .7427978516123 .7427978516123 .43800354 
123.1332015991122 .8283996582122 .5235977173121 .9140014648121 .6092987061 120.9997024536120 .6949005127120 .3900985718119 .7806015015119 .4757995605 119.1709976196118 .8662033081118 .5614013672118 .2565994263117 .9517974854 117.647102356117 .342300415117 .342300415117 .342300415117 .342300415117 .647102356 117.647102356117 .9517974854117 .9517974854118 .2565994263118 .2565994263 118.5614013672118 .8662033081118 .8662033081119 .1709976196119 .1709976196 119.1709976196118 .7694168091118 .1523513794117 .5436553955116 .9438934326 116.3536987305115 .7735671997115 .2041015625114 .6457748413114 .0991592407 113.5646514893113 .0427932739112 .5339660645112 .0386962891111 .5573196411 111.0903091431110 .6379776001110 .2007904053109 .7789764404109 .3729248047 108.9828414917 108.609085083 108.2518005371 107.9113464355 107.5879440308 107.2820663452 106.9940261841 106.7243652344 106.4734649658 106.2418823242 106.0298995972 105.8379364014105.6660995483 105.5146026611 105.3832778931 105.272026062105 .1804046631105 .1080322266105 .054145813105 .0180511475 104.9987487793104 .9953155518105 .0065231323105 .0311889648105 .0678710938 105.1151580811105 .1713943481105 .2348709106105 .3036804199105 .3758468628 105.4492111206105 .5214691162105 .5902099609105 .6528244019105 .7066879272 105.7489242554105 .7766876221105 .7869186401105 .7767791748105 .7432403564 105.6835021973105 .5941772461105 .4717941284105 .3120117188105 .1102752686 104.8603820801104 .5592193604104 .2033615112 -9999 -9999 -9999 -9999 -9999 -9999 -9999

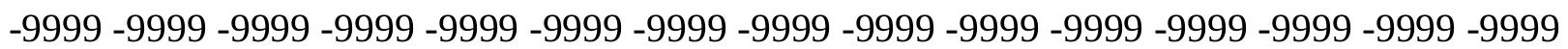

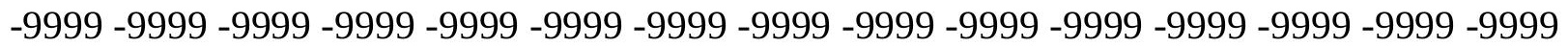
-9999 -

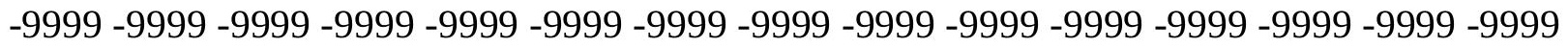
-9999 -

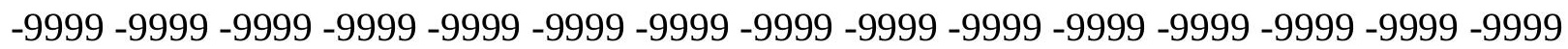

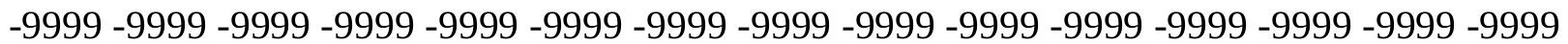

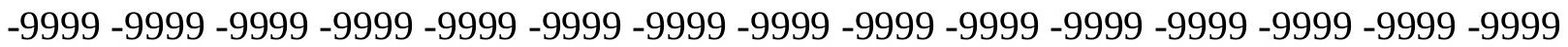
-9999 -9999 -9999 -9999 -9999 -9999 -9999 -9999 -9999 -9999

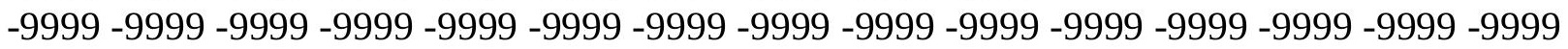

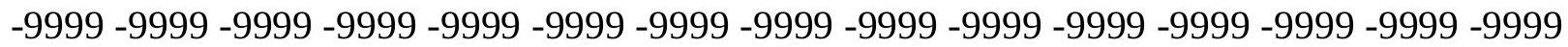
-9999 -9999 -9999 -9999 -9999 -9999 75.89148712158 76.50106811523 78.32978057861 78.9393463134879 .5489196777379 .8537063598680 .4632720947381 .07285308838 81.6824111938581 .9871978759882 .2919769287182 .2919769287182 .29197692871 82.2919769287181 .6824111938581 .0728530883880 .4632720947379 .24413299561 78.0249862670976 .8058471679775 .2819290161173 .7580032348672 .23407745361 70.7101516723669 .1862335205167 .6623001098666 .4431610107465 .22400665283 64.004882812563 .0905189514262 .4809494018661 .8713798522961 .87137985229 61.5666007995661 .5666007995663 .0905189514263 .3953094482463 .70008850098 64.004882812564 .3096618652364 .9192428588965 .5288009643665 .83358764648 66.4431610107467 .0527267456167 .3575134277367 .9670867919968 .27187347412 68.5766525268668 .8814392089869 .1862335205169 .1862335205167 .96708679199 69.4910125732471 .014930725172 .5388565063574 .062782287675 .28192901611 76.8058471679778 .3297805786179 .5489196777381 .0728530883882 .90155792236 84.12069702148 85.64462280273 86.86376190186 88.08290100098 88.99725341797 89.6068267822390 .2164001464890 .8259735107492 .0450973510793 .56903076172 
95.397743225196 .9216690063598 .1408081054799 .66472625732100 .8839035034 102.4077987671103 .6268997192104 .8460998535106 .0652008057107 .5891036987 108.8082962036110 .0273971558111 .24659729112 .1608963013113 .3800964355 114.2944030762115 .2088012695115 .818397522116 .4279022217117 .0374984741 117.647102356117 .9517974854117 .9517974854118 .2565994263118 .2565994263 118.5614013672118 .8662033081119 .1709976196119 .7806015015120 .0852966309 120.3900985718120 .6949005127120 .6949005127120 .9997024536121 .3044967651 121.6092987061121 .6092987061121 .6092987061121 .9140014648121 .9140014648 121.9140014648121 .9140014648121 .9140014648121 .9140014648121 .6092987061 121.3044967651120 .9997024536120 .6949005127120 .3900985718120 .0852966309 119.4757995605119 .1709976196119 .1709976196118 .8662033081118 .5614013672 118.2565994263117 .9517974854117 .647102356117 .647102356117 .342300415 117.342300415117 .0374984741117 .0374984741117 .342300415117 .342300415 117.647102356117 .647102356117 .9517974854118 .2565994263118 .2565994263 118.5614013672118 .8662033081118 .8662033081119 .1709976196119 .1709976196 119.4757995605119 .2978134155118 .6666183472118 .0433807373117 .4286651611 116.8231124878116 .2272338867115 .6416320801115 .0667724609114 .5032424927 113.9514541626113 .4119567871112 .8851394653112 .3715438843111 .8715286255 111.3855819702110 .9140472412110 .4574050903110 .015914917109 .5900115967 109.1799087524108 .786026001108 .4085540771108 .0479125977107 .7043914795 107.3785629272 107.07081604 106.781829834106.5120697021 106.26222229 106.032661438 105.8239135742105 .6361618042105 .4697341919105 .3245544434105 .200630188 105.0976104736105 .0152282715104 .9528121948104 .9097824097104 .8852386475 104.8783569336104 .8879852295104 .9130325317104 .9521179199105 .0038833618 105.0666885376105 .1388549805105 .2184677124105 .3035430908105 .3918685913 105.4811172485105 .5687942505105 .6522445679105 .7287368774105 .7953186035 105.8490219116105 .8866958618105 .9054107666105 .9020614624105 .8737411499 105.8169555664105 .7280044556105 .6021652222105 .4344558716105 .2193450928 104.9534454346 104.6359939575 104.2365036011 -9999 -9999 -9999 -9999 -9999 -9999 -9999 -9999 -9999 -9999 -9999 -9999 -9999 -9999 -9999 -9999 -9999 -9999 -9999 -9999 -9999 -9999 -9999 -9999 -9999 -9999 -9999 -9999 -9999 -9999 -9999 -9999 -9999 -9999 -9999 -9999 -9999

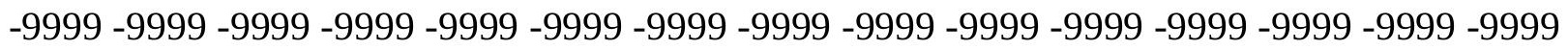

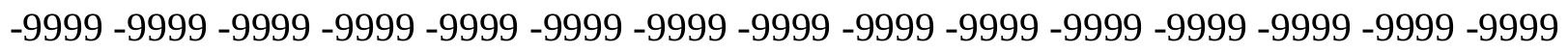

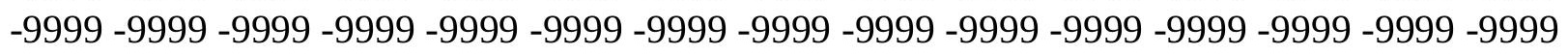
-9999 -9999 -9999 -9999 -9999 -9999 -9999 -9999 -9999 -9999 -9999 -9999 -9999 -9999 -9999 -

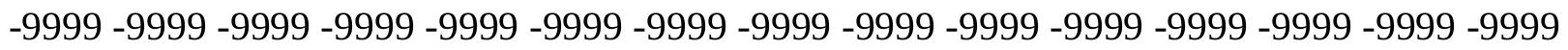

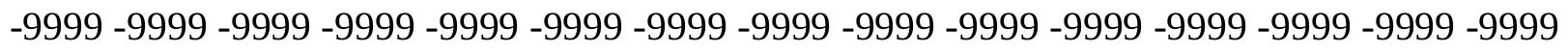
-9999-9999-9999-9999-9999-9999-9999-9999 -9999

-9999 -9999 -9999 -9999 -9999 -9999 -9999 -9999 -9999 -9999 -9999 -9999 -9999 -9999 -9999 -9999 -9999 -9999 -9999 -9999 -9999 -9999 -9999 -9999 -9999 -9999 -9999 -9999 -9999 -9999 -9999 -9999 -9999-9999-9999-9999-9999 78.32978057861 78.93934631348 79.24413299561 81.0728530883881 .6824111938582 .2919769287182 .9015579223683 .51112365723 83.81591033936 84.12069702148 84.42548370361 84.42548370361 84.12069702148 83.81591033936 83.2063369751 82.29197692871 81.07285308838 79.85370635986 78.3297805786176 .8058471679774 .9771423339873 .1484298706171 .31971740723 69.7957916259867 .9670867919966 .4431610107465 .2240066528364 .0048828125 
63.0905189514262 .1761703491261 .5666007995662 .7857398986861 .26181030273 62.7857398986862 .7857398986863 .0905189514263 .3953094482464 .0048828125 64.6144485473664 .9192428588965 .5288009643666 .1383666992266 .74794006348 67.3575134277367 .9670867919968 .2718734741268 .8814392089869 .18623352051 69.4910125732469 .7957916259870 .1005783081168 .8814392089870 .40535736084 71.9292907714873 .1484298706174 .6723632812575 .8914871215877 .41542053223 78.6345596313580 .1584930419981 .6824111938583 .5111236572385 .33984375 86.8637619018688 .3876876831189 .6068267822390 .5211791992291 .13075256348 91.4355392456191 .7403335571393 .2642517089894 .7881774902396 .31210327148 97.8360290527399 .05516815186100 .5791015625101 .7982025146103 .0174026489 104.2365036011105 .4557037354106 .6747970581107 .8938980103109 .4179000854 110.6370010376111 .8561019897112 .7705001831113 .9896011353114 .9039993286 115.818397522116 .4279022217117 .0374984741117 .342300415117 .9517974854 117.9517974854118 .2565994263118 .2565994263117 .647102356117 .9517974854 118.5614013672118 .8662033081119 .1709976196119 .1709976196119 .4757995605 119.7806015015119 .7806015015120 .0852966309120 .3900985718120 .6949005127 120.3900985718120 .3900985718120 .3900985718120 .3900985718120 .3900985718 120.3900985718120 .0852966309120 .0852966309120 .0852966309119 .7806015015 119.4757995605119 .1709976196118 .8662033081118 .8662033081118 .5614013672 118.2565994263118 .2565994263117 .9517974854117 .647102356117 .647102356 117.342300415117 .342300415117 .0374984741117 .0374984741117 .0374984741 117.0374984741117 .0374984741117 .0374984741117 .342300415117 .342300415 117.647102356117 .9517974854118 .2565994263118 .2565994263118 .5614013672 118.8662033081118 .8662033081119 .1709976196119 .4757995605119 .4757995605 119.7806015015119 .185798645118 .547668457117 .9176559448117 .2964019775 116.684425354116 .0823364258115 .4905929565114 .9097900391114 .3403625488 113.7828521729113 .2376708984112 .705368042112 .1863250732111 .6810531616 111.1899032593110 .7133865356110 .2518005371109 .8055877686109 .3750152588 108.9605331421108 .5623855591108 .1810531616107 .8168945312107 .4705581665 107.1425476074 106.8336181641 106.5443496704 106.2755355835106.0276412964 105.80128479105 .5967636108105 .4144897461105 .254486084105 .116897583 105.0014648438104 .9080505371104 .8361129761104 .7851867676104 .7544631958 104.7432479858104 .7504730225104 .7751312256104 .81590271104 .8715133667 104.9403152466105 .0206832886105 .1106796265105 .2083129883105 .3113327026 105.4173583984105 .5238265991105 .6280288696105 .7271194458105 .8180618286 105.8977890015105 .9630508423106 .0108108521106 .0379180908106 .0414047241 106.0177307129105 .963104248105 .8726425171105 .7412033081105 .5631561279 105.3363723755105 .0595855713104 .7102890015 -9999 -9999 -9999 -9999 -9999 -9999 -9999 -9999 -9999 -9999 -9999 -9999 -9999 -9999 -9999 -9999 -9999 -9999 -9999 -9999 -9999 -9999 -9999 -9999 -9999 -9999 -9999 -9999 -9999 -9999 -9999 -9999 -9999 -9999 -9999 -9999 -9999 -9999 -9999 -9999 -9999 -9999 -9999 -9999 -9999 -9999-9999 -9999 -9999 -9999-999 - -999 -9999 -9999 -9999 -9999 -9999 -9999 -9999 -9999 -9999 -9999 -9999 -9999 -9999 -9999 -9999 -9999 -9999 -9999 -9999 -9999 -9999 -9999 -9999 -9999 -9999 -9999 -9999 -9999 -9999 -9999 -9999 -9999 -9999 -9999 -9999 -9999 -9999 -9999 -9999 -9999 -9999 -9999 -9999 -9999 -9999 -9999 -9999 -9999 -9999 -9999 -9999 -9999 -9999 -9999 -9999 -9999 -9999 -9999 -9999 -9999 -

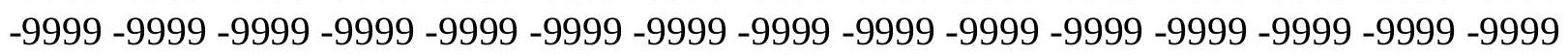


-9999 -9999 -9999 -9999 -9999 -9999 -9999 -9999 -9999

-9999 -9999 -9999 -9999 -9999 -9999 -9999 -9999 -9999 -9999 -9999 -9999 -9999 -9999 -9999 -9999 -9999 -9999 -9999 -9999 -9999 -9999 -9999 -9999 -9999 -9999 -9999 -9999 -9999 -9999 -9999 -9999 -9999 -9999 -9999 -9999 -9999 80.46327209473 80.46327209473 80.76805877686 81.0728530883883 .206336975183 .8159103393684 .4254837036185 .03504943848 85.6446228027385 .9494018554786 .254188537686 .254188537686 .2541885376 85.6446228027385 .0350494384884 .1206970214882 .9015579223681 .68241119385 79.8537063598678 .0249862670976 .1962814331174 .062782287672 .23407745361 70.4053573608468 .2718734741266 .7479400634865 .2240066528364 .0048828125 62.7857398986861 .8713798522961 .2618103027360 .9570198059162 .48094940186 62.4809494018662 .7857398986863 .0905189514263 .3953094482464 .0048828125 64.6144485473665 .2240066528365 .8335876464866 .4431610107467 .05272674561 67.6623001098668 .2718734741268 .8814392089869 .4910125732470 .10057830811 70.4053573608470 .7101516723671 .014930725171 .3197174072371 .31971740723 72.5388565063574 .062782287675 .2819290161176 .5010681152377 .72020721436 79.2441329956180 .7680587768682 .2919769287184 .1206970214886 .2541885376 88.0829010009889 .9116134643691 .4355392456192 .349891662692 .95947265625 93.2642517089893 .8738174438594 .7881774902396 .3121032714897 .53124237061 98.75038146973100 .2742996216101 .4934005737102 .4077987671103 .6268997192 104.8460998535106 .0652008057107 .2844009399108 .5035018921109 .7226028442 111.24659729112 .4656982422113 .3800964355114 .5991973877115 .5136032104 116.4279022217117 .0374984741117 .647102356117 .9517974854118 .2565994263 118.2565994263118 .2565994263117 .9517974854117 .9517974854117 .9517974854 117.9517974854118 .2565994263118 .5614013672118 .5614013672118 .5614013672 118.5614013672118 .8662033081118 .8662033081119 .1709976196119 .1709976196 118.8662033081118 .8662033081118 .5614013672118 .5614013672118 .5614013672 118.2565994263118 .2565994263118 .2565994263118 .2565994263117 .9517974854 117.9517974854117 .647102356117 .647102356117 .342300415117 .342300415 117.342300415117 .0374984741117 .0374984741117 .0374984741117 .0374984741 116.7326965332116 .7326965332116 .7326965332116 .7326965332116 .7326965332 116.7326965332116 .7326965332117 .0374984741117 .0374984741117 .342300415 117.647102356117 .647102356117 .9517974854118 .2565994263118 .5614013672 118.8662033081118 .8662033081119 .1709976196119 .4757995605119 .7806015015 119.7806015015119 .7096099854119 .0562591553118 .4106292725117 .7733535767 117.1449661255116 .5260543823115 .9171142578115 .3187179565114 .7313156128 114.155456543113 .5915679932113 .0402145386112 .5017929077111 .9768218994 111.4656906128110 .9689178467110 .486831665110 .0199050903109 .5684356689 109.1329116821108 .7136306763108 .3111190796107 .9258117676107 .5584335327 107.209564209 106.8800506592106.5705795288 106.2820281982 106.0149612427 105.7700958252105 .5478134155105 .3486557007105 .172744751105 .0203475952 104.8913574219104 .7857589722104 .7031326294104 .6431808472104 .6051940918 104.5886154175104 .5924530029104 .615814209104 .6574401855104 .7161178589 104.7902526855104 .8782272339104 .9780883789105 .0878448486105 .2051925659 105.3277053833105 .4527511597105 .5775375366105 .6991348267105 .8143997192 105.9201507568106 .013053894106 .0899810791106 .1477203369106 .1832962036 106.1932220459106 .1737670898106 .1202011108106 .027633667105 .8901824951 
105.701423645105 .4557037354105 .1509017944104 .8460998535 -9999 -9999 -9999 -9999 -9999 -9999 -9999 -9999 -9999 -9999 -9999 -9999 -9999 -9999 -9999 -9999 -9999 -9999 -9999 -9999 -9999 -9999 -9999 -9999 -9999 -9999 -9999 -9999 -9999 -9999 -9999 -9999 -9999 -9999 -9999 -9999 -9999 -9999 -9999 -9999 -9999 -9999 -9999 -9999 -9999 -9999 -9999 -9999 -9999 -9999 -9999 -9999 -9999 -9999 -9999 -9999 -9999 -9999 -9999 -9999 -9999-9999 -9999 -9999 -9999 -9999 -9999 -9999 -9999 -9999 -9999 -9999 -9999 -9999 -9999 -9999 -9999 -9999 -9999

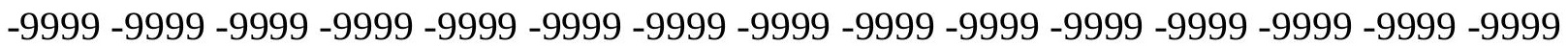
-9999 -9999 -9999 -9999 -9999 -9999 -9999 -9999 -9999 -9999 -9999 -9999 -9999 -9999 -9999 -999 -9999 -9999 -9999 -9999 -9999 -9999 -9999 -9999 -9999 -9999 -9999 -9999 -9999 -9999 -9999 -999 -9999 -9999 -9999 -9999 -9999 -9999 -9999 -9999 -9999 -9999 -9999

-9999 -9999 -9999 -9999 -9999 -9999 -9999 -9999 -9999 -9999 -9999 -9999 -9999 -9999 -9999

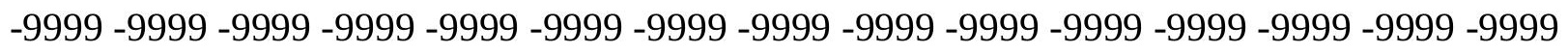
-9999 -9999 -9999 -9999 -9999 -9999 -9999 -9999 81.9871978759881 .98719787598 82.29197692871 82.90155792236 83.81591033936 85.9494018554786.86376190186 87.47332763672 87.77810668945 88.38768768311 88.38768768311 88.38768768311 87.7781066894587 .1685485839886 .254188537685 .0350494384883 .2063369751 81.6824111938579 .5489196777377 .4154205322375 .2819290161172 .84364318848 70.7101516723668 .8814392089866 .7479400634865 .2240066528363 .70008850098 62.4809494018661 .5666007995660 .9570198059160 .6522407531760 .65224075317 62.1761703491262 .4809494018663 .0905189514263 .3953094482464 .0048828125 64.6144485473665 .5288009643666 .1383666992266 .7479400634867 .35751342773 68.2718734741268 .8814392089869 .4910125732470 .1005783081170 .71015167236 71.3197174072371 .6244964599671 .9292907714872 .2340774536172 .23407745361 73.4532165527374 .9771423339876 .1962814331177 .110626220778 .32978057861 79.5489196777381 .0728530883882 .5967712402384 .7302627563587 .16854858398 89.6068267822391.7403335571393.56903076172 94.7881774902395.3977432251 95.7025299072396 .3121032714896 .9216690063597 .8360290527399 .05516815186 100.2742996216101 .1886978149102 .4077987671103 .3221969604104 .2365036011 105.4557037354106 .6747970581107 .8938980103109 .1130981445110 .3321990967 111.8561019897113 .075302124114 .2944030762115 .2088012695116 .1231002808 116.7326965332117 .342300415117 .9517974854118 .5614013672118 .5614013672 118.5614013672118 .2565994263117 .9517974854117 .9517974854117 .647102356 117.647102356117 .9517974854117 .647102356117 .647102356117 .647102356 117.647102356117 .342300415117 .342300415117 .342300415117 .342300415 117.0374984741117 .0374984741116 .7326965332116 .4279022217116 .4279022217 116.4279022217116 .4279022217116 .4279022217116 .1231002808116 .1231002808 116.1231002808116 .1231002808116 .1231002808116 .1231002808116 .1231002808 116.1231002808116 .1231002808116 .1231002808116 .1231002808116 .1231002808 116.1231002808116 .4279022217116 .4279022217116 .4279022217116 .4279022217 116.4279022217116 .7326965332116 .7326965332117 .0374984741117 .342300415 117.342300415117 .647102356117 .9517974854118 .2565994263118 .2565994263 118.5614013672118 .8662033081119 .1709976196119 .4757995605119 .4757995605 119.7806015015119 .7806015015119 .4757995605118 .9072875977118 .2537078857 117.6086196899116 .972618103116 .3461837769115 .7299118042115 .1242446899 114.5297393799113 .9468460083113 .3761367798112 .8180236816112 .2730407715 111.7416000366111 .2242355347110 .7212982178110 .2332839966109 .7605361938 
109.3035583496 108.8627090454108.4385681152108.0316238403107.6426620483 107.2723312378 106.9215774536106.5911560059106.2820358276105.9948654175 105.7304763794105 .4893493652105 .2721481323105 .0791091919104 .9106521606 104.7668075562104 .6477279663104 .5531387329104 .4828872681104 .4364089966 104.4132766724104 .4126205444104 .4336395264104 .4751586914104 .5360336304 104.6147003174104 .7095718384104 .818687439104 .9400405884105 .0712738037 105.2099151611105 .3532409668105 .4983901978105 .6423187256105 .781791687 105.9135055542106 .034034729106 .1401596069106 .2286376953106 .2965011597 106.3403396606 106.3565597534 106.3406829834 106.2878952026106.1925964355 106.0501480103105 .8540878296105 .5738525391105 .1509017944 -9999 -9999 -9999 -9999 -9999 -9999 -9999 -9999 -9999 -9999 -9999 -9999 -9999 -9999 -9999 -9999 -9999 -9999 -9999 -9999 -9999 -9999 -9999 -9999 -9999 -9999 -9999 -9999 -9999 -9999 -9999 -9999 -9999 -9999 -999 -9999 -9999 -9999 -9999 -9999 -9999 -9999 -9999 -9999 -9999 -9999 -9999 -9999 -9999 -9999 -9999 -9999 -9999 -9999 -9999 -9999 -9999 -9999 -9999 -9999 -9999 -9999 -9999 -9999 -9999 -9999 -9999 -9999 -9999 -9999 -9999 -9999 -9999 -9999 -9999 -9999 -9999 -9999 -9999 -9999

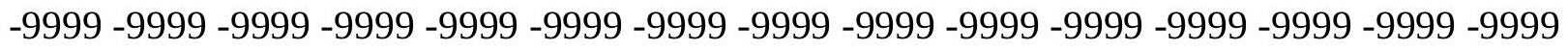

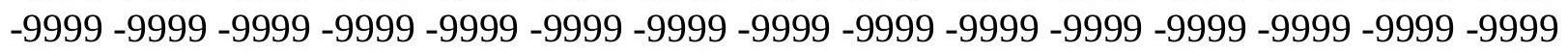

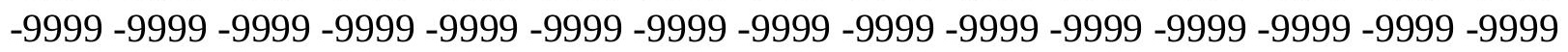
-9999 -9999 -9999 -9999 -9999 -9999 -9999 -9999 -9999 -9999 -9999

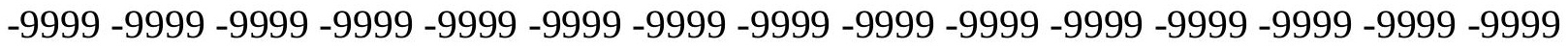

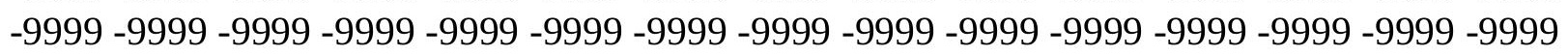
-9999 -9999 -9999-9999-9999 -9999 -9999 -9999 87.47332763672 82.90155792236 83.5111236572384 .1206970214885 .0350494384885 .9494018554786 .86376190186 88.9972534179789 .9116134643690 .2164001464890 .5211791992290 .21640014648 89.91161346436 89.302040100188.3876876831186.86376190186 85.33984375 83.2063369751 81.07285308838 78.6345596313576.1962814331173.75800323486 71.3197174072368 .8814392089867 .0527267456164 .9192428588963 .39530944824 62.1761703491261 .2618103027360 .6522407531760 .3474502563560 .34745025635 60.6522407531762 .4809494018663 .0905189514263 .7000885009864 .30966186523 64.9192428588965 .8335876464866 .4431610107467 .0527267456167 .96708679199 68.5766525268669 .4910125732470 .1005783081171 .014930725171 .62449645996 72.2340774536172 .8436431884873 .1484298706173 .4532165527373 .14842987061 74.6723632812575 .8914871215876 .8058471679778 .0249862670978 .63455963135 79.8537063598681 .0728530883882 .9015579223685 .3398437588 .08290100098 90.8259735107493 .5690307617295 .7025299072397 .2264633178797 .83602905273 98.1408081054798 .445587158299 .0551681518699 .66472625732100 .5791015625 101.4934005737102 .4077987671103 .3221969604103 .9317016602104 .8460998535 105.7603988647106 .979598999108 .1986999512109 .7226028442110 .9418029785 112.4656982422113 .6848983765114 .9039993286115 .818397522116 .7326965332 117.342300415117 .9517974854118 .2565994263118 .8662033081118 .8662033081 118.8662033081118 .2565994263117 .9517974854117 .9517974854117 .647102356 117.647102356117 .342300415117 .0374984741116 .7326965332116 .4279022217 116.4279022217116 .1231002808115 .818397522115 .5136032104115 .5136032104 115.2088012695114 .9039993286114 .5991973877114 .5991973877114 .2944030762 114.2944030762114 .2944030762114 .2944030762114 .2944030762114 .2944030762 114.2944030762114 .5991973877114 .5991973877114 .5991973877114 .9039993286 
114.9039993286115 .2088012695115 .2088012695115 .5136032104115 .5136032104 115.818397522115 .818397522115 .818397522116 .1231002808116 .1231002808 116.4279022217116 .4279022217116 .7326965332116 .7326965332117 .0374984741 117.342300415117 .647102356117 .647102356117 .9517974854118 .2565994263 118.5614013672118 .5614013672118 .8662033081119 .1709976196119 .1709976196 119.4757995605119 .4757995605119 .1709976196119 .1709976196118 .7372512817 118.0752182007117 .4218673706116 .7777023315116 .1432952881115 .5191116333 114.9057159424114 .303565979113 .7132339478113 .1351623535112 .5699005127 112.017868042111 .4796218872110 .9555206299110 .4460906982109 .9516983032 109.4728927612109 .0100631714108 .5638504028108 .1347808838107 .7236938477 107.3312988281106 .9585876465106 .6064071655106 .2758026123105 .9675140381 105.6824798584105 .4213027954105 .184753418104 .973236084104 .7873153687 104.6271820068104 .4931793213104 .3851776123104 .3031997681104 .2468414307 104.2158279419104 .2093963623104 .2268753052104 .2671737671104 .3292312622 104.4115066528104 .5124511719104 .6300964355104 .7624282837104 .9070129395 105.0613327026105 .2225646973105 .3877716064105 .5537872314105 .7172775269 105.8748168945106 .0228881836106 .1581878662106 .2774429321106 .3776855469 106.4555740356106 .5076141357106 .5295257568106 .5168304443106 .4638366699 106.363609314 106.2078475952106.005607605 105.7603988647 105.1509017944-9999-9999 -9999 -9999 -9999 -9999 -9999 -9999 -9999 -9999 -9999 -9999 -9999 -9999 -9999 -9999 -9999 -

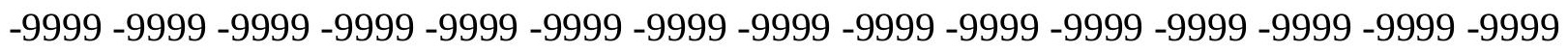
-9999 -9999 -9999 -9999 -9999 -9999 -9999 -9999 -9999 -9999 -9999 -9999 -9999 -9999 -9999 -9999 -9999 -9999 -9999 -9999 -9999 -9999 -9999 -9999 -9999 -9999 -9999 -9999 -9999 -9999 -

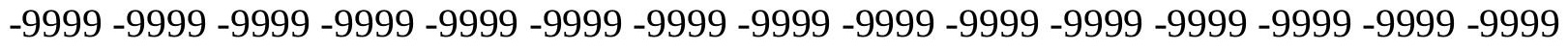

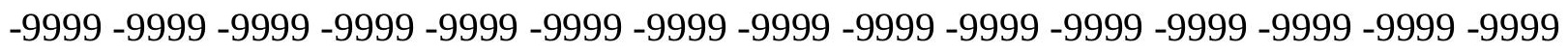
-9999 -9999 -9999 -9999 -9999 -9999 -9999 -9999 -9999 -9999 -9999 -9999 -9999 -9999 -9999 -

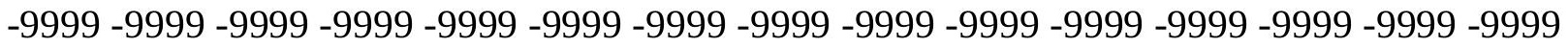
-9999 -9999 -9999 -9999 -9999 -9999 -9999 -9999 -9999 -9999 -9999 -9999 -9999 -9999 -9999 -9999 -9999 -9999 -9999 -9999 -9999 -9999 -9999 -9999 -9999 -9999 -9999 -9999 -9999 -9999 -9999 -9999 -9999 -9999 -9999 -9999 -9999 -9999 -9999 -9999 -9999 -9999 -9999 -9999 -9999 -9999 -9999 -9999 -9999 -9999 93.26425170898 89.3020401001 84.1206970214885 .0350494384886 .254188537687 .4733276367288 .38768768311 89.302040100190.2164001464892.0450973510792.3498916626 92.3498916626 92.0450973510791 .4355392456190 .5211791992288 .9972534179787 .16854858398 85.0350494384882 .5967712402379 .8537063598677 .110626220774 .36756896973 71.9292907714869 .1862335205167 .0527267456164 .9192428588963 .09051895142 61.8713798522960 .9570198059160 .3474502563560 .0426712036160 .04267120361 60.3474502563560 .9570198059163 .0905189514263 .7000885009864 .61444854736 65.2240066528366 .1383666992266 .7479400634867 .6623001098668 .27187347412 69.1862335205170 .1005783081170 .7101516723671 .6244964599672 .53885650635 73.1484298706173 .7580032348674 .3675689697374 .6723632812574 .36756896973 75.5867080688576 .8058471679777 .7202072143678 .6345596313579 .24413299561 79.8537063598681 .0728530883882 .5967712402385 .3398437588 .69246673584 92.349891662695 .7025299072398 .1408081054799 .66472625732100 .2742996216 100.5791015625100 .2742996216100 .5791015625101 .1886978149102 .1029968262 103.0174026489103.6268997192103.9317016602 104.5412979126105.1509017944 
106.0652008057107 .2844009399108 .8082962036110 .0273971558111 .551399231 112.7705001831114 .2944030762115 .2088012695116 .4279022217117 .0374984741 117.647102356117 .9517974854118 .2565994263118 .5614013672119 .1709976196 118.5614013672118 .2565994263118 .2565994263117 .9517974854117 .9517974854 117.342300415117 .0374984741116 .4279022217115 .818397522115 .5136032104 114.9039993286114 .5991973877114 .2944030762113 .6848983765113 .3800964355 113.075302124112 .7705001831112 .4656982422112 .4656982422112 .1608963013 112.1608963013112 .1608963013112 .1608963013112 .4656982422112 .4656982422 112.7705001831112 .7705001831113 .075302124113 .3800964355113 .6848983765 113.6848983765113 .9896011353114 .2944030762114 .5991973877114 .9039993286 115.2088012695115 .2088012695115 .5136032104115 .818397522115 .818397522 116.1231002808116 .4279022217116 .4279022217116 .7326965332117 .0374984741 117.0374984741117 .342300415117 .647102356117 .647102356117 .9517974854 118.2565994263118 .5614013672118 .5614013672118 .8662033081118 .8662033081 119.1709976196118 .8662033081118 .8662033081118 .5614013672118 .5614013672 118.2565994263117 .8736419678117 .2115402222116 .5587997437115 .9159011841 115.2834091187114 .6617889404114 .0516281128113 .4533843994112 .8676223755 112.2947692871111 .7353897095111 .1898574829110 .6587219238110 .142364502 109.6413726807109 .1561737061108 .6874389648108 .2357559204107 .8019943237 107.3868865967106 .9914932251106 .6166915894106 .2636260986105 .9331207275 105.6262359619105 .3436813354105 .0863876343104 .8549118042104 .6499938965 104.4720077515104 .3214874268104 .1984863281104 .1032104492104 .0354309082 103.9950332642103 .9813995361103 .9939956665104 .0318145752104 .0938873291 104.1787185669104 .2848052979104 .4101486206104 .5527267456104 .7100372314 104.8795013428105 .0581893921105 .2430801392105 .4308700562105 .6181182861 105.8012695312105 .9767303467106 .1411132812106 .2910995483106 .4237136841 106.5356521606106 .6234741211106 .6829452515106 .7094802856106 .6970596313 106.638343811106 .5227966309106 .3360290527106 .0652008057105 .7603988647 -9999 -9999 -9999 -9999 -9999 -9999 -9999 -9999 -9999 -9999 -9999 -9999 -9999 -9999 -9999 -9999 -9999 -9999 -9999 -9999 -9999 -9999 -9999 -9999 -9999 -9999 -9999 -9999 -9999 -9999 -9999 -999 -9999 -9999 -9999 -9999 -9999 -9999 -9999 -9999 -9999 -9999 -9999 -9999 -9999 -9999 -9999 -9999 -9999 -9999 -9999 -9999 -9999 -9999 -9999 -9999 -9999 -9999 -9999 -9999 -9999 -9999 -9999 -9999 -9999 -9999 -9999 -9999 -9999 -9999 -9999 -9999 -9999 -9999 -9999 -9999 -9999 -9999 -9999 -9999 -9999 -9999 -9999 -9999 -9999 -9999 -9999 -9999 -9999 -9999 -9999 -9999

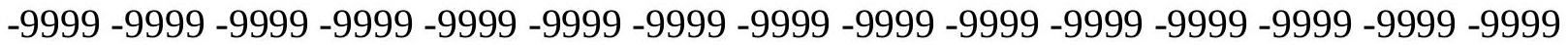
-9999 -9999 -9999 -9999 -9999 -9999 -9999 -9999 -9999 -9999 -9999 -9999 -9999 -9999 -9999 -9999 -9999 -9999 -9999 -9999 -9999 -9999 -9999 -9999 -9999 -9999 -9999 -9999

-9999 -9999 -9999 -9999 -9999 -9999 -9999 -9999 -9999 -9999 -9999 -9999 -9999 -9999 -9999 -9999 -9999 -9999 -9999 -9999 -9999 -9999 -9999 -9999 -9999 -9999 -9999 -9999 -9999 -9999 -9999 -9999 -9999 -9999 -9999 -9999 -9999 -9999 -9999 89.9116134643685 .03504943848 86.254188537687 .7781066894588 .9972534179790 .2164001464891 .13075256348 92.0450973510792 .6546783447392 .9594726562594 .7881774902394 .48339080811 93.8738174438592 .6546783447391 .1307525634889 .302040100186 .86376190186 84.1206970214881 .3776321411178 .3297805786175 .2819290161172 .23407745361 69.4910125732466 .7479400634864 .6144485473662 .7857398986861 .26181030273 60.3474502563559 .7378807067959 .7378807067959 .7378807067960 .34745025635 
60.9570198059161 .5666007995664 .004882812564 .9192428588965 .83358764648 66.4431610107467 .3575134277368 .2718734741268 .8814392089869 .79579162598 70.7101516723671 .6244964599672 .5388565063573 .4532165527374 .36756896973 74.9771423339875 .5867080688576 .1962814331175 .5867080688576 .80584716797 77.7202072143678 .6345596313579 .5489196777379 .8537063598680 .15849304199 80.7680587768682 .2919769287185 .0350494384888 .9972534179793 .56903076172 97.22646331787100 .2742996216101 .7982025146102 .4077987671102 .1029968262 101.4934005737101 .4934005737102 .4077987671103 .3221969604104 .2365036011 104.5412979126104 .5412979126104 .5412979126104 .8460998535105 .7603988647 107.2844009399 108.8082962036110.3321990967111.8561019897113.3800964355 114.5991973877115 .818397522116 .7326965332117 .647102356117 .9517974854 118.2565994263117 .9517974854117 .647102356117 .342300415117 .647102356 118.2565994263118 .5614013672118 .5614013672118 .2565994263117 .342300415 116.7326965332115 .818397522114 .9039993286113 .9896011353113 .3800964355 112.7705001831112 .4656982422111 .8561019897111 .551399231110 .9418029785 110.6370010376110 .3321990967110 .3321990967110 .0273971558110 .0273971558 110.0273971558110 .3321990967110 .3321990967110 .6370010376110 .9418029785 111.24659729111 .551399231111 .8561019897112 .1608963013112 .7705001831 113.075302124113 .3800964355113 .6848983765113 .9896011353114 .5991973877 114.9039993286115 .2088012695115 .2088012695115 .5136032104115 .818397522 116.1231002808116 .4279022217116 .4279022217116 .7326965332117 .0374984741 117.0374984741117 .342300415117 .647102356117 .647102356117 .9517974854 118.2565994263118 .2565994263118 .5614013672118 .5614013672118 .5614013672 118.5614013672118 .2565994263118 .2565994263117 .9517974854117 .9517974854 117.647102356117 .647102356116 .9763946533116 .3146209717115 .6628799438 115.0216369629114 .391494751113 .7729110718113 .1664733887112 .5726089478 111.9918899536111 .4247131348110 .8716125488110 .3329925537109 .8094711304 109.3015060425108 .8098068237108 .3349914551107 .8779525757107 .439453125 107.0205841064106 .6222686768106 .2456970215105 .8918075562105 .5617523193 105.2564086914104 .9768600464104 .723815918104 .4982376099104 .3006744385 104.1318893433103 .9921264648103 .8818130493103 .8008880615103 .7494430542 103.7270050049103 .7332000732103 .7671127319103 .8278884888103 .9140701294 104.0242080688104 .156288147104 .3082733154104 .4775772095104 .6615600586 104.857170105105 .0612716675105 .2704315186105 .4810943604105 .6895751953 105.8921966553106 .0854721069106 .2660751343106 .4309463501106 .5767822266 106.7001113892106 .7966384888106 .861541748106 .8880691528106 .8668441772 106.7821426392106 .6188583374106 .3700027466106 .0652008057105 .7603988647 -9999 -9999 -9999 -9999 -9999 -9999 -9999 -9999 -9999 -9999 -9999 -9999 -9999 -9999 -9999 -9999 -9999 -9999 -9999 -9999 -9999 -9999 -9999 -9999 -9999 -9999 -9999 -9999 -9999 -9999 -9999 -9999 -9999 -9999 -9999 -9999 -9999 -9999 -9999 -9999 -9999 -9999 -9999 -9999 -9999 - -999 -

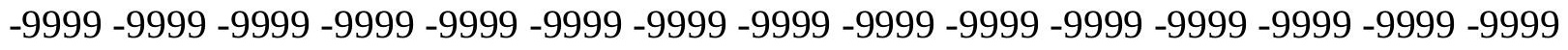

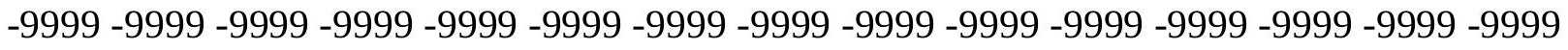
-9999 -9999 -9999 -9999 -9999 -9999 -9999 -9999 -9999 -9999 -9999 -9999 -9999 -9999 -9999 -9999 -9999 -9999 -9999 -9999 -9999 -9999 -9999 -9999-9999 -9999 -9999 -9999 -9999 -9999 -

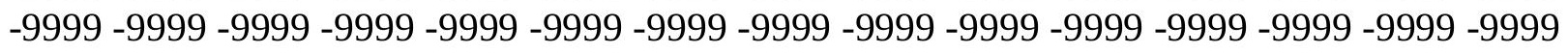
-9999 -9999 -9999 -9999 -9999 -9999 -9999 -9999 -9999 -9999 -9999 -9999 - 
-9999 -9999 -9999 -9999 -9999 -9999 -9999 -9999 -9999 -9999 -9999 -9999 -9999 -9999 -9999

-9999 -9999 -9999 -9999 -9999 -9999 -9999 -9999 -9999 -9999 -9999 -9999 -9999 -9999 -9999 -9999 -9999 -9999 -9999 -9999 -9999 -9999 -9999 -9999 88.69246673584 85.64462280273 87.47332763672 89.302040100190.8259735107492.04509735107 92.95947265625 93.8738174438594.4833908081195.0929565429795.397743225195.09295654297 94.7881774902393 .5690307617293 .5690307617291 .4355392456188 .99725341797 85.9494018554782 .5967712402379 .2441329956175 .8914871215872 .53885650635 69.4910125732466 .7479400634864 .3096618652362 .4809494018660 .95701980591 59.7378807067959 .1283111572359 .1283111572359 .4331016540560 .04267120361 60.9570198059161 .8713798522963 .0905189514264 .004882812566 .44316101074 67.0527267456167 .9670867919968 .5766525268669 .4910125732470 .40535736084 71.3197174072372 .2340774536173 .4532165527374 .3675689697375 .58670806885 76.5010681152377 .110626220777 .7202072143676 .8058471679777 .72020721436 78.6345596313579 .5489196777380 .4632720947380 .7680587768681 .07285308838 80.7680587768682 .2919769287184 .4254837036189 .302040100193 .87381744385 98.4455871582101 .1886978149102 .712600708103 .6268997192102 .4077987671 101.4934005737101 .4934005737102 .712600708104 .5412979126105 .1509017944 105.1509017944103 .9317016602103 .6268997192103 .9317016602105 .1509017944 106.6747970581108 .5035018921110 .6370010376112 .1608963013113 .6848983765 114.9039993286116 .1231002808117 .0374984741117 .647102356118 .2565994263 118.5614013672118 .2565994263117 .342300415115 .818397522117 .647102356 119.1709976196119 .4757995605119 .4757995605118 .5614013672117 .647102356 116.1231002808114 .9039993286113 .6848983765112 .7705001831111 .8561019897 111.24659729110 .6370010376110 .0273971558109 .4179000854109 .1130981445 108.5035018921108 .1986999512108 .1986999512107 .8938980103107 .8938980103 108.1986999512108 .1986999512108 .5035018921108 .8082962036109 .1130981445 109.7226028442110 .0273971558110 .6370010376110 .9418029785111 .551399231 112.1608963013112 .4656982422113 .075302124113 .3800964355113 .9896011353 114.2944030762114 .5991973877114 .9039993286115 .2088012695115 .5136032104 115.818397522116 .1231002808116 .4279022217116 .4279022217116 .7326965332 116.7326965332117 .0374984741117 .342300415117 .342300415117 .647102356 117.647102356117 .9517974854117 .9517974854117 .9517974854117 .9517974854 117.9517974854117 .647102356117 .647102356117 .342300415117 .342300415 117.342300415117 .342300415117 .342300415116 .7152862549116 .0441970825 115.3832397461114 .7330093384114 .0939788818113 .4667434692112 .8517303467 112.2495193481111 .6604995728111 .0852050781110 .5240631104109 .9776763916 109.4465408325108 .9314041138108 .4328994751107 .9519500732107 .4893417358 107.0461578369106 .6233673096106 .2222213745105 .8437271118105 .4891662598 105.1595535278104 .8561553955104 .579864502104 .3318481445104 .1128768921 103.9239425659103 .7655181885103 .6382522583103 .5423049927103 .4779815674 103.4449768066103 .4430847168103 .4715118408103 .5295257568103 .6157226562 103.7287063599103 .8664398193104 .0268630981104 .207321167104 .405090332 104.616973877104 .8397216797105 .0697631836105 .3034057617105 .5368423462 105.7662963867105 .9882049561106 .1991729736106 .3960494995106 .5754165649 106.7336959839106.8664932251 106.9687957764107.0333786011 107.0496292114 107.003074646106.881477356 106.6747970581 106.3700027466 106.3700027466-9999-9999 
-9999 -9999 -9999 -9999 -9999 -9999 -9999 -9999 -9999 -9999 -9999 -9999 -9999 -9999 -9999 -9999 -9999 -9999 -9999 -9999 -9999 -9999 -9999 -9999 -9999 -9999 -9999 -9999 -9999 -9999 -9999 -9999 -9999 -9999 -9999 -9999 -9999 -9999 -9999 -9999 -9999 -9999 -9999 -9999 -9999 -9999 -9999 -9999 -9999 -9999 -9999 -9999 -9999 -9999 -9999 -9999 -9999 -9999 -9999 -9999 -9999 -9999 -9999 -9999 -9999 -9999 -9999 -9999 -9999 -9999 -9999 -9999-9999 -9999 -9999 -9999 -9999 -9999 -9999 -9999 -9999 -9999 -9999 -9999 -9999 -9999 -9999 -9999 -9999 -9999

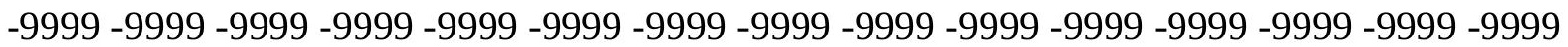
-9999 -9999 -9999 -9999 -9999 -9999 -9999 -9999 -9999 -9999 -9999 -9999 -9999 -9999 -9999 -9999 -9999 -9999 -9999 -9999 -9999 -9999 -9999 -9999 -9999 -9999

-9999 -9999 -9999 -9999 -9999 -9999 -9999 -9999 -9999 -9999 -9999 -9999 -9999 -9999 -9999 -9999 -9999 -9999 -9999 -9999 -9999 -9999 -9999 -9999 -9999 -9999 -9999 -9999 -9999 -9999 -9999 -9999 -9999 -9999 -9999 -9999 -9999 -9999 -9999 -9999 86.86376190186 89.302040100191 .4355392456192 .6546783447393 .8738174438594 .78817749023 95.7025299072396 .3121032714896 .9216690063597 .2264633178797 .53124237061 96.9216690063596 .0073165893694 .4833908081192 .349891662690 .82597351074 87.47332763672 84.12069702148 80.1584930419976.50106811523 73.14842987061 69.7957916259866 .7479400634864 .004882812561 .8713798522960 .04267120361 59.1283111572358 .5187492370658 .5187492370659 .1283111572360 .04267120361 61.2618103027362 .4809494018663 .7000885009864 .6144485473665 .52880096436 66.4431610107467 .0527267456169 .1862335205170 .1005783081170 .71015167236 71.6244964599672 .8436431884874 .062782287675 .2819290161176 .50106811523 77.7202072143678 .6345596313578 .9393463134879 .5489196777378 .93934631348 79.5489196777380 .1584930419981 .3776321411182 .5967712402383 .2063369751 82.9015579223681 .6824111938583 .8159103393690 .21640014648101 .4934005737 103.9317016602104 .2365036011105 .7603988647106 .979598999104 .5412979126 103.6268997192102 .712600708103 .0174026489106 .979598999106 .3700027466 104.8460998535102 .4077987671101 .4934005737102 .1029968262103 .6268997192 105.7603988647108 .1986999512110 .6370010376112 .4656982422113 .6848983765 114.9039993286115 .818397522116 .7326965332117 .647102356118 .5614013672 118.8662033081119 .1709976196118 .8662033081118 .8662033081119 .7806015015 120.3900985718120 .6949005127120 .3900985718119 .4757995605117 .647102356 115.818397522113 .9896011353112 .4656982422111 .24659729110 .3321990967 109.4179000854 108.8082962036108.1986999512 107.5891036987106.979598999 106.3700027466 106.0652008057 106.0652008057 105.7603988647105.7603988647 106.0652008057106 .3700027466106 .6747970581106 .979598999107 .5891036987 108.1986999512108 .8082962036109 .1130981445109 .7226028442110 .3321990967 110.9418029785111 .551399231112 .1608963013112 .7705001831113 .075302124 113.6848983765114 .2944030762114 .5991973877114 .9039993286115 .2088012695 115.5136032104115 .818397522116 .1231002808116 .1231002808116 .4279022217 116.4279022217116 .7326965332116 .7326965332117 .0374984741117 .0374984741 117.342300415117 .342300415117 .342300415117 .342300415117 .342300415117 .342300415 117.0374984741117 .0374984741116 .7326965332116 .7326965332116 .7326965332 116.7326965332117 .0374984741117 .1179122925116 .4274597168115 .7467498779 115.0763931274114 .4168701172113 .7687606812113 .1325149536112 .5086898804 111.8976745605111 .299987793110 .7160491943110 .1464767456109 .5917739868 109.052696228108 .5299072266108 .0243530273107 .5368347168107 .0684432983 
106.6201782227 106.1933288574 105.7889785767105.4085159302 105.0531082153 104.7242050171104 .4228897095104 .1505584717103 .9082183838103 .6971054077 103.5179519653103 .3716659546103 .2586288452103 .179397583103 .1338577271 103.1220169067103 .143196106103 .1968002319103 .2814941406103 .395942688 103.5380859375103 .7058486938103 .8964767456104 .1071624756104 .334564209 104.575302124104 .8256225586105 .0817184448105 .3396377563105 .5955047607 105.845664978106 .0866012573106 .3150024414106 .5272521973106 .719581604 106.8874664307 107.0259857178 107.1286849976 107.18724823 107.1873397827 107.1134185791106 .979598999106 .979598999106 .6747970581106 .3700027466 -9999 -9999 -9999 -9999 -9999 -9999 -9999 -9999 -9999 -9999 -9999 -9999 -9999 -9999 -9999 -9999 -9999 -9999 -9999 -9999 -9999 -9999 -9999 -9999 -9999 -9999 -9999 -9999 -9999 -9999 -9999 -9999 -9999 -9999 -9999 -9999 -9999 -9999 -9999 -9999 -9999 -9999 -9999 -9999 -9999 -9999 -9999 -999 -9999 -9999 -9999 -9999 -9999 -9999 -9999 -9999 -9999 -9999 -9999 -9999 -9999 -9999 -9999 -9999 -9999 -9999 -9999 -9999 -9999 -9999 -9999 -9999 -9999 -9999 -9999 -9999 -9999 -9999 -9999 -9999 -9999 -9999 -9999 -9999 -9999 -9999 -9999 -9999 -9999 -9999 -9999 -9999 -9999

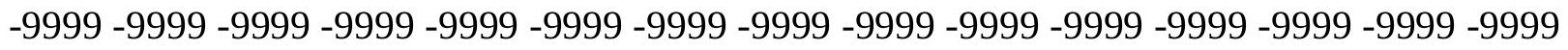

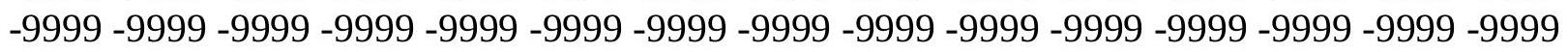
-9999 -9999 -9999 -9999 -9999 -9999 -9999 -9999 -9999 -9999

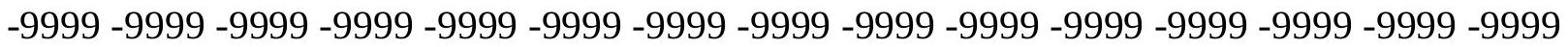

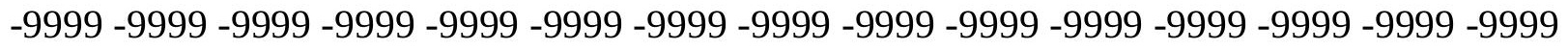
-9999 -9999 -9999-9999 -9999 -9999 -9999 -9999 -9999-9999 88.99725341797 92.0450973510793 .8738174438594 .7881774902395 .7025299072396 .61688232422 97.2264633178798.1408081054798.75038146973 99.3599472045999.66472625732 99.35994720459 98.7503814697396.9216690063594.4833908081191.43553924561 87.7781066894583 .8159103393681 .0728530883877 .110626220773 .14842987061 69.7957916259866 .4431610107463 .7000885009861 .2618103027359 .43310165405 58.2139587402357 .909179687558 .2139587402358 .8235282897960 .04267120361 61.5666007995663 .0905189514264 .3096618652365 .5288009643666 .44316101074 67.3575134277367 .9670867919968 .2718734741268 .8814392089869 .49101257324 71.9292907714873 .1484298706174 .6723632812576 .1962814331177 .72020721436 78.9393463134879 .8537063598680 .4632720947381 .0728530883881 .37763214111 80.4632720947380 .4632720947381 .9871978759884 .1206970214885 .03504943848 84.7302627563580 .7680587768681 .3776321411198 .75038146973115 .5136032104 116.1231002808113 .9896011353117 .9517974854121 .3044967651119 .7806015015 117.9517974854120 .6949005127120 .3900985718112 .7705001831106 .979598999 102.407798767199 .0551681518698 .445587158299 .66472625732101 .4934005737 104.2365036011107 .5891036987110 .3321990967112 .1608963013113 .6848983765 114.5991973877115 .5136032104116 .4279022217117 .342300415118 .2565994263 119.1709976196120 .0852966309120 .9997024536121 .6092987061122 .5235977173 121.9140014648122 .2188034058121 .6092987061119 .7806015015117 .342300415 114.9039993286112 .7705001831111 .24659729109 .7226028442108 .5035018921 107.5891036987106 .979598999106 .0652008057105 .4557037354104 .8460998535 104.5412979126104 .2365036011103 .9317016602103 .9317016602103 .9317016602 103.9317016602104 .5412979126104 .8460998535105 .4557037354106 .0652008057 106.6747970581 107.2844009399107.8938980103108.8082962036109.4179000854 110.0273971558110 .6370010376111 .24659729112 .1608963013112 .4656982422 
113.075302124113 .6848983765114 .2944030762114 .5991973877114 .9039993286 115.2088012695115 .5136032104115 .818397522115 .818397522116 .1231002808 116.1231002808116 .4279022217116 .4279022217116 .7326965332116 .7326965332 116.7326965332117 .0374984741117 .0374984741117 .0374984741117 .0374984741 116.7326965332116 .4279022217116 .4279022217116 .1231002808115 .818397522 115.818397522115 .818397522116 .4279022217116 .7326965332116 .8127288818 116.1123046875115 .4218444824114 .7418365479114 .072845459113 .4153289795 112.7698135376112 .1366729736111 .5164108276110 .9094390869110 .3163604736 109.7376785278109 .1741485596108 .6264572144108 .0955657959107 .5822906494 107.0877532959106 .6129684448106 .1592483521105 .7277603149105 .3199920654 104.93724823104 .5811462402104 .2529830933103 .9543838501103 .6865997314 103.4511795044103 .2491149902103 .0815963745102 .9492340088102 .8528442383 102.7925643921102 .7686157227102 .7805099487102 .827796936102 .9092330933 103.0235366821103 .1686630249103 .3424911499103 .5421981812103 .7648620605 104.0069732666104 .2649993896104 .5349884033104 .8129653931105 .0948257446 105.3766021729105 .6545181274105 .9248504639106 .1840133667106 .4281463623 106.6532516479 106.8547286987 107.0279922485107.16771698 107.2676544189 107.3209609985 107.2844009399 107.2844009399106.979598999 106.979598999 106.6747970581 -9999 -9999 -9999 -9999 -9999 -9999 -9999 -9999 -9999 -9999 -9999 -9999

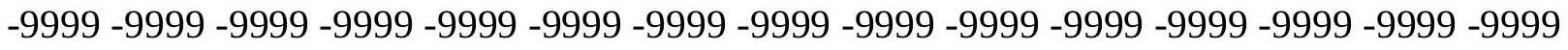
-9999 -9999 -9999 -9999 -9999 -9999 -9999 -9999 -9999 -9999 -9999 -9999 -9999 -9999 -9999 -9999 -9999 -9999 -9999 -9999 -9999 -9999 -9999 -9999 -9999 -9999 -9999 -9999 -9999 -9999 -9999 -9999 -9999 -9999 -9999 -9999 -9999 -9999 -9999 -9999 -9999 -9999-9999-9999-9999 -999 -9999 -9999 -9999 -9999 -9999 -9999 -9999 -9999 -9999 -9999 -9999 -9999 -9999 -9999 -9999 -

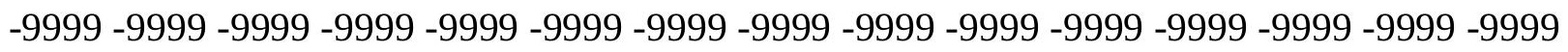
-9999 -9999 -9999 -9999 -9999 -9999 -9999 -9999 -9999 -9999 -9999 -9999 -9999 -9999 -9999 -9999 -9999 -9999 -9999 -9999 -9999 -9999 -9999 -9999 -9999 -9999 -9999 -9999 -9999 -9999

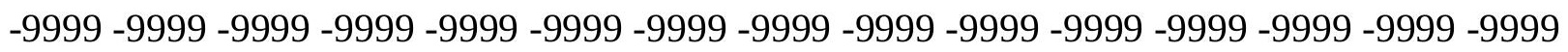

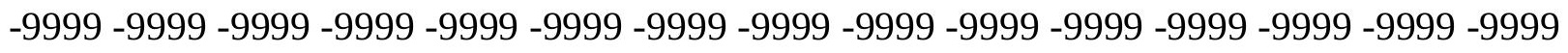
-9999 -9999 -9999 -9999 -9999 -9999 -9999 -9999 -9999 -9999 92.04509735107 95.397743225196 .3121032714896 .9216690063597 .5312423706198 .14080810547 98.7503814697399 .66472625732100 .2742996216101 .1886978149101 .7982025146 101.7982025146101 .188697814999 .3599472045996 .9216690063593 .26425170898 89.302040100184 .7302627563580 .4632720947375 .8914871215871 .92929077148 68.2718734741264 .9192428588963 .3953094482460 .6522407531758 .51874923706 57.2995986938556 .9948196411157 .2995986938558 .8235282897960 .34745025635 62.1761703491264 .004882812565 .5288009643666 .7479400634867 .66230010986 68.27187347412 68.57665252686 68.88143920898 69.1862335205169.79579162598 70.7101516723671 .9292907714873 .7580032348675 .5867080688577 .41542053223 77.4154205322380 .1584930419980 .7680587768679 .5489196777379 .54891967773 80.15849304199 81.3776321411183.51112365723 86.2541885376 88.38768768311 92.349891662696 .00731658936101 .7982025146109 .3966064453118 .0637664795 121.8013839722122 .669883728124 .5390090942126 .385055542126 .7121887207 126.4858016968128 .6192932129128 .3144989014121 .6092987061108 .1986999512 97.5312423706194 .7881774902395 .397743225196 .9216690063599 .05516815186 102.1029968262106 .0652008057109 .7226028442111 .551399231112 .7705001831 
113.3800964355114 .2944030762115 .2088012695116 .4279022217117 .647102356 119.1709976196120 .6949005127122 .2188034058122 .8283996582123 .1332015991 123.1332015991122 .8283996582122 .2188034058119 .1709976196116 .1231002808 113.3800964355111 .24659729109 .4179000854108 .1986999512106 .979598999 106.0652008057105 .1509017944104 .5412979126103 .6268997192103 .0174026489 102.4077987671102 .1029968262101 .7982025146101 .7982025146101 .7982025146 102.1029968262102 .712600708103 .3221969604103 .9317016602104 .5412979126 105.4557037354106 .0652008057106 .979598999107 .5891036987108 .5035018921 109.1130981445110 .0273971558110 .6370010376111 .24659729111 .8561019897 112.7705001831113 .075302124113 .6848983765114 .2944030762114 .5991973877 114.9039993286115 .2088012695115 .5136032104115 .5136032104115 .818397522 115.818397522115 .818397522116 .1231002808116 .1231002808116 .4279022217 116.4279022217116 .4279022217116 .4279022217116 .4279022217116 .4279022217 116.1231002808116 .1231002808115 .818397522115 .2088012695115 .2088012695 114.9039993286115 .2088012695115 .5136032104116 .1231002808117 .0374984741 116.4800643921115 .7695922852115 .0691680908114 .3793411255113 .7005462646 113.0332946777112 .3779449463111 .7349624634111 .1047286987110 .4878311157 109.8847579956109 .296257019108 .7230377197108 .166053772107 .626159668 107.1044845581106 .6020812988106 .120300293105 .6603622437105 .2238464355 104.8121795654104 .4271392822104 .0702438354103 .7433242798103 .4479370117 103.1859588623102 .9586868286102 .7675323486102 .6133117676102 .4971008301 102.419342041102 .3805923462102 .3805847168102 .4191055298102 .4950485229 102.6072387695102 .7536239624102 .9320831299103 .1397171021103 .3734970093 103.629699707103 .9045410156104 .1937942505104 .4932250977104 .7985305786 105.1056289673105 .4106292725105 .7095947266105 .9985351562106 .2732467651 106.529548645106 .7628936768106 .9689941406107 .1436843872107 .2835388184 107.3840408325 107.4334030151 107.2844009399 107.2844009399 107.2844009399 106.979598999106 .979598999 -9999 -9999 -9999 -9999 -9999 -9999 -9999 -9999 -9999 -9999 -9999 -9999 -9999 -9999 -9999 -9999 -9999 -9999 -9999 -9999 -9999 -9999 -9999 - -9999 -9999 -9999 -9999 -9999 -9999 -9999 -9999 -9999 -9999 -9999 -9999 -9999 -9999 -9999 -9999 -9999 -9999 -9999 -9999 -9999 -9999 -9999 -9999 -9999 -9999 -9999 -9999 -9999 -9999 -9999 -9999

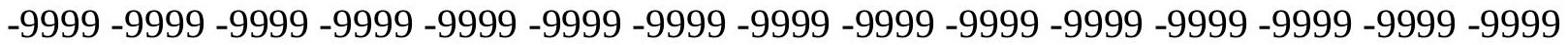

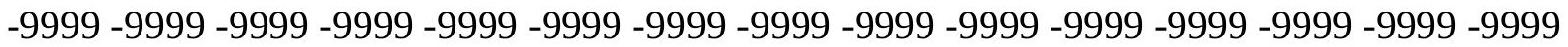
-9999 -9999 -9999 -9999 -9999 -9999 -9999 -9999 -9999 -9999 -9999 -9999 -9999 -9999 -9999 -9999 -9999 -9999 -9999 -9999 -9999 -9999 -9999 -9999 -9999 -9999 -9999 -9999 -9999 -9999 -9999 -9999 -9999 -9999 -9999 -9999 -9999 -9999 -9999 -9999 -9999 -9999 -9999 -9999 -9999 $-9999$

-9999 -9999 -9999 -9999 -9999 -9999 -9999 -9999 -9999 -9999 -9999 -9999 -9999 -9999 -9999 -

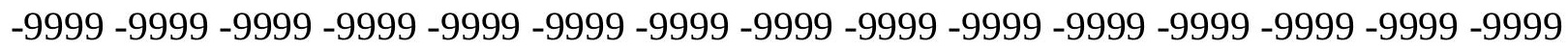
-9999 -9999 -9999 -9999 -9999 -9999 -9999 -9999 -9999 -9999 -9999 99.35994720459 99.3599472045998 .7503814697398 .7503814697399 .66472625732100 .2742996216 100.8839035034101 .7982025146102 .712600708103 .9317016602104 .2365036011 103.9317016602102 .102996826299 .0551681518695 .0929565429790 .52117919922 85.6446228027380 .7680587768676 .1962814331171 .9292907714868 .27187347412 64.9192428588961 .5666007995658 .5187492370656 .0804595947354 .55654144287 55.7756805419956 .6900291442958 .5187492370660 .6522407531763 .09051895142 
65.2240066528367 .0527267456168 .2718734741269 .1862335205169 .49101257324 69.7957916259869 .4910125732469 .4910125732469 .4910125732470 .40535736084 71.6244964599673 .7580032348676 .1962814331176 .8058471679778 .93934631348 80.1584930419980 .7680587768681 .0728530883881 .0728530883881 .37763214111 81.9871978759885 .0350494384889 .302040100196 .31210327148104 .2365036011 113.3800964355115 .2970504761117 .7787322998121 .2475204468124 .0457992554 125.5200576782126 .4706726074127 .2519302368127 .9568557739128 .9241027832 128.9241027832127 .0953979492120 .6949005127110 .332199096796 .31210327148 93.5690307617293 .5690307617294 .4833908081196 .3121032714899 .05516815186 103.6268997192108 .8082962036109 .7226028442110 .6370010376111 .551399231 112.4656982422113 .3800964355114 .5991973877116 .1231002808117 .9517974854 119.7806015015121 .6092987061122 .2188034058122 .5235977173122 .8283996582 121.6092987061119 .7806015015117 .0374984741113 .9896011353111 .551399231 109.4179000854 107.8938980103 106.6747970581 105.4557037354 104.5412979126 103.6268997192103 .0174026489102 .1029968262101 .4934005737100 .8839035034 100.274299621699 .9695205688599 .96952056885100 .2742996216100 .5791015625 101.1886978149101 .7982025146102 .4077987671103 .3221969604104 .2365036011 105.1509017944105 .7603988647106 .6747970581107 .5891036987108 .1986999512 109.1130981445110 .0273971558110 .6370010376111 .24659729112 .1608963013 112.7705001831113 .3800964355113 .6848983765114 .2944030762114 .5991973877 114.9039993286115 .2088012695115 .2088012695115 .2088012695115 .5136032104 115.5136032104115 .5136032104115 .818397522115 .818397522116 .1231002808 116.1231002808116 .1231002808116 .1231002808116 .1231002808115 .818397522 115.5136032104115 .2088012695114 .5991973877114 .2944030762114 .2944030762 114.2944030762114 .9039993286115 .5136032104116 .4279022217116 .8501434326 116.1198120117115 .3990859985114 .6885223389113 .9885025024113 .2995300293 112.6219100952111 .9560775757111 .3023834229110 .6613769531110 .033531189 109.4195709229108 .8202056885108 .2363967896107 .6690216064107 .1192398071 106.5881271362106 .0770797729105 .5873641968105 .1206359863104 .6784439087 104.2627105713103 .8751373291103 .517829895103 .1926345825102 .9017715454 102.6468353271102 .4293899536102 .2503051758102 .1109542847102 .0121994019 101.9550704956101 .9396591187101 .9661026001102 .0335845947102 .14112854 102.2866973877 102.4682006836102.6827011108 102.9270629883103.1972503662 103.4890518188103 .797744751104 .1186752319104 .4471740723104 .779045105 105.1103363037105 .4369430542105 .7545013428106 .0583953857106 .3442764282 106.6077346802 106.8447875977 107.0516357422 107.2252883911 107.2844009399 107.4613800049 107.5161743164 107.5891036987 107.5891036987 107.2844009399 107.2844009399 -9999 -9999 -9999 -9999 -9999 -9999 -9999 -9999 -9999 -9999 -9999 -9999

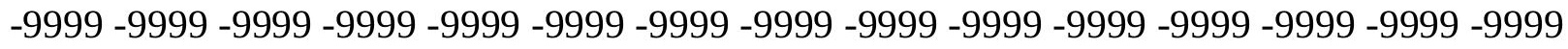

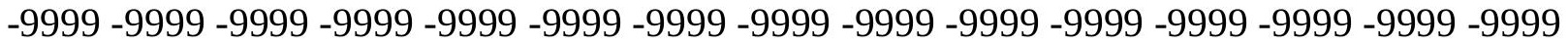

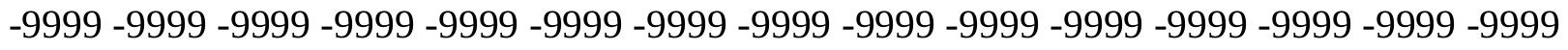

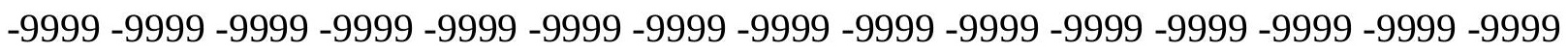

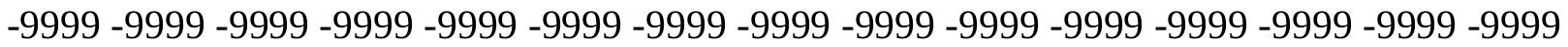

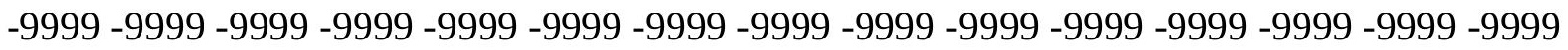

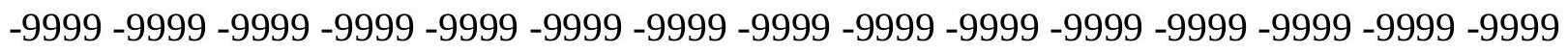
-9999 -9999 -9999 -9999 -9999 -9999 -9999 -9999 -9999 -9999 -9999 -9999 -9999 -9999 
-9999 -9999 -9999 -9999 -9999 -9999 -9999 -9999 -9999 -9999 -9999 -9999 -9999 -9999 -9999

-9999 -9999 -9999 -9999 -9999 -9999 -9999 -9999 -9999 -9999 -9999 -9999 -9999 -9999 -9999

-9999 -9999 -9999 -9999 -9999 -9999 -9999 -9999 -9999 -9999 -9999 108.8082962036

108.1986999512108 .5035018921108 .1986999512105 .7603988647101 .7982025146

102.1029968262103 .0174026489104 .2365036011105 .7603988647106 .6747970581

106.6747970581104 .5412979126101 .188697814996 .9216690063591 .74033355713

86.5589828491281 .0728530883876 .1962814331171 .9292907714868 .57665252686 65.2240066528361 .8713798522957 .909179687554 .8613204956153 .03261184692

52.7278289794954 .2517509460456 .9948196411160 .0426712036162 .78573989868 65.5288009643667 .3575134277368 .8814392089869 .4910125732469 .49101257324 69.1862335205168 .5766525268667 .9670867919967 .9670867919968 .27187347412 69.7957916259871 .9292907714874 .9771423339878 .0249862670980 .46327209473 82.2919769287182 .9015579223682 .9015579223682 .9015579223682 .90155792236 84.7302627563587 .1685485839892 .65467834473103 .3221969604114 .9039993286 122.2188034058122 .2600326538121 .9578704834122 .6919631958124 .1285705566 125.1628417969125 .1661987305124 .863067627124 .9010314941125 .2667007446 124.6570968628122 .8283996582118 .5614013672112 .4656982422103 .0174026489 95.0929565429794 .7881774902394 .4833908081193 .8738174438595 .3977432251 99.66472625732103 .3221969604106 .0652008057107 .8938980103109 .1130981445 110.3321990967111 .24659729112 .4656982422113 .9896011353115 .5136032104 117.0374984741118 .5614013672119 .1709976196120 .0852966309120 .6949005127 118.2565994263115 .818397522113 .3800964355110 .9418029785109 .1130981445 107.2844009399106 .3700027466105 .1509017944104 .2365036011103 .3221969604 102.712600708101 .7982025146100 .883903503499 .9695205688599 .35994720459 98.7503814697398 .445587158298 .445587158298 .7503814697399 .05516815186 99.66472625732100 .2742996216101 .1886978149102 .1029968262103 .0174026489 104.2365036011105 .1509017944105 .7603988647106 .6747970581107 .5891036987 108.1986999512109 .1130981445110 .0273971558110 .6370010376111 .551399231 112.1608963013112 .7705001831113 .3800964355113 .9896011353114 .2944030762 114.5991973877114 .5991973877114 .9039993286114 .9039993286114 .9039993286 114.9039993286115 .2088012695115 .2088012695115 .5136032104115 .5136032104 115.818397522116 .1231002808116 .1231002808116 .1231002808115 .818397522 115.2088012695114 .5991973877113 .9896011353113 .6848983765113 .3800964355 113.3800964355113 .9896011353114 .5991973877115 .5136032104116 .7326965332 116.4726638794115 .7318344116115 .0006713867114 .279548645113 .5688934326 112.8689880371112 .180229187111 .5029144287110 .8375473022110 .1845779419 109.544708252108 .9186248779108 .3073043823107 .7116317749107 .1327896118 106.5718917847106 .0303649902105 .5095367432105 .0111236572104 .5367584229 104.0885162354103 .668296814103 .2784881592102 .9212265015102 .5989532471 102.3134841919102 .0665130615101 .8589248657101 .6923141479101 .5681381226 101.4880981445101 .4528274536101 .4629974365101 .5182418823101 .6179885864 101.7602920532101 .9431304932102 .163520813102 .4182128906102 .7027359009 103.0122528076103 .3412399292103 .6843261719104 .0362930298104 .3926467896 104.749420166105 .1025085449105 .4473342896105 .7789916992106 .0929489136 106.3848495483 106.6509399414106.8875579834107.0930023193 107.2724838257 107.2844009399107 .5409011841107 .5891036987107 .5891036987107 .5891036987 
107.5891036987107 .5891036987 -9999 -9999 -9999 -9999 -9999 -9999 -9999 -9999 -9999 -9999 -9999 -9999 -9999 -9999 -9999 -9999 -9999 -9999 -9999 -9999 -9999 -9999 -9999 -9999 -9999 -9999 -9999 -9999 -9999 -9999 -9999 -9999 -9999 -9999 -9999 -9999 -9999 -9999 -9999 -9999 -9999 -9999 -9999 -9999 -9999 -9999 -9999 -9999 -9999 -9999 -9999 -9999 -9999 -9999 -9999 -9999 -9999 -9999 -9999 -9999 -9999 -9999 -9999 -9999 -9999 -9999 -9999 -9999 -9999 -9999 -9999 -9999 -9999 -9999 -9999 -9999 -9999 -9999 -9999 -9999 -9999 -9999 -9999 -9999 -9999 -9999 -9999 -9999 -9999 -9999 -9999 -9999 -9999 -9999 -9999 -9999 -9999 -9999 -9999

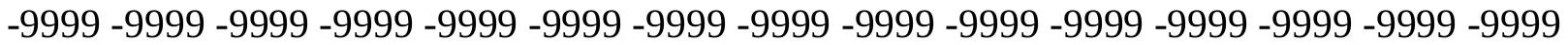

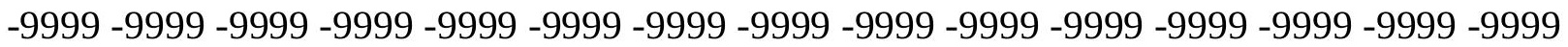
$-9999$

-9999 -9999 -9999 -9999 -9999 -9999 -9999 -9999 -9999 -9999 -9999 -9999 -9999 -9999 -9999 -9999 -9999 -9999 -9999 -9999 -9999 -9999 -9999 -9999 -9999 -9999 -9999 -9999 -9999 -9999 -9999 -9999 -9999 -9999 -9999 -9999 -9999 -9999 -9999 -9999 -9999 -9999 120.8421783447 123.0096817017126 .4858016968124 .0475006104120 .6949005127116 .1231002808 111.551399231107 .5891036987107 .5891036987109 .7226028442109 .4179000854 107.2844009399 103.017402648998.1408081054792.95947265625 87.16854858398 81.0728530883875 .5867080688571 .3197174072368 .8814392089866 .44316101074 62.7857398986857 .909179687553 .3373985290550 .8991203308151 .20389938354 53.6421813964857 .2995986938560 .9570198059164 .3096618652367 .35751342773 69.4910125732470 .7101516723671 .3197174072371 .3197174072370 .40535736084 69.1862335205168 .2718734741267 .6623001098667 .6623001098669 .18623352051 71.6244964599675 .2819290161178 .9393463134882 .2919769287184 .12069702148 85.0350494384884 .7302627563585 .9494018554787 .1685485839888 .69246673584 90.5211791992295 .3977432251108 .8082962036121 .6092987061124 .3523025513 123.1332015991122 .5235977173121 .9140014648122 .8283996582123 .7427978516 122.2188034058120 .6949005127119 .7806015015119 .1709976196118 .2565994263 116.7326965332115 .2088012695112 .7705001831108 .1986999512101 .4934005737 98.1408081054796 .9216690063595 .7025299072395 .0929565429796 .00731658936 98.4455871582102 .4077987671104 .5412979126106 .0652008057107 .5891036987 108.8082962036110 .0273971558111 .551399231112 .7705001831113 .9896011353 114.5991973877115 .2088012695115 .2088012695114 .9039993286113 .075302124 111.24659729109 .1130981445107 .5891036987106 .3700027466105 .4557037354 104.8460998535104 .2365036011103 .6268997192102 .712600708101 .7982025146 100.883903503499 .9695205688599 .0551681518698 .445587158297 .83602905273 97.5312423706197 .2264633178797 .5312423706197 .8360290527398 .4455871582 99.35994720459100 .2742996216101 .1886978149102 .4077987671103 .3221969604 104.2365036011105 .1509017944106 .0652008057106 .6747970581107 .5891036987 108.5035018921109 .1130981445110 .0273971558110 .9418029785111 .8561019897 112.4656982422113 .075302124113 .6848983765113 .9896011353114 .2944030762 114.5991973877114 .5991973877114 .5991973877114 .5991973877114 .5991973877 114.5991973877114 .5991973877114 .9039993286115 .2088012695115 .818397522 116.1231002808116 .4279022217116 .4279022217116 .1231002808115 .5136032104 114.5991973877113 .6848983765113 .075302124112 .4656982422112 .7705001831 113.3800964355113 .9896011353114 .9039993286115 .818397522116 .7326965332 116.0675888062115 .3160324097114 .5739593506113 .8417358398113 .1195907593 112.4078674316111 .7068252563111 .0169067383110 .3385314941109 .6723556519 
109.0190658569 108.3796157837 107.7549057007 107.1461334229 106.55443573 105.9812850952105 .4280395508104 .8964614868104 .3882827759103 .905708313 103.4508590698103 .0264053345102 .6346969604102 .2782363892101 .9587783813 101.6781539917101 .4375101 .2387771606101 .0840759277100 .975944519100 .9157562256 100.9048843384100 .9436340332101 .0320205688101 .1683807373101 .3507766724 101.5761566162101 .8410720825102 .1404876709102 .4687194824102 .819190979 103.185546875103 .5617675781103 .9428100586104 .3245162964104 .7029342651 105.0736236572105 .4316329956105 .7723236084106 .0913467407106 .3700027466 106.6504821777 106.6747970581 106.979598999 107.2844009399 107.2844009399 107.5891036987107 .5891036987107 .8938980103107 .8938980103107 .8938980103 -9999 -9999 -9999 -9999 -9999 -9999 -9999 -9999 -9999 -9999 -9999 -9999 -9999 -9999 -9999 -9999 -9999 -9999 -9999 -9999 -9999 -9999 -9999 -9999 -9999 -9999 -9999 -9999 -9999 -9999 -9999 -9999 -9999 -9999 -9999 -9999 -9999 -9999 -9999 -9999 -9999 -9999 -9999 -9999 -9999 -9999 -9999 -9999 -9999 -9999 -9999 -9999 -9999 -9999 -9999 -9999 -9999 -9999 -9999 -9999 -9999 -9999 -9999 -9999 -9999 -9999 -9999 -9999 -9999 -9999 -9999 -9999 -9999 -9999 -9999 -9999

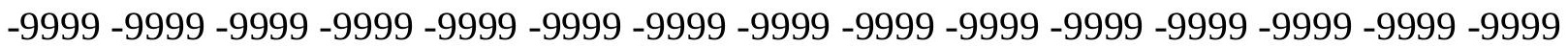

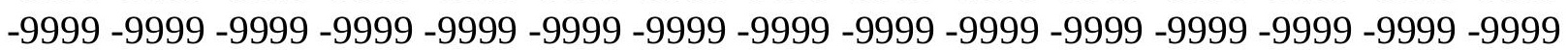

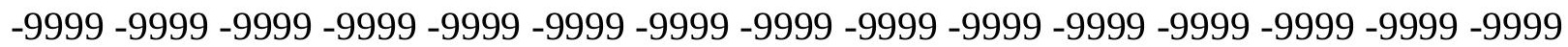
-9999 -9999 -9999 -9999 -9999 -9999 -9999 -9999 -9999

-9999 -9999 -9999 -9999 -9999 -9999 -9999 -9999 -9999 -9999 -9999 -9999 -9999 -9999 -9999 -9999 -9999 -9999 -9999 -9999 -9999 -9999 -9999 -9999 -9999 -9999 -9999 -9999 -9999 -9999 -9999 -9999 -9999 -9999 -9999 -9999 -9999 -9999 -9999 -9999 -9999 -9999 134.7095336914 137.4429321289139 .6392974854139 .3358154297137 .1986694336134 .5989074707 133.8007049561131 .3623962402128 .0097961426123 .1332015991116 .1231002808 109.1130981445104 .541297912699 .0551681518694 .1785964965888 .38768768311 81.0728530883874 .3675689697370 .4053573608469 .1862335205168 .57665252686 65.2240066528358 .5187492370651 .5086898803749 .0704002380449 .98476028442 53.6421813964857 .909179687562 .1761703491266 .1383666992269 .18623352051 71.3197174072372 .8436431884873 .1484298706172 .8436431884871 .62449645996 70.1005783081168 .5766525268667 .6623001098667 .3575134277368 .57665252686 71.6244964599675 .2819290161180 .1584930419984 .4254837036186 .86376190186 88.0829010009889 .302040100190 .2164001464891 .1307525634892 .65467834473 95.09295654297100 .2742996216110 .6370010376120 .0852966309122 .5235977173 122.2188034058121 .9140014648121 .3044967651121 .6092987061121 .3044967651 119.4757995605117 .342300415115 .818397522114 .9039993286113 .6848983765 113.075302124112 .7705001831112 .7705001831111 .551399231108 .8082962036 104.541297912699.6647262573297.5312423706196.3121032714897.22646331787 100.2742996216103 .6268997192104 .8460998535105 .1509017944104 .8460998535 106.0652008057107 .2844009399109 .1130981445110 .3321990967110 .9418029785 110.9418029785110 .6370010376110 .0273971558109 .1130981445107 .8938980103 106.3700027466105 .1509017944104 .5412979126103 .9317016602104 .2365036011 104.2365036011103 .9317016602103 .3221969604102 .4077987671101 .7982025146 100.883903503499 .66472625732100 .274299621699 .6647262573298 .75038146973 96.9216690063596 .6168823242296 .6168823242296 .9216690063597 .53124237061 98.445587158299 .66472625732100 .5791015625101 .7982025146103 .0174026489 103.9317016602104 .5412979126105 .4557037354106 .0652008057106 .979598999 
107.5891036987 108.5035018921 109.4179000854 110.3321990967 111.24659729 112.1608963013112 .7705001831113 .3800964355113 .6848983765113 .9896011353 114.2944030762114 .2944030762114 .5991973877114 .2944030762114 .2944030762 114.2944030762114 .2944030762114 .5991973877114 .9039993286115 .818397522 116.7326965332117 .0374984741117 .342300415117 .0374984741116 .1231002808 114.9039993286113 .6848983765112 .7705001831112 .1608963013112 .1608963013 112.7705001831113 .6848983765114 .2944030762115 .2088012695115 .818397522 116.4065322876115 .6348571777114 .8720397949114 .1184082031113 .3741378784 112.6394958496111 .9146957397111 .2001190186110 .496131897109 .8033599854 109.122467041108 .4543685913107 .799987793107 .1605072021106 .5370941162 105.9312210083105 .3442993164104 .7781219482104 .2345046997103 .7157745361 103.224281311102 .762878418102 .3340759277101 .9402389526101 .5828323364 101.2636947632100 .9845504761100 .7480926514100 .5571899414100 .4152755737 100.3246078491100 .2874603271100 .3050079346100 .3780975342100 .5055236816 100.6855545044100 .9149703979101 .1900177002101 .5048980713101 .8528747559 102.2260971069102 .6170043945103 .0185470581103 .4248962402103 .8314285278 103.9317016602103 .9317016602104 .5412979126105 .1509017944105 .4557037354 105.7603988647106 .0652008057106 .3700027466106 .6747970581106 .979598999 107.2844009399107 .5891036987107 .5891036987107 .8938980103107 .8938980103 108.1986999512 108.1986999512 -9999 -9999 -9999 -9999 -9999 -9999 -9999 -9999 -9999 -9999 -9999 -9999 -9999 -9999 -9999 -9999 -9999 -9999 -9999 -9999 -9999 -9999 -9999 -9999 -9999 -9999 -9999 -9999 -9999 -9999 -9999 -9999 -9999 -9999 -9999 -9999 -9999 -9999 -9999 -9999 -9999 -9999 -9999 -9999 -9999 -9999 -9999 -9999 -9999 -9999 -9999 -9999 -9999 -9999 -9999 -9999 -9999 -9999 -9999 -9999 -9999 -9999 -9999 -9999 -9999 -9999 -9999 -9999 -9999

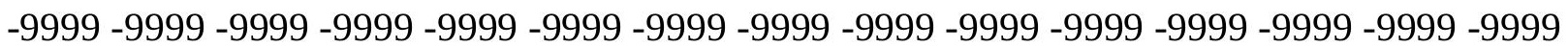
-9999 -9999 -9999 -9999 -9999 -9999 -9999 -9999 -9999 -9999 -9999 -9999 -9999 -9999 -9999 -9999 -9999 -9999 -9999 -9999 -9999 -9999 -9999 -9999 -9999 -9999 -9999 -9999 -9999 -9999 -9999 -9999 -9999 -9999 -9999 -9999 -9999 -9999 -9999 -9999 -9999 -9999 -9999 -9999 -9999 -9999 -9999 -9999 -9999 -9999 -9999 -9999 -9999 -9999 -9999 -9999 -9999 -9999 -9999 -9999

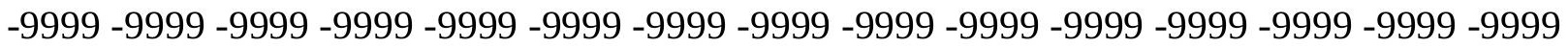
-9999 -9999 -9999 -9999 -9999 -9999 -9999 -9999 -9999 -9999 -9999 -9999 148.7598876953 151.3127593994153 .2271728516154 .067565918153 .7909240723153 .3262329102 152.9965209961152 .068359375150 .6708221436149 .6495056152141 .4203033447 132.5814971924124 .3523025513119 .1709976196113 .075302124103 .6268997192 92.6546783447378 .3297805786168 .8814392089874 .9771423339880 .46327209473 69.4910125732456 .3852500915549 .9847602844248 .1560516357450 .59432983398 55.4708900451761 .2618103027366 .7479400634870 .7101516723673 .75800323486 76.8058471679778 .9393463134879 .2441329956178 .3297805786177 .72020721436 76.8058471679775 .2819290161174 .062782287673 .7580032348674 .97714233398 77.4154205322380 .7680587768685 .9494018554790 .2164001464891 .74033355713 92.349891662693 .5690307617294 .4833908081195 .397743225197 .22646331787 100.5791015625105 .1509017944110 .9418029785116 .4279022217119 .4757995605 120.9997024536121 .3044967651121 .3044967651120 .3900985718118 .8662033081 116.7326965332114 .5991973877112 .4656982422110 .6370010376109 .7226028442 109.4179000854110 .0273971558111 .24659729112 .4656982422113 .3800964355 114.2944030762114 .5991973877115 .5136032104116 .1231002808116 .1231002808 
117.0374984741120 .9997024536123 .43800354120 .3900985718116 .1231002808 113.3800964355111 .24659729109 .7226028442108 .5035018921109 .1130981445 108.1986999512106 .979598999106 .3700027466105 .1509017944104 .2365036011 102.712600708102 .4077987671102 .1029968262102 .712600708103 .3221969604 104.2365036011103 .9317016602103 .3221969604102 .712600708102 .1029968262 101.188697814999 .96952056885100 .274299621699 .3599472045997 .22646331787 96.6168823242296 .3121032714896 .0073165893696 .3121032714896 .92166900635 97.8360290527399 .05516815186100 .2742996216101 .4934005737102 .712600708 103.6268997192104 .2365036011104 .8460998535105 .4557037354106 .0652008057 106.6747970581107 .5891036987108 .5035018921109 .7226028442110 .6370010376 111.8561019897112 .4656982422113 .3800964355113 .6848983765113 .9896011353 114.2944030762114 .5991973877114 .5991973877114 .5991973877114 .2944030762 113.9896011353113 .9896011353113 .9896011353114 .9039993286115 .818397522 117.342300415118 .2565994263118 .8662033081118 .5614013672117 .647102356 116.1231002808114 .5991973877113 .075302124112 .1608963013112 .1608963013 112.7705001831113 .3800964355113 .9896011353114 .2944030762114 .9039993286 115.5136032104115 .9573135376115 .1740493774114 .3992462158113 .6330337524 112.8756103516112 .1271133423111 .3878631592110 .6581954956109 .938659668 109.2298965454 108.5327835083107.8482284546107.1773986816106.5214691162 105.8819122314105 .2601623535104 .6580429077104 .0774383545103 .5208129883 102.9906539917102 .4898834229102 .0209350586101 .5860214233101 .1863479614 100.8237228394100 .5004806519100 .220352172999 .9871826171999 .80537414551 99.6781921386799 .6090164184699 .6001358032299 .6534500122199 .76849365234 99.94384765625100 .176109314100 .4610137939100 .7918243408101 .1605300903 101.5577545166101 .9744873047102 .4024353027102 .8348083496103 .2663269043 103.3221969604103 .0174026489103 .3221969604103 .6268997192104 .2365036011 104.8460998535105 .1509017944105 .4557037354106 .0652008057106 .3700027466 106.979598999107 .2844009399107 .5891036987107 .8938980103108 .1986999512 108.1986999512108 .5035018921 -9999 -9999 -9999 -9999 -9999 -9999 -9999 -9999 -9999 -9999 -9999 -9999 -9999 -9999 -9999 -9999 -9999 -9999 -9999 -9999 -9999 -9999 -9999 -9999 -9999 -9999 -9999 -9999 -9999 -9999 -9999 -9999 -9999 -9999 -9999 -9999 -9999 -9999 -9999 -

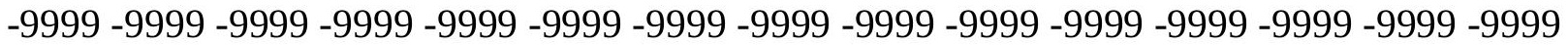
-9999 -9999 -9999 -9999 -9999 -9999 -9999 -9999 -9999 -9999 -9999 -9999 -9999 -9999 -9999 -9999 -9999 -9999 -9999 -9999 -9999 -9999 -9999 -9999 -9999 -9999 -9999 -9999 -9999 -9999 -9999 -9999 -9999 -9999 -9999 -9999 -9999 -9999 -9999 -9999 -9999 -9999 -9999 -9999 -9999 -9999 -9999 -9999 -9999 -9999 -9999 -9999 -9999 -9999 -9999 -9999 -9999 -9999 -9999 -9999

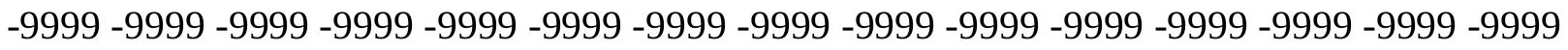

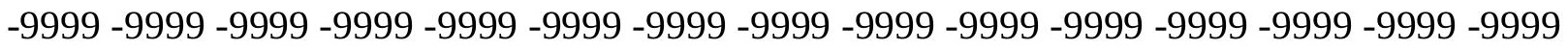
-9999 -9999 -9999 -9999 -9999 -9999 -9999 -9999 -9999 -9999 -9999 -9999 -9999 -9999 -9999 -9999 -9999 -9999 -9999 -9999 -9999 -9999 -9999 -9999 -9999 -9999 -9999 -9999 165.6324310303167 .684967041169 .2313995361170 .2747192383171 .1223907471 171.7985687256172 .2745056152172 .2072601318170 .6139068604166 .0972442627 160.6790161133157 .7079620361159 .7073974609152 .6972961426142 .0299072266 129.2288970947 115.5136032104 105.4557037354104.2365036011 101.7982025146 88.9972534179775 .5867080688568 .2718734741267 .0527267456171 .92929077148 79.8537063598687 .7781066894593 .5690307617293 .5690307617293 .87381744385 
99.66472625732104 .2365036011100 .579101562595 .397743225196 .00731658936 96.6168823242291 .4355392456186 .5589828491284 .7302627563585 .03504943848 85.9494018554787 .7781066894590 .5211791992292 .9594726562593 .87381744385 94.7881774902396 .3121032714897 .8360290527399 .35994720459101 .4934005737 104.5412979126107 .8938980103111 .8561019897115 .5136032104117 .9517974854 120.0852966309120 .9997024536120 .3900985718119 .1709976196117 .0374984741 114.5991973877111 .551399231108 .8082962036106 .0652008057104 .2365036011 103.9317016602106 .0652008057108 .8082962036110 .9418029785114 .9039993286 123.43800354131 .3623962402134 .1054992676134 .4102020264136 .2389984131 138.9819946289143 .5538024902146 .9064025879145 .3825073242143 .2489929199 143.5538024902143 .5538024902141 .1154937744137 .4580993652135 .0198059082 132.8863067627131 .6672058105128 .9241027832122 .2188034058114 .9039993286 110.0273971558105 .4557037354105 .1509017944104 .8460998535104 .8460998535 105.7603988647106 .6747970581106 .0652008057105 .1509017944103 .3221969604 102.4077987671100 .579101562599 .0551681518698 .445587158297 .83602905273 96.9216690063596 .3121032714895 .7025299072395 .7025299072396 .31210327148 97.5312423706198 .75038146973100 .2742996216101 .4934005737102 .712600708 103.6268997192104 .2365036011104 .5412979126104 .8460998535105 .1509017944 105.7603988647106 .6747970581107 .8938980103109 .1130981445110 .3321990967 111.551399231112 .4656982422113 .3800964355113 .9896011353114 .2944030762 114.5991973877114 .9039993286117 .0374984741117 .0374984741114 .9039993286 114.2944030762113 .6848983765113 .6848983765114 .2944030762116 .1231002808 118.2565994263120 .0852966309120 .9997024536120 .6949005127119 .4757995605 117.647102356116 .1231002808114 .5991973877112 .7705001831113 .3800964355 113.6848983765113 .6848983765113 .6848983765113 .6848983765113 .6848983765 113.9896011353114 .5991973877115 .2088012695114 .6846313477113 .8967590332 113.1167755127112 .3447723389111 .5809860229110 .8256912231110 .0793762207 109.342628479108 .6162872314107 .9012145996107 .1985549927106 .5094680786 105.8354034424105 .1778030396104 .5385055542103 .9194717407103 .3232803345 102.7524795532102 .2098464966101 .6975250244101 .2174758911100 .7708740234 100.359695434699 .9868698120199 .657089233499 .3752593994199 .1468963623 98.9764862060598 .8687973022598 .827430725198 .8556900024498 .95411682129 99.1218795776499 .3553085327199 .6494369506899 .99633789062100 .3865814209 100.8089752197101 .2528152466101 .7082901001102 .1674346924102 .6242599487 102.712600708102 .4077987671102 .1029968262102 .4077987671103 .0174026489 103.6268997192104 .2365036011104 .8460998535105 .4557037354106 .0652008057 106.3700027466106.979598999 107.2844009399 107.8938980103108.1986999512 108.5035018921108 .5035018921108 .5035018921 -9999 -9999 -9999 -9999 -9999 -9999 -9999 -9999 -9999 -9999 -9999 -9999 -9999 -9999 -9999 -9999 -9999 -9999 -9999 -9999 -9999 -9999 -9999 -9999 -9999 -9999 -9999 -9999 -9999 -9999 -9999 -9999 -9999 -9999 -9999 -9999 - -999 -

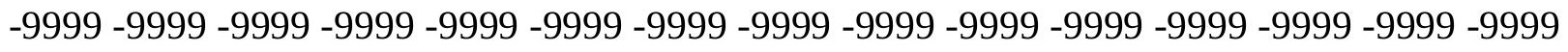

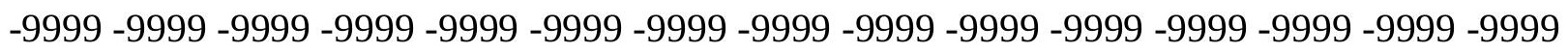
-9999 -9999 -9999 -9999 -9999 -9999 -9999 -9999 -9999 -9999 -9999 -9999 -9999 -9999 -9999 -9999 -9999 -9999 -9999 -9999 -9999 -9999 -9999 -9999 -9999 -9999 -9999 -9999 -9999 -9999 -

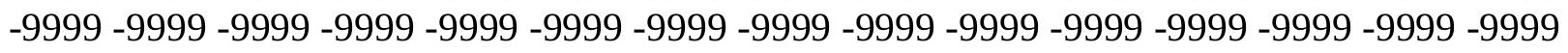

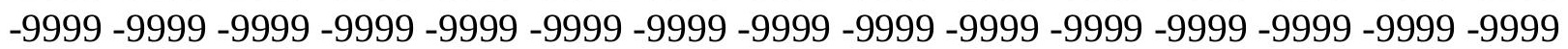


$-9999$

-9999 -9999 -9999 -9999 -9999 -9999 -9999 -9999 -9999 -9999 -9999 -9999 -9999 -9999 -9999

-9999 -9999 -9999 -9999 -9999 -9999 -9999 -9999 -9999 -9999 -9999 -9999 -9999 -9999 -9999

-9999 -9999 -9999 -9999 -9999 -9999 -9999 -9999 -9999 -9999 -9999 -9999 -9999

180.791305542182 .9972839355185 .0417022705186 .918838501188 .6782836914

190.3134765625191 .7147979736192 .5354766846192 .1069793701190 .6588745117

189.0766143799188 .8092346191188 .5631103516184 .4602813721176 .7007141113 167.803024292160 .9264984131149 .3446960449138 .6772003174128 .0097961426

115.2088012695103 .322196960496 .3121032714894 .78817749023100 .5791015625

109.4179000854117 .9517974854123 .7427978516121 .3044967651118 .8662033081 126.4858016968132 .8863067627125 .8762969971117 .9517974854120 .3900985718 122.2188034058114 .9039993286105 .7603988647102 .102996826299 .96952056885 97.2264633178795.7025299072395.0929565429795.397743225196.00731658936 97.2264633178799 .35994720459101 .4934005737103 .9317016602106 .0652008057 108.5035018921110 .9418029785113 .3800964355116 .1231002808118 .5614013672 120.0852966309120 .6949005127120 .0852966309118 .5614013672116 .1231002808 112.7705001831109 .1130981445105 .1509017944101 .798202514699 .35994720459 98.4455871582100 .5791015625104 .2365036011107 .2844009399113 .075302124 127.0953979492140 .8106994629145 .0776977539146 .6015930176151 .1734008789 155.4068145752155 .4028167725155 .4141693115155 .4401702881155 .4797058105 155.5316772461155 .5946655273155 .6672821045155 .7478637695155 .8347473145 155.9261322021156 .0201568604156 .1148071289154 .8307952881148 .7351074219 142.9441986084137 .4580993652131 .0576019287125 .2667007446120 .9997024536 116.7326965332111 .551399231105 .7603988647104 .5412979126105 .7603988647 103.6268997192100 .883903503499 .0551681518699 .0551681518698 .75038146973 97.5312423706196 .3121032714895 .7025299072395 .7025299072396 .00731658936 97.2264633178798 .75038146973100 .5791015625101 .7982025146103 .0174026489 103.6268997192103 .9317016602104 .2365036011104 .2365036011104 .2365036011 104.8460998535105 .7603988647106 .6747970581108 .1986999512109 .7226028442 111.24659729112 .4656982422113 .3800964355113 .9896011353114 .5991973877 115.2088012695118 .2565994263119 .1709976196118 .8662033081117 .647102356 114.9039993286113 .6848983765113 .075302124113 .9896011353116 .1231002808 119.1709976196121 .9140014648123 .43800354123 .1332015991121 .3044967651 119.7806015015118 .5614013672117 .9517974854117 .0374984741116 .4279022217 115.5136032104114 .5991973877113 .6848983765113 .075302124112 .7705001831 112.4656982422112 .7705001831113 .3800964355113 .9896011353114 .1657714844 113.3635940552112 .5683898926111 .7803421021110 .9996414185110 .2266998291 109.4620437622108 .7064361572107 .9606933594107 .2259216309106 .5032272339 105.7940216064105 .0997314453104 .422203064103 .7634658813103 .1261749268 102.5128479004101 .9259567261101 .3671722412100 .8380813599100 .3399581909 99.8751983642699 .4473419189599 .0618972778398 .7247772216898 .44272613525 98.2216949462998 .0681076049897 .9872055053797 .9840164184698 .06058502197 98.2169570922998 .4492721557698 .7514801025499 .1141357421999 .52621459961 99.97441101074100 .4468994141100 .929725647101 .4179458618101 .9004821777 102.1029968262101 .7982025146101 .4934005737101 .4934005737101 .7982025146 102.712600708103 .3221969604103 .9317016602104 .5412979126105 .4557037354 
106.0652008057106 .6747970581106 .979598999107 .5891036987108 .1986999512 108.5035018921 108.5035018921 108.8082962036 -9999 -9999 -9999 -9999 -9999 -9999 -9999 -9999 -9999 -9999 -9999 -9999 -9999 -9999 -9999 -9999 -9999 -9999 -9999 -9999 -9999 -9999 -9999 -9999 -9999 -9999 -9999 -9999 -9999 -9999 -9999 -9999 -9999 -9999 -9999 -9999 -9999 -9999 -9999 -9999 -9999 -9999 -9999 -9999 -9999 -9999-9999 -9999 -9999 -9999 -9999 -9999 -9999 -9999 -9999 -9999 -9999 -9999 -9999 -9999 -9999 -9999 -9999 -9999 -9999 -9999 -9999 -9999 -9999 -9999 -9999 -9999 -9999 -9999 -9999 -9999 -9999 -9999 -9999 -9999 -9999 -9999

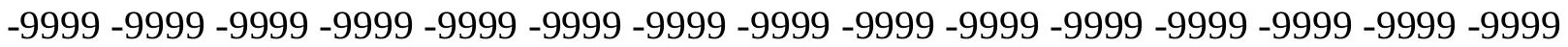

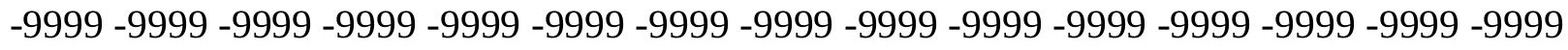

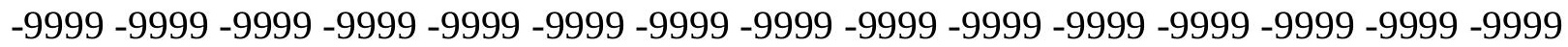
$-9999$

-9999 -9999 -9999 -9999 -9999 -9999 -9999 -9999 -9999 -9999 -9999 -9999 -9999 -9999 -9999 -9999 -9999 -9999 -9999 -9999 -9999 -9999 -9999 -9999 -9999 -9999 -9999 -9999 -9999 -9999 -9999 -9999 -9999 -9999 -9999 -9999 -9999 -9999 -9999 -9999 -9999 -9999 -9999 -9999 199.1238555908201 .5130157471203 .9226074219206 .3278656006208 .6796569824 210.8377227783212 .5571136475213 .630065918214 .2418518066214 .7754058838 215.3874206543214.9107513428212.4407653809207.5735473633201.3938903809 194.1583251953184 .7575378418174 .3450622559165 .1330871582159 .4026031494 150.8686065674142 .0299072266137 .1533050537139 .5915985107145 .6873016357 151.7830047607152 .024520874150 .4842529297150 .0800170898152 .849105835 154.6461486816151 .8406219482148 .264541626148 .0620422363149 .4278717041 150.2590942383140 .8106994629132 .2767028809123 .1332015991112 .7705001831 104.2365036011100 .579101562599 .9695205688599 .66472625732100 .8839035034 103.3221969604106 .6747970581110 .3321990967112 .7705001831113 .6848983765 114.5991973877116 .4279022217118 .8662033081120 .3900985718121 .6092987061 122.2188034058121 .3044967651119 .1709976196115 .818397522111 .8561019897 106.979598999102 .407798767198 .1408081054795 .0929565429793 .56903076172 98.75038146973105 .7603988647105 .4557037354107 .2844009399117 .9517974854 130.1432037354141 .4203033447151 .4781951904155 .6769256592155 .66456604 155.6697845459155 .6919403076155 .7303314209155 .7838287354155 .8512878418 155.9312591553156 .0222473145156 .122543335156 .2303924561156 .3438873291 156.4610443115156 .5797424316156 .6976928711156 .8125457764156 .9218139648 157.0229797363157 .1134338379154 .8307952881151 .7830047607147 .8208007812 141.4203033447134 .4102020264128 .0097961426121 .3044967651113 .075302124 104.236503601198 .7503814697399 .66472625732100 .883903503496 .92166900635 96.3121032714896 .0073165893695 .7025299072396 .0073165893697 .22646331787 99.05516815186100 .8839035034102 .4077987671103 .3221969604103 .9317016602 103.9317016602103 .6268997192103 .3221969604103 .3221969604103 .6268997192 104.2365036011105 .7603988647107 .5891036987109 .7226028442111 .551399231 112.7705001831113 .6848983765114 .2944030762115 .2088012695117 .647102356 120.6949005127121 .6092987061121 .3044967651119 .7806015015116 .4279022217 114.2944030762112 .4656982422113 .075302124115 .818397522119 .7806015015 123.1332015991126 .1809997559124 .9618988037123 .43800354120 .9997024536 121.6092987061121 .9140014648121 .6092987061120 .0852966309117 .647102356 115.5136032104113 .6848983765112 .7705001831111 .8561019897111 .24659729 110.9418029785111 .24659729112 .4656982422113 .3800964355113 .6167755127 
112.7988433838111 .9869537354111 .1812286377110 .3819961548109 .5896911621 108.8049850464108 .0286407471107 .2616729736106 .5051498413105 .7604064941 105.0288238525104 .31224823103 .6127548218102 .9329986572102 .275390625 101.6419830322101 .0338363647100 .452079772999 .8981399536199 .37490844727 98.886581420998 .4393920898498 .0401687622197 .6968917846797 .417137146 97.2092132568497 .0805053710997 .0377502441497 .0854873657297 .22554779053 97.4475097656297 .7592773437598 .1466979980598 .5900344848699 .07216644287 99.57730102539100 .0914382935100 .6036682129101 .107093811101 .4934005737 101.1886978149100 .8839035034100 .8839035034101 .1886978149101 .4934005737 102.4077987671103 .0174026489103 .9317016602104 .5412979126105 .4557037354 106.0652008057106 .6747970581107 .2844009399107 .8938980103108 .1986999512 108.5035018921108 .8082962036108 .8082962036 -9999 -9999 -9999 -9999 -9999 -9999 -9999 -9999 -9999 -9999 -9999 -9999 -9999 -9999 -9999 -9999 -9999 -9999 -9999 -9999 -9999 -9999 -9999 -9999 -9999 -9999 -9999 -9999 -9999 -9999 -9999 -9999 -9999 -9999 -9999 -9999 -9999 -9999 -9999 -9999 -9999 -9999 -9999 -9999 -9999 -9999 -9999 -9999 -9999 -9999 -9999 -9999

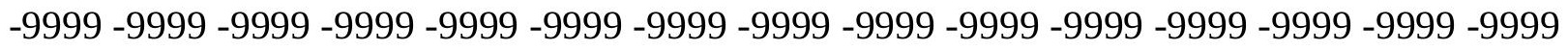

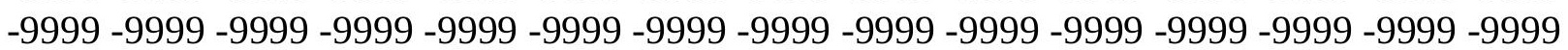
-9999 -9999 -9999 -9999 -9999 -9999 -9999 -9999 -9999 -9999 -9999 -9999 -9999 -9999 -9999 -999 -9999 -9999 -9999 -9999 -9999 -9999 -9999 -9999 -9999 -9999 -9999 -9999 -9999 -9999 -9999 -9999 -9999 -9999 -9999 -9999 -9999 -9999 -9999 -9999 -9999 -9999 -9999 -9999 -9999 -9999 -9999 -9999 -9999 -9999 -9999 -9999 -9999 -9999 -9999 -9999 -9999 -9999 -9999 -9999 -9999

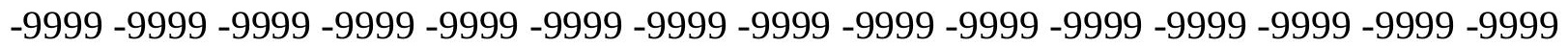
-9999 -9999 -9999 -9999 -9999 -9999 -9999 -9999 -9999 -9999 -9999 -9999 -9999 -9999 215.9219207764218 .5479736328221 .3105926514224 .1641235352227 .0386047363 229.8145446777232 .3398742676234 .5309295654236 .408782959238 .0201721191 239.1299285889239 .1713104248237 .6963500977234 .5018463135229 .8057250977 223.5410003662216 .0946350098208 .104675293200 .975112915194 .8478546143 188.0305480957181 .0350952148176 .4483642578175 .8021240234177 .9309082031 180.0176239014179 .9003295898178 .785369873178 .3182067871178 .6986083984 178.6948547363177 .5043029785175 .9669189453175 .3079528809175 .1818084717 173.130859375166 .5927734375157 .8720550537148 .7351074219131 .3623962402 116.4279022217109 .7226028442107 .2844009399105 .7603988647106 .979598999 109.1130981445112 .7705001831117 .342300415120 .9997024536122 .2188034058 122.2188034058125 .1707458496126 .8775558472126 .5200424194124 .6570968628 124.3523025513123 .1332015991120 .3900985718116 .4279022217111 .24659729 105.760398864799 .9695205688595 .0929565429791 .7403335571389 .3020401001 104.5412979126113 .3800964355115 .818397522115 .2088012695109 .7226028442 113.3800964355130 .1432037354147 .2111968994155 .9189147949155 .9132843018 155.9269104004155 .9591522217156 .0093383789156 .0763397217156 .158996582 156.2558135986156 .3652191162156 .4854125977156 .6145629883156 .7506256104 156.8915557861157 .0350189209157 .1785888672157 .3196411133157 .4554595947 157.5833129883157 .7003631592157 .8038482666157 .8908843994157 .9588317871 158.0049591064158 .0268859863153 .3069000244146 .6015930176138 .6772003174 131.0576019287124 .6570968628117 .0374984741106 .370002746695 .3977432251 97.5312423706196 .6168823242296 .0073165893696 .3121032714897 .83602905273 99.96952056885101 .7982025146103 .3221969604103 .9317016602103 .9317016602 
103.6268997192103 .0174026489102 .1029968262101 .7982025146101 .7982025146 102.712600708104 .5412979126106 .6747970581109 .4179000854111 .8561019897 113.3800964355114 .2944030762114 .5991973877115 .5136032104119 .7806015015 122.8283996582124 .3523025513123 .7427978516122 .2188034058118 .5614013672 115.5136032104114 .2944030762112 .4656982422116 .4279022217121 .6092987061 126.7906036377129 .8385009766128 .9241027832125 .5715026855122 .8283996582 124.0475006104125 .2802810669124 .370880127123 .4665374756119 .7806015015 115.5136032104113 .6848983765113 .3800964355112 .4656982422110 .9418029785 109.7226028442109 .7226028442111 .24659729112 .7705001831113 .6848983765 112.4656982422110 .3321990967108 .8082962036108 .1986999512107 .8938980103 107.2844009399 106.0652008057 105.4557037354104.2365036011 103.6268997192 104.8460998535104 .212097168103 .4711074829102 .7478027344102 .0443725586 101.3623809814 100.7022094727 100.064544677799.4508819580198.86465454102 98.3107223510797 .7959671020597 .3280334472796 .9160232543996 .56903839111 96.2973098754996 .1105575561596 .0162429809696 .0244216918996 .13920593262 96.3652191162196 .6969070434697 .1164398193497 .5988616943498 .12049102783 98.6590805053799 .1993713378999 .72941589355100 .2496948242100 .5791015625 100.2742996216100 .2742996216100 .2742996216100 .5791015625100 .8839035034 101.4934005737102 .1029968262103 .0174026489103 .9317016602104 .5412979126 105.4557037354106 .0652008057106 .979598999107 .5891036987108 .1986999512 108.5035018921108 .8082962036108 .8082962036 -9999 -9999 -9999 -9999 -9999 -9999 -9999 -9999 -9999 -9999 -9999 -9999 -9999 -9999 -9999 -9999 -9999 -9999 -9999 -9999 -9999 -9999 -9999 -9999 -9999 -9999 -9999 -9999 -9999 -9999 -9999 -9999 -9999 -9999 -9999 -9999 -9999 -9999 -9999 -9999 -9999 -9999 -9999 -9999 -9999 -9999 -9999 -9999 -9999 -9999 -9999 -9999 -9999 -9999 -9999 -9999 -9999 -9999 -9999 -9999 -9999 -9999 -9999 -9999 -9999 -9999 -9999 -9999 -9999 -9999 -9999 -9999 -9999 -9999 -9999 -9999 -9999 -9999 -9999 -9999 -9999 -9999 -9999 -9999 -9999 -9999 -9999 -9999 -9999 -9999 -9999 -9999 -9999 -9999 -9999 -9999 -9999

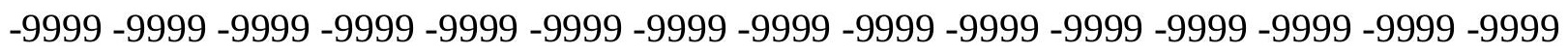
-9999 -9999 -9999 -9999 -9999 -9999 -9999 -9999 -9999 -9999 -9999 -9999 -9999 -9999 -9999 -9999 -9999 -9999 -9999 -9999 -9999 -9999 -9999 -9999 -9999 -9999 -9999 -9999 -9999 -9999 -9999 -9999 -9999 -9999 -9999 -9999 -9999 -9999 -9999-9999 -9999 -9999 -9999 -9999 - 9999 -9999 -9999 -9999 -9999 -9999 -9999 -9999 -9999 -9999 -9999 -9999 -9999 -9999 -9999 233.1637878418235.9573516846238.9570922852 242.1128845215 245.3547973633 248.5856933594251 .6946105957254 .5892791748257 .1878967285259 .3697814941 260.8778686523261 .3925170898260 .6227416992258 .4462280273254 .8590240479 249.9746856689244 .1762084961237 .9958953857232 .0054626465226 .09375 220.1222686768214 .3524017334209 .9417724609207 .5832214355206 .9141387939 206.582901001205 .8341369629204 .741973877203 .9420166016203 .4476165771 202.8778991699201 .9575500488200 .7276763916199 .2996368408197 .2134094238 193.1000213623186 .5005187988160 .1832427979160 .2885284424150 .9960174561 136.8484954834124 .3523025513116 .4279022217114 .2944030762115 .5136032104 117.0374984741120 .0852966309125 .5715026855129 .7922668457132 .7950897217 135.2880859375137 .4546203613137 .9901885986135 .7348022461131 .3623962402 128.3144989014125 .5715026855122 .5235977173117 .9517974854111 .8561019897 105.150901794499 .0551681518693 .8738174438589 .6068267822390 .21640014648 117.342300415120 .9997024536122 .2188034058122 .5235977173121 .9140014648 
109.7226028442115 .2088012695129 .533706665142 .9441986084153 .6116943359 156.173614502156 .2151641846156 .2765045166156 .3565216064156 .4540557861 156.5675506592156 .6954193115156 .8356781006156 .9864349365157 .1455383301 157.3108062744157 .4797821045157 .649810791157 .8179931641157 .9812927246 158.1367645264158 .2813415527158 .4120330811158 .5256958008158 .6194915771 158.6904754639158 .7360687256158 .7536468506158 .7411346436156 .9642944336 152.3925933838149 .9542999268145 .9920959473137 .4580993652126 .1809997559 113.3800964355101 .798202514697 .2264633178796 .9216690063599 .35994720459 101.7982025146103 .6268997192104 .5412979126104 .5412979126104 .2365036011 103.3221969604102 .1029968262100 .883903503499 .9695205688599 .66472625732 100.5791015625102 .712600708107 .2844009399109 .1130981445112 .4656982422 114.5991973877115 .2088012695114 .5991973877117 .0374984741120 .9997024536 123.7427978516125 .5715026855125 .8762969971124 .3523025513121 .3044967651 118.5614013672117 .647102356116 .4279022217119 .4757995605124 .6570968628 129.8385009766130 .4491424561129 .5039367676128 .562286377122 .2188034058 126.6913375854125 .7626724243124 .8388595581123 .9200286865122 .5235977173 115.818397522115 .2088012695114 .9039993286114 .9039993286111 .8561019897 109.1130981445110 .0273971558111 .551399231113 .9896011353114 .1452407837 113.2838363647110 .6370010376108 .1986999512108 .8082962036108 .5035018921 107.2844009399 105.7603988647 104.5412979126103.0174026489 101.1886978149 101.1886978149103 .6268997192103 .3426589966102 .5750579834101 .824546814 101.092124939100 .377609252999 .681228637799 .0045471191498 .35143280029 97.7273788452197 .13979339696 .5970153808696 .1090011596795 .68613433838 95.3404769897595 .0825347900494 .9237823486394 .8829193115294 .97537994385 95.207168579195 .5681686401496 .030967712496 .5577087402397 .11917877197 97.6881561279398 .2487945556698 .8020019531299 .0551681518699 .35994720459 99.3599472045999.3599472045999.3599472045999.6647262573299.96952056885 100.5791015625101 .1886978149102 .1029968262103 .0174026489103 .6268997192 104.5412979126105 .4557037354106 .3700027466106 .979598999107 .8938980103 108.1986999512108 .5035018921108 .8082962036108 .5035018921 -9999 -9999 -9999 -9999 -9999 -9999 -9999 -9999 -9999 -9999 -9999 -9999 -9999 -9999 -9999 -9999 -9999 -9999 -9999 -9999 -9999 -9999 -9999 -9999 -9999 -9999 -9999 -9999 -9999 -9999 -9999 -9999 -9999 -9999 -

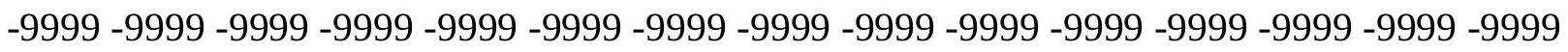
-9999 -9999 -9999 -9999 -9999 -9999 -9999 -9999 -9999 -9999 -9999 -9999 -9999 -9999 -9999 -9999 -9999 -9999 -9999 -9999 -9999 -9999 -9999 -9999 -9999 -9999 -9999 -9999 -9999 -9999 -

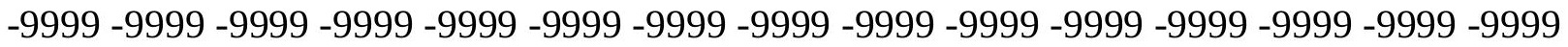

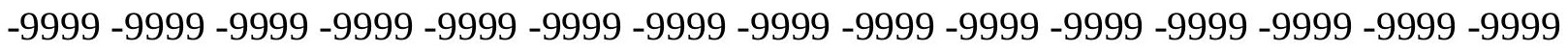

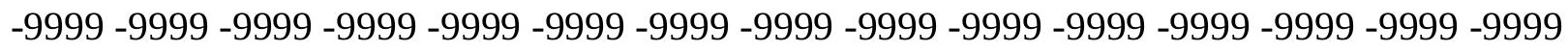
$-9999-9999$

-9999 -9999 -9999 -9999 -9999 -9999 -9999 -9999 -9999 -9999 -9999 -9999 -9999 -9999 -9999

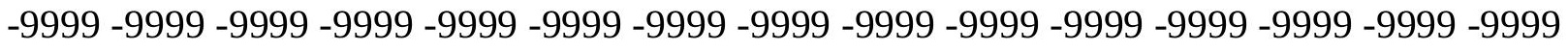
-9999 -9999 -9999 -9999 -9999 -9999 -9999 -9999 -9999 -9999 -9999 -9999 -9999 -9999 -9999 253.49559021256 .6480102539259 .9924926758263 .4650878906266 .9828796387 270.4426574707273 .7265930176276 .6966247559279 .1776733398280 .9553527832 281.8016967773281 .53125280 .0557861328277 .3797912598273 .6491394043 269.1290588379 264.1619567871 258.978729248 253.625793457248.201171875 
242.9907684326238 .513961792235 .1516113281232 .8222351074231 .0765991211 229.5862731934228 .2794342041227 .2614135742226 .470199585225 .6502227783 224.5027618408222 .7738494873220 .1962585449216 .3154907227210 .534942627 202.6876831055160 .5524597168160 .6680145264160 .7573699951157 .4830322266 144.1634063721132 .2767028809129 .533706665130 .4479980469129 .2288970947 131.8849334717135 .4690551758139 .3460388184143 .3466339111147 .4234313965 150.0347290039148 .9571533203145 .3825073242137 .7628936768132 .5814971924 128.0097961426124 .0475006104119 .1709976196112 .1608963013104 .8460998535 98.7503814697393 .2642517089888 .3876876831196 .31210327148112 .4656982422 121.6092987061124 .6570968628124 .6570968628121 .3044967651113 .6848983765 100.5791015625109 .1130981445121 .3044967651133 .8007049561142 .6394042969 152.0877990723156 .5316162109156 .6241455078156 .7362365723156 .8662872314 157.0126037598157 .1731262207157 .3458251953157 .5283813477157 .7185058594 157.9136199951158 .1108398438158 .3069763184158 .4987030029158 .6827697754 158.8558349609159 .0146484375159 .1558380127159 .2762908936159 .3728027344 159.4426269531159 .4829559326159 .4915618896159 .4661865234159 .4051818848 159.3067932129159 .1700744629158 .9939117432154 .8307952881139 .5915985107 124.6570968628114 .5991973877107 .2844009399102 .712600708104 .5412979126 105.7603988647105 .7603988647105 .4557037354104 .5412979126103 .0174026489 101.188697814999 .3599472045997 .8360290527397 .22646331787101 .1886978149 104.5412979126108 .1986999512110 .9418029785112 .7705001831115 .5136032104 116.4279022217114 .5991973877113 .9896011353114 .9039993286116 .4279022217 118.2565994263120 .6949005127123 .43800354128 .0097961426136 .7914886475 135.8258361816134 .8589782715133 .8919219971132 .9256591797131 .9610290527 130.9988250732130 .0396728516129 .0841369629128 .1326599121127 .1856231689 126.2432327271125 .3056793213124 .3730545044123 .4454193115122 .5227508545 121.6050262451120 .6921463013119 .7840118408118 .8804244995117 .9811935425 117.0860443115116 .1947021484115 .3068389893114 .4221572876113 .5403366089 112.6611557007111 .7844543457110 .9102249146110 .0385742188109 .1698150635 108.1986999512105 .4557037354103 .0174026489100 .274299621698 .75038146973 103.3221969604103 .2315750122102 .4192733765101 .6207962036100 .8365707397 100.065933227599 .3087997436598 .5667953491297 .8440704345797 .14655303955 96.4820480346795 .8592681884895 .2887268066494 .7816314697394 .35091400146 94.0088729858493 .7741165161193 .6773757934693 .7415161132893 .97757720947 94.374717712494 .8923339843895 .4675140380996 .0541687011796 .65103912354 97.2264633178797.5312423706197.5312423706197.8360290527398.14080810547 98.445587158298 .445587158298 .7503814697399 .3599472045999 .66472625732 100.2742996216100 .8839035034101 .7982025146102 .712600708103 .6268997192 104.5412979126105 .4557037354106 .3700027466107 .2844009399107 .8938980103 108.5035018921108 .5035018921108 .5035018921 -9999 -9999 -9999 -9999 -9999 -9999 -9999 -9999-9999 -

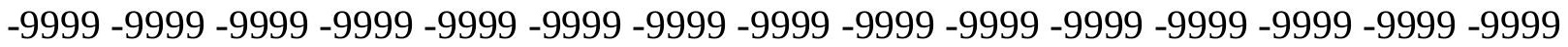
-9999 -

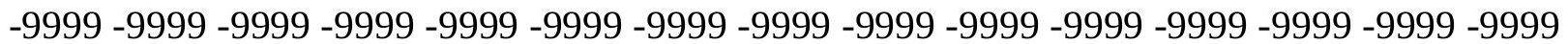

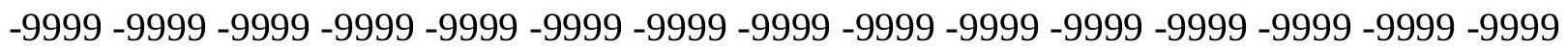


-9999 -9999 -9999 -9999 -9999 -9999 -9999 -9999 -9999 -9999 -9999 -9999 -9999 -9999 -9999 -9999 -9999 -9999 -9999 -9999 -9999 -9999 -9999 -9999 -9999 -9999 -9999 -9999 -9999

-9999 -9999 -9999 -9999 -9999 -9999 -9999 -9999 -9999 -9999 -9999 -9999 -9999 -9999 -9999 -9999 -9999 -9999 -9999 -9999 -9999 -9999 -9999 -9999 -9999 -9999 -9999 -9999 -9999 -9999 -9999 -9999 -9999 -9999 -9999 -9999 -9999 -9999 -9999 -9999 -9999 -9999 -9999 -9999 -9999 270.908416748274 .1448364258277 .5814208984281 .1622009277284 .8131103516 288.4330444336291 .8829040527294 .9994812012297 .5962219238299 .514831543 300.5630187988300 .6254882812299 .6484069824297 .659942627294 .7777709961 291.1811218262287 .0624694824282 .5466918945277 .7185974121272 .6925354004 267.7007751465263 .051574707259 .0191955566255 .69871521253 .0399932861 250.9488372803249 .3716430664248 .2338256836247 .3507385254246 .3725128174 244.8471221924242 .3455505371238 .5081939697233 .0467071533225 .7294616699 160.7945098877160 .9481811523161 .0738525391161 .1713104248161 .2408599854 161.282699585160 .9264984131154 .3262634277150 .4038085938147 .2237701416 145.5680389404145 .7176971436147 .6716461182150 .9607696533154 .9829406738 159.4026031494154 .8307952881147 .8208007812140 .5059967041134 .7149963379 129.8385009766124 .3523025513118 .5614013672111 .24659729104 .2365036011 98.7503814697393 .2642517089887 .7781066894598 .75038146973110 .3321990967 118.8662033081122 .8283996582122 .8283996582119 .4757995605113 .6848983765 89.302040100195 .3977432251104 .2365036011114 .5991973877122 .5235977173 133.8007049561152 .6972961426156 .8783111572157 .0047454834157 .1513061523 157.3162078857 157.4972839355 157.6923522949 157.8988952637 158.1144714355 158.3363037109158 .5613555908158 .7862243652159 .0072479248159 .2208404541 159.4233551025159 .6112670898159 .7808990479159 .9288330078160 .0516052246 160.1462402344160 .2097167969160 .2397155762160 .2338409424160 .1903686523 160.1074829102159 .9842529297159 .8195648193159 .6130523682159 .3642425537 147.8208007812138 .0677032471129 .533706665118 .5614013672110 .0273971558 107.8938980103107 .2844009399106 .0652008057104 .5412979126102 .712600708 100.579101562597 .8360290527395 .7025299072394 .4833908081197 .83602905273 101.4934005737105 .7603988647110 .0273971558112 .7705001831116 .1231002808 117.9517974854116 .7326965332114 .5991973877114 .2944030762115 .2088012695 116.7326965332119 .7806015015123 .7427978516131 .3623962402137 .4156188965 136.4368133545135 .4566650391134 .4762420654133 .4965515137132 .5184936523 131.5428771973130 .5703887939129 .6015930176128 .6369476318127 .6768264771 126.7214126587125 .770866394124 .8252029419123 .8844528198122 .9485168457 122.0172958374121 .0906295776120 .1683197021119 .2500991821118 .33568573 117.4247131348116 .5168228149115 .6115875244114 .7086105347113 .8074874878 112.9078826904112 .009513855111 .1122512817110 .2160797119109 .3211517334 108.4277954102107 .5365142822106 .6479721069105 .7630615234104 .8828430176 104.0087432861103 .1424026489102 .28540802101 .4385757446100 .6017532349 99.7739410400498 .9548721313598 .1462860107497 .3525009155396 .57969665527 95.8357772827195 .1295166015694 .4714431762793 .8730697631893 .3484954834 92.9081954956192 .5882415771592 .4226760864392 .4432678222792 .67127227783 93.1019668579193 .6854324340894 .3202514648494 .8880233764695 .48417663574 95.397743225195 .7025299072396 .0073165893696 .3121032714896 .92166900635 97.2264633178797.5312423706197.8360290527398.1408081054798.75038146973 
99.3599472045999 .96952056885100 .5791015625101 .4934005737102 .4077987671 103.6268997192104 .5412979126105 .4557037354106 .3700027466107 .2844009399 107.8938980103108 .1986999512107 .8938980103107 .5891036987 -9999 -9999 -9999 -9999 -9999 -9999 -9999 -9999 -9999 -9999 -9999 -9999 -9999 -9999 -9999 -9999 -9999 -9999 -9999 -9999 -9999 -9999 -9999 -9999 -9999 -9999 -9999 -9999-9999 -9999 -9999 -9999 -9999 -9999 -9999 -9999 -9999 -9999 -9999 -9999 -9999 -9999 -9999 -9999 -9999 -9999 -9999 -9999 -9999 -9999 -9999 -9999 -9999 -9999 -9999 -9999 -9999 -9999 -9999 -9999 -9999 -9999 -9999 -9999

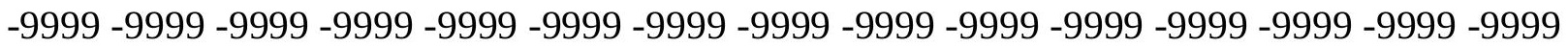

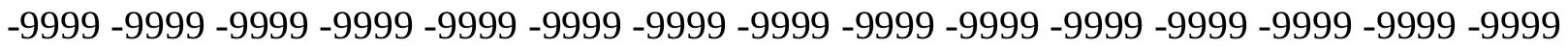
-9999 -9999 -9999 -9999 -9999 -9999 -9999 -9999 -9999 -9999 -9999 -9999 -9999 -9999 -9999

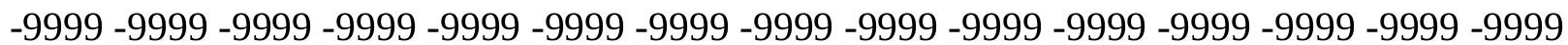
$-9999$

-9999 -9999 -9999 -9999 -9999 -9999 -9999 -9999 -9999 -9999 -9999 -9999 -9999 -9999 -9999 -9999 -9999 -9999 -9999 -9999 -9999 -9999 -9999 -9999 -9999 -9999 -9999 -9999 -9999 -9999 -9999 -9999 -9999 -9999 -9999 -9999 -9999 -9999 -9999 -9999 -9999 -9999 -9999 -9999 -9999 -9999 291.2299194336294.6730651855 298.2558288574 301.9057922363 305.536529541 308.9872741699312 .0958251953314 .6968383789316 .6122131348317 .7434082031 317.996887207317 .3430480957315 .8189086914313 .5160522461310 .5557861328 307.0491943359303 .0684204102298 .6638793945293 .9151611328288 .9816894531 284.1045837402279 .5508728027275 .5444641113272 .2300720215269 .6686706543 267.848449707266 .647644043265 .7790527344264 .7475891113262 .8871459961 259.5772094727254 .4705505371247 .6111450195161 .0090789795161 .2050933838 161.3708953857161 .5064544678161 .611618042161 .6867980957161 .7323303223 161.7491607666161 .7380828857161 .7003631592161 .6371459961157 .8694000244 153.6446533203152 .5696411133154 .2212982178155 .4403991699154 .2212982178 151.1734008789146 .2969055176140 .5059967041135 .3246002197129 .8385009766 123.43800354116 .7326965332110 .0273971558103 .626899719299 .96952056885 96.0073165893695 .70252990723102 .712600708110 .3321990967116 .7326965332 120.0852966309120 .0852966309117 .647102356113 .075302124107 .2844009399 85.0350494384890 .8259735107497 .53124237061103 .9317016602114 .5991973877 135.9342041016157 .1168060303157 .257522583157 .420791626157 .6047058105 157.8069458008158 .0251159668158 .2565155029158 .4983825684158 .7477264404 159.0013580322159 .2557067871159 .5068817139159 .7509613037159 .9838867188 160.2017974854160 .4007110596160 .5769348145160 .7266693115160 .8466796875 160.9337310791160 .9853515625160 .9990081787160 .9729309082160 .9052581787 160.7950744629160 .6412658691160 .443572998160 .2015838623159 .9156799316 159.5860595703151 .1734008789136 .2389984131121 .6092987061112 .4656982422 108.1986999512106 .0652008057104 .5412979126103 .017402648999 .96952056885 96.6168823242293 .5690307617291 .7403335571391 .7403335571396 .31210327148 101.1886978149106 .0652008057109 .4179000854113 .3800964355115 .818397522 115.2088012695113 .9896011353113 .075302124113 .3800964355114 .9039993286 118.2565994263122 .2188034058129 .2288970947138 .0293121338137 .037979126 136.045211792135 .0520782471134 .0596466064133 .0688171387132 .0804748535 131.0953063965130 .1139373779129 .1368408203128 .164352417127 .1966705322 126.2339019775125 .2760391235124 .3230285645123 .374710083122 .4309234619 121.4914245605120 .5559463501119 .6241378784118 .6956253052117 .7699584961 
116.8466873169115 .9252929688115 .0052719116114 .0861206055113 .1673812866 112.248664856111 .3296966553110 .4103317261109 .4905776978108 .5706176758 107.6508026123106 .7316818237105 .8139877319104 .8986282349103 .9867630005 103.0796661377102 .1784973145101 .2835769653100 .394210815499 .5090637207 98.6278381347797 .7524490356496 .8874282836996 .0391006469795 .21529388428 94.4245452880993 .6768341064592 .983123779392 .3574905395591 .80994415283 91.3932571411191 .1391830444391 .0871734619191 .2727279663191 .70970916748 92.359512329193 .0777816772593 .6182250976693 .5690307617293 .56903076172 93.8738174438594 .1785964965894 .7881774902395 .397743225195 .70252990723 96.0073165893696 .6168823242296 .9216690063597 .5312423706198 .14080810547 98.7503814697399 .66472625732100 .2742996216101 .1886978149102 .1029968262 103.3221969604104 .5412979126105 .4557037354106 .0652008057106 .6747970581 106.979598999106 .979598999106 .6747970581 -9999 -9999 -9999 -9999 -9999 -9999 -9999 -9999 -9999 -9999 -9999 -9999 -9999 -9999 -9999 -9999 -9999 -9999 -9999 -9999 -9999 -9999 -9999 -9999 -9999 -9999 -9999 -9999 -9999 -9999 -9999 -9999 -9999 -9999 -9999 -9999 -9999

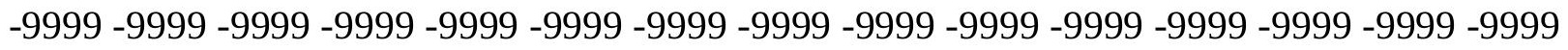

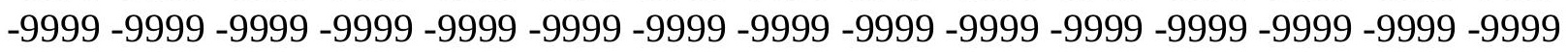
-9999 -9999 -9999 -9999 -9999 -9999 -9999 -9999 -9999 -9999 -9999 -9999 -9999 -9999 -9999 -999 -9999 -9999 -9999 -9999 -9999 -9999 -9999 -9999 -9999 -9999 -9999 -9999 -9999 -9999 -9999 -9999 -9999 -9999 -9999 -9999 -9999 -9999 -9999 -9999 -9999 -9999 -9999 -9999 -9999 -9999 -9999 -9999 -9999 -9999 -9999 -9999 -9999 -9999 -9999 -9999 -9999 -9999 -9999 -9999 -9999 -9999 -9999 -9999 -9999 -9999 -9999 -9999 -9999 -9999 -9999 -9999 -9999 -9999 -9999 -9999 -9999 -9999 -9999 -9999 -9999 -9999 -9999 -9999 -9999 -9999-9999-9999-9999 -999 -

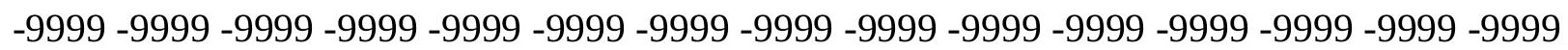
-9999 307.7194519043 311.1125183105 314.6213684082 318.170501709 321.6587219238 324.9654846191327 .9142150879330 .3941955566332 .24609375333 .3526000977 333.6586608887333 .1571350098331 .8879699707329 .927734375327 .3667602539 324.2793884277320 .7009887695316 .6217346191312 .0508728027307 .0726013184 301.9025878906296 .8512573242292 .2592468262288 .4006958008285 .4360351562 283.3961791992282 .1591186523281 .3924865723280 .4775085449278 .5067749023 274.4379577637268 .0509643555161 .1905059814161 .4331207275161 .643661499 161.8214263916161 .966506958162 .0788269043162 .1589813232162 .2074279785 162.2252807617162 .2135162354162 .1735534668162 .1066589355162 .0145111084 156.9639129639152 .6972961426151 .1734008789150 .5639038086148 .4304046631 145.6873016357141 .7250976562136 .8484954834131 .9720001221126 .7906036377 120.6949005127113 .9896011353110 .3321990967106 .979598999103 .3221969604 99.66472625732102 .4077987671107 .2844009399112 .1608963013116 .1231002808 118.2565994263118 .2565994263116 .1231002808112 .7705001831108 .5035018921 85.64462280273 84.73026275635 85.3398437591.1307525634899.66472625732 113.3800964355128 .9241027832144 .7729034424157 .67137146157 .8750610352 158.0994262695158 .3418884277158 .5994415283158 .8689575195154 .2212982178 152.0877990723155 .1356048584159 .9976654053160 .2732086182160 .5375213623 160.7863464355161 .0153503418161 .2205810547161 .3979492188161 .5438690186 161.6548614502161 .7282562256161 .7614135742161 .7525024414161 .6996307373 161.6018981934161 .4582519531161 .2685546875161 .0324401855160 .7504882812 160.4230194092160 .051071167154 .2212982178139 .5915985107127 .7050018311 
117.342300415 107.2844009399 105.1509017944 103.931701660299.66472625732 95.7025299072394 .1785964965891 .7403335571391 .1307525634891 .43553924561 95.3977432251100 .2742996216105 .1509017944108 .1986999512109 .7226028442 109.7226028442108 .8082962036108 .1986999512108 .1986999512109 .1130981445 111.551399231115 .5136032104121 .3044967651129 .8385009766137 .6279449463 136.6232757568135 .6181945801134 .6137695312133 .6109466553132 .6106262207 131.6135406494130 .6203613281129 .6315612793128 .6475067139127 .6683654785 126.6942367554125 .7250442505124 .7606964111123 .8009719849122 .8456344604 121.8943557739120 .9468002319120 .0025482178119 .0611343384118 .1220245361 117.184677124116 .2484817505115 .3128204346114 .3770828247113 .4406967163 112.5031509399111 .5640335083110 .6230545044109 .6800613403108 .7351150513 107.7884140015106 .8403778076105 .8915786743104 .9427337646103 .9946517944 103.0481567383102 .1039123535101 .1618423462100 .220832824799 .27928161621 98.3368301391697 .3956832885796 .460655212495 .5382919311594 .63633728027 93.7629165649492 .9271545410292 .1386871337991 .4096374511790 .75077819824 90.2267532348689 .8584213256889 .6901168823289 .771629333590 .14127349854 90.79213714691 .6238555908292 .349891662691 .7403335571392 .95947265625 93.87381744385 92.349891662692.9594726562593.8738174438594.17859649658 94.7881774902395 .0929565429795 .397743225196 .0073165893696 .61688232422 97.2264633178798.1408081054799.0551681518699.96952056885100.8839035034 102.1029968262103 .0174026489103 .9317016602104 .8460998535105 .419303894 105.7603988647105 .7603988647105 .7603988647105 .4557037354 -9999 -9999 -9999-9999 -9999 -9999 -9999 -9999 -9999 -9999 -9999 -9999 -9999 -9999 -9999 -9999 -9999 -9999 -9999 -9999 -9999 -9999 -9999 -9999 -9999 -9999 -9999 -9999 -9999 -9999 -9999 -9999 -9999 -9999 -9999 -9999 -9999 -9999 -9999 -9999 -9999 -9999 -9999 -9999 -9999 -9999 -9999 -9999 -9999 -9999 -9999 -9999 -9999 -9999 -9999 -9999 -9999 -9999 -9999 -9999 -9999 -9999 -9999 -9999 -9999 -9999 -9999 -9999 -9999 -9999 -9999 -9999 -9999 -9999 -9999 -9999 -9999 -9999 -9999

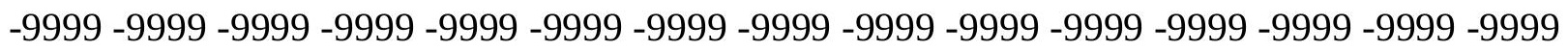
-9999 -9999 -9999 -9999 -9999 -9999 -9999 -9999 -9999 -9999 -9999 -9999 -9999 -9999 -9999 -9999 -9999 -9999 -9999 -9999 -9999 -9999 -9999 -9999 -9999 -9999 -9999 -9999 -9999 -9999 -9999 -9999 -9999 -9999 -9999 -9999 -9999 -9999 -9999 -9999 -9999 -9999 -9999 -9999 -9999 -9999 -9999 -9999 -9999 -9999 -9999 -9999 -9999 -9999 -9999 -9999 -9999 -9999 -9999 -9999 -

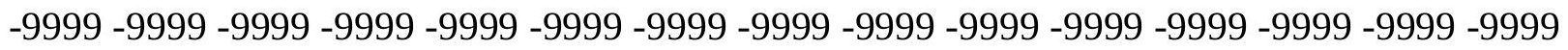
-9999 323.5018310547326.7644958496330.1107788086333.4629516602 336.7218322754 339.7684326172342 .4773254395344 .7436218262346 .4022827148347 .3594055176 347.5733642578347 .047454834345 .8235168457343 .9712524414341 .5725708008 338.693572998335 .3624267578331 .513092041327 .0242004395321 .9028930664 316.3231811523310 .7036437988305 .5249023438301 .1612854004297 .8330383301 295.5790100098294 .2907104492293 .6753234863293 .075012207291 .3637084961 286.8286132812161 .3318939209161 .6259918213161 .8858642578162 .1108398438 162.3002929688162 .4543609619162 .5731658936162 .6574554443162 .7078857422 162.725769043162 .7122650146162 .6689910889162 .5973815918162 .4992980957 154.8307952881149 .6495056152146 .6015930176144 .7729034424141 .7250976562 138.6772003174134 .7149963379130 .7528076172126 .7906036377122 .2188034058 119.4757995605116 .7326965332113 .3800964355110 .0273971558106 .3700027466 105.4557037354109 .1130981445112 .1608963013114 .9039993286117 .0374984741 
117.9517974854117 .647102356116 .1231002808113 .3800964355110 .0273971558 106.674797058187 .7781066894586 .254188537684 .4254837036187 .77810668945 92.349891662699 .35994720459113 .6848983765129 .533706665143 .2489929199 153.9165039062158 .6392059326158 .9246368408153 .0021057129140 .5059967041 133.8007049561133 .1911010742141 .7250976562151 .7830047607155 .1356048584 158.1835021973161 .625213623161 .8601226807162 .0656585693162 .2379302979 162.3731231689162 .4683837891162 .5209197998162 .5288238525162 .4902038574 162.4041900635162 .2698364258162 .087097168161 .8557891846161 .5766296387 161.2501220703160 .8774871826160 .4596862793156 .3547973633142 .9441986084 130.4479980469119 .1709976196110 .9418029785106 .0652008057103 .0174026489 98.1408081054793 .8738174438591 .1307525634889 .9116134643690 .21640014648 92.0450973510796 .31210327148100 .5791015625102 .1029968262102 .4077987671 102.712600708102 .4077987671102 .1029968262102 .1029968262102 .712600708 104.2365036011106 .979598999111 .551399231116 .4279022217126 .1809997559 137.1896057129136 .1734008789135 .1577911377134 .1438140869133 .1323547363 132.1241912842131 .1200256348130 .1203613281129 .125579834128 .1358642578 127.151260376126 .1716842651125 .1969833374124 .2268829346123 .2610702515 122.2991485596121 .3407058716120 .3852462769119 .432220459118 .4810256958 117.5310134888116 .5814819336115 .6317214966114 .6809997559113 .7286224365 112.7739562988111 .8164367676110 .8556442261109 .8912734985108 .9232330322 107.9515991211106 .9766540527105 .9987869263105 .0184707642104 .0361251831 103.0520935059102 .0664901733101 .0788879395100 .087936401499 .09196472168 98.0905914306697 .0863113403396 .0843124389695 .0914611816494 .1155166626 93.1642837524492 .2460250854591 .3688964843890 .5420532226689 .78137207031 89.1365432739388 .6279754638788 .2923202514688 .1847305297988 .37493133545 88.9158325195389 .7209396362390 .2164001464889 .9116134643689 .91161346436 91.7403335571392 .349891662692 .9594726562593 .5690307617294 .48339080811 94.7881774902395 .0929565429793 .8738174438594 .4833908081195 .09295654297 95.7025299072396 .6168823242297 .5312423706198 .445587158299 .66472625732 100.5791015625101 .7748794556102 .4077987671103 .3221969604103 .9286422729 104.2365036011 104.5412979126 104.2365036011 103.9317016602 -9999 -9999 -9999 -9999 -9999 -9999 -9999 -9999 -9999 -9999 -9999 -9999 -9999 -9999 -9999 -9999 -9999 -9999 -9999

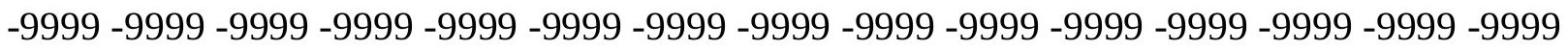
-9999 -9999 -9999 -9999 -9999 -9999 -9999 -9999 -9999 -9999 -9999 -9999 -9999 -9999 -9999 -9999 -9999 -9999 -9999 -9999 -9999 -9999 -9999 -9999 -9999 -9999 -9999 -9999 -9999 -9999 -9999 -9999 -9999 -9999 -9999 -9999 -9999 -9999 -9999 -9999 -9999 -9999 -9999 -9999 -9999

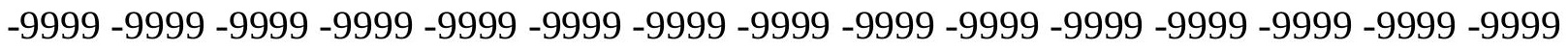

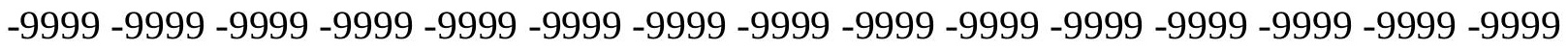
-9999 -9999 -9999 -9999 -9999 -9999 -9999 -9999 -9999 -9999 -9999 -9999 -9999 -9999 -9999 -9999 -9999 -9999 -9999 -9999 -9999 -9999 -9999 -9999 -9999 -9999 -9999 -9999 -9999 -9999 -

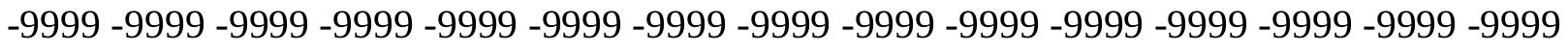

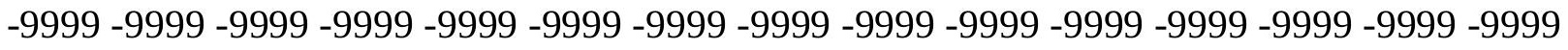
-9999 -9999 341.5162353516344.6206054688347.6921691895350.6365966797 353.3442687988355 .7494812012357 .6880187988359 .0331726074359 .7045593262 359.6637268066358 .9166564941357 .5056762695355 .4934082031352 .9644775391 349.9994506836 346.6579589844 342.9147033691338.4024658203 333.0132751465 
326.8240356445320 .5061950684314 .7164916992309 .9115600586306 .3204956055 303.9005737305302 .5198059082301 .985168457301 .7662658691300 .6811828613 296.8606872559161 .7767791748162 .0913085938162 .3684539795162 .607635498 162.8082733154162 .9706878662163 .0951080322163 .1825256348163 .2338256836 163.2505340576163 .2340698242163 .1862945557162 .4505004883155 .1356048584 149.3446960449144 .7729034424141 .1154937744137 .7628936768134 .1054992676 130.4479980469126 .4858016968123 .1332015991121 .9140014648122 .2188034058 121.3044967651118 .8662033081115 .818397522112 .4656982422109 .1130981445 113.075302124116 .1231002808117 .9517974854118 .8662033081119 .4757995605 119.4757995605118 .5614013672117 .0374984741114 .9039993286112 .1608963013 109.4179000854106 .674797058189 .9116134643688 .0829010009885 .33984375 81.3776321411186 .5589828491298 .14080810547112 .1608963013124 .6570968628 135.3246002197142 .9441986084143 .8585968018135 .3246002197124 .3523025513 119.4757995605120 .0852966309126 .7906036377135 .9342041016142 .0299072266 148.4304046631157 .2691040039162 .4962463379162 .7304229736162 .9293212891 163.0888061523163 .2058410645163 .2774658203163 .3016967773163 .2766113281 163.2014160156163 .0752563477162 .8982849121162 .6704711914162 .3927459717 162.065826416161 .6911621094161 .2698974609160 .8038787842154 .5260925293 142.9441986084129 .8385009766118 .8662033081112 .1608963013107 .8938980103 103.322196960499 .3599472045996 .0073165893693 .5690307617292 .3498916626 92.0450973510793 .5690307617295 .7025299072396 .9216690063597 .53124237061 97.8360290527397 .8360290527397 .5312423706196 .9216690063596 .92166900635 97.5312423706198 .75038146973101 .1886978149105 .1509017944112 .4656982422 123.7427978516136 .7162780762135 .6904144287134 .6661682129133 .6444854736 132.6261749268131 .6119537354130 .6023406982129 .5977630615128 .5983886719 127.6042938232126 .6153335571125 .6313323975124 .6519470215123 .6768188477 122.7054748535121 .7374267578120 .7720947266119 .8088684082118 .8470458984 117.8859024048116 .9246444702115 .9624633789114 .9985122681114 .0319671631 113.0620803833112 .0881347656111 .1095733643110 .1259307861109 .1369857788 108.1426849365107 .1431884766106 .1386642456105 .1293029785104 .1150741577 103.0958709717102 .0713043213101 .0406188965100 .002334594798 .95490264893 97.8981781005996 .8349838256895 .7709350585994 .7132644653393 .66989135742 92.6484832763791 .6567535400490 .7016448974689 .7892837524488 .93203735352 88.17493438721 87.51583862305 86.97507476807 86.59145355225 86.44333648682 86.6798019409287 .4361877441488 .3876876831188 .3876876831188 .38768768311 88.0829010009890 .2164001464891 .1307525634892 .349891662693 .03382873535 93.56776428223 93.5690307617293.87381744385 92.6546783447393.26425170898 93.8738174438594.7881774902395.7025299072396.9216690063597.83602905273 99.0242080688599 .96483612061100 .8494796753101 .6229171753102 .2404937744 102.6501846313102 .712600708102 .712600708102 .712600708102 .4077987671 -9999-9999 -9999 -9999 -9999 -9999 -9999 -9999 -9999 -9999 -9999 -9999 -9999 -9999 -9999 -9999 -9999 -

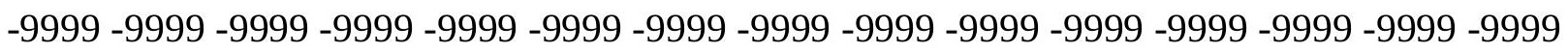
-9999 -9999 -9999 -9999 -9999 -9999 -9999 -9999 -9999 -9999 -9999 -9999 -9999 -9999 -9999 -9999 -9999 -9999 -9999 -9999 -9999 -9999 -9999 -9999 -9999 -9999 -9999 -9999 -9999 -9999 -9999 -9999 -9999 -9999 -9999 -9999 -9999 -9999 -9999 -9999 -9999 -9999 -9999 -9999 -9999 -

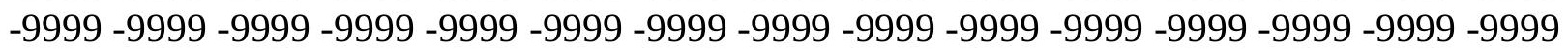


-9999 -9999 -9999 -9999 -9999 -9999 -9999 -9999 -9999 -9999 -9999 -9999 -9999 -9999 -9999 -9999 -9999 -9999 -9999 -9999 -9999 -9999 -9999 -9999 -9999 -9999 -9999 -9999 -9999 -9999 $-9999$

-9999 -9999 -9999 -9999 -9999 -9999 -9999 -9999 -9999 -9999 -9999 -9999 -9999 -9999 -9999 -9999 -9999 -9999 -9999 -9999 -9999 -9999 -9999 -9999 -9999 -9999 -9999 -9999 - -9999 - -9999 -

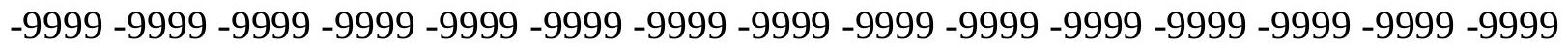
-9999 -9999 355.2396850586358.0255432129360.7504272461363.318145752 365.6347351074367 .6248168945369 .1307983398370 .0442810059370 .2845458984 369.8056335449368 .6061096191366 .7320556641364 .2394714355361 .1905517578 357.7069396973353 .8665771484349 .8894042969345 .3790588379339 .4042053223 332.3954467773325 .2588195801318 .8587646484313 .8586730957310 .2801818848 307.9115905762306 .4837646484305 .8631591797306 .0043029785305 .0899047852 161.8780212402162 .252456665162 .5875701904162 .8818511963163 .1347808838 163.3459014893163 .5157318115163 .6446990967163 .7340393066163 .784866333 163.799041748163 .7781982422151 .1734008789144 .7729034424145 .0776977539 142.0299072266138 .6772003174134 .7149963379130 .7528076172126 .4858016968 122.5235977173118 .8662033081120 .9997024536122 .8283996582123 .1332015991 121.9140014648120 .0852966309117 .342300415118 .2565994263121 .6092987061 123.1332015991124 .0475006104124 .0475006104123 .43800354122 .8283996582 122.2188034058120 .9997024536119 .1709976196117 .342300415115 .2088012695 112.7705001831110 .637001037693 .5690307617292 .0450973510789 .91161346436 87.7781066894585 .9494018554789 .91161346436100 .8839035034110 .3321990967 118.2565994263122 .8283996582122 .8283996582116 .7326965332109 .7226028442 109.1130981445112 .1608963013116 .4279022217122 .8283996582129 .8385009766 137.7628936768146 .9064025879157 .878692627163 .3933258057163 .6190032959 163.8026885986163 .9411468506164 .0312805176164 .071105957164 .0586242676 163.9931182861163 .8738708496163 .7012329102163 .4753875732163 .1975402832 162.8686523438162 .4904327393162 .0642547607161 .5921936035161 .0759735107 152.6972961426138 .9819946289125 .8762969971117 .9517974854112 .7705001831 109.1130981445106 .3700027466102 .407798767198 .7503814697396 .00731658936 94.1785964965892 .9594726562592 .349891662692 .6546783447393 .26425170898 93.5690307617293 .5690307617293 .2642517089892 .9594726562592 .3498916626 92.349891662692 .349891662693 .2642517089896 .92166900635101 .4934005737 103.3221969604111 .24659729132 .5814971924135 .1768493652134 .1459197998 133.1184387207132 .0951385498131 .0765838623130 .0632019043129 .05519104 128.0526123047127 .0553283691126 .0631332397125 .075630188124 .0923995972 123.1129150391122 .1366119385121 .1628265381120 .1908798218119 .2199935913 118.2493438721117 .2780685425116 .3052444458115 .3299407959114 .3511886597 113.3681259155112 .3798980713111 .3858108521110 .3852462769109 .3778533936 108.3634338379107 .3420257568106 .313583374105 .2779769897104 .2347335815 103.1832885742102 .1228485107101 .052429199299 .9704360961998 .87552642822 97.7680358886796 .6513824462995 .5316467285294 .4165039062593 .31410217285 92.2322235107491 .1783828735490 .1589889526489 .179412841888 .25308990479 87.39563751221 86.59851837158 85.85660552979 85.1739807128984.57193756104 84.1518936157284 .4254837036186 .8637619018687 .1685485839886 .55898284912 85.6446228027388 .0829010009888 .9972534179790 .2164001464891 .13075256348 
91.7403335571392 .0450973510792 .0450973510792 .349891662691 .13075256348 92.0450973510792 .9594726562593 .8738174438594 .7881774902396 .00731658936 97.0101928710998 .0016021728598 .9346618652399 .75616455078100 .4060745239 100.8467102051100 .8839035034100 .8839035034100 .8839035034100 .8839035034 100.5791015625 -9999 -9999 -9999 -9999 -9999 -9999 -9999 -9999 -9999 -9999 -9999 -9999 -9999 -9999 -9999 -9999 -9999 -9999 -9999 -9999 -9999 -9999 -9999 -9999 -9999 -9999 -9999 -9999 -9999 -9999 -9999 -9999 -9999 -9999 -9999 -9999 -9999 -9999 -9999 -9999 -9999 -9999

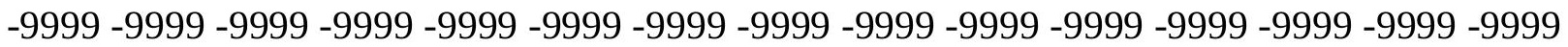
-9999 -9999 -9999 -9999 -9999 -9999 -9999 -9999 -9999 -9999 -9999 -9999 -9999 -9999 -9999 -9999 -9999 -9999 -9999 -9999 -9999 -9999 -9999 -9999 -9999 -9999 -9999 -9999 -9999 -9999 -

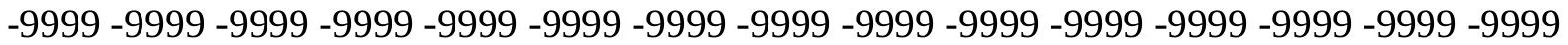

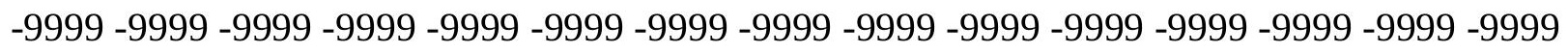
-9999 -9999-9999-9999-9999

-9999 -9999 -9999 -9999 -9999 -9999 -9999 -9999 -9999 -9999 -9999 -9999 -9999 -9999 -9999 -9999 -9999 -9999 -9999 -9999 -9999 -9999 -9999 -9999 -9999 -9999 -9999 -9999 -9999 -9999

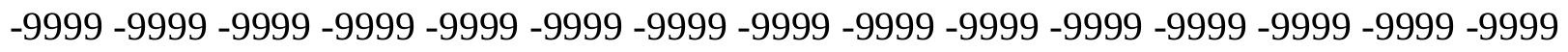
-9999 -9999 -9999 370.2710266113 372.5898742676 374.6880493164 376.5079040527 377.9595947266378 .928527832379 .2866210938378 .9442138672377 .8229064941 375.8934631348373 .2087097168369 .868347168365 .8412475586361 .2663574219 356.1620788574350 .845123291346 .5407104492339 .2258911133331 .6062011719 323.6817932129316 .6718139648312 .1000061035309 .0520935059307 .2233886719 306.3091125488305 .6994934082305 .3947143555161 .9218444824162 .3620452881 162.7609405518163 .1167144775163 .4277648926163 .6936798096163 .9142456055 164.0902404785164 .2223358154164 .3120727539164 .360824585164 .3707733154 164.3439025879145 .6873016357138 .6772003174137 .7628936768135 .3246002197 132.5814971924128 .3144989014123 .7427978516119 .4757995605124 .3523025513 131.9720001221134 .4102020264131 .9720001221140 .2012023926146 .9064025879 125.2667007446130 .7528076172136 .2389984131136 .8484954834134 .7149963379 132.5814971924130 .4479980469128 .6192932129127 .0953979492125 .5715026855 124.0475006104122 .2188034058120 .3900985718118 .5614013672116 .7326965332 114.9039993286113 .989601135396 .6168823242295 .7025299072394 .78817749023 94.1785964965892 .9594726562590 .5211791992297 .83602905273104 .2365036011 107.8938980103109 .1130981445105 .7603988647102 .712600708103 .3221969604 105.7603988647108 .8082962036113 .6848983765119 .4757995605126 .4858016968 133.4958953857143 .8585968018163 .0599975586164 .3082427979164 .5158691406 164.6751403809164 .782913208164 .8372039795164 .8360443115164 .7788238525 164.6649169922164 .4949188232164 .2692718506163 .9895019531163 .6568756104 163.2733764648162 .8406677246162 .3610839844161 .8365478516157 .2691040039 145.3825073242132 .8863067627123 .43800354116 .7326965332113 .075302124 110.6370010376107 .5891036987104 .2365036011100 .579101562596 .92166900635 94.1785964965892 .0450973510790 .2164001464889 .302040100189 .3020401001 89.9116134643690.2164001464890.21640014648 89.9116134643690.21640014648 90.2164001464890 .8259735107492 .0450973510792 .0450973510789 .91161346436 92.95947265625109 .7226028442129 .8385009766134 .6353302002133 .5997314453 132.5684204102131 .5419769287130 .5208740234129 .5052947998128 .4953613281 127.4908905029126 .4916763306125 .4972915649124 .5072555542123 .5209884644 
122.5378570557121 .5571289062120 .5780410767119 .5997390747118 .6213302612 117.6418533325116 .6602935791115 .6756286621114 .6867752075113 .6927490234 112.6925735474111 .6854171753110 .6705093384109 .6473770142108 .6156845093 107.5753250122106 .5260391235105 .4673919678104 .3985137939103 .318397522 102.2258911133101 .119857788199 .9987335205198 .8614425659297 .7088394165 96.5451660156295 .3772048950294 .2130966186593 .0613937377991 .93018341064 90.8273162841889 .7581405639688 .7319641113387 .7612762451286 .8392868042 85.944755554285 .0510864257884 .1342391967883 .1867294311582 .21360778809 80.4632720947380 .4632720947386 .254188537683 .8159103393682 .90155792236 85.3398437586 .5589828491287 .7781066894588 .9972534179789 .60682678223 90.2164001464890 .2164001464890 .2164001464889 .302040100189 .91161346436 90.8259735107491 .7403335571392 .6546783447393 .8367843627994 .8846206665 95.9411697387796.9397125244197.8194351196398.5285339355599.02045440674 99.2853469848699 .3406372070399 .0551681518699 .0551681518699 .05516815186 98.75038146973 -9999 -9999 -9999 -9999 -9999 -9999 -9999 -9999 -9999 -9999 -9999 -9999

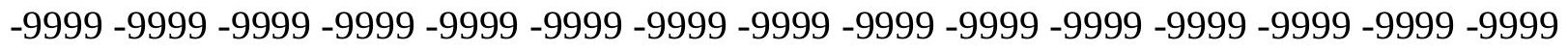
-9999 -9999 -9999 -9999 -9999 -9999 -9999 -9999 -9999 -9999 -9999 -9999 -9999 -9999 -9999 -9999 -9999 -9999 -9999 -9999 -9999 -9999 -9999 -9999 -9999 -9999 -9999 -9999 -9999 -9999 -999 -9999 -9999 -9999 -9999 -9999 -9999 -9999 -9999 -9999 -9999 -9999 -9999 -9999 -9999 -9999 -

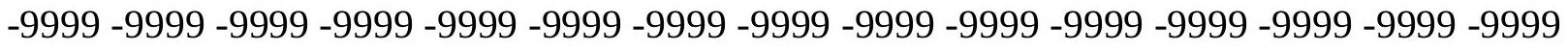
-9999 -9999 -9999 -9999 -9999 -9999 -9999 -9999 -9999 -9999 -9999 -9999 -9999 -9999 -9999 -9999 -9999 -9999 -9999 -9999 -9999 -9999 -9999 -9999 -9999 -9999 -9999 -9999 -9999 -9999 -9999 -9999-9999-9999

-9999 -9999 -9999 -9999 -9999 -9999 -9999 -9999 -9999 -9999 -9999 -9999 -9999 -9999 -9999 -

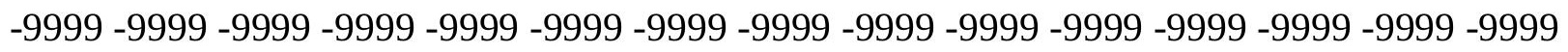

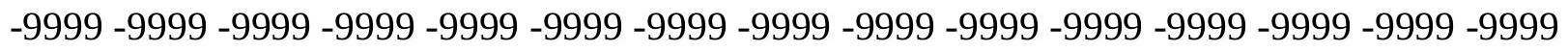
-9999 -9999 -9999 381.2428588867 383.0592346191384 .6089172363385 .796295166 386.5834960938386 .8687133789386 .545135498385 .4735412598383 .4970092773 380.5181274414376 .5690612793371 .915222168366 .5087585449360 .1270751953 353.5508117676345 .0168151855336 .7875976562329 .7774963379323 .0722045898 314.5382080078307 .2233886719303 .5660095215302 .0421142578301 .1276855469 301.7373046875303 .8707885742161 .8998565674162 .4113922119162 .8804931641 163.30418396163 .6805725098164 .0079040527164 .2858428955164 .5144348145 164.6948852539164 .8282470703164 .9164123535164 .9610748291164 .9648132324 158.1835021973145 .6873016357136 .8484954834131 .6672058105128 .9241027832 125.8762969971121 .6092987061120 .6949005127133 .1911010742154 .5260925293 163.015045166162 .7122497559159 .0977935791157 .878692627155 .4403991699 149.0399017334149 .9542999268156 .0500030518150 .2590942383144 .7729034424 140.2012023926136 .5437011719133 .4958953857131 .0576019287129 .2288970947 127.4001998901125 .5715026855124 .0475006104122 .2188034058120 .6949005127 119.4757995605118 .8662033081101 .1886978149101 .4934005737102 .1029968262 102.1029968262101 .188697814997 .8360290527392 .0450973510793 .26425170898 96.9216690063599 .3599472045999 .3599472045999 .0551681518699 .66472625732 101.1886978149103 .6268997192107 .2844009399111 .8561019897117 .342300415 121.3044967651129 .533706665149 .6495056152164 .9982452393165 .229598999 165.4089355469165 .5331573486165 .6004333496165 .6089324951165 .5581817627 
165.4477081299165 .2783508301165 .0508575439164 .7671356201164 .4287719727 164.0381011963163 .597076416163 .1083526611162 .5740356445158 .1835021973 149.0399017334138 .6772003174128 .9241027832120 .9997024536116 .7326965332 114.2944030762111 .8561019897109 .1130981445104 .8460998535100 .2742996216 96.6168823242293 .2642517089889 .302040100186 .254188537686 .2541885376 87.1685485839888 .0829010009888 .9972534179789 .6068267822390 .21640014648 91.1307525634891 .1307525634889 .6068267822387 .4733276367283 .51112365723 83.8159103393696 .00731658936110 .3321990967118 .5614013672121 .6092987061 113.6848983765107 .5891036987115 .2088012695126 .7906036377128 .9316711426 127.9212188721126 .9162216187125 .9162368774124 .920753479123 .9291152954 122.9406433105121 .954536438120 .9699554443119 .9859848022119 .0016326904 118.0158615112117 .0275726318116 .0356369019115 .0388946533114 .0362472534 113.0265884399112 .0089645386110 .9824829102109 .9465332031108 .9006576538 107.8446044922106 .7778701782105 .6997375488104 .6089935303103 .5043029785 102.3841323853101 .247215271100 .092147827198 .9183273315497 .72718811035 96.5237731933695 .3156738281294 .1116790771592 .9208755493291 .75204467773 90.6138305664189 .5141677856488 .4638977050887 .4740142822386 .52619934082 85.5920257568484 .6337356567483 .6126861572382 .5025558471781 .32364654541 80.1720809936578 .9393463134878 .9393463134879 .5489196777381 .68241119385 82.9015579223684 .1206970214885 .6446228027386 .8637619018687 .77810668945 88.0829010009888 .3876876831187 .7443847656287 .1685485839887 .77810668945 88.3876876831189 .5420837402390 .5183029174891 .5868301391692 .71152496338 93.8519592285294 .9331283569395 .8931732177796 .6771545410297 .24663543701 97.5888137817497 .7150726318497 .6753005981497 .5034332275497 .22646331787 97.22646331787 96.92166900635 96.92166900635 -9999 -9999 -9999 -9999 -9999 -9999 -9999 -9999 -9999 -9999 -9999 -9999 -9999 -9999 -9999 -9999 -9999 -9999 -9999 -9999 -9999 -9999 -9999 -9999 -9999 -9999 -9999 -9999 -9999 -9999 -9999 -9999 -9999 -9999 -9999 -9999 -9999

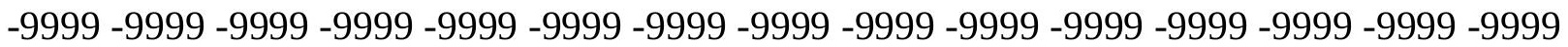

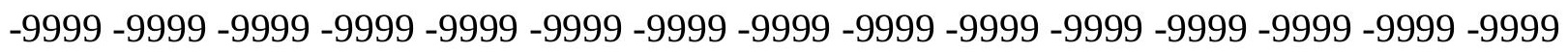
-9999 -9999 -9999 -9999 -9999 -9999 -9999 -9999 -9999 -9999 -9999 -9999 -9999 -9999 -9999 -9999 -9999 -9999 -9999 -9999 -9999 -9999 -9999 -9999 -9999 -9999 -9999 -9999 -9999 -9999

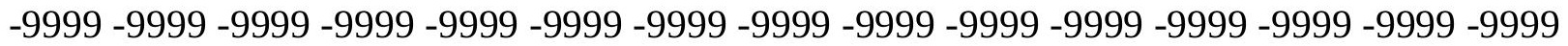
-9999 -9999 -9999 -9999-9999-9999-9999

-9999 -9999 -9999 -9999 -9999 -9999 -9999 -9999 -9999 -9999 -9999 -9999 -9999 -9999 -9999 -9999 -9999 -9999 -9999 -9999 -9999 -9999 -9999 -9999 -9999 -9999 -9999 -9999 -9999 -9999 -9999 -9999 -9999 -9999 -9999 -9999 -9999 -9999 -9999 -9999 -9999 -9999 -9999 -9999 -9999 -9999 -9999-9999 -9999 391.9996337891 392.8550415039 393.2559204102 393.2142028809 392.6602172852391 .516784668389 .6043701172386 .6066894531382 .2566223145 376.4485778809369 .6700744629362 .9991149902353 .8554992676344 .1023864746 334.9588928223326 .4248962402318 .8052062988311 .7951965332306 .3091125488 302.3468017578300 .5180969238300 .2132873535300 .5180969238302 .0421142578 304.4802856445162 .3899993896162 .9357910156163 .4347991943163 .8837585449 164.2807617188164 .6239624023164 .912979126165 .1480102539165 .330871582 165.4631958008165 .5473175049165 .5853729248165 .5804138184153 .0021057129 141.4203033447132 .8863067627127 .0953979492123 .1332015991120 .0852966309 129.533706665142 .3347015381157 .878692627163 .7940063477163 .4925842285 
163.1757965088162 .8454437256162 .5036773682162 .1526031494161 .7941741943 161.4296875161 .0603790283157 .2691040039151 .1734008789145 .6873016357 141.1154937744137 .7628936768135 .3246002197133 .1911010742131 .0576019287 129.533706665127 .7050018311126 .1809997559124 .6570968628123 .7427978516 123.43800354123 .7427978516106 .6747970581107 .8938980103109 .1130981445 109.4179000854106 .065200805796 .3121032714885 .6446228027390 .21640014648 93.8738174438595 .0929565429795 .397743225196 .3121032714897 .53124237061 99.66472625732103 .0174026489106 .6747970581110 .9418029785114 .2944030762 119.7806015015129 .8385009766141 .4203033447151 .1734008789158 .1835021973 159.7073974609158 .7929992676159 .4026031494159 .4026031494157 .5738983154 156.3547973633157 .5738983154159 .7073974609160 .9264984131161 .5361022949 161.8408966064161 .2312927246160 .3170013428157 .2691040039150 .2590942383 141.4203033447132 .8863067627125 .2667007446120 .6949005127117 .647102356 114.9039993286111 .8561019897108 .1986999512103 .931701660298 .75038146973 93.2642517089888 .6924667358485 .6446228027385 .3398437586 .2541885376 88.0829010009889 .9116134643691 .7403335571392 .9594726562593 .87381744385 93.5690307617292 .0450973510789 .6068267822386 .5589828491286 .55898284912 92.95947265625100 .5791015625104 .8460998535104 .846099853597 .22646331787 90.5211791992293 .2642517089899 .05516815186101 .7982025146105 .7603988647 113.9896011353120 .0852966309117 .9517974854120 .9997024536123 .3443756104 122.3545227051121 .3661804199120 .3783416748119 .3899536133118 .3999023438 117.4069976807116 .4100265503115 .4077377319114 .3989334106113 .3824081421 112.357093811111 .321975708110 .2763519287109 .2196121216108 .1513824463 107.0709228516105 .9772338867104 .8687973022103 .7440414429102 .6011734009 101.4387359619100 .255523681699 .05161285497 .8292160034296 .59404754639 95.3544235229594 .119842529392 .9001922607491 .7052078247190 .54486846924 89.4294357299888 .3752899169987 .3882675170986 .4519958496185 .53482055664 84.5990371704183 .6139373779382 .5761947631881 .5437927246180 .78977203369 81.35008239746 83.51112365723 77.1106262207 77.41542053223 80.15849304199 81.6824111938583 .206336975184 .7302627563585 .6446228027386 .2541885376 86.5589828491284 .7302627563584 .9766845703185 .5427093505986 .23627471924 87.1099624633888 .1460952758889 .3068313598690 .5429153442491 .79647827148 92.9908142089894 .053291320894 .9284057617295 .5836105346796 .00716400146 96.212326049896 .235908508396 .1440811157296 .0073165893695 .70252990723 95.3977432251 95.397743225195.3977432251 95.09295654297 -9999 -9999 -9999 -9999 -9999 -9999 -9999 -9999 -9999 -9999 -9999 -9999 -9999 -9999 -9999 -9999 -9999 -9999 -9999

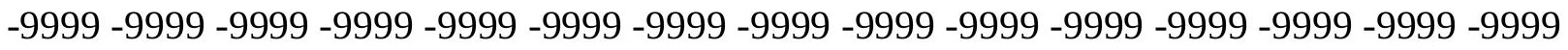

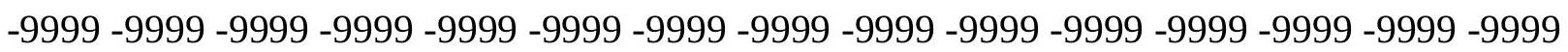
-9999 -9999 -9999 -9999 -9999 -9999 -9999 -9999 -9999 -9999 -9999 -9999 -9999 -9999 -9999 -9999 -9999 -9999 -9999 -9999 -9999 -9999 -9999 -9999 -9999 -9999 -9999 -9999 -9999 -9999 -9999 -9999 -9999 -9999 -9999 -9999 -9999 -9999 -9999-9999 -9999 -9999 -9999-999 - -999 -9999 -9999 -9999 -9999 -9999 -9999 -9999 -9999 -9999 -9999 -9999 -9999 -9999 -9999 -9999 - -999 -9999 -9999 -9999 -9999 -9999 -9999 -9999 -9999 -9999 -9999 -9999 -9999 -9999 -9999 -9999 -9999 -9999 -9999 -9999 -9999 -9999 -9999 -9999 -9999 -9999 -9999 -9999 -9999 -9999 -9999 -9999 -9999 -9999 -9999 -9999 -9999 -9999 -9999 -

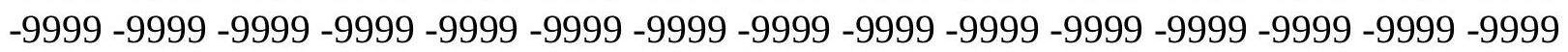


-9999 -9999 -9999 -9999 399.1804504395 399.2236022949398 .7117004395397 .5756530762 395.9118652344393 .7801818848390 .995513916386 .9274902344380 .9596252441 373.0570068359362 .6943054199352 .3316040039342 .8833007812333 .7396850586 324.5961914062316 .0621948242307 .8330078125302 .0421142578299 .9085998535 299.9085998535300 .2132873535301 .1276855469302 .3468017578304 .1755981445 162.2821960449162 .911529541163 .4934082031164 .0237579346164 .4989471436 164.9169464111165 .2758483887165 .5753173828165 .8155822754165 .9988555908 166.1275482178166 .2047424316166 .2331695557164 .2792053223147 .8208007812 136.5437011719128 .6192932129123 .1332015991126 .7906036377138 .0677032471 150.5639038086163 .0599975586164 .5902252197164 .2929534912163 .9785766602 163.6485443115163 .3043823242162 .9479064941162 .5807495117162 .2041625977 161.8185577393161 .4241485596160 .3170013428154 .2212982178149 .0399017334 144.7729034424141 .4203033447138 .9819946289136 .8484954834135 .0198059082 133.1911010742131 .6672058105130 .1432037354128 .6192932129128 .0097961426 127.4001998901127 .7050018311128 .9241027832111 .8561019897113 .3800964355 114.2944030762113 .380096435599 .9695205688586 .254188537685 .64462280273 89.9116134643691.4355392456192.0450973510793.2642517089894.78817749023 97.22646331787 100.2742996216103.6268997192 106.979598999 110.3321990967 113.3800964355112 .7705001831114 .5991973877125 .2667007446136 .5437011719 141.4203033447142 .9441986084140 .5059967041136 .8484954834135 .6293945312 135.9342041016138 .6772003174142 .3347015381145 .0776977539147 .5160064697 149.9542999268152 .0877990723153 .9165039062153 .6116943359148 .7351074219 142.0299072266135 .6293945312129 .2288970947124 .3523025513120 .3900985718 117.0374984741113 .9896011353110 .9418029785106 .674797058199 .66472625732 92.6546783447388 .3876876831185 .9494018554785 .6446228027386 .86376190186 89.6068267822392 .9594726562595 .397743225197 .2264633178797 .83602905273 97.5312423706196 .3121032714894 .7881774902394 .4833908081194 .17859649658 96.0073165893697 .5312423706198 .1408081054797 .2264633178793 .26425170898 89.302040100188 .6924667358488 .3876876831183 .5111236572380 .76805877686 87.1685485839893.8738174438591.43553924561 89.9116134643692.3498916626 98.75038146973106 .6747970581120 .3900985718119 .7857666016118 .7935028076 117.7981643677116 .7984619141115 .7930450439114 .7806549072113 .7599716187 112.729850769111 .689163208110 .6371078491109 .5729675293108 .4962463379 107.4059906006106 .3009338379105 .1792755127104 .039276123102 .8789978027 101.6969223022100 .491996765199 .2649459838998 .0188446044996 .76011657715 95.4976425170994 .2415847778393 .0027160644591 .7919082641690 .62087249756 89.5035095214888 .4558944702187 .4904632568486 .5906600952185 .7294921875 84.8757247924884 .0101547241283 .1555938720782 .4305953979582 .06027984619 82.0312347412180 .9841613769577 .7079010009875 .2819290161176 .50106811523 79.5489196777381 .3776321411183 .206336975184 .4254837036184 .73026275635 84.7302627563582 .9015579223682 .9015579223683 .206336975183 .79463195801 84.6739349365285 .7714996337987 .0373611450288 .4163894653389 .82109832764 91.1307525634892 .347793579193 .2642517089894 .0761413574294 .5751953125 94.8511276245194 .9410324096794 .8948440551894 .746932983494 .48339080811 94.1785964965893 .8738174438593 .8738174438593 .8738174438593 .87381744385 -9999 -9999 -9999 -9999 -9999 -9999 -9999 -9999 -9999 -9999 -9999 -9999 -9999 -9999 -9999 -9999 
-9999 -9999 -9999 -9999 -9999 -9999 -9999 -9999 -9999 -9999 -9999 -9999 -9999 -9999 -9999 -9999 -9999 -9999 -9999 -9999 -9999 -9999 -9999 -9999 -9999 -9999 -9999 -9999 -9999 -9999 -9999 -9999 -9999 -9999 -9999 -9999 -9999 -9999 -9999 -9999 -9999 -9999 -9999 -9999 -9999 -9999 -9999 -9999 -9999 -9999 -9999 -9999 -9999 -9999 -9999 -9999 -9999 -9999 -9999 -9999 -9999 -9999 -9999 -9999 -9999 -9999 -9999 -9999 -9999 -9999 -9999 -9999 -9999 -9999 -9999 -9999 -9999 -9999 -9999 -9999 -9999 -9999 -9999 -9999 -9999 -9999 -9999 -9999 -9999 -9999 -999 -9999 -9999 -9999 -9999 -9999 -9999 -9999 -9999 -9999 -9999

-9999 -9999 -9999 -9999 -9999 -9999 -9999 -9999 -9999 -9999 -9999 -9999 -9999 -9999 -9999 -9999 -9999 -9999 -9999 -9999 -9999 -9999 -9999 -9999 -9999 -9999 -9999 -9999 -9999 -9999 -9999 -9999 -9999 -9999 -9999 -9999 -9999 -9999 -9999 -9999 -9999 -9999 -9999 -9999 -9999 -9999 -9999 -9999 -9999 404.3894958496 403.4050292969 401.7546386719399 .3617248535 396.1836853027392 .7530517578389 .2106018066384 .3340148926376 .4096069336 365.7421875352 .6364135742339 .8353881836330 .3870849609322 .4627075195 313.6239013672305 .6994934082300 .2132873535297 .4703063965297 .4703063965 298.9942016602300 .5180969238302 .0421142578304 .1755981445162 .0711212158 162.789352417163 .4615936279164 .0817565918164 .6452941895165 .1481323242 165.5879516602165 .9627380371166 .272277832166 .5168457031166 .698928833 166.8214416504166 .8885345459166 .9038543701152 .0877990723138 .6772003174 130.7528076172131 .6672058105138 .3724975586148 .7351074219161 .2312927246 165.6713867188165 .3987579346165 .1071166992164 .7976989746164 .4713745117 164.1293182373163 .772567749163 .40234375163 .0194549561162 .6242523193 162.2161102295161 .7944030762161 .3598022461155 .1356048584150 .8686065674 147.5160064697144 .4682006836142 .0299072266140 .2012023926138 .3724975586 136.8484954834135 .3246002197133 .8007049561132 .5814971924131 .6672058105 131.3623962402131 .6672058105132 .2767028809133 .8007049561135 .6293945312 114.2944030762110 .027397155899 .9695205688587 .7781066894580 .46327209473 84.7302627563587 .1685485839888 .6924667358490 .8259735107492 .95947265625 95.7025299072398 .75038146973102 .1029968262105 .1509017944107 .8938980103 108.8082962036106 .979598999107 .2844009399114 .2944030762123 .1332015991 128.0097961426129 .533706665127 .4001998901124 .3523025513123 .1332015991 123.1332015991123 .43800354124 .9618988037128 .0097961426131 .6672058105 135.6293945312139 .2868041992143 .2489929199145 .9920959473144 .4682006836 140.8106994629136 .5437011719131 .3623962402126 .4858016968122 .2188034058 118.8662033081115 .818397522112 .1608963013106 .97959899998 .75038146973 91.1307525634888 .0829010009886 .8637619018686 .254188537687 .77810668945 92.349891662697 .53124237061100 .8839035034102 .712600708102 .712600708 102.1029968262102 .4077987671102 .4077987671102 .4077987671101 .7982025146 101.4934005737100 .579101562599 .3599472045998 .7503814697396 .92166900635 94.7881774902394 .1785964965891 .1307525634883 .8159103393678 .32978057861 79.8537063598682 .9015579223681 .0728530883877 .7202072143675 .89148712158 77.110626220781 .0728530883892 .3498916626110 .0273971558119 .1961288452 118.2006225586117 .2005767822116 .1945571899115 .1812362671114 .1592254639 113.1272888184112 .0842056274111 .0291061401109 .9611816406108 .8797988892 107.7838439941106 .6718139648105 .5416793823104 .3915786743103 .2195205688 102.0240478516100 .804336547999 .5616302490298 .2997131347797 .0256729126 95.7489013671994 .4801330566493 .2309570312592 .0133209228590 .84017181396 
89.72815704346 88.69525909424 87.75591278076 86.9043045043986.11386108398 85.360626220784 .631416320883 .9397125244183 .3241043090882 .7769317627 82.0174179077180 .3143844604578 .1942520141676 .2625427246175 .58670806885 76.1962814331178 .9393463134882 .2919769287183 .206336975183 .51112365723 82.9015579223681 .0728530883880 .7680587768680 .7680587768681 .37763214111 82.25743103027 83.4090576171984.81566619873 86.37600708008 87.97225189209 89.302040100190.5211791992291.7403335571392.6546783447393.31018066406 93.63191223145 93.7609024047993.7434997558693.618858337493.43864440918 93.2642517089892 .9594726562592 .6546783447392 .349891662692 .3498916626 92.349891662692 .65467834473 -9999 -9999 -9999 -9999 -9999 -9999 -9999 -9999 -9999 -9999 -9999 -9999 -9999 -9999 -9999 -9999 -9999 -9999 -9999 -9999 -9999 -9999 -9999 -9999 -9999 -9999 -9999 -9999 -9999 -9999 -9999 -9999 -9999 -9999 -9999 -9999 -9999 -9999 -9999

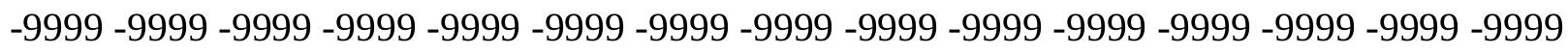

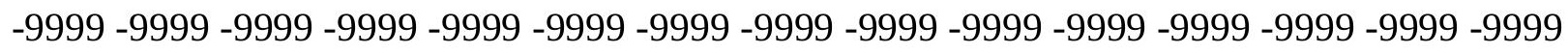
-9999 -9999 -9999 -9999 -9999 -9999 -9999 -9999 -9999 -9999 -9999 -9999 -9999 -9999 -9999

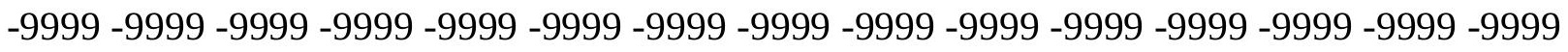
-9999 -9999 -9999 -9999 -9999 -9999 -9999 -9999 -9999 -9999 -9999 -9999 -9999 -9999 -9999 -9999 -9999 -9999 -9999 -9999 -9999 -9999 -9999 -9999 -9999 -9999 -9999 -9999 -9999 -9999 -9999 -9999 -9999 -9999 -9999 -9999 -9999 -9999 -9999 -9999 -9999 -9999 -9999 -9999 -9999 -

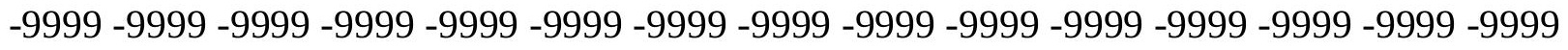
-9999 -9999 -9999 -9999-9999 405.1611633301401.8350524902 398.3541870117 393.1727905273387 .9914855957383 .7244873047377 .93359375368 .4851989746 356.2937927246341 .3593139648327 .3392028809318 .1957092285311 .1856079102 303.5660095215297 .4703063965295 .0320129395295 .3367919922296 .2510986328 298.0798950195300 .5180969238302 .9563903809161 .7424316406162 .5528869629 163.3204650879164 .0379638672164 .6985626221165 .2971343994165 .8290557861 166.2916259766166 .6826324463167 .0019378662167 .2499542236167 .4293823242 167.5435028076167 .5973510742165 .8031005859146 .2969055176140 .5059967041 140.5059967041145 .6873016357154 .8307952881166 .7285919189166 .4824829102 166.2155456543165 .9297027588165 .6261138916165 .3057250977164 .9690246582 164.6166534424164 .2490081787163 .8664703369163 .4686889648163 .0547790527 162.6229705811162 .1719207764161 .7021331787157 .2691040039153 .0021057129 149.3556060791 146.9064025879 145.0776977539143.2489929199141.7250976562 140.5059967041138 .9819946289137 .4580993652136 .2389984131135 .3246002197 135.0198059082135 .0198059082135 .6293945312136 .5437011719138 .0677032471 139.6868591309141 .054306030397 .8360290527389 .6068267822378 .32978057861 79.5489196777382 .5967712402385 .3398437588 .3876876831191 .43553924561 94.7881774902398 .14080810547101 .4934005737104 .2365036011106 .3700027466 107.2844009399107 .2844009399107 .8938980103110 .6370010376114 .2944030762 117.0374984741118 .2565994263117 .9517974854116 .4279022217115 .818397522 114.9039993286112 .7705001831111 .8561019897114 .2944030762118 .2565994263 122.5235977173126 .7906036377132 .2767028809136 .8484954834138 .3724975586 138.0677032471136 .2389984131132 .5814971924128 .3144989014123 .43800354 120.3900985718117 .0374984741113 .075302124107 .284400939998 .75038146973 90.8259735107488 .9972534179789 .302040100188 .6924667358490 .21640014648 96.31210327148103 .0174026489106 .6747970581108 .1986999512107 .5891036987 
106.3700027466107 .2844009399107 .8938980103108 .1986999512107 .5891036987 106.6747970581105 .4557037354104 .5412979126104 .2365036011103 .9317016602 104.2365036011105 .1509017944101 .493400573792 .349891662686 .2541885376 84.1206970214883 .206336975181 .3776321411178 .9393463134875 .89148712158 74.6723632812576 .5010681152380 .7680587768681 .0728530883885 .03504943848 98.4455871582113 .3800964355116 .6116104126115 .6000823975114 .5796203613 113.5489120483112 .5066833496111 .4519729614110 .3839187622109 .3017807007 108.2042922974 107.0897598267 105.9560089111 104.801109314103.623085022 102.4206314087101 .193183898999 .9424438476698 .6726989746197 .39151000977 96.1086883544994 .8354187011793 .5839233398492 .3669891357491 .1990814209 90.0966644287189 .079933166588 .1686019897587 .3574905395586 .63081359863 85.96545410156 85.34059906006 84.7397766113384.13507843018 83.43625640869 82.43871307373 81.01634979248 79.47676849365 78.31436920166 78.18704986572 79.2441329956178 .9393463134880 .4632720947381 .0728530883882 .29197692871 81.6824111938579 .2441329956178 .6345596313578 .3297805786178 .93934631348 79.8537063598681 .0728530883882 .6972045898484 .4254837036186 .2541885376 87.7781066894589 .302040100190 .5211791992291 .4355392456192 .20955657959 92.5453643798892 .6829681396592 .6793060302792 .5854492187592 .44857788086 92.2803802490292 .0450973510791 .7403335571391 .4355392456191 .13075256348 91.13075256348 91.13075256348 91.43553924561 -9999 -9999 -9999 -9999 -9999 -9999 -9999

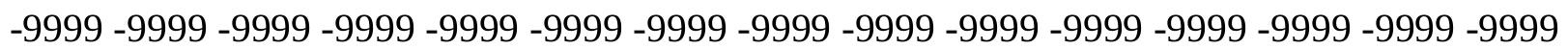
-9999 -9999 -9999 -9999 -9999 -9999 -9999 -9999 -9999 -9999 -9999 -9999 -9999 -9999 -9999 -9999 -9999 -9999 -9999 -9999 -9999 -9999 -9999 -9999 -9999 -9999 -9999 -9999 -9999 -9999 -

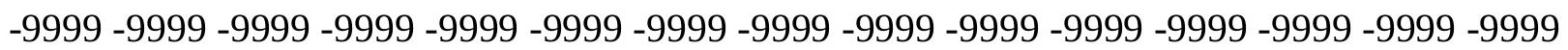
-9999 -9999 -9999 -9999 -9999 -9999 -9999 -9999 -9999 -9999 -9999 -9999 -9999 -9999 -9999 -9999 -9999 -9999 -9999 -9999 -9999 -9999 -9999 -9999 -9999 -9999 -9999 -9999 -9999 -9999

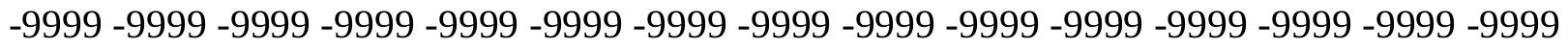
$-9999$

-9999 -9999 -9999 -9999 -9999 -9999 -9999 -9999 -9999 -9999 -9999 -9999 -9999 -9999 -9999 -9999 -9999 -9999 -9999 -9999 -9999 -9999 -9999 -9999 -9999 -9999 -9999 -9999 -9999 -9999 -9999 -9999 -9999 -9999 -9999 -9999 -9999 -9999 -9999 -9999 -9999 -9999 -9999 -9999 -9999 -9999 -9999 -9999 -9999 -9999 404.4498901367 398.3541870117392 .5632019043 387.0770874023381 .2861938477374 .5809020996365 .7421875354 .1603088379 340.749786377327 .9487915039316 .3670043945308 .4425048828302 .0421142578 296.2510986328292 .5936889648291 .6794128418292 .8984985352294 .7272033691 296.8606872559299 .9085998535161 .2890777588162 .1908569336163 .0559082031 163.8748474121164 .6396026611165 .3424987793165 .9777069092166 .5399475098 167.0260925293167 .4336090088167 .7623443604168 .0128326416168 .1880340576 168.2915649414168 .3291931152168 .3070678711161 .2312927246154 .2212982178 153.9165039062158 .7929992676167 .544631958167 .3019256592167 .0384979248 166.7565917969166 .4579925537166 .1436462402165 .8140716553165 .4692077637 165.1089019775164 .7326507568164 .3397521973163 .9284362793163 .4962768555 163.040222168162 .5582733154162 .0509338379159 .0977935791153 .6498718262 151.1955413818149 .0399017334147 .5160064697145 .9920959473145 .0776977539 143.8585968018142 .3347015381140 .8106994629139 .5915985107138 .6772003174 138.0677032471138 .0677032471138 .3724975586139 .2868041992140 .5059967041 
141.7250976562142 .9441986084143 .8585968018144 .7729034424145 .1192779541 145.3825073242145 .0776977539144 .1634063721142 .9441986084141 .1154937744 139.2868041992137 .4580993652135 .6293945312134 .1054992676132 .8863067627 108.5035018921108 .1986999512107 .5891036987108 .1986999512109 .4179000854 110.6370010376111 .551399231111 .551399231110 .9418029785110 .6370010376 110.0273971558109 .4179000854109 .7226028442110 .6370010376112 .7705001831 116.1231002808120 .3900985718125 .2667007446130 .1432037354132 .8863067627 134.7149963379135 .3246002197134 .1054992676130 .1432037354125 .2667007446 121.6092987061118 .2565994263115 .5136032104111 .24659729103 .3221969604 96.3121032714893 .5690307617293 .5690307617293 .8738174438596 .31210327148 102.1029968262107 .8938980103110 .9418029785111 .8561019897110 .3321990967 108.8082962036108 .1986999512107 .8938980103108 .8082962036109 .1130981445 108.5035018921107 .5891036987107 .2844009399107 .8938980103108 .1986999512 108.8082962036113 .9896011353121 .6092987061117 .647102356104 .2365036011 111.55139923194 .4833908081192 .349891662688 .6924667358483 .2063369751 78.3297805786177 .110626220776 .5010681152374 .3675689697376 .19628143311 86.8637619018699 .05516815186104 .8460998535106 .979598999106 .0652008057 113.9941940308112 .9561157227111 .9053039551110 .8408355713109 .7619018555 108.6671066284107 .5546340942106 .422203064105 .2679138184104 .0898895264 102.8869781494101 .6589279175100 .407783508399 .1381988525497 .85800170898 96.5772247314595 .3072891235494 .0607223510792 .8508148193491 .69231414795 90.6018295288189 .5985641479588 .7021865844787 .9238204956187 .24491119385 86.6431961059686 .0904235839885 .5516433715884 .9771423339884 .29137420654 83.4178543090882 .41210937581 .4864120483481 .006416320881 .27920532227 82.4617080688584 .1206970214880 .1584930419980 .4632720947379 .85370635986 80.1584930419977 .4154205322376 .1962814331175 .8914871215876 .19628143311 77.4154205322378 .9393463134880 .7680587768682 .8727035522584 .90058135986 86.8109970092888 .3876876831189 .6068267822390 .5211791992291 .25816345215 91.5642929077191 .675079345791 .6602096557691 .5760498046991 .46302032471 91.3334045410291 .2117385864391 .1307525634890 .8259735107490 .21640014648 89.9116134643689 .9116134643690 .2164001464890 .2164001464890 .52117919922 -9999 -9999 -9999 -9999 -9999 -9999 -9999 -9999 -9999 -9999 -9999 -9999 -9999 -9999 -9999 -9999

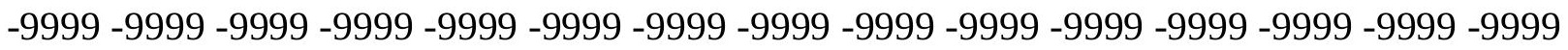
-9999 -9999 -9999 -9999 -9999 -9999 -9999 -9999 -9999 -9999 -9999 -9999 -9999 -9999 -9999 -9999 -9999 -9999 -9999 -9999 -9999 -9999 -9999 -9999 -9999 -9999 -9999 -9999 -9999 -9999 -

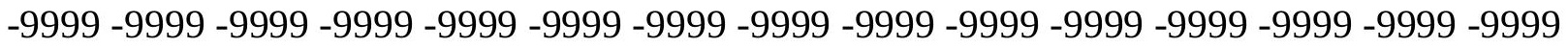

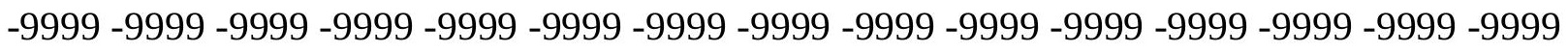

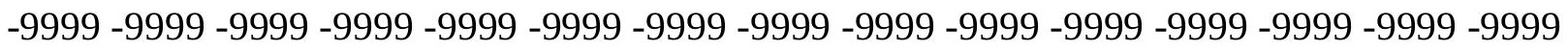
-9999 -9999-9999-9999-9999

-9999 -9999 -9999 -9999 -9999 -9999 -9999 -9999 -9999 -9999 -9999 -9999 -9999 -9999 -9999

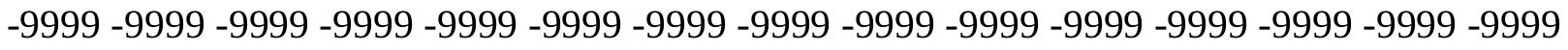

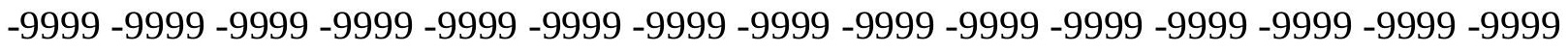
-9999 -9999 -9999 -9999 -9999 -9999 392.5632019043386 .4674987793380 .3717956543 373.0570068359362 .9991149902351 .112487793337 .7019042969324 .5961914062 314.5382080078306 .6138000488299 .2990112305293 .8128967285289 .8505859375 288.0219116211288.6315002441290.1553955078291.6794128418293.5080871582 
296.2510986328161 .6987915039162 .6585998535163 .5796813965164 .4515686035 165.2651977539166 .011932373166 .6851501465167 .278793335167 .7891998291 168.2134399414168 .5512237549168 .8031005859168 .9722595215169 .0627441406 169.0810546875169 .0344543457168 .9320526123166 .4127044678165 .4983062744 168.3763427734168 .1325378418167 .867980957167 .5861053467167 .2891540527 166.9786834717166 .6553344727166 .3191070557165 .9691009521165 .6040344238 165.2221984863164 .8215179443164 .3986053467163 .9492492676163 .4689788818 162.9552612305162 .408706665158 .3052978516155 .7496032715153 .0021057129 150.8686065674149 .3446960449148 .4304046631147 .8208007812146 .9064025879 145.3825073242143 .8585968018142 .6394042969141 .7250976562141 .1154937744 140.8106994629141 .1154937744141 .7250976562142 .6394042969143 .5538024902 144.1634063721145 .0776977539145 .6873016357145 .9920959473145 .6873016357 145.3825073242144 .4682006836143 .2489929199141 .7250976562139 .8963928223 137.7628936768135 .6293945312133 .8007049561131 .9720001221130 .7528076172 132.8863067627130 .5131072998130 .4105377197107 .2844009399107 .5891036987 107.8938980103107 .5891036987107 .5891036987107 .2844009399107 .5891036987 109.1130981445110 .9418029785110 .9418029785111 .24659729113 .6848983765 117.0374984741120 .6949005127124 .6570968628127 .7050018311130 .4479980469 133.1911010742134 .1054992676131 .0576019287126 .4858016968122 .5235977173 119.1709976196117 .647102356115 .2088012695109 .1130981445103 .0174026489 99.6647262573298 .7503814697399 .96952056885103 .0174026489107 .5891036987 112.1608963013113 .9896011353114 .5991973877112 .7705001831109 .7226028442 106.3700027466103 .6268997192104 .8460998535106 .979598999107 .8938980103 108.8082962036110 .3321990967111 .8561019897112 .1608963013111 .24659729 115.818397522118 .5614013672113 .075302124124 .9618988037115 .2088012695 109.1130981445123 .1332015991101 .798202514694 .1785964965886 .2541885376 81.9871978759879 .8537063598680 .1584930419983 .206336975190 .21640014648 95.0929565429785 .0350494384876 .1962814331184 .4254837036197 .53124237061 108.8082962036112 .3878479004111 .3306503296110 .2588348389109 .1709060669 108.0649871826106 .9387817383105 .7904663086104 .6183395386103 .4214477539 102.199798584100 .955741882399 .6941604614398 .4229583740297 .15211486816 95.8929672241294 .6579971313593 .4604873657292 .3155364990291 .23767089844 90.2455215454189 .3537521362388 .5934906005987 .9447937011787 .38648986816 86.889083862386 .4146575927785 .9210586547985 .3690872192484 .75514221191 84.1564483642683 .7311096191483 .6855087280384 .1177215576284 .68394470215 84.3880386352582 .0503311157279 .5489196777378 .6345596313577 .1106262207 77.110626220774 .062782287673 .4532165527373 .7580032348674 .97714233398 76.8058471679779 .2441329956181 .6824111938583 .8159103393685 .94940185547 87.7557830810588 .9972534179789 .9116134643690 .4205932617290 .63938903809 90.6844863891690 .6338653564590 .5465316772590 .4575424194390 .38667297363 90.3228683471790 .1938018798889 .9116134643689 .9116134643689 .3020401001 88.99725341797 88.69246673584 88.99725341797 89.3020401001 89.60682678223 -9999 -9999 -9999 -9999 -9999 -9999 -9999 -9999 -9999 -9999 -9999 -9999 -9999 -9999 -9999 -9999 -9999 -9999 -9999 -9999 -9999 -9999 -9999 -9999 -9999-9999 -9999 -9999 -9999 -9999 -9999 -9999 -9999 -9999 -9999 -9999 -9999 -9999 -9999 -9999 -9999 -9999 -9999 -9999 -9999 -9999 -

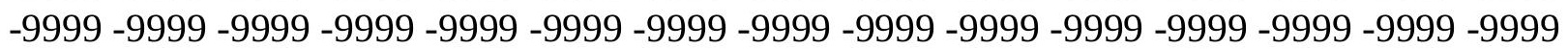


-9999 -9999 -9999 -9999 -9999 -9999 -9999 -9999 -9999 -9999 -9999 -9999 -9999 -9999 -9999 -9999 -9999 -9999 -9999 -9999 -9999 -9999 -9999 -9999 -9999 -9999 -9999 -9999 -9999 -9999

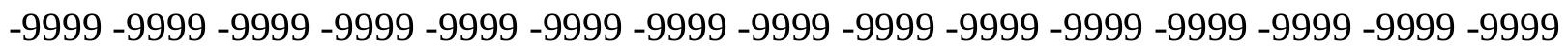
-9999 -9999 -9999-9999

-9999 -9999 -9999 -9999 -9999 -9999 -9999 -9999 -9999 -9999 -9999 -9999 -9999 -9999 -9999 -9999 -9999 -9999 -9999 -9999 -9999 -9999 -9999 -9999 -9999 -9999 -9999 -9999 -9999 -9999

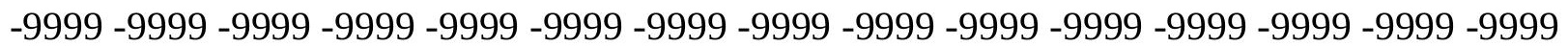
-9999 -9999 -9999 -9999 -9999 -9999 385.858001709379 .1527099609371 .5331115723 362.0846862793349 .8933105469336 .7875976562323 .6817932129312 .1000061035 303.5660095215296 .5559082031290 .1553955078284 .6693115234281 .6214904785 281.3167114258284 .3645019531287 .1076049805286 .4979858398286 .1932067871 161.0799560547162 .1269989014163 .1455383301164 .1236877441165 .0497436523 165.9135437012166 .7054138184167 .4178314209168 .0438690186168 .5792388916 169.020401001169 .3668212891169 .6188812256169 .7800292969169 .8546905518 169.850189209169 .774887085169 .6396179199169 .4553222656169 .2330322266 168.9818878174168 .7092895508168 .4204101562168 .1188812256167 .8069763184 167.4859771729167 .1560668945166 .8165130615166 .4652862549166 .0996246338 165.7161407471165 .311126709164 .8793029785164 .4145507812163 .9108886719 163.3653106689162 .6549987793160 .485244751157 .878692627154 .8307952881 152.6972961426151 .1734008789150 .2590942383149 .9542999268149 .6495056152 147.8208007812146 .2969055176145 .0776977539144 .1634063721143 .5538024902 143.5538024902143 .5538024902143 .8585968018144 .4682006836145 .0776977539 145.6873016357146 .2969055176146 .6015930176146 .6015930176146 .6015930176 145.9920959473145 .0776977539143 .8585968018142 .3347015381140 .8106994629 138.9819946289136 .8484954834134 .7149963379133 .1911010742132 .2767028809 133.1911010742135 .0198059082134 .3419799805138 .3724975586139 .2868041992 139.8963928223106 .0652008057106 .0652008057106 .0652008057106 .6747970581 108.1986999512109 .7226028442110 .0273971558110 .3321990967112 .1608963013 114.5991973877117 .647102356120 .6949005127123 .1332015991125 .8762969971 128.9241027832130 .4479980469129 .2288970947126 .1809997559123 .1332015991 120.3900985718118 .5614013672116 .4279022217112 .1608963013107 .5891036987 105.1509017944103 .9317016602105 .1509017944107 .5891036987111 .24659729 114.2944030762116 .4279022217117 .0374984741115 .5136032104110 .6370010376 102.102996826295 .0929565429795 .7025299072399 .96952056885104 .5412979126 109.1130981445112 .7705001831115 .2088012695116 .4279022217115 .818397522 113.3800964355118 .2565994263113 .9896011353121 .6092987061124 .6570968628 119.1709976196127 .704460144126 .7185134888105 .455703735496 .31210327148 90.8259735107488 .3876876831188 .9972534179790 .8259735107493 .56903076172 93.5690307617286 .8637619018681 .3776321411184 .7302627563592 .04509735107 99.66472625732106 .979598999111 .8520431519110 .7911758423109 .7142181396 108.6192779541107 .5041351318106 .3671035767105 .2066726685104 .0221481323 102.8137893677101 .5841903687100 .338356018199 .0840606689597 .83095550537 96.5899429321395 .3729934692494 .1929016113393 .0639572143692 .00090789795 91.0196456909290 .1367492675889 .3684158325288 .7343902587988 .20690155029 87.75682830811 87.3544006347786.97491455078 86.60652923584 86.267578125 86.0165939331185 .940849304286 .0962524414186 .3957214355586 .48320007324 
85.701316833584 .0740203857481 .3431091308677 .4154205322375 .58670806885 73.7580032348673 .4532165527371 .014930725171 .3197174072372 .84364318848 75.2819290161177 .7202072143680 .7680587768683 .5111236572385 .64462280273 87.4239807128988.6243438720789.302040100189.6240997314589.69561004639 89.6382293701289 .5366210937589 .4457092285289 .3913497924889 .37710571289 89.37998199463 89.35704040527 89.3020401001 89.2421646118288.99725341797 88.6924667358488 .3876876831187 .7781066894588 .0829010009888 .38768768311 88.6924667358489 .3020401001 -9999 -9999 -9999 -9999 -9999 -9999 -9999 -9999 -9999

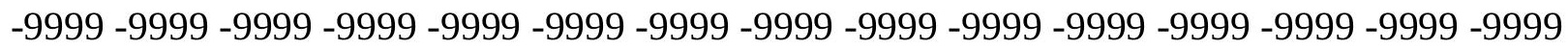

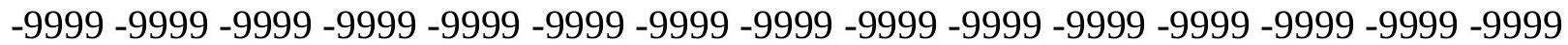

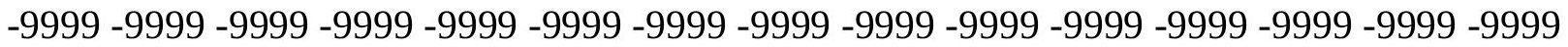

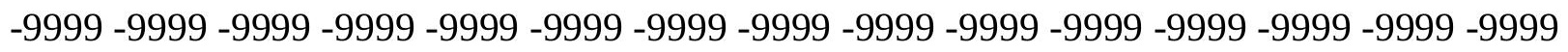

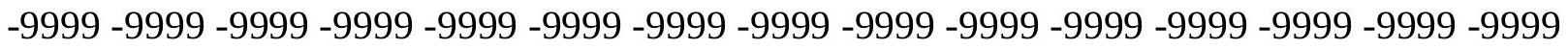

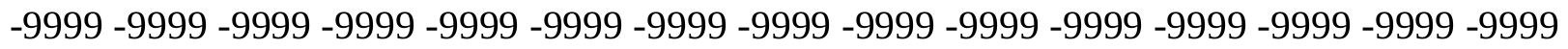
-9999 -9999 -9999 -9999 -9999 -9999 -9999 -9999 -9999

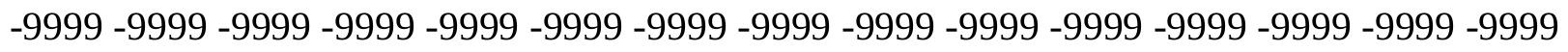

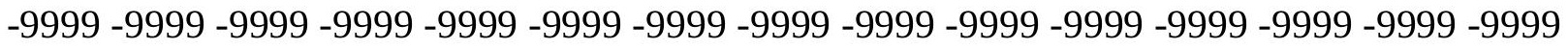
-9999-9999 -9999 -9999 -9999 -9999-9999 377.93359375371 .5331115723362 .3894958496 350.8077087402336 .7875976562322 .7674865723310 .5759887695300 .8229064941 292.8984985352286 .1932067871280 .0975036621275 .5257873535273 .0874938965 272.7827148438276 .4400939941279 .7927856445277 .3544921875160 .346862793 161.4674072266162 .5735321045163 .6511688232164 .6870269775165 .6680908203 166.5830841064167 .4211730957168 .1738891602168 .8332977295169 .394317627 169.8526763916170 .2073516846170 .4584197998170 .6094818115170 .6653137207 170.6340789795170 .5253143311170 .3516082764170 .1262969971169 .8632507324 169.5742340088169 .2685699463168 .9524688721168 .6299438477168 .3032989502 167.9735412598167 .6402130127167 .3014678955166 .9538269043166 .5927124023 166.2126159668165 .8076934814165 .3705749512164 .8932342529164 .3680877686 163.7915802002163 .164855957162 .4505004883159 .0977935791156 .3547973633 154.2212982178152 .3925933838151 .4781951904150 .8686065674150 .5639038086 149.3446960449 148.1255950928 147.2111968994 146.2969055176145.9920959473 145.6873016357145 .9920959473146 .2969055176146 .6015930176146 .9064025879 147.2111968994147 .5160064697147 .8208007812147 .8208007812147 .5160064697 146.9064025879145 .9920959473145 .0776977539143 .8585968018142 .3347015381 140.5059967041138 .6772003174137 .1533050537135 .6293945312135 .3246002197 135.6293945312136 .5437011719136 .8096618652138 .9819946289139 .8963928223 140.5059967041140 .8106994629141 .4203033447141 .7250976562106 .6747970581 107.5891036987108 .1986999512109 .1130981445110 .0273971558111 .551399231 113.6848983765115 .818397522118 .2565994263119 .7806015015121 .6092987061 124.3523025513126 .1809997559126 .1809997559124 .9618988037123 .1332015991 121.3044967651119 .1709976196116 .7326965332114 .2944030762111 .551399231 109.7226028442108 .8082962036109 .7226028442111 .24659729113 .3800964355 115.5136032104117 .647102356117 .9517974854115 .5136032104109 .4179000854 96.6168823242286 .254188537687 .1685485839893 .26425170898101 .7982025146 110.3321990967115 .5136032104118 .5614013672120 .0852966309120 .3900985718 
119.1709976196117 .9517974854117 .647102356119 .1709976196123 .1332015991 121.9140014648128 .0729522705127 .0942459106126 .1217269897122 .8283996582 101.798202514699 .3599472045999 .6647262573299 .9695205688598 .4455871582 96.3121032714896 .3121032714896 .9216690063595 .7025299072396 .00731658936 99.05516815186103 .3221969604106 .3700027466108 .8082962036110 .2946166992 109.2148895264 108.1154251099106.9947357178105.8515548706 104.6854324341 103.496925354102 .2888565063101 .066246032799 .8365631103598 .60887145996 97.39328765869 96.2008743286195.043380737393.934013366792.88645935059 91.9162368774491 .0370483398490 .2698516845789 .62416839689 .11801147461 88.7043609619188 .3708877563588 .1118392944387 .9297561645587 .84053039551 87.8704986572388 .0382843017688 .3116226196388 .550643920988 .48509216309 87.8209228515686 .5160217285284 .7658309936582 .5967712402373 .75800323486 71.9292907714870 .4053573608469 .1862335205169 .4910125732471 .31971740723 74.062782287677 .4154205322380 .4632720947383 .5111236572385 .94940185547 87.47332763672 88.3641967773488.72972106934 88.76997375488 88.63925170898 88.45676422119 88.30173492432 88.21964263916 88.22121429443 88.29692077637 88.4196929931688 .5550003051888 .6882476806688 .7594146728588 .69246673584 88.6924667358488 .0829010009887 .7781066894587 .4733276367287 .16854858398 87.4733276367288 .0829010009888 .3876876831188 .99725341797 -9999 -9999 -9999 -9999 -9999 -9999-9999 -9999 -9999 -9999 -9999 -9999 -9999-9999 -9999-9999 -9999-9999-9999 -9999 -9999 -9999 -9999 -9999 -9999 -9999 -9999 -9999 -9999 -9999 -9999 -9999 -9999 -9999 -9999 -9999 -9999 -9999 -9999 -9999 -9999 -9999 -9999 -9999 -9999 -9999 -9999 -9999 -9999 -9999 -9999 -9999 -9999 -9999 -9999 -9999 -9999 -9999 -9999 -9999 -9999 -9999 -9999 -9999 -9999 -9999 -9999 -9999 -9999 -9999 -9999 -9999 -9999 -9999 -9999 -9999 -9999 -9999 -9999 -

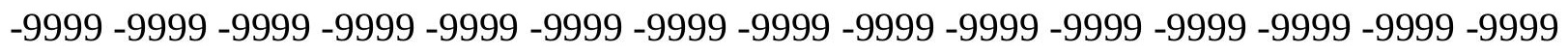
-9999 -9999 -9999 -9999 -9999 -9999 -9999 -9999 -9999 -9999 -9999 -9999 -9999 -9999 -9999 -9999 -9999 -9999 -9999 -9999 -9999 -9999 -9999 -9999 -9999 -9999 -9999

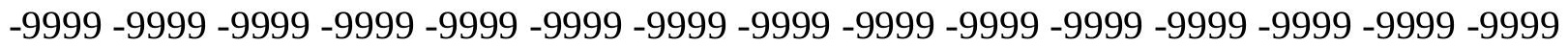
-9999 -9999 -9999 -9999 -9999 -9999 -9999 -9999 -9999 -9999 -9999 -9999 -9999 -9999 -9999 -9999 -9999 -9999 -9999 -9999 -9999 -9999 362.9991149902 354.7698974609 343.1879882812 325.2056884766307 .8330078125297 .1654968262289 .2410888672280 .4023132324 273.0874938965268 .5156860352265 .7726135254262 .7247924805260 .8960876465 261.2008972168261 .5056152344159 .5219573975160 .6962432861161 .8736724854 163.0386199951164 .1753997803165 .269241333166 .3058166504167 .272644043 168.1578216553168 .9517974854169 .6455688477170 .2330627441170 .7089996338 171.0716705322171 .3205871582171 .4593200684171 .492980957171 .4305725098 171.2828216553171 .064239502170 .7908935547170 .4801330566170 .1470184326 169.8032836914169 .4566650391169 .1116485596168 .7706298828168 .4342803955 168.1013946533167 .7685241699167 .430267334167 .0797729492166 .7091064453 166.3098449707165 .8722229004165 .3862457275164 .8427734375164 .2376098633 163.571975708162 .8541564941160 .3170013428157 .5738983154155 .4403991699 153.6116943359152 .3925933838151 .4781951904151 .1734008789150 .2590942383 149.6495056152148 .7351074219148 .4304046631148 .1255950928147 .8208007812 148.1255950928148 .1255950928148 .4304046631148 .7351074219149 .0399017334 149.0399017334149 .0399017334149 .0399017334148 .7351074219148 .1255950928 147.5160064697146 .6015930176145 .6873016357144 .4682006836142 .9441986084 
141.7250976562140 .2012023926139 .2868041992138 .6772003174138 .6772003174 138.9819946289139 .2488098145140 .5059967041140 .8106994629141 .4203033447 141.7250976562142 .0299072266142 .3347015381142 .6394042969142 .9441986084 143.2489929199143 .2489929199110 .0273971558111 .24659729112 .7705001831 114.5991973877116 .4279022217117 .9517974854119 .4757995605121 .6092987061 123.1332015991123 .43800354123 .1332015991122 .5235977173120 .9997024536 119.4757995605117 .647102356115 .818397522114 .2944030762113 .075302124 112.4656982422112 .7705001831113 .9896011353114 .9039993286115 .818397522 116.4279022217114 .5991973877109 .4179000854101 .493400573790 .21640014648 81.6824111938583 .5111236572391 .43553924561103 .0174026489114 .2944030762 119.7806015015121 .9140014648123 .43800354123 .43800354122 .8283996582 121.9140014648121 .9140014648121 .9140014648122 .5235977173122 .8283996582 128.4300079346127 .460144043126 .4972000122125 .5401382446124 .5878219604 123.6389083862109 .4179000854107 .5891036987104 .5412979126103 .0174026489 103.3221969604104 .2365036011103 .9317016602102 .712600708102 .712600708 103.6268997192105 .1509017944106 .979598999108 .8082962036109 .8492050171 108.7697982788107 .6702270508106 .5494995117105 .4074783325104 .2450332642 103.0652008057101 .8730010986100 .675430297999 .4807662963998 .29804992676 97.1370697021596 .008094787694 .9226913452193 .8930740356492 .93321990967 92.0607223510791 .289337158290 .6463317871190 .1253967285289 .72385406494 89.44281005859 89.29048919678 89.27687072754 89.40813446045 89.67865753174 90.0573196411190 .4676208496190 .772323608490 .7883071899490 .36837768555 89.3967437744187 .6428146362384 .4742431640679 .2441329956170 .40535736084 69.4910125732468 .8814392089868 .8814392089870 .7101516723674 .0627822876 77.7202072143681 .3776321411184 .1206970214886 .5589828491287 .77810668945 88.08290100098 87.997215271 87.70678710938 87.3493728637787.04851531982 86.8656616210986 .8239517211986 .9174728393687 .1238098144587 .41148376465 87.7411499023488 .0723876953188 .3592224121188 .5598373413188 .58522033691 88.38768768311 88.08290100098 87.77810668945 87.47332763672 87.16854858398 86.86376190186 87.16854858398 87.77810668945 88.08290100098 -9999 -9999 -9999 -9999 -9999 -9999 -9999 -9999 -9999 -9999 -9999 -9999 -9999 -9999 -9999 -9999 -9999 -9999 -9999 -9999 -9999 -9999 -9999 -9999 -9999 -9999 -9999 -9999 -9999 -9999 -9999 -9999 -9999-999 -999 -

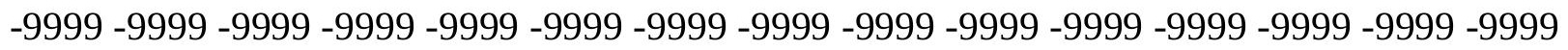

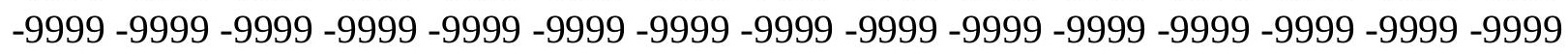
-9999 -9999 -9999 -9999 -9999 -9999 -9999 -9999 -9999 -9999 -9999 -9999 -9999 -9999 -9999

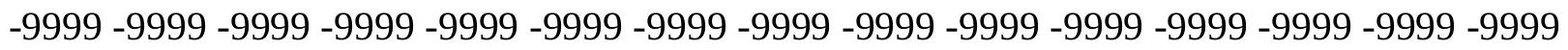

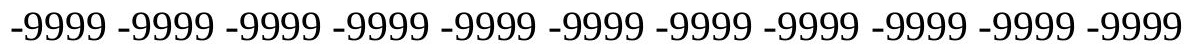

-9999 -9999 -9999 -9999 -9999 -9999 -9999 -9999 -9999 -9999 -9999 -9999 -9999 -9999 -9999 -

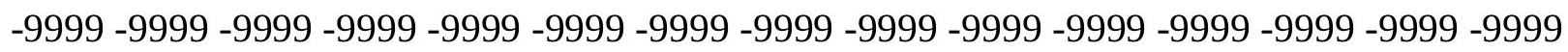

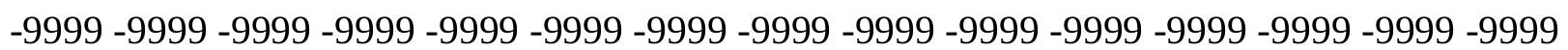
-9999-9999-9999-9999-9999-9999-9999 355.0747070312 347.4549865723335 .8731994629 315.4526062012295 .6416015625285 .5835876465278 .8783874512268 .8204956055 260.5913085938257 .5433959961256 .0195007324252 .3621063232248 .7046966553 245.0471954346158 .6373443604159 .8394317627161 .0657501221162 .299407959 163.5228424072164 .7185668945165 .8702697754166 .9623260498167 .9812164307 168.9139556885169 .75170 .4791412354171 .0940704346171 .5882263184171 .9587860107 
172.2044372559172 .3284606934172 .3361358643172 .2373657227172 .0442199707 171.7733612061171 .4440612793171 .0777282715170 .6934356689170 .3059692383 169.924987793169 .5558929443169 .2011871338168 .861038208168 .5331268311 168.2120361328167 .8897857666167 .5567779541167 .2023010254166 .8151855469 166.3830108643165 .8936309814165 .3363647461164 .7061920166164 .0042419434 163.2415618896161 .2312927246158 .7929992676156 .3547973633154 .5260925293 152.6972961426152 .3925933838151 .7830047607151 .1734008789150 .8686065674 150.2590942383149 .9542999268149 .9542999268149 .9542999268149 .9542999268 150.2590942383150 .2590942383150 .5639038086150 .5639038086150 .5639038086 150.5639038086150 .2590942383149 .9542999268149 .6495056152149 .0399017334 148.4304046631147 .8208007812146 .9064025879145 .9920959473144 .7729034424 143.8585968018143 .2489929199142 .6394042969142 .3347015381142 .3347015381 142.2353057861141 .7840270996142 .6394042969142 .6394042969142 .6394042969 142.9441986084142 .9441986084142 .9441986084142 .9441986084142 .9441986084 142.9441986084142 .6394042969142 .0299072266141 .4203033447113 .6848983765 115.2088012695117 .0374984741118 .5614013672119 .7806015015120 .9997024536 121.3044967651121 .6092987061121 .3044967651120 .6949005127119 .4757995605 118.2565994263117 .342300415116 .1231002808115 .5136032104114 .9039993286 115.2088012695115 .5136032104116 .1231002808115 .818397522114 .2944030762 110.6370010376103 .322196960494 .4833908081185 .9494018554781 .37763214111 84.4254837036193 .56903076172106 .3700027466118 .2565994263122 .8283996582 124.3523025513125 .5715026855125 .5715026855125 .2667007446124 .9618988037 124.6570968628124 .6570968628124 .6570968628123 .7427978516119 .4757995605 116.1231002808126 .8629226685125 .9178924561124 .9784317017124 .0432052612 123.1108016968122 .179649353121 .2481384277110 .3321990967109 .7226028442 109.4179000854110 .0273971558110 .0273971558108 .1986999512106 .6747970581 106.979598999108 .1986999512110 .0273971558110 .5187225342109 .4633331299 108.389175415107 .2955780029106 .1827774048105 .0520324707103 .9066009521 102.751449585101 .5930557251100 .438796997199 .2964782714898 .17433929443 97.0808334350696 .0253753662195 .0180816650494 .0726928710993 .20561218262 92.4344406127991 .76479339691 .2129974365290 .7968826293990 .5394821167 90.4672622680790 .5989608764690 .9321823120191 .4345321655392 .0373916626 92.638534545993 .108398437593 .3094863891693 .1070709228592 .33079528809 90.6873092651487 .5918579101683 .1482238769577 .4154205322369 .49101257324 69.4910125732471 .3197174072371 .6244964599675 .2819290161178 .93934631348 82.5967712402385 .3398437587 .1685485839887 .7781066894587 .47332763672 86.8637619018686 .241775512785 .6446228027385 .3220977783285 .17568206787 85.2326660156285 .4620742797985 .8442611694386 .3438339233486 .90921020508 87.4852752685588 .0119247436588 .428428649988 .6807327270588 .7660446167 88.69246673584 88.38768768311 88.08290100098 87.47332763672 86.86376190186 86.2541885376 86.2541885376 86.86376190186 87.16854858398 87.47332763672 -9999 -9999 -9999 -9999 -9999 -9999 -9999 -9999 -9999 -9999 -9999 -9999 -9999 -9999 -9999 -9999 -9999 -9999 -9999 -9999 -9999 -9999 -9999 -9999 -9999 -9999 -9999 -9999 -9999 -9999 -9999 -9999 -9999 -9999 -9999 -9999 -9999 -9999 -9999 -9999 -9999 -9999 -9999 -9999 -9999 -9999 -9999 -9999 -9999 -9999 -9999 -9999 -9999 -9999 -9999 -9999 -9999 -9999 -9999 -9999 -9999 -9999 -

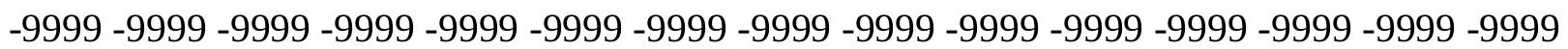


-9999 -9999 -9999 -9999 -9999 -9999 -9999 -9999 -9999 -9999 -9999 -9999 -9999 -9999 -9999 -9999 -9999 -9999 -9999 -9999 -9999 -9999 -9999 -9999 -9999 -9999

-9999 -9999 -9999 -9999 -9999 -9999 -9999 -9999 -9999 -9999 -9999 -9999 -9999 -9999 -9999 -9999 -9999 -9999 -9999 -9999 -9999 -9999 -9999 -9999 -9999 -9999 -9999 -9999 -9999 -9999 -9999 -9999 -9999 -9999 -9999 -9999 -9999 -9999 -9999 -9999 -9999 -9999 -9999 -9999 -9999 -9999 -9999 -9999 -9999 -9999 -9999 -9999 -9999 338.9211120605325 .5104980469 307.8330078125290 .7650146484278 .5736083984269 .4301147461259 .9816894531 252.6669006348249 .0093994141245 .9615936279242 .3041992188238 .3419952393 233.4653930664158 .9325866699160 .1789398193161 .4566345215162 .746307373 164.0280303955165 .2822570801166 .4911499023167 .6379699707168 .708404541 169.6887054443170 .5673675537171 .3329162598171 .9765014648172 .4897918701 172.8684387207173 .1097869873173 .2165374756173 .193939209173 .0528259277 172.8068084717172 .4751434326172 .0807647705171 .649810791171 .2061920166 170.768371582170 .3486328125169 .9536590576169 .5863647461169 .2459106445 168.928314209168 .6255950928168 .3266906738168 .0186462402167 .6876373291 167.319732666166 .9000854492166 .4142913818165 .8492279053165 .1997833252 164.4662780762163 .6594848633161 .8408966064159 .7073974609157 .5738983154 155.7451934814154 .2212982178153 .6116943359153 .0021057129152 .3925933838 152.0877990723151 .7830047607151 .7830047607151 .7830047607151 .7830047607 151.7830047607152 .0877990723152 .0877990723152 .0877990723152 .0877990723 152.0877990723152 .0877990723151 .7830047607151 .4781951904151 .1734008789 150.8686065674150 .5639038086149 .9542999268149 .6495056152149 .0399017334 148.4304046631147 .8208007812147 .5160064697146 .9064025879146 .6015930176 145.9920959473145 .6873016357144 .982711792144 .4682006836144 .1634063721 143.8585968018143 .5538024902143 .5538024902143 .2489929199143 .2489929199 142.9441986084142 .6394042969142 .3347015381141 .7250976562141 .1154937744 139.8963928223138 .6772003174137 .1533050537117 .342300415118 .5614013672 119.4757995605120 .0852966309120 .3900985718120 .3900985718120 .0852966309 119.4757995605118 .8662033081118 .2565994263117 .647102356117 .0374984741 116.7326965332116 .7326965332116 .7326965332116 .4279022217115 .2088012695 113.3800964355109 .4179000854103 .322196960496 .6168823242288 .38768768311 84.1206970214889 .302040100198 .75038146973109 .7226028442119 .1709976196 123.7427978516125 .8762969971127 .0953979492127 .4001998901127 .4001998901 127.4001998901127 .7050018311127 .7050018311127 .4001998901126 .1809997559 123.1332015991120 .9997024536120 .9997024536121 .9140014648122 .8283996582 124.4412536621123 .5253143311122 .6115341187121 .6982727051120 .783821106 114.9039993286113 .6848983765114 .2944030762113 .6848983765111 .8561019897 110.0273971558109 .7226028442110 .9418029785112 .2311019897111 .2198638916 110.1921005249109 .1471710205108 .0848083496107 .0056991577105 .9115905762 104.8060150146103 .6938781738102 .5811309814101 .4742736816100 .3798370361 99.3044586181698 .2545166015697 .2368698120196 .2588500976695 .33014678955 94.4712371826293 .6847915649492 .9759368896592 .3714675903391 .90802764893 91.636154174891 .6090850830191 .8623504638792 .3910217285293 .13947296143 94.002090454194 .8484725952195 .5444641113395 .9715652465896 .01301574707 95.5164337158294 .250144958591 .9636611938588 .489120483484 .05410766602 78.6345596313571 .3197174072371 .9292907714874 .062782287678 .02498626709 
81.07285308838 83.51112365723 85.64462280273 87.16854858398 87.16854858398 85.9494018554785 .0350494384884 .1206970214883 .5111236572383 .2063369751 83.206336975183 .4396057128983 .8447875976684 .4524612426885 .20863342285 86.0497741699286 .8999938964887 .6909561157288 .3574142456188 .86818695068 89.18522644043 89.25998687744 88.9972534179788.6924667358488.08290100098 87.1685485839886 .5589828491285 .9494018554785 .3398437585 .64462280273 85.9494018554786 .254188537686 .2541885376 -9999 -9999 -9999 -9999 -9999 -9999 -9999 -9999 -9999 -9999 -9999 -9999 -9999 -9999 -9999 -9999 -9999 -9999 -9999 -9999 -9999 -9999

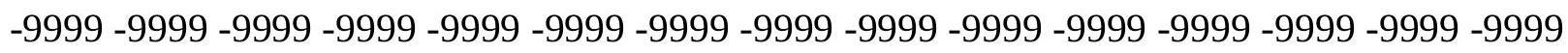
-9999 -9999 -9999 -9999 -9999 -9999 -9999 -9999 -9999 -9999 -9999 -9999 -9999 -9999 -9999 -

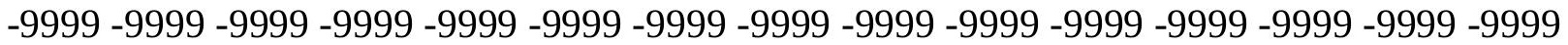
-9999 -9999 -9999 -9999 -9999 -9999 -9999 -9999 -9999 -9999 -9999 -9999 -9999 -9999 -9999 -

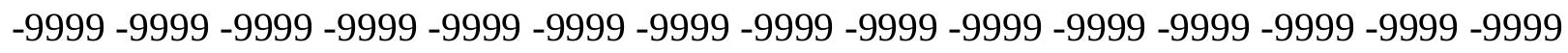
-9999 -9999 -9999-9999

-9999 -9999 -9999 -9999 -9999 -9999 -9999 -9999 -9999 -9999 -9999 -9999 -9999 -9999 -9999

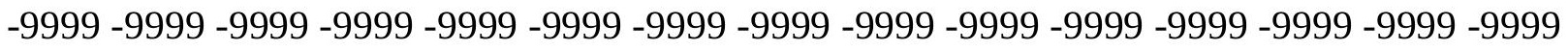

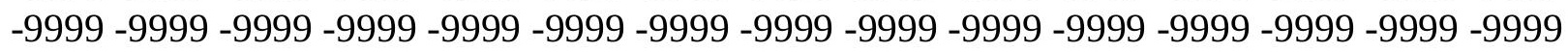
-9999 -9999 -9999 -9999 -9999 -9999 -9999 -9999 331.6062011719316 .6718139648 302.9563903809289 .2410888672275 .2210083008263 .0296020508254 .1907958984 247.7902984619242 .6089935303238 .3419952393234 .9893035889230 .7223052979 158.0206298828159 .2505340576160 .5410308838161 .8709106445163 .2174530029 164.5576171875165 .8695831299167 .1340484619168 .3337097168169 .4540863037 170.4811401367168 .8509979248171 .5939941406172 .8794555664173 .4132232666 173.8004455566174 .0366516113174 .123550415174 .0661315918173 .8760375977 173.5687713623173 .1666717529172 .6968536377172 .1908569336171 .6782684326 171.1824035645170 .7189025879170 .2962646484169 .9177093506169 .5811004639 169.2798919678 169.0026855469 168.7347106934168.4592132568 168.1589508057 167.8174591064167 .4178466797166 .944519043166 .3832550049165 .721572876 164.9653930664164 .1137542725162 .7552947998160 .6217956543158 .7929992676 157.2691040039155 .7451934814154 .8307952881154 .2212982178153 .9165039062 153.6116943359153 .3069000244153 .6116943359153 .6116943359153 .6116943359 153.9165039062153 .9165039062153 .9165039062153 .9165039062153 .9165039062 153.6116943359153 .6116943359153 .6116943359153 .3069000244153 .0021057129 153.0021057129152 .6972961426152 .6972961426152 .6972961426152 .3925933838 152.3925933838152 .0877990723151 .7830047607151 .4781951904151 .1734008789 150.2590942383149 .0399017334147 .8208007812146 .6015930176145 .6873016357 145.0776977539144 .4682006836144 .1634063721143 .5538024902143 .2489929199 142.9441986084142 .6394042969142 .0299072266141 .4203033447140 .8106994629 139.8963928223138 .3724975586137 .1533050537135 .3246002197133 .1911010742 131.0576019287118 .8662033081119 .4757995605119 .4757995605119 .4757995605 119.1709976196118 .8662033081118 .5614013672118 .2565994263117 .9517974854 117.647102356117 .647102356117 .0374984741116 .4279022217114 .9039993286 112.7705001831109 .7226028442106 .0652008057101 .798202514694 .78817749023 91.1307525634896 .92166900635105 .7603988647113 .075302124119 .1709976196 123.43800354125 .8762969971127 .4001998901128 .0097961426128 .6192932129 128.9241027832129 .2288970947129 .533706665129 .8385009766129 .533706665 
128.3144989014127 .4001998901125 .8762969971124 .9618988037124 .0475006104 123.1332015991123 .43800354123 .0390472412122 .146156311121 .2530441284 120.3579406738118 .5614013672117 .0374984741116 .4279022217114 .9039993286 113.6848983765113 .075302124113 .8976593018112 .9301757812111 .9482879639 110.9512329102109 .9387969971108 .9111328125107 .8694076538106 .8159332275 105.7546081543104 .6903533936103 .628692627102 .5753326416101 .535736084 100.51504516699 .5176315307698 .5475234985497 .608535766696 .7067489624 95.8522186279393 .5690307617292 .6546783447393 .6144104003993 .06784820557 92.734657287692 .7108535766693 .0596237182693 .7859191894594 .80484008789 95.9710083007897 .1021881103598 .0557250976698 .7246322631899 .0456161499 98.9453201293998 .3074417114397 .0254516601695 .0384826660292 .35181427002 89.1054000854584 .4254837036175 .5867080688579 .8537063598682 .29197692871 82.5967712402382 .9015579223683 .8159103393686 .254188537684 .42548370361 82.9015579223681 .9871978759881 .0728530883880 .7680587768680 .76805877686 81.0728530883881 .3776321411182 .0563812255982 .9472961425883 .99680328369 85.14688873291 86.29071807861 87.36040496826 88.28984832764 89.03534698486 89.559013366789 .8526916503989 .9116134643689 .302040100188 .69246673584 87.7781066894587 .1685485839886 .254188537685 .3398437584 .73026275635 84.7302627563585 .0350494384885 .0350494384885 .0350494384885 .03504943848 -9999 -9999 -9999-9999 -9999 -9999 -9999 -9999 -9999 -9999-9999 -9999 -9999 -9999 -9999 -9999

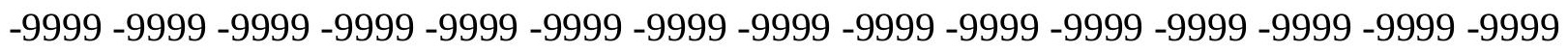
-9999 -9999 -9999 -9999 -9999 -9999 -9999 -9999 -9999 -9999 -9999 -9999 -9999 -9999 -9999 -9999 -9999 -9999 -9999 -9999 -9999 -9999 -9999 -9999 -9999 -9999 -9999 -9999 -9999 -9999 -

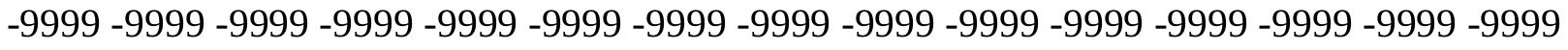

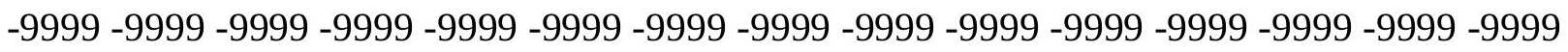
-9999 -9999 -9999 -9999 -9999 -9999 -9999 -9999

-9999 -9999 -9999 -9999 -9999 -9999 -9999 -9999 -9999 -9999 -9999 -9999 -9999 -9999 -9999

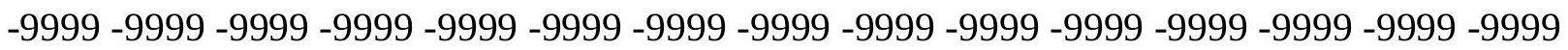

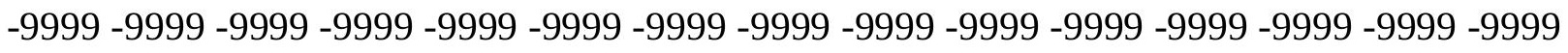
-9999 -9999 -9999 -9999 -9999 -9999 -9999 -9999 329.7774963379314 .2334899902 301.4324951172288 .9363098145275 .2210083008262 .1152038574251 .7525024414 244.1329040527 240.1707000732 237.1228027344234.3798065186 157.1589508057 158.3266906738159 .5895996094160 .9267120361162 .3140563965163 .7203369141 165.120300293166 .4856262207167 .8022766113169 .0518341064170 .2187957764 168.241394043168 .241394043170 .6797027588173 .8023986816174 .3584136963 174.754989624174 .9852142334175 .0495605469174 .9524993896174 .7064819336 174.3288421631173 .8455352783173 .2885131836172 .6953582764172 .102432251 171.5392150879171 .0261230469170 .5738677979170 .1859283447169 .8563232422 169.5841064453169 .3469390869169 .1227264404168 .8895263672168 .6262359619 168.3138885498167 .9378967285167 .4845123291166 .9370574951166 .2779083252 165.5018463135164 .6040344238163 .3648071289161 .5361022949160 .0122070312 158.4882965088157 .2691040039156 .3547973633155 .7451934814155 .4403991699 155.1356048584155 .1356048584155 .1356048584155 .1356048584155 .4403991699 155.4403991699155 .4403991699155 .4403991699155 .4403991699155 .4403991699 155.1356048584155 .1356048584155 .1356048584155 .1356048584155 .1356048584 155.1356048584155 .1356048584155 .4403991699155 .7451934814156 .0500030518 
156.3547973633156 .3547973633156 .6596069336156 .6596069336156 .0500030518 155.1356048584153 .3069000244150 .5639038086149 .0399017334147 .8208007812 146.6015930176145 .3825073242144 .7729034424143 .8585968018143 .5538024902 142.9441986084142 .3347015381142 .0299072266141 .4203033447140 .5059967041 139.5915985107138 .3724975586136 .8484954834135 .3246002197133 .4958953857 131.6672058105129 .8385009766127 .7050018311118 .8662033081118 .8662033081 118.8662033081118 .8662033081118 .8662033081118 .8662033081118 .5614013672 118.2565994263117 .9517974854117 .342300415116 .4279022217115 .2088012695 113.075302124110 .9418029785108 .5035018921106 .0652008057102 .712600708 101.7982025146107 .2844009399113 .6848983765117 .647102356120 .6949005127 123.43800354125 .5715026855126 .7906036377127 .7050018311128 .6192932129 129.2288970947129 .8385009766130 .7528076172131 .583984375130 .6420898438 129.7116851807128 .7923278809127 .8834991455126 .4858016968125 .2667007446 124.9618988037124 .3329772949123 .459854126122 .5893630981121 .7197341919 120.8491897583119 .9759292603119 .09815979118 .2142105103117 .3224182129 116.4213790894115 .5096817017114 .586151123113 .6497268677112 .6997909546 111.7360229492110 .7587127686109 .7685241699108 .7670974731107 .7572631836 106.743347168105 .7304458618104 .723815918103 .7286758423102 .7496871948 101.7909698486100 .855186462499 .9437866210999 .0566635131898 .19384002686 95.0929565429785 .3398437584 .1206970214885 .0350494384890 .21640014648 93.2642517089893 .8157348632894 .2320709228595 .1605453491296 .46839904785 97.9737014770599 .40531158447100 .6052932739101 .4781341553102 .0630340576 102.393196106102 .4646453857102 .2528076172101 .7541427612101 .0187072754 100.223396301399 .6647262573294 .4833908081190 .8259735107486 .55898284912 85.6446228027381 .3776321411178 .3297805786179 .2441329956179 .24413299561 78.6345596313578 .0249862670978 .0249862670977 .7202072143678 .02498626709 78.6345596313579 .2441329956180 .1584930419981 .3411941528382 .71484375 84.17749023438 85.6100769043 86.9674987793 88.1559753418 89.10972595215 89.805381774990 .2220687866290 .3008956909289 .9116134643688 .99725341797 88.38768768311 87.47332763672 86.86376190186 85.9494018554785.03504943848 84.4254837036183 .8159103393683 .8159103393684 .1206970214884 .12069702148 83.8159103393683 .81591033936 -9999 -9999 -9999 -9999 -9999 -9999 -9999 -9999 -9999

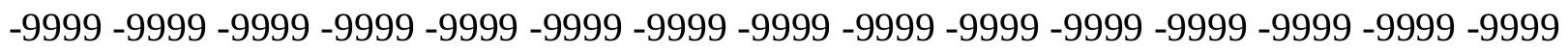
-9999 -9999 -9999 -9999 -9999 -9999 -9999 -9999 -9999 -9999 -9999 -9999 -9999 -9999 -9999 -9999 -9999 -9999 -9999 -9999 -9999 -9999 -9999 -9999 -9999 -9999 -9999 -9999 -9999 -9999

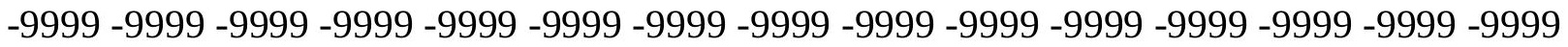

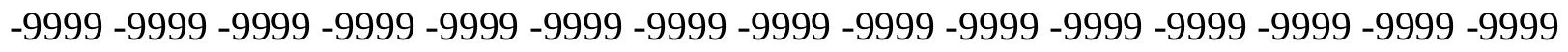

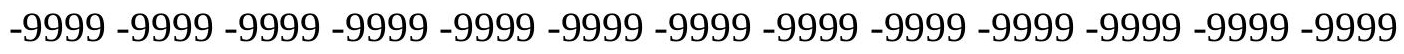
-9999 -9999 -9999 -9999 -9999 -9999 -9999 -9999 -9999 -9999 -9999 -9999 -9999 -9999 -9999 -9999 -9999 -9999 -9999 -9999 -9999 -9999 -9999 -9999 -9999 -9999 -9999 -9999 -9999 -9999 -

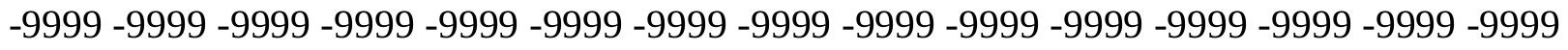
-9999 -9999-9999 -9999 -9999 -9999-9999-9999-9999 313.0143127441 301.1276855469 289.2410888672 276.7449035645264.5534973145252.9716033936244.1329040527 240.4754943848238 .9515075684156 .4184417725157 .4645843506158 .6467285156 159.9504241943161 .3453369141162 .8017883301164 .2762756348165 .7333831787 167.1486816406168 .5043792725169 .7953186035170 .6797027588169 .7653045654 
170.070098877171 .5939941406174 .337097168175 .3249053955175 .7305297852 175.9545898438175 .9923706055175 .8516998291175 .5428161621175 .0856628418 174.5097808838173 .8524932861173 .1583862305172 .4719390869171 .8312988281 171.2607269287170 .7749176025170 .3772735596170 .0728607178169 .8450622559 169.6615142822169 .4939575195169 .3074188232169 .0838165283168 .7976379395 168.4447479248168 .015335083167 .4974212646166 .8505249023166 .0648651123 165.1365356445163 .974395752162 .4505004883161 .2312927246160 .0122070312 158.7929992676157 .878692627157 .2691040039156 .6596069336156 .6596069336 156.6596069336156 .6596069336156 .6596069336156 .9642944336156 .9642944336 156.9642944336156 .9642944336156 .9642944336156 .6596069336156 .6596069336 156.6596069336156 .6596069336156 .6596069336156 .9642944336157 .2691040039 157.5738983154158 .1835021973158 .7929992676159 .4026031494160 .0122070312 160.6217956543161 .2312927246161 .5361022949161 .1127319336159 .8108673096 157.5738983154154 .5260925293151 .7830047607149 .6495056152147 .8208007812 146.2969055176145 .0776977539144 .1634063721143 .5538024902142 .9441986084 142.3347015381141 .7250976562141 .1154937744140 .2012023926139 .2868041992 138.3724975586137 .1533050537135 .6293945312134 .1054992676132 .2767028809 130.7528076172128 .9241027832127 .4001998901125 .5715026855118 .5614013672 118.5614013672118 .8662033081118 .8662033081118 .8662033081118 .5614013672 118.2565994263117 .647102356117 .0374984741115 .818397522114 .2944030762 112.4656982422110 .9418029785110 .0273971558110 .3321990967112 .1608963013 116.1231002808120 .0852966309121 .3044967651122 .2188034058123 .43800354 124.9618988037125 .5715026855126 .4858016968127 .0953979492128 .0097961426 128.9241027832130 .4479980469131 .8300476074130 .9022979736129 .9869384766 129.0836334229128 .1919250488127 .3109741211126 .4398117065125 .5771408081 124.7215881348123 .8715591431123 .0253829956122 .1812744141121 .3374099731 120.4919586182119 .6430664062118 .7889862061117 .927986145117 .0585403442 116.1791381836115 .288520813114 .385559082113 .4698181152112 .5413894653 111.6011657715110 .6504135132109 .6912384033108 .7268981934107 .7620697021 106.8021621704105 .8524475098104 .9179916382104 .0032272339103 .1120529175 102.2456207275101 .4030914307100 .582099914699 .7823486328197 .83602905273 92.0450973510789 .302040100189 .9116134643692 .0450973510793 .26425170898 93.5690307617293 .8738174438595 .7025299072398 .22832489014100 .0273132324 101.7834243774103 .1174850464104 .0760955811104 .8271942139105 .5171508789 106.2185668945106 .9480285645107 .7060012817108 .50831604109 .2282562256 109.2130050659108 .5035018921108 .8082962036101 .188697814984 .73026275635 76.8058471679773 .4532165527372 .5388565063573 .4532165527373 .75800323486 74.062782287674 .3675689697374 .9771423339875 .2819290161176 .19628143311 77.110626220778 .3297805786179 .5489196777381 .3776321411183 .07215118408 84.8029632568486 .4613113403387 .8868942260789 .0090408325289 .81330871582 90.2832946777390 .4104003906290 .2164001464889 .302040100188 .69246673584 87.7781066894587 .1685485839886 .5589828491285 .6446228027385 .03504943848 84.12069702148 83.206336975182.9015579223682.9015579223682.90155792236 82.9015579223682 .59677124023 -9999 -9999 -9999 -9999 -9999 -9999 -9999 -9999 -9999 -9999 -9999 -9999 -9999 -9999 -9999 -9999 -9999 -9999 -9999 -9999 -9999 -9999 -9999 -9999 -9999 -9999 -9999 -9999 -9999 -9999 -9999 -9999 -9999 -9999 -9999 -9999 -9999 -9999 -9999 
-9999 -9999 -9999 -9999 -9999 -9999 -9999 -9999 -9999 -9999 -9999 -9999 -9999 -9999 -9999 -9999 -9999 -9999 -9999 -9999 -9999 -9999 -9999 -9999 -9999 -9999 -9999 -9999 -9999 -9999 -

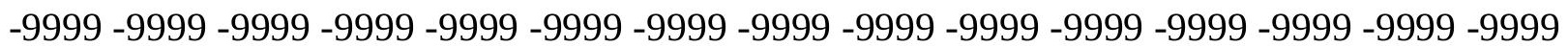
-9999 -9999 -9999 -9999 -9999 -9999 -9999 -9999 -9999 -9999 -9999 -9999

-9999 -9999 -9999 -9999 -9999 -9999 -9999 -9999 -9999 -9999 -9999 -9999 -9999 -9999 - -9999 -9999 -9999 -9999 -9999 -9999 -9999 -9999 -9999 -9999 -9999 -9999 -9999 -9999 -9999 -9999 -9999 -9999 -9999 -9999 -9999 -9999 -9999 -9999 -9999 -9999 -9999 -9999 -9999 -9999 -9999 -9999 -9999 -9999 -9999 -9999 -9999 -9999 -9999 -9999 311.4903869629300 .5180969238 289.8505859375281 .0119018555271 .8682861328260 .5913085938250 .8381958008 245.6567993164155 .923828125156 .7523956299157 .7638092041158 .9611816406 160.3220214844161 .803024292163 .3488006592164 .9014129639166 .4152069092 167.865737915169 .2393798828170 .5453491211171 .5939941406171 .2891998291 171.5939941406173 .1179962158175 .2514038086176 .3179626465176 .7346954346 176.9519805908176 .9586791992176 .7677764893176 .3860321045175 .8380432129 175.1568908691174 .3878631592173 .5772857666172 .7828674316172 .0473327637 171.4069366455170 .8847198486170 .4895935059170 .2237854004170 .0619812012 169.955368042169 .8515930176169 .715423584169 .5224914551169 .2586517334 168.9138793945168 .4979095459168 .0186767578167 .4209442139166 .6066741943 165.668548584164 .5839996338163 .3648071289162 .1457061768160 .9264984131 160.0122070312159 .0977935791158 .4882965088158 .1835021973157 .878692627 157.878692627157 .878692627158 .1835021973158 .1835021973158 .4882965088 158.4882965088158 .4882965088158 .1835021973157 .878692627157 .878692627 157.878692627158 .1835021973158 .1835021973158 .7929992676159 .4026031494 160.0122070312160 .9264984131161 .8408966064162 .7552947998163 .6696014404 164.5839996338165 .1934967041165 .8031005859165 .8031005859163 .9623565674 161.5465698242158 .1835021973154 .5260925293151 .4781951904149 .0399017334 147.2111968994145 .6873016357144 .7729034424143 .8585968018143 .2489929199 142.3347015381141 .7250976562141 .1154937744140 .2012023926139 .2868041992 138.3724975586137 .1533050537135 .9342041016134 .4102020264133 .1911010742 131.6672058105130 .1432037354128 .6192932129127 .0953979492125 .8762969971 118.2565994263118 .5614013672118 .5614013672118 .5614013672118 .5614013672 118.2565994263117 .9517974854117 .342300415116 .4279022217115 .2088012695 114.2944030762113 .3800964355113 .3800964355114 .9039993286117 .0374984741 120.0852966309121 .9140014648122 .2188034058122 .2188034058122 .5235977173 123.43800354123 .7427978516124 .3523025513124 .6570968628124 .9618988037 126.4858016968128 .3144989014130 .4479980469131 .1397399902130 .2405395508 128.6192932129127 .7050018311127 .4001998901126 .7694396973125 .928894043 125.0968093872124 .2715682983123 .4515075684122 .6348190308121 .8196487427 121.0041122437120 .1862945557119 .3643493652118 .5364532471117 .7009429932 116.8561782837116 .0007705688115 .1335067749114 .2539672852113 .3625793457 112.4608383179111 .5506668091110 .6346511841109 .7163696289108 .8007354736 107.8934173584106 .9999923706106 .1258468628105 .2757873535104 .4539718628 103.6612167358102 .8985671997102 .171333313101 .4661407471100 .769744873 97.8360290527395 .0929565429794 .7881774902395 .397743225196 .00731658936 96.6168823242297 .2264633178798 .4455871582100 .2742996216102 .1029968262 104.2365036011105 .4318847656106 .0652008057106 .3700027466107 .9614105225 
109.1206436157110 .5354003906112 .1259918213113 .7505874634115 .1675491333 115.9796524048116 .1231002808114 .5991973877105 .760398864782 .59677124023 64.9192428588968 .2718734741271 .3197174072372 .2340774536172 .84364318848 73.4532165527374 .062782287674 .3675689697374 .6723632812573 .75800323486 74.9771423339876 .1962814331177 .7202072143679 .8537063598681 .68241119385 83.8103179931685 .7672424316487 .3921432495188 .6488189697389 .52703857422 90.0004043579190 .1229858398489 .8805313110489 .302040100188 .69246673584 88.0829010009887 .4733276367286 .8637619018686 .5589828491285 .64462280273 85.0350494384884 .1206970214883 .206336975181 .9871978759881 .98719787598 81.9871978759881 .6824111938581 .6824111938581 .37763214111 -9999 -9999 -9999 -9999 -9999 -9999 -9999 -9999 -9999 -9999 -9999 -9999 -9999 -9999 -9999 -9999 -9999 -9999 -9999

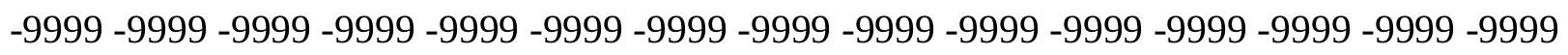
-9999 -9999 -9999 -9999 -9999 -9999 -9999 -9999 -9999 -9999 -9999 -9999 -9999 -9999 -9999 -9999 -9999 -9999 -9999 -9999 -9999 -9999 -9999 -9999 -9999 -9999 -9999 -9999 -9999 -9999 -9999 -9999 -9999 -9999 -9999 -9999 -9999 -9999 -9999 -9999 -9999 -9999 -9999 -9999 -9999

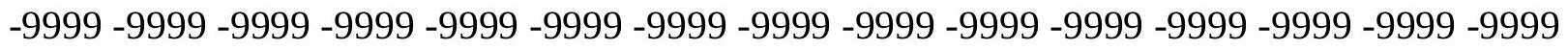
-9999 -9999 -9999 -9999 -9999 -9999 -9999 -9999 -9999 -9999 -9999 -9999 -9999 -9999 -9999 -9999 -9999 -9999 -9999 -9999 -9999 -9999 -9999 -9999 -9999 -9999 -9999 -9999 -9999 -9999 -

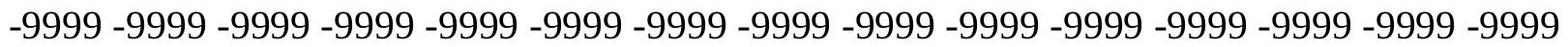
-9999 -9999 -9999 -9999-9999 -9999 -9999-9999 -9999-9999 297.4703063965 288.3266906738282.8406066895277.0497131348266.9917907715256.6290893555 250.2286071777156 .3442840576157 .0609283447158 .0186157227159 .2316894531 160.6705322266162 .2694244385163 .9394073486165 .5917205811167 .1624145508 168.6262512207 169.9925079346 171.286895752 171.8988037109 172.2035980225 173.1179962158174 .6419067383176 .4705963135177 .3498382568177 .7836914062 177.9907684326177 .9628601074177 .7099456787177 .2443695068176 .5968017578 175.7999572754174 .9008483887173 .9553375244173 .0277099609172 .1781616211 171.4543914795170 .8961486816170 .510925293170 .3099975586170 .238861084 170.2225952148170 .1918182373170 .0977783203169 .9253082275169 .6673278809 169.3135070801168 .8829040527168 .3914794922167 .9365997314167 .0222015381 166.1078948975165 .1934967041163 .974395752163 .0599975586161 .8408966064 160.9264984131160 .3170013428159 .7073974609159 .0977935791158 .7929992676 158.7929992676158 .7929992676159 .0977935791159 .4026031494159 .7073974609 159.7073974609159 .4026031494159 .4026031494159 .0977935791159 .0977935791 159.0977935791159 .4026031494159 .7073974609160 .3170013428161 .2312927246 162.1457061768163 .3648071289164 .5839996338165 .8031005859167 .0222015381 168.241394043168 .8509979248169 .4604949951169 .1557006836167 .3227844238 164.6853790283160 .9264984131156 .9642944336153 .3069000244150 .2590942383 147.8208007812146 .2969055176145 .0776977539144 .1634063721143 .2489929199 142.6394042969141 .7250976562141 .1154937744140 .2012023926139 .2868041992 138.3724975586 137.4580993652 136.2389984131 135.0198059082133.8007049561 132.5814971924131 .0576019287129 .8385009766128 .6192932129127 .0953979492 125.8762969971124 .3523025513118 .2565994263118 .2565994263118 .2565994263 118.2565994263117 .9517974854117 .647102356117 .0374984741116 .7326965332 116.1231002808115 .818397522116 .1231002808117 .342300415118 .5614013672 120.6949005127121 .9140014648122 .2188034058121 .9140014648121 .9140014648 
121.9140014648121 .3044967651120 .9997024536119 .7806015015119 .7806015015 122.2188034058124 .9618988037126 .7906036377127 .7050018311126 .7906036377 126.1809997559126 .1809997559126 .7906036377126 .7906036377126 .263343811 125.4561691284124 .6572723389123 .864982605123 .0774688721122 .2928619385 121.5091934204120 .7244873047119 .9367828369119 .1441421509118 .3447341919 117.5367660522116 .7186584473115 .8890609741115 .0475158691114 .1946334839 113.3323745728112 .4632492065111 .5902709961110 .7172241211109 .8490905762 108.9917602539108 .1511764526107 .3335113525106 .5445709229105 .789932251 105.0681533813104 .4017028809103 .7842559814103 .2036972046102 .6302261353 102.0158843994100 .274299621699 .0551681518698 .7503814697399 .05516815186 99.3599472045999 .96952056885101 .1886978149102 .712600708104 .5412979126 106.0652008057 107.2844009399 107.8938980103107.5891036987 107.2844009399 106.3700027466104.5412979126106.6747970581 112.7705001831 117.342300415 119.0435028076118 .1745758057113 .6848983765104 .846099853591 .74033355713 76.5010681152369 .4910125732469 .7957916259870 .7101516723672 .23407745361 73.1484298706173 .7580032348674 .062782287674 .062782287674 .0627822876 72.8436431884874 .3675689697375 .8914871215878 .0249862670980 .15849304199 82.5967712402384 .7302627563586 .5016021728587 .9466934204188 .85848999023 89.3104019165 89.42892456055 89.2804565429788.9972534179788.38768768311 88.0829010009887 .7781066894587 .4733276367287 .1685485839886 .55898284912 85.9494018554785 .0350494384884 .4254837036183 .206336975182 .59677124023 81.6824111938581 .0728530883880 .7680587768680 .7680587768680 .46327209473 80.15849304199 -9999 -9999 -9999 -9999 -9999 -9999 -9999 -9999 -9999 -9999 -9999 -9999 -9999 -9999 -9999 -9999 -9999 -9999 -9999 -9999 -9999 -9999 -9999 -9999 -9999 -9999-9999 -

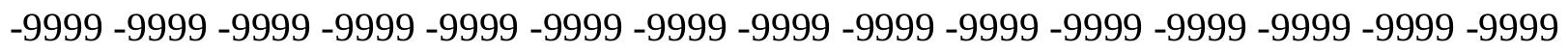
-9999 -9999 -9999 -9999 -9999 -9999 -9999 -9999 -9999 -9999 -9999 -9999 -9999 -9999 -9999

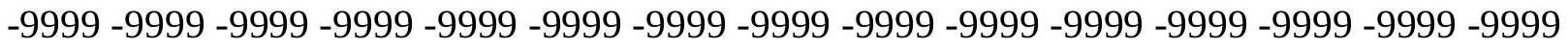

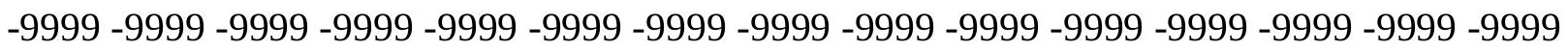
-9999 -9999-9999-9999 -9999

-9999 -9999 -9999 -9999 -9999 -9999 -9999 -9999 -9999 -9999 -9999 -9999 -9999 -9999 -9999 -9999 -9999 -9999 -9999 -9999 -9999 -9999 -9999 -9999 -9999 -9999 -9999 -9999 -9999 -9999

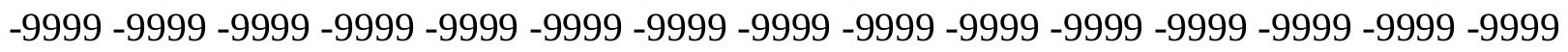
-9999 -9999 -9999 -9999-9999 -9999 -9999-9999-9999-9999 290.1553955078 282.8406066895 278.2687988281273.6971130371265.4678039551256.6290893555 156.4382476807156 .7509765625157 .3025817871158 .1797332764159 .4090576172 160.9556121826162 .724319458164 .5741424561166 .3636169434167 .995880127 169.4501953125170 .7707366943172 .0158538818172 .5084075928173 .4226989746 174.9467010498176 .165802002177 .6896972656178 .4222564697178 .8792572021 179.0715942383179 .0001831055178 .6729431152178 .1144561768177 .3582305908 176.4380340576175 .3916625977174 .2929382324173 .206451416172 .215637207 171.3992767334170 .6797027588170 .4363098145170 .3145141602170 .3598022461 170.4521789551170 .4945526123170 .4230957031170 .2376098633169 .9765319824 169.6167297363169 .1557006836168 .5462036133167 .9365997314167 .3269958496 166.4127044678165 .4983062744164 .5839996338163 .6696014404162 .7552947998 161.8408966064160 .9264984131160 .3170013428160 .0122070312159 .7073974609 159.7073974609159 .7073974609159 .7073974609160 .0122070312160 .3170013428 
160.6217956543160 .3170013428160 .0122070312160 .0122070312159 .7073974609 160.0122070312160 .3170013428160 .9264984131161 .8408966064162 .7552947998 163.974395752165 .1934967041166 .7174987793168 .5462036133169 .7653045654 171.2891998291172 .2035980225172 .5084075928171 .8988037109170 .0542449951 167.3037872314163.3648071289 159.0977935791 154.8307952881 151.1734008789 148.4304046631146 .9064025879145 .6873016357144 .4682006836143 .5538024902 142.6394042969142 .0299072266141 .1154937744140 .2012023926139 .5915985107 138.6772003174137 .7628936768136 .8484954834135 .6293945312134 .7149963379 133.4958953857132 .2767028809131 .0576019287129 .8385009766128 .6192932129 127.4001998901125 .8762969971124 .3523025513117 .9517974854117 .9517974854 117.9517974854117 .9517974854117 .647102356117 .647102356117 .647102356 117.647102356117 .647102356117 .647102356118 .2565994263119 .1709976196 120.6949005127121 .9140014648122 .2188034058122 .2188034058122 .2188034058 120.9997024536117 .9517974854114 .5991973877111 .24659729110 .9418029785 116.7326965332122 .2188034058123 .43800354122 .8283996582122 .8283996582 123.7427978516124 .9618988037126 .1809997559126 .4858016968126 .4858016968 125.7969512939125 .0258102417124 .2628097534123 .5060958862122 .7537689209 122.0037841797121 .2540817261120 .5025863647119 .747215271118 .9859542847 118.2168045044117 .4379348755116 .6478042603115 .8458480835115 .0327682495 114.2107543945113 .3826599121112 .5517501831111 .7218551636110 .8978805542 110.0857086182109 .2917404175108 .5230712891107 .7869720459107 .0906524658 106.4425964355105 .8671798706105 .3644638062104 .9223098755104 .5045166016 104.0501098633103 .490776062102 .712600708101 .7982025146101 .7982025146 101.7982025146102 .4077987671103 .3221969604104 .5412979126106 .0652008057 107.5891036987108.5035018921 108.8082962036108.5035018921 107.8938980103 106.979598999106 .0652008057106 .0652008057107 .8938980103116 .4279022217 118.5614013672116 .7326965332112 .7705001831106 .97959899999 .35994720459 89.6068267822378 .6345596313568 .2718734741272 .2340774536172 .23407745361 73.4532165527374 .062782287674 .062782287673 .7580032348673 .45321655273 73.4532165527372 .5388565063574 .3675689697376 .1962814331178 .32978057861 80.7680587768682 .9015579223685 .0350494384886 .8637619018687 .62943267822 88.1606674194388 .3549957275488 .2685699462988 .0829010009888 .08290100098 87.7781066894587 .7781066894587 .7781066894587 .7781066894587 .47332763672 86.8637619018686 .254188537685 .6446228027384 .7302627563583 .81591033936 82.9015579223681 .9871978759881 .0728530883880 .1584930419979 .85370635986 79.5489196777379 .5489196777379 .24413299561 -9999 -9999 -9999 -9999 -9999 -9999-9999

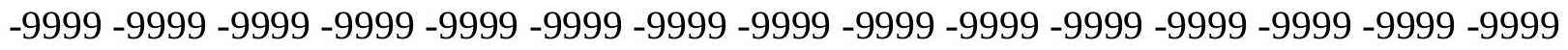

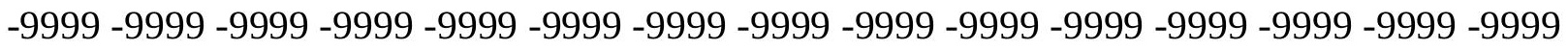

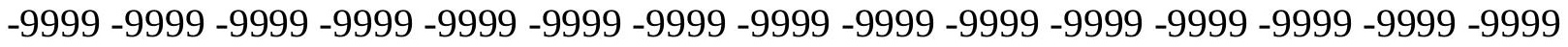
-9999 -9999 -9999 -9999 -9999 -9999 -9999 -9999 -9999 -9999 -9999 -9999 -9999 -9999 -9999 -

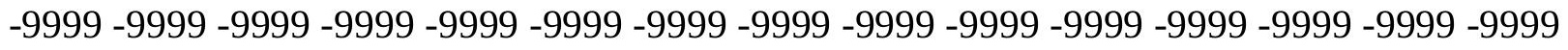
-9999 -9999-9999 -9999-9999-9999-9999-9999

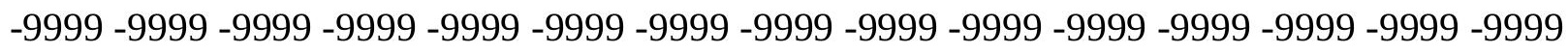
-9999 -9999 -9999 -9999 -9999 -9999 -9999 -9999 -9999-9999 -9999 -9999 -9999 -9999 -9999 -9999 -9999 -9999 -9999 -9999 -9999 -9999 -9999 -9999 -9999 -9999 -9999 -9999 -9999 -9999 -9999 -9999 -9999 -9999 -9999 -9999 -9999 -9999 -9999 -9999 277.0497131348 
271.5635070801267 .2966003418262 .1152038574255 .7147064209157 .1940765381 157.0835571289157 .1050109863157 .437210083158 .2036132812159 .4448699951 161.1392822266163 .1588134766165 .2781677246167 .2665863037168 .9698638916 170.3721313477171 .5737457275172 .7259521484173 .9379272461175 .2347259521 176.4705963135177 .6896972656178 .7807922363179 .5350494385180 .0051727295 180.1765289307180 .0475158691179 .6342468262178 .9678192139178 .1026306152 177.0705566406175 .8748016357174 .5958862305173 .3203277588172 .1753692627 171.2611541748170 .3748931885170 .070098877170 .230255127170 .4187469482 170.6176757812170 .7016296387170 .6434173584170 .3902282715170 .070098877 169.7653045654169 .1557006836168 .8509979248168 .241394043167 .6318054199 167.0222015381166 .1078948975165 .1934967041164 .2792053223163 .0599975586 162.4505004883161 .5361022949160 .9264984131160 .6217956543160 .3170013428 160.0122070312160 .0122070312160 .0122070312160 .3170013428160 .6217956543 160.6217956543160 .6217956543160 .3170013428160 .3170013428160 .3170013428 160.6217956543161 .2312927246161 .8408966064162 .7552947998163 .974395752 165.4983062744167 .0222015381168 .8509979248170 .6797027588172 .5084075928 173.7274932861174 .9467010498175 .2514038086174 .337097168172 .5084075928 169.6750488281165 .8031005859161 .2312927246156 .6596069336152 .0877990723 149.6495056152147 .8208007812146 .2969055176145 .0776977539143 .8585968018 142.9441986084142 .0299072266141 .4203033447140 .5059967041139 .5915985107 138.9819946289138 .0677032471137 .1533050537136 .2389984131135 .3246002197 134.4102020264133 .1911010742132 .2767028809131 .0576019287129 .8385009766 128.6192932129127 .4001998901125 .8762969971124 .0475006104117 .342300415 117.342300415117 .647102356117 .9517974854117 .9517974854118 .2565994263 118.5614013672118 .5614013672118 .5614013672118 .8662033081119 .1709976196 120.3900985718121 .6092987061122 .5235977173122 .5235977173122 .2188034058 120.3900985718115 .2088012695108 .8082962036102 .712600708100 .5791015625 107.8938980103116 .7326965332117 .9517974854117 .9517974854120 .0852966309 122.5235977173124 .0475006104125 .2667007446126 .1809997559126 .1809997559 126.1165771484125 .3744506836124 .6420898438123 .9176254272123 .1991195679 122.4844665527121 .7715072632121 .0580291748120 .3417892456119 .6205825806 118.8921356201118 .1543502808117 .405380249116 .6444778442115 .8722915649 115.0910873413114 .3037261963113 .513343811112 .7236099243111 .9391403198 111.1656723022110 .4097518921109 .6793365479108 .9830551147108 .3284454346 107.7393798828107 .2440109253106 .8428268433106 .5303421021106 .2718429565 105.9971466064 105.6110610962 105.0086364746 104.2365036011 103.9317016602 103.9317016602104 .2365036011105 .1509017944106 .0652008057107 .2844009399 108.1986999512109 .1130981445109 .1130981445108 .8082962036107 .8938980103 107.2844009399 106.979598999 108.1986999512110.6370010376112.7705001831 112.7705001831111 .24659729110 .0273971558107 .2844009399104 .5412979126 99.6647262573291 .4355392456181 .0728530883870 .7101516723672 .84364318848 74.3675689697374 .6723632812574 .3675689697373 .7580032348673 .14842987061 72.8436431884871 .014930725172 .5388565063574 .6723632812576 .80584716797 78.9393463134881 .0728530883882 .9015579223684 .7302627563585 .64462280273 86.5589828491286 .8637619018686 .8637619018687 .1685485839887 .16854858398 87.4733276367287 .7781066894588 .0829010009888 .3876876831188 .38768768311 
88.0829010009887 .7781066894587 .1685485839886 .254188537685 .33984375 84.4254837036183 .5111236572382 .5967712402381 .3776321411180 .46327209473 $79.2441329956178 .9393463134878 .6345596313578 .6345596313578 .32978057861-9999$ -9999 -9999 -9999 -9999 -9999 -9999 -9999 -9999 -9999 -9999 -9999 -9999 -9999 -9999 -9999 -9999 -9999 -9999 -9999 -9999 -9999 -9999 -9999 -9999-9999 -9999 -9999 -9999 -9999 -9999 -9999 -9999 -9999 -9999 -9999 -9999 -9999 -9999 -9999 -9999 -9999 -9999 -9999 -9999 -9999

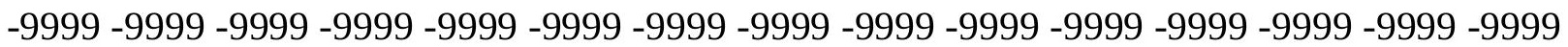

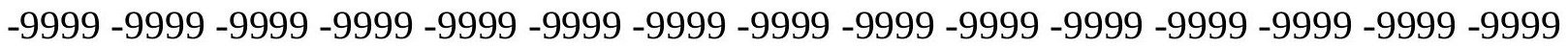
-9999 -9999 -9999 -9999 -9999 -9999 -9999 -9999 -9999 -9999 -9999 -9999 -9999 -9999 -9999 -9999 -9999 -9999 -9999 -9999 -9999 -9999 -9999 -9999 -9999 -9999 -9999

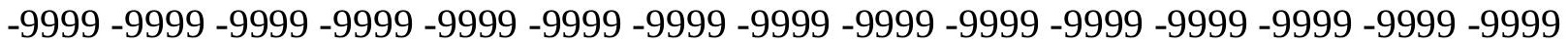
-9999 -9999 -9999 -9999 -9999 -9999 -9999 -9999 -9999 -9999 -9999 -9999 -9999 -9999 -9999 -9999 -9999 -9999 -9999 -9999 -9999 -9999 -9999 -9999 -9999 -9999 250.8381958008 246.5711975098240 .4754943848158 .5457305908158 .1836547852157 .6992797852 157.3565826416157 .4588012695158 .0783538818159 .3041534424161 .1931610107 163.5775299072166 .1096343994168 .3912658691170 .1835784912171 .4622039795 172.4515075684173 .42628479174 .5837097168175 .9518280029177 .4101409912 178.7661132812179 .8656311035180 .6486816406181 .1173858643181 .2581176758 181.0510559082180 .5338134766179 .7418518066178 .7580718994177 .6345825195 176.339553833174 .8446960449173 .3835754395171 .8988037109170 .9844970703 170.070098877170 .070098877170 .070098877170 .3748931885170 .6797027588 170.6797027588170 .6797027588170 .3748931885169 .7653045654169 .4604949951 169.1557006836168 .8509979248168 .5462036133167 .9365997314167 .3269958496 166.4127044678165 .4983062744164 .5839996338163 .3648071289162 .7552947998 161.8408966064161 .2312927246160 .6217956543160 .3170013428160 .3170013428 160.0122070312160 .3170013428160 .3170013428160 .3170013428160 .6217956543 160.6217956543160 .6217956543160 .6217956543160 .9264984131161 .2312927246 161.8408966064162 .4505004883163 .6696014404164 .8887023926166 .4127044678 168.241394043170 .3748931885172 .5084075928174 .337097168176 .165802002 177.3849029541177 .6896972656176 .7754058838174 .9467010498172 .2035980225 168.241394043163 .974395752159 .0977935791154 .8307952881151 .7830047607 149.3446960449147 .5160064697145 .6873016357144 .4682006836143 .2489929199 142.3347015381141 .4203033447140 .8106994629139 .8963928223139 .2868041992 138.3724975586137 .7628936768136 .8484954834135 .9342041016135 .0198059082 134.1054992676133 .1911010742132 .2767028809131 .0576019287130 .1432037354 128.9241027832127 .4001998901125 .8762969971123 .7427978516121 .3044967651 117.0374984741117 .647102356117 .9517974854118 .5614013672118 .8662033081 119.1709976196119 .4757995605119 .4757995605119 .7806015015120 .6949005127 121.6092987061122 .5235977173122 .5235977173121 .9140014648119 .4757995605 114.2944030762106 .065200805795 .397743225188 .3876876831191 .43553924561 99.35994720459106 .979598999113 .9896011353118 .8662033081121 .9140014648 124.0475006104124 .9618988037125 .5715026855125 .8762969971126 .1809997559 125.7001953125124 .9996871948124 .3087844849123 .6255264282122 .9477157593 122.2730941772121 .5993041992120 .9239501953120 .2445755005119 .558631897 118.8636856079118 .1575469971117 .4391479492116 .7088928223115 .9689025879 115.2217483521114 .4701004028113 .7170333862112 .9667282104112 .2244567871 
111.4966278076110 .7913589478110 .1182174683109 .4874420166108 .9338684082 108.4822540283108 .143371582107 .9202270508107 .7821655273107 .6407775879 107.364402771106 .979598999105 .7603988647105 .1509017944105 .1509017944 105.4557037354106 .0652008057106 .979598999107 .8938980103108 .8082962036 109.4179000854109 .4179000854108 .8082962036108 .1986999512107 .2844009399 107.2844009399 109.1130981445111.551399231 112.4656982422 110.6370010376 104.5412979126103 .9317016602105 .7603988647107 .2844009399106 .6747970581 102.71260070896 .3121032714887 .7781066894577 .4154205322376 .50106811523 74.9771423339874 .3675689697373 .4532165527372 .8436431884872 .23407745361 71.9292907714871 .3197174072373 .1484298706174 .9771423339877 .1106262207 78.9393463134880 .7680587768682 .2919769287183 .5111236572384 .12069702148 84.7302627563585 .3398437585 .6446228027386 .254188537686 .86376190186 87.4733276367288 .0829010009888 .6924667358489 .302040100189 .3020401001 88.9972534179788 .3876876831187 .7781066894586 .8637619018685 .94940185547 85.03504943848 84.12069702148 82.9015579223681.98719787598 80.76805877686 79.5489196777378 .3297805786178 .0249862670978 .0249862670977 .72020721436 -9999 -9999 -9999 -9999 -9999 -9999 -9999 -9999 -9999 -9999 -9999 -9999 -9999 -9999 -9999 -9999 -9999 -9999 -9999 -9999 -9999 -9999 -9999 -9999 -9999 -9999 -9999 -9999 -9999 -9999 -9999 -999 -9999 -9999 -9999 -9999 -9999 -9999 -9999 -9999 -9999 -9999 -9999 -9999 -9999 -9999 -9999 -9999 -9999 -9999 -9999 -9999 -9999 -9999 -9999 -9999 -9999 -9999 -9999 -9999 -9999 -9999 -9999 -9999 -9999 -9999 -9999 -9999 -9999 -9999 -9999 -9999 -9999 -9999 -9999 -9999 -9999 -9999 -9999-9999 -9999 -9999 -9999-9999 -9999 -9999-9999 -9999 -9999 -9999 -9999 -9999 -9999 -9999 -9999 -9999 -9999 -9999 -9999 -9999 -9999 -9999 -9999 -9999 -9999 -9999 -9999 -9999 -9999 -9999 -9999 -9999 -9999 -9999 -9999 -9999 -9999 -9999 -

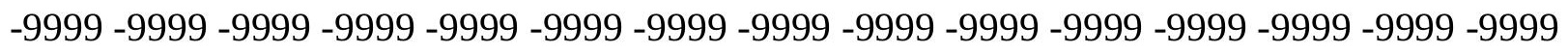
-9999 -9999 -9999 -9999 -9999 -9999 -9999 -9999 -9999 -9999 -9999 226.7601013184 221.2740020752160 .0250396729159 .8549346924159 .0737609863158 .1396942139 157.4952545166157 .4702301025157 .8554077148158 .9923400879161 .1089019775 163.9878234863167 .148727417169 .8771972656171 .7813110352172 .8170776367 173.4616088867171 .2891998291173 .1179962158176 .4705963135178 .3401489258 179.827545166180 .9632873535181 .7019195557182 .1195373535182 .2188873291 181.9253845215181 .2707214355180 .3548431396179 .2297821045177 .9911804199 176.7754058838174 .9467010498173 .4226989746172 .2035980225170 .9844970703 170.3748931885170 .070098877170 .070098877170 .070098877170 .3748931885 170.3748931885170 .070098877170 .070098877169 .7653045654169 .4604949951 169.1557006836168 .8509979248168 .5462036133167 .9365997314167 .3269958496 166.7174987793165 .4983062744164 .5839996338163 .6696014404162 .7552947998 161.8408966064161 .2312927246160 .6217956543160 .3170013428160 .0122070312 160.0122070312160 .0122070312160 .0122070312160 .0122070312160 .3170013428 160.3170013428160 .6217956543160 .6217956543160 .9264984131161 .5361022949 162.1457061768163 .0599975586163 .974395752165 .1934967041167 .0222015381 168.8509979248171 .2891998291173 .4226989746175 .8609924316177 .9945068359 179.2136993408179 .8231964111179 .2136993408177 .6896972656174 .9467010498 171.2891998291166 .7174987793162 .1457061768157 .878692627154 .2212982178 151.1734008789148 .7351074219146 .6015930176145 .0776977539143 .8585968018 142.6394042969141 .7250976562141 .1154937744140 .2012023926139 .5915985107 
138.9819946289138 .0677032471137 .4580993652136 .5437011719135 .9342041016 135.0198059082134 .1054992676133 .1911010742132 .2767028809131 .3623962402 130.1432037354128 .9241027832127 .4001998901125 .5715026855123 .1332015991 120.3900985718117 .0374984741117 .9517974854118 .2565994263118 .8662033081 119.4757995605119 .7806015015120 .0852966309120 .6949005127121 .3044967651 121.6092987061122 .2188034058122 .2188034058121 .3044967651118 .5614013672 113.6848983765106 .674797058194 .1785964965883 .8159103393682 .29197692871 86.8637619018699 .05516815186112 .1608963013118 .2565994263121 .9140014648 123.7427978516124 .6570968628125 .2667007446125 .5715026855125 .5715026855 125.5715026855125 .2667007446124 .6767425537124 .0300140381123 .390411377 122.7555847168122 .1230239868121 .4901351929120 .8542251587120 .2124404907 119.5619812012118 .9002838135118 .2258682251117 .5386428833116 .8402481079 116.1327209473115 .4179992676114 .6982345581113 .9767990112111 .551399231 107.5891036987111 .8547668457111 .1864776611110 .5539398193109 .9979095459 109.5432739258109 .1998291016108 .9828491211108 .8852539062108 .818862915 108.4969940186107.5891036987 106.3700027466106.0652008057 105.7603988647 106.0652008057106 .6747970581107 .5891036987108 .5035018921109 .1130981445 109.4179000854109 .4179000854109 .1130981445108 .5035018921107 .5891036987 106.979598999109 .7226028442112 .1608963013112 .7705001831110 .9418029785 106.979598999102 .4077987671100 .5791015625106 .6747970581110 .6370010376 111.8561019897109 .4179000854103 .931701660295 .397743225185 .33984375 76.1962814331173 .1484298706173 .4532165527372 .5388565063571 .62449645996 71.3197174072370 .7101516723671 .9292907714873 .7580032348675 .28192901611 77.110626220778 .6345596313579 .8537063598681 .0728530883881 .98719787598 82.5967712402383 .5111236572384 .1206970214885 .0350494384885 .94940185547 86.8637619018688 .0829010009889 .302040100189 .9116134643690 .21640014648 90.2164001464889 .6068267822388 .9972534179788 .3876876831187 .47332763672 86.5589828491285 .6446228027384 .7302627563583 .8159103393682 .59677124023 81.3776321411179 .8537063598678 .3297805786177 .7202072143677 .41542053223 77.110626220776 .80584716797 -9999 -9999 -9999 -9999 -9999 -9999 -9999 -9999 -9999 -9999 -9999 -9999 -9999 -9999 -9999 -9999 -9999 -9999 -9999 -9999 -9999 -9999 -9999 -9999

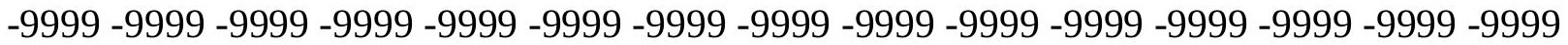

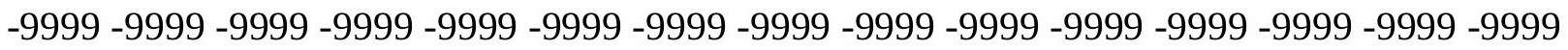
-9999 -9999 -9999 -9999 -9999 -9999 -9999 -9999 -9999 -9999 -9999 -9999 -9999 -9999 -9999 -

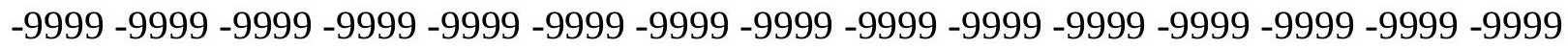
$-9999$

-9999 -9999 -9999 -9999 -9999 -9999 -9999 -9999 -9999 -9999 -9999 -9999 -9999 -9999 -9999

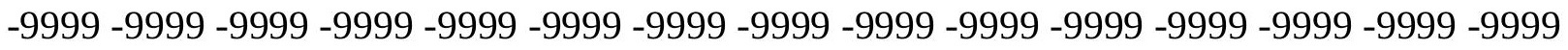
-9999 -9999 -9999 -9999 -9999 -9999 -9999 -9999 -9999 -9999 -9999 -9999 -9999 -9999 -9999 -9999 -9999 -9999 -9999 -9999 -9999 -9999 -9999 -9999 -9999 -9999 -9999 160.0157623291 160.9138641357161 .1754608154159 .562286377157 .8768920898157 .8834381104 157.7627410889157 .6393432617158 .6551361084160 .9317932129164 .3689575195 168.4060974121171 .9318847656173 .8507995605173 .7274932861172 .8132019043 172.5084075928174 .337097168177 .3849029541179 .4351654053181 .0074005127 182.02293396182 .5662994385182 .87109375182 .87109375182 .5662994385181 .6519012451 180.7375946045179 .5184020996177 .9945068359176 .4705963135174 .9467010498 
173.7274932861172 .5084075928171 .2891998291170 .6797027588170 .3748931885 170.070098877170 .070098877170 .070098877170 .070098877170 .070098877 169.7653045654169 .4604949951169 .1557006836169 .1557006836168 .8509979248 168.5462036133168 .241394043167 .6318054199166 .7174987793165 .4983062744 164.5839996338163 .3648071289162 .4505004883161 .5361022949160 .9264984131 160.3170013428160 .0122070312159 .7073974609159 .7073974609159 .7073974609 159.7073974609159 .7073974609160 .0122070312160 .0122070312160 .3170013428 160.6217956543161 .2312927246161 .5361022949162 .4505004883163 .0599975586 164.2792053223165 .4983062744167 .0222015381169 .1557006836171 .2891998291 174.0323028564177 .0802001953179 .5184020996181 .0424041748181 .9566955566 181.3471984863180 .1280059814177 .3849029541174 .0323028564169 .7653045654 165.1934967041160 .6217956543156 .3547973633153 .0021057129149 .9542999268 147.5160064697145 .6873016357144 .1634063721142 .9441986084142 .0299072266 141.1154937744140 .5059967041139 .8963928223139 .2868041992138 .3724975586 137.7628936768137 .1533050537136 .5437011719135 .6293945312135 .0198059082 134.1054992676133 .1911010742132 .2767028809131 .3623962402130 .4479980469 129.2288970947127 .4001998901124 .6570968628121 .6092987061118 .8662033081 117.342300415118 .2565994263118 .8662033081119 .4757995605119 .7806015015 120.3900985718120 .9997024536121 .3044967651121 .9140014648122 .2188034058 121.9140014648121 .3044967651119 .4757995605115 .5136032104110 .9418029785 106.3700027466 102.102996826298.7503814697399.05516815186105.7603988647 114.5991973877119 .7806015015122 .5235977173123 .7427978516124 .3523025513 124.6570968628124 .9618988037124 .9618988037124 .96189880037124 .9618988037 124.6570968628124 .0475006104123 .7427978516123 .1332015991122 .5235977173 122.036819458121 .44581604120 .8496704102120 .245223999119 .6295013428 119.0005264282118 .3575363159117 .7013244629117 .0330505371116 .3537368774 115.6643600464114 .9671401978113 .075302124113 .5641098022112 .8690872192 112.188079834111 .5297546387110 .9346694946110 .4152679443109 .9851303101 109.6557769775109 .4264831543109 .2860412598109 .1130981445107 .5891036987 106.6747970581 106.0652008057 106.0652008057 106.3700027466106.979598999 107.8938980103108 .5035018921109 .1130981445109 .7226028442109 .7226028442 109.7226028442109 .4179000854109 .1130981445109 .7226028442111 .8561019897 113.6848983765114 .2944030762113 .075302124110 .3321990967106 .979598999 104.2365036011 103.0174026489 113.075302124119.4757995605 121.6092987061 118.5614013672111 .8561019897103 .322196960492 .9594726562581 .07285308838 73.4532165527371 .3197174072370 .1005783081169 .7957916259870 .40535736084 71.3197174072372 .8436431884874 .062782287675 .2819290161176 .50106811523 77.7202072143678 .6345596313579 .5489196777380 .4632720947381 .37763214111 82.29197692871 83.51112365723 84.73026275635 86.2541885376 87.77810668945 89.302040100190.52117919922 91.1307525634891.1307525634890.52117919922 90.2164001464889 .302040100188 .6924667358487 .7781066894587 .16854858398 86.2541885376 85.33984375 84.42548370361 83.206336975181.98719787598 80.4632720947378 .9393463134877 .4154205322376 .8058471679776 .50106811523 76.1962814331175 .89148712158 -9999 -9999 -9999 -9999 -9999 -9999 -9999 -9999 -9999

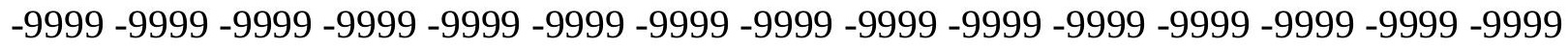

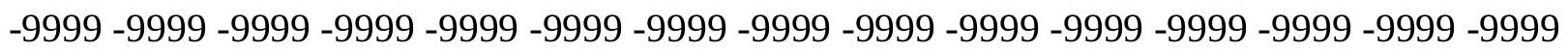


-9999 -9999 -9999 -9999 -9999 -9999 -9999 -9999 -9999 -9999 -9999 -9999 -9999 -9999 -9999 -9999 -9999 -9999 -9999 -9999 -9999 -9999 -9999 -9999 -9999 -9999 -9999 -9999 -9999 -9999 -9999 -9999 -9999 -9999 -9999 -9999 -9999 -9999 -9999 -9999 -9999 -9999 -9999 -9999 -9999 -9999 -9999 -9999 -9999 -9999 -9999 -9999 -9999 -9999 -9999 -9999 -9999 -9999 -9999 -9999 -9999 -9999 -9999 -9999 -9999 -9999 -9999 -9999 -9999 -9999 -9999-9999 -9999 -9999 -9999 -9999 -9999 -9999 -9999 -9999 -9999 -9999 -9999 -9999 -9999 -9999 -9999 -9999 -9999 -9999 -9999 -9999 -9999 -9999 -9999 -9999 -9999 -9999 -9999 -9999 -9999 159.6171264648 159.2563018799162 .4505004883159 .0977935791156 .0500030518159 .7073974609 158.7929992676157 .5738983154158 .7929992676160 .9264984131164 .2792053223 169.4604949951174 .6419067383176 .165802002176 .7754058838176 .7754058838 176.7754058838177 .3849029541178 .9089050293180 .7375946045182 .261505127 182.87109375183 .1759033203183 .1759033203182 .87109375182 .5662994385 181.6519012451180 .7375946045179 .5184020996177 .9945068359176 .7754058838 175.2514038086174 .0323028564172 .8132019043171 .8988037109171 .2891998291 170.6797027588170 .3748931885170 .070098877170 .070098877170 .070098877 169.7653045654169 .4604949951169 .4604949951169 .1557006836168 .8509979248 168.5462036133168 .241394043167 .9365997314167 .6318054199166 .4127044678 165.1934967041163 .974395752163 .0599975586162 .1457061768161 .2312927246 160.6217956543160 .0122070312159 .7073974609159 .4026031494159 .0977935791 159.0977935791159 .0977935791159 .0977935791159 .4026031494159 .7073974609 160.0122070312160 .6217956543161 .2312927246161 .5361022949162 .4505004883 163.3648071289164 .2792053223165 .4983062744167 .0222015381168 .5462036133 170.9844970703174 .0323028564177 .3849029541180 .432800293182 .5662994385 183.4806976318183 .4806976318182 .261505127180 .1280059814176 .7754058838 172.5084075928167 .9365997314163 .0599975586158 .4882965088154 .4498443604 150.8686065674148 .0606842041146 .2969055176144 .7729034424143 .5538024902 142.3347015381141 .4203033447140 .8106994629140 .2012023926139 .5915985107 138.9819946289138 .3724975586137 .7628936768136 .8484954834136 .2389984131 135.6293945312134 .7149963379133 .8007049561132 .8863067627132 .2767028809 131.0576019287130 .1432037354128 .9241027832125 .8762969971122 .5235977173 119.4757995605117 .0374984741117 .647102356118 .2565994263118 .8662033081 119.7806015015120 .3900985718120 .6949005127121 .3044967651121 .6092987061 121.9140014648121 .6092987061121 .3044967651120 .3900985718117 .647102356 115.818397522119 .4757995605122 .5235977173119 .4757995605116 .1231002808 116.7326965332118 .8662033081120 .9997024536122 .5235977173123 .43800354 123.7427978516124 .0475006104124 .3523025513124 .3523025513124 .3523025513 124.3523025513124 .0475006104123 .7427978516123 .1332015991122 .5235977173 121.9140014648122 .2188034058122 .0152664185121 .4660415649120 .9090042114 120.3407669067119 .7587509155119 .1613464355118 .5482788086117 .9195022583 117.274848938116 .6139373779115 .9374084473115 .2470703125114 .5460739136 113.8385772705113 .1298904419112 .4259796143111 .7526016235111 .1191177368 110.5287628174109 .9887542725109 .4672012329108 .9227294922108 .1986999512 106.979598999106 .0652008057106 .0652008057106 .0652008057106 .3700027466 106.979598999107 .5891036987108 .5035018921109 .1130981445109 .7226028442 110.0273971558110 .3321990967110 .6370010376111 .24659729112 .4656982422 114.2944030762116 .4279022217117 .0374984741116 .1231002808114 .2944030762 
111.8561019897110 .6370010376110 .6370010376112 .1608963013120 .3433380127 123.1539611816122 .8595199585119 .7775344849115 .0555267334109 .4179000854 98.445587158285 .9494018554774 .3675689697371 .9292907714871 .0149307251 71.014930725171 .6244964599672 .2340774536173 .1484298706174 .0627822876 74.9771423339875 .5867080688576 .5010681152377 .4154205322378 .32978057861 79.5489196777380 .4632720947381 .6824111938583 .206336975185 .03504943848 86.8637619018688 .9972534179790 .8259735107491 .4355392456191 .43553924561 91.1307525634890 .8259735107490 .2164001464889 .6068267822388 .99725341797 88.3876876831187 .7781066894586 .8637619018686 .254188537685 .33984375 84.42548370361 83.206336975181.6824111938580.15849304199 78.32978057861 76.5010681152376 .1962814331175 .8914871215875 .28192901611 -9999 -9999 -9999 -9999

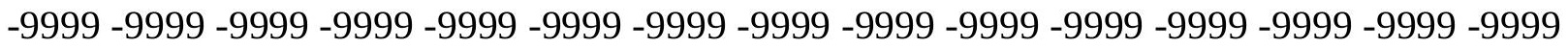

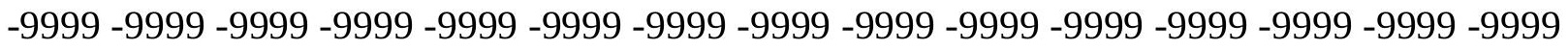

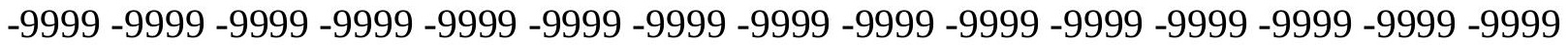

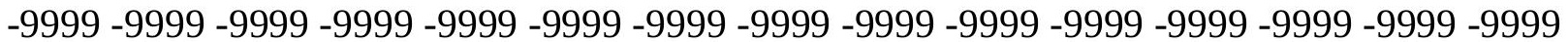

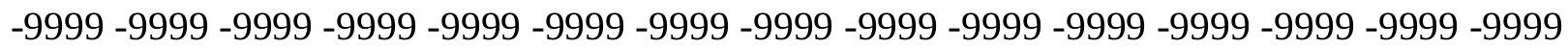
$-9999-9999-9999$

-9999 -9999 -9999 -9999 -9999 -9999 -9999 -999 -9999 -9999 -9999 -9999 -9999 -9999 -9999 -

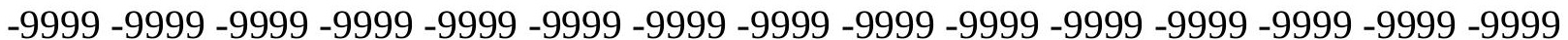

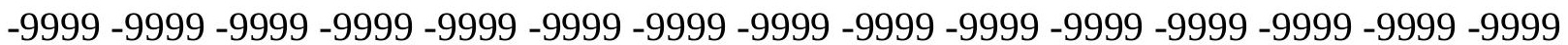
-9999 -9999 -9999 -9999 -9999 -9999 -9999 -9999 -9999 -9999 -9999 -9999 160.0122070312 153.0021057129155 .7451934814157 .5738983154159 .0977935791160 .6217956543 160.3170013428159 .7073974609160 .0122070312161 .8408966064165 .1934967041 170.6797027588175 .5561981201178 .2993011475179 .8231964111180 .432800293 180.432800293180 .432800293181 .0424041748181 .9566955566182 .87109375 183.1759033203183 .1759033203183 .1759033203182 .87109375182 .261505127 181.6519012451180 .7375946045179 .5184020996178 .2993011475177 .0802001953 175.5561981201174 .337097168173 .4226989746172 .5084075928171 .5939941406 170.9844970703170 .6797027588170 .3748931885170 .070098877169 .7653045654 169.7653045654169 .4604949951169 .1557006836168 .8509979248168 .5462036133 167.9365997314167 .6318054199167 .3269958496166 .7174987793165 .8031005859 164.5839996338163 .3648071289162 .4505004883161 .5361022949160 .6217956543 160.0122070312159 .4026031494159 .0977935791158 .7929992676158 .4882965088 158.4882965088158 .4882965088158 .4882965088158 .7929992676159 .4026031494 160.0122070312160 .3170013428160 .9264984131161 .5361022949162 .4505004883 163.3648071289164 .2792053223165 .4983062744166 .7174987793167 .9365997314 169.7653045654173 .1179962158177 .3849029541180 .7375946045183 .1759033203 184.3950042725184 .699798584184 .0901947021182 .261505127178 .9089050293 174.9467010498170 .070098877165 .1934967041160 .3170013428155 .7451934814 151.7830047607148 .9084472656146 .9064025879145 .3825073242143 .8585968018 142.6394042969141 .7250976562141 .1154937744140 .5059967041139 .8963928223 139.2868041992138 .6772003174138 .0677032471137 .4580993652136 .8484954834 135.9342041016135 .3246002197134 .4102020264133 .4958953857132 .5814971924 131.3623962402130 .1432037354128 .3144989014125 .8762969971122 .8283996582 120.0852966309117 .647102356116 .7326965332117 .647102356118 .2565994263 119.1709976196119 .7806015015120 .3900985718120 .9997024536121 .3044967651 
121.3044967651120 .9997024536120 .6949005127120 .0852966309119 .7806015015 120.0852966309120 .9997024536121 .6092987061122 .2188034058121 .9140014648 121.3044967651120 .9997024536121 .3044967651122 .2188034058122 .8283996582 123.1332015991123 .1332015991123 .43800354123 .43800354123 .43800354123 .43800354 123.1332015991123 .1332015991122 .8283996582122 .2188034058121 .9140014648 121.9140014648122 .2188034058122 .0548706055121 .5467758179121 .0278167725 120.4946975708119 .9447860718119 .3765182495118 .7883987427118 .1788482666 117.5458602905116 .8882369995116 .2056274414115 .4991989136114 .7706451416 114.0227584839113 .2584915161112 .4853439331111 .7110595703110 .9298171997 110.1272964478109 .2452468872108 .2133636475106 .979598999106 .0652008057 105.7603988647 105.7603988647 105.7603988647 106.3700027466 106.979598999 107.5891036987108 .1986999512108 .8082962036109 .4179000854110 .0273971558 110.6370010376111 .551399231112 .7705001831114 .5991973877116 .7326965332 119.1709976196120 .0852966309119 .1709976196117 .342300415115 .818397522 114.9039993286114 .5991973877113 .6848983765110 .6370010376120 .1246795654 121.4285736084121 .5391769409120 .4315338135117 .7574691772113 .3800964355 102.71260070890 .2164001464876 .5010681152373 .4532165527372 .84364318848 72.8436431884872 .8436431884872 .8436431884873 .1484298706173 .45321655273 74.062782287674 .6723632812575 .5867080688576 .5010681152377 .41542053223 78.6345596313580 .1584930419981 .6824111938583 .5111236572385 .64462280273 87.7781066894589 .9116134643690 .8259735107491 .1307525634891 .13075256348 91.1307525634890 .8259735107490 .5211791992289 .9116134643689 .60682678223 88.9972534179788 .3876876831187 .7781066894587 .1685485839886 .55898284912 85.64462280273 84.7302627563583.206336975181.6824111938579.85370635986 77.7202072143675 .5867080688575 .2819290161174 .67236328125 -9999 -9999 -9999 -9999 -9999 -9999 -9999 -9999 -9999 -9999 -9999 -9999 -9999 -9999 -9999 -9999 -9999 -9999 -

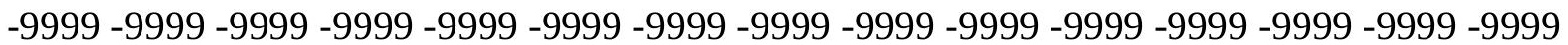

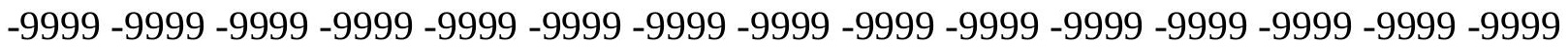

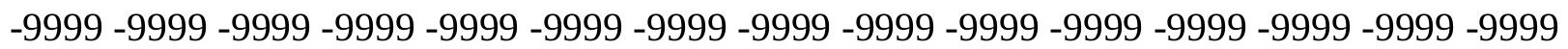

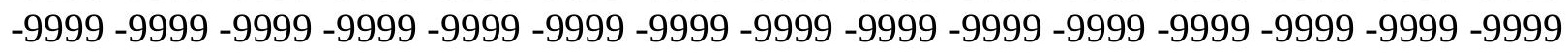
$-9999-9999$

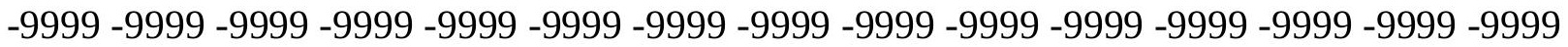

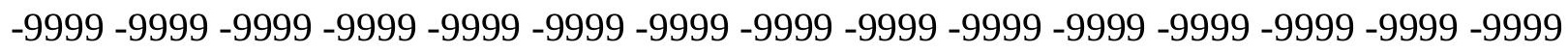

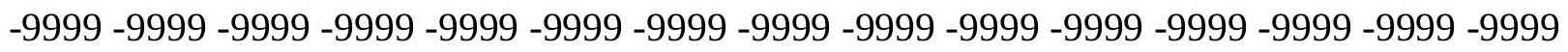
-9999 -9999 -9999 -9999 -9999 -9999 -9999 -9999 -9999 -9999 -9999 -9999 -9999 153.0021057129151 .1734008789157 .878692627161 .5361022949163 .0599975586 163.6696014404163 .6696014404163 .974395752165 .4983062744168 .241394043 172.2035980225176 .165802002179 .2136993408181 .3471984863183 .1759033203 182.5662994385182 .261505127182 .261505127182 .5662994385183 .1759033203 183.1759033203183 .4806976318183 .1759033203182 .87109375182 .261505127 181.6519012451180 .7375946045179 .5184020996178 .604095459177 .3849029541 176.165802002174 .9467010498174 .0323028564173 .1179962158172 .2035980225 171.5939941406171 .2891998291170 .6797027588170 .3748931885170 .070098877 169.4604949951169 .1557006836168 .8509979248168 .241394043167 .9365997314 167.3269958496167 .0222015381166 .4127044678165 .4983062744164 .5839996338 163.6696014404162 .4505004883161 .5361022949160 .6217956543159 .7073974609 
159.0977935791 158.7929992676 158.1835021973 158.1835021973157.878692627 157.878692627157 .878692627157 .878692627158 .4882965088159 .0977935791 159.7073974609160 .3170013428160 .9264984131161 .5361022949162 .4505004883 163.3648071289164 .2792053223165 .1934967041166 .4127044678167 .9365997314 167.6318054199171 .8988037109176 .7754058838179 .8231964111183 .1759033203 184.0901947021185 .0045928955185 .0045928955183 .7854003906180 .7375946045 176.4705963135171 .5939941406166 .7174987793161 .8408966064157 .2691040039 153.3069000244149 .9399261475147 .1550292969145 .6873016357144 .1634063721 142.9441986084142 .0299072266141 .4203033447140 .5059967041139 .8963928223 139.5915985107138 .9819946289138 .3724975586137 .7628936768137 .1533050537 136.2389984131135 .3246002197134 .4102020264133 .4958953857132 .5814971924 131.0576019287129 .533706665127 .7050018311125 .2667007446122 .5235977173 119.7806015015117 .9517974854116 .4279022217116 .4279022217117 .342300415 117.9517974854118 .8662033081119 .4757995605120 .0852966309120 .3900985718 120.3900985718120 .3900985718119 .7806015015119 .7806015015121 .6092987061 122.5235977173118 .2565994263114 .9039993286118 .8662033081122 .8283996582 122.8283996582121 .9140014648121 .9140014648122 .2188034058122 .2188034058 122.2188034058122 .2188034058122 .5235977173122 .5235977173122 .5235977173 122.5235977173122 .2188034058122 .2188034058121 .9140014648121 .9140014648 121.6092987061121 .6092987061121 .3044967651121 .6092987061121 .9140014648 121.6821746826121 .2007369995120 .7012634277120 .1806564331119 .6357040405 119.0631942749118 .4593963623117 .8211746216117 .1457061768116 .4315643311 115.6775817871114 .883682251114 .0502166748113 .1748657227112 .2592391968 111.2942047119110 .2602767944109 .0890197754107 .2844009399106 .3700027466 105.4557037354105 .1509017944105 .4557037354105 .7603988647106 .0652008057 106.6747970581107 .2844009399107 .8938980103108 .5035018921109 .1130981445 109.7226028442110 .6370010376111 .8561019897113 .3800964355115 .5136032104 117.9517974854120 .6949005127122 .8283996582120 .6949005127119 .4757995605 117.9517974854117 .0374984741115 .818397522113 .9896011353110 .9418029785 107.5891036987116 .6113357544119 .2449417114120 .7180862427120 .1131286621 117.2076339722 111.6650314331 105.150901794492.95947265625 80.15849304199 75.8914871215874 .6723632812573 .7580032348673 .1484298706172 .53885650635 72.5388565063572 .8436431884873 .4532165527374 .062782287674 .97714233398 75.8914871215877 .110626220778 .3297805786179 .8537063598681 .68241119385 83.8159103393686 .254188537688 .0829010009889 .6068267822390 .21640014648 90.8259735107491 .1307525634891 .1307525634890 .8259735107490 .52117919922 90.5211791992289 .9116134643689 .6068267822389 .302040100188 .99725341797 88.6924667358488 .3876876831187 .4733276367286 .5589828491285 .03504943848 83.206336975181 .0728530883878 .3297805786175 .2819290161174 .67236328125 74.3675689697373 .75800323486 -9999 -9999 -9999 -9999 -9999 -9999 -9999 -9999 -9999 -9999 -9999 -9999 -9999 -9999 -9999 -9999 -9999 -9999 -9999 -9999 -9999 -9999 -9999 -9999 -9999 -9999 -9999 -9999 -9999 -9999 -9999 -9999 -9999 -9999 -9999 -9999 -9999 -9999 -9999 -9999 -9999 -9999 -9999 -9999 -9999 -9999 -9999 -9999 -9999 -9999 -9999 -9999 -9999 -9999 -

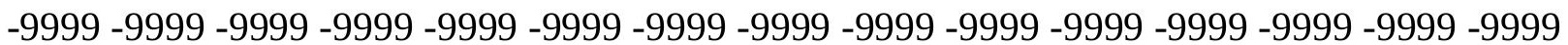
-9999 -9999 -9999 -9999 -9999 -9999 -9999 -9999 -9999 -9999

-9999 -9999 -9999 -9999 -9999 -9999 -9999 -9999 -9999 -9999 -9999 -9999 -9999 -9999 -9999 
-9999 -9999 -9999 -9999 -9999 -9999 -9999 -9999 -9999 -9999 -9999 -9999 -9999 -9999 -9999

-9999 -9999 -9999 -9999 -9999 -9999 -9999 -9999 -9999 -9999 -9999 -9999 -9999 -9999 -9999 -

-9999 -9999 -9999 -9999 -9999 -9999 -9999 -9999 -9999 -9999 -9999 -9999 -9999

163.0659484863167 .6318054199163 .974395752163 .974395752166 .1078948975

167.3269958496167 .6318054199167 .6318054199168 .5462036133170 .6797027588

173.7274932861176 .7754058838179 .5184020996181 .6519012451182 .87109375

183.1759033203183 .1759033203183 .1759033203183 .1759033203183 .1759033203 183.1759033203183 .1759033203183 .1759033203182 .87109375182 .261505127

181.6519012451180 .7375946045179 .8231964111178 .9089050293177 .6896972656

176.7754058838175 .5561981201174 .6419067383173 .7274932861173 .1179962158 172.2035980225171 .5939941406171 .2891998291170 .6797027588170 .070098877

169.7653045654169 .1557006836168 .5462036133167 .9365997314167 .3269958496 166.7174987793166 .1078948975165 .1934967041164 .5839996338163 .3648071289 162.4505004883161 .5361022949160 .3170013428159 .7073974609158 .7929992676 158.1835021973157 .878692627157 .5738983154157 .2691040039157 .2691040039 157.2691040039 157.2691040039 157.2691040039158.1835021973 158.7929992676 159.4026031494160 .3170013428160 .9264984131161 .5361022949162 .4505004883 163.0599975586164 .2792053223165 .1934967041166 .1078948975167 .0222015381 168.5462036133170 .9844970703174 .337097168177 .3849029541180 .432800293 182.5662994385184 .0901947021184 .699798584184 .3950042725181 .0424041748 177.0802001953172 .5084075928167 .6318054199162 .7552947998158 .1835021973 154.2212982178150 .8686065674147 .9318389893146 .2969055176144 .7729034424 143.2489929199142 .3347015381141 .4203033447140 .8106994629140 .2012023926 139.5915985107138 .9819946289138 .6772003174138 .0677032471137 .1533050537 136.5437011719135 .6293945312134 .7149963379133 .4958953857132 .2767028809 130.7528076172128 .9241027832126 .7906036377124 .3523025513121 .9140014648 119.4757995605117 .342300415115 .5136032104114 .9039993286115 .818397522 116.4279022217117 .342300415118 .2565994263118 .8662033081119 .1709976196 119.4757995605119 .4757995605119 .1709976196119 .4757995605120 .9997024536 121.3044967651118 .5614013672116 .4279022217118 .8662033081122 .2188034058 122.8283996582122 .2188034058121 .9140014648121 .9140014648121 .6092987061 121.6092987061121 .6092987061121 .6092987061121 .6092987061121 .6092987061 121.6092987061121 .3044967651120 .9997024536120 .6949005127120 .3900985718 120.0852966309120 .0852966309120 .0852966309120 .3900985718121 .3044967651 121.9140014648121 .8678207397121 .4226379395120 .9537124634120 .4558868408 119.9241027832119 .3528213501118 .7370605469118 .0715789795117 .3520355225 116.5738754272115 .73387146114 .8295593262113 .8610534668106 .6747970581 109.4179000854110 .5035324097109 .2077102661107 .5891036987106 .0652008057 105.1509017944105 .1509017944105 .1509017944105 .4557037354106 .0652008057 106.3700027466 106.979598999 107.5891036987107.8938980103108.5035018921 109.1130981445110 .0273971558111 .551399231113 .075302124115 .2088012695 117.647102356120 .0852966309121 .3044967651120 .9997024536119 .7806015015 118.2565994263116 .7326965332114 .9039993286112 .7705001831110 .3321990967 109.1130981445110 .3321990967115 .7127914429117 .7290496826117 .4265518188 116.1799468994114 .2473602295109 .8013381958102 .524131774995 .09295654297 84.1206970214877 .4154205322374 .9771423339873 .4532165527372 .53885650635 
71.9292907714872 .2340774536172 .5388565063573 .1484298706174 .0627822876 74.6723632812575 .5867080688577 .110626220778 .6345596313580 .15849304199 81.9871978759884 .4254837036186 .5589828491288 .0829010009889 .3020401001 90.2164001464890 .8259735107491 .1307525634891 .1307525634891 .13075256348 91.1307525634890 .8259735107490 .8259735107490 .5211791992290 .21640014648 90.2164001464890 .2164001464889 .9116134643688 .9972534179787 .77810668945 86.5589828491285 .0350494384882 .9015579223679 .5489196777375 .28192901611 74.062782287673 .7580032348673 .14842987061 -9999 -9999 -9999 -9999 -9999 -9999 -9999 -9999 -9999 -9999 -9999 -9999 -9999 -9999 -9999 -9999 -9999 -9999 -9999 -9999 -9999 -9999 -999 -9999 -9999 -9999 -9999 -9999 -9999 -9999 -9999 -9999 -9999 -9999 -9999 -9999 -9999 -9999 -

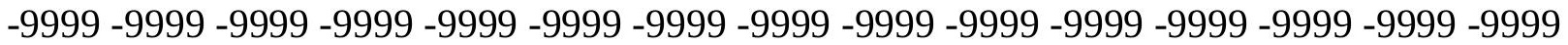
-9999 -9999 -9999 -9999 -9999 -9999 -9999 -9999 -9999 -9999 -9999 -9999 -9999 -9999 -9999 -9999 -9999 -9999 -9999 -9999 -9999-9999 -9999 -9999-9999 -9999 -9999 -9999 -9999 -9999 -9999 -9999 -9999 -9999 -9999 -9999 -9999 -9999 -9999 -9999 -9999 -9999 -9999 -9999 -9999 -9999 -9999 -9999 -9999 -9999 -9999 -9999 -9999 -9999 -9999 -9999

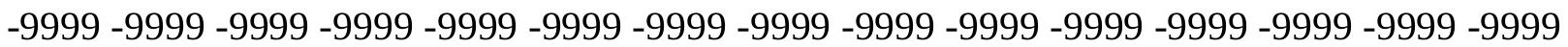

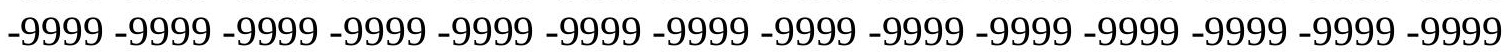
173.4425811768173 .9042510986175 .2514038086170 .9844970703170 .6797027588 170.3748931885170 .070098877170 .6797027588172 .2035980225174 .6419067383 177.0802001953179 .2136993408181 .0424041748181 .9566955566182 .87109375 182.87109375183 .1759033203182 .87109375182 .87109375182 .87109375183 .1759033203 183.1759033203182 .87109375182 .5662994385181 .9566955566181 .0424041748 180.1280059814179 .2136993408178 .2993011475177 .3849029541176 .4705963135 175.5561981201174 .6419067383173 .7274932861173 .1179962158172 .5084075928 171.5939941406170 .9844970703170 .3748931885169 .7653045654169 .1557006836 168.241394043167 .6318054199166 .7174987793166 .1078948975165 .1934967041 164.2792053223163 .3648071289162 .4505004883161 .2312927246160 .3170013428 159.4026031494158 .4882965088157 .878692627157 .2691040039156 .9642944336 156.6596069336156 .6596069336156 .6596069336156 .9642944336156 .9642944336 157.2691040039157 .878692627158 .7929992676159 .4026031494160 .3170013428 160.9264984131161 .5361022949162 .4505004883163 .0599975586163 .974395752 165.1934967041166 .1078948975167 .0222015381168 .5462036133170 .3748931885 172.2035980225174 .0323028564177 .3849029541180 .1280059814181 .9566955566 183.1759033203182 .5662994385180 .1280059814176 .7754058838172 .5084075928 167.6318054199163 .0599975586158 .7929992676154 .8307952881151 .4781951904 148.477355957145 .8990783691144 .7729034424143 .5538024902142 .3347015381 141.7250976562140 .8106994629140 .5059967041139 .8963928223139 .2868041992 138.6772003174138 .0677032471137 .4580993652136 .5437011719135 .6293945312 134.4102020264133 .1911010742131 .9720001221130 .1432037354128 .3144989014 125.8762969971123 .43800354120 .9997024536118 .5614013672116 .4279022217 114.2944030762112 .7705001831113 .6848983765114 .5991973877115 .5136032104 116.1231002808117 .0374984741117 .9517974854117 .9517974854118 .2565994263 118.5614013672118 .8662033081119 .1709976196119 .1709976196118 .5614013672 118.5614013672119 .1709976196120 .3900985718120 .9997024536120 .9997024536 121.3044967651121 .3044967651120 .9997024536120 .9997024536120 .9997024536 120.6949005127120 .6949005127120 .3900985718120 .3900985718120 .0852966309 
119.4757995605118 .8662033081118 .2565994263117 .647102356117 .9517974854 118.8662033081120 .0852966309121 .3044967651121 .9140014648121 .9140014648 121.9140014648121 .6092987061121 .2423095703120 .7564544678120 .2231292725 119.6356506348118 .986618042118 .2689971924117 .4747085571116 .5969161987 115.6293945312114 .5714569092113 .4144592285112 .1608581543110 .8296737671 109.4820251465108 .1986999512106 .3700027466105 .4557037354105 .1509017944 105.1509017944105 .4557037354105 .7603988647106 .3700027466106 .6747970581 106.979598999107 .2844009399107 .8938980103108 .5035018921109 .1130981445 110.3321990967111 .8561019897113 .9896011353116 .1231002808117 .9517974854 119.1709976196119 .4757995605118 .5614013672117 .342300415115 .5136032104 113.075302124110 .6370010376108 .1986999512106 .979598999108 .8082962036 112.4656982422112 .4656982422110 .3214492798111 .6514205933113 .1804275513 111.8126144409107 .025985717899 .7648468017691 .2973480224685 .03504943848 76.1962814331173 .7580032348672 .2340774536171 .6244964599671 .92929077148 72.5388565063573 .1484298706173 .7580032348674 .062782287674 .97714233398 75.8914871215877 .7202072143679 .2441329956181 .3776321411183 .2063369751 85.33984375 87.16854858398 88.38768768311 89.60682678223 90.21640014648 90.8259735107491 .1307525634891 .4355392456191 .4355392456191 .43553924561 91.4355392456191 .1307525634891 .1307525634890 .8259735107491 .13075256348 91.7403335571390 .5211791992289 .6068267822388 .9972534179788 .69246673584 87.7781066894585 .6446228027380 .7680587768675 .5867080688573 .75800323486 73.1484298706172 .53885650635 -9999 -9999 -9999 -9999 -9999 -9999 -9999 -9999 -9999 -9999 -9999 -9999 -9999 -9999 -9999 -9999 -9999 -9999 -9999 -9999 -9999 -9999 -9999 -9999 -9999 -9999 -9999 -9999 -9999 -9999 -9999 -9999 -9999 -9999 -9999 -9999 -9999 -9999 -9999 -9999 -9999 -9999 -9999 -9999 -9999 -9999 -9999 -9999 -9999 -9999 -9999 -9999 -9999 -9999 -9999 -9999 -9999 -9999 -9999 -9999 -9999 -9999 -9999 -9999 -9999 -9999 -9999 -9999 -9999 - -999 -9999 -9999 -9999 -9999-9999-9999-9999-9999

-9999 -9999 -9999 -9999 -9999 -9999 -9999 -9999 -9999 -9999 -9999 -9999 -9999 -9999 -9999 -9999 -9999 -9999 -9999 -9999 -9999 -9999 -9999 -9999 -9999 -9999 -9999 -9999 -9999 -9999 -9999 -9999 -9999 -9999 -9999 -9999 -9999 -9999 -9999 -9999 -9999 -9999 -9999 -9999 -9999 -9999 -9999 -9999 -9999 -9999 -9999 -9999 -9999 -9999 -9999 -9999 -9999-9999 -9999 -9999 -9999 181.0190582275 180.929397583 182.5662994385173.7274932861 170.9844970703 171.2891998291173 .1179962158175 .2514038086176 .7754058838178 .2993011475 179.8231964111180 .7375946045181 .6519012451182 .261505127182 .5662994385 182.5662994385182 .5662994385182 .87109375183 .1759033203183 .1759033203 183.1759033203182 .87109375181 .9566955566181 .3471984863180 .432800293 179.5184020996178 .9089050293177 .9945068359177 .0802001953176 .165802002 175.5561981201174 .6419067383173 .7274932861173 .1179962158172 .2035980225 171.5939941406170 .6797027588169 .7653045654168 .8509979248168 .241394043 167.3269958496166 .4127044678165 .1934967041164 .2792053223163 .3648071289 162.1457061768161 .2312927246160 .0122070312159 .0977935791158 .1835021973 157.2691040039156 .6596069336156 .3547973633156 .0500030518156 .0500030518 156.0500030518156 .3547973633156 .6596069336156 .9642944336157 .5738983154 158.1835021973159 .0977935791159 .7073974609160 .3170013428160 .9264984131 161.5361022949162 .4505004883163 .0599975586163 .974395752165 .1934967041 166.1078948975167 .3269958496168 .5462036133170 .070098877171 .2891998291 
173.1179962158175 .2514038086177 .6896972656179 .2136993408180 .1280059814 179.8231964111178 .2993011475175 .5561981201171 .8988037109167 .6318054199 163.0599975586158 .7929992676154 .8307952881151 .4781951904148 .7351074219 146.3074951172144 .0461730957143 .5538024902142 .6394042969141 .7250976562 141.1154937744140 .5059967041139 .8963928223139 .5915985107138 .9819946289 138.3724975586137 .4580993652136 .5437011719135 .6293945312134 .4102020264 133.1911010742131 .3623962402129 .533706665127 .7050018311125 .2667007446 122.8283996582120 .6949005127118 .2565994263116 .1231002808113 .9896011353 112.1608963013111 .24659729112 .1608963013113 .075302124113 .9896011353 117.647102356119 .4757995605117 .647102356116 .1231002808116 .7326965332 117.0374984741117 .342300415117 .647102356117 .647102356117 .9517974854 118.2565994263118 .5614013672119 .1709976196119 .7806015015120 .0852966309 120.0852966309120 .0852966309120 .0852966309119 .7806015015119 .4757995605 119.4757995605120 .6949005127119 .1709976196119 .1709976196118 .5614013672 117.9517974854117 .0374984741117 .0374984741117 .9517974854119 .1709976196 120.6949005127121 .6092987061121 .9140014648121 .9140014648121 .3044967651 120.9997024536120 .6949005127120 .9997024536121 .0650558472120 .5141601562 119.8913879395119 .1875118 .3914108276117 .4925079346116 .4799346924115 .3486785889 114.0904083252112 .7108612061111 .2402114868109 .7275390625108 .1986999512 106.6747970581105 .7603988647105 .4557037354105 .4557037354105 .4557037354 105.7603988647106 .0652008057106 .3700027466106 .3700027466106 .6747970581 106.979598999107 .2844009399107 .8938980103108 .8082962036110 .0273971558 111.551399231113 .6848983765115 .2088012695116 .7326965332117 .0374984741 116.7326965332115 .5136032104113 .3800964355110 .9418029785107 .5891036987 104.2365036011101 .7982025146101 .7982025146103 .9317016602103 .6268997192 100.2742996216107 .1885223389112 .0273895264112 .407371521108 .4222488403 101.468032836993 .4271392822385 .6080398559678 .7283325195374 .67236328125 72.2340774536171 .3197174072372 .2340774536173 .4532165527374 .36756896973 74.6723632812574 .6723632812574 .6723632812575 .8914871215877 .41542053223 79.2441329956181 .0728530883882 .5967712402384 .4254837036186 .2541885376 87.7781066894588 .9972534179789 .9116134643690 .8259735107491 .43553924561 91.7403335571391 .7403335571391 .7403335571391 .4355392456191 .43553924561 91.1307525634890 .8259735107490 .5211791992289 .9116134643690 .21640014648 90.2164001464890 .5211791992290 .8259735107491 .4355392456191 .74033355713 85.3398437579 .5489196777375 .2819290161173 .1484298706172 .53885650635 72.23407745361 -9999 -9999 -9999 -9999 -9999 -9999 -9999 -9999 -9999 -9999 -9999 -9999

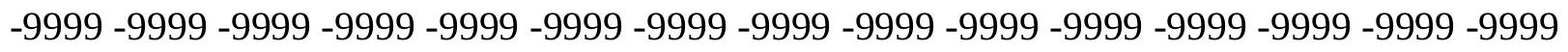

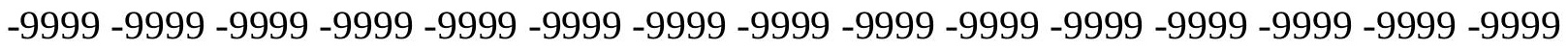
-9999 -9999 -9999 -9999 -9999 -9999 -9999 -9999 -9999 -9999 -9999 -9999 -9999 -9999 -9999 -9999 -9999 -9999 -9999 -9999 -9999 -9999 -9999 -9999 -9999 -9999 -9999 -9999 -9999 -9999 -9999-9999-9999-9999

-9999 -9999 -9999 -9999 -9999 -9999 -9999 -9999 -9999 -9999 -9999 -9999 -9999 -9999 -9999

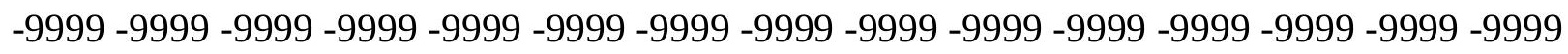
-9999 -9999 -9999 -9999 -9999 -9999 -9999 -9999 -9999 -9999 -9999 -9999 -9999 -9999 -9999 -

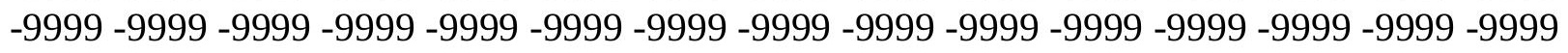
-9999-9999-9999 184.1304931641 179.3581848145175 .5290679932174 .0323028564 
174.0323028564175 .5561981201176 .4705963135177 .0802001953178 .2993011475 179.2136993408180 .432800293181 .3471984863181 .9566955566182 .261505127 182.261505127182 .5662994385183 .4806976318183 .7854003906183 .7854003906 183.4806976318182 .5662994385181 .6519012451180 .7375946045180 .1280059814 179.5184020996178 .604095459177 .9945068359177 .0802001953176 .4705963135 175.5561981201174 .6419067383174 .0323028564173 .1179962158172 .2035980225 170.9844970703170 .070098877169 .1557006836167 .9365997314167 .0222015381 165.8031005859164 .5839996338163 .6696014404162 .4505004883161 .2312927246 160.0122070312159 .0977935791157 .878692627156 .9642944336156 .3547973633 155.7451934814155 .4403991699155 .4403991699155 .4403991699155 .7451934814 156.0500030518156 .6596069336157 .2691040039157 .878692627158 .4882965088 159.0977935791159 .7073974609160 .3170013428160 .9264984131161 .5361022949 162.1457061768163 .0599975586163 .974395752164 .8887023926166 .1078948975 167.3269958496168 .2906494141169 .3734588623170 .5632781982172 .0532836914 173.7274932861175 .2514038086176 .4705963135177 .0802001953177 .0802001953 176.165802002174 .0323028564170 .9844970703167 .0222015381162 .7552947998 158.4882965088154 .5260925293151 .1734008789148 .7351074219146 .6015930176 144.378616333143 .8585968018142 .6394042969141 .7250976562141 .1154937744 140.5059967041140 .2012023926139 .5915985107138 .9819946289138 .3724975586 137.4580993652136 .5437011719135 .6293945312134 .4102020264132 .8863067627 131.3623962402129 .2288970947127 .0953979492124 .9618988037122 .5235977173 120.3900985718118 .2565994263116 .1231002808114 .5991973877113 .9896011353 114.5991973877118 .2565994263121 .9140014648119 .7806015015120 .6949005127 122.8283996582119 .4757995605114 .9039993286114 .2944030762114 .9039993286 115.2088012695115 .5136032104115 .818397522116 .1231002808116 .4279022217 116.4279022217117 .0374984741117 .9517974854118 .2565994263118 .5614013672 118.5614013672118 .2565994263118 .2565994263117 .9517974854119 .1709976196 118.8662033081119 .4757995605119 .7806015015119 .1709976196117 .9517974854 116.7326965332116 .7326965332117 .9517974854120 .0852966309121 .9140014648 122.8283996582122 .2188034058121 .6092987061120 .6949005127119 .7806015015 119.4757995605119 .4757995605119 .7806015015120 .0852966309120 .6949005127 120.107170105119 .328086853118 .4314117432117 .4015884399116 .2269668579 114.8966827393113 .4116821289111 .551399231110 .1047592163108 .5035018921 107.2844009399 106.3700027466106.0652008057 105.7603988647106.0652008057 106.0652008057106 .0652008057106 .0652008057106 .0652008057106 .0652008057 105.7603988647106 .0652008057106 .3700027466106 .6747970581107 .5891036987 108.8082962036110 .6370010376112 .4656982422113 .6848983765114 .5991973877 114.2944030762113 .075302124111 .24659729108 .5035018921104 .8460998535 100.883903503496 .6168823242292 .349891662696 .6168823242299 .66472625732 101.4934005737105 .7603988647112 .1608963013112 .2629699707108 .1008071899 100.41261291592 .0224533081184 .3936004638778 .6978073120174 .5108795166 72.1559448242271 .014930725173 .7580032348675 .8914871215876 .80584716797 76.8058471679776 .1962814331175 .5867080688576 .8058471679778 .32978057861 79.8537063598681 .0728530883882 .5967712402384 .1206970214885 .64462280273 86.8637619018688 .3876876831189 .6068267822390 .5211791992291 .13075256348 91.7403335571392 .0450973510791 .7403335571391 .4355392456191 .13075256348 
90.5211791992289 .9116134643689 .302040100188 .9972534179788 .99725341797 89.6068267822390 .2164001464891 .4355392456192 .0450973510790 .82597351074 87.1685485839882 .2919769287178 .0249862670974 .9771423339872 .53885650635 71.9292907714871 .62449645996 -9999 -9999 -9999 -9999 -9999 -9999 -9999 -9999 -9999 -9999 -9999 -9999 -9999 -9999 -9999 -9999 -9999 -9999 -9999 -9999 -9999 -9999 -9999 -9999 -9999 -9999 -9999 -9999 -9999 -9999 -9999 -9999 -9999 -9999 -9999 -9999 -9999 -9999 -9999 -9999 -9999 -9999 -9999 -9999 -9999 -9999 -9999 -9999 -9999 -9999 -9999 -9999 -9999 -9999

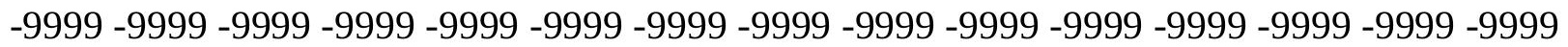
-9999 -9999 -9999-9999-9999-9999

-9999 -9999 -9999 -9999 -9999 -9999 -9999 -9999 -9999 -9999 -9999 -9999 -9999 -9999 -9999

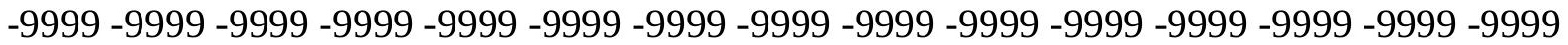
-9999 -9999 -9999 -9999 -9999 -9999 -9999 -9999 -9999 -9999 -9999 -9999 -9999 -9999 -9999 -9999 -9999 -9999 -9999 -9999 -9999 -9999 -9999 -9999 -9999 -9999 -9999 -9999 -9999 -9999 -9999 -9999 -9999 -9999-9999 179.6524353027 177.9264678955178 .0527801514 179.5184020996175 .8609924316175 .5561981201176 .7754058838177 .9945068359 178.9089050293180 .1280059814181 .0424041748181 .9566955566182 .5662994385 183.1759033203184 .0901947021185 .0045928955184 .699798584184 .0901947021 182.87109375181 .9566955566181 .0424041748180 .432800293180 .1280059814 179.5184020996178 .604095459177 .9945068359177 .3849029541176 .4705963135 175.5561981201174 .6419067383173 .7274932861172 .8132019043171 .5939941406 170.3748931885169 .1557006836167 .9365997314166 .7174987793165 .1934967041 163.974395752162 .7552947998161 .5361022949160 .3170013428159 .0977935791 157.878692627156 .9642944336156 .0500030518155 .4403991699154 .8307952881 154.5260925293154 .5260925293154 .8307952881155 .4403991699156 .0500030518 156.6596069336157 .2691040039158 .1835021973159 .0977935791159 .7073974609 160.0122070312160 .6217956543160 .9264984131161 .5361022949162 .1457061768 162.7552947998163 .6696014404164 .5839996338165 .8031005859166 .7501220703 167.6284637451168 .5384979248169 .6030578613170 .81199646172 .0803375244 173.1179962158173 .4226989746174 .0323028564174 .337097168174 .0323028564 172.8132019043170 .070098877166 .4127044678162 .1457061768157 .878692627 153.9165039062150 .8686065674148 .4304046631146 .6015930176144 .565032959 143.8585968018142 .6394042969142 .0299072266141 .4203033447140 .8106994629 140.2012023926139 .5915985107139 .2868041992138 .3724975586137 .7628936768 136.8484954834135 .6293945312134 .4102020264132 .8863067627131 .0576019287 129.2288970947127 .0953979492124 .9618988037122 .5235977173120 .3900985718 118.5614013672117 .0374984741116 .1231002808116 .1231002808117 .342300415 119.4757995605121 .9140014648122 .2188034058122 .2188034058122 .8283996582 121.3044967651118 .8662033081117 .647102356116 .1231002808115 .2088012695 114.9039993286114 .5991973877114 .5991973877114 .9039993286114 .9039993286 115.5136032104116 .1231002808117 .0374984741118 .8662033081118 .2565994263 117.647102356117 .342300415116 .7326965332117 .0374984741119 .1709976196 120.3900985718120 .6949005127120 .3900985718118 .8662033081116 .7326965332 116.1231002808121 .9140014648121 .9140014648124 .0475006104124 .0475006104 122.5235977173120 .9997024536119 .1709976196117 .9517974854117 .342300415 116.7326965332118 .5614013672119 .1709976196120 .0852966309120 .9997024536 120.2793121338119 .4124908447118 .4010543823117 .2257080078115 .872467041 
114.2944030762112 .1608963013110 .8583068848109 .1130981445108 .1986999512 107.2844009399 106.979598999 106.6747970581 106.3700027466106.3700027466 106.0652008057105 .7603988647105 .4557037354105 .1509017944104 .8460998535 104.8460998535104 .5412979126104 .8460998535105 .1509017944106 .0652008057 107.8938980103109 .7226028442111 .24659729111 .8561019897111 .8561019897 110.9418029785109 .1130981445106 .3700027466102 .71260070898 .75038146973 94.7881774902392 .9594726562594 .7881774902398 .14080810547102 .4077987671 106.979598999110 .6370010376110 .3321990967106 .674797058196 .46681213379 88.1013107299882 .113983154377 .3387985229573 .9868316650473 .21270751953 74.2754974365277 .110626220778 .6345596313580 .1584930419980 .46327209473 79.8537063598679 .2441329956179 .5489196777380 .1584930419981 .07285308838 81.6824111938582 .9015579223683 .8159103393685 .0350494384886 .2541885376 87.7781066894588 .9972534179790 .2164001464891 .1307525634891 .43553924561 91.7403335571391 .7403335571391 .4355392456190 .8259735107489 .91161346436 88.9972534179788 .0829010009887 .4733276367287 .4733276367288 .08290100098 88.99725341797 89.9116134643690.52117919922 89.3020401001 86.86376190186 83.206336975179 .8537063598676 .8058471679774 .3675689697372 .23407745361 71.6244964599671 .0149307251 -9999 -9999 -9999 -9999 -9999 -9999 -9999 -9999 -9999 -9999 -9999 -9999 -9999 -9999 -9999 -9999 -9999 -9999 -9999 -9999 -9999 -9999 -9999 -9999

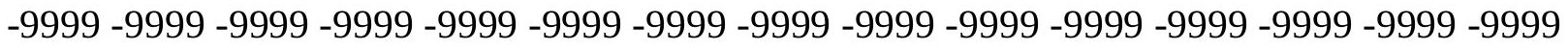

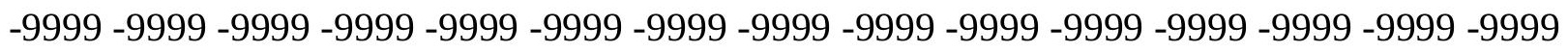
-9999 -9999 -9999 -9999 -9999 -9999 -9999 -9999 -9999 -9999 -9999 -9999 -9999 -9999 -9999 -9999 -9999-9999-9999-9999

-9999 -9999 -9999 -9999 -9999 -9999 -9999 -9999 -9999 -9999 -9999 -9999 -9999 -9999 -9999 -

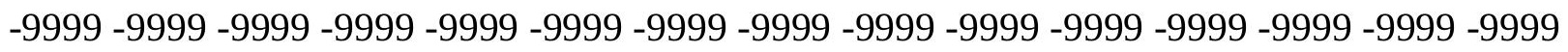
-9999 -9999 -9999 -9999 -9999 -9999 -9999 -9999 -9999 -9999 -9999 -9999 -9999 -9999 -9999 -9999 -9999 -9999 -9999 -9999-9999 -9999 -9999 -9999 -9999 -9999 -9999 -9999 -9999 - 9999 -9999 -9999-9999-9999-9999-9999-9999 180.8936157227 180.5279693604 179.8089141846 180.432800293175 .8609924316176 .4705963135177 .6896972656178 .9089050293 180.432800293181 .6519012451182 .5662994385183 .7854003906185 .0045928955 185.9188995361186 .2236938477184 .699798584183 .1759033203181 .9566955566 181.6519012451181 .0424041748180 .7375946045180 .1280059814179 .5184020996 178.9089050293178 .2993011475177 .6896972656176 .7754058838175 .8609924316 174.6419067383173 .4226989746172 .2035980225170 .6797027588169 .4604949951 167.9365997314166 .4127044678164 .8887023926163 .3648071289162 .1457061768 160.6217956543159 .4026031494158 .1835021973156 .9642944336156 .0500030518 155.1356048584154 .5260925293153 .9165039062153 .9165039062154 .2212982178 154.5260925293155 .1356048584155 .7451934814156 .6596069336157 .5738983154 158.4882965088159 .4026031494159 .7073974609160 .0122070312160 .3170013428 160.9264984131161 .2312927246161 .8408966064162 .4505004883163 .3648071289 164.2792053223165 .1225128174165 .8880615234166 .6426544189167 .4599914551 168.3991241455169 .4140014648170 .3611755371170 .9844970703170 .9844970703 170.9844970703171 .5939941406172 .2035980225171 .5804290771169 .4604949951 166.1078948975162 .1457061768157 .878692627153 .6116943359150 .8686065674 148.4304046631146 .6015930176144 .6701202393143 .8585968018142 .6394042969 142.0299072266141 .4203033447140 .8106994629140 .5059967041139 .8963928223 
139.2868041992138 .6772003174137 .7628936768136 .8484954834135 .6293945312 134.4102020264132 .8863067627131 .0576019287129 .2288970947127 .0953979492 124.9618988037122 .8283996582120 .9997024536119 .1709976196117 .9517974854 117.647102356117 .9517974854119 .1709976196120 .6949005127121 .9140014648 121.9140014648122 .5235977173122 .5235977173122 .2188034058121 .6092987061 121.9140014648119 .7806015015118 .8662033081119 .1709976196118 .8662033081 118.5614013672118 .2565994263117 .647102356117 .9517974854118 .8662033081 120.0852966309122 .8283996582127 .4001998901122 .5235977173120 .3900985718 119.7806015015119 .4757995605119 .4757995605120 .9997024536121 .6092987061 121.6092987061120 .6949005127122 .2188034058118 .5614013672121 .6092987061 124.7774353027124 .6533126831124 .5427017212122 .2188034058119 .7806015015 117.647102356115 .818397522117 .342300415120 .6949005127121 .9140014648 121.9140014648121 .9140014648121 .9080886841121 .2261886597120 .4175796509 119.4624252319118 .3397674561117 .0302581787115 .5287857056113 .8582611084 112.1329116821110 .6370010376109 .4179000854108 .5035018921107 .8938980103 107.5891036987106 .979598999106 .6747970581106 .3700027466105 .7603988647 105.1509017944104 .5412979126104 .2365036011103 .6268997192103 .3221969604 103.3221969604103 .3221969604103 .3221969604105 .4557037354107 .2844009399 108.8082962036109 .7226028442109 .7226028442108 .8082962036106 .979598999 104.8460998535101 .798202514698 .445587158295 .7025299072394 .48339080811 95.397743225198 .4455871582102 .1029968262105 .4557037354107 .5891036987 106.0652008057100 .274299621690 .2164001464882 .9015579223681 .07285308838 74.9876937866273 .8865509033275 .1120834350677 .6332778930780 .87054443359 82.2919769287184 .1206970214885 .0350494384884 .4254837036183 .51112365723 82.9015579223682 .5967712402382 .5967712402382 .9015579223683 .2063369751 83.81591033936 84.73026275635 85.64462280273 86.8637619018688.38768768311 89.6068267822390 .5211791992291 .1307525634891 .7403335571391 .74033355713 91.1307525634890 .2164001464889 .302040100188 .0829010009886 .55898284912 85.64462280273 85.33984375 85.94940185547 87.16854858398 88.08290100098 88.38768768311 87.77810668945 85.9494018554783.51112365723 80.76805877686 78.0249862670975 .5867080688573 .4532165527371 .6244964599671 .0149307251 70.71015167236 -9999 -9999 -9999 -9999 -9999 -9999 -9999 -9999 -9999 -9999 -9999 -9999

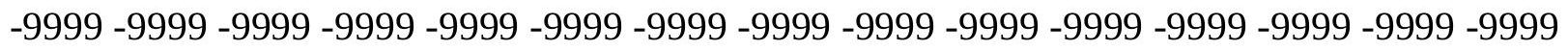
-9999 -9999 -9999 -9999 -9999 -9999 -9999 -9999 -9999 -9999 -9999 -9999 -9999 -9999 -9999 -9999 -9999 -9999 -9999 -9999 -9999 -9999 -9999 -9999 -9999 -9999 -9999 -9999 -9999 -9999 -999 -

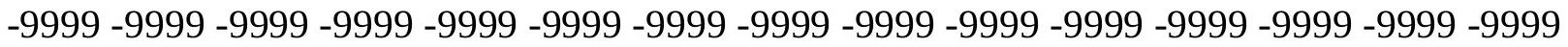
$-9999$

-9999 -9999 -9999 -9999 -9999 -9999 -9999 -9999 -9999 -9999 -9999 -9999 -9999 -9999 -9999 -9999 -9999 -9999 -9999 -9999 -9999 -9999 -9999 -9999 -9999 -9999 -9999 -9999 -9999 -9999 -9999 -9999 -9999 -9999 -9999 -9999 -9999 -9999 -9999 -9999 -9999 -9999 -9999 -9999 -9999 -

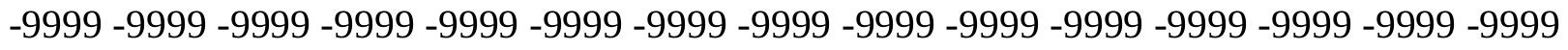
-9999 -9999-9999 -9999 -9999 -9999-9999 -9999-9999 181.7895812988 180.8647155762 179.5116119385179 .8231964111176 .4705963135177 .9945068359179 .8231964111 181.3471984863182 .5662994385183 .7854003906185 .0045928955186 .528503418 187.7476043701185 .3094024658182 .87109375182 .261505127181 .9566955566 181.6519012451181 .3471984863181 .0424041748180 .432800293180 .1280059814 
179.5184020996178 .9089050293177 .9945068359176 .7754058838175 .5561981201 174.337097168172 .8132019043171 .2891998291169 .4604949951167 .9365997314 166.1078948975164 .5839996338163 .0599975586161 .5361022949160 .0122070312 158.7929992676157 .2691040039156 .3547973633155 .4403991699154 .5260925293 153.9165039062153 .6116943359153 .3069000244153 .6116943359154 .5260925293 155.1356048584156 .0500030518156 .6596069336157 .5738983154158 .4882965088 159.4026031494159 .7073974609160 .0122070312160 .3170013428160 .6217956543 160.9264984131161 .2312927246161 .8408966064162 .7552947998163 .6696014404 164.1903076172164 .7535705566165 .3909454346166 .1394042969167 .0052642822 167.9156951904168 .7043762207169 .1557006836168 .8509979248168 .241394043 169.7653045654170 .4354400635170 .365020752168 .5462036133165 .8031005859 162.1457061768158 .1835021973154 .2212982178151 .1734008789148 .7351074219 146.6015930176144 .805770874143 .0395812988142 .9441986084142 .0299072266 141.7250976562141 .1154937744140 .5059967041140 .2012023926139 .5915985107 138.6772003174138 .0677032471136 .8484954834135 .9342041016134 .4102020264 132.8863067627131 .0576019287129 .2288970947127 .4001998901125 .2667007446 123.1332015991121 .6092987061120 .0852966309119 .1709976196118 .8662033081 119.1709976196120 .0852966309121 .3044967651122 .2188034058123 .43800354 124.9618988037121 .3044967651121 .3044967651121 .3044967651120 .6949005127 120.0852966309120 .3900985718122 .2188034058121 .6092987061121 .9140014648 120.6949005127119 .7806015015119 .7806015015120 .3900985718121 .9140014648 123.1332015991122 .8283996582123 .1332015991121 .9140014648121 .3044967651 121.6092987061120 .9997024536120 .9997024536121 .6092987061122 .8283996582 122.8283996582122 .2188034058120 .9997024536123 .43800354124 .7927932739 124.7220993042124 .0475006104120 .9997024536117 .9517974854115 .2088012695 118.2565994263123 .43800354124 .1883239746123 .9558486938123 .6441879272 123.2429275513122 .743637085122 .1360855103121 .4083175659120 .5445175171 119.5252685547118 .3303604126116 .9564285278115 .4211044312113 .7745513916 112.1608963013111 .24659729110 .0273971558109 .4179000854108 .5035018921 107.8938980103106 .979598999106 .3700027466105 .7603988647104 .8460998535 104.2365036011 103.6268997192103.0174026489 102.4077987671 102.1029968262 102.1029968262102 .712600708104 .2365036011105 .7603988647106 .979598999 107.5891036987 107.5891036987 106.979598999 105.4557037354103.6268997192 101.188697814998.7503814697396.9216690063596.3121032714896.92166900635 98.75038146973101 .4934005737103 .6268997192103 .9317016602101 .7982025146 96.6168823242289 .302040100182 .2919769287178 .9393463134871 .62449645996 76.5010681152377 .0847244262781 .5683975219786 .0961456298887 .92284393311 88.3876876831188 .8546905517688 .2797393798887 .1685485839885 .94940185547 85.33984375 84.7302627563584.42548370361 84.12069702148 84.12069702148 84.4254837036185 .3398437586 .254188537687 .4733276367288 .69246673584 89.9116134643690 .8259735107491 .1307525634891 .4355392456191 .13075256348 90.2164001464888 .9972534179787 .4733276367285 .6446228027384 .12069702148 83.5111236572384 .1206970214885 .3398437586 .254188537686 .86376190186 86.55898284912 85.03504943848 83.206336975181.07285308838 78.93934631348 76.8058471679774 .6723632812572 .8436431884871 .014930725170 .71015167236 70.40535736084 -9999 -9999 -9999 -9999 -9999 -9999 -9999 -9999 -9999 -9999 -9999 -9999 
-9999 -9999 -9999 -9999 -9999 -9999 -9999 -9999 -9999 -9999 -9999 -9999 -9999 -9999 -9999 -9999 -9999 -9999 -9999 -9999 -9999 -9999 -9999 -9999 -9999 -9999 -9999 -9999 -9999 -9999

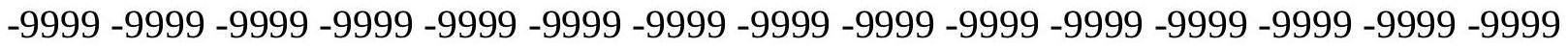
-9999 -9999 -9999 -9999 -9999 -9999 -9999 -9999 -9999 -9999 -9999 -9999 -9999 -9999 -9999 -9999 -9999 -9999 -9999 -9999 -9999 -9999 -9999 -9999 -9999 -9999 -9999-9999 -9999 -9999 -9999 -9999 -9999 -9999 -9999 -9999 -9999 -9999 -9999 -9999 -9999 -9999 -9999 -9999 -9999

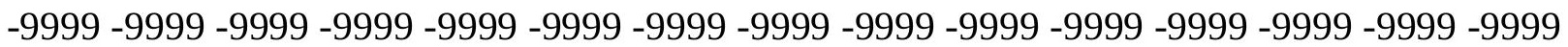
-9999 -9999 -9999 -9999 -9999 -9999 -9999 -9999 -9999 -9999 -9999 -9999 -9999 -9999 -9999 -9999 -9999 -9999 -9999 -9999 -9999 -9999 -9999 -9999 -9999 -9999 181.072845459 179.9435882568178 .6062164307178 .5988769531179 .5184020996181 .3471984863 182.261505127183 .1759033203184 .3950042725185 .6141052246186 .2236938477 185.3094024658184 .0901947021183 .4806976318182 .87109375182 .5662994385 181.9566955566181 .6519012451181 .3471984863181 .0424041748180 .7375946045 180.1280059814179 .2136993408177 .9945068359176 .7754058838175 .2514038086 173.4226989746171 .5939941406169 .7653045654167 .9365997314166 .1078948975 164.2792053223162 .4505004883160 .9264984131159 .4026031494157 .878692627 156.6596069336155 .7451934814154 .8307952881153 .9165039062153 .6116943359 153.3069000244153 .3069000244153 .9165039062154 .5260925293155 .1356048584 156.0500030518156 .9642944336157 .878692627158 .4882965088159 .0977935791 159.4026031494159 .7073974609160 .0122070312160 .3170013428160 .3170013428 160.6217956543161 .2312927246161 .8408966064162 .4064331055162 .8843383789 163.3385467529163 .8780212402164 .5746917725165 .4373168945166 .3720092773 167.1618347168167 .6318054199167 .6318054199167 .9365997314168 .6222686768 169.2266082764169 .3827819824168 .241394043165 .8031005859162 .4505004883 158.7929992676155 .1356048584151 .7830047607149 .0399017334146 .9064025879 145.0776977539143 .3182373047142 .9441986084142 .3347015381141 .7250976562 141.4203033447140 .8106994629140 .2012023926139 .8963928223138 .9819946289 138.0677032471137 .1533050537135 .9342041016134 .7149963379133 .1911010742 131.3623962402129 .533706665127 .7050018311125 .5715026855123 .7427978516 122.2188034058120 .6949005127119 .7806015015119 .4757995605119 .7806015015 120.3900985718121 .3044967651122 .2188034058123 .1332015991122 .8283996582 120.3900985718119 .4757995605119 .1709976196118 .2565994263117 .342300415 117.647102356119 .1709976196120 .6949005127121 .3044967651120 .6949005127 120.3900985718120 .0852966309120 .3900985718120 .9997024536121 .6092987061 121.3044967651121 .3044967651120 .9997024536120 .9997024536120 .9997024536 120.9997024536120 .9997024536121 .6092987061122 .2188034058122 .2188034058 124.9844589233124 .8578643799124 .7712631226124 .7204818726124 .0475006104 122.2188034058118 .8662033081115 .5136032104115 .5136032104123 .43800354 124.7302246094124 .6405029297124 .4826202393124 .2441253662123 .9152145386 123.4899520874122 .962600708122 .3279953003121 .5769577026120 .6988372803 119.6761474609118 .5058746338117 .1861419678115 .7465286255114 .2944030762 113.075302124111 .8561019897110 .6370010376109 .4179000854108 .5035018921 107.5891036987106 .3700027466105 .4557037354104 .5412979126103 .6268997192 103.0174026489102 .4077987671101 .7982025146101 .4934005737101 .7982025146 102.4077987671103 .6268997192104 .8460998535105 .7603988647106 .0652008057 106.0652008057105 .4557037354104 .2365036011102 .712600708100 .8839035034 
99.3599472045997.8360290527397.5312423706198.1408081054799.35994720459 100.5791015625101 .7982025146101 .493400573799 .3599472045995 .09295654297 91.1307525634891 .1307525634896 .0073165893682 .5967712402374 .97714233398 77.110626220788 .9972534179792 .1062088012792 .2152099609492 .51142883301 91.1307525634891 .7228088378990 .7879562377989 .9853897094789 .60682678223 86.86376190186 85.94940185547 85.33984375 84.73026275635 84.73026275635 85.33984375 85.94940185547 86.86376190186 87.77810668945 88.99725341797 89.91161346436 90.8259735107491 .1307525634890 .8259735107490 .2164001464888 .99725341797 87.1685485839885 .3398437583 .5111236572381 .6824111938582 .90155792236 84.4254837036185 .3398437585 .6446228027385 .3398437584 .4254837036183 .2063369751 81.3776321411179 .5489196777377 .7202072143675 .8914871215874 .0627822876 72.2340774536170 .7101516723670 .1005783081169 .79579162598 -9999 -9999 -9999 -9999 -9999 -9999 -9999 -9999 -9999 -9999 -9999 -9999 -9999 -9999 -9999 -9999 -9999 -9999 -9999 -9999 -9999 -9999 -9999 -9999 -9999 -9999 -9999 -9999 -9999 -9999 -9999 -9999 -9999 -9999 -9999 -9999 -9999 -9999 -9999 -9999 -9999 -9999 -9999 -9999 -9999 -9999 -9999 -9999 -9999

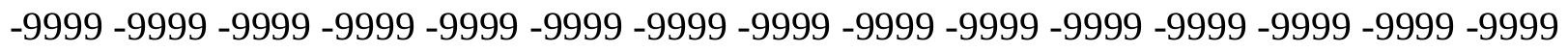
-9999 -9999 -9999 -9999-9999 -9999 -9999

-9999 -9999 -9999 -9999 -9999 -9999 -9999 -9999 -9999 -9999 -9999 -9999 -9999 -9999 -9999 -9999 -9999 -9999 -9999 -9999 -9999 -9999 -9999 -9999 -9999 -9999 -9999 -9999 -9999 -9999 -

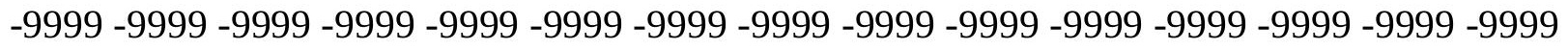

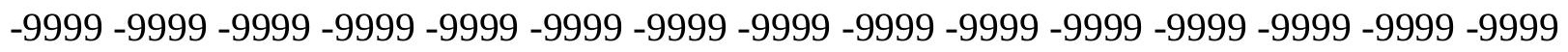
-9999 -9999 -9999 -9999 -9999 -9999 -9999 -9999 -9999 -9999 -9999 -9999 -9999 180.1806640625180 .061126709180 .7863616943181 .7280578613181 .6519012451 182.261505127182 .87109375183 .7854003906184 .699798584185 .3094024658 185.0045928955184 .3950042725183 .7854003906183 .1759033203182 .5662994385 182.261505127 182.261505127 182.261505127 181.9566955566181.3471984863 180.432800293179 .2136993408177 .6896972656176 .165802002174 .337097168 172.2035980225170 .070098877167 .9365997314166 .1078948975163 .974395752 162.1457061768160 .3170013428158 .7929992676157 .2691040039156 .0500030518 155.1356048584154 .2212982178153 .6116943359153 .3069000244153 .3069000244 153.6116943359153 .9165039062154 .8307952881155 .4403991699156 .3547973633 157.2691040039157 .878692627158 .4882965088159 .0977935791159 .4026031494 159.7073974609159 .7073974609159 .7073974609159 .7073974609160 .0122070312 160.0122070312160 .5305328369160 .9854736328161 .3522033691161 .6997680664 162.1384124756162 .7815856934163 .6860656738164 .7786102295165 .8087005615 166.4127044678167 .0222015381167 .6318054199168 .0741271973168 .516998291 168.6820373535168 .241394043166 .1078948975163 .3648071289159 .7073974609 155.7451934814152 .3925933838149 .3446960449146 .9064025879145 .3825073242 143.5989990234143 .2489929199142 .6394042969142 .0299072266141 .7250976562 141.1154937744140 .5059967041139 .8963928223139 .2868041992138 .3724975586 137.4580993652136 .2389984131135 .0198059082133 .4958953857131 .6672058105 129.8385009766128 .0097961426126 .1809997559124 .3523025513122 .5235977173 121.3044967651120 .3900985718120 .0852966309119 .7806015015120 .3900985718 120.6949005127121 .3044967651121 .6092987061120 .9997024536119 .7806015015 118.2565994263116 .4279022217115 .2088012695113 .9896011353112 .4656982422 115.5136032104117 .647102356118 .8662033081119 .1709976196119 .1709976196 
118.8662033081118 .8662033081118 .8662033081118 .8662033081118 .8662033081 118.5614013672118 .5614013672118 .5614013672118 .5614013672118 .5614013672 118.8662033081119 .1709976196119 .4757995605119 .4757995605123 .1332015991 124.6216812134124 .5704956055124 .5607833862123 .43800354120 .0852966309 116.4279022217114 .9039993286114 .5991973877124 .9590682983124 .9935760498 124.9770202637124 .8916320801124 .7239074707124 .4637985229124 .1069412231 123.653213501123 .10521698122 .4669189453121 .7373046875120 .918510437 120.0046310425118 .9700698853117 .7824325562116 .4279022217114 .9039993286 113.3800964355111 .8561019897110 .3321990967108 .8082962036107 .5891036987 106.3700027466105 .1509017944104 .2365036011103 .3221969604102 .4077987671 101.7982025146101 .4934005737101 .1886978149101 .4934005737102 .1029968262 103.0174026489104 .2365036011104 .5412979126104 .5412979126104 .5412979126 103.9317016602103 .0174026489101 .7982025146100 .579101562599 .35994720459 98.7503814697398 .445587158298 .7503814697399 .3599472045999 .96952056885 100.579101562599 .9695205688598 .1408081054795 .397743225195 .70252990723 95.7025299072393 .5690307617286 .8637619018684 .4254837036185 .64462280273 99.3599472045993 .8738174438594 .3895874023495 .073936462495 .08866119385 89.9116134643692.0450973510792.9594726562591.71202850342 89.6626663208 87.7781066894586 .8637619018685 .9494018554785 .6446228027386 .55898284912 86.254188537686 .5589828491286 .8637619018688 .0829010009889 .60682678223 90.5211791992291 .1307525634891 .1307525634890 .5211791992289 .3020401001 87.7781066894586 .254188537684 .4254837036183 .5111236572383 .51112365723 84.4254837036185 .0350494384885 .3398437585 .0350494384884 .12069702148 83.206336975181 .6824111938580 .1584930419978 .3297805786176 .80584716797 74.9771423339873 .4532165527371 .6244964599670 .1005783081169 .79579162598 69.18623352051 -9999 -9999 -9999 -9999 -9999 -9999 -9999 -9999 -9999 -9999 -9999 -9999

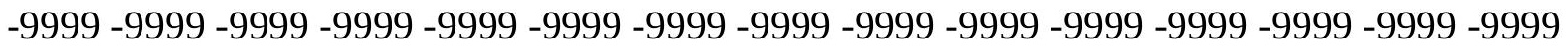

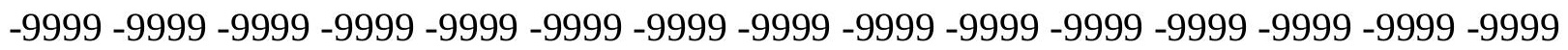
-9999 -9999 -9999 -9999 -9999 -9999 -9999 -9999 -9999 -9999 -9999 -9999 -9999 -9999 -9999 -9999 -9999 -9999 -9999 -9999 -9999 -9999 -9999 -9999 -9999 -9999 -9999 -9999

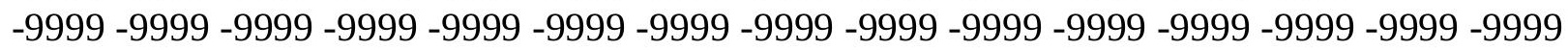
-9999 -9999 -9999 -9999 -9999 -9999 -9999 -9999 -9999 -9999 -9999 -9999 -9999 -9999 -9999 -

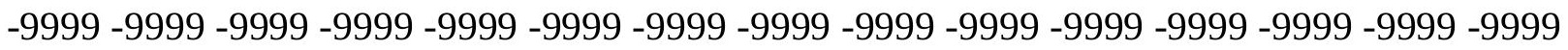
-9999 -9999 -9999 -9999 -9999 -9999 -9999 -9999 -9999 -9999 -9999 -9999 -9999 -9999 -9999 -9999 -9999 -9999 -9999 -9999 -9999 -9999 -9999 -9999 -9999 -9999 -9999 -9999 -9999 -9999 182.5438995361183 .6367340088185 .4118041992187 .7476043701180 .7375946045 181.6519012451183 .1759033203185 .0045928955185 .9188995361185 .6141052246 184.699798584183 .4806976318182 .87109375182 .87109375183 .1759033203 183.1759033203183 .1759033203182 .5662994385181 .6519012451180 .432800293 178.9089050293177 .0802001953174 .9467010498172 .8132019043170 .3748931885 168.241394043165 .8031005859163 .6696014404161 .8408966064160 .0122070312 158.1835021973156 .6596069336155 .4403991699154 .5260925293153 .9165039062 153.3069000244153 .3069000244153 .3069000244153 .6116943359154 .2212982178 155.1356048584156 .0500030518156 .9642944336157 .5738983154158 .1835021973 158.7929992676159 .0977935791159 .4026031494159 .4026031494159 .4026031494 159.4026031494159 .0977935791159 .0977935791159 .0866546631159 .0977935791 
159.5744934082159 .7953186035159 .9911193848160 .279586792160 .8137664795 161.7084655762162 .9888458252164 .5839996338165 .4983062744166 .4127044678 167.0575256348167 .5796813965167 .9844512939168 .1595611572167 .971862793 166.7174987793163 .974395752160 .6217956543156 .6596069336152 .6972961426 149.6495056152147 .2111968994145 .3825073242143 .8136749268143 .5538024902 142.9441986084142 .3347015381142 .0299072266141 .4203033447141 .1154937744 140.5059967041139 .5915985107138 .6772003174137 .7628936768136 .5437011719 135.3246002197133 .8007049561132 .2767028809130 .4479980469128 .6192932129 126.4858016968124 .9618988037123 .1332015991121 .9140014648120 .6949005127 120.0852966309119 .7806015015119 .7806015015120 .0852966309120 .3900985718 120.0852966309119 .7806015015118 .5614013672117 .342300415115 .5136032104 113.075302124111 .551399231111 .24659729112 .4656982422114 .5991973877 115.818397522116 .4279022217116 .4279022217116 .1231002808116 .1231002808 115.5136032104115 .2088012695114 .9039993286114 .9039993286114 .5991973877 114.5991973877114 .5991973877114 .9039993286114 .9039993286115 .2088012695 115.2088012695116 .7326965332123 .1332015991124 .3130722046124 .2925643921 124.3188400269122 .5235977173117 .647102356116 .1231002808116 .1231002808 119.1709976196125 .0300292969125 .1302642822125 .1816101074125 .1640319824 125.0606307983124 .8638458252124 .5640106201124 .1639251709123 .6744918823 123.114654541122 .5083236694121 .8768157959121 .2193450928120 .480255127 119.5478057861118 .2565994263116 .4279022217114 .2944030762112 .4656982422 110.6370010376109 .1130981445107 .5891036987106 .0652008057104 .8460998535 103.9317016602102 .712600708102 .1029968262101 .1886978149100 .8839035034 100.8839035034100 .8839035034101 .4934005737102 .4077987671103 .0174026489 103.3221969604103 .3221969604103 .0174026489102 .4077987671101 .7982025146 100.883903503499 .9695205688599 .3599472045998 .7503814697398 .75038146973 99.0551681518699 .3599472045999 .6647262573299 .6647262573299 .35994720459 98.1408081054796 .3121032714894 .4833908081192 .9594726562592 .65467834473 92.9594726562593 .5690307617292 .349891662692 .0450973510788 .99725341797 96.0073165893695 .9527359008896 .5588073730592 .0450973510788 .08290100098 94.1785964965893 .2642517089892 .222518920990 .4753265380988 .69246673584 88.0829010009888 .9972534179790 .2164001464888 .6924667358486 .86376190186 87.1685485839888 .6924667358489 .6068267822390 .5211791992291 .13075256348 91.4355392456190 .8259735107490 .2164001464888 .6924667358487 .47332763672 86.254188537685 .3398437585 .0350494384885 .0350494384885 .3398437585 .33984375 85.0350494384884 .1206970214883 .206336975181 .9871978759880 .76805877686 79.2441329956177 .7202072143676 .1962814331174 .3675689697372 .84364318848 71.014930725169 .4910125732469 .1862335205168 .88143920898 -9999 -9999 -9999 -9999 -9999 -9999 -9999 -9999 -9999 -9999 -9999 -9999 -9999 -9999 -9999 -9999 -9999 -9999 -9999 -9999 -9999 -9999 -9999 -9999 -9999 -9999 -9999 -9999 -9999 -9999 -9999 -9999 -9999 -9999 -

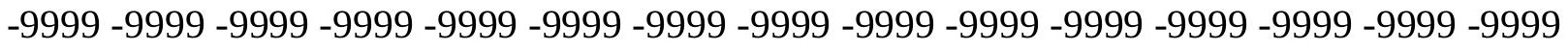
-9999 -9999 -9999 -9999 -9999 -9999 -9999 -9999 -9999 -9999 -9999 -9999 -9999 -9999 -9999 -9999 -9999-9999-9999-9999

-9999 -9999 -9999 -9999 -9999 -9999 -9999 -9999 -9999 -9999 -9999 -9999 -9999 -9999 -9999

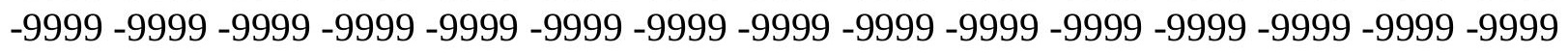

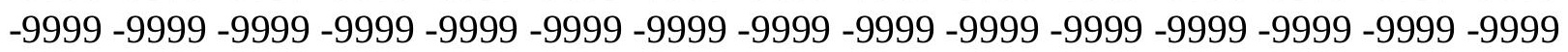


-9999 -9999 -9999 -9999 -9999 -9999 -9999 -9999 -9999 -9999 -9999 -9999 -9999 -9999 -9999 -9999 -9999 -9999 -9999 -9999 -9999 -9999 -9999 -9999 -9999 -9999 -9999 -9999 -9999 -9999 -9999 -9999 187.9749603271 188.7276153564188.4989929199190.795501709 183.7854003906185 .6141052246186 .2236938477185 .9188995361185 .0045928955 183.7854003906182 .87109375183 .1759033203183 .7854003906184 .0901947021 184.0901947021183 .7854003906182 .87109375181 .6519012451179 .8231964111 177.9945068359175 .5561981201173 .1179962158170 .6797027588168 .241394043 165.8031005859163 .6696014404161 .2312927246159 .4026031494157 .5738983154 156.0500030518154 .8307952881154 .2212982178153 .6116943359153 .3069000244 153.3069000244153 .6116943359153 .9165039062154 .8307952881155 .4403991699 156.3547973633157 .2691040039158 .1835021973158 .7929992676159 .4026031494 159.7073974609159 .7073974609159 .7073974609159 .4026031494159 .0977935791 158.7929992676158 .1835021973157 .878692627157 .5738983154157 .878692627 158.4086761475158 .4049530029158 .467590332158 .8096160889159 .6030731201 160.9588317871162 .4505004883164 .2792053223165 .4798278809166 .2870483398 166.9202880859167 .3973693848167 .6340637207167 .4984283447166 .8697662354 164.8887023926161 .5361022949157 .2691040039152 .6972961426149 .6495056152 147.5160064697145 .6873016357144 .0868530273143 .8585968018143 .2489929199 142.6394042969142 .3347015381142 .0299072266141 .4203033447140 .8106994629 140.2012023926139 .2868041992138 .0677032471136 .8484954834135 .6293945312 134.1054992676132 .5814971924130 .7528076172128 .9241027832127 .0953979492 125.2667007446123 .7427978516122 .2188034058120 .9997024536120 .0852966309 119.4757995605119 .1709976196119 .1709976196119 .1709976196118 .8662033081 118.5614013672117 .647102356116 .4279022217114 .9039993286112 .7705001831 110.6370010376109 .4179000854110 .3321990967111 .551399231112 .4656982422 113.075302124113 .075302124112 .7705001831112 .1608963013111 .551399231 110.9418029785110 .3321990967110 .0273971558109 .7226028442109 .7226028442 109.7226028442109 .7226028442109 .7226028442109 .7226028442109 .4179000854 124.1020965576123 .43800354122 .2188034058122 .5235977173119 .7806015015 116.7326965332115 .818397522115 .818397522116 .4279022217121 .9140014648 124.9738769531125 .1217269897125 .2242431641125 .2605133057125 .2214126587 125.0820922852124 .8295516968124 .4543762207123 .9727554321123 .4322509766 122.8768157959122 .3601379395121 .9000930786121 .4230957031120 .7057342529 119.4757995605117 .342300415114 .9039993286112 .7705001831110 .6370010376 108.8082962036107 .2844009399105 .7603988647104 .2365036011103 .3221969604 102.1029968262101 .4934005737100 .8839035034100 .2742996216100 .2742996216 100.2742996216100 .8839035034101 .1886978149101 .4934005737101 .7982025146 101.7982025146101 .4934005737101 .1886978149100 .579101562599 .96952056885 99.3599472045999 .0551681518698 .7503814697398 .7503814697398 .75038146973 99.0551681518699 .3599472045999 .6647262573299 .3599472045998 .4455871582 97.5312423706196 .9216690063596 .6168823242297 .2264633178799 .35994720459 101.798202514697 .8360290527394 .1785964965891 .1307525634899 .60682678223 94.5161666870197 .0624237060596 .0073165893685 .6446228027387 .16854858398 91.4355392456192 .9594726562593 .2642517089892 .3302307128992 .04509735107 92.9594726562596 .3121032714895 .7025299072391 .1307525634890 .21640014648 91.4355392456190 .8259735107491 .4355392456191 .4355392456191 .43553924561 
91.1307525634890 .5211791992289 .6068267822388 .9972534179788 .08290100098 87.1685485839886 .5589828491286 .254188537685 .9494018554785 .64462280273 85.0350494384884 .4254837036183 .5111236572382 .5967712402381 .37763214111 79.8537063598678 .6345596313577 .110626220775 .5867080688573 .75800323486 $72.2340774536170 .4053573608468 .8814392089868 .5766525268668 .27187347412-9999$ -9999 -9999 -9999 -9999 -9999 -9999 -9999 -9999 -9999 -9999 -9999 -9999 -9999 -9999 -9999 -9999 -9999 -9999 -9999 -9999 -9999 -9999 -9999 -9999 -9999 -9999 -9999 -9999 -9999 -9999

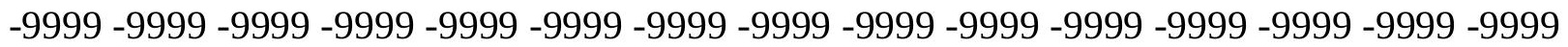

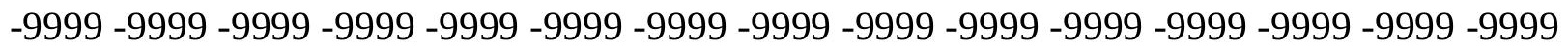
-9999 -9999 -9999 -9999 -9999 -9999 -9999

-9999 -9999 -9999 -9999 -9999 -9999 -9999 -9999 -9999 -9999 -9999 -9999 -9999 -9999 -9999 -9999 -9999 -9999 -9999 -9999 -9999 -9999 -9999 -9999 -9999 -9999 -9999 -9999 -9999 -9999 -9999 -9999 -9999 -9999 -9999 -9999 -9999 -9999 -9999 -9999 -9999 -9999 -9999 -9999 -9999 -9999 -9999 -9999 -9999 -9999 -9999 -9999 -9999 -9999 -9999 -9999 -9999 -9999 -9999 -9999 -9999 -9999 -9999 -9999 -9999 -9999 -9999 -9999 -9999 -9999 -9999 -9999 -9999 -9999 -9999 -9999 -9999-9999 191.6327972412192.9563903809 193.1154327393192 .1475219727 192.9290008545185 .9188995361185 .9188995361184 .699798584183 .4806976318 182.87109375183 .4806976318184 .0901947021184 .699798584185 .0045928955 184.699798584183 .7854003906182 .5662994385180 .7375946045178 .604095459 176.165802002173 .7274932861170 .9844970703168 .241394043165 .8031005859 163.3648071289160 .9264984131158 .7929992676156 .9642944336155 .7451934814 154.5260925293153 .6116943359153 .0021057129153 .0021057129153 .0021057129 153.6116943359154 .2212982178155 .1356048584156 .0500030518156 .9642944336 158.1835021973159 .0977935791159 .7073974609160 .3170013428160 .3170013428 160.0122070312160 .0122070312159 .7073974609159 .0977935791158 .1835021973 157.5738983154156 .6596069336156 .0500030518156 .3547973633156 .9642944336 157.1401672363156 .9578704834157 .0159759521157 .5738983154159 .0977935791 160.9264984131163 .0599975586164 .2490386963165 .1920471191165 .971862793 166.5786590576166 .9355621338166 .8934173584166 .2666625977164 .9476776123 162.7552947998158 .1835021973153 .6116943359149 .9542999268147 .5160064697 145.9920959473144 .375869751144 .1634063721143 .5538024902143 .2489929199 142.6394042969142 .3347015381142 .0299072266141 .4203033447140 .5059967041 139.5915985107138 .6772003174137 .1533050537135 .9342041016134 .4102020264 132.8863067627131 .3623962402129 .533706665127 .4001998901125 .5715026855 124.0475006104122 .5235977173120 .9997024536120 .0852966309119 .1709976196 118.5614013672118 .2565994263118 .2565994263117 .9517974854117 .647102356 117.0374984741116 .1231002808114 .9039993286113 .075302124111 .551399231 109.7226028442107 .8938980103108 .5035018921108 .8082962036109 .1130981445 109.1130981445108 .5035018921107 .8938980103106 .979598999105 .7603988647 105.1509017944104 .5412979126103 .9317016602103 .9317016602103 .6268997192 103.6268997192103 .6268997192103 .6268997192103 .9317016602112 .4656982422 115.5136032104114 .9039993286113 .6848983765111 .8561019897112 .4656982422 113.3800964355113 .6848983765118 .5614013672123 .1332015991124 .7791366577 124.9487762451125 .0741119385125 .1486129761125 .1588058472125 .0768356323 124.8646774292124 .4903488159123 .9631271362123 .3517074585122 .7309646606 122.1971054077121 .8102798462121 .4950790405120 .9662246704119 .7806015015 
117.0374984741114 .5991973877112 .1608963013110 .0273971558108 .1986999512 106.3700027466104 .8460998535103 .6268997192102 .4077987671101 .4934005737 100.579101562599 .9695205688599 .6647262573299 .6647262573299 .66472625732 99.6647262573299 .96952056885100 .2742996216100 .2742996216100 .2742996216 99.9695205688599 .6647262573299 .3599472045998 .7503814697398 .4455871582 98.1408081054798 .1408081054798 .445587158298 .7503814697399 .05516815186 99.3599472045999 .6647262573299 .3599472045999 .3599472045998 .75038146973 98.7503814697398 .7503814697399 .96952056885101 .7982025146102 .4077987671 100.274299621696 .6168823242292 .0450973510787 .7781066894593 .56903076172 96.2516632080198 .1315155029388 .6924667358486 .254188537687 .47332763672 91.4355392456192 .9594726562593 .5690307617293 .8738174438595 .3977432251 98.4297866821397 .908897399995 .9895553588995 .2620239257896 .31210327148 94.4833908081192 .349891662691 .1307525634890 .8259735107491 .13075256348 89.9116134643689 .9116134643690 .2164001464889 .6068267822388 .69246673584 87.7781066894587 .1685485839886 .5589828491286 .254188537685 .64462280273 84.7302627563584 .1206970214882 .9015579223681 .9871978759880 .76805877686 79.5489196777378 .0249862670976 .5010681152374 .9771423339873 .14842987061 71.6244964599669 .7957916259868 .2718734741267 .9670867919967 .66230010986 -9999 -9999 -9999 -9999 -9999 -9999 -9999 -9999 -9999 -9999 -9999 -9999 -9999 -9999 -9999 -9999

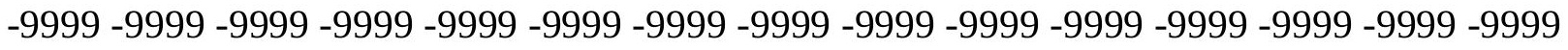
-9999 -9999 -9999 -9999 -9999 -9999 -9999 -9999 -9999 -9999 -9999 -9999 -9999 -9999 -9999 -9999 -9999 -9999 -9999 -9999 -9999 -9999 -9999 -9999 -9999 -9999 -9999 -9999 -9999 -9999 -9999 -9999 -9999 -9999-9999-9999

-9999 -9999 -9999 -9999 -9999 -9999 -9999 -9999 -9999 -9999 -9999 -9999 -9999 -9999 -9999 -

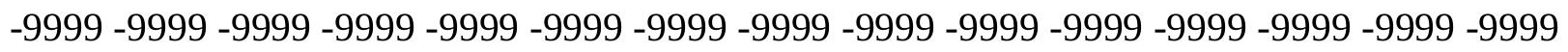
-9999 -9999 -9999 -9999 -9999 -9999 -9999 -9999 -9999 -9999 -9999 -9999 -9999 -9999 -9999 -9999 -9999 -9999 -9999 -9999 -9999 -9999 -9999 -9999 -9999 -9999 -9999 -9999 -9999 -9999 -9999 -9999 -9999 -9999 -9999 -9999 -9999 -9999 -9999 -9999 -9999 -9999 -9999 -9999 -9999 -9999 -9999-9999-9999 195.9095458984 196.6177215576 196.9495544434195.600402832 192.2854309082188 .6620025635183 .1759033203182 .261505127182 .261505127 183.1759033203184 .0901947021185 .3094024658185 .6141052246185 .6141052246 184.699798584183 .4806976318181 .3471984863179 .2136993408176 .4705963135 174.0323028564171 .2891998291168 .241394043165 .4983062744163 .0599975586 160.6217956543158 .4882965088156 .6596069336155 .1356048584153 .9165039062 153.0021057129152 .6972961426152 .6972961426153 .0021057129153 .6116943359 154.5260925293155 .4403991699156 .6596069336157 .878692627158 .7929992676 160.0122070312160 .6217956543161 .2312927246161 .5361022949161 .2312927246 160.9264984131160 .3170013428159 .4026031494158 .1835021973156 .9642944336 155.7451934814154 .8307952881154 .5260925293155 .4403991699156 .3547973633 156.0444946289155 .7451934814156 .6596069336157 .5738983154159 .4026031494 161.2548065186162 .6674346924163 .7621765137164 .6717071533165 .4011230469 165.8772277832165 .9605560303165 .394821167163 .8804016113161 .4778900146 157.878692627153 .3069000244149 .9542999268147 .5160064697145 .9920959473 144.5652618408144 .4682006836143 .8585968018143 .5538024902143 .2489929199 142.9441986084142 .3347015381141 .7250976562141 .1154937744140 .2012023926 138.9819946289137 .7628936768136 .2389984131134 .7149963379133 .1911010742 
131.3623962402129.533706665 127.7050018311125 .8762969971124 .3523025513 122.5235977173121 .3044967651120 .0852966309118 .8662033081118 .2565994263 117.647102356117 .342300415117 .0374984741117 .0374984741116 .7326965332 116.1231002808115 .2088012695113 .9896011353112 .4656982422110 .9418029785 109.1130981445106 .979598999105 .4557037354105 .4557037354104 .8460998535 103.9317016602103 .0174026489101 .7982025146100 .579101562599 .05516815186 98.445587158298 .1408081054797 .8360290527398 .1408081054798 .4455871582 98.445587158298 .75038146973100 .5791015625102 .4077987671104 .5412979126 104.2365036011104 .8460998535106 .0652008057108 .5035018921109 .7226028442 114.9039993286119 .7806015015123 .43800354124 .446144104124 .5984573364 124.7096557617124 .7885971069124 .8329238892124 .8081665039124 .6428527832 124.252784729123 .6306686401122 .8470306396121 .9140014648120 .0852966309 120.3900985718120 .3900985718120 .0852966309118 .2565994263116 .1231002808 113.6848983765111 .24659729109 .1130981445106 .979598999105 .4557037354 103.9317016602102 .4077987671101 .4934005737100 .579101562599 .66472625732 99.0551681518698 .7503814697398 .7503814697398 .7503814697398 .75038146973 98.7503814697398 .7503814697398 .7503814697398 .7503814697398 .4455871582 98.4455871582 98.1408081054797.8360290527397.5312423706197.53124237061 97.5312423706197 .8360290527398 .1408081054798 .7503814697399 .05516815186 99.6647262573299 .9695205688599 .9695205688599 .9695205688599 .96952056885 100.2742996216100 .5791015625101 .7982025146102 .1029968262100 .5791015625 97.5312423706193 .5690307617288 .9972534179784 .4254837036193 .26425170898 97.0599136352599 .3462753295993 .8738174438587 .4733276367288 .38768768311 90.5211791992293 .2642517089893 .8738174438595 .0929565429799 .53466033936 99.3362503051898 .6888656616298 .1117324829197 .4993438720795 .9144744873 92.349891662690 .2164001464888 .9972534179788 .0829010009887 .47332763672 88.6924667358491 .1307525634890 .5211791992289 .6068267822388 .69246673584 88.0829010009887 .1685485839886 .5589828491285 .9494018554785 .33984375 84.4254837036183 .5111236572382 .5967712402381 .3776321411180 .15849304199 78.9393463134877 .4154205322375 .8914871215874 .3675689697372 .53885650635 70.7101516723668 .8814392089867 .6623001098667 .35751342773 -9999 -9999 -9999 -9999 -9999 -9999 -9999 -9999 -9999 -9999 -9999 -9999 -9999 -9999 -9999 -9999 -9999 -9999 -9999

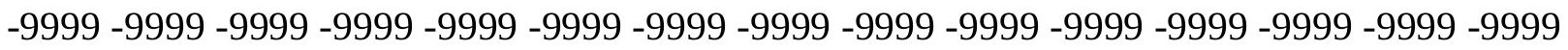

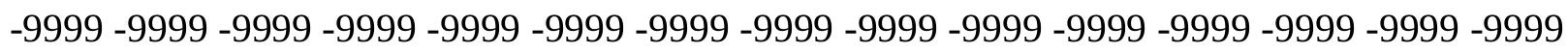

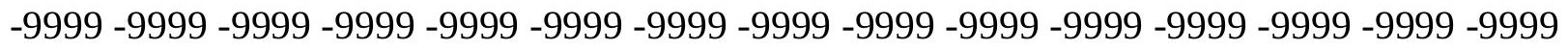
$-9999-9999-9999$

-9999 -9999 -9999 -9999 -9999 -9999 -9999 -9999 -9999 -9999 -9999 -9999 -9999 -9999 - 9999-

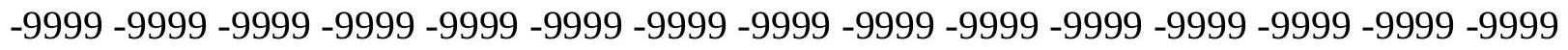

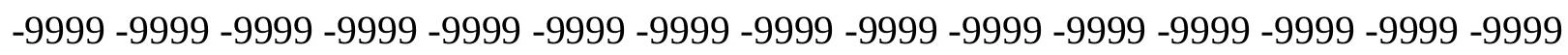
-9999 -9999 -9999 -9999 -9999 -9999 -9999 -9999 -9999 -9999 -9999 -9999 -9999 -9999 -9999 -999 -

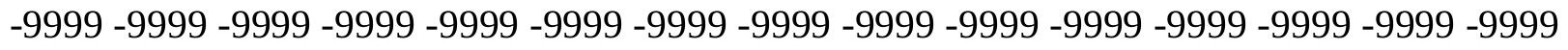
-9999 -9999-9999 -9999-9999 199.8418121338 200.5713653564 199.9650115967 198.3590545654195 .2534179688190 .795501709180 .1280059814180 .432800293 181.3471984863183 .4806976318185 .0045928955185 .9188995361186 .2236938477 185.3094024658184 .0901947021181 .9566955566179 .5184020996176 .7754058838 174.0323028564171 .2891998291168 .241394043165 .4983062744162 .7552947998 
160.3170013428157 .878692627156 .0500030518154 .2212982178153 .3069000244 152.3925933838152 .0877990723152 .3925933838152 .6972961426153 .6116943359 154.5260925293155 .7451934814156 .9642944336158 .4882965088159 .7073974609 160.9264984131161 .8408966064162 .4505004883162 .7552947998162 .7552947998 162.1457061768161 .2312927246160 .0122070312158 .4882965088156 .9642944336 155.4403991699154 .2212982178153 .3069000244154 .8307952881156 .0082397461 155.8194885254156 .0500030518156 .6596069336156 .3547973633158 .1835021973 159.5003967285160 .8249053955161 .9895324707162 .9838409424163 .7772674561 164.2882080078164 .4111633301163 .974395752162 .1457061768159 .4026031494 155.1356048584151 .7830047607149 .0399017334147 .2111968994145 .9920959473 144.703125144 .7729034424144 .1634063721143 .8585968018143 .5538024902 143.2489929199142 .9441986084142 .3347015381141 .7250976562140 .8106994629 139.5915985107138 .0677032471136 .5437011719135 .0198059082133 .4958953857 131.6672058105129 .8385009766128 .0097961426126 .1809997559124 .6570968628 122.8283996582121 .6092987061120 .0852966309118 .8662033081117 .9517974854 117.342300415116 .7326965332116 .7326965332116 .7326965332116 .7326965332 116.4279022217115 .818397522114 .9039993286113 .6848983765112 .4656982422 110.9418029785108 .8082962036106 .6747970581104 .2365036011101 .7982025146 100.883903503499 .6647262573298 .1408081054796 .9216690063595 .3977432251 94.4833908081193 .5690307617293 .8738174438594 .4833908081194 .17859649658 94.1785964965894 .4833908081195 .7025299072396 .3121032714897 .22646331787 99.66472625732104 .2365036011107 .5891036987110 .0273971558113 .075302124 117.0374984741120 .9997024536123 .43800354123 .9801330566124 .0721588135 124.1134643555124 .1440734863124 .0475006104123 .7427978516123 .7427978516 123.7361526489122 .9804916382121 .9331893921120 .3900985718118 .8662033081 118.5614013672118 .2565994263117 .342300415115 .818397522113 .9896011353 111.8561019897109 .4179000854107 .5891036987105 .4557037354103 .9317016602 102.4077987671101 .1886978149100 .274299621699 .3599472045998 .75038146973 98.1408081054797.8360290527397.8360290527397.8360290527397.53124237061 97.5312423706197 .5312423706197 .5312423706197 .2264633178797 .22646331787 96.9216690063596 .6168823242296 .6168823242296 .3121032714896 .31210327148 96.6168823242296 .9216690063597 .5312423706198 .1408081054798 .75038146973 99.6647262573299 .96952056885100 .2742996216100 .5791015625100 .8839035034 100.8839035034101 .1886978149101 .7982025146101 .4934005737100 .2742996216 97.5312423706194 .4833908081190 .8259735107485 .0350494384879 .54891967773 96.0073165893697 .6301879882898 .7503814697390 .2164001464890 .21640014648 90.8259735107491 .1307525634891 .7403335571392 .9594726562595 .3977432251 98.1408081054799.0551681518698.4455871582 97.2264633178794.17859649658 91.1307525634888 .6924667358487 .1685485839885 .9494018554785 .03504943848 86.8637619018689 .6068267822390 .2164001464889 .9116134643689 .3020401001 88.38768768311 87.77810668945 87.16854858398 86.2541885376 85.64462280273 85.0350494384884 .1206970214883 .206336975182 .2919769287181 .07285308838 79.8537063598678 .6345596313577 .110626220775 .5867080688573 .75800323486 $71.9292907714870 .1005783081167 .9670867919967 .0527267456166 .74794006348-9999$ -9999 -9999 -9999 -9999 -9999 -9999 -9999 -9999 -9999 -9999 -9999 -9999 -9999 -9999 -9999 -9999 -9999 -9999 -9999 -9999 -9999 -9999 -9999 -9999 -9999 -9999 -9999 -9999 -9999 -9999 
-9999 -9999 -9999 -9999 -9999 -9999 -9999 -9999 -9999 -9999 -9999 -9999 -9999 -9999 -9999 -9999 -9999 -9999 -9999 -9999 -9999 -9999 -9999 -9999 -9999 -9999 -9999 -9999 -9999 -9999 -9999 -9999-9999-9999-9999

-9999 -9999 -9999 -9999 -9999 -9999 -9999 -9999 -9999 -9999 -9999 -9999 -9999 -9999 -9999 -9999 -9999 -9999 -9999 -9999 -9999 -9999 -9999 -9999 -9999 -9999 -9999-9999 -9999 -9999 -

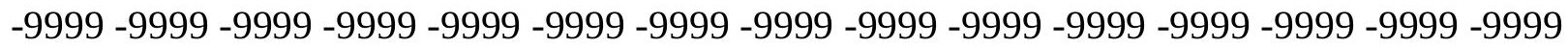

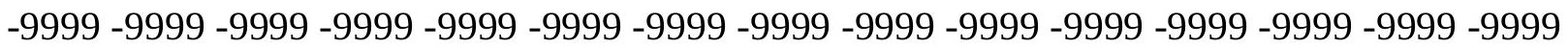

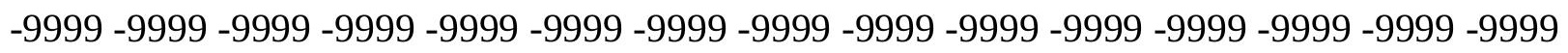
-9999 -9999 -9999 -9999 -9999 -9999 204.135269165 204.8497924805 204.7774810791 203.2149810791 198.212097168186.2236938477175.8609924316177.3849029541 181.6519012451184 .0901947021185 .6141052246186 .528503418185 .9188995361 184.3950042725182 .261505127179 .8231964111177 .0802001953174 .0323028564 171.2891998291168 .241394043165 .4983062744162 .4505004883159 .7073974609 157.2691040039155 .1356048584153 .6116943359152 .3925933838151 .7830047607 151.7830047607152 .0877990723152 .6972961426153 .6116943359154 .8307952881 156.0500030518157 .5738983154159 .0977935791160 .6217956543162 .1457061768 163.0599975586163 .974395752164 .2792053223164 .2792053223163 .3648071289 162.1457061768160 .6217956543159 .0977935791157 .2691040039155 .7451934814 154.5260925293154 .2212982178155 .1356048584155 .9158477783155 .7493133545 155.8788604736156 .0500030518155 .1356048584156 .3543395996157 .6718139648 158.8687438965159 .9632720947160 .9304199219161 .6998748779162 .1517181396 162.0995483398161 .2312927246159 .0977935791155 .4403991699151 .4781951904 149.6495056152148 .1255950928146 .9064025879145 .9920959473144 .7507324219 144.7729034424144 .4682006836144 .4682006836144 .1634063721143 .8585968018 143.5538024902142 .9441986084142 .3347015381141 .4203033447139 .8963928223 138.3724975586136 .8484954834135 .3246002197133 .4958953857131 .6672058105 130.1432037354128 .3144989014126 .4858016968124 .9618988037123 .43800354 121.9140014648120 .6949005127119 .1709976196117 .9517974854117 .0374984741 116.7326965332116 .4279022217116 .7326965332117 .0374984741117 .0374984741 116.7326965332116 .1231002808115 .2088012695114 .2944030762112 .7705001831 111.24659729109 .1130981445106 .979598999104 .2365036011100 .8839035034 99.6647262573299 .05516815186101 .4934005737105 .1509017944109 .7226028442 111.8561019897108 .8082962036104 .5412979126101 .188697814998 .75038146973 97.2264633178796 .61688232422101 .1886978149109 .7226028442122 .1806945801 119.1709976196116 .4279022217117 .0374984741117 .647102356120 .0852966309 122.2188034058123 .3208007812123 .4273376465123 .4029083252123 .1332015991 122.5235977173122 .5235977173122 .8283996582122 .8283996582122 .8283996582 121.9681015015120 .6309432983118 .8662033081117 .647102356116 .4279022217 115.5136032104114 .5991973877113 .075302124111 .24659729109 .4179000854 107.2844009399 105.4557037354103.6268997192102.1029968262 100.8839035034 99.6647262573298 .7503814697397 .8360290527397 .2264633178796 .92166900635 96.6168823242296 .6168823242296 .6168823242296 .3121032714896 .00731658936 96.0073165893696 .0073165893695 .7025299072395 .7025299072395 .3977432251 95.397743225195 .0929565429795 .0929565429795 .397743225195 .3977432251 96.0073165893696 .6168823242297 .5312423706198 .445587158299 .35994720459 99.96952056885100 .5791015625100 .8839035034101 .1886978149101 .1886978149 
101.4934005737101 .1886978149100 .883903503499 .3599472045997 .22646331787 94.4833908081191 .4355392456188 .9972534179784 .4254837036187 .16854858398 92.0450973510796 .9216690063595 .7025299072393 .2642517089895 .09295654297 93.5690307617292 .0450973510792 .6546783447393 .8738174438595 .3977432251 95.397743225194 .7881774902393 .2642517089891 .4355392456189 .60682678223 88.0829010009886 .8637619018685 .9494018554784 .7302627563586 .55898284912 88.9972534179790 .2164001464890 .2164001464889 .6068267822388 .99725341797 88.0829010009887 .4733276367286 .8637619018686 .254188537685 .64462280273 84.7302627563584 .1206970214883 .206336975182 .2919769287181 .07285308838 79.5489196777378 .3297805786176 .5010681152374 .9771423339872 .84364318848 71.014930725168 .5766525268666 .4431610107466 .13836669922 -9999 -9999 -9999 -9999 -9999 -9999 -9999 -9999 -9999 -9999 -9999 -9999 -9999 -9999 -9999 -9999 -9999 -9999 -9999 -9999 -9999 -9999 -9999 -9999 -9999 -9999 -9999 -9999 -9999 -9999 -9999 -9999 -9999 -9999 -9999 -9999 -9999 -9999 -9999 -9999 -9999 -9999 -9999 -9999 -9999 -9999 -9999 -9999 - 9999 -9999 -9999 -9999 -9999 -9999 -9999 -9999 -9999 -9999 -9999 -9999 -9999 -9999 -9999 -9999 $-9999-9999$

-9999 -9999 -9999 -9999 -9999 -9999 -9999 -9999 -9999 -9999 -9999 -9999 -9999 -9999 -9999 -9999 -9999 -9999 -9999 -9999 -9999 -9999 -9999 -9999 -9999 -9999 -9999 -9999 -9999 -9999 -999 -9999 -9999 -9999 -9999 -9999 -9999 -9999 -9999 -9999 -9999 -9999 -9999 -9999 -9999 -9999 -

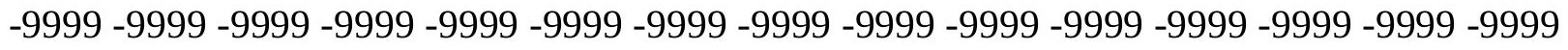

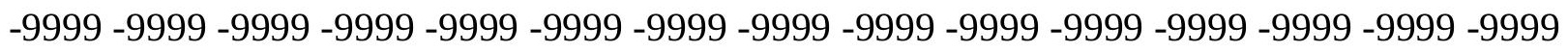
-9999 -9999 -9999 -9999 -9999 -9999 -9999 209.2554931641 210.4225769043210.3860931396 208.5179595947203.596496582170.070098877171.8988037109 177.0802001953 181.9566955566185 .0045928955186 .528503418185 .9188995361184 .3950042725 182.261505127 179.8231964111 177.0802001953 174.0323028564171.2891998291 168.241394043165 .1934967041162 .1457061768159 .4026031494156 .6596069336 154.5260925293152 .6972961426151 .7830047607151 .1734008789151 .1734008789 151.7830047607152 .3925933838153 .6116943359154 .8307952881156 .3547973633 158.1835021973159 .7073974609161 .5361022949163 .0599975586164 .2792053223 165.4983062744165 .8031005859165 .8031005859164 .8887023926163 .3648071289 161.5361022949159 .7073974609157 .878692627156 .3547973633155 .4403991699 155.4403991699156 .0500030518155 .8394012451155 .5147094727155 .2850189209 154.955581665154 .7014007568155 .0494842529155 .8954467773156 .8283691406 157.7362365723158 .5603942871159 .2134246826159 .5249328613159 .2397155762 158.1835021973156 .0500030518153 .0021057129150 .2590942383148 .4304046631 147.2111968994146 .2969055176145 .6873016357144 .6556091309145 .0776977539 144.7729034424144 .7729034424144 .4682006836144 .4682006836144 .1634063721 143.8585968018142 .9441986084142 .0299072266140 .5059967041138 .9819946289 137.1533050537135 .6293945312133 .8007049561131 .9720001221130 .1432037354 128.6192932129127 .0953979492125 .5715026855124 .0475006104122 .8283996582 121.6092987061120 .0852966309118 .5614013672117 .342300415116 .7326965332 117.0374984741117 .342300415117 .9517974854118 .2565994263118 .2565994263 117.9517974854117 .0374984741116 .1231002808114 .9039993286113 .3800964355 111.8561019897110 .0273971558107 .8938980103106 .3700027466106 .0652008057 107.5891036987110 .9418029785116 .4279022217123 .43800354124 .2053604126 122.8283996582115 .2088012695109 .7226028442106 .0652008057104 .2365036011 
104.5412979126107 .8938980103115 .818397522121 .8542404175121 .8539123535 121.6092987061120 .9997024536121 .9140014648122 .3573074341122 .6410522461 122.8190078735122 .8360671997122 .6588821411122 .2188034058121 .9140014648 121.6092987061121 .6092987061121 .6092987061121 .9140014648120 .3900985718 118.8662033081117 .342300415115 .5136032104114 .2944030762112 .7705001831 111.551399231110 .0273971558108 .1986999512106 .3700027466104 .5412979126 103.0174026489101 .493400573799 .9695205688599 .0551681518697 .83602905273 97.2264633178796 .3121032714895 .7025299072395 .397743225195 .3977432251 95.0929565429795 .0929565429794 .7881774902394 .7881774902394 .48339080811 94.4833908081194 .1785964965894 .1785964965894 .1785964965893 .87381744385 93.8738174438593 .8738174438593 .8738174438594 .1785964965894 .78817749023 95.397743225196 .6168823242297 .8360290527398 .7503814697399 .66472625732 100.2742996216100 .5791015625100 .8839035034101 .1886978149100 .8839035034 100.883903503499 .9695205688598 .7503814697396 .9216690063594 .48339080811 91.4355392456187 .7781066894584 .1206970214887 .1685485839889 .91161346436 89.91161346436 94.4833908081196.92166900635 97.8360290527397.83602905273 96.0073165893692 .0450973510795 .397743225196 .6168823242295 .70252990723 94.7881774902393 .2642517089891 .7403335571389 .6068267822388 .08290100098 86.8637619018686 .5589828491286 .8637619018688 .6924667358490 .52117919922 91.4355392456191 .1307525634890 .2164001464889 .302040100188 .69246673584 87.7781066894587 .1685485839886 .8637619018686 .254188537685 .64462280273 85.0350494384884 .1206970214883 .206336975181 .9871978759880 .76805877686 79.5489196777377 .7202072143675 .8914871215874 .062782287671 .92929077148 69.4910125732467 .0527267456165 .8335876464865 .52880096436 -9999 -9999 -9999 -9999 -9999 -9999 -9999 -9999 -9999 -9999 -9999 -9999 -9999 -9999 -9999 -9999 -9999 -9999 -9999 -9999 -9999 -9999 -9999 -9999 -9999 -9999 -9999 -9999 -9999 -9999 -9999 -9999 -9999 -9999 -9999 -9999 -9999 -9999 -9999 -9999 -9999 -9999 -9999 -9999 -9999 -9999 -9999 -9999 -9999

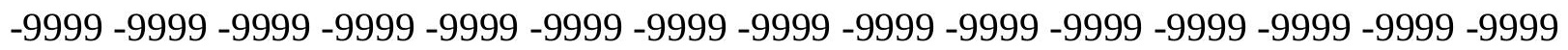
$-9999$

-9999 -9999 -9999 -9999 -9999 -9999 -9999 -9999 -9999 -9999 -9999 -9999 -9999 -9999 -9999 -9999 -9999 -9999 -9999 -9999 -9999 -9999 -9999 -9999 -9999 -9999 -9999 -9999 -9999 -9999 -9999 -9999 -9999 -9999 -9999 -9999 -9999 -9999 -9999 -9999 -9999 -9999 -9999 -9999 -9999 -

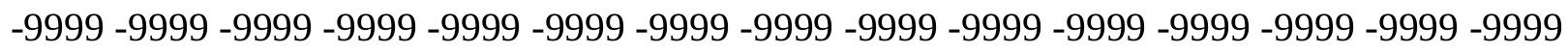

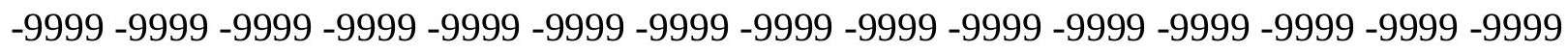
-9999 -9999 -9999 -9999-9999 -9999 -9999 -9999 214.6299133301215 .7017822266 213.9349822998204 .6880340576184 .3950042725167 .0222015381172 .8132019043 179.5184020996184 .3950042725186 .2236938477185 .6141052246184 .0901947021 181.9566955566179 .5184020996176 .7754058838174 .0323028564171 .2891998291 168.241394043165 .1934967041162 .1457061768159 .0977935791156 .3547973633 153.9165039062152 .0877990723150 .8686065674150 .2590942383150 .5639038086 151.1734008789152 .3925933838153 .6116943359155 .1356048584156 .6596069336 158.4882965088160 .3170013428162 .1457061768163 .6696014404165 .4983062744 166.7174987793167 .3269958496167 .3269958496166 .1078948975164 .2792053223 162.1457061768160 .0122070312158 .1835021973156 .9642944336156 .3547973633 156.3547973633156 .3288116455155 .6851806641155 .1432189941154 .64453125 154.1627349854153 .8974304199153 .8968353271154 .2541351318154 .785369873 
155.3671569824155 .924987793156 .3791809082156 .5641174316156 .1190338135 154.8307952881153 .3069000244150 .8686065674149 .0399017334147 .5160064697 146.6015930176145 .9920959473145 .3080444336144 .4408721924143 .4114990234 144.7729034424144 .7729034424144 .7729034424144 .7729034424144 .4682006836 144.1634063721143 .5538024902142 .3347015381140 .8106994629139 .2868041992 137.4580993652135 .9342041016134 .1054992676132 .2767028809130 .4479980469 128.9241027832127 .7050018311126 .4858016968125 .2667007446124 .0475006104 122.8283996582121 .6092987061120 .0852966309118 .5614013672117 .342300415 117.9517974854118 .8662033081119 .4757995605119 .7806015015120 .0852966309 119.7806015015119 .1709976196118 .2565994263117 .0374984741115 .818397522 114.5991973877113 .3800964355112 .1608963013111 .8561019897112 .4656982422 114.5991973877118 .5614013672124 .0475006104124 .4158401489123 .8360977173 123.2179412842122 .2188034058116 .7326965332112 .7705001831111 .551399231 112.7705001831115 .5136032104118 .2565994263120 .3900985718120 .6949005127 120.3900985718121 .5879135132121 .716583252121 .6092987061122 .2188034058 122.3489379883122 .2466583252121 .9140014648121 .3044967651120 .6949005127 120.3900985718120 .0852966309120 .0852966309119 .4757995605118 .2565994263 116.7326965332114 .9039993286113 .075302124113 .075302124112 .1608963013 108.1986999512106 .6747970581105 .1509017944103 .3221969604101 .7982025146 100.274299621699 .0551681518697 .8360290527396 .9216690063596 .00731658936 95.397743225194 .7881774902394 .1785964965893 .8738174438593 .87381744385 93.5690307617293 .5690307617293 .2642517089892 .9594726562592 .95947265625 92.9594726562592 .6546783447392 .6546783447392 .6546783447392 .65467834473 92.6546783447392 .6546783447392 .6546783447392 .9594726562593 .26425170898 94.1785964965895 .0929565429796 .6168823242298 .1408081054799 .05516815186 99.6647262573299 .96952056885100 .2742996216100 .2742996216100 .2742996216 99.9695205688599 .0551681518697 .8360290527396 .0073165893693 .87381744385 91.1307525634888 .3876876831186 .8637619018688 .0829010009890 .82597351074 90.8259735107492 .0450973510798 .1408081054798 .7503814697399 .35994720459 97.22646331787 97.5312423706199.4142608642699.0551681518697.53124237061 96.3121032714895 .7025299072396 .6168823242297 .2486877441493 .56903076172 90.5211791992289 .9116134643690 .5211791992292 .0450973510793 .56903076172 94.1785964965892 .9594726562591 .1307525634890 .2164001464889 .3020401001 88.3876876831187 .7781066894587 .4733276367286 .8637619018686 .55898284912 85.9494018554785 .0350494384884 .1206970214883 .206336975181 .98719787598 80.7680587768678 .9393463134877 .4154205322375 .2819290161173 .14842987061 70.7101516723667 .9670867919965 .5288009643665 .2240066528365 .83358764648 -9999 -9999 -9999 -9999 -9999 -9999 -9999 -9999 -9999 -9999 -9999 -9999 -9999 -9999 -9999 -9999 -9999 -9999 -9999 -9999 -9999 -9999 -9999 -9999 -9999 -9999 -9999 -9999 -9999 -9999 -9999 -9999 -9999 -9999 -9999 -9999 -9999 -9999 -9999 -9999 -9999 -9999 -9999 -9999 -9999 -9999 -

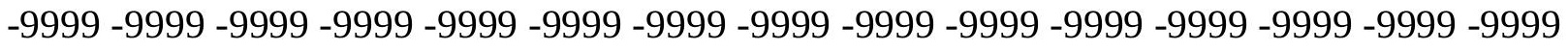
$-9999-9999-9999$ -9999 -9999 -9999 -9999 -9999 -9999 -9999 -9999 -9999 -9999 -9999 -9999 -9999 -9999 -9999 -9999 -9999 -9999 -9999 -9999 -9999 -9999 -9999 -9999 -9999 -9999 -9999 -9999 -9999 -9999 -9999 -9999 -9999 -9999 -9999 -9999 -9999 -9999 -9999 -9999 -9999 -9999 -9999 -9999 -9999 -9999 -9999 -9999 -9999 -9999 -9999 -9999 -9999 -9999 -9999 -9999 -9999 -9999 -9999 -9999 
-9999 -9999 -9999 -9999 -9999 -9999 -9999 -9999 -9999 -9999 -9999 -9999 -9999 -9999 -9999 -9999 -9999 -9999 -9999 -9999 -9999 -9999 -9999 -9999 217.6200714111215 .9188842773 210.1645202637201 .4629974365163 .0599975586169 .1557006836176 .4705963135 184.0901947021185 .0045928955184 .3950042725183 .1759033203181 .0424041748 178.9089050293176 .4705963135173 .7274932861170 .9844970703168 .241394043 165.1934967041162 .1457061768159 .0977935791156 .0500030518153 .3069000244 151.1734008789149 .9542999268149 .6495056152150 .2590942383151 .1734008789 152.3925933838153 .6116943359155 .1356048584156 .9642944336158 .7929992676 160.6217956543162 .4505004883164 .2792053223166 .1078948975167 .6318054199 168.5462036133168 .5462036133167 .3269958496165 .1934967041162 .4505004883 160.3170013428158 .4882965088157 .5738983154156 .9642944336156 .9642944336 156.2679901123155 .4560089111154 .7207489014154 .0386505127153 .4303283691 152.9726867676152 .7098846436152 .6567687988152 .7559509277152 .9211273193 153.090927124153 .2203826904153 .2580871582153 .0021057129151 .4781951904 149.9542999268148 .7351074219147 .8208007812146 .6015930176145 .8867797852 145.4874267578144 .9960327148144 .1950683594143 .2827453613144 .7729034424 145.0776977539145 .0776977539145 .0776977539144 .7729034424144 .4682006836 143.8585968018142 .6394042969141 .4203033447139 .5915985107138 .0677032471 136.2389984131134 .4102020264132 .5814971924130 .7528076172129 .2288970947 128.3144989014127 .4001998901126 .4858016968125 .8762969971124 .6570968628 123.43800354121 .9140014648120 .6949005127119 .7806015015120 .0852966309 120.6949005127121 .3044967651121 .9140014648121 .9140014648121 .6092987061 120.9997024536120 .3900985718119 .4757995605118 .5614013672117 .647102356 116.7326965332116 .4279022217116 .4279022217117 .647102356120 .0852966309 123.43800354124 .6039733887124 .0881271362123 .5421524048122 .9507904053 122.2924346924120 .6949005127117 .647102356116 .7326965332118 .2565994263 121.9140014648121 .6092987061122 .2188034058122 .2188034058121 .9140014648 121.6092987061121 .6092987061121 .9140014648121 .9140014648121 .9140014648 121.6092987061120 .9997024536120 .3900985718119 .7806015015119 .1709976196 118.5614013672117 .9517974854117 .0374984741115 .818397522113 .9896011353 112.1608963013112 .1608963013111 .24659729106 .6747970581105 .1509017944 103.3221969604101 .7982025146100 .274299621698 .7503814697397 .53124237061 96.3121032714895 .397743225194 .7881774902394 .1785964965893 .87381744385 93.2642517089892 .6546783447392 .349891662692 .349891662692 .04509735107 92.0450973510791 .7403335571391 .4355392456191 .4355392456191 .43553924561 91.4355392456191 .4355392456191 .4355392456191 .4355392456191 .43553924561 91.4355392456191 .4355392456191 .4355392456192 .0450973510792 .3498916626 93.2642517089895 .0929565429797 .2264633178798 .1408081054798 .4455871582 99.0551681518699 .3599472045999 .3599472045999 .3599472045999 .05516815186 98.1408081054796 .9216690063595 .397743225193 .5690307617291 .43553924561 89.60682678223 88.69246673584 89.302040100190.2164001464890.82597351074 91.1307525634893 .8738174438594 .4833908081196 .6168823242297 .83602905273 99.35994720459100 .5791015625100 .274299621699 .0551681518698 .4455871582 98.445587158299 .0687561035298 .5138549804797 .2264633178794 .48339080811 93.5690307617293 .8738174438595 .397743225196 .6339569091896 .42105865479 95.2530822753993.2642517089891.13075256348 89.91161346436 89.3020401001 
88.69246673584 88.08290100098 87.77810668945 87.16854858398 86.86376190186 86.254188537685 .3398437584 .4254837036183 .206336975181 .98719787598 80.4632720947378 .6345596313576 .8058471679774 .3675689697371 .92929077148 69.1862335205166 .4431610107464 .9192428588965 .52880096436 -9999 -9999 -9999 -9999 -9999 -9999 -9999 -9999 -9999 -9999 -9999 -9999 -9999 -9999 -9999 -9999 -9999 -9999 -9999 -9999 -9999 -9999 -9999 -9999 -9999 -9999 -9999 -9999 -9999 -9999 -9999 -9999 -9999 -9999 -9999 -9999 -9999 -9999 -9999 -9999 -9999 -9999 -9999 -9999 -9999 -9999 -9999 -9999 -9999

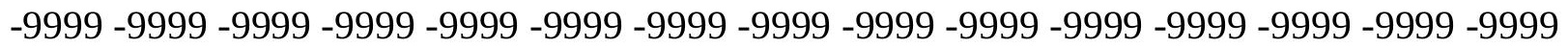
-9999 -9999 -9999 -9999 -9999 -9999 -9999 -9999 -9999 -9999 -9999 -9999 -9999 -9999 -9999 -9999 -9999 -9999 -9999 -9999 -9999 -9999 -9999 -9999 -9999 -9999 -9999 -9999 -9999 -9999 -9999 -9999 -9999 -9999 -9999 -9999 -9999 -9999 -9999 -9999 -9999 -9999 -9999 -9999 -9999 -9999 -9999 -9999 -9999 -9999 -9999 -9999 -9999 -9999 -9999 -9999 -9999 -9999 -9999 -9999

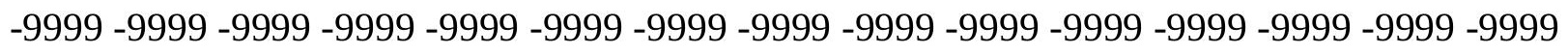
-9999 -9999 -9999 -9999 -9999 -9999 -9999 -9999 -9999 -9999 257.5433959961 209.9137573242 197.9156646729 182.261505127 165.8031005859171.5939941406 178.604095459181 .6519012451182 .261505127181 .3471984863179 .8231964111 177.9945068359175 .8609924316173 .4226989746170 .9844970703168 .241394043 165.4983062744162 .4505004883159 .4026031494156 .0500030518153 .0021057129 150.2590942383149 .3446960449149 .3446960449149 .9542999268150 .8686065674 152.0877990723153 .6116943359155 .4403991699156 .9642944336158 .7929992676 160.6217956543162 .4505004883164 .5839996338166 .1078948975167 .6318054199 168.8509979248169 .7653045654167 .6318054199165 .1934967041162 .7552947998 160.3170013428158 .7929992676157 .878692627157 .2691040039157 .2030944824 156.1490020752155 .1846618652154 .290435791153 .454574585152 .6947937012 152.0344696045151 .5063171387151 .0960235596150 .7797851562150 .4902954102 150.1892852783149 .8394927979149 .4646759033149 .0399017334147 .5160064697 146.9064025879146 .6015930176146 .0260620117145 .3293304443144 .7443695068 144.3877258301144 .2354125977143 .9497528076143 .125213623142 .243637085 144.5150299072144 .6439208984144 .7618560791144 .7729034424144 .4682006836 143.8585968018142 .9441986084141 .4203033447140 .2012023926138 .3724975586 136.5437011719134 .7149963379132 .8863067627131 .0576019287129 .8385009766 129.2288970947128 .6192932129128 .0097961426127 .7050018311126 .7906036377 125.5715026855124 .3523025513123 .1332015991122 .5235977173122 .5235977173 122.8283996582123 .43800354124 .0475006104124 .0475006104124 .0475006104 123.43800354122 .5235977173121 .6092987061120 .6949005127120 .0852966309 119.7806015015119 .4757995605120 .0852966309121 .3044967651123 .1332015991 124.7383270264124 .258605957123 .7972869873123 .3269424438122 .8215332031 122.255317688121 .620475769120 .3900985718120 .0852966309120 .6949005127 121.3044967651122 .8283996582123 .43800354123 .1332015991122 .8283996582 122.5235977173122 .2188034058121 .9140014648121 .9140014648121 .3044967651 120.6949005127120 .0852966309119 .1709976196118 .2565994263117 .342300415 116.7326965332115 .5136032104114 .2944030762113 .075302124111 .24659729 110.9418029785110 .0273971558109 .4179000854103 .6268997192101 .7982025146 99.9695205688598 .445587158297 .2264633178796 .0073165893694 .78817749023 93.8738174438593 .2642517089892 .9594726562592 .6546783447392 .3498916626 91.7403335571391 .1307525634890 .8259735107490 .8259735107490 .52117919922 
90.5211791992290 .2164001464890 .2164001464889 .9116134643689 .91161346436 89.9116134643690 .2164001464890 .2164001464890 .2164001464890 .21640014648 90.2164001464890 .5211791992290 .5211791992290 .5211791992290 .82597351074 91.1307525634893 .2642517089895 .0929565429796 .3121032714896 .92166900635 97.5312423706197 .8360290527398 .1408081054798 .1408081054797 .83602905273 97.2264633178796 .0073165893694 .7881774902393 .2642517089891 .74033355713 90.5211791992289 .9116134643689 .9116134643690 .5211791992290 .82597351074 91.4355392456192 .6546783447394 .1785964965896 .3121032714897 .83602905273 99.3599472045999 .9695205688599 .9695205688599 .6647262573299 .66472625732 99.6647262573299 .9695205688599 .6647262573298 .445587158296 .92166900635 96.0073165893696 .0073165893697 .2264633178798 .2106704711998 .30621337891 97.0700683593894 .7881774902392 .0450973510790 .8259735107489 .91161346436 89.60682678223 88.9972534179788.69246673584 88.08290100098 87.77810668945 87.1685485839886 .5589828491285 .6446228027384 .7302627563583 .2063369751 81.9871978759880 .1584930419978 .3297805786175 .8914871215873 .45321655273 70.7101516723668 .2718734741265 .5288009643665 .2240066528365 .83358764648 -9999 -9999 -9999 -9999 -9999 -9999 -9999 -9999 -9999 -9999 -9999 -9999 -9999 -9999 -9999 -9999 -9999 -9999 -9999 -9999 -9999 -9999 -9999 -9999 -9999 -9999 -9999 -9999 -9999 -9999 -9999 -9999 -9999 -9999 -9999 -9999 -9999 -9999 -9999 -9999 -9999 -9999 -9999 -9999 -9999 -9999 -

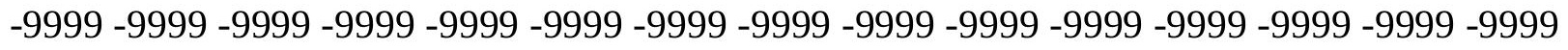
$-9999-9999$

-9999 -9999 -9999 -9999 -9999 -9999 -9999 -9999 -9999 -9999 -9999 -9999 -9999 -9999 -9999 -9999 -9999 -9999 -9999 -9999 -9999 -9999 -9999 -9999 -9999 -9999 -9999 -9999 -9999 -9999 -

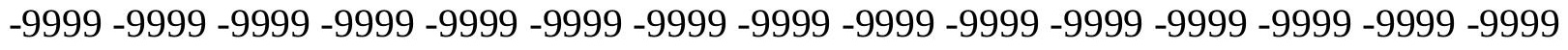
-9999 -9999 -9999 -9999 -9999 -9999 -9999 -9999 -9999 -9999 -9999 -9999 -9999 -9999 -9999 -9999 -9999 -9999 -9999 -9999 -9999 -9999 -9999 -9999 -9999 -9999 -9999 -9999 -9999 -9999 -9999 -9999 -9999 -9999 -9999 -9999 -9999 -9999 -9999 -9999 -9999 207.8813018799 197.4218444824182 .5897674561160 .3170013428168 .241394043175 .2514038086 178.604095459179 .5184020996179 .5184020996178 .604095459177 .0802001953 175.2514038086173 .1179962158170 .9844970703168 .241394043165 .8031005859 163.0599975586160 .3170013428156 .9642944336153 .3069000244149 .6495056152 149.0399017334 149.3446960449 149.9542999268151.1734008789152.3925933838 153.9165039062155 .4403991699156 .9642944336158 .7929992676160 .6217956543 162.4505004883164 .2792053223165 .8031005859167 .3269958496168 .241394043 168.241394043167 .0222015381164 .8887023926162 .7552947998160 .6217956543 159.0977935791 158.1835021973 157.5738983154 157.1217498779 155.9674682617 154.8847045898153 .8589324951152 .887802124151 .9732818604151 .1273345947 150.3522338867149 .6323547363148 .941192627148 .2330780029147 .4552612305 146.538848877145 .4781951904144 .4682006836143 .5538024902143 .8585968018 144.4682006836144 .2431030273143 .8752288818143 .5226745605143 .3027801514 143.2193145752143 .2516479492142 .9398040771142 .1623077393143 .7044525146 143.88331604144 .0489044189144 .1907806396144 .3006286621143 .8585968018 142.9441986084141 .7250976562140 .5059967041138 .9819946289137 .1533050537 135.3246002197133 .4958953857131 .6672058105130 .7528076172130 .1432037354 129.8385009766129 .533706665129 .2288970947128 .9241027832127 .7050018311 126.4858016968125 .2667007446124 .9618988037124 .9618988037125 .2667007446 
125.8762969971126 .1809997559126 .4858016968126 .1809997559125 .2667007446 124.3523025513123 .7427978516122 .8283996582122 .2188034058121 .9140014648 121.9140014648122 .2188034058123 .1332015991124 .3523025513124 .3548583984 123.9179229736123 .5302658081123 .1678771973122 .8051223755122 .4069213867 121.953125121 .6092987061121 .6092987061121 .9140014648122 .5235977173123 .43800354 123.7427978516123 .7427978516123 .43800354122 .8283996582122 .5235977173 121.9140014648121 .3044967651120 .6949005127119 .7806015015118 .8662033081 117.9517974854117 .0374984741115 .818397522114 .5991973877113 .3800964355 111.8561019897110 .3321990967108 .5035018921108 .8082962036107 .8938980103 107.2844009399 100.274299621698.445587158296.9216690063595.3977432251 94.1785964965893 .2642517089892 .349891662691 .4355392456190 .82597351074 91.1307525634891 .4355392456191 .1307525634890 .5211791992289 .91161346436 89.6068267822389 .302040100189 .302040100188 .9972534179788 .99725341797 88.9972534179788 .6924667358488 .6924667358488 .6924667358488 .99725341797 88.9972534179788.9972534179788.99725341797 89.302040100189.3020401001 89.60682678223 89.60682678223 89.60682678223 90.21640014648 91.43553924561 92.9594726562594 .1785964965895 .0929565429795 .7025299072396 .31210327148 96.6168823242296 .6168823242296 .6168823242296 .0073165893699 .05516815186 98.445587158296 .0073165893692 .0450973510791 .1307525634890 .52117919922 90.5211791992290 .8259735107491 .4355392456192 .0450973510792 .95947265625 94.4833908081196 .0073165893697 .2264633178798 .445587158299 .05516815186 99.6647262573299 .6647262573299 .6647262573299 .9695205688599 .96952056885 99.6647262573298 .7503814697397 .8360290527396 .9216690063596 .61688232422 97.2264633178798 .445587158299 .0551681518697 .8360290527395 .3977432251 92.9594726562591 .7403335571390 .8259735107490 .2164001464889 .91161346436 89.6068267822389 .302040100188 .6924667358488 .3876876831187 .77810668945 86.8637619018685 .9494018554784 .7302627563583 .5111236572381 .68241119385 79.8537063598677 .7202072143675 .2819290161172 .8436431884870 .10057830811 67.0527267456164 .9192428588965 .52880096436 -9999 -9999 -9999 -9999 -9999 -9999 -9999 -9999 -9999 -9999 -9999 -9999 -9999 -9999 -9999 -9999 -9999 -9999 -9999 -9999 -9999 -9999 -9999 -9999 -9999 -9999 -9999 -9999 -9999 -9999 -9999 -9999 -9999 -9999 -9999 -9999 -9999

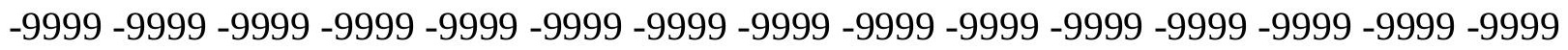

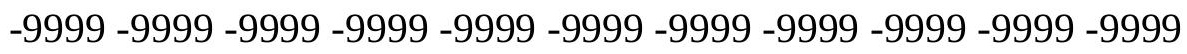

-9999 -9999 -9999 -9999 -9999 -9999 -9999 -9999 -9999 -9999 -9999 -9999 -9999 -9999 -9999

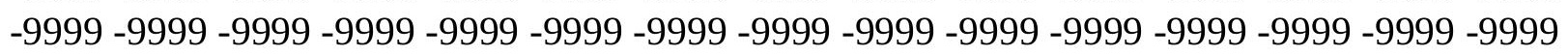

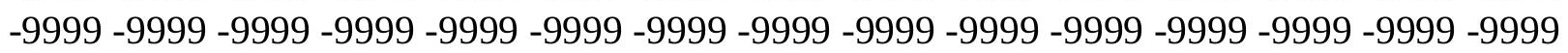

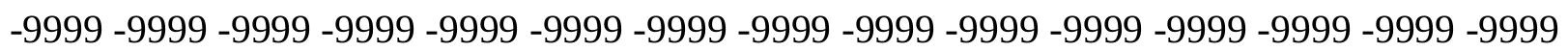

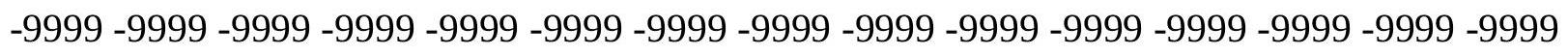
-9999 -9999-9999-9999 -9999 -9999-9999 -9999 -9999-9999-9999 -9999 197.4364929199 188.8260498047185 .6141052246170 .070098877174 .337097168175 .8609924316 176.7754058838177 .0802001953176 .7754058838175 .8609924316174 .6419067383 172.8132019043170 .6797027588168 .241394043165 .8031005859163 .3648071289 160.9264984131158 .4882965088154 .5260925293151 .4781951904150 .2590942383 149.9542999268150 .5639038086151 .4781951904152 .6972961426153 .9165039062 155.4403991699156 .9642944336158 .7929992676160 .3170013428162 .1457061768 163.6696014404165 .1934967041166 .1078948975166 .7174987793166 .7174987793 
165.8031005859164 .2792053223162 .4505004883160 .6217956543159 .0977935791 158.1835021973157 .5738983154156 .9434509277155 .7290039062154 .5626373291 153.4367828369152 .3489227295151 .2993164062150 .2857818604149 .2992706299 148.3268890381147 .3299713135146 .2859191895145 .1649017334143 .9055786133 142.3271636963140 .2012023926140 .5059967041141 .7250976562142 .3787994385 142.5401000977142 .4565429688142 .3266296387142 .2575836182142 .2760162354 142.3841400146142 .5697937012142 .0704345703143 .0064697266143 .227432251 143.4329223633143 .6127319336143 .7585906982143 .8585968018143 .2489929199 142.0299072266141 .1154937744139 .5915985107138 .0677032471136 .2389984131 134.7149963379133 .1911010742132 .2767028809131 .6672058105131 .0576019287 130.7528076172130 .7528076172130 .1432037354129 .2288970947128 .3144989014 127.4001998901126 .7906036377126 .7906036377127 .0953979492127 .7050018311 128.3144989014128 .6192932129128 .0097961426127 .0953979492126 .1809997559 125.2667007446124 .3523025513124 .0475006104123 .43800354123 .43800354 123.7427978516124 .0475006104124 .4314956665123 .9641799927123 .5677032471 123.2515335083123 .0034790039122 .809211731122 .6345214844122 .4412078857 122.2188034058122 .2188034058122 .5235977173123 .1332015991123 .7427978516 123.7427978516123 .7427978516123 .43800354122 .8283996582122 .2188034058 121.6092987061120 .6949005127119 .7806015015118 .8662033081117 .647102356 116.7326965332115 .2088012695113 .9896011353112 .4656982422110 .9418029785 109.4179000854107 .5891036987105 .4557037354106 .6747970581106 .0652008057 99.0551681518696 .9216690063595 .0929565429793 .8738174438592 .65467834473 91.7403335571390 .8259735107490 .2164001464889 .6068267822389 .60682678223 89.9116134643690 .5211791992289 .9116134643689 .302040100188 .69246673584 88.38768768311 88.08290100098 87.77810668945 87.77810668945 87.77810668945 87.7781066894587 .7781066894587 .7781066894587 .7781066894587 .77810668945 87.7781066894588 .0829010009888 .0829010009888 .3876876831188 .38768768311 88.6924667358488 .6924667358488 .9972534179789 .302040100190 .21640014648 91.1307525634892 .0450973510792 .9594726562593 .8738174438594 .48339080811 95.0929565429795 .397743225195 .0929565429797 .53124237061100 .5791015625 100.883903503498 .445587158294 .1785964965891 .4355392456191 .13075256348 91.1307525634891 .1307525634891 .7403335571392 .349891662693 .26425170898 94.4833908081195 .7025299072396 .6168823242297 .8360290527398 .4455871582 98.7503814697399 .0551681518699 .3599472045999 .6647262573299 .66472625732 99.3599472045998 .7503814697397 .8360290527396 .6168823242296 .00731658936 95.397743225195 .7025299072396 .0073165893695 .7025299072394 .78817749023 93.5690307617292 .349891662691 .7403335571391 .1307525634890 .82597351074 90.5211791992290 .2164001464889 .9116134643689 .302040100188 .69246673584 88.0829010009887 .1685485839886 .254188537685 .0350494384883 .51112365723 81.6824111938579 .8537063598677 .4154205322374 .6723632812571 .92929077148 68.8814392089866 .1383666992265 .2240066528365 .83358764648 -9999 -9999 -9999 -9999 -9999 -9999 -9999 -9999 -9999 -9999 -9999 -9999 -9999 -9999 -9999 -9999 -9999 -9999 -9999 -9999 -9999 -9999 -9999 -9999 -9999 -9999 -9999 -9999 -9999 -9999 -9999 -9999 -9999 -9999 -9999 -9999 -9999 -9999 -9999 -9999 -9999 -9999 -9999 -9999 -9999 -9999 -9999 -9999 -9999 -9999 -9999 -9999 -9999 -9999 -9999 -9999 -9999 -9999 -9999 -9999 -9999 -9999 -9999 -9999 -9999 -9999 -9999 -9999 -9999 -9999 -9999 -9999 -9999 -9999 -9999 -9999 -9999 
-9999 -9999 -9999 -9999 -9999 -9999 -9999 -9999 -9999 -9999 -9999 -9999 -9999 -9999 -9999 -9999 -9999 -9999 -9999 -9999 -9999 -9999 -9999 -9999 -9999 -9999 -9999 -9999 -9999 -9999 -9999 -9999 -9999 -9999 -9999 -9999 -9999 -9999 -9999 -9999 -9999 -9999 -9999 -9999 -9999 -9999 -9999 -9999 -9999 -9999 -9999 -9999 -9999 -9999 -9999 -9999 -9999 -9999 -9999 -9999 -9999 -9999 -9999 -9999 -9999 -9999 -9999 -9999 -9999 -9999 -9999 -9999 -9999 192.2556762695185 .6337280273176 .4705963135172 .8132019043172 .8132019043 174.337097168175 .2514038086175 .5561981201174 .9467010498174 .0323028564 172.2035980225170 .3748931885168 .241394043166 .1078948975163 .6696014404 161.2312927246158 .4882965088155 .7451934814153 .0021057129151 .4781951904 151.1734008789151 .1734008789151 .7830047607153 .0021057129154 .2212982178 155.4403991699156 .9642944336158 .4882965088160 .0122070312161 .5361022949 162.7552947998163 .974395752164 .8887023926165 .1934967041165 .1934967041 164.2792053223163 .0599975586161 .8408966064160 .3170013428159 .0977935791 158.1835021973157 .5738983154156 .6806488037155 .4462432861154 .2339019775 153.0408172607151 .8648223877150 .7036437988149 .5521240234148 .400100708 147.232208252146 .0216369629144 .7682037354143 .4629669189142 .1047058105 140.8449401855140 .2012023926139 .5915985107140 .5059967041140 .8709411621 141.1073455811141 .2055511475141 .2554779053141 .3284606934141 .4606170654 141.6559906006141 .9005584717141 .9846496582141 .3952178955142 .6778717041 142.9160003662143 .1267852783143 .3023376465143 .4354400635143 .5202026367 142.6394042969141 .7250976562140 .5059967041138 .9819946289137 .4580993652 136.2389984131134 .7149963379133 .8007049561133 .1911010742132 .5814971924 131.9720001221131 .6672058105131 .0576019287130 .4479980469129 .533706665 128.6192932129128 .3144989014128 .3144989014128 .6192932129129 .2288970947 129.8385009766130 .4479980469129 .533706665128 .6192932129127 .4001998901 126.4858016968125 .5715026855124 .9618988037124 .6570968628124 .3523025513 124.3523025513124 .0475006104124 .011505127123 .5601654053123 .1927947998 122.9228515625122 .7640914917122 .7010116577122 .7165985107122 .8283996582 122.5235977173122 .8283996582123 .1332015991123 .43800354123 .7427978516 123.7427978516123 .43800354123 .1332015991122 .5235977173121 .9140014648 120.9997024536120 .0852966309118 .8662033081117 .647102356116 .4279022217 115.2088012695113 .6848983765112 .1608963013110 .6370010376108 .8082962036 106.979598999105 .1509017944104 .8460998535104 .2365036011103 .9317016602 96.0073165893693 .8738174438592 .349891662691 .1307525634889 .91161346436 89.3020401001 88.6924667358488.08290100098 87.7781066894588.08290100098 88.38768768311 88.38768768311 88.38768768311 87.77810668945 87.47332763672 86.8637619018686 .8637619018686 .5589828491286 .5589828491286 .55898284912 86.5589828491286 .5589828491286 .5589828491286 .8637619018686 .86376190186 86.8637619018687 .1685485839887 .1685485839887 .4733276367287 .47332763672 87.7781066894587 .7781066894588 .0829010009888 .3876876831188 .99725341797 89.9116134643690.52117919922 91.13075256348 92.3498916626 92.95947265625 93.5690307617293 .8738174438593 .8738174438596 .00731658936100 .5791015625 102.4077987671100 .579101562596 .9216690063593 .2642517089891 .43553924561 91.4355392456191 .7403335571392 .0450973510792 .6546783447393 .56903076172 94.4833908081195 .397743225196 .3121032714896 .9216690063597 .53124237061 98.1408081054798 .445587158298 .7503814697398 .7503814697398 .75038146973 
98.445587158298 .1408081054797 .2264633178796 .0073165893695 .09295654297 93.5690307617292 .349891662693 .5690307617294 .1785964965893 .87381744385 93.26425170898 92.6546783447392.0450973510791.7403335571391.43553924561 91.1307525634890 .8259735107490 .8259735107490 .5211791992289 .91161346436 89.3020401001 88.6924667358487.77810668945 86.86376190186 85.33984375 83.81591033936 81.98719787598 79.54891967773 77.1106262207 74.0627822876 71.014930725167 .6623001098664 .9192428588965 .52880096436 -9999 -9999 -9999 -9999 -9999 -9999 -9999 -9999 -9999 -9999 -9999 -9999 -9999 -9999 -9999 -9999 -9999 -9999 -9999

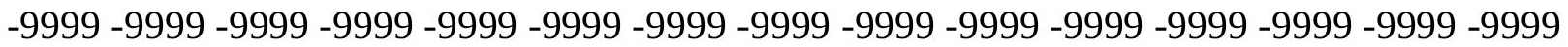
-9999 -9999 -9999 -9999 -9999 -9999 -9999 -9999 -9999 -9999 -9999 -9999 -9999 -9999 -9999 -9999 -9999 -9999 -9999 -9999 -9999 -9999 -9999 -9999 -9999 -9999 -9999 -9999 -9999 -9999 -9999 -9999 -9999 -9999 -9999 -9999 -9999 -9999 -9999 -9999 -9999 -9999 -9999 -9999 -9999 -9999 -9999 -9999 -9999 -9999 -9999 -9999 -9999 -9999 -9999 -9999 -9999 -9999 -9999 -9999 -9999 -9999 -9999 -9999 -9999 -9999 -9999 -9999 -9999 -9999 -9999 -9999 -9999 -9999 -9999 -9999 -9999 -9999 -9999 -9999 -9999 -9999 -9999 -9999 -9999 -9999 -9999 -9999

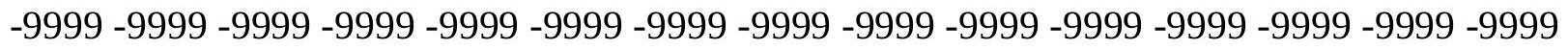
-9999 -9999 -9999 -9999 -9999 -9999 -9999 -9999 -9999 -9999 -9999 -9999 -9999 -9999 185.7409210205177 .7861022949167 .9365997314170 .9844970703172 .8132019043 173.7274932861174 .337097168174 .0323028564173 .4226989746171 .8988037109 170.070098877167 .9365997314165 .8031005859163 .6696014404161 .2312927246 158.7929992676156 .3547973633154 .2212982178152 .6972961426152 .0877990723 152.0877990723152 .3925933838153 .3069000244154 .2212982178155 .4403991699 156.9642944336158 .1835021973159 .4026031494160 .6217956543161 .8408966064 162.7552947998163 .3648071289163 .6696014404163 .6696014404163 .0599975586 162.1457061768160 .9264984131160 .0122070312159 .0977935791158 .1835021973 157.5597991943156 .3609924316155 .1423034668153 .9185943604152 .6906890869 151.4579925537150 .218460083148 .9678192139147 .6987915039146 .4031219482 145.0658416748143 .715927124142 .3883666992141 .154510498140 .147567749 139.5372619629139 .2533874512139 .4710845947139 .7865142822140 .0278625488 140.208770752140 .3760223389140 .5707702637140 .7998809814141 .0704193115 141.3609619141141 .6574249268141 .4373016357142 .2361755371142 .4998168945 142.7348175049142 .9339752197143 .0904083252143 .198348999142 .9441986084 142.3347015381141 .4203033447140 .2012023926138 .9819946289137 .7628936768 136.5437011719135 .3246002197134 .4102020264133 .8007049561133 .1911010742 132.5814971924131 .9720001221131 .0576019287130 .4479980469129 .533706665 129.2288970947129 .2288970947129 .533706665129 .8385009766130 .4479980469 130.7528076172130 .1432037354129 .2288970947128 .3144989014127 .4001998901 126.4858016968125 .8762969971125 .2667007446124 .6570968628124 .3523025513 123.7427978516123 .43800354122 .5235977173121 .9140014648122 .2188034058 122.409614563122 .4381027222122 .5235977173122 .5235977173122 .5235977173 122.8283996582123 .1332015991123 .43800354123 .43800354123 .43800354123 .1332015991 122.5235977173121 .9140014648120 .9997024536120 .0852966309119 .1709976196 117.9517974854116 .4279022217115 .2088012695113 .6848983765112 .1608963013 110.3321990967108 .5035018921106 .6747970581104 .8460998535102 .712600708 102.4077987671102 .1029968262101 .798202514693 .2642517089891 .13075256348 89.91161346436 88.69246673584 87.77810668945 87.16854858398 86.55898284912 
86.2541885376 86.2541885376 86.2541885376 86.55898284912 86.55898284912 86.5589828491286 .254188537685 .9494018554785 .6446228027385 .64462280273 85.6446228027385 .6446228027385 .6446228027385 .6446228027385 .64462280273 85.6446228027385 .9494018554785 .9494018554786 .254188537686 .2541885376 86.55898284912 86.55898284912 86.86376190186 87.16854858398 87.16854858398 87.4733276367287 .7781066894588 .3876876831188 .9972534179789 .60682678223 90.2164001464891 .1307525634891 .7403335571392 .349891662692 .65467834473 92.9594726562592 .9594726562599 .05516815186101 .7982025146101 .4934005737 96.9216690063591 .7403335571391 .7403335571391 .7403335571392 .04509735107 92.349891662692 .9594726562593 .5690307617294 .1785964965895 .09295654297 95.7025299072396 .3121032714896 .9216690063597 .5312423706197 .83602905273 98.1408081054798.1408081054798.1408081054797.8360290527397.22646331787 96.3121032714895 .397743225194 .1785964965892 .9594726562592 .04509735107 92.349891662692 .9594726562593 .2642517089892 .9594726562592 .95947265625 92.349891662692 .0450973510792 .0450973510791 .7403335571391 .43553924561 91.4355392456191 .1307525634890 .8259735107490 .5211791992289 .91161346436 89.3020401001 88.38768768311 87.47332763672 85.9494018554784.12069702148 81.9871978759879 .2441329956176 .1962814331173 .1484298706169 .79579162598 66.4431610107465 .2240066528365 .83358764648 -9999 -9999 -9999 -9999 -9999 -9999 -9999

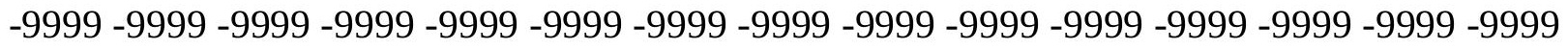
-9999 -9999 -9999 -9999 -9999 -9999 -9999 -9999 -9999 -9999 -9999 -9999 -9999 -9999 -9999 -9999 -9999 -9999 -9999 -9999 -9999 -9999 -9999 -9999 -9999 -9999 -9999 -9999 -9999 -9999 -9999 -9999 -9999 -9999 -9999 -9999 -9999 -9999 -9999

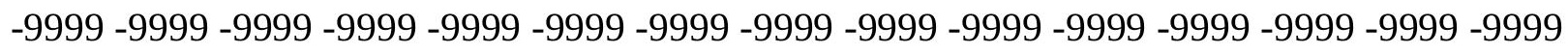

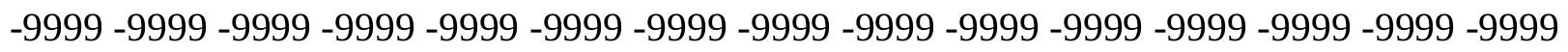
-9999 -9999 -9999 -9999 -9999 -9999 -9999 -9999 -9999 -9999 -9999 -9999 -9999 -9999 -9999 -9999 -9999 -9999 -9999 -9999 -9999 -9999 -9999 -9999 -9999 -9999 -9999 -9999 -9999 -9999

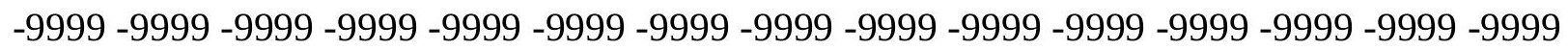
-9999 -9999 -9999 -9999 -9999 -9999 -9999 -9999 -9999 -9999 -9999 -9999 -9999 -9999 186.7674255371181 .0092926025177 .3849029541171 .2891998291171 .5939941406 172.5084075928173 .4226989746173 .4226989746172 .8132019043171 .5939941406 169.7653045654167 .6318054199165 .4983062744163 .3648071289161 .2312927246 158.7929992676156 .6596069336154 .8307952881153 .6116943359152 .6972961426 152.6972961426153 .0021057129153 .6116943359154 .5260925293155 .4403991699 156.6596069336157 .878692627158 .7929992676160 .0122070312160 .9264984131 161.5361022949162 .1457061768162 .1457061768162 .1457061768161 .8408966064 160.9264984131160 .3170013428159 .4026031494158 .4882965088157 .878692627 157.1477813721156 .0181732178154 .84425354153 .6393737793152 .4070129395 151.1492004395149 .8661956787148 .5573730469147 .2215423584145 .8570404053 144.4689788818143 .099899292141 .8093261719140 .6710205078139 .7752075195 139.1635284424138 .9057922363138 .89012146139 .0732116699139 .2830047607 139.5061035156139 .7449493408140 .0141601562140 .3121185303140 .6320648193 140.9562988281141 .2805480957141 .5171356201141 .0589447021142 .1837921143 142.4364776611142 .6534423828142 .8281860352142 .9551086426143 .0290374756 142.9441986084142 .3347015381141 .4203033447140 .2012023926139 .2868041992 138.0677032471136 .8484954834135 .9342041016135 .3246002197134 .4102020264 
133.8007049561132 .8863067627131 .9720001221131 .0576019287130 .1432037354 129.533706665129 .533706665129 .8385009766130 .1432037354130 .4479980469 130.4479980469130 .1432037354129 .533706665128 .6192932129127 .7050018311 126.7906036377126 .1809997559125 .5715026855124 .9618988037124 .3354949951 123.43800354122 .8283996582121 .9140014648121 .3044967651121 .3044967651 121.6092987061121 .9140014648122 .2188034058122 .2188034058122 .5235977173 122.8283996582122 .8283996582123 .1332015991123 .1332015991122 .8283996582 122.5235977173121 .9140014648120 .9997024536120 .0852966309119 .1709976196 117.9517974854116 .7326965332115 .2088012695113 .6848983765112 .1608963013 110.3321990967108 .5035018921106 .6747970581104 .8460998535102 .712600708 100.579101562599 .9695205688599 .6647262573293 .5690307617291 .43553924561 89.6068267822388 .0829010009887 .1685485839885 .9494018554785 .33984375 84.7302627563584 .4254837036184 .4254837036184 .7302627563584 .73026275635 84.7302627563584 .7302627563584 .7302627563584 .7302627563584 .42548370361 84.4254837036184 .4254837036184 .4254837036184 .7302627563584 .73026275635 84.7302627563585 .0350494384885 .0350494384885 .3398437585 .64462280273 85.6446228027385 .9494018554785 .9494018554786 .254188537686 .55898284912 86.5589828491286 .8637619018687 .4733276367287 .7781066894588 .38768768311 88.9972534179789 .6068267822390 .2164001464890 .8259735107491 .43553924561 91.7403335571392 .0450973510792 .0450973510795 .397743225197 .83602905273 96.9216690063593 .5690307617291 .7403335571391 .7403335571391 .74033355713 92.0450973510792 .349891662692 .9594726562593 .5690307617294 .17859649658 94.7881774902395 .397743225196 .0073165893696 .3121032714896 .61688232422 97.2264633178797 .2264633178797 .5312423706197 .2264633178796 .92166900635 96.6168823242295 .7025299072394 .7881774902393 .8738174438592 .95947265625 92.349891662692 .349891662692 .6546783447392 .9594726562592 .95947265625 92.9594726562592 .6546783447392 .349891662692 .349891662692 .04509735107 92.0450973510792 .0450973510792 .0450973510791 .7403335571391 .74033355713 91.1307525634890 .8259735107490 .2164001464889 .302040100188 .08290100098 86.5589828491284 .4254837036181 .6824111938578 .6345596313575 .28192901611 71.6244964599668 .2718734741264 .9192428588965 .52880096436 -9999 -9999 -9999 -9999 -9999 -9999 -9999 -9999 -9999 -9999 -9999 -9999 -9999 -9999 -9999 -9999 -9999 -9999 -9999

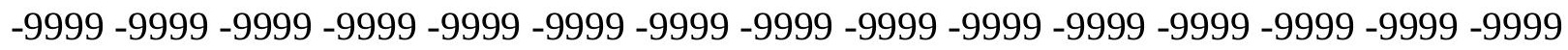

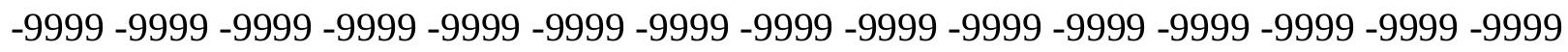
-9999 -9999 -9999 -9999 -9999 -9999 -9999 -9999 -9999 -9999 -9999 -9999

-9999 -9999 -9999 -9999 -9999 -9999 -9999 -9999 -9999 -9999 -9999 -9999 -9999 -9999 -9999

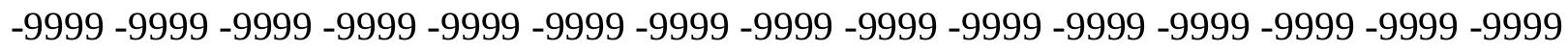

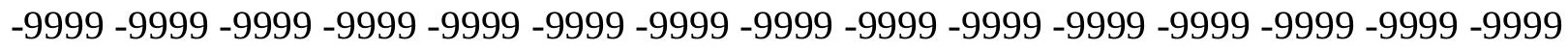
-9999 -9999 -9999 -9999 -9999 -9999 -9999 -9999 -9999 -9999 -9999 -9999 -9999 -9999 -9999 -

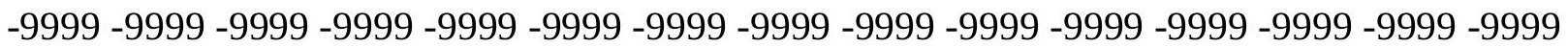

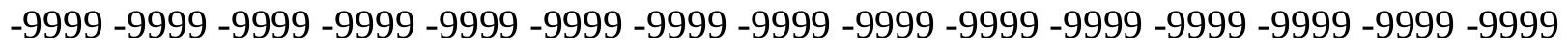
184.7664337158179 .5384979248170 .070098877170 .6797027588172 .2035980225 173.1179962158173 .1179962158172 .5084075928170 .9844970703169 .1557006836 167.0222015381164 .8887023926162 .7552947998160 .6217956543158 .7929992676 156.9642944336155 .1356048584153 .9165039062153 .3069000244153 .0021057129 153.0021057129153 .6116943359154 .2212982178155 .1356048584156 .3547973633 
157.2691040039 158.1835021973159.0977935791 159.7073974609160 .3170013428 160.9264984131160 .9264984131160 .9264984131160 .6217956543160 .0122070312 159.4026031494158 .7929992676158 .1835021973157 .5738983154156 .7304840088 155.6880493164154 .5817108154153 .4205627441152 .2106781006150 .9571685791 149.6639404297148 .3352661133146 .9759674072145 .5943908691144 .204864502 142.8610229492141 .6188659668140 .5397644043139 .6809692383139 .0807800293 138.7516326904138 .6450042725138 .7115936279138 .8779907227139 .096496582 139.3636322021139 .674621582140 .0068817139140 .3484649658140 .6913146973 141.0305786133141 .3606567383141 .2409515381141 .9674530029142 .2311553955 142.4602355957142 .6485137939142 .7904663086142 .8809814453142 .9168701172 142.8953094482142 .6394042969141 .7250976562140 .8106994629139 .5915985107 138.6772003174137 .4580993652136 .5437011719135 .6293945312134 .7149963379 133.8007049561132 .5814971924131 .6672058105130 .4479980469129 .8385009766 129.533706665129 .8385009766130 .1432037354130 .1432037354130 .1432037354 129.8385009766129 .2288970947128 .6192932129127 .7050018311127 .0613174438 126.1809997559125 .4295272827124 .6570968628123 .9670257568123 .1332015991 122.5235977173121 .6092987061120 .9997024536120 .9997024536120 .9997024536 121.3044967651121 .6092987061121 .9140014648122 .2188034058122 .2188034058 122.5235977173122 .5235977173122 .5235977173122 .2188034058121 .6092987061 120.9997024536120 .0852966309119 .1709976196117 .9517974854116 .7326965332 115.2088012695113 .6848983765112 .1608963013110 .6370010376108 .8082962036 106.979598999104 .8460998535103 .0174026489100 .883903503498 .4455871582 96.3121032714897 .5312423706192 .0450973510790 .2164001464888 .69246673584 87.1685485839885 .6446228027384 .7302627563583 .8159103393683 .2063369751 82.9015579223682 .9015579223682 .9015579223682 .9015579223683 .2063369751 83.206336975183.206336975183.206336975183.206336975183.51112365723 83.5111236572383 .5111236572383 .8159103393683 .8159103393684 .12069702148 84.4254837036184 .4254837036184 .7302627563585 .0350494384885 .3398437585 .33984375 85.6446228027385 .9494018554785 .9494018554786 .254188537686 .55898284912 86.86376190186 87.47332763672 88.08290100098 88.38768768311 88.99725341797 89.60682678223 90.2164001464890.5211791992291.1307525634891.43553924561 91.4355392456191 .7403335571391 .7403335571391 .7403335571391 .74033355713 91.7403335571391 .7403335571391 .7403335571392 .0450973510792 .3498916626 92.9594726562593 .2642517089893 .8738174438594 .4833908081194 .78817749023 95.397743225195 .7025299072396 .3121032714896 .6168823242296 .61688232422 96.6168823242296 .6168823242296 .3121032714896 .0073165893695 .3977432251 94.4833908081193 .5690307617292 .9594726562592 .6546783447392 .65467834473 92.6546783447392 .9594726562592 .9594726562592 .9594726562592 .95947265625 92.6546783447392 .6546783447392 .349891662692 .349891662692 .3498916626 92.349891662692 .6546783447392 .6546783447392 .349891662692 .04509735107 91.7403335571391 .1307525634890 .5211791992288 .9972534179786 .86376190186 84.1206970214881 .0728530883877 .4154205322373 .7580032348670 .10057830811 66.4431610107465 .2240066528365 .52880096436 -9999 -9999 -9999 -9999 -9999 -9999 -9999 -9999 -9999 -9999 -9999 -9999 -9999 -9999 -9999 -9999 -9999 -9999 -9999 -9999 -9999 -9999 -9999 -9999 -9999 -9999 -9999 -9999 -9999 -9999 -9999 -9999 -9999 -9999 -9999 -9999 -9999 -

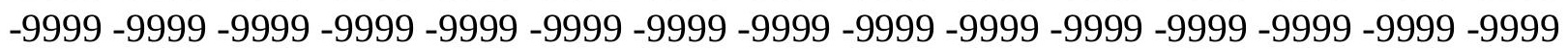


-9999 -9999 -9999 -9999 -9999 -9999 -9999 -9999

-9999 -9999 -9999 -9999 -9999 -9999 -9999 -9999 -9999 -9999 -9999 -9999 -9999 -9999 -9999

-9999 -9999 -9999 -9999 -9999 -9999 -9999 -9999 -9999 -9999 -9999 -9999 -9999 -9999 -9999

-9999 -9999 -9999 -9999 -9999 -9999 -9999 -9999 -9999 -9999 -9999 -9999 -9999 -9999 -9999

-9999 -9999 -9999 -9999 -9999 -9999 -9999 -9999 -9999 -9999 -9999 -9999 -9999 -9999 -9999

-9999 -9999 -9999 -9999 -9999 -9999 -9999 -9999 -9999 -9999 -9999 -9999 -9999 -9999 -9999 -

-9999 -9999 -9999 -9999 -9999 -9999 -9999 -9999 -9999 -9999 -9999 -9999 -9999 -9999 -9999

-9999 184.9128265381 183.1759033203170.3748931885172.5084075928 173.4226989746

173.4226989746172 .2035980225170 .6797027588168 .5462036133166 .4127044678

164.2792053223162 .1457061768160 .0122070312158 .1835021973156 .6596069336

155.1356048584154 .2212982178153 .6116943359153 .0021057129153 .3069000244 153.6116943359154 .2212982178154 .8307952881155 .7451934814156 .6596069336 157.5738983154158 .1835021973158 .7929992676159 .4026031494159 .7073974609 159.7073974609159 .7073974609159 .4026031494159 .0977935791158 .7929992676 158.1835021973157 .878692627157 .1873779297156 .3447570801155 .4060974121 154.3827819824153 .2843017578152 .1186218262150 .8940887451149 .6185455322 148.3014678955146 .9543457031145 .5920257568144 .2360229492142 .9319000244 141.7362365723140 .7008666992139 .8635101318139 .249420166138 .8623657227 138.6835479736138 .6695556641138 .7768249512138 .9745941162139 .236114502 139.5443878174139 .8797454834140 .2210998535140 .5650482178140 .90574646 141.2370605469141 .4423370361141 .0284576416142 .1156158447142 .3511047363 142.548248291142 .7016296387142 .8061218262142 .8583068848142 .8547210693 142.7923736572142 .6674499512142 .3347015381141 .1154937744139 .8963928223 138.9819946289137 .7628936768136 .8484954834135 .6293945312134 .7149963379 133.4958953857132 .2767028809131 .0576019287129 .8385009766129 .8385009766 129.8385009766130 .1432037354130 .1432037354130 .1432037354129 .8385009766 129.2288970947128 .5769195557127 .6857452393126 .8116836548125 .9604568481 125.1399230957124 .3596191406123 .6306533813122 .8283996582122 .2188034058 121.6092987061120 .9997024536120 .6949005127120 .6949005127120 .6949005127 120.9997024536121 .3044967651121 .6092987061121 .6092987061121 .9140014648 121.9140014648121 .6092987061121 .3044967651120 .6949005127119 .7806015015 118.8662033081117 .9517974854116 .7326965332115 .2088012695113 .9896011353 112.4656982422110 .6370010376108 .8082962036107 .2844009399105 .1509017944 103.3221969604101 .188697814999 .0551681518696 .6168823242294 .48339080811 92.349891662690 .8259735107489 .302040100187 .7781066894586 .2541885376 84.7302627563583 .5111236572382 .2919769287181 .6824111938581 .37763214111 81.0728530883881 .3776321411181 .3776321411181 .6824111938581 .68241119385 81.9871978759881 .9871978759882 .2919769287182 .5967712402382 .59677124023 82.9015579223683 .206336975183 .206336975183 .5111236572383 .81591033936 84.1206970214884 .4254837036184 .4254837036184 .7302627563585 .03504943848 85.3398437585 .6446228027385 .9494018554786 .254188537686 .55898284912 86.8637619018687 .1685485839887 .7781066894588 .0829010009888 .69246673584 89.302040100189 .6068267822390 .2164001464890 .5211791992290 .82597351074 91.1307525634891 .4355392456191 .4355392456191 .4355392456191 .43553924561 91.4355392456191 .7403335571391 .7403335571392 .0450973510792 .3498916626 92.6546783447393 .2642517089893 .5690307617293 .8738174438594 .48339080811 
94.7881774902395 .397743225195 .7025299072396 .0073165893696 .00731658936 96.0073165893696 .0073165893695 .7025299072395 .397743225194 .78817749023 94.1785964965893 .5690307617293 .2642517089892 .9594726562592 .95947265625 92.9594726562592 .9594726562592 .9594726562592 .9594726562592 .95947265625 92.9594726562592 .6546783447392 .6546783447392 .6546783447392 .65467834473 92.9594726562593 .2642517089893 .2642517089893 .5690307617293 .26425170898 93.2642517089892 .9594726562592 .349891662691 .4355392456189 .3020401001 86.2541885376 83.206336975179.54891967773 75.89148712158 72.23407745361 68.2718734741264 .9192428588965 .2240066528365 .52880096436 -9999 -9999 -9999 -9999 -9999 -9999 -9999 -9999 -9999 -9999 -9999 -9999 -9999 -9999 -9999 -9999 -9999 -9999 -9999 -9999 -9999 -9999 -9999 -9999 -9999 -9999 -9999 -9999 -9999 -9999 -9999 -9999 -9999 -9999 -

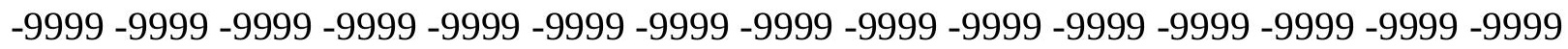
-9999 -9999 -9999 -9999 -9999 -9999 -9999 -9999 -9999-9999

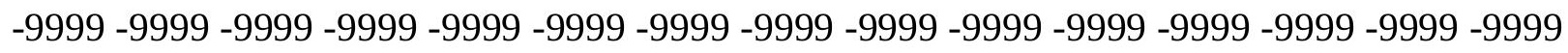
-9999 -9999 -9999 -9999 -9999 -9999 -9999 -9999 -9999 -9999 -9999 -9999 -9999 -9999 -9999

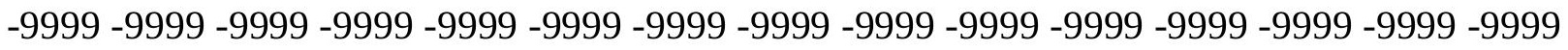
-9999 -9999 -9999 -9999 -9999 -9999 -9999 -9999 -9999 -9999 -9999 -9999 -9999 -9999 -9999 -9999 -9999 -9999 -9999 -9999 -9999 -9999 -9999 -9999 -9999 -9999 -9999 -9999 -9999 -9999 -9999 -9999 -9999 -9999 -9999 -9999 -9999 -9999 -9999 -9999 -9999 -9999 -9999 -9999 -9999 -9999 189.2179107666184.7198486328 176.4705963135173.4226989746174.0323028564 173.4226989746171 .8988037109170 .070098877167 .6318054199165 .4983062744 163.3648071289161 .2312927246159 .4026031494157 .5738983154156 .0500030518 154.8307952881153 .9165039062153 .3069000244153 .0021057129153 .0021057129 153.3069000244153 .9165039062154 .5260925293155 .1356048584156 .0500030518 156.6596069336157 .2691040039157 .878692627158 .1835021973158 .4882965088 158.7929992676158 .7929992676158 .4882965088158 .1835021973157 .878692627 157.5738983154157 .2691040039156 .7525939941156 .033493042155 .2047576904 154.2740478516153 .251159668152 .1457061768150 .9688873291149 .7323760986 148.4501953125147 .1384277344145 .8181152344144 .5137634277143 .262802124 142.1148223877141 .1109924316140 .2819976807139 .6529846191139 .2214660645 138.9787597656138 .8973236084138 .9490203857139 .1000671387139 .3288879395 139.6127471924139 .9207611084140 .2439117432140 .5735778809140 .9024963379 141.2239227295141 .531829834141 .2700500488142 .086151123142 .3221588135 142.5234527588142 .6848297119142 .8011474609142 .8684539795142 .8823699951 142.838394165142 .7307891846142 .5546569824142 .3049316406141 .4203033447 140.2012023926138 .9819946289137 .7628936768136 .5437011719135 .3246002197 134.1054992676132 .8863067627131 .6672058105130 .7528076172130 .4479980469 130.1432037354130 .1432037354130 .1432037354129 .8385009766129 .533706665 128.9241027832128 .3144989014127 .499130249126 .6099853516125 .7401885986 124.8975830078124 .0920944214123 .3356018066122 .638633728121 .9140014648 121.3044967651120 .6949005127120 .3900985718120 .3900985718120 .3900985718 120.6949005127120 .6949005127120 .9997024536120 .9997024536120 .9997024536 120.9997024536120 .6949005127120 .0852966309119 .4757995605118 .5614013672 117.647102356116 .7326965332115 .2088012695113 .9896011353112 .4656982422 110.9418029785109 .1130981445107 .2844009399105 .4557037354103 .6268997192 101.798202514699 .6647262573297 .5312423706195 .397743225193 .26425170898 
91.1307525634889 .9116134643688 .9972534179787 .4733276367285 .94940185547 84.1206970214882 .2919769287181 .0728530883880 .1584930419979 .85370635986 79.8537063598679 .8537063598680 .1584930419980 .1584930419980 .46327209473 80.7680587768681 .0728530883881 .3776321411181 .6824111938581 .98719787598 82.29197692871 82.59677124023 82.90155792236 83.2063369751 83.51112365723 83.8159103393683 .8159103393684 .1206970214884 .4254837036184 .73026275635 85.0350494384885 .3398437585 .6446228027385 .9494018554786 .2541885376 86.5589828491287 .1685485839887 .4733276367288 .0829010009888 .38768768311 88.9972534179789 .302040100189 .9116134643690 .2164001464890 .52117919922 90.8259735107491 .1307525634891 .1307525634891 .4355392456191 .43553924561 91.4355392456191 .4355392456191 .4355392456191 .7403335571392 .04509735107 92.6546783447392 .9594726562593 .2642517089893 .5690307617293 .87381744385 94.4833908081194 .7881774902395 .0929565429795 .397743225195 .3977432251 95.397743225195 .397743225195 .0929565429794 .7881774902394 .48339080811 94.1785964965893 .8738174438593 .5690307617293 .2642517089893 .26425170898 93.2642517089893.2642517089893.2642517089893.2642517089893.26425170898 92.9594726562592 .9594726562592 .6546783447392 .6546783447392 .95947265625 93.2642517089893 .8738174438594 .1785964965894 .4833908081194 .48339080811 94.4833908081194 .4833908081193 .8738174438592 .9594726562590 .82597351074 88.0829010009885 .0350494384881 .6824111938578 .0249862670974 .0627822876 70.1005783081166 .4431610107464 .9192428588965 .52880096436 -9999 -9999 -9999 -9999 -9999 -9999 -9999 -9999 -9999 -9999 -9999 -9999 -9999 -9999 -9999 -9999 -9999 -9999 -9999 -9999 -9999 -9999 -9999 -9999 -9999 -9999 -9999 -9999 -9999 -9999 -9999 -9999 -9999 -9999 -9999 -9999 -9999 -9999 -9999 -9999 -9999 -9999 -9999 -9999 -9999 -9999 -9999 -9999 -999 -999 -9999 -9999 -9999 -9999 -9999 -9999 -9999 -9999 -9999 -9999

-9999 -9999 -9999 -9999 -9999 -9999 -9999 -9999 -9999 -9999 -9999 -9999 -9999 -9999 -9999 -9999 -9999 -9999 -9999 -9999 -9999 -9999 -9999 -9999 -9999 -9999 -9999 -9999 -9999 -9999 -

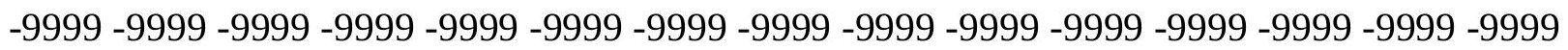
-9999 -9999 -9999 -9999 -9999 -9999 -9999 -9999 -9999 -9999 -9999 -9999 -9999 -9999 -9999

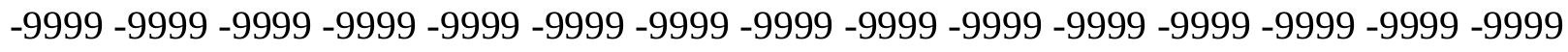
-9999 -9999 -9999 -9999 -9999 -9999 -9999 -9999 -9999 -9999 -9999 -9999-9999 -9999 -9999 -9999 -9999 190.2830047607 185.3418121338175.2514038086174.6419067383 173.4226989746171 .2891998291169 .1557006836166 .7174987793164 .2792053223 162.1457061768160 .0122070312158 .1835021973156 .6596069336155 .4403991699 154.5260925293153 .6116943359153 .0021057129152 .6972961426152 .6972961426 153.0021057129153 .3069000244153 .9165039062154 .5260925293155 .1356048584 155.7451934814156 .3547973633156 .9642944336157 .2691040039157 .5738983154 157.5738983154157 .5738983154157 .5738983154157 .2691040039157 .2691040039 156.9642944336156 .6596069336156 .4241333008155 .8284301758155 .1105194092 154.276550293153 .3363494873152 .3008422852151 .1838531494150 .0002441406 148.7677459717147 .5062866211146 .2393188477144 .9940185547143 .7997894287 142.6989898682141 .7259368896140 .9061889648140 .2575683594139 .7906494141 139.491973877139 .3515014648139 .340133667139 .4365386963139 .6150360107 139.8472290039140 .1150817871140 .4051971436140 .7071075439141 .0123748779 141.3136749268141 .6047515869141 .5093994141141 .1218719482142 .3670501709 142.5678253174142 .73387146142 .8600463867142 .9417114258142 .9731903076 
142.9482269287142 .8589630127142 .698348999142 .4593963623142 .1373901367 141.4203033447140 .2012023926138 .9819946289137 .7628936768136 .2389984131 135.0198059082133 .8007049561132 .5814971924131 .6672058105131 .0576019287 130.7528076172130 .4479980469130 .1432037354129 .8385009766129 .533706665 128.9241027832128 .2781219482127 .3657989502126 .4634475708125 .5764541626 124.7121658325123 .8814697266123 .0928649902122 .3612289429121 .6092987061 120.9997024536120 .6750106812120 .3900985718120 .0852966309120 .0852966309 120.0852966309120 .3900985718120 .3900985718120 .3900985718120 .3900985718 120.0852966309119 .4757995605119 .1709976196118 .2565994263117 .342300415 116.4279022217115 .2088012695113 .9896011353112 .4656982422110 .9418029785 109.4179000854107 .5891036987106 .0652008057104 .2365036011102 .4077987671 100.274299621698 .445587158296 .3121032714894 .1785964965892 .3498916626 90.8259735107489 .6068267822388 .6924667358487 .4733276367285 .33984375 82.9015579223681 .0728530883879 .5489196777378 .9393463134878 .32978057861 78.3297805786178 .6345596313578 .9393463134879 .2441329956179 .54891967773 79.8537063598680 .1584930419980 .4632720947381 .0728530883881 .37763214111 81.6824111938581 .9871978759882 .2919769287182 .9015579223683 .2063369751 83.5111236572383 .8159103393684 .1206970214884 .4254837036184 .73026275635 85.0350494384885 .3398437585 .6446228027385 .9494018554786 .2541885376 86.5589828491287 .1685485839887 .4733276367288 .0829010009888 .38768768311 88.6924667358489 .302040100189 .6068267822389 .9116134643690 .21640014648 90.5211791992290 .8259735107491 .1307525634891 .1307525634891 .13075256348 91.4355392456191 .4355392456191 .4355392456191 .4355392456192 .04509735107 92.349891662692 .6546783447392 .9594726562593 .2642517089893 .56903076172 93.8738174438594.1785964965894.4833908081194.7881774902394.78817749023 94.7881774902394 .7881774902394 .7881774902394 .4833908081194 .17859649658 94.1785964965893 .8738174438593 .5690307617293 .5690307617293 .26425170898 93.2642517089893 .5690307617293 .5690307617293 .5690307617293 .56903076172 93.2642517089893 .2642517089893 .2642517089892 .9594726562593 .56903076172 93.8738174438594 .4833908081195 .0929565429795 .397743225195 .70252990723 95.7025299072395 .397743225195 .0929565429793 .8738174438592 .3498916626 89.9116134643686 .8637619018683 .5111236572379 .8537063598676 .19628143311 72.2340774536168 .2718734741264 .9192428588965 .2240066528365 .52880096436 -9999 -9999 -9999 -9999 -9999 -9999 -9999 -9999 -9999 -9999 -9999 -9999 -9999 -9999 -9999 -9999 -9999 -9999 -9999 -9999 -9999 -9999 -9999 -9999 -9999 -9999 -9999 -9999 -9999 -9999 -9999 -

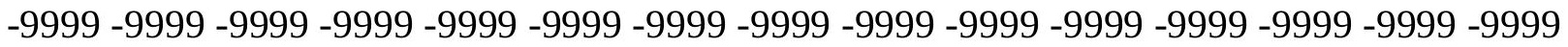
-9999 -9999 -9999-9999 -9999 -9999-9999 -9999 -9999 -9999 -9999 -9999 -

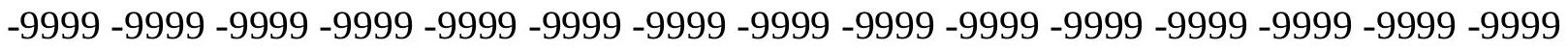

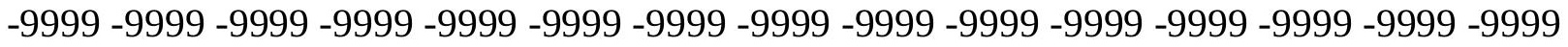
-9999 -9999 -9999 -9999 -9999 -9999 -9999 -9999 -9999 -9999 -9999 -9999 -9999 -9999 -9999 -

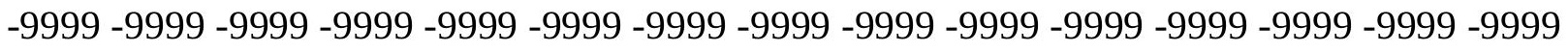

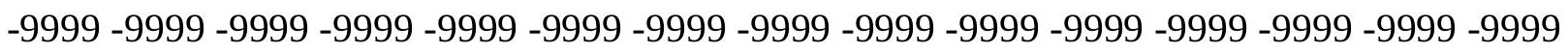
-9999 -9999 -9999 -9999 -9999 -9999 -9999 -9999 -9999 -9999 -9999 -9999 -9999 -9999 -9999 -9999 -9999-9999 196.1683349609 197.1959991455174.0323028564172.5084075928 170.3748931885167 .9365997314165 .4983062744163 .0599975586160 .6217956543 158.7929992676157 .2691040039155 .7451934814154 .5260925293153 .6116943359 
153.0021057129152 .6972961426152 .3925933838152 .3925933838152 .6972961426 153.0021057129153 .3069000244153 .9165039062154 .5260925293155 .1356048584 155.7451934814156 .0500030518156 .3547973633156 .6596069336156 .9642944336 156.9642944336156 .6596069336156 .6596069336156 .6596069336156 .3547973633 156.3547973633156 .0500030518155 .756149292155 .1464996338154 .4085845947 153.5526123047152 .5908813477151 .5394439697150 .4157409668149 .240234375 148.0351715088146 .8254852295145 .6377868652144 .5017089844143 .44581604 142.5007324219141 .6893768311141 .0303039551140 .528427124140 .1830444336 139.9823455811139 .9089202881139 .940536499140 .0537872314140 .2280578613 140.4453430176140 .6913757324140 .9547271729141 .2263183594141 .4983520508 141.7644500732141 .7359313965141 .3713989258142 .4793395996142 .6750183105 142.8423156738142 .9763641357143 .071685791143 .1211242676143 .1164093018 143.0472869873142 .904083252142 .6774291992142 .3608856201141 .9492645264 141.1154937744139 .8963928223138 .6772003174137 .1533050537135 .9342041016 134.7149963379133 .8007049561132 .8863067627131 .9720001221131 .3623962402 131.0576019287130 .4479980469129 .8385009766129 .533706665128 .9241027832 128.2113342285127 .2928009033126 .3797988892125 .477142334124 .5955429077 123.7402420044122 .9182891846122 .1522521973121 .4546432495120 .8740997314 120.3900985718120 .0852966309120 .0852966309119 .7806015015119 .7806015015 119.7806015015119 .7806015015119 .4757995605119 .4757995605118 .8662033081 118.5614013672117 .9517974854117 .0374984741116 .1231002808114 .9039993286 113.6848983765112 .4656982422110 .9418029785109 .4179000854107 .8938980103 106.3700027466104 .5412979126102 .712600708100 .883903503499 .05516815186 97.2264633178795.397743225193.5690307617291.7403335571390.21640014648 88.9972534179788 .0829010009887 .1685485839884 .1206970214881 .37763214111 79.5489196777378 .3297805786177 .4154205322377 .110626220777 .1106262207 77.4154205322377 .7202072143678 .0249862670978 .6345596313578 .93934631348 79.5489196777379 .8537063598680 .4632720947380 .7680587768681 .37763214111 81.6824111938582 .2919769287182 .5967712402382 .9015579223683 .2063369751 83.5111236572383 .8159103393684 .1206970214884 .7302627563585 .03504943848 85.3398437585 .6446228027385 .9494018554786 .254188537686 .86376190186 87.16854858398 87.47332763672 88.08290100098 88.38768768311 88.69246673584 89.3020401001 89.60682678223 89.9116134643690.2164001464890.52117919922 90.5211791992290 .8259735107491 .1307525634891 .1307525634891 .13075256348 91.1307525634891 .1307525634891 .4355392456191 .7403335571392 .04509735107 92.349891662692 .349891662692 .6546783447393 .2642517089893 .56903076172 93.8738174438593 .8738174438594 .1785964965894 .4833908081194 .48339080811 94.4833908081194 .4833908081194 .1785964965894 .1785964965893 .87381744385 93.8738174438593 .5690307617293 .5690307617293 .5690307617293 .56903076172 93.5690307617293 .5690307617293 .8738174438593 .8738174438593 .87381744385 93.8738174438593 .5690307617293 .8738174438594 .1785964965894 .78817749023 95.397743225195 .7025299072396 .3121032714896 .6168823242296 .61688232422 96.6168823242296 .0073165893695 .0929565429793 .5690307617291 .43553924561 88.6924667358485 .3398437581 .6824111938578 .0249862670974 .0627822876 70.4053573608466 .4431610107464 .9192428588965 .22400665283 -9999 -9999 -9999 -9999 -9999 -9999 -9999 -9999 -9999 -9999 -9999 -9999 -9999 -9999 -9999 -9999 -9999 -9999 -9999 
-9999 -9999 -9999 -9999 -9999 -9999 -9999 -9999 -9999 -9999 -9999 -9999 -9999 -9999 -9999 -9999 -9999 -9999 -9999 -9999 -9999 -9999 -9999 -9999 -9999 -9999 -9999 -9999 -9999 -9999 -9999 -9999 -9999 -9999 -9999 -9999-9999 -9999 -9999

-9999 -9999 -9999 -9999 -9999 -9999 -9999 -9999 -9999 -9999 -9999 -9999 -9999 -9999 -9999 -9999 -9999 -9999 -9999 -9999 -9999 -9999 -9999 -9999 -9999 -9999 -9999-9999 -9999 -9999 -9999 -9999 -9999 -9999 -9999 -9999 -9999 -9999 -9999 -9999 -9999 -9999 -9999 -9999 -9999

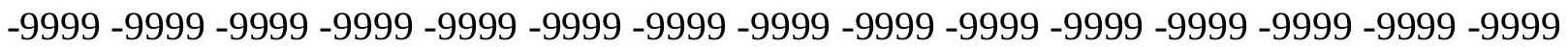
-9999 -9999 -9999 -9999 -9999 -9999 -9999 -9999 -9999 -9999 -9999 -9999 -9999 -9999 -9999 -999 -

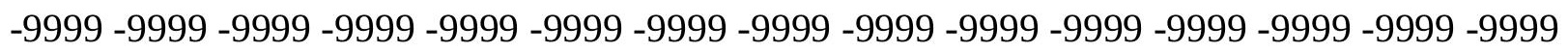
-9999-9999-9999 200.9616394043194.8969573975 180.7375946045 170.6797027588 168.8509979248166 .4127044678163 .974395752161 .2312927246159 .0977935791 157.2691040039155 .7451934814154 .5260925293153 .6116943359153 .0021057129 152.3925933838152 .0877990723152 .0877990723152 .0877990723152 .0877990723 152.3925933838153 .0021057129153 .3069000244153 .9165039062154 .5260925293 154.8307952881155 .4403991699155 .7451934814156 .0500030518156 .0500030518 156.0500030518156 .0500030518156 .0500030518156 .0500030518155 .7451934814 155.7451934814155 .7451934814155 .7451934814155 .3292388916154 .6819763184 153.9066772461153 .0170593262152 .0311584473150 .9683837891149 .85105896 148.7027282715147 .5486907959146 .4149475098145 .3274383545144 .3122711182 143.3934020996142 .5923156738141 .9233856201141 .394821167141 .005355835 140.7482452393140 .6096496582140 .5732421875140 .6199645996140 .7320404053 140.8923950195141 .0868988037141 .3038024902141 .5337982178141 .7689361572 142.0027313232141 .9360809326141 .5980834961141 .2751617432142 .8376312256 143.0026550293143 .1421813965143 .250213623143 .318069458143 .3352813721 143.2889099121143 .1661529541142 .9546356201142 .6455535889142 .232208252 141.7128448486140 .5059967041139 .2868041992138 .0677032471136 .8484954834 135.6293945312134 .7149963379133 .4958953857132 .8863067627131 .9720001221 131.3623962402130 .7528076172130 .1432037354129 .533706665128 .9241027832 128.0097961426127 .2860107422126 .3653106689125 .4489974976124 .5507736206 123.6781005859122 .8261947632121 .9140014648121 .3044967651120 .6949005127 120.3900985718120 .0852966309119 .7806015015119 .4757995605119 .4757995605 119.1709976196119 .1709976196118 .8662033081118 .5614013672117 .9517974854 117.342300415116 .7326965332115 .818397522114 .5991973877113 .6848983765 112.4656982422110 .9418029785109 .4179000854108 .1986999512106 .3700027466 104.8460998535103 .3221969604101 .493400573799 .6647262573298 .14080810547 96.3121032714894 .4833908081192 .6546783447390 .8259735107489 .3020401001 87.7781066894586 .254188537684 .4254837036181 .6824111938579 .54891967773 77.7202072143676 .8058471679776 .5010681152376 .1962814331176 .50106811523 76.5010681152377 .110626220777 .4154205322378 .0249862670978 .32978057861 78.9393463134879 .5489196777379 .8537063598680 .4632720947381 .07285308838 81.3776321411181 .9871978759882 .2919769287182 .5967712402383 .2063369751 83.5111236572383 .8159103393684 .1206970214884 .7302627563585 .03504943848 85.3398437585 .6446228027385 .9494018554786 .5589828491286 .86376190186 87.1685485839887 .7781066894588 .0829010009888 .3876876831188 .69246673584 88.9972534179789 .302040100189 .6068267822389 .9116134643690 .21640014648 90.5211791992290 .5211791992290 .8259735107490 .8259735107491 .13075256348 
91.1307525634891 .1307525634891 .1307525634891 .4355392456191 .74033355713 91.7403335571392 .0450973510792 .349891662692 .6546783447392 .95947265625 93.2642517089893 .5690307617293 .8738174438593 .8738174438593 .87381744385 94.1785964965894 .1785964965893 .8738174438593 .8738174438593 .87381744385 93.8738174438593 .8738174438593 .8738174438593 .8738174438593 .87381744385 93.8738174438593 .8738174438594 .1785964965894 .1785964965894 .17859649658 94.1785964965894 .4833908081194 .7881774902395 .0929565429795 .3977432251 96.0073165893696 .6168823242297 .2264633178797 .5312423706197 .53124237061 97.5312423706196 .9216690063596 .0073165893694 .4833908081192 .65467834473 90.2164001464887 .1685485839883 .8159103393680 .1584930419976 .19628143311 $72.2340774536168 .2718734741266 .1383666992264 .9192428588964 .91924285889-9999$ -9999 -9999 -9999 -9999 -9999 -9999 -9999 -9999 -9999 -9999 -9999 -9999 -9999 -9999 -9999 -9999 -9999 -9999 -9999 -9999 -9999 -9999 -9999 -9999 -9999 -9999 -9999 -9999 -9999 -9999 -9999 -9999 -9999 -9999 -9999 -9999 -9999 -9999 -9999 -9999 -9999 -9999 -9999 -9999 -9999 -9999 -9999 -9999 -9999 -9999 -9999 -9999 -9999 -9999 -9999 -9999

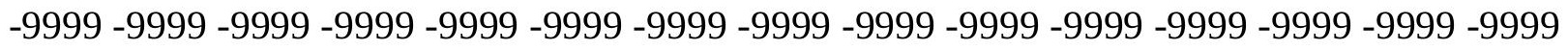
-9999 -9999 -9999 -9999 -9999 -9999 -9999 -9999 -9999 -9999 -9999 -9999 -9999 -9999 -9999 -9999 -9999 -9999 -9999 -9999 -9999 -9999 -9999 -9999 -9999 -9999 -9999 -9999 -9999 -9999 -9999 -9999 -9999 -9999 -9999 -9999 -9999 -9999 -9999 -9999 -9999 -9999 -9999 -9999 -9999 -

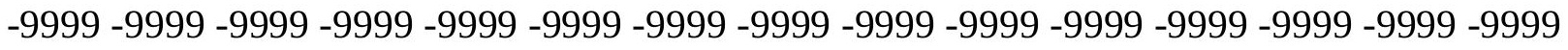

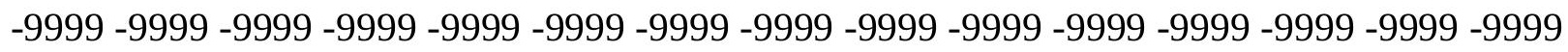
-9999 -9999 -9999 -9999 197.0351867676 186.0981903076168.8509979248 167.3269958496 164.8887023926161 .8408966064159 .4026031494157 .2691040039155 .7451934814 154.5260925293153 .3069000244152 .6972961426152 .0877990723151 .7830047607 151.4781951904151 .4781951904151 .4781951904151 .7830047607152 .0877990723 152.3925933838153 .0021057129153 .3069000244153 .9165039062154 .2212982178 154.8307952881155 .1356048584155 .4403991699155 .4403991699155 .4403991699 155.4403991699155 .4403991699155 .4403991699155 .4403991699155 .4403991699 155.4403991699155 .4403991699155 .4403991699155 .1059112549154 .4024810791 153.5789489746152 .6537017822151 .6480865479150 .5855102539149 .4899902344 148.3865356445147 .2998199463146 .2535858154145 .270904541144 .3725891113 143.5775909424142 .8991241455142 .3455963135141 .9171142578141 .6089782715 141.4105529785141 .3094940186141 .2907104492141 .3392181396141 .4395294189 141.578125141 .7433166504141 .9258422852142 .1178283691142 .3129577637 142.0934295654141 .7916412354141 .5171661377143 .0487518311143 .2075958252 143.349609375143 .4686584473143 .5549926758143 .5959625244143 .5758361816 143.4780578613143 .2861022949142 .9878845215142 .5746002197142 .0434417725 141.3968658447140 .2012023926138 .9819946289137 .7628936768136 .5437011719 135.3246002197134 .4102020264133 .4958953857132 .5814971924131 .9720001221 131.3623962402130 .4479980469129 .8385009766128 .9241027832128 .2712097168 127.3516311646126 .4277877808125 .4977340698124 .5697250366123 .6920166016 122.8283996582121 .9140014648121 .3044967651120 .6949005127120 .3900985718 119.7806015015119 .4757995605119 .1709976196119 .1709976196118 .8662033081 118.5614013672117 .9517974854117 .647102356117 .0374984741116 .1231002808 115.5136032104114 .2944030762113 .3800964355112 .1608963013110 .9418029785 109.4179000854 108.1986999512 106.6747970581 105.1509017944103.6268997192 
101.7982025146100 .274299621698 .7503814697396 .9216690063595 .3977432251 93.5690307617292 .0450973510790 .2164001464888 .3876876831186 .2541885376 84.1206970214881 .3776321411178 .9393463134877 .110626220776 .19628143311 75.5867080688575 .5867080688575 .5867080688575 .5867080688576 .19628143311 76.5010681152376 .8058471679777 .4154205322378 .0249862670978 .63455963135 78.9393463134879 .5489196777380 .1584930419980 .7680587768681 .37763214111 81.6824111938582 .2919769287182 .5967712402382 .9015579223683 .51112365723 83.8159103393684 .1206970214884 .7302627563585 .0350494384885 .33984375 85.9494018554786 .254188537686 .5589828491286 .8637619018687 .47332763672 87.7781066894588 .0829010009888 .3876876831188 .6924667358488 .99725341797 89.3020401001 89.60682678223 89.9116134643690.21640014648 90.21640014648 90.5211791992290 .5211791992290 .8259735107490 .8259735107490 .82597351074 91.1307525634891 .1307525634891 .1307525634891 .4355392456191 .43553924561 91.7403335571392 .0450973510792 .349891662692 .6546783447392 .95947265625 93.2642517089893 .2642517089893 .5690307617293 .5690307617293 .87381744385 93.87381744385 93.8738174438593.8738174438593.87381744385 93.87381744385 93.87381744385 93.8738174438593.8738174438593.87381744385 94.17859649658 94.1785964965894 .4833908081194 .4833908081194 .7881774902394 .78817749023 95.0929565429795 .397743225196 .0073165893696 .3121032714896 .92166900635 97.5312423706197 .8360290527398 .1408081054798 .445587158298 .14080810547 97.8360290527396 .9216690063595 .7025299072393 .8738174438591 .43553924561 88.6924667358485 .6446228027381 .9871978759878 .3297805786174 .0627822876 70.1005783081166 .1383666992264 .6144485473664 .61444854736 -9999 -9999 -9999 -9999 -9999 -9999 -9999 -9999 -9999 -9999 -9999 -9999 -9999 -9999 -9999 -9999 -9999 -9999 -9999 -9999 -9999 -9999 -9999 -9999 -9999 -9999 -9999 -9999 -9999 -9999 -9999 -9999 -9999 -9999 -9999 -9999 -9999 -9999 -9999 -9999 -9999 -9999 -9999 -9999 -9999 -9999 -9999 -9999 -9999 -9999 -9999 -9999 -9999 -9999 -9999 -9999 -9999

-9999 -9999 -9999 -9999 -9999 -9999 -9999 -9999 -9999 -9999 -9999 -9999 -9999 -9999 -9999 -9999 -9999 -9999 -9999 -9999 -9999 -9999 -9999 -9999 -9999 -9999 -9999 -9999 -9999 -9999 -9999 -9999 -9999 -9999 -9999 -9999 -9999 -9999 -9999 -9999 -9999 -9999 -9999 -9999 -9999 -9999 -9999 -9999 -9999 -9999 -9999 -9999 -9999 -9999 -9999 -9999 -9999 -9999 -9999 -9999 -9999 -9999 -9999 -9999 -9999 -9999 -9999 -9999 -9999 -9999 -9999 -9999 -9999 -9999 -9999 -

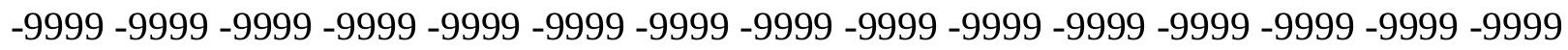
-9999 -9999 -9999 -9999-9999 195.4445800781 189.8811035156166 .1078948975 162.4505004883159 .4026031494157 .2691040039155 .4403991699154 .2212982178 153.0021057129152 .3925933838151 .7830047607151 .1734008789151 .1734008789 150.8686065674150 .8686065674151 .1734008789151 .4781951904151 .7830047607 152.0877990723152 .3925933838153 .0021057129153 .3069000244153 .9165039062 154.2212982178154 .5260925293154 .8307952881155 .1356048584155 .1356048584 155.1356048584155 .1356048584155 .1356048584155 .1356048584155 .1356048584 155.1356048584155 .1356048584154 .8307952881154 .8307952881154 .8307952881 154.2707824707153 .397644043152 .4419403076151 .4276123047150 .3784790039 149.3187866211 148.2717895508 147.2593688965 146.3024597168 145.4197845459 144.6283111572143 .9402160645143 .363494873142 .8991241455142 .5440063477 142.2900390625142 .1280059814142 .0460510254142 .0318450928142 .0714874268 142.1522521973142 .2626800537142 .3937225342142 .5377197266142 .4967193604 
142.1932983398141 .943862915141 .7330932617141 .5453338623143 .449005127 143.589553833143 .7169647217143 .8193664551143 .8873443604143 .9002532959 143.8386535645143 .6720275879143 .3882446289142 .9740753174142 .428237915 141.7250976562140 .8106994629139 .5915985107138 .3724975586137 .1533050537 136.2389984131135 .3246002197134 .1054992676133 .4958953857132 .5814971924 131.6672058105130 .7528076172130 .1432037354129 .2288970947128 .3144989014 127.4001998901126 .4858016968125 .5715026855124 .6570968628123 .7427978516 122.8283996582121 .9140014648121 .3044967651120 .6949005127120 .3900985718 119.7806015015119 .4757995605119 .1709976196118 .5614013672118 .2565994263 117.647102356117 .342300415116 .7326965332115 .818397522115 .2088012695 114.2944030762113 .075302124111 .8561019897110 .6370010376109 .4179000854 108.1986999512106 .6747970581105 .1509017944103 .6268997192102 .1029968262 100.579101562599 .3599472045997 .8360290527396 .3121032714894 .78817749023 92.9594726562591 .4355392456189 .6068267822387 .4733276367285 .03504943848 82.5967712402379 .5489196777376 .1962814331175 .5867080688575 .28192901611 74.9771423339874 .9771423339875 .2819290161175 .5867080688575 .89148712158 76.1962814331176 .8058471679777 .110626220777 .7202072143678 .32978057861 78.9393463134879 .5489196777380 .1584930419980 .4632720947381 .07285308838 81.6824111938582 .2919769287182 .5967712402383 .206336975183 .51112365723 83.8159103393684 .4254837036184 .7302627563585 .0350494384885 .64462280273 85.9494018554786 .5589828491286 .8637619018687 .1685485839887 .47332763672 88.0829010009888 .3876876831188 .6924667358488 .9972534179789 .3020401001 89.6068267822389 .6068267822389 .9116134643690 .2164001464890 .21640014648 90.2164001464890 .5211791992290 .5211791992290 .8259735107490 .82597351074 90.8259735107490 .8259735107491 .1307525634891 .1307525634891 .13075256348 91.4355392456191 .7403335571392 .0450973510792 .349891662692 .65467834473 92.9594726562592 .9594726562593 .2642517089893 .2642517089893 .56903076172 93.5690307617293 .5690307617293 .5690307617293 .5690307617293 .87381744385 93.8738174438593.8738174438594.1785964965894.1785964965894.48339080811 94.4833908081194 .7881774902395 .0929565429795 .0929565429795 .3977432251 95.7025299072396 .3121032714896 .6168823242297 .2264633178797 .83602905273 98.1408081054798 .7503814697399 .0551681518699 .0551681518699 .05516815186 98.445587158297 .8360290527396 .6168823242295 .0929565429792 .95947265625 90.5211791992287 .4733276367284 .1206970214880 .1584930419976 .19628143311 72.2340774536167 .9670867919964 .3096618652364 .3096618652364 .61444854736 -9999 -9999 -9999 -9999 -9999 -9999 -9999 -9999 -9999 -9999 -9999 -9999 -9999 -9999 -9999 -9999

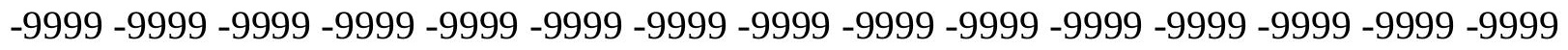

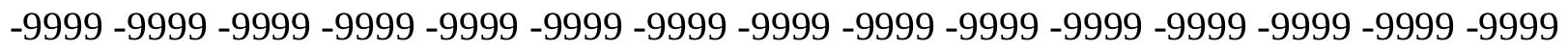
-9999 -9999 -9999 -9999 -9999 -9999 -9999 -9999 -9999 -9999 -9999 -9999 -9999 -9999 -9999 -9999 -9999 -9999 -9999 -9999 -9999 -9999 -9999 -9999 -9999

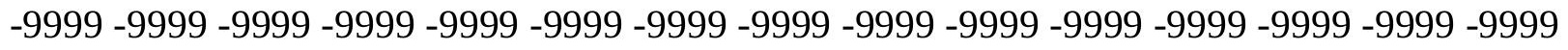

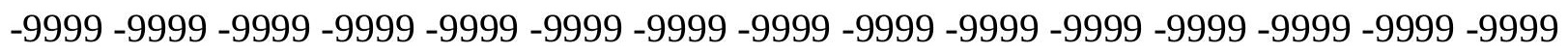
-9999 -9999 -9999 -9999 -9999 -9999 -9999 -9999 -9999 -9999 -9999 -9999 -9999 -9999 -9999 -9999 -9999 -9999 -9999 -9999 -9999 -9999 -9999 -9999 -9999 -9999 -9999 -9999 -9999 -9999 -

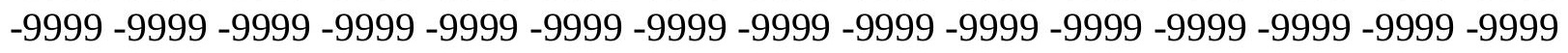
-9999 -9999 -9999 -9999-9999 202.2195587158 191.7244110107171 .5939941406 
159.0977935791156 .6596069336155 .1356048584153 .9165039062152 .6972961426 151.7830047607151 .1734008789150 .8686065674150 .5639038086150 .5639038086 150.5639038086150 .5639038086150 .8686065674151 .1734008789151 .4781951904 151.7830047607152 .0877990723152 .6972961426153 .0021057129153 .6116943359 153.9165039062154 .5260925293154 .8307952881154 .8307952881155 .1356048584 155.1356048584155 .1356048584155 .1356048584155 .1356048584155 .1356048584 154.8307952881154 .8307952881154 .5260925293154 .5260925293154 .2212982178 154.2212982178153 .9165039062153 .337310791152 .36277771151 .3521728516 150.3285827637149 .3138122559148 .3282165527147 .3911437988146 .5198822021 145.7299041748145 .0321044922144 .4337921143143 .9363098145143 .5378265381 143.2324066162143 .0133514404142 .8715515137142 .7969055176142 .7769622803 142.7996826172142 .8539581299142 .9309539795142 .6394042969142 .4699859619 142.225692749142 .0516815186141 .9245452881141 .8219451904143 .7201080322 143.8535003662143 .9833831787144 .1054534912144 .2066040039144 .2667541504 144.2486114502144 .1165924072143 .8422851562143 .4231109619142 .8594818115 142.1549224854141 .1154937744140 .2012023926138 .9819946289138 .0677032471 136.8484954834135 .9342041016135 .0198059082134 .1054992676133 .1911010742 132.2501983643131 .3282012939130 .4479980469129 .533706665128 .6192932129 127.7050018311126 .7906036377125 .8762969971124 .9618988037123 .7427978516 122.8283996582121 .9140014648121 .3044967651120 .6949005127120 .0852966309 119.7806015015119 .1709976196118 .8662033081118 .2565994263117 .647102356 117.0374984741116 .4279022217115 .818397522114 .9039993286113 .9896011353 113.075302124111 .8561019897110 .6370010376109 .4179000854107 .8938980103 106.6747970581105 .1509017944103 .6268997192102 .4077987671100 .8839035034 99.6647262573298 .1408081054796 .9216690063595 .397743225193 .87381744385 92.6546783447390 .8259735107488 .9972534179786 .8637619018684 .42548370361 81.6824111938578 .9393463134876 .8058471679775 .5867080688574 .97714233398 74.9771423339874 .9771423339875 .2819290161175 .5867080688575 .89148712158 76.1962814331176 .8058471679777 .110626220777 .7202072143678 .32978057861 78.9393463134879 .5489196777380 .1584930419980 .7680587768681 .07285308838 81.6824111938582 .2919769287182 .5967712402383 .206336975183 .51112365723 84.1206970214884 .4254837036185 .0350494384885 .3398437585 .94940185547 86.254188537686 .5589828491287 .1685485839887 .4733276367287 .77810668945 88.0829010009888 .3876876831188 .6924667358488 .9972534179789 .3020401001 89.6068267822389 .6068267822389 .9116134643689 .9116134643690 .21640014648 90.2164001464890 .2164001464890 .5211791992290 .5211791992290 .52117919922 90.8259735107490 .8259735107490 .8259735107490 .8259735107491 .13075256348 91.1307525634891 .4355392456191 .7403335571392 .0450973510792 .3498916626 92.6546783447392 .6546783447392 .9594726562592 .9594726562593 .26425170898 93.2642517089893 .5690307617293 .5690307617293 .5690307617293 .87381744385 93.87381744385 93.8738174438594.1785964965894.4833908081194.48339080811 94.7881774902395 .0929565429795 .397743225195 .7025299072396 .00731658936 96.6168823242296 .9216690063597 .5312423706197 .8360290527398 .4455871582 99.0551681518699 .3599472045999 .6647262573299 .6647262573299 .66472625732 99.3599472045998 .445587158297 .5312423706196 .0073165893694 .17859649658 92.0450973510789 .302040100185 .9494018554781 .9871978759878 .02498626709 
74.062782287669 .7957916259866 .1383666992264 .004882812564 .30966186523 -9999-9999 -9999 -9999 -9999 -9999 -9999 -9999 -9999 -9999 -9999 -9999 -9999 -9999 -9999 -9999 -9999

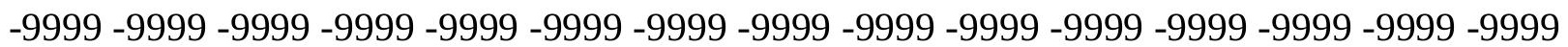

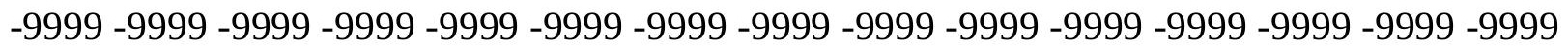
-9999 -9999-9999 -9999 -9999 -9999 -9999 -9999 -9999 -9999 -9999 -9999 -9999 -9999 -9999 -9999 -9999 -9999 -9999 -9999 -9999 -9999 -9999 -9999 -9999 -9999 -9999 -9999 -9999 -9999 -9999 -9999 -9999 -9999 -9999 -9999 -9999 -9999 -9999

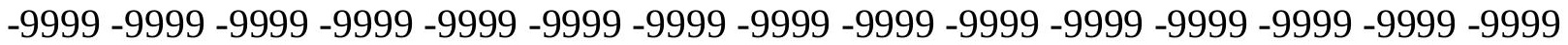

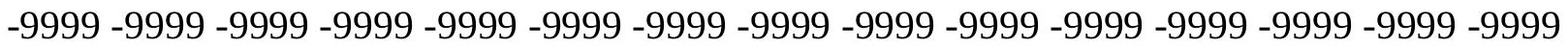
-9999 -9999 -9999 -9999 -9999 -9999 -9999 -9999 -9999 -9999 -9999 -9999 -9999 -9999 -9999 -9999 -9999 -9999 -9999 -9999 -9999 -9999 -9999 -9999 -9999 -9999 -9999 -9999 -9999 -9999 -9999 -9999 -9999 -9999-9999 207.157043457 198.5417327881 185.9188995361 155.1356048584154 .5260925293153 .6116943359152 .3925933838151 .4781951904 150.5639038086150 .2590942383149 .9542999268149 .9542999268149 .9542999268 150.2590942383150 .2590942383150 .5639038086150 .8686065674151 .1734008789 151.4781951904152 .0877990723152 .3925933838153 .0021057129153 .3069000244 153.9165039062154 .2212982178154 .5260925293154 .8307952881155 .1356048584 155.1356048584155 .4403991699155 .4403991699155 .4403991699155 .1356048584 154.8307952881154 .5260925293154 .5260925293154 .2212982178153 .9165039062 153.6116943359153 .0021057129152 .3925933838152 .0877990723151 .4781951904 151.1734008789150 .4101715088149 .4451599121148 .52293396147 .6596984863 146.8695831299146 .1622467041145 .544052124145 .0163879395144 .578414917 144.2259979248143 .9544830322143 .7568359375143 .6248016357143 .5471801758 143.5126342773143 .2489929199142 .6394042969142 .3347015381142 .0299072266 142.1943817139142 .1266479492142 .1030426025142 .1029815674144 .0157775879 144.1337127686144 .2613372803144 .4032440186144 .5474853516144 .6635742188 144.7017669678144 .6094207764144 .3433837891143 .9096374512143 .3238677979 142.5912475586141 .7199707031140 .7541809082139 .5915985107138 .6772003174 137.4580993652136 .5437011719135 .6293945312134 .7149963379133 .4958953857 132.5814971924131 .6672058105130 .7528076172129 .8385009766128 .9241027832 128.0097961426127 .0953979492126 .1809997559124 .9618988037124 .0475006104 123.1332015991122 .2188034058121 .6092987061120 .9997024536120 .3900985718 119.7806015015119 .1709976196118 .5614013672117 .9517974854117 .342300415 116.4279022217115 .818397522114 .9039993286113 .9896011353112 .7705001831 111.551399231110 .6370010376109 .1130981445107 .8938980103106 .6747970581 105.1509017944103 .6268997192102 .4077987671101 .188697814999 .66472625732 98.445587158297 .2264633178796 .0073165893694 .7881774902393 .56903076172 92.0450973510790 .5211791992288 .9972534179786 .8637619018684 .73026275635 81.9871978759879 .5489196777377 .7202072143676 .5010681152375 .89148712158 75.5867080688575 .5867080688575 .5867080688575 .8914871215876 .19628143311 76.5010681152376 .8058471679777 .4154205322378 .0249862670978 .32978057861 78.9393463134879 .5489196777380 .1584930419980 .7680587768681 .37763214111 81.6824111938582 .2919769287182 .9015579223683 .206336975183 .81591033936 84.1206970214884 .7302627563585 .0350494384885 .6446228027385 .94940185547 86.5589828491286 .8637619018687 .1685485839887 .7781066894588 .08290100098 88.38768768311 88.69246673584 88.99725341797 89.302040100189.3020401001 
89.6068267822389 .6068267822389 .9116134643689 .9116134643690 .21640014648 90.2164001464890 .2164001464890 .2164001464890 .2164001464890 .52117919922 90.5211791992290 .5211791992290 .8259735107490 .8259735107490 .82597351074 91.1307525634891 .4355392456191 .4355392456191 .7403335571392 .04509735107 92.349891662692 .6546783447392 .6546783447392 .9594726562592 .95947265625 93.2642517089893 .2642517089893 .5690307617293 .5690307617293 .56903076172 93.8738174438594 .1785964965894 .1785964965894 .4833908081194 .78817749023 95.0929565429795 .397743225195 .7025299072396 .0073165893696 .61688232422 96.9216690063597 .5312423706198 .1408081054798 .445587158299 .05516815186 99.6647262573299 .96952056885100 .2742996216100 .2742996216100 .2742996216 99.9695205688599 .0551681518698 .1408081054796 .9216690063595 .3977432251 93.5690307617291 .1307525634887 .4733276367283 .8159103393679 .85370635986 75.5867080688571 .6244964599667 .6623001098664 .004882812564 .0048828125 64.30966186523 -9999 -9999 -9999 -9999 -9999 -9999 -9999 -9999 -9999 -9999 -9999 -9999 -9999 -9999 -9999 -9999 -9999 -9999 -9999 -9999 -9999 -9999 -9999 -9999 -9999 -9999 -9999

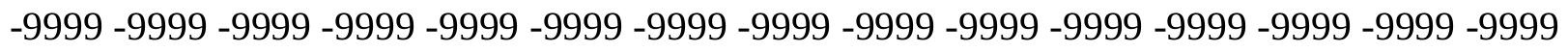
-9999 -9999 -9999 -9999 -9999 -9999 -9999 -9999 -9999 -9999 -9999 -9999 -9999 -9999 -9999 -9999 -9999 -9999 -9999 -9999 -9999 -9999 -9999 -9999 -9999 -9999 -9999 -9999 -9999 -9999 -9999 -9999 -9999 -9999 -9999 -9999 -9999 -9999 -9999 -9999 -9999 -9999 -9999 -

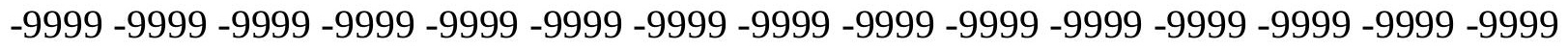

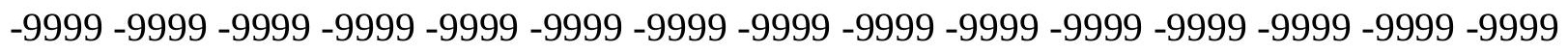
-9999 -9999 -9999 -9999 -9999 -9999 -9999 -9999 -9999 -9999 -9999 -9999 -9999 -9999 -9999 -9999 -9999 -9999 -9999 -9999 -9999 -9999 -9999 -9999 -9999 -9999 -9999 -9999 -9999 -9999 -9999-9999-9999-9999-9999-9999 204.6727905273 192.718963623171 .5939941406 154.5260925293153 .0021057129151 .4781951904150 .5639038086149 .9542999268 149.6495056152149 .6495056152149 .6495056152149 .6495056152149 .9542999268 150.2590942383150 .5639038086150 .8686065674151 .1734008789151 .4781951904 152.0877990723152 .3925933838153 .0021057129153 .3069000244153 .9165039062 154.5260925293154 .8307952881155 .1356048584155 .4403991699155 .7451934814 155.7451934814156 .0500030518155 .7451934814155 .4403991699155 .1356048584 154.8307952881154 .2212982178153 .9165039062153 .6116943359153 .0021057129 152.3925933838151 .7830047607151 .1734008789150 .5639038086150 .2590942383 149.6495056152149 .3446960449149 .0399017334148 .4304046631147 .8208007812 147.3208465576146.6846008301 146.1298828125145.6565704346 145.2619781494 144.9430236816144 .6941223145144 .5082702637144 .3753662109143 .5538024902 142.6394042969142 .0299072266141 .7250976562141 .4203033447141 .7250976562 142.0299072266142 .2890625142 .4081573486142 .5123138428144 .4217681885 144.5386810303144 .6967468262144 .8844299316145 .0699005127145 .1797943115 145.133605957144 .8657836914144 .3855285645143 .7847290039142 .9441986084 142.0299072266141 .1154937744140 .2012023926139 .2868041992138 .0677032471 137.1533050537136 .2389984131135 .0198059082134 .1054992676133 .1911010742 132.2767028809131 .3623962402130 .4479980469129 .2288970947128 .3144989014 127.4001998901126 .1809997559125 .2667007446124 .3523025513123 .43800354 122.5235977173121 .6092987061120 .9997024536120 .3900985718119 .4757995605 118.8662033081118 .2565994263117 .647102356116 .7326965332115 .818397522 114.9039993286113 .9896011353112 .7705001831111 .8561019897110 .6370010376 
109.1130981445107 .8938980103106 .3700027466105 .1509017944103 .6268997192 102.4077987671100 .883903503499 .6647262573298 .445587158297 .53124237061 96.3121032714895 .397743225194 .1785964965893 .2642517089892 .04509735107 90.8259735107488 .9972534179787 .1685485839885 .0350494384882 .90155792236 81.0728530883879 .2441329956178 .0249862670977 .110626220776 .80584716797 76.5010681152376 .5010681152376 .5010681152376 .8058471679777 .1106262207 77.4154205322377 .7202072143678 .3297805786178 .6345596313579 .24413299561 79.8537063598680 .4632720947381 .0728530883881 .3776321411181 .98719787598 82.5967712402382 .9015579223683 .5111236572383 .8159103393684 .42548370361 84.7302627563585 .3398437585 .9494018554786 .254188537686 .86376190186 87.1685485839887 .4733276367288 .0829010009888 .3876876831188 .69246673584 88.9972534179789 .302040100189 .302040100189 .6068267822389 .60682678223 89.9116134643689 .9116134643689 .9116134643689 .9116134643689 .91161346436 90.2164001464890 .2164001464890 .2164001464890 .2164001464890 .21640014648 90.5211791992290 .5211791992290 .5211791992290 .8259735107491 .13075256348 91.1307525634891 .4355392456191 .7403335571391 .7403335571392 .04509735107 92.349891662692 .6546783447392 .6546783447392 .9594726562592 .95947265625 93.2642517089893.2642517089893.5690307617293.5690307617293.87381744385 94.1785964965894 .1785964965894 .4833908081194 .7881774902395 .3977432251 95.7025299072396 .0073165893696 .6168823242296 .9216690063597 .53124237061 98.1408081054798 .445587158299 .0551681518699 .6647262573299 .96952056885 100.5791015625100 .5791015625100 .8839035034100 .5791015625100 .2742996216 99.6647262573299 .0551681518697 .8360290527396 .3121032714894 .48339080811 92.0450973510788 .9972534179785 .3398437581 .3776321411177 .41542053223

73.1484298706169 .1862335205165 .2240066528363 .7000885009864 .0048828125 -9999 -9999 -9999 -9999 -9999 -9999 -9999 -9999 -9999 -9999 -9999 -9999 -9999 -9999 -9999 -9999 -9999 -9999 -9999 -9999 -9999 -9999 -9999 -9999 -9999 -9999 -9999 -9999 -9999 -9999 -9999 -

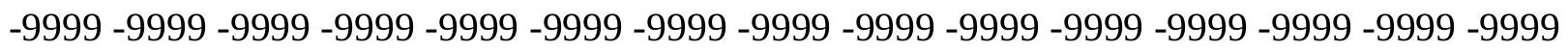
-9999 -9999 -9999 -9999 -9999 -9999 -9999 -9999 -9999

-9999 -9999 -9999 -9999 -9999 -9999 -9999 -9999 -9999 -9999 -9999 -9999 -9999 -9999 -9999 -9999 -9999 -9999 -9999 -9999 -9999 -9999 -9999 -9999-9999 -9999 -9999 -9999 -9999 -9999 -9999 -9999 -9999 -9999 -9999 -9999 -9999 -9999 -9999 -9999 -9999 -9999 -9999 -9999 -9999 -

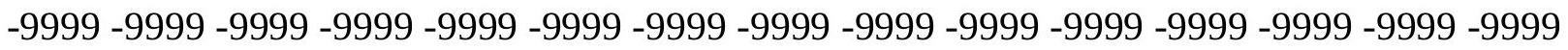
-9999 -9999 -9999 -9999 -9999 -9999 -9999 -9999 -9999 -9999 -9999 -9999 -9999 -9999 -9999 -9999 -9999 -9999 -9999 -9999 -9999 -9999 -9999 -9999 -9999 -9999 -9999 -9999 -9999 -9999 -9999 -9999 -9999 -9999 -9999 -9999 211.1934509277 203.7291412354 193.8433074951 156.6596069336152 .3925933838150 .5639038086149 .6495056152149 .3446960449 149.3446960449149 .3446960449149 .6495056152149 .9542999268150 .2590942383 150.5639038086150 .8686065674150 .8686065674151 .4781951904151 .7830047607 152.0877990723152 .3925933838153 .0021057129153 .6116943359154 .2212982178 154.8307952881155 .4403991699156 .0500030518156 .3547973633156 .6596069336 156.9642944336156 .9642944336156 .9642944336156 .3547973633155 .7451934814 155.1356048584154 .5260925293153 .9165039062153 .3069000244152 .6972961426 151.7830047607150 .8686065674150 .2590942383149 .6495056152149 .3446960449 149.3446960449149 .0399017334148 .7351074219148 .1255950928147 .5160064697 147.2111968994146 .6015930176146 .2969055176146 .2969055176146 .2969055176 
145.9700164795145 .6743927002145 .3825073242143 .8585968018142 .6394042969 141.7250976562141 .1154937744140 .8106994629140 .8106994629141 .1154937744 141.4203033447142 .0299072266142 .763381958142 .9810943604144 .4682006836 144.8036346436144 .9663543701145 .1947784424145 .4429168701145 .6374969482 145.6318206787145 .3825073242144 .7729034424144 .1634063721143 .5538024902 142.6394042969141 .7250976562140 .8106994629139 .5915985107138 .6772003174 137.7628936768136 .5437011719135 .6293945312134 .7149963379133 .8007049561 132.5814971924131 .6672058105130 .7528076172129 .8385009766128 .6192932129 127.7050018311126 .7906036377125 .5715026855124 .6570968628123 .7427978516 122.8283996582121 .9140014648121 .3044967651120 .3900985718119 .4757995605 118.8662033081117 .9517974854117 .0374984741116 .1231002808115 .2088012695 114.2944030762113 .075302124111 .8561019897110 .6370010376109 .4179000854 107.8938980103106 .6747970581105 .1509017944103 .6268997192102 .4077987671 100.883903503499 .6647262573298 .445587158297 .5312423706196 .31210327148 95.397743225194 .7881774902393 .8738174438592 .9594726562592 .04509735107 90.8259735107489 .6068267822388 .0829010009886 .254188537684 .12069702148 82.2919769287180 .7680587768679 .5489196777378 .6345596313578 .02498626709 77.7202072143677 .4154205322377 .4154205322377 .4154205322377 .72020721436 78.0249862670978 .3297805786178 .6345596313579 .2441329956179 .54891967773 80.1584930419980 .7680587768681 .3776321411181 .6824111938582 .29197692871 82.5967712402383 .206336975183 .8159103393684 .1206970214884 .73026275635 85.0350494384885 .6446228027386 .254188537686 .5589828491287 .16854858398 87.4733276367287 .7781066894588 .3876876831188 .6924667358488 .99725341797 89.302040100189 .302040100189 .6068267822389 .6068267822389 .91161346436 89.9116134643689 .9116134643689 .9116134643689 .9116134643689 .91161346436 89.9116134643689 .9116134643690 .2164001464890 .2164001464890 .21640014648 90.2164001464890 .5211791992290 .5211791992290 .8259735107490 .82597351074 91.1307525634891 .1307525634891 .4355392456191 .7403335571392 .04509735107 92.0450973510792 .349891662692 .6546783447392 .6546783447392 .95947265625 92.9594726562593 .2642517089893 .5690307617293 .5690307617293 .87381744385 94.1785964965894 .4833908081194 .7881774902395 .0929565429795 .3977432251 96.0073165893696 .3121032714896 .9216690063597 .5312423706197 .83602905273 98.445587158299 .0551681518699 .6647262573299 .96952056885100 .5791015625 100.8839035034101 .1886978149101 .1886978149101 .1886978149100 .8839035034 100.274299621699 .3599472045998 .445587158296 .9216690063595 .09295654297 92.6546783447389 .9116134643686 .5589828491282 .9015579223678 .93934631348 $74.6723632812570 .7101516723666 .4431610107463 .3953094482463 .39530944824-9999$ -9999 -9999 -9999 -9999 -9999 -9999 -9999 -9999 -9999 -9999 -9999 -9999 -9999 -9999 -9999 -9999 -9999 -9999 -9999 -9999 -9999 -9999 -9999 -9999 -9999 -9999 -9999 -9999 -9999 -9999 -9999 -9999 -9999 -9999 -9999 -9999 -9999 -9999 -9999 -9999 -9999 -9999 -9999 -9999 -9999 -9999 -9999 -9999 -9999 -9999 -9999 -9999 -9999 -9999

-9999 -9999 -9999 -9999 -9999 -9999 -9999 -9999 -9999 -9999 -9999 -9999 -9999 -9999 -9999 -9999 -9999 -9999 -9999 -9999 -9999 -9999 -9999 -9999 -9999 -9999 -9999 -9999 -9999 -9999 -9999 -9999 -9999 -9999 -9999 -9999 -9999 -9999 -9999 -9999 -9999 -9999 -9999 -9999 -9999 -999 -9999 -9999 -9999 -9999 -9999 -9999 -9999 -9999 -9999 -9999 -9999 -9999 -9999 -9999 -9999

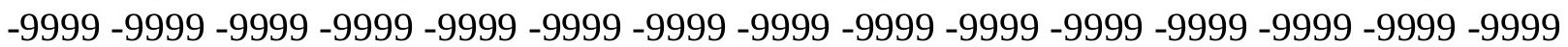


-9999 -9999 -9999 -9999 -9999 -9999 -9999 -9999 -9999 -9999 -9999 -9999 -9999 -9999 -9999 -9999 -9999 -9999 -9999 -9999 -9999 251.7525024414208 .8157043457196 .4878997803 174.9467010498150 .8686065674149 .9542999268149 .6495056152149 .6495056152 149.6495056152149 .6495056152149 .9542999268150 .2590942383150 .5639038086 150.8686065674151 .1734008789151 .4781951904151 .7830047607152 .0877990723 152.3925933838152 .6972961426153 .3069000244153 .6116943359154 .5260925293 155.1356048584156 .0500030518156 .9642944336157 .5738983154158 .1835021973 158.4882965088158 .4882965088158 .1835021973157 .5738983154156 .6596069336 155.7451934814154 .8307952881153 .9165039062153 .0021057129152 .3925933838 151.1734008789149 .9542999268149 .3446960449149 .0399017334149 .0399017334 149.0399017334148 .7351074219148 .4304046631148 .1255950928147 .5160064697 146.6015930176145 .9920959473145 .3825073242145 .0776977539145 .0776977539 144.7729034424144 .4682006836143 .5538024902142 .3347015381141 .3566589355 140.5059967041140 .2012023926139 .8963928223140 .2012023926140 .5059967041 141.1154937744141 .7250976562142 .6394042969143 .2489929199143 .7943572998 144.7729034424145 .2025604248145 .4479064941145 .7327575684145 .9920959473 145.9920959473145 .6873016357145 .0776977539144 .4682006836143 .8585968018 142.9441986084142 .0299072266141 .1154937744140 .2012023926139 .2868041992 138.0677032471137 .1533050537136 .2389984131135 .3246002197134 .1054992676 133.1911010742132 .2767028809131 .0576019287130 .1432037354129 .2288970947 128.0097961426127 .0953979492125 .8762969971124 .9618988037124 .0475006104 123.1332015991122 .2188034058121 .3044967651120 .3900985718119 .4757995605 118.5614013672117 .647102356116 .7326965332115 .818397522114 .5991973877 113.3800964355112 .1608963013110 .9418029785109 .7226028442108 .1986999512 106.6747970581105 .1509017944103 .9317016602102 .4077987671100 .8839035034 99.66472625732 98.445587158297.2264633178796.3121032714895.3977432251 94.7881774902394 .1785964965893 .5690307617292 .9594726562592 .3498916626 91.4355392456190 .2164001464888 .9972534179787 .4733276367285 .64462280273 84.1206970214882 .5967712402381 .3776321411180 .4632720947379 .54891967773 79.2441329956178 .6345596313578 .6345596313578 .6345596313578 .63455963135 78.6345596313578 .9393463134879 .2441329956179 .5489196777380 .15849304199 80.7680587768681 .3776321411181 .6824111938581 .9871978759882 .59677124023 82.9015579223683 .5111236572383 .8159103393684 .4254837036185 .03504943848 85.3398437585 .9494018554786 .254188537686 .8637619018687 .47332763672 87.7781066894588 .0829010009888 .6924667358488 .9972534179789 .3020401001 89.302040100189 .6068267822389 .6068267822389 .9116134643689 .91161346436 89.9116134643689 .9116134643689 .9116134643689 .9116134643689 .91161346436 89.9116134643689 .9116134643689 .9116134643689 .9116134643690 .21640014648 90.2164001464890 .2164001464890 .5211791992290 .5211791992290 .82597351074 90.8259735107491 .1307525634891 .4355392456191 .7403335571391 .74033355713 92.0450973510792 .349891662692 .349891662692 .6546783447392 .95947265625 92.9594726562593 .2642517089893 .2642517089893 .5690307617293 .87381744385 94.1785964965894 .4833908081194 .7881774902395 .0929565429795 .70252990723 96.0073165893696 .6168823242297 .2264633178797 .8360290527398 .14080810547 98.7503814697399 .3599472045999 .96952056885100 .2742996216100 .8839035034 101.1886978149101 .4934005737101 .4934005737101 .4934005737101 .1886978149 
100.579101562599 .9695205688598 .7503814697397 .5312423706195 .70252990723 93.5690307617290 .8259735107487 .7781066894584 .1206970214880 .15849304199 76.1962814331171 .9292907714867 .6623001098663 .7000885009863 .09051895142 63.39530944824 -9999 -9999 -9999 -9999 -9999 -9999 -9999 -9999 -9999 -9999 -9999 -9999 -9999 -9999 -9999 -9999 -9999 -9999 -9999 -9999 -9999 -9999 -9999 -9999 -9999 -9999 -9999 -9999 -9999 -9999 -9999 -9999 -9999 -9999 -9999 -9999 -9999 -9999 -9999 -9999 -9999 -9999 -9999 -9999 -9999 -9999 -9999 -9999 -9999 -9999 -9999 -9999 -9999 -9999

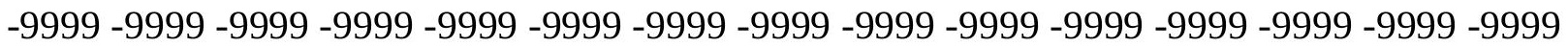

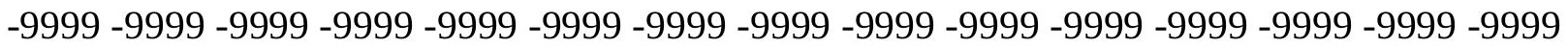
-9999 -9999 -9999 -9999 -9999 -9999 -9999 -9999 -9999 -9999 -9999 -9999 -9999 -9999 -9999 -

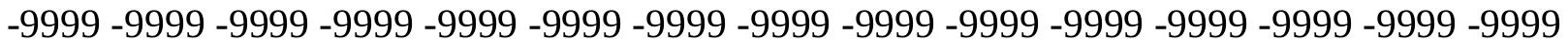
-9999 -9999 -9999 -9999 -9999 -9999 -9999 -9999 -9999 -9999 -9999 -9999 -9999 -9999 -9999

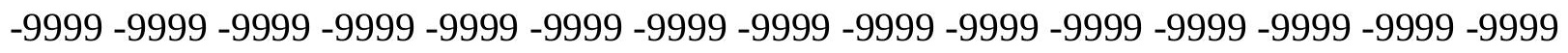
-9999 -9999 -9999 -9999 -9999 -9999 257.2385864258 209.0128326416 199.5558319092 187.1381072998152 .3925933838150 .2590942383150 .2590942383150 .2590942383 150.2590942383150 .5639038086150 .8686065674151 .1734008789151 .4781951904 151.4781951904151 .7830047607152 .0877990723152 .3925933838152 .6972961426 153.0021057129153 .3069000244153 .6116943359154 .2212982178154 .8307952881 155.7451934814156 .6596069336157 .878692627159 .0977935791160 .0122070312 160.6217956543160 .6217956543160 .0122070312159 .0977935791157 .878692627 156.6596069336155 .4403991699153 .9165039062152 .6972961426151 .4781951904 150.2590942383149 .3446960449148 .7351074219148 .7351074219149 .0399017334 149.0399017334149 .0399017334148 .7351074219148 .1255950928147 .2111968994 146.2969055176145 .3825073242144 .4682006836143 .5538024902143 .2489929199 142.6394042969142 .0299072266141 .4203033447140 .5059967041139 .5915985107 139.2868041992138 .9819946289139 .2868041992139 .5915985107140 .2012023926 140.8106994629141 .4203033447142 .3347015381143 .2489929199144 .1634063721 144.7729034424145 .3825073242145 .6873016357145 .9920959473145 .9920959473 145.9920959473145 .6873016357145 .3825073242144 .7729034424144 .1634063721 143.2489929199142 .3347015381141 .4203033447140 .5059967041139 .5915985107 138.6772003174137 .7628936768136 .5437011719135 .6293945312134 .7149963379 133.4958953857132 .5814971924131 .6672058105130 .4479980469129 .533706665 128.3144989014127 .4001998901126 .4858016968125 .2667007446124 .3523025513 123.43800354122 .5235977173121 .6092987061120 .3900985718119 .4757995605 118.5614013672117 .647102356116 .4279022217115 .2088012695113 .9896011353 112.7705001831111 .551399231110 .0273971558108 .5035018921106 .979598999 105.4557037354103 .9317016602102 .4077987671100 .883903503499 .66472625732 98.445587158296.9216690063596.0073165893695.0929565429794.17859649658 93.8738174438593 .5690307617293 .5690307617293 .2642517089892 .95947265625 92.349891662691 .1307525634890 .2164001464888 .6924667358487 .16854858398 85.94940185547 84.42548370361 83.2063369751 82.29197692871 81.37763214111 80.7680587768680 .1584930419979 .8537063598679 .5489196777379 .54891967773 79.5489196777379 .8537063598679 .8537063598680 .1584930419980 .76805877686 81.0728530883881 .6824111938581 .9871978759882 .2919769287182 .90155792236 83.2063369751 83.81591033936 84.12069702148 84.73026275635 85.33984375 85.64462280273 86.2541885376 86.55898284912 87.16854858398 87.77810668945 
88.0829010009888 .3876876831188 .9972534179789 .302040100189 .60682678223 89.6068267822389 .9116134643689 .9116134643689 .9116134643689 .91161346436 89.9116134643689 .9116134643689 .9116134643689 .9116134643689 .91161346436 89.9116134643689 .9116134643689 .9116134643689 .9116134643689 .91161346436 89.9116134643690.2164001464890.2164001464890.5211791992290.52117919922 90.8259735107491 .1307525634891 .1307525634891 .4355392456191 .74033355713 92.0450973510792 .0450973510792 .349891662692 .6546783447392 .65467834473 92.9594726562592 .9594726562593 .2642517089893 .5690307617293 .87381744385 94.1785964965894 .4833908081194 .7881774902395 .0929565429795 .70252990723 96.3121032714896 .9216690063597 .5312423706197 .8360290527398 .4455871582 99.0551681518699 .66472625732100 .2742996216100 .5791015625101 .1886978149 101.4934005737101 .4934005737101 .7982025146101 .4934005737101 .4934005737 100.8839035034100 .274299621699 .0551681518697 .8360290527396 .31210327148 94.1785964965891 .7403335571388 .6924667358485 .3398437581 .37763214111 77.4154205322373 .1484298706168 .8814392089864 .6144485473662 .78573989868 63.09051895142 -9999 -9999 -9999 -9999 -9999 -9999 -9999 -9999 -9999 -9999 -9999 -9999 -9999 -9999 -9999 -9999 -9999 -9999 -9999 -9999 -9999 -9999 -9999 -9999 -9999 -9999 -9999 -9999 -9999 -9999 -9999 -9999 -9999 -9999 -9999 -9999 -9999 -9999 -9999 -9999 -9999 -9999 -9999 -9999 -9999 -9999 -9999 -9999 -9999 -9999 -9999 -9999 -9999 -9999

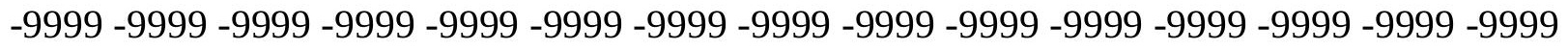

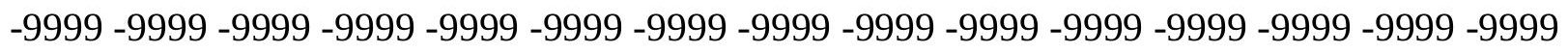
-9999 -9999 -9999 -9999 -9999 -9999 -9999 -9999 -9999 -9999 -9999 -9999 -9999 -9999 -9999 -9999 -9999 -9999 -9999 -9999 -9999 -9999 -9999 -9999 -9999 -9999 -9999 -9999 -9999 -9999 -

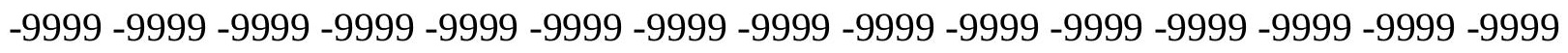

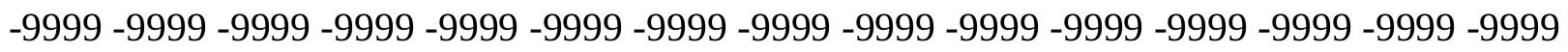
-9999 -9999-9999 -9999 -9999-9999-9999 220.7480163574 197.0820617676182.4520263672 164.5839996338152 .6972961426152 .0877990723151 .7830047607151 .4781951904 151.7830047607152 .0877990723152 .0877990723152 .3925933838152 .6972961426 152.6972961426153 .0021057129153 .3069000244153 .3069000244153 .9165039062 154.2212982178154 .5260925293155 .1356048584155 .7451934814156 .6596069336 157.878692627159 .4026031494160 .9264984131162 .4505004883163 .0599975586 163.0599975586162 .1457061768160 .9264984131159 .7073974609158 .4882965088 156.6596069336154 .8307952881152 .6972961426150 .8686065674149 .3446960449 148.7351074219148 .7351074219149 .3446960449149 .6495056152149 .9542999268 149.9542999268149 .3446960449148 .7351074219147 .5160064697146 .2969055176 144.7729034424143 .5538024902142 .3347015381141 .1154937744140 .2012023926 139.5915985107138 .9819946289138 .3724975586138 .0677032471138 .0677032471 138.0677032471138 .6772003174138 .9819946289139 .8963928223140 .5059967041 141.4203033447142 .3347015381143 .2489929199144 .1634063721145 .0776977539 145.6873016357145 .9920959473146 .2969055176146 .2969055176146 .2969055176 145.9920959473145 .6873016357145 .0776977539144 .4682006836143 .5538024902 142.9441986084142 .0299072266141 .1154937744140 .2012023926138 .9819946289 138.0677032471137 .1533050537135 .9342041016135 .0198059082134 .1054992676 132.8863067627131 .9720001221130 .7528076172129 .8385009766128 .9241027832 127.7050018311126 .7906036377125 .5715026855124 .6570968628123 .7427978516 122.5235977173121 .6092987061120 .6949005127119 .4757995605118 .5614013672 
117.342300415116 .1231002808114 .9039993286113 .6848983765112 .1608963013 110.6370010376109 .1130981445107 .5891036987106 .0652008057104 .2365036011 102.712600708101 .188697814999 .6647262573298 .445587158296 .92166900635 95.7025299072394 .7881774902393 .8738174438593 .2642517089892 .95947265625 93.2642517089893 .2642517089893 .5690307617293 .5690307617292 .95947265625 92.349891662691 .4355392456190 .2164001464888 .9972534179787 .47332763672 86.254188537685 .0350494384884 .1206970214883 .206336975182 .29197692871 81.6824111938581 .3776321411180 .7680587768680 .7680587768680 .46327209473 80.7680587768680 .7680587768681 .0728530883881 .0728530883881 .68241119385 81.9871978759882 .2919769287182 .9015579223683 .206336975183 .51112365723 84.1206970214884 .4254837036185 .0350494384885 .6446228027385 .94940185547 86.5589828491287 .1685485839887 .4733276367288 .0829010009888 .38768768311 88.6924667358489 .302040100189 .6068267822389 .9116134643689 .91161346436 90.2164001464890 .2164001464890 .2164001464890 .2164001464890 .21640014648 89.9116134643689 .9116134643689 .9116134643689 .9116134643689 .91161346436 89.60682678223 89.60682678223 89.91161346436 89.91161346436 89.91161346436 89.9116134643690 .2164001464890 .2164001464890 .5211791992290 .82597351074 90.8259735107491 .1307525634891 .4355392456191 .7403335571392 .04509735107 92.0450973510792 .349891662692 .349891662692 .6546783447392 .95947265625 92.9594726562593 .2642517089893 .5690307617293 .5690307617293 .87381744385 94.4833908081194 .7881774902395 .397743225195 .7025299072396 .31210327148 96.9216690063597 .5312423706198 .1408081054798 .7503814697399 .35994720459 99.96952056885100 .5791015625100 .8839035034101 .1886978149101 .4934005737 101.7982025146101 .7982025146101 .7982025146101 .4934005737100 .8839035034 100.274299621699 .3599472045998 .1408081054796 .6168823242294 .78817749023 92.6546783447389 .9116134643686 .5589828491282 .5967712402378 .32978057861 74.3675689697370 .1005783081165 .8335876464862 .4809494018662 .78573989868 -9999 -9999 -9999 -9999 -9999 -9999 -9999 -9999 -9999 -9999 -9999 -9999 -9999 -9999 -9999 -9999 -9999 -9999 -9999 -9999 -9999 -9999 -9999 -9999 -9999 -9999 -9999 -9999 -9999 -9999 -9999 -9999 -9999 -9999 -9999 -9999 -9999 -9999 -9999 -9999 -9999 -9999 -9999 -9999 -9999 -9999 -9999 -9999 -9999 -9999 -9999 -9999 -9999 -9999

-9999 -9999 -9999 -9999 -9999 -9999 -9999 -9999 -9999 -9999 -9999 -9999 -9999 -9999 -9999

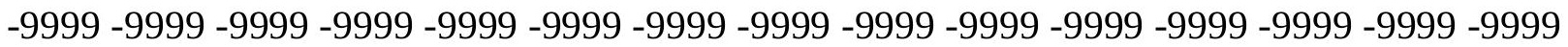
-9999 -9999 -9999 -9999 -9999 -9999 -9999 -9999 -9999 -9999 -9999 -9999 -9999 -9999 -9999 -9999 -9999 -9999 -9999 -9999 -9999 -9999 -9999 -9999 -9999 -9999 -9999 -9999 -9999 -9999 -9999 -9999 -9999 -9999 -9999 -9999 -9999 -9999 -9999 -9999 -9999 -9999 -9999 -9999 -9999

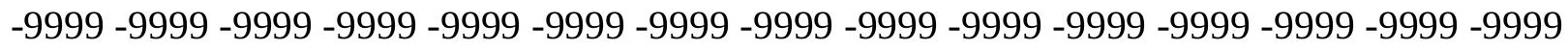
-9999 -9999 -9999-9999-9999 -9999-9999 222.5149688721 212.6125183105 180.30078125 167.6839447021156 .9642944336153 .9165039062153 .6116943359153 .3069000244 153.6116943359153 .6116943359153 .6116943359153 .9165039062153 .9165039062 154.2212982178154 .2212982178154 .5260925293154 .8307952881155 .1356048584 155.7451934814156 .0500030518156 .3547973633156 .6596069336157 .5738983154 158.7929992676160 .6217956543162 .7552947998164 .5839996338165 .8031005859 165.4983062744164 .2792053223163 .0599975586161 .8408966064160 .6217956543 158.7929992676156 .3547973633153 .6116943359150 .8686065674149 .3446960449 149.0399017334149 .9542999268150 .8686065674151 .7830047607152 .0877990723 
151.7830047607150 .8686065674149 .6495056152148 .1255950928146 .2969055176 144.4682006836142 .6394042969141 .1154937744139 .5915985107138 .3724975586 137.4580993652136 .8484954834136 .8484954834136 .8484954834137 .1533050537 137.4580993652138 .0677032471138 .9819946289139 .8963928223140 .8106994629 141.7250976562142 .9441986084143 .8585968018144 .7729034424145 .6873016357 146.2969055176146 .6015930176146 .9064025879146 .9064025879146 .6015930176 146.6015930176145 .9920959473145 .3825073242144 .7729034424144 .1634063721 143.2489929199142 .3347015381141 .4203033447140 .5059967041139 .5915985107 138.3724975586137 .4580993652136 .5437011719135 .3246002197134 .4102020264 133.1911010742132 .2767028809131 .3623962402130 .1432037354129 .2288970947 128.0097961426127 .0953979492125 .8762969971124 .9618988037123 .7427978516 122.8283996582121 .9140014648120 .6949005127119 .7806015015118 .5614013672 117.342300415116 .1231002808114 .5991973877113 .075302124111 .551399231 110.0273971558108 .1986999512106 .6747970581104 .8460998535103 .3221969604 101.798202514699 .9695205688598 .7503814697397 .2264633178796 .00731658936 94.4833908081193 .5690307617292 .6546783447392 .0450973510792 .3498916626 92.9594726562593 .2642517089893 .8738174438594 .1785964965894 .17859649658 93.5690307617292 .9594726562591 .7403335571390 .5211791992289 .3020401001 88.0829010009886 .8637619018685 .6446228027384 .7302627563583 .81591033936 83.206336975182 .5967712402382 .2919769287181 .6824111938581 .68241119385 81.3776321411181 .3776321411181 .6824111938581 .6824111938581 .98719787598 82.2919769287182 .5967712402383 .206336975183 .5111236572383 .81591033936 84.4254837036184 .7302627563585 .3398437585 .9494018554786 .2541885376 86.8637619018687 .4733276367287 .7781066894588 .3876876831188 .69246673584 88.9972534179789 .6068267822389 .9116134643690 .2164001464890 .21640014648 90.2164001464890 .2164001464890 .2164001464890 .2164001464890 .21640014648 89.91161346436 89.9116134643689.91161346436 89.9116134643689.60682678223 89.6068267822389 .6068267822389 .6068267822389 .6068267822389 .60682678223 89.9116134643689 .9116134643690 .2164001464890 .5211791992290 .52117919922 90.8259735107491 .1307525634891 .4355392456191 .7403335571391 .74033355713 92.0450973510792 .349891662692 .349891662692 .6546783447392 .65467834473 92.9594726562593 .2642517089893 .2642517089893 .5690307617293 .87381744385 94.1785964965894 .7881774902395 .397743225196 .0073165893696 .61688232422 97.2264633178797 .8360290527398 .445587158299 .0551681518699 .66472625732 100.2742996216100 .5791015625101 .1886978149101 .4934005737101 .7982025146 101.7982025146101 .7982025146101 .7982025146101 .4934005737101 .1886978149 100.579101562599 .6647262573298 .445587158297 .2264633178795 .3977432251 93.2642517089890 .8259735107487 .4733276367283 .5111236572379 .54891967773 75.2819290161171 .3197174072367 .0527267456163 .0905189514262 .48094940186 62.48094940186 -9999 -9999 -9999 -9999 -9999 -9999 -9999 -9999 -9999 -9999 -9999 -9999

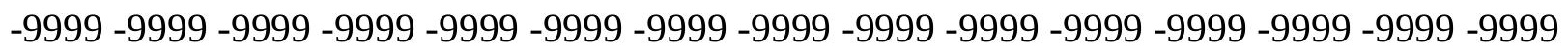

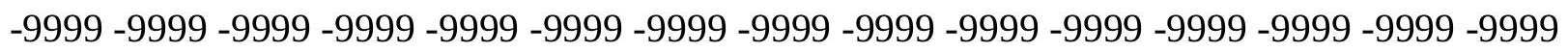
-9999 -9999 -9999 -9999 -9999 -9999 -9999 -9999 -9999 -9999 -9999

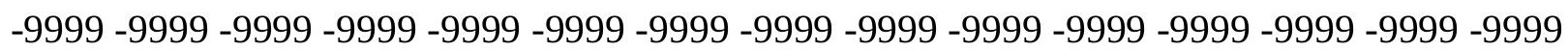

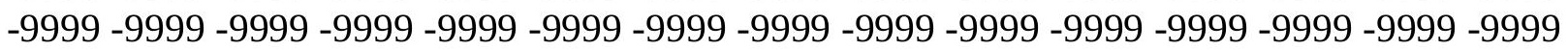

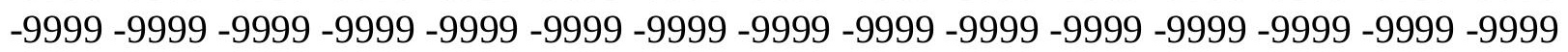


-9999 -9999 -9999 -9999 -9999 -9999 -9999 -9999 -9999 -9999 -9999 -9999 -9999 -9999 -9999 -9999 -9999 -9999 -9999 -9999 -9999 -9999 -9999 -9999 -9999 -9999 -9999 -9999 -9999 -9999 -9999 -9999 -9999 -9999 -9999 -9999 -9999 -9999 -9999 -9999 -9999 -9999 -9999 -9999 -9999 -9999 -9999 -9999 -9999 -9999 -9999 -9999 224.1169586182 214.8941497803 200.3894958496 169.0178070068160 .7613983154155 .7451934814155 .7451934814155 .7451934814 155.4403991699155 .4403991699155 .4403991699155 .7451934814155 .7451934814 155.7451934814155 .7451934814156 .0500030518156 .6596069336157 .2691040039 157.878692627158 .4882965088158 .4882965088158 .1835021973158 .4882965088 159.7073974609161 .5361022949164 .2792053223167 .0222015381168 .5462036133 167.9365997314166 .1078948975164 .8887023926163 .974395752163 .3648071289 162.4505004883159 .7073974609155 .4403991699151 .7830047607150 .2590942383 150.8686065674152 .3925933838153 .9165039062154 .8307952881155 .1356048584 154.2212982178153 .0021057129151 .1734008789149 .0399017334146 .6015930176 144.4682006836142 .3347015381140 .2012023926138 .3724975586136 .8484954834 135.9342041016135 .3246002197135 .6293945312135 .9342041016136 .5437011719 137.4580993652138 .3724975586139 .2868041992140 .2012023926141 .4203033447 142.6394042969143 .5538024902144 .7729034424145 .6873016357146 .2969055176 146.9064025879147 .2111968994147 .5160064697147 .5160064697147 .2111968994 146.9064025879146 .6015930176145 .9920959473145 .0776977539144 .4682006836 143.5538024902142 .6394042969141 .7250976562140 .8106994629139 .8963928223 138.9819946289137 .7628936768136 .8484954834135 .6293945312134 .7149963379 133.8007049561132 .5814971924131 .6672058105130 .4479980469129 .533706665 128.3144989014127 .4001998901126 .1809997559125 .2667007446124 .0475006104 123.1332015991121 .9140014648120 .6949005127119 .7806015015118 .5614013672 117.342300415115 .818397522114 .2944030762112 .7705001831110 .9418029785 109.1130981445107 .5891036987105 .7603988647103 .9317016602102 .1029968262 100.579101562599 .0551681518697 .5312423706196 .0073165893694 .78817749023 93.5690307617292 .6546783447391 .7403335571391 .1307525634891 .74033355713 92.6546783447393 .5690307617294 .4833908081194 .7881774902395 .09295654297 95.0929565429794 .4833908081193 .2642517089892 .349891662691 .13075256348 89.6068267822388 .6924667358487 .4733276367286 .5589828491285 .64462280273 84.7302627563584 .1206970214883 .5111236572382 .9015579223682 .59677124023 82.2919769287182 .2919769287182 .2919769287182 .2919769287182 .59677124023 82.5967712402382 .9015579223683 .5111236572383 .8159103393684 .12069702148 84.7302627563585 .0350494384885 .6446228027386 .254188537686 .55898284912 87.16854858398 87.77810668945 88.08290100098 88.69246673584 88.99725341797 89.302040100189 .9116134643690 .2164001464890 .5211791992290 .52117919922 90.5211791992290 .5211791992290 .5211791992290 .2164001464890 .21640014648 90.2164001464889 .9116134643689 .9116134643689 .6068267822389 .60682678223 89.6068267822389 .6068267822389 .6068267822389 .6068267822389 .60682678223 89.6068267822389 .9116134643689 .9116134643690 .2164001464890 .52117919922 90.8259735107491 .1307525634891 .4355392456191 .4355392456191 .74033355713 92.0450973510792 .349891662692 .349891662692 .6546783447392 .65467834473 92.9594726562592 .9594726562593 .2642517089893 .5690307617293 .87381744385 94.1785964965894 .7881774902395 .397743225196 .0073165893696 .61688232422 97.2264633178797.8360290527398.445587158299.0551681518699.66472625732 
100.2742996216100 .8839035034101 .1886978149101 .4934005737101 .7982025146 101.7982025146101 .7982025146101 .7982025146101 .4934005737101 .1886978149 100.579101562599 .6647262573298 .7503814697397 .2264633178795 .70252990723 93.5690307617291 .1307525634888 .0829010009884 .4254837036180 .46327209473 76.5010681152372 .2340774536168 .2718734741264 .004882812562 .17617034912 62.17617034912 -9999 -9999 -9999 -9999 -9999 -9999 -9999 -9999 -9999 -9999 -9999 -9999 -9999 -9999 -9999 -9999 -9999 -9999 -9999 -9999 -9999 -9999 -9999 -9999 -9999 -9999 -9999

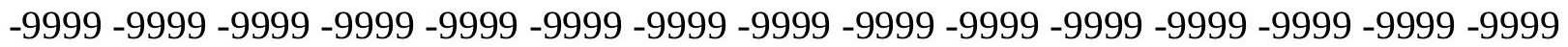
-9999 -9999 -9999 -9999 -9999 -9999 -9999 -9999 -9999 -9999 -9999 -9999 -9999 -9999 -9999 -9999 -9999 -9999 -9999 -9999 -9999 -9999 -9999 -9999 -9999 -9999 -9999 -9999 -9999 -9999 -9999 -9999 -9999 -9999 -9999 -9999 -9999 -9999 -9999 -9999 -9999 -999 -9999 -9999 -9999 -9999 -9999 -9999 -9999 -9999 -9999 -9999 -9999 -9999 -9999 -9999 -9999 -999 -9999 -9999 -9999 -9999 -9999 -9999 -9999 -9999 -9999 -9999 -9999 -9999 -9999 -9999 -9999 -9999 -9999 -9999 -9999 -9999 -9999 -9999 -9999 -9999 -9999 -9999 -9999 -9999 -9999 -9999 -9999 -9999 -9999 -9999 -9999 -9999 -9999 -9999 -9999 -9999 -9999 -9999 -9999 -9999 -9999 -9999 -9999-9999 -9999 -9999 -9999-9999 225.3104248047 217.4451751709 205.4556427002 189.8811035156163 .7372894287159 .4026031494158 .2567596436158 .1835021973 157.878692627157 .5738983154157 .5738983154157 .5738983154157 .5738983154 157.878692627157 .878692627158 .4882965088159 .4026031494160 .3170013428 161.2312927246161 .8408966064161 .5361022949160 .6217956543159 .7073974609 160.3170013428162 .4505004883165 .1934967041167 .9365997314170 .9844970703 169.1557006836167 .3269958496165 .8031005859165 .4983062744166 .7174987793 166.723526001165 .4983062744159 .4026031494153 .3069000244152 .3925933838 154.5260925293156 .9642944336158 .7929992676159 .7073974609159 .4026031494 157.878692627155 .7451934814153 .0021057129150 .2590942383147 .5160064697 144.7729034424142 .6394042969140 .2012023926138 .0677032471136 .2389984131 135.0198059082135 .0198059082135 .3246002197136 .2389984131136 .8484954834 137.7628936768138 .6772003174139 .8963928223141 .1154937744142 .3347015381 143.5538024902144 .7729034424145 .9920959473146 .9064025879147 .5160064697 148.1219787598148 .2519378662148 .3780059814148 .4304046631148 .1255950928 147.5160064697147 .2111968994146 .2969055176145 .6873016357144 .7729034424 143.8585968018142 .9441986084142 .0299072266141 .1154937744140 .2012023926 139.2868041992138 .0677032471137 .1533050537135 .9342041016135 .0198059082 134.1054992676132 .8863067627131 .9720001221130 .7528076172129 .8385009766 128.6192932129127 .7050018311126 .4858016968125 .5715026855124 .3523025513 123.1332015991122 .2188034058120 .9997024536119 .7806015015118 .5614013672 117.342300415115 .818397522113 .9896011353112 .1608963013110 .3321990967 108.5035018921106 .6747970581104 .8460998535103 .0174026489101 .1886978149 99.6647262573297 .8360290527396 .6168823242295 .0929565429793 .87381744385 92.9594726562592 .0450973510791 .4355392456191 .4355392456191 .74033355713 92.65467834473 93.8738174438594.7881774902395.7025299072396.31210327148 96.3121032714895 .7025299072394 .7881774902393 .5690307617292 .65467834473 91.4355392456190 .2164001464888 .9972534179788 .0829010009887 .16854858398 86.254188537685 .3398437584 .7302627563584 .1206970214883 .51112365723 83.206336975182 .9015579223682 .9015579223682 .9015579223682 .90155792236 83.206336975183 .206336975183 .8159103393684 .1206970214884 .42548370361 
85.0350494384885 .3398437585 .9494018554786 .5589828491286 .86376190186 87.47332763672 88.08290100098 88.38768768311 88.9972534179789.3020401001 89.6068267822389 .9116134643690 .5211791992290 .8259735107490 .82597351074 90.8259735107490 .8259735107490 .5211791992290 .5211791992290 .21640014648 90.2164001464889 .9116134643689 .9116134643689 .6068267822389 .60682678223 89.6068267822389 .302040100189 .302040100189 .302040100189 .60682678223 89.6068267822389 .6068267822389 .9116134643690 .2164001464890 .52117919922 90.5211791992290 .8259735107491 .1307525634891 .4355392456191 .74033355713 92.0450973510792 .349891662692 .349891662692 .6546783447392 .65467834473 92.6546783447392 .9594726562593 .2642517089893 .5690307617293 .87381744385 94.1785964965894 .7881774902395 .397743225196 .0073165893696 .61688232422 97.2264633178797 .8360290527398 .7503814697399 .3599472045999 .96952056885 100.2742996216100 .8839035034101 .1886978149101 .4934005737101 .7982025146 102.1029968262102 .1029968262101 .7982025146101 .4934005737101 .1886978149 100.579101562599 .6647262573298 .7503814697397 .5312423706196 .00731658936 93.8738174438591 .4355392456188 .3876876831185 .0350494384881 .37763214111 77.4154205322373 .4532165527369 .1862335205165 .2240066528361 .87137985229 61.87137985229 -9999 -9999 -9999 -9999 -9999 -9999 -9999 -9999 -9999 -9999 -9999 -9999 -9999 -9999 -9999 -9999 -9999 -9999 -9999 -9999 -9999 -9999 -9999 -9999 -9999 -9999 -9999 -9999 -9999 -9999 -9999 -9999 -9999 -9999 -9999 -9999 -9999 -9999 -9999 -9999 -9999 -9999 -9999 -9999 -9999 -9999 -9999 -9999 -9999 -9999 -9999 -9999 -9999

-9999 -9999 -9999 -9999 -9999 -9999 -9999 -9999 -9999 -9999 -9999 -9999 -9999 -9999 -9999 -9999 -9999 -9999 -9999 -9999 -9999 -9999 -9999 -9999 -9999 -9999 -9999 -9999 -9999 -9999 -9999 -9999 -9999 -9999 -9999 -9999 -9999 -9999 -9999 -9999 -9999 -9999 -9999 -9999 -9999 -9999 -9999 -9999 -9999 -9999 -9999 -9999 -9999 -9999 -9999 -9999 -9999 -9999 -9999 -9999 -9999 -9999 -9999 -9999 -9999 -9999 -9999 -9999 -9999 -9999 -9999 -9999 -9999 -9999 -9999 -9999 -9999 -9999 -9999 -9999-9999 -9999 -9999 -9999 -9999 -9999 -9999 -9999 -9999 - 9999 -9999 -9999 -9999 -9999 -9999 -9999 -9999 -9999 219.8227233887210 .6661529541 197.500793457177 .9945068359162 .7866210938160 .9594116211160 .2760009766 159.9364318848159 .7073974609159 .4026031494159 .4026031494159 .7073974609 160.0122070312160 .3170013428161 .2312927246162 .4505004883163 .6696014404 165.1934967041166 .1078948975165 .8031005859163 .6696014404161 .2312927246 160.3170013428163 .3648071289166 .7174987793167 .3269958496167 .6318054199 168.5462036133168 .241394043166 .4127044678165 .8031005859168 .0158843994 167.5604400635167 .0074920654165 .4983062744154 .8307952881158 .1835021973 161.5361022949163 .3367156982162 .4941253662161 .6359710693160 .7718505859 159.9120483398158 .7929992676155 .4403991699151 .7830047607148 .7351074219 145.6873016357143 .5538024902141 .1154937744139 .2868041992137 .1533050537 135.3246002197135 .9342041016136 .5437011719137 .1533050537138 .0677032471 138.9819946289139 .8963928223141 .1154937744142 .3347015381143 .8585968018 145.0776977539146 .6015930176147 .8208007812148 .7351074219148 .941192627 149.0030670166149 .1085357666149 .2000732422149 .202255249149 .0399017334 148.4304046631147 .8208007812146 .9064025879145 .9920959473145 .3825073242 144.4682006836143 .2489929199142 .3347015381141 .4203033447140 .5059967041 139.2868041992138 .3724975586137 .4580993652136 .2389984131135 .3246002197 134.4102020264133 .1911010742132 .2767028809131 .0576019287130 .1432037354 
128.9241027832128 .0097961426126 .7906036377125 .5715026855124 .6570968628 123.43800354122 .2188034058120 .9997024536120 .0852966309118 .8662033081 117.342300415115 .5136032104113 .6848983765111 .8561019897110 .0273971558 107.8938980103105 .7603988647103 .9317016602102 .1029968262100 .2742996216 98.445587158296 .9216690063595 .7025299072394 .4833908081193 .26425170898 92.349891662691 .7403335571391 .4355392456191 .4355392456192 .04509735107 92.9594726562594 .1785964965895 .397743225196 .3121032714897 .22646331787 97.5312423706196 .9216690063596 .0073165893695 .0929565429793 .87381744385 92.6546783447391 .7403335571390 .5211791992289 .6068267822388 .38768768311 87.4733276367286 .5589828491285 .6446228027385 .0350494384884 .42548370361 83.8159103393683 .5111236572383 .206336975183 .206336975183 .2063369751 83.51112365723 83.51112365723 83.81591033936 84.42548370361 84.73026275635 85.3398437585 .6446228027386 .254188537686 .8637619018687 .16854858398 87.7781066894588 .3876876831188 .6924667358488 .9972534179789 .60682678223 89.9116134643690 .2164001464890 .5211791992290 .8259735107490 .82597351074 90.8259735107490 .8259735107490 .5211791992290 .5211791992290 .21640014648 90.2164001464889 .9116134643689 .9116134643689 .6068267822389 .60682678223 89.302040100189.302040100189.302040100189.302040100189.3020401001 89.6068267822389 .6068267822389 .9116134643689 .9116134643690 .21640014648 90.5211791992290 .8259735107491 .1307525634891 .7403335571392 .04509735107 92.349891662692 .349891662692 .349891662692 .6546783447392 .65467834473 92.6546783447392 .9594726562592 .9594726562593 .2642517089893 .87381744385 94.1785964965894 .7881774902395 .397743225196 .0073165893696 .61688232422 97.5312423706198 .1408081054798 .7503814697399 .3599472045999 .96952056885 100.5791015625100 .8839035034101 .4934005737101 .7982025146101 .7982025146 102.1029968262101 .7982025146101 .7982025146101 .4934005737100 .8839035034 100.274299621699 .6647262573298 .7503814697397 .5312423706196 .00731658936 94.1785964965891 .7403335571388 .9972534179785 .6446228027382 .29197692871 78.3297805786174 .3675689697370 .4053573608466 .4431610107462 .48094940186 61.56660079956 -9999 -9999 -9999 -9999 -9999 -9999 -9999 -9999 -9999 -9999 -9999 -9999 -9999 -9999 -9999 -9999 -9999 -9999 -9999 -9999 -9999 -9999 -9999 -9999 -9999 -9999 -9999 -9999 -9999 -9999 -9999 -9999 -9999 -9999 -9999 -9999 -9999 -9999 -9999 -9999 -9999 -9999 -

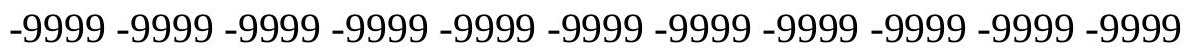

-9999 -9999 -9999 -9999 -9999 -9999 -9999 -9999 -9999 -9999 -9999 -9999 -9999 -9999 -9999 -9999 -9999 -9999 -9999 -9999 -9999 -9999 -9999 -9999 -9999 -9999 -9999 -9999 -9999 -9999 -9999 -9999 -9999 -9999 -9999 -9999 -9999 -9999 -9999 -9999 -9999 -9999 -9999 -9999 -9999

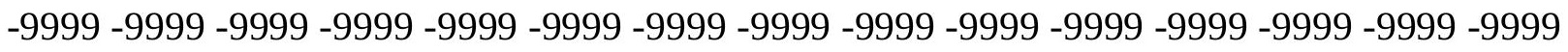

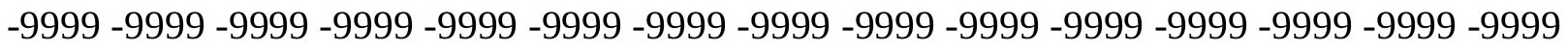
-9999 -9999 -9999 -9999 -9999 -9999 -9999 -9999 -9999 -9999 -9999 -9999 -9999 -9999 -9999 -9999 -9999 -9999 -9999 -9999 -9999 -9999 -9999 220.5136566162213 .2009124756 202.6820983887182 .87109375167 .9365997314163 .974395752162 .3616027832 161.8575897217161 .5361022949161 .4264373779161 .5361022949161 .8408966064 162.1457061768163 .0599975586163 .974395752165 .4983062744167 .3269958496 169.4604949951171 .2891998291171 .8988037109168 .8509979248163 .0599975586 159.4026031494164 .8887023926170 .9844970703169 .695892334168 .865020752 169.1188201904169 .2839813232169 .0083770752169 .0046691895168 .6976165771 
168.3036499023167 .8045806885167 .2122650146164 .8056488037164 .422668457 165.0967712402164 .3078918457163 .4917602539162 .657333374161 .8135986328 160.9702758789160 .137298584157 .2922363281153 .3069000244149 .9542999268 147.2111968994145 .0776977539143 .2489929199141 .7250976562140 .2012023926 138.9819946289138 .6470336914138 .9819946289139 .5915985107139 .8963928223 140.5059967041141 .4203033447142 .3347015381143 .8585968018145 .3825073242 147.2111968994 148.7351074219149.6495056152 149.8138427734149.7899780273 149.8227996826149 .877746582149 .9045715332149 .8279876709149 .566192627 149.0399017334148 .4304046631147 .5160064697146 .6015930176145 .6873016357 144.7729034424143 .5538024902142 .6394042969141 .7250976562140 .8106994629 139.5915985107138 .6772003174137 .4580993652136 .5437011719135 .6293945312 134.4102020264133 .4958953857132 .5814971924131 .3623962402130 .4479980469 129.2288970947128 .3144989014127 .0953979492125 .8762969971124 .9618988037 123.7427978516122 .5235977173121 .3044967651120 .0852966309119 .1709976196 117.342300415115 .5136032104113 .6848983765111 .551399231109 .4179000854 107.2844009399 105.1509017944 103.0174026489 101.188697814999.35994720459 97.5312423706196 .0073165893694 .7881774902393 .5690307617292 .65467834473 92.0450973510791 .7403335571391 .4355392456191 .7403335571392 .65467834473 93.5690307617294 .4833908081195 .7025299072396 .6168823242297 .53124237061 97.8360290527397 .5312423706196 .9216690063596 .0073165893695 .09295654297 93.8738174438592 .9594726562591 .7403335571390 .8259735107489 .60682678223 88.6924667358487 .4733276367286 .5589828491285 .9494018554785 .03504943848 84.4254837036184 .1206970214883 .8159103393683 .5111236572383 .51112365723 83.5111236572383 .8159103393684 .1206970214884 .7302627563585 .03504943848 85.6446228027385 .9494018554786 .5589828491287 .1685485839887 .47332763672 88.08290100098 88.38768768311 88.9972534179789.302040100189.60682678223 89.9116134643690 .5211791992290 .5211791992290 .8259735107490 .82597351074 90.8259735107490 .8259735107490 .8259735107490 .5211791992290 .21640014648 90.2164001464889 .9116134643689 .9116134643689 .6068267822389 .60682678223 89.302040100189.302040100189.302040100189.302040100189.302040100189.3020401001 89.6068267822389 .6068267822389 .9116134643690 .2164001464890 .52117919922 90.8259735107491 .1307525634891 .7403335571392 .0450973510792 .3498916626 92.6546783447392 .6546783447392 .6546783447392 .6546783447392 .65467834473 92.9594726562592 .9594726562593 .2642517089893 .8738174438594 .17859649658 94.7881774902395 .397743225196 .0073165893696 .9216690063597 .53124237061 98.1408081054798.7503814697399.3599472045999.96952056885 100.5791015625 101.1886978149101 .4934005737101 .7982025146101 .7982025146102 .1029968262 102.1029968262101 .7982025146101 .4934005737100 .8839035034100 .2742996216 99.6647262573299 .0551681518697 .8360290527396 .3121032714894 .48339080811 92.349891662689 .6068267822386 .5589828491282 .9015579223679 .24413299561 $75.2819290161171 .3197174072367 .3575134277363 .3953094482461 .56660079956-9999$ -9999 -9999 -9999 -9999 -9999 -9999 -9999 -9999 -9999 -9999 -9999 -9999 -9999 -9999 -9999 -9999 -9999 -9999 -9999 -9999 -9999 -9999 -9999 -9999 -9999 -9999 -9999 -9999 -9999 -9999 -

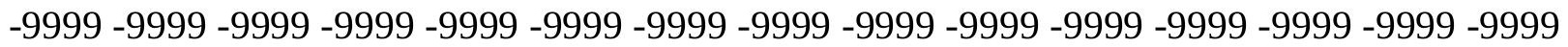
-9999 -9999 -9999 -9999-9999-9999-9999

-9999 -9999 -9999 -9999 -9999 -9999 -9999 -9999 -9999 -9999 -9999 -9999 -9999 -9999 -9999 
-9999 -9999 -9999 -9999 -9999 -9999 -9999 -9999 -9999 -9999 -9999 -9999 -9999 -9999 -9999 -9999 -9999 -9999 -9999 -9999 -9999 -9999 -9999 -9999 -9999 -9999 -9999 -9999 -9999 -9999

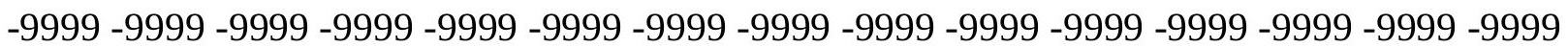
-9999 -9999 -9999 -9999 -9999 -9999 -9999 -9999 -9999 -9999 -9999 -9999 -9999 -9999 -9999 -9999 -9999 -9999 -9999 -9999 -9999 -9999 -9999 -9999 -9999 -9999 -9999 -9999 -9999 - -9999 -9999 -9999 -9999 -9999-9999 -9999 -9999 -9999 218.7945709229 211.4834289551 199.9389953613182 .261505127168 .8509979248165 .1934967041163 .974395752 163.3648071289163 .0599975586163 .0599975586163 .3648071289163 .974395752 164.5839996338165 .4983062744166 .7174987793168 .5462036133170 .6797027588 173.4226989746175 .8609924316174 .5165405273171 .1994628906167 .0233459473 165.1016998291167 .1714324951170 .1116943359170 .7827911377170 .3045043945 169.9460754395169 .845413208169 .7419281006169 .5706939697169 .3196258545 168.9797210693168 .5334014893167 .993057251167 .3788299561166 .7073822021 165.9880371094165 .2301940918164 .4424438477163 .6333618164162 .8113861084 161.9857330322161 .1661224365158 .9281158447155 .1356048584151 .4781951904 149.0399017334 147.3606872559 145.8447723389144.5696105957 143.4678344727 142.6632995605142 .3390350342142 .6938476562142 .6394042969142 .6394042969 142.6394042969142 .9441986084144 .1634063721145 .6873016357147 .5160064697 149.3446960449150 .8686065674152 .3925933838153 .0021057129153 .6116943359 153.3069000244153 .0021057129152 .3925933838151 .7830047607149 .9743041992 149.4691162109148 .7621765137147 .8855743408146 .9064025879145 .9920959473 145.0776977539143 .8585968018142 .9441986084141 .7250976562140 .8106994629 139.8963928223138 .6772003174137 .7628936768136 .8484954834135 .6293945312 134.7149963379133 .8007049561132 .5814971924131 .6672058105130 .7528076172 129.533706665128 .6192932129127 .4001998901126 .1809997559125 .2667007446 124.0475006104122 .8283996582121 .6092987061120 .6949005127119 .4757995605 117.647102356115 .5136032104113 .3800964355111 .24659729108 .8082962036 106.6747970581104 .2365036011102 .1029968262100 .274299621698 .4455871582 96.6168823242295 .397743225194 .1785964965892 .9594726562592 .3498916626 91.7403335571391 .7403335571391 .7403335571392 .0450973510792 .95947265625 93.8738174438594 .7881774902396 .0073165893696 .9216690063597 .53124237061 97.8360290527397 .8360290527397 .2264633178796 .6168823242295 .70252990723 94.7881774902393 .8738174438592 .9594726562591 .7403335571390 .82597351074 89.60682678223 88.38768768311 87.47332763672 86.55898284912 85.64462280273 85.0350494384884 .4254837036184 .1206970214883 .8159103393683 .81591033936 83.8159103393684 .1206970214884 .4254837036184 .7302627563585 .33984375 85.9494018554786 .254188537686 .8637619018687 .4733276367287 .77810668945 88.38768768311 88.69246673584 89.3020401001 89.60682678223 89.91161346436 90.2164001464890 .5211791992290 .8259735107490 .8259735107490 .82597351074 90.8259735107490 .8259735107490 .8259735107490 .5211791992290 .52117919922 90.2164001464889 .9116134643689 .9116134643689 .6068267822389 .60682678223 89.302040100189.302040100189.302040100189.302040100189.302040100189.3020401001 89.302040100189.60682678223 89.9116134643690.2164001464890.52117919922 90.8259735107491 .1307525634891 .7403335571392 .349891662692 .65467834473 92.6546783447392 .6546783447392 .6546783447392 .6546783447392 .65467834473 92.6546783447392 .9594726562593 .2642517089893 .5690307617294 .17859649658 
94.7881774902395 .397743225196 .3121032714896 .9216690063597 .53124237061 98.445587158299 .0551681518699 .66472625732100 .2742996216100 .8839035034 101.1886978149101 .4934005737101 .7982025146102 .1029968262102 .1029968262 102.1029968262101 .7982025146101 .4934005737101 .1886978149100 .5791015625 99.9695205688599 .0551681518698 .1408081054796 .6168823242294 .78817749023 92.6546783447390 .2164001464887 .1685485839883 .8159103393680 .15849304199 76.1962814331172 .2340774536167 .9670867919964 .004882812561 .26181030273 61.26181030273 -9999 -9999 -9999 -9999 -9999 -9999 -9999 -9999 -9999 -9999 -9999 -9999 -9999 -9999 -9999 -9999 -9999 -9999 -9999 -9999 -9999 -9999 -9999 -9999 -9999 -9999 -9999 -9999 -9999 -9999 -9999 -9999 -9999 -9999 -9999 -9999 -9999 -9999 -9999 -9999 -9999 -9999 -9999 -9999 -9999 -9999 -9999 -9999 -9999 -9999 -9999 -9999

-9999 -9999 -9999 -9999 -9999 -9999 -9999 -9999 -9999 -9999 -9999 -9999 -9999 -9999 -9999 -9999 -9999 -9999 -9999 -9999 -9999 -9999 -9999 -9999 -9999 -9999 -9999 -9999 -9999 -9999 -9999 -9999 -9999 -9999 -9999 -9999 -9999 -9999 -9999 -9999 -9999 -9999 -9999 -9999 -9999 -9999 -9999 -9999 -9999 -9999 -9999 -9999 -9999 -9999 -9999 -9999 -9999 -9999 -9999 -9999

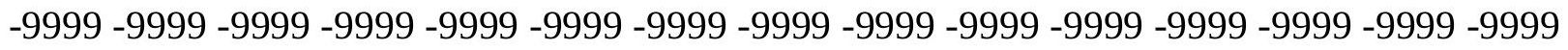

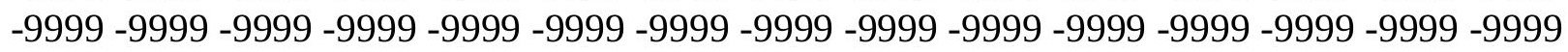
-9999 -9999 -9999 -9999 -9999 -9999 -9999 -9999 214.6806030273 207.19140625 193.8433074951179 .2136993408167 .9365997314165 .1934967041164 .5839996338 164.2792053223164 .2792053223164 .5839996338165 .1934967041165 .8031005859 166.4127044678167 .6318054199169 .1557006836170 .9844970703173 .4226989746 175.794921875176 .8924255371175 .9348907471173 .4018554688170 .6392364502 169.2314605713172 .1637878418174 .8650054932176 .8508453369177 .140335083 176.3354187012175 .4211425781175 .1039123535175 .6741333008176 .8777770996 177.9630584717178 .143157959177 .3613433838176 .2783813477175 .5510559082 175.4417877197175 .4270935059174 .8757781982173 .404586792170 .9523468018 167.7119598389164 .0203094482160 .2629241943156 .6596069336152 .6972961426 151.1734008789150 .0227966309148 .8204956055147 .8942871094147 .164932251 146.6512145996146 .4434509277146 .6304321289146 .6015930176145 .6873016357 145.0776977539145 .0776977539145 .6873016357147 .5160064697149 .6495056152 151.7830047607153 .6116943359155 .1356048584155 .5232086182155 .5299835205 155.3462371826154 .9843139648154 .2212982178153 .0021057129152 .0877990723 150.8686065674148 .9951324463148 .1429443359147 .2110900879146 .2589416504 145.0776977539144 .1634063721142 .9441986084142 .0299072266140 .8106994629 139.8963928223138 .9819946289138 .0677032471136 .8484954834135 .9342041016 135.0198059082133 .8007049561132 .8863067627131 .9720001221131 .0576019287 129.8385009766128 .9241027832127 .7050018311126 .7906036377125 .5715026855 124.3523025513123 .1332015991121 .9140014648120 .6949005127119 .4757995605 117.647102356115 .5136032104113 .075302124110 .6370010376108 .1986999512 105.7603988647103 .6268997192101 .188697814999 .3599472045997 .53124237061 95.7025299072394 .4833908081193 .2642517089892 .349891662691 .74033355713 91.4355392456191 .4355392456191 .7403335571392 .349891662693 .26425170898 94.1785964965895 .0929565429796 .0073165893696 .9216690063597 .53124237061 97.8360290527397 .8360290527397 .5312423706196 .9216690063596 .31210327148 95.397743225194 .7881774902393 .5690307617292 .6546783447391 .43553924561 90.2164001464888 .9972534179787 .7781066894586 .8637619018685 .94940185547 
85.3398437584 .7302627563584 .4254837036184 .1206970214884 .12069702148 84.1206970214884 .1206970214884 .4254837036185 .0350494384885 .64462280273 85.9494018554786 .5589828491287 .1685485839887 .7781066894588 .38768768311 88.6924667358488 .9972534179789 .6068267822389 .9116134643690 .21640014648 90.5211791992290 .5211791992290 .8259735107490 .8259735107490 .82597351074 90.8259735107490 .8259735107490 .8259735107490 .5211791992290 .52117919922 90.2164001464889 .9116134643689 .9116134643689 .6068267822389 .60682678223 89.302040100189.302040100189.302040100188.9972534179788.99725341797 89.302040100189.302040100189.60682678223 89.60682678223 89.91161346436 90.2164001464890 .8259735107491 .1307525634891 .7403335571392 .3498916626 92.9594726562592 .6546783447392 .6546783447392 .6546783447392 .65467834473 92.6546783447392 .6546783447392 .9594726562593 .2642517089893 .56903076172 94.1785964965894 .7881774902395 .397743225196 .3121032714896 .92166900635 97.8360290527398 .445587158299 .3599472045999 .96952056885100 .2742996216 100.8839035034101 .1886978149101 .7982025146101 .7982025146102 .1029968262 102.1029968262102 .1029968262101 .7982025146101 .4934005737101 .1886978149 100.5791015625100 .274299621699 .3599472045998 .445587158297 .22646331787 95.397743225193 .2642517089890 .8259735107488 .0829010009884 .73026275635 81.0728530883877 .110626220773 .1484298706168 .8814392089864 .61444854736 60.9570198059161 .26181030273 -9999 -9999-9999 -9999 -9999 -9999 -9999 -9999 -9999 -9999 -9999 -9999 -9999 -9999 -9999 -9999 -9999 -9999 -9999 -9999 -9999 -9999 -9999 -9999 -9999 -9999 -9999 -9999 -9999 -9999 -9999 -9999 -9999 -9999 -9999 -9999 -9999 -9999 -9999 -9999 -9999 -9999 -9999 -9999 -9999 -9999 -9999 -9999 -9999 -9999 -9999 -9999 -

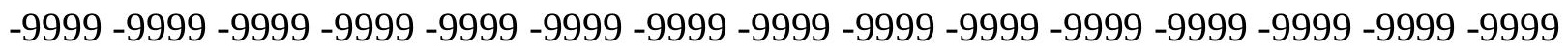

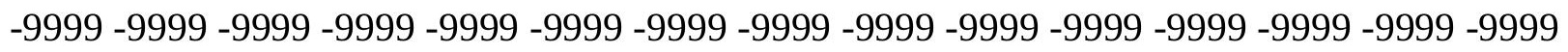
-9999 -9999 -9999 -9999 -9999 -9999 -9999 -9999 -9999 -9999 -9999 -9999 -9999 -9999 -9999

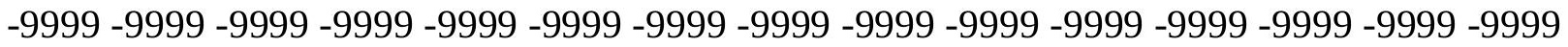

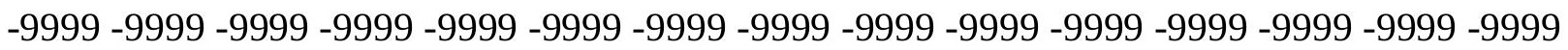

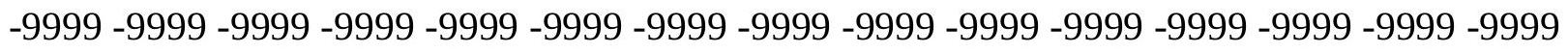
-9999 -9999 -9999 -9999-9999 -9999 -9999 -9999 -9999 202.6820983887 187.1381072998 174.9467010498164 .5839996338164 .8887023926164 .8887023926164 .8887023926 165.4983062744165 .8031005859166 .4127044678167 .3269958496168 .241394043 169.4604949951170 .9844970703173 .1179962158175 .2514038086177 .6896972656 179.5184020996180 .432800293177 .6469268799172 .8132019043166 .7174987793 174.337097168178 .2043914795180 .5788116455180 .720993042178 .604095459 177.9945068359176 .7754058838177 .5435028076178 .37449646179 .4176940918 180.0388336182180 .0603637695179 .6439971924179 .0748596191178 .5398712158 177.8582000732176 .6766204834174 .6616973877171 .8142547607168 .3633270264 164.6878967285161 .1785430908158 .1473083496155 .7451934814153 .9999237061 152.8316802979152 .0915222168151 .6125640869151 .2684173584151 .0105895996 150.8685302734150 .9058990479151 .1734008789149 .6495056152148 .1255950928 147.2111968994147 .5160064697149 .3446960449151 .7830047607154 .5260925293 156.9642944336157 .2997283936157 .3681945801157 .2417602539156 .9261322021 156.4320220947155 .7451934814154 .5260925293153 .0021057129151 .7830047607 150.2590942383149 .0399017334147 .4387969971146 .4707946777145 .3825073242 144.1634063721143 .2302398682142 .0299072266141 .1154937744139 .8963928223 
138.9819946289138 .0677032471137 .1533050537136 .2389984131135 .0198059082 134.1054992676133 .1911010742132 .2767028809131 .0576019287130 .1432037354 129.2288970947128 .0097961426127 .0953979492125 .8762969971124 .6570968628 123.43800354122 .2188034058120 .9997024536119 .1709976196117 .342300415 115.2088012695112 .7705001831110 .3321990967107 .5891036987105 .1509017944 102.712600708100 .579101562598 .445587158296 .6168823242295 .09295654297 93.5690307617292 .6546783447392 .0450973510791 .4355392456191 .43553924561 91.4355392456192 .0450973510792 .6546783447393 .5690307617294 .48339080811 95.397743225196.3121032714896.92166900635 97.5312423706197.53124237061 97.5312423706197 .2264633178796 .9216690063596 .3121032714895 .70252990723 95.0929565429794 .1785964965892 .9594726562591 .7403335571390 .52117919922 89.302040100188.08290100098 87.16854858398 86.2541885376 85.64462280273 85.0350494384884 .4254837036184 .1206970214884 .1206970214884 .12069702148 84.4254837036184 .7302627563585 .0350494384885 .6446228027386 .2541885376 86.8637619018687 .4733276367288 .0829010009888 .6924667358488 .99725341797 89.3020401001 89.60682678223 89.9116134643690.2164001464890.52117919922 90.8259735107490 .8259735107490 .8259735107491 .1307525634891 .13075256348 90.8259735107490 .8259735107490 .5211791992290 .5211791992290 .21640014648 90.2164001464889 .9116134643689 .6068267822389 .6068267822389 .3020401001 89.302040100189.302040100189.302040100189.302040100189.302040100189.3020401001 89.6068267822389 .6068267822389 .9116134643690 .2164001464890 .82597351074 91.1307525634891 .7403335571392 .349891662692 .6546783447392 .65467834473 92.6546783447392 .6546783447392 .6546783447392 .6546783447392 .65467834473 92.9594726562593 .2642517089893 .5690307617294 .1785964965895 .09295654297 95.7025299072396 .6168823242297 .2264633178798 .1408081054798 .75038146973 99.3599472045999 .96952056885100 .5791015625101 .1886978149101 .4934005737 101.7982025146102 .1029968262102 .1029968262102 .1029968262102 .1029968262 101.7982025146101 .7982025146101 .4934005737100 .8839035034100 .2742996216 99.6647262573298 .7503814697397 .5312423706196 .0073165893694 .17859649658 91.7403335571388 .9972534179785 .9494018554781 .9871978759878 .02498626709 74.062782287669 .7957916259865 .5288009643661 .5666007995660 .95701980591 -9999 -9999 -9999 -9999 -9999 -9999 -9999 -9999 -9999 -9999 -9999 -9999 -9999 -9999 -9999 -9999 -

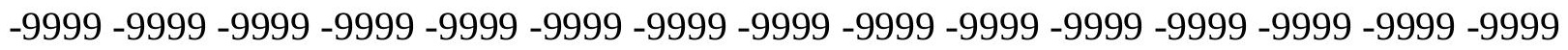

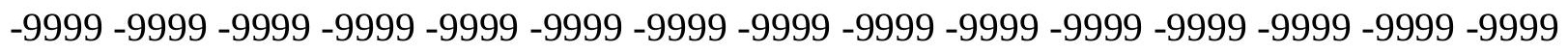
-9999 -9999 -9999-9999-9999-9999

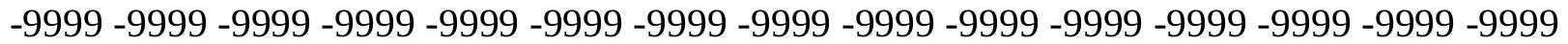

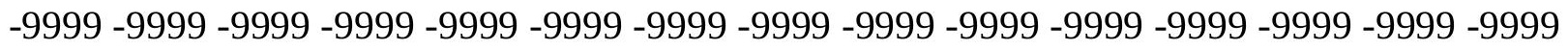

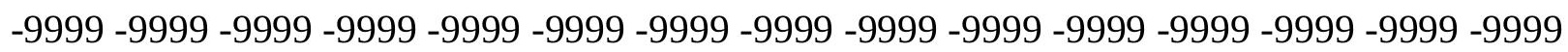

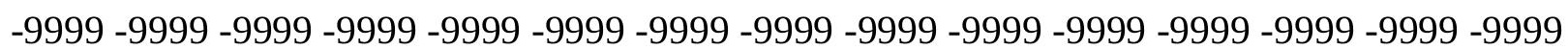

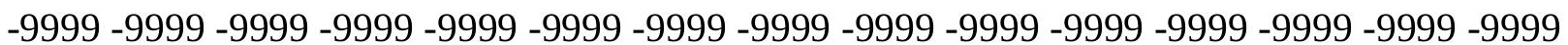

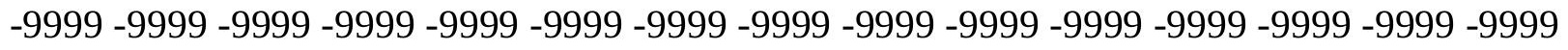
-9999 -9999 -9999 -9999 -9999 -9999 -9999 -9999 -9999 191.1002960205 179.8231964111 169.7653045654166 .1078948975164 .8887023926164 .8887023926165 .4983062744 166.1078948975166 .7174987793167 .6318054199168 .5462036133169 .7653045654 170.9844970703172 .5084075928174 .337097168176 .4705963135178 .2993011475 179.5184020996179 .5184020996177 .6896972656174 .6419067383173 .4226989746 
176.7754058838181 .3471984863184 .0901947021183 .4806976318181 .6519012451 180.1280059814179 .2136993408178 .9089050293179 .5184020996180 .7375946045 181.5479278564182 .0539245605181 .9580841064181 .3347167969180 .4941101074 179.5534820557177 .9476776123175 .5266876221172 .311126709168 .6030883789 164.9046936035161 .6597900391159 .1217041016157 .3205718994156 .1999359131 155.6663970947155 .5440673828155 .6291809082155 .7277526855155 .717590332 155.5825500488155 .4095306396155 .3344268799154 .2212982178151 .4781951904 149.6495056152149 .6495056152151 .4781951904154 .8307952881157 .878692627 159.2010040283159 .3020477295159 .2107391357158 .9313049316158 .4701385498 157.8364715576157 .0432739258155 .7451934814153 .9165039062152 .3925933838 150.8686065674149 .3446960449147 .8208007812146 .6015930176145 .3825073242 144.1634063721143 .2489929199142 .0299072266141 .1154937744139 .8963928223 138.9819946289138 .0677032471137 .1533050537136 .2389984131135 .3246002197 134.4102020264133 .4958953857132 .2767028809131 .3623962402130 .4479980469 129.533706665128 .3144989014127 .4001998901126 .1809997559125 .2667007446 124.0475006104122 .5235977173120 .9997024536119 .1709976196117 .342300415 114.9039993286112 .4656982422109 .7226028442106 .979598999104 .5412979126 101.798202514699 .6647262573297 .5312423706195 .7025299072394 .17859649658 92.9594726562592 .0450973510791 .4355392456191 .1307525634891 .13075256348 91.4355392456192 .0450973510792 .9594726562593 .8738174438594 .78817749023 95.397743225196 .3121032714896 .9216690063597 .2264633178797 .22646331787 97.2264633178796 .9216690063596 .6168823242296 .0073165893695 .70252990723 95.0929565429794 .1785964965892 .9594726562591 .7403335571390 .52117919922 89.302040100188.08290100098 86.86376190186 86.2541885376 85.33984375 85.0350494384884 .4254837036184 .4254837036184 .1206970214884 .12069702148 84.4254837036184 .7302627563585 .3398437585 .9494018554786 .55898284912 87.1685485839888 .0829010009888 .3876876831188 .9972534179789 .3020401001 89.6068267822389 .9116134643690 .2164001464890 .5211791992290 .82597351074 90.8259735107491 .1307525634891 .1307525634891 .1307525634891 .13075256348 90.8259735107490 .8259735107490 .8259735107490 .5211791992290 .21640014648 90.2164001464889 .9116134643689 .9116134643689 .6068267822389 .60682678223 89.302040100189.302040100189.302040100189.302040100189.302040100189.3020401001 89.6068267822389 .6068267822389 .9116134643690 .2164001464890 .52117919922 91.1307525634891 .7403335571392 .0450973510792 .349891662692 .65467834473 92.6546783447392 .6546783447392 .6546783447392 .6546783447392 .65467834473 92.9594726562593 .2642517089893 .8738174438594 .4833908081195 .09295654297 96.0073165893696 .6168823242297 .5312423706198 .445587158299 .05516815186 99.66472625732100 .2742996216100 .8839035034101 .4934005737101 .7982025146 102.1029968262102 .1029968262102 .1029968262102 .1029968262102 .1029968262 102.1029968262101 .7982025146101 .4934005737101 .1886978149100 .5791015625 99.9695205688599 .0551681518698 .1408081054796 .6168823242295 .09295654297 92.9594726562590 .2164001464886 .8637619018683 .206336975178 .93934631348 74.9771423339870 .7101516723666 .4431610107462 .1761703491260 .65224075317 -9999 -9999 -9999 -9999 -9999 -9999 -9999 -9999 -9999 -9999 -9999 -9999 -9999 -9999 -9999 -9999 -9999 -9999 -9999 -9999 -9999 -9999 -9999 -9999 -9999 -9999 -9999 -9999 -9999 -9999 -9999 -

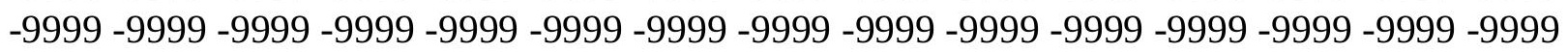


-9999 -9999 -9999 -9999-9999 -9999

-9999 -9999 -9999 -9999 -9999 -9999 -9999 -9999 -9999 -9999 -9999 -9999 -9999 -9999 -9999

-9999 -9999 -9999 -9999 -9999 -9999 -9999 -9999 -9999 -9999 -9999 -9999 -9999 -9999 -9999

-9999 -9999 -9999 -9999 -9999 -9999 -9999 -9999 -9999 -9999 -9999 -9999 -9999 -9999 -9999

-9999 -9999 -9999 -9999 -9999 -9999 -9999 -9999 -9999 -9999 -9999 -9999-9999 -9999 -9999 -

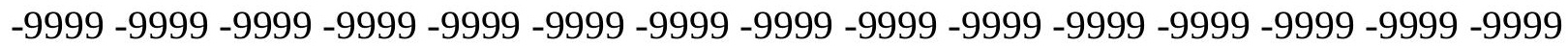

-9999 -9999 -9999 -9999 -9999 -9999 -9999 -9999 -9999 -9999 -9999 -9999 -9999 -9999 -9999 -

-9999 -9999 -9999 -9999-9999 -9999 -9999 -9999 -9999 181.3471984863172 .5084075928

166.7174987793165 .4983062744164 .5839996338164 .8887023926165 .4983062744

166.7174987793167 .6318054199168 .5462036133169 .7653045654170 .6797027588

172.2035980225173 .4226989746175 .2514038086176 .7754058838178 .2993011475

179.2136993408179 .2136993408177 .9945068359177 .0802001953177 .0802001953

178.9089050293181 .6519012451183 .4806976318183 .7854003906182 .87109375

181.6519012451180 .7375946045180 .432800293180 .7375946045181 .3471984863

182.261505127183 .1759033203183 .1759033203182 .261505127181 .0424041748

180.432800293178 .5447540283175 .9575958252172 .5196533203168 .5046691895

163.974395752161 .8283996582159 .8454284668158 .6937255859158 .2498321533

158.4440765381159 .0599060059159 .8301544189160 .461730957160 .7044677734

160.5021972656160 .0056152344159 .4837799072159 .1831359863156 .3547973633

153.3069000244152 .0877990723154 .8307952881159 .0977935791161 .2987823486

161.3884124756161 .2921905518161 .0145721436160 .5612640381159 .9384460449

159.1543884277158 .2210845947156 .6596069336154 .8307952881153 .0021057129

151.1734008789149 .6495056152148 .1255950928146 .6015930176145 .3825073242

144.1634063721142 .9441986084142 .0299072266141 .1154937744139 .8963928223

138.9819946289138 .0677032471137 .1533050537136 .2389984131135 .3246002197

134.4102020264133 .4958953857132 .5814971924131 .6672058105130 .7528076172

129.8385009766128 .6192932129127 .7050018311126 .4858016968125 .5715026855 124.3523025513122 .8283996582121 .3044967651119 .4757995605117 .342300415

114.9039993286112 .1608963013109 .4179000854106 .6747970581103 .9317016602 101.188697814998 .7503814697396 .6168823242294 .7881774902393 .26425170898 92.0450973510791 .4355392456190 .8259735107490 .8259735107491 .13075256348 91.4355392456192 .0450973510792 .9594726562593 .8738174438594 .78817749023 95.7025299072396 .3121032714896 .6168823242296 .9216690063596 .92166900635 96.6168823242296 .3121032714895 .7025299072395 .397743225194 .78817749023 94.1785964965893 .5690307617292 .349891662691 .1307525634889 .91161346436 88.6924667358487 .4733276367286 .5589828491285 .9494018554785 .33984375 84.7302627563584 .4254837036184 .1206970214884 .1206970214884 .42548370361 84.4254837036185 .0350494384885 .6446228027386 .254188537686 .86376190186 87.7781066894588 .3876876831188 .9972534179789 .302040100189 .91161346436 90.2164001464890 .2164001464890 .5211791992290 .8259735107490 .82597351074 91.1307525634891 .1307525634891 .1307525634891 .1307525634891 .13075256348 90.8259735107490 .8259735107490 .8259735107490 .5211791992290 .52117919922 90.2164001464890 .2164001464889 .9116134643689 .6068267822389 .60682678223 89.60682678223 89.3020401001 89.302040100189.302040100189.60682678223 89.60682678223 89.60682678223 89.91161346436 89.9116134643690.21640014648 90.8259735107491 .1307525634891 .7403335571392 .0450973510792 .3498916626 
92.6546783447392 .6546783447392 .6546783447392 .6546783447392 .65467834473 92.9594726562592 .9594726562593 .5690307617293 .8738174438594 .48339080811 95.397743225196 .3121032714897 .2264633178797 .8360290527398 .75038146973 99.35994720459100 .2742996216100 .8839035034101 .1886978149101 .7982025146 102.1029968262102 .1029968262102 .4077987671102 .4077987671102 .4077987671 102.4077987671102 .1029968262101 .7982025146101 .7982025146101 .4934005737 100.8839035034100 .274299621699 .6647262573298 .7503814697397 .22646331787 95.7025299072393 .5690307617291 .1307525634887 .7781066894584 .12069702148 79.8537063598675 .5867080688571 .3197174072367 .0527267456162 .78573989868 60.34745025635 -9999 -9999 -9999 -9999 -9999 -9999 -9999 -9999 -9999 -9999 -9999 -9999 -9999 -9999 -9999 -9999 -9999 -9999 -9999 -9999 -9999 -9999 -9999 -9999 -9999 -9999 -9999 -9999 -9999 -9999 -9999 -9999 -9999 -9999 -9999 -9999 -9999 -9999 -9999 -9999 -9999 - -9999 -9999 -9999 -9999 -9999 -9999 -9999 -9999 -9999 -9999 -9999

-9999 -9999 -9999 -9999 -9999 -9999 -9999 -9999 -9999 -9999 -9999 -9999 -9999 -9999 -9999 -9999 -9999 -9999 -9999 -9999 -9999 -9999 -9999 -9999 -9999 -9999 -9999 -9999 -9999 -9999

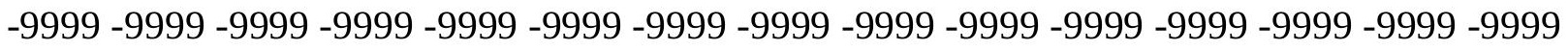
-9999 -9999 -9999 -9999 -9999 -9999 -9999 -9999 -9999 -9999 -9999 -9999 -9999 -9999 -9999 -9999 -9999 -9999 -9999 -9999 -9999 -9999 -9999 -9999 -9999 -9999 -9999 -9999 -9999 -9999 -9999 -9999 -9999 -9999 -9999 -9999 -9999 -9999 -9999 -9999 -9999 -9999 -9999 -9999 -9999 -9999 -9999-9999-9999-9999-9999-9999-9999-9999 173.7274932861 166.4127044678 163.0599975586163 .3648071289163 .6696014404164 .5839996338165 .8031005859 167.0222015381168 .241394043169 .4604949951170 .3748931885171 .5939941406 172.8132019043174 .0323028564175 .5561981201176 .7754058838177 .9945068359 178.9089050293178 .9089050293178 .604095459178 .604095459178 .9089050293 180.1280059814181 .9566955566182 .87109375183 .4806976318182 .87109375 182.261505127 181.6519012451 181.3471984863181.3471984863181.9566955566 182.261505127182 .5662994385182 .5662994385181 .6519012451180 .7375946045 179.5184020996178 .2993011475175 .8609924316172 .5084075928168 .241394043 164.2792053223161 .5361022949160 .6217956543159 .9622650146160 .1921539307 161.075088501162 .4723358154164 .0384979248165 .3240661621165 .8265686035 165.4408416748164 .449798584163 .3439178467162 .5864105225162 .3584136963 160.6217956543155 .7451934814161 .8408966064163 .6447753906163 .7008209229 163.5561981201163 .2308502197162 .7405853271162 .0937194824161 .2956237793 160.3529205322159 .2752838135157 .5738983154155 .4403991699153 .3069000244 151.4781951904149 .6495056152148 .1255950928146 .6015930176145 .3825073242 144.1634063721142 .9441986084141 .7250976562140 .8106994629139 .8963928223 138.9819946289138 .0677032471137 .1533050537136 .2389984131135 .3246002197 134.626083374133 .8007049561132 .8863067627131 .9720001221131 .0576019287 129.8385009766128 .9241027832128 .0097961426127 .0953979492125 .8762969971 124.6570968628123 .1332015991121 .3044967651119 .4757995605117 .342300415 114.5991973877111 .8561019897109 .1130981445106 .0652008057103 .3221969604 100.274299621697 .8360290527395 .7025299072393 .5690307617292 .3498916626 91.4355392456190 .8259735107490 .5211791992290 .5211791992290 .82597351074 91.4355392456192 .0450973510792 .9594726562593 .8738174438594 .78817749023 95.7025299072396 .3121032714896 .6168823242296 .6168823242296 .31210327148 95.7025299072395 .0929565429794 .4833908081193 .8738174438593 .56903076172 
92.9594726562592 .349891662691 .4355392456189 .9116134643688 .69246673584 87.7781066894586 .8637619018685 .9494018554785 .3398437584 .73026275635 84.4254837036184 .1206970214884 .1206970214884 .1206970214884 .42548370361 84.7302627563585 .0350494384885 .6446228027386 .5589828491287 .16854858398 88.0829010009888 .6924667358489 .302040100189 .9116134643690 .21640014648 90.5211791992290 .8259735107490 .8259735107491 .1307525634891 .43553924561 91.4355392456191 .1307525634891 .1307525634891 .1307525634891 .13075256348 91.1307525634890 .8259735107490 .8259735107490 .8259735107490 .52117919922 90.5211791992290 .2164001464890 .2164001464889 .9116134643689 .91161346436 89.6068267822389 .6068267822389 .6068267822389 .6068267822389 .91161346436 89.9116134643689 .9116134643690 .2164001464890 .2164001464890 .52117919922 90.8259735107491 .4355392456191 .7403335571392 .349891662692 .65467834473 92.9594726562592 .9594726562592 .9594726562592 .9594726562592 .95947265625 93.2642517089893 .2642517089893 .5690307617294 .1785964965895 .09295654297 95.7025299072396 .6168823242297 .5312423706198 .445587158299 .35994720459 99.96952056885100 .5791015625101 .1886978149101 .7982025146102 .1029968262 102.4077987671102 .4077987671102 .712600708102 .712600708102 .4077987671 102.4077987671102 .1029968262102 .1029968262101 .7982025146101 .4934005737 101.1886978149100 .883903503499 .9695205688599 .0551681518697 .83602905273 96.3121032714894 .4833908081191 .7403335571388 .6924667358484 .73026275635 80.7680587768676 .5010681152371 .9292907714867 .6623001098663 .39530944824 60.34745025635 -9999 -9999 -9999 -9999 -9999 -9999 -9999 -9999 -9999 -9999 -9999 -9999 -9999 -9999 -9999 -9999 -9999 -9999 -9999 -9999 -9999 -9999 -9999 -9999 -9999 -9999 -9999 -

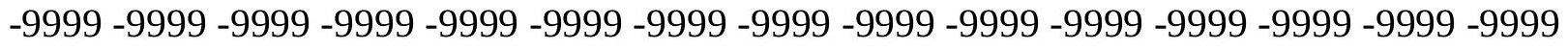
-9999 -9999-9999-9999-9999-9999-9999-9999-9999-9999 - -999 - -999 -

-9999 -9999 -9999 -9999 -9999 -9999 -9999 -9999 -9999 -9999 -9999 -9999 -9999 -9999 -9999 -9999 -9999 -9999 -9999 -9999 -9999 -9999 -9999 -9999 -9999 -9999 -9999 -9999 -9999 -9999 -

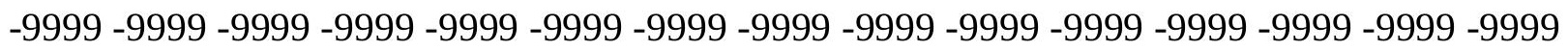
-9999 -9999 -9999 -9999 -9999 -9999 -9999 -9999 -9999 -9999 -9999 -9999 -9999 -9999 -9999 -9999 -9999 -9999 -9999 -9999 -9999 -9999 -9999 -9999 -9999 -9999 -9999 -9999 -9999 -9999 -9999 -9999 -9999 -9999 -9999 -9999 -9999 -9999 -9999 -9999 -9999 -9999-9999 -9999 -9999 -9999 -9999 -9999 -9999 -9999 -9999-9999 -9999 -9999 169.4604949951 163.0599975586 159.7073974609160 .9264984131162 .4505004883164 .2792053223165 .8031005859 167.3269958496168.5462036133169.7653045654170.9844970703172.2035980225 173.1179962158174 .337097168175 .5561981201176 .4705963135177 .6896972656 178.2993011475178 .9089050293178 .9089050293179 .2136993408179 .8231964111 180.7375946045181 .6519012451182 .5662994385182 .87109375182 .5662994385 182.261505127181 .9566955566181 .6519012451181 .6519012451181 .9566955566 182.261505127182 .261505127181 .9566955566181 .0424041748180 .1280059814 178.604095459177 .0802001953174 .6419067383171 .5939941406168 .241394043 165.1934967041162 .7552947998161 .8408966064161 .2312927246162 .1457061768 163.3648071289165 .4670562744167 .986831665170 .0283966064170 .8007965088 170.0501251221168 .3008728027166 .4525756836165 .3037872314165 .0207977295 165.3170623779165 .8017272949166 .1640777588166 .255279541166 .0630493164 165.6485900879165 .0658569336164 .342300415163 .4870910645162 .5033569336 161.3954315186160 .169418335158 .1835021973155 .7451934814153 .3069000244 
151.1734008789149 .3446960449147 .8208007812146 .2969055176145 .0776977539 143.8585968018142 .6394042969141 .7250976562140 .8106994629139 .8963928223 138.9819946289138 .0677032471137 .1533050537136 .5437011719135 .6293945312 134.7149963379133 .8007049561132 .8863067627131 .9720001221131 .0576019287 130.1432037354129 .2288970947128 .3144989014127 .0953979492126 .1809997559 124.9618988037123 .43800354121 .9140014648119 .7806015015117 .342300415 114.5991973877111 .8561019897108 .8082962036105 .7603988647102 .712600708 99.6647262573296 .9216690063594 .4833908081192 .6546783447391 .43553924561 90.5211791992289 .9116134643689 .9116134643689 .9116134643690 .52117919922 91.1307525634892 .0450973510792 .9594726562593 .8738174438594 .78817749023 95.7025299072396 .3121032714896 .3121032714896 .3121032714895 .70252990723 94.7881774902393 .5690307617292 .6546783447391 .7403335571391 .13075256348 90.8259735107490 .5211791992289 .302040100188 .0829010009887 .16854858398 86.254188537685 .6446228027385 .0350494384884 .4254837036184 .12069702148 83.8159103393683 .8159103393683 .8159103393684 .1206970214884 .42548370361 84.7302627563585 .3398437585 .9494018554786 .8637619018687 .47332763672 88.3876876831188 .9972534179789 .9116134643690 .5211791992290 .82597351074 91.1307525634891 .4355392456191 .4355392456191 .7403335571391 .74033355713 91.7403335571391 .4355392456191 .1307525634891 .1307525634891 .13075256348 91.1307525634891 .1307525634890 .8259735107490 .8259735107490 .82597351074 90.5211791992290 .5211791992290 .2164001464890 .2164001464889 .91161346436 89.9116134643689 .9116134643689 .9116134643689 .9116134643690 .21640014648 90.5211791992290 .5211791992290 .5211791992290 .5211791992290 .82597351074 91.1307525634891 .7403335571392 .349891662692 .6546783447392 .95947265625 93.2642517089893 .5690307617293 .5690307617293 .5690307617293 .56903076172 93.5690307617293 .8738174438594 .1785964965894 .7881774902395 .3977432251 96.3121032714897 .2264633178798 .1408081054799 .0551681518699 .96952056885 100.5791015625101 .1886978149101 .7982025146102 .1029968262102 .4077987671 102.712600708103 .0174026489103 .0174026489103 .0174026489102 .712600708 102.712600708102 .4077987671102 .1029968262102 .1029968262101 .7982025146 101.4934005737101 .1886978149100 .579101562599 .6647262573298 .4455871582 96.9216690063595 .0929565429792 .349891662689 .302040100185 .33984375 81.3776321411176 .8058471679772 .5388565063567 .9670867919963 .39530944824 60.04267120361 -9999 -9999 -9999 -9999 -9999 -9999 -9999 -9999 -9999 -9999 -9999 -9999 -9999 -9999 -9999 -9999 -9999 -9999 -9999 -9999 -9999 -9999 -9999 -9999 -9999 -9999 -9999

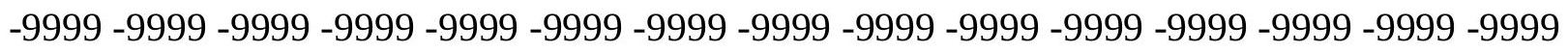
-9999 -9999 -9999-9999-9999-9999-9999-9999-9999-9999

-9999 -9999 -9999 -9999 -9999 -9999 -9999 -9999 -9999 -9999 -9999 -9999 -9999 -9999 -9999 -9999 -9999 -9999 -9999 -9999 -9999 -9999 -9999 -9999 -9999 -9999 -9999 -9999 -9999 -9999 -9999 -9999 -9999 -9999 -9999 -9999 -9999 -9999 -9999 -9999 -9999 -9999 -9999 -9999 -9999 -

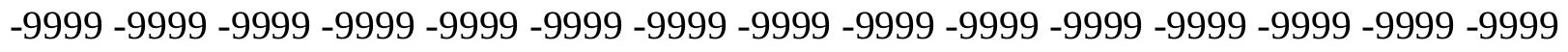

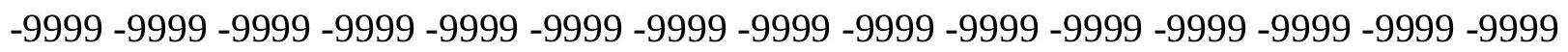

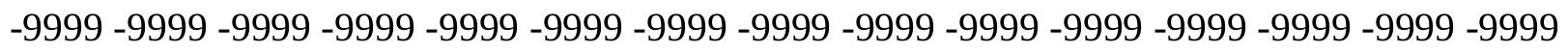
-9999 -9999 -9999-9999 -9999-9999-9999-9999-9999-9999 163.0599975586 157.2691040039160.0122070312 162.1457061768 163.974395752165 .8031005859 167.6318054199168 .8509979248170 .3748931885171 .2891998291172 .5084075928 
173.4226989746174 .337097168175 .2514038086175 .8609924316176 .7754058838 177.6896972656178 .2993011475178 .9089050293179 .2136993408179 .8231964111 180.432800293181 .3471984863181 .6519012451181 .9566955566181 .9566955566 181.9566955566181 .6519012451181 .6519012451181 .6519012451181 .6519012451 181.6519012451181 .6519012451181 .0424041748180 .432800293179 .2136993408 177.9945068359176 .165802002174 .0323028564171 .5939941406168 .8509979248 166.4127044678164 .5839996338163 .3648071289163 .3648071289163 .974395752 165.4983062744167 .6318054199171 .2891998291173 .9764404297175 .0610351562 173.7629241943170 .7901763916168 .1548461914166 .8993225098166 .9664001465 167.6930541992168 .4541015625168 .8588409424168 .759475708168 .2787628174 167.5711975098166 .7222442627165 .7613677979164 .6932830811163 .51902771 162.2424468994160 .8692169189158 .1835021973155 .4403991699153 .0021057129 150.8686065674149 .0399017334147 .5160064697145 .9920959473144 .7729034424 143.5538024902142 .3347015381141 .4203033447140 .5059967041139 .5915985107 138.9819946289138 .0677032471137 .1533050537136 .5437011719135 .6293945312 134.7149963379134 .1054992676133 .1911010742132 .2767028809131 .3602142334 130.4479980469129 .533706665128 .3144989014127 .4001998901126 .4858016968 125.2667007446123 .7427978516122 .2188034058120 .0852966309117 .647102356 114.9039993286111 .8561019897108 .8082962036105 .4557037354102 .4077987671 99.3599472045996 .3121032714893 .8738174438591 .7403335571390 .52117919922 89.9116134643689 .6068267822389 .302040100189 .6068267822390 .21640014648 90.8259735107491 .7403335571392 .6546783447393 .5690307617294 .48339080811 95.397743225196 .0073165893696 .0073165893695 .7025299072394 .48339080811 93.2642517089891 .4355392456189 .9116134643688 .9972534179788 .08290100098 87.4733276367287 .1685485839886 .5589828491285 .6446228027385 .03504943848 84.4254837036184 .1206970214883 .8159103393683 .5111236572383 .2063369751 83.206336975183 .206336975183 .5111236572383 .8159103393684 .12069702148 84.7302627563585 .3398437585 .9494018554786 .8637619018687 .77810668945 88.3876876831189 .302040100190 .2164001464891 .1307525634891 .74033355713 92.0450973510792 .0450973510792 .349891662692 .349891662692 .04509735107 91.7403335571391 .7403335571391 .4355392456191 .1307525634891 .13075256348 91.1307525634891 .1307525634891 .1307525634891 .1307525634890 .82597351074 90.8259735107490 .8259735107490 .5211791992290 .5211791992290 .52117919922 90.2164001464890 .2164001464890 .5211791992290 .5211791992290 .82597351074 91.1307525634891 .4355392456191 .4355392456191 .4355392456191 .43553924561 92.0450973510792 .6546783447392 .9594726562593 .5690307617293 .87381744385 94.1785964965894 .1785964965894 .4833908081194 .4833908081194 .48339080811 94.4833908081194 .4833908081194 .7881774902395 .397743225196 .31210327148 97.2264633178798.1408081054799.0551681518699.96952056885 100.5791015625 101.1886978149101 .7982025146102 .4077987671102 .712600708103 .0174026489 103.3221969604103 .3221969604103 .3221969604103 .3221969604103 .0174026489 102.712600708102 .4077987671102 .4077987671102 .4077987671102 .1029968262 102.1029968262101 .4934005737101 .1886978149100 .274299621699 .05516815186 97.5312423706195 .397743225192 .9594726562589 .9116134643686 .2541885376 81.9871978759877 .4154205322372 .8436431884867 .9670867919963 .09051895142 60.0426712036160 .04267120361 -9999 -9999 -9999 -9999 -9999 -9999 -9999 -9999 -9999 
-9999 -9999 -9999 -9999 -9999 -9999 -9999 -9999 -9999 -9999 -9999 -9999 -9999 -9999 -9999 -9999 -9999 -9999 -9999 -9999 -9999 -9999 -9999 -9999 -9999 -9999 -9999 -9999 -9999 -9999 -9999 -9999 -9999 -9999 -9999 -9999 -9999 -9999 -9999 -9999 -9999 -9999

-9999 -9999 -9999 -9999 -9999 -9999 -9999 -9999 -9999 -9999 -9999 -9999 -9999 -9999 -9999 -9999 -9999 -9999 -9999 -9999 -9999 -9999 -9999 -9999 -9999 -9999 -9999 -9999 -9999 -9999 -9999 -9999 -9999 -9999 -9999 -9999 -9999 -9999 -9999 -9999 -9999 -9999 -9999 -9999 -9999 -9999 -9999 -9999 -9999 -9999 -9999 -9999 -9999 -9999 -9999 -9999 -9999 -9999 -9999 -9999

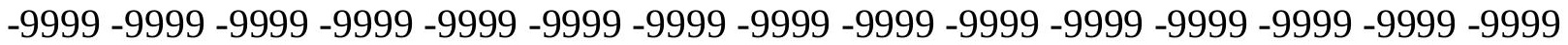

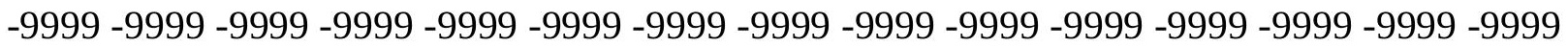
-9999 -9999 -9999 -9999 -9999 -9999 -9999 -9999 -9999 -9999 167.6318054199 160.3170013428161 .5361022949162 .7552947998164 .2792053223166 .1078948975 167.9365997314169 .4604949951170 .6797027588171 .5939941406172 .5084075928 173.1179962158173 .7274932861174 .6419067383175 .2514038086175 .8609924316 176.7754058838177 .6896972656178 .2993011475178 .9089050293179 .5184020996 180.1280059814180 .432800293180 .7375946045181 .0424041748181 .3471984863 181.3471984863181 .3471984863181 .3471984863181 .3471984863181 .3471984863 181.0424041748181 .0424041748180 .432800293179 .5184020996178 .604095459 177.0802001953175 .5561981201173 .7274932861171 .5939941406169 .4604949951 167.3269958496166 .1078948975165 .1934967041165 .1934967041165 .8031005859 167.3269958496169 .7653045654172 .8132019043175 .8609924316177 .3849029541 175.5561981201170 .070098877165 .1934967041167 .1504516602168 .0281219482 169.5756530762170 .8349761963171 .3155517578170 .9410705566170 .1496734619 169.1773376465168 .0998687744166 .9275512695165 .657989502164 .2972412109 162.8527374268160 .9264984131158 .1835021973155 .1356048584152 .6972961426 150.5639038086148 .4304046631146 .9064025879145 .3825073242144 .1634063721 143.2489929199142 .0299072266141 .1154937744140 .2012023926139 .5915985107 138.6772003174138 .0677032471137 .1533050537136 .5437011719135 .6293945312 135.0198059082134 .1054992676133 .1911010742132 .2767028809131 .3623962402 130.4479980469129 .533706665128 .6192932129127 .4001998901126 .4858016968 125.2667007446124 .0475006104122 .5235977173120 .6949005127118 .2565994263 115.2088012695112 .1608963013108 .8082962036105 .4557037354102 .1029968262 99.0551681518696 .0073165893693 .2642517089891 .1307525634889 .91161346436 89.302040100188.9972534179788.9972534179789.3020401001 89.60682678223 90.2164001464891 .1307525634892 .0450973510793 .2642517089894 .17859649658 95.0929565429795 .7025299072395 .7025299072394 .7881774902393 .26425170898 91.1307525634888 .9972534179786 .8637619018685 .0350494384884 .12069702148 83.5111236572383 .206336975182 .9015579223682 .5967712402382 .29197692871 82.29197692871 82.29197692871 82.29197692871 82.29197692871 82.29197692871 82.2919769287182 .5967712402382 .9015579223683 .206336975183 .81591033936 84.4254837036185 .3398437586 .254188537686 .8637619018687 .77810668945 88.6924667358489 .6068267822390 .5211791992291 .7403335571392 .65467834473 92.9594726562592 .9594726562592 .6546783447392 .6546783447392 .3498916626 92.0450973510791 .7403335571391 .4355392456191 .4355392456191 .43553924561 91.1307525634891 .1307525634891 .1307525634891 .1307525634891 .13075256348 91.1307525634891 .1307525634890 .8259735107490 .8259735107490 .82597351074 90.8259735107490 .8259735107490 .8259735107491 .1307525634891 .74033355713 
92.0450973510792 .349891662692 .6546783447392 .6546783447392 .95947265625 93.2642517089893 .5690307617294 .1785964965894 .4833908081194 .78817749023 95.0929565429795.397743225195.397743225195.397743225195.3977432251 95.397743225195 .397743225195 .397743225196 .3121032714897 .22646331787 98.1408081054799 .0551681518699 .96952056885100 .8839035034101 .4934005737 102.1029968262102 .712600708103 .0174026489103 .3221969604103 .6268997192 103.6268997192103 .6268997192103 .6268997192103 .6268997192103 .3221969604 103.0174026489102.712600708 102.712600708 102.712600708 102.4077987671 102.4077987671102 .1029968262101 .4934005737100 .883903503499 .66472625732 98.1408081054796 .3121032714893 .5690307617290 .5211791992286 .86376190186 82.5967712402378 .0249862670973 .1484298706167 .9670867919963 .09051895142 59.7378807067960 .04267120361 -9999 -9999-9999 -9999 -9999 -9999 -9999 -9999 -9999 -9999 -9999 -9999 -9999 -9999 -9999 -9999 -9999 -9999 -9999 -9999 -9999 -9999 -9999 -9999

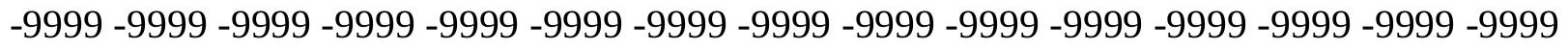
-9999 -9999 -9999 -9999 -9999 -9999 -9999 -9999 -9999 -9999 -9999 -9999 -

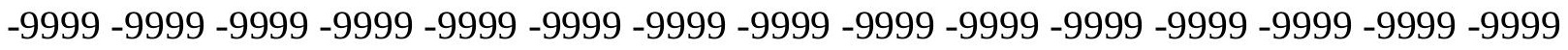
-9999 -9999 -9999 -9999 -9999 -9999 -9999 -9999 -9999 -9999 -9999 -9999 -9999 -9999 -9999 -9999 -9999 -9999 -9999 -9999 -9999 -9999 -9999 -9999 -9999 -9999 -9999 -9999 -9999 -9999 -9999 -9999 -9999 -9999 -9999 -9999 -9999 -9999 -9999 -9999 -9999 -9999 -9999 -9999 -9999 -

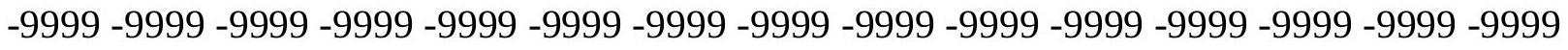

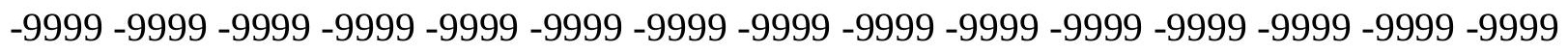
-9999 -9999 -9999 -9999 -9999 -9999 -9999 -9999 -9999-9999 175.8609924316 169.1557006836163 .974395752163 .6696014404164 .8887023926166 .4127044678 168.241394043169 .7653045654170 .9844970703171 .8988037109172 .5084075928 173.1179962158173 .4226989746173 .7274932861174 .337097168174 .9467010498 175.8609924316176 .7754058838177 .3849029541177 .9945068359178 .604095459 179.2136993408179 .5184020996179 .8231964111180 .1280059814180 .432800293 180.432800293180 .432800293180 .7375946045180 .7375946045180 .432800293 180.432800293180 .1280059814179 .5184020996178 .604095459177 .6896972656 176.4705963135174 .9467010498173 .1179962158171 .2891998291169 .7653045654 168.241394043167 .3269958496166 .7174987793166 .7174987793167 .3269958496 168.5462036133170 .3748931885172 .5084075928174 .0323028564174 .0323028564 171.8988037109168 .241394043165 .8031005859166 .4127044678168 .0671539307 170.692199707172 .8344421387173 .1168670654172 .3920288086171 .3820800781 170.2881011963169 .0927429199167 .7660064697166 .322555542164 .7899780273 163.1881561279160 .6217956543157 .5738983154154 .8307952881152 .0877990723 149.6495056152147 .8208007812146 .2969055176144 .7729034424143 .8585968018 142.6394042969141 .7250976562140 .8106994629140 .2012023926139 .2868041992 138.6772003174138 .0677032471137 .1533050537136 .5437011719135 .9342041016 135.0198059082134 .1054992676133 .4958953857132 .5814971924131 .6672058105 130.7528076172129 .533706665128 .6192932129127 .7050018311126 .4858016968 125.2667007446124 .0475006104122 .8283996582121 .3044967651118 .5614013672 115.5136032104112 .4656982422109 .1130981445105 .7603988647102 .4077987671 99.0551681518696 .0073165893693 .5690307617291 .4355392456189 .91161346436 88.9972534179788 .6924667358488 .6924667358488 .6924667358489 .3020401001 89.6068267822390 .5211791992291 .4355392456192 .349891662693 .56903076172 
94.4833908081195 .0929565429795 .0929565429794 .1785964965891 .74033355713 88.6924667358485 .6446228027382 .9015579223680 .7680587768679 .54891967773 78.9393463134878 .6345596313578 .9393463134879 .2441329956179 .54891967773 79.8537063598680 .4632720947380 .7680587768680 .7680587768680 .76805877686 81.0728530883881 .3776321411181 .9871978759882 .5967712402383 .51112365723 84.4254837036185 .0350494384885 .9494018554786 .8637619018687 .77810668945 88.6924667358489 .6068267822390 .5211791992291 .7403335571393 .26425170898 93.26425170898 93.2642517089892.9594726562592.6546783447392.3498916626 92.0450973510791 .7403335571391 .4355392456191 .4355392456191 .43553924561 91.4355392456191 .4355392456191 .4355392456191 .4355392456191 .43553924561 91.4355392456191 .4355392456191 .4355392456191 .4355392456191 .43553924561 91.4355392456191 .4355392456191 .4355392456192 .0450973510792 .65467834473 93.2642517089893 .5690307617293 .8738174438594 .1785964965894 .48339080811 94.7881774902395 .0929565429795 .397743225196 .0073165893696 .00731658936 96.3121032714896 .6168823242296 .6168823242296 .6168823242296 .92166900635 96.9216690063596 .9216690063597 .2264633178797 .8360290527398 .75038146973 99.66472625732100 .2742996216101 .1886978149101 .7982025146102 .4077987671 103.0174026489103 .6268997192103 .9317016602103 .9317016602104 .2365036011 104.2365036011104 .2365036011104 .2365036011103 .9317016602103 .6268997192 103.3221969604 103.3221969604 103.0174026489103.0174026489103.0174026489 102.712600708102 .4077987671102 .1029968262101 .1886978149100 .2742996216 98.7503814697396 .9216690063594 .4833908081191 .4355392456187 .77810668945 83.5111236572378 .6345596313573 .4532165527368 .2718734741263 .09051895142 59.7378807067959 .73788070679 -9999 -9999 -9999 -9999 -9999 -9999 -9999 -9999 -9999 -9999 -9999 -9999 -9999 -9999 -9999 -9999 -9999 -9999 -9999 -9999 -9999 -9999 -9999 -9999 -9999 -9999 -9999 -9999 -9999 -9999 -9999 -9999 -9999 -9999 -9999 -9999 -9999 -9999 -9999 -9999 -9999 -9999 -9999 -9999 -9999 -9999 -9999 -9999 -9999 -9999 -9999 -

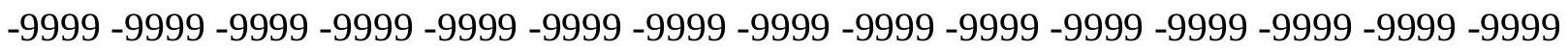
-9999 -9999 -9999 -9999 -9999 -9999 -9999 -9999 -9999 -9999 -9999 -9999 -9999 -9999 -9999 -9999 -9999 -9999 -9999 -9999 -9999 -9999 -9999 -9999 -9999 -9999 -9999 -9999 -9999 -9999 -9999 -9999 -9999 -9999 -9999 -9999 -9999 -9999 -9999 -9999 -9999 -9999 -9999 -9999 -9999 -9999 -9999 -9999 -9999 -9999 -9999 -9999 -9999 -9999 -9999 -9999 -9999 -9999 -9999 -9999 -

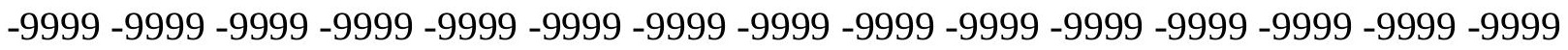
-9999 -9999 -9999 -9999 -9999 -9999 -9999 -9999 -9999 -9999 -9999 180.7375946045 171.2891998291165 .8031005859165 .4983062744167 .3269958496168 .8509979248 170.3748931885171 .2891998291171 .8988037109172 .5084075928172 .8132019043 173.1179962158173 .1179962158173 .1179962158174 .0323028564174 .9467010498 175.5561981201176 .4705963135177 .0802001953177 .3849029541177 .9945068359 178.2993011475178 .9089050293179 .2136993408179 .5184020996179 .5184020996 179.8231964111179 .8231964111179 .8231964111179 .5184020996179 .2136993408 178.9089050293178 .2993011475177 .3849029541176 .4705963135175 .2514038086 174.0323028564172 .5084075928170 .9844970703169 .7653045654168 .5462036133 167.9365997314167 .3269958496167 .3269958496167 .9365997314168 .8509979248 170.070098877171 .2891998291171 .5939941406170 .9844970703169 .1557006836 166.7174987793165 .1934967041164 .8887023926166 .7174987793170 .3748931885 174.0323028564173 .3153076172172 .5039978027171 .7181549072170 .7812652588 
169.6222686768168 .2039642334166 .6271057129164 .9489593506163 .0599975586 160.3170013428157 .2691040039154 .2212982178151 .1734008789149 .3446960449 147.5160064697145 .9920959473144 .4682006836143 .2489929199142 .3347015381 141.4203033447140 .5059967041139 .8963928223139 .2868041992138 .3724975586 137.7628936768137 .1533050537136 .5437011719135 .9342041016135 .0198059082 134.4102020264133 .4958953857132 .5814971924131 .6672058105130 .7528076172 129.8385009766128 .6192932129127 .7050018311126 .4858016968125 .2667007446 124.0475006104122 .8283996582120 .9997024536118 .5614013672115 .818397522 112.7705001831109 .4179000854106 .0652008057103 .017402648999 .66472625732 96.6168823242293 .8738174438591 .7403335571390 .2164001464889 .3020401001 88.69246673584 88.38768768311 88.38768768311 88.69246673584 88.99725341797 89.6068267822390 .5211791992291 .4355392456192 .349891662693 .56903076172 94.1785964965894 .1785964965892 .9594726562589 .9116134643685 .64462280273 81.6824111938578 .0249862670975 .8914871215874 .3675689697374 .0627822876 74.3675689697374 .9771423339875 .5867080688576 .5010681152377 .41542053223 78.3297805786179 .2441329956178 .9393463134879 .2441329956179 .54891967773 80.1584930419981 .0728530883881 .9871978759882 .9015579223683 .81591033936 84.7302627563585 .9494018554786 .8637619018687 .7781066894588 .69246673584 89.6068267822390 .2164001464890 .8259735107492 .349891662692 .95947265625 92.9594726562592 .6546783447392 .349891662692 .0450973510791 .74033355713 91.7403335571391 .4355392456191 .4355392456191 .7403335571391 .74033355713 91.4355392456191 .4355392456191 .7403335571391 .7403335571391 .74033355713 91.7403335571391 .7403335571392 .0450973510792 .0450973510792 .04509735107 92.349891662692 .6546783447393 .2642517089893 .8738174438594 .48339080811 95.0929565429795 .7025299072396 .0073165893696 .3121032714896 .61688232422 96.9216690063597 .2264633178797 .5312423706197 .5312423706197 .83602905273 98.1408081054798 .1408081054798 .1408081054798 .445587158298 .4455871582 98.7503814697399 .0551681518699 .66472625732100 .2742996216101 .1886978149 101.7982025146102 .4077987671103 .0174026489103 .6268997192103 .9317016602 104.5412979126104 .5412979126104 .8460998535104 .8460998535104 .8460998535 104.8460998535104 .5412979126104 .2365036011104 .2365036011103 .9317016602 103.6268997192103 .3221969604103 .3221969604103 .3221969604103 .0174026489 102.712600708102 .4077987671101 .7982025146100 .883903503499 .35994720459 97.5312423706195 .397743225192 .349891662688 .6924667358484 .42548370361 79.5489196777374 .062782287668 .5766525268663 .0905189514259 .43310165405 59.73788070679 -9999 -9999 -9999 -9999 -9999 -9999 -9999 -9999 -9999 -9999 -9999 -9999

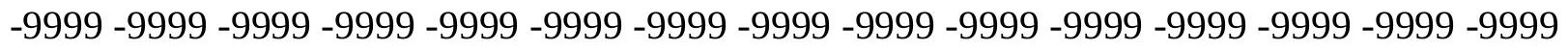

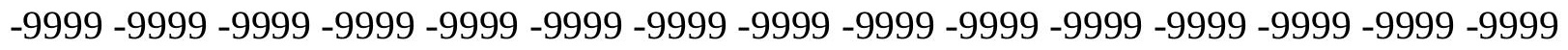
-9999 -9999 -9999 -9999 -9999 -9999 -9999 -9999 -9999 -9999 -9999 -9999 -9999 -9999 -9999 -9999 -9999 -9999 -9999 -9999 -9999 -9999 -9999 -9999

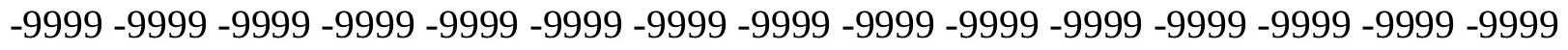

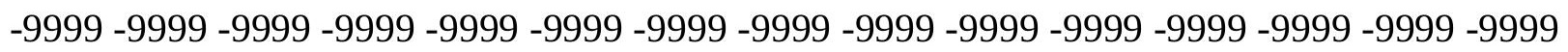
-9999 -9999 -9999 -9999 -9999 -9999 -9999 -9999 -9999 -9999 -9999 -9999 -9999 -9999 -9999 -9999 -9999 -9999 -9999 -9999 -9999 -9999 -9999 -9999 -9999 -9999 -9999 -9999 -9999 -9999 -9999 -9999 -9999 -9999 -9999 -9999 -9999 -9999 -9999 -9999 -9999 -9999 -9999 -9999 -9999 -9999 -9999 -9999 -9999 -9999 -9999 -9999 -9999 -9999 -9999 -9999 -9999 183.4806976318 
176.7754058838170 .6797027588168 .241394043169 .4604949951170 .6797027588 171.5939941406172 .2035980225172 .5084075928172 .8132019043172 .8132019043 172.8132019043172 .8132019043173 .4226989746174 .0323028564174 .6419067383 175.2514038086175 .8609924316176 .165802002176 .7754058838177 .0802001953 177.6896972656177 .9945068359178 .2993011475178 .604095459178 .604095459 178.604095459178 .604095459178 .2993011475177 .9945068359177 .6896972656 177.0802001953176 .165802002175 .2514038086174 .0323028564172 .8132019043 171.5939941406170 .3748931885169 .4604949951168 .241394043167 .6318054199 167.3269958496167 .3269958496167 .6318054199168 .241394043168 .8509979248 169.1557006836169 .1557006836168 .241394043166 .7174987793165 .1934967041 163.974395752163 .974395752165 .1934967041167 .6318054199169 .7653045654 171.2891998291171 .2891998291171 .1360626221170 .6655731201169 .6279296875 168.1749725342166 .5160217285164 .7291259766162 .4505004883161 .032043457 159.1815185547154 .2212982178151 .4781951904149 .3446960449147 .2111968994 145.6873016357144 .1634063721142 .9441986084142 .0299072266141 .1154937744 140.2012023926139 .5915985107138 .9819946289138 .3724975586137 .7628936768 137.1533050537136 .5437011719135 .9342041016135 .3246002197134 .7149963379 133.8007049561132 .8863067627131 .9720001221131 .0576019287129 .8385009766 128.6192932129127 .4001998901126 .1809997559125 .2667007446123 .7427978516 122.5235977173120 .6949005127118 .5614013672116 .1231002808113 .3800964355 110.3321990967106 .979598999103 .6268997192100 .579101562597 .53124237061 94.7881774902392 .6546783447390 .8259735107489 .6068267822388 .69246673584 88.0829010009887 .7781066894587 .7781066894588 .0829010009888 .69246673584 89.302040100190 .2164001464890 .8259735107491 .7403335571392 .3498916626 92.349891662691 .4355392456186 .8637619018681 .6824111938576 .80584716797 72.8436431884870 .4053573608469 .1862335205169 .1862335205169 .79579162598 71.014930725172 .2340774536173 .4532165527374 .6723632812575 .89148712158 76.5010681152376 .8058471679777 .110626220778 .0249862670978 .93934631348 80.1584930419981 .3776321411182 .2919769287183 .206336975184 .42548370361 85.6446228027386 .5589828491287 .7781066894588 .6924667358489 .3020401001 89.9116134643690.8259735107491.4355392456192.0450973510792.3498916626 92.349891662691 .7403335571391 .4355392456191 .4355392456191 .13075256348 91.4355392456191 .7403335571391 .7403335571391 .7403335571391 .74033355713 91.7403335571391 .7403335571391 .7403335571392 .0450973510792 .04509735107 92.349891662692 .349891662692 .6546783447392 .9594726562593 .26425170898 93.8738174438594 .4833908081195 .0929565429796 .0073165893696 .92166900635 97.5312423706198 .1408081054798 .445587158298 .445587158298 .75038146973 99.0551681518699 .0551681518699 .3599472045999 .3599472045999 .66472625732 99.6647262573299 .96952056885100 .2742996216100 .2742996216100 .5791015625 101.1886978149101 .4934005737102 .1029968262102 .712600708103 .3221969604 103.9317016602104 .5412979126104 .8460998535105 .1509017944105 .4557037354 105.4557037354105 .7603988647105 .7603988647105 .4557037354105 .4557037354 105.1509017944104 .8460998535104 .5412979126104 .2365036011103 .9317016602 103.9317016602103 .6268997192103 .6268997192103 .3221969604103 .3221969604 102.712600708102 .1029968262101 .4934005737100 .274299621698 .4455871582 96.3121032714893 .5690307617289 .9116134643685 .3398437580 .46327209473 
74.6723632812568 .8814392089863 .3953094482459 .4331016540559 .43310165405 -9999 -9999 -9999 -9999 -9999 -9999 -9999 -9999 -9999 -9999 -9999 -9999 -9999 -9999 -9999 -9999 -9999 -9999 -9999 -9999 -9999 -9999 -9999 -9999 -9999 -9999 -9999 -9999 -9999 -9999 -9999 -9999 -9999 -9999 -9999 -9999 -9999 -9999 -9999 -9999 -9999 -9999 -9999 -9999 -9999 -9999 -9999 -9999-9999-9999-9999

-9999 -9999 -9999 -9999 -9999 -9999 -9999 -9999 -9999 -9999 -9999 -9999 -9999 -9999 -9999 -9999 -9999 -9999 -9999 -9999 -9999 -9999 -9999 -9999 -9999 -9999 -9999 -9999 -9999 -9999 -9999 -9999 -9999 -9999 -9999 -9999 -9999 -9999 -9999 -9999 -9999 -9999 -9999 -9999 -9999 -999 -9999 -9999 -9999 -9999 -9999 -9999 -9999 -9999 -9999 -9999 -9999 -9999 -9999 -9999 -9999 -9999 -9999 -9999 -9999 -9999 -9999 -9999 -9999 -9999 -9999 -9999 -9999 -9999 -9999 -9999 -9999 -9999 -9999 -9999 -9999 -9999 -9999 -9999 -9999 -9999 -9999 -9999 -9999 -9999 -9999 -9999 -9999 -9999 -9999 -9999 -9999 -9999 -9999 -9999 -9999 -9999 -9999 -9999 192.624206543185 .3094024658177 .6896972656170 .3748931885171 .2891998291 171.8988037109172 .5084075928172 .5084075928172 .8132019043172 .5084075928 172.5084075928172 .8132019043172 .8132019043173 .1179962158173 .7274932861 174.0323028564174 .337097168174 .9467010498175 .2514038086175 .8609924316 176.165802002176 .7754058838177 .0802001953177 .3849029541177 .3849029541 177.3849029541177 .3849029541177 .0802001953176 .7754058838176 .165802002 175.5561981201174 .6419067383173 .7274932861172 .5084075928171 .5939941406 170.3748931885169 .4604949951168 .241394043167 .6318054199167 .0222015381 166.4127044678166 .4127044678166 .4127044678166 .4127044678166 .7174987793 166.7174987793166 .4127044678165 .4983062744164 .2792053223163 .3648071289 162.7552947998162 .7552947998163 .6696014404165 .1934967041167 .0222015381 168.241394043169 .1557006836169 .7653045654170 .070098877168 .986328125 167.6350860596165 .9572143555164 .0987091064161 .8408966064159 .4026031494 156.6596069336154 .2212982178151 .4781951904149 .3446960449147 .2111968994 145.3825073242143 .8585968018142 .6394042969141 .7250976562140 .8106994629 139.8963928223139 .2868041992138 .6772003174138 .3724975586137 .7628936768 137.1533050537136 .5437011719135 .9342041016135 .3246002197134 .7149963379 134.1054992676133 .1911010742132 .2767028809131 .0576019287130 .1432037354 128.9241027832127 .7050018311126 .1809997559124 .9618988037123 .7427978516 122.2188034058120 .6949005127118 .7810211182116 .3912658691113 .8115386963 111.0558929443108 .1986999512104 .8460998535101 .798202514698 .75038146973 95.7025299072393 .2642517089891 .4355392456189 .6068267822388 .69246673584 87.7781066894587 .4733276367287 .1685485839887 .1685485839887 .47332763672 88.0829010009888 .3876876831188 .9972534179789 .302040100189 .3020401001 88.6924667358486 .5589828491282 .2919769287176 .8058471679771 .62449645996 67.3575134277364 .9192428588964 .3096618652364 .6144485473665 .83358764648 67.3575134277369 .1862335205170 .7101516723672 .2340774536173 .45321655273 74.3675689697374 .9771423339875 .2819290161176 .5010681152378 .02498626709 79.5489196777380 .4632720947381 .6824111938582 .5967712402383 .81591033936 85.0350494384886 .254188537687 .4733276367288 .3876876831188 .99725341797 89.60682678223 90.2164001464890.8259735107491.4355392456191.43553924561 91.4355392456191 .1307525634890 .8259735107490 .5211791992290 .82597351074 91.1307525634891 .7403335571392 .0450973510792 .0450973510792 .04509735107 92.0450973510792 .0450973510792 .0450973510792 .349891662692 .65467834473 
92.6546783447393 .2642517089893 .5690307617293 .8738174438594 .48339080811 95.0929565429795 .7025299072396 .6168823242297 .5312423706198 .4455871582 99.3599472045999 .96952056885100 .2742996216100 .5791015625100 .5791015625 100.5791015625100 .8839035034100 .8839035034101 .1886978149101 .1886978149 101.4934005737101 .7982025146102 .1029968262102 .1029968262102 .712600708 103.0174026489103 .3221969604103 .9317016602104 .5412979126104 .8460998535 105.4557037354105 .7603988647106 .0652008057106 .3700027466106 .3700027466 106.6747970581106 .6747970581106 .3700027466106 .3700027466106 .0652008057 105.7603988647105 .1509017944104 .8460998535104 .5412979126104 .2365036011 104.2365036011103 .9317016602103 .9317016602103 .6268997192103 .3221969604 103.0174026489102 .712600708101 .7982025146100 .883903503499 .35994720459 97.22646331787 94.4833908081191.13075256348 86.55898284912 81.37763214111 75.5867080688569 .7957916259864 .004882812559 .4331016540559 .43310165405 -9999 -9999 -9999 -9999 -9999 -9999 -9999 -9999 -9999 -9999 -9999 -9999 -9999 -9999 -9999 -9999 -9999 -9999 -9999 -9999 -9999 -9999 -9999 -9999 -9999 -9999 -9999 -9999 -9999 -9999 -9999

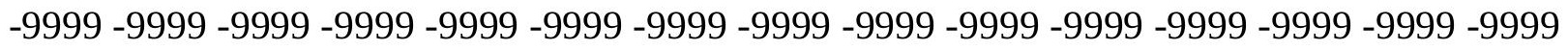
-9999 -9999-9999-9999-9999

-9999 -9999 -9999 -9999 -9999 -9999 -9999 -9999 -9999 -9999 -9999 -9999 -9999 -9999 -9999 -9999 -9999 -9999 -9999 -9999 -9999 -9999 -9999 -9999 -9999 -9999 -9999 -9999 -9999 -9999 -

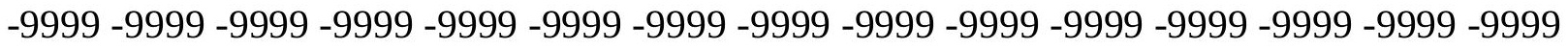

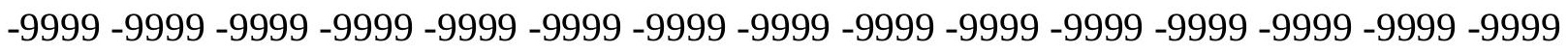
-9999 -9999 -9999 -9999 -9999 -9999 -9999 -9999 -9999 -9999 -9999 -9999 -9999 -9999 -9999 -9999 -9999 -9999 -9999 -9999 -9999 -9999 -9999 -9999 -9999 -9999 -9999 -9999 -9999 -9999 -9999 -9999-9999 -9999-9999 -9999 -9999 -9999 -9999 -9999 -9999 -9999 -9999 -9999 197.4802398682192 .0146026611184 .0901947021176 .165802002172 .2035980225 172.5084075928172 .5084075928172 .5084075928172 .5084075928172 .5084075928 172.5084075928172 .5084075928172 .5084075928172 .5084075928172 .8132019043 173.1179962158173 .4226989746174 .0323028564174 .337097168174 .9467010498 175.2514038086175 .5561981201175 .8609924316176 .165802002176 .165802002 175.8609924316175 .5561981201174 .9467010498174 .337097168173 .7274932861 172.8132019043171 .8988037109170 .6797027588169 .7653045654168 .8509979248 167.9365997314167 .0222015381166 .1078948975165 .4983062744164 .8887023926 164.5839996338164 .2792053223164 .2792053223163 .974395752163 .6696014404 163.0599975586162 .4505004883161 .5361022949160 .9264984131160 .6217956543 160.9264984131161 .8408966064163 .0599975586164 .5839996338166 .1078948975 167.3269958496167 .9365997314168 .241394043167 .6318054199166 .7174987793 164.8887023926163 .0232696533160 .9264984131158 .4882965088156 .3547973633 153.9165039062151 .4781951904149 .3446960449147 .2111968994145 .0776977539 143.5538024902142 .3347015381141 .1154937744140 .2012023926139 .5915985107 138.9819946289138 .3724975586138 .0677032471137 .4580993652137 .1533050537 136.5437011719136 .2389984131135 .6293945312135 .0198059082134 .4102020264 133.4958953857132 .5814971924131 .3623962402130 .4479980469129 .2288970947 127.7050018311126 .4858016968124 .9618988037123 .7427978516122 .2188034058 120.9997024536119 .4757995605117 .342300415114 .1475143433111 .5511245728 108.7863693237105 .8720245361103 .017402648999 .9695205688596 .92166900635 94.1785964965892 .0450973510789 .9116134643688 .6924667358487 .47332763672 
86.8637619018686 .5589828491286 .254188537686 .254188537686 .55898284912 86.5589828491286 .8637619018686 .5589828491285 .9494018554784 .42548370361 81.6824111938577 .4154205322372 .2340774536166 .7479400634861 .87137985229 60.0426712036160 .0426712036160 .9570198059162 .4809494018664 .61444854736 66.4431610107468 .2718734741270 .1005783081171 .9292907714873 .45321655273 74.062782287673 .7580032348676 .5010681152378 .0249862670978 .93934631348 79.8537063598680 .7680587768681 .9871978759883 .206336975184 .42548370361 85.6446228027387 .1685485839887 .7781066894588 .3876876831188 .99725341797 89.6068267822389 .9116134643690 .2164001464890 .5211791992290 .21640014648 89.9116134643689 .6068267822389 .6068267822389 .9116134643690 .82597351074 91.7403335571392 .0450973510792 .0450973510792 .0450973510792 .04509735107 92.0450973510792 .349891662692 .6546783447392 .9594726562593 .26425170898 93.8738174438594 .1785964965894 .7881774902395 .397743225196 .31210327148 96.9216690063597 .8360290527399 .0551681518699 .96952056885100 .8839035034 101.7982025146102 .1029968262102 .1029968262102 .4077987671102 .4077987671 102.4077987671102 .712600708102 .712600708103 .0174026489103 .3221969604 103.6268997192103 .9317016602104 .2365036011104 .5412979126104 .8460998535 105.4557037354105 .7603988647106 .0652008057106 .6747970581106 .979598999 107.2844009399 107.2844009399 107.5891036987107.5891036987 107.5891036987 107.2844009399107 .2844009399106 .979598999106 .6747970581106 .0652008057 105.7603988647105 .4557037354104 .8460998535104 .5412979126104 .2365036011 104.2365036011103 .9317016602103 .9317016602103 .6268997192103 .3221969604 103.0174026489102 .1029968262101 .188697814999 .9695205688598 .14080810547 95.7025299072392 .349891662687 .7781066894582 .2919769287176 .50106811523

$70.7101516723664 .9192428588959 .4331016540559 .1283111572359 .12831115723-9999$ -9999 -9999 -9999 -9999 -9999 -9999 -9999 -9999 -9999 -9999 -9999 -9999 -9999 -9999 -9999 -9999 -9999 -9999 -9999 -9999 -9999 -9999 -9999 -9999 -9999 -9999 -9999 -9999 -9999 -9999 -

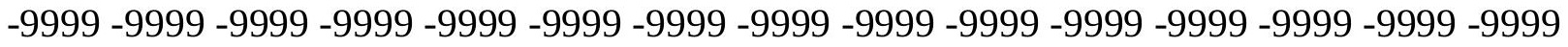
-9999 -9999 -9999-9999

-9999 -9999 -9999 -9999 -9999 -9999 -9999 -9999 -9999 -9999 -9999 -9999 -9999 -9999 -9999 -9999 -9999 -9999 -9999 -9999 -9999 -9999 -9999 -9999 -9999 -9999 -9999 -9999 -9999 -9999

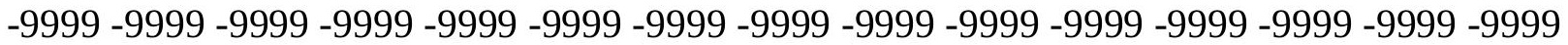

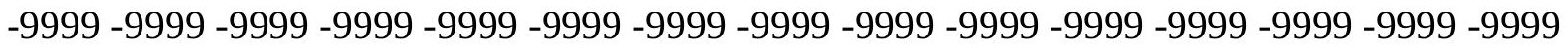
-9999 -9999 -9999 -9999 -9999 -9999 -9999 -9999 -9999 -9999 -9999 -9999 -9999 -9999 -9999 -9999 -9999 -9999 -9999 -9999 -9999 -9999 -9999 -9999 -9999 -9999 -9999 -9999 -9999 -9999 -9999 -9999 -9999 -9999 -9999 -9999 -9999 -9999 -9999 -9999 -9999 -9999 -9999 -9999 -9999 -9999 197.1959991455188.966796875 180.7375946045172.5084075928172.5084075928 172.5084075928172 .5084075928172 .5084075928172 .2035980225171 .8988037109 171.5939941406171 .5939941406171 .5939941406171 .5939941406171 .8988037109 172.5084075928172 .8132019043173 .4226989746173 .7274932861174 .337097168 174.6419067383174 .6419067383174 .6419067383174 .337097168174 .0323028564 173.1179962158172 .5084075928171 .5939941406170 .6797027588169 .7653045654 168.5462036133167 .6318054199166 .7174987793165 .8031005859164 .8887023926 164.2792053223 163.3648071289 162.7552947998 162.1457061768 161.8408966064 161.2312927246160 .6217956543160 .3170013428159 .7073974609159 .0977935791 158.4882965088158 .1835021973157 .878692627158 .4882965088159 .4026031494 
160.9264984131162 .4505004883164 .2792053223165 .4983062744166 .4127044678 166.7174987793166 .4127044678165 .1934967041163 .6696014404161 .5361022949 159.6620025635157 .5738983154155 .7451934814153 .6116943359151 .1734008789 148.7351074219146 .6015930176144 .7729034424142 .9441986084141 .7250976562 140.8106994629139 .8963928223139 .2868041992138 .6772003174138 .0677032471 137.7628936768137 .4580993652137 .1533050537136 .8484954834136 .2389984131 135.9342041016135 .3246002197134 .4102020264133 .8007049561132 .8863067627 131.9720001221130 .7528076172129 .533706665128 .3144989014126 .7906036377 125.2667007446123 .7427978516122 .8283996582121 .6092987061120 .3900985718 118.5614013672116 .4279022217111 .8661880493109 .2142944336106 .4649581909 103.6167449951100 .680679321397 .7842864990295 .0929565429792 .3498916626 90.2164001464888 .6924667358487 .1685485839886 .5589828491285 .94940185547 85.33984375 85.33984375 85.03504943848 84.73026275635 84.42548370361 83.81591033936 82.5967712402380 .4632720947377 .4154205322373 .4532165527368 .57665252686 63.3953094482459 .1283111572357 .2995986938557 .2995986938558 .21395874023 60.0426712036162 .4809494018664 .6144485473666 .4431610107468 .57665252686 70.4053573608472 .5388565063574 .9771423339878 .3297805786177 .72020721436 78.0249862670978 .6345596313579 .2441329956180 .1584930419981 .07285308838 82.2919769287183 .5111236572384 .7302627563585 .9494018554786 .86376190186 87.4733276367288 .0829010009888 .6924667358488 .9972534179789 .3020401001 89.3020401001 89.3020401001 88.69246673584 88.3876876831188.08290100098 88.6924667358489 .9116134643691 .7403335571391 .7403335571391 .74033355713 91.7403335571392 .0450973510792 .0450973510792 .349891662692 .95947265625 93.2642517089893 .8738174438594 .4833908081195 .0929565429795 .70252990723 96.3121032714897 .2264633178798 .1408081054799 .05516815186100 .2742996216 101.1886978149102 .4077987671103 .0174026489103 .6268997192103 .6268997192 103.9317016602103 .9317016602104 .2365036011104 .2365036011104 .5412979126 104.8460998535104 .8460998535105 .1509017944105 .4557037354106 .0652008057 106.3700027466 106.6747970581 107.2844009399107.5891036987107.8938980103 108.1986999512108 .5035018921108 .5035018921108 .8082962036108 .8082962036 108.8082962036108 .5035018921108 .1986999512107 .8938980103107 .5891036987 107.2844009399 106.6747970581 106.0652008057 105.7603988647105 .1509017944 104.8460998535104 .5412979126104 .2365036011103 .9317016602103 .9317016602 103.6268997192103 .6268997192103 .0174026489102 .4077987671101 .4934005737 100.274299621698 .445587158296 .0073165893692 .9594726562588 .38768768311 83.206336975177 .4154205322371 .6244964599665 .8335876464860 .34745025635 59.1283111572359 .12831115723 -9999 -9999 -9999 -9999 -9999 -9999 -9999 -9999 -9999

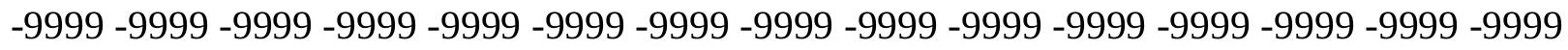

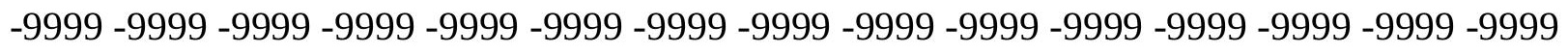
-9999 -9999 -9999 -9999 -9999 -9999 -9999-9999 -9999 -9999 -9999 -

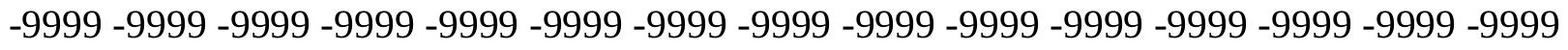

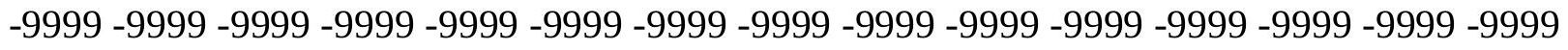
-9999 -9999 -9999 -9999 -9999 -9999 -9999 -9999 -9999 -9999 -9999 -9999 -9999 -9999 -9999 -9999 -9999 -9999 -9999 -9999 -9999 -9999 -9999 -9999-9999 -9999 -9999 -9999 -9999 -9999 -9999 -9999 -9999 -9999 -9999 -9999 -9999 -9999 -9999 -9999 -9999 -9999 -9999 -9999 -9999 -

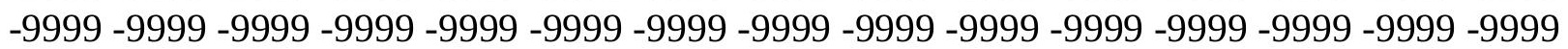


-9999 -9999 -9999 -9999 -9999 -9999 -9999 -9999 -9999 -9999 -9999 -9999 -9999 -9999 -9999 -9999 -9999 198.9465332031 192.3193969727 184.0901947021 175.8609924316 172.5084075928172 .8132019043172 .8132019043172 .2035980225171 .2891998291 170.6797027588170 .3748931885170 .070098877170 .070098877170 .3748931885 170.9844970703171 .2891998291171 .8988037109172 .5084075928172 .8132019043 173.1179962158173 .4226989746173 .1179962158172 .8132019043172 .2035980225 171.2891998291170 .3748931885169 .4604949951168 .241394043167 .3269958496 166.1078948975165 .1934967041164 .2792053223163 .3648071289162 .4505004883 161.8408966064160 .9264984131160 .3170013428159 .4026031494158 .7929992676 157.878692627156 .9642944336156 .3547973633155 .7451934814155 .1356048584 154.8307952881154 .5260925293154 .8307952881155 .4403991699156 .6596069336 158.4882965088160 .3170013428162 .4505004883163 .974395752165 .1934967041 165.4983062744164 .8887023926163 .974395752162 .1457061768160 .0122070312 157.878692627156 .0500030518154 .2212982178152 .4305725098150 .2590942383 147.8208007812145 .6873016357143 .8585968018142 .3347015381140 .8106994629 139.8963928223139 .2868041992138 .6772003174138 .0677032471137 .7628936768 137.4580993652137 .1533050537137 .1533050537136 .8484954834136 .2389984131 135.9342041016135 .3246002197134 .7149963379134 .1054992676133 .1911010742 132.2767028809131 .0576019287130 .1432037354128 .9241027832127 .4001998901 126.1809997559124 .6570968628123 .7427978516122 .8283996582121 .6092987061 120.0852966309117 .9517974854115 .818397522113 .075302124106 .7973480225 103.9963607788101 .139625549398 .3006820678795 .5506591796992 .95947265625 90.5211791992288 .6924667358487 .1685485839885 .9494018554785 .33984375 84.73026275635 84.12069702148 83.51112365723 83.2063369751 82.29197692871 81.0728530883879 .5489196777377 .4154205322374 .062782287670 .40535736084 66.1383666992261 .8713798522958 .2139587402356 .3852500915555 .47089004517 56.3852500915558 .2139587402360 .9570198059163 .0905189514264 .91924285889 67.3575134277369 .4910125732471 .9292907714874 .6723632812576 .80584716797 77.7202072143678 .0249862670978 .3297805786178 .6345596313579 .24413299561 80.1584930419981 .0728530883882 .2919769287183 .5111236572384 .73026275635 85.6446228027386 .5589828491287 .1685485839887 .4733276367288 .08290100098 88.0829010009888 .0829010009888 .0829010009887 .7781066894587 .47332763672 87.16854858398 87.16854858398 88.6924667358490.21640014648 91.13075256348 91.4355392456191 .4355392456191 .7403335571392 .0450973510792 .65467834473 92.9594726562593 .5690307617294 .1785964965894 .7881774902395 .70252990723 96.3121032714897 .2264633178798 .1408081054799 .35994720459100 .2742996216 101.1886978149102 .4077987671103 .3221969604104 .2365036011104 .5412979126 105.1509017944105 .1509017944105 .4557037354105 .7603988647106 .0652008057 106.0652008057106 .3700027466106 .6747970581106 .979598999107 .2844009399 107.5891036987108 .1986999512108 .5035018921109 .1130981445109 .4179000854 109.7226028442109 .7226028442110 .0273971558110 .0273971558110 .0273971558 110.0273971558109 .7226028442109 .4179000854109 .1130981445108 .8082962036 108.5035018921107 .8938980103107 .2844009399106 .6747970581106 .0652008057 105.4557037354104 .8460998535104 .5412979126104 .2365036011103 .9317016602 103.9317016602103 .9317016602103 .6268997192103 .3221969604102 .712600708 101.7982025146100 .579101562598 .7503814697396 .3121032714893 .26425170898 
88.9972534179783.8159103393678.32978057861 72.53885650635 66.74794006348 61.2618103027358 .8235282897958 .82352828979 -9999 -9999 -9999 -9999 -9999 -9999 -9999 -9999 -9999 -9999 -9999 -9999 -9999 -9999 -9999 -9999 -9999 -9999 -9999 -9999 -9999 -9999 -9999 -9999 -9999 -9999 -9999 -9999 -9999 -9999 -9999 -9999 -9999 -9999 -9999 -9999 -9999 -9999 -9999 -9999 -9999 -9999 -9999 -9999 -9999 -9999 -9999 -9999 -9999 -9999 -9999 -9999 -9999 -9999 -9999 -9999 -9999 -9999 -9999 -9999 -9999 -9999 -9999 -9999 -9999

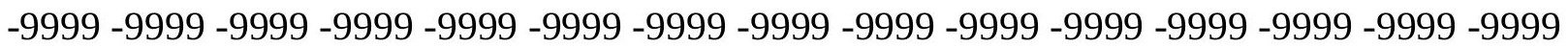
-9999 -9999 -9999 -9999 -9999 -9999 -9999 -9999 -9999 -9999 -9999 -9999 -9999 -9999 -9999 -9999 -9999 -9999 -9999 -9999 -9999 -9999 -9999 -9999 -9999 -9999 -9999 -9999 -9999 -9999 -9999 -9999 -9999 -9999 -9999 -9999 -9999 -9999 -9999 -9999 -9999 -9999 -9999 -9999 -9999 -9999 -9999 -9999 -9999 -9999 -9999 -9999 -9999 -9999 -9999 -9999 -9999 -9999 -9999 -9999 -999 -

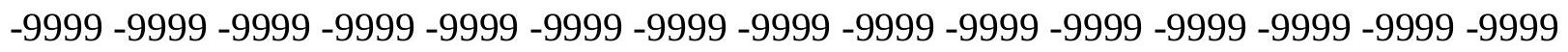
-9999 -9999 -9999 -9999 195.0625186 .8332977295179 .2136993408173 .1179962158 173.1179962158171 .8988037109170 .6797027588169 .4604949951168 .8509979248 168.5462036133168 .8509979248168 .8509979248169 .1557006836169 .7653045654 170.3748931885170 .9844970703171 .5939941406171 .8988037109171 .8988037109 171.5939941406170 .9844970703170 .3748931885169 .1557006836167 .9365997314 166.7174987793165 .4983062744164 .2792053223163 .3648071289162 .1457061768 161.2312927246160 .3170013428159 .7073974609158 .7929992676157 .878692627 156.9642944336156 .0500030518155 .1356048584154 .2212982178153 .0021057129 152.0877990723151 .4781951904150 .8686065674150 .5639038086150 .5639038086 150.8686065674151 .7830047607153 .3069000244155 .4403991699157 .878692627 160.3170013428162 .1457061768163 .6696014404163 .974395752163 .6696014404 162.4505004883160 .3170013428157 .878692627155 .7451934814153 .6116943359 152.0877990723150 .2590942383148 .1255950928145 .9920959473144 .1634063721 142.3347015381141 .1154937744139 .8963928223138 .9819946289138 .3724975586 137.7628936768137 .4580993652137 .4580993652137 .1533050537137 .1533050537 136.8484954834136 .5437011719136 .5437011719136 .2389984131135 .6293945312 135.0198059082134 .4102020264133 .8007049561132 .8863067627131 .6672058105 130.7528076172129 .533706665128 .3144989014127 .0953979492125 .8762969971 124.9618988037124 .0475006104122 .8283996582121 .6092987061119 .7806015015 117.647102356114 .9039993286111 .8561019897104 .2770233154101 .4733581543 98.6697006225695.9183731079193.2821350097790.82597351074 88.69246673584 87.1685485839885 .9494018554785 .0350494384884 .1206970214883 .51112365723 82.5967712402381 .6824111938580 .4632720947378 .9393463134877 .1106262207 74.9771423339871 .9292907714868 .5766525268664 .9192428588961 .56660079956 58.5187492370656 .3852500915555 .1661109924355 .1661109924356 .99481964111 59.4331016540561 .5666007995664 .004882812566 .4431610107468 .88143920898 71.014930725173 .4532165527375 .5867080688577 .110626220777 .72020721436 78.0249862670978 .3297805786178 .6345596313579 .2441329956180 .15849304199 81.3776321411182 .5967712402383 .8159103393684 .7302627563585 .33984375 85.94940185547 86.55898284912 86.86376190186 87.16854858398 87.16854858398 87.1685485839886 .8637619018686 .5589828491286 .5589828491286 .86376190186 88.0829010009889 .302040100190 .2164001464890 .8259735107491 .13075256348 91.4355392456192 .0450973510792 .6546783447393 .2642517089893 .87381744385 94.4833908081195 .397743225196 .3121032714897 .2264633178798 .14080810547 
99.05516815186100 .2742996216101 .1886978149102 .4077987671103 .3221969604 104.2365036011105 .1509017944105 .7603988647106 .0652008057106 .6747970581 106.979598999107 .2844009399107 .2844009399107 .5891036987107 .8938980103 108.1986999512108 .5035018921108 .8082962036109 .4179000854109 .7226028442 110.3321990967110 .6370010376110 .9418029785111 .24659729111 .24659729111 .24659729 111.24659729111 .24659729110 .9418029785110 .9418029785110 .6370010376 110.0273971558109 .7226028442109 .1130981445108 .5035018921107 .8938980103 106.979598999 106.3700027466 105.7603988647 104.8460998535104.5412979126 104.2365036011103 .9317016602103 .9317016602103 .6268997192103 .6268997192 103.0174026489102 .4077987671101 .7982025146100 .274299621698 .75038146973 96.3121032714893 .2642517089889 .6068267822384 .4254837036178 .93934631348 $73.1484298706167 .3575134277362 .1761703491258 .8235282897958 .82352828979-9999$ -9999 -9999 -9999 -9999 -9999 -9999 -9999 -9999 -9999 -9999 -9999 -9999 -9999 -9999 -9999 -9999 -9999 -9999 -9999 -9999 -9999 -9999 -9999 -9999 -9999 -9999 -9999 -9999 -9999 -9999 -

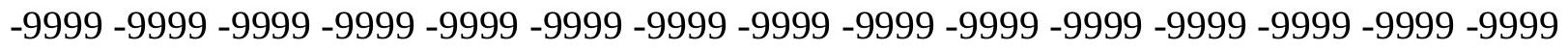
-9999-9999-9999-9999

-9999 -9999 -9999 -9999 -9999 -9999 -9999 -9999 -9999 -9999 -9999 -9999 -9999 -9999 -9999

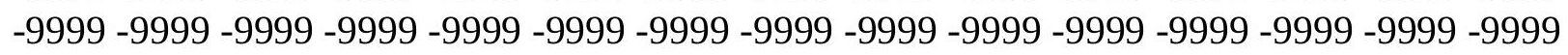

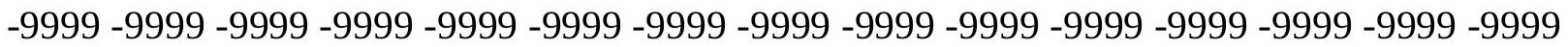

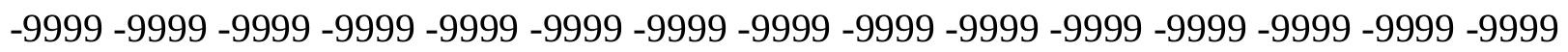

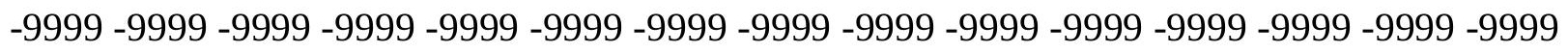

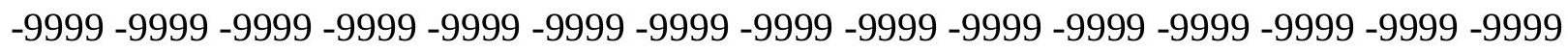

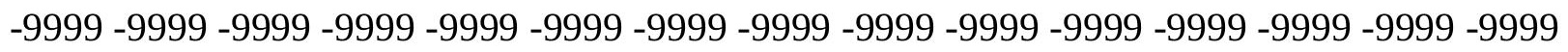
-9999 -9999-9999-9999-9999 195.1721343994 189.5764007568 182.261505127 175.2514038086171 .2891998291169 .1557006836167 .9365997314167 .3269958496 167.3269958496 167.3269958496167.3269958496167.6318054199168.241394043 168.8509979248169 .7653045654170 .3748931885170 .6797027588170 .6797027588 170.070098877169 .4604949951168 .241394043167 .0222015381165 .4983062744 163.974395752162 .4505004883161 .2312927246160 .0122070312159 .0977935791 158.1835021973157 .2691040039156 .3547973633155 .4403991699154 .5260925293 153.6116943359152 .6972961426151 .4781951904149 .9542999268148 .7351074219 147.5160064697146 .9064025879146 .2969055176145 .9920959473146 .2969055176 146.6015930176147 .8208007812149 .6495056152151 .7830047607154 .8307952881 157.878692627160 .3170013428161 .8408966064162 .4505004883162 .1457061768 160.6217956543158 .4882965088155 .7451934814153 .0021057129150 .8686065674 149.0399017334147 .2111968994145 .6873016357143 .8585968018142 .0299072266 140.5059967041139 .2868041992138 .3724975586137 .7628936768137 .1533050537 136.8484954834136 .8484954834136 .8484954834136 .5437011719136 .5437011719 136.5437011719136 .5437011719136 .5437011719136 .2389984131135 .9342041016 135.3246002197134 .7149963379134 .1054992676133 .1911010742132 .2767028809 131.3623962402130 .1432037354129 .2288970947128 .0097961426127 .0953979492 126.1809997559125 .2667007446124 .3523025513123 .1332015991121 .6092987061 119.7806015015117 .0374984741113 .6848983765110 .0273971558101 .7919387817 99.0325164794996 .3147964477593 .6932983398491 .1307525634888 .99725341797 87.16854858398 85.9494018554785.03504943848 83.81591033936 82.90155792236 81.9871978759880 .7680587768679 .2441329956177 .7202072143675 .58670806885 
73.1484298706170 .7101516723667 .6623001098664 .6144485473661 .87137985229 59.4331016540556 .9948196411155 .7756805419955 .4708900451756 .38525009155 58.5187492370660 .9570198059163 .3953094482465 .8335876464868 .57665252686 70.7101516723672 .8436431884875 .2819290161176 .8058471679777 .72020721436 78.0249862670978 .0249862670978 .0249862670978 .3297805786179 .24413299561 80.4632720947381 .6824111938582 .5967712402383 .5111236572384 .42548370361 85.0350494384885 .3398437585 .9494018554785 .9494018554786 .2541885376 86.2541885376 86.2541885376 86.2541885376 86.2541885376 86.86376190186 87.4733276367288 .6924667358489 .6068267822390 .2164001464890 .82597351074 91.4355392456192 .0450973510792 .6546783447393 .2642517089894 .17859649658 95.0929565429796 .0073165893696 .9216690063597 .8360290527398 .75038146973 99.96952056885100 .8839035034102 .1029968262103 .0174026489104 .2365036011 105.1509017944106 .0652008057106 .6747970581107 .2844009399107 .5891036987 108.1986999512108 .5035018921108 .8082962036109 .1130981445109 .4179000854 109.7226028442110 .0273971558110 .3321990967110 .9418029785111 .24659729 111.551399231112 .1608963013112 .4656982422112 .7705001831112 .4656982422 112.4656982422112 .4656982422112 .4656982422112 .1608963013111 .8561019897 111.551399231110 .9418029785110 .6370010376109 .7226028442109 .1130981445 108.5035018921107 .5891036987106 .6747970581106 .0652008057105 .1509017944 104.5412979126103 .9317016602103 .9317016602103 .6268997192103 .6268997192 103.3221969604103 .0174026489102 .4077987671101 .4934005737100 .2742996216 98.445587158296 .3121032714893 .2642517089889 .9116134643684 .73026275635 79.2441329956173 .7580032348668 .2718734741262 .7857398986858 .51874923706 58.51874923706 -9999 -9999 -9999 -9999 -9999 -9999 -9999 -9999 -9999 -9999 -9999 -9999 -9999 -9999 -9999 -9999 -9999 -9999 -9999 -9999 -9999 -9999 -9999 -9999 -9999 -9999 -9999 -9999 -9999 -9999 -9999 -9999 -9999 -9999 -9999 -9999 -9999 -9999 -9999-9999 -9999 -9999 - -999 -9999 -9999 -9999 -9999-9999-9999-9999-9999

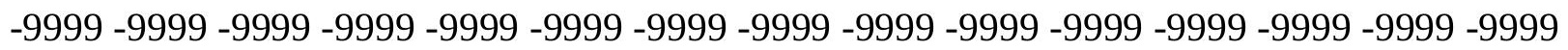
-9999 -9999 -9999 -9999 -9999 -9999 -9999 -9999 -9999 -9999 -9999 -9999 -9999 -9999 -9999 -9999 -9999 -9999 -9999 -9999 -9999 -9999 -9999 -9999 -9999 -9999 -9999 -9999 -9999 -9999 -9999 -9999 -9999 -9999 -9999 -9999 -9999 -9999 -9999-9999 -9999 -9999 -9999 -9999 -9999 -9999 -9999 -9999 -9999 -9999 -9999 -9999 -9999 -9999 -9999 -9999 -9999 -9999 -9999 -9999 -

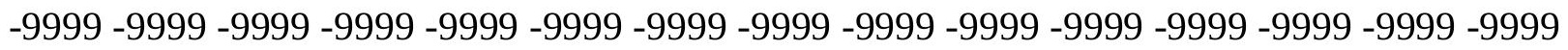
-9999 -9999 -9999 -9999 -9999 -9999 -9999 -9999 -9999 -9999 -9999 -9999 -9999 -9999 -9999 -9999 -9999 -9999 -9999-9999 -9999 -9999 188.9563446045183 .4806976318176 .7754058838 171.5939941406167 .3269958496166 .1078948975165 .8031005859165 .8031005859 166.1078948975166 .4127044678166 .7174987793167 .6318054199168 .5462036133 169.1557006836169 .4604949951169 .4604949951168 .8509979248167 .9365997314 166.4127044678164 .8887023926163 .0599975586160 .9264984131159 .0977935791 157.878692627156 .6596069336155 .4403991699154 .5260925293153 .6116943359 152.6972961426151 .7830047607150 .8686065674149 .9542999268148 .7351074219 147.2111968994145 .3825073242143 .8585968018142 .6394042969142 .0299072266 141.4203033447141 .1154937744141 .4203033447142 .0299072266143 .2489929199 145.0776977539147 .5160064697150 .8686065674154 .5260925293157 .5738983154 159.7073974609160 .3170013428160 .0122070312158 .4882965088156 .3547973633 153.3069000244149 .6495056152147 .8208007812145 .9920959473144 .1634063721 
142.3347015381140 .8106994629139 .5915985107138 .3724975586137 .4075927734 136.5752410889136 .2389984131135 .9342041016135 .9342041016135 .9342041016 135.9342041016135 .9342041016136 .2389984131136 .2389984131136 .2389984131 136.2389984131136 .2389984131135 .9342041016135 .6293945312135 .0198059082 134.4102020264133 .8007049561132 .8863067627131 .9720001221131 .0576019287 130.1432037354129 .2288970947128 .3144989014127 .4001998901126 .4858016968 125.5715026855124 .6570968628123 .43800354121 .9140014648118 .8662033081 115.5136032104111 .8561019897107 .8938980103103 .931701660296 .83257293701 94.2834472656291 .7403335571389 .809005737388 .0829010009886 .55898284912 85.3398437584 .1206970214882 .9015579223681 .6824111938580 .15849304199 78.6345596313576 .8058471679774 .6723632812572 .5388565063570 .10057830811 67.6623001098665 .2240066528362 .7857398986860 .9570198059158 .51874923706 56.6900291442956 .0804595947356 .3852500915557 .909179687560 .34745025635 63.0905189514265 .8335876464868 .8814392089871 .6244964599674 .0627822876 76.1962814331177 .7202072143678 .3297805786178 .3297805786178 .32978057861 78.3297805786178 .3297805786179 .2441329956180 .1584930419981 .07285308838 81.9871978759882 .5967712402383 .206336975183 .8159103393684 .42548370361 84.7302627563585 .0350494384885 .3398437585 .3398437585 .6446228027385 .64462280273 85.9494018554786 .5589828491287 .4733276367288 .0829010009888 .99725341797 89.9116134643690 .5211791992291 .1307525634891 .7403335571392 .65467834473 93.5690307617294 .4833908081195 .397743225196 .3121032714897 .22646331787 98.445587158299 .35994720459100 .5791015625101 .7982025146102 .712600708 103.9317016602104 .8460998535105 .7603988647106 .6747970581107 .5891036987 108.1986999512108 .8082962036109 .1130981445109 .7226028442110 .0273971558 110.3321990967110 .6370010376110 .9418029785111 .24659729111 .551399231 112.1608963013112 .4656982422112 .7705001831113 .3800964355113 .6848983765 113.6848983765113 .6848983765113 .6848983765113 .6848983765113 .3800964355 113.075302124112 .7705001831112 .4656982422111 .8561019897111 .24659729 110.6370010376109 .7226028442109 .1130981445108 .1986999512107 .2844009399 106.3700027466105 .4557037354104 .5412979126103 .9317016602103 .6268997192 103.6268997192103 .3221969604103 .0174026489102 .712600708101 .7982025146 100.883903503499 .6647262573297 .8360290527395 .7025299072392 .95947265625 89.302040100184 .7302627563579 .5489196777374 .062782287668 .88143920898

63.7000885009858 .8235282897958 .21395874023 -9999 -9999 -9999 -9999 -9999 -9999 -9999 -9999 -9999 -9999 -9999 -9999 -9999 -9999 -9999 -9999 -9999 -9999 -9999 -9999 -9999 -9999 -9999 -9999 -9999 -9999 -9999 -9999 -9999 -9999 -9999 -9999 -9999 -9999 -9999 -9999 -9999 -9999 -9999 -9999 -9999 -9999 -9999 -9999 -9999 -9999 -9999 -9999 -9999 -9999

-9999 -9999 -9999 -9999 -9999 -9999 -9999 -9999 -9999 -9999 -9999 -9999 -9999 -9999 -9999 -9999 -9999 -9999 -9999 -9999 -9999 -9999 -9999 -9999 -9999 -9999 -9999 -9999 -9999 -9999 -9999 -9999 -9999 -9999 -9999 -9999 -9999 -9999 -9999 -9999 -9999 -9999 -9999 -9999 -9999 -9999 -9999 -9999 -9999 -9999 -9999 -9999 -9999 -9999 -9999 -9999 -9999 -9999 -9999 -9999 -9999 -9999 -9999 -9999 -9999 -9999 -9999 -9999 -9999 -9999 -9999 -9999 -9999 -9999 -9999 -9999 -9999 -9999 -9999 -9999 -9999 -9999 -9999 -9999 -9999 -9999 -9999 -9999 -9999 -9999 -9999 -9999 -9999 -9999 -9999 -9999 -9999 -9999 -9999 -9999 -9999 -9999 -9999 -9999 -9999 -9999 -9999 -9999 -9999 -9999 -9999 -9999 -9999 -9999 183.4354095459180 .1280059814 176.165802002172 .2035980225168 .241394043164 .8887023926164 .8887023926 
164.8887023926165 .4983062744166 .4127044678167 .3269958496168 .241394043 168.5462036133168 .241394043167 .3269958496166 .1078948975164 .5839996338 162.7552947998160 .3170013428157 .5738983154155 .7451934814154 .2212982178 153.0021057129152 .0877990723151 .1734008789149 .9542999268148 .7351074219 147.5160064697146 .9064025879146 .2969055176145 .0776977539143 .2489929199 140.5059967041138 .6772003174137 .4580993652136 .8484954834136 .5437011719 136.2389984131136 .2389984131136 .8484954834138 .0677032471139 .5915985107 142.0299072266145 .6873016357149 .9542999268153 .9165039062156 .0500030518 156.9642944336156 .9642944336156 .0500030518153 .9165039062151 .1734008789 147.8208007812144 .7729034424142 .3347015381140 .5059967041138 .9819946289 137.4580993652136 .5437011719135 .6293945312135 .0198059082134 .6107177734 134.0906677246134 .4102020264134 .7149963379134 .7149963379135 .0198059082 135.3246002197135 .6293945312135 .9342041016136 .2389984131136 .2389984131 136.2389984131135 .9342041016135 .9342041016135 .3246002197134 .7149963379 134.1054992676133 .1911010742132 .5814971924131 .6672058105130 .7528076172 129.8385009766128 .9241027832128 .3144989014127 .4001998901126 .4858016968 125.5715026855124 .6570968628122 .8283996582120 .3900985718117 .342300415 113.6848983765110 .0273971558105 .7603988647101 .798202514695 .06920623779 92.8160247802790 .8292922973689 .16098785487 .7781066894586 .2541885376 85.0350494384883 .5111236572381 .6824111938580 .1584930419978 .32978057861 76.5010681152374 .6723632812572 .5388565063570 .4053573608467 .96708679199 65.8335876464863 .7000885009861 .8713798522959 .7378807067957 .9091796875 56.9948196411156 .9948196411157 .909179687560 .0426712036163 .09051895142 66.7479400634870 .4053573608473 .7580032348676 .5010681152378 .32978057861 79.2441329956179 .5489196777379 .2441329956178 .9393463134878 .63455963135 78.9393463134879 .2441329956179 .8537063598680 .4632720947381 .07285308838 81.9871978759882 .5967712402382 .9015579223683 .5111236572383 .81591033936 84.1206970214884 .4254837036184 .7302627563585 .0350494384885 .33984375 85.6446228027386 .254188537687 .1685485839887 .7781066894588 .69246673584 89.6068267822390 .2164001464890 .8259735107491 .7403335571392 .65467834473 93.5690307617294 .4833908081195 .7025299072396 .6168823242297 .83602905273 98.7503814697399 .96952056885101 .1886978149102 .4077987671103 .6268997192 104.5412979126105 .7603988647106 .6747970581107 .5891036987108 .5035018921 109.1130981445109 .7226028442110 .3321990967110 .6370010376111 .24659729 111.551399231111 .8561019897112 .1608963013112 .4656982422112 .7705001831 113.075302124113 .3800964355113 .9896011353114 .2944030762114 .5991973877 114.5991973877114 .5991973877114 .5991973877114 .5991973877114 .2944030762 114.2944030762113 .6848983765113 .3800964355112 .7705001831112 .1608963013 111.24659729110 .3321990967109 .4179000854108 .5035018921107 .5891036987 106.6747970581105 .7603988647104 .8460998535104 .2365036011103 .9317016602 103.6268997192103 .3221969604102 .712600708102 .1029968262101 .4934005737 100.274299621699.0551681518697.2264633178794.7881774902392.04509735107 88.3876876831184 .4254837036179 .5489196777374 .6723632812569 .49101257324 64.6144485473660 .0426712036158 .21395874023 -9999 -9999 -9999 -9999 -9999 -9999 -9999 -9999 -9999 -9999 -9999 -9999 -9999 -9999 -9999 -9999 -9999 -9999 -9999 -9999 -9999 -9999 -

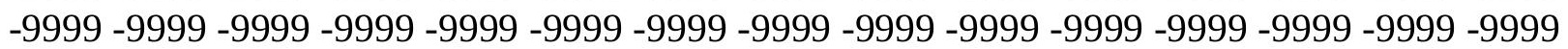


-9999 -9999 -9999 -9999 -9999 -9999 -9999 -9999 -9999 -9999 -9999 -9999 -9999

-9999 -9999 -9999 -9999 -9999 -9999 -9999 -9999 -9999 -9999 -9999 -9999 -9999 -9999 -9999

-9999 -9999 -9999 -9999 -9999 -9999 -9999 -9999 -9999 -9999 -9999 -9999 -9999 -9999 -9999

-9999 -9999 -9999 -9999 -9999 -9999 -9999 -9999 -9999 -9999 -9999 -9999 -9999 -9999 -9999

-9999 -9999 -9999 -9999 -9999 -9999 -9999 -9999 -9999 -9999 -9999 -9999 -9999 -9999 -9999

-9999 -9999 -9999 -9999 -9999 -9999 -9999 -9999 -9999 -9999 -9999 -9999 -9999 -9999 -9999 -

-9999 -9999 -9999 -9999 -9999 -9999 -9999 -9999 -9999 -9999 -9999 -9999 -9999 -9999 -9999

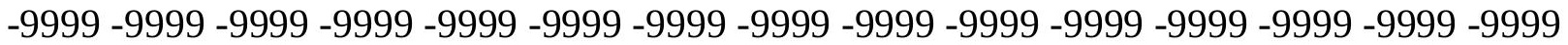

-9999 -9999 -9999 -9999 -9999 -9999 -9999 -9999 -9999 -9999 -9999 -9999 178.6149749756

176.7754058838173 .1179962158170 .070098877167 .0222015381164 .5839996338

164.8887023926166 .4127044678167 .3269958496167 .6318054199167 .0222015381

165.8031005859164 .5839996338163 .0599975586160 .6217956543157 .2691040039

154.2212982178152 .0877990723150 .2590942383149 .0399017334148 .1255950928

147.5160064697146 .2969055176144 .7729034424142 .9441986084142 .0299072266

142.3347015381142 .0299072266138 .9819946289135 .0198059082133 .1911010742

132.2767028809131 .9720001221131 .6672058105131 .3623962402131 .0576019287

131.3623962402132 .5814971924133 .8007049561135 .6293945312138 .3724975586

142.9441986084149 .0399017334150 .2590942383151 .4781951904152 .6972961426

153.0021057129151 .4781951904148 .7351074219145 .0776977539141 .7250976562

138.6772003174136 .5437011719135 .0198059082134 .1054992676133 .1911010742 132.8863067627132 .5814971924132 .5814971924132 .3466339111131 .9223632812 133.1911010742133 .4958953857134 .1054992676134 .4102020264135 .0198059082 135.3246002197135 .6293945312135 .9342041016136 .2389984131135 .9342041016 135.9342041016135 .3246002197135 .0198059082134 .4102020264133 .4958953857 132.8863067627131 .9720001221131 .0576019287130 .4479980469129 .533706665 128.9241027832128 .0097961426127 .4001998901126 .4858016968125 .2667007446 123.7427978516121 .3044967651118 .5614013672115 .5136032104111 .8561019897 107.8938980103104 .2365036011100 .274299621696 .9216690063591 .95645904541 90.2858047485488 .8003463745187 .3773040771585 .9494018554784 .12069702148 82.2919769287180 .4632720947378 .6345596313577 .110626220775 .28192901611 73.1484298706171 .3197174072369 .1862335205167 .0527267456165 .22400665283 63.0905189514261 .2618103027359 .7378807067958 .5187492370657 .9091796875 58.2139587402360 .0426712036163 .3953094482467 .9670867919972 .53885650635 76.5010681152379 .5489196777381 .0728530883881 .3776321411181 .07285308838 80.4632720947379 .8537063598679 .5489196777379 .2441329956179 .24413299561 79.5489196777380 .1584930419980 .7680587768681 .0728530883881 .68241119385 82.2919769287182 .5967712402383 .206336975183 .5111236572383 .81591033936 84.1206970214884 .4254837036185 .0350494384885 .3398437585 .94940185547 86.8637619018687 .4733276367288 .3876876831189 .302040100189 .91161346436 90.8259735107491 .7403335571392 .6546783447393 .5690307617294 .78817749023 95.7025299072396 .9216690063598 .1408081054799 .35994720459100 .5791015625 101.7982025146103 .0174026489103 .9317016602105 .1509017944106 .3700027466 107.2844009399 108.1986999512109.1130981445110.0273971558 110.6370010376 111.24659729111 .551399231112 .1608963013112 .4656982422112 .7705001831 113.075302124113 .3800964355113 .6848983765113 .9896011353114 .2944030762 114.5991973877114 .9039993286115 .2088012695115 .5136032104115 .5136032104 
115.5136032104115 .5136032104115 .2088012695115 .2088012695114 .5991973877 114.2944030762113 .6848983765112 .7705001831112 .1608963013111 .24659729 110.0273971558109 .1130981445107 .8938980103106 .979598999106 .0652008057 105.1509017944104 .5412979126103 .9317016602103 .3221969604103 .0174026489 102.4077987671101 .7982025146100 .883903503499 .6647262573298 .14080810547 96.3121032714894 .1785964965891 .1307525634887 .7781066894583 .81591033936 79.5489196777374 .9771423339870 .1005783081165 .5288009643660 .95701980591 58.5187492370657 .9091796875 -9999 -9999 -9999 -9999 -9999 -9999 -9999 -9999 -9999

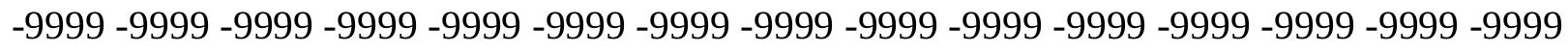
-9999 -9999 -9999 -9999 -9999 -9999 -9999 -9999 -9999 -9999 -9999 -9999 -9999 -9999 -9999 -9999 -9999 -9999 -9999 -9999 -9999 -9999 -9999 -9999 -9999

-9999 -9999 -9999 -9999 -9999 -9999 -9999 -9999 -9999 -9999 -9999 -9999 -9999 -9999 -9999 -9999 -9999 -9999 -9999 -9999 -9999 -9999 -9999 -9999 -9999 -9999 -9999 -9999 -9999 -9999 -9999 -9999 -9999 -9999 -9999 -9999 -9999 -9999 -9999 -9999 -9999 -9999 -9999 -9999 -9999 -9999 -9999 -9999 -9999 -9999 -9999 -9999 -9999 -9999 -9999 -9999 -9999 -9999 -9999 -9999

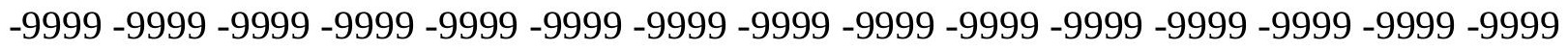
-9999 -9999 -9999 -9999 -9999 -9999 -9999 -9999 -9999 -9999 -9999 -9999 -9999 -9999 -9999 -9999 -9999 -9999 -9999 -9999 -9999 -9999 -9999 -9999 -9999 -9999 -9999 -9999 -9999 -9999 -

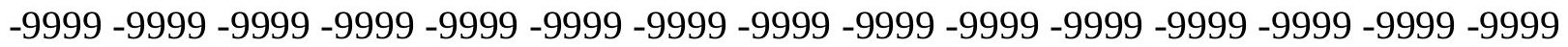
174.8592376709172 .7412719727172 .8132019043170 .9844970703169 .1557006836 167.3269958496167 .3269958496165 .1934967041163 .6696014404162 .4505004883 160.9264984131159 .0977935791153 .9165039062150 .8686065674148 .4304046631 146.6015930176145 .3825073242144 .4682006836143 .8585968018142 .3347015381 141.1154937744138 .3724975586137 .7628936768138 .3724975586140 .2012023926 134.7149963379128 .6192932129127 .7050018311127 .4001998901127 .0953979492 126.7906036377126 .4858016968125 .8762969971125 .5715026855127 .4001998901 127.7050018311128 .3144989014129 .8385009766132 .8863067627137 .1533050537 140.8106994629144 .4682006836147 .8208007812149 .0399017334148 .4304046631 145.6873016357141 .4203033447137 .4580993652134 .4102020264132 .2767028809 130.7528076172130 .1432037354129 .8385009766129 .8385009766129 .8385009766 130.1432037354130 .4479980469130 .4415588379129 .9268188477131 .9720001221 132.5814971924133 .4958953857134 .1054992676134 .7149963379135 .3246002197 135.6293945312135 .9342041016135 .9342041016135 .6293945312135 .3246002197 135.0198059082134 .4102020264133 .8007049561132 .8863067627132 .2767028809 131.3623962402130 .7528076172129 .8385009766129 .2288970947128 .6192932129 127.7050018311126 .7906036377125 .8762969971124 .3523025513122 .2188034058 119.7806015015117 .0374984741113 .6848983765110 .3321990967106 .6747970581 103.322196960499 .9695205688596 .6168823242291 .4458541870189 .87384033203 88.39421081543 86.86376190186 84.73026275635 82.90155792236 81.07285308838 79.5489196777378 .0249862670976 .1962814331174 .6723632812572 .84364318848 70.7101516723668 .8814392089867 .0527267456165 .2240066528363 .39530944824 61.8713798522960 .6522407531759 .7378807067959 .7378807067960 .65224075317 64.9192428588970 .1005783081175 .2819290161179 .8537063598682 .90155792236 84.1206970214883 .5111236572382 .5967712402381 .6824111938580 .76805877686 80.1584930419979 .5489196777379 .5489196777379 .5489196777379 .85370635986 80.1584930419980 .4632720947381 .0728530883881 .3776321411181 .98719787598 
82.2919769287182 .9015579223683 .206336975183 .5111236572384 .12069702148 84.4254837036185 .0350494384885 .6446228027386 .5589828491287 .16854858398 88.0829010009888 .9972534179789 .9116134643690 .8259735107491 .74033355713 92.6546783447393 .8738174438594 .7881774902396 .0073165893697 .22646331787 98.445587158299 .66472625732100 .8839035034102 .1029968262103 .3221969604 104.5412979126105 .7603988647106 .979598999107 .8938980103108 .8082962036 109.7226028442110 .6370010376111 .24659729111 .8561019897112 .4656982422 113.075302124113 .3800964355113 .6848983765113 .9582214355113 .9896011353 114.2944030762114 .5991973877114 .9039993286115 .2088012695115 .5136032104 115.7753067017115 .818397522116 .1231002808116 .1231002808116 .1231002808 116.1231002808115 .818397522115 .5136032104114 .9039993286114 .2944030762 113.6848983765112 .7705001831111 .8561019897110 .6370010376109 .4179000854 108.5035018921107 .2844009399106 .3700027466105 .4557037354104 .5412979126 103.9317016602103 .3221969604102 .712600708102 .1029968262101 .1886978149 100.274299621699 .0551681518697 .5312423706195 .397743225193 .26425170898 90.5211791992287 .1685485839883 .5111236572379 .5489196777375 .28192901611 $71.014930725166 .7479400634862 .7857398986860 .0426712036158 .82352828979-9999$ -9999 -9999 -9999 -9999 -9999 -9999 -9999 -9999 -9999 -9999 -9999 -9999 -9999 -9999 -9999 -9999 -9999 -9999 -9999 -9999 -9999 -9999 -9999 -9999 -9999 -9999 -9999 -9999 -9999 -9999 -

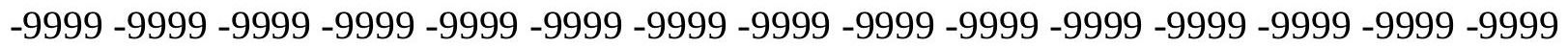
$-9999-9999-9999$

-9999 -9999 -9999 -9999 -9999 -9999 -9999 -9999 -9999 -9999 -9999 -9999 -9999 -9999 -9999 -9999 -9999 -9999 -9999 -9999 -9999 -9999 -9999 -9999 -9999 -9999 -9999 -9999 -9999 -9999 -9999 -9999 -9999 -9999 -9999 -9999 -9999 -9999 -9999 -9999 -9999 -9999 -9999 -9999 -9999 -9999 -9999 -9999 -9999 -9999 -9999 -9999 -9999 -9999 -9999 -9999 -9999 -9999 -9999 -9999 -9999 -9999 -9999 -9999 -9999 -9999 -9999 -9999 -9999 -9999 -9999 -9999 -9999 -9999 -9999 -9999 -9999 -9999 -9999 -9999 -9999 -9999 -9999 -9999 -9999 -9999 -9999 -9999 -9999 -9999

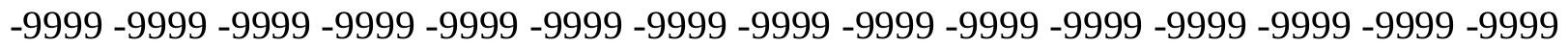
-9999 -9999 -9999 -9999 -9999 -9999 -9999 -9999 -9999 -9999 -9999 -9999 -9999 -9999 -9999 -9999 -9999-9999 175.1296539307 173.590927124173 .1405487061174 .6419067383 173.1179962158171 .2891998291169 .4604949951167 .3269958496164 .8887023926 162.1457061768159 .7073974609157 .2691040039155 .1356048584153 .3069000244 152.3925933838151 .4781951904150 .2590942383148 .7351074219146 .6015930176 144.4682006836142 .0299072266139 .8963928223137 .7628936768135 .9342041016 134.1054992676132 .2767028809130 .7528076172129 .2288970947128 .3144989014 127.7050018311127 .7050018311128 .6192932129129 .2288970947126 .4858016968 124.6570968628125 .8762969971129 .2288970947133 .4958953857138 .3724975586 143.2489929199145 .6873016357144 .4682006836141 .4203033447136 .8484954834 132.5814971924129 .533706665127 .4001998901126 .4858016968126 .1809997559 126.1809997559126 .4858016968127 .0953979492127 .7050018311128 .3144989014 128.9241027832128 .5304718018130 .4479980469131 .0576019287131 .9720001221 132.8863067627133 .8007049561134 .4102020264135 .0198059082135 .3246002197 135.6293945312135 .6293945312135 .3246002197134 .7149963379134 .1054992676 133.4958953857132 .8863067627132 .2767028809131 .3623962402130 .7528076172 130.1432037354129 .2288970947128 .6192932129128 .0097961426127 .0953979492 126.1809997559124 .6570968628123 .1332015991120 .9997024536118 .5614013672 
115.818397522112 .7705001831109 .7226028442106 .3700027466103 .0174026489 99.6647262573296 .6168823242291 .0463256835989 .4004974365287 .61178588867 85.6446228027383 .8159103393682 .2919769287180 .7680587768679 .54891967773 78.0249862670976 .5010681152374 .6723632812573 .1484298706171 .31971740723 69.4910125732467 .6623001098666 .1383666992264 .6144485473663 .39530944824 62.7857398986862 .7857398986864 .6144485473667 .9670867919972 .84364318848 77.7202072143682 .5967712402386 .5589828491286 .254188537685 .33984375 84.1206970214882 .5967712402381 .3776321411180 .4632720947379 .85370635986 79.5489196777379 .5489196777379 .5489196777379 .8537063598680 .15849304199 80.4632720947380 .7680587768681 .3776321411181 .6824111938582 .29197692871 82.5967712402383 .206336975183 .5111236572384 .1206970214884 .73026275635 85.3398437586 .254188537686 .8637619018687 .7781066894588 .69246673584 89.60682678223 90.5211791992291.7403335571392.6546783447393.87381744385 95.0929565429796.3121032714897.5312423706198.7503814697399.96952056885 101.4934005737102 .712600708103 .9317016602105 .1509017944106 .3700027466 107.2844009399108 .5035018921109 .4179000854110 .3321990967111 .24659729 112.1608963013112 .7705001831113 .3800964355113 .6848983765113 .9896011353 114.2944030762114 .5991973877114 .5991973877114 .9039993286115 .2088012695 115.2088012695115 .5136032104115 .818397522116 .1231002808116 .4279022217 116.7326965332116 .7326965332117 .0374984741116 .7326965332116 .7326965332 116.4279022217115 .818397522115 .2088012695114 .2944030762113 .3800964355 112.1608963013111 .24659729110 .0273971558108 .8082962036107 .5891036987 106.6747970581105 .4557037354104 .5412979126103 .9317016602103 .0174026489 102.4077987671101 .4934005737100 .579101562599 .6647262573298 .14080810547 96.6168823242294 .7881774902392 .349891662689 .9116134643686 .86376190186 83.206336975179 .5489196777375 .8914871215871 .9292907714867 .96708679199 64.3096618652361 .2618103027359 .73788070679 -9999 -9999 -9999 -9999 -9999 -9999 -9999 -9999 -9999 -9999 -9999 -9999 -9999 -9999 -9999 -9999 -9999 -9999 -9999 -9999 -9999 -9999 -9999 -9999 -9999 -9999 -9999 -9999 -9999 -9999 -9999 -9999 -9999 -9999 -9999 -9999 -9999 -9999 -9999 -9999 -9999 -9999 -9999 -9999 -9999 -9999 -9999 -9999 -9999 -9999 -9999 -9999 -9999 -9999 -9999 -9999 -9999 -9999 -9999 -9999 -9999 -9999 -9999 -9999 -9999 -9999 -9999 -9999 -9999 -9999 -9999 -9999 -9999 -9999 -9999 -9999 -9999 -9999 -9999 -

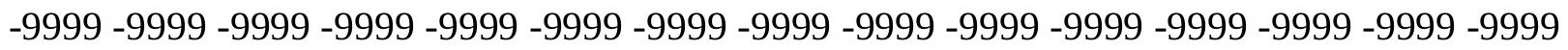
-9999 -9999 -9999 -9999 -9999 -9999 -9999 -9999 -9999 -9999 -9999 -9999 -9999 -9999 -9999 -9999 -9999 -9999 -9999 -9999 -9999 -9999 -9999 -9999 -9999 -9999 -9999 -9999 -9999 -9999 -

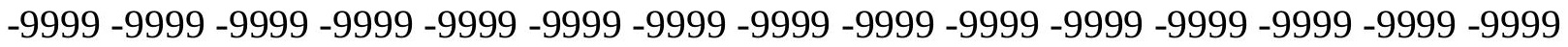

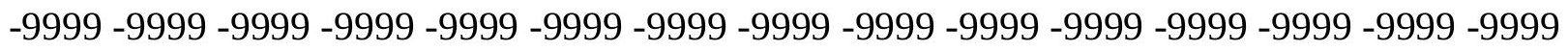

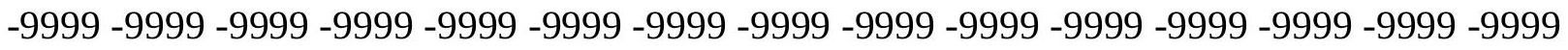
-9999 -9999 -9999 -9999 -9999 -9999 -9999 -9999 -9999 -9999 -9999 -9999 -9999 - 9999 - -999 -9999 -9999 -9999 -9999 -9999-9999 -9999 -9999 -9999 -9999 -9999 -9999 -9999 -9999 - 9999 -9999 135.9342041016 134.1054992676 131.9720001221 129.533706665143.8585968018 126.1809997559126 .7906036377125 .2667007446129 .533706665133 .4958953857 137.1533050537144 .4682006836150 .2590942383146 .9064025879139 .8963928223 132.8863067627126 .7906036377124 .3523025513122 .8283996582121 .9140014648 122.2188034058122 .5235977173123 .43800354124 .3523025513125 .2667007446 126.1809997559126 .7906036377126 .9273376465126 .2214126587129 .533706665 
130.4479980469131 .6672058105132 .5814971924133 .8007049561134 .4102020264 135.0198059082135 .3246002197135 .0198059082134 .7149963379134 .4102020264 133.8007049561133 .1911010742132 .5814971924131 .6672058105131 .0576019287 130.4479980469129 .8385009766129 .2288970947128 .6192932129128 .0097961426 127.0953979492126 .1809997559125 .2667007446123 .7427978516121 .9140014648 120.0852966309117 .9517974854115 .5136032104112 .7705001831109 .7226028442 106.6747970581103 .322196960499 .6647262573296 .3121032714892 .65467834473 88.8563385009886 .8637619018685 .0350494384883 .8159103393682 .90155792236 81.6824111938580 .4632720947378 .9393463134877 .4154205322375 .89148712158 74.062782287672 .2340774536170 .7101516723669 .1862335205167 .96708679199 66.7479400634866 .4431610107466 .7479400634868 .5766525268671 .62449645996 75.5867080688580 .1584930419984 .1206970214886 .5589828491287 .16854858398 86.254188537684 .7302627563583 .206336975181 .9871978759880 .76805877686 79.8537063598679 .5489196777379 .2441329956179 .2441329956179 .24413299561 79.5489196777379 .8537063598680 .1584930419980 .7680587768681 .07285308838 81.6824111938582 .2919769287182 .5967712402383 .206336975183 .81591033936 84.4254837036185 .3398437585 .9494018554786 .8637619018687 .77810668945 88.6924667358489 .6068267822390 .5211791992291 .7403335571392 .95947265625 94.1785964965895 .397743225196 .6168823242297 .8360290527399 .05516815186 100.5791015625101 .7982025146103 .0174026489104 .2365036011105 .4557037354 106.6747970581107 .8938980103109 .1130981445110 .0273971558110 .9418029785 111.8561019897112 .4656982422113 .3800964355113 .9896011353114 .2944030762 114.5991973877114 .9039993286114 .9039993286114 .9039993286115 .2088012695 115.2088012695115 .5136032104115 .818397522116 .1231002808116 .4279022217 116.7326965332117 .0374984741117 .342300415117 .342300415117 .5665359497 117.342300415117 .0374984741116 .7326965332115 .818397522114 .9039993286 113.9896011353112 .7705001831111 .551399231110 .3321990967109 .1130981445 107.8938980103106 .6747970581105 .4557037354104 .5412979126103 .6268997192 102.712600708102 .1029968262101 .188697814999 .9695205688598 .75038146973 97.5312423706196 .0073165893693 .8738174438591 .7403335571389 .3020401001 86.254188537683 .206336975179 .8537063598676 .1962814331172 .53885650635 68.8814392089865 .5288009643662 .4809494018660 .65224075317 -9999 -9999 -9999 -9999 -9999 -9999 -9999 -9999 -9999 -9999 -9999 -9999 -9999 -9999 -9999 -9999 -9999 -9999 -9999 -

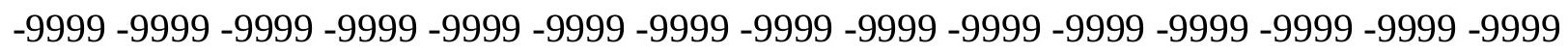
-9999 -9999 -9999 -9999 -9999 -9999 -9999 -9999 -9999 -9999 -9999 -9999 -9999 -9999 -9999

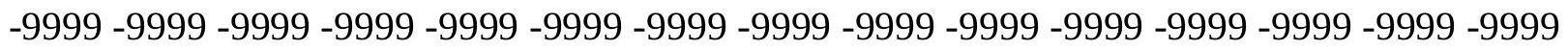

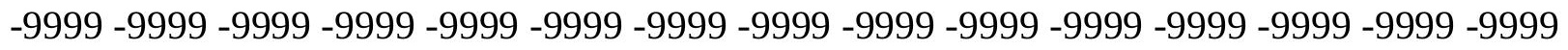

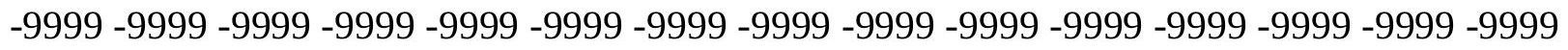

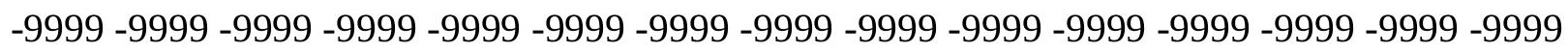
-9999 -9999 -9999 -9999 -9999 -9999 -9999 -9999 -9999 -9999 -9999 -9999 -9999 -9999 -9999 -

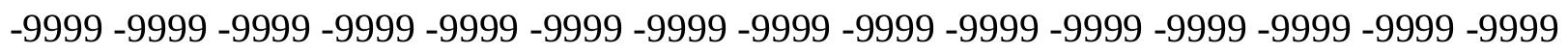

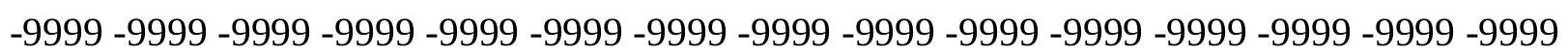
-9999 -9999 -9999 -9999 -9999 -9999 -9999 -9999 -9999 -9999 -9999 -9999 -9999 -9999 -9999 -9999 -9999 -9999 -9999 -9999 -9999 -9999 -9999 -9999 -9999 -9999 -9999 -9999 -9999 -9999 -9999 -9999 -9999 -9999 -9999 -9999 -9999 -9999 -9999 -9999 -9999 -9999 -9999 -9999 -9999 -9999 -9999 -9999 -9999 -9999 -9999 -9999 130.7528076172128.6192932129 143.8585968018 
126.7906036377129 .8385009766139 .8963928223153 .3069000244143 .8585968018 136.8484954834131 .9720001221127 .7050018311124 .0475006104120 .9997024536 118.5614013672118 .5614013672119 .1709976196120 .3900985718121 .6092987061 122.8283996582123 .7427978516124 .3523025513125 .2667007446124 .4137649536 127.0953979492128 .6192932129129 .8385009766131 .3623962402132 .5814971924 133.8007049561134 .4102020264134 .7149963379134 .4102020264134 .1054992676 133.8007049561133 .1911010742132 .5814971924131 .9720001221131 .0576019287 130.4479980469129 .8385009766129 .2288970947128 .6192932129128 .0097961426 127.4001998901126 .7906036377126 .1809997559125 .2667007446124 .3523025513 122.8283996582121 .6092987061119 .7806015015117 .9517974854115 .818397522 113.3800964355110 .6370010376107 .2844009399103 .626899719299 .66472625732 95.7025299072391 .7403335571388 .6924667358487 .1685485839886 .2541885376 85.6446228027384 .7302627563583 .5111236572382 .2919769287180 .76805877686 79.2441329956177 .4154205322375 .5867080688574 .062782287672 .538855650635 71.6244964599670 .7101516723670 .4053573608471 .014930725172 .53885650635 74.9771423339878 .0249862670981 .6824111938584 .4254837036186 .2541885376 86.8637619018686 .254188537684 .7302627563583 .5111236572381 .98719787598 80.7680587768679 .8537063598679 .2441329956178 .9393463134878 .93934631348 78.9393463134879 .2441329956179 .5489196777379 .8537063598680 .15849304199 80.7680587768681 .3776321411181 .6824111938582 .2919769287182 .90155792236 83.5111236572384 .1206970214885 .0350494384885 .9494018554786 .55898284912 87.4733276367288 .3876876831189 .6068267822390 .5211791992291 .74033355713 92.9594726562594 .1785964965895 .397743225196 .9216690063598 .14080810547 99.35994720459100 .8839035034102 .1029968262103 .6268997192104 .8460998535 106.0652008057 107.2844009399 108.5035018921 109.4179000854110.6370010376 111.551399231112 .4656982422113 .075302124113 .6848983765114 .2944030762 114.8163833618115 .2088012695115 .2088012695115 .2088012695115 .2088012695 115.2088012695115 .2088012695115 .5136032104115 .818397522116 .1231002808 116.4279022217117 .0374984741117 .342300415117 .647102356117 .9517974854 117.9517974854 117.9517974854 117.7432327271 117.342300415116.7326965332 115.5136032104114 .5991973877113 .3800964355111 .8561019897110 .6370010376 109.1130981445107 .8938980103106 .6747970581105 .4557037354104 .5412979126 103.3221969604102 .4077987671101 .4934005737100 .579101562599 .35994720459 98.1408081054796.9216690063595.397743225193.2642517089891.13075256348 88.69246673584 85.94940185547 83.206336975179.8537063598676.80584716797 73.4532165527370 .1005783081166 .7479400634863 .3953094482461 .56660079956 -9999

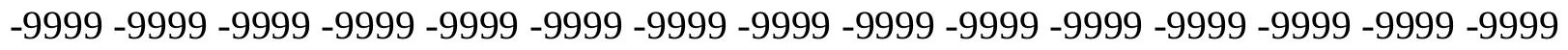

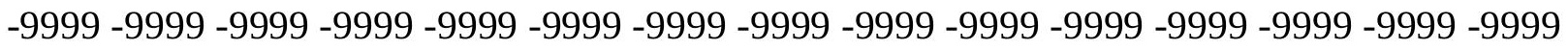

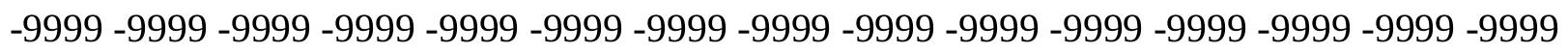
$-9999-9999-9999$ -9999 -9999 -9999 -9999 -9999 -9999 -9999 -9999 -9999 -9999 -9999 -9999 -9999 -9999 -9999 -

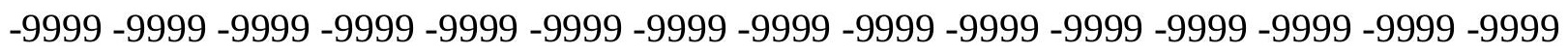

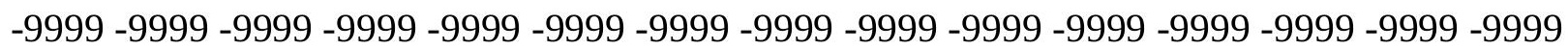

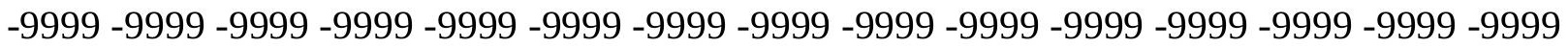

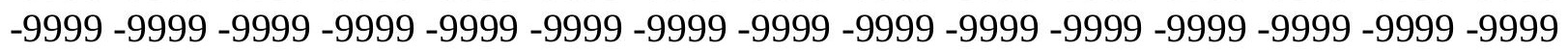

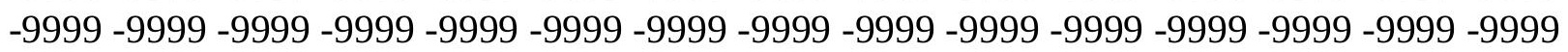


-9999 -9999 -9999 -9999 -9999 -9999 -9999 -9999 -9999 -9999 -9999 -9999 -9999 -9999 -9999 -9999 -9999 -9999 -9999 -9999 -9999 -9999 -9999 -9999 -9999 -9999 -9999 -9999 -9999 -9999

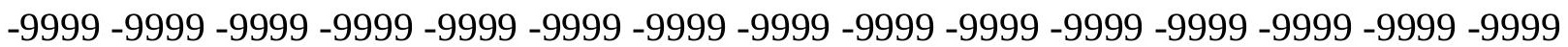
-9999 -9999 -9999 -9999 -9999 -9999 -9999 -9999 -9999 -9999 -9999 -9999 -9999 -9999 -9999 -9999 -9999 -9999 -9999 -9999 -9999 -9999 -9999 -9999 -9999 -9999 -9999 -9999 128.6192932129132 .8863067627131 .6672058105129 .8385009766127 .7050018311 125.5715026855123 .43800354121 .6092987061120 .0852966309118 .5614013672 117.647102356119 .1709976196120 .0852966309120 .9997024536121 .9140014648 122.5235977173122 .0178451538124 .6570968628126 .1809997559127 .7050018311 129.8385009766131 .3623962402132 .8863067627133 .4958953857133 .8007049561 133.4958953857133 .1911010742132 .8863067627132 .2767028809131 .6672058105 131.0576019287130 .1432037354129 .533706665128 .9241027832128 .3144989014 128.0097961426127 .4001998901127 .0953979492126 .4858016968125 .8762969971 125.2667007446124 .6570968628123 .7427978516122 .8283996582121 .6092987061 120.3900985718118 .8662033081117 .0374984741114 .5991973877111 .551399231 107.8938980103103 .626899719299 .3599472045995 .0929565429791 .43553924561 90.4701843261789 .620529174888 .9972534179788 .3876876831187 .16854858398 85.9494018554784 .4254837036182 .9015579223681 .0728530883879 .54891967773 77.7202072143676 .5010681152375 .2819290161174 .6723632812574 .36756896973 74.9771423339875 .8914871215877 .7202072143680 .1584930419982 .59677124023 84.7302627563585 .9494018554786 .254188537685 .6446228027384 .73026275635 83.206336975181 .9871978759880 .7680587768679 .8537063598679 .24413299561 78.6345596313578 .6345596313578 .6345596313578 .9393463134879 .24413299561 79.5489196777379 .8537063598680 .4632720947380 .7680587768681 .37763214111 81.9871978759882 .5967712402383 .5111236572384 .1206970214884 .73026275635 85.6446228027386 .5589828491287 .4733276367288 .3876876831189 .60682678223 90.8259735107491 .7403335571392 .9594726562594 .4833908081195 .70252990723 97.2264633178798 .445587158299 .96952056885101 .1886978149102 .712600708 103.9317016602105 .1509017944106 .3700027466107 .5891036987108 .8082962036 110.0273971558110 .9418029785111 .8561019897112 .7705001831113 .3800964355 114.2944030762114 .7754592896115 .2088012695115 .2088012695115 .2088012695 115.2088012695115 .2088012695115 .2088012695115 .2088012695115 .5136032104 115.5136032104116 .1231002808116 .4279022217117 .0374984741117 .342300415 117.9517974854118 .2565994263118 .5614013672118 .5614013672118 .2644424438 117.7882003784117 .0756225586116 .0748596191114 .9039993286113 .6848983765 112.1608963013110 .6370010376109 .1130981445107 .8938980103106 .3700027466 105.1509017944104 .2365036011103 .0174026489102 .1029968262101 .1886978149 99.9695205688599 .0551681518697 .8360290527396 .3121032714894 .78817749023 92.9594726562590 .8259735107488 .3876876831185 .9494018554782 .90155792236 80.1584930419977 .110626220774 .062782287670 .7101516723667 .66230010986 64.6144485473662 .48094940186 -9999 -9999 -9999 -9999 -9999 -9999 -9999 -9999 -9999

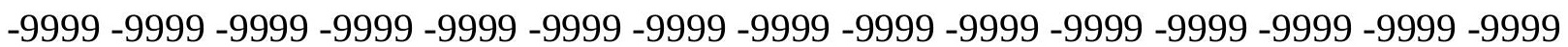
-9999 -9999 -9999 -9999 -9999 -9999 -9999 -9999 -9999 -9999 -9999 -9999 -9999 -9999 -9999 -9999 -9999 -9999 -9999 -9999 -9999 -9999 -9999 -9999 -9999 -9999 -9999 -9999 -9999 -9999 -9999 -9999 -9999 -9999 -9999 -9999 -9999 -9999 -9999 -9999

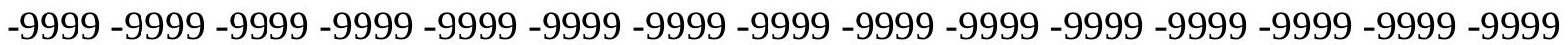


-9999 -9999 -9999 -9999 -9999 -9999 -9999 -9999 -9999 -9999 -9999 -9999 -9999 -9999 -9999 -9999 -9999 -9999 -9999 -9999 -9999 -9999 -9999 -9999 -9999 -9999 -9999 -9999 -9999 -9999

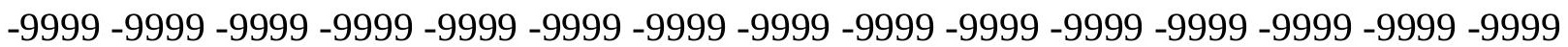
-9999 -9999 -9999 -9999 -9999 -9999 -9999 -9999 -9999 -9999 -9999 -9999 -9999 -9999 -9999 -9999 -9999 -9999 -9999 -9999 -9999 -9999 -9999 -9999 -9999 -9999 -9999 -9999 -9999 -9999 -9999 -9999 -9999 -9999 -9999 -9999 -9999 -9999 -9999 -9999 -9999 -9999 -9999 -9999 -9999 -9999 -9999 -9999 -9999 -9999 -9999 -9999 -9999 -9999 -9999 -9999 -9999 -9999 -9999 -9999

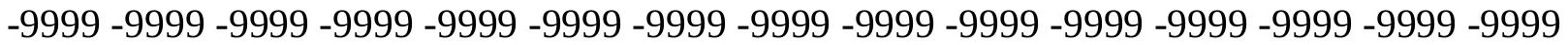
-9999 -9999 -9999 -9999 -9999 -9999 -9999 -9999 -9999 -9999 -9999 -9999 -9999 -9999 -9999 -9999 -9999 -9999 -9999 125.5715026855 124.6570968628123 .43800354121 .9140014648 120.3900985718118 .8662033081117 .9517974854118 .2565994263118 .8662033081 119.7806015015119 .3401412964118 .9322662354123 .1332015991125 .2667007446 127.7050018311129 .8385009766131 .6672058105132 .2767028809132 .5814971924 132.2767028809131 .9720001221131 .3623962402130 .7528076172130 .1432037354 129.533706665128 .9241027832128 .3144989014127 .7050018311127 .0953979492 126.7906036377126 .4858016968126 .1809997559125 .8762969971125 .5715026855 125.2667007446124 .6570968628124 .3523025513123 .7427978516123 .1332015991 122.5235977173121 .9140014648120 .6949005127118 .8662033081115 .818397522 112.1608963013108 .1986999512104 .2365036011100 .274299621697 .22646331787 95.397743225193 .2637481689592 .928298950292 .6546783447391 .43553924561 90.2164001464888 .6924667358486 .8637619018685 .0350494384883 .2063369751 81.6824111938580 .1584930419979 .2441329956178 .6345596313578 .32978057861 78.3297805786178 .9393463134880 .1584930419981 .6824111938583 .51112365723 84.7302627563585 .6446228027385 .6446228027385 .0350494384884 .12069702148 82.9015579223681 .6824111938580 .4632720947379 .5489196777378 .93934631348 78.6345596313578 .3297805786178 .3297805786178 .6345596313578 .93934631348 79.2441329956179 .5489196777380 .1584930419980 .7680587768681 .07285308838 81.9871978759882 .5967712402383 .206336975184 .1206970214884 .73026275635 85.6446228027386 .5589828491287 .4733276367288 .6924667358489 .60682678223 90.8259735107492 .0450973510793 .2642517089894 .7881774902396 .00731658936 97.5312423706198 .75038146973100 .2742996216101 .4934005737103 .0174026489 104.2365036011105 .7603988647106 .979598999108 .1986999512109 .4179000854 110.3321990967111 .24659729112 .1608963013113 .075302124113 .9896011353 114.5991973877114 .9039993286115 .2088012695115 .5136032104115 .2088012695 115.2088012695114 .9039993286114 .9039993286114 .9039993286115 .2088012695 115.2088012695115 .818397522116 .1231002808116 .7326965332117 .647102356 117.9517974854118 .5614013672118 .8662033081118 .8662033081118 .5915145874 118.0582199097117 .3015670776116 .3418807983115 .1759490967113 .6848983765 112.1608963013110 .6370010376109 .1130981445107 .5891036987106 .3700027466 105.1509017944103 .9317016602102 .712600708101 .7982025146100 .8839035034 99.6647262573298 .445587158297 .2264633178795 .7025299072394 .17859649658 92.349891662690 .2164001464888 .0829010009885 .6446228027382 .90155792236 80.1584930419977 .4154205322374 .3675689697371 .6244964599668 .57665252686 65.5288009643663 .39530944824 -9999 -9999 -9999 -9999 -9999 -9999 -9999 -9999 -9999 -9999 -9999 -9999 -9999 -9999 -9999 -9999 -9999 -9999 -9999 -9999 -9999 -9999 -9999 -9999

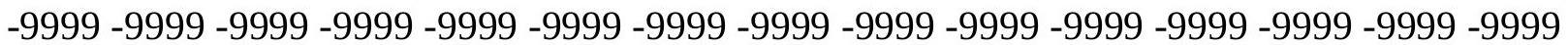


-9999 -9999 -9999 -9999 -9999 -9999 -9999 -9999 -9999 -9999

-9999 -9999 -9999 -9999 -9999 -9999 -9999 -9999 -9999 -9999 -9999 -9999 -9999 -9999 -9999

-9999 -9999 -9999 -9999 -9999 -9999 -9999 -9999 -9999 -9999 -9999 -9999 -9999 -9999 -9999

-9999 -9999 -9999 -9999 -9999 -9999 -9999 -9999 -9999 -9999 -9999 -9999 -9999 -9999 -9999

-9999 -9999 -9999 -9999 -9999 -9999 -9999 -9999 -9999 -9999 -9999 -9999 -9999 -9999 -9999 -

-9999 -9999 -9999 -9999 -9999 -9999 -9999 -9999 -9999 -9999 -9999 -9999 -9999 -9999 -9999 -

-9999 -9999 -9999 -9999 -9999 -9999 -9999 -9999 -9999 -9999 -9999 -9999 -9999 -9999 -9999

-9999 -9999 -9999 -9999 -9999 -9999 -9999 -9999 -9999 -9999 -9999 -9999 -9999 -9999 -9999 -

-9999 -9999 -9999 -9999 -9999 -9999 -9999 -9999 -9999 -9999 -9999 -9999 -9999 -9999 -9999

-9999 -9999 -9999 -9999 -9999 -9999 -9999 -9999 -9999 -9999 -9999 -9999 -9999 -9999 -9999 -

-9999 -9999 -9999 -9999 -9999 -9999 -9999 -9999 -9999 -9999 -9999 -9999 -9999 -9999 -9999

-9999 -9999 -9999 -9999 -9999 -9999 -9999 -9999 -9999 -9999 -9999 -9999 -9999 -9999 -9999

-9999 -9999 -9999 -9999 -9999 -9999 -9999 -9999 -9999 121.6092987061119 .7806015015

118.2565994263117 .0374984741116 .4279022217117 .0374984741117 .2326660156

119.4757995605121 .6092987061124 .9618988037128 .0097961426130 .4479980469

130.7528076172130 .4479980469130 .4479980469130 .1432037354129 .533706665

129.2288970947 128.6192932129 128.0097961426127.4001998901 126.7906036377

126.1809997559125 .5715026855125 .2667007446124 .9618988037124 .9618988037

124.6570968628124 .6570968628124 .6570968628124 .6570968628124 .3523025513 124.3523025513124 .3523025513124 .3523025513124 .0475006104123 .7427978516 122.8283996582120 .0852966309116 .7326965332113 .075302124109 .4179000854 106.3700027466103 .6268997192101 .493400573799 .9695205688596 .73207855225 96.4069290161195 .7403259277394 .7881774902392 .9594726562591 .13075256348 88.9972534179787 .1685485839885 .3398437583 .8159103393682 .90155792236 82.2919769287181 .9871978759881 .6824111938581 .6824111938582 .29197692871 82.9015579223683 .8159103393684 .7302627563585 .0350494384885 .03504943848 84.4254837036183 .5111236572382 .5967712402381 .3776321411180 .15849304199 79.2441329956178 .6345596313578 .3297805786178 .3297805786178 .32978057861 78.3297805786178 .6345596313578 .9393463134879 .5489196777379 .85370635986 80.4632720947381 .0728530883881 .6824111938582 .2919769287183 .2063369751 84.1206970214884 .7302627563585 .6446228027386 .5589828491287 .77810668945 88.6924667358489 .9116134643691 .1307525634892 .349891662693 .56903076172 95.0929565429796 .3121032714897 .8360290527399 .35994720459100 .5791015625 102.1029968262103 .3221969604104 .8460998535106 .0652008057107 .2844009399 108.5035018921109 .7226028442110 .9418029785111 .8561019897112 .7705001831 113.3800964355113 .9896011353114 .5991973877115 .2088012695115 .2088012695 115.2088012695115 .2088012695114 .9039993286114 .9039993286114 .5991973877 114.5991973877114 .5991973877114 .9039993286115 .2088012695115 .818397522 116.7326965332117 .342300415118 .2565994263118 .8662033081119 .1709976196 119.1709976196118 .7783889771118 .1986541748117 .4219741821116 .4479980469 115.2879943848113 .9698257446112 .4656982422110 .6370010376109 .1130981445 107.5891036987106 .0652008057104 .5412979126103 .6268997192102 .4077987671 101.4934005737100 .274299621699 .3599472045998 .1128768920996 .79039764404 95.3740310668993 .8738174438592 .0450973510789 .9116134643687 .77810668945 85.6446228027383 .206336975180 .4632720947377 .7202072143674 .97714233398 72.2340774536169 .4910125732466 .4431610107464 .30966186523 -9999 -9999 -9999 -9999 
-9999 -9999 -9999 -9999 -9999 -9999 -9999 -9999 -9999 -9999 -9999 -9999 -9999 -9999 -9999 -9999 -9999 -9999 -9999 -9999 -9999 -9999 -9999 -9999 -9999 -9999 -9999 -9999 -9999 -9999

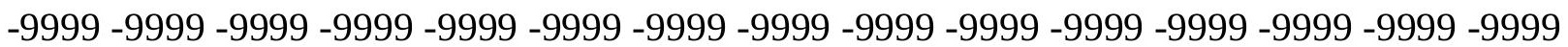
-9999 -9999 -9999 -9999 -9999 -9999 -9999 -9999 -9999 -9999 -9999 -9999 -9999 -9999 -9999 -9999 -9999 -9999 -9999 -9999 -9999 -9999 -9999 -9999 -9999 -9999 -9999 -9999 -9999 -9999 -9999 -9999 -9999 -9999 -9999 -9999 -9999 -9999 -9999 -9999 -9999 -9999 -9999 -9999 -9999 -9999 -9999 -9999 -9999 -9999 -9999 -9999 -9999 -9999 -9999 -9999 -9999 -9999 -9999 -9999

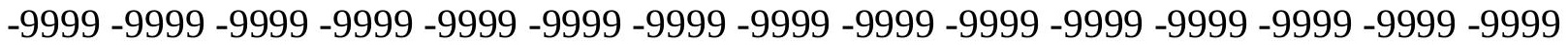

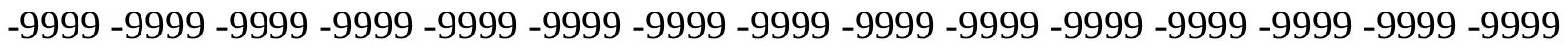
-9999 -9999 -9999 -9999 -9999 -9999 -9999 -9999 -9999 -9999 -9999 -9999 -9999 -9999 -9999 -9999 -9999 -9999 -9999 -9999 -9999 -9999 -9999 -9999 -9999 -9999 -9999 -9999 -9999 -9999 -9999 -9999 -9999 -9999 -9999 -9999 -9999 -9999 -9999 -9999 -9999 -9999 -9999 -9999 -9999

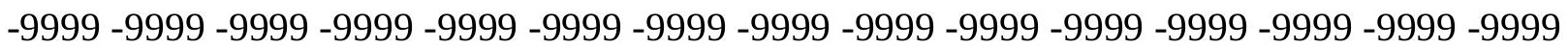
-9999 -9999 -9999 -9999 -9999 -9999 -9999 -9999 -9999 -9999 -9999 -9999 -9999 -9999 -9999 -9999 -9999 -9999 -9999 -9999 -9999 -9999 -9999 -9999 -9999 -9999 120.0852966309 117.9517974854116 .7326965332115 .2088012695113 .9896011353114 .9039993286 117.0374984741121 .3044967651126 .4858016968128 .3144989014128 .0097961426 127.7050018311127 .7050018311127 .7050018311127 .7050018311127 .0953979492 126.7906036377126 .1809997559125 .5715026855124 .9618988037124 .3523025513 124.0475006104123 .7427978516123 .43800354123 .43800354123 .43800354123 .7427978516 123.7427978516124 .0475006104124 .3523025513124 .6570968628124 .9618988037 125.2667007446125 .5715026855125 .5715026855124 .9618988037123 .1332015991 120.3900985718117 .647102356114 .9039993286112 .1608963013109 .7226028442 107.5891036987105 .7603988647103 .9317016602100 .090072631899 .64264678955 98.8183441162197 .5312423706195 .7025299072393 .2642517089890 .82597351074 88.69246673584 87.16854858398 86.2541885376 85.9494018554785.33984375 84.4254837036183 .8159103393683 .8159103393684 .1206970214884 .42548370361 84.7302627563585 .0350494384884 .7302627563584 .1206970214883 .2063369751 82.2919769287181 .0728530883880 .1584930419978 .9393463134878 .63455963135 78.3297805786178 .3297805786178 .3297805786178 .3297805786178 .63455963135 78.9393463134879 .5489196777379 .8537063598680 .4632720947381 .07285308838 81.6824111938582 .5967712402383 .206336975184 .1206970214885 .03504943848 85.9494018554786 .8637619018687 .7781066894588 .9972534179789 .91161346436 91.1307525634892 .6546783447393 .8738174438595 .397743225196 .92166900635 98.1408081054799 .66472625732101 .1886978149102 .4077987671103 .9317016602 105.4557037354106 .6747970581107 .8938980103109 .1130981445110 .3321990967 111.24659729112 .1608963013113 .075302124113 .6848983765114 .2944030762 114.9039993286115 .2088012695115 .2088012695115 .2088012695114 .9039993286 114.9039993286114 .5991973877114 .2944030762113 .9896011353113 .9896011353 114.2944030762114 .5991973877115 .5136032104116 .4279022217117 .342300415 118.2565994263118 .8662033081119 .1709976196119 .1709976196118 .8663253784 118.2507781982117 .4534301758116 .4784545898115 .3370513916113 .9896011353 112.1608963013110 .6370010376108 .8082962036107 .2844009399105 .4557037354 104.5412979126103 .3221969604102 .1029968262101 .188697814999 .96952056885 99.0551681518697 .8360290527396 .3121032714895 .0897140502993 .26425170898 91.7398910522589 .8029098510787 .7781066894585 .3398437583 .2063369751 
80.7680587768678 .0249862670975 .5867080688572 .8436431884870 .10057830811 67.3575134277364 .9192428588963 .09051895142 -9999 -9999 -9999 -9999 -9999 -9999 -9999 -9999 -9999 -9999 -9999 -9999 -9999 -9999 -9999 -9999 -9999 -9999 -9999 -9999 -9999 -9999

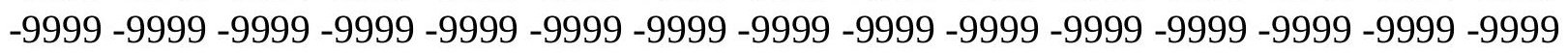
-9999 -9999 -9999-9999 -9999 -9999-9999 -9999 -9999-9999-9999 -9999 -9999 -9999 -9999 -9999 -9999 -9999 -9999 -9999 -9999 -9999 -9999 -9999 -9999 -9999

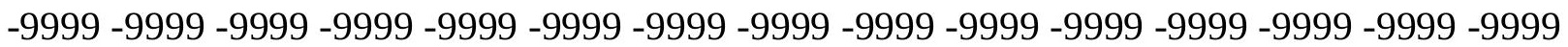

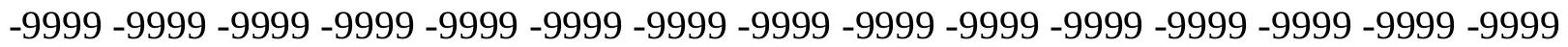
-9999 -9999 -9999 -9999 -9999 -9999 -9999 -9999 -9999 -9999 -9999 -9999 -9999 -9999 -9999 -9999 -9999 -9999 -9999 -9999 -9999 -9999 -9999 -9999 -9999 -9999 -9999 -9999 -9999 -9999 -9999 -9999 -9999 -9999 -9999 -9999 -9999 -9999 -9999 -9999 -9999 -9999 -9999 -9999 -9999 -

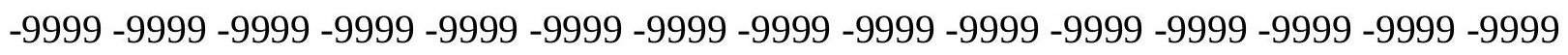
-9999 -9999 -9999 -9999 -9999 -9999 -9999 -9999 -9999 -9999 -9999 -9999 -9999 -9999 -9999 -9999 -9999 -9999 -9999 -9999 -9999 -9999 -9999 -9999 -9999 -9999 -9999 -9999 -9999 -9999 -9999 -9999 -9999 -9999 -9999 -9999 -9999 -9999 -9999 -9999 -9999 -9999 -9999 -9999 -9999

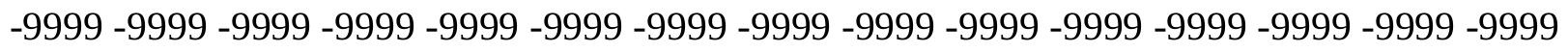
-9999 -9999 -9999 -9999 -9999 -9999 -9999 -9999 -9999 -9999 -9999 -9999 -9999 117.647102356116 .1231002808114 .5991973877113 .3800964355112 .4656982422 114.2944030762126 .1809997559123 .7427978516123 .1332015991124 .0475006104 124.6570968628124 .9618988037125 .2667007446124 .9618988037124 .3523025513 124.0475006104123 .43800354122 .8283996582122 .2188034058121 .9140014648 121.6092987061121 .6092987061121 .6092987061121 .9140014648122 .2188034058 122.8283996582123 .43800354124 .0475006104124 .6570968628125 .2667007446 125.8762969971126 .4858016968126 .7906036377126 .4858016968125 .2667007446 123.7427978516121 .6092987061119 .7806015015117 .647102356115 .818397522 113.3800964355111 .24659729109 .1130981445107 .2844009399103 .2184906006 102.5944213867101 .6486663818100 .274299621697 .5312423706194 .48339080811 91.4355392456189 .6068267822388 .9972534179789 .302040100187 .77810668945 86.5589828491285 .6446228027385 .3398437585 .0350494384885 .03504943848 85.0350494384884 .7302627563584 .4254837036183 .8159103393683 .2063369751 82.2919769287181 .0728530883880 .1584930419979 .2441329956178 .93934631348 78.6345596313578 .3297805786178 .3297805786178 .6345596313578 .63455963135 79.2441329956179 .5489196777380 .1584930419980 .4632720947381 .07285308838 81.9871978759882 .5967712402383 .5111236572384 .4254837036185 .33984375 86.254188537687 .1685485839888 .0829010009889 .302040100190 .52117919922 91.7403335571392 .9594726562594 .4833908081195 .7025299072397 .22646331787 98.75038146973100 .2742996216101 .4934005737103 .0174026489104 .5412979126 105.7603988647107 .2844009399108 .5035018921109 .7226028442110 .6370010376 111.8561019897112 .7705001831113 .3800964355113 .9896011353114 .5991973877 114.9039993286115 .2088012695115 .2088012695115 .2088012695114 .9039993286 114.5991973877114 .2944030762113 .6848983765113 .3800964355113 .3800964355 113.6848983765113 .9896011353114 .9039993286116 .1231002808117 .342300415 118.2565994263118 .8662033081119 .1709976196119 .1709976196118 .8662033081 118.243888855117 .4359817505116 .4279022217115 .2088012695113 .6848983765 112.1608963013110 .3321990967108 .8082962036107 .2844009399105 .4557037354 104.2365036011103 .0174026489102 .1029968262100 .883903503499 .66472625732 
98.7503814697397 .5312423706196 .0073165893694 .7881774902393 .25684356689 91.4355392456189 .6068267822387 .4733276367285 .3398437583 .2063369751 80.7680587768678 .3297805786175 .8914871215873 .4532165527370 .71015167236 67.9670867919965 .5288009643663 .70008850098 -9999 -9999 -9999 -9999 -9999 -9999 -9999 -9999 -9999 -9999 -9999 -9999 -9999 -9999 -9999 -9999 -9999 -9999 -9999 -9999 -9999 -9999 -

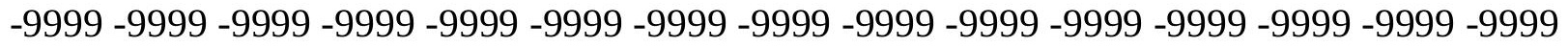
-9999 -9999 -9999 -9999 -9999 -9999 -9999 -9999 -9999 -9999 -9999 -9999 -9999 -9999 -9999 -9999 -9999 -9999 -9999 -9999 -9999 -9999 -9999 -9999 -9999 -9999 -9999 -9999 -9999 -9999 -9999 -9999 -9999 -9999 -9999 -9999 -9999 -9999 -9999 -9999 -9999 -9999 -9999 -9999 -9999 -9999 -9999 -9999 -9999 -9999 -9999 -9999 -9999 -9999 -9999 -9999 -9999 -9999 -9999 -9999 -9999 -9999 -9999 -9999 -9999 -9999 -9999 -9999 -9999 -9999 -9999 -

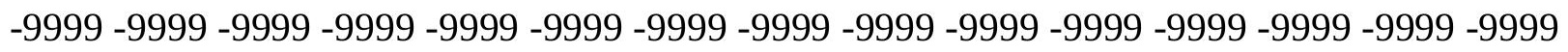
-9999 -9999 -9999 -9999 -9999 -9999 -9999 -9999 -9999 -9999 -9999 -9999 -9999 -9999 -9999 -9999 -9999 -9999 -9999 -9999 -9999 -9999 -9999 -9999 -9999 -9999 -9999 -9999 -9999 -9999 -9999 -9999 -9999 -9999 -9999 -9999 -9999 -9999 -9999 -9999 -9999 -9999 -9999 -9999 -9999

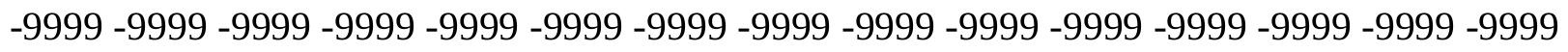

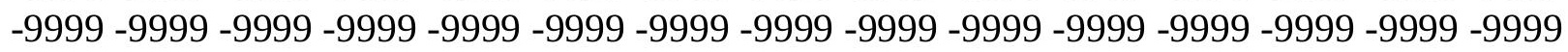

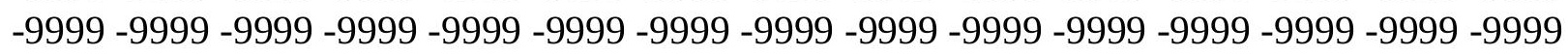
-9999 -9999 -9999 -9999 -9999 -9999 -9999 -9999 -9999 -9999 -9999 -9999 -9999 -9999 -9999 118.5614013672114 .2944030762113 .3800964355112 .7705001831112 .7705001831 114.5991973877117 .647102356119 .7806015015121 .3044967651122 .2188034058 122.5235977173122 .5235977173121 .9140014648121 .3044967651120 .6949005127 120.0852966309119 .7806015015119 .4757995605119 .1709976196119 .1709976196 119.4757995605120 .0852966309120 .6949005127121 .6092987061122 .2188034058 123.1332015991124 .3523025513125 .2667007446126 .1809997559126 .7906036377 127.4001998901127 .4001998901126 .7906036377126 .1809997559124 .9618988037 123.7427978516122 .2188034058120 .9997024536118 .5614013672116 .1231002808 113.6848983765111 .8561019897110 .3321990967106 .0068740845105 .1743927002 103.7563400269101 .566741943498 .7503814697394 .7881774902391 .43553924561 90.5211791992290 .5211791992289 .9116134643688 .6924667358487 .47332763672 86.5589828491285 .9494018554785 .6446228027385 .3398437585 .03504943848 84.4254837036184 .1206970214883 .206336975182 .5967712402381 .37763214111 80.7680587768679 .8537063598679 .2441329956178 .9393463134878 .63455963135 78.6345596313578 .9393463134879 .2441329956179 .5489196777379 .85370635986 80.4632720947380 .7680587768681 .3776321411182 .2919769287182 .90155792236 83.8159103393684 .7302627563585 .6446228027386 .5589828491287 .77810668945 88.69246673584 89.9116134643691.1307525634892.349891662693.56903076172 95.0929565429796 .3121032714897 .8360290527399 .35994720459100 .8839035034 102.1029968262103 .6268997192105 .1509017944106 .3700027466107 .8938980103 109.1130981445110 .3321990967111 .24659729112 .1608963013113 .075302124 113.9896011353114 .5991973877114 .9039993286115 .2088012695115 .5136032104 115.2088012695115 .2088012695114 .9039993286114 .2944030762113 .9896011353 113.3800964355113 .075302124112 .7705001831112 .7705001831113 .3800964355 114.5991973877115 .818397522117 .0374984741117 .9517974854118 .5614013672 118.8662033081118 .8662033081118 .5614013672117 .9517974854117 .0374984741 116.1231002808114 .9039993286113 .3800964355111 .8561019897110 .3321990967 
108.8082962036106 .979598999105 .7603988647104 .2365036011103 .0174026489 101.7982025146100 .883903503499 .6647262573298 .445587158297 .22646331787 96.0073165893694 .4833908081192 .9594726562591 .1307525634889 .3020401001 87.47332763672 85.33984375 83.2063369751 81.07285308838 78.63455963135

76.1962814331173 .7580032348671 .3197174072368 .8814392089866 .44316101074 64.30966186523 -9999 -9999 -9999 -9999 -9999 -9999 -9999 -9999 -9999 -9999 -9999 -9999 -9999 -9999 -9999 -9999 -9999 -9999 -9999 -9999 -9999 -9999 -9999 -9999 -9999 -9999 -9999

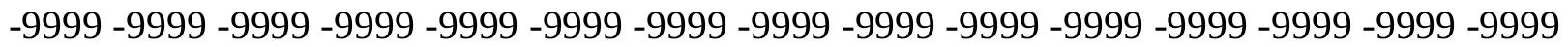
-9999 -9999 -9999-9999-9999-9999

-9999 -9999 -9999 -9999 -9999 -9999 -9999 -9999 -9999 -9999 -9999 -9999 -9999 -9999 -9999 -9999 -9999 -9999 -9999 -9999 -9999 -9999 -9999 -9999 -9999 -9999 -9999 -9999 -9999 -9999 -9999 -9999 -9999 -9999 -9999 -9999 -9999 -9999 -9999 -9999 -9999 -9999 -9999 -9999 -9999 -9999 -9999 -9999 -9999 -9999 -9999 -9999 -9999 -9999 -9999 -9999 -9999 -9999 -9999 -9999 -9999 -9999 -9999 -9999 -9999 -9999 -9999 -9999 -9999 -9999 -9999 -9999 -9999 -9999 - 9999 -9999 -9999 -9999 -9999 -9999 -9999 -9999 -9999 -9999 -9999 -9999 -9999 -9999 -9999 -9999

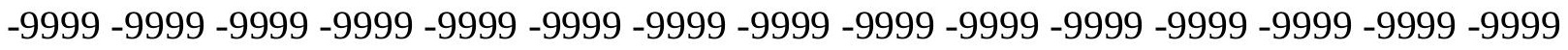
-9999 -9999 -9999 -9999 -9999 -9999 -9999 -9999 -9999 -9999 -9999 -9999 -9999 -9999 -9999 -9999 -9999 -9999 -9999 -9999 -9999 -9999 -9999 -9999 -9999 -9999 -9999 -9999 -9999 -9999 -9999 -9999 -9999 -9999 -9999 -9999 -9999 -9999 -9999 -9999 -9999 -9999 -9999 -9999 -9999 -

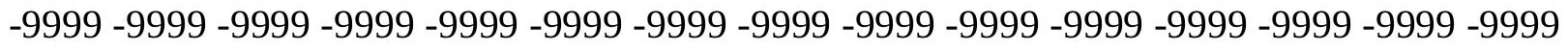

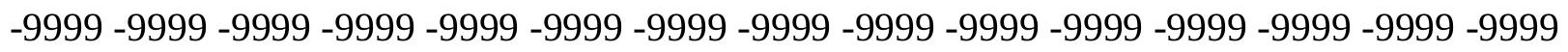
-9999 -9999 114.2944030762 113.9896011353114.2944030762 114.9039993286 115.2088012695116 .1231002808117 .9517974854119 .1709976196119 .7806015015 119.7806015015119 .4757995605118 .8662033081118 .2565994263117 .647102356 117.0374984741116 .7326965332116 .7326965332116 .7326965332117 .342300415 117.9517974854118 .8662033081120 .0852966309120 .9997024536122 .2188034058 123.43800354124 .6570968628125 .8762969971126 .7906036377127 .7050018311 128.0097961426128 .0097961426127 .7050018311127 .0953979492126 .4858016968 125.2667007446124 .0475006104121 .9140014648119 .7806015015117 .647102356 115.818397522114 .2944030762113 .075302124111 .551399231107 .0448379517 105.2526168823102 .874603271599 .6647262573293 .5690307617293 .56903076172 92.9594726562592 .0450973510790 .8259735107489 .302040100188 .08290100098 87.1685485839886 .5589828491285 .9494018554785 .3398437585 .03504943848 84.4254837036183 .8159103393682 .9015579223682 .2919769287181 .37763214111 80.4632720947380 .1584930419979 .5489196777379 .5489196777379 .24413299561 79.5489196777379 .5489196777380 .1584930419980 .4632720947380 .76805877686 81.37763214111 81.98719787598 82.59677124023 83.51112365723 84.42548370361 85.33984375 86.2541885376 87.16854858398 88.38768768311 89.3020401001 90.5211791992291 .7403335571392 .9594726562594 .1785964965895 .70252990723 97.2264633178798.445587158299.96952056885 101.4934005737103 .0174026489 104.2365036011105 .7603988647106 .979598999108 .5035018921109 .7226028442 110.6370010376111 .8561019897112 .7705001831113 .6848983765114 .2944030762 114.9039993286115 .2088012695115 .5136032104115 .5136032104115 .5136032104 115.2088012695114 .9039993286114 .2944030762113 .9896011353113 .3800964355 112.7705001831112 .1608963013112 .1608963013113 .075302124114 .2944030762 115.5136032104116 .4279022217117 .647102356117 .9517974854118 .2565994263 
118.2565994263117.9517974854 117.342300415 116.4279022217115.5136032104 114.2944030762113 .075302124111 .551399231110 .0273971558108 .5035018921 106.979598999105 .4557037354104 .2365036011103 .0174026489101 .7982025146 100.579101562599 .3599472045998 .445587158296 .9216690063595 .70252990723 94.1785964965892 .6546783447391 .1307525634889 .302040100187 .47332763672 85.3398437583 .5111236572381 .0728530883878 .9393463134876 .50106811523 $74.3675689697371 .9292907714869 .1862335205166 .7479400634864 .91924285889-9999$ -9999 -9999 -9999 -9999 -9999 -9999 -9999 -9999 -9999 -9999 -9999 -9999 -9999 -9999 -9999

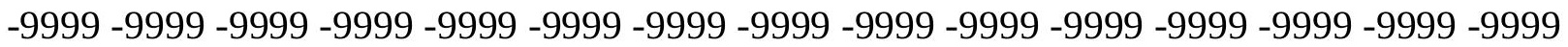

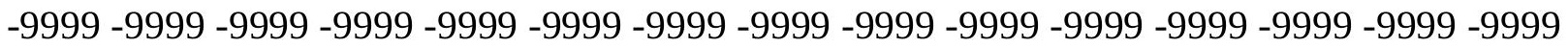
$-9999-9999$

-9999 -9999 -9999 -9999 -9999 -9999 -9999 -9999 -9999 -9999 -9999 -9999 -9999 -9999 -9999 -9999 -9999 -9999 -9999 -9999 -9999 -9999 -9999 -9999 -9999 -9999 -9999 -9999 -9999 -9999 -9999 -9999 -9999 -9999 -9999 -9999 -9999 -9999 -9999 -9999 -9999 -9999 -9999 -9999 -9999 -9999 -9999 -9999 -9999 -9999 -9999 -9999 -9999 -9999 -9999 -9999 -9999 -9999 -9999 -9999 -9999 -9999 -9999 -9999 -9999 -9999 -9999 -9999 -9999 -9999 -9999 -9999 -9999 - -9999 - -9999 -9999 -9999 -9999 -9999 -9999 -9999 -9999 -9999 -9999 -9999 -9999 -9999 -9999 -9999 -9999 -9999 -9999 -9999 -9999 -9999 -9999 -9999 -9999 -9999 -9999 -9999 -9999 -9999 -9999 -9999 -999 -9999 -9999 -9999 -9999 -9999 -9999 -9999 -9999 -9999 -9999 -9999 -9999 -9999 -9999 -9999

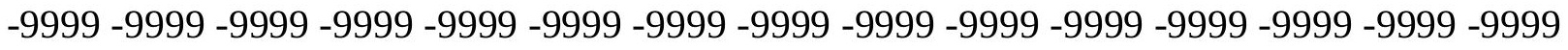
-9999 -9999 -9999 -9999 -9999 -9999 -9999 -9999 -9999 -9999 -9999 -9999 -9999 -9999 -9999 -9999 -9999 -9999 -9999 -9999 -9999 -9999 -9999 -9999 -9999 -9999 -9999 -9999 -9999 -9999 -9999 -9999 -9999 -9999 -9999 -9999 -9999 -9999 -9999 -9999 -9999 -9999 -9999 -9999 -9999 -9999 -9999 -9999 -9999 116.1231002808 117.0374984741 117.342300415 117.0374984741 116.1231002808116 .1231002808116 .7326965332116 .7326965332116 .4279022217 115.818397522115 .2088012695114 .5991973877113 .9896011353113 .6848983765 113.9896011353114 .2944030762114 .9039993286115 .818397522117 .0374984741 118.2565994263119 .4757995605120 .9997024536122 .5235977173124 .0475006104 125.2667007446126 .4858016968127 .4001998901128 .3144989014128 .6192932129 128.9241027832128 .6192932129128 .0097961426127 .4001998901126 .1809997559 124.6570968628122 .8283996582120 .9997024536119 .1709976196117 .9517974854 116.7326965332115 .5136032104114 .5991973877108 .6655349731106 .7045288086 104.4346923828102 .71260070899 .0551681518696 .9216690063595 .09295654297 93.2642517089891 .7403335571390 .2164001464888 .6924667358487 .77810668945 86.8637619018686 .254188537685 .6446228027385 .3398437584 .73026275635 84.1206970214883 .206336975182 .2919769287181 .6824111938581 .07285308838 80.4632720947380 .1584930419980 .1584930419980 .4632720947380 .46327209473 80.7680587768681 .3776321411181 .6824111938582 .2919769287182 .59677124023 83.5111236572384 .1206970214885 .0350494384885 .9494018554786 .86376190186 88.0829010009888 .9972534179790 .2164001464891 .4355392456192 .65467834473 93.8738174438595.0929565429796.61688232422 97.8360290527399.35994720459 100.8839035034102 .1029968262103 .6268997192105 .1509017944106 .3700027466 107.8938980103109 .1130981445110 .3321990967111 .24659729112 .4656982422 113.3800964355114 .2944030762114 .9039993286115 .2088012695115 .818397522 115.818397522115 .818397522115 .818397522115 .5136032104114 .9039993286 114.5991973877113 .9896011353113 .3800964355112 .7705001831112 .4656982422 
112.4656982422113 .075302124113 .9896011353115 .2088012695116 .1231002808 117.0374984741117 .342300415117 .647102356117 .647102356117 .342300415 116.7326965332115 .818397522114 .9039993286113 .9896011353112 .4656982422 111.24659729109 .7226028442108 .5035018921106 .979598999105 .4557037354 104.2365036011103 .0174026489101 .7982025146100 .579101562599 .35994720459 98.1408081054796.9216690063595.7025299072394.1785964965892.65467834473 91.1307525634889 .302040100187 .4733276367285 .5533447265683 .51112365723 81.3776321411179 .2441329956176 .8058471679774 .6723632812572 .23407745361 69.7957916259867 .3575134277365 .52880096436 -9999 -9999 -9999 -9999 -9999 -9999 -9999 -9999 -9999 -9999 -9999 -9999 -9999 -9999 -9999 -9999 -9999 -9999 -9999 -9999 -9999 -9999 -9999 -9999 -9999 -9999 -9999 -9999 -9999 -9999 -9999 -9999 -9999 -9999 -9999 -9999 -9999 -

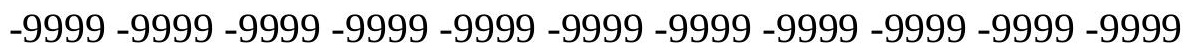

-9999 -9999 -9999 -9999 -9999 -9999 -9999 -9999 -9999 -9999 -9999 -9999 -9999 -9999 -9999 -9999 -9999 -9999 -9999 -9999 -9999 -9999 -9999 -9999 -9999 -9999 -9999 -9999 -9999 -9999 -9999 -9999 -9999 -9999 -9999 -9999 -9999 -9999 -9999 -9999 -9999 -9999 -9999 -9999 -9999

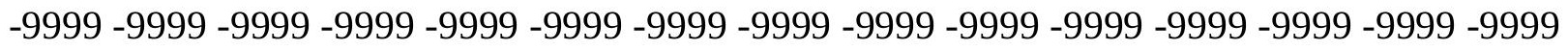
-9999 -9999 -9999 -9999 -9999 -9999 -9999 -9999 -9999 -9999 -9999 -9999 -9999 -9999 -9999 -9999 -9999 -9999 -9999 -9999 -9999 -9999 -9999 -9999 -9999 -9999 -9999 -9999 -9999 -9999 -

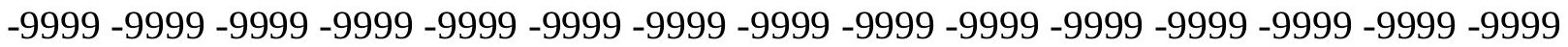

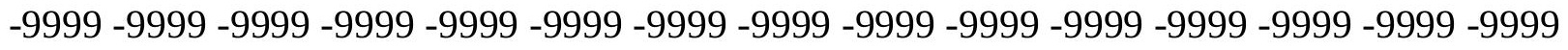

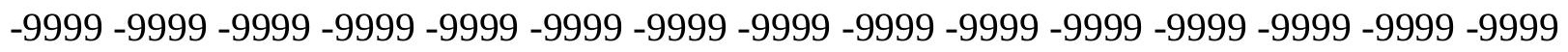
-9999 -9999 -9999 -9999 -9999 -9999 -9999 -9999 -9999 -9999 -9999 -9999 -9999 -9999 -9999 -9999 -9999 -9999 -9999 -9999 -9999 -9999 -9999 -9999 -9999 -9999 -9999 -9999 -9999 -9999 -

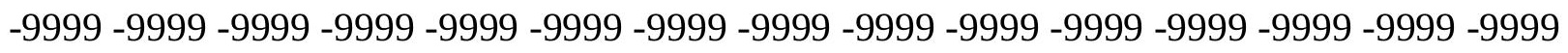
-9999-9999-9999-9999-9999-9999-9999 118.8662033081117 .9517974854116 .7326965332 114.9039993286113 .6848983765113 .3800964355113 .075302124112 .4656982422 111.551399231110 .9418029785110 .9418029785110 .9418029785111 .551399231 112.1608963013113 .3800964355114 .9039993286116 .4279022217117 .9517974854 119.4757995605121 .3044967651122 .8283996582124 .3523025513125 .8762969971 127.0953979492128 .0097961426128 .9241027832129 .2288970947129 .2288970947 129.2288970947 128.6192932129 127.4001998901 126.1809997559 124.6570968628 123.1332015991121 .9140014648120 .6949005127119 .7806015015118 .8662033081 118.2565994263117 .9517974854110 .3387374878108 .6418914795106 .7617111206 104.1055908203101 .798202514699 .0551681518696 .6168823242294 .48339080811 92.6546783447390 .8259735107489 .302040100188 .0829010009887 .47332763672 87.1685485839886 .8637619018686 .254188537685 .3398437584 .73026275635 83.8159103393682 .9015579223682 .2919769287181 .6824111938581 .37763214111 81.3776321411181 .6824111938581 .9871978759882 .2919769287182 .59677124023 82.9015579223683 .206336975183 .8159103393684 .4254837036185 .03504943848 85.9494018554786 .8637619018687 .7781066894588 .9972534179790 .21640014648 91.1307525634892 .349891662693 .5690307617294 .7881774902396 .00731658936 97.5312423706198 .75038146973100 .2742996216101 .4934005737103 .0174026489 104.5412979126105 .7603988647107 .2844009399108 .5035018921109 .7226028442 110.9418029785112 .1608963013113 .075302124113 .9896011353114 .5991973877 115.2088012695115 .818397522116 .1231002808116 .4279022217116 .1231002808 116.1231002808115 .5136032104115 .2088012695114 .5991973877113 .9896011353 
113.6848983765113 .075302124112 .7705001831112 .7705001831113 .3800964355 113.9896011353114 .9039993286115 .818397522116 .4279022217116 .7326965332 117.0374984741117 .0374984741116 .4279022217116 .1231002808115 .2088012695 114.2944030762113 .3800964355112 .1608963013110 .9418029785109 .4179000854 108.1986999512106 .6747970581105 .4557037354104 .2365036011103 .0174026489 101.7982025146100 .579101562599 .3599472045998 .1408081054796 .92166900635 95.397743225194 .1785964965892 .6546783447390 .8259735107489 .3020401001 87.47332763672 85.55059814453 83.51112365723 81.37763214111 79.24413299561 77.110626220774 .9771423339872 .5388565063570 .1005783081167 .96708679199 66.13836669922 -9999 -9999 -9999 -9999 -9999 -9999 -9999 -9999 -9999 -9999 -9999 -9999 -9999 -9999 -9999 -9999 -9999 -9999 -9999 -9999 -9999 -9999 -9999 -9999 -9999 -9999 -9999

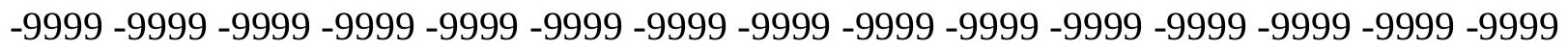
-9999 -9999 -9999-9999-9999-9999

-9999 -9999 -9999 -9999 -9999 -9999 -9999 -9999 -9999 -9999 -9999 -9999 -9999 -9999 -9999 -9999 -9999 -9999 -9999 -9999 -9999 -9999 -9999 -9999 -9999 -9999 -9999 -9999 -9999 -9999

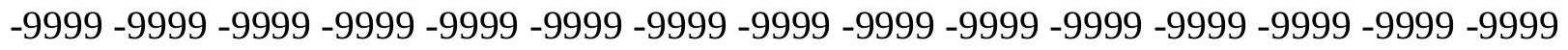
-9999 -9999 -9999 -9999 -9999 -9999 -9999 -9999 -9999 -9999 -9999 -9999 -9999 -9999 -9999 -

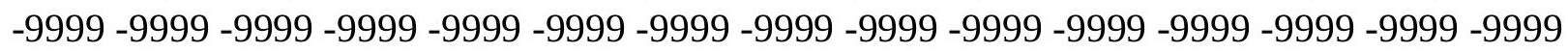

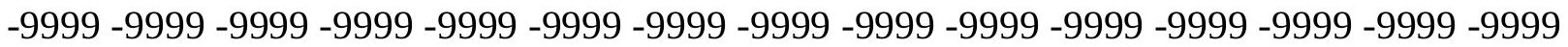

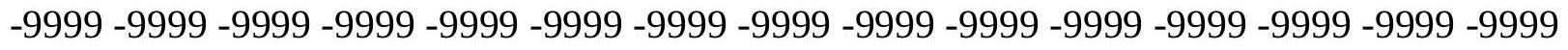

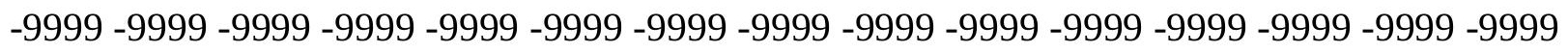

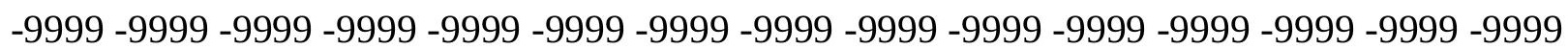
-9999 -9999 -9999 -9999 -9999 -9999 -9999 -9999 -9999 -9999 -9999 -9999 -9999 -9999 -9999 -

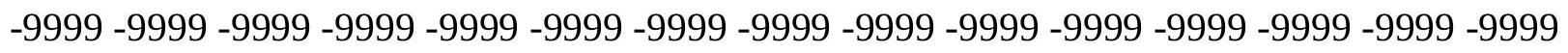

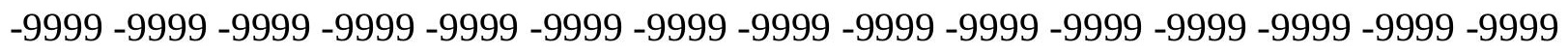

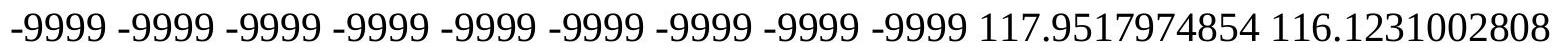
113.9896011353111 .8561019897110 .0273971558109 .4179000854108 .5035018921 107.8938980103107 .5891036987107 .8938980103108 .5035018921109 .7226028442 110.9418029785112 .4656982422114 .2944030762116 .1231002808117 .9517974854 119.7806015015121 .6092987061123 .43800354124 .9618988037126 .4858016968 127.7050018311128 .6192932129129 .2288970947129 .533706665129 .533706665 128.9241027832128 .3144989014127 .4001998901126 .1809997559124 .9618988037 123.7427978516122 .5235977173121 .9140014648121 .3044967651120 .9997024536 120.6949005127120 .3900985718118 .8662033081109 .9586334229107 .7844314575 105.3354873657102 .7536468506100 .274299621697 .8360290527395 .70252990723 93.5690307617291 .7403335571390 .2164001464889 .6068267822389 .3020401001 88.69246673584 88.38768768311 87.47332763672 86.55898284912 85.64462280273 84.7302627563583 .8159103393683 .206336975182 .9015579223682 .90155792236 83.2063369751 83.51112365723 83.81591033936 84.12069702148 84.42548370361 84.7302627563585 .0350494384885 .3398437586 .254188537687 .16854858398 88.0829010009888 .9972534179790 .2164001464891 .4355392456192 .3498916626 93.5690307617294 .7881774902396 .0073165893697 .2264633178798 .4455871582 99.96952056885101 .1886978149102 .712600708103 .9317016602105 .4557037354 106.6747970581108 .1986999512109 .4179000854110 .6370010376111 .551399231 112.7705001831113 .6848983765114 .5991973877115 .2088012695115 .818397522 116.4279022217116 .7326965332116 .7326965332116 .7326965332116 .4279022217 
115.818397522115 .5136032104114 .9039993286114 .2944030762113 .9896011353 113.3800964355113 .075302124113 .3800964355113 .6848983765113 .9896011353 114.5991973877115 .2088012695115 .818397522116 .1231002808116 .1231002808 116.1231002808115 .818397522115 .2088012695114 .5991973877113 .6848983765 112.7705001831111 .551399231110 .3321990967109 .1130981445107 .8938980103 106.6747970581105 .4557037354103 .9317016602102 .712600708101 .4934005737 100.579101562599 .3599472045998 .1408081054796 .6168823242295 .3977432251 93.8738174438592 .349891662690 .8259735107489 .302040100187 .47332763672 85.5727462768683 .5111236572381 .6824111938579 .5489196777377 .41542053223 75.2819290161172 .8436431884870 .7101516723668 .2718734741266 .44316101074 -9999 -9999 -9999 -9999 -9999 -9999 -9999 -9999 -9999 -9999 -9999 -9999 -9999 -9999 -9999 -9999

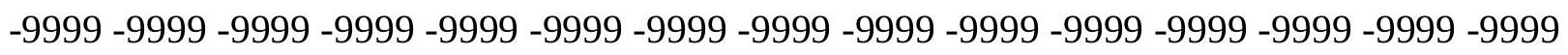

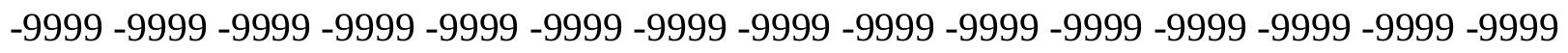
$-9999-9999$

-9999 -9999 -9999 -9999 -9999 -9999 -9999 -9999 -9999 -9999 -9999 -9999 -9999 -9999 -9999

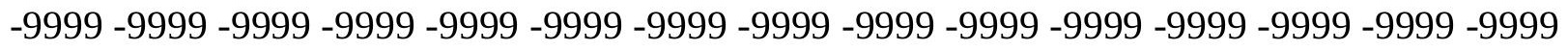
-9999 -9999 -9999 -9999 -9999 -9999 -9999 -9999 -9999 -9999 -9999 -9999 -9999 -9999 -9999 -

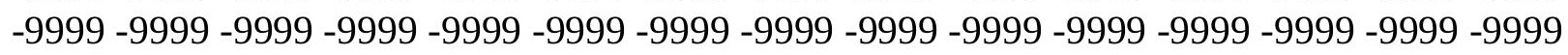

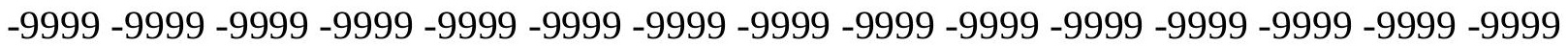

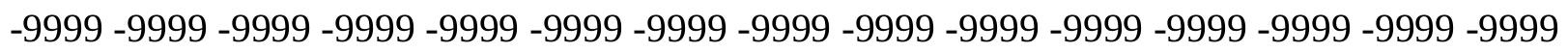

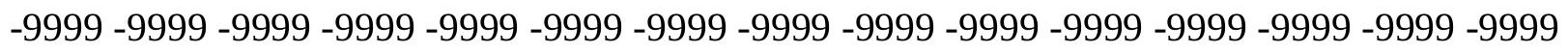

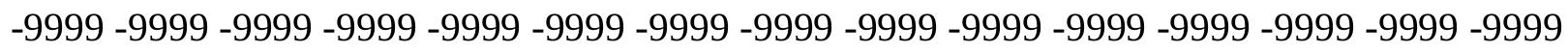
-9999 -9999 -9999 -9999 -9999 -9999 -9999 -9999 -9999 -9999 -9999 -9999 -9999 -9999 -9999 -

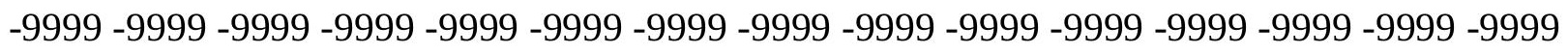

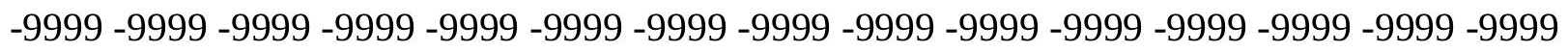

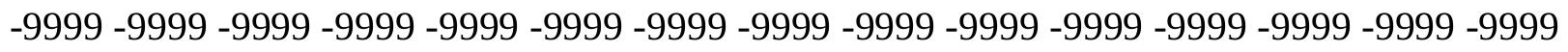
-9999 -9999 -9999 -9999 -9999 -9999 -9999 -9999 -9999 -9999 117.0374984741 114.9039993286112 .4656982422110 .0273971558107 .2844009399105 .4557037354 104.5412979126104 .5412979126104 .8460998535105 .7603988647107 .2844009399 108.8082962036110 .3321990967112 .4656982422114 .2944030762116 .4279022217 118.2565994263120 .3900985718122 .2188034058124 .0475006104125 .5715026855 126.7906036377128 .0097961426128 .6192932129129 .2288970947129 .2288970947 128.9241027832128 .6192932129127 .7050018311126 .7906036377125 .8762969971 124.9618988037124 .0475006104123 .1332015991122 .8283996582122 .2188034058 122.2188034058121 .6092987061119 .7806015015117 .0374984741113 .6848983765 108.3960342407106 .0235137939103 .6455612183101 .390678405899 .35994720459 97.2264633178795 .0929565429793 .5690307617292 .6546783447392 .04509735107 91.7403335571391 .1307525634890 .2164001464889 .302040100188 .08290100098 86.8637619018685 .9494018554785 .0350494384885 .0350494384885 .03504943848 85.33984375 85.64462280273 85.94940185547 86.2541885376 86.2541885376 86.2541885376 86.5589828491286 .8637619018687 .4733276367288 .3876876831189 .60682678223 90.5211791992291 .7403335571392 .6546783447393 .8738174438594 .78817749023 96.0073165893697 .2264633178798 .445587158299 .66472625732100 .8839035034 102.1029968262103 .6268997192104 .8460998535106 .3700027466107 .5891036987 108.8082962036110 .0273971558111 .24659729112 .4656982422113 .3800964355 114.2944030762115 .2088012695115 .818397522116 .4279022217116 .7326965332 
117.0374984741 117.0374984741 117.0374984741 116.7326965332116.4279022217 115.818397522115 .2088012695114 .5991973877114 .2944030762113 .6848983765 113.6848983765113 .6848983765113 .6848983765113 .9896011353114 .5991973877 114.9039993286115 .2088012695115 .5136032104115 .5136032104115 .2088012695 114.9039993286114 .5991973877113 .6848983765113 .075302124112 .1608963013 110.9418029785110 .0273971558108 .8082962036107 .5891036987106 .3700027466 105.1509017944103 .9317016602102 .712600708101 .4934005737100 .2742996216 99.0551681518697 .8360290527396 .6168823242295 .397743225193 .87381744385 92.349891662690 .8259735107489 .302040100187 .4733276367285 .64462280273 83.8159103393681 .6824111938579 .5489196777377 .4154205322375 .28192901611 73.1484298706171 .014930725168 .5766525268666 .74794006348 -9999 -9999 -9999 -9999 -9999 -9999 -9999 -9999 -9999 -9999 -9999 -9999 -9999 -9999 -9999-9999 -9999 -9999 -9999 -

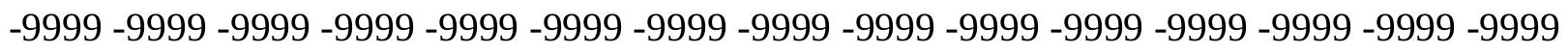
-9999 -9999 -9999 -9999 -9999 -9999 -9999 -9999 -9999 -9999 -9999 -9999 -9999 -9999 -9999 -9999 -9999 -9999 -9999 -9999 -9999 -9999 -9999 -9999 -9999 -9999 -9999 -9999 -9999

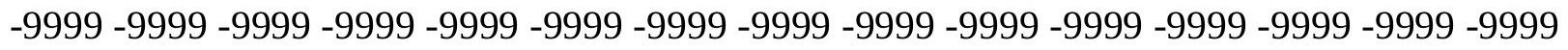
-9999 -9999 -9999 -9999 -9999 -9999 -9999 -9999 -9999 -9999 -9999 -9999 -9999 -9999 -9999 -

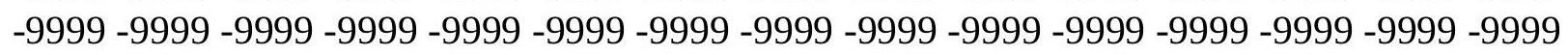

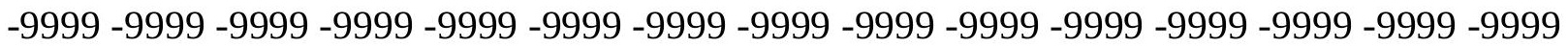

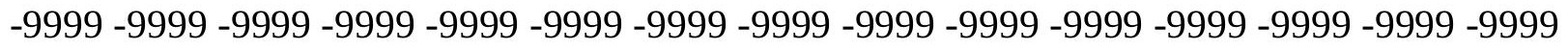

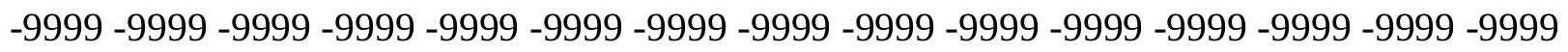

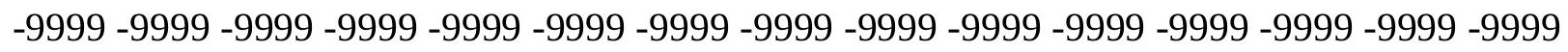
-9999 -9999 -9999 -9999 -9999 -9999 -9999 -9999 -9999 -9999 -9999 -9999 -9999 -9999 -9999 -

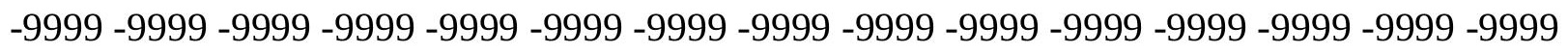

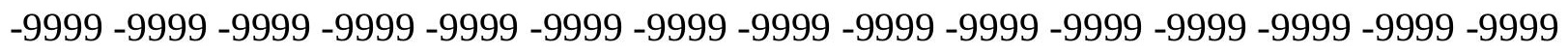

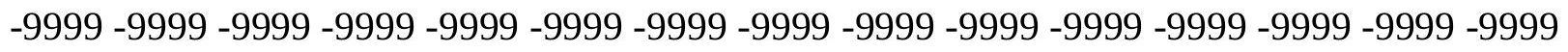
-9999 -9999 -9999 -9999 -9999 -9999 -9999 -9999 -9999 -9999 -9999 -9999 114.9039993286 111.8561019897108 .1986999512105 .1509017944102 .1029968262101 .4934005737 102.1029968262103 .3221969604104 .8460998535106 .3700027466108 .1986999512 110.3321990967112 .4656982422114 .5991973877116 .7326965332118 .8662033081 120.9997024536122 .8283996582124 .3523025513125 .8762969971126 .7906036377 127.7050018311128 .3144989014128 .6192932129128 .6192932129128 .3144989014 128.0097961426127 .0953979492126 .4858016968125 .5715026855124 .6570968628 124.0475006104123 .43800354122 .8283996582122 .2188034058121 .6092987061 120.3900985718118 .5614013672116 .1231002808113 .075302124110 .3321990967 106.8539352417104 .7945098877102 .830871582100 .97182464699 .35994720459 97.8360290527396 .6168823242295 .7025299072395 .0929565429794 .48339080811 93.5690307617292 .349891662691 .1307525634889 .9116134643688 .38768768311 87.4733276367287 .4733276367287 .7781066894588 .0829010009888 .38768768311 88.6924667358488 .6924667358488 .6924667358488 .6924667358488 .38768768311 88.6924667358489 .302040100190 .2164001464891 .4355392456192 .3498916626 93.2642517089894 .1785964965895 .397743225196 .3121032714897 .53124237061 98.445587158299 .66472625732100 .8839035034102 .1029968262103 .3221969604 104.5412979126106 .0652008057107 .2844009399108 .5035018921109 .7226028442 110.9418029785112 .1608963013113 .075302124113 .9896011353114 .9039993286 115.818397522116 .4279022217116 .7326965332117 .342300415117 .647102356 
117.647102356117 .342300415117 .0374984741116 .7326965332116 .1231002808 115.5136032104114 .9039993286114 .5991973877113 .9896011353113 .9896011353 113.6848983765113 .9896011353113 .9896011353114 .2944030762114 .5991973877 114.5991973877114 .9039993286114 .9039993286114 .5991973877114 .2944030762 113.6848983765113 .075302124112 .4656982422111 .551399231110 .3321990967 109.4179000854108 .5035018921107 .2844009399106 .0652008057104 .8460998535 103.6268997192102 .712600708101 .4934005737100 .274299621699 .05516815186 97.8360290527396 .6168823242295 .0929565429793 .8738174438592 .3498916626 90.8259735107488 .9972534179787 .4733276367285 .6446228027383 .81591033936 81.6824111938579 .8537063598677 .7202072143675 .5867080688573 .45321655273 71.014930725168 .8814392089867 .05272674561 -9999 -9999 -9999 -9999 -9999 -9999 -9999 -9999 -9999 -9999 -9999 -9999 -9999 -9999 -9999 -9999 -9999 -9999 -9999 -9999 -9999 -9999

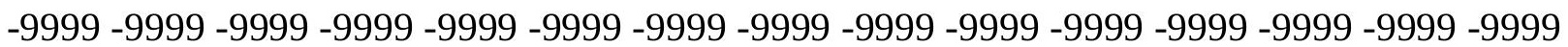
-9999 -9999 -9999 -9999 -9999 -9999 -9999 -9999 -9999 -9999 -9999 -9999 -9999 -9999 -9999 -9999 -9999 -9999 -9999 -9999 -9999 -9999 -9999 -9999 -9999 -9999 -9999 -9999 -9999 -9999 -9999 -9999 -9999 -9999 -9999 -9999 -9999 -9999 -9999 -9999 -9999 -9999 -9999 -9999 -9999 -9999 -9999 -9999 -9999 -9999 -9999 -9999 -9999 -9999 -9999 -9999 -9999 -9999 -9999 -9999 -9999 -9999 -9999 -9999 -9999 -9999 -9999 -9999 -9999 -9999 -9999 -9999 -9999 -9999 -9999 -9999 -9999 -9999 -9999 -9999 -9999 -9999 -9999 -9999 -9999 -9999 -9999 -9999 -9999 -9999 -9999 -9999 -9999 -9999 -9999 -9999 -9999 -9999 -9999 -9999 -9999

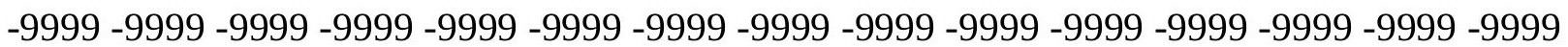
-9999 -9999 -9999 -9999 -9999 -9999 -9999 -9999 -9999 -9999 -9999 -9999 -9999 -9999 -9999 -9999 -9999 -9999 -9999 -9999 -9999 -9999 -9999 -9999 -9999 -9999 -9999 -9999 -9999 -9999 -9999 -9999 -9999 -9999 -9999 -9999 -9999 -9999 -9999 -9999 -9999 -9999 -9999 -9999 -9999

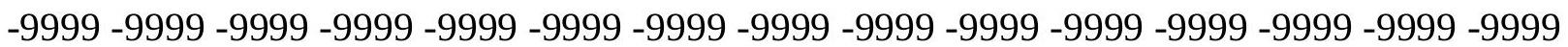
-9999 -9999 -9999 -9999 -9999 -9999 -9999 -9999 -9999 -9999 -9999 -9999 -9999 -9999 -9999 -9999 -9999 -9999 -9999 -9999 -9999 -9999 -9999 -9999 -9999 -9999 -9999 -9999 -9999 113.3800964355109 .7226028442105 .4557037354101 .188697814999 .66472625732 101.4934005737102 .712600708104 .5412979126106 .3700027466108 .5035018921 110.6370010376113 .075302124115 .2088012695117 .342300415119 .4757995605 121.3044967651123 .1332015991124 .6570968628125 .8762969971126 .7906036377 127.4001998901128 .0097961426128 .0097961426128 .0097961426127 .7050018311 127.0953979492126 .4858016968125 .8762969971125 .2667007446124 .3523025513 123.43800354122 .8283996582121 .9140014648121 .6092987061120 .9997024536 119.7806015015117 .9517974854116 .1231002808113 .9896011353111 .8561019897 108.0368423462106 .2821502686104 .6589736938103 .1828842163101 .80859375 100.579101562599 .6647262573299 .0551681518698 .1408081054797 .22646331787 96.3121032714895 .0929565429793 .5690307617292 .0450973510790 .52117919922 90.8259735107491 .1307525634891 .7403335571391 .7403335571392 .04509735107 92.0450973510791 .7403335571391 .4355392456191 .1307525634890 .82597351074 91.7403335571392 .6546783447393 .5690307617294 .4833908081195 .3977432251 96.0073165893696 .9216690063597 .8360290527398 .7503814697399 .96952056885 100.8839035034102 .1029968262103 .3221969604104 .5412979126105 .7603988647 106.979598999108 .1986999512109 .7226028442110 .6370010376111 .8561019897 113.075302124113 .9896011353114 .9039993286115 .5136032104116 .1231002808 116.7326965332117 .342300415117 .647102356117 .9517974854117 .9517974854 
117.9517974854117 .342300415117 .0374984741116 .4279022217115 .818397522 115.2088012695114 .5991973877114 .2944030762113 .9896011353113 .9896011353 113.9896011353113 .9896011353113 .9896011353114 .2944030762114 .2944030762 114.2944030762113 .9896011353113 .9896011353113 .3800964355113 .075302124 112.4656982422111 .551399231110 .6370010376110 .0273971558108 .8082962036 107.8938980103106 .6747970581105 .7603988647104 .5412979126103 .6268997192 102.4077987671101 .188697814999 .9695205688599 .0551681518697 .83602905273 96.3121032714895 .0929565429793 .8738174438592 .349891662690 .82597351074 88.99725341797 87.47332763672 85.64462280273 83.81591033936 81.98719787598 79.8537063598678 .0249862670975 .8914871215873 .4532165527371 .31971740723 69.1862335205167 .35751342773 -9999 -9999 -9999 -9999 -9999 -9999 -9999 -9999 -9999 -9999 -9999 -9999 -9999 -9999 -9999 -9999 -9999 -9999 -9999 -9999 -9999 -9999 -9999 -9999 -9999 -9999 -9999 -9999 -9999 -9999 -9999 -9999 -9999 -9999 -9999 -9999 -9999 -9999 -9999 -9999 -9999 -9999-9999 -9999 -9999 -9999 -9999 -9999

-9999 -9999 -9999 -9999 -9999 -9999 -9999 -9999 -9999 -9999 -9999 -9999 -9999 -9999 -9999

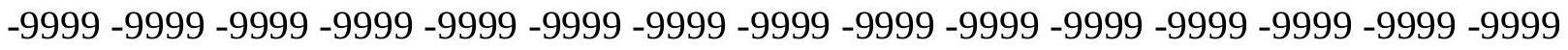
-9999 -9999 -9999 -9999 -9999 -9999 -9999 -9999 -9999 -9999 -9999 -9999 -9999 -9999 -9999 -9999 -9999 -9999 -9999 -9999 -9999 -9999 -9999 -9999 -9999 -9999 -9999 -9999 -9999 -9999 -999 -9999 -9999 -9999 -9999 -9999 -9999 -9999 -9999 -9999 -9999 -9999 -9999 -9999 -9999 -9999 -9999 -9999 -9999 -9999 -9999 -9999 -9999 -9999 -9999 -9999 -9999 -9999 -9999 -9999 -9999 -9999 -9999 -9999 -9999 -9999 -9999 -9999 -9999 -9999 -9999 -9999 -9999 -9999 -9999 -9999 -9999 -9999 -9999 -9999 -9999 -9999 -9999 -9999 -9999 -9999 -9999 -9999 -9999 -9999 -9999 -9999 -9999 -9999 -9999 -9999 -9999 -9999 -9999 -9999 -9999 -9999 -9999 -9999 -9999 -9999 -9999 -9999 -9999 -9999 -9999 -9999 -9999 -9999 -9999 -9999 -9999 -9999 -9999 -9999 -9999 -9999 -9999 -9999 -9999 -9999 -9999 -9999 -9999 -9999 -9999 -9999 -9999 -9999 -9999 -9999 -9999 -9999 -9999 -9999 -9999 -9999 -9999 -9999 -9999 -9999 -9999 -9999 -9999 -9999 -9999 -9999 -9999 -9999 -9999 -9999 -9999 -9999 -9999 -9999 -9999 -9999 -9999 -9999 -9999 -9999 115.2088012695111 .551399231107 .2844009399103 .3221969604103 .3221969604 100.8839035034102 .712600708104 .5412979126106 .6747970581109 .1130981445 111.24659729113 .6848983765115 .818397522117 .9517974854120 .0852966309 121.6092987061123 .1332015991124 .3523025513125 .5715026855126 .1809997559 126.7906036377127 .0953979492127 .0953979492127 .0953979492126 .7906036377 126.4858016968125 .8762969971125 .2667007446124 .6570968628123 .7427978516 122.8283996582121 .6092987061121 .9140014648121 .6092987061120 .9997024536 120.0852966309118 .8662033081117 .342300415115 .5136032104113 .6848983765 111.8561019897108 .2083511353106 .907623291105 .7276611328104 .7106170654 103.9317016602103 .3221969604102 .4077987671101 .7982025146100 .8839035034 99.6647262573298 .445587158297 .2264633178796 .0073165893695 .70252990723 95.7025299072395 .7025299072395 .7025299072395 .7025299072395 .70252990723 95.397743225194 .7881774902394 .4833908081194 .4833908081194 .78817749023 95.397743225196 .0073165893696 .6168823242297 .5312423706198 .14080810547 98.7503814697399 .66472625732100 .5791015625101 .4934005737102 .4077987671 103.3221969604104 .5412979126105 .7603988647106 .979598999108 .1986999512 109.4179000854110 .6370010376111 .8561019897112 .7705001831113 .6848983765 114.5991973877115 .5136032104116 .1231002808116 .7326965332117 .0374984741 117.647102356117 .9517974854117 .9517974854118 .2565994263117 .9517974854 
117.647102356117 .0374984741116 .4279022217115 .818397522115 .5136032104 114.9039993286114 .5991973877114 .2944030762113 .9896011353113 .9896011353 113.9896011353113 .9896011353113 .9896011353113 .6848983765113 .6848983765 113.3800964355113 .075302124112 .7705001831112 .1608963013111 .551399231 110.9418029785110 .0273971558109 .4179000854108 .1986999512107 .2844009399 106.3700027466105 .4557037354104 .2365036011103 .3221969604102 .1029968262 101.188697814999 .9695205688598 .7503814697397 .5312423706196 .31210327148 95.0929565429793 .5690307617292 .349891662690 .8259735107489 .3020401001 87.4733276367285 .6446228027383 .8159103393681 .9871978759880 .15849304199 78.0249862670975 .8914871215873 .7580032348671 .6244964599669 .18623352051 67.66230010986 -9999 -9999 -9999 -9999 -9999 -9999 -9999 -9999 -9999 -9999 -9999 -9999 -9999 -9999 -9999 -9999 -9999 -9999 -9999 -9999 -9999 -9999 -9999 -9999 -9999 -9999 -9999

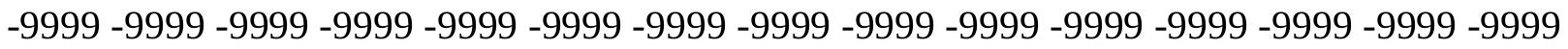
-9999 -9999 -9999-9999-9999-9999

-9999 -9999 -9999 -9999 -9999 -9999 -9999 -9999 -9999 -9999 -9999 -9999 -9999 -9999 -9999 -9999 -9999 -9999 -9999 -9999 -9999 -9999 -9999 -9999 -9999 -9999 -9999 -9999 -9999 -9999 -

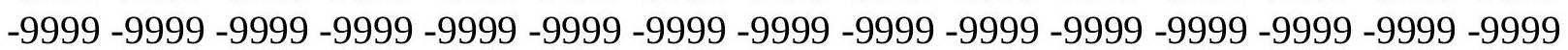
-9999 -9999 -9999 -9999 -9999 -9999 -9999 -9999 -9999 -9999 -9999 -9999 -9999 -9999 -9999 -9999 -9999 -9999 -9999 -9999 -9999 -9999 -9999 -9999 -9999 -9999 -9999 -9999 -9999 -9999 -9999 -9999 -9999 -9999 -9999 -9999 -9999 -9999 -9999 -9999 -9999 -9999 -9999 -9999 -9999

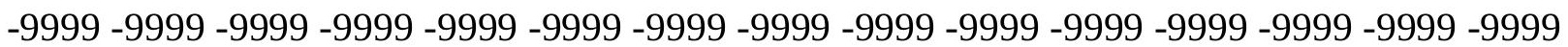
-9999 -9999 -9999 -9999 -9999 -9999 -9999 -9999 -9999 -9999 -9999 -9999 -9999 -9999 -9999 -9999 -9999 -9999 -9999 -9999 -9999 -9999 -9999 -9999 -9999 -9999 -9999 -9999 -9999 -9999 -9999 -9999 -9999 -9999 -9999 -9999 -9999 -9999 -9999 -9999 -9999 -9999 -9999 -9999 -9999

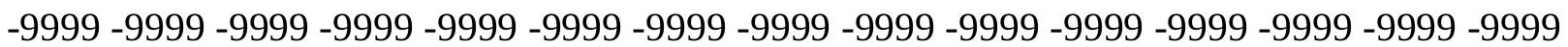
-9999 -9999 -9999 -9999 -9999 -9999 -9999 -9999 -9999 -9999 -9999 -9999 -9999 -9999 -9999 -9999 -9999 -9999 -9999 -9999 -9999 -9999 -9999 -9999 -9999 -9999 -9999 -9999 -9999 -9999 -9999 -9999 112.7705001831 109.1130981445105.4557037354102.1029968262 101.7982025146103 .0174026489105 .1509017944107 .5891036987110 .0273971558 112.1608963013114 .5991973877116 .7326965332118 .5614013672120 .3900985718 121.9140014648123 .1332015991124 .0475006104124 .9618988037125 .5715026855 125.8762969971126 .1809997559126 .1809997559126 .1809997559126 .1809997559 125.8762969971125 .2667007446124 .6570968628124 .0475006104123 .43800354 122.8283996582122 .8283996582122 .8283996582122 .5235977173121 .9140014648 121.3044967651120 .3900985718119 .1709976196117 .647102356115 .818397522 113.9896011353112 .1608963013109 .5976257324108 .7892913818108 .1365814209 107.5596237183106 .979598999106 .3700027466105 .7603988647105 .1509017944 103.9317016602103 .0174026489102 .1029968262101 .1886978149100 .8839035034 100.5791015625100 .274299621699 .9695205688599 .6647262573299 .35994720459 98.7503814697398 .445587158298 .1408081054798 .1408081054798 .4455871582 99.0551681518699 .3599472045999 .96952056885100 .2742996216100 .8839035034 101.4934005737102 .1029968262103 .0174026489103 .9317016602104 .8460998535 105.7603988647106 .979598999107 .8938980103109 .1130981445110 .3321990967 111.551399231112 .7705001831113 .6848983765114 .5991973877115 .5136032104 116.1231002808116 .7326965332117 .0374984741117 .342300415117 .647102356 117.9517974854117 .9517974854117 .9517974854117 .9517974854117 .647102356 
117.0374984741116 .4279022217115 .818397522115 .5136032104114 .9039993286 114.5991973877114 .2944030762113 .9896011353113 .9896011353113 .6848983765 113.6848983765113 .3800964355113 .3800964355113 .075302124112 .7705001831 112.4656982422112 .1608963013111 .551399231110 .9418029785110 .3321990967 109.4179000854108.5035018921 107.8938980103106.979598999 105.7603988647 104.8460998535103 .9317016602103 .0174026489101 .7982025146100 .8839035034 99.6647262573298 .7503814697397 .5312423706196 .3121032714895 .09295654297 93.5690307617292 .349891662690 .8259735107489 .302040100187 .47332763672 85.6446228027384 .1206970214881 .9871978759880 .1584930419978 .02498626709 $76.1962814331174 .062782287671 .6244964599669 .4910125732467 .66230010986-9999$ -9999 -9999 -9999 -9999 -9999 -9999 -9999 -9999 -9999 -9999 -9999 -9999 -9999 -9999 -9999 -9999 -9999 -9999 -9999 -9999 -9999 -9999 -9999 -9999 -9999 -9999 -9999 -9999 -9999 -9999 -

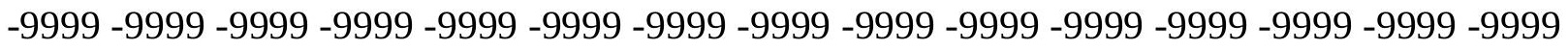
-9999 -9999

-9999 -9999 -9999 -9999 -9999 -9999 -9999 -9999 -9999 -9999 -9999 -9999 -9999 -9999 -9999

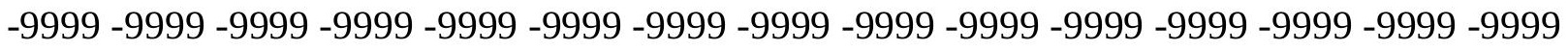
-9999 -9999 -9999 -9999 -9999 -9999 -9999 -9999 -9999 -9999 -9999 -9999 -9999 -9999 -9999 -9999 -9999 -9999 -9999 -9999 -9999 -9999 -9999 -9999 -9999 -9999 -9999 -9999 -9999 -9999 -

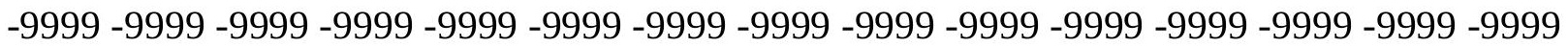

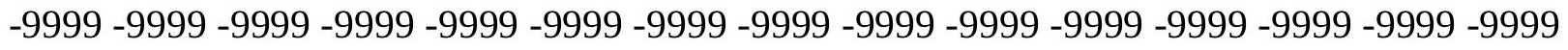

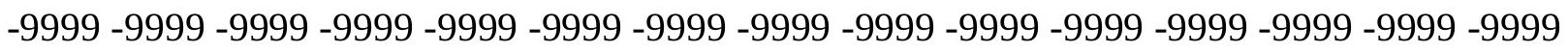
-9999 -9999 -9999 -9999 -9999 -9999 -9999 -9999 -9999 -9999 -9999 -9999 -9999 -9999 -9999 -9999 -9999 -9999 -9999 -9999 -9999 -9999 -9999 -9999 -9999 -9999 -9999 -9999 -9999 -9999 -

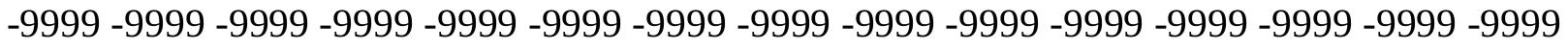

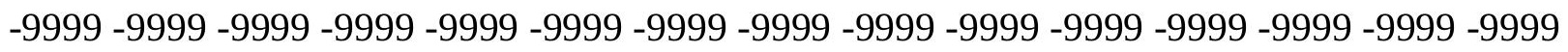
-9999 -9999 -9999 -9999 -9999 -9999 -9999 -9999 -9999 -9999 -9999 -9999 -9999 -9999 -9999 -9999 -9999 -9999 -9999 -9999 -9999 -9999 -9999 -9999 -9999 -9999 -9999 -9999 -9999 -9999 -9999 -9999 -9999-9999 110.3321990967 106.3700027466 105.7603988647 102.712600708 103.6268997192106 .0652008057108 .5035018921110 .9418029785113 .075302124 115.2088012695117 .0374984741118 .8662033081120 .3900985718121 .6092987061 122.8283996582123 .7427978516124 .3523025513124 .6570968628125 .2667007446 125.2667007446125 .5715026855125 .5715026855125 .2667007446125 .2667007446 124.9618988037124 .6570968628124 .0475006104124 .0475006104124 .0475006104 124.0475006104124 .0475006104124 .0475006104123 .43800354123 .1332015991 122.2188034058121 .3044967651119 .7806015015117 .9517974854116 .1231002808 114.9039993286113 .6848983765112 .2322540283111 .8203125111 .4800643921 111.1742477417110 .9418029785110 .6370010376110 .0273971558109 .1130981445 108.1986999512106 .979598999106 .0652008057105 .4557037354104 .8460998535 104.5412979126103 .9317016602103 .6268997192103 .0174026489102 .712600708 102.1029968262102 .1029968262102 .1029968262102 .1029968262102 .1029968262 102.4077987671102 .712600708103 .0174026489103 .3221969604103 .9317016602 104.5412979126105 .1509017944106 .0652008057106 .979598999107 .8938980103 109.1130981445110 .3321990967111 .551399231112 .4656982422113 .6848983765 114.5991973877115 .5136032104116 .1231002808116 .7326965332117 .0374984741 117.342300415117 .647102356117 .647102356117 .9517974854117 .9517974854 117.9517974854117 .647102356117 .342300415117 .0374984741116 .4279022217 
115.818397522115 .5136032104115 .2088012695114 .5991973877114 .2944030762 113.9896011353113 .6848983765113 .6848983765113 .3800964355113 .075302124 112.7705001831112 .4656982422112 .1608963013111 .8561019897111 .24659729 110.9418029785110 .3321990967109 .4179000854108 .8082962036107 .8938980103 107.2844009399 106.3700027466105.4557037354104.5412979126103.6268997192 102.4077987671101 .4934005737100 .579101562599 .3599472045998 .4455871582 97.2264633178796 .0073165893694 .7881774902393 .5690307617292 .3498916626 90.8259735107489 .302040100187 .4733276367285 .8680953979584 .12069702148 82.2919769287180 .1584930419978 .3297805786176 .1962814331174 .0627822876 71.9292907714869 .7957916259867 .96708679199 -9999 -9999 -9999 -9999 -9999 -9999 -9999 -9999 -9999 -9999 -9999 -9999 -9999 -9999 -9999 -9999 -9999 -9999 -9999 -9999 -9999 -9999 -9999 -9999 -9999 -9999 -9999 -9999 -9999 -9999 -9999 -9999 -9999 -9999 -9999 -9999 -9999 -9999 -9999 -9999 -9999 -9999 -9999 -9999 -9999 -9999 -9999 -9999 -9999 -9999 -9999 -9999 -9999 -9999 -9999 -9999 -9999 -9999 -9999 -9999 -9999 -9999 -9999 -9999 -9999 -9999 -9999 -9999 -9999 -9999 -9999 -9999 -9999 -9999 -9999 -9999 -9999 -9999

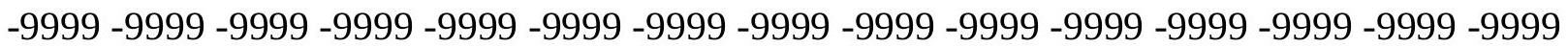

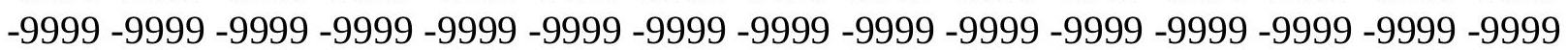
-9999 -9999 -9999 -9999 -9999 -9999 -9999 -9999 -9999 -9999 -9999 -9999 -9999 -9999 -9999 -9999 -9999 -9999 -9999 -9999 -9999 -9999 -9999 -9999 -9999 -9999 -9999 -9999 -9999 -9999 -9999 -9999 -9999 -9999 -9999 -9999 -9999 -9999 -9999 -9999 -9999 -9999 -9999 -9999 -9999

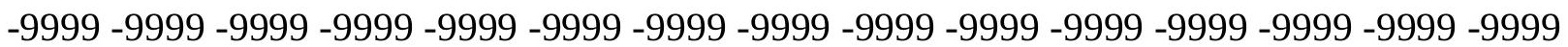
-9999 -9999 -9999 -9999 -9999 -9999 -9999 -9999 -9999 -9999 -9999 -9999 -9999 -9999 -9999 -9999 -9999 -9999 -9999 -9999 -9999 -9999 -9999 -9999 -9999 -9999 -9999 -9999 -9999 -9999 -9999 -9999 -9999 -9999 -9999 -9999 -9999 -9999 -9999 -9999 -9999 -9999 -9999 -9999 -9999

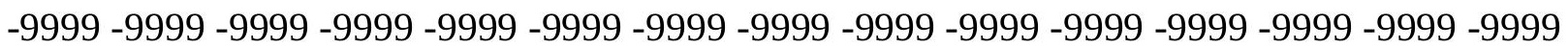
-9999 -9999 -9999 -9999 -9999 -9999 -9999 -9999 -9999 -9999 -9999 -9999 -9999 -9999 -9999 -9999 -9999 -9999 -9999 -9999 110.3321990967106 .3700027466103 .6268997192 104.2365036011105 .1509017944107 .2844009399109 .7226028442111 .8561019897 113.9896011353115 .818397522117 .342300415118 .8662033081120 .0852966309 121.3044967651122 .2188034058122 .8283996582123 .43800354123 .7427978516 124.3523025513124 .6570968628124 .6570968628124 .9618988037124 .9618988037 124.9618988037124 .9618988037124 .9618988037124 .9618988037125 .2667007446 125.5715026855125 .5715026855125 .5715026855125 .5715026855125 .2667007446 124.6570968628124 .0475006104122 .8283996582121 .3044967651119 .7806015015 118.5614013672117 .647102356116 .7326965332116 .4279022217115 .8309402466 115.7874069214115 .8067321777115 .818397522115 .818397522115 .2088012695 113.9896011353112 .7705001831111 .551399231110 .3321990967109 .7226028442 109.1130981445108 .5035018921107 .8938980103107 .2844009399106 .6747970581 106.3700027466105 .7603988647105 .4557037354105 .1509017944105 .1509017944 104.8460998535104 .8460998535105 .1509017944105 .1509017944105 .4557037354 106.0652008057106 .6747970581107 .2844009399108 .1986999512109 .1130981445 110.0273971558111 .24659729112 .4656982422113 .6848983765114 .5991973877 115.5136032104116 .1231002808116 .7326965332117 .0374984741117 .342300415 117.647102356117 .647102356117 .647102356117 .647102356117 .647102356117 .647102356 117.342300415117 .0374984741116 .7326965332116 .4279022217115 .818397522 115.5136032104114 .9039993286114 .5991973877114 .2944030762113 .9896011353 
113.6848983765113 .3800964355113 .075302124112 .7705001831112 .4656982422 112.1608963013111 .551399231111 .24659729110 .6370010376110 .0273971558 109.4179000854108 .8082962036108 .1986999512107 .2844009399106 .6747970581 105.7603988647104 .8460998535103 .9317016602103 .0174026489102 .1029968262 101.1886978149 100.274299621699.3599472045998.1408081054797.22646331787 96.0073165893694 .7881774902393 .5690307617292 .349891662690 .82597351074 89.302040100187.77810668945 85.9494018554784.12069702148 82.29197692871 80.4632720947378 .3297805786176 .1962814331174 .062782287671 .92929077148 69.7957916259867 .96708679199 -9999 -9999 -9999 -9999 -9999 -9999 -9999 -9999 -9999 -9999 -9999 -9999 -9999 -9999 -9999 -9999 -9999 -9999 -9999 -9999 -9999 -9999 -9999 -9999 -9999 -9999 -9999 -9999 -9999 -9999 -9999 -9999 -9999 -9999 -9999 -9999 -9999 -9999 -9999 -9999 -9999 -9999 -9999 -9999 -9999 -9999 -9999 -9999

-9999 -9999 -9999 -9999 -9999 -9999 -9999 -9999 -9999 -9999 -9999 -9999 -9999 -9999 -9999 -9999 -9999 -9999 -9999 -9999 -9999 -9999 -9999 -9999 -9999 -9999 -9999 -9999 -9999 -9999 -9999 -9999 -9999 -9999 -9999 -9999 -9999 -9999 -9999 -9999 -9999 -9999 -9999 -9999 -9999

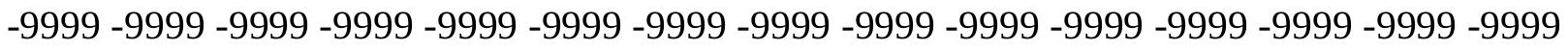

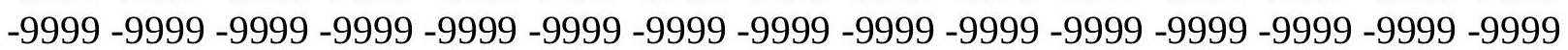
-9999 -9999 -9999 -9999 -9999 -9999 -9999 -9999 -9999 -9999 -9999 -9999 -9999 -9999 -9999 -999 -9999 -9999 -9999 -9999 -9999 -9999 -9999 -9999 -9999 -9999 -9999 -9999 -9999 -9999 -9999 -9999 -9999 -9999 -9999 -9999 -9999 -9999 -9999 -9999 -9999 -9999 -9999 -9999 -9999 -9999 -9999 -9999 -9999 -9999 -9999 -9999 -9999 -9999 -9999 -9999 -9999 -9999 -9999 -9999 -9999 -9999 -9999 -9999 -9999 -9999 -9999 -9999 -9999 -9999 -9999 -9999 -9999 -9999 -9999 -9999 -9999 -9999 -9999 -9999 -9999 -9999 -9999 -9999 -9999 -9999 -9999 -9999 -9999 -9999 -9999 -9999 -9999 -9999 -9999 -9999 -9999 -9999 -9999 -9999 -9999 -9999 -9999 -9999 -9999 -9999 -9999 -9999 -9999 -9999 -9999 -9999 -9999 -9999 -9999 -9999 -9999 -9999 -9999 -9999 -9999 -9999 -9999 -9999 -9999 -9999-9999-9999 106.0652008057 105.1509017944106 .0652008057 106.3700027466108 .5035018921110 .6370010376112 .7705001831114 .5991973877 116.1231002808117 .342300415118 .5614013672119 .7806015015120 .6949005127 121.3044967651121 .9140014648122 .5235977173123 .1332015991123 .43800354 123.7427978516124 .3523025513124 .6570968628124 .9618988037125 .2667007446 125.5715026855125 .8762969971126 .1809997559126 .4858016968126 .7906036377 127.0953979492127 .0953979492127 .0953979492126 .7906036377126 .1809997559 124.9618988037124 .0475006104122 .8283996582121 .6092987061120 .9997024536 120.3900985718120 .0852966309120 .0852966309120 .0852966309120 .2072143555 120.3692626953120 .3638534546119 .9710083008119 .1709976196117 .647102356 116.4279022217115 .2088012695114 .2944030762113 .3800964355112 .7705001831 112.1608963013111 .551399231110 .9418029785110 .3321990967109 .7226028442 108.8082962036108.5035018921 107.8938980103107.5891036987 107.2844009399 107.2844009399 107.2844009399 107.2844009399107.5891036987107.8938980103 108.5035018921109 .1130981445110 .0273971558110 .9418029785112 .1608963013 113.3800964355114 .2944030762115 .2088012695116 .1231002808116 .7326965332 117.342300415 117.342300415 117.647102356 117.647102356 117.647102356 117.647102356 117.342300415117 .342300415117 .342300415117 .0374984741116 .7326965332 116.4279022217116 .1231002808115 .818397522115 .2088012695114 .9039993286 114.5991973877113 .9896011353113 .6848983765113 .3800964355113 .075302124 112.7705001831112 .1608963013111 .8561019897111 .551399231110 .9418029785 
110.6370010376110 .0273971558109 .4179000854108 .8082962036108 .1986999512 107.5891036987 106.6747970581 106.0652008057 105.1509017944104.2365036011 103.6268997192102 .712600708101 .7982025146100 .883903503499 .96952056885 99.0551681518698 .1408081054796 .9216690063596 .0073165893694 .78817749023 93.5690307617292 .349891662690 .8259735107489 .302040100187 .77810668945 86.254188537684 .4254837036182 .5967712402380 .4632720947378 .63455963135 76.5010681152374 .3675689697371 .9292907714869 .7957916259868 .27187347412 -9999 -9999 -9999 -9999 -9999 -9999 -9999 -9999 -9999 -9999 -9999 -9999 -9999 -9999 -9999 -9999 -9999 -9999 -9999 -9999 -9999 -9999 -9999 -9999 -9999 -9999 -9999 -9999 -9999 -9999 -9999 -

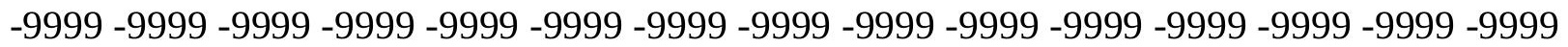
$-9999-9999$

-9999 -9999 -9999 -9999 -9999 -9999 -9999 -9999 -9999 -9999 -9999 -9999 -9999 -9999 -9999 -9999 -9999 -9999 -9999 -9999 -9999 -9999 -9999 -9999 -9999 -9999 -9999 -9999 -9999 -9999 -9999 -9999 -9999 -9999 -9999 -9999 -9999 -9999 -9999 -9999 -9999 -9999 -9999 -9999 -9999 -9999 -9999 -9999 -9999 -9999 -9999 -9999 -9999 -9999 -9999 -9999 -9999 -9999 -9999 -9999

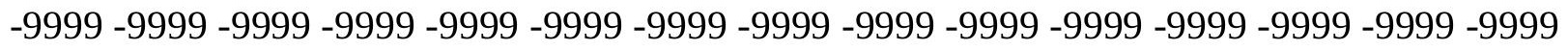
-9999 -9999 -9999 -9999 -9999 -9999 -9999 -9999 -9999 -9999 -9999 -9999 -9999 -9999 -9999 -

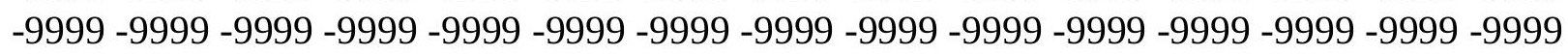
-9999 -9999 -9999 -9999 -9999 -9999 -9999 -9999 -9999 -9999 -9999 -9999 -9999 -9999 -9999 -999 -

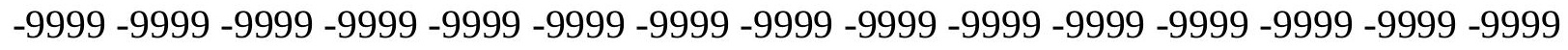

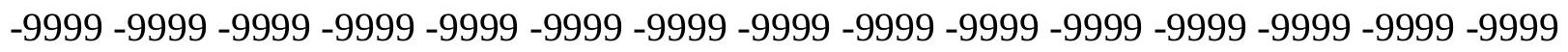

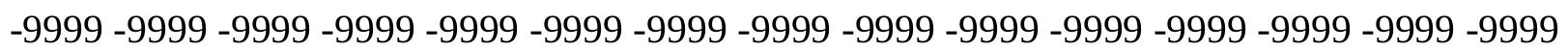
-9999 -9999 -9999 -9999 -9999 -9999 -9999 -9999 -9999 -9999 -9999 -9999 -9999 -9999 -9999 -

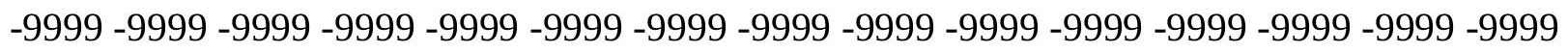
-9999 -9999-9999 -9999 -9999 -9999 -9999-9999 -9999 108.8082962036 107.5891036987 107.8938980103109 .7226028442111 .551399231113 .3800964355114 .5991973877 116.1231002808117 .0374984741117 .9517974854118 .8662033081119 .7806015015 120.3900985718120 .9997024536121 .6092987061122 .2188034058122 .8283996582 123.43800354124 .0475006104124 .6570968628125 .2667007446125 .8762969971 126.4858016968127 .0953979492127 .4001998901128 .0097961426128 .3144989014 128.3144989014128 .6192932129128 .3144989014127 .7050018311127 .0953979492 126.1809997559125 .2667007446124 .3523025513123 .7427978516123 .43800354 123.43800354123 .43800354123 .7427978516124 .0475006104124 .3523025513 124.2121353149123 .8541183472123 .0520782471121 .8054504395120 .3900985718 119.1709976196118 .2565994263117 .647102356117 .0374984741116 .4279022217 115.818397522114 .9039993286113 .9896011353113 .075302124112 .1608963013 111.551399231110 .6370010376110 .0273971558109 .4179000854109 .1130981445 108.8082962036108 .8082962036108 .8082962036109 .1130981445109 .7226028442 110.3321990967110 .9418029785111 .8561019897112 .7705001831113 .9896011353 114.9039993286115 .818397522116 .7119827271117 .342300415117 .647102356 117.647102356117 .647102356117 .647102356117 .342300415117 .342300415 117.0374984741117 .0374984741116 .7326965332116 .7326965332116 .4279022217 116.1231002808115 .818397522115 .5136032104115 .2088012695114 .5991973877 114.2944030762113 .9896011353113 .3800964355113 .075302124112 .7705001831 112.1608963013111 .8561019897111 .551399231110 .9418029785110 .6370010376 110.0273971558109 .4179000854108 .8082962036108 .1986999512107 .5891036987 
106.979598999106 .0652008057105 .4557037354104 .5412979126103 .9317016602 103.0174026489102 .1029968262101 .1886978149100 .579101562599 .66472625732 98.7503814697397 .8360290527396 .9216690063596 .0073165893694 .78817749023 93.5690307617292 .349891662691 .1307525634889 .6068267822388 .08290100098 86.254188537684 .4254837036182 .5967712402380 .7680587768678 .63455963135 76.5010681152374 .3675689697372 .2340774536169 .7957916259868 .27187347412 -9999 -9999 -9999 -9999 -9999 -9999 -9999 -9999 -9999 -9999 -9999 -9999 -9999 -9999 -9999 -9999

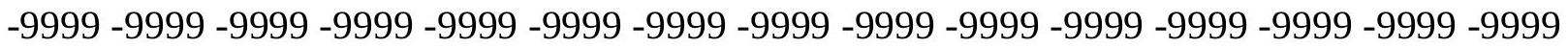

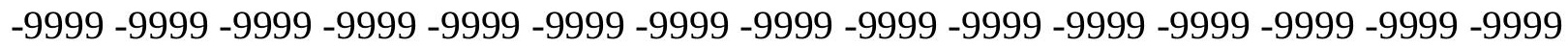
-9999-9999

-9999 -9999 -9999 -9999 -9999 -9999 -9999 -9999 -9999 -9999 -9999 -9999 -9999 -9999 -9999 -9999 -9999 -9999 -9999 -9999 -9999 -9999 -9999 -9999 -9999 -9999 -9999 -9999 -9999 -9999 -9999 -9999 -9999 -9999 -9999 -9999 -9999 -9999 -9999 -9999 -9999 -9999 -9999 -9999 -9999 -9999 -9999 -9999 -9999 -9999 -9999 -9999 -9999 -9999 -9999 -9999 -9999 -9999 -9999 -9999 -9999 -9999 -9999 -9999 -9999 -9999 -9999 -9999 -9999 -9999 -9999 -9999 -9999 -9999 -9999

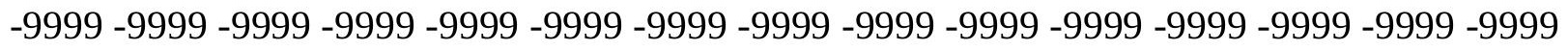

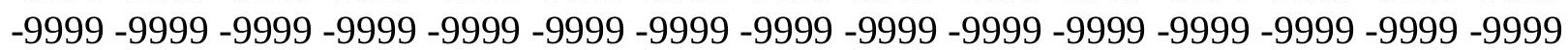

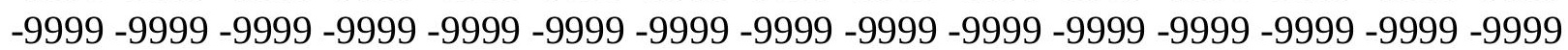
-9999 -9999 -9999 -9999 -9999 -9999 -9999 -9999 -9999 -9999 -9999 -9999 -9999 -9999 -9999 -9999 -9999 -9999 -9999 -9999 -9999 -9999 -9999 -9999 -9999 -9999 -9999 -9999 -9999 -9999

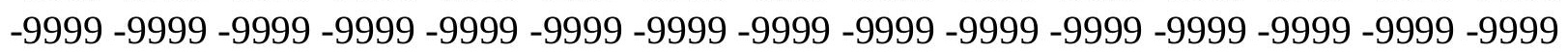

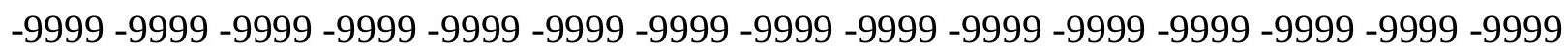
-9999 -9999 -9999 -9999 -9999 -9999 -9999 -9999 -9999 -9999 -9999 -9999 -9999 -9999 -9999 -9999 -9999 -9999 -9999 -9999 -9999 -9999 -9999 -9999 -9999 109.1130981445 108.8082962036109 .1130981445110 .3321990967111 .8561019897113 .3800964355 114.5991973877115 .5136032104116 .4279022217117 .0374984741117 .9517974854 118.5614013672119 .4757995605120 .0852966309120 .6949005127121 .6092987061 122.2188034058123 .1332015991124 .0475006104124 .9618988037125 .8762969971 126.4858016968127 .4001998901128 .0097961426128 .6192932129129 .2288970947 129.533706665129 .533706665129 .533706665129 .2288970947128 .6192932129 128.0097961426127 .0953979492126 .4858016968126 .1809997559125 .8762969971 125.8762969971126 .1809997559126 .4858016968126 .7906036377127 .0953979492 127.0953979492126 .7906036377126 .1809997559124 .9618988037123 .7427978516 122.8283996582121 .9140014648121 .3044967651120 .6949005127120 .3900985718 119.7806015015118 .5614013672117 .647102356116 .4279022217115 .2088012695 114.2944030762113 .3800964355112 .4656982422111 .551399231110 .9418029785 110.6370010376110 .3321990967110 .3321990967110 .3321990967110 .6370010376 110.9418029785111 .551399231112 .4656982422113 .3800964355114 .2944030762 115.5136032104116 .4279022217117 .0374984741117 .647102356117 .9517974854 117.9517974854117 .647102356117 .342300415117 .0374984741117 .0374984741 116.7326965332116 .7326965332116 .4279022217116 .4279022217116 .1231002808 115.818397522115 .5136032104115 .2088012695114 .9039993286114 .2944030762 113.9896011353113 .6848983765113 .075302124112 .7705001831112 .4656982422 111.8561019897111 .551399231110 .9418029785110 .3321990967110 .0273971558 109.4179000854108 .8082962036108 .1986999512107 .5891036987106 .979598999 106.0652008057 105.4557037354104.8460998535103.9317016602 103.3221969604 
102.4077987671101 .7982025146100 .883903503499 .9695205688599 .35994720459 98.445587158297 .8360290527396 .9216690063596 .0073165893694 .78817749023 93.5690307617292 .349891662691 .1307525634889 .6068267822388 .08290100098 86.5589828491284 .6697006225682 .5967712402380 .7680587768678 .63455963135 76.5010681152374 .3675689697372 .2340774536169 .7957916259868 .27187347412 -9999 -9999 -9999 -9999 -9999 -9999 -9999 -9999 -9999 -9999 -9999 -9999 -9999 -9999 -9999 -9999

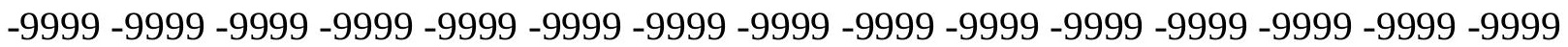

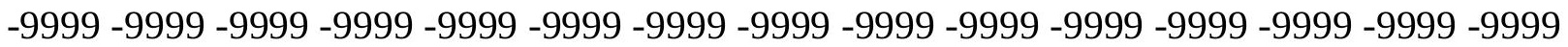
-9999-9999

-9999 -9999 -9999 -9999 -9999 -9999 -9999 -9999 -9999 -9999 -9999 -9999 -9999 -9999 -9999

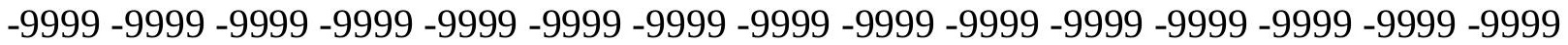
-9999 -9999 -9999 -9999 -9999 -9999 -9999 -9999 -9999 -9999 -9999 -9999 -9999 -9999 -9999 -9999 -9999 -9999 -9999 -9999 -9999 -9999 -9999 -9999 -9999 -9999 -9999 -9999 -9999 -9999 -9999 -9999 -9999 -9999 -9999 -9999 -9999 -9999 -9999 -9999 -9999 -9999 -9999 -9999 - 9999 -9999 -9999 -9999 -9999 -9999 -9999 -9999 -9999 -9999 -9999 -9999 -9999 -9999 -9999 -9999 -9999 -9999 -9999 -9999 -9999 -9999 -9999 -9999 -9999 -9999 -9999 -9999 -9999 - -9999 - -9999 -9999 -9999 -9999 -9999 -9999 -9999 -9999 -9999 -9999 -9999 -9999 -9999 -9999 -9999 -9999 -9999 -9999 -9999 -9999 -9999 -9999 -9999 -9999 -9999 -9999 -9999 -9999 -9999 -9999 -9999 -999 -9999 -9999 -9999 -9999 -9999 -9999 -9999 -9999 -9999 -9999 -9999 -9999 -9999 -9999 -9999 -

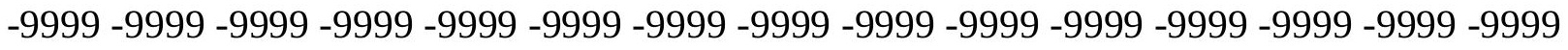
-9999 -9999 -9999 -9999 -9999 -9999 -9999 -9999 -9999 -9999 -9999 -9999 -9999 -9999 -9999 -999 -9999 -9999 -9999 -9999 -9999 -9999 -9999 -9999 -9999 -9999 -9999 -9999 -9999 -9999 -9999 -9999 -9999 -9999 -9999 -9999 -9999 -9999 -9999 -9999 -9999 -9999 110.9418029785 110.0273971558110 .0273971558110 .6370010376111 .8561019897113 .075302124 113.9896011353114 .5991973877115 .5136032104116 .1231002808116 .7326965332 117.647102356118 .2565994263119 .1709976196120 .0852966309121 .3044967651 122.2188034058123 .43800354124 .3523025513125 .5715026855126 .4858016968 127.4001998901128 .3144989014129 .2288970947129 .8385009766130 .1432037354 130.1432037354130 .1432037354130 .1432037354129 .8385009766129 .2288970947 128.6192932129128 .3144989014128 .0097961426127 .7050018311128 .0097961426 128.0097961426128 .3144989014128 .6192932129128 .9241027832128 .9241027832 128.6192932129128 .0097961426127 .4001998901126 .4858016968125 .5715026855 124.6570968628124 .3523025513123 .7427978516123 .43800354122 .8820114136 121.8478851318120 .3900985718119 .1709976196117 .9517974854116 .7326965332 115.5136032104114 .5991973877113 .6848983765112 .7705001831112 .1608963013 111.551399231111 .24659729111 .24659729111 .551399231111 .551399231112 .1608963013 112.7705001831113 .6848983765114 .5991973877115 .5136032104116 .4279022217 117.342300415 117.9517974854 117.9517974854 117.647102356 117.342300415 117.0374984741116 .7326965332116 .4279022217116 .4279022217116 .1231002808 116.1231002808116 .1231002808115 .818397522115 .5136032104115 .2088012695 114.9039993286114 .5991973877114 .2944030762113 .6848983765113 .3800964355 112.7705001831112 .4656982422111 .8561019897111 .551399231110 .9418029785 110.6370010376110 .0273971558109 .4179000854108 .8082962036108 .1986999512 107.5891036987106 .979598999106 .3700027466105 .4557037354104 .8460998535 104.2365036011103 .3221969604102 .712600708102 .1029968262101 .1886978149 100.579101562599 .6647262573299 .0551681518698 .445587158297 .53124237061 
96.6168823242296 .0073165893694 .7881774902393 .8738174438592 .65467834473 91.1307525634889 .9116134643688 .3876876831186 .5589828491284 .73026275635 82.9015579223680 .7680587768678 .9393463134876 .8058471679774 .36756896973 72.2340774536170 .1005783081168 .27187347412 -9999 -9999 -9999 -9999 -9999 -9999 -9999 -9999 -9999 -9999 -9999 -9999 -9999 -9999 -9999 -9999 -9999 -9999 -9999 -9999 -9999 -9999 -9999 -9999 -9999 -9999 -9999 -9999 -9999 -9999 -9999 -9999 -9999 -9999 -9999 -9999 -9999 -9999 -9999 -9999 -9999 -9999 -9999 -9999 -9999 -9999 -9999 -9999

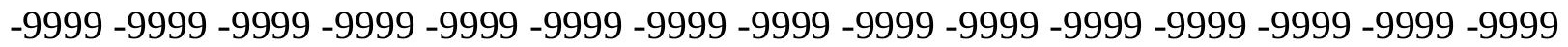

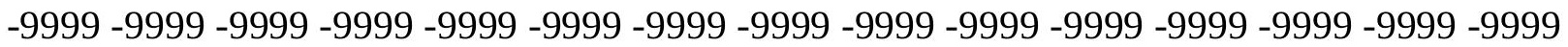
-9999 -9999 -9999 -9999 -9999 -9999 -9999 -9999 -9999 -9999 -9999 -9999 -9999 -9999 -9999 -9999 -9999 -9999 -9999 -9999 -9999 -9999 -9999 -9999 -9999 -9999 -9999 -9999 -9999 -9999 -999 -9999 -9999 -9999 -9999 -9999 -9999 -9999 -9999 -9999 -9999 -9999 -9999 -9999 -9999 -9999 -9999 -9999 -9999 -9999 -9999 -9999 -9999 -9999 -9999 -9999 -9999 -9999 -9999 -9999 -9999 -9999 -9999 -9999 -9999 -9999 -9999 -9999 -9999 -9999 -9999 -9999 -9999 -9999 -9999 -9999 -9999 -9999 -9999 -9999 -9999 -9999 -9999 -9999 -9999 -9999 -9999 -9999 -9999 -9999 -9999

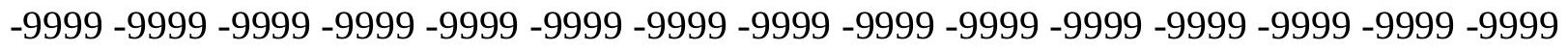
-9999 -9999 -9999 -9999 -9999 -9999 -9999 -9999 -9999 -9999 -9999 -9999 -9999 -9999 -9999 -

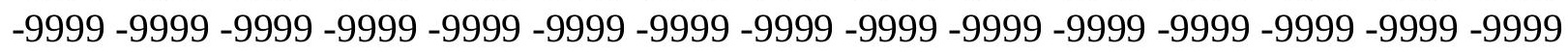

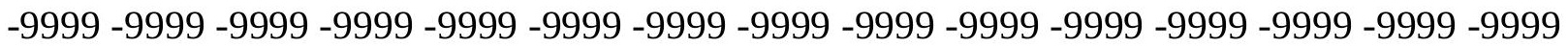

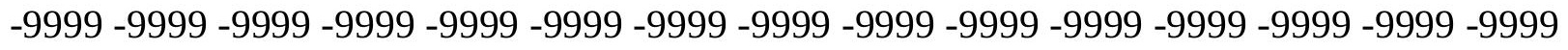
-9999 -9999 -9999 -9999 -9999 -9999 -9999 -9999 -9999 -9999 -9999 -9999 112.1608963013 110.9418029785110 .6370010376110 .6370010376111 .24659729112 .1608963013 112.7705001831113 .3800964355114 .2944030762114 .9039993286115 .818397522 116.7326965332117 .647102356118 .5614013672119 .7806015015120 .9997024536 122.2188034058123 .7427978516124 .9618988037126 .1809997559127 .4001998901 128.3144989014129 .2288970947130 .1432037354130 .4479980469130 .7528076172 130.7528076172130 .7528076172130 .4479980469130 .1432037354129 .8385009766 129.533706665129 .2288970947129 .2288970947129 .2288970947129 .533706665 129.8385009766130 .1432037354130 .1432037354130 .1432037354130 .1432037354 129.533706665128 .9241027832128 .3144989014127 .7050018311127 .0953979492 126.4858016968126 .1809997559125 .8762969971124 .9618988037124 .0475006104 122.8283996582121 .6092987061120 .3900985718118 .8662033081117 .647102356 116.4279022217115 .2088012695114 .2944030762113 .3800964355112 .7705001831 112.4656982422112 .1608963013112 .1608963013112 .1608963013112 .4656982422 112.7705001831113 .3800964355114 .2944030762115 .2088012695116 .1231002808 117.0374984741117 .647102356117 .647102356117 .342300415117 .0374984741 116.7326965332116 .4279022217116 .1231002808116 .1231002808115 .818397522 115.818397522115 .818397522115 .5136032104115 .2088012695114 .9039993286 114.5991973877114 .2944030762113 .9896011353113 .3800964355113 .075302124 112.4656982422112 .1608963013111 .551399231110 .9418029785110 .6370010376 110.0273971558109 .4179000854108 .8082962036108 .1986999512107 .5891036987 106.979598999 106.3700027466105.7603988647 104.8460998535104.2365036011 103.6268997192103 .0174026489102 .1029968262101 .4934005737100 .8839035034 100.274299621699 .3599472045998 .7503814697398 .1408081054797 .53124237061 96.6168823242296 .0073165893695 .0929565429793 .8738174438592 .65467834473 91.4355392456189 .9116134643688 .3876876831186 .8637619018685 .03504943848 
82.90155792236 81.0728530883878.93934631348 76.80584716797 74.67236328125 72.2340774536170 .1005783081168 .27187347412 -9999 -9999 -9999 -9999 -9999 -9999 -9999 -9999 -9999 -9999 -9999 -9999 -9999 -9999 -9999 -9999 -9999 -9999 -9999 -9999 -9999 -9999 -9999 -9999 -9999 -9999 -9999 -9999 -9999 -9999 -9999 -9999 -9999 -9999 -9999 -9999 -9999 -9999 -9999 -9999 -9999 -9999 -9999 -9999 -9999 -9999 -9999 -9999 -9999 -9999 -9999 -9999 -9999 -9999 -9999 -9999 -9999 -9999 -9999 -9999 -9999 -9999 -9999

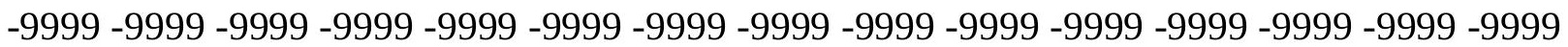

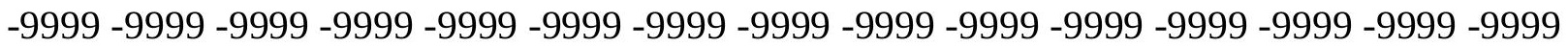
-9999 -9999 -9999 -9999 -9999 -9999 -9999 -9999 -9999 -9999 -9999 -9999 -9999 -9999 -9999 -9999 -9999 -9999 -9999 -9999 -9999 -9999 -9999 -9999 -9999 -9999 -9999 -9999 -9999 -9999 -

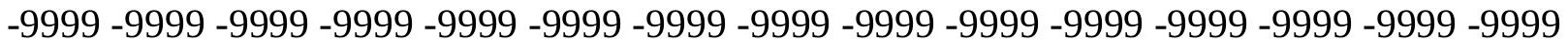
-9999 -9999 -9999 -9999 -9999 -9999 -9999 -9999 -9999 -9999 -9999 -9999 -9999 -9999 -9999 -9999 -9999 -9999 -9999 -9999 -9999 -9999 -9999 -9999 -9999 -9999 -9999 -9999 -9999 -9999 -9999 -9999 -9999 -9999 -9999 -9999 -9999 -9999 -9999 -9999 -9999 -9999 -9999 -9999 -9999 -9999 -9999 -9999 -9999 -9999 -9999 -9999 -9999 -9999 -9999 -9999 -9999 -9999 -9999 -9999

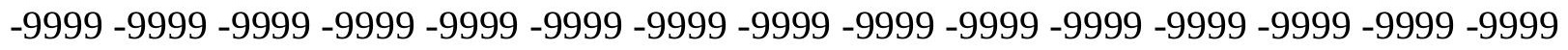

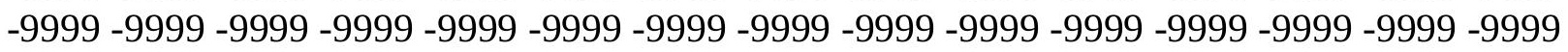

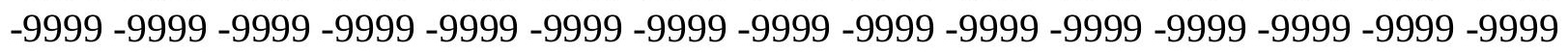
-9999 -9999 -9999 -9999 -9999 -9999 -9999 -9999 -9999 -9999 -9999 -9999 -9999 112.7705001831111 .24659729110 .3321990967109 .4179000854110 .3321990967 110.9418029785111 .551399231112 .1608963013113 .075302124113 .6848983765 114.5991973877115 .818397522117 .0374984741118 .2565994263119 .7806015015 121.3044967651122 .8283996582124 .3523025513125 .5715026855127 .0953979492 128.3144989014129 .2288970947130 .1432037354130 .7528076172131 .0576019287 131.0576019287131 .0576019287130 .7528076172130 .7528076172130 .4479980469 130.1432037354129 .8385009766129 .8385009766129 .8385009766130 .1432037354 130.4479980469130 .7528076172130 .7528076172130 .7528076172130 .7528076172 130.4479980469130 .1432037354129 .533706665129 .2288970947128 .6192932129 128.3144989014127 .7050018311127 .4001998901126 .4858016968125 .5715026855 124.6570968628123 .43800354122 .2188034058120 .6949005127119 .1709976196 117.647102356116 .4279022217115 .5136032104114 .5991973877113 .6848983765 113.075302124112 .7705001831112 .4656982422112 .4656982422112 .4656982422 112.7705001831113 .3800964355113 .6848983765114 .2944030762115 .2088012695 115.818397522116 .4279022217116 .7326965332116 .7326965332116 .4279022217 116.1231002808116 .1231002808115 .818397522115 .818397522115 .5136032104 115.5136032104115 .5136032104115 .2088012695114 .9039993286114 .5991973877 114.2944030762113 .9896011353113 .6848983765113 .075302124112 .7705001831 112.1608963013111 .8561019897111 .24659729110 .6370010376110 .0273971558 109.7226028442109 .1130981445108 .5035018921107 .8938980103106 .979598999 106.3700027466105.7603988647 105.1509017944 104.5412979126103.6268997192 103.0174026489102 .4077987671101 .7982025146100 .8839035034100 .2742996216 99.6647262573299 .0551681518698 .445587158298 .1408081054797 .53124237061 96.6168823242296 .0073165893695 .0929565429794 .1785964965892 .95947265625 91.7403335571390 .2164001464888 .6924667358486 .8637619018685 .03504943848 83.206336975181 .0728530883878 .9393463134876 .8058471679774 .67236328125 72.2340774536170 .1005783081168 .27187347412 -9999 -9999 -9999 -9999 -9999 -9999 -9999 
-9999 -9999 -9999 -9999 -9999 -9999 -9999 -9999 -9999 -9999 -9999 -9999 -9999 -9999 -9999 -9999 -9999 -9999 -9999 -9999 -9999 -9999 -9999 -9999 -9999 -9999 -9999 -9999 -9999 -9999 -9999 -9999 -9999 -9999 -9999 -9999 -9999 -9999 -9999 -9999 -9999

-9999 -9999 -9999 -9999 -9999 -9999 -9999 -9999 -9999 -9999 -9999 -9999 -9999 -9999 -9999 -9999 -9999 -9999 -9999 -9999 -9999 -9999 -9999 -9999 -9999 -9999 -9999 -9999 -9999 -9999 -9999 -9999 -9999 -9999 -9999 -9999 -9999 -9999 -9999 -9999 -9999 -9999 -9999 -9999 -9999 -9999 -9999 -9999 -9999 -9999 -9999 -9999 -9999 -9999 -9999 -9999 -9999 -9999 -9999 -9999

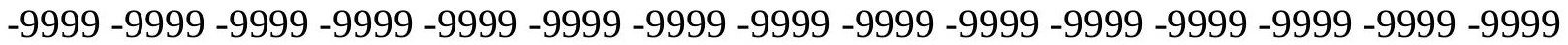

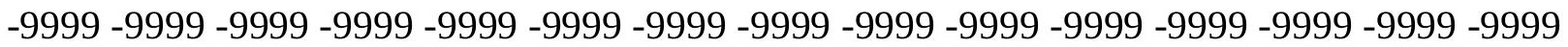
-9999 -9999 -9999 -9999 -9999 -9999 -9999 -9999 -9999 -9999 -9999 -9999 -9999 -9999 -9999 -9999 -9999 -9999 -9999 -9999 -9999 -9999 -9999 -9999 -9999 -9999 -9999 -9999 -9999 -9999 -9999 -9999 -9999 -9999 -9999 -9999 -9999 -9999 -9999 -9999 -9999 -9999 -9999 -9999 -9999

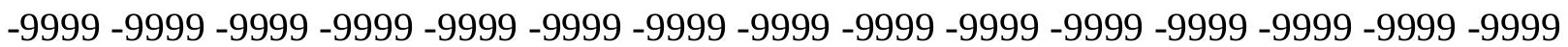
-9999 -9999 -9999 -9999 -9999 -9999 -9999 -9999 -9999 -9999 -9999 -9999 -9999 -9999 -9999 -9999 -9999 -9999 -9999 -9999 -9999 -9999 -9999 -9999 -9999 -9999 -9999 -9999 -9999 -9999

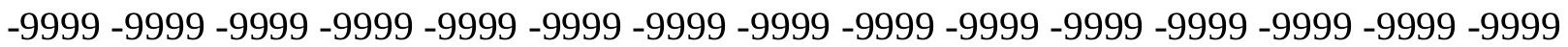
-9999 -9999 -9999 -9999 -9999 -9999 -9999 -9999 -9999 -9999 -9999 -9999 -9999 -9999 113.075302124110 .6370010376109 .7226028442108 .8082962036108 .8082962036 109.4179000854110 .0273971558110 .9418029785111 .551399231112 .7705001831 113.6848983765115 .2088012695116 .7326965332118 .2565994263119 .7806015015 121.6092987061123 .43800354124 .9618988037126 .4858016968128 .0097961426 129.2288970947130 .1432037354130 .7528076172131 .0576019287131 .3623962402 131.0576019287131 .0576019287130 .7528076172130 .4479980469130 .1432037354 130.1432037354130 .1432037354130 .1432037354130 .1432037354130 .4479980469 130.7528076172131 .0576019287131 .0576019287131 .0576019287130 .7528076172 130.7528076172130 .4479980469130 .1432037354129 .533706665129 .2288970947 128.9241027832128 .3144989014127 .7050018311126 .7906036377125 .5715026855 124.3523025513123 .1332015991121 .6092987061120 .3900985718118 .8662033081 117.647102356116 .4279022217115 .5136032104114 .5991973877113 .9896011353 113.3800964355113 .075302124112 .7705001831112 .7705001831112 .7705001831 112.7705001831113 .075302124113 .3800964355113 .9896011353114 .5991973877 115.2088012695115 .5136032104115 .818397522115 .818397522115 .818397522 115.5136032104115 .5136032104115 .5136032104115 .5136032104115 .2088012695 115.2088012695114 .9039993286114 .5991973877114 .2944030762113 .9896011353 113.6848983765113 .3800964355112 .7705001831112 .4656982422111 .8561019897 111.24659729110 .9418029785110 .3321990967109 .7226028442109 .1130981445 108.5035018921107 .8938980103107 .2844009399106 .6747970581106 .0652008057 105.1509017944104 .5412979126103 .9317016602103 .0174026489102 .4077987671 101.7982025146101 .1886978149100 .579101562599 .9695205688599 .35994720459 99.0551681518698 .445587158297 .8360290527397 .5312423706196 .92166900635 96.0073165893695 .397743225194 .1785964965893 .2642517089892 .04509735107 90.5211791992288 .9972534179787 .1685485839885 .3398437583 .2063369751 81.3776321411178 .9393463134876 .8058471679774 .6723632812572 .23407745361 69.7957916259868 .27187347412 -9999 -9999 -9999 -9999 -9999 -9999 -9999 -9999 -9999 -9999 -9999 -9999 -9999 -9999 -9999 -9999 -9999 -9999 -9999 -9999 -9999 -9999 -9999 -9999

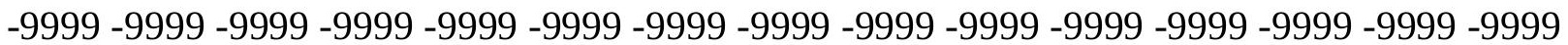


-9999 -9999 -9999 -9999 -9999 -9999 -9999 -9999 -9999

-9999 -9999 -9999 -9999 -9999 -9999 -9999 -9999 -9999 -9999 -9999 -9999 -9999 -9999 -9999

-9999 -9999 -9999 -9999 -9999 -9999 -9999 -9999 -9999 -9999 -9999 -9999 -9999 -9999 -9999

-9999 -9999 -9999 -9999 -9999 -9999 -9999 -9999 -9999 -9999 -9999 -9999 -9999 -9999 -9999

-9999 -9999 -9999 -9999 -9999 -9999 -9999 -9999 -9999 -9999 -9999 -9999 -9999 -9999 -9999 -

-9999 -9999 -9999 -9999 -9999 -9999 -9999 -9999 -9999 -9999 -9999 -9999 -9999 -9999 -9999 -

-9999 -9999 -9999 -9999 -9999 -9999 -9999 -9999 -9999 -9999 -9999 -9999 -9999 -9999 -9999 -

-9999 -9999 -9999 -9999 -9999 -9999 -9999 -9999 -9999 -9999 -9999 -9999 -9999 -9999 -9999

-9999 -9999 -9999 -9999 -9999 -9999 -9999 -9999 -9999 -9999 -9999 -9999 -9999 -9999 -9999

-9999 -9999 -9999 -9999 -9999 -9999 -9999 -9999 -9999 -9999 -9999 -9999 -9999 -9999 -9999 -

-9999 -9999 -9999 -9999 -9999 -9999 -9999 -9999 -9999 -9999 -9999 -9999 -9999 -9999 -9999

-9999 -9999 -9999 -9999 -9999 -9999 -9999 -9999 -9999 -9999 -9999 -9999 -9999 -9999 -9999

-9999 -9999 -9999 -9999 -9999 -9999 -9999 -9999 -9999 -9999 -9999 -9999 -9999 -9999 -9999 -

-9999 -9999 -9999 -9999 -9999 -9999 -9999 -9999 -9999 -9999 -9999 -9999 -9999 -9999 -9999

-9999 -9999 -9999 -9999 -9999 -9999 -9999 -9999 -9999 -9999 -9999 -9999 -9999 -9999 -9999

113.075302124109 .7226028442108 .8082962036107 .8938980103107 .2844009399

107.8938980103108 .8082962036109 .4179000854110 .6370010376111 .8561019897

113.075302124114 .9039993286116 .4279022217118 .2565994263120 .3900985718

122.2188034058124 .0475006104125 .8762969971127 .4001998901128 .6192932129 129.8385009766130 .4479980469130 .7528076172131 .0576019287131 .0576019287 130.7528076172130 .7528076172130 .4479980469130 .1432037354129 .8385009766 129.8385009766129 .8385009766130 .1432037354130 .1432037354130 .4479980469 130.4479980469130 .7528076172130 .7528076172130 .7528076172130 .7528076172 130.7528076172130 .4479980469130 .1432037354129 .8385009766129 .2288970947 128.9241027832128 .0097961426127 .0953979492126 .1809997559124 .9618988037 123.7427978516122 .2188034058120 .9997024536119 .4757995605118 .2565994263 117.0374984741116 .1231002808115 .2088012695114 .2944030762113 .6848983765 113.3800964355112 .7705001831112 .4656982422112 .4656982422112 .4656982422 112.4656982422112 .4656982422112 .7705001831113 .3800964355113 .9896011353 114.2944030762114 .9039993286114 .9039993286115 .2088012695115 .2088012695 115.2088012695115 .2088012695115 .2088012695114 .9039993286114 .9039993286 114.5991973877114 .2944030762113 .9896011353113 .6848983765113 .3800964355 113.075302124112 .4656982422112 .1608963013111 .551399231110 .9418029785 110.3321990967110 .0273971558109 .4179000854108 .8082962036108 .1986999512 107.5891036987106 .6747970581106 .0652008057105 .4557037354104 .8460998535 103.9317016602103 .3221969604102 .712600708102 .1029968262101 .1886978149 100.579101562599 .9695205688599 .6647262573299 .0551681518698 .75038146973 98.1408081054797 .8360290527397 .5312423706196 .9216690063596 .31210327148 95.397743225194 .4833908081193 .5690307617292 .349891662690 .82597351074 89.3020401001 87.47332763672 85.63288879395 83.51112365723 81.37763214111 79.2441329956176 .8058471679774 .6723632812572 .2340774536169 .79579162598 68.27187347412 -9999 -9999 -9999 -9999 -9999 -9999 -9999 -9999 -9999 -9999 -9999 -9999 -9999 -9999 -9999 -9999 -9999 -9999 -9999 -9999 -9999 -9999 -9999 -9999 -9999 -9999 -9999 -9999 -9999 -9999 -9999 -9999 -9999 -9999 -9999 -9999 -9999 -9999 -9999 -9999 -9999 -9999 -9999 -9999 -9999 -9999-9999 -9999

-9999 -9999 -9999 -9999 -9999 -9999 -9999 -9999 -9999 -9999 -9999 -9999 -9999 -9999 -9999 
-9999 -9999 -9999 -9999 -9999 -9999 -9999 -9999 -9999 -9999 -9999 -9999 -9999 -9999 -9999 -9999 -9999 -9999 -9999 -9999 -9999 -9999 -9999 -9999 -9999 -9999 -9999 -9999 -9999 -9999

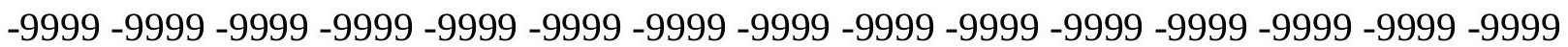
-9999 -9999 -9999 -9999 -9999 -9999 -9999 -9999 -9999 -9999 -9999 -9999 -9999 -9999 -9999 -9999 -9999 -9999 -9999 -9999 -9999 -9999 -9999 -9999 -9999 -9999 -9999 -9999 -9999 -9999 -9999 -9999 -9999 -9999 -9999 -9999 -9999 -9999 -9999 -9999 -9999 -9999 -9999 -9999 -9999 -9999 -9999 -9999 -9999 -9999 -9999 -9999 -9999 -9999 -9999 -9999 -9999 -9999 -9999 -9999 -9999 -9999 -9999 -9999 -9999 -9999 -9999 -9999 -9999 -9999 -9999 -9999 -9999 -9999 -9999 -9999 -9999 -9999 -9999 -9999 -9999 -9999 -9999 -9999 -9999 -9999 -9999 -9999 -9999 -9999 -9999 -9999 -9999 -9999 -9999 -9999 -9999 -9999 -9999 -9999 -9999 -9999 -9999 -9999 -9999 -9999 -9999 -9999 -9999 -9999 -9999 -9999 -9999 -9999 -9999 -9999 -9999 -9999 -9999 -9999 -9999 -9999 -9999 -9999 -9999 -9999 -9999 -9999 -9999 -9999 -9999 -9999 -9999 -9999 -9999 -9999 -9999 -9999 -9999 -9999 -9999 -9999 -9999 -9999 -9999 -9999 -9999 -9999 -9999 -9999 -9999 -9999 109.4179000854107.8938980103106.979598999106.0652008057 106.6747970581107 .2844009399108 .5035018921109 .7226028442111 .24659729 112.7705001831114 .9039993286116 .7326965332118 .8662033081120 .9997024536 122.8283996582124 .9618988037126 .7906036377128 .3144989014129 .2288970947 130.1432037354130 .4479980469130 .7528076172130 .4479980469130 .4479980469 130.1432037354129 .8385009766129 .533706665129 .533706665129 .2288970947 129.2288970947129 .2288970947129 .533706665129 .533706665129 .8385009766 130.1432037354130 .4479980469130 .4479980469130 .4479980469130 .4479980469 130.4479980469130 .1432037354129 .8385009766129 .533706665128 .9241027832 128.3144989014127 .4001998901126 .1809997559125 .2667007446124 .0475006104 122.5235977173121 .3044967651120 .0852966309118 .8662033081117 .647102356 116.7326965332115 .5136032104114 .9039993286113 .9896011353113 .3800964355 113.075302124112 .4656982422112 .1608963013111 .8561019897111 .8561019897 111.551399231111 .551399231112 .1608963013112 .7705001831113 .3800964355 113.9896011353114 .2944030762114 .5991973877114 .9039993286114 .9039993286 114.9039993286114 .9039993286114 .5991973877114 .5991973877114 .2944030762 113.9896011353113 .6848983765113 .3800964355113 .075302124112 .7705001831 112.1608963013111 .8561019897111 .24659729110 .6370010376110 .0273971558 109.4179000854108 .8082962036108 .1986999512107 .5891036987106 .979598999 106.3700027466105 .7603988647104 .8460998535104 .2365036011103 .6268997192 103.0174026489102 .1029968262101 .4934005737100 .8839035034100 .2742996216 99.6647262573299 .0551681518698 .7503814697398 .445587158298 .14080810547 97.8360290527397 .5312423706197 .2264633178796 .6168823242295 .70252990723 94.7881774902393 .8738174438592 .6546783447391 .1307525634889 .3020401001 87.47332763672 85.64462280273 83.51112365723 81.37763214111 79.24413299561 76.8058471679774 .6723632812572 .2340774536169 .7957916259868 .27187347412 -9999 -9999 -9999 -9999 -9999 -9999 -9999 -9999 -9999 -9999 -9999 -9999 -9999 -9999 -9999 -9999 -9999 -9999 -9999 -9999 -9999 -9999 -9999 -9999 -9999 -9999 -9999 -9999 -9999 -9999 -9999

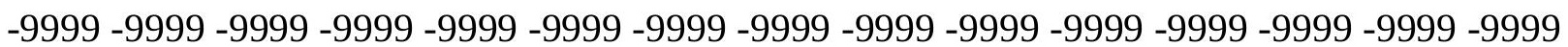
$-9999-9999$

-9999 -9999 -9999 -9999 -9999 -9999 -9999 -9999 -9999 -9999 -9999 -9999 -9999 -9999 -9999 -9999 -9999 -9999 -9999 -9999 -9999 -9999 -9999 -9999 -9999 -9999 -9999 -9999 -9999 -9999

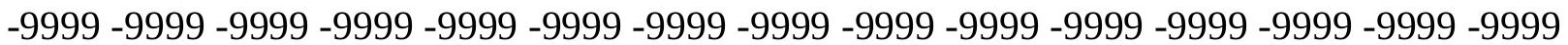


-9999 -9999 -9999 -9999 -9999 -9999 -9999 -9999 -9999 -9999 -9999 -9999 -9999 -9999 -9999 -9999 -9999 -9999 -9999 -9999 -9999 -9999 -9999 -9999 -9999 -9999 -9999 -9999 -9999 -9999 -9999 -9999 -9999 -9999 -9999 -9999 -9999 -9999 -9999 -9999 -9999 -9999 -9999 -9999 -9999 -9999 -9999 -9999 -9999 -9999 -9999 -9999 -9999 -9999 -9999 -9999 -9999 -9999 -9999 -9999 -9999 -9999 -9999 -9999 -9999 -9999 -9999 -9999 -9999 -9999 -9999 -9999 -9999 -9999 -9999 -9999 -9999 -9999 -9999 -9999 -9999 -9999 -9999 -9999 -9999 -9999 -9999 -9999 -9999 -9999 -9999 -9999 -9999 -9999 -9999 -9999 -9999 -9999 -9999 -9999 -9999 -9999 -9999 -9999 -9999

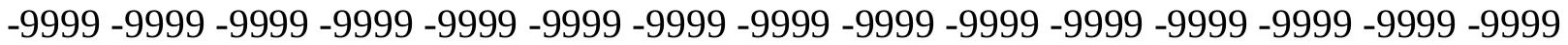

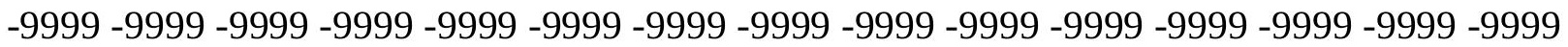
-9999 -9999 -9999 -9999 -9999 -9999 -9999 -9999 -9999 -9999 -9999 -9999 -9999 -9999 -9999 -9999 -9999 -9999 -9999 -9999 -9999 -9999 -9999 -9999 -9999 -9999 -9999 -9999 -9999 -9999 -9999 -9999-9999 109.4179000854106.979598999 106.0652008057 105.1509017944 105.4557037354106 .3700027466107 .5891036987109 .1130981445110 .9418029785 112.7705001831114 .9039993286117 .342300415119 .4757995605121 .6092987061 123.7427978516125 .8762969971127 .4001998901128 .6192932129129 .533706665 129.8385009766129 .8385009766129 .8385009766129 .533706665129 .2288970947 129.2288970947128 .9241027832128 .6192932129128 .3144989014128 .3144989014 128.3144989014128 .6192932129128 .6192932129128 .9241027832129 .2288970947 129.533706665129 .8385009766129 .8385009766130 .1432037354129 .8385009766 129.8385009766129 .533706665129 .2288970947128 .6192932129128 .0097961426 127.0953979492126 .1809997559124 .9618988037123 .7427978516122 .5235977173 121.3044967651120 .0852966309119 .1709976196117 .9517974854117 .0374984741 116.1231002808115 .2088012695114 .2944030762113 .6848983765113 .075302124 112.4656982422112 .1608963013111 .8561019897111 .551399231111 .24659729 111.24659729111 .551399231112 .1608963013112 .7705001831113 .3800964355 113.9896011353114 .2944030762114 .2944030762114 .5991973877114 .5991973877 114.5991973877114 .5991973877114 .2944030762114 .2944030762113 .9896011353 113.6848983765113 .3800964355112 .7705001831112 .4656982422111 .8561019897 111.551399231110 .9418029785110 .3321990967109 .7226028442109 .1130981445 108.5035018921107 .8938980103107 .2844009399106 .6747970581106 .0652008057 105.1509017944104 .5412979126103 .9317016602103 .3221969604102 .4077987671 101.7982025146101 .1886978149100 .579101562599 .6647262573299 .35994720459 98.7503814697398 .445587158298 .1408081054798 .1408081054797 .83602905273 97.5312423706197 .2264633178796 .9216690063596 .3121032714895 .3977432251 94.1785964965892 .9594726562591 .4355392456189 .6068267822387 .77810668945 85.8584747314583 .6272048950281 .3776321411179 .2441329956176 .80584716797 74.3675689697372 .2340774536169 .7957916259868 .27187347412 -9999 -9999 -9999 -9999 -9999 -9999 -9999 -9999 -9999 -9999 -9999 -9999 -9999 -9999 -9999 -9999 -9999 -9999 -9999 -9999 -9999 -9999 -9999 -9999 -9999 -9999 -9999 -9999 -9999 -9999 -9999 -9999 -9999 -9999 -9999 -9999 -9999 -9999 -9999 -9999 -9999 -9999 -9999 -9999 -9999 -9999 -9999 -9999 -9999 -9999 -9999 -9999 -9999 -9999 -9999 -9999 -9999 -9999 -9999 -9999 -9999 -9999 -9999

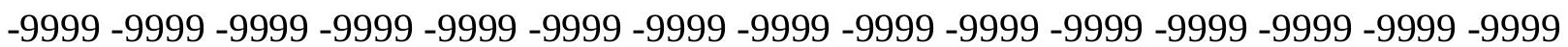
-9999 -9999 -9999 -9999 -9999 -9999 -9999 -9999 -9999 -9999 -9999 -9999 -9999 -9999 -9999 -9999 -9999 -9999 -9999 -9999 -9999 -9999 -9999 -9999 -9999 -9999 -9999 -9999 -9999 -9999 -9999 -9999 -9999 -9999 -9999 -9999 -9999 -9999 -9999 -9999 -9999 -9999 -9999 -9999 -9999

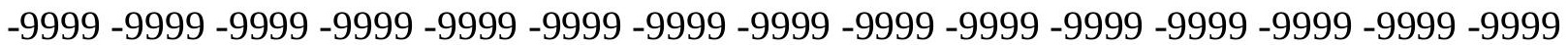


-9999 -9999 -9999 -9999 -9999 -9999 -9999 -9999 -9999 -9999 -9999 -9999 -9999 -9999 -9999 -9999 -9999 -9999 -9999 -9999 -9999 -9999 -9999 -9999 -9999 -9999 -9999 -9999 -9999 -9999

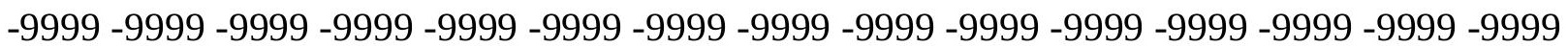
-9999 -9999 -9999 -9999 -9999 -9999 -9999 -9999 -9999 -9999 -9999 -9999 -9999 -9999 -9999 -9999 -9999 -9999 -9999 -9999 -9999 -9999 -9999 -9999 -9999 -9999 -9999 -9999 -9999 -9999 -9999 -9999 -9999 -9999 -9999 -9999 -9999 -9999 -9999 -9999 -9999 -9999 -9999 -9999 -9999 -9999 -9999 -9999 -9999 -9999 -9999 -9999 -9999 -9999 -9999 -9999 -9999 -9999 -9999 -9999 -9999 -9999 -9999 -9999 -9999 -9999 -9999 -9999 -9999 -9999 -9999 -9999 -9999 -9999 -9999 -9999 -9999 -9999 -9999 110.0273971558 106.0652008057 105.1509017944104.2365036011 104.2365036011105 .4557037354106 .979598999108 .8082962036110 .9418029785 113.075302124115 .5136032104117 .647102356120 .0852966309122 .2188034058 124.6570968628126 .4858016968128 .0097961426128 .6192932129128 .9241027832 128.9241027832128 .9241027832128 .6192932129128 .3144989014128 .0097961426 127.7050018311127 .4001998901127 .4001998901127 .0953979492127 .0953979492 127.0953979492127 .4001998901127 .7050018311128 .0097961426128 .6192932129 128.9241027832129 .2288970947129 .2288970947129 .2288970947129 .2288970947 129.2288970947128 .6192932129128 .3144989014127 .7050018311126 .7906036377 125.8762969971124 .6570968628123 .7427978516122 .5235977173121 .3044967651 120.3900985718119 .1709976196118 .2565994263117 .342300415116 .4279022217 115.5136032104114 .5991973877113 .9896011353113 .3800964355112 .7705001831 112.1608963013111 .551399231111 .24659729111 .24659729111 .24659729111 .551399231 111.8561019897112 .4656982422113 .075302124113 .3800964355113 .9896011353 113.9896011353114 .2944030762114 .2944030762114 .2944030762114 .2944030762 114.2944030762113 .9896011353113 .6848983765113 .3800964355113 .075302124 112.4656982422112 .1608963013111 .551399231111 .24659729110 .6370010376 110.0273971558109 .4179000854108 .8082962036108 .1986999512107 .5891036987 106.979598999106 .3700027466105 .7603988647104 .8460998535104 .2365036011 103.6268997192102 .712600708102 .1029968262101 .4934005737100 .8839035034 99.9695205688599 .3599472045998 .7503814697398 .445587158298 .14080810547 98.1408081054798 .1408081054797 .8360290527397 .8360290527397 .53124237061 97.2264633178796 .6168823242295 .7025299072394 .7881774902393 .26425170898 91.7403335571389 .9116134643688 .0829010009885 .9494018554783 .70238494873 81.3776321411179 .2441329956176 .8058471679774 .3675689697371 .92929077148 69.4910125732467 .96708679199 -9999 -9999 -9999 -9999 -9999 -9999 -9999 -9999 -9999 -9999 -9999 -9999 -9999 -9999 -9999 -9999 -9999 -9999 -9999 -9999 -9999 -9999 -9999 -9999 -9999 -9999 -9999 -9999 -9999 -9999 -9999 -9999 -9999 -9999 -9999 -9999 -9999 -9999 -9999 -9999 -9999 -9999 -9999 -9999 -9999 -9999 -9999 -9999

-9999 -9999 -9999 -9999 -9999 -9999 -9999 -9999 -9999 -9999 -9999 -9999 -9999 -9999 -9999 -9999 -9999 -9999 -9999 -9999 -9999 -9999 -9999 -9999 -9999 -9999 -9999 -9999 -9999 -9999 -9999 -9999 -9999 -9999 -9999 -9999 -9999 -9999 -9999 -9999 -9999 -9999 -9999 - -9999 -9999 -9999 -9999 -9999 -9999 -9999 -9999 -9999 -9999 -9999 -9999 -9999 -9999 -9999 -9999 -9999

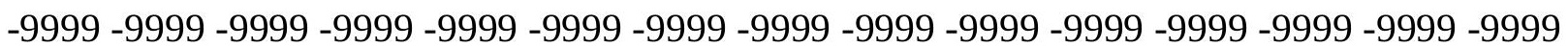
-9999 -9999 -9999 -9999 -9999 -9999 -9999 -9999 -9999 -9999 -9999 -9999 -9999 -9999 -9999 -9999 -9999 -9999 -9999 -9999 -9999 -9999 -9999 -9999 -9999 -9999 -9999 -9999 -9999 -9999 -999 -9999 -9999 -9999 -9999 -9999 -9999 -9999 -9999 -9999 -9999 -9999 -9999 -9999 -9999 -9999

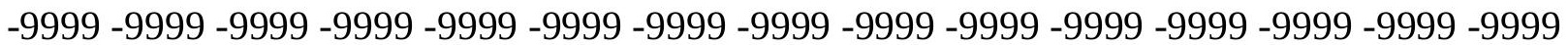


-9999 -9999 -9999 -9999 -9999 -9999 -9999 -9999 -9999 -9999 -9999 -9999 -9999 -9999 -9999 -9999 -9999 -9999 -9999 -9999 -9999 -9999 -9999 -9999 -9999 -9999 -9999 -9999 -9999 -9999

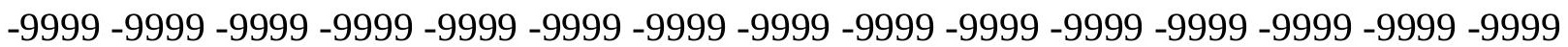
-9999 -9999 -9999 -9999 -9999 -9999 -9999 -9999 -9999 -9999 -9999 -9999 -9999 -9999 -9999 -9999 -9999 -9999 -9999 -9999 -9999 -9999 -9999 -9999 -9999 -9999 -9999 -9999 -9999 -9999 -9999 -9999 -9999 -9999 -9999 110.6370010376107 .8938980103104 .5412979126 103.9317016602105 .1509017944105 .1509017944106 .979598999109 .1130981445 111.24659729113 .3800964355115 .818397522118 .2565994263120 .6949005127 122.8283996582124 .9618988037127 .0953979492127 .4001998901127 .7050018311 127.7050018311127 .4001998901127 .0953979492127 .0953979492126 .7906036377 126.4858016968126 .1809997559125 .8762969971125 .8762969971125 .5715026855 125.8762969971125 .8762969971126 .4858016968126 .7906036377127 .4001998901 127.7050018311128 .3144989014128 .3144989014128 .6192932129128 .6192932129 128.3144989014128 .0097961426127 .7050018311127 .0953979492126 .1809997559 125.2667007446124 .3523025513123 .1332015991122 .2188034058121 .3044967651 120.0852966309119 .1709976196118 .2565994263117 .342300415116 .4279022217 115.818397522114 .9039993286114 .2944030762113 .3800964355112 .7705001831 112.4656982422111 .8561019897111 .551399231111 .24659729111 .24659729111 .551399231 111.8561019897112 .4656982422112 .7705001831113 .3800964355113 .6848983765 113.9896011353113 .9896011353114 .2944030762114 .2944030762113 .9896011353 113.9896011353113 .6848983765113 .6848983765113 .075302124112 .7705001831 112.4656982422111 .8561019897111 .551399231110 .9418029785110 .3321990967 109.7226028442109 .1130981445108 .5035018921107 .8938980103107 .2844009399 106.6747970581106 .0652008057105 .4557037354104 .5412979126103 .9317016602 103.3221969604102 .712600708101 .7982025146101 .1886978149100 .5791015625 99.6647262573299 .0551681518698 .445587158298 .1408081054797 .83602905273 97.8360290527398 .1408081054798 .1408081054798 .1408081054798 .14080810547 97.8360290527397 .2264633178796 .3121032714895 .0929565429793 .56903076172 92.0450973510790 .2164001464888 .0829010009885 .9494018554783 .81591033936 81.3776321411179 .2441329956176 .8058471679774 .3675689697371 .92929077148 69.4910125732467 .96708679199 -9999 -9999 -9999 -9999 -9999 -9999 -9999 -9999 -9999 -9999 -9999 -9999 -9999 -9999 -9999 -9999 -9999 -9999 -9999 -9999 -9999 -9999 -9999 -9999 -9999 -9999 -9999 -9999 -9999 -9999 -9999 -9999 -9999 -9999 -9999 -9999 -9999 -9999 -9999 -9999 -9999 -9999 -9999 -9999 -9999 -9999 -9999 -9999 -9999 -9999 -9999 -9999 -9999 -9999 -9999 -9999 -9999 -9999 -9999 -9999 -9999 -9999 -9999 -9999 -9999 -9999 -9999 -9999 -9999 -9999 -9999 -9999 -9999 -9999 -9999 -9999 -9999 -9999 -9999 -9999 -9999 -9999 -9999 -9999 -9999 -9999 -9999 -9999 -9999 -9999 -9999 -9999 -9999

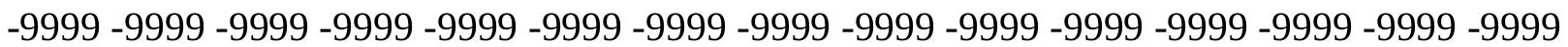
-9999 -9999 -9999 -9999 -9999 -9999 -9999 -9999 -9999 -9999 -9999 -9999 -9999 -9999 -9999 -9999 -9999 -9999 -9999 -9999 -9999 -9999 -9999 -9999 -9999 -9999 -9999 -9999 -9999 -9999 -9999 -9999 -9999 -9999 -9999 -9999 -9999 -9999 -9999 -9999 -9999 -9999 -9999 -9999 -9999

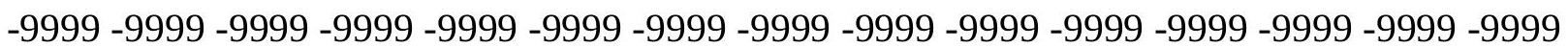
-9999 -9999 -9999 -9999 -9999 -9999 -9999 -9999 -9999 -9999 -9999 -9999 -9999 -9999 -9999 -9999 -9999 -9999 -9999 -9999 -9999 -9999 -9999 -9999 -9999 -9999 -9999 -9999 -9999 -9999 -999 -9999 -9999 -9999 -9999 -9999 -9999 -9999 -9999 -9999 -9999 -9999 -9999 -9999 -9999 -9999

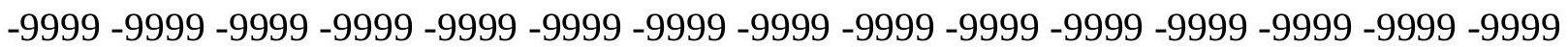


-9999 -9999 -9999 -9999 -9999 -9999 -9999 -9999 -9999 -9999 -9999 -9999 -9999 -9999 -9999 -9999 -9999 -9999 -9999 -9999 -9999 -9999 -9999 -9999 -9999 -9999 -9999 -9999 -9999 -9999 -9999 -9999 -9999 -9999 -9999 -9999 111.24659729 107.2844009399 104.8460998535 103.9317016602103 .6268997192105 .1509017944107 .2844009399109 .4179000854 111.551399231113 .9896011353116 .1231002808118 .5614013672120 .9997024536 123.1332015991124 .6570968628125 .5715026855125 .8762969971125 .8762969971 125.8762969971125 .5715026855125 .5715026855125 .2667007446124 .9618988037 124.6570968628124 .6570968628124 .3523025513124 .0475006104124 .0475006104 124.3523025513124 .9618988037125 .5715026855126 .1809997559126 .7906036377 127.0953979492127 .4001998901127 .7050018311127 .7050018311127 .7050018311 127.4001998901127 .0953979492126 .4858016968125 .5715026855124 .6570968628 123.7427978516122 .5235977173121 .6092987061120 .9997024536120 .0852966309 119.1709976196118 .2565994263117 .647102356116 .7326965332115 .818397522 115.2088012695114 .5991973877113 .6848983765113 .075302124112 .7705001831 112.1608963013111 .8561019897111 .8561019897111 .8561019897111 .8561019897 112.1608963013112 .4656982422113 .075302124113 .3800964355113 .6848983765 113.9896011353113 .9896011353113 .9896011353113 .9896011353113 .9896011353 113.9896011353113 .6848983765113 .3800964355113 .075302124112 .7705001831 112.1608963013111 .8561019897111 .24659729110 .6370010376110 .0273971558 109.4179000854108 .8082962036108 .1986999512107 .5891036987106 .979598999 106.3700027466105 .7603988647105 .1509017944104 .2365036011103 .6268997192 103.0174026489102 .4077987671101 .7982025146101 .1886978149100 .2742996216 99.6647262573298 .7503814697398 .1408081054797 .8360290527397 .83602905273 98.1408081054798 .445587158298 .445587158298 .7503814697398 .75038146973 98.445587158297 .8360290527396 .9216690063595 .7025299072394 .00782775879 92.1962280273490 .2830810546988 .2609176635785 .9494018554783 .81591033936 81.3776321411178 .9393463134876 .5010681152374 .062782287671 .62449645996 69.1862335205167 .66230010986 -9999 -9999 -9999 -9999 -9999 -9999 -9999 -9999 -9999 -9999 -9999 -9999 -9999 -9999 -9999 -9999 -9999 -9999 -9999 -9999 -9999 -9999 -9999 -9999 -9999 -9999 -9999 -9999 -9999 -9999 -9999 -9999 -9999 -9999 -9999 -9999 -9999 -9999 -9999 -9999 -9999 -9999 -9999 -9999 -9999 -9999 -9999 -9999

-9999 -9999 -9999 -9999 -9999 -9999 -9999 -9999 -9999 -9999 -9999 -9999 -9999 -9999 -9999 -9999 -9999 -9999 -9999 -9999 -9999 -9999 -9999 -9999 -9999 -9999 -9999 -9999 -9999 -9999 -9999 -9999 -9999 -9999 -9999 -9999 -9999 -9999 -9999 -9999 -9999 -9999 -9999 -9999 -9999 -9999 -9999 -9999 -9999 -9999 -9999 -9999 -9999 -9999 -9999 -9999 -9999 -9999 -9999 -9999 -9999 -9999 -9999 -9999 -9999 -9999 -9999 -9999 -9999 -9999 -9999 -9999 -9999 -9999 -9999

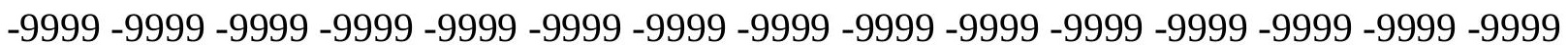

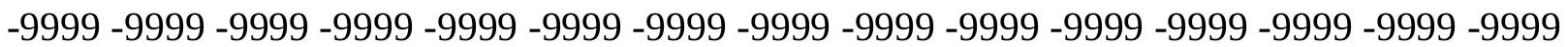
-9999 -9999 -9999 -9999 -9999 -9999 -9999 -9999 -9999 -9999 -9999 -9999 -9999 -9999 -9999 -9999 -9999 -9999 -9999 -9999 -9999 -9999 -9999 -9999 -9999 -9999 -9999 -9999 - -9999 -9999 -9999 -9999 -9999 -9999 -9999 -9999 -9999 -9999 -9999 -9999 -9999 -9999 -9999 -9999 -9999

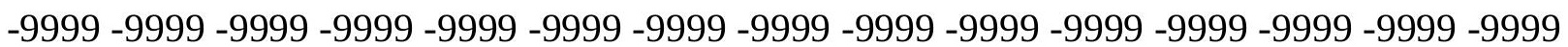
-9999 -9999 -9999 -9999 -9999 -9999 -9999 -9999 -9999 -9999 -9999 -9999 -9999 -9999 -9999 -9999 -9999 -9999 -9999 -9999 -9999 -9999 -9999 -9999 -9999 -9999 -9999 -9999 -9999 -9999 -999 -9999 -9999 -9999 -9999 -9999 -9999 -9999 -9999 -9999 -9999 -9999 -9999 -9999 -9999 -9999 -9999 -9999 -9999 -9999 -9999 -9999-9999 112.1608963013 108.5035018921105 .7603988647 
104.2365036011 105.1509017944 105.1509017944 107.2844009399109.4179000854 111.551399231113 .9896011353116 .4279022217118 .5614013672120 .3900985718 121.9140014648123 .1332015991123 .43800354123 .7427978516123 .7427978516 123.7427978516123 .7427978516123 .43800354123 .43800354123 .1332015991 122.8283996582122 .8283996582122 .5235977173122 .5235977173122 .8283996582 123.43800354124 .3523025513124 .9618988037125 .5715026855126 .1809997559 126.4858016968126 .7906036377126 .7906036377126 .7906036377126 .7906036377 126.1809997559125 .5715026855124 .9618988037124 .0475006104123 .1332015991 121.9140014648121 .3044967651120 .6949005127120 .0852966309119 .1709976196 118.5614013672117 .647102356117 .0374984741116 .1231002808115 .5136032104 114.9039993286114 .2944030762113 .6848983765113 .075302124112 .7705001831 112.4656982422112 .1608963013112 .1608963013112 .1608963013112 .4656982422 112.7705001831113 .075302124113 .3800964355113 .6848983765113 .9896011353 113.9896011353113 .9896011353113 .9896011353113 .9896011353113 .6848983765 113.6848983765113 .3800964355113 .075302124112 .4656982422112 .1608963013 111.551399231110 .9418029785110 .6370010376110 .0273971558109 .4179000854 108.8082962036108 .1986999512107 .5891036987106 .6747970581106 .0652008057 105.4557037354104 .8460998535104 .2365036011103 .6268997192103 .0174026489 102.1029968262101 .4934005737100 .8839035034100 .274299621699 .66472625732 99.0551681518698.1408081054797.8360290527398.1408081054798.4455871582 98.7503814697399 .0551681518699 .3599472045999 .3599472045999 .05516815186 98.445587158297 .3277359008895 .6962585449293 .9804382324292 .17028045654 90.2539672851688 .2172698974685 .9494018554783 .8159103393681 .37763214111 78.6345596313576 .1962814331173 .7580032348671 .3197174072368 .88143920898 67.35751342773 -9999 -9999 -9999 -9999 -9999 -9999 -9999 -9999 -9999 -9999 -9999 -9999 -9999 -9999 -9999 -9999 -9999 -9999 -9999 -9999 -9999 -9999 -9999 -9999 -9999 -9999 -9999 -9999 -9999 -9999 -9999 -9999 -9999 -9999 -9999 -9999 -9999 -9999 -9999 -9999 -9999 -9999 -9999 -9999 -9999 -9999-9999-9999

-9999 -9999 -9999 -9999 -9999 -9999 -9999 -9999 -9999 -9999 -9999 -9999 -9999 -9999 -9999 -9999 -9999 -9999 -9999 -9999 -9999 -9999 -9999 -9999 -9999 -9999 -9999 -9999 -9999 -9999 -9999 -9999 -9999 -9999 -9999 -9999 -9999 -9999 -9999 -9999 -9999 -9999 -9999 -9999 -9999

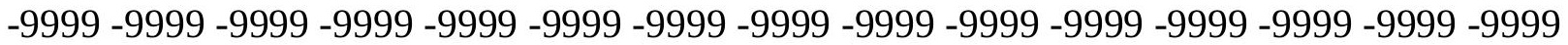

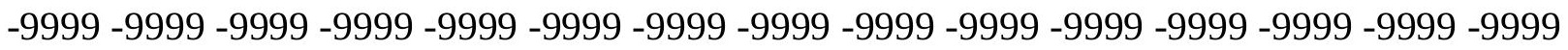
-9999 -9999 -9999 -9999 -9999 -9999 -9999 -9999 -9999 -9999 -9999 -9999 -9999 -9999 -9999 -9999 -9999 -9999 -9999 -9999 -9999 -9999 -9999 -9999 -9999 -9999 -9999 -9999 -9999 -9999 -9999 -9999 -9999 -9999 -9999 -9999 -9999 -9999 -9999 -9999 -9999 -9999 -9999 -9999 -9999

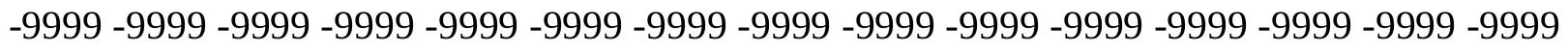

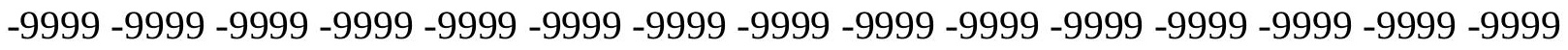
-9999 -9999 -9999 -9999 -9999 -9999 -9999 -9999 -9999 -9999 -9999 -9999 -9999 -9999 -9999 -9999 -9999 -9999 -9999 -9999 -9999 -9999 -9999 -9999 -9999 -9999 -9999 -9999 -9999 -9999 -

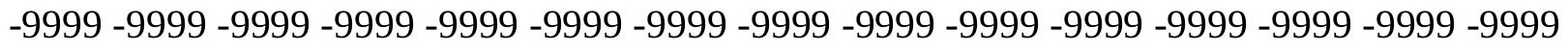
-9999 -9999 -9999 -9999 -9999 -9999 -9999 -9999 -9999 -9999 -9999 -9999 -9999 -9999 -9999 - -999 -9999 -9999 -9999 -9999 -9999 -9999-9999 -9999 113.075302124109 .4179000854 106.979598999104 .5412979126103 .3221969604105 .1509017944107 .2844009399 109.4179000854111 .8561019897113 .9896011353116 .1231002808117 .9517974854 119.4757995605120 .3900985718120 .9997024536121 .6092987061121 .9140014648 
121.9140014648121 .9140014648121 .6092987061121 .6092987061121 .6092987061 121.3044967651121 .3044967651121 .3044967651121 .3044967651121 .6092987061 122.2188034058123 .1332015991123 .7427978516124 .3523025513124 .9618988037 125.5715026855125 .8762969971126 .1809997559126 .1809997559125 .8762969971 125.5715026855124 .9618988037124 .3523025513123 .7427978516122 .8283996582 121.9140014648120 .9997024536120 .3900985718119 .7806015015119 .1709976196 118.5614013672117 .647102356117 .0374984741116 .4279022217115 .818397522 115.2088012695114 .5991973877113 .9896011353113 .6848983765113 .075302124 113.075302124112 .7705001831112 .7705001831112 .7705001831112 .7705001831 113.075302124113 .3800964355113 .6848983765113 .6848983765113 .9896011353 113.9896011353113 .9896011353113 .9896011353113 .9896011353113 .6848983765 113.6848983765113 .3800964355112 .7705001831112 .4656982422111 .8561019897 111.551399231110 .9418029785110 .3321990967109 .7226028442109 .1130981445 108.5035018921107 .8938980103107 .2844009399106 .6747970581106 .0652008057 105.1509017944104 .5412979126103 .9317016602103 .3221969604102 .712600708 102.1029968262101 .4934005737100 .8839035034100 .579101562599 .96952056885 99.3599472045998 .7503814697398 .445587158298 .7503814697399 .05516815186 99.6647262573299 .9695205688599 .9695205688599 .9695205688599 .66472625732 98.7693328857497 .225311279395 .6032638549893 .8912963867292 .07965087891 90.151924133388 .0951766967885 .8874969482483 .5111236572381 .07285308838 78.6345596313575 .8914871215873 .4532165527371 .014930725168 .57665252686 67.05272674561 -9999 -9999 -9999 -9999 -9999 -9999 -9999 -9999 -9999 -9999 -9999 -9999 -9999 -9999 -9999 -9999 -9999 -9999 -9999 -9999 -9999 -9999 -9999 -9999 -9999 -9999 -9999 -9999 -9999 -9999 -9999 -9999 -9999 -9999 -9999 -9999 -9999 -9999 -9999 -9999 -9999 -9999 -9999 -9999 -9999 -9999-9999-9999

-9999 -9999 -9999 -9999 -9999 -9999 -9999 -9999 -9999 -9999 -9999 -9999 -9999 -9999 -9999 -9999 -9999 -9999 -9999 -9999 -9999 -9999 -9999 -9999 -9999 -9999 -9999 -9999 -9999 -9999 -9999 -9999 -9999 -9999 -9999 -9999 -9999 -9999 -9999 -9999 -9999 -9999 -9999 -9999 -9999 -9999 -9999 -9999 -9999 -9999 -9999 -9999 -9999 -9999 -9999 -9999 -9999 -9999 -9999 -9999

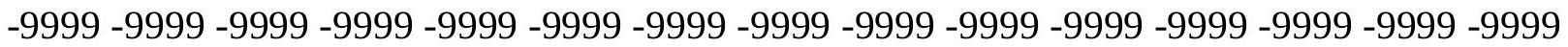
-9999 -9999 -9999 -9999 -9999 -9999 -9999 -9999 -9999 -9999 -9999 -9999 -9999 -9999 -9999 -

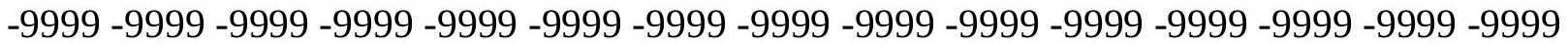
-9999 -9999 -9999 -9999 -9999 -9999 -9999 -9999 -9999 -9999 -9999 -9999 -9999 -9999 -9999 -9999 -9999 -9999 -9999 -9999 -9999 -9999 -9999 -9999 -9999 -9999 -9999 -9999 -9999 -9999 -

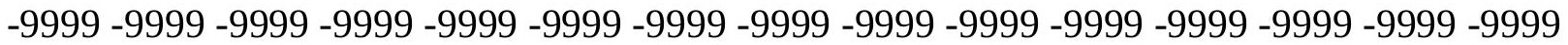
-9999 -9999 -9999 -9999 -9999 -9999 -9999 -9999 -9999 -9999 -9999 -9999 -9999 -9999 -9999 -9999 -9999 -9999 -9999 -9999 -9999 -9999 -9999 -9999 -9999 -9999 -9999 -9999 -9999 -9999

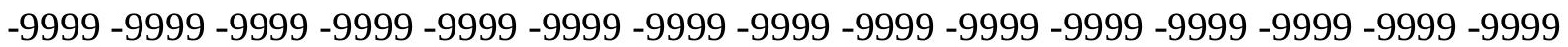
-9999 -9999 -9999 -9999 -9999 -9999 -9999 -9999 -9999 -9999 -9999 -9999 -9999 -9999 -9999 -9999 -9999 -9999 -9999 -9999 -9999 -9999 -9999 -9999 113.9896011353110 .3321990967 107.8938980103105 .1509017944103 .0174026489105 .1509017944107 .2844009399 109.4179000854111 .551399231113 .3800964355115 .2088012695116 .7326965332 117.9517974854118 .5614013672119 .1709976196119 .4757995605119 .7806015015 119.7806015015119 .7806015015119 .7806015015119 .7806015015119 .7806015015 119.7806015015119 .7806015015120 .0852966309120 .6949005127121 .3044967651 121.9140014648122 .5235977173123 .43800354124 .0475006104124 .6570968628 
124.9618988037125 .2667007446125 .2667007446125 .2667007446124 .9618988037 124.3523025513123 .7427978516123 .1332015991122 .5235977173121 .6092987061 120.9997024536120 .3900985718119 .7806015015119 .1709976196118 .5614013672 117.9517974854117 .342300415116 .7326965332116 .1231002808115 .5136032104 114.9039993286114 .5991973877113 .9896011353113 .6848983765113 .3800964355 113.3800964355113 .3800964355113 .3800964355113 .3800964355113 .3800964355 113.6848983765113 .9896011353113 .9896011353113 .9896011353114 .2944030762 114.2944030762 113.9896011353113.9896011353113.6848983765 113.6848983765 113.075302124112 .7705001831112 .4656982422111 .8561019897111 .24659729 110.6370010376110 .3321990967109 .7226028442109 .1130981445108 .1986999512 107.5891036987 106.979598999 106.3700027466105.7603988647 105.1509017944 104.5412979126103 .9317016602103 .3221969604102 .712600708102 .1029968262 101.4934005737101 .1886978149100 .5791015625100 .274299621699 .66472625732 99.3599472045999 .3599472045999 .6647262573299 .96952056885100 .2742996216 100.5791015625100 .8839035034100 .5791015625100 .063186645598 .59531402588 97.0611267089895 .4463653564593 .7367706298891 .9222030639689 .98544311523 87.9028015136785 .6446228027383 .206336975180 .7680587768678 .02498626709 75.5867080688573 .1484298706170 .7101516723668 .2718734741266 .74794006348 -9999 -9999 -9999 -9999 -9999 -9999 -9999 -9999 -9999 -9999 -9999 -9999 -9999 -9999 -9999 -9999 -9999 -9999 -9999 -9999 -9999 -9999 -9999 -9999 -9999 -9999 -9999 -9999 -9999 -9999 -9999 -

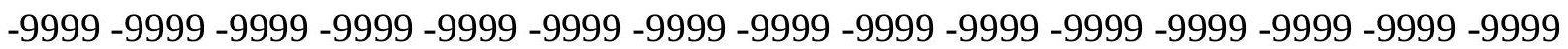
-9999-9999

-9999 -9999 -9999 -9999 -9999 -9999 -9999 -9999 -9999 -9999 -9999 -9999 -9999 -9999 -9999 -9999 -9999 -9999 -9999 -9999 -9999 -9999 -9999 -9999 -9999 -9999 -9999 -9999 -9999 -9999 -

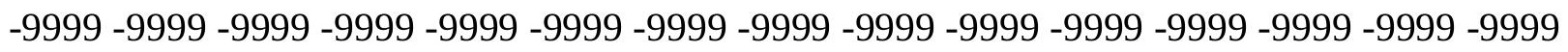
-9999 -9999 -9999 -9999 -9999 -9999 -9999 -9999 -9999 -9999 -9999 -9999 -9999 -9999 -9999 -9999 -9999 -9999 -9999 -9999 -9999 -9999 -9999 -9999 -9999 -9999 -9999 -9999 -9999 -9999

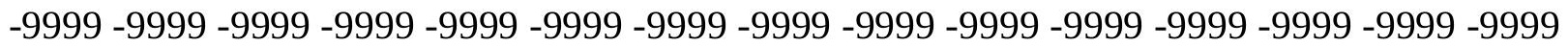
-9999 -9999 -9999 -9999 -9999 -9999 -9999 -9999 -9999 -9999 -9999 -9999 -9999 -9999 -9999 -9999 -9999 -9999 -9999 -9999 -9999 -9999 -9999 -9999 -9999 -9999 -9999 -9999 -9999 -9999 -9999 -9999 -9999 -9999 -9999 -9999 -9999 -9999 -9999 -9999 -9999 -9999 -9999 -9999 -9999

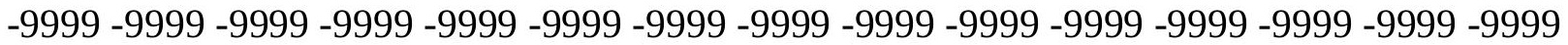

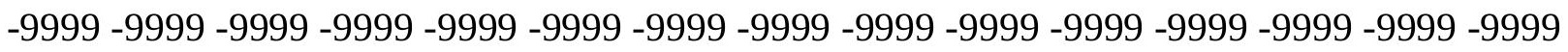
-9999 -9999 -9999 -9999 -9999 -9999 -9999 -9999 -9999 -9999 -9999 -9999 -9999 -9999 -9999

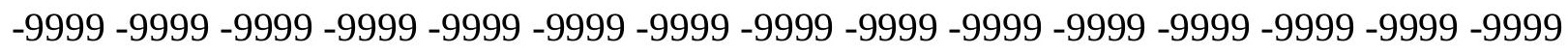
-9999 -9999 -9999 -9999 -9999-9999 -9999 -9999 -9999 -9999 -9999 -9999 -9999 - 9999 - -999 -9999 -9999 -9999 -9999 -9999 -9999 -9999 -9999 -9999 -9999 -9999 110.9418029785 108.1986999512105 .1509017944103 .3221969604105 .1509017944107 .2844009399 109.1130981445111 .24659729112 .7705001831114 .2944030762115 .2088012695 116.1231002808116 .7326965332117 .342300415117 .647102356117 .647102356 117.9517974854 117.9517974854 117.9517974854 118.2565994263 118.2565994263 118.5614013672118 .8662033081119 .4757995605120 .0852966309120 .6949005127 121.6092987061122 .2188034058122 .8283996582123 .43800354124 .0475006104 124.3523025513124.6570968628 124.3523025513124 .3523025513124 .0475006104 123.43800354122 .8283996582122 .2188034058121 .6092987061120 .9997024536 120.3900985718119 .7806015015119 .1709976196118 .5614013672117 .9517974854 
117.647102356117 .0374984741116 .4279022217115 .818397522115 .5136032104 114.9039993286114 .5991973877114 .2944030762113 .9896011353113 .9896011353 113.9896011353113 .9896011353113 .9896011353113 .9896011353113 .9896011353 114.2944030762114 .2944030762114 .2944030762114 .2944030762114 .2944030762 114.2944030762113 .9896011353113 .9896011353113 .6848983765113 .3800964355 112.7705001831112 .4656982422111 .8561019897111 .24659729110 .6370010376 110.0273971558109 .4179000854108 .8082962036108 .1986999512107 .5891036987 106.979598999106 .3700027466105 .4557037354104 .8460998535104 .2365036011 103.6268997192103 .3221969604102 .712600708102 .1029968262101 .7982025146 101.1886978149100 .8839035034100 .5791015625100 .2742996216100 .2742996216 100.2742996216100 .5791015625100 .8839035034101 .1886978149101 .4934005737 101.4934005737101 .225265502999 .8180999755998 .3565521240296 .82910919189 95.2198181152393 .512695312591 .6957168579189 .7514266967887 .64968109131 85.3398437582 .9015579223680 .1584930419977 .7202072143675 .28192901611 72.5388565063570 .1005783081167 .9670867919966 .44316101074 -9999 -9999 -9999 -9999 -9999 -9999 -9999 -9999 -9999 -9999 -9999 -9999 -9999 -9999 -9999 -9999 -9999 -9999 -9999

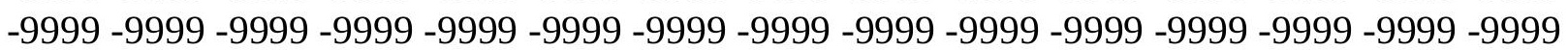
-9999 -9999 -9999 -9999 -9999 -9999 -9999 -9999 -9999 -9999 -9999 -9999 -9999 -9999 -9999 -9999 -9999 -9999 -9999 -9999 -9999 -9999 -9999 -9999 -9999 -9999 -9999 -9999 -9999 -9999 -9999 -9999 -9999 -9999 -9999 -9999 -9999 -9999 -9999 -9999 -9999 -9999 -9999 -9999

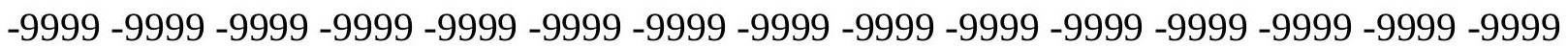
-9999 -9999 -9999 -9999 -9999 -9999 -9999 -9999 -9999 -9999 -9999 -9999 -9999 -9999 -9999 -9999 -9999 -9999 -9999 -9999 -9999 -9999 -9999 -9999 -9999 -9999 -9999 -9999 -9999 -9999 -9999 -9999 -9999 -9999 -9999 -9999 -9999 -9999 -9999 -9999 -9999 -9999 -9999 -9999 -9999

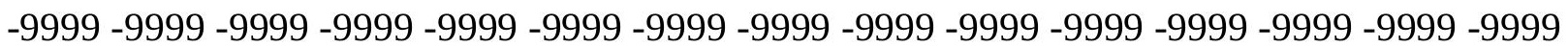
-9999 -9999 -9999 -9999 -9999 -9999 -9999 -9999 -9999 -9999 -9999 -9999 -9999 -9999 -9999 -9999 -9999 -9999 -9999 -9999 -9999 -9999 -9999 -9999 -9999 -9999 -9999 -9999 -9999 -9999 -9999 -9999 -9999 -9999 -9999 -9999 -9999 -9999 -9999 -9999 -9999 -9999 -9999 -9999 -9999 -9999 -9999 -9999 -9999 -9999 -9999 -9999 -9999 -9999 -9999 -9999 -9999 -9999 -9999 -9999

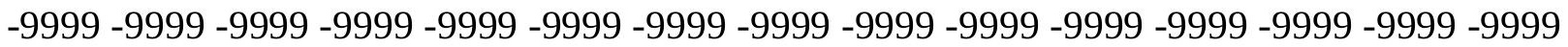
-9999 -9999 -9999 -9999 -9999 -9999 -9999 -9999 -9999 -9999 -9999 -9999 -9999 -9999 -9999 -

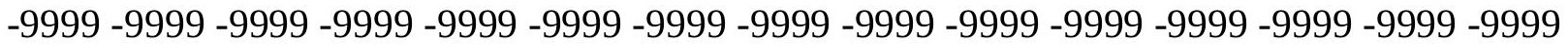
-9999 -9999 -9999 -9999 -9999 -9999 -9999 -9999 -9999 -9999 -9999 -9999 110.6370010376 107.5891036987104 .8460998535103 .0174026489105 .1509017944106 .979598999 108.8082962036110 .3321990967111 .8561019897112 .7705001831113 .6848983765 114.2944030762114 .9039993286115 .2088012695115 .5136032104115 .818397522 116.1231002808116 .4279022217116 .4279022217116 .7326965332117 .342300415 117.647102356118 .2565994263118 .8662033081119 .7806015015120 .3900985718 121.3044967651121 .9140014648122 .5235977173123 .1332015991123 .43800354 123.7427978516123 .7427978516123 .7427978516123 .43800354123 .1332015991 122.5235977173121 .9140014648121 .3044967651120 .6949005127120 .3900985718 119.7806015015119 .1709976196118 .8662033081118 .2565994263117 .647102356 117.342300415116 .7326965332116 .4279022217115 .818397522115 .5136032104 115.2088012695114 .9039993286114 .5991973877114 .5991973877114 .5991973877 114.2944030762114 .2944030762114 .5991973877114 .5991973877114 .5991973877 114.5991973877114 .5991973877114 .5991973877114 .5991973877114 .2944030762 
114.2944030762113 .9896011353113 .6848983765113 .3800964355112 .7705001831 112.4656982422111 .8561019897111 .24659729110 .6370010376110 .0273971558 109.4179000854108 .8082962036107 .8938980103107 .2844009399106 .6747970581 106.0652008057105 .4557037354104 .8460998535104 .2365036011103 .6268997192 103.0174026489102 .712600708102 .1029968262101 .7982025146101 .4934005737 101.1886978149100 .8839035034100 .8839035034100 .8839035034100 .8839035034 101.1886978149101 .7982025146102 .1029968262102 .4077987671102 .2797088623 100.915901184199 .5082855224698 .0481719970796 .523849487394 .91837310791 93.2129898071391 .3903808593889 .430938720787 .3220596313585 .03504943848 82.2919769287179 .8537063598677 .110626220774 .6723632812572 .23407745361 69.4910125732467 .3575134277365 .83358764648 -9999 -9999 -9999 -9999 -9999 -9999 -9999 -9999 -9999 -9999 -9999 -9999 -9999 -9999 -9999 -9999 -9999 -9999 -9999 -9999 -9999 -9999

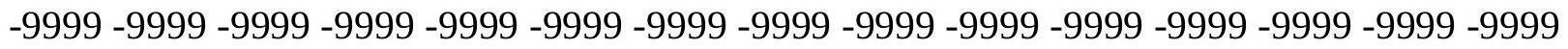
-9999 -9999 -9999 -9999 -9999 -9999 -9999 -9999 -9999 -9999 -9999 -9999 -9999 -9999 -9999 -9999 -9999 -9999 -9999 -9999 -9999 -9999 -9999 -9999 -9999 -9999

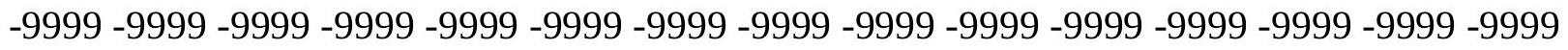
-9999 -9999 -9999 -9999 -9999 -9999 -9999 -9999 -9999 -9999 -9999 -9999 -9999 -9999 -9999 -9999 -9999 -9999 -9999 -9999 -9999 -9999 -9999 -9999 -9999 -9999 -9999 -9999 -9999 -9999 -9999 -9999 -9999 -9999 -9999 -9999 -9999 -9999 -9999 -9999 -9999 -9999 -9999 -9999 -9999 -

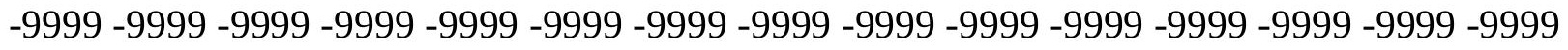

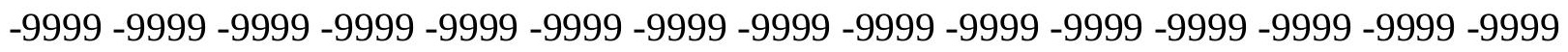
-9999 -9999 -9999 -9999 -9999 -9999 -9999 -9999 -9999 -9999 -9999 -9999 -9999 -9999 -9999 -9999 -9999 -9999 -9999 -9999 -9999 -9999 -9999 -9999 -9999 -9999 -9999-9999-9999-9999 -999 -

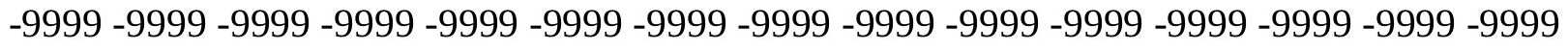

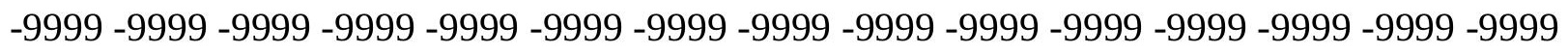
-9999 -9999 -9999 -9999 -9999 -9999 -9999 -9999 -9999 -9999 -9999 -9999 -9999 -9999 -9999 -9999 -9999 -9999 -9999 -9999 -9999 -9999 -9999 -9999 -9999 -9999 -9999 -9999 -9999 -9999

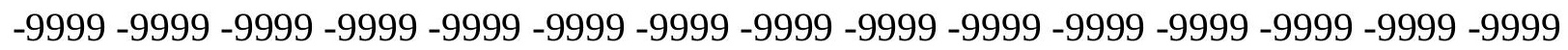
-9999 -9999 -9999 -9999 -9999 -9999 -9999 -9999 -9999 -9999 -9999 -9999 -9999 110.0273971558107 .2844009399104 .2365036011103 .3221969604105 .1509017944 106.979598999108 .1986999512109 .4179000854110 .6370010376111 .24659729 112.1608963013112 .7705001831113 .075302124113 .3800964355113 .6848983765 114.2944030762114 .5991973877114 .9039993286115 .2088012695115 .818397522 116.4279022217117 .0374984741117 .647102356118 .5614013672119 .4757995605 120.0852966309120 .9997024536121 .6092987061122 .5235977173122 .8283996582 123.1332015991123 .43800354123 .1332015991123 .1332015991122 .5235977173 122.2188034058121 .6092987061121 .3044967651120 .6949005127120 .3900985718 119.7806015015119 .1709976196118 .8662033081118 .2565994263117 .9517974854 117.647102356117 .0374984741116 .7326965332116 .4279022217116 .1231002808 115.818397522115 .5136032104115 .2088012695115 .2088012695114 .9039993286 114.9039993286114 .9039993286114 .9039993286114 .9039993286114 .9039993286 114.9039993286114 .9039993286114 .9039993286114 .9039993286114 .5991973877 114.2944030762113 .9896011353113 .6848983765113 .3800964355112 .7705001831 112.4656982422111 .8561019897111 .24659729110 .6370010376110 .0273971558 109.4179000854108 .5035018921107 .8938980103107 .2844009399106 .6747970581 106.0652008057 105.4557037354104.8460998535104.2365036011 103.6268997192 
103.0174026489102 .712600708102 .1029968262101 .7982025146101 .4934005737 101.1886978149101 .1886978149101 .1886978149101 .1886978149101 .4934005737 101.7982025146102 .1029968262102 .712600708103 .0174026489101 .9175567627 100.544937133899 .1301956176897 .6651306152396 .138534545994 .5333404541 92.8269500732490 .9964370727589 .0161743164186 .8414611816484 .42548370361 81.6824111938579 .2441329956176 .5010681152374 .062782287671 .62449645996 68.8814392089867 .0527267456165 .52880096436 -9999 -9999 -9999 -9999 -9999 -9999 -9999 -9999 -9999 -9999 -9999 -9999 -9999 -9999 -9999 -9999 -9999 -9999 -9999 -9999 -9999 -9999

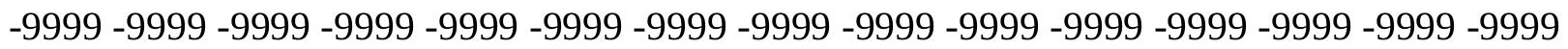
-9999 -9999 -9999 -9999 -9999 -9999 -9999 -9999 -9999 -9999 -9999

-9999 -9999 -9999 -9999 -9999 -9999 -9999 -9999 -9999 -9999 -9999 -9999 -9999 -9999 -9999

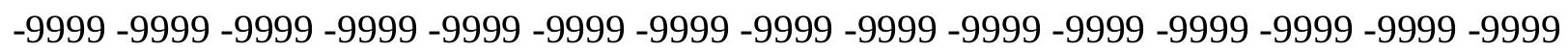
-9999 -9999 -9999 -9999 -9999 -9999 -9999 -9999 -9999 -9999 -9999 -9999 -9999 -9999 -9999 -9999 -9999 -9999 -9999 -9999 -9999 -9999 -9999 -9999 -9999 -9999 -9999 -9999 -9999 -9999 -9999 -9999 -9999 -9999 -9999 -9999 -9999 -9999 -9999 -9999 -9999 -9999 -9999 -9999 -9999

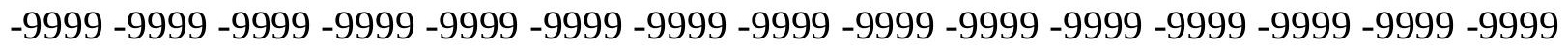

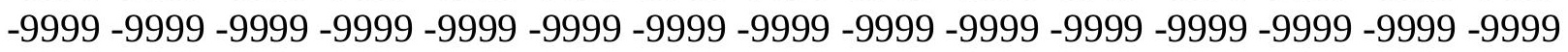

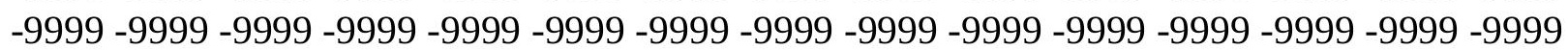
-9999 -9999 -9999 -9999 -9999 -9999 -9999 -9999 -9999 -9999 -9999 -9999 -9999 -9999 -9999 -9999 -9999 -9999 -9999 -9999 -9999 -9999 -9999 -9999 -9999 -9999 -9999 -9999 -9999 -9999

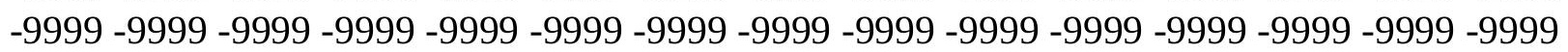

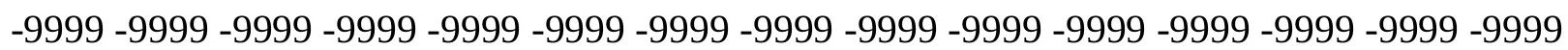
-9999 -9999 -9999 -9999 -9999 -9999 -9999 -9999 -9999 -9999 -9999 -9999-9999-9999-9999 -999 -

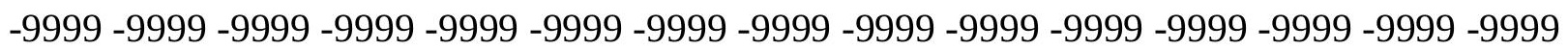
-9999 -9999 -9999 -9999 -9999 -9999 -9999 -9999 -9999 -9999 -9999 -9999 -9999 -9999 109.7226028442106 .979598999104 .5412979126103 .9317016602105 .1509017944 106.3700027466107 .2844009399108 .1986999512109 .1130981445109 .7226028442 110.3321990967110 .9418029785111 .24659729111 .8561019897112 .1608963013 112.7705001831113 .075302124113 .6848983765114 .2944030762114 .9039993286 115.818397522116 .7326965332117 .647102356118 .2565994263119 .1709976196 120.0852966309120 .9997024536121 .6092987061122 .2188034058122 .8283996582 122.8283996582122 .8283996582122 .5235977173122 .2188034058121 .9140014648 121.6092987061121 .3044967651120 .6949005127120 .3900985718119 .7806015015 119.4757995605119 .1709976196118 .5614013672118 .2565994263117 .9517974854 117.342300415117 .0374984741116 .7326965332116 .4279022217116 .1231002808 116.1231002808115 .818397522115 .818397522115 .5136032104115 .5136032104 115.5136032104115 .5136032104115 .5136032104115 .5136032104115 .5136032104 115.2088012695115 .2088012695115 .2088012695114 .9039993286114 .5991973877 114.2944030762113 .9896011353113 .3800964355113 .075302124112 .4656982422 111.8561019897111 .24659729110 .6370010376110 .0273971558109 .1130981445 108.5035018921107 .8938980103107 .2844009399106 .3700027466105 .7603988647 105.1509017944104 .5412979126103 .9317016602103 .6268997192103 .0174026489 102.4077987671102 .1029968262101 .7982025146101 .4934005737101 .1886978149 101.1886978149101 .1886978149101 .1886978149101 .4934005737102 .1029968262 102.4077987671102 .712600708102 .8534698486101 .5012588501100 .1124572754 98.6827316284297 .204521179295 .6673812866294 .054405212492 .34172821045 
90.4987335205188 .488426208586 .254188537683 .8159103393681 .07285308838 78.6345596313575 .8914871215873 .4532165527370 .7101516723668 .27187347412 66.4431610107464 .91924285889 -9999 -9999 -9999 -9999 -9999 -9999 -9999 -9999 -9999 -9999 -9999 -9999 -9999 -9999 -9999 -9999 -9999 -9999 -9999 -9999 -9999 -9999 -9999 -9999 -9999 -9999 -9999 -9999 -9999 -9999 -9999 -9999 -9999 -9999 -9999 -9999 -9999 -9999 - -9999 -9999 -9999 -9999 -9999 -9999 -9999 -9999 -9999 -9999

-9999 -9999 -9999 -9999 -9999 -9999 -9999 -9999 -9999 -9999 -9999 -9999 -9999 -9999 -9999

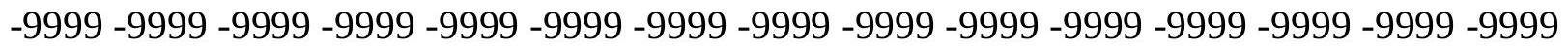

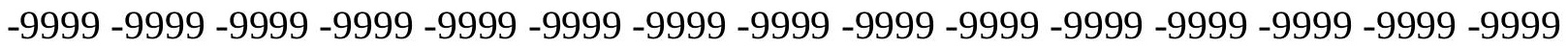
-9999 -9999 -9999 -9999 -9999 -9999 -9999 -9999 -9999 -9999 -9999 -9999 -9999 -9999 -9999

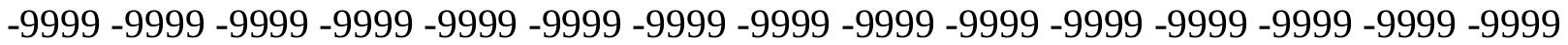
-9999 -9999 -9999 -9999 -9999 -9999 -9999 -9999 -9999 -9999 -9999 -9999 -9999 -9999 -9999 -9999 -9999 -9999 -9999 -9999 -9999 -9999 -9999 -9999 -9999 -9999 -9999 -9999 -9999 -9999 -9999 -9999 -9999 -9999 -9999 -9999 -9999 -9999 -9999 -9999 -9999 -9999 -9999 -9999 -9999 -9999 -9999 -9999 -9999 -9999 -9999 -9999 -9999 -9999 -9999 -9999 -9999 -9999 -9999 -9999

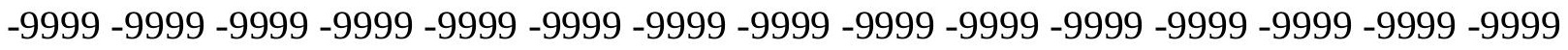

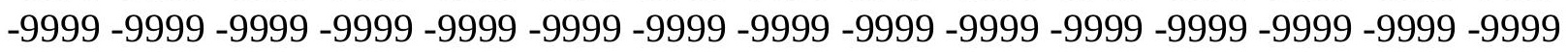
-9999 -9999 -9999 -9999 -9999 -9999 -9999 -9999 -9999 -9999 -9999 -9999 -9999 -9999 -9999 -999 -9999 -9999 -9999 -9999 -9999 -9999 -9999 -9999 -9999 -9999 -9999 -9999 -9999 -9999 -9999 -9999 -9999 -9999 -9999 -9999 -9999 -9999 -9999 -9999 -9999 -9999 -9999 -9999 -9999 -9999 -9999 -9999 -9999 -9999 -9999 -9999 -9999 -9999 -9999 -9999 -9999 -9999 -9999 -9999 -9999 110.0273971558107 .5891036987104 .8460998535103 .6268997192104 .2365036011 105.1509017944106 .0652008057106 .6747970581107 .5891036987108 .1986999512 108.8082962036109 .1130981445109 .7226028442110 .3321990967110 .9418029785 111.551399231112 .1608963013112 .7705001831113 .6848983765114 .5991973877 115.5136032104116 .4279022217117 .342300415118 .2565994263119 .1709976196 120.0852966309120 .9997024536121 .6092987061122 .2188034058122 .2188034058 122.2188034058121 .9140014648121 .9140014648121 .6092987061121 .3044967651 120.9997024536120 .6949005127120 .3900985718120 .0852966309119 .4757995605 119.1709976196118 .8662033081118 .5614013672118 .2565994263117 .647102356 117.647102356117 .342300415117 .0374984741116 .7326965332116 .4279022217 116.4279022217116 .4279022217116 .1231002808116 .1231002808116 .1231002808 116.1231002808115 .818397522115 .818397522115 .818397522115 .818397522 115.5136032104115 .5136032104115 .2088012695114 .9039993286114 .5991973877 113.9896011353113 .6848983765113 .075302124112 .4656982422111 .8561019897 111.24659729110 .6370010376110 .0273971558109 .1130981445108 .5035018921 107.8938980103106.979598999 106.3700027466105.7603988647105.1509017944 104.5412979126103 .9317016602103 .3221969604103 .0174026489102 .4077987671 102.1029968262101 .7982025146101 .4934005737101 .1886978149101 .1886978149 101.1886978149101 .1886978149101 .4934005737101 .7982025146102 .1029968262 102.712600708102 .4086837769101 .032791137799 .6198883056698 .16628265381 96.6651687622195 .1070709228593 .4760742187591 .7449417114389 .87967681885 87.8548126220785 .6446228027382 .9015579223680 .4632720947377 .72020721436 75.2819290161172 .5388565063570 .1005783081167 .6623001098665 .83358764648 64.30966186523 -9999 -9999 -9999 -9999 -9999 -9999 -9999 -9999 -9999 -9999 -9999 -9999 -9999 -9999 -9999 -9999 -9999 -9999 -9999 -9999 -9999 -9999 -9999 -9999 -9999 -9999 -9999 
-9999 -9999 -9999 -9999 -9999 -9999 -9999 -9999 -9999 -9999 -9999 -9999 -9999 -9999 -9999 -9999 -9999 -9999 -9999-9999 -9999

-9999 -9999 -9999 -9999 -9999 -9999 -9999 -9999 -9999 -9999 -9999 -9999 -9999 -9999 -9999 -9999 -9999 -9999 -9999 -9999 -9999 -9999 -9999 -9999 -9999 -9999 -9999 -9999 -9999 -9999 -9999 -9999 -9999 -9999 -9999 -9999 -9999 -9999 -9999 -9999 -9999 -9999-9999 -9999 -9999 -9999 -9999 -9999 -9999 -9999 -9999 -9999 -9999 -9999 -9999 -9999 -9999 -9999 -9999 -9999

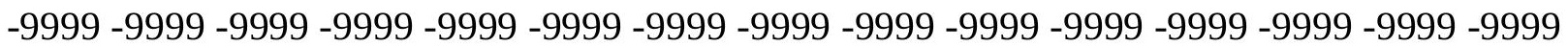
-9999 -9999 -9999 -9999 -9999 -9999 -9999 -9999 -9999 -9999 -9999 -9999 -9999 -9999 -9999 -9999 -9999 -9999 -9999 -9999 -9999 -9999 -9999 -9999 -9999 -9999 -9999 -9999 -9999 -9999 -9999 -9999 -9999 -9999 -9999 -9999 -9999 -9999 -9999 -9999 -9999 -9999 -9999 -9999 -9999 -

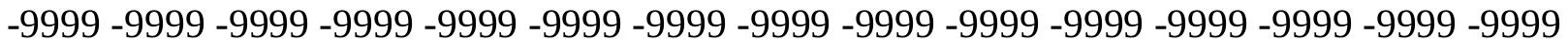

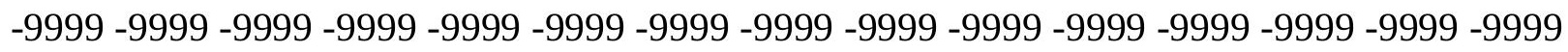
-9999 -9999 -9999 -9999 -9999 -9999 -9999 -9999 -9999 -9999 -9999 -9999 -9999 -9999 -9999 -9999 -9999 -9999 -9999 -9999 -9999 -9999 -9999 -9999 -9999 -9999 -9999 -9999 -9999 -9999 -9999 -9999 -9999 -9999 -9999 -9999 -9999 -9999 -9999 -9999 -9999 -9999 -9999 -9999 -9999

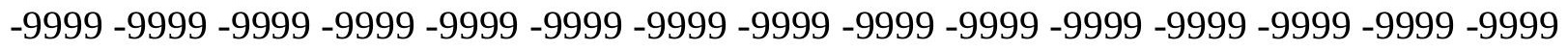

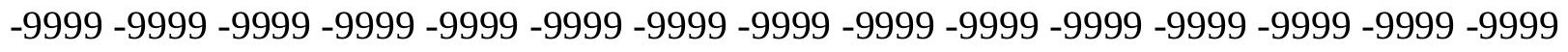
-9999 110.6370010376 107.8938980103104.8460998535102.1029968262 103.0174026489 103.6268997192104 .5412979126105 .4557037354106 .0652008057106 .6747970581 107.2844009399 107.8938980103108.5035018921 109.1130981445109.7226028442 110.6370010376111 .24659729112 .1608963013113 .3800964355114 .2944030762 115.2088012695116 .4279022217117 .342300415118 .5614013672119 .4757995605 120.3900985718121 .3044967651121 .9140014648121 .6092987061121 .6092987061 121.3044967651121 .3044967651121 .3044967651121 .3044967651120 .9997024536 120.6949005127120 .3900985718120 .0852966309119 .7806015015119 .4757995605 119.1709976196118 .8662033081118 .5614013672118 .2565994263117 .9517974854 117.647102356117 .342300415117 .342300415117 .0374984741117 .0374984741 116.7326965332116 .7326965332116 .7326965332116 .4279022217116 .4279022217 116.4279022217 116.4279022217 116.1231002808 116.1231002808115.818397522 115.818397522115 .5136032104115 .2088012695114 .9039993286114 .2944030762 113.9896011353113 .3800964355112 .7705001831112 .1608963013111 .551399231 110.6370010376110 .0273971558109 .4179000854108 .5035018921107 .8938980103 106.979598999 106.3700027466105.7603988647 105.1509017944 104.5412979126 103.9317016602103 .3221969604102 .712600708102 .4077987671101 .7982025146 101.4934005737101 .1886978149101 .1886978149100 .8839035034100 .8839035034 100.8839035034101 .1886978149101 .4934005737101 .7982025146102 .1029968262 101.9231491089 100.516830444399.0720062255997.5853424072396.05081176758 94.4599990844792 .7987518310591 .0410232543989 .1464004516687 .05089569092 84.7302627563582 .2919769287179 .5489196777377 .110626220774 .36756896973 71.9292907714869 .4910125732467 .0527267456165 .2240066528363 .70008850098 -9999 -9999 -9999 -9999 -9999 -9999 -9999 -9999 -9999 -9999 -9999 -9999 -9999 -9999 -9999 -9999

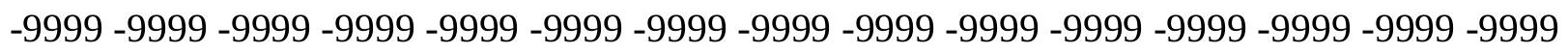

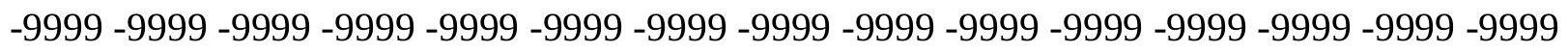
$-9999-9999$

-9999 -9999 -9999 -9999 -9999 -9999 -9999 -9999 -9999 -9999 -9999 -9999 -9999 -9999 -9999

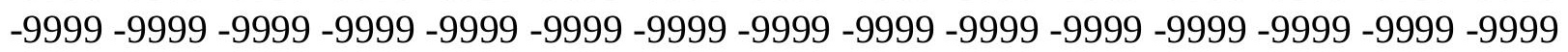


-9999 -9999 -9999 -9999 -9999 -9999 -9999 -9999 -9999 -9999 -9999 -9999 -9999 -9999 -9999 -9999 -9999 -9999 -9999 -9999 -9999 -9999 -9999 -9999 -9999 -9999 -9999 -9999 -9999 -9999

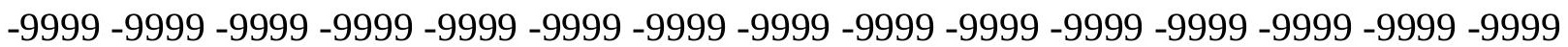
-9999 -9999 -9999 -9999 -9999 -9999 -9999 -9999 -9999 -9999 -9999 -9999 -9999 -9999 -9999 -9999 -9999 -9999 -9999 -9999 -9999 -9999 -9999 -9999 -9999 -9999 -9999 -9999 -9999 -9999 -9999 -9999 -9999 -9999 -9999 -9999 -9999 -9999 -9999 -9999 -9999 -9999 -9999 -9999 -9999 -9999 -9999 -9999 -9999 -9999 -9999 -9999 -9999 -9999 -9999 -9999 -9999 -9999 -9999 -9999

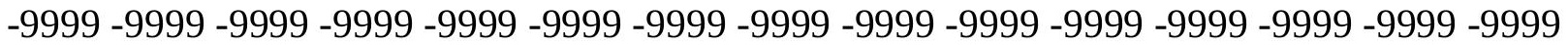
-9999 -9999 -9999 -9999 -9999 -9999 -9999 -9999 -9999 -9999 -9999 -9999 -9999 -9999 -9999 -9999 -9999 -9999 -9999 -9999 -9999 -9999 -9999 -9999 -9999 -9999 -9999 -9999 -9999 -9999 -9999 -9999 -9999 -9999 -9999 -9999 -9999 -9999 -9999 -9999 -9999 -9999 -9999 -9999 -9999 -9999 -9999 -9999 -9999 -9999 -9999 -9999 -9999 -9999 -9999 -9999 -9999 -9999 -9999 -9999

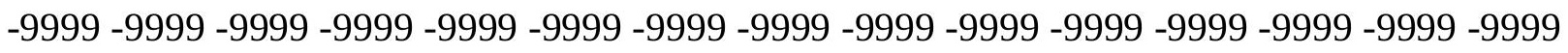
-9999 -9999 110.9418029785 107.5891036987 104.2365036011 100.8839035034 101.7982025146102 .712600708103 .3221969604103 .9317016602104 .5412979126 105.1509017944105 .7603988647106 .6747970581107 .2844009399108 .1986999512 108.8082962036110 .0273971558110 .9418029785112 .1608963013113 .075302124 114.2944030762115 .5136032104116 .7326965332117 .647102356118 .8662033081 119.7806015015120 .3900985718120 .9997024536120 .6949005127120 .6949005127 120.6949005127120 .9997024536120 .9997024536120 .9997024536120 .9997024536 120.9997024536120 .6949005127120 .3900985718120 .0852966309119 .7806015015 119.4757995605119 .1709976196118 .8662033081118 .5614013672118 .2565994263 117.9517974854117 .9517974854117 .647102356117 .647102356117 .342300415 117.342300415117 .342300415117 .0374984741117 .0374984741117 .0374984741 117.0374984741116 .7326965332116 .7326965332116 .4279022217116 .4279022217 116.1231002808115 .818397522115 .5136032104114 .9039993286114 .5991973877 113.9896011353113 .3800964355112 .7705001831112 .1608963013111 .551399231 110.9418029785110 .0273971558109 .4179000854108 .5035018921107 .8938980103 106.979598999106 .3700027466105 .7603988647105 .1509017944104 .5412979126 103.9317016602103 .3221969604102 .712600708102 .1029968262101 .7982025146 101.4934005737101 .1886978149100 .8839035034100 .5791015625100 .5791015625 100.5791015625100 .5791015625100 .5791015625100 .8839035034100 .8839035034 100.883903503499 .9599914550898 .4760437011796 .9478607177795 .36968231201 93.733955383392 .0292816162190 .2349624633888 .314727783286 .20183563232 83.8159103393681 .3776321411178 .6345596313576 .1962814331173 .75800323486 71.014930725168 .5766525268666 .1383666992264 .6144485473663 .09051895142 -9999 -9999 -9999 -9999 -9999 -9999 -9999 -9999 -9999 -9999 -9999 -9999 -9999 -9999 -9999 -9999

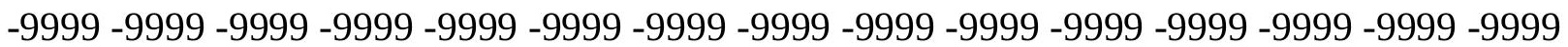

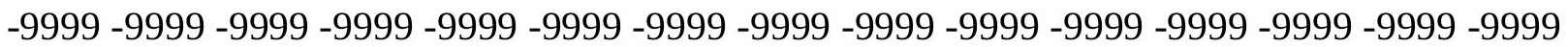
$-9999-9999$ -9999 -9999 -9999 -9999 -9999 -9999 -9999 -9999 -9999 -9999 -9999 -9999 -9999 -9999 -9999

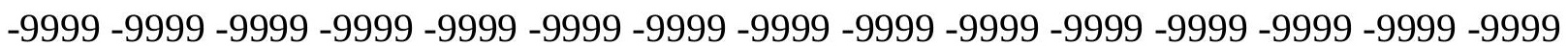
-9999 -9999 -9999 -9999 -9999 -9999 -9999 -9999 -9999 -9999 -9999 -9999 -9999 -9999 -9999 -9999 -9999 -9999 -9999 -9999 -9999 -9999 -9999 -9999 -9999 -9999 -9999 -9999 -9999 -9999 -9999 -9999 -9999 -9999 -9999 -9999 -9999 -9999 -9999 -9999 -9999 -9999 -9999 -9999 -9999

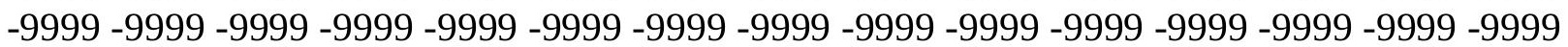


-9999 -9999 -9999 -9999 -9999 -9999 -9999 -9999 -9999 -9999 -9999 -9999 -9999 -9999 -9999 -9999 -9999 -9999 -9999 -9999 -9999 -9999 -9999 -9999 -9999 -9999 -9999 -9999 -9999 -9999 -9999 -9999 -9999 -9999 -9999 -9999 -9999 -9999 -9999 -9999 -9999 -9999 -9999 -9999 -9999 -9999 -9999 -9999 -9999 -9999 -9999 -9999 -9999 -9999 -9999 -9999 -9999 -9999 -9999 -9999 -9999 -9999 -9999 -9999 -9999 -9999 -9999 -9999 -9999 -9999 -9999 -9999 -9999 -9999 -9999 -9999 -9999 -9999 -9999 -9999 -9999 -9999 -9999 -9999 -9999 -9999 -9999 -9999 -9999 -9999 -9999 -9999 -9999 -9999 -9999 -9999 -9999 -9999 -9999 -9999 -9999 -9999 -9999 -9999 -9999

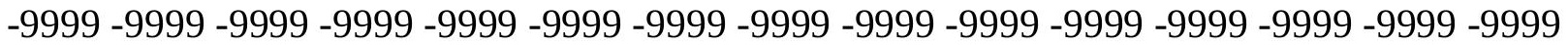
-9999 -9999 -9999 -9999 -9999 -9999 -9999 -9999 -9999 -9999 -9999 -9999 -9999 -9999 -9999 -9999 -9999 -9999 -9999 106.3700027466 103.0174026489100.8839035034100.8839035034 101.4934005737102 .1029968262102 .712600708103 .3221969604103 .9317016602 104.8460998535105 .4557037354106 .3700027466107 .2844009399108 .5035018921 109.4179000854110 .6370010376112 .1608963013113 .3800964355114 .5991973877 115.818397522117 .0374984741118 .2565994263119 .1709976196120 .0852966309 120.3900985718120 .0852966309119 .7806015015120 .0852966309120 .6949005127 120.9997024536120 .9997024536120 .9997024536120 .9997024536120 .6949005127 120.3900985718120 .0852966309119 .7806015015119 .4757995605119 .1709976196 119.1709976196118 .8662033081118 .5614013672118 .5614013672118 .2565994263 118.2565994263117 .9517974854117 .9517974854117 .9517974854117 .647102356 117.647102356117 .647102356117 .342300415117 .342300415117 .342300415 117.0374984741117 .0374984741116 .7326965332116 .4279022217116 .1231002808 115.818397522115 .2088012695114 .9039993286114 .2944030762113 .6848983765 113.075302124112 .4656982422111 .8561019897110 .9418029785110 .3321990967 109.4179000854108 .8082962036107 .8938980103107 .2844009399106 .3700027466 105.7603988647104 .8460998535104 .2365036011103 .6268997192103 .0174026489 102.4077987671102 .1029968262101 .4934005737101 .1886978149100 .8839035034 100.2742996216100 .274299621699 .9695205688599 .9695205688599 .96952056885 99.6647262573299 .6647262573299 .6647262573299 .3599472045999 .05516815186 97.8434219360496 .2670745849694 .6373825073292 .9473114013791 .18521118164 89.33464050293 87.3858795166 85.33984375 82.9015579223680.46327209473 77.7202072143675 .2819290161172 .8436431884870 .4053573608467 .96708679199 65.5288009643664 .004882812562 .48094940186 -9999 -9999 -9999 -9999 -9999 -9999 -9999 -9999 -9999 -9999 -9999 -9999 -9999 -9999 -9999 -9999 -9999 -9999 -9999 -9999 -9999 -9999 -9999 -9999 -9999 -9999 -9999 -9999 -9999 -9999 -9999 -9999 -9999 -9999 -9999 -9999 -9999 -9999 -9999 -9999 -9999 -9999 -9999 -9999 -9999 -9999 -9999 -9999

-9999 -9999 -9999 -9999 -9999 -9999 -9999 -9999 -9999 -9999 -9999 -9999 -9999 -9999 -9999

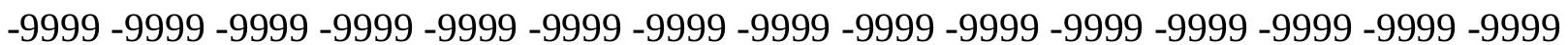
-9999 -9999 -9999 -9999 -9999 -9999 -9999 -9999 -9999 -9999 -9999 -9999 -9999 -9999 -9999 -9999 -9999 -9999 -9999 -9999 -9999 -9999 -9999 -9999 -9999 -9999 -9999 -9999 -9999 -9999 -9999 -9999 -9999 -9999 -9999 -9999 -9999 -9999 -9999 -9999 -9999 -9999 -9999 - -9999 -9999 -9999 -9999 -9999 -9999 -9999 -9999 -9999 -9999 -9999 -9999 -9999 -9999 -9999 -9999 -9999

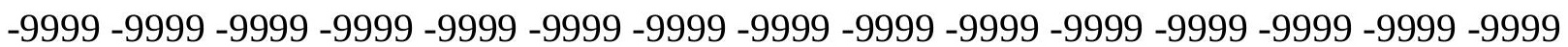
-9999 -9999 -9999 -9999 -9999 -9999 -9999 -9999 -9999 -9999 -9999 -9999 -9999 -9999 -9999 -9999 -9999 -9999 -9999 -9999 -9999 -9999 -9999 -9999 -9999 -9999 -9999 -9999 -9999 -9999 -9999 -9999 -9999 -9999 -9999 -9999 -9999 -9999 -9999 -9999 -9999 -9999 -9999 -9999 -9999

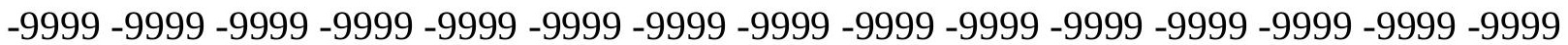


-9999 -9999 -9999 -9999 -9999 -9999 -9999 -9999 -9999 -9999 -9999 -9999 -9999 -9999 -9999 -9999 -9999 -9999 -9999 -9999 -9999 -9999 -9999 -9999 -9999 -9999 -9999 -9999 -9999 -9999 -9999 -9999 -9999 -9999 -9999 -9999 -9999 -9999 -9999 -9999 -9999 -9999 -9999 -9999 -9999 -9999 -9999 -9999 -9999 -9999 -9999 -9999 -9999 -9999 -9999 -9999 -9999 -9999 -9999 -9999 -9999 -9999-9999 -9999 -9999 104.8460998535 101.4934005737 100.2742996216 99.66472625732100 .2742996216100 .8839035034101 .4934005737102 .1029968262 103.0174026489103 .9317016602104 .8460998535105 .7603988647106 .979598999 108.1986999512109 .4179000854110 .9418029785112 .4656982422113 .6848983765 115.2088012695116 .7326965332117 .9517974854119 .1709976196119 .7806015015 120.0852966309120 .0852966309119 .1709976196120 .0852966309120 .6949005127 120.9997024536121 .3044967651121 .3044967651121 .3044967651120 .9997024536 120.6949005127120 .3900985718120 .0852966309119 .7806015015119 .4757995605 119.4757995605119 .1709976196118 .8662033081118 .8662033081118 .5614013672 118.5614013672118 .5614013672118 .2565994263118 .2565994263118 .2565994263 117.9517974854117 .9517974854117 .9517974854117 .647102356117 .647102356 117.647102356117 .342300415117 .0374984741116 .7326965332116 .4279022217 116.1231002808115 .818397522115 .2088012695114 .5991973877113 .9896011353 113.3800964355112 .7705001831111 .8561019897111 .24659729110 .3321990967 109.4179000854108 .8082962036107 .8938980103107 .2844009399106 .3700027466 105.7603988647104 .8460998535104 .2365036011103 .6268997192103 .0174026489 102.4077987671101 .7982025146101 .1886978149100 .8839035034100 .2742996216 99.9695205688599 .6647262573299 .3599472045999 .0551681518699 .05516815186 98.7503814697398 .445587158298 .445587158297 .8360290527397 .53124237061 96.6168823242295 .397743225193 .8723907470792 .1228637695390 .30156707764 88.3937606811586 .3562545776484 .1206970214881 .9871978759879 .54891967773 76.8058471679774 .3675689697371 .9292907714869 .4910125732467 .05272674561 64.6144485473663 .3953094482462 .17617034912 -9999 -9999 -9999 -9999 -9999 -9999-9999 -9999 -9999 -9999 -9999 -9999 -9999 -9999 -9999 -9999 -9999 -9999 -9999 -9999 -9999 -9999

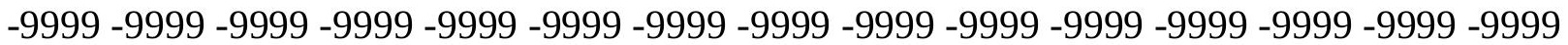
-9999 -9999 -9999 -9999 -9999 -9999 -9999 -9999 -9999 -9999 -9999 -9999 -9999 -9999 -9999 -9999 -9999 -9999 -9999 -9999 -9999 -9999 -9999 -9999 -9999 -9999 -9999 -9999 -9999 -9999 -9999 -9999 -9999 -9999 -9999 -9999 -9999 -9999 -9999 -9999 -9999 -9999 -9999 -9999 -9999 -9999 -9999 -9999 -9999 -9999 -9999 -9999 -9999 -9999 -9999 -9999 -9999 -9999 -9999 -9999 -9999 -9999 -9999 -9999 -9999 -9999 -9999 -9999 -9999 -9999 -9999

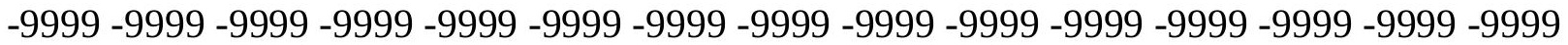
-9999 -9999 -9999 -9999 -9999 -9999 -9999 -9999 -9999 -9999 -9999 -9999 -9999 -9999 -9999

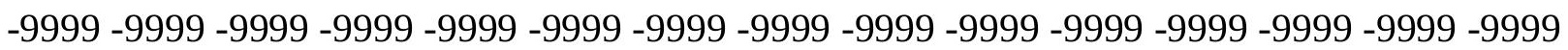

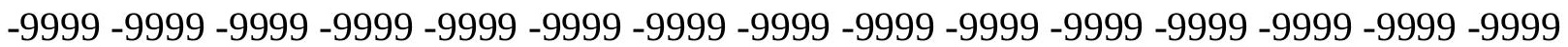
-9999 -9999 -9999 -9999 -9999 -9999 -9999 -9999 -9999 -9999 -9999 -9999 -9999 -9999 -9999 -9999 -9999 -9999 -9999 -9999 -9999 -9999 -9999 -9999 -9999 -9999 -9999 -9999 - -9999 -9999 -9999 -9999 -9999 -9999 -9999 -9999 -9999 -9999 -9999 -9999 -9999 -9999 -9999 -9999 -9999

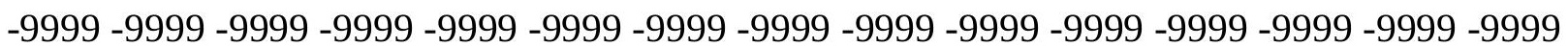
-9999 -9999 -9999 -9999 -9999 -9999 -9999 -9999 -9999 -9999 -9999 -9999 -9999 -9999 -9999 -9999 -9999 -9999 -9999 -9999 -9999 -9999 -9999 -9999 -9999 -9999 -9999 -9999 -9999 -9999 -9999 -9999 -9999 -9999 -9999 -9999 -9999 -9999 -9999 -9999 -9999 -9999 -9999 -9999 -9999 -9999 -9999 -9999 -9999 -9999 -9999 103.6268997192 100.5791015625 99.35994720459 
98.7503814697399 .0551681518699 .66472625732100 .5791015625101 .1886978149 102.1029968262103 .3221969604104 .2365036011105 .4557037354106 .979598999 108.5035018921110 .0273971558111 .551399231113 .075302124114 .5991973877 116.1231002808117 .647102356119 .1709976196120 .0852966309120 .6949005127 120.6949005127120 .3900985718120 .6949005127120 .9997024536121 .3044967651 121.6092987061121 .6092987061121 .3044967651121 .3044967651120 .9997024536 120.6949005127120 .3900985718120 .0852966309119 .7806015015119 .7806015015 119.4757995605119 .4757995605119 .1709976196119 .1709976196118 .8662033081 118.8662033081118 .8662033081118 .5614013672118 .5614013672118 .5614013672 118.5614013672118 .2565994263118 .2565994263117 .9517974854117 .9517974854 117.647102356117 .647102356117 .342300415117 .0374984741116 .4279022217 116.1231002808115 .5136032104114 .9039993286114 .2944030762113 .6848983765 112.7705001831112 .1608963013111 .24659729110 .3321990967109 .7226028442 108.8082962036108 .1986999512107 .2844009399106 .3700027466105 .7603988647 104.8460998535104 .2365036011103 .6268997192102 .712600708102 .1029968262 101.4934005737100 .8839035034100 .579101562599 .9695205688599 .35994720459 99.0551681518698.445587158298.1408081054797.8360290527397.53124237061 97.2264633178796 .9216690063596 .6168823242296 .0073165893695 .09295654297 93.8738174438592 .6546783447391 .1307525634889 .302040100187 .44470214844 85.3398437583 .206336975180 .7680587768678 .6345596313576 .19628143311 73.4532165527371 .014930725168 .5766525268666 .4431610107464 .0048828125 62.7857398986861 .56660079956 -9999 -9999-9999 -9999 -9999 -9999 -9999 -9999 -9999 -9999 -9999 -9999 -9999 -9999 -9999 -9999 -9999 -9999 -9999 -9999 -9999 -9999 -9999 -9999

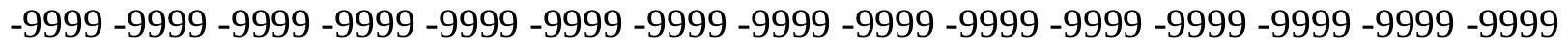
-9999-9999 -9999-9999-9999-9999-9999-9999 -9999

-9999 -9999 -9999 -9999 -9999 -9999 -9999 -9999 -9999 -9999 -9999 -9999 -9999 -9999 -9999

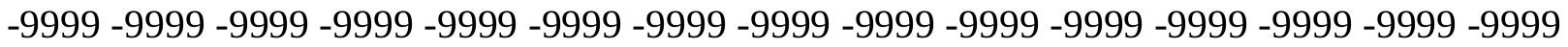

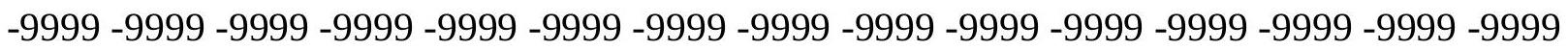

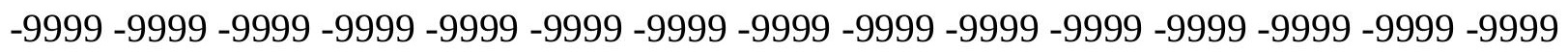

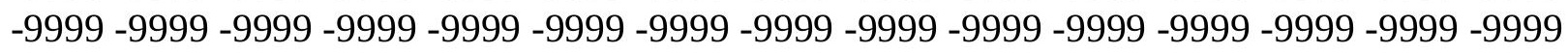
-9999 -9999 -9999 -9999 -9999 -9999 -9999 -9999 -9999 -9999 -9999 -9999 -9999 -9999 -9999

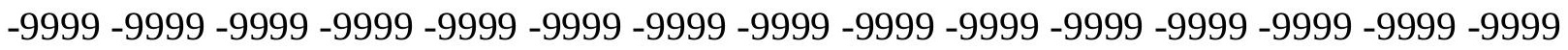

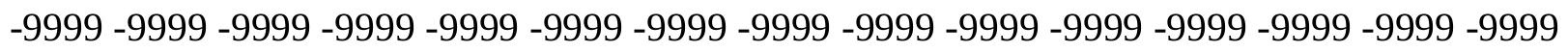

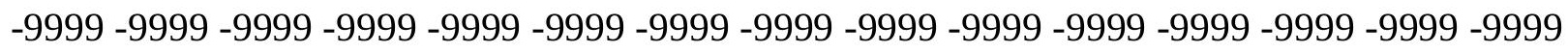

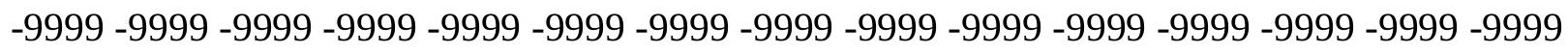

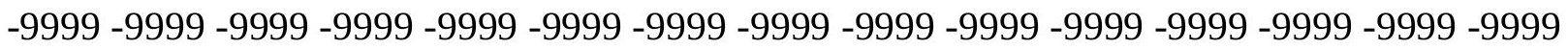

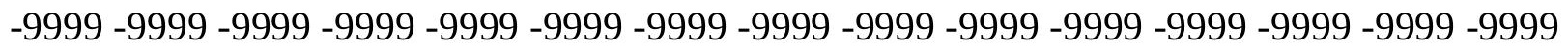

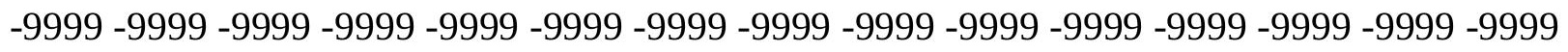

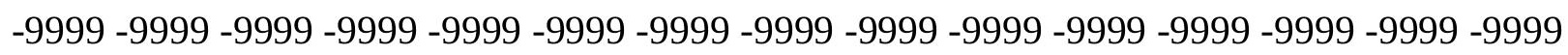
-9999 -9999 -9999 -9999 -9999 -9999 -9999 -9999 -9999 -9999 -9999 -9999 -9999 -9999 -9999 -9999 -9999 -9999 -9999-9999 -9999 -9999 -9999 99.66472625732 98.75038146973 98.1408081054798.1408081054798.7503814697399.66472625732 100.5791015625 101.4934005737102 .712600708104 .2365036011105 .7603988647107 .2844009399 108.8082962036110 .6370010376112 .4656982422113 .9896011353115 .818397522 117.647102356119 .1709976196120 .6949005127121 .6092987061121 .6092987061 121.3044967651121 .3044967651121 .6092987061121 .9140014648121 .9140014648 
121.9140014648121 .6092987061121 .6092987061121 .3044967651120 .9997024536 120.6949005127120 .3900985718120 .0852966309120 .0852966309119 .7806015015 119.7806015015119 .4757995605119 .4757995605119 .4757995605119 .1709976196 119.1709976196119 .1709976196119 .1709976196118 .8662033081118 .8662033081 118.8662033081118 .5614013672118 .5614013672118 .2565994263118 .2565994263 117.9517974854117 .647102356117 .342300415117 .0374984741116 .4279022217 115.818397522115 .2088012695114 .5991973877113 .6848983765113 .075302124 112.1608963013111 .551399231110 .6370010376109 .7226028442108 .8082962036 108.1986999512107 .2844009399106 .3700027466105 .7603988647104 .8460998535 104.2365036011103 .3221969604102 .712600708102 .1029968262101 .4934005737 100.579101562599 .9695205688599 .3599472045999 .0551681518698 .4455871582 97.83602905273 97.2264633178796.9216690063596.3121032714896.00731658936 95.7025299072395 .0929565429794 .4833908081193 .8738174438592 .65467834473 91.4355392456189 .9116134643688 .3876876831186 .5300979614384 .42548370361 82.2919769287179 .8537063598677 .7202072143675 .2819290161172 .84364318848 70.4053573608467 .9670867919965 .5288009643663 .3953094482462 .17617034912 60.95701980591 -9999 -9999 -9999 -9999 -9999 -9999 -9999 -9999 -9999 -9999 -9999 -9999 -9999 -9999 -9999 -9999 -9999 -9999 -9999 -9999 -9999 -9999 -9999 -9999 -9999 -9999 -9999 -9999 -9999 -9999 -9999 -9999 -9999 -9999 -9999 -9999 -9999 -9999 -9999 -9999 -9999 -9999 -9999 -9999 -9999 -9999 -9999-9999

-9999 -9999 -9999 -9999 -9999 -9999 -9999 -9999 -9999 -9999 -9999 -9999 -9999 -9999 -9999

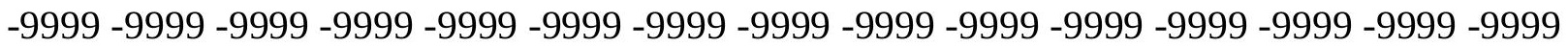
-9999 -9999 -9999 -9999 -9999 -9999 -9999 -9999 -9999 -9999 -9999 -9999 -9999 -9999 -9999 -9999 -9999 -9999 -9999 -9999 -9999 -9999 -9999 -9999 -9999 -9999 -9999 -9999 -9999 -9999 -9999 -9999 -9999 -9999 -9999 -9999 -9999 -9999 -9999 -9999 -9999 -9999 -9999 -9999 -9999 -9999 -9999 -9999 -9999 -9999 -9999 -9999 -9999 -9999 -9999 -9999 -9999 -9999 -9999 -9999 -9999 -9999 -9999 -9999 -9999 -9999 -9999 -9999 -9999 -9999 -9999 -9999 -9999 -9999 -9999 -

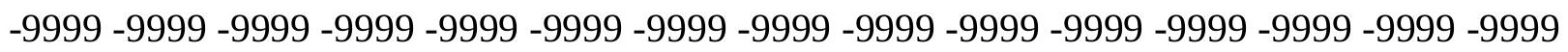
-9999 -9999 -9999 -9999 -9999 -9999 -9999 -9999 -9999 -9999 -9999 -9999 -9999 -9999 -9999 -9999 -9999 -9999 -9999 -9999 -9999 -9999 -9999 -9999 -9999 -9999 -9999 -9999 -9999 -9999 -9999 -9999 -9999 -9999 -9999 -9999 -9999 -9999 -9999 -9999 -9999 -9999 -9999 -9999 -9999

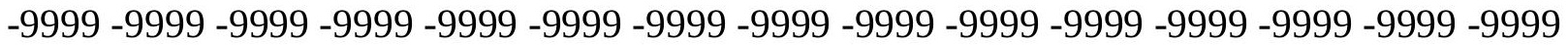

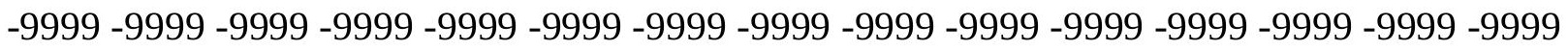
-9999 -9999 -9999 -9999 -9999 -9999 -9999 -9999 -9999 -9999 -9999 -9999 -9999 -9999 -9999 -9999 -9999 -9999 -9999 -9999 -9999 -9999 -9999 -9999 -9999 -9999 -9999 -9999 -9999 -9999 -9999 -9999-9999 -9999 -9999-9999-9999-9999-9999 99.35994720459 98.14080810547 97.5312423706197 .5312423706198 .1408081054799 .05516815186100 .2742996216 101.4934005737103 .0174026489104 .5412979126106 .3700027466108 .1986999512 110.0273971558111 .8561019897113 .6848983765115 .5136032104117 .342300415 119.1709976196120 .6949005127121 .6092987061122 .2188034058122 .2188034058 122.2188034058122 .2188034058122 .2188034058122 .2188034058122 .2188034058 121.9140014648121 .6092987061121 .6092987061121 .3044967651120 .9997024536 120.6949005127120 .3900985718120 .3900985718120 .0852966309120 .0852966309 120.0852966309119 .7806015015119 .7806015015119 .7806015015119 .4757995605 119.4757995605119 .4757995605119 .4757995605119 .1709976196119 .1709976196 119.1709976196118.8662033081 118.8662033081 118.5614013672118 .2565994263 
118.2565994263 117.647102356117.342300415 116.7326965332116.1231002808 115.5136032104114 .9039993286113 .9896011353113 .3800964355112 .4656982422 111.551399231110 .6370010376110 .0273971558109 .1130981445108 .1986999512 107.2844009399106 .6747970581105 .7603988647104 .8460998535104 .2365036011 103.3221969604102 .712600708101 .7982025146101 .1886978149100 .5791015625 99.6647262573299 .0551681518698 .445587158297 .5312423706196 .92166900635 96.3121032714895 .7025299072395 .0929565429794 .7881774902394 .48339080811 93.8738174438593 .2642517089892 .6546783447391 .4355392456190 .21640014648 88.9972534179787 .1685485839885 .3398437583 .5111236572381 .37763214111 79.2441329956176 .8058471679774 .3675689697371 .9292907714869 .49101257324 67.3575134277364 .9192428588962 .7857398986861 .5666007995660 .34745025635 -9999 -9999 -9999 -9999 -9999 -9999 -9999 -9999 -9999 -9999 -9999 -9999 -9999 -9999 -9999 -9999 -9999 -9999 -9999 -9999 -9999 -9999 -9999 -9999 -9999 -9999 -9999 -9999 -9999 -9999 -9999 -9999 -9999 -9999 -9999 -9999 -9999 -9999 -9999 -9999 -9999 -9999 -9999 -9999 -9999 -9999 $-9999-9999$

-9999 -9999 -9999 -9999 -9999 -9999 -9999 -9999 -9999-9999 -9999 -9999 -9999 -9999 -9999 -

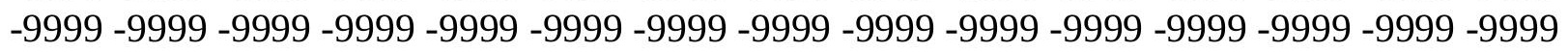

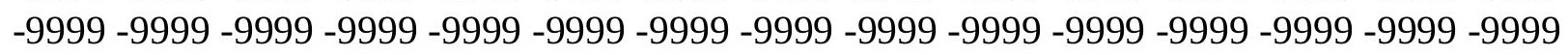

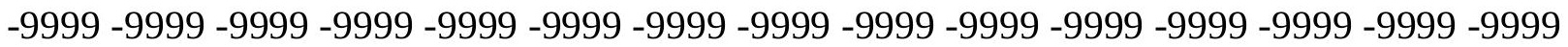

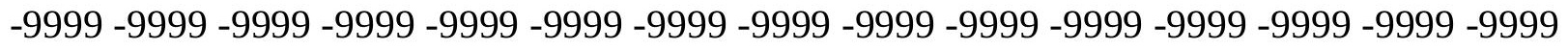

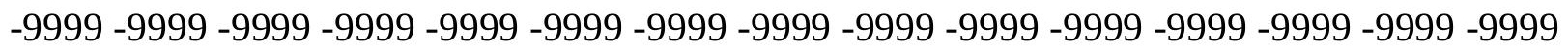

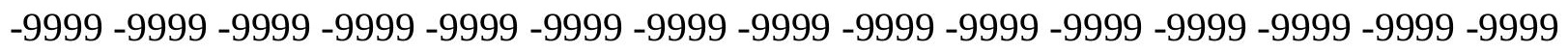
-9999 -9999 -9999 -9999 -9999 -9999 -9999 -9999 -9999 -9999 -9999 -9999 -9999 -9999 -9999 -

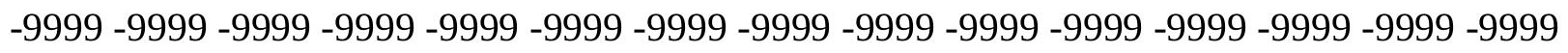

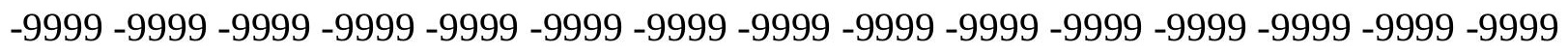
-9999 -9999 -9999 -9999 -9999 -9999 -9999 -9999 -9999 -9999 -9999 -9999 -9999 -9999 -9999 -9999 -9999 -9999 -9999 -9999 -9999 -9999 -9999 -9999 -9999 -9999 -9999 -9999 -9999 - -9999 -

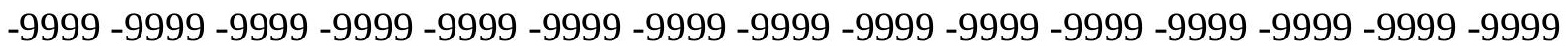
-9999 -9999 -9999 -9999 -9999 -9999 -9999 -9999 -9999 -9999 -9999 -9999 -9999 -9999 -9999

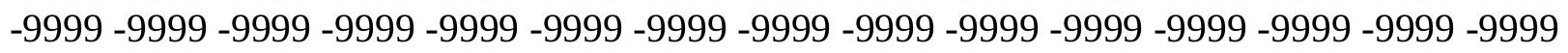
-9999 -9999 -9999-9999 -9999-9999 -9999 -9999 -9999 -9999 99.35994720459 97.5312423706197 .2264633178796 .9216690063597 .8360290527398 .75038146973 100.2742996216101 .7982025146103 .6268997192105 .4557037354107 .2844009399 109.1130981445111 .24659729113 .3800964355115 .2088012695117 .342300415 119.1709976196120 .6949005127121 .6092987061122 .2188034058122 .5235977173 122.8283996582122 .8283996582122 .8283996582122 .5235977173122 .5235977173 122.2188034058121 .9140014648121 .6092987061121 .6092987061121 .3044967651 120.9997024536120 .6949005127120 .6949005127120 .3900985718120 .3900985718 120.3900985718120 .0852966309120 .0852966309120 .0852966309120 .0852966309 119.7806015015119 .7806015015119 .7806015015119 .7806015015119 .4757995605 119.4757995605119 .1709976196119 .1709976196118 .8662033081118 .8662033081 118.5614013672118 .2565994263117 .647102356117 .342300415116 .7326965332 115.818397522115 .2088012695114 .2944030762113 .3800964355112 .7705001831 111.8561019897110 .9418029785110 .0273971558109 .1130981445108 .1986999512 107.2844009399106 .6747970581105 .7603988647104 .8460998535103 .9317016602 103.3221969604102 .4077987671101 .7982025146100 .8839035034100 .2742996216 
99.3599472045998.7503814697397.83602905273 97.2264633178796.31210327148 95.397743225194 .4833908081194 .1785964965893 .8738174438593 .26425170898 92.9594726562592 .349891662691 .4355392456190 .5211791992289 .3020401001 88.0829010009886 .254188537684 .4254837036182 .5967712402380 .46327209473 78.3297805786176 .1962814331173 .7580032348671 .3197174072368 .88143920898 66.7479400634864 .3096618652362 .1761703491260 .9570198059159 .73788070679 -9999 -9999 -9999 -9999 -9999 -9999 -9999 -9999 -9999 -9999 -9999 -9999 -9999 -9999 -9999 -9999

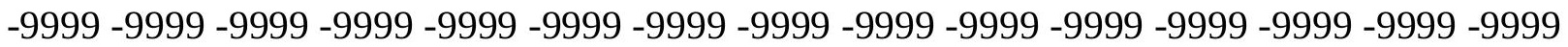

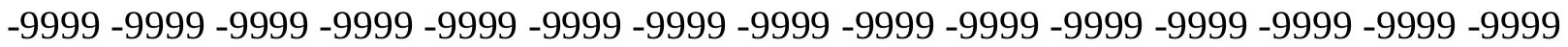
$-9999-9999$

-9999 -9999 -9999 -9999 -9999 -9999 -9999 -9999 -9999 -9999 -9999 -9999 -9999 -9999 -9999 -9999 -9999 -9999 -9999 -9999 -9999 -9999 -9999 -9999 -9999 -9999 -9999 -9999 -9999 -9999 -9999 -9999 -9999 -9999 -9999 -9999 -9999 -9999 -9999 -9999 -9999 -9999 -9999 -9999 -9999 -9999 -9999 -9999 -9999 -9999 -9999 -9999 -9999 -9999 -9999 -9999 -9999 -9999 -9999 -9999 -9999 -9999 -9999 -9999 -9999 -9999 -9999 -9999 -9999 -9999 -9999 -9999 -9999 -9999 -9999

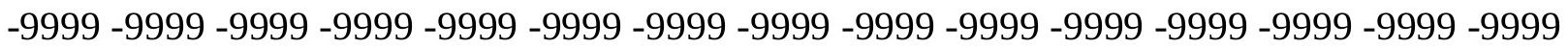

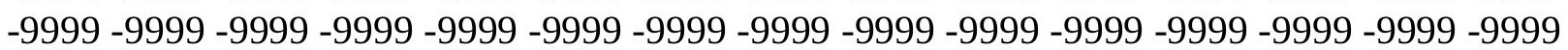
-9999 -9999 -9999 -9999 -9999 -9999 -9999 -9999 -9999 -9999 -9999 -9999 -9999 -9999 -9999 -999 -9999 -9999 -9999 -9999 -9999 -9999 -9999 -9999 -9999 -9999 -9999 -9999 -9999 -9999 -9999 -9999 -9999 -9999 -9999 -9999 -9999 -9999 -9999 -9999 -9999 -9999 -9999 -9999 -9999 -9999 -9999 -9999 -9999 -9999 -9999 -9999 -9999 -9999 -9999 -9999 -9999 -9999 -9999 -9999 -9999 -999 -9999 -9999 -9999 -9999 -9999 -9999 -9999 -9999 -9999 -9999 -9999 -9999 -9999 -9999 -9999 -9999 -9999 -9999 -9999 -9999 -9999 -9999 -9999 -9999 -9999 -9999 -9999 -9999 -9999 -9999 -9999 -9999 -9999 -9999 -9999 -9999 -9999 -9999 -9999 -9999 -9999 -9999 -9999 -9999 -9999 -9999 -9999 -9999 -9999 -9999 -9999 -9999 -9999 -9999 -9999 -9999 -9999 -9999 -9999 -9999 -9999 -9999-9999 -9999 -9999 -9999-9999 -9999 -9999 -9999 -9999 -9999 98.4455871582 97.5312423706197 .2264633178797 .5312423706199 .05516815186100 .8839035034 102.712600708104 .5412979126106 .6747970581108 .5035018921110 .9418029785 113.075302124115 .2088012695117 .0374984741118 .8662033081120 .6949005127 121.6092987061122 .5235977173122 .8283996582123 .1332015991123 .1332015991 123.1332015991122 .8283996582122 .5235977173122 .5235977173122 .2188034058 121.9140014648121 .6092987061121 .6092987061121 .3044967651120 .9997024536 120.9997024536120 .6949005127120 .6949005127120 .6949005127120 .6949005127 120.3900985718120 .3900985718120 .3900985718120 .3900985718120 .0852966309 120.0852966309120 .0852966309119 .7806015015119 .7806015015119 .7806015015 119.4757995605119 .4757995605119 .1709976196118 .8662033081118 .5614013672 118.2565994263117 .647102356117 .0374984741116 .1231002808115 .5136032104 114.5991973877113 .6848983765112 .7705001831111 .8561019897110 .9418029785 110.0273971558109 .1130981445108 .5035018921107 .5891036987106 .6747970581 105.7603988647104 .8460998535103 .9317016602103 .3221969604102 .4077987671 101.4934005737100 .883903503499 .9695205688599 .3599472045998 .4455871582 97.5312423706196 .6168823242295 .7025299072394 .7881774902393 .56903076172 93.2642517089892 .9594726562592 .6546783447392 .0450973510791 .43553924561 90.5211791992289 .6068267822388 .3876876831187 .1685485839885 .64462280273 83.8159103393681 .9871978759879 .8537063598677 .7202072143675 .58670806885 73.1484298706170 .7101516723668 .2718734741266 .1383666992263 .70008850098 
62.17617034912 60.65224075317 -9999 -9999 -9999 -9999 -9999 -9999 -9999 -9999 -9999 -9999 -9999 -9999 -9999 -9999 -9999 -9999 -9999 -9999 -9999 -9999 -9999 -9999 -9999 -9999 -9999 -9999 -9999 -9999 -9999 -9999 -9999 -9999 -9999 -9999 -9999 -9999 -9999 -9999 -9999 -9999 -9999 -9999 -9999 -9999 -9999 -9999 -9999 -9999 -9999

-9999 -9999 -9999 -9999 -9999 -9999 -9999 -9999 -9999 -9999 -9999 -9999 -9999 -9999 -9999 -9999 -9999 -9999 -9999 -9999 -9999 -9999 -9999 -9999 -9999 -9999 -9999 -9999 -9999 -9999 -9999 -9999 -9999 -9999 -9999 -9999 -9999 -9999 -9999 -9999 -9999 -9999 -9999 -9999 -9999

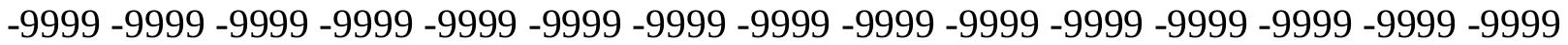
-9999 -9999 -9999 -9999 -9999 -9999 -9999 -9999 -9999 -9999 -9999 -9999 -9999 -9999 -9999 -9999 -9999 -9999 -9999 -9999 -9999 -9999 -9999 -9999 -9999 -9999 -9999 -9999 -9999 -9999 -9999 -9999 -9999 -9999 -9999 -9999 -9999 -9999 -9999 -9999 -9999 -9999 -9999 -9999 -9999 -9999 -9999 -9999 -9999 -9999 -9999 -9999 -9999 -9999 -9999 -9999 -9999 -9999 -9999 -9999

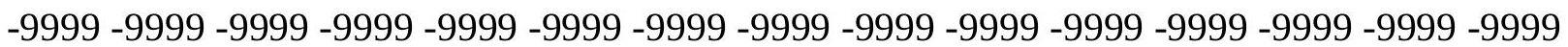
-9999 -9999 -9999 -9999 -9999 -9999 -9999 -9999 -9999 -9999 -9999 -9999 -9999 -9999 -9999 -9999 -9999 -9999 -9999 -9999 -9999 -9999 -9999 -9999 -9999 -9999 -9999 -9999 -9999 -9999

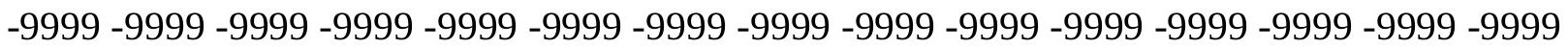

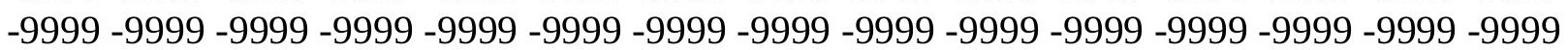
-9999 -9999 -9999 -9999 -9999 -9999 -9999 -9999 -9999 -9999 -9999 -9999 -9999 -9999 -9999 -9999 -9999 -9999 -9999 -9999 -9999 -9999 -9999 -9999 -9999 -9999 -9999 -9999 -9999 -9999 -9999 -9999 -9999 -9999 -9999 -9999 -9999 -9999 -9999 -9999 -9999 -9999 -9999 100.579101562599 .0551681518698 .1408081054798 .14080810547100 .2742996216 102.4077987671103 .9317016602106 .0652008057108 .1986999512110 .3321990967 112.7705001831115 .2088012695117 .0374984741118 .8662033081120 .3900985718 121.6092987061122 .5235977173122 .8283996582123 .1332015991123 .1332015991 123.1332015991122 .8283996582122 .8283996582122 .5235977173122 .2188034058 122.2188034058121 .9140014648121 .6092987061121 .6092987061121 .3044967651 121.3044967651120 .9997024536120 .9997024536120 .9997024536120 .9997024536 120.6949005127120 .6949005127120 .6949005127120 .6949005127120 .3900985718 120.3900985718120 .3900985718120 .0852966309120 .0852966309120 .0852966309 119.7806015015119 .7806015015119 .4757995605119 .1709976196118 .8662033081 118.5614013672117 .9517974854117 .342300415116 .4279022217115 .5136032104 114.5991973877113 .9896011353113 .075302124112 .1608963013111 .24659729 110.3321990967109 .4179000854108 .5035018921107 .5891036987106 .6747970581 105.7603988647104 .8460998535103 .9317016602103 .3221969604102 .4077987671 101.4934005737100 .579101562599 .9695205688599 .0551681518698 .14080810547 97.2264633178796.3121032714895.397743225194.4833908081193.56903076172 92.9594726562592 .349891662692 .0450973510791 .4355392456190 .82597351074 89.9116134643688 .9972534179787 .7781066894586 .5589828491285 .03504943848 83.2063369751 81.3776321411179.24413299561 77.1106262207 74.97714233398 72.5388565063570 .4053573608467 .9670867919965 .5288009643663 .39530944824 61.2618103027360 .95701980591 -9999 -9999 -9999 -9999 -9999 -9999 -9999 -9999 -9999

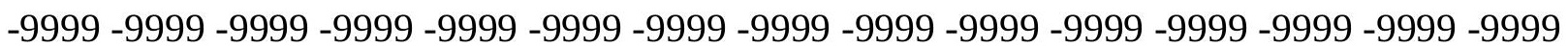
-9999 -9999 -9999 -9999 -9999 -9999 -9999 -9999 -9999 -9999 -9999 -9999 -9999 -9999 -9999 -9999 -9999 -9999 -9999 -9999 -9999 -9999 -9999 -9999 -9999 -9999 -9999 -9999 -9999 -9999 -9999 -9999 -9999 -9999 -9999 -9999 -9999 -9999 -9999 -9999

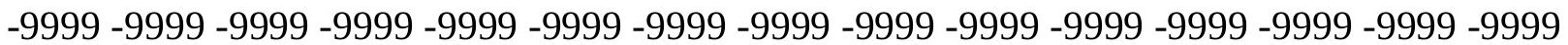


-9999 -9999 -9999 -9999 -9999 -9999 -9999 -9999 -9999 -9999 -9999 -9999 -9999 -9999 -9999 -9999 -9999 -9999 -9999 -9999 -9999 -9999 -9999 -9999 -9999 -9999 -9999 -9999 -9999 -9999 -9999 -9999 -9999 -9999 -9999 -9999 -9999 -9999 -9999 -9999 -9999 -9999 -9999 -9999 -9999 -9999 -9999 -9999 -9999 -9999 -9999 -9999 -9999 -9999 -9999 -9999 -9999 -9999 -9999 -9999 -9999 -9999 -9999 -9999 -9999 -9999 -9999 -9999 -9999 -9999 -9999 -9999 -9999 -9999 -9999 -9999 -9999 -9999 -9999 -9999 -9999 -9999 -9999 -9999 -9999 -9999 -9999 -9999 -9999 -9999 -9999 -9999 -9999 -9999 -9999 -9999 -9999 -9999 -9999 -9999 -9999 -9999 -9999 -9999 -9999

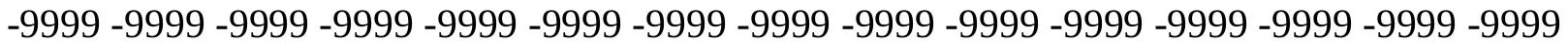
-9999 -9999 -9999 -9999 -9999 -9999 -9999 -9999 -9999 -9999 -9999 -9999 -9999 -9999 -9999 -9999 -9999 -9999 -9999 -9999 -9999 -9999 -9999 -9999 -9999 -9999 -9999 -9999 -9999 -9999 -9999 -9999 -9999 -9999 -9999 -9999 -9999 -9999 -9999 -9999 -9999 -9999 -9999 -9999 -9999 -9999 -9999 -9999 -9999 -9999 -9999 -9999 -9999 -9999 -9999 -9999 -9999 -9999 -9999 -9999 -9999 -9999 -9999 -9999 -9999 -9999 -9999 -9999 -9999 -9999 -9999 -9999 -9999 -9999 -9999 -9999 -9999 -9999 -9999 -9999 -9999 -9999 -9999 -9999 -9999 -9999 -9999 -9999 -9999 103.3221969604102 .4077987671101 .4934005737100 .8839035034102 .1029968262 103.3221969604105 .4557037354107 .5891036987110 .3321990967112 .7705001831 115.2088012695117 .342300415119 .1709976196120 .6949005127121 .6092987061 122.5235977173122 .8283996582123 .1332015991123 .1332015991123 .1332015991 122.8283996582122 .8283996582122 .5235977173122 .5235977173122 .2188034058 122.2188034058121 .9140014648121 .9140014648121 .6092987061121 .6092987061 121.3044967651121 .3044967651121 .3044967651121 .3044967651120 .9997024536 120.9997024536120 .9997024536120 .9997024536120 .6949005127120 .6949005127 120.6949005127120 .3900985718120 .3900985718120 .3900985718120 .0852966309 120.0852966309119 .7806015015119 .4757995605119 .1709976196118 .8662033081 118.2565994263117 .342300415116 .7326965332115 .818397522114 .9039993286 113.9896011353113 .075302124112 .1608963013111 .24659729110 .3321990967 109.4179000854108 .5035018921107 .5891036987106 .6747970581105 .7603988647 104.8460998535103 .9317016602103 .3221969604102 .4077987671101 .4934005737 100.579101562599 .6647262573299 .0551681518698 .1408081054797 .22646331787 96.3121032714895 .397743225194 .4833908081193 .5690307617292 .95947265625 92.349891662691 .7403335571391 .1307525634890 .2164001464889 .3020401001 88.38768768311 87.16854858398 85.9494018554784.42548370361 82.59677124023 80.7680587768678 .9393463134876 .8058471679774 .6723632812572 .23407745361 70.1005783081167 .6623001098665 .2240066528362 .7857398986861 .87137985229 61.26181030273 -9999 -9999 -9999 -9999 -9999 -9999 -9999 -9999 -9999 -9999 -9999 -9999 -9999 -9999 -9999 -9999 -9999 -9999 -9999 -9999 -9999 -9999 -9999 -9999 -9999 -9999 -9999

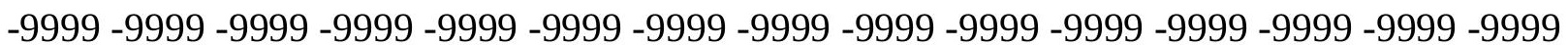
-9999 -9999 -9999 -9999 -9999 -9999 -9999 -9999 -9999 -9999 -9999 -9999 -9999 -9999 -9999 -9999 -9999 -9999 -9999 -9999 -9999 -9999 -9999 -9999 -9999 -9999 -9999 -9999 -9999 -9999 -9999 -9999 -9999 -9999 -9999 -9999 -9999 -9999 -9999 -9999 -9999 -9999 -9999 -9999 -9999 -9999 -9999 -9999 -9999 -9999 -9999 -9999

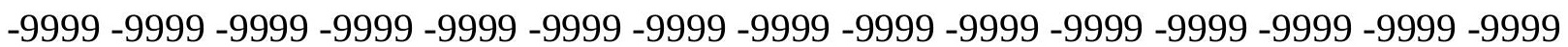
-9999 -9999 -9999 -9999 -9999 -9999 -9999 -9999 -9999 -9999 -9999 -9999 -9999 -9999 -9999 -9999 -9999 -9999 -9999 -9999 -9999 -9999 -9999 -9999 -9999 -9999 -9999 -9999 -9999 -9999 -999 -9999 -9999 -9999 -9999 -9999 -9999 -9999 -9999 -9999 -9999 -9999 -9999 -9999 -9999 -9999

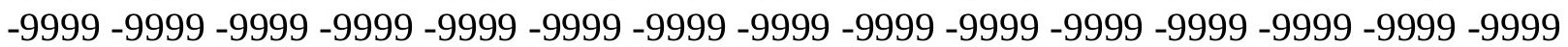


-9999 -9999 -9999 -9999 -9999 -9999 -9999 -9999 -9999 -9999 -9999 -9999 -9999 -9999 -9999 -9999 -9999 -9999 -9999 -9999 -9999 -9999 -9999 -9999 -9999 -9999 -9999 -9999 -9999 -9999 -9999 -9999 -9999 -9999 -9999 -9999 -9999 -9999 -9999 -9999 -9999 -9999 -9999 -9999 -9999 -9999 -9999 -9999 -9999 -9999 -9999 -9999 -9999 -9999 -9999 -9999 -9999 -9999 -9999 -9999 -9999 -9999 -9999 -9999 -9999 -9999 -9999 -9999 -9999 -9999 -9999 -9999 -9999 -9999 -9999 -9999 -9999 -9999 -9999 -9999 -9999 -9999 -9999 -9999 -9999 -9999 -9999 -9999 -9999 -9999 -

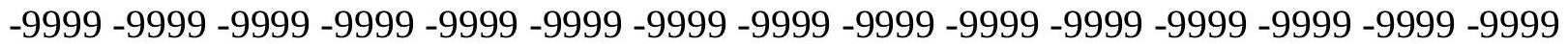
-9999 -9999 -9999 -9999 -9999 -9999 -9999 -9999 -9999 -9999 -9999 -9999 -9999 -9999 107.5891036987106 .979598999106 .3700027466105 .7603988647105 .7603988647 105.7603988647105 .7603988647107 .5891036987110 .3321990967113 .075302124 115.5136032104117 .647102356119 .4757995605120 .6949005127121 .9140014648 122.5235977173122 .8283996582122 .8283996582122 .8283996582122 .8283996582 122.8283996582122 .8283996582122 .5235977173122 .5235977173122 .2188034058 122.2188034058122 .2188034058121 .9140014648121 .9140014648121 .9140014648 121.6092987061121 .6092987061121 .6092987061121 .6092987061121 .3044967651 121.3044967651121 .3044967651121 .3044967651120 .9997024536120 .9997024536 120.9997024536120 .6949005127120 .6949005127120 .3900985718120 .3900985718 120.0852966309120 .0852966309119 .7806015015119 .4757995605118 .8662033081 118.2565994263117 .647102356116 .7326965332115 .818397522114 .9039993286 113.9896011353113 .075302124112 .1608963013111 .24659729110 .3321990967 109.4179000854108 .5035018921107 .5891036987106 .6747970581105 .7603988647 104.8460998535104 .2365036011103 .3221969604102 .4077987671101 .4934005737 100.579101562599 .6647262573299 .0551681518698 .1408081054797 .22646331787 96.3121032714895 .397743225194 .4833908081193 .5690307617292 .95947265625 92.349891662691 .4355392456190 .8259735107489 .9116134643689 .3020401001 88.0829010009886 .8637619018685 .6446228027384 .1206970214882 .29197692871 80.7680587768678 .6345596313576 .5010681152374 .3675689697372 .23407745361 69.7957916259867 .3575134277365 .2240066528362 .7857398986862 .48094940186 61.26181030273 -9999 -9999 -9999 -9999 -9999 -9999 -9999 -9999 -9999 -9999 -9999 -9999 -9999 -9999 -9999 -9999 -9999 -9999 -9999 -9999 -9999 -9999 -9999 -9999 -9999 -9999 -9999 -9999 -9999 -9999 -9999 -9999 -9999 -9999 -9999 -9999 -9999 -9999 -9999 -9999 -9999 -9999 -9999 -9999 -9999 -9999 -9999 -9999 -9999 -9999 -9999 -9999 -9999 -9999 -9999 -9999 -9999 -9999 -9999 -9999 -9999 -9999 -9999 -9999 -9999 -9999 -9999 -9999 -9999 -9999 -9999 -9999 -9999 -9999 -9999 -9999 -9999 -9999 -9999

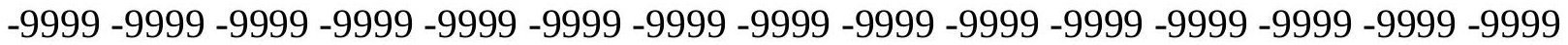
-9999 -9999 -9999 -9999 -9999 -9999 -9999 -9999 -9999 -9999 -9999 -9999 -9999 -9999 -9999

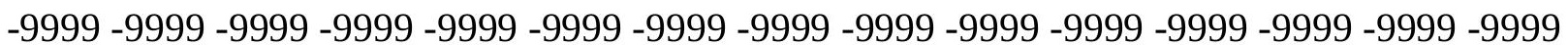

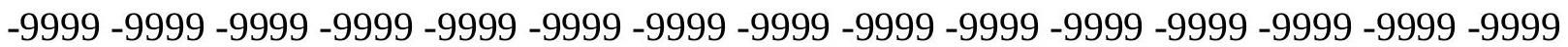
-9999 -9999 -9999 -9999 -9999 -9999 -9999 -9999 -9999 -9999 -9999 -9999 -9999 -9999 -9999 -9999 -9999 -9999 -9999 -9999 -9999 -9999 -9999 -9999 -9999 -9999 -9999 -9999 - -9999 -9999 -9999 -9999 -9999 -9999 -9999 -9999 -9999 -9999 -9999 -9999 -9999 -9999 -9999 -9999 -9999

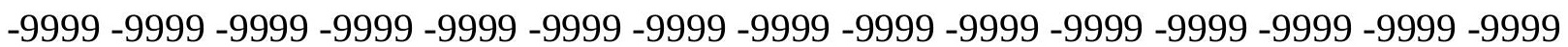
-9999 -9999 -9999 -9999 -9999 -9999 -9999 -9999 -9999 -9999 -9999 -9999 -9999 -9999 -9999 -9999 -9999 -9999 -9999 -9999 -9999 -9999 -9999 -9999 -9999 -9999 -9999 -9999 -9999 -9999 -9999 -9999 -9999 -9999 -9999 -9999 -9999 -9999 -9999 -9999 -9999 -9999 -9999 -9999 -9999

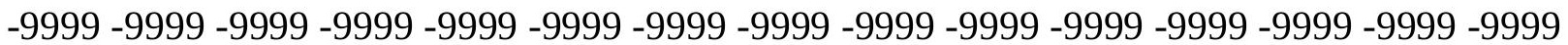


-9999 -9999 -9999 -9999 -9999 -9999 -9999 -9999 -9999 -9999 -9999 -9999 -9999 -9999 -9999 -9999 -9999 -9999 -9999 -9999 -9999 -9999 -9999 -9999 -9999 -9999 -9999 -9999 -9999 -9999 111.8561019897111 .24659729110 .9418029785110 .9418029785111 .24659729 111.8561019897112 .1608963013112 .1608963013113 .3800964355115 .5136032104 117.9517974854119 .7806015015120 .9997024536121 .9140014648122 .2188034058 122.5235977173122 .5235977173122 .5235977173122 .5235977173122 .5235977173 122.5235977173122 .5235977173122 .5235977173122 .5235977173122 .5235977173 122.2188034058122 .2188034058122 .2188034058122 .2188034058121 .9140014648 121.9140014648121 .9140014648121 .9140014648121 .6092987061121 .6092987061 121.6092987061121 .3044967651121 .3044967651121 .3044967651120 .9997024536 120.9997024536120 .6949005127120 .6949005127120 .3900985718120 .3900985718 120.0852966309119 .7806015015119 .4757995605118 .8662033081118 .2565994263 117.647102356116 .7326965332115 .818397522114 .9039993286113 .9896011353 113.075302124112 .1608963013111 .24659729110 .3321990967109 .4179000854 108.5035018921107 .5891036987106 .6747970581106 .0652008057105 .1509017944 104.2365036011 103.3221969604102.4077987671 101.4934005737 100.5791015625 99.9695205688599 .0551681518698 .1408081054797 .2264633178796 .31210327148 95.397743225194 .7881774902393 .8738174438593 .2642517089892 .3498916626 91.7403335571390 .8259735107489 .9116134643688 .9972534179788 .08290100098 86.8637619018685 .3398437583 .8159103393682 .2919769287180 .46327209473 78.6345596313576 .5010681152374 .3675689697372 .2340774536169 .79579162598 $67.6623001098665 .2240066528362 .7857398986862 .4809494018661 .87137985229-9999$ -9999 -9999 -9999 -9999 -9999 -9999 -9999 -9999 -9999 -9999 -9999 -9999 -9999 -9999 -9999 -9999 -9999 -9999 -9999 -9999 -9999 -9999 -9999 -9999 -9999 -9999 -9999 -9999 -9999 -9999 -9999 -9999 -9999 -9999 -9999 -9999 -9999 -9999 -9999 -9999 -9999 -9999 -9999 -9999 -9999 -9999-9999-9999

-9999 -9999 -9999 -9999 -9999 -9999 -9999 -9999 -9999 -9999 -9999 -9999 -9999 -9999 -9999

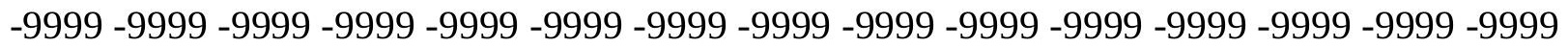
-9999 -9999 -9999 -9999 -9999 -9999 -9999 -9999 -9999 -9999 -9999 -9999 -9999 -9999 -9999 -

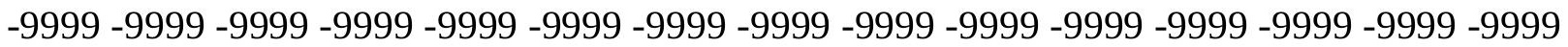

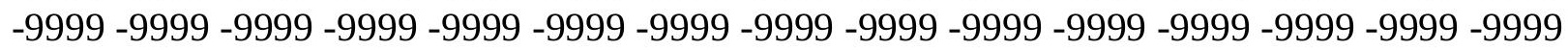

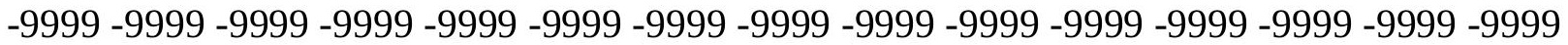
-9999 -9999 -9999 -9999 -9999 -9999 -9999 -9999 -9999-9999 -9999 -9999 -9999-9999-999 - -999 -9999 -9999 -9999 -9999 -9999 -9999 -9999 -9999 -9999 -9999 -9999 -9999 -9999 -9999 -9999 -9999 -9999 -9999 -9999 -9999 -9999 -9999 -9999 -9999 -9999 -9999 -9999 -9999 -9999 -9999 -9999 -9999 -9999 -9999 -9999 -9999 -9999 -9999 -9999 -9999 -9999 -9999 -9999 -9999 -9999

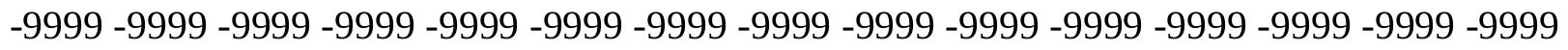

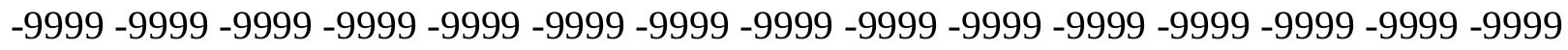
-9999 -9999 -9999 -9999 -9999 -9999 -9999 -9999 -9999 -9999 -9999 -9999 -9999 -9999 -9999 -9999 -9999 -9999 -9999 -9999 -9999 -9999 -9999 -9999 -9999 -9999 -9999 -9999 -9999 -9999 -

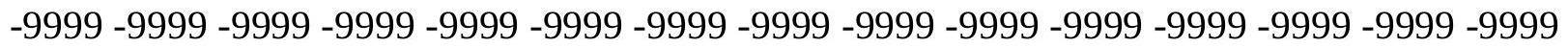
-9999 -9999 -9999 -9999 -9999 -9999 -9999 -9999 -9999 -9999 -9999 -9999 -9999 -9999 -9999 -9999 116.4279022217 116.1231002808 116.4279022217 117.0374984741 117.9517974854 118.8662033081119 .4757995605119 .1709976196117 .9517974854118 .5614013672 120.3900985718121 .3044967651121 .9140014648121 .9140014648122 .2188034058 122.2188034058122 .2188034058122 .2188034058122 .5235977173122 .5235977173 
122.5235977173122 .5235977173122 .5235977173122 .5235977173122 .5235977173 122.5235977173122 .5235977173122 .2188034058122 .2188034058122 .2188034058 122.2188034058122 .2188034058121 .9140014648121 .9140014648121 .9140014648 121.6092987061121 .6092987061121 .3044967651121 .3044967651120 .9997024536 120.9997024536120 .6949005127120 .6949005127120 .3900985718120 .0852966309 119.7806015015119 .4757995605118 .8662033081118 .2565994263117 .342300415 116.7326965332115 .818397522114 .9039993286113 .9896011353113 .075302124 112.1608963013111 .24659729110 .3321990967109 .4179000854108 .5035018921 107.8938980103106 .979598999106 .0652008057105 .1509017944104 .2365036011 103.3221969604102 .4077987671101 .7982025146100 .883903503499 .96952056885 99.0551681518698 .445587158297 .5312423706196 .6168823242295 .70252990723 95.0929565429794.1785964965893.2642517089892.6546783447391.74033355713 90.8259735107489 .9116134643688 .9972534179788 .0829010009886 .86376190186 85.3398437583 .8159103393682 .2919769287180 .4632720947378 .63455963135 76.8058471679774 .6723632812572 .5388565063570 .1005783081167 .96708679199 65.5288009643663 .3953094482463 .0905189514262 .48094940186 -9999 -9999 -9999 -9999 -9999 -9999 -9999 -9999 -9999 -9999 -9999 -9999 -9999 -9999 -9999 -9999 -9999 -9999 -9999 -9999 -9999 -9999 -9999 -9999 -9999 -9999 -9999 -9999 -9999 -9999 -9999 -9999 -9999 -9999 -9999 -9999 -9999 -9999 -9999 -9999 -9999 -9999 -9999 -9999 -9999 -9999 -9999 -9999 -9999 -999 -

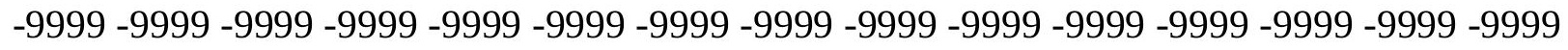

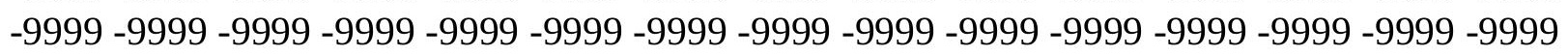

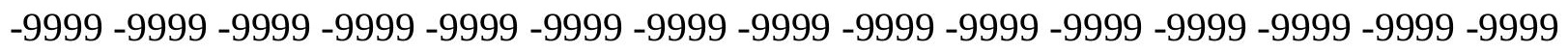
-9999 -9999 -9999 -9999 -9999 -9999 -9999 -9999 -9999 -9999 -9999 -9999 -9999 -9999 -9999 -

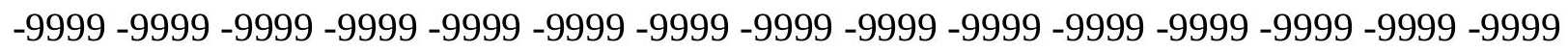

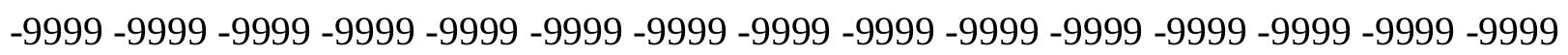
-9999 -9999 -9999 -9999 -9999 -9999 -9999 -9999 -9999 -9999 -9999 -9999 -9999 -9999 -9999 -9999 -9999 -9999 -9999 -9999 -9999 -9999 -9999 -9999 -9999 -9999 -9999 -9999 -9999 - -9999 -

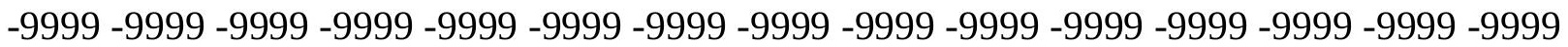

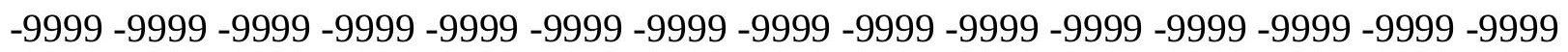

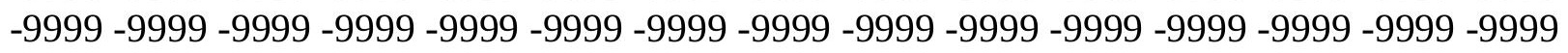
-9999 -9999 -9999 -9999 -9999 -9999 -9999 -9999 -9999 -9999 -9999 -9999 -9999 -9999 -9999 -9999 -9999 -9999 -9999 -9999 -9999 -9999 -9999 -9999 -9999 -9999 -9999 -9999 -9999 -9999 -

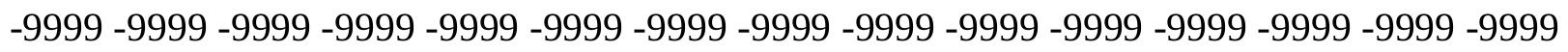

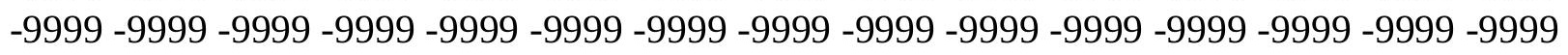

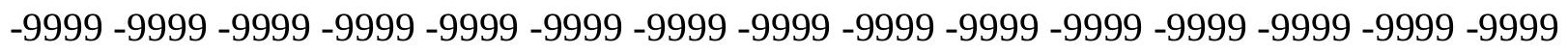
-9999 121.3044967651 121.6092987061 121.6092987061 122.5235977173 124.3523025513 126.1809997559127 .4001998901127 .7050018311126 .4858016968123 .43800354 120.6949005127121 .3044967651121 .6092987061121 .6092987061121 .6092987061 121.6092987061121 .9140014648121 .9140014648122 .2188034058122 .2188034058 122.5235977173122 .5235977173122 .5235977173122 .5235977173122 .5235977173 122.5235977173122 .5235977173122 .5235977173122 .5235977173122 .5235977173 122.5235977173122 .2188034058122 .2188034058122 .2188034058121 .9140014648 121.9140014648121 .9140014648121 .6092987061121 .3044967651121 .3044967651 120.9997024536120 .9997024536120 .6949005127120 .3900985718120 .0852966309 119.7806015015119 .1709976196118 .5614013672117 .9517974854117 .342300415 116.4279022217115 .818397522114 .9039993286113 .9896011353113 .075302124 
112.1608963013111 .24659729110 .3321990967109 .4179000854108 .5035018921 107.8938980103106 .979598999106 .0652008057105 .1509017944104 .2365036011 103.6268997192102 .712600708101 .7982025146100 .8839035034100 .2742996216 99.3599472045998 .445587158297 .8360290527396 .9216690063596 .00731658936 95.397743225194 .4833908081193 .5690307617292 .9594726562592 .04509735107 91.1307525634890 .2164001464889 .302040100188 .0829010009888 .52935791016 86.5471115112384 .1206970214882 .5967712402380 .7680587768678 .93934631348 76.8058471679774 .9771423339872 .8436431884870 .7101516723668 .57665252686 66.44316101074 64.30966186523 62.17617034912 61.56660079956 -9999 -9999 -9999 -9999 -9999 -9999 -9999 -9999 -9999 -9999 -9999 -9999 -9999 -9999 -9999 -9999 -9999 -9999 -9999

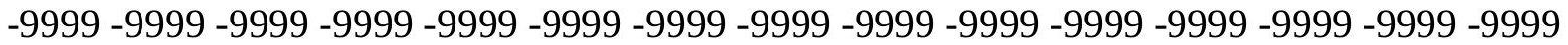
-9999 -9999 -9999 -9999 -9999 -9999 -9999 -9999 -9999 -9999 -9999 -9999 -9999 -9999 -9999 -9999 -9999 -9999 -9999 -9999 -9999 -9999 -9999 -9999 -9999 -9999 -9999 -9999 -9999 -9999 -9999 -9999 -9999 -9999 -9999 -9999 -9999 -9999 -9999 -9999 -9999 -9999 -9999 -9999 -9999 -9999 -9999 -9999 -9999 -9999 -9999 -9999 -9999 -9999 -9999 -9999 -9999 -9999 -9999 -9999

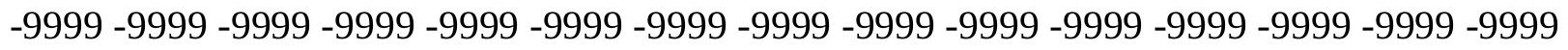

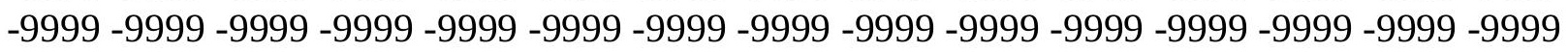

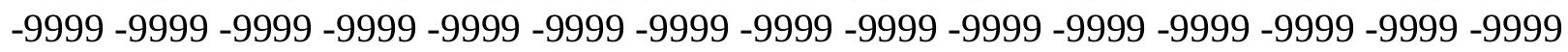

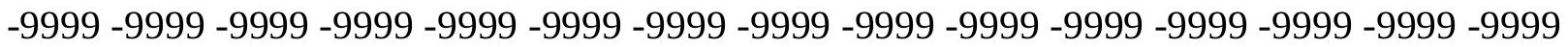

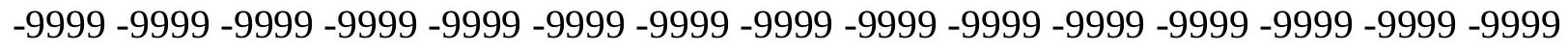

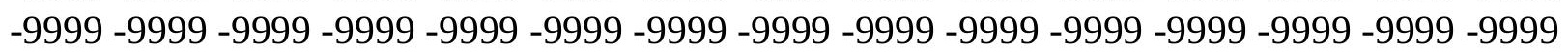

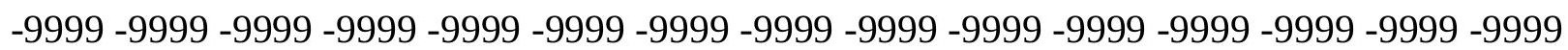
-9999 -9999 -9999 -9999 -9999 -9999 -9999 -9999 -9999 -9999 -9999 -9999 -9999 -9999 -9999 -9999 -9999 -9999 -9999 -9999 -9999 -9999 -9999 -9999 -9999 -9999 -9999 -9999 -9999 -9999 -

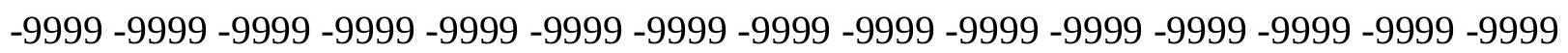
-9999 -9999 -9999 -9999 -9999 -9999 -9999 -9999 -9999 -9999 -9999 -9999 -9999 -9999 -9999 -9999 -9999 -9999 -9999 -9999 -9999 -9999 -9999 -9999 -9999 -9999 -9999 -9999 -9999 -9999

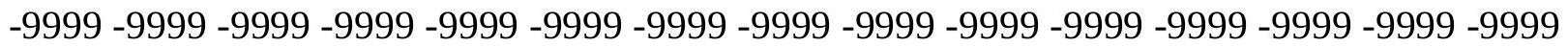
-9999-9999 127.4001998901 128.3144989014129.2288970947 131.0576019287 133.1911010742135 .3246002197136 .5437011719134 .7149963379131 .0576019287 126.7906036377122 .2188034058120 .9997024536120 .3900985718120 .6949005127 120.9997024536121 .3044967651121 .6092987061121 .9140014648122 .2188034058 122.5235977173122 .5235977173122 .8283996582122 .8283996582122 .8283996582 122.8283996582122 .8283996582122 .8283996582122 .8283996582122 .8283996582 122.8283996582122 .5235977173122 .5235977173122 .5235977173122 .2188034058 122.2188034058121 .9140014648121 .9140014648121 .6092987061121 .3044967651 120.9997024536120 .9997024536120 .6949005127120 .3900985718119 .7806015015 119.4757995605119 .1709976196118 .5614013672117 .9517974854117 .0374984741 116.4279022217115 .5136032104114 .5991973877113 .9896011353113 .075302124 112.1608963013111 .24659729110 .3321990967109 .4179000854108 .5035018921 107.8938980103106 .979598999106 .0652008057105 .1509017944104 .5412979126 103.6268997192102 .712600708102 .1029968262101 .1886978149100 .2742996216 99.6647262573298.7503814697398.1408081054797.2264633178796.61688232422 95.7025299072394 .7881774902394 .1785964965893 .2642517089892 .3498916626 91.4355392456190 .5211791992289 .6068267822388 .3876876831187 .16854858398 86.6867599487384 .4254837036182 .5967712402381 .0728530883879 .24413299561 
77.4154205322375 .2819290161173 .4532165527371 .3197174072369 .18623352051 67.0527267456165 .2240066528363 .0905189514262 .48094940186 -9999 -9999 -9999 -9999 -9999 -9999 -9999 -9999 -9999 -9999 -9999 -9999 -9999 -9999 -9999 -9999 -9999 -9999 -9999 -9999 -9999 -9999 -9999 -9999 -9999 -9999 -9999 -9999 -9999 -9999 -9999 -9999 -9999 -9999 -9999 -9999 -9999 -9999 -9999 -9999 -9999 -9999 -9999 -9999 -9999 -9999-9999 -9999 -9999 -9999 -9999 -9999 -9999 -9999 -9999 -9999 -9999 -9999 -9999 -9999 -9999 -9999 -9999 -9999

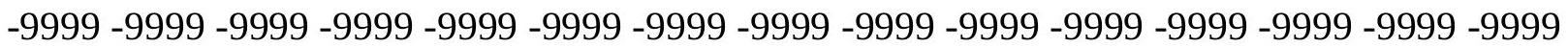

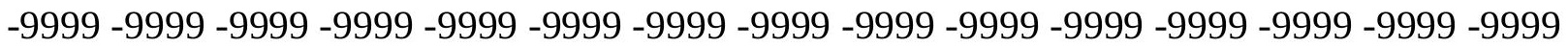

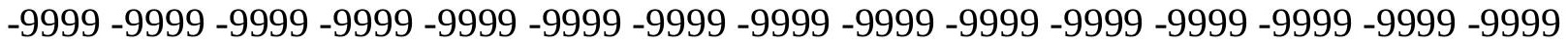
-9999 -9999 -9999 -9999 -9999 -9999 -9999 -9999 -9999 -9999 -9999 -9999 -9999 -9999 -9999

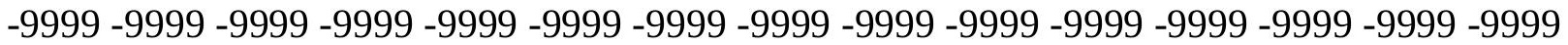
-9999 -9999 -9999 -9999 -9999 -9999 -9999 -9999 -9999 -9999 -9999 -9999 -9999 -9999 -9999 -9999 -9999 -9999 -9999 -9999 -9999 -9999 -9999 -9999 -9999 -9999 -9999 -9999 -9999 -9999 -9999 -9999 -9999 -9999 -9999 -9999 -9999 -9999 -9999 -9999 -9999 -9999 -9999 -9999 - 9999 -9999 -9999 -9999 -9999 -9999 -9999 -9999 -9999 -9999 -9999 -9999 -9999 -9999 -9999 -9999

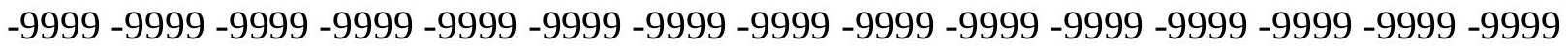
-9999 -9999 -9999 -9999 -9999 -9999 -9999 -9999 -9999 -9999 -9999 -9999 -9999 -9999 -9999 -9999 -9999 -9999 -9999 -9999 -9999 -9999 -9999 -9999 -9999 -9999 -9999 -9999 -9999 -9999 -9999 -9999 -9999 -9999 -9999 -9999 -9999 -9999 -9999 -9999 -9999 -9999 -9999 -9999 -9999 -

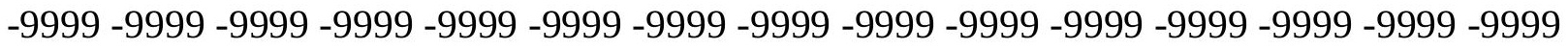

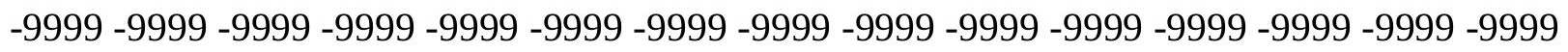
-9999 -9999 133.4958953857 135.6293945312 137.0478668213138.9361877441

141.6518249512144 .7729034424145 .0776977539141 .7250976562137 .4580993652 132.5814971924127 .7050018311122 .5235977173119 .1709976196120 .0852966309 120.6949005127120 .9997024536121 .6092987061121 .9140014648122 .2188034058 122.5235977173122 .5235977173122 .8283996582122 .8283996582123 .1332015991 123.1332015991123 .1332015991123 .1332015991123 .1332015991123 .1332015991 122.8283996582122 .8283996582122 .8283996582122 .5235977173122 .5235977173 122.2188034058122 .2188034058121 .9140014648121 .6092987061121 .3044967651 121.3044967651120 .9997024536120 .6949005127120 .0852966309119 .7806015015 119.4757995605118 .8662033081118 .2565994263117 .647102356117 .0374984741 116.1231002808115 .5136032104114 .5991973877113 .6848983765112 .7705001831 111.8561019897111 .24659729110 .3321990967109 .4179000854108 .5035018921 107.8938980103106 .979598999106 .0652008057105 .4557037354104 .5412979126 103.6268997192103 .0174026489102 .1029968262101 .4934005737100 .5791015625 99.9695205688599 .0551681518698 .445587158297 .8360290527396 .92166900635 96.3121032714895 .397743225194 .4833908081193 .8738174438592 .95947265625 92.0450973510791 .1307525634889 .9116134643688 .6924667358487 .47332763672 86.254188537684 .7302627563583 .1946792602581 .3776321411179 .85370635986 78.0249862670975 .8914871215874 .062782287671 .9292907714870 .10057830811 67.9670867919966 .1383666992264 .3096618652363 .39530944824 -9999 -9999 -9999 -9999 -9999 -9999 -9999 -9999 -9999 -9999 -9999 -9999 -9999 -9999 -9999 -9999 -9999 -9999 -9999 -9999 -9999 -9999 -9999 -9999 -9999 -9999 -9999 -9999 -9999 -9999 -9999 -9999 -9999 -9999 -9999 -9999 -9999 -9999 -9999 -9999 -9999 -9999 -9999-9999 -9999 -9999 -9999 -9999 -9999 -9999 -9999 -9999 -9999 -9999 -9999 -9999 -9999 -9999 -9999 -9999 -9999 -9999 -9999 -9999 -

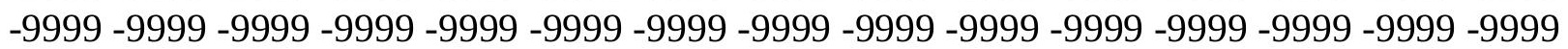


-9999 -9999 -9999 -9999 -9999 -9999 -9999 -9999 -9999 -9999 -9999 -9999 -9999 -9999 -9999 -9999 -9999 -9999 -9999 -9999 -9999 -9999 -9999 -9999 -9999 -9999 -9999 -9999 -9999 -9999 -9999 -9999 -9999 -9999 -9999 -9999 -9999 -9999 -9999 -9999 -9999 -9999 -9999 -9999 -9999 -9999 -9999 -9999 -9999 -9999 -9999 -9999 -9999 -9999 -9999 -9999 -9999 -9999 -9999 -9999 -9999 -9999 -9999 -9999 -9999 -9999 -9999 -9999 -9999 -9999 -9999 -9999 -9999 -9999 -9999 -9999 -9999 -9999 -9999 -9999 -9999 -9999 -9999 -9999 -9999 -9999 -9999 -9999 -9999 -9999 -9999 -9999 -9999 -9999 -9999 -9999 -9999 -9999 -9999 -9999 -9999 -9999 -9999 -9999 -9999

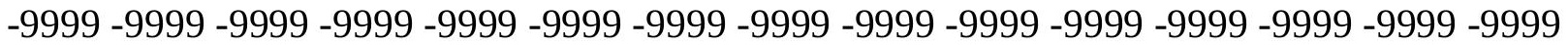
-9999 -9999 -9999 -9999 -9999 -9999 -9999 -9999 -9999 -9999 -9999 -9999 -9999 -9999 -9999 -9999 -9999 -9999 -9999 -9999 -9999 -9999 -9999 -9999 -9999 -9999 -9999 -9999 -9999 -9999 -

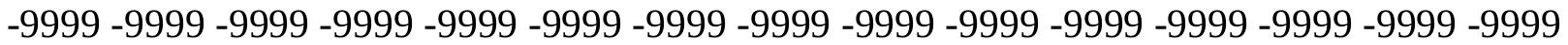
-9999 -9999 -9999 -9999 -9999 -9999 -9999 -9999 -9999 -9999 -9999 -9999 -9999 -9999 -9999

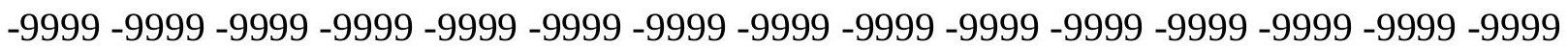
-9999 -9999 -9999 -9999 -9999 -9999 -9999 -9999 -9999 -9999 -9999 -9999 -9999 -9999 -9999 -9999 -9999 -9999 142.0299072266143.7263946533 145.7486724854148 .2743530273 150.555770874151 .1734008789146 .2969055176142 .0299072266137 .1533050537 131.9720001221126 .7906036377121 .6092987061120 .3900985718120 .6949005127 120.9997024536121 .3044967651121 .6092987061122 .2188034058122 .5235977173 122.8283996582123 .1332015991123 .1332015991123 .1332015991123 .43800354 123.43800354123 .43800354123 .43800354123 .1332015991123 .1332015991123 .1332015991 122.8283996582122 .8283996582122 .5235977173122 .5235977173122 .2188034058 121.9140014648121 .6092987061121 .6092987061121 .3044967651120 .9997024536 120.3900985718120 .0852966309119 .7806015015119 .1709976196118 .5614013672 117.9517974854117 .342300415116 .7326965332115 .818397522115 .2088012695 114.2944030762113 .3800964355112 .7705001831111 .8561019897110 .9418029785 110.3321990967109 .4179000854108 .5035018921107 .8938980103106 .979598999 106.0652008057105 .4557037354104 .5412979126103 .9317016602103 .3221969604 102.4077987671101 .7982025146100 .8839035034100 .274299621699 .66472625732 98.7503814697398 .1408081054797 .5312423706196 .6168823242296 .00731658936 95.0929565429794 .4833908081193 .5690307617292 .6546783447391 .43553924561 90.5211791992289 .302040100188 .0829010009886 .5589828491285 .33984375 83.691818237381 .9871978759880 .4632720947378 .6345596313576 .80584716797 74.6723632812572 .8436431884871 .014930725169 .1862335205167 .35751342773 65.5288009643664 .61444854736 -9999 -9999 -9999 -9999 -9999 -9999 -9999 -9999 -9999 -9999 -9999 -9999 -9999 -9999 -9999 -9999 -9999 -9999 -9999 -9999 -9999 -9999 -9999 -9999 -9999 -9999 -9999 -9999 -9999 -9999 -9999 -9999 -9999 -9999 -9999 -9999 -9999 -9999 -9999 -9999 -9999 -9999 -9999 -9999 -9999 -9999 -9999 -9999 -9999

-9999 -9999 -9999 -9999 -9999 -9999 -9999 -9999 -9999 -9999 -9999 -9999 -9999 -9999 -9999 -9999 -9999 -9999 -9999 -9999 -9999 -9999 -9999 -9999 -9999 -9999 -9999 -9999 -9999 -9999 -9999 -9999 -9999 -9999 -9999 -9999 -9999 -9999 -9999 -9999 -9999 -9999 -9999 -9999 -9999 -9999 -9999 -9999 -9999 -9999 -9999 -9999 -9999 -9999 -9999 -9999 -9999 -9999 -9999 -9999

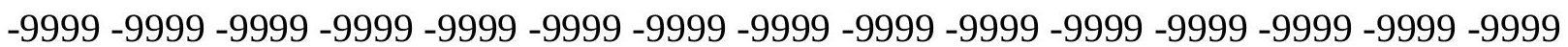
-9999 -9999 -9999 -9999 -9999 -9999 -9999 -9999 -9999 -9999 -9999 -9999 -9999 -9999 -9999 -9999 -9999 -9999 -9999 -9999 -9999 -9999 -9999 -9999 -9999 -9999 -9999 -9999 -9999 -9999 -9999 -9999 -9999 -9999 -9999 -9999 -9999 -9999 -9999 -9999 -9999 -9999 -9999 -9999 -9999

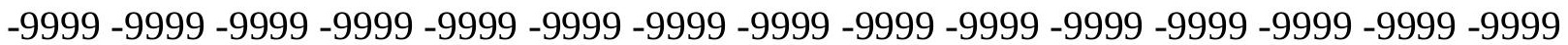


-9999 -9999 -9999 -9999 -9999 -9999 -9999 -9999 -9999 -9999 -9999 -9999 -9999 -9999 -9999 -9999 -9999 -9999 -9999 -9999 -9999 -9999 -9999 -9999 -9999 -9999 -9999 -9999 -9999 -9999 -9999 -9999 -9999 -9999 -9999 -9999 -9999 -9999 -9999 -9999 -9999 -9999 -9999 -9999 -9999 -9999 -9999 -9999 -9999 -9999 -9999 -9999 -9999 -9999 -9999 -9999 -9999 -9999 -9999 -9999 -9999 -9999 -9999 -9999 -9999 -9999 -9999 -9999 -9999 -9999 -9999 -9999 -9999 -9999 -9999 -9999 -9999 -9999 -9999 -9999 -9999 -9999 -9999 -9999 -9999 -9999 -9999 -9999 -9999 -9999 -9999 -9999 -9999 -9999 -9999 -9999 -9999 -9999 -9999 -9999 -9999 -9999 -9999 -9999 -9999 -9999 -9999-9999 145.5695495605 148.1784820557150 .4228820801152 .4598999023 153.6370849609152 .7195281982149 .0399017334144 .7729034424140 .5059967041 135.3246002197130 .1432037354124 .9618988037120 .0852966309120 .3900985718 120.6949005127121 .3044967651121 .6092987061122 .2188034058122 .5235977173 122.8283996582123 .1332015991123 .43800354123 .43800354123 .43800354123 .7427978516 123.7427978516123 .43800354123 .43800354123 .43800354123 .1332015991123 .1332015991 122.8283996582122 .8283996582122 .5235977173122 .2188034058121 .9140014648 121.9140014648121 .6092987061121 .3044967651120 .6949005127120 .3900985718 120.0852966309119 .4757995605118 .8662033081118 .5614013672117 .647102356 117.0374984741116 .4279022217115 .818397522114 .9039993286113 .9896011353 113.3800964355112 .4656982422111 .551399231110 .9418029785110 .0273971558 109.4179000854108 .5035018921107 .8938980103106 .979598999106 .3700027466 105.4557037354104 .8460998535104 .2365036011103 .3221969604102 .712600708 102.1029968262101 .1886978149100 .579101562599 .9695205688599 .35994720459 98.7503814697397 .8360290527397 .2264633178796 .6168823242295 .70252990723 95.0929565429794 .1785964965893 .2642517089892 .0450973510791 .13075256348 89.91161346436 88.69246673584 87.16854858398 85.9494018554784.32837677002 82.5967712402381 .0728530883879 .2441329956177 .4154205322375 .58670806885 73.7580032348671 .9292907714870 .1005783081168 .2718734741266 .44316101074 65.83358764648 -9999 -9999 -9999 -9999 -9999 -9999 -9999 -9999 -9999 -9999 -9999 -9999 -9999 -9999 -9999 -9999 -9999 -9999 -9999 -9999 -9999 -9999 -9999 -9999 -9999 -9999 -9999

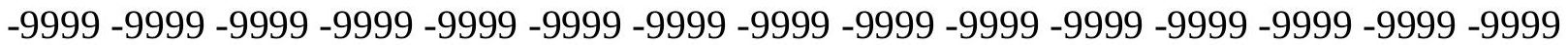
-9999 -9999 -9999 -9999 -9999 -9999 -9999 -9999 -9999 -9999 -9999 -9999 -9999 -9999 -9999 -9999 -9999 -9999 -9999 -9999 -9999 -9999

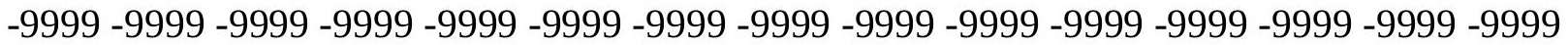
-9999 -9999 -9999 -9999 -9999 -9999 -9999 -9999 -9999 -9999 -9999 -9999 -9999 -9999 -9999 -9999 -9999 -9999 -9999 -9999 -9999 -9999 -9999 -9999 -9999 -9999 -9999 -9999 -9999 -9999 -9999 -9999 -9999 -9999 -9999 -9999 -9999 -9999 -9999 -9999 -9999 -9999 -9999 -9999 -9999 -9999 -9999 -9999 -9999 -9999 -9999 -9999 -9999 -9999 -9999 -9999 -9999 -9999 -9999 -9999

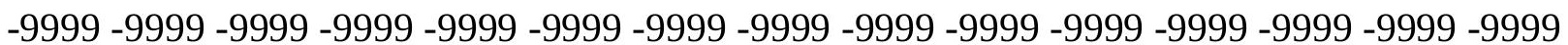

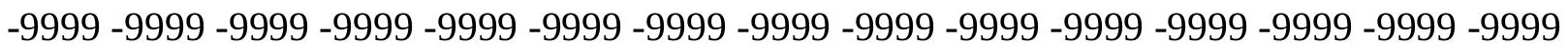
-9999 -9999 -9999 -9999 -9999 -9999 -9999 -9999 -9999 -9999 -9999 -9999 -9999 -9999 -9999 -9999 -9999 -9999 -9999 -9999 -9999 -9999 -9999 -9999 -9999 -9999 -9999 -9999 - -9999 -9999 -9999 -9999 -9999 -9999 -9999 -9999 -9999 -9999 -9999 -9999 -9999 -9999 -9999 -9999 -9999

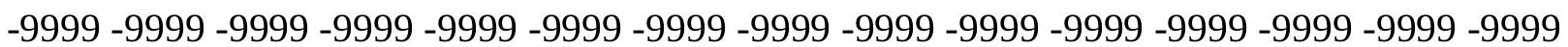
-9999 -9999 -9999 -9999 -9999 -9999 -9999 -9999 -9999 -9999 -9999 -9999 -9999 -9999 -9999 -9999 -9999 -9999 -9999 -9999 -9999 -9999 -9999 -9999 -9999 -9999 -9999 -9999 -9999 -9999 -9999 -9999 -9999 -9999 -9999 -9999 -9999 -9999 -9999 -9999 -9999 -9999 -9999 -9999 -9999

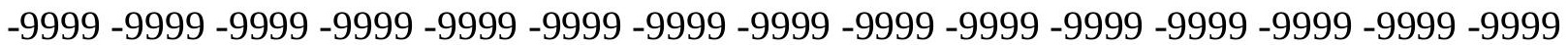


-9999 -9999 -9999-9999 150.8187713623 153.0364837646154.6134033203 155.1100311279 153.8657226562150 .8358459473146 .2969055176142 .3347015381137 .7628936768 132.5814971924127 .4001998901122 .5235977173120 .0852966309120 .3900985718 120.9997024536121 .9140014648122 .2188034058122 .8283996582123 .1332015991 123.43800354123 .43800354123 .7427978516123 .7427978516123 .7427978516 123.7427978516123 .7427978516123 .7427978516123 .43800354123 .43800354 123.1332015991123 .1332015991122 .8283996582122 .5235977173122 .5235977173 122.2188034058121 .9140014648121 .6092987061120 .9997024536120 .6949005127 120.3900985718119 .7806015015119 .1709976196118 .8662033081118 .2565994263 117.647102356116 .7326965332116 .1231002808115 .5136032104114 .5991973877 113.9896011353113 .075302124112 .1608963013111 .551399231110 .6370010376 110.0273971558109 .1130981445108 .5035018921107 .5891036987106 .979598999 106.3700027466105 .4557037354104 .8460998535104 .2365036011103 .6268997192 103.0174026489102 .4077987671101 .7982025146101 .1886978149100 .2742996216 99.6647262573299 .0551681518698 .445587158297 .8360290527397 .22646331787 96.3121032714895 .7025299072394 .7881774902393 .8738174438592 .95947265625 91.7403335571390 .5211791992289 .302040100188 .0829010009886 .55898284912 85.0350494384883 .5111236572381 .6824111938580 .1584930419978 .32978057861 76.5010681152374 .6723632812573 .1484298706171 .3197174072369 .49101257324 67.6623001098666 .74794006348 -9999 -9999 -9999 -9999 -9999 -9999 -9999 -9999 -9999 -9999 -9999 -9999 -9999 -9999 -9999 -9999 -9999 -9999 -9999 -9999 -9999 -9999 -9999 -9999 -9999 -9999 -9999 -9999 -9999 -9999 -9999 -9999 -9999 -9999 -9999 -9999 -9999 -9999 -9999 -9999 -9999 -9999 -9999 -9999 -9999 -9999 -9999 -9999 -9999

-9999 -9999 -9999 -9999 -9999 -9999 -9999 -9999 -9999 -9999 -9999 -9999 -9999 -9999 -9999 -9999 -9999 -9999 -9999 -9999 -9999 -9999 -9999 -9999 -9999 -9999 -9999 -9999 -9999 -9999 -9999 -9999 -9999 -9999 -9999 -9999 -9999 -9999 -9999 -9999 -9999 -9999 -9999 -9999 -9999 -9999 -9999 -9999 -9999 -9999 -9999 -9999 -9999 -9999 -9999 -9999 -9999 -9999 -9999 -9999

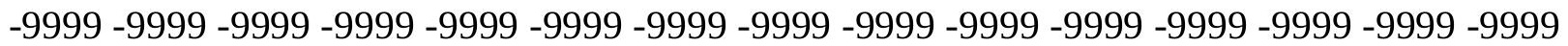

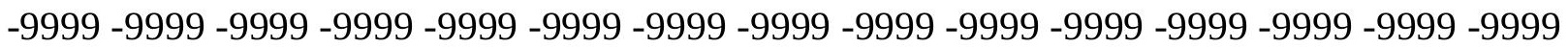
-9999 -9999 -9999 -9999 -9999 -9999 -9999 -9999 -9999 -9999 -9999 -9999 -9999 -9999 -9999 -9999 -9999 -9999 -9999 -9999 -9999 -9999 -9999 -9999 -9999 -9999 -9999 -9999 -9999 -9999 -

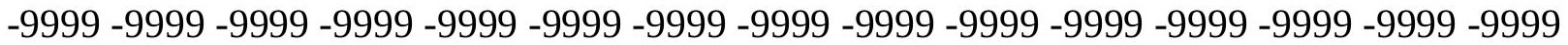

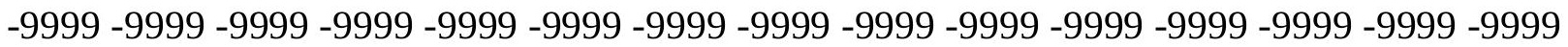
-9999 -9999 -9999 -9999 -9999 -9999 -9999 -9999 -9999 -9999 -9999 -9999 -9999 -9999 -9999 -

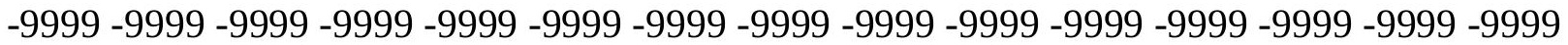
-9999 -9999 -9999 -9999 -9999 -9999 -9999 -9999 -9999 -9999 -9999 -9999 -9999 -9999 -9999

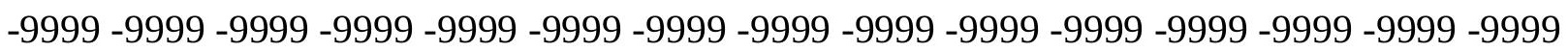

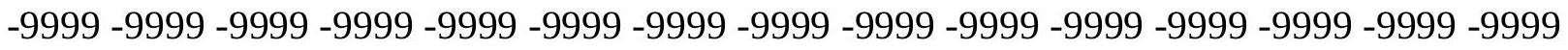
-9999 -9999 -9999 -9999 -9999 -9999 -9999 -9999 -9999 -9999 -9999 -9999 -9999 -9999 -9999 -9999 -9999 -9999 -9999 152.1250152588 154.1861114502155 .4741210938155 .7430114746 154.6820678711152 .2168579102148 .4304046631143 .5538024902138 .9819946289 134.1054992676 129.2288970947 124.3523025513120.9997024536120.3900985718 121.3044967651121 .9140014648122 .5235977173123 .1332015991123 .43800354 123.7427978516123 .7427978516124 .0475006104124 .0475006104124 .0475006104 124.0475006104124 .0475006104124 .0475006104123 .7427978516123 .7427978516 123.43800354123 .1332015991123 .1332015991122 .8283996582122 .5235977173 
122.2188034058121 .9140014648121 .3044967651120 .9997024536120 .6949005127 120.0852966309119 .7806015015119 .1709976196118 .5614013672117 .9517974854 117.342300415116 .4279022217115 .818397522115 .2088012695114 .2944030762 113.6848983765112 .7705001831111 .8561019897111 .24659729110 .3321990967 109.7226028442109 .1130981445108 .1986999512107 .5891036987106 .979598999 106.3700027466105 .7603988647105 .1509017944104 .5412979126103 .9317016602 103.3221969604102 .712600708102 .1029968262101 .4934005737100 .8839035034 100.274299621699 .6647262573299 .0551681518698 .445587158297 .83602905273 97.2264633178796 .3121032714895 .397743225194 .4833908081193 .56903076172 92.6546783447391 .4355392456189 .9116134643688 .6924667358487 .16854858398 85.6446228027384 .1206970214882 .5967712402380 .7680587768679 .24413299561 77.4154205322375 .8914871215874 .062782287672 .2340774536170 .71015167236 68.8814392089867 .96708679199 -9999 -9999 -9999 -9999 -9999 -9999 -9999 -9999 -9999 -9999 -9999 -9999 -9999 -9999 -9999 -9999 -9999 -9999 -9999 -9999 -9999 -9999 -9999 -9999 -9999 -9999 -9999 -9999 -9999 -9999 -9999 -9999 -9999 -9999 -9999 -9999 -9999 -9999 -9999 -9999 -9999 -9999-9999-9999-9999-9999 -9999 -9999-9999

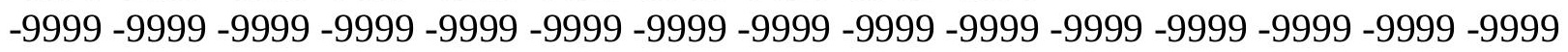
-9999 -9999 -9999 -9999 -9999 -9999 -9999 -9999 -9999 -9999 -9999 -9999 -9999 -9999 -9999 -

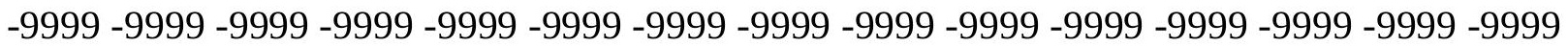

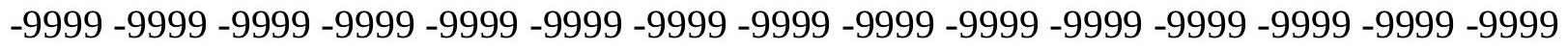

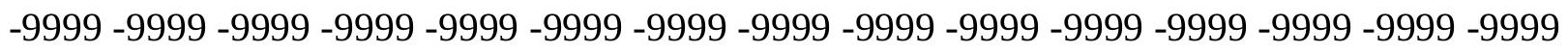

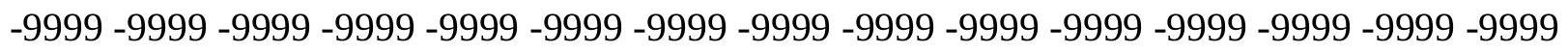
-9999 -9999 -9999 -9999 -9999 -9999 -9999 -9999 -9999 -9999 -9999 -9999 -9999 -9999 -9999 -

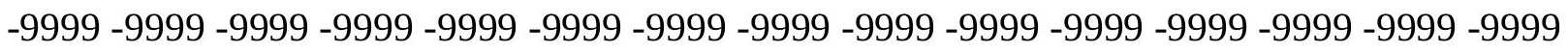

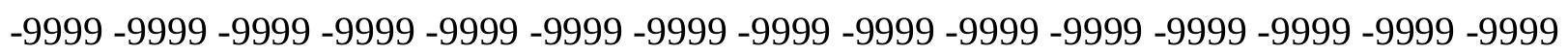
-9999 -9999 -9999 -9999 -9999 -9999 -9999 -9999 -9999 -9999 -9999 -9999 -9999 -9999 -9999 -9999 -9999 -9999 -9999 -9999 -9999 -9999 -9999 -9999 -9999 -9999 -9999 -9999 -9999 - -9999 -

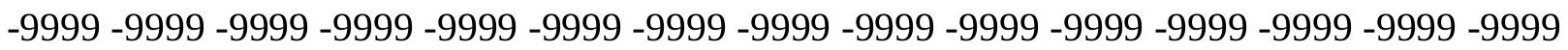

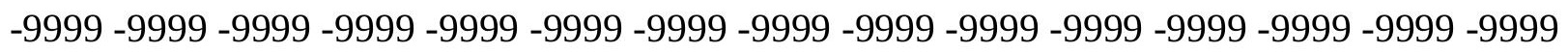

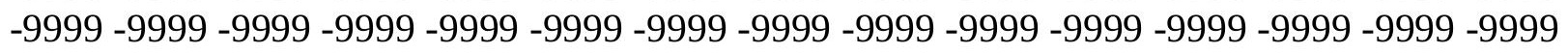
-9999 -9999 -9999 -9999 -9999 -9999 -9999 -9999 -9999 -9999 -9999 -9999 -9999 -9999 -9999

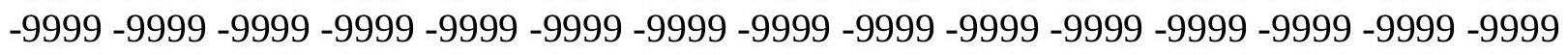
-9999 -9999-9999 -9999-9999 154.2893829346155.4113616943155.7160491943 155.0269927979153 .1484680176149 .9542999268143 .8585968018139 .5915985107 135.0198059082130 .1432037354125 .5715026855122 .5235977173121 .3044967651 121.9140014648122 .5235977173122 .8283996582123 .43800354123 .7427978516 123.7427978516124 .0475006104124 .0475006104124 .3523025513124 .3523025513 124.3523025513124 .3523025513124 .0475006104124 .0475006104123 .7427978516 123.7427978516123 .43800354123 .1332015991122 .8283996582122 .5235977173 122.2188034058121 .9140014648121 .3044967651120 .9997024536120 .3900985718 120.0852966309119 .4757995605118 .8662033081118 .2565994263117 .647102356 117.0374984741116 .1231002808115 .5136032104114 .9039993286113 .9896011353 113.3800964355112 .4656982422111 .8561019897110 .9418029785110 .3321990967 109.4179000854108 .8082962036108 .1986999512107 .5891036987106 .979598999 106.3700027466 105.7603988647105.1509017944104.5412979126103.9317016602 103.3221969604103 .0174026489102 .4077987671101 .7982025146101 .1886978149 
100.8839035034100 .274299621699 .6647262573299 .0551681518698 .4455871582 97.8360290527397 .2264633178796 .3121032714895 .397743225194 .48339080811 93.2642517089892 .0450973510790 .8259735107489 .6068267822388 .08290100098 86.5589828491285 .0350494384883 .5111236572381 .6824111938580 .15849304199 78.3297805786176 .8058471679774 .9771423339873 .4532165527371 .62449645996 70.1005783081169 .18623352051 -9999 -9999 -9999 -9999 -9999 -9999 -9999 -9999 -9999 -9999 -9999 -9999 -9999 -9999 -9999 -9999 -9999 -9999 -9999 -9999 -9999 -9999 -9999 -9999

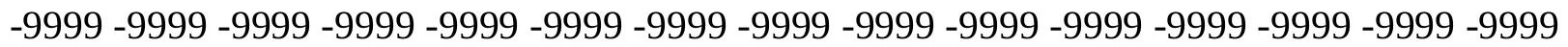
-9999 -9999 -9999 -9999 -9999 -9999 -9999 -9999 -9999 -9999

-9999 -9999 -9999 -9999 -9999 -9999 -9999 -9999 -9999 -9999 -9999 -9999 -9999 -9999 -9999 -9999 -9999 -9999 -9999 -9999 -9999 -9999 -9999 -9999 -9999 -9999 -9999 -9999 -9999 -9999 -9999 -9999 -9999 -9999 -9999 -9999 -9999 -9999 -9999 -9999 -9999 -9999 -9999 -9999 -9999 -999 -9999 -9999 -9999 -9999 -9999 -9999 -9999 -9999 -9999 -9999 -9999 -9999 -9999 -9999 -9999 -9999 -9999 -9999 -9999 -9999 -9999 -9999 -9999 -9999 -9999 -9999 -9999 -9999 -9999 -9999 -9999 -9999 -9999 -9999 -9999 -9999 -9999 -9999 -9999 -9999 -9999 -9999 -9999 -9999 -9999

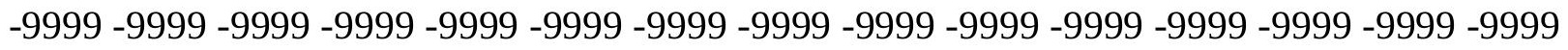
-9999 -9999 -9999 -9999 -9999 -9999 -9999 -9999 -9999 -9999 -9999 -9999 -9999 -9999 -9999 -9999 -9999 -9999 -9999 -9999 -9999 -9999 -9999 -9999 -9999 -9999 -9999 -9999 -9999 -9999 -9999 -9999 -9999 -9999 -9999 -9999 -9999 -9999 -9999 -9999 -9999 -9999 -9999 -9999 -9999 -

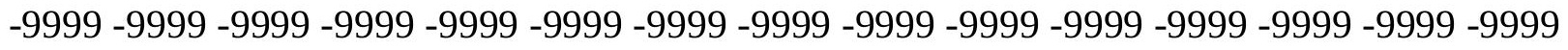

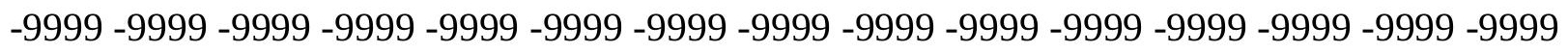
-9999 -9999 -9999 -9999 -9999 -9999 -9999 -9999 -9999 -9999 -9999 -9999 -9999 -9999 -9999 -9999 -9999 -9999 -9999 -9999 -9999 -9999 -9999 -9999 -9999 -9999 -9999 -9999 -9999 -9999 -

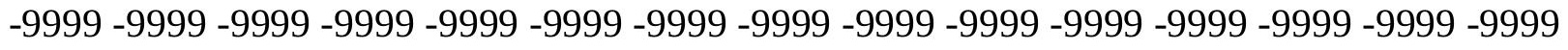

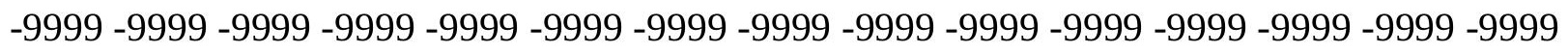
-9999 -9999-9999 -9999-9999-9999 154.5440216064 155.0175323486154.7579803467 153.275680542149 .952911377144 .7729034424139 .2868041992135 .0198059082 130.4479980469126 .1809997559121 .9140014648122 .2188034058122 .5235977173 123.1332015991123 .43800354123 .7427978516124 .0475006104124 .0475006104 124.3523025513124 .3523025513124 .3523025513124 .6570968628124 .3523025513 124.3523025513124 .3523025513124 .0475006104124 .0475006104123 .7427978516 123.43800354123 .1332015991122 .8283996582122 .5235977173122 .2188034058 121.9140014648121 .3044967651120 .9997024536120 .3900985718119 .7806015015 119.1709976196118 .5614013672117 .9517974854117 .342300415116 .7326965332 115.818397522115 .2088012695114 .5991973877113 .6848983765113 .075302124 112.1608963013111 .551399231110 .6370010376110 .0273971558109 .4179000854 108.8082962036108 .1986999512107 .5891036987106 .979598999106 .3700027466 105.7603988647105 .1509017944104 .8460998535104 .2365036011103 .6268997192 103.3221969604102 .712600708102 .1029968262101 .7982025146101 .1886978149 100.8839035034100 .274299621699 .9695205688599 .3599472045998 .75038146973 97.83602905273 97.2264633178796.3121032714895.397743225194.17859649658 92.9594726562591 .7403335571390 .2164001464888 .9972534179787 .46168518066 85.9494018554784 .1206970214882 .5967712402381 .0728530883879 .54891967773 77.7202072143676 .1962814331174 .3675689697372 .8436431884871 .31971740723 70.40535736084 -9999 -9999 -9999 -9999 -9999 -9999 -9999 -9999 -9999 -9999 -9999 -9999 -9999 -9999 -9999 -9999 -9999 -9999 -9999 -9999 -9999 -9999 -9999 -9999 -9999 -9999 -9999 
-9999 -9999 -9999 -9999 -9999 -9999 -9999 -9999 -9999 -9999 -9999 -9999 -9999 -9999 -9999 -9999 -9999 -9999 -9999-9999-9999-9999

-9999 -9999 -9999 -9999 -9999 -9999 -9999 -9999 -9999 -9999 -9999 -9999 -9999 -9999 -9999 -9999 -9999 -9999 -9999 -9999 -9999 -9999 -9999 -9999 -9999 -9999 -9999 -9999 -9999 -9999 -9999 -9999 -9999 -9999 -9999 -9999 -9999 -9999 -9999 -9999 -9999 -9999-9999 -9999 -9999 -9999 -9999 -9999 -9999 -9999 -9999 -9999 -9999 -9999 -9999 -9999 -9999 -9999 -9999 -9999

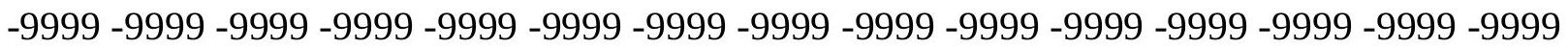
-9999 -9999 -9999 -9999 -9999 -9999 -9999 -9999 -9999 -9999 -9999 -9999 -9999 -9999 -9999 -999 -

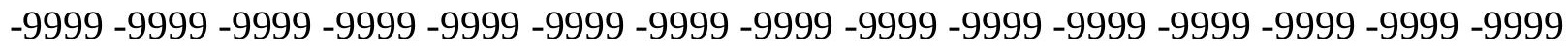
-9999 -9999 -9999 -9999 -9999 -9999 -9999 -9999 -9999 -9999 -9999 -9999 -9999 -9999 -9999 -

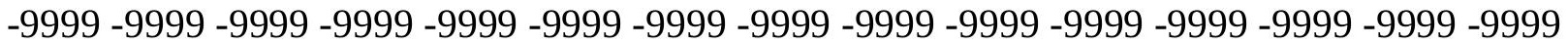
-9999 -9999 -9999 -9999 -9999 -9999 -9999 -9999 -9999 -9999 -9999 -9999 -9999 -9999 -9999 -9999 -9999 -9999 -9999 -9999 -9999 -9999 -9999 -9999 -9999 -9999 -9999 -9999 -9999 -9999 -9999 -9999 -9999 -9999 -9999 -9999 -9999 -9999 -9999 -9999 -9999 -9999 -9999 -9999 -9999 -9999 -9999 -9999 -9999 -9999 -9999 -9999 -9999 -9999 -9999 -9999 -9999 -9999 -9999 -9999

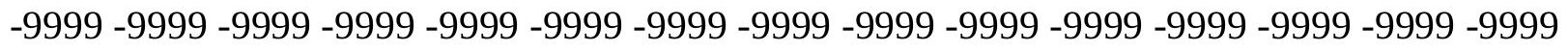
-9999 -9999 -9999 -9999 -9999 -9999 -9999 -9999 -9999 -9999 -9999 -9999 -9999 -9999 -9999 -9999 -9999 -9999 -9999 -9999 -9999 -9999 -9999 -9999 -9999 -9999 -9999 -9999 -9999 -9999 -9999 -9999 -9999 -9999 -9999 -9999 152.9009857178153 .6274871826153 .8298492432 152.9343109131150 .2077178955145 .3825073242138 .6772003174134 .4102020264 130.1432037354126 .1809997559122 .5235977173122 .8283996582123 .1332015991 123.43800354123 .7427978516124 .0475006104124 .3523025513124 .3523025513 124.6570968628124 .6570968628124 .6570968628124 .6570968628124 .6570968628 124.6570968628124 .6570968628124 .3523025513124 .0475006104124 .0475006104 123.7427978516123 .43800354123 .1332015991122 .5235977173122 .2188034058 121.6092987061121 .3044967651120 .6949005127120 .3900985718119 .7806015015 119.1709976196118 .5614013672117 .647102356117 .0374984741116 .4279022217 115.5136032104114 .9039993286114 .2944030762113 .3800964355112 .7705001831 111.8561019897111 .24659729110 .3321990967109 .7226028442109 .1130981445 108.5035018921 107.8938980103 107.2844009399 106.979598999 106.3700027466 105.7603988647105 .4557037354104 .8460998535104 .5412979126103 .9317016602 103.6268997192103 .0174026489102 .712600708102 .1029968262101 .7982025146 101.4934005737100 .8839035034100 .579101562599 .9695205688599 .35994720459 98.7503814697398 .1408081054797 .2264633178796 .3121032714895 .09295654297 93.8738174438592 .6546783447391 .1307525634889 .6068267822388 .08290100098 86.5589828491285 .0350494384883 .5111236572381 .9871978759880 .46327209473 78.6345596313577 .110626220775 .5867080688574 .062782287672 .23407745361 71.31971740723 -9999 -9999 -9999 -9999 -9999 -9999 -9999 -9999 -9999 -9999 -9999 -9999 -9999 -9999 -9999 -9999 -9999 -9999 -9999 -9999 -9999 -9999 -9999 -9999 -9999 -9999 -9999 -

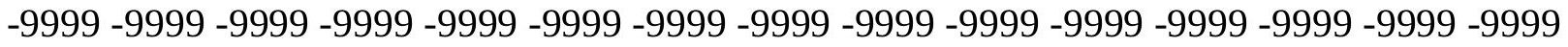
-9999 -9999 -9999 -9999-9999-9999-9999

-9999 -9999 -9999 -9999 -9999 -9999 -9999 -9999 -9999 -9999 -9999 -9999 -9999 -9999 -9999 -9999 -9999 -9999 -9999 -9999 -9999 -9999 -9999 -9999 -9999 -9999 -9999 -9999 -9999 -9999 -9999 -9999 -9999 -9999 -9999 -9999 -9999 -9999 -9999 -9999 -9999 -9999 -9999 -9999 -9999 -

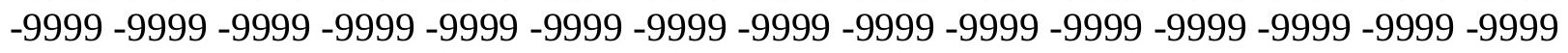

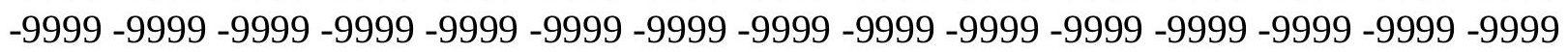


-9999 -9999 -9999 -9999 -9999 -9999 -9999 -9999 -9999 -9999 -9999 -9999 -9999 -9999 -9999 -9999 -9999 -9999 -9999 -9999 -9999 -9999 -9999 -9999 -9999 -9999 -9999 -9999 -9999 -9999 -9999 -9999 -9999 -9999 -9999 -9999 -9999 -9999 -9999 -9999 -9999 -9999 -9999 -9999 -9999 -9999 -9999 -9999 -9999 -9999 -9999 -9999 -9999 -9999 -9999 -9999 -9999 -9999 -9999 -9999 -9999 -9999 -9999 -9999 -9999 -9999 -9999 -9999 -9999 -9999 -9999 -9999 -9999 -9999 -9999 -9999 -9999 -9999 -9999 -9999 -9999 -9999 -9999 -9999 -9999 -9999 -9999 -9999 -9999 -9999 -9999 -9999 -9999 -9999 -9999 -9999 -9999 -9999 -9999 -9999 -9999 -9999 -9999 -9999 -9999

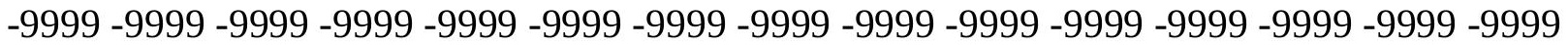
-9999 -9999 -9999 -9999 -9999 -9999 -9999 -9999 -9999 -9999 -9999 -9999 -9999 -9999 -9999 -9999 -9999 -9999 -9999 -9999 -9999 -9999 -9999 -9999 -9999 -9999 -9999 -9999 -9999 -9999 -9999 -9999 -9999 -9999 -9999 -9999 -9999 -9999 -9999 -9999 -9999 -9999 -9999 -9999 -9999 -999 -9999 -9999 -9999 -9999-9999-9999-9999 151.7328491211 152.2579193115151 .9183654785 150.2590942383145 .0776977539138 .3724975586133 .4958953857129 .8385009766 126.1809997559122 .5235977173123 .1332015991123 .43800354123 .7427978516 124.0475006104124 .3523025513124 .3523025513124 .6570968628124 .9618988037 124.9618988037124 .9618988037124 .9618988037124 .9618988037124 .9618988037 124.6570968628124 .6570968628124 .3523025513124 .0475006104123 .7427978516 123.43800354123 .1332015991122 .5235977173122 .2188034058121 .6092987061 121.3044967651120 .6949005127120 .0852966309119 .4757995605118 .8662033081 118.2565994263117 .647102356116 .7326965332116 .1231002808115 .2088012695 114.5991973877113 .6848983765113 .075302124112 .4656982422111 .551399231 110.9418029785110 .0273971558109 .4179000854108 .8082962036108 .1986999512 107.8938980103107 .2844009399106 .6747970581106 .3700027466105 .7603988647 105.4557037354105 .1509017944104 .5412979126104 .2365036011103 .9317016602 103.3221969604103 .0174026489102 .712600708102 .4077987671101 .7982025146 101.4934005737101 .1886978149100 .8839035034100 .274299621699 .66472625732 99.0551681518698 .1408081054797 .2264633178796 .0073165893694 .7425994873 93.3650283813591 .9587631225690 .5127792358488 .9972534179787 .47332763672 85.9494018554784 .4254837036182 .9015579223681 .3776321411179 .85370635986 78.0249862670976 .5010681152374 .9771423339873 .4532165527372 .53885650635 -9999 -9999 -9999 -9999 -9999 -9999 -9999 -9999 -9999 -9999 -9999 -9999 -9999 -9999 -9999 -9999 -9999 -9999 -9999 -9999 -9999 -9999 -9999 -9999 -9999 -9999 -9999 -9999 -9999 -9999 -9999 -9999 -9999 -9999 -9999 -9999 -9999 -9999 -9999 -9999 -9999 -9999 -9999 -9999 -9999 -9999 -9999-9999-9999

-9999 -9999 -9999 -9999 -9999 -9999 -9999 -9999 -9999 -9999 -9999 -9999 -9999 -9999 -9999 -9999 -9999 -9999 -9999 -9999 -9999 -9999 -9999 -9999 -9999 -9999 -9999 -9999 -9999 -9999 -9999 -9999 -9999 -9999 -9999 -9999 -9999 -9999 -9999 -9999 -9999 -9999 -9999 -9999 -9999

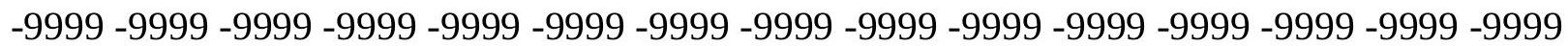
-9999 -9999 -9999 -9999 -9999 -9999 -9999 -9999 -9999 -9999 -9999 -9999 -9999 -9999 -9999 -9999 -9999 -9999 -9999 -9999 -9999 -9999 -9999 -9999 -9999 -9999 -9999 -9999 -9999 -9999 -

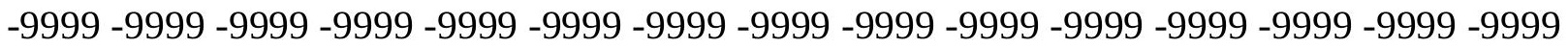
-9999 -9999 -9999 -9999 -9999 -9999 -9999 -9999 -9999 -9999 -9999 -9999 -9999 -9999 -9999 -9999 -9999 -9999 -9999 -9999 -9999 -9999 -9999 -9999 -9999 -9999 -9999 -9999 -9999 -9999 -9999 -9999 -9999 -9999 -9999 -9999 -9999 -9999 -9999 -9999 -9999 -9999 -9999 -9999 -9999 -999 -9999 -9999 -9999 -9999 -9999 -9999 -9999 -9999 -9999 -9999 -9999 -9999 -9999 -9999 -9999

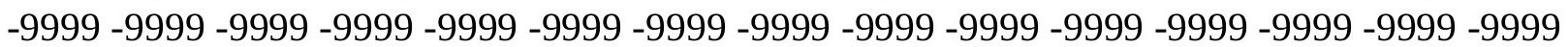


-9999 -9999 -9999 -9999 -9999 -9999 -9999 -9999 -9999 -9999 -9999 -9999 -9999 -9999 -9999 -9999 -9999 -9999 -9999 -9999 -9999 -9999 -9999 -9999 -9999 -9999 -9999 -9999 -9999 -9999

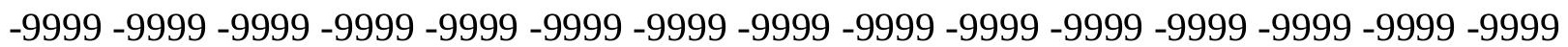
-9999 -9999 -9999 -9999 -9999 -9999 -9999 -9999 -9999 -9999 -9999 -9999 -9999 -9999 -9999 -9999 -9999 -9999 -9999 -9999 -9999-9999 149.7038116455 150.2722320557 149.7831420898 147.8208007812143 .2489929199137 .4580993652132 .2767028809129 .2288970947 125.5715026855122 .5235977173123 .1332015991123 .7427978516124 .0475006104 124.3523025513124 .3523025513124 .6570968628124 .9618988037124 .9618988037 125.2667007446125 .2667007446125 .2667007446125 .2667007446124 .9618988037 124.9618988037124 .6570968628124 .3523025513124 .3523025513123 .7427978516 123.43800354123 .1332015991122 .8283996582122 .2188034058121 .6092987061 121.3044967651120 .6949005127120 .0852966309119 .4757995605118 .5614013672 117.9517974854117 .342300415116 .4279022217115 .818397522114 .9039993286 114.2944030762113 .3800964355112 .7705001831111 .8561019897111 .24659729 110.6370010376110 .0273971558109 .1130981445108 .8082962036108 .1986999512 107.5891036987107 .2844009399106 .6747970581106 .3700027466105 .7603988647 105.4557037354105 .1509017944104 .8460998535104 .5412979126104 .2365036011 103.6268997192103 .3221969604103 .0174026489102 .712600708102 .4077987671 102.1029968262101 .7982025146101 .4934005737101 .1886978149100 .5791015625 99.9695205688599 .0551681518697 .9081268310596 .6275711059695 .32633972168 94.0022888183692 .6516952514691 .2713623046989 .8555908203188 .38768768311 86.8637619018685 .3398437583 .8159103393682 .2919769287180 .76805877686 $79.2441329956177 .7202072143675 .8914871215874 .3675689697373 .45321655273-9999$ -9999 -9999 -9999 -9999 -9999 -9999 -9999 -9999 -9999 -9999 -9999 -9999 -9999 -9999 -9999 -9999 -9999 -9999 -9999 -9999 -9999 -9999 -9999 -9999 -9999 -9999 -9999 -9999 -9999 -9999 -9999 -9999 -9999 -9999 -9999 -9999 -9999 -9999 -9999 -9999 -9999 -9999 -9999 -9999 -9999 $-9999-9999-9999$

-9999 -9999 -9999 -9999 -9999 -9999 -9999 -9999 -9999 -9999 -9999 -9999 -9999 -9999 -9999 -9999 -9999 -9999 -9999 -9999 -9999 -9999 -9999 -9999 -9999 -9999 -9999 -9999 -9999 -9999 -9999 -9999 -9999 -9999 -9999 -9999 -9999 -9999 -9999 -9999 -9999 -9999 -9999 -9999 -9999 -9999 -9999 -9999 -9999 -9999 -9999 -9999 -9999 -9999 -9999 -9999 -9999 -9999 -9999 -9999 -9999 -9999 -9999 -9999 -9999 -9999 -9999 -9999 -9999 -9999 -9999 -9999 -9999 -9999 -9999 -9999 -9999 -9999 -9999 -9999 -9999 -9999 -9999 -9999 -9999 -9999 -9999 -9999 -9999 -9999 -9999 -9999 -9999 -9999 -9999 -9999 -9999 -9999 -9999 -9999 -9999 -9999 -9999 -9999 -9999

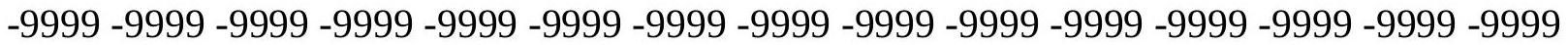
-9999 -9999 -9999 -9999 -9999 -9999 -9999 -9999 -9999 -9999 -9999 -9999 -9999 -9999 -9999 -9999 -9999 -9999 -9999 -9999 -9999 -9999 -9999 -9999 -9999 -9999 -9999 -9999 -9999 -9999

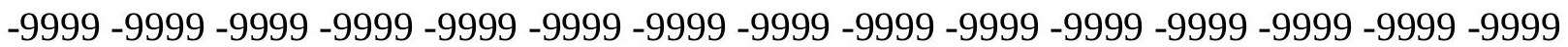
-9999 -9999 -9999 -9999 -9999 -9999 -9999 -9999 -9999 -9999 -9999 -9999 -9999 -9999 -9999 -9999 -9999 -9999 -9999 -9999 -9999 -9999 -9999 -9999 -9999 -9999 -9999 -9999 - -9999 -9999 -9999 -9999 -9999 -9999 -9999 -9999 -9999 -9999 -9999 -9999 -9999 -9999 -9999 -9999 -9999

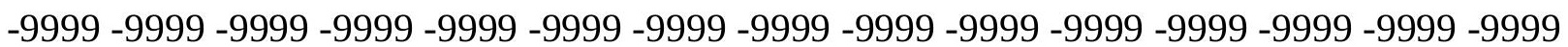
-9999 -9999 -9999 -9999 -9999 -9999 -9999 -9999 -9999 -9999 -9999 -9999 -9999 -9999 -9999 -9999 -9999 -9999 -9999 -9999 -9999 -9999 -9999 148.1255950928146 .9064025879 144.7729034424141 .1154937744136 .2389984131131 .6672058105128 .6192932129 125.2667007446122 .5235977173123 .1332015991123 .43800354124 .0475006104 
124.3523025513124 .6570968628124 .9618988037125 .2667007446125 .2667007446 125.5715026855125 .5715026855125 .5715026855125 .5715026855125 .2667007446 125.2667007446124 .9618988037124 .6570968628124 .3523025513124 .0475006104 123.7427978516123 .1332015991122 .8283996582122 .2188034058121 .6092987061 120.9997024536120 .3900985718119 .7806015015119 .1709976196118 .5614013672 117.647102356117 .0374984741116 .4279022217115 .5136032104114 .5991973877 113.9896011353113 .075302124112 .4656982422111 .551399231110 .9418029785 110.3321990967109 .7226028442109 .1130981445108 .5035018921107 .8938980103 107.5891036987106 .979598999106 .6747970581106 .3700027466105 .7603988647 105.4557037354105 .1509017944104 .8460998535104 .5412979126104 .2365036011 103.9317016602103 .6268997192103 .6268997192103 .3221969604103 .0174026489 102.712600708102 .4077987671102 .1029968262101 .7982025146101 .4934005737 100.783470153899 .5913009643698 .3792495727597 .1470108032295 .8941116333 94.6190490722793 .3188018798891 .9910049438590 .6434783935589 .3020401001 87.7781066894586 .254188537684 .7302627563583 .206336975181 .68241119385 $80.1584930419978 .6345596313577 .110626220775 .2819290161174 .36756896973-9999$ -9999 -9999 -9999 -9999 -9999 -9999 -9999 -9999 -9999 -9999 -9999 -9999 -9999 -9999 -9999 -9999 -9999 -9999 -9999 -9999 -9999 -9999 -9999 -9999 -9999 -9999 -9999 -9999 -9999 -9999 -

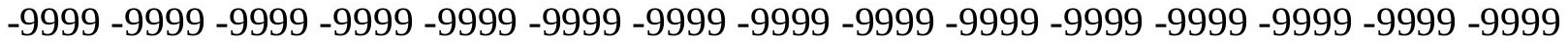
-9999 -9999-9999

-9999 -9999 -9999 -9999 -9999 -9999 -9999 -9999 -9999 -9999 -9999 -9999 -9999 -9999 -9999 -9999 -9999 -9999 -9999 -9999 -9999 -9999 -9999 -9999 -9999 -9999 -9999 -9999 -9999 -9999 -9999 -9999 -9999 -9999 -9999 -9999 -9999 -9999 -9999 -9999 -9999 -9999 -9999 -9999 -9999 -9999 -9999 -9999 -9999 -9999 -9999 -9999 -9999 -9999 -9999 -9999 -9999 -9999 -9999 -9999 -9999 -9999 -9999 -9999 -9999 -9999 -9999 -9999 -9999 -9999 -9999 -9999 -9999 -9999 -9999 -9999 -9999 -9999 -9999 -9999 -9999 -9999 -9999 -9999 -9999 -9999 -9999 -9999 -9999 -9999 -9999 -9999 -9999 -9999 -9999 -9999 -9999 -9999 -9999 -9999 -9999 -9999 -9999 -9999 -9999 -

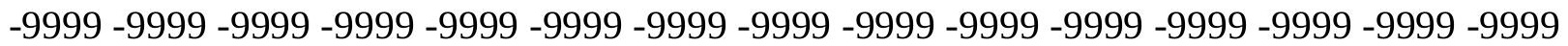
-9999 -9999 -9999 -9999 -9999 -9999 -9999 -9999 -9999 -9999 -9999 -9999 -9999 -9999 -9999 -9999 -9999 -9999 -9999 -9999 -9999 -9999 -9999 -9999 -9999 -9999 -9999 -9999 -9999 -999 -9999 -9999 -9999 -9999 -9999 -9999 -9999 -9999 -9999 -9999 -9999 -9999 -9999 -9999 -9999 -9999 -9999 -9999 -9999 -9999 -9999 -9999 -9999 -9999 -9999 -9999 -9999 -9999 -9999 -9999

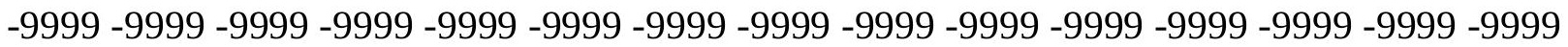

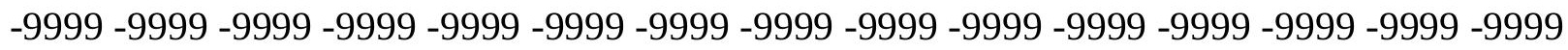
-9999 -9999 -9999 -9999 -9999 -9999 -9999 -9999 -9999 -9999 -9999 -9999 -9999 -9999 -9999 -9999 -9999 -9999 -9999 -9999 -9999 -9999 -9999 -9999 -9999 -9999 -9999 -9999 -9999 - 9999 -9999 -9999 -9999 -9999-9999 -9999 -9999 -9999 145.9920959473144 .4682006836 142.3347015381138 .9819946289135 .0198059082131 .0576019287127 .7050018311 124.6570968628121 .9140014648122 .8283996582123 .43800354124 .0475006104 124.6570968628124 .9618988037125 .2667007446125 .5715026855125 .5715026855 125.8762969971125 .8762969971125 .8762969971125 .5715026855125 .5715026855 125.2667007446125 .2667007446124 .9618988037124 .6570968628124 .0475006104 123.7427978516123 .1332015991122 .8283996582122 .2188034058121 .6092987061 120.9997024536120 .3900985718119 .7806015015119 .1709976196118 .2565994263 117.647102356116 .7326965332116 .1231002808115 .2088012695114 .2944030762 113.6848983765112 .7705001831112 .1608963013111 .24659729110 .6370010376 
110.0273971558109 .4179000854108 .8082962036108 .1986999512107 .8938980103 107.2844009399 106.979598999106.6747970581 106.3700027466106.0652008057 105.7603988647105 .4557037354105 .1509017944104 .8460998535104 .5412979126 104.5412979126104 .2365036011103 .9317016602103 .6268997192103 .3221969604 103.0174026489102 .712600708102 .4077987671102 .4077987671102 .2843399048 101.1547088623100 .006095886298 .8381423950297 .6497497558696 .43966674805 95.2058868408293 .9462585449292 .6606063842891 .3356475830189 .91161346436 88.38768768311 86.86376190186 85.33984375 84.12069702148 82.59677124023 81.0728530883879 .5489196777378 .0249862670976 .1962814331175 .58670806885 -9999 -9999 -9999 -9999 -9999 -9999 -9999 -9999 -9999 -9999 -9999 -9999 -9999 -9999 -9999 -9999 -9999 -9999 -9999 -9999 -9999 -9999 -9999 -9999 -9999 -9999 -9999 -9999 -9999 -9999 -9999 -999 -

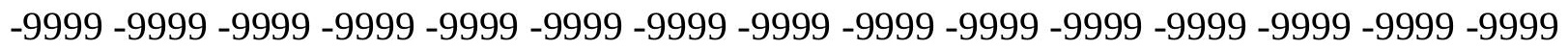
-9999 -9999-9999

-9999 -9999 -9999 -9999 -9999 -9999 -9999 -9999 -9999 -9999 -9999 -9999 -9999 -9999 -9999 -9999 -9999 -9999 -9999 -9999 -9999 -9999 -9999 -9999 -9999 -9999 -9999 -9999 -9999 -9999

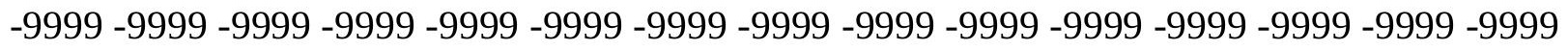
-9999 -9999 -9999 -9999 -9999 -9999 -9999 -9999 -9999 -9999 -9999 -9999 -9999 -9999 -9999 -

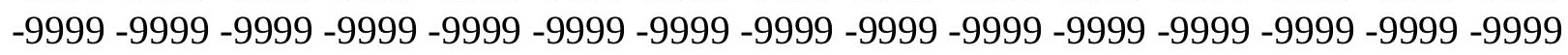

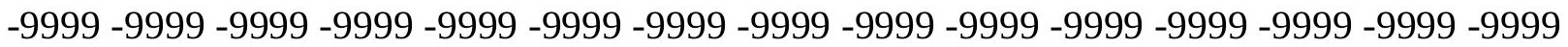

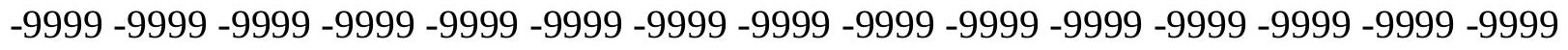

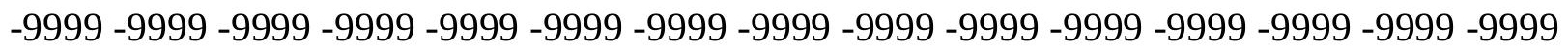

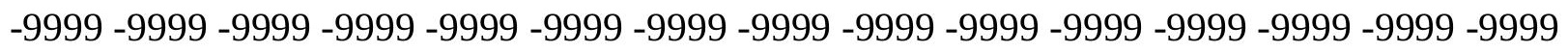
-9999 -9999 -9999 -9999 -9999 -9999 -9999 -9999 -9999 -9999 -9999 -9999 -9999 -9999 -9999 -

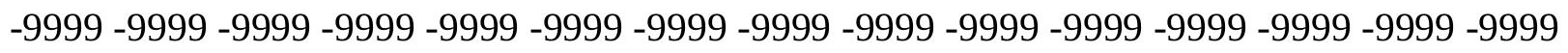

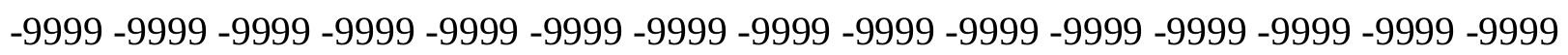
-9999 -9999 -9999 -9999 -9999 -9999 -9999 -9999 -9999 -9999 -9999 -9999 -9999 -9999 -9999

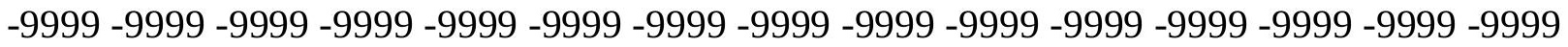

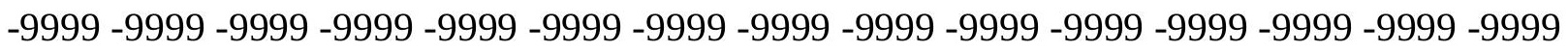

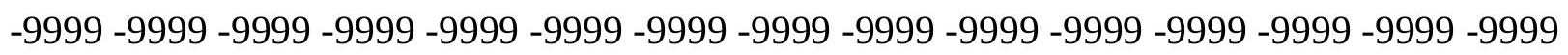
-9999 -9999-9999 -9999 -9999 -9999-9999-9999 -9999 142.6394042969 140.5059967041 137.4580993652133 .8007049561129 .8385009766126 .7906036377124 .0475006104 121.3044967651122 .5235977173123 .43800354124 .0475006104124 .6570968628 125.2667007446125 .5715026855125 .8762969971125 .8762969971126 .1809997559 126.1809997559126 .1809997559125 .8762969971125 .8762969971125 .5715026855 125.2667007446124 .9618988037124 .6570968628124 .3523025513123 .7427978516 123.43800354122 .8283996582122 .2188034058121 .6092987061120 .9997024536 120.3900985718119 .7806015015118 .8662033081118 .2565994263117 .342300415 116.4279022217115 .818397522114 .9039993286113 .9896011353113 .3800964355 112.4656982422111 .8561019897110 .9418029785110 .3321990967109 .7226028442 109.1130981445108 .5035018921107 .8938980103107 .5891036987107 .2844009399 106.6747970581106 .3700027466106 .0652008057105 .7603988647105 .7603988647 105.4557037354105 .1509017944105 .1509017944104 .8460998535104 .5412979126 104.5412979126104 .2365036011103 .9317016602103 .6268997192103 .3221969604 102.712600708102 .712600708102 .712600708102 .6056289673101 .5155715942 100.407196044999 .2794647216898 .1305007934696 .9580383300895 .75891113281 94.5298461914193 .2686614990291 .9711456298890 .5211791992289 .3020401001 
87.7781066894586 .254188537684 .7302627563583 .206336975181 .68241119385 80.1584930419978 .6345596313577 .110626220776 .50106811523 -9999 -9999 -9999 -9999 -9999 -9999 -9999 -9999 -9999 -9999 -9999 -9999 -9999 -9999 -9999 -9999 -9999 -9999 -9999 -9999 -9999 -9999 -9999 -9999 -9999 -9999 -9999 -9999 -9999 -9999 -9999 -9999 -9999 -9999 -9999 -9999 -9999 -9999 -9999 -9999 -9999 -9999 -9999 -9999 -9999 -9999-9999 -9999 -9999 -9999 -9999 -9999 -9999 -9999 -9999 -9999 -9999 -9999 -9999 -9999 -9999 -9999 -9999 -9999 -9999 -9999 -9999 -9999 -9999 -9999 -9999 -9999 -9999 -9999 -9999 -9999 -9999 -9999 -9999

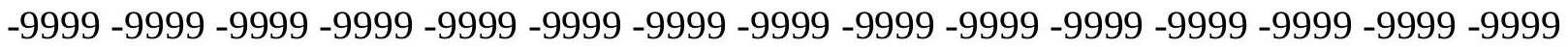

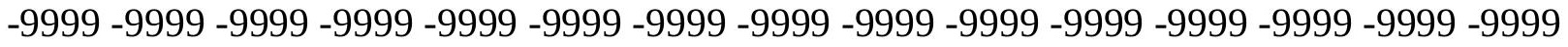
-9999 -9999 -9999 -9999 -9999 -9999 -9999 -9999 -9999 -9999 -9999 -9999 -9999 -9999 -9999

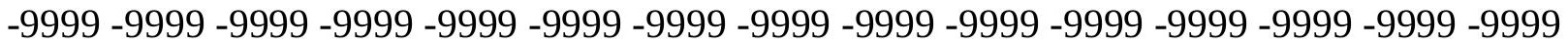
-9999 -9999 -9999 -9999 -9999 -9999 -9999 -9999 -9999 -9999 -9999 -9999 -9999 -9999 -9999 -9999 -9999 -9999 -9999 -9999 -9999 -9999 -9999 -9999 -9999 -9999 -9999 -9999 -9999 -9999 -9999 -9999 -9999 -9999 -9999 -9999 -9999 -9999 -9999 -9999 -9999 -9999 -9999 -9999 - 9999 -9999 -9999 -9999 -9999 -9999 -9999 -9999 -9999 -9999 -9999 -9999 -9999 -9999 -9999 -9999

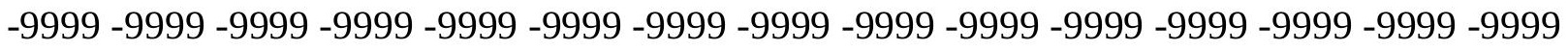
-9999 -9999 -9999 -9999 -9999 -9999 -9999 -9999 -9999 -9999 -9999 -9999 -9999 -9999 -9999 -9999 -9999 -9999 -9999 -9999 -9999 -9999 -9999 -9999 -9999 -9999 -9999 -9999 -9999 - 9999 -9999 -9999 -9999 -9999 -9999 -9999 -9999 -9999 -9999 -9999 -9999 -9999 -9999 -9999 -9999 -

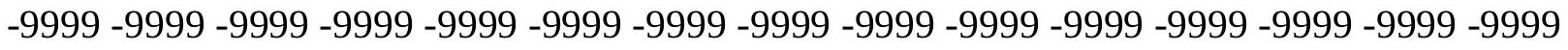

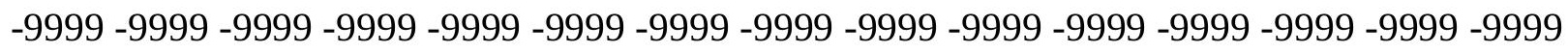
-9999 -9999 -9999 -9999 -9999 -9999-9999 -9999 -9999 141.1154937744 138.9819946289 135.9342041016132 .5814971924128 .9241027832125 .8762969971123 .1332015991 121.6092987061122 .5235977173123 .43800354124 .3523025513124 .9618988037 125.5715026855125 .8762969971126 .1809997559126 .4858016968126 .4858016968 126.4858016968126 .4858016968126 .4858016968126 .1809997559125 .8762969971 125.5715026855125 .2667007446124 .9618988037124 .3523025513124 .0475006104 123.43800354122 .8283996582122 .2188034058121 .6092987061120 .9997024536 120.3900985718119 .4757995605118 .8662033081117 .9517974854117 .0374984741 116.4279022217115 .5136032104114 .5991973877113 .6848983765113 .075302124 112.1608963013111 .551399231110 .6370010376110 .0273971558109 .4179000854 108.8082962036108 .1986999512107 .5891036987107 .2844009399106 .979598999 106.6747970581 106.3700027466106.0652008057 105.7603988647105.7603988647 105.4557037354105 .4557037354105 .1509017944105 .1509017944104 .8460998535 104.8460998535104 .5412979126104 .2365036011103 .9317016602103 .3221969604 102.712600708102 .712600708102 .712600708103 .3221969604101 .8611602783 100.78960418799 .6983642578198 .5848007202197 .4456405639696 .27645111084 95.0744476318493 .8425598144592 .5829010009891 .1307525634889 .91161346436 88.3876876831186.86376190186 85.64462280273 84.12069702148 82.59677124023 81.0728530883879 .5489196777378 .0249862670977 .1106262207 -9999 -9999 -9999 -9999 -9999 -9999 -9999 -9999 -9999 -9999 -9999 -9999 -9999 -9999 -9999 -9999 -9999-9999 -9999 -

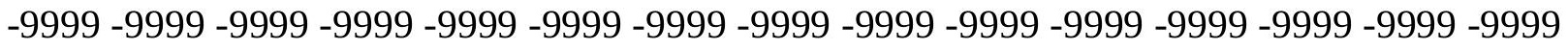
-9999 -9999 -9999 -9999 -9999 -9999 -9999 -9999 -9999 -9999 -9999 -9999 -9999 -9999 -9999 -9999 -9999 -9999 -9999 -9999 -9999 -9999 -9999 -9999-9999 -9999 -9999 -9999 -9999 -9999 -9999 -9999 -9999 -9999 -9999 -9999 -9999 -9999 -9999 -9999 -9999 -9999 -9999 -9999 -9999 -

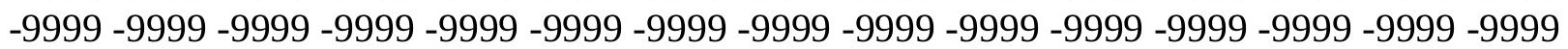


-9999 -9999 -9999 -9999 -9999 -9999 -9999 -9999 -9999 -9999 -9999 -9999 -9999 -9999 -9999 -9999 -9999 -9999 -9999 -9999 -9999 -9999 -9999 -9999 -9999 -9999 -9999 -9999 -9999 -9999 -9999 -9999 -9999 -9999 -9999 -9999 -9999 -9999 -9999 -9999 -9999 -9999 -9999 -9999 -9999 -9999 -9999 -9999 -9999 -9999 -9999 -9999 -9999 -9999 -9999 -9999 -9999 -9999 -9999 -9999 -9999 -9999 -9999 -9999 -9999 -9999 -9999 -9999 -9999 -9999 -9999 -9999 -9999 -9999 -9999 -9999 -9999 -9999 -9999 -9999 -9999 -9999 -9999 -9999 -9999 -9999 -9999 -9999 -9999 -9999 -9999 -9999 -9999 -9999 -9999 -9999 -9999 -9999 -9999 -9999 -9999 -9999 -9999 -9999 -9999

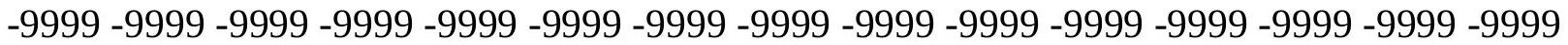
-9999 -9999 -9999 -9999 -9999 -9999 -9999 -9999 -9999 -9999 -9999 -9999 -9999 -9999 -9999 -9999 -9999 -9999 -9999 -9999 -9999 -9999 -9999 -9999 -9999 -9999 -9999 -9999 -9999 -9999 -

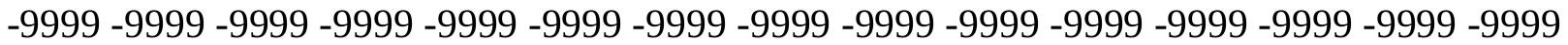
-9999 -9999 -9999 -9999 -9999 -9999 -9999 -9999 -9999 -9999 -9999 -9999 -9999 -9999 -9999

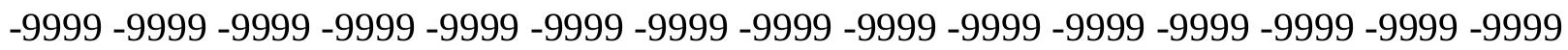
-9999 -9999 -9999 -9999 -9999 -9999 -9999 -9999 -9999 -9999 138.0677032471 135.0198059082131 .6672058105128 .0097961426124 .9618988037122 .2188034058 121.9140014648122 .8283996582123 .7427978516124 .6570968628125 .2667007446 125.8762969971126 .4858016968126 .7906036377126 .7906036377127 .0953979492 126.7906036377126 .7906036377126 .7906036377126 .4858016968126 .1809997559 125.8762969971125 .5715026855124 .9618988037124 .6570968628124 .0475006104 123.43800354122 .8283996582122 .2188034058121 .6092987061120 .9997024536 120.0852966309119 .4757995605118 .5614013672117 .9517974854117 .0374984741 116.1231002808115 .2088012695114 .2944030762113 .3800964355112 .7705001831 111.8561019897110 .9418029785110 .3321990967109 .7226028442109 .1130981445 108.5035018921107 .8938980103107 .2844009399106 .979598999106 .6747970581 106.3700027466106 .0652008057106 .0652008057105 .7603988647105 .7603988647 105.4557037354105 .4557037354105 .4557037354105 .4557037354105 .1509017944 105.1509017944104 .8460998535104 .5412979126104 .2365036011103 .6268997192 102.712600708102 .4077987671102 .712600708104 .2365036011105 .4557037354 105.7603988647100 .09154510599 .0101699829197 .9016342163196 .76107025146 95.5858688354594 .3764572143693 .135604858491 .7403335571390 .52117919922 88.9972534179787 .7781066894586 .254188537684 .7302627563583 .2063369751 81.9871978759880 .1584930419978 .6345596313578 .02498626709 -9999 -9999 -9999 -9999 -9999 -9999 -9999 -9999 -9999 -9999 -9999 -9999 -9999 -9999 -9999 -9999 -9999 -9999 -9999 -9999 -9999 -9999 -9999 -9999 -9999 -9999 -9999 -9999 -9999 -9999 -9999 -9999 -9999 -9999

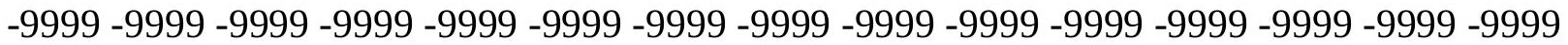
-9999 -9999 -9999 -9999 -9999 -9999 -9999 -9999 -9999 -9999 -9999 -9999 -9999 -9999 -9999

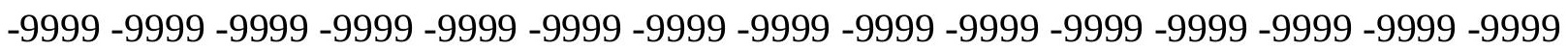

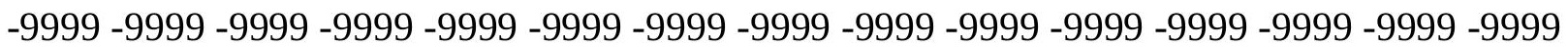
-9999 -9999 -9999 -9999 -9999 -9999 -9999 -9999 -9999 -9999 -9999 -9999 -9999 -9999 -9999 -9999 -9999 -9999 -9999 -9999 -9999 -9999 -9999 -9999 -9999 -9999 -9999 -9999 -9999 -9999 -9999 -9999 -9999 -9999 -9999 -9999 -9999 -9999 -9999 -9999 -9999 -9999 -9999 -9999 -9999

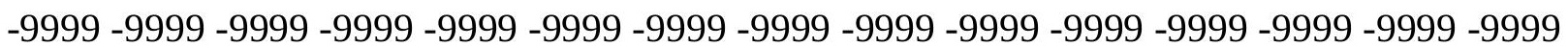
-9999 -9999 -9999 -9999 -9999 -9999 -9999 -9999 -9999 -9999 -9999 -9999 -9999 -9999 -9999 -9999 -9999 -9999 -9999 -9999 -9999 -9999 -9999 -9999 -9999 -9999 -9999 -9999 -9999 -9999 -9999 -9999 -9999 -9999 -9999 -9999 -9999 -9999 -9999 -9999 -9999 -9999 -9999 -9999 -9999

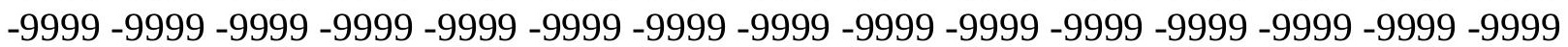


-9999 -9999 -9999 -9999 -9999 -9999 -9999 -9999 -9999 -9999 -9999 -9999 -9999 -9999 -9999 -9999 -9999 -9999 -9999 -9999 -9999 -9999 -9999 -9999 -9999 -9999 -9999 -9999 -9999 -9999

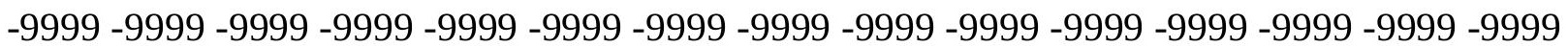
-9999 -9999 -9999 -9999 -9999 -9999 -9999 -9999 -9999 -9999 -9999 -9999 -9999 -9999 -9999 -9999 -9999 -9999 -9999 -9999 -9999 -9999 -9999 -9999 -9999 -9999 -9999 -9999 -9999 -9999 -9999 -9999 -9999 -9999 -9999 -9999 -9999 -9999 -9999 -9999 137.3426818848 134.4102020264130 .7528076172126 .7906036377123 .7427978516121 .6092987061 122.2188034058123 .1332015991124 .0475006104124 .9618988037125 .8762969971 126.4858016968126 .7906036377127 .0953979492127 .4001998901127 .4001998901 127.4001998901127 .4001998901127 .0953979492126 .7906036377126 .4858016968 126.1809997559125 .5715026855125 .2667007446124 .6570968628124 .3523025513 123.7427978516123 .1332015991122 .5235977173121 .6092987061120 .9997024536 120.0852966309119 .4757995605118 .5614013672117 .647102356116 .7326965332 115.818397522114 .9039993286113 .9896011353113 .075302124112 .4656982422 111.551399231110 .6370010376110 .0273971558109 .1130981445108 .5035018921 107.8938980103107 .5891036987106 .979598999106 .6747970581106 .3700027466 106.0652008057106 .0652008057105 .7603988647105 .7603988647105 .7603988647 105.7603988647105 .7603988647105 .4557037354105 .4557037354105 .4557037354 105.4557037354105 .1509017944104 .8460998535104 .5412979126103 .9317016602 103.0174026489102 .1029968262102 .1029968262105 .1509017944107 .8938980103 108.5035018921106 .674797058199 .4046707153398 .3252105712997 .21313476562 96.0073165893694 .7881774902393 .5690307617292 .349891662691 .01042175293 89.6068267822388 .3876876831186 .8637619018685 .6446228027384 .12069702148 82.5967712402381 .0728530883879 .5489196777378 .63455963135 -9999 -9999 -9999 -9999 -9999 -9999 -9999 -9999 -9999 -9999 -9999 -9999 -9999 -9999 -9999 -9999 -9999 -9999 -9999 -9999 -9999 -9999 -9999 -9999 -9999 -9999 -9999 -9999 -9999 -9999 -9999 -9999 -9999 -9999 -9999 -9999 -9999 -9999 -9999 -9999 -9999 -9999 -9999 -9999 -9999 -9999 -9999 -9999 -9999 -9999 -9999 -9999 -9999 -9999 -9999 -9999 -9999 -9999 -9999 -9999 -9999 -9999 -9999 -9999 -9999 -9999 -9999 -9999 -9999 -9999 -9999 -9999 -9999 -9999 -9999 -9999 -9999 -9999 -9999 -9999 -9999 -9999 -9999 -9999 -9999 -9999 -9999 -9999 -9999 -9999 -9999 -9999 -9999 -9999 -999 -9999 -9999 -9999 -9999 -9999 -9999 -9999 -9999 -9999 -9999 -9999 -9999 -9999 -9999 -9999 -9999 -9999 -9999 -9999 -9999 -9999 -9999 -9999 -9999 -9999 -9999 -9999 -9999 -9999 -9999 -9999 -9999 -9999 -9999 -9999 -9999 -9999 -9999 -9999 -9999 -9999 -9999 -9999 -9999 -9999 -9999 -9999 -9999 -9999 -9999 -9999 -9999 -9999 -9999 -9999 -9999 -9999 -9999 -9999 -9999 -

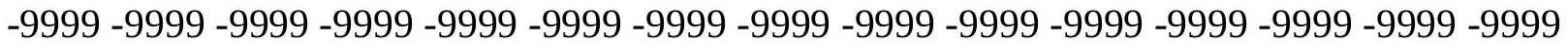
-9999 -9999 -9999 -9999 -9999 -9999 -9999 -9999 -9999 -9999 -9999 -9999 -9999 -9999 -9999 -9999 -9999 -9999 -9999 -9999 -9999 -9999 -9999 -9999 -9999 -9999 -9999 -9999 -9999 -9999

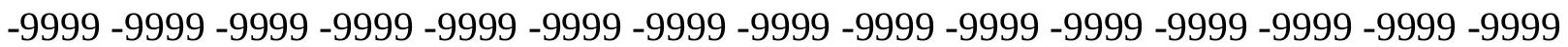
-9999 -9999 -9999 -9999 -9999 -9999 -9999 -9999 -9999 -9999 -9999 -9999 -9999 -9999 -9999 -9999 -9999 -9999 -9999 -9999 -9999 -9999 -9999 -9999 -9999 -9999 -9999 -9999 -9999 -9999 -9999 -9999 -9999 -9999 -9999 -9999 -9999 -9999 -9999 -9999 -9999 -9999 -9999 -9999 -9999

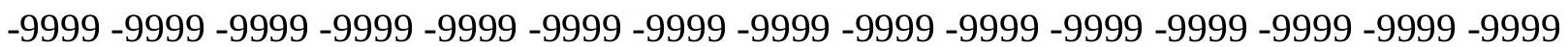
-9999 -9999 -9999 -9999 -9999 -9999 -9999 -9999 -9999 -9999 -9999 -9999 -9999 -9999 -9999 -999 -9999 -9999 -9999 -9999 -9999 -9999 -9999 -9999 -9999 -9999 -9999 133.6478271484 129.9161834717126 .1809997559123 .1332015991121 .3044967651122 .5235977173 123.43800354124 .6570968628125 .5715026855126 .4858016968127 .0953979492 
127.4001998901127 .7050018311128 .0097961426128 .0097961426128 .0097961426 127.7050018311127 .4001998901127 .0953979492126 .7906036377126 .4858016968 125.8762969971125 .5715026855124 .9618988037124 .3523025513123 .7427978516 123.1332015991122 .5235977173121 .6092987061120 .9997024536120 .0852966309 119.4757995605118 .5614013672117 .647102356116 .7326965332115 .818397522 114.9039993286113 .9896011353112 .7705001831112 .1608963013111 .24659729 110.3321990967109 .4179000854108 .8082962036108 .1986999512107 .5891036987 107.2844009399 106.6747970581 106.3700027466106.0652008057 105.7603988647 105.7603988647105 .7603988647105 .7603988647105 .4557037354105 .7603988647 105.7603988647105 .7603988647105 .7603988647105 .7603988647105 .7603988647 105.4557037354105 .1509017944104 .5412979126103 .9317016602103 .3221969604 102.1029968262103 .0174026489106 .3700027466110 .3321990967111 .551399231 107.5891036987102 .71260070899 .3599472045997 .5312423706196 .00731658936 95.0929565429793 .8738174438592 .6546783447391 .4355392456190 .21640014648 88.9972534179787 .4733276367286 .254188537684 .7302627563583 .2063369751

81.6824111938580 .1584930419979 .24413299561 -9999 -9999 -9999 -9999 -9999 -9999 -9999 -9999 -9999 -9999 -9999 -9999 -9999 -9999 -9999 -9999 -9999 -9999 -9999 -9999 -9999 -9999 -

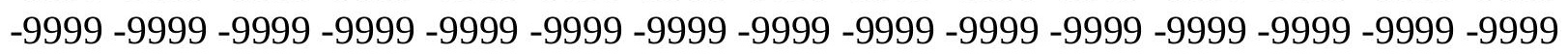
-9999 -9999 -9999 -9999 -9999 -9999 -9999 -9999 -9999 -9999 -9999 -9999

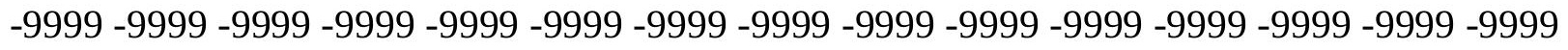

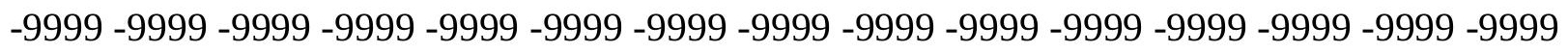

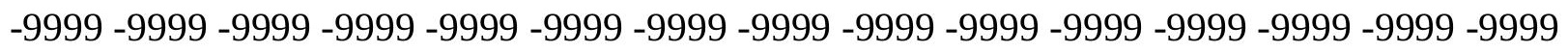
-9999 -9999 -9999 -9999 -9999 -9999 -9999 -9999 -9999 -9999 -9999 -9999 -9999 -9999 -9999 -

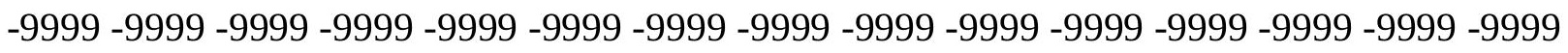

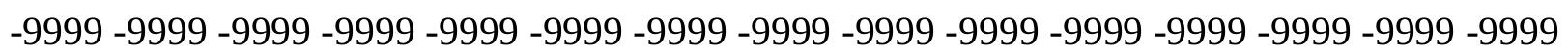
-9999 -9999 -9999 -9999 -9999 -9999 -9999 -9999 -9999 -9999 -9999 -9999 -9999 -9999 -9999

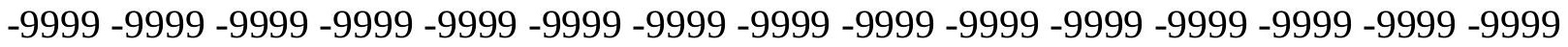

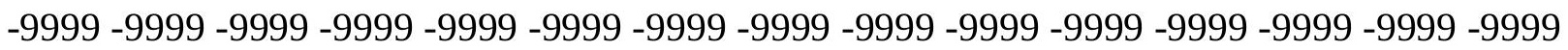

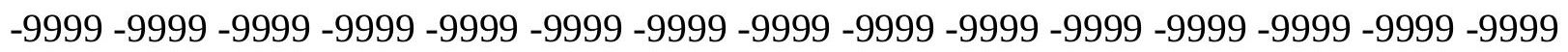

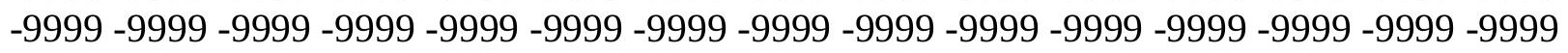
-9999 -9999 -9999 -9999 -9999 -9999 -9999 -9999 -9999 -9999 -9999 -9999 -9999 -9999 -9999 -9999 -9999 -9999 -9999 -9999 -9999 -9999 -9999 -9999 -9999 -9999 -9999 -9999 -9999 -9999 -

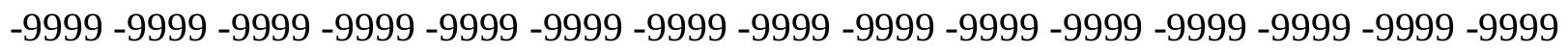

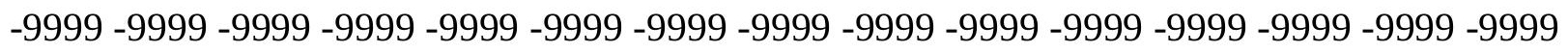
-9999 -9999 -9999 -9999 -9999 -9999 -9999 -9999 -9999 -9999 -9999 -9999 -9999 -9999 -9999 -999 -9999 -9999 -9999 -9999-9999-9999 -9999 -9999 -9999 -9999-9999-9999 129.3653869629 125.8762969971122 .2188034058121 .3044967651122 .5235977173124 .0475006104 125.2667007446126 .1809997559127 .0953979492128 .0097961426128 .3144989014 128.6192932129128 .6192932129128 .6192932129128 .3144989014128 .3144989014 128.0097961426127 .4001998901127 .0953979492126 .7906036377126 .1809997559 125.5715026855124 .9618988037124 .6570968628124 .0475006104123 .1332015991 122.5235977173121 .9140014648120 .9997024536120 .0852966309119 .4757995605 118.5614013672117 .647102356116 .4279022217115 .5136032104114 .5991973877 113.6848983765112 .7705001831111 .551399231110 .6370010376110 .0273971558 109.1130981445108 .5035018921107 .8938980103107 .2844009399106 .6747970581 106.3700027466 106.0652008057 105.7603988647 105.4557037354 105.4557037354 
105.4557037354105 .4557037354105 .4557037354105 .4557037354105 .7603988647 105.7603988647105 .7603988647105 .7603988647105 .7603988647105 .7603988647 105.4557037354104 .8460998535104 .2365036011103 .0174026489101 .7982025146 102.4077987671105 .7603988647110 .9418029785115 .5136032104104 .8460998535 99.9695205688598 .1408081054796 .9216690063596 .0073165893695 .3977432251 94.1785964965893 .2642517089892 .0450973510790 .8259735107489 .60682678223 88.0829010009886 .5589828491285 .3398437583 .8159103393682 .29197692871 80.4632720947379 .85370635986 -9999 -9999 -9999 -9999 -9999 -9999 -9999 -9999 -9999

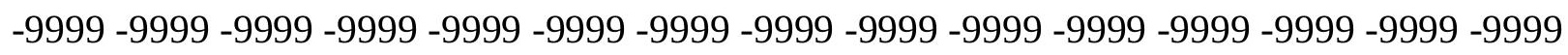
-9999 -9999 -9999 -9999 -9999 -9999 -9999 -9999 -9999 -9999 -9999 -9999 -9999 -9999 -9999 -9999 -9999 -9999 -9999 -9999 -9999 -9999 -9999 -9999 -9999

-9999 -9999 -9999 -9999 -9999 -9999 -9999 -9999 -9999 -9999 -9999 -9999 -9999 -9999 -9999 -9999 -9999 -9999 -9999 -9999 -9999 -9999 -9999 -9999 -9999 -9999 -9999 -9999 -9999 -9999 -9999 -9999 -9999 -9999 -9999 -9999 -9999 -9999 -9999 -9999 -9999 -9999 -9999 -9999 -9999 -9999 -9999 -9999 -9999 -9999 -9999 -9999 -9999 -9999 -9999 -9999 -9999 -9999 -9999 -9999

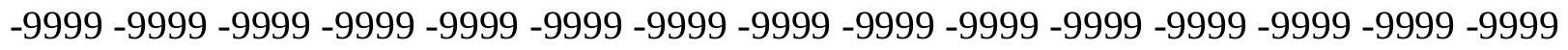
-9999 -9999 -9999 -9999 -9999 -9999 -9999 -9999 -9999 -9999 -9999 -9999 -9999 -9999 -9999 -9999 -9999 -9999 -9999 -9999 -9999 -9999 -9999 -9999 -9999 -9999 -9999 -9999 -9999 -9999 -

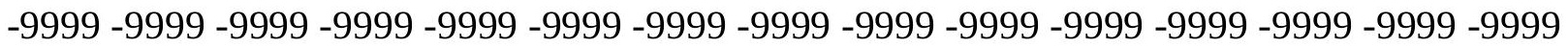

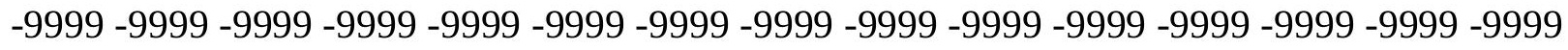

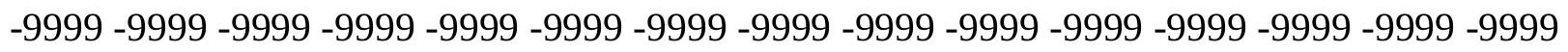
-9999 -9999 -9999 -9999 -9999 -9999 -9999 -9999 -9999 -9999 -9999 -9999 -9999 -9999 -9999 -9999 -9999 -9999 -9999 -9999 -9999 -9999 -9999 -9999 -9999 -9999 -9999 -9999 -9999 -9999 -

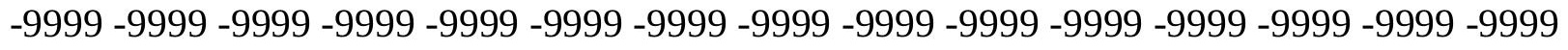

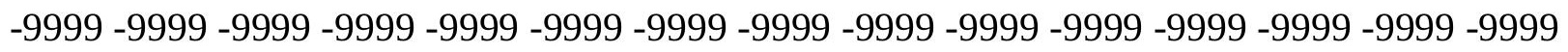
-9999 -9999 -9999 -9999 -9999 -9999 -9999 -9999 -9999 -9999 -9999 -9999 -9999 -9999 -9999 -9999 -9999 -9999 -9999 -9999 -9999 -9999 -9999 -9999 -9999 -9999 -9999 -9999 -9999 - -9999 -9999 -9999-9999 -9999-9999 -9999-9999 -9999 -9999 -9999-9999-9999 129.213180542 124.6411895752121 .3044967651121 .3044967651122 .8283996582124 .3523025513 125.8762969971127 .4001998901128 .3144989014128 .9241027832129 .2288970947 129.2288970947129 .2288970947129 .2288970947128 .9241027832128 .6192932129 128.3144989014128 .0097961426127 .4001998901126 .7906036377126 .4858016968 125.8762969971125 .2667007446124 .6570968628124 .0475006104123 .43800354 122.5235977173121 .9140014648120 .9997024536120 .3900985718119 .4757995605 118.5614013672117 .342300415116 .4279022217115 .5136032104114 .2944030762 113.3800964355112 .4656982422111 .24659729110 .3321990967109 .4179000854 108.8082962036107 .8938980103107 .2844009399106 .6747970581106 .3700027466 105.7603988647105 .4557037354105 .4557037354105 .1509017944105 .1509017944 105.1509017944105 .1509017944105 .4557037354105 .4557037354105 .7603988647 105.7603988647106 .0652008057106 .0652008057105 .7603988647105 .7603988647 105.4557037354105 .1509017944104 .2365036011102 .712600708100 .8839035034 99.96952056885104 .2365036011107 .5891036987106 .370002746698 .4455871582 97.8360290527397 .2264633178796 .6168823242296 .3121032714895 .70252990723 94.7881774902393 .8738174438592 .6546783447391 .4355392456189 .91161346436 88.6924667358487 .1685485839885 .6446228027384 .1206970214882 .59677124023 81.0728530883880 .46327209473 -9999 -9999 -9999 -9999 -9999 -9999 -9999 -9999 -9999 
-9999 -9999 -9999 -9999 -9999 -9999 -9999 -9999 -9999 -9999 -9999 -9999 -9999 -9999 -9999 -9999 -9999 -9999 -9999 -9999 -9999 -9999 -9999 -9999 -9999 -9999 -9999 -9999 -9999 -9999 -9999 -9999 -9999 -9999 -9999 -9999 -9999 -9999 -9999 -9999

-9999 -9999 -9999 -9999 -9999 -9999 -9999 -9999 -9999 -9999 -9999 -9999 -9999 -9999 -9999 -9999 -9999 -9999 -9999 -9999 -9999 -9999 -9999 -9999 -9999 -9999 -9999 -9999 -9999 -9999 -9999 -9999 -9999 -9999 -9999 -9999 -9999 -9999 -9999 -9999 -9999 -9999 -9999 -9999 -9999 -9999 -9999 -9999 -9999 -9999 -9999 -9999 -9999 -9999 -9999 -9999 -9999 -9999 -9999 -9999

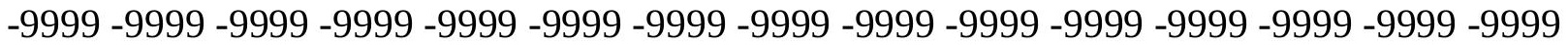
-9999 -9999 -9999 -9999 -9999 -9999 -9999 -9999 -9999 -9999 -9999 -9999 -9999 -9999 -9999 -9999 -9999 -9999 -9999 -9999 -9999 -9999 -9999 -9999 -9999 -9999 -9999 -9999 -9999 -9999 -

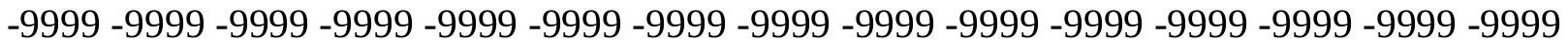
-9999 -9999 -9999 -9999 -9999 -9999 -9999 -9999 -9999 -9999 -9999 -9999 -9999 -9999 -9999

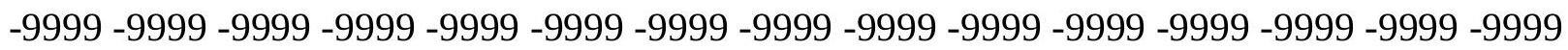
-9999 -9999 -9999 -9999 -9999 -9999 -9999 -9999 -9999 -9999 -9999 -9999 -9999 -9999 -9999 -9999 -9999 -9999 -9999 -9999 -9999 -9999 -9999 -9999 -9999 -9999 -9999 -9999 -9999 -9999

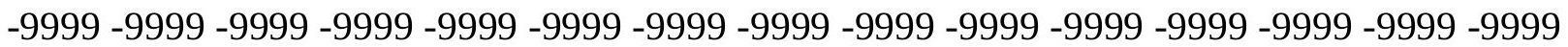

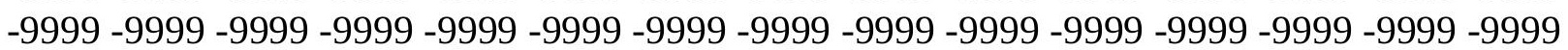
-9999 -9999 -9999 -9999 -9999 -9999 -9999 -9999 -9999 -9999 -9999 -9999 -9999 -9999 -9999 -9999 -9999 -9999 -9999 -9999 -9999 -9999 -9999 -9999 -9999 -9999 -9999 -9999 -9999 -9999 -9999 -9999 -9999 -9999 -9999 -9999 -9999 -9999 -9999 -9999 -9999 -9999 -9999 124.7431640625120 .9997024536120 .9997024536123 .1332015991125 .2667007446 127.0953979492128 .6192932129129 .533706665129 .8385009766130 .1432037354 130.1432037354130 .1432037354129 .8385009766129 .533706665129 .2288970947 128.6192932129128 .3144989014127 .7050018311127 .0953979492126 .4858016968 126.1809997559125 .5715026855124 .9618988037124 .0475006104123 .43800354 122.8283996582121 .9140014648121 .3044967651120 .3900985718119 .4757995605 118.5614013672117 .342300415116 .4279022217115 .5136032104114 .2944030762 113.075302124112 .1608963013110 .9418029785110 .0273971558109 .1130981445 108.1986999512107 .5891036987106 .6747970581106 .0652008057105 .7603988647 105.4557037354105 .1509017944104 .8460998535104 .8460998535104 .8460998535 104.8460998535105 .1509017944105 .1509017944105 .4557037354105 .7603988647 105.7603988647106 .0652008057106 .0652008057105 .7603988647105 .7603988647 105.4557037354104 .8460998535103 .9317016602102 .712600708101 .4934005737 101.4934005737103 .0174026489104 .2365036011102 .407798767199 .35994720459 97.5312423706197 .2264633178796 .9216690063596 .6168823242296 .31210327148 95.397743225194 .3282394409293 .1500854492291 .8902359008890 .52117919922 89.302040100187 .7781066894586 .254188537684 .7302627563583 .2063369751 81.3776321411181 .07285308838 -9999 -9999 -9999 -9999 -9999 -9999 -9999 -9999 -9999 -9999 -9999 -9999 -9999 -9999 -9999 -9999 -9999 -9999 -9999 -9999 -9999 -9999 -9999 -9999 -9999 -9999 -9999 -9999 -9999 -9999 -9999 -9999 -9999 -9999 -9999 -9999 -9999 -9999 -9999 -9999 -9999 -9999 -9999 -9999 -9999 -9999 -9999 -9999 -9999

-9999 -9999 -9999 -9999 -9999 -9999 -9999 -9999 -9999 -9999 -9999 -9999 -9999 -9999 -9999 -9999 -9999 -9999 -9999 -9999 -9999 -9999 -9999 -9999 -9999 -9999 -9999 -9999 -9999 -9999 -9999 -9999 -9999 -9999 -9999 -9999 -9999 -9999 -9999 -9999 -9999 -9999 -9999 -9999 -9999 -9999 -9999 -9999 -9999 -9999 -9999 -9999 -9999 -9999 -9999 -9999 -9999 -9999 -9999 -9999

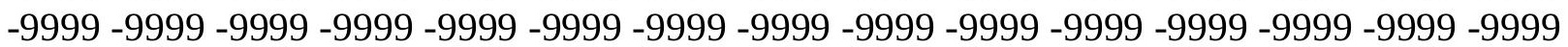


-9999 -9999 -9999 -9999 -9999 -9999 -9999 -9999 -9999 -9999 -9999 -9999 -9999 -9999 -9999 -9999 -9999 -9999 -9999 -9999 -9999 -9999 -9999 -9999 -9999 -9999 -9999 -9999 -9999 -9999 -9999 -9999 -9999 -9999 -9999 -9999 -9999 -9999 -9999 -9999 -9999 -9999 -9999 -9999 -9999 -9999 -9999 -9999 -9999 -9999 -9999 -9999 -9999 -9999 -9999 -9999 -9999 -9999 -9999 -9999 -9999 -9999 -9999 -9999 -9999 -9999 -9999 -9999 -9999 -9999 -9999 -9999 -9999 -9999 -9999 -9999 -9999 -9999 -9999 -9999 -9999 -9999 -9999 -9999 -9999 -9999 -9999 -9999 -9999 -9999 -9999 -9999 -9999 -9999 -9999 -9999 -9999 -9999 -9999 -9999 -9999 -9999 -9999 -9999 -9999

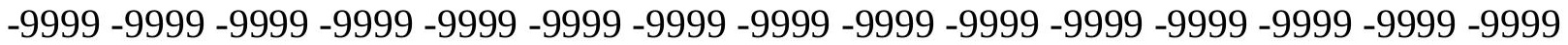
-9999 -9999 -9999 -9999 -9999 -9999 -9999 -9999 -9999 -9999 -9999 -9999 -9999 -9999 -9999 -9999 -9999 -9999 -9999 -9999 -9999 -9999 -9999 -9999 -9999 -9999 -9999 -9999 -9999 -9999 -

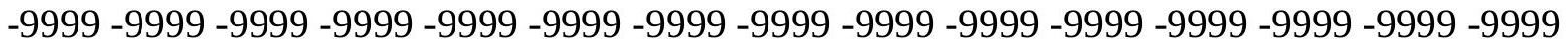
-9999 -9999 -9999 -9999 -9999 -9999 -9999 -9999 -9999 -9999 -9999 -9999 -9999 127.2230682373 121.3044967651 121.9140014648 124.6570968628 127.0953979492 128.9241027832130 .1432037354130 .7528076172131 .0576019287131 .3623962402 131.0576019287130 .7528076172130 .4479980469130 .1432037354129 .533706665 128.9241027832128 .6192932129128 .0097961426127 .4001998901126 .7906036377 126.1809997559125 .5715026855124 .9618988037124 .3523025513123 .7427978516 122.8283996582122 .2188034058121 .3044967651120 .3900985718119 .4757995605 118.5614013672117 .647102356116 .4279022217115 .2088012695114 .2944030762 113.075302124111 .8561019897110 .6370010376109 .7226028442108 .8082962036 107.8938980103106 .979598999106 .3700027466105 .7603988647105 .1509017944 104.8460998535104 .5412979126104 .5412979126104 .5412979126104 .5412979126 104.5412979126104 .8460998535104 .8460998535105 .1509017944105 .4557037354 105.7603988647106 .0652008057106 .0652008057105 .7603988647105 .4557037354 105.1509017944104 .5412979126103 .9317016602103 .0174026489102 .4077987671 102.4077987671103 .0174026489103 .0174026489101 .7982025146100 .2742996216 98.7503814697398 .1408081054797 .8360290527397 .5312423706196 .92166900635 96.0073165893695 .0929565429793 .5257263183692 .3353576660291 .13075256348 89.6068267822388 .0829010009886 .5589828491285 .0350494384883 .51112365723 81.9871978759881 .37763214111 -9999 -9999 -9999 -9999 -9999 -9999 -9999 -9999 -9999 -9999 -9999 -9999 -9999 -9999 -9999 -9999 -9999 -9999 -9999 -9999 -9999 -9999 -9999 -9999 -9999 -9999 -9999 -9999 -9999 -9999 -9999 -9999 -9999 -9999 -9999 -9999 -9999 -9999 -9999 -9999 -9999 -9999 -9999 -9999 -9999 -9999 -9999 -9999 -9999

-9999 -9999 -9999 -9999 -9999 -9999 -9999 -9999 -9999 -9999 -9999 -9999 -9999 -9999 -9999

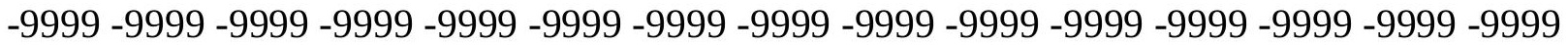
-9999 -9999 -9999 -9999 -9999 -9999 -9999 -9999 -9999 -9999 -9999 -9999 -9999 -9999 -9999 -9999 -9999 -9999 -9999 -9999 -9999 -9999 -9999 -9999 -9999 -9999 -9999 -9999 -9999 -9999

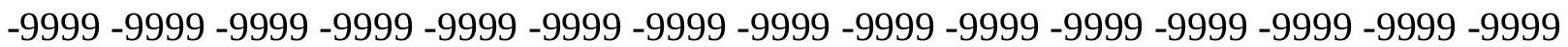
-9999 -9999 -9999 -9999 -9999 -9999 -9999 -9999 -9999 -9999 -9999 -9999 -9999 -9999 -9999 -9999 -9999 -9999 -9999 -9999 -9999 -9999 -9999 -9999 -9999 -9999 -9999 -9999 -9999 -9999 -9999 -9999 -9999 -9999 -9999 -9999 -9999 -9999 -9999 -9999 -9999 -9999 -9999 -9999 -9999

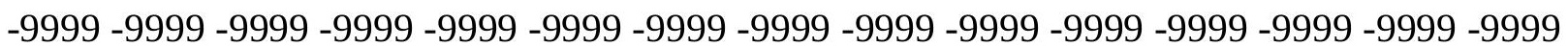
-9999 -9999 -9999 -9999 -9999 -9999 -9999 -9999 -9999 -9999 -9999 -9999 -9999 -9999 -9999 -9999 -9999 -9999 -9999 -9999 -9999 -9999 -9999 -9999 -9999 -9999 -9999 -9999 -9999 -9999 -9999 -9999 -9999 -9999 -9999 -9999 -9999 -9999 -9999 -9999 -9999 -9999 -9999 -9999 -9999

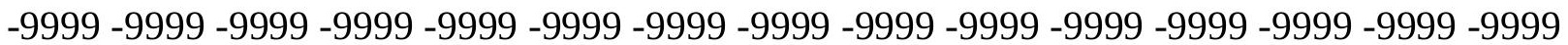


-9999 -9999 -9999 -9999 -9999 -9999 -9999 -9999 -9999 -9999 -9999 -9999 -9999 -9999 -9999 -9999 -9999 -9999 -9999 -9999 -9999 -9999 -9999 -9999 -9999 -9999 -9999 -9999 -9999 -9999

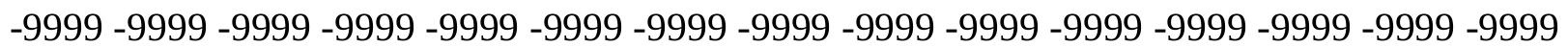
-9999 -9999 -9999 -9999 -9999 -9999 -9999 -9999 -9999 -9999 -9999 -9999 -9999 -9999 127.4001998901124 .9618988037127 .0953979492129 .2288970947130 .7528076172 131.9720001221132 .2767028809132 .2767028809132 .2767028809131 .9720001221 131.6672058105131 .0576019287130 .4479980469129 .8385009766129 .2288970947 128.9241027832128 .3144989014127 .7050018311127 .0953979492126 .4858016968 125.8762969971125 .2667007446124 .3523025513123 .7427978516123 .1332015991 122.2188034058121 .6092987061120 .6949005127119 .7806015015118 .5614013672 117.647102356116 .4279022217115 .2088012695113 .9896011353112 .7705001831 111.551399231110 .3321990967109 .4179000854108 .1986999512107 .2844009399 106.3700027466105 .7603988647105 .1509017944104 .5412979126104 .2365036011 103.9317016602103 .9317016602103 .9317016602103 .9317016602104 .2365036011 104.5412979126104 .8460998535105 .1509017944105 .4557037354105 .7603988647 106.0652008057106 .0652008057105 .7603988647105 .4557037354104 .8460998535 104.5412979126103 .9317016602103 .3221969604103 .0174026489103 .0174026489 103.3221969604103 .6268997192102 .712600708101 .4934005737100 .5791015625 99.6647262573299 .3599472045998 .445587158297 .8360290527396 .61688232422 95.397743225194 .1785964965892 .6307830810591 .3591995239389 .91161346436 88.38768768311 86.86376190186 85.33984375 83.81591033936 82.29197692871 81.68241119385 -9999 -9999 -9999 -9999 -9999 -9999 -9999 -9999 -9999 -9999 -9999 -9999 -9999 -9999 -9999 -9999 -9999 -9999 -9999 -9999 -9999 -9999 -9999 -9999 -9999 -9999 -9999 -9999 -9999 -9999 -9999 -9999 -9999 -9999 -9999 -9999 -9999 -9999 -9999 -9999 -9999 -9999 -9999 -9999 -9999 -9999 -9999 -9999 -9999

-9999 -9999 -9999 -9999 -9999 -9999 -9999 -9999 -9999 -9999 -9999 -9999 -9999 -9999 -9999 -9999 -9999 -9999 -9999 -9999 -9999 -9999 -9999 -9999 -9999 -9999 -9999 -9999 -9999 -9999 -9999 -9999 -9999 -9999 -9999 -9999 -9999 -9999 -9999 -9999 -9999 -9999 -9999 -9999 -9999 -9999 -9999 -9999 -9999 -9999 -9999 -9999 -9999 -9999 -9999 -9999 -9999 -9999 -9999 -9999 -9999 -9999 -9999 -9999 -9999 -9999 -9999 -9999 -9999 -9999 -9999 -9999 -9999 -9999 -9999 -9999 -9999 -9999 -9999 -9999 -9999 -9999 -9999 -9999 -9999 -9999 -9999 -9999 -9999 -9999 -9999 -9999 -9999 -9999 -9999 -9999 -9999 -9999 -9999 -9999 -9999 -9999 -9999 -9999 -9999 -9999 -9999 -9999 -9999 -9999 -9999 -9999 -9999 -9999 -9999 -9999 -9999 -9999 -9999 -9999 -9999 -9999 -9999 -9999 -9999 -9999 -9999 -9999 -9999 -9999 -9999 -9999 -9999 -9999 -9999

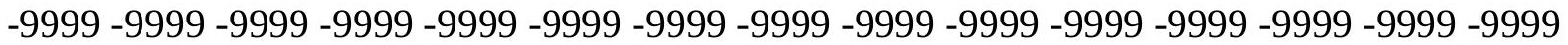
-9999 -9999 -9999 -9999 -9999 -9999 -9999 -9999 -9999 -9999 -9999 -9999 -9999 -9999 -9999

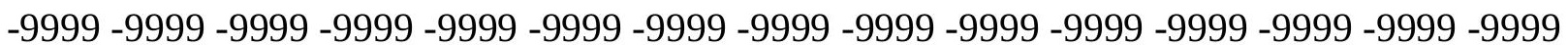

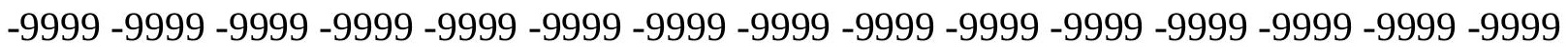
-9999 -9999 -9999 -9999 -9999 -9999 -9999 -9999 -9999 -9999 -9999 -9999 -9999 -9999 -9999 -9999 -9999 -9999 -9999 -9999 -9999 -9999 -9999 -9999 -9999 -9999 -9999 -9999 - -9999 -9999 -9999 -9999 -9999 -9999 -9999 -9999 -9999 -9999 -9999 -9999 -9999 -9999 -9999 -9999 -9999 -9999 -9999 -9999 -9999 -9999 -9999 -9999 -9999 -9999 -9999 -9999 -9999 -9999 -9999 135.3246002197130 .1432037354130 .4479980469131 .9720001221133 .1911010742 133.8007049561133 .8007049561133 .4958953857133 .1911010742132 .5814971924 132.2767028809131 .6672058105131 .0576019287130 .1432037354129 .533706665 128.9241027832128 .3144989014127 .7050018311127 .0953979492126 .4858016968 
125.8762969971125 .2667007446124 .6570968628124 .0475006104123 .1332015991 122.5235977173121 .6092987061120 .6949005127119 .7806015015118 .8662033081 117.9517974854116 .7326965332115 .5136032104113 .9896011353112 .7705001831 111.551399231110 .0273971558108 .8082962036107 .5891036987106 .6747970581 105.7603988647105 .1509017944104 .5412979126103 .9317016602103 .6268997192 103.6268997192103 .3221969604103 .3221969604103 .6268997192103 .9317016602 104.2365036011104 .5412979126104 .8460998535105 .4557037354106 .0652008057 106.3700027466106 .3700027466105 .7603988647105 .1509017944104 .5412979126 104.2365036011103 .9317016602103 .9317016602103 .6268997192103 .6268997192 103.6268997192103 .6268997192103 .3221969604102 .4077987671101 .7982025146 101.1886978149100 .579101562599 .6647262573298 .445587158297 .22646331787 96.0073165893694 .7881774902392 .8181533813591 .5401535034290 .21640014648 88.9972534179787 .1685485839885 .6446228027384 .1206970214882 .59677124023 81.98719787598 -9999 -9999 -9999 -9999 -9999 -9999 -9999 -9999 -9999 -9999 -9999 -9999 -9999 -9999 -9999 -9999 -9999 -9999 -9999 -9999 -9999 -9999 -9999 -9999 -9999 -9999 -9999

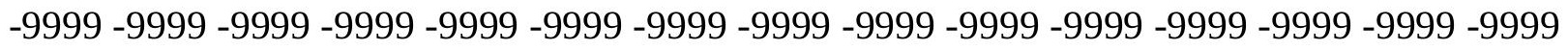
-9999 -9999 -9999 -9999-9999-9999-9999

-9999 -9999 -9999 -9999 -9999 -9999 -9999 -9999 -9999 -9999 -9999 -9999 -9999 -9999 -9999 -9999 -9999 -9999 -9999 -9999 -9999 -9999 -9999 -9999 -9999 -9999 -9999 -9999 -9999 -9999 -

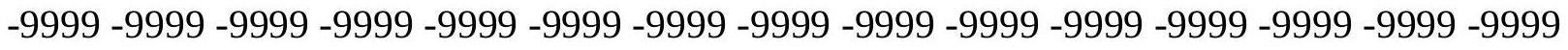
-9999 -9999 -9999 -9999 -9999 -9999 -9999 -9999 -9999 -9999 -9999 -9999 -9999 -9999 -9999 -9999 -9999 -9999 -9999 -9999 -9999 -9999 -9999 -9999 -9999 -9999 -9999 -9999 -9999 -9999 -9999 -9999 -9999 -9999 -9999 -9999 -9999 -9999 -9999 -9999 -9999 -9999 -9999 -9999 -9999 -9999 -9999 -9999 -9999 -9999 -9999 -9999 -9999 -9999 -9999 -9999 -9999 -9999 -9999 -9999 -

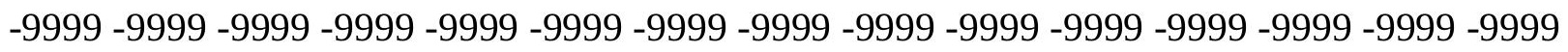
-9999 -9999 -9999 -9999 -9999 -9999 -9999 -9999 -9999 -9999 -9999 -9999 -9999 -9999 -9999 -9999 -9999 -9999 -9999 -9999 -9999 -9999 -9999 -9999 -9999 -9999 -9999 -9999 -9999 -9999

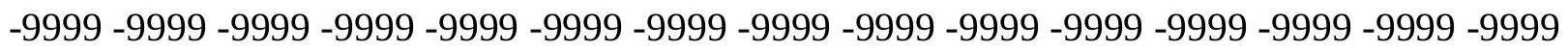
-9999 -9999 -9999 -9999 -9999 -9999 -9999 -9999 -9999 -9999 -9999 -9999 -9999 -9999 -9999 -9999 -9999 -9999 -9999 -9999 -9999 -9999 -9999 -9999 -9999 -9999 -9999 -9999 -9999 -9999 -9999 -9999 -9999 -9999 -9999 -9999 -9999 -9999 -9999 -9999 -9999 -9999 -9999 -9999 -9999

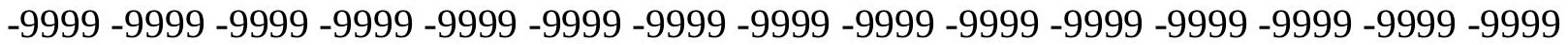

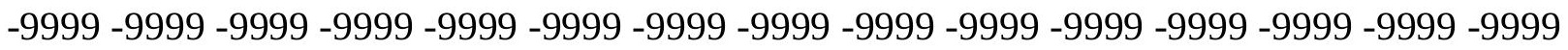
-9999 -9999 -9999 -9999 -9999 -9999 -9999 -9999 -9999 -9999 -9999 -9999 -9999 -9999 -9999 135.0198059082134 .7149963379134 .7149963379135 .3246002197135 .3246002197 135.0198059082134 .4102020264133 .8007049561133 .1911010742132 .5814971924 131.9720001221131 .0576019287130 .4479980469129 .8385009766129 .2288970947 128.6192932129128 .0097961426127 .4001998901126 .4858016968125 .8762969971 125.2667007446124 .6570968628124 .0475006104123 .43800354122 .5235977173 121.9140014648120 .9997024536120 .0852966309119 .1709976196117 .9517974854 116.7326965332115 .5136032104114 .2944030762112 .7705001831111 .24659729 109.7226028442108 .5035018921107 .2844009399106 .0652008057105 .1509017944 104.2365036011103 .6268997192103 .3221969604103 .0174026489103 .0174026489 102.712600708103 .0174026489103 .0174026489103 .3221969604103 .6268997192 104.2365036011104 .8460998535105 .4557037354106 .3700027466106 .979598999 106.979598999106 .3700027466105 .1509017944104 .5412979126104 .2365036011 
104.2365036011 103.9317016602 103.9317016602103 .9317016602103 .6268997192 103.6268997192103 .3221969604103 .0174026489102 .712600708102 .4077987671 101.4934005737100 .274299621699 .0551681518697 .8360290527396 .61688232422 95.0929565429793 .5690307617291 .7038879394590 .4082107543988 .99725341797 87.4733276367285 .9494018554784 .4254837036182 .5967712402382 .29197692871 -9999 -9999 -9999 -9999 -9999 -9999 -9999 -9999 -9999 -9999 -9999 -9999 -9999 -9999 -9999 -9999 -9999 -9999 -9999 -9999 -9999 -9999 -9999 -9999 -9999 -9999 -9999 -9999 -9999 -9999 -9999

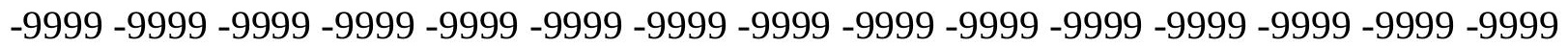
-9999-9999-9999

-9999 -9999 -9999 -9999 -9999 -9999 -9999 -9999 -9999 -9999 -9999 -9999 -9999 -9999 -9999

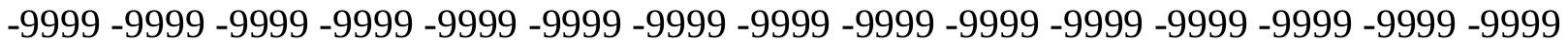
-9999 -9999 -9999 -9999 -9999 -9999 -9999 -9999 -9999 -9999 -9999 -9999 -9999 -9999 -9999 -9999 -9999 -9999 -9999 -9999 -9999 -9999 -9999 -9999 -9999 -9999 -9999 -9999 -9999 -9999 -9999 -9999 -9999 -9999 -9999 -9999 -9999 -9999 -9999 -9999 -9999 -9999 -9999 -9999 -9999 -9999 -9999 -9999 -9999 -9999 -9999 -9999 -9999 -9999 -9999 -9999 -9999 -9999 -9999 -9999

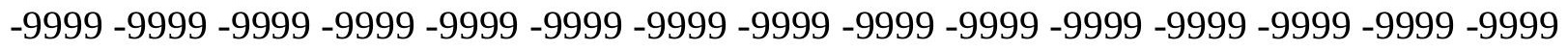
-9999 -9999 -9999 -9999 -9999 -9999 -9999 -9999 -9999 -9999 -9999 -9999 -9999 -9999 -9999 -

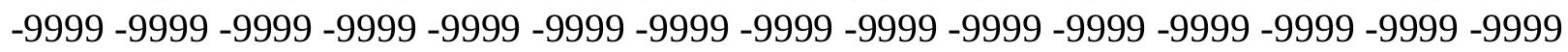

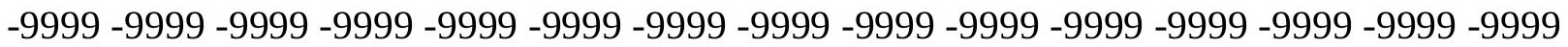

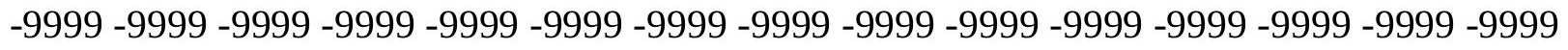

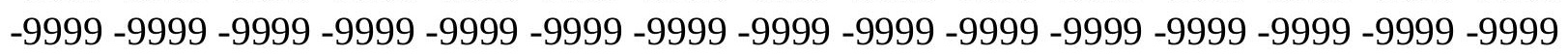

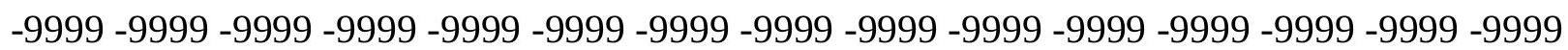
-9999 -9999 -9999 -9999 -9999 -9999 -9999 -9999 -9999 -9999 -9999 -9999 -9999 -9999 -9999 -

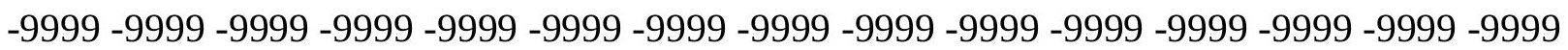

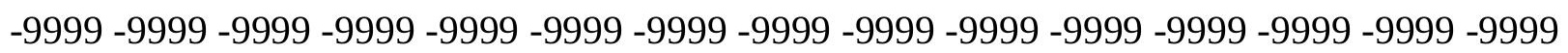

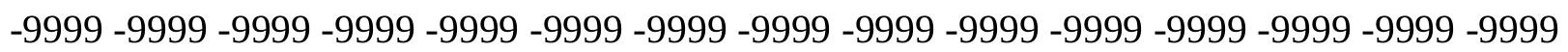
140.5059967041139 .2868041992137 .4580993652136 .8484954834136 .5437011719 135.9342041016135 .3246002197134 .4102020264133 .4958953857132 .8863067627 131.9720001221131 .3623962402130 .7528076172129 .8385009766129 .2288970947 128.6192932129128 .0097961426127 .4001998901126 .7906036377126 .1809997559 125.5715026855124 .9618988037124 .3523025513123 .43800354122 .8283996582 122.2188034058121 .3044967651120 .3900985718119 .4757995605118 .2565994263 117.0374984741115 .818397522114 .2944030762112 .7705001831111 .24659729 109.4179000854108 .1986999512106 .6747970581105 .4557037354104 .5412979126 103.6268997192103 .0174026489102 .712600708102 .4077987671102 .1029968262 102.1029968262102 .4077987671102 .712600708103 .0174026489103 .3221969604 103.9317016602104 .5412979126105 .4557037354106 .6747970581107 .8938980103 108.5035018921107 .8938980103104 .8460998535104 .8460998535104 .5412979126 104.5412979126104 .2365036011103 .9317016602103 .9317016602103 .6268997192 103.3221969604103 .0174026489103 .0174026489103 .0174026489102 .712600708 101.7982025146100 .883903503499 .6647262573298 .1408081054796 .92166900635 95.397743225193 .8738174438592 .349891662690 .4966278076289 .1343460083 $87.7781066894586 .254188537684 .4254837036182 .9015579223682 .59677124023-9999$ -9999 -9999 -9999 -9999 -9999 -9999 -9999 -9999 -9999 -9999 -9999 -9999 -9999 -9999 -9999

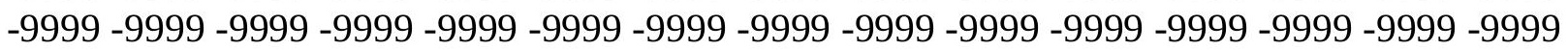

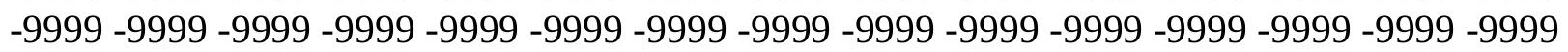


-9999 -9999 -9999

-9999 -9999 -9999 -9999 -9999 -9999 -9999 -9999 -9999 -9999 -9999 -9999 -9999 -9999 -9999

-9999 -9999 -9999 -9999 -9999 -9999 -9999 -9999 -9999 -9999 -9999 -9999 -9999 -9999 - 9999 -

-9999 -9999 -9999 -9999 -9999 -9999 -9999 -9999 -9999 -9999 -9999 -9999 -9999 -9999 -9999

-9999 -9999 -9999 -9999 -9999 -9999 -9999 -9999 -9999 -9999 -9999 -9999-9999 -9999 -9999 -

-9999 -9999 -9999 -9999 -9999 -9999 -9999 -9999 -9999 -9999 -9999 -9999 -9999 -9999 -9999

-9999 -9999 -9999 -9999 -9999 -9999 -9999 -9999 -9999 -9999 -9999 -9999 -9999 -9999 -9999 -999 -

-9999 -9999 -9999 -9999 -9999 -9999 -9999 -9999 -9999 -9999 -9999 -9999 -9999 -9999 -9999

-9999 -9999 -9999 -9999 -9999 -9999 -9999 -9999 -9999 -9999 -9999 -9999 -9999 -9999 -9999 -

-9999 -9999 -9999 -9999 -9999 -9999 -9999 -9999 -9999 -9999 -9999 -9999 -9999 -9999 -9999 -

-9999 -9999 -9999 -9999 -9999 -9999 -9999 -9999 -9999 -9999 -9999 -9999 -9999 -9999 -9999

-9999 -9999 -9999 -9999 -9999 -9999 -9999 -9999 -9999 -9999 -9999 -9999 -9999 -9999 -9999

-9999 -9999 -9999 -9999 -9999 -9999 -9999 -9999 -9999 -9999 -9999 -9999 -9999 -9999 -9999

-9999 -9999 -9999 -9999 -9999 -9999 -9999 -9999 -9999 -9999 -9999 -9999 -9999 -9999 -9999 -

-9999 -9999 -9999 -9999 -9999 -9999 -9999 -9999 -9999 -9999 -9999 -9999 -9999 -9999 -9999

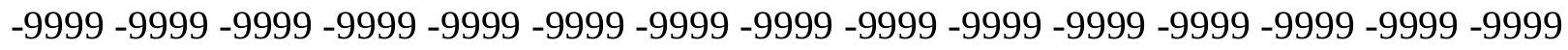

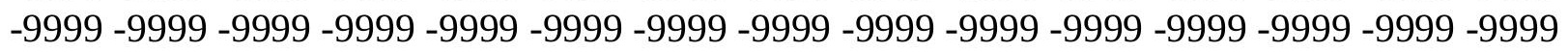

-9999 -9999 -9999 -9999 -9999 -9999 -9999 -9999 -9999 -9999 -9999 -9999 -9999 -9999 -9999 -

-9999 143.2489929199 140.2012023926137.7628936768 137.1533050537136.2389984131

135.3246002197134 .4102020264133 .4958953857132 .8863067627131 .9720001221

131.3623962402130 .7528076172129 .8385009766129 .2288970947128 .6192932129

128.0097961426127 .4001998901126 .7906036377126 .1809997559125 .5715026855

124.9618988037124 .3523025513123 .7427978516123 .1332015991122 .5235977173 121.6092987061120 .6949005127119 .7806015015118 .8662033081117 .342300415

116.1231002808114 .2944030762112 .7705001831110 .9418029785109 .1130981445 107.5891036987106 .0652008057104 .8460998535103 .6268997192103 .0174026489 102.1029968262101 .7982025146101 .4934005737101 .4934005737101 .4934005737 101.7982025146102 .1029968262102 .4077987671103 .0174026489103 .6268997192 104.2365036011105 .4557037354106 .6747970581108 .1986999512109 .7226028442 110.9418029785107 .5891036987105 .7603988647105 .1509017944104 .5412979126 104.2365036011103 .9317016602103 .6268997192103 .3221969604103 .0174026489 102.4077987671102 .712600708103 .0174026489102 .712600708102 .1029968262 101.188697814999 .9695205688598 .445587158297 .2264633178795 .70252990723 94.1785964965892 .6546783447391 .1307525634889 .2150344848687 .77810668945 86.254188537684 .7302627563583 .206336975182 .90155792236 -9999 -9999 -9999 -9999 -9999 -9999 -9999 -9999 -9999 -9999 -9999 -9999 -9999 -9999 -9999 -9999 -9999 -9999 -9999

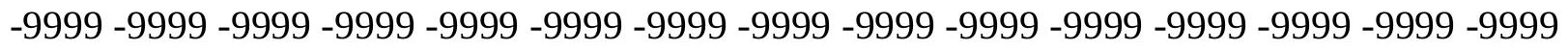

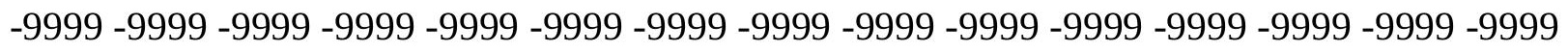
-9999 -9999 -9999 -9999 -9999 -9999 -9999 -9999 -9999 -9999 -9999 -9999 -9999 -9999 -9999 -9999 -9999 -9999 -9999 -9999 -9999 -9999 -9999 -9999 -9999 -9999 -9999 -9999 -9999 -9999 -

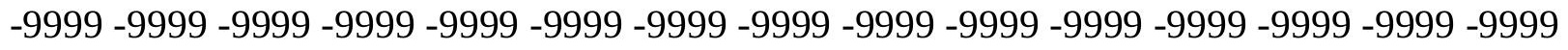

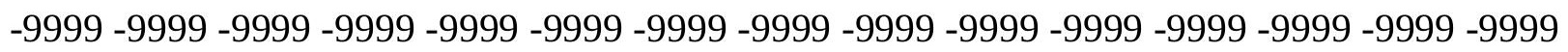

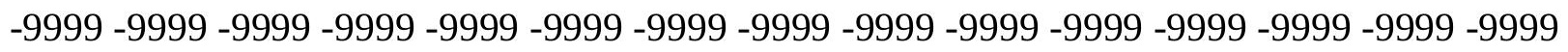
-9999 -9999 -9999 -9999 -9999 -9999 -9999 -9999 -9999 -9999 -9999 -9999 -9999 -9999 -9999 -

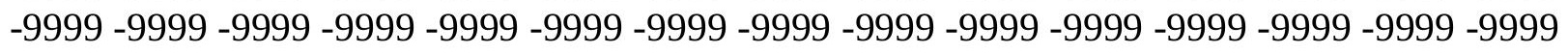

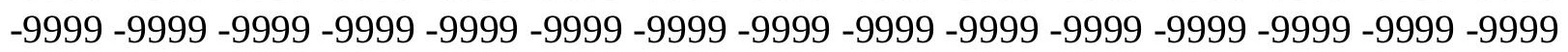


-9999 -9999 -9999 -9999 -9999 -9999 -9999 -9999 -9999 -9999 -9999 -9999 -9999 -9999 -9999 -9999 -9999 -9999 -9999 -9999 -9999 -9999 -9999 -9999 -9999 -9999 -9999 -9999 -9999 -9999 -9999 -9999 -9999 -9999 -9999 -9999 -9999 -9999 -9999 -9999 -9999 -9999 -9999 -9999 -9999 -9999 -9999 -9999 -9999 -9999 -9999 -9999 -9999 -9999 -9999 -9999 -9999 -9999 -9999 -9999 -9999 -9999 -9999 -9999 -9999 -9999 -9999 -9999 -9999 -9999 -9999 -9999 -9999 -9999 -9999 -9999 -9999 -9999 -9999 -9999 -9999 -9999 -9999 -9999 -9999 -9999 -9999 -9999 -9999 -9999 -9999 -9999 -9999 -9999 -9999 -9999 -9999 -9999 -9999 -9999 -9999 -9999 -9999 -9999 -9999

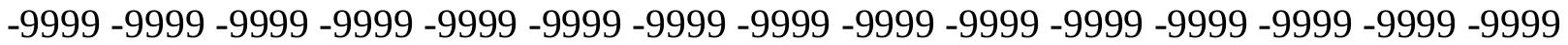
-9999 -9999 -9999 -9999 -9999 -9999 -9999 -9999 -9999 -9999 -9999 -9999 -9999 -9999 -9999 -9999 144.4682006836141.1154937744 137.7628936768 136.8484954834135.9342041016 135.0198059082134 .1054992676133 .4958953857132 .5814971924131 .9720001221 131.3623962402130 .4479980469129 .8385009766129 .2288970947128 .6192932129 128.0097961426127 .4001998901126 .7906036377126 .1809997559125 .5715026855 124.9618988037124 .3523025513123 .7427978516123 .1332015991122 .5235977173 121.9140014648121 .3044967651120 .3900985718119 .1709976196117 .9517974854 116.4279022217114 .5991973877112 .7705001831110 .9418029785108 .8082962036 106.979598999105 .4557037354103 .9317016602103 .0174026489102 .1029968262 101.4934005737100 .8839035034100 .8839035034100 .8839035034100 .8839035034 101.1886978149101 .4934005737102 .1029968262102 .4077987671103 .0174026489 103.9317016602104 .8460998535106 .3700027466107 .8938980103109 .1130981445 109.4179000854108 .1986999512106 .6747970581105 .4557037354104 .8460998535 104.5412979126104 .2365036011103 .6268997192103 .3221969604103 .0174026489 102.712600708102 .712600708103 .0174026489102 .712600708102 .4077987671 101.493400573799 .9695205688598 .7503814697397 .2264633178795 .70252990723 94.1785964965892 .6546783447391 .1307525634889 .6068267822387 .86421203613 86.254188537684 .7302627563583 .206336975182 .90155792236 -9999 -9999 -9999 -9999 -9999 -9999 -9999 -9999 -9999 -9999 -9999 -9999 -9999 -9999 -9999 -9999 -9999 -9999 -9999 -9999 -9999 -9999 -9999 -9999 -9999 -9999 -9999 -9999 -9999 -9999 -9999 -9999 -9999 -9999 -9999 -9999 -9999 -9999 -9999 -9999 -9999 -9999 -9999 -9999 -9999 -9999 -9999 -9999 -9999 -9999 -9999 -9999 -9999 -9999 -9999 -9999 -9999 -9999 -9999 -9999 -9999 -9999 -9999 -9999 -9999 -9999 -9999 -9999 -9999 -9999 -9999 -9999 -9999 -9999 -9999 -9999 -9999 -9999 -9999 -9999 -9999 -9999 -9999 -9999 -9999 -9999 -9999 -9999 -9999 -9999 -9999 -9999 -9999 -9999 -9999 -9999 -9999 -9999 -9999 -9999 -9999 -9999 -9999 -9999 -9999 -9999 -9999 -9999 -9999 -9999 -9999 -9999 -9999 -9999 -9999 -9999 -9999 -9999 -9999 -9999 -9999 -9999 -9999 -9999

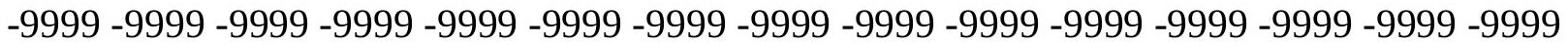
-9999 -9999 -9999 -9999 -9999 -9999 -9999 -9999 -9999 -9999 -9999 -9999 -9999 -9999 -9999 -9999 -9999 -9999 -9999 -9999 -9999 -9999 -9999 -9999 -9999 -9999 -9999 -9999 -9999 -9999

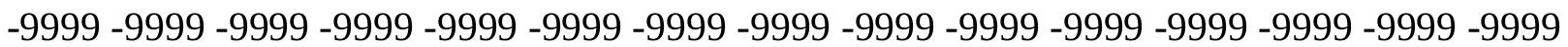
-9999 -9999 -9999 -9999 -9999 -9999 -9999 -9999 -9999 -9999 -9999 -9999 -9999 -9999 -9999 -9999 -9999 -9999 -9999 -9999 -9999 -9999 -9999 -9999 -9999 -9999 -9999 -9999 -9999 -9999 -9999 -9999 -9999 -9999 -9999 -9999 -9999 -9999 -9999 -9999 -9999 -9999 -9999 -9999 -9999

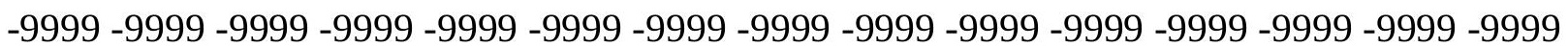
-9999 -9999 -9999 -9999 -9999 -9999 -9999 -9999 -9999 -9999 -9999 -9999 -9999 -9999 -9999 -999 -9999 -9999 -9999 -9999 -9999 -9999 -9999 -9999 -9999 -9999 -9999 -9999 -9999 -9999 -9999 -9999 -9999 -9999 -9999 -9999 -9999 -9999 -9999 -9999 -9999 -9999 -9999 -9999 -9999 -9999

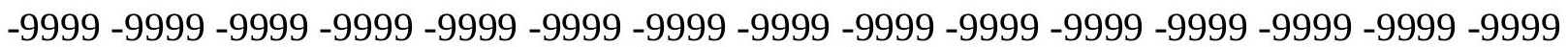


-9999 -9999 139.8963928223136.8484954834135.6293945312135.0198059082 134.4102020264133 .4958953857132 .8863067627132 .2767028809131 .6672058105 131.0576019287130 .4479980469129 .8385009766129 .2288970947128 .6192932129 128.0097961426127 .4001998901126 .7906036377126 .1809997559125 .5715026855 124.9618988037124 .6570968628124 .0475006104123 .43800354122 .8283996582 122.2188034058121 .6092987061120 .6949005127119 .7806015015118 .5614013672 117.0374984741115 .2088012695113 .075302124110 .9418029785108 .5035018921 106.3700027466104 .5412979126103 .3221969604102 .1029968262101 .1886978149 100.5791015625100 .274299621699 .96952056885100 .2742996216100 .2742996216 100.5791015625101 .1886978149101 .4934005737102 .1029968262102 .712600708 103.3221969604104 .5412979126105 .4557037354106 .979598999107 .8938980103 107.8938980103107 .5891036987106 .6747970581105 .7603988647104 .8460998535 104.5412979126104 .2365036011103 .6268997192103 .3221969604103 .0174026489 103.0174026489103 .0174026489103 .0174026489102 .712600708102 .4077987671 101.4934005737100 .274299621698 .7503814697397 .2264633178795 .70252990723 94.1785964965892 .6546783447391 .1307525634889 .6068267822388 .08290100098 86.254188537684 .7302627563583 .206336975182 .90155792236 -9999 -9999 -9999 -9999 -9999 -9999 -9999 -9999 -9999 -9999 -9999 -9999 -9999 -9999 -9999 -9999 -9999 -9999 -9999 -9999 -9999 -9999 -9999 -9999 -9999 -9999 -9999 -9999 -9999 -9999 -9999 -9999 -9999 -9999 -9999 -9999 -9999 -9999 -9999 -9999 -9999 -9999 -9999 -9999 -9999 -9999 -9999 -9999 -9999 -9999 -9999 -9999 -9999 -9999 -9999 -9999 -9999 -9999 -9999 -9999 -9999 -9999 -9999 -9999

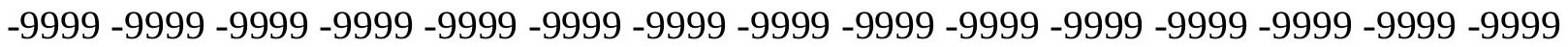
-9999 -9999 -9999 -9999 -9999 -9999 -9999 -9999 -9999 -9999 -9999 -9999 -9999 -9999 -9999 -9999 -9999 -9999 -9999 -9999 -9999 -9999 -9999 -9999 -9999 -9999 -9999 -9999 -9999 -9999 -9999 -9999 -9999 -9999 -9999 -9999 -9999 -9999 -9999 -9999 -9999 -9999 -9999 -9999 -9999 -9999 -9999 -9999 -9999 -9999 -9999 -9999 -9999 -9999 -9999 -9999 -9999 -9999 -9999 -9999 -

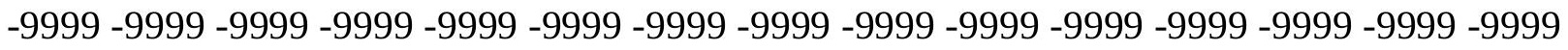

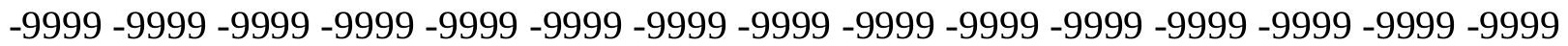
-9999 -9999 -9999 -9999 -9999 -9999 -9999 -9999 -9999 -9999 -9999 -9999 -9999 -9999 -9999

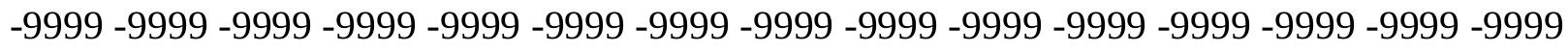
-9999 -9999 -9999 -9999 -9999 -9999 -9999 -9999 -9999 -9999 -9999 -9999 -9999 -9999 -9999

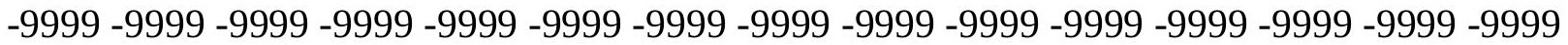

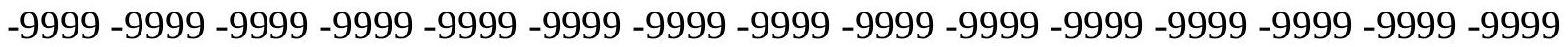
-9999 -9999 -9999 -9999 -9999 -9999 -9999 -9999 -9999 -9999 -9999 -9999 -9999 -9999 -9999 -9999 -9999 -9999 -9999 -9999 -9999 -9999 -9999 -9999 -9999 -9999 -9999 -9999 -9999 -9999 -9999 -9999 -9999 -9999 -9999 -9999 -9999 -9999 -9999 -9999 -9999 -9999 -9999 -9999 -9999

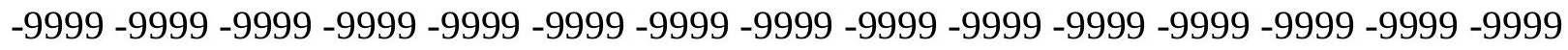
-9999 -9999 138.0677032471 135.3246002197133.8007049561 133.4958953857 133.1911010742132 .8863067627132 .2767028809131 .6672058105131 .3623962402 130.7528076172130 .1432037354129 .533706665128 .9241027832128 .6192932129 128.0097961426127 .4001998901126 .7906036377126 .1809997559125 .5715026855 125.2667007446124 .6570968628124 .0475006104123 .43800354123 .1332015991 122.5235977173121 .9140014648121 .3044967651120 .3900985718119 .1709976196 117.647102356115 .818397522113 .3800964355110 .9418029785108 .1986999512 105.7603988647103 .6268997192102 .1029968262100 .883903503499 .96952056885 99.6647262573299 .3599472045999 .3599472045999 .3599472045999 .66472625732 
100.2742996216100 .5791015625101 .1886978149101 .4934005737102 .1029968262 103.0174026489103 .6268997192104 .8460998535105 .7603988647106 .3700027466 106.6747970581106 .3700027466106 .0652008057105 .4557037354104 .8460998535 104.5412979126104 .2365036011103 .9317016602103 .6268997192103 .3221969604 103.0174026489103 .0174026489102 .712600708102 .712600708102 .4077987671 101.188697814999 .9695205688598 .445587158297 .2264633178795 .70252990723 94.1785964965892 .6546783447391 .1307525634889 .6068267822388 .08290100098 86.5589828491284 .7302627563583 .206336975183 .2063369751 -9999 -9999 -9999 -9999 -9999 -9999 -9999 -9999 -9999 -9999 -9999 -9999 -9999 -9999 -9999 -9999 -9999 -9999 -9999 -9999 -9999 -9999 -9999 -9999 -9999 -9999 -9999 -9999 -9999 -9999 -9999 -9999 -9999 -9999 -9999 -9999 -9999 -9999 -9999 -9999 -9999 -9999 -9999 -9999 -9999 -9999 -9999 -9999 -9999 -999 -9999 -9999 -9999 -9999 -9999 -9999 -9999 -9999 -9999 -9999 -9999 -9999 -9999 -9999 -9999 -999 -9999 -9999 -9999 -9999 -9999 -9999 -9999 -9999 -9999 -9999 -9999 -9999 -9999 -9999 -9999 -9999 -9999 -9999 -9999 -9999 -9999 -9999 -9999 -9999 -9999 -9999 -9999 -9999 -9999 -9999 -9999 -9999 -9999 -9999 -9999 -9999 -9999 -9999 -9999 -9999 -9999 -9999 -9999 -9999 -9999

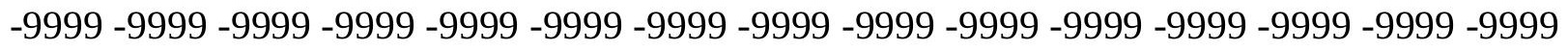
-9999 -9999 -9999 -9999 -9999 -9999 -9999 -9999 -9999 -9999 -9999 -9999 -9999 -9999 -9999 -

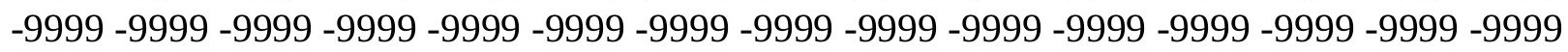

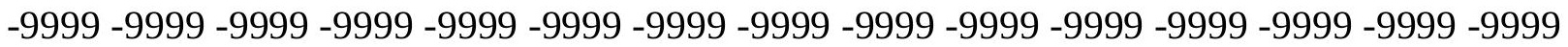

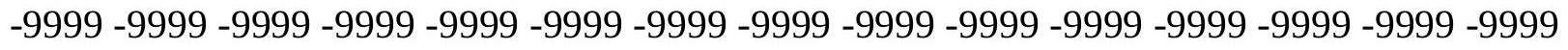

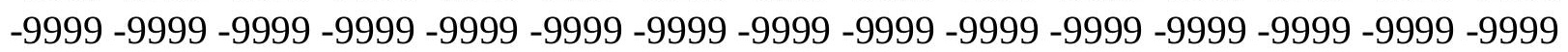

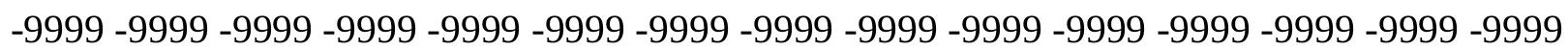
-9999 -9999 -9999 -9999 -9999 -9999 -9999 -9999 -9999 -9999 -9999 -9999 -9999 -9999 -9999 -

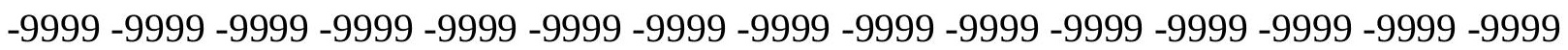

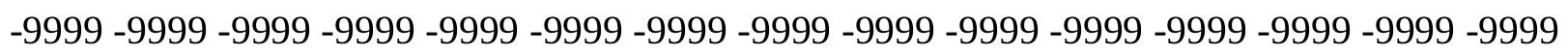
-9999 -9999 -9999 -9999 -9999 -9999 -9999 -9999 -9999 -9999 -9999 -9999 -9999 -9999 -9999 -9999 -9999 -9999 -9999 -9999 -9999 -9999 -9999 -9999 -9999 -9999 -9999 -9999 -9999 - -9999 -

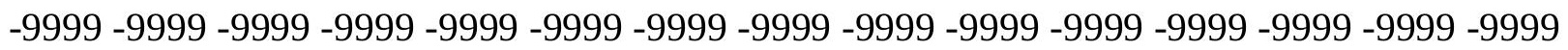
-9999-9999 135.9342041016133.8007049561 132.5814971924132.2767028809 131.9720001221131 .9720001221131 .6672058105131 .3623962402130 .7528076172 130.4479980469129 .8385009766129 .533706665128 .9241027832128 .3144989014 128.0097961426127 .4001998901126 .7906036377126 .1809997559125 .5715026855 125.2667007446124 .6570968628124 .0475006104123 .43800354123 .1332015991 122.5235977173122 .2188034058121 .6092987061120 .9997024536120 .0852966309 118.5614013672116 .4279022217113 .9896011353110 .9418029785107 .8938980103 105.1509017944102 .712600708100 .883903503499 .9695205688599 .05516815186 98.7503814697398 .7503814697398 .7503814697399 .0551681518699 .35994720459 99.6647262573299 .96952056885100 .5791015625101 .1886978149101 .7982025146 102.4077987671103 .0174026489103 .9317016602104 .5412979126105 .1509017944 105.4557037354105 .4557037354105 .4557037354104 .8460998535104 .5412979126 104.5412979126104 .2365036011103 .9317016602103 .6268997192103 .3221969604 103.0174026489102 .712600708102 .4077987671102 .1029968262101 .7982025146 100.883903503499 .6647262573298 .1408081054796 .9216690063595 .3977432251 94.1785964965892 .6546783447391 .1307525634889 .6068267822388 .08290100098 86.2541885376 84.73026275635 83.2063369751 83.2063369751 -9999-9999 -9999 -9999 -9999 -9999 -9999 -9999 -9999 -9999 -9999 -9999 -9999 -9999 -9999 -9999 -9999 -9999 -9999 
-9999 -9999 -9999 -9999 -9999 -9999 -9999 -9999 -9999 -9999 -9999 -9999 -9999 -9999 -9999 -9999 -9999 -9999 -9999 -9999 -9999 -9999 -9999 -9999 -9999 -9999 -9999 -9999 -9999 -9999 -9999 -9999 -9999 -9999 -9999 -9999 -9999 -9999 -9999 -9999 -9999 -9999 -9999 -9999 -9999 -9999 -9999 -9999 -9999 -9999 -9999 -9999 -9999 -9999 -9999 -9999 -9999 -9999 -9999 -9999 -9999 -9999 -9999 -9999 -9999 -9999 -9999 -9999 -9999 -9999 -9999 -9999 -9999 -9999 -9999 -9999 -9999 -9999 -9999 -9999 -9999 -9999 -9999 -9999 -9999 -9999 -9999 -9999 -9999 -9999 -9999 -9999 -9999 -9999 -9999 -9999 -9999 -9999 -9999 -9999 -9999 -9999 -9999 -9999 -9999

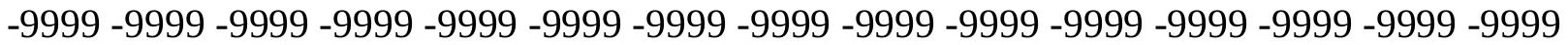
-9999 -9999 -9999 -9999 -9999 -9999 -9999 -9999 -9999 -9999 -9999 -9999 -9999 -9999 -9999 -9999 -9999 -9999 -9999 -9999 -9999 -9999 -9999 -9999 -9999 -9999 -9999 -9999 -9999 -9999 -

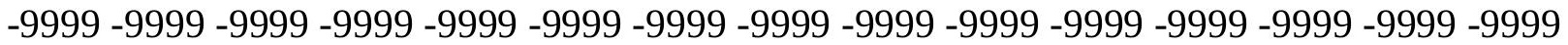
-9999 -9999 -9999 -9999 -9999 -9999 -9999 -9999 -9999 -9999 -9999 -9999 -9999 -9999 -9999

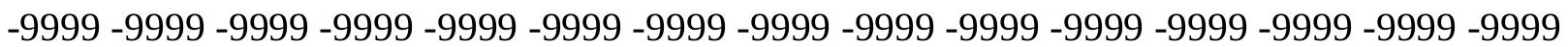
-9999 -9999 -9999 -9999 -9999 -9999 -9999 -9999 -9999 -9999 -9999 -9999 -9999 -9999 -9999 -9999 -9999 -9999 -9999 -9999 -9999 -9999 -9999 -9999 -9999 -9999 -9999 -9999 -9999 -9999 -9999 -9999 -9999 -9999 -9999 -9999 -9999 -9999 -9999 -9999 -9999 -9999 -9999 -9999 -9999 -

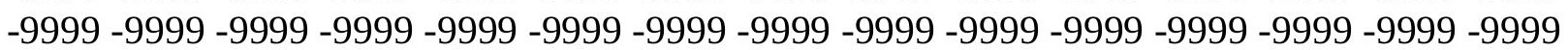
-9999 -9999 -9999 -9999 -9999 -9999 -9999 -9999 -9999 -9999 -9999 -9999 -9999 -9999 -9999 -9999 -9999 -9999 -9999 -9999 -9999 -9999 -9999 -9999 -9999 -9999 -9999 -9999 -9999 -9999 -9999 -9999-9999 133.1911010742131.6672058105 131.3623962402131.0576019287 131.0576019287131 .0576019287130 .7528076172130 .4479980469130 .1432037354 129.533706665129 .2288970947128 .6192932129128 .3144989014127 .7050018311 127.4001998901126 .7906036377126 .1809997559125 .5715026855124 .9618988037 124.6570968628124 .0475006104123 .43800354123 .1332015991122 .5235977173 122.2188034058121 .9140014648121 .6092987061120 .6949005127119 .4757995605 117.342300415114 .5991973877111 .24659729107 .5891036987104 .2365036011 101.493400573799 .6647262573298 .7503814697398 .1408081054798 .14080810547 98.1408081054798 .1408081054798 .445587158298 .7503814697399 .35994720459 99.66472625732100 .2742996216100 .8839035034101 .4934005737102 .1029968262 102.712600708103 .3221969604103 .9317016602104 .2365036011104 .5412979126 104.8460998535104 .8460998535104 .5412979126104 .5412979126104 .2365036011 104.2365036011 103.9317016602 103.6268997192103.3221969604 103.0174026489 102.4077987671101 .7982025146101 .4934005737100 .883903503499 .96952056885 99.0551681518697 .8360290527396 .6168823242295 .397743225193 .87381744385 92.349891662691 .1307525634889 .6068267822387 .7781066894586 .2541885376 84.7302627563583 .206336975183 .2063369751 -9999 -9999 -9999 -9999 -9999 -9999 -9999 -9999 -9999 -9999 -9999 -9999 -9999 -9999 -9999 -9999 -9999 -9999 -9999 -9999 -9999 -9999

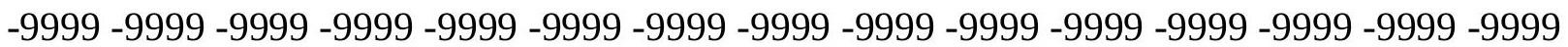
-9999 -9999 -9999 -9999 -9999 -9999 -9999 -9999 -9999 -9999 -9999 -9999 -9999 -9999 -9999 -9999 -9999 -9999 -9999 -9999 -9999 -9999 -9999 -9999 -9999 -9999 -9999 -9999 -9999 -9999 -9999 -9999 -9999 -9999 -9999 -9999 -9999 -9999 -9999 -9999 -9999 -9999

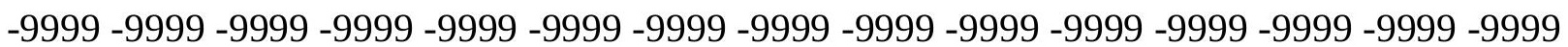
-9999 -9999 -9999 -9999 -9999 -9999 -9999 -9999 -9999 -9999 -9999 -9999 -9999 -9999 -9999 -999 -9999 -9999 -9999 -9999 -9999 -9999 -9999 -9999 -9999 -9999 -9999 -9999 -9999 -9999 -9999 -9999 -9999 -9999 -9999 -9999 -9999 -9999 -9999 -9999 -9999 -9999 -9999 -9999 -9999 -9999

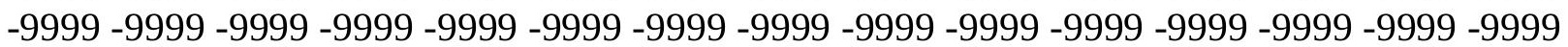


-9999 -9999 -9999 -9999 -9999 -9999 -9999 -9999 -9999 -9999 -9999 -9999 -9999 -9999 -9999 -9999 -9999 -9999 -9999 -9999 -9999 -9999 -9999 -9999 -9999 -9999 -9999 -9999 -9999 -9999 -9999 -9999 -9999 -9999 -9999 -9999 -9999 -9999 -9999 -9999 -9999 -9999 -9999 -9999 -9999 -9999 -9999 -9999 -9999 -9999 -9999 -9999 -9999 -9999 -9999 -9999 -9999 -9999 -9999 -9999 -9999 -9999 -9999 -9999 -9999 -9999 -9999 -9999 -9999 -9999 -9999 -9999 -9999 -9999 -9999 -9999 -9999 -9999 -9999 -9999 -9999 -9999 -9999 -9999 -9999 -9999 -9999 -9999 -9999 -9999 -9999 -9999 -9999 -9999 -9999 -9999 -9999 -9999 -9999 -9999 -9999 -9999 -9999 -9999 -9999

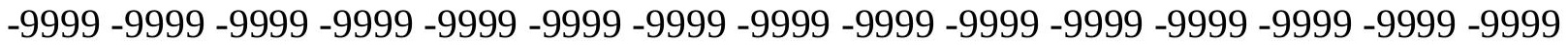

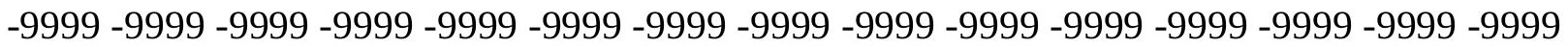
-9999 -9999 -9999 -9999 -9999 -9999 -9999 -9999 -9999 -9999 -9999 -9999 -9999 -9999 -9999 -999 -9999 -9999-9999 133.8007049561 131.9720001221 130.4479980469 130.4479980469 130.4479980469130 .4479980469130 .1432037354130 .1432037354129 .8385009766 129.2288970947 128.9241027832128.6192932129128.3144989014127.7050018311 127.4001998901126 .7906036377126 .1809997559125 .5715026855124 .9618988037 124.3523025513123 .7427978516123 .1332015991122 .8283996582122 .5235977173 122.2188034058122 .2188034058121 .9140014648121 .3044967651120 .3900985718 118.5614013672115 .5136032104111 .24659729107 .2844009399103 .3221969604 100.274299621698 .7503814697397 .8360290527397 .5312423706197 .53124237061 97.5312423706197 .8360290527398 .1408081054798 .445587158298 .75038146973 99.3599472045999 .96952056885100 .5791015625101 .1886978149101 .7982025146 102.1029968262102 .712600708103 .3221969604103 .6268997192103 .9317016602 104.2365036011104 .2365036011104 .2365036011104 .2365036011104 .2365036011 104.2365036011103 .9317016602103 .6268997192103 .6268997192103 .0174026489 102.4077987671101 .1886978149100 .8839035034100 .274299621699 .35994720459 98.445587158297 .5312423706196 .3121032714895 .0929565429793 .87381744385 92.349891662690 .8259735107489 .302040100187 .7781066894586 .2541885376 84.7302627563583 .206336975183 .2063369751 -9999 -9999 -9999 -9999 -9999 -9999 -9999 -9999 -9999 -9999 -9999 -9999 -9999 -9999 -9999 -9999 -9999 -9999 -9999 -9999 -9999 -9999

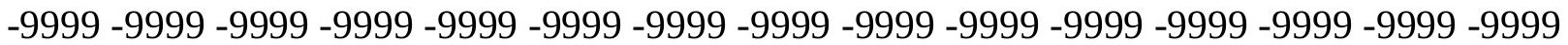
-9999 -9999 -9999 -9999 -9999 -9999 -9999 -9999 -9999 -9999 -9999 -9999 -9999 -9999 -9999 -9999 -9999 -9999 -9999 -9999 -9999 -9999 -9999 -9999 -9999 -9999 -9999

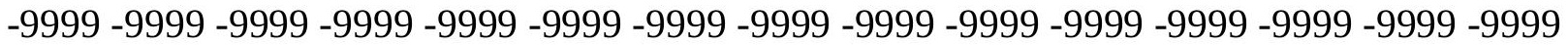
-9999 -9999 -9999 -9999 -9999 -9999 -9999 -9999 -9999 -9999 -9999 -9999 -9999 -9999 -9999 -9999 -9999 -9999 -9999 -9999 -9999 -9999 -9999 -9999 -9999 -9999 -9999 -9999 -9999 -9999 -

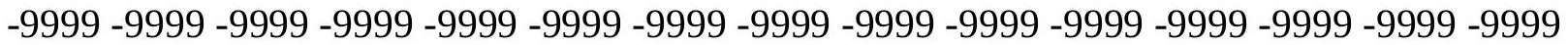
-9999 -9999 -9999 -9999 -9999 -9999 -9999 -9999 -9999 -9999 -9999 -9999 -9999 -9999 -9999 -9999 -9999 -9999 -9999 -9999 -9999 -9999 -9999 -9999 -9999 -9999 -9999 -9999 -9999 -9999

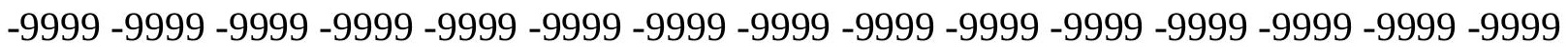
-9999 -9999 -9999 -9999 -9999 -9999 -9999 -9999 -9999 -9999 -9999 -9999 -9999 -9999 -9999 -9999 -9999 -9999 -9999 -9999 -9999 -9999 -9999 -9999 -9999 -9999 -9999 -9999 -9999 -9999 -9999 -9999 -9999 -9999 -9999 -9999 -9999 -9999 -9999 -9999 -9999 -9999 -9999 -9999 -9999 -9999 -9999 -9999 -9999 -9999 -9999 -9999 -9999 -9999 -9999 -9999 -9999 -9999 -9999 -9999 -9999 -9999 -9999 -9999 -9999 -9999 -9999 -9999 -9999 -9999 -9999 -9999 -9999 -9999 -9999 -9999 -9999 -9999 -9999 -9999 -9999 -9999 -9999 -9999 -9999 -9999 -9999 -9999 -9999 -9999 -9999 -9999 -9999 -9999 -9999 -9999 -9999 -9999 -9999 -9999 -9999 -9999 -9999 -9999 -9999

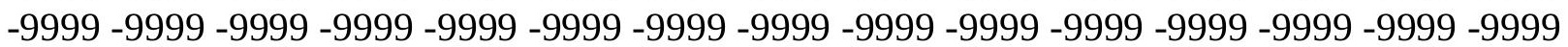


-9999 -9999 -9999 -9999 -9999 -9999 -9999 -9999 -9999 -9999 -9999 -9999 -9999 -9999 -9999 -9999 -9999 -9999-9999 132.5814971924 130.7528076172 130.1432037354 130.1432037354 130.1432037354129 .8385009766129 .8385009766129 .533706665129 .2288970947 128.9241027832128 .6192932129128 .0097961426127 .7050018311127 .0953979492 126.7906036377126 .1809997559125 .5715026855124 .9618988037124 .3523025513 123.7427978516123 .1332015991122 .5235977173121 .9140014648121 .9140014648 121.9140014648121 .9140014648121 .6092987061120 .9997024536119 .4757995605 115.818397522111 .551399231107 .2844009399103 .017402648999 .35994720459 98.14080810547 97.5312423706197.2264633178797.2264633178797.22646331787 97.5312423706197 .8360290527398 .1408081054798 .7503814697399 .05516815186 99.66472625732100 .2742996216100 .8839035034101 .4934005737101 .7982025146 102.4077987671102 .712600708103 .3221969604103 .6268997192103 .9317016602 103.9317016602104 .2365036011104 .2365036011104 .2365036011103 .9317016602 103.9317016602103 .6268997192103 .3221969604103 .0174026489102 .712600708 101.4934005737100 .579101562599 .9695205688599 .0551681518698 .14080810547 97.2264633178796.0073165893694.7881774902393.5690307617292.3498916626 90.8259735107489 .302040100187 .7781066894586 .254188537684 .73026275635 83.206336975183 .2063369751 -9999 -9999 -9999 -9999 -9999 -9999 -9999 -9999 -9999 -9999 -9999 -9999 -9999 -9999 -9999 -9999 -9999 -9999 -9999 -9999 -9999 -9999 -9999 -9999 -9999

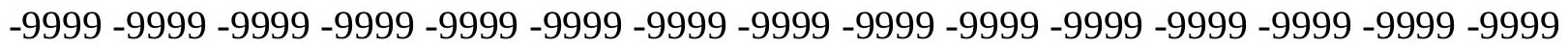
-9999 -9999 -9999 -9999 -9999 -9999 -9999 -9999 -9999

-9999 -9999 -9999 -9999 -9999 -9999 -9999 -9999 -9999 -9999 -9999 -9999 -9999 -9999 -999 -9999 -9999 -9999 -9999 -9999 -9999 -9999 -9999 -9999 -9999 -9999 -9999 -9999 -9999 -9999 -9999 -9999 -9999 -9999 -9999 -9999 -9999 -9999 -9999 -9999 -9999 -9999 -9999 -9999 -9999 -9999 -9999 -9999 -9999 -9999 -9999 -9999 -9999 -9999 -9999 -9999 -9999 -9999 -9999 -9999 -9999 -9999 -9999 -9999 -9999 -9999 -9999 -9999 -9999 -9999 -9999 -9999 -9999 -9999 -9999 -9999 -9999 -9999 -9999 -9999 -9999 -9999 -9999 -9999 -9999 -9999 -9999 -9999 -9999 -9999

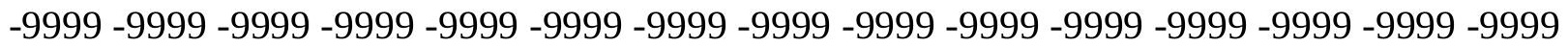
-9999 -9999 -9999 -9999 -9999 -9999 -9999 -9999 -9999 -9999 -9999 -9999 -9999 -9999 -9999 -9999 -9999 -9999 -9999 -9999 -9999 -9999 -9999 -9999 -9999 -9999 -9999 -9999 -9999 -9999 -9999 -9999 -9999 -9999 -9999 -9999 -9999 -9999 -9999 -9999 -9999 -9999 -9999 -9999 -9999

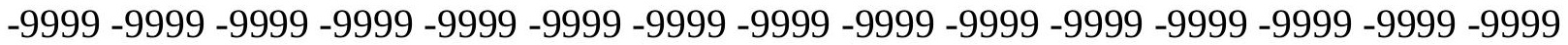

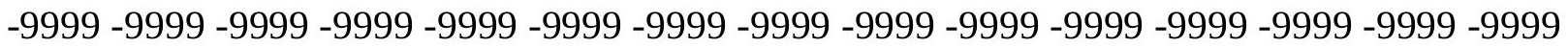
-9999 -9999 -9999 -9999 -9999 -9999 -9999 -9999 -9999 -9999 -9999 -9999 -9999 -9999 -9999 -9999 -9999 -9999 -9999 -9999 -9999 -9999 -9999 -9999 -9999 -9999 -9999 -9999 -9999 -9999 -9999 -9999 -9999 -9999 -9999 -9999 -9999 -9999 -9999 -9999 -9999 -9999 -9999 -9999 -9999

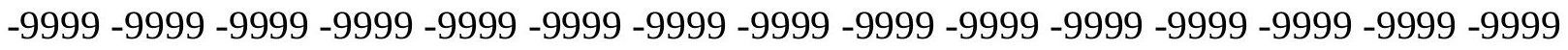

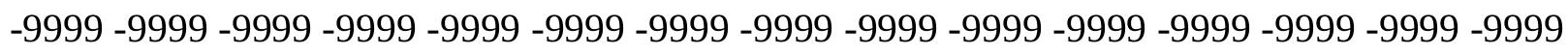
-9999 -9999 -9999 -9999 133.4958953857 131.6672058105130 .1432037354129 .8385009766 129.8385009766129 .533706665129 .533706665129 .2288970947128 .9241027832 128.6192932129128 .3144989014128 .0097961426127 .7050018311127 .0953979492 126.7906036377126 .1809997559125 .5715026855124 .9618988037124 .3523025513 123.43800354122 .8283996582121 .9140014648121 .3044967651121 .3044967651 121.6092987061121 .6092987061121 .3044967651120 .3900985718118 .5614013672 115.5136032104111 .551399231107 .2844009399103 .3221969604100 .2742996216 98.7503814697397 .8360290527397 .2264633178797 .2264633178797 .22646331787 
97.5312423706197 .8360290527398 .1408081054798 .445587158299 .05516815186 99.6647262573299 .96952056885100 .5791015625101 .1886978149101 .7982025146 102.1029968262102 .712600708103 .0174026489103 .3221969604103 .6268997192 103.9317016602103 .9317016602103 .9317016602103 .9317016602103 .9317016602 103.6268997192103 .6268997192103 .3221969604103 .0174026489102 .4077987671 101.4934005737100 .579101562599 .6647262573298 .7503814697397 .83602905273 96.9216690063595 .7025299072394 .7881774902393 .5690307617292 .04509735107 90.5211791992289 .302040100187 .7781066894586 .254188537684 .42548370361 83.206336975182 .90155792236 -9999 -9999 -9999 -9999 -9999 -9999 -9999 -9999 -9999 -9999 -9999 -9999 -9999 -9999 -9999 -9999 -9999 -9999 -9999 -9999 -9999 -9999 -9999 -9999 -9999 -9999 -9999 -9999 -9999 -9999 -9999 -9999 -9999 -9999 -9999 -9999 -9999 -9999 -9999 -9999 -9999 -9999 -9999-9999 -9999-9999 -9999 -9999 -9999

-9999 -9999 -9999 -9999 -9999 -9999 -9999 -9999 -9999 -9999 -9999 -9999 -9999 -9999 -9999 -9999 -9999 -9999 -9999 -9999 -9999 -9999 -9999 -9999 -9999 -9999 -9999 -9999 -9999 - 9999 -9999 -9999 -9999 -9999 -9999 -9999 -9999 -9999 -9999 -9999 -9999 -9999 -9999 -9999 -9999

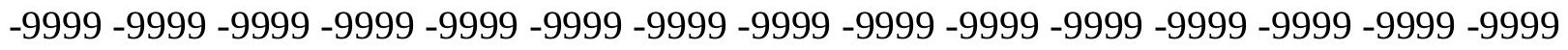
-9999 -9999 -9999 -9999 -9999 -9999 -9999 -9999 -9999 -9999 -9999 -9999 -9999 -9999 -9999 -9999 -9999 -9999 -9999 -9999 -9999 -9999 -9999 -9999 -9999 -9999 -9999 -9999 -9999 -9999 -9999 -9999 -9999 -9999 -9999 -9999 -9999 -9999 -9999 -9999 -9999 -9999 -9999 -9999 -9999 -

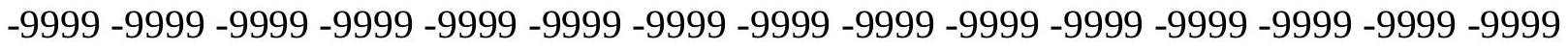

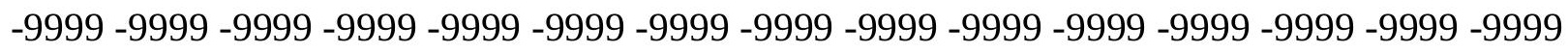
-9999 -9999 -9999 -9999 -9999 -9999 -9999 -9999 -9999 -9999 -9999 -9999 -9999 -9999 -9999 -9999 -9999 -9999 -9999 -9999 -9999 -9999 -9999 -9999 -9999 -9999 -9999 -9999 -9999 -9999 -

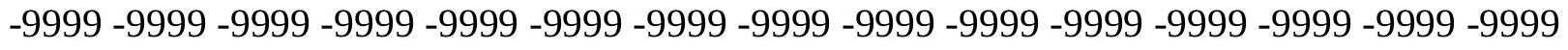

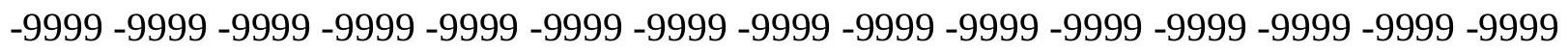
-9999 -9999 -9999 -9999 -9999 -9999 -9999 -9999 -9999 -9999 -9999 -9999 -9999 -9999 -9999 -9999 -9999 -9999 -9999 -9999 -9999 -9999 -9999 -9999 -9999 -9999 -9999 -9999 -9999 -9999

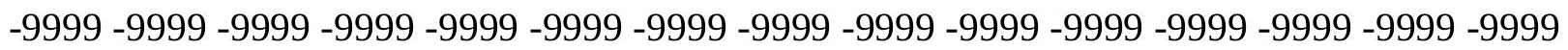

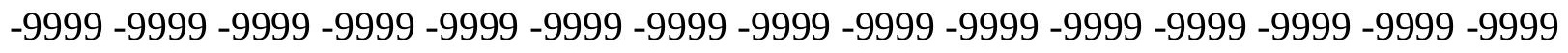
-9999 -9999 -9999 -9999 -9999 132.5814971924130 .4479980469129 .8385009766 129.8385009766129 .533706665129 .2288970947129 .2288970947128 .9241027832 128.6192932129128 .3144989014128 .0097961426127 .7050018311127 .4001998901 126.7906036377126 .1809997559125 .8762969971125 .2667007446124 .3523025513 123.7427978516122 .8283996582121 .6092987061120 .9997024536120 .9997024536 121.3044967651121 .3044967651120 .6949005127119 .7806015015117 .647102356 114.9039993286111 .24659729107 .5891036987104 .2365036011101 .4934005737 99.6647262573298 .445587158297 .8360290527397 .5312423706197 .53124237061 97.5312423706197 .8360290527398 .1408081054798 .445587158299 .05516815186 99.3599472045999 .96952056885100 .5791015625100 .8839035034101 .4934005737 102.1029968262102 .4077987671102 .712600708103 .0174026489103 .3221969604 103.6268997192103 .6268997192103 .9317016602103 .9317016602103 .6268997192 103.6268997192103 .3221969604103 .0174026489102 .712600708102 .1029968262 101.1886978149 100.274299621699.3599472045998.445587158297.53124237061 96.6168823242295 .7025299072394 .4833908081193 .2642517089892 .04509735107 90.5211791992288 .9972534179787 .4733276367285 .9494018554784 .42548370361 82.9015579223682 .90155792236 -9999 -9999 -9999 -9999 -9999 -9999 -9999 -9999 -9999 
-9999 -9999 -9999 -9999 -9999 -9999 -9999 -9999 -9999 -9999 -9999 -9999 -9999 -9999 -9999 -9999 -9999 -9999 -9999 -9999 -9999 -9999 -9999 -9999 -9999 -9999 -9999 -9999 -9999 -9999 -9999 -9999 -9999 -9999 -9999 -9999 -9999 -9999 -9999 -9999

-9999 -9999 -9999 -9999 -9999 -9999 -9999 -9999 -9999 -9999 -9999 -9999 -9999 -9999 -9999 -9999 -9999 -9999 -9999 -9999 -9999 -9999 -9999 -9999-9999 -9999 -9999 -9999 -9999 -9999 -9999 -9999 -9999 -9999 -9999 -9999 -9999 -9999 -9999 -9999 -9999 -9999 -9999 -9999 -9999 -

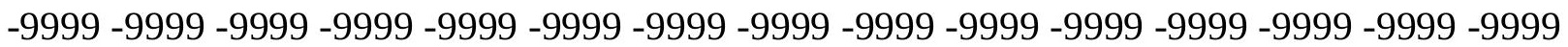

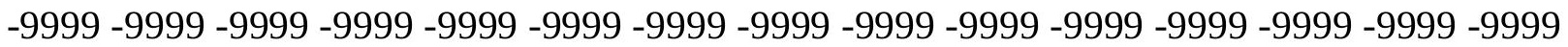
-9999 -9999 -9999 -9999 -9999 -9999 -9999 -9999 -9999 -9999 -9999 -9999 -9999 -9999 -9999 -9999 -9999 -9999 -9999 -9999 -9999 -9999 -9999 -9999 -9999 -9999 -9999 -9999 -9999 -9999

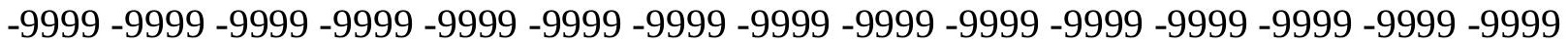
-9999 -9999 -9999 -9999 -9999 -9999 -9999 -9999 -9999 -9999 -9999 -9999 -9999 -9999 -9999 -9999 -9999 -9999 -9999 -9999 -9999 -9999 -9999 -9999 -9999 -9999 -9999 -9999 -9999 -9999 -9999 -9999 -9999 -9999 -9999 -9999 -9999 -9999 -9999 -9999 -9999 -9999 -9999 -9999 - 9999 -9999 -9999 -9999 -9999 -9999 -9999 -9999 -9999 -9999 -9999 -9999 -9999 -9999 -9999 -9999

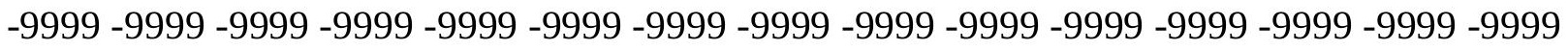
-9999 -9999 -9999 -9999 -9999 -9999 -9999 -9999 -9999 -9999 -9999 -9999 -9999 -9999 -9999 -9999 -9999 -9999 -9999 -9999 -9999 -9999 -9999 -9999 -9999 -9999 -9999 -9999 -9999 -9999 -999 -9999 -9999 -9999 -9999 -9999 -9999 -9999 -9999 -9999 -9999 -9999 -9999 -9999 -9999 -9999 -9999 -9999 -9999 -9999 -9999 -9999 -9999 -9999 -9999 -9999 -9999 -9999 -9999 -9999 -9999 -9999 -9999 -9999 -9999-9999 133.4958953857 131.3623962402129 .8385009766 129.533706665129 .533706665129 .2288970947128 .9241027832128 .9241027832 128.6192932129128 .3144989014128 .0097961426127 .7050018311127 .4001998901 126.7906036377126 .4858016968125 .8762969971125 .2667007446124 .6570968628 123.7427978516122 .8283996582121 .9140014648121 .3044967651121 .3044967651 120.9997024536120 .6949005127120 .0852966309118 .8662033081117 .0374984741 114.2944030762111 .24659729108 .1986999512105 .1509017944102 .712600708 100.579101562599 .3599472045998 .445587158298 .1408081054797 .83602905273 97.8360290527397 .8360290527398 .1408081054798 .445587158299 .05516815186 99.3599472045999 .96952056885100 .2742996216100 .8839035034101 .1886978149 101.7982025146102 .1029968262102 .712600708103 .0174026489103 .3221969604 103.3221969604103 .6268997192103 .6268997192103 .6268997192103 .6268997192 103.3221969604103 .3221969604103 .0174026489102 .4077987671101 .7982025146 101.1886978149100 .274299621699 .3599472045998 .445587158297 .53124237061 96.6168823242295 .7025299072394 .4833908081193 .2642517089891 .74033355713 90.5211791992288 .9972534179787 .4733276367285 .9494018554784 .42548370361 82.9015579223682 .90155792236 -9999 -9999 -9999 -9999 -9999 -9999 -9999 -9999 -9999

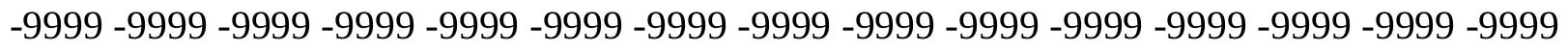
-9999 -9999 -9999 -9999 -9999 -9999 -9999 -9999 -9999 -9999 -9999 -9999 -9999 - 9999 - -9999 -9999 -9999 -9999 -9999 -9999 -9999 -9999 -9999 -9999 -9999

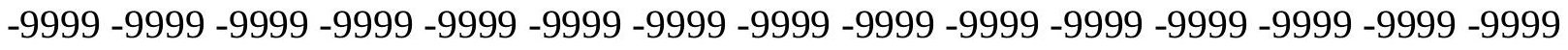

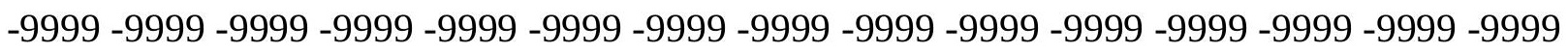
-9999 -9999 -9999 -9999 -9999 -9999 -9999 -9999 -9999 -9999 -9999 -9999 -9999 -9999 -9999 -9999 -9999 -9999 -9999 -9999 -9999 -9999 -9999 -9999-9999 -9999 -9999 -9999 -9999 -9999 -9999 -9999 -9999 -9999 -9999 -9999 -9999 -9999 -9999 -9999 -9999 -9999 -9999 -9999 -9999 -

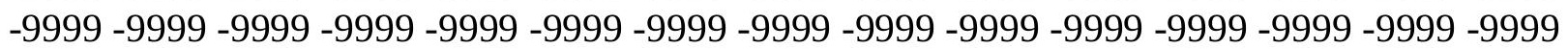


-9999 -9999 -9999 -9999 -9999 -9999 -9999 -9999 -9999 -9999 -9999 -9999 -9999 -9999 -9999 -9999 -9999 -9999 -9999 -9999 -9999 -9999 -9999 -9999 -9999 -9999 -9999 -9999 -9999 -9999 -9999 -9999 -9999 -9999 -9999 -9999 -9999 -9999 -9999 -9999 -9999 -9999 -9999 -9999 -9999 -9999 -9999 -9999 -9999 -9999 -9999 -9999 -9999 -9999 -9999 -9999 -9999 -9999 -9999 -9999 -9999 -9999 -9999 -9999 -9999 -9999 -9999 -9999 -9999 -9999 -9999 -9999 -9999 -9999 -9999 -9999 -9999 -9999 -9999 -9999 -9999 -9999 -9999 -9999 -9999 -9999 -9999 -9999 -9999 -9999 -9999 -9999 -9999 -9999 -9999 -9999 -9999 -9999 -9999 -9999 -9999 -9999 -9999 -9999 -9999

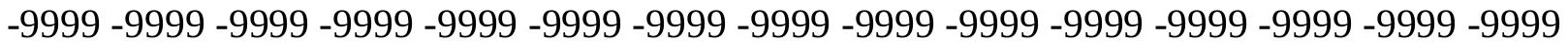
-9999 -9999 -9999 -9999 -9999 -9999 -9999 -9999 -9999 -9999 -9999 -9999 -9999 -9999 -9999 -9999 -9999 -9999 -9999 -9999 -9999 -9999 -9999 -9999 -9999 -9999 -9999 -9999 -9999 -9999 -9999 -9999 -9999 -9999 -9999 -9999 -9999 -9999 -9999 -9999 -9999 -9999 -9999 -9999 -9999 -9999 -9999 -9999 -9999 -9999 -9999 132.5814971924130 .4479980469129 .533706665 129.533706665129 .2288970947128 .9241027832128 .9241027832128 .6192932129 128.3144989014128 .3144989014127 .7050018311127 .4001998901127 .0953979492 126.4858016968126 .1809997559125 .5715026855124 .9618988037124 .0475006104 123.43800354122 .5235977173121 .9140014648121 .6092987061121 .3044967651 120.6949005127119 .7806015015118 .2565994263116 .4279022217113 .9896011353 111.24659729108 .5035018921105 .7603988647103 .6268997192101 .7982025146 100.274299621699 .3599472045998 .7503814697398 .445587158298 .14080810547 98.1408081054798 .445587158298 .7503814697399 .0551681518699 .35994720459 99.96952056885100 .2742996216100 .8839035034101 .1886978149101 .4934005737 102.1029968262102 .4077987671102 .712600708103 .0174026489103 .3221969604 103.3221969604103 .6268997192103 .6268997192103 .6268997192103 .3221969604 103.0174026489102 .712600708102 .4077987671101 .7982025146100 .8839035034 100.274299621699 .3599472045998 .445587158297 .5312423706196 .61688232422 95.397743225194 .4833908081193 .2642517089891 .7403335571390 .52117919922 88.9972534179787 .4733276367285 .9494018554784 .4254837036182 .90155792236 82.90155792236 -9999 -9999 -9999 -9999 -9999 -9999 -9999 -9999 -9999 -9999 -9999 -9999 -9999 -9999 -9999 -9999 -9999 -9999 -9999 -9999 -9999 -9999 -9999 -9999 -9999 -9999 -9999

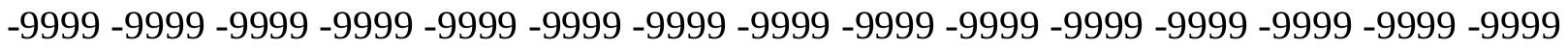
-9999 -9999 -9999 -9999 -9999 -9999 -9999

-9999 -9999 -9999 -9999 -9999 -9999 -9999 -9999 -9999 -9999 -9999 -9999 -9999 -9999 -9999 -9999 -9999 -9999 -9999 -9999 -9999 -9999 -9999 -9999 -9999 -9999 -9999 -9999 -9999 -9999 -9999 -9999 -9999 -9999 -9999 -9999 -9999 -9999 -9999 -9999 -9999 -9999 -9999 -9999 -9999 -

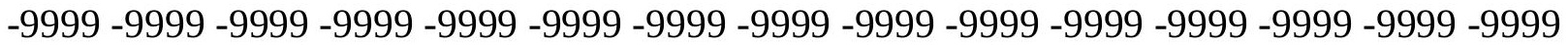
-9999 -9999 -9999 -9999 -9999 -9999 -9999 -9999 -9999 -9999 -9999 -9999 -9999 -9999 -9999 -9999 -9999 -9999 -9999 -9999 -9999 -9999 -9999 -9999 -9999 -9999 -9999 -9999 -9999 -9999

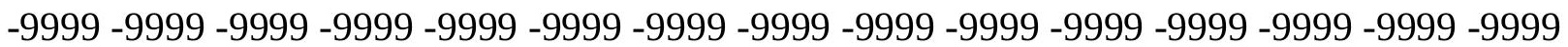
-9999 -9999 -9999 -9999 -9999 -9999 -9999 -9999 -9999 -9999 -9999 -9999 -9999 -9999 -9999 -9999 -9999 -9999 -9999 -9999 -9999 -9999 -9999 -9999 -9999 -9999 -9999 -9999 -9999 -9999 -9999 -9999 -9999 -9999 -9999 -9999 -9999 -9999 -9999 -9999 -9999 -9999 -9999 -9999 -9999 -999 -9999 -9999 -9999 -9999 -9999 -9999 -9999 -9999 -9999 -9999 -9999 -9999 -9999 -9999 -9999 -9999 -9999 -9999 -9999 -9999 -9999 -9999 -9999 -9999 -9999 -9999 -9999 -9999 -9999 -9999 -9999 -9999 -9999 -9999 -9999 -9999 -9999 -9999 -9999 -9999 -9999 -9999 -9999 -9999 -9999 -999 -9999 -9999 -9999 -9999 -9999 -9999 -9999 -9999 -9999 -9999 -9999 -9999 -9999 -9999 -9999

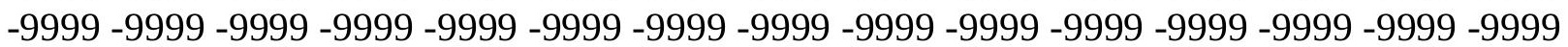


-9999 -9999 -9999 -9999 -9999 -9999 -9999 -9999 -9999 -9999 -9999 -9999 -9999 -9999 -9999 -9999 -9999 -9999 -9999 -9999 -9999 -9999 -9999 -9999 -9999 -9999 -9999 -9999 -9999 -9999 -9999 -9999 -9999 -9999 -9999 -9999 133.4958953857 131.3623962402 129.533706665 129.533706665129 .2288970947129 .2288970947128 .9241027832128 .6192932129 128.6192932129128 .3144989014128 .0097961426127 .7050018311127 .4001998901 126.7906036377126 .4858016968125 .8762969971125 .2667007446124 .3523025513 123.7427978516123 .1332015991122 .5235977173121 .9140014648121 .3044967651 120.6949005127119 .4757995605117 .9517974854116 .1231002808113 .9896011353 111.551399231108 .8082962036106 .6747970581104 .5412979126102 .712600708 101.1886978149100 .274299621699 .3599472045998 .7503814697398 .75038146973 98.445587158298 .7503814697398 .7503814697399 .0551681518699 .35994720459 99.96952056885100 .2742996216100 .5791015625101 .1886978149101 .4934005737 101.7982025146102 .4077987671102 .712600708103 .0174026489103 .0174026489 103.3221969604103 .3221969604103 .3221969604103 .3221969604103 .3221969604 103.0174026489102 .712600708102 .1029968262101 .4934005737100 .8839035034 100.274299621699 .3599472045998 .445587158297 .5312423706196 .61688232422 95.397743225194 .4833908081192 .9594726562591 .7403335571390 .21640014648 88.9972534179787 .4733276367285 .9494018554784 .4254837036182 .90155792236 82.90155792236 -9999 -9999 -9999 -9999 -9999 -9999 -9999 -9999 -9999 -9999 -9999 -9999 -9999 -9999 -9999 -9999 -9999 -9999 -9999 -9999 -9999 -9999 -9999 -9999 -9999 -9999 -9999

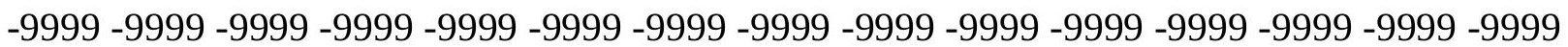
-9999 -9999 -9999-9999-9999-9999-9999 -9999 -9999 -9999 -9999 -9999 -9999 -9999 -9999 -9999 -9999 -9999 -9999 -9999 -9999 -9999 -9999 -9999 -9999 -9999 -9999 -9999 -9999 -9999 -9999 -9999 -9999 -9999 -9999 -9999 -9999

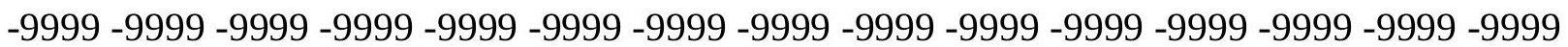
-9999 -9999 -9999 -9999 -9999 -9999 -9999 -9999 -9999 -9999 -9999 -9999 -9999 -9999 -9999 -9999 -9999 -9999 -9999 -9999 -9999 -9999 -9999 -9999 -9999 -9999 -9999 -9999 -9999 -9999 -9999 -9999 -9999 -9999 -9999 -9999 -9999 -9999 -9999 -9999 -9999 -9999 -9999 -9999 -9999 -9999 -9999 -9999 -9999 -9999 -9999 -9999 -9999 -9999 -9999 -9999 -9999 -9999 -9999 -9999 -9999 -9999 -9999 -9999 -9999 -9999 -9999 -9999 -9999 -9999 -9999 -9999 -9999 -9999 -9999 -9999 -9999 -9999 -9999 -9999 -9999 -9999 -9999 -9999 -9999 -9999 -9999 -9999 -9999 -9999 -9999 -9999 -9999 -9999 -9999 -9999 -9999 -9999 -9999 -9999 -9999 -9999 -9999 -9999 -9999 -9999 -9999 -9999 -9999 -9999 -9999 -9999 -9999 -9999 -9999 -9999 -9999 -9999 -9999 -9999 -9999 -9999 -9999 -9999 -9999 -9999 -9999 -9999 -9999 -9999 -9999 -9999 -9999 -9999 -9999 -

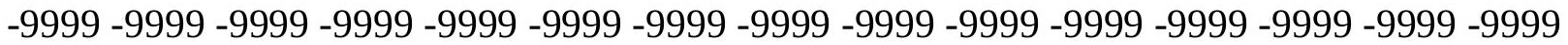
-9999 -9999 -9999 -9999 -9999 -9999 -9999 -9999 -9999 -9999 -9999 -9999 -9999 -9999 -9999 -9999 -9999 -9999 -9999 -9999 -9999 -9999 -9999 -9999 -9999 -9999 -9999 -9999 -9999 -9999

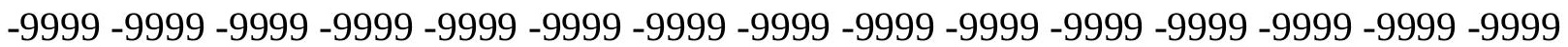
-9999 -9999 -9999 -9999 -9999 -9999 -9999 -9999 -9999 -9999 -9999 -9999 -9999 -9999 -9999 -9999 -9999 -9999 -9999 -9999 -9999 -9999 132.5814971924130 .4479980469129 .533706665 129.2288970947129 .2288970947128 .9241027832128 .9241027832128 .6192932129 128.6192932129128 .3144989014128 .0097961426127 .4001998901127 .0953979492 126.7906036377126 .1809997559125 .5715026855124 .9618988037124 .3523025513 123.7427978516122 .8283996582122 .2188034058121 .6092987061120 .6949005127 119.4757995605117 .9517974854115 .818397522113 .6848983765111 .551399231 109.1130981445106 .979598999105 .1509017944103 .3221969604101 .7982025146 
100.883903503499 .9695205688599 .3599472045999 .0551681518699 .05516815186 99.0551681518699 .0551681518699 .3599472045999 .6647262573299 .96952056885 100.2742996216100 .5791015625101 .1886978149101 .4934005737101 .7982025146 102.1029968262102 .4077987671102 .712600708103 .0174026489103 .3221969604 103.3221969604103 .3221969604103 .3221969604103 .0174026489103 .0174026489 102.712600708102 .1029968262101 .4934005737100 .8839035034100 .2742996216 99.3599472045998.445587158297.5312423706196.61688232422 95.3977432251 94.1785964965892 .9594726562591 .7403335571390 .2164001464888 .99725341797 87.4733276367285 .9494018554784 .4254837036182 .9015579223682 .90155792236 -9999

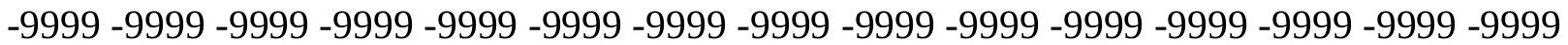

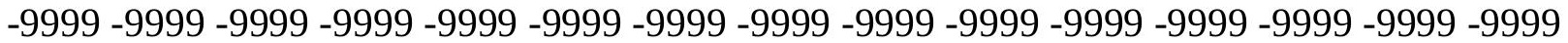

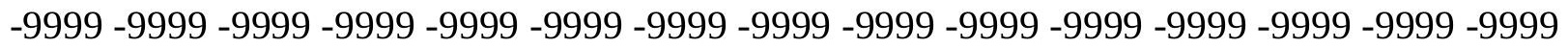
$-9999-9999-9999$

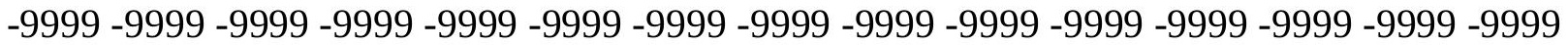

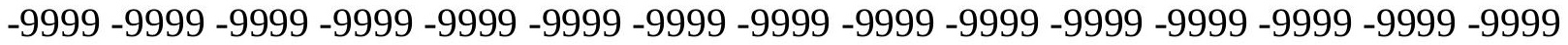

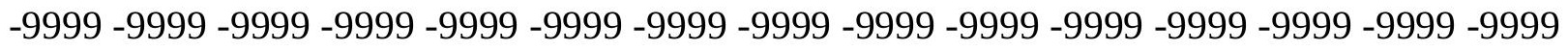

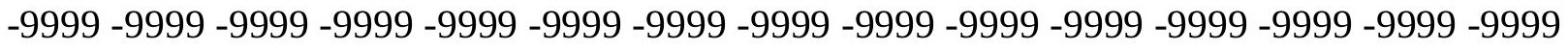

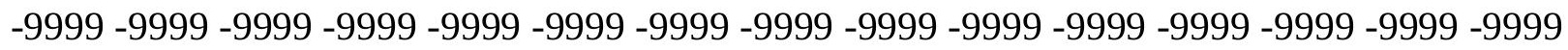

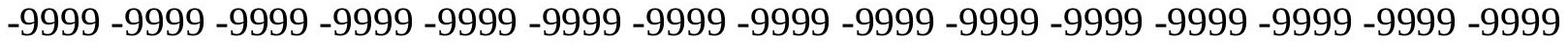

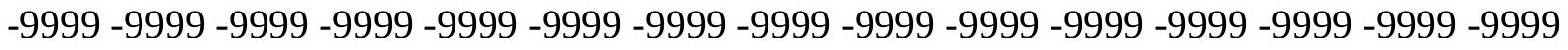

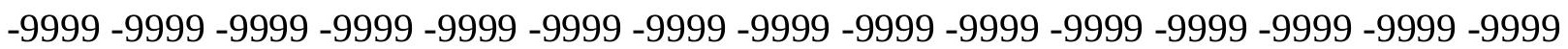

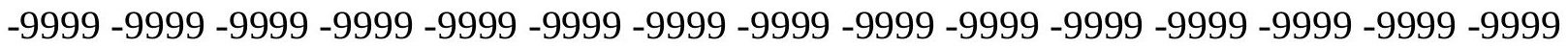

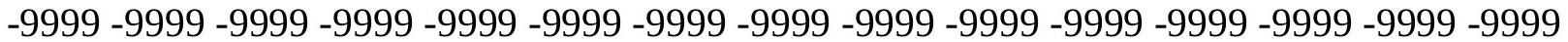

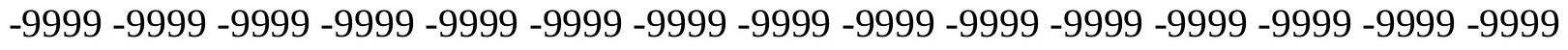

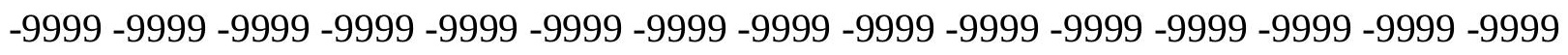

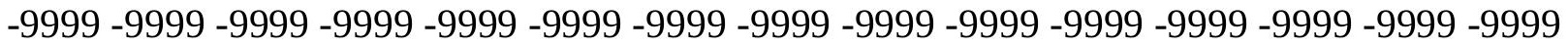

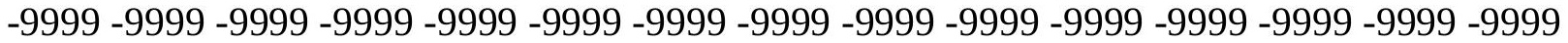

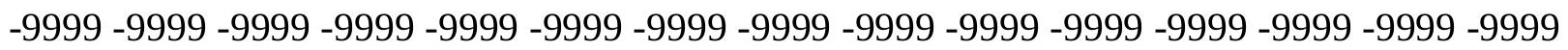

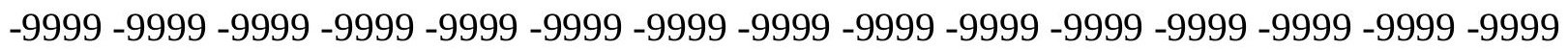

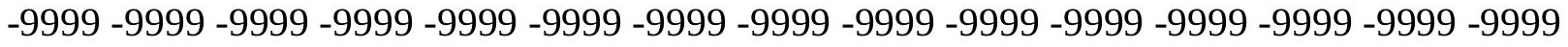
-9999 -9999 -9999 -9999 -9999 -9999 -9999 133.4958953857 131.6672058105 129.8385009766 129.533706665129 .2288970947129 .2288970947128 .9241027832128 .9241027832 128.6192932129128 .6192932129128 .3144989014128 .0097961426127 .4001998901 127.0953979492126 .4858016968125 .8762969971125 .2667007446124 .6570968628 124.0475006104123 .43800354122 .5235977173121 .9140014648120 .6949005127 119.4757995605117 .647102356115 .818397522113 .6848983765111 .551399231 109.4179000854 107.2844009399 105.4557037354 103.9317016602 102.4077987671 101.4934005737100 .579101562599 .9695205688599 .3599472045999 .35994720459 99.0551681518699 .3599472045999 .3599472045999 .6647262573299 .96952056885 100.2742996216100 .5791015625100 .8839035034101 .4934005737101 .7982025146 102.1029968262102 .4077987671102 .712600708103 .0174026489103 .0174026489 103.3221969604103 .3221969604103 .3221969604103 .0174026489103 .0174026489 102.712600708102 .1029968262101 .4934005737100 .8839035034100 .2742996216 99.6647262573298 .7503814697397 .8360290527396 .6168823242295 .3977432251 94.4833908081192 .9594726562591 .7403335571390 .2164001464888 .99725341797 87.4733276367285 .9494018554784 .4254837036182 .9015579223682 .90155792236 -9999 
-9999 -9999 -9999 -9999 -9999 -9999 -9999 -9999 -9999 -9999 -9999 -9999 -9999 -9999 -9999 -9999 -9999 -9999 -9999 -9999 -9999 -9999 -9999 -9999 -9999 -9999 -9999 -9999 -9999 -9999 -9999 -9999 -9999 -9999 -9999 -9999 -9999 -9999 -9999 -9999 -9999 -9999 -9999 -9999 -9999 -9999 -9999-9999

-9999 -9999 -9999 -9999 -9999 -9999 -9999 -9999 -9999 -9999 -9999 -9999 -9999 -9999 -9999 -9999 -9999 -9999 -9999 -9999 -9999 -9999 -9999 -9999 -9999 -9999 -9999 -9999 -9999 -9999 -9999 -9999 -9999 -9999 -9999 -9999 -9999 -9999 -9999 -9999 -9999 -9999 -9999 -9999 -9999 -9999 -9999 -9999 -9999 -9999 -9999 -9999 -9999 -9999 -9999 -9999 -9999 -9999 -9999 -9999

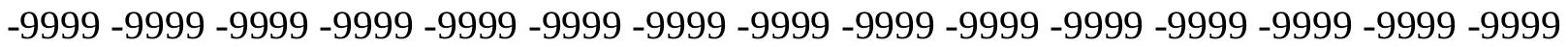
-9999 -9999 -9999 -9999 -9999 -9999 -9999 -9999 -9999 -9999 -9999 -9999 -9999 -9999 -9999 -

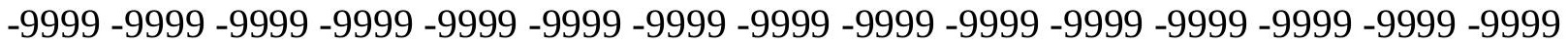
-9999 -9999 -9999 -9999 -9999 -9999 -9999 -9999 -9999 -9999 -9999 -9999 -9999 -9999 -9999 -9999 -9999 -9999 -9999 -9999 -9999 -9999 -9999 -9999 -9999 -9999 -9999 -9999 -9999 -9999 -9999 -9999 -9999 -9999 -9999 -9999 -9999 -9999 -9999 -9999 -9999 -9999 -9999 -9999 -9999 -9999 -9999 -9999 -9999 -9999 -9999 -9999 -9999 -9999 -9999 -9999 -9999 -9999 -9999 -9999

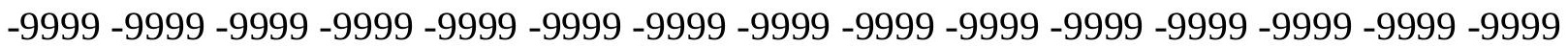

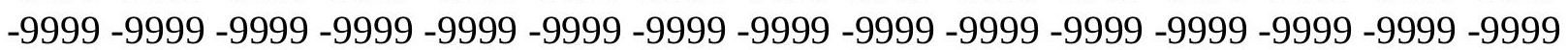
-9999 -9999 -9999 -9999 -9999 -9999 -9999 -9999 -9999 -9999 -9999 -9999 -9999 -9999 -9999 -9999 -9999 -9999 -9999 -9999 -9999 -9999 -9999 -9999 -9999 -9999 -9999 -9999 -9999 -9999 -9999 -9999 -9999 -9999 -9999 -9999 -9999 -9999 -9999 -9999 -9999 -9999 -9999 -9999 -9999 -9999 -9999 -9999 -9999 -9999 -9999 -9999 -9999 -9999 -9999 -9999 -9999 -9999 -9999 -9999 -9999 -9999 -9999 -9999 -9999 -9999 -9999 -9999 132.8863067627130 .7528076172 129.8385009766129 .533706665129 .533706665129 .2288970947129 .2288970947 128.9241027832128 .9241027832128 .6192932129128 .3144989014127 .7050018311 127.4001998901126 .7906036377126 .1809997559125 .5715026855124 .9618988037 124.0475006104123 .43800354122 .8283996582121 .9140014648120 .6949005127 119.1709976196117 .647102356115 .5136032104113 .6848983765111 .551399231 109.4179000854107 .5891036987105 .7603988647104 .2365036011103 .0174026489 101.7982025146100 .8839035034100 .274299621699 .9695205688599 .66472625732 99.3599472045999 .3599472045999 .6647262573299 .6647262573299 .96952056885 100.2742996216100 .5791015625100 .8839035034101 .4934005737101 .7982025146 102.1029968262102 .4077987671102 .712600708102 .712600708103 .0174026489 103.0174026489103 .3221969604103 .3221969604103 .0174026489103 .0174026489 102.712600708102 .1029968262101 .7982025146101 .1886978149100 .2742996216 99.6647262573298 .7503814697397 .8360290527396 .6168823242295 .70252990723 94.4833908081192 .9594726562591 .7403335571390 .2164001464888 .99725341797 87.4733276367285 .9494018554784 .1206970214882 .9015579223682 .90155792236 -9999 -9999 -9999 -9999 -9999 -9999 -9999 -9999 -9999 -9999 -9999 -9999 -9999 -9999 -9999 -9999 -9999 -9999 -9999 -9999 -9999 -9999 -9999 -9999 -9999 -9999 -9999 -9999 -9999 -9999 -9999 -9999 -9999 -9999 -9999 -9999 -9999 -9999 -9999 -9999 -9999 -9999 -9999 -9999 -9999 -9999 $-9999-9999-9999$

-9999 -9999 -9999 -9999 -9999 -9999 -9999 -9999 -9999 -9999 -9999 -9999 -9999 -9999 -9999 -9999 -9999 -9999 -9999 -9999 -9999 -9999 -9999 -9999 -9999 -9999 -9999 -9999 -9999 -9999 -9999 -9999 -9999 -9999 -9999 -9999 -9999 -9999 -9999 -9999 -9999 -9999 -9999 -9999 -9999 -9999 -9999 -9999 -9999 -9999 -9999 -9999 -9999 -9999 -9999 -9999 -9999 -9999 -9999 -9999

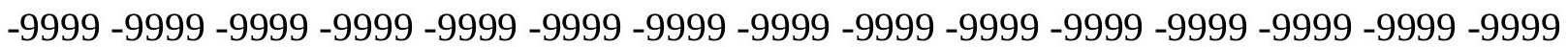


-9999 -9999 -9999 -9999 -9999 -9999 -9999 -9999 -9999 -9999 -9999 -9999 -9999 -9999 -9999 -9999 -9999 -9999 -9999 -9999 -9999 -9999 -9999 -9999 -9999 -9999 -9999 -9999 -9999 -9999 -9999 -9999 -9999 -9999 -9999 -9999 -9999 -9999 -9999 -9999 -9999 -9999 -9999 -9999 -9999 -9999 -9999 -9999 -9999 -9999 -9999 -9999 -9999 -9999 -9999 -9999 -9999 -9999 -9999 -9999 -9999 -9999 -9999 -9999 -9999 -9999 -9999 -9999 -9999 -9999 -9999 -9999 -9999 -9999 -9999 -9999 -9999 -9999 -9999 -9999 -9999 -9999 -9999 -9999 -9999 -9999 -9999 -9999 -9999 -9999 -9999 -9999 -9999 -9999 -9999 -9999 -9999 -9999 -9999 -9999 -9999 -9999 -9999 -9999 -9999

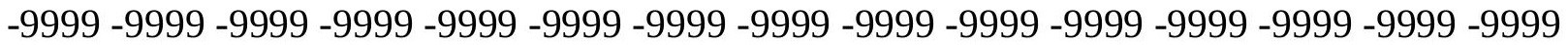
-9999 -9999 -9999 -9999 -9999 -9999 -9999 -9999 -9999 -9999 -9999 -9999 -9999 -9999 -9999 -9999 -9999 -9999 -9999 -9999 -9999 -9999 -9999 -9999 -9999 -9999 -9999 -9999 -9999 -9999 -9999 -9999 -9999 -9999 -9999 -9999 -9999 -9999 -9999 -9999 -9999 -9999 -9999 -9999 -9999 -9999 -9999 -9999 -9999 -9999 -9999 -9999 -9999 -9999 -9999 -9999 -9999 -9999 -9999 -9999 -9999 -9999 -9999-9999 -9999 -9999-9999 -9999 133.8007049561131 .9720001221 130.1432037354129 .8385009766129 .8385009766129 .533706665129 .533706665 129.533706665129 .2288970947128 .9241027832128 .6192932129128 .3144989014 127.7050018311127 .0953979492126 .4858016968125 .5715026855124 .9618988037 124.3523025513123 .43800354122 .5235977173121 .6092987061120 .6949005127 119.1709976196117 .0374984741115 .2088012695113 .3800964355111 .24659729 109.4179000854107 .5891036987106 .0652008057104 .5412979126103 .3221969604 102.1029968262101 .1886978149100 .5791015625100 .274299621699 .96952056885 99.6647262573299 .6647262573299 .6647262573299 .9695205688599 .96952056885 100.2742996216100 .5791015625100 .8839035034101 .1886978149101 .7982025146 102.1029968262102 .4077987671102 .712600708102 .712600708103 .0174026489 103.0174026489103 .0174026489103 .0174026489103 .0174026489103 .0174026489 102.712600708102 .1029968262101 .7982025146101 .1886978149100 .5791015625 99.6647262573298 .7503814697397 .8360290527396 .9216690063595 .70252990723 94.4833908081193 .2642517089891 .7403335571390 .2164001464888 .99725341797 87.4733276367285 .9494018554784 .1206970214882 .9015579223682 .90155792236 -9999 -9999 -9999 -9999 -9999 -9999 -9999 -9999 -9999 -9999 -9999 -9999 -9999 -9999 -9999 -9999

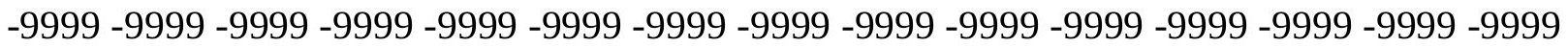
-9999 -9999 -9999 -9999 -9999 -9999 -9999 -9999 -9999 -9999 -9999 -9999 -9999 -9999 -9999 -9999 -9999-9999

-9999 -9999 -9999 -9999 -9999 -9999 -9999 -9999 -9999 -9999 -9999 -9999 -9999 -9999 -9999 -9999 -9999 -9999 -9999 -9999 -9999 -9999 -9999 -9999 -9999 -9999 -9999 -9999 -9999 -9999 -9999 -9999 -9999 -9999 -9999 -9999 -9999 -9999 -9999 -9999 -9999 -9999 -9999 -9999 -9999 -9999 -9999 -9999 -9999 -9999 -9999 -9999 -9999 -9999 -9999 -9999 -9999 -9999 -9999 -9999 -9999 -9999 -9999 -9999 -9999 -9999 -9999 -9999 -9999 -9999 -9999 -9999 -9999 -9999 -9999

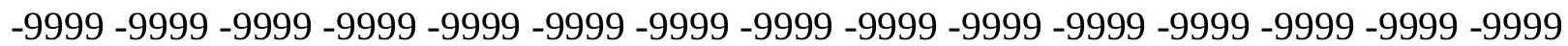
-9999 -9999 -9999 -9999 -9999 -9999 -9999 -9999 -9999 -9999 -9999 -9999 -9999 -9999 -9999 -9999 -9999 -9999 -9999 -9999 -9999 -9999 -9999 -9999 -9999 -9999 -9999 -9999 -9999 -9999 -9999 -9999 -9999 -9999 -9999 -9999 -9999 -9999 -9999 -9999 -9999 -9999 -9999 -9999 -9999 -999 -9999 -9999 -9999 -9999 -9999 -9999 -9999 -9999 -9999 -9999 -9999 -9999 -9999 -9999 -9999 -9999 -9999 -9999 -9999 -9999 -9999 -9999 -9999 -9999 -9999 -9999 -9999 -9999 -9999 -9999 -9999 -9999 -9999 -9999 -9999 -9999 -9999 -9999 -9999 -9999 -9999 -9999 -9999 -9999 -9999 -999 -9999 -9999 -9999 -9999 -9999 -9999 -9999 -9999 -9999 -9999 -9999 -9999 -9999 -9999 -9999

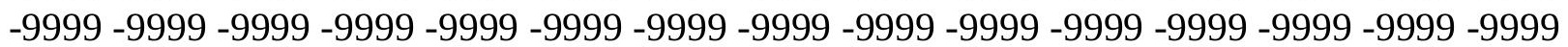


-9999 -9999 -9999 -9999 -9999 -9999 -9999 -9999 -9999 -9999 -9999 -9999 -9999 -9999 -9999 -9999 -9999 -9999 -9999 -9999 -9999 -9999 -9999 -9999 -9999 -9999 -9999 -9999 -9999 -9999 -9999 -9999 -9999 -9999 -9999 -9999 -9999 -9999 -9999 -9999 -9999 -9999 -9999 -9999 -9999 -9999 -9999 -9999 -9999 -9999 -9999 -9999 -9999 -9999 133.1911010742 131.3623962402 130.1432037354130 .1432037354130 .1432037354129 .8385009766129 .8385009766 129.533706665129 .533706665128 .9241027832128 .6192932129128 .0097961426 127.4001998901126 .7906036377125 .8762969971124 .9618988037124 .0475006104 123.1332015991122 .2188034058121 .3044967651120 .0852966309118 .2565994263 116.7326965332114 .5991973877112 .7705001831110 .9418029785109 .1130981445 107.5891036987106 .0652008057104 .5412979126103 .3221969604102 .4077987671 101.4934005737100 .8839035034100 .274299621699 .9695205688599 .96952056885 99.6647262573299 .9695205688599 .96952056885100 .2742996216100 .2742996216 100.5791015625100 .8839035034101 .1886978149101 .7982025146102 .1029968262 102.4077987671102 .4077987671102 .712600708103 .0174026489103 .0174026489 103.0174026489103 .0174026489103 .0174026489103 .0174026489102 .712600708 102.4077987671101 .7982025146101 .1886978149100 .579101562599 .66472625732 98.7503814697397 .8360290527396 .9216690063595 .7025299072394 .48339080811 93.2642517089891 .7403335571390 .2164001464888 .9972534179787 .47332763672 85.9494018554784 .1206970214882 .9015579223682 .90155792236 -9999 -9999 -9999 -9999 -9999 -9999 -9999 -9999 -9999 -9999 -9999 -9999 -9999 -9999 -9999 -9999 -9999 -9999 -9999

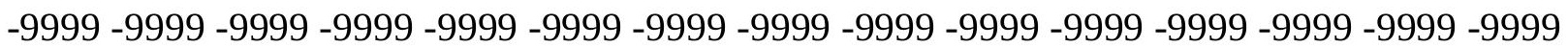
-9999 -9999 -9999 -9999 -9999 -9999 -9999 -9999 -9999 -9999 -9999 -9999 -9999 -9999 -9999 -9999 -9999 -9999 -9999 -9999 -9999 -9999 -9999 -9999 -9999 -9999 -9999 -9999 -9999 -9999 -9999 -9999 -9999 -9999 -9999 -9999 -9999 -9999 -9999 -9999 -9999 -9999 -9999 -9999 -9999

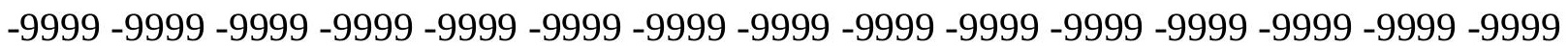
-9999 -9999 -9999 -9999 -9999 -9999 -9999 -9999 -9999 -9999 -9999 -9999 -9999 -9999 -9999 -9999 -9999 -9999 -9999 -9999 -9999 -9999 -9999 -9999 -9999 -9999 -9999 -9999 -9999 -9999 -9999 -9999 -9999 -9999 -9999 -9999 -9999 -9999 -9999 -9999 -9999 -9999 -9999 -9999 -9999 -9999 -9999 -9999 -9999 -9999 -9999 -9999 -9999 -9999 -9999 -9999 -9999 -9999 -9999 -9999 -9999 -9999 -9999 -9999 -9999 -9999 -9999 -9999 -9999 -9999 -9999 -9999 -9999 -9999 -9999 -9999 -9999 -9999 -9999 -9999 -9999 -9999 -9999 -9999 -9999 -9999 -9999 -9999 -9999 -9999 -9999 -9999 -9999 -9999 -9999 -9999 -9999 -9999 -9999 -9999 -9999 -9999 -9999 -9999 -9999 -9999 -9999 -9999 -9999 -9999 -9999 -9999 -9999 -9999 -9999 -9999 -9999 -9999 -9999 -9999 -9999 -9999 -9999 -9999 -9999 -9999 -9999 -9999 -9999 -9999 -9999 -9999 -9999 -9999 -9999 -

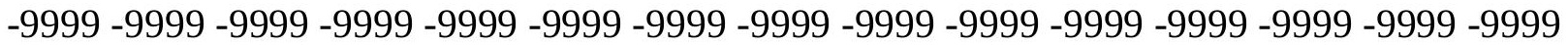
-9999 -9999 -9999 -9999 -9999 -9999 -9999 -9999 -9999 -9999 -9999 -9999 -9999 -9999 -9999 -9999 -9999 -9999 -9999 -9999 -9999 -9999 -9999 -9999 -9999 -9999 -9999 -9999 -9999 -9999

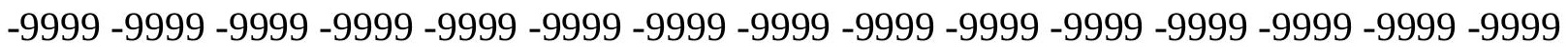
-9999 -9999 -9999 -9999 -9999 -9999 -9999 -9999 -9999 -9999 -9999 -9999 -9999 -9999 -9999 -9999 -9999 -9999 -9999 -9999 -9999 -9999 -9999 -9999 -9999 132.5814971924 131.0576019287130 .4479980469130 .4479980469130 .4479980469130 .4479980469 130.1432037354129 .8385009766129 .533706665128 .9241027832128 .3144989014 127.7050018311126 .7906036377125 .8762969971124 .9618988037123 .7427978516 122.8283996582121 .6092987061120 .3900985718119 .1709976196117 .647102356 115.818397522113 .9896011353112 .1608963013110 .6370010376108 .8082962036 107.2844009399 105.7603988647 104.5412979126103.3221969604 102.4077987671 
101.4934005737100 .8839035034100 .5791015625100 .274299621699 .96952056885 99.9695205688599 .9695205688599 .96952056885100 .2742996216100 .5791015625 100.5791015625100 .8839035034101 .1886978149101 .4934005737101 .7982025146 102.1029968262102 .4077987671102 .712600708103 .0174026489103 .0174026489 103.0174026489103 .0174026489103 .0174026489103 .0174026489102 .712600708 102.4077987671101 .7982025146101 .1886978149100 .579101562599 .96952056885 99.0551681518697 .8360290527396 .9216690063595 .7025299072394 .48339080811 93.2642517089891 .7403335571390 .2164001464888 .9972534179787 .47332763672 85.9494018554784 .1206970214882 .9015579223682 .90155792236 -9999 -9999 -9999 -9999 -9999 -9999 -9999 -9999 -9999 -9999 -9999 -9999 -9999 -9999 -9999 -9999 -9999 -9999 -9999

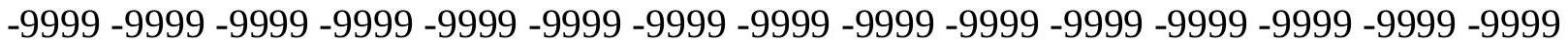
-9999 -9999 -9999 -9999 -9999 -9999 -9999 -9999 -9999 -9999 -9999 -9999 -9999 -9999 -9999 -9999 -9999 -9999 -9999 -9999 -9999 -9999 -9999 -9999 -9999 -9999 -9999 -9999 -9999 -9999 -9999 -9999 -9999 -9999 -9999 -9999 -9999 -9999 -9999 -9999 -9999 -9999 -9999 -9999 - 9999 -9999 -9999 -9999 -9999 -9999 -9999 -9999 -9999 -9999 -9999 -9999 -9999 -9999 -9999 -9999

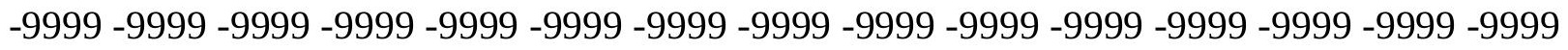
-9999 -9999 -9999 -9999 -9999 -9999 -9999 -9999 -9999 -9999 -9999 -9999 -9999 -9999 -9999 -9999 -9999 -9999 -9999 -9999 -9999 -9999 -9999 -9999 -9999 -9999 -9999 -9999 -9999 -9999 -9999 -9999 -9999 -9999 -9999 -9999 -9999 -9999 -9999 -9999 -9999 -9999 -9999 -9999 -9999 -

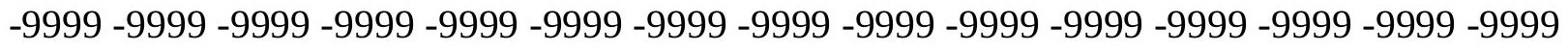
-9999 -9999 -9999 -9999 -9999 -9999 -9999 -9999 -9999 -9999 -9999 -9999 -9999 -9999 -9999 -9999 -9999 -9999 -9999 -9999 -9999 -9999 -9999 -9999 -9999 -9999 -9999 -9999 -9999 -9999 -9999 -9999 -9999 -9999 -9999 -9999 -9999 -9999 -9999 -9999 -9999 -9999 -9999 -9999 -9999 -9999 -9999 -9999 -9999 -9999 -9999 -9999 -9999 -9999 -9999 -9999 -9999 -9999 -9999 -9999 -

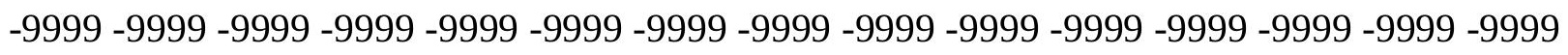
-9999 -9999 -9999 -9999 -9999 -9999 -9999 -9999 -9999 -9999 -9999 -9999 -9999 -9999 -9999 -9999 -9999 -9999 -9999 -9999 -9999 -9999 -9999 -9999 -9999 -9999 -9999 -9999 -9999 -9999 -

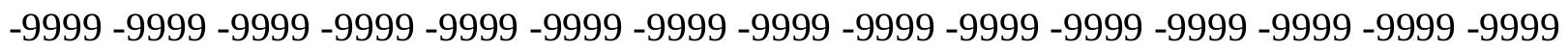
-9999 -9999 -9999 -9999 -9999 -9999 -9999 -9999 -9999 -9999 -9999 -9999 -9999 -9999 -9999 -9999 -9999 -9999 -9999 -9999 -9999 -9999 -9999 -9999 -9999 134.1054992676 132.2767028809130 .7528076172130 .7528076172130 .7528076172130 .7528076172 130.7528076172130 .4479980469130 .1432037354129 .533706665128 .9241027832 128.0097961426126 .7906036377125 .8762969971124 .6570968628123 .43800354 122.2188034058120 .9997024536119 .4757995605117 .9517974854116 .4279022217 114.9039993286113 .075302124111 .551399231110 .0273971558108 .5035018921 106.979598999105 .4557037354104 .2365036011103 .3221969604102 .4077987671 101.4934005737101 .1886978149100 .5791015625100 .274299621699 .96952056885 99.9695205688599 .9695205688599 .96952056885100 .2742996216100 .5791015625 100.8839035034100 .8839035034101 .1886978149101 .4934005737101 .7982025146 102.1029968262102 .4077987671102 .712600708103 .0174026489103 .0174026489 103.0174026489103 .0174026489103 .0174026489103 .0174026489102 .712600708 102.4077987671102 .1029968262101 .4934005737100 .579101562599 .96952056885 99.0551681518698 .1408081054796 .9216690063595 .7025299072394 .48339080811 93.2642517089891 .7403335571390 .2164001464888 .9972534179787 .47332763672 85.9494018554784 .1206970214883 .2063369751 -9999 -9999 -9999 -9999 -9999 -9999 -9999 -9999 -9999 -9999 -9999 -9999 -9999 -9999 -9999 -9999 -9999 -9999 -9999 -9999 -9999 -9999 
-9999 -9999 -9999 -9999 -9999 -9999 -9999 -9999 -9999 -9999 -9999 -9999 -9999 -9999 -9999 -9999 -9999 -9999 -9999 -9999 -9999 -9999 -9999 -9999 -9999 -9999 -9999 -9999 -

-9999 -9999 -9999 -9999 -9999 -9999 -9999 -9999 -9999 -9999 -9999 -9999 -9999 -9999 -9999 -9999 -9999 -9999 -9999 -9999 -9999 -9999 -9999 -9999 -9999 -9999 -9999 -9999 -9999 -9999 -9999 -9999 -9999 -9999 -9999 -9999 -9999 -9999 -9999-9999 -9999 -9999 -9999 -9999 -9999 -9999 -9999 -9999 -9999 -9999 -9999 -9999 -9999 -9999 -9999 -9999 -9999 -9999 -9999 -9999 -

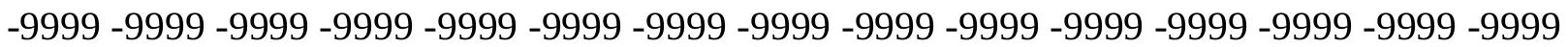

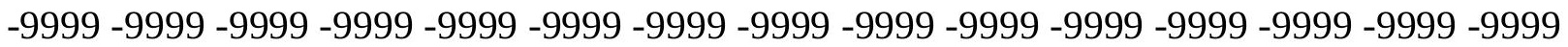

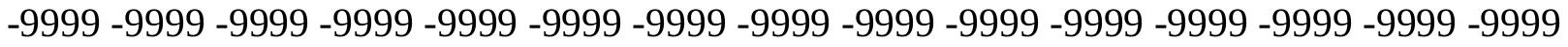
-9999 -9999 -9999 -9999 -9999 -9999 -9999 -9999 -9999 -9999 -9999 -9999 -9999 -9999 -9999 -9999 -9999 -9999 -9999 -9999 -9999 -9999 -9999 -9999 -9999 -9999 -9999 -9999 -9999 -9999 -9999 -9999 -9999 -9999 -9999 -9999 -9999 -9999 -9999 -9999 -9999 -9999 -9999 -9999 -9999 -9999 -9999 -9999 -9999 -9999 -9999 -9999 -9999 -9999 -9999 -9999 -9999 -9999 -9999 -9999 -9999 -9999 -9999 -9999 -9999 -9999 -9999 -9999 -9999 -9999 -9999 -9999 -9999 -9999 - 9999 -9999 -9999 -9999 -9999 -9999 -9999 -9999 -9999 -9999 -9999 -9999 -9999 -9999 -9999 -9999

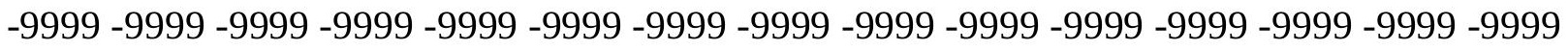
-9999 -9999 -9999 -9999 -9999 -9999 -9999 -9999 -9999 -9999 -9999 -9999 -9999 -9999 -9999 -9999 -9999 -9999 -9999 -9999 -9999 -9999 -9999 -9999 -9999 -9999 -9999 -9999 -9999 -9999 -9999 -9999 -9999 -9999 -9999 -9999 -9999 -9999 -9999 -9999 -9999 -9999 -9999 -9999 -9999 -9999 -9999 -9999 -9999 -9999 -9999 -9999 -9999 -9999-9999-9999 133.8007049561 132.2767028809 131.3623962402 131.3623962402 131.3623962402 131.3623962402 131.0576019287130 .7528076172129 .8385009766129 .2288970947128 .0097961426 127.0953979492125 .5715026855124 .3523025513123 .1332015991121 .6092987061 120.0852966309118 .5614013672117 .0374984741115 .5136032104113 .9896011353 112.1608963013110 .6370010376109 .1130981445107 .5891036987106 .3700027466 105.1509017944103 .9317016602103 .0174026489102 .1029968262101 .4934005737 100.8839035034100 .5791015625100 .274299621699 .9695205688599 .96952056885 99.9695205688599 .96952056885100 .2742996216100 .5791015625100 .8839035034 101.1886978149101 .1886978149101 .4934005737101 .7982025146102 .1029968262 102.4077987671102 .712600708103 .0174026489103 .0174026489103 .0174026489 103.3221969604103 .0174026489103 .0174026489102 .712600708102 .4077987671 102.1029968262101 .4934005737100 .8839035034101 .7982025146100 .8839035034 99.9695205688599 .0551681518697 .8360290527396 .6168823242295 .3977432251 93.8738174438592 .0450973510788 .9972534179787 .4733276367285 .94940185547 84.1206970214883 .2063369751 -9999 -9999 -9999 -9999 -9999 -9999 -9999 -9999 -9999 -9999 -9999 -9999 -9999 -9999 -9999 -9999 -9999 -9999 -9999 -9999 -9999 -9999 -9999 -9999

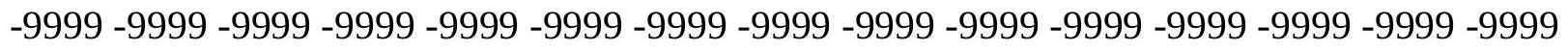
-9999 -9999 -9999 -9999-9999 -9999 -9999 -9999 -9999-9999-9999 -

-9999 -9999 -9999 -9999 -9999 -9999 -9999 -9999 -9999 -9999 -9999 -9999 -9999 -9999 - 9999 -9999 -9999 -9999 -9999 -9999 -9999 -9999 -9999 -9999 -9999 -9999 -9999 -9999 -9999 -9999 -

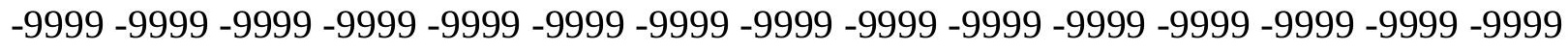

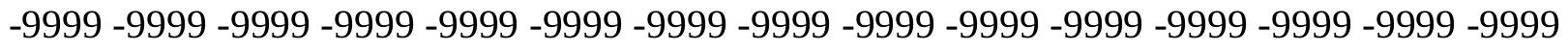
-9999 -9999 -9999 -9999 -9999 -9999 -9999 -9999 -9999 -9999 -9999 -9999 -9999 -9999 -9999 -9999 -9999 -9999 -9999 -9999 -9999 -9999 -9999 -9999-9999 -9999 -9999 -9999 -9999 -9999 -9999 -9999 -9999 -9999 -9999 -9999 -9999 -9999 -9999 -9999 -9999 -9999 -9999 -9999 -9999 -

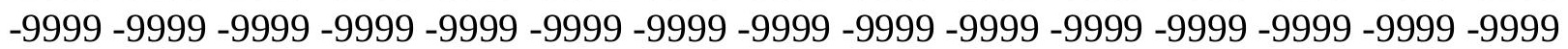


-9999 -9999 -9999 -9999 -9999 -9999 -9999 -9999 -9999 -9999 -9999 -9999 -9999 -9999 -9999 -9999 -9999 -9999 -9999 -9999 -9999 -9999 -9999 -9999 -9999 -9999 -9999 -9999 -9999 -9999 -9999 -9999 -9999 -9999 -9999 -9999 -9999 -9999 -9999 -9999 -9999 -9999 -9999 -9999 -9999 -9999 -9999 -9999 -9999 -9999 -9999 -9999 -9999 -9999 -9999 -9999 -9999 -9999 -9999 -9999 -9999 -9999 -9999 -9999 -9999 -9999 -9999 -9999 -9999 -9999 -9999 -9999 -9999 -9999 -9999 -9999 -9999 -9999 -9999 -9999 -9999 -9999 -9999 -9999 -9999 -9999 -9999 -9999 -9999 -9999 -9999 -9999 -9999 -9999 -9999 -9999 -9999 -9999 -9999 -9999 -9999 -9999 -9999 -9999 -9999 -9999 -9999 -9999 -9999 -9999 -9999 -9999 -9999 -9999 -9999 -9999 -9999 -9999 -9999 -9999 -9999 -9999 -9999 -9999 -9999 -9999 -9999 -9999 -9999 -9999 -9999 -9999 -9999 -9999 -9999 -9999 -9999 -9999 -9999 -9999 -9999 -9999 -9999 -9999 -9999 -9999 135.6293945312 134.1054992676132 .2767028809132 .2767028809132 .2767028809131 .9720001221 131.6672058105131 .0576019287130 .4479980469129 .533706665128 .3144989014 126.7906036377125 .5715026855124 .0475006104122 .2188034058120 .6949005127 119.1709976196117 .647102356115 .818397522114 .2944030762112 .7705001831 111.24659729109 .7226028442108 .1986999512106 .979598999105 .7603988647 104.5412979126103 .6268997192102 .712600708101 .7982025146101 .1886978149 100.8839035034100 .5791015625100 .274299621699 .9695205688599 .96952056885 99.9695205688599 .96952056885100 .2742996216100 .5791015625100 .8839035034 101.1886978149101 .4934005737101 .7982025146101 .7982025146102 .1029968262 102.4077987671102 .712600708103 .0174026489103 .0174026489103 .0174026489 103.3221969604103 .0174026489103 .0174026489102 .712600708102 .4077987671 102.1029968262101 .4934005737102 .4077987671101 .7982025146101 .1886978149 100.274299621699 .3599472045998 .445587158297 .5312423706196 .31210327148 95.0929565429793 .2642517089891 .4355392456187 .4733276367285 .64462280273 84.1206970214883 .2063369751 -9999 -9999 -9999 -9999 -9999 -9999 -9999 -9999 -9999 -9999 -9999 -9999 -9999 -9999 -9999 -9999 -9999 -9999 -9999 -9999 -9999 -9999 -9999 -9999 -9999 -9999 -9999 -9999 -9999 -9999 -9999 -9999 -9999 -9999 -9999 -9999 -9999 -9999 -9999 -9999 -9999 -9999 -9999 -9999 -9999 -9999 -9999 -9999 -9999 -9999 -9999 -9999 -9999 -9999 -9999 -9999 -9999 -9999 -9999 -9999 -9999 -9999 -9999 -9999 -9999 -9999 -9999 -9999 -9999 -9999 -9999 -9999 -9999 -9999 -9999 -9999 -9999 -9999 -9999 -9999 -9999 -9999 -9999 -9999 -9999 -9999 -9999 -9999 -9999 -9999 -9999 -9999 -9999 -9999 -9999 -9999 -9999 -9999 -9999 -9999 -9999 -9999 -9999 -9999 -9999 -9999 -9999 -9999 -9999 -9999 -9999 -9999 -9999 -9999 -9999 -9999 -9999 -9999 -9999 -9999 -9999 -9999 -9999 -9999 -9999 -9999 -9999 -9999 -9999 -9999 -9999 -9999 -9999 -9999 -9999 -9999 -9999 -9999 -9999 -9999

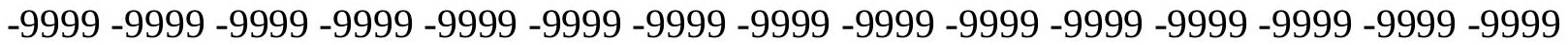
-9999 -9999 -9999 -9999 -9999 -9999 -9999 -9999 -9999 -9999 -9999 -9999 -9999 -9999 -9999 -9999 -9999 -9999 -9999 -9999 -9999 -9999 -9999 -9999 -9999 -9999 -9999 -9999 -9999 -9999

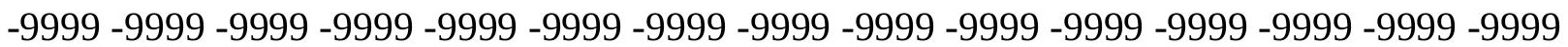
-9999 -9999 -9999 -9999 -9999 -9999 -9999 -9999 -9999 -9999 -9999 -9999 -9999 -9999 -9999 -9999 -9999 -9999 -9999 -9999 -9999 -9999 -9999 -9999 -9999 -9999 -9999 -9999 -9999 -9999 -9999 -9999 -9999 -9999 -9999 -9999 -9999 -9999 -9999 -9999 -9999 -9999 -9999 -9999 -9999

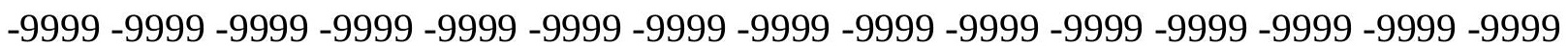
-9999 -9999 -9999 -9999 -9999 -9999 -9999 -9999 -9999 -9999 -9999 -9999 -9999 -9999 -9999 -9999 -9999 -9999 -9999 -9999 -9999 -9999 -9999 -9999 -9999 -9999 -9999 -9999 -9999 -9999 -9999 -9999 -9999 -9999 -9999 -9999 -9999 -9999 -9999 -9999 -9999 -9999 -9999 -9999 -9999 -9999 -9999 -9999 -9999 -9999 -9999 -9999 -9999 -9999 -9999 -9999 -9999 135.9342041016 
134.4102020264133 .1911010742132 .8863067627132 .5814971924132 .2767028809 131.6672058105130 .7528076172129 .533706665128 .3144989014126 .7906036377 124.9618988037123 .43800354121 .6092987061119 .7806015015117 .9517974854 116.4279022217114 .5991973877113 .075302124111 .551399231110 .0273971558 108.8082962036107 .2844009399106 .0652008057104 .8460998535103 .9317016602 103.0174026489102 .1029968262101 .4934005737100 .8839035034100 .5791015625 100.274299621699 .9695205688599 .9695205688599 .9695205688599 .96952056885 99.96952056885100 .2742996216100 .5791015625100 .8839035034101 .1886978149 101.4934005737101 .7982025146101 .7982025146102 .1029968262102 .4077987671 102.712600708103 .0174026489103 .0174026489103 .0174026489103 .0174026489 103.0174026489103 .0174026489103 .0174026489102 .712600708102 .1029968262 101.7982025146102 .4077987671102 .1029968262101 .1886978149100 .5791015625 99.6647262573298 .7503814697397 .8360290527396 .9216690063595 .70252990723 93.8738174438591 .4355392456187 .1685485839885 .6446228027384 .12069702148 83.2063369751 -9999 -9999 -9999 -9999 -9999 -9999 -9999 -9999 -9999 -9999 -9999 -9999 -9999 -9999 -9999 -9999 -9999 -9999 -9999 -9999 -9999 -9999 -9999 -9999 -9999 -9999 -9999

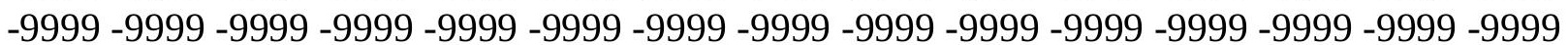
-9999 -9999 -9999 -9999 -9999 -9999-9999 -9999 -9999 -9999 -9999 -9999 -9999 -9999 -9999 -9999 -9999 -9999 -9999 -9999 -9999 -9999 -9999 -9999 -9999 -9999 -9999 -9999 -9999 -9999 -9999 -9999 -9999 -9999 -9999 -9999 -9999 -9999

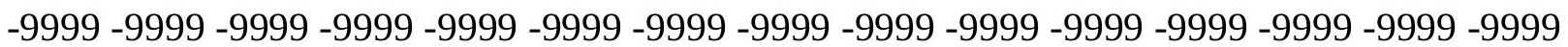
-9999 -9999 -9999 -9999 -9999 -9999 -9999 -9999 -9999 -9999 -9999 -9999 -9999 -9999 -9999 -9999 -9999 -9999 -9999 -9999 -9999 -9999 -9999 -9999 -9999 -9999 -9999 -9999 -9999 -9999 -9999 -9999 -9999 -9999 -9999 -9999 -9999 -9999 -9999 -9999 -9999 -9999 -9999 -9999 -9999

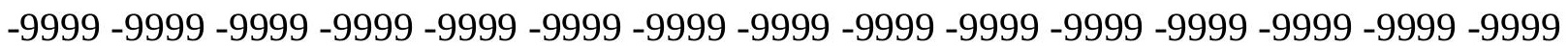
-9999 -9999 -9999 -9999 -9999 -9999 -9999 -9999 -9999 -9999 -9999 -9999 -9999 -9999 -9999 -9999 -9999 -9999 -9999 -9999 -9999 -9999 -9999 -9999 -9999 -9999 -9999 -9999 -9999 -9999 -9999 -9999 -9999 -9999 -9999 -9999 -9999 -9999 -9999 -9999 -9999 -9999 -9999 -9999 -9999 -9999 -9999 -9999 -9999 -9999 -9999 -9999 -9999 -9999 -9999 -9999 -9999 -9999 -9999 -9999 -9999 -9999 -9999 -9999 -9999 -9999 -9999 -9999 -9999 -9999 -9999 -9999 -9999 -9999 -9999 -9999 -9999 -9999 -9999 -9999 -9999 -9999 -9999 -9999 -9999 -9999 -9999 -9999 -9999 -9999 -9999 -9999 -9999 -9999 -9999 -9999 -9999 -9999 -9999 -9999 -9999 -9999 -9999 -9999 -9999 -9999 -9999 -9999 -9999 -9999 -9999 -9999 -9999 -9999 -9999 -9999 -9999 -9999 -9999 -9999 -9999 -9999 -9999 -9999 -9999 -9999 -9999 -9999 -9999 -9999 -9999 -9999 -9999 -9999 -9999

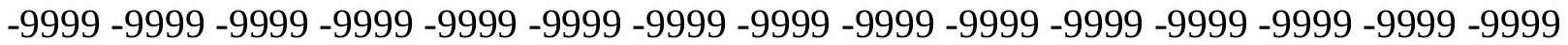
-9999 -9999 -9999 -9999 -9999 -9999 -9999 -9999 -9999 -9999 -9999 -9999 -9999 136.5437011719135 .0198059082133 .4958953857133 .1911010742132 .8863067627 132.2767028809131 .0576019287129 .8385009766128 .3144989014126 .4858016968 124.6570968628122 .5235977173120 .6949005127118 .5614013672116 .7326965332 115.2088012695113 .3800964355111 .8561019897110 .3321990967108 .8082962036 107.5891036987106 .3700027466105 .1509017944104 .2365036011103 .3221969604 102.4077987671101 .7982025146101 .1886978149100 .5791015625100 .2742996216 99.9695205688599 .9695205688599 .6647262573299 .6647262573299 .96952056885 99.96952056885100 .2742996216100 .5791015625100 .8839035034101 .1886978149 101.4934005737101 .7982025146102 .1029968262102 .1029968262102 .4077987671 102.712600708103 .0174026489103 .0174026489103 .0174026489103 .0174026489 
103.0174026489103.0174026489102.712600708 102.712600708 102.1029968262 101.7982025146100 .8839035034101 .7982025146101 .1886978149100 .5791015625 99.6647262573299 .0551681518698 .1408081054797 .2264633178796 .00731658936 94.4833908081191 .7403335571387 .1685485839885 .6446228027384 .12069702148 83.2063369751 -9999 -9999 -9999 -9999 -9999 -9999 -9999-9999 -9999 -9999 -9999 -9999 -9999 -9999 -9999 -9999 -9999 -9999 -9999 -9999 -9999 -9999 -9999 -9999 -9999 -9999 -9999

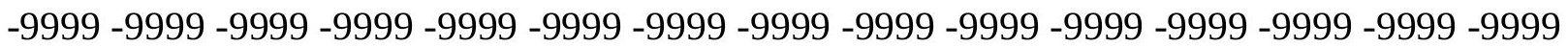
-9999 -9999 -9999 -9999 -9999 -9999 -9999 -9999

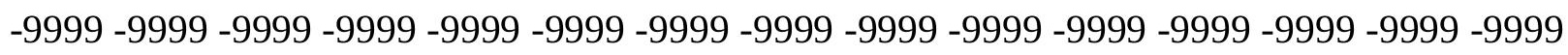
-9999 -9999 -9999 -9999 -9999 -9999 -9999 -9999 -9999 -9999 -9999 -9999 -9999 -9999 -9999 -

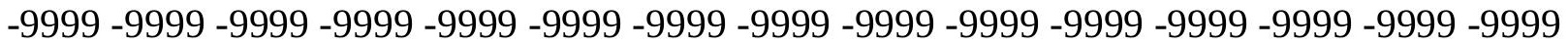
-9999 -9999 -9999 -9999 -9999 -9999 -9999 -9999 -9999 -9999 -9999 -9999 -9999 -9999 -9999 -9999 -9999 -9999 -9999 -9999 -9999 -9999 -9999 -9999 -9999 -9999 -9999 -9999 -9999 -9999 -9999 -9999 -9999 -9999 -9999 -9999 -9999 -9999 -9999 -9999 -9999 -9999 -9999 -9999 -9999 -9999 -9999 -9999 -9999 -9999 -9999 -9999 -9999 -9999 -9999 -9999 -9999 -9999 -9999 -9999

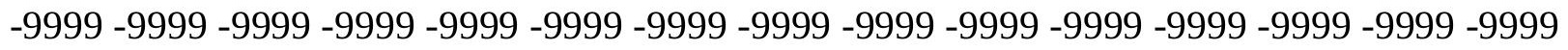
-9999 -9999 -9999 -9999 -9999 -9999 -9999 -9999 -9999 -9999 -9999 -9999 -9999 -9999 -9999 -

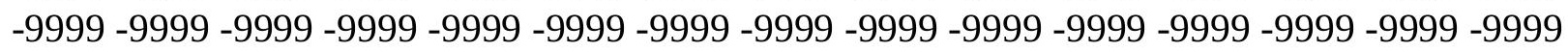

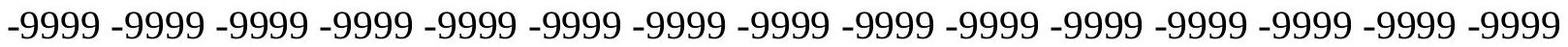

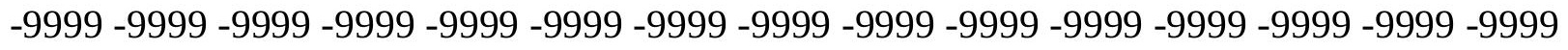
-9999 -9999 -9999 -9999 -9999 -9999 -9999 -9999 -9999 -9999 -9999 -9999 -9999 -9999 -9999 -999 -

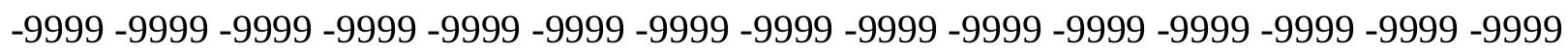
-9999 -9999 -9999 -9999 -9999 -9999 -9999 -9999 -9999 -9999 -9999 -9999 -9999 -9999 -9999 -9999 -9999 -9999 -9999 -9999 -9999 -9999 -9999 -9999 -9999 -9999 -9999 -9999 -9999 -9999 -

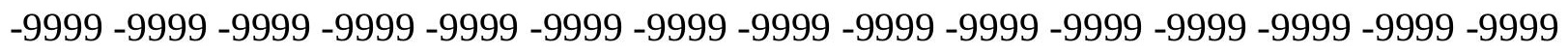
-9999 -9999 -9999 -9999 -9999 -9999 -9999 -9999 -9999 -9999 -9999 -9999 -9999 -9999 137.4580993652135 .6293945312133 .8007049561133 .1911010742132 .5814971924 131.3623962402129 .8385009766128 .0097961426125 .8762969971123 .7427978516 121.6092987061119 .4757995605117 .342300415115 .5136032104113 .6848983765 111.8561019897110 .3321990967108 .8082962036107 .5891036987106 .3700027466 105.1509017944104 .2365036011103 .3221969604102 .4077987671101 .7982025146 101.1886978149100 .5791015625100 .274299621699 .9695205688599 .66472625732 99.6647262573299 .6647262573299 .6647262573299 .6647262573299 .96952056885 100.2742996216100 .5791015625100 .5791015625100 .8839035034101 .4934005737 101.7982025146102 .1029968262102 .1029968262102 .4077987671102 .712600708 103.0174026489103.0174026489103.0174026489103.0174026489103.0174026489 103.0174026489102.712600708 102.4077987671 102.1029968262 101.7982025146 100.883903503499 .96952056885100 .8839035034100 .274299621699 .66472625732 98.7503814697398 .1408081054797 .5312423706196 .6168823242295 .09295654297 92.6546783447389 .6068267822385 .6446228027383 .8159103393683 .2063369751 -9999 -9999 -9999 -9999 -9999 -9999 -9999 -9999 -9999 -9999 -9999 -9999 -9999 -9999 -9999 -9999

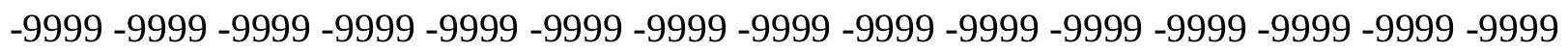

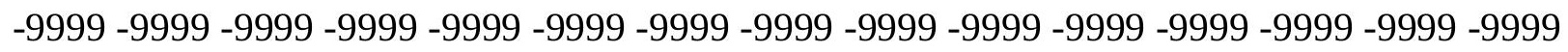
-9999 -9999 -9999-9999

-9999 -9999 -9999 -9999 -9999 -9999 -9999 -9999 -9999 -9999 -9999 -9999 -9999 -9999 -9999

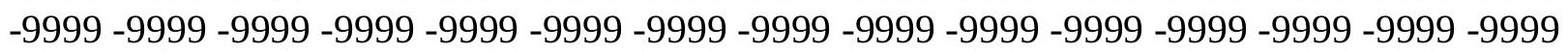


-9999 -9999 -9999 -9999 -9999 -9999 -9999 -9999 -9999 -9999 -9999 -9999 -9999 -9999 -9999 -9999 -9999 -9999 -9999 -9999 -9999 -9999 -9999 -9999 -9999 -9999 -9999 -9999 -9999 -9999 -9999 -9999 -9999 -9999 -9999 -9999 -9999 -9999 -9999 -9999 -9999 -9999 -9999 -9999 -9999 -9999 -9999 -9999 -9999 -9999 -9999 -9999 -9999 -9999 -9999 -9999 -9999 -9999 -9999 -9999 -9999 -9999 -9999 -9999 -9999 -9999 -9999 -9999 -9999 -9999 -9999 -9999 -9999 -9999 -9999 -9999 -9999 -9999 -9999 -9999 -9999 -9999 -9999 -9999 -9999 -9999 -9999 -9999 -9999 -9999 -9999 -9999 -9999 -9999 -9999 -9999 -9999 -9999 -9999 -9999 -9999 -9999 -9999 -9999 -9999

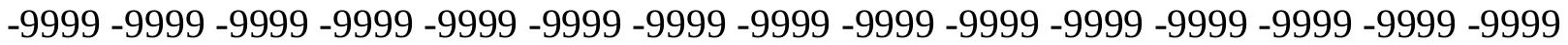
-9999 -9999 -9999 -9999 -9999 -9999 -9999 -9999 -9999 -9999 -9999 -9999 -9999 -9999 -9999 -9999 -9999 -9999 -9999 -9999 -9999 -9999 -9999 -9999 -9999 -9999 -9999 -9999 -9999 -9999 -

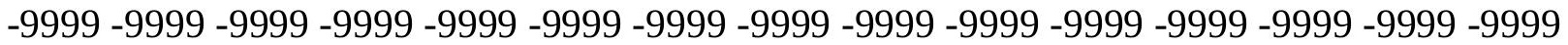
-9999 -9999 -9999 -9999 -9999 -9999 -9999 -9999 -9999 -9999 -9999 -9999 -9999 -9999 -9999

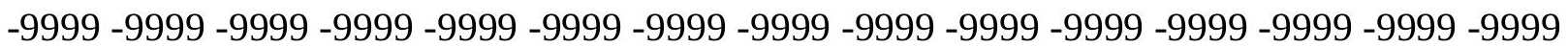
-9999 -9999 -9999 -9999 -9999 -9999 -9999 -9999 -9999 -9999 -9999 -9999 -9999 -9999 -9999 -9999 -9999 -9999 -9999 -9999 -9999 -9999 -9999 -9999 -9999 -9999 -9999 -9999 -9999 -9999 -9999 -9999 -9999 -9999 -9999 -9999 -9999 -9999 -9999 -9999 -9999 -9999 -9999 -9999 -9999 138.3724975586135 .9342041016133 .4958953857132 .8863067627131 .3623962402 129.8385009766127 .7050018311125 .2667007446122 .8283996582120 .3900985718 118.2565994263115 .818397522113 .9896011353112 .1608963013110 .3321990967 108.8082962036107 .2844009399106 .0652008057104 .8460998535103 .9317016602 103.0174026489102 .1029968262101 .4934005737100 .8839035034100 .2742996216 99.9695205688599 .6647262573299 .6647262573299 .3599472045999 .35994720459 99.3599472045999 .3599472045999 .6647262573299 .9695205688599 .96952056885 100.2742996216100 .5791015625100 .8839035034101 .1886978149101 .7982025146 102.1029968262102 .1029968262102 .4077987671102 .712600708103 .0174026489 103.0174026489103 .0174026489103 .0174026489103 .0174026489102 .712600708 102.4077987671102 .1029968262101 .7982025146101 .7982025146100 .8839035034 99.9695205688598 .7503814697399 .6647262573299 .0551681518698 .75038146973 98.1408081054797 .5312423706196 .9216690063595 .7025299072394 .17859649658 91.1307525634885 .3398437583 .8159103393682 .90155792236 -9999 -9999 -9999 -9999 -9999 -9999 -9999 -9999 -9999 -9999 -9999 -9999 -9999 -9999 -9999 -9999 -9999 -9999 -9999 -9999 -9999 -9999 -9999 -9999 -9999 -9999 -9999 -9999 -9999 -9999 -9999 -9999 -9999 -9999

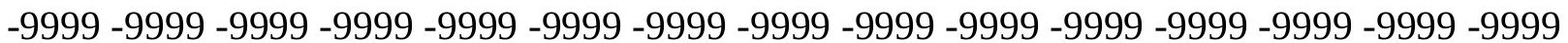
$-9999$

-9999 -9999 -9999 -9999 -9999 -9999 -9999 -9999 -9999 -9999 -9999 -9999 -9999 -9999 -9999 -9999 -9999 -9999 -9999 -9999 -9999 -9999 -9999 -9999 -9999 -9999 -9999 -9999 -9999 -9999 -9999 -9999 -9999 -9999 -9999 -9999 -9999 -9999 -9999 -9999 -9999 -9999 -9999 -9999 -9999

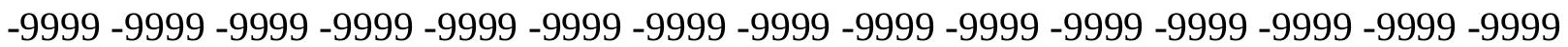
-9999 -9999 -9999 -9999 -9999 -9999 -9999 -9999 -9999 -9999 -9999 -9999 -9999 -9999 -9999 -9999 -9999 -9999 -9999 -9999 -9999 -9999 -9999 -9999 -9999 -9999 -9999 -9999 -9999 -9999 -9999 -9999 -9999 -9999 -9999 -9999 -9999 -9999 -9999 -9999 -9999 -9999 -9999 -9999 -9999

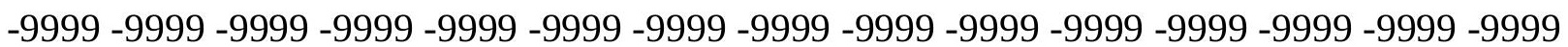
-9999 -9999 -9999 -9999 -9999 -9999 -9999 -9999 -9999 -9999 -9999 -9999 -9999 -9999 -9999 -9999 -9999 -9999 -9999 -9999 -9999 -9999 -9999 -9999 -9999 -9999 -9999 -9999 -9999 -9999 -9999 -9999 -9999 -9999 -9999 -9999 -9999 -9999 -9999 -9999 -9999 -9999 -9999 -9999 -9999

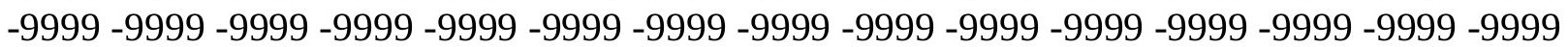


-9999 -9999 -9999 -9999 -9999 -9999 -9999 -9999 -9999 -9999 -9999 -9999 -9999 -9999 -9999 -9999 -9999 -9999 -9999 -9999 -9999 -9999 -9999 -9999 -9999 -9999 -9999 -9999 -9999 -9999 -9999 -9999 -9999 -9999 -9999 -9999 -9999 -9999 -9999 -9999 -9999 -9999 -9999 -9999 -9999 -9999 -9999 -9999 -9999 -9999 -9999 -9999 -9999 -9999 -9999 -9999 -9999 -9999 -9999 -9999 -9999 -9999 -9999 -9999 -9999 -9999 -9999 -9999 -9999 -9999 -9999 -9999 -9999 -9999 -9999 -9999 -9999 -9999 -9999 -9999 -9999 -9999 -9999 -9999 -9999 -9999 -9999 -9999 -9999 -9999 -9999 138.9819946289 135.6293945312 132.5814971924131.3623962402129.533706665 127.0953979492124 .3523025513121 .6092987061119 .1709976196116 .4279022217 114.2944030762112 .1608963013110 .3321990967108 .5035018921107 .2844009399 105.7603988647104 .5412979126103 .6268997192102 .712600708101 .7982025146 101.1886978149100 .579101562599 .9695205688599 .6647262573299 .35994720459 99.3599472045999 .0551681518699 .0551681518699 .0551681518699 .05516815186 99.3599472045999 .3599472045999 .6647262573299 .96952056885100 .2742996216 100.5791015625100 .8839035034101 .1886978149101 .7982025146102 .1029968262 102.1029968262102 .4077987671102 .712600708102 .712600708103 .0174026489 103.0174026489103 .0174026489102 .712600708102 .4077987671102 .1029968262 101.4934005737101 .1886978149100 .8839035034100 .274299621699 .66472625732 98.7503814697397 .5312423706198 .7503814697398 .445587158297 .83602905273 97.5312423706196 .9216690063596 .3121032714895 .0929565429793 .26425170898 88.0829010009883 .5111236572382 .90155792236 -9999 -9999 -9999 -9999 -9999 -9999 -9999 -9999 -9999 -9999 -9999 -9999 -9999 -9999 -9999 -9999 -9999 -9999 -9999 -9999 -9999 -9999 -9999 -9999 -9999 -9999 -9999 -9999 -9999 -9999 -9999 -9999 -9999 -9999 -9999-999 - -9999 -9999 -9999 -9999 -9999 -9999 -9999 -9999 -9999 -9999 -9999 -9999 -9999 -9999 -9999 -9999 -9999 -9999 -9999 -9999 -9999 -9999 -9999 -9999 -9999 -9999 -9999 -9999 -9999

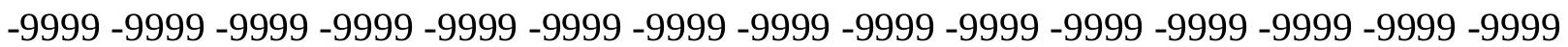
-9999 -9999 -9999 -9999 -9999 -9999 -9999 -9999 -9999 -9999 -9999 -9999 -9999 -9999 -9999 -9999 -9999 -9999 -9999 -9999 -9999 -9999 -9999 -9999 -9999 -9999 -9999 -9999 -9999 -9999 -9999 -9999 -9999 -9999 -9999 -9999 -9999 -9999 -9999 -9999 -9999 -9999 -9999 -9999 -9999 -9999 -9999 -9999 -9999 -9999 -9999 -9999 -9999 -9999 -9999 -9999 -9999 -9999 -9999 -9999 -9999 -9999 -9999 -9999 -9999 -9999 -9999 -9999 -9999 -9999 -9999 -9999 -9999 -9999 -9999 -9999 -9999 -9999 -9999 -9999 -9999 -9999 -9999 -9999 -9999 -9999 -9999 -9999 -9999 -9999 -

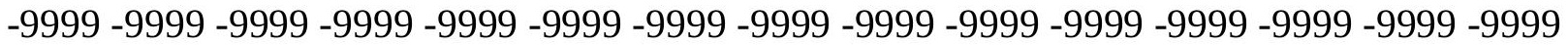
-9999 -9999 -9999 -9999 -9999 -9999 -9999 -9999 -9999 -9999 -9999 -9999 -9999 -9999 -9999 -9999 -9999 -9999 -9999 -9999 -9999 -9999 -9999 -9999 -9999 -9999 -9999 -9999 -9999 -9999 -9999 -9999 -9999 -9999 -9999 -9999 -9999 -9999 -9999 -9999 -9999 -9999 -9999 -9999 -9999 -9999 -9999 -9999 -9999 -9999 -9999 -9999 -9999 -9999 -9999 -9999 -9999 -9999 -9999 -9999 -9999 -9999 -9999 -9999 -9999 -9999 -9999 -9999 -9999 -9999 -9999 -9999 -9999 -9999 -9999

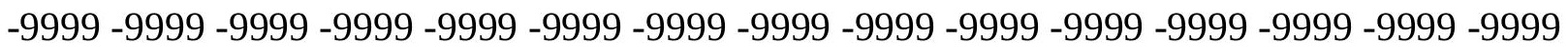
-9999 -9999 -9999 -9999 -9999 -9999 -9999 -9999 -9999 -9999 -9999 -9999 -9999 -9999 -9999 -9999 -9999 -9999 -9999 -9999 -9999 -9999 -9999 -9999 -9999 -9999 -9999 -9999 -9999 -9999 -9999 -9999 -9999 -9999 -9999 -9999 -9999 -9999 -9999 -9999 -9999 -9999 -9999 -9999 -9999 -9999 -9999 138.6772003174134.7149963379 131.0576019287 128.6192932129 126.1809997559123 .1332015991120 .0852966309117 .342300415114 .5991973877 112.4656982422110 .3321990967108 .5035018921106 .979598999105 .4557037354 104.2365036011103 .0174026489102 .1029968262101 .4934005737100 .5791015625 99.9695205688599 .6647262573299 .3599472045999 .0551681518698 .75038146973 
98.7503814697398 .7503814697398 .7503814697398 .7503814697399 .05516815186 99.0551681518699 .3599472045999 .6647262573299 .96952056885100 .2742996216 100.5791015625100 .8839035034101 .1886978149101 .4934005737102 .1029968262 102.1029968262102 .4077987671102 .712600708102 .712600708103 .0174026489 103.0174026489102 .712600708102 .712600708102 .4077987671101 .7982025146 101.1886978149100 .2742996216100 .274299621699 .9695205688599 .35994720459 98.445587158297 .5312423706198 .445587158298 .1408081054797 .83602905273 97.2264633178796 .9216690063596 .0073165893695 .0929565429792 .65467834473 89.302040100183 .206336975182 .59677124023 -9999 -9999 -9999 -9999 -9999 -9999 -9999 -9999 -9999 -9999 -9999 -9999 -9999 -9999 -9999 -9999 -9999 -9999 -9999 -9999 -9999 -9999

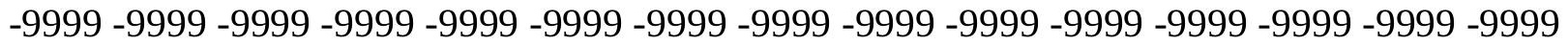
-9999 -9999 -9999 -9999 -9999 -9999 -9999 -9999 -9999 -9999 -9999 -9999 -9999 -

-9999 -9999 -9999 -9999 -9999 -9999 -9999 -9999 -9999 -9999 -9999 -9999 -9999 -9999 -9999 -9999 -9999 -9999 -9999 -9999 -9999 -9999 -9999 -9999 -9999 -9999 -9999 -9999 -9999 -9999 -9999 -9999 -9999 -9999 -9999 -9999 -9999 -9999 -9999 -9999 -9999 -9999 -9999 -9999 -9999

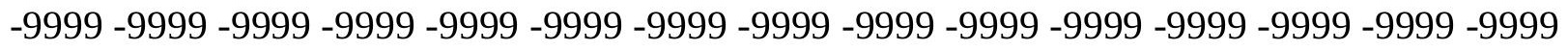

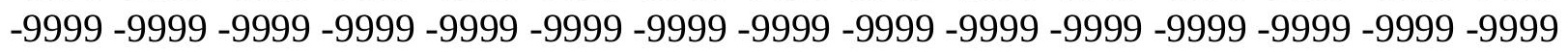

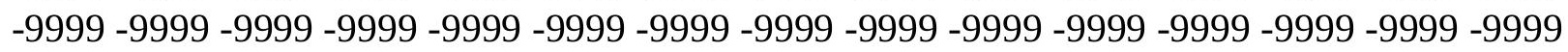
-9999 -9999 -9999 -9999 -9999 -9999 -9999 -9999 -9999 -9999 -9999 -9999 -9999 -9999 -9999 -999 -

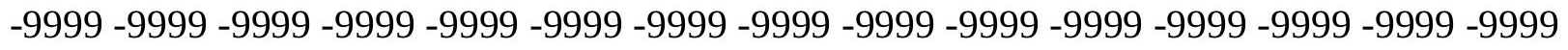

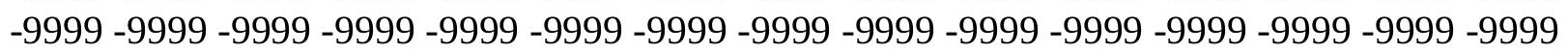

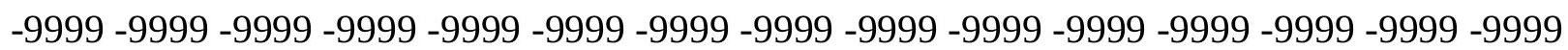
-9999 -9999 -9999 -9999 -9999 -9999 -9999 -9999 -9999 -9999 -9999 -9999 -9999 -9999 -9999 -9999 -9999 -9999 -9999 -9999 -9999 -9999 -9999 -9999 -9999 -9999 -9999 -9999 -9999 -9999 -

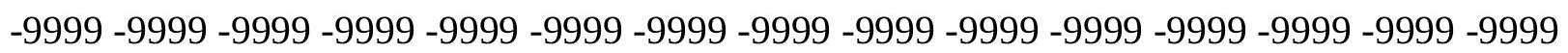
-9999 -9999 -9999 -9999 -9999 -9999 -9999 -9999 -9999 -9999 -9999 -9999 -9999 -9999 -9999 -9999 -9999 -9999 -9999 -9999 -9999 -9999 -9999 -9999 -9999 -9999 -9999 -9999 -9999 - -9999 -

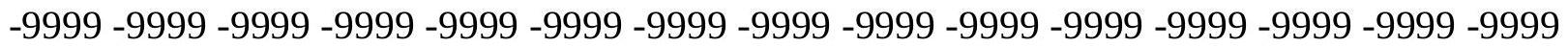

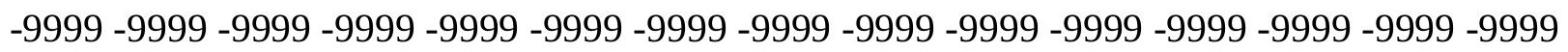

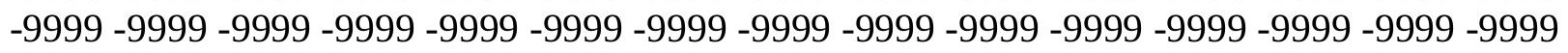
-9999 -9999-9999 137.4580993652 132.8863067627 127.7050018311 124.6570968628 121.6092987061118 .2565994263115 .5136032104112 .7705001831110 .3321990967 108.1986999512106 .3700027466105 .1509017944103 .6268997192102 .712600708 101.4934005737100 .883903503499 .9695205688599 .3599472045999 .05516815186 98.7503814697398 .445587158298 .1408081054798 .1408081054798 .14080810547 98.1408081054798 .445587158298 .445587158298 .7503814697398 .75038146973 99.0551681518699 .3599472045999 .96952056885100 .2742996216100 .5791015625 100.8839035034101 .1886978149101 .4934005737102 .1029968262102 .1029968262 102.4077987671102 .712600708102 .712600708103 .0174026489103 .0174026489 102.712600708102 .712600708102 .1029968262101 .7982025146101 .1886978149 100.5791015625100 .274299621699 .6647262573299 .3599472045998 .4455871582 97.5312423706196 .6168823242297 .8360290527397 .5312423706196 .92166900635 96.3121032714895.397743225194.1785964965892.04509735107 89.3020401001 82.9015579223682 .29197692871 -9999 -9999 -9999 -9999 -9999 -9999 -9999 -9999 -9999 -9999 -9999 -9999 -9999 -9999 -9999 -9999 -9999 -9999 -9999 -9999 -9999 -9999 -9999 -9999

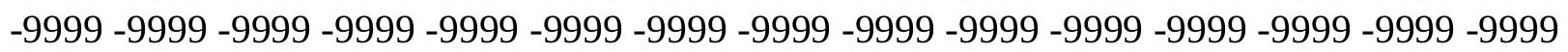


-9999 -9999 -9999 -9999 -9999 -9999 -9999 -9999 -9999 -9999 -9999

-9999 -9999 -9999 -9999 -9999 -9999 -9999 -9999 -9999 -9999 -9999 -9999 -9999 -9999 -9999

-9999 -9999 -9999 -9999 -9999 -9999 -9999 -9999 -9999 -9999 -9999 -9999 -9999 -9999 -9999

-9999 -9999 -9999 -9999 -9999 -9999 -9999 -9999 -9999 -9999 -9999 -9999 -9999 -9999 -9999

-9999 -9999 -9999 -9999 -9999 -9999 -9999 -9999 -9999 -9999 -9999 -9999 -9999 -9999 -9999 -

-9999 -9999 -9999 -9999 -9999 -9999 -9999 -9999 -9999 -9999 -9999 -9999 -9999 -9999 -9999 -

-9999 -9999 -9999 -9999 -9999 -9999 -9999 -9999 -9999 -9999 -9999 -9999 -9999 -9999 -9999 -

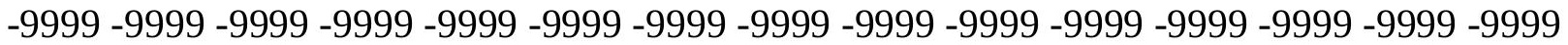

-9999 -9999 -9999 -9999 -9999 -9999 -9999 -9999 -9999 -9999 -9999 -9999 -9999 -9999 -9999

-9999 -9999 -9999 -9999 -9999 -9999 -9999 -9999 -9999 -9999 -9999 -9999 -9999 -9999 -9999 -

-9999 -9999 -9999 -9999 -9999 -9999 -9999 -9999 -9999 -9999 -9999 -9999 -9999 -9999 -9999 -

-9999 -9999 -9999 -9999 -9999 -9999 -9999 -9999 -9999 -9999 -9999 -9999 -9999 -9999 -9999

-9999 -9999 -9999 -9999 -9999 -9999 -9999 -9999 -9999 -9999 -9999 -9999 -9999 -9999 -9999 -

-9999 -9999 -9999 -9999 -9999 -9999 -9999 -9999 -9999 -9999 -9999 -9999 -9999 -9999 -9999 -

-9999 -9999 -9999 -9999 -9999 -9999 -9999 -9999 -9999 -9999 -9999 -9999 -9999 -9999 -9999

-9999 -9999 -9999 -9999 -9999 -9999 -9999 -9999 -9999 -9999 -9999 -9999 -9999 -9999 -9999

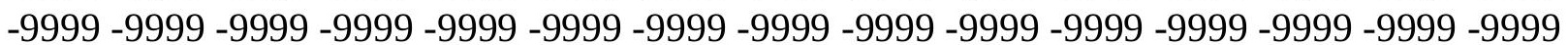

-9999 -9999 -9999 -9999 -9999 -9999 -9999 -9999 -9999 -9999 -9999 -9999 -9999 -9999 -9999 -

-9999 -9999 -9999 -9999 -9999 -9999 -9999 -9999 -9999 -9999 -9999 -9999 -9999 -9999 -9999 -999 -

-9999 -9999 -9999 -9999 135.0198059082 129.8385009766124.3523025513 119.4757995605

116.4279022217113 .075302124110 .3321990967107 .8938980103106 .0652008057

104.5412979126103 .3221969604102 .1029968262100 .883903503499 .96952056885

99.3599472045998.7503814697398.445587158297.8360290527397.83602905273

97.5312423706197 .5312423706197 .5312423706197 .5312423706197 .83602905273

97.8360290527398 .1408081054798 .445587158298 .7503814697399 .05516815186

99.3599472045999 .6647262573299 .96952056885100 .5791015625100 .8839035034

101.1886978149101 .4934005737102 .1029968262102 .4077987671102 .4077987671

102.712600708102 .712600708103 .0174026489103 .0174026489102 .712600708

102.712600708102 .1029968262101 .7982025146101 .1886978149100 .8839035034

100.274299621699 .9695205688599 .3599472045998 .445587158297 .53124237061

96.6168823242297 .5312423706196 .9216690063596 .6168823242295 .70252990723

94.4833908081192 .9594726562590 .8259735107488 .3876876831182 .59677124023

81.98719787598 -9999 -9999 -9999 -9999 -9999 -9999 -9999 -9999 -9999 -9999 -9999 -9999

-9999 -9999 -9999 -9999 -9999 -9999 -9999 -9999 -9999 -9999 -9999 -9999 -9999 -9999 -9999

-9999 -9999 -9999 -9999 -9999 -9999 -9999 -9999 -9999 -9999 -9999 -9999 -9999 -9999 -9999 -

-9999 -9999 -9999 -9999 -9999 -9999 -9999 -9999

-9999 -9999 -9999 -9999 -9999 -9999 -9999 -9999 -9999 -9999 -9999 -9999-9999-9999-9999 -

-9999 -9999 -9999 -9999 -9999 -9999 -9999 -9999 -9999 -9999 -9999 -9999 -9999 -9999 -9999 -

-9999 -9999 -9999 -9999 -9999 -9999 -9999 -9999 -9999 -9999 -9999 -9999 -9999 -9999 -9999 -

-9999 -9999 -9999 -9999 -9999 -9999 -9999 -9999 -9999 -9999 -9999 -9999 -9999 -9999 -9999 -

-9999 -9999 -9999 -9999 -9999 -9999 -9999 -9999 -9999 -9999 -9999 -9999 -9999 -9999 -9999

-9999 -9999 -9999 -9999 -9999 -9999 -9999 -9999 -9999 -9999 -9999 -9999-9999-9999-9999 -

-9999 -9999 -9999 -9999 -9999 -9999 -9999 -9999 -9999 -9999 -9999 -9999 -9999 -9999 -9999 -

-9999 -9999 -9999 -9999 -9999 -9999 -9999 -9999 -9999 -9999 -9999 -9999 -9999 -9999 -9999 -

-9999 -9999 -9999 -9999 -9999 -9999 -9999 -9999 -9999 -9999 -9999 -9999 -9999 -9999 -9999

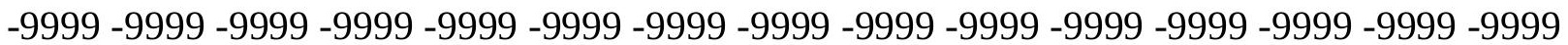


-9999 -9999 -9999 -9999 -9999 -9999 -9999 -9999 -9999 -9999 -9999 -9999 -9999 -9999 -9999 -9999 -9999 -9999 -9999 -9999 -9999 -9999 -9999 -9999 -9999 -9999 -9999 -9999 -9999 -9999 -9999 -9999 -9999 -9999 -9999 -9999 -9999 -9999 -9999 -9999 -9999 -9999 -9999 -9999 -9999 -9999 -9999 -9999 -9999 -9999 -9999 -9999 -9999 -9999 -9999 -9999 -9999 -9999 -9999 -9999 -9999 -9999 -9999 -9999 -9999 -9999 -9999 -9999 -9999 -9999 -9999 -9999 -9999 -9999 -9999 -9999 -9999 -9999 -9999 -9999 -9999 -9999 -9999 -9999 -9999 -9999 -9999 -9999 -9999 -9999 -9999 -9999 -9999 -9999 -9999 -9999 -9999 -9999 -9999 -9999 -9999 -9999 -9999 -9999 -9999 -9999 -9999 -9999 -9999 -9999 -9999 -9999 -9999 -9999 -9999 -9999 -9999 -9999 -9999 -9999 -9999 -9999 -9999 -9999-9999 131.9720001221 126.4858016968 120.6949005127 114.9039993286110 .9418029785107 .8938980103105 .7603988647104 .2365036011 102.712600708101 .4934005737100 .274299621699 .3599472045998 .75038146973 98.1408081054797.5312423706197.2264633178796.9216690063596.92166900635 96.9216690063596 .9216690063596 .9216690063597 .2264633178797 .22646331787 97.5312423706197 .8360290527398 .1408081054798 .445587158298 .75038146973 99.3599472045999 .6647262573299 .96952056885100 .5791015625100 .8839035034 101.1886978149101 .4934005737101 .7982025146102 .4077987671102 .4077987671 102.712600708103 .0174026489103 .0174026489103 .0174026489102 .712600708 102.712600708102 .4077987671102 .1029968262101 .4934005737101 .1886978149 100.5791015625100 .274299621699 .3599472045998 .7503814697397 .83602905273 96.6168823242297 .2264633178796 .6168823242296 .0073165893695 .09295654297 93.5690307617292 .0450973510789 .6068267822386 .8637619018682 .29197692871 81.68241119385 -9999 -9999 -9999 -9999 -9999 -9999 -9999 -9999 -9999 -9999 -9999 -9999 -9999 -9999 -9999 -9999 -9999 -9999 -9999 -9999 -9999 -9999 -9999 -9999 -9999 -9999 -9999 -9999 -9999 -9999 -9999 -9999 -9999 -9999 -9999 -9999 -9999 -9999 -9999 -9999 -9999 -9999 -9999 -9999 -9999 -9999 -9999 -9999 -9999 -9999

-9999 -9999 -9999 -9999 -9999 -9999 -9999 -9999 -9999 -9999 -9999 -9999 -9999 -9999 -9999 -9999 -9999 -9999 -9999 -9999 -9999 -9999 -9999 -9999 -9999 -9999 -9999 -9999 -9999 -9999 -9999 -9999 -9999 -9999 -9999 -9999 -9999 -9999 -9999 -9999 -9999 -9999 -9999 -9999 -9999 -9999 -9999 -9999 -9999 -9999 -9999 -9999 -9999 -9999 -9999 -9999 -9999 -9999 -9999 -9999 -9999 -9999 -9999 -9999 -9999 -9999 -9999 -9999 -9999 -9999 -9999 -9999 -9999 -9999 -9999 -999 -9999 -9999 -9999 -9999 -9999 -9999 -9999 -9999 -9999 -9999 -9999 -9999 -9999 -9999 -9999 -

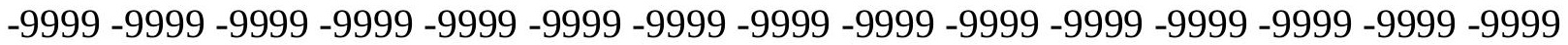
-9999 -9999 -9999 -9999 -9999 -9999 -9999 -9999 -9999 -9999 -9999 -9999 -9999 -9999 -9999 -9999 -9999 -9999 -9999 -9999 -9999 -9999 -9999 -9999 -9999 -9999 -9999 -9999 -9999 -9999 -

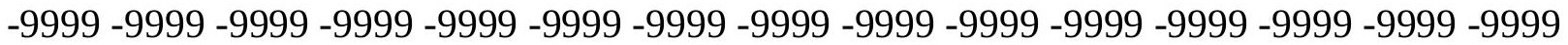
-9999 -9999 -9999 -9999 -9999 -9999 -9999 -9999 -9999 -9999 -9999 -9999 -9999 -9999 -9999 -9999 -9999 -9999 -9999 -9999 -9999 -9999 -9999 -9999 -9999 -9999 -9999 -9999 -9999 -9999

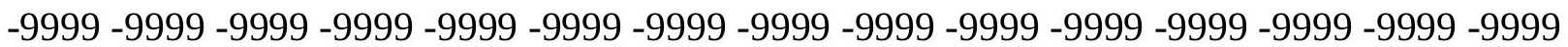
-9999 -9999 -9999 -9999 -9999 -9999 -9999 -9999 -9999 -9999 -9999 -9999 -9999 -9999 -9999 -9999 -9999 -9999 -9999 -9999 -9999 -9999 -9999 -9999 -9999 -9999 -9999 -9999 -9999 -9999 -9999 -9999 -9999 -9999 -9999 -9999 -9999 -9999 -9999 -9999 -9999 -9999 -9999 -9999 -9999

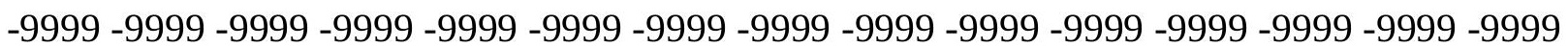
-9999 -9999 -9999 -9999 -9999 -9999 -9999 -9999 -9999 -9999 -9999 -9999 -9999 -9999 -9999 -9999 -9999 -9999 -9999 -9999 -9999-9999 122.5235977173116 .7326965332110 .9418029785 105.7603988647103 .9317016602102 .4077987671101 .188697814999 .96952056885 99.0551681518698 .1408081054797 .2264633178796 .6168823242296 .31210327148 
96.0073165893696 .0073165893696 .0073165893696 .0073165893696 .31210327148 96.3121032714896 .6168823242296 .9216690063597 .2264633178797 .53124237061 97.8360290527398 .445587158298 .7503814697399 .0551681518699 .66472625732 99.96952056885100 .2742996216100 .8839035034101 .1886978149101 .4934005737 101.7982025146102 .4077987671102 .4077987671102 .712600708103 .0174026489 103.0174026489103 .0174026489103 .0174026489102 .712600708102 .4077987671 102.1029968262101 .7982025146101 .4934005737100 .8839035034100 .5791015625 99.6647262573299.0551681518698.1408081054796.9216690063595.70252990723 96.3121032714895 .7025299072394 .4833908081192 .9594726562591 .13075256348 88.6924667358485 .9494018554781 .9871978759881 .37763214111 -9999 -9999 -9999 -9999 -9999 -9999 -9999 -9999 -9999 -9999 -9999 -9999 -9999 -9999 -9999 -9999 -9999 -9999 -9999

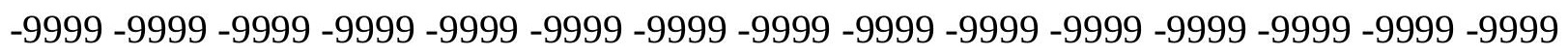
-9999 -9999 -9999 -9999 -9999 -9999 -9999 -9999 -9999 -9999 -9999 -9999 -9999 -9999 -999 -999 $-9999$

-9999 -9999 -9999 -9999 -9999 -9999 -9999 -9999 -9999 -9999 -9999 -9999 -9999 -9999 -9999 -

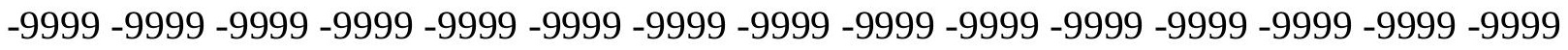
-9999 -9999 -9999 -9999 -9999 -9999 -9999 -9999 -9999 -9999 -9999 -9999 -9999 -9999 -9999 -9999 -9999 -9999 -9999 -9999 -9999 -9999 -9999 -9999 -9999 -9999 -9999 -9999 -9999 -9999 -

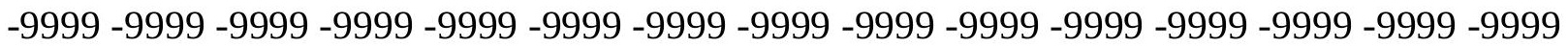

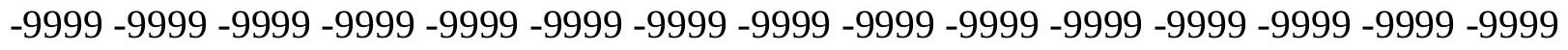

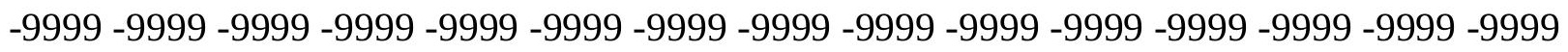
-9999 -9999 -9999 -9999 -9999 -9999 -9999 -9999 -9999 -9999 -9999 -9999 -9999 -9999 -9999 -9999 -9999 -9999 -9999 -9999 -9999 -9999 -9999 -9999 -9999 -9999 -9999 -9999 -9999 -9999 -

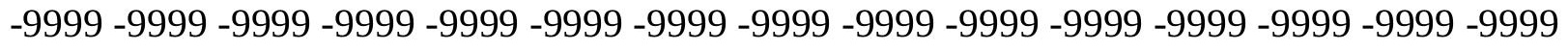

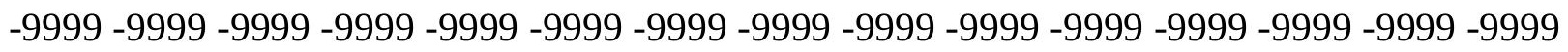
-9999 -9999 -9999 -9999 -9999 -9999 -9999 -9999 -9999 -9999 -9999 -9999 -9999 -9999 -9999

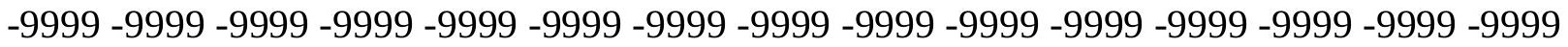

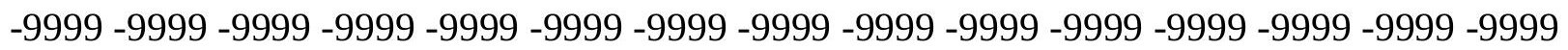
-9999 -9999 -9999 -9999 -9999 -9999 -9999 -9999 -9999 -9999 -9999 -9999 -9999 -9999 -9999 -9999 -9999 -9999 -9999 -9999 -9999 -9999 -9999 -9999 -9999 -9999 -9999 -9999 -9999 -9999 -9999 -9999 -9999 -9999 -9999 -9999 -9999 -9999 -9999 -9999 -9999 -9999-9999 -9999 -9999 -9999 -9999 -9999 -9999 -9999 -9999 -9999 -9999 -9999 -9999 -9999 -9999 -9999 -9999 -9999 -9999 -9999 -9999 -9999 -9999 -9999-9999 -9999 118.5614013672112 .7705001831 107.5891036987 102.4077987671 101.188697814999.6647262573298.75038146973 97.5312423706196 .6168823242296 .0073165893695 .397743225195 .09295654297 95.0929565429795 .0929565429795 .0929565429795 .397743225195 .70252990723 96.0073165893696 .3121032714896 .6168823242296 .9216690063597 .22646331787 97.83602905273 98.1408081054798.445587158299.0551681518699.35994720459 99.96952056885100 .2742996216100 .8839035034101 .1886978149101 .4934005737 101.7982025146102 .1029968262102 .4077987671102 .712600708103 .0174026489 103.0174026489103 .0174026489103 .0174026489103 .0174026489102 .712600708 102.4077987671102 .1029968262101 .7982025146101 .4934005737100 .8839035034 100.274299621699 .3599472045998 .445587158297 .2264633178795 .70252990723 96.0073165893695 .0929565429793 .8738174438592 .349891662690 .21640014648 88.0829010009885 .6446228027381 .6824111938581 .07285308838 -9999 -9999 -9999 -9999 -9999 -9999 -9999 -9999 -9999 -9999 -9999 -9999 -9999 -9999 -9999 -9999 -9999 -9999 -9999 
-9999 -9999 -9999 -9999 -9999 -9999 -9999 -9999 -9999 -9999 -9999 -9999 -9999 -9999 -9999 -9999 -9999 -9999 -9999 -9999 -9999 -9999 -9999 -9999 -9999 -9999 -9999 -9999 -9999 -9999 $-9999$

-9999 -9999 -9999 -9999 -9999 -9999 -9999 -9999 -9999 -9999 -9999 -9999 -9999 -9999 -9999 -9999 -9999 -9999 -9999 -9999 -9999 -9999 -9999 -9999 -9999 -9999 -9999-9999 -9999 -9999 -9999 -9999 -9999 -9999 -9999 -9999 -9999 -9999 -9999 -9999 -9999 -9999 -9999 -9999 -9999 -9999 -9999 -9999 -9999 -9999 -9999 -9999 -9999 -9999 -9999 -9999 -9999 -9999 -9999 -9999 -9999 -9999 -9999 -9999 -9999 -9999 -9999 -9999 -9999 -9999 -9999 -9999 -9999 -9999 -9999 -9999 -9999 -9999 -9999 -9999 -9999 -9999 -9999 -9999 -9999 -9999 -9999 -9999 -9999 -9999 -9999 -9999 -9999 -9999 -9999 -9999 -9999 -9999 -9999 -9999 -9999 -9999 -9999 -9999 -9999 -9999 -9999 -9999 -9999 -9999 -9999 -9999 -9999 -9999 -9999 -9999 -9999 -9999 -9999 -9999 -999 -9999 -9999 -9999 -9999 -9999 -9999 -9999 -9999 -9999 -9999 -9999 -9999 -9999 -9999 -9999 -9999 -9999 -9999 -9999 -9999 -9999 -9999 -9999 -9999 -9999 -9999 -9999 -9999 -9999 -9999 -9999 -9999 -9999 -9999 -9999 -9999 -9999 -9999 -9999 -9999 -9999 -9999 -9999 -9999 -9999 -9999 -9999 -9999 -9999 -9999 -9999 -9999 -9999 -9999 -9999 -9999 -9999 -9999 -9999 -9999

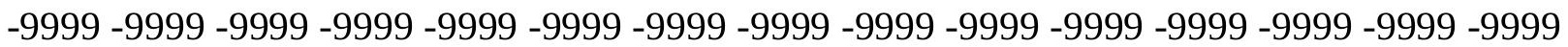

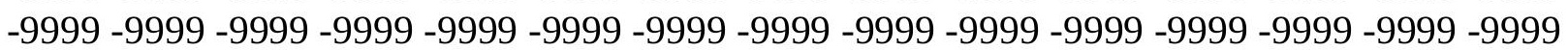
-9999 -9999 -9999 -9999 -9999 -9999 -9999 -9999 -9999 -9999 -9999 -9999 -9999 -9999 -9999 -999 -9999 -9999 -9999 -9999 -9999 -9999 -9999 -9999 -9999 -9999 -9999 -9999 -9999 -9999 -9999 -9999 -9999 -9999 -9999 -9999 -9999 -9999 -9999 -9999 -9999 -9999 -9999 -9999 -9999 -9999 -9999 -9999 -9999 -9999 -9999 -9999 -9999 -9999 -9999 -9999 -9999 -9999 -9999 -9999 -9999 -9999 -9999 -9999 -9999 -9999 -9999 -9999 -9999 -9999 114.9039993286109 .7226028442 104.5412979126100 .274299621698 .7503814697397 .5312423706196 .31210327148 95.397743225194 .7881774902394 .4833908081194 .1785964965894 .17859649658 94.1785964965894 .4833908081194 .7881774902395 .0929565429795 .3977432251 96.0073165893696 .3121032714896 .6168823242297 .2264633178797 .53124237061 98.1408081054798 .445587158299 .0551681518699 .3599472045999 .96952056885 100.2742996216100 .5791015625101 .1886978149101 .4934005737101 .7982025146 102.1029968262102 .4077987671102 .712600708103 .0174026489103 .0174026489 103.0174026489103 .0174026489103 .0174026489103 .0174026489102 .712600708 102.4077987671102 .1029968262101 .7982025146101 .1886978149100 .5791015625 99.6647262573298 .7503814697397 .5312423706196 .0073165893694 .48339080811 94.7881774902393 .2642517089891 .7403335571389 .6068267822387 .47332763672 85.0350494384881 .0728530883880 .46327209473 -9999 -9999 -9999 -9999 -9999 -9999 -9999 -9999 -9999 -9999 -9999 -9999 -9999 -9999 -9999 -9999 -9999 -9999 -9999 -9999 -9999 -9999 -9999 -9999 -9999 -9999 -9999 -9999 -9999 -9999 -9999 -9999 -9999 -9999 -9999 -9999 -9999 -

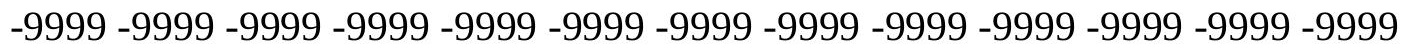

-9999 -9999 -9999 -9999 -9999 -9999 -9999 -9999 -9999 -9999 -9999 -9999 -9999 - -9999 - -9999 -9999 -9999 -9999 -9999 -9999 -9999 -9999 -9999 -9999 -9999 -9999 -9999 -9999 -9999 -9999 -9999 -9999 -9999 -9999 -9999 -9999 -9999 -9999 -9999 -9999 -9999 -9999 -9999 -9999 -9999 -

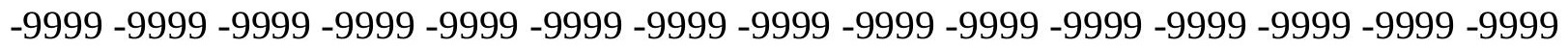
-9999 -9999 -9999 -9999 -9999 -9999 -9999 -9999 -9999 -9999 -9999 -9999 -9999 -9999 -9999 -9999 -9999 -9999 -9999 -9999 -9999 -9999 -9999 -9999 -9999 -9999 -9999 -9999 -9999 -9999 -9999 -9999 -9999 -9999 -9999 -9999 -9999 -9999 -9999 -9999 -9999 -9999 -9999 -9999 -9999 -9999 -9999 -9999 -9999 -9999 -9999 -9999 -9999 -9999 -9999 -9999 -9999 -9999 -9999 -9999 -

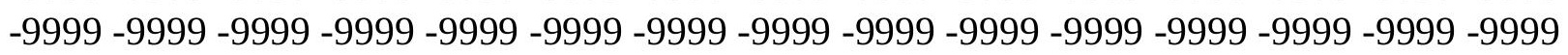


-9999 -9999 -9999 -9999 -9999 -9999 -9999 -9999 -9999 -9999 -9999 -9999 -9999 -9999 -9999 -9999 -9999 -9999 -9999 -9999 -9999 -9999 -9999 -9999 -9999 -9999 -9999 -9999 -9999 -9999 -9999 -9999 -9999 -9999 -9999 -9999 -9999 -9999 -9999 -9999 -9999 -9999 -9999 -9999 -9999 -9999 -9999 -9999 -9999 -9999 -9999 -9999 -9999 -9999 -9999 -9999 -9999 -9999 -9999 -9999 -9999 -9999 -9999 -9999 -9999 -9999 -9999 -9999 -9999 -9999 -9999 -9999 -9999 -9999 -9999 -9999 -9999 -9999 -9999 -9999 -9999 -9999 -9999 -9999 -9999 -9999 -9999 -9999 -9999 -9999 -9999 -9999 -9999 -9999 -9999 -9999 -9999 -9999 -9999 -9999 -9999 -9999 -9999 -9999 -9999

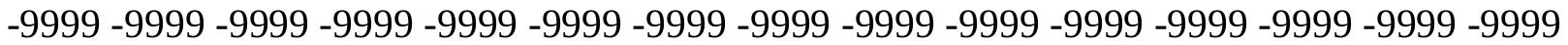
-9999 -9999 -9999 -9999 -9999 -9999 -9999 -9999 -9999 -9999 -9999 -9999 -9999 -9999 -9999 -9999 -9999 -9999 -9999 -9999 -9999 -9999 -9999 -9999 -9999 111.8561019897 106.979598999102 .102996826298 .1408081054796 .6168823242295 .3977432251 94.4833908081193 .5690307617293 .2642517089893 .2642517089893 .26425170898 93.5690307617293 .8738174438594 .4833908081194 .7881774902395 .09295654297 95.7025299072396 .0073165893696 .6168823242296 .9216690063597 .53124237061 97.8360290527398 .445587158298 .7503814697399 .3599472045999 .66472625732 100.2742996216100 .5791015625101 .1886978149101 .4934005737101 .7982025146 102.1029968262102 .4077987671102 .712600708103 .0174026489103 .0174026489 103.0174026489103 .3221969604103 .0174026489103 .0174026489103 .0174026489 102.712600708102 .712600708102 .1029968262101 .7982025146100 .8839035034 99.9695205688599 .0551681518697 .8360290527396 .3121032714894 .48339080811 94.4833908081192 .9594726562591 .1307525634888 .9972534179786 .86376190186 84.7302627563580 .7680587768679 .85370635986 -9999 -9999 -9999 -9999 -9999 -9999 -9999 -9999 -9999 -9999 -9999 -9999 -9999 -9999 -9999 -9999 -9999 -9999 -9999 -9999 -9999 -9999 -9999 -9999 -9999 -9999 -9999 -9999 -9999 -9999 -9999 -9999 -9999 -9999 -9999 -9999 -9999 -9999 -9999 -9999 -9999 -9999 -9999 -9999 -9999 -9999 -9999 -9999 -9999 -9999 -9999 -9999 -9999 -9999 -9999 -9999 -9999 -9999 -9999 -9999 -9999 -9999 -9999 -9999 -9999 -9999 -9999 -9999 -9999 -9999 -9999 -9999 -9999 -9999 -9999 -9999 -9999 -9999 -9999 -9999 -9999 -9999 -9999 -9999 -9999 -9999 -9999 -9999 -9999 -9999 -9999 -9999 -9999 -9999 -9999 -9999 -9999 -9999 -9999 -9999 -9999 -9999 -9999 -9999 -9999 -9999 -9999 -9999 -9999 -9999

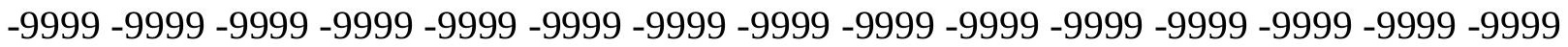
-9999 -9999 -9999 -9999 -9999 -9999 -9999 -9999 -9999 -9999 -9999 -9999 -9999 -9999 -9999 -

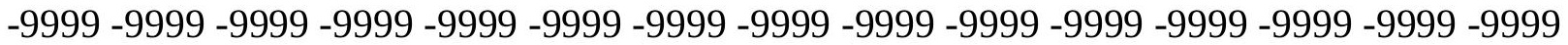
-9999 -9999 -9999 -9999 -9999 -9999 -9999 -9999 -9999 -9999 -9999 -9999 -9999 -9999 -9999 -9999 -9999 -9999 -9999 -9999 -9999 -9999 -9999 -9999 -9999 -9999 -9999 -9999 -9999 -9999 -

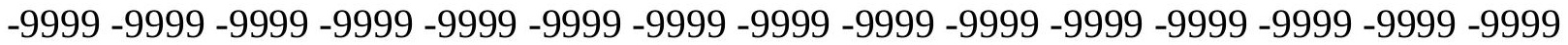
-9999 -9999 -9999 -9999 -9999 -9999 -9999 -9999 -9999 -9999 -9999 -9999 -9999 -9999 -9999 -9999 -9999 -9999 -9999 -9999 -9999 -9999 -9999 -9999 -9999 -9999 -9999 -9999 -9999 -9999

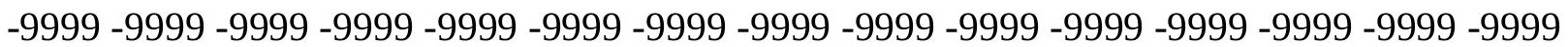
-9999 -9999 -9999 -9999 -9999 -9999 -9999 -9999 -9999 -9999 -9999 -9999 -9999 -9999 -9999 -9999 -9999 -9999 -9999 -9999 -9999 -9999 -9999 -9999 -9999 -9999 -9999 -9999 -9999 -9999 -

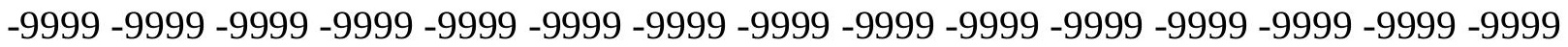
-9999 -9999 -9999 -9999 -9999 -9999 -9999 -9999 -9999 -9999 -9999 -9999 -9999 -9999 -9999 -9999 -9999 -9999 -9999 -9999 -9999 -9999 -9999 -9999 -9999 -9999 -9999 -9999 -9999 -9999 -9999 -9999 -9999 -9999 -9999 -9999 -9999 -9999 -9999 -9999 -9999 109.1130981445 104.541297912699 .9695205688596 .0073165893694 .4833908081193 .26425170898 92.6546783447392 .349891662692 .6546783447392 .9594726562593 .26425170898 
93.5690307617294 .1785964965894 .4833908081195 .0929565429795 .3977432251 96.0073165893696 .3121032714896 .9216690063597 .2264633178797 .83602905273 98.445587158298 .7503814697399 .3599472045999 .66472625732100 .2742996216 100.5791015625101 .1886978149101 .4934005737101 .7982025146102 .1029968262 102.4077987671102 .712600708103 .0174026489103 .0174026489103 .0174026489 103.3221969604103 .3221969604103 .3221969604103 .3221969604103 .0174026489 103.0174026489102 .4077987671102 .1029968262101 .4934005737100 .5791015625 99.3599472045997 .8360290527396 .3121032714894 .4833908081192 .65467834473 92.349891662690 .5211791992288 .6924667358486 .5589828491284 .12069702148 80.4632720947379 .24413299561 -9999 -9999 -9999 -9999 -9999 -9999 -9999 -9999 -9999 -9999 -9999 -9999 -9999 -9999 -9999 -9999 -9999 -9999 -9999 -9999 -9999 -9999 -9999 -9999 -9999 -9999 -9999 -9999 -9999 -9999 -9999 -9999 -9999 -9999 -9999 -9999 -9999 -9999 -9999 -9999 -9999 -9999 -9999 -9999 -9999 -9999 -9999 -9999 -9999 -9999 -9999 -9999 -9999 -9999 -9999 -9999 -9999 -9999 -9999 -9999 -9999 -9999 -9999 -9999 -9999 -9999 -9999 -9999 -9999 -9999 -9999 -9999 -9999 -9999 -9999 -9999 -9999 -9999 -9999 -9999

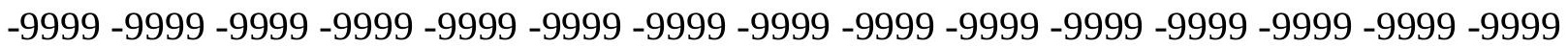

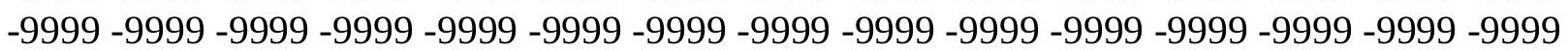
-9999 -9999 -9999 -9999 -9999 -9999 -9999 -9999 -9999 -9999 -9999 -9999 -9999 -9999 -9999 -9999 -9999 -9999 -9999 -9999 -9999 -9999 -9999 -9999 -9999 -9999 -9999 -9999 -9999 -9999 -9999 -9999 -9999 -9999 -9999 -9999 -9999 -9999 -9999 -9999 -9999 -9999 -9999 -9999 -9999

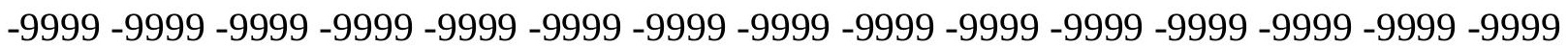
-9999 -9999 -9999 -9999 -9999 -9999 -9999 -9999 -9999 -9999 -9999 -9999 -9999 -9999 -9999 -9999 -9999 -9999 -9999 -9999 -9999 -9999 -9999 -9999 -9999 -9999 -9999 -9999 -9999 -9999 -9999 -9999 -9999 -9999 -9999 -9999 -9999 -9999 -9999 -9999 -9999 -9999 -9999 -9999 -9999

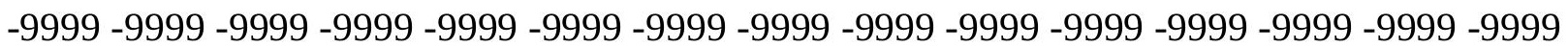
-9999 -9999 -9999 -9999 -9999 -9999 -9999 -9999 -9999 -9999 -9999 -9999 -9999 -9999 -9999 -9999 -9999 -9999 -9999 -9999 -9999 -9999 -9999 -9999 -9999 -9999 -9999 -9999 -9999 -9999 -9999 -9999 -9999 -9999 -9999 -9999 -9999 -9999 -9999 -9999 -9999 -9999 -9999 -9999 -9999

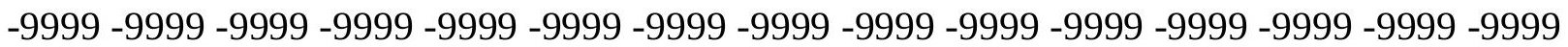

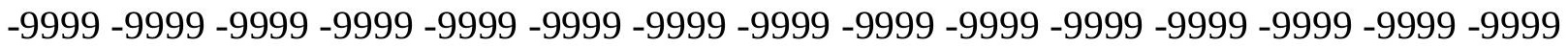
-9999 -9999 -9999 -9999 -9999 -9999 -9999 -9999 -9999 -9999 -9999 -9999 -9999 -9999 -9999 -9999 -9999 -9999 -9999 -9999 -9999 -9999 -9999 -9999 -9999 -9999 -9999 106.6747970581 102.102996826297 .5312423706193 .5690307617292 .0450973510791 .74033355713 91.7403335571392 .0450973510792 .6546783447392 .9594726562593 .26425170898 93.8738174438594 .4833908081194 .7881774902395 .397743225195 .70252990723 96.3121032714896 .9216690063597 .2264633178797 .8360290527398 .14080810547 98.7503814697399 .3599472045999 .66472625732100 .2742996216100 .5791015625 101.1886978149101 .4934005737101 .7982025146102 .1029968262102 .4077987671 102.712600708103 .0174026489103 .0174026489103 .0174026489103 .3221969604 103.3221969604103 .3221969604103 .3221969604103 .3221969604103 .0174026489 102.712600708102 .4077987671101 .7982025146100 .883903503499 .66472625732 98.1408081054796 .3121032714894 .4833908081192 .349891662690 .52117919922 89.9116134643687 .7781066894585 .6446228027383 .5111236572379 .85370635986 78.63455963135 -9999 -9999 -9999 -9999 -9999 -9999 -9999 -9999 -9999 -9999 -9999 -9999 -9999 -9999 -9999 -9999 -9999 -9999 -9999 -9999 -9999 -9999 -9999 -9999 -9999 -9999 -9999

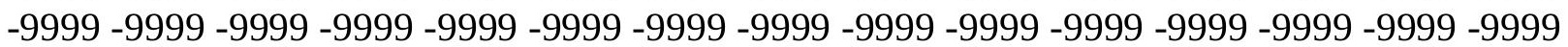


-9999 -9999 -9999 -9999 -9999 -9999 -9999 -9999

-9999 -9999 -9999 -9999 -9999 -9999 -9999 -9999 -9999 -9999 -9999 -9999 -9999 -9999 -9999

-9999 -9999 -9999 -9999 -9999 -9999 -9999 -9999 -9999 -9999 -9999 -9999 -9999 -9999 -9999

-9999 -9999 -9999 -9999 -9999 -9999 -9999 -9999 -9999 -9999 -9999 -9999 -9999 -9999 -9999

-9999 -9999 -9999 -9999 -9999 -9999 -9999 -9999 -9999 -9999 -9999 -9999 -9999 -9999 -9999 -

-9999 -9999 -9999 -9999 -9999 -9999 -9999 -9999 -9999 -9999 -9999 -9999 -9999 -9999 -9999 -

-9999 -9999 -9999 -9999 -9999 -9999 -9999 -9999 -9999 -9999 -9999 -9999 -9999 -9999 -9999 -

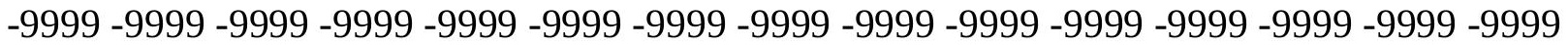

-9999 -9999 -9999 -9999 -9999 -9999 -9999 -9999 -9999 -9999 -9999 -9999 -9999 -9999 -9999

-9999 -9999 -9999 -9999 -9999 -9999 -9999 -9999 -9999 -9999 -9999 -9999 -9999 -9999 -9999 -

-9999 -9999 -9999 -9999 -9999 -9999 -9999 -9999 -9999 -9999 -9999 -9999 -9999 -9999 -9999 -

-9999 -9999 -9999 -9999 -9999 -9999 -9999 -9999 -9999 -9999 -9999 -9999 -9999 -9999 -9999

-9999 -9999 -9999 -9999 -9999 -9999 -9999 -9999 -9999 -9999 -9999 -9999 -9999 -9999 -9999 -

-9999 -9999 -9999 -9999 -9999 -9999 -9999 -9999 -9999 -9999 -9999 -9999 -9999 -9999 -9999 -

-9999 -9999 -9999 -9999 -9999 -9999 -9999 -9999 -9999 -9999 -9999 -9999 -9999 -9999 -9999

-9999 -9999 -9999 -9999 -9999 -9999 -9999 -9999 -9999 -9999 -9999 -9999 -9999 -9999 -9999

-9999 -9999 -9999 -9999 -9999 -9999 -9999 -9999 -9999 -9999 -9999 -9999 -9999 -9999 -9999

-9999 -9999 -9999 -9999 -9999 -9999 -9999 -9999 -9999 -9999 -9999 -9999 -9999 -9999 -9999 -

-9999 -9999 -9999 -9999 -9999 -9999 -9999 -9999 -9999 -9999 -9999 -9999 -9999 -9999 -9999 -

-9999 -9999 -9999 -9999 -9999 -9999 -9999 -9999 -9999 -9999 -9999 -9999 -9999

103.931701660299 .3599472045994 .7881774902391 .1307525634891 .43553924561

93.2642517089893 .8738174438594 .4833908081194 .4833908081193 .26425170898

93.8738174438594 .1785964965894 .7881774902395 .397743225195 .70252990723 96.3121032714896 .9216690063597 .2264633178797 .8360290527398 .14080810547 98.7503814697399 .3599472045999 .66472625732100 .2742996216100 .5791015625 100.8839035034101 .4934005737101 .7982025146102 .1029968262102 .4077987671 102.712600708102 .712600708103 .0174026489103 .0174026489103 .0174026489 103.3221969604103 .3221969604103 .3221969604103 .3221969604103 .3221969604 103.0174026489102 .712600708102 .1029968262101 .188697814999 .96952056885 98.445587158296 .3121032714894 .4833908081192 .0450973510789 .91161346436 89.302040100187 .1685485839885 .0350494384882 .9015579223679 .24413299561 78.02498626709 -9999 -9999 -9999 -9999 -9999 -9999 -9999 -9999 -9999 -9999 -9999 -9999 -9999 -9999 -9999 -9999 -9999 -9999 -9999 -9999 -9999 -9999 -9999 -9999 -9999 -9999 -9999 -9999 -9999 -9999 -9999 -9999 -9999 -9999 -9999 -9999 -9999 -9999 -9999 -9999 -9999 -9999 -9999 -9999 -9999 -9999 -9999 -9999 -9999 -9999

-9999 -9999 -9999 -9999 -9999 -9999 -9999 -9999 -9999 -9999 -9999 -9999 -9999 -9999 -9999 -9999 -9999 -9999 -9999 -9999 -9999 -9999 -9999 -9999 -9999 -9999 -9999 -9999 -9999 -9999 -9999 -9999 -9999 -9999 -9999 -9999 -9999 -9999 -9999 -9999 -9999 -9999 -9999 -9999 -9999 -9999 -9999 -9999 -9999 -9999 -9999 -9999 -9999 -9999 -9999 -9999 -9999 -9999 -9999 -9999 -9999 -9999 -9999 -9999 -9999 -9999 -9999 -9999 -9999 -9999 -9999 -9999 -9999 -9999 -9999 -9999 -9999 -9999 -9999 -9999 -9999 -9999 -9999 -9999 -9999 -9999 -9999 -9999 -9999 -9999 -9999 -9999 -9999 -9999 -9999 -9999 -9999 -9999 -9999 -9999 -9999 -9999-9999-9999-9999 -9999 -9999 -9999 -9999 -9999 -9999 -9999 -9999 -9999 -9999 -9999 -9999 -9999 -9999 -9999 -9999 -9999 -9999 -9999 -9999 -9999 -9999 -9999 -9999 -9999 -9999 -9999 -9999 -9999 -9999 -9999 -9999 -9999 -9999 -9999 -9999 -9999 -9999 -9999 -9999 -9999 -9999 -9999 -9999 -9999 -9999 -9999 -9999 -9999 -9999 -9999 -9999 -9999 -9999 -9999 -9999 -9999 -9999 -9999 -9999 
-9999 -9999 -9999 -9999 -9999 -9999 -9999 -9999 -9999 -9999 -9999 -9999 -9999 -9999 -9999 -9999 -9999 -9999 -9999 -9999 -9999 -9999 -9999 -9999 -9999 -9999 -9999 -9999 -9999 -9999 -9999 -9999 -9999 -9999 -9999 -9999 -9999 -9999 -9999 -9999 -9999 -9999 -9999 -9999 -9999 -9999 -9999 -9999 -9999 -9999 -9999 -9999 -9999 -9999 -9999 -9999 -9999 -9999 -9999 -9999 -9999 -9999 -9999 -9999 -9999 -9999 -9999 -9999 -9999 -9999 -9999 -9999 -9999 -9999 -9999 -9999 -9999 -9999 -9999 -9999 -9999 -9999 -9999 -9999 -9999 -9999 -9999 -9999 -9999 -9999 -

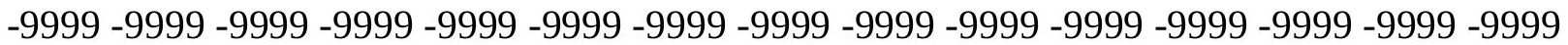
-9999 -9999 -9999 -9999 -9999 -9999 -9999 -9999 -9999 -9999 -9999 -9999 -9999 -9999 101.188697814996 .6168823242292 .6546783447392 .0450973510794 .17859649658 94.7881774902394 .7881774902395 .0929565429795 .0929565429793 .87381744385 94.4833908081195 .0929565429795 .397743225196 .0073165893696 .31210327148 96.9216690063597 .2264633178797 .8360290527398 .1408081054798 .75038146973 99.3599472045999 .66472625732100 .2742996216100 .5791015625100 .8839035034 101.4934005737101 .7982025146102 .1029968262102 .4077987671102 .712600708 102.712600708103 .0174026489103 .0174026489103 .0174026489103 .3221969604 103.3221969604103 .3221969604103 .3221969604103 .3221969604103 .0174026489 102.712600708102 .1029968262101 .188697814999 .9695205688598 .4455871582 96.3121032714893 .8738174438591 .7403335571389 .6068267822387 .16854858398 $86.5589828491284 .4254837036181 .9871978759878 .3297805786177 .41542053223-9999$ -9999 -9999 -9999 -9999 -9999 -9999 -9999 -9999 -9999 -9999 -9999 -9999 -9999 -9999 -9999

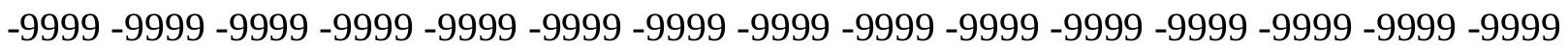

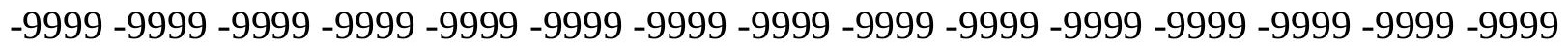
-9999 -9999-9999 -9999

-9999 -9999 -9999 -9999 -9999 -9999 -9999 -9999 -9999 -9999 -9999 -9999 -9999 -9999 -9999

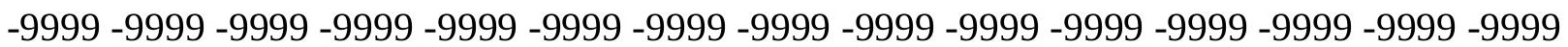
-9999 -9999 -9999 -9999 -9999 -9999 -9999 -9999 -9999 -9999 -9999 -9999 -9999 -9999 -9999 -9999 -9999 -9999 -9999 -9999 -9999 -9999 -9999 -9999 -9999 -9999 -9999 -9999 -9999 -9999 -9999 -9999 -9999 -9999 -9999 -9999 -9999 -9999 -9999 -9999 -9999 -9999 -9999 -9999 -9999 -9999 -9999 -9999 -9999 -9999 -9999 -9999 -9999 -9999 -9999 -9999 -9999 -9999 -9999 -9999 -9999 -9999 -9999 -9999 -9999 -9999 -9999 -9999 -9999 -9999 -9999 -9999 -9999 -9999 -9999 -9999 -9999 -9999 -9999 -9999 -9999 -9999 -9999 -9999 -9999 -9999 -9999 -9999 -9999 -9999 -

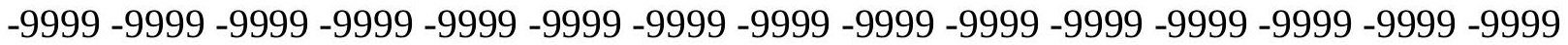
-9999 -9999 -9999 -9999 -9999 -9999 -9999 -9999 -9999 -9999 -9999 -9999 -9999 -9999 -9999 -9999 -9999 -9999 -9999 -9999 -9999 -9999 -9999 -9999 -9999 -9999 -9999 -9999 -9999 -9999 -9999 -9999 -9999 -9999 -9999 -9999 -9999 -9999 -9999 -9999 -9999 -9999 -9999 -9999 -9999 -9999 -9999 -9999 -9999 -9999 -9999 -9999 -9999 -9999 -9999 -9999 -9999 -9999 -9999 -9999 -9999 -9999 -9999 -9999 -9999 -9999 -9999 -9999 -9999 -9999 -9999 -9999 -9999 -9999 -9999

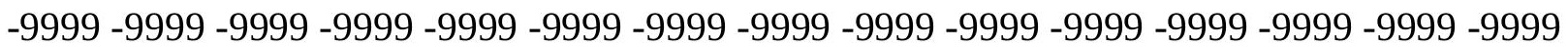
-9999 -9999 -9999 -9999 -9999 -9999 -9999 -9999 -9999 -9999 -9999 -9999 -9999 -9999 -9999 -9999 -9999 -9999 -9999 -9999 -9999 -9999 -9999 -9999 -9999 -9999 -9999 -9999 -9999 -9999 -9999 -9999 -9999 -9999 -9999 -9999 -9999 -9999 -9999 -9999 -9999 -9999 -9999 -9999 -9999 -9999 -9999 -9999 -9999 -9999 -9999 -9999 -9999 -9999 -9999 -9999 -9999 -9999 -9999 -9999 98.1408081054794.1785964965892.9594726562595.0929565429795.3977432251 95.397743225195 .397743225195 .7025299072395 .7025299072394 .78817749023 95.0929565429795 .7025299072396 .0073165893696 .6168823242296 .92166900635 97.5312423706197 .8360290527398 .445587158298 .7503814697399 .35994720459 
99.6647262573299 .96952056885100 .5791015625100 .8839035034101 .1886978149 101.7982025146102 .1029968262102 .1029968262102 .4077987671102 .712600708 102.712600708103 .0174026489103 .0174026489103 .0174026489103 .0174026489 103.0174026489103 .0174026489103 .0174026489102 .712600708102 .4077987671 101.7982025146101 .188697814999 .9695205688597 .8360290527395 .70252990723 93.5690307617291 .1307525634888 .6924667358486 .5589828491285 .64462280273 83.5111236572381 .0728530883877 .4154205322376 .50106811523 -9999 -9999 -9999 -9999 -9999 -9999 -9999 -9999 -9999 -9999 -9999 -9999 -9999 -9999 -9999 -9999 -9999 -9999 -9999 -9999 -9999 -9999 -9999 -9999 -9999 -9999 -9999 -9999 -9999 -9999 -9999 -9999 -9999 -9999

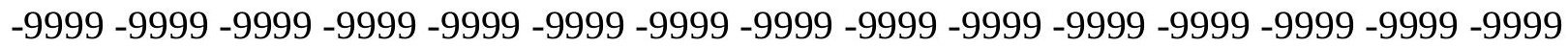
$-9999$

-9999 -9999 -9999 -9999 -9999 -9999 -9999 -9999 -9999 -9999 -9999 -9999 -9999 -9999 -9999 -9999 -9999 -9999 -9999 -9999 -9999 -9999 -9999 -9999 -9999 -9999 -9999 -9999 -9999 -9999 -9999 -9999 -9999 -9999 -9999 -9999 -9999 -9999 -9999 -9999 -9999 -9999 -9999 -9999 -9999 -9999 -9999 -9999 -9999 -9999 -9999 -9999 -9999 -9999 -9999 -9999 -9999 -9999 -9999 -9999

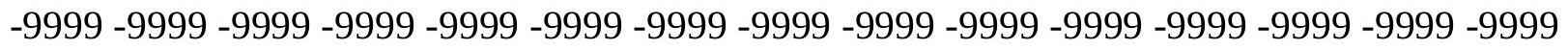
-9999 -9999 -9999 -9999 -9999 -9999 -9999 -9999 -9999 -9999 -9999 -9999 -9999 -9999 -9999 -

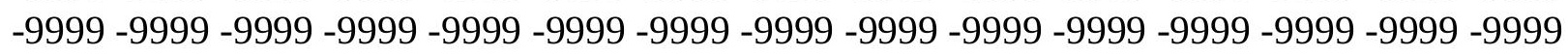
-9999 -9999 -9999 -9999 -9999 -9999 -9999 -9999 -9999 -9999 -9999 -9999 -9999 -9999 -9999 -999 -

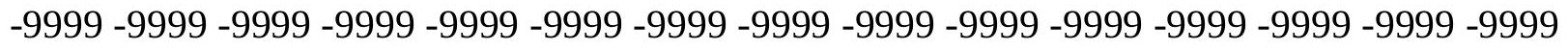

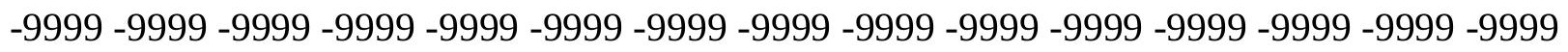

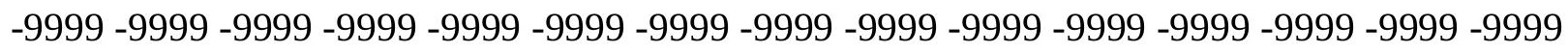
-9999 -9999 -9999 -9999 -9999 -9999 -9999 -9999 -9999 -9999 -9999 -9999 -9999 -9999 -9999 -

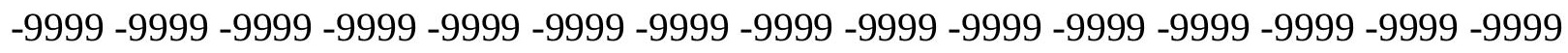

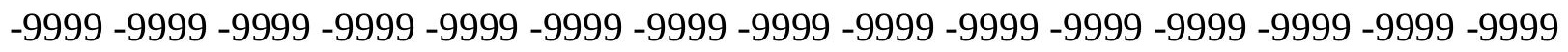
-9999 -9999 -9999 -9999 -9999 -9999 -9999 -9999 -9999 -9999 -9999 -9999 -9999 -9999 -9999

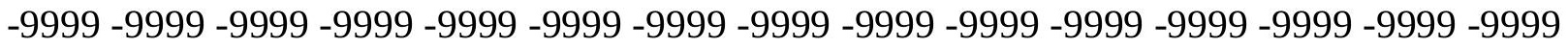

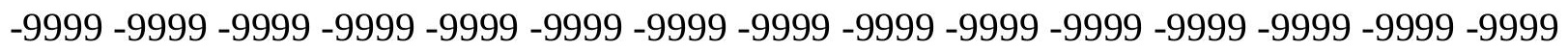
-9999 -9999 -9999 -9999 -9999 -9999 -9999 -9999 -9999 -9999 -9999 -9999 -9999 -9999 -9999

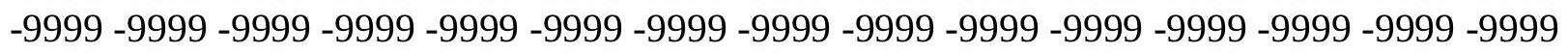
-9999 95.0929565429793.8738174438595.7025299072395.7025299072396.00731658936 96.0073165893696 .3121032714896 .3121032714895 .0929565429795 .3977432251 96.0073165893696 .3121032714896 .6168823242297 .2264633178797 .53124237061 97.8360290527398 .445587158298 .7503814697399 .3599472045999 .66472625732 99.96952056885100 .5791015625100 .8839035034101 .1886978149101 .4934005737 101.7982025146102 .1029968262102 .4077987671102 .4077987671102 .712600708 102.712600708102 .712600708102 .712600708102 .712600708102 .712600708102 .712600708 102.4077987671102 .4077987671101 .7982025146101 .1886978149100 .2742996216 99.0551681518697 .2264633178795 .0929565429792 .6546783447390 .21640014648 88.0829010009885 .6446228027383 .206336975182 .5967712402380 .15849304199 76.5010681152375 .89148712158 -9999 -9999-9999 -9999 -9999 -9999 -9999 -9999 -9999 -9999 -9999 -9999 -9999 -9999 -9999 -9999 -9999 -9999 -9999 -9999 -9999 -9999 -9999 -9999 -

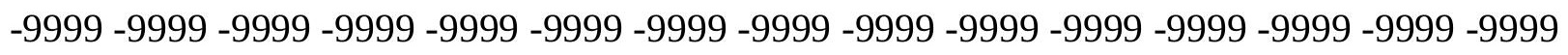
-9999 -9999 -9999 -9999 -9999 -9999 -9999 -9999 -9999 -9999 -9999

-9999 -9999 -9999 -9999 -9999 -9999 -9999 -9999 -9999 -9999 -9999 -9999 -9999 -9999 -9999

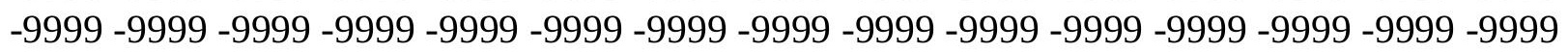


-9999 -9999 -9999 -9999 -9999 -9999 -9999 -9999 -9999 -9999 -9999 -9999 -9999 -9999 -9999 -9999 -9999 -9999 -9999 -9999 -9999 -9999 -9999 -9999 -9999 -9999 -9999 -9999 -9999 -9999 -9999 -9999 -9999 -9999 -9999 -9999 -9999 -9999 -9999 -9999 -9999 -9999 -9999 -9999 -9999 -9999 -9999 -9999 -9999 -9999 -9999 -9999 -9999 -9999 -9999 -9999 -9999 -9999 -9999 -9999 -9999 -9999 -9999 -9999 -9999 -9999 -9999 -9999 -9999 -9999 -9999 -9999 -9999 -9999 -9999 -9999 -9999 -9999 -9999 -9999 -9999 -9999 -9999 -9999 -9999 -9999 -9999 -9999 -9999 -9999 -9999 -9999 -9999 -9999 -9999 -9999 -9999 -9999 -9999 -9999 -9999 -9999 -9999 -9999 -9999

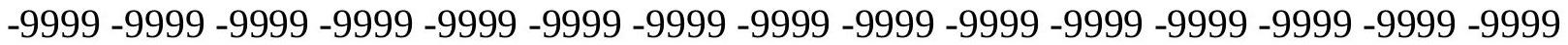
-9999 -9999 -9999 -9999 -9999 -9999 -9999 -9999 -9999 -9999 -9999 -9999 -9999 -9999 -9999 -9999 -9999 -9999 -9999 -9999 -9999 -9999 -9999 -9999 -9999 -9999 -9999 -9999 -9999 -9999 -

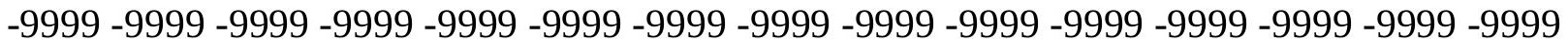
-9999 -9999 -9999 -9999 -9999 -9999 -9999 -9999 -9999 -9999 -9999 -9999 -9999 -9999 -9999

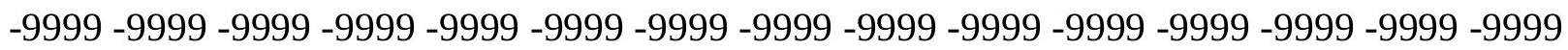
-9999 -9999 -9999 -9999 -9999 -9999 -9999 -9999 -9999 -9999 -9999 -9999 -9999 -9999 -9999 -9999 -9999 -9999 -9999 -9999 -9999 -9999 -9999 -9999 -9999 -9999 -9999 -9999 -9999 -9999 -9999 -9999 -9999 -9999 -9999 -9999 -9999 -9999 -9999 -9999 -9999 -9999 -9999 -9999 -9999 -9999 -9999 -9999 -9999 -9999 -9999 -9999 -9999 -9999 -9999 -9999 -9999 -9999 -9999 -9999 -9999 -9999 94.17859649658 94.4833908081196.0073165893696.31210327148 96.6168823242296 .9216690063596 .9216690063595 .397743225196 .00731658936 96.3121032714896 .6168823242296 .9216690063597 .2264633178797 .53124237061 98.1408081054798 .445587158298 .7503814697399 .3599472045999 .66472625732 99.96952056885100 .5791015625100 .8839035034101 .1886978149101 .4934005737 101.7982025146102 .1029968262102 .1029968262102 .4077987671102 .4077987671 102.4077987671102 .4077987671102 .4077987671102 .4077987671102 .4077987671 102.1029968262101 .7982025146101 .4934005737100 .8839035034100 .2742996216 99.0551681518697 .8360290527396 .0073165893693 .8738174438591 .74033355713 89.302040100187.16854858398 84.73026275635 82.2919769287181.68241119385 77.7202072143675 .8914871215874 .97714233398 -9999 -9999 -9999 -9999 -9999 -9999 -9999 -9999 -9999 -9999 -9999 -9999 -9999 -9999 -9999 -9999 -9999 -9999 -9999 -9999 -9999 -9999

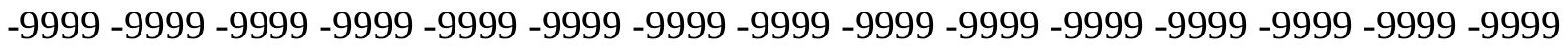
-9999 -9999 -9999 -9999 -9999 -9999 -9999 -9999 -9999 -9999 -9999 -9999 -9999 -9999 -9999 -9999 -9999 -9999 -9999 -9999 -9999 -9999 -9999 -9999 -9999 -9999 -9999 -9999 -9999 -9999 -9999 -9999 -9999 -9999 -9999 -9999 -9999 -9999 -9999 -9999 -9999 -9999 -9999 -9999 -9999 -9999 -9999 -9999 -9999 -9999 -9999 -9999 -9999 -9999 -9999 -9999 -9999 -9999 -

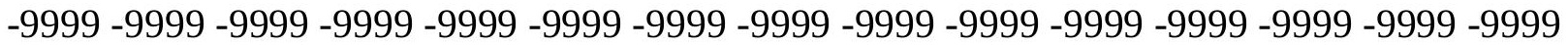
-9999 -9999 -9999 -9999 -9999 -9999 -9999 -9999 -9999 -9999 -9999 -9999 -9999 -9999 -9999 -9999 -9999 -9999 -9999 -9999 -9999 -9999 -9999 -9999 -9999 -9999 -9999 -9999 -9999 -9999

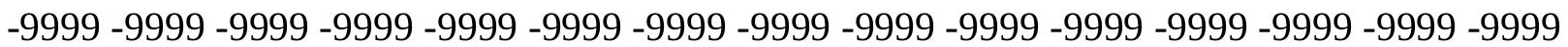
-9999 -9999 -9999 -9999 -9999 -9999 -9999 -9999 -9999 -9999 -9999 -9999 -9999 -9999 -9999 -9999 -9999 -9999 -9999 -9999 -9999 -9999 -9999 -9999 -9999 -9999 -9999 -9999 -9999 -9999 -9999 -9999 -9999 -9999 -9999 -9999 -9999 -9999 -9999 -9999 -9999 -9999 -9999 -9999 -9999 -9999 -9999 -9999 -9999 -9999 -9999 -9999 -9999 -9999 -9999 -9999 -9999 -9999 -9999 -9999 -9999 -9999 -9999 -9999 -9999 -9999 -9999 -9999 -9999 -9999 -9999 -9999 -9999 -9999 -9999 -9999 -9999 -9999 -9999 -9999 -9999 -9999 -9999 -9999 -9999 -9999 -9999 -9999 -9999 -9999 -9999 -9999 -9999 -9999 -9999 -9999 -9999 -9999 -9999 -9999 -9999 -9999 -9999 -9999 -9999

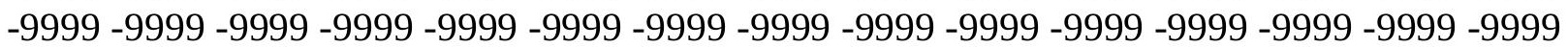


-9999 -9999 -9999 -9999 -9999 -9999 -9999 -9999 -9999 -9999 -9999 -9999 -9999 -9999 -9999 -9999 -9999 -9999 -9999 -9999 -9999 -9999 -9999 -9999 -9999 -9999 -9999 -9999 -9999 -9999 -9999 -9999 -9999 -9999 -9999 -9999 -9999 -9999 -9999 -9999 -9999 -9999 -9999 -9999 -9999 -9999 -9999 -9999 -9999 -9999 -9999 -9999 -9999 -9999 -9999 -9999 -9999 -9999 -9999 -9999 -9999 -9999 94.1785964965894.7881774902394.7881774902396.92166900635 97.2264633178797.5312423706197.5312423706196.0073165893696.31210327148 96.6168823242296 .9216690063597 .2264633178797 .5312423706197 .83602905273 98.1408081054798 .445587158299 .0551681518699 .3599472045999 .66472625732 99.96952056885100 .5791015625100 .8839035034101 .1886978149101 .4934005737 101.7982025146101 .7982025146102 .1029968262102 .1029968262102 .1029968262 102.1029968262102 .1029968262102 .1029968262102 .1029968262101 .7982025146 101.4934005737101 .1886978149100 .579101562599 .9695205688599 .05516815186 97.8360290527396 .3121032714894 .7881774902392 .6546783447390 .52117919922 88.38768768311 85.94940185547 83.81591033936 81.37763214111 79.24413299561 77.110626220774 .97714233398 -9999 -9999 -9999 -9999 -9999 -9999 -9999 -9999 -9999 -9999 -9999 -9999 -9999 -9999 -9999 -9999 -9999 -9999 -9999 -9999 -9999 -9999 -9999 -9999

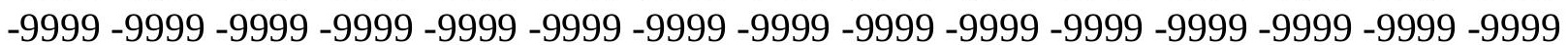
-9999 -9999 -9999 -9999 -9999 -9999 -9999 -9999 -9999 -9999 -9999 -9999 -9999 -9999 -9999 -9999 -9999 -9999 -9999 -9999 -9999 -9999 -9999 -9999 -9999 -9999 -9999 -9999 -9999 -9999 -9999 -9999 -9999 -9999 -9999 -9999 -9999 -9999 -9999 -9999 -9999 -9999

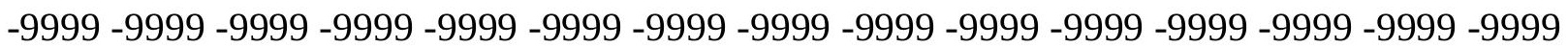
-9999 -9999 -9999 -9999 -9999 -9999 -9999 -9999 -9999 -9999 -9999 -9999 -9999 -9999 -9999 -9999 -9999 -9999 -9999 -9999 -9999 -9999 -9999 -9999 -9999 -9999 -9999 -9999 -9999 -9999 -9999 -9999 -9999 -9999 -9999 -9999 -9999 -9999 -9999 -9999 -9999 -9999 -9999 -9999 -9999

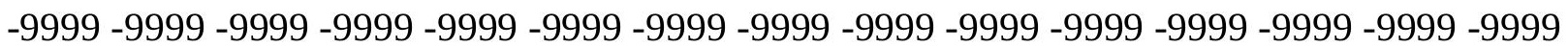
-9999 -9999 -9999 -9999 -9999 -9999 -9999 -9999 -9999 -9999 -9999 -9999 -9999 -9999 -9999 -9999 -9999 -9999 -9999 -9999 -9999 -9999 -9999 -9999 -9999 -9999 -9999 -9999 -9999 -9999 -9999 -9999 -9999 -9999 -9999 -9999 -9999 -9999 -9999 -9999 -9999 -9999 -9999 -9999 -9999 -9999 -9999 -9999 -9999 -9999 -9999 -9999 -9999 -9999 -9999 -9999 -9999 -9999 -9999 -9999 -9999 -9999 -9999 -9999 -9999 -9999 -9999 -9999 -9999 -9999 -9999 -9999 -9999 -9999 -9999 -9999 -9999 -9999 -9999 -9999 -9999 -9999 -9999 -9999 -9999 -9999 -9999 -9999 -9999 -9999 -9999 -9999 -9999 -9999 -9999 -9999 -9999 -9999 -9999 -9999 -9999 -9999 -9999 -9999 -9999 -9999 -9999 -9999 -9999 -9999 -9999 -9999 -9999 -9999 -9999 -9999 -9999 -9999 -9999 -9999 -9999 -9999 -9999 -9999 -9999 -9999 -9999 -9999 -9999 -9999 -9999 -9999 -9999 -9999 -9999 -9999 -9999 -9999 -9999 -9999 -9999 -9999 -9999 -9999 -9999 -9999 -9999 -9999 -9999 -9999 -9999 -9999 -9999 -9999 -9999 -9999 -9999 -9999 -9999 -9999 -9999 -9999 -9999 -9999 -9999 -9999 -9999 -9999 -9999 -9999 -9999 -9999 -9999 -9999 -9999 -9999 -9999 -9999 -9999 -9999 -9999 -9999 -9999 94.4833908081195.0929565429796.0073165893697.83602905273 98.1408081054796 .6168823242296 .6168823242296 .9216690063596 .92166900635 97.22646331787 97.5312423706197.8360290527397.8360290527398.4455871582 98.7503814697399 .0551681518699 .3599472045999 .6647262573299 .96952056885 100.5791015625100 .8839035034101 .1886978149101 .1886978149101 .4934005737 101.7982025146101 .7982025146101 .7982025146101 .7982025146101 .7982025146 101.7982025146101 .7982025146101 .4934005737101 .1886978149100 .8839035034 100.274299621699 .6647262573299 .0551681518697 .8360290527396 .61688232422 95.0929565429793 .2642517089891 .4355392456189 .302040100187 .16854858398 
84.73026275635 84.12069702148 81.98719787598 79.5489196777375 .89148712158 74.36756896973 -9999 -9999 -9999 -9999 -9999 -9999 -9999 -9999 -9999 -9999 -9999 -9999 -9999 -9999 -9999 -9999 -9999 -9999 -9999 -9999 -9999 -9999 -9999 -9999 -9999 -9999 -9999 -9999 -9999 -9999 -9999 -9999 -9999 -9999 -9999 -9999 -9999 -9999 -9999 -9999 -9999 -9999 -9999 -9999-9999 -9999 -9999 -9999 -9999 -9999 -9999 -9999 -9999 -9999 -9999 -9999 -9999 -9999 -9999 -9999 -9999 -9999 -9999 -9999 -9999 -9999

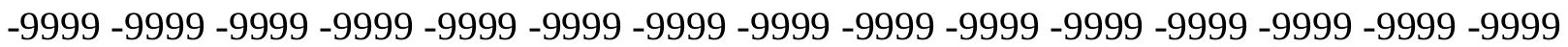
-9999 -9999 -9999 -9999 -9999 -9999 -9999 -9999 -9999 -9999 -9999 -9999 -9999 -9999 -9999 -9999 -9999 -9999 -9999 -9999 -9999 -9999 -9999 -9999 -9999 -9999 -9999 -9999 -9999 -9999 -9999 -9999 -9999 -9999 -9999 -9999 -9999 -9999 -9999 -9999 -9999 -9999 -9999 -9999 -9999 -9999 -9999 -9999 -9999 -9999 -9999 -9999 -9999 -9999 -9999 -9999 -9999 -9999 -9999 -9999 -

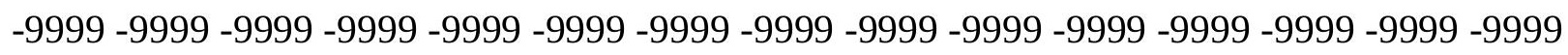
-9999 -9999 -9999 -9999 -9999 -9999 -9999 -9999 -9999 -9999 -9999 -9999 -9999 -9999 -9999 -9999 -9999 -9999 -9999 -9999 -9999 -9999 -9999 -9999 -9999 -9999 -9999 -9999 -9999 -9999 -9999 -9999 -9999 -9999 -9999 -9999 -9999 -9999 -9999 -9999 -9999 -9999 -9999 -9999 -9999

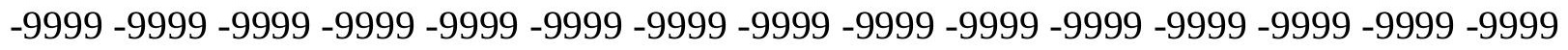
-9999 -9999 -9999 -9999 -9999 -9999 -9999 -9999 -9999 -9999 -9999 -9999 -9999 -9999 -9999 -9999 -9999 -9999 -9999 -9999 -9999 -9999 -9999 -9999 -9999 -9999 -9999 -9999 -9999 -9999 -

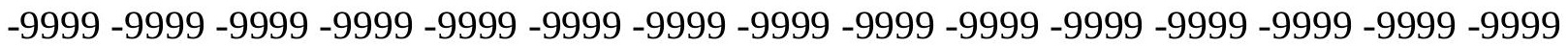

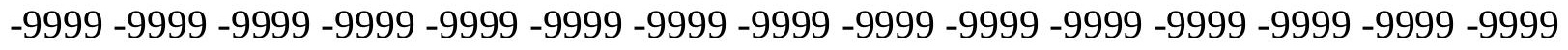

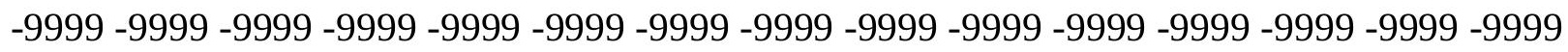

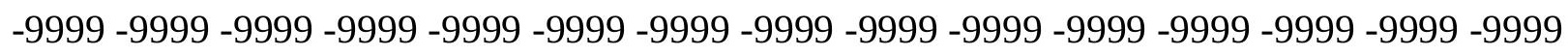
-9999 -9999 -9999 -9999 -9999 -9999 -9999 -9999 -9999 -9999 -9999 -9999 -9999 -9999 -9999 -

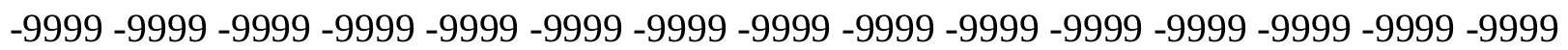
-9999 -9999 -9999-9999 95.3977432251 96.61688232422 98.75038146973 97.22646331787 97.22646331787 97.2264633178797.2264633178797.5312423706197.53124237061 97.8360290527397 .8360290527398 .1408081054798 .445587158298 .75038146973 99.0551681518699 .3599472045999 .66472625732100 .2742996216100 .5791015625 100.8839035034100 .8839035034101 .1886978149101 .4934005737101 .4934005737 101.4934005737101 .7982025146101 .7982025146101 .4934005737101 .4934005737 101.1886978149100 .8839035034100 .579101562599 .9695205688599 .35994720459 98.7503814697397 .8360290527396 .6168823242295 .397743225193 .56903076172 91.7403335571389 .9116134643687 .7781066894585 .6446228027385 .03504943848 $82.9015579223680 .7680587768678 .6345596313574 .9771423339873 .45321655273-9999$ -9999 -9999 -9999 -9999 -9999 -9999 -9999 -9999 -9999 -9999 -9999 -9999 -9999 -9999 -9999

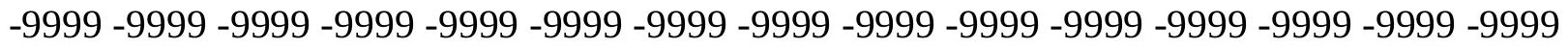

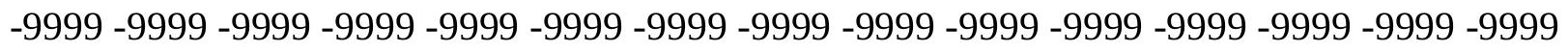
-9999 -9999-9999-9999-9999

-9999 -9999 -9999 -9999 -9999 -9999 -9999 -9999 -9999 -9999 -9999 -9999 -9999 -9999 -9999 -9999 -9999 -9999 -9999 -9999 -9999 -9999 -9999 -9999 -9999 -9999 -9999 -9999 -9999 -9999 -

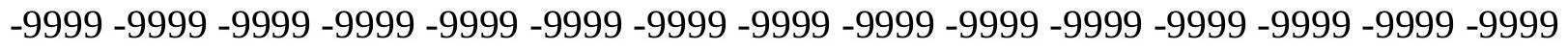

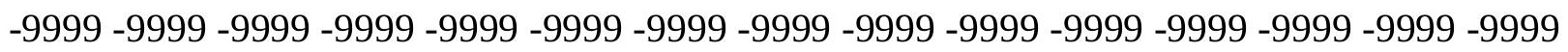
-9999 -9999 -9999 -9999 -9999 -9999 -9999 -9999 -9999 -9999 -9999 -9999 -9999 -9999 -9999 -9999 -9999 -9999 -9999 -9999 -9999 -9999 -9999 -9999 -9999 -9999 -9999 -9999 -9999 -9999 -9999 -9999 -9999 -9999 -9999 -9999 -9999 -9999 -9999 -9999 -9999 -9999 -9999 -9999 -9999 -

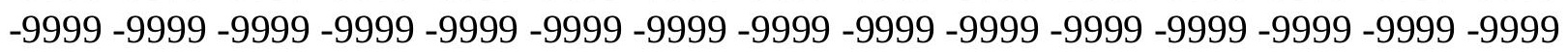


-9999 -9999 -9999 -9999 -9999 -9999 -9999 -9999 -9999 -9999 -9999 -9999 -9999 -9999 -9999 -9999 -9999 -9999 -9999 -9999 -9999 -9999 -9999 -9999 -9999 -9999 -9999 -9999 -9999 -9999 -9999 -9999 -9999 -9999 -9999 -9999 -9999 -9999 -9999 -9999 -9999 -9999 -9999 -9999 -9999 -9999 -9999 -9999 -9999 -9999 -9999 -9999 -9999 -9999 -9999 -9999 -9999 -9999 -9999 -9999 -9999 -9999 -9999 -9999 -9999 -9999 -9999 -9999 -9999 -9999 -9999 -9999 -9999 -9999 -9999 -9999 -9999 -9999 -9999 -9999 -9999 -9999 -9999 -9999 -9999 -9999 -9999 -9999 -9999 -9999 -9999 -9999 -9999 -9999 -9999 -9999 -9999 -9999 -9999 -9999 -9999 -9999 -9999 -9999 -9999

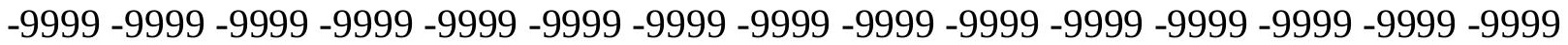
-9999 -9999 -9999 -9999 -9999 -9999 -9999 -9999 -9999 -9999 -9999 -9999 -9999 -9999 -9999 -9999 -9999 -9999 -9999 -9999 -9999 -9999 -9999 -9999 -9999 -9999 -9999 -9999 -9999 -9999 -9999 -9999 -9999 -9999 -9999 -9999 -9999 -9999 -9999 -9999 -9999 -9999 -9999 -9999 -9999 -9999 -9999 -9999 -9999 -9999 97.5312423706198.1408081054798.14080810547 97.8360290527397 .8360290527397 .8360290527397 .8360290527397 .83602905273 97.8360290527398 .1408081054798 .445587158298 .7503814697399 .05516815186 99.3599472045999 .6647262573299 .96952056885100 .2742996216100 .5791015625 100.5791015625100 .8839035034101 .1886978149101 .1886978149101 .4934005737 101.4934005737101 .4934005737101 .4934005737101 .1886978149101 .1886978149 100.8839035034100 .274299621699 .9695205688599 .3599472045998 .4455871582 97.8360290527396 .6168823242295 .397743225193 .8738174438592 .3498916626 90.5211791992288 .6924667358486 .5589828491285 .9494018554783 .81591033936 81.9871978759879 .5489196777377 .4154205322375 .2819290161172 .53885650635 -9999 -9999 -9999 -9999 -9999 -9999 -9999 -9999 -9999 -9999 -9999 -9999 -9999 -9999 -9999 -9999 -9999 -9999 -9999 -9999 -9999 -9999 -9999 -9999 -9999 -9999 -9999 -9999 -9999 -9999 -9999 -9999 -9999 -9999 -9999 -9999 -9999 -9999 -9999 -9999 -9999 -9999 -9999 -9999 -9999 -9999 -9999 -9999-9999-9999-9999

-9999 -9999 -9999 -9999 -9999 -9999 -9999 -9999 -9999 -9999 -9999 -9999 -9999 -9999 -9999 -9999 -9999 -9999 -9999 -9999 -9999 -9999 -9999 -9999 -9999 -9999 -9999 -9999 -9999 -9999 -9999 -9999 -9999 -9999 -9999 -9999 -9999 -9999 -9999 -9999 -9999 -9999 -9999 -9999 -9999 -9999 -9999 -9999 -9999 -9999 -9999 -9999 -9999 -9999 -9999 -9999 -9999 -9999 -9999 -9999

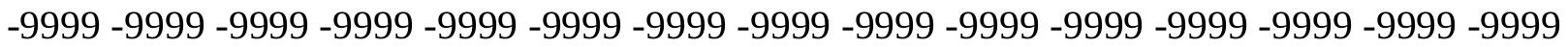
-9999 -9999 -9999 -9999 -9999 -9999 -9999 -9999 -9999 -9999 -9999 -9999 -9999 -9999 -9999 -

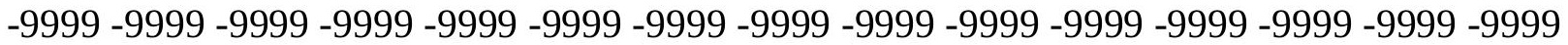
-9999 -9999 -9999 -9999 -9999 -9999 -9999 -9999 -9999 -9999 -9999 -9999 -9999 -9999 -9999 -9999 -9999 -9999 -9999 -9999 -9999 -9999 -9999 -9999 -9999 -9999 -9999 -9999 -9999 -9999 -

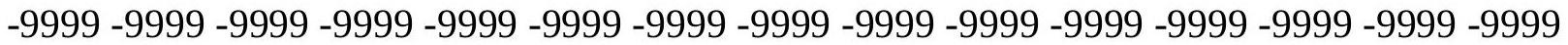
-9999 -9999 -9999 -9999 -9999 -9999 -9999 -9999 -9999 -9999 -9999 -9999 -9999 -9999 -9999 -9999 -9999 -9999 -9999 -9999 -9999 -9999 -9999 -9999 -9999 -9999 -9999 -9999 -9999 -9999

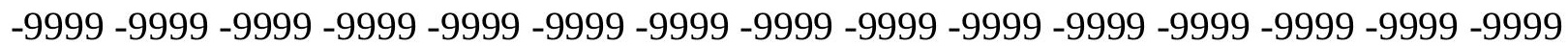
-9999 -9999 -9999 -9999 -9999 -9999 -9999 -9999 -9999 -9999 -9999 -9999 -9999 -9999 -9999 -9999 -9999 -9999 -9999 -9999 -9999 -9999 -9999 -9999 -9999 -9999 -9999 -9999 -9999 -9999 -9999 -9999 -9999 -9999 -9999 -9999 -9999 -9999 -9999 -9999 -9999 -9999 -9999 -9999 -9999 -999 -9999 -9999 -9999 -9999 -9999 -9999 -9999 -9999 -9999 -9999 -9999 -9999 -9999 -9999 -9999 -9999 -9999 -9999 -9999 -9999 -9999 -9999 -9999 -9999 -9999 -9999 -9999 -9999 -9999 -9999 -9999 -9999 -9999 -9999 -9999 -9999 -9999 -9999 -9999 -9999 -9999 -9999 -9999 -9999 -9999 -9999 -9999 -9999 -9999 -9999 99.0551681518699.0551681518698.75038146973 98.445587158298 .1408081054798 .1408081054798 .1408081054798 .14080810547 
98.1408081054798 .445587158298 .445587158298 .7503814697399 .05516815186 99.3599472045999 .6647262573299 .96952056885100 .2742996216100 .5791015625 100.5791015625100 .8839035034101 .1886978149101 .1886978149101 .1886978149 101.1886978149101 .1886978149101 .1886978149100 .8839035034100 .5791015625 100.274299621699 .9695205688599 .3599472045998 .445587158297 .83602905273 96.6168823242295 .397743225194 .1785964965892 .6546783447391 .13075256348 89.302040100187.16854858398 86.86376190186 84.7302627563582.90155792236 $80.7680587768678 .3297805786176 .1962814331172 .5388565063571 .92929077148-9999$ -9999 -9999 -9999 -9999 -9999 -9999 -9999 -9999 -9999 -9999 -9999 -9999 -9999 -9999 -9999 -9999 -9999 -9999 -9999 -9999 -9999 -9999 -9999 -9999 -9999 -9999 -9999 -9999 -9999 -9999 -9999 -9999 -9999 -9999 -9999 -9999 -9999 -9999 -9999 -9999 -9999 -9999 -9999 -9999 -9999 -9999 -9999-9999-9999-9999

-9999 -9999 -9999 -9999 -9999 -9999 -9999 -9999 -9999 -9999 -9999 -9999 -9999 -9999 -9999 -9999 -9999 -9999 -9999 -9999 -9999 -9999 -9999 -9999 -9999 -9999 -9999 -9999 -9999 -9999 -9999 -9999 -9999 -9999 -9999 -9999 -9999 -9999 -9999 -9999 -9999 -9999 -9999 -9999 -9999

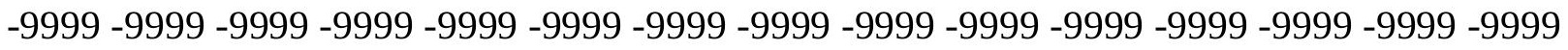

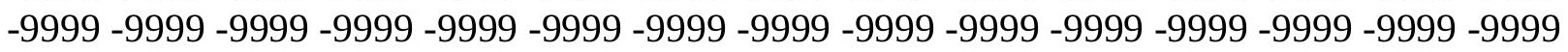
-9999 -9999 -9999 -9999 -9999 -9999 -9999 -9999 -9999 -9999 -9999 -9999 -9999 -9999 -9999 -999 -9999 -9999 -9999 -9999 -9999 -9999 -9999 -9999 -9999 -9999 -9999 -9999 -9999 -9999 -9999 -9999 -9999 -9999 -9999 -9999 -9999 -9999 -9999 -9999 -9999 -9999 -9999 -9999 -9999 -9999 -9999 -9999 -9999 -9999 -9999 -9999 -9999 -9999 -9999 -9999 -9999 -9999 -9999 -9999 -9999 -9999 -9999 -9999 -9999 -9999 -9999 -9999 -9999 -9999 -9999 -9999 -9999 -9999 -9999 -9999 -9999 -9999 -9999 -9999 -9999 -9999 -9999 -9999 -9999 -9999 -9999 -9999 -9999 -9999 -9999 -9999 -9999 -9999 -9999 -9999 -9999 -9999 -9999 -9999 -9999 -9999 -9999 -9999 -9999 -9999 -9999 -9999 -9999 -9999 -9999 -9999 -9999 -9999 -9999 -9999 -9999 -9999 -9999 -9999 -9999 -9999 -9999 -9999 -9999 -9999 -9999 -9999 -9999 -9999 -9999 -9999 -9999 -9999 -9999 -9999 -9999 -9999 -9999 -9999 -9999 -9999 -9999 -9999 -9999 -9999 -9999 -9999 -9999 -9999 -9999 -

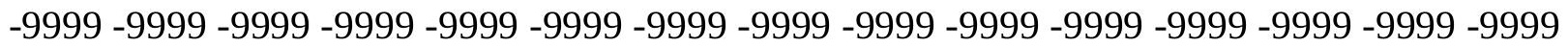

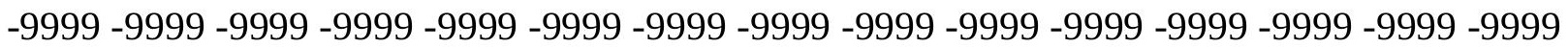
-9999 -9999 -9999 -9999 -9999 -9999 -9999 -9999 -9999 -9999 -9999 -9999 -9999 -9999 -9999 -9999 -9999 -9999 -9999 -9999 -9999 -9999 -9999 -9999 -9999 -9999 -9999 -9999 -9999 -9999 -9999 -9999 -9999 -9999 -9999 -9999 99.96952056885 99.35994720459 98.75038146973 98.445587158298 .1408081054798 .1408081054798 .1408081054798 .4455871582 98.445587158298 .7503814697399 .0551681518699 .3599472045999 .35994720459 99.6647262573299 .96952056885100 .2742996216100 .5791015625100 .5791015625 100.8839035034100 .8839035034101 .1886978149101 .1886978149101 .1886978149 100.8839035034100 .8839035034100 .5791015625100 .274299621699 .96952056885 99.3599472045998 .7503814697397 .8360290527396 .9216690063595 .70252990723 94.4833908081192 .9594726562591 .4355392456189 .6068267822389 .3020401001 87.4733276367285 .6446228027383 .8159103393681 .6824111938579 .24413299561 77.110626220773 .7580032348671 .9292907714871 .0149307251 -9999 -9999 -9999 -9999 -9999 -9999 -9999 -9999 -9999 -9999 -9999 -9999 -9999 -9999 -9999 -9999 -9999 -9999 -9999 -9999 -9999 -9999 -9999 -9999 -9999 -9999 -9999 -9999 -9999 -9999 -9999 -9999 -9999 -9999 -

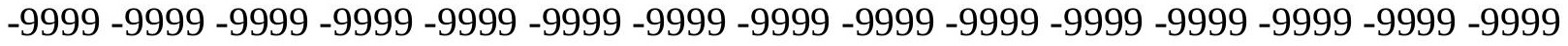
$-9999-9999$

-9999 -9999 -9999 -9999 -9999 -9999 -9999 -9999 -9999 -9999 -9999 -9999 -9999 -9999 -9999 
-9999 -9999 -9999 -9999 -9999 -9999 -9999 -9999 -9999 -9999 -9999 -9999 -9999 -9999 -9999 -9999 -9999 -9999 -9999 -9999 -9999 -9999 -9999 -9999 -9999 -9999 -9999 -9999 -9999 -9999 -9999 -9999 -9999 -9999 -9999 -9999 -9999 -9999 -9999 -9999 -9999 -9999 -9999 -9999 -9999 -9999 -9999 -9999 -9999 -9999 -9999 -9999 -9999 -9999 -9999 -9999 -9999 -9999 -9999 -9999 -9999 -9999 -9999 -9999 -9999 -9999 -9999 -9999 -9999 -9999 -9999 -9999 -9999 -9999 -9999 -9999 -9999 -9999 -9999 -9999 -9999 -9999 -9999 -9999 -9999 -9999 -9999 -9999 -9999 -9999 -9999 -9999 -9999 -9999 -9999 -9999 -9999 -9999 -9999 -9999 -9999 -9999 -9999 -9999 -9999

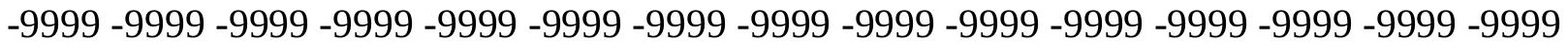
-9999 -9999 -9999 -9999 -9999 -9999 -9999 -9999 -9999 -9999 -9999 -9999 -9999 -9999 -9999 -9999 -9999 -9999 -9999 -9999 -9999 -9999 -9999 -9999 -9999 -9999 -9999 -9999 -9999 -9999 -

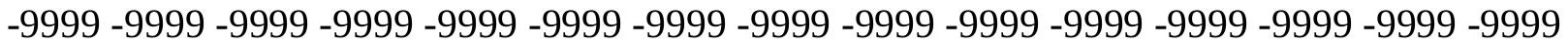
-9999 -9999 -9999 -9999 -9999 -9999 -9999 -9999 -9999 -9999 -9999 -9999 -9999 -9999 -9999

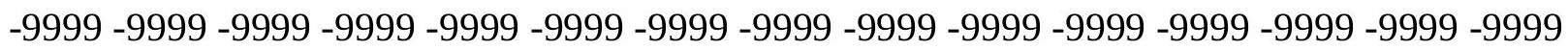
-9999 -9999 -9999 -9999 -9999 -9999 -9999 -9999 -9999 -9999 -9999 -9999 -9999 -9999 -9999 -9999 -9999 -9999 -9999 -9999 -9999 -9999 -9999 -9999 -9999 -9999 -9999 -9999 -9999 -9999 -9999 -9999 -9999 -9999 -9999 -9999 -9999 -9999 -9999 -9999 -9999 -9999 -9999 -9999 -9999 -9999 -9999 -9999 -9999 -9999 -9999 -9999 -9999 -9999 -9999 -9999 -9999 -9999 -9999 -9999 -9999 -9999 -9999 -9999 -9999 -9999 -9999 -9999 -9999 -9999 -9999 -9999 -9999 -9999 -9999 -9999 -9999 -9999 -9999 -9999 -9999-9999 99.35994720459 98.75038146973 98.4455871582 98.445587158298 .445587158298 .445587158298 .445587158298 .75038146973 99.0551681518699 .0551681518699 .3599472045999 .6647262573299 .96952056885 99.96952056885100 .2742996216100 .5791015625100 .5791015625100 .8839035034 100.8839035034100 .8839035034100 .8839035034100 .8839035034100 .8839035034 100.5791015625100 .274299621699 .9695205688599 .3599472045998 .75038146973 98.1408081054797.2264633178796.3121032714895.0929565429793.56903076172 92.0450973510790 .5211791992290 .2164001464888 .3876876831186 .55898284912 84.7302627563582 .5967712402380 .4632720947378 .0249862670974 .36756896973 72.5388565063571 .014930725170 .10057830811 -9999 -9999 -9999 -9999 -9999 -9999 -9999 -9999 -9999 -9999 -9999 -9999 -9999 -9999 -9999 -9999 -9999 -9999 -9999 -9999 -9999 -9999

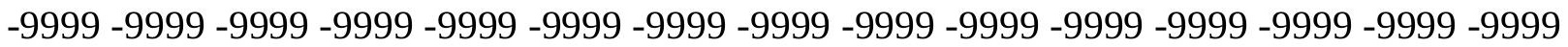
-9999 -9999 -9999 -9999 -9999 -9999 -9999 -9999 -9999 -9999 -9999 -9999 -9999 -9999 -9999 -9999 -9999 -9999 -9999 -9999 -9999 -9999 -9999 -9999 -9999 -9999 -9999 -9999 -9999 -9999 -9999 -9999 -9999 -9999 -9999 -9999 -9999 -9999 -9999 -9999 -9999 -9999 -9999 -9999 -9999 -9999 -9999 -9999 -9999 -9999 -9999 -9999 -9999 -9999 -9999 -9999 -9999 -9999 -9999 -

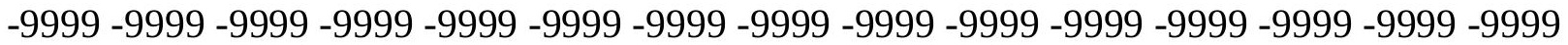
-9999 -9999 -9999 -9999 -9999 -9999 -9999 -9999 -9999 -9999 -9999 -9999 -9999 -9999 -9999 -9999 -9999 -9999 -9999 -9999 -9999 -9999 -9999 -9999 -9999 -9999 -9999 -9999 -9999 -9999

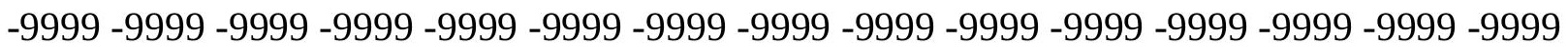
-9999 -9999 -9999 -9999 -9999 -9999 -9999 -9999 -9999 -9999 -9999 -9999 -9999 -9999 -9999 -9999 -9999 -9999 -9999 -9999 -9999 -9999 -9999 -9999 -9999 -9999 -9999 -9999 -9999 -9999 -9999 -9999 -9999 -9999 -9999 -9999 -9999 -9999 -9999 -9999 -9999 -9999 -9999 -9999 -9999 -999 -9999 -9999 -9999 -9999 -9999 -9999 -9999 -9999 -9999 -9999 -9999 -9999 -9999 -9999 -9999 -9999 -9999 -9999 -9999 -9999 -9999 -9999 -9999 -9999 -9999 -9999 -9999 -9999 -9999 -9999 -9999 -9999 -9999 -9999 -9999 -9999 -9999 -9999 -9999 -9999 -9999 -9999 -9999 -9999 -9999 -9999 -9999 -9999 -9999 -9999 -9999 -9999 -9999 -9999 -9999 -9999 -9999 -9999 -9999 -9999

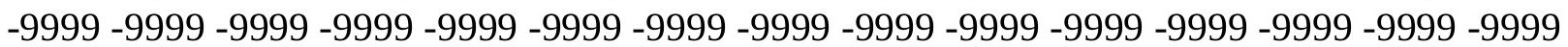


-9999 -9999 -9999 -9999 -9999 -9999 -9999 -9999 -9999 -9999 -9999 -9999 -9999 -9999 -9999 -9999 -9999 -9999 -9999 -9999 -9999 -9999 -9999 -9999 -9999 -9999 -9999 -9999 -9999 -9999

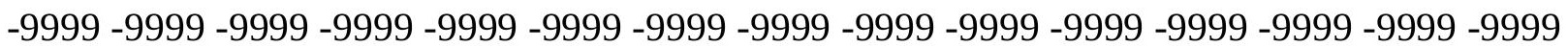
-9999 -9999 -9999 -9999 -9999 -9999 -9999 -9999 -9999 -9999 -9999 -9999 -9999 -9999 -9999 -9999 -9999 -9999 -9999 -9999 -9999 -9999 98.75038146973 98.4455871582 98.4455871582 99.9695205688598 .445587158298 .7503814697398 .7503814697399 .05516815186 99.0551681518699 .3599472045999 .6647262573299 .9695205688599 .96952056885 100.2742996216100 .2742996216100 .5791015625100 .5791015625100 .8839035034 100.8839035034100 .8839035034100 .8839035034100 .8839035034100 .5791015625 100.5791015625100 .274299621699 .6647262573299 .0551681518698 .4455871582 97.5312423706196 .6168823242295 .397743225194 .1785964965892 .65467834473 91.1307525634891 .1307525634889 .302040100187 .4733276367285 .64462280273 83.5111236572381 .3776321411179 .2441329956176 .8058471679773 .14842987061 71.3197174072370 .10057830811 -9999 -9999 -9999 -9999 -9999 -9999 -9999 -9999 -9999 -9999 -9999 -9999 -9999 -9999 -9999 -9999 -9999 -9999 -9999 -9999 -9999 -9999 -9999 -9999 -9999 -9999 -9999 -9999 -9999 -9999 -9999 -9999 -9999 -9999 -9999 -9999 -9999 -9999 -9999 -999 -9999 -9999 -9999 -9999 -9999 -9999 -9999 -9999 -9999 -9999 -9999 -9999 -9999 -9999 -9999 -9999 -9999 -9999 -9999 -9999 -9999 -9999 -9999 -9999 -9999 -9999 -9999 -9999 -9999 -9999 -9999 -9999 -9999 -9999 -9999 -9999 -9999 -9999 -9999 -9999 -9999 -9999 -9999 -9999 -9999 -9999 -9999 -9999 -9999 -9999 -9999 -9999 -9999 -9999 -9999 -9999 -9999 -9999

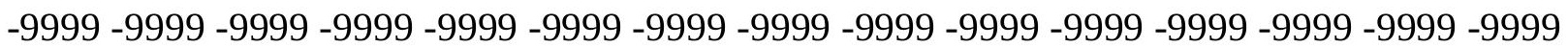
-9999 -9999 -9999 -9999 -9999 -9999 -9999 -9999 -9999 -9999 -9999 -9999 -9999 -9999 -9999 -9999 -9999 -9999 -9999 -9999 -9999 -9999 -9999 -9999 -9999 -9999 -9999 -9999 -9999 -9999 -9999 -9999 -9999 -9999 -9999 -9999 -9999 -9999 -9999 -9999 -9999 -9999 -9999 -9999 -9999

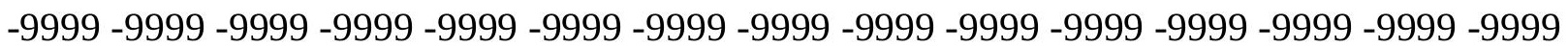
-9999 -9999 -9999 -9999 -9999 -9999 -9999 -9999 -9999 -9999 -9999 -9999 -9999 -9999 -9999 -9999 -9999 -9999 -9999 -9999 -9999 -9999 -9999 -9999 -9999 -9999 -9999 -9999 -9999 -9999 -9999 -9999 -9999 -9999 -9999 -9999 -9999 -9999 -9999 -9999 -9999 -9999 -9999 -9999 -9999 -9999 -9999 -9999 -9999 -9999 -9999 -9999 -9999 -9999 -9999 -9999 -9999 -9999 -9999 -9999 -9999 -9999 -9999 -9999 -9999 -9999 -9999 -9999 -9999 -9999 -9999 -9999 -9999 -9999 -9999 -9999 -9999 -9999 -9999 -9999 -9999 -9999 -9999 -9999 -9999 -9999 -9999 -9999 -9999 -9999 -9999 -9999 -9999 -9999 -9999 -9999 -9999 -9999 -9999 -9999 -9999 -9999 -9999 -9999 -9999 -9999 -9999 -9999 -9999 -9999 -9999 -9999 -9999 -9999 -9999 -9999 -9999 -9999 -9999 -9999 -9999 -9999 -9999 -9999 -9999 -9999 -9999 -9999 -9999 -9999 -9999 -9999 -9999 -9999 -9999 -9999 -9999 -9999 -9999 -9999 -9999 -9999 -9999 -9999 -9999 -9999 -9999 -9999 -9999 -9999 -9999 -9999 -9999 -9999 -9999 -9999 -9999 -9999 -9999 -9999 -9999 -9999 -9999 -9999 -9999 -9999 -9999 -9999 -9999 -9999 -9999 -9999 -9999 98.1408081054798.4455871582 99.96952056885100 .274299621698 .7503814697399 .0551681518699 .35994720459 99.3599472045999 .6647262573299 .9695205688599 .96952056885100 .2742996216 100.2742996216100 .5791015625100 .5791015625100 .8839035034100 .8839035034 100.8839035034100 .8839035034100 .8839035034100 .8839035034100 .5791015625 100.274299621699 .9695205688599 .6647262573299 .0551681518698 .14080810547 97.2264633178796.3121032714895.0929565429793.5690307617292.04509735107 92.0450973510790 .5211791992288 .6924667358486 .8637619018684 .73026275635 82.5967712402380 .4632720947378 .0249862670975 .5867080688572 .23407745361 70.4053573608469 .49101257324 -9999 -9999 -9999 -9999 -9999 -9999 -9999 -9999 -9999 
-9999 -9999 -9999 -9999 -9999 -9999 -9999 -9999 -9999 -9999 -9999 -9999 -9999 -9999 -9999 -9999 -9999 -9999 -9999 -9999 -9999 -9999 -9999 -9999 -9999 -9999 -9999 -9999 -9999 -9999 -9999 -9999 -9999 -9999 -9999 -9999 -9999 -9999 -9999 -9999 -9999 -9999 -9999

-9999 -9999 -9999 -9999 -9999 -9999 -9999 -9999 -9999 -9999 -9999 -9999 -9999 -9999 -9999 -9999 -9999 -9999 -9999 -9999 -9999 -9999 -9999 -9999 -9999 -9999 -9999 -9999 -9999 -9999 -9999 -9999 -9999 -9999 -9999 -9999 -9999 -9999 -9999 -9999 -9999 -9999 -9999 -9999 -9999 -9999 -9999 -9999 -9999 -9999 -9999 -9999 -9999 -9999 -9999 -9999 -9999 -9999 -9999 -9999 -

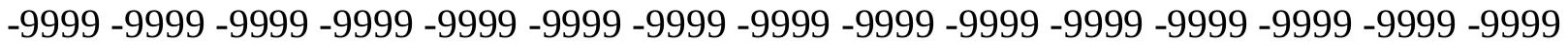
-9999 -9999 -9999 -9999 -9999 -9999 -9999 -9999 -9999 -9999 -9999 -9999 -9999 -9999 -9999 -9999 -9999 -9999 -9999 -9999 -9999 -9999 -9999 -9999 -9999 -9999 -9999 -9999 -9999 -9999 -

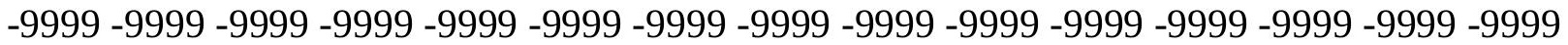
-9999 -9999 -9999 -9999 -9999 -9999 -9999 -9999 -9999 -9999 -9999 -9999 -9999 -9999 -9999

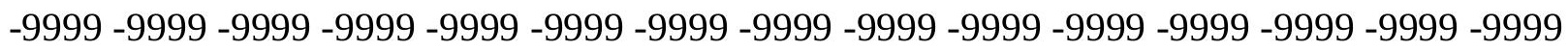
-9999 -9999 -9999 -9999 -9999 -9999 -9999 -9999 -9999 -9999 -9999 -9999 -9999 -9999 -9999 -9999 -9999 -9999 -9999 -9999 -9999 -9999 -9999 -9999 -9999 -9999 -9999 -9999 -9999 -9999 -9999 -9999 -9999 -9999 -9999 -9999 -9999 -9999 -9999 -9999 -9999 -9999 -9999 -9999 -9999 -9999 -9999 -9999 -9999 -9999 -9999 -9999 -9999 -9999 -9999 -9999 -9999 -9999 -9999 -9999 -9999 -9999 -9999 -9999 -9999 -9999 -9999 -9999 -9999 -9999 -9999 -9999 -9999 -9999 -9999 -9999 -9999 -9999 -9999 -9999 -9999 -9999 -9999 -9999 -9999 -9999 -9999 -9999 -9999 -9999 -9999 -9999 -9999 -9999 -9999 -9999 -9999 -9999 -9999 -9999 -9999 -9999 -9999 -9999 -9999

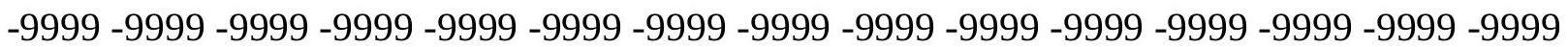
-9999 -9999 -9999 -9999 -9999 -9999 -9999 -9999 -9999 -9999 -9999 -9999 -9999 -9999 -9999 -9999 -9999 -9999 -9999 -9999 -9999 -9999 -9999 -9999 98.4455871582 98.75038146973 100.5791015625100 .883903503499 .3599472045999 .6647262573299 .96952056885 99.96952056885100 .2742996216100 .2742996216100 .2742996216100 .5791015625 100.5791015625100 .5791015625100 .8839035034100 .8839035034100 .8839035034 100.8839035034100 .8839035034100 .8839035034100 .5791015625100 .2742996216 99.9695205688599 .3599472045998 .7503814697398 .1408081054797 .22646331787 96.0073165893694 .7881774902393 .2642517089891 .4355392456191 .43553924561 89.9116134643688 .0829010009885 .9494018554783 .8159103393681 .68241119385 79.2441329956176 .8058471679774 .6723632812571 .014930725169 .49101257324 68.57665252686 -9999 -9999 -9999 -9999 -9999 -9999 -9999 -9999 -9999 -9999 -9999 -9999 -9999 -9999 -9999 -9999 -9999 -9999 -9999 -9999 -9999 -9999 -9999 -9999 -9999 -9999 -9999 -9999 -9999 -9999 -9999 -9999 -9999 -9999 -9999 -9999 -9999 -9999 -9999 -9999 -9999 -999 -999 -9999 -9999 -9999 -9999 -9999 -9999 -9999 -9999 -9999-9999

-9999 -9999 -9999 -9999 -9999 -9999 -9999 -9999 -9999 -9999 -9999 -9999 -9999 -9999 -9999 -9999 -9999 -9999 -9999 -9999 -9999 -9999 -9999 -9999 -9999 -9999 -9999 -9999 -9999 -9999

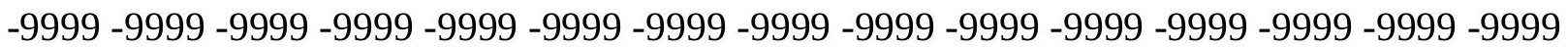
-9999 -9999 -9999 -9999 -9999 -9999 -9999 -9999 -9999 -9999 -9999 -9999 -9999 -9999 -9999 -9999 -9999 -9999 -9999 -9999 -9999 -9999 -9999 -9999 -9999 -9999 -9999 -9999 -9999 -9999 -9999 -9999 -9999 -9999 -9999 -9999 -9999 -9999 -9999 -9999 -9999 -9999 -9999 -9999 -9999 -9999 -9999 -9999 -9999 -9999 -9999 -9999 -9999 -9999 -9999 -9999 -9999 -9999 -9999 -9999 -9999 -9999 -9999 -9999 -9999 -9999 -9999 -9999 -9999 -9999 -9999 -9999 -9999 -9999 -9999 -9999 -9999 -9999 -9999 -9999 -9999 -9999 -9999 -9999 -9999 -9999 -9999 -9999 -9999 -9999 -9999 -9999 -9999 -9999 -9999 -9999 -9999 -9999 -9999 -9999 -9999 -9999 -9999 -9999 -9999

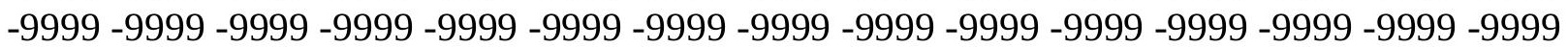


-9999 -9999 -9999 -9999 -9999 -9999 -9999 -9999 -9999 -9999 -9999 -9999 -9999 -9999 -9999 -9999 -9999 -9999 -9999 -9999 -9999 -9999 -9999 -9999 -9999 -9999 -9999 -9999 -9999 -9999 -9999 -9999 -9999 -9999 -9999 -9999 -9999 -9999 -9999 -9999 -9999 -9999 -9999 -9999 -9999 -9999 -9999 -9999 -9999 -9999 -9999 -9999 -9999 -9999 -9999 -9999 -9999 -9999 -9999 -9999 -9999 -9999 -9999 -9999 -9999 -9999 -9999 -9999 -9999 -9999 -9999 -9999 -9999 -9999 -9999 -9999 -9999 -9999 -9999 -9999 -9999 -9999 -9999 -9999 -9999 -9999 -9999 -9999 -9999 -9999 -9999 -9999 -9999 -9999 -9999 -9999 -9999 -9999 -9999 -9999 -9999 -9999 -9999 -9999 -9999 -9999 -9999 -9999 -9999 -9999 -9999 -9999 -9999 -9999 -9999 -9999 -9999 -9999 -9999 -9999 -9999 -9999 -9999 -9999 -9999 -9999 -9999 -9999 -9999 98.75038146973 99.05516815186 99.35994720459101 .188697814999 .9695205688599 .96952056885100 .2742996216 100.2742996216100 .2742996216100 .5791015625100 .5791015625100 .5791015625 100.5791015625100 .8839035034100 .8839035034100 .8839035034100 .8839035034 100.8839035034100 .8839035034100 .8839035034100 .5791015625100 .2742996216 99.9695205688599 .3599472045998 .7503814697398 .1408081054796 .92166900635 95.7025299072394 .4833908081192 .9594726562592 .9594726562591 .43553924561 89.60682678223 87.77810668945 85.6446228027383.206336975180.76805877686 78.3297805786175 .8914871215873 .4532165527369 .7957916259868 .88143920898 -9999 -9999 -9999 -9999 -9999 -9999 -9999 -9999 -9999 -9999 -9999 -9999 -9999 -9999 -9999 -9999 -9999 -9999 -9999 -9999 -9999 -9999 -9999 -9999 -9999 -9999 -9999 -9999 -9999 -9999 -9999

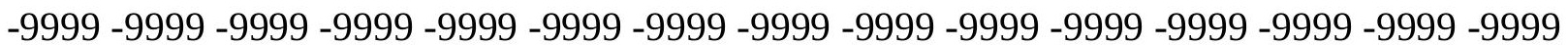
-9999 -9999 -9999 -9999 -9999 -9999 -9999

-9999 -9999 -9999 -9999 -9999 -9999 -9999 -9999 -9999 -9999 -9999 -9999 -9999 -9999 -9999 -9999 -9999 -9999 -9999 -9999 -9999 -9999 -9999 -9999 -9999 -9999 -9999 -9999 -9999 -9999 -9999 -9999 -9999 -9999 -9999 -9999 -9999 -9999 -9999 -9999 -9999 -9999 -9999 -9999 -9999

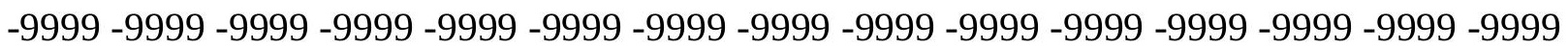
-9999 -9999 -9999 -9999 -9999 -9999 -9999 -9999 -9999 -9999 -9999 -9999 -9999 -9999 -9999 -9999 -9999 -9999 -9999 -9999 -9999 -9999 -9999 -9999 -9999 -9999 -9999 -9999 -9999 -9999 -9999 -9999 -9999 -9999 -9999 -9999 -9999 -9999 -9999 -9999 -9999 -9999 -9999 -9999 -9999 -9999 -9999 -9999 -9999 -9999 -9999 -9999 -9999 -9999 -9999 -9999 -9999 -9999 -9999 -9999 -9999 -9999 -9999 -9999 -9999 -9999 -9999 -9999 -9999 -9999 -9999 -9999 -9999 -9999 -9999 -9999 -9999 -9999 -9999 -9999 -9999 -9999 -9999 -9999 -9999 -9999 -9999 -9999 -9999 -9999 -9999 -9999 -9999 -9999 -9999 -9999 -9999 -9999 -9999 -9999 -9999 -9999 -9999 -9999 -9999 -9999 -9999 -9999 -9999 -9999 -9999 -9999 -9999 -9999 -9999 -9999 -9999 -9999 -9999 -9999 -9999 -9999 -9999 -9999 -9999 -9999 -9999 -9999 -9999 -9999 -9999 -9999 -9999 -9999 -9999 -9999 -9999 -9999 -9999 -9999 -9999 -9999 -9999 -9999 -9999 -9999 -9999 -9999 -9999 -9999 -9999 -9999 -9999 -9999 -9999 -9999 -9999 -9999 -9999 -9999 -9999 -9999 -9999 -9999 -9999 -9999 -9999 -9999 -9999 -9999 -9999 -9999 -9999 -9999 -9999 -9999 -9999 -9999 -9999 -9999

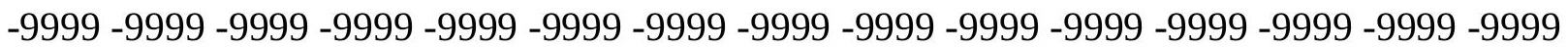
-9999 -9999 -9999 -9999 -9999 -9999 -9999 -9999 -9999 -9999 -9999 -9999 -9999 -9999 -9999 -9999 -9999 -9999 -9999 -9999 -9999 -9999 -9999 -9999 -9999 -9999 -9999 -9999 -9999 -9999 -999 -9999 -9999 -9999 -9999 -9999 -9999 -9999 -9999 -9999 -9999 99.66472625732 99.96952056885100 .2742996216100 .2742996216100 .5791015625100 .5791015625 100.5791015625100 .5791015625100 .5791015625100 .8839035034100 .8839035034 100.8839035034100 .8839035034100 .8839035034100 .8839035034100 .8839035034 100.8839035034100 .8839035034100 .8839035034100 .8839035034100 .5791015625 99.9695205688599 .6647262573299 .0551681518698 .1408081054797 .22646331787 
96.0073165893694 .4833908081192 .9594726562592 .6546783447391 .13075256348 89.3020401001 87.47332763672 85.03504943848 82.9015579223680.15849304199 $77.7202072143674 .9771423339870 .7101516723669 .1862335205167 .96708679199-9999$ -9999 -9999 -9999 -9999 -9999 -9999 -9999 -9999 -9999 -9999 -9999 -9999 -9999 -9999 -9999 -9999 -9999 -9999 -9999 -9999 -9999 -9999 -9999 -9999 -9999 -9999 -9999-9999 -9999 -9999 -

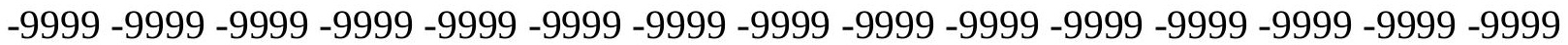
-9999 -9999 -9999 -9999 -9999 -9999 -9999

-9999 -9999 -9999 -9999 -9999 -9999 -9999 -9999 -9999 -9999 -9999 -9999 -9999 -9999 -9999 -9999 -9999 -9999 -9999 -9999 -9999 -9999 -9999 -9999 -9999 -9999 -9999 -9999 -9999 -9999 -9999 -9999 -9999 -9999 -9999 -9999 -9999 -9999 -9999 -9999 -9999 -9999 -9999 -9999 -9999

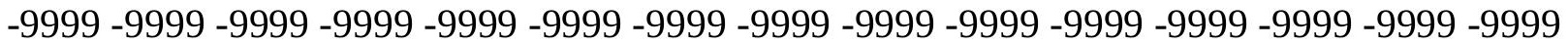
-9999 -9999 -9999 -9999 -9999 -9999 -9999 -9999 -9999 -9999 -9999 -9999 -9999 -9999 -9999 -9999 -9999 -9999 -9999 -9999 -9999 -9999 -9999 -9999 -9999 -9999 -9999 -9999 -9999 -9999 -9999 -9999 -9999 -9999 -9999 -9999 -9999 -9999 -9999 -9999 -9999 -9999 -9999 -9999 - 9999 -9999 -9999 -9999 -9999 -9999 -9999 -9999 -9999 -9999 -9999 -9999 -9999 -9999 -9999 -9999

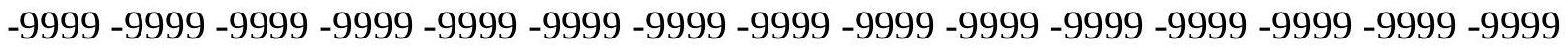
-9999 -9999 -9999 -9999 -9999 -9999 -9999 -9999 -9999 -9999 -9999 -9999 -9999 -9999 -9999 -9999 -9999 -9999 -9999 -9999 -9999 -9999 -9999 -9999 -9999 -9999 -9999 -9999 -9999 -9999 -9999 -9999 -9999 -9999 -9999 -9999 -9999 -9999 -9999 -9999 -9999 -9999 -9999 -9999 -9999 -9999 -9999 -9999 -9999 -9999 -9999 -9999 -9999 -9999 -9999 -9999 -9999 -9999 -9999 -9999 -9999 -9999 -9999 -9999 -9999 -9999 -9999 -9999 -9999 -9999 -9999 -9999 -9999 -9999 -9999 -9999 -9999 -9999 -9999 -9999 -9999 -9999 -9999 -9999 -9999 -9999 -9999 -9999 -9999 -9999 -9999 -9999 -9999 -9999 -9999 -9999 -9999 -9999 -9999 -9999 -9999 -9999 -9999 -9999 -9999 -9999 -9999 -9999 -9999 -9999 -9999 -9999 -9999 -9999 -9999 -9999 -9999 -9999 -9999 -9999 -9999 -9999 -9999 -9999 -9999 -9999 -9999 -9999 -9999 -9999 -9999 -9999 -9999 -9999 -9999 -9999 -9999 -9999 -9999 -9999 -9999 -9999 -9999 -9999 -9999 -9999 -9999 -9999 -9999 -9999 -9999 -9999 -9999 -9999 -9999 -9999 -9999 -9999 -9999 -9999 -9999 100.8839035034 100.8839035034100 .8839035034100 .8839035034100 .8839035034100 .8839035034 100.8839035034100 .8839035034100 .8839035034100 .8839035034100 .8839035034 100.8839035034100 .8839035034100 .8839035034100 .8839035034101 .1886978149 101.1886978149100 .8839035034100 .8839035034100 .5791015625100 .2742996216 99.6647262573299 .0551681518698 .445587158297 .2264633178796 .00731658936 94.4833908081192 .9594726562592 .9594726562591 .1307525634889 .3020401001 87.1685485839885 .0350494384882 .2919769287179 .8537063598677 .1106262207 74.3675689697371 .6244964599668 .2718734741267 .05272674561 -9999 -9999 -9999 -9999 -9999 -9999 -9999 -9999 -9999 -9999 -9999 -9999 -9999 -9999 -9999 -9999 -9999 -9999 -9999

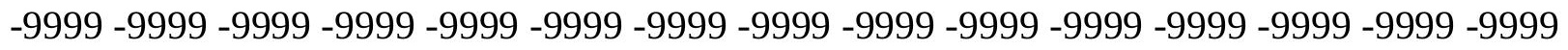

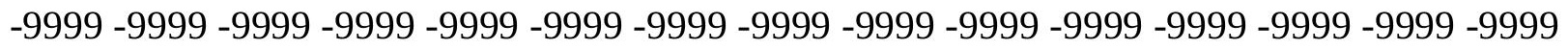
-9999 -9999 -9999-9999

-9999 -9999 -9999 -9999 -9999 -9999 -9999 -9999 -9999 -9999 -9999 -9999 -9999 -9999 -9999

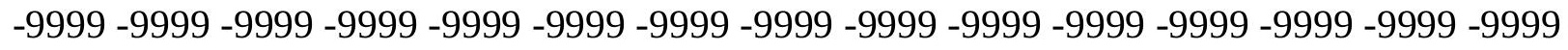

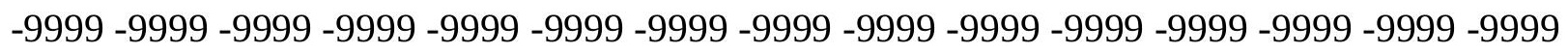
-9999 -9999 -9999 -9999 -9999 -9999 -9999 -9999 -9999 -9999 -9999 -9999 -9999 -9999 -9999 -9999 -9999 -9999 -9999 -9999 -9999 -9999 -9999 -9999-9999 -9999 -9999 -9999 -9999 -9999 -9999 -9999 -9999 -9999 -9999 -9999 -9999 -9999 -9999 -9999 -9999 -9999 -9999 -9999 -9999 -

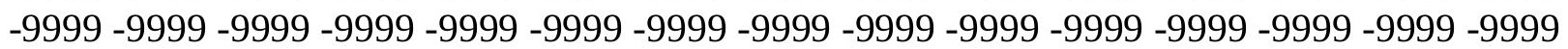


-9999 -9999 -9999 -9999 -9999 -9999 -9999 -9999 -9999 -9999 -9999 -9999 -9999 -9999 -9999 -9999 -9999 -9999 -9999 -9999 -9999 -9999 -9999 -9999 -9999 -9999 -9999 -9999 -9999 -9999 -9999 -9999 -9999 -9999 -9999 -9999 -9999 -9999 -9999 -9999 -9999 -9999 -9999 -9999 - 9999 -9999 -9999 -9999 -9999 -9999 -9999 -9999 -9999 -9999 -9999 -9999 -9999 -9999 -9999 -9999 -9999 -9999 -9999 -9999 -9999 -9999 -9999 -9999 -9999-9999 -9999 -9999 -9999 -9999 -9999 -9999 -9999 -9999 -9999 -9999 -9999 -9999 -9999 -9999 -9999 -9999 -9999 -9999 -9999 -9999 -

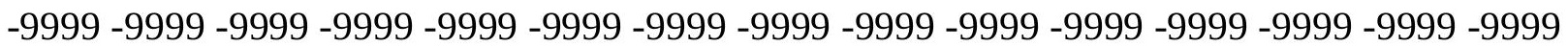

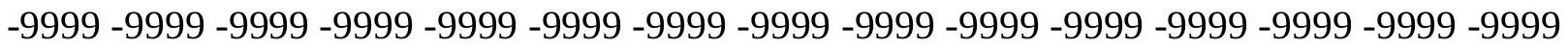

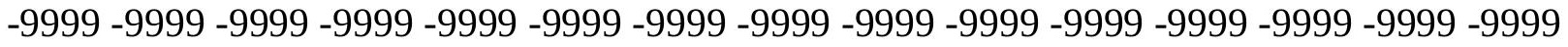
-9999 -9999 -9999 -9999 -9999 -9999 -9999 -9999 -9999 -9999 -9999 -9999 -9999 -9999 -9999 -9999 -9999 -9999 -9999 -9999 -9999 -9999 -9999 -9999 -9999 -9999 -9999 -9999 -9999 -9999 -9999 -9999 -9999 -9999 -9999 -9999 -9999 -9999 -9999 -9999 -9999 -9999 -9999 -9999 -9999 -9999 -9999 -9999 -9999 -9999 -9999 -9999 -9999 -9999 -9999 -9999 -9999 101.4934005737 101.4934005737101 .4934005737101 .1886978149101 .1886978149101 .1886978149 101.1886978149101 .1886978149100 .8839035034100 .8839035034100 .8839035034 100.8839035034100 .8839035034101 .1886978149101 .1886978149101 .1886978149 101.1886978149101 .1886978149100 .8839035034100 .579101562599 .96952056885 99.3599472045998.7503814697397.5312423706196.3121032714895.09295654297 93.2642517089893 .2642517089891 .4355392456189 .6068267822387 .16854858398 84.7302627563582 .2919769287179 .5489196777376 .5010681152373 .75800323486 69.4910125732467 .66230010986 -9999 -9999 -9999 -9999 -9999 -9999 -9999 -9999 -9999 -9999 -9999 -9999 -9999 -9999 -9999 -9999 -9999 -9999 -9999 -9999 -9999 -9999 -9999 -9999 -9999 -9999 -9999 -9999 -9999 -9999 -9999 -9999 -9999 -9999 -9999 -9999 -9999 -9999 -9999 -9999 -9999 -9999 -9999 -9999 -9999 -9999 -9999 -9999 -9999 -9999 -9999 -9999 -9999 -9999 -

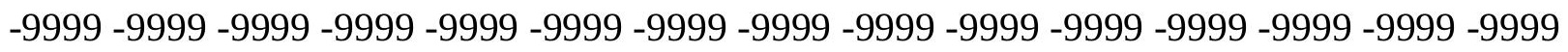
-9999 -9999 -9999 -9999 -9999 -9999 -9999 -9999 -9999 -9999 -9999 -9999 -9999 -9999 -9999 -9999 -9999 -9999 -9999 -9999 -9999 -9999 -9999 -9999 -9999 -9999 -9999 -9999 -9999 -9999

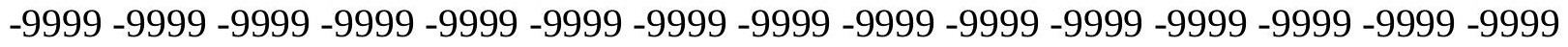
-9999 -9999 -9999 -9999 -9999 -9999 -9999 -9999 -9999 -9999 -9999 -9999 -9999 -9999 -9999 -9999 -9999 -9999 -9999 -9999 -9999 -9999 -9999 -9999 -9999 -9999 -9999 -9999 -9999 -999 -9999 -9999 -9999 -9999 -9999 -9999 -9999 -9999 -9999 -9999 -9999 -9999 -9999 -9999 -9999 -9999 -9999 -9999 -9999 -9999 -9999 -9999 -9999 -9999 -9999 -9999 -9999 -9999 -9999 -9999 -

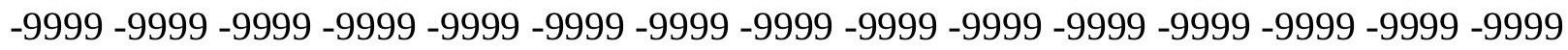

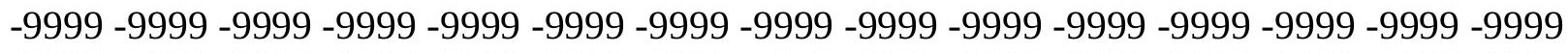
-9999 -9999 -9999 -9999 -9999 -9999 -9999 -9999 -9999 -9999 -9999 -9999 -9999 -9999 -9999 -

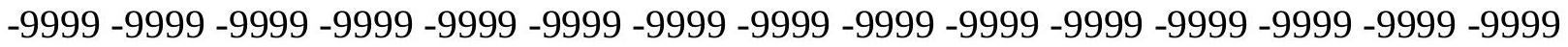

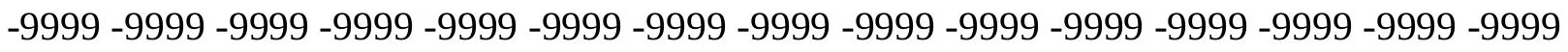

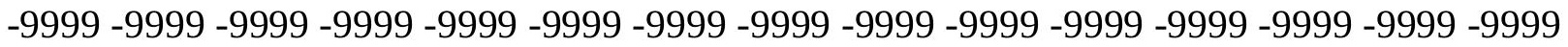

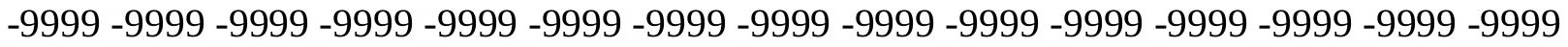
-9999 -9999 -9999 -9999 -9999 -9999 -9999 -9999 -9999 -9999 -9999 -9999 -9999 -9999 -9999 -

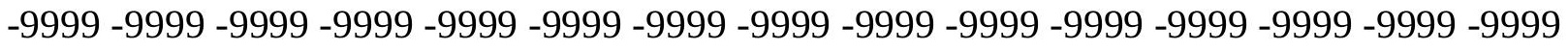

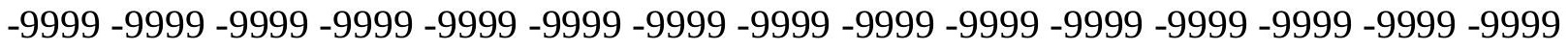
-9999 -9999 -9999 -9999 -9999 -9999 -9999 -9999 -9999 -9999 -9999 -9999 -9999 -9999 -9999 -9999 -9999 -9999 -9999 -9999 -9999 -9999 -9999 -9999 -9999 -9999 -9999 -999 102.1029968262102 .1029968262101 .7982025146101 .4934005737101 .4934005737 101.1886978149101 .1886978149101 .1886978149100 .8839035034100 .8839035034 
100.8839035034100 .8839035034101 .1886978149101 .1886978149101 .1886978149 101.1886978149101 .1886978149101 .1886978149100 .8839035034100 .5791015625 99.9695205688599 .0551681518698 .1408081054796 .9216690063595 .3977432251 93.8738174438593 .5690307617292 .0450973510789 .9116134643687 .47332763672 85.0350494384882 .2919769287179 .2441329956176 .1962814331173 .14842987061 68.8814392089866 .74794006348 -9999 -9999 -9999 -9999 -9999 -9999 -9999 -9999 -9999 -9999 -9999 -9999 -9999 -9999 -9999 -9999 -9999 -9999 -9999 -9999 -9999 -9999 -9999 -9999

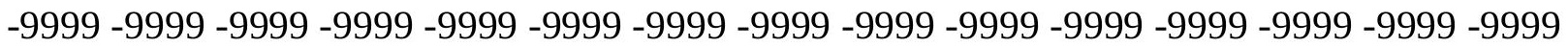
-9999 -9999 -9999 -9999 -9999 -9999 -9999 -9999 -9999 -9999 -9999 -9999 -9999 -9999 -9999 -9999 -9999 -9999 -9999 -9999 -9999 -9999 -9999 -9999 -9999 -9999 -9999 -9999 -9999 -9999 -

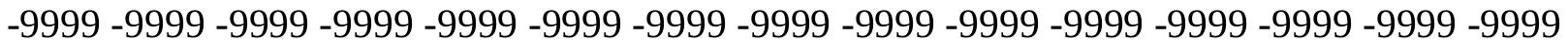
-9999 -9999 -9999 -9999 -9999 -9999 -9999 -9999 -9999 -9999 -9999 -9999 -9999 -9999 -9999 -9999 -9999 -9999 -9999 -9999 -9999 -9999 -9999 -9999 -9999 -9999 -9999 -9999 -9999 -9999 -9999 -9999 -9999 -9999 -9999 -9999 -9999 -9999 -9999 -9999 -9999 -9999 -9999 -9999 -9999 -9999 -9999 -9999 -9999 -9999 -9999 -9999 -9999 -9999 -9999 -9999 -9999 -9999 -9999 -9999

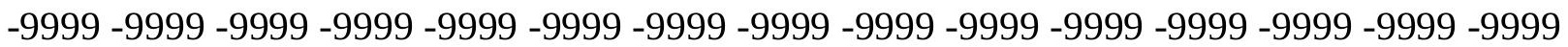

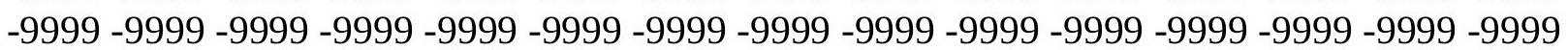
-9999 -9999 -9999 -9999 -9999 -9999 -9999 -9999 -9999 -9999 -9999 -9999 -9999 -9999 -9999 -9999 -9999 -9999 -9999 -9999 -9999 -9999 -9999 -9999 -9999 -9999 -9999 -9999 -9999 -9999 -9999 -9999 -9999 -9999 -9999 -9999 -9999 -9999 -9999 -9999 -9999 -9999 -9999 -9999 -9999 -9999 -9999 -9999 -9999 -9999 -9999 -9999 -9999 -9999 -9999 -9999 -9999 -9999 -9999 -9999 -9999 -9999 -9999 -9999 -9999 -9999 -9999 -9999 -9999 -9999 -9999 -9999 -9999 -9999 -9999 -9999 -9999 -9999 -9999 -9999 -9999 -9999 -9999 -9999 -9999 -9999 -9999 -9999 -9999 -9999 -9999 -9999 -9999 -9999 -9999 -9999 -9999 -9999 -9999 -9999 -9999 -9999 -9999 -9999 -9999 -9999 -9999 -9999 -9999 -9999 -9999 -9999 -9999 -9999 -9999 -9999 -9999 -9999 -9999 -9999 -9999 -9999 -9999 -9999 -9999 -9999 -9999 -9999 -9999 -9999 -9999 -9999 -9999 -9999 -9999 -9999 -9999 -9999 -9999 -9999 -9999 -9999 -9999 -9999 -9999 -9999 -9999 -9999 -9999 -9999 -

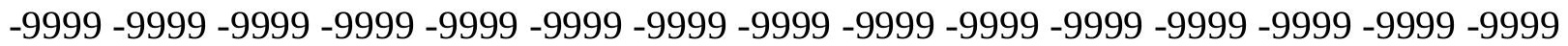
-9999 -9999 -9999 -9999 -9999 -9999 -9999 -9999 -9999 -9999 -9999 -9999 -9999 -9999 102.712600708102 .1029968262101 .7982025146101 .4934005737101 .4934005737 101.1886978149101 .1886978149100 .8839035034100 .8839035034100 .8839035034 100.8839035034101 .1886978149101 .1886978149101 .1886978149101 .4934005737 101.4934005737101 .4934005737101 .1886978149100 .8839035034100 .2742996216 99.6647262573298 .7503814697397 .5312423706196 .0073165893694 .48339080811 94.4833908081192 .6546783447390 .5211791992287 .7781066894585 .33984375 82.29197692871 79.24413299561 75.89148712158 71.0149307251 67.96708679199-9999 -9999 -9999 -9999 -9999 -9999 -9999 -9999 -9999 -9999 -9999 -9999 -9999 -9999 -9999 -9999

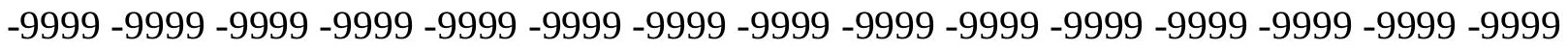
-9999 -9999 -9999 -9999 -9999 -9999 -9999 -9999 -9999 -9999 -9999 -9999 -9999 -9999 -9999 -9999 -9999 -9999 -9999 -9999 -9999 -9999 -9999 -9999

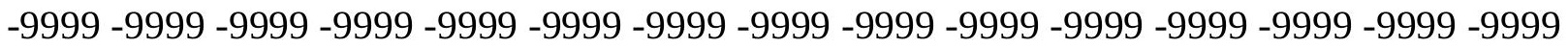
-9999 -9999 -9999 -9999 -9999 -9999 -9999 -9999 -9999 -9999 -9999 -9999 -9999 -9999 -9999 -9999 -9999 -9999 -9999 -9999 -9999 -9999 -9999 -9999 -9999 -9999 -9999 -9999 -9999 -9999 -9999 -9999 -9999 -9999 -9999 -9999 -9999 -9999 -9999 -9999 -9999 -9999 -9999 -9999 -9999 -9999 -9999 -9999 -9999 -9999 -9999 -9999 -9999 -9999 -9999 -9999 -9999 -9999 -9999 -9999

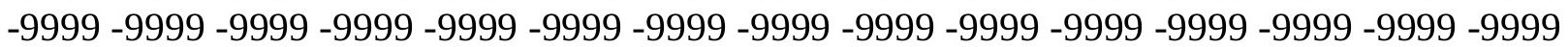


-9999 -9999 -9999 -9999 -9999 -9999 -9999 -9999 -9999 -9999 -9999 -9999 -9999 -9999 -9999 -9999 -9999 -9999 -9999 -9999 -9999 -9999 -9999 -9999 -9999 -9999 -9999 -9999 -9999 -9999 -

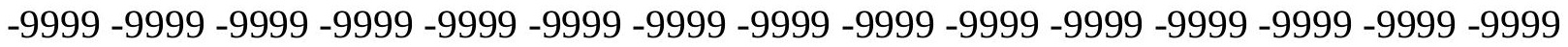
-9999 -9999 -9999 -9999 -9999 -9999 -9999 -9999 -9999 -9999 -9999 -9999 -9999 -9999 -9999 -9999 -9999 -9999 -9999 -9999 -9999 -9999 -9999 -9999-9999 -9999 -9999 -9999 -9999 -9999 -9999 -9999 -9999 -9999 -9999 -9999 -9999 -9999 -9999 -9999 -9999 -9999 -9999 -9999 -9999 -9999 -9999 -9999 -9999 -9999 -9999 -9999 -9999 -9999 -9999 -9999 -9999 -9999 -9999 -9999

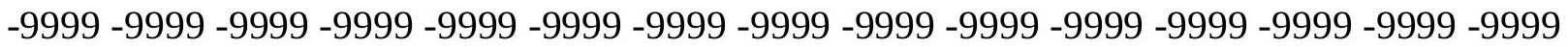

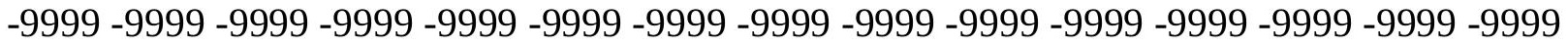
-9999 -9999 -9999 -9999 -9999 -9999 -9999 -9999 -9999 -9999 -9999 -9999 -9999 -9999 -9999 -9999 -9999 -9999 -9999 -9999 -9999 -9999 -9999 -9999 -9999 -9999 -9999 -9999 -9999 -9999 -9999 -9999 -9999 -9999 -9999 -9999 -9999 -9999 -9999 -9999 -9999 -9999 -9999 -9999 -9999 -9999 -9999 -9999 -9999 -9999 -9999 -9999 -9999 -9999 -9999 -9999 -9999 -9999 -9999 -9999 -9999 -9999 -9999 -9999 -9999 -9999 -9999 -9999 -9999 -9999 -9999 -9999 -9999 -9999 -9999 102.712600708102 .1029968262101 .7982025146101 .4934005737101 .1886978149 100.8839035034100 .8839035034100 .8839035034100 .8839035034100 .8839035034 100.8839035034101 .1886978149101 .4934005737101 .4934005737101 .7982025146 101.7982025146101 .4934005737101 .1886978149100 .8839035034100 .2742996216 99.3599472045998 .445587158296 .9216690063595 .397743225195 .09295654297 93.26425170898 91.13075256348 88.3876876831185.64462280273 82.59677124023 79.2441329956174 .3675689697370 .7101516723667 .35751342773 -9999 -9999 -9999-9999 -9999 -9999 -9999 -9999 -9999 -9999 -9999 -9999 -9999 -9999 -9999 -9999 -9999 -9999 -9999 -9999 -9999 -9999 -9999 -9999 -9999 -9999 -9999 -9999 -9999 -9999 -9999 -9999 -9999 -9999 -

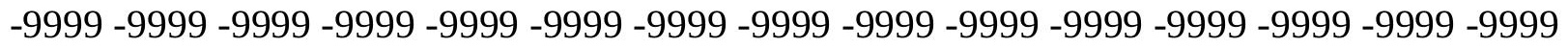
-9999 -9999 -9999-9999-9999-9999

-9999 -9999 -9999 -9999 -9999 -9999 -9999 -9999 -9999 -9999 -9999 -9999 -9999 -9999 -9999 -9999 -9999 -9999 -9999 -9999 -9999 -9999 -9999 -9999 -9999 -9999 -9999 -9999 -9999 -9999 -

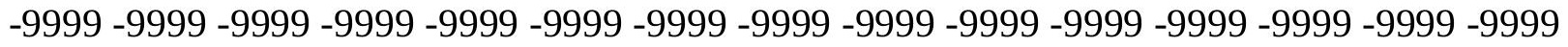
-9999 -9999 -9999 -9999 -9999 -9999 -9999 -9999 -9999 -9999 -9999 -9999 -9999 -9999 -9999 -9999 -9999 -9999 -9999 -9999 -9999 -9999 -9999 -9999 -9999 -9999 -9999 -9999 -9999 -999 -9999 -9999 -9999 -9999 -9999 -9999 -9999 -9999 -9999-9999 -9999 -9999 -9999 -9999 -9999 -9999 -9999 -9999 -9999 -9999 -9999 -9999 -9999 -9999 -9999 -9999 -9999 -9999 -9999 -9999 -

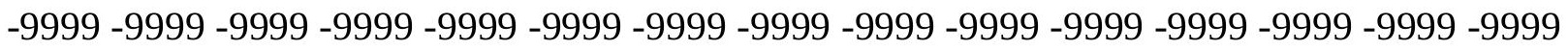

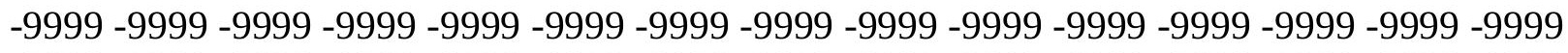
-9999 -9999 -9999 -9999 -9999 -9999 -9999 -9999 -9999 -9999 -9999 -9999 -9999 -9999 -9999 -9999 -9999 -9999 -9999 -9999 -9999 -9999 -9999 -9999 -9999 -9999 -9999 -9999 -9999 - -9999 -

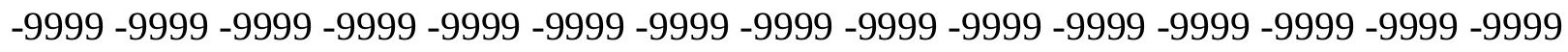

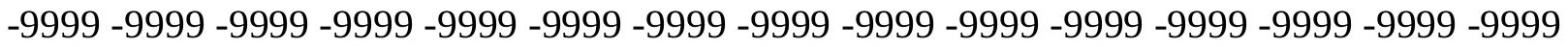

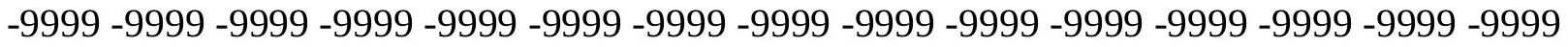
-9999 -9999 -9999 -9999 -9999 -9999 -9999 -9999 -9999 -9999 -9999 -9999 -9999 -9999 -9999 -

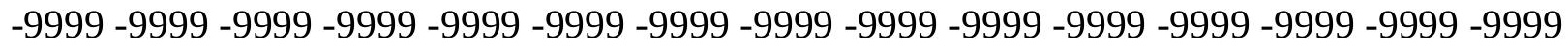

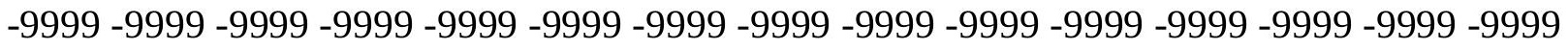
-9999 -9999 -9999 -9999 -9999 -9999 -9999 -9999 -9999 -9999 -9999 -9999 -9999 -9999 -9999 -9999 -9999 -9999 -9999 -9999 -9999 -9999 -9999 -9999-9999 -9999 -9999 -9999 -9999 -9999 -9999 -9999 -9999 -9999 -9999 -9999 -9999 -9999 -9999 -9999 -9999 -9999 -9999 -9999 -9999 -9999102.4077987671 101.7982025146103.0174026489101.1886978149100.8839035034 
100.5791015625100 .5791015625100 .5791015625100 .5791015625100 .8839035034 101.1886978149101 .1886978149101 .4934005737101 .7982025146101 .7982025146 101.7982025146101 .7982025146101 .1886978149100 .8839035034100 .2742996216 99.0551681518697 .8360290527396 .3121032714896 .3121032714894 .17859649658 92.0450973510789 .302040100186 .254188537682 .9015579223679 .54891967773 74.3675689697370 .71015167236 -9999 -9999 -9999 -9999 -9999 -9999 -9999 -9999 -9999 -9999 -9999 -9999 -9999 -9999 -9999 -9999 -9999 -9999 -9999 -9999 -9999 -9999 -9999 -9999 -9999 -9999 -9999 -9999 -9999 -9999 -9999 -9999 -9999 -9999 -9999 -9999 -9999 -9999 -9999

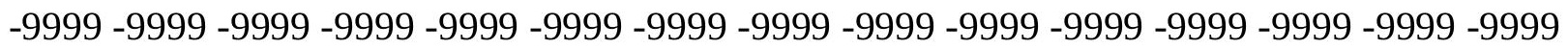
$-9999-9999$

-9999 -9999 -9999 -9999 -9999 -9999 -9999 -9999 -9999 -9999 -9999 -9999 -9999 -9999 -9999 -9999 -9999 -9999 -9999 -9999 -9999 -9999 -9999 -9999 -9999 -9999 -9999 -9999 -9999 -9999 -9999 -9999 -9999 -9999 -9999 -9999 -9999 -9999 -9999 -9999 -9999 -9999 -9999 -9999 -9999 -9999 -9999 -9999 -9999 -9999 -9999 -9999 -9999 -9999 -9999 -9999 -9999 -9999 -9999 -9999 -9999 -9999 -9999 -9999 -9999 -9999 -9999 -9999 -9999 -9999 -9999 -9999 -9999 -9999 -9999

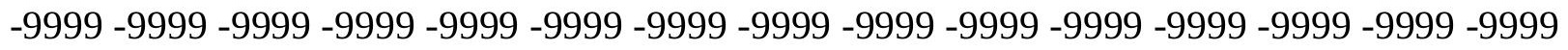

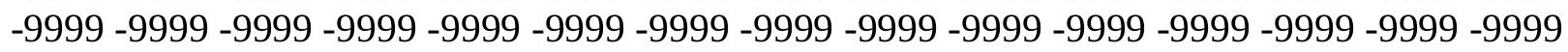

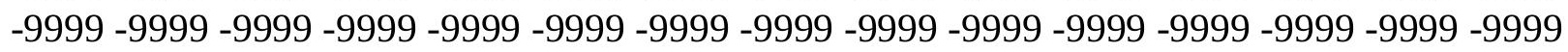

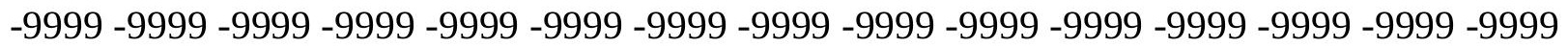
-9999 -9999 -9999 -9999 -9999 -9999 -9999 -9999 -9999 -9999 -9999 -9999 -9999 -9999 -9999 -

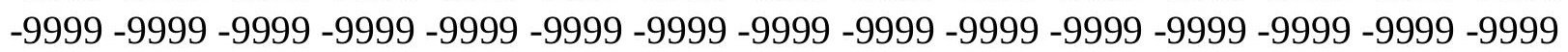

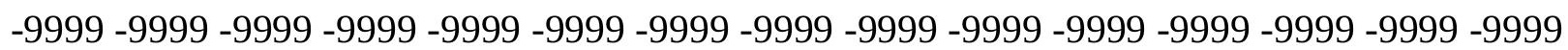
-9999 -9999 -9999 -9999 -9999 -9999 -9999 -9999 -9999 -9999 -9999 -9999 -9999 -9999 -9999 -9999 -9999 -9999 -9999 -9999 -9999 -9999 -9999 -9999 -9999 -9999 -9999 -9999 -9999 -9999 -

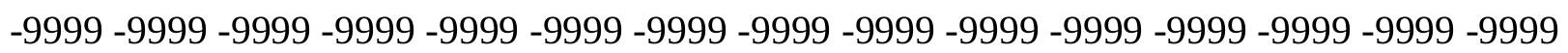

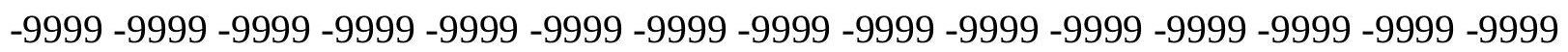
-9999 -9999 -9999 -9999 -9999 -9999 -9999 -9999 -9999 -9999 -9999 -9999 -9999 -9999 - -9999 -

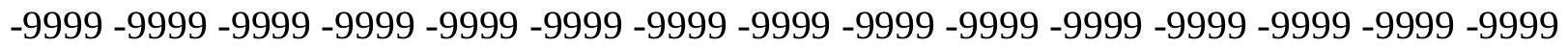

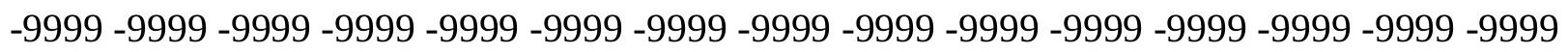

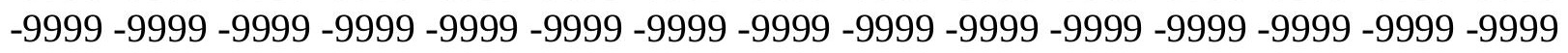
-9999-9999 102.1029968262 101.4934005737 100.8839035034100.5791015625

100.5791015625100 .2742996216100 .2742996216100 .2742996216100 .5791015625 100.8839035034101 .1886978149101 .4934005737101 .7982025146102 .1029968262 102.1029968262102 .1029968262101 .7982025146101 .4934005737100 .8839035034 99.9695205688599 .0551681518697 .5312423706197 .2264633178795 .3977432251 92.9594726562589 .9116134643686 .8637619018683 .5111236572378 .32978057861 74.67236328125 -9999 -9999 -9999 -9999 -9999 -9999 -9999 -9999 -9999 -9999 -9999 -9999 -9999 -9999 -9999 -9999 -9999 -9999 -9999 -9999 -9999 -9999 -9999 -9999 -9999 -9999 -9999 - -999 -

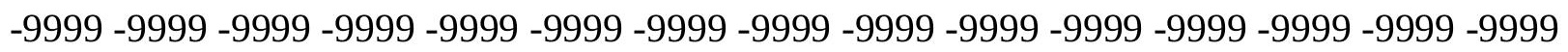
-9999 -9999 -9999 -9999 -9999 -9999 -9999 -9999 -9999 -9999 -9999 -9999 -9999 -9999 -9999 -

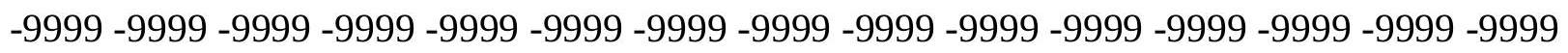

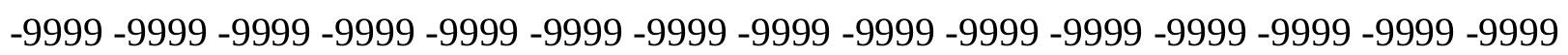

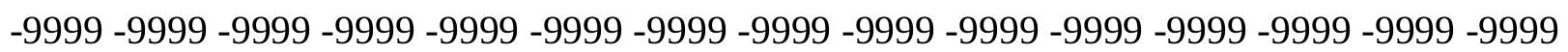
-9999 -9999 -9999 -9999 -9999 -9999 -9999 -9999 -9999 -9999 -9999 -9999 -9999 -9999 -9999 -

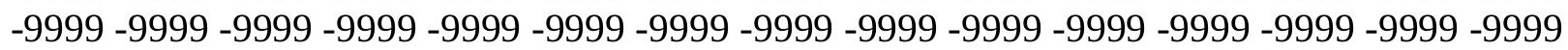

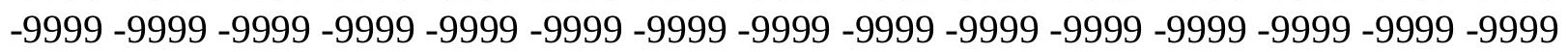


-9999 -9999 -9999 -9999 -9999 -9999 -9999 -9999 -9999 -9999 -9999 -9999 -9999 -9999 -9999 -9999 -9999 -9999 -9999 -9999 -9999 -9999 -9999 -9999 -9999 -9999 -9999 -9999 -9999 -9999 -

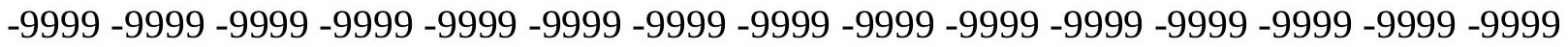
-9999 -9999 -9999 -9999 -9999 -9999 -9999 -9999 -9999 -9999 -9999 -9999 -9999 -9999 -9999 -9999 -9999 -9999 -9999 -9999 -9999 -9999 -9999 -9999-9999 -9999 -9999 -9999 -9999 -9999 -9999 -9999 -9999 -9999 -9999 -9999 -9999 -9999 -9999 -9999 -9999 -9999 -9999 -9999 -9999 -9999 -9999 -9999 -9999 -9999 -9999 -9999 -9999 -9999 -9999 -9999 -9999 -9999 -9999 -9999

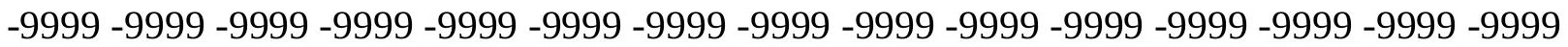

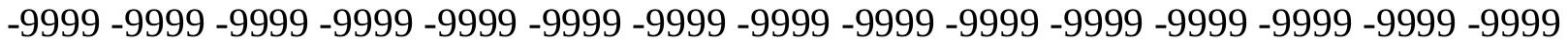
-9999 -9999 -9999 -9999 -9999 -9999 -9999 -9999 -9999 -9999 -9999 -9999 -9999 -9999 -9999 -9999 -9999 -9999 -9999 -9999 -9999 -9999 -9999 -9999 -9999 -9999 -9999 -9999 -9999 -9999 -9999 -9999 -9999 -9999 -9999 -9999 -9999 -9999 -9999 -9999 -9999 -9999 -9999 -9999 -9999 -9999 -9999 -9999 -9999 -9999 -9999 -9999 -9999 -9999 -9999 -9999 -9999 -9999 -9999 -9999 -9999 -9999 -9999 -9999 -9999 -9999 -9999 -9999 -9999 -9999 -9999 -9999 -9999 -9999 -9999 -9999 -9999 -9999 101.7982025146101.1886978149100.5791015625100.2742996216 100.274299621699 .9695205688599 .96952056885100 .2742996216100 .5791015625 100.8839035034101 .4934005737101 .7982025146102 .1029968262102 .1029968262 102.1029968262102 .1029968262102 .1029968262101 .7982025146101 .1886978149 99.9695205688598 .7503814697398 .445587158296 .6168823242293 .87381744385 90.8259735107487 .4733276367282 .2919769287178 .63455963135 -9999 -9999 -9999 -9999 -9999 -9999 -9999 -9999 -9999 -9999 -9999 -9999 -9999 -9999 -9999 -9999 -9999 -9999 -9999

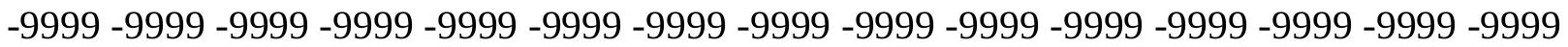
-9999 -9999 -9999 -9999 -9999 -9999 -9999 -9999 -9999 -9999 -9999 -9999 -9999 -9999 -9999 -9999 -9999 -9999 -9999 -9999 -9999 -9999 -9999 -9999

-9999 -9999 -9999 -9999 -9999 -9999 -9999 -9999 -9999 -9999 -9999 -9999 -9999 -9999 -9999 -9999 -9999 -9999 -9999 -9999 -9999 -9999 -9999 -9999 -9999 -9999 -9999 -9999 -9999 -9999 -9999 -9999 -9999 -9999 -9999 -9999 -9999 -9999 -9999 -9999 -9999 -9999 -9999 -9999 -9999 -

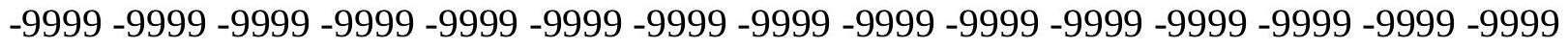
-9999 -9999 -9999 -9999 -9999 -9999 -9999 -9999 -9999 -9999 -9999 -9999 -9999 -9999 -9999 -9999 -9999 -9999 -9999 -9999 -9999 -9999 -9999 -9999 -9999 -9999 -9999 -9999 -9999 -999 -9999 -9999 -9999 -9999 -9999 -9999 -9999 -9999 -9999-9999 -9999 -9999 -9999 -9999 -9999 -9999 -9999 -9999 -9999 -9999 -9999 -9999 -9999 -9999 -9999 -9999 -9999 -9999 -9999 -9999 -

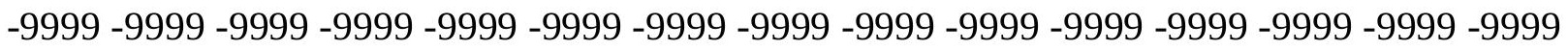

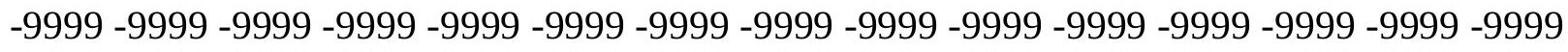
-9999 -9999 -9999 -9999 -9999 -9999 -9999 -9999 -9999 -9999 -9999 -9999 -9999 -9999 -9999 -

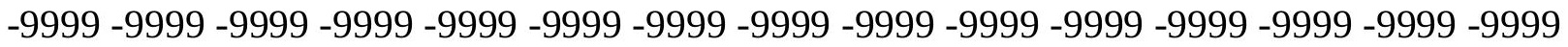

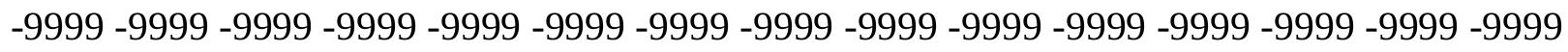

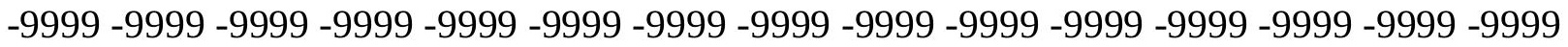

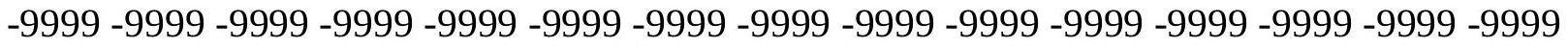
-9999 -9999 -9999 -9999 -9999 -9999 -9999 -9999 -9999 -9999 -9999 -9999 -9999 -9999 -9999 -

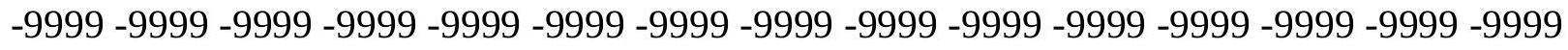

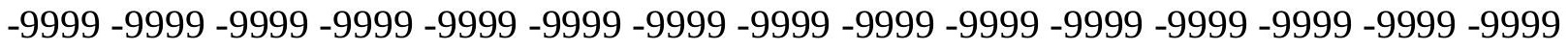
-9999 -9999 -9999 -9999 -9999 -9999 -9999 -9999 -9999 -9999 -9999 -9999 -9999 -9999 -9999 -9999 -9999 -9999 -9999 -9999 -9999 -9999 -9999 -9999 -9999 -9999 -9999 -9999 -9999 -9999 -9999 -9999 -9999 -9999 101.4934005737 100.8839035034 100.274299621699.96952056885 99.6647262573299 .6647262573299 .6647262573299 .96952056885100 .2742996216 
100.8839035034101 .4934005737101 .7982025146102 .1029968262102 .1029968262 102.4077987671102 .4077987671102 .4077987671102 .1029968262101 .1886978149 99.9695205688599 .9695205688597 .5312423706195 .0929565429791 .74033355713 86.5589828491282 .90155792236 -9999 -9999 -9999 -9999 -9999 -9999 -9999 -9999 -9999 -9999 -9999 -9999 -9999 -9999 -9999 -9999 -9999 -9999 -9999 -9999 -9999-9999 -9999 -9999 -9999 -9999 -9999 -9999 -9999 -9999 -9999 -9999 -9999 -9999 -9999 -9999 -9999 -9999 -9999

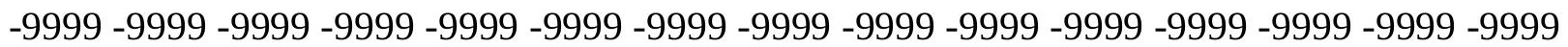
-9999 -9999-9999-9999-9999

-9999 -9999 -9999 -9999 -9999 -9999 -9999 -9999 -9999 -9999 -9999 -9999 -9999 -9999 -9999 -9999 -9999 -9999 -9999 -9999 -9999 -9999 -9999 -9999 -9999 -9999 -9999 -9999 -9999 -9999 -9999 -9999 -9999 -9999 -9999 -9999 -9999 -9999 -9999 -9999 -9999 -9999 -9999 -9999 -9999 -999 -9999 -9999 -9999 -9999 -9999 -9999 -9999 -9999 -9999 -9999 -9999 -9999 -9999 -9999 -9999 -9999 -9999 -9999 -9999 -9999 -9999 -9999 -9999 -9999 -9999 -9999 -9999 -9999 -9999 -9999 -9999 -9999 -9999 -9999 -9999 -9999 -9999 -9999 -9999 -9999 -9999 -9999 -9999 -9999 -9999 -9999 -9999 -9999 -9999 -9999 -9999 -9999 -9999 -9999 -9999 -9999 -9999 -9999 -9999 -9999

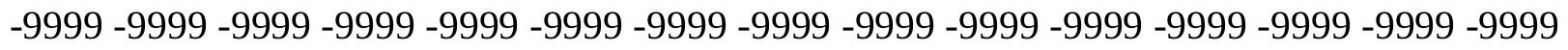

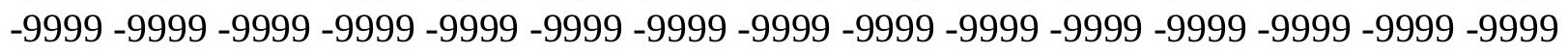

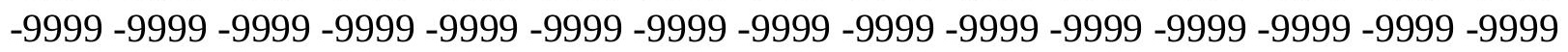

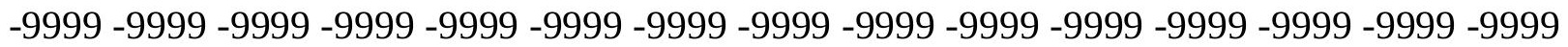

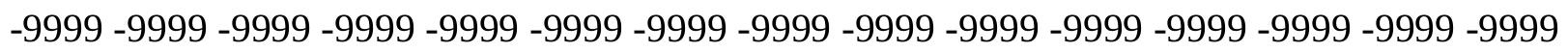

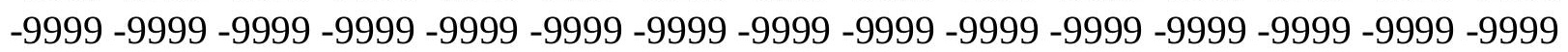

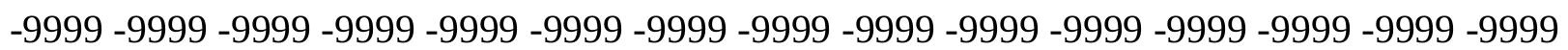
-9999 -9999 -9999 -9999 -9999 -9999 -9999 -9999 -9999 -9999 -9999 -9999 -9999 -9999 -9999 -9999 -9999 -9999 -9999 -9999 -9999 -9999 -9999 -9999 -9999 -9999 -9999 -9999 -9999 -9999 -

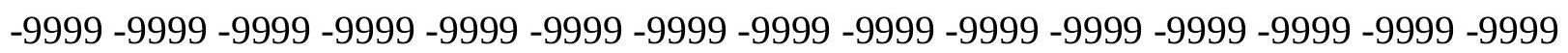

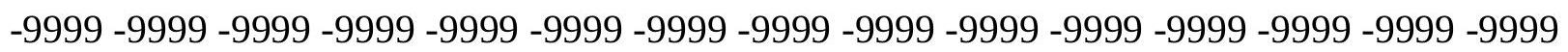

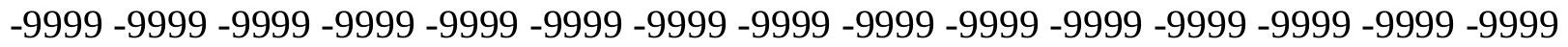

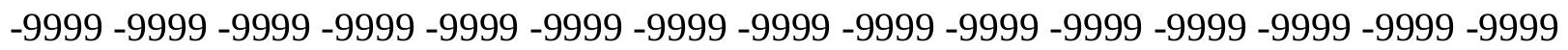
-9999 -9999 -9999 -9999-9999-9999 100.2742996216 99.96952056885 99.66472625732 99.3599472045999 .3599472045999 .3599472045999 .66472625732100 .2742996216 100.8839035034101 .1886978149101 .4934005737102 .1029968262102 .4077987671 102.712600708103 .0174026489102 .712600708102 .4077987671101 .1886978149 $99.6647262573298 .7503814697394 .4833908081191 .1307525634887 .16854858398-9999$ -9999 -9999 -9999 -9999 -9999 -9999 -9999 -9999 -9999 -9999 -9999 -9999 -9999 -9999 -9999 -9999 -9999 -9999 -9999 -9999 -9999 -9999 -9999 -9999 -9999 -9999 -9999 -9999 -9999 -9999 -

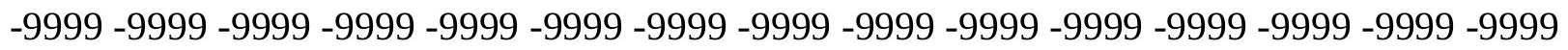

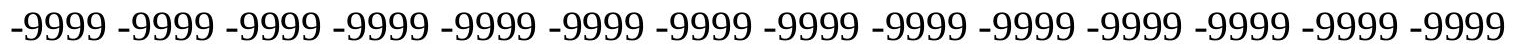

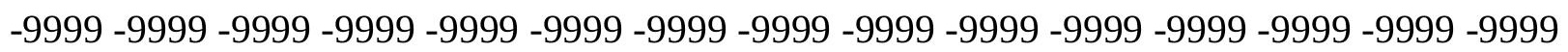

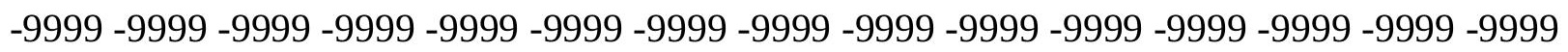
-9999 -9999 -9999 -9999 -9999 -9999 -9999 -9999 -9999 -9999 -9999 -9999 -9999 -9999 -9999 -

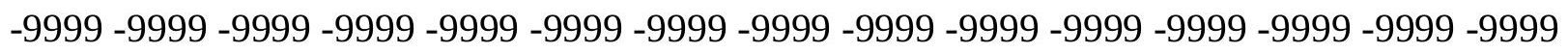

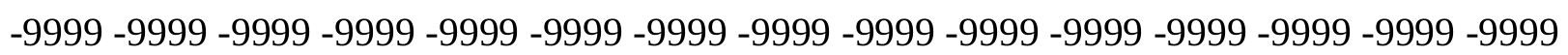
-9999 -9999 -9999 -9999 -9999 -9999 -9999 -9999 -9999 -9999 -9999 -9999 -9999 -9999 -9999 -9999 -9999 -9999 -9999 -9999 -9999 -9999 -9999 -9999 -9999 -9999 -9999 -9999 -9999 -9999 -

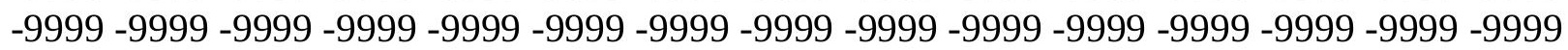

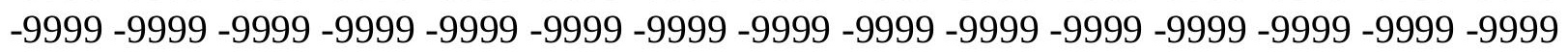


-9999 -9999 -9999 -9999 -9999 -9999 -9999 -9999 -9999 -9999 -9999 -9999 -9999 -9999 -9999 -9999 -9999 -9999 -9999 -9999 -9999 -9999 -9999 -9999 -9999 -9999 -9999 -9999 -9999 -9999 -

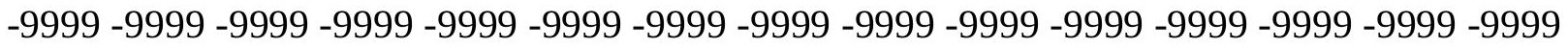
-9999 -9999 -9999 -9999 -9999 -9999 -9999 -9999 -9999 -9999 -9999 -9999 -9999 -9999 -9999 -9999 -9999 -9999 -9999 -9999 -9999 -9999 -9999 -9999-9999 -9999 -9999 -9999 -9999 -9999 -9999 -9999 -9999 -9999 -9999 -9999 -9999 -9999 -9999 -9999 -9999 -9999 -9999 -9999 -9999 -9999 -9999 -9999 -9999 -9999 -9999 -9999 -9999 -9999 -9999 -9999 -9999 -9999 -9999 -9999

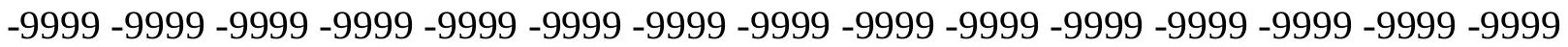

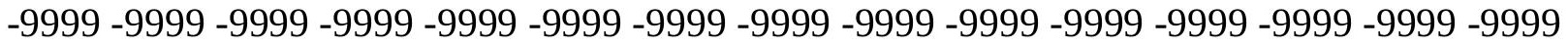
-9999 -9999 -9999 -9999 -9999 -9999 -9999 -9999 -9999 -9999 -9999 -9999 -9999 -9999 -9999 -9999 -9999 -9999 -9999 -9999 -9999 -9999 -9999 -9999 -9999 -9999 -9999 -9999 -9999 -9999 -9999 -9999 -9999 -9999-9999 -9999 -9999 99.96952056885 99.66472625732 99.05516815186 99.0551681518699 .0551681518699 .3599472045999 .6647262573299 .96952056885 100.5791015625101 .1886978149101 .7982025146102 .4077987671103 .0174026489 103.3221969604103 .3221969604103 .0174026489102 .1029968262100 .5791015625 98.14080810547 95.3977432251 91.74033355713 -9999 -9999 -9999 -9999 -9999 -9999 -9999 -9999 -9999 -9999 -9999 -9999 -9999 -9999 -9999 -9999 -9999 -9999 -9999 -9999 -9999 -9999 -9999 -9999 -9999 -9999 -9999 -9999 -9999 -9999 -9999 -9999 -9999 -9999 -9999 -9999 -9999 -9999 -9999 -9999 -9999 -9999 -9999 -9999 -9999 -9999 -9999 -9999 -9999 -9999 -9999 -9999 -9999 -9999 -9999 -9999 -9999 -9999 -9999 -9999 -9999

-9999 -9999 -9999 -9999 -9999 -9999 -9999 -9999 -9999 -9999 -9999 -9999 -9999 -9999 -9999 -9999 -9999 -9999 -9999 -9999 -9999 -9999 -9999 -9999 -9999 -9999 -9999 -9999 -9999 -9999 -9999 -9999 -9999 -9999 -9999 -9999 -9999 -9999 -9999 -9999 -9999 -9999 -9999 -9999 -9999 -9999 -9999 -9999 -9999 -9999 -9999 -9999 -9999 -9999 -9999 -9999 -9999 -9999 -9999 -9999 -

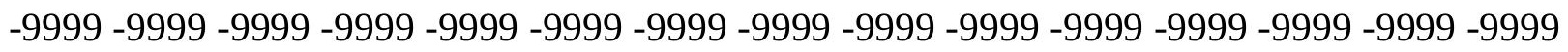
-9999 -9999 -9999 -9999 -9999 -9999 -9999 -9999 -9999 -9999 -9999 -9999 -9999 -9999 -9999 -9999 -9999 -9999 -9999 -9999 -9999 -9999 -9999 -9999 -9999 -9999 -9999 -9999 -9999 -9999 -

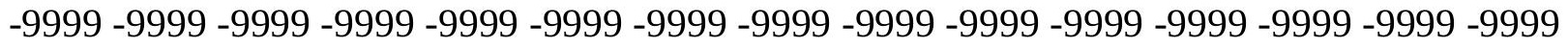
-9999 -9999 -9999 -9999 -9999 -9999 -9999 -9999 -9999 -9999 -9999 -9999 -9999 -9999 -9999 -9999 -9999 -9999 -9999 -9999 -9999 -9999 -9999 -9999 -9999 -9999 -9999 -9999 -9999 -999 -9999 -9999 -9999 -9999 -9999 -9999 -9999 -9999 -9999 -9999 -9999 -9999 -9999 -9999 -9999 -9999 -9999 -9999 -9999 -9999 -9999 -9999 -9999 -9999 -9999 -9999 -9999 -9999 -9999 -9999 -

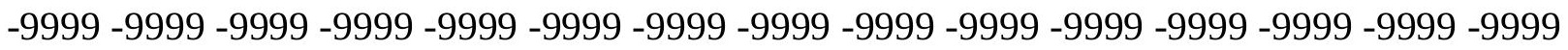

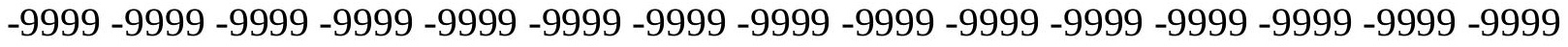
-9999 -9999 -9999 -9999 -9999 -9999 -9999 -9999 -9999 -9999 -9999 -9999 -9999 -9999 -9999 -

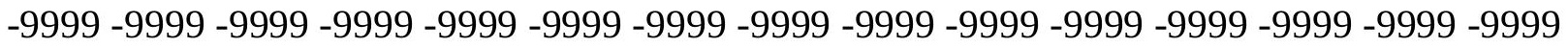

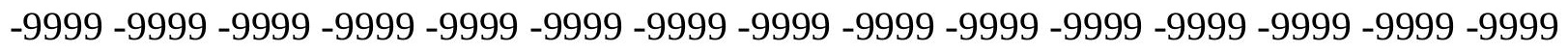

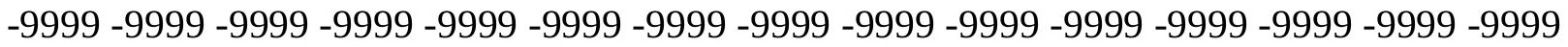

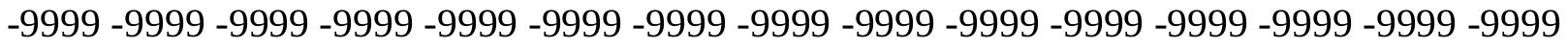
-9999 -9999 -9999 -9999 -9999 -9999 -9999 -9999 -9999 -9999 -9999 -9999 -9999 -9999 - 9999 -9999 -9999 -9999 -9999 -9999 -9999 -9999 -9999 99.66472625732 99.35994720459 99.0551681518699 .0551681518699 .0551681518699 .3599472045999 .66472625732 100.2742996216100 .8839035034101 .7982025146102 .4077987671103 .0174026489 103.6268997192103 .6268997192103 .3221969604102 .712600708101 .1886978149 99.05516815186 -9999 -9999 -9999 -9999 -9999 -9999 -9999 -9999 -9999 -9999 -9999 -9999 -9999 -9999 -9999 -9999 -9999 -9999 -9999 -9999 -9999 -9999 -9999 -9999 -9999 -9999 -9999 
-9999 -9999 -9999 -9999 -9999 -9999 -9999 -9999 -9999 -9999 -9999 -9999 -9999 -9999 -9999 -9999 -9999 -9999 -9999 -9999 -9999 -9999 -9999 -9999 -9999 -9999 -9999 -9999 -9999 -9999 -9999 -9999 -9999-9999-9999-9999

-9999 -9999 -9999 -9999 -9999 -9999 -9999 -9999 -9999 -9999 -9999 -9999 -9999 -9999 -9999 -9999 -9999 -9999 -9999 -9999 -9999 -9999 -9999 -9999 -9999 -9999 -9999 -9999 -9999 -9999 -9999 -9999 -9999 -9999 -9999 -9999 -9999 -9999 -9999 -9999 -9999 -9999 -9999 -9999 -9999 -9999 -9999 -9999 -9999 -9999 -9999 -9999 -9999 -9999 -9999 -9999 -9999 -9999 -9999 -9999

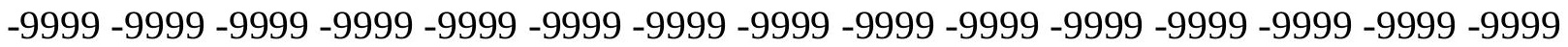
-9999 -9999 -9999 -9999 -9999 -9999 -9999 -9999 -9999 -9999 -9999 -9999 -9999 -9999 -9999 -9999 -9999 -9999 -9999 -9999 -9999 -9999 -9999 -9999 -9999 -9999 -9999 -9999 -9999 -9999 -

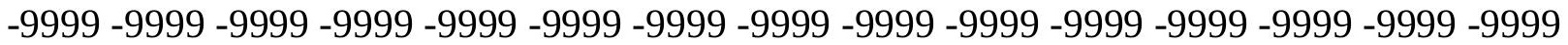
-9999 -9999 -9999 -9999 -9999 -9999 -9999 -9999 -9999 -9999 -9999 -9999 -9999 -9999 -9999 -9999 -9999 -9999 -9999 -9999 -9999 -9999 -9999 -9999 -9999 -9999 -9999 -9999 -9999 -9999 -9999 -9999 -9999 -9999 -9999 -9999 -9999 -9999 -9999 -9999 -9999 -9999 -9999 -9999 -9999 -9999 -9999 -9999 -9999 -9999 -9999 -9999 -9999 -9999 -9999 -9999 -9999 -9999 -9999 -9999

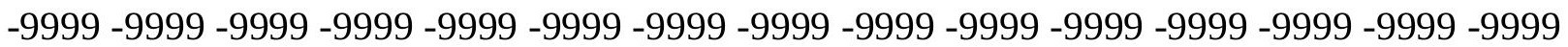
-9999 -9999 -9999 -9999 -9999 -9999 -9999 -9999 -9999 -9999 -9999 -9999 -9999 -9999 -9999 -9999 -9999 -9999 -9999 -9999 -9999 -9999 -9999 -9999 -9999 -9999 -9999 -9999 -9999 -9999 -9999 -9999 -9999 -9999 -9999 -9999 -9999 -9999 -9999 -9999 -9999 -9999 -9999 -9999 -9999 -9999 -9999 -9999 -9999 -9999 -9999 -9999 -9999 -9999 -9999 -9999 -9999 -9999 -9999 -9999 -9999 -9999 -9999 -9999 -9999 -9999 -9999 -9999 -9999 -9999 -9999 -9999 -9999 -9999 -9999 -9999 -9999 -9999 -9999 -9999 -9999 -9999 -9999 -9999 -9999 -9999 -9999 -9999 -9999 -9999 -9999 -9999 -9999 -9999 -9999 -9999 -9999 -9999 -9999 -9999 -9999 -9999 -9999 -9999 -9999 -9999 -9999 -9999 -9999 -9999 -9999 -9999 -9999 -9999 -9999 -9999 -9999 -9999 -9999 -9999 -9999 -9999 -9999 -9999 -9999 -9999 -9999 -9999 -9999 -9999 -9999 -9999 -9999 -9999 -9999 -9999 -9999 -9999 -9999 -9999 -9999 -9999 -9999 -9999 -9999 -9999 -9999 -9999 -9999 -9999 -9999 -9999 -9999 -9999 -9999 -9999 -9999 -9999 -9999 -9999 -9999 -9999 -9999 -9999 -9999 -9999 -9999 -9999 -9999 -9999 -9999 -9999 -9999 -9999 -9999 -9999 -9999 -9999 -9999 -9999 -9999 -9999 -9999 -9999 -9999 -9999 -9999 -9999 -9999 -9999 -9999 -9999 -9999 -9999 -9999 -9999 -9999 -9999 -9999 -9999 -9999 -9999 -9999 -9999 -9999 -9999 -9999 -9999 -9999 -9999 -9999 -9999 -9999 -9999 -9999 -9999 -9999 -9999 -9999 -9999 -9999 -9999 -9999 -9999 -

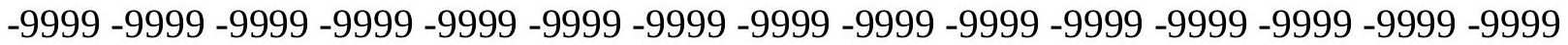
-9999 -9999 -9999 -9999 -9999 -9999 -9999 -9999 -9999 -9999 -9999 -9999 -9999 -9999 -9999 -9999 -9999 -9999 -9999 -9999 -9999 -9999 -9999 -9999 -9999 -9999 -9999 -9999 -9999 -9999 -9999 -9999 -9999 -9999 -9999 -9999 -9999 -9999 -9999 -9999 -9999 -9999 -9999 -9999 -9999 -9999 -9999 -9999 -9999 -9999 -9999 -9999 -9999 -9999 -9999 -9999 -9999 -9999 -9999 -9999 -9999 -9999 -9999 -9999 -9999 -9999 -9999 -9999 -9999 -9999 -9999 -9999 -9999 -9999 -9999

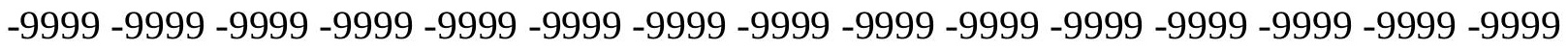
-9999 -9999 -9999 -9999 -9999 -9999 -9999 -9999 -9999 -9999 -9999 -9999 -9999 -9999 -9999 -9999 -9999 -9999 -9999 -9999 -9999 -9999 -9999 -9999 -9999 -9999 -9999 -9999 -9999 -9999 -9999 -9999 -9999 -9999 -9999 -9999 -9999 -9999 -9999 -9999 -9999 -9999 -9999 -9999 -9999 -999 -9999 -9999 -9999 -9999 -9999 -9999 -9999 -9999 -9999 -9999 -9999 -9999 -9999 -9999 -9999 -9999 -9999 -9999 -9999 -9999 -9999 -9999 -9999 -9999 -9999 -9999 -9999 -9999 -9999 -9999 -9999 -9999 -9999 -9999 -9999 -9999 -9999 -9999 -9999 -9999 -9999 -9999 -9999 -9999 -9999 -9999 -9999 -9999 -9999 -9999 -9999 -9999 -9999 -9999 -9999 -9999 -9999 -9999 -9999 -9999

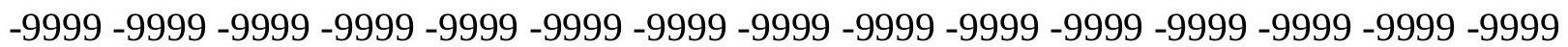


-9999 -9999 -9999 -9999 -9999 -9999 -9999 -9999 -9999 -9999 -9999 -9999 -9999 -9999 -9999 -9999 -9999 -9999 -9999 -9999 -9999 -9999 -9999 -9999 -9999 -9999 -9999 -9999 -9999 -9999 -

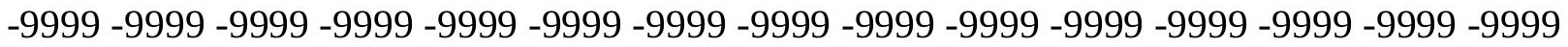
-9999 -9999 -9999 -9999 -9999 -9999 -9999 -9999 -9999 -9999 -9999 -9999 -9999 -9999 -9999 -9999 -9999 -9999 -9999 -9999 -9999 -9999 -9999 -9999-9999 -9999 -9999 -9999 -9999 -9999 -9999 -9999 -9999 -9999 -9999 -9999 -9999 -9999 -9999 -9999 -9999 -9999 -9999 -9999 -9999 -9999 -9999 -9999 -9999 -9999 -9999 -9999 -9999 -9999 -9999 -9999 -9999 -9999 -9999 -9999

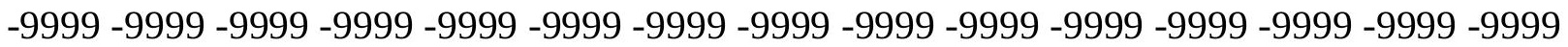
-9999 -9999 -9999 -9999 -9999 -9999 -9999 -9999 -9999 -9999 -9999 -9999 -9999 -9999 -9999 -9999 -9999 -9999 -9999 -9999 -9999 -9999 -9999 -9999 -9999 -9999 -9999 -9999 -9999

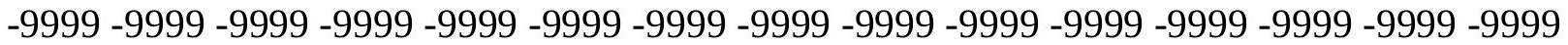
-9999 -9999 -9999 -9999 -9999 -9999 -9999 -9999 -9999 -9999 -9999 -9999 -9999 -9999 -9999 -9999 -9999 -9999 -9999 -9999 -9999 -9999 -9999 -9999 -9999 -9999 -9999 -9999 -9999 -9999 -9999 -9999 -9999 -9999 -9999 -9999 -9999 -9999 -9999 -9999 -9999 -9999 -9999 -9999 - 9999 -9999 -9999 -9999 -9999 -9999 -9999 -9999 -9999 -9999 -9999 -9999 -9999 -9999 -9999 -9999

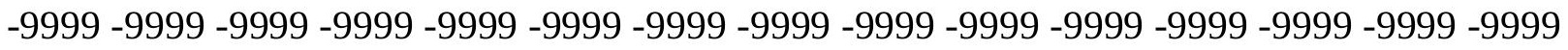
-9999 -9999 -9999 -9999 -9999 -9999 -9999 -9999 -9999 -9999 -9999 -9999 -9999 -9999 -9999 -9999 -9999 -9999 -9999 -9999 -9999 -9999 -9999 -9999 -9999 -9999 -9999 -9999 -9999 -9999 -9999 -9999 -9999 -9999 -9999 -9999 -9999 -9999 -9999 -9999 -9999 -9999 -9999 -9999 -9999 -

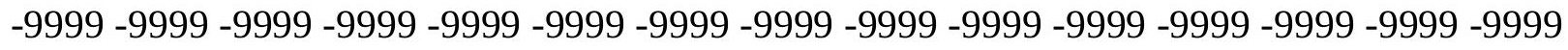

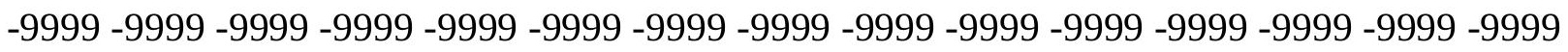
-9999 -9999 -9999 -9999 -9999 -9999 -9999 -9999 -9999 -9999 -9999 -9999 -9999 -9999 -9999 -9999 -9999 -9999 -9999 -9999 -9999 -9999 -9999 -9999 -9999 -9999 -9999 -9999 -9999 -9999 -9999 -9999 -9999 -9999 -9999 -9999 -9999 -9999 -9999 -9999 -9999 -9999 -9999 -9999 -9999 -

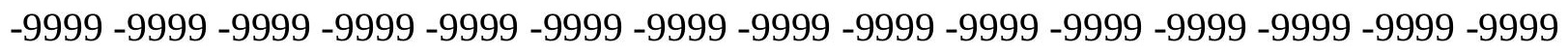
-9999 -9999 -9999 -9999 -9999 -9999 -9999 -9999 -9999 -9999 -9999 -9999 -9999 -9999 -9999 -9999 -9999 -9999 -9999 -9999 -9999 -9999 -9999 -9999 -9999 -9999 -9999 -9999 -9999 -9999 -

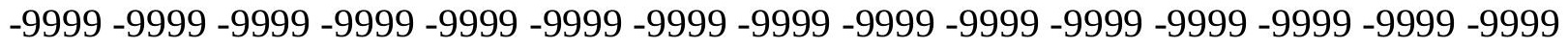
-9999 -9999 -9999 -9999 -9999 -9999 -9999 -9999 -9999 -9999 -9999 -9999 -9999 -9999 -9999 -9999 -9999 -9999 -9999 -9999 -9999 -9999 -9999 -9999 -9999 -9999 -9999 -9999 -9999 -999 -9999 -9999 -9999 -9999 -9999 -9999 -9999 -9999 -9999 -9999 -9999 -9999 -9999 -9999 -9999 -9999 -9999 -9999 -9999 -9999 -9999 -9999 -9999 -9999 -9999 -9999 -9999 -9999 -9999 -9999 -

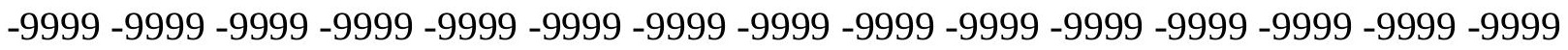

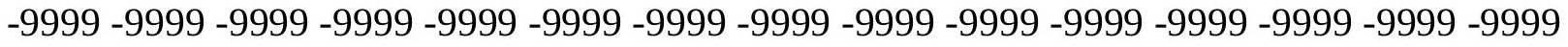
-9999 -9999 -9999 -9999 -9999 -9999 -9999 -9999 -9999 -9999 -9999 -9999 -9999 -9999 -

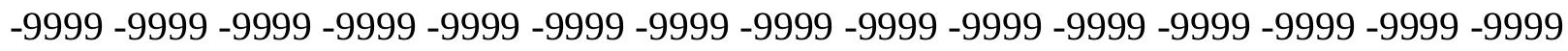

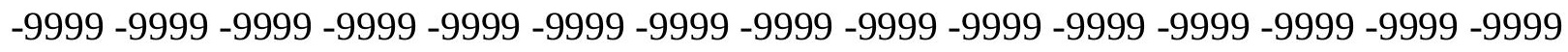

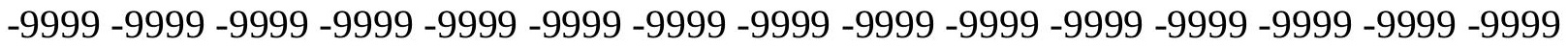
-9999 -9999 -9999 -9999 -9999 -9999 -9999 -9999 -9999 -9999 -9999 -9999 -9999 - 9999 - -999 -9999 -9999 -9999 -9999 -9999 -9999 -9999 -9999 -9999 -9999 -9999 -9999 -9999 -9999 -9999 -

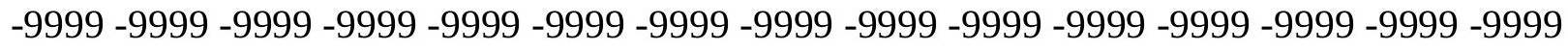

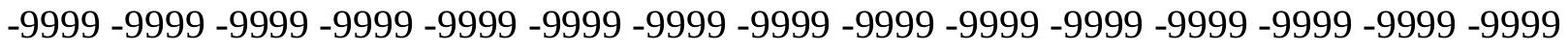
-9999 -9999 -9999 -9999 -9999 -9999 -9999 -9999 -9999 -9999 -9999 -9999 -9999 -9999 -9999 -9999 -9999 -9999 -9999 -9999 -9999 -9999 -9999 -9999-9999 -9999 -9999 -9999 -9999 -9999 -9999 -9999 -9999 -9999 -9999 -9999 -9999 -9999 -9999 -9999 -9999 -9999 -9999 -9999 -9999 -

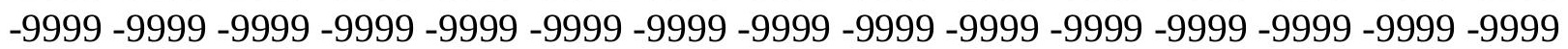


-9999 -9999 -9999 -9999 -9999 -9999 -9999 -9999 -9999 -9999 -9999 -9999 -9999 -9999 -9999 -9999 -9999 -9999 -9999 -9999 -9999 -9999 -9999 -9999 -9999 -9999 -9999 -9999 -9999 -9999 -

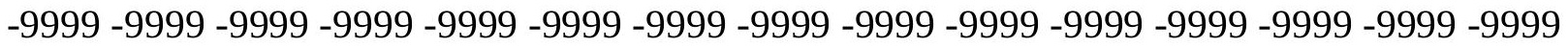
-9999 -9999 -9999 -9999 -9999 -9999 -9999 -9999 -9999 -9999 -9999 -9999 -9999 -9999 -9999 -9999 -9999 -9999 -9999 -9999 -9999 -9999 -9999 -9999-9999 -9999 -9999 -9999 -9999 -9999 -9999 -9999 -9999 -9999 -9999 -9999 -9999 -9999 -9999 -9999 -9999 -9999 -9999 -9999 -9999 -9999 -9999 -9999 -9999 -9999 -9999 -9999 -9999 -9999 -9999 -9999 -9999 -9999 -9999 -9999

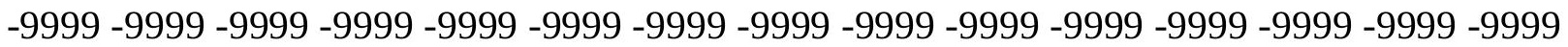

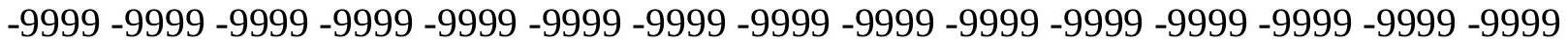
-9999 -9999 -9999 -9999 -9999 -9999 -9999 -9999 -9999 -9999 -9999 -9999 -9999 -9999 -9999 -9999 -9999 -9999 -9999 -9999 -9999 -9999 -9999 -9999 -9999 -9999 -9999 -9999 -9999 -9999 -9999 -9999 -9999 -9999 -9999 -9999 -9999 -9999 -9999 -9999 -9999 -9999 -9999 -9999 -9999 -9999 -9999 -9999 -9999 -9999 -9999 -9999 -9999 -9999 -9999 -9999 -9999 -9999 -9999 -9999 -9999 -9999 -9999 -9999 -9999 -9999 -9999 -9999 -9999 -9999 -9999 -9999 -9999 -9999 -9999 -9999 -9999 -9999 -9999 -9999 -9999 -9999 -9999 -9999 -9999 -9999 -9999 -9999 -9999 -9999 -9999 -9999 -9999 -9999 -9999 -9999 -9999 -9999 -9999 -9999 -9999 -9999 - 9999 - -999 -

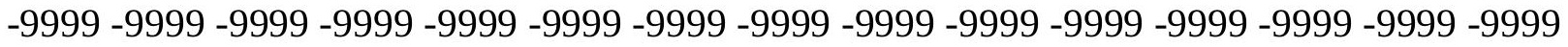
-9999 -9999 -9999 -9999 -9999 -9999 -9999 -9999 -9999 -9999 -9999 -9999 -9999 -9999 -9999 -9999 -9999 -9999 -9999 -9999 -9999 -9999 -9999 -9999 -9999 -9999 -9999 -9999 -9999 -9999 -

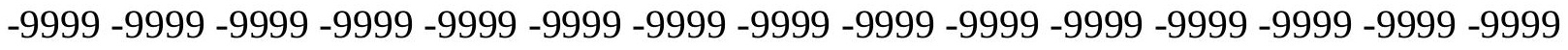
-9999 -9999 -9999 -9999 -9999 -9999 -9999 -9999 -9999 -9999 -9999 -9999 -9999 -9999 -9999

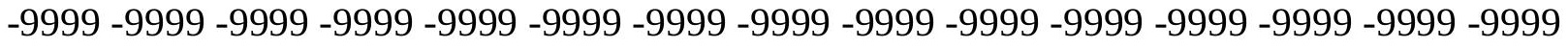
-9999 -9999 -9999 -9999 -9999 -9999 -9999 -9999 -9999 -9999 -9999 -9999 -9999 -9999 -9999 -9999 -9999 -9999 -9999 -9999 -9999 -9999 -9999 -9999 -9999 -9999 -9999 -9999 -9999 -9999 -

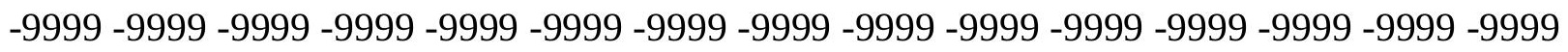
-9999 -9999 -9999 -9999 -9999 -9999 -9999 -9999 -9999 -9999 -9999 -9999 -9999 -9999 -9999 -9999 -9999 -9999 -9999 -9999 -9999 -9999 -9999 -9999 -9999 -9999 -9999 -9999 -9999 -9999 -

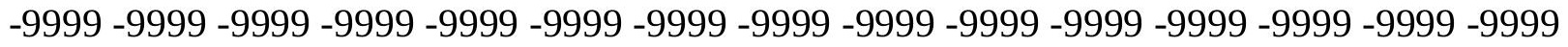
-9999 -9999 -9999 -9999 -9999 -9999 -9999 -9999 -9999 -9999 -9999 -9999 -9999 -9999 -9999 -9999 -9999 -9999 -9999 -9999 -9999 -9999 -9999 -9999 -9999 -9999 -9999 -9999 -9999 -999 -

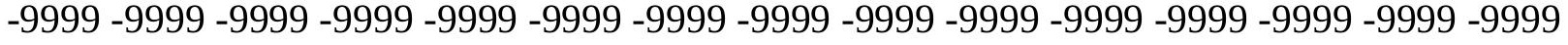
-9999 -9999 -9999 -9999 -9999 -9999 -9999 -9999 -9999 -9999 -9999 -9999 -9999 -9999 -9999 -

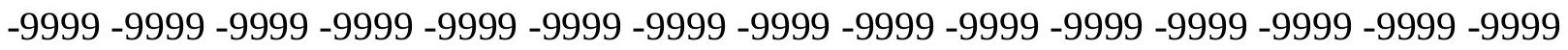

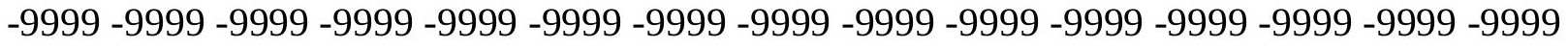

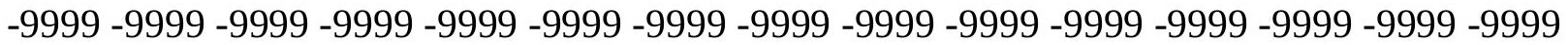
-9999 -9999 -9999 -9999 -9999 -9999 -9999 -9999 -9999 -9999 -9999 -9999 -9999 -9999 -9999 -

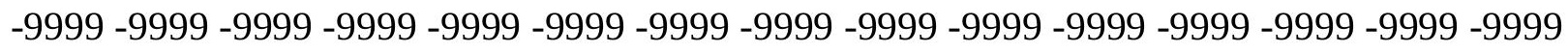

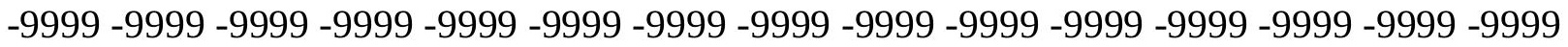
-9999 -9999 -9999 -9999 -9999 -9999 -9999 -9999 -9999 -9999 -9999 -9999 -9999 - 9999 - -999 -9999 -9999 -9999 -9999 -9999 -9999 -9999 -9999 -9999 -9999 -9999 -9999 -9999 -9999 -9999 -

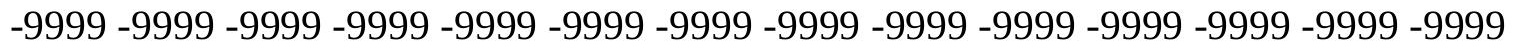

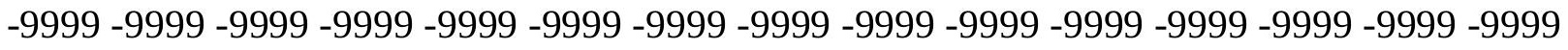
-9999 -9999 -9999 -9999 -9999 -9999 -9999 -9999 -9999 -9999 -9999 -9999 -9999 -9999 -9999 -9999 -9999 -9999 -9999 -9999 -9999 -9999 -9999 -9999-9999 -9999 -9999 -9999 -9999 -9999 -9999 -9999 -9999 -9999 -9999 -9999 -9999 -9999 -9999 -9999 -9999 -9999 -9999 -9999 -9999 -

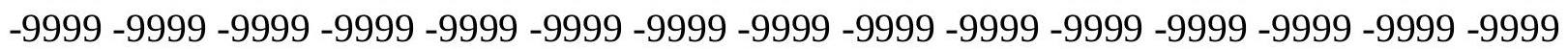


-9999 -9999 -9999 -9999 -9999 -9999 -9999 -9999 -9999 -9999 -9999 -9999 -9999 -9999 -9999 -9999 -9999 -9999 -9999 -9999 -9999 -9999 -9999 -9999 -9999 -9999 -9999 -9999 -9999 -9999 -9999 -9999 -9999 -9999 -9999 -9999 -9999 -9999 -9999 -9999 -9999 -9999 -9999 -9999 - 9999 -9999 -9999 -9999 -9999 -9999 -9999 -9999 -9999 -9999 -9999 -9999 -9999 -9999 -9999 -9999 -9999 -9999 -9999 -9999 -9999 -9999 -9999 -9999 -9999-9999 -9999 -9999 -9999 -9999 -9999 -9999 -9999 -9999 -9999 -9999 -9999 -9999 -9999 -9999 -9999 -9999 -9999 -9999 -9999 -9999 -9999 -9999 -9999 -9999 -9999 -9999 -9999 -9999 -9999 -9999 -9999 -9999 -9999 -9999 -9999

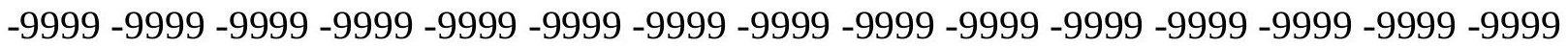
-9999 -9999 -9999 -9999 -9999 -9999 -9999 -9999 -9999 -9999 -9999 -9999 -9999 -9999 -9999 -9999 -9999 -9999 -9999 -9999 -9999 -9999 -9999 -9999 -9999 -9999 -9999 -9999 -9999 -9999

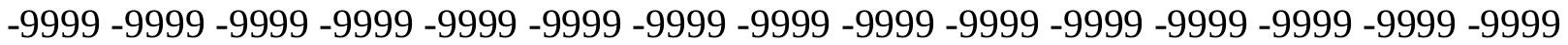
-9999 -9999 -9999 -9999 -9999 -9999 -9999 -9999 -9999 -9999 -9999 -9999 -9999 -9999 -9999 -9999 -9999 -9999 -9999 -9999 -9999 -9999 -9999 -9999 -9999 -9999 -9999 -9999 -9999 -9999 -

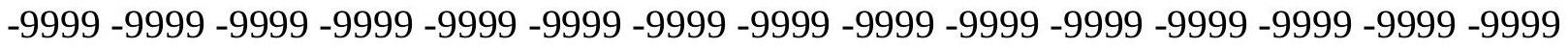
-9999 -9999 -9999 -9999 -9999 -9999 -9999 -9999 -9999 -9999 -9999 -9999 -9999 -9999 -9999

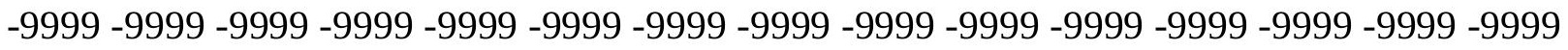
-9999 -9999 -9999 -9999 -9999 -9999 -9999 -9999 -9999 -9999 -9999 -9999 -9999 -9999 -9999 -9999 -9999 -9999 -9999 -9999 -9999 -9999 -9999 -9999 -9999 -9999 -9999 -9999 -9999 - 9999 -9999 -9999 -9999 -9999 -9999 -9999 -9999 -9999 -9999 -9999 -9999 -9999 -9999 -9999 -9999 -9999 -9999 -9999 -9999 -9999 -9999 -9999 -9999 -9999 -9999 -9999 -9999 -9999 -9999 -9999 -9999 -9999 -9999 -9999 -9999 -9999 -9999 -9999 -9999 -9999 -9999 -9999 -9999 -9999 -9999 -9999 -9999 -9999 -9999 -9999 -9999 -9999 -9999 -9999 -9999 -9999 -9999 -9999 -9999 -9999 -9999 -9999 -9999 -9999 -9999 -9999 -9999 -9999 -9999 -9999 -9999 -9999 -9999 -9999 -9999 -9999 -9999 -9999 -9999 -9999 -9999 -9999 -9999 -9999 -9999 -9999 -9999 -9999 -9999 -9999 -9999 -9999 -9999 -9999 -9999 -9999 -9999 -9999 -9999 -9999 -9999 -9999 -9999 -9999 -9999 -9999 -9999 -9999 -9999 -9999 -9999 -9999 -9999 -9999 -9999 -9999 -9999 -9999 -9999 -9999 -9999 -9999 -9999 -9999 -9999 -9999 -9999 -9999 -9999 -9999 -9999 -9999 -9999 -9999 -9999 -9999 -9999 -9999 -9999 -9999 -9999 -9999 -9999 -9999 -9999 -9999 -9999 -9999 -9999 -9999 -9999 -9999 -9999 -9999 -9999 -9999 -9999 -9999 -9999 -9999 -9999 -9999 -9999 -9999 -9999 -9999 -9999 -9999 -9999 -9999 -9999 -9999 -9999 -9999 -9999 -9999 -9999 -9999 -999 -9999 -9999 -9999 -9999 -9999 -9999 -9999 -9999 -9999 -9999 -9999 -9999 -9999 -9999 -9999 -9999 -9999 -9999 -9999 -9999 -9999 -9999 -9999 -9999 -9999 -9999 -9999 -9999 -9999 -9999 -

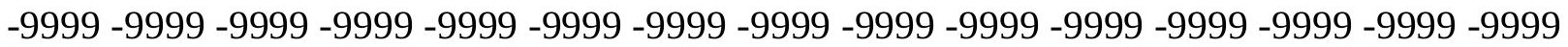

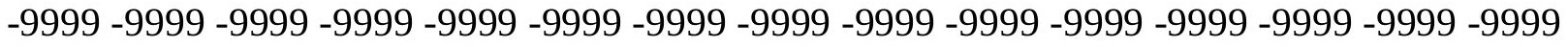

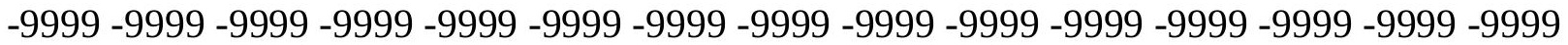
-9999 -9999 -9999 -9999 -9999 -9999 -9999 -9999 -9999 -9999 -9999 -9999 -9999 -9999 -9999

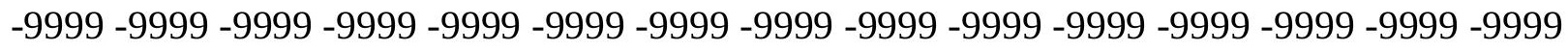

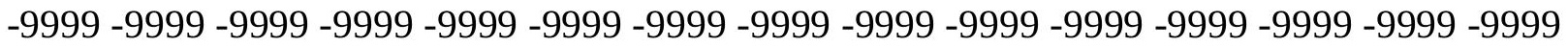

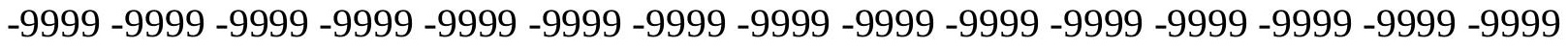
-9999 -9999 -9999 -9999 -9999 -9999 -9999 -9999 -9999 -9999 -9999 -9999 -9999 -9999 -9999 -

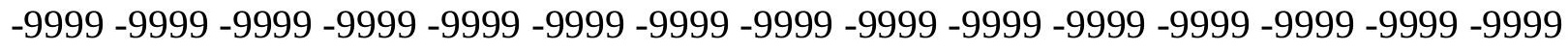

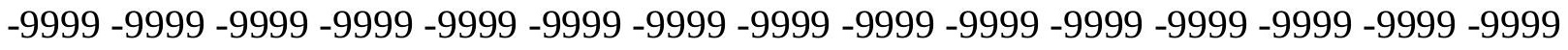
-9999 -9999 -9999 -9999 -9999 -9999 -9999 -9999 -9999 -9999 -9999 -9999 -9999 -9999 -9999 -9999 -9999 -9999 -9999 -9999 -9999 -9999 -9999 -9999-9999 -9999 -9999 -9999 -9999 -9999 -9999 -9999 -9999 -9999 -9999 -9999 -9999 -9999 -9999 -9999 -9999 -9999 -9999 -9999 -9999 -

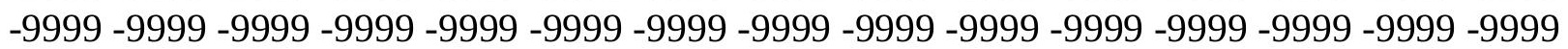


-9999 -9999 -9999 -9999 -9999 -9999 -9999 -9999 -9999 -9999 -9999 -9999 -9999 -9999 -9999 -9999 -9999 -9999 -9999 -9999 -9999 -9999 -9999 -9999 -9999 -9999 -9999 -9999 -9999 -9999 -9999 -9999 -9999 -9999 -9999 -9999 -9999 -9999 -9999 -9999 -9999 -9999 -9999 -9999 -9999 -9999 -9999 -9999 -9999 -9999 -9999 -9999 -9999 -9999 -9999 -9999 -9999 -9999 -9999 -9999 -9999 -9999 -9999 -9999 -9999 -9999 -9999 -9999 -9999 -9999 -9999 -9999 -9999 -9999 -9999 -9999 -9999 -9999 -9999 -9999 -9999 -9999 -9999 -9999 -9999 -9999 -9999 -9999 -9999 -9999 -9999 -9999 -9999 -9999 -9999 -9999 -9999 -9999 -9999 -9999 -9999 -9999 -9999 -9999 -

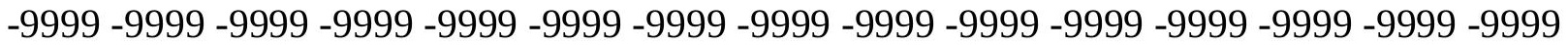
-9999 -9999 -9999 -9999 -9999 -9999 -9999 -9999 -9999 -9999 -9999 -9999 -9999 -9999 -9999 -9999 -9999 -9999 -9999 -9999 -9999 -9999 -9999 -9999 -9999 -9999 -9999 -9999 -9999 -9999 -

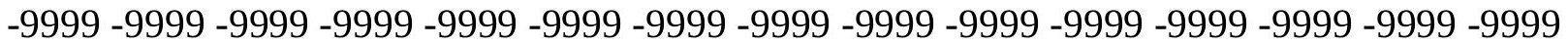
-9999 -9999 -9999 -9999 -9999 -9999 -9999 -9999 -9999 -9999 -9999 -9999 -9999 -9999 -9999 -9999 -9999 -9999 -9999 -9999 -9999 -9999 -9999 -9999 -9999 -9999 -9999 -9999 -9999 -9999 -9999 -9999 -9999 -9999 -9999 -9999 -9999 -9999 -9999 -9999 -9999 -9999 -9999 -9999 -9999 -9999 -9999 -9999 -9999 -9999 -9999 -9999 -9999 -9999 -9999 -9999 -9999 -9999 -9999 -9999 -9999 -9999 -9999 -9999 -9999 -9999 -9999 -9999 -9999 -9999 -9999 -9999 -9999 -9999 -9999 -9999 -9999 -9999 -9999 -9999 -9999 -9999 -9999 -9999 -9999 -9999 -9999 -9999 -9999 -9999 -9999 -9999 -9999 -9999 -9999 -9999 -9999 -9999 -9999 -9999 -9999 -9999 -9999 -9999 -9999 -9999 -9999 -9999 -9999 -9999 -9999 -9999 -9999 -9999 -9999 -9999 -9999 -9999 -9999 -9999 -9999 -9999 -9999 -9999 -9999 -9999 -9999 -9999 -9999 -9999 -9999 -9999 -9999 -9999 -9999

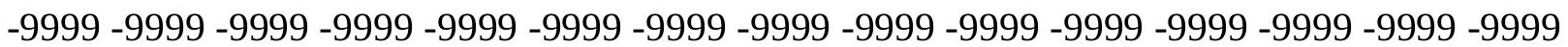
-9999 -9999 -9999 -9999 -9999 -9999 -9999 -9999 -9999 -9999 -9999 -9999 -9999 -9999 -9999 -9999 -9999 -9999 -9999 -9999 -9999 -9999 -9999 -9999 -9999 -9999 -9999 -9999 -9999 -9999 -9999 -9999 -9999 -9999 -9999 -9999 -9999 -9999 -9999 -9999 -9999 -9999 -9999 -9999 -9999

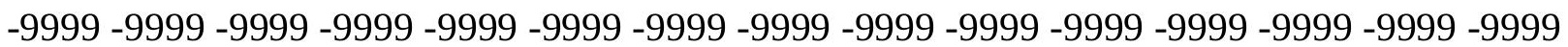
-9999 -9999 -9999 -9999 -9999 -9999 -9999 -9999 -9999 -9999 -9999 -9999 -9999 -9999 -9999 -9999 -9999 -9999 -9999 -9999 -9999 -9999 -9999 -9999 -9999 -9999 -9999 -9999 -9999 -9999 -9999 -9999 -9999 -9999 -9999 -9999 -9999 -9999 -9999 -9999 -9999 -9999 -9999 -9999

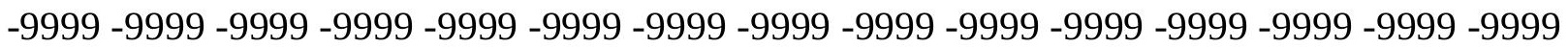
-9999 -9999 -9999 -9999 -9999 -9999 -9999 -9999 -9999 -9999 -9999 -9999 -9999 -9999 -9999 -9999 -9999 -9999 -9999 -9999 -9999 -9999 -9999 -9999 -9999 -9999 -9999 -9999 -9999 -9999 -

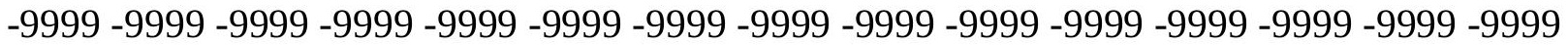
-9999 -9999 -9999 -9999 -9999 -9999 -9999 -9999 -9999 -9999 -9999 -9999 -9999 -9999 -9999 -9999 -9999 -9999 -9999 -9999 -9999 -9999 -9999 -9999 -9999 -9999 -9999 -9999 -9999 -9999 -9999 -9999 -9999 -9999 -9999 -9999 -9999 -9999 -9999 -9999 -9999 -9999 -9999 -9999 -9999 -9999 -9999 -9999 -9999 -9999 -9999 -9999 -9999 -9999 -9999 -9999 -9999 -9999 -9999 -9999 -9999 -9999 -9999 -9999 -9999 -9999 -9999 -9999 -9999 -9999 -9999 -9999 -9999 -9999 -9999

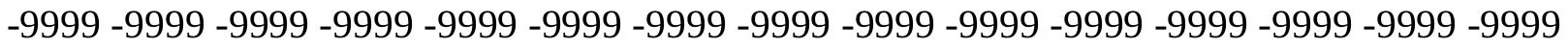
-9999 -9999 -9999 -9999 -9999 -9999 -9999 -9999 -9999 -9999 -9999 -9999 -9999 -9999 -9999 -9999 -9999 -9999 -9999 -9999 -9999 -9999 -9999 -9999 -9999 -9999 -9999 -9999 -9999 -9999 -

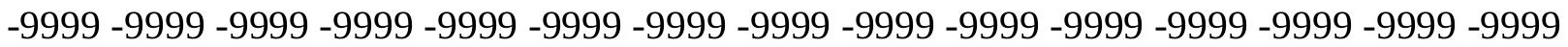
-9999 -9999 -9999 -9999 -9999 -9999 -9999 -9999 -9999 -9999 -9999 -9999 -9999 -9999 -9999 -9999 -9999 -9999 -9999 -9999 -9999 -9999 -9999 -9999 -9999 -9999 -9999 -9999 -9999 -9999 -9999 -9999 -9999 -9999 -9999 -9999 -9999 -9999 -9999 -9999 -9999 -9999 -9999 -9999 -9999 -9999 -9999 -9999 -9999 -9999 -9999 -9999 -9999 -9999 -9999 -9999 -9999 -9999 -9999 -9999

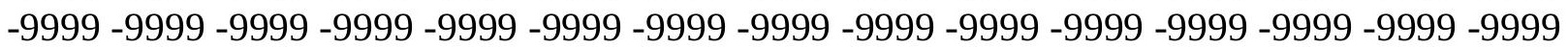


-9999 -9999 -9999 -9999 -9999 -9999 -9999 -9999 -9999 -9999 -9999 -9999 -9999 -9999 -9999 -9999 -9999 -9999 -9999 -9999 -9999 -9999 -9999 -9999 -9999 -9999 -9999 -9999 -9999 -9999 -

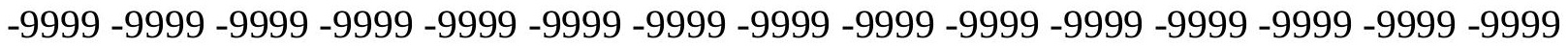
-9999 -9999 -9999 -9999 -9999 -9999 -9999 -9999 -9999 -9999 -9999 -9999 -9999 -9999 -9999 -9999 -9999 -9999 -9999 -9999 -9999 -9999 -9999 -9999-9999 -9999 -9999 -9999 -9999 -9999 -9999 -9999 -9999 -9999 -9999 -9999 -9999 -9999 -9999 -9999 -9999 -9999 -9999 -9999 -9999 -9999 -9999 -9999 -9999 -9999 -9999 -9999 -9999 -9999 -9999 -9999 -9999 -9999 -9999 -

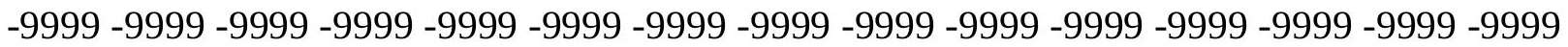

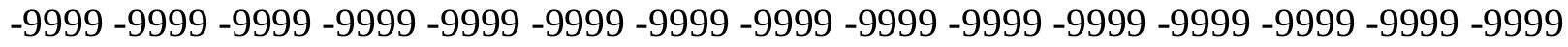
-9999 -9999 -9999 -9999 -9999 -9999 -9999 -9999 -9999 -9999 -9999 -9999 -9999 -9999 -9999 -9999 -9999 -9999 -9999 -9999 -9999 -9999 -9999 -9999 -9999 -9999 -9999 -9999 -9999 -9999 -9999 -9999 -9999 -9999 -9999 -9999 -9999 -9999 -9999 -9999 -9999 -9999 -9999 -9999 -9999 -9999 -9999 -9999 -9999 -9999 -9999 -9999 -9999 -9999 -9999 -9999 -9999 -9999 -9999 -9999 -9999 -9999 -9999 -9999 -9999 -9999 -9999 -9999 -9999 -9999 -9999 -9999 -9999 -9999 -9999 -9999 -9999 -9999 -9999 -9999 -9999 -9999 -9999 -9999 -9999 -9999 -9999 -9999 -9999 -9999 -

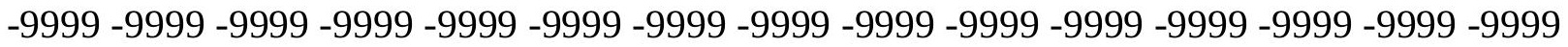
-9999 -9999 -9999 -9999 -9999 -9999 -9999 -9999 -9999 -9999 -9999 -9999 -9999 -9999 -9999 -9999 -9999 -9999 -9999 -9999 -9999 -9999 -9999 -9999 -9999 -9999 -9999 -9999 -9999 -9999 -9999 -9999 -9999 -9999 -9999 -9999 -9999 -9999 -9999 -9999 -9999 -9999 -9999 -9999 -9999 -

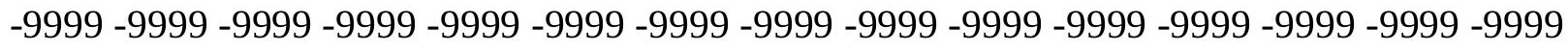

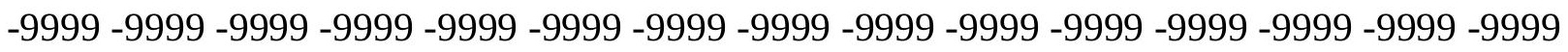

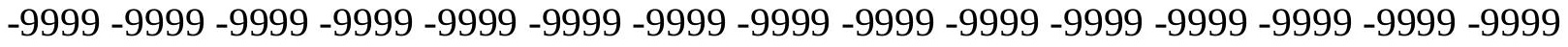
-9999 -9999 -9999 -9999 -9999 -9999 -9999 -9999 -9999 -9999 -9999 -9999 -9999 -9999 -9999 -9999 -9999 -9999 -9999 -9999 -9999 -9999 -9999 -9999 -9999 -9999 -9999 -9999 -9999 -9999 -

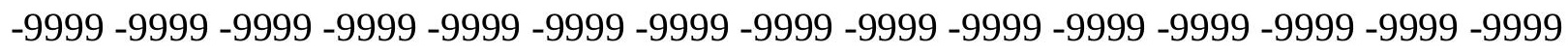
-9999 -9999 -9999 -9999 -9999 -9999 -9999 -9999 -9999 -9999 -9999 -9999 -9999 -9999 -9999 -9999 -9999 -9999 -9999 -9999 -9999 -9999 -9999 -9999 -9999 -9999 -9999 -9999 -9999 -9999 -

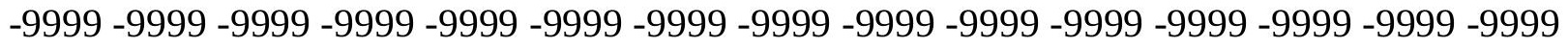
-9999 -9999 -9999 -9999 -9999 -9999 -9999 -9999 -9999 -9999 -9999 -9999 -9999 -9999 -9999 -9999 -9999 -9999 -9999 -9999 -9999 -9999 -9999 -9999 -9999 -9999 -9999 -9999 -9999 -999 -9999 -9999 -9999 -9999 -9999 -9999 -9999 -9999 -9999 -9999 -9999 -9999 -9999 -9999 -9999 -

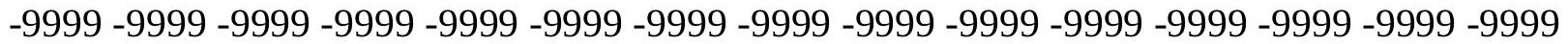

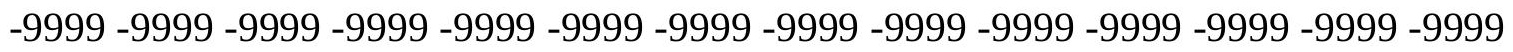

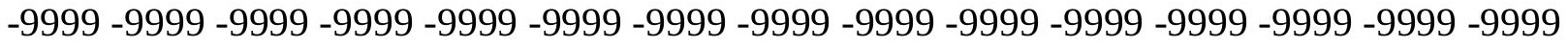

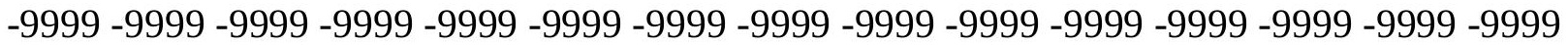

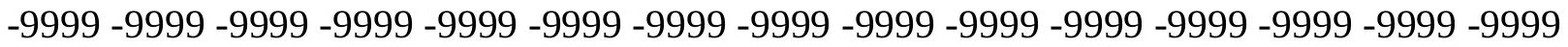

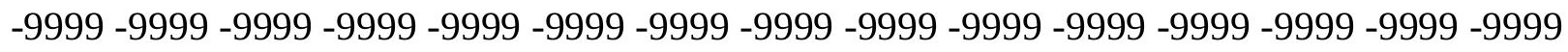

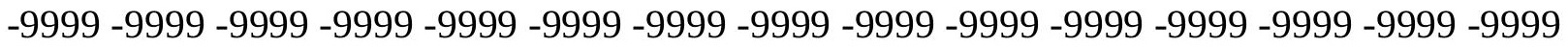

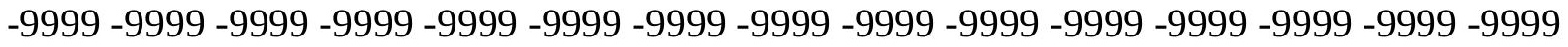
-9999 -9999 -9999 -9999 -9999 -9999 -9999 -9999 -9999 -9999 -9999 -9999 -9999 -9999 -9999 -

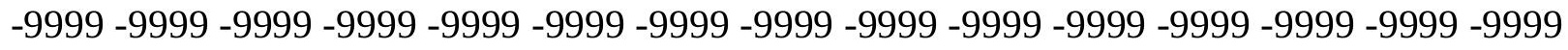

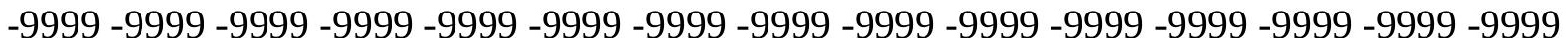
-9999 -9999 -9999 -9999 -9999 -9999 -9999 -9999 -9999 -9999 -9999 -9999 -9999 -9999 -9999 -9999 -9999 -9999 -9999 -9999 -9999 -9999 -9999 -9999-9999 -9999 -9999 -9999 -9999 -9999 -9999 -9999 -9999 -9999 -9999 -9999 -9999 -9999 -9999 -9999 -9999 -9999 -9999 -9999 -9999 -

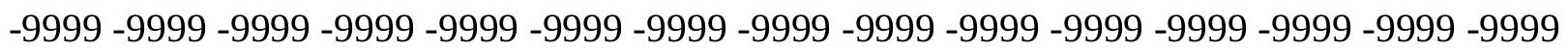


-9999 -9999 -9999 -9999 -9999 -9999 -9999 -9999 -9999 -9999 -9999 -9999 -9999 -9999 -9999 -9999 -9999 -9999 -9999 -9999 -9999 -9999 -9999 -9999 -9999 -9999 -9999 -9999 -9999 -9999 -

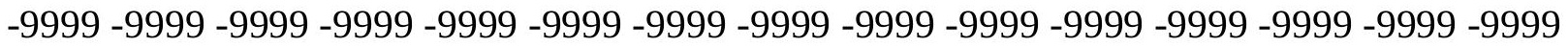
-9999 -9999 -9999 -9999 -9999 -9999 -9999 -9999 -9999 -9999 -9999 -9999 -9999 -9999 -9999 -9999 -9999 -9999 -9999 -9999 -9999 -9999 -9999 -9999-9999 -9999 -9999 -9999 -9999 -9999 -9999 -9999 -9999 -9999 -9999 -9999 -9999 -9999 -9999 -9999 -9999 -9999 -9999 -9999 -9999 -9999 -9999 -9999 -9999 -9999 -9999 -9999 -9999 -9999 -9999 -9999 -9999 -9999 -9999 -9999

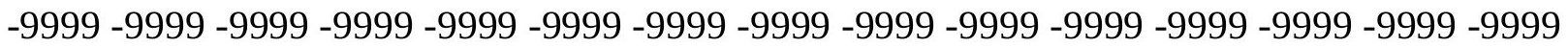

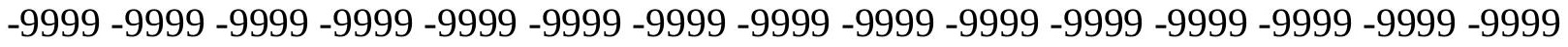
-9999 -9999 -9999 -9999 -9999 -9999 -9999 -9999 -9999 -9999 -9999 -9999 -9999 -9999 -9999 -9999 -9999 -9999 -9999 -9999 -9999 -9999 -9999 -9999 -9999 -9999 -9999 -9999 -9999 -9999 -9999 -9999 -9999 -9999 -9999 -9999 -9999 -9999 -9999 -9999 -9999 -9999 -9999 -9999 -9999 -9999 -9999 -9999 -9999 -9999 -9999 -9999 -9999 -9999 -9999 -9999 -9999 -9999 -9999 -9999 -9999 -9999 -9999 -9999 -9999 -9999 -9999 -9999 -9999 -9999 -9999 -9999 -9999 -9999 -9999 -9999 -9999 -9999 -9999 -9999 -9999 -9999 -9999 -9999 -9999 -9999 -9999 -9999 -9999 -

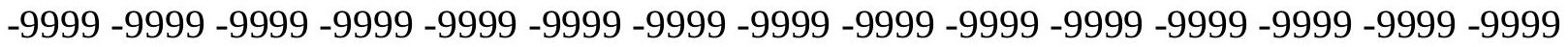
-9999 -9999 -9999 -9999 -9999 -9999 -9999 -9999 -9999 -9999 -9999 -9999 -9999 -9999 -9999 -9999 -9999 -9999 -9999 -9999 -9999 -9999 -9999 -9999 -9999 -9999 -9999 -9999 -9999 -9999 -9999 -9999 -9999 -9999 -9999 -9999 -9999 -9999 -9999 -9999 -9999 -9999 -9999 -9999 -9999 -

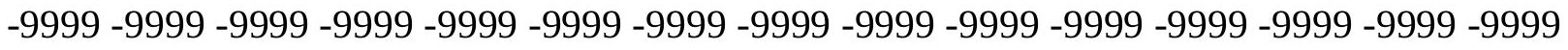
-9999 -9999 -9999 -9999 -9999 -9999 -9999 -9999 -9999 -9999 -9999 -9999 -9999 -9999 -9999

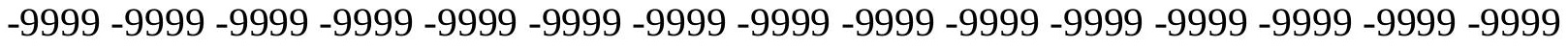
-9999 -9999 -9999 -9999 -9999 -9999 -9999 -9999 -9999 -9999 -9999 -9999 -9999 -9999 -9999 -9999 -9999 -9999 -9999 -9999 -9999 -9999 -9999 -9999 -9999 -9999 -9999 -9999 -9999 -9999 -

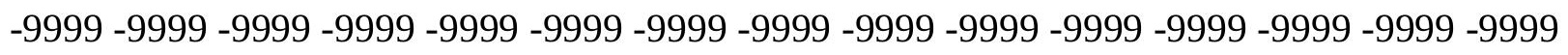
-9999 -9999 -9999 -9999 -9999 -9999 -9999 -9999 -9999 -9999 -9999 -9999 -9999 -9999 -9999 -9999 -9999 -9999 -9999 -9999 -9999 -9999 -9999 -9999 -9999 -9999 -9999 -9999 -9999 -9999 -

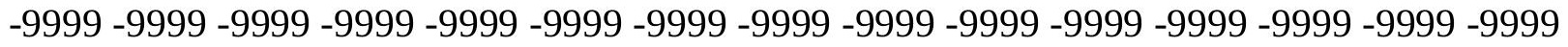
-9999 -9999 -9999 -9999 -9999 -9999 -9999 -9999 -9999 -9999 -9999 -9999 -9999 -9999 -9999 -9999 -9999 -9999 -9999 -9999 -9999 -9999 -9999 -9999 -9999 -9999 -9999 -9999 -9999 -999 -9999 -9999 -9999 -9999 -9999 -9999 -9999 -9999 -9999 -9999 -9999 -9999 -9999 -9999 -9999 -9999 -9999 -9999 -9999 -9999 -9999 -9999 -9999 -9999 -9999 -9999 -9999 -9999 -9999 -9999 -

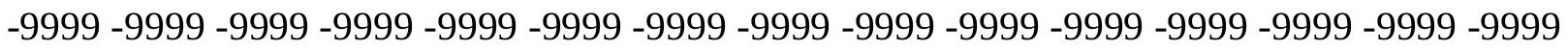

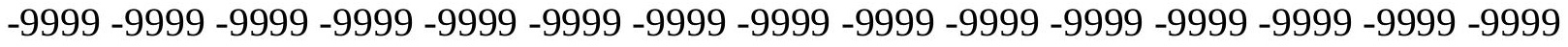

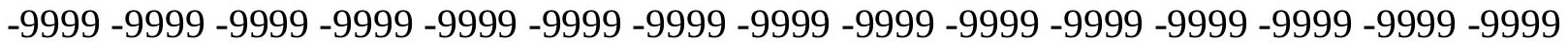
-9999 -9999 -9999 -9999 -9999 -9999 -9999 -9999 -9999 -9999 -9999 -9999 -9999 -9999 -9999 -

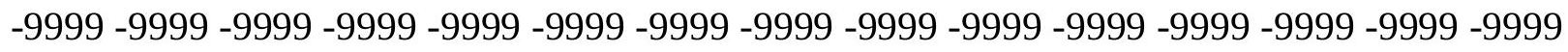

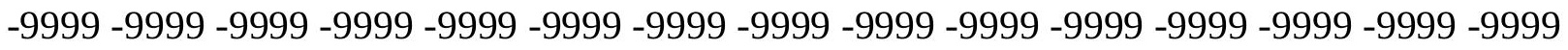
-9999 -9999 -9999 -9999 -9999 -9999 -9999 -9999 -9999 -9999 -9999 -9999 -9999 -9999 - -999 -9999 -9999 -9999 -9999 -9999 -9999 -9999 -9999 -9999 -9999 -9999 -9999 -9999 -9999 -9999 -

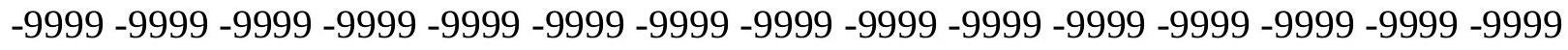

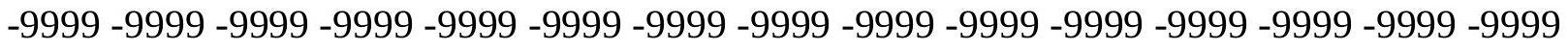
-9999 -9999 -9999 -9999 -9999 -9999 -9999 -9999 -9999 -9999 -9999 -9999 -9999 -9999 -9999 -9999 -9999 -9999 -9999 -9999 -9999 -9999 -9999 -9999-9999 -9999 -9999 -9999 -9999 -9999 -9999 -9999 -9999 -9999 -9999 -9999 -9999 -9999 -9999 -9999 -9999 -9999 -9999 -9999 -9999 -

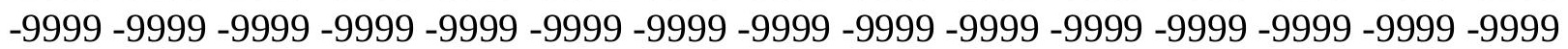


-9999 -9999 -9999 -9999 -9999 -9999 -9999 -9999 -9999 -9999 -9999 -9999 -9999 -9999 -9999 -9999 -9999 -9999 -9999 -9999 -9999 -9999 -9999 -9999 -9999 -9999 -9999 -9999 -9999 -9999 -

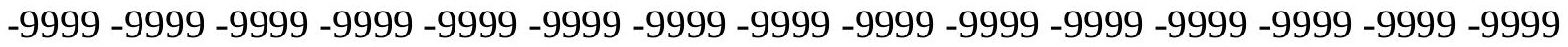
-9999 -9999 -9999 -9999 -9999 -9999 -9999 -9999 -9999 -9999 -9999 -9999 -9999 -9999 -9999 -9999 -9999 -9999 -9999 -9999 -9999 -9999 -9999 -9999-9999 -9999 -9999 -9999 -9999 -9999 -9999 -9999 -9999 -9999 -9999 -9999 -9999 -9999 -9999 -9999 -9999 -9999 -9999 -9999 -9999 -9999 -9999 -9999 -9999 -9999 -9999 -9999 -9999 -9999 -9999 -9999 -9999 -9999 -9999 -9999

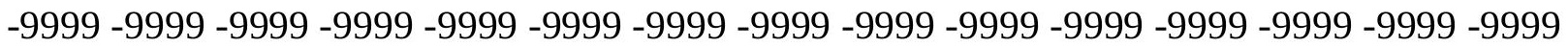

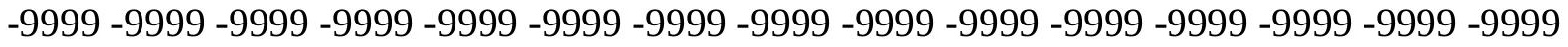
-9999 -9999 -9999 -9999 -9999 -9999 -9999 -9999 -9999 -9999 -9999 -9999 -9999 -9999 -9999 -9999 -9999 -9999 -9999 -9999 -9999 -9999 -9999 -9999 -9999 -9999 -9999 -9999 -9999 -9999 -9999 -9999 -9999 -9999 -9999 -9999 -9999 -9999 -9999 -9999 -9999 -9999 -9999 -9999 -9999 -9999 -9999 -9999 -9999 -9999 -9999 -9999 -9999 -9999 -9999 -9999 -9999 -9999 -9999 -9999 -

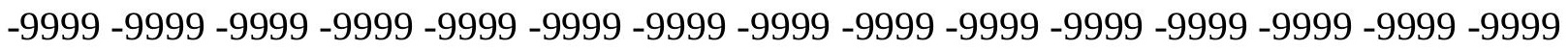
-9999 -9999 -9999 -9999 -9999 -9999 -9999 -9999 -9999 -9999 -9999 -9999 -9999 -9999 -9999 -

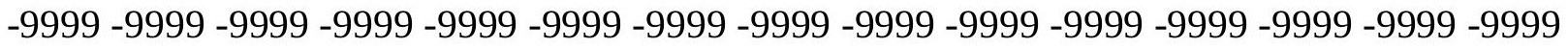
-9999 -9999 -9999 -9999 -9999 -9999 -9999 -9999 -9999 -9999 -9999 -9999 -9999 -9999 -9999 -9999 -9999 -9999 -9999 -9999 -9999 -9999 -9999 -9999 -9999 -9999 -9999 -9999 -9999 -9999 -9999 -9999 -9999 -9999 -9999 -9999 -9999 -9999 -9999 -9999 -9999 -9999 -9999 -9999 - -999 -

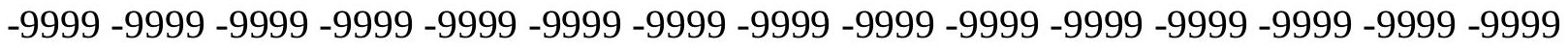

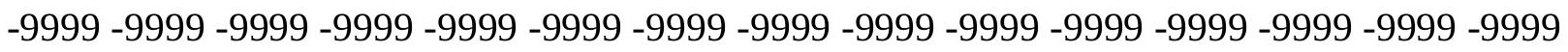
-9999 -9999 -9999 -9999 -9999 -9999 -9999 -9999 -9999 -9999 -9999 -9999 -9999 -9999 -9999 -9999 -9999 -9999 -9999 -9999 -9999 -9999 -9999 -9999 -9999 -9999 -9999 -9999 -9999 -9999 -9999 -9999 -9999 -9999 -9999 -9999 -9999 -9999 -9999 -9999 -9999 -9999 -9999 -9999 -9999 -

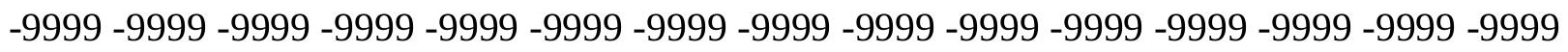
-9999 -9999 -9999 -9999 -9999 -9999 -9999 -9999 -9999 -9999 -9999 -9999 -9999 -9999 -9999 -9999 -9999 -9999 -9999 -9999 -9999 -9999 -9999 -9999 -9999 -9999 -9999 -9999 -9999 -9999 -

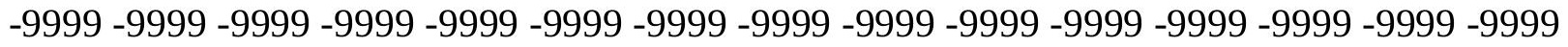
-9999 -9999 -9999 -9999 -9999 -9999 -9999 -9999 -9999 -9999 -9999 -9999 -9999 -9999 -9999 -9999 -9999 -9999 -9999 -9999 -9999 -9999 -9999 -9999 -9999 -9999 -9999 -9999 -9999 -999 -

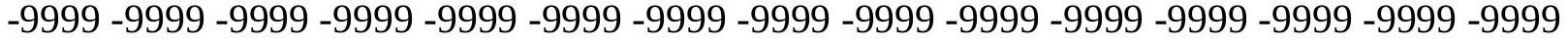
-9999 -9999 -9999 -9999 -9999 -9999 -9999 -9999 -9999 -9999 -9999 -9999 -9999 -9999 -9999 -

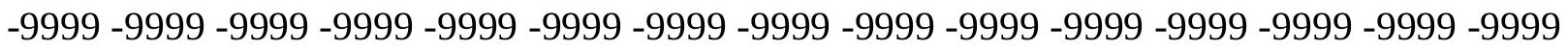

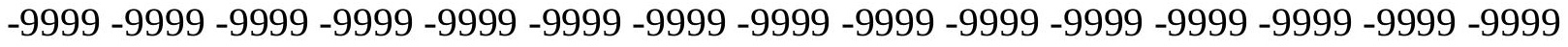

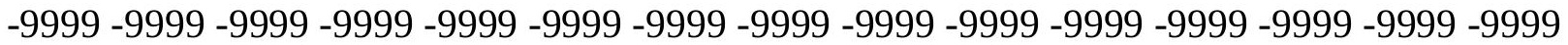

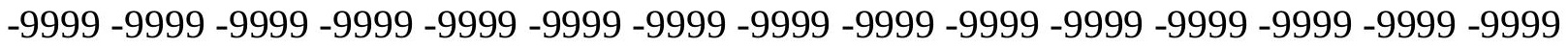

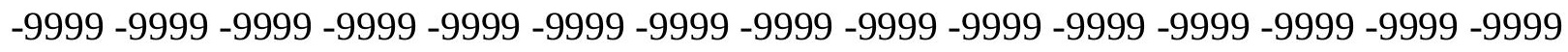

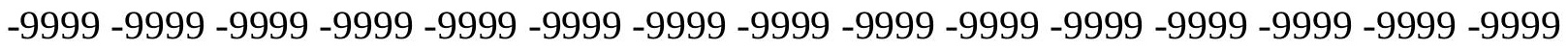

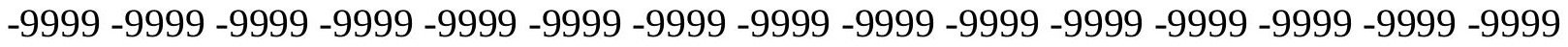
-9999 -9999 -9999 -9999 -9999 -9999 -9999 -9999 -9999 -9999 -9999 -9999 -9999 -9999 -9999 -

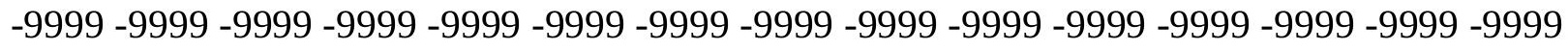

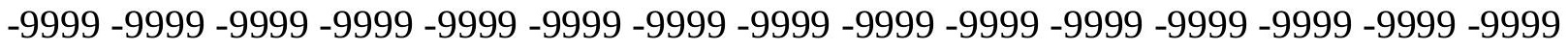
-9999 -9999 -9999 -9999 -9999 -9999 -9999 -9999 -9999 -9999 -9999 -9999 -9999 -9999 -9999 -9999 -9999 -9999 -9999 -9999 -9999 -9999 -9999 -9999 -9999 -9999 -9999 -9999 -9999 -9999 -9999 -9999 -9999 -9999 -9999 -9999 -9999 -9999 -9999 -9999 -9999 -9999 -9999 -9999 -

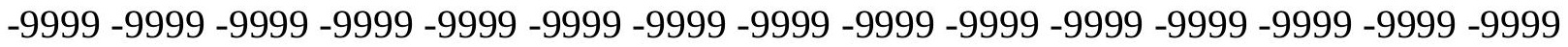


-9999 -9999 -9999 -9999 -9999 -9999 -9999 -9999 -9999 -9999 -9999 -9999 -9999 -9999 -9999 -9999 -9999 -9999 -9999 -9999 -9999 -9999 -9999 -9999 -9999 -9999 -9999 -9999 -9999 -9999 -

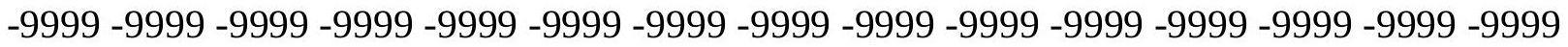
-9999 -9999 -9999 -9999 -9999 -9999 -9999 -9999 -9999 -9999 -9999 -9999 -9999 -9999 -9999 -9999 -9999 -9999 -9999 -9999 -9999 -9999 -9999 -9999-9999 -9999 -9999 -9999 -9999 -9999 -9999 -9999 -9999 -9999 -9999 -9999 -9999 -9999 -9999 -9999 -9999 -9999 -9999 -9999 -9999 -9999 -9999 -9999 -9999 -9999 -9999 -9999 -9999 -9999 -9999 -9999 -9999 -9999 -9999 -9999

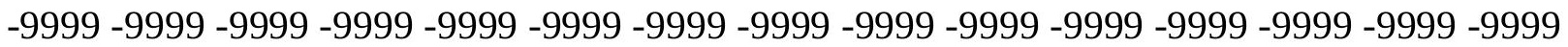

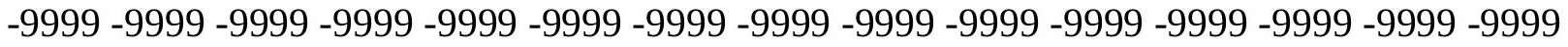
-9999 -9999 -9999 -9999 -9999 -9999 -9999 -9999 -9999 -9999 -9999 -9999 -9999 -9999 -9999 -9999 -9999 -9999 -9999 -9999 -9999 -9999 -9999 -9999 -9999 -9999 -9999 -9999 -9999 -9999 -9999 -9999 -9999 -9999 -9999 -9999 -9999 -9999 -9999 -9999 -9999 -9999 -9999 -9999 -9999 -9999 -9999 -9999 -9999 -9999 -9999 -9999 -9999 -9999 -9999 -9999 -9999 -9999 -9999 -9999 -

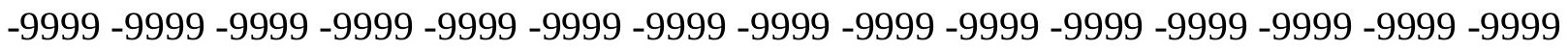
-9999 -9999 -9999 -9999 -9999 -9999 -9999 -9999 -9999 -9999 -9999 -9999 -9999 -9999 -9999 -

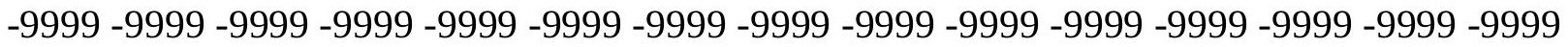
-9999 -9999 -9999 -9999 -9999 -9999 -9999 -9999 -9999 -9999 -9999 -9999 -9999 -9999 -9999 -9999 -9999 -9999 -9999 -9999 -9999 -9999 -9999 -9999 -9999 -9999 -9999 -9999 -9999 - 9999 -9999 -9999 -9999 -9999 -9999 -9999 -9999 -9999 -9999 -9999 -9999 -9999 -9999 -9999 -9999 -

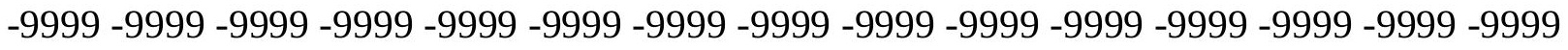

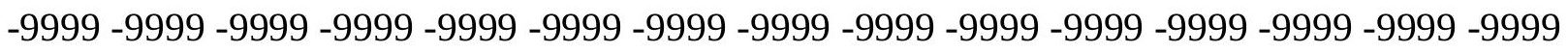
-9999 -9999 -9999 -9999 -9999 -9999 -9999 -9999 -9999 -9999 -9999 -9999 -9999 -9999 - 9999 -9999 -9999 -9999 -9999 -9999 -9999 -9999 -9999 -9999 -9999 -9999 -9999 -9999 -9999 -9999 -9999 -9999 -9999 -9999 -9999 -9999 -9999 -9999 -9999 -9999 -9999 -9999 -9999 -9999 -9999 -9999 -9999 -9999 -9999 -9999 -9999 -9999 -9999 -9999 -9999 -9999 -9999 -9999 -9999 -9999 -9999 -9999 -9999 -9999 -9999 -9999 -9999 -9999 -9999 -9999 -9999 -9999 -9999 -9999 -9999 -9999 -9999 -9999 -9999 -9999 -9999 -9999 -9999 -9999 -9999 -9999 -9999 -9999 -9999 -

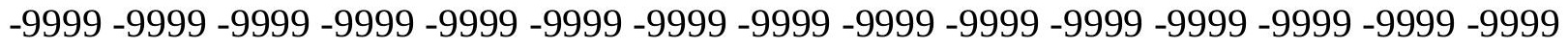
-9999 -9999 -9999 -9999 -9999 -9999 -9999 -9999 -9999 -9999 -9999 -9999 -9999 -9999 -9999 -9999 -9999 -9999 -9999 -9999 -9999 -9999 -9999 -9999 -9999 -9999 -9999 -9999 -9999 -999 -9999 -9999 -9999 -9999 -9999 -9999 -9999 -9999 -9999 -9999 -9999 -9999 -9999 -9999 -9999 -9999 -9999 -9999 -9999 -9999 -9999 -9999 -9999 -9999 -9999 -9999 -9999 -9999 -9999 -9999 -

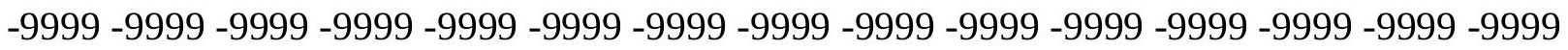

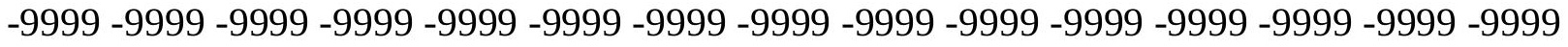

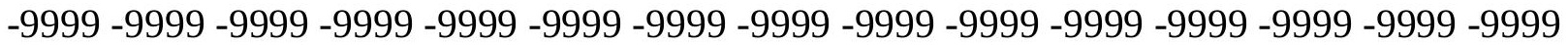

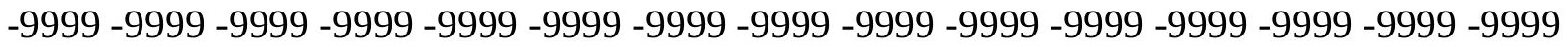

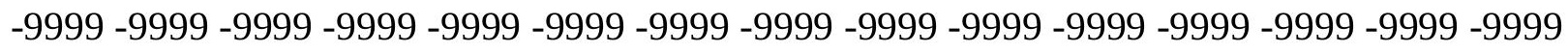

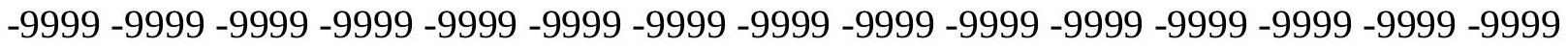

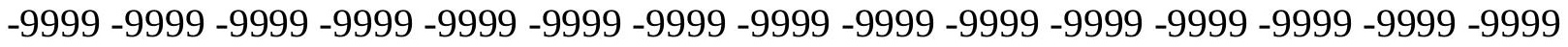
-9999 -9999 -9999 -9999 -9999 -9999 -9999 -9999 -9999 -9999 -9999 -9999 -9999 -9999 -9999 -

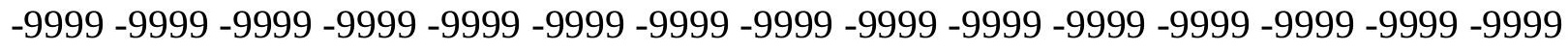

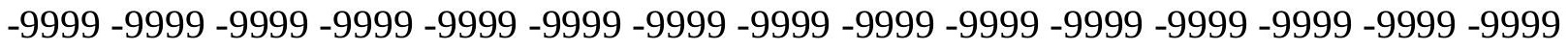
-9999 -9999 -9999 -9999 -9999 -9999 -9999 -9999 -9999 -9999 -9999 -9999 -9999 -9999 -9999 -9999 -9999 -9999 -9999 -9999 -9999 -9999 -9999 -9999-9999 -9999 -9999 -9999 -9999 -9999 -9999 -9999 -9999 -9999 -9999 -9999 -9999 -9999 -9999 -9999 -9999 -9999 -9999 -9999 -9999 -

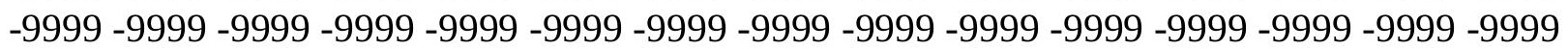


-9999 -9999 -9999 -9999 -9999 -9999 -9999 -9999 -9999 -9999 -9999 -9999 -9999 -9999 -9999 -9999 -9999 -9999 -9999 -9999 -9999 -9999 -9999 -9999 -9999 -9999 -9999 -9999 -9999 -9999 -9999 -9999 -9999 -9999 -9999 -9999 -9999 -9999 -9999 -9999 -9999 -9999 -9999 -9999 - 9999 -9999 -9999 -9999 -9999 -9999 -9999 -9999 -9999 -9999 -9999 -9999 -9999 -9999 -9999 -9999 -9999 -9999 -9999 -9999 -9999 -9999 -9999 -9999 -9999 -9999 -9999 -9999 -9999 -9999 -9999 -9999 -9999 -9999 -9999 -9999 -9999 -9999 -9999 -9999 -9999 -9999 -9999 -9999 -9999 -9999 -9999 -9999 -9999 -9999 -9999 -9999 -9999 -9999 -9999 -9999 -9999 -9999 -9999 -9999

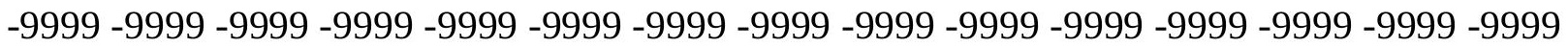

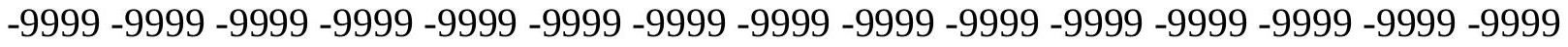
-9999 -9999 -9999 -9999 -9999 -9999 -9999 -9999 -9999 -9999 -9999 -9999 -9999 -9999 -9999 -9999 -9999 -9999 -9999 -9999 -9999 -9999 -9999 -9999 -9999 -9999 -9999 -9999 -9999 -9999 -9999 -9999 -9999 -9999 -9999 -9999 -9999 -9999 -9999 -9999 -9999 -9999 -9999 -9999 -9999 -9999 -9999 -9999 -9999 -9999 -9999 -9999 -9999 -9999 -9999 -9999 -9999 -9999 -9999 -9999 -9999 -9999 -9999 -9999 -9999 -9999 -9999 -9999 -9999 -9999 -9999 -9999 -9999 -9999 -9999 -9999 -9999 -9999 -9999 -9999 -9999 -9999 -9999 -9999 -9999 -9999 -9999 -9999 -9999 -9999 -

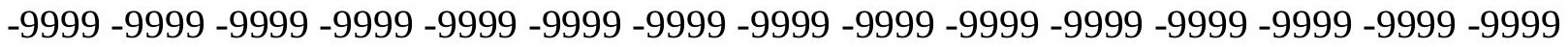
-9999 -9999 -9999 -9999 -9999 -9999 -9999 -9999 -9999 -9999 -9999 -9999 -9999 -9999 -9999 -9999 -9999 -9999 -9999 -9999 -9999 -9999 -9999 -9999 -9999 -9999 -9999 -9999 -9999 - 9999 -9999 -9999 -9999 -9999 -9999 -9999 -9999 -9999 -9999 -9999 -9999 -9999 -9999 -9999 -9999 -

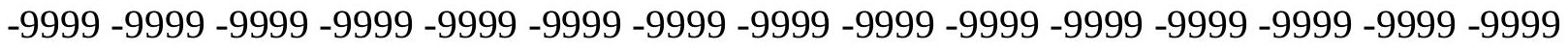

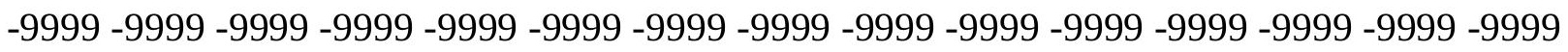

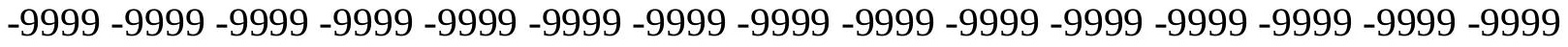
-9999 -9999 -9999 -9999 -9999 -9999 -9999 -9999 -9999 -9999 -9999 -9999 -9999 -9999 -9999 -9999 -9999 -9999 -9999 -9999 -9999 -9999 -9999 -9999 -9999 -9999 -9999 -9999 -9999 -9999 -

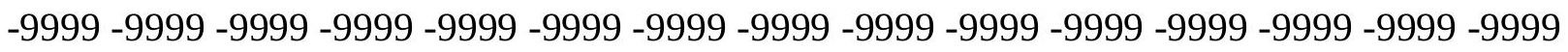
-9999 -9999 -9999 -9999 -9999 -9999 -9999 -9999 -9999 -9999 -9999 -9999 -9999 -9999 -9999 -9999 -9999 -9999 -9999 -9999 -9999 -9999 -9999 -9999 -9999 -9999 -9999 -9999 -9999 -9999 -

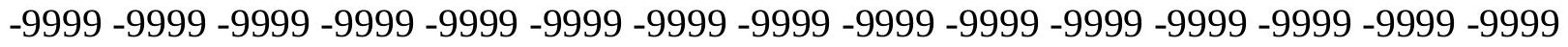
-9999 -9999 -9999 -9999 -9999 -9999 -9999 -9999 -9999 -9999 -9999 -9999 -9999 -9999 -9999 -9999 -9999 -9999 -9999 -9999 -9999 -9999 -9999 -9999 -9999 -9999 -9999 -9999 -9999 -999 -9999 -9999 -9999 -9999 -9999 -9999 -9999 -9999 -9999 -9999 -9999 -9999 -9999 -9999 -9999 -9999 -9999 -9999 -9999 -9999 -9999 -9999 -9999 -9999 -9999 -9999 -9999 -9999 -9999 -

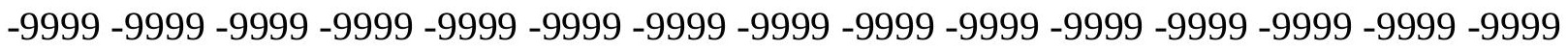

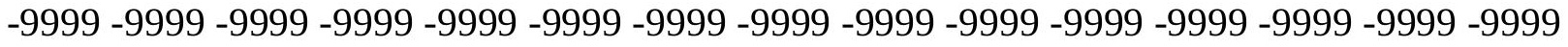

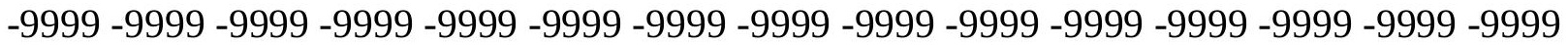

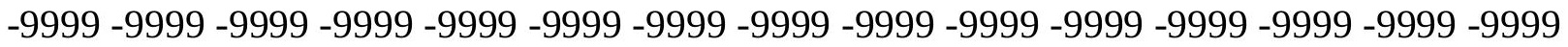

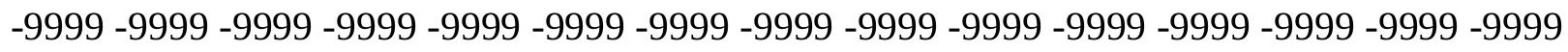

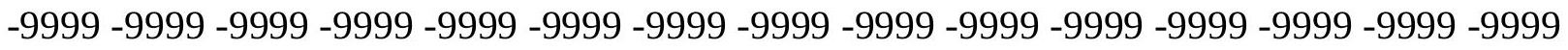

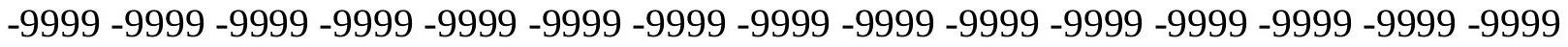
-9999 -9999 -9999 -9999 -9999 -9999 -9999 -9999 -9999 -9999 -9999 -9999 -9999 -9999 -9999 -

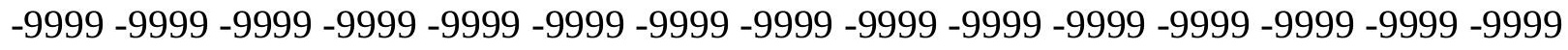

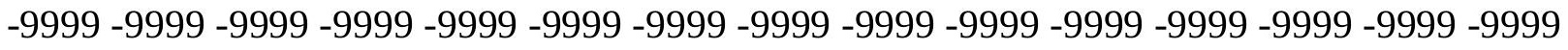
-9999 -9999 -9999 -9999 -9999 -9999 -9999 -9999 -9999 -9999 -9999 -9999 -9999 -9999 -9999 -9999 -9999 -9999 -9999 -9999 -9999 -9999 -9999 -9999-9999 -9999 -9999 -9999 -9999 -9999 -9999 -9999 -9999 -9999 -9999 -9999 -9999 -9999 -9999 -9999 -9999 -9999 -9999 -9999 -9999 -

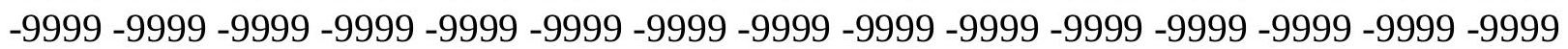


-9999 -9999 -9999 -9999 -9999 -9999 -9999 -9999 -9999 -9999 -9999 -9999 -9999 -9999 -9999 -9999 -9999 -9999 -9999 -9999 -9999 -9999 -9999 -9999 -9999 -9999 -9999 -9999 -9999 -9999 -

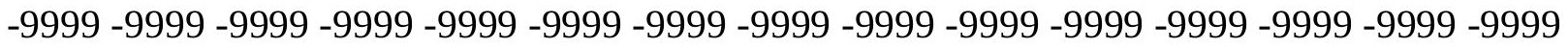
-9999 -9999 -9999 -9999 -9999 -9999 -9999 -9999 -9999 -9999 -9999 -9999 -9999 -9999 -9999 -9999 -9999 -9999 -9999 -9999 -9999 -9999 -9999 -9999-9999 -9999 -9999 -9999 -9999 -9999 -9999 -9999 -9999 -9999 -9999 -9999 -9999 -9999 -9999 -9999 -9999 -9999 -9999 -9999 -9999 -9999 -9999 -9999 -9999 -9999 -9999 -9999 -9999 -9999 -9999 -9999 -9999 -9999 -9999 -9999

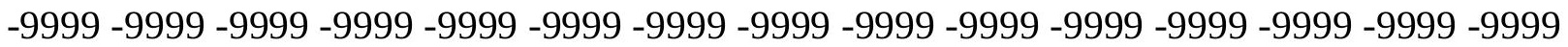

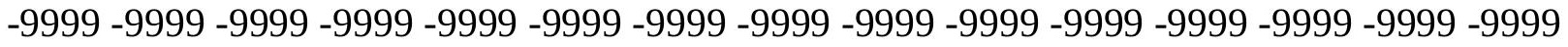

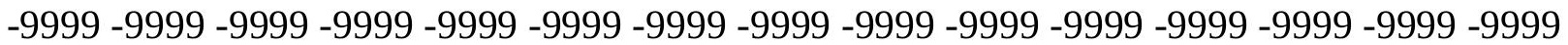
-9999 -9999 -9999 -9999 -9999 -9999 -9999 -9999 -9999 -9999 -9999 -9999 -9999 -9999 -9999 -9999 -9999 -9999 -9999 -9999 -9999 -9999 -9999 -9999 -9999 -9999 -9999 -9999 -9999 -9999 -9999 -9999 -9999 -9999 -9999 -9999 -9999 -9999 -9999 -9999 -9999 -9999 -9999 -9999 -

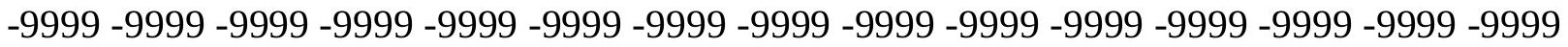
-9999 -9999 -9999 -9999 -9999 -9999 -9999 -9999 -9999 -9999 -9999 -9999 -9999 -9999 -9999 -

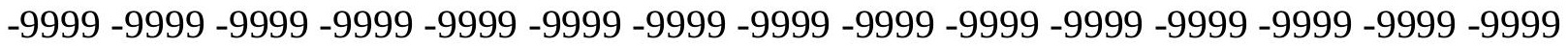
-9999 -9999 -9999 -9999 -9999 -9999 -9999 -9999 -9999 -9999 -9999 -9999 -9999 -9999 -9999 -9999 -9999 -9999 -9999 -9999 -9999 -9999 -9999 -9999 -9999 -9999 -9999 -9999 -9999 -9999 -9999 -9999 -9999 -9999 -9999 -9999 -9999 -9999 -9999 -9999 -9999 -9999 -9999 -9999 -9999 -

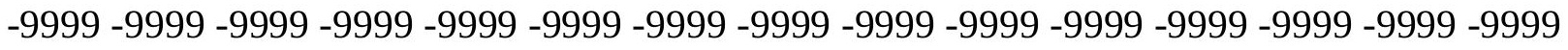

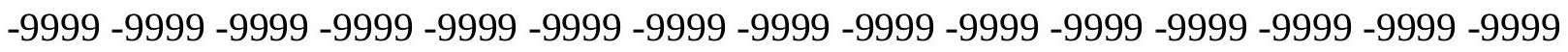
-9999 -9999 -9999 -9999 -9999 -9999 -9999 -9999 -9999 -9999 -9999 -9999 -9999 -9999 -9999 -9999 -9999 -9999 -9999 -9999 -9999 -9999 -9999 -9999 -9999 -9999 -9999 -9999 -9999 -9999 -9999 -9999 -9999 -9999 -9999 -9999 -9999 -9999 -9999 -9999 -9999 -9999 -9999 -9999 -9999 -

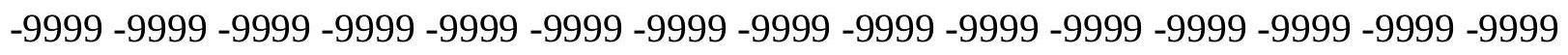
-9999 -9999 -9999 -9999 -9999 -9999 -9999 -9999 -9999 -9999 -9999 -9999 -9999 -9999 -9999 -9999 -9999 -9999 -9999 -9999 -9999 -9999 -9999 -9999 -9999 -9999 -9999 -9999 -9999 -9999 -

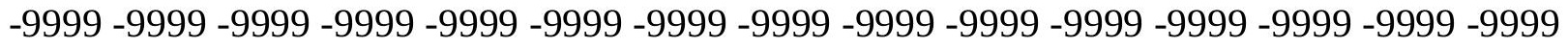
-9999 -9999 -9999 -9999 -9999 -9999 -9999 -9999 -9999 -9999 -9999 -9999 -9999 -9999 -9999 -9999 -9999 -9999 -9999 -9999 -9999 -9999 -9999 -9999 -9999 -9999 -9999 -9999 -9999 -999 -9999 -9999 -9999 -9999 -9999 -9999 -9999 -9999 -9999 -9999 -9999 -9999 -9999 -9999 -9999 -9999 -9999 -9999 -9999 -9999 -9999 -9999 -9999 -9999 -9999 -9999 -9999 -9999 -9999 -9999 -

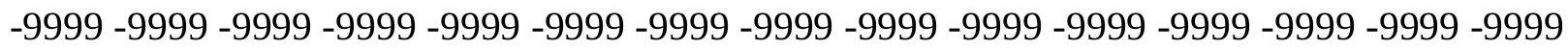

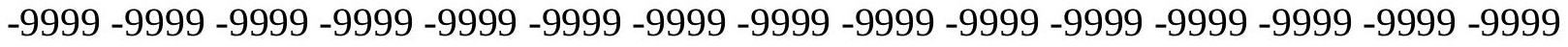

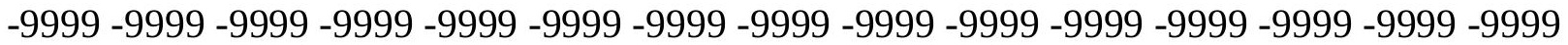
-9999 -9999 -9999 -9999 -9999 -9999 -9999 -9999 -9999 -9999 -9999 -9999 -9999 -9999 -9999 -

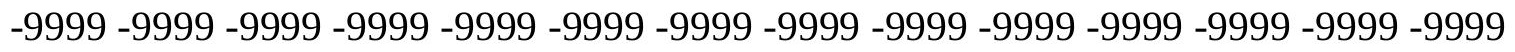

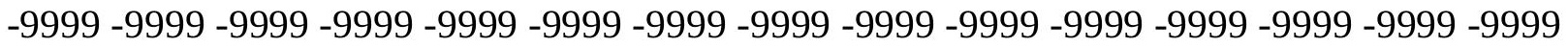
-9999 -9999 -9999 -9999 -9999 -9999 -9999 -9999 -9999 -9999 -9999 -9999 -9999 - 9999 - -999 -9999 -9999 -9999 -9999 -9999 -9999 -9999 -9999 -9999 -9999 -9999 -9999 -9999 -9999 -9999 -

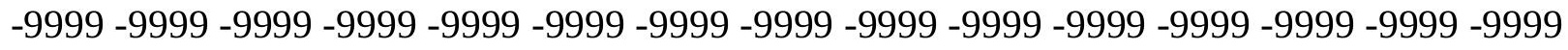

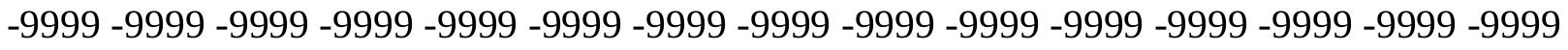
-9999 -9999 -9999 -9999 -9999 -9999 -9999 -9999 -9999 -9999 -9999 -9999 -9999 -9999 -9999 -9999 -9999 -9999 -9999 -9999 -9999 -9999 -9999 -9999-9999 -9999 -9999 -9999 -9999 -9999 -9999 -9999 -9999 -9999 -9999 -9999 -9999 -9999 -9999 -9999 -9999 -9999 -9999 -9999 -9999 -

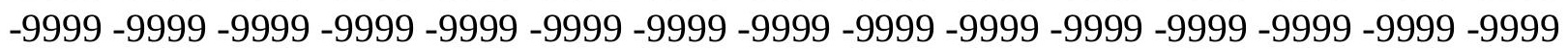


-9999 -9999 -9999 -9999 -9999 -9999 -9999 -9999 -9999 -9999 -9999 -9999 -9999 -9999 -9999 -9999 -9999 -9999 -9999 -9999 -9999 -9999 -9999 -9999 -9999 -9999 -9999 -9999 -9999 -9999 -

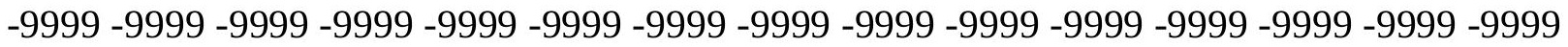
-9999 -9999 -9999 -9999 -9999 -9999 -9999 -9999 -9999 -9999 -9999 -9999 -9999 -9999 -9999 -9999 -9999 -9999 -9999 -9999 -9999 -9999 -9999 -9999-9999 -9999 -9999 -9999 -9999 -9999 -9999 -9999 -9999 -9999 -9999 -9999 -9999 -9999 -9999 -9999 -9999 -9999 -9999 -9999 -9999 -9999 -9999 -9999 -9999 -9999 -9999 -9999 -9999 -9999 -9999 -9999 -9999 -9999 -9999 -9999

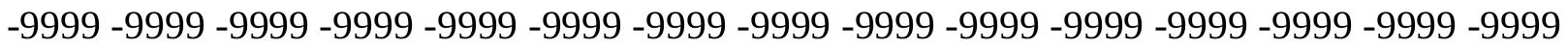

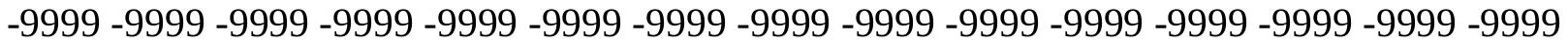
-9999 -9999 -9999 -9999 -9999 -9999 -9999 -9999 -9999 -9999 -9999 -9999 -9999 -9999 -9999 -9999 -9999 -9999 -9999 -9999 -9999 -9999 -9999 -9999 -9999 -9999 -9999 -9999 -9999 -9999 -9999 -9999 -9999 -9999 -9999 -9999 -9999 -9999 -9999 -9999 -9999 -9999 -9999 -9999 -9999 -9999 -9999 -9999 -9999 -9999 -9999 -9999 -9999 -9999 -9999 -9999 -9999 -9999 -9999 -9999 -9999 -9999 -9999 -9999 -9999 -9999 -9999 -9999 -9999 -9999 -9999 -9999 -9999 -9999 -9999 -9999 -9999 -9999 -9999 -9999 -9999 -9999 -9999 -9999 -9999 -9999 -9999 -9999 -9999 -9999 -

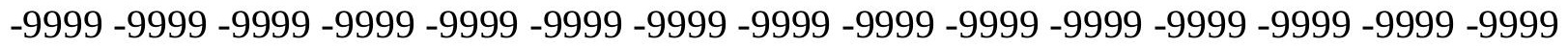
-9999 -9999 -9999 -9999 -9999 -9999 -9999 -9999 -9999 -9999 -9999 -9999 -9999 -9999 -9999 -9999 -9999 -9999 -9999 -9999 -9999 -9999 -9999 -9999 -9999 -9999 -9999 -9999 -9999 -9999 -9999 -9999 -9999 -9999 -9999 -9999 -9999 -9999 -9999 -9999 -9999 -9999 -9999 -9999 -

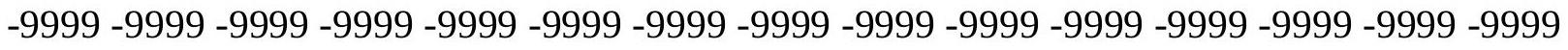
-9999 -9999 -9999 -9999 -9999 -9999 -9999 -9999 -9999 -9999 -9999 -9999 -9999 -9999 -9999 -999 -

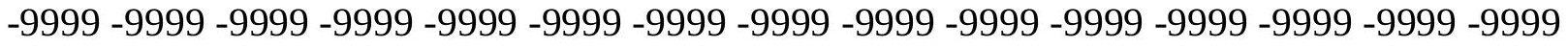
-9999 -9999 -9999 -9999 -9999 -9999 -9999 -9999 -9999 -9999 -9999 -9999 -9999 -9999 -9999 -9999 -9999 -9999 -9999 -9999 -9999 -9999 -9999 -9999 -9999 -9999 -9999 -9999 -9999 -9999 -9999 -9999 -9999 -9999 -9999 -9999 -9999 -9999 -9999 -9999 -9999 -9999 -9999 -9999 -9999 -9999 -9999 -9999 -9999 -9999 -9999 -9999 -9999 -9999 -9999 -9999 -9999 -9999 -9999 -9999 -9999 -9999 -9999 -9999 -9999 -9999 -9999 -9999 -9999 -9999 -9999 -9999 -9999 -9999 -9999 -

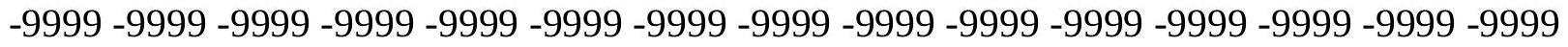
-9999 -9999 -9999 -9999 -9999 -9999 -9999 -9999 -9999 -9999 -9999 -9999 -9999 -9999 -9999 -9999 -9999 -9999 -9999 -9999 -9999 -9999 -9999 -9999 -9999 -9999 -9999 -9999 -9999 -999 -9999 -9999 -9999 -9999 -9999 -9999 -9999 -9999 -9999 -9999 -9999 -9999 -9999 -9999 -9999 -9999 -9999 -9999 -9999 -9999 -9999 -9999 -9999 -9999 -9999 -9999 -9999 -9999 -9999 -9999 -

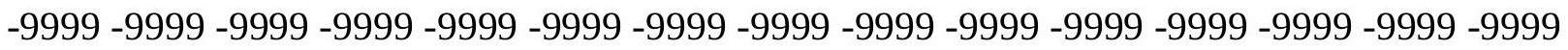

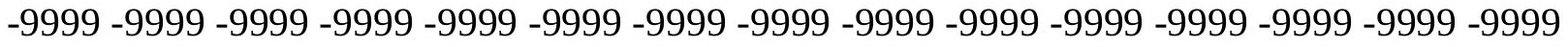

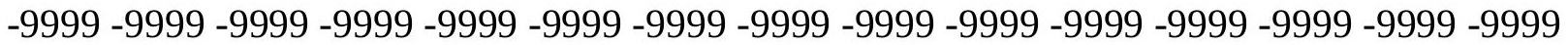
-9999 -9999 -9999 -9999 -9999 -9999 -9999 -9999 -9999 -9999 -9999 -9999 -9999 -9999 -9999

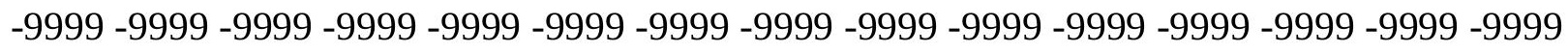

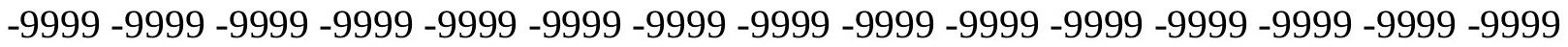
-9999 -9999 -9999 -9999 -9999 -9999 -9999 -9999 -9999 -9999 -9999 -9999 -9999 - 9999 - -999 -9999 -9999 -9999 -9999 -9999 -9999 -9999 -9999 -9999 -9999 -9999 -9999 -9999 -9999 -9999 -

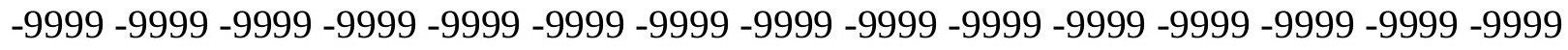

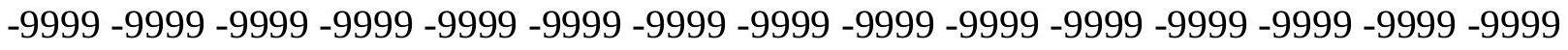
-9999 -9999 -9999 -9999 -9999 -9999 -9999 -9999 -9999 -9999 -9999 -9999 -9999 -9999 -9999 -9999 -9999 -9999 -9999 -9999 -9999 -9999 -9999 -9999 -9999 -9999 -9999 -9999 -9999 -9999 -9999 -9999 -9999 -9999 -9999 -9999 -9999 -9999 -9999 -9999 -9999 -9999 -9999 -9999 -

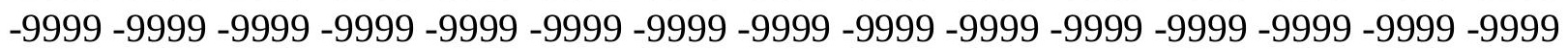


-9999 -9999 -9999 -9999 -9999 -9999 -9999 -9999 -9999 -9999 -9999 -9999 -9999 -9999 -9999 -9999 -9999 -9999 -9999 -9999 -9999 -9999 -9999 -9999 -9999 -9999 -9999 -9999 -9999 -9999 -9999 -9999 -9999 -9999 -9999 -9999 -9999 -9999 -9999 -9999 -9999 -9999 -9999 -9999 - 9999 -9999 -9999 -9999 -9999 -9999 -9999 -9999 -9999 -9999 -9999 -9999 -9999 -9999 -9999 -9999 -9999 -9999 -9999 -9999 -9999 -9999 -9999 -9999 -9999-9999 -9999 -9999 -9999 -9999 -9999 -9999 -9999 -9999 -9999 -9999 -9999 -9999 -9999 -9999 -9999 -9999 -9999 -9999 -9999 -9999 -9999 -9999 -9999 -9999 -9999 -9999 -9999 -9999 -9999 -9999 -9999 -9999 -9999 -9999 -9999

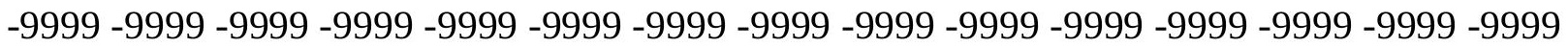

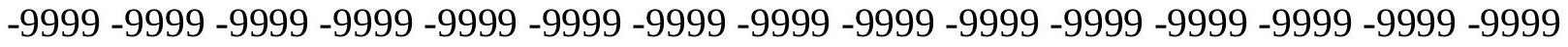
-9999 -9999 -9999 -9999 -9999 -9999 -9999 -9999 -9999 -9999 -9999 -9999 -9999 -9999 -9999 -9999 -9999 -9999 -9999 -9999 -9999 -9999 -9999 -9999 -9999 -9999 -9999 -9999 -9999 -9999 -9999 -9999 -9999 -9999 -9999 -9999 -9999 -9999 -9999 -9999 -9999 -9999 -9999 -9999 -9999 -9999 -9999 -9999 -9999 -9999 -9999 -9999 -9999 -9999 -9999 -9999 -9999 -9999 -9999 -9999 -

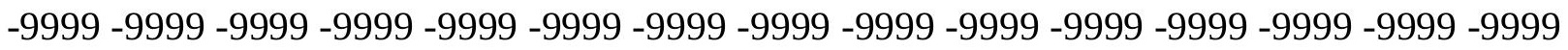
-9999 -9999 -9999 -9999 -9999 -9999 -9999 -9999 -9999 -9999 -9999 -9999 -9999 -9999 -9999 -

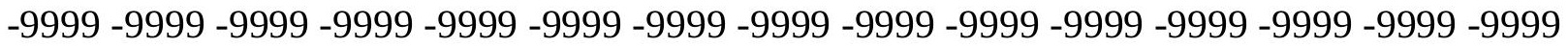
-9999 -9999 -9999 -9999 -9999 -9999 -9999 -9999 -9999 -9999 -9999 -9999 -9999 -9999 -9999 -9999 -9999 -9999 -9999 -9999 -9999 -9999 -9999 -9999 -9999 -9999 -9999 -9999 -9999 -9999 -9999 -9999 -9999 -9999 -9999 -9999 -9999 -9999 -9999 -9999 -9999 -9999 -9999 -9999 -9999 -

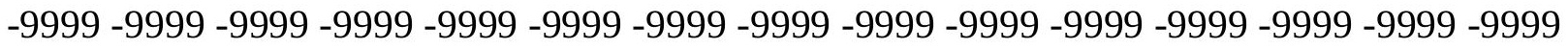
-9999 -9999 -9999 -9999 -9999 -9999 -9999 -9999 -9999 -9999 -9999 -9999 -9999 -9999 -9999 -999 -9999 -9999 -9999 -9999 -9999 -9999 -9999 -9999 -9999 -9999 -9999 -9999 -9999 -9999 - 9999 -9999 -9999 -9999 -9999 -9999 -9999 -9999 -9999 -9999 -9999 -9999 -9999 -9999 -9999 -

-9999 -9999 -9999 -9999 -9999 -9999 -9999 -9999 -9999 -9999 -9999 -9999 -9999 -9999 -9999 -

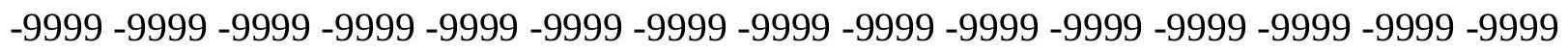
-9999 -9999 -9999 -9999 -9999 -9999 -9999 -9999 -9999 -9999 -9999 -9999 -9999 -9999 -9999 -9999 -9999 -9999 -9999 -9999 -9999 -9999 -9999 -9999 -9999 -9999 -9999 -9999 -9999 -9999 -

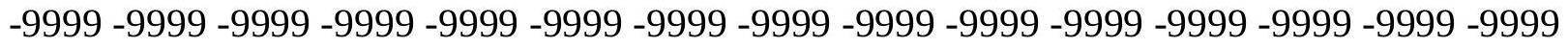
-9999 -9999 -9999 -9999 -9999 -9999 -9999 -9999 -9999 -9999 -9999 -9999 -9999 -9999 -9999 -9999 -9999 -9999 -9999 -9999 -9999 -9999 -9999 -9999 -9999 -9999 -9999 -9999 -9999 -999 -

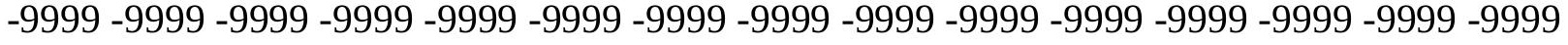
-9999 -9999 -9999 -9999 -9999 -9999 -9999 -9999 -9999 -9999 -9999 -9999 -9999 -9999 -9999 -

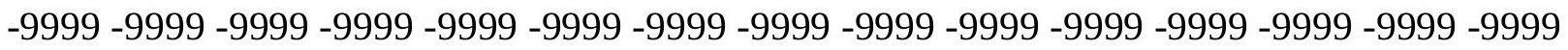

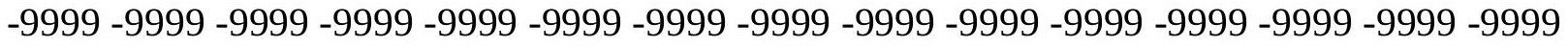

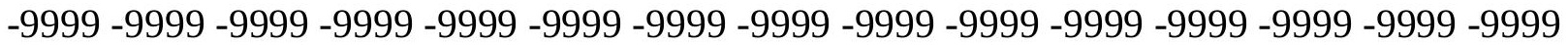

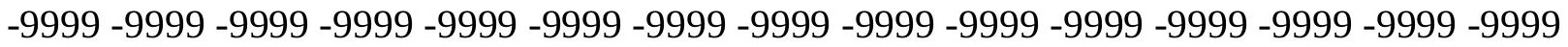

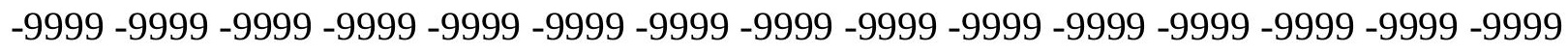

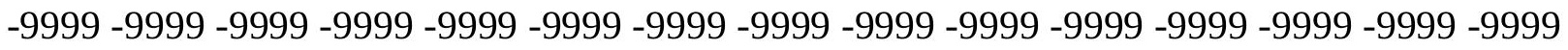

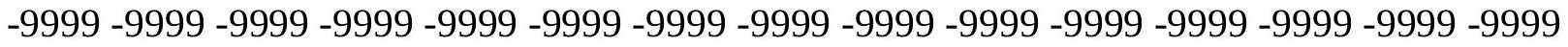
-9999 -9999 -9999 -9999 -9999 -9999 -9999 -9999 -9999 -9999 -9999 -9999 -9999 -9999 -9999 -

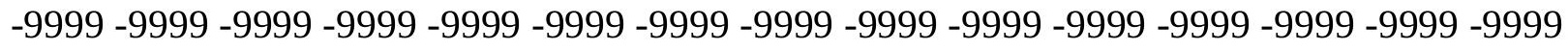

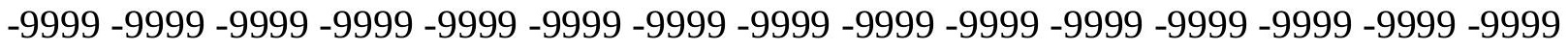
-9999 -9999 -9999 -9999 -9999 -9999 -9999 -9999 -9999 -9999 -9999 -9999 -9999 -9999 -9999 -9999 -9999 -9999 -9999 -9999 -9999 -9999 -9999 -9999-9999 -9999 -9999 -9999 -9999 -9999 -9999 -9999 -9999 -9999 -9999 -9999 -9999 -9999 -9999 -9999 -9999 -9999 -9999 -9999 -9999 -

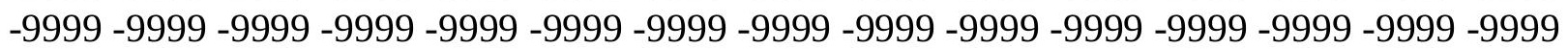


-9999 -9999 -9999 -9999 -9999 -9999 -9999 -9999 -9999 -9999 -9999 -9999 -9999 -9999 -9999 -9999 -9999 -9999 -9999 -9999 -9999 -9999 -9999 -9999 -9999 -9999 -9999 -9999 -9999 -9999 -9999 -9999 -9999 -9999 -9999 -9999 -9999 -9999 -9999 -9999 -9999 -9999 -9999 -9999 -9999 -9999 -9999 -9999 -9999 -9999 -9999 -9999 -9999 -9999 -9999 -9999 -9999 -9999 -9999 -9999 -9999 -9999 -9999 -9999 -9999 -9999 -9999 -9999-9999 -9999 -9999 -9999 -9999 -9999 -9999 -9999 -9999 -9999 -9999 -9999 -9999 -9999 -9999 -9999 -9999 -9999 -9999 -9999 -9999 -9999 -9999 -9999 -9999 -9999 -9999 -9999 -9999 -9999 -9999 -9999 -9999 -9999 -9999 -9999

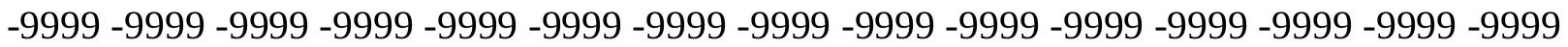

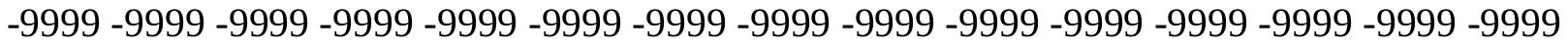
-9999 -9999 -9999 -9999 -9999 -9999 -9999 -9999 -9999 -9999 -9999 -9999 -9999 -9999 -9999 -9999 -9999 -9999 -9999 -9999 -9999 -9999 -9999 -9999 -9999 -9999 -9999 -9999 -9999 -9999 -9999 -9999 -9999 -9999 -9999 -9999 -9999 -9999 -9999 -9999 -9999 -9999 -9999 -9999 -9999 -9999 -9999 -9999 -9999 -9999 -9999 -9999 -9999 -9999 -9999 -9999 -9999 -9999 -9999 -9999 -

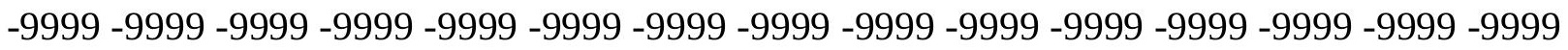
-9999 -9999 -9999 -9999 -9999 -9999 -9999 -9999 -9999 -9999 -9999 -9999 -9999 -9999 -9999 -

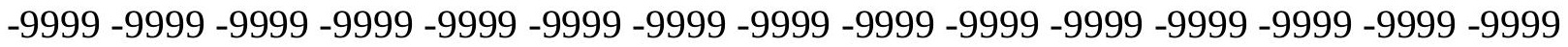
-9999 -9999 -9999 -9999 -9999 -9999 -9999 -9999 -9999 -9999 -9999 -9999 -9999 -9999 -9999 -9999 -9999 -9999 -9999 -9999 -9999 -9999 -9999 -9999 -9999 -9999 -9999 -9999 -9999 -9999 -9999 -9999 -9999 -9999 -9999 -9999 -9999 -9999 -9999 -9999 -9999 -9999 -9999 -9999 -9999 -

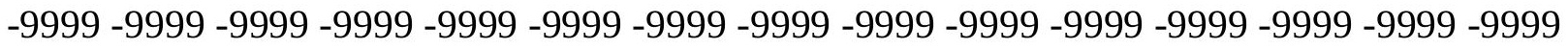

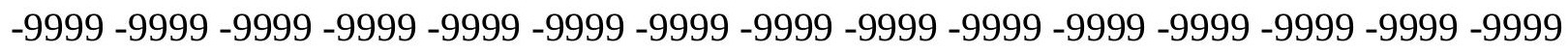
-9999 -9999 -9999 -9999 -9999 -9999 -9999 -9999 -9999 -9999 -9999 -9999 -9999 -9999 -9999 -9999 -9999 -9999 -9999 -9999 -9999 -9999 -9999 -9999 -9999 -9999 -9999 -9999 -9999 -9999 -9999 -9999 -9999 -9999 -9999 -9999 -9999 -9999 -9999 -9999 -9999 -9999 -9999 -9999 -9999 -

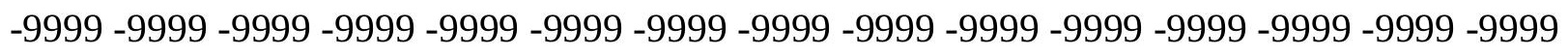
-9999 -9999 -9999 -9999 -9999 -9999 -9999 -9999 -9999 -9999 -9999 -9999 -9999 -9999 -9999 -9999 -9999 -9999 -9999 -9999 -9999 -9999 -9999 -9999 -9999 -9999 -9999 -9999 -9999 -9999 -

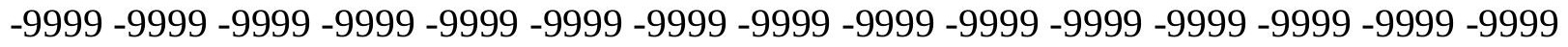
-9999 -9999 -9999 -9999 -9999 -9999 -9999 -9999 -9999 -9999 -9999 -9999 -9999 -9999 -9999 -9999 -9999 -9999 -9999 -9999 -9999 -9999 -9999 -9999 -9999 -9999 -9999 -9999 - -999 -

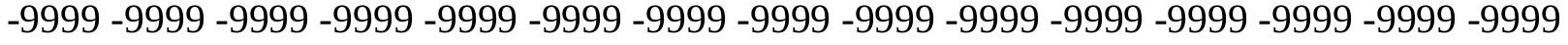
-9999 -9999 -9999 -9999 -9999 -9999 -9999 -9999 -9999 -9999 -9999 -9999 -9999 -9999 -9999 -

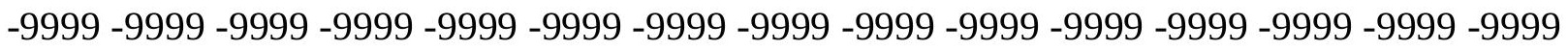

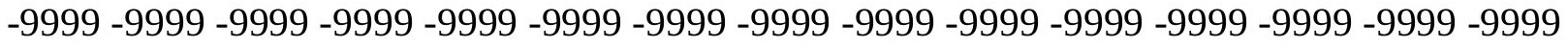

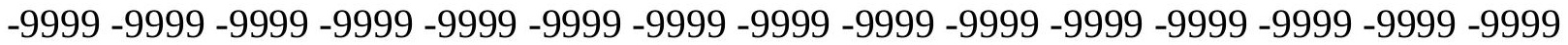

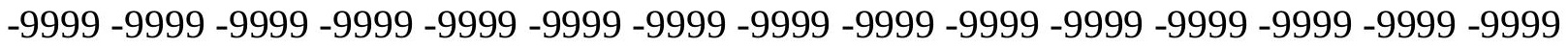

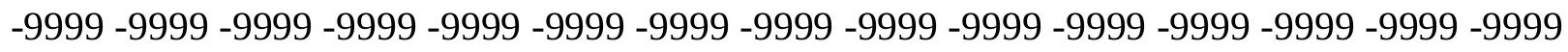

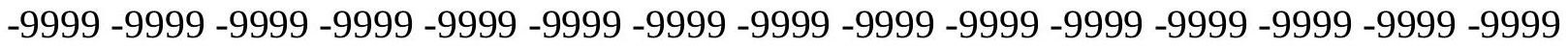

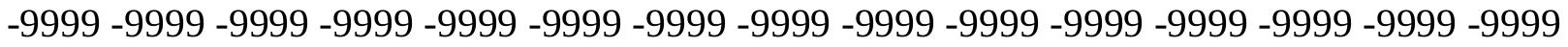
-9999 -9999 -9999 -9999 -9999 -9999 -9999 -9999 -9999 -9999 -9999 -9999 -9999 -9999 -9999 -

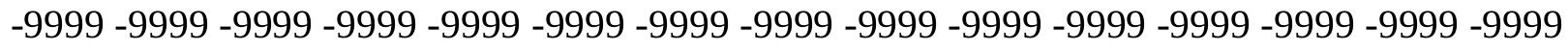

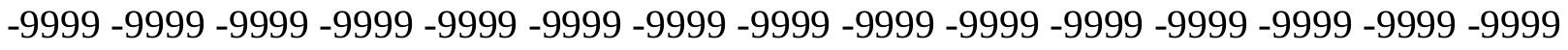
-9999 -9999 -9999 -9999 -9999 -9999 -9999 -9999 -9999 -9999 -9999 -9999 -9999 -9999 -9999 -9999 -9999 -9999 -9999 -9999 -9999 -9999 -9999 -9999-9999 -9999 -9999 -9999 -9999 -9999 -9999 -9999 -9999 -9999 -9999 -9999 -9999 -9999 -9999 -9999 -9999 -9999 -9999 -9999 -9999 -

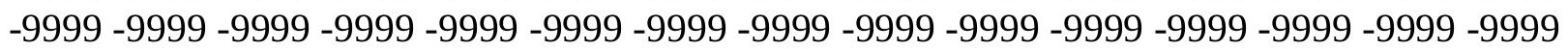


-9999 -9999 -9999 -9999 -9999 -9999 -9999 -9999 -9999 -9999 -9999 -9999 -9999 -9999 -9999 -9999 -9999 -9999 -9999 -9999 -9999 -9999 -9999 -9999 -9999 -9999 -9999 -9999 -9999 -9999 -

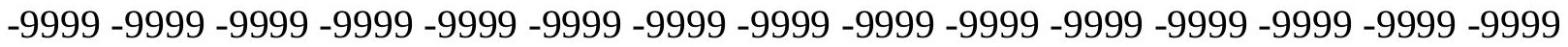
-9999 -9999 -9999 -9999 -9999 -9999 -9999 -9999 -9999 -9999 -9999 -9999 -9999 -9999 -9999 -9999 -9999 -9999 -9999 -9999 -9999 -9999 -9999 -9999-9999 -9999 -9999 -9999 -9999 -9999 -9999 -9999 -9999 -9999 -9999 -9999 -9999 -9999 -9999 -9999 -9999 -9999 -9999 -9999 -9999 -9999 -9999 -9999 -9999 -9999 -9999 -9999 -9999 -9999 -9999 -9999 -9999 -9999 -9999 -9999

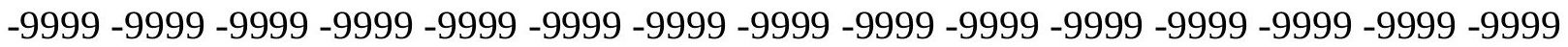
-9999 -9999 -9999 -9999 -9999 -9999 -9999 -9999 -9999 -9999 -9999 -9999 -9999 -9999 -9999 -9999 -9999 -9999 -9999 -9999 -9999 -9999 -9999 -9999 -9999 -9999 -9999 -9999 -9999

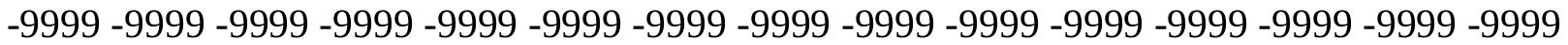
-9999 -9999 -9999 -9999 -9999 -9999 -9999 -9999 -9999 -9999 -9999 -9999 -9999 -9999 -9999 -9999 -9999 -9999 -9999 -9999 -9999 -9999 -9999 -9999 -9999 -9999 -9999 -9999 -9999 -9999 -9999 -9999 -9999 -9999 -9999 -9999 -9999 -9999 -9999 -9999 -9999 -9999 -9999 -9999 - 9999 -9999 -9999 -9999 -9999 -9999 -9999 -9999 -9999 -9999 -9999 -9999 -9999 -9999 -9999 -9999

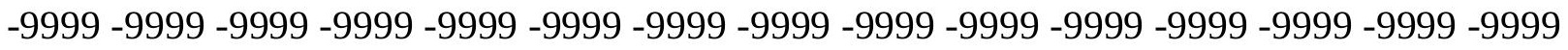
-9999 -9999 -9999 -9999 -9999 -9999 -9999 -9999 -9999 -9999 -9999 -9999 -9999 -9999 -9999 -9999 -9999 -9999 -9999 -9999 -9999 -9999 -9999 -9999 -9999 -9999 -9999 -9999 -9999 -9999 -9999 -9999 -9999 -9999 -9999 -9999 -9999 -9999 -9999 -9999 -9999 -9999 -9999 -9999 -9999 -

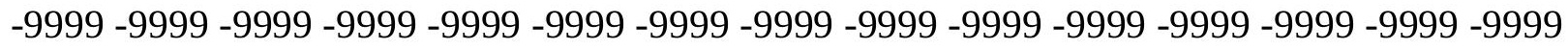

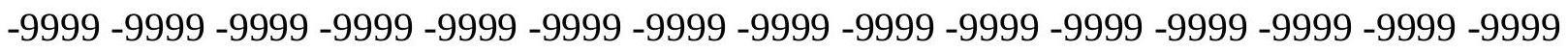
-9999 -9999 -9999 -9999 -9999 -9999 -9999 -9999 -9999 -9999 -9999 -9999 -9999 -9999 -9999 -9999 -9999 -9999 -9999 -9999 -9999 -9999 -9999 -9999 -9999 -9999 -9999 -9999 -9999 -9999 -9999 -9999 -9999 -9999 -9999 -9999 -9999 -9999 -9999 -9999 -9999 -9999 -9999 -9999 -9999 -

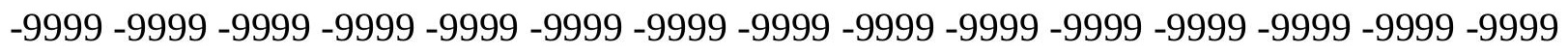
-9999 -9999 -9999 -9999 -9999 -9999 -9999 -9999 -9999 -9999 -9999 -9999 -9999 -9999 -9999 -9999 -9999 -9999 -9999 -9999 -9999 -9999 -9999 -9999 -9999 -9999 -9999 -9999 -9999 -9999 -

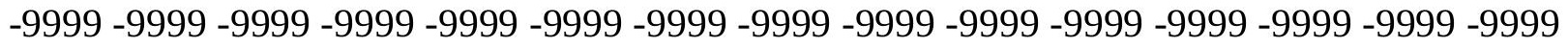
-9999 -9999 -9999 -9999 -9999 -9999 -9999 -9999 -9999 -9999 -9999 -9999 -9999 -9999 -9999 -9999 -9999 -9999 -9999 -9999 -9999 -9999 -9999 -9999 -9999 -9999 -9999 -9999 -9999 -999 -9999 -9999 -9999 -9999 -9999 -9999 -9999 -9999 -9999 -9999 -9999 -9999 -9999 -9999 -9999 -9999 -9999 -9999 -9999 -9999 -9999 -9999 -9999 -9999 -9999 -9999 -9999 -9999 -9999 -9999 -

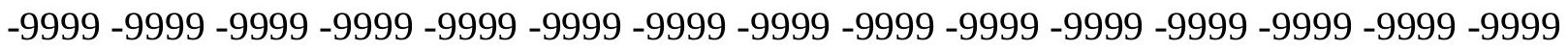

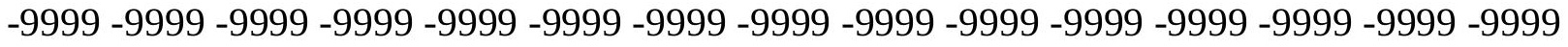
-9999 -9999 -9999 -9999 -9999 -9999 -9999 -9999 -9999 -9999 -9999 -9999 -9999 -9999 -

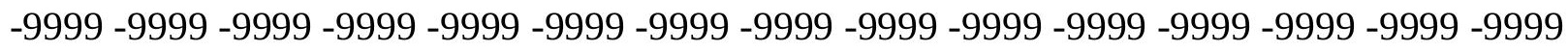

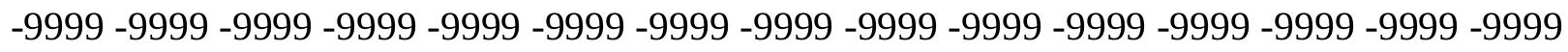

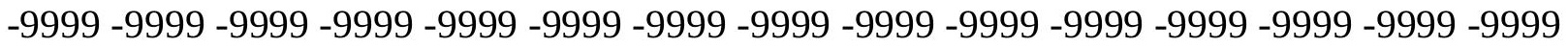
-9999 -9999 -9999 -9999 -9999 -9999 -9999 -9999 -9999 -9999 -9999 -9999 -9999 - 9999 - -999 -9999 -9999 -9999 -9999 -9999 -9999 -9999 -9999 -9999 -9999 -9999 -9999 -9999 -9999 -9999 -

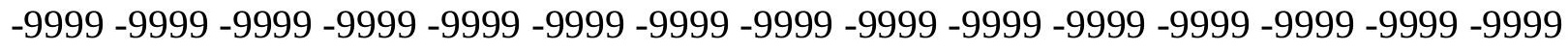

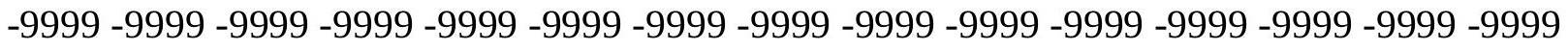
-9999 -9999 -9999 -9999 -9999 -9999 -9999 -9999 -9999 -9999 -9999 -9999 -9999 -9999 -9999 -9999 -9999 -9999 -9999 -9999 -9999 -9999 -9999 -9999-9999 -9999 -9999 -9999 -9999 -9999 -9999 -9999 -9999 -9999 -9999 -9999 -9999 -9999 -9999 -9999 -9999 -9999 -9999 -9999 -9999 -

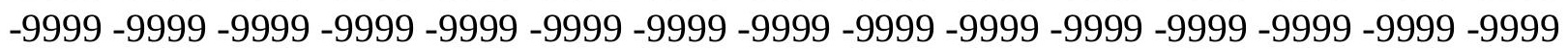


-9999 -9999 -9999 -9999 -9999 -9999 -9999 -9999 -9999 -9999 -9999 -9999 -9999 -9999 -9999 -9999 -9999 -9999 -9999 -9999 -9999 -9999 -9999 -9999 -9999 -9999 -9999 -9999 -9999 -9999 -

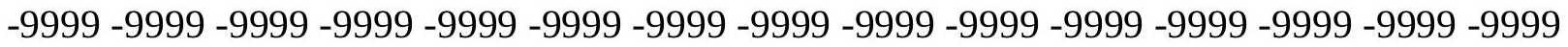
-9999 -9999 -9999 -9999 -9999 -9999 -9999 -9999 -9999 -9999 -9999 -9999 -9999 -9999 -9999 -9999 -9999 -9999 -9999 -9999 -9999 -9999 -9999 -9999-9999 -9999 -9999 -9999 -9999 -9999 -9999 -9999 -9999 -9999 -9999 -9999 -9999 -9999 -9999 -9999 -9999 -9999 -9999 -9999 -9999 -9999 -9999 -9999 -9999 -9999 -9999 -9999 -9999 -9999 -9999 -9999 -9999 -9999 -9999 -9999

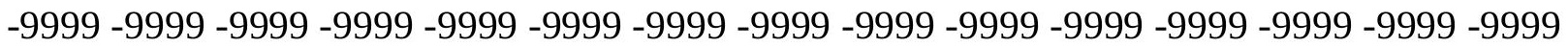

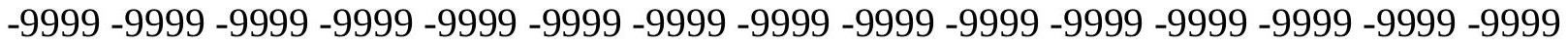
-9999 -9999 -9999 -9999 -9999 -9999 -9999 -9999 -9999 -9999 -9999 -9999 -9999 -9999 -9999 -9999 -9999 -9999 -9999 -9999 -9999 -9999 -9999 -9999 -9999 -9999 -9999 -9999 -9999 -9999 -9999 -9999 -9999 -9999 -9999 -9999 -9999 -9999 -9999 -9999 -9999 -9999 -9999 -9999 -9999 -9999 -9999 -9999 -9999 -9999 -9999 -9999 -9999 -9999 -9999 -9999 -9999 -9999 -9999 -9999 -9999 -9999 -9999 -9999 -9999 -9999 -9999 -9999 -9999 -9999 -9999 -9999 -9999 -9999 -9999 -9999 -9999 -9999 -9999 -9999 -9999 -9999 -9999 -9999 -9999 -9999 -9999 -9999 -9999 -9999 -9999 -9999 -9999 -9999 -9999 -9999 -9999 -9999 -9999 -9999 -9999 -9999 - 9999 - -999 -

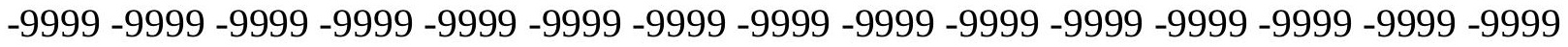
-9999 -9999 -9999 -9999 -9999 -9999 -9999 -9999 -9999 -9999 -9999 -9999 -9999 -9999 -9999 -9999 -9999 -9999 -9999 -9999 -9999 -9999 -9999 -9999 -9999 -9999 -9999 -9999 -9999 -9999 -

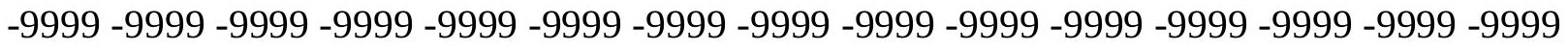
-9999 -9999 -9999 -9999 -9999 -9999 -9999 -9999 -9999 -9999 -9999 -9999 -9999 -9999 -9999

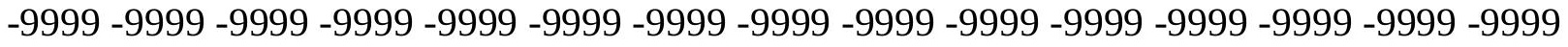
-9999 -9999 -9999 -9999 -9999 -9999 -9999 -9999 -9999 -9999 -9999 -9999 -9999 -9999 -9999 -9999 -9999 -9999 -9999 -9999 -9999 -9999 -9999 -9999 -9999 -9999 -9999 -9999 -9999 -9999 -

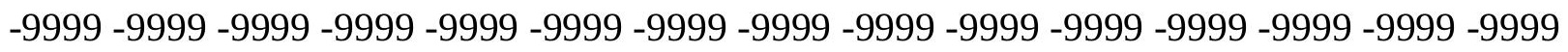
-9999 -9999 -9999 -9999 -9999 -9999 -9999 -9999 -9999 -9999 -9999 -9999 -9999 -9999 -9999 -9999 -9999 -9999 -9999 -9999 -9999 -9999 -9999 -9999 -9999 -9999 -9999 -9999 -9999 -9999 -

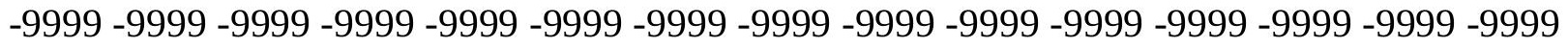
-9999 -9999 -9999 -9999 -9999 -9999 -9999 -9999 -9999 -9999 -9999 -9999 -9999 -9999 -9999 -9999 -9999 -9999 -9999 -9999 -9999 -9999 -9999 -9999 -9999 -9999 -9999 -9999 -9999 -999 -

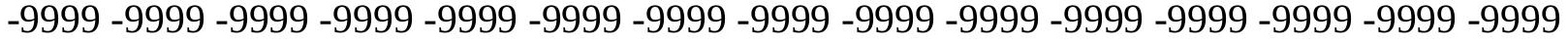
-9999 -9999 -9999 -9999 -9999 -9999 -9999 -9999 -9999 -9999 -9999 -9999 -9999 -9999 -9999 -

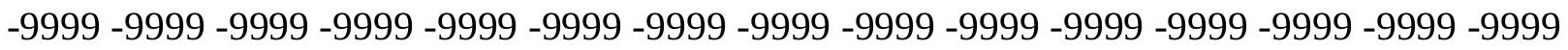

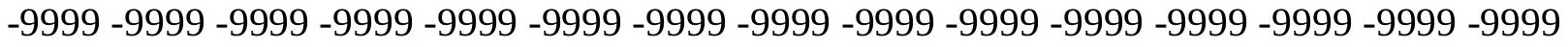

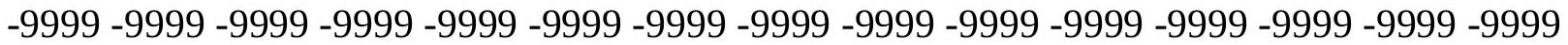
-9999 -9999 -9999 -9999 -9999 -9999 -9999 -9999 -9999 -9999 -9999 -9999 -9999 -9999 -9999 -

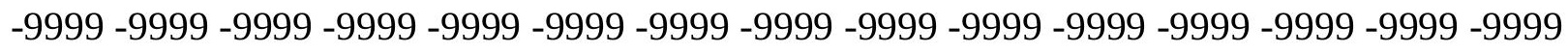

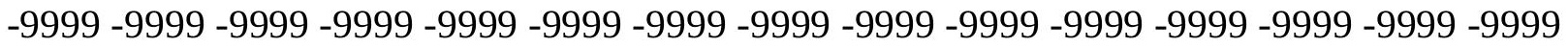
-9999 -9999 -9999 -9999 -9999 -9999 -9999 -9999 -9999 -9999 -9999 -9999 -9999 - 9999 - -999 -9999 -9999 -9999 -9999 -9999 -9999 -9999 -9999 -9999 -9999 -9999 -9999 -9999 -9999 -9999 -

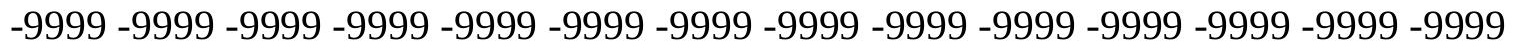

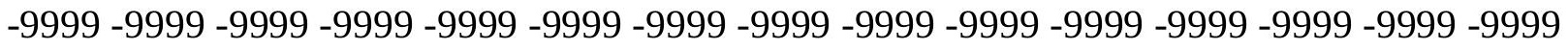
-9999 -9999 -9999 -9999 -9999 -9999 -9999 -9999 -9999 -9999 -9999 -9999 -9999 -9999 -9999 -9999 -9999 -9999 -9999 -9999 -9999 -9999 -9999 -9999-9999 -9999 -9999 -9999 -9999 -9999 -9999 -9999 -9999 -9999 -9999 -9999 -9999 -9999 -9999 -9999 -9999 -9999 -9999 -9999 -9999 -

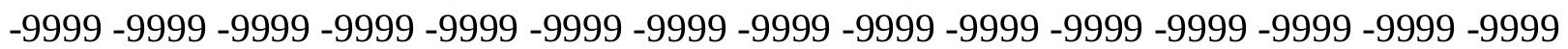


-9999 -9999 -9999 -9999 -9999 -9999 -9999 -9999 -9999 -9999 -9999 -9999 -9999 -9999 -9999 -9999 -9999 -9999 -9999 -9999 -9999 -9999 -9999 -9999 -9999 -9999 -9999 -9999 -9999 -9999 -9999 -9999 -9999 -9999 -9999 -9999 -9999 -9999 -9999 -9999 -9999 -9999 -9999 -9999 - 9999 -9999 -9999 -9999 -9999 -9999 -9999 -9999 -9999 -9999 -9999 -9999 -9999 -9999 -9999 -9999 -9999 -9999 -9999 -9999 -9999 -9999 -9999 -9999 -9999-9999 -9999 -9999 -9999 -9999 -9999 -9999 -9999 -9999 -9999 -9999 -9999 -9999 -9999 -9999 -9999 -9999 -9999 -9999 -9999 -9999 -9999 -9999 -9999 -9999 -9999 -9999 -9999 -9999 -9999 -9999 -9999 -9999 -9999 -9999 -9999

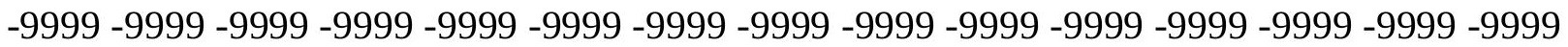
-9999 -9999 -9999 -9999 -9999 -9999 -9999 -9999 -9999 -9999 -9999 -9999 -9999 -9999 -9999 -9999 -9999 -9999 -9999 -9999 -9999 -9999 -9999 -9999 -9999 -9999 -9999 -9999 -9999 -9999

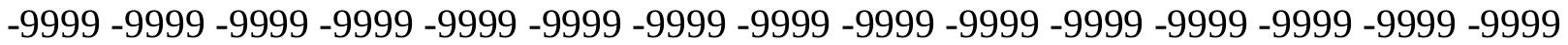
-9999 -9999 -9999 -9999 -9999 -9999 -9999 -9999 -9999 -9999 -9999 -9999 -9999 -9999 -9999 -9999 -9999 -9999 -9999 -9999 -9999 -9999 -9999 -9999 -9999 -9999 -9999 -9999 -9999 -9999 -

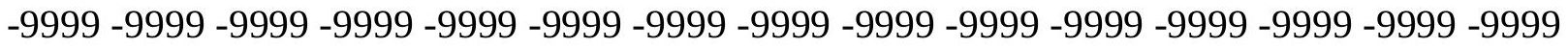
-9999 -9999 -9999 -9999 -9999 -9999 -9999 -9999 -9999 -9999 -9999 -9999 -9999 -9999 -9999

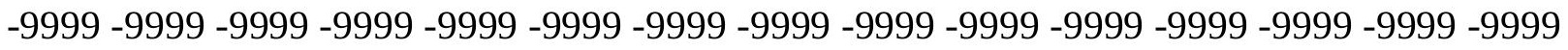
-9999 -9999 -9999 -9999 -9999 -9999 -9999 -9999 -9999 -9999 -9999 -9999 -9999 -9999 -9999 -9999 -9999 -9999 -9999 -9999 -9999 -9999 -9999 -9999 -9999 -9999 -9999 -9999 -9999 - 9999 -9999 -9999 -9999 -9999 -9999 -9999 -9999 -9999 -9999 -9999 -9999 -9999 -9999 -9999 -9999 -9999 -9999 -9999 -9999 -9999 -9999 -9999 -9999 -9999 -9999 -9999 -9999 -9999 -9999 -9999 -9999 -9999 -9999 -9999 -9999 -9999 -9999 -9999 -9999 -9999 -9999 -9999 -9999 -9999 -9999 -9999 -9999 -9999 -9999 -9999 -9999 -9999 -9999 -9999 -9999 -9999 -9999 -9999 -9999 -9999 -9999 -9999 -9999 -9999 -9999 -9999 -9999 -9999 -9999 -9999 -9999 -9999 -9999 -9999 -9999 -9999 -9999 -9999 -9999 -9999 -9999 -9999 -9999 -9999 -9999 -9999 -9999 -9999 -9999 -9999 -9999 -9999 -9999 -9999 -9999 -9999 -9999 -9999 -9999 -9999 -9999 -9999 -9999 -9999 -9999 -9999 -9999 -9999 -9999 -9999 -9999 -9999 -9999 -9999 -9999 -9999 -9999 -9999 -9999 -9999 -9999 -9999 -9999 -9999 -9999 -9999 -9999 -9999 -9999 -9999 -9999 -9999 -9999 -9999 -9999 -9999 -9999 -9999 -9999 -9999 -9999 -9999 -9999 -9999 -9999 -9999 -9999 -9999 -9999 -9999 -9999 -9999 -9999 -9999 -9999 -9999 -9999 -9999 -9999 -9999 -9999 -9999 -9999 -9999 -9999 -9999 -9999 -9999 -9999 -9999 -9999 -9999 -9999 -9999 -9999 -9999 -9999 -9999 -999 -9999 -9999 -9999 -9999 -9999 -9999 -9999 -9999 -9999 -9999 -9999 -9999 -9999 -9999 -9999 -9999 -9999 -9999 -9999 -9999 -9999 -9999 -9999 -9999 -9999 -9999 -9999 -9999 -9999 -9999 -

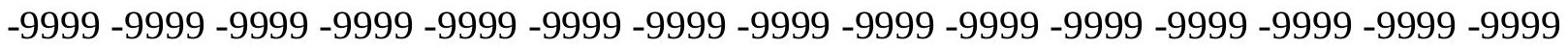

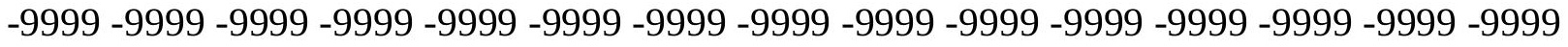

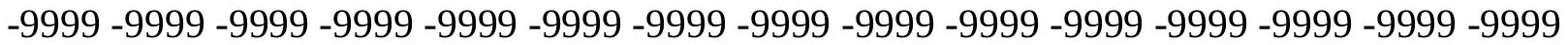
-9999 -9999 -9999 -9999 -9999 -9999 -9999 -9999 -9999 -9999 -9999 -9999 -9999 -9999 -9999

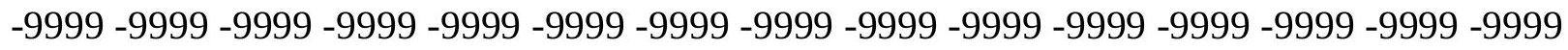

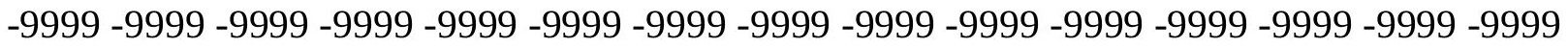

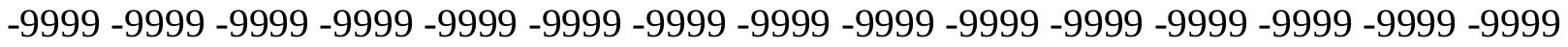
-9999 -9999 -9999 -9999 -9999 -9999 -9999 -9999 -9999 -9999 -9999 -9999 -9999 -9999 -9999 -

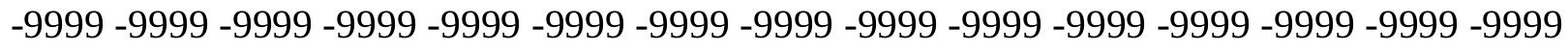

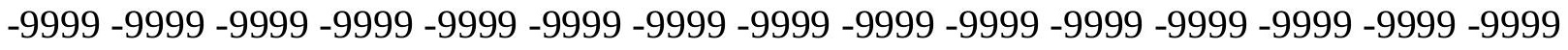
-9999 -9999 -9999 -9999 -9999 -9999 -9999 -9999 -9999 -9999 -9999 -9999 -9999 -9999 -9999 -9999 -9999 -9999 -9999 -9999 -9999 -9999 -9999 -9999-9999 -9999 -9999 -9999 -9999 -9999 -9999 -9999 -9999 -9999 -9999 -9999 -9999 -9999 -9999 -9999 -9999 -9999 -9999 -9999 -9999 -

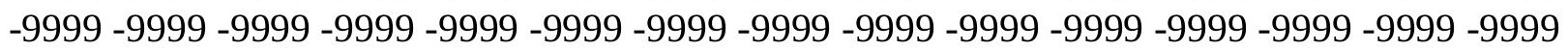


-9999 -9999 -9999 -9999 -9999 -9999 -9999 -9999 -9999 -9999 -9999 -9999 -9999 -9999 
u6top_elev 


$\begin{array}{ll}\text { ncols } & 389 \\ \text { nrows } & 437 \\ \text { xllcorner } & 545925 \\ \text { yllcorner } & 100925 \\ \text { cellsize } & 150\end{array}$

NODATA_value -9999

-9999 -9999 -9999 -9999 -9999 -9999 -9999 -9999 -9999 -9999 -9999 -9999 -9999 -9999 -9999 -9999 -9999 -9999 -9999 -9999 -9999 -9999 -9999 -9999 -9999 -9999 -9999 -9999 -9999 -9999 -999 -9999 -9999 -9999 -9999 -9999 -9999 -9999 -9999 -9999 -9999 -9999 -9999 -9999 -9999 -9999 -9999 -9999 -9999 -9999 -9999 -9999 -9999 -9999 -9999 -9999 -9999 -9999 -9999 -9999 -9999

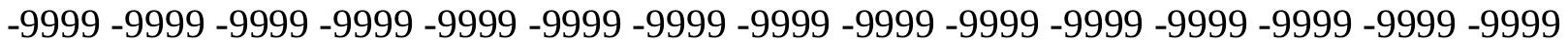
-9999 -9999 -9999 -9999 -9999 -9999 -9999 -9999 -9999 -9999 -9999 -9999 -9999 -9999 -9999 -9999 -9999 -9999 -9999 -9999 -9999 -9999 -9999 -9999 -9999 -9999 -9999 -9999 -9999 -9999 -9999 -9999 -9999 -9999 -9999 -9999 -9999 -9999 -9999 -9999 -9999 -9999 -9999 -9999 - 9999 -9999 -9999 -9999 -9999 -9999 -9999 -9999 -9999 -9999 -9999 -9999 -9999 -9999 -9999 -9999

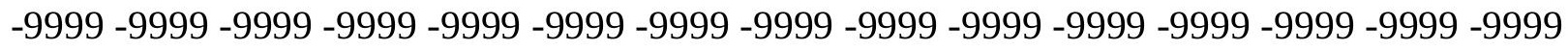
-9999 -9999 -9999 -9999 -9999 -9999 -9999 -9999 -9999 -9999 -9999 -9999 -9999 -9999 -9999 -9999 -9999 -9999 -9999 -9999 -9999 -9999 -9999 -9999 -9999 -9999 -9999 -9999 -9999 -9999 -999 -9999 -9999 -9999 -9999 -9999 -9999 -9999 -9999 -9999 -9999 -9999 -9999 -9999 -9999 -9999 -9999 -9999 -9999 -9999 -9999 -9999 -9999 -9999 -9999 -9999 -9999 -9999 -9999 -9999 -9999 -9999 -9999 -9999 -9999 -9999 -9999 -9999 -9999 -9999 -9999 -9999 -9999 -9999 -9999 -9999 -9999 -9999 -9999 -9999 -9999 -9999 -9999 -9999 -9999 -9999 -9999 -9999 -9999 -9999 -9999 -9999 -9999 -9999 -9999 -9999 -9999 -9999 -9999 -9999 -9999 -9999 -9999 -9999 -9999 -9999 -9999 -9999 -9999 -9999 -9999 -9999 -9999 -9999 -9999 -9999 -9999 -9999 -9999 -9999 -9999 -9999 -9999 -9999 -9999 -9999 -9999 -9999 -9999 -9999 -9999 -9999 -9999 -9999 -9999 -9999 -9999 -9999 -9999 -9999 -9999 -9999 -9999 -9999 -9999 -9999 -9999 -9999 -9999 -9999 -9999 -9999 -9999 -9999 -9999 -9999 -9999 -9999 -9999 -9999 -9999 -9999 -9999 -9999 -9999 -9999 -9999 -9999 -9999 -9999 -9999 -9999 -9999 -9999 -9999 -9999 -9999 -9999 -9999 -9999 -9999 -9999 -9999 -9999 -9999 -9999 -9999 -9999 -9999 -9999 -9999 -9999 -9999 -9999 -9999 -9999 -9999 -9999 -9999 -9999 -9999 -9999 -9999 -9999 -9999 -9999 -9999 -9999 -9999 -9999 -999 -9999 -9999 -9999 -9999 -9999 -9999 -9999 -9999 -9999 -9999 -9999 -9999 -9999 -9999 -9999 -9999 -9999 -9999 -9999 -9999 -9999 -9999 -9999 -9999 -9999 -9999 -9999 -9999 -9999 -

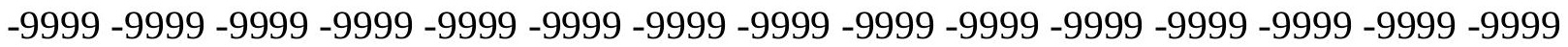
-9999 -9999 -9999 -9999 -9999 -9999 -9999 -9999 -9999 -9999 -9999 -9999 -9999 -9999 -9999 -9999 -9999 -9999 -9999 -9999 -9999 -9999 -9999 -9999 -9999 -9999 -9999 -9999 -9999 -9999 -

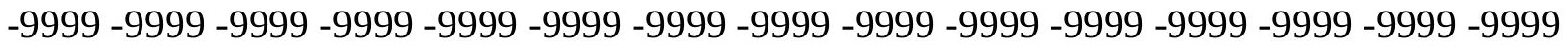

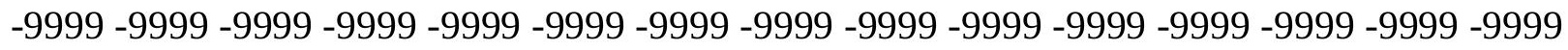
-9999 -9999 -9999 -9999 -9999 -9999 -9999 -9999 -9999 -9999 -9999 -9999 -9999 - 9999 - -9999 -9999 -9999 -9999 -9999 -9999 -9999 -9999 -9999 -9999 -9999 -9999 -9999 -9999 - 9999 - -999 -9999 -9999 -9999 -9999 -9999 -9999 -9999 -9999 -9999 -9999 -9999 -9999 -9999 -9999 -9999 -

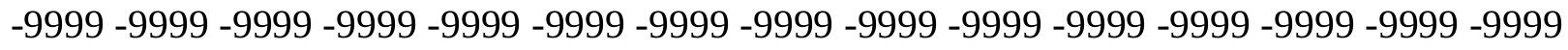

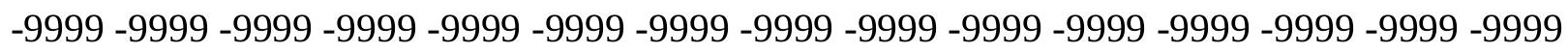
-9999 -9999 -9999 -9999 -9999 -9999 -9999 -9999 -9999 -9999 -9999 -9999 -9999 -9999 -9999 -9999 -9999 -9999 -9999 -9999 -9999 -9999 -9999 -9999-9999 -9999 -9999 -9999 -9999 -9999 -9999 -9999 -9999 -9999 -9999 -9999 -9999 -9999 -9999 -9999 -9999 -9999 -9999 -9999 -9999 -

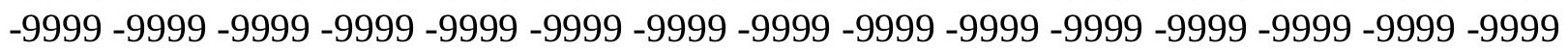


-9999 -9999 -9999 -9999 -9999 -9999 -9999 -9999 -9999 -9999 -9999 -9999 -9999 -9999 -9999 -9999 -9999 -9999 -9999 -9999 -9999 -9999 -9999 -9999 -9999 -9999 -9999 -9999 -9999 -9999 -

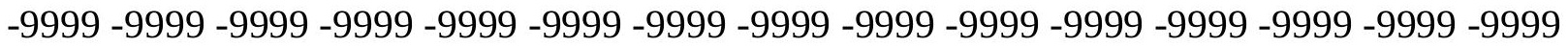
-9999 -9999 -9999 -9999 -9999 -9999 -9999 -9999 -9999 -9999 -9999 -9999 -9999 -9999 -9999 -9999 -9999 -9999 -9999 -9999 -9999 -9999 -9999 -9999-9999 -9999 -9999 -9999 -9999 -9999 -9999 -9999 -9999 -9999 -9999 -9999 -9999 -9999 -9999 -9999 -9999 -9999 -9999 -9999 -9999 -9999 -9999 -9999 -9999 -9999 -9999 -9999 -9999 -9999 -9999 -9999 -9999 -9999 -9999 -9999

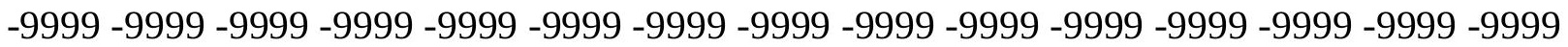

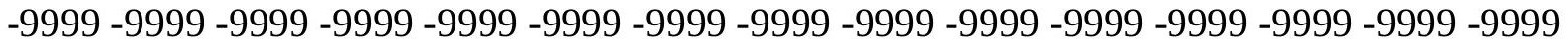
-9999 -9999 -9999 -9999 -9999 -9999 -9999 -9999 -9999 -9999 -9999 -9999 -9999 -9999 -9999 -9999 -9999 -9999 -9999 -9999 -9999 -9999 -9999 -9999 -9999 -9999 -9999 -9999 -9999 -9999 -9999 -9999 -9999 -9999 -9999 -9999 -9999 -9999 -9999 -9999 -9999 -9999 -9999 -9999 -9999 -9999 -9999 -9999 -9999 -9999 -9999 -9999 -9999 -9999 -9999 -9999 -9999 -9999 -9999 -9999 -9999 -9999 -9999 -9999 -9999 -9999 -9999 -9999 -9999 -9999 -9999 -9999 -9999 - 9999 -9999 -9999 -9999 -9999 -9999 -9999 -9999 -9999 -9999 -9999 -9999 -9999 -9999 -9999 -9999

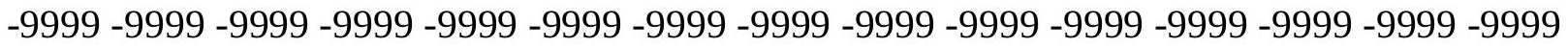
-9999 -9999 -9999 -9999 -9999 -9999 -9999 -9999 -9999 -9999 -9999 -9999 -9999 -9999 -9999 -9999 -9999 -9999 -9999 -9999 -9999 -9999 -9999 -9999 -9999 -9999 -9999 -9999 -9999 -9999 -9999 -9999 -9999 -9999 -9999 -9999 -9999 -9999 -9999 -9999 -9999 -9999 -9999 -9999 -9999 -

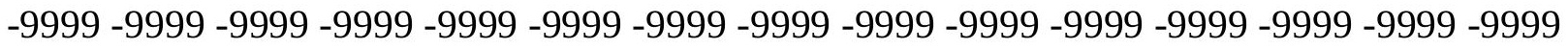

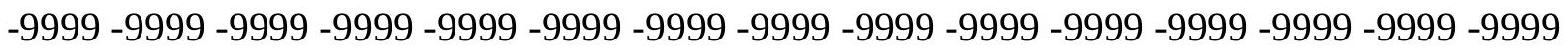
-9999 -9999 -9999 -9999 -9999 -9999 -9999 -9999 -9999 -9999 -9999 -9999 -9999 -9999 -9999 -9999 -9999 -9999 -9999 -9999 -9999 -9999 -9999 -9999 -9999 -9999 -9999 -9999 -9999 -9999 -9999 -9999 -9999 -9999 -9999 -9999 -9999 -9999 -9999 -9999 -9999 -9999 -9999 -9999 -9999 -

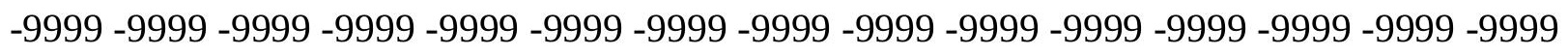
-9999 -9999 -9999 -9999 -9999 -9999 -9999 -9999 -9999 -9999 -9999 -9999 -9999 -9999 -9999 -9999 -9999 -9999 -9999 -9999 -9999 -9999 -9999 -9999 -9999 -9999 -9999 -9999 -9999 -9999 -

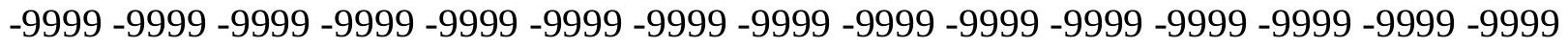
-9999 -9999 -9999 -9999 -9999 -9999 -9999 -9999 -9999 -9999 -9999 -9999 -9999 -9999 -9999 -9999 -9999 -9999 -9999 -9999 -9999 -9999 -9999 -9999 -9999 -9999 -9999 -9999 -9999 -999 -9999 -9999 -9999 -9999 -9999 -9999 -9999 -9999 -9999 -9999 -9999 -9999 -9999 -9999 -9999 -9999 -9999 -9999 -9999 -9999 -9999 -9999 -9999 -9999 -9999 -9999 -9999 -9999 -9999 -9999 -

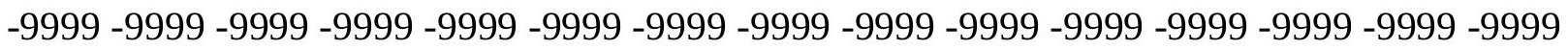

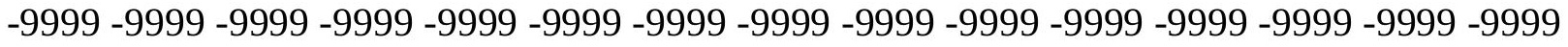

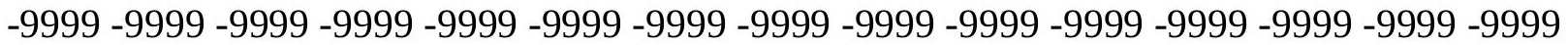

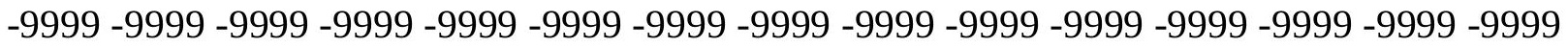

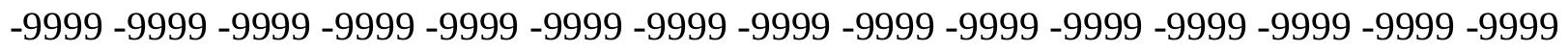

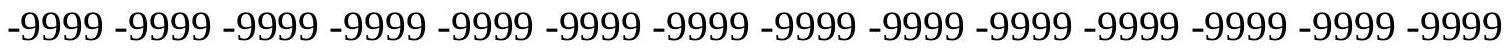
-9999 -9999 -9999 -9999 -9999 -9999 -9999 -9999 -9999 -9999 -9999 -9999 -9999 -9999 -9999 -9999 -9999 -9999 -9999 -9999 -9999 -9999 -9999 -9999 -9999 -9999 -9999 -9999 -9999 -9999 -

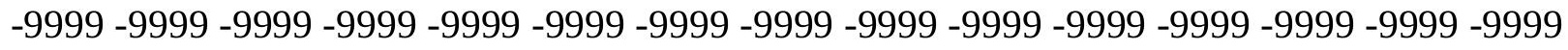

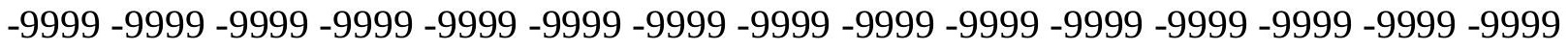
-9999 -9999 -9999 -9999 -9999 -9999 -9999 -9999 -9999 -9999 -9999 -9999 -9999 -9999 -9999 -9999 -9999 -9999 -9999 -9999 -9999 -9999 -9999 -9999-9999 -9999 -9999 -9999 -9999 -9999 -9999 -9999 -9999 -9999 -9999 -9999 -9999 -9999 -9999 -9999 -9999 -9999 -9999 -9999 -9999 -

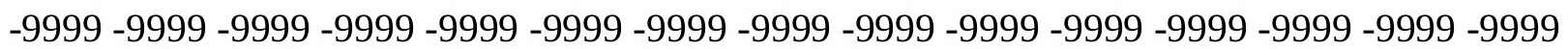


-9999 -9999 -9999 -9999 -9999 -9999 -9999 -9999 -9999 -9999 -9999 -9999 -9999 -9999 -9999 -9999 -9999 -9999 -9999 -9999 -9999 -9999 -9999 -9999 -9999 -9999 -9999 -9999 -9999 -9999 -9999 -9999 -9999 -9999 -9999 -9999 -9999 -9999 -9999 -9999 -9999 -9999 -9999 -9999 - 9999 -9999 -9999 -9999 -9999 -9999 -9999 -9999 -9999 -9999 -9999 -9999 -9999 -9999 -9999 -9999 -9999 -9999 -9999 -9999 -9999 -9999 -9999 -9999 -9999 -9999 -9999 -9999 -9999 -9999 -9999 -9999 -9999 -9999 -9999 -9999 -9999 -9999 -9999 -9999 -9999 -9999 -9999 -9999 -9999 -9999 -9999 -9999 -9999 -9999 -9999 -9999 -9999 -9999 -9999 -9999 -9999 -9999 -9999 -9999 -9999

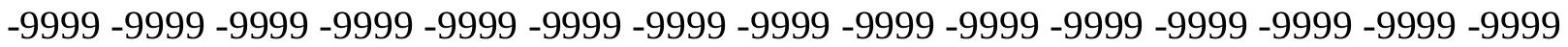
-9999 -9999 -9999 -9999 -9999 -9999 -9999 -9999 -9999 -9999 -9999 -9999 -9999 -9999 -9999 -9999 -9999 -9999 -9999 -9999 -9999 -9999 -9999 -9999 -9999 -9999 -9999 -9999 -9999 -9999

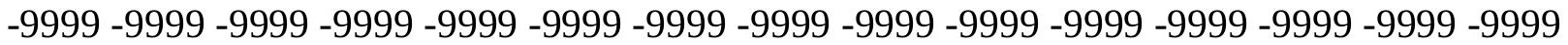
-9999 -9999 -9999 -9999 -9999 -9999 -9999 -9999 -9999 -9999 -9999 -9999 -9999 -9999 -9999 -9999 -9999 -9999 -9999 -9999 -9999 -9999 -9999 -9999 -9999 -9999 -9999 -9999 -9999 -9999 -

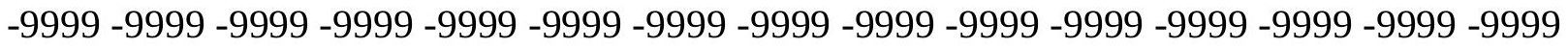
-9999 -9999 -9999 -9999 -9999 -9999 -9999 -9999 -9999 -9999 -9999 -9999 -9999 -9999 -9999

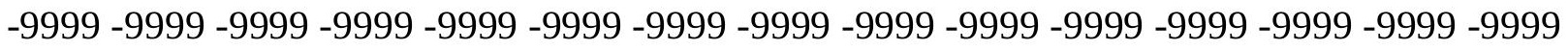
-9999 -9999 -9999 -9999 -9999 -9999 -9999 -9999 -9999 -9999 -9999 -9999 -9999 -9999 -9999 -9999 -9999 -9999 -9999 -9999 -9999 -9999 -9999 -9999 -9999 -9999 -9999 -9999 -9999 - -999 -9999 -9999 -9999 -9999 -9999 -9999 -9999 -9999 -9999 -9999 -9999 -9999 -9999 -9999 -9999 -9999 -9999 -9999 -9999 -9999 -9999 -9999 -9999 -9999 -9999 -9999 -9999 -9999 -9999 -9999 -9999 -9999 -9999 -9999 -9999 -9999 -9999 -9999 -9999 -9999 -9999 -9999 -9999 -9999 -9999 -999 -9999 -9999 -9999 -9999 -9999 -9999 -9999 -9999 -9999 -9999 -9999 -9999 -9999 -9999 -9999 -9999 -9999 -9999 -9999 -9999 -9999 -9999 -9999 -9999 -9999 -9999 -9999 -9999 -9999 -9999 -9999 -9999 -9999 -9999 -9999 -9999 -9999 -9999 -9999 -9999 -9999 -9999 -9999 -9999 -9999 -9999 -9999 -9999 -9999 -9999 -9999 -9999 -9999 -9999 -9999 -9999 -9999 -9999 -9999 -9999 -9999 -9999 -9999 -9999 -9999 -9999 -9999 -9999 -9999 -9999 -9999 -9999 -9999 -9999 -9999 -9999 -9999 -9999 -9999 -9999 -9999 -9999 -9999 -9999 -9999 -9999 -9999 -9999 -9999 -9999 -9999 -9999 -9999 -9999 -9999 -9999 -9999 -9999 -9999 -9999 -9999 -9999 -9999 -9999 -9999 -9999 -9999 -9999 -9999 -9999 -9999 -9999 -9999 -9999 -9999 -9999 -9999 -9999 -9999 -9999 -9999 -9999 -9999 -9999 -9999 -9999 -9999 -9999 -9999 -9999 -9999 -9999 -9999 -9999 -999 -9999 -9999 -9999 -9999 -9999 -9999 -9999 -9999 -9999 -9999 -9999 -9999 -9999 -9999 -9999 -9999 -9999 -9999 -9999 -9999 -9999 -9999 -9999 -9999 -9999 -9999 -9999 -9999 -9999 -9999 -

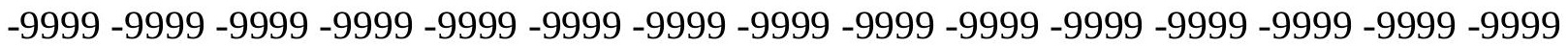

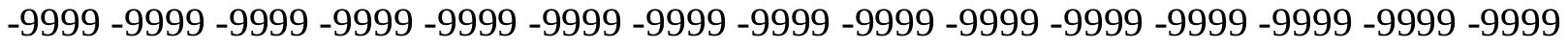

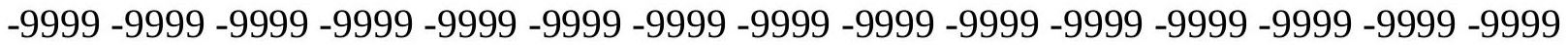
-9999 -9999 -9999 -9999 -9999 -9999 -9999 -9999 -9999 -9999 -9999 -9999 -9999 -9999 -9999

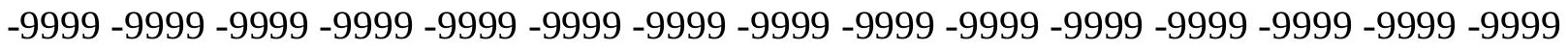

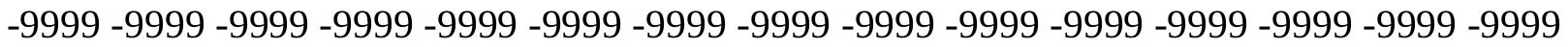

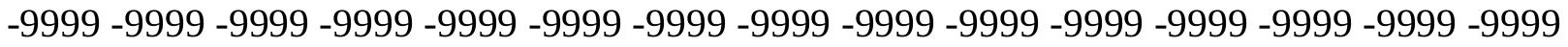
-9999 -9999 -9999 -9999 -9999 -9999 -9999 -9999 -9999 -9999 -9999 -9999 -9999 -9999 -9999 -

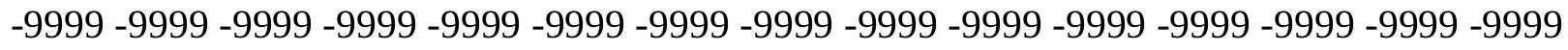

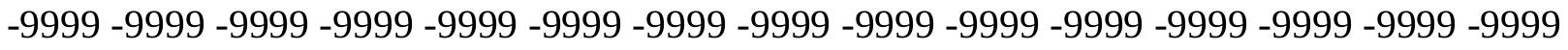
-9999 -9999 -9999 -9999 -9999 -9999 -9999 -9999 -9999 -9999 -9999 -9999 -9999 -9999 -9999 -9999 -9999 -9999 -9999 -9999 -9999 -9999 -9999 -9999 -9999 -9999 -9999 -9999 - -9999 -9999 -9999 -9999 -9999 -9999 -9999 -9999 -9999 -9999 -9999 -9999 -9999 -9999 -9999 -9999 -

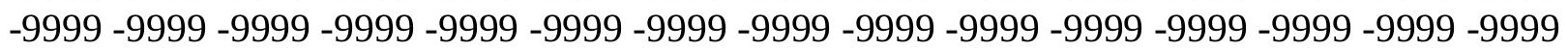


-9999 -9999 -9999 -9999 -9999 -9999 -9999 -9999 -9999 -9999 -9999 -9999 -9999 -9999 -9999 -9999 -9999 -9999 -9999 -9999 -9999 -9999 -9999 -9999 -9999 -9999 -9999 -9999 -9999 -9999 -9999 -9999 -9999 -9999 -9999 -9999 -9999 -9999 -9999 -9999 -9999 -9999 -9999 -9999 - 9999 -9999 -9999 -9999 -9999 -9999 -9999 -9999 -9999 -9999 -9999 -9999 -9999 -9999 -9999 -9999 -9999 -9999 -9999 -9999 -9999 -9999 -9999 -9999 -9999-9999 -9999 -9999 -9999 -9999 -9999 -9999 -9999 -9999 -9999 -9999 -9999 -9999 -9999 -9999 -9999 -9999 -9999 -9999 -9999 -9999 -9999 -9999 -9999 -9999 -9999 -9999 -9999 -9999 -9999 -9999 -9999 -9999 -9999 -9999 -9999

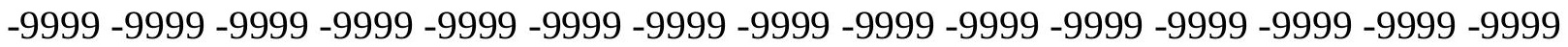

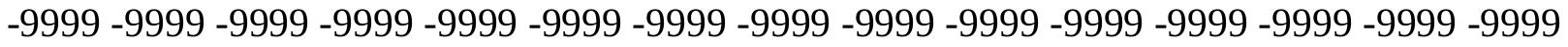
-9999 -9999 -9999 -9999 -9999 -9999 -9999 -9999 -9999 -9999 -9999 -9999 -9999 -9999 -9999

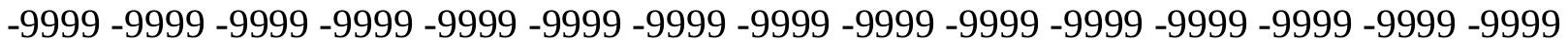
-9999 -9999 -9999 -9999 -9999 -9999 -9999 -9999 -9999 -9999 -9999 -9999 -9999 -9999 -9999 -9999 -9999 -9999 -9999 -9999 -9999 -9999 -9999 -9999 -9999 -9999 -9999 -9999 -9999 -9999 -

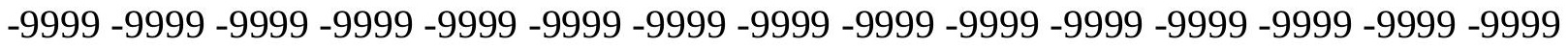
-9999 -9999 -9999 -9999 -9999 -9999 -9999 -9999 -9999 -9999 -9999 -9999 -9999 -9999 -9999

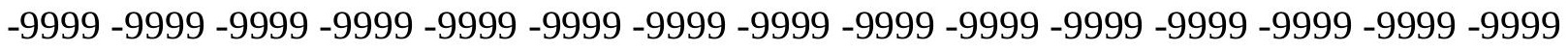
-9999 -9999 -9999 -9999 -9999 -9999 -9999 -9999 -9999 -9999 -9999 -9999 -9999 -9999 -9999 -9999 -9999 -9999 -9999 -9999 -9999 -9999 -9999 -9999 -9999 -9999 -9999 -9999 -9999 -9999 -9999 -9999 -9999 -9999 -9999 -9999 -9999 -9999 -9999 -9999 -9999 -9999 -9999 -9999 -9999 -9999 -9999 -9999 -9999 -9999 -9999 -9999 -9999 -9999 -9999 -9999 -9999 -9999 -9999 -9999 -9999 -9999 -9999 -9999 -9999 -9999 -9999 -9999 -9999 -9999 -9999 -9999 -9999 -9999 -9999 -999 -9999 -9999 -9999 -9999 -9999 -9999 -9999 -9999 -9999 -9999 -9999 -9999 -9999 -9999 -9999 -9999 -9999 -9999 -9999 -9999 -9999 -9999 -9999 -9999 -9999 -9999 -9999 -9999 -9999 -9999 -9999 -9999 -9999 -9999 -9999 -9999 -9999 -9999 -9999 -9999 -9999 -9999 -9999 -9999 -9999 -9999 -9999 -9999 -9999 -9999 -9999 -9999 -9999 -9999 -9999 -9999 -9999 -9999 -9999 -9999 -9999 -9999 -9999 -9999 -9999 -9999 -9999 -9999 -9999 -9999 -9999 -9999 -9999 -9999 -9999 -9999 -9999 -9999 -9999 -9999 -9999 -9999 -9999 -9999 -9999 -9999 -9999 -9999 -9999 -9999 -9999 -9999 -9999 -9999 -9999 -9999 -9999 -9999 -9999 -9999 -9999 -9999 -9999 -9999 -9999 -9999 -9999 -9999 -9999 -9999 -9999 -9999 -9999 -9999 -9999 -9999 -9999 -9999 -9999 -9999 -9999 -9999 -9999 -9999 -9999 -9999 -9999 -9999 -9999 -9999 -9999 -9999 -9999 -999 -9999 -9999 -9999 -9999 -9999 -9999 -9999 -9999 -9999 -9999 -9999 -9999 -9999 -9999 -9999 -9999 -9999 -9999 -9999 -9999 -9999 -9999 -9999 -9999 -9999 -9999 -9999 -9999 -9999 -9999 -

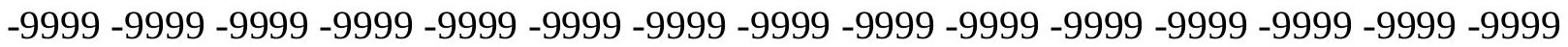

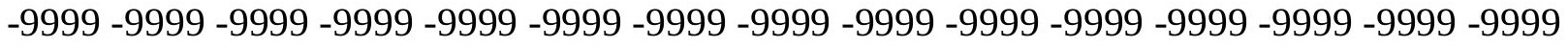

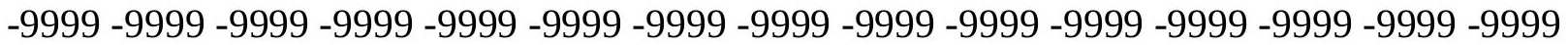
-9999 -9999 -9999 -9999 -9999 -9999 -9999 -9999 -9999 -9999 -9999 -9999 -9999 -9999 -9999

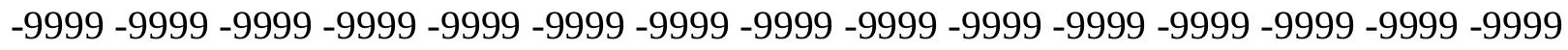

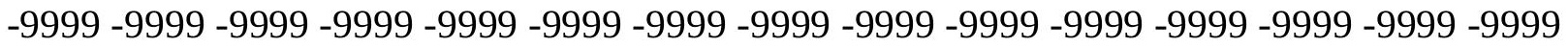
-9999 -9999 -9999 -9999 -9999 -9999 -9999 -9999 -9999 -9999 -9999 -9999 -9999 -9999 -9999 -9999 -9999 -9999 -9999 -9999 -9999 -9999 -9999 -9999 -9999 -9999 -9999 -9999 -9999 -9999 -

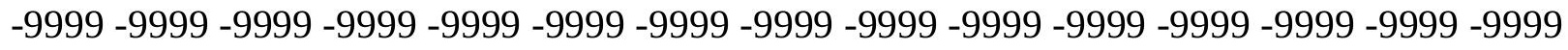

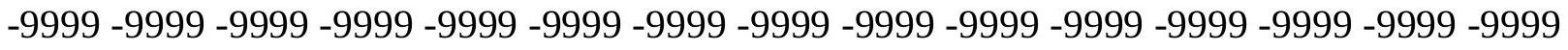
-9999 -9999 -9999 -9999 -9999 -9999 -9999 -9999 -9999 -9999 -9999 -9999 -9999 -9999 -9999 -9999 -9999 -9999 -9999 -9999 -9999 -9999 -9999 -9999-9999 -9999 -9999 -9999 -9999 -9999 -9999 -9999 -9999 -9999 -9999 -9999 -9999 -9999 -9999 -9999 -9999 -9999 -9999 -9999 -9999 -

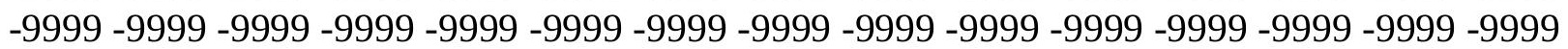


-9999 -9999 -9999 -9999 -9999 -9999 -9999 -9999 -9999 -9999 -9999 -9999 -9999 -9999 -9999 -9999 -9999 -9999 -9999 -9999 -9999 -9999 -9999 -9999 -9999 -9999 -9999 -9999 -9999 -9999 -9999 -9999 -9999 -9999 -9999 -9999 -9999 -9999 -9999 -9999 -9999 -9999 -9999 -9999 - 9999 -9999 -9999 -9999 -9999 -9999 -9999 -9999 -9999 -9999 -9999 -9999 -9999 -9999 -9999

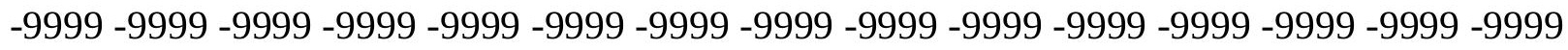
-9999 -9999 -9999 -9999 -9999 -9999 -9999 -9999 -9999 -9999 -9999 -9999 -9999 -9999 -9999 -9999 -9999 -9999 -9999 -9999 -9999 -9999 -9999 -9999 -9999 -9999 -9999 -9999 -9999 -9999

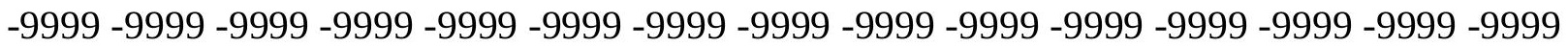

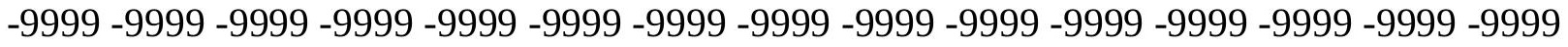
-9999 -9999 -9999 -9999 -9999 -9999 -9999 -9999 -9999 -9999 -9999 -9999 -9999 -9999 -9999 -9999 -9999 -9999 -9999 -9999 -9999 -9999 -9999 -9999 -9999 -9999 -9999 -9999 -9999 -9999 -9999 -9999 -9999 -9999 -9999 -9999 -9999 -9999 -9999 -9999 -9999 -9999 -9999 -9999 -9999 -9999 -9999 -9999 -9999 -9999 -9999 -9999 -9999 -9999 -9999 -9999 -9999 -9999 -9999 -9999 -

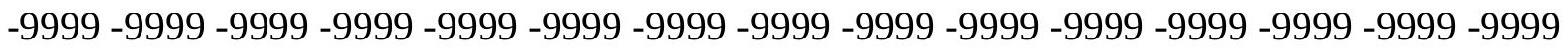
-9999 -9999 -9999 -9999 -9999 -9999 -9999 -9999 -9999 -9999 -9999 -9999 -9999 -9999 -9999 -

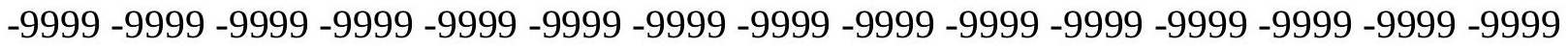
-9999 -9999 -9999 -9999 -9999 -9999 -9999 -9999 -9999 -9999 -9999 -9999 -9999 -9999 -9999 -9999 -9999 -9999 -9999 -9999 -9999 -9999 -9999 -9999 -9999 -9999 -9999 -9999 -9999 -9999 -9999 -9999 -9999 -9999 -9999 -9999 -9999 -9999 -9999 -9999 -9999 -9999 -9999 -9999 -9999 -

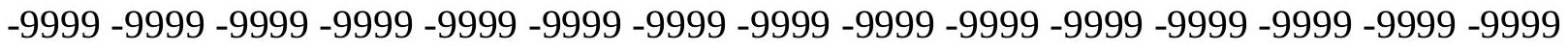
-9999 -9999 -9999 -9999 -9999 -9999 -9999 -9999 -9999 -9999 -9999 -9999 -9999 -9999 -9999

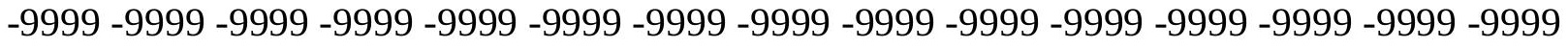
-9999 -9999 -9999 -9999 -9999 -9999 -9999 -9999 -9999 -9999 -9999 -9999 -9999 -9999 -9999 -9999 -9999 -9999 -9999 -9999 -9999 -9999 -9999 -9999 -9999 -9999 -9999 -9999 -9999 -9999 -9999 -9999 -9999 -9999 -9999 -9999 -9999 -9999 -9999 -9999 -9999 -9999 -9999 -9999 -9999 -9999 -9999 -9999 -9999 -9999 -9999 -9999 -9999 -9999 -9999 -9999 -9999 -9999 -9999 -9999 -9999 -9999 -9999 -9999 -9999 -9999 -9999 -9999 -9999 -9999 -9999 -9999 -9999 -9999 -9999 -9999 -9999 -9999 -9999 -9999 -9999 -9999 -9999 -9999 -9999 -9999 -9999 -9999 -9999 -9999 -9999 -9999 -9999 -9999 -9999 -9999 -9999 -9999 -9999 -9999 -9999 -9999 -9999 -9999 -9999 -9999 -9999 -9999 -9999 -9999 -9999 -9999 -9999 -9999 -9999 -9999 -9999 -9999 -9999 -9999 -9999 -9999 -9999 -9999 -9999 -9999 -9999 -9999 -9999 -9999 -9999 -9999 -9999 -9999 -9999 -9999 -9999 -9999 -9999 -9999 -9999 -9999 -9999 -9999 -9999 -9999 -9999 -9999 -9999 -

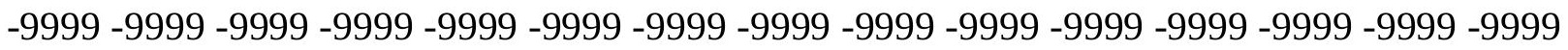

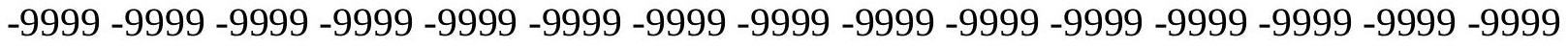
-9999 -9999 -9999 -9999 -9999 -9999 -9999 -9999 -9999 -9999 -9999 -9999 -9999 -9999 -9999 -

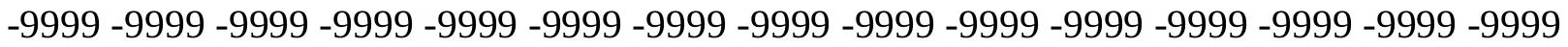

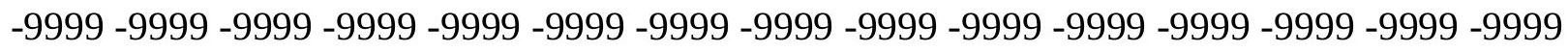

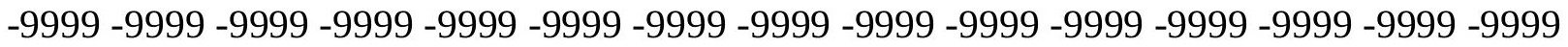

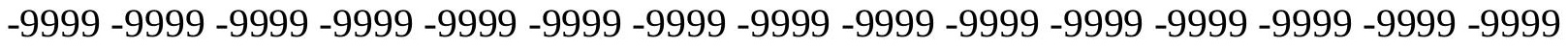
-9999 -9999 -9999 -9999 -9999 -9999 -9999 -9999 -9999 -9999 -9999 -9999 -9999 -9999 -9999 -

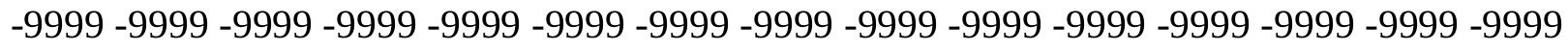

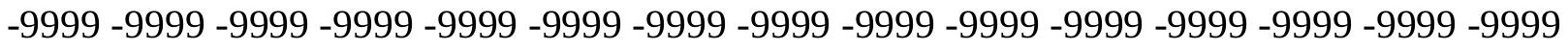
-9999 -9999 -9999 -9999 -9999 -9999 -9999 -9999 -9999 -9999 -9999 -9999 -9999 -9999 -9999 -9999 -9999 -9999 -9999 -9999 -9999 -9999 -9999 -9999-9999 -9999 -9999 -9999 -9999 -9999 -9999 -9999 -9999 -9999 -9999 -9999 -9999 -9999 -9999 -9999 -9999 -9999 -9999 -9999 -9999 -

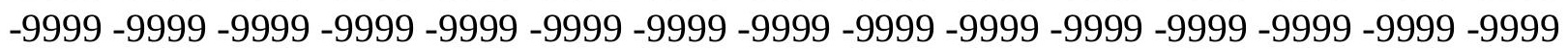


-9999 -9999 -9999 -9999 -9999 -9999 -9999 -9999 -9999 -9999 -9999 -9999 -9999 -9999 -9999 -9999 -9999 -9999 -9999 -9999 -9999 -9999 -9999 -9999 -9999 -9999 -9999 -9999 -9999 -9999 -9999 -9999 -9999 -9999 -9999 -9999 -9999 -9999 -9999 -9999 -9999 -9999 -9999 -9999 - 9999 -9999 -9999 -9999 -9999 -9999 -9999 -9999 -9999 -9999 -9999 -9999 -9999 -9999 -9999 -9999 -9999 -9999 -9999 -9999 -9999 -9999 -9999 -9999 -9999 -9999 -9999 -9999 -9999 -9999 -9999 -9999 -9999 -9999 -9999 -9999 -9999 -9999 -9999 -9999 -9999 -9999 -9999 -9999 -9999 -9999 -9999 -9999 -9999 -9999 -9999 -9999 -9999 -9999 -9999 -9999 -9999 -9999 -9999 -9999 -9999

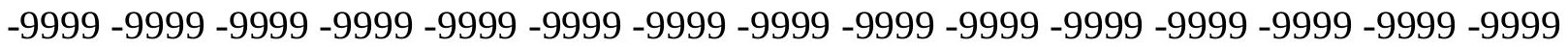

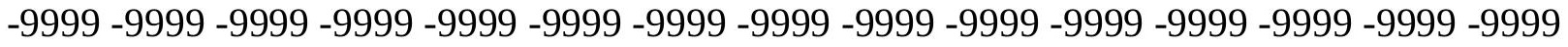
-9999 -9999 -9999 -9999 -9999 -9999 -9999 -9999 -9999 -9999 -9999 -9999 -9999 -9999 -9999 -9999 -9999 -9999 -9999 -9999 -9999 -9999 -9999 -9999 -9999 -9999 -9999 -9999 -9999 -9999 -9999 -9999 -9999 -9999 -9999 -9999 -9999 -9999 -9999 -9999 -9999 -9999 -9999 -9999 -9999 -9999 -9999 -9999 -9999 -9999 -9999 -9999 -9999 -9999 -9999 -9999 -9999 -9999 -9999 -9999 -9999 -9999 -9999 -9999 -9999 -9999 -9999 -9999 -9999 -9999 -9999 -9999 -9999 -9999 -9999 -9999 -9999 -9999 -9999 -9999 -9999 -9999 -9999 -9999 -9999 -9999 -9999 -9999 -9999 -

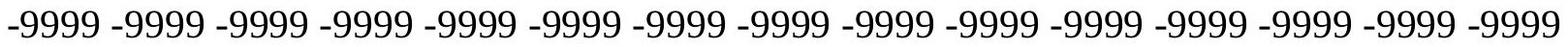
-9999 -9999 -9999 -9999 -9999 -9999 -9999 -9999 -9999 -9999 -9999 -9999 -9999 -9999 -9999 -9999 -9999 -9999 -9999 -9999 -9999 -9999 -9999 -9999 -9999 -9999 -9999 -9999 -9999 -9999 -9999 -9999 -9999 -9999 -9999 -9999 -9999 -9999 -9999 -9999 -9999 -9999 -9999 -9999 -9999 -9999 -9999 -9999 -9999 -9999 -9999 -9999 -9999 -9999 -9999 -9999 -9999 -9999 -9999 -9999 -9999 -9999 -9999 -9999 -9999 -9999 -9999 -9999 -9999 -9999 -9999 -9999 -9999 -9999 -9999 -999 -9999 -9999 -9999 -9999 -9999 -9999 -9999 -9999 -9999 -9999 -9999 -9999 -9999 -9999 -9999 -9999 -9999 -9999 -9999 -9999 -9999 -9999 -9999 -9999 -9999 -9999 -9999 -9999 -9999 -9999 -9999 -9999 -9999 -9999 -9999 -9999 -9999 -9999 -9999 -9999 -9999 -9999 -9999 -9999 -9999 -9999 -9999 -9999 -9999 -9999 -9999 -9999 -9999 -9999 -9999 -9999 -9999 -9999 -9999 -9999 -9999 -9999 -9999 -9999 -9999 -9999 -9999 -9999 -9999 -9999 -9999 -9999 -9999 -9999 -9999 -9999 -9999 -9999 -9999 -9999 -9999 -9999 -9999 -9999 -9999 -9999 -9999 -9999 -9999 -9999 -9999 -9999 -9999 -9999 -9999 -9999 -9999 -9999 -9999 -9999 -9999 -9999 -9999 -9999 -9999 -9999 -9999 -9999 -9999 -9999 -9999 -9999 -9999 -9999 -9999 -9999 -9999 -9999 -9999 -9999 -9999 -9999 -9999 -9999 -9999 -9999 -9999 -9999 -9999 -9999 -9999 -9999 -9999 -9999 -999 -9999 -9999 -9999 -9999 -9999 -9999 -9999 -9999 -9999 -9999 -9999 -9999 -9999 -9999 -9999 -9999 -9999 -9999 -9999 -9999 -9999 -9999 -9999 -9999 -9999 -9999 -9999 -9999 -9999 -9999 -

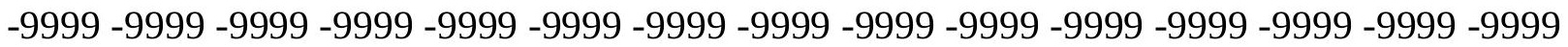

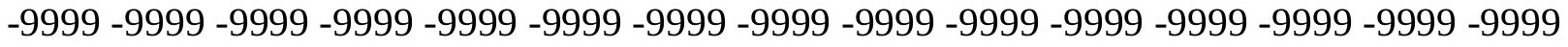

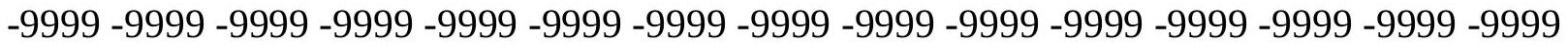
-9999 -9999 -9999 -9999 -9999 -9999 -9999 -9999 -9999 -9999 -9999 -9999 -9999 -9999 -9999 -9999 -9999 -9999 -9999 -9999 -9999 -9999 -9999 -9999 -9999 -9999 -9999 -9999 -9999 -

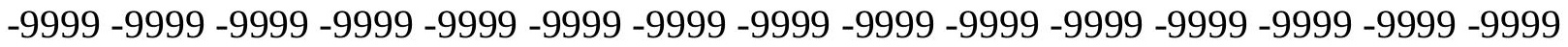
-9999 -9999 -9999 -9999 -9999 -9999 -9999 -9999 -9999 -9999 -9999 -9999 -9999 -9999 -9999 -9999 -9999 -9999 -9999 -9999 -9999 -9999 -9999 -9999 -9999 -9999 -9999 -9999 -9999 -9999 -

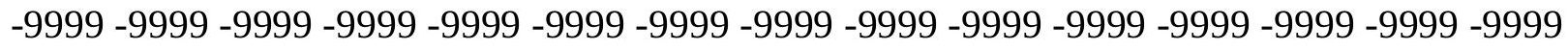

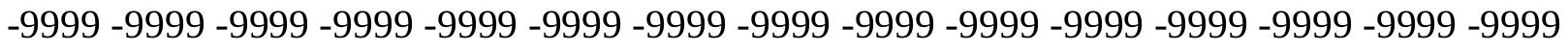
-9999 -9999 -9999 -9999 -9999 -9999 -9999 -9999 -9999 -9999 -9999 -9999 -9999 -9999 -9999 -9999 -9999 -9999 -9999 -9999 -9999 -9999 -9999 -9999-9999 -9999 -9999 -9999 -9999 -9999 -9999 -9999 -9999 -9999 -9999 -9999 -9999 -9999 -9999 -9999 -9999 -9999 -9999 -9999 -9999 -

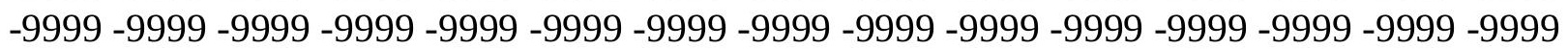


-9999 -9999 -9999 -9999 -9999 -9999 -9999 -9999 -9999 -9999 -9999 -9999 -9999 -9999 -9999 -9999 -9999 -9999 -9999 -9999 -9999 -9999 -9999 -9999 -9999 -9999 -9999 -9999 -9999 -9999 -

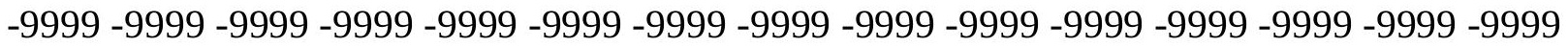
-9999 -9999 -9999 -9999 -9999 -9999 -9999 -9999 -9999 -9999 -9999 -9999 -9999 -9999 -9999 -9999 -9999 -9999 -9999 -9999 -9999 -9999 -9999 -9999-9999 -9999 -9999 -9999 -9999 -9999 -9999 -9999 -9999 -9999 -9999 -9999 -9999 -9999 -9999 -9999 -9999 -9999 -9999 -9999 -9999 -9999 -9999 -9999 -9999 -9999 -9999 -9999 -9999 -9999 -9999 -9999 -9999 -9999 -9999 -9999

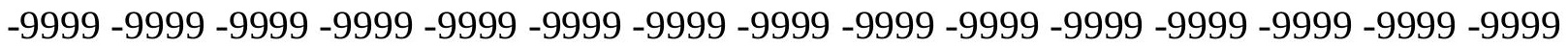

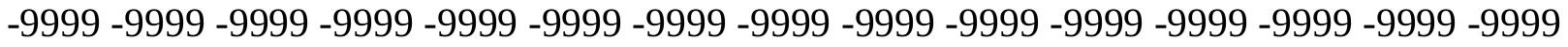
-9999 -9999 -9999 -9999 -9999 -9999 -9999 -9999 -9999 -9999 -9999 -9999 -9999 -9999 -9999 -9999 -9999 -9999 -9999 -9999 -9999 -9999 -9999 -9999 -9999 -9999 -9999 -9999 -9999 -9999 -9999 -9999 -9999 -9999 -9999 -9999 -9999 -9999 -9999 -9999 -9999 -9999 -9999 -9999 -9999 -9999 -9999 -9999 -9999 -9999 -9999 -9999 -9999 -9999 -9999 -9999 -9999 -9999 -9999 -9999 -9999 -9999 -9999 -9999 -9999 -9999 -9999 -9999 -9999 -9999 -9999 -9999 -9999 -9999 -9999 -9999 -9999 -9999 -9999 -9999 -9999 -9999 -9999 -9999 -9999 -9999 -9999 -9999 -9999 -9999 -

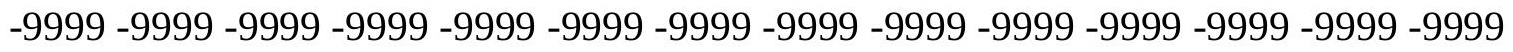
-9999 -9999 -9999 -9999 -9999 -9999 -9999 -9999 -9999 -9999 -9999 -9999 -9999 -9999 -9999 -9999 -9999 -9999 -9999 -9999 -9999 -9999 -9999 -9999 -9999 -9999 -9999 -9999 -9999 -9999 -9999 -9999 -9999 -9999 -9999 -9999 -9999 -9999 -9999 -9999 -9999 -9999 -9999 -9999 -9999 -

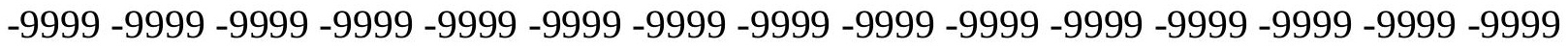

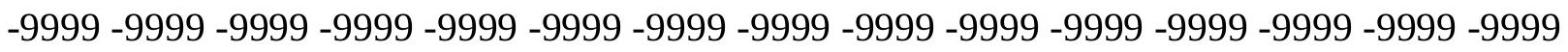
-9999 -9999 -9999 -9999 -9999 -9999 -9999 -9999 -9999 -9999 -9999 -9999 -9999 -9999 - 9999 -9999 -9999 -9999 -9999 -9999 -9999 -9999 -9999 -9999 -9999 -9999 -9999 -9999 -9999 -9999 -9999 -9999 -9999 -9999 -9999 -9999 -9999 -9999 -9999 -9999 -9999 -9999 -9999 -9999 -9999 -

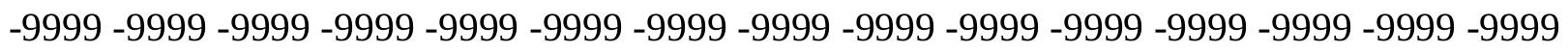
-9999 -9999 -9999 -9999 -9999 -9999 -9999 -9999 -9999 -9999 -9999 -9999 -9999 -9999 -9999 -9999 -9999 -9999 -9999 -9999 -9999 -9999 -9999 -9999 -9999 -9999 -9999 -9999 -9999 -9999 -

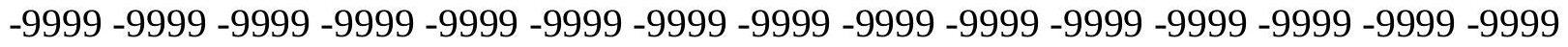
-9999 -9999 -9999 -9999 -9999 -9999 -9999 -9999 -9999 -9999 -9999 -9999 -9999 -9999 -9999 -9999 -9999 -9999 -9999 -9999 -9999 -9999 -9999 -9999 -9999 -9999 -9999 -9999 -9999 -999 -

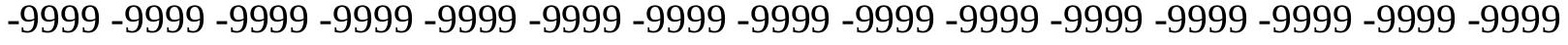
-9999 -9999 -9999 -9999 -9999 -9999 -9999 -9999 -9999 -9999 -9999 -9999 -9999 -9999 -9999 -

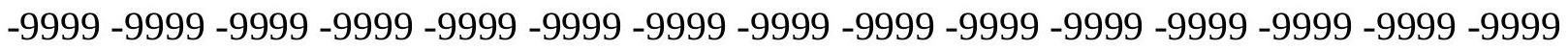

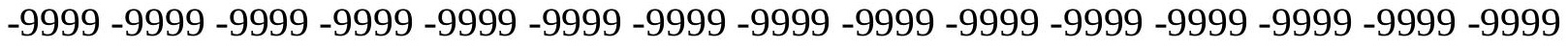

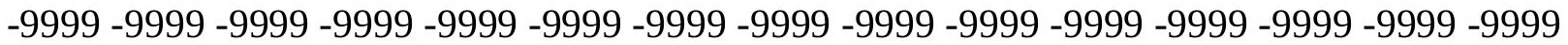
-9999 -9999 -9999 -9999 -9999 -9999 -9999 -9999 -9999 -9999 -9999 -9999 -9999 -9999 -9999 -

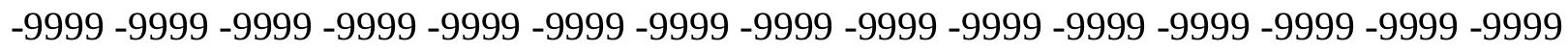

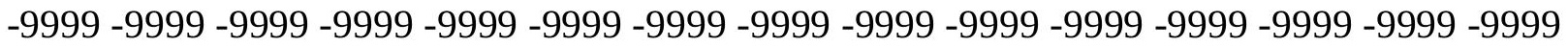
-9999 -9999 -9999 -9999 -9999 -9999 -9999 -9999 -9999 -9999 -9999 -9999 -9999 - 9999 - -999 -9999 -9999 -9999 -9999 -9999 -9999 -9999 -9999 -9999 -9999 -9999 -9999 -9999 -9999 -9999 -

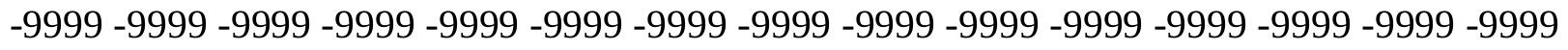

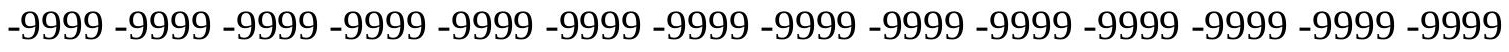
-9999 -9999 -9999 -9999 -9999 -9999 -9999 -9999 -9999 -9999 -9999 -9999 -9999 -9999 -9999 -9999 -9999 -9999 -9999 -9999 -9999 -9999 -9999 -9999-9999 -9999 -9999 -9999 -9999 -9999 -9999 -9999 -9999 -9999 -9999 -9999 -9999 -9999 -9999 -9999 -9999 -9999 -9999 -9999 -9999 -

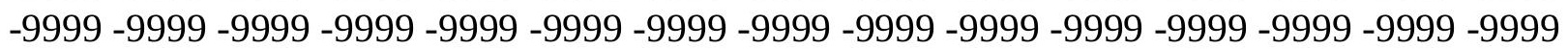


-9999 -9999 -9999 -9999 -9999 -9999 -9999 -9999 -9999 -9999 -9999 -9999 -9999 -9999 -9999 -9999 -9999 -9999 -9999 -9999 -9999 -9999 -9999 -9999 -9999 -9999 -9999 -9999 -9999 -9999 -

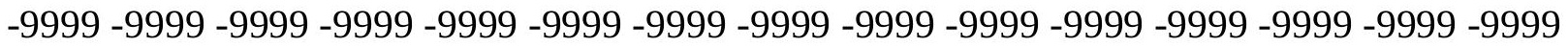
-9999 -9999 -9999 -9999 -9999 -9999 -9999 -9999 -9999 -9999 -9999 -9999 -9999 -9999 -9999 -9999 -9999 -9999 -9999 -9999 -9999 -9999 -9999 -9999-9999 -9999 -9999 -9999 -9999 -9999 -9999 -9999 -9999 -9999 -9999 -9999 -9999 -9999 -9999 -9999 -9999 -9999 -9999 -9999 -9999 -9999 -9999 -9999 -9999 -9999 -9999 -9999 -9999 -9999 -9999 -9999 -9999 -9999 -9999 -9999

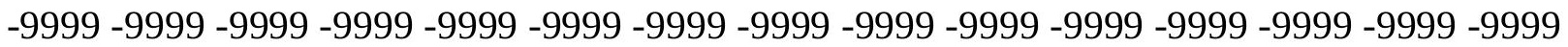

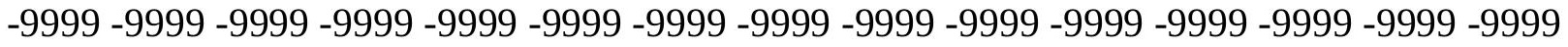
-9999 -9999 -9999 -9999 -9999 -9999 -9999 -9999 -9999 -9999 -9999 -9999 -9999 -9999 -9999 -9999 -9999 -9999 -9999 -9999 -9999 -9999 -9999 -9999 -9999 -9999 -9999 -9999 -9999 -9999 -9999 -9999 -9999 -9999 -9999 -9999 -9999 -9999 -9999 -9999 -9999 -9999 -9999 -9999 -9999 -9999 -9999 -9999 -9999 -9999 -9999 -9999 -9999 -9999 -9999 -9999 -9999 -9999 -9999 -9999 -

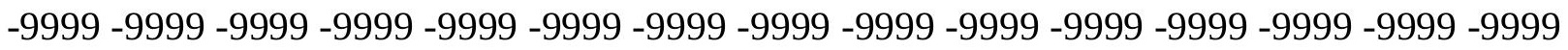
-9999 -9999 -9999 -9999 -9999 -9999 -9999 -9999 -9999 -9999 -9999 -9999 -9999 -9999 -9999 -

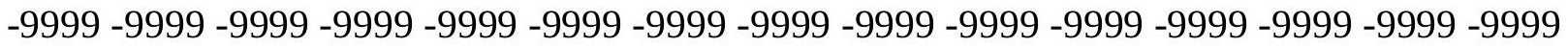
-9999 -9999 -9999 -9999 -9999 -9999 -9999 -9999 -9999 -9999 -9999 -9999 -9999 -9999 -9999 -9999 -9999 -9999 -9999 -9999 -9999 -9999 -9999 -9999 -9999 -9999 -9999 -9999 -9999 -9999 -9999 -9999 -9999 -9999 -9999 -9999 -9999 -9999 -9999 -9999 -9999 -9999 -9999 -9999 -9999 -

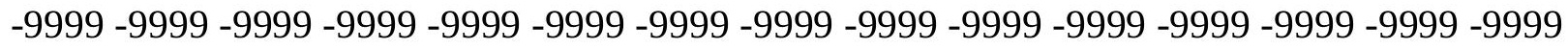

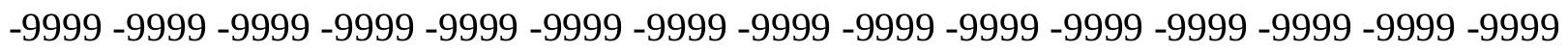
-9999 -9999 -9999 -9999 -9999 -9999 -9999 -9999 -9999 -9999 -9999 -9999 -9999 -9999 -9999 -9999 -9999 -9999 -9999 -9999 -9999 -9999 -9999 -9999 -9999 -9999 -9999 -9999 -9999 -9999 -9999 -9999 -9999 -9999 -9999 -9999 -9999 -9999 -9999 -9999 -9999 -9999 -9999 -9999 -

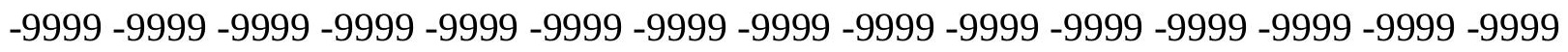
-9999 -9999 -9999 -9999 -9999 -9999 -9999 -9999 -9999 -9999 -9999 -9999 -9999 -9999 -9999 -9999 -9999 -9999 -9999 -9999 -9999 -9999 -9999 -9999 -9999 -9999 -9999 -9999 -9999 -9999 -

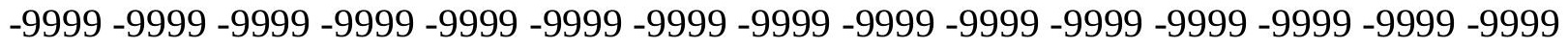
-9999 -9999 -9999 -9999 -9999 -9999 -9999 -9999 -9999 -9999 -9999 -9999 -9999 -9999 -9999 -9999 -9999 -9999 -9999 -9999 -9999 -9999 -9999 -9999 -9999 -9999 -9999 -9999 -9999 -999 -

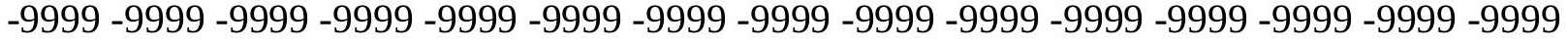
-9999 -9999 -9999 -9999 -9999 -9999 -9999 -9999 -9999 -9999 -9999 -9999 -9999 -9999 -9999 -

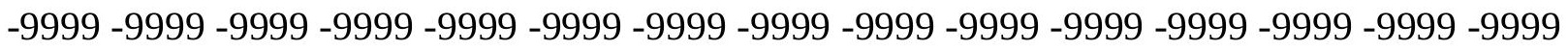

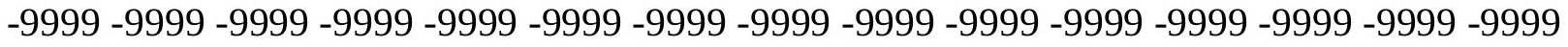

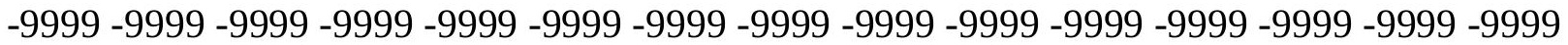

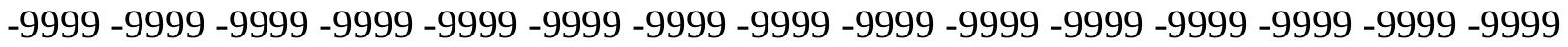

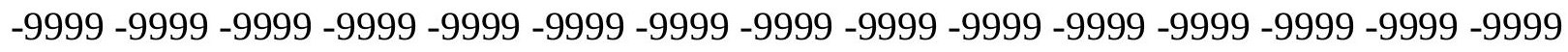

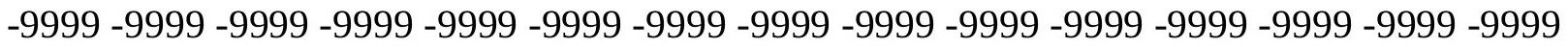

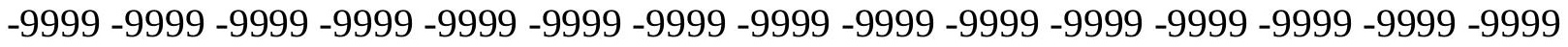
-9999 -9999 -9999 -9999 -9999 -9999 -9999 -9999 -9999 -9999 -9999 -9999 -9999 -9999 -9999 -

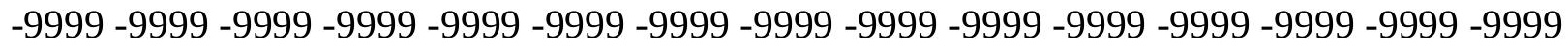

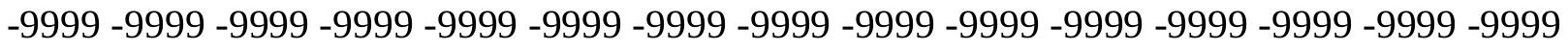
-9999 -9999 -9999 -9999 -9999 -9999 -9999 -9999 -9999 -9999 -9999 -9999 -9999 -9999 -9999 -9999 -9999 -9999 -9999 -9999 -9999 -9999 -9999 -9999-9999 -9999 -9999 -9999 -9999 -9999 -9999 -9999 -9999 -9999 -9999 -9999 -9999 -9999 -9999 -9999 -9999 -9999 -9999 -9999 -9999 -

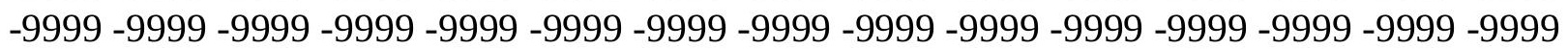


-9999 -9999 -9999 -9999 -9999 -9999 -9999 -9999 -9999 -9999 -9999 -9999 -9999 -9999 -9999 -9999 -9999 -9999 -9999 -9999 -9999 -9999 -9999 -9999 -9999 -9999 -9999 -9999 -9999 -

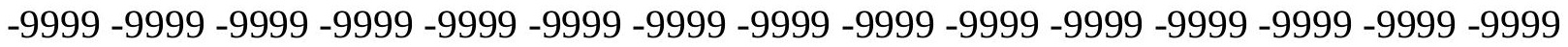
-9999 -9999 -9999 -9999 -9999 -9999 -9999 -9999 -9999 -9999 -9999 -9999 -9999 -9999 -9999 -9999 -9999 -9999 -9999 -9999 -9999 -9999 -9999 -9999 -9999 -9999 -9999 -9999 -9999 -9999 -9999 -9999 -9999 -9999 -9999 -9999 -9999 -9999 -9999 -9999 -9999 -9999 -9999 -9999 -9999 -9999 -9999 -9999 -9999 -9999 -9999 -9999 -9999 -9999 -9999 -9999 -9999 -9999 -9999 -9999

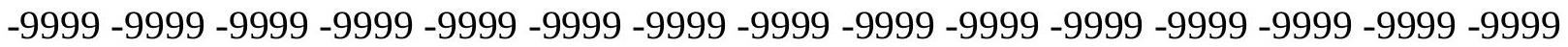

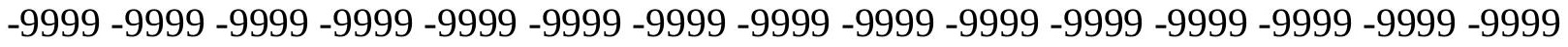
-9999 -9999 -9999 -9999 -9999 -9999 -9999 -9999 -9999 -9999 -9999 -9999 -9999 -9999 -9999 -9999 -9999 -9999 -9999 -9999 -9999 -9999 -9999 -9999 -9999 -9999 -9999 -9999 -9999 -9999 -9999 -9999 -9999 -9999 -9999 -9999 -9999 -9999 -9999 -9999 -9999 -9999 -9999 -9999 -9999 -9999 -9999 -9999 -9999 -9999 -9999 -9999 -9999 -9999 -9999 -9999 -9999 -9999 -9999 -9999 -9999 -9999 -9999 -9999 -9999 -9999 -9999 -9999 -9999 -9999 -9999 -9999 -9999 -9999 -9999 -9999 -9999 -9999 -9999 -9999 -9999 -9999 -9999 -9999 -9999 -9999 -9999 -9999 -9999 -9999 -

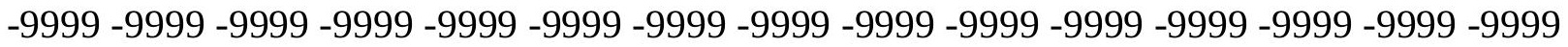
-9999 -9999 -9999 -9999 -9999 -9999 -9999 -9999 -9999 -9999 -9999 -9999 -9999 -9999 -9999 -9999 -9999 -9999 -9999 -9999 -9999 -9999 -9999 -9999 -9999 -9999 -9999 -9999 -9999 - 9999 -9999 -9999 -9999 -9999 -9999 -9999 -9999 -9999 -9999 -9999 -9999 -9999 -9999 -9999 -9999 -

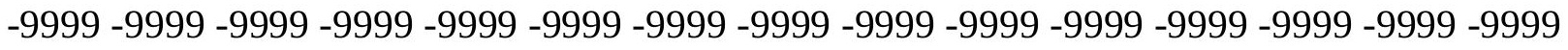

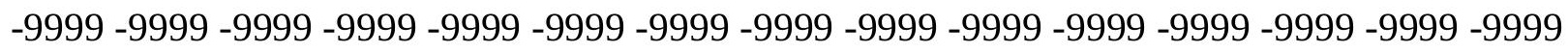

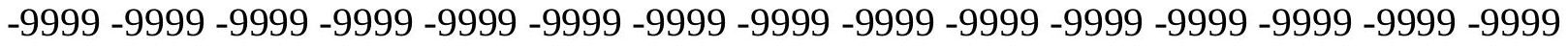
-9999 -9999 -9999 -9999 -9999 -9999 -9999 -9999 -9999 -9999 -9999 -9999 -9999 -9999 -9999 -9999 -9999 -9999 -9999 -9999 -9999 -9999 -9999 -9999 -9999 -9999 -9999 -9999 -9999 -9999 -

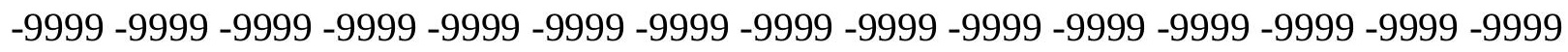
-9999 -9999 -9999 -9999 -9999 -9999 -9999 -9999 -9999 -9999 -9999 -9999 -9999 -9999 -9999 -9999 -9999 -9999 -9999 -9999 -9999 -9999 -9999 -9999 -9999 -9999 -9999 -9999 -9999 -9999 -9999 -9999 -9999 -9999 -9999 -9999 -9999 -9999 -9999 -9999 -9999 -9999 -9999 -9999 -9999 -9999 -9999 -9999 -9999 -9999 -9999 -9999 -9999 -9999 -9999 -9999 -9999 -9999 -9999 -9999 -9999 -9999 -9999 -9999 -9999 -9999 -9999 -9999 -9999 -9999 -9999 -9999 -9999 -999 -

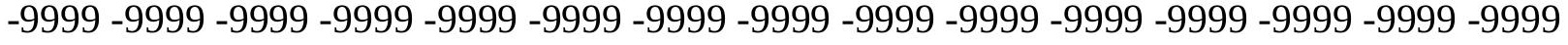
-9999 -9999 -9999 -9999 -9999 -9999 -9999 -9999 -9999 -9999 -9999 -9999 -9999 -9999 -9999 -

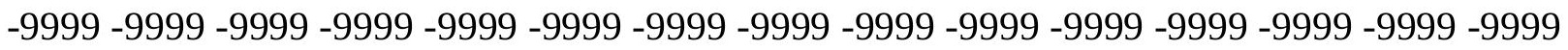

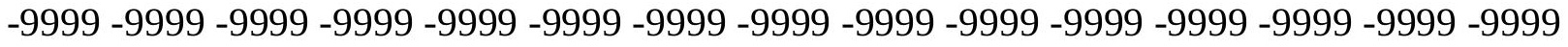

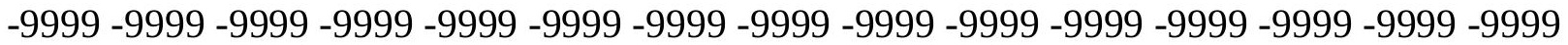

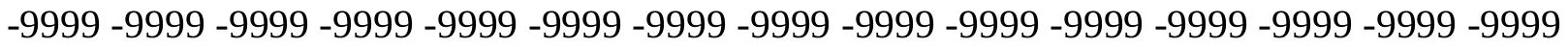

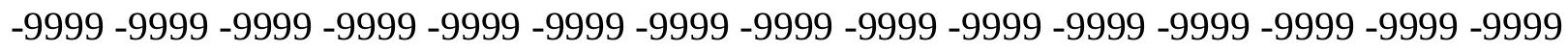

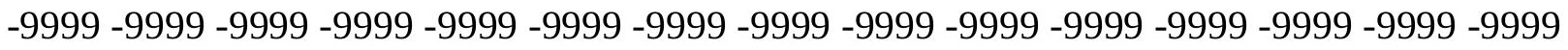

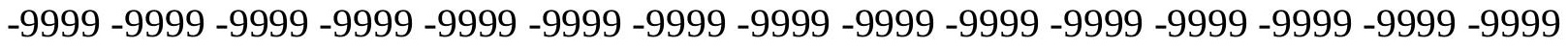
-9999 -9999 -9999 -9999 -9999 -9999 -9999 -9999 -9999 -9999 -9999 -9999 -9999 -9999 -9999 -

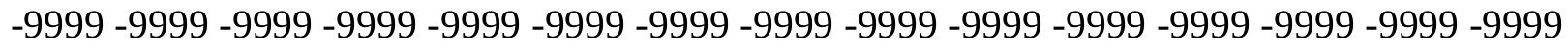

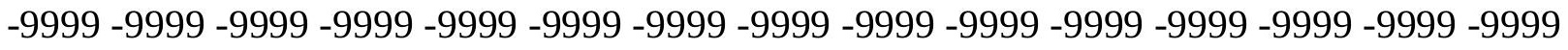
-9999 -9999 -9999 -9999 -9999 -9999 -9999 -9999 -9999 -9999 -9999 -9999 -9999 -9999 -9999 -9999 -9999 -9999 -9999 -9999 -9999 -9999 -9999 -9999-9999 -9999 -9999 -9999 -9999 -9999 -9999 -9999 -9999 -9999 -9999 -9999 -9999 -9999 -9999 -9999 -9999 -9999 -9999 -9999 -9999 -

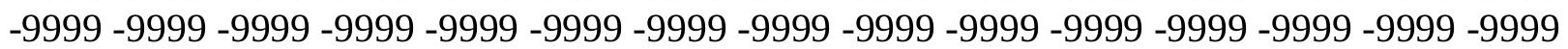


-9999 -9999 -9999 -9999 -9999 -9999 -9999 -9999 -9999 -9999 -9999 -9999 -9999 -9999 -9999 -9999 -9999 -9999 -9999 -9999 -9999 -9999 -9999 -9999 -9999 -9999 -9999 -9999 -9999 -9999 -

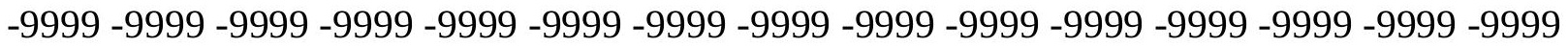
-9999 -9999 -9999 -9999 -9999 -9999 -9999 -9999 -9999 -9999 -9999 -9999 -9999 -9999 -9999 -9999 -9999 -9999 -9999 -9999 -9999 -9999 -9999 -9999-9999 -9999 -9999 -9999 -9999 -9999 -9999 -9999 -9999 -9999 -9999 -9999 -9999 -9999 -9999 -9999 -9999 -9999 -9999 -9999 -9999 -

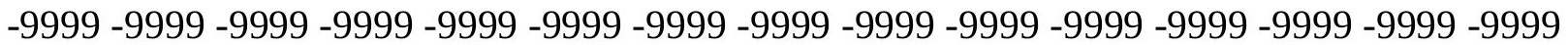
-9999 -9999 -9999 -9999 -9999 -9999 -9999 -9999 -9999 -9999 -9999 -9999 -9999 -9999 -9999 -9999 -9999 -9999 -9999 -9999 -9999 -9999 -9999 -9999 -9999 -9999 -9999 -9999 -9999 -9999 -9999 -9999 -9999 -9999 -9999 -9999 -9999 -9999 -9999 -9999 -9999 -9999 -9999 -9999 -9999 -9999 -9999 -9999 -9999 -9999 -9999 -9999 -9999 -9999 -9999 -9999 -9999 -9999 -9999 -9999 -9999 -9999 -9999 -9999 -9999 -9999 -9999 -9999 -9999 -9999 -9999 -9999 -9999 -9999 -9999 -9999 -9999 -9999 -9999 -9999 -9999 -9999 -9999 -9999 -9999 -9999 -9999 -9999 -9999 -9999 -9999 -9999 -9999 -9999 -9999 -9999 -9999 -9999 -9999 -9999 -9999 -9999 -9999 -9999 -9999 -9999 -9999 -9999 -9999 -9999 -9999 -9999 -9999 -9999 -9999 -9999 -9999 -9999 -9999 -

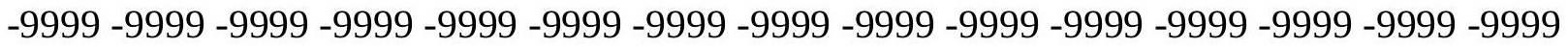
-9999 -9999 -9999 -9999 -9999 -9999 -9999 -9999 -9999 -9999 -9999 -9999 -9999 -9999 -9999 -9999 -9999 -9999 -9999 -9999 -9999 -9999 -9999 -9999 -9999 -9999 -9999 -9999 -9999 -9999 -9999 -9999 -9999 -9999 -9999 -9999 -9999 -9999 -9999 -9999 -9999 -9999 -9999 -9999 -9999 -

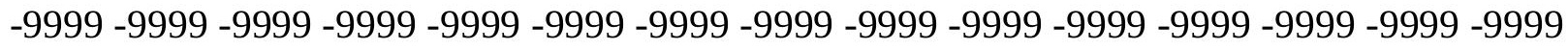

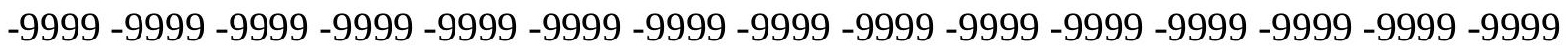
-9999 -9999 -9999 -9999 -9999 -9999 -9999 -9999 -9999 -9999 -9999 -9999 -9999 -9999 - 9999 -9999 -9999 -9999 -9999 -9999 -9999 -9999 -9999 -9999 -9999 -9999 -9999 -9999 -9999 -9999 -9999 -9999 -9999 -9999 -9999 -9999 -9999 -9999 -9999 -9999 -9999 -9999 -9999 -9999 -9999 -

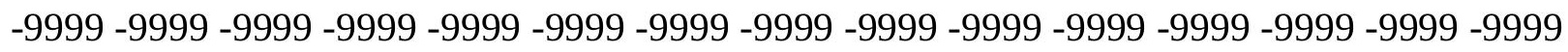
-9999 -9999 -9999 -9999 -9999 -9999 -9999 -9999 -9999 -9999 -9999 -9999 -9999 -9999 -9999 -9999 -9999 -9999 -9999 -9999 -9999 -9999 -9999 -9999 -9999 -9999 -9999 -9999 -9999 -9999 -

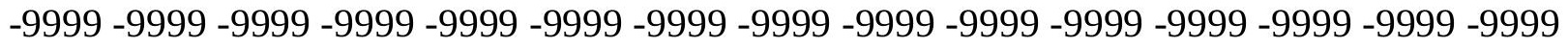
-9999 -9999 -9999 -9999 -9999 -9999 -9999 -9999 -9999 -9999 -9999 -9999 -9999 -9999 -9999 -9999 -9999 -9999 -9999 -9999 -9999 -9999 -9999 -9999 -9999 -9999 -9999 -9999 -9999 -999 -9999 -9999 -9999 -9999 -9999 -9999 -9999 -9999 -9999 -9999 -9999 -9999 -9999 -9999 -9999 -9999 -9999 -9999 -9999 -9999 -9999 -9999 -9999 -9999 -9999 -9999 -9999 -9999 -9999 -9999 -

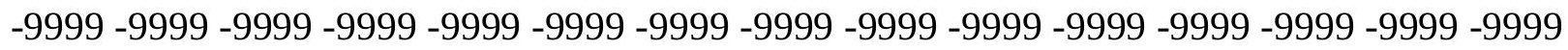

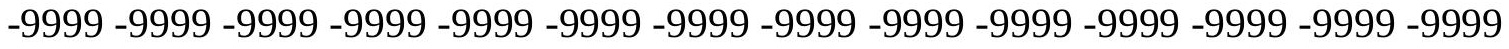
-9999 -9999 -9999 -9999 -9999 -9999 -9999 -9999 -9999 -9999 -9999 -9999 -9999 -9999 -9999

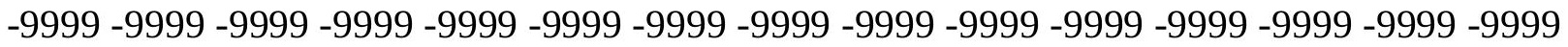

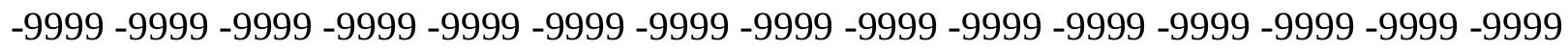

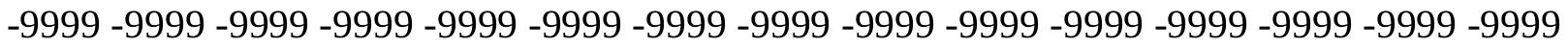

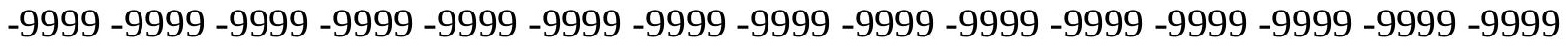
-9999 -9999 -9999 -9999 -9999 -9999 -9999 -9999 -9999 -9999 -9999 -9999 -9999 -9999 -9999 -

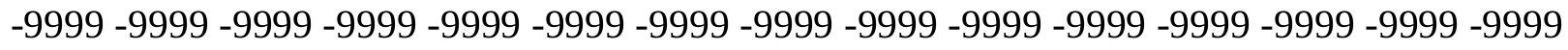

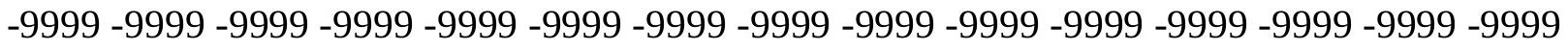
-9999 -9999 -9999 -9999 -9999 -9999 -9999 -9999 -9999 -9999 -9999 -9999 -9999 -9999 -9999 -9999 -9999 -9999 -9999 -9999 -9999 -9999 -9999 -9999-9999 -9999 -9999 -9999 -9999 -9999 -9999 -9999 -9999 -9999 -9999 -9999 -9999 -9999 -9999 -9999 -9999 -9999 -9999 -9999 -9999 -

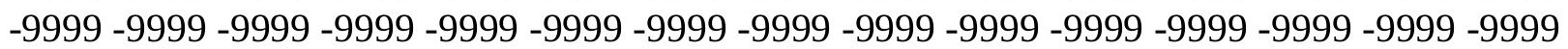


-9999 -9999 -9999 -9999 -9999 -9999 -9999 -9999 -9999 -9999 -9999 -9999 -9999 -9999 -9999 -9999 -9999 -9999 -9999 -9999 -9999 -9999 -9999 -9999 -9999 -9999 -9999 -9999 -9999 -9999 -

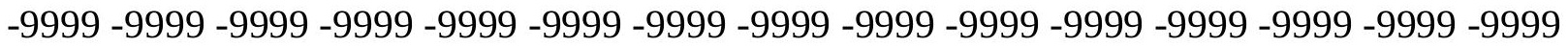
-9999 -9999 -9999 -9999 -9999 -9999 -9999 -9999 -9999 -9999 -9999 -9999 -9999 -9999 -9999 -9999 -9999 -9999 -9999 -9999 -9999 -9999 -9999 -9999-9999 -9999 -9999 -9999 -9999 -9999 -9999 -9999 -9999 -9999 -9999 -9999 -9999 -9999 -9999 -9999 -9999 -9999 -9999 -9999 -9999 -9999 -9999 -9999 -9999 -9999 -9999 -9999 -9999 -9999 -9999 -9999 -9999 -9999 -9999 -9999

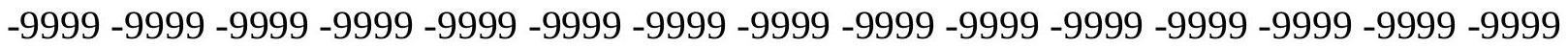

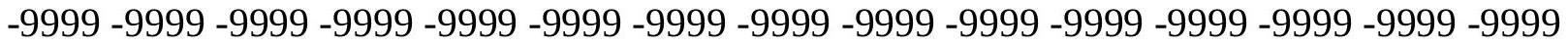
-9999 -9999 -9999 -9999 -9999 -9999 -9999 -9999 -9999 -9999 -9999 -9999 -9999 -9999 -9999 -9999 -9999 -9999 -9999 -9999 -9999 -9999 -9999 -9999 -9999 -9999 -9999 -9999 -9999 -9999 -9999 -9999 -9999 -9999 -9999 -9999 -9999 -9999 -9999 -9999 -9999 -9999 -9999 -9999 -9999 -9999 -9999 -9999 -9999 -9999 -9999 -9999 -9999 -9999 -9999 -9999 -9999 -9999 -9999 -9999 -9999 -9999 -9999 -9999 -9999 -9999 -9999 -9999 -9999 -9999 -9999 -9999 -9999 -9999 -9999 -9999 -9999 -9999 -9999 -9999 -9999 -9999 -9999 -9999 -9999 -9999 -9999 -9999 -9999

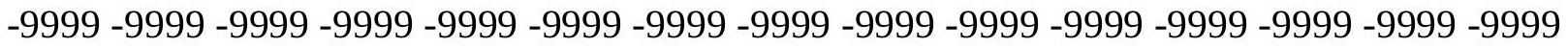
-9999 -9999 -9999 -9999 -9999 -9999 -9999 -9999 -9999 -9999 -9999 -9999 -9999 -9999 -9999 -9999 -9999 -9999 -9999 -9999 -9999 -9999 -9999 -9999 -9999 -9999 -9999 -9999 -9999 -9999 -9999 -9999 -9999 -9999 -9999 -9999 -9999 -9999 -9999 -9999 -9999 -9999 -9999 -9999 -9999 -

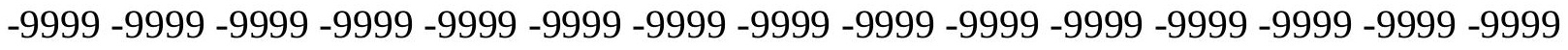

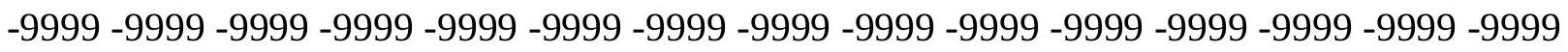
-9999 -9999 -9999 -9999 -9999 -9999 -9999 -9999 -9999 -9999 -9999 -9999 -9999 -9999 -9999 -9999 -9999 -9999 -9999 -9999 -9999 -9999 -9999 -9999 -9999 -9999 -9999 -9999 -9999 -9999 -9999 -9999 -9999 -9999 -9999 -9999 -9999 -9999 -9999 -9999 -9999 -9999 -9999 -9999 -9999 -

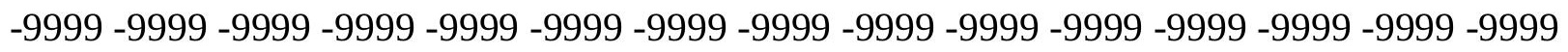
-9999 -9999 -9999 -9999 -9999 -9999 -9999 -9999 -9999 -9999 -9999 -9999 -9999 -9999 -9999 -9999 -9999 -9999 -9999 -9999 -9999 -9999 -9999 -9999 -9999 -9999 -9999 -9999 -9999 -9999 -

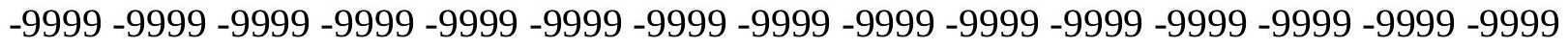
-9999 -9999 -9999 -9999 -9999 -9999 -9999 -9999 -9999 -9999 -9999 -9999 -9999 -9999 -9999 -9999 -9999 -9999 -9999 -9999 -9999 -9999 -9999 -9999 -9999 -9999 -9999 -9999 -9999 -999 -9999 -9999 -9999 -9999 -9999 -9999 -9999 -9999 -9999 -9999 -9999 -9999 -9999 -9999 -9999 -9999 -9999 -9999 -9999 -9999 -9999 -9999 -9999 -9999 -9999 -9999 -9999 -9999 -9999 -9999 -

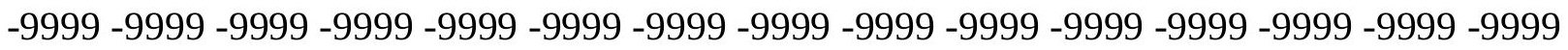

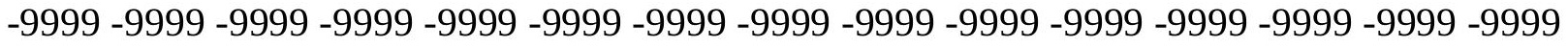

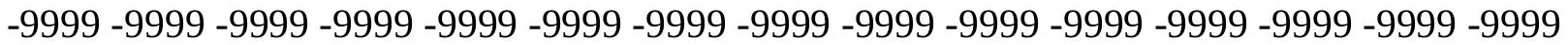

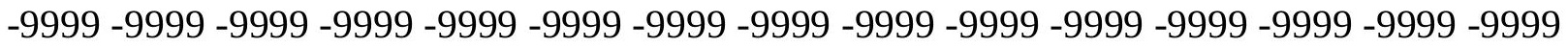

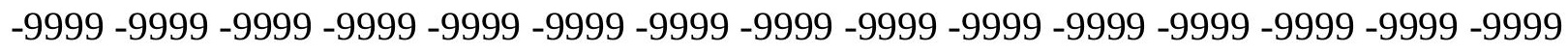

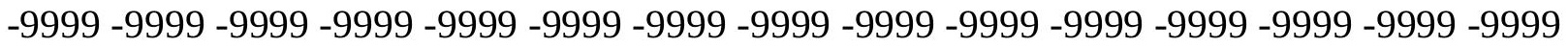
-9999 -9999 -9999 -9999 -9999 -9999 -9999 -9999 -9999 -9999 -9999 -9999 -9999 - 9999 - -999 -9999 -9999 -9999 -9999 -9999 -9999 -9999 -9999 -9999 -9999 -9999 -9999 -9999 -9999 - -999 -

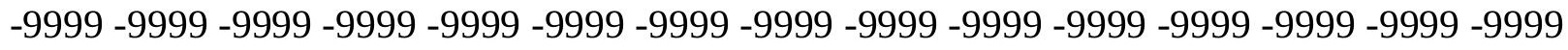

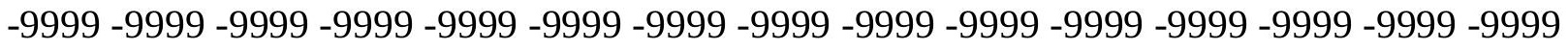
-9999 -9999 -9999 -9999 -9999 -9999 -9999 -9999 -9999 -9999 -9999 -9999 -9999 -9999 -9999 -9999 -9999 -9999 -9999 -9999 -9999 -9999 -9999 -9999-9999 -9999 -9999 -9999 -9999 -9999 -9999 -9999 -9999 -9999 -9999 -9999 -9999 -9999 -9999 -9999 -9999 -9999 -9999 -9999 -9999 -

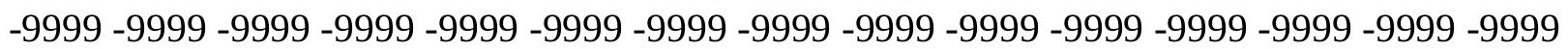


-9999 -9999 -9999 -9999 -9999 -9999 -9999 -9999 -9999 -9999 -9999 -9999 -9999 -9999 -9999 -9999 -9999 -9999 -9999 -9999 -9999 -9999 -9999 -9999 -9999 -9999 -9999 -9999 -9999 -9999 -9999 -9999 -9999 -9999 -9999 -9999 -9999 -9999 -9999 -9999 -9999 -9999 -9999 -9999 -9999 -9999 -9999 -9999 -9999 -9999 -9999 -9999 -9999 -9999 -9999 -9999 -9999 -9999 -9999 -9999 -9999 -9999 -9999 -9999 -9999 -9999 -9999 -9999 -9999 -9999 -9999 -9999 -9999 -9999 -9999 -9999 -9999 -9999 -9999 -9999 -9999 -9999 -9999 -9999 -9999 -9999 -9999 -9999 -9999 -9999 -9999 -9999 -9999 -9999 -9999 -9999 -9999 -9999 -9999 -9999 -9999 -9999 -9999 -9999 -9999 -

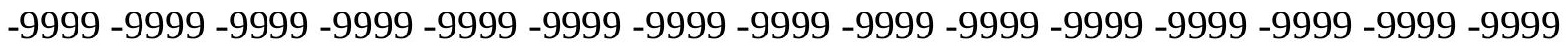
-9999 -9999 -9999 -9999 -9999 -9999 -9999 -9999 -9999 -9999 -9999 -9999 -9999 -9999 -9999 -9999 -9999 -9999 -9999 -9999 -9999 -9999 -9999 -9999 -9999 -9999 -9999 -9999 -9999 -9999 -

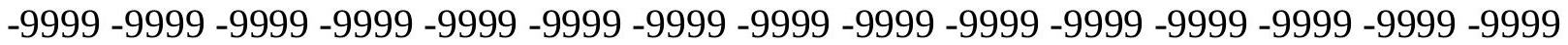
-9999 -9999 -9999 -9999 -9999 -9999 -9999 -9999 -9999 -9999 -9999 -9999 -9999 -9999 -9999 -9999 -9999 -9999 -9999 -9999 -9999 -9999 -9999 -9999 -9999 -9999 -9999 -9999 -9999 -9999 -9999 -9999 -9999 -9999 -9999 -9999 -9999 -9999 -9999 -9999 -9999 -9999 -9999 -9999 -9999 -9999 -9999 -9999 -9999 -9999 -9999 -9999 -9999 -9999 -9999 -9999 -9999 -9999 -9999 -9999

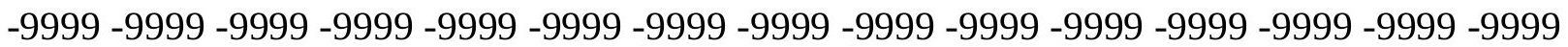
-9999 -9999 -9999 -9999 -9999 -9999 -9999 -9999 -9999 -9999 -9999 -9999 -9999 -9999 -9999 -9999 -9999 -9999 -9999 -9999 -9999 -9999 -9999 -9999 -9999 -9999 -9999 -9999 -9999 -9999 -9999 -9999 -9999 -9999 -9999 -9999 -9999 -9999 -9999 -9999 -9999 -9999 -9999 -9999 -9999 -9999 -9999 -9999 -9999 -9999 -9999 -9999 -9999 -9999 -9999 -9999 -9999 -9999 -9999 -9999 -9999 -9999 -9999 -9999 -9999 -9999 -9999 -9999 -9999 -9999 -9999 -9999 -9999 -9999 -9999 -9999 -9999 -9999 -9999 -9999 -9999 -9999 -9999 -9999 -9999 -9999 -9999 -9999 -9999 -9999 -9999 -9999 -9999 -9999 -9999 -9999 -9999 -9999 -9999 -9999 -9999 -9999 -9999 -9999 -9999 -9999 -9999 -9999 -9999 -9999 -9999 -9999 -9999 -9999 -9999 -9999 -9999 -9999 -9999 -9999 -9999 -9999 -9999 -9999 -9999 -9999 -9999 -9999 -9999 -9999 -9999 -9999 -9999 -9999 -9999 -9999 -9999 -9999 -9999 -9999 -9999 -9999 -9999 -9999 -9999 -9999 -9999 -9999 -9999 -9999 -9999 -9999 -9999 -9999 -9999 -9999 -9999 -9999 -9999 -9999 -9999 -9999 -9999 -9999 -9999 -9999 -9999 -9999 -9999 -9999 -9999 -9999 -9999 -9999 -9999 -9999 -9999 -9999 -9999

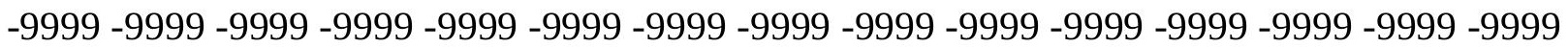
-9999 -9999 -9999 -9999 -9999 -9999 -9999 -9999 -9999 -9999 -9999 -9999 -9999 -9999 -9999 -9999 -9999 -9999 -9999 -9999 -9999 -9999 -9999 -9999 -9999 -9999 -9999 -9999 -9999 -9999 -

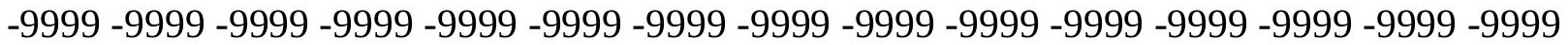
-9999 -9999 -9999 -9999 -9999 -9999 -9999 -9999 -9999 -9999 -9999 -9999 -9999 -9999 -9999 -9999 -9999 -9999 -9999 -9999 -9999 -9999 -9999 -9999 -9999 -9999 -9999 -9999 -9999 -9999 -9999 -9999 -9999 -9999 -9999 -9999 -9999 -9999 -9999 -9999 -9999 -9999 -9999 -9999 -9999 -9999 -9999 -9999 -9999 -9999 -9999 -9999 -9999 -9999 -9999 -9999 -9999 -9999 -9999 -9999 -9999 -9999 -9999 -9999 -9999 -9999 -9999 -9999 -9999 -9999 -9999 -9999 -9999 -9999 -9999

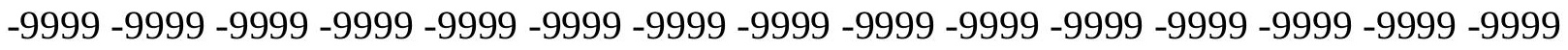
-9999 -9999 -9999 -9999 -9999 -9999 -9999 -9999 -9999 -9999 -9999 -9999 -9999 -9999 -9999 -9999 -9999 -9999 -9999 -9999 -9999 -9999 -9999 -9999 -9999 -9999 -9999 -9999 -9999 -9999 -9999 -9999 -9999 -9999 -9999 -9999 -9999 -9999 -9999 -9999 -9999 -9999 -9999 -9999 -9999 -999 -9999 -9999 -9999 -9999 -9999 -9999 -9999 -9999 -9999 -9999 -9999 -9999 -9999 -9999 -9999 -9999 -9999 -9999 -9999 -9999 -9999 -9999 -9999 -9999 -9999 -9999 -9999 -9999 -9999 -9999 -9999 -9999 -9999 -9999 -9999 -9999 -9999 -9999 -9999 -9999 -9999 -9999 -9999 -9999 -9999 -9999 -9999 -9999 -9999 -9999 -9999 -9999 -9999 -9999 -9999 -9999 -9999 -9999 -9999 -9999 -9999 -9999 -9999 -9999 -9999 -9999 -9999 -9999 -9999 -9999 -9999 -9999 -9999 -9999 
-9999 -9999 -9999 -9999 -9999 -9999 -9999 -9999 -9999 -9999 -9999 -9999 -9999 -9999 -9999 -9999 -9999 -9999 -9999 -9999 -9999 -9999 -9999 -9999 -9999 -9999 -9999 -9999 -9999 -9999 -

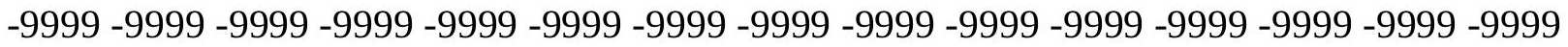
-9999 -9999 -9999 -9999 -9999 -9999 -9999 -9999 -9999 -9999 -9999 -9999 -9999 -9999 -9999 -9999 -9999 -9999 -9999 -9999 -9999 -9999 -9999 -9999-9999 -9999 -9999 -9999 -9999 -9999 -9999 -9999 -9999 -9999 -9999 -9999 -9999 -9999 -9999 -9999 -9999 -9999 -9999 -9999 -9999 -9999 -9999 -9999 -9999 -9999 -9999 -9999 -9999 -9999 -9999 -9999 -9999 -9999 -9999 -9999

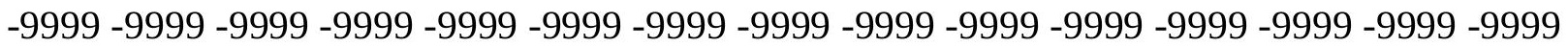

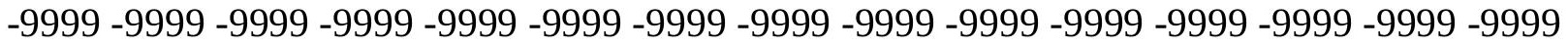
-9999 -9999 -9999 -9999 -9999 -9999 -9999 -9999 -9999 -9999 -9999 -9999 -9999 -9999 -9999 -9999 -9999 -9999 -9999 -9999 -9999 -9999 -9999 -9999 -9999 -9999 -9999 -9999 -9999 -9999 -9999 -9999 -9999 -9999 -9999 -9999 -9999 -9999 -9999 -9999 -9999 -9999 -9999 -9999 -9999 -9999 -9999 -9999 -9999 -9999 -9999 -9999 -9999 -9999 -9999 -9999 -9999 -9999 -9999 -9999 -

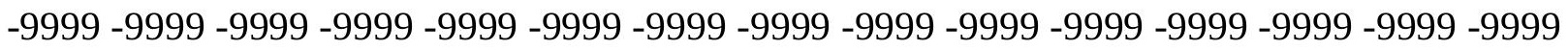
-9999 -9999 -9999 -9999 -9999 -9999 -9999 -9999 -9999 -9999 -9999 -9999 -9999 -9999 -9999 -

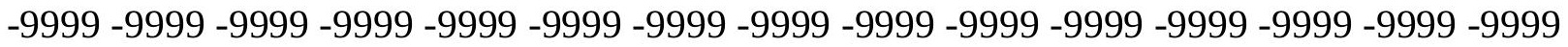
-9999 -9999 -9999 -9999 -9999 -9999 -9999 -9999 -9999 -9999 -9999 -9999 -9999 -9999 -9999 -9999 -9999 -9999 -9999 -9999 -9999 -9999 -9999 -9999 -9999 -9999 -9999 -9999 -9999 -9999 -9999 -9999 -9999 -9999 -9999 -9999 -9999 -9999 -9999 -9999 -9999 -9999 -9999 -9999 -9999 -

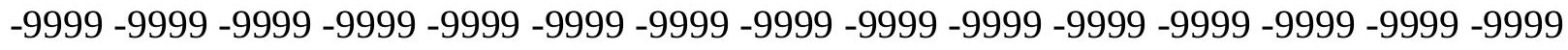

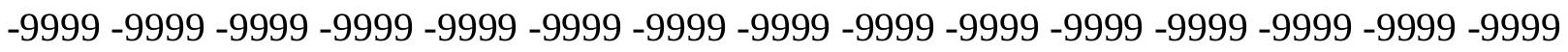

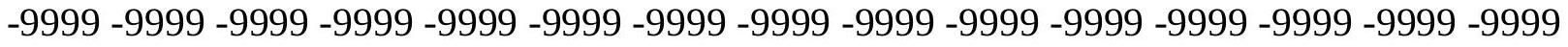
-9999 -9999 -9999 -9999 -9999 -9999 -9999 -9999 -9999 -9999 -9999 -9999 -9999 -9999 -9999 -9999 -9999 -9999 -9999 -9999 -9999 -9999 -9999 -9999 -9999 -9999 -9999 -9999 -9999 -9999 -

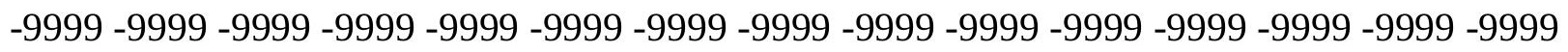
-9999 -9999 -9999 -9999 -9999 -9999 -9999 -9999 -9999 -9999 -9999 -9999 -9999 -9999 -9999 -9999 -9999 -9999 -9999 -9999 -9999 -9999 -9999 -9999 -9999 -9999 -9999 -9999 -9999 -

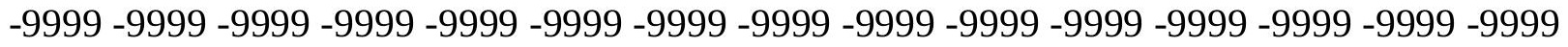
-9999 -9999 -9999 -9999 -9999 -9999 -9999 -9999 -9999 -9999 -9999 -9999 -9999 -9999 -9999 -9999 -9999 -9999 -9999 -9999 -9999 -9999 -9999 -9999 -9999 -9999 -9999 -9999 -9999 -999 -

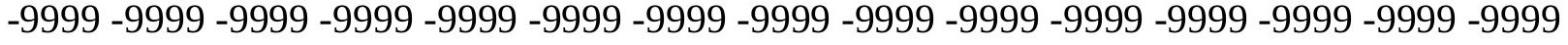
-9999 -9999 -9999 -9999 -9999 -9999 -9999 -9999 -9999 -9999 -9999 -9999 -9999 -9999 -9999 -

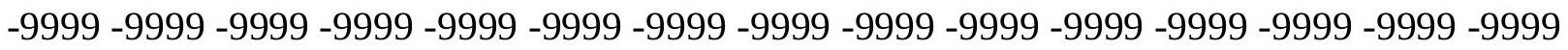

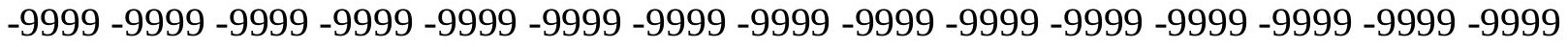

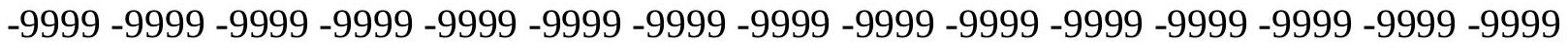
-9999 -9999 -9999 -9999 -9999 -9999 -9999 -9999 -9999 -9999 -9999 -9999 -9999 -9999 -9999

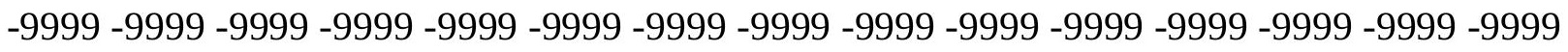

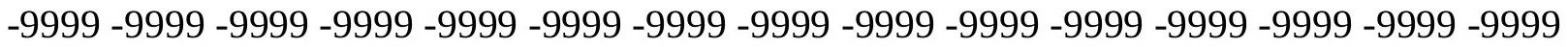
-9999 -9999 -9999 -9999 -9999 -9999 -9999 -9999 -9999 -9999 -9999 -9999 -9999 - 9999 - -999 -9999 -9999 -9999 -9999 -9999 -9999 -9999 -9999 -9999 -9999 -9999 -9999 -9999 -9999 -9999 -

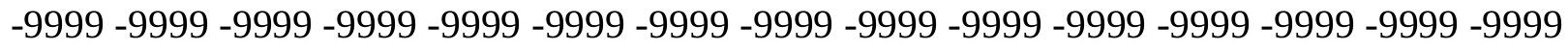

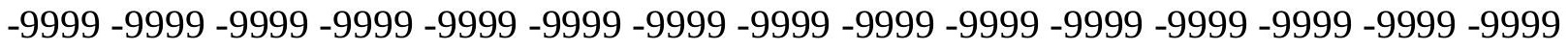
-9999 -9999 -9999 -9999 -9999 -9999 -9999 -9999 -9999 -9999 -9999 -9999 -9999 -9999 -9999 -9999 -9999 -9999 -9999 -9999 -9999 -9999 -9999 -9999-9999 -9999 -9999 -9999 -9999 -9999 -9999 -9999 -9999 -9999 -9999 -9999 -9999 -9999 -9999 -9999 -9999 -9999 -9999 -9999 -9999 -

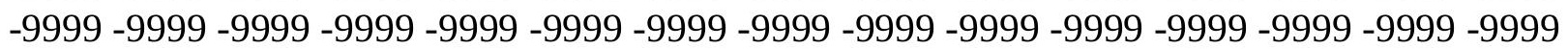


-9999 -9999 -9999 -9999 -9999 -9999 -9999 -9999 -9999 -9999 -9999 -9999 -9999 -9999 -9999 -9999 -9999 -9999 -9999 -9999 -9999 -9999 -9999 -9999 -9999 -9999 -9999 -9999 -9999 -9999 -9999 -9999 -9999 -9999 -9999 -9999 -9999 -9999 -9999 -9999 -9999 -9999 -9999 -9999 - 9999 -9999 -9999 -9999 -9999 -9999 -9999 -9999 -9999 -9999 -9999 -9999 -9999 -9999 -9999 -9999 -9999 -9999 -9999 -9999 -9999 -9999 -9999 -9999 -9999 -9999 -9999 -9999 -9999 -9999 - -9999 -9999 -9999 -9999 -9999 -9999 -9999 -9999 -9999 -9999 -9999 -9999 -9999 -9999 -9999 -9999 -9999 -9999 -9999 -9999 -9999 -9999 -9999 -9999 -9999 -9999 -9999 -9999 -9999 -9999

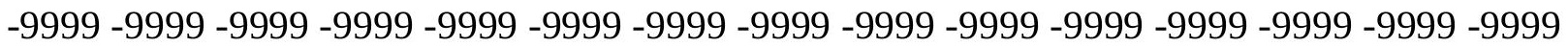

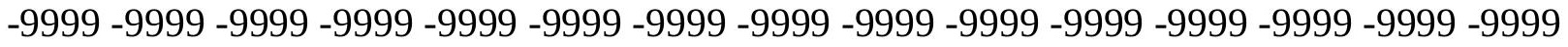
-9999 -9999 -9999 -9999 -9999 -9999 -9999 -9999 -9999 -9999 -9999 -9999 -9999 -9999 -9999

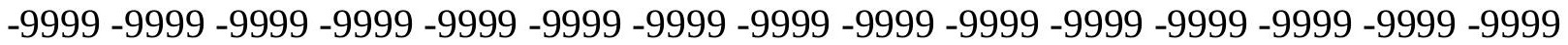
-9999 -9999 -9999 -9999 -9999 -9999 -9999 -9999 -9999 -9999 -9999 -9999 -9999 -9999 -9999 -9999 -9999 -9999 -9999 -9999 -9999 -9999 -9999 -9999 -9999 -9999 -9999 -9999 -9999 -9999 -9999 -9999 -9999 -9999 -9999 -9999 -9999 -9999 -9999 -9999 -9999 -9999 -9999 -9999 - -9999 -9999 -9999 -9999 -9999 -9999 -9999 -9999 -9999 -9999 -9999 -9999 -9999 -9999 -9999 -9999

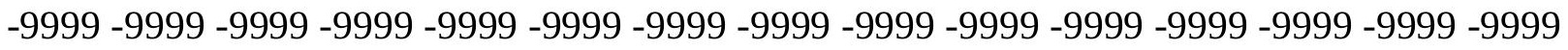
-9999 -9999 -9999 -9999 -9999 -9999 -9999 -9999 -9999 -9999 -9999 -9999 -9999 -9999 -9999 -9999 -9999 -9999 -9999 -9999 -9999 -9999 -9999 -9999 -9999 -9999 -9999 -9999 -9999 -9999 -9999 -9999 -9999 -9999 -9999 -9999 -9999 -9999 -9999 -9999 -9999 -9999 -9999 -9999 -9999 -

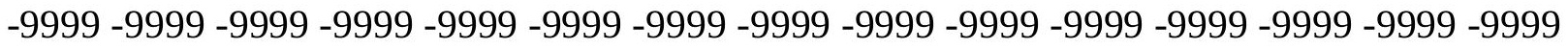
-9999 -9999 -9999 -9999 -9999 -9999 -9999 -9999 -9999 -9999 -9999 -9999 -9999 -9999 -9999 -999 -9999 -9999 -9999 -9999 -9999 -9999 -9999 -9999 -9999 -9999 -9999 -9999 -9999 -9999 -9999 -9999 -9999 -9999 -9999 -9999 -9999 -9999 -9999 -9999 -9999 -9999 -9999 -9999 -9999 -9999 -9999 -9999 -9999 -9999 -9999 -9999 -9999 -9999 -9999 -9999 -9999 -9999 -9999 -9999 -9999 -9999 -9999 -9999 -9999 -9999 -9999 -9999 -9999 -9999 -9999 -9999 -9999 -9999 -9999 -9999 -9999 -9999 -9999 -9999 -9999 -9999 -9999 -9999 -9999 -9999 -9999 -9999 -9999 -9999 -9999 -9999 -9999 -9999 -9999 -9999 -9999 -9999 -9999 -9999 -9999 -9999 -9999 -9999 -9999 -9999 -9999 -9999 -9999 -9999 -9999 -9999 -9999 -9999 -9999 -9999 -9999 -9999 -9999 -9999 -9999 -9999 -9999 -9999 -9999 -9999 -9999 -9999 -9999 -9999 -9999 -9999 -9999 -9999 -9999 -9999 -9999 -9999 -9999 -9999 -9999 -9999 -9999 -9999 -9999 -9999 -9999 -9999 -9999 -9999 -999 -9999 -9999 -9999 -9999 -9999 -9999 -9999 -9999 -9999 -9999 -9999 -9999 -9999 -9999 -9999 -9999 -9999 -9999 -9999 -9999 -9999 -9999 -9999 -9999 -9999 -9999 -9999 -9999 -9999 -

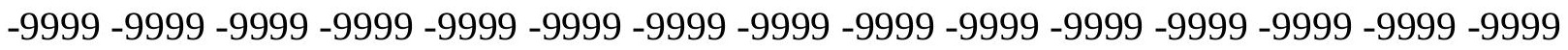

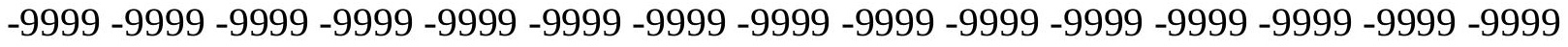

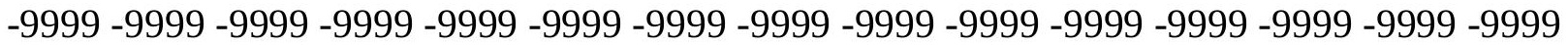
-9999 -9999 -9999 -9999 -9999 -9999 -9999 -9999 -9999 -9999 -9999 -9999 -9999 -9999 -9999 -

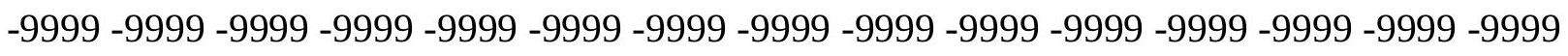

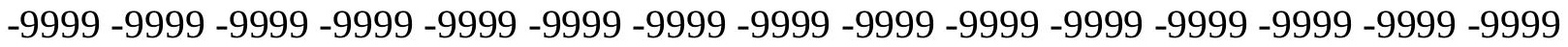

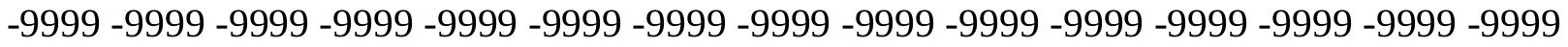
-9999 -9999 -9999 -9999 -9999 -9999 -9999 -9999 -9999 -9999 -9999 -9999 -9999 -9999 -9999 -

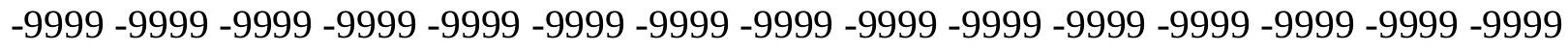

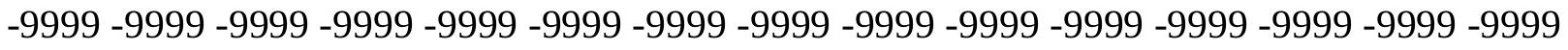
-9999 -9999 -9999 -9999 -9999 -9999 -9999 -9999 -9999 -9999 -9999 -9999 -9999 -9999 -9999 -9999 -9999 -9999 -9999 -9999 -9999 -9999 -9999 -9999-9999 -9999 -9999 -9999 -9999 -9999 -9999 -9999 -9999 -9999 -9999 -9999 -9999 -9999 -9999 -9999 -9999 -9999 -9999 -9999 -9999 -

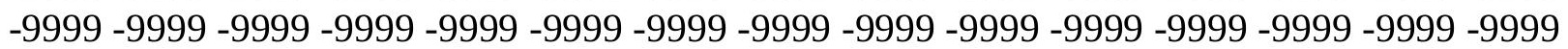


-9999 -9999 -9999 -9999 -9999 -9999 -9999 -9999 -9999 -9999 -9999 -9999 -9999 -9999 -9999 -9999 -9999 -9999 -9999 -9999 -9999 -9999 -9999 -9999 -9999 -9999 -9999 -9999 -9999 -9999 -

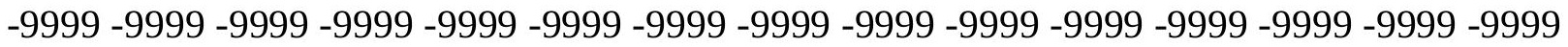
-9999 -9999 -9999 -9999 -9999 -9999 -9999 -9999 -9999 -9999 -9999 -9999 -9999 -9999 -9999 -9999 -9999 -9999 -9999 -9999 -9999 -9999 -9999 -9999-9999 -9999 -9999 -9999 -9999 -9999 -9999 -9999 -9999 -9999 -9999 -9999 -9999 -9999 -9999 -9999 -9999 -9999 -9999 -9999 -9999 -9999 -9999 -9999 -9999 -9999 -9999 -9999 -9999 -9999 -9999 -9999 -9999 -9999 -9999 -9999

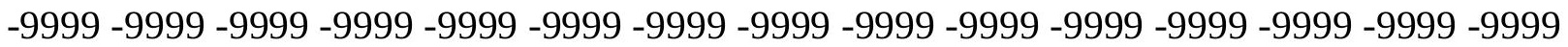

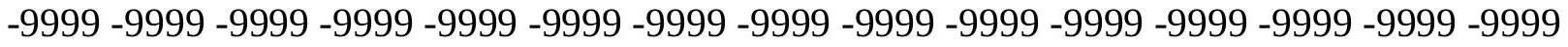
-9999 -9999 -9999 -9999 -9999 -9999 -9999 -9999 -9999 -9999 -9999 -9999 -9999 -9999 -9999 -9999 -9999 -9999 -9999 -9999 -9999 -9999 -9999 -9999 -9999 -9999 -9999 -9999 -9999 -9999 -9999 -9999 -9999 -9999 -9999 -9999 -9999 -9999 -9999 -9999 -9999 -9999 -9999 -9999 -9999 -9999 -9999 -9999 -9999 -9999 -9999 -9999 -9999 -9999 -9999 -9999 -9999 -9999 -9999 -9999 -9999 -9999 -9999 -9999 -9999 -9999 -9999 -9999 -9999 -9999 -9999 -9999 -9999 - 9999 -9999 -9999 -9999 -9999 -9999 -9999 -9999 -9999 -9999 -9999 -9999 -9999 -9999 -9999 -9999

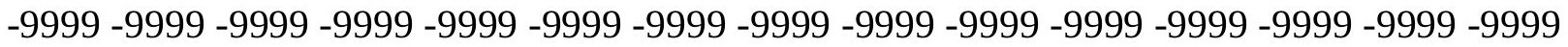
-9999 -9999 -9999 -9999 -9999 -9999 -9999 -9999 -9999 -9999 -9999 -9999 -9999 -9999 -9999 -9999 -9999 -9999 -9999 -9999 -9999 -9999 -9999 -9999 -9999 -9999 -9999 -9999 -9999 -9999 -9999 -9999 -9999 -9999 -9999 -9999 -9999 -9999 -9999 -9999 -9999 -9999 -9999 -9999 -9999 -

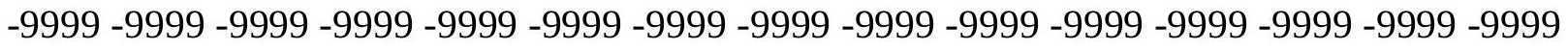

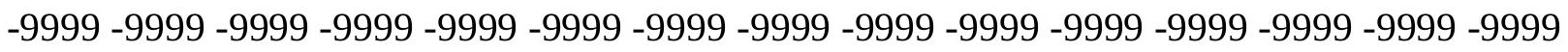
-9999 -9999 -9999 -9999 -9999 -9999 -9999 -9999 -9999 -9999 -9999 -9999 -9999 -9999 -9999 -9999 -9999 -9999 -9999 -9999 -9999 -9999 -9999 -9999 -9999 -9999 -9999 -9999 -9999 -9999 -9999 -9999 -9999 -9999 -9999 -9999 -9999 -9999 -9999 -9999 -9999 -9999 -9999 -9999 -9999 -

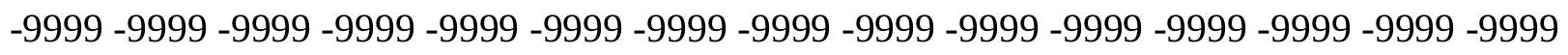
-9999 -9999 -9999 -9999 -9999 -9999 -9999 -9999 -9999 -9999 -9999 -9999 -9999 -9999 -9999 -9999 -9999 -9999 -9999 -9999 -9999 -9999 -9999 -9999 -9999 -9999 -9999 -9999 -9999 -9999 -

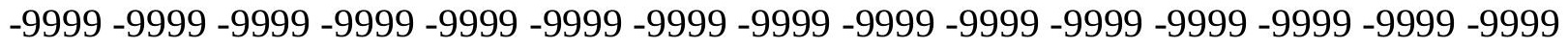
-9999 -9999 -9999 -9999 -9999 -9999 -9999 -9999 -9999 -9999 -9999 -9999 -9999 -9999 -9999 -9999 -9999 -9999 -9999 -9999 -9999 -9999 -9999 -9999 -9999 -9999 -9999 -9999 -9999 -999 -9999 -9999 -9999 -9999 -9999 -9999 -9999 -9999 -9999 -9999 -9999 -9999 -9999 -9999 -9999 -9999 -9999 -9999 -9999 -9999 -9999 -9999 -9999 -9999 -9999 -9999 -9999 -9999 -9999 -9999 -

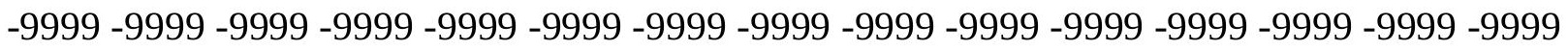

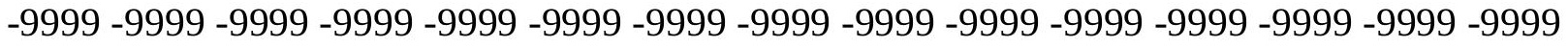

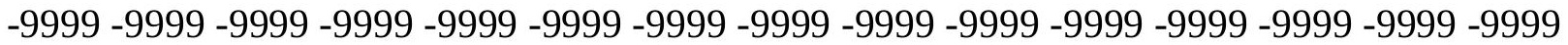

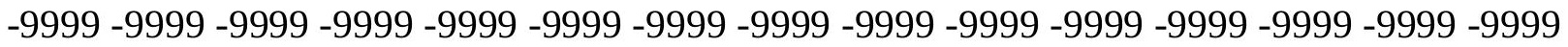

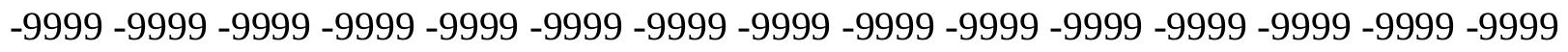

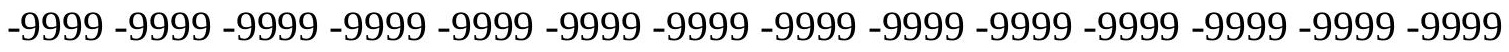
-9999 -9999 -9999 -9999 -9999 -9999 -9999 -9999 -9999 -9999 -9999 -9999 -9999 -9999 -9999 -9999 -9999 -9999 -9999 -9999 -9999 -9999 -9999 -9999 -9999 -9999 -9999 -9999 -9999 -9999 -

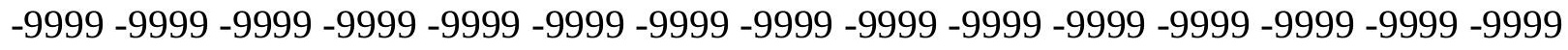

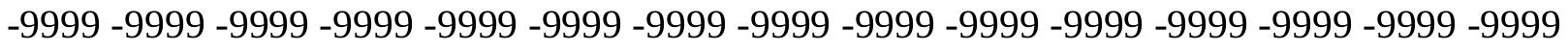
-9999 -9999 -9999 -9999 -9999 -9999 -9999 -9999 -9999 -9999 -9999 -9999 -9999 -9999 -9999 -9999 -9999 -9999 -9999 -9999 -9999 -9999 -9999 -9999-9999 -9999 -9999 -9999 -9999 -9999 -9999 -9999 -9999 -9999 -9999 -9999 -9999 -9999 -9999 -9999 -9999 -9999 -9999 -9999 -9999 -

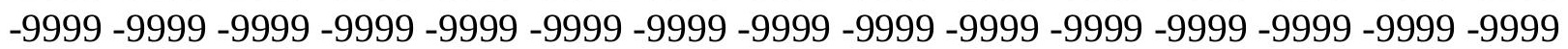


-9999 -9999 -9999 -9999 -9999 -9999 -9999 -9999 -9999 -9999 -9999 -9999 -9999 -9999 -9999 -9999 -9999 -9999 -9999 -9999 -9999 -9999 -9999 -9999 -9999 -9999 -9999 -9999 -9999 -9999 -9999 -9999 -9999 -9999 -9999 -9999 -9999 -9999 -9999 -9999 -9999 -9999 -9999 -9999 - 9999 -9999 -9999 -9999 -9999 -9999 -9999 -9999 -9999 -9999 -9999 -9999 -9999 -9999 -9999 -9999 -9999 -9999 -9999 -9999 -9999 -9999 -9999 -9999 -9999 -9999 -9999 -9999 -9999 -9999 -9999 -9999 -9999 -9999 -9999 -9999 -9999 -9999 -9999 -9999 -9999 -9999 -9999 -9999 -9999 -9999 -9999 -9999 -9999 -9999 -9999 -9999 -9999 -9999 -9999 -9999 -9999 -9999 -9999 -9999 -9999

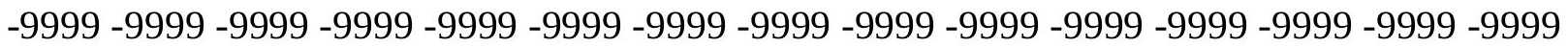
-9999 -9999 -9999 -9999 -9999 -9999 -9999 -9999 -9999 -9999 -9999 -9999 -9999 -9999 -9999 -9999 -9999 -9999 -9999 -9999 -9999 -9999 -9999 -9999 -9999 -9999 -9999 -9999 -9999 -9999

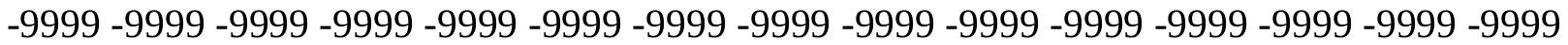
-9999 -9999 -9999 -9999 -9999 -9999 -9999 -9999 -9999 -9999 -9999 -9999 -9999 -9999 -9999 -9999 -9999 -9999 -9999 -9999 -9999 -9999 -9999 -9999 -9999 -9999 -9999 -9999 -9999 -9999 -

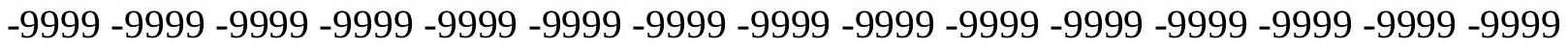
-9999 -9999 -9999 -9999 -9999 -9999 -9999 -9999 -9999 -9999 -9999 -9999 -9999 -9999 -9999

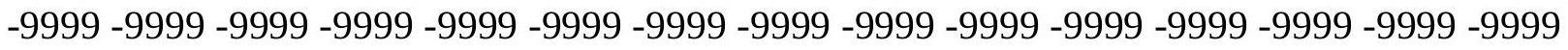
-9999 -9999 -9999 -9999 -9999 -9999 -9999 -9999 -9999 -9999 -9999 -9999 -9999 -9999 -9999 -9999 -9999 -9999 -9999 -9999 -9999 -9999 -9999 -9999 -9999 -9999 -9999 -9999 -9999 - -999 -9999 -9999 -9999 -9999 -9999 -9999 -9999 -9999 -9999 -9999 -9999 -9999 -9999 -9999 -9999 -9999 -9999 -9999 -9999 -9999 -9999 -9999 -9999 -9999 -9999 -9999 -9999 -9999 -9999 -9999 -9999 -9999 -9999 -9999 -9999 -9999 -9999 -9999 -9999 -9999 -9999 -9999 -9999 -9999 -9999 -999 -9999 -9999 -9999 -9999 -9999 -9999 -9999 -9999 -9999 -9999 -9999 -9999 -9999 -9999 -9999 -9999 -9999 -9999 -9999 -9999 -9999 -9999 -9999 -9999 -9999 -9999 -9999 -9999 -9999 -9999 -9999 -9999 -9999 -9999 -9999 -9999 -9999 -9999 -9999 -9999 -9999 -9999 -9999 -9999 -9999 -9999 -9999 -9999 -9999 -9999 -9999 -9999 -9999 -9999 -9999 -9999 -9999 -9999 -9999 -9999 -9999 -9999 -9999 -9999 -9999 -9999 -9999 -9999 -9999 -9999 -9999 -9999 -9999 -9999 -9999 -9999 -9999 -9999 -9999 -9999 -9999 -9999 -9999 -9999 -9999 -9999 -9999 -9999 -9999 -9999 -9999 -9999 -9999 -9999 -9999 -9999 -9999 -9999 -9999 -9999 -9999 -9999 -9999 -9999 -9999 -9999 -9999 -9999 -9999 -9999 -9999 -9999 -9999 -9999 -9999 -9999 -9999 -9999 -9999 -9999 -9999 -9999 -9999 -9999 -9999 -9999 -9999 -9999 -9999 -9999 -9999 -9999 -9999 -9999 -999 -9999 -9999 -9999 -9999 -9999 -9999 -9999 -9999 -9999 -9999 -9999 -9999 -9999 -9999 -9999 -9999 -9999 -9999 -9999 -9999 -9999 -9999 -9999 -9999 -9999 -9999 -9999 -9999 -9999 -9999 -

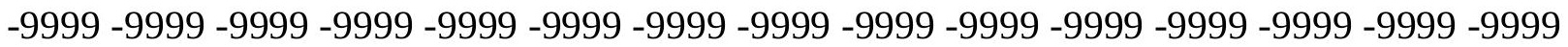

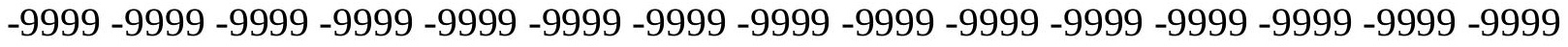

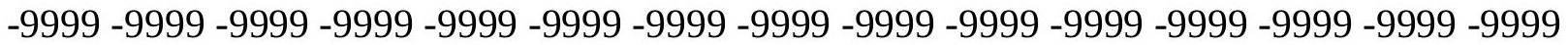
-9999 -9999 -9999 -9999 -9999 -9999 -9999 -9999 -9999 -9999 -9999 -9999 -9999 -9999 -9999

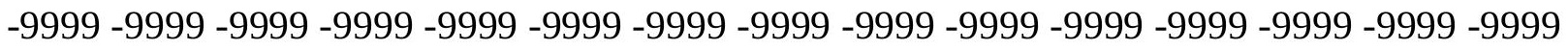

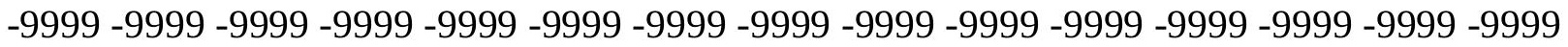

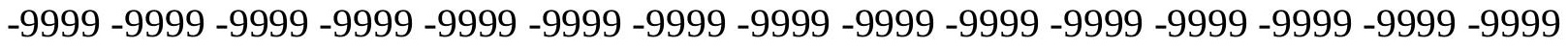
-9999 -9999 -9999 -9999 -9999 -9999 -9999 -9999 -9999 -9999 -9999 -9999 -9999 -9999 -9999 -

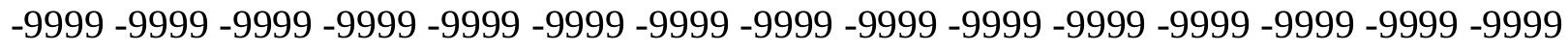

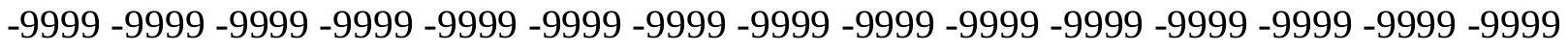
-9999 -9999 -9999 -9999 -9999 -9999 -9999 -9999 -9999 -9999 -9999 -9999 -9999 -9999 -9999 -9999 -9999 -9999 -9999 -9999 -9999 -9999 -9999 -9999 -9999 -9999 -9999 -9999 - -9999 -9999 -9999 -9999 -9999 -9999 -9999 -9999 -9999 -9999 -9999 -9999 -9999 -9999 -9999 -9999 -

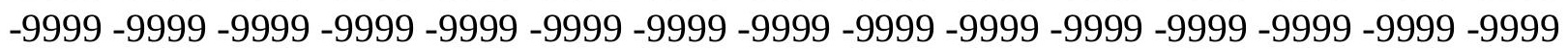


-9999 -9999 -9999 -9999 -9999 -9999 -9999 -9999 -9999 -9999 -9999 -9999 -9999 -9999 -9999 -9999 -9999 -9999 -9999 -9999 -9999 -9999 -9999 -9999 -9999 -9999 -9999 -9999 -9999 -9999 -9999 -9999 -9999 -9999 -9999 -9999 -9999 -9999 -9999 -9999 -9999 -9999 -9999 -9999 - 9999 -9999 -9999 -9999 -9999 -9999 -9999 -9999 -9999 -9999 -9999 -9999 -9999 -9999 -9999 -9999 -9999 -9999 -9999 -9999 -9999 -9999 -9999 -9999 -9999-9999 -9999 -9999 -9999 -9999 -9999 -9999 -9999 -9999 -9999 -9999 -9999 -9999 -9999 -9999 -9999 -9999 -9999 -9999 -9999 -9999 -9999 -9999 -9999 -9999 -9999 -9999 -9999 -9999 -9999 -9999 -9999 -9999 -9999 -9999 -9999

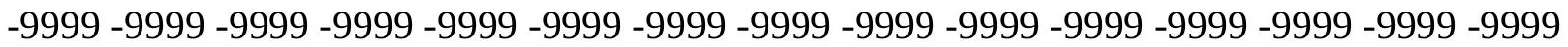

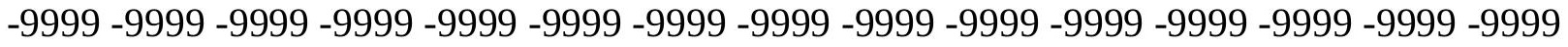
-9999 -9999 -9999 -9999 -9999 -9999 -9999 -9999 -9999 -9999 -9999 -9999 -9999 -9999 -9999

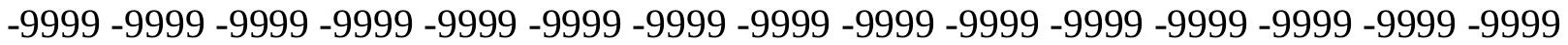
-9999 -9999 -9999 -9999 -9999 -9999 -9999 -9999 -9999 -9999 -9999 -9999 -9999 -9999 -9999 -9999 -9999 -9999 -9999 -9999 -9999 -9999 -9999 -9999 -9999 -9999 -9999 -9999 -9999 -9999 -

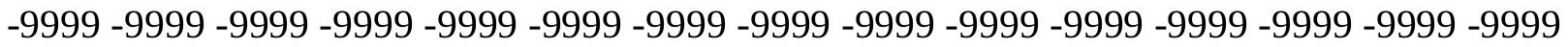
-9999 -9999 -9999 -9999 -9999 -9999 -9999 -9999 -9999 -9999 -9999 -9999 -9999 -9999 -9999

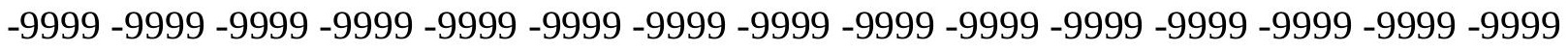
-9999 -9999 -9999 -9999 -9999 -9999 -9999 -9999 -9999 -9999 -9999 -9999 -9999 -9999 -9999 -9999 -9999 -9999 -9999 -9999 -9999 -9999 -9999 -9999 -9999 -9999 -9999 -9999 -9999 -9999 -9999 -9999 -9999 -9999 -9999 -9999 -9999 -9999 -9999 -9999 -9999 -9999 -9999 -9999 -9999 -9999 -9999 -9999 -9999 -9999 -9999 -9999 -9999 -9999 -9999 -9999 -9999 -9999 -9999 -9999 -9999 -9999 -9999 -9999 -9999 -9999 -9999 -9999 -9999 -9999 -9999 -9999 -9999 -9999 -9999 -999 -9999 -9999 -9999 -9999 -9999 -9999 -9999 -9999 -9999 -9999 -9999 -9999 -9999 -9999 -9999 -9999 -9999 -9999 -9999 -9999 -9999 -9999 -9999 -9999 -9999 -9999 -9999 -9999 -9999 -9999 -9999 -9999 -9999 -9999 -9999 -9999 -9999 -9999 -9999 -9999 -9999 -9999 -9999 -9999 -9999 -9999 -9999 -9999 -9999 -9999 -9999 -9999 -9999 -9999 -9999 -9999 -9999 -9999 -9999 -9999 -9999 -9999 -9999 -9999 -9999 -9999 -9999 -9999 -9999 -9999 -9999 -9999 -9999 -9999 -9999 -9999 -9999 -9999 -9999 -9999 -9999 -9999 -9999 -9999 -9999 -9999 -9999 -9999 -9999 -9999 -9999 -9999 -9999 -9999 -9999 -9999 -9999 -9999 -9999 -9999 -9999 -9999 -9999 -9999 -9999 -9999 -9999 -9999 -9999 -9999 -9999 -9999 -9999 -9999 -9999 -9999 -9999 -9999 -9999 -9999 -9999 -9999 -9999 -9999 -9999 -9999 -9999 -9999 -9999 -9999 -9999 -9999 -9999 -999 -9999 -9999 -9999 -9999 -9999 -9999 -9999 -9999 -9999 -9999 -9999 -9999 -9999 -9999 -9999 -9999 -9999 -9999 -9999 -9999 -9999 -9999 -9999 -9999 -9999 -9999 -9999 -9999 -9999 -9999 -

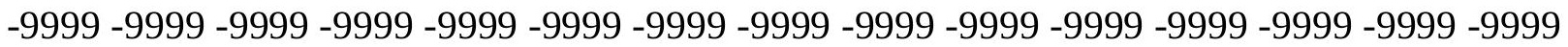

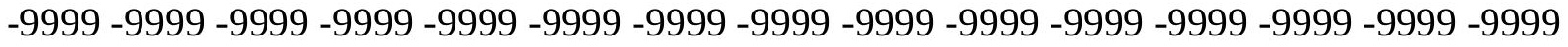

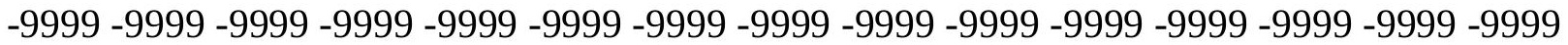
-9999 -9999 -9999 -9999 -9999 -9999 -9999 -9999 -9999 -9999 -9999 -9999 -9999 -9999 -9999

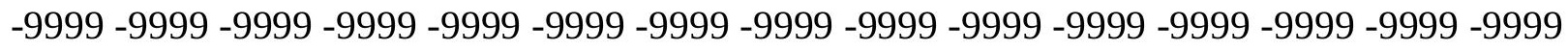

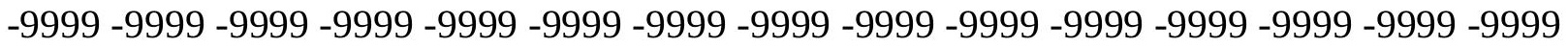
-9999 -9999 -9999 -9999 -9999 -9999 -9999 -9999 -9999 -9999 -9999 -9999 -9999 -9999 -9999 -9999 -9999 -9999 -9999 -9999 -9999 -9999 -9999 -9999 -9999 -9999 -9999 -9999 -9999 -9999 -

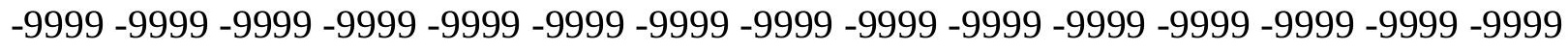

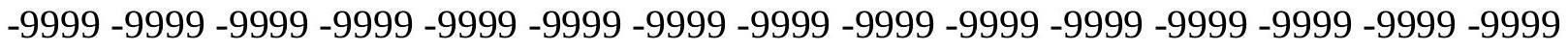
-9999 -9999 -9999 -9999 -9999 -9999 -9999 -9999 -9999 -9999 -9999 -9999 -9999 -9999 -9999 -9999 -9999 -9999 -9999 -9999 -9999 -9999 -9999 -9999-9999 -9999 -9999 -9999 -9999 -9999 -9999 -9999 -9999 -9999 -9999 -9999 -9999 -9999 -9999 -9999 -9999 -9999 -9999 -9999 -9999 -

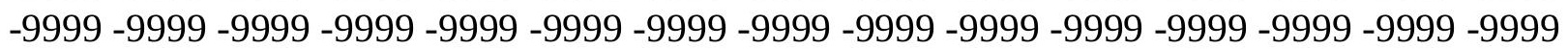


-9999 -9999 -9999 -9999 -9999 -9999 -9999 -9999 -9999 -9999 -9999 -9999 -9999 -9999 -9999 -9999 -9999 -9999 -9999 -9999 -9999 -9999 -9999 -9999 -9999 -9999 -9999 -9999 -9999 -9999 -9999 -9999 -9999 -9999 -9999 -9999 -9999 -9999 -9999 -9999 -9999 -9999 -9999 -9999 - 9999 -9999 -9999 -9999 -9999 -9999 -9999 -9999 -9999 -9999 -9999 -9999 -9999 -9999 -9999

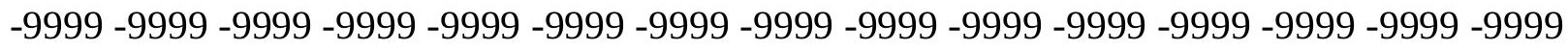
-9999 -9999 -9999 -9999 -9999 -9999 -9999 -9999 -9999 -9999 -9999 -9999 -9999 -9999 -9999 -9999 -9999 -9999 -9999 -9999 -9999 -9999 -9999 -9999 -9999 -9999 -9999 -9999 -9999 -9999

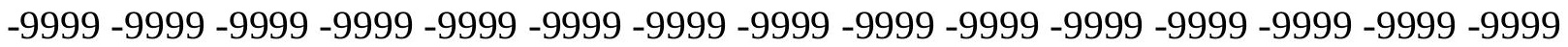

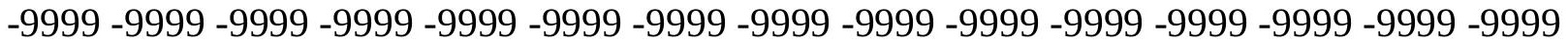
-9999 -9999 -9999 -9999 -9999 -9999 -9999 -9999 -9999 -9999 -9999 -9999 -9999 -9999 -9999 -9999 -9999 -9999 -9999 -9999 -9999 -9999 -9999 -9999 -9999 -9999 -9999 -9999 -9999 -9999 -9999 -9999 -9999 -9999 -9999 -9999 -9999 -9999 -9999 -9999 -9999 -9999 -9999 -9999 -9999 -9999 -9999 -9999 -9999 -9999 -9999 -9999 -9999 -9999 -9999 -9999 -9999 -9999 -9999 -9999 -

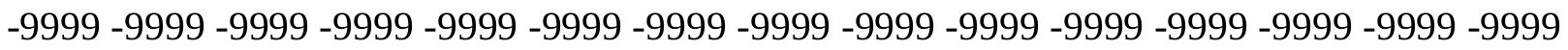
-9999 -9999 -9999 -9999 -9999 -9999 -9999 -9999 -9999 -9999 -9999 -9999 -9999 -9999 -9999 -

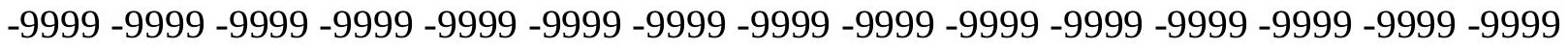
-9999 -9999 -9999 -9999 -9999 -9999 -9999 -9999 -9999 -9999 -9999 -9999 -9999 -9999 -9999 -9999 -9999 -9999 -9999 -9999 -9999 -9999 -9999 -9999 -9999 -9999 -9999 -9999 -9999 -9999 -9999 -9999 -9999 -9999 -9999 -9999 -9999 -9999 -9999 -9999 -9999 -9999 -9999 -9999 -9999 -

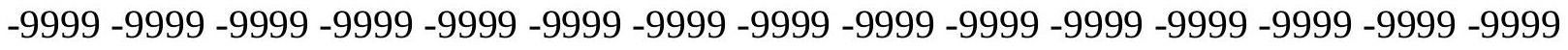
-9999 -9999 -9999 -9999 -9999 -9999 -9999 -9999 -9999 -9999 -9999 -9999 -9999 -9999 -9999

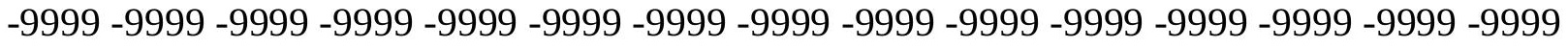
-9999 -9999 -9999 -9999 -9999 -9999 -9999 -9999 -9999 -9999 -9999 -9999 -9999 -9999 -9999 -9999 -9999 -9999 -9999 -9999 -9999 -9999 -9999 -9999 -9999 -9999 -9999 -9999 -9999 -9999 -9999 -9999 -9999 -9999 -9999 -9999 -9999 -9999 -9999 -9999 -9999 -9999 -9999 -9999 -9999 -9999 -9999 -9999 -9999 -9999 -9999 -9999 -9999 -9999 -9999 -9999 -9999 -9999 -9999 -9999 -9999 -9999 -9999 -9999 -9999 -9999 -9999 -9999 -9999 -9999 -9999 -9999 -9999 -9999 -9999 -9999 -9999 -9999 -9999 -9999 -9999 -9999 -9999 -9999 -9999 -9999 -9999 -9999 -9999 -9999 -9999 -9999 -9999 -9999 -9999 -9999 -9999 -9999 -9999 -9999 -9999 -9999 -9999 -9999 -9999 -9999 -9999 -9999 -9999 -9999 -9999 -9999 -9999 -9999 -9999 -9999 -9999 -9999 -9999 -9999 -9999 -9999 -9999 -9999 -9999 -9999 -9999 -9999 -9999 -9999 -9999 -9999 -9999 -9999 -9999 -9999 -9999 -9999 -9999 -9999 -9999 -9999 -9999 -9999 -9999 -9999 -9999 -9999 -9999 -

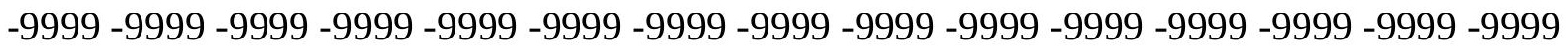

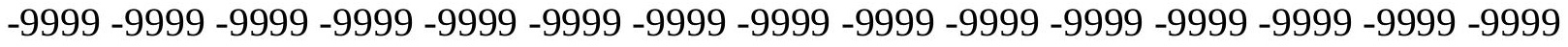
-9999 -9999 -9999 -9999 -9999 -9999 -9999 -9999 -9999 -9999 -9999 -9999 -9999 -9999 -9999 -

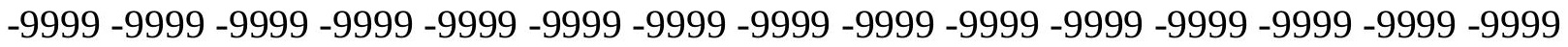

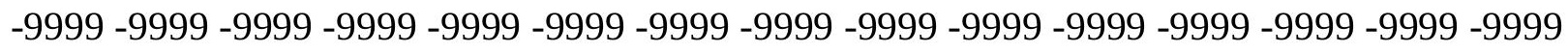

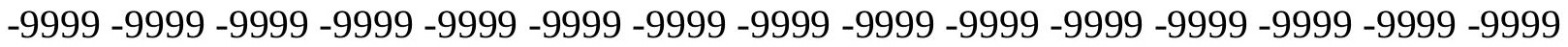

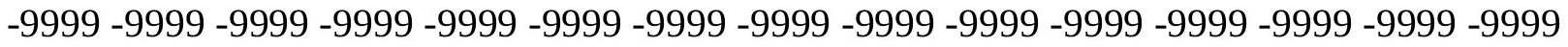
-9999 -9999 -9999 -9999 -9999 -9999 -9999 -9999 -9999 -9999 -9999 -9999 -9999 -9999 -9999 -

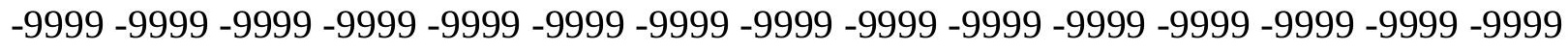

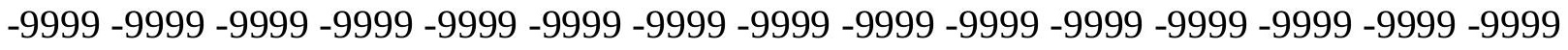
-9999 -9999 -9999 -9999 -9999 -9999 -9999 -9999 -9999 -9999 -9999 -9999 -9999 -9999 -9999 -9999 -9999 -9999 -9999 -9999 -9999 -9999 -9999 -9999-9999 -9999 -9999 -9999 -9999 -9999 -9999 -9999 -9999 -9999 -9999 -9999 -9999 -9999 -9999 -9999 -9999 -9999 -9999 -9999 -9999 -

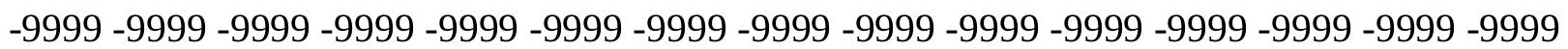


-9999 -9999 -9999 -9999 -9999 -9999 -9999 -9999 -9999 -9999 -9999 -9999 -9999 -9999 -9999 -9999 -9999 -9999 -9999 -9999 -9999 -9999 -9999 -9999 -9999 -9999 -9999 -9999 -9999 -9999 -9999 -9999 -9999 -9999 -9999 -9999 -9999 -9999 -9999 -9999 -9999 -9999 -9999 -9999 - 9999 -9999 -9999 -9999 -9999 -9999 -9999 -9999 -9999 -9999 -9999 -9999 -9999 -9999 -9999 -9999 -9999 -9999 -9999 -9999 -9999 -9999 -9999 -9999 -9999 -9999 -9999 -9999 -9999 -9999 -9999 -9999 -9999 -9999 -9999 -9999 -9999 -9999 -9999 -9999 -9999 -9999 -9999 -9999 -9999 -9999 -9999 -9999 -9999 -9999 -9999 -9999 -9999 -9999 -9999 -9999 -9999 -9999 -9999 -9999 -9999

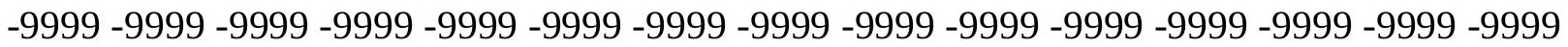

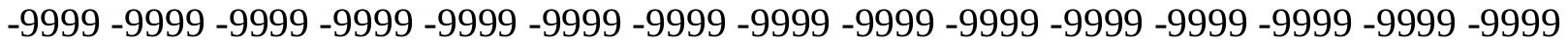
-9999 -9999 -9999 -9999 -9999 -9999 -9999 -9999 -9999 -9999 -9999 -9999 -9999 -9999 -9999 -9999 -9999 -9999 -9999 -9999 -9999 -9999 -9999 -9999 -9999 -9999 -9999 -9999 -9999 -9999 -9999 -9999 -9999 -9999 -9999 -9999 -9999 -9999 -9999 -9999 -9999 -9999 -9999 -9999 -9999 -9999 -9999 -9999 -9999 -9999 -9999 -9999 -9999 -9999 -9999 -9999 -9999 -9999 -9999 -9999 -9999 -9999 -9999 -9999 -9999 -9999 -9999 -9999 -9999 -9999 -9999 -9999 -9999 -9999 -9999 -9999 -9999 -9999 -9999 -9999 -9999 -9999 -9999 -9999 -9999 -9999 -9999 -9999 -9999 -

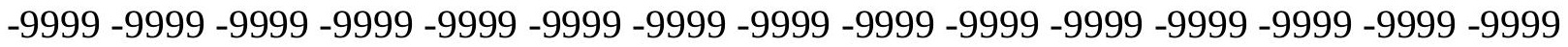
-9999 -9999 -9999 -9999 -9999 -9999 -9999 -9999 -9999 -9999 -9999 -9999 -9999 -9999 -9999 -9999 -9999 -9999 -9999 -9999 -9999 -9999 -9999 -9999 -9999 -9999 -9999 -9999 -9999 -9999 -9999 -9999 -9999 -9999 -9999 -9999 -9999 -9999 -9999 -9999 -9999 -9999 -9999 -9999 -9999 -9999 -9999 -9999 -9999 -9999 -9999 -9999 -9999 -9999 -9999 -9999 -9999 -9999 -9999 -9999 -9999 -9999 -9999 -9999 -9999 -9999 -9999 -9999 -9999 -9999 -9999 -9999 -9999 -9999 -9999 -999 -9999 -9999 -9999 -9999 -9999 -9999 -9999 -9999 -9999 -9999 -9999 -9999 -9999 -9999 -9999 -9999 -9999 -9999 -9999 -9999 -9999 -9999 -9999 -9999 -9999 -9999 -9999 -9999 -9999 -9999 -9999 -9999 -9999 -9999 -9999 -9999 -9999 -9999 -9999 -9999 -9999 -9999 -9999 -9999 -9999 -9999 -9999 -9999 -9999 -9999 -9999 -9999 -9999 -9999 -9999 -9999 -9999 -9999 -9999 -9999 -9999 -9999 -9999 -9999 -9999 -9999 -9999 -9999 -9999 -9999 -9999 -9999 -9999 -9999 -9999 -9999 -9999 -9999 -9999 -9999 -9999 -9999 -9999 -9999 -9999 -9999 -9999 -9999 -9999 -9999 -9999 -9999 -9999 -9999 -9999 -9999 -9999 -9999 -9999 -9999 -9999 -9999 -9999 -9999 -9999 -9999 -9999 -9999 -9999 -9999 -9999 -9999 -9999 -9999 -9999 -9999 -9999 -9999 -9999 -9999 -9999 -9999 -9999 -9999 -9999 -9999 -9999 -9999 -9999 -9999 -9999 -9999 -9999 -9999 -999 -9999 -9999 -9999 -9999 -9999 -9999 -9999 -9999 -9999 -9999 -9999 -9999 -9999 -9999 -9999 -9999 -9999 -9999 -9999 -9999 -9999 -9999 -9999 -9999 -9999 -9999 -9999 -9999 -9999 -9999 -

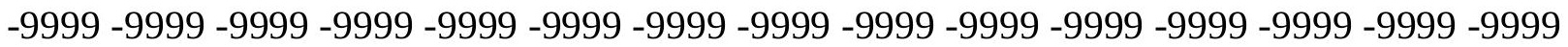

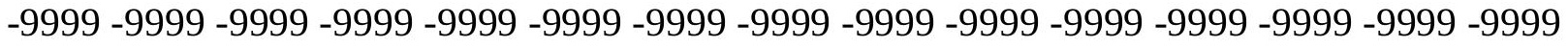

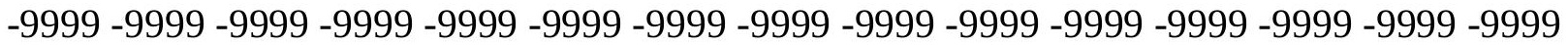
-9999 -9999 -9999 -9999 -9999 -9999 -9999 -9999 -9999 -9999 -9999 -9999 -9999 -9999 -9999 -9999 -9999 -9999 -9999 -9999 -9999 -9999 -9999 -9999 -9999 -9999 -9999 -9999 -9999 -

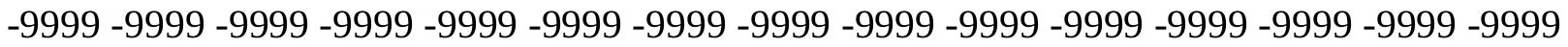
-9999 -9999 -9999 -9999 -9999 -9999 -9999 -9999 -9999 -9999 -9999 -9999 -9999 -9999 -9999 -9999 -9999 -9999 -9999 -9999 -9999 -9999 -9999 -9999 -9999 -9999 -9999 -9999 -9999 -9999 -

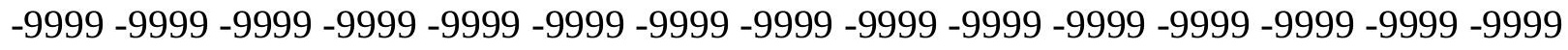

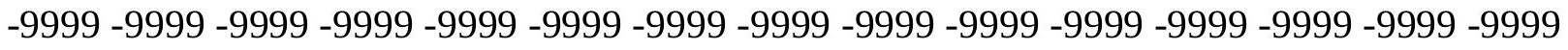
-9999 -9999 -9999 -9999 -9999 -9999 -9999 -9999 -9999 -9999 -9999 -9999 -9999 -9999 -9999 -9999 -9999 -9999 -9999 -9999 -9999 -9999 -9999 -9999-9999 -9999 -9999 -9999 -9999 -9999 -9999 -9999 -9999 -9999 -9999 -9999 -9999 -9999 -9999 -9999 -9999 -9999 -9999 -9999 -9999 -

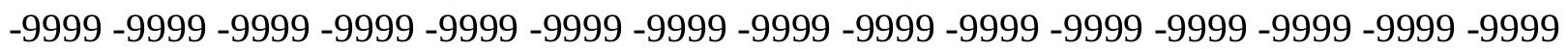


-9999 -9999 -9999 -9999 -9999 -9999 -9999 -9999 -9999 -9999 -9999 -9999 -9999 -9999 -9999 -9999 -9999 -9999 -9999 -9999 -9999 -9999 -9999 -9999 -9999 -9999 -9999 -9999 -9999 -9999 -

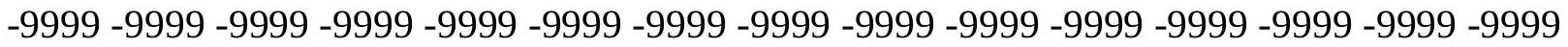
-9999 -9999 -9999 -9999 -9999 -9999 -9999 -9999 -9999 -9999 -9999 -9999 -9999 -9999 -9999 -9999 -9999 -9999 -9999 -9999 -9999 -9999 -9999 -9999-9999 -9999 -9999 -9999 -9999 -9999 -9999 -9999 -9999 -9999 -9999 -9999 -9999 -9999 -9999 -9999 -9999 -9999 -9999 -9999 -9999 -9999 -9999 -9999 -9999 -9999 -9999 -9999 -9999 -9999 -9999 -9999 -9999 -9999 -9999 -9999

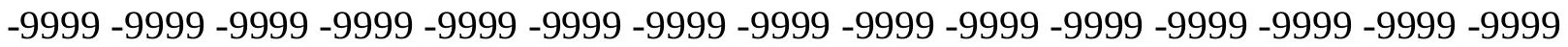

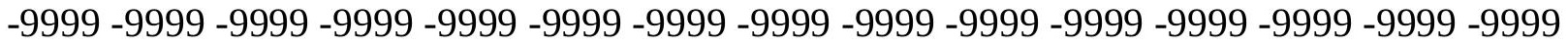
-9999 -9999 -9999 -9999 -9999 -9999 -9999 -9999 -9999 -9999 -9999 -9999 -9999 -9999 -9999 -9999 -9999 -9999 -9999 -9999 -9999 -9999 -9999 -9999 -9999 -9999 -9999 -9999 -9999 -9999 -9999 -9999 -9999 -9999 -9999 -9999 -9999 -9999 -9999 -9999 -9999 -9999 -9999 -9999 -9999 -9999 -9999 -9999 -9999 -9999 -9999 -9999 -9999 -9999 -9999 -9999 -9999 -9999 -9999 -9999 -9999 -9999 -9999 -9999 -9999 -9999 -9999 -9999 -9999 -9999 -9999 -9999 -9999 -9999 -9999 -9999 -9999 -9999 -9999 -9999 -9999 -9999 -9999 -9999 -9999 -9999 -9999 -9999 -9999 -9999 -

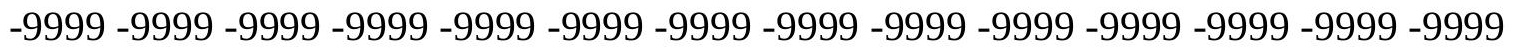
-9999 -9999 -9999 -9999 -9999 -9999 -9999 -9999 -9999 -9999 -9999 -9999 -9999 -9999 -9999 -9999 -9999 -9999 -9999 -9999 -9999 -9999 -9999 -9999 -9999 -9999 -9999 -9999 -9999 -9999 -9999 -9999 -9999 -9999 -9999 -9999 -9999 -9999 -9999 -9999 -9999 -9999 -9999 -9999 -9999 -

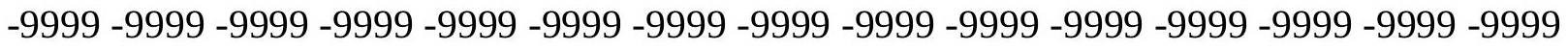

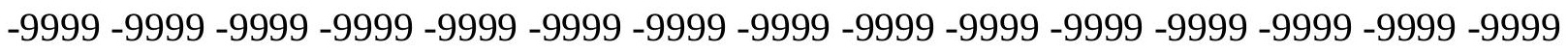
-9999 -9999 -9999 -9999 -9999 -9999 -9999 -9999 -9999 -9999 -9999 -9999 -9999 -9999 - 9999 -9999 -9999 -9999 -9999 -9999 -9999 -9999 -9999 -9999 -9999 -9999 -9999 -9999 -9999 -9999 -9999 -9999 -9999 -9999 -9999 -9999 -9999 -9999 -9999 -9999 -9999 -9999 -9999 -9999 -9999 -

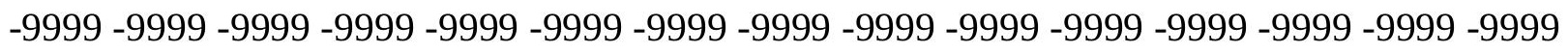
-9999 -9999 -9999 -9999 -9999 -9999 -9999 -9999 -9999 -9999 -9999 -9999 -9999 -9999 -9999 -9999 -9999 -9999 -9999 -9999 -9999 -9999 -9999 -9999 -9999 -9999 -9999 -9999 -9999 -9999 -

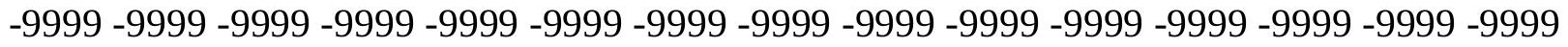
-9999 -9999 -9999 -9999 -9999 -9999 -9999 -9999 -9999 -9999 -9999 -9999 -9999 -9999 -9999 -9999 -9999 -9999 -9999 -9999 -9999 -9999 -9999 -9999 -9999 -9999 -9999 -9999 -9999 -999 -

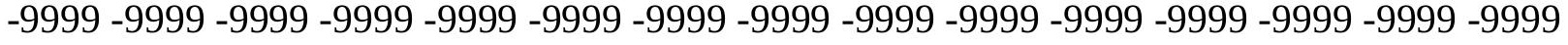
-9999 -9999 -9999 -9999 -9999 -9999 -9999 -9999 -9999 -9999 -9999 -9999 -9999 -9999 -9999 -

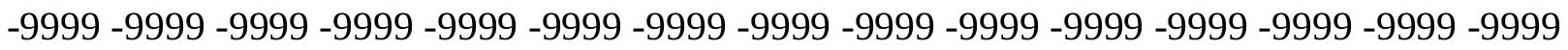

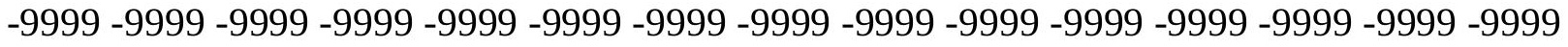

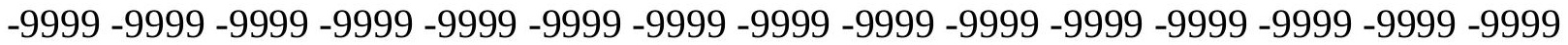
-9999 -9999 -9999 -9999 -9999 -9999 -9999 -9999 -9999 -9999 -9999 -9999 -9999 -9999 -9999 -

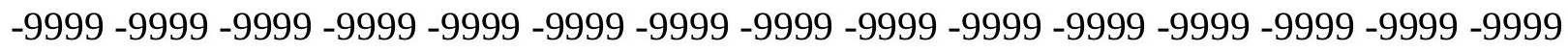

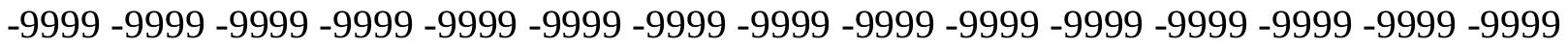
-9999 -9999 -9999 -9999 -9999 -9999 -9999 -9999 -9999 -9999 -9999 -9999 -9999 - 9999 - -999 -9999 -9999 -9999 -9999 -9999 -9999 -9999 -9999 -9999 -9999 -9999 -9999 -9999 -9999 -9999 -

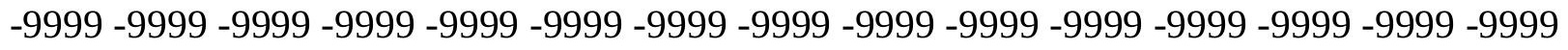

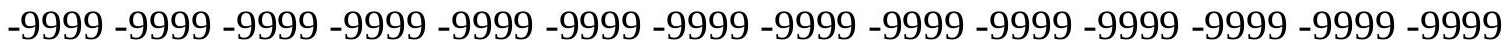
-9999 -9999 -9999 -9999 -9999 -9999 -9999 -9999 -9999 -9999 -9999 -9999 -9999 -9999 -9999 -9999 -9999 -9999 -9999 -9999 -9999 -9999 -9999 -9999-9999 -9999 -9999 -9999 -9999 -9999 -9999 -9999 -9999 -9999 -9999 -9999 -9999 -9999 -9999 -9999 -9999 -9999 -9999 -9999 -9999 -

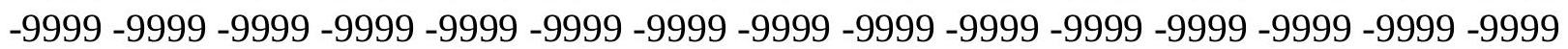


-9999 -9999 -9999 -9999 -9999 -9999 -9999 -9999 -9999 -9999 -9999 -9999 -9999 -9999 -9999 -9999 -9999 -9999 -9999 -9999 -9999 -9999 -9999 -9999 -9999 -9999 -9999 -9999 -9999 -9999 -

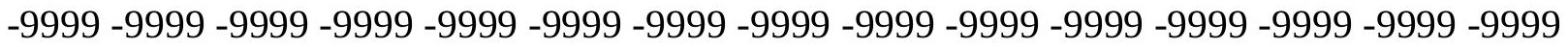
-9999 -9999 -9999 -9999 -9999 -9999 -9999 -9999 -9999 -9999 -9999 -9999 -9999 -9999 -9999 -9999 -9999 -9999 -9999 -9999 -9999 -9999 -9999 -9999-9999 -9999 -9999 -9999 -9999 -9999 -9999 -9999 -9999 -9999 -9999 -9999 -9999 -9999 -9999 -9999 -9999 -9999 -9999 -9999 -9999 -9999 -9999 -9999 -9999 -9999 -9999 -9999 -9999 -9999 -9999 -9999 -9999 -9999 -9999 -9999

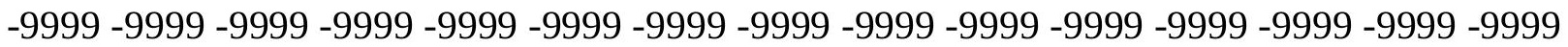

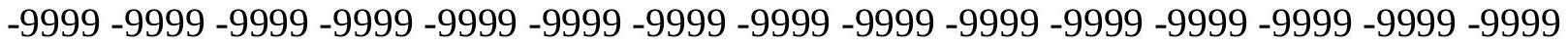
-9999 -9999 -9999 -9999 -9999 -9999 -9999 -9999 -9999 -9999 -9999 -9999 -9999 -9999 -9999 -9999 -9999 -9999 -9999 -9999 -9999 -9999 -9999 -9999 -9999 -9999 -9999 -9999 -9999 -9999 -9999 -9999 -9999 -9999 -9999 -9999 -9999 -9999 -9999 -9999 -9999 -9999 -9999 -9999 -9999 -9999 -9999 -9999 -9999 -9999 -9999 -9999 -9999 -9999 -9999 -9999 -9999 -9999 -9999 -9999 -

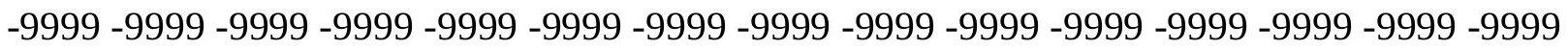
-9999 -9999 -9999 -9999 -9999 -9999 -9999 -9999 -9999 -9999 -9999 -9999 -9999 -9999 -9999 -

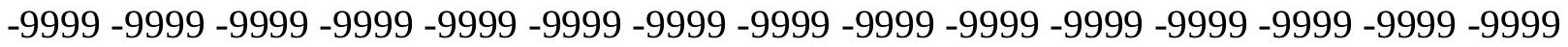
-9999 -9999 -9999 -9999 -9999 -9999 -9999 -9999 -9999 -9999 -9999 -9999 -9999 -9999 -9999 -9999 -9999 -9999 -9999 -9999 -9999 -9999 -9999 -9999 -9999 -9999 -9999 -9999 -9999 -9999 -9999 -9999 -9999 -9999 -9999 -9999 -9999 -9999 -9999 -9999 -9999 -9999 -9999 -9999 -9999 -

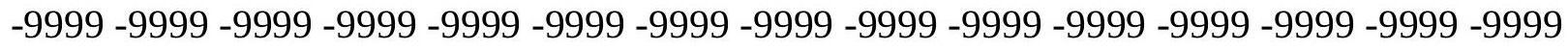

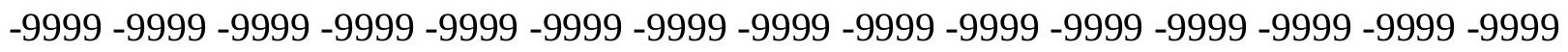
-9999 -9999 -9999 -9999 -9999 -9999 -9999 -9999 -9999 -9999 -9999 -9999 -9999 -9999 -9999 -9999 -9999 -9999 -9999 -9999 -9999 -9999 -9999 -9999 -9999 -9999 -9999 -9999 -9999 -9999 -9999 -9999 -9999 -9999 -9999 -9999 -9999 -9999 -9999 -9999 -9999 -9999 -9999 -9999 -

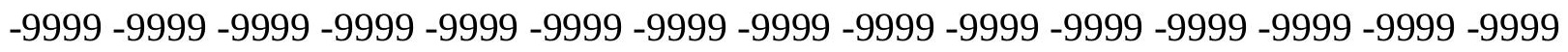
-9999 -9999 -9999 -9999 -9999 -9999 -9999 -9999 -9999 -9999 -9999 -9999 -9999 -9999 -9999 -9999 -9999 -9999 -9999 -9999 -9999 -9999 -9999 -9999 -9999 -9999 -9999 -9999 -9999 -9999 -

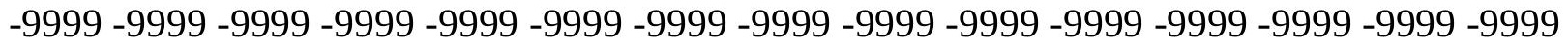
-9999 -9999 -9999 -9999 -9999 -9999 -9999 -9999 -9999 -9999 -9999 -9999 -9999 -9999 -9999 -9999 -9999 -9999 -9999 -9999 -9999 -9999 -9999 -9999 -9999 -9999 -9999 -9999 -9999 -999 -

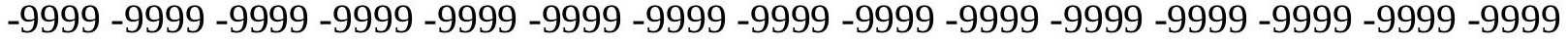
-9999 -9999 -9999 -9999 -9999 -9999 -9999 -9999 -9999 -9999 -9999 -9999 -9999 -9999 -9999 -

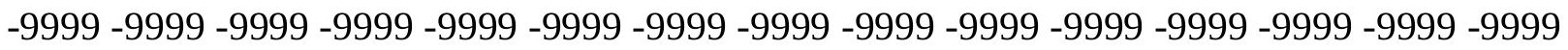

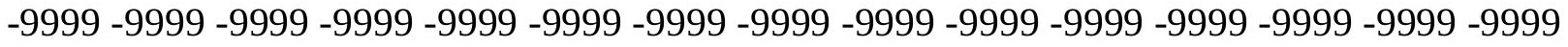

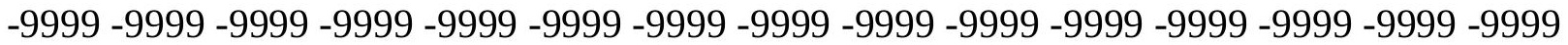

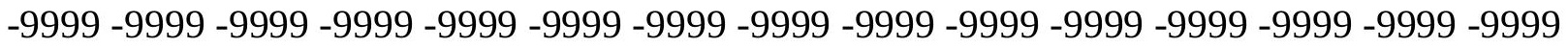

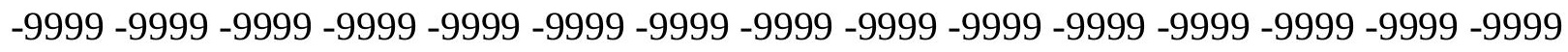

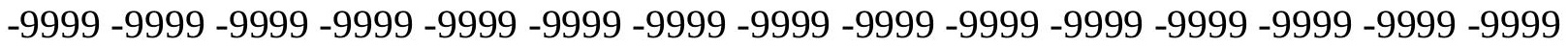

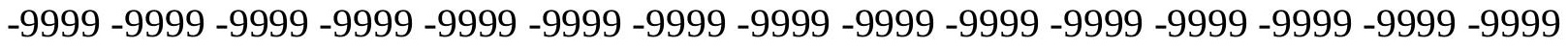
-9999 -9999 -9999 -9999 -9999 -9999 -9999 -9999 -9999 -9999 -9999 -9999 -9999 -9999 -9999 -

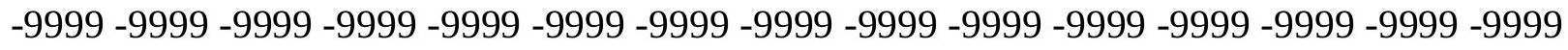

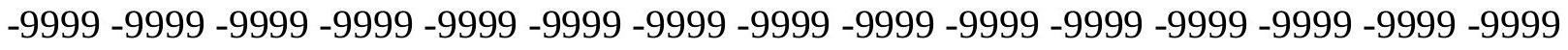
-9999 -9999 -9999 -9999 -9999 -9999 -9999 -9999 -9999 -9999 -9999 -9999 -9999 -9999 -9999 -9999 -9999 -9999 -9999 -9999 -9999 -9999 -9999 -9999-9999 -9999 -9999 -9999 -9999 -9999 -9999 -9999 -9999 -9999 -9999 -9999 -9999 -9999 -9999 -9999 -9999 -9999 -9999 -9999 -9999 -

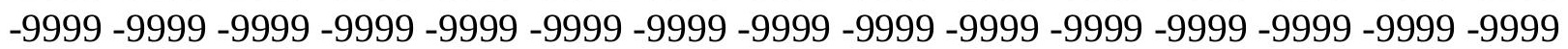


-9999 -9999 -9999 -9999 -9999 -9999 -9999 -9999 -9999 -9999 -9999 -9999 -9999 -9999 -9999 -9999 -9999 -9999 -9999 -9999 -9999 -9999 -9999 -9999 -9999 -9999 -9999 -9999 -9999 -

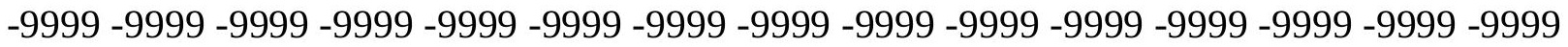
-9999 -9999 -9999 -9999 -9999 -9999 -9999 -9999 -9999 -9999 -9999 -9999 -9999 -9999 -9999 -9999 -9999 -9999 -9999 -9999 -9999 -9999 -9999 -9999 -9999 -9999 -9999 -9999 -9999 -9999 -9999 -9999 -9999 -9999 -9999 -9999 -9999 -9999 -9999 -9999 -9999 -9999 -9999 -9999 -9999 -9999 -9999 -9999 -9999 -9999 -9999 -9999 -9999 -9999 -9999 -9999 -9999 -9999 -9999 -9999

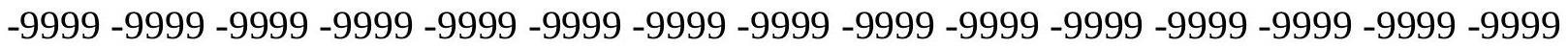

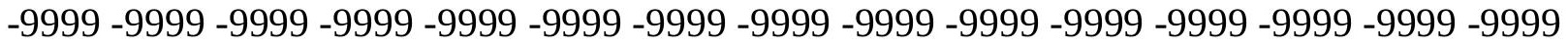
-9999 -9999 -9999 -9999 -9999 -9999 -9999 -9999 -9999 -9999 -9999 -9999 -9999 -9999 -9999 -9999 -9999 -9999 -9999 -9999 -9999 -9999 -9999 -9999 -9999 -9999 -9999 -9999 -9999 -9999 -9999 -9999 -9999 -9999 -9999 -9999 -9999 -9999 -9999 -9999 -9999 -9999 -9999 -9999 -9999 -9999 -9999 -9999 -9999 -9999 -9999 -9999 -9999 -9999 -9999 -9999 -9999 -9999 -9999 -9999 -9999 -9999 -9999 -9999 -9999 -9999 -9999 -9999 -9999 -9999 -9999 -9999 -9999 -9999 -9999 -9999 -9999 -9999 -9999 -9999 -9999 -9999 -9999 -9999 -9999 -9999 -9999 -9999 -9999 -9999 -

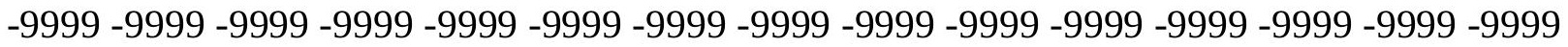
-9999 -9999 -9999 -9999 -9999 -9999 -9999 -9999 -9999 -9999 -9999 -9999 -9999 -9999 -9999 -9999 -9999 -9999 -9999 -9999 -9999 -9999 -9999 -9999 -9999 -9999 -9999 -9999 -9999 - 9999 -9999 -9999 -9999 -9999 -9999 -9999 -9999 -9999 -9999 -9999 -9999 -9999 -9999 -9999 -9999 -

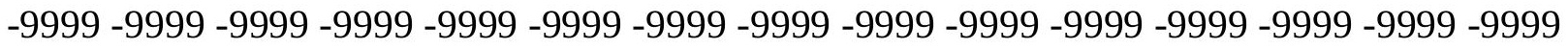

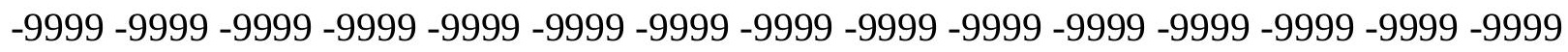

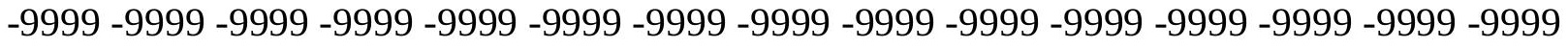
-9999 -9999 -9999 -9999 -9999 -9999 -9999 -9999 -9999 -9999 -9999 -9999 -9999 -9999 -9999 -9999 -9999 -9999 -9999 -9999 -9999 -9999 -9999 -9999 -9999 -9999 -9999 -9999 -9999 -9999 -

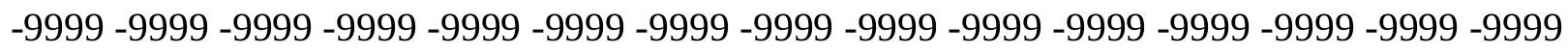
-9999 -9999 -9999 -9999 -9999 -9999 -9999 -9999 -9999 -9999 -9999 -9999 -9999 -9999 -9999 -9999 -9999 -9999 -9999 -9999 -9999 -9999 -9999 -9999 -9999 -9999 -9999 -9999 -9999 -9999 -9999 -9999 -9999 -9999 -9999 -9999 -9999 -9999 -9999 -9999 -9999 -9999 -9999 -9999 -9999 -9999 -9999 -9999 -9999 -9999 -9999 -9999 -9999 -9999 -9999 -9999 -9999 -9999 -9999 -9999 -9999 -9999 -9999 -9999 -9999 -9999 -9999 -9999 -9999 -9999 -9999 -9999 -9999 -999 -

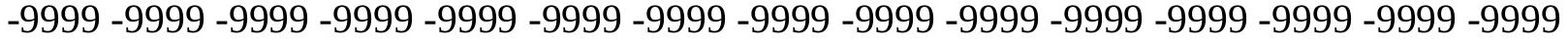
-9999 -9999 -9999 -9999 -9999 -9999 -9999 -9999 -9999 -9999 -9999 -9999 -9999 -9999 -9999 -

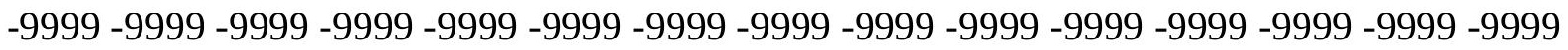

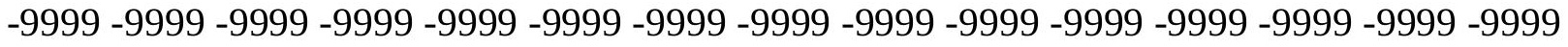

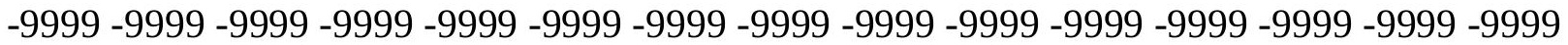

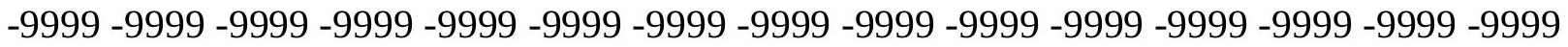

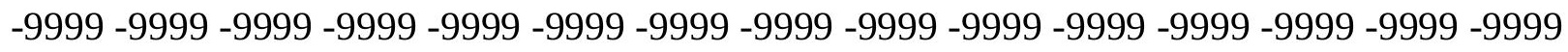

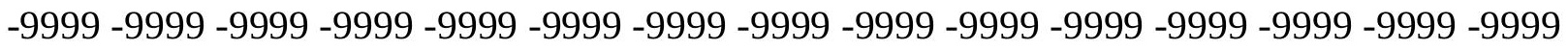

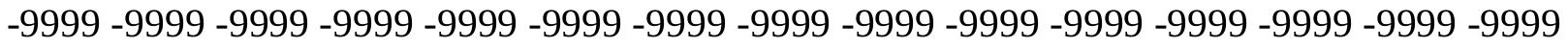
-9999 -9999 -9999 -9999 -9999 -9999 -9999 -9999 -9999 -9999 -9999 -9999 -9999 -9999 -9999 -

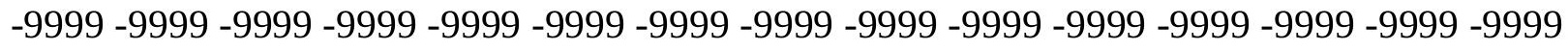

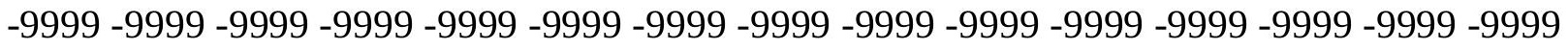
-9999 -9999 -9999 -9999 -9999 -9999 -9999 -9999 -9999 -9999 -9999 -9999 -9999 -9999 -9999 -9999 -9999 -9999 -9999 -9999 -9999 -9999 -9999 -9999-9999 -9999 -9999 -9999 -9999 -9999 -9999 -9999 -9999 -9999 -9999 -9999 -9999 -9999 -9999 -9999 -9999 -9999 -9999 -9999 -9999 -

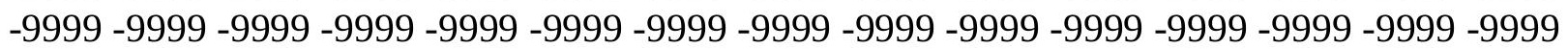


-9999 -9999 -9999 -9999 -9999 -9999 -9999 -9999 -9999 -9999 -9999 -9999 -9999 -9999 -9999 -9999 -9999 -9999 -9999 -9999 -9999 -9999 -9999 -9999 -9999 -9999 -9999 -9999 -9999 -9999 -

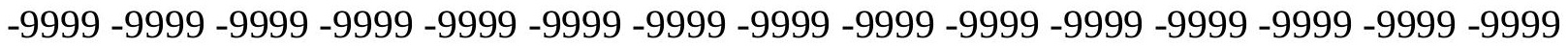
-9999 -9999 -9999 -9999 -9999 -9999 -9999 -9999 -9999 -9999 -9999 -9999 -9999 -9999 -9999 -9999 -9999 -9999 -9999 -9999 -9999 -9999 -9999 -9999-9999 -9999 -9999 -9999 -9999 -9999 -9999 -9999 -9999 -9999 -9999 -9999 -9999 -9999 -9999 -9999 -9999 -9999 -9999 -9999 -9999 -

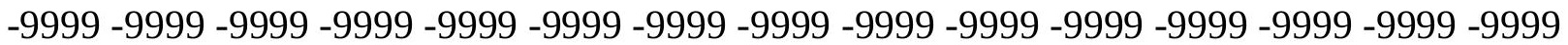
-9999 -9999 -9999 -9999 -9999 -9999 -9999 -9999 -9999 -9999 -9999 -9999 -9999 -9999 -9999 -9999 -9999 -9999 -9999 -9999 -9999 -9999 -9999 -9999 -9999 -9999 -9999 -9999 -9999 -9999 -9999 -9999 -9999 -9999 -9999 -9999 -9999 -9999 -9999 -9999 -9999 -9999 -9999 -9999 -9999 -9999 -9999 -9999 -9999 -9999 -9999 -9999 -9999 -9999 -9999 -9999 -9999 -9999 -9999 -9999 -9999 -9999 -9999 -9999 -9999 -9999 -9999 -9999 -9999 -9999 -9999 -9999 -9999 -9999 -9999 -9999 -9999 -9999 -9999 -9999 -9999 -9999 -9999 -9999 -9999 -9999 -9999 -9999 -9999 -9999 -9999 -9999 -9999 -9999 -9999 -9999 -9999 -9999 -9999 -9999 -9999 -9999 -9999 -9999 -9999 -9999 -9999 -9999 -9999 -9999 -9999 -9999 -9999 -9999 -9999 -9999 -9999 -9999 -9999 -

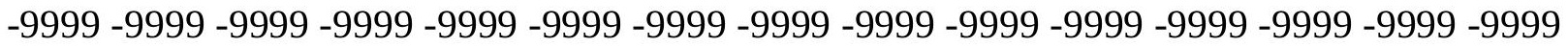
-9999 -9999 -9999 -9999 -9999 -9999 -9999 -9999 -9999 -9999 -9999 -9999 -9999 -9999 -9999 -9999 -9999 -9999 -9999 -9999 -9999 -9999 -9999 -9999 -9999 -9999 -9999 -9999 -9999 -9999 -9999 -9999 -9999 -9999 -9999 -9999 -9999 -9999 -9999 -9999 -9999 -9999 -9999 -9999 -9999 -

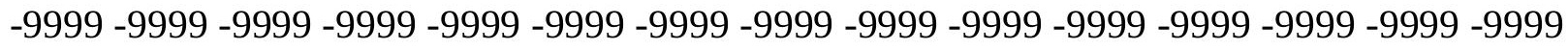

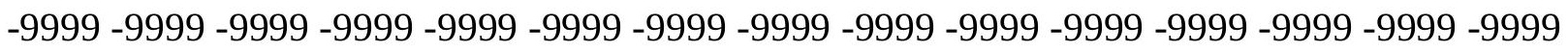
-9999 -9999 -9999 -9999 -9999 -9999 -9999 -9999 -9999 -9999 -9999 -9999 -9999 -9999 - 9999 -9999 -9999 -9999 -9999 -9999 -9999 -9999 -9999 -9999 -9999 -9999 -9999 -9999 -9999 -9999 -9999 -9999 -9999 -9999 -9999 -9999 -9999 -9999 -9999 -9999 -9999 -9999 -9999 -9999 -9999 -

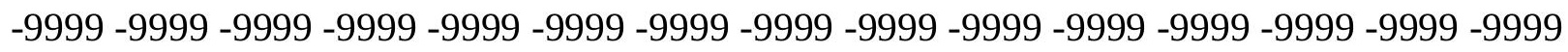
-9999 -9999 -9999 -9999 -9999 -9999 -9999 -9999 -9999 -9999 -9999 -9999 -9999 -9999 -9999 -9999 -9999 -9999 -9999 -9999 -9999 -9999 -9999 -9999 -9999 -9999 -9999 -9999 -9999 -9999 -

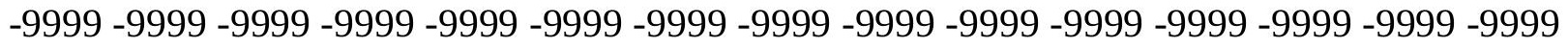
-9999 -9999 -9999 -9999 -9999 -9999 -9999 -9999 -9999 -9999 -9999 -9999 -9999 -9999 -9999 -9999 -9999 -9999 -9999 -9999 -9999 -9999 -9999 -9999 -9999 -9999 -9999 -9999 -9999 -999 -9999 -9999 -9999 -9999 -9999 -9999 -9999 -9999 -9999 -9999 -9999 -9999 -9999 -9999 -9999 -9999 -9999 -9999 -9999 -9999 -9999 -9999 -9999 -9999 -9999 -9999 -9999 -9999 -9999 -9999 -

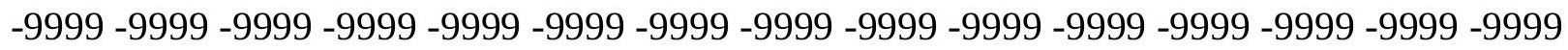

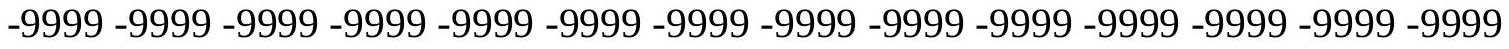
-9999 -9999 -9999 -9999 -9999 -9999 -9999 -9999 -9999 -9999 -9999 -9999 -9999 -9999 -9999

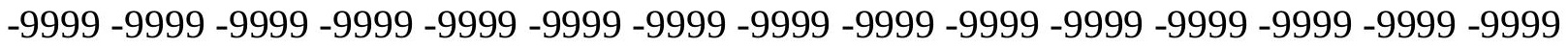

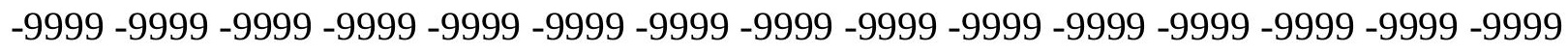

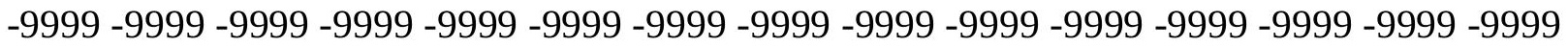

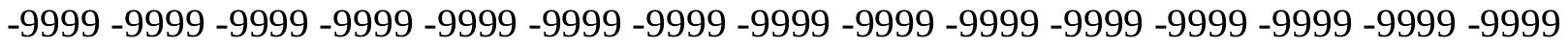
-9999 -9999 -9999 -9999 -9999 -9999 -9999 -9999 -9999 -9999 -9999 -9999 -9999 -9999 -9999 -

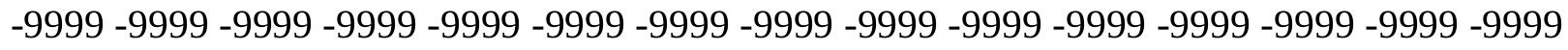

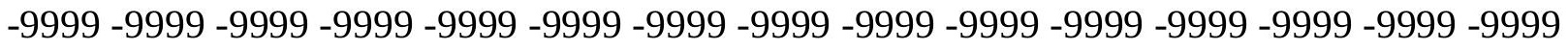
-9999 -9999 -9999 -9999 -9999 -9999 -9999 -9999 -9999 -9999 -9999 -9999 -9999 -9999 -9999 -9999 -9999 -9999 -9999 -9999 -9999 -9999 -9999 -9999-9999 -9999 -9999 -9999 -9999 -9999 -9999 -9999 -9999 -9999 -9999 -9999 -9999 -9999 -9999 -9999 -9999 -9999 -9999 -9999 -9999 -

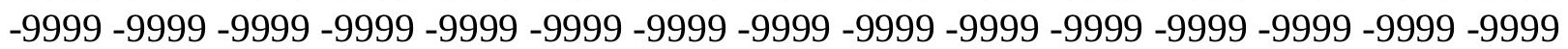


-9999 -9999 -9999 -9999 -9999 -9999 -9999 -9999 -9999 -9999 -9999 -9999 -9999 -9999 -9999 -9999 -9999 -9999 -9999 -9999 -9999 -9999 -9999 -9999 -9999 -9999 -9999 -9999 -9999 -9999 -

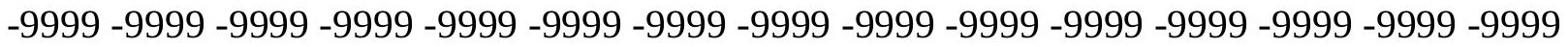
-9999 -9999 -9999 -9999 -9999 -9999 -9999 -9999 -9999 -9999 -9999 -9999 -9999 -9999 -9999 -9999 -9999 -9999 -9999 -9999 -9999 -9999 -9999 -9999-9999 -9999 -9999 -9999 -9999 -9999 -9999 -9999 -9999 -9999 -9999 -9999 -9999 -9999 -9999 -9999 -9999 -9999 -9999 -9999 -9999 -9999 -9999 -9999 -9999 -9999 -9999 -9999 -9999 -9999 -9999 -9999 -9999 -9999 -9999 -9999

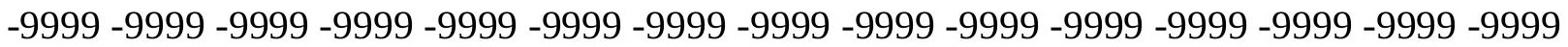

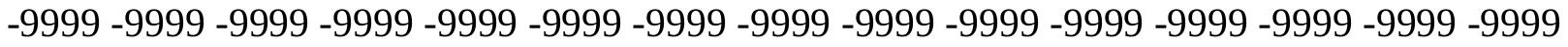
-9999 -9999 -9999 -9999 -9999 -9999 -9999 -9999 -9999 -9999 -9999 -9999 -9999 -9999 -9999 -9999 -9999 -9999 -9999 -9999 -9999 -9999 -9999 -9999 -9999 -9999 -9999 -9999 -9999 -9999 -9999 -9999 -9999 -9999 -9999 -9999 -9999 -9999 -9999 -9999 -9999 -9999 -9999 -9999 -9999 -9999 -9999 -9999 -9999 -9999 -9999 -9999 -9999 -9999 -9999 -9999 -9999 -9999 -9999 -9999 -9999 -9999 -9999 -9999 -9999 -9999 -9999 -9999 -9999 -9999 -9999 -9999 -9999 -9999 -9999 -9999 -9999 -9999 -9999 -9999 -9999 -9999 -9999 -9999 -9999 -9999 -9999 -9999 -9999

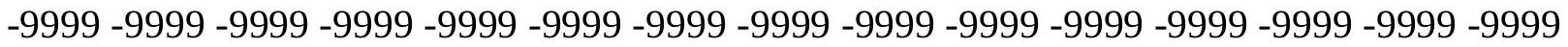
-9999 -9999 -9999 -9999 -9999 -9999 -9999 -9999 -9999 -9999 -9999 -9999 -9999 -9999 -9999 -9999 -9999 -9999 -9999 -9999 -9999 -9999 -9999 -9999 -9999 -9999 -9999 -9999 -9999 -9999 -9999 -9999 -9999 -9999 -9999 -9999 -9999 -9999 -9999 -9999 -9999 -9999 -9999 -9999 -9999 -

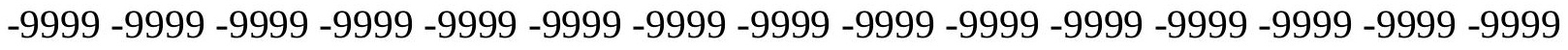

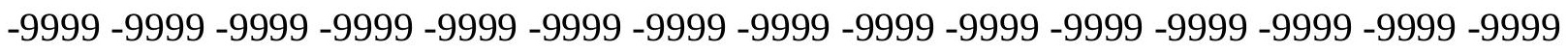
-9999 -9999 -9999 -9999 -9999 -9999 -9999 -9999 -9999 -9999 -9999 -9999 -9999 -9999 -9999 -9999 -9999 -9999 -9999 -9999 -9999 -9999 -9999 -9999 -9999 -9999 -9999 -9999 -9999 -9999 -9999 -9999 -9999 -9999 -9999 -9999 -9999 -9999 -9999 -9999 -9999 -9999 -9999 -9999 -9999 -

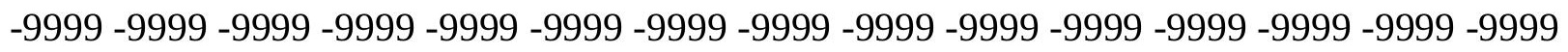
-9999 -9999 -9999 -9999 -9999 -9999 -9999 -9999 -9999 -9999 -9999 -9999 -9999 -9999 -9999 -9999 -9999 -9999 -9999 -9999 -9999 -9999 -9999 -9999 -9999 -9999 -9999 -9999 -9999 -9999 -

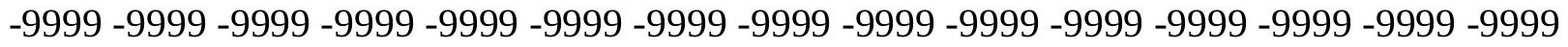
-9999 -9999 -9999 -9999 -9999 -9999 -9999 -9999 -9999 -9999 -9999 -9999 -9999 -9999 -9999 -9999 -9999 -9999 -9999 -9999 -9999 -9999 -9999 -9999 -9999 -9999 -9999 -9999 -9999 -999 -9999 -9999 -9999 -9999 -9999 -9999 -9999 -9999 -9999 -9999 -9999 -9999 -9999 -9999 -9999 -9999 -9999 -9999 -9999 -9999 -9999 -9999 -9999 -9999 -9999 -9999 -9999 -9999 -9999 -9999 -

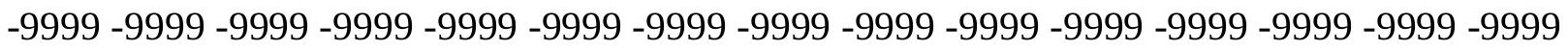

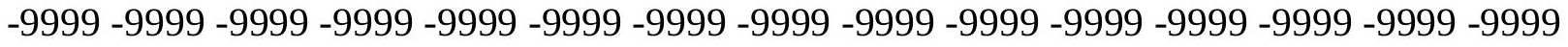

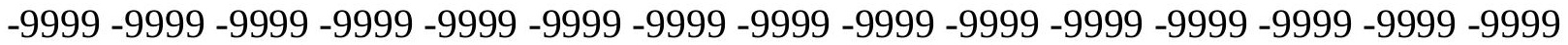

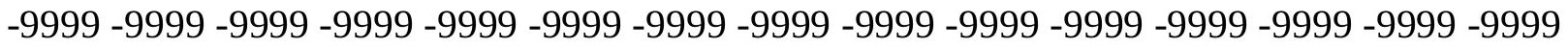

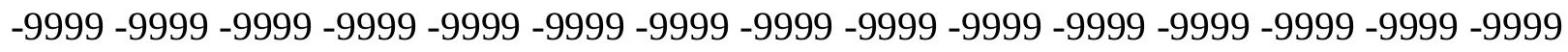

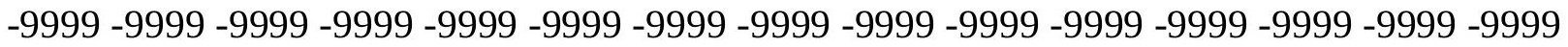
-9999 -9999 -9999 -9999 -9999 -9999 -9999 -9999 -9999 -9999 -9999 -9999 -9999 - 9999 - -999 -9999 -9999 -9999 -9999 -9999 -9999 -9999 -9999 -9999 -9999 -9999 -9999 -9999 -9999 - -999 -

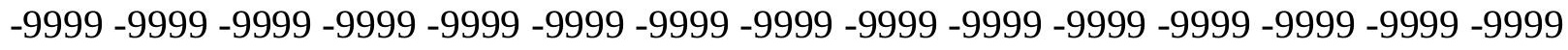

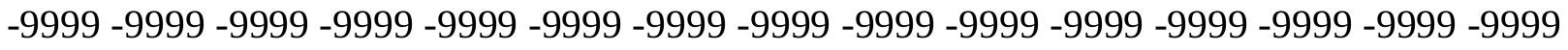
-9999 -9999 -9999 -9999 -9999 -9999 -9999 -9999 -9999 -9999 -9999 -9999 -9999 -9999 -9999 -9999 -9999 -9999 -9999 -9999 -9999 -9999 -9999 -9999-9999 -9999 -9999 -9999 -9999 -9999 -9999 -9999 -9999 -9999 -9999 -9999 -9999 -9999 -9999 -9999 -9999 -9999 -9999 -9999 -9999 -

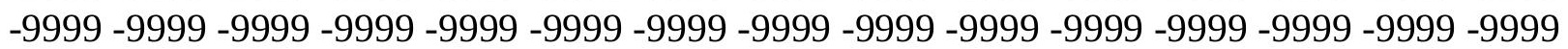


-9999 -9999 -9999 -9999 -9999 -9999 -9999 -9999 -9999 -9999 -9999 -9999 -9999 -9999 -9999 -9999 -9999 -9999 -9999 -9999 -9999 -9999 -9999 -9999 -9999 -9999 -9999 -9999 -9999 -9999 -9999 -9999 -9999 -9999 -9999 -9999 -9999 -9999 -9999 -9999 -9999 -9999 -9999 -9999 -9999 -9999 -9999 -9999 -9999 -9999 -9999 -9999 -9999 -9999 -9999 -9999 -9999 -9999 -9999 -9999 -9999 -9999 -9999 -9999 -9999 -9999 -9999 -9999 -9999 -9999 -9999 -9999 -9999 -9999 -9999 -9999 -9999 -9999 -9999 -9999 -9999 -9999 -9999 -9999 -9999 -9999 -9999 -9999 -9999 -9999 -9999 -9999 -9999 -9999 -9999 -9999 -9999 -9999 -9999 -9999 -9999 -9999 -9999 -9999 -9999 -

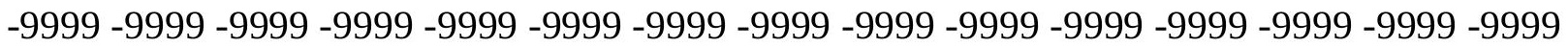
-9999 -9999 -9999 -9999 -9999 -9999 -9999 -9999 -9999 -9999 -9999 -9999 -9999 -9999 -9999 -9999 -9999 -9999 -9999 -9999 -9999 -9999 -9999 -9999 -9999 -9999 -9999 -9999 -9999 -9999 -

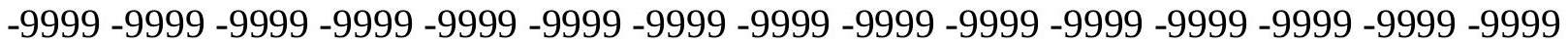
-9999 -9999 -9999 -9999 -9999 -9999 -9999 -9999 -9999 -9999 -9999 -9999 -9999 -9999 -9999 -9999 -9999 -9999 -9999 -9999 -9999 -9999 -9999 -9999 -9999 -9999 -9999 -9999 -9999 -9999 -9999 -9999 -9999 -9999 -9999 -9999 -9999 -9999 -9999 -9999 -9999 -9999 -9999 -9999 -9999 -9999 -9999 -9999 -9999 -9999 -9999 -9999 -9999 -9999 -9999 -9999 -9999 -9999 -9999 -9999

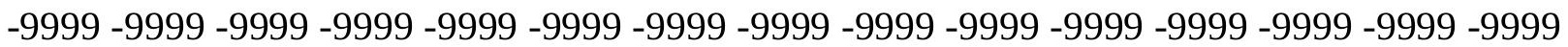
-9999 -9999 -9999 -9999 -9999 -9999 -9999 -9999 -9999 -9999 -9999 -9999 -9999 -9999 -9999 -9999 -9999 -9999 -9999 -9999 -9999 -9999 -9999 -9999 -9999 -9999 -9999 -9999 -9999 -9999 -9999 -9999 -9999 -9999 -9999 -9999 -9999 -9999 -9999 -9999 -9999 -9999 -9999 -9999 -9999 -9999 -9999 -9999 -9999 -9999 -9999 -9999 -9999 -9999 -9999 -9999 -9999 -9999 -9999 -9999 -9999 -9999 -9999 -9999 -9999 -9999 -9999 -9999 -9999 -9999 -9999 -9999 -9999 -9999 -9999 -9999 -9999 -9999 -9999 -9999 -9999 -9999 -9999 -9999 -9999 -9999 -9999 -9999 -9999 -9999 -9999 -9999 -9999 -9999 -9999 -9999 -9999 -9999 -9999 -9999 -9999 -9999 -9999 -9999 -9999 -9999 -9999 -9999 -9999 -9999 -9999 -9999 -9999 -9999 -9999 -9999 -9999 -9999 -9999 -9999 -9999 -9999 -9999 -9999 -9999 -9999 -9999 -9999 -9999 -9999 -9999 -9999 -9999 -9999 -9999 -9999 -9999 -9999 -9999 -9999 -9999 -9999 -9999 -9999 -9999 -9999 -9999 -9999 -9999 -9999 -9999 -9999 -9999 -9999 -9999 -9999 -9999 -9999 -9999 -9999 -9999 -9999 -9999 -9999 -9999 -9999 -9999 -9999 -9999 -9999 -9999 -9999 -9999 -9999 -9999 -9999 -9999 -9999 -9999

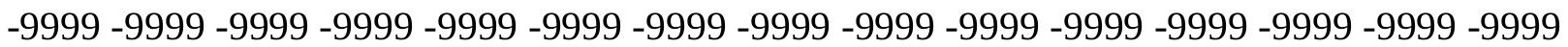
-9999 -9999 -9999 -9999 -9999 -9999 -9999 -9999 -9999 -9999 -9999 -9999 -9999 -9999 -9999 -9999 -9999 -9999 -9999 -9999 -9999 -9999 -9999 -9999 -9999 -9999 -9999 -9999 -9999 -9999 -

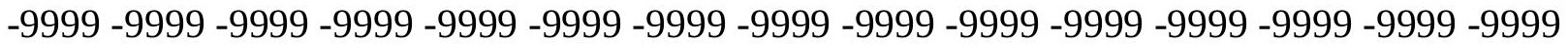
-9999 -9999 -9999 -9999 -9999 -9999 -9999 -9999 -9999 -9999 -9999 -9999 -9999 -9999 -9999 -9999 -9999 -9999 -9999 -9999 -9999 -9999 -9999 -9999 -9999 -9999 -9999 -9999 -9999 -9999 -9999 -9999 -9999 -9999 -9999 -9999 -9999 -9999 -9999 -9999 -9999 -9999 -9999 -9999 -9999 -9999 -9999 -9999 -9999 -9999 -9999 -9999 -9999 -9999 -9999 -9999 -9999 -9999 -9999 -9999 -9999 -9999 -9999 -9999 -9999 -9999 -9999 -9999 -9999 -9999 -9999 -9999 -9999 -9999 -9999

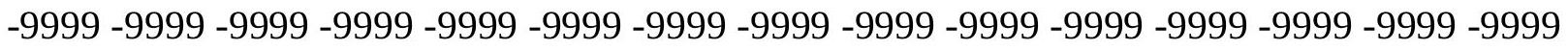
-9999 -9999 -9999 -9999 -9999 -9999 -9999 -9999 -9999 -9999 -9999 -9999 -9999 -9999 -9999 -9999 -9999 -9999 -9999 -9999 -9999 -9999 -9999 -9999 -9999 -9999 -9999 -9999 -9999 -9999 -9999 -9999 -9999 -9999 -9999 -9999 -9999 -9999 -9999 -9999 -9999 -9999 -9999 -9999 -9999 -999 -9999 -9999 -9999 -9999 -9999 -9999 -9999 -9999 -9999 -9999 -9999 -9999 -9999 -9999 -9999 -9999 -9999 -9999 -9999 -9999 -9999 -9999 -9999 -9999 -9999 -9999 -9999 -9999 -9999 -9999 -9999 -9999 -9999 -9999 -9999 -9999 -9999 -9999 -9999 -9999 -9999 -9999 -9999 -9999 -9999 -9999 -9999 -9999 -9999 -9999 -9999 -9999 -9999 -9999 -9999 -9999 -9999 -9999 -9999 -9999 -9999 -9999 -9999 -9999 -9999 -9999 -9999 -9999 -9999 -9999 -9999 -9999 -9999 -9999 
-9999 -9999 -9999 -9999 -9999 -9999 -9999 -9999 -9999 -9999 -9999 -9999 -9999 -9999 -9999 -9999 -9999 -9999 -9999 -9999 -9999 -9999 -9999 -9999 -9999 -9999 -9999 -9999 -9999 -9999 -

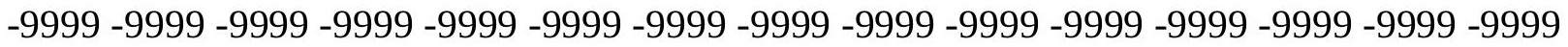
-9999 -9999 -9999 -9999 -9999 -9999 -9999 -9999 -9999 -9999 -9999 -9999 -9999 -9999 -9999 -9999 -9999 -9999 -9999 -9999 -9999 -9999 -9999 -9999-9999 -9999 -9999 -9999 -9999 -9999 -9999 -9999 -9999 -9999 -9999 -9999 -9999 -9999 -9999 -9999 -9999 -9999 -9999 -9999 -9999 -9999 -9999 -9999 -9999 -9999 -9999 -9999 -9999 -9999 -9999 -9999 -9999 -9999 -9999 -9999

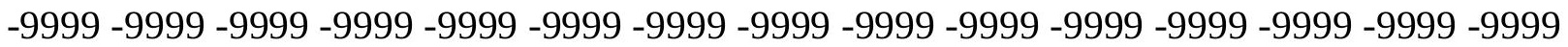

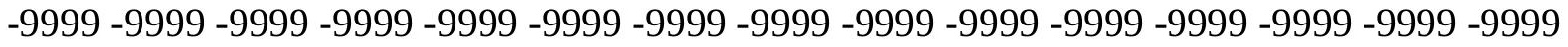
-9999 -9999 -9999 -9999 -9999 -9999 -9999 -9999 -9999 -9999 -9999 -9999 -9999 -9999 -9999 -9999 -9999 -9999 -9999 -9999 -9999 -9999 -9999 -9999 -9999 -9999 -9999 -9999 -9999 -9999 -9999 -9999 -9999 -9999 -9999 -9999 -9999 -9999 -9999 -9999 -9999 -9999 -9999 -9999 -9999 -9999 -9999 -9999 -9999 -9999 -9999 -9999 -9999 -9999 -9999 -9999 -9999 -9999 -9999 -9999 -

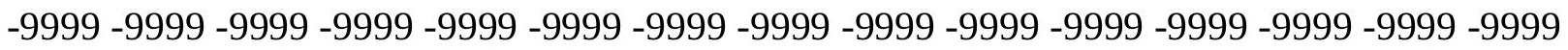
-9999 -9999 -9999 -9999 -9999 -9999 -9999 -9999 -9999 -9999 -9999 -9999 -9999 -9999 -9999 -

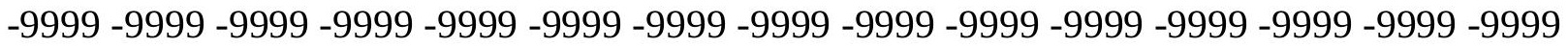
-9999 -9999 -9999 -9999 -9999 -9999 -9999 -9999 -9999 -9999 -9999 -9999 -9999 -9999 -9999 -9999 -9999 -9999 -9999 -9999 -9999 -9999 -9999 -9999 -9999 -9999 -9999 -9999 -9999 -9999 -9999 -9999 -9999 -9999 -9999 -9999 -9999 -9999 -9999 -9999 -9999 -9999 -9999 -9999 -9999 -

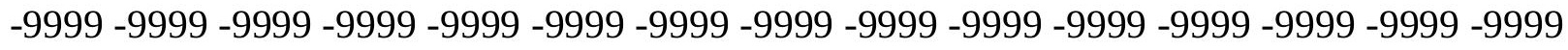

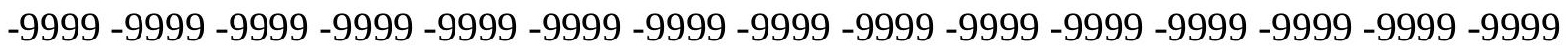

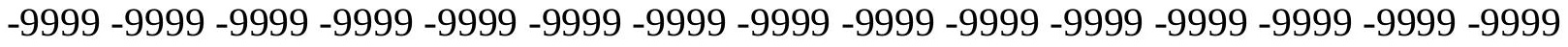
-9999 -9999 -9999 -9999 -9999 -9999 -9999 -9999 -9999 -9999 -9999 -9999 -9999 -9999 -9999 -9999 -9999 -9999 -9999 -9999 -9999 -9999 -9999 -9999 -9999 -9999 -9999 -9999 -9999 -9999 -

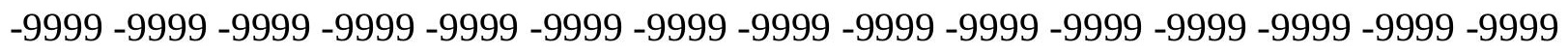
-9999 -9999 -9999 -9999 -9999 -9999 -9999 -9999 -9999 -9999 -9999 -9999 -9999 -9999 -9999 -9999 -9999 -9999 -9999 -9999 -9999 -9999 -9999 -9999 -9999 -9999 -9999 -9999 -9999 -

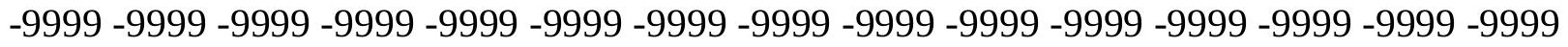
-9999 -9999 -9999 -9999 -9999 -9999 -9999 -9999 -9999 -9999 -9999 -9999 -9999 -9999 -9999 -9999 -9999 -9999 -9999 -9999 -9999 -9999 -9999 -9999 -9999 -9999 -9999 -9999 -9999 -999 -

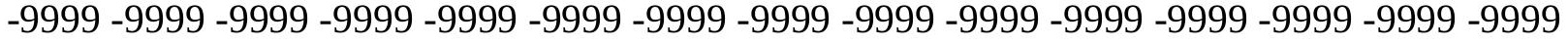
-9999 -9999 -9999 -9999 -9999 -9999 -9999 -9999 -9999 -9999 -9999 -9999 -9999 -9999 -9999 -

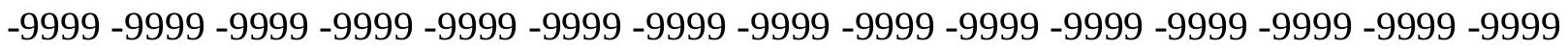

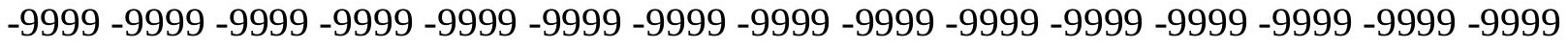

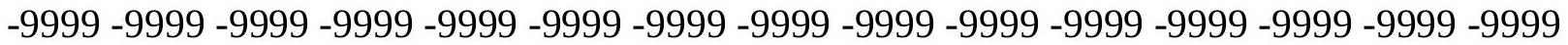
-9999 -9999 -9999 -9999 -9999 -9999 -9999 -9999 -9999 -9999 -9999 -9999 -9999 -9999 -9999

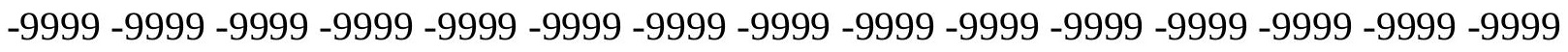

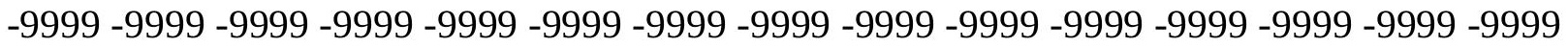
-9999 -9999 -9999 -9999 -9999 -9999 -9999 -9999 -9999 -9999 -9999 -9999 -9999 - 9999 - -999 -9999 -9999 -9999 -9999 -9999 -9999 -9999 -9999 -9999 -9999 -9999 -9999 -9999 -9999 -9999 -

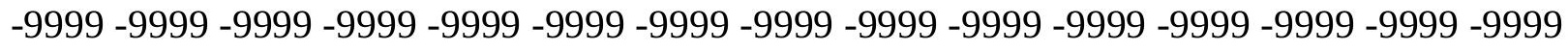

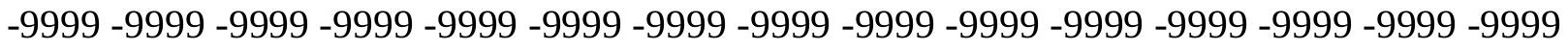
-9999 -9999 -9999 -9999 -9999 -9999 -9999 -9999 -9999 -9999 -9999 -9999 -9999 -9999 -9999 -9999 -9999 -9999 -9999 -9999 -9999 -9999 -9999 -9999-9999 -9999 -9999 -9999 -9999 -9999 -9999 -9999 -9999 -9999 -9999 -9999 -9999 -9999 -9999 -9999 -9999 -9999 -9999 -9999 -9999 -

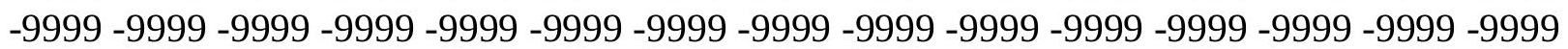


-9999 -9999 -9999 -9999 -9999 -9999 -9999 -9999 -9999 -9999 -9999 -9999 -9999 -9999 -9999 -9999 -9999 -9999 -9999 -9999 -9999 -9999 -9999 -9999 -9999 -9999 -9999 -9999 -9999 -9999 -9999 -9999 -9999 -9999 -9999 -9999 -9999 -9999 -9999 -9999 -9999 -9999 -9999 -9999 -9999 -9999 -9999 -9999 -9999 -9999 -9999 -9999 -9999 -9999 -9999 -9999 -9999 -9999 -9999 -9999 -9999 -9999 -9999 -9999 -9999 -9999 -9999 -9999 -9999 -9999 -9999 -9999 -9999 -9999 -9999 -9999 -9999 -9999 -9999 -9999 -9999 -9999 -9999 -9999 -9999 -9999 -9999 -9999 -9999 -9999 -9999 -9999 -9999 -9999 -9999 -9999 -9999 -9999 -9999 -9999 -9999 -9999 -9999 -9999

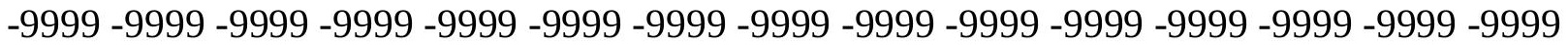

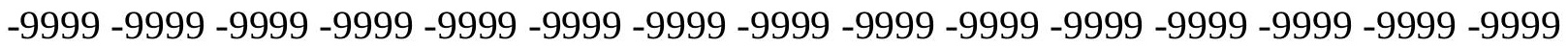
-9999 -9999 -9999 -9999 -9999 -9999 -9999 -9999 -9999 -9999 -9999 -9999 -9999 -9999 -9999 -

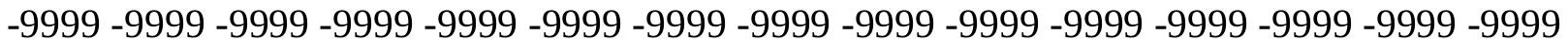
-9999 -9999 -9999 -9999 -9999 -9999 -9999 -9999 -9999 -9999 -9999 -9999 -9999 -9999 -9999

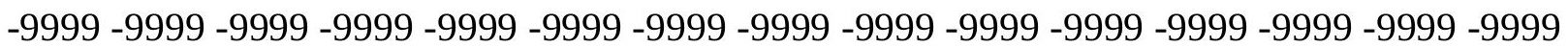
-9999 -9999 -9999 -9999 -9999 -9999 -9999 -9999 -9999 -9999 -9999 -9999 -9999 -9999 -9999 -9999 -9999 -9999 -9999 -9999 -9999 -9999 -9999 -9999 -9999 -9999 -9999 -9999 -9999 -9999 -9999 -9999 -9999 -9999 -9999 213.0447998047 211.8256988525 211.2160949707 210.6065063477210 .6065063477210 .9113006592211 .2160949707211 .520904541 212.1304016113212 .7400054932213 .3495941162214 .2639007568214 .8735046387 214.8735046387214 .5686950684214 .8735046387215 .4830932617216 .3973999023 217.3117980957 217.6165924072 217.6165924072 217.9214019775 217.9214019775 217.9214019775 217.9214019775 217.9214019775 217.9214019775 217.9214019775 217.9214019775 217.9214019775 217.9214019775 217.6165924072 217.3117980957 217.0070037842216 .7021942139216 .3973999023216 .0926971436215 .4830932617 214.8735046387214 .5686950684213 .959197998214 .2639007568214 .5686950684 214.5686950684214 .5686950684214 .5686950684214 .2639007568213 .959197998 213.959197998213 .6544036865213 .6544036865213 .3495941162213 .6544036865 -9999 -9999 -9999 -9999 -9999 -9999 -9999 -9999 -9999 -9999 -9999 -9999 -9999 -9999 -9999 -9999 -9999 -9999 -9999 -9999 -9999 -9999 -9999 -9999 -9999 -9999 -9999 -9999 -9999 -9999 -9999 -9999 -9999 -9999 -9999 -9999 -9999 -9999 -9999 -9999 -9999 -9999 -9999 -9999 -9999 -9999 -9999 -9999 -9999 -9999 -9999 -9999 -9999 -9999 -9999 -9999 -9999 -9999 -9999 -9999 -9999 -9999 -9999 -9999 -9999 -9999 -9999 -9999 -9999 -9999 -9999 -9999 -9999 -9999 -9999 -9999 -

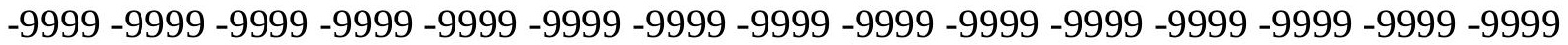
-9999 -9999 -9999 -9999 -9999 -9999 -9999 -9999 -9999 -9999 -9999 -9999 -9999 -9999 -9999 -9999 -9999 -9999 -9999 -9999 -9999 -9999 -9999 -9999 -9999 -9999 -9999 -9999 -9999 -9999 -

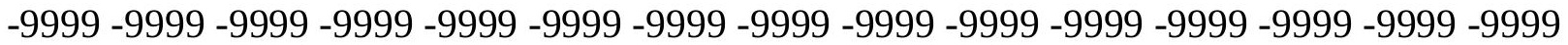
-9999 -9999 -9999 -9999 -9999 -9999 -9999 -9999 -9999 -9999 -9999 -9999 -9999 -9999 -9999 -9999 -9999 -9999 -9999 -9999 -9999 -9999 -9999 -9999 -9999 -9999 -9999 -9999 -9999 -9999

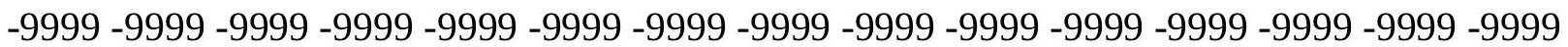
-9999 -9999 -9999 -9999 -9999 -9999 -9999 -9999 -9999 -9999 -9999 -9999 -9999 -9999 -9999 -9999 -9999 -9999 -9999 -9999 -9999 -9999 -9999 -9999 -9999 -9999 -9999 -9999 -9999 -9999 -9999 -9999 -9999 -9999 -9999 -9999 -9999 -9999 -9999 -9999 -9999 -9999 -9999 -9999 -9999 -9999 -9999 -9999 -9999 -9999 -9999 -9999 -9999 -9999 -9999 -9999 -9999 -9999 -9999 -9999 -9999 -9999 -9999 -9999 -9999 -9999 -9999 -9999 -9999 -9999 -9999 -9999 -9999 -9999 -9999 -9999 -9999 -9999 -9999 -9999 -9999 -9999 -9999 -9999 -9999 -9999 -9999 -9999 -9999 -9999 -9999 -9999 -9999 -9999 -9999 -9999 -9999 -9999 -9999 -9999 -9999 -9999 -9999 -9999 -9999

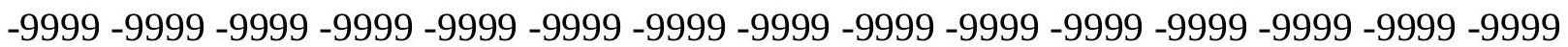


-9999 -9999 -9999 -9999 -9999 -9999 -9999 -9999 -9999 -9999 -9999 -9999 -9999 -9999 -9999 -9999 -9999 -9999 -9999 -9999 -9999 -9999 216.0926971436214.8735046387 213.6544036865 212.4351959229211 .520904541210 .6065063477210 .3016967773210 .3016967773 210.3016967773209 .9969024658208 .4730072021206 .6443023682205 .1204071045 203.2917022705 202.3773040771201.4629974365 201.158203125 201.158203125 201.158203125201 .7678070068202 .3773040771202 .9868927002203 .596496582 204.2059936523204 .8155975342206 .6443023682205 .425201416206 .0346984863 206.6443023682207 .8634033203209 .3874053955210 .6065063477211 .520904541 212.4351959229213 .3495941162213 .6544036865213 .6544036865213 .3495941162 213.0447998047212 .7400054932212 .4351959229211 .8256988525211 .520904541 210.9113006592210 .3016967773209 .692199707209 .0825958252208 .4730072021 207.5587005615206 .9490966797206 .0346984863205 .1204071045204 .2059936523 203.9011993408204 .8155975342203 .596496582203 .9011993408204 .2059936523 204.2059936523203 .9011993408203 .596496582203 .596496582203 .2917022705 202.9868927002202 .9868927002202 .6820983887202 .3773040771202 .0724945068 201.4629974365201 .158203125201 .158203125201 .4629974365201 .158203125 201.158203125202 .0724945068202 .6820983887202 .3773040771202 .0724945068 201.7678070068202 .0724945068 -9999 -9999 -9999 -9999 -9999 -9999 -9999 -9999 -9999 -9999 -9999 -9999 -9999 -9999 -9999 -9999 -9999 -9999 -9999 -9999 -9999 -9999 -9999 -9999

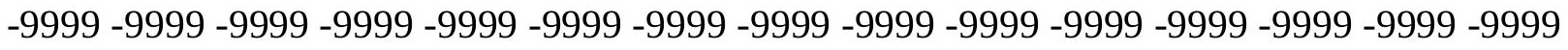
-9999 -9999 -9999 -9999 -9999 -9999 -9999 -9999 -9999 -9999 -9999 -9999 -9999 -9999 -9999

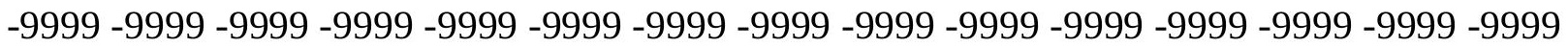
-9999 -9999 -9999 -9999 -9999 -9999 -9999 -9999 -9999 -9999 -9999 -9999 -9999 -9999 -9999 -9999 -9999 -9999 -9999 -9999 -9999 -9999 -9999 -9999 -9999 -9999 -9999 -9999 -9999 -9999 -9999 -9999 -9999 -9999 -9999 -9999 -9999 -9999 -9999 -9999 -9999 -9999 -9999 -9999 -9999 -9999 -9999 -9999 -9999 -9999 -9999 -9999 -9999 -9999 -9999 -9999 -9999 -9999 -9999 -9999 -9999 -9999 -9999 -9999 -9999 -9999 -9999 -9999 -9999 -9999 -9999 -9999 -9999 -9999 -9999 -9999 -9999 -9999 -9999 -9999 -9999 -9999 -9999 -9999 -9999 -9999 -9999 -9999 -9999 -9999 -9999 -9999 -9999 -9999 -9999 -9999 -9999 -9999 -9999 -9999 -9999 -9999 -9999 -9999 -9999 -9999 -9999 -9999 -9999-9999-9999-9999 -9999

-9999 -9999 -9999 -9999 -9999 -9999 -9999 -9999 -9999 -9999 -9999 -9999 -9999 -9999 -9999

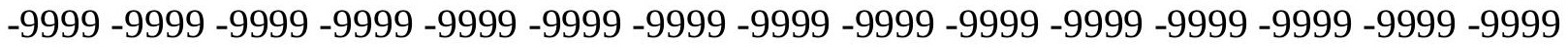

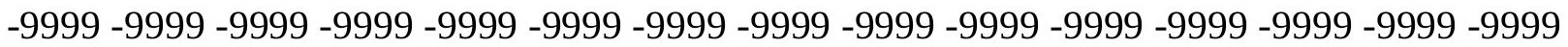
-9999 -9999 -9999 -9999 -9999 -9999 -9999 -9999 -9999 -9999 -9999 -9999 -9999 -9999 -9999 -9999 -9999 -9999 -9999 -9999 -9999 -9999 -9999 -9999 -9999 -9999 -9999 -9999 -9999 -9999 -9999 -9999 -9999 -9999 -9999 -9999 -9999 -9999 -9999 -9999 -9999 -9999 -9999 -9999 -9999

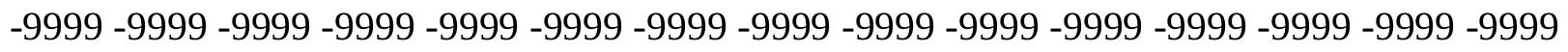
-9999 -9999 -9999 -9999-9999 -9999 -9999 -9999 208.7778015137208 .7778015137 208.7778015137208 .7778015137208 .7778015137208 .7778015137208 .7778015137 209.0825958252 209.692199707 209.9969024658 208.7778015137207.5587005615 207.8634033203207 .8634033203206 .6443023682205 .1204071045203 .2917022705 201.7678070068200 .8533935547200 .5485992432200 .8533935547201 .4629974365 201.7678070068201 .4629974365200 .2438049316198 .7198944092196 .5863952637 194.4528961182193 .8433074951193 .5386047363193 .5386047363194 .1481018066195 .0625 195.9768066406197 .1959991455198 .4151000977199 .6342926025200 .5485992432 201.4629974365 202.3773040771202.9868927002 203.596496582 204.2059936523 
205.425201416206 .6443023682207 .8634033203208 .7778015137209 .692199707 210.3016967773210 .6065063477210 .6065063477210 .3016967773209 .9969024658 209.692199707209 .3874053955209 .0825958252208 .4730072021207 .8634033203 207.25390625206 .6443023682206 .0346984863205 .1204071045204 .5108032227 203.596496582202 .9868927002202 .0724945068201 .4629974365200 .8533935547 200.5485992432200 .2438049316200 .2438049316199 .9389953613199 .6342926025 198.7198944092198 .1103057861197 .1959991455196 .2816009521195 .6721038818 194.7577056885193 .8433074951192 .624206543191 .7097930908190 .4907073975 190.4907073975189 .2716064453189 .5764007568189 .2716064453188 .966796875 189.2716064453189 .5764007568189 .5764007568189 .5764007568190 .1858978271 190.795501709191 .7097930908192 .3193969727192 .9290008545192 .9290008545 192.9290008545192 .0146026611190 .795501709190 .1858978271191 .7097930908 193.5386047363194 .4528961182195 .0625195 .0625 -9999 -9999 -9999 -9999 -9999 -9999 -9999 -9999 -9999 -9999 -9999 -9999 -9999 -9999 -9999 -9999 -9999 -9999 -9999 -9999 -9999 -9999 -9999 -9999 -9999 -9999 -9999 -9999 -9999 -9999 -9999 -9999 -9999 -9999 -9999 -9999

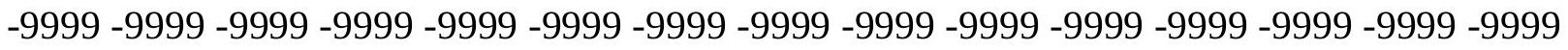
-9999 -9999 -9999 -9999 -9999 -9999 -9999 -9999 -9999 -9999 -9999 -9999 -9999 -9999 -9999 -9999 -9999 -9999 -9999 -9999 -9999 -9999 -9999 -9999 -9999 -9999 -9999 -9999 -9999 -9999 -9999 -9999 -9999 -9999 -9999 -9999 -9999 -9999 -9999 -9999 -9999 -9999 -9999 -9999 -9999 -

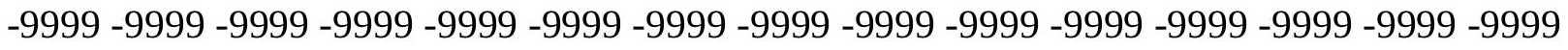

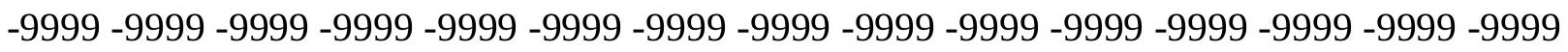
-9999 -9999 -9999 -9999 -9999 -9999 -9999 -9999 -9999 -9999 -9999 -9999 -9999 -9999 -9999 -9999 -9999 -9999 -9999 -9999 -9999 -9999 -9999 -9999 -9999 -9999 -9999 -9999 -9999 -9999 -9999 -9999 -9999 -9999 -9999 -9999 -9999 -9999 -9999 -9999 -9999 -9999 -9999 -9999 -9999 -9999 -9999 -9999 -9999 -9999 -9999 -9999 -9999 -9999 -9999 -9999 -9999 -9999 -9999 -9999 -9999 -9999 -9999 -9999 -9999 -9999 -9999 -9999 -9999 -9999 -9999 -9999 -9999 -9999 -9999 -9999 -9999 -9999 -9999 -9999 -9999 -9999 -9999 -9999 -9999 -9999 -9999 -9999 -

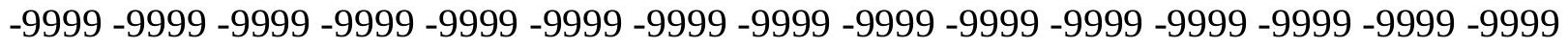
-9999 -9999 -9999 -9999 -9999 -9999 -9999 -9999 -9999 -9999 -9999 -9999 -9999 -9999 -9999 -9999 -9999 -9999 -9999 -9999 -9999 -9999 -9999 -9999 -9999 -9999 -9999 -9999 -9999 -9999 -9999 -9999 -9999 -9999 -9999 -9999 -9999-9999 -9999 196.2816009521 196.891204834 197.8054962158198 .4151000977199 .329498291199 .9389953613200 .2438049316 200.8533935547201 .4629974365201 .7678070068202 .0724945068202 .0724945068 202.3773040771202 .3773040771202 .3773040771202 .0724945068201 .7678070068 201.4629974365201 .158203125200 .8533935547200 .8533935547200 .5485992432 200.5485992432200 .2438049316198 .7198944092197 .1959991455196 .5863952637 196.5863952637 195.9768066406195.3672943115 194.4528961182193.8433074951 193.233795166194 .4528961182195 .6721038818196 .5863952637197 .500793457 197.500793457196 .891204834195 .6721038818194 .1481018066192 .624206543 191.7097930908191 .4051055908191 .4051055908192 .0146026611192 .624206543 193.5386047363194 .7577056885195 .9768066406196 .891204834198 .1103057861 199.0247039795199 .9389953613200 .5485992432201 .158203125202 .0724945068 202.9868927002204 .2059936523205 .1204071045206 .0346984863206 .6443023682 207.25390625 207.5587005615 207.5587005615 207.5587005615 207.25390625 206.9490966797206 .3394927979206 .0346984863205 .425201416204 .3440704346 203.8892211914203 .3220977783202 .6108093262201 .9001464844201 .1364135742 
200.3951416016199 .6609954834198 .9956817627198 .4100494385197 .8054962158 197.500793457197 .1559753418196 .7263031006196 .2725830078195 .7547302246 195.1610107422194 .5135803223193 .762298584193 .0080871582192 .1598052979 191.2276611328190 .2701873779189 .2565612793188 .1911468506187 .1381072998 186.2236938477185 .6141052246185 .0933380127184 .6075134277184 .0901947021 183.7605285645183 .4280395508183 .1266021729182 .87109375182 .7689819336 182.5662994385182 .4226531982182 .1246337891181 .7910766602181 .3979949951 180.9319152832180 .5411376953180 .306930542180 .432800293181 .1337738037 182.2268829346183 .4163513184184 .3982086182185 .1516265869185 .6980133057 186.2428131104186 .8417816162187 .4827880859188 .1913299561188 .9421539307 189.5196685791189 .7800598145 -9999 -9999 -9999 -9999 -9999 -9999 -9999 -9999 -9999 -9999 -9999 -9999 -9999 -9999 -9999 -9999 -9999 -9999 -9999 -9999 -9999 -9999 -9999 -9999 -9999 -9999 -9999 -9999 -9999 -9999 -9999 -9999 -9999 -9999 -9999 -9999 -9999 -9999 -9999 -9999 -9999 -9999 -9999 -9999 -9999 -9999 -9999 -9999 -9999 -9999 -9999 -9999 -9999 - 9999 -9999 -9999 -9999 -9999 -9999 -9999 -9999 -9999 -9999 -9999 -9999 -9999 -9999 -9999 -9999

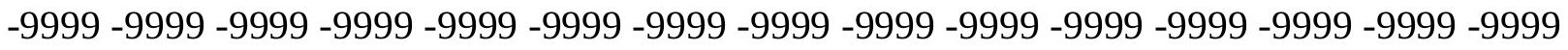
-9999 -9999 -9999 -9999 -9999 -9999 -9999 -9999 -9999 -9999 -9999 -9999 -9999 -9999 -9999 -9999 -9999 -9999 -9999 -9999 -9999 -9999 -9999 -9999 -9999 -9999 -9999 -9999 -9999 -9999 -9999 -9999 -9999 -9999 -9999 -9999 -9999 -9999 -9999 -9999 -9999 -9999 -9999 -9999 -9999 -

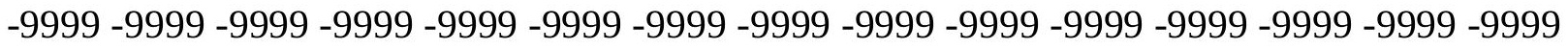
-9999 -9999 -9999 -9999 -9999 -9999 -9999 -9999 -9999 -9999 -9999 -9999 -9999 -9999 -9999 -9999-9999

-9999 -9999 -9999 -9999 -9999 -9999 -9999 -9999 -9999 -9999 -9999 -9999 -9999 -9999 -9999 -9999 -9999 -9999 -9999 -9999 -9999 -9999 -9999 -9999 -9999 -9999 -9999 -9999 -9999 -9999 -9999 -9999 -9999 -9999 -9999 -9999 -9999 -9999 -9999 -9999 -9999 -9999 -9999 -9999 -9999 -9999 -9999 -9999 -9999 -9999 -9999 -9999 -9999 -9999 -9999 -9999 -9999 -9999 -9999 -9999 -9999 -9999 -9999 -9999 -9999 -9999 -9999 -9999 -9999 -9999 -9999 -9999 -9999 -9999 -9999

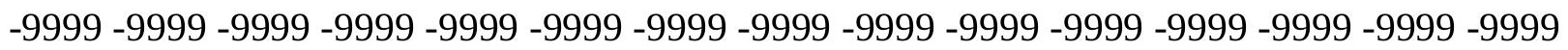
-9999 -9999 -9999 185.6141052246186.528503418 187.4429016113188.3571929932 189.2716064453190 .1858978271191 .1002960205191 .7097930908192 .624206543 193.5386047363194 .1481018066195 .0625195 .6721038818196 .2816009521196 .5863952637 196.891204834197 .1959991455197 .500793457197 .500793457197 .500793457 197.500793457197 .500793457197 .500793457197 .1959991455197 .1959991455 196.891204834196 .891204834196 .891204834196 .5863952637195 .9768066406 195.3672943115194 .7577056885194 .1481018066193 .8433074951193 .5386047363 193.233795166192 .3193969727192 .0146026611191 .7097930908192 .3193969727 193.233795166 194.1481018066194.7577056885 194.7577056885194.1481018066 192.9290008545191 .7097930908190 .795501709189 .8811035156189 .5764007568 189.5764007568189 .8811035156190 .4907073975191 .4051055908192 .3193969727 193.5386047363194 .4528961182195 .3672943115196 .2816009521197 .1959991455 198.1103057861198 .7198944092199 .6342926025200 .5485992432201 .4629974365 202.0724945068 202.9868927002 203.596496582 203.9011993408204.2059936523 204.5108032227204 .2059936523204 .2059936523203 .9011993408203 .2917022705 202.3882751465202 .0251312256201 .6248931885201 .1223297119200 .5485992432 199.6342926025199 .0247039795198 .1103057861197 .500793457196 .5863952637 195.9768066406195 .3672943115194 .7577056885194 .4528961182194 .1481018066 
193.5386047363193 .233795166192 .624206543192 .0146026611191 .4051055908 190.4907073975189 .8811035156188 .966796875188 .0523986816187 .1381072998 186.2236938477185 .0045928955184 .0901947021183 .1759033203182 .5662994385 181.9566955566181 .6519012451181 .0424041748180 .7375946045180 .432800293 180.1280059814179 .8231964111179 .8231964111179 .8231964111179 .5184020996 179.2136993408178 .9089050293178 .604095459177 .9945068359177 .6896972656 177.3849029541177 .3849029541178 .2993011475179 .5184020996181 .0424041748 181.9566955566182 .87109375183 .1759033203183 .7854003906184 .3950042725 185.0045928955185 .6141052246186 .528503418187 .1381072998187 .1381072998 187.1381072998186 .8332977295186 .528503418185 .850982666185 .0816955566 184.0597229004 183.2969207764 -9999 -9999 -9999 -9999 -9999 -9999 -9999 -9999 -9999 -9999 -9999 -9999 -9999 -9999 -9999 -9999 -9999 -9999 -9999 -9999 -9999 -9999 -9999 -9999 -9999 -9999 -9999 -9999 -9999 -9999 -9999 -9999 -9999 -9999 -9999 -9999 -9999 -9999 -9999 -9999 -9999 -9999 -9999 -9999 -9999 -9999 -9999 -9999 -9999 -9999 -9999 -9999 -9999 -9999 -9999 -9999 -9999 -9999 -9999 -9999 -9999 -9999 -9999 -9999 -9999 -9999 -9999 -9999 -9999

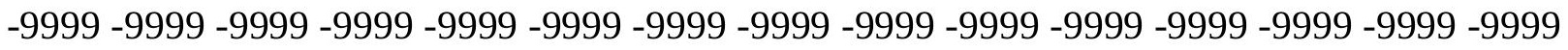
-9999 -9999 -9999 -9999 -9999 -9999 -9999 -9999 -9999 -9999 -9999 -9999 -9999 -9999 -9999 -9999 -9999 -9999 -9999 -9999 -9999 -9999 -9999 -9999 -9999 -9999 -9999 -9999 -9999 -9999 -

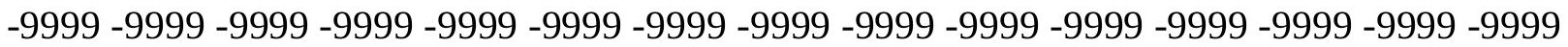

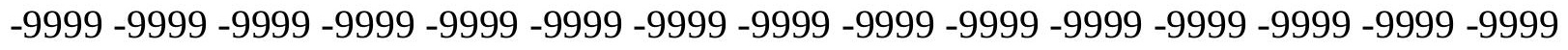
-9999 -9999 -9999 -9999 -9999 -9999 -9999 -9999 -9999 -9999

-9999 -9999 -9999 -9999 -9999 -9999 -9999 -9999 -9999 -9999 -9999 -9999 -9999 -9999 -999 -9999 -9999 -9999 -9999 -9999 -9999 -9999 -9999 -9999 -9999 -9999 -9999 -9999 -9999 -9999 -

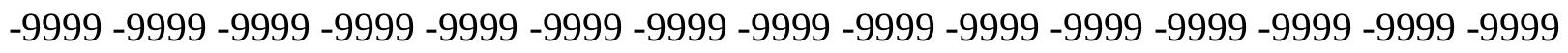
-9999 -9999 -9999 -9999 -9999 -9999 -9999 -9999 -9999 -9999 -9999 -9999 -9999 -9999 -9999 -9999 -9999 -9999 -9999 -9999 -9999 -9999 -9999 -9999 -9999 -9999 -9999 -9999 -9999 -9999 -9999 -9999 -9999 -9999 -9999 -9999 -9999 -9999 -9999 -9999 -9999 -9999 -9999 -9999 177.6896972656178.604095459179.8231964111 181.0424041748181.9566955566 183.1759033203184 .0901947021186 .528503418186 .2236938477187 .4429016113 188.3571929932189 .2716064453189 .8811035156190 .795501709191 .7097930908 192.3193969727192 .9290008545193 .5386047363194 .1481018066194 .4528961182 194.7577056885195 .0625195 .3672943115195 .3672943115195 .3672943115195 .3672943115 195.3672943115195 .3672943115195 .0625195 .0625195 .0625194 .7577056885 194.4528961182193 .8433074951193 .233795166192 .624206543192 .0146026611 191.7097930908191 .4051055908191 .1002960205190 .4907073975190 .1858978271 190.1858978271190 .4907073975191 .1002960205191 .7097930908192 .0146026611 191.7097930908191 .4051055908190 .4907073975189 .5764007568188 .966796875 188.0523986816187 .7476043701187 .7476043701188 .0523986816188 .6620025635 189.2716064453190.1858978271 191.1002960205 192.0146026611192 .9290008545 193.8433074951194 .7577056885195 .3672943115196 .2816009521196 .891204834 197.8054962158198 .4151000977199 .329498291199 .9389953613200 .5485992432 200.8533935547201 .158203125201 .158203125201 .158203125200 .4330444336 200.2958831787200 .0199890137199 .5712127686199 .1105499268198 .7198944092 198.1103057861197 .1959991455196 .5863952637195 .6721038818195 .0625194 .4528961182 193.5386047363192 .9290008545192 .3193969727191 .7097930908191 .1002960205 190.795501709190 .1858978271189 .8811035156189 .2716064453188 .6620025635 
187.7476043701 187.1381072998 186.2236938477 185.3094024658184.699798584 183.7854003906182 .87109375181 .9566955566181 .0424041748180 .1280059814 179.5184020996178 .9089050293178 .604095459177 .9945068359177 .6896972656 177.3849029541177 .0802001953177 .0802001953176 .7754058838176 .7754058838 176.4705963135176 .165802002175 .8609924316175 .5561981201175 .2514038086 174.9467010498174 .9467010498175 .2514038086176 .165802002177 .0802001953 178.2993011475179 .5184020996180 .432800293181 .0424041748181 .6519012451 182.261505127182 .87109375183 .4806976318184 .0901947021184 .3950042725 184.3950042725184 .0901947021183 .7854003906183 .4806976318182 .87109375 182.261505127180 .7375946045178 .2993011475178 .9089050293179 .8231964111 181.0424041748 -9999 -9999 -9999 -9999 -9999 -9999 -9999 -9999 -9999 -9999 -9999 -9999

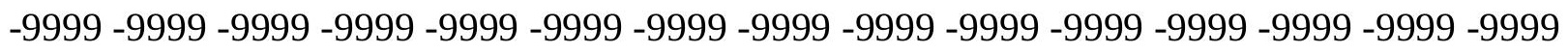
-9999 -9999 -9999 -9999 -9999 -9999 -9999 -9999 -9999 -9999 -9999 -9999 -9999 -9999 -9999 -9999 -9999 -9999 -9999 -9999 -9999 -9999 -9999 -9999 -9999 -9999 -9999 -9999 -9999 -9999 -9999 -9999 -9999 -9999 -9999 -9999 -9999 -9999 -9999 -9999 -9999 -9999 -9999 -9999 -9999

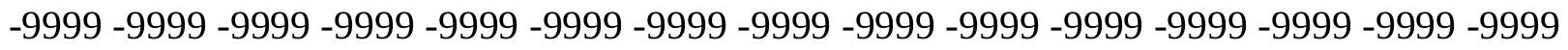
-9999 -9999 -9999 -9999 -9999 -9999 -9999 -9999 -9999 -9999 -9999 -9999 -9999 -9999 -9999 -9999 -9999 -9999 -9999 -9999 -9999 -9999 -9999 -9999 -9999 -9999 -9999 -9999 -9999 -9999 -9999 -9999 -9999 -9999 -9999 -9999 -9999 -9999 -9999 -9999 -9999 -9999 -9999 -9999 -9999 -

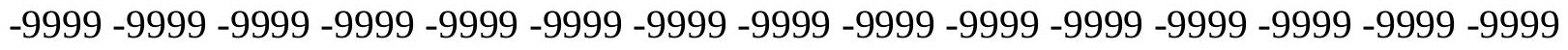
-9999-9999-9999-9999

-9999 -9999 -9999 -9999 -9999 -9999 -9999 -9999 -9999 -9999 -9999 -9999 -9999 -9999 -9999 -9999 -9999 -9999 -9999 -9999 -9999 -9999 -9999 -9999 -9999 -9999 -9999 -9999 -9999 -9999 -

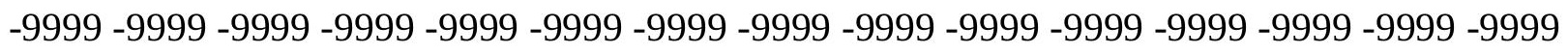

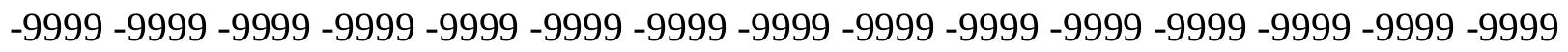
-9999 -9999 -9999 -9999 -9999 -9999 -9999 -9999 -9999 -9999 -9999 -9999 -9999 -9999 -9999 -9999 -9999 -9999 -9999 -9999 -9999 -9999 -9999 -9999 -9999 -9999 -9999 172.2035980225 173.4226989746174 .9467010498176 .165802002177 .0802001953178 .2993011475 179.5184020996180 .7375946045181 .9566955566183 .1759033203184 .3950042725 185.3094024658186 .2236938477187 .1381072998188 .0523986816188 .966796875 189.5764007568190 .4907073975191 .1002960205191 .4051055908192 .0146026611 192.3193969727192 .9290008545193 .233795166193 .233795166193 .5386047363 193.5386047363193 .5386047363193 .5386047363193 .233795166193 .233795166 192.9290008545192 .9290008545192 .624206543192 .3193969727191 .7097930908 191.4051055908190 .795501709190 .1858978271189 .8811035156189 .2716064453 188.966796875188 .6620025635188 .3571929932188 .3571929932188 .6620025635 188.966796875189 .2716064453189 .2716064453188 .966796875188 .6620025635 188.0523986816 187.4429016113186.8332977295 186.2236938477185.9188995361 185.9188995361186 .2236938477186 .528503418187 .1381072998187 .7476043701 188.6620025635189 .5764007568190 .4907073975191 .1002960205192 .0146026611 192.9290008545193 .5386047363194 .4528961182195 .0625195 .6721038818196 .2816009521 196.891204834197 .500793457197 .8054962158198 .1103057861198 .1103057861 197.7099609375 197.6784210205 197.490814209 197.1959991455 196.5863952637 195.9768066406195 .3672943115194 .7577056885194 .1481018066193 .5386047363 192.624206543192 .0146026611191 .1002960205190 .4907073975189 .8811035156 189.2716064453188 .6620025635188 .0523986816187 .4429016113186 .8332977295 
186.2236938477 185.6141052246185.0045928955 184.3950042725183.4806976318 182.87109375181 .9566955566181 .0424041748180 .1280059814179 .5184020996 178.604095459177 .6896972656177 .0802001953176 .4705963135175 .8609924316 175.2514038086174 .9467010498174 .6419067383174 .337097168174 .0323028564 174.0323028564173 .7274932861173 .7274932861173 .4226989746173 .4226989746 173.1179962158172 .8132019043172 .5084075928172 .5084075928172 .5084075928 173.1179962158173 .7274932861174 .9467010498175 .8609924316177 .0802001953 177.6896972656178 .604095459179 .2136993408179 .8231964111180 .432800293 181.0424041748181 .6519012451181 .9566955566182 .261505127181 .9566955566 181.6519012451181 .3471984863180 .432800293179 .2136993408177 .6896972656 175.8609924316173 .4226989746172 .2035980225173 .4226989746174 .9467010498 -9999 -9999 -9999 -9999 -9999 -9999 -9999 -9999 -9999 -9999 -9999 -9999 -9999 -9999 -9999 -9999 -9999 -9999 -9999 -9999 -9999 -9999 -9999 -9999 -9999 -9999 -9999 -9999 -9999 -9999 -9999 -9999 -9999 -9999 -9999 -9999 -9999 -9999 -9999 -9999 -9999 -9999 -9999 -9999 -9999 -9999 -9999 -9999 -9999 -9999 -9999 -9999 -9999 -9999 -9999 -9999 -9999 -9999 -9999 -9999 -9999

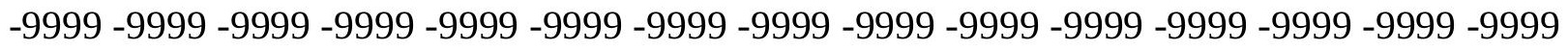
-9999 -9999 -9999 -9999 -9999 -9999 -9999 -9999 -9999 -9999 -9999 -9999 -9999 -9999 -9999 -9999 -9999 -9999 -9999 -9999 -9999 -9999 -9999 -9999 -9999 -9999 -9999 -9999 -9999 -9999 -

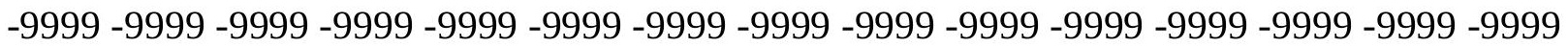

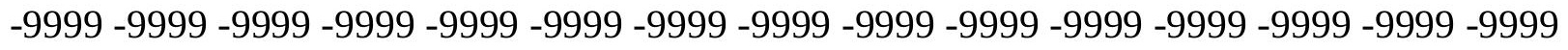

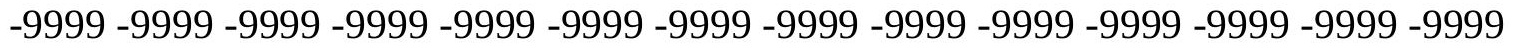
-9999 -9999 -9999 -9999 -9999 -9999 -9999 -9999 -9999 -9999 -9999 -9999 -9999 -9999 -9999 -9999 -9999 -9999 -9999 -9999 -9999 -9999 -9999 -9999 -9999 -9999 -9999 -9999 -9999 -9999 -

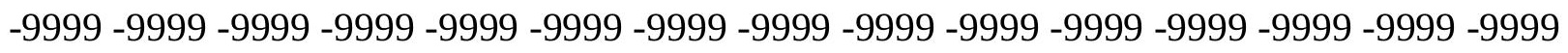

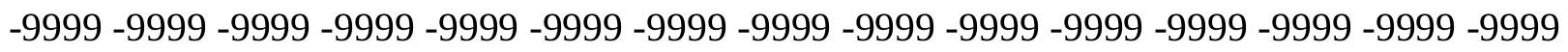

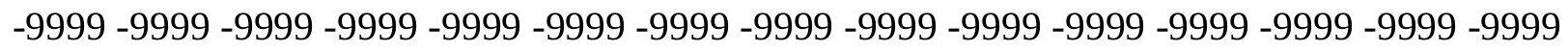
-9999 -9999 -9999 -9999 -9999 -9999 -9999 -9999 -9999 -9999 166.7174987793 168.241394043169.4604949951 170.9844970703172 .2035980225173 .7274932861 174.9467010498176 .4705963135177 .6896972656178 .9089050293180 .1280059814 181.3471984863182 .261505127183 .4806976318184 .3950042725185 .3094024658 186.2236938477186 .8332977295187 .7476043701188 .3571929932188 .966796875 189.5764007568190 .1858978271190 .4907073975190 .795501709191 .1002960205 191.4051055908191 .4051055908191 .4051055908191 .4051055908191 .4051055908 191.4051055908191 .1002960205191 .1002960205190 .795501709190 .4907073975 190.1858978271189 .5764007568189 .2716064453188 .6620025635188 .0523986816 187.7476043701187 .4429016113187 .1381072998186 .8332977295186 .528503418 186.528503418186 .528503418186 .8332977295186 .8332977295186 .8332977295 186.528503418186 .2236938477185 .6141052246185 .3094024658184 .699798584 184.3950042725184 .0901947021184 .0901947021184 .3950042725184 .699798584 185.0045928955185 .6141052246186 .528503418187 .1381072998188 .0523986816 188.6620025635189 .5764007568190 .1858978271190 .795501709191 .7097930908 192.3193969727192 .9290008545193 .5386047363193 .8433074951194 .4528961182 194.7577056885194 .7577056885194 .7509613037194 .7577056885194 .7577056885 194.4528961182193 .8433074951193 .5386047363192 .9290008545192 .3193969727 191.7097930908191 .1002960205190 .1858978271189 .5764007568188 .6620025635 188.0523986816187 .1381072998186 .528503418185 .9188995361185 .3094024658 
184.699798584184 .0901947021183 .4806976318182 .87109375182 .261505127 181.6519012451180 .7375946045180 .1280059814179 .2136993408178 .604095459 177.6896972656176 .7754058838176 .165802002175 .2514038086174 .6419067383 173.7274932861173 .1179962158172 .8132019043172 .2035980225171 .8988037109 171.5939941406171 .2891998291171 .2891998291170 .9844970703170 .9844970703 170.6797027588170 .6797027588170 .3748931885170 .3748931885170 .070098877 170.070098877170 .070098877170 .3748931885170 .9844970703171 .5939941406 172.5084075928173 .4226989746174 .337097168175 .2514038086176 .165802002 176.7754058838177 .6896972656178 .2993011475178 .9089050293179 .2136993408 179.5184020996179 .8231964111179 .8231964111179 .5184020996178 .9089050293 177.9945068359176 .7754058838175 .2514038086173 .1179962158170 .6797027588 168.241394043166 .4127044678167 .9365997314169 .4604949951 -9999 -9999 -9999 -9999 -9999 -9999 -9999 -9999 -9999 -9999 -9999 -9999 -9999 -9999 -9999 -9999 -9999 -9999 -9999 -9999 -9999 -9999 -9999 -9999 -9999 -9999 -9999 -9999 -9999 -9999 -9999 -9999 -9999 -9999 -9999 -9999 -9999 -9999 -9999 -9999 -9999 -9999 -9999 -9999 -9999 -9999 -9999 -9999 -9999

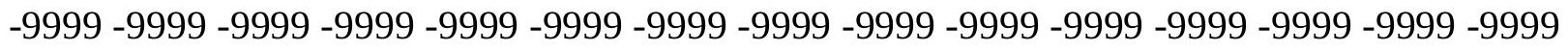
-9999 -9999 -9999 -9999 -9999 -9999 -9999 -9999 -9999 -9999 -9999 -9999 -9999 -9999 -9999 -9999 -9999 -9999 -9999 -9999 -9999 -9999 -9999 -9999 -9999 -9999 -9999 -9999 -9999 -9999 -

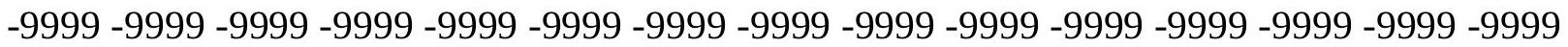

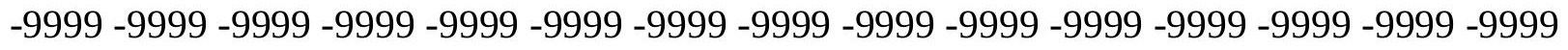

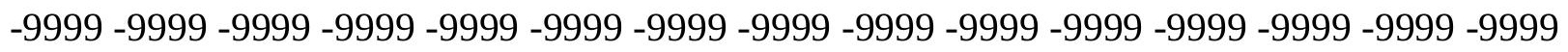
-9999 -9999-9999 -9999-9999-9999-9999-9999-9999-9999 -9999 -9999 -9999 -9999 -9999 -9999 -9999 -9999 -9999 -9999 -9999 -9999 -9999 -9999 -9999

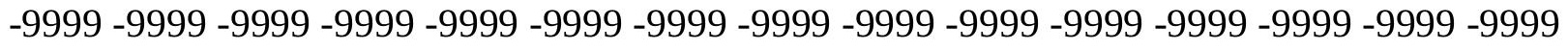

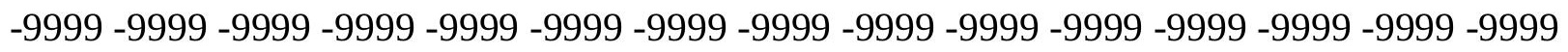
-9999 -9999 -9999 -9999 -9999 -9999 -9999 -9999 -9999 -9999 -9999 -9999 -9999 -9999 -9999 -9999 -9999 -9999 -9999 -9999-9999 -9999 -9999 -9999 -9999 -9999 -9999 -9999 -9999 - 9999 -9999 -9999 -9999 -9999-9999 -9999-9999 -9999 161.5361022949163 .0599975586 164.2792053223165 .4983062744167 .0222015381168 .8509979248170 .3748931885 171.5939941406173 .1179962158174 .337097168175 .8609924316177 .0802001953 178.2993011475179 .2136993408180 .432800293181 .3471984863182 .5662994385 183.1759033203184 .0901947021185 .0045928955185 .6141052246186 .2236938477 186.8332977295187 .4429016113188 .0523986816188 .3571929932188 .6620025635 188.966796875189 .2716064453189 .2716064453189 .2716064453189 .2716064453 189.2716064453189 .2716064453188 .966796875188 .966796875188 .6620025635 188.3571929932188 .0523986816187 .7476043701187 .1381072998186 .528503418 186.2236938477185 .9188995361185 .3094024658185 .0045928955185 .0045928955 184.699798584184 .699798584184 .699798584184 .3950042725184 .3950042725 184.3950042725184 .0901947021183 .7854003906183 .4806976318183 .1759033203 182.5662994385182 .261505127182 .261505127182 .261505127182 .261505127 182.5662994385182 .87109375183 .4806976318184 .0901947021184 .699798584 185.3094024658186 .2236938477186 .8332977295187 .4429016113188 .0523986816 188.6620025635189 .2716064453189 .8811035156190 .4907073975190 .795501709 191.1002960205191 .4051055908191 .6796722412191 .6998291016191 .7097930908 191.4051055908191 .1002960205190 .795501709190 .1858978271189 .8811035156 189.2716064453 188.3571929932 187.7476043701 187.1381072998 186.2236938477 
185.6141052246184 .699798584184 .0901947021183 .4806976318182 .5662994385 181.9566955566181 .3471984863180 .7375946045180 .1280059814179 .5184020996 178.9089050293177 .9945068359177 .3849029541176 .4705963135175 .8609924316 174.9467010498174 .337097168173 .4226989746172 .8132019043171 .8988037109 171.2891998291170 .6797027588170 .070098877169 .7653045654169 .1557006836 168.8509979248168 .5462036133168 .241394043168 .241394043167 .9365997314 167.9365997314167 .9365997314167 .6318054199167 .6318054199167 .6318054199 167.6318054199167 .6318054199167 .9365997314168 .241394043168 .5462036133 169.4604949951170 .070098877170 .9844970703171 .8988037109172 .8132019043 173.7274932861174 .337097168175 .2514038086175 .8609924316176 .4705963135 176.7754058838177 .0802001953177 .0802001953177 .0802001953176 .7754058838 176.165802002175 .2514038086174 .0323028564172 .5084075928170 .6797027588 168.241394043166 .1078948975163 .974395752162 .1457061768163 .3648071289 165.1934967041167 .0222015381 -9999 -9999 -9999 -9999 -9999 -9999 -9999 -9999 -9999 -9999 -9999 -9999 -9999 -9999 -9999 -9999 -9999 -9999 -9999 -9999 -9999 -9999 -9999 -9999

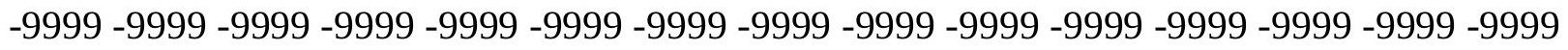
-9999 -9999 -9999 -9999 -9999 -9999 -9999 -9999 -9999 -9999 -9999 -9999 -9999 -9999 -9999 -9999 -9999 -9999 -9999 -9999 -9999 -9999 -9999 -9999 -9999 -9999 -9999 -9999 -9999 -9999 -9999 -9999 -9999 -9999 -9999 -9999 -9999 -9999 -9999 -9999 -9999 -9999 -9999 -9999 -9999

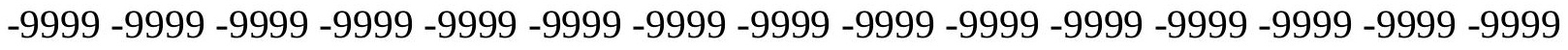

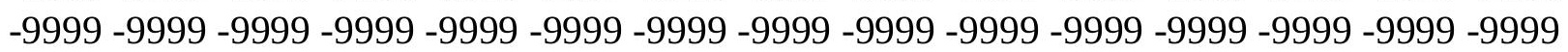
-9999 -9999 -9999 -9999 -9999 -9999 -9999 -9999 -9999 -9999 -9999 -9999 -9999 -9999 -9999 -

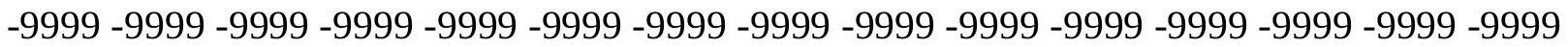
-9999 -9999-9999

-9999 -9999 -9999 -9999 -9999 -9999 -9999 -9999 -9999 -9999 -9999 -9999 -9999 -9999 -9999 -9999 -9999 -9999 -9999 -9999 -9999 -9999 -9999 -9999 -9999 -9999 -9999 -9999 -9999 -9999 -9999 -9999 -9999 -9999 -9999 -9999 -9999 -9999 -9999 -9999 -9999 -9999 -9999 -9999 -9999

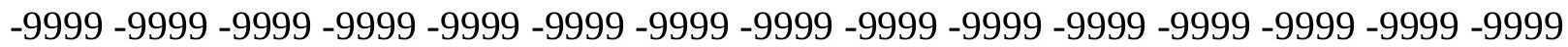
-9999 -9999 -9999 -9999 -9999 -9999 -9999 -9999 -9999 -9999 -9999 -9999 -9999 -9999 -9999 -9999 -9999 -9999 -9999 -9999 -9999 156.3547973633 157.878692627 159.0977935791 160.3170013428161 .8408966064163 .3648071289165 .1934967041166 .7174987793 168.241394043169 .7653045654171 .2891998291172 .5084075928173 .7274932861 174.9467010498176 .165802002177 .3849029541178 .2993011475179 .5184020996 180.432800293181 .3471984863182 .261505127182 .87109375183 .7854003906 184.3950042725185 .0045928955185 .3094024658185 .9188995361186 .2236938477 186.528503418186 .8332977295187 .1381072998187 .1381072998187 .1381072998 187.1381072998187 .1381072998187 .1381072998187 .1381072998186 .8332977295 186.528503418186 .2236938477185 .9188995361185 .6141052246185 .0045928955 184.699798584184 .3950042725183 .7854003906183 .4806976318183 .1759033203 182.87109375182 .87109375182 .5662994385182 .5662994385182 .261505127182 .261505127 181.9566955566181 .6519012451181 .6519012451181 .0424041748180 .7375946045 180.432800293180 .432800293180 .1280059814180 .1280059814180 .432800293 180.432800293180 .7375946045181 .3471984863181 .9566955566182 .261505127 182.87109375183 .4806976318184 .0901947021184 .699798584185 .3094024658 185.9188995361186 .528503418187 .1381072998187 .4429016113187 .7476043701 188.0523986816 188.3571929932 188.3571929932 188.3571929932188.3571929932 
188.3571929932188 .0523986816187 .4429016113187 .1381072998186 .528503418 185.9188995361185 .3094024658184 .699798584183 .7854003906183 .1759033203 182.261505127181 .6519012451180 .7375946045180 .1280059814179 .5184020996 178.604095459177 .9945068359177 .3849029541176 .7754058838176 .165802002 175.2514038086174 .6419067383173 .7274932861173 .1179962158172 .5084075928 171.5939941406170 .9844970703170 .070098877169 .4604949951168 .8509979248 167.9365997314167 .6318054199167 .0222015381166 .4127044678166 .1078948975 165.8031005859165 .4983062744165 .1934967041165 .1934967041165 .1934967041 164.8887023926164 .8887023926164 .8887023926164 .8887023926164 .8887023926 165.1934967041165 .1934967041165 .4983062744165 .8031005859166 .4127044678 167.0222015381167 .9365997314168 .8509979248169 .4604949951170 .3748931885 171.2891998291171 .8988037109172 .8132019043173 .1179962158173 .7274932861 174.0323028564174 .337097168174 .6419067383174 .337097168174 .0323028564 173.4226989746172 .8132019043171 .5939941406169 .7653045654167 .9365997314 166.1078948975163 .974395752161 .8408966064160 .0122070312158 .1835021973 159.4026031494 161.5361022949 163.3648071289 -9999 -9999 -9999 -9999 -9999 -9999 -9999 -9999 -9999 -9999 -9999 -9999 -9999 -9999 -9999 -9999 -9999 -9999 -9999 -9999 -9999 -9999 -9999 -9999 -9999 -9999 -9999 -9999 -9999 -9999 -9999 -9999 -9999 -9999 -9999 -9999 -9999 -

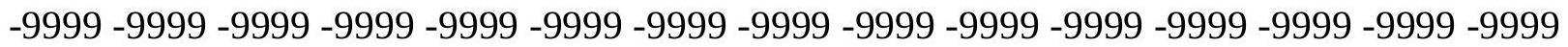
-9999 -9999 -9999 -9999 -9999 -9999 -9999 -9999 -9999 -9999 -9999 -9999 -9999 -9999 -9999 -

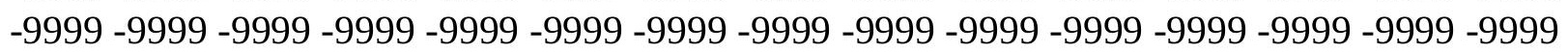

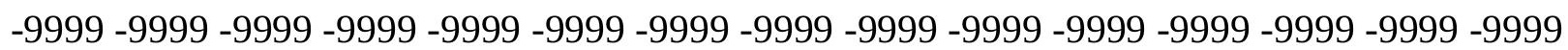
-9999 -9999 -9999 -9999 -9999 -9999 -9999 -9999 -9999 -9999 -9999 -9999-9999-9999-9999 -999 -

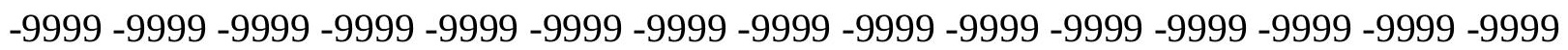

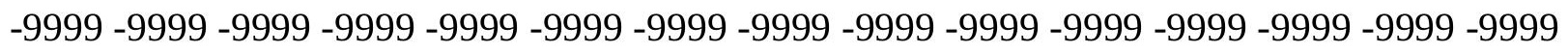
-9999 -9999 -9999-9999

-9999 -9999 -9999 -9999 -9999 -9999 -9999 -9999 -9999 -9999 -9999 -9999 -9999 -9999 -9999

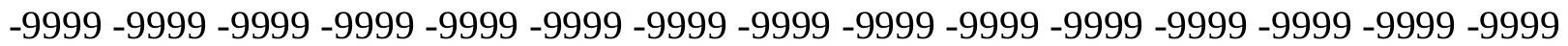

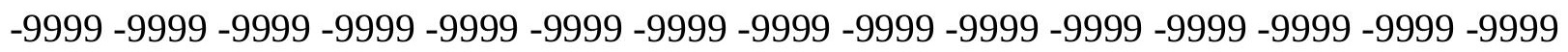

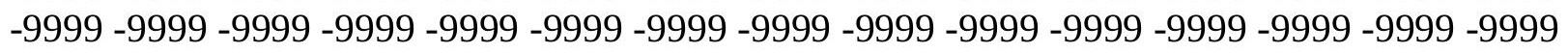
-9999 -9999 -9999 -9999 -9999 -9999 -9999 -9999 -9999 -9999 -9999 -9999 -9999 -9999 -9999 -9999 -9999 -9999 -9999 151.1734008789 152.6972961426153 .9165039062155 .1356048584 156.6596069336158 .1835021973159 .7073974609161 .5361022949163 .0599975586 164.8887023926166 .4127044678167 .9365997314169 .1557006836170 .3748931885 171.8988037109173 .1179962158174 .337097168175 .2514038086176 .4705963135 177.3849029541178 .2993011475179 .2136993408180 .1280059814180 .7375946045 181.6519012451182 .261505127182 .87109375183 .4806976318183 .7854003906 184.0901947021184 .3950042725184 .699798584185 .0045928955185 .0045928955 185.3094024658185 .3094024658185 .0045928955185 .0045928955185 .0045928955 184.699798584184 .3950042725184 .0901947021183 .7854003906183 .4806976318 183.1759033203182 .5662994385182 .261505127181 .9566955566181 .6519012451 181.3471984863181 .0424041748180 .7375946045180 .432800293180 .432800293 180.1280059814179 .8231964111179 .8231964111179 .5184020996179 .2136993408 178.9089050293178 .604095459178 .604095459178 .2993011475178 .2993011475 178.2993011475178 .2993011475178 .604095459178 .604095459179 .2136993408 179.5184020996180 .1280059814180 .432800293181 .0424041748181 .6519012451 
182.261505127182 .87109375183 .1759033203183 .7854003906184 .0901947021 184.699798584185 .0045928955185 .0045928955185 .3094024658185 .3094024658 185.3094024658185 .3094024658185 .0045928955184 .699798584184 .3950042725 183.7854003906183 .1759033203182 .87109375181 .9566955566181 .3471984863 180.7375946045179 .8231964111179 .2136993408178 .2993011475177 .6896972656 176.7754058838176 .165802002175 .5561981201174 .6419067383174 .0323028564 173.4226989746172 .5084075928171 .8988037109171 .2891998291170 .3748931885 169.7653045654168 .8509979248168 .241394043167 .3269958496166 .7174987793 166.1078948975165 .4983062744164 .8887023926164 .2792053223163 .6696014404 163.3648071289163 .0599975586162 .7552947998162 .4505004883162 .4505004883 162.1457061768162 .1457061768162 .1457061768162 .1457061768162 .1457061768 162.1457061768162 .4505004883162 .4505004883162 .7552947998163 .0599975586 163.6696014404164 .2792053223164 .8887023926165 .4983062744166 .4127044678 167.0222015381167 .9365997314168 .8509979248169 .4604949951170 .070098877 170.6797027588171 .2891998291171 .5939941406171 .8988037109171 .8988037109 171.5939941406171 .2891998291170 .6797027588170 .070098877168 .8509979248 167.3269958496165 .4983062744163 .6696014404161 .8408966064160 .0122070312 158.1835021973156 .6596069336156 .0500030518156 .6596069336158 .1835021973 160.0122070312 -9999 -9999 -9999 -9999 -9999 -9999 -9999 -9999 -9999 -9999 -9999 -9999

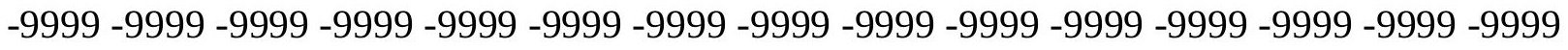
-9999 -9999 -9999 -9999 -9999 -9999 -9999 -9999 -9999 -9999 -9999 -9999 -9999 -9999 -9999 -9999 -9999 -9999 -9999 -9999 -9999 -9999 -9999 -9999 -9999 -9999 -9999 -9999 -9999 -9999 -9999 -9999 -9999 -9999 -9999 -9999 -9999 -9999 -9999 -9999 -9999 -9999-9999-9999-9999 -999 -9999 -9999 -9999 -9999 -9999 -9999 -9999 -9999 -9999 -9999 -9999 -9999 -9999 -9999 -9999 -9999 -9999 -9999 -9999 -9999 -9999 -9999 -9999 -9999 -9999 -9999 -9999 -9999 -9999 -9999 -9999 -9999 -9999 -9999 -9999 -9999 -9999 -9999 -9999 -9999 -9999 -9999 -9999 -9999 -9999

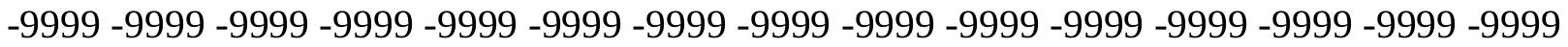
-9999 -9999 -9999 -9999 -9999 -9999 -9999 -9999 -9999 -9999 -9999 -9999 -9999 -9999 -9999 -9999 -9999 -9999 -9999 -9999 -9999 -9999 -9999 -9999 -9999 -9999 -9999 -9999 -9999 -9999 -9999 -9999 -9999 -9999 -9999 -9999 -9999 -9999 -9999 -9999 -9999 -9999 -9999 -9999 -9999 -9999 -9999 -9999 -9999 -9999 -9999 -9999 -9999 -9999 -9999 -9999 -9999 -9999

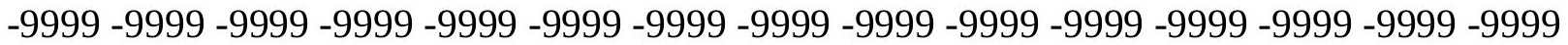

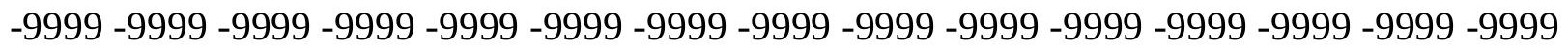
-9999 -9999 145.9920959473147.5160064697 148.7351074219 150.2590942383 151.4781951904153 .0021057129154 .8307952881156 .3547973633158 .1835021973 159.7073974609161 .2312927246162 .7552947998164 .2792053223165 .8031005859 167.3269958496168 .5462036133169 .7653045654170 .9844970703172 .2035980225 173.4226989746174 .337097168175 .2514038086176 .4705963135177 .0802001953 177.9945068359178 .9089050293179 .5184020996180 .1280059814180 .7375946045 181.3471984863181 .6519012451181 .9566955566182 .261505127182 .5662994385 182.87109375182 .87109375182 .87109375182 .87109375182 .87109375182 .87109375 182.87109375182 .5662994385182 .261505127181 .9566955566181 .6519012451 181.3471984863181 .0424041748180 .7375946045180 .1280059814179 .8231964111 179.5184020996179 .2136993408178 .9089050293178 .604095459178 .2993011475 178.2993011475177 .9945068359177 .6896972656177 .3849029541177 .3849029541 177.0802001953176 .7754058838176 .4705963135176 .4705963135176 .165802002 
176.165802002176 .165802002176 .165802002176 .4705963135176 .4705963135 176.7754058838177 .3849029541177 .6896972656177 .9945068359178 .604095459 179.2136993408179 .5184020996180 .1280059814180 .432800293181 .0424041748 181.3471984863181 .6519012451181 .9566955566181 .9566955566182 .261505127 182.261505127182 .261505127181 .9566955566181 .9566955566181 .6519012451 181.0424041748180 .7375946045180 .1280059814179 .5184020996178 .9089050293 178.2993011475177 .3849029541176 .7754058838175 .8609924316175 .2514038086 174.337097168173 .7274932861172 .8132019043172 .2035980225171 .5939941406 170.6797027588170 .070098877169 .1557006836168 .5462036133167 .6318054199 167.0222015381166 .4127044678165 .4983062744164 .8887023926163 .974395752 163.3648071289162 .7552947998162 .1457061768161 .5361022949161 .2312927246 160.6217956543160 .3170013428160 .0122070312159 .7073974609159 .4026031494 159.4026031494159 .4026031494159 .4026031494159 .4026031494159 .4026031494 159.4026031494159 .7073974609159 .7073974609160 .0122070312160 .3170013428 160.9264984131161 .2312927246161 .8408966064162 .4505004883163 .3648071289 163.974395752164 .8887023926165 .4983062744166 .1078948975167 .0222015381 167.6318054199168 .241394043168 .5462036133168 .8509979248169 .1557006836 169.1557006836168 .8509979248168 .5462036133167 .9365997314167 .3269958496 166.1078948975164 .8887023926163 .3648071289161 .5361022949160 .0122070312 158.1835021973156 .6596069336155 .4403991699154 .5260925293153 .9165039062 154.2212982178155 .1356048584156 .6596069336 -9999 -9999 -9999 -9999 -9999 -9999 -9999 -9999 -9999 -9999 -9999 -9999 -9999 -9999 -9999 -9999 -9999 -9999 -9999 -9999 -9999 -9999 -9999 -9999 -9999 -9999 -9999 -9999 -9999 -9999 -9999 -9999 -9999 -9999 -9999 -9999 -9999 -9999 -9999 -9999 -9999 -9999 -9999 -9999 -9999 -9999 -9999 -9999 -9999 -9999 -9999 -9999 -9999 -9999 -9999 -9999 -9999 -9999 -9999 -9999 -9999 -9999 -9999 -9999 -9999 -9999 -9999 -9999 -9999 -9999 -9999 -9999 -9999 -9999 -9999 -9999 -9999 -9999 -9999 -9999 -9999 -9999 -9999 -9999 -9999 -9999 -9999 -9999 -9999 -9999 -9999 -9999 -9999 -9999 -9999 -9999 -9999

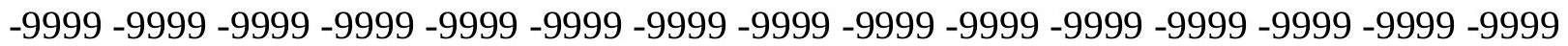
-9999 -9999 -9999 -9999 -9999 -9999 -9999 -9999 -9999 -9999 -9999 -9999 -9999 -9999 -9999

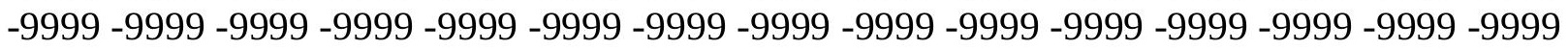
-9999 -9999

-9999 -9999 -9999 -9999 -9999 -9999 -9999 -9999 -9999 -9999 -9999 -9999 -9999 -9999 -9999 -9999 -9999 -9999 -9999 -9999 -9999 -9999 -9999 -9999-9999 -9999 -9999 -9999-9999-999 - -999 -9999 -9999 -9999 -9999 -9999 -9999 -9999 -9999 -9999 -9999 -9999 -9999 -9999 -9999 -9999 -9999 -9999 -9999 -9999 -9999 -9999 -9999 -9999 -9999 -9999 -9999 -9999 -9999 -9999 -9999 -9999 -9999 -9999 -9999 -9999 -9999 -9999 -9999 -9999 -9999 -9999 -9999 -9999 -9999 -9999 -9999 142.3347015381 143.8585968018 145.0776977539 146.2969055176148.1255950928 149.3446960449151 .1734008789153 .0021057129154 .5260925293156 .3547973633 157.878692627159 .4026031494160 .9264984131162 .4505004883163 .974395752 165.1934967041166 .7174987793167 .9365997314169 .1557006836170 .070098877 171.2891998291172 .2035980225173 .4226989746174 .337097168175 .2514038086 175.8609924316176 .7754058838177 .3849029541177 .9945068359178 .604095459 179.2136993408179 .5184020996179 .8231964111180 .1280059814180 .432800293 180.7375946045180 .7375946045180 .7375946045180 .7375946045180 .7375946045 180.7375946045180 .432800293180 .432800293180 .1280059814179 .8231964111 179.5184020996179 .2136993408178 .9089050293178 .604095459178 .2993011475 
177.6896972656177 .3849029541177 .0802001953176 .7754058838176 .4705963135 176.165802002176 .165802002175 .8609924316175 .5561981201175 .2514038086 174.9467010498174 .9467010498174 .6419067383174 .337097168174 .337097168 174.0323028564174 .0323028564174 .0323028564174 .0323028564174 .337097168 174.337097168174 .6419067383174 .9467010498175 .2514038086175 .8609924316 176.165802002176 .4705963135177 .0802001953177 .3849029541177 .6896972656 177.9945068359178 .2993011475178 .604095459178 .9089050293179 .2136993408 179.2136993408179 .2136993408179 .2136993408178 .9089050293178 .604095459 178.2993011475177 .9945068359177 .3849029541177 .0802001953176 .4705963135 175.8609924316174 .9467010498174 .337097168173 .7274932861172 .8132019043 172.2035980225171 .2891998291170 .3748931885169 .7653045654168 .8509979248 168.241394043167 .3269958496166 .7174987793165 .8031005859165 .1934967041 164.2792053223163 .6696014404162 .7552947998162 .1457061768161 .5361022949 160.6217956543160 .0122070312159 .4026031494158 .7929992676158 .4882965088 157.878692627157 .5738983154157 .2691040039156 .9642944336156 .6596069336 156.3547973633156 .3547973633156 .3547973633156 .3547973633156 .3547973633 156.6596069336156 .6596069336156 .9642944336157 .2691040039157 .5738983154 157.878692627158 .4882965088158 .7929992676159 .4026031494160 .0122070312 160.9264984131161 .5361022949162 .4505004883163 .0599975586163 .6696014404 164.2792053223164 .8887023926165 .4983062744165 .8031005859166 .1078948975 166.4127044678166 .4127044678166 .1078948975165 .8031005859165 .1934967041 164.5839996338163 .6696014404162 .4505004883160 .9264984131159 .4026031494 157.878692627156 .6596069336155 .1356048584153 .9165039062153 .3069000244 $152.6972961426152 .3925933838152 .3925933838152 .6972961426155 .1356048584-9999$ -9999 -9999 -9999 -9999 -9999 -9999 -9999 -9999 -9999 -9999 -9999 -9999 -9999 -9999 -9999 -9999 -9999 -9999 -9999 -9999 -9999 -9999 -9999 -9999 -9999 -9999 -9999 -9999 -9999 -9999 -9999 -9999 -9999 -9999 -9999 -9999 -9999 -9999 -9999 -9999 -9999 -9999 -9999 -9999 -9999

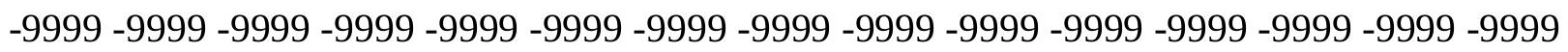
-9999 -9999 -9999 -9999 -9999 -9999 -9999 -9999 -9999 -9999 -9999 -9999 -9999 -9999 -9999 -9999 -9999 -9999 -9999 -9999 -9999 -9999 -9999 -9999 -9999 -9999 -9999 -9999 -9999 -9999 -9999 -9999 -9999 -9999 -9999 -9999 -9999 -9999 -9999 -9999 -9999 -9999 -9999 -9999 -9999 -9999 -9999 -9999 -9999 -9999 -9999 -9999 -9999 -9999 -9999 -9999 -9999 -9999 -9999 -9999 -

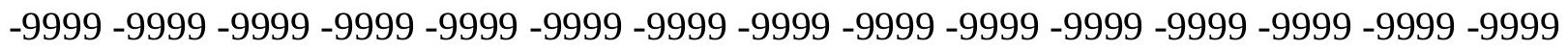
-9999 -9999 -9999 -9999-9999 -9999 -9999

-9999 -9999 -9999 -9999 -9999 -9999 -9999 -9999 -9999 -9999 -9999 -9999 -9999 -9999 -9999

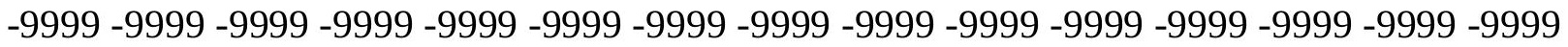

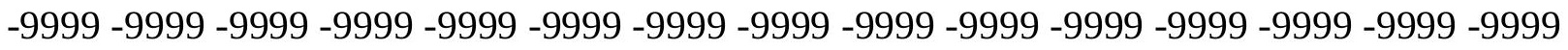

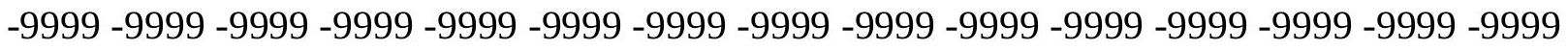
-9999 -9999 -9999 -9999 -9999 -9999 -9999 -9999 -9999 -9999 -9999 -9999 -9999 -9999 -9999 138.6772003174140 .2012023926141 .4203033447142 .9441986084144 .7729034424 146.2969055176147 .8208007812149 .3446960449151 .1734008789152 .6972961426 154.5260925293156 .0500030518157 .5738983154159 .0977935791160 .6217956543 161.8408966064163 .3648071289164 .5839996338165 .8031005859167 .0222015381 168.241394043169 .1557006836170 .3748931885171 .2891998291172 .2035980225 173.1179962158173 .7274932861174 .6419067383175 .2514038086175 .8609924316 176.4705963135176 .7754058838177 .3849029541177 .6896972656177 .9945068359 
178.2993011475178 .604095459178 .604095459178 .604095459178 .604095459 178.604095459178 .604095459178 .2993011475178 .2993011475177 .9945068359 177.6896972656177 .3849029541177 .0802001953176 .7754058838176 .4705963135 176.165802002175 .8609924316175 .5561981201174 .9467010498174 .6419067383 174.337097168174 .337097168174 .0323028564173 .7274932861173 .4226989746 173.1179962158172 .8132019043172 .5084075928172 .5084075928172 .2035980225 172.2035980225171 .8988037109171 .8988037109171 .8988037109171 .8988037109 171.8988037109172 .2035980225172 .5084075928172 .8132019043172 .8132019043 173.4226989746173 .7274932861174 .0323028564174 .337097168174 .6419067383 174.9467010498175 .2514038086175 .5561981201175 .8609924316175 .8609924316 176.165802002176 .165802002176 .165802002175 .8609924316175 .8609924316 175.5561981201175 .2514038086174 .6419067383174 .337097168173 .7274932861 173.1179962158172 .5084075928171 .8988037109171 .2891998291170 .3748931885 169.7653045654168 .8509979248168 .241394043167 .3269958496166 .4127044678 165.8031005859164 .8887023926164 .2792053223163 .3648071289162 .4505004883 161.8408966064160 .9264984131160 .3170013428159 .4026031494158 .7929992676 158.1835021973157 .5738983154156 .9642944336156 .3547973633155 .7451934814 155.1356048584154 .8307952881154 .5260925293154 .2212982178153 .9165039062 153.6116943359153 .6116943359153 .6116943359153 .6116943359153 .6116943359 153.6116943359153 .9165039062154 .2212982178154 .2212982178154 .8307952881 155.1356048584155 .4403991699156 .0500030518156 .6596069336157 .2691040039 157.878692627158 .4882965088159 .0977935791160 .0122070312160 .6217956543 161.2312927246161 .8408966064162 .4505004883162 .7552947998163 .3648071289 163.3648071289163 .6696014404163 .6696014404163 .3648071289163 .0599975586 162.7552947998161 .8408966064160 .9264984131160 .0122070312158 .7929992676 157.5738983154156 .0500030518154 .8307952881153 .6116943359152 .6972961426 151.7830047607151 .4781951904151 .1734008789151 .4781951904153 .6116943359 153.3069000244154 .2212982178 -9999 -9999 -9999 -9999 -9999 -9999 -9999 -9999 -9999 -9999 -9999 -9999 -9999 -9999 -9999 -9999 -9999 -9999 -9999 -9999 -9999 -9999 -9999 -9999 -9999 -9999 -9999 -9999 -9999 -9999 -9999 -9999 -9999 -9999 -9999 -9999 -9999 -9999 -9999 -9999 -9999 -9999 -9999 -9999 -9999 -9999 -9999 -9999 -9999 -9999 -9999 -9999 -9999 -9999 -

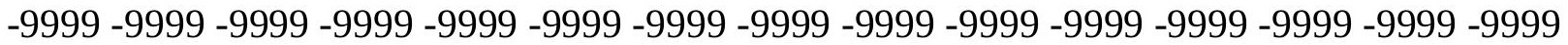
-9999 -9999 -9999 -9999 -9999 -9999 -9999 -9999 -9999 -9999 -9999 -9999 -9999 -9999 -9999 -9999 -9999 -9999 -9999 -9999 -9999 -9999 -9999 -9999 -9999 -9999 -9999 -9999 -9999 -9999 -9999 -9999 -9999 -9999 -9999 -9999 -9999 -9999 -9999 -9999 -9999 -9999 -9999 -9999 -9999 -9999 -9999 -9999 -9999 -9999 -9999 -9999 -9999 -9999 -9999 -9999 -9999 -9999 -9999 -9999 -9999 -9999 -9999 -9999 -9999 -9999 -9999 -9999 -9999 -9999 -9999 -9999 -9999

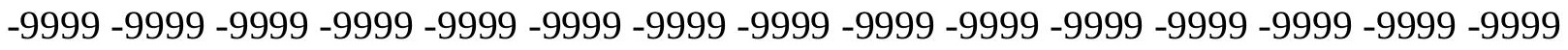
-9999 -9999 -9999 -9999 -9999 -9999 -9999 -9999 -9999 -9999 -9999 -9999 -9999 -9999 -9999 -9999 -9999 -9999 -9999 -9999 -9999 -9999 -9999 -9999 -9999 -9999 -9999 -9999 -9999 -9999 -

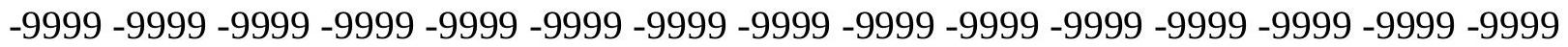
-9999 -9999 -9999 -9999 -9999 -9999 -9999 -9999 -9999 -9999 -9999 -9999 -9999 133.4958953857135 .0198059082136 .2389984131137 .7628936768139 .2868041992 141.1154937744142 .9441986084144 .4682006836145 .9920959473147 .8208007812 149.3446960449151 .1734008789152 .6972961426154 .2212982178155 .7451934814 157.2691040039 158.4882965088160.0122070312 161.2312927246162.7552947998 
163.974395752164 .8887023926166 .1078948975167 .3269958496168 .241394043 169.1557006836170 .070098877170 .9844970703171 .5939941406172 .5084075928 173.1179962158173 .7274932861174 .337097168174 .6419067383175 .2514038086 175.5561981201175 .8609924316176 .165802002176 .165802002176 .4705963135 176.4705963135176 .4705963135176 .4705963135176 .4705963135176 .165802002 176.165802002175 .8609924316175 .5561981201175 .2514038086174 .9467010498 174.6419067383174 .337097168174 .0323028564173 .7274932861173 .4226989746 173.1179962158172 .8132019043172 .2035980225171 .8988037109171 .8988037109 171.5939941406171 .2891998291170 .9844970703170 .6797027588170 .3748931885 170.3748931885170 .070098877169 .7653045654169 .7653045654169 .7653045654 169.7653045654169 .7653045654169 .7653045654170 .070098877170 .070098877 170.3748931885170 .6797027588170 .9844970703171 .2891998291171 .5939941406 171.8988037109172 .2035980225172 .2035980225172 .5084075928172 .8132019043 173.1179962158173 .1179962158173 .1179962158173 .1179962158173 .1179962158 172.8132019043172 .8132019043172 .5084075928172 .2035980225171 .5939941406 171.2891998291170 .6797027588170 .070098877169 .4604949951168 .8509979248 167.9365997314167 .3269958496166 .4127044678165 .8031005859164 .8887023926 164.2792053223163 .3648071289162 .4505004883161 .8408966064160 .9264984131 160.0122070312159 .4026031494158 .4882965088157 .878692627156 .9642944336 156.3547973633155 .4403991699154 .8307952881154 .2212982178153 .6116943359 153.0021057129152 .3925933838152 .0877990723151 .4781951904151 .1734008789 150.8686065674150 .8686065674150 .5639038086150 .5639038086150 .5639038086 150.5639038086150 .8686065674150 .8686065674151 .1734008789151 .4781951904 151.7830047607152 .0877990723152 .6972961426153 .0021057129153 .6116943359 154.2212982178154 .8307952881155 .4403991699156 .0500030518156 .6596069336 157.5738983154158 .1835021973158 .7929992676159 .4026031494159 .7073974609 160.3170013428160 .6217956543160 .9264984131160 .9264984131160 .9264984131 160.9264984131160 .6217956543160 .0122070312159 .4026031494158 .4882965088 157.5738983154156 .6596069336155 .4403991699154 .2212982178153 .3069000244 152.0877990723151 .1734008789150 .5639038086150 .2590942383150 .2590942383 $150.2590942383152 .6972961426151 .4781951904151 .1734008789151 .7830047607-9999$ -9999 -9999 -9999 -9999 -9999 -9999 -9999 -9999 -9999 -9999 -9999 -9999 -9999 -9999 -9999

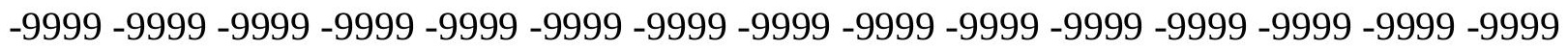
-9999 -9999 -9999 -9999 -9999 -9999 -9999 -9999 -9999 -9999 -9999 -9999 -9999 -9999 -9999 -9999 -9999 -9999 -9999 -9999 -9999 -9999 -9999 -9999 -9999 -9999 -9999 -9999 -9999 -9999

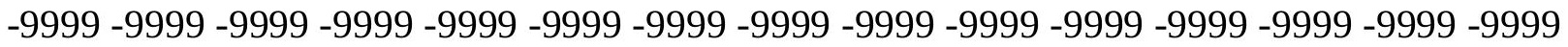

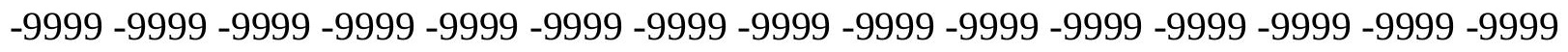

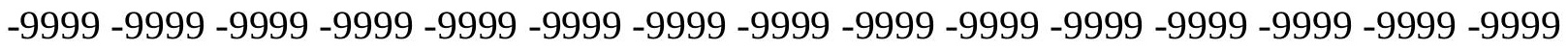
-9999 -9999 -9999 -9999 -9999 -9999 -9999 -9999 -9999 -9999 -9999 -9999 -9999 -9999 -9999 -9999 -9999 -9999 -9999 -9999 -9999 -9999 -9999 -9999 -9999 -9999 -9999 -9999 -9999 -9999 -9999 -9999-9999-9999-9999

-9999 -9999 -9999 -9999 -9999 -9999 -9999 -9999 -9999 -9999 -9999 -9999 -9999 -9999 -9999 -

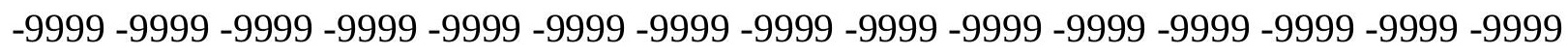
-9999 -9999 -9999 -9999 -9999 -9999 -9999 -9999 -9999 -9999 -9999 -9999 -9999 -9999 -9999 -9999 -9999 -9999 -9999 -9999 -9999 -9999 -9999 -9999 -9999 -9999 -9999 -9999 -9999 -9999 -9999 -9999 -9999 -9999 -9999 -9999 -9999 -9999 -9999 -9999 -9999 -9999 129.8385009766 
131.3623962402132 .8863067627134 .1054992676135 .9342041016137 .7628936768 139.2868041992141 .1154937744142 .9441986084144 .4682006836145 .9920959473 147.8208007812149 .3446960449150 .8686065674152 .3925933838153 .9165039062 155.4403991699156 .6596069336158 .1835021973159 .4026031494160 .6217956543 161.8408966064163 .0599975586164 .2792053223165 .1934967041166 .1078948975 167.0222015381167 .9365997314168 .8509979248169 .7653045654170 .3748931885 170.9844970703171 .5939941406172 .2035980225172 .5084075928173 .1179962158 173.4226989746173 .7274932861174 .0323028564174 .0323028564174 .337097168 174.337097168174 .337097168174 .337097168174 .0323028564174 .0323028564 173.7274932861173 .7274932861173 .4226989746173 .1179962158172 .8132019043 172.5084075928172 .2035980225171 .8988037109171 .5939941406171 .2891998291 170.9844970703170 .6797027588170 .070098877169 .7653045654169 .4604949951 169.1557006836169 .1557006836168 .8509979248168 .5462036133168 .241394043 167.9365997314167 .9365997314167 .6318054199167 .6318054199167 .6318054199 167.6318054199167 .6318054199167 .6318054199167 .6318054199167 .9365997314 167.9365997314168 .241394043168 .5462036133168 .8509979248168 .8509979248 169.1557006836169 .4604949951169 .7653045654169 .7653045654170 .070098877 170.070098877170 .3748931885170 .3748931885170 .070098877170 .070098877 170.070098877169 .7653045654169 .4604949951169 .1557006836168 .5462036133 168.241394043167 .6318054199167 .0222015381166 .4127044678165 .8031005859 164.8887023926164 .2792053223163 .3648071289162 .7552947998161 .8408966064 160.9264984131160 .3170013428159 .4026031494158 .4882965088157 .878692627 156.9642944336156 .0500030518155 .4403991699154 .5260925293153 .6116943359 153.0021057129152 .3925933838151 .4781951904150 .8686065674150 .2590942383 149.9542999268149 .3446960449149 .0399017334148 .4304046631148 .1255950928 148.1255950928147 .8208007812147 .8208007812147 .5160064697147 .8208007812 147.8208007812147 .8208007812148 .1255950928148 .4304046631148 .7351074219 149.0399017334149 .6495056152149 .9542999268150 .5639038086151 .1734008789 151.7830047607152 .3925933838153 .0021057129153 .6116943359154 .2212982178 154.8307952881155 .7451934814156 .3547973633156 .6596069336157 .2691040039 157.5738983154157 .878692627158 .1835021973158 .1835021973158 .1835021973 158.1835021973157 .878692627157 .5738983154156 .9642944336156 .3547973633 155.4403991699154 .5260925293153 .6116943359152 .3925933838151 .4781951904 150.5639038086149 .9542999268149 .3446960449148 .7351074219148 .7351074219 148.7351074219149 .0399017334148 .7351074219147 .8208007812148 .1255950928 148.4304046631 -9999 -9999 -9999 -9999 -9999 -9999 -9999 -9999 -9999 -9999 -9999 -9999

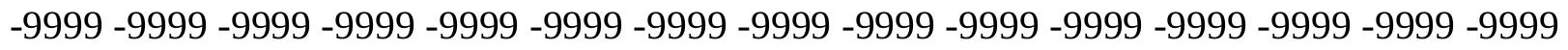

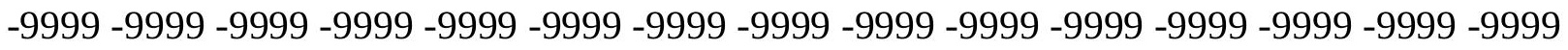
-9999 -9999 -9999 -9999 -9999 -9999 -9999 -9999 -9999 -9999 -9999 -9999 -9999 -9999 -9999 -9999 -9999 -9999 -9999 -9999 -9999 -9999 -9999 -9999 -9999 -9999 -9999 -9999 -9999 -9999 -

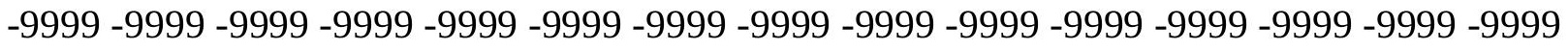

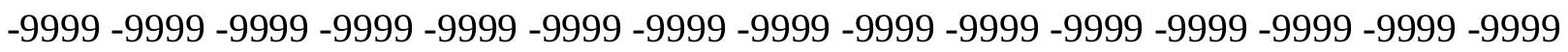
-9999 -9999 -9999 -9999 -9999 -9999 -9999 -9999 -9999 -9999 -9999 -9999 -9999 -9999 -9999 -

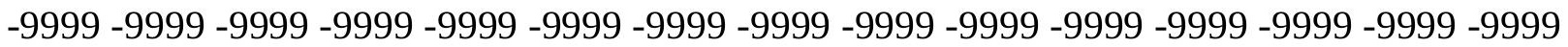
-9999 -9999 -9999 -9999-9999-9999-9999-9999

-9999 -9999 -9999 -9999 -9999 -9999 -9999 -9999 -9999 -9999 -9999 -9999 -9999 -9999 -9999 
-9999 -9999 -9999 -9999 -9999 -9999 -9999 -9999 -9999 -9999 -9999 -9999 -9999 -9999 -9999 -9999 -9999 -9999 -9999 -9999 -9999 -9999 -9999 -9999 -9999 -9999 -9999 -9999 -9999 -9999 -9999 -9999 -9999 -9999 -9999 -9999 -9999 -9999 -9999 -9999 -9999 -9999 -9999 -9999 -9999 -9999 -9999 -9999 -9999 -9999 -9999 -9999 -9999 -9999 -9999 -9999 126.4858016968 127.7050018311129 .2288970947130 .7528076172132 .5814971924134 .1054992676 135.9342041016137 .7628936768139 .2868041992141 .1154937744142 .6394042969 144.4682006836145 .9920959473147 .5160064697149 .0399017334150 .5639038086 152.0877990723153 .6116943359154 .8307952881156 .0500030518157 .5738983154 158.7929992676160 .0122070312160 .9264984131162 .1457061768163 .0599975586 164.2792053223165 .1934967041166 .1078948975166 .7174987793167 .6318054199 168.241394043168 .8509979248169 .4604949951170 .070098877170 .3748931885 170.6797027588171 .2891998291171 .5939941406171 .5939941406171 .8988037109 171.8988037109172 .2035980225172 .2035980225172 .2035980225171 .8988037109 171.8988037109171 .5939941406171 .5939941406171 .2891998291170 .9844970703 170.6797027588170 .3748931885170 .070098877169 .7653045654169 .4604949951 169.1557006836168 .8509979248168 .241394043167 .9365997314167 .6318054199 167.3269958496167 .0222015381166 .7174987793166 .4127044678166 .4127044678 166.1078948975165 .8031005859165 .8031005859165 .4983062744165 .4983062744 165.4983062744165 .1934967041165 .1934967041165 .4983062744165 .4983062744 165.4983062744165 .8031005859165 .8031005859166 .1078948975166 .1078948975 166.4127044678166 .7174987793166 .7174987793167 .0222015381167 .0222015381 167.3269958496 167.3269958496167.3269958496167.3269958496 167.3269958496 167.0222015381167 .0222015381166 .7174987793166 .4127044678166 .1078948975 165.4983062744165 .1934967041164 .5839996338163 .974395752163 .3648071289 162.7552947998161 .8408966064161 .2312927246160 .3170013428159 .7073974609 158.7929992676157 .878692627157 .2691040039156 .3547973633155 .4403991699 154.5260925293153 .9165039062153 .0021057129152 .0877990723151 .4781951904 150.5639038086149 .9542999268149 .0399017334148 .4304046631147 .8208007812 147.2111968994146 .6015930176146 .2969055176145 .6873016357145 .3825073242 145.0776977539145 .0776977539144 .7729034424144 .7729034424144 .7729034424 144.7729034424145 .0776977539145 .0776977539145 .3825073242145 .6873016357 146.2969055176146 .6015930176147 .2111968994147 .5160064697148 .1255950928 148.7351074219149 .3446960449149 .9542999268150 .5639038086151 .1734008789 151.7830047607152 .3925933838153 .0021057129153 .6116943359154 .2212982178 154.8307952881155 .1356048584155 .4403991699155 .7451934814155 .7451934814 155.7451934814155 .7451934814155 .4403991699155 .1356048584154 .5260925293 153.9165039062153 .3069000244152 .3925933838151 .4781951904150 .5639038086 149.6495056152149 .0399017334148 .1255950928147 .8208007812147 .2111968994 146.9064025879146 .9064025879146 .6015930176146 .2969055176145 .3825073242 144.4682006836144 .7729034424145 .3825073242 -9999 -9999 -9999 -9999 -9999 -9999 -9999 -9999 -9999 -9999 -9999 -9999 -9999 -9999 -9999 -9999 -9999 -9999 -9999 -9999 -9999 -9999

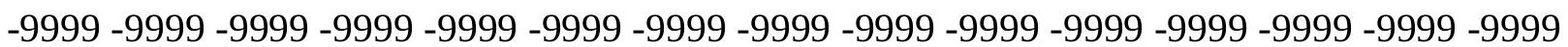
-9999 -9999 -9999 -9999 -9999 -9999 -9999 -9999 -9999 -9999 -9999 -9999 -9999 -9999 -9999 -9999 -9999 -9999 -9999 -9999 -9999 -9999 -9999 -9999 -9999 -9999 -9999 -9999 -9999 -9999 -999 -

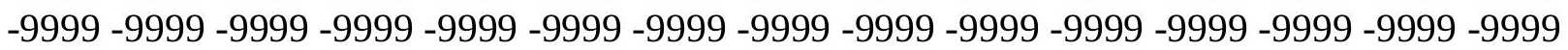

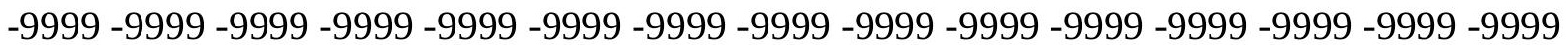


-9999 -9999 -9999 -9999 -9999 -9999 -9999 -9999 -9999 -9999 -9999 -9999 -9999 -9999 -9999 -9999 -9999 -9999 -9999 -9999 -9999 -9999 -9999 -9999 -9999 -9999 -9999 -9999 -9999 -9999 -9999 -9999 -9999 -9999 -9999 -9999 -9999 -9999 -9999 -9999 -9999 -9999

-9999 -9999 -9999 -9999 -9999 -9999 -9999 -9999 -9999 -9999 -9999 -9999 -9999 -9999 -9999 -9999 -9999 -9999 -9999 -9999 -9999 -9999 -9999 -9999 -9999 -9999 -9999 -9999 -9999 -9999 -9999 -9999 -9999 -9999 -9999 -9999 -9999 -9999 -9999 -9999 -9999 -9999 -9999 -9999 -9999 -9999 -9999 -9999 -9999 -9999 -9999 -9999 -9999 -9999 -9999 -9999 -9999 -9999 -9999 -9999 -9999 -9999 -9999 -9999 -9999 -9999 -9999 -9999 -9999 121.3044967651122 .8283996582 124.3523025513125 .5715026855127 .4001998901129 .2288970947130 .7528076172 132.5814971924134 .4102020264135 .9342041016137 .7628936768139 .2868041992 141.1154937744142 .6394042969144 .1634063721145 .6873016357147 .2111968994 148.7351074219150 .2590942383151 .7830047607153 .0021057129154 .2212982178 155.4403991699156 .6596069336157 .878692627159 .0977935791160 .3170013428 161.2312927246162 .1457061768163 .0599975586163 .974395752164 .5839996338 165.4983062744166 .1078948975166 .7174987793167 .3269958496167 .9365997314 168.241394043168 .5462036133168 .8509979248169 .1557006836169 .4604949951 169.7653045654169 .7653045654169 .7653045654169 .7653045654169 .7653045654 169.7653045654169 .7653045654169 .4604949951169 .1557006836169 .1557006836 168.8509979248168 .5462036133168 .241394043167 .9365997314167 .6318054199 167.3269958496167 .0222015381166 .4127044678166 .1078948975165 .8031005859 165.4983062744165 .1934967041164 .8887023926164 .5839996338164 .2792053223 163.974395752163 .974395752163 .6696014404163 .3648071289163 .3648071289 163.3648071289163 .0599975586163 .0599975586163 .0599975586163 .0599975586 163.0599975586163 .3648071289163 .3648071289163 .3648071289163 .6696014404 163.6696014404163 .974395752163 .974395752164 .2792053223164 .2792053223 164.5839996338164 .5839996338164 .5839996338164 .5839996338164 .5839996338 164.5839996338164 .2792053223163 .974395752163 .6696014404163 .3648071289 163.0599975586162 .7552947998162 .1457061768161 .5361022949160 .9264984131 160.3170013428159 .7073974609159 .0977935791158 .1835021973157 .5738983154 156.6596069336155 .7451934814154 .8307952881154 .2212982178153 .3069000244 152.3925933838151 .4781951904150 .5639038086149 .9542999268149 .0399017334 148.1255950928147 .5160064697146 .6015930176145 .9920959473145 .3825073242 144.7729034424144 .1634063721143 .5538024902143 .2489929199142 .6394042969 142.3347015381142 .3347015381142 .0299072266142 .0299072266142 .0299072266 142.0299072266142 .0299072266142 .3347015381142 .6394042969142 .9441986084 143.2489929199143 .5538024902144 .1634063721144 .4682006836145 .0776977539 145.6873016357146 .2969055176146 .9064025879147 .5160064697148 .1255950928 148.7351074219149 .3446960449149 .9542999268150 .5639038086151 .1734008789 151.7830047607152 .0877990723152 .6972961426153 .0021057129153 .0021057129 153.3069000244153 .3069000244153 .0021057129153 .0021057129152 .6972961426 152.0877990723151 .7830047607150 .8686065674150 .2590942383149 .6495056152 148.7351074219148 .1255950928147 .2111968994146 .6015930176145 .9920959473 145.6873016357145 .0776977539144 .7729034424144 .4682006836143 .5538024902 142.6394042969141 .7250976562141 .1154937744141 .4203033447142 .0299072266 -9999 -9999 -9999 -9999 -9999 -9999 -9999 -9999 -9999 -9999 -9999 -9999 -9999 -9999 -9999 -9999

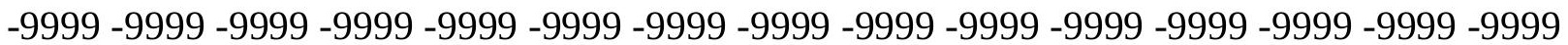


-9999 -9999 -9999 -9999 -9999 -9999 -9999 -9999 -9999 -9999 -9999 -9999 -9999 -9999 -9999 -9999 -9999 -9999 -9999 -9999 -9999 -9999 -9999 -9999 -9999 -9999 -9999 -9999 -9999 -9999

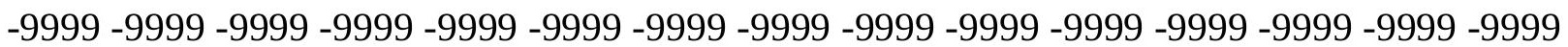
-9999 -9999 -9999 -9999 -9999 -9999 -9999 -9999 -9999 -9999 -9999 -9999 -9999 -9999 -9999 -9999 -9999 -9999 -9999 -9999 -9999 -9999 -9999 -9999 -9999 -9999 -9999 -9999 -9999 -9999 -9999 -9999 -9999 -9999 -9999 -9999 -9999 -9999 -9999 -9999 -9999 -9999 -9999 -9999 -9999

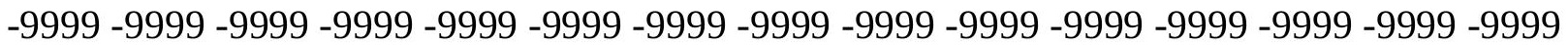
-9999-9999

-9999 -9999 -9999 -9999 -9999 -9999 -9999 -9999 -9999 -9999 -9999 -9999 -9999 -9999 -9999 -9999 -9999 -9999 -9999 -9999 -9999 -9999 -9999 -9999 -9999 -9999 -9999 -9999 -9999 -9999 -9999 -9999 -9999 -9999 -9999 -9999 -9999 -9999 -9999 -9999 -9999 -9999 -9999 -9999 -9999 -9999 -9999 -9999 -9999 -9999 -9999 -9999 -9999 -9999 -9999 -9999 -9999 -9999 -9999 -9999 -9999 -9999 -9999 -9999 -9999 -9999 -9999 -9999 117.9517974854119 .4757995605 120.6949005127122 .2188034058124 .0475006104125 .8762969971127 .4001998901 129.2288970947131 .0576019287132 .5814971924134 .4102020264136 .2389984131 137.7628936768139 .2868041992141 .1154937744142 .6394042969144 .1634063721 145.6873016357146 .9064025879148 .4304046631149 .9542999268151 .1734008789 152.3925933838153 .6116943359154 .8307952881156 .0500030518157 .2691040039 158.1835021973159 .0977935791160 .0122070312160 .9264984131161 .8408966064 162.7552947998163 .3648071289163 .974395752164 .5839996338165 .1934967041 165.4983062744166 .1078948975166 .4127044678166 .7174987793167 .0222015381 167.3269958496167 .3269958496167 .6318054199167 .6318054199167 .6318054199 167.6318054199167 .6318054199167 .3269958496167 .3269958496167 .0222015381 167.0222015381166 .7174987793166 .4127044678166 .1078948975165 .8031005859 165.4983062744165 .1934967041164 .5839996338164 .2792053223163 .974395752 163.6696014404163 .3648071289163 .0599975586162 .7552947998162 .4505004883 162.1457061768161 .8408966064161 .5361022949161 .5361022949161 .2312927246 161.2312927246160 .9264984131160 .9264984131160 .9264984131160 .9264984131 160.9264984131160 .9264984131160 .9264984131160 .9264984131161 .2312927246 161.2312927246161 .2312927246161 .5361022949161 .5361022949161 .5361022949 161.8408966064161 .8408966064161 .8408966064161 .8408966064161 .8408966064 161.8408966064161 .5361022949161 .5361022949161 .2312927246160 .9264984131 160.6217956543160 .3170013428159 .7073974609159 .0977935791158 .7929992676 158.1835021973157 .5738983154156 .6596069336156 .0500030518155 .1356048584 154.5260925293153 .6116943359153 .0021057129152 .0877990723151 .1734008789 150.2590942383149 .3446960449148 .4304046631147 .8208007812146 .9064025879 145.9920959473145 .0776977539144 .4682006836143 .5538024902142 .9441986084 142.3347015381141 .7250976562141 .1154937744140 .5059967041140 .2012023926 139.5915985107139 .5915985107139 .2868041992138 .9819946289138 .9819946289 138.9819946289139 .2868041992139 .2868041992139 .5915985107139 .8963928223 140.2012023926140 .5059967041141 .1154937744141 .4203033447142 .0299072266 142.6394042969143 .2489929199143 .8585968018144 .4682006836145 .0776977539 145.6873016357146 .6015930176147 .2111968994147 .8208007812148 .1255950928 148.7351074219149 .3446960449149 .6495056152149 .9542999268150 .2590942383 150.5639038086150 .5639038086150 .8686065674150 .5639038086150 .5639038086 150.2590942383149 .9542999268149 .3446960449148 .7351074219148 .1255950928 
147.5160064697146 .9064025879146 .2969055176145 .6873016357144 .7729034424 144.1634063721143 .8585968018143 .2489929199142 .6394042969142 .0299072266 141.4203033447140 .2012023926139 .2868041992138 .3724975586138 .0677032471 138.6772003174139 .2868041992 -9999 -9999 -9999 -9999 -9999 -9999 -9999 -9999 -9999 -9999 -9999 -9999 -9999 -9999 -9999 -9999 -9999 -9999 -9999 -9999 -9999 -9999 -9999 -9999 -9999 -9999 -9999 -9999 -9999 -9999 -9999 -9999 -9999 -9999 -9999 -9999 -9999 -9999 -9999

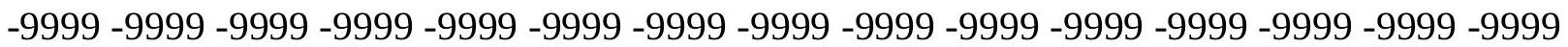

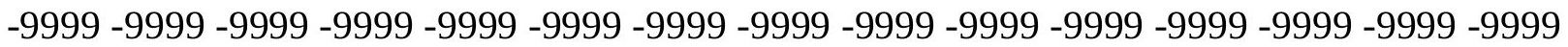
-9999 -9999 -9999 -9999 -9999 -9999 -9999 -9999 -9999 -9999 -9999 -9999 -9999 -9999 -9999 -9999 -9999 -9999 -9999 -9999 -9999 -9999 -9999 -9999 -9999 -9999 -9999 -9999 -9999 -9999 -

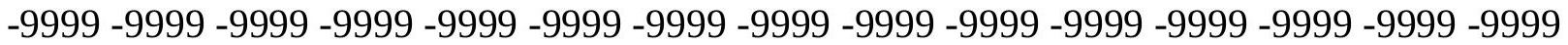

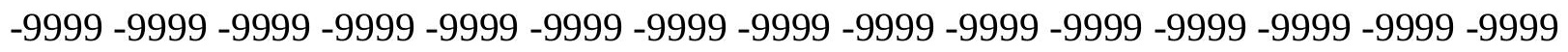
-9999 -9999 -9999 -9999 -9999 -9999-9999 -9999

-9999 -9999 -9999 -9999 -9999 -9999 -9999 -9999 -9999 -9999 -9999 -9999 -9999 -9999 -9999 -9999 -9999 -9999 -9999 -9999 -9999 -9999 -9999 -9999 -9999 -9999 -9999 -9999 -9999 -9999

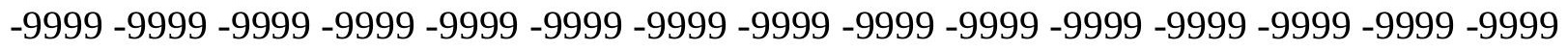

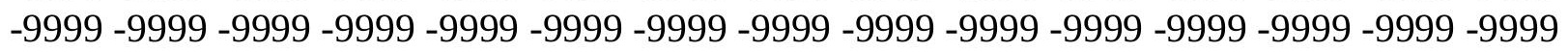
-9999 -9999-9999 -9999-9999-9999-9999 114.5991973877 115.818397522117 .342300415 119.1709976196120 .6949005127122 .5235977173124 .3523025513125 .8762969971 127.7050018311129 .533706665131 .0576019287132 .8863067627134 .4102020264 136.2389984131137 .7628936768139 .2868041992140 .8106994629142 .3347015381 143.8585968018145 .3825073242146 .6015930176148 .1255950928149 .3446960449 150.5639038086151 .7830047607153 .0021057129154 .2212982178155 .1356048584 156.3547973633157 .2691040039158 .1835021973159 .0977935791159 .7073974609 160.6217956543161 .2312927246161 .8408966064162 .4505004883163 .0599975586 163.3648071289163 .974395752164 .2792053223164 .5839996338164 .8887023926 165.1934967041165 .1934967041165 .4983062744165 .4983062744165 .4983062744 165.4983062744165 .4983062744165 .1934967041164 .5770111084164 .4299468994 164.2384338379163 .9991455078163 .7434539795163 .4800262451163 .2083282471 162.9290008545162 .6428985596162 .3391418457162 .0188751221161 .6646575928 161.3049468994160 .9528198242160 .6401062012160 .3473968506160 .3170013428 160.0122070312159 .7073974609159 .4026031494159 .4026031494159 .0977935791 158.7929992676158 .7929992676158 .7929992676158 .4882965088158 .4882965088 158.4882965088158 .4882965088158 .4882965088158 .7929992676158 .7929992676 158.7929992676158 .7929992676159 .0977935791159 .0977935791159 .0977935791 159.0977935791159 .0977935791159 .0977935791159 .0977935791159 .0977935791 159.0977935791158 .7929992676158 .7929992676158 .4882965088158 .1835021973 157.878692627157 .2691040039156 .9642944336156 .3547973633155 .7451934814 155.1356048584154 .5260925293153 .9165039062153 .3069000244152 .3925933838 151.7830047607150 .8686065674149 .9542999268149 .0399017334148 .1255950928 147.5160064697146 .6015930176145 .6873016357144 .7729034424143 .8585968018 142.9441986084142 .3347015381141 .4203033447140 .5059967041139 .8963928223 139.2868041992138 .6772003174138 .0677032471137 .4580993652137 .1533050537 136.8484954834136 .5437011719136 .2389984131136 .2389984131136 .2389984131 136.2389984131136 .5437011719136 .5437011719136 .8484954834137 .1533050537 137.4580993652138 .0677032471138 .6772003174138 .9819946289139 .5915985107 
140.2012023926140 .8106994629141 .4203033447142 .0299072266142 .9441986084 143.5538024902144 .1634063721144 .7729034424145 .3825073242145 .9920959473 146.2969055176146 .9064025879147 .2111968994147 .5160064697147 .8208007812 148.1255950928148 .1255950928148 .4304046631148 .1255950928148 .1255950928 147.8208007812147 .5160064697147 .2111968994146 .6015930176146 .2969055176 145.6873016357145 .0776977539144 .4682006836143 .8585968018143 .2489929199 142.6394042969142 .0299072266141 .4203033447140 .5059967041139 .8963928223 138.9819946289138 .0677032471137 .1533050537136 .2389984131135 .0198059082 135.3246002197 135.9342041016 -9999 -9999 -9999 -9999 -9999 -9999 -9999 -9999 -9999 -9999 -9999 -9999 -9999 -9999 -9999 -9999 -9999 -9999 -9999 -9999 -9999 -9999 -9999 -9999 -9999 -9999 -9999 -9999 -9999 -9999 -9999 -9999 -9999 -9999 -9999 -9999 -9999 -9999 -9999 -9999 -9999 -9999 -9999 -9999 -9999 -9999 -9999 -9999 -9999 -9999 -9999 -9999 -9999 -9999 -999 -9999 -9999 -9999 -9999 -9999 -9999 -9999 -9999 -9999 -9999 -9999 -9999 -9999 -9999 -9999 -9999 -9999 -9999 -9999 -9999 -9999 -9999 -9999 -9999 -9999 -9999 -9999 -9999 -9999 -9999 -9999 -9999 -9999 -9999 -9999 -9999 -9999 -9999 -9999 -9999 -9999 -9999 -9999 -9999 -9999

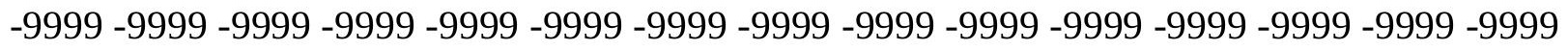

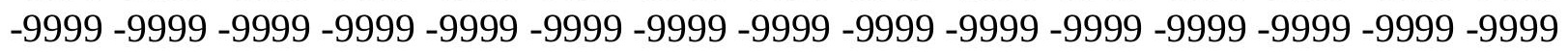
-9999 -9999 -9999 -9999 -9999 -9999 -9999 -9999

-9999 -9999 -9999 -9999 -9999 -9999 -9999 -9999 -9999 -9999 -9999 -9999 -9999 -9999 -9999

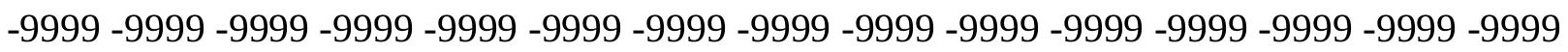

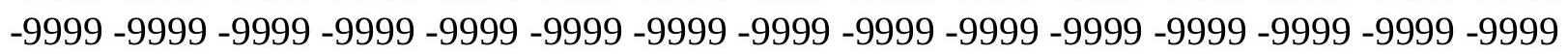

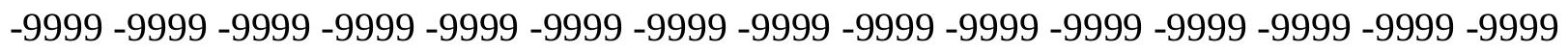
-9999 -9999 -9999 -9999-9999-9999 110.9418029785 112.4656982422 113.9896011353 115.5136032104117 .342300415119 .1709976196120 .9997024536122 .8283996582 124.3523025513126 .1809997559128 .0097961426129 .533706665131 .3623962402 132.8863067627134 .4102020264136 .2389984131137 .7628936768139 .2868041992 140.8106994629142 .0299072266143 .5538024902144 .7729034424146 .2969055176 147.5160064697148 .7351074219149 .9542999268151 .1734008789152 .0877990723 153.3069000244154 .2212982178155 .1356048584156 .0500030518156 .9642944336 157.878692627158 .4882965088159 .0977935791159 .7073974609160 .3170013428 160.9264984131161 .2312927246161 .8408966064162 .1457061768162 .4505004883 162.7552947998162 .7552947998163 .0599975586162 .5299530029162 .6535797119 162.7432403564162 .8196258545162 .8651275635162 .8470306396162 .7115783691 162.5757751465162 .3346252441162 .0548400879161 .7642669678161 .4739837646 161.18359375160 .8963623047160 .6217956543160 .3071746826160 .0012817383 159.6298675537159 .1944732666158 .8192901611158 .501449585158 .2017974854 157.90965271157 .6343994141157 .3923797607157 .1868591309156 .9642944336 156.788848877156 .6083831787156 .4525146484156 .3295135498156 .2133789062 156.1218109131156 .053527832156 .3547973633156 .3547973633156 .3547973633 156.3547973633156 .3547973633156 .3547973633156 .6596069336156 .6596069336 156.6596069336156 .6596069336156 .6596069336156 .6596069336156 .6596069336 156.3547973633156 .3547973633156 .0500030518156 .0500030518155 .7451934814 155.4403991699155 .1356048584154 .5260925293154 .2212982178153 .6116943359 153.0021057129152 .3925933838151 .7830047607151 .1734008789150 .2590942383 149.6495056152148 .7351074219148 .1255950928147 .2111968994146 .2969055176 145.3825073242144 .4682006836143 .5538024902142 .6394042969141 .7250976562 
141.1154937744140 .2012023926139 .2868041992138 .3724975586137 .7628936768 136.8484954834136 .2389984131135 .6293945312135 .0198059082134 .7149963379 134.1054992676133 .8007049561133 .8007049561133 .4958953857133 .4958953857 133.4958953857133 .4958953857133 .8007049561133 .8007049561134 .4102020264 134.7149963379135 .0198059082135 .6293945312136 .2389984131136 .5437011719 137.1533050537137 .7628936768138 .6772003174139 .2868041992139 .8963928223 140.5059967041141 .1154937744141 .7250976562142 .3347015381142 .9441986084 143.5538024902144 .1634063721144 .4682006836145 .0776977539145 .3825073242 145.6873016357145 .6873016357145 .9920959473145 .9920959473145 .9920959473 145.9920959473145 .6873016357145 .3825073242145 .0776977539144 .7729034424 144.1634063721143 .5538024902143 .2489929199142 .6394042969142 .0299072266 141.4203033447140 .8106994629139 .8963928223139 .2868041992138 .6772003174 137.7628936768136 .8484954834135 .9342041016135 .0198059082134 .1054992676 133.1911010742132 .2767028809132 .8863067627134 .1054992676 -9999 -9999 -9999 -9999 -9999 -9999 -9999 -9999 -9999 -9999 -9999 -9999 -9999 -9999 -9999 -9999 -9999 -9999 -9999

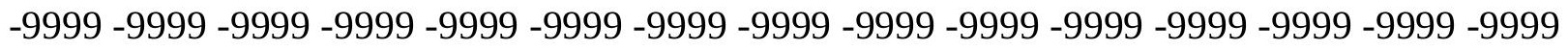
-9999 -9999 -9999 -9999 -9999 -9999 -9999 -9999 -9999 -9999 -9999 -9999 -9999 -9999 -9999 -9999 -9999 -9999 -9999 -9999 -9999 -9999 -9999 -9999 -9999 -9999 -9999 -9999 -9999 -9999 -9999 -9999 -9999 -9999 -9999 -9999 -9999 -9999 -9999 -9999 -9999 -9999 -9999 -9999 -9999

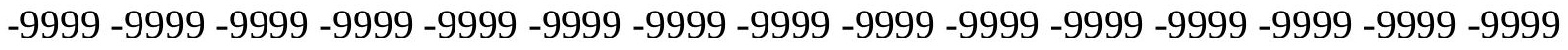

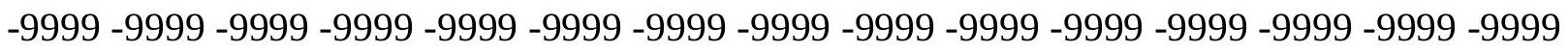

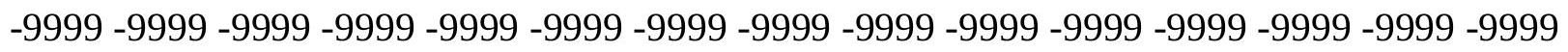
-9999 -9999 -9999 -9999 -9999 -9999 -9999 -9999 -9999 -9999 -9999 -9999 -

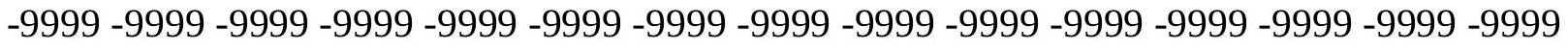

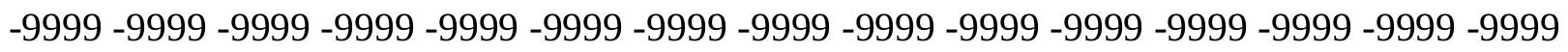
-9999 -9999 -9999 -9999 -9999 -9999 -9999 -9999 -9999 -9999 -9999 -9999 -9999 -9999 -9999 -9999 -9999 -9999 -9999 -9999 -9999 -9999 -9999 -9999 -9999 -9999 -9999 -9999 -9999 -9999 -9999 -9999 -9999 -9999-9999 107.5891036987 109.1130981445 110.6370010376 112.1608963013113 .9896011353115 .818397522117 .647102356119 .4757995605 121.3044967651122 .8283996582124 .6570968628126 .4858016968128 .0097961426 129.8385009766131 .3623962402132 .8863067627134 .4102020264135 .9342041016 137.4580993652138 .9819946289140 .5059967041141 .7250976562143 .2489929199 144.4682006836145 .6873016357146 .9064025879148 .1255950928149 .3446960449 150.2590942383151 .4781951904152 .3925933838153 .3069000244154 .2212982178 154.8307952881155 .7451934814156 .3547973633156 .9642944336157 .5738983154 158.1835021973158 .7929992676159 .0977935791159 .7073974609159 .3536376953 159.704864502160 .0218963623160 .2946472168160 .5353393555160 .7014770508 160.7779998779160 .8238983154160 .8743743896160 .9264984131160 .9264984131 160.6217956543160 .6217956543160 .3170013428160 .0122070312159 .7073974609 159.4026031494159 .0977935791158 .7929992676158 .4882965088158 .1835021973 157.878692627157 .5738983154156 .9642944336156 .6596069336156 .3547973633 156.0500030518155 .7451934814155 .4403991699155 .1356048584154 .9789733887 154.8227233887154 .5260925293154 .3924865723154 .2212982178154 .15574646 154.0257720947153 .9165039062153 .8461761475153 .8232574463153 .8198394775 153.8194274902153 .8171844482153 .8126068115153 .8051757812153 .7909393311 153.7596435547153 .6923522949153 .6136627197153 .5235748291153 .445526123 
153.337020874153 .9165039062153 .6116943359153 .6116943359153 .3069000244 153.0021057129152 .6972961426152 .3925933838151 .7830047607151 .4781951904 150.8686065674150 .2590942383149 .6495056152149 .0399017334148 .4304046631 147.8208007812146 .9064025879145 .9920959473145 .3825073242144 .4682006836 143.5538024902142 .6394042969141 .7250976562140 .8106994629139 .8963928223 138.9819946289138 .0677032471137 .4580993652136 .5437011719135 .6293945312 134.7149963379134 .1054992676133 .4958953857132 .8863067627132 .2767028809 131.6672058105131 .3623962402131 .0576019287130 .7528076172130 .7528076172 130.7528076172130 .7528076172130 .7528076172131 .0576019287131 .3623962402 131.6672058105132 .2767028809132 .5814971924133 .1911010742133 .8007049561 134.4102020264135 .0198059082135 .6293945312136 .2389984131136 .8484954834 137.4580993652138 .3724975586138 .9819946289139 .5915985107140 .2012023926 140.8106994629141 .1154937744141 .7250976562142 .3347015381142 .6394042969 142.9441986084143 .2489929199143 .5538024902143 .5538024902143 .5538024902 143.5538024902143 .5538024902143 .5538024902143 .2489929199142 .9441986084 142.6394042969142 .0299072266141 .7250976562141 .1154937744140 .5059967041 140.2012023926139 .5915985107138 .9819946289138 .0677032471137 .4580993652 136.8484954834135 .9342041016135 .0198059082134 .1054992676133 .1911010742 132.2767028809 131.0576019287 130.1432037354 130.1432037354 131.3623962402-9999 -9999 -9999 -9999 -9999 -9999 -9999 -9999 -9999 -9999 -9999 -9999 -9999 -9999 -9999 -9999

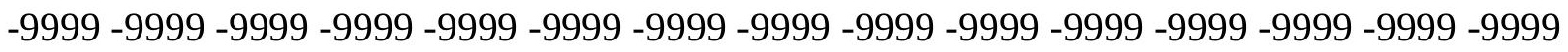
-9999 -9999 -9999 -9999 -9999 -9999 -9999 -9999 -9999 -9999 -9999 -9999 -9999 -9999 -9999 -9999 -9999 -9999 -9999 -9999 -9999 -9999 -9999 -9999 -9999 -9999 -9999 -9999 -9999 -9999 -

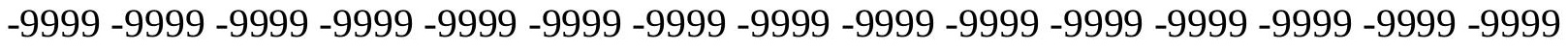

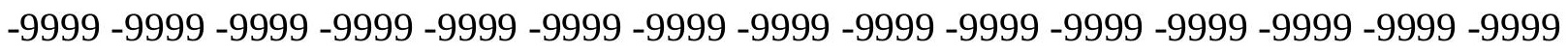
-9999 -9999 -9999 -9999 -9999 -9999 -9999 -9999 -9999 -9999 -9999 -9999 -9999 -9999 -9999

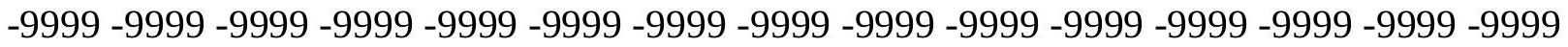

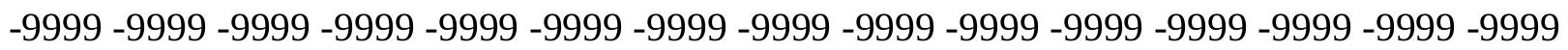
-9999 -9999 -9999 -9999 -9999 -9999 -9999 -9999 -9999 -9999 -9999 -9999 -9999 -9999 -9999 -9999 -9999 -9999 -9999 -9999 -9999 -9999 -9999 -9999 -9999 -9999 -9999 -9999 -9999 -9999 -9999 -9999 -9999 -9999 -9999 -9999 -9999 -9999 -9999 -9999 -9999 -9999 -9999 -9999 -9999 -9999 -9999 -9999 -9999 -9999 -9999 -9999 -9999 -9999 -9999 -9999 -9999 -9999 -9999 -9999 -9999 -9999-9999 -9999-9999 105.7603988647 107.2844009399 108.8082962036 110.6370010376112 .4656982422114 .2944030762116 .1231002808117 .9517974854 119.7806015015121 .6092987061123 .1332015991124 .9618988037126 .4858016968 128.3144989014129 .8385009766131 .3623962402132 .8863067627134 .4102020264 135.9342041016137 .4580993652138 .6772003174140 .2012023926141 .4203033447 142.6394042969143 .8585968018145 .0776977539146 .2969055176147 .5160064697 148.4304046631149 .3446960449150 .2590942383151 .1734008789152 .0877990723 153.0021057129153 .6116943359154 .5260925293155 .1356048584155 .08152771 155.6699523926156 .2261199951156 .7145080566157 .1718292236157 .5779724121 157.8978118896158 .1371307373158 .392288208158 .6532745361158 .7929992676 158.7929992676158 .7929992676158 .7929992676158 .7929992676158 .4882965088 158.4882965088158 .1835021973158 .1835021973157 .878692627157 .5738983154 157.2691040039156 .9642944336156 .6596069336156 .3547973633156 .0500030518 155.4403991699155 .1356048584154 .8307952881154 .5260925293154 .2212982178 
153.9165039062153 .6116943359153 .3069000244153 .0021057129152 .6972961426 152.6972961426152 .3925933838152 .0877990723152 .0877990723151 .7830047607 151.7830047607151 .6739807129151 .602722168151 .4781951904151 .4781951904 151.4781951904151 .4781951904151 .4781951904151 .6241455078151 .6209869385 151.6054382324151 .5356292725151 .4143676758151 .3400878906151 .3035888672 151.2244110107151 .081237793150 .928314209150 .6746826172150 .3745880127 150.0506286621149 .7129516602149 .3198852539148 .8522949219148 .3385620117 147.725692749147 .0463256836146 .3644561768145 .6821136475144 .9878692627 144.2456207275143 .4560546875142 .6381225586141 .8047943115140 .9505004883 140.0596160889139 .1499176025138 .2421264648137 .3458099365136 .4498748779 135.5525970459134 .6549224854133 .7597503662132 .8714752197131 .9947967529 131.1553497314130 .37890625129 .6687927246129 .0294494629129 .533706665 128.9241027832128 .6192932129128 .3144989014128 .0097961426128 .0097961426 128.0097961426128 .0097961426128 .3144989014128 .6192932129128 .9241027832 129.2288970947129 .8385009766130 .1432037354130 .7528076172131 .3623962402 131.9720001221132 .5814971924133 .4958953857134 .1054992676134 .7149963379 135.3246002197135 .9342041016136 .5437011719137 .4580993652137 .7628936768 138.3724975586138 .9819946289139 .5915985107139 .8963928223140 .5059967041 140.8106994629141 .1154937744141 .1154937744141 .4203033447141 .4203033447 141.4203033447141 .4203033447141 .4203033447141 .1154937744140 .8106994629 140.5059967041140 .2012023926139 .5915985107139 .2868041992138 .6772003174 138.0677032471137 .7628936768136 .8484954834136 .2389984131135 .6293945312 134.7149963379134 .1054992676133 .1911010742132 .2767028809131 .3623962402 130.1432037354129 .2288970947128 .3144989014127 .4001998901128 .6192932129 129.8385009766 -9999 -9999 -9999 -9999 -9999 -9999 -9999 -9999 -9999 -9999 -9999 -9999 -9999 -9999 -9999 -9999 -9999 -9999 -9999 -9999 -9999 -9999 -9999 -9999 -9999 -9999 -9999

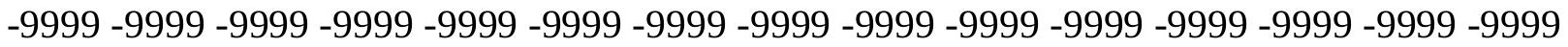

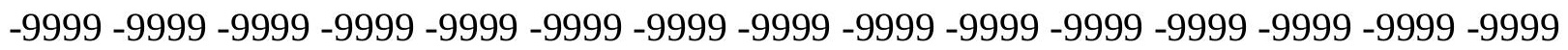
-9999 -9999 -9999 -9999 -9999 -9999 -9999 -9999 -9999 -9999 -9999 -9999 -9999 -9999 -9999 -9999 -9999 -9999 -9999 -9999 -9999 -9999 -9999 -9999 -9999 -9999 -9999 -9999 -9999 -9999 -9999 -9999 -9999 -9999 -9999 -9999 -9999 -9999 -9999 -9999 -9999 -9999 -9999 -9999 -9999 -9999 -9999 -9999 -9999 -9999 -9999 -9999 -9999 -9999 -9999 -9999 -9999 -9999 -9999 -9999 -

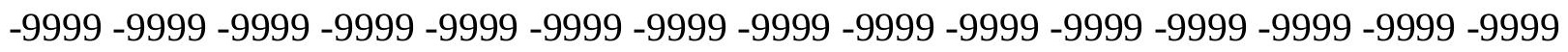
-9999 -9999-9999

-9999 -9999 -9999 -9999 -9999 -9999 -9999 -9999 -9999 -9999 -9999 -9999 -9999 -9999 -9999

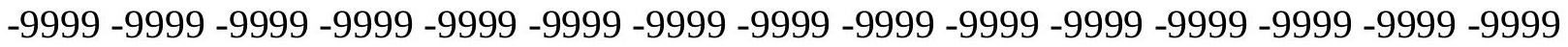

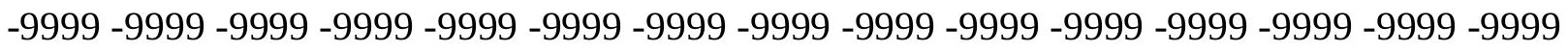

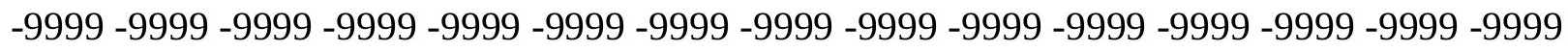
-9999 -9999 -9999 -9999 102.4077987671 103.9317016602105 .4557037354107 .2844009399 109.1130981445110 .9418029785113 .075302124114 .9039993286116 .4279022217 118.2565994263120 .0852966309121 .6092987061123 .43800354124 .9618988037 126.7906036377128 .3144989014129 .8385009766131 .3623962402132 .8863067627 134.4102020264135 .6293945312137 .1533050537138 .3724975586139 .5915985107 140.8106994629142 .0299072266143 .2489929199144 .4682006836145 .3825073242 146.6015930176147 .5160064697148 .4304046631149 .3446960449149 .6600952148 150.5042572021151 .2944030762152 .0397491455152 .7088470459153 .340927124 
153.9114074707154 .4142608643154 .8307952881155 .310333252155 .6945800781 156.0500030518156 .0500030518156 .3547973633156 .6596069336156 .6596069336 156.6596069336156 .6596069336156 .6596069336156 .6596069336156 .3547973633 156.3547973633156 .0500030518155 .7451934814155 .7451934814155 .4403991699 155.1356048584154 .8307952881154 .5260925293153 .9165039062153 .6116943359 153.3069000244153 .0021057129152 .6972961426152 .3925933838152 .0877990723 151.7830047607151 .4781951904151 .1734008789150 .8686065674150 .5639038086 150.2590942383150 .2590942383149 .9542999268149 .6495056152149 .6495056152 149.6495056152149 .3446960449149 .3446960449149 .3446960449149 .3446960449 149.3446960449149 .3446960449149 .3446960449149 .3446960449149 .3446960449 149.3446960449149 .3446960449149 .0399017334149 .0399017334149 .0399017334 149.0399017334148 .7351074219148 .7351074219148 .4304046631148 .1255950928 147.8208007812147 .5160064697147 .2111968994146 .6015930176146 .2969055176 145.612487793144 .9272460938144 .2745819092143 .637588501142 .9882202148 142.2725830078141 .4562988281140 .6105041504139 .8284606934138 .9773864746 138.0734558105137 .1426239014136 .2300109863135 .3388671875134 .4389953613 133.5379943848132 .631652832131 .7247009277130 .8180236816129 .9182739258 129.0371246338128 .2297515869127 .5345611572126 .9237823486126 .3096618652 125.7838973999125 .385307312125 .1257705688124 .9985809326124 .9512176514 124.9616012573125 .0153884888125 .0353393555125 .0914306641126 .4858016968 126.7906036377127 .4001998901128 .0097961426128 .6192932129129 .2288970947 129.8385009766130 .4479980469131 .0576019287131 .9720001221132 .5814971924 133.1911010742133 .8007049561134 .4102020264135 .0198059082135 .6293945312 136.2389984131136 .8484954834137 .4580993652137 .7628936768138 .0677032471 138.6772003174138 .6772003174138 .9819946289139 .2868041992139 .2868041992 139.2868041992139 .2868041992139 .2868041992138 .9819946289138 .6772003174 138.6772003174138 .0677032471137 .7628936768137 .4580993652136 .8484954834 136.2389984131135 .6293945312135 .0198059082134 .4102020264133 .8007049561 132.8863067627132 .2767028809131 .3623962402130 .4479980469129 .533706665 128.6192932129127 .4001998901126 .4858016968125 .5715026855125 .8762969971 127.4001998901 -9999 -9999 -9999 -9999 -9999 -9999 -9999 -9999 -9999 -9999 -9999 -9999 -9999 -9999 -9999 -9999 -9999 -9999 -9999 -9999 -9999 -9999 -9999 -9999 -9999 -9999 -9999 -

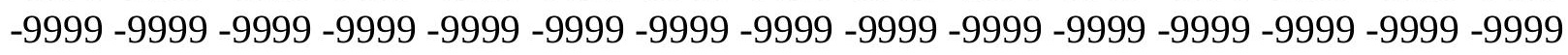
-9999 -9999 -9999 -9999 -9999 -9999 -9999 -9999 -9999 -9999 -9999 -9999 -9999 -9999 -9999 -9999 -9999 -9999 -9999 -9999 -9999 -9999 -9999 -9999 -9999 -9999 -9999 -9999 -9999 -9999 -

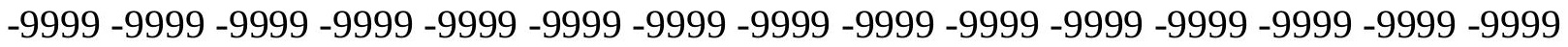

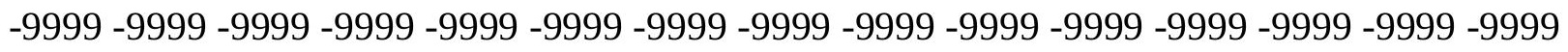

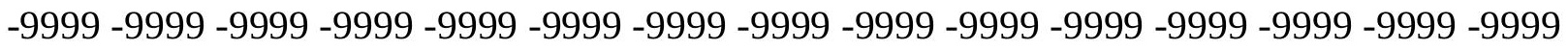
-9999 -9999 -9999 -9999 -9999 -9999 -9999 -9999 -9999 -9999 -9999 -9999 -9999 -9999 -9999 -9999 -9999-9999

-9999 -9999 -9999 -9999 -9999 -9999 -9999 -9999 -9999 -9999 -9999 -9999 -9999 -9999 - 9999 -

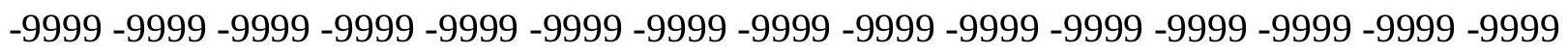

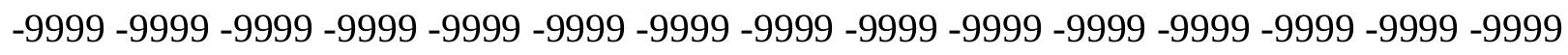
-9999 -9999 -9999 -9999 -9999 -9999 -9999 -9999 -9999 -9999 -9999 -9999 -9999 -9999 -9999 -9999 -9999 -9999 99.35994720459 100.5791015625102.1029968262103.9317016602 105.7603988647107 .8938980103109 .7226028442111 .551399231113 .3800964355 
115.2088012695117 .0374984741118 .5614013672120 .3900985718121 .9140014648 123.7427978516125 .2667007446126 .7906036377128 .3144989014129 .8385009766 131.3623962402132 .5814971924134 .1054992676135 .3246002197136 .8484954834 138.0677032471139 .2868041992140 .5059967041141 .4203033447142 .2671813965 143.3394470215144 .3677062988145 .3418579102146 .2559356689147 .1346893311 147.9866943359148 .7899475098149 .5905303955150 .2590942383150 .8686065674 151.4582061768152 .0877990723152 .3925933838153 .0021057129153 .3069000244 153.6116943359153 .9165039062153 .9165039062154 .2212982178154 .2212982178 154.5260925293154 .5260925293154 .5260925293154 .5260925293154 .2212982178 154.2212982178153 .9165039062153 .9165039062153 .6116943359153 .3069000244 153.0021057129152 .6972961426152 .3925933838152 .0877990723151 .7830047607 151.4781951904151 .1734008789150 .8686065674150 .5639038086149 .9542999268 149.6495056152149 .3446960449149 .0399017334148 .7351074219148 .4304046631 148.4304046631148 .1255950928147 .8208007812147 .5160064697147 .5160064697 147.2111968994147 .2111968994147 .2111968994147 .2111968994146 .9064025879 146.9064025879146 .9064025879146 .9064025879146 .9064025879146 .9064025879 146.9064025879146 .9064025879146 .9064025879146 .6015930176146 .6015930176 146.6015930176146 .6015930176146 .2969055176145 .9920959473145 .9920959473 145.6873016357145 .3825073242145 .0776977539144 .7729034424144 .1634063721 143.8585968018143 .2489929199142 .6394042969142 .0299072266141 .4203033447 140.8106994629140 .2012023926139 .2868041992138 .3724975586137 .7628936768 136.8484954834135 .9342041016135 .0198059082134 .1054992676133 .1911010742 132.2767028809131 .3623962402130 .4479980469129 .533706665128 .6192932129 127.7050018311126 .7906036377125 .8762969971125 .2667007446124 .6570968628 124.0475006104123 .43800354123 .1332015991122 .8283996582122 .8283996582 122.8283996582122 .8283996582123 .1332015991123 .1388015747123 .3093414307 123.5905914307123 .8383560181124 .0476531982125 .8762969971126 .4858016968 127.0953979492127 .7050018311128 .3144989014129 .2288970947129 .8385009766 130.4479980469131 .0576019287131 .9720001221132 .5814971924133 .1911010742 133.8007049561134 .1054992676134 .7149963379135 .3246002197135 .6293945312 135.9342041016136 .5437011719136 .5437011719136 .8484954834137 .1533050537 137.1533050537137 .1533050537137 .1533050537137 .1533050537136 .8484954834 136.8484954834136 .5437011719136 .2389984131135 .9342041016135 .3246002197 135.0198059082134 .4102020264133 .8007049561133 .1911010742132 .5814971924 131.9720001221131 .3623962402130 .4479980469129 .533706665128 .6192932129 127.7050018311126 .7906036377125 .8762969971124 .9618988037123 .7427978516 123.43800354124 .6570968628 -9999 -9999 -9999 -9999 -9999 -9999 -9999 -9999 -9999 -9999

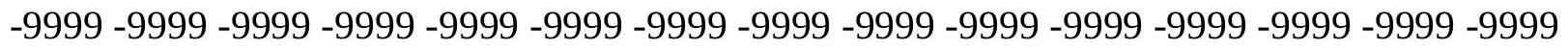
-9999 -9999 -9999 -9999 -9999 -9999 -9999 -9999 -9999 -9999 -9999 -9999 -9999 -9999 -9999 -

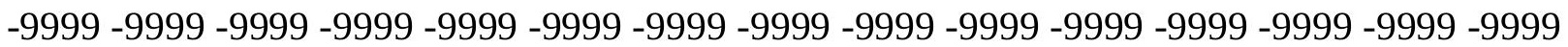

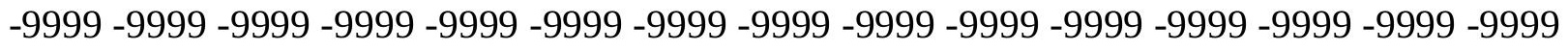

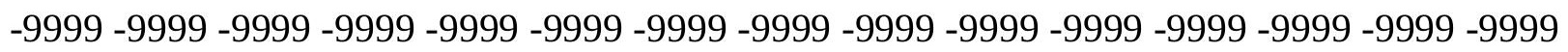
-9999 -9999 -9999 -9999 -9999 -9999 -9999 -9999 -9999 -9999 -9999 -9999 -9999 -9999 -9999 -9999 -9999 -9999 -9999 -9999 -9999 -9999 -9999 -9999 -9999 -9999 -9999 -9999 -9999 -9999 -

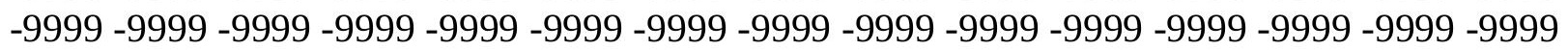
-9999 -9999 -9999 -9999 -9999 
-9999 -9999 -9999 -9999 -9999 -9999 -9999 -9999 -9999 -9999 -9999 -9999 -9999 -9999 -9999 -9999 -9999 -9999 -9999 -9999 -9999 -9999 -9999 -9999 -9999 -9999 -9999 -9999 -9999 -9999

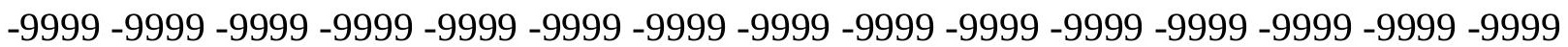
-9999 -9999 -9999 -9999 -9999 -9999 -9999 -9999 -9999 -9999 -9999 -9999 -9999 -9999 -9999 -9999 -9999 96.0073165893697.5312423706198.75038146973 100.5791015625 102.712600708104 .5412979126106 .3700027466108 .5035018921110 .3321990967 112.1608963013113 .6848983765115 .5136032104117 .342300415118 .8662033081 120.6949005127122 .2188034058123 .7427978516125 .2667007446126 .7906036377 128.3144989014129 .533706665131 .0576019287132 .2767028809133 .8007049561 135.0198059082135 .9912414551137 .2392425537138 .4691009521139 .5915985107 140.6780853271141 .7102966309142 .7570800781143 .7135314941144 .530380249 145.3825073242146 .2969055176146 .9064025879147 .8208007812148 .4304046631 149.0399017334149 .3446960449149 .9542999268150 .2590942383150 .8686065674 151.1734008789151 .4781951904151 .7830047607151 .7830047607152 .0877990723 152.0877990723152 .3925933838152 .3925933838152 .3925933838152 .3925933838 152.0877990723152 .0877990723151 .7830047607151 .7830047607151 .4781951904 151.1734008789150 .8686065674150 .5639038086150 .2590942383149 .9542999268 149.6495056152149 .3446960449149 .0399017334148 .4304046631148 .1255950928 147.8208007812147 .5160064697147 .2111968994146 .9064025879146 .6015930176 146.2969055176145 .9920959473145 .6873016357145 .6873016357145 .3825073242 145.0776977539145 .0776977539145 .0776977539144 .7729034424144 .7729034424 144.7729034424144 .7729034424144 .4682006836144 .4682006836144 .4682006836 144.4682006836144 .4682006836144 .4682006836144 .4682006836144 .4682006836 144.1634063721144 .1634063721144 .1634063721143 .8585968018143 .5538024902 143.5538024902143 .2489929199142 .9441986084142 .6394042969142 .3347015381 141.7250976562141 .4203033447140 .8106994629140 .2012023926139 .5915985107 138.9819946289138 .3724975586137 .7628936768136 .8484954834136 .2389984131 135.3246002197134 .4102020264133 .4958953857132 .8863067627131 .9720001221 130.7528076172129 .8385009766128 .9241027832128 .0097961426127 .0953979492 126.1809997559125 .2667007446124 .3523025513123 .43800354122 .8283996582 121.9140014648121 .6092987061120 .9997024536120 .6949005127120 .3900985718 120.3900985718120 .3900985718120 .3900985718120 .6949005127120 .9997024536 121.3044967651121 .9140014648122 .2110137939122 .552116394122 .8646392822 123.1719284058124 .9618988037125 .8762969971126 .4858016968127 .0953979492 127.7050018311128 .6192932129129 .2288970947129 .8385009766130 .4479980469 131.0576019287131 .6672058105132 .2767028809132 .8863067627133 .1911010742 133.4958953857134 .1054992676134 .4102020264134 .7149963379134 .7149963379 135.0198059082135 .0198059082135 .3246002197135 .3246002197135 .0198059082 135.0198059082134 .7149963379134 .7149963379134 .4102020264134 .1054992676 133.4958953857133 .1911010742132 .5814971924132 .2767028809131 .6672058105 131.0576019287130 .1432037354129 .533706665128 .6192932129128 .0097961426 127.0953979492126 .1809997559125 .2667007446124 .3523025513123 .43800354 122.5235977173121 .3044967651122 .5235977173123 .7427978516 -9999 -9999 -9999-9999 -9999 -9999 -9999 -9999 -9999 -9999 -9999 -9999 -9999 -9999 -9999 -9999 -9999 -9999 -9999 -9999 -9999 -9999 -9999 -9999 -9999 -9999 -9999 -9999 -9999 -9999 -9999 -9999 -9999 -9999

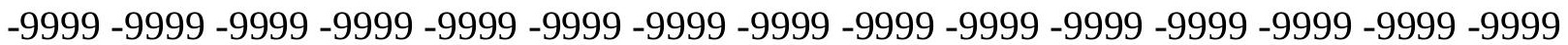


-9999 -9999 -9999 -9999 -9999 -9999 -9999 -9999 -9999 -9999 -9999 -9999 -9999 -9999 -9999 -9999 -9999 -9999 -9999 -9999 -9999 -9999 -9999 -9999 -9999 -9999 -9999 -9999 -9999 -9999

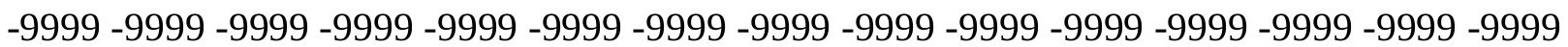
-9999 -9999 -9999 -9999 -9999 -9999 -9999 -9999 -9999 -9999 -9999 -9999 -9999 -9999 -9999 -9999 -9999 -9999 -9999 -9999 -9999 -9999 -9999 -9999 -9999 -9999 -9999-9999 -9999 -9999 -9999 -9999 -9999 -9999 -9999 -9999 -9999 -9999 -9999 -9999

-9999 -9999 -9999 -9999 -9999 -9999 -9999 -9999 -9999 -9999 -9999 -9999 -9999 -9999 -9999 -9999 -9999 -9999 -9999 -9999 -9999 -9999 -9999 -9999 -9999 -9999 -9999 -9999 -9999 -9999

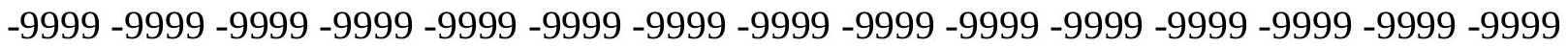
-9999 -9999 -9999 -9999 -9999 -9999 -9999 -9999 -9999 -9999 -9999 -9999 -9999 -9999 -9999 -9999 92.6546783447394.1785964965895.7025299072397.5312423706199.35994720459 101.4934005737103 .3221969604105 .1509017944107 .2844009399109 .1130981445 110.9418029785112 .4656982422114 .2944030762115 .818397522117 .647102356 119.1709976196120 .6949005127122 .2188034058123 .7427978516125 .2667007446 126.7906036377128 .0097961426129 .2093505859130 .5948944092131 .9340667725 133.2241821289134 .4641265869135 .6293945312136 .8402557373138 .0677032471 138.9819946289139 .8963928223141 .1154937744142 .0299072266142 .6394042969 143.5538024902144 .4682006836145 .0776977539145 .6873016357146 .2969055176 146.9064025879147 .5160064697147 .8208007812148 .4304046631148 .7351074219 149.0399017334149 .3446960449149 .6495056152149 .6495056152149 .9542999268 149.9542999268150 .2590942383150 .2590942383150 .2590942383149 .9542999268 149.9542999268149 .9542999268149 .6495056152149 .3446960449149 .3446960449 149.0399017334148 .7351074219148 .4304046631148 .1255950928147 .8208007812 147.5160064697146 .9064025879146 .6015930176146 .2969055176145 .9920959473 145.6873016357145 .3825073242144 .7729034424144 .4682006836144 .1634063721 144.1634063721143 .8585968018143 .5538024902143 .2489929199143 .2489929199 142.9441986084142 .9441986084142 .6394042969142 .6394042969142 .3347015381 142.3347015381142 .3347015381142 .3347015381142 .3347015381142 .3347015381 142.3347015381142 .0299072266142 .0299072266142 .0299072266142 .0299072266 142.0299072266141 .7250976562141 .7250976562141 .4203033447141 .4203033447 141.1154937744140 .8106994629140 .5059967041140 .2012023926139 .8963928223 139.5915985107138 .9819946289138 .3724975586138 .0677032471137 .4580993652 136.8484954834136 .2389984131135 .3246002197134 .7149963379133 .8007049561 133.1911010742132 .2767028809131 .3623962402130 .4479980469129 .533706665 128.6192932129127 .7050018311126 .7906036377125 .8762969971124 .6570968628 123.7427978516122 .8283996582121 .9140014648120 .9997024536120 .3900985718 119.4757995605118 .8662033081118 .5614013672118 .2565994263117 .9517974854 117.9517974854117 .9517974854118 .2565994263118 .5614013672118 .8662033081 119.1709976196119 .7806015015120 .3900985718120 .9997024536121 .3793029785 121.8147354126122 .2405014038122 .6338653564124 .6570968628125 .2667007446 125.8762969971126 .7906036377127 .4001998901128 .0097961426128 .6192932129 129.2288970947129 .8385009766130 .1432037354130 .7528076172131 .3623962402 131.6672058105131 .9720001221132 .2767028809132 .5814971924132 .8863067627 133.1911010742133 .1911010742133 .1911010742133 .1911010742133 .1911010742 133.1911010742132 .8863067627132 .5814971924132 .5814971924132 .2767028809 131.6672058105131 .3623962402130 .7528076172130 .4479980469129 .8385009766 
129.2288970947 128.6192932129 127.7050018311 127.0953979492126.1809997559 125.5715026855124 .6570968628123 .7427978516122 .8283996582121 .9140014648 120.9997024536123 .43800354120 .0852966309121 .6092987061 -9999 -9999 -9999 -9999 -9999 -9999 -9999 -9999 -9999 -9999 -9999 -9999 -9999 -9999 -9999 -9999 -9999 -9999 -9999 -9999 -9999 -9999 -9999 -9999 -9999 -9999 -9999 -9999-9999 -9999 -9999 -9999 -9999 -9999 -9999 -9999 -9999 -9999 -9999 -9999 -9999 -9999 -9999 -9999 -9999 -9999 -9999 -9999 -9999

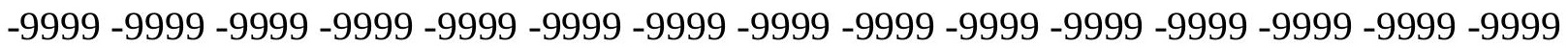

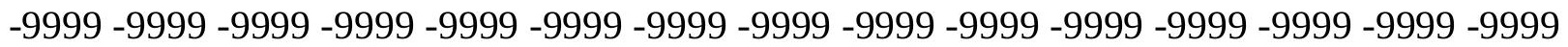
-9999 -9999 -9999 -9999 -9999 -9999 -9999 -9999 -9999 -9999 -9999 -9999 -9999 -9999 -9999 -9999 -9999 -9999 -9999 -9999 -9999 -9999 -9999 -9999 -9999 -9999 -9999 -9999 -9999 -9999 -9999 -9999 -9999 -9999 -9999 -9999 -9999 -9999 -9999 -9999 -9999 -9999 -9999 -9999 -9999 -9999 -9999 -9999 -9999 -9999 -9999 -9999 -9999 -9999 -9999

-9999 -9999 -9999 -9999 -9999 -9999 -9999 -9999 -9999 -9999 -9999 -9999 -9999 -9999 -9999 -9999 -9999 -9999 -9999 -9999 -9999 -9999 -9999 -9999 -9999 -9999 -9999 -9999 -9999 -9999 -9999 -9999 -9999 -9999 -9999 -9999 -9999 -9999 -9999 -9999 -9999 -9999 -9999 -9999 -9999

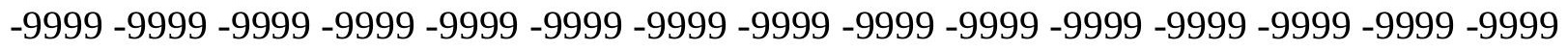
89.6068267822391.1307525634892.6546783447394.1785964965896.31210327148 98.14080810547100 .2742996216102 .1029968262104 .2365036011106 .0652008057 107.8938980103109 .7226028442111 .24659729113 .075302124114 .5991973877 116.4279022217117 .9517974854119 .4757995605120 .9997024536122 .0602798462 123.5295410156124 .9677505493126 .3952484131127 .7944793701129 .1622161865 130.4479980469131 .6672058105132 .8863067627134 .1054992676135 .0198059082 136.2389984131137 .1533050537138 .0677032471139 .2868041992139 .8963928223 140.8106994629141 .7250976562142 .3347015381143 .2489929199143 .8585968018 144.4682006836145 .0776977539145 .3825073242145 .9920959473146 .2969055176 146.6015930176146 .9064025879147 .2111968994147 .5160064697147 .8208007812 147.8208007812147 .8208007812148 .1255950928148 .1255950928148 .1255950928 147.8208007812147 .8208007812147 .5160064697147 .5160064697147 .2111968994 146.9064025879146 .9064025879146 .6015930176146 .2969055176145 .6873016357 145.3825073242145 .0776977539144 .7729034424144 .4682006836144 .1634063721 143.5538024902143 .2489929199142 .9441986084142 .6394042969142 .3347015381 142.0299072266141 .7250976562141 .4203033447141 .1154937744141 .1154937744 140.8106994629140 .8106994629140 .5059967041140 .5059967041140 .2012023926 140.2012023926140 .2012023926140 .2012023926139 .8963928223139 .8963928223 139.8963928223139 .8963928223139 .8963928223139 .8963928223139 .8963928223 139.5915985107139 .5915985107139 .5915985107139 .2868041992139 .2868041992 138.9819946289138 .9819946289138 .6772003174138 .3724975586138 .0677032471 137.7628936768137 .1533050537136 .8484954834136 .2389984131135 .6293945312 135.3246002197134 .7149963379134 .1054992676133 .1911010742132 .5814971924 131.6672058105131 .0576019287130 .1432037354129 .2288970947128 .3144989014 127.4001998901126 .4858016968125 .5715026855124 .6570968628123 .7427978516 122.5235977173121 .6092987061120 .6949005127119 .7806015015118 .8662033081 117.9517974854117 .342300415116 .7326965332116 .1231002808115 .818397522 115.5136032104115 .5136032104115 .818397522115 .818397522116 .4279022217 116.7326965332117 .342300415117 .9517974854118 .5614013672119 .1709976196 119.7806015015120 .4052352905121 .0045852661121 .510055542121 .9031829834 
122.23777771124 .0475006104124 .9618988037125 .5715026855126 .1809997559 126.7906036377127 .4001998901128 .0097961426128 .3144989014128 .9241027832 129.2288970947129 .8385009766130 .1432037354130 .4479980469130 .7528076172 131.0576019287131 .0576019287131 .3623962402131 .3623962402131 .3623962402 131.3623962402131 .0576019287131 .0576019287130 .7528076172130 .7528076172 130.4479980469129 .8385009766129 .533706665129 .2288970947128 .6192932129 128.0097961426127 .4001998901126 .7906036377126 .1809997559125 .5715026855 124.6570968628123 .7427978516123 .1332015991122 .2188034058121 .6092987061 120.6949005127120 .0852966309119 .1709976196118 .5614013672119 .4757995605 120.9997024536 -9999 -9999 -9999 -9999 -9999 -9999 -9999 -9999 -9999 -9999 -9999 -9999 -9999 -9999 -9999 -9999 -9999 -9999 -9999 -9999 -9999 -9999 -9999 -9999 -9999 -9999 -9999 -9999 -9999 -9999 -9999 -9999 -9999 -9999 -9999 -9999 -9999 -9999 -9999 -9999 -9999 -9999 -999 -9999 -9999 -9999 -9999 -9999 -9999 -9999 -9999 -9999 -9999 -9999 -9999 -9999 -9999 -9999 -9999 -9999 -9999 -9999 -9999 -9999 -9999 -9999 -9999 -9999 -9999 -9999 -9999 -9999 -9999 -9999 -9999 -9999 -9999 -9999 -9999 -9999 -9999 -9999 -9999 -9999 -9999 -9999 -9999 -9999

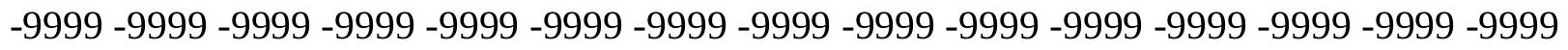

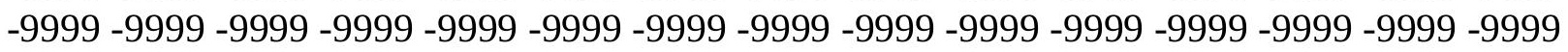
-9999 -9999 -9999 -9999 -9999 -9999 -9999 -9999 -9999 -9999 -9999 -9999 -9999 -9999 -9999 $-9999$

-9999 -9999 -9999 -9999 -9999 -9999 -9999 -9999 -9999 -9999 -9999 -9999 -9999 -9999 -9999

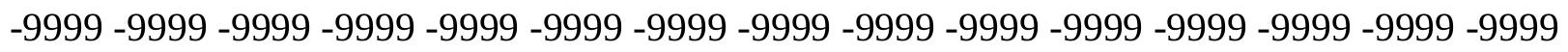

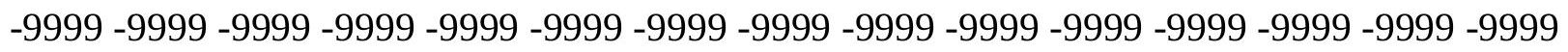
-9999 -9999 -9999 -9999 -9999 -9999 -9999 -9999 -9999 -9999 -9999 -9999 -9999 -9999 86.5589828491288 .0829010009889 .6068267822392 .349891662692 .95947265625 95.0929565429797.2264633178799.35994720459 101.1886978149 103.0174026489 104.8460998535106 .6747970581108 .5035018921110 .0273971558111 .8561019897 113.3800964355114 .7305297852116 .3064498901117 .8303756714119 .3231887817 120.7688293457122 .1939544678123 .5878753662124 .9541549683126 .3695144653 127.7050018311128 .9241027832130 .1432037354131 .3623962402132 .2767028809 133.4958953857 134.4102020264 135.3246002197136.5437011719137.4580993652 138.0677032471138 .9819946289139 .8963928223140 .5059967041141 .1154937744 141.7250976562142 .3347015381142 .9441986084143 .5538024902143 .8585968018 144.1634063721144 .7729034424145 .0776977539145 .0776977539145 .3825073242 145.6873016357145 .6873016357145 .6873016357145 .9920959473145 .9920959473 145.6873016357145 .6873016357145 .6873016357145 .3825073242145 .3825073242 145.0776977539144 .7729034424144 .4682006836144 .1634063721143 .8585968018 143.5538024902143 .2489929199142 .9441986084142 .6394042969142 .0299072266 141.7250976562141 .4203033447141 .1154937744140 .8106994629140 .5059967041 140.2012023926139 .8963928223139 .5915985107139 .2868041992138 .9819946289 138.6772003174138 .6772003174138 .3724975586138 .3724975586138 .0677032471 138.0677032471137 .7628936768137 .7628936768137 .7628936768137 .7628936768 137.7628936768137 .7628936768137 .7628936768137 .4580993652137 .4580993652 137.4580993652137 .4580993652137 .4580993652137 .1533050537137 .1533050537 136.8484954834136 .8484954834136 .5437011719136 .2389984131136 .2389984131 135.9342041016135 .3246002197135 .0198059082134 .7149963379134 .1054992676 133.8007049561133 .1911010742132 .5814971924131 .9720001221131 .3623962402 
130.4479980469129 .8385009766128 .9241027832128 .3144989014127 .4001998901 126.4858016968125 .5715026855124 .6570968628123 .7427978516122 .5235977173 121.6092987061120 .6949005127119 .4757995605118 .5614013672117 .647102356 116.4279022217115 .818397522114 .9039993286114 .2944030762113 .9896011353 113.3800964355113 .3800964355113 .3800964355113 .6848983765113 .9896011353 114.2944030762114 .9039993286115 .5136032104116 .1231002808116 .7326965332 117.342300415118 .2565994263118 .8662033081119 .7806015015120 .3020629883 120.8419723511121 .2405471802121 .5404891968121 .7989196777123 .7427978516 124.3523025513124 .9618988037125 .5715026855126 .1809997559126 .4858016968 127.0953979492127 .4001998901128 .0097961426128 .3144989014128 .6192932129 128.9241027832129 .2288970947129 .2288970947129 .533706665129 .533706665 129.533706665129 .533706665129 .533706665129 .2288970947128 .9241027832 128.9241027832128 .6192932129128 .3144989014127 .7050018311127 .4001998901 126.7906036377126 .4858016968125 .8762969971125 .2667007446124 .6570968628 123.7427978516123 .1332015991122 .5235977173121 .6092987061120 .9997024536 120.0852966309119 .4757995605118 .5614013672117 .9517974854117 .342300415 117.342300415118 .8662033081 -9999 -9999 -9999 -9999 -9999 -9999 -9999 -9999 -9999 -9999 -9999 -9999 -9999 -9999 -9999 -9999 -9999 -9999 -9999 -9999 -9999 -9999 -9999 -9999 -9999 -9999 -9999 -9999 -9999 -9999 -9999 -9999 -9999 -9999 -9999 -9999 -9999 -9999 -9999 -

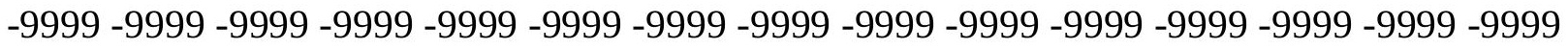

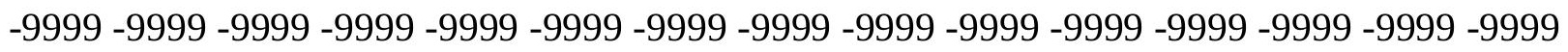
-9999 -9999 -9999 -9999 -9999 -9999 -9999 -9999 -9999 -9999 -9999 -9999 -9999 -9999 -9999 -9999 -9999 -9999 -9999 -9999 -9999 -9999 -9999 -9999 -9999 -9999 -9999 -9999 -9999 -9999 -

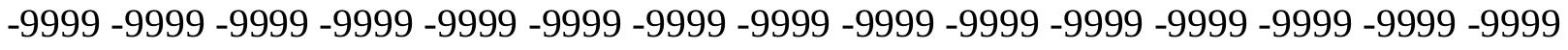
-9999 -9999 -9999 -9999 -9999 -9999 -9999 -9999 -9999 -9999 -9999 -9999 -9999 - -9999 - -999 -9999 -9999 -9999-9999

-9999 -9999 -9999 -9999 -9999 -9999 -9999 -9999 -9999 -9999 -9999 -9999 -9999 -9999 -9999

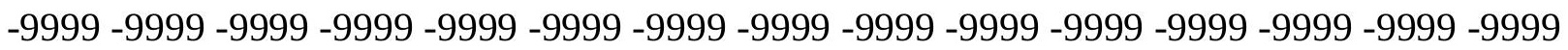

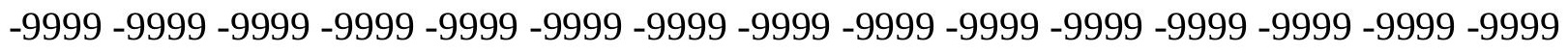
-9999 -9999 -9999 -9999 -9999 -9999 -9999 -9999 -9999 -9999 -9999 -9999 -9999 -9999 85.0350494384886 .5589828491287 .7781066894589 .9116134643692 .04509735107 94.1785964965896 .3121032714898 .4455871582100 .2742996216102 .1029968262 103.9317016602105 .7603988647107 .1586685181108 .8350524902110 .4532089233 112.0244216919113 .6029052734115 .1537628174116 .6476287842118 .0702896118 119.4757995605120 .8488006592122 .2188034058123 .43800354124 .9618988037 126.1809997559127 .4001998901128 .3144989014129 .533706665130 .7528076172 131.6672058105132 .5814971924133 .8007049561134 .7149963379135 .6293945312 136.2389984131137 .1533050537138 .0677032471138 .6772003174139 .2868041992 139.8963928223140 .5059967041141 .1154937744141 .4203033447142 .0299072266 142.3347015381142 .6394042969142 .9441986084143 .2489929199143 .2489929199 143.5538024902143 .5538024902143 .8585968018143 .8585968018143 .8585968018 143.5538024902143 .5538024902143 .5538024902143 .2489929199143 .2489929199 142.9441986084142 .6394042969142 .3347015381142 .0299072266141 .7250976562 141.4203033447141 .1154937744140 .8106994629140 .2012023926139 .8963928223 139.5915985107139 .2868041992138 .9819946289138 .3724975586138 .0677032471 137.7628936768137 .4580993652137 .1533050537136 .8484954834136 .8484954834 
136.5437011719136 .2389984131136 .2389984131135 .9342041016135 .9342041016 135.6293945312135 .6293945312135 .6293945312135 .6293945312135 .3246002197 135.3246002197135 .3246002197135 .3246002197135 .3246002197135 .3246002197 135.3246002197135 .3246002197135 .0198059082135 .0198059082135 .0198059082 134.7149963379134 .7149963379134 .4102020264134 .1054992676134 .1054992676 133.8007049561133 .1911010742132 .8863067627132 .5814971924131 .9720001221 131.6672058105131 .0576019287130 .4479980469129 .8385009766129 .2288970947 128.6192932129128 .0097961426127 .0953979492126 .1809997559125 .5715026855 124.6570968628123 .7427978516122 .8283996582121 .9140014648120 .6949005127 119.7806015015118 .5614013672117 .647102356116 .4279022217115 .5136032104 114.5991973877113 .6848983765112 .7705001831112 .1608963013111 .551399231 111.24659729111 .24659729111 .24659729111 .551399231111 .8561019897112 .4656982422 113.075302124113 .6848983765114 .5991973877115 .2088012695115 .818397522 116.7326965332117 .342300415118 .2565994263118 .8662033081119 .7806015015 120.1521682739120 .5307693481120 .8639297485121 .1278915405122 .8283996582 123.43800354124 .0475006104124 .3523025513124 .9618988037125 .2667007446 125.8762969971126 .1809997559126 .4858016968126 .7906036377127 .0953979492 127.4001998901127 .4001998901127 .7050018311127 .7050018311127 .7050018311 127.7050018311127 .7050018311127 .4001998901127 .4001998901127 .0953979492 126.7906036377126 .4858016968126 .1809997559125 .5715026855125 .2667007446 124.6570968628124 .0475006104123 .7427978516122 .8283996582122 .2188034058 121.6092987061120 .9997024536120 .0852966309119 .4757995605118 .8662033081 117.9517974854117 .342300415116 .7326965332116 .1231002808115 .5136032104 116.7326965332118 .2565994263 -9999 -9999 -9999 -9999 -9999 -9999 -9999 -9999 -9999 -9999 -9999 -9999 -9999 -9999 -9999 -9999 -9999 -9999 -9999 -9999 -9999 -9999 -9999 -9999 -9999 -9999 -9999 -9999 -9999 -9999 -9999 -9999 -9999 -9999 -9999 -9999 -9999 -9999 -9999 -9999 -9999 -9999 -9999 -9999 -9999 -9999 -9999 -9999 -9999 -9999 -9999 -9999 -9999 -9999

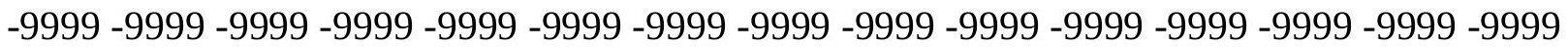
-9999 -9999 -9999 -9999 -9999 -9999 -9999 -9999 -9999 -9999 -9999 -9999 -9999 -9999 -9999

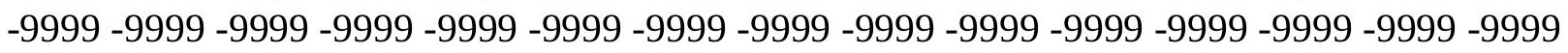
-9999 -9999 -9999 -9999 -9999 -9999 -9999 -9999 -9999 -9999 -9999 -9999 -9999 -9999 -9999

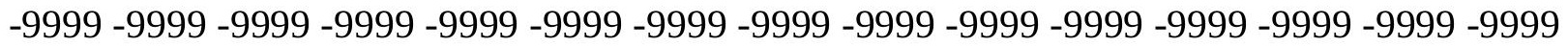
$-9999-9999-9999$

-9999 -9999 -9999 -9999 -9999 -9999 -9999 -9999 -9999 -9999 -9999 -9999 -9999 -9999 -9999 -9999 -9999 -9999 -9999 -9999 -9999 -9999 -9999 -9999 -9999 -9999 -9999 -9999 -9999 -9999 -9999 -9999 -9999 -9999 -9999 -9999 -9999 -9999 -9999 -9999 -9999 -9999 -9999 -9999 -9999 -9999 -9999 -9999 -9999 -9999 -9999 -9999 -9999 -9999 -9999 -9999 -9999 -9999 81.9871978759883 .5111236572385 .0350494384887 .1685485839889 .3020401001 91.4355392456193 .5690307617295 .397743225197 .5312423706199 .35994720459 101.1555175781102 .85597229104 .5412979126106 .2634811401107 .8938980103 109.4179000854110 .9418029785112 .4656982422113 .9896011353115 .5136032104 116.7326965332118 .2565994263119 .4757995605120 .6949005127122 .2188034058 123.43800354124 .6570968628125 .5715026855126 .7906036377128 .0097961426 128.9241027832130 .1432037354131 .0576019287131 .9720001221132 .8863067627 133.8007049561134 .4102020264135 .3246002197135 .9342041016136 .8484954834 137.4580993652138 .0677032471138 .6772003174138 .9819946289139 .5915985107 
139.8963928223140 .2012023926140 .5059967041140 .8106994629141 .1154937744 141.4203033447141 .4203033447141 .4203033447141 .7250976562141 .7250976562 141.7250976562141 .7250976562141 .4203033447141 .4203033447141 .1154937744 141.1154937744140 .8106994629140 .5059967041140 .2012023926139 .8963928223 139.5915985107139 .2868041992138 .9819946289138 .3724975586138 .0677032471 137.7628936768137 .4580993652136 .8484954834136 .5437011719136 .2389984131 135.9342041016135 .6293945312135 .3246002197135 .0198059082134 .7149963379 134.4102020264134 .1054992676134 .1054992676133 .8007049561133 .8007049561 133.4958953857133 .4958953857133 .4958953857133 .1911010742133 .1911010742 133.1911010742133 .1911010742133 .1911010742133 .1911010742133 .1911010742 133.1911010742133 .1911010742133 .1911010742132 .8863067627132 .8863067627 132.8863067627132 .5814971924132 .5814971924132 .2767028809132 .2767028809 131.9720001221131 .6672058105131 .3623962402131 .0576019287130 .4479980469 130.1432037354129 .8385009766129 .2288970947128 .6192932129128 .0097961426 127.4001998901126 .7906036377126 .1809997559125 .2667007446124 .6570968628 123.7427978516122 .8283996582121 .9140014648120 .9997024536120 .0852966309 119.1709976196117 .9517974854117 .0374984741115 .818397522114 .9039993286 113.6848983765112 .7705001831111 .8561019897110 .9418029785110 .3321990967 109.7226028442109 .4179000854109 .4179000854109 .4179000854109 .7226028442 110.3321990967110 .9418029785111 .551399231112 .1608963013113 .075302124 113.6848983765114 .5991973877115 .5136032104116 .1231002808116 .7326965332 117.647102356118 .2565994263118 .8662033081119 .4757995605119 .8952713013 120.2044677734120 .4579315186120 .674911499122 .2188034058122 .8283996582 123.1332015991123 .7427978516124 .0475006104124 .3523025513124 .9618988037 125.2667007446125 .2667007446125 .5715026855125 .8762969971125 .8762969971 125.8762969971126 .1809997559125 .8762969971125 .8762969971125 .8762969971 125.5715026855125 .5715026855125 .2667007446124 .9618988037124 .3523025513 124.0475006104123 .7427978516123 .1332015991122 .5235977173121 .9140014648 121.3044967651120 .6949005127120 .0852966309119 .4757995605118 .8662033081 117.9517974854117 .342300415116 .7326965332116 .1231002808115 .5136032104 114.9039993286114 .2944030762114 .5991973877116 .4279022217 -9999 -9999 -9999 -9999 -9999 -9999 -9999 -9999 -9999 -9999 -9999 -9999 -9999 -9999 -9999 -9999 -9999 -9999 -9999

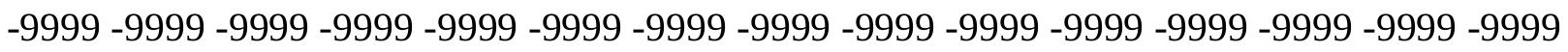
-9999 -9999 -9999 -9999 -9999 -9999 -9999 -9999 -9999 -9999 -9999 -9999 -9999 -9999 -9999 -9999 -9999 -9999 -9999 -9999 -9999 -9999 -9999 -9999 -9999 -9999 -9999 -9999 -9999 -9999 -

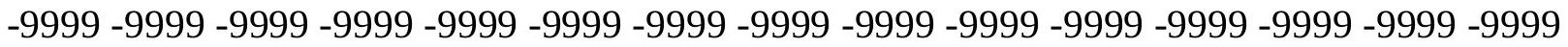

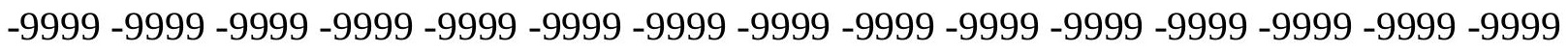

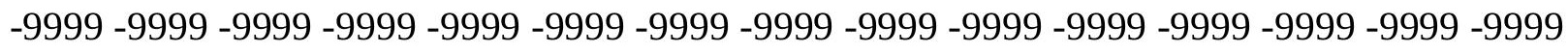
-9999 -9999 -9999 -9999 -9999 -9999 -9999 -9999 -9999 -9999 -9999 -9999 -9999 -9999 -9999 -9999 -9999 -9999 -9999-9999-9999-9999-9999

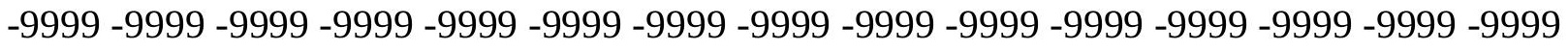

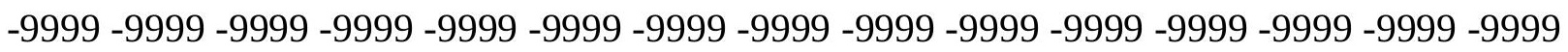
-9999 -9999 -9999 -9999 -9999 -9999 -9999 -9999 -9999 -9999 -9999 -9999 -9999 -9999 -9999 -9999 -9999 -9999 -9999 -9999 -9999 -9999 -9999 -9999 -9999 -9999 -9999 -9999 80.4632720947381 .9871978759884 .1206970214886 .5589828491288 .69246673584 90.8157958984492 .8792266845794 .7881774902396 .8446502685598 .69812011719 
100.2742996216102.0996704102 103.6268997192105.4557037354106.979598999 108.5035018921110 .0273971558111 .24659729112 .7705001831114 .2944030762 115.5136032104116 .7326965332118 .2565994263119 .4757995605120 .6949005127 121.9140014648122 .8283996582124 .0475006104125 .2667007446126 .1809997559 127.4001998901128 .3144989014129 .2288970947130 .1432037354131 .0576019287 131.9720001221132 .8863067627133 .4958953857134 .1054992676135 .0198059082 135.6293945312136 .2389984131136 .5437011719137 .1533050537137 .4580993652 138.0677032471138 .3724975586138 .6772003174138 .9819946289138 .9819946289 139.2868041992 139.2868041992139.5915985107 139.5915985107 139.5915985107 139.5915985107139 .5915985107139 .2868041992139 .2868041992138 .9819946289 138.9819946289138 .6772003174138 .3724975586138 .0677032471137 .7628936768 137.4580993652137 .1533050537136 .5437011719136 .2389984131135 .9342041016 135.6293945312135 .0198059082134 .7149963379134 .4102020264134 .1054992676 133.4958953857133 .1911010742132 .8863067627132 .5814971924132 .2767028809 132.2767028809131 .9720001221131 .6672058105131 .6672058105131 .3623962402 131.3623962402131 .3623962402131 .0576019287131 .0576019287131 .0576019287 131.0576019287131 .0576019287131 .0576019287131 .0576019287131 .0576019287 131.0576019287131 .0576019287131 .0576019287130 .7528076172130 .7528076172 130.7528076172130 .7528076172130 .4479980469130 .4479980469130 .1432037354 129.8385009766129 .533706665129 .2288970947128 .9241027832128 .6192932129 128.3144989014128 .0097961426127 .4001998901126 .7906036377126 .1809997559 125.8762969971124 .9618988037124 .3523025513123 .7427978516122 .8283996582 122.2188034058121 .3044967651120 .3900985718119 .4757995605118 .5614013672 117.647102356116 .4279022217115 .5136032104114 .2944030762113 .3800964355 112.1608963013111 .24659729110 .0273971558109 .1130981445108 .5035018921 107.8938980103107 .5891036987107 .5891036987107 .5891036987108 .1986999512 108.8082962036109 .4179000854110 .3321990967110 .9418029785111 .8561019897 112.7705001831113 .3800964355114 .2944030762114 .9039993286115 .818397522 116.4279022217117 .0374984741117 .647102356118 .2565994263118 .8662033081 119.1709976196119 .4673538208119 .8155975342120 .0288238525120 .1067504883 121.6092987061121 .9140014648122 .5235977173122 .8283996582123 .1332015991 123.43800354123 .7427978516124 .0475006104124 .0475006104124 .3523025513 124.3523025513124 .3523025513124 .3523025513124 .3523025513124 .3523025513 124.0475006104123 .7427978516123 .43800354123 .1332015991122 .8283996582 122.5235977173122 .2188034058121 .6092987061120 .9997024536120 .3900985718 120.0852966309119 .4757995605118 .5614013672117 .9517974854117 .342300415 116.7326965332116 .1231002808115 .5136032104114 .9039993286114 .2944030762 113.3800964355112 .7705001831112 .7705001831114 .2944030762 -9999 -9999-9999-9999 -9999 -9999 -9999 -9999 -9999 -9999 -9999 -9999 -9999 -9999 -9999 -9999 -9999 -9999 -9999 -9999 -9999 -9999 -9999 -9999 -9999 -9999 -9999 -9999 -9999 -9999 -9999 -9999 -9999 - -999 -

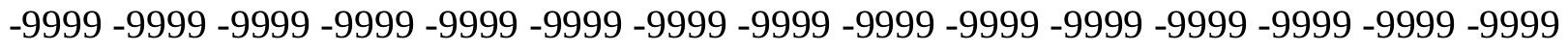

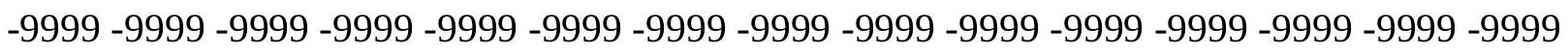
-9999 -9999 -9999 -9999 -9999 -9999 -9999 -9999 -9999 -9999 -9999 -9999 -9999 -9999 -9999 -9999 -9999 -9999 -9999 -9999 -9999 -9999 -9999 -9999 -9999 -9999 -9999 -9999 -9999 -9999 -

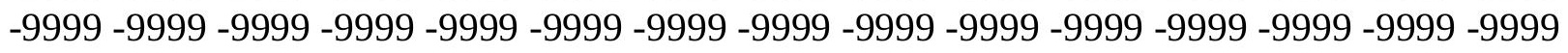

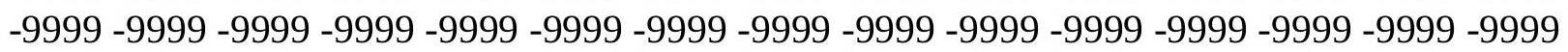


-9999 -9999 -9999 -9999 -9999 -9999 -9999 -9999

-9999 -9999 -9999 -9999 -9999 -9999 -9999 -9999 -9999 -9999 -9999 -9999 -9999 -9999 -9999

-9999 -9999 -9999 -9999 -9999 -9999 -9999 -9999 -9999 -9999 -9999 -9999 -9999 -9999 -9999

-9999 -9999 -9999 -9999 -9999 -9999 -9999 -9999 -9999 -9999 -9999 -9999 -9999 -9999 -9999

-9999 -9999 -9999 -9999 -9999 -9999 -9999 -9999 -9999 -9999 -9999 -9999 77.41542053223

78.9393463134881 .0728530883883 .5111236572385 .9222717285288 .08290100098 90.2164001464892 .3422470092894 .3065490722796 .248184204198 .14080810547 99.66472625732101 .4934005737103 .0174026489104 .5412979126106 .0652008057 107.2844009399108 .8082962036110 .3321990967111 .551399231113 .075302124 114.2944030762115 .5136032104116 .7326965332117 .9517974854119 .1709976196 120.3900985718121 .3044967651122 .5235977173123 .7427978516124 .6570968628 125.5715026855126 .4858016968127 .7050018311128 .6192932129129 .2288970947 130.1432037354131 .0576019287131 .6672058105132 .2767028809133 .1911010742 133.8007049561134 .1054992676134 .7149963379135 .3246002197135 .6293945312 135.9342041016136 .2389984131136 .5437011719136 .8484954834137 .1533050537 137.1533050537137 .4580993652137 .4580993652137 .4580993652137 .4580993652 137.4580993652137 .4580993652137 .1533050537137 .1533050537136 .8484954834 136.8484954834136 .5437011719136 .2389984131135 .9342041016135 .6293945312 135.3246002197134 .7149963379134 .4102020264134 .1054992676133 .8007049561 133.1911010742132 .8863067627132 .5814971924131 .9720001221131 .6672058105 131.3623962402131 .0576019287130 .7528076172130 .4479980469130 .1432037354 129.8385009766129 .533706665129 .533706665129 .2288970947129 .2288970947 128.9241027832128 .9241027832128 .9241027832128 .9241027832128 .9241027832 128.9241027832128 .9241027832128 .9241027832128 .9241027832128 .9241027832 128.9241027832128 .9241027832128 .9241027832128 .9241027832128 .6192932129 128.6192932129128 .6192932129128 .6192932129128 .3144989014128 .3144989014 128.0097961426127 .7050018311127 .4001998901127 .0953979492126 .7906036377 126.4858016968126 .1809997559125 .5715026855125 .2667007446124 .6570968628 124.0475006104123 .43800354122 .8283996582122 .2188034058121 .6092987061 120.6949005127119 .7806015015119 .1709976196118 .2565994263117 .342300415 116.1231002808115 .2088012695113 .9896011353113 .075302124111 .8561019897 110.9418029785109 .7226028442108 .8082962036107 .5891036987106 .979598999 106.3700027466105 .7603988647105 .7603988647106 .0652008057106 .6747970581 107.5891036987108 .5035018921109 .1130981445110 .0273971558110 .9418029785 111.8561019897112 .4656982422113 .3800964355113 .9896011353114 .9039993286 115.5136032104116 .1231002808116 .4279022217117 .0374984741117 .647102356 117.9517974854118 .2565994263118 .8662033081119 .1081542969119 .2514266968 119.2311325073120 .3900985718120 .9997024536121 .3044967651121 .6092987061 121.9140014648122 .2188034058122 .5235977173122 .5235977173122 .8283996582 122.8283996582122 .8283996582122 .8283996582122 .8283996582122 .5235977173 122.5235977173122 .2188034058121 .9140014648121 .6092987061121 .3044967651 120.9997024536120 .6949005127120 .0852966309119 .4757995605119 .1709976196 118.5614013672117 .9517974854117 .342300415116 .7326965332116 .1231002808 115.5136032104114 .9039993286113 .9896011353113 .3800964355112 .7705001831 $112.1608963013111 .551399231110 .9418029785112 .1608963013113 .6848983765-9999$ -9999 -9999 -9999 -9999 -9999 -9999 -9999 -9999 -9999 -9999 -9999 -9999 -9999 -9999 -9999 
-9999 -9999 -9999 -9999 -9999 -9999 -9999 -9999 -9999 -9999 -9999 -9999 -9999 -9999 -9999 -9999 -9999 -9999 -9999 -9999 -9999 -9999 -9999 -9999 -9999 -9999 -9999 -9999 -9999 -9999 -9999 -9999 -9999 -9999 -9999 -9999 -9999 -9999 -9999 -9999 -9999 -9999 -9999 -9999 -9999 -9999 -9999 -9999 -9999 -9999 -9999 -9999 -9999 -9999 -9999 -9999 -9999 -9999 -9999 -9999 -9999 -9999 -9999 -9999 -9999 -9999 -9999 -9999 -9999 -9999 -9999 -9999 -9999 -9999 -9999 -9999 -9999 -9999 -9999 -9999 -9999 -9999 -9999 -9999 -9999 -9999 -9999 -9999 -9999 -9999 -9999 -9999 -9999 -9999 -9999 -9999 -9999 -9999 -9999 -9999 -9999 -9999 -9999 -9999 -9999 -9999 -9999 -9999 -9999 -9999 -9999 -9999 -9999 -9999-9999

-9999 -9999 -9999 -9999 -9999 -9999 -9999 -9999 -9999 -9999 -9999 -9999 -9999 -9999 -9999 -9999 -9999 -9999 -9999 -9999 -9999 -9999 -9999 -9999 -9999 -9999 -9999 -9999 -9999 -9999

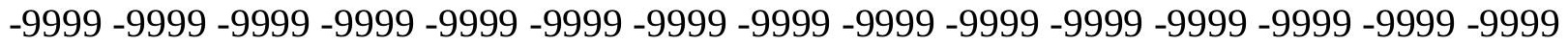
-9999 -9999 -9999 -9999 -9999 -9999 -9999 -9999 -9999 -9999 -9999 74.67236328125 76.1962814331177 .4154205322380 .1584930419982 .9015579223685 .33984375 87.7781066894589 .9116134643692 .0450973510793 .8738174438595 .70252990723 97.5312423706199 .05516815186100 .5791015625102 .1029968262103 .6268997192 105.1509017944106 .3700027466107 .8938980103109 .1130981445110 .3321990967 111.8561019897113 .075302124114 .2944030762115 .5136032104116 .4279022217 117.647102356118 .8662033081119 .7806015015120 .9997024536121 .9140014648 123.1332015991124 .0475006104124 .9618988037125 .8762969971126 .7906036377 127.7050018311128 .3144989014129 .2288970947129 .8385009766130 .4479980469 131.3623962402131 .6672058105132 .2767028809132 .8863067627133 .1911010742 133.8007049561134 .1054992676134 .4102020264134 .7149963379135 .0198059082 135.0198059082135 .3246002197135 .3246002197135 .3246002197135 .6293945312 135.3246002197135 .3246002197135 .3246002197135 .3246002197135 .0198059082 134.7149963379134 .7149963379134 .4102020264134 .1054992676133 .8007049561 133.4958953857132 .8863067627132 .5814971924132 .2767028809131 .9720001221 131.3623962402131 .0576019287130 .7528076172130 .1432037354129 .8385009766 129.533706665129 .2288970947128 .9241027832128 .3144989014128 .0097961426 128.0097961426127 .7050018311127 .4001998901127 .0953979492127 .0953979492 127.0953979492126 .7906036377126 .7906036377126 .7906036377126 .7906036377 126.7906036377126 .7906036377126 .7906036377126 .7906036377126 .7906036377 126.7906036377126 .7906036377126 .7906036377126 .7906036377126 .7906036377 126.7906036377126 .7906036377126 .7906036377126 .4858016968126 .4858016968 126.4858016968126 .1809997559125 .8762969971125 .8762969971125 .5715026855 125.2667007446124 .9618988037124 .3523025513124 .0475006104123 .7427978516 123.1332015991122 .5235977173121 .9140014648121 .3044967651120 .6949005127 120.0852966309119 .4757995605118 .5614013672117 .9517974854117 .0374984741 116.1231002808114 .9039993286113 .9896011353113 .075302124111 .8561019897 110.6370010376109 .7226028442108 .5035018921107 .5891036987106 .6747970581 105.7603988647105 .1509017944104 .5412979126104 .5412979126104 .8460998535 105.7603988647106 .6747970581107 .5891036987108 .5035018921109 .4179000854 110.3321990967110 .9418029785111 .8561019897112 .7705001831113 .3800964355 113.9896011353114 .5991973877115 .2088012695115 .5136032104115 .818397522 116.4279022217116 .7326965332117 .0374984741117 .342300415117 .9517974854 118.2565994263118 .2254867554118 .1941375732119 .4757995605119 .7806015015 120.0852966309120 .3900985718120 .6949005127120 .9997024536120 .9997024536 
121.3044967651 121.3044967651 121.3044967651 121.3044967651 121.3044967651 121.3044967651120 .9997024536120 .6949005127120 .6949005127120 .3900985718 119.7806015015119 .4757995605119 .1709976196118 .5614013672118 .2565994263 117.647102356117 .0374984741116 .4279022217116 .1231002808115 .5136032104 114.5991973877113 .9896011353113 .3800964355112 .7705001831112 .1608963013 111.551399231110 .9418029785110 .3321990967109 .7226028442110 .0273971558 111.551399231 -9999 -9999 -9999 -9999 -9999 -9999 -9999 -9999 -9999 -9999 -9999 -9999 -9999 -9999 -9999 -9999 -9999 -9999 -9999 -9999 -9999 -9999 -9999 -9999 -9999 -9999 -9999 -9999 -9999 -9999 -9999 -9999 -9999 -9999 -9999 -9999 -9999 -9999 -9999 -9999 -9999 -9999 -9999 -9999 -9999 -9999 -9999 -9999 -9999 -9999 -9999 -9999 -9999 -9999 -9999 -9999 -9999 -9999 -9999 -9999 -9999 -9999 -9999 -9999 -9999 -9999 -9999 -9999 -9999 -9999 -9999 -9999 -

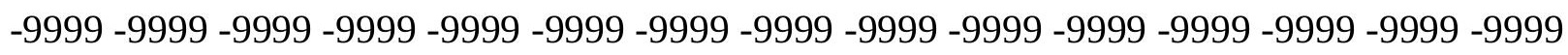
-9999 -9999 -9999 -9999 -9999 -9999 -9999 -9999 -9999 -9999 -9999 -9999 -9999 -9999 -9999 -9999 -9999 -9999 -9999 -9999 -9999 -9999 -9999 -9999 -9999 -9999 -9999 -9999 -9999 -9999 -9999 -9999 -9999 -9999 -9999 -9999 -9999 -9999 -9999 -9999 -9999 -9999 -9999 -9999

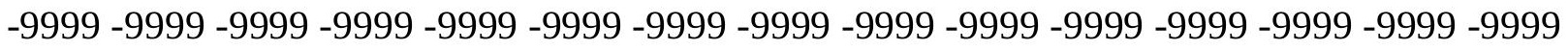

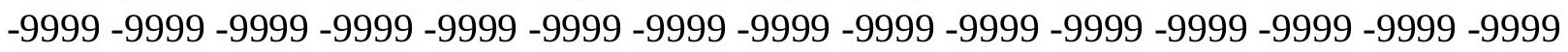

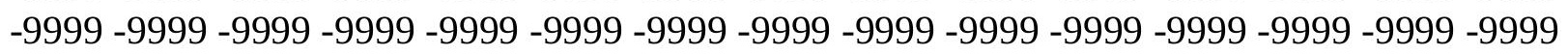
-9999 -9999 -9999 -9999 -9999 -9999 -9999 -9999 -9999 -9999 -9999 72.17794799805 74.5961761474676 .8058471679779 .8537063598682 .5967712402385 .33984375 87.7781066894589 .9116134643692 .0450973510793 .8738174438595 .3977432251 97.2264633178798 .7503814697399 .96952056885101 .4934005737103 .0174026489 104.2365036011105 .4557037354106 .6747970581107 .8938980103109 .4179000854 110.6370010376111 .8561019897112 .7705001831113 .9896011353115 .2088012695 116.1231002808117 .342300415118 .5614013672119 .4757995605120 .3900985718 121.3044967651122 .5235977173123 .43800354124 .3523025513124 .9618988037 125.8762969971126 .7906036377127 .4001998901128 .0097961426128 .9241027832 129.533706665129 .8385009766130 .4479980469131 .0576019287131 .3623962402 131.9720001221132 .2767028809132 .5814971924132 .8863067627132 .8863067627 133.1911010742133 .1911010742133 .4958953857133 .4958953857133 .4958953857 133.4958953857133 .4958953857133 .1911010742133 .1911010742132 .8863067627 132.8863067627132 .5814971924132 .2767028809131 .9720001221131 .6672058105 131.3623962402130 .7528076172130 .4479980469130 .1432037354129 .533706665 129.2288970947128 .9241027832128 .3144989014128 .0097961426127 .7050018311 127.0953979492126 .7906036377126 .4858016968126 .1809997559125 .8762969971 125.5715026855125 .2667007446125 .2667007446124 .9618988037124 .9618988037 124.6570968628124 .6570968628124 .6570968628124 .6570968628124 .3523025513 124.3523025513124 .6570968628124 .6570968628124 .6570968628124 .6570968628 124.6570968628124 .6570968628124 .6570968628124 .6570968628124 .9618988037 124.9618988037124 .9618988037124 .6570968628124 .6570968628124 .6570968628 124.6570968628124 .3523025513124 .3523025513124 .0475006104123 .7427978516 123.43800354123 .1332015991122 .8283996582122 .5235977173122 .2188034058 121.6092987061121 .3044967651120 .6949005127120 .0852966309119 .4757995605 118.8662033081118 .2565994263117 .342300415116 .7326965332115 .818397522 114.9039993286113 .9896011353113 .075302124112 .1608963013110 .9418029785 110.0273971558108 .8082962036107 .5891036987106 .6747970581105 .7603988647 
104.8460998535104 .2365036011103 .6268997192103 .3221969604104 .2365036011 105.1509017944106 .0652008057106 .979598999107 .8938980103108 .8082962036 109.7226028442110 .6370010376111 .24659729112 .1608963013112 .7705001831 113.3800964355113 .9896011353114 .2944030762114 .5991973877114 .9039993286 115.2088012695115 .5136032104115 .818397522116 .1231002808116 .4279022217 116.7326965332117 .0374984741117 .1996231079117 .1574707031118 .2565994263 118.5614013672118 .8662033081119 .1709976196119 .4757995605119 .7806015015 119.7806015015119 .7806015015120 .0852966309120 .0852966309119 .7806015015 119.7806015015119 .4757995605119 .4757995605119 .1709976196118 .8662033081 118.5614013672118 .2565994263117 .647102356117 .342300415116 .7326965332 116.4279022217115 .818397522115 .2088012695114 .5991973877113 .9896011353 113.3800964355112 .7705001831112 .1608963013111 .551399231110 .9418029785 110.3321990967109 .7226028442108 .8082962036108 .1986999512108 .5035018921 109.4179000854 -9999 -9999 -9999 -9999 -9999 -9999 -9999 -9999 -9999 -9999 -9999 -9999 -9999 -9999 -9999 -9999 -9999 -9999 -9999 -9999 -9999 -9999 -9999 -9999 -9999 -9999 -9999

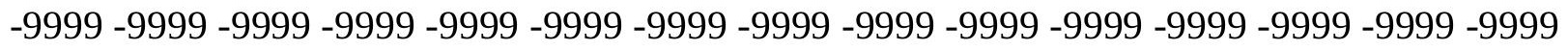
-9999 -9999 -9999 -9999 -9999 -9999 -9999 -9999 -9999 -9999 -9999 -9999 -9999 -9999 -9999 -9999 -9999 -9999 -9999 -9999 -9999 -9999 -9999 -9999 -9999 -9999 -9999 -9999 -9999 -9999 -

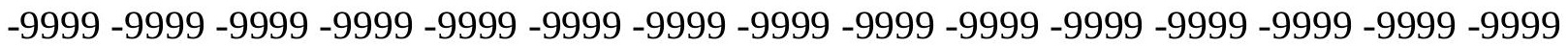

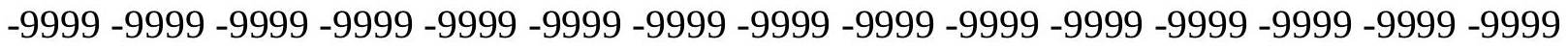

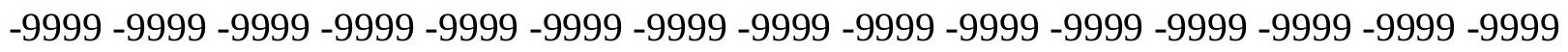
-9999 -9999 -9999 -9999 -9999 -9999 -9999 -9999 -9999 -9999 -9999 -9999 -9999 -9999 -9999 -9999 -9999 -9999 -9999 -9999 -9999 -9999 -9999 -9999 -9999 -9999 -9999 -9999 -9999 -

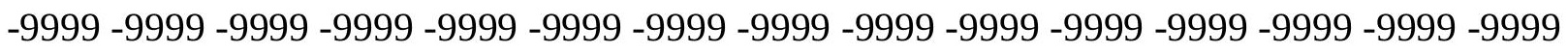

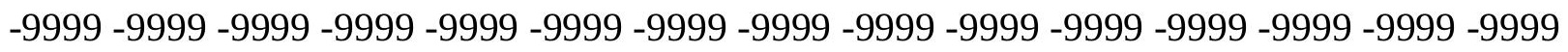
-9999 -9999 -9999 -9999 -9999 -9999 -9999 -9999-9999-9999-9999 71.27305603027 73.4532165527376 .7555465698279 .8537063598682 .5967712402385 .33984375 87.7781066894589 .9116134643692 .0450973510793 .8738174438595 .3977432251 96.9216690063598 .1408081054799 .66472625732100 .8839035034102 .1029968262 103.3221969604104 .5412979126105 .7603988647106 .979598999108 .1986999512 109.4179000854110 .3321990967111 .551399231112 .7705001831113 .6848983765 114.9039993286115 .818397522117 .0374984741117 .9517974854118 .8662033081 119.7806015015120 .6949005127121 .6092987061122 .5235977173123 .43800354 124.0475006104124 .9618988037125 .5715026855126 .4858016968127 .0953979492 127.7050018311128 .3144989014128 .6192932129129 .2288970947129 .533706665 129.8385009766130 .4479980469130 .7528076172130 .7528076172131 .0576019287 131.3623962402131 .3623962402131 .3623962402131 .3623962402131 .3623962402 131.3623962402131 .3623962402131 .3623962402131 .0576019287131 .0576019287 130.7528076172130 .4479980469130 .1432037354129 .8385009766129 .533706665 129.2288970947128 .6192932129128 .3144989014128 .0097961426127 .4001998901 127.0953979492126 .7906036377126 .1809997559125 .8762969971125 .2667007446 124.9618988037124 .6570968628124 .3523025513124 .0475006104123 .7427978516 123.43800354123 .1332015991122 .8283996582122 .8283996582122 .5235977173 122.5235977173122 .5235977173122 .2188034058122 .2188034058122 .2188034058 122.2188034058122 .5235977173122 .5235977173122 .5235977173122 .5235977173 122.5235977173122 .8283996582122 .8283996582122 .8283996582122 .8283996582 
122.8283996582122 .8283996582122 .8283996582122 .8283996582122 .8283996582 122.8283996582122 .8283996582122 .5235977173122 .5235977173122 .2188034058 121.9140014648121 .9140014648121 .6092987061120 .9997024536120 .6949005127 120.3900985718120 .0852966309119 .4757995605118 .8662033081118 .2565994263 117.647102356117 .0374984741116 .4279022217115 .818397522114 .9039993286 113.9896011353113 .075302124112 .1608963013111 .24659729110 .3321990967 109.1130981445108 .1986999512107 .2844009399106 .0652008057105 .1509017944 104.5412979126103 .9317016602103 .3221969604103 .3221969604103 .9317016602 104.8460998535105 .7603988647106 .6747970581107 .5891036987108 .5035018921 109.4179000854110 .3321990967111 .24659729111 .8561019897112 .4656982422 113.075302124113 .3800964355113 .6848983765113 .9896011353114 .2944030762 114.2944030762114 .5991973877114 .5991973877114 .9039993286115 .2088012695 115.5136032104115 .818397522116 .1231002808116 .0742416382116 .0291290283 117.0374984741117 .647102356117 .9517974854117 .9517974854118 .2565994263 118.5614013672118 .5614013672118 .5614013672118 .5614013672118 .5614013672 118.5614013672118 .2565994263117 .9517974854117 .9517974854117 .647102356 117.342300415116 .7326965332116 .4279022217116 .1231002808115 .5136032104 115.2088012695114 .5991973877113 .9896011353113 .3800964355112 .7705001831 112.1608963013111 .551399231110 .9418029785110 .3321990967109 .7226028442 109.1130981445108 .5035018921107 .5891036987106 .979598999106 .979598999 107.2844009399 108.8082962036 -9999 -9999 -9999 -9999 -9999 -9999 -9999 -9999 -9999 -9999 -9999 -9999 -9999 -9999 -9999 -9999 -9999 -9999 -9999 -9999 -9999 -9999 -9999 -9999 -9999 -9999 -9999 -9999 -9999 -9999 -9999 -9999 -9999 -9999 -9999 -9999-9999-9999-9999 -999 -9999 -9999 -9999 -9999 -9999 -9999 -9999 -9999 -9999 -9999 -9999 -9999 -9999 -9999 -9999 -9999 -9999 -9999 -9999 -9999 -9999 -9999 -9999 -9999 -9999 -9999 -9999 -9999 -9999 -9999 -9999 -9999 -9999 -9999 -9999 -9999 -9999 -9999 -9999 -9999 -9999 -9999 -9999 -9999 -9999 -9999 -9999 -9999 -9999 -9999 -9999 -9999 -9999 -9999 -9999 -9999 -9999 -9999 -9999 -9999

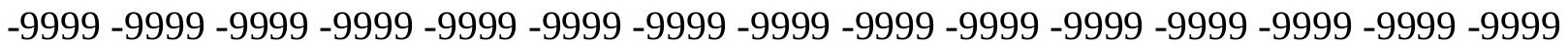

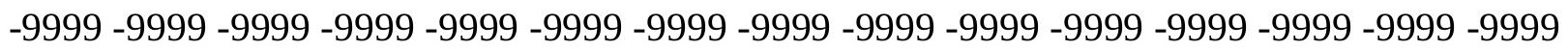
$-9999$

-9999 -9999 -9999 -9999 -9999 -9999 -9999 -9999 -9999 -9999 -9999 -9999 -9999 -9999 -9999

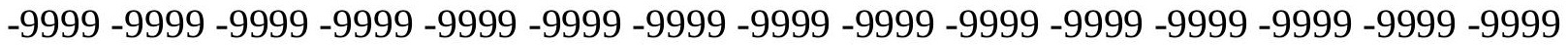

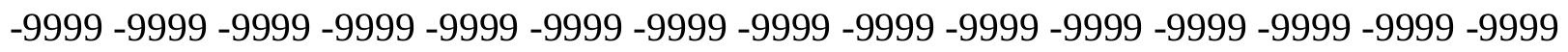
-9999 -9999 -9999 -9999 -9999 -9999 -9999 -9999 -9999 -9999 68.51533508301 70.3582077026472 .8436431884876 .5010681152379 .8537063598682 .90155792236 85.6446228027388 .0829010009890 .2164001464892 .0450973510793 .87381744385 95.397743225196 .6168823242297 .8360290527399 .05516815186100 .2742996216 101.4934005737102 .712600708103 .6268997192104 .8460998535105 .7603988647 106.979598999108 .1986999512109 .1130981445110 .3321990967111 .24659729 112.4656982422113 .3800964355114 .2944030762115 .5136032104116 .4279022217 117.342300415118 .2565994263119 .1709976196120 .0852966309120 .9997024536 121.6092987061122 .5235977173123 .1332015991124 .0475006104124 .6570968628 125.2667007446125 .8762969971126 .4858016968126 .7906036377127 .4001998901 127.7050018311128 .0097961426128 .3144989014128 .6192932129128 .9241027832 129.2288970947129 .2288970947129 .533706665129 .533706665129 .533706665 129.533706665129 .533706665129 .2288970947129 .2288970947129 .2288970947 
128.9241027832128 .6192932129128 .3144989014128 .0097961426127 .7050018311 127.4001998901127 .0953979492126 .7906036377126 .1809997559125 .8762969971 125.2667007446124 .9618988037124 .3523025513124 .0475006104123 .7427978516 123.1332015991122 .8283996582122 .5235977173122 .2188034058121 .6092987061 121.3044967651121 .3044967651120 .9997024536120 .6949005127120 .6949005127 120.3900985718120 .3900985718120 .3900985718120 .0852966309120 .0852966309 120.0852966309120 .3900985718120 .3900985718120 .3900985718120 .3900985718 120.6949005127120 .6949005127120 .6949005127120 .9997024536120 .9997024536 120.9997024536120 .9997024536121 .3044967651121 .3044967651121 .3044967651 121.3044967651121 .3044967651120 .9997024536120 .9997024536120 .9997024536 120.6949005127120 .6949005127120 .3900985718120 .0852966309119 .7806015015 119.4757995605119 .1709976196118 .8662033081118 .2565994263117 .9517974854 117.342300415116 .7326965332116 .1231002808115 .5136032104114 .9039993286 114.2944030762113 .3800964355112 .4656982422111 .551399231110 .6370010376 109.7226028442108 .8082962036107 .8938980103106 .6747970581105 .7603988647 105.1509017944104 .5412979126103 .9317016602103 .6268997192103 .6268997192 104.2365036011104 .8460998535105 .7603988647106 .6747970581107 .5891036987 108.5035018921109 .4179000854110 .3321990967110 .9418029785111 .8561019897 112.1608963013112 .7705001831113 .075302124113 .3800964355113 .3800964355 113.3800964355113 .3800964355113 .3800964355113 .6848983765113 .6848983765 113.6848983765113 .9896011353114 .2944030762114 .5991973877114 .8678970337 114.9624176025115 .0016784668116 .1231002808116 .4279022217116 .7326965332 117.0374984741117 .0374984741117 .342300415117 .342300415117 .342300415 117.342300415117 .0374984741117 .0374984741116 .7326965332116 .4279022217 116.1231002808115 .818397522115 .5136032104115 .2088012695114 .9039993286 114.2944030762113 .6848983765113 .3800964355112 .7705001831112 .1608963013 111.551399231110 .9418029785110 .3321990967109 .7226028442109 .1130981445 108.5035018921107 .8938980103107 .2844009399106 .3700027466105 .7603988647 105.4557037354105 .7603988647106 .6747970581 -9999 -9999 -9999 -9999 -9999 -9999 -9999 -9999 -9999 -9999 -9999 -9999 -9999 -9999 -9999 -9999 -9999 -9999 -9999 -9999 -9999 -9999 -9999 -9999 -9999 -9999 -9999 -9999 -9999 -9999 -9999 -9999 -9999 -9999 -9999 -9999 -9999 -9999 -9999 -9999 -9999 -9999 -9999 -9999 -9999 -9999 -9999 -9999 -9999 -9999 -9999 -9999 -

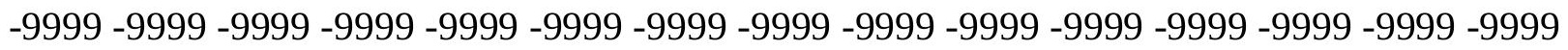
-9999 -9999 -9999 -9999 -9999 -9999 -9999 -9999 -9999 -9999 -9999 -9999 -9999 -9999 -9999 -9999 -9999 -9999 -9999 -9999 -9999 -9999 -9999 -9999 -9999 -9999 -9999 -9999 -9999 -9999 -

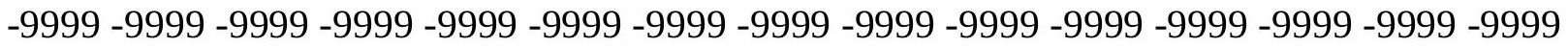

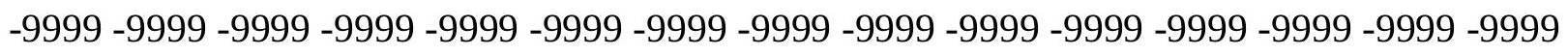
-9999-9999-9999

-9999 -9999 -9999 -9999 -9999 -9999 -9999 -9999 -9999 -9999 -9999 -9999 -9999 -9999 -9999 -9999 -9999 -9999 -9999 -9999 -9999 -9999 -9999 -9999 -9999 -9999 -9999 -9999 -9999 -9999 -

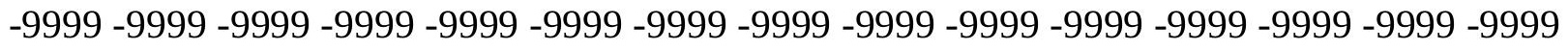
-9999 -9999 -9999-9999 -9999-9999-9999-9999-9999 -9999 67.96708679199 69.1862335205172 .5388565063576 .5010681152380 .1584930419983 .51112365723 86.254188537688 .6924667358490 .8259735107492 .6546783447394 .17859649658 95.397743225196 .6168823242297 .8360290527398 .7503814697399 .66472625732 100.8839035034101 .7982025146102 .712600708103 .9317016602104 .8460998535 
105.7603988647106 .979598999107 .8938980103109 .1130981445110 .0273971558 110.9418029785111 .8561019897113 .075302124113 .9896011353114 .9039993286 115.818397522116 .7326965332117 .647102356118 .5614013672119 .1709976196 120.0852966309120 .6949005127121 .6092987061122 .2188034058122 .8283996582 123.43800354124 .0475006104124 .6570968628124 .9618988037125 .5715026855 125.8762969971126 .1809997559126 .4858016968126 .7906036377127 .0953979492 127.4001998901127 .4001998901127 .4001998901127 .7050018311127 .7050018311 127.7050018311127 .4001998901127 .4001998901127 .4001998901127 .0953979492 126.7906036377126 .7906036377126 .4858016968126 .1809997559125 .5715026855 125.2667007446124 .9618988037124 .6570968628124 .0475006104123 .7427978516 123.1332015991122 .8283996582122 .2188034058121 .9140014648121 .6092987061 120.9997024536120 .6949005127120 .0852966309119 .7806015015119 .4757995605 119.1709976196118 .8662033081118 .8662033081118 .5614013672118 .2565994263 118.2565994263118 .2565994263117 .9517974854117 .9517974854117 .9517974854 118.2565994263118 .2565994263118 .2565994263118 .2565994263118 .5614013672 118.5614013672118 .8662033081118 .8662033081119 .1709976196119 .1709976196 119.1709976196119 .4757995605119 .4757995605119 .4757995605119 .4757995605 119.4757995605119 .4757995605119 .4757995605119 .4757995605119 .4757995605 119.4757995605119 .1709976196119 .1709976196118 .8662033081118 .5614013672 118.2565994263117 .9517974854117 .647102356117 .342300415116 .7326965332 116.4279022217115 .818397522115 .5136032104114 .9039993286114 .2944030762 113.3800964355112 .7705001831111 .8561019897111 .24659729110 .3321990967 109.4179000854108 .5035018921107 .5891036987106 .6747970581106 .0652008057 105.1509017944104 .5412979126104 .2365036011104 .0473327637104 .1260375977 104.527961731105 .1394119263105 .9296340942106 .8121795654107 .7394180298 108.7072677612109 .7226028442110 .2514572144110 .6732711792111 .1180725098 111.5714035034112 .0193023682112 .4494628906112 .8522567749113 .075302124 112.7705001831112 .7705001831112 .7705001831112 .4656982422112 .4656982422 112.4656982422112 .7705001831113 .075302124113 .3800964355113 .6848983765 113.8575439453114 .0132446289114 .9039993286115 .2088012695115 .5136032104 115.818397522116 .1231002808116 .1231002808116 .1231002808116 .1231002808 116.1231002808115 .818397522115 .818397522115 .5136032104115 .2088012695 115.2088012695114 .5991973877114 .2944030762113 .9896011353113 .6848983765 113.075302124112 .7705001831112 .1608963013111 .551399231110 .9418029785 110.6370010376110 .0273971558109 .4179000854108 .8082962036108 .1986999512 107.2844009399 106.6747970581 106.0652008057 105.4557037354104.5412979126 104.2365036011104 .2365036011104 .5412979126 -9999 -9999 -9999 -9999 -9999 -9999 -9999

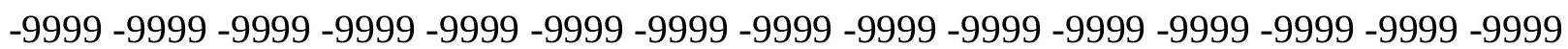

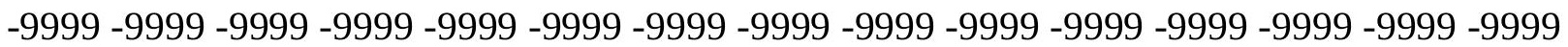
-9999 -9999 -9999 -9999 -9999 -9999 -9999 -9999 -9999 -9999 -9999 -9999 -9999 -9999 -9999 -9999 -9999 -9999 -9999 -9999 -9999 -9999 -9999 -9999 -9999 -9999 -9999 -9999 -9999 -9999

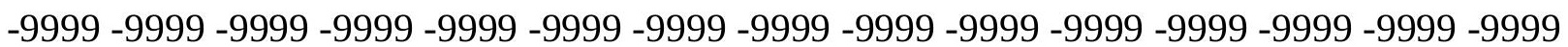
-9999 -9999 -9999 -9999 -9999 -9999 -9999 -9999 -9999 -9999 -9999 -9999 -9999 -9999 -9999 -9999 -9999 -9999 -9999 -9999 -9999 -9999 -9999 -9999 -9999 -9999 -9999 -9999 -9999 -9999 -999 -9999 -9999 -9999 -9999 -9999 -9999 -9999 -9999 -9999 -9999 -9999 -9999 -9999 -9999 -9999 -9999 -9999-9999 
-9999 -9999 -9999 -9999 -9999 -9999 -9999 -9999 -9999 -9999 -9999 -9999 -9999 -9999 -9999 -9999 -9999 -9999 -9999 -9999 -9999 -9999 -9999 -9999 -9999 -9999 -9999 -9999 -9999 -9999 -9999 -9999 -9999 -9999 -9999 -9999 -9999 -9999 -9999 -9999 -9999 -9999 -9999 -9999 -9999 -9999 -9999 -9999 -9999 -9999 -9999 -9999 -9999 -9999 -9999 66.74794006348 67.9670867919972 .2340774536176 .8058471679780 .7680587768684 .42548370361 87.1685485839889 .6068267822391 .4355392456192 .9594726562594 .48339080811 95.397743225196 .6168823242297 .5312423706198 .445587158299 .35994720459 100.2742996216100 .8839035034101 .7982025146102 .712600708103 .9317016602 104.8460998535105 .7603988647106 .6747970581107 .5891036987108 .8082962036 109.7226028442110 .6370010376111 .551399231112 .4656982422113 .3800964355 114.2944030762115 .2088012695115 .818397522116 .7326965332117 .647102356 118.2565994263119 .1709976196119 .7806015015120 .3900985718120 .9997024536 121.6092987061122 .2188034058122 .8283996582123 .1332015991123 .7427978516 124.0475006104124 .3523025513124 .6570968628124 .9618988037125 .2667007446 125.2667007446125 .5715026855125 .5715026855125 .5715026855125 .5715026855 125.5715026855125 .5715026855125 .5715026855125 .2667007446125 .2667007446 124.9618988037124 .6570968628124 .3523025513124 .0475006104123 .7427978516 123.43800354122 .8283996582122 .5235977173121 .9140014648121 .6092987061 120.9997024536120 .6949005127120 .0852966309119 .7806015015119 .1709976196 118.8662033081118 .5614013672117 .9517974854117 .647102356117 .342300415 117.0374984741116 .7326965332116 .4279022217116 .4279022217116 .1231002808 116.1231002808116 .1231002808115 .818397522115 .818397522116 .1231002808 116.1231002808116 .1231002808116 .1231002808116 .4279022217116 .4279022217 116.7326965332116 .7326965332117 .0374984741117 .342300415117 .342300415 117.647102356117 .647102356117 .647102356117 .9517974854117 .9517974854 117.9517974854117 .9517974854118 .2565994263117 .9517974854117 .9517974854 117.9517974854117 .9517974854117 .647102356117 .647102356117 .342300415 117.342300415117 .0374984741116 .7326965332116 .4279022217116 .1231002808 115.5136032104115 .2088012695114 .5991973877114 .2944030762113 .6848983765 113.075302124112 .4656982422111 .551399231110 .9418029785110 .0273971558 109.1130981445108 .5035018921107 .5891036987106 .979598999106 .0652008057 105.4557037354105 .1509017944104 .7562637329104 .5772171021104 .6584014893 104.9800262451105 .5332794189106 .2477874756107 .0850524902108 .0006866455 108.7947540283109 .1006164551109 .4521560669109 .8377151489110 .2453079224 110.6625671387111 .0777053833111 .4800262451111 .8604049683112 .211517334 112.4656982422112 .1608963013111 .8561019897111 .551399231111 .551399231 111.551399231111 .551399231111 .8561019897112 .1608963013112 .4656982422 112.7705001831113 .0618591309113 .2504653931113 .9896011353114 .2944030762 114.5991973877114 .9039993286114 .9039993286114 .9039993286114 .9039993286 114.9039993286114 .9039993286114 .5991973877114 .5991973877114 .2944030762 113.9896011353113 .6848983765113 .3800964355112 .7705001831112 .4656982422 112.1608963013111 .551399231110 .9418029785110 .6370010376110 .0273971558 109.4179000854108 .8082962036108 .1986999512107 .5891036987106 .979598999 106.3700027466105 .7603988647104 .8460998535104 .2365036011103 .6268997192 102.712600708103 .0174026489103 .0174026489103 .9317016602 -9999 -9999 -9999 -9999 -9999 -9999 -9999 -9999 -9999 -9999 -9999 -9999 -9999 -9999 -9999 -9999 -9999 -9999 -9999 
-9999 -9999 -9999 -9999 -9999 -9999 -9999 -9999 -9999 -9999 -9999 -9999 -9999 -9999 -9999 -9999 -9999 -9999 -9999 -9999 -9999 -9999 -9999 -9999 -9999 -9999 -9999 -9999 -9999 -9999 -9999 -9999 -9999 -9999 -9999 -9999 -9999 -9999 -9999 -9999 -9999 -9999 -9999 -9999 -9999 -9999 -9999 -9999 -9999 -9999 -9999 -9999 -9999 -9999 -9999 -9999 -9999 -9999 -9999 -9999 -9999 -9999 -9999 -9999 -9999 -9999 -9999 -9999 -9999 -9999 -9999 -9999-9999 -9999 -9999 -9999 -9999 -9999 -9999 -9999 -9999 -9999 -9999 -9999 -9999 -9999 -9999 -9999 -9999 -9999

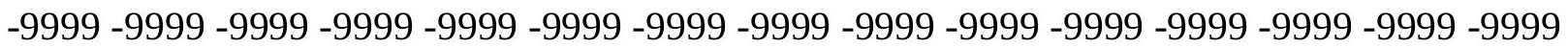
-9999 -9999 -9999-9999-9999

-9999 -9999 -9999 -9999 -9999 -9999 -9999 -9999 -9999 -9999 -9999 -9999 -9999 -9999 -9999 -9999 -9999 -9999 -9999 -9999 -9999 -9999 -9999 -9999 -9999 -9999 -9999 -9999 -9999 -9999 -9999 -9999 -9999 -9999 -9999 -9999 -9999 -9999 -9999 -9999 -9999 -9999 -9999 -9999 -9999 -9999 -9999-9999 -9999-9999-9999-9999-9999-9999 64.0048828125 65.52880096436 67.3575134277372 .8436431884877 .7202072143681 .9871978759885 .64462280273 88.3876876831190 .5211791992292 .349891662693 .5690307617294 .78817749023 95.7025299072396 .6168823242297 .2264633178798 .1408081054798 .75038146973 99.35994720459100 .2742996216101 .1886978149101 .7982025146102 .712600708 103.6268997192104 .5412979126105 .4557037354106 .3700027466107 .2844009399 108.1986999512109 .1130981445110 .0273971558110 .9418029785111 .8561019897 112.7705001831113 .6848983765114 .2944030762115 .2088012695115 .818397522 116.7326965332117 .342300415118 .2565994263118 .8662033081119 .4757995605 120.0852966309120 .3900985718120 .9997024536121 .6092987061121 .9140014648 122.2188034058122 .5235977173122 .8283996582123 .1332015991123 .43800354 123.43800354123 .7427978516123 .7427978516123 .7427978516123 .7427978516 123.7427978516123 .7427978516123 .43800354123 .43800354123 .1332015991 122.8283996582122 .5235977173122 .5235977173121 .9140014648121 .6092987061 121.3044967651120 .9997024536120 .3900985718120 .0852966309119 .4757995605 119.1709976196118 .5614013672118 .2565994263117 .647102356117 .0374984741 116.7326965332116 .4279022217115 .818397522115 .5136032104115 .2088012695 114.9039993286114 .5991973877114 .2944030762114 .2944030762113 .9896011353 113.9896011353113 .9896011353113 .6848983765113 .9896011353113 .9896011353 113.9896011353113 .9896011353114 .2944030762114 .5991973877114 .5991973877 114.9039993286114 .9039993286115 .2088012695115 .5136032104115 .5136032104 115.818397522116 .1231002808116 .1231002808116 .4279022217116 .4279022217 116.4279022217116 .7326965332116 .7326965332116 .7326965332116 .7326965332 116.7326965332116 .7326965332116 .7326965332116 .4279022217116 .4279022217 116.1231002808116 .1231002808115 .818397522115 .5136032104115 .2088012695 114.9039993286114 .5991973877114 .2944030762113 .6848983765113 .075302124 112.7705001831112 .1608963013111 .551399231110 .6370010376110 .0273971558 109.1130981445108 .5035018921107 .8938980103106 .979598999106 .3700027466 106.0652008057105 .6761016846105 .3456954956105 .1820068359105 .2403869629 105.5219955444106 .0125198364106 .6660766602107 .4465255737107 .877456665 108.0992965698108 .3732833862108 .6901321411109 .0392684937109 .4100799561 109.7917022705110 .1738510132110 .5469741821110 .9023132324111 .2321395874 111.5289077759111 .551399231111 .24659729110 .6370010376110 .3321990967 110.3321990967110 .3321990967110 .6370010376110 .9418029785111 .24659729 111.8561019897112 .1608963013112 .3953704834112 .5516738892113 .3800964355 
113.6848983765113 .6848983765113 .9896011353113 .9896011353113 .9896011353 113.9896011353113 .6848983765113 .6848983765113 .3800964355113 .075302124 112.7705001831112 .4656982422112 .1608963013111 .8561019897111 .24659729 110.9418029785110 .6370010376110 .0273971558109 .4179000854108 .8082962036 108.5035018921107 .8938980103107 .2844009399106 .6747970581106 .0652008057 105.1509017944104 .5412979126103 .9317016602103 .3221969604102 .4077987671 101.7982025146101 .4934005737101 .4934005737101 .4934005737 -9999 -9999 -9999 -9999 -9999 -9999 -9999 -9999 -9999 -9999 -9999 -9999 -9999 -9999 -9999 -9999 -9999 -9999 -9999

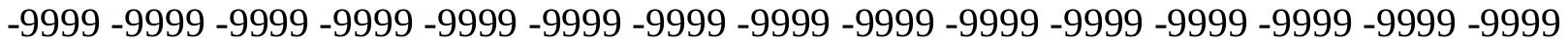
-9999 -9999 -9999 -9999 -9999 -9999 -9999 -9999 -9999 -9999 -9999 -9999 -9999 -9999 -9999

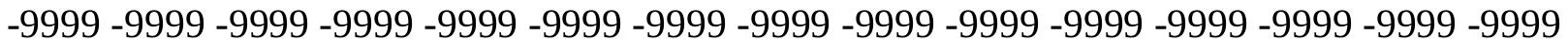
-9999 -9999 -9999 -9999 -9999 -9999 -9999 -9999 -9999 -9999 -9999 -9999 -9999 -9999 -9999 -9999 -9999 -9999 -9999 -9999 -9999 -9999 -9999 -9999 -9999 -9999 -9999 -9999 -9999 -9999 -9999 -9999 -9999 -9999 -9999 -9999 -9999 -9999 -9999 -9999 -9999 -9999 -9999 -9999 -9999 -9999 -9999 -9999 -9999 -9999 -9999 -9999 -9999 -9999 -9999 -9999 -9999 -9999 -9999 - -9999 -9999 -9999 -9999 -9999-9999

-9999 -9999 -9999 -9999 -9999 -9999 -9999 -9999 -9999 -9999 -9999 -9999 -9999 -9999 -9999 -9999 -9999 -9999 -9999 -9999 -9999 -9999 -9999 -9999 -9999 -9999 -9999 -9999 -9999 -9999 -9999 -9999 -9999 -9999 -9999 -9999 -9999 -9999 -9999 -9999 -9999 -9999 -9999 -9999 -9999 -9999 -9999-9999 -9999 -9999 -9999-9999-9999-9999 62.78573989868 64.30966186523 68.5766525268674 .3675689697379 .5489196777383 .8159103393687 .47332763672 89.9116134643691.7403335571393.2642517089894.1785964965895.09295654297 96.0073165893696 .6168823242297 .2264633178797 .5312423706198 .14080810547 98.7503814697399 .35994720459100 .2742996216100 .8839035034101 .7982025146 102.4077987671103 .3221969604104 .2365036011105 .1509017944106 .0652008057 106.979598999107 .8938980103108 .5035018921109 .4179000854110 .3321990967 111.24659729111 .8561019897112 .7705001831113 .6848983765114 .2944030762 115.2088012695115 .818397522116 .4279022217117 .0374984741117 .647102356 118.2565994263118 .8662033081119 .1709976196119 .7806015015120 .0852966309 120.3900985718120 .6949005127120 .9997024536121 .3044967651121 .6092987061 121.6092987061121 .9140014648121 .9140014648121 .9140014648121 .9140014648 121.9140014648121 .6092987061121 .6092987061121 .3044967651121 .3044967651 120.9997024536120 .6949005127120 .3900985718120 .0852966309119 .7806015015 119.1709976196118 .8662033081118 .5614013672117 .9517974854117 .647102356 117.0374984741116 .4279022217116 .1231002808115 .5136032104115 .2088012695 114.5991973877114 .2944030762113 .6848983765113 .3800964355113 .075302124 112.7705001831112 .4656982422112 .1608963013111 .8561019897111 .8561019897 111.8561019897111 .8561019897111 .8561019897111 .8561019897111 .8561019897 111.8561019897112 .1608963013112 .4656982422112 .4656982422112 .7705001831 113.075302124113 .3800964355113 .3800964355113 .6848983765113 .9896011353 114.2944030762114 .2944030762114 .5991973877114 .9039993286114 .9039993286 115.2088012695115 .2088012695115 .5136032104115 .5136032104115 .5136032104 115.5136032104115 .5136032104115 .5136032104115 .5136032104115 .5136032104 115.2088012695115 .2088012695114 .9039993286114 .9039993286114 .5991973877 114.2944030762113 .9896011353113 .6848983765113 .3800964355112 .7705001831 112.4656982422111 .8561019897111 .24659729110 .6370010376110 .0273971558 
109.4179000854108 .8082962036108 .1986999512107 .5891036987106 .979598999 106.6747970581106 .2653808594105 .9570541382105 .8076400757105 .8568572998 106.1078338623106 .5453338623107 .0450057983107 .1184005737107 .2540817261 107.446762085107 .6885681152107 .9709091187108 .2842025757108 .6190795898 108.9658889771109 .3154602051109 .6591262817109 .9887008667110 .2966308594 110.5756607056110 .8196029663110 .6370010376110 .0273971558109 .4179000854 109.4179000854109 .4179000854109 .4179000854109 .7226028442110 .3321990967 110.6370010376111 .24659729111 .5509719849111 .7557525635111 .9218063354 112.4656982422112 .7705001831112 .7705001831113 .075302124113 .075302124 112.7705001831112 .7705001831112 .4656982422112 .4656982422112 .1608963013 111.8561019897111 .551399231111 .24659729110 .9418029785110 .3321990967 110.0273971558109 .4179000854109 .1130981445108 .5035018921107 .8938980103 107.2844009399 106.6747970581 106.3700027466105.4557037354104.8460998535 104.2365036011103 .6268997192103 .0174026489102 .1029968262101 .4934005737 100.8839035034100 .2742996216100 .2742996216100 .2742996216 -9999 -9999 -9999 -9999 -9999 -9999 -9999 -9999 -9999 -9999 -9999 -9999 -9999 -9999 -9999 -9999 -9999 -9999 -9999 -9999 -9999 -9999 -9999 -9999 -9999 -9999 -9999 -9999 -9999 -9999 -9999 -9999 -9999 -9999 -9999 -9999 -9999 -9999 -9999 -9999 -9999 -9999 -9999 -9999 -9999 -9999 -9999 -9999 -9999 -

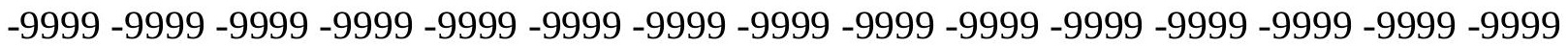

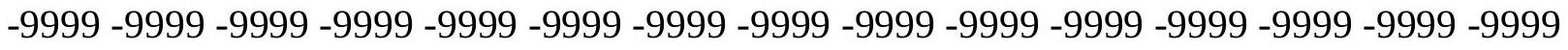

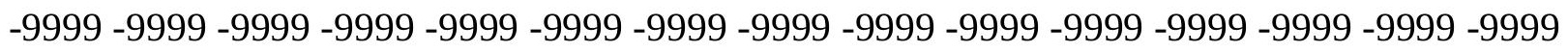
-9999 -9999 -9999 -9999 -9999 -9999 -9999 -9999 -9999 -9999 -9999 -9999 -9999 -9999 -9999 -

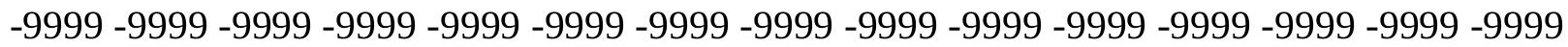
-9999 -9999-9999-9999-9999

-9999 -9999 -9999 -9999 -9999 -9999 -9999 -9999 -9999-9999 -9999 -9999 -9999 -9999 -999 -9999 -9999 -9999 -9999 -9999 -9999 -9999 -9999 -9999 -9999 -9999 -9999 -9999 -9999 -9999 -9999 -9999 -9999 -9999 -9999 -9999 -9999 -9999 -9999 -9999 -9999 -9999 -9999 -9999 -9999 -9999 -9999-9999 -9999 -9999 -9999-9999-9999 -9999 61.87137985229 63.39530944824 70.1005783081176 .8058471679782 .2919769287186 .5589828491289 .60682678223 91.7403335571392 .9594726562594 .1785964965894 .7881774902395 .3977432251 96.0073165893696 .3121032714896 .9216690063597 .2264633178797 .53124237061 98.1408081054798 .7503814697399 .0551681518699 .96952056885100 .5791015625 101.4934005737102 .1029968262103 .0174026489103 .9317016602104 .5412979126 105.4557037354106 .3700027466107 .2844009399107 .8938980103108 .8082962036 109.7226028442110 .3321990967111 .24659729111 .8561019897112 .7705001831 113.3800964355113 .9896011353114 .9039993286115 .5136032104116 .1231002808 116.4279022217117 .0374984741117 .647102356117 .9517974854118 .2565994263 118.8662033081119 .1709976196119 .1709976196119 .4757995605119 .7806015015 119.7806015015120 .0852966309120 .0852966309120 .0852966309120 .0852966309 120.0852966309119 .7806015015119 .7806015015119 .4757995605119 .4757995605 119.1709976196118 .8662033081118 .5614013672118 .2565994263117 .647102356 117.342300415117 .0374984741116 .4279022217116 .1231002808115 .5136032104 114.9039993286114 .5991973877113 .9896011353113 .3800964355113 .075302124 112.4656982422112 .1608963013111 .551399231111 .24659729110 .9418029785 110.6370010376110 .3321990967110 .0273971558110 .0273971558109 .7226028442 109.7226028442109 .7226028442109 .7226028442109 .7226028442110 .0273971558 
110.0273971558110 .3321990967110 .3321990967110 .6370010376110 .9418029785 111.24659729111 .551399231111 .8561019897112 .1608963013112 .4656982422 112.7705001831112 .7705001831113 .075302124113 .3800964355113 .6848983765 113.6848983765113 .9896011353114 .2944030762114 .2944030762114 .2944030762 114.5991973877114 .5991973877114 .5991973877114 .5991973877114 .5991973877 114.5991973877114 .2944030762114 .2944030762114 .2944030762113 .9896011353 113.9896011353113 .6848983765113 .3800964355113 .075302124112 .7705001831 112.1608963013111 .8561019897111 .24659729110 .6370010376110 .3321990967 109.7226028442109 .1130981445108 .5035018921107 .8938980103107 .5891036987 107.2238769531106 .8600234985106 .5758056641106 .4404449463106 .4832763672 106.596244812106 .5235137939106 .5136947632106 .5657196045106 .6760635376 106.8399505615107 .050201416107 .2990036011107 .5776748657107 .8778762817 108.1910629272108 .5090560913108 .824005127109 .1284255981109 .4153518677 109.6782073975109 .9117355347110 .0273971558109 .4179000854108 .8082962036 108.5035018921108 .5035018921108 .5035018921108 .8082962036109 .1130981445 109.7226028442110 .3321990967110 .6370010376110 .9418029785111 .2125015259 111.551399231111 .8561019897112 .1608963013112 .1608963013112 .1608963013 111.8561019897111 .8561019897111 .551399231111 .551399231111 .24659729 110.9418029785110 .6370010376110 .3321990967109 .7226028442109 .4179000854 109.1130981445108 .5035018921108 .1986999512107 .5891036987106 .979598999 106.3700027466105 .7603988647105 .1509017944104 .5412979126103 .9317016602 103.3221969604102 .712600708102 .1029968262101 .1886978149100 .5791015625 99.9695205688599 .3599472045999 .0551681518699 .0551681518699 .05516815186 -9999 -9999 -9999 -9999 -9999 -9999 -9999 -9999 -9999 -9999 -9999 -9999 -9999 -9999 -9999 -9999

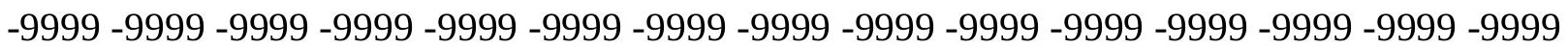
-9999 -9999 -9999 -9999 -9999 -9999 -9999 -9999 -9999 -9999 -9999 -9999 -9999 -9999 -9999 -9999 -9999 -9999 -9999 -9999 -9999 -9999 -9999 -9999 -9999 -9999 -9999 -9999 -9999 -9999 -9999 -9999 -9999 -9999 -9999 -9999 -9999 -9999 -9999 -9999 -9999 -9999 -9999 -9999 -9999 -9999 -9999 -9999 -9999 -9999 -9999 -9999 -9999 -9999 -9999 -9999 -9999 -9999 -9999 -9999

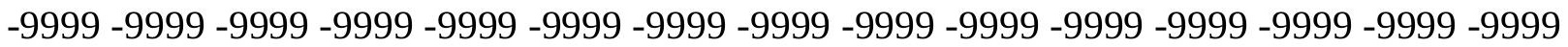
-9999 -9999 -9999 -9999 -9999 -9999 -9999 -9999 -9999 -9999 -9999 -9999 -9999 -9999 -9999 -9999 -9999 -9999 -9999 -9999 -9999 -9999 -9999 -9999 -9999 -9999 -9999 -9999 -9999 -9999 -9999 -9999 -9999 -9999 -9999 -9999 -9999 -9999 -9999 -9999 -9999 -9999 -9999 -9999 -9999 -9999 -9999 -9999 -9999 -9999 -9999 -9999 -9999 -9999 -9999 -9999 -9999 -9999 -9999 -9999 -9999 -9999 -9999 -9999 -9999 -9999 -9999 -9999 -9999 -9999 -9999 -9999 -9999 -9999 -9999 59.1283111572360 .65224075317 64.3096618652372 .5388565063580 .1584930419985 .6446228027389 .60682678223 92.0450973510793 .2642517089894 .1785964965894 .7881774902395 .3977432251 95.7025299072396 .0073165893696 .3121032714896 .3121032714896 .61688232422 96.9216690063597 .2264633178797 .8360290527398 .1408081054798 .75038146973 99.35994720459100 .2742996216100 .8839035034101 .7982025146102 .4077987671 103.3221969604104 .2365036011104 .8460998535105 .7603988647106 .6747970581 107.2844009399 108.1986999512108.8082962036109.7226028442110.3321990967 111.24659729111 .8561019897112 .4656982422113 .075302124113 .6848983765 114.2944030762114 .9039993286115 .5136032104115 .818397522116 .1231002808 116.7326965332117 .0374984741117 .342300415117 .647102356117 .647102356 
117.9517974854117 .9517974854118 .2565994263118 .2565994263118 .2565994263 118.2565994263117 .9517974854117 .9517974854117 .9517974854117 .647102356 117.342300415117 .342300415117 .0374984741116 .7326965332116 .1231002808 115.818397522115 .5136032104114 .9039993286114 .5991973877113 .9896011353 113.3800964355113 .075302124112 .4656982422111 .8561019897111 .551399231 110.9418029785110 .3321990967110 .0273971558109 .4179000854109 .1130981445 108.8082962036108 .5035018921108 .1986999512107 .8938980103107 .8938980103 107.5891036987107 .5891036987107 .5891036987107 .5891036987107 .8938980103 107.8938980103108 .1986999512108 .1986999512108 .5035018921108 .8082962036 109.1130981445109 .4179000854109 .7226028442110 .0273971558110 .6370010376 110.9418029785111 .24659729111 .551399231111 .8561019897112 .1608963013 112.1608963013112 .4656982422112 .7705001831113 .075302124113 .075302124 113.3800964355113 .3800964355113 .6848983765113 .6848983765113 .6848983765 113.6848983765113 .6848983765113 .6848983765113 .6848983765113 .6848983765 113.6848983765113 .3800964355113 .3800964355113 .075302124113 .075302124 112.7705001831112 .1608963013111 .8561019897111 .551399231110 .9418029785 110.3321990967109 .9638519287109 .3608856201108 .80027771108 .2855911255 107.8193740845107 .4041290283107 .0412216187106 .7321395874106 .4775161743 106.2786636353106 .1364822388106 .052406311106 .0264587402106 .0579910278 106.1439743042106 .2801513672106 .4600601196106 .6767425537106 .9224472046 107.1897201538 107.4709396362 107.7588882446108.0465393066108.3271865845 108.594581604108 .8430099487109 .0680847168109 .2669525146108 .8082962036 108.1986999512107 .8938980103107 .5891036987107 .5891036987107 .8938980103 108.5035018921108 .8082962036109 .4179000854109 .7226028442110 .3321990967 110.5099105835110 .6627807617110 .9418029785111 .24659729111 .24659729111 .24659729 111.24659729110 .9418029785110 .9418029785110 .6370010376110 .3321990967 110.0273971558109 .7226028442109 .4179000854108 .8082962036108 .5035018921 108.1986999512107 .5891036987107 .2844009399106 .6747970581106 .0652008057 105.4557037354104 .8460998535104 .5412979126103 .6268997192103 .0174026489 102.4077987671101 .7982025146101 .1886978149100 .579101562599 .66472625732 $99.0551681518698 .445587158297 .8360290527397 .8360290527397 .83602905273-9999$ -9999 -9999 -9999 -9999 -9999 -9999 -9999 -9999 -9999 -9999 -9999 -9999 -9999 -9999 -9999

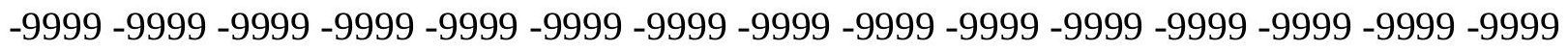
-9999 -9999 -9999 -9999 -9999 -9999 -9999 -9999 -9999 -9999 -9999 -9999 -9999 -9999 -9999 -9999 -9999 -9999 -9999 -9999 -9999 -9999 -9999 -9999 -9999 -9999 -9999 -9999 -9999 -9999 -9999 -9999 -9999 -9999 -9999 -9999 -9999 -9999 -9999 -9999 -9999 -9999 -9999 -9999 -9999

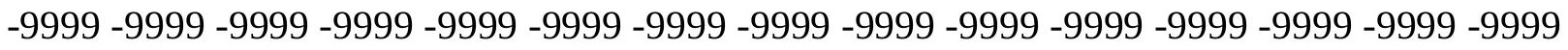

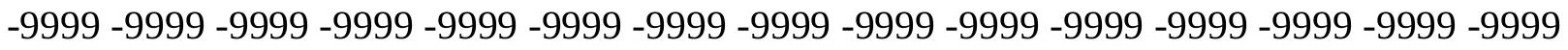
-9999 -9999 -9999 -9999 -9999 -9999 -9999 -9999 -9999 -9999 -9999 -9999 -9999 -9999 -9999 -9999 -9999 -9999 -9999-9999-9999-9999

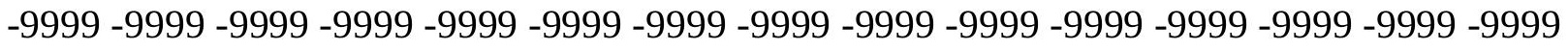

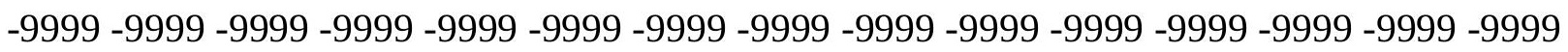

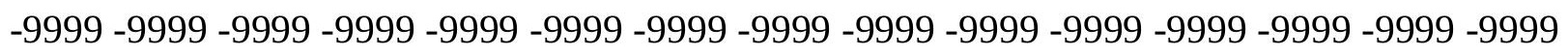
-9999 -9999 -9999 -9999 -9999 -9999 -9999 -9999 58.21395874023 59.73788070679 66.7479400634876 .1962814331184 .4254837036189 .9116134643692 .65467834473 94.1785964965894 .7881774902395 .0929565429795 .397743225195 .70252990723 
95.7025299072395 .7025299072396 .0073165893696 .0073165893696 .00731658936 96.3121032714896 .6168823242296 .9216690063597 .2264633178797 .83602905273 98.445587158299 .0551681518699 .66472625732100 .5791015625101 .1886978149 102.1029968262102 .712600708103 .6268997192104 .2365036011105 .1509017944 105.7603988647106 .6747970581107 .2844009399108 .1986999512108 .8082962036 109.4179000854 110.3321990967110.9418029785111.551399231 112.1608963013 112.7705001831113 .075302124113 .6848983765113 .9896011353114 .5991973877 114.9039993286115 .2088012695115 .5136032104115 .818397522115 .818397522 116.1231002808116 .1231002808116 .4279022217116 .4279022217116 .4279022217 116.4279022217116 .1231002808116 .1231002808116 .1231002808115 .818397522 115.5136032104115 .2088012695114 .9039993286114 .5991973877114 .2944030762 113.9896011353113 .6848983765113 .075302124112 .4656982422112 .1608963013 111.551399231110 .9418029785110 .6370010376110 .0273971558109 .4179000854 109.1130981445108 .5035018921107 .8938980103107 .5891036987106 .979598999 106.6747970581106 .3700027466106 .0652008057105 .7603988647105 .7603988647 105.7603988647105 .4557037354105 .4557037354105 .7603988647105 .7603988647 106.0652008057106 .3700027466106 .3700027466106 .6747970581107 .2844009399 107.5891036987107 .8938980103108 .1986999512108 .5035018921109 .1130981445 109.4179000854109 .7226028442110 .0273971558110 .3321990967110 .6370010376 110.9418029785111 .24659729111 .551399231111 .8561019897112 .1608963013 112.1608963013112 .4656982422112 .7705001831112 .7705001831112 .7705001831 113.075302124113 .075302124113 .075302124113 .075302124113 .075302124113 .075302124 113.075302124113 .075302124113 .075302124112 .7705001831112 .7705001831 112.4656982422112 .1274490356111 .4173812866110 .7328262329110 .0780944824 109.456993103 108.8734283447 108.3305435181 107.8315582275 107.3787994385 106.9745788574106 .6201248169106 .3167037964106 .0646286011105 .864692688 105.7171936035105 .6231460571105 .5825653076105 .5951004028105 .6582489014 105.7683181763105 .9195861816106 .1059188843106 .3205490112106 .5569458008 106.8083114624107 .0682296753107 .3304519653107 .5890808105107 .8386383057 108.0742111206108 .2921676636108 .490272522108 .6685180664107 .8938980103 107.5891036987 107.2844009399 107.2844009399 107.2844009399 107.8938980103 108.1986999512108 .8082962036109 .1130981445109 .4179000854109 .7782516479 110.0196914673110 .3321990967110 .3321990967110 .3321990967110 .3321990967 110.3321990967110 .3321990967110 .0273971558109 .7226028442109 .4179000854 109.1130981445108 .8082962036108 .5035018921108 .1986999512107 .5891036987 107.2844009399 106.6747970581 106.3700027466105.7603988647105.1509017944 104.8460998535104 .2365036011103 .6268997192103 .0174026489102 .4077987671 101.4934005737100 .8839035034100 .274299621699 .6647262573299 .05516815186 98.1408081054797 .5312423706196 .9216690063596 .6168823242296 .61688232422 -9999 -9999 -9999 -9999 -9999 -9999 -9999 -9999 -9999 -9999 -9999 -9999 -9999 -9999 -9999 -9999

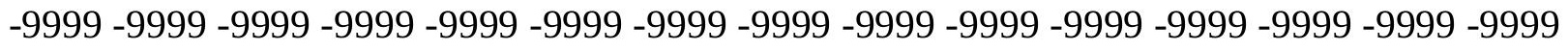

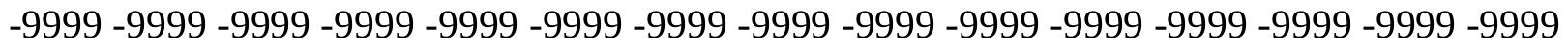
-9999 -9999 -9999 -9999 -9999 -9999 -9999 -9999 -9999 -9999 -9999 -9999 -9999 -9999 -9999 -9999 -9999 -9999 -9999 -9999 -9999 -9999 -9999 -9999 -9999 -9999 -9999 -9999 -9999 -9999 -

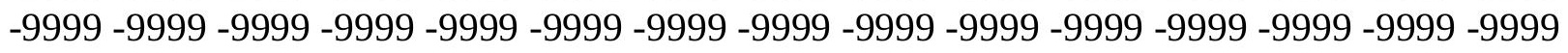

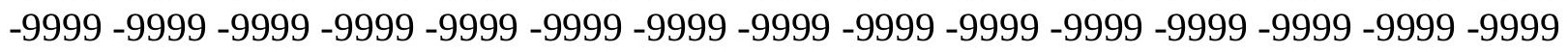


-9999 -9999 -9999 -9999 -9999 -9999 -9999 -9999 -9999 -9999 -9999 -9999 -9999 -9999 -9999 -9999 -9999 -9999 -9999-9999-9999-9999

-9999 -9999 -9999 -9999 -9999 -9999 -9999 -9999 -9999 -9999 -9999 -9999 -9999 -9999 -9999 -9999 -9999 -9999 -9999 -9999 -9999 -9999 -9999 -9999 -9999 -9999 -9999 -9999 -9999 -9999 -9999 -9999 -9999 -9999 -9999 -9999 -9999 -9999 -9999 -9999 -9999 -9999 -9999 -9999 -9999 -9999 -9999 -9999 -9999-9999 -9999-9999 -9999 57.29959869385 58.82352828979 68.8814392089880 .1584930419989 .302040100193 .8738174438595 .3977432251 95.7025299072395 .7025299072395 .7025299072395 .397743225195 .3977432251 95.397743225195 .397743225195 .397743225195 .397743225195 .397743225195 .3977432251 95.397743225195 .7025299072396 .0073165893696 .6168823242297 .22646331787 97.8360290527398 .445587158299 .0551681518699 .96952056885100 .5791015625 101.4934005737102 .1029968262103 .0174026489103 .6268997192104 .2365036011 105.1509017944105 .7603988647106 .6747970581107 .2844009399107 .8938980103 108.5035018921109 .1130981445109 .7226028442110 .3321990967110 .9418029785 111.551399231111 .8561019897112 .4656982422112 .7705001831113 .075302124 113.3800964355113 .6848983765113 .9896011353114 .2944030762114 .2944030762 114.5991973877114 .5991973877114 .5991973877114 .5991973877114 .5991973877 114.5991973877114 .2944030762114 .2944030762113 .9896011353113 .6848983765 113.3800964355113 .075302124112 .7705001831112 .4656982422112 .1608963013 111.551399231111 .24659729110 .6370010376110 .3321990967109 .7226028442 109.1130981445108 .5035018921108 .1986999512107 .5891036987106 .979598999 106.3700027466106.0652008057 105.4557037354105.1509017944 104.8460998535 104.2365036011104 .2365036011103 .9317016602103 .6268997192103 .6268997192 103.6268997192103 .6268997192103 .6268997192103 .9317016602104 .2365036011 104.5412979126104 .8460998535105 .1509017944105 .4557037354105 .7603988647 106.3700027466106 .6747970581106 .979598999107 .5891036987107 .8938980103 108.1986999512108 .8082962036109 .1130981445109 .4179000854109 .7226028442 110.0273971558110 .6370010376110 .9418029785110 .9418029785111 .24659729 111.551399231111 .8561019897111 .8561019897112 .1608963013112 .1608963013 112.4656982422112 .4656982422112 .7705001831112 .7705001831112 .7705001831 112.7705001831113 .075302124113 .075302124112 .7705001831112 .7705001831 112.2936401367111 .5832214355110 .8943634033110 .2307662964109 .5963745117 108.9946365356108 .4291305542107 .9026947021107 .418258667106 .977935791 106.5838317871106 .2370452881105 .9387054443105 .688949585105 .4882125854 105.3363113403105 .2337265015105 .1802978516105 .1757583618105 .2180328369 105.3040313721105 .4287643433105 .5868988037105 .772567749105 .9802398682 106.203994751 106.4381027222 106.6769561768 106.9154434204 107.1488265991 107.3729095459 107.5845336914107.7818145752107.9646911621 107.8938980103 107.2844009399 106.979598999 106.6747970581 106.979598999 107.2844009399 107.5891036987108 .1986999512108 .5035018921108 .8522949219109 .1727600098 109.4179000854 109.649887085109.7226028442 109.7226028442109.7226028442 109.7226028442109 .4179000854109 .4179000854109 .1130981445108 .8082962036 108.5035018921108 .1986999512107 .5891036987107 .2844009399106 .979598999 106.3700027466106 .0652008057105 .4557037354105 .1509017944104 .5412979126 103.9317016602103 .3221969604102 .712600708102 .1029968262101 .4934005737 100.8839035034100 .274299621699 .3599472045998 .7503814697398 .14080810547 
97.5312423706196 .9216690063596 .0073165893695 .397743225195 .3977432251 95.3977432251 -9999 -9999 -9999 -9999 -9999 -9999 -9999 -9999 -9999 -9999 -9999 -9999 -9999 -9999 -9999 -9999 -9999 -9999 -9999 -9999 -9999 -9999 -9999 -9999 -9999 -9999 -9999 -9999 -9999 -9999 -9999 -9999 -9999 -9999 -9999 -9999 -9999 -9999 -9999 -9999 -9999 -9999 -9999 -9999 -9999 -9999 -9999 -9999 -9999 -9999 -9999 -9999 -9999 -9999 -9999 -9999 -9999 -9999 -9999 -9999 -9999 -9999 -9999 -9999 -9999 -9999 -9999 -9999 -9999 -9999 -9999 -9999 -9999 -9999 -9999 -9999 -9999 -9999 -9999 -9999 -9999 -9999 -9999 -9999 -9999 -9999 -9999

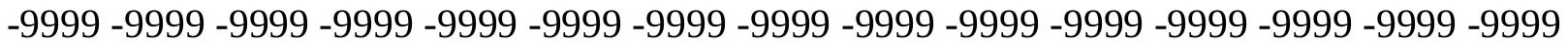

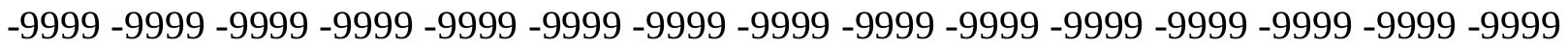
-9999 -9999 -9999 -9999 -9999 -9999 -9999 -9999 -9999 -9999

-9999 -9999 -9999 -9999 -9999 -9999 -9999 -9999 -9999 -9999 -9999 -9999 -9999 -9999 -9999 -9999 -9999 -9999 -9999 -9999 -9999 -9999 -9999 -9999 -9999 -9999 -9999 -9999 -9999 -9999

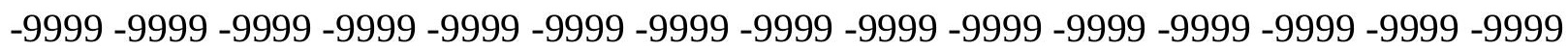
-9999 -9999 -9999 -9999 -9999 -9999 -9999 -9999 56.38525009155 59.43310165405 70.4053573608482 .2919769287193 .5690307617295 .7025299072396 .31210327148 96.0073165893695 .7025299072395 .397743225195 .0929565429795 .09295654297 95.0929565429795 .0929565429794 .7881774902394 .7881774902394 .48339080811 94.4833908081194 .4833908081194 .7881774902395 .0929565429795 .3977432251 96.0073165893696 .6168823242297 .2264633178797 .8360290527398 .75038146973 99.3599472045999 .96952056885100 .5791015625101 .4934005737102 .1029968262 103.0174026489103 .6268997192104 .2365036011104 .8460998535105 .7603988647 106.3700027466106 .979598999107 .5891036987108 .1986999512108 .8082962036 109.4179000854109 .7226028442110 .3321990967110 .6370010376111 .24659729 111.551399231111 .8561019897112 .1608963013112 .1608963013112 .4656982422 112.4656982422112 .7705001831112 .7705001831112 .7705001831112 .7705001831 112.7705001831112 .7705001831112 .4656982422112 .4656982422112 .1608963013 111.8561019897111 .8561019897111 .551399231110 .9418029785110 .6370010376 110.3321990967109 .7226028442109 .4179000854108 .8082962036108 .5035018921 107.8938980103107 .2844009399106 .6747970581106 .0652008057105 .7603988647 105.1509017944104 .5412979126103 .9317016602103 .6268997192103 .0174026489 102.712600708102 .4077987671102 .1029968262101 .7982025146101 .7982025146 101.7982025146101 .7982025146101 .7982025146101 .7982025146102 .1029968262 102.4077987671102 .712600708103 .0174026489103 .3221969604103 .9317016602 104.2365036011104 .5412979126105 .1509017944105 .4557037354106 .0652008057 106.6747970581106 .979598999107 .2844009399107 .8938980103108 .1986999512 108.8082962036109 .1130981445109 .4179000854109 .7226028442110 .0273971558 110.3321990967110 .6370010376110 .9418029785111 .24659729111 .551399231 111.551399231111 .8561019897112 .1608963013112 .1608963013112 .4656982422 112.4656982422112 .7705001831112 .7705001831112 .7705001831113 .075302124 112.4878234863111 .7791061401111 .0884094238110 .419342041109 .7752761841 109.1597824097108 .5759887695108 .0271835327107 .5159301758107 .0448913574 106.6159591675106 .2310714722105 .8911972046105 .5973587036105 .349609375 105.1481628418104 .992515564104 .8826904297104 .8181991577104 .7986831665 104.8223648071104 .8866577148104 .9873275757105 .1198043823105 .2789993286 105.4602661133105 .6586608887105 .8691940308106 .086807251106 .3070068359 106.5257720947106 .7394790649106 .9452056885107 .1410903931107 .3268280029 
107.5031967163 107.2844009399 106.6747970581 106.6747970581 106.6747970581 106.979598999107 .2844009399107 .8938980103108 .1986999512108 .4451370239 108.7025299072108 .8082962036109 .1130981445109 .1130981445109 .1130981445 109.1130981445109 .1130981445108 .8082962036108 .5035018921108 .1986999512 107.8938980103107 .5891036987107 .2844009399106 .979598999106 .6747970581 106.0652008057105 .7603988647105 .1509017944104 .8460998535104 .2365036011 103.6268997192103 .3221969604102 .712600708102 .1029968262101 .4934005737 100.883903503499 .9695205688599 .3599472045998 .7503814697398 .14080810547 97.5312423706196 .6168823242296 .0073165893695 .397743225194 .78817749023 94.1785964965894 .17859649658 -9999 -9999 -9999 -9999 -9999 -9999 -9999 -9999 -9999 -9999 -9999 -9999 -9999 -9999 -9999 -9999 -9999 -9999 -9999 -9999 -9999 -9999 -9999 -9999

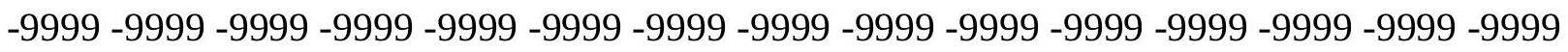
-9999 -9999 -9999 -9999 -9999 -9999 -9999 -9999 -9999 -9999 -9999 -9999 -9999 -9999 -9999 -9999 -9999 -9999 -9999 -9999 -9999 -9999 -9999 -9999 -9999 -9999 -9999 -9999 -9999 -9999 -9999 -9999 -9999 -9999 -9999 -9999 -9999 -9999 -9999 -9999 -9999 -9999 -9999 -9999 -9999

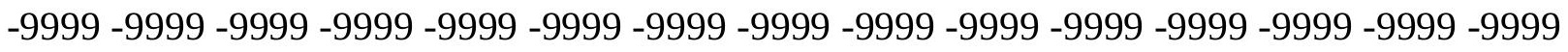
-9999 -9999 -9999 -9999 -9999 -9999 -9999 -9999 -9999 -9999 -9999 -9999 -9999 -9999 -9999 -9999 -9999 -9999 -9999 -9999 -9999 -9999 -9999 -9999 -9999 -9999 -9999 -9999 -9999 -9999 -9999 -9999 -9999 -9999 -9999 -9999 -9999 -9999 -9999 -9999 -9999 -9999 -9999 -

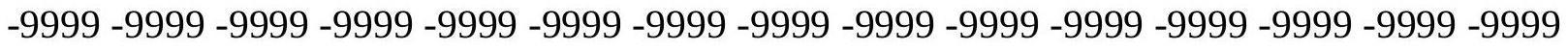

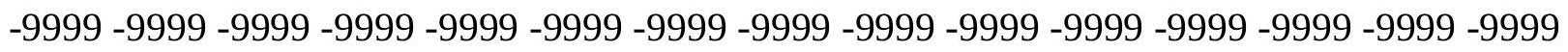
-9999 -9999 -9999 -9999 -9999 -9999 -9999 -9999 55.47089004517 60.95701980591 71.014930725181 .3776321411189 .6068267822393 .8738174438594 .78817749023 95.0929565429794 .7881774902394 .4833908081194 .4833908081194 .17859649658 94.1785964965894 .1785964965894 .1785964965893 .8738174438593 .56903076172 93.5690307617293 .5690307617293 .5690307617293 .8738174438594 .17859649658 94.7881774902395 .397743225196 .0073165893696 .6168823242297 .22646331787 98.1408081054798 .7503814697399 .3599472045999 .96952056885100 .5791015625 101.4934005737102 .1029968262102 .712600708103 .3221969604104 .2365036011 104.8460998535105 .4557037354106 .0652008057106 .6747970581107 .2844009399 107.8938980103108 .1986999512108 .8082962036109 .1130981445109 .4179000854 109.7226028442110 .0273971558110 .3321990967110 .6370010376110 .6370010376 110.9418029785110 .9418029785110 .9418029785110 .9418029785110 .9418029785 110.9418029785110 .9418029785110 .6370010376110 .6370010376110 .3321990967 110.3321990967110 .0273971558109 .7226028442109 .4179000854108 .8082962036 108.5035018921108 .1986999512107 .5891036987106 .979598999106 .6747970581 106.0652008057 105.4557037354104.8460998535104.2365036011 103.6268997192 103.3221969604102 .712600708102 .1029968262101 .7982025146101 .1886978149 100.8839035034100 .5791015625100 .274299621699 .9695205688599 .96952056885 99.6647262573299 .6647262573299 .9695205688599 .96952056885100 .2742996216 100.5791015625100 .8839035034101 .1886978149101 .7982025146102 .1029968262 102.712600708103 .3221969604103 .6268997192104 .2365036011104 .8460998535 105.1509017944105 .7603988647106 .0652008057106 .6747970581107 .2844009399 107.5891036987108 .1986999512108 .5035018921108 .8082962036109 .4179000854 109.7226028442110 .0273971558110 .3321990967110 .6370010376110 .9418029785 111.24659729111 .24659729111 .551399231111 .8561019897112 .1608963013 
112.4656982422112 .4656982422112 .7705001831113 .075302124112 .7098388672 112.0040969849111 .3135681152110 .6413269043109 .9907150269109 .3647994995 108.7668304443108 .1996383667107 .666229248107 .1689453125106 .7101974487 106.2916717529105 .915145874105 .581489563105 .2916183472105 .0455322266 104.8433532715104 .6844100952104 .5683746338104 .4944229126104 .4619827271 104.4693984985104 .5145339966104 .5938186646104 .7033996582104 .8388900757 104.9963684082105 .1717605591105 .3609161377105 .5593261719105 .7629928589 105.9684448242106 .1725616455106 .3725280762106 .5663070679106 .7531661987 106.9333190918106 .979598999106 .6747970581106 .3700027466106 .3700027466 106.6747970581106 .979598999107 .5891036987107 .8938980103108 .1233139038 108.1986999512108 .3867340088108 .5035018921108 .5035018921108 .5035018921 108.5035018921108 .5035018921108 .1986999512107 .8938980103107 .5891036987 107.2844009399106.979598999106.6747970581 106.3700027466106.0652008057 105.4557037354105 .1509017944104 .5412979126104 .2365036011103 .6268997192 103.0174026489102 .4077987671101 .7982025146101 .1886978149100 .5791015625 99.96952056885 99.3599472045998.7503814697398.1408081054797.22646331787 96.6168823242296 .0073165893695 .397743225194 .4833908081193 .87381744385 93.26425170898 93.26425170898 92.95947265625 -9999 -9999 -9999 -9999 -9999 -9999 -9999 -9999 -9999 -9999 -9999 -9999 -9999 -9999 -9999 -9999 -9999 -9999 -9999 -9999 -9999 -9999

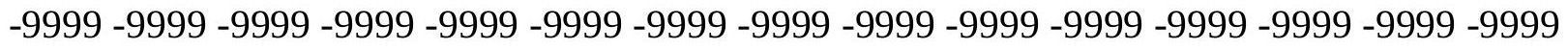

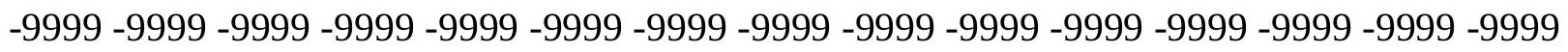
-9999 -9999 -9999 -9999 -9999 -9999 -9999 -9999 -9999 -9999 -9999 -9999 -9999 -9999 -9999 -9999 -9999 -9999 -9999 -9999 -9999 -9999 -9999 -9999 -9999 -9999 -9999 -9999 -9999 -9999 -

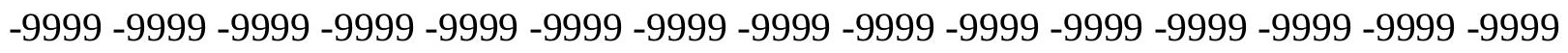

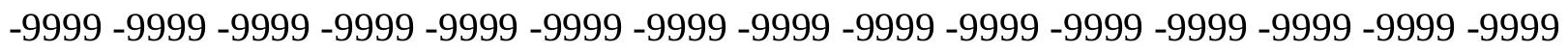
-9999 -9999 -9999 -9999 -9999 -9999 -9999 -9999 -9999 -9999 -9999 -9999 -9999 -9999 -

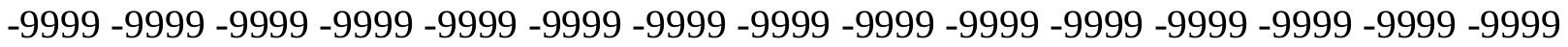

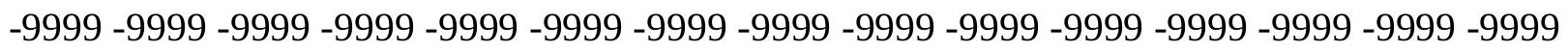

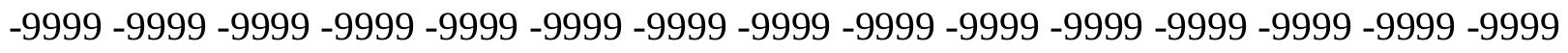
-9999 -9999 -9999 -9999-9999 -9999-9999 53.33739852905 54.86132049561 61.26181030273 69.7957916259878 .3297805786185 .3398437589 .6068267822391 .74033355713 92.65467834473 92.95947265625 92.9594726562593.2642517089893.26425170898 93.2642517089893.2642517089893.2642517089892.9594726562592.65467834473 92.349891662692 .349891662692 .349891662692 .6546783447392 .95947265625 93.5690307617294 .1785964965894 .7881774902395 .397743225196 .00731658936 96.6168823242297 .2264633178797 .8360290527398 .445587158299 .35994720459 99.96952056885100 .5791015625101 .1886978149101 .7982025146102 .712600708 103.3221969604103 .9317016602104 .5412979126105 .1509017944105 .7603988647 106.0652008057106 .6747970581106 .979598999107 .5891036987107 .8938980103 108.1986999512108 .5035018921108 .5035018921108 .8082962036109 .1130981445 109.1130981445109 .1130981445109 .1130981445109 .4179000854109 .1130981445 109.1130981445109 .1130981445109 .1130981445108 .8082962036108 .8082962036 108.5035018921108 .1986999512107 .8938980103107 .5891036987107 .2844009399 106.6747970581106 .3700027466105 .7603988647105 .4557037354104 .8460998535 104.2365036011103 .6268997192103 .0174026489102 .4077987671102 .1029968262 101.4934005737100 .8839035034100 .274299621699 .9695205688599 .35994720459 
99.0551681518698 .7503814697398 .445587158298 .1408081054798 .14080810547 97.8360290527397 .8360290527398 .1408081054798 .1408081054798 .4455871582 98.7503814697399 .3599472045999 .66472625732100 .2742996216100 .5791015625 101.1886978149101 .7982025146102 .4077987671102 .712600708103 .3221969604 103.9317016602104 .5412979126105 .1509017944105 .4557037354106 .0652008057 106.6747970581106 .979598999107 .5891036987107 .8938980103108 .5035018921 108.8082962036109 .4179000854109 .7226028442110 .0273971558110 .3321990967 110.6370010376110 .9418029785111 .24659729111 .551399231111 .8561019897 112.1608963013112 .4656982422112 .7705001831112 .9603271484112 .2583389282 111.5691986084110 .8957519531110 .240776062109 .6073379517108 .9982528687 108.4164962769107 .8646240234107 .3453826904106 .8609008789106 .4133911133 106.0043563843105 .6353988647105 .3072967529105 .0208969116104 .7761611938 104.5731658936104 .4112014771104 .2897491455104 .2076873779104 .1642150879 104.1576843262104 .1862716675104 .2469787598104 .3366012573104 .4513549805 104.587928772104 .7429351807104 .9129714966105 .0941314697105 .2828598022 105.4761047363105 .6711196899105 .8651733398106 .0560379028106 .2425460815 106.424369812106 .6015396118106 .6747970581106 .3700027466106 .3700027466 106.6747970581106 .979598999107 .2844009399107 .5891036987107 .749458313 107.8590545654107 .9755859375108 .076171875108 .1986999512108 .1986999512 107.8938980103107 .8938980103107 .5891036987107 .2844009399106 .979598999 106.6747970581106 .3700027466106 .0652008057105 .7603988647105 .4557037354 104.8460998535104 .5412979126103 .9317016602103 .3221969604103 .0174026489 102.4077987671101 .7982025146101 .1886978149100 .579101562599 .96952056885 99.3599472045998 .7503814697398 .1408081054797 .2264633178796 .61688232422 96.0073165893695 .0929565429794 .4833908081193 .8738174438593 .26425170898 92.3498916626 92.04509735107 92.04509735107 -9999 -9999 -9999 -9999 -9999 -9999 -9999 -9999 -9999 -9999 -9999 -9999 -9999 -9999 -9999 -9999 -9999 -9999 -9999 -9999 -9999 -9999

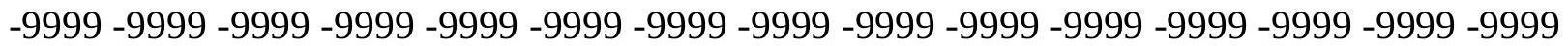
-9999 -9999 -9999 -9999 -9999 -9999 -9999 -9999 -9999 -9999 -9999 -9999 -9999 -9999 -9999

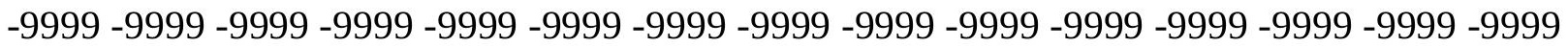
-9999 -9999 -9999 -9999 -9999 -9999 -9999 -9999 -9999 -9999 -9999 -9999 -9999 -9999 -9999

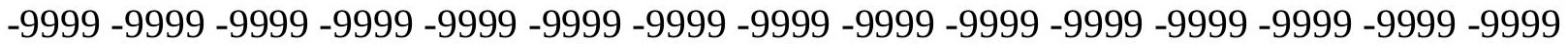
-9999 -9999 -9999 -9999 -9999 -9999 -9999 -9999 -9999 -9999 -9999 -9999 -9999 -9999 -999 -9999 -9999 -9999 -9999 -9999 -9999 -9999 -9999 -9999 -9999 -9999 -9999 -9999 -9999 -9999 -9999 -9999 -9999 -9999 -9999 -9999 -9999 -9999 -9999 -9999 -9999 -9999 -9999 -9999 -9999 -9999 -9999 -9999 -9999 -9999 -9999 -9999 -9999 -9999 -9999 -9999 -9999 -9999 -9999 -

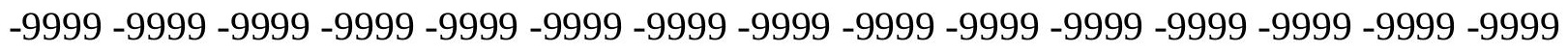
-9999 -9999 -9999 -9999 -9999-9999 -9999 52.42303848267 53.9469718933160 .34745025635 67.6623001098674 .9771423339880 .7680587768685 .3398437588 .08290100098 89.6068267822390.5211791992291.1307525634891.4355392456192.04509735107 92.0450973510792.0450973510792.0450973510792.0450973510791.74033355713 91.4355392456191 .1307525634891 .1307525634891 .4355392456192 .04509735107 92.6546783447392 .9594726562593 .5690307617294 .1785964965894 .78817749023 95.397743225196 .0073165893696 .6168823242297 .2264633178797 .83602905273 98.445587158299 .0551681518699 .66472625732100 .2742996216100 .8839035034 101.7982025146102 .4077987671103 .0174026489103 .6268997192103 .9317016602 
104.5412979126105 .1509017944105 .4557037354105 .7603988647106 .0652008057 106.3700027466106 .6747970581106 .979598999107 .2844009399107 .2844009399 107.2844009399107 .5891036987107 .5891036987107 .5891036987107 .5891036987 107.5891036987107 .2844009399107 .2844009399107 .2844009399106 .979598999 106.6747970581106 .6747970581106 .3700027466105 .7603988647105 .4557037354 105.1509017944104 .5412979126104 .2365036011103 .6268997192103 .0174026489 102.712600708102 .1029968262101 .4934005737100 .8839035034100 .2742996216 99.6647262573299 .0551681518698 .445587158298 .1408081054797 .53124237061 97.2264633178796 .9216690063596 .6168823242296 .3121032714896 .31210327148 96.3121032714896 .3121032714896 .3121032714896 .6168823242296 .92166900635 97.2264633178797 .8360290527398 .1408081054798 .7503814697399 .35994720459 99.66472625732100 .2742996216100 .8839035034101 .4934005737102 .1029968262 102.712600708103 .3221969604103 .9317016602104 .5412979126105 .1509017944 105.7603988647106 .3700027466106 .6747970581107 .2844009399107 .5891036987 108.1986999512108 .5035018921109 .1130981445109 .4179000854109 .7226028442 110.0273971558110 .6370010376110 .9418029785111 .24659729111 .551399231 111.8561019897112 .1608963013112 .4656982422112 .5417556763111 .8548126221 111.181312561110 .5238723755109 .8850250244109 .2675704956108 .674079895 108.1072998047107 .5695419312107 .0633163452106 .5905532837106 .1533050537 105.7528991699105 .3907699585105 .0676193237104 .7842330933104 .5405502319 104.3366394043104 .1717910767104 .0454483032103 .9563522339103 .9034881592 103.8852157593103 .8998260498103 .9447860718104 .0174179077104 .1144866943 104.2331390381104 .3704833984104 .5237197876104 .6895370483104 .8648071289 105.0467605591105 .2329559326105 .420753479105 .6078491211105 .792755127 105.9747009277106 .1531600952106 .3274078369106 .4964904785106 .6593017578 106.6747970581106 .9638519287107 .1050338745107 .2394943237107 .3668746948 107.4890213013107 .6031188965107 .6955184937107 .7207183838107 .5891036987 107.5891036987107 .2844009399107 .2844009399106 .979598999106 .6747970581 106.3700027466105 .7603988647105 .4557037354105 .1509017944104 .8460998535 104.2365036011103 .9317016602103 .3221969604103 .0174026489102 .4077987671 101.7982025146101 .1886978149100 .579101562599 .9695205688599 .35994720459 98.7503814697398 .1408081054797 .5312423706196 .6168823242296 .00731658936 95.397743225194 .4833908081193 .8738174438592 .9594726562592 .3498916626 91.7403335571390 .8259735107490 .8259735107490 .82597351074 -9999 -9999 -9999-9999 -9999 -9999 -9999 -9999 -9999 -9999 -9999 -9999 -9999 -9999 -9999 -9999 -9999 -9999 -9999

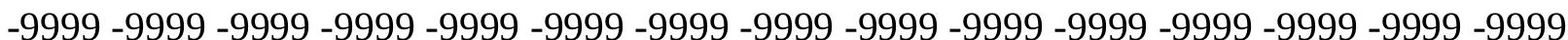

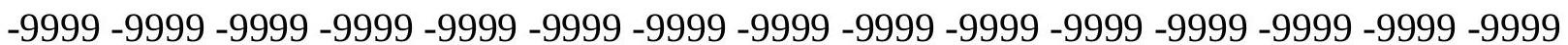

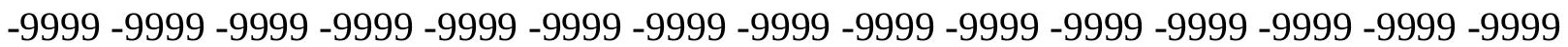
-9999 -9999 -9999 -9999 -9999 -9999 -9999 -9999 -9999 -9999 -9999 -9999 -9999 -9999 -9999 -9999 -9999 -9999 -9999 -9999 -9999 -9999 -9999 -9999 -9999 -9999 -9999 -9999 - -9999 -9999 -9999 -9999 -9999 -9999 -9999 -9999 -9999 -9999 -9999 -9999 -9999 -9999 -9999 -9999 -9999

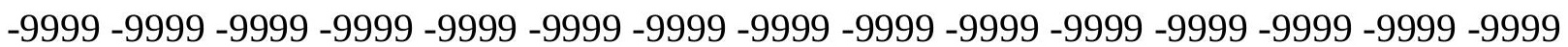
$-9999$

-9999 -9999 -9999 -9999 -9999 -9999 -9999 -9999 -9999 -9999 -9999 -9999 -9999 -9999 -9999 -9999 -9999 -9999 -9999 -9999 -9999 -9999 -9999 -9999 -9999 -9999 -9999 -9999 -9999 -9999

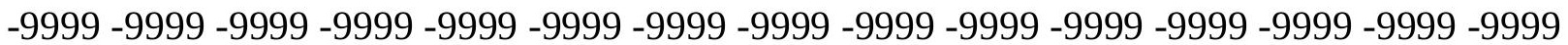


-9999 -9999 -9999 -9999 -9999 -9999 -9999 51.8134689331153.33739852905 59.12831115723 65.5288009643671 .6244964599677 .110626220781 .0728530883884 .42548370361 86.5589828491288 .0829010009888 .9972534179789 .9116134643690 .52117919922 90.8259735107490 .8259735107490 .8259735107490 .8259735107490 .82597351074 90.5211791992290 .2164001464890 .2164001464890 .5211791992291 .13075256348 91.4355392456192 .0450973510792 .6546783447392 .9594726562593 .56903076172 94.1785964965894 .7881774902395 .0929565429795 .7025299072396 .31210327148 96.9216690063597 .5312423706198 .1408081054798 .7503814697399 .35994720459 100.2742996216100 .8839035034101 .4934005737101 .7982025146102 .4077987671 103.0174026489103 .3221969604103 .9317016602104 .2365036011104 .5412979126 104.8460998535105 .1509017944105 .1509017944105 .4557037354105 .4557037354 105.7603988647105 .7603988647105 .7603988647105 .7603988647105 .7603988647 105.7603988647105 .7603988647105 .4557037354105 .4557037354105 .1509017944 105.1509017944104 .8460998535104 .5412979126104 .2365036011103 .9317016602 103.6268997192103 .0174026489102 .712600708102 .1029968262101 .4934005737 100.8839035034100 .274299621699 .6647262573299 .0551681518698 .4455871582 97.8360290527397 .2264633178796 .9216690063596 .3121032714896 .00731658936 95.397743225195 .0929565429794 .7881774902394 .7881774902394 .48339080811 94.4833908081194 .4833908081194 .7881774902394 .7881774902395 .3977432251 95.7025299072396 .3121032714896 .6168823242297 .2264633178797 .83602905273 98.445587158299 .0551681518699 .66472625732100 .2742996216100 .8839035034 101.7982025146102 .4077987671103 .0174026489103 .6268997192104 .2365036011 104.8460998535105 .4557037354106 .0652008057106 .3700027466106 .979598999 107.5891036987107 .8938980103108 .5035018921108 .8082962036109 .4179000854 109.7226028442110 .0273971558110 .3321990967110 .9418029785111 .24659729 111.551399231112 .1608963013112 .4656982422112 .1706695557111 .4979629517 110.8391799927110 .196723938109 .5729141235108 .9703063965108 .391242981 107.8382644653107 .3134841919106 .8191757202106 .3571243286105 .9291992188 105.5365905762105 .1806030273104 .8618469238104 .5810546875104 .3381500244 104.1332015991103 .9655532837103 .8346633911103 .7392959595103 .6783752441 103.6502304077103 .6532592773103 .6851501465103 .7436294556103 .8259429932 103.9296188354104 .0520477295104 .1908416748104 .3432312012104 .5065002441 104.6780929565104 .8557128906105 .0369338989105 .2194900513105 .4017486572 105.5825805664105 .7610473633105 .9361114502106 .1068191528106 .2723846436 106.4324951172106 .587020874106 .7359008789106 .8785552979107 .0137863159 107.1391220093107 .2466278076107 .3209152222107 .2844009399107 .2844009399 107.2844009399106 .979598999106 .6747970581106 .3700027466106 .0652008057 105.7603988647105 .4557037354105 .1509017944104 .5412979126104 .2365036011 103.9317016602103 .3221969604102 .712600708102 .4077987671101 .7982025146 101.1886978149100 .579101562599 .9695205688599 .3599472045998 .75038146973 98.1408081054797 .5312423706196 .9216690063596 .0073165893695 .3977432251 94.4833908081193 .8738174438593 .2642517089892 .349891662691 .43553924561 90.8259735107489 .9116134643689 .9116134643689 .91161346436 -9999 -9999 -9999 -9999 -9999 -9999 -9999 -9999 -9999 -9999 -9999 -9999 -9999 -9999 -9999 -9999 -9999 -9999 -9999 -9999 -9999 -9999 -9999 -9999 -9999 -9999 -9999 -9999 -9999 -9999 -9999 -9999 -9999 -9999

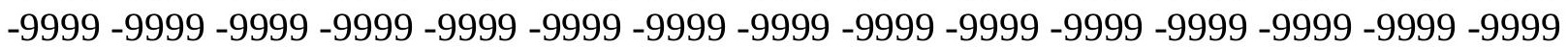


-9999 -9999 -9999 -9999 -9999 -9999 -9999 -9999 -9999 -9999 -9999 -9999 -9999 -9999 -9999 -9999 -9999 -9999 -9999 -9999 -9999 -9999 -9999 -9999 -9999 -9999 -9999 -9999 -9999 -9999 -9999 -9999 -9999 -9999 -9999 -9999 -9999 -9999 -9999 -9999 -9999 -9999 -9999 -9999 -9999 -9999 -9999 -9999 -9999 -9999 -9999 -9999 -9999 -9999 -9999 -9999 -9999 -9999 -9999 -9999

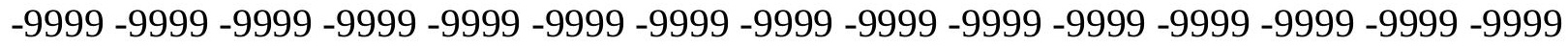
$-9999$

-9999 -9999 -9999 -9999 -9999 -9999 -9999 -9999 -9999 -9999 -9999 -9999 -9999 -9999 -9999 -9999 -9999 -9999 -9999 -9999 -9999 -9999 -9999 -9999 -9999 -9999 -9999 -9999 -9999 -9999 -999 -

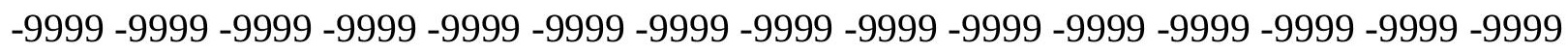
-9999 -9999 -9999 -9999-9999 -9999 -9999 51.20389938354 52.42303848267 57.9091796875 63.3953094482468 .8814392089873 .7580032348677 .7202072143681 .07285308838 83.51112365723 85.33984375 86.86376190186 88.08290100098 88.69246673584 89.302040100189 .6068267822389 .6068267822389 .6068267822389 .60682678223 89.6068267822389 .6068267822389 .6068267822389 .9116134643690 .21640014648 90.5211791992290 .8259735107491 .4355392456191 .7403335571392 .3498916626 92.9594726562593 .2642517089893 .8738174438594 .4833908081194 .78817749023 95.397743225196 .0073165893696 .6168823242297 .2264633178797 .83602905273 98.7503814697399 .3599472045999 .96952056885100 .2742996216100 .8839035034 101.4934005737101 .7982025146102 .4077987671102 .712600708103 .0174026489 103.3221969604103 .3221969604103 .6268997192103 .6268997192103 .9317016602 103.9317016602103 .9317016602104 .2365036011104 .2365036011104 .2365036011 103.9317016602103 .9317016602103 .9317016602103 .9317016602103 .6268997192 103.3221969604103 .3221969604103 .0174026489102 .712600708102 .4077987671 101.7982025146101 .4934005737100 .8839035034100 .579101562599 .96952056885 99.3599472045998.7503814697398.1408081054797.5312423706196.92166900635 96.3121032714895 .7025299072395 .0929565429794 .7881774902394 .17859649658 93.8738174438593 .5690307617293 .2642517089893 .2642517089892 .95947265625 92.9594726562592 .9594726562592 .9594726562593 .2642517089893 .87381744385 94.1785964965894 .7881774902395 .397743225196 .0073165893696 .61688232422 97.2264633178797.8360290527398.445587158299.3599472045999.96952056885 100.5791015625101 .1886978149102 .1029968262102 .712600708103 .3221969604 103.9317016602104 .5412979126105 .1509017944105 .7603988647106 .3700027466 106.979598999 107.5891036987 107.8938980103108.5035018921 108.8082962036 109.4179000854109 .7226028442110 .0273971558110 .6370010376110 .9418029785 111.24659729111 .8561019897112 .1608963013111 .8452606201111 .1860122681 110.5410614014109 .9126358032109 .3028259277108 .7139968872108 .1482772827 107.6080093384107 .095123291106 .6117248535106 .1594161987105 .7399368286 105.3543548584105 .0038528442104 .6889801025104 .4103927612104 .1680221558 103.9619293213103 .791519165103 .6563339233103 .5551986694103 .4870910645 103.4504165649103 .4436569214103 .4646682739103 .5114059448103 .5814666748 103.6726989746103 .7827301025103 .9093780518104 .0502319336104 .2029647827 104.365196228104 .5347518921104 .7093505859104 .8869094849105 .0657348633 105.2444992065105 .4219436646105 .5967941284105 .7680282593105 .9349746704 106.0974578857 106.2552261353106.407585144106.5531158447106.6897277832 106.8131103516106 .9158401489106 .9869537354106 .979598999106 .979598999 106.6747970581 106.6747970581 106.3700027466106.0652008057 105.7603988647 
105.4557037354104 .8460998535104 .5412979126104 .2365036011103 .6268997192 103.3221969604102 .712600708102 .4077987671101 .7982025146101 .1886978149 100.8839035034100 .274299621699 .6647262573299 .0551681518698 .14080810547 97.5312423706196 .9216690063596 .3121032714895 .397743225194 .78817749023 93.87381744385 93.2642517089892.349891662691.7403335571390.82597351074 $89.9116134643689 .302040100188 .9972534179788 .6924667358488 .69246673584-9999$ -9999 -9999 -9999 -9999 -9999 -9999 -9999 -9999 -9999 -9999 -9999 -9999 -9999 -9999 -9999

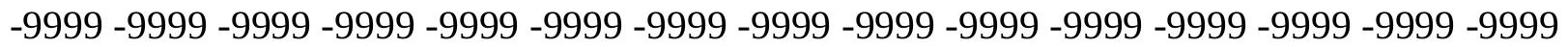

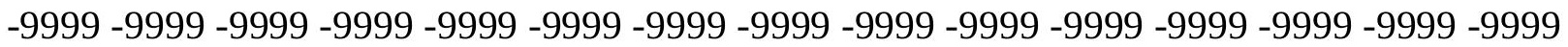
-9999 -9999 -9999 -9999 -9999 -9999 -9999 -9999 -9999 -9999 -9999 -9999 -9999 -9999 -9999

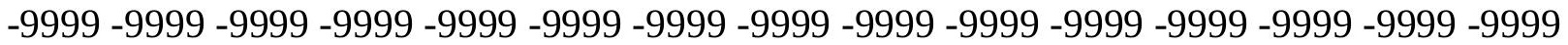
-9999 -9999 -9999 -9999 -9999 -9999 -9999 -9999 -9999 -9999 -9999 -9999 -9999 -9999 -9999 -999 -9999 -9999 -9999 -9999 -9999 -9999 -9999 -9999 -9999 -9999 -9999 -9999 -9999 -9999 -9999 -9999 -9999 -9999 -9999 -9999 -9999 -9999 -9999 -9999 -9999 -9999 -9999 -9999 -9999 -9999 -9999 -9999-9999

-9999 -9999 -9999 -9999 -9999 -9999 -9999 -9999 -9999 -9999 -9999 -9999 -9999 -9999 -9999 -

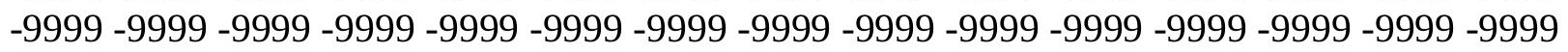

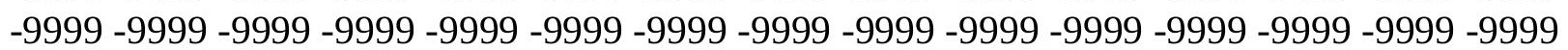
-9999 -9999 -9999 -9999 -9999-9999 -9999 50.59432983398 52.1182594299356.99481964111 61.8713798522966 .7479400634871 .014930725174 .9771423339878 .32978057861 81.07285308838 83.2063369751 84.73026275635 86.2541885376 87.16854858398 87.7781066894588 .0829010009888 .3876876831188 .6924667358488 .69246673584 88.6924667358488 .6924667358488 .6924667358488 .9972534179789 .3020401001 89.60682678223 89.9116134643690.21640014648 90.8259735107491.13075256348 91.7403335571392 .0450973510792 .349891662692 .9594726562593 .56903076172 93.8738174438594 .4833908081195 .0929565429795 .7025299072396 .31210327148 97.2264633178797 .8360290527398 .445587158298 .7503814697399 .35994720459 99.96952056885100 .2742996216100 .5791015625101 .1886978149101 .4934005737 101.4934005737101 .7982025146102 .1029968262102 .1029968262102 .1029968262 102.4077987671102 .4077987671102 .4077987671102 .4077987671102 .4077987671 102.4077987671102 .4077987671102 .1029968262102 .1029968262102 .1029968262 101.7982025146101 .4934005737101 .4934005737101 .1886978149100 .8839035034 100.274299621699 .9695205688599 .3599472045999 .0551681518698 .4455871582 97.83602905273 97.2264633178796.61688232422 96.0073165893695.3977432251 94.7881774902394 .1785964965893 .5690307617293 .2642517089892 .65467834473 92.349891662692 .0450973510791 .7403335571391 .7403335571391 .43553924561 91.4355392456191 .4355392456191 .4355392456191 .7403335571392 .3498916626 92.9594726562593 .5690307617294 .1785964965894 .7881774902395 .3977432251 96.0073165893696 .6168823242297 .5312423706198 .1408081054798 .75038146973 99.66472625732100 .2742996216101 .1886978149101 .7982025146102 .4077987671 103.3221969604103 .9317016602104 .5412979126105 .1509017944105 .7603988647 106.3700027466 106.979598999 107.5891036987 107.8938980103108.5035018921 108.8082962036109 .4179000854109 .7226028442110 .3321990967110 .6370010376 110.9418029785111 .551399231111 .8561019897111 .5642471313110 .9176940918 110.2857284546109 .6704025269109 .0736160278108 .497543335107 .9441375732 107.4155578613106 .91355896106 .4400939941105 .9966278076105 .5847625732 
105.2054672241104 .8598327637104 .5483398438104 .2715911865104 .0295181274 103.8221893311103 .6490631104103 .5097427368103 .4031829834103 .3284606934 103.2840881348103 .268699646103 .2803115845103 .3170700073103 .3767776489 103.4575271606103 .5571365356103 .6735839844103 .8046417236103 .9482192993 104.1021194458104 .2642822266104 .4325714111104 .6050491333104 .7800216675 104.9560470581105 .1316680908105 .3054275513105 .4761428833105 .643081665 105.8059616089105 .9642944336106 .1170043945106 .2620773315106 .3966445923 106.5160446167106 .6136322021106 .6805953979106 .7077484131106 .6747970581 106.3700027466106 .3497314453106 .0652008057105 .7603988647105 .1509017944 104.8460998535104 .5412979126104 .2365036011103 .6268997192103 .3221969604 103.0174026489102 .4077987671101 .7982025146101 .4934005737100 .8839035034 100.274299621699 .6647262573299 .0551681518698 .445587158297 .83602905273 97.2264633178796 .3121032714895 .7025299072395 .0929565429794 .17859649658 93.5690307617292 .6546783447391 .7403335571391 .1307525634890 .21640014648 89.302040100188.3876876831187.77810668945 87.77810668945 87.77810668945 -9999 -9999 -9999 -9999 -9999 -9999 -9999 -9999 -9999 -9999 -9999 -9999 -9999 -9999 -9999 -9999 -9999 -9999 -9999 -9999 -9999 -9999 -9999 -9999 -9999 -9999 -9999 -9999 -9999 -9999 -9999 -9999 -9999 -9999 -9999 -9999 -9999 -9999 -9999 -9999 -9999 -9999 -9999 -9999 -9999 -9999 -

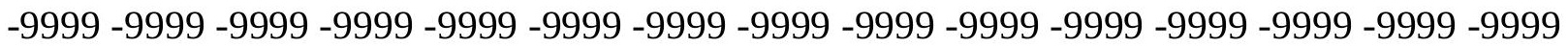

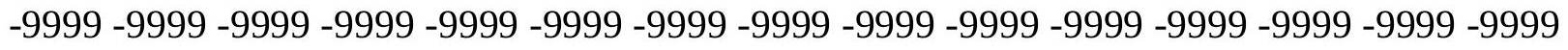

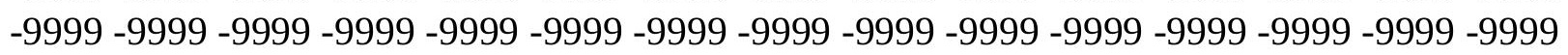

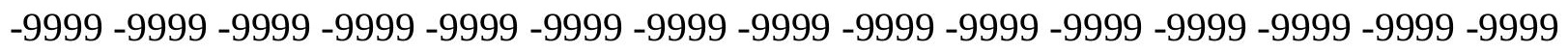

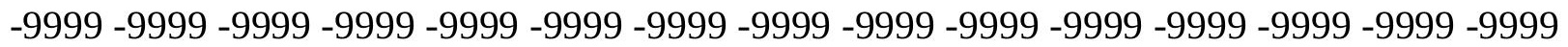
$-9999-9999-9999$

-9999 -9999 -9999 -9999 -9999 -9999 -9999 -9999 -9999 -9999 -9999 -9999 -9999 -9999 -9999 -9999 -9999 -9999 -9999 -9999 -9999 -9999 -9999 -9999 -9999 -9999 -9999 -9999 -9999 -9999 -9999 -9999 -9999 -9999 -9999 -9999 -9999 -9999 -9999 -9999 -9999 -9999 -9999 -9999 -9999 -9999 -9999 -9999-9999-9999 -9999-9999 49.9847602844251 .8134689331156 .08045959473 60.6522407531764 .9192428588968 .8814392089872 .8436431884875 .89148712158 78.6345596313581 .0728530883882 .9015579223684 .4254837036185 .33984375 86.254188537686 .8637619018687 .1685485839887 .4733276367287 .47332763672 87.47332763672 87.77810668945 87.77810668945 88.08290100098 88.38768768311 88.6924667358488 .9972534179789 .302040100189 .6068267822389 .91161346436 90.2164001464890 .8259735107491 .1307525634891 .4355392456192 .04509735107 92.349891662692 .9594726562593 .5690307617294 .1785964965894 .78817749023 95.7025299072396 .3121032714896 .9216690063597 .5312423706197 .83602905273 98.445587158298 .7503814697399 .0551681518699 .3599472045999 .66472625732 99.96952056885100 .2742996216100 .2742996216100 .5791015625100 .5791015625 100.5791015625100 .5791015625100 .5791015625100 .5791015625100 .5791015625 100.5791015625100 .5791015625100 .5791015625100 .5791015625100 .2742996216 100.274299621699 .9695205688599 .9695205688599 .6647262573299 .35994720459 98.7503814697398 .445587158298 .1408081054797 .5312423706196 .92166900635 96.3121032714895 .7025299072395 .0929565429794 .4833908081193 .87381744385 93.2642517089892 .6546783447392 .0450973510791 .7403335571391 .43553924561 91.1307525634890 .8259735107490 .5211791992290 .2164001464890 .21640014648 90.2164001464890 .2164001464890 .2164001464890 .5211791992291 .13075256348 
91.7403335571392 .349891662692 .9594726562593 .5690307617294 .17859649658 94.7881774902395 .7025299072396 .3121032714897 .2264633178797 .83602905273 98.7503814697399 .35994720459100 .2742996216100 .8839035034101 .7982025146 102.4077987671103 .3221969604103 .9317016602104 .5412979126105 .4557037354 106.0652008057106 .6747970581107 .2844009399107 .5891036987108 .1986999512 108.5035018921109 .1130981445109 .4179000854110 .0273971558110 .3321990967 110.6370010376111 .24659729111 .551399231111 .3257827759110 .6911773682 110.0713882446109 .4682769775108 .8835906982108 .3193283081107 .7772750854 107.2594146729106 .767364502106 .3029327393105 .8674621582105 .4624404907 105.0887451172104 .7473831177104 .4387969971104 .1635360718103 .9215393066 103.7128829956103 .537071228103 .3937683105103 .2820358276103 .2010650635 103.1495132446103 .1261749268103 .1292495728103 .1570663452103 .207611084 103.2791213989103 .3695755005103 .4770965576103 .5995635986103 .7350463867 103.8814544678104 .036857605104 .1992416382104 .3667907715104 .5378036499 104.7107467651104 .8840408325105 .0560684204105 .225479126105 .3913421631 105.5531234741105 .7100753784105 .8608093262106 .0030059814106 .1334075928 106.2472076416106 .3380203247106 .3975448608106 .4159011841106 .3700027466 106.2564544678106 .0489807129105 .7603988647105 .4557037354104 .8460998535 104.5412979126104 .2365036011103 .9317016602103 .3221969604103 .0174026489 102.4077987671102 .1029968262101 .4934005737100 .8839035034100 .5791015625 99.9695205688599 .3599472045998 .7503814697398 .1408081054797 .22646331787 96.6168823242296 .0073165893695 .397743225194 .4833908081193 .87381744385 92.9594726562592 .0450973510791 .4355392456190 .5211791992289 .60682678223 88.6924667358487 .7781066894587 .1685485839886 .8637619018686 .86376190186 86.86376190186 -9999 -9999 -9999 -9999 -9999 -9999 -9999 -9999 -9999 -9999 -9999 -9999 -9999 -9999 -9999 -9999 -9999 -9999 -9999 -9999 -9999 -9999 -9999 -9999 -9999 -9999 -9999 -9999 -9999 -9999 -9999 -9999 -9999 -9999 -9999 -9999 -9999 -9999 -9999 -9999 -9999 -9999 -9999 -9999 -9999 -9999 -9999 -9999 -9999 -9999 -9999 -9999 -9999 -9999 -9999 -9999 -9999 -9999 -9999 -9999 -9999 -9999 -9999 -9999 -9999 -9999 -9999 -9999 -9999 -9999 -9999 -9999

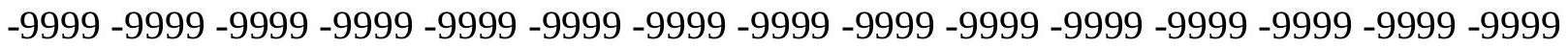
-9999 -9999 -9999 -9999 -9999 -9999 -9999 -9999 -9999 -9999 -9999 -9999 -9999 -9999 -9999 -

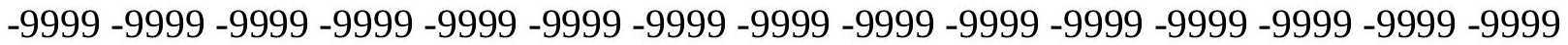
-9999 -9999 -9999-9999-9999-9999

-9999 -9999 -9999 -9999 -9999 -9999 -9999 -9999 -9999 -9999 -9999 -9999 -9999 -9999 -9999

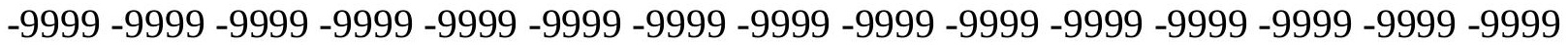
-9999 -9999 -9999 -9999 -9999 -9999 -9999 -9999 -9999 -9999 -9999 -9999 -9999 -9999 -9999 -9999 -9999 -9999 -9999 -9999 -9999 -9999 49.3751907348651 .2038993835455 .47089004517 59.4331016540563 .3953094482467 .3575134277370 .7101516723674 .0627822876 76.8058471679778 .9393463134881 .0728530883882 .5967712402383 .81591033936 84.73026275635 85.33984375 85.9494018554786.2541885376 86.2541885376 86.5589828491286 .8637619018686 .8637619018687 .1685485839887 .47332763672 87.4733276367287 .7781066894588 .0829010009888 .3876876831188 .69246673584 89.302040100189 .6068267822389 .9116134643690 .2164001464890 .52117919922 91.1307525634891 .4355392456192 .0450973510792 .6546783447393 .56903076172 94.1785964965894 .7881774902395 .397743225196 .0073165893696 .31210327148 96.9216690063597 .2264633178797 .5312423706197 .8360290527398 .14080810547 
98.445587158298 .445587158298 .7503814697398 .7503814697398 .75038146973 99.0551681518699 .0551681518699 .0551681518699 .0551681518699 .05516815186 99.0551681518699 .0551681518699 .0551681518698 .7503814697398 .75038146973 98.7503814697398 .445587158298 .445587158298 .1408081054797 .83602905273 97.5312423706196 .9216690063596 .6168823242296 .0073165893695 .3977432251 94.7881774902394 .1785964965893 .5690307617292 .9594726562592 .3498916626 91.7403335571391 .1307525634890 .8259735107490 .5211791992290 .21640014648 89.9116134643689 .6068267822389 .302040100188 .9972534179788 .99725341797 88.9972534179788 .9972534179789 .302040100189 .6068267822389 .91161346436 90.5211791992291 .1307525634891 .7403335571392 .349891662693 .26425170898 93.8738174438594 .7881774902395 .397743225196 .3121032714896 .92166900635 97.8360290527398 .7503814697399 .35994720459100 .2742996216101 .1886978149 101.7982025146102 .712600708103 .3221969604104 .2365036011104 .8460998535 105.4557037354106 .0652008057106 .6747970581107 .2844009399107 .8938980103 108.1986999512108 .8082962036109 .1130981445109 .7226028442110 .0273971558 110.3321990967110 .9418029785111 .24659729111 .1284942627110 .5051193237 109.8967056274109 .3049697876108 .7315063477108 .1781539917107 .6465301514 107.1384887695106 .6555099487106 .1992645264105 .7709960938105 .3720779419 105.0033340454104 .6656951904104 .3595581055104 .0854568481103 .8433151245 103.6332244873103 .4547348022103 .3075637817103 .190864563103 .1039352417 103.0455780029103 .0147247314103 .0097579956103 .0291976929103 .0711975098 103.1341400146103 .2161026001103 .3153457642103 .4298782349103 .5578613281 103.6973114014103 .8464050293104 .0032196045104 .1660079956104 .3330688477 104.502784729104 .6734695435104 .8433914185105 .0109863281105 .1750488281 105.3347930908105 .4891662598105 .6365127563105 .7742767334105 .899055481 106.0060119629106 .0888900757106 .1394882202106 .1484527588106 .0999298096 105.9783096313105 .7603988647105 .4557037354105 .1509017944104 .5412979126 104.2365036011103 .9317016602103 .6268997192103 .0174026489102 .712600708 102.1029968262101 .7982025146101 .1886978149100 .579101562599 .96952056885 99.6647262573299 .0551681518698 .1408081054797 .5312423706196 .92166900635 96.3121032714895 .7025299072394 .7881774902394 .1785964965893 .26425170898 92.6546783447391 .7403335571390 .8259735107489 .9116134643688 .99725341797 88.08290100098 87.16854858398 86.55898284912 85.9494018554785.94940185547 85.94940185547 -9999 -9999 -9999 -9999 -9999 -9999 -9999 -9999 -9999 -9999 -9999 -9999 -9999 -9999 -9999 -9999 -9999 -9999 -9999 -9999 -9999 -9999 -9999 -9999 -9999 -9999 -9999 -9999 -9999 -9999 -9999 -9999 -9999 -9999 -9999 -9999 -9999 -9999 -9999 -9999 -9999 -9999

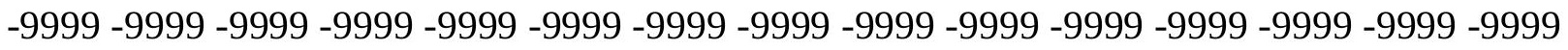

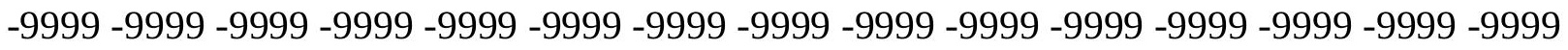
-9999 -9999 -9999 -9999 -9999 -9999 -9999 -9999 -9999 -9999 -9999 -9999 -9999 -9999 -9999 -9999 -9999 -9999 -9999 -9999 -9999 -9999 -9999 -9999 -9999 -9999 -9999 -9999 -9999 -9999 -

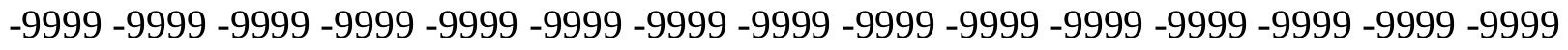
-9999 -9999-9999 -9999-9999-9999

-9999 -9999 -9999 -9999 -9999 -9999 -9999 -9999 -9999 -9999 -9999 -9999 -9999 -9999 -9999 -9999 -9999 -9999 -9999 -9999 -9999 -9999 -9999 -9999 -9999 -9999 -9999 -9999 -9999 -9999 -9999 -9999 -9999 -9999 -9999 -9999 -9999 -9999 -9999 -9999 -9999 -9999 -9999 -9999 -9999 -9999 -9999 -9999 -9999 -9999 -9999 47.54647827148 48.765621185350 .89912033081 
54.5565414428758 .5187492370662 .1761703491265 .8335876464869 .18623352051 72.2340774536174 .9771423339877 .110626220779 .2441329956180 .76805877686 81.9871978759883 .206336975183 .8159103393684 .4254837036185 .03504943848 85.3398437585 .6446228027385 .6446228027385 .9494018554786 .2541885376 86.254188537686 .5589828491286 .8637619018687 .1685485839887 .47332763672 87.7781066894588 .0829010009888 .3876876831188 .6924667358488 .99725341797 89.302040100189 .6068267822390 .2164001464890 .8259735107491 .43553924561 92.0450973510792 .6546783447393 .2642517089893 .8738174438594 .48339080811 95.0929565429795 .397743225195 .7025299072396 .3121032714896 .31210327148 96.6168823242296 .9216690063596 .9216690063596 .9216690063597 .22646331787 97.2264633178797 .2264633178797 .2264633178797 .2264633178797 .22646331787 97.2264633178797 .2264633178797 .2264633178797 .2264633178797 .22646331787 97.22646331787 97.2264633178796.9216690063596.9216690063596.61688232422 96.3121032714896 .0073165893695 .7025299072395 .0929565429794 .78817749023 94.1785964965893 .5690307617292 .9594726562592 .349891662691 .74033355713 91.1307525634890 .5211791992289 .9116134643689 .6068267822389 .3020401001 88.9972534179788 .6924667358488 .3876876831188 .0829010009888 .08290100098 88.0829010009888 .0829010009888 .0829010009888 .3876876831188 .69246673584 88.9972534179789 .6068267822390 .2164001464890 .8259735107491 .43553924561 92.349891662692.9594726562593.5690307617294.4833908081195.3977432251 96.0073165893696 .9216690063597 .8360290527398 .7503814697399 .66472625732 100.5791015625101 .1886978149102 .1029968262103 .0174026489103 .6268997192 104.5412979126105 .1509017944105 .7603988647106 .3700027466106 .979598999 107.5891036987108 .1986999512108 .5035018921108 .8082962036109 .4179000854 109.7226028442110 .0273971558110 .3321990967110 .9418029785110 .9706573486 110.3578033447109 .7599945068109 .1788253784108 .6157455444108 .0724411011 107.5503997803107 .0513305664106 .5765991211106 .1277542114105 .705947876 105.3124694824104 .9480667114104 .6136245728104 .3095092773104 .0362319946 103.7937316895103 .5820846558103 .4009017944103 .2499465942103 .1284484863 103.0358123779102 .970954895102 .9329299927102 .9202957153102 .9317245483 102.9655532837103 .0202941895103 .0941314697103 .1854476929103 .2923660278 103.4131622314103 .5459442139103 .6889572144103 .8403625488103 .9984512329 104.1614990234104 .327835083104 .4956817627104 .6632003784104 .8286132812 104.9904403687105 .1475830078105 .2987213135105 .4419708252105 .5745239258 105.6928787231105 .7922821045105 .8667068481105 .9082641602105 .9078140259 105.8532791138105 .7276535034105 .4557037354105 .1509017944104 .8460998535 104.5412979126103 .9317016602103 .6268997192103 .3221969604102 .712600708 102.4077987671101 .7982025146101 .4934005737100 .8839035034100 .2742996216 99.6647262573299 .0551681518698 .445587158297 .8360290527397 .22646331787 96.6168823242296 .0073165893695 .0929565429794 .4833908081193 .56903076172 92.9594726562592 .0450973510791 .1307525634890 .5211791992289 .60682678223 88.6924667358487 .7781066894586 .8637619018685 .9494018554785 .33984375 85.0350494384885 .0350494384885 .03504943848 -9999 -9999 -9999 -9999 -9999 -9999 -9999 -9999 -9999 -9999 -9999 -9999 -9999 -9999 -9999 -9999 -9999 -9999 -9999 -9999 -9999 -9999 -9999 -9999 -9999 -9999 -9999 -9999 -9999 -9999 -9999 -9999 -9999 -9999 -9999 -9999 -9999 -

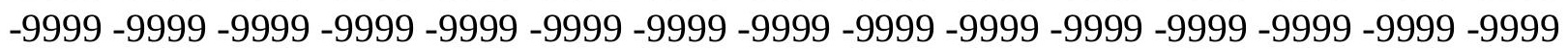


-9999 -9999 -9999 -9999 -9999 -9999 -9999 -9999 -9999 -9999 -9999 -9999 -9999 -9999 -9999 -9999 -9999 -9999 -9999 -9999 -9999 -9999 -9999 -9999 -9999 -9999 -9999 -9999 -9999 -9999

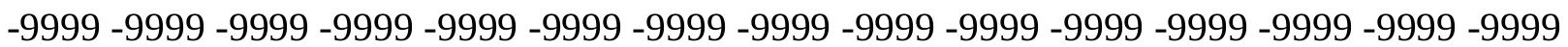
-9999 -9999 -9999 -9999 -9999 -9999 -9999 -9999 -9999 -9999 -9999 -9999 -9999 -9999 -9999 -9999 -9999 -9999-9999 -9999-9999-9999 -9999 -9999-9999

-9999 -9999 -9999 -9999 -9999 -9999 -9999 -9999 -9999 -9999 -9999 -9999 -9999 -9999 -9999 -9999 -9999 -9999 -9999 -9999 -9999 -9999 -9999 -9999 -9999 -9999 -9999 -9999 -9999 -9999 -9999 -9999 -9999 -9999 -9999 -9999 -9999 -9999 -9999 -9999 -9999 -9999 -9999 -9999 -9999 -9999 -9999 -9999 -9999 -9999 -9999 46.9369087219248 .4608306884850 .59432983398 53.9469718933157 .6043891906761 .2618103027364 .6144485473667 .66230010986 70.7101516723673 .1484298706175 .5867080688577 .4154205322379 .24413299561 80.4632720947381 .6824111938582 .2919769287183 .206336975183 .51112365723 84.1206970214884 .4254837036184 .7302627563585 .0350494384885 .03504943848 85.3398437585 .6446228027385 .6446228027385 .9494018554786 .2541885376 86.5589828491286 .8637619018687 .1685485839887 .4733276367287 .77810668945 88.08290100098 88.38768768311 88.69246673584 89.3020401001 89.91161346436 90.5211791992291 .1307525634891 .7403335571392 .349891662692 .95947265625 93.5690307617293 .8738174438594 .4833908081194 .7881774902394 .78817749023 95.0929565429795 .0929565429795 .397743225195 .397743225195 .3977432251 95.397743225195 .397743225195 .7025299072395 .7025299072395 .70252990723 95.7025299072395 .7025299072395 .7025299072395 .7025299072395 .70252990723 95.7025299072395 .7025299072395 .397743225195 .397743225195 .09295654297 95.0929565429794 .7881774902394 .4833908081193 .8738174438593 .26425170898 92.9594726562592 .349891662691 .7403335571391 .1307525634890 .52117919922 89.91161346436 89.3020401001 88.69246673584 88.3876876831188.08290100098 87.7781066894587 .4733276367287 .1685485839887 .1685485839887 .16854858398 87.1685485839887 .1685485839887 .1685485839887 .4733276367287 .77810668945 88.0829010009888 .6924667358489 .302040100189 .9116134643690 .52117919922 91.4355392456192 .0450973510792 .9594726562593 .5690307617294 .48339080811 95.397743225196 .3121032714897 .2264633178798 .1408081054799 .05516815186 99.96952056885100 .8839035034101 .7982025146102 .4077987671103 .3221969604 104.2365036011104 .8460998535105 .7603988647106 .3700027466106 .979598999 107.2844009399 107.8938980103 108.1986999512108.5035018921 109.1130981445 109.4179000854109 .7226028442110 .0273971558110 .3321990967110 .6370010376 110.2479629517109 .6600112915109 .0886154175108 .5351028442108 .0010223389 107.4877471924106 .9968490601106 .529586792106 .0874099731105 .67137146 105.2826919556104 .9220657349104 .5903320312104 .2878341675104 .0150604248 103.7719497681103 .5586166382103 .3746948242103 .2200088501103 .0938568115 102.9957199097102 .924621582102 .8797454834102 .8597717285102 .86353302 102.889503479102 .9363174438103 .0023117065103 .0859451294103 .1854629517 103.2992553711103 .4254989624103 .5625152588103 .7085189819103 .8618240356 104.0206832886104 .1833877563104 .3480987549104 .5128707886104 .6757659912 104.8350296021104 .9892196655105 .1367645264105 .2755889893105 .4027252197 105.5145568848105 .6063842773105 .6725082397105 .7055587769105 .6970062256 105.6351089478105 .5048141479105 .293006897104 .8460998535104 .5412979126 104.2365036011103 .9317016602103 .3221969604103 .0174026489102 .712600708 
102.1029968262101 .4934005737101 .1886978149100 .579101562599 .96952056885 99.3599472045999 .0551681518698 .445587158297 .5312423706196 .92166900635 96.3121032714895 .7025299072394 .7881774902394 .1785964965893 .26425170898 92.6546783447391 .7403335571390 .8259735107490 .2164001464889 .3020401001 88.38768768311 87.47332763672 86.55898284912 85.6446228027385.03504943848 84.4254837036184 .4254837036184 .42548370361 -9999 -9999 -9999 -9999 -9999 -9999 -9999 -9999 -9999 -9999 -9999 -9999 -9999 -9999 -9999 -9999 -9999 -9999 -9999 -9999 -9999 -9999

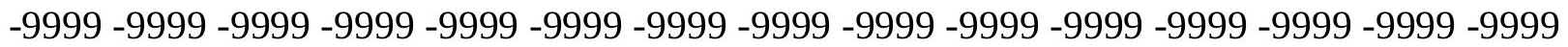
-9999 -9999 -9999 -9999 -9999 -9999 -9999 -9999 -9999 -9999 -9999 -9999 -9999 -9999 -9999 -9999 -9999 -9999 -9999 -9999 -9999 -9999 -9999 -9999 -9999 -9999 -9999 -9999 -9999 -9999 -9999 -9999 -9999 -9999 -9999 -9999 -9999 -9999 -9999 -9999 -9999 -9999 -9999 -9999 -9999 -999 -9999 -9999 -9999 -9999 -9999 -9999 -9999 -9999 -9999 -9999 -9999 -9999 -9999 -9999 -9999 -

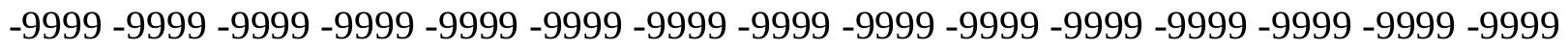
-9999 -9999 -9999 -9999 -9999 -9999 -9999 -9999 -9999 -9999

-9999 -9999 -9999 -9999 -9999 -9999 -9999 -9999 -9999 -9999 -9999 -9999 -9999 -9999 -9999

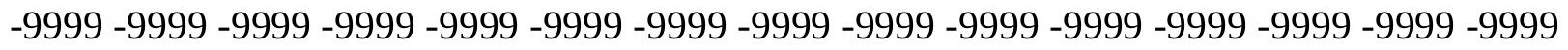

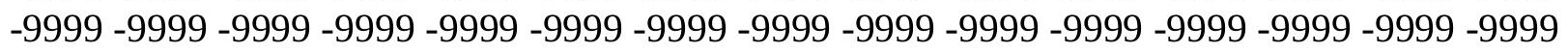
-9999 -9999 -9999 -9999 -9999 -9999 46.63212966919 48.15605163574 50.28955078125 53.3373985290556 .6900291442960 .0426712036163 .3953094482466 .44316101074 69.1862335205171 .6244964599674 .062782287675 .8914871215877 .41542053223 78.9393463134880 .1584930419981 .0728530883881 .6824111938582 .29197692871 82.9015579223683 .206336975183 .5111236572383 .8159103393684 .12069702148 84.4254837036184 .4254837036184 .7302627563585 .0350494384885 .03504943848 85.3398437585 .6446228027385 .9494018554786 .254188537686 .55898284912 86.8637619018687 .1685485839887 .4733276367288 .0829010009888 .69246673584 89.302040100189 .9116134643690 .5211791992290 .8259735107491 .43553924561 92.0450973510792 .6546783447392 .9594726562593 .2642517089893 .26425170898 93.5690307617293 .5690307617293 .5690307617293 .8738174438593 .87381744385 93.87381744385 93.8738174438593.8738174438593.8738174438593.87381744385 93.8738174438593.8738174438594.1785964965894.1785964965894.17859649658 94.1785964965894 .1785964965893 .8738174438593 .8738174438593 .87381744385 93.5690307617293 .2642517089892 .9594726562592 .6546783447392 .04509735107 91.4355392456191 .1307525634890 .5211791992289 .9116134643689 .3020401001 88.69246673584 88.08290100098 87.77810668945 87.47332763672 87.16854858398 86.8637619018686 .5589828491286 .254188537686 .254188537686 .2541885376 86.254188537686 .254188537686 .5589828491286 .5589828491287 .16854858398 87.47332763672 88.08290100098 88.38768768311 88.99725341797 89.91161346436 90.5211791992291 .1307525634892 .0450973510792 .9594726562593 .56903076172 94.4833908081195 .397743225196 .3121032714897 .5312423706198 .4455871582 99.35994720459100 .2742996216101 .1886978149102 .1029968262103 .0174026489 103.9317016602104 .8460998535105 .4557037354106 .0652008057106 .6747970581 107.2844009399 107.5891036987107.8938980103108.5035018921 108.8082962036 109.1130981445109 .1130981445109 .4179000854109 .7226028442110 .0273971558 110.1739044189109 .5950546265109 .0326690674108 .4879379272107 .9623031616 107.4570159912106 .9735336304106 .5130157471106 .0768051147105 .6659011841 105.2814331055104 .9240646362104 .594581604104 .2933044434104 .0207214355 
103.7767715454103 .5615921021103 .3748703003103 .2164535522103 .0857315063 102.9822540283102 .9051437378102 .8536605835102 .8266372681102 .8230133057 102.8414077759102 .8805618286102 .9389266968103 .0150756836103 .1073608398 103.2142562866103 .334022522103 .4650344849103 .6055374146103 .7538757324 103.9082946777 104.0670471191 104.2282409668 104.3898849487104.549911499 104.7063140869104 .8573303223105 .0010910034105 .1353759766105 .2571868896 105.3629226685105 .4478759766105 .5065689087105 .5320663452105 .516418457 105.4481048584105 .3115844727105 .0951461792104 .8178634644104 .5412979126 103.9317016602103 .6268997192103 .3221969604102 .712600708102 .4077987671 101.7982025146101 .4934005737100 .8839035034100 .274299621699 .96952056885 99.3599472045998 .7503814697398 .1408081054797 .5312423706196 .61688232422 96.0073165893695 .397743225194 .7881774902393 .8738174438593 .26425170898 92.349891662691 .4355392456190 .5211791992289 .9116134643688 .99725341797 88.08290100098 87.16854858398 86.2541885376 85.33984375 84.73026275635 84.1206970214883 .8159103393683 .8159103393683 .81591033936 -9999 -9999 -9999 -9999 -9999 -9999 -9999 -9999 -9999 -9999 -9999 -9999 -9999-9999 -9999 -9999 -9999-9999-9999 -9999 -9999 -9999 -9999 -9999 -9999 -9999 -9999 -9999 -9999 -9999 -9999 -9999 -9999 -9999 -9999 -9999 -9999 -9999 -9999 -9999 -9999 -9999 -9999 -9999 -9999 -9999 -9999 -9999 -9999 -

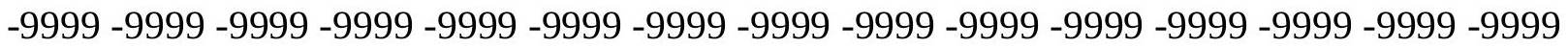

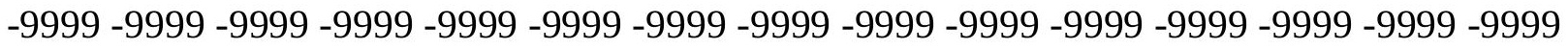

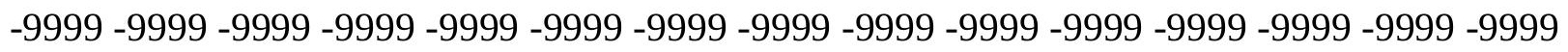

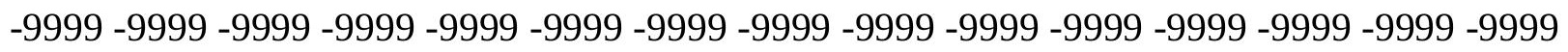
-9999 -9999 -9999 -9999 -9999 -9999 -9999 -9999 -9999 -9999 -9999 -9999 -

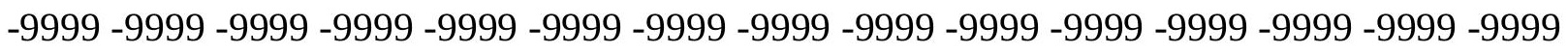

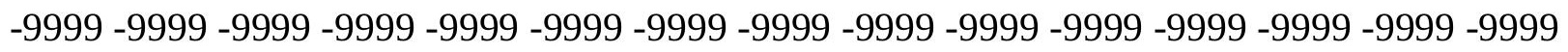

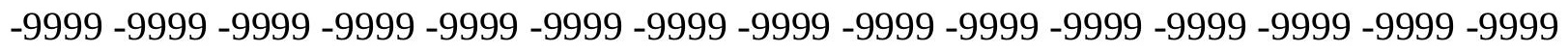
-9999 -9999 -9999 -9999 -9999 -9999 46.32733917236 47.85126113892 49.67998123169 52.7278289794956 .0804595947359 .1283111572362 .1761703491265 .22400665283 67.9670867919970 .4053573608472 .5388565063574 .3675689697375 .89148712158 77.4154205322378 .6345596313579 .5489196777380 .4632720947381 .07285308838 81.6824111938581 .9871978759882 .2919769287182 .5967712402382 .90155792236 83.2063369751 83.51112365723 83.51112365723 83.81591033936 84.12069702148 84.1206970214884 .4254837036184 .7302627563585 .0350494384885 .03504943848 85.6446228027385 .9494018554786 .254188537686 .8637619018687 .16854858398 87.7781066894588 .3876876831188 .9972534179789 .6068267822389 .91161346436 90.5211791992291 .1307525634891 .4355392456191 .7403335571391 .74033355713 91.7403335571392 .0450973510792 .0450973510792 .0450973510792 .04509735107 92.0450973510792 .0450973510792 .0450973510792 .349891662692 .3498916626 92.349891662692.349891662692.3498916626 92.3498916626 92.349891662692.3498916626 92.6546783447392 .6546783447392 .349891662692 .349891662692 .3498916626 92.0450973510791 .7403335571391 .4355392456190 .8259735107490 .21640014648 89.91161346436 89.302040100188.6924667358488.08290100098 87.77810668945 87.16854858398 86.86376190186 86.55898284912 86.2541885376 85.94940185547 85.6446228027385 .6446228027385 .3398437585 .3398437585 .3398437585 .64462280273 85.6446228027385 .9494018554786 .254188537686 .8637619018687 .16854858398 87.77810668945 88.38768768311 88.99725341797 89.9116134643690.52117919922 
91.43553924561 92.0450973510792.9594726562593.8738174438594.78817749023 95.7025299072396 .9216690063597 .8360290527398 .7503814697399 .96952056885 100.8839035034101 .7982025146102 .712600708103 .6268997192104 .5412979126 105.4557037354106 .0652008057106 .6747970581106 .979598999107 .5891036987 107.8938980103108 .1986999512108 .5035018921108 .5035018921108 .8082962036 109.1130981445109 .4179000854109 .7226028442110 .0273971558109 .5638580322 109.0097198486108 .4730072021107 .9550552368107 .4570083618106 .9802246094 106.5257568359106 .0948638916105 .6884841919105 .3076782227104 .9530563354 104.6253890991104 .3249664307104 .0522689819103 .8072509766103 .5900650024 103.4004440308103 .23828125103 .1030349731102 .9943161011102 .9113311768 102.8534545898102 .8195953369102 .8088226318102 .8198547363102 .8515548706 102.9024734497102 .9712905884103 .0564422607103 .15650177103 .2697753906 103.3947067261103 .5295639038103 .6727218628103 .8223953247103 .9768295288 104.1341094971104 .2922134399104 .4489822388104 .6022338867104 .7498931885 104.8898086548105 .0196304321105 .1364135742105 .2367019653105 .31590271 105.3686218262105 .388168335105 .3669204712105 .2942504883105 .1574935913 104.946647644104 .6465454102104 .2365036011103 .9317016602103 .6268997192 103.0174026489102 .712600708102 .1029968262101 .7982025146101 .1886978149 100.8839035034100 .274299621699 .6647262573299 .0551681518698 .4455871582 97.8360290527397 .2264633178796 .6168823242296 .0073165893695 .09295654297 94.4833908081193 .5690307617292 .9594726562592 .0450973510791 .43553924561 90.5211791992289 .6068267822388 .6924667358487 .7781066894586 .86376190186 86.2541885376 85.33984375 84.73026275635 83.8159103393683.2063369751 83.2063369751 83.2063369751 -9999 -9999 -9999 -9999 -9999 -9999 -9999 -9999 -9999 -9999 -9999 -9999 -9999 -9999 -9999 -9999 -9999 -9999 -9999 -9999 -9999 -9999 -9999 -9999 -9999 -9999 -9999 -9999 -9999 -9999 -9999 -9999 -9999 -9999 -9999 -9999 -9999 -9999 -9999 -9999 -9999 -9999

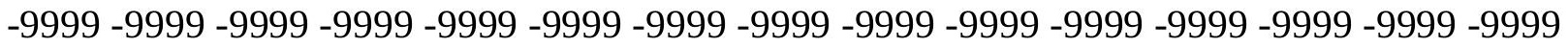

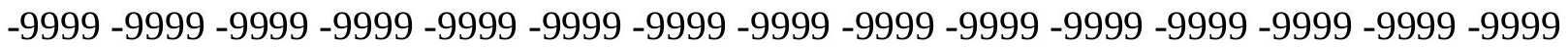
-9999 -9999 -9999 -9999 -9999 -9999 -9999 -9999 -9999 -9999 -9999 -9999 -9999 -9999 -9999

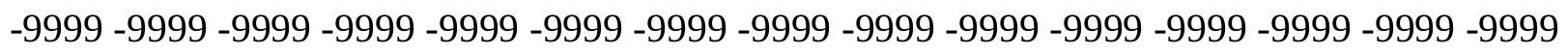

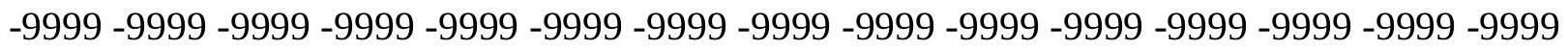
-9999 -9999-9999-9999

-9999 -9999 -9999 -9999 -9999 -9999 -9999 -9999 -9999 -9999 -9999 -9999 -9999 -9999 -9999

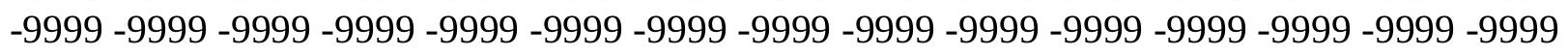
-9999 -9999 -9999 -9999 -9999 -9999 -9999 -9999 -9999 -9999 -9999 -9999 -9999 -9999 -9999 -999 -9999 -9999 -9999 -9999 -9999-9999 46.02254867554 47.54647827148 49.07040023804 52.1182594299355 .4708900451758 .5187492370661 .2618103027364 .0048828125 66.7479400634868 .8814392089871 .014930725172 .8436431884874 .67236328125 76.1962814331177 .4154205322378 .3297805786179 .2441329956179 .85370635986 80.4632720947380 .7680587768681 .3776321411181 .6824111938581 .98719787598 81.9871978759882 .2919769287182 .5967712402382 .5967712402382 .90155792236 83.2063369751 83.2063369751 83.51112365723 83.81591033936 84.12069702148 84.4254837036184 .7302627563585 .0350494384885 .3398437585 .94940185547 86.254188537686 .8637619018687 .4733276367288 .0829010009888 .38768768311 88.9972534179789 .6068267822389 .9116134643689 .9116134643690 .21640014648 90.2164001464890 .2164001464890 .2164001464890 .2164001464890 .52117919922 
90.5211791992290 .5211791992290 .5211791992290 .5211791992290 .52117919922 90.5211791992290 .8259735107490 .8259735107490 .8259735107490 .82597351074 90.8259735107490 .8259735107491 .1307525634891 .1307525634891 .13075256348 90.8259735107490 .8259735107490 .5211791992290 .2164001464889 .60682678223 88.9972534179788 .6924667358488 .0829010009887 .4733276367287 .16854858398 86.5589828491286 .254188537685 .9494018554785 .6446228027385 .33984375 85.0350494384884 .7302627563584 .7302627563584 .7302627563584 .73026275635 84.7302627563585 .0350494384885 .0350494384885 .3398437585 .64462280273 86.2541885376 86.55898284912 87.16854858398 87.77810668945 88.38768768311 88.9972534179789 .9116134643690 .5211791992291 .4355392456192 .3498916626 93.2642517089894 .1785964965895 .0929565429796 .3121032714897 .22646331787 98.445587158299 .35994720459100 .5791015625101 .4934005737102 .712600708 103.6268997192104 .5412979126105 .1509017944106 .0652008057106 .6747970581 106.979598999107 .2844009399107 .5891036987107 .8938980103108 .1986999512 108.1986999512108 .5035018921108 .8082962036108 .8082962036109 .1130981445 109.4179000854109 .5648574829109 .0182189941108 .48878479107 .9777832031 107.4862594604107 .0154724121106 .5663986206106 .1402206421105 .7377929688 105.3601226807105 .0077896118104 .6815185547104 .3816070557104 .108505249 103.8621902466103 .642829895103 .4501953125103 .2842330933103 .1444625854 103.0305557251102 .9418029785102 .8776550293102 .8371200562102 .8193588257 102.8231811523102 .8475646973102 .8911514282102 .9527206421103 .0307846069 103.1239929199103 .2307281494103 .3494567871103 .4784927368103 .6162109375 103.7608337402103 .9105987549104 .0635757446104 .2177200317104 .3708267212 104.5205993652104 .6647491455104 .8008651733104 .9264984131105 .038734436 105.1342773438105 .2088012695105 .2571334839105 .272857666105 .2488861084 105.1756668091105 .0403442383104 .832572937104 .5412979126104 .2365036011 103.9317016602103 .3221969604103 .0174026489102 .712600708102 .1029968262 101.7982025146101 .1886978149100 .579101562599 .9695205688599 .66472625732 99.0551681518698 .445587158297 .8360290527396 .9216690063596 .31210327148 95.7025299072395 .0929565429794 .1785964965893 .5690307617292 .65467834473 92.0450973510791 .1307525634890 .2164001464889 .6068267822388 .69246673584 87.7781066894586 .8637619018686 .254188537685 .3398437584 .73026275635 $83.8159103393683 .206336975182 .5967712402382 .5967712402382 .59677124023-9999$ -9999 -9999 -9999 -9999 -9999 -9999 -9999 -9999 -9999 -9999 -9999 -9999 -9999 -9999 -9999 -9999 -9999 -9999 -9999 -9999 -9999 -9999 -9999 -9999 -9999 -9999 -9999 -9999 -9999 -9999 -999 -

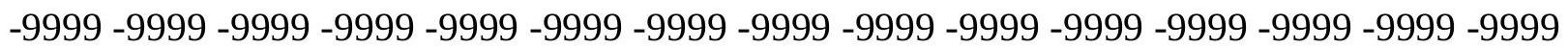

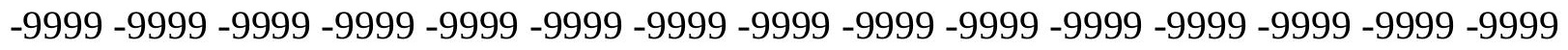

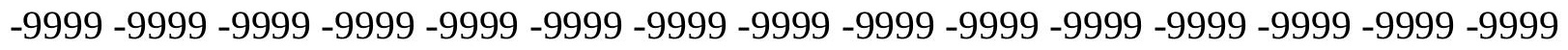

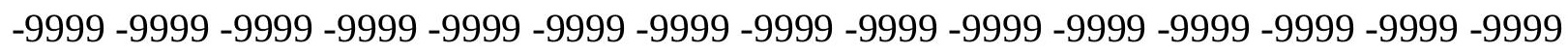
-9999 -9999 -9999 -9999 -9999 -9999 -9999 -9999 -9999 -9999 -9999 -9999 -9999 -9999 -9999 -

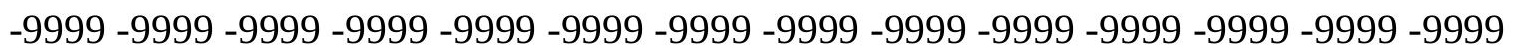

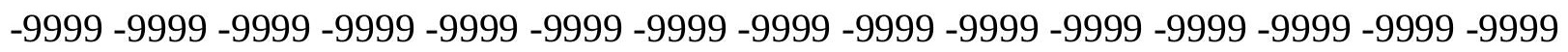
-9999 -9999 -9999 -9999 -9999 -9999 -9999 -9999 -9999 -9999 -9999 -9999 -9999 -9999 -9999

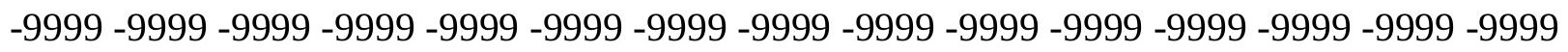
-9999 -9999 -9999 -9999 -9999-9999 46.02254867554 47.24169921875 49.37519073486 52.1182594299354 .8613204956157 .909179687560 .6522407531763 .09051895142 
65.5288009643667 .9670867919969 .7957916259871 .6244964599673 .45321655273 74.6723632812575 .8914871215877 .110626220778 .0249862670978 .63455963135 79.2441329956179 .8537063598680 .1584930419980 .4632720947380 .76805877686 81.0728530883881 .0728530883881 .3776321411181 .6824111938581 .68241119385 81.9871978759881 .9871978759882 .2919769287182 .5967712402382 .90155792236 83.2063369751 83.51112365723 83.81591033936 84.12069702148 84.42548370361 85.0350494384885 .3398437585 .9494018554786 .5589828491286 .86376190186 87.47332763672 87.77810668945 88.08290100098 88.38768768311 88.38768768311 88.3876876831188 .6924667358488 .6924667358488 .6924667358488 .69246673584 88.6924667358488 .6924667358488 .6924667358488 .6924667358488 .99725341797 88.9972534179788 .9972534179788 .9972534179789 .302040100189 .3020401001 89.302040100189 .302040100189 .6068267822389 .6068267822389 .60682678223 89.60682678223 89.3020401001 89.3020401001 88.69246673584 88.38768768311 87.7781066894587 .4733276367286 .8637619018686 .5589828491286 .2541885376 85.6446228027385 .3398437585 .0350494384884 .7302627563584 .42548370361 84.4254837036184 .1206970214884 .1206970214884 .1206970214884 .12069702148 84.1206970214884 .4254837036184 .4254837036184 .7302627563585 .03504943848 85.6446228027385 .9494018554786 .5589828491287 .1685485839887 .77810668945 88.38768768311 89.3020401001 89.9116134643690.8259735107491.74033355713 92.6546783447393 .5690307617294 .7881774902395 .7025299072396 .92166900635 97.8360290527399 .05516815186100 .2742996216101 .4934005737102 .4077987671 103.6268997192104 .5412979126105 .1509017944106 .0652008057106 .6747970581 106.979598999107 .2844009399107 .5891036987107 .5891036987107 .8938980103 107.8938980103108 .1986999512108 .1986999512108 .5035018921108 .8082962036 109.1130981445109 .4179000854109 .0570144653108 .5341262817108 .0293502808 107.5436477661107 .0782012939106 .633895874106 .2118377686105 .8128128052 105.4377822876105 .0872955322104 .7620315552104 .4622802734104 .1884918213 103.9406585693103 .7189559937103 .5231933594103 .3533554077103 .209022522 103.0899429321102 .9954681396102 .9251251221102 .8780059814102 .8533477783 102.8500595093102 .8672027588102 .9035110474102 .9578475952103 .0288162231 103.1151123047103 .2151870728103 .3275527954103 .450553894103 .582572937 103.7218399048103 .8665924072104 .0148773193104 .1646575928104 .3137054443 104.4596710205104 .6001205444104 .7325210571104 .8543014526104 .9625701904 105.054145813105 .1249923706105 .1703872681105 .184425354105 .1606521606 105.090675354104 .9641418457104 .7718200684104 .521774292104 .2365036011 103.9317016602103 .3221969604103 .0174026489102 .4077987671102 .1029968262 101.4934005737101 .1886978149100 .579101562599 .9695205688599 .35994720459 98.7503814697398 .1408081054797 .5312423706196 .9216690063596 .31210327148 95.7025299072394 .7881774902394 .1785964965893 .2642517089892 .65467834473 91.7403335571391 .1307525634890 .2164001464889 .302040100188 .38768768311 87.7781066894586 .8637619018685 .9494018554785 .3398437584 .73026275635 83.8159103393683 .206336975182 .5967712402381 .9871978759882 .29197692871 -9999 -9999 -9999 -9999 -9999 -9999 -9999 -9999 -9999 -9999 -9999 -9999 -9999 -9999 -9999 -9999 -9999 -9999 -9999 -9999 -9999 -9999 -9999 -9999 -9999 -9999 -9999 -9999 -9999 -9999 -9999 -9999 -9999 -9999 -9999 -9999 -9999 -9999 -9999 -9999 -9999 -9999 -9999 -9999 -9999 -9999 -

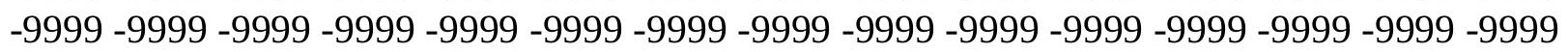


-9999 -9999 -9999 -9999 -9999 -9999 -9999 -9999 -9999 -9999 -9999 -9999 -9999 -9999 -9999 -9999 -9999 -9999 -9999 -9999 -9999 -9999 -9999 -9999 -9999 -9999 -9999 -9999 -9999 -9999 -9999 -9999 -9999 -9999 -9999 -9999 -9999 -9999 -9999 -9999 -9999 -9999 -9999 -9999 -9999 -9999 -9999 -9999 -9999 -9999 -9999 -9999 -9999 -9999 -9999 -9999 -9999 -9999 -9999 -9999 -9999 -9999 -9999 -9999 -9999 -9999 -9999 -9999 -9999 -9999 -9999-9999 -9999 -9999 -9999 -9999 -9999 -9999 -9999 -9999 -9999 -9999 -9999 -9999 -9999 -9999 -9999 -9999 -9999

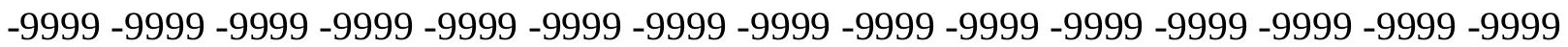
-9999 -9999 -9999 -9999 -9999 -9999 45.717769622847 .2416992187549 .37519073486 52.1182594299354 .5565414428757 .2995986938560 .0426712036162 .48094940186 64.6144485473666 .7479400634868 .8814392089870 .4053573608472 .23407745361 73.4532165527374 .6723632812575 .8914871215876 .5010681152377 .41542053223 78.0249862670978 .6345596313578 .9393463134879 .2441329956179 .54891967773 79.8537063598680 .1584930419980 .1584930419980 .4632720947380 .76805877686 80.7680587768681 .0728530883881 .0728530883881 .3776321411181 .68241119385 81.9871978759881 .9871978759882 .2919769287182 .9015579223683 .2063369751 83.5111236572384 .1206970214884 .4254837036184 .7302627563585 .33984375 85.6446228027385 .9494018554786 .254188537686 .5589828491286 .55898284912 86.8637619018686 .8637619018686 .8637619018686 .8637619018686 .86376190186 86.8637619018686 .8637619018687 .1685485839887 .1685485839887 .16854858398 87.1685485839887 .4733276367287 .4733276367287 .4733276367287 .77810668945 87.7781066894587 .7781066894588 .0829010009888 .0829010009888 .08290100098 88.0829010009887 .7781066894587 .7781066894587 .4733276367287 .16854858398 86.5589828491286 .254188537685 .9494018554785 .6446228027385 .03504943848 84.7302627563584 .4254837036184 .1206970214884 .1206970214883 .81591033936 83.5111236572383 .5111236572383 .5111236572383 .5111236572383 .51112365723 83.5111236572383 .8159103393684 .1206970214884 .4254837036184 .73026275635 85.0350494384885 .6446228027385 .9494018554786 .5589828491287 .16854858398 88.0829010009888 .6924667358489 .302040100190 .2164001464891 .13075256348 92.0450973510793 .2642517089894 .1785964965895 .397743225196 .31210327148 97.5312423706198 .7503814697399 .96952056885101 .1886978149102 .4077987671 103.3221969604104 .5412979126105 .4557037354106 .0652008057106 .6747970581 106.979598999 107.2844009399 107.5891036987 107.5891036987 107.5891036987 107.5891036987107 .5891036987107 .8938980103108 .1986999512108 .5035018921 108.8082962036109 .1130981445109 .1246109009108 .6075592041108 .1083145142 107.6277618408107 .1669998169106 .7268600464106 .3083572388105 .9122238159 105.5393600464105 .190284729104 .8656616211104 .5657577515104 .2910079956 104.0414352417103 .8172225952103 .6182022095103 .4444046021103 .295463562 103.1711807251103 .0709991455102 .9944839478102 .9408187866102 .9093093872 102.8989486694102 .9088745117102 .9378967285102 .9849700928103 .0487518311 103.1280212402103 .221282959103 .3270950317103 .4438095093103 .5698547363 103.7034606934103 .8428573608103 .9860916138104 .1311340332104 .2757644653 104.4176025391104 .5541687012104 .6828460693104 .8010177612104 .9057922363 104.994102478105 .0621948242105 .1058731079105 .1199035645105 .0986175537 105.0348205566104 .9194717407104 .7447433472104 .5120239258104 .2365036011 103.9317016602103 .3221969604103 .0174026489102 .4077987671102 .1029968262 101.4934005737100 .8839035034100 .579101562599 .9695205688599 .35994720459 
98.75038146973 98.1408081054797.5312423706196.9216690063596.31210327148 95.397743225194 .7881774902394 .1785964965893 .2642517089892 .65467834473 91.7403335571390 .8259735107490 .2164001464889 .302040100188 .38768768311 87.7781066894586 .8637619018685 .9494018554785 .3398437584 .73026275635 83.81591033936 83.206336975182.59677124023 81.98719787598 81.68241119385 81.98719787598 -9999 -9999 -9999 -9999 -9999 -9999 -9999 -9999 -9999 -9999 -9999 -9999 -9999 -9999 -9999 -9999 -9999 -9999 -9999 -9999 -9999 -9999 -9999 -9999 -9999 -9999 -9999

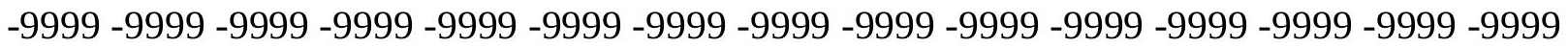
-9999 -9999 -9999 -9999 -9999 -9999 -9999 -9999 -9999 -9999 -9999 -9999 -9999 -9999 -9999 -9999 -9999 -9999 -9999 -9999 -9999 -9999 -9999 -9999 -9999 -9999 -9999 -9999 -9999 -9999

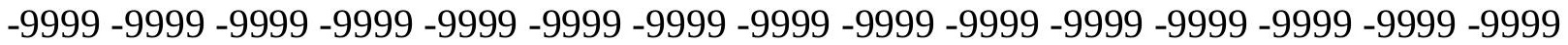
-9999 -9999 -9999 -9999 -9999 -9999 -9999 -9999 -9999 -9999 -9999 -9999 -9999 -9999 -9999 -9999 -9999 -9999 -9999 -9999-9999 -9999 -9999 -9999 -9999 -9999 -9999 -9999 -999 -999 - -999 -9999 -9999

-9999 -9999 -9999 -9999 -9999 -9999 -9999 -9999 -9999 -9999 -9999 -9999 -9999 -9999 -9999

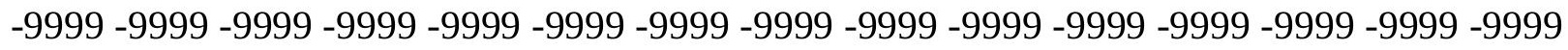
-9999 -9999 -9999 -9999 -9999 -9999 -9999 -9999 -9999 -9999 -9999 -9999 -9999 -9999 -9999 -9999 -9999 -9999 -9999 -9999 -9999 45.717769622847 .2416992187549 .67998123169 52.1182594299354 .5565414428756 .9948196411159 .4331016540561 .56660079956 63.7000885009865 .8335876464867 .6623001098669 .4910125732471 .0149307251 72.2340774536173 .4532165527374 .6723632812575 .5867080688576 .19628143311 76.8058471679777 .4154205322377 .7202072143678 .3297805786178 .63455963135 78.9393463134878 .9393463134879 .2441329956179 .2441329956179 .54891967773 79.5489196777379 .8537063598679 .8537063598680 .1584930419980 .46327209473 80.4632720947380 .7680587768681 .0728530883881 .3776321411181 .68241119385 81.9871978759882 .5967712402382 .9015579223683 .206336975183 .51112365723 83.8159103393684 .1206970214884 .4254837036184 .7302627563584 .73026275635 85.0350494384885 .0350494384885 .0350494384885 .0350494384885 .03504943848 85.3398437585 .3398437585 .3398437585 .3398437585 .6446228027385 .64462280273 85.6446228027385 .9494018554785 .9494018554786 .254188537686 .2541885376 86.254188537686 .5589828491286 .5589828491286 .5589828491286 .55898284912 86.5589828491286 .254188537685 .9494018554785 .9494018554785 .64462280273 85.33984375 85.03504943848 84.73026275635 84.12069702148 84.12069702148 83.8159103393683 .5111236572383 .206336975183 .206336975182 .90155792236 82.9015579223682 .9015579223682 .9015579223682 .9015579223683 .2063369751 83.206336975183.51112365723 83.81591033936 84.12069702148 84.73026275635 85.0350494384885 .6446228027386 .254188537686 .8637619018687 .47332763672 88.0829010009888 .9972534179789 .9116134643690 .8259735107491 .74033355713 92.6546783447393 .5690307617294 .7881774902396 .0073165893697 .22646331787 98.445587158299 .66472625732101 .1886978149102 .4077987671103 .6268997192 104.5412979126105 .4557037354106 .3700027466106 .979598999107 .2844009399 107.5891036987107 .5891036987107 .2844009399107 .2844009399107 .2844009399 107.2844009399 107.5891036987 107.5891036987107.8938980103108.5035018921 108.8082962036109 .1130981445108 .7079620361108 .2135696411107 .7375183105 107.2808227539106.8442459106106.4287414551 106.0349884033105.6638336182 105.3157653809104 .9914169312104 .6910400391104 .4150695801104 .1635360718 
103.9366378784103 .7342224121103 .5563735962103 .4027557373103 .2732315063 103.1673049927103 .0846176147103 .0243988037102 .9860458374102 .9686050415 102.971282959102 .9929733276103 .0326919556103 .0891723633103 .1612548828 103.2474975586103 .3465118408103 .4566802979103 .5764465332103 .7040634155 103.8377609253103 .9755935669104 .1155471802104 .2554244995104 .3928527832 104.5253372192104 .6502304077104 .7648849487104 .8664398193104 .9519729614 105.0180358887105 .0609054565105 .0760040283105 .0582504272105 .0010681152 104.8970489502104 .7365112305104 .5161819458104 .2365036011103 .9317016602 103.3221969604103 .0174026489102 .4077987671102 .1029968262101 .4934005737 100.8839035034100 .579101562599 .9695205688599 .3599472045998 .75038146973 98.1408081054797 .5312423706196 .9216690063596 .0073165893695 .3977432251 94.7881774902393 .8738174438593 .2642517089892 .6546783447391 .74033355713 90.8259735107490 .2164001464889 .302040100188 .3876876831187 .77810668945 86.8637619018686 .254188537685 .3398437584 .7302627563583 .81591033936 83.2063369751 82.59677124023 81.98719787598 81.37763214111 81.37763214111 -9999 -9999 -9999 -9999 -9999 -9999 -9999 -9999 -9999 -9999 -9999 -9999 -9999 -9999 -9999 -9999 -9999 -9999 -9999 -9999 -9999 -9999 -9999 -9999 -9999 -9999 -9999 -9999 -9999 -9999 -9999 -9999 -9999 -9999 -9999 -9999 -9999 -9999 -9999 -9999 -9999 -9999 -9999 -9999 -9999 -9999 -

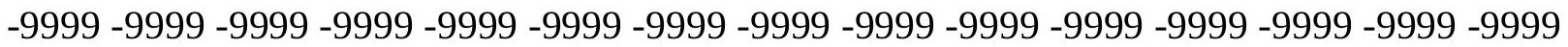

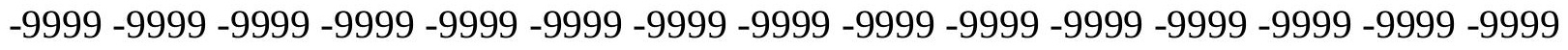

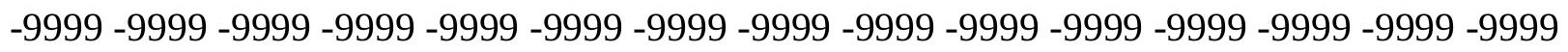

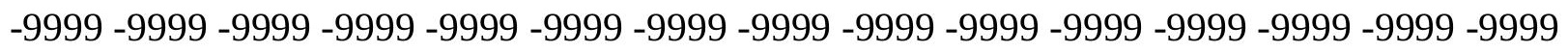
-9999 -9999 -9999 -9999 -9999 -9999 -9999 -9999 -9999 -9999 -9999 -9999 -9999 -

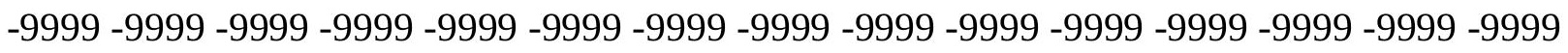

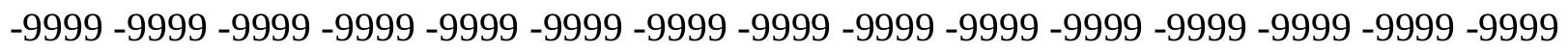

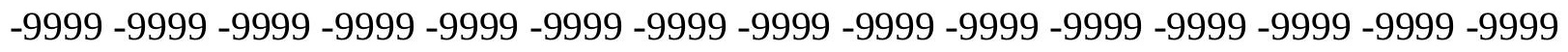
-9999 -9999 -9999-9999 -9999 -9999 45.7177696228 47.24169921875 49.67998123169 51.8134689331154 .2517509460456 .6900291442958 .8235282897960 .95701980591 63.0905189514264 .9192428588966 .7479400634868 .5766525268669 .79579162598 71.3197174072372 .5388565063573 .4532165527374 .3675689697374 .97714233398 75.8914871215876 .1962814331176 .8058471679777 .110626220777 .41542053223 77.7202072143678 .0249862670978 .0249862670978 .3297805786178 .32978057861 78.6345596313578 .6345596313578 .9393463134878 .9393463134879 .24413299561 79.2441329956179 .5489196777379 .8537063598680 .1584930419980 .46327209473 80.7680587768681 .0728530883881 .3776321411181 .6824111938581 .98719787598 82.2919769287182 .5967712402382 .5967712402382 .9015579223682 .90155792236 83.206336975183.2063369751 83.2063369751 83.206336975183.51112365723 83.5111236572383 .5111236572383 .5111236572383 .8159103393683 .81591033936 83.81591033936 84.12069702148 84.12069702148 84.42548370361 84.42548370361 84.7302627563584 .7302627563585 .0350494384885 .0350494384885 .03504943848 85.0350494384885 .0350494384885 .0350494384884 .7302627563584 .73026275635 84.4254837036184 .1206970214883 .8159103393683 .5111236572383 .51112365723 83.206336975182 .9015579223682 .9015579223682 .5967712402382 .59677124023 82.2919769287182 .2919769287182 .2919769287182 .2919769287182 .59677124023 82.5967712402382 .9015579223683 .206336975183 .5111236572383 .81591033936 84.1206970214884 .7302627563585 .3398437585 .6446228027386 .2541885376 
87.1685485839887 .7781066894588 .3876876831189 .302040100190 .21640014648 91.1307525634892 .349891662693 .2642517089894 .4833908081195 .70252990723 96.9216690063598 .1408081054799 .66472625732100 .8839035034102 .4077987671 103.6268997192104 .5412979126105 .7603988647106 .6747970581107 .2844009399 107.5891036987 107.5891036987 107.5891036987 107.2844009399106.979598999 106.979598999 106.979598999 106.979598999 107.2844009399 107.5891036987 107.8938980103108 .5035018921108 .8082962036108 .8340148926108 .3438339233 107.8716430664107 .4183959961106 .9848022461106 .5717544556106 .1798858643 105.8099822998105 .4625091553105 .1380691528104 .8369140625104 .559463501 104.3057479858104 .0759811401103 .8700485229103 .688041687103 .5296707153 103.3948440552103 .2831268311103 .1942138672103 .1274185181103 .0821685791 103.0576019287103 .0529785156103 .0672531128103 .0994949341103 .1485137939 103.213218689103 .2922134399103 .3841552734103 .4874725342103 .6006469727 103.7219314575103 .8495788574103 .9816741943104 .1162109375104 .2510070801 104.3837280273104 .5119018555104 .6328735352104 .7439956665104 .8424453735 104.9254379272104 .9898223877105 .0322875977105 .0487670898105 .034614563 104.9835739136104 .8880767822104 .7389831543104 .5316848755104 .2365036011 103.9317016602103 .3221969604103 .0174026489102 .4077987671102 .1029968262 101.4934005737100 .8839035034100 .579101562599 .9695205688599 .35994720459 98.7503814697398 .1408081054797 .5312423706196 .9216690063596 .00731658936 95.397743225194 .7881774902393 .8738174438593 .2642517089892 .65467834473 91.7403335571390 .8259735107490 .2164001464889 .302040100188 .69246673584 87.7781066894586 .8637619018686 .254188537685 .3398437584 .73026275635 83.8159103393683 .206336975182 .5967712402381 .9871978759881 .07285308838 81.0728530883881 .37763214111 -9999 -9999-9999 -9999 -9999 -9999 -9999 -9999 -9999 -9999 -9999 -9999 -9999 -9999 -9999 -9999 -9999 -9999 -9999 -9999 -9999 -9999 -9999 -9999 -9999 -9999 -9999 -9999 -9999 -9999 -9999 -9999 -9999 -9999 -9999 -9999 -9999 -9999 -9999

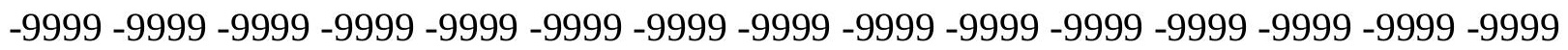
-9999 -9999 -9999 -9999 -9999 -9999 -9999 -9999 -9999 -9999 -9999 -9999 -9999 -9999 -9999 -9999 -9999 -9999 -9999 -9999 -9999 -9999 -9999 -9999 -9999 -9999 -9999 -9999 -9999 -9999 -9999 -9999 -9999 -9999 -9999 -9999 -9999 -9999 -9999 -9999 -9999 -9999 -9999 -9999 -9999

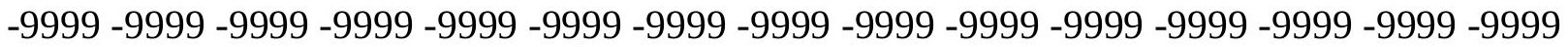
-9999-9999-9999 -9999

-9999 -9999 -9999 -9999 -9999 -9999 -9999 -9999 -9999 -9999 -9999 -9999 -9999 -9999 -9999 -9999 -9999 -9999 -9999 -9999 -9999 -9999 -9999 -9999 -9999 -9999 -9999 -9999 -9999 -9999 -9999 -9999 -9999 -9999 -9999 -9999 -9999 -9999 -9999 -9999 -9999 -9999 -9999 -9999 - -9999 -9999 -9999-9999 -9999-9999-9999 45.7177696228 47.24169921875 49.67998123169 51.8134689331153 .9469718933156 .3852500915558 .5187492370660 .34745025635 62.4809494018664 .3096618652365 .8335876464867 .6623001098668 .88143920898 70.4053573608471 .3197174072372 .5388565063573 .4532165527374 .0627822876 74.6723632812575 .2819290161175 .5867080688576 .1962814331176 .50106811523 76.5010681152376 .8058471679777 .110626220777 .110626220777 .41542053223 77.4154205322377 .4154205322377 .7202072143677 .7202072143678 .02498626709 78.0249862670978 .3297805786178 .6345596313578 .6345596313578 .93934631348 79.2441329956179 .5489196777379 .8537063598680 .1584930419980 .15849304199 80.4632720947380 .7680587768680 .7680587768681 .0728530883881 .07285308838 
81.37763214111 81.37763214111 81.37763214111 81.68241119385 81.68241119385 81.6824111938581 .6824111938581 .9871978759881 .9871978759882 .29197692871 82.2919769287182 .5967712402382 .5967712402382 .9015579223682 .90155792236 83.206336975183 .206336975183 .5111236572383 .5111236572383 .51112365723 83.5111236572383 .5111236572383 .5111236572383 .5111236572383 .51112365723 83.206336975183 .206336975182 .9015579223682 .9015579223682 .59677124023 82.2919769287182 .2919769287181 .9871978759881 .9871978759881 .98719787598 81.9871978759881 .9871978759881 .9871978759881 .9871978759881 .98719787598 82.2919769287182 .5967712402382 .9015579223683 .206336975183 .51112365723 83.8159103393684 .4254837036184 .7302627563585 .3398437585 .94940185547 86.5589828491287 .4733276367288 .0829010009888 .9972534179789 .91161346436 90.8259735107491 .7403335571392 .9594726562594 .1785964965895 .3977432251 96.6168823242298 .1408081054799 .35994720459100 .8839035034102 .4077987671 103.6268997192104 .8460998535106 .0652008057106 .979598999107 .5891036987 107.8938980103107 .8938980103107 .5891036987107 .2844009399106 .6747970581 106.3700027466106 .3700027466106 .6747970581106 .979598999107 .2844009399 107.8938980103108 .1986999512108 .5035018921108 .8082962036108 .4981460571 108.0291824341 107.5787811279 107.1475906372 106.7364578247 106.3459625244 105.976852417105 .6295623779105 .3046569824105 .0024032593104 .7231903076 104.4670639038104 .2342453003104 .0246429443103 .8383560181103 .6751480103 103.5349502563103 .4173736572103 .3221817017103 .2487411499103 .1965408325 103.1647720337103 .1527557373103 .1594924927103 .1841201782103 .2255020142 103.2826004028103 .3540802002103 .438659668103 .5348052979103 .6410369873 103.7556304932103 .8768768311104 .0028762817104 .1316452026104 .2610397339 104.3887557983104 .5123519897104 .6292037964104 .736656189104 .8319396973 104.9124069214104 .9751281738105 .0171279907105 .0347213745105 .0236740112 104.9781341553104 .8909606934104 .7522125244104 .5471191406104 .2365036011 103.9317016602103 .6268997192103 .0174026489102 .712600708102 .1029968262 101.4934005737101 .1886978149100 .579101562599 .9695205688599 .35994720459 98.75038146973 98.1408081054797.5312423706196.9216690063596.31210327148 95.397743225194 .7881774902394 .1785964965893 .2642517089892 .65467834473 91.7403335571391 .1307525634890 .2164001464889 .302040100188 .69246673584 87.7781066894587 .1685485839886 .254188537685 .3398437584 .73026275635 84.1206970214883 .206336975182 .5967712402381 .9871978759881 .07285308838 80.7680587768681 .07285308838 -9999 -9999 -9999 -9999 -9999 -9999 -9999 -9999 -9999 -9999 -9999 -9999 -9999 -9999 -9999 -9999 -9999 -9999 -9999 -9999 -9999 -9999 -9999 -9999

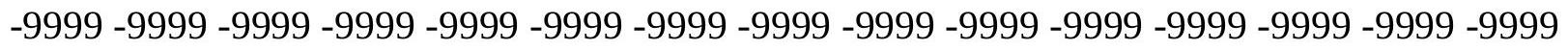

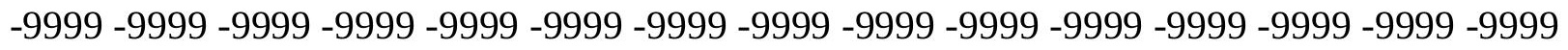

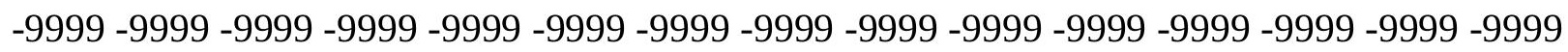

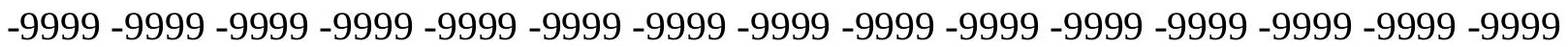

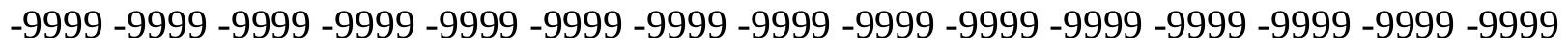

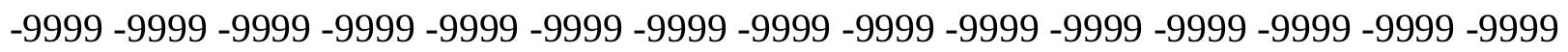
-9999 -9999 -9999-9999

-9999 -9999 -9999 -9999 -9999 -9999 -9999 -9999 -9999 -9999 -9999 -9999 -9999 -9999 -9999 -9999 -9999 -9999 -9999 -9999 -9999 -9999 -9999 -9999 -9999 -9999 -9999 -9999 -9999 -9999 -

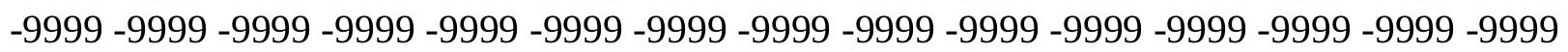


-9999 -9999 -9999 -9999 -9999 -9999 45.7177696228 47.5464782714849.67998123169 51.8134689331155 .4708900451757 .6043891906757 .909179687560 .04267120361 61.8713798522963 .7000885009865 .2240066528366 .7479400634868 .27187347412 69.4910125732470 .4053573608471 .6244964599672 .2340774536173 .14842987061 73.7580032348674 .3675689697374 .6723632812574 .9771423339875 .28192901611 75.5867080688575 .8914871215875 .8914871215876 .1962814331176 .19628143311 76.1962814331176 .5010681152376 .5010681152376 .8058471679776 .80584716797 76.8058471679777 .110626220777 .110626220777 .4154205322377 .41542053223 77.7202072143678 .0249862670978 .3297805786178 .3297805786178 .63455963135 78.9393463134878 .9393463134879 .2441329956179 .2441329956179 .54891967773 79.5489196777379 .5489196777379 .5489196777379 .8537063598679 .85370635986 79.8537063598680 .1584930419980 .1584930419980 .4632720947380 .46327209473 80.7680587768680 .7680587768681 .0728530883881 .0728530883881 .37763214111 81.6824111938581 .6824111938581 .9871978759881 .9871978759882 .29197692871 82.29197692871 82.29197692871 82.29197692871 82.29197692871 82.29197692871 82.2919769287181 .9871978759881 .9871978759881 .9871978759881 .68241119385 81.6824111938581 .6824111938581 .3776321411181 .3776321411181 .37763214111 81.3776321411181 .3776321411181 .3776321411181 .6824111938581 .68241119385 81.9871978759882 .2919769287182 .5967712402382 .9015579223683 .2063369751 83.5111236572384 .1206970214884 .7302627563585 .0350494384885 .64462280273 86.254188537687 .1685485839887 .7781066894588 .6924667358489 .60682678223 90.5211791992291 .4355392456192 .349891662693 .5690307617295 .09295654297 96.3121032714897 .8360290527399 .35994720459100 .8839035034102 .1029968262 103.6268997192104 .8460998535106 .0652008057107 .2844009399107 .8938980103 108.1986999512108 .1986999512107 .8938980103107 .2844009399106 .6747970581 106.0652008057106 .0652008057106 .3700027466106 .6747970581107 .2844009399 107.5891036987107 .8938980103108 .1986999512108 .5035018921108 .6753234863 108.2089767456107 .7608108521107 .331451416106 .9216766357106 .5320358276 106.1632461548105 .8156967163105 .4899520874105 .1862487793104 .9049835205 104.6462020874104 .4101257324104 .1966781616104 .0059890747103 .8378295898 103.6921691895103 .5686645508103 .4671173096103 .3869552612103 .3277206421 103.2886505127103 .2691192627103 .2681884766103 .2850418091103 .3185958862 103.3678665161103 .4315719604103 .5084838867103 .5971298218103 .6960678101 103.8036193848103 .9180984497104 .0376358032104 .1602859497104 .2839355469 104.4063262939104 .5250396729104 .6374816895104 .741027832104 .8329467773 104.9106750488104 .9714889526105 .0126953125105 .0309295654105 .0223770142 104.9817581177104 .9022445679104 .772567749104 .5766143799104 .2961044312 103.9317016602103 .6268997192103 .0174026489102 .712600708102 .1029968262 101.7982025146101 .1886978149100 .579101562599 .9695205688599 .35994720459 98.7503814697398 .1408081054797 .5312423706196 .9216690063596 .31210327148 95.7025299072394 .7881774902394 .1785964965893 .2642517089892 .65467834473 91.7403335571391 .1307525634890 .2164001464889 .6068267822388 .69246673584 87.7781066894587 .1685485839886 .254188537685 .6446228027384 .73026275635 84.1206970214883 .206336975182 .5967712402381 .6824111938581 .07285308838 80.4632720947380 .4632720947380 .76805877686 -9999 -9999 -9999 -9999 -9999 -9999 -9999 -9999 -9999 -9999 -9999 -9999 -9999 -9999 -9999 -9999 -9999 -9999 -9999 -9999 -9999 -9999 
-9999 -9999 -9999 -9999 -9999 -9999 -9999 -9999 -9999 -9999 -9999 -9999 -9999 -9999 -9999 -9999 -9999 -9999 -9999 -9999 -9999 -9999 -9999 -9999 -9999 -9999 -9999 -9999 -9999 -9999

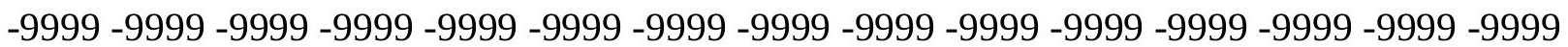
-9999 -9999 -9999 -9999 -9999 -9999 -9999 -9999 -9999 -9999 -9999 -9999 -9999 -9999 -9999 -9999 -9999 -9999 -9999 -9999 -9999 -9999 -9999 -9999 -9999 -9999 -9999-9999 -9999 -9999 -9999 -9999 -9999 -9999 -9999 -9999 -9999 -9999 -9999 -9999 -9999 -9999 -9999 -9999 -9999 -9999 -9999-9999-9999-9999

-9999 -9999 -9999 -9999 -9999 -9999 -9999 -9999 -9999 -9999 -9999 -9999 -9999 -9999 -9999 -9999 -9999 -9999 -9999 -9999 -9999 -9999 -9999 -9999 -9999 -9999 -9999 -9999 -9999 -9999 -9999 -9999 -9999 -9999 -9999 -9999 -9999 -9999 -9999 -9999 -9999 -9999 -9999 -9999 -9999 -9999 -9999 -9999 -9999 -9999 -9999 46.02254867554 47.54647827148 49.67998123169 51.8134689331156 .0804595947357 .909179687560 .0426712036161 .56660079956 63.0905189514263 .0905189514264 .6144485473666 .1383666992267 .35751342773 68.5766525268669 .7957916259870 .7101516723671 .3197174072372 .23407745361 72.8436431884873 .1484298706173 .7580032348674 .062782287674 .36756896973 74.6723632812574 .6723632812574 .9771423339874 .9771423339875 .28192901611 75.2819290161175 .2819290161175 .2819290161175 .5867080688575 .58670806885 75.5867080688575 .8914871215875 .8914871215875 .8914871215876 .19628143311 76.1962814331176 .5010681152376 .5010681152376 .8058471679776 .80584716797 77.110626220777 .110626220777 .4154205322377 .4154205322377 .72020721436 77.7202072143677 .7202072143678 .0249862670978 .0249862670978 .02498626709 78.3297805786178 .3297805786178 .3297805786178 .6345596313578 .93934631348 78.9393463134879 .2441329956179 .5489196777379 .5489196777379 .85370635986 80.1584930419980 .1584930419980 .4632720947380 .7680587768680 .76805877686 81.0728530883881 .0728530883881 .0728530883881 .0728530883881 .07285308838 81.0728530883881 .0728530883881 .0728530883881 .0728530883881 .07285308838 81.0728530883881 .0728530883881 .0728530883881 .0728530883881 .07285308838 81.0728530883881 .0728530883881 .0728530883881 .3776321411181 .37763214111 81.6824111938581 .9871978759882 .2919769287182 .5967712402382 .90155792236 83.5111236572383 .8159103393684 .4254837036185 .0350494384885 .64462280273 86.254188537686 .8637619018687 .4733276367288 .3876876831189 .3020401001 89.9116134643691.1307525634892.0450973510793.2642517089894.78817749023 96.0073165893697 .5312423706199 .05516815186100 .5791015625102 .1029968262 103.6268997192105 .1509017944106 .3700027466107 .5891036987108 .1986999512 108.8082962036108 .8082962036108 .1986999512107 .5891036987106 .6747970581 106.3700027466106 .3700027466106 .3700027466106 .6747970581106 .979598999 107.2844009399 107.5891036987 107.8938980103108.1986999512108.5035018921 108.4101486206107 .9636154175107 .5354766846107 .1264953613106 .7371749878 106.3682022095 106.0199432373105.6929397583105.3874130249 105.103767395 104.842048645104 .6024780273104 .3850021362104 .189743042104 .0165100098 103.8652801514103 .7357559204103 .6277618408103 .5407791138103 .4744033813 103.4279174805103 .4007415771103 .391998291103 .4009017944103 .4264297485 103.4676361084103 .5233078003103 .5922622681103 .6730804443103 .7643814087 103.8645248413103 .9718704224104 .0845794678104 .2007522583104 .3182983398 104.435005188104 .5484924316104 .6562042236104 .7555389404104 .8437957764 104.9184646606104 .9769897461105 .0169372559105 .0352706909105 .0285644531 
104.992149353104 .9198989868104 .8022155762104 .6248474121104 .3775100708 104.0531845093103 .6268997192103 .3221969604102 .712600708102 .4077987671 101.7982025146101 .1886978149100 .5791015625100 .274299621699 .66472625732 99.0551681518698 .445587158297 .8360290527396 .9216690063596 .31210327148 95.7025299072395 .0929565429794 .1785964965893 .5690307617292 .65467834473 92.0450973510791 .1307525634890 .5211791992289 .6068267822388 .69246673584 88.0829010009887 .1685485839886 .5589828491285 .6446228027384 .73026275635 84.1206970214883 .206336975182 .5967712402381 .6824111938581 .07285308838 80.1584930419980 .1584930419980 .46327209473 -9999 -9999 -9999 -9999 -9999 -9999 -9999 -9999 -9999 -9999 -9999 -9999 -9999 -9999 -9999 -9999 -9999 -9999 -9999 -9999 -9999 -9999 -9999 -9999 -9999 -9999 -9999 -9999 -9999 -9999 -9999 -9999 -9999 -9999 -9999 -9999 -9999 -999 -9999 -9999 -9999 -9999 -9999 -9999 -9999 -9999 -9999 -9999 -9999 -9999 -9999 -9999 -9999 -9999 -9999 -9999 -9999 -9999 -9999 -9999 -9999 -9999 -9999 -9999 -9999 -9999 -9999 -9999 -9999 -9999 -9999 -9999 -9999 -9999 -9999 -9999 -9999 -9999 -9999 -9999 -9999 -9999 -9999 -9999 -9999 -9999 -9999 -9999 -9999 -9999 -9999 -9999 -9999 -9999 -9999 -9999 -9999 -9999

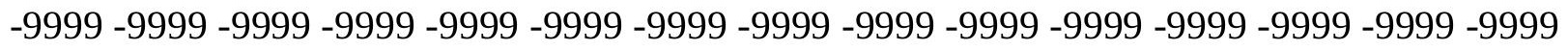
-9999 -9999-9999-9999-9999

-9999 -9999 -9999 -9999 -9999 -9999 -9999 -9999 -9999 -9999 -9999 -9999 -9999 -9999 -9999 -9999 -9999 -9999 -9999 -9999 -9999 -9999 -9999 -9999 -9999 -9999 -9999 -9999 -9999 -9999 -

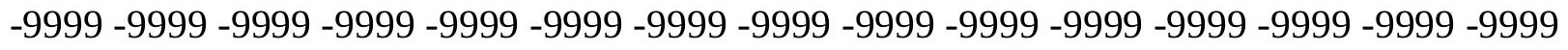
-9999 -9999 -9999 -9999-9999 -9999 46.32733917236 47.85126113892 49.67998123169 51.8134689331156 .3852500915558 .8235282897960 .6522407531762 .17617034912 63.7000885009864 .9192428588965 .8335876464865 .5288009643666 .74794006348 67.9670867919968 .8814392089869 .7957916259870 .7101516723671 .31971740723 71.9292907714872 .5388565063572 .8436431884873 .1484298706173 .45321655273 73.7580032348673 .7580032348674 .062782287674 .062782287674 .0627822876 74.062782287674 .3675689697374 .3675689697374 .3675689697374 .36756896973 74.3675689697374 .3675689697374 .6723632812574 .6723632812574 .67236328125 74.9771423339874 .9771423339874 .9771423339875 .2819290161175 .28192901611 75.2819290161175 .5867080688575 .5867080688575 .5867080688575 .89148712158 75.8914871215875 .8914871215876 .1962814331176 .1962814331176 .19628143311 76.5010681152376 .5010681152376 .8058471679776 .8058471679777 .1106262207 77.4154205322377 .7202072143677 .7202072143678 .0249862670978 .32978057861 78.6345596313578 .9393463134878 .9393463134879 .2441329956179 .54891967773 79.5489196777379 .8537063598679 .8537063598680 .1584930419980 .15849304199 80.1584930419980 .1584930419980 .4632720947380 .4632720947380 .46327209473 80.4632720947380 .4632720947380 .4632720947380 .4632720947380 .46327209473 80.7680587768680 .7680587768680 .7680587768681 .0728530883881 .37763214111 81.3776321411181 .6824111938581 .9871978759882 .2919769287182 .90155792236 83.2063369751 83.81591033936 84.12069702148 84.73026275635 85.33984375 85.9494018554786 .5589828491287 .4733276367288 .0829010009888 .99725341797 89.9116134643690 .8259735107491 .7403335571392 .9594726562594 .48339080811 95.7025299072397 .2264633178798 .75038146973100 .2742996216102 .1029968262 103.6268997192105 .1509017944106 .3700027466107 .5891036987108 .8082962036 109.1130981445109 .1130981445108 .5035018921107 .5891036987106 .979598999 106.6747970581106 .3700027466106 .3700027466106 .6747970581106 .979598999 
107.2844009399 107.5891036987107.8938980103108.1986999512108.5035018921 108.5035018921108 .1861572266107 .7586517334107 .3498840332106 .9603347778 106.5906524658106 .2411956787105 .9124832153105 .6047363281105 .3183441162 105.0533599854104 .8100204468104 .5882720947104 .3882522583104 .2097702026 104.0528411865103 .9171676636103 .8026123047103 .708694458103 .635055542 103.5810241699103 .5460739136103 .5293502808103 .530128479103 .5474319458 103.5803604126103 .627746582103 .6884689331103 .7611618042103 .8444900513 103.9368896484104 .0367431641104 .1422653198104 .2515945435104 .3626785278 104.4733505249104 .5812683105104 .6839065552104 .7787017822104 .8629837036 104.9342956543104 .9901885986105 .0283889771105 .0462188721105 .0406265259 105.0074462891104 .9415283203104 .83543396104 .6809082031104 .4716873169 104.2236785889103 .9317016602103 .3221969604103 .0174026489102 .4077987671 101.7982025146101 .4934005737100 .8839035034100 .274299621699 .66472625732 99.0551681518698 .445587158297 .8360290527397 .2264633178796 .61688232422 95.7025299072395 .0929565429794 .4833908081193 .5690307617292 .95947265625 92.0450973510791 .4355392456190 .5211791992289 .6068267822388 .99725341797 88.0829010009887 .4733276367286 .5589828491285 .6446228027385 .03504943848 84.12069702148 83.5111236572382.59677124023 81.6824111938581.07285308838 80.1584930419979 .5489196777379 .8537063598679 .85370635986 -9999 -9999 -9999 -9999

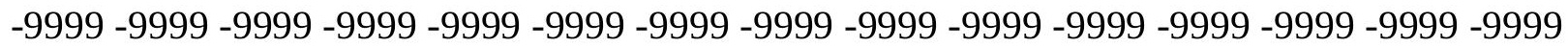

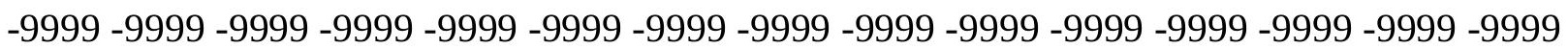

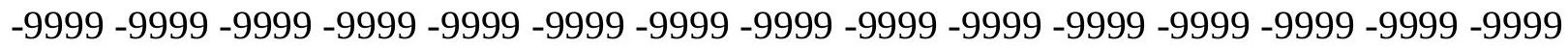
-9999 -

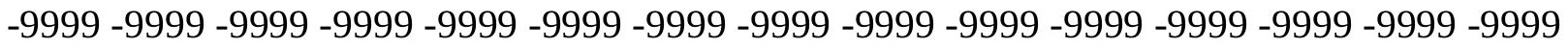

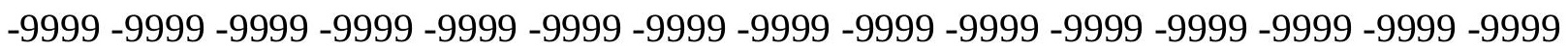

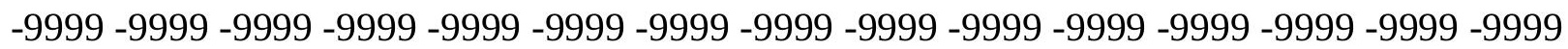
-9999 -9999 -9999 -9999 -9999 -9999 -9999

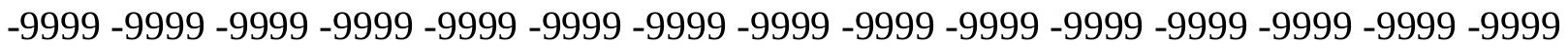

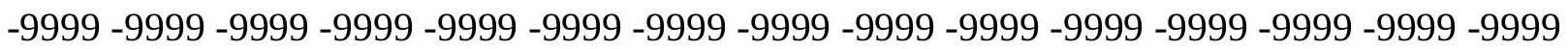

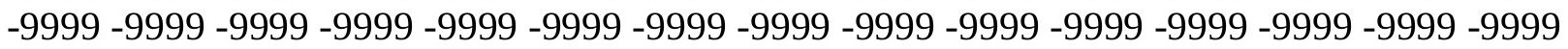
-9999 -9999 -9999 -9999 -9999 -9999 46.63212966919 47.85126113892 49.98476028442 51.8134689331156 .9948196411159 .4331016540561 .2618103027363 .09051895142 64.6144485473665 .8335876464866 .7479400634867 .6623001098667 .96708679199 67.3575134277368 .2718734741269 .1862335205169 .7957916259870 .40535736084 71.014930725171 .6244964599671 .9292907714872 .2340774536172 .53885650635 72.8436431884872 .8436431884872 .8436431884873 .1484298706173 .14842987061 73.1484298706173 .1484298706173 .1484298706173 .1484298706173 .14842987061 73.1484298706173 .1484298706173 .1484298706173 .4532165527373 .45321655273 73.4532165527373 .4532165527373 .4532165527373 .7580032348673 .75800323486 73.7580032348673 .7580032348674 .062782287674 .062782287674 .0627822876 74.062782287674 .3675689697374 .3675689697374 .3675689697374 .67236328125 74.6723632812574 .9771423339874 .9771423339875 .2819290161175 .58670806885 75.8914871215875 .8914871215876 .1962814331176 .5010681152376 .80584716797 77.110626220777 .4154205322377 .7202072143678 .0249862670978 .32978057861 78.3297805786178 .6345596313578 .9393463134878 .9393463134879 .24413299561 79.2441329956179 .5489196777379 .5489196777379 .5489196777379 .85370635986 
79.8537063598679 .8537063598679 .8537063598680 .1584930419980 .15849304199 80.4632720947380 .4632720947380 .7680587768680 .7680587768681 .07285308838 81.3776321411181 .6824111938581 .9871978759882 .2919769287182 .59677124023 83.206336975183 .5111236572384 .1206970214884 .7302627563585 .33984375 85.9494018554786 .5589828491287 .1685485839888 .0829010009888 .69246673584 89.60682678223 90.5211791992291.7403335571392.9594726562594.17859649658 95.7025299072397 .2264633178798 .75038146973100 .2742996216101 .7982025146 103.3221969604104 .8460998535106 .3700027466107 .5891036987108 .8082962036 109.4179000854109 .1130981445108 .5035018921107 .5891036987106 .979598999 106.6747970581106 .6747970581106 .6747970581106 .6747970581106 .979598999 107.2844009399107 .5891036987107 .8938980103108 .1986999512108 .1986999512 108.5035018921108 .4277114868108 .0002288818107 .5910720825107 .2007064819 106.8297729492106 .4785919189106 .1476821899105 .8372650146105 .5477218628 105.2791061401105 .0316696167104 .8053588867104 .6003189087104 .4163818359 104.2535552979104 .1115646362103 .9903030396103 .8893127441103 .808265686 103.7465438843103 .7036514282103 .6787872314103 .6712646484103 .6801452637 103.7045822144103 .7434463501103 .7956848145103 .8599777222103 .935043335 104.0193710327104 .1114044189104 .2093963623104 .3115310669104 .4158096313 104.5200958252104 .6220932007104 .719329834104 .8092651367104 .8892822266 104.9569854736105 .0099639893105 .0460510254105 .0627670288105 .0574188232 105.0262832642104 .9650192261104 .8681640625104 .7312927246104 .5489273071 104.3119659424103 .9317016602103 .6268997192103 .0174026489102 .4077987671 102.1029968262101 .4934005737100 .8839035034100 .274299621699 .96952056885 99.35994720459 98.75038146973 97.83602905273 97.2264633178796.61688232422 96.0073165893695 .397743225194 .4833908081193 .8738174438592 .95947265625 92.349891662691 .4355392456190 .8259735107489 .9116134643688 .99725341797 88.3876876831187 .4733276367286 .5589828491285 .9494018554785 .03504943848 84.1206970214883 .5111236572382 .5967712402381 .9871978759881 .07285308838 80.1584930419979 .5489196777379 .2441329956179 .54891967773 -9999 -9999 -9999-9999 -9999 -9999 -9999 -9999 -9999 -9999 -9999 -9999 -9999 -9999 -9999 -9999 -9999 -9999 -9999 -9999 -9999 -9999 -9999 -9999 -9999 -9999 -9999 -9999 -9999 -9999 -9999 -9999 -9999 -9999

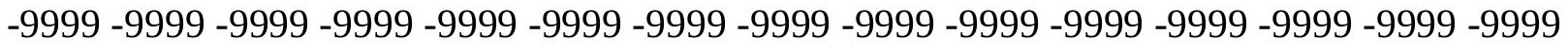

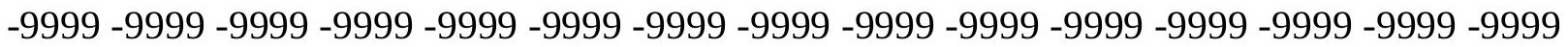
-9999 -9999 -9999 -9999 -9999 -9999 -9999 -9999 -9999 -9999 -9999 -9999 -9999 -9999 -9999 -9999 -9999 -9999 -9999 -9999 -9999 -9999 -9999 -9999 -9999 -9999 -9999 -9999 -9999 -9999 -

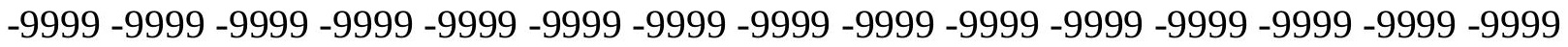
-9999 -9999 -9999 -9999-9999-9999-9999

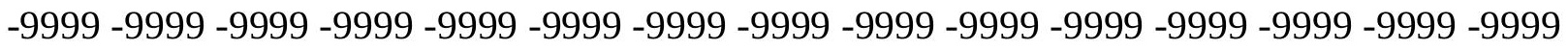
-9999 -9999 -9999 -9999 -9999 -9999 -9999 -9999 -9999 -9999 -9999 -9999 -9999 -9999 -9999 -9999 -9999 -9999 -9999 -9999 -9999 -9999 -9999 -9999 -9999 -9999 -9999 -9999 -9999 -999 -9999 -9999 -9999 -9999 -9999 -9999 46.9369087219248.15605163574 49.98476028442 55.1661109924357 .909179687560 .0426712036162 .1761703491264 .0048828125 65.5288009643666 .7479400634867 .6623001098668 .5766525268668 .88143920898 69.1862335205167 .6623001098668 .5766525268669 .1862335205169 .79579162598 70.4053573608470 .7101516723671 .014930725171 .3197174072371 .62449645996 71.9292907714871 .9292907714871 .9292907714872 .2340774536172 .23407745361 
72.2340774536172 .2340774536172 .2340774536172 .2340774536171 .92929077148 71.9292907714871 .9292907714871 .9292907714871 .9292907714871 .92929077148 71.9292907714871 .9292907714871 .9292907714872 .2340774536172 .23407745361 72.2340774536172 .2340774536172 .2340774536172 .2340774536172 .23407745361 72.5388565063572 .5388565063572 .5388565063572 .8436431884872 .84364318848 73.1484298706173 .1484298706173 .4532165527373 .7580032348673 .75800323486 74.062782287674 .3675689697374 .6723632812574 .9771423339875 .28192901611 75.5867080688575 .8914871215876 .5010681152376 .8058471679777 .1106262207 77.4154205322377 .4154205322377 .7202072143678 .0249862670978 .32978057861 78.3297805786178 .6345596313578 .9393463134878 .9393463134879 .24413299561 79.2441329956179 .5489196777379 .5489196777379 .8537063598679 .85370635986 80.1584930419980 .1584930419980 .4632720947380 .7680587768681 .07285308838 81.3776321411181 .6824111938581 .9871978759882 .2919769287182 .59677124023 83.2063369751 83.51112365723 84.12069702148 84.7302627563585.03504943848 85.6446228027386 .5589828491287 .1685485839887 .7781066894588 .69246673584 89.60682678223 90.52117919922 91.4355392456192.6546783447394.17859649658 95.397743225196 .9216690063598 .445587158299 .96952056885101 .4934005737 103.0174026489104 .5412979126105 .7603988647107 .2844009399108 .8082962036 109.7226028442109 .1130981445108 .1986999512107 .2844009399106 .979598999 106.6747970581 106.6747970581 106.6747970581 106.979598999106.979598999 107.2844009399 107.5891036987107.8938980103107.8938980103108.1986999512 108.1986999512108 .5035018921108 .259262085107 .8491134644107 .4573516846 107.0845870972106 .7311477661106 .3975219727106 .083946228105 .7907943726 105.5181427002105 .2662200928105 .0350036621104 .8246307373104 .6349563599 104.4659881592104 .3174667358104 .1893005371104 .0810470581103 .9924163818 103.9228286743103 .8718185425103 .8386383057103 .8226318359103 .8228988647 103.8386459351103 .8687896729103 .9123077393103 .967956543104 .0345077515 104.1104812622104 .1943969727104 .2845535278104 .3791885376104 .4763336182 104.5739135742104 .6696853638104 .76121521104 .8460159302104 .9215087891 104.9853286743105 .0351333618105 .0688095093105 .0839309692105 .0779800415 105.0476608276104 .9892349243104 .8979644775104 .7689743042104 .5957336426 104.3607635498104 .0345458984103 .6268997192103 .3221969604102 .712600708 102.1029968262101 .7982025146101 .1886978149100 .579101562599 .96952056885 99.3599472045998.7503814697398.1408081054797.5312423706196.92166900635 96.3121032714895 .397743225194 .7881774902393 .8738174438593 .26425170898 92.349891662691 .7403335571390 .8259735107490 .2164001464889 .3020401001 88.38768768311 87.77810668945 86.86376190186 85.9494018554785.33984375 84.4254837036183 .5111236572382 .5967712402381 .9871978759881 .07285308838 80.1584930419979 .5489196777378 .6345596313578 .9393463134878 .93934631348 -9999 -9999 -9999 -9999 -9999 -9999 -9999 -9999 -9999 -9999 -9999 -9999 -9999 -9999 -9999 -9999

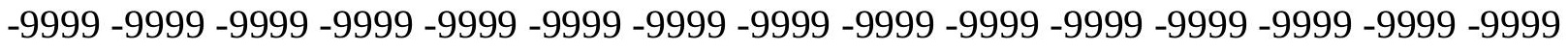

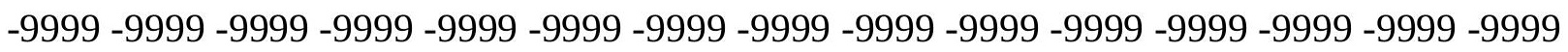
-9999 -9999 -9999 -9999 -9999 -9999 -9999 -9999 -9999 -9999 -9999 -9999 -9999 -9999 -9999 -9999 -9999 -9999 -9999 -9999 -9999 -9999 -9999 -9999 -9999 -9999 -9999 -9999 -9999 -9999 -9999 -9999 -9999 -9999 -9999 -9999 -9999 -9999 -9999 -9999 -9999 -9999 -9999 -9999 -9999 -

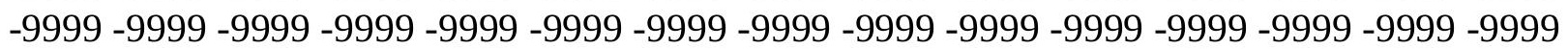


-9999 -9999 -9999 -9999 -9999 -9999 -9999 -9999 -9999

-9999 -9999 -9999 -9999 -9999 -9999 -9999 -9999 -9999 -9999 -9999 -9999 -9999 -9999 -9999

-9999 -9999 -9999 -9999 -9999 -9999 -9999 -9999 -9999 -9999 -9999 -9999 -9999 -9999 -9999

-9999 -9999 -9999 -9999 -9999 -9999 -9999 -9999 -9999 -9999 -9999 -9999 -9999 -9999 -9999

-9999 -9999 -9999 -9999 -9999 -9999 47.54647827148 48.765621185350 .28955078125

55.7756805419958 .5187492370660 .9570198059163 .0905189514264 .91924285889 66.4431610107467 .6623001098668 .8814392089869 .4910125732469 .79579162598 70.1005783081170 .1005783081169 .4910125732468 .5766525268669 .18623352051 69.7957916259870 .1005783081170 .4053573608470 .7101516723670 .71015167236 71.014930725171 .014930725171 .014930725171 .014930725171 .014930725171 .0149307251 71.014930725171 .014930725171 .014930725171 .014930725171 .0149307251 70.7101516723670 .7101516723670 .7101516723670 .7101516723670 .71015167236 70.7101516723670 .7101516723670 .7101516723670 .7101516723670 .71015167236 70.7101516723670 .7101516723670 .7101516723670 .7101516723670 .71015167236 70.7101516723671 .014930725171 .014930725171 .014930725171 .31971740723 71.6244964599671 .6244964599671 .9292907714872 .2340774536172 .53885650635 72.8436431884873 .1484298706173 .4532165527374 .062782287674 .36756896973 74.6723632812574 .9771423339875 .5867080688575 .8914871215876 .19628143311 76.5010681152376 .8058471679777 .110626220777 .4154205322377 .72020721436 78.0249862670978 .0249862670978 .3297805786178 .6345596313578 .93934631348 78.9393463134879 .2441329956179 .5489196777379 .5489196777379 .85370635986 80.1584930419980 .4632720947380 .4632720947380 .7680587768681 .07285308838 81.3776321411181 .9871978759882 .2919769287182 .5967712402383 .2063369751 83.5111236572384 .1206970214884 .7302627563585 .0350494384885 .64462280273 86.254188537687 .1685485839887 .7781066894588 .6924667358489 .3020401001 90.5211791992291 .4355392456192 .6546783447393 .8738174438595 .3977432251 96.6168823242298 .1408081054799 .66472625732101 .1886978149102 .4077987671 103.9317016602105 .1509017944106 .6747970581107 .8938980103108 .5035018921 108.5035018921107 .5891036987106 .6747970581106 .6747970581106 .6747970581 106.6747970581106 .979598999106 .979598999107 .2844009399107 .2844009399 107.5891036987107 .8938980103107 .8938980103108 .1986999512108 .1986999512 108.1986999512108 .1986999512108 .1233215332107 .7295532227107 .3543701172 106.9981002808106 .6612243652106 .343963623106 .0467071533105 .76953125 105.5126876831105 .2761535645105 .0600738525104 .8643112183104 .6888885498 104.5335540771104 .3982162476104 .2824630737104 .1860275269104 .1083602905 104.0490341187104 .0073394775103 .9826583862103 .9741287231103 .9809951782 104.0022125244104 .0368270874104 .0836181641104 .141418457104 .2088088989 104.2843551636104 .3664169312104 .4532699585104 .543006897104 .6335983276 104.7228546143104 .8084106445104 .887840271104 .9585876465105 .0182952881 105.0646591187105 .0956115723105 .1087722778105 .1016159058105 .0710449219 105.0136642456104 .9249191284104 .7993087769104 .6282272339104 .3970031738 104.096534729103 .7310256958103 .3221969604103 .0174026489102 .4077987671 101.7982025146101 .1886978149100 .8839035034100 .274299621699 .66472625732 99.0551681518698 .445587158297 .8360290527396 .9216690063596 .31210327148 95.7025299072395 .0929565429794 .1785964965893 .5690307617292 .65467834473 92.0450973510791 .1307525634890 .2164001464889 .6068267822388 .69246673584 
87.7781066894587 .1685485839886 .254188537685 .3398437584 .42548370361 83.8159103393682 .9015579223681 .9871978759881 .0728530883880 .15849304199 79.5489196777378 .6345596313578 .3297805786178 .32978057861 -9999 -9999 -9999 -9999 -9999 -9999 -9999 -9999 -9999 -9999 -9999 -9999 -9999 -9999 -9999 -9999 -9999 -9999 -9999 -9999 -9999 -9999 -9999 -9999 -9999 -9999 -9999 -9999 -9999 -9999 -9999-9999 -9999 -9999 -9999 -9999 -9999 -9999 -9999 -9999 -9999 -9999 -9999 -9999 -9999 -9999 -9999 -9999 -9999

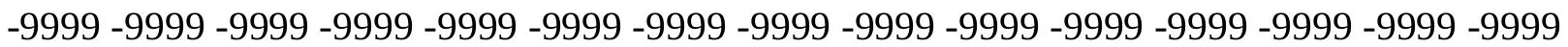

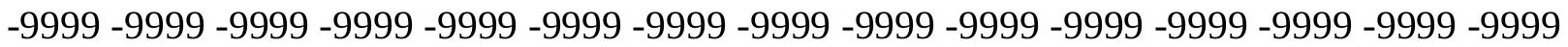
-9999 -9999 -9999 -9999 -9999 -9999 -9999 -9999 -9999 -9999 -9999 -9999 -9999 -9999 -9999

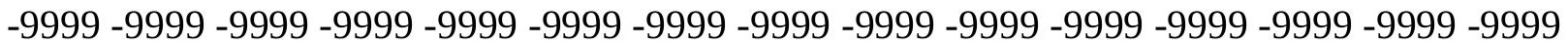
-9999 -9999-9999-9999-9999-9999

-9999 -9999 -9999 -9999 -9999 -9999 -9999 -9999 -9999 -9999 -9999 -9999 -9999 -9999 -9999 -9999 -9999 -9999 -9999 -9999 -9999 -9999 -9999 -9999 -9999 -9999 -9999 -9999 -9999 -9999 -9999 -9999 -9999 -9999 -9999 -9999 -9999 -9999 -9999 -9999 -9999 -9999 -9999 -9999 -9999 -9999 -9999 -9999 -9999 -9999 -9999 48.1560516357449 .3751907348650 .59432983398 56.3852500915559 .1283111572361 .8713798522964 .004882812565 .83358764648 67.3575134277368 .8814392089869 .7957916259870 .4053573608471 .0149307251 71.014930725171 .014930725170 .4053573608469 .7957916259868 .57665252686 69.1862335205169 .4910125732469 .7957916259869 .7957916259870 .10057830811 70.1005783081170 .1005783081170 .1005783081170 .1005783081170 .10057830811 70.1005783081170 .1005783081170 .1005783081169 .7957916259869 .79579162598 69.7957916259869 .4910125732469 .4910125732469 .4910125732469 .49101257324 69.1862335205169 .1862335205169 .1862335205169 .1862335205169 .18623352051 68.8814392089868 .8814392089868 .8814392089868 .8814392089868 .88143920898 69.1862335205169 .1862335205169 .1862335205169 .4910125732469 .49101257324 69.7957916259869 .7957916259870 .1005783081170 .4053573608470 .71015167236 71.014930725171 .3197174072371 .6244964599672 .2340774536172 .53885650635 72.8436431884873 .4532165527373 .7580032348674 .3675689697374 .67236328125 74.9771423339875 .5867080688575 .8914871215876 .1962814331176 .50106811523 76.8058471679777 .110626220777 .4154205322377 .7202072143678 .02498626709 78.3297805786178 .6345596313578 .9393463134879 .2441329956179 .54891967773 79.8537063598679 .8537063598680 .1584930419980 .4632720947380 .76805877686 81.0728530883881 .6824111938581 .9871978759882 .2919769287182 .59677124023 83.206336975183.51112365723 84.12069702148 84.73026275635 85.33984375 85.9494018554786 .5589828491287 .1685485839887 .7781066894588 .69246673584 89.302040100190.21640014648 91.4355392456192.6546783447393.87381744385 95.0929565429796 .6168823242297 .8360290527399 .35994720459100 .5791015625 102.1029968262103 .3221969604104 .2365036011105 .7603988647106 .979598999 107.5891036987107 .5891036987107 .2844009399106 .979598999106 .6747970581 106.6747970581 106.979598999 106.979598999 107.2844009399 107.2844009399 107.5891036987 107.5891036987 107.8938980103107.8938980103108.1986999512 108.1986999512108 .1986999512108 .1986999512108 .1986999512108 .0165176392 107.6383209229107 .2786254883106 .9379196167106 .6164245605106 .3145294189 106.0323257446105 .770072937105 .5277557373105 .3055343628105 .1032791138 104.9210205078104 .7585144043104 .6156845093104 .4921417236104 .3876266479 104.3016281128104 .233757019104 .1833267212104 .1497573853104 .1322250366 
104.1300201416104 .1421356201104 .1676483154104 .2053985596104 .2542648315 104.3128662109104 .3798294067104 .4535598755104 .5324020386104 .6144866943 104.697845459104 .7803497314104 .8597183228104 .9335784912104 .9994125366 105.0548553467105 .0975952148105 .1255722046105 .1364593506105 .1277236938 105.0962905884105 .0389404297104 .9513397217104 .8281555176104 .6623306274 104.4438247681104 .1709747314103 .8514404297103 .4724502563103 .0174026489 102.712600708102 .1029968262101 .4934005737100 .8839035034100 .2742996216 99.9695205688599 .3599472045998 .7503814697397 .8360290527397 .22646331787 96.6168823242296 .0073165893695 .0929565429794 .4833908081193 .87381744385 92.9594726562592 .0450973510791 .4355392456190 .5211791992289 .91161346436 88.9972534179788 .0829010009887 .1685485839886 .5589828491285 .64462280273 84.7302627563583 .8159103393682 .9015579223681 .9871978759881 .37763214111 80.4632720947379 .5489196777378 .6345596313577 .7202072143677 .72020721436 78.02498626709 -9999 -9999 -9999 -9999 -9999 -9999 -9999 -9999 -9999 -9999 -9999 -9999 -9999 -9999 -9999 -9999 -9999 -9999 -9999 -9999 -9999 -9999 -9999 -9999 -9999 -9999 -9999

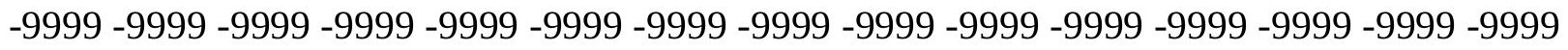
-9999 -9999 -9999 -9999 -9999 -9999 -9999 -9999 -9999 -9999 -9999 -9999 -9999 -9999 -9999 -9999 -9999 -9999 -9999 -9999 -9999 -9999 -9999 -9999 -9999 -9999 -9999 -9999 -9999 -9999 -

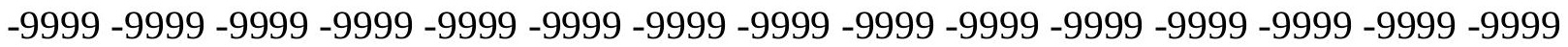

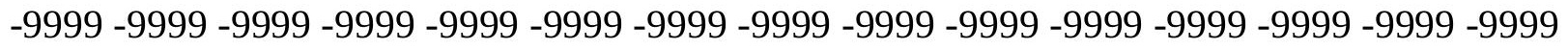
-9999 -9999 -9999 -9999 -9999 -9999 -9999 -9999 -9999 -9999 -9999 -9999 -

-9999 -9999 -9999 -9999 -9999 -9999 -9999 -9999 -9999 -9999 -9999 -9999 -9999 -9999 -999 -9999 -9999 -9999 -9999 -9999 -9999 -9999 -9999 -9999 -9999 -9999 -9999 -9999 -9999 -9999 -

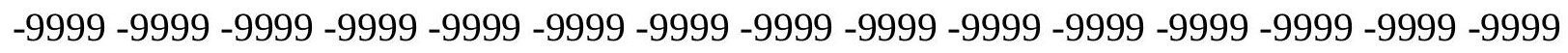
-9999 -9999 -9999 -9999-9999 -9999 48.765621185349 .9847602844252 .42303848267 57.2995986938560 .0426712036162 .4809494018664 .9192428588966 .74794006348 68.5766525268669 .7957916259870 .7101516723671 .6244964599671 .92929077148 71.9292907714871 .9292907714871 .6244964599670 .7101516723669 .79579162598 68.5766525268668 .8814392089868 .8814392089869 .1862335205169 .18623352051 69.4910125732469 .4910125732469 .4910125732469 .4910125732469 .18623352051 69.1862335205169 .1862335205168 .8814392089868 .8814392089868 .88143920898 68.5766525268668 .5766525268668 .2718734741268 .2718734741267 .96708679199 67.9670867919967 .9670867919967 .6623001098667 .6623001098667 .66230010986 67.3575134277367 .3575134277367 .3575134277367 .3575134277367 .35751342773 67.3575134277367 .3575134277367 .6623001098667 .6623001098667 .96708679199 67.9670867919968 .2718734741268 .5766525268668 .8814392089869 .18623352051 69.4910125732469 .7957916259870 .4053573608470 .7101516723671 .31971740723 71.6244964599672 .2340774536172 .5388565063573 .1484298706173 .75800323486 74.062782287674 .6723632812574 .9771423339875 .2819290161175 .89148712158 76.1962814331176 .5010681152377 .110626220777 .4154205322377 .72020721436 78.0249862670978 .3297805786178 .6345596313578 .9393463134879 .24413299561 79.5489196777379 .8537063598680 .1584930419980 .4632720947380 .76805877686 81.3776321411181 .6824111938581 .9871978759882 .2919769287182 .90155792236 83.2063369751 83.81591033936 84.12069702148 84.73026275635 85.33984375 85.9494018554786 .5589828491287 .1685485839887 .7781066894588 .69246673584 89.302040100190.2164001464891.4355392456192.349891662693.56903076172 
95.0929565429796 .3121032714897 .5312423706199 .05516815186100 .2742996216 101.4934005737102 .712600708103 .9317016602105 .1509017944106 .0652008057 106.979598999107 .2844009399106 .979598999106 .979598999106 .979598999 106.979598999106 .979598999107 .2844009399107 .2844009399107 .5891036987 107.5891036987107 .8938980103107 .8938980103108 .1986999512108 .1986999512 108.1986999512108 .1986999512108 .1986999512108 .1986999512108 .1986999512 107.8938980103107 .5721054077107 .2269821167106 .900680542106 .5935897827 106.305809021 106.037612915 105.7890090942 105.5601577759105.3509368896 105.1613922119104 .9913024902104 .8405990601104 .7089004517104 .5959854126 104.5013504028104 .4246520996104 .3652267456104 .3225326538104 .2957839966 104.2842941284104 .287109375104 .3033370972104 .3318557739104 .37159729 104.4212341309104 .4794311523104 .544631958104 .6152572632104 .6894836426 104.765411377104 .8409805298104 .9139709473104 .9820861816105 .0428771973 105.0939559937105 .1329879761105 .1578903198105 .1663208008105 .1558227539 105.1233825684105 .0658874512104 .9794158936104 .8594818115104 .7006988525 104.4983596802104 .2507553101103 .9652252197103 .6268997192103 .3221969604 102.712600708102 .4077987671101 .7982025146101 .1886978149100 .5791015625 99.9695205688599 .3599472045998 .7503814697398 .1408081054797 .53124237061 96.9216690063596 .3121032714895 .397743225194 .7881774902393 .87381744385 93.2642517089892 .349891662691 .7403335571390 .8259735107489 .91161346436 89.3020401001 88.38768768311 87.47332763672 86.55898284912 85.64462280273 85.0350494384884 .1206970214883 .206336975182 .2919769287181 .37763214111 80.4632720947379 .5489196777378 .6345596313577 .7202072143677 .41542053223 77.4154205322378 .32978057861 -9999 -9999 -9999 -9999 -9999 -9999 -9999 -9999 -9999 -9999 -9999 -9999 -9999 -9999 -9999 -9999 -9999 -9999 -9999 -9999 -9999 -9999 -9999 -9999 -9999 -9999 -9999 -9999 -9999 -9999 -9999 -9999 -9999 -9999 -9999 -9999 -9999 -9999 -9999 -9999 -9999 -9999 -9999 -9999 -9999 -9999 -9999 -9999 -9999 -9999 -9999 -9999 -9999 -9999

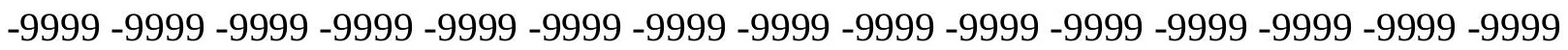
-9999 -9999 -9999 -9999 -9999 -9999 -9999 -9999 -9999 -9999 -9999 -9999 -9999 -9999 -9999

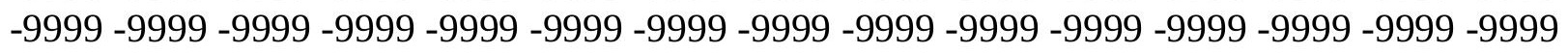
-9999 -9999 -9999 -9999 -9999 -9999 -9999 -9999 -9999 -9999 -9999 -9999 -9999 -9999 -9999 -9999 -9999 -9999 -9999 -9999 -9999 -9999 -9999 -9999 -9999 -9999 -9999 -9999 -9999 -

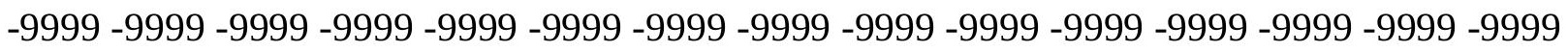

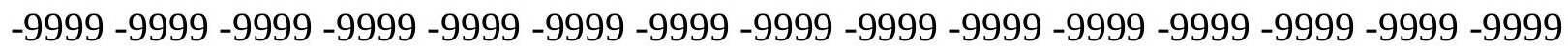
-9999 -9999 -9999 -9999 -9999 -9999 -9999 50.59432983398 53.0326118469257.9091796875 60.6522407531763 .3953094482465 .8335876464867 .6623001098669 .49101257324 70.7101516723671 .9292907714872 .5388565063572 .8436431884873 .14842987061 72.8436431884872 .5388565063571 .6244964599670 .7101516723669 .49101257324 68.2718734741268 .2718734741268 .5766525268668 .5766525268668 .57665252686 68.5766525268668 .5766525268668 .5766525268668 .5766525268668 .27187347412 68.2718734741267 .9670867919967 .9670867919967 .6623001098667 .66230010986 67.3575134277367 .0527267456167 .0527267456166 .7479400634866 .74794006348 66.4431610107466 .4431610107466 .1383666992266 .1383666992266 .13836669922 65.8335876464865 .8335876464865 .8335876464865 .8335876464865 .83358764648 65.8335876464865 .8335876464866 .1383666992266 .1383666992266 .44316101074 66.7479400634867 .0527267456167 .3575134277367 .6623001098667 .96708679199 
68.5766525268668 .8814392089869 .4910125732469 .7957916259870 .40535736084 71.014930725171 .6244964599671 .9292907714872 .5388565063573 .14842987061 73.7580032348674 .062782287674 .6723632812575 .2819290161175 .58670806885 76.1962814331176 .5010681152376 .8058471679777 .4154205322377 .72020721436 78.0249862670978 .6345596313578 .9393463134879 .2441329956179 .54891967773 79.8537063598680 .1584930419980 .7680587768681 .0728530883881 .37763214111 81.6824111938582 .2919769287182 .5967712402382 .9015579223683 .51112365723 83.8159103393684 .4254837036185 .0350494384885 .3398437585 .94940185547 86.5589828491287 .1685485839888 .0829010009888 .6924667358489 .60682678223 90.2164001464891 .1307525634892 .349891662693 .5690307617294 .78817749023 96.3121032714897 .5312423706198 .7503814697399 .96952056885101 .1886978149 102.4077987671103 .6268997192104 .5412979126105 .7603988647106 .3700027466 106.6747970581106 .979598999106 .979598999106 .979598999106 .979598999 107.2844009399 107.2844009399 107.5891036987107.5891036987107.8938980103 107.8938980103107 .8938980103108 .1986999512108 .1986999512108 .1986999512 108.1986999512108 .1986999512108 .1986999512108 .1986999512107 .8938980103 107.8778076172107 .527671814107 .1959762573106 .8831176758106 .5892028809 106.3145217896106 .0590820312105 .8230743408105 .6063919067105 .4090805054 105.2309494019105 .0719299316104 .931678772104 .8099746704104 .7063674927 104.6205062866104 .5517883301104 .4996948242104 .4634628296104 .4424591064 104.4357528687104 .442489624104 .4615859985104 .4920196533104 .5325088501 104.5817489624104 .6382522583104 .7004776001104 .7666702271104 .8349914551 104.9034423828104 .9699020386105 .0321426392105 .0877761841105 .134437561 105.1697692871105 .1916275024105 .1976623535105 .1854934692105 .1522293091 105.0949707031105 .0102005005104 .8942871094104 .7431945801104 .5543441772 104.3277435303104 .0685577393103 .7778778076103 .441368103103 .0174026489 102.4077987671102 .1029968262101 .4934005737100 .8839035034100 .2742996216 99.6647262573299 .0551681518698 .445587158297 .8360290527397 .22646331787 96.6168823242295 .7025299072395 .0929565429794 .1785964965893 .56903076172 92.6546783447392 .0450973510791 .1307525634890 .2164001464889 .60682678223 88.6924667358487 .7781066894586 .8637619018685 .9494018554785 .03504943848 84.1206970214883 .206336975182 .2919769287181 .3776321411180 .46327209473 79.5489196777378 .9393463134878 .0249862670977 .110626220777 .1106262207 77.1106262207 -9999 -9999 -9999 -9999 -9999 -9999 -9999 -9999 -9999 -9999 -9999 -9999 -9999 -9999 -9999 -9999 -9999 -9999 -9999 -9999 -9999 -9999 -9999 -9999 -9999 -9999 -9999

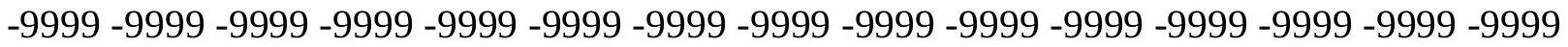

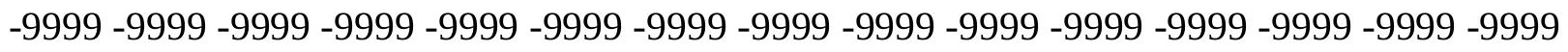

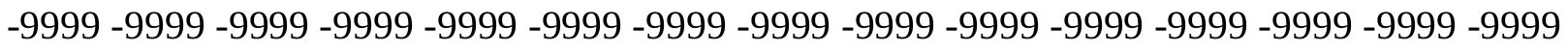
-9999 -9999 -9999 -9999 -9999 -9999 -9999 -9999 -9999 -9999 -9999 -9999 -9999 -9999 -9999 -9999 -9999 -9999 -9999 -9999 -9999 -9999 -9999 -9999 -9999 -9999 -9999 -9999 -9999 - -999 -9999 -9999 -9999 -9999 -9999 -9999 -9999 -9999 -9999-9999-9999 -

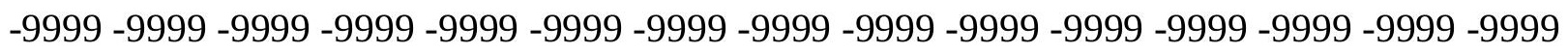
-9999 -9999 -9999 -9999 -9999 -9999 -9999 -9999 -9999 -9999 -9999 -9999 -9999 -9999 -9999 -9999 -9999 -9999 -9999 -9999 -9999 -9999 -9999 -9999 -9999 -9999 -9999 -9999 -9999 -9999 -9999 -9999-9999-9999-9999 -9999-9999 51.2038993835453.64218139648 58.51874923706 61.5666007995664 .3096618652366 .7479400634868 .8814392089870 .40535736084 
71.6244964599672 .8436431884873 .4532165527373 .7580032348674 .0627822876 73.7580032348673 .4532165527372 .8436431884871 .6244964599670 .40535736084 67.6623001098667 .9670867919967 .9670867919967 .9670867919967 .96708679199 67.9670867919967 .9670867919967 .6623001098667 .6623001098667 .35751342773 67.3575134277367 .0527267456167 .0527267456166 .7479400634866 .44316101074 66.1383666992266 .1383666992265 .8335876464865 .5288009643665 .52880096436 65.2240066528364 .9192428588964 .9192428588964 .6144485473664 .61444854736 64.3096618652364 .3096618652364 .3096618652364 .3096618652364 .30966186523 64.3096618652364 .3096618652364 .6144485473664 .6144485473664 .91924285889 65.2240066528365 .5288009643665 .8335876464866 .1383666992266 .74794006348 67.0527267456167 .6623001098668 .2718734741268 .5766525268669 .18623352051 69.7957916259870 .4053573608471 .014930725171 .6244964599672 .23407745361 72.8436431884873 .4532165527374 .062782287674 .6723632812574 .97714233398 75.5867080688576 .1962814331176 .5010681152377 .110626220777 .41542053223 78.0249862670978 .3297805786178 .9393463134879 .2441329956179 .54891967773 79.8537063598680 .4632720947380 .7680587768681 .0728530883881 .37763214111 81.9871978759882 .2919769287182 .9015579223683 .206336975183 .81591033936 84.1206970214884 .7302627563585 .0350494384885 .6446228027386 .2541885376 86.8637619018687 .4733276367288 .0829010009888 .6924667358489 .60682678223 90.5211791992291 .4355392456192 .349891662693 .5690307617294 .78817749023 96.0073165893697 .2264633178798 .7503814697399 .96952056885101 .1886978149 102.1029968262103 .3221969604104 .2365036011105 .1509017944105 .7603988647 106.3700027466 106.6747970581 106.979598999 106.979598999 107.2844009399 107.2844009399 107.5891036987 107.5891036987 107.5891036987107.8938980103 107.8938980103108 .1986999512108 .1986999512108 .1986999512108 .1986999512 108.1986999512108 .1986999512108 .1986999512108 .1986999512108 .1986999512 107.8938980103107 .8394241333107 .5017471313107 .1825332642106 .8819046021 106.6001663208106 .3373413086106 .0936355591105 .8689498901105 .6633682251 105.4766921997105 .3088912964105 .1596298218105 .028717041104 .915725708 104.8203430176104 .741973877104 .6801528931104 .6341552734104 .6033554077 104.5868606567104 .5838699341104 .5933303833104 .6142501831104 .6453781128 104.6854782104104 .7330932617104 .7867355347104 .8447265625104 .9052810669 104.9664764404105 .0262756348105 .08253479105 .1329345703105 .175163269 105.2068557739105 .2258377075105 .2297592163105 .2162704468105 .1826400757 105.1262130737105 .0438537598104 .9325332642104 .7891387939104 .6117248535 104.3991851807104 .1520996094103 .8709640503103 .5387649536103 .1596221924 102.712600708102 .1029968262101 .7982025146101 .1886978149100 .5791015625 99.96952056885 99.3599472045998.75038146973 98.1408081054797.53124237061 96.9216690063596 .0073165893695 .397743225194 .4833908081193 .87381744385 92.9594726562592 .349891662691 .4355392456190 .5211791992289 .91161346436 88.9972534179788.08290100098 87.16854858398 86.2541885376 85.33984375 84.4254837036183 .5111236572382 .5967712402381 .6824111938580 .76805877686 79.8537063598678 .9393463134878 .0249862670977 .110626220776 .50106811523 76.8058471679777 .72020721436 -9999 -9999 -9999 -9999 -9999 -9999 -9999 -9999 -9999 -9999 -9999 -9999 -9999 -9999 -9999 -9999 -9999 -9999 -9999 -9999 -9999 -9999 -9999 -9999

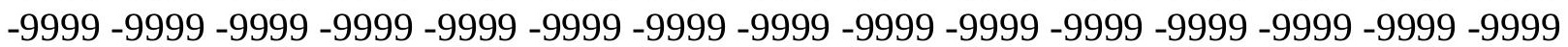


-9999 -9999 -9999 -9999 -9999 -9999 -9999 -9999 -9999 -9999 -9999 -9999 -9999 -9999 -9999 -9999 -9999 -9999 -9999 -9999 -9999 -9999 -9999 -9999 -9999 -9999 -9999 -9999 -9999 -9999

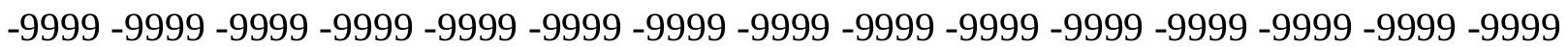
-9999 -9999 -9999 -9999 -9999 -9999 -9999 -9999 -9999 -9999 -9999 -9999 -9999 -9999 -9999 -9999 -9999 -9999 -9999 -9999 -9999 -9999 -9999 -9999 -9999 -9999 -9999 -9999 -9999 -9999 -9999 -9999 -9999 -9999 -9999 -9999 -9999 -9999 -9999 -9999 -9999 -9999 -9999 -9999 -9999 -9999 -9999 -9999 -9999 -9999 -9999 -9999 -9999 -9999 -9999 -9999 -9999 -9999 -9999 -9999 -9999 -9999 -9999 -9999 -9999 -9999 -9999 -9999 -9999 -9999 -9999 -9999 -9999 -9999 -9999 -9999 -9999 -9999 -9999-9999 52.11825942993 53.0326118469258 .82352828979 62.1761703491264 .9192428588967 .6623001098669 .4910125732471 .31971740723 72.5388565063573 .7580032348674 .3675689697374 .6723632812574 .97714233398 74.6723632812574 .3675689697373 .7580032348672 .5388565063571 .31971740723 69.7957916259867 .3575134277367 .3575134277367 .3575134277367 .35751342773 67.3575134277367 .0527267456167 .0527267456166 .7479400634866 .74794006348 66.4431610107466 .1383666992266 .1383666992265 .8335876464865 .52880096436 65.2240066528364 .9192428588964 .6144485473664 .6144485473664 .30966186523 64.004882812563 .7000885009863 .7000885009863 .3953094482463 .09051895142 63.0905189514262 .7857398986862 .7857398986862 .7857398986862 .78573989868 62.7857398986862 .7857398986863 .0905189514263 .0905189514263 .39530944824 63.7000885009864 .004882812564 .3096618652364 .9192428588965 .22400665283 65.8335876464866 .4431610107467 .0527267456167 .6623001098668 .27187347412 68.8814392089869 .4910125732470 .1005783081170 .7101516723671 .31971740723 72.2340774536172 .8436431884873 .4532165527374 .062782287674 .67236328125 75.2819290161175 .8914871215876 .1962814331176 .8058471679777 .41542053223 77.7202072143678 .3297805786178 .6345596313579 .2441329956179 .54891967773 80.1584930419980 .4632720947380 .7680587768681 .3776321411181 .68241119385 82.2919769287182 .5967712402382 .9015579223683 .5111236572383 .81591033936 84.4254837036185 .0350494384885 .3398437585 .9494018554786 .55898284912 87.1685485839887 .7781066894588 .3876876831188 .9972534179789 .60682678223 90.5211791992291 .4355392456192 .6546783447393 .5690307617294 .78817749023 96.0073165893697 .2264633178798 .445587158299 .66472625732100 .8839035034 102.1029968262103 .0174026489103 .9317016602104 .8460998535105 .4557037354 106.0652008057106 .3700027466106 .6747970581106 .979598999107 .2844009399 107.2844009399 107.5891036987 107.5891036987 107.8938980103107.8938980103 108.1986999512108 .1986999512108 .1986999512108 .5035018921108 .5035018921 108.5035018921108 .5035018921108 .5035018921108 .1986999512108 .1986999512 108.1958007812107 .8938980103107 .8173370361107 .4911880493107 .1832733154 106.8939056396106 .6231384277106 .3711776733106 .1379547119105 .9235610962 105.7278289795105 .550743103105 .3919906616105 .251411438105 .1286087036 105.0232849121104 .9348831177104 .8629684448104 .8068466187104 .7659301758 104.7393569946104 .7263565063104 .7259216309104 .7370758057104 .7586212158 104.7893600464104 .8278884888104 .8727722168104 .9223937988104 .9750366211 105.0288543701105 .0818939209105 .1321029663105 .1772537231105 .21509552 105.2433013916105 .2596740723105 .2618789673105 .2475967407105 .214225769 105.1592941284105 .0799865723104 .9736633301104 .837600708104 .6698913574 104.4686508179104 .2326126099103 .9595184326103 .6454696655103 .2820129395 
102.8661575317102 .4077987671102 .1029968262101 .4934005737100 .8839035034 100.274299621699 .6647262573299 .0551681518698 .445587158297 .83602905273 97.2264633178796.3121032714895.7025299072395.0929565429794.17859649658 93.2642517089892 .6546783447391 .7403335571390 .8259735107490 .21640014648 89.3020401001 88.38768768311 87.47332763672 86.55898284912 85.64462280273 84.7302627563583 .8159103393682 .9015579223681 .9871978759881 .07285308838 80.1584930419978 .9393463134878 .0249862670977 .4154205322376 .50106811523 76.1962814331176 .50106811523 -9999 -9999 -9999 -9999 -9999 -9999 -9999 -9999 -9999 -9999 -9999 -9999 -9999 -9999 -9999 -9999 -9999 -9999 -9999 -9999 -9999 -9999 -9999 -9999 -9999 -9999 -9999 -9999 -9999 -9999 -9999 -9999 -9999 -9999 -9999 -9999 -9999 -9999 -9999

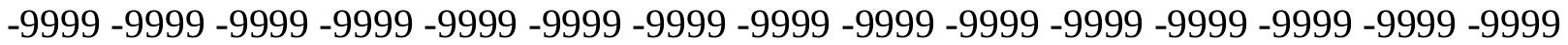
-9999 -9999 -9999 -9999 -9999 -9999 -9999 -9999 -9999 -9999 -9999 -9999 -9999 -9999 -9999 -999 -9999 -9999 -9999 -9999 -9999 -9999 -9999 -9999 -9999 -9999 -9999 -9999 -9999 -9999 -9999 -9999 -9999 -9999 -9999 -9999 -9999 -9999 -9999 -9999 -9999 -9999 -9999 -9999 -9999 -9999 -9999 -9999 -9999 -9999 -9999 -9999 -9999 -9999 -9999 -9999 -9999 -9999 -9999 -

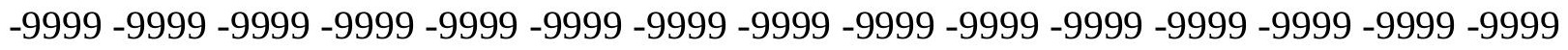
-9999 -9999 -9999 -9999 -9999 -9999 -9999 -9999 -9999 -9999 -9999 -9999 -9999 -9999 -9999 -9999 -9999 -9999 -9999 -9999 -9999 -9999 -9999 -9999 -9999 -9999 -9999 -9999 -9999 -9999 -9999 -9999 -9999 -9999 -9999-9999 -9999 53.03261184692 53.9469718933159 .43310165405 62.7857398986865 .8335876464868 .2718734741270 .4053573608471 .92929077148 73.4532165527374 .3675689697374 .9771423339875 .5867080688575 .58670806885 75.5867080688575 .2819290161174 .6723632812573 .7580032348672 .23407745361 70.7101516723668 .8814392089866 .7479400634866 .7479400634866 .74794006348 66.4431610107466 .4431610107466 .1383666992266 .1383666992265 .83358764648 65.5288009643665 .2240066528365 .2240066528364 .9192428588964 .61444854736 64.3096618652364 .004882812563 .7000885009863 .3953094482463 .09051895142 62.7857398986862 .4809494018662 .4809494018662 .1761703491261 .87137985229 61.5666007995661 .5666007995661 .5666007995661 .2618103027361 .26181030273 61.2618103027361 .5666007995661 .5666007995661 .8713798522961 .87137985229 62.1761703491262 .4809494018663 .0905189514263 .3953094482464 .0048828125 64.6144485473665 .2240066528365 .8335876464866 .4431610107467 .05272674561 67.9670867919968 .5766525268669 .1862335205170 .1005783081170 .71015167236 71.3197174072372 .2340774536172 .8436431884873 .4532165527374 .0627822876 74.9771423339875 .5867080688576 .1962814331176 .5010681152377 .1106262207 77.7202072143678 .3297805786178 .9393463134879 .2441329956179 .85370635986 80.1584930419980 .7680587768681 .0728530883881 .6824111938581 .98719787598 82.29197692871 82.90155792236 83.2063369751 83.81591033936 84.12069702148 84.73026275635 85.33984375 85.64462280273 86.2541885376 86.86376190186 87.1685485839887 .7781066894588 .3876876831189 .302040100189 .91161346436 90.8259735107491 .7403335571392 .6546783447393 .5690307617294 .78817749023 96.0073165893697 .2264633178798 .445587158299 .66472625732100 .5791015625 101.7982025146102 .712600708103 .6268997192104 .5412979126105 .1509017944 105.7603988647106 .3700027466106 .6747970581106 .979598999107 .2844009399 107.2844009399 107.5891036987107.8938980103107.8938980103108.1986999512 108.1986999512108 .1986999512108 .5035018921108 .5035018921108 .5035018921 108.5035018921108 .5035018921108 .5035018921108 .5035018921108 .5035018921 
108.1986999512108 .1986999512108 .1422576904107 .8085861206107 .492805481 107.1952362061106 .9159469604106 .6551742554106 .4128570557106 .1891098022 105.9837875366105 .7968902588105 .6281509399105 .4774246216105 .344329834 105.2286148071105 .1297531128105 .0473327637104 .9806976318104 .9292984009 104.8923034668104 .8689727783104 .8583221436104 .8594284058104 .871131897 104.8922729492104 .9214935303104 .9574279785104 .9985046387105 .0431060791 105.0894470215105 .1356658936105 .1797943115105 .2197189331105 .2532730103 105.2781906128105 .2922897339105 .2932434082105 .2787780762105 .2463607788 105.193649292105 .1180114746105 .0170822144104 .8883209229104 .7298355103 104.5395736694104 .315788269104 .0567550659103 .761100769103 .4281158447 103.0622024536102 .6919326782102 .2889175415101 .7982025146101 .1886978149 100.579101562599 .9695205688599 .3599472045998 .7503814697398 .14080810547 97.5312423706196 .6168823242296 .0073165893695 .397743225194 .48339080811 93.8738174438592 .9594726562592 .0450973510791 .4355392456190 .52117919922 89.60682678223 88.6924667358487.77810668945 86.86376190186 85.94940185547 85.03504943848 84.12069702148 83.2063369751 82.2919769287181.07285308838 80.1584930419979 .2441329956178 .3297805786177 .4154205322376 .50106811523 75.8914871215876 .1962814331177 .1106262207 -9999 -9999 -9999 -9999 -9999 -9999 -9999 -9999 -9999 -9999 -9999 -9999 -9999 -9999 -9999 -9999 -9999 -9999 -9999 -9999 -9999 -9999

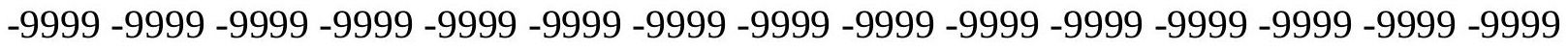

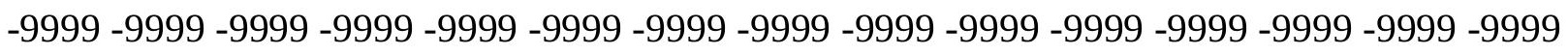
-9999 -9999 -9999 -9999 -9999 -9999 -9999 -9999 -9999 -9999 -9999 -9999 -9999 -9999 -9999 -9999 -9999 -9999 -9999 -9999 -9999 -9999 -9999 -9999 -9999 -9999 -9999 -9999 -9999 -9999 -9999 -9999 -9999 -9999 -9999 -9999 -9999 -9999 -9999 -9999 -9999 -9999 -9999 -9999 -9999 -9999 -9999 -9999 -9999 -9999 -9999 -9999 -9999 -9999 -9999 -9999 -9999 -9999 -9999 -9999 -9999 -9999 -9999 -9999 -9999 -9999 -9999 -9999 -9999 -9999 -9999 -9999 -9999 -9999 -9999 -9999 -9999 -9999 -9999 -9999 -9999 -9999 -9999 -9999 -9999 -9999 -9999 -9999 -9999

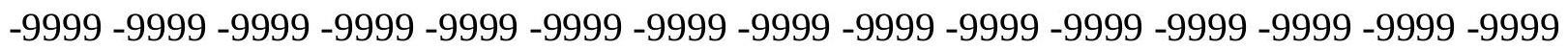
-9999 -9999-9999 -9999 -9999-9999-9999 53.9469718933154.8613204956155.47089004517 63.0905189514266 .1383666992268 .8814392089870 .7101516723672 .53885650635 73.7580032348674 .6723632812575 .5867080688575 .8914871215876 .19628143311 76.1962814331175 .8914871215875 .2819290161174 .6723632812573 .45321655273 71.9292907714870 .1005783081166 .4431610107466 .1383666992266 .13836669922 65.8335876464865 .8335876464865 .5288009643665 .2240066528365 .22400665283 64.9192428588964 .6144485473664 .3096618652364 .004882812563 .70008850098 63.3953094482463 .0905189514262 .7857398986862 .4809494018662 .17617034912 61.8713798522961 .5666007995661 .2618103027360 .9570198059160 .65224075317 60.3474502563560 .3474502563560 .0426712036160 .0426712036160 .04267120361 60.0426712036160 .0426712036160 .0426712036160 .3474502563560 .65224075317 60.9570198059161 .2618103027361 .5666007995662 .1761703491262 .78573989868 63.3953094482464 .004882812564 .6144485473665 .5288009643666 .13836669922 67.0527267456167 .6623001098668 .5766525268669 .1862335205170 .10057830811 70.7101516723671 .6244964599672 .2340774536173 .1484298706173 .75800323486 74.6723632812575 .2819290161175 .8914871215876 .5010681152377 .1106262207 77.7202072143678 .3297805786178 .9393463134879 .5489196777379 .85370635986 80.4632720947380 .7680587768681 .3776321411181 .6824111938582 .29197692871 
82.5967712402383 .206336975183 .5111236572384 .1206970214884 .73026275635 85.0350494384885 .6446228027385 .9494018554786 .5589828491287 .16854858398 87.4733276367288 .0829010009888 .6924667358489 .302040100190 .21640014648 90.8259735107491 .7403335571392 .6546783447393 .8738174438594 .78817749023 96.0073165893697 .2264633178798 .1408081054799 .35994720459100 .5791015625 101.4934005737102 .712600708103 .3221969604104 .2365036011104 .8460998535 105.4557037354106 .0652008057106 .3700027466106 .6747970581106 .979598999 107.2844009399 107.5891036987107.8938980103107.8938980103108.1986999512 108.1986999512108 .5035018921108 .5035018921108 .5035018921108 .5035018921 108.8082962036108 .8082962036108 .8082962036108 .5035018921108 .5035018921 108.5035018921108 .5035018921108 .4759063721108 .1341323853107 .8099060059 107.5035629272107 .2151947021106 .9450378418106 .6930770874106 .4594268799 106.2439727783106.0467453003105.8674926758105.7061157227105.56224823 105.4356689453105 .3258895874105 .2325210571105 .1549530029105 .0926589966 105.0448608398105 .0108337402104 .9896316528104 .9803771973104 .9819488525 104.9932250977105 .0129089355105 .039680481105 .0720596313105 .1084976196 105.1472930908105 .186668396105 .2247390747105 .2595062256105 .2888946533 105.3107299805105 .3228607178105 .3230056763105 .308921814105 .2781448364 105.2284011841105 .1571807861105 .06224823104 .9412612915104 .7924575806 104.6139907837104 .4045791626104 .1634063721103 .8901977539103 .5872650146 103.2580490112102 .9054031372102 .4077987671102 .0326385498101 .4934005737 100.8839035034100 .274299621699 .6647262573299 .0551681518698 .4455871582 97.8360290527397 .2264633178796 .3121032714895 .7025299072394 .78817749023 94.1785964965893 .2642517089892 .6546783447391 .7403335571390 .82597351074 89.91161346436 88.99725341797 88.08290100098 87.16854858398 86.2541885376 85.3398437584 .4254837036183 .5111236572382 .2919769287181 .37763214111 80.4632720947379 .5489196777378 .6345596313577 .7202072143676 .80584716797 75.8914871215875 .5867080688576 .1962814331177 .72020721436 -9999 -9999 -9999 -9999 -9999 -9999 -9999 -9999 -9999 -9999 -9999 -9999 -9999 -9999 -9999 -9999 -9999 -9999 -9999 -9999 -9999 -9999 -9999 -9999 -9999 -9999 -9999 -9999 -9999 -9999 -9999 -9999 -9999 -9999 -9999 -9999 -9999 -9999 -9999 -9999 -9999 -9999 -9999 -9999 -9999 -9999 -9999 -9999 -9999 -9999 -9999 -9999 -9999 -9999 -9999 -9999 -9999 -9999 -9999 -9999 -9999 -9999 -9999 -9999 -

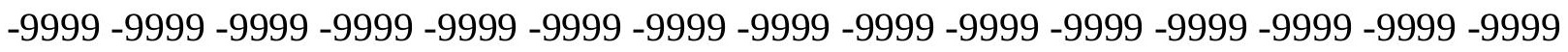
-9999 -9999 -9999 -9999 -9999 -9999 -9999 -9999 -9999 -9999 -9999 -9999 -9999 -9999 -9999

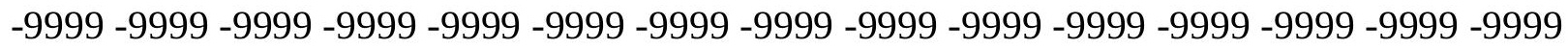
$-9999$

-9999 -9999 -9999 -9999 -9999 -9999 -9999 -9999 -9999 -9999 -9999 -9999 -9999 -9999 -9999

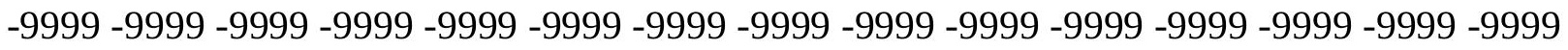
-9999 -9999 -9999 -9999 -9999 -9999 -9999 -9999 -9999 -9999 -9999 -9999 -9999 -9999 -9999 -9999 -9999 -9999 -9999 -9999 -9999-9999 -9999 55.7756805419957 .9091796875 63.3953094482466 .7479400634869 .1862335205171 .014930725172 .53885650635 73.7580032348674 .9771423339875 .8914871215876 .5010681152376 .80584716797 76.8058471679776 .8058471679776 .1962814331175 .2819290161174 .36756896973 72.8436431884871 .014930725168 .8814392089865 .8335876464865 .52880096436 65.5288009643665 .2240066528364 .9192428588964 .6144485473664 .30966186523 64.004882812563 .7000885009863 .3953094482463 .0905189514264 .61444854736 
64.3096618652364 .004882812563 .7000885009863 .0905189514260 .95701980591 60.6522407531760 .3474502563560 .0426712036159 .7378807067959 .43310165405 59.1283111572359 .1283111572358 .8235282897958 .8235282897958 .51874923706 58.5187492370658 .8235282897958 .8235282897959 .1283111572359 .12831115723 59.4331016540560 .0426712036160 .3474502563560 .9570198059161 .56660079956 62.1761703491262 .7857398986863 .7000885009864 .3096618652365 .22400665283 66.1383666992267 .0527267456167 .6623001098668 .5766525268669 .49101257324 70.4053573608471 .014930725171 .9292907714872 .8436431884873 .45321655273 74.3675689697374 .9771423339875 .8914871215876 .5010681152377 .1106262207 77.7202072143678 .3297805786178 .9393463134879 .5489196777380 .15849304199 80.7680587768681 .0728530883881 .6824111938582 .2919769287182 .59677124023 83.206336975183.51112365723 84.12069702148 84.4254837036185.03504943848 85.33984375 85.94940185547 86.2541885376 86.86376190186 87.47332763672 87.7781066894588 .3876876831188 .9972534179789 .6068267822390 .21640014648 91.1307525634892 .0450973510792 .9594726562593 .8738174438595 .09295654297 96.0073165893697 .2264633178798 .1408081054799 .35994720459100 .2742996216 101.4934005737102 .4077987671103 .3221969604103 .9317016602104 .5412979126 105.1509017944105 .7603988647106 .3700027466106 .6747970581106 .979598999 107.2844009399107 .5891036987107 .8938980103107 .8938980103108 .1986999512 108.1986999512108 .5035018921108 .5035018921108 .8082962036108 .8082962036 108.8082962036108 .8082962036108 .8082962036108 .8082962036108 .8082962036 108.8082962036108 .8082962036108 .8082962036108 .467338562108 .1340866089 107.818397522107 .5203781128107 .2402801514106 .9781036377106 .7340011597 106.5078735352106 .2997741699106 .1094818115105 .9369277954105 .7817764282 105.6438446045105 .5226593018105 .4178848267105 .3289260864105 .2553100586 105.1962814331105 .1511535645105 .1190338135105 .099067688105 .0901794434 105.0913085938105 .1011962891105 .1186141968105 .1421356201105 .1703109741 105.2015151978105 .2340621948105 .2661514282105 .2958831787105 .3212738037 105.3402404785105 .3507003784105 .3504257202105 .3372268677105 .3087234497 105.2626800537105 .1966781616105 .1085662842104 .9961547852104 .8578872681 104.6922073364104 .498260498104 .2754516602104 .0241928101103 .7447738647 103.4367828369103 .0940093994102 .7029037476102 .2560806274101 .7504577637 101.1886978149100 .579101562599 .9695205688599 .3599472045998 .75038146973 98.1408081054797 .5312423706196 .9216690063596 .0073165893695 .3977432251 94.4833908081193 .8738174438592 .9594726562592 .0450973510791 .13075256348 90.2164001464889 .302040100188 .3876876831187 .4733276367286 .55898284912 85.64462280273 84.73026275635 83.8159103393682.90155792236 81.68241119385 80.7680587768679 .8537063598678 .9393463134878 .0249862670977 .1106262207 76.1962814331175 .2819290161175 .2819290161176 .50106811523 -9999-9999 -9999 -9999 -9999 -9999 -9999 -9999 -9999 -9999 -9999 -9999 -9999 -9999 -9999 -9999 -9999 -9999 -9999

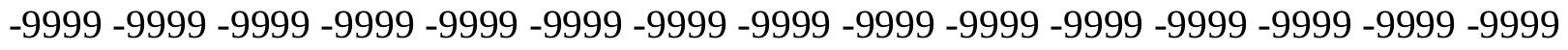

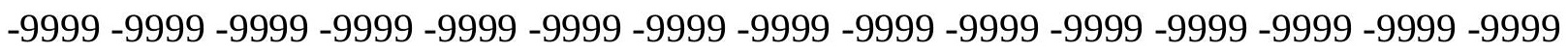
-9999 -9999 -9999 -9999 -9999 -9999 -9999 -9999 -9999 -9999 -9999 -9999 -9999 -9999 -9999 -9999 -9999 -9999 -9999 -9999 -9999 -9999 -9999 -9999 -9999 -9999 -9999 -9999 -9999 -9999 -

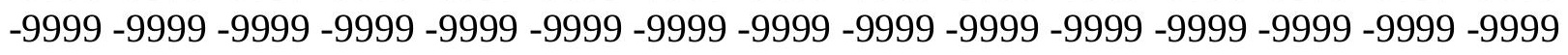

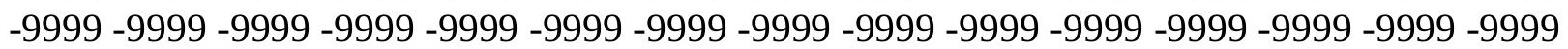


$-9999$

-9999 -9999 -9999 -9999 -9999 -9999 -9999 -9999 -9999 -9999 -9999 -9999 -9999 -9999 -9999

-9999 -9999 -9999 -9999 -9999 -9999 -9999 -9999 -9999 -9999 -9999 -9999 -9999 -9999 -9999

-9999 -9999 -9999 -9999 -9999 -9999 -9999 -9999 -9999 -9999 -9999 -9999 -9999 -9999 -9999

-9999 -9999 -9999 -9999 -9999 -9999 -9999 -9999 56.69002914429 57.29959869385

62.7857398986866 .4431610107468 .8814392089870 .4053573608471 .92929077148 73.4532165527374 .6723632812575 .8914871215876 .5010681152377 .1106262207 77.4154205322377 .4154205322377 .110626220776 .1962814331175 .28192901611 73.7580032348671 .9292907714869 .7957916259867 .3575134277364 .91924285889 64.9192428588964 .6144485473664 .3096618652364 .004882812563 .70008850098 63.3953094482464 .6144485473664 .6144485473664 .6144485473664 .61444854736 64.3096618652364 .004882812563 .3953094482463 .0905189514262 .48094940186 61.5666007995659 .4331016540559 .1283111572358 .8235282897958 .51874923706 58.2139587402357 .909179687557 .6043891906757 .6043891906757 .29959869385 57.2995986938557 .2995986938557 .6043891906757 .6043891906757 .9091796875 58.2139587402358 .8235282897959 .1283111572359 .7378807067960 .34745025635 61.2618103027361 .8713798522962 .7857398986863 .3953094482464 .30966186523 65.2240066528366 .1383666992267 .0527267456167 .9670867919968 .88143920898 69.7957916259870 .7101516723671 .6244964599672 .5388565063573 .45321655273 74.062782287674 .9771423339875 .8914871215876 .5010681152377 .1106262207 78.0249862670978 .6345596313579 .2441329956179 .8537063598680 .46327209473 81.0728530883881 .3776321411181 .9871978759882 .5967712402382 .90155792236 83.5111236572383 .8159103393684 .4254837036185 .0350494384885 .33984375 85.9494018554786 .254188537686 .8637619018687 .1685485839887 .77810668945 88.3876876831188 .6924667358489 .302040100189 .9116134643690 .52117919922 91.4355392456192.349891662693.2642517089894.1785964965895.09295654297 96.0073165893697 .2264633178798 .1408081054799 .35994720459100 .2742996216 101.1886978149102 .1029968262103 .0174026489103 .6268997192104 .5412979126 105.1509017944105 .4557037354106 .0652008057106 .6747970581106 .979598999 107.2844009399 107.5891036987 107.8938980103107.8938980103108.1986999512 108.5035018921108 .5035018921108 .8082962036108 .8082962036108 .8082962036 108.8082962036109 .1130981445109 .1130981445109 .1130981445109 .1130981445 109.1130981445109 .1130981445109 .1130981445108 .8076553345108 .4648132324 108.1392059326107 .8309631348107 .5403594971107 .2674179077107 .0123062134 106.7749557495106 .5554428101106 .3535766602106 .1693191528106 .0023651123 105.8525619507105 .7194824219105 .6028137207105 .5019989014105 .4166030884 105.3459014893105 .2892608643105 .2458114624105 .2147598267105 .1950759888 105.1857452393105 .185585022105 .1934432983105 .2079696655105 .2277908325 105.2513885498105 .2771606445105 .3033905029105 .3282623291105 .3498840332 105.3662567139105 .3753662109105 .3750534058105 .3632125854105 .3375320435 105.2958526611105 .235824585105 .1553497314105 .0523605347104 .9254074097 104.7731704712104 .5949020386104 .3898468018104 .1576309204103 .8969421387 103.6049423218103 .2751693726102 .9017868042102 .4791641235102 .0102233887 101.4934005737101 .0105667114100 .579101562599 .9695205688599 .35994720459 98.445587158297 .8360290527397 .2264633178796 .6168823242295 .70252990723 95.0929565429794 .1785964965893 .2642517089892 .6546783447391 .74033355713 
90.8259735107489 .9116134643688 .9972534179788 .0829010009887 .16854858398 85.9494018554785 .0350494384884 .1206970214883 .206336975181 .98719787598 81.0728530883880 .1584930419979 .2441329956178 .3297805786177 .41542053223 76.5010681152375 .5867080688574 .6723632812575 .5867080688577 .1106262207 -9999 -9999 -9999 -9999 -9999 -9999 -9999 -9999 -9999 -9999 -9999 -9999 -9999 -9999 -9999 -9999 -9999 -9999 -9999 -9999 -9999 -9999 -9999 -9999 -9999 -9999 -9999 -9999 -9999 -9999 -9999

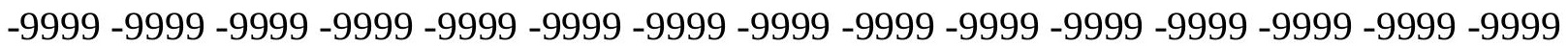

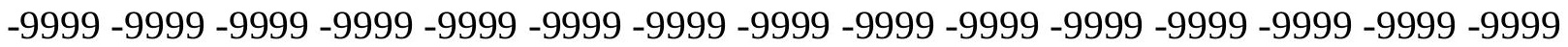
-9999 -9999 -9999 -9999 -9999 -9999 -9999 -9999 -9999 -9999 -9999 -9999 -9999 -9999 -9999 -9999 -9999 -9999 -9999 -9999 -9999 -9999 -9999 -9999 -9999 -9999 -9999 -9999 -9999 -9999 -

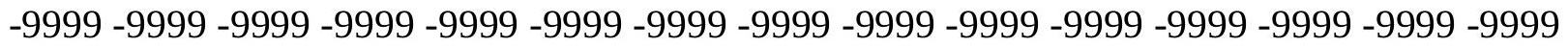
-9999 -9999-9999

-9999 -9999 -9999 -9999 -9999 -9999 -9999 -9999 -9999 -9999 -9999 -9999 -9999 -9999 -9999 -9999 -9999 -9999 -9999 -9999 -9999 -9999 -9999 -9999 -9999 -9999 -9999 -9999 -9999 -9999 -9999 -9999 -9999 -9999 -9999 -9999 -9999 -9999 -9999 -9999 -9999 -9999 -9999 -9999 -9999 -9999 -9999-9999 -9999 -9999 -9999 -9999 -9999 57.9091796875 58.21395874023 58.8235282897964 .6144485473667 .0527267456169 .1862335205171 .0149307251 72.5388565063574 .062782287675 .5867080688576 .5010681152377 .41542053223 77.7202072143677 .7202072143677 .7202072143677 .110626220776 .19628143311 74.6723632812573 .1484298706171 .014930725168 .5766525268664 .61444854736 64.3096618652364 .004882812563 .7000885009863 .3953094482463 .09051895142 64.6144485473664 .6144485473664 .6144485473664 .6144485473664 .61444854736 64.3096618652364 .004882812563 .7000885009863 .0905189514262 .48094940186 61.5666007995660 .6522407531758 .2139587402357 .909179687557 .60438919067 56.9948196411156 .9948196411156 .6900291442956 .3852500915556 .38525009155 56.3852500915556 .3852500915556 .3852500915556 .3852500915556 .69002914429 56.9948196411157 .6043891906758 .2139587402358 .8235282897959 .43310165405 60.0426712036160 .9570198059161 .8713798522962 .7857398986863 .70008850098 64.6144485473665 .5288009643666 .7479400634867 .6623001098668 .57665252686 69.4910125732470 .4053573608471 .3197174072372 .2340774536173 .14842987061 74.062782287674 .9771423339875 .8914871215876 .5010681152377 .41542053223 78.0249862670978 .9393463134879 .5489196777380 .1584930419980 .76805877686 81.3776321411181 .9871978759882 .2919769287182 .9015579223683 .51112365723 83.81591033936 84.42548370361 84.73026275635 85.33984375 85.94940185547 86.254188537686 .8637619018687 .1685485839887 .7781066894588 .08290100098 88.6924667358488 .9972534179789 .6068267822390 .2164001464890 .82597351074 91.7403335571392 .6546783447393 .5690307617294 .4833908081195 .3977432251 96.3121032714897 .2264633178798 .1408081054799 .0551681518699 .96952056885 100.8839035034101 .7982025146102 .712600708103 .6268997192104 .2365036011 104.8460998535105 .4557037354106 .0652008057106 .3700027466106 .6747970581 107.2844009399 107.5891036987107.8938980103108.1986999512 108.1986999512 108.5035018921108 .8082962036108 .8082962036108 .8082962036109 .1130981445 109.1130981445109 .1130981445109 .1130981445109 .4179000854109 .4179000854 109.4179000854109 .4179000854109 .4179000854109 .1546478271108 .8016357422 108.4655380249108 .1465072632107 .844833374107 .5605621338107 .2938766479 107.0447463989106 .8132705688106 .5992889404106 .4027862549106 .2234954834 
106.0613098145 105.9158172607 105.7867431641 105.6735839844105.5759277344 105.4930953979105 .4244918823105 .3693008423105 .3267669678105 .2959213257 105.2758255005105 .2653579712105 .2634506226105 .2688446045105 .2802581787 105.2962493896105 .315322876105 .3358459473105 .356086731105 .3742141724 105.3883132935105 .3964385986105 .3965148926105 .3864898682105 .3641662598 105.3274459839105 .2740478516105 .2019348145105 .1090927124104 .9940872192 104.8556137085104 .6928482056104 .5046615601104 .2899017334104 .046295166 103.7705383301103 .4580993652103 .1056060791102 .711555481102 .2819442749 101.8333892822101 .3763885498100 .8809890747100 .274299621699 .66472625732 99.0551681518698 .445587158297 .5312423706196 .9216690063596 .31210327148 95.397743225194 .4833908081193 .8738174438592 .9594726562592 .04509735107 91.1307525634890 .2164001464889 .302040100188 .3876876831187 .47332763672 86.5589828491285 .3398437584 .4254837036183 .5111236572382 .59677124023 81.3776321411180 .4632720947379 .5489196777378 .6345596313577 .41542053223 76.5010681152375 .8914871215874 .9771423339874 .9771423339876 .19628143311 -9999 -9999 -9999 -9999 -9999 -9999 -9999 -9999 -9999 -9999 -9999 -9999 -9999 -9999 -9999 -9999 -9999 -9999 -9999 -9999 -9999 -9999 -9999 -9999 -9999 -9999 -9999 -9999 -9999 -9999 -9999 -9999 -9999 -9999 -9999 -9999 -9999 -9999 -9999 -9999 -9999 -9999 -9999 -9999 -9999 -9999 -

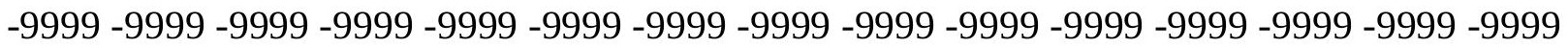

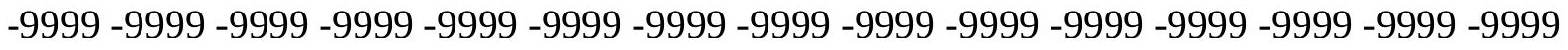

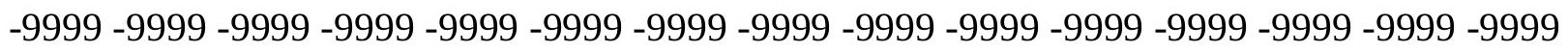

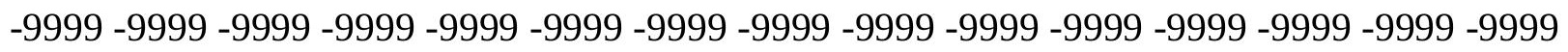
-9999 -9999-9999

-9999 -9999 -9999 -9999 -9999 -9999 -9999 -9999 -9999 -9999 -9999 -9999 -9999 -9999 -9999

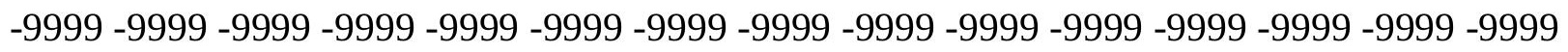

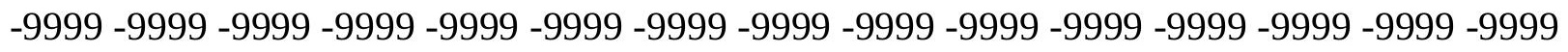
-9999 -9999-9999 -9999 -9999 -9999-9999 -9999 -9999 59.12831115723 59.43310165405 59.7378807067964 .6144485473667 .3575134277369 .4910125732471 .31971740723 73.1484298706174 .6723632812576 .1962814331177 .110626220777 .72020721436 78.0249862670978 .0249862670977 .7202072143676 .8058471679775 .58670806885 74.062782287671 .9292907714869 .4910125732467 .0527267456163 .70008850098 63.7000885009863 .3953094482463 .0905189514264 .6144485473664 .61444854736 64.6144485473664 .6144485473664 .6144485473664 .6144485473664 .30966186523 64.004882812563 .7000885009863 .0905189514262 .4809494018661 .56660079956 60.6522407531759 .7378807067956 .9948196411156 .6900291442956 .38525009155 56.0804595947355 .7756805419955 .4708900451755 .1661109924355 .16611099243 55.1661109924355 .1661109924355 .4708900451755 .4708900451756 .08045959473 56.3852500915556 .9948196411157 .6043891906758 .5187492370659 .12831115723 60.0426712036160 .9570198059161 .8713798522963 .0905189514264 .0048828125 65.2240066528366 .1383666992267 .0527267456168 .2718734741269 .18623352051 70.4053573608471 .3197174072372 .2340774536173 .1484298706174 .0627822876 74.9771423339875 .8914871215876 .8058471679777 .4154205322378 .32978057861 78.9393463134879 .8537063598680 .4632720947381 .0728530883881 .68241119385 82.2919769287182 .9015579223683 .206336975183 .8159103393684 .42548370361 84.73026275635 85.33984375 85.94940185547 86.2541885376 86.86376190186 87.1685485839887 .7781066894588 .0829010009888 .6924667358488 .99725341797 
89.6068267822389 .9116134643690 .5211791992291 .1307525634892 .04509735107 92.9594726562593 .8738174438594 .7881774902395 .7025299072396 .31210327148 97.2264633178798.1408081054799.0551681518699.96952056885100.8839035034 101.7982025146102 .4077987671103 .3221969604103 .9317016602104 .5412979126 105.1509017944105 .7603988647106 .3700027466106 .6747970581107 .2844009399 107.5891036987107 .8938980103108 .1986999512108 .1986999512108 .5035018921 108.8082962036108 .8082962036109 .1130981445109 .1130981445109 .4179000854 109.4179000854109 .4179000854109 .4179000854109 .4179000854109 .7226028442 109.7226028442109 .7226028442109 .5078277588109 .1440734863108 .796913147 108.4665222168108 .1532211304107 .8570556641107 .5782470703107 .3167800903 107.0727920532 106.8461456299 106.6368560791 106.4447021484 106.2695922852 106.1111602783105 .9691772461105 .843170166105 .7327651978105 .6373214722 105.5562973022105 .4889221191105 .4345092773105 .3921432495105 .3609619141 105.3399353027105 .3280792236105 .3242111206105 .3271560669105 .3355712891 105.3480453491105 .36302948105 .378868103105 .3937911987105 .4059677124 105.4135055542105 .4143981934105 .4066696167105 .3881988525105 .3569717407 105.3107833862105 .2476577759105 .1655731201105 .0630493164104 .9386520386 104.7913284302104 .6196670532104 .4220581055104 .1958999634103 .9383392334 103.646270752103 .3180084229102 .9535980225102 .5579223633102 .1354751587 101.6839294434101 .1809844971100 .579101562599 .9695205688599 .35994720459 98.7503814697398 .1408081054797 .2264633178796 .6168823242296 .00731658936 95.0929565429794 .1785964965893 .5690307617292 .6546783447391 .74033355713 90.8259735107489 .9116134643688 .9972534179787 .7781066894586 .86376190186 85.9494018554785 .0350494384883 .8159103393682 .9015579223681 .68241119385 80.7680587768679 .8537063598678 .9393463134877 .7202072143676 .80584716797 $76.1962814331175 .2819290161174 .3675689697375 .2819290161176 .80584716797-9999$ -9999 -9999 -9999 -9999 -9999 -9999 -9999 -9999 -9999 -9999 -9999 -9999 -9999 -9999 -9999

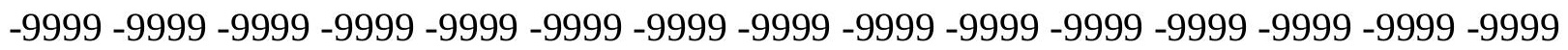
-9999 -9999 -9999 -9999 -9999 -9999 -9999 -9999 -9999 -9999 -9999 -9999 -9999 -9999 -9999 -9999 -9999 -9999 -9999 -9999 -9999 -9999 -9999 -9999 -9999 -9999 -9999 -9999 -9999 -999 -9999 -9999 -9999 -9999 -9999 -9999 -9999 -9999 -9999-9999 -9999 -9999 -9999 -9999 -9999 -9999 -9999 -9999 -9999 -9999 -9999 -9999 -9999 -9999 -9999 -9999 -9999 -9999 -9999 -9999 -

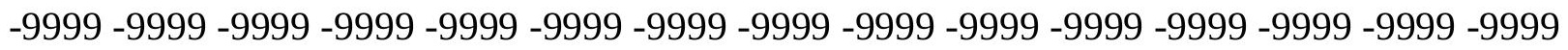
$-9999-9999$

-9999 -9999 -9999 -9999 -9999 -9999 -9999 -9999 -9999 -9999 -9999 -9999 -9999 -9999 -9999

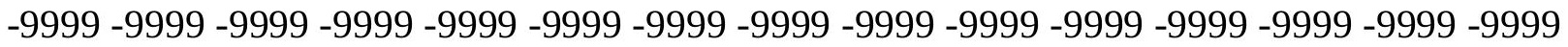

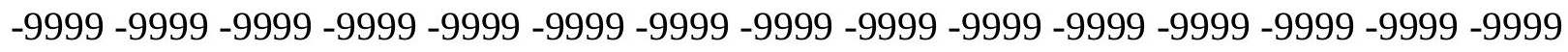
-9999 -9999-9999 -9999 -9999-9999-9999-9999-9999 60.34745025635 60.34745025635 60.6522407531761 .2618103027362 .1761703491267 .3575134277369 .49101257324 71.6244964599673 .7580032348675 .2819290161176 .8058471679777 .72020721436 78.3297805786178 .3297805786178 .0249862670977 .4154205322376 .50106811523 74.9771423339872 .8436431884870 .7101516723667 .9670867919963 .39530944824 63.0905189514262 .7857398986864 .3096618652364 .3096618652364 .61444854736 64.6144485473664 .6144485473664 .6144485473664 .6144485473664 .30966186523 64.004882812563 .7000885009863 .0905189514262 .7857398986861 .87137985229 60.9570198059159 .7378807067958 .5187492370655 .7756805419955 .47089004517 
55.1661109924354 .8613204956154 .5565414428754 .2517509460454 .25175094604 54.2517509460454 .2517509460454 .2517509460454 .5565414428754 .86132049561 55.4708900451756 .0804595947356 .6900291442957 .6043891906758 .51874923706 59.4331016540560 .3474502563561 .2618103027362 .4809494018663 .70008850098 64.6144485473665 .8335876464867 .0527267456167 .9670867919969 .18623352051 70.1005783081171 .3197174072372 .2340774536173 .1484298706174 .0627822876 75.2819290161176 .1962814331176 .8058471679777 .7202072143678 .63455963135 79.2441329956180 .1584930419980 .7680587768681 .3776321411181 .98719787598 82.5967712402383 .206336975183 .8159103393684 .4254837036184 .73026275635 85.3398437585 .9494018554786 .254188537686 .8637619018687 .16854858398 87.7781066894588 .0829010009888 .6924667358488 .9972534179789 .60682678223 89.9116134643690 .5211791992290 .8259735107491 .7403335571392 .65467834473 93.5690307617294 .1785964965895 .0929565429795 .7025299072396 .61688232422 97.5312423706198 .1408081054799 .0551681518699 .96952056885100 .8839035034 101.4934005737102 .4077987671103 .0174026489103 .9317016602104 .5412979126 105.1509017944105 .7603988647106 .0652008057106 .6747970581106 .979598999 107.5891036987107 .8938980103108 .1986999512108 .5035018921108 .8082962036 108.8082962036109 .1130981445109 .1130981445109 .4179000854109 .4179000854 109.7226028442109 .7226028442109 .7226028442109 .7226028442109 .7226028442 110.0273971558110 .0273971558109 .8667831421109 .4917144775109 .1329269409 108.7906188965108 .4651107788108 .1564941406107 .8649978638107 .590637207 107.3335800171107 .0937194824106 .87109375106 .6655197144106 .4769439697 106.3050460815106 .1496276855106 .0102539062105 .8865890503105 .7780380249 105.6841201782105 .6041183472105 .5374145508105 .4831619263105 .4405899048 105.4087524414105 .386756897105 .3735198975105 .3679580688105 .368812561 105.374786377105 .3843917847105 .3960571289105 .4080657959105 .4186630249 105.425994873105 .4281311035105 .4231491089105 .4090270996105 .3837966919 105.3453521729105 .2917480469105 .2209701538105 .131439209105 .0215301514 104.8899307251104 .7350006104104 .555015564104 .3474807739104 .1100006104 103.8402709961103 .5373306274103 .200958252102 .8320236206102 .4320602417 101.9943695068101 .4934005737100 .9912643433100 .468254089499 .96952056885 99.0551681518698 .445587158297 .8360290527397 .2264633178796 .31210327148 95.7025299072394 .7881774902393 .8738174438592 .9594726562592 .04509735107 91.1307525634890 .2164001464889 .302040100188 .3876876831187 .47332763672 86.2541885376 85.33984375 84.42548370361 83.206336975182.29197692871 81.0728530883880 .1584930419979 .2441329956178 .3297805786177 .1106262207 76.5010681152375 .5867080688574 .6723632812574 .6723632812575 .89148712158 -9999 -9999 -9999 -9999 -9999 -9999 -9999 -9999 -9999 -9999 -9999 -9999 -9999 -9999 -9999 -9999 -9999 -9999 -9999 -9999 -9999 -9999 -9999 -9999 -9999 -9999 -9999 -9999 -9999 -9999 -9999 -9999 -9999 -9999 -9999 -9999 -9999 -9999 -9999 -9999 -9999 -9999 -9999 -9999 -9999 -9999 -

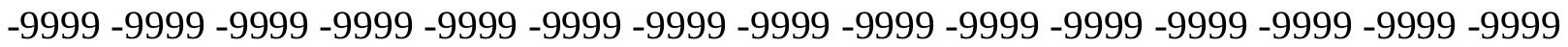
-9999 -9999 -9999 -9999 -9999 -9999 -9999 -9999 -9999 -9999 -9999 -9999 -9999 -9999 -9999 -9999 -9999 -9999 -9999 -9999 -9999 -9999 -9999 -9999 -9999 -9999 -9999 -9999 -9999 -9999 -

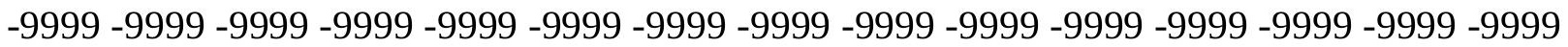
$-9999-9999$

-9999 -9999 -9999 -9999 -9999 -9999 -9999 -9999 -9999 -9999 -9999 -9999 -9999 -9999 -9999 
-9999 -9999 -9999 -9999 -9999 -9999 -9999 -9999 -9999 -9999 -9999 -9999 -9999 -9999 -9999

-9999 -9999 -9999 -9999 -9999 -9999 -9999 -9999 -9999 -9999 -9999 -9999 -9999 -9999 -9999 -9999 -9999 -9999 -9999 -9999 -9999 -9999 -9999 -9999 -9999 61.56660079956

61.5666007995661 .8713798522962 .4809494018663 .3953094482467 .35751342773 69.7957916259872 .2340774536174 .3675689697375 .8914871215877 .1106262207 78.0249862670978 .6345596313578 .3297805786178 .0249862670977 .1106262207 75.5867080688573 .7580032348671 .6244964599669 .1862335205163 .09051895142 62.7857398986864 .004882812564 .3096618652364 .3096618652364 .61444854736 64.6144485473664 .6144485473664 .6144485473664 .6144485473664 .30966186523 64.004882812563 .7000885009863 .3953094482462 .7857398986861 .87137985229 60.9570198059159 .7378807067958 .5187492370657 .2995986938554 .86132049561 54.5565414428754 .2517509460453 .9469718933153 .6421813964853 .33739852905 53.3373985290553 .3373985290553 .3373985290553 .6421813964853 .94697189331 54.5565414428755 .1661109924355 .7756805419956 .6900291442957 .60438919067 58.5187492370659 .7378807067960 .9570198059162 .1761703491263 .09051895142 64.3096618652365 .5288009643666 .7479400634867 .9670867919968 .88143920898 70.1005783081171 .3197174072372 .2340774536173 .4532165527374 .36756896973 75.2819290161176 .1962814331177 .110626220778 .0249862670978 .93934631348 79.8537063598680 .4632720947381 .3776321411181 .9871978759882 .59677124023 83.2063369751 83.81591033936 84.42548370361 84.73026275635 85.33984375 85.94940185547 86.2541885376 86.86376190186 87.16854858398 87.77810668945 88.0829010009888 .6924667358488 .9972534179789 .6068267822389 .91161346436 90.5211791992291 .1307525634891 .4355392456192 .6546783447393 .26425170898 93.8738174438594.4833908081195.397743225196.0073165893696.92166900635 97.5312423706198 .445587158299 .0551681518699 .96952056885100 .5791015625 101.4934005737102 .1029968262103 .0174026489103 .6268997192104 .2365036011 104.8460998535105 .4557037354106 .0652008057106 .6747970581106 .979598999 107.5891036987107 .8938980103108 .1986999512108 .5035018921108 .8082962036 109.1130981445109 .1130981445109 .4179000854109 .4179000854109 .7226028442 109.7226028442109 .7226028442110 .0273971558110 .0273971558110 .0273971558 110.3321990967110 .3321990967110 .231086731109 .8441390991109 .4731674194 109.1183700562108 .7800979614108 .4584655762108 .153717041107 .8659133911 107.5952301025107 .3415985107107 .1050872803106 .8855514526106 .6829681396 106.4970626831106 .3276672363106 .1743850708106 .0369415283105 .9147949219 105.8075027466105 .7144241333105 .635017395105 .5685119629105 .5142440796 105.4713439941105 .4390335083105 .416305542105 .4021911621105 .3955154419 105.395072937105 .3994369507105 .4071273804105 .4164810181105 .4257888794 105.433265686105 .4370346069105 .4352264404105 .4258956909105 .4071350098 105.3769073486105 .3333053589105 .2743225098105 .1982650757105 .1033401489 104.9880065918104 .8504257202104 .6888809204104 .501121521104 .2851028442 104.03881073103 .7613143921103 .4517822266103 .1093444824102 .7326049805 102.3190765381101 .8689804077101 .3921737671100 .8839035034100 .2742996216 99.6647262573299 .0551681518698 .1408081054797 .5312423706196 .92166900635 96.0073165893695 .0929565429794 .4833908081193 .5690307617292 .65467834473 91.7403335571390 .8259735107489 .9116134643688 .6924667358487 .77810668945 86.8637619018685 .6446228027384 .7302627563583 .8159103393682 .59677124023 
81.6824111938580 .4632720947379 .5489196777378 .6345596313577 .72020721436 76.8058471679775 .8914871215874 .9771423339874 .062782287675 .28192901611 76.50106811523 -9999 -9999 -9999 -9999 -9999 -9999 -9999 -9999 -9999 -9999 -9999 -9999 -9999 -9999 -9999 -9999 -9999 -9999 -9999 -9999 -9999 -9999 -9999 -9999 -9999 -9999 -9999 -9999 -9999 -9999 -9999 -9999 -9999 -9999 -9999 -9999-9999 -9999 -9999 -9999 -9999 -9999 -9999 -9999 -9999 -9999 -9999 -9999 -9999 -9999 -9999 -9999 -9999 -9999 -9999 -9999 -9999

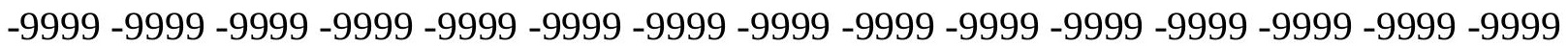

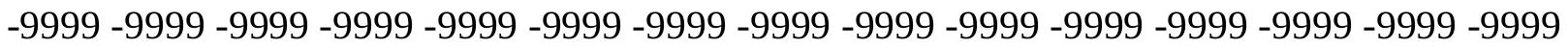

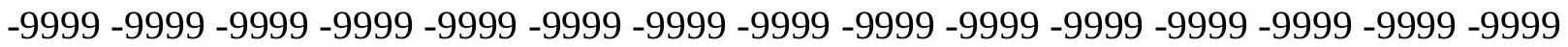
-9999 -9999 -9999-9999-9999

-9999 -9999 -9999 -9999 -9999 -9999 -9999 -9999 -9999 -9999 -9999 -9999 -9999 -9999 -9999 -9999 -9999 -9999 -9999 -9999 -9999 -9999 -9999 -9999 -9999 -9999 -9999 -9999 -9999 -9999 -9999 -9999 -9999 -9999 -9999 -9999 -9999 -9999 -9999 -9999 -9999 -9999 -9999 -9999 -9999 -999 -9999 -9999 -9999 -9999 -9999 -9999 -9999 -9999 -9999 -9999 -9999 62.48094940186 62.4809494018662 .7857398986863 .3953094482464 .004882812567 .66230010986 70.4053573608472 .8436431884874 .6723632812576 .5010681152377 .72020721436 78.3297805786178 .3297805786178 .3297805786177 .4154205322376 .19628143311 74.6723632812572 .5388565063570 .1005783081167 .3575134277362 .17617034912 64.004882812564 .004882812564 .3096618652364 .3096618652364 .61444854736 64.6144485473664 .6144485473664 .6144485473664 .3096618652364 .0048828125 63.7000885009863 .3953094482462 .7857398986861 .8713798522960 .95701980591 60.0426712036158 .8235282897957 .2995986938554 .2517509460453 .94697189331 53.6421813964853 .3373985290553 .0326118469252 .7278289794952 .42303848267 52.4230384826752 .4230384826752 .7278289794953 .0326118469253 .64218139648 54.2517509460455 .1661109924356 .0804595947356 .9948196411158 .21395874023 59.1283111572360 .3474502563561 .5666007995663 .0905189514264 .30966186523 65.5288009643666 .7479400634867 .9670867919968 .8814392089870 .10057830811 71.3197174072372 .5388565063573 .4532165527374 .6723632812575 .58670806885 76.5010681152377 .4154205322378 .3297805786179 .2441329956180 .15849304199 81.0728530883881 .6824111938582 .2919769287183 .206336975183 .81591033936 84.4254837036184 .7302627563585 .3398437585 .9494018554786 .2541885376 86.8637619018687 .1685485839887 .7781066894588 .0829010009888 .69246673584 88.9972534179789 .6068267822389 .9116134643690 .5211791992291 .13075256348 92.0450973510793 .5690307617293 .2642517089893 .5690307617294 .17859649658 94.7881774902395 .7025299072396 .3121032714896 .9216690063597 .53124237061 98.445587158299 .0551681518699 .96952056885100 .5791015625101 .4934005737 102.1029968262102 .712600708103 .6268997192104 .2365036011104 .8460998535 105.4557037354106 .0652008057106 .6747970581106 .979598999107 .5891036987 107.8938980103108 .1986999512108 .5035018921108 .8082962036109 .1130981445 109.4179000854109 .4179000854109 .7226028442109 .7226028442110 .0273971558 110.0273971558110 .3321990967110 .3321990967110 .3321990967110 .3321990967 110.6370010376110 .6003799438110 .2010040283109 .8172836304109 .4494400024 109.0978469849 108.7626342773 108.4440841675108.1422653198 107.8573913574 107.5894241333107 .338470459107 .1044158936106 .8872680664106 .6867904663 106.5028686523106 .335144043106 .1833877563106 .0471191406105 .9259643555 105.8193435669105 .72681427105 .6476974487105 .5814208984105 .5272140503 
105.4843978882105 .4520645142105 .4293441772105 .4151382446105 .4083328247 105.4075698853105 .4114303589105 .4183273315105 .4266052246105 .4345169067 105.4402542114105 .4420013428105 .4378509521105 .4259719849105 .4043960571 105.3712234497105 .3244628906105 .262336731105 .1829147339105 .0844726562 104.9650497437104 .822883606104 .6558914185104 .4622497559104 .2400131226 103.9879760742103 .7047424316103 .3890075684103 .0386581421102 .6524353027 102.230506897101 .7744140625101 .1886978149100 .579101562599 .96952056885 99.35994720459 98.75038146973 98.14080810547 97.2264633178796.61688232422 95.7025299072394 .7881774902394 .1785964965893 .2642517089892 .3498916626 91.4355392456190 .21640014648 89.3020401001 88.38768768311 87.16854858398 86.254188537685 .3398437584 .1206970214883 .206336975181 .98719787598 81.0728530883879 .8537063598678 .9393463134878 .0249862670976 .80584716797 75.8914871215875 .2819290161174 .3675689697374 .062782287675 .58670806885 -9999 -9999 -9999 -9999 -9999 -9999 -9999 -9999 -9999 -9999 -9999 -9999 -9999 -9999 -9999 -9999 -9999 -9999 -9999 -9999 -9999 -9999 -9999 -9999 -9999 -9999 -9999 -9999 -9999 -9999 -9999

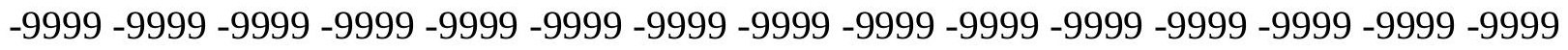
-9999 -9999 -9999 -9999 -9999 -9999 -9999 -9999 -9999 -9999 -9999 -9999 -9999 -9999 -9999 -9999 -9999 -9999 -9999 -9999 -9999 -9999 -9999 -9999 -9999 -9999 -9999 -9999 -9999 -9999 -9999 -9999 -9999 -9999 -9999 -9999 -9999 -9999 -9999 -9999 -9999 -9999 -9999 -9999 -9999 -

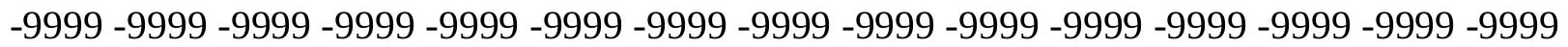
$-9999$

-9999 -9999 -9999 -9999 -9999 -9999 -9999 -9999 -9999 -9999 -9999 -9999 -9999 -9999 -9999 -9999 -9999 -9999 -9999 -9999 -9999 -9999 -9999 -9999 -9999 -9999 -9999 -9999 -9999 -9999 -9999 -9999 -9999 -9999 -9999 -9999 -9999 -9999 -9999 -9999 -9999 -9999 -9999 -9999 -9999 -9999 -9999 -9999 -9999 -9999 -9999-9999 -9999 -9999-9999 -9999 63.39530944824 63.3953094482464 .6144485473663 .7000885009864 .3096618652364 .61444854736 67.6623001098670 .7101516723673 .1484298706175 .2819290161176 .50106811523 77.7202072143678 .0249862670978 .0249862670977 .7202072143676 .50106811523 75.2819290161173 .1484298706171 .014930725168 .2718734741263 .70008850098 64.004882812564 .004882812564 .3096618652364 .3096618652364 .61444854736 64.6144485473664 .6144485473664 .6144485473664 .6144485473664 .30966186523 64.004882812563 .3953094482462 .7857398986862 .1761703491261 .26181030273 60.0426712036158 .8235282897957 .6043891906756 .0804595947353 .64218139648 53.0326118469252 .7278289794952 .4230384826752 .1182594299351 .81346893311 51.8134689331151 .8134689331152 .1182594299352 .4230384826753 .03261184692 53.6421813964854 .5565414428755 .4708900451756 .3852500915557 .60438919067 58.8235282897960 .0426712036161 .5666007995662 .7857398986864 .0048828125 65.5288009643666 .7479400634867 .9670867919969 .1862335205170 .40535736084 71.6244964599672 .5388565063573 .7580032348674 .9771423339875 .89148712158 76.8058471679778 .0249862670978 .9393463134879 .8537063598680 .76805877686 81.3776321411182 .2919769287182 .9015579223683 .5111236572384 .12069702148 84.7302627563585 .3398437585 .9494018554786 .254188537686 .86376190186 87.4733276367287 .7781066894588 .3876876831188 .6924667358488 .99725341797 89.6068267822389 .9116134643690 .5211791992290 .8259735107491 .43553924561 92.349891662692 .9594726562593 .2642517089893 .8738174438594 .48339080811 95.0929565429795 .7025299072396 .3121032714897 .2264633178797 .83602905273 
98.445587158299 .0551681518699 .96952056885100 .5791015625101 .1886978149 102.1029968262102 .712600708103 .6268997192104 .2365036011104 .8460998535 105.4557037354106 .0652008057106 .6747970581106 .979598999107 .5891036987 107.8938980103108 .5035018921108 .8082962036109 .1130981445109 .4179000854 109.4179000854109 .7226028442110 .0273971558110 .0273971558110 .3321990967 110.3321990967110 .3321990967110 .3321990967110 .6370010376110 .6370010376 110.6370010376110 .9418029785110 .5619430542110 .1649169922109 .7834777832 109.418006897 109.0686645508 108.7357559204 108.4193649292 108.1197433472 107.8368911743107 .570930481107 .3217849731107 .089515686106 .8739089966 106.6748962402106 .4921722412106 .3255691528106 .1746520996106 .0391311646 105.9185180664105 .8124465942105 .7203445435105 .6417388916105 .5759735107 105.5224609375105 .4803924561105 .4489822388105 .4272155762105 .4140548706 105.4082183838105 .4083557129105 .4129257202105 .4203491211105 .4289245605 105.4368972778105 .442489624105 .443862915105 .4392166138105 .4266433716 105.4042739868105 .3701095581105 .3223114014105 .2588577271105 .1778869629 105.0773544312104 .9554214478104 .8100357056104 .6394271851104 .441619873 104.2151184082103 .958114624103 .6689682007103 .3454818726102 .9860534668 102.5890655518102 .1526794434101 .6704864502101 .135848999100 .5569763184 99.9695205688599 .3599472045998 .445587158297 .8360290527397 .22646331787 96.3121032714895 .397743225194 .4833908081193 .5690307617292 .65467834473 91.7403335571390 .8259735107489 .9116134643688 .9972534179787 .77810668945 86.8637619018685 .6446228027384 .7302627563583 .5111236572382 .59677124023 81.3776321411180 .1584930419979 .2441329956178 .3297805786177 .1106262207 76.1962814331175 .2819290161174 .3675689697373 .4532165527374 .36756896973 75.58670806885 -9999 -9999 -9999 -9999 -9999 -9999 -9999 -9999 -9999 -9999 -9999 -9999 -9999 -9999 -9999 -9999 -9999 -9999 -9999 -9999 -9999 -9999 -9999 -9999 -9999 -9999 -9999

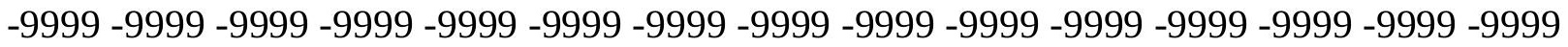

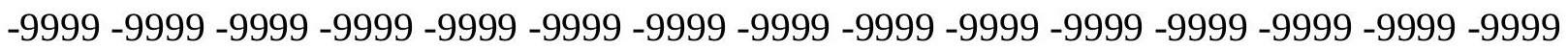
-9999 -9999 -9999 -9999 -9999 -9999 -9999 -9999 -9999 -9999 -9999 -9999 -9999 -9999 -9999

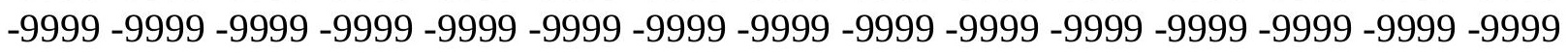

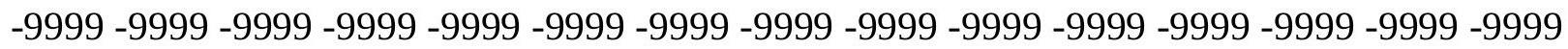
-9999 -9999 -9999-9999

-9999 -9999 -9999 -9999 -9999 -9999 -9999 -9999 -9999 -9999 -9999 -9999 -9999 -9999 -9999

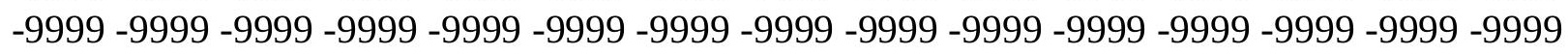

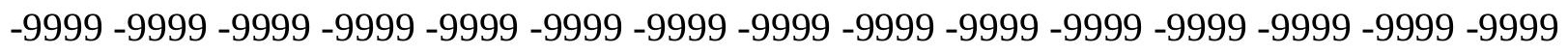
-9999 -9999-9999-9999-9999 -9999-9999 -9999 -9999-9999 -9999-9999 64.30966186523 63.7000885009863 .7000885009864 .3096618652364 .6144485473664 .91924285889 68.2718734741271 .3197174072373 .4532165527374 .9771423339876 .50106811523 77.4154205322377 .7202072143677 .4154205322376 .8058471679775 .58670806885 73.7580032348671 .3197174072368 .8814392089863 .7000885009863 .70008850098 64.004882812564 .3096618652364 .3096618652364 .6144485473664 .61444854736 64.6144485473664 .6144485473664 .6144485473664 .3096618652364 .0048828125 63.7000885009863 .0905189514262 .1761703491261 .5666007995660 .34745025635 59.1283111572357 .909179687556 .3852500915553 .3373985290553 .03261184692 52.4230384826752 .1182594299351 .8134689331151 .5086898803751 .20389938354 51.2038993835451 .5086898803751 .8134689331152 .4230384826753 .03261184692 
53.9469718933154 .8613204956156 .0804595947357 .2995986938558 .82352828979 60.0426712036161 .5666007995662 .7857398986864 .3096618652365 .52880096436 66.7479400634867 .9670867919969 .4910125732470 .7101516723671 .62449645996 72.8436431884874 .062782287675 .2819290161176 .1962814331177 .41542053223 78.3297805786179 .2441329956180 .1584930419981 .0728530883881 .98719787598 82.9015579223683 .5111236572384 .1206970214884 .7302627563585 .33984375 85.9494018554786 .5589828491286 .8637619018687 .4733276367287 .77810668945 88.3876876831188 .6924667358489 .302040100189 .6068267822390 .21640014648 90.5211791992290 .8259735107491 .4355392456191 .4355392456191 .74033355713 92.0450973510792 .6546783447393 .5690307617294 .4833908081195 .09295654297 96.0073165893696 .6168823242297 .2264633178797 .8360290527398 .4455871582 99.0551681518699 .96952056885100 .5791015625101 .1886978149102 .1029968262 102.712600708103 .3221969604104 .2365036011104 .8460998535105 .4557037354 106.0652008057106 .6747970581106 .979598999107 .5891036987108 .1986999512 108.5035018921108 .8082962036109 .1130981445109 .4179000854109 .7226028442 110.0273971558110 .0273971558110 .3321990967110 .3321990967110 .6370010376 110.6370010376110 .6370010376110 .6370010376110 .9418029785110 .9418029785 110.9418029785110 .9266586304110 .5157928467110 .1202163696109 .7403182983 109.3762893677 109.0284576416108.696937561 108.3820114136108.0837020874 107.8021697998107 .5373764038107 .2894134521107 .0581054688106 .8434295654 106.6451416016106 .4631195068106 .2970199585106 .1466293335106 .0115509033 105.8915100098105 .7860412598105 .6947860718105 .6171798706105 .5527496338 105.5007781982105 .4605560303105 .4311523438105 .4115982056105 .400680542 105.3971176147105 .3994369507105 .4061126709105 .4154891968105 .4258804321 105.4355392456105 .4426956177105 .4455718994105 .4422988892105 .4310302734 105.4097824097105 .3766479492105 .3295516968105 .2665328979105 .1854705811 105.0844421387104 .9613342285104 .8142929077104 .6412353516104 .4404220581 104.2097549438103 .9473648071103 .6508102417103 .3178482056102 .9454803467 102.5304031372102 .0688400269101 .4934005737101 .0132675171100 .2742996216 99.6647262573299 .0551681518698 .445587158297 .5312423706196 .92166900635 96.0073165893695 .0929565429794 .1785964965893 .2642517089892 .3498916626 91.4355392456190 .5211791992289 .302040100188 .3876876831187 .47332763672 86.254188537685 .0350494384884 .1206970214882 .9015579223681 .68241119385 80.7680587768679 .5489196777378 .6345596313577 .4154205322376 .50106811523 75.2819290161174 .3675689697373 .4532165527373 .1484298706174 .67236328125 -9999 -9999 -9999 -9999 -9999 -9999 -9999 -9999 -9999 -9999 -9999 -9999 -9999 -9999 -9999 -9999

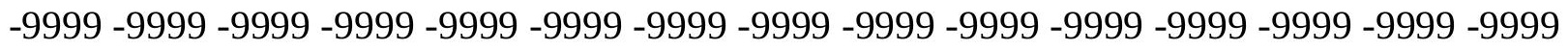

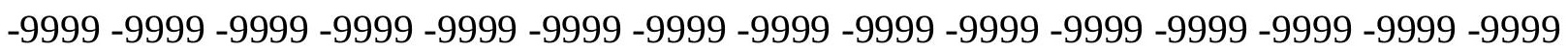
-9999 -9999 -9999 -9999 -9999 -9999 -9999 -9999 -9999 -9999 -9999 -9999 -9999 -9999 -9999 -9999 -9999 -9999 -9999 -9999 -9999 -9999 -9999 -9999 -9999 -9999 -9999 -9999 -9999 -9999 -999 -

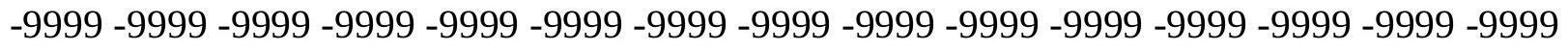
-9999 -9999 -9999 -9999 -9999 -9999 -9999 -9999 -9999 -9999 -9999 -9999 -9999 -9999 -9999 -9999 -9999 -9999 -9999 -9999 -9999 -9999 -9999 -9999 -9999 -9999 -9999 -9999 -9999 -9999 -9999 -9999 -9999 -9999 -9999 -9999 -9999 -9999 -9999 -9999 -9999 -9999 -9999 -9999 -9999

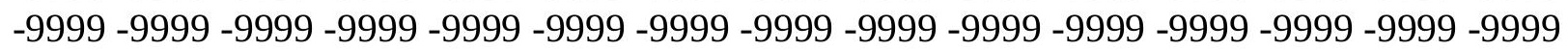
-9999 -9999 -9999 -9999 -9999 -9999 -9999 -9999 -9999 -9999 -9999 -9999 65.22400665283 
64.6144485473664 .004882812564 .3096618652364 .6144485473664 .61444854736 64.6144485473668 .2718734741271 .014930725172 .8436431884874 .67236328125 75.8914871215876 .8058471679776 .8058471679776 .5010681152375 .58670806885 73.7580032348671 .6244964599669 .1862335205163 .3953094482463 .70008850098 64.004882812564 .3096618652364 .6144485473664 .6144485473664 .61444854736 64.9192428588964 .9192428588964 .6144485473664 .6144485473664 .30966186523 64.004882812563 .3953094482462 .4809494018661 .8713798522960 .95701980591 59.7378807067958 .2139587402356 .6900291442955 .1661109924353 .03261184692 52.4230384826752 .1182594299351 .5086898803751 .2038993835450 .89912033081 50.8991203308151 .2038993835451 .5086898803751 .8134689331152 .72782897949 53.6421813964854 .8613204956156 .0804595947357 .2995986938558 .82352828979 60.0426712036161 .5666007995663 .0905189514264 .3096618652365 .83358764648 67.0527267456168 .2718734741269 .7957916259871 .014930725172 .23407745361 73.4532165527374 .3675689697375 .5867080688576 .8058471679777 .72020721436 78.9393463134879 .8537063598680 .7680587768681 .6824111938582 .59677124023 83.5111236572384 .1206970214884 .7302627563585 .3398437585 .94940185547 86.5589828491286 .8637619018687 .4733276367288 .0829010009888 .38768768311 88.9972534179789 .302040100189 .9116134643690 .2164001464890 .52117919922 90.8259735107491 .1307525634891 .4355392456191 .4355392456191 .13075256348 91.1307525634892 .0450973510793 .2642517089894 .1785964965895 .09295654297 96.0073165893696 .6168823242297 .2264633178797 .8360290527398 .4455871582 99.0551681518699 .96952056885100 .5791015625101 .1886978149102 .1029968262 102.712600708103 .3221969604104 .2365036011104 .8460998535105 .4557037354 106.0652008057 106.6747970581 107.2844009399 107.5891036987108.1986999512 108.5035018921108 .8082962036109 .4179000854109 .7226028442110 .0273971558 110.0273971558110 .3321990967110 .3321990967110 .6370010376110 .6370010376 110.9418029785110 .9418029785110 .9418029785110 .9418029785110 .9418029785 110.9418029785111 .24659729110 .8696136475110 .4593582153110 .0644989014 109.6852416992109 .3219451904108 .9747467041108 .6439590454108 .3296279907 108.0319671631107 .7509536743107 .4867248535107 .2391433716107 .0082244873 106.7937927246106 .5958023071106 .4139709473106 .2481918335106 .09815979 105.9637145996105 .8444824219105 .7402267456105 .6504821777105 .5748825073 105.5127868652105 .4635848999105 .426399231105 .4003448486105 .3842697144 105.3769683838105 .3770141602105 .3829574585105 .393196106105 .4061050415 105.4199752808105 .43309021105 .443687439105 .4499435425105 .450012207 105.4419250488105 .4237213135105 .3932876587105 .3486022949105 .2874450684 105.2078094482105 .1074752808104 .9844512939104 .836479187104 .6615982056 104.4575271606104 .2221908569103 .9529037476103 .6469726562103 .3008041382 102.9108428955102 .4736480713101 .9898147583101 .4605789185100 .8839035034 100.274299621699 .6647262573299 .0551681518698 .1408081054797 .53124237061 96.6168823242295 .7025299072394 .7881774902393 .8738174438592 .95947265625 92.0450973510791 .1307525634889 .9116134643688 .9972534179787 .77810668945 86.8637619018685 .6446228027384 .4254837036183 .5111236572382 .29197692871 81.0728530883880 .1584930419978 .9393463134877 .7202072143676 .50106811523 75.5867080688574 .3675689697373 .4532165527372 .8436431884873 .75800323486 74.97714233398 -9999 -9999 -9999 -9999 -9999 -9999 -9999 -9999 -9999 -9999 -9999 -9999 
-9999 -9999 -9999 -9999 -9999 -9999 -9999 -9999 -9999 -9999 -9999 -9999 -9999 -9999 -9999 -9999 -9999 -9999 -9999 -9999 -9999 -9999 -9999 -9999 -9999 -9999 -9999 -9999 -9999 -9999

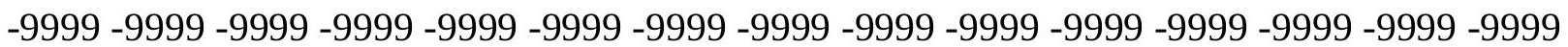
-9999 -9999 -9999 -9999 -9999 -9999 -9999 -9999 -9999 -9999 -9999 -9999 -9999 -9999 -9999 -9999 -9999 -9999 -9999 -9999 -9999 -9999 -9999 -9999 -9999 -9999 -9999 -9999 -9999 -9999

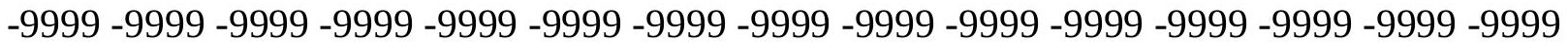
-9999-9999-9999

-9999 -9999 -9999 -9999 -9999 -9999 -9999 -9999 -9999 -9999 -9999 -9999 -9999 -9999 -9999 -9999 -9999 -9999 -9999 -9999 -9999 -9999 -9999 -9999 -9999 -9999 -9999 -9999 -9999 -9999 -9999 -9999 -9999 -9999 -9999 -9999 -9999 -9999 -9999 -9999 -9999 -9999 -9999 -9999 -9999 -9999 -9999 -9999 -9999 -9999 -9999 -9999 -9999 -9999 -9999 -9999 -9999 -9999 65.5288009643664 .9192428588964 .6144485473664 .6144485473664 .61444854736 64.3096618652364 .3096618652367 .0527267456169 .4910125732471 .92929077148 73.7580032348675 .2819290161175 .8914871215875 .5867080688574 .97714233398 73.4532165527371 .3197174072369 .1862335205166 .7479400634863 .70008850098 64.004882812564 .3096618652364 .6144485473664 .6144485473664 .91924285889 64.9192428588964 .9192428588964 .9192428588964 .9192428588964 .61444854736 64.3096618652363 .7000885009863 .0905189514262 .1761703491261 .26181030273 60.3474502563558 .8235282897957 .2995986938555 .4708900451753 .33739852905 52.7278289794952 .1182594299351 .5086898803751 .2038993835450 .89912033081 50.8991203308150 .8991203308151 .2038993835451 .8134689331152 .42303848267 53.3373985290554 .5565414428756 .0804595947357 .2995986938558 .82352828979 60.3474502563561 .8713798522963 .3953094482464 .9192428588966 .13836669922 67.6623001098668 .8814392089870 .1005783081171 .3197174072372 .53885650635 73.7580032348674 .9771423339876 .1962814331177 .110626220778 .32978057861 79.5489196777380 .4632720947381 .3776321411182 .2919769287183 .2063369751 84.1206970214884 .7302627563585 .3398437585 .9494018554786 .55898284912 87.1685485839887 .4733276367288 .0829010009888 .3876876831188 .99725341797 89.6068267822389 .9116134643690 .5211791992290 .8259735107491 .13075256348 91.4355392456191 .4355392456191 .4355392456191 .4355392456191 .43553924561 91.4355392456192 .349891662693 .2642517089894 .1785964965895 .09295654297 96.0073165893696 .6168823242297 .2264633178797 .8360290527398 .4455871582 99.0551681518699 .66472625732100 .5791015625101 .1886978149101 .7982025146 102.712600708103 .3221969604104 .2365036011104 .8460998535105 .4557037354 106.0652008057106 .6747970581107 .2844009399107 .8938980103108 .1986999512 108.8082962036109 .1130981445109 .4179000854109 .7226028442110 .0273971558 110.3321990967110 .6370010376110 .6370010376110 .9418029785110 .9418029785 110.9418029785110 .9418029785110 .9418029785111 .24659729111 .24659729111 .24659729 111.24659729111 .2261505127110 .8006896973110 .390335083109 .9953155518 109.6160049438109 .2525863647108 .905380249108 .5744781494108 .2601165771 107.962310791107 .6812362671107 .4167938232107 .169052124106 .9378890991 106.7233505249106 .5252380371106 .3435440063106 .1780548096106 .0287322998 105.8953170776105 .7776794434105 .6754608154105 .588394165105 .5159072876 105.4574813843105 .4123001099105 .3795623779105 .3581695557105 .3469848633 105.3446502686105 .3498001099105 .3608703613105 .3763122559105 .3944473267 105.4136047363105 .4320526123105 .4479827881105 .4595565796105 .4647979736 
105.461730957105 .4482040405105 .4221191406105 .3811950684105 .3233184814 105.246131897105 .1474838257105 .0249481201104 .876373291104 .6993026733 104.4915084839104 .2501220703103 .9722518921103 .6542129517103 .2926864624 102.8842086792102 .4077987671101 .9182739258101 .3815155029100 .8839035034 100.274299621699 .3599472045998 .7503814697397 .8360290527397 .22646331787 96.3121032714895 .397743225194 .4833908081193 .5690307617292 .65467834473 91.7403335571390 .5211791992289 .6068267822388 .3876876831187 .47332763672 86.254188537685 .0350494384884 .1206970214882 .9015579223681 .68241119385 80.4632720947379 .2441329956178 .0249862670976 .8058471679775 .89148712158 74.6723632812573 .4532165527372 .5388565063572 .8436431884874 .0627822876 -9999 -9999 -9999 -9999 -9999 -9999 -9999 -9999 -9999 -9999 -9999 -9999 -9999 -9999 -9999 -9999 -9999 -9999 -9999 -9999 -9999 -9999 -9999 -9999 -9999 -9999 -9999 -9999 -9999 -9999 -9999 -9999 -9999 -9999 -9999 -9999 -9999 -9999 -9999 -9999 -9999 -9999 -9999 -9999 -9999 -9999 -9999 -9999 -9999 -9999 -9999 -9999 -9999 -9999 -9999 -9999 -9999 -9999 -9999 -9999 -9999 -9999 -9999 -9999 -9999 -9999 -9999 -9999 -9999 -9999 -9999 -9999 -9999 -9999 -9999 -9999

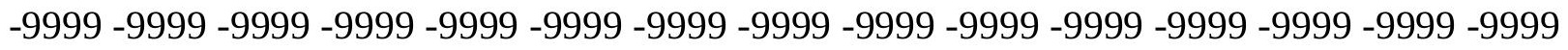
-9999 -9999 -9999 -9999 -9999 -9999 -9999 -9999 -9999 -9999 -9999 -9999 -9999 -9999 -9999 -9999 -9999 -9999 -9999 -9999 -9999 -9999 -9999 -9999 -9999 -9999 -9999 -9999 -9999 -9999 -9999 -9999 -9999 -9999 -9999 -9999 -9999 -9999 -9999 -9999 -9999 -9999 -9999 -9999 -

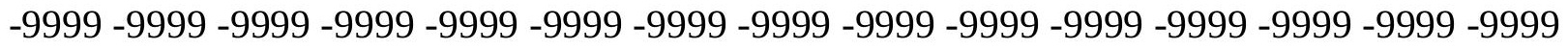
-9999 -9999-9999 -9999-9999 -9999 -9999 -9999 -9999 -9999 -9999 -9999 -9999 -9999 65.5288009643664 .6144485473664 .3096618652364 .3096618652364 .0048828125 63.7000885009863 .3953094482463 .0905189514268 .2718734741271 .0149307251 73.1484298706174 .3675689697374 .3675689697373 .7580032348672 .23407745361 70.7101516723668 .5766525268663 .3953094482463 .7000885009864 .0048828125 64.3096618652364 .6144485473664 .9192428588964 .9192428588965 .22400665283 65.2240066528365 .2240066528365 .2240066528364 .9192428588964 .61444854736 64.3096618652363 .7000885009862 .7857398986862 .1761703491260 .95701980591 59.7378807067957 .909179687556 .0804595947353 .6421813964853 .03261184692 52.7278289794952 .1182594299351 .5086898803751 .2038993835450 .89912033081 50.8991203308151 .2038993835451 .8134689331152 .4230384826753 .64218139648 54.8613204956156 .3852500915557 .909179687559 .4331016540560 .95701980591 62.4809494018664 .004882812565 .5288009643666 .7479400634868 .27187347412 69.4910125732470 .7101516723671 .9292907714873 .1484298706174 .36756896973 75.5867080688576 .5010681152377 .7202072143678 .9393463134879 .85370635986 81.0728530883881 .9871978759882 .9015579223683 .8159103393684 .73026275635 85.33984375 85.94940185547 86.55898284912 87.16854858398 87.47332763672 88.0829010009888 .6924667358488 .9972534179789 .6068267822389 .91161346436 90.5211791992291 .1307525634891 .4355392456191 .7403335571392 .04509735107 92.0450973510792 .0450973510792 .0450973510792 .0450973510792 .04509735107 92.6546783447393 .5690307617294 .4833908081195 .0929565429796 .00731658936 96.6168823242297 .2264633178797 .8360290527398 .445587158299 .05516815186 99.96952056885100 .5791015625101 .1886978149102 .1029968262102 .712600708 103.3221969604104 .2365036011104 .8460998535105 .4557037354106 .0652008057 106.6747970581107 .2844009399107 .8938980103108 .5035018921108 .8082962036 109.4179000854109 .7226028442110 .0273971558110 .3321990967110 .6370010376 
110.6370010376110 .9418029785110 .9418029785111 .24659729111 .24659729111 .24659729 111.24659729111 .24659729111 .24659729111 .24659729111 .24659729111 .24659729 111.143989563110 .717628479110 .3063201904109 .9104766846109 .5302886963 109.1661224365108 .8180999756108 .4864883423108 .1713256836107 .8728256226 107.5909423828107 .3257980347107 .077331543106 .845664978106 .6307067871 106.4325485229106 .2510910034106 .0864105225105 .9383621216105 .8069229126 105.6918411255105 .5929336548105 .5097198486105 .4417572021105 .3882904053 105.3485946655105 .3216323853105 .3063430786105 .3014373779105 .3056259155 105.3174057007105 .3352890015105 .3576431274105 .3828430176105 .4091720581 105.4348449707105 .4580078125105 .4766921997105 .488899231105 .49243927 105.4851608276105 .4647064209105 .4288406372105 .3750991821105 .3011627197 105.2044372559105 .0826034546104 .9330749512104 .7534713745104 .5407943726 104.2920837402104 .0038223267103 .6731185913103 .2965164185102 .8696594238 102.3921966553101 .7982025146101 .1886978149100 .579101562599 .96952056885 99.3599472045998.445587158297.8360290527396.9216690063596.00731658936 95.0929565429794.1785964965893.2642517089892.349891662691.13075256348 90.2164001464888 .9972534179788 .0829010009886 .8637619018685 .64462280273 84.4254837036183 .206336975182 .2919769287181 .0728530883879 .85370635986 78.6345596313577 .4154205322375 .8914871215874 .6723632812573 .45321655273 73.7580032348672 .5388565063573 .14842987061 -9999 -9999 -9999 -9999 -9999 -9999 -9999

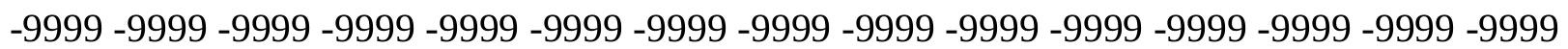
-9999 -9999 -9999 -9999 -9999 -9999 -9999 -9999 -9999 -9999 -9999 -9999 -9999 -9999 -9999 -9999 -9999 -9999 -9999 -9999 -9999 -9999 -9999 -9999 -9999 -9999 -9999-9999-9999-9999 -999 -9999 -9999 -9999 -9999 -9999 -9999 -9999 -9999 -9999 -9999 -9999 -9999 -9999 -9999 -9999 -9999 -9999 -9999 -9999 -9999 -9999 -9999 -9999 -9999 -9999 -9999 -9999 -9999 -9999 -9999 -9999 -9999 -9999 -9999 -9999 -9999 -9999 -9999 -9999 -9999 -9999 -9999 -9999 -9999 -9999 -9999 -9999 -9999 -9999 -9999 -9999 -9999 -9999

-9999 -9999 -9999 -9999 -9999 -9999 -9999 -9999 -9999 -9999 -9999 -9999 -9999 -9999 -9999 -9999 -9999 -9999 -9999 -9999 -9999 -9999 -9999 -9999 -9999 -9999 -9999 -9999 -9999 -9999 -9999 -9999 -9999 -9999 -9999 -9999 -9999 -9999 -9999 -9999 -9999 -9999 -9999 -9999 -9999 -9999 -9999 -9999 -9999 -9999 -9999 -9999 -9999 -9999 -9999 -9999 -9999 -9999 -9999 -9999 65.2240066528364 .6144485473663 .7000885009863 .3953094482463 .39530944824 63.0905189514262 .7857398986862 .4809494018667 .3575134277370 .40535736084 72.5388565063572 .5388565063571 .6244964599670 .4053573608468 .88143920898 67.3575134277363 .3953094482463 .7000885009864 .004882812564 .30966186523 64.6144485473664 .9192428588965 .2240066528365 .2240066528365 .52880096436 65.5288009643665 .5288009643665 .2240066528365 .2240066528364 .61444854736 64.3096618652363 .7000885009862 .7857398986861 .8713798522960 .65224075317 58.8235282897956 .9948196411154 .5565414428753 .9469718933153 .33739852905 52.7278289794952 .1182594299351 .8134689331151 .5086898803751 .20389938354 51.5086898803751 .8134689331152 .7278289794953 .9469718933155 .47089004517 56.9948196411158 .5187492370660 .0426712036161 .8713798522963 .39530944824 64.9192428588966 .1383666992267 .6623001098668 .8814392089870 .10057830811 71.3197174072372 .5388565063573 .7580032348674 .9771423339875 .89148712158 77.110626220778 .3297805786179 .5489196777380 .4632720947381 .68241119385 82.5967712402383 .8159103393684 .7302627563585 .3398437585 .94940185547 
86.5589828491287 .1685485839887 .7781066894588 .0829010009888 .69246673584 88.9972534179789 .6068267822390 .2164001464890 .5211791992291 .13075256348 91.7403335571392 .0450973510792 .349891662692 .349891662692 .65467834473 92.6546783447392 .6546783447392 .6546783447392 .9594726562593 .26425170898 93.8738174438594 .7881774902395 .397743225196 .0073165893696 .61688232422 97.2264633178797 .8360290527398 .445587158299 .0551681518699 .96952056885 100.5791015625101 .1886978149102 .1029968262102 .712600708103 .3221969604 104.2365036011104 .8460998535105 .4557037354106 .3700027466106 .979598999 107.5891036987 107.8938980103108.5035018921 109.1130981445109.4179000854 109.7226028442110 .3321990967110 .6370010376110 .6370010376110 .9418029785 111.24659729111 .24659729111 .24659729111 .24659729111 .24659729111 .24659729 111.24659729111 .24659729111 .24659729111 .24659729111 .24659729111 .24659729 111.0462188721110 .6181182861110 .2052154541109 .8077392578109 .4260787964 109.0603866577108 .7109603882108 .3778839111108 .0613861084107 .7614898682 107.4783630371107 .2120132446106 .9626541138106 .7302780151106 .5150909424 106.3171234131 106.1365737915 105.9733963013105.8276824951 105.6992797852 105.588104248105 .4937362671105 .4158248901105 .3536834717105 .3066635132 105.2737731934105 .2540588379105 .2462844849105 .2492446899105 .261505127 105.2816390991105 .3080596924105 .3392028809105 .3733444214105 .4087295532 105.4434967041105 .4756774902105 .5032272339105 .52394104105 .5355987549 105.5357818604105 .5221405029105 .4920959473105 .4431762695105 .3726577759 105.2780609131105 .1566772461105 .0059967041104 .8229370117104 .6044921875 104.3472595215104 .0485687256103 .7043838501103 .3089599609102 .8544387817 102.3469848633101 .7982025146101 .1886978149100 .579101562599 .96952056885 99.0551681518698 .445587158297 .5312423706196 .6168823242295 .70252990723 94.7881774902393 .8738174438592 .9594726562592 .0450973510790 .82597351074 89.9116134643688 .6924667358487 .4733276367286 .254188537685 .03504943848 83.8159103393682 .5967712402381 .3776321411180 .1584930419978 .93934631348 77.7202072143676 .5010681152375 .2819290161173 .7580032348672 .84364318848 72.5388565063572 .5388565063573 .75800323486 -9999 -9999 -9999 -9999 -9999 -9999 -9999 -9999 -9999 -9999 -9999 -9999 -9999 -9999 -9999 -9999 -9999 -9999 -9999 -9999 -9999 -9999 -9999 -9999 -9999 -9999 -9999 -9999 -9999 -9999 -9999 -9999 -9999 -9999 -9999 -9999 -9999 -

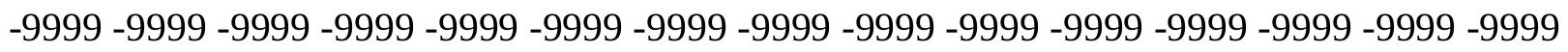

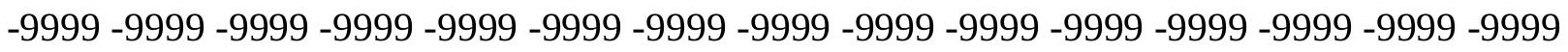
-9999 -9999 -9999 -9999 -9999 -9999 -9999 -9999 -9999 -9999 -9999 -9999 -9999 -9999 -9999

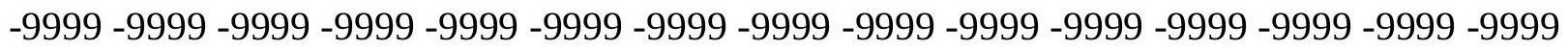
-9999 -9999 -9999-9999-9999-9999-9999

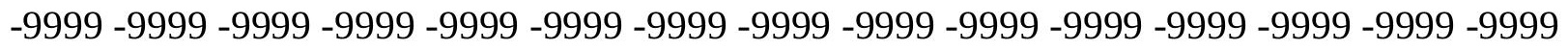
-9999 -9999 -9999 -9999 -9999 -9999 -9999 -9999 -9999 -9999 -9999 -9999 -9999 -9999 -9999 -9999 -9999 -9999 -9999 -9999 -9999 -9999 -9999 -9999 -9999 -9999 -9999 -9999 -9999 - -999 -

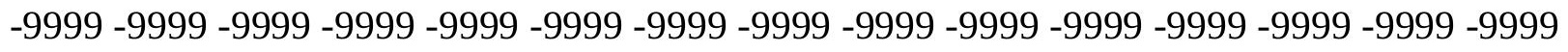
-999964.9192428588964.004882812563.0905189514262.7857398986862.48094940186 62.1761703491261 .8713798522961 .5666007995666 .4431610107469 .49101257324 69.4910125732468 .5766525268667 .6623001098666 .7479400634863 .09051895142 63.3953094482463 .7000885009864 .004882812564 .3096618652364 .91924285889 65.2240066528365 .5288009643665 .5288009643665 .8335876464865 .83358764648 
65.8335876464865 .8335876464865 .5288009643665 .2240066528364 .91924285889 64.3096618652363 .7000885009862 .7857398986861 .5666007995660 .04267120361 57.909179687555 .7756805419955 .1661109924354 .5565414428753 .94697189331 53.3373985290552 .7278289794952 .1182594299351 .8134689331151 .81346893311 52.4230384826753 .3373985290554 .5565414428756 .0804595947357 .9091796875 59.7378807067961 .2618103027363 .0905189514264 .6144485473666 .13836669922 67.3575134277368 .5766525268669 .7957916259871 .014930725172 .23407745361 73.1484298706174 .3675689697375 .5867080688576 .8058471679777 .72020721436 78.9393463134880 .1584930419981 .3776321411182 .2919769287183 .51112365723 84.4254837036185 .3398437585 .9494018554786 .5589828491287 .16854858398 87.7781066894588 .3876876831188 .6924667358488 .9972534179789 .60682678223 89.9116134643690.5211791992291.1307525634892.0450973510792.3498916626 92.9594726562592 .9594726562593 .2642517089893 .2642517089893 .26425170898 93.2642517089893 .2642517089893 .5690307617293 .8738174438594 .48339080811 94.7881774902395 .397743225196 .0073165893696 .6168823242297 .22646331787 97.8360290527398 .445587158299 .0551681518699 .96952056885100 .5791015625 101.1886978149102 .1029968262102 .712600708103 .6268997192104 .2365036011 104.8460998535105 .7603988647106 .3700027466106 .979598999107 .5891036987 108.1986999512108 .8082962036109 .1130981445109 .7226028442110 .0273971558 110.3321990967110 .6370010376110 .9418029785111 .24659729111 .24659729 111.551399231111 .551399231111 .551399231111 .551399231111 .24659729111 .24659729 111.24659729111 .24659729111 .24659729111 .24659729111 .24659729111 .24659729 110.9305877686110 .5001296997110 .084854126109 .6851806641109 .3012924194 108.9335098267 108.5819625854 108.246925354 107.9284439087107.6267623901 107.3419570923 107.0743255615 106.82396698 106.5912017822 106.3761672974 106.1791992188106 .0003585815105 .83984375105 .697593689105 .5736160278 105.467590332105 .3792266846105 .3079147339105 .2530822754105 .2138214111 105.1892471313105 .1781921387105 .1795578003105 .1919555664105 .2140426636 105.2442855835105 .2811584473105 .3229522705105 .3679428101105 .4142379761 105.4598770142105 .502784729105 .5407180786105 .5713882446105 .5923233032 105.6010742188105 .5949478149105 .5713424683105 .5274047852105 .4605331421 105.3678970337105 .2468795776105 .0943145752104 .9071273804104 .6817932129 104.4153594971104 .1024627686103 .7349777222103 .309387207102 .8463134766 102.4077987671101 .7982025146101 .1886978149100 .579101562599 .66472625732 99.0551681518698 .1408081054797 .2264633178796 .6168823242295 .70252990723 94.7881774902393 .5690307617292 .6546783447391 .4355392456190 .52117919922 89.302040100188 .0829010009887 .1685485839885 .9494018554784 .73026275635 83.2063369751 81.98719787598 80.7680587768679.54891967773 78.32978057861 76.8058471679775 .5867080688574 .3675689697373 .1484298706172 .23407745361 72.5388565063572 .84364318848 -9999 -9999 -9999 -9999 -9999 -9999 -9999 -9999 -9999

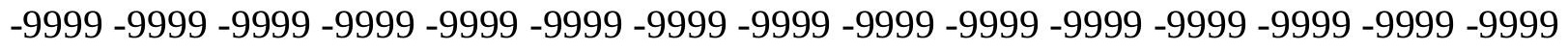

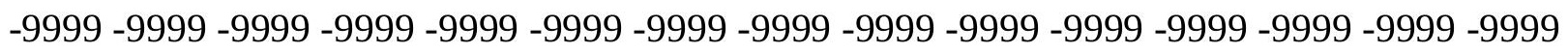
-9999 -9999 -9999 -9999 -9999 -9999 -9999 -9999 -9999 -9999 -9999 -9999 -9999 -9999 -9999 -9999 -9999 -9999 -9999 -9999 -9999 -9999 -9999 -9999 -9999 -9999 -9999 -9999 -9999 -9999 -9999 -9999 -9999 -9999 -9999 -9999 -9999 -9999 -9999 -9999 -9999 -9999 -9999 -9999 -9999 -

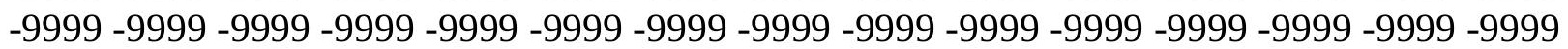


-9999 -9999 -9999 -9999 -9999

-9999 -9999 -9999 -9999 -9999 -9999 -9999 -9999 -9999 -9999 -9999 -9999 -9999 -9999 -

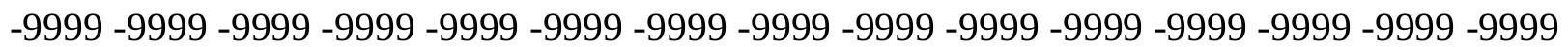

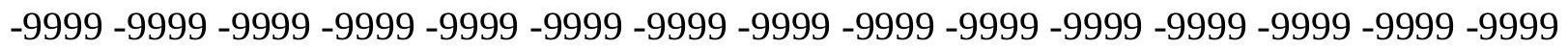

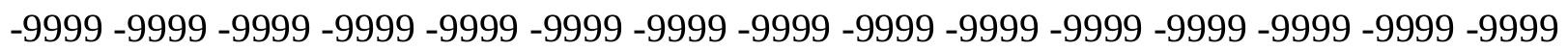

-9999-9999 64.30966186523 63.39530944824 62.4809494018661.87137985229

61.8713798522961 .5666007995661 .2618103027360 .9570198059160 .95701980591

60.6522407531760 .6522407531762 .1761703491262 .4809494018662 .78573989868

63.3953094482463 .7000885009864 .004882812564 .6144485473664 .91924285889

65.2240066528365 .5288009643665 .8335876464866 .1383666992266 .44316101074 66.4431610107466 .4431610107466 .1383666992266 .1383666992265 .83358764648 65.2240066528364 .6144485473663 .7000885009862 .7857398986860 .95701980591 57.6043891906756 .9948196411156 .6900291442956 .0804595947355 .47089004517 54.8613204956154 .2517509460453 .6421813964853 .0326118469253 .03261184692 53.3373985290554 .2517509460455 .7756805419957 .6043891906759 .43310165405 61.2618103027363 .0905189514264 .6144485473666 .1383666992267 .35751342773 68.5766525268669 .7957916259871 .014930725171 .9292907714873 .14842987061 74.062782287675 .2819290161176 .1962814331177 .4154205322378 .32978057861 79.5489196777380 .7680587768681 .9871978759882 .9015579223684 .12069702148 85.0350494384885 .9494018554786 .5589828491287 .4733276367287 .77810668945 88.3876876831188 .6924667358489 .302040100189 .6068267822389 .91161346436 90.5211791992291 .1307525634892 .0450973510792 .6546783447393 .26425170898 93.5690307617293 .8738174438593 .8738174438593 .8738174438593 .87381744385 93.8738174438593 .8738174438594 .1785964965894 .4833908081194 .78817749023 95.0929565429795 .7025299072396 .3121032714896 .6168823242297 .22646331787 97.8360290527398 .445587158299 .0551681518699 .96952056885100 .5791015625 101.1886978149102 .1029968262102 .712600708103 .6268997192104 .2365036011 105.1509017944105 .7603988647106 .3700027466107 .2844009399107 .8938980103 108.5035018921108 .8082962036109 .4179000854110 .0273971558110 .3321990967 110.6370010376110 .9418029785111 .24659729111 .551399231111 .551399231 111.551399231111 .551399231111 .551399231111 .551399231111 .551399231111 .24659729 111.24659729111 .24659729110 .9418029785110 .9418029785110 .9418029785 110.9418029785111 .2436676025110 .7951660156110 .3615951538109 .9434051514 109.540802002 109.1541366577 108.7835769653 108.4294433594108.0918273926 107.7710266113107 .4672012329107 .1807250977106 .9118118286106 .6608886719 106.4282226562106 .2142562866106 .0191574097105 .84324646105 .6865463257 105.5491638184105.430847168 105.331413269 105.2503128052105.1870727539 105.1408538818105 .1108627319105 .0960083008105 .0952835083105 .1073684692 105.1310043335105 .1647033691105 .206993103105 .256187439105 .3105697632 105.3682403564 105.4272384644 105.4854354858 105.5405731201 105.5902862549 105.6320495605105 .6633148193105 .6812973022105 .683265686105 .666267395 105.627571106105 .5642471313105 .4735717773105 .3522949219105 .1971740723 105.0043334961104 .7700195312104 .4882125854104 .1547546387103 .7614822388 103.2883300781102 .712600708102 .4077987671101 .7982025146100 .8839035034 100.274299621699 .6647262573298 .7503814697398 .1408081054797 .22646331787 96.3121032714895 .397743225194 .4833908081193 .2642517089892 .3498916626 
91.1307525634890 .2164001464888 .9972534179787 .7781066894586 .55898284912 85.3398437584 .1206970214882 .5967712402381 .3776321411180 .15849304199 78.9393463134877 .4154205322376 .1962814331174 .9771423339873 .75800323486 72.8436431884872 .5388565063572 .5388565063573 .45321655273 -9999 -9999 -9999 -9999 -9999 -9999 -9999 -9999 -9999 -9999 -9999 -9999 -9999 -9999 -9999 -9999 -9999 -9999 -9999 -9999 -9999 -9999 -9999 -9999 -9999 -9999 -9999 -9999 -9999 -9999 -9999 -9999 -9999 -9999

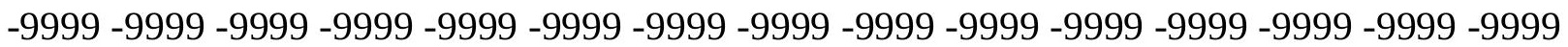

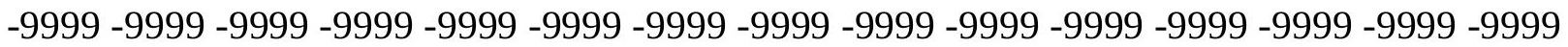

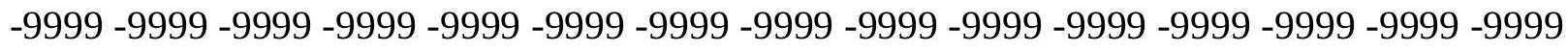
-9999 -9999 -9999 -9999 -9999 -9999 -9999 -9999 -9999 -9999 -9999 -9999 -9999 -9999 -9999 -9999 -9999 -9999 -9999 -9999 -9999 -9999 -9999 -9999

-9999 -9999 -9999 -9999 -9999 -9999 -9999 -9999 -9999 -9999 -9999 -9999 -9999 -9999 -9999 -9999 -9999 -9999 -9999 -9999 -9999 -9999 -9999 -9999 -9999 -9999 -9999 -9999 -9999 -9999 -9999 -9999 -9999 -9999 -9999 -9999 -9999 -9999 -9999 -9999 -9999 -9999 -9999 -9999 - 9999 -9999 -9999 -9999 -9999 -9999 -9999 -9999 -9999 -9999 -9999 -9999 -9999 -9999 -9999 -9999 -9999 -9999-999963.3953094482462.4809494018661.56660079956 61.26181030273 60.9570198059160 .6522407531760 .6522407531760 .3474502563560 .34745025635 61.8713798522962 .1761703491262 .4809494018662 .7857398986863 .39530944824 63.7000885009864 .3096618652364 .6144485473665 .2240066528365 .52880096436 66.1383666992266 .4431610107466 .7479400634866 .7479400634867 .05272674561 67.0527267456167 .0527267456166 .7479400634866 .4431610107466 .13836669922 65.5288009643664 .6144485473663 .7000885009862 .1761703491259 .12831115723 58.8235282897958 .5187492370658 .2139587402357 .6043891906756 .99481964111 56.0804595947355 .4708900451754 .8613204956154 .2517509460454 .55654144287 55.7756805419957 .2995986938559 .4331016540561 .5666007995663 .39530944824 64.9192428588966 .4431610107467 .9670867919969 .1862335205170 .40535736084 71.3197174072372 .2340774536173 .1484298706174 .062782287675 .28192901611 76.1962814331177 .110626220778 .0249862670979 .2441329956180 .15849304199 81.3776321411182 .5967712402383 .5111236572384 .7302627563585 .64462280273 86.5589828491287 .4733276367287 .7781066894588 .3876876831188 .69246673584 89.302040100189 .6068267822389 .9116134643690 .5211791992291 .13075256348 91.7403335571392 .6546783447393 .8738174438594 .4833908081194 .78817749023 94.7881774902394 .4833908081194 .4833908081194 .4833908081194 .48339080811 94.4833908081194 .4833908081194 .7881774902395 .0929565429795 .3977432251 95.7025299072396 .3121032714896 .9216690063597 .2264633178797 .83602905273 98.445587158299 .3599472045999 .96952056885100 .5791015625101 .4934005737 102.1029968262103 .0174026489103 .6268997192104 .5412979126105 .1509017944 106.0652008057106 .6747970581107 .2844009399107 .8938980103108 .5035018921 109.1130981445109 .7226028442110 .0273971558110 .6370010376110 .9418029785 111.24659729111 .551399231111 .551399231111 .8561019897111 .8561019897 111.8561019897111 .8561019897111 .551399231111 .551399231111 .24659729111 .24659729 110.9418029785110 .9418029785110 .9418029785110 .6370010376110 .6370010376 110.9418029785110 .9418029785110 .6379776001110 .2007904053109 .7789764404 109.3729248047108 .9828414917108 .609085083108 .2518005371107 .9113464355 107.5879440308107 .2820663452106 .9940261841106 .7243652344106 .4734649658 106.2418823242106 .0298995972105 .8379364014105 .6660995483105 .5146026611 
105.3832778931105 .272026062105 .1804046631105 .1080322266105 .054145813 105.0180511475104 .9987487793104 .9953155518105 .0065231323105 .0311889648 105.0678710938105 .1151580811105 .1713943481105 .2348709106105 .3036804199 105.3758468628105 .4492111206105 .5214691162105 .5902099609105 .6528244019 105.7066879272105 .7489242554105 .7766876221105 .7869186401105 .7767791748 105.7432403564105 .6835021973105 .5941772461105 .4717941284105 .3120117188 105.1102752686104 .8603820801104 .5592193604104 .2033615112103 .7937240601 103.3221969604102 .712600708102 .1029968262101 .4934005737100 .8839035034 100.274299621699 .3599472045998 .7503814697397 .8360290527396 .92166900635 96.0073165893695 .0929565429794 .1785964965892 .9594726562592 .04509735107 90.8259735107489 .6068267822388 .3876876831187 .1685485839885 .94940185547 84.7302627563583 .5111236572382 .2919769287180 .7680587768679 .54891967773 78.3297805786177 .110626220775 .8914871215874 .6723632812573 .45321655273 72.5388565063572 .5388565063572 .84364318848 -9999 -9999 -9999 -9999 -9999 -9999 -9999 -9999 -9999 -9999 -9999 -9999 -9999 -9999 -9999 -9999 -9999 -9999 -9999 -9999 -9999 -9999

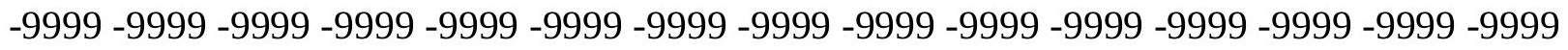
-9999 -9999 -9999 -9999 -9999 -9999 -9999 -9999 -9999 -9999 -9999 -9999 -9999 -9999 -9999 -9999 -9999 -9999 -9999 -9999 -9999 -9999 -9999 -9999 -9999 -9999 -9999 -9999 -9999 -9999 -

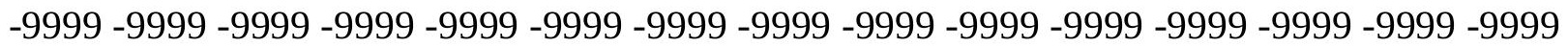

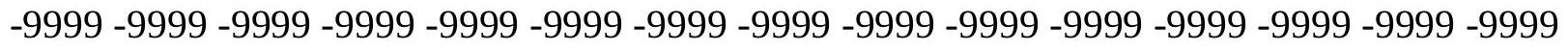
-9999 -9999 -9999-9999-9999-9999

-9999 -9999 -9999 -9999 -9999 -9999 -9999 -9999 -9999 -9999 -9999 -9999 -9999 -9999 -9999 -9999 -9999 -9999 -9999 -9999 -9999 -9999 -9999 -9999 -9999 -9999 -9999 -9999 -9999 -9999 -

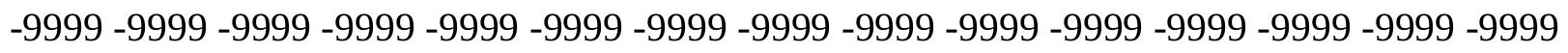

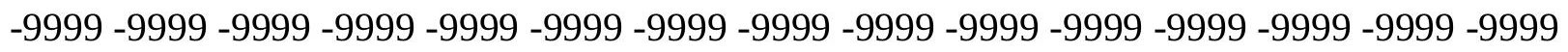
-9999 -9999 -9999 -9999 62.48094940186 61.56660079956 60.9570198059160.34745025635 60.3474502563560 .0426712036160 .0426712036161 .5666007995661 .87137985229 62.1761703491262 .4809494018662 .7857398986863 .3953094482464 .0048828125 64.3096618652364 .9192428588965 .5288009643665 .8335876464866 .44316101074 66.7479400634867 .0527267456167 .3575134277367 .6623001098667 .66230010986 67.6623001098667 .6623001098667 .3575134277367 .0527267456166 .44316101074 65.8335876464864 .6144485473663 .3953094482461 .2618103027360 .95701980591 60.9570198059160 .6522407531760 .3474502563559 .7378807067959 .12831115723 58.2139587402357 .2995986938556 .6900291442956 .6900291442957 .9091796875 60.0426712036162 .1761703491264 .3096618652366 .1383666992267 .66230010986 68.8814392089870 .1005783081171 .3197174072372 .2340774536172 .84364318848 73.7580032348674 .6723632812575 .2819290161176 .1962814331177 .1106262207 78.0249862670978 .9393463134879 .8537063598681 .0728530883881 .98719787598 83.2063369751 84.12069702148 85.33984375 86.55898284912 87.47332763672 88.0829010009888 .3876876831188 .6924667358488 .9972534179789 .60682678223 89.9116134643690.52117919922 91.1307525634891.7403335571392.65467834473 93.8738174438595 .0929565429795 .397743225195 .397743225195 .3977432251 95.397743225195.0929565429795.0929565429794.7881774902394.78817749023 95.0929565429795 .0929565429795 .397743225195 .7025299072396 .00731658936 96.3121032714896 .9216690063597 .5312423706198 .1408081054798 .75038146973 99.3599472045999 .96952056885100 .5791015625101 .4934005737102 .1029968262 
103.0174026489103 .6268997192104 .5412979126105 .4557037354106 .0652008057 106.979598999107 .5891036987108 .1986999512108 .8082962036109 .4179000854 110.0273971558110 .3321990967110 .9418029785111 .24659729111 .551399231 111.8561019897111 .8561019897112 .1608963013112 .1608963013112 .1608963013 111.8561019897111 .8561019897111 .551399231111 .24659729110 .9418029785 110.9418029785110 .6370010376110 .6370010376110 .3321990967110 .3321990967 110.3321990967110 .6370010376110 .6370010376110 .4574050903110 .015914917 109.5900115967109 .1799087524108 .786026001108 .4085540771108 .0479125977 107.7043914795107 .3785629272107 .07081604106 .781829834106 .5120697021 106.26222229106 .032661438105 .8239135742105 .6361618042105 .4697341919 105.3245544434105 .200630188105 .0976104736105 .0152282715104 .9528121948 104.9097824097104 .8852386475104 .8783569336104 .8879852295104 .9130325317 104.9521179199105 .0038833618105 .0666885376105 .1388549805105 .2184677124 105.3035430908105 .3918685913105 .4811172485105 .5687942505105 .6522445679 105.7287368774105 .7953186035105 .8490219116105 .8866958618105 .9054107666 105.9020614624105 .8737411499105 .8169555664105 .7280044556105 .6021652222 105.4344558716105 .2193450928104 .9534454346104 .6359939575104 .2365036011 103.9317016602103 .3221969604102 .712600708102 .1029968262101 .4934005737 100.8839035034100 .274299621699 .3599472045998 .445587158297 .83602905273 96.9216690063596 .0073165893694 .7881774902393 .8738174438592 .65467834473 91.7403335571390 .5211791992289 .302040100188 .0829010009886 .86376190186 85.6446228027384 .1206970214882 .9015579223681 .6824111938580 .46327209473 78.9393463134877 .7202072143676 .5010681152375 .5867080688574 .36756896973 73.4532165527372 .5388565063572 .8436431884873 .45321655273 -9999 -9999 -9999-9999

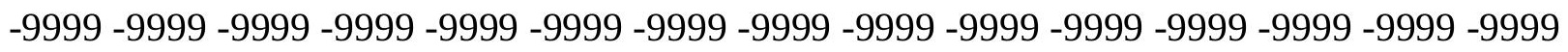
-9999 -9999 -9999 -9999 -9999 -9999 -9999 -9999 -9999 -9999 -9999 -9999 -9999 -9999 -9999 -

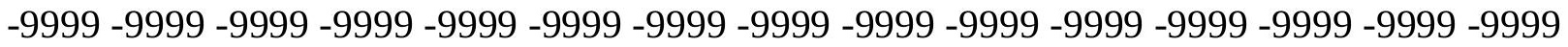

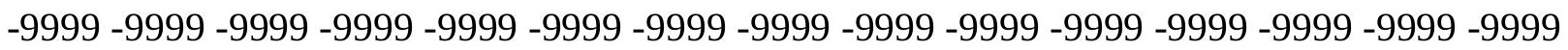
-9999 -9999 -9999 -9999 -9999 -9999 -9999 -9999 -9999 -9999 -9999 -9999 -9999 -9999 -9999

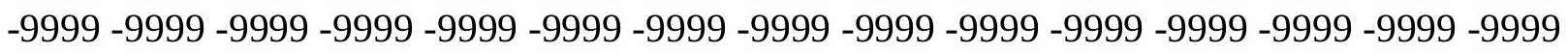
-9999 -9999 -9999 -9999 -9999 -9999-9999 -9999

-9999 -9999 -9999 -9999 -9999 -9999 -9999 -9999 -9999 -9999 -9999 -9999 -9999 -9999 -9999

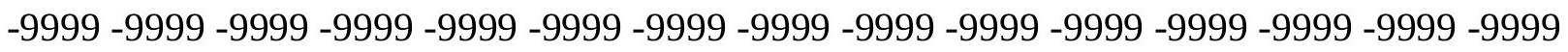
-9999 -9999 -9999 -9999 -9999 -9999 -9999 -9999 -9999 -9999 -9999 -9999 -9999 -9999 -9999

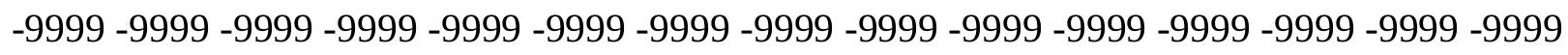
-9999 -9999 -9999 -9999 -9999 61.5666007995660 .6522407531760 .04267120361 61.2618103027359 .7378807067961 .2618103027361 .2618103027361 .56660079956 61.8713798522962 .4809494018663 .0905189514263 .3953094482464 .0048828125 64.6144485473665 .2240066528365 .8335876464866 .4431610107466 .74794006348 67.3575134277367 .6623001098667 .9670867919968 .2718734741268 .57665252686 68.5766525268668 .5766525268668 .5766525268668 .2718734741267 .66230010986 67.0527267456166 .1383666992264 .9192428588963 .3953094482463 .39530944824 63.3953094482463 .3953094482463 .3953094482463 .0905189514262 .78573989868 61.8713798522960 .9570198059160 .0426712036159 .4331016540561 .26181030273 63.7000885009865 .8335876464867 .6623001098669 .4910125732470 .71015167236 71.9292907714872 .8436431884873 .4532165527374 .062782287674 .67236328125 
75.2819290161176 .1962814331176 .8058471679777 .4154205322378 .32978057861 78.9393463134879 .8537063598680 .7680587768681 .6824111938582 .59677124023 83.5111236572384 .7302627563585 .9494018554786 .8637619018688 .08290100098 88.3876876831188 .6924667358488 .9972534179789 .302040100189 .91161346436 90.2164001464890 .8259735107491 .4355392456192 .349891662693 .56903076172 95.0929565429796 .3121032714896 .3121032714896 .3121032714896 .00731658936 95.7025299072395 .7025299072395 .397743225195 .397743225195 .3977432251 95.397743225195 .397743225195 .7025299072395 .7025299072396 .00731658936 96.6168823242296 .9216690063597 .5312423706198 .1408081054798 .75038146973 99.3599472045999 .96952056885100 .5791015625101 .4934005737102 .4077987671 103.0174026489103 .9317016602104 .8460998535105 .4557037354106 .3700027466 106.979598999107 .8938980103108 .5035018921109 .1130981445109 .7226028442 110.3321990967110 .6370010376111 .24659729111 .551399231111 .8561019897 112.1608963013112 .1608963013112 .1608963013112 .4656982422112 .1608963013 112.1608963013111 .8561019897111 .551399231111 .24659729110 .9418029785 110.6370010376110 .6370010376110 .3321990967110 .0273971558110 .0273971558 110.0273971558110 .0273971558110 .3321990967110 .3321990967110 .2518005371 109.8055877686109 .3750152588108 .9605331421108 .5623855591108 .1810531616 107.8168945312107 .4705581665107 .1425476074106 .8336181641106 .5443496704 106.2755355835106 .0276412964105 .80128479105 .5967636108105 .4144897461 105.254486084105 .116897583105 .0014648438104 .9080505371104 .8361129761 104.7851867676104 .7544631958104 .7432479858104 .7504730225104 .7751312256 104.81590271104 .8715133667104 .9403152466105 .0206832886105 .1106796265 105.2083129883105 .3113327026105 .4173583984105 .5238265991105 .6280288696 105.7271194458105 .8180618286105 .8977890015105 .9630508423106 .0108108521 106.0379180908106 .0414047241106 .0177307129105 .963104248105 .8726425171 105.7412033081105 .5631561279105 .3363723755105 .0595855713104 .7102890015 104.2365036011103 .9317016602103 .3221969604102 .712600708102 .1029968262 101.4934005737100 .883903503499 .9695205688599 .3599472045998 .4455871582 97.5312423706196 .6168823242295 .7025299072394 .4833908081193 .56903076172 92.349891662691 .4355392456190 .2164001464888 .9972534179787 .47332763672 86.254188537685 .0350494384883 .8159103393682 .5967712402381 .07285308838 79.8537063598678 .6345596313577 .4154205322376 .1962814331175 .28192901611 74.3675689697373 .1484298706172 .8436431884873 .14842987061 -9999 -9999 -9999 -9999 -9999 -9999 -9999 -9999 -9999 -9999 -9999 -9999 -9999 -9999 -9999 -9999 -9999 -9999 -9999 -9999 -9999 -9999 -9999 -9999 -9999 -9999 -9999 -9999 -9999 -9999 -9999 -9999 -9999 - -9999 -

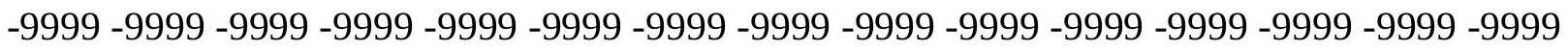

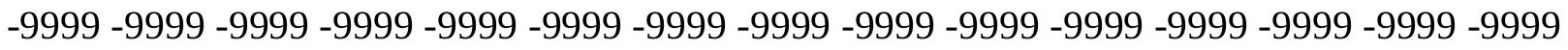
-9999 -9999 -9999 -9999 -9999 -9999 -9999 -9999 -9999 -9999 -9999 -9999 -9999 -9999 -9999 -

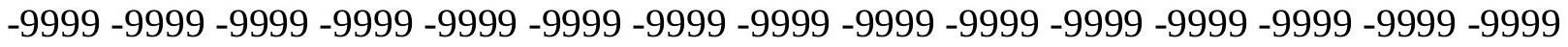
-9999 -9999 -9999-9999-9999 -9999-9999-9999

-9999 -9999 -9999 -9999 -9999 -9999 -9999 -9999 -9999 -9999 -9999 -9999 -9999 -9999 -9999 -9999 -9999 -9999 -9999 -9999 -9999 -9999 -9999 -9999 -9999 -9999 -9999 -9999 -9999 -9999 -9999 -9999 -9999 -9999 -9999 -9999 -9999 -9999 -9999 -9999 -9999 -9999 -9999 -9999 -9999 -

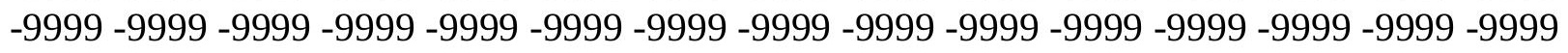
-9999 -9999 -9999 -9999 -9999-9999 60.34745025635 59.7378807067959 .43310165405 
60.9570198059160 .9570198059161 .2618103027361 .5666007995661 .87137985229 62.4809494018663 .0905189514263 .7000885009864 .3096618652364 .91924285889 65.5288009643666 .1383666992266 .7479400634867 .3575134277367 .96708679199 68.5766525268668 .8814392089869 .1862335205169 .4910125732469 .79579162598 69.7957916259869 .4910125732469 .4910125732469 .1862335205168 .57665252686 67.6623001098665 .5288009643665 .8335876464866 .1383666992266 .44316101074 66.7479400634867 .3575134277367 .3575134277367 .3575134277367 .05272674561 66.1383666992265 .5288009643665 .5288009643666 .7479400634868 .57665252686 70.4053573608471 .9292907714873 .4532165527374 .3675689697374 .97714233398 75.5867080688575 .8914871215876 .5010681152376 .8058471679777 .1106262207 77.7202072143678 .3297805786178 .6345596313579 .2441329956180 .15849304199 80.7680587768681 .6824111938582 .2919769287183 .206336975184 .12069702148 85.03504943848 86.2541885376 87.16854858398 88.08290100098 88.38768768311 88.6924667358489 .302040100189 .6068267822390 .2164001464890 .52117919922 91.1307525634892 .0450973510792 .9594726562594 .1785964965895 .3977432251 96.3121032714896 .6168823242296 .6168823242296 .3121032714896 .31210327148 96.0073165893696 .0073165893695 .7025299072395 .7025299072395 .70252990723 95.7025299072395 .7025299072396 .0073165893696 .3121032714896 .61688232422 96.9216690063597 .5312423706198 .1408081054798 .7503814697399 .35994720459 99.96952056885100 .8839035034101 .4934005737102 .4077987671103 .0174026489 103.9317016602104 .8460998535105 .7603988647106 .3700027466107 .2844009399 107.8938980103108 .8082962036109 .4179000854110 .0273971558110 .3321990967 110.9418029785111 .551399231111 .8561019897112 .1608963013112 .1608963013 112.4656982422112 .4656982422112 .4656982422112 .4656982422112 .1608963013 111.8561019897111 .551399231111 .24659729110 .9418029785110 .6370010376 110.3321990967110 .0273971558109 .7226028442109 .7226028442109 .7226028442 109.7226028442109 .7226028442109 .7226028442110 .0273971558110 .0199050903 109.5684356689109 .1329116821108 .7136306763108 .3111190796107 .9258117676 107.5584335327107 .209564209106 .8800506592106 .5705795288106 .2820281982 106.0149612427105 .7700958252105 .5478134155105 .3486557007105 .172744751 105.0203475952104 .8913574219104 .7857589722104 .7031326294104 .6431808472 104.6051940918104 .5886154175104 .5924530029104 .615814209104 .6574401855 104.7161178589104 .7902526855104 .8782272339104 .9780883789105 .0878448486 105.2051925659105 .3277053833105 .4527511597105 .5775375366105 .6991348267 105.8143997192105 .9201507568106 .013053894106 .0899810791106 .1477203369 106.1832962036106 .1932220459106 .1737670898106 .1202011108106 .027633667 105.8901824951105 .701423645105 .4557037354105 .1509017944104 .8460998535 104.2365036011103 .9317016602103 .3221969604102 .712600708102 .1029968262 101.4934005737100 .883903503499 .9695205688599 .3599472045998 .4455871582 97.5312423706196 .6168823242295 .397743225194 .4833908081193 .26425170898 92.0450973510790 .8259735107489 .6068267822388 .3876876831187 .16854858398 85.9494018554784 .7302627563583 .206336975181 .9871978759880 .76805877686 79.5489196777378 .3297805786177 .110626220776 .1962814331174 .97714233398 74.062782287673 .1484298706173 .1484298706173 .45321655273 -9999 -9999 -9999 -9999 -9999 -9999 -9999 -9999 -9999 -9999 -9999 -9999 -9999 -9999 -9999 -9999 -9999 -9999 -9999 -9999 -9999 -9999 -9999 -9999 -9999 -9999 -9999 -9999 -9999 -9999 -9999 -9999 -9999 -9999 
-9999 -9999 -9999 -9999 -9999 -9999 -9999 -9999 -9999 -9999 -9999 -9999 -9999 -9999 -9999 -9999 -9999 -9999 -9999 -9999 -9999 -9999 -9999 -9999 -9999 -9999 -9999 -9999 -9999 -9999

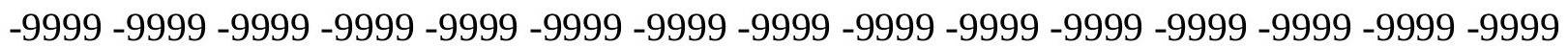
-9999 -9999 -9999 -9999 -9999 -9999 -9999 -9999 -9999 -9999 -9999 -9999 -9999 -9999 -9999 -9999 -9999 -9999 -9999 -9999 -9999 -9999

-9999 -9999 -9999 -9999 -9999 -9999 -9999 -9999 -9999 -9999 -9999 -9999 -9999 -9999 -9999 -9999 -9999 -9999 -9999 -9999 -9999 -9999 -9999 -9999 -9999 -9999 -9999 -9999 -9999 -9999

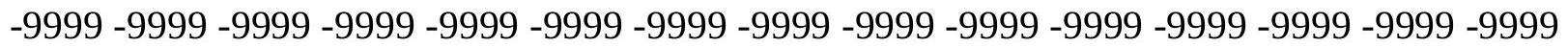
-9999 -9999 -9999 -9999 -9999 -9999 -9999 -9999 -9999 -9999 -9999 -9999 -9999 -9999 -9999 -9999 -9999 -9999 -9999 -9999-9999 -9999 59.43310165405 59.1283111572359 .12831115723 60.6522407531760 .9570198059161 .5666007995661 .8713798522962 .48094940186 63.0905189514264 .004882812564 .6144485473665 .2240066528365 .83358764648 66.7479400634867 .3575134277367 .9670867919968 .5766525268669 .18623352051 69.7957916259870 .1005783081170 .4053573608470 .7101516723671 .0149307251 71.014930725170 .7101516723670 .7101516723670 .1005783081169 .79579162598 67.6623001098667 .9670867919968 .5766525268669 .4910125732470 .71015167236 71.6244964599672 .5388565063572 .8436431884872 .8436431884872 .53885650635 72.2340774536172 .2340774536173 .1484298706174 .3675689697375 .58670806885 76.8058471679777 .7202072143678 .3297805786178 .3297805786178 .63455963135 78.6345596313578 .6345596313578 .9393463134878 .9393463134879 .24413299561 79.8537063598680 .1584930419980 .7680587768681 .3776321411181 .98719787598 82.5967712402383 .206336975184 .1206970214884 .7302627563585 .64462280273 86.5589828491287 .1685485839887 .7781066894588 .3876876831188 .69246673584 89.302040100189 .6068267822390 .2164001464890 .8259735107491 .43553924561 92.349891662693 .5690307617294 .4833908081195 .7025299072396 .31210327148 96.6168823242296 .9216690063596 .6168823242296 .6168823242296 .31210327148 96.0073165893696 .0073165893696 .0073165893695 .7025299072395 .70252990723 96.0073165893696 .0073165893696 .3121032714896 .6168823242297 .22646331787 97.5312423706198 .1408081054798 .7503814697399 .3599472045999 .96952056885 100.8839035034101 .4934005737102 .4077987671103 .3221969604104 .2365036011 104.8460998535105 .7603988647106 .6747970581107 .5891036987108 .1986999512 108.8082962036109 .7226028442110 .3321990967110 .6370010376111 .24659729 111.551399231112 .1608963013112 .4656982422112 .4656982422112 .7705001831 112.7705001831112 .7705001831112 .4656982422112 .1608963013111 .8561019897 111.551399231111 .24659729110 .6370010376110 .3321990967110 .0273971558 109.7226028442109 .4179000854109 .4179000854109 .1130981445109 .1130981445 109.1130981445109 .4179000854109 .4179000854109 .7226028442109 .7605361938 109.3035583496108.8627090454108.4385681152108.0316238403107.6426620483 107.2723312378 106.9215774536106.5911560059 106.2820358276 105.9948654175 105.7304763794105 .4893493652105 .2721481323105 .0791091919104 .9106521606 104.7668075562104 .6477279663104 .5531387329104 .4828872681104 .4364089966 104.4132766724104 .4126205444104 .4336395264104 .4751586914104 .5360336304 104.6147003174104 .7095718384104 .818687439104 .9400405884105 .0712738037 105.2099151611105 .3532409668105 .4983901978105 .6423187256105 .781791687 105.9135055542106 .034034729106 .1401596069106 .2286376953106 .2965011597 106.3403396606106 .3565597534106 .3406829834106 .2878952026106 .1925964355 
106.0501480103 105.8540878296105.5738525391 105.1509017944104.8460998535 104.2365036011103 .9317016602103 .3221969604102 .712600708102 .1029968262 101.4934005737100 .883903503499 .9695205688599 .0551681518698 .14080810547 97.2264633178796 .3121032714895 .0929565429794 .1785964965892 .95947265625 91.7403335571390 .5211791992289 .302040100188 .0829010009886 .86376190186 85.6446228027384 .4254837036182 .9015579223681 .6824111938580 .46327209473 79.2441329956178 .0249862670977 .110626220775 .8914871215874 .97714233398 74.062782287673 .1484298706173 .4532165527374 .0627822876 -9999 -9999 -9999-9999 -9999 -9999 -9999 -9999 -9999 -9999 -9999 -9999 -9999 -9999 -9999 -9999 -9999 -9999 -9999 -9999 -9999 -9999 -9999 -9999 -9999 -9999 -9999 -9999 -9999 -9999 -9999 -9999 -9999 -9999 -9999 -9999 -9999 -9999 -9999 -9999 -9999 -9999 -9999 -9999 -9999 -9999 -9999 -9999 -9999 -9999 -9999 -9999 -9999 -9999 -9999 -9999 -9999 -9999 -9999 -9999 -9999 -9999 -9999 -9999 -9999 -9999 -9999 -9999 -9999 -9999 -9999 -9999 -9999 -9999 -9999 -9999 -9999 -9999 -9999 -9999 -9999 -9999 -9999 -9999 -9999 -9999 -9999 -9999 -9999 -9999 -9999 -9999 -9999 -9999 -9999 -9999 -9999-9999-9999-9999

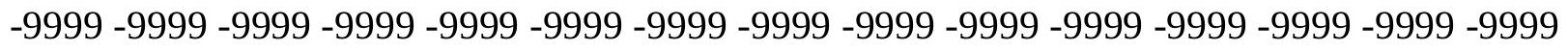

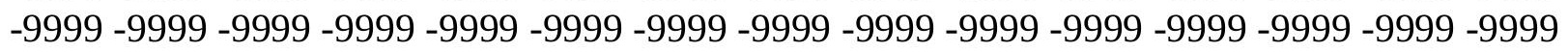

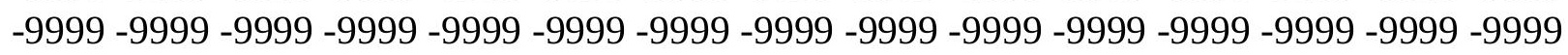

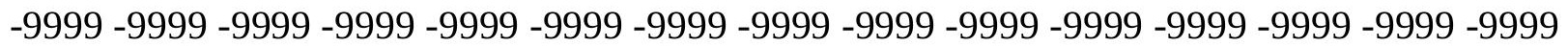
-9999 -9999-9999 -9999-9999 -9999 -9999 -9999 58.82352828979 58.82352828979 59.1283111572360 .9570198059161 .5666007995662 .1761703491262 .78573989868 63.3953094482464 .3096618652364 .9192428588965 .5288009643666 .44316101074 67.0527267456167 .9670867919968 .5766525268669 .4910125732470 .10057830811 70.7101516723671 .3197174072371 .6244964599671 .9292907714872 .23407745361 72.2340774536172 .2340774536172 .2340774536172 .2340774536171 .92929077148 71.9292907714870 .4053573608471 .3197174072372 .5388565063574 .67236328125 76.5010681152378 .0249862670978 .9393463134879 .5489196777379 .54891967773 79.2441329956179 .5489196777379 .8537063598680 .7680587768681 .68241119385 82.2919769287182 .5967712402382 .2919769287181 .9871978759881 .68241119385 81.0728530883881 .0728530883880 .7680587768681 .0728530883881 .07285308838 81.3776321411181 .6824111938581 .9871978759882 .5967712402383 .2063369751 83.8159103393684 .1206970214884 .7302627563585 .3398437585 .94940185547 86.8637619018687 .1685485839887 .7781066894588 .3876876831188 .69246673584 89.302040100189 .9116134643690 .5211791992291 .1307525634892 .04509735107 92.9594726562593 .8738174438594 .7881774902395 .7025299072396 .31210327148 96.6168823242296 .9216690063596 .9216690063596 .6168823242296 .61688232422 96.3121032714896 .3121032714896 .0073165893696 .0073165893696 .00731658936 96.0073165893696 .3121032714896 .3121032714896 .6168823242297 .22646331787 97.5312423706198 .1408081054798 .7503814697399 .3599472045999 .96952056885 100.8839035034101 .4934005737102 .4077987671103 .3221969604104 .2365036011 105.1509017944106 .0652008057106 .979598999107 .5891036987108 .5035018921 109.1130981445109 .7226028442110 .3321990967110 .9418029785111 .551399231 111.8561019897112 .1608963013112 .4656982422112 .7705001831112 .7705001831 113.075302124112 .7705001831112 .7705001831112 .4656982422112 .1608963013 111.551399231111 .24659729110 .6370010376110 .0273971558109 .7226028442 109.4179000854109 .1130981445108 .8082962036108 .8082962036108 .5035018921 
108.5035018921108 .8082962036108 .8082962036109 .1130981445109 .4179000854 109.4728927612109 .0100631714108 .5638504028108 .1347808838107 .7236938477 107.3312988281 106.9585876465106.6064071655 106.2758026123 105.9675140381 105.6824798584105 .4213027954105 .184753418104 .973236084104 .7873153687 104.6271820068104 .4931793213104 .3851776123104 .3031997681104 .2468414307 104.2158279419104.2093963623104.2268753052 104.2671737671 104.3292312622 104.4115066528104 .5124511719104 .6300964355104 .7624282837104 .9070129395 105.0613327026105 .2225646973105 .3877716064105 .5537872314105 .7172775269 105.8748168945106 .0228881836106 .1581878662106 .2774429321106 .3776855469 106.4555740356106 .5076141357106 .5295257568106 .5168304443106 .4638366699 106.363609314106 .2078475952106 .005607605105 .7603988647105 .1509017944 104.8460998535104 .5412979126103 .9317016602103 .3221969604102 .712600708 102.1029968262101 .4934005737100 .579101562599 .9695205688599 .05516815186 98.1408081054797 .2264633178796 .0073165893695 .0929565429793 .87381744385 92.6546783447391 .4355392456190 .2164001464888 .9972534179787 .77810668945 86.5589828491285 .3398437583 .8159103393682 .5967712402381 .37763214111 80.1584930419979 .2441329956178 .0249862670976 .8058471679775 .89148712158 74.9771423339874 .062782287673 .4532165527373 .7580032348674 .97714233398 -9999 -9999 -9999 -9999 -9999 -9999 -9999 -9999 -9999 -9999 -9999 -9999 -9999 -9999 -9999 -9999

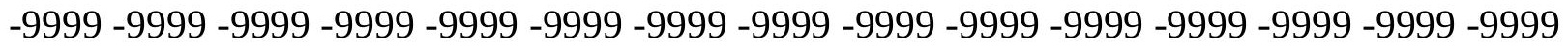

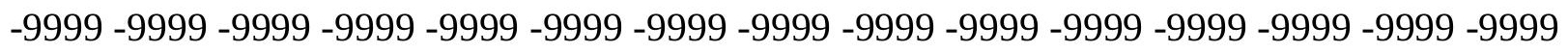
-9999 -9999 -9999 -9999 -9999 -9999 -9999 -9999 -9999 -9999 -9999 -9999 -9999 -9999 -9999 -9999 -9999 -9999 -9999 -9999 -9999 -9999 -9999 -9999 -9999 -9999 -9999 -9999 -9999 -9999 -

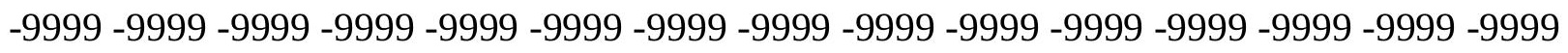
-9999 -9999 -9999-9999-9999 -9999-9999-9999

-9999 -9999 -9999 -9999 -9999 -9999 -9999 -9999 -9999 -9999 -9999 -9999 -9999 -9999 -9999

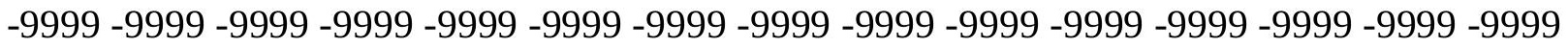

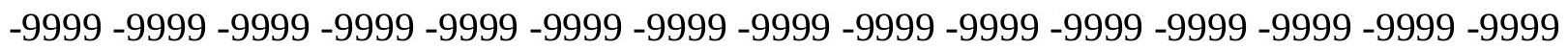

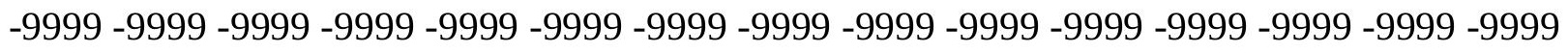
-9999 -9999 -9999 -9999 -9999 -9999 -9999 -9999 -9999 58.51874923706 58.82352828979 59.4331016540561 .5666007995662 .1761703491263 .0905189514263 .70008850098 64.6144485473665 .2240066528366 .1383666992266 .7479400634867 .66230010986 68.5766525268669 .1862335205170 .1005783081171 .014930725171 .62449645996 72.2340774536172 .8436431884873 .1484298706173 .4532165527373 .75800323486 74.062782287674 .062782287674 .3675689697374 .3675689697374 .67236328125 74.9771423339875 .8914871215875 .5867080688578 .6345596313581 .68241119385 84.1206970214885 .9494018554786 .5589828491286 .8637619018686 .55898284912 86.254188537686 .5589828491287 .1685485839887 .4733276367287 .77810668945 87.4733276367286 .5589828491285 .6446228027384 .4254837036183 .81591033936 83.2063369751 82.90155792236 82.90155792236 82.9015579223683.2063369751 83.5111236572383 .8159103393684 .1206970214884 .4254837036185 .03504943848 85.3398437585 .9494018554786 .254188537686 .5589828491287 .16854858398 87.47332763672 87.77810668945 88.3876876831188.6924667358489.3020401001 89.9116134643690.82597351074 91.4355392456192.3498916626 93.26425170898 94.1785964965895 .0929565429795 .7025299072396 .3121032714896 .61688232422 96.9216690063596 .9216690063596 .9216690063596 .6168823242296 .61688232422 
96.3121032714896 .3121032714896 .0073165893696 .0073165893696 .00731658936 96.3121032714896 .6168823242296 .6168823242297 .2264633178797 .53124237061 98.1408081054798 .7503814697399 .3599472045999 .96952056885100 .8839035034 101.7982025146102 .4077987671103 .3221969604104 .2365036011105 .1509017944 106.0652008057106 .979598999107 .8938980103108 .8082962036109 .4179000854 110.0273971558110 .6370010376111 .24659729111 .551399231112 .1608963013 112.4656982422112 .7705001831113 .075302124113 .075302124113 .075302124 113.075302124112 .7705001831112 .4656982422112 .1608963013111 .551399231 110.9418029785110 .3321990967110 .0273971558109 .4179000854109 .1130981445 108.8082962036108 .5035018921108 .1986999512108 .1986999512108 .1986999512 108.1986999512108 .5035018921108 .8082962036109 .1130981445109 .6413726807 109.1561737061 108.6874389648 108.2357559204 107.8019943237 107.3868865967 106.9914932251106 .6166915894106 .2636260986105 .9331207275105 .6262359619 105.3436813354105 .0863876343104 .8549118042104 .6499938965104 .4720077515 104.3214874268104 .1984863281104 .1032104492104 .0354309082103 .9950332642 103.9813995361103 .9939956665104 .0318145752104 .0938873291104 .1787185669 104.2848052979104 .4101486206104 .5527267456104 .7100372314104 .8795013428 105.0581893921105 .2430801392105 .4308700562105 .6181182861105 .8012695312 105.9767303467106 .1411132812106 .2910995483106 .4237136841106 .5356521606 106.6234741211106 .6829452515106 .7094802856106 .6970596313106 .638343811 106.5227966309106 .3360290527106 .0652008057105 .7603988647105 .4557037354 104.8460998535104 .5412979126103 .9317016602103 .3221969604102 .712600708 102.1029968262101 .4934005737100 .579101562599 .9695205688599 .05516815186 97.8360290527396 .9216690063596 .0073165893694 .7881774902393 .56903076172 92.349891662691 .1307525634889 .9116134643688 .6924667358487 .47332763672 86.254188537685 .0350494384883 .8159103393682 .5967712402381 .37763214111 80.1584930419978 .9393463134878 .0249862670976 .8058471679775 .89148712158 74.9771423339874 .062782287673 .7580032348674 .062782287675 .28192901611 -9999 -9999 -9999 -9999 -9999 -9999 -9999 -9999 -9999 -9999 -9999 -9999 -9999 -9999 -9999 -9999 -9999 -9999 -9999 -9999 -9999 -9999 -9999 -9999 -9999 -9999 -9999 -9999 -9999 -9999 -9999 -9999 -9999 -9999 -9999 -9999 -9999 -9999 -9999 -9999 -9999 -9999 -9999 -9999 -9999 -9999 -9999 -9999 -9999 -9999 -9999 -9999 -9999 -9999 -9999 -9999 -9999 -9999 -9999 -9999 -9999 -9999 -

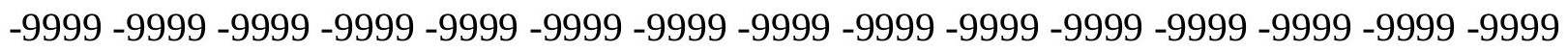

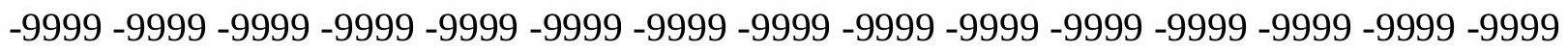
-9999 -9999 -9999-9999-9999-9999

-9999 -9999 -9999 -9999 -9999 -9999 -9999 -9999 -9999 -9999 -9999 -9999 -9999 -9999 -9999

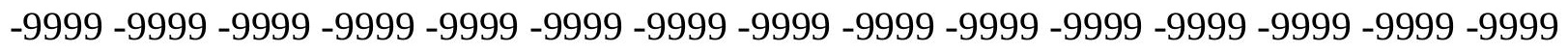

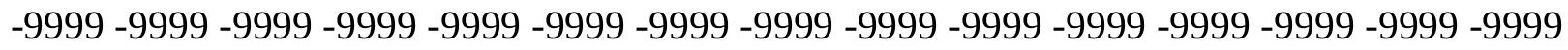
-9999 -9999 -9999 -9999 -9999 -9999 -9999 -9999 -9999 -9999 -9999 -9999 -9999 -9999 -9999 -9999 -9999 -9999 -9999 -9999 -9999 -9999 -9999 -9999 -9999 58.51874923706 59.43310165405 60.0426712036162.4809494018663.39530944824 64.30966186523 64.9192428588965 .8335876464866 .7479400634867 .3575134277368 .27187347412 69.1862335205170 .1005783081171 .014930725171 .9292907714872 .84364318848 73.4532165527374 .062782287674 .6723632812574 .9771423339875 .28192901611 75.8914871215876 .1962814331176 .5010681152377 .110626220777 .41542053223 78.0249862670979 .2441329956181 .3776321411182 .5967712402387 .16854858398 
90.5211791992292 .9594726562593 .8738174438593 .8738174438593 .56903076172 92.9594726562592 .6546783447392 .9594726562593 .5690307617293 .26425170898 92.349891662690 .5211791992288 .6924667358487 .1685485839885 .94940185547 85.3398437585 .0350494384884 .7302627563584 .7302627563585 .03504943848 85.0350494384885 .3398437585 .6446228027385 .9494018554786 .2541885376 86.5589828491286 .8637619018687 .1685485839887 .1685485839887 .47332763672 87.7781066894588 .0829010009888 .3876876831188 .6924667358489 .3020401001 90.2164001464890 .8259735107491 .7403335571392 .6546783447393 .56903076172 94.4833908081195 .0929565429796 .0073165893696 .3121032714896 .61688232422 96.9216690063596 .9216690063596 .9216690063596 .6168823242296 .61688232422 96.3121032714896 .3121032714896 .0073165893696 .0073165893696 .00731658936 96.3121032714896 .3121032714896 .6168823242297 .2264633178797 .53124237061 98.1408081054798 .7503814697399 .3599472045999 .96952056885100 .8839035034 101.7982025146102 .712600708103 .6268997192104 .5412979126105 .4557037354 106.3700027466 107.2844009399108.1986999512108.8082962036109.7226028442 110.3321990967110 .9418029785111 .24659729111 .8561019897112 .1608963013 112.4656982422112 .7705001831113 .075302124113 .075302124113 .3800964355 113.075302124113 .075302124112 .7705001831112 .1608963013111 .551399231 110.9418029785110 .3321990967109 .7226028442109 .1130981445108 .8082962036 108.5035018921108 .1986999512107 .8938980103107 .8938980103107 .5891036987 107.5891036987107 .8938980103108 .1986999512108 .8082962036109 .1130981445 109.3015060425108 .8098068237108 .3349914551107 .8779525757107 .439453125 107.0205841064106 .6222686768106 .2456970215105 .8918075562105 .5617523193 105.2564086914104 .9768600464104 .723815918104 .4982376099104 .3006744385 104.1318893433103 .9921264648103 .8818130493103 .8008880615103 .7494430542 103.7270050049103 .7332000732103 .7671127319103 .8278884888103 .9140701294 104.0242080688104 .156288147104 .3082733154104 .4775772095104 .6615600586 104.857170105105 .0612716675105 .2704315186105 .4810943604105 .6895751953 105.8921966553106 .0854721069106 .2660751343106 .4309463501106 .5767822266 106.7001113892106 .7966384888106 .861541748106 .8880691528106 .8668441772 106.7821426392106 .6188583374106 .3700027466106 .0652008057105 .7603988647 105.4557037354105 .1509017944104 .5412979126104 .2365036011103 .6268997192 103.0174026489102 .1029968262101 .4934005737100 .579101562599 .66472625732 98.7503814697397 .8360290527396 .9216690063595 .7025299072394 .48339080811 93.2642517089892 .0450973510790 .8259735107489 .6068267822388 .38768768311 87.1685485839885 .9494018554784 .7302627563583 .5111236572382 .29197692871 81.0728530883879 .8537063598678 .9393463134877 .7202072143676 .80584716797 $75.8914871215874 .9771423339874 .062782287673 .7580032348674 .36756896973-9999$ -9999 -9999 -9999 -9999 -9999 -9999 -9999 -9999 -9999 -9999 -9999 -9999 -9999 -9999 -9999 -9999 -9999 -9999 -9999 -9999 -9999 -9999 -9999 -9999 -9999 -9999 -9999 -9999 -9999 -9999 -

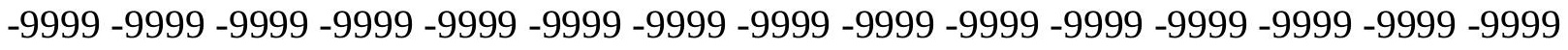

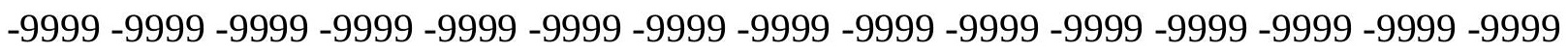
-9999 -9999 -9999 -9999 -9999 -9999 -9999 -9999 -9999 -9999 -9999 -9999 -9999 -9999 -9999 -9999 -9999 -9999 -9999 -9999 -9999 -9999 -9999 -9999 -9999 -9999 -9999 -9999 -9999 -9999 -9999 -9999 -9999 -9999-9999-9999-9999

-9999 -9999 -9999 -9999 -9999 -9999 -9999 -9999 -9999 -9999 -9999 -9999 -9999 -9999 -9999 
-9999 -9999 -9999 -9999 -9999 -9999 -9999 -9999 -9999 -9999 -9999 -9999 -9999 -9999 -9999 -9999 -9999 -9999 -9999 -9999 -9999 -9999 -9999 -9999 -9999 -9999 -9999 -9999 -9999 -9999

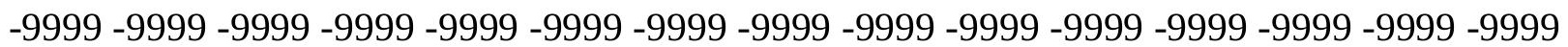
-9999 -9999 -9999 -9999 -9999 -9999 -9999 -9999 -9999 -9999 -9999 59.43310165405 60.3474502563561 .5666007995662 .4809494018664 .9192428588965 .52880096436 66.4431610107467 .0527267456167 .9670867919968 .8814392089869 .79579162598 70.7101516723671 .9292907714872 .8436431884874 .062782287674 .97714233398 75.5867080688576 .1962814331176 .5010681152377 .110626220777 .41542053223 78.3297805786178 .9393463134879 .8537063598680 .1584930419980 .46327209473 81.3776321411184 .4254837036188 .3876876831192 .6546783447397 .22646331787 99.35994720459100 .5791015625100 .579101562599 .6647262573298 .4455871582 98.1408081054798 .445587158299 .3599472045998 .7503814697396 .61688232422 93.8738174438591 .1307525634889 .302040100188 .0829010009887 .16854858398 86.8637619018686 .5589828491286 .8637619018686 .8637619018687 .16854858398 87.4733276367287 .4733276367287 .7781066894587 .7781066894587 .77810668945 88.0829010009887 .7781066894587 .7781066894587 .7781066894588 .08290100098 88.0829010009888 .3876876831188 .9972534179789 .6068267822390 .21640014648 91.1307525634892 .0450973510792 .9594726562593 .8738174438594 .78817749023 95.397743225196 .0073165893696 .6168823242296 .9216690063596 .92166900635 96.9216690063596 .9216690063596 .6168823242296 .6168823242296 .31210327148 96.3121032714896 .0073165893696 .0073165893696 .0073165893696 .31210327148 96.3121032714896 .6168823242296 .9216690063597 .5312423706197 .83602905273 98.445587158299 .3599472045999 .96952056885100 .8839035034101 .7982025146 102.712600708103 .6268997192104 .5412979126105 .4557037354106 .3700027466 107.2844009399108 .1986999512109 .1130981445109 .7226028442110 .3321990967 110.9418029785111 .551399231111 .8561019897112 .1608963013112 .4656982422 112.7705001831113 .075302124113 .3800964355113 .3800964355113 .3800964355 113.075302124112 .7705001831112 .1608963013111 .551399231110 .9418029785 110.0273971558109 .4179000854108 .8082962036108 .5035018921108 .1986999512 107.8938980103107 .5891036987107 .2844009399107 .2844009399107 .2844009399 107.5891036987107 .8938980103108 .5035018921109 .1130981445109 .4179000854 108.9314041138108 .4328994751107 .9519500732107 .4893417358107 .0461578369 106.6233673096106 .2222213745105 .8437271118105 .4891662598105 .1595535278 104.8561553955104 .579864502104 .3318481445104 .1128768921103 .9239425659 103.7655181885103 .6382522583103 .5423049927103 .4779815674103 .4449768066 103.4430847168103 .4715118408103 .5295257568103 .6157226562103 .7287063599 103.8664398193104 .0268630981104 .207321167104 .405090332104 .616973877 104.8397216797105 .0697631836105 .3034057617105 .5368423462105 .7662963867 105.9882049561106 .1991729736106 .3960494995106 .5754165649106 .7336959839 106.8664932251106 .9687957764107 .0333786011107 .0496292114107 .003074646 106.881477356106 .6747970581106 .3700027466106 .3700027466106 .0652008057 105.4557037354105 .1509017944104 .8460998535104 .2365036011103 .6268997192 103.0174026489102 .1029968262101 .4934005737100 .579101562599 .66472625732 98.7503814697397 .8360290527396 .6168823242295 .397743225194 .17859649658 93.2642517089891 .7403335571390 .5211791992289 .302040100188 .08290100098 86.8637619018685 .6446228027384 .4254837036183 .206336975181 .98719787598 
80.7680587768679 .8537063598678 .6345596313577 .7202072143676 .80584716797 75.8914871215874 .6723632812573 .7580032348673 .7580032348674 .67236328125 -9999 -9999 -9999 -9999 -9999 -9999 -9999 -9999 -9999 -9999 -9999 -9999 -9999 -9999 -9999 -9999 -9999 -9999 -9999 -9999 -9999 -9999 -9999 -9999 -9999 -9999 -9999 -9999 -9999 -9999 -9999 -9999 -9999 -9999 -9999 -9999 -9999 -9999 -9999 -9999 -9999 -9999 -9999-9999 -9999 -9999 -9999 -9999 -9999 -9999 -9999 -9999 -9999 -9999 -9999 -9999 -9999 -9999 -9999 -9999 -9999

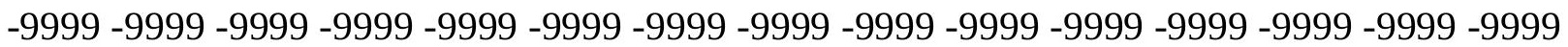
-9999 -9999 -9999 -9999 -9999 -9999 -9999 -9999 -9999 -9999 -9999 -9999 -9999 -9999 -9999 -9999 -9999 -9999-9999-9999-9999

-9999 -9999 -9999 -9999 -9999 -9999 -9999 -9999 -9999 -9999 -9999 -9999 -9999 -9999 -9999

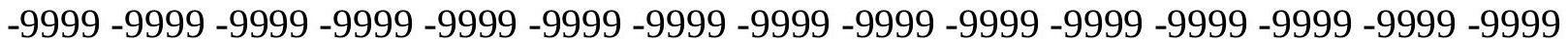

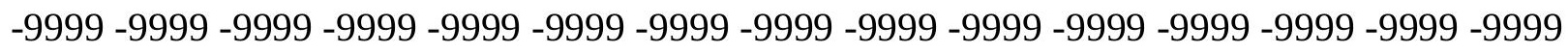

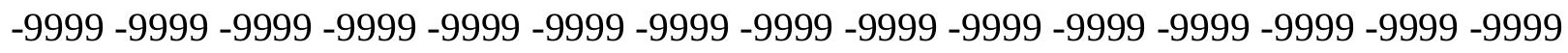
-9999 -9999 -9999 -9999 -9999 -9999 -9999 -9999 -9999 -9999 -9999 -9999 -9999 62.1761703491263 .0905189514264 .004882812564 .9192428588965 .52880096436 67.6623001098668 .5766525268669 .1862335205170 .1005783081171 .31971740723 72.5388565063573 .7580032348674 .9771423339876 .1962814331177 .1106262207 77.4154205322378 .0249862670978 .3297805786179 .2441329956180 .15849304199 81.1717071533282 .0946578979582 .845001220782 .9015579223681 .68241119385 83.8159103393690 .2164001464896 .74346923828100 .6431808472103 .2338867188 104.5634918213104 .7792282104104 .2117156982103 .4980316162102 .712600708 103.0174026489105 .4557037354103 .931701660299 .9695205688595 .70252990723 92.6546783447390 .8259735107489 .6068267822388 .9972534179788 .69246673584 88.6924667358488 .6924667358488 .9972534179789 .302040100189 .3020401001 89.6068267822389 .6068267822389 .302040100189 .302040100188 .99725341797 88.69246673584 88.38768768311 88.38768768311 88.08290100098 88.38768768311 88.3876876831188 .9972534179789 .6068267822390 .5211791992291 .43553924561 92.349891662693 .5690307617294 .4833908081195 .397743225196 .00731658936 96.6168823242296 .9216690063596 .9216690063597 .2264633178796 .92166900635 96.9216690063596 .6168823242296 .6168823242296 .3121032714896 .00731658936 96.0073165893696 .0073165893696 .0073165893696 .0073165893696 .31210327148 96.6168823242296 .9216690063597 .2264633178797 .8360290527398 .4455871582 99.0551681518699 .96952056885100 .5791015625101 .4934005737102 .4077987671 103.6268997192104 .5412979126105 .7603988647106 .6747970581107 .5891036987 108.5035018921109 .4179000854110 .0273971558110 .6370010376110 .9418029785 111.551399231111 .8561019897112 .1608963013112 .4656982422112 .7705001831 113.075302124113 .3800964355113 .3800964355113 .3800964355113 .3800964355 113.075302124112 .4656982422111 .551399231110 .6370010376110 .0273971558 109.1130981445108 .5035018921108 .1986999512107 .8938980103107 .5891036987 107.2844009399 107.2844009399 107.2844009399 107.2844009399 107.5891036987 107.8938980103108 .1986999512108 .8082962036109 .4179000854109 .052696228 108.5299072266108 .0243530273107 .5368347168107 .0684432983106 .6201782227 106.1933288574 105.7889785767 105.4085159302 105.0531082153 104.7242050171 104.4228897095104 .1505584717103 .9082183838103 .6971054077103 .5179519653 103.3716659546103 .2586288452103 .179397583103 .1338577271103 .1220169067 103.143196106 103.1968002319103.2814941406103.395942688103.5380859375 
103.7058486938103 .8964767456104 .1071624756104 .334564209104 .575302124 104.8256225586105 .0817184448105 .3396377563105 .5955047607105 .845664978 106.0866012573106 .3150024414106 .5272521973106 .719581604106 .8874664307 107.0259857178 107.1286849976 107.18724823 107.1873397827 107.1134185791 106.979598999106.979598999 106.6747970581 106.3700027466106.0652008057 105.7603988647105 .1509017944104 .8460998535104 .2365036011103 .6268997192 103.0174026489102 .4077987671101 .4934005737100 .579101562599 .66472625732 98.445587158297 .5312423706196 .3121032714895 .0929565429794 .17859649658 92.9594726562591 .7403335571390 .2164001464888 .9972534179787 .77810668945 86.5589828491285 .3398437584 .1206970214882 .9015579223681 .98719787598 80.7680587768679 .5489196777378 .6345596313577 .4154205322376 .50106811523 75.5867080688574 .3675689697373 .4532165527373 .7580032348674 .97714233398 -9999 -9999 -9999 -9999 -9999 -9999 -9999 -9999 -9999 -9999 -9999 -9999 -9999 -9999 -9999 -9999 -9999 -9999 -9999 -9999 -9999 -9999 -9999 -9999 -9999 -9999 -9999 -9999 -9999 -9999 -9999 -9999 -9999 -9999 -9999 -9999 -9999 -9999 -9999 -9999 -9999 -9999 -9999 -9999 -9999 -9999

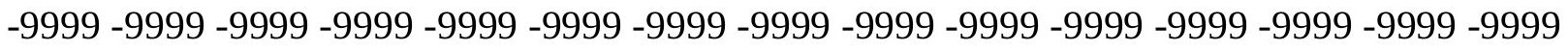
-9999 -9999 -9999 -9999 -9999 -9999 -9999 -9999 -9999 -9999 -9999 -9999 -9999 -9999 -9999 -9999 -9999 -9999 -9999 -9999 -9999 -9999 -9999 -9999 -9999 -9999 -9999 -9999 -9999 -9999 -9999 -9999 -9999-9999-9999

-9999 -9999 -9999 -9999 -9999 -9999 -9999 -9999 -9999 -9999 -9999 -9999 -9999 -9999 - -9999 -

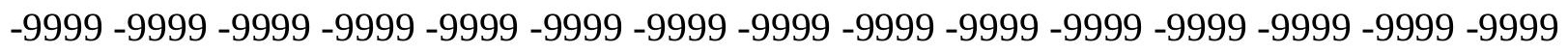

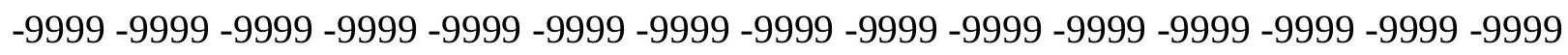
-9999 -9999 -9999 -9999 -9999 -9999 -9999 -9999 -9999 -9999 -9999 -9999 -9999 -9999 -9999 -9999 -9999 -9999 -9999-9999 -9999 -9999 -9999 -9999-9999 -9999 -9999 -9999 -9999 64.004882812564 .9192428588965 .8335876464866 .4431610107466 .74794006348 67.35751342773 67.9670867919970.40535736084 71.62449645996 73.14842987061 74.6723632812576 .1962814331177 .4154205322378 .3297805786178 .93934631348 79.5489196777379 .8537063598680 .4632720947380 .4632720947381 .98719787598 84.1206970214885 .0350494384884 .7302627563580 .7680587768681 .37763214111 95.7407073974699 .52395629883102 .8746795654105 .3935394287106 .8535614014 107.3813171387107 .2715759277106 .982963562106 .8941574097107 .0583724976 106.6498336792104 .3687896729100 .274299621695 .7025299072392 .95947265625 91.4355392456190 .5211791992290 .2164001464890 .2164001464890 .52117919922 90.8259735107491 .1307525634891 .4355392456191 .7403335571391 .74033355713 91.4355392456190 .8259735107490 .2164001464889 .6068267822388 .99725341797 88.69246673584 88.38768768311 88.38768768311 88.38768768311 88.69246673584 89.302040100189 .9116134643690 .8259735107492 .0450973510792 .95947265625 94.1785964965895 .0929565429796 .0073165893696 .6168823242296 .92166900635 97.22646331787 97.2264633178797.2264633178797.2264633178796.92166900635 96.6168823242296 .3121032714896 .3121032714896 .0073165893696 .00731658936 95.7025299072395 .7025299072396 .0073165893696 .0073165893696 .31210327148 96.6168823242297 .2264633178797 .5312423706198 .1408081054799 .05516815186 99.66472625732100 .5791015625101 .4934005737102 .4077987671103 .6268997192 104.5412979126105 .7603988647106 .6747970581107 .8938980103108 .8082962036 109.4179000854110 .3321990967110 .6370010376111 .24659729111 .551399231 111.8561019897112 .1608963013112 .4656982422112 .7705001831113 .075302124 
113.075302124113 .3800964355113 .6848983765113 .6848983765113 .075302124 112.4656982422111 .551399231110 .6370010376109 .7226028442108 .8082962036 108.1986999512107 .8938980103107 .5891036987107 .2844009399107 .2844009399 106.979598999106 .979598999107 .2844009399107 .2844009399107 .8938980103 108.1986999512108 .5035018921109 .1130981445109 .1741485596108 .6264572144 108.0955657959107 .5822906494107 .0877532959106 .6129684448106 .1592483521 105.7277603149105 .3199920654104 .93724823104 .5811462402104 .2529830933 103.9543838501103 .6865997314103 .4511795044103 .2491149902103 .0815963745 102.9492340088102 .8528442383102 .7925643921102 .7686157227102 .7805099487 102.827796936102 .9092330933103 .0235366821103 .1686630249103 .3424911499 103.5421981812103 .7648620605104 .0069732666104 .2649993896104 .5349884033 104.8129653931105 .0948257446105 .3766021729105 .6545181274105 .9248504639 106.1840133667 106.4281463623106.6532516479 106.8547286987 107.0279922485 107.16771698107 .2676544189107 .3209609985107 .2844009399107 .2844009399 106.979598999106 .979598999106 .6747970581106 .3700027466106 .3700027466 105.7603988647105 .4557037354104 .8460998535104 .5412979126103 .6268997192 103.0174026489102 .1029968262101 .4934005737100 .579101562599 .35994720459 98.445587158297 .2264633178796 .0073165893695 .0929565429793 .87381744385 92.6546783447391 .4355392456189 .9116134643688 .6924667358487 .47332763672 86.254188537685 .0350494384883 .8159103393682 .9015579223681 .68241119385 80.46327209473 79.24413299561 78.32978057861 77.1106262207 76.19628143311 74.9771423339874 .062782287673 .4532165527374 .062782287675 .28192901611 -9999 -9999 -9999 -9999 -9999 -9999 -9999 -9999 -9999 -9999 -9999 -9999 -9999 -9999 -9999 -9999 -9999 -9999 -9999 -9999 -9999 -9999 -9999 -9999 -9999 -9999 -9999 -9999 -9999 -9999 -9999 -9999 -9999 -9999 -9999 -9999 -9999 -9999 -9999 -9999 -9999 -9999 -9999 -9999 -9999 -9999 -9999 -9999 -9999 -9999 -9999 -9999 -9999 -9999 -9999 -9999 -9999 -9999 -9999 -9999 -9999 -9999 -9999 -9999 -9999 -9999 -9999 -9999 -9999 -9999 -9999 -9999 -9999 -9999 -9999 -9999 -9999

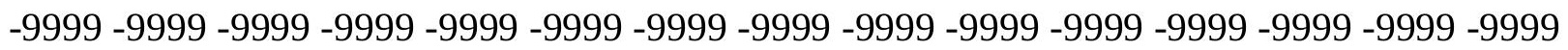
-9999 -9999-9999

-9999 -9999 -9999 -9999 -9999 -9999 -9999 -9999 -9999 -9999 -9999 -9999 -9999 -9999 -9999 -9999 -9999 -9999 -9999 -9999 -9999 -9999 -9999 -9999 -9999 -9999 -9999 -9999 -9999 -9999 -9999 -9999 -9999 -9999 -9999 -9999 -9999 -9999 -9999 -9999 -9999 -9999 -9999 -9999 -9999 -

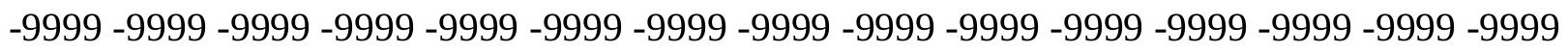

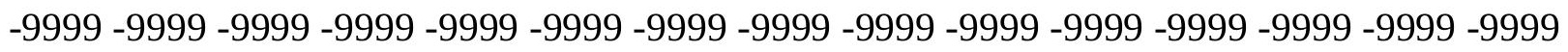
66.1383666992266 .7479400634867 .0527267456167 .3575134277367 .66230010986 68.2718734741269 .1862335205170 .4053573608472 .2340774536174 .0627822876 75.8914871215877 .4154205322378 .6345596313579 .2441329956179 .54891967773 79.5489196777380 .1584930419981 .3776321411183 .5111236572386 .2541885376 88.3876876831190.24643707275 92.4616241455195.175926208598.27857971191 101.4633102417104 .3147201538106 .5492935181108 .0105056763108 .7211761475 108.8865127563108 .753364563108 .4623947144107 .8649215698106 .3748245239 103.507591247697 .5312423706194 .1785964965892 .6546783447392 .04509735107 91.4355392456191 .4355392456191 .7403335571392 .349891662692 .95947265625 93.5690307617293 .8738174438593 .8738174438593 .8738174438593 .26425170898 92.349891662691 .4355392456190 .2164001464889 .302040100188 .69246673584 88.38768768311 88.3876876831188.38768768311 88.99725341797 89.60682678223 
90.5211791992291 .4355392456192 .6546783447393 .8738174438594 .78817749023 96.0073165893696 .6168823242297 .2264633178797 .5312423706197 .53124237061 97.5312423706197 .5312423706197 .2264633178796 .9216690063596 .61688232422 96.3121032714896 .0073165893695 .7025299072395 .7025299072395 .70252990723 95.7025299072395 .7025299072395 .7025299072396 .0073165893696 .31210327148 96.9216690063597 .5312423706198 .1408081054798 .7503814697399 .35994720459 100.2742996216101 .1886978149102 .4077987671103 .6268997192104 .5412979126 105.7603988647106 .979598999107 .8938980103108 .8082962036109 .7226028442 110.3321990967110 .9418029785111 .24659729111 .551399231111 .8561019897 111.8561019897112 .1608963013112 .4656982422112 .7705001831113 .075302124 113.3800964355113 .6848983765113 .6848983765113 .3800964355112 .7705001831 111.551399231110 .3321990967109 .4179000854108 .5035018921107 .8938980103 107.5891036987107 .2844009399107 .2844009399106 .979598999106 .979598999 106.979598999107 .2844009399107 .5891036987107 .8938980103108 .1986999512 108.5035018921109 .1130981445109 .296257019108 .7230377197108 .166053772 107.626159668107 .1044845581106 .6020812988106 .120300293105 .6603622437 105.2238464355104 .8121795654104 .4271392822104 .0702438354103 .7433242798 103.4479370117103 .1859588623102 .9586868286102 .7675323486102 .6133117676 102.4971008301102 .419342041102 .3805923462102 .3805847168102 .4191055298 102.4950485229102 .6072387695102 .7536239624102 .9320831299103 .1397171021 103.3734970093103 .629699707103 .9045410156104 .1937942505104 .4932250977 104.7985305786105 .1056289673105 .4106292725105 .7095947266105 .9985351562 106.2732467651106 .529548645106 .7628936768106 .9689941406107 .1436843872 107.2835388184107 .3840408325107 .4334030151107 .2844009399107 .2844009399 107.2844009399 106.979598999 106.979598999 106.6747970581 106.3700027466 106.0652008057 105.4557037354105.1509017944104.5412979126103.9317016602 103.0174026489102 .1029968262101 .1886978149100 .274299621699 .35994720459 98.1408081054796 .9216690063595 .7025299072394 .7881774902393 .56903076172 92.349891662691 .1307525634889 .6068267822388 .3876876831187 .16854858398 85.9494018554784 .7302627563583 .8159103393682 .5967712402381 .37763214111 80.1584930419978 .9393463134878 .0249862670976 .8058471679775 .58670806885 74.6723632812573 .4532165527373 .4532165527374 .062782287675 .28192901611 -9999 -9999 -9999 -9999 -9999 -9999 -9999 -9999 -9999 -9999 -9999 -9999 -9999 -9999 -9999 -9999

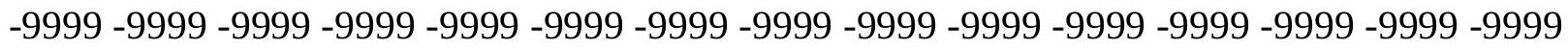
-9999 -9999 -9999 -9999 -9999 -9999 -9999 -9999 -9999 -9999 -9999 -9999 -9999 -9999 -9999 -

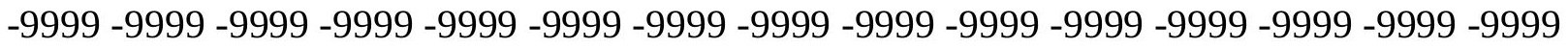

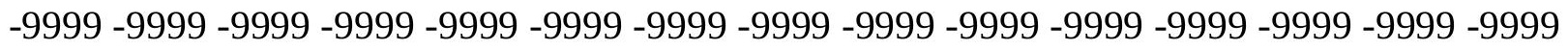

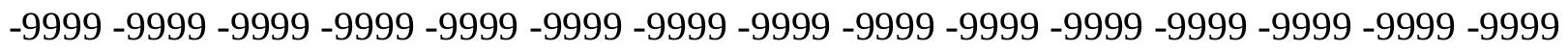
-9999 -9999-9999

-9999 -9999 -9999 -9999 -9999 -9999 -9999 -9999 -9999 -9999 -9999 -9999 -9999 -9999 -9999

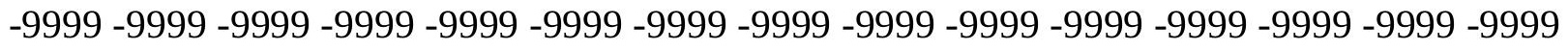

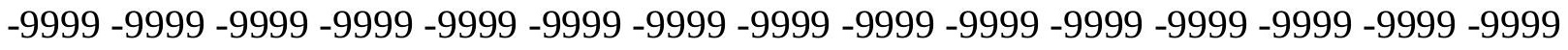
-9999 -9999 -9999 -9999 -9999 -9999 -9999 -9999 -9999 -9999 -9999 -9999 -9999 -9999 -9999 -9999 -9999 -9999 -9999 -9999 -9999 -9999 -9999 -9999 -9999 -9999 -9999 -9999 -9999 -9999 -999967.9670867919968.2718734741267.9670867919967.9670867919967.96708679199 68.8814392089870 .1005783081172 .2340774536174 .6723632812576 .46012878418 
78.0512313842879 .4094848632880 .6156158447381 .0728530883881 .07285308838 81.3776321411181 .9871978759885 .0350494384889 .302040100191 .08742523193 92.980049133395 .1414260864397 .57564544678100 .1992340088102 .8078079224 105.1513824463107 .0257797241108 .3261871338109 .0376434326109 .2577056885 109.0938034058108 .560546875107 .4892196655105 .5747146606102 .6276016235 96.3121032714893 .5690307617292 .9594726562592 .9594726562592 .65467834473 92.6546783447393 .2642517089894 .1785964965895 .0929565429796 .00731658936 96.6168823242296 .3121032714896 .0073165893695 .0929565429793 .87381744385 92.349891662690 .5211791992288 .9972534179788 .3876876831188 .38768768311 88.6924667358488 .6924667358489 .302040100189 .9116134643691 .13075256348 92.349891662693 .8738174438595 .0929565429796 .0073165893696 .92166900635 97.5312423706197 .8360290527398 .1408081054798 .1408081054797 .83602905273 97.8360290527397 .2264633178796 .9216690063596 .6168823242296 .31210327148 96.0073165893695 .7025299072395 .397743225195 .397743225195 .3977432251 95.397743225195 .7025299072395 .7025299072396 .3121032714896 .61688232422 97.2264633178797.8360290527398.445587158299.35994720459 100.2742996216 101.1886978149102 .1029968262103 .3221969604104 .5412979126105 .7603988647 106.979598999108 .1986999512109 .1130981445110 .0273971558110 .6370010376 111.24659729111 .551399231111 .551399231111 .551399231111 .8561019897 111.8561019897112 .1608963013112 .4656982422112 .7705001831113 .075302124 113.6848983765113 .6848983765113 .6848983765112 .4656982422111 .24659729 110.0273971558109 .1130981445108 .5035018921107 .8938980103107 .5891036987 107.2844009399 107.2844009399 107.2844009399 107.2844009399 107.2844009399 107.2844009399 107.5891036987 107.8938980103108.1986999512 108.5035018921 109.1130981445109 .4179000854108 .8202056885108 .2363967896107 .6690216064 107.1192398071106 .5881271362106 .0770797729105 .5873641968105 .1206359863 104.6784439087104 .2627105713103 .8751373291103 .517829895103 .1926345825 102.9017715454102 .6468353271102 .4293899536102 .2503051758102 .1109542847 102.0121994019101 .9550704956101 .9396591187101 .9661026001102 .0335845947 102.14112854102 .2866973877102 .4682006836102 .6827011108102 .9270629883 103.1972503662103 .4890518188103 .797744751104 .1186752319104 .4471740723 104.779045105105 .1103363037105 .4369430542105 .7545013428106 .0583953857 106.3442764282 106.6077346802 106.8447875977 107.0516357422 107.2252883911 107.2844009399 107.4613800049 107.5161743164107.5891036987 107.5891036987 107.2844009399 107.2844009399106.979598999106.979598999 106.6747970581 106.0652008057105 .7603988647105 .1509017944104 .5412979126103 .6268997192 103.0174026489102 .1029968262101 .188697814999 .9695205688599 .05516815186 97.83602905273 96.61688232422 95.397743225194.1785964965892.95947265625 91.7403335571390 .5211791992289 .302040100188 .0829010009886 .86376190186 85.6446228027384 .4254837036183 .206336975182 .2919769287181 .07285308838 79.8537063598678 .6345596313577 .4154205322376 .1962814331175 .28192901611 $74.062782287673 .1484298706173 .1484298706174 .3675689697375 .58670806885-9999$ -9999 -9999 -9999 -9999 -9999 -9999 -9999 -9999 -9999 -9999 -9999 -9999 -9999 -9999 -9999 -9999 -9999 -9999 -9999 -9999 -9999 -9999 -9999 -9999-9999 -9999 -9999 -9999 -9999 -9999 -9999 -9999 -9999 -9999 -9999 -9999 -9999 -9999 -9999 -9999 -9999 -9999 -9999 -9999 -9999 -

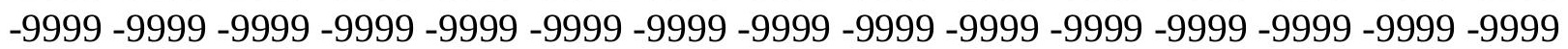


-9999 -9999 -9999 -9999 -9999 -9999 -9999 -9999 -9999 -9999 -9999 -9999 -9999 -9999 -9999 -9999 -9999 -9999 -9999 -9999 -9999 -9999 -9999 -9999 -9999 -9999 -9999 -9999 -9999 -9999 $-9999-9999$

-9999 -9999 -9999 -9999 -9999 -9999 -9999 -9999 -9999 -9999 -9999 -9999 -9999 -9999 -9999

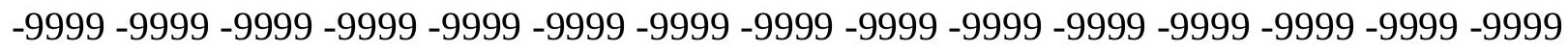
-9999 -9999 -9999 -9999 -9999 -9999 -9999 -9999 -9999 -9999 -9999 -9999 -9999 -9999 -9999 -9999 -9999 -9999 -9999 -9999 -9999 -9999 -9999 -9999 -9999 -9999 -9999 -9999 -9999 -9999 -9999 -9999 -9999 -9999 -9999 -9999 -9999 -9999 -9999 -9999 -9999 -9999 -9999 -9999 -9999 -9999 69.49101257324 69.1862335205168.57665252686 67.9670867919967.96708679199 68.2718734741269 .7957916259871 .9292907714874 .9771423339877 .80847930908 79.4632644653380 .9519805908282 .3949279785282 .9015579223682 .90155792236 82.9015579223684 .7302627563587 .1685485839891 .7433319091893 .4839630127 95.3467483520597 .3444976806699 .45556640625101 .6145095825103 .694442749 105.5316619873106 .9951019287108 .0145645142108 .5609436035108 .6798934937 108.4114685059107 .7360076904106 .5457458496104 .7110824585102 .2156982422 99.33261108398 95.0929565429794.7881774902394.28381347656 93.87381744385 93.8738174438594 .7881774902396 .0073165893697 .8360290527398 .75038146973 99.3599472045999 .0551681518698 .445587158297 .5312423706196 .00731658936 93.5690307617290 .8259735107488 .9972534179788 .3876876831188 .99725341797 89.6068267822389 .6068267822390 .2164001464891 .1307525634892 .65467834473 93.8738174438595.397743225196.6168823242297.5312423706198.14080810547 98.7503814697398 .7503814697398 .7503814697398 .7503814697398 .4455871582 97.8360290527397 .5312423706196 .9216690063596 .3121032714896 .00731658936 95.7025299072395 .397743225195 .0929565429795 .0929565429795 .09295654297 95.0929565429795 .397743225195 .397743225196 .0073165893696 .31210327148 96.92166900635 97.5312423706198.1408081054799.0551681518699.96952056885 100.8839035034102 .1029968262103 .3221969604104 .5412979126105 .7603988647 107.2844009399108 .5035018921109 .7226028442110 .6370010376111 .24659729 111.551399231111 .551399231111 .551399231111 .551399231111 .551399231111 .551399231 111.8561019897112 .1608963013112 .7705001831113 .075302124113 .3800964355 113.3800964355113 .075302124112 .1608963013110 .6370010376109 .7226028442 108.8082962036108 .1986999512107 .8938980103107 .5891036987107 .5891036987 107.2844009399 107.2844009399 107.2844009399 107.5891036987 107.5891036987 107.8938980103108 .1986999512108 .5035018921108 .8082962036109 .1130981445 109.4179000854108 .9186248779108 .3073043823107 .7116317749107 .1327896118 106.5718917847106 .0303649902105 .5095367432105 .0111236572104 .5367584229 104.0885162354103 .668296814103 .2784881592102 .9212265015102 .5989532471 102.3134841919102 .0665130615101 .8589248657101 .6923141479101 .5681381226 101.4880981445101 .4528274536101 .4629974365101 .5182418823101 .6179885864 101.7602920532101 .9431304932102 .163520813102 .4182128906102 .7027359009 103.0122528076103 .3412399292103 .6843261719104 .0362930298104 .3926467896 104.749420166105 .1025085449105 .4473342896105 .7789916992106 .0929489136 106.3848495483106 .6509399414106 .8875579834107 .0930023193107 .2724838257 107.2844009399107 .5409011841107 .5891036987107 .5891036987107 .5891036987 107.5891036987107 .5891036987107 .2844009399106 .979598999106 .6747970581 106.3700027466 105.7603988647105.1509017944104.5412979126103.6268997192 
102.712600708101 .7982025146100 .883903503499 .6647262573298 .75038146973 97.5312423706196 .3121032714895 .0929565429793 .8738174438592 .65467834473 91.4355392456190 .2164001464888 .9972534179787 .7781066894586 .55898284912 85.3398437584 .1206970214882 .9015579223681 .6824111938580 .46327209473

79.2441329956178 .3297805786177 .110626220775 .8914871215874 .36756896973 73.1484298706172 .8436431884873 .4532165527374 .67236328125 -9999 -9999 -9999 -9999 -9999 -9999 -9999 -9999 -9999 -9999 -9999 -9999 -9999 -9999 -9999 -9999 -9999 -9999 -9999

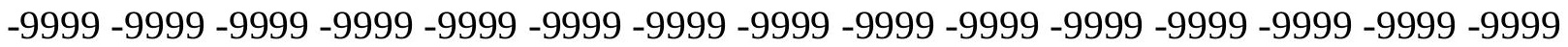

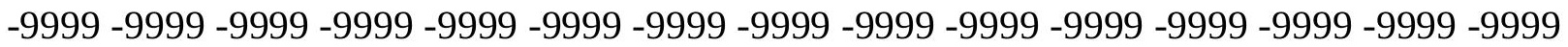
-9999 -9999 -9999 -9999 -9999 -9999 -9999 -9999 -9999 -9999 -9999 -9999 -9999 -9999 -9999 -9999 -9999 -9999 -9999 -9999 -9999 -9999 -9999 -9999 -9999 -9999 -9999 -9999 -9999 -9999 -9999 -9999 -9999 -9999 -9999 -9999 -9999 -9999 -9999 -9999 -9999 -9999 -9999 -9999 -9999 -9999 -9999 -9999 -9999 -9999 -9999 -9999 -9999 -9999 -9999 -9999 -9999 -9999 -9999 -9999 -9999 -9999 -9999 -9999 -9999 -9999 -9999 -9999 -9999 -9999 -9999 -9999 -9999 -9999 -9999 -9999 -9999 -9999 -9999 -9999 -9999 -9999 -9999 -9999 -9999 -9999 -9999 -9999 -9999

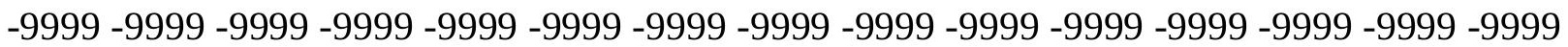
-9999 -9999 -9999 -9999 -9999 -9999 -9999 -9999 -9999 -9999 -9999 -9999 -9999 -9999 -9999 -9999 -9999 70.40535736084 69.1862335205168.27187347412 67.66230010986 67.6623001098669 .1862335205171 .6244964599675 .2819290161178 .93934631348 81.6296310424883 .1536254882884 .6455535888784 .7302627563585 .94940185547 87.1685485839888 .6924667358490 .5211791992294 .014511108495 .68902587891 97.4104537963999 .17767333984100 .9421157837102 .6561737061104 .231842041 105.5732498169106 .5855636597107 .2391433716107 .5117111206107 .436088562 107.0490570068106 .3547973633105 .3165664673103 .8947753906102 .1242218018 100.199150085498 .4441604614397 .1612167358496 .3911514282295 .70252990723 95.0929565429796 .0073165893698 .14080810547100 .5791015625101 .7982025146 102.1029968262101 .7982025146100 .883903503499 .9695205688598 .75038146973 96.3121032714892 .349891662688 .9972534179789 .6068267822391 .13075256348 91.7403335571391 .7403335571391 .4355392456193 .2642517089894 .78817749023 96.3121032714897 .5312423706198 .445587158299 .0551681518699 .66472625732 99.9695205688599 .6647262573299 .6647262573299 .0551681518698 .75038146973 98.1408081054797 .5312423706196 .9216690063596 .3121032714895 .70252990723 95.397743225195 .0929565429794 .7881774902394 .7881774902394 .78817749023 94.7881774902395 .0929565429795 .397743225195 .7025299072396 .00731658936 96.6168823242297 .2264633178797 .8360290527398 .7503814697399 .66472625732 100.5791015625101 .7982025146103 .0174026489104 .2365036011105 .7603988647 107.2844009399108 .8082962036110 .3321990967111 .24659729111 .8561019897 111.8561019897111 .8561019897111 .551399231111 .24659729111 .24659729111 .24659729 111.551399231112 .1608963013112 .4656982422113 .075302124113 .3800964355 113.075302124112 .4656982422111 .551399231110 .3321990967109 .4179000854 108.5035018921108 .1986999512107 .8938980103107 .8938980103107 .5891036987 107.5891036987107 .5891036987107 .5891036987107 .8938980103107 .8938980103 108.1986999512108 .5035018921108 .5035018921108 .8082962036109 .1130981445 109.4179000854109 .0190658569108 .3796157837107 .7549057007107 .1461334229 106.55443573105 .9812850952105 .4280395508104 .8964614868104 .3882827759 103.905708313103 .4508590698103 .0264053345102 .6346969604102 .2782363892 
101.9587783813101 .6781539917101 .4375101 .2387771606101 .0840759277100 .975944519 100.9157562256100 .9048843384100 .9436340332101 .0320205688101 .1683807373 101.3507766724 101.5761566162101.8410720825 102.1404876709 102.4687194824 102.819190979103 .185546875103 .5617675781103 .9428100586104 .3245162964 104.7029342651105 .0587158203105 .29737854105 .5708236694105 .8963088989 106.274597168106 .6504821777106 .6747970581106 .979598999107 .2844009399 107.2844009399 107.5891036987107.5891036987107.8938980103107.8938980103 107.8938980103 107.8938980103 107.5891036987 107.2844009399106.979598999 106.3700027466 105.7603988647 105.1509017944 104.2365036011 103.6268997192 102.4077987671101 .4934005737100 .579101562599 .3599472045998 .14080810547 97.2264633178796.0073165893694.7881774902393.5690307617292.3498916626 91.1307525634889 .9116134643688 .6924667358487 .4733276367286 .2541885376 85.03504943848 83.8159103393682.59677124023 81.3776321411180.15849304199 78.9393463134877 .7202072143676 .5010681152375 .2819290161174 .0627822876 73.1484298706172 .8436431884873 .4532165527374 .67236328125 -9999 -9999 -9999 -9999 -9999 -9999 -9999 -9999 -9999 -9999 -9999 -9999 -9999 -9999 -9999 -9999 -9999 -9999 -9999 -9999 -9999 -9999 -9999 -9999 -9999 -9999 -9999 -9999 -9999 -9999 -9999 -9999 -9999 -9999 -9999 -9999 -9999 -9999 -9999 -9999 -9999 -9999 -9999 -9999 -9999 -9999 -9999 -9999 -9999 -

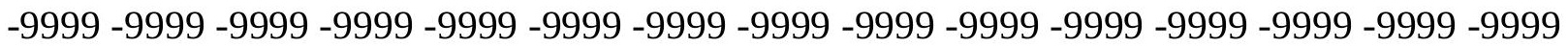

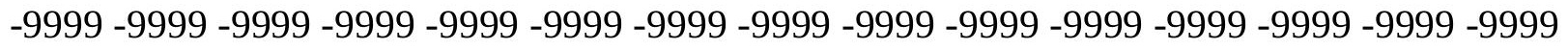

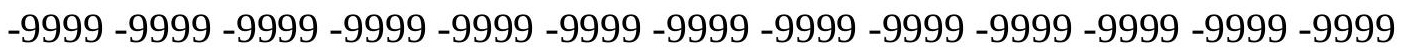

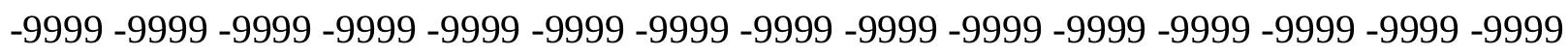
-9999 -9999 -9999 -9999 -9999 -9999 -9999 -9999 -9999 -9999 -9999 -9999 -9999 -9999 -9999 -

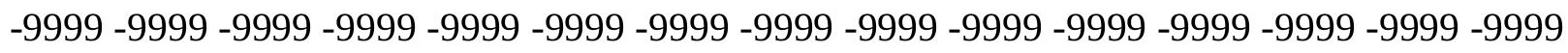

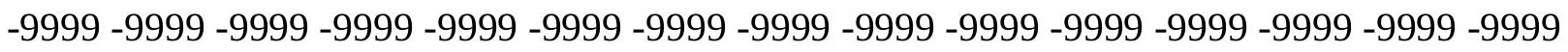

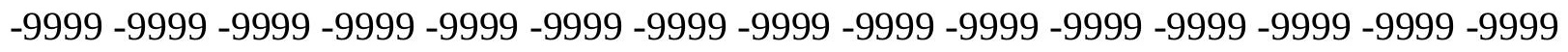
-9999 -9999 71.6244964599670.1005783081168.57665252686 67.66230010986 67.3575134277368 .5766525268671 .6244964599675 .2819290161180 .15849304199 84.42548370361 85.94387054443 87.37117004395 88.8078842163190.21640014648 91.1307525634892 .6546783447394 .7105865478596 .2164535522597 .73638916016 99.25390625100 .7373886108102 .1513977051103 .4349517822104 .5367584229 105.3897247314105 .937461853106 .165763855106 .0855178833105 .7522888184 105.2365036011104 .5981445312103 .8681869507103 .0503845215102 .145614624 101.2007141113100 .298896789699 .5416259765698 .9793777465897 .53124237061 96.3121032714897 .22646331787100 .2742996216102 .2038040161103 .4785308838 104.1170578003104 .2365036011103 .0174026489102 .712600708102 .712600708 101.493400573797 .8360290527390 .2164001464894 .1785964965896 .00731658936 95.7025299072395 .0929565429795 .397743225196 .6168823242297 .83602905273 99.0551681518699 .96952056885100 .5791015625101 .1886978149101 .1886978149 101.1886978149100 .8839035034100 .274299621699 .6647262573298 .75038146973 98.1408081054797 .2264633178796 .6168823242296 .0073165893695 .3977432251 95.0929565429794 .4833908081194 .4833908081194 .1785964965894 .48339080811 94.4833908081194 .7881774902395 .0929565429795 .397743225195 .70252990723 96.3121032714896 .9216690063597 .5312423706198 .445587158299 .35994720459 100.2742996216101 .4934005737102 .712600708104 .2365036011105 .7603988647 107.5891036987109 .4179000854110 .9418029785112 .1608963013112 .7705001831 
112.7705001831112 .4656982422111 .8561019897111 .24659729110 .9418029785 110.9418029785111 .551399231112 .1608963013112 .7705001831113 .3800964355 113.6848983765113 .3800964355112 .7705001831111 .551399231110 .3321990967 109.1130981445108 .5035018921108 .5035018921108 .1986999512108 .1986999512 108.1986999512108 .1986999512108 .1986999512108 .1986999512108 .1986999512 108.5035018921108 .5035018921108 .8082962036108 .8082962036109 .1130981445 109.1130981445109 .1130981445109 .122467041108 .4543685913107 .799987793 107.1605072021106 .5370941162105 .9312210083105 .3442993164104 .7781219482 104.2345046997103 .7157745361103 .224281311102 .762878418102 .3340759277 101.9402389526101 .5828323364101 .2636947632100 .9845504761100 .7480926514 100.5571899414100 .4152755737100 .3246078491100 .2874603271100 .3050079346 100.3780975342100 .5055236816100 .6855545044100 .9149703979101 .1900177002 101.5048980713101 .8528747559102 .2260971069102 .6170043945103 .0185470581 103.3221969604103 .3221969604103 .6268997192103 .9317016602104 .3045654297 104.6517486572105 .0375366211105 .4698257446105 .9560241699106 .3700027466 106.6747970581106 .979598999107 .2844009399107 .5891036987107 .5891036987 107.8938980103107 .8938980103108 .1986999512108 .1986999512107 .8938980103 107.8938980103107 .2844009399106 .979598999106 .3700027466105 .7603988647 104.8460998535104 .2365036011103 .3221969604102 .1029968262101 .1886978149 99.9695205688599 .0551681518697 .8360290527396 .6168823242295 .3977432251 94.1785964965892 .9594726562591 .7403335571390 .5211791992289 .3020401001 88.0829010009886 .8637619018685 .6446228027384 .4254837036183 .2063369751 81.9871978759880 .7680587768679 .5489196777378 .3297805786177 .1106262207 75.8914871215874 .9771423339874 .062782287673 .1484298706172 .53885650635 73.7580032348674 .97714233398 -9999 -9999 -9999 -9999 -9999 -9999 -9999 -9999 -9999 -9999 -9999 -9999 -9999 -9999 -9999 -9999 -9999 -9999 -9999 -9999 -9999 -9999 -9999 -9999 -9999 -9999 -9999 -9999 -9999 -9999 -9999 -9999 -9999 -9999 -9999 -9999 -9999 -9999 -9999

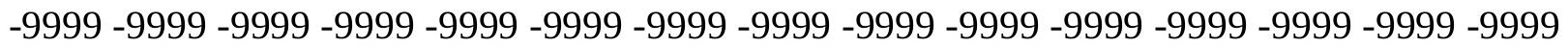
-9999 -9999 -9999 -9999 -9999 -9999 -9999 -9999 -9999 -9999 -9999 -9999 -9999 -9999 -9999 -9999 -9999 -9999 -9999 -9999 -9999 -9999 -9999 -9999 -9999 -9999 -9999 -9999 -9999 -9999 -9999 -9999 -9999 -9999 -9999 -9999 -9999

-9999 -9999 -9999 -9999 -9999 -9999 -9999 -9999 -9999 -9999 -9999 -9999 -9999 -9999 -9999

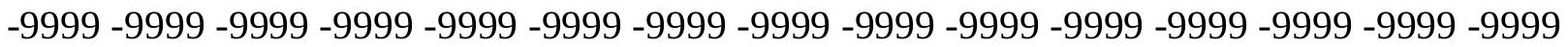
-9999 -9999 -9999 -9999 -9999 -9999 -9999 -9999 -9999 -9999 -9999 -9999 -9999 -9999 -9999 -9999 -9999 -9999 -9999 -9999 -9999 -9999 -9999 -9999 -9999 -9999 -9999 -9999 -9999 -9999 -9999 -9999 -9999 -9999 -9999 -9999 -9999 -9999 -9999 -9999 -9999 -9999 -9999 -9999 -9999 -9999 -9999-9999 76.80584716797 75.28192901611 74.0627822876 73.75800323486 74.9771423339877 .4154205322380 .7680587768685 .9494018554787 .9953994751 89.254188537690.52065277191.8054504394593.1045532226694.41806793213 95.7374572753997 .0607147216898 .3810272216899 .68353271484100 .9433288574 102.1238861084103 .1797103882104 .0607681274104 .7145004272105 .0969696045 105.1772079468104 .9399642944104 .4506759644103 .7980651855103 .1041717529 102.5068054199102 .1203842163101 .9837112427102 .0359954834102 .1369781494 102.1616897583102 .0237045288101 .7533569336101 .4730072021101 .3864517212 101.6879806519102 .480796814103 .545135498104 .604385376105 .3378982544 105.6184082031105 .5886077881105 .8605651855106 .4342880249106 .9849472046 
107.8938980103106 .3700027466102 .712600708102 .71260070899 .96952056885 98.7503814697399 .35994720459100 .5791015625101 .4934005737102 .1029968262 102.4077987671103 .0174026489103 .0174026489103 .0174026489102 .4077987671 101.7982025146100 .883903503499 .9695205688598 .7503814697397 .83602905273 97.2264633178796 .3121032714895 .7025299072395 .0929565429794 .48339080811 94.1785964965893 .8738174438593 .8738174438594 .1785964965894 .17859649658 94.4833908081194 .7881774902395 .0929565429795 .397743225195 .70252990723 96.3121032714897 .2264633178798 .1408081054799 .0551681518699 .96952056885 101.1886978149102 .4077987671103 .6268997192105 .4557037354107 .5891036987 110.0273971558111 .8561019897113 .075302124113 .9896011353113 .9896011353 113.3800964355112 .4656982422111 .551399231110 .9418029785110 .9418029785 111.8561019897112 .7705001831113 .6848983765114 .5991973877114 .9039993286 114.5991973877113 .6848983765112 .4656982422110 .9418029785109 .7226028442 109.1130981445109 .1130981445109 .1130981445108 .8082962036108 .8082962036 108.5035018921108 .5035018921108 .5035018921108 .5035018921108 .8082962036 109.1130981445109 .1130981445109 .4179000854109 .1130981445109 .1130981445 109.1130981445108 .8082962036108 .5327835083107 .8482284546107 .1773986816 106.5214691162105 .8819122314105 .2601623535104 .6580429077104 .0774383545 103.5208129883102 .9906539917102 .4898834229102 .0209350586101 .5860214233 101.1863479614100 .8237228394100 .5004806519100 .220352172999 .98718261719 99.8053741455199 .6781921386799 .6090164184699 .6001358032299 .65345001221 99.7684936523499 .94384765625100 .176109314100 .4610137939100 .7918243408 101.1605300903101 .5577545166101 .9744873047102 .1029968262101 .7982025146 101.7982025146102 .1029968262102 .712600708103 .1342773438103 .6016540527 104.0795135498104 .5856933594105 .1362838745105 .4557037354106 .0652008057 106.3700027466106 .979598999107 .2844009399107 .5891036987107 .8938980103 108.1986999512108 .1986999512108 .5035018921108 .1986999512108 .1986999512 107.8938980103107 .2844009399106 .979598999106 .3700027466105 .4557037354 104.5412979126103 .6268997192102 .712600708101 .7982025146100 .5791015625 99.6647262573298 .445587158297 .2264633178796 .0073165893694 .78817749023 93.8738174438592 .6546783447391 .4355392456190 .2164001464888 .99725341797 87.7781066894586 .5589828491285 .3398437584 .1206970214882 .90155792236 81.6824111938580 .4632720947379 .2441329956178 .0249862670976 .80584716797 75.8914871215874 .6723632812573 .7580032348672 .8436431884872 .84364318848 74.062782287675 .28192901611 -9999 -9999 -9999 -9999 -9999 -9999 -9999 -9999 -9999 -9999 -9999 -9999 -9999 -9999 -9999 -9999 -9999 -9999 -9999 -9999 -9999 -9999 -9999 -9999 -9999 -9999 -9999 -9999 -9999 -9999 -9999 -9999 -9999 -9999 -9999 -9999 -9999 -9999 -9999 -9999 -9999 -9999 -9999 -9999 -9999 -9999 -9999 -9999 -9999 -9999 -9999 -9999 - -9999 - -9999 -9999 -9999 -9999 -9999 -9999 -9999 -9999 -9999 -9999 -9999 -9999 -9999 -9999 -9999 -9999 -9999 -9999 -9999 -9999 -9999 -9999 -9999 -9999 -9999 -9999 -9999 -9999 -9999 -9999 -9999 -9999 -9999 -9999-9999-9999-9999

-9999 -9999 -9999 -9999 -9999 -9999 -9999 -9999 -9999 -9999 -9999 -9999 -9999 -9999 -9999 -9999 -9999 -9999 -9999 -9999 -9999 -9999 -9999 -9999 -9999 -9999 -9999 -9999 -9999 -9999 -9999 -9999 -9999 -9999 -9999 -9999 -9999 -9999 -9999 -9999 -9999 -9999 -9999 -9999 -9999 -9999 -9999 -9999 -9999 -9999 -9999 -9999 -9999 -9999 -9999 -9999 -9999 -9999 -9999 -9999

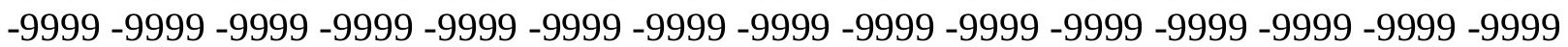


-9999 -9999 -9999 -9999 86.71574401855 86.55898284912 84.73026275635 85.03504943848 85.9494018554787 .7781066894590 .5211791992292 .0007858276493 .00439453125 94.032928466895 .0840072631896 .1527099609497 .2397155761798 .33992004395 99.44327545166100 .5335235596101 .5864334106102 .5687713623103 .4379882812 104.1455841064104 .6403503418104 .872795105104 .8029632568104 .4053421021 103.7010421753102 .7639694214101 .7154693604100 .7293548584100 .0325546265 99.86881256104100 .3573074341101 .4230728149102 .6675415039103 .7596740723 104.3517990112104 .4262390137104 .0917663574103 .6926116943103 .5488586426 103.8283843994104 .4712142944105 .2901306152106 .0723800659106 .707359314 107.3734436035 108.2440414429 109.4540100098 110.8475265503111 .7106933594 111.1476745605108 .7906951904106 .6583786011104 .4417190552103 .040435791 102.8940048218103 .4530639648104 .0736999512104 .4968414307104 .8127288818 105.1509017944105 .1509017944104 .5412979126103 .6268997192102 .712600708 101.493400573799 .9695205688598 .7503814697397 .8360290527396 .92166900635 96.0073165893695 .397743225194 .4833908081193 .8738174438593 .56903076172 93.5690307617293 .5690307617293 .8738174438594 .1785964965894 .17859649658 94.4833908081194 .7881774902395 .0929565429795 .397743225196 .00731658936 96.9216690063597 .8360290527399 .0551681518699 .96952056885100 .8839035034 101.7982025146103 .3221969604105 .1509017944107 .8938980103110 .6370010376 113.075302124114 .9039993286115 .5136032104115 .5136032104114 .5991973877 113.075302124111 .8561019897111 .24659729111 .24659729112 .4656982422 113.9896011353115 .5136032104116 .7326965332117 .0374984741116 .4279022217 115.5136032104114 .2944030762112 .7705001831110 .9418029785110 .9418029785 110.9418029785110 .3321990967110 .0273971558109 .7226028442109 .4179000854 109.1130981445109 .1130981445109 .1130981445109 .4179000854109 .7226028442 110.0273971558109 .7226028442109 .4179000854109 .1130981445108 .8082962036 108.5035018921108 .5035018921107 .9012145996107 .1985549927106 .5094680786 105.8354034424105 .1778030396104 .5385055542103 .9194717407103 .3232803345 102.7524795532102 .2098464966101 .6975250244101 .2174758911100 .7708740234 100.359695434699 .9868698120199 .657089233499 .3752593994199 .1468963623 98.9764862060598 .8687973022598 .827430725198 .8556900024498 .95411682129 99.1218795776499 .3553085327199 .6494369506899 .99633789062100 .3865814209 100.8089752197101 .1886978149100 .5791015625100 .2742996216100 .2742996216 100.2742996216100 .8839035034101 .7982025146102 .4077987671103 .0174026489 103.6055526733104 .2365036011104 .8460998535105 .4557037354106 .0652008057 106.3700027466106 .979598999107 .2844009399107 .8938980103108 .1986999512 108.5035018921108 .5035018921108 .5035018921108 .5035018921108 .1986999512 107.8938980103107 .2844009399106 .6747970581106 .0652008057105 .1509017944 104.2365036011103 .3221969604102 .1029968262101 .188697814999 .96952056885 99.0551681518697 .8360290527396 .6168823242295 .7025299072394 .48339080811 93.26425170898 92.0450973510790.82597351074 89.60682678223 88.38768768311 87.1685485839885 .9494018554784 .7302627563583 .5111236572382 .29197692871 81.0728530883879 .8537063598678 .6345596313577 .7202072143676 .50106811523 75.5867080688574 .6723632812573 .7580032348672 .8436431884873 .14842987061 74.3675689697375 .58670806885 -9999 -9999 -9999 -9999 -9999 -9999 -9999 -9999 -9999 -9999 -9999 -9999 -9999 -9999 -9999 -9999 -9999 -9999 -9999 -9999 -9999 -9999 -9999 -9999 
-9999 -9999 -9999 -9999 -9999 -9999 -9999 -9999 -9999 -9999 -9999 -9999 -9999 -9999 -9999 -9999 -9999 -9999 -9999 -9999 -9999 -9999 -9999 -9999 -9999 -9999 -9999 -9999 -9999 -9999 -9999 -9999 -9999 -9999 -9999 -9999 -9999 -9999 -9999 -9999 -9999 -9999 -9999 -9999 -9999 -9999 -9999 -9999 -9999 -9999 -9999 -9999 -9999 -9999 -9999 -9999 -9999 -9999 -9999 -9999 -9999 -9999-9999-9999-9999

-9999 -9999 -9999 -9999 -9999 -9999 -9999 -9999 -9999 -9999 -9999 -9999 -9999 -9999 -9999

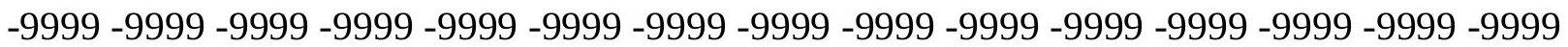
-9999 -9999 -9999 -9999 -9999 -9999 -9999 -9999 -9999 -9999 -9999 -9999 -9999 -9999 -9999 -999 -9999 -9999 -9999 -9999 -9999 -9999 -9999 -9999 -9999 -9999 -9999 -9999 -9999 -9999 -9999 -9999 -9999 -9999 -9999 -9999 -9999 -9999 -9999 -9999 -9999 -9999 -9999 -9999 -9999 -9999 -9999 -9999 -9999 -9999 92.6066589355593.06994628906 93.5406188964894.03548431396 94.576591491795 .1574172973695 .0929565429795 .397743225196 .00731658936 97.2264633178798 .5793151855599 .35930633545100 .1701278687101 .0052947998 101.8506164551102 .6833190918103 .4714279175104 .174621582104 .7432785034 105.1247406006105 .2625656128105 .1066970825104 .6166381836103 .7679901123 102.6021270752101 .191688537699 .6664505004998 .2183761596797 .1350402832 96.823104858497 .6605300903399 .63524627686102 .1990280151104 .5153961182 106.0928497314106 .5848007202106 .1499023438105 .3498153687104 .7076644897 104.5332946777104 .8563690186105 .5287857056106 .3731994629107 .2942581177 108.3302001953109 .5412597656110 .9244613647112 .2610092163112 .978477478 112.6305770874111 .2550582886109 .2632217407107 .4944000244106 .2222137451 105.7220993042105 .7991333008106 .0910568237106 .3592605591106 .5591506958 106.5815887451106 .2905426025105 .5409851074104 .5055160522103 .3221969604 102.1029968262100 .274299621698 .445587158297 .5312423706196 .92166900635 96.0073165893694 .7881774902394 .1785964965893 .2642517089892 .95947265625 92.9594726562593 .2642517089893 .5690307617293 .8738174438594 .17859649658 94.4833908081194 .4833908081194 .7881774902395 .0929565429795 .70252990723 96.6168823242297 .8360290527399 .0551681518699 .96952056885100 .8839035034 101.4934005737102 .4077987671104 .5412979126107 .5891036987111 .24659729 114.2944030762116 .7326965332117 .647102356117 .342300415116 .1231002808 114.5991973877112 .7705001831111 .551399231111 .8561019897113 .3800964355 115.818397522118 .2565994263119 .7806015015120 .0852966309119 .1709976196 118.2565994263117 .342300415116 .4279022217115 .5136032104114 .5991973877 113.3800964355112 .1608963013111 .24659729110 .6370010376110 .0273971558 109.7226028442109 .4179000854109 .4179000854110 .0273971558110 .6370010376 110.6370010376110 .6370010376110 .0273971558109 .1130981445108 .5035018921 108.1986999512107 .8938980103107 .5891036987106 .979598999106 .5032272339 105.7940216064105 .0997314453104 .422203064103 .7634658813103 .1261749268 102.5128479004101 .9259567261101 .3671722412100 .8380813599100 .3399581909 99.8751983642699 .4473419189599 .0618972778398 .7247772216898 .44272613525 98.2216949462998 .0681076049897 .9872055053797 .9840164184698 .06058502197 98.2169570922998 .4492721557698 .7514801025499 .1141357421999 .52621459961 99.9744110107499 .9695205688599 .0551681518698 .445587158298 .4455871582 98.7503814697399 .35994720459100 .2742996216101 .1886978149101 .7982025146 102.5465621948103 .2953948975103 .9317016602104 .5412979126105 .4557037354 106.0652008057 106.6747970581 106.979598999 107.5891036987108.1986999512 
108.5035018921108 .5035018921108 .8082962036108 .8082962036108 .5035018921 108.1986999512107 .5891036987106 .979598999106 .3700027466105 .4557037354 104.5412979126103 .6268997192102 .712600708101 .4934005737100 .5791015625 99.3599472045998 .445587158297 .2264633178796 .0073165893695 .09295654297 93.8738174438592 .6546783447391 .4355392456190 .2164001464888 .99725341797 87.7781066894586 .8637619018685 .6446228027384 .4254837036183 .2063369751 81.9871978759880 .7680587768679 .5489196777378 .3297805786177 .41542053223 76.1962814331175 .2819290161174 .3675689697373 .7580032348672 .84364318848 73.4532165527374 .67236328125 -9999 -9999 -9999 -9999 -9999 -9999 -9999 -9999 -9999 -9999 -9999 -9999 -9999 -9999 -9999 -9999 -9999 -9999 -9999 -9999 -9999 -9999 -9999 -9999

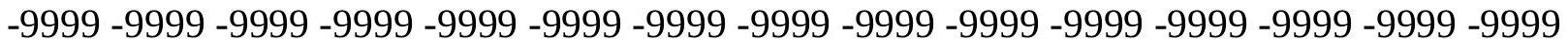
-9999 -9999 -9999 -9999 -9999 -9999 -9999 -9999 -9999 -9999 -9999 -9999 -9999 -9999 -9999 -9999 -9999 -9999 -9999 -9999 -9999 -9999 -9999 -9999 -9999 -9999 -9999 -9999 -9999 -9999 -9999 -9999 -9999 -9999 -9999 -9999 -9999 -9999 -9999 -9999 -9999 -9999 -9999 -9999 -9999 -9999 -9999-9999-9999-9999

-9999 -9999 -9999 -9999 -9999-9999 -9999 -9999 -9999 -9999 -9999 -9999 -9999 -9999 -9999 -

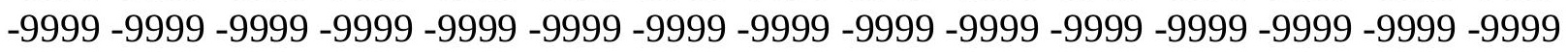

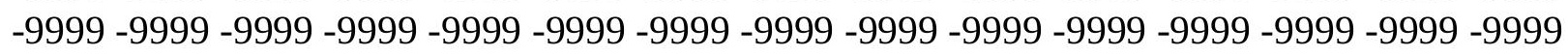

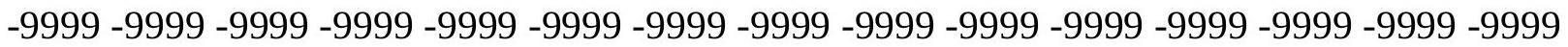

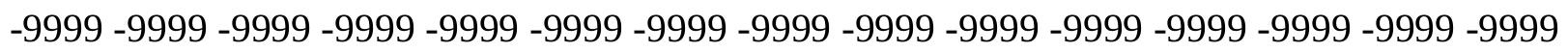
-9999 -9999-9999-9999-9999 99.45214080811 99.79100036621 100.0862045288 100.3583145142100 .6236801147100 .579101562599 .9695205688599 .66472625732 100.8839035034102 .2386245728102 .6787872314103 .1694946289103 .7041244507 104.2664489746104 .8286590576105 .3526535034105 .7902374268106 .0860214233 106.1775054932106 .0048370361105 .5116043091104 .6533737183103 .4008331299 101.801002502499 .9194946289197 .8744277954195 .8236694335993 .98628997803 92.811935424893 .2642517089895 .397743225199 .66472625732103 .4047393799 106.6582870483107 .5895996094107 .106552124105 .8764038086104 .8319702148 104.3893508911 104.5821762085 105.2509078979 106.2049179077 107.3177032471 108.537689209109 .8450927734111 .1635818481112 .2839508057112 .889465332 112.7440719604111 .8913345337110 .5609359741109 .2509918213108 .2547073364 107.7123641968107 .5663299561107 .6287612915107 .721282959107 .7286224365 107.5262145996107 .014465332106 .1504821777105 .0079574585103 .6539840698 102.0657958984100 .133277893198 .1408081054797 .8360290527397 .22646331787 95.7025299072394 .7881774902393 .5690307617292 .9594726562592 .3498916626 92.6546783447393 .2642517089893 .5690307617294 .1785964965894 .17859649658 94.4833908081194 .4833908081194 .4833908081194 .7881774902395 .09295654297 96.0073165893697 .5312423706199 .35994720459100 .5791015625100 .8839035034 100.8839035034101 .4934005737103 .6268997192107 .2844009399112 .1608963013 116.1231002808119 .1709976196120 .0852966309119 .7806015015118 .2565994263 116.1231002808113 .6848983765112 .1608963013112 .4656982422114 .5991973877 118.5614013672122 .2188034058124 .3523025513124 .0475006104122 .2188034058 120.9997024536120 .9997024536121 .6092987061121 .3044967651119 .4757995605 116.7326965332114 .2944030762112 .4656982422111 .8561019897110 .9418029785 110.3321990967109 .7226028442109 .7226028442110 .6370010376111 .551399231 111.8561019897111 .551399231110 .3321990967109 .1130981445108 .1986999512 
107.8938980103107 .2844009399106 .6747970581106 .0652008057105 .4557037354 105.1509017944105 .0288238525104 .31224823103 .6127548218102 .9329986572 102.275390625101 .6419830322101 .0338363647100 .452079772999 .89813995361 99.3749084472798 .886581420998 .4393920898498 .0401687622197 .69689178467 97.41713714697 .2092132568497 .0805053710997 .0377502441497 .08548736572 97.2255477905397 .4475097656297 .7592773437598 .1466979980598 .59003448486 99.0721664428798 .445587158297 .5312423706196 .9216690063596 .61688232422 97.2264633178797 .8360290527398 .7503814697399 .66472625732100 .5791015625 101.4934005737102 .2944412231103 .0174026489103 .8980941772104 .5412979126 105.4509811401106 .0652008057106 .6747970581107 .2844009399107 .8938980103 108.1986999512108 .5035018921108 .8082962036108 .8082962036108 .5035018921 108.1986999512107 .8938980103107 .2844009399106 .3700027466105 .7603988647 104.8460998535103 .9317016602103 .0174026489101 .7982025146100 .8839035034 99.9695205688598 .7503814697397 .5312423706196 .6168823242295 .3977432251 94.1785964965893 .2642517089892 .0450973510790 .8259735107489 .60682678223 88.69246673584 87.47332763672 86.2541885376 85.03504943848 83.81591033936 82.5967712402381 .3776321411180 .4632720947379 .2441329956178 .02498626709 77.110626220776 .1962814331175 .2819290161174 .3675689697373 .75800323486 73.4532165527373 .7580032348674 .97714233398 -9999 -9999 -9999 -9999 -9999 -9999 -9999 -9999 -9999 -9999 -9999 -9999 -9999 -9999 -9999 -9999 -9999 -9999 -9999 -9999 -9999 -9999 -9999 -9999 -9999 -9999 -9999 -9999 -9999 -9999 -9999 -9999 -9999 -9999 -9999 -9999 -9999 -9999 -9999 -9999 -9999 -9999 -9999 -9999 -9999 -9999 -9999 -9999 -9999 -9999 -9999 -9999 -9999 -9999 -9999 -9999 -9999 -9999 -9999 -9999 -9999 -9999 -9999 -9999 -9999 -9999 -9999

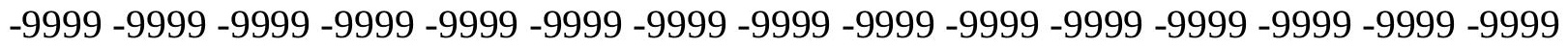
-9999 -9999 -9999-9999-9999-9999

-9999 -9999 -9999 -9999 -9999 -9999 -9999 -9999 -9999 -9999 -9999 -9999 -9999 -9999 -9999 -9999 -9999 -9999 -9999 -9999 -9999 -9999 -9999 -9999 -9999 -9999 -9999 -9999 -9999 -9999

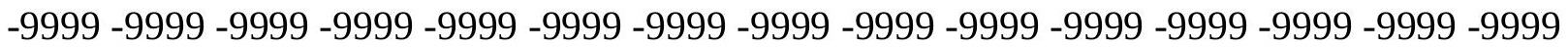
-9999 -9999 -9999 -9999 -9999 -9999 -9999 -9999 -9999 -9999 -9999 -9999 -9999 -9999 -9999 -9999 -9999 -9999 -9999 -9999 -9999 -9999 -9999 -9999 -9999 -9999 -9999 -9999 -9999 -9999 -9999 -9999 -9999 -9999 -9999 -9999 106.5068206787 106.5683441162 106.5424499512 106.4555740356106 .3342514038106 .2049865723105 .7603988647106 .0176010132 106.0012588501106 .0563583374106 .1899490356106 .397857666106 .6633987427 106.9553756714107 .2296676636107 .4311523438107 .4940795898107 .3490219116 106.9267425537106 .1630783081105 .0068054199103 .4252624512101 .4441375732 99.133514404396 .590820312593 .9394378662191 .3056716918988 .7551651001 86.5589828491286 .5589828491292 .0450973510799 .66472625732105 .1509017944 106.5627975464106 .1390151978104 .6946258545103 .5630950928103 .2085876465 103.5684127808104 .4271697998105 .5719299316106 .8497314453108 .1694793701 109.4702606201110 .6672286987111 .6180038452112 .1579055786112 .180229187 111.7115402222110 .9264831543110 .0771789551109 .3875808716108 .9521255493 108.7541275024108 .69115448108 .6472549438108 .4866256714108 .1193771362 107.4661483765106 .5055618286105 .2830123901103 .8308792114102 .1665267944 100.424263000598 .9551620483498 .0603103637797 .2072372436595 .3977432251 94.7881774902393 .5690307617292 .349891662691 .7403335571392 .3498916626 93.2642517089893 .8738174438594 .4833908081194 .4833908081194 .48339080811 
94.4833908081194 .4833908081194 .4833908081194 .7881774902395 .3977432251 96.9216690063599 .66472625732101 .7982025146101 .4934005737100 .2742996216 99.96952056885101 .7982025146106 .979598999113 .075302124118 .2565994263 121.3044967651122 .8283996582122 .2188034058120 .6949005127118 .2565994263 115.5136032104112 .7705001831112 .4656982422116 .4279022217120 .5325241089 123.8662719727125 .8695144653126 .105682373125 .2493438721122 .8283996582 124.0475006104124 .4608230591123 .8455886841122 .0346450806119 .4102554321 115.5136032104113 .6848983765113 .2275924683112 .14478302110 .9418029785 109.7226028442109 .7226028442111 .24659729111 .867515564112 .0404663086 111.5621643066110 .3321990967108 .8082962036108 .1986999512107 .5570373535 106.8040313721106 .000038147105 .1509017944103 .9317016602103 .0174026489 103.3221969604104 .212097168103 .4711074829102 .7478027344102 .0443725586 101.3623809814100 .7022094727100 .064544677799 .4508819580198 .86465454102 98.3107223510797 .7959671020597 .3280334472796 .9160232543996 .56903839111 96.2973098754996 .1105575561596 .0162429809696 .0244216918996 .13920593262 96.3652191162196 .6969070434697 .1164398193497 .5988616943498 .12049102783 97.2264633178796 .6168823242296 .0073165893695 .7025299072396 .00731658936 96.9216690063597 .8360290527398 .7503814697399 .66472625732100 .5791015625 101.1886978149102 .1029968262102 .9823379517103 .8094787598104 .5412979126 105.4148254395106 .0652008057106 .8935317993107 .5499954224108 .1351623535 108.5035018921108 .8082962036108 .8082962036108 .8082962036108 .5035018921 107.8938980103107 .2844009399106 .6747970581105 .7603988647104 .8460998535 103.9317016602103 .0174026489102 .1029968262101 .188697814999 .96952056885 99.0551681518698 .1408081054796 .9216690063596 .0073165893694 .78817749023 93.5690307617292 .6546783447391 .4355392456190 .2164001464889 .3020401001 88.0829010009886 .8637619018685 .6446228027384 .4254837036183 .51112365723 82.2919769287181 .0728530883879 .8537063598678 .9393463134877 .72020721436 76.8058471679775 .8914871215874 .9771423339874 .3675689697373 .75800323486 72.8436431884874 .062782287675 .58670806885 -9999 -9999 -9999 -9999 -9999 -9999 -9999 -9999 -9999 -9999 -9999 -9999 -9999 -9999 -9999 -9999 -9999 -9999 -9999 -9999 -9999 -9999 -9999 -9999 -9999 -9999 -9999 -9999 -9999 -9999 -9999 -9999 -9999 -9999 -9999 -9999 -9999 -

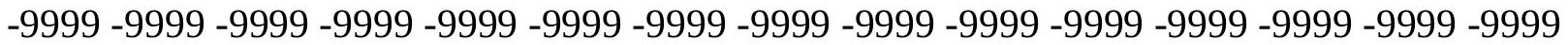

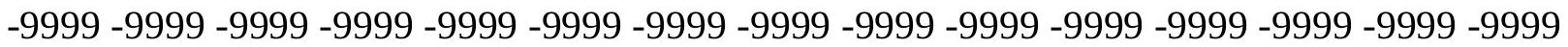

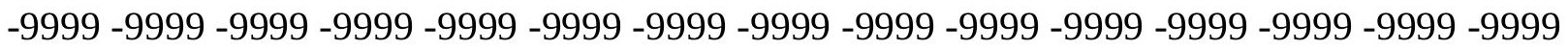
$-9999-9999-9999-9999-9999$

-9999 -9999 -9999 -9999 -9999 -9999 -9999 -9999 -9999 -9999 -9999 -9999 -9999 -9999 -9999

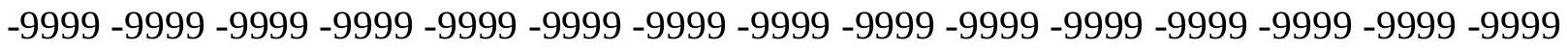

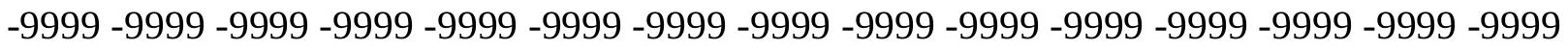
-9999 -9999 -9999 -9999 -9999 -9999 -9999 -9999 -9999 -9999 -9999 -9999 -9999 -9999 -9999 -9999 -9999 -9999 -9999 -9999 -9999 -9999 -9999 -9999 -9999 -9999 -9999 -9999 -9999 -9999 -9999 -9999 -9999 -9999 -9999 -9999 113.6718521118113 .4570236206113 .0859451294 112.5956954956112 .0266189575111 .423828125110 .8277587891110 .2764587402 109.803024292109 .4312973022109 .1761550903109 .0378723145109 .0021743774 109.0352325439109 .085395813109 .092918396108 .9779434204108 .6626281738 108.0657653809107 .1132278442105 .744430542103 .9175338745101 .6532974243 98.9959106445396 .0443725585992 .9278640747189 .6068267822386 .2541885376 
83.2063369751 82.59677124023 86.254188537691.7403335571396.31210327148 103.3221969604102 .5341033936101 .2474441528100 .7195739746100 .9907531738 101.8662414551103 .1208496094104 .5553131104106 .0225143433107 .4290008545 108.7132797241109 .8153762817110 .660987854111 .1772460938111 .3292388916 111.1504440308110 .7538223267110 .2844238281109 .8763885498109 .5956344604 109.4353027344109 .3322219849109 .1955337524108 .9292831421108 .4613571167 107.7323303223106 .7361450195105 .5033340454104 .0777130127102 .5331878662 101.013954162699 .740097045998 .6998901367297 .7898025512796 .86878967285 95.9063491821395 .0251464843893 .8738174438591 .1307525634892 .3498916626 93.5690307617294 .4833908081194 .7881774902394 .7881774902394 .48339080811 94.1785964965894 .4833908081194 .4833908081196 .3121032714896 .00731658936 97.22646331787101 .7982025146105 .7603988647106 .0652008057105 .1509017944 104.8460998535106 .3700027466110 .6370010376115 .5136032104119 .4757995605 122.2188034058124 .0475006104124 .3523025513123 .7427978516120 .788230896 118.0581970215116 .474067688116 .4279022217119 .287361145122 .181854248 124.9006729126126 .7168960571127 .400932312127 .2799530029122 .2188034058 126.6518707275125 .7626724243124 .8388595581123 .6114349365121 .275932312 115.818397522115 .2088012695114 .8347473145113 .5182647705111 .8561019897 109.1130981445110 .0273971558111 .551399231112 .1000671387112 .0105438232 111.4740066528110 .5603713989108 .1986999512108 .4126815796107 .4398803711 106.5223693848105 .5603713989104 .5175628662103 .0174026489101 .1886978149 101.1886978149103 .6268997192103 .3426589966102 .5750579834101 .824546814 101.092124939100 .377609252999 .681228637799 .0045471191498 .35143280029 97.7273788452197 .13979339696 .5970153808696 .1090011596795 .68613433838 95.3404769897595 .0825347900494 .9237823486394 .8829193115294 .97537994385 95.207168579195 .5681686401496 .030967712496 .5577087402397 .11917877197 96.3121032714895 .397743225195 .0929565429795 .0929565429795 .3977432251 96.0073165893696 .6168823242297 .5312423706198 .445587158299 .35994720459 100.2742996216101 .1886978149101 .9911270142102 .8435134888103 .6268997192 104.5412979126105 .3609619141106 .1239624023106 .8238677979107 .4460906982 107.9758605957 108.4054870605 108.7324981689108.5035018921 108.1986999512 107.8938980103 107.2844009399 106.3700027466105.7603988647104.8460998535 103.9317016602103 .0174026489102 .1029968262101 .1886978149100 .2742996216 99.35994720459 98.1408081054797.2264633178796.3121032714895.09295654297 94.1785964965892 .9594726562592 .0450973510790 .8259735107489 .60682678223 88.6924667358487 .4733276367286 .254188537685 .3398437584 .12069702148 82.9015579223681 .6824111938580 .7680587768679 .5489196777378 .63455963135 77.4154205322376 .5010681152375 .5867080688574 .6723632812573 .75800323486 72.8436431884873 .1484298706174 .6723632812576 .19628143311 -9999 -9999 -9999 -9999 -9999 -9999 -9999 -9999 -9999 -9999 -9999 -9999 -9999 -9999 -9999 -9999 -9999 -9999 -9999

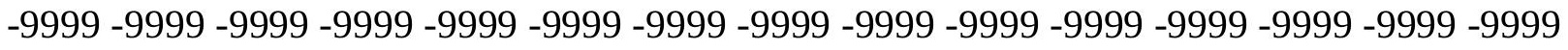

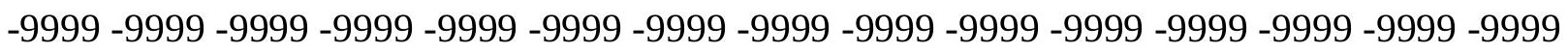
-9999 -9999 -9999 -9999 -9999 -9999 -9999 -9999 -9999 -9999 -9999 -9999 -9999 -9999 -9999 -9999 -9999 -9999 -9999 -9999-9999 -9999 -9999 -9999 -9999 -9999 -9999 -9999 -999 -999 -999 -9999 -9999 -9999 -9999-9999-9999-9999

-9999 -9999 -9999 -9999 -9999 -9999 -9999 -9999 -9999 -9999 -9999 -9999 -9999 -9999 -9999 
-9999 -9999 -9999 -9999 -9999 -9999 -9999 -9999 -9999 -9999 -9999 -9999 -9999 -9999 -9999 -9999 -9999 -9999 -9999 -9999 -9999 -9999 -9999 -9999 -9999 -9999 -9999 -9999 -9999 -9999 -9999 -9999 -9999 -9999 -9999 -9999 -9999 -9999 -9999 -9999 -9999 -9999 -9999 -9999 -9999 -9999 -9999 -9999 -9999 -9999 -9999 -9999 -9999 -9999 -9999 -9999 -9999 -9999 -9999 -9999 -9999 -9999 -9999 -9999 -9999-9999-9999 120.7188491821119 .9479675293118 .9945831299 117.9164047241116 .7757644653115 .6357498169114 .5516891479113 .5727233887 112.7353591919112 .0632171631111 .5654907227111 .2303771973111 .0183639526 110.8821258545110 .7474136353110 .5290756226110 .1270141602109 .4542236328 108.4126358032106 .931968689104 .968460083102 .523101806699 .62728118896 96.3632812592 .9077148437588 .3876876831186 .5589828491281 .68241119385 79.8537063598681 .0728530883884 .4254837036188 .6924667358494 .48339080811 95.4669876098695 .8508529663196 .7383270263798 .071289062599 .7127456665 101.5049438477103 .3018875122104 .9904708862106 .4989852905107 .7886428833 108.8362579346109 .6226654053110 .1353683472110 .3822174072110 .4042892456 110.2758331299110 .0851821899109 .9075164795109 .7811126709109 .6968917847 109.6092910767109 .4370574951109 .1253662109108 .6217956543107 .8879318237 106.920791626105 .7583694458104 .4487304688103 .0789413452101 .7626647949 100.63064575299 .6858139038198 .9179382324298 .3029785156297 .8391418457 97.5326004028397 .4755401611398 .50653076172101 .188697814996 .00731658936 95.397743225195 .0929565429794 .4833908081193 .8738174438593 .87381744385 94.1785964965893 .5690307617292 .9594726562596 .0073165893699 .66472625732 103.0174026489106 .6747970581109 .4179000854111 .8561019897113 .9896011353 115.2088012695114 .5991973877113 .9896011353114 .9039993286116 .4279022217 118.2565994263120 .6949005127123 .43800354122 .7456817627120 .7927398682 119.7578659058120 .0246734619121 .5503768921123 .6818618774125 .7787628174 127.3503494263 128.2060241699 128.4468841553128.1326599121 127.1856231689 126.2432327271125 .3056793213124 .3730545044122 .5447235107120 .2886886597 118.1594848633116 .3431625366114 .8945999146113 .8122406006113 .0937957764 112.6992492676112 .5119552612112 .3536529541112 .0320968628111 .4306259155 110.5720443726109 .5571975708108 .5023193359107 .4691467285106 .4731445312 105.4855117798104 .5120697021103 .0174026489100 .274299621698 .75038146973 103.3221969604103 .2315750122102 .4192733765101 .6207962036100 .8365707397 100.065933227599 .3087997436598 .5667953491297 .8440704345797 .14655303955 96.4820480346795 .8592681884895 .2887268066494 .7816314697394 .35091400146 94.0088729858493 .7741165161193 .6773757934693 .7415161132893 .97757720947 94.374717712494 .8923339843895 .4675140380996 .0073165893695 .09295654297 94.7881774902394 .4833908081194 .4833908081194 .7881774902395 .3977432251 96.0073165893696 .6168823242297 .5312423706198 .445587158299 .35994720459 99.96952056885100 .8839035034101 .7752609253102 .6893844604103 .5835723877 104.4411087036105 .2522583008106 .0048904419106 .6697006226107 .2294769287 107.6724624634108 .0022888184108 .225769043107 .8938980103107 .5891036987 106.979598999106 .3700027466105 .4557037354104 .8460998535103 .9317016602 103.0174026489102 .1029968262101 .1886978149100 .274299621699 .35994720459 98.445587158297 .5312423706196 .3121032714895 .397743225194 .48339080811 93.5690307617292 .349891662691 .4355392456190 .2164001464889 .3020401001 88.08290100098 87.16854858398 85.9494018554784.7302627563583.81591033936 
82.5967712402381 .3776321411180 .4632720947379 .2441329956178 .32978057861 77.110626220776 .1962814331175 .2819290161174 .3675689697373 .45321655273 72.5388565063573 .7580032348675 .28192901611 -9999 -9999 -9999 -9999 -9999 -9999 -9999 -9999 -9999 -9999 -9999 -9999 -9999 -9999 -9999 -9999 -9999 -9999 -9999 -9999 -9999 -9999 -9999 -9999 -9999 -9999 -9999 -9999 -9999 -9999 -9999 -9999 -9999 -9999 -9999 -9999 -9999 -9999 -9999 -9999 -9999 -9999 -9999 -9999 -9999 -9999 -9999 -9999 -9999 -9999 -9999 -9999 -9999 -9999 -9999 -9999 -9999 -9999 -9999 -9999 -9999 -9999 -9999 -9999 -9999 -9999 -9999

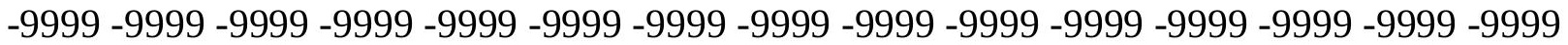
-9999 -9999-9999-9999

-9999 -9999 -9999 -9999 -9999 -9999 -9999 -9999 -9999 -9999 -9999 -9999 -9999 -9999 -9999 -9999 -9999 -9999 -9999 -9999 -9999 -9999 -9999 -9999 -9999 -9999 -9999 -9999 -9999 -9999 -9999 -9999 -9999 -9999 -9999 -9999 -9999 -9999 -9999 -9999 -9999 -9999 -9999 -9999 -9999

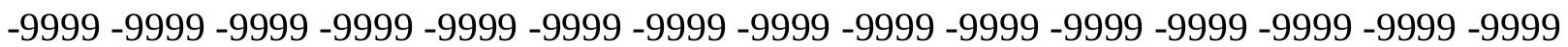
-9999 -9999 -9999 -9999 -9999 -9999 -9999 -9999 -9999 -9999 -9999 -9999 -9999 -9999 -9999 -9999 -9999 -9999 -9999 -9999 -9999 -9999 128.3215026855127 .0846786499125 .6041259766 123.9423065186122 .1939697266120 .4409179688118 .7586669922117 .2238998413 115.8840942383114 .7720413208113 .9131164551113 .2776565552112 .8503417969 112.5671920776112 .3568344116112 .12109375111 .7481002808111 .1074905396 110.0848846436108 .5972518921106 .5993804932104 .0858230591101 .0878677368 97.680107116793 .2642517089887 .7781066894586 .8637619018685 .03504943848 81.0728530883879 .2441329956181 .9871978759881 .3776321411184 .73026275635 87.7446594238390 .1616363525492 .6451187133895 .1011810302797 .50905609131 99.83782196045102 .0009841919103 .9144363403105 .5300445557106 .837310791 107.8500061035108 .5929794312109 .0964508057109 .3975143433109 .5434875488 109.5899658203109 .5924606323109 .5922012329109 .605255127109 .6145095825 109.5753250122109 .4261703491109 .1354293823108 .6628417969107 .9847869873 107.1102981567106 .0714492798104 .923538208103 .7497634888102 .6320648193 101.6799316406100 .9260406494100 .4076156616100 .1695556641100 .283744812 100.8730316162102 .1408615112104 .3578796387106 .7792434692108 .5035018921 101.493400573796 .0073165893693 .8738174438592 .6546783447392 .65467834473 95.0929565429794 .4833908081193 .2642517089894 .1785964965896 .31210327148 99.96952056885104 .2365036011108 .5035018921112 .4656982422115 .7057723999 117.7201919556116 .7326965332114 .5991973877114 .2944030762115 .2088012695 116.7326965332119 .7806015015123 .7427978516124 .0501174927122 .8981704712 122.2629318237122 .4596862793123 .4742126465124 .9742889404126 .5318145752 127.8078155518128 .6291503906128 .9874572754128 .6369476318127 .6768264771 126.7214126587125 .770866394124 .8252029419123 .3695907593121 .3460083008 119.3719863892117 .6080474854116 .130531311114 .9687271118114 .1128311157 113.5107498169113 .0661315918112 .6539077759112 .1485137939111 .479095459 110.6390533447109 .6770553589108 .6575241089107 .6375045776106 .6572418213 105.732635498104 .911315918104 .3285903931104 .1516571045104 .5035629272 104.0087432861103 .1424026489102 .28540802101 .4385757446100 .6017532349 99.7739410400498 .9548721313598 .1462860107497 .3525009155396 .57969665527 95.8357772827195 .1295166015694 .4714431762793 .8730697631893 .3484954834 92.9081954956192 .5882415771592 .4226760864392 .4432678222792 .67127227783 93.1019668579193 .6854324340894 .3202514648494 .7881774902394 .17859649658 
93.8738174438593.8738174438593.8738174438594.1785964965894.78817749023 95.397743225196 .0073165893696 .6168823242297 .2264633178798 .14080810547 98.7503814697399 .66472625732100 .5791015625101 .4934005737102 .4077987671 103.3820953369104 .2535934448105 .0793457031105 .8029403687106 .3891525269 106.8435668945107 .1679458618107 .3807067871107 .4933319092106 .979598999 106.3700027466105 .7603988647105 .1509017944104 .2365036011103 .6268997192 102.712600708101 .7982025146101 .1886978149100 .274299621699 .35994720459 98.445587158297 .5312423706196 .6168823242295 .7025299072394 .78817749023 93.8738174438592 .6546783447391 .7403335571390 .8259735107489 .60682678223 88.6924667358487 .7781066894586 .5589828491285 .3398437584 .42548370361 83.2063369751 82.29197692871 81.07285308838 79.85370635986 78.93934631348 77.7202072143676 .8058471679775 .8914871215874 .6723632812573 .75800323486 72.8436431884872 .8436431884874 .062782287675 .58670806885 -9999 -9999 -9999 -9999 -9999 -9999 -9999 -9999 -9999 -9999 -9999 -9999 -9999 -9999 -9999 -9999 -9999 -9999 -9999 -9999 -9999 -9999 -9999 -9999 -9999 -9999 -9999 -9999 -9999 -9999 -9999 -9999 -9999 -9999

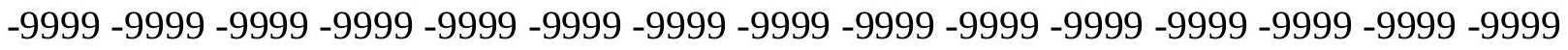
-9999 -9999 -9999 -9999 -9999 -9999 -9999 -9999 -9999 -9999 -9999 -9999 -9999 -9999 -9999 -9999 -9999 -9999 -9999 -9999 -9999 -9999 -9999 -9999 -9999 -9999 -9999 -9999 -9999 -9999 -9999 -9999 -9999-9999-9999-9999

-9999 -9999 -9999 -9999 -9999 -9999 -9999 -9999 -9999 -9999 -9999 -9999 -9999 -9999 -9999 -

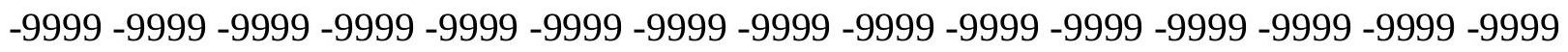
-9999 -9999 -9999 -9999 -9999 -9999 -9999 -9999 -9999 -9999 -9999 -9999 -9999 -9999 -9999 -9999 -9999 -9999 -9999 -9999 -9999 -9999 -9999 -9999 -9999 -9999 -9999 -9999 -9999 -9999 -

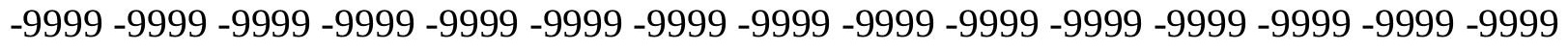
-9999 -9999-9999 -9999-9999 -9999 -9999-9999 134.4562683105 132.3573455811 130.0291595459127 .5857315063125 .141494751122 .8052520752120 .6790542603 118.825592041117 .2801818848116 .0539703369115 .1353530884114 .502243042 114.1129150391113 .895614624113 .7387619019113 .5051269531113 .0128097534 112.1153335571110 .7135238647108 .7679901123106 .2865982056103 .318359375 99.9413299560596 .0073165893692 .349891662689 .6068267822386 .86376190186 84.7302627563583 .8159103393684 .4254837036184 .4254837036183 .51112365723 82.5967712402385 .0350494384889 .8510208129992 .8042144775495 .67596435547 98.40273284912100 .8604736328102 .9562072754104 .6508636475105 .9559783936 106.9173355103107 .5965881348108 .0582427979108 .36302948108 .5661849976 108.7155609131108 .8486175537108 .9859085083109 .1263656616109 .2487640381 109.2849121094 109.2163848877 109.0058288574 108.6220626831 108.0531692505 107.3116607666 106.4315872192105.4680328369104.4989852905 103.5897750854 102.8401031494102 .3091583252102 .067817688102 .2005462646102 .8110275269 104.0197296143105 .9342498779108 .4262008667110 .4982070923110 .8780288696 108.098487854105 .455703735496 .9216690063591 .1307525634892 .65467834473 95.0929565429794 .4833908081193 .2642517089891 .7403335571391 .74033355713 94.7881774902399 .66472625732104 .5412979126109 .4179000854113 .3800964355 115.818397522115 .2088012695113 .9896011353113 .075302124113 .3800964355 114.9039993286118 .2565994263122 .2188034058124 .9072113037124 .3282470703 124.0202941895124 .2149200439124 .9180603027125 .9613418579127 .0867385864 128.0653991699128 .751663208129 .0933074951129 .0843505859128 .164352417 
127.1966705322126 .2339019775125 .2760391235123 .8493499756122 .0472412109 120.2580108643118 .6016540527117 .1545562744115 .9550552368114 .9966659546 114.2367706299113 .6009140015113 .0023345947112 .3653488159111 .6350250244 110.8018035889109 .881942749108 .9143371582107 .9458999634107 .0305252075 106.20728302105 .5217514038105 .0752563477104 .9542617798104 .8986282349 103.9867630005103 .0796661377102 .1784973145101 .2835769653100 .3942108154 99.509063720798 .6278381347797 .7524490356496 .8874282836996 .03910064697 95.2152938842894 .4245452880993 .6768341064592 .983123779392 .35749053955 91.8099441528391 .3932571411191 .1391830444391 .0871734619191 .27272796631 91.7097091674892 .359512329193 .0777816772593 .2642517089892 .95947265625 92.9594726562593 .2642517089893 .2642517089893 .5690307617294 .17859649658 94.4833908081195 .0929565429795 .7025299072396 .3121032714896 .92166900635 97.5312423706198 .445587158299 .35994720459100 .2742996216101 .1886978149 102.1029968262103 .1022262573104 .0423278809104 .8325653076105 .4493560791 105.9024658203106 .2183837891106 .412147522106 .5081939697106 .3700027466 105.7603988647105 .1509017944104 .5412979126103 .9317016602103 .0174026489 102.4077987671101 .4934005737100 .883903503499 .9695205688599 .05516815186 98.445587158297 .5312423706196 .6168823242295 .7025299072394 .78817749023 93.8738174438592 .9594726562592 .0450973510791 .1307525634890 .21640014648 89.302040100188 .0829010009887 .1685485839886 .254188537685 .03504943848 83.8159103393682 .9015579223681 .6824111938580 .7680587768679 .54891967773 78.3297805786177 .4154205322376 .1962814331175 .2819290161174 .36756896973 73.1484298706172 .5388565063573 .1484298706174 .6723632812576 .19628143311 -9999 -9999 -9999 -9999 -9999 -9999 -9999 -9999 -9999 -9999 -9999 -9999 -9999 -9999 -9999 -9999 -9999 -9999 -9999 -9999 -9999 -9999 -9999 -9999 -9999 -9999 -9999 -9999 -9999 -9999 -9999 -9999 -9999 -9999 -9999 -9999 -9999 -9999 -9999 -9999 -9999 -9999 -9999 -9999 -9999 -9999 -9999 -9999 -9999 -9999 -9999 -9999 -9999 -9999 -9999 -9999 -9999 -9999 -9999 -9999 -9999 -999 -

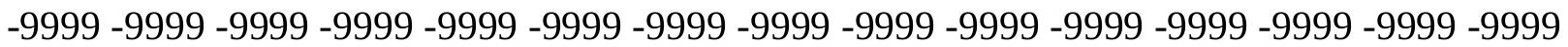
-9999 -9999 -9999 -9999 -9999 -9999-9999 -9999

-9999 -9999 -9999 -9999 -9999 -9999 -9999 -9999 -9999 -9999 -9999 -9999 -9999 -9999 -9999 -9999 -9999 -9999 -9999 -9999 -9999 -9999 -9999 -9999 -9999 -9999 -9999 -9999 -9999 -9999 -9999 -9999 -9999 -9999 -9999 -9999 -9999 -9999 -9999 -9999 -9999 -9999 -9999 -9999-999 -999 -

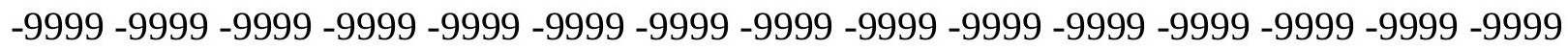

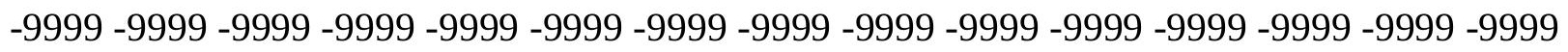
-9999 -9999 -9999 -9999 -9999 -9999 -9999 -9999 -9999 139.168762207136 .0750427246 132.8464202881129 .6292419434126 .5966796875123 .8582992554121 .4867019653 119.5130844116117 .9353027344116 .7385482788115 .9118652344115 .4416503906 115.2876815796115 .3109664917115 .3547210693115 .1304321289114 .4514465332 113.195526123111 .353843689108 .9630050659106 .0987930298102 .8908920288 99.5139236450296 .3121032714893 .2642517089890 .8259735107488 .99725341797 88.08290100098 87.47332763672 87.16854858398 86.86376190186 86.2541885376 85.6446228027384 .7302627563585 .3398437591 .1307525634897 .46012878418 100.0832901001102 .2749176025103 .9807662964105 .2232131958106 .0750045776 106.6320724487106 .9919128418107 .2390823364107 .4388961792107 .6362533569 107.859375108 .1161117554108 .3798904419108 .6213226318108 .7945556641 108.8607254028108 .7825317383108 .5352096558108 .1109161377107 .5263519287 
106.8188095093106 .0461807251105 .2759780884104 .5768356323104 .026473999 103.7119827271103 .7161102295104 .1287078857105 .039932251106 .511177063 108.4940109253110 .6534042358112 .316986084112 .5205230713111 .0967254639 107.7021560669102 .8403549194100 .274299621698 .445587158298 .4455871582 95.7025299072392 .6546783447390 .2164001464889 .6068267822391 .43553924561 95.3977432251100 .2742996216105 .1509017944108 .1986999512109 .7226028442 109.7226028442108 .8082962036108 .1986999512108 .1986999512109 .1130981445 111.551399231115 .5136032104121 .3044967651125 .2053375244125 .141456604 125.3595657349125 .873550415126 .6064758301127 .400970459128 .1170043945 128.6378173828128 .9085235596128 .8732910156128 .5137176514127 .6683654785 126.6942367554125 .5497817993124 .0651855469122 .4732513428120 .8693084717 119.342880249117 .9625244141116 .7650909424115 .749786377114 .8861999512 114.1243209839113 .4052658081112 .677734375111 .9060897827111 .0755691528 110.1938323975109 .2852478027108 .3869628906107 .5453186035106 .8165283203 106.2334136963105 .856590271105 .737449646104 .9427337646103 .9946517944 103.0481567383102 .1039123535101 .1618423462100 .220832824799 .27928161621 98.33683013916 97.3956832885796.460655212495.5382919311594.63633728027 93.7629165649492 .9271545410292 .1386871337991 .4096374511790 .75077819824 90.2267532348689 .8584213256889 .6901168823289 .771629333590 .14127349854 90.79213714691 .6238555908291 .4355392456191 .1307525634891 .43553924561 92.349891662692 .349891662692 .6546783447393 .2642517089893 .87381744385 94.1785964965894 .7881774902395 .0929565429795 .7025299072396 .31210327148 96.9216690063597 .5312423706198 .445587158299 .66472625732100 .5791015625 101.7982025146102 .8775482178103 .7363128662104 .3637619019104 .8222427368 105.1288604736105 .3071670532105 .3785552979105 .3716506958104 .8460998535 104.2365036011103 .6268997192103 .0174026489102 .4077987671101 .7982025146 101.1886978149100 .274299621699 .6647262573299 .0551681518698 .14080810547 97.5312423706196 .6168823242295 .7025299072395 .0929565429794 .17859649658 93.2642517089892 .349891662691 .7403335571390 .8259735107489 .60682678223 88.6924667358487 .7781066894586 .8637619018685 .6446228027384 .73026275635 83.5111236572382 .5967712402381 .3776321411180 .1584930419979 .24413299561 78.0249862670976 .8058471679775 .8914871215874 .6723632812573 .75800323486 $72.8436431884872 .5388565063573 .7580032348675 .2819290161176 .80584716797-9999$ -9999 -9999 -9999 -9999 -9999 -9999 -9999 -9999 -9999 -9999 -9999 -9999 -9999 -9999 -9999

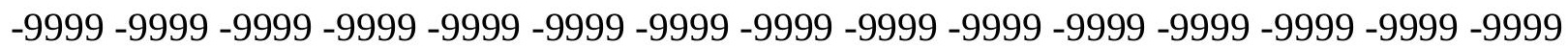

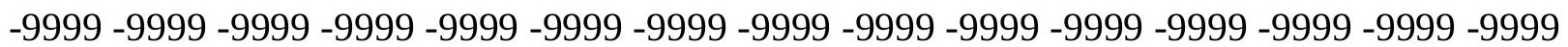

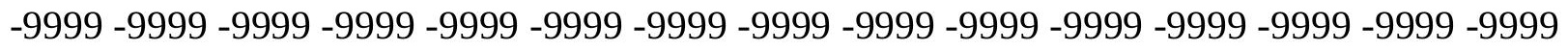

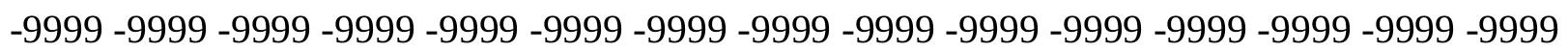
-9999 -9999 -9999 -9999 -9999 -9999 -9999

-9999 -9999 -9999 -9999 -9999 -9999 -9999 -9999 -9999 -9999 -9999 -9999 -9999 -9999 -9999

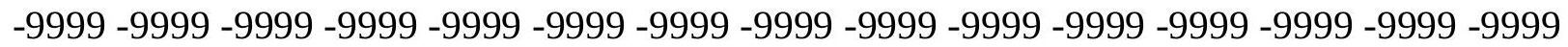
-9999 -9999 -9999 -9999 -9999 -9999 -9999 -9999 -9999 -9999 -9999 -9999 -9999 -9999 -9999 -9999 -9999 -9999 -9999 -9999 -9999 -9999 -9999 -9999 -9999 -9999 -9999 -9999 -9999 -9999 -9999 -9999 -9999 -9999 -9999 -9999 -9999 -9999 -9999 -9999 -9999 -9999 -9999 -9999 -9999 -9999 -9999 -9999 -9999 -9999 -9999 -9999 -9999 -9999 145.9300231934141 .9532775879 137.8396148682133 .8000030518130 .0274047852126 .6619873047123 .7818069458 
121.4043502808119 .5011367798118 .0315933228116 .9980926514116 .4389038086 116.4020385742116 .763168335117 .2174987793117 .4032821655116 .9943466187 115.8908157349114 .1501083374111 .856918335109 .0906143188106 .0713577271 103.017402648999 .6647262573296 .9216690063594 .4833908081192 .65467834473 91.4355392456190 .8259735107490 .5211791992289 .9116134643689 .60682678223 88.6924667358487 .7781066894586 .254188537684 .4254837036187 .77810668945 92.349891662699 .35994720459103 .6343841553104 .7120132446105 .3528366089 105.6901397705105 .8605270386105 .978302002106 .1180267334106 .3243179321 106.6159744263106 .9837799072107 .3965530396107 .8050613403108 .1591644287 108.4072723389108 .5038070679108 .424659729108 .165977478107 .7486190796 107.2128677368106 .6165771484106 .0268173218105 .5136947632105 .1502685547 105.0222320557105 .2095870972105 .7872314453106 .8091201782108 .2715988159 110.047492981111 .8116836548113 .0666885376113 .2726669312112 .2250061035 109.7417755127106 .8383560181104 .2979049683102 .06058502299 .88166046143 96.949630737393 .7437744140691 .1307525634899 .9116134643690 .21640014648 92.0450973510796 .31210327148100 .5791015625102 .1029968262102 .4077987671 102.712600708102 .4077987671102 .1029968262102 .1029968262102 .712600708 104.2365036011 106.979598999 111.551399231 116.4279022217125.755859375 125.9994735718126 .4020309448126 .9225845337127 .4815444946127 .9854278564 128.3659362793128 .5425567627128 .4638519287128 .1000061035127 .4525756836 126.5410842896125 .4053497314124 .1005020142122 .6972808838121 .2659835815 119.8761291504118 .5833282471117 .4188537598116 .3883209229115 .4730224609 114.6405944824113 .8525238037113 .0742950439112 .2806777954111 .4602432251 110.6167678833109 .767791748108 .941986084108 .1770477295107 .5188140869 106.998008728106 .6503829956105 .9987869263105 .0184707642104 .0361251831 103.0520935059102 .0664901733101 .0788879395100 .087936401499 .09196472168 98.0905914306697 .0863113403396 .0843124389695 .0914611816494 .1155166626 93.1642837524492 .2460250854591 .3688964843890 .5420532226689 .78137207031 89.1365432739388 .6279754638788 .2923202514688 .1847305297988 .37493133545 88.9158325195389 .6068267822388 .9972534179788 .9972534179789 .60682678223 90.2164001464890 .8259735107491 .4355392456192 .0450973510792 .95947265625 93.2642517089893 .5690307617293 .8738174438594 .1785964965894 .48339080811 95.0929565429795 .7025299072396 .6168823242297 .8360290527399 .05516815186 100.2742996216101 .4934005737102 .4077987671103 .0595932007103 .568031311 103.8804321289104 .0414581299104 .086517334103 .9317016602103 .6268997192 103.3221969604102 .712600708102 .1029968262101 .7982025146101 .1886978149 100.579101562599 .9695205688599 .0551681518698 .445587158297 .83602905273 97.2264633178796 .6168823242295 .7025299072395 .0929565429794 .17859649658 93.5690307617292 .6546783447392 .0450973510791 .1307525634890 .21640014648 89.302040100188.38768768311 87.47332763672 86.2541885376 85.33984375 84.12069702148 83.2063369751 81.98719787598 80.7680587768679.85370635986 78.6345596313577 .4154205322376 .5010681152375 .2819290161174 .36756896973 $73.4532165527372 .5388565063573 .1484298706174 .3675689697375 .89148712158-9999$ -9999 -9999 -9999 -9999 -9999 -9999 -9999 -9999 -9999 -9999 -9999 -9999 -9999 -9999 -9999 -9999 -9999 -9999 -9999 -9999 -9999 -9999 -9999 -9999 -9999 -9999 -9999 -9999 -9999 -9999 -

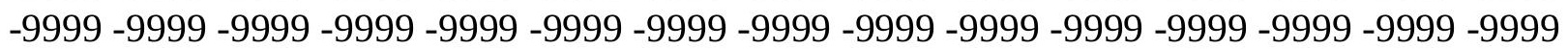


-9999 -9999 -9999 -9999 -9999 -9999 -9999 -9999 -9999 -9999 -9999 -9999 -9999 -9999 -9999 -9999 -9999 -9999 -9999 -9999 -9999 -9999 -9999 -9999 -9999 -9999 -9999 -9999 -9999 -9999 -9999 -9999 -9999 -9999-9999 -9999 -9999

-9999 -9999 -9999 -9999 -9999 -9999 -9999 -9999 -9999 -9999 -9999 -9999 -9999 -9999 -9999 -9999 -9999 -9999 -9999 -9999 -9999 -9999 -9999 -9999 -9999 -9999 -9999-9999 -9999 -9999 -9999 -9999 -9999 -9999 -9999 -9999 -9999 -9999 -9999 -9999 -9999 -9999 -9999 -9999 -9999

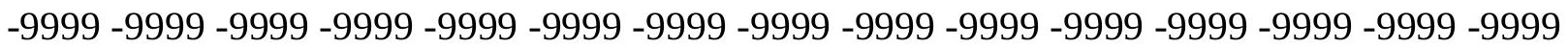
-9999 -9999 -9999 -9999 -9999 -9999 -9999 -9999 -9999 -9999 -9999 -9999 -9999 -9999 -9999 -9999 -9999 -9999 -9999-9999-9999 -9999 -9999-9999-9999 147.605682373 142.4873352051137 .5293426514132 .96875128 .9680786133125 .6032028198 122.8677902222120 .686958313118 .9636077881117 .6661529541116 .9651412964 116.9991836548117 .950012207118 .9931182861119 .7928771973119 .5812988281 118.5693969727116 .8657684326114 .6305465698111 .9321670532108 .8566741943 105.7603988647102 .71260070899 .9695205688597 .8360290527396 .00731658936 94.7881774902394 .1785964965893 .5690307617292 .9594726562592 .65467834473 92.0450973510791 .1307525634889 .9116134643688 .0829010009885 .33984375 81.3776321411186 .5589828491298 .14080810547104 .4867858887104 .7726135254 104.7542495728104 .6188201904104 .5192337036104 .538444519104 .733833313 105.102973938105 .6157836914106 .2190628052106 .8484725952107 .4259643555 107.8973770142 108.2011108398 108.3115158081 108.2265472412107.971496582 107.5909957886107 .1468276978106 .708946228106 .3507461548106 .1422958374 106.1568069458106 .4611358643107 .1068191528108 .1122436523109 .4335098267 110.9257354736112 .3242492676113 .2765426636113 .4632034302112 .6827545166 110.9978256226108 .8399581909106 .4409255981103 .9964523315101 .2670822144 98.3710174560595 .5806198120193 .7017517089893 .4263305664192 .3498916626 92.0450973510793 .5690307617295 .7025299072396 .9216690063597 .53124237061 97.8360290527397 .8360290527397 .5312423706196 .9216690063596 .92166900635 97.5312423706198 .75038146973101 .1886978149105 .1509017944112 .4656982422 123.7427978516126 .5840301514126 .9706878662127 .3737640381127 .7339782715 127.9851379395128 .0721740723127 .946647644127 .587059021126 .9882583618 126.1717300415125 .166343689124 .0202941895122 .7820281982121 .5089569092 120.2532119751119 .0581130981117 .9499893188116 .9374847412116 .0114364624 115.1525726318114 .3361358643113 .5392150879112 .7446289062111 .9445571899 111.1421966553110 .3507843018109 .5919036865108 .8937225342108 .2870941162 107.8014678955107 .1431884766106 .1386642456105 .1293029785104 .1150741577 103.0958709717102 .0713043213101 .0406188965100 .002334594798 .95490264893 97.8981781005996 .8349838256895 .7709350585994 .7132644653393 .66989135742 92.6484832763791 .6567535400490 .7016448974689 .7892837524488 .93203735352 88.1749343872187 .5158386230586 .9750747680786 .5914535522586 .44333648682 86.6798019409287 .1685485839886 .254188537686 .254188537687 .16854858398 87.7781066894588 .6924667358489 .6068267822390 .8259735107491 .74033355713 92.0450973510792 .0450973510792 .349891662692 .6546783447392 .65467834473 93.2642517089893.8738174438594.4833908081195.7025299072396.92166900635 98.445587158299 .66472625732100 .5791015625101 .4934005737102 .1029968262 102.4618148804102 .5876617432102 .6138076782102 .5904998779102 .4077987671 102.1029968262101 .4934005737101 .1886978149100 .5791015625100 .2742996216 
99.6647262573299 .0551681518698 .445587158298 .1408081054797 .53124237061 96.9216690063596 .3121032714895 .7025299072395 .0929565429794 .48339080811 93.5690307617292 .9594726562592 .349891662691 .4355392456190 .52117919922 89.9116134643688 .9972534179788 .0829010009886 .8637619018685 .94940185547 84.7302627563583 .8159103393682 .5967712402381 .6824111938580 .46327209473 79.2441329956178 .3297805786177 .110626220776 .1962814331174 .97714233398 74.062782287673 .7580032348673 .7580032348673 .7580032348674 .97714233398 76.50106811523 -9999 -9999 -9999 -9999 -9999 -9999 -9999 -9999 -9999 -9999 -9999 -9999 -9999 -9999 -9999 -9999 -9999 -9999 -9999 -9999 -9999 -9999 -9999 -9999 -9999 -9999 -9999 -9999 -9999 -9999 -9999 -9999 -9999 -9999 -9999 -9999 -9999 -9999 -9999 -9999 -9999 -9999 -

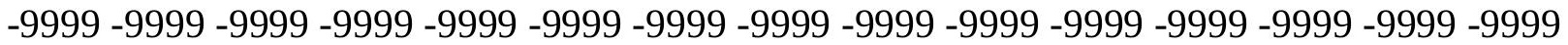

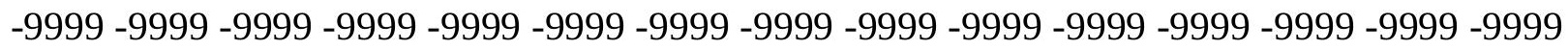
-9999 -9999 -9999 -9999 -9999 -9999 -9999 -9999 -9999-9999

-9999 -9999 -9999 -9999 -9999 -9999 -9999 -9999 -9999 -9999 -9999 -9999 -9999 -9999 -9999 -9999 -9999 -9999 -9999 -9999 -9999 -9999 -9999 -9999 -9999 -9999 -9999 -9999 -9999 -9999

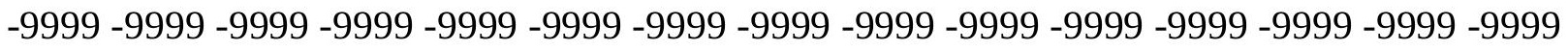

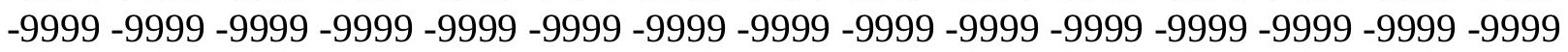
-9999 -9999 -9999 -9999 -9999 -9999 -9999 -9999 -9999 -9999 -9999 -9999 -9999 -9999 -9999 -9999 -9999 -9999 -9999 -9999 -9999 -9999 -9999 -9999 -9999 -9999 146.6587524414 140.6664581299135 .2632141113130 .6244506836126 .8082504272123 .7733917236 121.3938674927119 .481048584117 .841796875116 .8500061035116 .7862319946 118.5272064209120 .8722610474122 .1885528564121 .9644622803120 .9119415283 119.1452178955116 .8231506348114 .2944030762110 .9418029785107 .8938980103 105.1509017944102 .712600708100 .579101562598 .7503814697397 .53124237061 96.9216690063598 .7503814697399 .6647262573298 .445587158295 .09295654297 94.4833908081193 .5690307617292 .0450973510789 .9116134643687 .77810668945 85.9494018554789 .91161346436100 .8839035034104 .3330993652103 .7852401733 103.2006378174102 .7891693115102 .654045105102 .8435516357103 .3239593506 104.0334243774104 .8795547485105 .7869720459106 .6479797363107 .3768386841 107.9096908569108 .2224197388108 .3030929565108 .1930007935107 .9412307739 107.6164016724107 .2942657471107 .0505142212106 .9563903809107 .0657272339 107.4315719604108 .0814590454109 .0074386597110 .1484832764111 .3714447021 112.471862793113 .2059249878113 .3574523926112 .7934341431111 .5593490601 109.7970352173107 .6549377441105 .2496490479102 .631416320899 .99449920654 97.6874160766696 .217491149995 .9900360107496 .0073165893694 .17859649658 92.9594726562592 .349891662692 .6546783447393 .2642517089893 .56903076172 93.5690307617293 .2642517089892 .9594726562592 .349891662692 .3498916626 92.349891662693 .2642517089896 .92166900635101 .4934005737103 .3221969604 111.24659729126 .8361358643127 .1353988647127 .383972168127 .5371246338 127.5508880615127 .3920059204127 .0400848389126 .4933624268125 .7638168335 124.8779754639123 .8696212769122 .7797164917121 .6504516602120 .5223999023 119.4289779663118 .3923492432117 .4222793579116 .516204834115 .6637268066 114.8496856689114 .0594940186113 .2819366455112 .5125732422111 .7545089722 111.0181350708110 .3190155029109 .6770782471109 .1131591797108 .3634338379 107.3420257568 106.313583374 105.2779769897 104.2347335815103.1832885742 102.1228485107101 .052429199299 .9704360961998 .8755264282297 .76803588867 
96.6513824462995 .5316467285294 .4165039062593 .3141021728592 .23222351074 91.1783828735490 .1589889526489 .179412841888 .2530899047987 .39563751221 86.5985183715885 .8566055297985 .1739807128984 .5719375610484 .15189361572 84.4254837036183 .206336975183 .5111236572384 .4254837036185 .33984375 86.5589828491287 .4733276367288 .6924667358489 .6068267822390 .21640014648 90.5211791992290 .5211791992290 .8259735107490 .8259735107491 .13075256348 91.4355392456192 .349891662693 .5690307617294 .7881774902396 .31210327148 97.5312423706198 .7503814697399 .66472625732100 .2742996216100 .8467102051 100.8839035034100 .8839035034100 .8839035034100 .8839035034100 .5791015625 100.274299621699 .9695205688599 .6647262573299 .0551681518698 .75038146973 98.445587158297 .8360290527397 .5312423706196 .9216690063596 .31210327148 96.0073165893695 .397743225194 .7881774902394 .1785964965893 .87381744385 93.2642517089892 .349891662691 .7403335571391 .1307525634890 .21640014648 89.302040100188 .3876876831187 .4733276367286 .5589828491285 .64462280273 84.4254837036183 .206336975182 .2919769287181 .0728530883879 .85370635986 78.9393463134877 .7202072143676 .8058471679775 .8914871215874 .97714233398 74.3675689697374 .062782287673 .7580032348674 .062782287675 .58670806885 76.80584716797 -9999 -9999 -9999 -9999 -9999 -9999 -9999 -9999 -9999 -9999 -9999 -9999 -9999 -9999 -9999 -9999 -9999 -9999 -9999 -9999 -9999 -9999 -9999 -9999 -9999 -9999 -9999 -

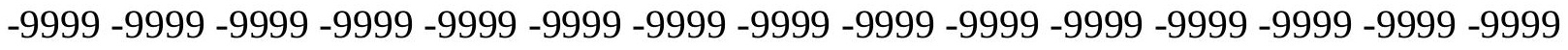
-9999 -9999 -9999 -9999 -9999 -9999 -9999 -9999 -9999 -9999 -9999 -9999 -9999 -9999 -9999 -9999 -9999 -9999 -9999 -9999 -9999 -9999 -9999 -9999 -9999 -9999 -9999 -9999 -9999 -9999 -9999 -9999 -9999 -9999 -9999 -9999 -9999 -9999 -9999

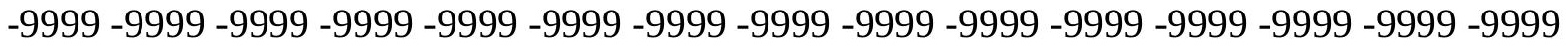

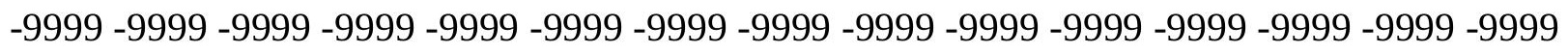
-9999 -9999 -9999 -9999 -9999 -9999 -9999 -9999 -9999 -9999 -9999 -9999 -9999 -9999 -9999 -9999 -9999 -9999 -9999 -9999 -9999 -9999 -9999 -9999 -9999 -9999 -9999 -9999 -9999 -9999

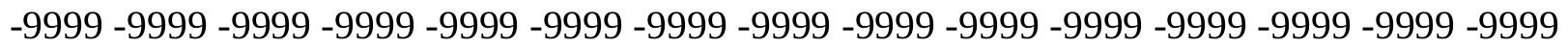
-9999 -9999 -9999 -9999 -9999 -9999 -9999 -9999 -9999 -9999 -9999 150.167678833 143.0064239502136 .7148742676131 .4548187256127 .2232437134123 .9307861328 121.4365997314119 .4270629883117 .6074676514115 .7750473022115 .818397522 117.342300415124 .0475006104124 .0475006104123 .7427978516122 .5235977173 120.6949005127117 .9517974854115 .2088012695112 .4656982422109 .4179000854 106.979598999104 .5412979126102 .712600708101 .188697814999 .96952056885 99.05516815186100 .8839035034102 .712600708102 .712600708101 .1886978149 97.8360290527397 .2264633178796 .6168823242295 .7025299072394 .78817749023 94.1785964965892 .9594726562590 .5211791992297 .83602905273102 .7040252686 101.5188751221100 .7072143555100 .3941574097100 .6105575562101 .2660293579 102.2493591309103 .4200363159104 .6522598267105 .825668335106 .8433227539 107.6244430542108 .1426391602108 .3883590698108 .4051971436108 .2537460327 108.0064926147107 .7584686279107 .5876922607107 .5609817505107 .7253417969 108.1146087646108 .7339019775109 .5618057251110 .5336227417111 .5355148315 112.4120483398112 .9903564453113 .1173706055112 .7015838623111 .7388763428 110.2813339233108 .4228439331106 .2681503296103 .9580917358101 .7124176025 99.84458160498 .7038497924898 .5414886474699 .4452819824296 .92166900635 94.1785964965892 .0450973510790 .2164001464889 .302040100189 .3020401001 
89.9116134643690.2164001464890.21640014648 89.9116134643690.21640014648 90.2164001464890 .8259735107492 .0450973510792 .0450973510789 .91161346436 92.95947265625109 .7226028442126 .7977523804126 .9697723389127 .0531387329 127.0171051025126 .8380661011126 .5007095337126 .0034866333125 .3547515869 124.5747375488123 .6895675659122 .7311935425121 .7322006226120 .7238540649 119.7323074341118 .7759246826117 .8648223877117 .0002593994116 .177772522 115.3887786865114 .6245880127113 .8785095215113 .1484832764112 .4376144409 111.7538375854111 .1081466675110 .5138931274109 .6473770142108 .6156845093 107.5753250122106 .5260391235105 .4673919678104 .3985137939103 .318397522 102.2258911133101 .119857788199 .9987335205198 .8614425659297 .7088394165 96.5451660156295 .3772048950294 .2130966186593 .0613937377991 .93018341064 90.8273162841889 .7581405639688 .7319641113387 .7612762451286 .8392868042 85.944755554285 .0510864257884 .1342391967883 .1867294311582 .21360778809 80.4632720947380 .4632720947381 .0728530883881 .6824111938582 .90155792236 83.8159103393685 .0350494384886 .254188537687 .4733276367288 .08290100098 88.6924667358488 .6924667358488 .6924667358488 .6924667358488 .99725341797 89.3020401001 89.9116134643691.1307525634892.349891662693.87381744385 95.397743225196 .9216690063597 .8194351196398 .445587158298 .75038146973 99.0551681518699 .0551681518699 .0551681518699 .0551681518699 .05516815186 98.7503814697398 .445587158298 .445587158298 .1408081054797 .83602905273 97.2264633178796 .9216690063596 .6168823242296 .3121032714896 .00731658936 95.397743225195 .0929565429794 .4833908081194 .1785964965893 .56903076172 93.2642517089892 .6546783447392 .0450973510791 .4355392456190 .82597351074 89.91161346436 88.99725341797 88.08290100098 87.16854858398 86.2541885376 85.0350494384883 .8159103393682 .9015579223681 .6824111938580 .76805877686 79.5489196777378 .6345596313577 .4154205322376 .5010681152375 .89148712158 75.2819290161174 .6723632812574 .062782287673 .1484298706174 .36756896973 75.89148712158 -9999 -9999 -9999 -9999 -9999 -9999 -9999 -9999 -9999 -9999 -9999 -9999 -9999 -9999 -9999 -9999 -9999 -9999 -9999 -9999 -9999 -9999 -9999 -9999 -9999 -9999-9999 - -999 -9999 -9999 -9999 -9999 -9999 -9999 -9999 -9999 -9999 -9999 -9999 -9999 -9999 -9999 -9999 -9999 -9999 -9999 -9999 -9999 -9999 -9999 -9999 -9999 -9999 -9999 -9999 -9999 -9999 -9999 -9999 -9999 -9999 -9999 -9999 -9999 -9999 -9999 -9999 -9999 -9999 -9999-9999 -9999 -9999 -9999-9999 -9999-9999-9999-9999-9999-9999-9999

-9999 -9999 -9999 -9999 -9999 -9999 -9999 -9999 -9999 -9999 -9999 -9999 -9999 -9999 -9999 -9999 -9999 -9999 -9999 -9999 -9999 -9999 -9999 -9999 -9999 -9999 -9999 -9999 -9999 -9999 -

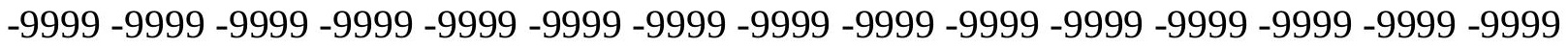

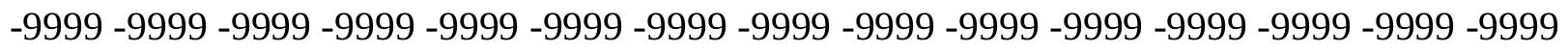

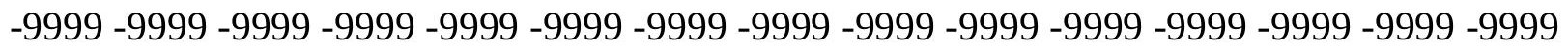
-9999 -9999 -9999 -9999 -9999 -9999 -9999 -9999 -9999 -9999 -9999 -9999 144.2626800537 137.0908660889131 .2925109863126 .7040023804123 .1354293823120 .4188079834 118.4433135986117 .0374984741113 .075302124114 .2944030762115 .818397522 127.0953979492125 .5715026855124 .3523025513122 .8283996582120 .6949005127 118.2565994263115 .818397522113 .075302124110 .3321990967107 .8938980103 105.7603988647103 .9317016602102 .712600708101 .7982025146100 .8839035034 100.5791015625103 .6268997192104 .8460998535104 .2365036011100 .8839035034 101.1886978149 101.1886978149 101.4934005737 102.1029968262 102.1029968262 
101.188697814997.8360290527392.0450973510793.2642517089896.92166900635 98.1419296264697 .6761398315497 .991630554298 .92394256592100 .2752456665 101.8375396729103 .4494628906104 .9809570312106 .3112335205107 .3577270508 108.0759658813108 .4740142822108 .5899200439108 .5037307739108 .3012390137 108.0840148926107 .9451751709107 .9471740723108 .132774353108 .5225982666 109.0959854126109 .8328933716110 .668838501111 .5067977905112 .2279281616 112.7050323486112 .8274078369112 .5228652954111 .7668228149110 .5813674927 109.0283126831107 .2061004639105 .2726593018103 .4344558716101 .9520339966 101.0727233887100 .9647369385101 .6859893799100 .274299621696 .61688232422 93.2642517089889 .302040100186 .254188537686 .254188537687 .16854858398 88.0829010009888 .9972534179789 .6068267822390 .2164001464891 .13075256348 91.1307525634889 .6068267822387 .4733276367283 .5111236572383 .81591033936 96.00731658936110 .3321990967118 .5614013672121 .6092987061113 .6848983765 107.5891036987115 .2088012695125 .5442123413124 .969291687124 .284034729 123.5085449219122 .6676330566121 .7864608765120 .8894348145119 .9971237183 119.1249923706118 .2826538086117 .4736328125116 .6970977783115 .9489517212 115.2246551514114 .520652771113 .836517334113 .1750106812112 .5420913696 111.9451446533110 .9824829102109 .9465332031108 .9006576538107 .8446044922 106.7778701782105 .6997375488104 .6089935303103 .5043029785102 .3841323853 101.247215271100 .092147827198 .9183273315497 .7271881103596 .52377319336 95.3156738281294 .1116790771592 .9208755493291 .7520446777390 .61383056641 89.5141677856488 .4638977050887 .4740142822386 .5261993408285 .59202575684 84.63373565674 83.61268615723 82.5025558471781.32364654541 80.17208099365 78.9393463134878 .9393463134879 .5489196777380 .1584930419981 .37763214111 82.5967712402384 .1206970214885 .3398437586 .254188537686 .55898284912 86.8637619018686 .8637619018686 .5589828491286 .5589828491286 .86376190186 87.4733276367288 .3876876831189 .6068267822391 .4355392456192 .95947265625 94.4833908081195 .397743225196 .0073165893696 .3121032714896 .61688232422 96.9216690063596 .9216690063597 .2264633178797 .2128295898497 .22646331787 96.9216690063596 .9216690063596 .6168823242296 .6168823242296 .31210327148 96.0073165893695 .7025299072395 .397743225195 .0929565429794 .78817749023 94.4833908081194 .1785964965893 .8738174438593 .5690307617293 .26425170898 92.6546783447392 .349891662691 .7403335571391 .1307525634890 .21640014648 89.6068267822388 .6924667358487 .7781066894586 .5589828491285 .64462280273 84.4254837036183 .5111236572382 .2919769287181 .3776321411180 .15849304199 79.2441329956178 .3297805786177 .4154205322376 .5010681152375 .58670806885 74.9771423339874 .3675689697373 .4532165527373 .1484298706174 .67236328125 76.19628143311 -9999 -9999 -9999 -9999 -9999 -9999 -9999 -9999 -9999 -9999 -9999 -9999 -9999 -9999 -9999 -9999 -9999 -9999 -9999 -9999 -9999 -9999 -9999 -9999 -9999 -9999 -9999 -9999 -9999 -9999 -9999 -9999 -9999 -9999 -9999 -9999 -9999 -9999 -9999 -9999 -9999 -9999 -

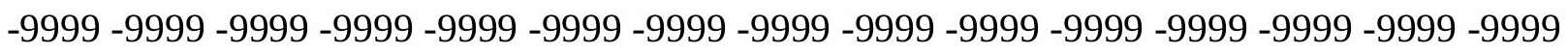
-9999 -9999 -9999 -9999 -9999 -9999 -9999 -9999 -9999 -9999 -9999 -9999 -9999 -9999 -9999 - -999 -9999 -9999 -9999 -9999-9999-9999-9999-9999 -9999 -9999 -9999 -9999 -9999 -9999 -9999 -9999 -9999 -9999 -9999 -9999 -9999 -9999 -9999 -9999 -9999 -9999 -9999 -9999 -9999 -9999 -9999 -9999 -9999 -9999 -9999 -9999 -9999 -9999 -9999 -9999 -9999 -9999 -9999 -9999 -9999 -9999 -9999 -9999 -9999 -9999 -9999 -9999 -9999 
-9999 -9999 -9999 -9999 -9999 -9999 -9999 -9999 -9999 -9999 -9999 -9999 -9999 -9999 -9999

-9999 -9999 -9999 -9999 -9999 -9999 -9999 -9999 -9999 -9999 -9999 -9999 -9999 -9999 -9999 -

-9999 -9999 -9999 -9999 -9999 -9999 -9999 -9999 -9999 -9999 -9999 -9999 144.0228118896 136.1434020996130 .0567169189125 .2041397095121 .2732772827118 .2919387817 116.1231002808111 .8561019897112 .1608963013113 .075302124114 .2944030762 128.9241027832126 .7906036377124 .9618988037122 .8283996582120 .3900985718 118.2565994263115 .5136032104113 .075302124110 .6370010376108 .1986999512 106.3700027466104.8460998535103.6268997192102.712600708 102.4077987671 102.1029968262102 .4077987671105 .1509017944105 .1509017944103 .6268997192 104.2365036011105 .4557037354106 .6747970581107 .8938980103109 .1130981445 108.8452224731106 .065200805796 .3121032714885 .6446228027390 .21640014648 93.8738174438594 .430252075294 .9858856201296 .3121032714897 .53124237061 99.66472625732102 .2107849121104 .1353912354105 .8129959106107 .1331939697 108.0421142578108 .5518875122108 .7305450439108 .6714706421108 .4736022949 108.2585906982108 .1198196411108 .1212234497108 .299987793108 .6643371582 109.205406189109 .8707809448110 .6103897095111 .3416595459111 .9667358398 112.3924865723112 .5359725952112 .337310791111 .7689361572110 .8406295776 109.5949478149108 .1211624146106 .5702819824105 .12059021103 .96900177 103.2966079712103 .2360839844103 .8156661987103 .931701660298 .75038146973 93.26425170898 88.69246673584 85.64462280273 85.33984375 86.2541885376 88.0829010009889 .9116134643691 .7403335571392 .9594726562593 .87381744385 93.5690307617292 .0450973510789 .6068267822386 .5589828491286 .55898284912 92.95947265625100 .5791015625104 .8460998535104 .846099853597 .22646331787 90.5211791992293 .2642517089899 .05516815186101 .7982025146105 .7603988647 113.9896011353120 .0852966309117 .9517974854120 .9997024536120 .2448272705 119.4572982788118 .6886062622117 .9432983398117 .2228088379116 .525932312 115.8509216309115 .1963272095114 .5625610352113 .9519271851113 .3686294556 112.357093811111 .321975708110 .2763519287109 .2196121216108 .1513824463 107.0709228516105 .9772338867104 .8687973022103 .7440414429102 .6011734009 101.4387359619100 .255523681699 .05161285497 .8292160034296 .59404754639 95.3544235229594 .119842529392 .9001922607491 .7052078247190 .54486846924 89.4294357299888 .3752899169987 .3882675170986 .4519958496185 .53482055664 84.5990371704183 .6139373779382 .5761947631881 .5437927246180 .78977203369 79.9436187744179 .0207748413177 .110626220777 .4154205322378 .63455963135 80.1584930419981 .6824111938583 .206336975184 .1206970214884 .73026275635 85.0350494384884 .7302627563584 .4254837036184 .1206970214884 .12069702148 84.4254837036185 .3398437586 .5589828491288 .0829010009889 .91161346436 92.0450973510792 .6546783447393 .2642517089893 .5690307617294 .17859649658 94.4833908081194 .7881774902395 .0929565429795 .0929565429795 .3977432251 95.397743225195 .397743225195 .397743225195 .0929565429795 .09295654297 95.0929565429794.7881774902394.4833908081194.4833908081194.17859649658 94.1785964965893 .8738174438593 .5690307617293 .2642517089893 .26425170898 92.6546783447392 .349891662692 .0450973510791 .4355392456190 .82597351074 89.91161346436 88.99725341797 88.08290100098 87.16854858398 86.2541885376 85.0350494384884 .1206970214882 .9015579223681 .9871978759880 .76805877686 79.8537063598678 .9393463134878 .0249862670977 .110626220776 .19628143311 
75.2819290161174 .6723632812573 .7580032348672 .8436431884873 .45321655273 75.28192901611 -9999 -9999 -9999 -9999 -9999 -9999 -9999 -9999 -9999 -9999 -9999 -9999 -9999 -9999 -9999 -9999 -9999 -9999 -9999 -9999 -9999 -9999 -9999 -9999 -9999 -9999 -9999 -9999 -9999 -9999 -9999 -9999 -9999 -9999 -9999 -9999 -9999 -9999 -9999 -9999 -9999 -9999 -9999 -9999 -9999 -9999 -9999 -9999 -9999 -9999 -9999 -9999 -9999 -9999 -9999 -9999 -9999

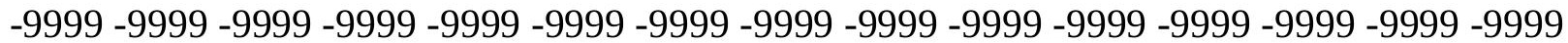
-9999 -9999 -9999 -9999 -9999 -9999 -9999 -9999 -9999 -9999 -9999 -9999 -9999 -9999 -9999 -9999 -9999 -9999 -9999 -9999 -9999 -9999 -9999

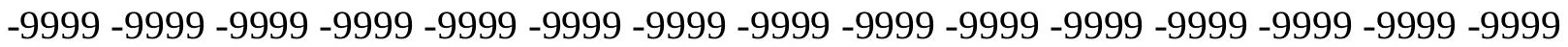
-9999 -9999 -9999 -9999 -9999 -9999 -9999 -9999 -9999 -9999 -9999 -9999 -9999 -9999 -9999 -9999 -9999 -9999 -9999 -9999 -9999 -9999 -9999 -9999 -9999 -9999 -9999 -9999 -9999 -9999 -9999 -9999 -9999 -9999 -9999 -9999 -9999 -9999 -9999 -9999 -9999 -9999 -9999 -9999 -9999 -9999 -9999 -9999 -9999 -9999 -9999 -9999 -9999 -9999 -9999-9999 -9999 -9999 133.6832122803127 .8479156494122 .8808135986118 .5614013672114 .9039993286 111.24659729110 .9418029785111 .24659729111 .551399231133 .4958953857 129.8385009766127 .0953979492124 .6570968628122 .2188034058119 .7806015015 117.342300415114 .9039993286112 .4656982422110 .0273971558108 .1986999512 106.3700027466104 .8460998535103 .9317016602103 .3221969604103 .0174026489 103.0174026489103 .3221969604103 .9317016602104 .8460998535105 .7603988647 106.979598999108 .1986999512110 .0273971558111 .841545105112 .4366531372 110.6969833374106 .947547912699 .9695205688586 .254188537685 .64462280273 89.9116134643690 .6391601562591 .6670379638793 .2642517089894 .78817749023 97.22646331787100 .2742996216103 .3410720825105 .3911895752106 .9908905029 108.0604705811108 .6394119263108 .8112182617108 .7180480957108 .4959335327 108.262008667108 .1113739014108 .1024856567108 .2607116699108 .6013336182 109.0990982056109 .7243881226110 .4050445557111 .0847549438111 .6622390747 112.0820007324112 .2766418457112 .1937103271111 .8105239868111 .1212844849 110.1701202393109 .042350769107 .8545074463106 .7488250732105 .8854217529 105.3851852417105 .3566207886105 .8227767944106 .674797058199 .66472625732 92.6546783447388 .3876876831185 .9494018554785 .6446228027386 .86376190186 89.6068267822392.95947265625 95.397743225197.2264633178797.83602905273 97.5312423706196 .3121032714894 .7881774902394 .4833908081194 .17859649658 96.0073165893697 .5312423706198 .1408081054797 .2264633178793 .26425170898 89.302040100188 .6924667358488 .3876876831183 .5111236572380 .76805877686 87.1685485839893 .8738174438591 .4355392456189 .9116134643692 .3498916626 98.75038146973106 .6747970581118 .4125366211117 .7536239624117 .1141891479 116.4942398071115 .8936080933115 .3130569458114 .7542037964113 .7599716187 112.729850769111 .689163208110 .6371078491109 .5729675293108 .4962463379 107.4059906006106 .3009338379105 .1792755127104 .039276123102 .8789978027 101.6969223022100 .491996765199 .2649459838998 .0188446044996 .76011657715 95.4976425170994 .2415847778393 .0027160644591 .7919082641690 .62087249756 89.5035095214888 .4558944702187 .4904632568486 .5906600952185 .7294921875 84.8757247924884 .0101547241283 .1555938720782 .4305953979581 .46276092529 80.089149475179 .0504302978577 .7079010009875 .2819290161176 .50106811523 78.0249862670979 .8537063598681 .6824111938582 .9015579223683 .2063369751 83.206336975182 .5967712402381 .9871978759881 .6824111938581 .37763214111 
81.3776321411181 .9871978759882 .9015579223684 .4254837036185 .94940185547 87.7781066894588 .9972534179789 .9116134643690 .5211791992291 .43553924561 92.0450973510792 .349891662692 .9594726562593 .2642517089893 .26425170898 93.5690307617293 .5690307617293 .7552566528393 .8738174438593 .87381744385 93.8738174438593 .5690307617293 .5690307617293 .5690307617293 .56903076172 93.2642517089893 .2642517089893 .2642517089892 .9594726562592 .95947265625 92.6546783447392 .349891662692 .0450973510791 .7403335571391 .13075256348 90.2164001464889 .302040100188 .3876876831187 .4733276367286 .55898284912 85.6446228027384 .4254837036183 .5111236572382 .2919769287181 .37763214111 80.4632720947379 .2441329956178 .3297805786177 .4154205322376 .80584716797 75.8914871215874 .9771423339874 .062782287673 .1484298706172 .53885650635 74.062782287675 .58670806885 -9999 -9999 -9999 -9999 -9999 -9999 -9999 -9999 -9999 -9999 -9999 -9999 -9999 -9999 -9999 -9999 -9999 -9999 -9999 -9999 -9999 -9999 -9999 -9999 -9999 -9999 -9999 -9999 -9999 -9999 -9999 -9999 -9999 -9999 -9999 -9999 -9999 -9999 - 9999 -9999 -9999 -9999 -9999 -9999 -9999 -9999 -9999 -9999 -9999 -9999 -9999 -9999 -9999 -9999

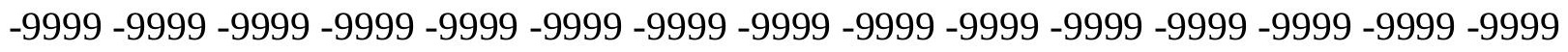
-9999 -9999-9999-9999-9999-9999-9999 -9999 -9999-9999

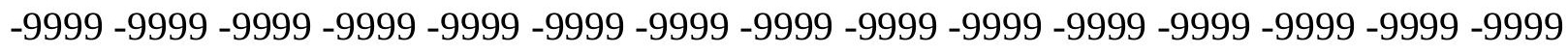
-9999 -9999 -9999 -9999 -9999 -9999 -9999 -9999 -9999 -9999 -9999 -9999 -9999 -9999 -9999 -

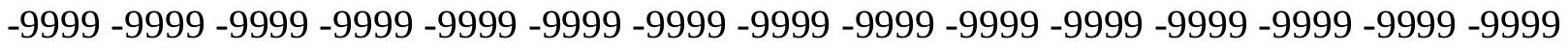

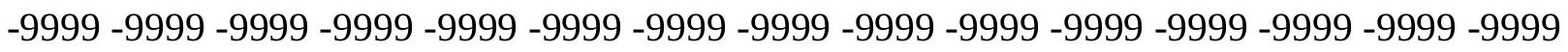
-9999 -9999 -9999 -9999 -9999 -9999 -9999 -9999 -9999 -9999 -9999 -9999 -9999 -9999 -9999 -9999 -9999 -9999 -9999 -9999 -9999 -9999 -9999 -9999 -9999 -9999 -9999 -9999 -9999 124.9618988037120 .0852966309114 .9039993286110 .6370010376110 .3321990967 110.0273971558110 .0273971558113 .075302124132 .5814971924129 .533706665 126.7906036377124 .0475006104121 .3044967651118 .8662033081116 .1231002808 113.6848983765111 .24659729109 .1130981445107 .2844009399105 .7603988647 104.5412979126103 .6268997192103 .3221969604103 .0174026489103 .3221969604 103.9317016602104 .5412979126105 .7603988647106 .979598999108 .1986999512 110.0273971558111 .551399231113 .3800964355114 .5991973877111 .8014221191 106.897018432699 .9695205688587 .7781066894580 .4632720947384 .73026275635 86.4145736694388 .2586059570390 .8259735107492 .9594726562595 .70252990723 98.75038146973102 .1029968262105 .1205291748106 .9966506958108 .1781158447 106.979598999107 .2844009399108 .6216583252108 .3339614868108 .0804824829 107.9185943604107 .89868927108 .0433807373108 .3623733521108 .8417282104 109.4377975464110 .1018218994110 .763885498111 .3528442383111 .8073577881 112.0818939209112 .1286621094111 .9251785278111 .4718475342110 .8048706055 109.9918212891 109.1305923462 108.3302612305 107.705078125 107.3530654907 107.3432769775 107.7110748291 106.97959899998.75038146973 91.13075256348 88.0829010009886 .8637619018686 .254188537687 .7781066894592 .3498916626 97.53124237061100 .8839035034102 .712600708102 .712600708102 .1029968262 102.4077987671102 .4077987671102 .4077987671101 .7982025146101 .4934005737 100.579101562599 .3599472045998 .7503814697396 .9216690063594 .78817749023 94.1785964965891 .1307525634883 .8159103393678 .3297805786179 .85370635986 82.9015579223681 .0728530883877 .7202072143675 .8914871215877 .1106262207 81.0728530883892 .3498916626110 .0273971558117 .7073898315117 .145401001 
116.6009902954116 .0749740601115 .1812362671114 .1592254639113 .1272888184 112.0842056274111 .0291061401109 .9611816406108 .8797988892107 .7838439941 106.6718139648105 .5416793823104 .3915786743103 .2195205688102 .0240478516 100.804336547999 .5616302490298 .2997131347797 .025672912695 .74890136719 94.4801330566493 .2309570312592 .0133209228590 .8401718139689 .72815704346 88.6952590942487 .7559127807686 .9043045043986 .1138610839885 .3606262207 84.631416320883 .9397125244183 .3241043090882 .0707778930780 .8137588501 79.7936935424878 .1942520141676 .2625427246175 .5867080688576 .19628143311 78.9393463134880 .7680587768681 .6824111938581 .9871978759881 .37763214111 80.7680587768679 .8537063598678 .9393463134878 .3297805786178 .02498626709 78.0249862670978 .9393463134879 .8537063598681 .6824111938583 .2063369751 84.7302627563586 .254188537687 .4733276367288 .3876876831189 .3020401001 89.9116134643690 .5211791992291 .1307525634891 .4355392456191 .74033355713 92.0450973510792 .0450973510792 .3190307617292 .349891662692 .3498916626 92.6546783447392 .6546783447392 .6546783447392 .6546783447392 .65467834473 92.6546783447392 .6546783447392 .6546783447392 .6546783447392 .65467834473 92.349891662692 .0450973510791 .7403335571391 .1307525634890 .52117919922 89.60682678223 88.9972534179787.77810668945 86.86376190186 85.94940185547 85.0350494384883 .8159103393682 .9015579223681 .6824111938580 .76805877686 79.8537063598678 .9393463134878 .0249862670977 .110626220776 .19628143311 75.2819290161174 .6723632812573 .7580032348673 .1484298706172 .84364318848 74.6723632812576 .19628143311 -9999 -9999 -9999 -9999 -9999 -9999 -9999 -9999 -9999 -9999 -9999 -9999 -9999 -9999 -9999 -9999 -9999 -9999 -9999 -9999 -9999 -9999 -9999 -9999 -9999 -9999 -9999 -9999 -9999 -9999 -9999 -9999 -9999 -9999 -9999 -9999 -9999 -9999 -9999 -9999 -9999 -9999 -9999 -9999 -9999 -9999 -9999 -9999 -9999 -9999 -9999 -9999 -9999 -9999 -9999 -9999 -9999 -9999 -9999 -9999 -9999 -9999 -9999 -9999 -9999 -9999-9999 -9999 -9999 - -999 -9999 -9999 -9999 -9999 -9999 -9999-9999 -9999 -9999

-9999 -9999 -9999 -9999 -9999 -9999 -9999 -9999 -9999 -9999 -9999 -9999 -9999 -9999 -9999 -9999 -9999 -9999 -9999 -9999 -9999 -9999 -9999 -9999 -9999 -9999 -9999 -9999 -9999 -9999 -9999 -9999 -9999 -9999 -9999 -9999 -9999 -9999 -9999 -9999 -9999 -9999 -9999 -9999 -9999 -9999 -9999 -9999 -9999 -9999 -9999 -9999 -9999 -9999 -9999 -9999 -9999 -9999 -9999 -9999 -9999 -9999 -9999 -9999 -9999 -9999 -9999 -9999 -9999 -9999 -9999 -9999 -9999 -9999 -9999 -9999 -9999 -9999 -9999 -9999 -9999 -9999 -9999 -9999 -9999 -9999 -9999 -9999 -9999 120.9997024536116 .1231002808111 .24659729110 .0273971558109 .4179000854 108.8082962036108 .5035018921108 .5035018921131 .3623962402128 .3144989014 125.2667007446122 .5235977173119 .7806015015117 .0374984741114 .2944030762 111.8561019897109 .4179000854107 .5891036987105 .7603988647104 .5412979126 103.6268997192103 .0174026489102 .712600708102 .712600708103 .0174026489 103.6268997192104 .5412979126105 .7603988647107 .2844009399108 .5035018921 110.0273971558111 .551399231112 .7705001831113 .075302124111 .24659729 106.065200805797 .8360290527389 .6068267822378 .3297805786179 .54891967773 82.1942749023485 .1418685913188 .3876876831191 .4355392456194 .78817749023 98.14080810547101 .4934005737104 .2365036011106 .3700027466107 .2844009399 107.2844009399107 .8938980103108 .323928833107 .9839782715107 .7172698975 107.555519104107 .5297317505107 .6628799438107 .974899292108 .447227478 109.0475921631109 .7233123779110 .4158477783111 .053314209111 .5859222412 
111.9633026123112 .1505661011112 .1355056763111 .9137268066111 .513053894 110.9851608276110 .4034347534109 .8526687622109 .4173202515109 .1766662598 109.1870803833109 .4817886353107 .284400939998 .7503814697390 .82597351074 88.9972534179789 .302040100188 .6924667358490 .2164001464896 .31210327148 103.0174026489106 .6747970581108 .1986999512107 .5891036987106 .3700027466 107.2844009399 107.8938980103108.1986999512107.5891036987106.6747970581 105.4557037354104 .5412979126104 .2365036011103 .9317016602104 .2365036011 105.1509017944101 .493400573792 .349891662686 .254188537684 .12069702148 83.206336975181 .3776321411178 .9393463134875 .8914871215874 .67236328125 76.5010681152380 .7680587768681 .0728530883885 .0350494384898 .4455871582 113.3800964355116 .6116104126115 .6000823975114 .5796203613113 .5489120483 112.5066833496111 .4519729614110 .3839187622109 .3017807007108 .2042922974 107.0897598267105 .9560089111104 .801109314103 .623085022102 .4206314087 101.193183898999 .9424438476698 .6726989746197 .3915100097796 .10868835449 94.8354187011793 .5839233398492 .3669891357491 .199081420990 .09666442871 89.0799331665 88.16860198975 87.35749053955 86.63081359863 85.96545410156 85.3405990600684 .7397766113384 .1350784301883 .1006317138782 .04689025879 81.0163497924879 .4767684936578 .3143692016678 .1870498657279 .24413299561 78.9393463134880 .4632720947381 .0728530883880 .7680587768680 .15849304199 78.9393463134877 .7202072143676 .5010681152375 .5867080688574 .67236328125 74.3675689697374 .3675689697375 .2819290161176 .8058471679778 .63455963135 80.7680587768682 .5967712402384 .1206970214885 .6446228027386 .55898284912 87.4733276367288 .3876876831188 .9972534179789 .6068267822389 .91161346436 90.2164001464890 .5211791992290 .8259735107490 .8259735107491 .09994506836 91.1307525634891 .4355392456191 .4355392456191 .7403335571391 .74033355713 91.7403335571392 .0450973510792 .0450973510792 .349891662692 .3498916626 92.349891662692 .0450973510791 .7403335571391 .4355392456190 .82597351074 89.9116134643688 .9972534179788 .0829010009887 .1685485839886 .2541885376 85.3398437584 .1206970214883 .206336975182 .2919769287181 .07285308838 80.1584930419979 .2441329956178 .3297805786177 .4154205322376 .50106811523 75.8914871215874 .9771423339874 .3675689697374 .062782287673 .75800323486 73.4532165527375 .28192901611 -9999 -9999 -9999 -9999 -9999 -9999 -9999 -9999 -9999

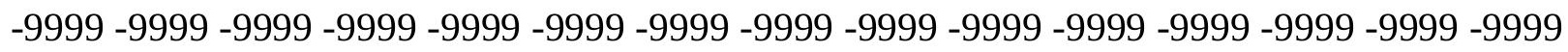

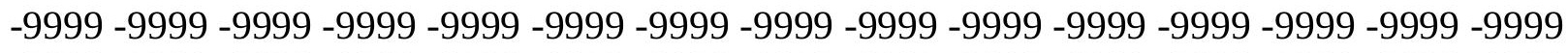
-9999 -9999 -9999 -9999 -9999 -9999 -9999 -9999 -9999 -9999 -9999 -9999 -9999 -9999 -9999 -

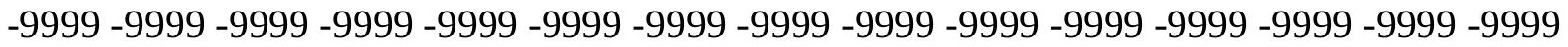
-9999-9999 -9999-9999-9999-9999-9999-9999 -9999

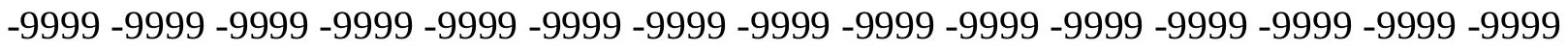
-9999 -9999 -9999 -9999 -9999 -9999 -9999 -9999 -9999 -9999 -9999 -9999 -9999 - 9999 - -999 -9999 -9999 -9999 -9999 -9999 -9999 -9999 -9999 -9999 -9999 -9999 -9999 -9999 -9999 -9999 -

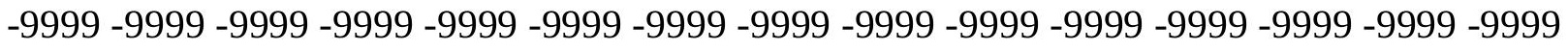

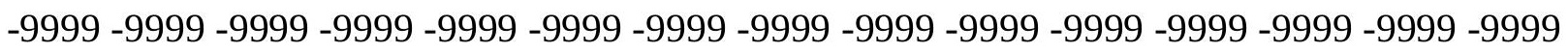
-9999 -9999 -9999 -9999 -9999 -9999 -9999 -9999 -9999 -9999 -9999 -9999 -9999 -9999 -9999 110.9418029785110 .0273971558108 .8082962036107 .8938980103107 .2844009399 106.979598999106 .6747970581128 .9241027832125 .8762969971123 .1332015991 120.3900985718117 .342300415114 .2944030762111 .551399231109 .1130981445 
106.979598999105 .4557037354103 .9317016602102 .712600708102 .1029968262 101.7982025146101 .4934005737101 .7982025146102 .1029968262103 .0174026489 103.9317016602105 .1509017944106 .6747970581107 .8938980103109 .4179000854 110.3321990967110 .9418029785110 .3321990967107 .8938980103103 .0174026489 95.7025299072387 .1685485839879 .2441329956175 .2819290161178 .93934631348 82.5967712402386 .254188537689 .9116134643693 .5690307617297 .83602905273 102.1029968262105 .7603988647107 .5891036987108 .5035018921108 .1986999512 107.5891036987 107.8249664307 107.4750213623 107.2201004028 107.0780410767 107.0386428833107 .1620483398107 .4711608887107 .9543457031108 .5832672119 109.3007354736110.0470199585110.7717285156111.4130020142 111.9203109741 112.2733078003112 .4562606812112 .4596557617112 .30078125112 .0187072754 111.6692047119111 .3183898926111 .0339431763110 .8798446655110 .9029464722 111.1367797852111 .24659729103 .322196960496 .3121032714893 .56903076172 93.5690307617293 .8738174438596 .31210327148102 .1029968262107 .8938980103 110.9418029785111 .8561019897110 .3321990967108 .8082962036108 .1986999512 107.8938980103108 .8082962036109 .1130981445108 .5035018921107 .5891036987 107.2844009399 107.8938980103108.1986999512108.8082962036113.9896011353 121.6092987061117 .647102356104 .2365036011111 .55139923194 .48339080811 92.349891662688 .6924667358483 .206336975178 .3297805786177 .1106262207 76.5010681152374 .3675689697376 .1962814331186 .8637619018699 .05516815186 104.8460998535106 .979598999106 .0652008057113 .9941940308112 .9561157227 111.9053039551110 .8408355713109 .7619018555108 .6671066284107 .5546340942 106.422203064105 .2679138184104 .0898895264102 .8869781494101 .6589279175 100.407783508399 .1381988525497 .8580017089896 .5772247314595 .30728912354 94.0607223510792 .8508148193491 .6923141479590 .6018295288189 .59856414795 88.70218658447 87.92382049561 87.2449111938586.64319610596 86.09042358398 85.5516433715884 .9771423339884 .2913742065483 .4178543090882 .412109375 81.4864120483481 .006416320881 .2792053222781 .5565414428781 .47777557373 80.1584930419980 .4632720947379 .8537063598678 .6345596313577 .1106262207 75.5867080688574 .062782287672 .5388565063571 .3197174072370 .40535736084 70.1005783081170 .7101516723672 .2340774536174 .3675689697376 .80584716797 78.9393463134881 .0728530883882 .9015579223684 .1206970214885 .33984375 86.2541885376 86.86376190186 87.47332763672 88.08290100098 88.38768768311 88.6924667358488 .9972534179789 .302040100189 .6068267822389 .88262176514 90.1772842407290 .2164001464890 .5211791992290 .8259735107491 .13075256348 91.1307525634891 .4355392456191 .7403335571391 .7403335571392 .04509735107 92.0450973510791 .7403335571391 .4355392456190 .8259735107489 .91161346436 88.99725341797 88.08290100098 87.16854858398 86.2541885376 85.33984375 84.4254837036183 .5111236572382 .5967712402381 .6824111938580 .46327209473 79.5489196777378 .6345596313578 .0249862670977 .110626220776 .19628143311 75.5867080688574 .9771423339874 .3675689697374 .062782287673 .75800323486 74.3675689697376 .19628143311 -9999 -9999 -9999 -9999 -9999 -9999 -9999 -9999 -9999 -9999 -9999 -9999 -9999 -9999 -9999 -9999 -9999 -9999 -9999 -9999 -9999 -9999 -9999 -9999 -9999 -9999 -9999 -9999 -9999 -9999 -9999 -9999 -9999 -9999 -9999 -9999 -9999 -9999 -9999 -9999 -9999 -9999 -9999 -9999 -9999 -9999 -9999 -9999 -9999 -9999 -9999 -9999 -9999 -9999 -

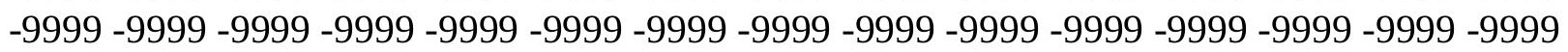


-9999 -9999 -9999 -9999 -9999 -9999 -9999 -9999

-9999 -9999 -9999 -9999 -9999 -9999 -9999 -9999 -9999 -9999 -9999 -9999 -9999 -9999 -9999

-9999 -9999 -9999 -9999 -9999 -9999 -9999 -9999 -9999 -9999 -9999 -9999 -9999 -9999 -9999

-9999 -9999 -9999 -9999 -9999 -9999 -9999 -9999 -9999 -9999 -9999 -9999 -9999 -9999 -9999

-9999 -9999 -9999 -9999 -9999 -9999 -9999 -9999 -9999 -9999 -9999 -9999 -9999 -9999 -9999 -

-9999 -9999 -9999 -9999 -9999 -9999 -9999 -9999 -9999 -9999 -9999 -9999 -9999 -9999 -9999 -

-9999 -9999 -9999 -9999 -9999 -9999 -9999 -9999 -9999 -9999 -9999 -9999 -9999 -9999 -9999 -999 -

-9999 108.1986999512 106.979598999 106.0652008057 105.1509017944 104.5412979126

128.9241027832125 .2667007446122 .5235977173120 .0852966309117 .342300415

114.2944030762110 .9418029785108 .1986999512106 .0652008057104 .2365036011

102.712600708101 .4934005737100 .8839035034100 .274299621699 .96952056885

99.96952056885100 .2742996216100 .8839035034101 .7982025146102 .712600708

103.9317016602105 .4557037354106 .6747970581107 .5891036987108 .5035018921

108.5035018921107 .5891036987104 .8460998535100 .579101562594 .48339080811

87.1685485839879 .2441329956172 .5388565063575 .5867080688579 .85370635986

84.1206970214888 .0829010009892 .6546783447397 .22646331787102 .4077987671

106.6747970581109 .1130981445109 .7226028442109 .1130981445107 .5891036987

107.2844009399 106.9339065552106.7095031738106.5463790894 106.4992370605

106.608039856106 .9234390259107 .4208908081108 .0943069458108 .8690567017

109.688911438110 .5127563477111 .2862701416111 .9507522583112 .4889221191

112.8814849854113 .109664917113 .1746826172113 .1044082642112 .9428329468

112.7440032959112 .5655593872112 .4655227661112 .492980957112 .6707458496

113.0157394409109 .1130981445103 .017402648999 .6647262573298 .75038146973 99.96952056885103 .0174026489107 .5891036987112 .1608963013113 .9896011353 114.5991973877112 .7705001831109 .7226028442106 .3700027466103 .6268997192 104.8460998535106 .979598999107 .8938980103108 .8082962036110 .3321990967

111.8561019897112 .1608963013111 .24659729115 .818397522118 .5614013672 113.075302124123 .40990448115 .2088012695109 .1130981445122 .3340835571 101.798202514694 .1785964965886 .254188537681 .9871978759879 .85370635986 80.1584930419983 .206336975190 .2164001464895 .0929565429785 .03504943848 76.1962814331184 .4254837036197 .53124237061108 .8082962036112 .3878479004 111.3306503296110 .2588348389109 .1709060669108 .0649871826106 .9387817383 105.7904663086104 .6183395386103 .4214477539102 .199798584100 .9557418823 99.6941604614398 .4229583740297 .1521148681695 .8929672241294 .65799713135 93.4604873657292 .3155364990291 .2376708984490 .2455215454189 .35375213623 88.5934906005987 .9447937011787 .3864898681686 .889083862386 .41465759277 85.9210586547985 .3690872192484 .7551422119184 .1564483642683 .73110961914 83.6855087280384 .1177215576283 .8241424560583 .3046035766682 .05033111572 79.5489196777378 .6345596313577 .110626220775 .5867080688573 .75800323486 71.9292907714870 .1005783081168 .5766525268667 .0527267456166 .13836669922 66.4431610107467 .9670867919970 .7101516723673 .4532165527376 .19628143311 78.6345596313580 .4632720947381 .9871978759883 .206336975184 .12069702148 85.0350494384885 .6446228027386 .254188537686 .5589828491287 .16854858398 87.4733276367287 .7781066894588 .0829010009888 .3876876831188 .69246673584 88.9972534179789 .302040100189 .6068267822389 .9116134643690 .21640014648 90.5211791992290 .8259735107491 .1307525634891 .4355392456191 .43553924561 
91.4355392456191 .4355392456190 .5211791992289 .9116134643688 .99725341797 88.0829010009887 .1685485839886 .254188537685 .3398437584 .42548370361 83.5111236572382 .5967712402381 .6824111938580 .7680587768679 .85370635986 78.9393463134878 .3297805786177 .4154205322376 .5010681152375 .89148712158 75.2819290161174 .6723632812574 .062782287673 .4532165527373 .45321655273 75.2819290161177 .1106262207 -9999 -9999 -9999 -9999 -9999 -9999 -9999 -9999 -9999 -9999 -9999 -9999 -9999 -9999 -9999 -9999 -9999 -9999 -9999 -9999 -9999 -9999 -9999 -9999

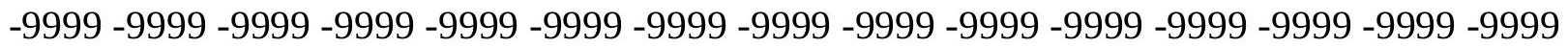
-9999 -9999 -9999 -9999 -9999 -9999 -9999 -9999 -9999 -9999 -9999 -9999 -9999 -9999 -9999 -9999 -9999 -9999 -9999 -9999 -9999 -9999 -9999 -9999 -9999 -9999 -9999 -9999 -9999 -9999 -999 -9999 -9999 -9999 -9999 -9999 -9999 -9999

-9999 -9999 -9999 -9999 -9999 -9999 -9999 -9999 -9999 -9999 -9999 -9999 -9999 -9999 -9999 -9999 -9999 -9999 -9999 -9999 -9999 -9999 -9999 -9999 -9999 -9999 -9999 -9999 -9999 -9999 -9999 -9999 -9999 -9999 -9999 -9999 -9999 -9999 -9999 -9999 -9999 -9999 -9999 -9999 -9999 -9999 -9999 -9999 -9999 -9999 -9999 -9999 -9999 -9999 -9999 -9999 -9999 -9999 -9999 -9999

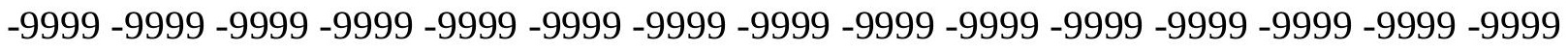
-9999 -9999 -9999 -9999 -9999 -9999 -9999 -9999 -9999 -9999 -9999 -9999 -9999 -9999 -9999 -9999 106.3700027466105.1509017944103.9317016602 103.0174026489102.4077987671 123.43800354120 .6949005127117 .9517974854115 .5136032104113 .3800964355 110.0273971558106 .6747970581104 .2365036011102 .4077987671100 .8839035034 99.6647262573299 .0551681518698 .445587158298 .1408081054797 .83602905273 98.1408081054798.445587158299.0551681518699.96952056885 101.1886978149 102.4077987671103 .3221969604104 .5412979126105 .4557037354106 .0652008057 106.0652008057 104.8460998535 103.0174026489 99.66472625732 97.22646331787 88.3876876831180 .4632720947372 .2340774536173 .1484298706177 .72020721436 81.9871978759886 .5589828491291 .1307525634895 .70252990723100 .5791015625 104.8460998535107 .2844009399108 .5035018921108 .1986999512107 .5891036987 106.979598999106 .3700027466106 .3700027466106 .0652008057106 .0191726685 106.0652008057106 .0652008057106 .6747970581107 .6742019653108 .4888305664 109.3727493286110 .304145813111 .2197265625112 .0492401123112 .7847137451 113.3893280029113 .8340072632114 .10181427114 .2168197632114 .2029876709 114.1186294556114 .0075302124113 .9356307983113 .9472045898114 .071395874 114.3208007812112 .1608963013107 .5891036987105 .1509017944103 .9317016602 105.1509017944107 .5891036987111 .24659729114 .2944030762116 .4279022217 117.0374984741115 .5136032104110 .6370010376102 .102996826295 .09295654297 95.7025299072399 .96952056885104 .5412979126109 .1130981445112 .7705001831 115.2088012695116 .4279022217115 .818397522113 .3800964355118 .2565994263 113.9896011353121 .6092987061123 .1158294678119 .1709976196122 .4734420776 122.1241836548105 .455703735496 .3121032714890 .8259735107488 .38768768311 88.9972534179790 .8259735107493 .5690307617293 .5690307617286 .86376190186 81.3776321411184 .7302627563592 .0450973510799 .66472625732106 .979598999 111.8520431519110 .7911758423109 .7142181396108 .6192779541107 .5041351318 106.3671035767105 .2066726685104 .0221481323102 .8137893677101 .5841903687 100.338356018199 .0840606689597 .8309555053796 .5899429321395 .37299346924 94.1929016113393 .0639572143692 .0009078979591 .0196456909290 .13674926758 89.36841583252 88.73439025879 88.20690155029 87.75682830811 87.35440063477 
86.9749145507886 .6065292358486 .26757812586 .0165939331185 .9408493042 86.0962524414186 .3957214355586 .4832000732485 .6773376464884 .07402038574 81.3431091308677 .4154205322375 .5867080688573 .7580032348671 .92929077148 70.1005783081168 .5766525268666 .7479400634864 .9192428588963 .09051895142 62.7857398986864 .9192428588967 .9670867919971 .3197174072374 .0627822876 76.5010681152378 .6345596313580 .1584930419981 .3776321411182 .29197692871 82.9015579223683 .8159103393684 .4254837036184 .7302627563585 .33984375 85.6446228027386 .254188537686 .5589828491286 .8637619018687 .16854858398 87.7781066894588 .077011108488 .3876876831188 .6924667358489 .08753967285 89.6068267822389 .9116134643690 .2164001464890 .5211791992290 .82597351074 90.8259735107490 .5211791992289 .9116134643689 .302040100188 .69246673584 87.7781066894587 .1685485839886 .254188537685 .3398437584 .42548370361 83.51112365723 82.9015579223681.98719787598 81.07285308838 80.15849304199 79.2441329956178 .3297805786177 .7202072143676 .8058471679776 .19628143311 75.5867080688574 .9771423339874 .3675689697373 .4532165527372 .84364318848 74.3675689697376 .19628143311 -9999 -9999 -9999 -9999 -9999 -9999 -9999 -9999 -9999 -9999 -9999 -9999 -9999 -9999 -9999 -9999 -9999 -9999 -9999 -9999 -9999 -9999 -9999 -9999 -9999 -9999 -9999 -9999 -9999 -9999 -9999 -9999 -9999 -9999 -9999 -9999 -9999 -9999 -9999 -9999 -9999 -9999 -9999 -9999 -9999 -9999 -9999 -9999 -9999 -9999 -9999 -9999 -9999 -9999 -

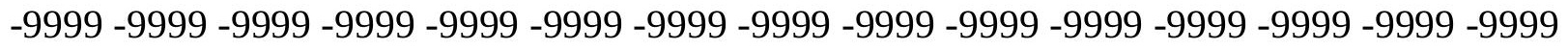
-9999 -9999 -9999 -9999-9999-9999-9999

-9999 -9999 -9999 -9999 -9999 -9999 -9999 -9999 -9999 -9999 -9999 -9999 -9999 -9999 -9999 -9999 -9999 -9999 -9999 -9999 -9999 -9999 -9999 -9999 -9999 -9999 -9999 -9999 -9999 -9999 -

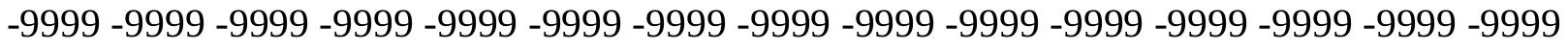

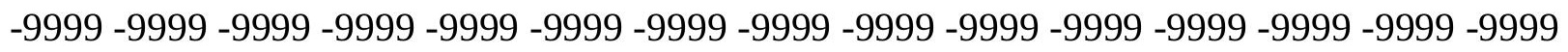
-9999 -9999 -9999 -9999 -9999 -9999 -9999 -9999 -9999 -9999 -9999 -9999 -9999 -9999 -9999 -

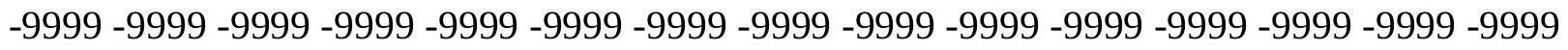
-9999 -9999 103.0174026489101.7982025146100.883903503499.96952056885 117.647102356115 .2088012695112 .4656982422110 .0273971558107 .2844009399 104.2365036011101 .493400573799 .6647262573298 .1408081054797 .22646331787 96.6168823242296 .0073165893695 .7025299072395 .7025299072395 .70252990723 96.0073165893696 .3121032714896 .9216690063597 .8360290527399 .05516815186 99.96952056885101 .1886978149102 .1029968262103 .0174026489103 .6268997192 103.6268997192103 .0174026489101 .493400573799 .6647262573298 .75038146973 94.7881774902388 .9972534179781 .0728530883871 .6244964599675 .58670806885 80.1584930419984 .7302627563589 .302040100193 .8738174438598 .14080810547 101.7982025146104 .2365036011106 .0652008057106 .979598999106 .979598999 106.6747970581106 .3700027466106 .0652008057105 .7603988647105 .7603988647 106.0652008057106 .0652008057106 .6747970581107 .4782180786108 .1986999512 109.1130981445110 .0273971558111 .2110366821112 .1994400024113 .1217956543 113.9336090088114 .5850143433115 .0512695312115 .3190765381115 .4265441895 115.419342041115 .3516464233115 .2741241455115 .256362915115 .3199539185 115.4861984253114 .2944030762111 .551399231109 .7226028442108 .8082962036 109.7226028442111 .24659729113 .3800964355115 .5136032104117 .647102356 117.9517974854115 .5136032104109 .417900085496 .6168823242286 .2541885376 87.1685485839893 .26425170898101 .7982025146110 .3321990967115 .5136032104 
118.5614013672120 .0852966309120 .3900985718119 .1709976196117 .9517974854 117.647102356119 .1709976196123 .1332015991121 .9140014648122 .6081390381 122.3078842163121 .9977340698121 .6820297241101 .798202514699 .35994720459 99.6647262573299 .9695205688598 .445587158296 .3121032714896 .31210327148 96.9216690063595 .7025299072396 .0073165893699 .05516815186103 .3221969604 106.3700027466108 .8082962036110 .2946166992109 .2148895264108 .1154251099 106.9947357178105 .8515548706104 .6854324341103 .496925354102 .2888565063 101.066246032799.8365631103598.6088714599697.3932876586996.20087432861 95.043380737393 .934013366792 .8864593505991 .9162368774491 .03704833984 90.2698516845789 .62416839689 .1180114746188 .7043609619188 .37088775635 88.1118392944387 .9297561645587 .8405303955187 .8704986572388 .03828430176 88.3116226196388 .550643920988 .4850921630987 .8209228515686 .51602172852 84.7658309936582 .2249221801873 .7580032348671 .9292907714870 .40535736084 69.1862335205167 .9670867919966 .4431610107464 .6144485473662 .48094940186 60.6522407531764 .004882812567 .3575134277370 .7101516723673 .14842987061 75.2819290161177 .110626220778 .3297805786179 .5489196777380 .46327209473 81.3776321411181 .9871978759882 .5967712402383 .206336975183 .81591033936 84.1206970214884 .4254837036185 .0350494384885 .3398437585 .94940185547 86.254188537686 .5589828491287 .1685485839887 .4733276367287 .92504119873 88.2155303955188 .4325561523489 .302040100189 .6068267822389 .60682678223 89.9116134643689 .6068267822389 .302040100188 .6924667358488 .08290100098 87.47332763672 86.86376190186 85.9494018554785.33984375 84.42548370361 83.5111236572382 .9015579223681 .9871978759881 .0728530883880 .15849304199 79.5489196777378 .6345596313578 .0249862670977 .110626220776 .50106811523 75.8914871215874 .9771423339874 .3675689697374 .062782287673 .75800323486 73.7580032348675 .2819290161177 .1106262207 -9999 -9999 -9999 -9999 -9999 -9999 -9999 -9999 -9999 -9999 -9999 -9999 -9999 -9999 -9999 -9999 -9999 -9999 -9999 -9999 -9999 -9999

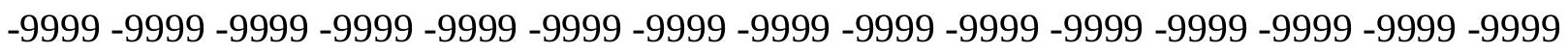
-9999 -9999 -9999 -9999 -9999 -9999 -9999 -9999 -9999 -9999 -9999 -9999 -9999 -9999 -9999 -9999 -9999 -9999 -9999 -9999 -9999 -9999 -9999 -9999 -9999 -9999 -9999 -9999 -9999 -9999 -9999 -9999 -9999 -9999 -9999 -9999-9999 -9999

-9999 -9999 -9999 -9999 -9999 -9999 -9999 -9999 -9999 -9999 -9999 -9999 -9999 -9999 -9999

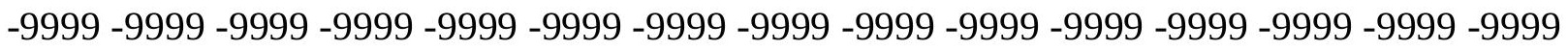
-9999 -9999 -9999 -9999 -9999 -9999 -9999 -9999 -9999 -9999 -9999 -9999 -9999 -9999 -9999 -9999 -9999 -9999 -9999 -9999 -9999 -9999 -9999 -9999 -9999 -9999 -9999 -9999 -9999 -9999 -

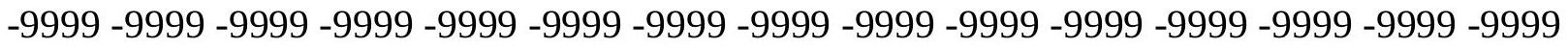

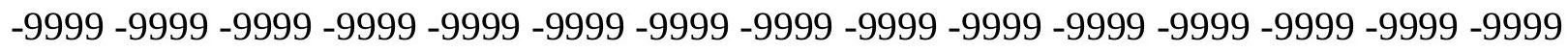
-9999-9999 100.883903503499 .6647262573298 .7503814697397 .83602905273 111.551399231109 .1130981445106 .6747970581103 .9317016602101 .1886978149 98.445587158296 .0073165893694 .4833908081193 .8738174438593 .56903076172 93.5690307617293.2642517089893.2642517089893.2642517089893.26425170898 93.5690307617294 .1785964965894 .7881774902395 .7025299072396 .61688232422 97.5312423706198 .445587158299 .66472625732100 .2742996216100 .8839035034 101.1886978149101 .1886978149100 .8839035034100 .274299621699 .66472625732 98.7503814697396 .9216690063591 .4355392456181 .3776321411175 .58670806885 78.0249862670982 .5967712402386 .8637619018691 .1307525634895 .09295654297 
98.4455871582101 .1886978149103 .3221969604105 .1509017944106 .3700027466 106.3700027466106 .0652008057105 .7603988647105 .7603988647106 .0652008057 106.0652008057106 .6747970581106 .979598999107 .5891036987108 .1986999512 109.1130981445110 .0273971558111 .24659729112 .3647537231113 .4350128174 114.4448394775115 .2960281372115 .9412918091116 .3408279419116 .5495147705 116.6079711914116 .5563354492116 .4680557251116 .4008789062116 .3988265991 116.4883956909115 .818397522114 .2944030762113 .075302124112 .4656982422 112.7705001831113 .9896011353114 .9039993286115 .818397522116 .4279022217 114.5991973877109 .4179000854101 .493400573790 .2164001464881 .68241119385 83.5111236572391 .43553924561103 .0174026489114 .2944030762119 .7806015015 121.9140014648123 .43800354123 .43800354122 .8283996582121 .9140014648 121.9140014648121 .9140014648122 .5235977173122 .8283996582122 .7273483276 122.4698562622122 .2038574219121 .9329681396121 .6605758667121 .3903198242 109.4179000854107 .5891036987104 .5412979126103 .0174026489103 .3221969604 104.2365036011103 .9317016602102 .712600708102 .712600708103 .6268997192 105.1509017944106 .979598999108 .8082962036109 .8492050171108 .7697982788 107.6702270508106 .5494995117105 .4074783325104 .2450332642103 .0652008057 101.8730010986100 .675430297999 .4807662963998 .2980499267697 .13706970215 96.008094787694 .9226913452193 .8930740356492 .9332199096792 .06072235107 91.289337158290 .6463317871190 .1253967285289 .7238540649489 .44281005859 89.29048919678 89.27687072754 89.40813446045 89.6786575317490.05731964111 90.4676208496190 .772323608490 .7883071899490 .3683776855589 .39674377441 87.6428146362384 .4742431640679 .2441329956170 .4053573608469 .49101257324 68.8814392089868 .2718734741267 .6623001098666 .4431610107465 .22400665283 64.9192428588966 .4431610107468 .8814392089871 .3197174072373 .14842987061 74.9771423339876 .1962814331177 .4154205322378 .3297805786178 .93934631348 79.8537063598680 .4632720947381 .0728530883881 .6824111938581 .98719787598 82.5967712402382 .9015579223683 .5111236572383 .8159103393684 .42548370361 84.7302627563585 .3398437585 .6446228027386 .254188537686 .70523071289 87.10892486572 87.38624572754 87.55444335938 88.3876876831188.69246673584 88.6924667358488.6924667358488.3876876831188.08290100098 87.47332763672 86.8637619018686 .254188537685 .6446228027385 .0350494384884 .12069702148 83.5111236572382 .5967712402381 .9871978759881 .0728530883880 .46327209473 79.5489196777378 .9393463134878 .0249862670977 .4154205322376 .80584716797 75.8914871215875 .2819290161174 .6723632812574 .3675689697374 .0627822876 74.062782287674 .6723632812576 .50106811523 -9999 -9999 -9999 -9999 -9999 -9999 -9999

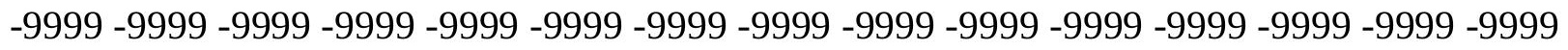

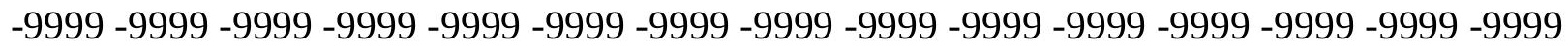

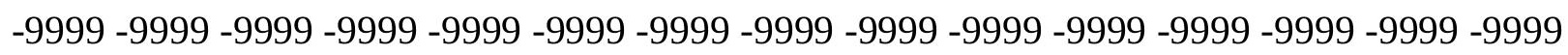
-9999 -9999 -9999 -9999 -9999 -9999 -9999 -9999 -9999 -9999 -9999 -9999 -9999 -9999 -9999 -9999 -9999 -9999-9999-9999 -9999-9999-9999

-9999 -9999 -9999 -9999 -9999 -9999 -9999 -9999 -9999 -9999 -9999 -9999 -9999 -9999 -9999 -

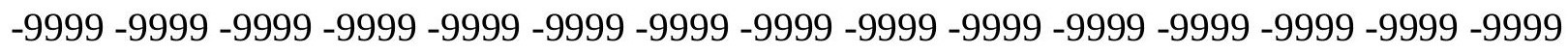
-9999 -9999 -9999 -9999 -9999 -9999 -9999 -9999 -9999 -9999 -9999 -9999 -9999 -9999 -9999 -

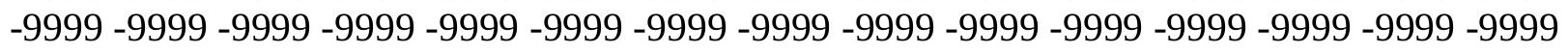

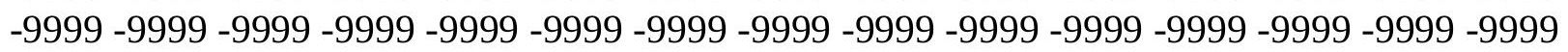


-9999 -9999 -9999 -9999 -9999 -9999 -9999 -9999 -9999 -9999 -9999 -9999 -9999 -9999 -9999 -9999 -9999-9999 98.1408081054796.92166900635 96.00731658936105.1509017944 103.0174026489100 .579101562598 .1408081054795 .7025299072392 .95947265625 90.2164001464890 .2164001464890 .2164001464890 .2164001464890 .52117919922 90.5211791992290 .8259735107490 .8259735107490 .8259735107491 .43553924561 91.7403335571392 .349891662692 .9594726562593 .8738174438594 .78817749023 95.7025299072396 .6168823242297 .5312423706198 .445587158299 .05516815186 99.6647262573299 .96952056885100 .8839035034101 .7982025146103 .3221969604 105.4557037354107 .893898010391 .4355392456184 .7302627563579 .24413299561 80.1584930419984 .4254837036188 .3876876831192 .0450973510795 .09295654297 97.83602905273100 .5791015625102 .712600708104 .5412979126104 .8460998535 105.1509017944105 .4557037354106 .0652008057106 .3700027466106 .6747970581 106.979598999107 .5891036987107 .8938980103108 .8082962036109 .4179000854 110.3321990967111 .24659729112 .4656982422113 .5730361938114 .7459869385 115.8541488647116 .6301345825117 .1551589966117 .4712982178117 .6048049927 117.5713272095117 .4572525024117 .3489608765117 .2870635986117 .3063354492 117.342300415116 .1231002808115 .5136032104114 .9039993286115 .2088012695 115.5136032104116 .1231002808115 .818397522114 .2944030762110 .6370010376 103.322196960494 .4833908081185 .9494018554781 .3776321411184 .42548370361 93.56903076172106 .3700027466118 .2565994263122 .8283996582123 .7293395996 123.7741775513123 .7759780884123 .7362213135123 .6576385498123 .5432128906 123.397102356123 .2241210938123 .0300369263119 .4757995605116 .1231002808 122.3717193604122 .1401138306121 .9076309204121 .6777496338121 .4545211792 121.2421951294121 .044921875110 .3321990967109 .7226028442109 .4179000854 110.0273971558110 .0273971558108 .1986999512106 .6747970581106 .979598999 108.1986999512110 .0273971558110 .5187225342109 .4633331299108 .389175415 107.2955780029 106.1827774048 105.0520324707 103.9066009521 102.751449585 101.5930557251100 .438796997199 .2964782714898 .1743392944397 .08083343506 96.0253753662195 .0180816650494 .0726928710993 .2056121826292 .43444061279 91.76479339691 .2129974365290 .7968826293990 .539482116790 .46726226807 90.5989608764690 .9321823120191 .4345321655392 .037391662692 .6385345459 93.108398437593 .3094863891693 .1070709228592 .3307952880990 .68730926514 87.5918579101683 .1482238769577 .4154205322369 .4910125732469 .49101257324 69.7957916259870 .4053573608470 .4053573608470 .4053573608470 .10057830811 70.7101516723671 .6244964599672 .8436431884874 .062782287674 .67236328125 75.5867080688576 .1962814331177 .110626220777 .7202072143678 .32978057861 78.9393463134879 .5489196777379 .8537063598680 .4632720947380 .76805877686 81.3776321411181 .6824111938582 .2919769287182 .9015579223683 .2063369751 83.8159103393684 .4254837036184 .7302627563585 .3398437585 .94940185547 86.254188537686 .4978103637786 .6361236572386 .6971817016687 .47332763672 87.47332763672 87.47332763672 87.16854858398 86.55898284912 86.2541885376 85.6446228027385 .0350494384884 .4254837036183 .8159103393683 .2063369751 82.5967712402381 .6824111938581 .0728530883880 .4632720947379 .54891967773 78.9393463134878 .3297805786177 .4154205322376 .8058471679776 .19628143311 75.5867080688574 .9771423339874 .6723632812574 .3675689697374 .0627822876 73.7580032348675 .5867080688577 .41542053223 -9999 -9999 -9999 -9999 -9999 -9999 -9999 
-9999 -9999 -9999 -9999 -9999 -9999 -9999 -9999 -9999 -9999 -9999 -9999 -9999 -9999 -9999 -9999 -9999 -9999 -9999 -9999 -9999 -9999 -9999 -9999 -9999 -9999 -9999 -9999 -9999 -9999 -9999 -9999 -9999 -9999 -9999 -9999 -9999 -9999 -9999 -9999 -9999 -9999 -9999 -9999 -9999 -9999 -9999 -9999 -9999 -9999 -9999 -9999 -9999 -9999 -9999 -9999 -9999 -9999 -9999 -9999 -9999 -9999 -9999-9999-9999-9999-9999

-9999 -9999 -9999 -9999 -9999 -9999 -9999 -9999 -9999 -9999 -9999 -9999 -9999 -9999 -9999

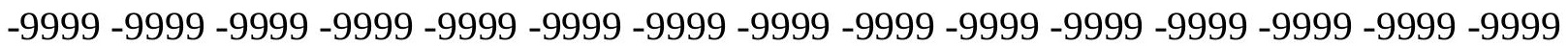
-9999 -9999 -9999 -9999 -9999 -9999 -9999 -9999 -9999 -9999 -9999 -9999 -9999 -9999 -9999 -999 -9999 -9999 -9999 -9999 -9999 -9999 -9999 -9999 -9999 -9999 -9999 -9999 -9999 -9999 -9999 -9999 -9999 -9999 -9999 -9999 -9999 -9999 -9999 -9999 -9999 -9999 -9999 -9999 -9999 -9999 -9999 -9999 -9999 -9999 -9999 -9999 -9999 -9999 -9999 -9999 -9999 -9999 -9999 -9999 -9999 -9999 -9999-9999-9999 96.00731658936 101.1886978149 99.35994720459 97.22646331787 95.0929565429792 .9594726562590 .8259735107488 .6924667358487 .16854858398 86.8637619018686 .8637619018687 .4733276367287 .7781066894588 .08290100098 88.38768768311 88.38768768311 88.69246673584 88.9972534179789.60682678223 90.2164001464890 .5211791992291 .4355392456192 .349891662692 .95947265625 93.8738174438595.0929565429796.0073165893697.2264633178797.83602905273 99.05516815186100 .2742996216102 .4077987671104 .8460998535106 .3700027466 103.626899719293 .8738174438589 .302040100185 .3398437582 .29197692871 81.6824111938585 .3398437588 .6924667358491 .7403335571394 .17859649658 96.9216690063599 .05516815186100 .8839035034102 .1029968262103 .0174026489 104.5412979126106 .0652008057106 .3700027466106 .3700027466106 .979598999 107.8938980103108 .5035018921109 .1130981445110 .0273971558110 .6370010376 111.24659729112 .1608963013113 .3800964355114 .5991973877116 .1231002808 116.8594360352117 .5526351929118 .075958252118 .298576355118 .2916107178 118.195098877118 .052772522117 .948387146117 .9241943359117 .9767913818 117.647102356117 .0374984741116 .7326965332116 .7326965332116 .7326965332 116.4279022217115 .2088012695113 .3800964355109 .4179000854103 .3221969604 96.6168823242288 .3876876831184 .1206970214889 .302040100198 .75038146973 109.7226028442119 .1709976196123 .4850921631123 .585647583123 .6446228027 123.6628799438123 .6416015625123 .5834732056123 .4914398193123 .3694839478 123.222366333123 .056060791122 .8760070801120 .9997024536120 .9997024536 121.9140014648122 .0973968506121 .904296875121 .7191772461121 .5467834473 121.392364502120 .783821106114 .9039993286113 .6848983765114 .2944030762 113.6848983765111 .8561019897110 .0273971558109 .7226028442110 .9418029785 112.2311019897111 .2198638916110 .1921005249109 .1471710205108 .0848083496 107.0056991577105 .9115905762104 .8060150146103 .6938781738102 .5811309814 101.4742736816100 .379837036199 .3044586181698 .2545166015697 .23686981201 96.2588500976695 .3301467895594 .4712371826293 .1920623779391 .92855072021 92.2953262329191 .9080276489391 .636154174891 .6090850830191 .86235046387 92.3910217285293 .1394729614394 .002090454194 .8484725952195 .54446411133 95.9715652465896 .0130157470795 .5164337158294 .250144958591 .96366119385 88.489120483484 .0541076660278 .6345596313571 .3197174072371 .92929077148 74.062782287675 .8914871215875 .8914871215875 .2819290161174 .97714233398 74.9771423339874 .6723632812574 .6723632812574 .6723632812574 .97714233398 75.5867080688575 .8914871215876 .5010681152377 .110626220777 .72020721436 
78.0249862670978 .6345596313578 .9393463134879 .2441329956179 .85370635986 80.1584930419980 .7680587768681 .3776321411181 .6824111938582 .29197692871 82.9015579223683 .5111236572383 .8159103393684 .4254837036185 .03504943848 85.3398437585 .5667877197385 .6925735473685 .7363815307685 .72377777186 .2541885376 85.9494018554785 .9494018554785 .3398437585 .0350494384884 .42548370361 84.1206970214883 .5111236572382 .9015579223682 .2919769287181 .68241119385 80.7680587768680 .1584930419979 .5489196777378 .9393463134878 .32978057861 77.7202072143677 .110626220776 .5010681152375 .8914871215875 .28192901611 74.9771423339874 .6723632812574 .3675689697373 .7580032348674 .67236328125 76.19628143311 -9999 -9999 -9999 -9999 -9999 -9999 -9999 -9999 -9999 -9999 -9999 -9999 -9999 -9999 -9999 -9999 -9999 -9999 -9999 -9999 -9999 -9999 -9999 -9999 -9999 -9999 -9999 -9999 -9999 -9999 -9999 -9999 -9999 -9999 -9999 -9999 -9999 -9999 -9999 -9999 -9999 -9999 -9999 -9999 -9999 -9999 -9999 -9999 -9999 -9999 -9999 -9999 -9999 -9999 -9999 -9999 -9999 -9999 -9999 -9999 -9999 -9999 -9999 -9999 -9999 -9999 -9999 -9999 -9999 -9999 -9999 -9999 $-9999-9999$

-9999 -9999 -9999 -9999 -9999 -9999 -9999 -9999 -9999-9999 -9999 -9999 -9999 -9999 -9999 -

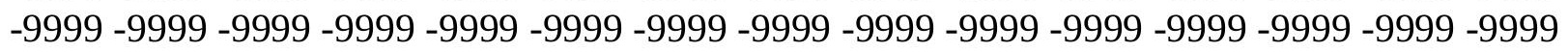

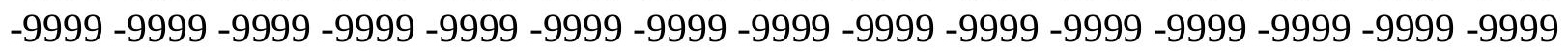

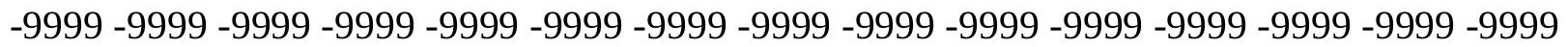

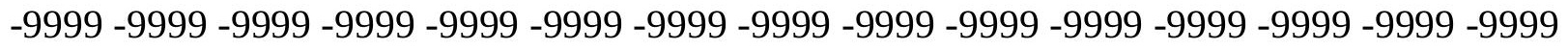

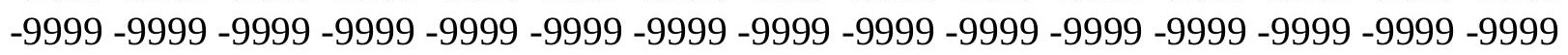
-9999 -9999-9999-9999 95.3977432251 96.0073165893694.1785964965892.04509735107 89.91161346436 88.3876876831186.8637619018685.33984375 84.42548370361 84.1206970214884 .4254837036185 .0350494384885 .3398437585 .94940185547 86.254188537686 .5589828491286 .8637619018687 .1685485839887 .47332763672 88.08290100098 88.38768768311 88.99725341797 89.9116134643690.52117919922 91.1307525634892 .349891662693 .8738174438595 .0929565429796 .00731658936 97.2264633178798 .75038146973100 .8839035034102 .712600708103 .0174026489 100.274299621695 .397743225191 .4355392456189 .302040100186 .55898284912 84.1206970214882 .2919769287185 .3398437588 .0829010009890 .52117919922 92.9594726562594 .7881774902396 .6168823242298 .1408081054799 .96952056885 102.4077987671104 .5412979126105 .1509017944105 .4557037354106 .6747970581 107.8938980103108 .8082962036109 .7226028442110 .3321990967110 .6370010376 111.24659729111 .8561019897112 .7705001831113 .9896011353115 .2088012695 116.4279022217117 .342300415118 .2565994263118 .4784698486118 .6201400757 118.5820999146118 .4574356079118 .3596572876118 .3153076172118 .3425674438 118.2565994263117 .9517974854117 .647102356117 .647102356117 .0374984741 116.4279022217114 .9039993286112 .7705001831109 .7226028442106 .0652008057 101.798202514694 .7881774902391 .1307525634896 .92166900635105 .7603988647 113.075302124119 .1709976196123 .3174057007123 .4276275635123 .4982757568 123.5300598145123 .523979187123 .4826812744123 .4092941284123 .3078079224 123.1828384399123 .0403213501122 .8858566284122 .7238540649122 .5576629639 122.3904876709122 .2255401611122 .0661849976121 .9164810181121 .7814483643 121.6674041748121 .2530441284120 .3579406738118 .5614013672117 .0374984741 116.4279022217114 .9039993286113 .6848983765113 .075302124113 .8976593018 112.9301757812111 .9482879639110 .9512329102109 .9387969971108 .9111328125 
107.8694076538106 .8159332275105 .7546081543104 .6903533936103 .628692627 102.5753326416101 .535736084100 .51504516699 .5176315307698 .54752349854 97.608535766696 .706748962495 .0745544433690 .3306808471788 .53942871094 90.1121139526492 .5409164428792 .734657287692 .7108535766693 .05962371826 93.7859191894594.8048400878995.9710083007897.1021881103598.05572509766 98.7246322631899 .045616149998 .9453201293998 .3074417114397 .02545166016 95.0384826660292 .3518142700288 .8809738159284 .4254837036175 .58670806885 79.8537063598681 .9871978759881 .0728530883878 .9393463134877 .41542053223 77.110626220775 .5867080688574 .6723632812574 .3675689697374 .67236328125 74.6723632812574 .9771423339875 .5867080688575 .8914871215876 .19628143311 76.8058471679777 .110626220777 .4154205322378 .0249862670978 .32978057861 78.6345596313579 .2441329956179 .8537063598680 .1584930419980 .76805877686 81.3776321411181 .9871978759882 .5967712402382 .9015579223683 .51112365723 84.1206970214884 .4254837036184 .6303100585984 .7268142700284 .74926757812 84.7253265380984 .6622314453185 .0350494384884 .7302627563584 .42548370361 83.81591033936 83.51112365723 82.90155792236 82.29197692871 81.98719787598 81.3776321411180 .7680587768680 .1584930419979 .5489196777378 .93934631348 78.3297805786177 .7202072143677 .110626220776 .5010681152375 .89148712158 75.5867080688574 .9771423339874 .6723632812574 .3675689697373 .75800323486 73.4532165527374 .9771423339876 .50106811523 -9999 -9999 -9999 -9999 -9999 -9999 -9999 -9999 -9999 -9999 -9999 -9999 -9999 -9999 -9999 -9999-9999 -9999 -9999 -9999 -9999 -9999 -9999 -9999 -9999 -9999 -9999 -9999 -9999 -9999 -9999 -9999 -9999 -9999 -9999 -9999 -9999 -9999 -9999 -9999 -9999 -9999 -9999 -9999 -9999 -9999 -9999 -9999 -9999 -9999 -9999 -9999 -

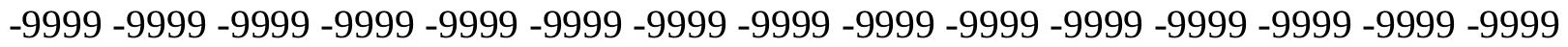
-9999 -9999 -9999-9999-9999-9999

-9999 -9999 -9999 -9999 -9999 -9999 -9999 -9999 -9999 -9999 -9999 -9999 -9999 -9999 -9999 -9999 -9999 -9999 -9999 -9999 -9999 -9999 -9999 -9999 -9999 -9999 -9999 -9999 -9999 -9999 -

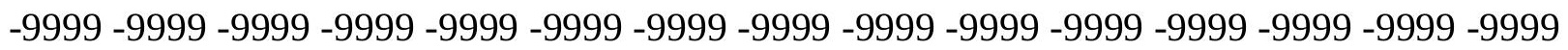
-9999 -9999 -9999 -9999 -9999 -9999 -9999 -9999 -9999 -9999 -9999 -9999 -9999 -9999 -9999 -9999 -9999 -9999 -9999 -9999 -9999 -9999 -9999 -9999 -9999 -9999 -9999 -9999 -9999 -9999 -9999 -9999 -9999 -9999 -9999 -9999 -9999 -9999 -9999 -9999 -9999 -9999 -9999 -9999 -9999 -9999 -9999 -9999 -9999 -9999 90.82597351074 89.3020401001 87.77810668945 85.9494018554784 .7302627563583 .5111236572382 .5967712402382 .29197692871 82.2919769287182 .5967712402382 .9015579223683 .5111236572384 .12069702148 84.4254837036184 .7302627563585 .0350494384885 .3398437585 .64462280273 85.9494018554786 .5589828491286 .8637619018687 .4733276367288 .08290100098 88.9972534179790.2164001464892.0450973510792.6546783447393.56903076172 94.7881774902396 .3121032714898 .1408081054799 .3599472045999 .35994720459 97.8360290527395 .0929565429792 .6546783447391 .4355392456189 .91161346436 87.7781066894585 .6446228027382 .9015579223684 .4254837036186 .55898284912 88.6924667358490 .5211791992292 .349891662693 .8738174438595 .70252990723 97.8360290527399 .96952056885101 .4934005737103 .3221969604105 .7603988647 107.5891036987109 .1130981445109 .7226028442110 .0273971558110 .3321990967 110.6370010376111 .551399231112 .1608963013113 .3800964355114 .2944030762 115.5136032104116 .4279022217117 .342300415117 .9517974854118 .5614013672 118.5210723877118 .507598877118 .4898757935118 .486869812118 .5149307251 
118.5892333984118 .5614013672118 .2565994263117 .9517974854117 .342300415 116.4279022217115 .2088012695113 .075302124110 .9418029785108 .5035018921 106.0652008057102 .712600708101 .7982025146107 .2844009399113 .6848983765 117.647102356120 .6949005127123 .1291503906123 .2472839355123 .3268966675 123.3688659668123 .3743972778123 .3462295532123 .2877349854123 .2031707764 123.097114563122 .9752197266122 .8430099487122 .7050170898122 .5645980835 122.424911499122 .2892456055122 .160987854122 .0441360474121 .9438247681 121.8671875121 .7197341919120 .8491897583119 .9759292603119 .09815979 118.2142105103117 .3224182129116 .4213790894115 .5096817017114 .586151123 113.6497268677112 .6997909546111 .7360229492110 .7587127686109 .7685241699 108.7670974731107 .7572631836106 .743347168105 .7304458618104 .723815918 103.7286758423102 .7496871948101 .7909698486100 .855186462499 .94378662109 99.0566635131898 .1938400268693 .2642517089884 .1206970214880 .76805877686 84.4254837036189 .9116134643689 .7810211181691 .3186187744194 .23207092285 95.1605453491296 .4683990478597 .9737014770599 .40531158447100 .6052932739 101.4781341553102 .0630340576102 .393196106102 .4646453857102 .2528076172 101.13650512798 .7341918945395 .9011383056692 .8482437133889 .97455596924 87.6943206787185 .8523406982484 .1206970214879 .8537063598676 .19628143311 74.9771423339874 .3675689697374 .062782287673 .7580032348673 .75800323486 74.062782287674 .3675689697374 .6723632812574 .9771423339875 .28192901611 75.5867080688575 .8914871215876 .1962814331176 .5010681152376 .80584716797 77.4154205322377 .7202072143678 .3297805786178 .9393463134879 .24413299561 79.8537063598680 .4632720947381 .0728530883881 .6824111938582 .29197692871 82.5967712402383 .206336975183 .5111236572383 .6691284179783 .71231079102 83.75354003906 83.7601928710983.70740509033 83.57698822021 83.51112365723 83.206336975182.9015579223682.29197692871 81.98719787598 81.37763214111 81.0728530883880 .4632720947379 .8537063598679 .2441329956178 .63455963135 78.3297805786177 .7202072143677 .110626220776 .5010681152376 .19628143311 75.5867080688575 .2819290161174 .6723632812574 .3675689697374 .0627822876 73.4532165527373 .7580032348675 .28192901611 -9999 -9999 -9999 -9999 -9999 -9999 -9999 -9999 -9999 -9999 -9999 -9999 -9999 -9999 -9999 -9999 -9999 -9999 -9999 -9999 -9999 -9999

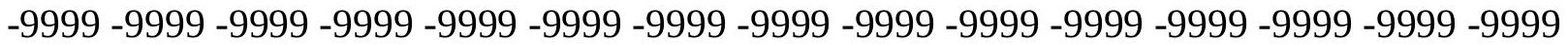

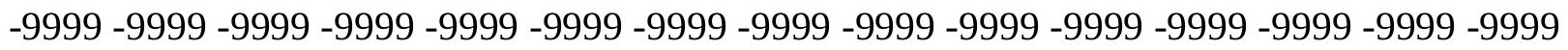

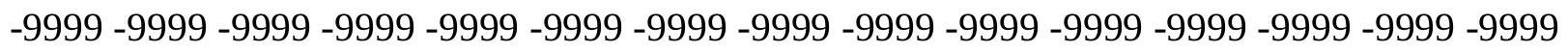
-9999 -9999 -9999-9999-9999-9999

-9999 -9999 -9999 -9999 -9999 -9999 -9999 -9999 -9999 -9999 -9999 -9999 -9999 -9999 -9999

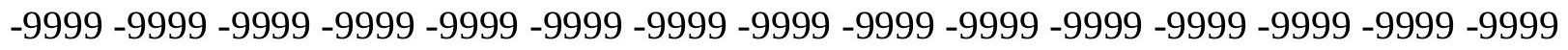

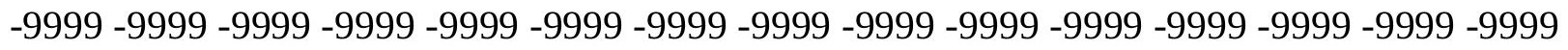

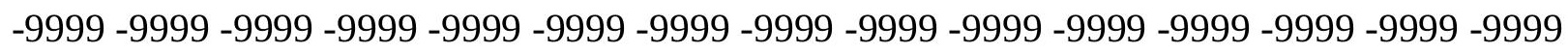
-9999 -9999 -9999 -9999 -9999 -9999 -9999 -9999 -9999 -9999 -9999 -9999 -9999 -9999 -9999 -

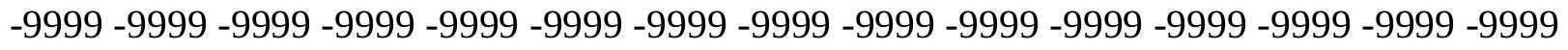
-9999 -9999 -9999-9999 -9999 -9999 84.73026275635 83.51112365723 82.29197692871 81.3776321411180 .7680587768680 .4632720947380 .4632720947380 .46327209473 80.7680587768681 .3776321411181 .9871978759882 .2919769287182 .90155792236 83.206336975183 .5111236572383 .8159103393684 .1206970214884 .12069702148 84.4254837036184 .7302627563585 .3398437585 .6446228027386 .55898284912 
87.7781066894588 .9972534179789 .9116134643690 .8259735107492 .04509735107 93.5690307617294 .7881774902396 .0073165893696 .3121032714895 .70252990723 94.4833908081192 .9594726562592 .6546783447392 .0450973510790 .82597351074 89.302040100186 .8637619018683 .8159103393682 .9015579223684 .73026275635 86.254188537687 .7781066894589 .6068267822391 .4355392456192 .65467834473 94.4833908081197 .22646331787100 .5791015625103 .6268997192106 .3700027466 107.8938980103108 .8082962036109 .1130981445109 .4179000854110 .0273971558 110.6370010376111 .551399231112 .4656982422113 .6848983765114 .5991973877 115.5136032104116 .4279022217117 .0374984741117 .647102356117 .9517974854 118.2565994263118 .3528747559118 .4226303101118 .4988327026118 .586227417 118.6860351562118 .5614013672118 .2565994263117 .647102356117 .0374984741 115.818397522114 .2944030762112 .4656982422110 .9418029785110 .0273971558 110.3321990967112 .1608963013116 .1231002808120 .0852966309121 .3044967651 122.2188034058122 .9175796509123 .0420074463123 .1281585693123 .1771240234 123.1906509399123 .1718521118123 .1244506836123 .0530853271122 .9624862671 122.8580322266122 .7449951172122 .6279830933122 .5105514526122 .3957672119 122.286819458122 .1870498657122 .1005172729122 .0324630737121 .9902877808 121.9825592041121 .3374099731120 .4919586182119 .6430664062118 .7889862061 117.927986145117 .0585403442116 .1791381836115 .288520813114 .385559082 113.4698181152112 .5413894653111 .6011657715110 .6504135132109 .6912384033 108.7268981934107 .7620697021106 .8021621704105 .8524475098104 .9179916382 104.0032272339103 .1120529175102 .2456207275101 .4030914307100 .5820999146 99.7823486328186 .5589828491274 .9771423339869 .1862335205172 .53885650635 79.5489196777382 .2919769287184 .7302627563589 .302040100194 .48339080811 96.147178649999 .56122589111101 .7834243774103 .1174850464104 .0760955811 104.8271942139105 .5171508789106 .2185668945105 .9629440308105 .4979400635 104.4343795776102 .625961303799 .9372787475696 .5459823608492 .6996307373 88.2563018798882 .5756225585975 .2819290161171 .9292907714871 .92929077148 72.5388565063572 .5388565063572 .8436431884873 .1484298706173 .45321655273 73.4532165527373 .7580032348674 .062782287674 .062782287674 .36756896973 74.6723632812574 .9771423339875 .2819290161175 .5867080688575 .89148712158 76.1962814331176 .8058471679777 .4154205322378 .0249862670978 .32978057861 78.9393463134879 .5489196777380 .1584930419980 .7680587768681 .37763214111 81.6824111938582 .2919769287182 .5967712402382 .5967712402382 .74543762207 82.8758850097782 .8699035644582 .7683868408282 .5967712402382 .29197692871 81.9871978759881 .6824111938581 .3776321411181 .0728530883880 .46327209473 80.1584930419979 .5489196777379 .2441329956178 .6345596313578 .02498626709 77.7202072143677 .110626220776 .5010681152376 .1962814331175 .58670806885 75.2819290161174 .6723632812574 .3675689697373 .7580032348673 .45321655273 72.8436431884874 .062782287675 .28192901611 -9999 -9999 -9999 -9999 -9999 -9999 -9999 -9999 -9999 -9999 -9999 -9999 -9999 -9999 -9999 -9999 -9999 -9999 -9999 -9999 -9999 -9999 -

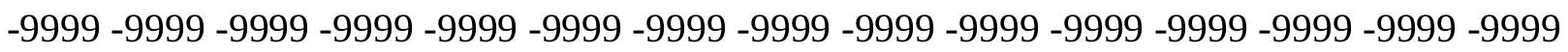
-9999 -9999 -9999 -9999 -9999 -9999 -9999 -9999 -9999 -9999 -9999 -9999 -9999 -9999 -9999 -

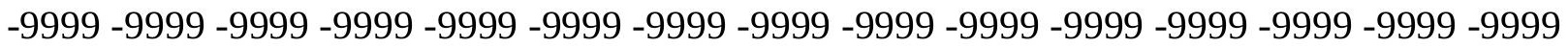
-9999 -9999-9999-9999-9999

-9999 -9999-9999 -9999 -9999 -9999 -9999 -9999 -9999 -9999 -9999 -9999 -9999 -9999 -9999 
-9999 -9999 -9999 -9999 -9999 -9999 -9999 -9999 -9999 -9999 -9999 -9999 -9999 -9999 -9999 -9999 -9999 -9999 -9999 -9999 -9999 -9999 -9999 -9999 -9999 -9999 -9999 -9999 -9999 -9999 -9999 -9999 -9999 -9999 -9999 -9999 -9999 -9999 -9999 -9999 -9999 -9999 -9999 -9999 -9999 -9999 -9999 -9999 -9999 -9999 -9999 -9999 -9999 -9999 -9999 -9999 -9999 -9999 -9999 -9999 -9999 -9999 -9999 -9999 -9999 -9999 -9999 -9999 -9999 -9999 -9999 -9999 -9999 -9999 -9999 -9999 -9999 -9999 -9999 -9999 -9999 80.46327209473 79.8537063598679 .24413299561 78.6345596313578 .6345596313578 .6345596313578 .6345596313579 .24413299561 79.5489196777380 .1584930419980 .7680587768681 .0728530883881 .68241119385 81.9871978759881 .9871978759882 .2919769287182 .5967712402382 .59677124023 82.5967712402382 .9015579223683 .206336975183 .5111236572384 .12069702148 85.0350494384885 .9494018554786 .8637619018688 .0829010009889 .3020401001 90.5211791992291 .7403335571392 .9594726562593 .5690307617293 .87381744385 93.5690307617293 .2642517089893 .2642517089893 .2642517089892 .95947265625 92.349891662690 .2164001464887 .4733276367283 .8159103393680 .76805877686 81.6824111938582 .9015579223685 .0350494384887 .4733276367288 .99725341797 90.8259735107493 .8738174438596 .9216690063599 .96952056885102 .712600708 104.8460998535106 .0652008057106 .979598999107 .5891036987108 .5035018921 109.4179000854110 .6370010376111 .551399231112 .7705001831113 .6848983765 114.5991973877115 .5136032104116 .1231002808116 .7326965332117 .342300415 117.647102356117 .9517974854118 .1427841187118 .3087921143118 .433883667 118.5327301025118 .5614013672118 .2565994263117 .9517974854117 .342300415 116.4279022217115 .2088012695114 .2944030762113 .3800964355113 .3800964355 114.9039993286117 .0374984741120 .0852966309121 .9140014648122 .2188034058 122.2188034058122 .5235977173122 .8131790161122 .9035949707122 .9565734863 122.9744644165122 .9610595703122 .9206314087122 .858291626122 .7790527344 122.6881408691122 .5905990601122 .4910507202122 .3932266235122 .3001251221 122.2147216797122 .1403045654122 .0810546875122 .0422744751122 .031211853 122.0562210083121 .8196487427121 .0041122437120 .1862945557119 .3643493652 118.5364532471117 .7009429932116 .8561782837116 .0007705688115 .1335067749 114.2539672852113 .3625793457112 .4608383179111 .5506668091110 .6346511841 109.7163696289108 .8007354736107 .8934173584106 .9999923706106 .1258468628 105.2757873535104 .4539718628103 .6612167358102 .8985671997102 .171333313 101.466140747173 .4532165527371 .3197174072369 .7957916259871 .31971740723 73.1484298706175 .5867080688577 .4154205322379 .8537063598682 .90155792236 88.0829010009892 .9594726562597 .53124237061101 .1886978149103 .9317016602 102.7942276001102 .834777832103 .9834289551105 .7539901733107 .355796814 108.4299621582108 .2560501099106 .1823501587102 .286186218396 .9803237915 90.4890899658282 .5967712402364 .9192428588967 .9670867919969 .79579162598 70.7101516723671 .3197174072371 .9292907714872 .5388565063572 .84364318848 73.1484298706173 .1484298706173 .1484298706173 .1484298706173 .45321655273 73.4532165527373 .7580032348674 .062782287674 .3675689697374 .67236328125 74.9771423339875 .5867080688575 .8914871215876 .5010681152377 .1106262207 77.7202072143678 .3297805786178 .9393463134879 .2441329956179 .85370635986 80.4632720947380 .7680587768681 .3776321411181 .6824111938581 .68241119385 81.9871978759881 .9871978759881 .9403610229581 .6824111938581 .61998748779 81.3776321411181 .0728530883880 .7680587768680 .4632720947380 .15849304199 
79.8537063598679 .2441329956178 .9393463134878 .3297805786178 .02498626709 77.4154205322377 .110626220776 .5010681152375 .8914871215875 .58670806885 74.9771423339874 .6723632812574 .062782287673 .7580032348673 .14842987061 72.5388565063572 .8436431884874 .0627822876 -9999 -9999 -9999 -9999 -9999 -9999 -9999 -9999 -9999 -9999 -9999 -9999 -9999 -9999 -9999 -9999 -9999 -9999 -9999-9999 -9999 -9999 -9999 -9999 -9999 -9999 -9999 -9999 -9999 -9999 -9999 -9999 -9999 -9999 -9999 -9999 -9999

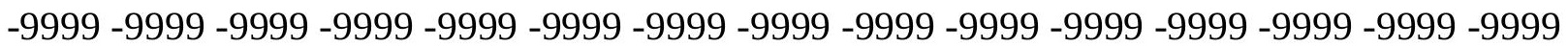

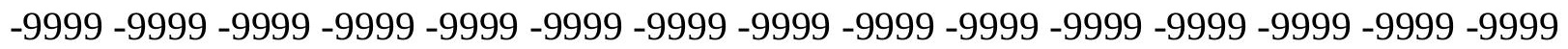
-9999 -9999-9999-9999-9999

-9999 -9999 -9999 -9999 -9999 -9999 -9999 -9999 -9999 -9999 -9999 -9999 -9999 -9999 -9999 -9999 -9999 -9999 -9999 -9999 -9999 -9999 -9999 -9999 -9999 -9999 -9999 -9999 -9999 -9999 -9999 -9999 -9999 -9999 -9999 -9999 -9999 -9999 -9999 -9999 -9999 -9999 -9999 -9999 -9999 -9999 -9999 -9999 -9999 -9999 -9999 -9999 -9999 -9999 -9999 -9999 -9999 -9999 -9999 -9999 -9999 -9999 -9999 -9999 -9999 -9999 -9999 -9999 -9999 -9999 -9999 -9999 -9999 -9999 -9999 -9999 -9999 -9999 -9999 -9999 -9999 -9999 -9999 -9999 -9999 -9999 -9999 -9999 -9999 -9999 -9999 -9999-9999 -9999 -9999-9999-9999 76.50106811523 76.1962814331176.50106811523 76.5010681152376 .8058471679777 .4154205322378 .0249862670978 .63455963135 79.2441329956179 .5489196777380 .1584930419980 .4632720947380 .76805877686 80.7680587768681 .0728530883881 .0728530883881 .0728530883881 .07285308838 81.0728530883881 .3776321411181 .6824111938581 .9871978759882 .29197692871 82.90155792236 83.81591033936 85.03504943848 86.55898284912 87.77810668945 89.302040100190.5211791992291.4355392456192.0450973510792.65467834473 92.9594726562593 .2642517089893 .8738174438594 .1785964965893 .87381744385 92.6546783447390 .8259735107488 .0829010009884 .4254837036178 .93934631348 78.9393463134881 .3776321411184 .1206970214886 .254188537688 .38768768311 90.8259735107493 .2642517089895 .7025299072398 .14080810547100 .2742996216 102.1029968262103 .9317016602105 .1509017944106 .6747970581107 .8938980103 109.1130981445110 .3321990967111 .551399231112 .4656982422113 .3800964355 114.2944030762115 .2088012695115 .818397522116 .4279022217117 .0374984741 117.342300415117 .647102356117 .9517974854118 .1360549927118 .2290267944 118.2565994263118 .2565994263117 .9517974854117 .647102356117 .0374984741 116.7326965332116 .1231002808115 .818397522116 .1231002808117 .342300415 118.5614013672120 .6949005127121 .808380127122 .051574707121 .9140014648 121.9140014648121 .9140014648121 .3044967651120 .9997024536119 .7806015015 119.7806015015122 .2188034058122 .6207046509122 .5478897095122 .465675354 122.3789291382122 .2922744751122 .209602356122 .1339035034122 .0679397583 122.0148696899121 .9788513184121 .9650650024121 .9803314209122 .0322570801 122.1290740967121 .5091934204120 .7244873047119 .9367828369119 .1441421509 118.3447341919117 .5367660522116 .7186584473115 .8890609741115 .0475158691 114.1946334839113 .3323745728112 .4632492065111 .5902709961110 .7172241211 109.8490905762108 .9917602539108 .1511764526107 .3335113525106 .5445709229 105.789932251105 .0681533813104 .4017028809103 .7842559814103 .2036972046 71.014930725169 .7957916259869 .1862335205170 .1005783081172 .23407745361 73.7580032348674 .3675689697375 .2819290161177 .7202072143680 .15849304199 82.2919769287185 .0350494384888 .3876876831190 .5211791992292 .04509735107 93.2642517089895 .70252990723100 .5791015625104 .6784286499109 .6115493774 
111.9993972778110 .9985046387106 .8896408081100 .885986328193 .61054992676 85.5229721069376 .5010681152369 .4910125732468 .2718734741269 .18623352051 70.7101516723671 .6244964599672 .2340774536172 .5388565063572 .53885650635 72.5388565063572 .5388565063572 .5388565063572 .5388565063572 .53885650635 72.5388565063572 .8436431884873 .1484298706173 .4532165527373 .75800323486 74.062782287674 .6723632812574 .9771423339875 .5867080688576 .19628143311 76.8058471679777 .4154205322378 .0249862670978 .6345596313579 .24413299561 79.5489196777380 .1584930419980 .4632720947380 .7680587768680 .76805877686 81.0728530883881 .0728530883881 .0042419433680 .7680587768680 .64616394043 80.4410018920980 .1584930419979 .8537063598679 .5489196777379 .24413299561 78.9393463134878 .6345596313578 .0249862670977 .7202072143677 .41542053223 76.8058471679776 .5010681152375 .8914871215875 .2819290161174 .97714233398 74.3675689697374 .062782287673 .4532165527372 .8436431884871 .92929077148 71.6244964599672 .8436431884874 .36756896973 -9999 -9999 -9999 -9999 -9999 -9999 -9999 -9999 -9999 -9999 -9999 -9999 -9999 -9999 -9999 -9999 -9999 -9999 -9999 -9999 -9999 -9999

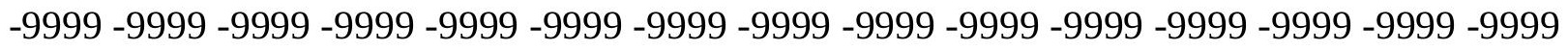
-9999 -9999 -9999 -9999 -9999 -9999 -9999 -9999 -9999 -9999 -9999 -9999 -9999 -9999 -9999 -9999 -9999 -9999 -9999 -9999 -9999 -9999 -9999 -9999 -9999 -9999 -9999 -9999 -9999 -9999 -9999 -9999-9999-9999

-9999 -9999 -9999 -9999 -9999 -9999 -9999 -9999 -9999 -9999 -9999 -9999 -9999 -9999 -9999 -

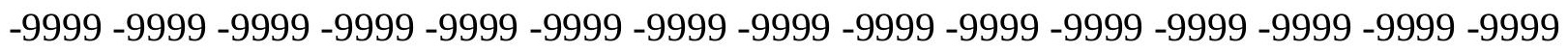

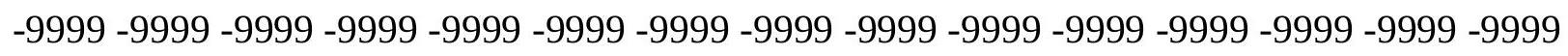
-9999 -9999 -9999 -9999 -9999 -9999 -9999 -9999 -9999 -9999 -9999 -9999 -9999 -9999 -9999 -

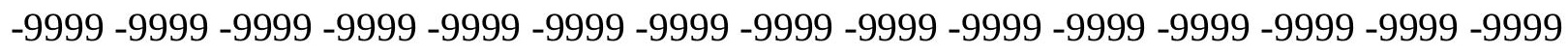

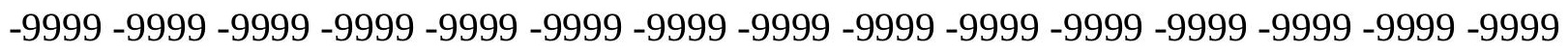
-9999 -9999 -9999 -9999-9999-9999-9999 73.45321655273 73.7580032348674 .36756896973 74.9771423339875 .5867080688576 .1962814331176 .8058471679777 .72020721436 78.3297805786178 .9393463134879 .2441329956179 .5489196777379 .85370635986 79.8537063598679 .8537063598679 .8537063598679 .5489196777379 .54891967773 79.5489196777379 .5489196777379 .5489196777379 .8537063598680 .15849304199 80.4632720947381 .0728530883882 .5967712402384 .1206970214885 .64462280273 87.1685485839888 .3876876831189 .6068267822390 .5211791992291 .43553924561 92.349891662693 .2642517089893 .8738174438594 .4833908081194 .48339080811 94.1785964965893 .2642517089892 .0450973510790 .5211791992285 .03504943848 82.2919769287181 .6824111938582 .5967712402383 .8159103393685 .94940185547 87.7781066894589 .9116134643691 .4355392456193 .2642517089895 .70252990723 98.4455871582100 .5791015625102 .712600708104 .2365036011106 .0652008057 107.5891036987108 .8082962036110 .0273971558111 .24659729112 .1608963013 113.075302124113 .9896011353114 .5991973877115 .5136032104116 .1231002808 116.7326965332117 .0374984741117 .342300415117 .647102356117 .7352294922 117.8359909058117 .9517974854117 .9517974854117 .647102356117 .647102356 117.647102356117 .647102356117 .647102356117 .647102356118 .2565994263 119.1709976196120 .6949005127121 .5234985352121 .7764282227121 .9936294556 122.1703033447120 .9997024536117 .9517974854114 .5991973877111 .24659729 110.9418029785116 .7326965332122 .2188034058122 .2678604126122 .1882858276 122.1064987183122 .0270614624121 .9539871216121 .890335083121 .8387756348 
121.802154541121 .784324646121 .7899856567121 .8252410889121 .8968963623 122.0127716064122 .0037841797121 .2540817261120 .5025863647119 .747215271 118.9859542847118 .2168045044117 .4379348755116 .6478042603115 .8458480835 115.0327682495114 .2107543945113 .3826599121112 .5517501831111 .7218551636 110.8978805542110 .0857086182109 .2917404175108 .5230712891107 .7869720459 107.0906524658106 .4425964355105 .8671798706105 .3644638062104 .9223098755 69.7957916259869 .4910125732469 .7957916259870 .4053573608471 .92929077148 73.1484298706174 .062782287674 .6723632812574 .9771423339874 .97714233398 75.8914871215877 .4154205322377 .4154205322377 .110626220777 .41542053223 76.8058471679778 .6345596313585 .6446228027396 .00731658936107 .2844009399 112.9813461304113 .0781326294109 .372428894103 .802963256897 .18383026123 90.0465698242283 .0377960205177 .097793579168 .2718734741270 .71015167236 70.7101516723671 .9292907714872 .5388565063572 .5388565063572 .23407745361 71.9292907714871 .9292907714871 .6244964599671 .6244964599671 .62449645996 71.6244964599671 .9292907714871 .9292907714872 .2340774536172 .53885650635 72.8436431884873 .4532165527373 .7580032348674 .3675689697374 .97714233398 75.5867080688576 .1962814331176 .8058471679777 .4154205322378 .02498626709 78.6345596313578 .9393463134879 .2441329956179 .5489196777379 .85370635986 79.8537063598680 .1584930419980 .1584930419980 .1584930419979 .85370635986 79.7557296752979 .5489196777379 .4276580810579 .2441329956178 .93934631348 78.6345596313578 .3297805786178 .0249862670977 .4154205322377 .1106262207 76.8058471679776 .1962814331175 .8914871215875 .2819290161174 .67236328125 74.3675689697373 .7580032348673 .1484298706172 .2340774536171 .62449645996 70.7101516723671 .9292907714873 .14842987061 -9999 -9999 -9999 -9999 -9999 -9999 -9999 -9999 -9999 -9999 -9999 -9999 -9999 -9999 -9999 -9999 -9999 -9999 -9999 -9999 -9999 -9999 -9999 -9999 -9999 -9999 -9999 -9999 -9999 -9999 -9999 -9999 -9999 -9999 -9999 -9999 -9999 -9999 -9999 -9999 -9999 -9999 -9999 -9999 -9999 -9999 -9999 -9999 -9999 -9999 -9999 -9999

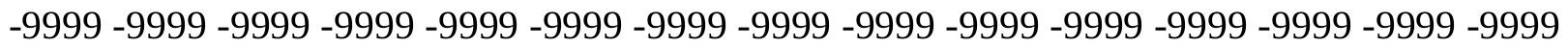
-9999 -9999-9999 -9999

-9999 -9999 -9999 -9999 -9999 -9999 -9999 -9999 -9999 -9999 -9999 -9999 -9999 -9999 -9999 -9999 -9999 -9999 -9999 -9999 -9999 -9999 -9999 -9999 -9999 -9999 -9999 -9999 -9999 -9999

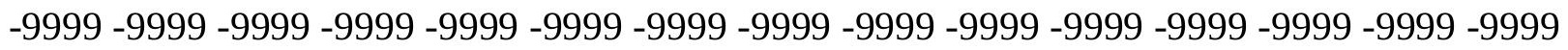

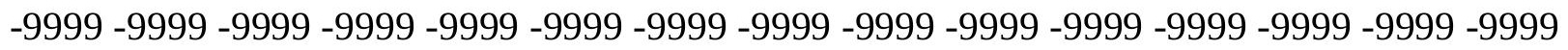

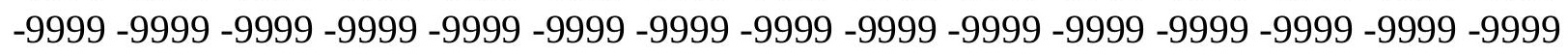
-9999 -9999 -9999 -9999 -9999 -9999 -9999 -9999 -9999 -9999 -9999 -9999 -9999 -9999 -9999 -9999 -9999 -9999 -9999 -9999 -9999 -9999 -9999 71.6244964599672 .53885650635 73.4532165527374 .3675689697375 .2819290161176 .1962814331176 .80584716797 77.7202072143678 .3297805786178 .6345596313578 .9393463134878 .93934631348 78.9393463134878 .9393463134878 .6345596313578 .3297805786178 .32978057861 78.0249862670978 .0249862670978 .0249862670978 .0249862670978 .32978057861 78.6345596313579 .2441329956180 .4632720947381 .9871978759883 .51112365723 85.0350494384886 .5589828491287 .7781066894589 .302040100190 .52117919922 91.7403335571392 .6546783447392 .9594726562594 .1785964965894 .48339080811 94.7881774902394 .4833908081193 .5690307617291 .7403335571388 .99725341797 86.254188537685 .0350494384885 .0350494384885 .3398437586 .2541885376 86.86376190186 86.86376190186 87.47332763672 88.9972534179791.74033355713 
94.7881774902397 .2264633178799 .66472625732101 .7982025146103 .6268997192 105.4557037354107 .2844009399108 .5035018921109 .4179000854110 .6370010376 111.551399231112 .4656982422113 .3800964355114 .2944030762114 .9039993286 115.5136032104116 .1231002808116 .4279022217116 .7326965332117 .0374984741 117.1809692383117 .342300415117 .647102356117 .9517974854117 .9517974854 118.2565994263118 .5614013672118 .5614013672118 .5614013672118 .8662033081 119.1709976196120 .3900985718121 .2264938354121 .4934387207121 .7203979492 121.9016265869120 .3900985718115 .2088012695108 .8082962036102 .712600708 100.5791015625107 .8938980103116 .7326965332117 .9517974854117 .9517974854 120.0852966309121 .6886291504121 .6190643311121 .5616760254121 .5190353394 121.4935531616121 .4884033203121 .5074462891121 .555847168121 .6395263672 121.7659072876121 .9429168701121 .7715072632121 .0580291748120 .3417892456 119.6205825806118 .8921356201118 .1543502808117 .405380249116 .6444778442 115.8722915649115 .0910873413114 .3037261963113 .513343811112 .7236099243 111.9391403198111 .1656723022110 .4097518921109 .6793365479108 .9830551147 108.3284454346107 .7393798828107 .2440109253106 .8428268433106 .5303421021 69.7957916259869 .7957916259870 .1005783081170 .7101516723671 .62449645996 72.8436431884873 .4532165527374 .062782287674 .3675689697374 .0627822876 73.4532165527372 .2340774536171 .014930725169 .7957916259865 .83358764648 62.1761703491262 .7857398986870 .7101516723682 .5967712402397 .22646331787 109.7226028442109 .9416046143108 .0184173584104 .4926986694100 .0654067993 95.0820007324289 .861885070884 .6628952026479 .7750625610470 .71015167236 71.3197174072372 .8436431884873 .1484298706172 .8436431884872 .23407745361 71.6244964599671 .3197174072371 .014930725170 .7101516723670 .71015167236 70.7101516723671 .014930725171 .014930725171 .3197174072371 .62449645996 71.6244964599672 .2340774536172 .5388565063573 .1484298706173 .75800323486 74.3675689697374 .9771423339875 .5867080688576 .1962814331176 .80584716797 77.4154205322378 .0249862670978 .3297805786178 .6345596313578 .93934631348 79.2441329956179 .2441329956179 .2441329956179 .2441329956179 .24413299561 79.2441329956178 .9393463134878 .8422012329178 .6345596313578 .6130065918 78.3297805786178 .0249862670977 .7202072143677 .4154205322376 .80584716797 76.5010681152375 .8914871215875 .5867080688574 .9771423339874 .67236328125 74.062782287673 .4532165527372 .8436431884872 .2340774536171 .31971740723 70.4053573608470 .7101516723671 .9292907714873 .14842987061 -9999 -9999 -9999 -9999 -9999 -9999 -9999 -9999 -9999 -9999 -9999 -9999 -9999 -9999 -9999 -9999 -9999 -9999 -9999

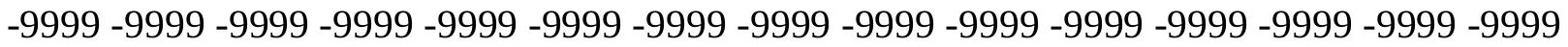

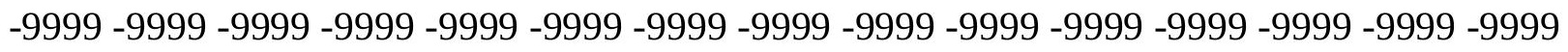

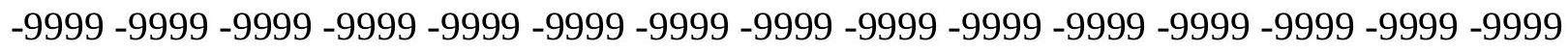
-9999 -9999 -9999 -9999-9999-9999

-9999 -9999 -9999 -9999 -9999 -9999 -9999 -9999 -9999 -9999 -9999 -9999 -9999 -9999 -9999

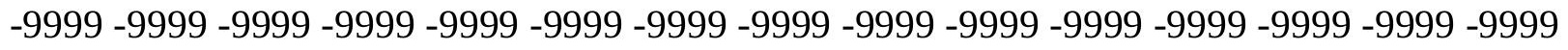

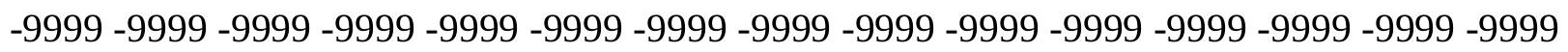

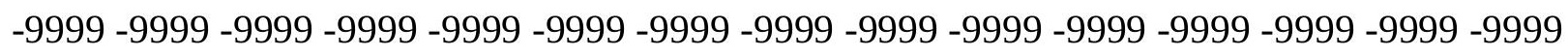
-9999 -9999 -9999 -9999 -9999 -9999 -9999 -9999 -9999 -9999 -9999 -9999 -9999 -9999 -9999 -

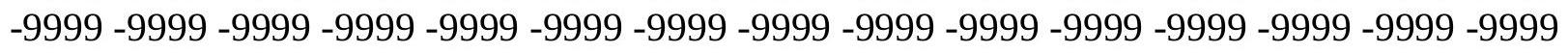
-9999 -9999 -9999 -9999-9999 -9999 -9999-9999 -9999 71.0149307251 72.23407745361 
73.1484298706174 .3675689697375 .2819290161176 .5010681152377 .41542053223 78.0249862670978 .3297805786178 .3297805786178 .3297805786178 .32978057861 78.0249862670977 .7202072143677 .4154205322377 .110626220776 .80584716797 76.5010681152376 .5010681152376 .5010681152376 .8058471679777 .1106262207 78.0249862670978 .9393463134880 .4632720947381 .9871978759883 .51112365723 85.0350494384886 .254188537687 .7781066894589 .302040100190 .52117919922 91.7403335571392 .6546783447393 .2642517089893 .8738174438594 .48339080811 94.4833908081193 .8738174438592 .349891662690 .5211791992288 .38768768311 87.1685485839886 .8637619018687 .1685485839887 .4733276367288 .08290100098 88.3876876831188 .3876876831188 .6924667358490 .2164001464892 .04509735107 94.1785964965896 .6168823242298 .75038146973100 .8839035034103 .0174026489 104.8460998535106 .3700027466107 .5891036987108 .8082962036110 .0273971558 110.9418029785112 .1608963013113 .075302124113 .6848983765114 .5991973877 114.9039993286115 .5136032104115 .818397522116 .1231002808116 .4279022217 116.7326965332117 .0374984741117 .5866012573117 .9517974854118 .4867935181 118.8653106689119 .1709976196119 .4757995605119 .4757995605119 .7806015015 120.6001663208120 .9236068726121 .2097167969121 .4483718872121 .6331100464 119.4757995605 114.2944030762 106.065200805795.3977432251 88.38768768311 91.4355392456199 .35994720459106 .979598999113 .9896011353118 .8662033081 121.2674407959121 .1949462891121 .1379547119121 .098739624121 .0790328979 121.0810852051121 .1075820923121 .1624984741121 .250793457121 .3793182373 121.5562210083121 .7919082642121 .5993041992120 .9239501953120 .2445755005 119.558631897118 .8636856079118 .1575469971117 .4391479492116 .7088928223 115.9689025879115 .2217483521114 .4701004028113 .7170333862112 .9667282104 112.2244567871111 .4966278076110 .7913589478110 .1182174683109 .4874420166 108.9338684082108 .4822540283108 .143371582107 .920227050870 .10057830811 70.4053573608470 .7101516723671 .014930725171 .6244964599672 .23407745361 72.8436431884873 .1484298706173 .1484298706172 .8436431884871 .92929077148 70.7101516723668 .5766525268666 .1383666992263 .7000885009862 .48094940186 62.1761703491263 .3953094482466 .4431610107479 .8537063598693 .26425170898 99.35994720459101 .7982025146101 .705078125100 .881469726699 .42779541016 97.0244598388793 .4283752441488 .6215591430783 .2070465087977 .41542053223 74.9771423339873 .4532165527372 .8436431884871 .9292907714871 .31971740723 70.7101516723670 .4053573608470 .1005783081170 .1005783081170 .10057830811 70.4053573608470 .4053573608470 .4053573608470 .7101516723670 .71015167236 71.014930725171 .3197174072371 .9292907714872 .5388565063573 .14842987061 73.7580032348674 .3675689697375 .2819290161175 .8914871215876 .50106811523 77.110626220777 .4154205322377 .7202072143678 .0249862670978 .32978057861 78.3297805786178 .6345596313578 .6345596313578 .6345596313578 .63455963135 78.6345596313578 .3297805786178 .2743301391678 .0249862670977 .99210357666 77.7202072143677 .4154205322377 .110626220776 .8058471679776 .19628143311 75.8914871215875 .2819290161174 .9771423339874 .3675689697373 .75800323486 73.1484298706172 .5388565063571 .9292907714871 .3197174072370 .40535736084 69.7957916259870 .7101516723671 .92929077148 -9999 -9999 -9999 -9999 -9999 -9999 -9999 -9999 -9999 -9999 -9999 -9999 -9999 -9999 -9999 -9999 -9999 -9999 -9999 -9999 -9999 -9999 -

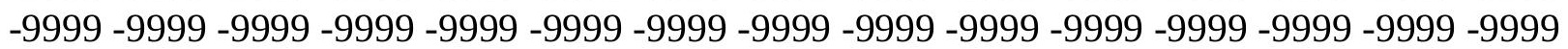


-9999 -9999 -9999 -9999 -9999 -9999 -9999 -9999 -9999 -9999 -9999 -9999 -9999 -9999 -9999

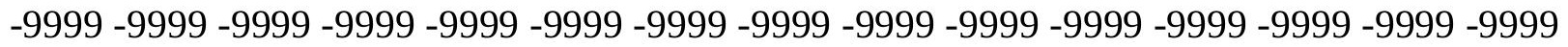
-9999 -9999-9999

-9999 -9999 -9999 -9999 -9999 -9999 -9999 -9999 -9999 -9999 -9999 -9999 -9999 -9999 -9999 -9999 -9999 -9999 -9999 -9999 -9999 -9999 -9999 -9999 -9999 -9999 -9999 -9999 - -9999 - -9999 -

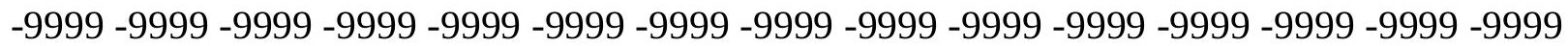

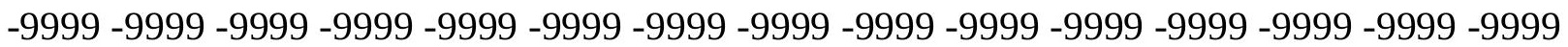
-9999 -9999 -9999 -9999 -9999 -9999 -9999 -9999 -9999 -9999 -9999 -9999 -9999 -9999 -9999

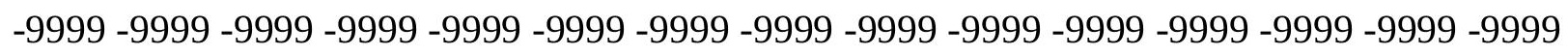
-9999 -9999 -9999 -9999 -9999 -9999 -9999-9999 -9999 69.79579162598 71.0149307251 72.2340774536173 .4532165527374 .6723632812575 .8914871215877 .1106262207 77.7202072143678 .0249862670978 .0249862670977 .7202072143677 .41542053223 77.110626220776 .5010681152376 .1962814331175 .8914871215875 .58670806885 75.2819290161174 .9771423339875 .2819290161175 .2819290161175 .89148712158 76.5010681152377 .4154205322378 .6345596313580 .1584930419981 .68241119385 83.2063369751 84.73026275635 86.2541885376 87.77810668945 89.3020401001 90.5211791992291 .7403335571392 .6546783447393 .2642517089893 .26425170898 93.5690307617292 .9594726562592 .0450973510790 .5211791992289 .3020401001 88.0829010009887 .7781066894587 .7781066894588 .0829010009888 .69246673584 89.302040100189 .6068267822390 .5211791992291 .7403335571393 .56903076172 95.0929565429796 .3121032714897 .8360290527398 .75038146973100 .2742996216 102.4077987671104 .5412979126106 .6747970581108 .1986999512109 .7226028442 110.9418029785112 .1608963013113 .075302124113 .9896011353114 .5991973877 115.2088012695115 .5136032104115 .5136032104115 .5136032104115 .818397522 115.818397522116 .4279022217117 .0259780884117 .6071166992118 .0924911499 118.4650650024118 .7950286865119 .1320266724119 .4927978516119 .8790512085 120.2656555176120 .6240692139120 .9350204468121 .1862716675121 .3044967651 118.5614013672113 .6848983765106 .674797058194 .1785964965883 .81591033936 82.2919769287186 .8637619018699 .05516815186112 .1608963013118 .2565994263 120.7539749146120 .6719360352120 .6095809937120 .5685806274120 .5497894287 120.5542297363120 .5831375122120 .6390457153120 .7256546021120 .8489532471 121.0168533325121 .2402648926121 .5317687988121 .4901351929120 .8542251587 120.2124404907119 .5619812012118 .9002838135118 .2258682251117 .5386428833 116.8402481079116 .1327209473115 .4179992676114 .6982345581113 .9767990112 111.551399231107 .5891036987111 .8547668457111 .1864776611110 .5539398193 109.9979095459 109.5432739258109.1998291016108.982849121170.71015167236 71.014930725171 .014930725171 .3197174072371 .3197174072371 .62449645996 71.9292907714871 .9292907714871 .6244964599671 .014930725170 .40535736084 68.8814392089867 .0527267456164 .9192428588963 .3953094482464 .30966186523 63.0905189514264 .6144485473667 .3575134277370 .7101516723674 .36756896973 82.29197692871 88.6924667358494.7881774902398.37548065186101.8151245117 103.5278701782102 .490005493298 .5338363647592 .8842468261786 .9030456543 81.3192825317476 .1962814331172 .5388565063571 .9292907714871 .0149307251 70.1005783081169 .7957916259869 .4910125732469 .4910125732469 .79579162598 69.7957916259869 .7957916259869 .7957916259869 .7957916259869 .79579162598 70.1005783081170 .4053573608470 .7101516723671 .3197174072371 .92929077148 
72.8436431884873 .4532165527374 .3675689697374 .9771423339875 .89148712158 76.1962814331176 .8058471679777 .110626220777 .4154205322377 .41542053223 77.7202072143677 .7202072143678 .0249862670978 .0249862670978 .02498626709 78.0249862670978 .0249862670978 .0249862670977 .7202072143677 .61351776123 77.4154205322377 .110626220776 .8058471679776 .5010681152376 .19628143311 75.5867080688575 .2819290161174 .6723632812574 .3675689697373 .75800323486 73.1484298706172 .5388565063571 .9292907714871 .3197174072370 .71015167236 70.1005783081171 .014930725171 .014930725172 .23407745361 -9999 -9999 -9999 -9999 -9999 -9999 -9999 -9999 -9999 -9999 -9999 -9999 -9999 -9999 -9999 -9999-9999 -9999 -9999 -9999 -9999 -9999 -9999 -9999 -9999 -9999 -9999 -9999 -9999 -9999 -9999 -9999 -9999 -9999

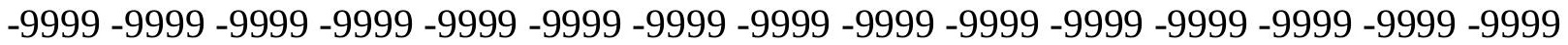

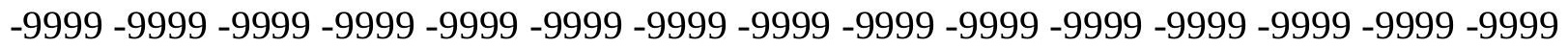
-9999 -9999-9999-9999-9999

-9999 -9999 -9999 -9999 -9999 -9999 -9999 -9999 -9999 -9999 -9999 -9999 -9999 -9999 -9999 -9999 -9999 -9999 -9999 -9999 -9999 -9999 -9999 -9999 -9999 -9999 -9999 -9999 -9999 -9999

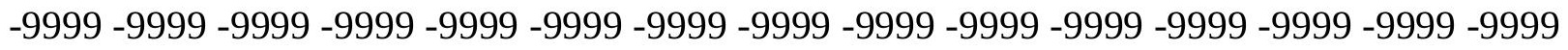
-9999 -9999 -9999 -9999 -9999 -9999 -9999 -9999 -9999 -9999 -9999 -9999 -9999 -9999 -9999 -9999 -9999 -9999 -9999 -9999 -9999 -9999 -9999 -9999 -9999 -9999 -9999 -9999 -9999 -9999 -

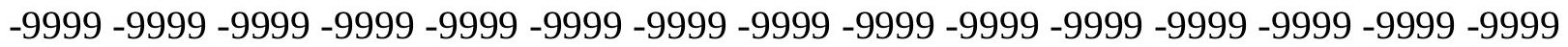
-9999 -9999 -9999-9999 -9999 -9999 -9999 -9999 -9999-9999 70.10057830811 71.3197174072372 .8436431884874 .062782287675 .5867080688576 .80584716797 77.4154205322377 .7202072143677 .4154205322377 .110626220776 .50106811523 76.1962814331175 .5867080688574 .9771423339874 .6723632812574 .36756896973 74.062782287673 .7580032348673 .7580032348674 .062782287674 .36756896973 74.9771423339875 .8914871215877 .110626220778 .3297805786179 .85370635986 81.37763214111 82.90155792236 84.73026275635 86.2541885376 87.77810668945 88.9972534179790 .5211791992291 .4355392456192 .0450973510792 .3498916626 92.0450973510791 .7403335571391 .1307525634889 .9116134643688 .99725341797 88.08290100098 87.77810668945 87.77810668945 88.38768768311 88.99725341797 89.9116134643690.8259735107493.5690307617293.2642517089894.48339080811 96.0073165893697 .5312423706198 .7503814697399 .96952056885101 .4934005737 103.6268997192105 .7603988647107 .5891036987109 .4179000854110 .6370010376 112.1608963013113 .075302124113 .9896011353114 .9039993286115 .5136032104 115.5136032104115 .5136032104115 .2088012695114 .9039993286114 .5991973877 114.9039993286115 .5136032104116 .4279022217117 .1807098389117 .6797332764 118.0149536133118 .3167648315118 .6577529907119 .056602478119 .4914474487 119.9358596802120 .3409500122120 .6815109253120 .9442672729121 .1241760254 119.4757995605115 .5136032104110 .9418029785106 .3700027466102 .1029968262 98.7503814697399 .05516815186105 .7603988647114 .5991973877119 .7806015015 120.1371612549120 .0388793945119 .9654846191119 .9179382324119 .8959274292 119.8990249634119 .9267272949119 .9797592163120 .0601501465120 .1725387573 120.3240585327120 .5254516602120 .7900924683121 .1346969604121 .44581604 120.8496704102120 .245223999119 .6295013428119 .0005264282118 .3575363159 117.7013244629117 .0330505371116 .3537368774115 .6643600464114 .9671401978 113.075302124113 .5641098022112 .8690872192112 .188079834111 .5297546387 110.9346694946110 .4152679443109 .9851303101109 .655776977571 .62449645996 
71.3197174072371 .3197174072371 .014930725171 .014930725171 .0149307251 71.014930725170 .7101516723670 .4053573608469 .7957916259868 .88143920898 67.6623001098666 .1383666992264 .6144485473663 .7000885009863 .39530944824 64.004882812564 .9192428588966 .7479400634868 .5766525268669 .18623352051 68.5766525268673 .1484298706181 .6824111938591 .43553924561100 .7602005005 108.2640838623110 .1281738281107 .6013183594102 .375259399495 .88115692139 89.0152206420982 .4296493530376 .6152191162171 .9292907714870 .71015167236 69.7957916259869 .1862335205169 .1862335205169 .4910125732469 .49101257324 69.4910125732469 .4910125732469 .1862335205169 .1862335205169 .18623352051 69.1862335205169 .4910125732469 .7957916259870 .4053573608471 .0149307251 71.9292907714872 .8436431884873 .7580032348674 .3675689697375 .28192901611 75.5867080688576 .1962814331176 .5010681152376 .5010681152376 .80584716797 77.110626220777 .110626220777 .4154205322377 .4154205322377 .72020721436 77.7202072143677 .7202072143677 .7202072143677 .4154205322377 .41542053223 77.110626220776 .8058471679776 .5010681152376 .1962814331175 .89148712158 75.5867080688574 .9771423339874 .6723632812574 .062782287673 .45321655273 72.8436431884872 .2340774536171 .6244964599671 .014930725170 .71015167236 70.1005783081169 .7957916259869 .7957916259871 .0149307251 -9999 -9999 -9999 -9999 -9999 -9999 -9999 -9999 -9999 -9999 -9999 -9999 -9999 -9999 -9999 -9999 -9999 -9999 -9999 -9999 -9999 -9999 -9999 -9999 -9999 -9999 -9999 -9999 -9999 -9999 -9999 -9999 -9999 -9999

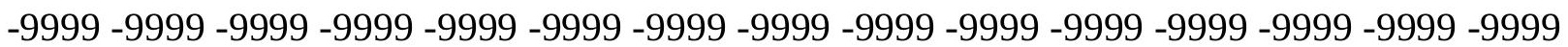

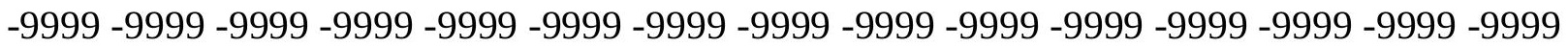
$-9999-9999-9999-9999-9999$

-9999 -9999 -9999 -9999 -9999 -9999 -9999 -9999 -9999 -9999 -9999 -9999 -9999 -9999 -9999 -9999 -9999 -9999 -9999 -9999 -9999 -9999 -9999 -9999 -9999 -9999 -9999 -9999 -9999 -9999 -9999 -9999 -9999 -9999 -9999 -9999 -9999 -9999 -9999 -9999 -9999 -9999 -9999 -9999 -9999 -9999 -9999 -9999 -9999 -9999 -9999 -9999 -9999 -9999 -9999 -9999 -9999 -9999 -9999 -9999 -9999 -9999 -9999 -9999 -9999 -9999 -9999 -9999 -9999 -9999 -9999 -9999 -9999 -9999 -9999

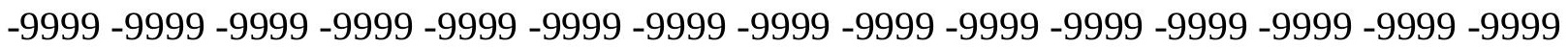
-9999 -9999 -9999 -9999 -9999 -9999 -9999 -9999 -9999 -9999 -9999 70.71015167236 71.9292907714873 .4532165527374 .9771423339876 .1962814331177 .1106262207 77.110626220776 .8058471679776 .1962814331175 .5867080688575 .28192901611 74.6723632812574 .062782287673 .4532165527373 .1484298706172 .84364318848 72.5388565063572 .5388565063572 .8436431884873 .1484298706173 .75800323486 74.3675689697375 .2819290161176 .5010681152378 .0249862670979 .54891967773 81.0728530883882 .5967712402384 .4254837036185 .9494018554787 .47332763672 88.6924667358489 .9116134643690 .8259735107491 .1307525634891 .13075256348 90.8259735107490 .5211791992289 .9116134643690 .8259735107493 .26425170898 90.2164001464889 .302040100189 .6068267822390 .2164001464890 .82597351074 91.7403335571392 .6546783447393 .8738174438595 .0929565429796 .61688232422 98.1408081054799 .35994720459100 .8839035034102 .712600708104 .5412979126 106.3700027466108 .1986999512110 .0273971558111 .551399231112 .7705001831 113.6848983765114 .5991973877115 .2088012695115 .818397522115 .818397522 115.5136032104114 .9039993286113 .9896011353112 .7705001831113 .9896011353 114.9039993286115 .818397522116 .7326965332117 .1407165527117 .4483337402 117.7306518555118 .105506897118 .5794525146119 .1082305908119 .6306838989 
120.092338562120 .4636077881120 .7323608398120 .8968963623120 .3900985718 117.647102356115 .818397522119 .4757995605120 .5481033325119 .4757995605 116.1231002808116 .7326965332118 .8662033081119 .5575561523119 .4066543579 119.2855377197119 .195854187119 .1377487183119 .1096038818119 .1092910767 119.1342544556119 .1829681396119 .2552719116119 .3538131714119 .4842300415 119.6564559937119 .8839569092120 .1845397949120 .5778045654121 .0853805542 120.9090042114120 .3407669067119 .7587509155119 .1613464355118 .5482788086 117.9195022583117 .274848938116 .6139373779115 .9374084473115 .2470703125 114.5460739136113 .8385772705113 .1298904419112 .4259796143111 .7526016235 111.1191177368110 .5287628174109 .9887542725109 .467201232971 .62449645996 71.3197174072370 .7101516723670 .4053573608470 .1005783081169 .79579162598 69.4910125732468 .8814392089868 .2718734741267 .3575134277366 .44316101074 65.5288009643664 .6144485473664 .3096618652364 .3096618652365 .22400665283 66.7479400634867 .9670867919968 .2718734741267 .0527267456166 .13836669922 64.9192428588966 .4431610107478 .3297805786193 .87381744385109 .1130981445 113.1883621216113 .1035690308109 .705871582103 .93338012796 .83380126953 89.4326019287182 .6503524780377 .1636962890673 .4532165527370 .10057830811 69.1862335205169 .1862335205169 .7957916259869 .7957916259869 .79579162598 69.4910125732469 .1862335205168 .8814392089868 .5766525268668 .57665252686 68.5766525268669 .1862335205169 .7957916259870 .4053573608471 .31971740723 72.2340774536173 .1484298706174 .062782287674 .6723632812575 .28192901611 75.5867080688575 .8914871215876 .1962814331176 .1962814331176 .50106811523 76.8058471679776 .8058471679777 .110626220777 .110626220777 .41542053223 77.4154205322377 .4154205322377 .110626220777 .110626220777 .1106262207 76.8058471679776 .5010681152376 .1716766357475 .8635253906275 .28192901611 74.9771423339874 .3675689697374 .062782287673 .4532165527372 .84364318848 72.2340774536171 .6244964599671 .014930725170 .7101516723670 .10057830811 69.7957916259869 .7957916259870 .1005783081171 .31971740723 -9999 -9999 -9999 -9999 -9999 -9999 -9999 -9999 -9999 -9999 -9999 -9999 -9999 -9999 -9999 -9999 -9999 -9999 -9999 -9999 -9999 -9999 -9999 -9999 -9999 -9999 -9999 -9999 -9999 -9999 -9999 -9999 -9999 -9999 -9999 -9999 -9999 -9999 -9999 -9999 -9999 -9999 -9999 -9999 -9999 -9999 -9999 -9999 -9999

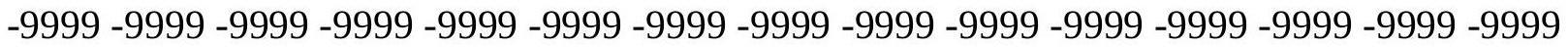
-9999-9999-9999 -9999

-9999 -9999 -9999 -9999 -9999 -9999 -9999 -9999 -9999 -9999 -9999 -9999 -9999 -9999 -9999 -9999 -9999 -9999 -9999 -9999 -9999 -9999 -9999 -9999 -9999 -9999 -9999 -9999 -9999 -9999 -

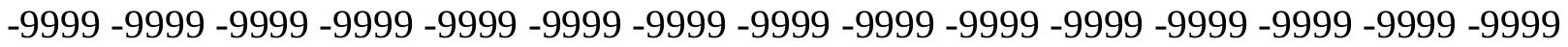

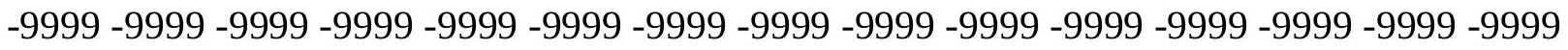

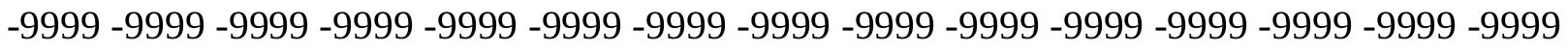
-9999 -9999 -9999 -9999 -9999 -9999 -9999 -9999 -9999 -9999 -9999 -9999 -9999 -9999 -9999 -9999 -9999 -9999 -9999 -9999 -9999 -9999 -9999 -9999 -9999 -9999 69.79579162598 71.3197174072372 .5388565063574 .062782287675 .2819290161175 .89148712158 75.8914871215875 .8914871215875 .2819290161174 .6723632812574 .0627822876 73.4532165527372 .8436431884872 .2340774536171 .9292907714871 .62449645996 71.3197174072371 .3197174072371 .3197174072371 .6244964599672 .23407745361 72.8436431884873 .7580032348674 .6723632812575 .8914871215877 .41542053223 79.2441329956180 .7680587768682 .5967712402384 .1206970214885 .64462280273 
87.1685485839888 .0829010009888 .9972534179789 .6068267822389 .91161346436 89.9116134643689 .9116134643690 .2164001464890 .8259735107491 .74033355713 91.1307525634890 .8259735107491 .1307525634891 .1307525634891 .43553924561 92.349891662692 .9594726562594 .1785964965895 .397743225196 .92166900635 98.445587158299 .96952056885101 .4934005737103 .3221969604105 .1509017944 106.979598999108 .8082962036110 .3321990967111 .8561019897113 .075302124 114.2944030762114 .9039993286115 .5136032104115 .818397522115 .5136032104 115.2088012695114 .5991973877113 .6848983765113 .075302124113 .6848983765 114.2944030762114 .5991973877115 .818397522116 .4044723511116 .6800918579 116.968711853117 .4360198975118 .0619506836118 .7390136719119 .3723526001 119.9008560181120 .2969207764120 .5595321655120 .6931762695120 .0852966309 119.7806015015120 .0852966309120 .2720031738120 .0247268677119 .7559127808 119.4806289673119 .2122573853118 .9620819092118 .7394180298118 .5507583618 118.4004364014118 .2897415161118 .2180786133118 .1823959351118 .1786880493 118.2019805908118 .2480392456118 .3138580322118 .399307251118 .5077438354 118.647354126118 .8310546875119 .0770721436119 .4068450928119 .8444366455 120.4118499756121 .0278167725120 .4946975708119 .9447860718119 .3765182495 118.7883987427118 .1788482666117 .5458602905116 .8882369995116 .2056274414 115.4991989136114 .7706451416114 .0227584839113 .2584915161112 .4853439331 111.7110595703110 .9298171997110 .1272964478109 .245246887272 .23407745361 71.014930725170 .4053573608469 .4910125732469 .1862335205168 .57665252686 68.2718734741267 .6623001098667 .0527267456166 .4431610107465 .83358764648 65.2240066528364 .9192428588964 .9192428588965 .5288009643666 .44316101074 68.2718734741269 .7957916259871 .014930725171 .3197174072369 .79579162598 64.6144485473663 .3953094482464 .6144485473676 .5010681152393 .56903076172 108.5035018921112 .8174362183113 .0152359009109 .5796661377103 .3801803589 96.2450637817489 .394668579183 .486747741778 .3281860351673 .63285827637 69.4910125732470 .4053573608470 .7101516723670 .7101516723670 .40535736084 69.7957916259869 .1862335205168 .5766525268668 .2718734741268 .27187347412 68.2718734741268 .5766525268669 .1862335205169 .7957916259870 .71015167236 71.6244964599672 .5388565063573 .4532165527374 .3675689697374 .67236328125 74.9771423339875 .2819290161175 .5867080688575 .8914871215875 .89148712158 76.1962814331176 .5010681152376 .8058471679776 .8058471679777 .1106262207 77.110626220777 .110626220777 .110626220777 .110626220776 .80584716797 76.5010681152376 .5010681152375 .8914871215875 .5867080688575 .28192901611 74.6723632812574 .3675689697373 .7580032348673 .4532165527372 .84364318848 72.2340774536171 .6244964599671 .014930725170 .7101516723670 .10057830811 69.7957916259869 .1862335205168 .8814392089870 .40535736084 -9999 -9999 -9999 -9999 -9999 -9999 -9999 -9999 -9999 -9999 -9999 -9999 -9999 -9999 -9999 -9999 -9999 -9999 -9999 -9999 -9999 -9999 -9999 -9999 -9999 -9999 -9999 -9999 -9999 -9999 -9999 -9999 -9999 -9999 -

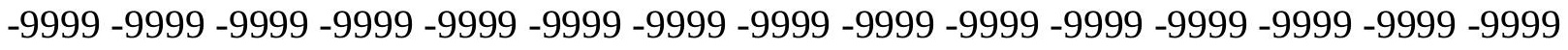
-9999 -9999 -9999 -9999 -9999 -9999 -9999 -9999 -9999 -9999 -9999 -9999 -9999 -9999 -9999 -9999 -9999-9999-9999

-9999 -9999 -9999 -9999 -9999 -9999 -9999 -9999 -9999 -9999 -9999 -9999 -9999 -9999 -9999

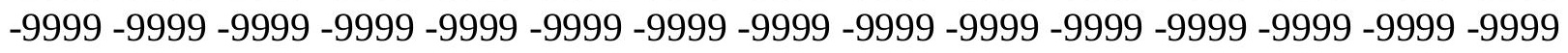

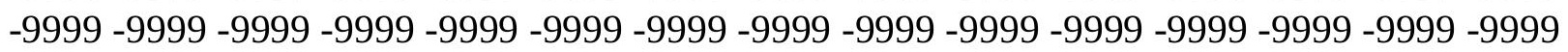


-9999 -9999 -9999 -9999 -9999 -9999 -9999 -9999 -9999 -9999 -9999 -9999 -9999 -9999 -9999 -9999 -9999 -9999 -9999 -9999 -9999 -9999 -9999 -9999 -9999 -9999 -9999 -9999 -9999 -9999 -9999 -9999 -9999 -9999 -9999 -9999 -9999 -9999 -9999 -9999 -9999 -9999 -9999 -9999 -9999 -9999 -9999 -9999 -9999 -9999 -9999 -9999 -9999 -9999 -9999 -9999 -9999 70.40535736084 71.6244964599672 .8436431884873 .7580032348674 .3675689697374 .67236328125 74.6723632812574 .062782287673 .7580032348673 .1484298706172 .53885650635 71.9292907714871 .3197174072370 .7101516723670 .4053573608470 .10057830811 70.1005783081170 .1005783081170 .4053573608470 .7101516723671 .0149307251 71.6244964599672 .8436431884874 .062782287675 .5867080688577 .1106262207 78.6345596313580 .4632720947381 .9871978759883 .8159103393685 .03504943848 86.254188537687 .4733276367288 .0829010009888 .6924667358488 .99725341797 88.9972534179788 .9972534179788 .9972534179789 .302040100189 .91161346436 90.2164001464890 .8259735107491 .1307525634891 .7403335571392 .3498916626 93.2642517089894 .4833908081195 .7025299072397 .2264633178798 .75038146973 100.2742996216102 .1029968262103 .9317016602105 .4557037354107 .2844009399 109.1130981445110 .6370010376112 .1608963013113 .3800964355114 .2944030762 115.2088012695115 .5136032104115 .818397522115 .5136032104115 .2088012695 114.5991973877113 .6848983765113 .3800964355113 .3800964355113 .6848983765 113.9896011353114 .5991973877115 .5136032104115 .60987854115 .9373626709 116.6390914917117 .5556716919118 .4650726318119 .2362594604119 .82006073 120.2130661011120 .3900985718119 .7806015015119 .7806015015120 .3013305664 120.0620117188118 .2565994263114 .9039993286118 .8662033081118 .7264785767 118.3861846924118 .0718078613117 .7938766479117 .5597457886117 .3742752075 117.2387084961117 .151802063117 .1091308594117 .1046066284117 .1305389404 117.1794509888117 .2448043823117 .322807312117 .4135131836117 .5224075317 117.6608200073117 .8468170166118 .1033782959118 .4573974609118 .9337844849 119.5589141846120 .3670654297120 .7012634277120 .1806564331119 .6357040405 119.0631942749118 .4593963623117 .8211746216117 .1457061768116 .4315643311 115.6775817871114 .883682251114 .0502166748113 .1748657227112 .2592391968 111.2942047119110 .2602767944108 .508766174371 .9292907714870 .40535736084 69.4910125732468 .5766525268667 .9670867919967 .3575134277366 .74794006348 66.4431610107465 .8335876464865 .2240066528364 .9192428588964 .61444854736 64.6144485473665 .2240066528366 .1383666992267 .3575134277369 .18623352051 71.3197174072373 .1484298706175 .2819290161177 .110626220770 .10057830811 65.8335876464864 .6144485473665 .8335876464872 .5388565063588 .69246673584 105.1509017944111 .5557556152111 .2200622559107 .1259841919101 .1027755737 95.40122222990 .0841140747184 .8431625366279 .8111343383875 .83493041992 74.062782287672 .2340774536171 .9292907714871 .3197174072370 .40535736084 69.7957916259868 .8814392089868 .2718734741267 .9670867919967 .96708679199 68.2718734741268 .5766525268669 .4910125732470 .4053573608471 .31971740723 72.2340774536173 .1484298706173 .7580032348674 .3675689697374 .67236328125 74.6723632812574 .9771423339875 .2819290161175 .5867080688575 .89148712158 76.1962814331176 .5010681152376 .8058471679776 .8058471679776 .80584716797 77.110626220777 .110626220776 .8058471679776 .8058471679776 .50106811523 76.1962814331175 .8914871215875 .5867080688575 .1732559204174 .67236328125 74.3675689697373 .7580032348673 .1484298706172 .8436431884872 .23407745361 
71.6244964599671 .014930725170 .7101516723670 .1005783081169 .49101257324 68.8814392089869 .7957916259869 .1862335205170 .71015167236 -9999 -9999 -9999 -9999 -9999 -9999 -9999 -9999 -9999 -9999 -9999 -9999 -9999 -9999 -9999 -9999 -9999 -9999 -9999 -9999 -9999 -9999 -9999 -9999 -9999 -9999 -9999 -9999 -9999 -9999 -9999 -9999 -9999 -9999 -9999 -9999 -9999 -9999 -9999 -9999 -9999 -9999 -9999-9999 -9999 -9999 -9999 -9999 -9999 -

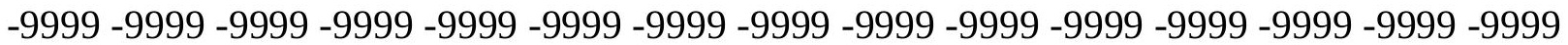
-9999 -9999 -9999

-9999 -9999 -9999 -9999 -9999 -9999 -9999 -9999 -9999 -9999 -9999 -9999 -9999 -9999 -9999 -9999 -9999 -9999 -9999 -9999 -9999 -9999 -9999 -9999 -9999 -9999 -9999 -9999 -9999 -9999 -9999 -9999 -9999 -9999 -9999 -9999 -9999 -9999 -9999 -9999 -9999 -9999 -9999 -9999 -9999 -

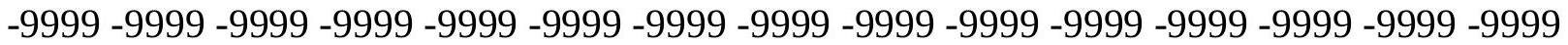
-9999 -9999 -9999 -9999 -9999 -9999 -9999 -9999 -9999 -9999 -9999 -9999 -9999 -9999 -9999 -

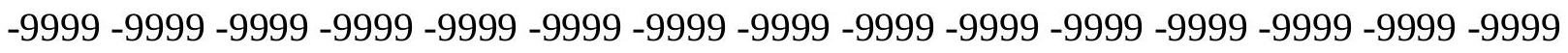
-9999 -9999 -9999 -9999 -9999 -9999 -9999 -9999 -9999 -9999 -9999 -9999 69.49101257324 70.7101516723671 .6244964599672 .5388565063573 .1484298706173 .45321655273 73.1484298706173 .1484298706172 .5388565063571 .9292907714871 .31971740723 70.7101516723670 .1005783081169 .4910125732469 .1862335205168 .88143920898 68.5766525268668 .5766525268668 .8814392089868 .8814392089869 .18623352051 69.7957916259870 .7101516723671 .9292907714873 .4532165527374 .97714233398 76.8058471679778 .6345596313580 .1584930419981 .6824111938583 .2063369751 84.4254837036185 .6446228027386 .5589828491287 .1685485839887 .47332763672 87.7781066894587 .4733276367287 .1685485839886 .254188537688 .08290100098 89.302040100190 .2164001464890 .8259735107491 .4355392456192 .04509735107 92.9594726562594 .1785964965895 .7025299072397 .2264633178798 .75038146973 100.5791015625102 .1029968262103 .9317016602105 .7603988647107 .5891036987 109.4179000854110 .9418029785112 .1608963013113 .3800964355114 .2944030762 115.2088012695115 .5136032104115 .5136032104115 .5136032104115 .2088012695 114.5991973877113 .9896011353113 .6848983765113 .3800964355113 .3800964355 113.3800964355114 .5991973877113 .9896011353114 .0012207031114 .6590499878 115.8754882812117 .2267990112118 .2565994263118 .8662033081119 .1709976196 119.4757995605119 .4757995605119 .1709976196119 .4757995605119 .927482605 119.5911407471118 .5614013672116 .4279022217118 .3089675903117 .8651885986 117.4418029785117 .0529403687116 .7106781006116 .4235916138116 .1975860596 116.0341949463115 .9319152832115 .8849487305115 .8851547241115 .9217376709 115.983543396116 .059715271116 .1418762207116 .2256317139116 .3124313354 116.4109115601116 .5378799438116 .7178344727116 .983039856117 .3583755493 117.8840484619118 .6111907959119 .5668792725120 .7460021973120 .4558868408 119.9241027832119 .3528213501118 .7370605469118 .0715789795117 .3520355225 116.5738754272115 .73387146114 .8295593262113 .8610534668106 .6747970581 109.4179000854110 .5035324097109 .207710266170 .7101516723669 .18623352051 68.2718734741267 .3575134277366 .4431610107466 .1383666992265 .52880096436 65.2240066528364 .6144485473664 .3096618652364 .3096618652364 .0048828125 64.3096618652364 .9192428588966 .1383666992267 .3575134277369 .49101257324 71.6244964599673 .7580032348675 .5867080688575 .2819290161171 .92929077148 67.9670867919965 .5288009643664 .3096618652365 .8335876464865 .52880096436 84.73026275635105 .4557037354107 .8415145874105 .8908233643102 .2983398438 
99.5382385253996 .2286300659292 .1652526855587 .1255493164182 .19989776611 78.1140441894575 .2819290161174 .6723632812571 .9292907714871 .0149307251 70.1005783081169 .4910125732468 .8814392089868 .5766525268668 .27187347412 68.2718734741268 .8814392089869 .4910125732470 .4053573608471 .31971740723 72.2340774536172 .8436431884873 .4532165527373 .7580032348674 .0627822876 74.3675689697374 .6723632812574 .9771423339875 .2819290161175 .58670806885 75.8914871215876 .5010681152376 .5010681152376 .8058471679776 .80584716797 77.110626220777 .110626220776 .8058471679776 .8058471679776 .50106811523 76.1962814331175 .8914871215875 .5867080688574 .9771423339874 .67236328125 74.062782287673 .7580032348673 .1484298706172 .5388565063572 .23407745361 71.6244964599671 .014930725170 .7101516723670 .1005783081169 .49101257324 68.8814392089868 .2718734741268 .5766525268669 .79579162598 -9999 -9999 -9999 -9999 -9999 -9999 -9999 -9999 -9999 -9999 -9999 -9999 -9999 -9999 -9999 -9999 -9999 -9999 -9999 -9999 -9999 -9999 -9999 -9999 -9999 -9999 -9999 -9999 -9999 -9999 -9999 -9999 -9999 -9999 -9999 -9999 -9999 -9999 -9999 -9999 -9999 -9999 -9999 -9999 -9999 -9999 -9999 -9999 -9999

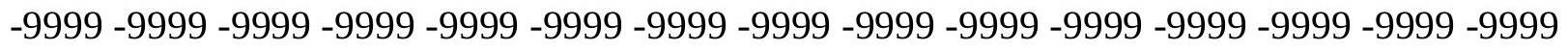
-9999 -9999-9999

-9999 -9999 -9999 -9999 -9999 -9999 -9999 -9999 -9999 -9999 -9999 -9999 -9999 -9999 -9999 -9999 -9999 -9999 -9999 -9999 -9999 -9999 -9999 -9999 -9999 -9999 -9999 -9999 -9999 -9999 -

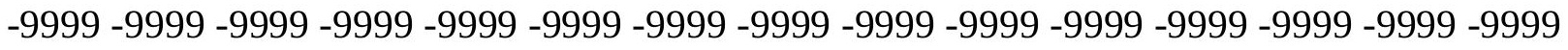

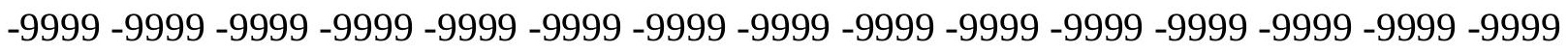
-9999 -9999 -9999 -9999 -9999 -9999 -9999 -9999 -9999 -9999 -9999 -9999 -9999 -9999 -9999 -9999 -9999 -9999 -9999 -9999 -9999 -9999 -9999 -9999 -9999 -9999 -9999 -9999 -9999 -9999 -9999 -9999 -9999 -9999 -9999 -9999 -9999 -9999 -9999 -9999 -9999 -9999 -9999 69.49101257324 70.7101516723671.31971740723 71.9292907714871 .92929077148 71.9292907714871 .6244964599671 .3197174072371 .014930725170 .40535736084 69.4910125732468 .8814392089868 .2718734741267 .9670867919967 .35751342773 67.0527267456166 .7479400634866 .7479400634866 .7479400634867 .05272674561 67.6623001098668 .5766525268670 .1005783081171 .6244964599673 .14842987061 74.9771423339876 .5010681152378 .3297805786179 .8537063598681 .37763214111 82.5967712402383 .8159103393684 .7302627563585 .6446228027386 .2541885376 86.5589828491286 .5589828491286 .254188537686 .5589828491287 .47332763672 88.6924667358489 .6068267822390 .2164001464890 .8259735107491 .43553924561 92.6546783447393 .8738174438595 .397743225197 .2264633178798 .75038146973 100.5791015625102 .4077987671104 .2365036011106 .0652008057107 .8938980103 109.4179000854110 .9418029785112 .1608963013113 .3800964355114 .2944030762 114.9039993286115 .2088012695115 .5136032104115 .5136032104115 .2088012695 114.5991973877114 .2944030762113 .6848983765113 .3800964355113 .075302124 112.4656982422112 .1608963013112 .1608963013112 .1259078979113 .4616241455 114.5991973877115 .5136032104116 .1231002808117 .0374984741117 .9517974854 117.9517974854118 .2565994263118 .5614013672118 .8662033081119 .1709976196 119.050163269118 .5336303711117 .9875793457117 .4328460693116 .8883209229 116.371673584115 .8986740112115 .4833984375115 .1363296509114 .8650512695 114.6720504761114 .5559005737114 .5097427368114 .5233154297114 .5826263428 114.6722946167114 .7764968872114 .8812866211114 .9765930176115 .0583496094 115.1307907104115 .2081832886115 .3167648315115 .4819717407115 .7482757568 
116.1677093506116 .814491272117 .7241363525118 .8762359619120 .2141647339 120.7564544678120 .2231292725119 .6356506348118 .986618042118 .2689971924 117.4747085571116 .5969161987115 .6293945312114 .5714569092113 .4144592285 108.5035018921110 .8296737671109 .482025146568 .5766525268667 .66230010986 66.4431610107465 .8335876464865 .2240066528364 .6144485473664 .30966186523 64.004882812563 .7000885009863 .3953094482463 .3953094482463 .39530944824 63.7000885009864 .3096618652365 .5288009643666 .7479400634868 .57665252686 70.4053573608472 .2340774536173 .4532165527372 .8436431884871 .0149307251 68.2718734741265 .8335876464864 .6144485473664 .6144485473667 .66230010986 70.4053573608481 .68241119385100 .274299621697 .3312149047998 .77741241455 100.6224746704101 .229736328199 .2284545898493 .883377075287 .5406036377 81.8812026977577 .9668731689575 .5867080688572 .5388565063571 .31971740723 70.4053573608470 .1005783081169 .7957916259869 .7957916259869 .49101257324 69.1862335205169 .1862335205169 .7957916259870 .7101516723671 .62449645996 72.2340774536172 .8436431884873 .1484298706173 .4532165527373 .75800323486 74.062782287674 .3675689697374 .6723632812575 .2819290161175 .58670806885 76.1962814331176 .5010681152376 .8058471679776 .8058471679777 .1106262207 77.110626220777 .110626220777 .110626220776 .8058471679776 .50106811523 76.1962814331175 .8914871215875 .5867080688574 .9771423339874 .67236328125 74.062782287673 .6311492919973 .1484298706172 .5388565063572 .23407745361 71.6244964599671 .014930725170 .7101516723670 .1005783081169 .49101257324 69.1862335205168 .5766525268668 .2718734741268 .88143920898 -9999 -9999 -9999 -9999 -9999 -9999 -9999 -9999 -9999 -9999 -9999 -9999 -9999 -9999 -9999 -9999 -9999 -9999 -9999 -9999 -9999 -9999 -9999 -9999 -9999 -9999 -9999 -9999 -9999 -9999 -9999 -9999 -9999 -9999 -9999 -9999 -9999 -9999 -9999 -9999 -9999 -9999 -9999 -9999 -9999 -9999 -9999 -9999 -9999

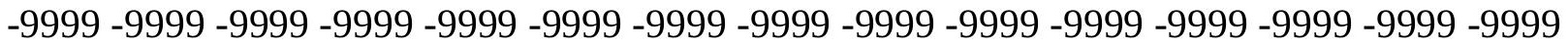
-9999 -9999 -9999

-9999 -9999 -9999 -9999 -9999 -9999 -9999 -9999 -9999 -9999 -9999 -9999 -9999 -9999 -999 -9999 -9999 -9999 -9999 -9999 -9999 -9999 -9999 -9999 -9999 -9999 -9999 -9999 -9999 -9999 -9999 -9999 -9999 -9999 -9999 -9999 -9999 -9999 -9999 -9999 -9999 -9999 -9999 -9999 -9999 -9999 -9999 -9999 -9999 -9999 -9999 -9999 -9999 -9999 -9999 -9999 -9999 -9999 -9999 -9999

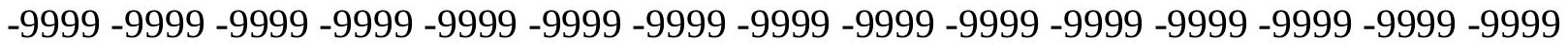

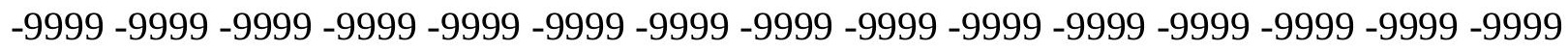
-9999 -9999 -9999 -9999 -9999 -9999 -9999 -9999 -9999 -9999 -9999 -9999 -9999 -9999 69.4910125732470 .1005783081170 .4053573608470 .7101516723670 .71015167236 70.4053573608470 .1005783081169 .7957916259869 .1862335205168 .57665252686 67.9670867919967 .3575134277366 .7479400634866 .1383666992265 .52880096436 64.9192428588964 .6144485473664 .6144485473664 .9192428588965 .52880096436 66.7479400634868 .2718734741269 .7957916259871 .3197174072373 .14842987061 74.6723632812576 .5010681152378 .0249862670979 .5489196777380 .76805877686 81.98719787598 83.2063369751 84.12069702148 85.03504943848 85.64462280273 85.9494018554786 .254188537686 .5589828491287 .4733276367288 .38768768311 89.3020401001 89.9116134643690.5211791992291.1307525634892.04509735107 93.5690307617295 .0929565429796 .9216690063598 .4455871582100 .2742996216 102.4077987671104 .2365036011106 .0652008057107 .5891036987109 .4179000854 110.9418029785112 .1608963013113 .3800964355113 .9896011353114 .9039993286 
115.2088012695115 .2088012695115 .2088012695114 .9039993286114 .5991973877 114.2944030762113 .6848983765113 .3800964355112 .7705001831112 .1608963013 111.551399231110 .3321990967110 .3321990967111 .24659729112 .1608963013 113.075302124113 .9896011353117 .647102356119 .4757995605117 .647102356 116.1231002808116 .7326965332117 .0374984741117 .342300415117 .647102356 117.647102356117 .110710144116 .4422607422115 .7889862061115 .1692352295 114.6030349731114 .1058807373113 .6929092407113 .3706817627113 .1496582031 113.0198974609112 .9850006104113 .0238800049113 .1220779419113 .2598190308 113.4155807495113 .5691375732113 .7035064697113 .807434082113 .8787002563 113.924697876113 .9741973877114 .0394363403114 .18334198114 .479888916 115.0411224365115 .9179229736117 .0689086914118 .3647842407119 .7213821411 120.968536377120 .5141601562119 .8913879395119 .1875118 .3914108276117 .4925079346 116.4799346924115 .3486785889107 .8938980103108 .5035018921110 .0273971558 109.727539062566 .7479400634865 .8335876464864 .9192428588964 .0048828125 63.7000885009863 .0905189514262 .7857398986862 .7857398986862 .48094940186 62.4809494018662 .1761703491262 .4809494018662 .7857398986863 .39530944824 64.3096618652365 .2240066528366 .7479400634868 .2718734741269 .49101257324 70.4053573608470 .1005783081168 .8814392089867 .3575134277365 .83358764648 65.2240066528365 .8335876464868 .5766525268673 .1484298706178 .93934631348 81.3776321411178 .0249862670991 .4355392456197 .04627227783105 .167678833 104.949989318898 .7448196411190 .8082351684683 .7840881347778 .63139343262 74.9732894897572 .2871017456170 .4053573608470 .1005783081171 .0149307251 71.6244964599671 .9292907714871 .6244964599670 .7101516723670 .40535736084 70.7101516723671 .6244964599672 .2340774536172 .8436431884873 .14842987061 73.1484298706173 .4532165527373 .4532165527373 .7580032348674 .36756896973 74.6723632812575 .2819290161175 .8914871215876 .1962814331176 .80584716797 77.110626220777 .110626220777 .4154205322377 .4154205322377 .41542053223 77.110626220776 .8058471679776 .8058471679776 .1962814331175 .89148712158 75.5867080688574 .9771423339874 .6723632812574 .062782287673 .45321655273 73.1308746337972 .5388565063572 .2340774536171 .6244964599671 .0149307251 70.7101516723670 .1005783081169 .7957916259869 .1862335205168 .88143920898 68.5766525268668 .5766525268669 .49101257324 -9999 -9999 -9999 -9999 -9999 -9999 -9999 -9999 -9999 -9999 -9999 -9999 -9999 -9999 -9999 -9999 -9999 -9999 -9999 -9999 -9999 -9999 -

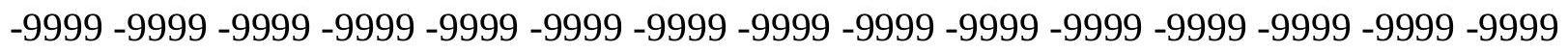
-9999 -9999 -9999 -9999 -9999 -9999 -9999 -9999 -9999 -9999 -9999 -9999 -9999 -9999 -9999 -9999 -9999 -9999 -9999 -9999 -9999 -9999 -9999 -9999 -9999 -9999 -9999 -9999 -9999 -

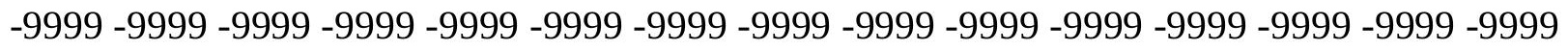

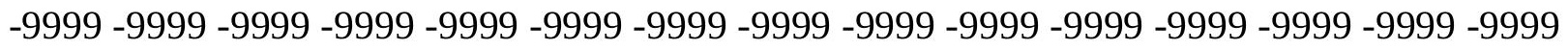

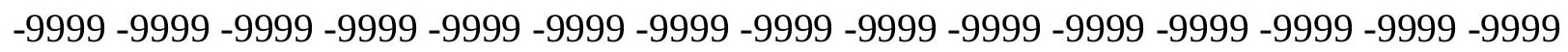
-9999 -9999 -9999 -9999 -9999 -9999 -9999 -9999 -9999 -9999 -9999 -9999 -9999 -9999 -9999 -

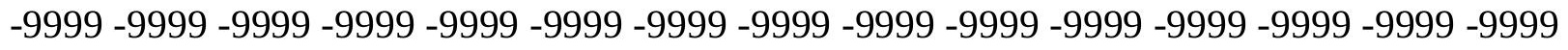

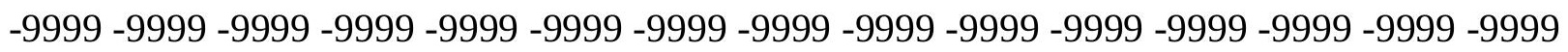
-9999 -9999 -9999 -9999 -9999 -9999 -9999 -9999 -9999 -9999 -9999 -9999 -9999 -9999 68.2718734741268 .8814392089869 .1862335205169 .4910125732469 .49101257324 69.4910125732469 .1862335205168 .5766525268668 .2718734741267 .66230010986 67.0527267456166 .4431610107465 .8335876464864 .9192428588964 .0048828125 
63.3953094482462 .7857398986862 .4809494018662 .7857398986863 .70008850098 65.2240066528366 .4431610107468 .2718734741269 .7957916259871 .62449645996 73.1484298706174 .6723632812576 .1962814331177 .7202072143678 .93934631348 80.4632720947381 .6824111938582 .9015579223684 .1206970214885 .03504943848 85.64462280273 86.2541885376 86.86376190186 87.47332763672 88.38768768311 88.9972534179789 .6068267822390 .2164001464890 .8259735107492 .04509735107 93.2642517089894 .7881774902396 .6168823242298 .4455871582100 .2742996216 102.1029968262103 .9317016602105 .7603988647107 .5891036987109 .1130981445 110.6370010376111 .8561019897113 .075302124113 .9896011353114 .5991973877 114.9039993286115 .2088012695115 .2088012695114 .9039993286114 .5991973877 114.2944030762113 .9896011353113 .3800964355112 .7705001831112 .1608963013 111.8561019897111 .551399231111 .8561019897114 .5991973877117 .3522186279 119.2229003906 119.7806015015120.6949005127 121.095451355 119.4757995605 114.9039993286114 .2944030762114 .9039993286115 .2088012695115 .5136032104 115.818397522116 .1145172119115 .3268280029114 .5591964722113 .8276672363 113.1585617065112 .5751342773112 .0876159668111 .7160720825111 .4651260376 111.334236145111 .3147583008111 .3932647705111 .5506820679111 .7617034912 111.9981460571112 .2375717163112 .4501037598112 .6237335205112 .7349624634 112.7911605835112 .7936477661112 .7679367065112 .7708587646112 .9071044922 113.3562011719114 .2053375244115 .397354126116 .6376037598117 .8437042236 118.821472168119 .4667358398120 .0398101807120 .107170105119 .328086853 118.2565994263114 .5991973877110 .6370010376106 .979598999108 .8082962036 110.0273971558110 .104759216364 .6144485473663 .7000885009863 .09051895142 62.4809494018661 .8713798522961 .8713798522961 .5666007995661 .26181030273 61.2618103027361 .2618103027361 .2618103027361 .2618103027361 .56660079956 61.8713798522962 .4809494018663 .3953094482464 .3096618652365 .52880096436 66.4431610107467 .3575134277367 .3575134277366 .7479400634865 .83358764648 65.2240066528365 .5288009643667 .0527267456169 .7957916259873 .75800323486 76.5010681152374 .9771423339872 .8436431884866 .1383666992286 .86376190186 110.3321990967107 .012275695899 .7024765014691 .0567016601683 .3182220459 77.6845092773474 .0824584960972 .0016021728570 .6295928955169 .79579162598 72.5388565063574 .062782287674 .9771423339874 .6723632812573 .75800323486 72.2340774536172 .8436431884873 .7580032348674 .062782287674 .0627822876 73.7580032348673 .7580032348673 .4532165527373 .4532165527373 .75800323486 74.3675689697374 .9771423339875 .5867080688576 .1962814331176 .80584716797 77.1106262207 77.41542053223 77.72020721436 77.72020721436 77.72020721436 77.7202072143677 .4154205322377 .110626220776 .8058471679776 .50106811523 75.8914871215875 .5867080688574 .9771423339874 .6723632812574 .0627822876 73.4532165527373 .1484298706172 .5388565063571 .9292907714871 .62449645996 71.014930725170 .7101516723670 .1005783081169 .7957916259869 .49101257324 69.1862335205168 .8814392089868 .2718734741269 .18623352051 -9999 -9999 -9999 -9999 -9999 -9999 -9999 -9999 -9999 -9999 -9999 -9999 -9999 -9999 -9999 -9999 -9999 -9999 -

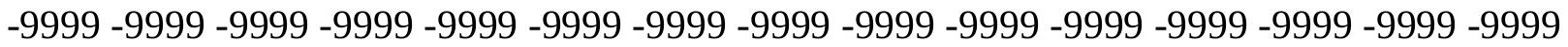
-9999 -

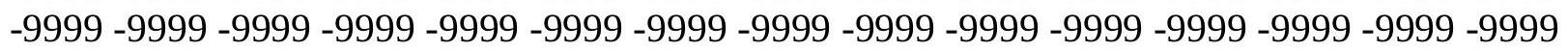
$-9999-9999$ 
-9999 -9999 -9999 -9999 -9999 -9999 -9999 -9999 -9999 -9999 -9999 -9999 -9999 -9999 -9999 -9999 -9999 -9999 -9999 -9999 -9999 -9999 -9999 -9999 -9999 -9999 -9999 -9999 -9999 -9999 -

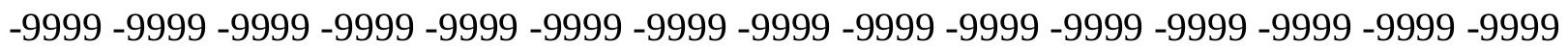
-9999 -9999 -9999 -9999 -9999 -9999 -9999 -9999 -9999 -9999 -9999 -9999 -9999 -9999 -9999

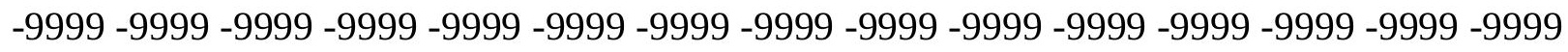
-9999 -9999 -9999 -9999 -9999 -9999 -9999 -9999 -9999 -9999 -9999 -9999 -9999 -9999 -9999 -9999 -9999 -9999 -9999 -9999 -9999 -9999 -9999 -9999 -9999 -9999 -9999 -9999 -9999 -9999 67.9670867919968 .2718734741268 .2718734741268 .2718734741268 .27187347412 67.9670867919967 .6623001098667 .0527267456166 .7479400634866 .13836669922 65.5288009643664 .9192428588964 .004882812563 .0905189514262 .17617034912 61.2618103027360 .6522407531761 .2618103027362 .4809494018664 .0048828125 65.5288009643667 .0527267456168 .5766525268670 .1005783081171 .62449645996 73.1484298706174 .6723632812575 .8914871215877 .4154205322378 .93934631348 80.4632720947381 .6824111938583 .206336975184 .1206970214885 .33984375 86.254188537686 .8637619018687 .7781066894588 .3876876831188 .99725341797 89.302040100189 .9116134643690 .8259735107491 .7403335571392 .95947265625 94.4833908081196 .3121032714898 .1408081054799 .96952056885102 .1029968262 103.9317016602105 .7603988647107 .5891036987109 .1130981445110 .6370010376 111.8561019897112 .7705001831113 .6848983765114 .2944030762114 .9039993286 114.9039993286114 .9039993286114 .9039993286114 .5991973877114 .2944030762 113.9896011353113 .6848983765113 .075302124112 .7705001831112 .7705001831 113.3800964355114 .5991973877116 .7326965332119 .1709976196120 .3661956787 121.1445007324121 .516418457121 .4615249634121 .0485992432118 .8662033081 117.647102356116 .1231002808115 .2088012695114 .9039993286114 .5991973877 114.5991973877114 .0823059082113 .1909942627112 .3416061401111 .5659179688 110.885269165110 .3283615112109 .9100799561109 .640586853109 .5196533203 109.5330657959109 .6725006104109 .9172668457110 .2320327759110 .5849990845 110.9517822266111 .2945175171111 .5812759399111 .7901000977111 .8963012695 111.9002914429111 .7953262329111 .6435928345111 .5874252319111 .8575134277 112.664855957113 .9056930542115 .2298126221115 .8305435181116 .7326965332 116.7326965332116 .7326965332116 .1231002808114 .2944030762114 .9039993286 115.818397522114 .9039993286112 .7705001831111 .8561019897111 .551399231 110.858306884862 .7857398986861 .8713798522961 .2618103027360 .65224075317 60.3474502563560 .3474502563560 .0426712036160 .0426712036160 .04267120361 60.0426712036160 .0426712036160 .0426712036160 .3474502563560 .65224075317 60.6522407531760 .9570198059161 .5666007995662 .4809494018663 .70008850098 64.3096618652364 .9192428588964 .6144485473664 .6144485473664 .61444854736 65.5288009643667 .0527267456169 .7957916259872 .5388565063573 .75800323486 73.1484298706171 .6244964599673 .1484298706181 .3776321411193 .87381744385 103.322196960497 .4250717163188 .5656204223680 .9818496704175 .85736846924 73.4461135864372 .5564727783272 .604354858473 .9549560546976 .80584716797 77.110626220778 .9393463134879 .2441329956178 .3297805786177 .1106262207 76.8058471679776 .8058471679776 .5010681152375 .8914871215874 .97714233398 74.3675689697374 .062782287673 .7580032348674 .3675689697374 .97714233398 75.5867080688576 .1962814331176 .8058471679777 .4154205322377 .72020721436 78.0249862670978 .3297805786178 .3297805786178 .0249862670978 .02498626709 
77.7202072143677 .4154205322377 .110626220776 .5010681152376 .19628143311 75.5867080688574 .9771423339874 .6723632812574 .062782287673 .45321655273 72.8436431884872 .5388565063571 .9292907714871 .6244964599671 .0149307251 70.7101516723670 .4053573608469 .7957916259869 .4910125732469 .18623352051 68.8814392089868 .5766525268668 .88143920898 -9999 -9999 -9999 -9999 -9999 -9999 -9999 -9999 -9999 -9999 -9999 -9999 -9999 -9999 -9999 -9999 -9999 -9999 -9999 -9999 -9999 -9999 -9999 -9999 -9999 -9999 -9999 -9999 -9999 -9999 -9999 -9999 -9999 -9999 -9999 -9999 -9999 -9999 -9999 -9999 -9999 -9999 -9999 -9999 -9999 -9999 -9999 -9999 -9999 -9999 -999 -999 -9999 -9999 -9999 -9999 -9999 -9999 -9999 -9999 -9999 -9999 -9999 -9999 -9999 -9999 -9999 -9999 -9999 -9999 -9999 -9999 -9999 -9999 -9999 -9999 -9999 -9999 -9999 -9999 -9999 -9999 -9999 -9999 -9999 -9999 -9999 -9999 -9999 -9999 -9999 -9999 -9999 -9999 -9999 -9999 -9999 -9999 -9999 -9999 -9999 -9999 -9999 -9999 -9999 -9999 -9999 -9999 -9999 -9999 -9999 -9999 -9999 -9999 -9999 -9999 -9999 -9999 -9999 -9999 -9999 -9999 -9999 -9999 -9999 -9999 -9999 -9999 -9999 -9999 -9999 -9999 -9999 -9999 -9999 -9999 -9999 -9999 -9999 -9999 -9999 -9999 -9999 -9999 -9999 -9999 -9999 -9999 -9999 -9999 -9999 -9999 -9999 -9999 -9999 -9999 -9999 -9999 -9999 -9999 -9999 -9999 -9999 -9999 -9999 -9999 -9999 -9999 -9999 -9999 -9999 -9999 67.05272674561 67.35751342773 67.35751342773 67.0527267456167.05272674561 66.7479400634866 .1383666992265 .8335876464865 .5288009643664 .91924285889 64.3096618652363 .3953094482462 .4809494018661 .5666007995660 .65224075317 59.7378807067960 .6522407531762 .1761703491263 .3953094482464 .91924285889 66.4431610107467 .6623001098669 .1862335205170 .7101516723671 .92929077148 73.1484298706174 .6723632812575 .8914871215877 .4154205322378 .93934631348 80.7680587768682 .2919769287183 .5111236572384 .7302627563585 .94940185547 86.8637619018687 .4733276367288 .0829010009888 .6924667358488 .99725341797 89.6068267822390 .5211791992291 .4355392456192 .9594726562594 .48339080811 96.0073165893697 .8360290527399 .96952056885101 .7982025146103 .6268997192 105.4557037354107 .2844009399108 .8082962036110 .3321990967111 .551399231 112.7705001831113 .3800964355113 .9896011353114 .5991973877114 .9039993286 114.9039993286114 .9039993286114 .5991973877114 .5991973877114 .2944030762 113.9896011353113 .6848983765113 .6848983765113 .9896011353114 .9039993286 116.4279022217117 .9517974854118 .8662033081120 .6949005127121 .2812957764 121.6194229126121 .4623413086120 .899017334120 .0308761597119 .00365448 117.9148101807116 .8290405273115 .7726898193114 .7594146729113 .7390594482 112.7164764404111 .7052230835110 .7344818115109 .8413696289109 .0625610352 108.4315490723107 .9716873169107 .695526123107 .6026763916107 .6814804077 107.9133300781108 .2714920044108 .7225494385109 .232460022109 .7664794922 110.2855148315110 .747543335111 .1125259399111 .3413848877111 .4044647217 111.2892456055111 .0359802246110 .7806167603110 .7835388184111 .3972854614 112.6264038086114 .5991973877113 .6848983765113 .3800964355113 .6848983765 115.2088012695116 .1231002808117 .0374984741117 .9517974854119 .4624252319 118.3397674561117 .0302581787115 .2088012695113 .8582611084112 .1329116821 60.6522407531760 .3474502563559 .7378807067959 .4331016540559 .12831115723 58.8235282897958 .8235282897958 .8235282897958 .8235282897958 .82352828979 58.8235282897958 .8235282897958 .8235282897958 .8235282897958 .82352828979 58.8235282897959 .1283111572360 .0426712036161 .2618103027362 .17617034912 62.7857398986863 .0905189514263 .3953094482464 .004882812564 .91924285889 
66.7479400634868 .8814392089871 .014930725172 .5388565063573 .14842987061 74.6723632812578 .6345596313585 .6446228027393 .5690307617296 .31210327148 92.6546783447385 .3398437578 .3486404418974 .5343704223674 .25314331055 73.8865509033275 .1120834350677 .6332778930780 .2349243164181 .90051269531 83.2063369751 84.12069702148 83.51112365723 82.29197692871 81.37763214111 80.4632720947379 .5489196777378 .3297805786176 .8058471679775 .58670806885 74.6723632812574 .6723632812574 .9771423339875 .5867080688576 .50106811523 77.4154205322378 .0249862670978 .3297805786178 .6345596313578 .93934631348 78.9393463134878 .9393463134878 .6345596313578 .3297805786178 .02498626709 77.7202072143677 .4154205322376 .8058471679776 .1962814331175 .58670806885 75.2819290161174 .6723632812574 .062782287673 .4532165527372 .84364318848 72.5388565063571 .9292907714871 .6244964599671 .014930725170 .71015167236 70.4053573608470 .1005783081169 .4910125732469 .1862335205168 .88143920898 68.5766525268668 .5766525268669 .18623352051 -9999 -9999 -9999 -9999 -9999 -9999 -9999 -9999 -9999 -9999 -9999 -9999 -9999 -9999 -9999 -9999 -9999 -9999 -9999 -9999 -9999 -9999

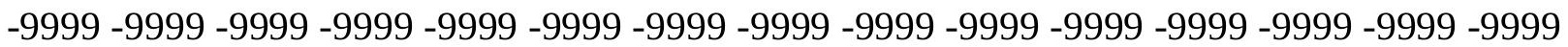

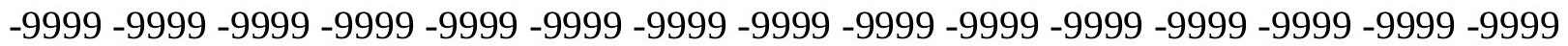
-9999 -9999 -9999 -9999 -9999 -9999 -9999 -9999 -9999 -9999 -9999 -9999 -9999 -9999 -9999 -9999 -9999 -9999 -9999 -9999 -9999 -9999 -9999 -9999 -9999 -9999 -9999 -9999 -9999 -9999 -9999 -9999 -9999 -9999 -9999 -9999 -9999 -9999 -9999 -9999 -9999 -9999 -9999

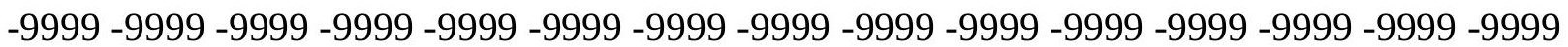
-9999 -9999 -9999 -9999 -9999 -9999 -9999 -9999 -9999 -9999 -9999 -9999 -9999 -9999 -9999 -9999 -9999 -9999 -9999 -9999 -9999 -9999 -9999 -9999 -9999 -9999 -9999 -9999 -9999 -9999 -9999 -9999 -9999 -9999 -9999 -9999 -9999 -9999 -9999 -9999 -9999 -9999 -9999 -9999 -9999 -9999 -9999 -9999 -9999 -9999 -9999 -9999 -9999 -9999 -9999 -9999 -9999 -9999 -9999 -9999 -999966.13836669922 66.13836669922 66.1383666992266.1383666992265.83358764648 65.8335876464865 .5288009643665 .2240066528364 .9192428588964 .30966186523 64.004882812563 .3953094482462 .7857398986861 .8713798522961 .26181030273 60.9570198059161 .5666007995662 .4809494018663 .7000885009864 .91924285889 66.1383666992267 .3575134277368 .5766525268669 .7957916259871 .0149307251 72.2340774536173 .4532165527374 .6723632812576 .1962814331178 .02498626709 79.5489196777381 .0728530883882 .5967712402384 .1206970214885 .33984375 86.254188537686 .8637619018687 .4733276367288 .0829010009888 .38768768311 89.302040100190.2164001464891.1307525634892.6546783447394.17859649658 96.0073165893697 .8360290527399 .66472625732101 .4934005737103 .6268997192 105.4557037354106 .979598999108 .8082962036110 .0273971558111 .24659729 112.4656982422113 .3800964355113 .9896011353114 .2944030762114 .5991973877 114.5991973877114 .9039993286114 .5991973877114 .5991973877114 .5991973877 114.2944030762114 .2944030762114 .5991973877115 .2088012695116 .1231002808 117.0374984741118 .2565994263118 .5614013672118 .8662033081120 .3900985718 120.9997024536120 .8525466919120 .2430343628119 .2739715576118 .1173477173 116.8982162476115 .7174377441114 .5951919556113 .5066604614112 .4114837646 111.293762207110 .1681594849109 .0712509155108 .0519638062107 .1617126465 106.4453353882105 .9358520508105 .6503219604105 .5892333984105 .7385406494 106.0731811523106 .5620193481107 .1720275879107 .8694000244108 .616645813 109.3694839478110 .0754241943110 .6774673462111 .1209487915111 .3605880737 
111.3738327026111 .1726303101110 .8313598633110 .6073532104111 .1775512695 112.7705001831111 .24659729112 .1608963013115 .818397522117 .647102356 118.5614013672119 .1709976196119 .7806015015120 .3900985718120 .5445175171 119.5252685547118 .3303604126116 .9564285278115 .4211044312113 .7745513916 61.8713798522960 .6522407531759 .7378807067957 .909179687557 .60438919067 57.6043891906757 .6043891906757 .2995986938557 .2995986938557 .29959869385 57.2995986938557 .2995986938557 .6043891906757 .6043891906757 .29959869385 57.6043891906757 .6043891906758 .5187492370659 .4331016540560 .34745025635 60.9570198059161 .5666007995662 .1761703491263 .0905189514264 .30966186523 65.8335876464867 .9670867919969 .7957916259871 .6244964599673 .75800323486 76.8058471679781 .3776321411187 .1685485839892 .0450973510794 .17859649658 92.0450973510785 .9494018554777 .7202072143677 .4154205322371 .62449645996 76.5010681152377 .0847244262781 .5683975219784 .2607192993286 .16904449463 87.4600601196388 .3876876831187 .7781066894586 .8637619018685 .64462280273 84.4254837036182 .9015579223681 .0728530883878 .9393463134876 .80584716797 75.8914871215875 .5867080688576 .1962814331177 .110626220778 .02498626709 78.9393463134879 .2441329956179 .5489196777379 .8537063598679 .85370635986 79.8537063598679 .5489196777379 .2441329956178 .9393463134878 .63455963135 78.0249862670977 .4154205322377 .110626220776 .5010681152375 .89148712158 75.2819290161174 .6723632812574 .062782287673 .4532165527372 .84364318848 72.2340774536171 .9292907714871 .3197174072371 .014930725170 .71015167236 70.4053573608469 .7957916259869 .4910125732469 .1862335205168 .88143920898 68.2718734741268 .2718734741268 .88143920898 -9999 -9999 -9999 -9999 -9999 -9999 -9999 -9999 -9999 -9999 -9999 -9999 -9999 -9999 -9999 -9999 -9999 -9999 -9999 -9999 -9999 -9999 -9999 -9999 -9999 -9999 -9999 -9999 -9999 -9999 -9999 -9999 -9999 -9999 -9999 -9999 -9999 -9999 -9999 -9999 -9999 -9999 -9999 -9999 -9999 -9999 -9999 -9999 -9999 -9999 -9999 -9999 -9999 -9999 -9999 -9999 -9999 -9999 -9999 -9999 -9999 -9999 -9999 -9999 - 9999 -

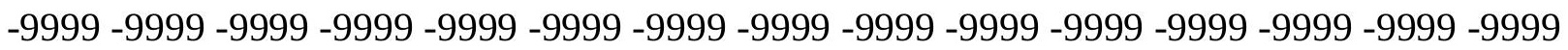
-9999 -9999 -9999 -9999 -9999 -9999 -9999 -9999 -9999 -9999 -9999 -9999 -9999 -9999 -9999 -9999 -9999 -9999 -9999 -9999 -9999 -9999 -9999 -9999 -9999 -9999 -9999 -9999 -9999 -9999 -9999 -9999 -9999 -9999 -9999 -9999 -9999 -9999 -9999-9999 -9999 -9999 -9999 -9999 -9999 -9999 -9999 -9999 -9999 -9999 -9999 -9999 -9999 -9999 -9999 -9999 -9999 -9999 -9999 -9999 -

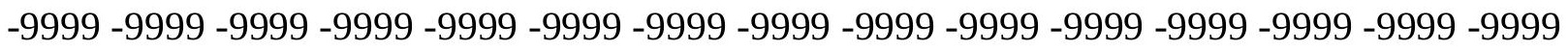
-9999 -9999 -9999 -9999 -9999 -9999 -9999 -9999 -9999 -9999 -9999 -9999 -9999 -9999 -9999 -9999 -9999 65.2240066528365.2240066528365.2240066528365.22400665283 64.9192428588964 .6144485473664 .6144485473664 .3096618652364 .30966186523 64.004882812563 .7000885009863 .3953094482463 .0905189514262 .78573989868 62.7857398986863 .3953094482464 .004882812564 .6144485473665 .52880096436 66.1383666992267 .0527267456167 .9670867919968 .8814392089870 .10057830811 71.3197174072372 .5388565063573 .7580032348675 .2819290161177 .1106262207 78.6345596313580 .1584930419981 .6824111938583 .206336975184 .12069702148 85.0350494384885 .9494018554786 .5589828491287 .1685485839887 .77810668945 88.6924667358489 .6068267822390 .8259735107492 .349891662693 .87381744385 95.7025299072397 .5312423706199 .35994720459101 .4934005737103 .3221969604 105.1509017944106 .979598999108 .5035018921110 .0273971558111 .24659729 112.1608963013113 .075302124113 .6848983765113 .9896011353114 .2944030762 
114.5991973877114 .5991973877114 .5991973877114 .5991973877114 .5991973877 114.9039993286114 .9039993286115 .5136032104115 .818397522116 .7326965332 117.342300415117 .9517974854117 .9517974854117 .647102356118 .2565994263 118.8662033081119 .4757995605118 .9077606201117 .9754486084116 .7780075073 115.5196990967114 .3480224609113 .2567367554112 .1828689575111 .0672683716 109.8864212036108 .6584701538107 .4321670532106 .2730407715105 .2499847412 104.424156189103 .8408660889103 .5246429443103 .4774856567103 .6821136475 104.1084747314104 .7235107422105 .4976806641106 .4034881592107 .4066619873 108.4567565918109 .4860687256110 .4173583984111 .1813354492111 .7291259766 112.0461578369112 .1617889404112 .1580276489112 .1111907959112 .1608963013 115.5136032104120 .0852966309121 .6092987061121 .9140014648121 .9140014648 121.9140014648121 .6092987061121 .6092987061121 .9140014648121 .5769577026 120.6988372803119 .6761474609118 .5058746338117 .1861419678115 .7465286255 60.6522407531759 .7378807067958 .8235282897958 .2139587402356 .38525009155 56.0804595947356 .0804595947356 .0804595947356 .0804595947356 .08045959473 56.0804595947356 .0804595947356 .3852500915556 .3852500915556 .38525009155 56.3852500915556 .6900291442957 .2995986938558 .2139587402358 .82352828979 59.7378807067960 .3474502563561 .2618103027362 .1761703491263 .39530944824 64.9192428588966 .7479400634868 .8814392089871 .3197174072374 .0627822876 77.4154205322381 .9871978759886 .8637619018690 .8259735107492 .65467834473 92.0450973510789 .9116134643689 .9116134643694 .7881774902381 .07285308838 74.9771423339877 .110626220785 .471267700288 .0938644409289 .55963897705 90.3606643676890 .6823196411190 .5211791992289 .6068267822388 .99725341797 88.0829010009886 .5589828491284 .1206970214881 .3776321411178 .93934631348 77.110626220777 .110626220778 .3297805786179 .5489196777380 .15849304199 80.7680587768681 .0728530883881 .0728530883881 .0728530883881 .07285308838 80.7680587768680 .4632720947380 .1584930419979 .5489196777378 .93934631348 78.6345596313577 .7202072143677 .110626220776 .5010681152375 .89148712158 75.2819290161174 .6723632812573 .7580032348673 .1484298706172 .84364318848 72.2340774536171 .6244964599671 .3197174072371 .014930725170 .57302856445 70.1005783081169 .7957916259869 .4910125732469 .1862335205168 .57665252686 68.2718734741267 .9670867919968 .57665252686 -9999 -9999 -9999 -9999 -9999 -9999 -9999 -9999 -9999 -9999 -9999 -9999 -9999 -9999 -9999 -9999 -9999 -9999 -9999 -9999 -9999 -9999 -9999 -9999 -9999 -9999 -9999 -9999 -9999 -9999 -9999 -9999 -9999 -9999 -9999 -9999 -9999 -9999 -9999 -9999 -9999 -9999 -9999 -9999 -9999 -9999 -9999 -9999 -9999 -9999 -9999 -9999 -9999 -9999 -9999 -9999 -9999 -9999 -9999 -9999 -9999 -9999 -9999 -9999 -9999 -9999 -9999 -9999 -9999 -9999 -9999 -9999 -9999 -9999 -9999 -9999 -9999 -9999 -9999 -9999

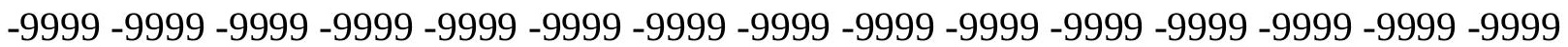
-9999 -9999 -9999 -9999 -9999 -9999 -9999 -9999 -9999 -9999 -9999 -9999 -9999 -9999 -9999 -9999 -9999 -9999 -9999 -9999 -9999 -9999 -9999 -9999 -9999 -9999 -9999 -9999 -9999 -9999 -

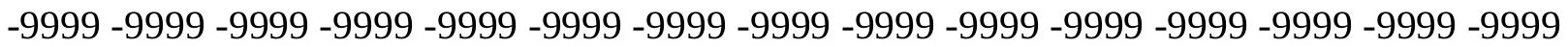
-9999 -9999 -9999 -9999 -9999 -9999 -9999 -9999 -9999 -9999 -9999 -9999 -9999 -9999 -9999 -9999 -9999 -9999 -9999 -9999 -9999 -9999 -9999 -9999 -9999 -9999 -9999 -9999 -9999 -9999 -999 -999 -999 -999 -9999 -9999 64.61444854736 64.3096618652364.3096618652364.30966186523 64.3096618652364 .004882812564 .004882812564 .004882812564 .0048828125 64.004882812564 .004882812564 .3096618652364 .3096618652364 .61444854736 
65.2240066528365 .5288009643665 .8335876464866 .1383666992266 .44316101074 66.7479400634867 .0527267456167 .6623001098668 .2718734741269 .18623352051 70.4053573608471 .6244964599673 .1484298706174 .6723632812576 .50106811523 78.0249862670979 .2441329956180 .7680587768681 .9871978759882 .90155792236 83.81591033936 84.73026275635 85.33984375 86.2541885376 87.16854858398 88.0829010009888 .9972534179790 .5211791992292 .0450973510793 .56903076172 95.397743225197 .2264633178799 .05516815186101 .1886978149103 .0174026489 104.8460998535106 .6747970581108 .1986999512109 .7226028442110 .9418029785 111.8561019897112 .7705001831113 .3800964355113 .9896011353114 .2944030762 114.2944030762114 .5991973877114 .5991973877114 .5991973877114 .9039993286 115.2088012695115 .5136032104115 .818397522116 .4279022217117 .0374984741 117.647102356117 .647102356117 .647102356116 .7326965332115 .818397522 116.4279022217116 .7326965332116 .7326965332116 .1231002808114 .8792037964 113.7329711914112 .4656982422111 .7987670898110 .8427963257109 .7753295898 108.5720214844107 .2595748901105 .9035491943104 .588760376103 .4048233032 102.4331207275101 .7351303101101 .3473129272101 .2748413086101 .4981307983 101.9809265137102 .6903915405103 .6069564819104 .7219085693106 .0151596069 107.4297485352108 .8709335327110 .2264328003111 .4065475464112 .3722686768 113.146522522113 .8075408936114 .5064849854114 .9039993286114 .5991973877 123.1332015991124 .9935760498124 .9770202637124 .8916320801124 .7239074707 124.4637985229123 .7427978516123 .1332015991122 .5235977173121 .9140014648 121.6092987061120 .918510437120 .0046310425118 .9700698853117 .7824325562 59.1283111572358 .2139587402357 .6043891906756 .6900291442954 .86132049561 54.8613204956154 .8613204956154 .8613204956154 .8613204956154 .86132049561 55.1661109924355 .1661109924355 .1661109924355 .1661109924355 .47089004517 55.4708900451756 .0804595947356 .3852500915556 .9948196411157 .9091796875 58.5187492370659 .4331016540560 .3474502563561 .2618103027362 .48094940186 64.004882812565 .8335876464867 .9670867919970 .4053573608473 .45321655273 77.110626220781 .3776321411185 .6446228027389 .302040100191 .74033355713 92.6546783447392 .9594726562593 .2642517089891 .1307525634884 .42548370361 80.7680587768684 .1392135620188 .7164916992290 .8379592895591 .46298217773 91.5910644531291 .4600219726689 .9116134643690 .5211791992291 .43553924561 91.1307525634889 .302040100187 .4733276367284 .7302627563581 .98719787598 78.9393463134880 .1584930419981 .6824111938582 .5967712402382 .90155792236 82.9015579223682 .9015579223682 .5967712402382 .2919769287181 .98719787598 81.6824111938581 .3776321411180 .7680587768680 .1584930419979 .54891967773 78.9393463134878 .0249862670977 .4154205322376 .8058471679775 .89148712158 75.2819290161174 .3675689697373 .7580032348673 .1484298706172 .53885650635 71.9292907714871 .6244964599671 .3197174072370 .7101516723670 .40535736084 70.0328521728569 .691261291569 .1862335205168 .8814392089868 .57665252686 67.9670867919967 .6623001098668 .27187347412 -9999 -9999 -9999 -9999 -9999 -9999 -9999 -9999 -9999 -9999 -9999 -9999 -9999 -9999 -9999 -9999-9999 -9999-9999 -9999 -9999 -9999-9999 -9999 -9999 -9999 -9999 -9999 -9999 -9999 -9999 -9999 -9999 -9999 -9999 -9999 -9999 -9999 -9999 -9999 -9999 -9999 -9999 -9999 -9999 -9999 -9999 -9999 -9999 -9999 -9999 -9999 -9999 -9999 -9999 -9999 -9999 -9999 -9999 -9999 -9999 -9999 -9999 -9999 -9999 -9999 -9999 -9999 -9999 -9999 -9999 -9999 -9999 -9999 -9999 -9999 -9999 -9999 -9999 -9999 
-9999 -9999 -9999 -9999 -9999 -9999 -9999 -9999 -9999 -9999 -9999 -9999 -9999 -9999 -9999 -9999 -9999 -9999 -9999 -9999 -9999 -9999 -9999 -9999 -9999 -9999 -9999 -9999 -9999 -9999 -9999 -9999 -9999 -9999 -9999 -9999 -9999 -9999 -9999 -9999 -9999 -9999 -9999 -9999 -9999 -9999 -9999 -9999 -9999 -9999 -9999 -9999 -9999 -9999 -9999 -9999 -9999 -9999 -9999 -9999 -9999 -9999 -9999 -9999 -9999 -9999 -9999 -9999 -9999 -9999 -9999 -9999-9999 -9999 -9999 -

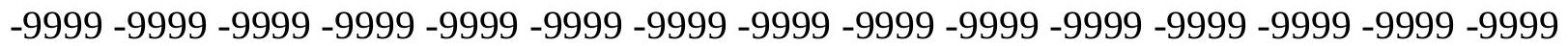
-9999 -9999-999963.7000885009863.7000885009863.39530944824 63.39530944824 63.3953094482463 .7000885009863 .7000885009864 .004882812564 .30966186523 64.6144485473665 .2240066528365 .8335876464866 .7479400634867 .35751342773 67.9670867919967 .9670867919967 .6623001098667 .3575134277367 .05272674561 67.0527267456167 .3575134277367 .6623001098668 .5766525268669 .79579162598 71.014930725172 .5388565063574 .3675689697375 .8914871215877 .1106262207 78.3297805786179 .5489196777380 .4632720947381 .3776321411182 .29197692871 83.206336975184 .1206970214885 .0350494384886 .254188537687 .16854858398 88.69246673584 89.9116134643691.4355392456193.2642517089895.09295654297 96.9216690063599 .05516815186100 .8839035034102 .712600708104 .8460998535 106.3700027466108 .1986999512109 .4179000854110 .6370010376111 .8561019897 112.4656982422113 .075302124113 .6848983765113 .9896011353113 .9896011353 114.2944030762114 .2944030762114 .5991973877114 .9039993286115 .2088012695 115.818397522116 .1231002808116 .7326965332117 .342300415117 .647102356 117.342300415117 .0374984741116 .4279022217115 .2088012695114 .2944030762 113.9896011353113 .6848983765113 .3800964355112 .4656982422111 .551399231 110.9251785278110 .290473938109 .5429229736108 .5894851685107 .4057693481 106.0334625244104 .5548324585103 .0733566284101 .7019577026100 .5442352295 99.6836547851699.1722335815499.0244750976699.2150192260799.69873809814 100.4406814575101 .4394454956102 .728515625104 .3284454346106 .1816940308 108.1348800659110 .0092773438111 .662322998113 .0851745605114 .3655929565 115.681930542116 .1231002808116 .1231002808119 .1709976196125 .0300292969 125.1302642822125 .1816101074125 .1640319824125 .0606307983124 .8638458252 124.5640106201124 .0475006104123 .1332015991121 .9140014648121 .6092987061 120.9997024536120 .0852966309119 .4757995605118 .866203308157 .60438919067 56.9948196411156 .0804595947355 .4708900451754 .8613204956153 .33739852905 53.3373985290553 .3373985290553 .6421813964853 .6421813964853 .94697189331 53.9469718933154 .2517509460454 .2517509460454 .5565414428754 .86132049561 55.1661109924355 .7756805419956 .0804595947356 .6900291442957 .60438919067 58.2139587402359 .1283111572360 .0426712036161 .2618103027362 .78573989868 64.3096618652366 .4431610107469 .1862335205172 .2340774536175 .58670806885 79.5489196777383 .8159103393687 .4733276367290 .2164001464892 .04509735107 92.6546783447391 .7403335571386 .8637619018680 .7680587768678 .02498626709 83.8159103393690 .5211791992288 .9972534179791 .1961212158291 .04122161865 90.6676330566490 .5941390991288 .0829010009892 .6546783447391 .74033355713 91.1307525634889 .9116134643688 .3876876831186 .254188537685 .03504943848 85.0350494384885 .6446228027385 .9494018554785 .9494018554785 .33984375 84.7302627563584 .1206970214883 .5111236572383 .206336975182 .59677124023 82.2919769287181 .6824111938580 .7680587768680 .1584930419979 .24413299561 78.3297805786177 .7202072143676 .8058471679775 .8914871215875 .28192901611 
74.3675689697373 .7580032348673 .1484298706172 .5388565063571 .92929077148 71.6244964599671 .014930725170 .7101516723670 .4053573608469 .79579162598 69.4455718994169 .1241989135768 .8503799438568 .2718734741267 .96708679199 67.3575134277367 .9670867919968 .57665252686 -9999 -9999 -9999 -9999 -9999 -9999 -9999 -9999 -9999 -9999 -9999 -9999 -9999 -9999 -9999 -9999 -9999 -9999 -9999 -9999 -9999 -9999 -9999 -9999 -9999 -9999 -9999 -9999 -9999 -9999 -9999 -9999 -9999 -9999 -9999 -9999 -9999

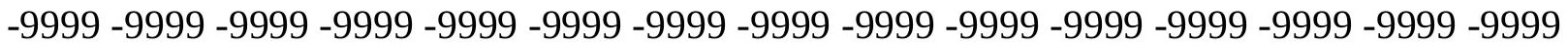
-9999 -9999 -9999 -9999 -9999 -9999 -9999 -9999 -9999 -9999 -9999 -9999

-9999 -9999 -9999 -9999 -9999 -9999 -9999 -9999 -9999 -9999 -9999 -9999 -9999 -9999 -9999 -9999 -9999 -9999 -9999 -9999 -9999 -9999 -9999 -9999 -9999 -9999 -9999 -9999 -9999 -9999

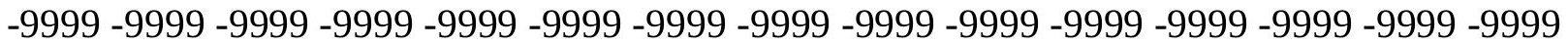
-9999 -9999 -9999 -9999 -9999 -9999 -9999 -9999 -9999 -9999 -9999 -9999 -9999 -9999 -9999

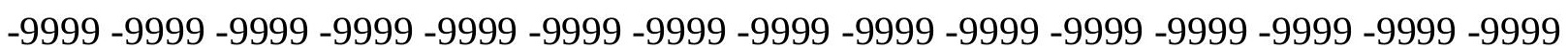
-9999 -9999 -9999 -9999 -9999 -9999 -9999 -9999 -9999 -9999 -9999 -9999 -9999 -9999 -9999 -9999 -9999 -9999 -9999 -9999 -9999 -9999 -9999 -9999 -9999 -9999 -9999 -9999 -9999 -9999 -9999 -9999 -9999 -9999 62.78573989868 62.78573989868 62.7857398986862 .78573989868 63.0905189514263 .3953094482463 .7000885009864 .3096618652364 .91924285889 65.8335876464867 .0527267456168 .2718734741269 .4910125732470 .10057830811 69.7957916259869 .1862335205168 .2718734741267 .6623001098667 .05272674561 67.0527267456167 .0527267456167 .9670867919968 .8814392089870 .40535736084 72.2340774536173 .7580032348675 .2819290161176 .5010681152377 .41542053223 78.3297805786179 .2441329956180 .1584930419981 .0728530883881 .98719787598 82.9015579223684 .1206970214885 .3398437586 .5589828491288 .08290100098 89.302040100191 .1307525634892 .6546783447394 .4833908081196 .61688232422 98.75038146973100 .5791015625102 .712600708104 .5412979126106 .3700027466 107.8938980103109 .4179000854110 .6370010376111 .551399231112 .4656982422 113.075302124113 .3800964355113 .6848983765113 .9896011353113 .9896011353 113.9896011353114 .2944030762114 .9039993286115 .2088012695115 .818397522 116.4279022217116 .7326965332117 .342300415117 .342300415117 .342300415 116.7326965332115 .818397522114 .9039993286113 .6848983765112 .4656982422 111.24659729110 .6370010376110 .0273971558109 .4179000854109 .0872192383 108.791595459108 .2993927002107 .5048980713106 .3769454956104 .9816970825 103.4024581909101 .7609710693100 .194938659798 .8276672363397 .77570343018 97.1014633178796 .8462448120196 .9579849243297 .3855285644598 .07125854492 99.04137420654100 .409538269102 .2963027954104 .6787796021107 .2804412842 109.7692718506111 .8900527954113 .6843032837115 .3633041382115 .818397522 115.818397522116 .4279022217121 .9140014648124 .9738769531125 .1217269897 125.2242431641125 .2605133057125 .2214126587125 .0820922852124 .8295516968 124.3523025513123 .43800354122 .2188034058121 .3044967651120 .3900985718 119.4757995605118 .8662033081118 .561401367256 .0804595947355 .16611099243 54.5565414428753 .9469718933151 .8134689331151 .8134689331151 .81346893311 52.1182594299352 .4230384826752 .4230384826752 .7278289794953 .03261184692 53.3373985290553 .6421813964853 .9469718933154 .2517509460454 .55654144287 54.8613204956155 .1661109924355 .7756805419956 .3852500915556 .99481964111 57.909179687558 .8235282897959 .7378807067961 .2618103027362 .78573989868 64.9192428588967 .0527267456170 .1005783081173 .4532165527377 .1106262207 
81.0728530883884 .7302627563587 .7781066894590 .2164001464891 .13075256348 89.302040100184 .4254837036176 .8058471679768 .5766525268677 .41542053223 83.8159103393688 .0829010009889 .3157882690488 .824783325288 .35273742676 88.7785110473685 .6446228027387 .1685485839889 .9116134643691 .43553924561 91.7403335571391 .4355392456190 .5211791992290 .5211791992289 .91161346436 90.2164001464889 .6068267822388 .6924667358487 .7781066894586 .55898284912 85.3398437584 .7302627563584 .1206970214883 .5111236572383 .2063369751 82.2919769287181 .3776321411180 .4632720947379 .5489196777378 .63455963135 77.7202072143676 .8058471679775 .8914871215875 .2819290161174 .36756896973 73.7580032348672 .8436431884872 .2340774536171 .9292907714871 .31971740723 70.7101516723670 .4053573608470 .1005783081169 .7957916259869 .18623352051 68.838165283268 .5709457397568 .2718734741267 .6623001098667 .35751342773 67.3575134277368 .27187347412 -9999 -9999 -9999 -9999 -9999 -9999 -9999 -9999 -9999 -9999 -9999 -9999 -9999 -9999 -9999 -9999 -9999 -9999 -9999 -9999 -9999 -9999 -9999 -9999 -9999 -9999 -9999 -9999 -9999 -9999 -9999 -9999 -9999 -9999 -9999 -9999 -9999 -9999 -9999 -

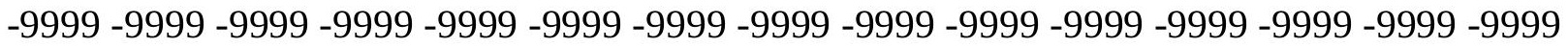
-9999 -9999 -9999 -9999 -9999 -9999 -9999 -9999 -9999 -9999 -9999 -9999 -9999 -9999 -9999 -9999 -9999 -9999 -9999 -9999 -9999 -9999 -9999 -9999 -9999 -9999 -9999 -9999 -9999 -9999 -9999 -9999 -9999 -9999 -9999 -9999 -9999 -9999 -9999 -9999 -9999 -9999 -9999 -9999 -9999 -9999 -9999 -9999 -9999 -9999 -9999 -9999 -9999 -9999 -9999 -9999 -9999 -9999 -9999 -9999 -9999 -9999 -9999 -9999 -9999 -9999 -9999 -9999 -9999 -9999 -9999 -9999 -9999 -9999 -9999 -9999 -9999 -9999 -9999 -9999 -9999 -9999 -9999 -9999 -9999 -9999 -9999 -9999 -9999 -9999 -9999 -9999 -9999 -9999 -9999 -9999 -9999 -9999 -9999 -9999 -9999 -9999 -9999 -9999 -9999 -9999 -9999 -9999 -9999 -9999 -9999 -9999 -9999 -9999 -9999 -9999 -9999 -9999-999962.1761703491262.1761703491262.1761703491262.48094940186 62.7857398986863 .0905189514263 .7000885009864 .3096618652365 .22400665283 66.1383666992267 .6623001098668 .8814392089870 .7101516723671 .92929077148 71.014930725170 .1005783081168 .8814392089867 .9670867919967 .05272674561 66.7479400634866 .4431610107467 .0527267456167 .9670867919969 .79579162598 71.6244964599673 .4532165527374 .6723632812575 .5867080688576 .50106811523 77.110626220777 .7202072143678 .6345596313579 .5489196777380 .46327209473 81.6824111938582 .9015579223684 .4254837036185 .9494018554787 .47332763672 88.9972534179790.5211791992292.349891662694.1785964965896.31210327148 98.4455871582100 .5791015625102 .4077987671104 .5412979126106 .0652008057 107.8938980103109 .1130981445110 .3321990967111 .551399231112 .1608963013 112.7705001831113 .075302124113 .3800964355113 .3800964355113 .6848983765 113.6848983765113 .9896011353114 .5991973877115 .2088012695115 .818397522 116.1231002808116 .7326965332117 .0374984741117 .0374984741117 .0374984741 116.4279022217115 .5136032104114 .2944030762112 .7705001831111 .24659729 110.0273971558108 .8082962036107 .8938980103107 .2844009399107 .2844009399 107.2615814209 107.0317230225 106.3938446045 105.3645324707 104.0029373169 102.3678588867100 .612350463998 .8848724365297 .3401336669996 .1233291626 95.3245239257894.9787597656295.0183181762795.3597259521595.88566589355 96.6569747924897 .9142761230599 .98900604248103 .0018997192106 .524230957 109.7142410278112 .2427368164111 .8561019897112 .4656982422113 .3800964355 113.6848983765118 .5614013672123 .1332015991124 .7791366577124 .9487762451 
125.0741119385125 .1486129761125 .1588058472125 .0768356323124 .8646774292 124.3523025513123 .43800354122 .2188034058120 .9997024536119 .4757995605 118.5614013672117 .9517974854117 .64710235654 .5565414428753 .64218139648 52.7278289794952 .1182594299350 .2895507812550 .2895507812550 .59432983398 50.5943298339850 .8991203308151 .2038993835451 .5086898803751 .81346893311 52.4230384826752 .7278289794953 .0326118469253 .3373985290553 .64218139648 53.9469718933154 .2517509460454 .8613204956155 .1661109924355 .77568054199 56.3852500915557 .2995986938558 .2139587402359 .4331016540560 .95701980591 62.4809494018664 .6144485473667 .3575134277370 .4053573608473 .75800323486 77.4154205322381 .0728530883884 .7302627563587 .4733276367288 .99725341797 88.3876876831184 .7302627563578 .3297805786174 .062782287676 .19628143311 80.7680587768684 .4254837036186 .5589828491284 .8383712768684 .43759918213 85.81354522705 88.12040710449 86.2541885376 87.47332763672 89.91161346436 91.4355392456192 .0450973510792 .349891662692 .349891662692 .65467834473 92.9594726562592 .0450973510791 .1307525634889 .9116134643688 .08290100098 86.254188537685 .6446228027385 .0350494384884 .4254837036183 .81591033936 82.9015579223681 .9871978759880 .7680587768679 .8537063598678 .63455963135 77.7202072143676 .8058471679775 .8914871215874 .9771423339874 .36756896973 73.4532165527372 .8436431884872 .2340774536171 .6244964599671 .0149307251 70.7101516723670 .1005783081169 .7957916259869 .4910125732468 .88143920898 68.5766525268668 .2718734741267 .9670867919967 .6623001098667 .35751342773 67.0527267456167 .66230010986 -9999 -9999-9999 -9999 -9999 -9999 -9999 -9999 -9999 -9999 -9999 -9999 -9999 -9999 -9999 -9999 -9999 -9999 -9999 -9999 -9999 -9999 -9999 -9999 -9999 -9999 -9999 -9999 -9999 -9999 -9999 -9999 -9999 -9999 -9999 -9999 -9999 -9999 -9999 -9999 -9999 -9999 -9999 -9999 -9999 -9999 -9999 -9999 -9999 -9999 -9999 -9999 -9999 -9999 -9999 -9999 -9999 -9999 -9999 -9999 -9999 -9999 -9999 -9999 -9999 -9999 -9999 -9999 -9999 -9999 -9999 -9999 -9999 -9999 -9999 -9999 -9999 -9999 -9999

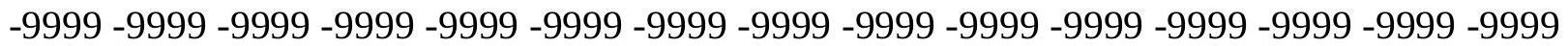
-9999 -9999 -9999 -9999 -9999 -9999 -9999 -9999 -9999 -9999 -9999 -9999 -9999 -9999 -9999 -9999 -9999 -9999 -9999 -9999 -9999 -9999 -9999 -9999 -9999 -9999 -9999 -9999 -9999 -9999 -9999 -9999 -9999 -9999 -9999 -9999 -9999 -9999 -9999 -9999 -9999 -9999 -9999 -9999 -9999

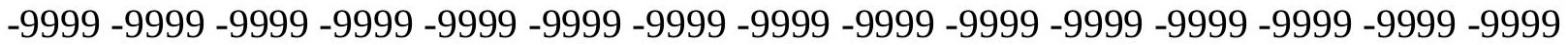

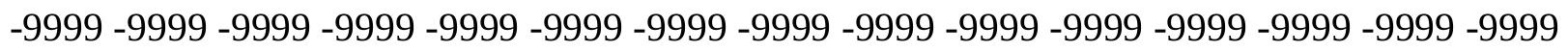
-9999 -9999 -9999 -9999 -9999 61.56660079956 61.56660079956 61.87137985229 62.1761703491262 .7857398986863 .3953094482464 .004882812564 .91924285889 66.1383666992267 .6623001098668 .8814392089870 .4053573608471 .31971740723 71.014930725170 .1005783081168 .8814392089867 .9670867919967 .05272674561 66.1383666992265 .8335876464866 .1383666992267 .0527267456168 .88143920898 71.014930725173 .1484298706173 .7580032348674 .3675689697374 .97714233398 75.8914871215876 .1962814331177 .110626220778 .0249862670979 .24413299561 80.4632720947381 .9871978759883 .5111236572385 .3398437586 .86376190186 88.6924667358490 .2164001464891 .7403335571393 .8738174438596 .00731658936 98.14080810547100 .2742996216102 .4077987671104 .2365036011106 .0652008057 107.8938980103109 .1130981445110 .3321990967111 .24659729112 .1608963013 112.4656982422112 .7705001831113 .075302124113 .075302124113 .3800964355 113.3800964355113 .6848983765114 .2944030762114 .5991973877115 .2088012695 
115.818397522116 .1231002808116 .7326965332116 .7326965332116 .4279022217 115.818397522114 .9039993286113 .3800964355111 .8561019897110 .3321990967 108.5035018921107 .2844009399106 .0652008057105 .4557037354105 .4557037354 105.4557037354105 .4557037354104 .9389648438104 .13306427102 .845413208 101.2397155762 99.487167358497.6782760620196.0944213867294.83950042725 94.1918640136793 .8099670410293 .9450836181694 .1935195922994 .4507522583 94.8030395507895 .6480026245197 .64825439453101 .3214416504104 .5412979126 104.2365036011104 .8460998535106 .0652008057108 .5035018921109 .7226028442 114.9039993286119 .7806015015123 .43800354124 .446144104124 .5984573364 124.7096557617124 .7885971069124 .8329238892124 .8081665039124 .6428527832 123.7427978516123 .1332015991122 .2188034058120 .0852966309118 .2565994263 117.647102356117 .0374984741116 .427902221753 .0326118469252 .11825942993 51.2038993835450 .2895507812548 .765621185348 .765621185349 .07040023804 49.3751907348649 .6799812316949 .9847602844250 .2895507812550 .89912033081 51.2038993835451 .8134689331152 .4230384826752 .7278289794953 .03261184692 53.3373985290553 .3373985290553 .6421813964853 .9469718933154 .25175094604 54.8613204956155 .4708900451756 .0804595947357 .2995986938558 .51874923706 59.7378807067961 .5666007995663 .7000885009866 .1383666992269 .18623352051 72.8436431884876 .8058471679780 .7680587768684 .4254837036187 .16854858398 88.0829010009887 .7781066894582 .5967712402379 .2441329956178 .63455963135 80.1584930419981 .6824111938581 .6824111938579 .5489196777379 .28923797607 82.8170242309687 .1500625610490 .2786178588987 .4733276367288 .38768768311 90.5211791992291 .7403335571392 .349891662692 .9594726562593 .56903076172 93.8738174438593 .5690307617292 .9594726562592 .0450973510789 .60682678223 88.0829010009886 .8637619018685 .9494018554785 .3398437584 .42548370361 83.5111236572382 .2919769287181 .0728530883879 .8537063598678 .63455963135 77.7202072143676 .8058471679775 .8914871215874 .9771423339874 .0627822876 73.1484298706172 .5388565063571 .9292907714871 .3197174072370 .71015167236 70.4053573608469 .7957916259869 .4910125732469 .1862335205168 .57665252686 68.2718734741267 .9670867919967 .6623001098667 .3575134277367 .05272674561 66.7479400634867 .3575134277367 .96708679199 -9999 -9999 -9999 -9999 -9999 -9999 -9999 -9999 -9999 -9999 -9999 -9999 -9999 -9999 -9999 -9999 -9999 -9999 -9999 -9999 -9999 -9999

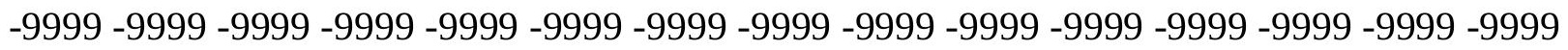

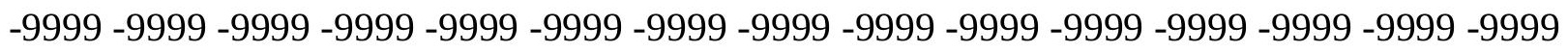
-9999 -9999 -9999 -9999 -9999 -9999 -9999 -9999 -9999 -9999 -9999

-9999 -9999 -9999 -9999 -9999 -9999 -9999 -9999 -9999 -9999 -9999 -9999 -9999 -9999 -9999

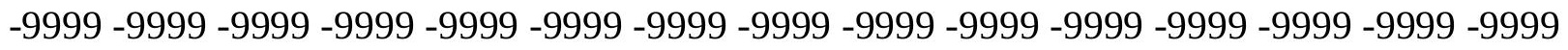

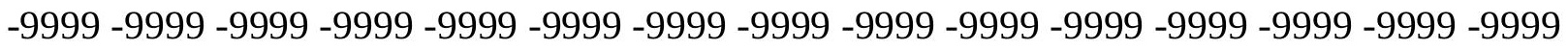
-9999 -9999 -9999 -9999 -9999 -9999 -9999 -9999 -9999 -9999 -9999 -9999 -9999 -9999 -9999 -9999 -9999 -9999 -9999 -9999 -9999 -9999 -9999 -9999 -9999 -9999 -9999 -9999 -9999 -9999 -

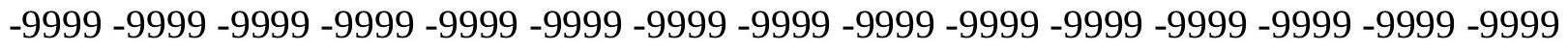

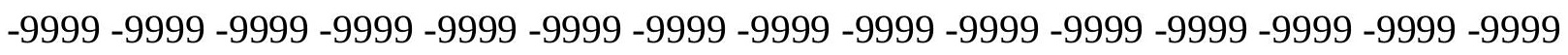
-9999 -9999 -9999 -9999 -9999 -9999 61.2618103027361.56660079956 61.87137985229 62.4809494018663 .0905189514263 .7000885009864 .6144485473665 .83358764648 67.0527267456168 .2718734741269 .1862335205170 .1005783081170 .10057830811 69.49101257324 68.8814392089867.9670867919967.05272674561 66.13836669922 
65.5288009643665 .2240066528366 .4431610107468 .2718734741269 .79579162598 71.3197174072372 .2340774536172 .8436431884873 .4532165527374 .36756896973 74.6723632812575 .2819290161176 .1962814331177 .7202072143679 .24413299561 81.0728530883883 .206336975184 .7302627563586 .5589828491288 .38768768311 89.9116134643691.7403335571393.8738174438596.0073165893698.14080810547 100.2742996216102 .4077987671104 .2365036011106 .0652008057107 .5891036987 109.1130981445110 .3321990967111 .24659729111 .8561019897112 .1608963013 112.4656982422112 .7705001831112 .7705001831112 .7705001831113 .075302124 113.075302124113 .6848983765113 .9896011353114 .5991973877114 .9039993286 115.5136032104115 .818397522115 .818397522115 .818397522115 .2088012695 113.9896011353112 .4656982422110 .6370010376108 .8082962036106 .979598999 105.4557037354104 .2365036011103 .6268997192103 .0174026489103 .0174026489 102.712600708102 .712600708102 .4077987671101 .044265747199 .64848327637 98.1206970214896 .3597183227594 .8872451782294 .1076660156294 .17859649658 93.5690307617293 .8738174438594 .4833908081194 .1785964965894 .17859649658 94.3960952758895 .7025299072396 .3121032714897 .2264633178799 .66472625732 104.2365036011107 .5891036987110 .0273971558113 .075302124117 .0374984741 120.9997024536123 .43800354123 .9801330566124 .0721588135124 .1134643555 124.1440734863124 .0475006104123 .7427978516123 .43800354122 .8283996582 121.9140014648120 .6949005127119 .1709976196117 .342300415116 .4279022217 115.5136032104114 .903999328651 .5086898803750 .2895507812549 .37519073486 46.9369087219246 .9369087219247 .2416992187547 .5464782714847 .85126113892 48.1560516357448 .4608306884849 .0704002380449 .6799812316950 .28955078125 50.8991203308151 .5086898803752 .1182594299352 .1182594299352 .11825942993 52.1182594299352 .4230384826752 .4230384826752 .7278289794953 .03261184692 53.6421813964853 .9469718933154 .8613204956155 .4708900451756 .38525009155 57.6043891906759 .1283111572361 .5666007995663 .7000885009867 .05272674561 71.6244964599676 .5010681152381 .0728530883884 .7302627563587 .16854858398 87.1685485839885 .3398437582 .9015579223681 .3776321411181 .07285308838 80.4632720947378 .9393463134876 .5010681152373 .7580032348680 .97101593018 88.27260589691 .5799865722790 .2164001464890 .2164001464890 .82597351074 91.1307525634891 .7403335571392 .9594726562593 .8738174438594 .48339080811 94.4833908081193 .5690307617292 .0450973510790 .5211791992288 .99725341797 87.7781066894586 .5589828491285 .7021179199284 .8040008544983 .81591033936 82.2919769287181 .0728530883879 .8537063598678 .6345596313577 .72020721436 76.5010681152375 .5867080688574 .6723632812573 .7580032348672 .84364318848 72.2340774536171 .6244964599671 .014930725170 .4053573608469 .79579162598 69.49101257324 68.88143920898 68.57665252686 68.2718734741267.96708679199 67.6623001098667 .3575134277367 .033615112366 .7479400634866 .44316101074 67.0527267456167 .66230010986 -9999 -9999 -9999 -9999 -9999 -9999 -9999 -9999 -9999

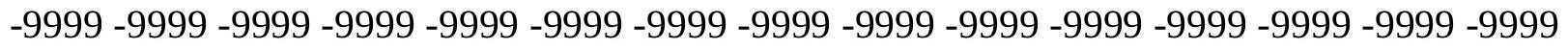

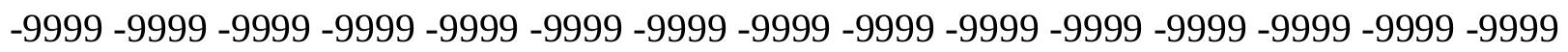

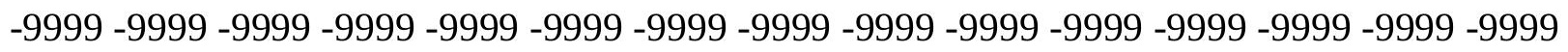
-9999 -9999 -9999 -9999 -9999 -9999 -9999 -9999 -9999

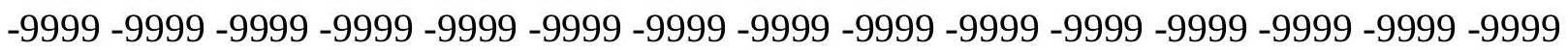

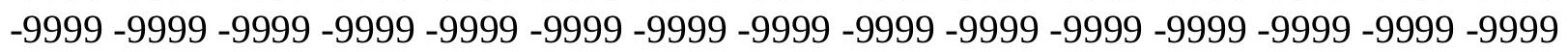


-9999 -9999 -9999 -9999 -9999 -9999 -9999 -9999 -9999 -9999 -9999 -9999 -9999 -9999 -9999 -9999 -9999 -9999 -9999 -9999 -9999 -9999 -9999 -9999 -9999 -9999 -9999 -9999 -9999 -9999 -9999 -9999 -9999 -9999 -9999 -9999 -9999 -9999 -9999 -9999 -9999 -9999 -9999 -9999 -9999 -9999 -9999 -9999 -9999 -9999 -9999 -9999 -9999 -9999 -9999 -9999 -9999 -9999 -9999 -9999 -9999 -9999 -9999 -9999 -9999 -9999 -9999 -9999 -9999 -9999 -9999 -9999 -9999 -9999 -9999 -9999 -9999 -9999 -9999 -9999-9999 60.65224075317 60.9570198059161.56660079956 62.1761703491262 .7857398986863 .3953094482464 .3096618652365 .22400665283 66.1383666992267 .0527267456167 .9670867919968 .5766525268668 .88143920898 68.8814392089868 .5766525268668 .2718734741267 .3575134277366 .74794006348 66.1383666992265 .8335876464866 .4431610107467 .6623001098668 .57665252686 69.7957916259870 .4053573608471 .014930725171 .6244964599671 .92929077148 72.5388565063573 .4532165527374 .6723632812576 .5010681152378 .63455963135 80.7680587768682 .9015579223684 .7302627563586 .5589828491288 .08290100098 89.9116134643691.7403335571393.8738174438596.0073165893698.14080810547 100.2742996216102 .4077987671104 .2365036011106 .0652008057107 .5891036987 109.1130981445110 .3321990967111 .24659729111 .551399231111 .8561019897 112.1608963013112 .1608963013112 .1608963013112 .1608963013112 .1608963013 112.4656982422112 .7705001831113 .075302124113 .3800964355113 .6848983765 113.9896011353114 .2944030762114 .5991973877114 .2944030762113 .9896011353 112.7705001831110 .9418029785108 .8082962036106 .6747970581104 .8460998535 103.3221969604102 .1029968262101 .1886978149100 .5791015625100 .2742996216 99.9695205688599 .3599472045999 .0551681518698 .1408081054797 .22646331787 96.0073165893694 .4833908081192 .9594726562594 .4833908081195 .09295654297 98.1408081054798 .445587158297 .8360290527396 .6168823242295 .70252990723 95.397743225196 .0073165893699 .66472625732107 .8938980103122 .1806945801 116.7326965332114 .9039993286115 .5136032104117 .647102356120 .0852966309 122.2188034058123 .3208007812123 .4273376465123 .4029083252123 .1332015991 122.5235977173122 .2188034058121 .9140014648121 .6092987061120 .9997024536 120.0852966309118 .8662033081117 .647102356116 .1231002808114 .9039993286 113.989601135351 .2038993835449 .9847602844248 .4608306884847 .24169921875 45.1082000732445 .4129791259845 .4129791259845 .717769622846 .02254867554 46.6321296691946 .9369087219247 .5464782714848 .1560516357449 .07040023804 49.6799812316950 .5943298339851 .2038993835451 .2038993835450 .89912033081 50.8991203308150 .8991203308150 .8991203308150 .8991203308151 .20389938354 51.5086898803751 .8134689331152 .1182594299352 .7278289794953 .03261184692 53.3373985290553 .9469718933154 .8613204956156 .9948196411160 .65224075317 65.5288009643671 .6244964599677 .4154205322381 .9871978759885 .33984375 86.8637619018686 .8637619018685 .6446228027384 .4254837036182 .90155792236 81.0728530883878 .9393463134877 .110626220776 .5010681152379 .85370635986 91.1307525634890 .2644500732493 .2703552246193 .2642517089895 .09295654297 93.5690307617292 .0450973510792 .6546783447393 .8738174438595 .19750213623 95.2093505859494 .4833908081192 .9594726562591 .1307525634889 .48504638672 88.0675811767686 .8637619018685 .8284606933684 .7302627563583 .51112365723 82.2919769287180 .7680587768679 .5489196777378 .3297805786177 .41542053223 76.1962814331175 .2819290161174 .3675689697373 .4532165527372 .53885650635 71.9292907714871 .014930725170 .4053573608469 .7957916259869 .49101257324 
68.8814392089868 .5766525268668 .2718734741267 .9670867919967 .66230010986 67.0527267456166 .7479400634866 .4431610107466 .1383666992265 .83358764648 66.7479400634867 .35751342773 -9999 -9999 -9999 -9999 -9999 -9999 -9999 -9999 -9999 -9999 -9999 -9999 -9999 -9999 -9999 -9999 -9999 -9999 -9999 -9999 -9999 -9999 -9999 -9999 -9999 -9999 -9999 -9999 -9999 -9999 -9999 -9999 -9999 -9999 -9999 -9999-9999 -9999 -9999 -

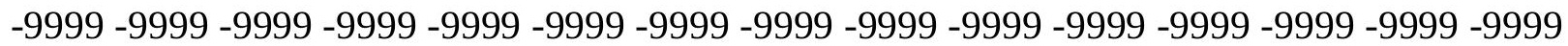
-9999 -9999 -9999 -9999 -9999 -9999 -9999 -9999 -9999

-9999 -9999 -9999 -9999 -9999 -9999 -9999 -9999 -9999 -9999 -9999 -9999 -9999 -9999 -9999 -9999 -9999 -9999 -9999 -9999 -9999 -9999 -9999 -9999 -9999 -9999 -9999 -9999 -9999 -9999 -9999 -9999 -9999 -9999 -9999 -9999 -9999 -9999 -9999 -9999 -9999 -9999 -9999 -9999 -9999 -9999 -9999 -9999 -9999 -9999 -9999 -9999 -9999 -9999 -9999 -9999 -9999 -9999 -9999 -9999 -999 -9999 -9999 -9999 -9999 -9999 -9999 -9999 -9999 -9999 -9999 -9999 -9999 -9999 -9999 -9999 -9999 -9999 -9999 -9999 -9999 -9999 -9999 -9999 -9999 -9999 -9999 -9999 -9999 -9999 -9999 -9999 -9999 -9999 -9999 -9999 -9999 -9999 -9999 -9999 -9999 -9999 -9999 -9999 -9999 -9999 -9999 -9999-9999 -9999 -9999-9999-9999 60.65224075317 61.2618103027361.87137985229 62.4809494018663 .0905189514263 .7000885009864 .3096618652365 .22400665283 65.8335876464866 .4431610107467 .0527267456167 .6623001098668 .27187347412 68.5766525268668 .5766525268667 .9670867919967 .3575134277367 .05272674561 66.7479400634866 .7479400634867 .3575134277367 .6623001098668 .27187347412 68.8814392089869 .1862335205169 .4910125732469 .7957916259870 .40535736084 71.3197174072373 .1484298706175 .2819290161178 .0249862670980 .46327209473 82.9015579223685 .0350494384886 .8637619018688 .3876876831190 .21640014648 92.0450973510793 .8738174438596 .0073165893698 .14080810547100 .2742996216 102.4077987671104 .2365036011106 .0652008057107 .5891036987109 .1130981445 110.0273971558110 .9418029785111 .551399231111 .551399231111 .551399231 111.551399231111 .551399231111 .551399231111 .24659729111 .551399231111 .551399231 111.551399231111 .8561019897112 .1608963013112 .1608963013112 .4656982422 112.4656982422112 .4656982422112 .1608963013110 .9418029785109 .1130981445 106.3700027466104 .2365036011102 .4077987671100 .883903503499 .66472625732 98.7503814697398 .1408081054797 .5312423706196 .9216690063596 .31210327148 95.397743225194 .4833908081193 .5690307617292 .0450973510790 .52117919922 88.9972534179794 .48339080811102 .4077987671112 .4656982422106 .979598999 103.0174026489100 .274299621699 .0551681518699 .05516815186101 .1886978149 106.3700027466 114.2944030762 121.3044967651 121.8539123535120.0852966309 119.4757995605120 .3900985718122 .3573074341122 .6410522461122 .8190078735 122.5235977173121 .9140014648121 .3044967651120 .6949005127120 .3900985718 119.7806015015119 .4757995605118 .8662033081117 .9517974854117 .0374984741 115.818397522114 .5991973877113 .3800964355112 .465698242249 .98476028442 48.4608306884846 .9369087219245 .4129791259843 .5842704772943 .58427047729 43.8890609741244 .1938400268644 .4986305236844 .8034095764245 .41297912598 46.0225486755446 .6321296691947 .5464782714848 .1560516357449 .07040023804 49.3751907348649 .6799812316949 .3751907348649 .3751907348649 .37519073486 49.0704002380449 .0704002380449 .3751907348649 .3751907348649 .67998123169 49.6799812316949 .6799812316949 .3751907348648 .765621185348 .46083068848 48.1560516357449 .3751907348653 .0326118469259 .1283111572366 .74794006348 73.7580032348679 .2441329956183 .5111236572386 .254188537687 .77810668945 
87.7781066894586 .8637619018685 .3398437583 .206336975181 .07285308838 79.5489196777379 .2441329956180 .1584930419980 .7680587768682 .90155792236 94.1785964965896 .5526351928797 .4442062377997 .1176452636795 .66184234619 92.0450973510795 .0929565429796 .3121032714895 .7025299072394 .78817749023 93.2642517089891 .4055252075289 .5145950317488 .0097274780386 .75408172607 85.6446228027384 .4254837036183 .206336975181 .6824111938580 .46327209473 79.2441329956178 .0249862670976 .8058471679775 .5867080688574 .67236328125 73.7580032348672 .8436431884871 .9292907714871 .3197174072370 .71015167236 70.1005783081169 .4910125732468 .8814392089868 .5766525268667 .96708679199 67.6623001098667 .3575134277367 .0527267456166 .7479400634866 .44316101074 66.1383666992265 .8335876464865 .5288009643666 .1383666992266 .74794006348 -9999 -9999 -9999 -9999 -9999 -9999 -9999 -9999 -9999 -9999 -9999 -9999 -9999 -9999 -9999 -9999 -9999 -9999 -9999 -9999 -9999 -9999 -9999 -9999 -9999 -9999 -9999 -9999 -9999 -9999 -9999 -9999 -9999 -9999 -9999 -9999 -9999 -9999 -9999 -9999 -9999 -9999 -9999 -9999 -9999 -9999 -9999 -9999 -9999 -9999 -9999 -9999 -9999 -9999 -9999 -9999 -9999 -9999 -9999 -9999 -9999 -9999 -9999

-9999 -9999 -9999 -9999 -9999 -9999 -9999 -9999 -9999 -9999 -9999 -9999 -9999 -9999 -9999 -9999 -9999 -9999 -9999 -9999 -9999 -9999 -9999 -9999 -9999 -9999 -9999 -9999 -9999 -9999 -9999 -9999 -9999 -9999 -9999 -9999 -9999 -9999 -9999 -9999 -9999 -9999 -9999 -9999 -9999 -

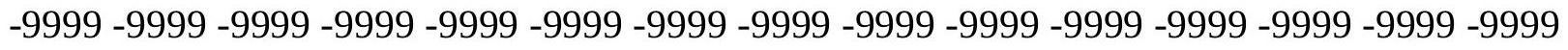

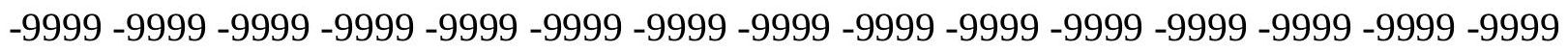
-9999 -9999 -9999 -9999 -9999 -9999 -9999 -9999 -9999 -9999 -9999 -9999 -9999 -9999 -9999 -9999 -9999 -9999 -9999 -9999 -9999 -9999 -9999 -9999 -9999 -9999 -9999 -9999 -9999 -9999 -9999 -9999 -9999 -9999 -9999 -9999 -9999 60.34745025635 60.9570198059161.56660079956 62.1761703491262 .7857398986863 .0905189514263 .7000885009864 .30966186523 64.6144485473665 .2240066528365 .8335876464866 .7479400634867 .96708679199 68.5766525268669 .1862335205168 .8814392089868 .5766525268667 .96708679199 67.6623001098667 .6623001098667 .6623001098667 .6623001098667 .35751342773 67.9670867919968 .2718734741268 .2718734741267 .9670867919968 .27187347412 69.4910125732471 .9292907714874 .9771423339878 .0249862670981 .07285308838 83.8159103393685 .6446228027387 .1685485839888 .6924667358490 .21640014648 92.0450973510794 .1785964965896 .3121032714898 .14080810547100 .2742996216 102.4077987671104 .2365036011106 .0652008057107 .5891036987108 .8082962036 110.0273971558110 .9418029785110 .9418029785110 .9418029785110 .9418029785 110.6370010376110 .6370010376110 .3321990967110 .3321990967110 .0273971558 110.0273971558110 .0273971558110 .0273971558110 .0273971558110 .0273971558 109.7226028442109 .7226028442109 .4179000854109 .1130981445108 .5035018921 105.7603988647103 .0174026489100 .883903503499 .0551681518697 .83602905273 96.6168823242295 .7025299072395 .0929565429796 .0073165893693 .87381744385 93.2642517089892 .6546783447391 .4355392456190 .8259735107490 .52117919922 90.5211791992292 .9594726562598 .14080810547105 .1509017944110 .3321990967 109.4179000854 106.0652008057 103.0174026489101.4934005737101.7982025146 103.9317016602108 .5035018921114 .2944030762118 .5614013672120 .6949005127 120.3900985718120 .3900985718120 .6949005127121 .6092987061121 .6092987061 121.3044967651120 .6949005127120 .0852966309119 .4757995605118 .8662033081 118.2565994263117 .647102356117 .0374984741116 .4279022217115 .818397522 
114.5991973877113 .6848983765112 .7705001831111 .551399231110 .6370010376 49.0704002380446 .9369087219245 .1082000732441 .7555618286142 .06034851074 42.0603485107442 .0603485107442 .3651313781742 .66992187543 .27949142456 43.5842704772944 .1938400268645 .1082000732445 .717769622846 .32733917236 47.2416992187547 .5464782714847 .8512611389247 .8512611389247 .54647827148 47.5464782714847 .5464782714847 .2416992187547 .2416992187547 .24169921875 47.2416992187547 .2416992187546 .9369087219246 .0225486755444 .80340957642 43.2794914245641 .7555618286141 .4507789611844 .4986305236852 .72782897949 62.4809494018670 .1005783081176 .1962814331181 .3776321411185 .94940185547 88.9972534179790 .2164001464889 .6068267822388 .0829010009885 .94940185547 84.1206970214882 .2919769287181 .6824111938581 .3776321411181 .68241119385 84.12069702148 88.6924667358495.09295654297 97.2264633178797.83602905273 96.0073165893694 .7881774902397 .8360290527396 .6168823242295 .3977432251 94.4833908081193 .2642517089891 .4355392456188 .9972534179787 .77810668945 86.254188537685 .0350494384883 .8159103393682 .2919769287181 .07285308838 79.8537063598678 .6345596313577 .4154205322376 .1962814331174 .97714233398 74.062782287673 .1484298706172 .2340774536171 .3197174072370 .71015167236 70.1005783081169 .4910125732468 .8814392089868 .2718734741267 .96708679199 67.6623001098667 .0527267456166 .7479400634866 .4431610107466 .13836669922 65.8335876464865 .5288009643665 .2240066528365 .1838378906265 .29056549072 66.4431610107467 .05272674561 -9999 -9999 -9999 -9999 -9999 -9999 -9999 -9999 -9999 -9999 -9999 -9999 -9999 -9999 -9999 -9999 -9999 -9999 -9999 -9999 -9999 -9999 -9999 -9999 -9999 -9999 -9999 -9999 -9999 -9999 -9999 -9999 -9999 -9999 -9999 -9999 -9999 -9999 -9999 -

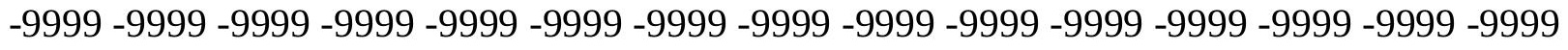
-9999 -9999 -9999 -9999 -9999 -9999 -9999 -9999

-9999 -9999 -9999 -9999 -9999 -9999 -9999 -9999 -9999 -9999 -9999 -9999 -9999 -9999 -9999 -9999 -9999 -9999 -9999 -9999 -9999 -9999 -9999 -9999 -9999 -9999 -9999 -9999 -9999 -9999 -

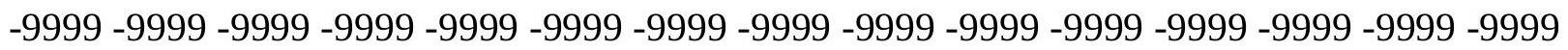
-9999 -9999 -9999 -9999 -9999 -9999 -9999 -9999 -9999 -9999 -9999 -9999 -9999 -9999 -9999 -9999 -9999 -9999 -9999 -9999 -9999 -9999 -9999 -9999 -9999 -9999 -9999 -9999 -9999 -9999 -9999 -9999 -9999 -9999 -9999 -9999 -9999 -9999 -9999 -9999 -9999 -9999-9999 -9999 -9999 -9999 -9999 -9999 -9999 -9999 -9999 -9999 -9999 -9999 -9999 -9999 -9999 -9999 -9999 -9999 -9999 -9999 -9999 -9999-9999 -9999 -9999 -9999 60.9570198059161.56660079956 61.8713798522962 .4809494018662 .7857398986863 .0905189514263 .39530944824 63.7000885009864 .004882812564 .6144485473666 .1383666992267 .66230010986 68.8814392089869 .7957916259870 .1005783081169 .4910125732469 .18623352051 68.8814392089868 .5766525268668 .2718734741268 .2718734741267 .96708679199 67.9670867919967 .6623001098667 .3575134277367 .0527267456167 .05272674561 67.9670867919971 .014930725174 .9771423339879 .2441329956182 .59677124023 85.0350494384886 .8637619018688 .3876876831189 .6068267822390 .82597351074 92.6546783447394 .4833908081196 .6168823242298 .4455871582100 .5791015625 102.4077987671104 .2365036011105 .7603988647107 .2844009399108 .5035018921 109.4179000854110 .0273971558110 .3321990967110 .0273971558110 .0273971558 109.7226028442109 .4179000854109 .1130981445108 .8082962036108 .5035018921 108.5035018921108 .1986999512107 .8938980103107 .5891036987106 .979598999 106.6747970581106 .0652008057105 .4557037354104 .2365036011102 .712600708 
100.579101562598 .445587158296 .9216690063595 .397743225195 .70252990723 96.3121032714896 .6168823242296 .0073165893695 .397743225194 .78817749023 94.1785964965893 .2642517089892 .349891662692 .0450973510791 .74033355713 92.6546783447395 .397743225199 .35994720459104 .2365036011107 .2844009399 107.8938980103106 .3700027466104 .2365036011103 .0174026489103 .0174026489 104.8460998535107 .8938980103111 .8561019897115 .2088012695117 .342300415 118.2565994263118 .5614013672118 .8662033081119 .1709976196119 .4757995605 119.1709976196118 .5614013672117 .9517974854117 .0374984741116 .4279022217 115.818397522115 .2088012695114 .5991973877113 .9896011353113 .3800964355 112.4656982422111 .551399231110 .6370010376109 .722602844249 .98476028442 47.8512611389245 .4129791259843 .2794914245640 .2316398620640 .23163986206 40.2316398620640 .5364189147940 .5364189147940 .8412094116241 .45077896118 41.7555618286142 .3651313781743 .2794914245643 .8890609741244 .49863052368 45.1082000732445 .717769622845 .717769622846 .0225486755445 .7177696228 45.717769622845 .717769622845 .4129791259845 .4129791259845 .10820007324 45.1082000732444 .8034095764244 .1938400268643 .2794914245641 .45077896118 39.3172798156736 .8790016174335 .0502891540535 .3550796508846 .93690872192 59.7378807067966 .1383666992272 .2340774536178 .9393463134885 .03504943848 89.9116134643692 .349891662692 .349891662690 .8259735107488 .99725341797 86.8637619018685 .0350494384883 .8159103393683 .206336975183 .81591033936 85.64462280273 88.0829010009891.1307525634893.5690307617293.87381744385 97.5312423706198 .1408081054794 .7881774902394 .7881774902393 .87381744385 93.2642517089892 .6546783447391 .4355392456188 .9972534179787 .16854858398 85.6446228027384 .1206970214882 .9015579223681 .6824111938580 .15849304199 78.9393463134877 .7202072143676 .5010681152375 .5867080688574 .36756896973 73.4532165527372 .5388565063571 .6244964599670 .7101516723670 .10057830811 69.4910125732468 .8814392089868 .2718734741267 .6623001098667 .35751342773 67.0527267456166 .4431610107466 .1383666992265 .8335876464865 .52880096436 65.2240066528364 .9192428588964 .6144485473664 .772048950265 .03646087646 66.1383666992266 .74794006348 -9999 -9999 -9999 -9999 -9999 -9999 -9999 -9999 -9999 -9999 -9999 -9999 -9999 -9999 -9999 -9999 -9999 -9999 -9999 -9999 -9999 -9999 -9999 -9999 -9999 -9999 -9999 -9999 -9999 -9999 -9999 -9999 -9999 -9999 -9999 -9999 -9999 -9999 -9999 -

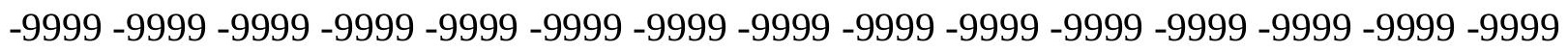
-9999 -9999 -9999 -9999 -9999 -9999 -9999 -9999

-9999 -9999 -9999 -9999 -9999 -9999 -9999 -9999 -9999 -9999 -9999 -9999 -9999 -9999 -9999

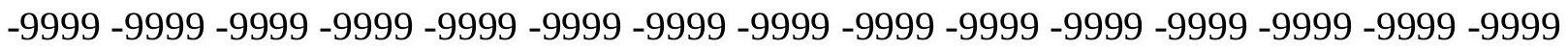

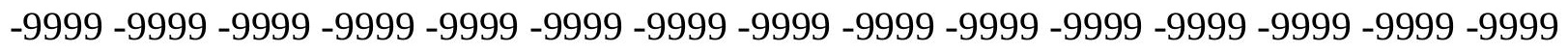

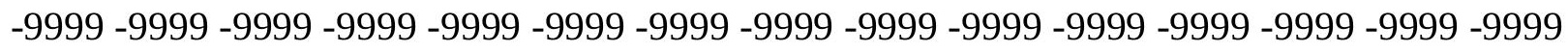
-9999 -9999 -9999 -9999 -9999 -9999 -9999 -9999 -9999 -9999 -9999 -9999 -9999 -9999 -9999 -9999 -9999 -9999 -9999 -9999 -9999 -9999 -9999 -9999 -9999 -9999 -9999 -9999 -9999 -9999 -

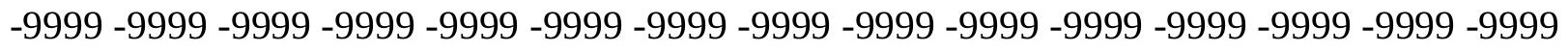
-9999 -9999-9999 -9999 -9999 -9999-9999 -9999 -9999 61.56660079956 61.87137985229 62.4809494018662 .7857398986863 .0905189514263 .0905189514263 .39530944824 63.3953094482463 .7000885009865 .5288009643667 .6623001098669 .18623352051 70.7101516723670 .7101516723670 .4053573608470 .1005783081169 .79579162598 69.7957916259869 .4910125732469 .4910125732469 .1862335205168 .88143920898 
68.2718734741267 .6623001098667 .0527267456166 .7479400634867 .05272674561 71.6244964599676 .5010681152381 .0728530883884 .7302627563587 .16854858398 88.3876876831189 .302040100190 .5211791992291 .7403335571393 .56903076172 95.397743225197 .2264633178799 .05516815186100 .8839035034102 .4077987671 104.2365036011105 .4557037354106 .979598999107 .8938980103108 .8082962036 109.1130981445109 .4179000854109 .1130981445108 .8082962036108 .5035018921 108.1986999512107 .8938980103107 .2844009399106 .979598999106 .3700027466 105.7603988647105 .1509017944104 .5412979126103 .9317016602103 .0174026489 102.1029968262100 .883903503499 .0551681518696 .9216690063594 .78817749023 93.2642517089895 .0929565429796 .6168823242297 .5312423706197 .83602905273 97.8360290527397 .2264633178796 .6168823242295 .7025299072394 .78817749023 93.8738174438593.2642517089892.9594726562593.2642517089894.17859649658 96.3121032714899 .35994720459102 .4077987671104 .8460998535105 .4557037354 104.8460998535103 .6268997192103 .0174026489103 .0174026489104 .2365036011 105.7603988647109 .1130981445111 .8561019897113 .6848983765114 .5991973877 115.2088012695115 .818397522116 .1231002808116 .4279022217116 .1231002808 115.818397522115 .2088012695114 .5991973877113 .9896011353113 .3800964355 112.7705001831112 .1608963013111 .551399231110 .9418029785110 .3321990967 109.4179000854108 .5035018921107 .893898010349 .0704002380446 .32733917236 43.8890609741241 .4507789611839 .0125007629438 .7077102661138 .70771026611 38.7077102661139 .0125007629439 .0125007629439 .3172798156739 .92684936523 40.5364189147941 .1459884643642 .0603485107442 .66992187542 .97470092773 43.5842704772943 .8890609741243 .8890609741243 .8890609741243 .88906097412 43.5842704772943 .5842704772943 .2794914245643 .2794914245642 .97470092773 42.66992187542 .0603485107441 .1459884643639 .0125007629436 .26942825317 33.8311500549334 .4407196044935 .0502891540542 .66992187552 .11825942993 59.7378807067967 .0527267456175 .2819290161183 .8159103393691 .13075256348 94.1785964965895 .0929565429794 .1785964965891 .7403335571389 .60682678223 87.47332763672 85.94940185547 85.03504943848 85.33984375 86.2541885376 87.7781066894589 .6068267822390 .5211791992290 .5211791992289 .91161346436 89.9116134643691.4355392456191.7403335571391.4355392456191.43553924561 91.1307525634889 .9116134643688 .3876876831186 .5589828491284 .73026275635 83.2063369751 81.98719787598 80.46327209473 79.24413299561 78.02498626709 76.8058471679775 .5867080688574 .6723632812573 .4532165527372 .53885650635 71.6244964599670 .7101516723670 .1005783081169 .1862335205168 .57665252686 67.9670867919967 .6623001098667 .0527267456166 .7479400634866 .13836669922 65.8335876464865 .5288009643665 .2240066528364 .9192428588964 .91924285889 64.3096618652364 .004882812564 .6144485473664 .9550094604565 .15697479248 66.44316101074 -9999 -9999 -9999 -9999 -9999 -9999 -9999 -9999 -9999 -9999 -9999 -9999 -9999 -9999 -9999 -9999 -9999 -9999 -9999 -9999 -9999 -9999 -9999 -9999 -9999 -9999 -9999

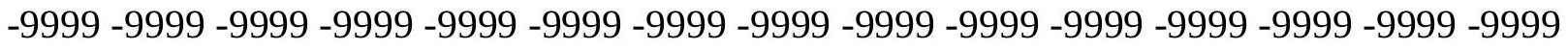

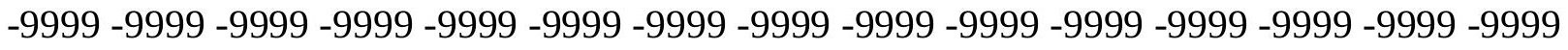
-9999 -9999 -9999-9999-9999 -9999 -9999 -9999 -9999 -9999 -9999 -9999 -9999 -9999 -9999 -9999 -9999 -9999 -9999 -9999 -9999 -9999 -9999 -9999 -9999 -9999 -9999 -9999 -9999 -9999 -9999 -9999 -9999 -9999 -9999 -

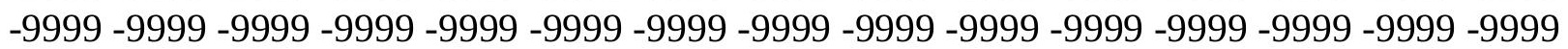


-9999 -9999 -9999 -9999 -9999 -9999 -9999 -9999 -9999 -9999 -9999 -9999 -9999 -9999 -9999 -9999 -9999 -9999 -9999 -9999 -9999 -9999 -9999 -9999 -9999 -9999 -9999 -9999 -9999 -9999 -9999 -9999 -9999 -9999 -9999 -9999 -9999 -9999 -9999 -9999 -9999 -9999 -9999 -9999 -9999 -9999 -9999 -9999 -9999 -9999 -9999 -9999 -9999 -9999 -9999 -9999 -9999 -9999 -9999 -9999 -9999 -9999 -9999 -9999 -9999 -9999 -9999 -9999 -9999 61.87137985229 62.17617034912 62.4809494018662 .7857398986863 .0905189514263 .0905189514263 .39530944824 63.7000885009864 .3096618652365 .8335876464867 .6623001098669 .49101257324 70.7101516723671 .014930725171 .014930725170 .7101516723670 .71015167236 70.7101516723670 .7101516723670 .7101516723670 .4053573608470 .10057830811 69.49101257324 68.57665252686 67.9670867919968.2718734741269.79579162598 73.4532165527378 .3297805786183 .5111236572387 .1685485839889 .3020401001 89.9116134643690.52117919922 91.4355392456192.6546783447394.17859649658 96.0073165893697 .8360290527399 .35994720459100 .8839035034102 .712600708 103.9317016602105 .1509017944106 .3700027466107 .2844009399107 .8938980103 108.1986999512108 .1986999512107 .8938980103107 .5891036987107 .2844009399 106.6747970581106 .3700027466105 .7603988647105 .1509017944104 .2365036011 103.6268997192102 .712600708101 .7982025146100 .579101562599 .35994720459 98.1408081054796 .3121032714894 .1785964965891 .4355392456189 .3020401001 92.9594726562596 .0073165893698 .1408081054799 .3599472045999 .66472625732 99.35994720459 98.445587158297.5312423706196.6168823242295.3977432251 94.7881774902394 .1785964965893 .8738174438593 .8738174438594 .78817749023 96.3121032714898 .4455871582100 .5791015625102 .1029968262103 .0174026489 103.0174026489102 .4077987671102 .4077987671102 .4077987671103 .0174026489 104.5412979126106 .3700027466108 .5035018921110 .0273971558110 .9418029785 111.8561019897112 .4656982422112 .7705001831113 .075302124113 .075302124 112.7705001831112 .4656982422111 .8561019897111 .24659729110 .9418029785 110.3321990967109 .7226028442109 .1130981445108 .5035018921107 .8938980103 107.2844009399 106.3700027466 105.760398864748.15605163574 45.10820007324 42.0603485107439 .3172798156737 .4885711669937 .1837806701737 .18378067017 37.1837806701737 .1837806701737 .1837806701737 .4885711669938 .09814071655 38.7077102661139 .3172798156739 .9268493652340 .5364189147941 .14598846436 41.4507789611841 .7555618286142 .0603485107442 .0603485107442 .06034851074 41.7555618286141 .7555618286141 .4507789611841 .1459884643640 .84120941162 40.5364189147940 .2316398620639 .3172798156736 .8790016174334 .44071960449 32.6120109558132 .3072204589834 .7455101013239 .622070312546 .63212966919 53.3373985290560 .3474502563571 .014930725181 .3776321411190 .21640014648 95.7025299072397 .5312423706196 .9216690063594 .4833908081191 .43553924561 89.302040100187 .4733276367286 .5589828491286 .254188537686 .55898284912 87.16854858398 87.7781066894588.3876876831188.3876876831188.08290100098 88.08290100098 88.6924667358489.302040100189.302040100189.3020401001 88.9972534179788 .0829010009886 .8637619018685 .3398437583 .51112365723 82.2919769287180 .7680587768679 .5489196777378 .3297805786177 .1106262207 75.8914871215874 .6723632812573 .4532165527372 .5388565063571 .62449645996 70.7101516723669 .7957916259869 .1862335205168 .5766525268667 .96708679199 67.3575134277366 .7479400634866 .4431610107465 .8335876464865 .52880096436 65.2240066528364 .9192428588964 .6144485473664 .3096618652364 .30966186523 
64.004882812564 .004882812564 .6144485473664 .9192428588965 .14015960693 66.13836669922 -9999 -9999 -9999 -9999 -9999 -9999 -9999 -9999 -9999 -9999 -9999 -9999 -9999 -9999 -9999 -9999 -9999 -9999 -9999 -9999 -9999 -9999 -9999 -9999 -9999 -9999 -9999 -9999 -9999 -9999 -9999 -9999 -9999 -9999 -9999 -9999 -9999 -9999 -9999 -9999 -9999 -9999

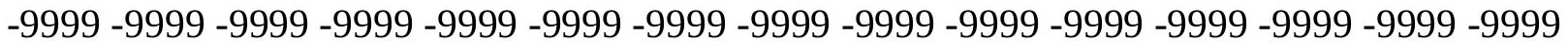
-9999 -9999-9999-9999-9999

-9999 -9999 -9999 -9999 -9999 -9999 -9999 -9999 -9999 -9999 -9999 -9999 -9999 -9999 -9999

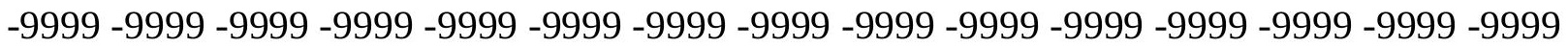

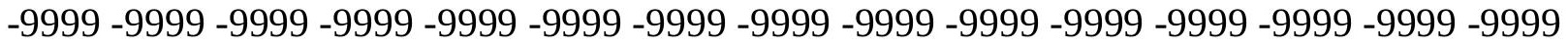
-9999 -9999 -9999 -9999 -9999 -9999 -9999 -9999 -9999 -9999 -9999 -9999 -9999 -9999 -9999

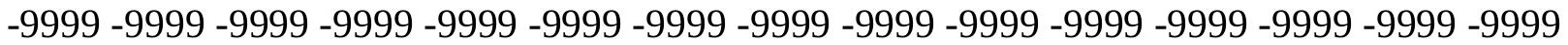
-9999 -9999 -9999 -9999 -9999 -9999 -9999 -9999 -9999 -9999 -9999 -9999 -9999 -9999 -9999 -

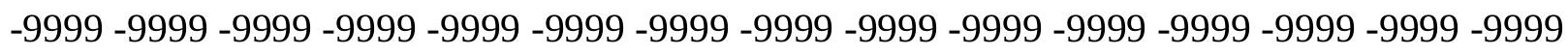
-9999 -9999 -9999 -9999 -9999 -9999 -9999 -9999 -9999 -9999 62.48094940186 62.7857398986862 .7857398986863 .0905189514263 .3953094482463 .70008850098 64.004882812564 .9192428588966 .1383666992267 .6623001098669 .18623352051 70.4053573608471 .014930725171 .3197174072371 .3197174072371 .31971740723 71.3197174072371 .6244964599671 .9292907714871 .9292907714871 .62449645996 70.7101516723669 .7957916259869 .7957916259870 .4053573608472 .23407745361 75.5867080688580 .1584930419985 .3398437589 .9116134643690 .82597351074 90.8259735107491 .1307525634892 .349891662693 .5690307617295 .09295654297 96.6168823242298 .1408081054799 .66472625732101 .1886978149102 .712600708 103.9317016602104 .8460998535105 .7603988647106 .3700027466106 .979598999 106.979598999106 .979598999106 .6747970581106 .3700027466105 .7603988647 105.1509017944104 .5412979126103 .9317016602103 .0174026489102 .1029968262 100.883903503499 .9695205688598 .7503814697397 .2264633178796 .00731658936 94.1785964965892 .349891662689 .9116134643688 .3876876831190 .82597351074 93.8738174438596 .9216690063599 .66472625732101 .1886978149101 .4934005737 100.579101562599 .3599472045998 .1408081054796 .9216690063596 .00731658936 95.0929565429794 .4833908081194 .1785964965894 .4833908081195 .09295654297 96.3121032714897 .5312423706199 .0551681518699 .96952056885100 .8839035034 100.8839035034101 .1886978149101 .1886978149101 .4934005737102 .1029968262 103.0174026489104 .2365036011105 .4557037354106 .3700027466107 .2844009399 108.1986999512108 .8082962036109 .1130981445109 .4179000854109 .7226028442 109.4179000854109 .4179000854108 .8082962036108 .5035018921107 .8938980103 107.5891036987106 .979598999106 .6747970581106 .0652008057105 .4557037354 105.1509017944104 .541297912650 .5943298339846 .9369087219243 .58427047729 40.5364189147936 .5742111206136 .2694282531735 .9646492004435 .65985870361 35.6598587036135 .3550796508835 .3550796508835 .6598587036136 .26942825317 36.8790016174337 .4885711669938 .0981407165538 .4029312133839 .01250076294 39.3172798156739 .622070312539 .9268493652339 .9268493652340 .23163986206 39.9268493652339 .9268493652339 .622070312539 .3172798156739 .01250076294 38.7077102661138 .0981407165536 .8790016174335 .0502891540533 .22158050537 32.0024414062531 .6976509094233 .5263595581137 .1837806701742 .36513137817 48.4608306884856 .0804595947366 .1383666992278 .0249862670988 .99725341797 96.0073165893699 .0551681518699 .3599472045996 .9216690063592 .65467834473 
90.5211791992288 .6924667358487 .4733276367286 .5589828491286 .2541885376 86.254188537686 .254188537686 .5589828491286 .5589828491286 .55898284912 86.5589828491286 .8637619018687 .1685485839887 .4733276367287 .47332763672 86.8637619018686 .254188537685 .0350494384883 .8159103393682 .29197692871 80.7680587768679 .5489196777378 .0249862670976 .8058471679775 .89148712158 74.6723632812573 .4532165527372 .5388565063571 .6244964599670 .71015167236 69.7957916259868 .8814392089868 .2718734741267 .6623001098667 .05272674561 66.4431610107466 .1383666992265 .5288009643665 .2240066528364 .91924285889 64.6144485473664 .3096618652364 .004882812563 .7000885009863 .70008850098 63.3953094482463 .7000885009864 .3096618652364 .9192428588965 .11140441895 65.2188568115266 .44316101074 -9999 -9999 -9999 -9999 -9999 -9999 -9999 -9999 -9999 -9999 -9999 -9999 -9999 -9999 -9999 -9999 -9999 -9999 -9999 -9999 -9999 -9999 -9999 -9999 -9999 -9999 -9999 -9999 -9999 -9999 -9999 -9999 -9999 -9999 -9999 -9999 -9999 -9999 -9999 -9999 -9999 -9999 -9999 -9999 -9999 -9999 -9999 -9999 -9999 -9999 -9999 -9999 -9999 -9999 -9999 -9999 -9999 -9999-9999 -9999-9999

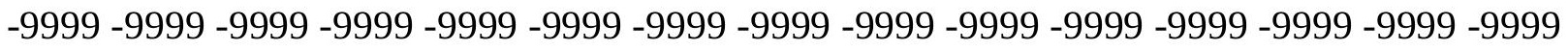
-9999 -9999 -9999 -9999 -9999 -9999 -9999 -9999 -9999 -9999 -9999 -9999 -9999 -9999 -9999 -9999 -9999 -9999 -9999 -9999 -9999 -9999 -9999 -9999 -9999 -9999 -9999 -9999 -9999 -9999 -999 -9999 -9999 -9999 -9999 -9999 -9999 -9999 -9999 -9999 -9999 -9999 -9999 -9999 -9999 -9999

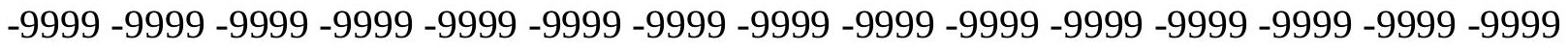
-9999 -9999 -9999 -9999 -9999 -9999 -9999 -9999 -9999 -9999 -9999 -9999 -9999 -9999 -9999 -999 -

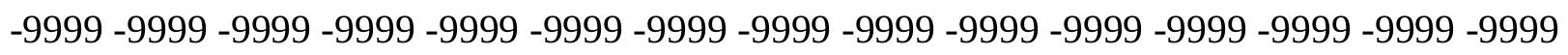
-9999 -9999 -9999 -9999 -9999 -9999 -9999 -9999 -9999 -9999 -9999 62.78573989868 63.0905189514263 .3953094482463 .7000885009864 .004882812564 .61444854736 65.5288009643666 .7479400634867 .9670867919969 .1862335205170 .10057830811 70.7101516723671 .014930725171 .3197174072371 .6244964599671 .92929077148 72.2340774536172 .8436431884873 .4532165527372 .5388565063571 .62449645996 71.014930725171 .014930725171 .9292907714874 .062782287677 .1106262207 81.0728530883885 .3398437588 .9972534179790 .5211791992291 .43553924561 92.0450973510792 .9594726562594 .4833908081195 .7025299072397 .22646331787 98.7503814697399 .96952056885101 .1886978149102 .4077987671103 .6268997192 104.5412979126105 .1509017944105 .7603988647105 .7603988647106 .0652008057 105.7603988647105 .4557037354104 .8460998535104 .2365036011103 .6268997192 102.712600708101 .7982025146100 .883903503499 .6647262573298 .4455871582 97.2264633178795.7025299072394.1785964965892.6546783447390.82597351074 88.99725341797 86.86376190186 88.9972534179792.0450973510795.09295654297 98.14080810547100 .8839035034103 .0174026489102 .4077987671101 .1886978149 99.66472625732 98.445587158297.2264633178796.0073165893695.3977432251 94.7881774902394 .4833908081194 .4833908081195 .0929565429795 .70252990723 96.6168823242297 .5312423706198 .445587158299 .0551681518699 .35994720459 99.6647262573299 .6647262573299 .96952056885100 .5791015625101 .1886978149 101.7982025146102 .712600708103 .3221969604103 .9317016602104 .5412979126 105.1509017944105 .4557037354105 .7603988647106 .0652008057106 .0652008057 106.0652008057105 .7603988647105 .4557037354105 .1509017944104 .8460998535 104.2365036011103 .9317016602103 .6268997192103 .3221969604102 .712600708 102.407798767148 .765621185345 .4129791259842 .0603485107438 .70771026611 
35.3550796508835 .0502891540534 .4407196044934 .4407196044934 .13592910767 34.1359291076734 .1359291076734 .1359291076734 .4407196044935 .05028915405 35.6598587036135 .9646492004436 .5742111206136 .8790016174337 .48857116699 37.7933502197338 .0981407165538 .0981407165538 .4029312133838 .40293121338 38.0981407165537 .7933502197337 .4885711669937 .1837806701736 .57421112061 35.9646492004434 .7455101013233 .5263595581132 .0024414062531 .08807945251 31.0880794525132 .3072204589835 .0502891540539 .0125007629444 .19384002686 51.2038993835460 .3474502563572 .2340774536186 .8637619018694 .48339080811 99.05516815186100 .883903503499 .0551681518695 .397743225191 .74033355713 89.302040100187 .4733276367286 .254188537685 .3398437585 .03504943848 84.7302627563584 .7302627563584 .7302627563584 .7302627563585 .03504943848 85.03504943848 85.33984375 85.33984375 85.33984375 84.73026275635 84.12069702148 83.206336975181.98719787598 80.46327209473 79.24413299561 78.02498626709 76.8058471679775 .5867080688574 .3675689697373 .4532165527372 .23407745361 71.3197174072370 .4053573608469 .4910125732468 .5766525268667 .96708679199 67.3575134277366 .7479400634866 .1383666992265 .5288009643665 .22400665283 64.9192428588964 .3096618652364 .004882812563 .7000885009863 .70008850098 63.3953094482463 .0905189514263 .0905189514263 .0905189514263 .70008850098 64.004882812564 .6144485473664 .9192428588965 .1833419799866 .13836669922 -9999 -9999 -9999 -9999 -9999 -9999 -9999 -9999 -9999 -9999 -9999 -9999 -9999 -9999 -9999 -9999

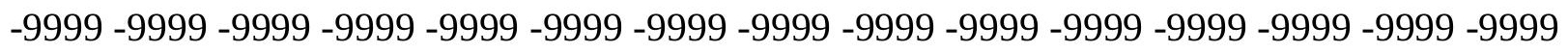
-9999 -9999 -9999 -9999 -9999 -9999 -9999 -9999 -9999 -9999 -9999 -9999 -9999 -9999 -9999 -9999 -9999 -9999 -9999 -9999 -9999 -9999 -9999 -9999 -9999 -9999 -9999 -9999 -9999 -9999 -

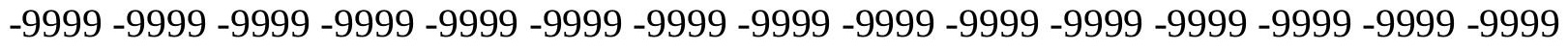

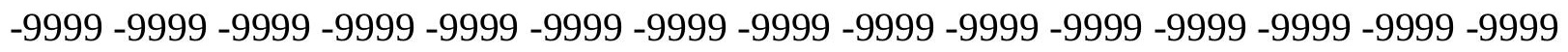
-9999 -9999 -9999 -9999 -9999 -9999 -9999 -9999 -9999 -9999 -9999 -9999 -9999 -9999 -9999 -

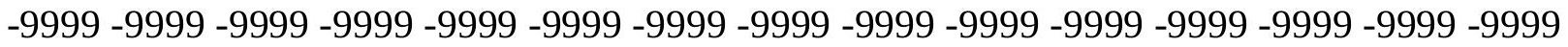

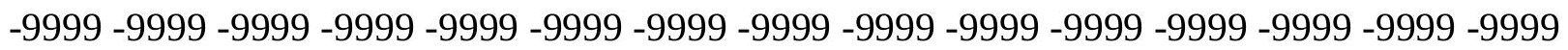
-9999 -9999 -9999 -9999 -9999 -9999 -9999 -9999 -9999 -9999 -9999 -9999 -9999 -9999 -9999 -9999 -9999 -9999 -9999 -9999 -9999 -9999 -9999 -9999 -9999 -9999 -9999 -9999 -9999 -9999 -9999 -9999 -9999 -9999 -9999 -9999 -9999 -9999 -9999 -9999 -9999 63.09051895142 63.3953094482463 .7000885009864 .004882812564 .3096618652365 .22400665283 65.8335876464866 .7479400634867 .9670867919968 .8814392089869 .79579162598 70.4053573608470 .7101516723671 .014930725171 .3197174072371 .62449645996 72.2340774536172 .5388565063572 .8436431884872 .5388565063571 .92929077148 71.6244964599671 .9292907714873 .1484298706174 .9771423339877 .72020721436 81.0728530883884 .4254837036187 .1685485839889 .302040100190 .52117919922 92.04509735107 93.2642517089894.7881774902396.3121032714897.53124237061 99.05516815186100 .2742996216101 .4934005737102 .4077987671103 .3221969604 103.9317016602104 .5412979126104 .8460998535104 .8460998535104 .8460998535 104.5412979126103 .9317016602103 .3221969604102 .712600708101 .7982025146 100.883903503499 .9695205688598 .7503814697397 .5312423706196 .00731658936 94.4833908081192 .9594726562591 .1307525634889 .6068267822388 .08290100098 86.254188537686 .8637619018690 .2164001464893 .5690307617296 .31210327148 99.05516815186100 .8839035034102 .1029968262101 .7982025146100 .8839035034 99.35994720459 98.1408081054796.9216690063596.0073165893695.09295654297 
94.7881774902394 .4833908081194 .4833908081194 .7881774902395 .09295654297 95.7025299072396 .3121032714896 .9216690063597 .2264633178797 .83602905273 97.8360290527398 .1408081054798 .445587158298 .7503814697399 .05516815186 99.6647262573299 .96952056885100 .2742996216100 .5791015625101 .1886978149 101.4934005737101 .7982025146102 .4077987671102 .712600708102 .712600708 102.712600708102 .4077987671102 .4077987671102 .1029968262101 .7982025146 101.4934005737101 .4934005737101 .1886978149100 .8839035034100 .5791015625 100.274299621648 .765621185344 .1938400268640 .2316398620637 .48857116699 34.4407196044933 .8311500549333 .2215805053733 .2215805053732 .91679000854 32.9167900085432 .6120109558132 .9167900085432 .9167900085433 .52635955811 33.8311500549334 .1359291076734 .7455101013235 .0502891540535 .65985870361 35.9646492004436 .2694282531736 .5742111206136 .5742111206136 .57421112061 36.5742111206136 .2694282531735 .9646492004435 .3550796508834 .74551010132 34.1359291076733 .2215805053732 .0024414062530 .7833003997830 .17373085022 30.1737308502231 .0880794525132 .9167900085435 .9646492004440 .53641891479 46.3273391723653 .6421813964862 .4809494018677 .4154205322389 .60682678223 97.53124237061100 .274299621699 .9695205688595 .397743225191 .43553924561 88.6924667358486 .8637619018685 .3398437584 .4254837036183 .51112365723 83.2063369751 83.2063369751 83.206336975183.2063369751 83.206336975183.2063369751 83.5111236572383 .5111236572383 .206336975182 .5967712402381 .98719787598 81.0728530883880 .1584930419978 .9393463134877 .7202072143676 .50106811523 75.2819290161174 .062782287673 .1484298706171 .9292907714871 .0149307251 70.1005783081169 .1862335205168 .2718734741267 .6623001098666 .74794006348 66.1383666992265 .8335876464865 .2240066528364 .6144485473664 .30966186523 64.004882812563 .7000885009863 .3953094482463 .0905189514262 .78573989868 62.4809494018662 .4809494018662 .4809494018662 .7857398986863 .39530944824 64.004882812564 .3096618652364 .9192428588965 .1064224243265 .1978225708 -9999 -9999 -9999 -9999 -9999 -9999 -9999 -9999 -9999 -9999 -9999 -9999 -9999 -9999 -9999 -9999 -9999 -9999 -9999 -9999 -9999 -9999 -9999 -9999 -9999 -9999 -9999 -9999 -9999 -9999 -9999 -9999 -9999 -9999 -9999 -9999 -9999 -9999 -9999 -9999 -9999 -9999 -9999 -9999 -9999 -9999 -9999 -9999 -9999 -9999 -9999 -9999 -9999 -9999 -9999 -9999 -9999 -9999 -9999 -9999 - 9999 -9999 -9999 -9999 -9999 -9999 -9999 -9999 -9999 -9999 -9999 -9999 -9999 -9999 -9999 -9999 -

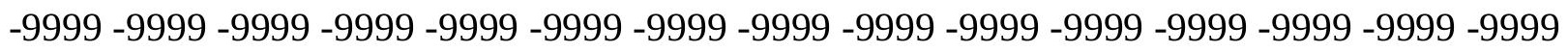
-9999 -9999 -9999 -9999 -9999 -9999 -9999 -9999 -9999 -9999 -9999 -9999 -9999 -9999 -9999 -9999 -9999 -9999 -9999 -9999 -9999 -9999 -9999 -9999 -9999 -9999 -9999 -9999 -9999 -9999 -

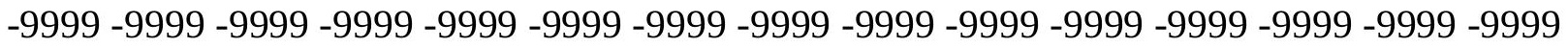

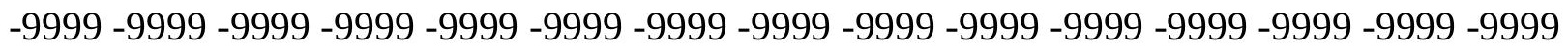

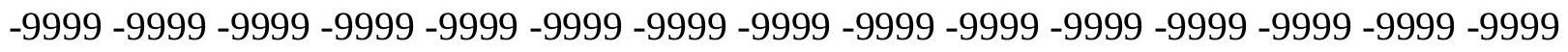
-9999 -9999-9999 -9999 -9999 -9999 -9999 -9999 -9999 -9999 -9999 -9999 63.39530944824 63.7000885009864 .3096618652364 .6144485473665 .5288009643666 .13836669922 67.0527267456167 .9670867919968 .8814392089869 .4910125732469 .79579162598 70.4053573608470 .4053573608470 .7101516723671 .014930725171 .31971740723 71.6244964599671 .6244964599671 .6244964599671 .6244964599671 .62449645996 71.9292907714873 .1484298706174 .9771423339877 .110626220779 .85370635986 82.5967712402385 .0350494384887 .1685485839888 .9972534179791 .13075256348 92.9594726562594 .7881774902396 .3121032714897 .8360290527399 .05516815186 
100.2742996216101 .1886978149102 .1029968262102 .712600708103 .3221969604 103.6268997192103 .9317016602103 .9317016602103 .6268997192103 .3221969604 102.712600708102 .1029968262101 .1886978149100 .274299621699 .05516815186 97.8360290527396 .6168823242295 .397743225193 .8738174438592 .3498916626 90.5211791992288 .9972534179787 .1685485839885 .6446228027384 .73026275635 88.0829010009891 .7403335571394 .7881774902397 .2264633178799 .05516815186 100.2742996216100 .8839035034100 .579101562599 .6647262573298 .4455871582 97.22646331787 96.3121032714895.397743225194.4833908081194.17859649658 93.8738174438593 .8738174438594 .1785964965894 .4833908081194 .78817749023 95.0929565429795 .7025299072396 .0073165893696 .0073165893696 .31210327148 96.6168823242296 .6168823242296 .9216690063596 .9216690063597 .22646331787 97.2264633178797 .2264633178797 .5312423706197 .5312423706197 .83602905273 98.445587158298 .7503814697399 .0551681518699 .3599472045999 .35994720459 99.3599472045999 .0551681518699 .0551681518699 .0551681518698 .75038146973 98.7503814697398 .445587158298 .445587158298 .1408081054753 .03261184692 47.8512611389242 .9747009277339 .0125007629434 .1359291076733 .22158050537 32.6120109558132 .3072204589832 .0024414062532 .0024414062531 .69765090942 31.6976509094231 .6976509094231 .6976509094232 .0024414062532 .30722045898 32.6120109558132 .9167900085433 .2215805053733 .8311500549334 .13592910767 34.4407196044935 .0502891540535 .0502891540535 .0502891540535 .05028915405 35.0502891540534 .4407196044934 .1359291076733 .5263595581132 .61201095581 31.6976509094230 .7833003997829 .8689403533929 .2593708038328 .95458984375 29.5641593933131 .0880794525133 .5263595581137 .1837806701741 .75556182861 48.1560516357456 .6900291442968 .2718734741281 .9871978759893 .87381744385 96.3121032714895 .397743225192 .0450973510789 .6068267822387 .16854858398 85.0350494384883 .8159103393682 .5967712402381 .9871978759881 .37763214111 81.37763214111 81.3776321411181.37763214111 81.37763214111 81.37763214111 81.3776321411181 .3776321411181 .0728530883880 .4632720947379 .85370635986 78.9393463134878 .0249862670977 .110626220775 .8914871215874 .67236328125 73.7580032348672 .5388565063571 .6244964599670 .7101516723669 .49101257324 68.8814392089867 .9670867919967 .0527267456166 .4431610107465 .83358764648 65.2240066528364 .6144485473664 .3096618652363 .7000885009863 .39530944824 63.0905189514262 .7857398986862 .7857398986862 .4809494018662 .17617034912 61.8713798522961 .8713798522962 .4809494018662 .7857398986863 .39530944824 63.7000885009864 .3096618652364 .6144485473664 .9192428588965 .13053894043 65.83358764648 -9999 -9999 -9999 -9999 -9999 -9999 -9999 -9999 -9999 -9999 -9999 -9999

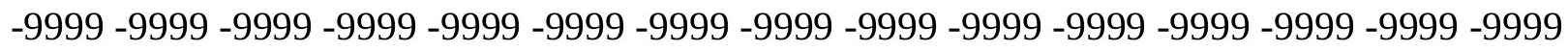

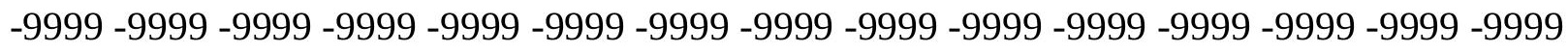
-9999 -9999 -9999 -9999 -9999 -9999 -9999 -9999 -9999 -9999 -9999 -9999 -9999 -9999 -9999 -9999 -9999-9999

-9999 -9999 -9999 -9999 -9999 -9999 -9999 -9999 -9999 -9999 -9999 -9999 -9999 -9999 - 9999 -

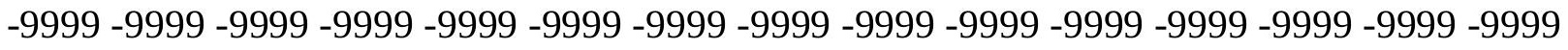
-9999 -9999 -9999 -9999 -9999 -9999 -9999 -9999 -9999 -9999 -9999 -9999 -9999 -9999 -9999 -9999 -9999 -9999 -9999 -9999 -9999 -9999 -9999 -9999 -9999 -9999 -9999 -9999 -9999 -9999 -

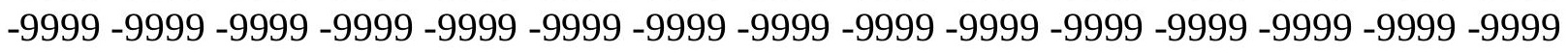

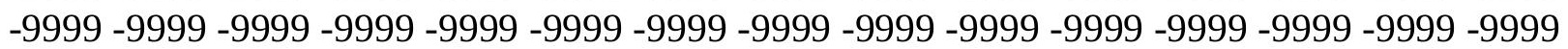


-9999 -9999 -9999 -9999 -9999 -9999 -9999 -9999 -9999 -9999 -9999 -9999 -9999 -9999 -9999 -9999 -9999 -9999 -9999 -9999 -9999 -9999 -9999 -9999 -9999 -9999 -9999 63.39530944824 64.004882812564 .3096618652364 .9192428588965 .5288009643666 .44316101074 67.0527267456167 .9670867919968 .5766525268668 .8814392089869 .49101257324 69.7957916259869 .7957916259870 .1005783081170 .1005783081170 .40535736084 70.4053573608470 .4053573608470 .4053573608470 .4053573608470 .71015167236 71.3197174072372 .5388565063573 .7580032348675 .8914871215878 .02498626709 80.1584930419982 .2919769287184 .4254837036186 .5589828491289 .3020401001 92.0450973510793 .8738174438595 .7025299072397 .5312423706198 .75038146973 99.96952056885100 .8839035034101 .7982025146102 .4077987671102 .712600708 103.0174026489103 .0174026489102 .712600708102 .4077987671102 .1029968262 101.4934005737100 .579101562599 .6647262573298 .7503814697397 .53124237061 96.3121032714894 .7881774902393 .5690307617292 .0450973510790 .21640014648 88.6924667358486 .8637619018685 .3398437583 .8159103393685 .94940185547 89.9116134643693.5690307617296.0073165893697.5312423706198.75038146973 99.3599472045999.3599472045998.75038146973 98.1408081054796.92166900635 96.0073165893695 .0929565429794 .1785964965893 .8738174438593 .26425170898 93.2642517089893 .2642517089893 .2642517089893 .5690307617293 .87381744385 93.8738174438594 .1785964965894 .4833908081194 .4833908081194 .78817749023 94.7881774902394 .7881774902394 .7881774902394 .7881774902394 .48339080811 94.4833908081194 .4833908081194 .1785964965894 .1785964965894 .48339080811 94.7881774902395 .397743225195 .7025299072396 .0073165893696 .00731658936 96.0073165893696 .0073165893696 .0073165893696 .0073165893696 .00731658936 96.0073165893696 .0073165893696 .0073165893696 .0073165893651 .81346893311 46.0225486755441 .7555618286137 .4885711669933 .2215805053732 .00244140625 31.3928699493431 .0880794525131 .0880794525131 .0880794525130 .78330039978 30.4785099029530 .4785099029530 .4785099029530 .4785099029530 .78330039978 31.0880794525131 .3928699493431 .6976509094232 .0024414062532 .61201095581 32.9167900085433 .5263595581133 .8311500549333 .8311500549333 .83115005493 33.8311500549333 .2215805053732 .9167900085432 .3072204589831 .39286994934 30.4785099029529 .5641593933128 .9545898437528 .3450202941928 .04022979736 28.3450202941929 .5641593933131 .3928699493434 .4407196044938 .40293121338 43.8890609741250 .8991203308159 .1283111572372 .8436431884883 .51112365723 88.38768768311 88.9972534179787.77810668945 85.9494018554784.12069702148 82.5967712402381 .3776321411180 .4632720947379 .8537063598679 .24413299561 79.2441329956179 .2441329956179 .2441329956179 .2441329956179 .24413299561 79.2441329956179 .2441329956178 .9393463134878 .3297805786177 .72020721436 76.8058471679775 .8914871215874 .9771423339874 .062782287673 .14842987061 71.9292907714871 .014930725170 .1005783081169 .1862335205168 .27187347412 67.3575134277366 .7479400634865 .8335876464865 .2240066528364 .61444854736 64.3096618652363 .7000885009863 .3953094482463 .0905189514262 .78573989868 62.4809494018662 .1761703491261 .8713798522961 .5666007995661 .56660079956 61.5666007995661 .8713798522962 .4809494018662 .7857398986863 .09051895142 63.7000885009864 .004882812564 .3096618652364 .9192428588965 .02531433105 65.06209564209 -9999 -9999 -9999 -9999 -9999 -9999 -9999 -9999 -9999 -9999 -9999 -9999 -9999 -9999 -9999 -9999 -9999 -9999 -9999 -9999 -9999 -9999 -9999 -9999 -9999 -9999 -9999 
-9999 -9999 -9999 -9999 -9999 -9999 -9999 -9999 -9999 -9999 -9999 -9999 -9999 -9999 -9999 -9999 -9999 -9999 -9999 -9999 -9999 -9999 -9999 -9999 -9999 -9999 -9999 -9999 -9999 -9999 -9999-9999-9999

-9999 -9999 -9999 -9999 -9999 -9999 -9999 -9999 -9999 -9999 -9999 -9999 -9999 -9999 -9999 -9999 -9999 -9999 -9999 -9999 -9999 -9999 -9999 -9999 -9999 -9999 -9999 -9999 - -9999 - -9999 -9999 -9999 -9999 -9999 -9999 -9999 -9999 -9999 -9999 -9999 -9999 -9999 -9999 -9999 -9999 -9999 -9999 -9999 -9999 -9999 -9999 -9999 -9999 -9999 -9999 -9999 -9999 -9999 -9999 -9999 -9999 -9999 -9999 -9999 -9999 -9999 -9999 -9999 -9999 -9999 -9999 -9999 -9999 -9999 -9999 -9999 -9999 -9999 -9999 -9999 -9999 -9999 -9999 -9999 -9999 -9999 -9999 -9999 -9999 -9999

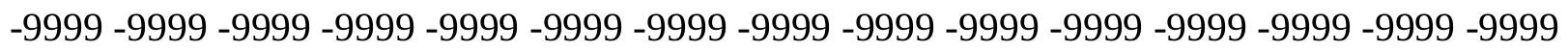
-9999 -9999 -9999 -9999 -9999 -9999 -9999 -9999 -9999 -9999 -9999 -9999 -9999 64.004882812564 .6144485473665 .2240066528365 .8335876464866 .44316101074 67.0527267456167 .6623001098668 .2718734741268 .5766525268668 .88143920898 68.8814392089869 .1862335205169 .1862335205169 .1862335205168 .88143920898 68.8814392089868 .8814392089868 .8814392089869 .1862335205169 .49101257324 70.1005783081171 .014930725172 .5388565063574 .062782287675 .58670806885 77.4154205322379 .2441329956181 .0728530883883 .5111236572386 .55898284912 89.9116134643692.6546783447395.0929565429796.92166900635 98.4455871582 99.66472625732100 .5791015625101 .1886978149101 .7982025146102 .1029968262 102.1029968262102 .1029968262101 .7982025146101 .4934005737100 .8839035034 99.9695205688599 .3599472045998 .1408081054797 .2264633178796 .00731658936 94.4833908081193 .2642517089891 .7403335571390 .2164001464888 .69246673584 86.8637619018685 .3398437583 .8159103393683 .5111236572387 .16854858398 91.4355392456195 .7025299072396 .6168823242297 .2264633178797 .53124237061 97.8360290527397 .5312423706196 .9216690063596 .0073165893695 .09295654297 94.1785964965893 .5690307617292 .9594726562592 .6546783447392 .3498916626 92.349891662692 .349891662692 .349891662692 .349891662692 .65467834473 92.6546783447392 .9594726562592 .9594726562592 .9594726562592 .95947265625 92.9594726562592 .6546783447392 .6546783447392 .349891662692 .3498916626 92.0450973510791 .7403335571391 .1307525634890 .8259735107491 .43553924561 91.7403335571392 .0450973510792 .349891662692 .6546783447392 .95947265625 92.9594726562592 .9594726562592 .9594726562592 .9594726562593 .26425170898 93.2642517089893.2642517089893.2642517089856.38525009155 49.98476028442 43.5842704772937 .4885711669934 .1359291076732 .3072204589831 .08807945251 30.1737308502229 .8689403533929 .8689403533930 .1737308502229 .86894035339 29.5641593933129 .2593708038329 .2593708038329 .2593708038329 .25937080383 29.5641593933129 .8689403533930 .1737308502230 .4785099029531 .08807945251 31.6976509094232 .3072204589832 .6120109558132 .6120109558132 .61201095581 32.6120109558132 .3072204589832 .0024414062531 .3928699493430 .47850990295 29.8689403533928 .9545898437528 .0402297973627 .430660247827 .4306602478 27.430660247828 .3450202941930 .1737308502232 .6120109558135 .96464920044 40.8412094116247 .2416992187555 .1661109924365 .2240066528373 .75800323486 79.2441329956181 .6824111938582 .2919769287181 .6824111938580 .46327209473 79.5489196777378 .3297805786177 .7202072143677 .110626220777 .1106262207 77.1106262207 77.1106262207 77.1106262207 77.41542053223 77.41542053223 77.110626220776 .8058471679776 .5010681152376 .1962814331175 .58670806885 
74.6723632812574 .062782287673 .1484298706172 .2340774536171 .31971740723 70.4053573608469 .4910125732468 .5766525268667 .6623001098666 .74794006348 66.1383666992265 .5288009643664 .9192428588964 .3096618652363 .70008850098 63.0905189514262 .7857398986862 .4809494018662 .1761703491261 .87137985229 61.5666007995661 .5666007995661 .2618103027360 .9570198059161 .26181030273 61.5666007995661 .8713798522962 .4809494018662 .7857398986863 .09051895142 63.3953094482464 .004882812564 .3096618652364 .6144485473664 .81312561035 64.93489074707 -9999 -9999 -9999 -9999 -9999 -9999 -9999 -9999 -9999 -9999 -9999 -9999 -9999 -9999 -9999 -9999 -9999-9999 -9999 -9999 -9999 -9999 -9999 -9999 -9999 -9999 -9999 -9999 -9999 -9999 -9999 -9999 -9999 -9999 -9999 -9999 -9999 -9999 -9999 -9999 -9999 -9999 -

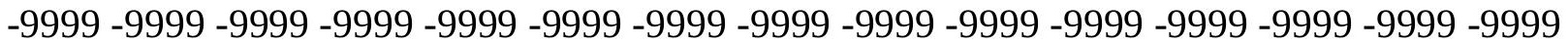
-9999 -9999-9999

-9999 -9999 -9999 -9999 -9999 -9999 -9999 -9999 -9999 -9999 -9999 -9999 -9999 -9999 -9999 -9999 -9999 -9999 -9999 -9999 -9999 -9999 -9999 -9999 -9999 -9999 -9999 -9999 -9999 -9999 -9999 -9999 -9999 -9999 -9999 -9999 -9999 -9999 -9999 -9999 -9999 -9999 -9999 -9999 -9999

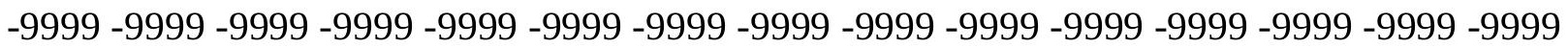

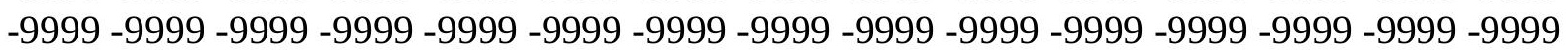
-9999 -9999 -9999 -9999 -9999 -9999 -9999 -9999 -9999 -9999 -9999 -9999 -9999 -9999 -9999 -999 -9999 -9999 -9999 -9999 -9999 -9999 -9999 -9999 -9999 -9999 -9999 -9999 -9999 -9999 -9999 -9999 -9999 -9999 -9999 -9999 -9999 -9999 -9999 -9999 -9999 -9999 -9999 -9999 -9999 64.6144485473665 .2240066528366 .1383666992266 .7479400634867 .35751342773 67.6623001098668 .2718734741268 .2718734741268 .5766525268668 .27187347412 68.2718734741267 .9670867919967 .9670867919967 .6623001098667 .66230010986 67.3575134277367 .3575134277367 .6623001098667 .9670867919968 .57665252686 69.4910125732470 .7101516723671 .9292907714873 .1484298706174 .67236328125 75.8914871215877 .7202072143680 .1584930419983 .5111236572387 .47332763672 91.1307525634893 .8738174438596 .3121032714897 .8360290527399 .05516815186 99.96952056885100 .5791015625101 .1886978149101 .1886978149101 .1886978149 101.1886978149100 .8839035034100 .274299621699 .6647262573299 .05516815186 98.1408081054796 .9216690063595 .7025299072394 .4833908081193 .26425170898 91.7403335571390 .5211791992288 .9972534179787 .1685485839885 .64462280273 84.1206970214884 .1206970214885 .6446228027388 .3876876831191 .74033355713 94.4833908081196 .0073165893696 .3121032714896 .0073165893695 .70252990723 95.0929565429794 .4833908081193 .8738174438592 .9594726562592 .3498916626 91.7403335571391 .4355392456191 .1307525634891 .1307525634891 .13075256348 91.1307525634891 .1307525634891 .1307525634891 .4355392456191 .43553924561 91.4355392456191 .4355392456191 .4355392456191 .1307525634890 .82597351074 90.5211791992290 .2164001464890 .2164001464889 .9116134643689 .60682678223 89.3020401001 88.69246673584 88.38768768311 88.69246673584 88.99725341797 89.302040100189 .302040100189 .6068267822389 .9116134643689 .91161346436 89.9116134643689 .9116134643690 .2164001464890 .2164001464890 .52117919922 90.5211791992290 .8259735107454 .5565414428747 .2416992187540 .23163986206 35.9646492004433 .2215805053731 .0880794525129 .8689403533929 .25937080383 28.9545898437528 .9545898437528 .9545898437528 .6497993469228 .34502029419 28.0402297973627 .7354507446328 .0402297973628 .0402297973628 .34502029419 28.6497993469228 .9545898437529 .2593708038330 .1737308502230 .78330039978 
31.0880794525131 .3928699493431 .6976509094231 .6976509094231 .69765090942 31.6976509094231 .3928699493430 .7833003997830 .1737308502229 .25937080383 28.3450202941927 .7354507446327 .1258792877226 .8210906982427 .12587928772 27.7354507446329 .2593708038331 .3928699493434 .4407196044939 .01250076294 44.4986305236851 .8134689331159 .4331016540566 .1383666992271 .0149307251 74.3675689697375 .8914871215876 .5010681152376 .5010681152375 .89148712158 75.2819290161174 .6723632812574 .6723632812574 .6723632812574 .97714233398 74.9771423339874 .9771423339875 .2819290161174 .9771423339874 .97714233398 74.6723632812574 .3675689697374 .062782287673 .4532165527372 .53885650635 71.9292907714871 .014930725170 .4053573608469 .4910125732468 .57665252686 67.9670867919967 .0527267456166 .1383666992265 .5288009643664 .91924285889 64.3096618652363 .7000885009863 .0905189514262 .7857398986862 .17617034912 61.8713798522961 .5666007995661 .5666007995661 .2618103027360 .95701980591 60.9570198059160 .6522407531760 .9570198059161 .2618103027361 .56660079956 61.8713798522962 .4809494018662 .7857398986863 .0905189514263 .39530944824 63.7000885009864 .004882812564 .3096618652364 .6144485473664 .83489990234 -9999 -9999 -9999 -9999 -9999 -9999 -9999 -9999 -9999 -9999 -9999 -9999 -9999 -9999 -9999 -9999 -9999 -9999 -9999 -9999 -9999 -9999 -9999 -9999 -9999 -9999 -9999 -9999 -9999 -9999 -9999 -999 -

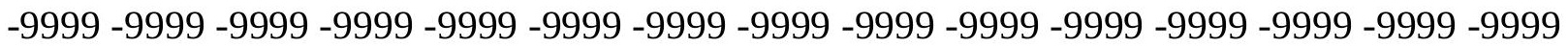
-9999 -9999 -9999 -9999 -9999 -9999 -9999 -9999 -9999 -9999 -9999 -9999 -9999 -9999 -9999 -9999 -9999 -9999 -9999 -9999 -9999 -9999 -9999 -9999 -9999 -9999 -9999 -9999 -9999 -9999 -9999 -9999 -9999 -9999 -9999 -9999 -9999 -9999 -9999 -9999 -9999 -9999 -9999 -9999 -9999 -9999 -9999 -9999 -9999 -9999 -9999 -9999 -9999 -9999 -9999 -9999-9999-9999-9999 -999 -9999 -9999 -9999 -9999 -9999 -9999 -9999 -9999 -9999 -9999 -9999 -9999 -9999 -9999 -9999 -9999 -9999 -9999 -9999 -9999 -9999 -9999 -9999 -9999 -9999 -9999 -9999 -9999 -9999 -9999 -9999 -9999 -9999 -9999 -9999 -9999 -9999 -9999 -9999 -9999 -9999 -9999 -9999 -9999 -9999

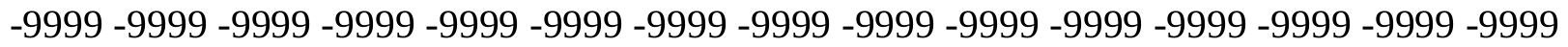
-9999 -9999 -9999 -9999 -9999 -9999 -9999 -9999 -9999 -9999 -9999 -9999 -9999 -9999 64.9192428588965 .5288009643666 .4431610107467 .0527267456167 .66230010986 67.9670867919968 .2718734741268 .2718734741267 .9670867919967 .96708679199 67.3575134277367 .0527267456166 .7479400634866 .4431610107466 .13836669922 65.8335876464865 .8335876464866 .1383666992266 .4431610107467 .05272674561 67.6623001098668 .5766525268669 .7957916259870 .7101516723671 .92929077148 73.1484298706174 .6723632812576 .5010681152380 .7680587768685 .33984375 89.60682678223 92.9594726562595.397743225197.2264633178798.4455871582 99.3599472045999 .96952056885100 .2742996216100 .5791015625100 .5791015625 100.274299621699 .9695205688599 .3599472045998 .7503814697397 .83602905273 96.9216690063595 .7025299072394 .4833908081193 .2642517089892 .04509735107 90.5211791992289 .302040100187 .7781066894586 .254188537685 .3398437585 .33984375 85.9494018554787 .1685485839889 .302040100191 .7403335571393 .56903076172 94.4833908081194 .4833908081194 .1785964965893 .5690307617292 .95947265625 92.0450973510791 .4355392456190 .8259735107490 .2164001464889 .91161346436 89.9116134643689 .9116134643689 .9116134643689 .9116134643689 .91161346436 89.9116134643689 .9116134643689 .9116134643689 .9116134643689 .91161346436 89.9116134643689 .6068267822389 .302040100188 .9972534179788 .69246673584 88.38768768311 88.08290100098 87.77810668945 87.47332763672 86.86376190186 
86.55898284912 86.2541885376 86.2541885376 86.2541885376 86.55898284912 86.8637619018686 .8637619018687 .1685485839887 .1685485839887 .16854858398 87.1685485839887 .4733276367287 .4733276367287 .7781066894587 .77810668945 88.0829010009852 .4230384826744 .1938400268638 .0981407165535 .05028915405 32.3072204589830 .1737308502228 .9545898437528 .3450202941928 .04022979736 27.7354507446327 .430660247827 .430660247827 .1258792877226 .82109069824 26.8210906982426 .5163097381626 .8210906982427 .1258792877227 .4306602478 27.7354507446328 .3450202941928 .9545898437529 .8689403533930 .17373085022 30.4785099029530 .4785099029530 .7833003997831 .0880794525131 .08807945251 30.7833003997830 .4785099029529 .8689403533928 .9545898437528 .34502029419 27.7354507446327 .1258792877226 .8210906982427 .1258792877227 .73545074463 28.9545898437530 .7833003997833 .5263595581137 .4885711669942 .36513137817 48.1560516357454 .2517509460459 .7378807067963 .7000885009867 .66230010986 70.1005783081171 .6244964599672 .2340774536172 .2340774536171 .92929077148 71.6244964599671 .9292907714872 .2340774536172 .5388565063572 .84364318848 72.8436431884873 .1484298706172 .8436431884872 .8436431884872 .53885650635 72.2340774536171 .6244964599671 .3197174072370 .7101516723670 .10057830811 69.1862335205168 .5766525268667 .6623001098667 .0527267456166 .44316101074 65.5288009643664 .9192428588964 .3096618652363 .7000885009863 .39530944824 62.7857398986862 .1761703491261 .8713798522961 .5666007995661 .26181030273 60.9570198059160 .9570198059160 .6522407531760 .6522407531760 .65224075317 60.9570198059161 .2618103027361 .5666007995661 .8713798522962 .17617034912 62.4809494018662 .7857398986863 .0905189514263 .3953094482463 .70008850098 64.004882812564 .3096618652364 .6144485473664 .7529907226664 .83693695068 -9999 -9999 -9999 -9999 -9999 -9999 -9999 -9999 -9999 -9999 -9999 -9999 -9999 -9999 -9999 -9999 -9999 -9999 -9999 -9999 -9999 -9999 -9999 -9999 -9999 -9999 -9999 -9999 -9999 -9999 -9999 -

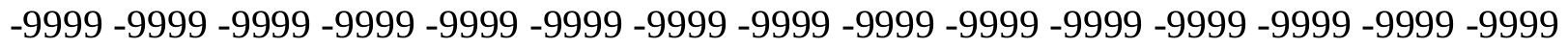

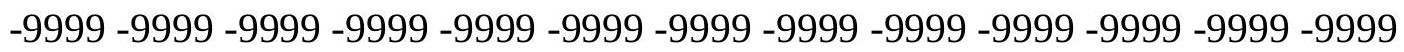

-9999 -9999 -9999 -9999 -9999 -9999 -9999 -9999 -9999 -9999 -9999 -9999 -9999 -9999 -9999 -9999 -9999 -9999 -9999 -9999 -9999 -9999 -9999 -9999 -9999 -9999 -9999 -9999 -9999 -9999 -9999 -9999 -9999 -9999 -9999 -9999 -9999 -9999 -9999 -9999 -9999 -9999-9999 -9999 -9999 -9999 -9999 -9999 -9999 -9999 -9999 -9999 -9999 -9999 -9999 -9999 -9999 -9999 -9999 -9999 -

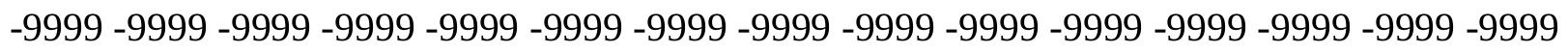
-9999 -9999 -9999 -9999 -9999 -9999 -9999 -9999 -9999 -9999 -9999 -9999 -9999 -9999 -9999 -9999 -9999 -9999 -9999 -9999 -9999 -9999 -9999 -9999 -9999 -9999 -9999 -9999 -9999 -9999 -9999 -9999 -9999 -9999 -9999-9999 -9999 -9999 -9999 -9999 -9999 -9999 -9999 -9999 - -9999 66.1383666992266 .7479400634867 .3575134277367 .9670867919968 .27187347412 68.2718734741268 .2718734741267 .9670867919967 .3575134277366 .74794006348 66.1383666992265 .5288009643665 .2240066528364 .6144485473664 .30966186523 64.3096618652364 .3096618652364 .6144485473665 .2240066528365 .83358764648 66.7479400634867 .6623001098668 .8814392089870 .1005783081171 .31971740723 72.8436431884875 .2819290161178 .9393463134883 .5111236572388 .08290100098 92.0450973510794 .1785964965896 .0073165893697 .2264633178798 .14080810547 99.0551681518699 .3599472045999 .6647262573299 .6647262573299 .35994720459 99.0551681518698 .445587158297 .8360290527396 .9216690063596 .00731658936 94.7881774902393 .5690307617292 .349891662690 .8259735107489 .60682678223 
88.38768768311 87.77810668945 86.86376190186 86.8637619018686.86376190186 87.4733276367288 .6924667358489 .9116134643691 .4355392456192 .3498916626 92.9594726562592 .6546783447392 .0450973510791 .4355392456190 .52117919922 89.60682678223 88.9972534179788.69246673584 88.38768768311 88.38768768311 88.38768768311 88.38768768311 88.38768768311 88.38768768311 88.38768768311 88.6924667358488 .6924667358488 .6924667358488 .3876876831188 .38768768311 88.0829010009888 .0829010009887 .7781066894587 .4733276367286 .86376190186 86.5589828491286 .254188537685 .6446228027385 .3398437585 .03504943848 84.4254837036184 .4254837036184 .1206970214884 .1206970214884 .12069702148 84.1206970214884 .4254837036184 .4254837036184 .4254837036184 .73026275635 84.7302627563584 .7302627563584 .7302627563584 .7302627563585 .03504943848 85.0350494384849 .6799812316939 .622070312536 .8790016174333 .83115005493 31.3928699493429 .5641593933128 .3450202941927 .430660247827 .12587928772 26.8210906982426 .5163097381626 .2115192413325 .906740188625 .60194969177 25.6019496917725 .6019496917725 .6019496917725 .906740188626 .21151924133 26.5163097381627 .430660247828 .0402297973628 .9545898437529 .25937080383 29.2593708038329 .5641593933129 .8689403533930 .1737308502230 .47850990295 30.4785099029529 .8689403533929 .2593708038328 .6497993469228 .04022979736 27.7354507446327 .1258792877227 .1258792877227 .430660247827 .73545074463 28.9545898437530 .7833003997833 .2215805053736 .5742111206140 .53641891479 45.4129791259850 .2895507812554 .8613204956158 .8235282897962 .17617034912 65.2240066528367 .0527267456168 .2718734741268 .8814392089869 .18623352051 69.1862335205169 .7957916259870 .1005783081170 .4053573608470 .71015167236 71.014930725171 .014930725170 .7101516723670 .7101516723670 .40535736084 70.1005783081169 .7957916259869 .1862335205168 .5766525268667 .96708679199 67.3575134277366 .7479400634866 .1383666992265 .5288009643664 .91924285889 64.3096618652363 .7000885009863 .0905189514262 .7857398986862 .48094940186 61.8713798522961 .5666007995661 .2618103027360 .9570198059160 .65224075317 60.6522407531760 .3474502563560 .3474502563560 .3474502563560 .65224075317 60.9570198059161 .2618103027361 .5666007995661 .8713798522962 .17617034912 62.4809494018662 .4809494018662 .7857398986863 .0905189514263 .39530944824 63.7000885009864 .004882812564 .3096618652364 .6144485473664 .74952697754 -9999 -9999 -9999 -9999 -9999 -9999 -9999 -9999 -9999 -9999 -9999 -9999 -9999 -9999 -9999 -9999 -9999 -9999 -9999 -9999 -9999 -9999 -9999 -9999 -9999 -9999 -9999 -9999 -9999 -9999 -9999 -9999 -9999 -9999 -9999 -9999 -9999 -9999 -9999 -9999 -9999 -9999 -9999 -9999 -9999 -9999 -9999 -9999 -9999 -9999 -9999 -9999 -9999 -9999 -9999 -9999 -9999 -9999 - 9999 -

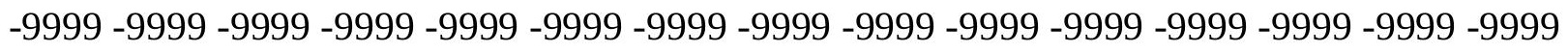

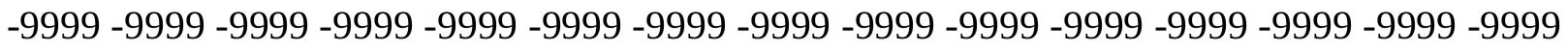
-9999 -9999 -9999 -9999 -9999 -9999 -9999 -9999 -9999 -9999 -9999 -9999 -9999 - 9999 - -999 -9999 -9999 -9999 -9999 -9999 -9999 -9999 -9999 -9999 -9999 -9999 -9999 -9999 -9999 - -999 -

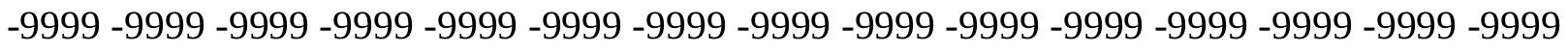

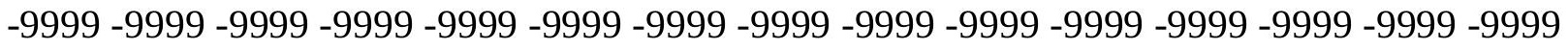
-9999 -9999 -9999 -9999 -9999 -9999 -9999 -9999 -9999 -9999 -9999 -9999 -9999 -9999 -9999 -9999 -9999 -9999 -9999 -9999 -9999 -9999 -9999 -9999 -9999 -9999 -9999 -9999 -9999 -9999 -9999 67.35751342773 67.9670867919968.5766525268668.8814392089868.88143920898 68.2718734741267 .9670867919967 .0527267456166 .4431610107465 .52880096436 
64.9192428588964 .004882812563 .7000885009863 .0905189514263 .09051895142 63.0905189514263 .3953094482463 .7000885009864 .3096618652365 .22400665283 66.1383666992267 .0527267456168 .2718734741269 .7957916259871 .62449645996 74.3675689697378 .0249862670981 .9871978759886 .254188537689 .91161346436 92.6546783447394 .7881774902396 .0073165893697 .2264633178797 .83602905273 98.445587158298 .7503814697398 .7503814697398 .445587158298 .14080810547 97.5312423706196 .9216690063596 .3121032714895 .0929565429794 .17859649658 93.2642517089892 .0450973510790 .8259735107490 .2164001464889 .3020401001 88.69246673584 88.3876876831188.08290100098 88.38768768311 88.99725341797 89.6068267822390 .5211791992291 .4355392456191 .7403335571391 .74033355713 91.1307525634890 .21640014648 89.3020401001 88.38768768311 87.47332763672 87.16854858398 86.86376190186 86.8637619018686.86376190186 86.86376190186 86.8637619018687 .1685485839887 .1685485839887 .1685485839887 .16854858398 87.1685485839887 .1685485839887 .1685485839886 .8637619018686 .55898284912 86.5589828491286 .254188537685 .6446228027385 .3398437584 .73026275635 84.4254837036183 .8159103393683 .5111236572383 .206336975182 .59677124023 82.2919769287182 .2919769287181 .9871978759881 .9871978759881 .98719787598 81.9871978759881 .9871978759881 .9871978759881 .9871978759881 .98719787598 81.9871978759881 .9871978759882 .2919769287182 .2919769287155 .47089004517 47.24169921875 38.09814071655 35.35507965088 32.91679000854 30.47850990295 28.9545898437527 .7354507446327 .1258792877226 .5163097381625 .9067401886 25.6019496917725 .2971591949524 .9923801422124 .6875991821324 .38281059265 24.3828105926524 .3828105926524 .6875991821324 .9923801422125 .29715919495 26.2115192413326 .8210906982427 .430660247827 .7354507446328 .04022979736 28.3450202941928 .6497993469229 .2593708038329 .5641593933129 .56415939331 29.2593708038328 .9545898437528 .6497993469228 .0402297973627 .73545074463 27.7354507446327 .7354507446327 .7354507446328 .3450202941929 .25937080383 30.7833003997832 .9167900085435 .6598587036139 .0125007629442 .97470092773 46.9369087219250 .8991203308154 .5565414428757 .909179687560 .65224075317 63.0905189514264 .6144485473665 .8335876464866 .4431610107467 .05272674561 67.6623001098668 .2718734741268 .5766525268668 .8814392089868 .88143920898 68.8814392089868 .8814392089868 .5766525268668 .2718734741267 .96708679199 67.6623001098667 .0527267456166 .7479400634866 .1383666992265 .52880096436 65.2240066528364 .6144485473664 .004882812563 .7000885009863 .09051895142 62.4809494018662 .1761703491261 .8713798522961 .8713798522961 .56660079956 61.2618103027360 .6522407531760 .6522407531760 .6522407531760 .34745025635 60.3474502563560 .3474502563560 .6522407531760 .9570198059161 .26181030273 61.5666007995661 .5666007995661 .8713798522962 .1761703491262 .48094940186 62.4809494018662 .7857398986863 .0905189514263 .3953094482463 .39530944824 63.7000885009864 .004882812564 .3096618652364 .61444854736 -9999 -9999 -9999 -9999 -9999 -9999 -9999 -9999 -9999 -9999 -9999 -9999 -9999 -9999 -9999 -9999 -9999 -9999 -9999 -

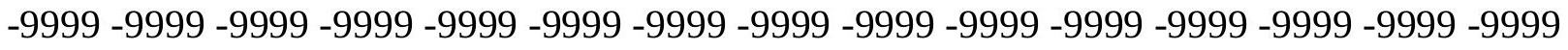
-9999 -9999 -9999 -9999 -9999 -9999 -9999 -9999 -9999 -9999 -9999 -9999 -9999 -9999 -9999 -9999 -9999 -9999 -9999 -9999 -9999 -9999 -9999 -9999 -9999

-9999 -9999 -9999 -9999 -9999 -9999 -9999 -9999 -9999 -9999 -9999 -9999 -9999 -9999 -9999

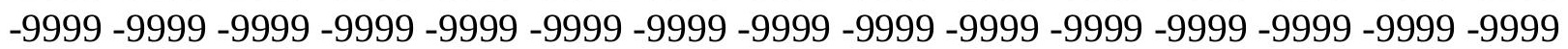


-9999 -9999 -9999 -9999 -9999 -9999 -9999 -9999 -9999 -9999 -9999 -9999 -9999 -9999 -9999 -9999 -9999 -9999 -9999 -9999 -9999 -9999 -9999 -9999 -9999 -9999 -9999 -9999 -9999 -9999

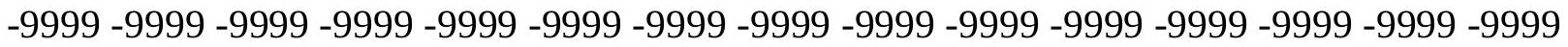
-9999 -9999 -9999 -9999 -9999 -9999 -9999 -9999 -9999 -9999 -9999 -9999 -9999 -9999 -9999 -9999 -9999 -9999 -9999 -9999 -9999 -9999 -9999 -9999 -9999 -9999 -9999-9999 -9999 -9999 -9999 -9999 -9999 -9999 -9999 -9999 -9999 -9999 -9999 -9999 -9999 -9999 -9999 -9999 -9999 -999968.2718734741268.8814392089869.4910125732469.4910125732469.49101257324 68.8814392089867 .9670867919967 .0527267456166 .1383666992265 .22400665283 64.3096618652363 .3953094482462 .7857398986862 .1761703491261 .87137985229 61.8713798522962 .1761703491262 .4809494018663 .0905189514264 .0048828125 64.9192428588965 .8335876464867 .3575134277368 .8814392089871 .0149307251 73.7580032348676 .8058471679780 .4632720947384 .4254837036187 .77810668945 90.8259735107492 .9594726562594 .7881774902396 .0073165893696 .92166900635 97.5312423706197 .8360290527397 .8360290527397 .8360290527397 .53124237061 97.2264633178796 .9216690063596 .3121032714895 .397743225194 .48339080811 93.5690307617292 .349891662691 .4355392456190 .8259735107490 .21640014648 89.6068267822389 .302040100189 .302040100189 .6068267822389 .91161346436 90.5211791992291 .1307525634891 .1307525634891 .1307525634890 .52117919922 89.9116134643688 .9972534179787 .7781066894586 .5589828491285 .64462280273 85.3398437585 .3398437585 .3398437585 .3398437585 .6446228027385 .64462280273 85.6446228027385 .9494018554785 .9494018554785 .9494018554785 .94940185547 85.9494018554785 .6446228027385 .6446228027385 .3398437585 .03504943848 84.4254837036184 .1206970214883 .8159103393683 .206336975182 .59677124023 82.2919769287181 .6824111938581 .3776321411180 .7680587768680 .46327209473 80.1584930419980 .1584930419979 .8537063598679 .8537063598679 .85370635986 79.8537063598679 .8537063598679 .5489196777379 .5489196777379 .54891967773 79.5489196777381 .3776321411181 .9871978759849 .9847602844239 .01250076294 36.5742111206134 .1359291076732 .0024414062529 .8689403533928 .64979934692 27.430660247826 .5163097381625 .906740188625 .2971591949524 .99238014221 24.3828105926524 .0780296325723 .7732391357423 .4684505462623 .46845054626 23.4684505462623 .4684505462623 .7732391357424 .0780296325724 .68759918213 25.2971591949525 .906740188626 .5163097381626 .8210906982427 .12587928772 27.7354507446328 .0402297973628 .3450202941928 .6497993469228 .64979934692 28.6497993469228 .3450202941928 .0402297973628 .0402297973628 .04022979736 28.3450202941928 .6497993469228 .9545898437529 .8689403533931 .08807945251 32.6120109558135 .0502891540537 .7933502197341 .1459884643644 .49863052368 47.85126113892 51.20389938354 54.55654144287 57.29959869385 59.43310165405 61.5666007995663 .0905189514264 .3096618652365 .2240066528365 .83358764648 66.4431610107466 .7479400634866 .7479400634867 .0527267456167 .05272674561 66.7479400634866 .7479400634866 .4431610107466 .1383666992265 .83358764648 65.2240066528364 .9192428588964 .3096618652364 .004882812563 .70008850098 63.3953094482463 .0905189514262 .4809494018662 .1761703491261 .56660079956 61.2618103027361 .2618103027361 .5666007995661 .5666007995661 .56660079956 61.2618103027361 .2618103027360 .6522407531761 .8713798522960 .34745025635 60.6522407531760 .9570198059161 .2618103027361 .2618103027361 .56660079956 61.8713798522961 .8713798522962 .1761703491262 .1761703491262 .48094940186 
62.7857398986862 .7857398986863 .0905189514263 .3953094482463 .70008850098 63.7000885009864 .004882812564 .30966186523 -9999 -9999 -9999 -9999 -9999 -9999 -9999 -9999 -9999 -9999 -9999 -9999 -9999 -9999 -9999 -9999 -9999 -9999 -9999 -9999 -9999 -9999 -9999 -9999 -9999 -9999 -9999 -9999 -9999 -9999 -9999 -9999 -9999 -9999 -9999 -9999 -9999 -9999 -9999 -9999 -9999 -9999 -9999 -9999 -9999 -9999-9999 -9999 -9999 -9999 -9999 - -9999 -9999 -9999 -9999 -9999-9999-9999-9999

-9999 -9999 -9999 -9999 -9999 -9999 -9999 -9999 -9999 -9999 -9999 -9999 -9999 -9999 -9999

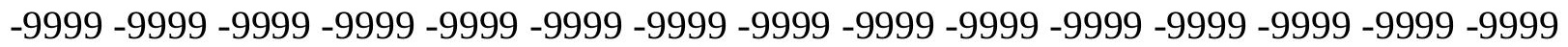
-9999 -9999 -9999 -9999 -9999 -9999 -9999 -9999 -9999 -9999 -9999 -9999 -9999 -9999 -9999 -9999 -9999 -9999 -9999 -9999 -9999 -9999 -9999 -9999 -9999 -9999 -9999 -9999 -9999 -9999 -9999 -9999 -9999 -9999 -9999 -9999 -9999 -9999 -9999 -9999 -9999 -9999 -9999 -9999 -9999 -9999 -9999 -9999 -9999 -9999 -9999 -9999 -9999 -9999 -9999 -9999 -9999 -9999 -9999 -9999 -9999 -9999 -9999 -9999 -9999 -9999 -9999 -9999 -9999 -9999 -9999 -9999 -9999 -9999 -9999 -9999 -9999 -9999 -9999 -9999 -9999 -9999 -9999 -9999 -9999 -9999 -9999 -9999 -9999 -9999 -9999 -9999 70.1005783081170.7101516723670.7101516723670.10057830811 69.49101257324 68.57665252686 67.3575134277366.13836669922 65.22400665283 64.3096618652363 .0905189514262 .4809494018661 .8713798522961 .26181030273 61.2618103027361 .5666007995661 .8713798522962 .4809494018663 .09051895142 64.004882812565 .2240066528366 .4431610107468 .2718734741270 .40535736084 72.8436431884875 .8914871215879 .2441329956182 .5967712402385 .94940185547 88.99725341797 91.4355392456193.26425170898 96.31210327148 97.22646331787 97.83602905273101 .188697814997 .2264633178797 .2264633178797 .22646331787 96.9216690063596 .6168823242296 .0073165893695 .397743225194 .48339080811 93.8738174438592 .9594726562592 .0450973510791 .4355392456190 .82597351074 90.5211791992290 .2164001464890 .2164001464890 .2164001464890 .52117919922 91.1307525634891 .4355392456190 .8259735107490 .5211791992289 .60682678223 88.6924667358487 .7781066894586 .8637619018685 .6446228027384 .73026275635 84.4254837036184 .1206970214884 .1206970214884 .4254837036184 .42548370361 84.4254837036184 .7302627563584 .7302627563584 .7302627563584 .73026275635 84.7302627563584 .7302627563584 .4254837036184 .1206970214883 .81591033936 83.5111236572383 .206336975182 .5967712402382 .2919769287181 .68241119385 81.0728530883880 .4632720947380 .1584930419979 .5489196777379 .24413299561 78.9393463134878 .3297805786178 .3297805786178 .0249862670977 .72020721436 77.7202072143677 .7202072143677 .4154205322377 .4154205322377 .41542053223 77.110626220778 .9393463134879 .8537063598680 .7680587768647 .85126113892 37.4885711669935 .3550796508833 .2215805053731 .3928699493430 .47850990295 28.6497993469227 .430660247826 .2115192413325 .6019496917724 .99238014221 24.3828105926523 .7732391357423 .4684505462623 .1636695861822 .85887908936 22.5541000366222 .5541000366222 .5541000366222 .5541000366222 .85887908936 23.4684505462623 .7732391357424 .3828105926524 .9923801422125 .60194969177 25.906740188626 .5163097381627 .1258792877227 .430660247827 .73545074463 28.0402297973628 .0402297973628 .0402297973628 .0402297973628 .04022979736 28.3450202941928 .9545898437529 .2593708038329 .8689403533930 .47850990295 31.3928699493432 .6120109558134 .4407196044936 .8790016174339 .6220703125 42.3651313781745 .4129791259848 .4608306884851 .5086898803753 .94697189331 56.3852500915558 .5187492370660 .3474502563561 .8713798522963 .39530944824 
64.004882812564 .6144485473664 .9192428588965 .2240066528365 .22400665283 65.2240066528364 .9192428588964 .9192428588964 .6144485473664 .30966186523 64.004882812563 .7000885009863 .3953094482462 .7857398986862 .48094940186 62.1761703491262 .1761703491261 .8713798522961 .8713798522961 .56660079956 60.9570198059160 .6522407531761 .2618103027361 .5666007995661 .87137985229 62.1761703491262 .1761703491262 .4809494018661 .8713798522960 .65224075317 60.6522407531760 .9570198059161 .2618103027361 .2618103027361 .56660079956 61.5666007995661 .8713798522961 .8713798522962 .1761703491262 .17617034912 62.4809494018662 .7857398986862 .7857398986863 .0905189514263 .09051895142 $63.3953094482463 .7000885009863 .7000885009864 .004882812564 .30966186523-9999$ -9999 -9999 -9999 -9999 -9999 -9999 -9999 -9999 -9999 -9999 -9999 -9999 -9999 -9999 -9999 -9999 -9999 -9999 -9999 -9999 -9999 -9999 -9999 -9999 -9999 -9999 -9999 -9999 -9999 -9999 -9999 -9999 -9999 -9999 -9999 -9999 -9999 -9999 -9999 -9999 -9999 -9999 -9999 -9999 -9999 -9999 -9999 -9999 -9999 -9999 -9999 -9999 -9999 -9999 -9999 -9999 -9999 -9999 -9999 -9999 -9999 -9999 -9999 -9999 -9999 -9999 -9999 -9999 -9999 -9999 -9999 -9999

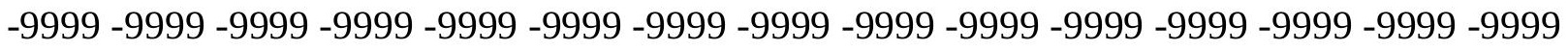
-9999 -9999 -9999 -9999 -9999 -9999 -9999 -9999 -9999 -9999 -9999 -9999 -9999 -9999 -9999 -9999 -9999 -9999 -9999 -9999 -9999 -9999 -9999 -9999 -9999 -9999 -9999 -9999 -9999 -9999 -9999 -9999 -9999 -9999 -9999 -9999 -9999 -9999 -9999 -9999 -9999 -9999 -9999 -9999 -9999 -

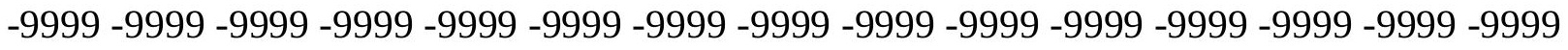

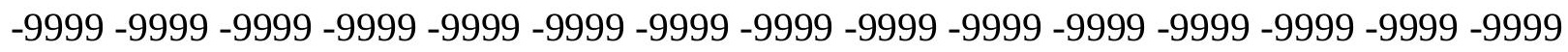
-9999 -9999 -9999 -9999 -9999 -9999 -9999 -9999 -9999 -9999 -9999 -9999 -9999 -9999 -9999 -9999 -9999 71.62449645996 72.23407745361 71.92929077148 71.31971740723 70.1005783081168 .8814392089867 .6623001098666 .7479400634865 .52880096436 64.6144485473663 .3953094482462 .4809494018661 .8713798522961 .26181030273 61.2618103027361 .2618103027361 .5666007995662 .1761703491262 .78573989868 63.7000885009864 .9192428588966 .1383666992267 .9670867919969 .79579162598 72.2340774536174 .9771423339878 .0249862670981 .0728530883884 .12069702148 87.16854858398 89.6068267822393.26425170898 97.8360290527399.05516815186 99.96952056885100 .2742996216100 .579101562596 .3121032714896 .61688232422 96.3121032714896 .3121032714895 .7025299072395 .0929565429794 .48339080811 93.8738174438593 .2642517089892 .6546783447392 .0450973510791 .43553924561 91.1307525634890 .8259735107490 .8259735107490 .8259735107490 .82597351074 90.8259735107490 .8259735107490 .5211791992289 .6068267822388 .99725341797 88.0829010009886 .8637619018685 .9494018554785 .0350494384884 .12069702148 83.81591033936 83.51112365723 83.51112365723 83.51112365723 83.51112365723 83.51112365723 83.51112365723 83.81591033936 83.81591033936 83.81591033936 83.5111236572383 .5111236572383 .206336975182 .9015579223682 .59677124023 82.2919769287181 .6824111938581 .0728530883880 .7680587768680 .15849304199 79.5489196777378 .9393463134878 .6345596313578 .0249862670977 .41542053223 77.110626220776 .8058471679776 .5010681152376 .1962814331175 .89148712158 75.5867080688575 .5867080688575 .2819290161175 .2819290161174 .97714233398 76.5010681152377 .110626220778 .0249862670978 .9393463134846 .63212966919 36.8790016174334 .4407196044932 .3072204589830 .4785099029529 .56415939331 28.3450202941927 .1258792877226 .2115192413325 .2971591949524 .68759918213 24.0780296325723 .4684505462623 .1636695861822 .5541000366222 .24930953979 
21.9445304870621 .6397399902321 .334960937521 .334960937521 .63973999023 21.9445304870622 .5541000366222 .8588790893623 .4684505462624 .07802963257 24.6875991821325 .2971591949525 .906740188626 .5163097381626 .82109069824 27.1258792877227 .430660247827 .7354507446328 .0402297973628 .34502029419 28.6497993469229 .2593708038330 .1737308502230 .1737308502230 .78330039978 31.3928699493432 .6120109558134 .1359291076735 .9646492004438 .09814071655 40.5364189147943 .2794914245646 .0225486755448 .765621185351 .20389938354 53.6421813964856 .0804595947358 .2139587402360 .0426712036161 .26181030273 62.4809494018663 .0905189514263 .3953094482463 .3953094482463 .39530944824 63.3953094482463 .3953094482463 .0905189514263 .0905189514262 .78573989868 62.4809494018662 .1761703491261 .8713798522961 .5666007995661 .26181030273 61.2618103027361 .2618103027361 .2618103027361 .2618103027360 .95701980591 60.9570198059160 .9570198059161 .2618103027361 .8713798522962 .48094940186 62.7857398986863 .0905189514263 .3953094482463 .7000885009864 .0048828125 60.9570198059161 .2618103027361 .5666007995661 .5666007995661 .56660079956 61.8713798522961 .8713798522961 .8713798522962 .1761703491262 .17617034912 62.4809494018662 .4809494018662 .7857398986862 .7857398986863 .09051895142 63.0905189514263 .3953094482463 .3953094482463 .7000885009864 .0048828125 -9999 -9999 -9999 -9999 -9999 -9999 -9999 -9999 -9999 -9999 -9999 -9999 -9999 -9999 -9999 -9999

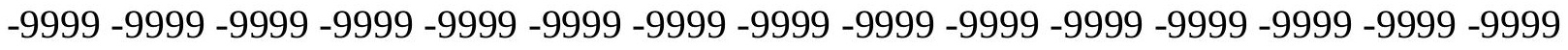

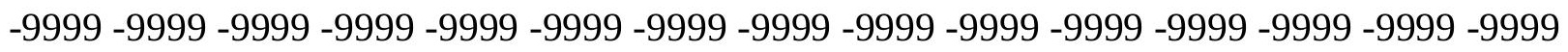
-9999 -9999 -9999 -9999 -9999 -9999 -9999 -9999 -9999 -9999 -9999 -9999 -9999 -9999 -9999 -9999 -9999 -9999 -9999 -9999 -9999 -9999 -9999 -9999 -9999 -9999 -9999 -

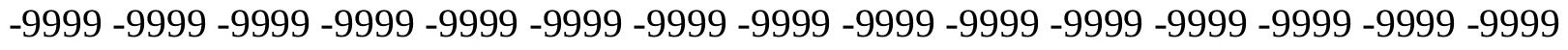

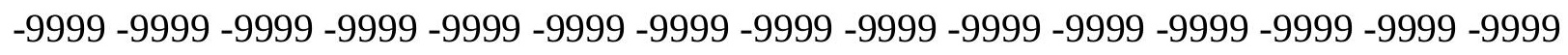
-9999 -9999 -9999 -9999 -9999 -9999 -9999 -9999 -9999 -9999 -9999 -9999 -9999 -9999 -9999 -9999 -9999 -9999 -9999 -9999 -9999 -9999 -9999 -9999 -9999 -9999 -9999 -9999 -9999 -9999 -

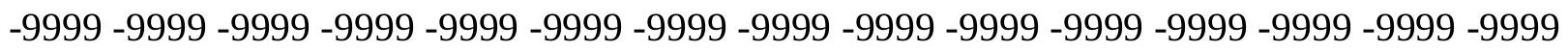
-9999 -9999 -9999 -9999 -9999 -9999 -9999 -9999 -9999 -9999 -9999 -9999 -9999 -9999 -9999 -9999 -9999 -9999 -9999 -9999 -9999 -9999 -9999 -9999 -9999 -9999 -9999 -9999 -9999 -9999 -9999 -9999-9999 73.75800323486 73.4532165527372 .2340774536170 .71015167236 69.4910125732468 .2718734741267 .3575134277366 .1383666992265 .22400665283 64.3096618652363 .3953094482462 .7857398986861 .8713798522961 .87137985229 61.8713798522962 .1761703491262 .4809494018663 .0905189514264 .0048828125 64.9192428588966 .1383666992267 .9670867919969 .7957916259871 .92929077148 74.3675689697377 .110626220779 .8537063598682 .5967712402385 .33984375 88.0829010009895.0929565429796.9216690063598.1408081054798.75038146973 99.3599472045999 .6647262573299 .6647262573299 .6647262573295 .70252990723 95.7025299072395 .397743225195 .0929565429794 .4833908081194 .17859649658 93.5690307617292 .9594726562592 .349891662691 .7403335571391 .43553924561 91.4355392456191 .1307525634890 .8259735107490 .8259735107490 .52117919922 90.2164001464889 .6068267822388 .9972534179788 .0829010009887 .16854858398 86.254188537685 .3398437584 .4254837036183 .8159103393683 .51112365723 83.206336975182 .9015579223682 .9015579223682 .9015579223682 .90155792236 82.9015579223682 .9015579223682 .9015579223682 .5967712402382 .59677124023 82.29197692871 81.98719787598 81.68241119385 81.3776321411180.76805877686 
80.4632720947379 .8537063598679 .2441329956178 .6345596313578 .32978057861 77.7202072143677 .110626220776 .5010681152375 .8914871215875 .58670806885 74.9771423339874 .6723632812574 .3675689697374 .062782287673 .75800323486 73.4532165527373 .1484298706173 .1484298706172 .8436431884874 .36756896973 74.6723632812575 .5867080688576 .5010681152346 .6321296691936 .87900161743 34.4407196044932 .0024414062529 .8689403533928 .9545898437528 .04022979736 27.1258792877226 .2115192413325 .6019496917724 .6875991821324 .07802963257 23.4684505462622 .8588790893622 .2493095397921 .6397399902321 .3349609375 20.7253894805920 .4206008911120 .1158199310320 .4206008911120 .42060089111 21.0301704406721 .6397399902322 .2493095397922 .8588790893623 .77323913574 24.3828105926524 .9923801422125 .6019496917725 .906740188626 .51630973816 26.8210906982427 .430660247827 .7354507446328 .0402297973628 .64979934692 29.2593708038329 .8689403533930 .4785099029530 .7833003997831 .39286994934 32.3072204589833 .5263595581134 .7455101013236 .8790016174339 .01250076294 41.1459884643643 .8890609741246 .3273391723648 .765621185351 .20389938354 53.6421813964855 .7756805419957 .6043891906759 .4331016540560 .95701980591 61.2618103027361 .5666007995661 .5666007995661 .5666007995661 .56660079956 61.8713798522961 .5666007995661 .5666007995661 .2618103027361 .26181030273 60.9570198059160 .6522407531760 .6522407531760 .3474502563560 .65224075317 60.6522407531760 .9570198059160 .9570198059160 .9570198059161 .26181030273 61.5666007995661 .8713798522962 .4809494018662 .7857398986863 .39530944824 63.7000885009864 .004882812564 .004882812564 .3096618652361 .56660079956 61.5666007995661 .5666007995661 .8713798522961 .8713798522961 .87137985229 61.8713798522961 .8713798522962 .1761703491262 .1761703491262 .17617034912 62.4809494018662 .4809494018662 .7857398986862 .7857398986863 .09051895142 63.0905189514263 .3953094482463 .3953094482463 .70008850098 -9999 -9999 -9999 -9999 -9999 -9999 -9999 -9999 -9999 -9999 -9999 -9999 -9999 -9999 -9999 -9999 -9999 -9999 -9999

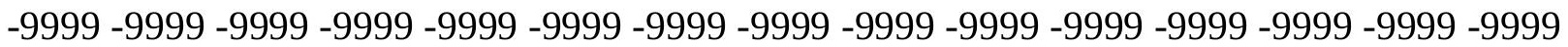
-9999 -9999 -9999 -9999 -9999 -9999 -9999 -9999 -9999 -9999 -9999 -9999 -9999 -9999 -9999 -9999 -9999 -9999 -9999 -9999 -9999-9999 -9999 -9999 -9999 -9999 -9999 -9999 -9999 -9999 -9999 -9999 -9999 -9999 -9999 -9999 -9999 -9999 -9999

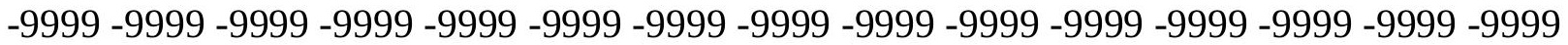

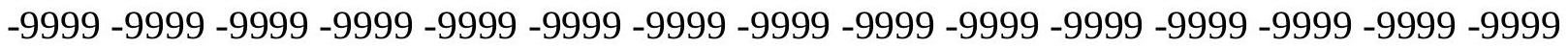
-9999 -9999 -9999 -9999 -9999 -9999 -9999 -9999 -9999 -9999 -9999 -9999 -9999 -9999 -9999 -9999 -9999 -9999 -9999 -9999 -9999 -9999 -9999 -9999 -9999 -9999 -9999 -9999 -9999 -9999 -9999 -9999 -9999 -9999 -9999 -9999 -9999 -9999 -9999 -9999 -9999 -9999 -9999 -9999 -9999

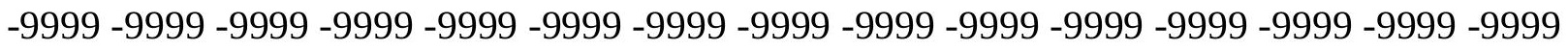

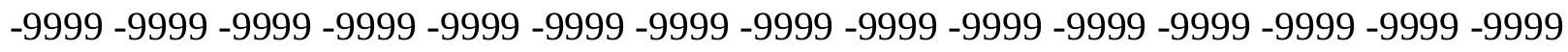
-9999 -9999 -9999 -9999 74.36756896973 72.8436431884871 .3197174072370 .10057830811 69.1862335205168 .2718734741267 .6623001098666 .7479400634866 .13836669922 65.5288009643664 .6144485473663 .3953094482463 .3953094482463 .39530944824 63.3953094482463 .7000885009864 .004882812564 .6144485473665 .52880096436 66.7479400634868 .2718734741270 .1005783081171 .9292907714874 .0627822876 76.5010681152378 .9393463134881 .3776321411184 .1206970214888 .38768768311 93.8738174438595 .7025299072396 .9216690063597 .8360290527398 .4455871582 98.7503814697399 .0551681518699 .0551681518699 .0551681518695 .3977432251 
95.0929565429795 .0929565429794 .7881774902394 .1785964965893 .56903076172 93.2642517089892 .6546783447392 .0450973510791 .7403335571391 .43553924561 91.1307525634890 .8259735107490 .5211791992289 .9116134643689 .60682678223 88.9972534179788 .3876876831187 .4733276367286 .5589828491285 .94940185547 85.0350494384884 .1206970214883 .5111236572383 .206336975182 .59677124023 82.5967712402382 .2919769287182 .2919769287182 .2919769287181 .98719787598 81.9871978759881 .9871978759881 .6824111938581 .6824111938581 .37763214111 81.0728530883880 .7680587768680 .1584930419979 .8537063598679 .24413299561 78.6345596313578 .0249862670977 .4154205322376 .8058471679776 .19628143311 75.5867080688574 .9771423339874 .6723632812574 .062782287673 .45321655273 73.1484298706172 .8436431884872 .2340774536171 .9292907714871 .62449645996 71.3197174072371 .014930725170 .4053573608470 .1005783081171 .92929077148 72.5388565063573 .7580032348646 .3273391723638 .0981407165535 .35507965088 32.9167900085430 .7833003997829 .5641593933128 .3450202941927 .73545074463 26.8210906982425 .906740188624 .9923801422124 .3828105926523 .46845054626 22.8588790893622 .2493095397921 .6397399902321 .0301704406720 .42060089111 19.811029434219 .2014598846419 .2014598846419 .2014598846419 .8110294342 20.4206008911121 .334960937521 .9445304870622 .5541000366223 .46845054626 24.0780296325724 .6875991821325 .2971591949525 .906740188626 .51630973816 26.8210906982427 .430660247828 .0402297973628 .6497993469229 .25937080383 29.8689403533930 .1737308502230 .7833003997831 .0880794525131 .69765090942 32.6120109558133 .8311500549335 .3550796508837 .1837806701739 .31727981567 41.7555618286144 .1938400268646 .6321296691949 .0704002380451 .20389938354 53.3373985290555 .4708900451757 .2995986938558 .5187492370659 .12831115723 59.7378807067959 .7378807067960 .0426712036160 .0426712036160 .34745025635 60.3474502563560 .3474502563560 .0426712036160 .0426712036160 .04267120361 59.7378807067959 .7378807067959 .7378807067960 .0426712036160 .34745025635 60.6522407531760 .9570198059161 .2618103027361 .5666007995661 .87137985229 62.4809494018663 .0905189514263 .3953094482463 .7000885009864 .0048828125 64.3096618652364 .6144485473664 .6144485473661 .8713798522961 .87137985229 61.8713798522961 .8713798522961 .8713798522961 .8713798522961 .87137985229 61.8713798522962 .1761703491262 .1761703491262 .1761703491262 .17617034912 62.4809494018662 .4809494018662 .4809494018662 .7857398986862 .78573989868 63.0905189514263 .0905189514263 .3953094482463 .39530944824 -9999 -9999 -9999-9999 -9999 -9999 -9999 -9999 -9999 -9999 -9999 -9999 -9999 -9999 -9999 -9999 -9999 -9999 -9999 -9999 -9999 -9999 -9999 -9999 -9999 -9999 -9999 -9999 -9999 -9999 -9999 -9999 -9999 -9999

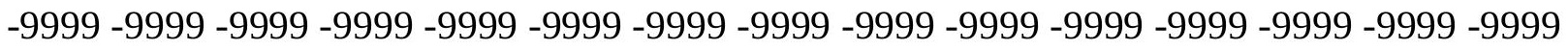
-9999 -9999 -9999 -9999-9999-9999-9999-9999

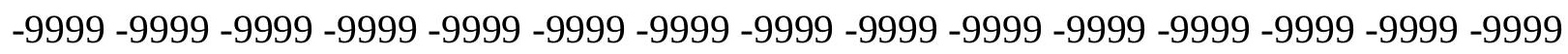
-9999 -9999 -9999 -9999 -9999 -9999 -9999 -9999 -9999 -9999 -9999 -9999 -9999 -9999 -9999 -

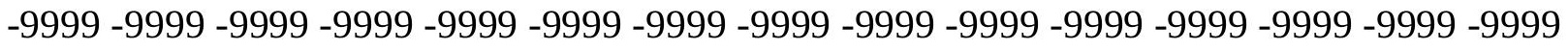

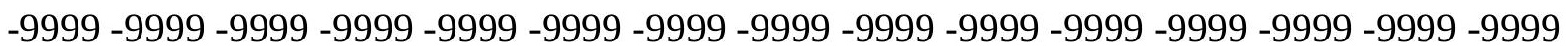
-9999 -9999 -9999 -9999 -9999 -9999 -9999 -9999 -9999 -9999 -9999 -9999 -9999 -9999 -9999 -9999 -9999 -9999 -9999 -9999 -9999 -9999 -9999 -9999 -9999 -9999 -9999 -9999 -9999 -9999 -9999 -9999 -9999 -9999 -9999 -9999 -9999 -9999 -9999 -9999 -9999 -9999 -9999 -9999 -9999 -9999 -9999 -9999 -9999 -9999 -9999 -9999 -9999 -9999 -9999 -9999 -9999 -9999 -9999 -9999 
-9999 -9999 -9999 -9999 74.97714233398 73.45321655273 72.23407745361 71.0149307251 70.1005783081169 .7957916259869 .4910125732469 .1862335205168 .88143920898 68.2718734741267 .6623001098666 .7479400634866 .1383666992265 .83358764648 65.5288009643665 .5288009643665 .5288009643666 .1383666992266 .74794006348 67.9670867919969 .1862335205170 .7101516723672 .5388565063574 .36756896973 76.1962814331178 .3297805786180 .4632720947383 .206336975190 .21640014648 92.6546783447394 .7881774902396 .0073165893696 .9216690063597 .53124237061 97.8360290527398 .445587158298 .445587158298 .7503814697398 .75038146973 95.0929565429795 .0929565429794 .7881774902394 .4833908081193 .87381744385 93.5690307617292 .9594726562592 .349891662691 .7403335571391 .43553924561 90.8259735107490 .5211791992289 .9116134643689 .6068267822388 .99725341797 88.38768768311 87.77810668945 86.86376190186 86.2541885376 85.33984375 84.7302627563584 .1206970214883 .5111236572382 .9015579223682 .59677124023 82.2919769287181 .9871978759881 .6824111938581 .6824111938581 .68241119385 81.37763214111 81.37763214111 81.07285308838 80.76805877686 80.46327209473 80.1584930419979 .5489196777379 .2441329956178 .6345596313578 .02498626709 77.4154205322376 .8058471679776 .1962814331175 .5867080688574 .97714233398 74.3675689697373 .7580032348673 .1484298706172 .5388565063571 .92929077148 71.6244964599671 .014930725170 .7101516723670 .1005783081169 .79579162598 69.1862335205168 .8814392089868 .2718734741267 .9670867919967 .66230010986 68.8814392089870 .1005783081149 .0704002380439 .9268493652336 .87900161743 34.1359291076732 .0024414062530 .4785099029529 .2593708038328 .34502029419 27.430660247826 .2115192413325 .6019496917724 .6875991821323 .77323913574 23.1636695861822 .5541000366221 .6397399902321 .0301704406720 .11581993103 19.2014598846418.59189033508 18.28710937518.28710937518.89668083191 19.5062503814720 .4206008911121 .0301704406721 .9445304870622 .55410003662 23.4684505462624 .0780296325724 .6875991821325 .2971591949525 .9067401886 26.5163097381627 .1258792877227 .7354507446328 .3450202941928 .95458984375 29.5641593933129 .8689403533930 .4785099029530 .7833003997831 .39286994934 32.0024414062532 .9167900085434 .1359291076735 .6598587036137 .79335021973 39.9268493652342 .0603485107444 .4986305236846 .6321296691949 .07040023804 51.2038993835453 .0326118469254 .8613204956156 .0804595947356 .99481964111 57.6043891906758 .2139587402358 .5187492370658 .8235282897959 .12831115723 59.1283111572359 .1283111572359 .1283111572359 .1283111572359 .12831115723 59.1283111572359 .4331016540559 .4331016540559 .7378807067960 .04267120361 60.3474502563560 .9570198059161 .2618103027361 .8713798522962 .48094940186 63.0905189514263 .3953094482464 .004882812564 .004882812564 .30966186523 64.6144485473664 .9192428588964 .9192428588961 .8713798522962 .17617034912 62.1761703491261 .8713798522961 .8713798522961 .8713798522961 .87137985229 61.8713798522961 .8713798522962 .1761703491262 .1761703491262 .17617034912 62.1761703491262 .1761703491262 .4809494018662 .4809494018662 .48094940186 62.7857398986862 .7857398986863 .0905189514263 .09051895142 -9999 -9999-9999-9999 -9999 -9999 -9999 -9999 -9999 -9999 -9999 -9999 -9999 -9999 -9999 -9999 -9999 -9999 -9999 -9999 -9999 -9999 -9999 -9999 -9999 -9999 -9999 -9999-9999 -9999 -9999 -9999 -9999 -9999 -

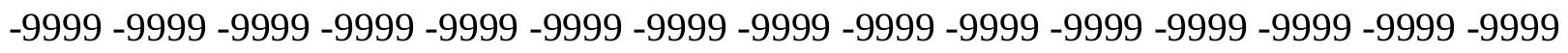
-9999 -9999 -9999 -9999 -9999 -9999 -9999 -9999 
-9999 -9999 -9999 -9999 -9999 -9999 -9999 -9999 -9999 -9999 -9999 -9999 -9999 -9999 -9999 -9999 -9999 -9999 -9999 -9999 -9999 -9999 -9999 -9999 -9999 -9999 -9999 -9999 -9999 -9999

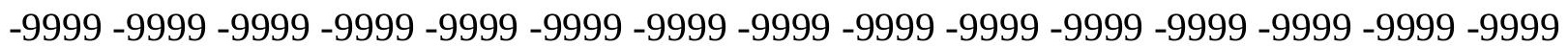
-9999 -9999 -9999 -9999 -9999 -9999 -9999 -9999 -9999 -9999 -9999 -9999 -9999 -9999 -9999

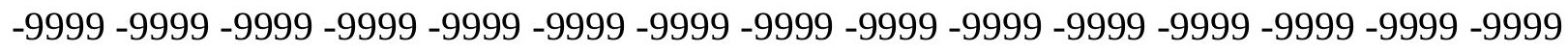
-9999 -9999 -9999 -9999 -9999 -9999 -9999 -9999 -9999 -9999 -9999 -9999 -9999 -9999 -9999 -9999 -9999 -9999 -9999 -9999 -9999 -9999 -9999 -9999 -9999 -9999 -9999 -9999 -9999 -9999 -9999 -9999 -9999 -9999 -9999 -9999 -9999 -9999 -9999 -9999 -9999 -9999 -9999 -9999 -9999 -9999 -9999 -9999-9999 -9999 74.97714233398 73.45321655273 72.53885650635 72.2340774536172 .2340774536172 .5388565063572 .5388565063572 .53885650635 72.5388565063571 .9292907714871 .014930725170 .1005783081169 .18623352051 68.5766525268668 .2718734741267 .9670867919968 .2718734741268 .57665252686 69.4910125732470 .4053573608471 .9292907714873 .4532165527374 .97714233398 76.8058471679778 .6345596313580 .4632720947382 .5967712402386 .55898284912 91.7403335571393 .5690307617294 .7881774902395 .7025299072396 .61688232422 97.2264633178797.8360290527398.1408081054798.445587158298.4455871582 98.445587158295 .0929565429795 .0929565429794 .7881774902394 .48339080811 93.8738174438593 .2642517089892 .6546783447391 .7403335571391 .13075256348 90.5211791992289 .9116134643689 .6068267822388 .9972534179788 .38768768311 87.7781066894587 .1685485839886 .5589828491285 .6446228027385 .03504943848 84.4254837036183 .8159103393683 .206336975182 .9015579223682 .29197692871 81.9871978759881 .6824111938581 .3776321411181 .3776321411181 .07285308838 80.7680587768680 .7680587768680 .4632720947380 .1584930419979 .85370635986 79.2441329956178 .9393463134878 .3297805786177 .7202072143677 .1106262207 76.5010681152375 .8914871215875 .2819290161174 .3675689697373 .75800323486 73.1484298706172 .5388565063571 .9292907714871 .3197174072370 .71015167236 70.1005783081169 .4910125732469 .1862335205168 .5766525268667 .96708679199 67.3575134277366 .7479400634866 .1383666992265 .5288009643664 .91924285889 64.6144485473664 .3096618652346 .0225486755442 .3651313781738 .70771026611 35.9646492004433 .5263595581131 .6976509094230 .4785099029529 .25937080383 28.0402297973627 .1258792877226 .2115192413325 .2971591949524 .38281059265 23.7732391357422 .8588790893622 .2493095397921 .334960937520 .42060089111 19.5062503814718 .5918903350817 .6775398254417 .9823207855218 .59189033508 19.2014598846419 .811029434220 .7253894805921 .334960937522 .24930953979 22.8588790893623 .4684505462624 .0780296325724 .6875991821325 .29715919495 26.2115192413326 .8210906982427 .430660247828 .0402297973628 .64979934692 29.2593708038329 .5641593933130 .1737308502230 .4785099029530 .78330039978 31.0880794525132 .0024414062532 .9167900085434 .4407196044935 .96464920044 38.0981407165540 .2316398620642 .3651313781744 .4986305236846 .63212966919 48.765621185350 .8991203308152 .4230384826753 .9469718933154 .86132049561 55.7756805419956 .3852500915556 .9948196411157 .6043891906757 .9091796875 58.2139587402358 .2139587402358 .5187492370658 .5187492370658 .51874923706 58.8235282897958 .8235282897959 .1283111572359 .4331016540560 .04267120361 60.3474502563560 .9570198059161 .5666007995662 .1761703491262 .78573989868 63.3953094482464 .004882812564 .3096618652364 .3096618652364 .91924285889 64.9192428588965 .2240066528365 .2240066528362 .1761703491262 .17617034912 
62.1761703491262 .1761703491262 .1761703491261 .8713798522961 .87137985229 61.8713798522961 .8713798522961 .8713798522961 .8713798522961 .87137985229 61.8713798522962 .1761703491262 .1761703491262 .1761703491262 .48094940186 62.4809494018662 .4809494018662 .7857398986862 .78573989868 -9999 -9999 -9999 -9999 -9999 -9999 -9999 -9999 -9999 -9999 -9999 -9999 -9999 -9999 -9999 -9999 -9999 -9999 -9999 -

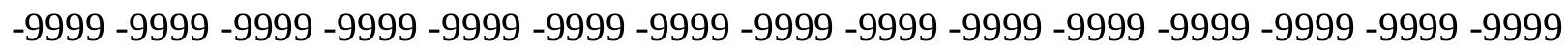

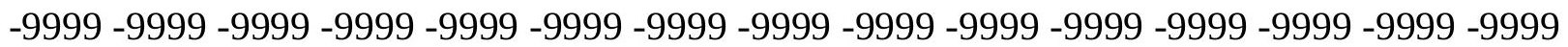
-9999 -9999 -9999 -9999-9999-9999-9999 -9999

-9999 -9999 -9999 -9999 -9999 -9999 -9999 -9999 -9999 -9999 -9999 -9999 -9999 -9999 -9999

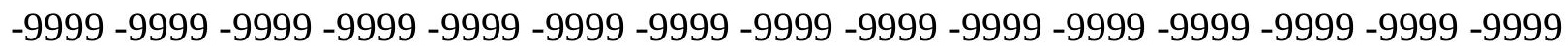
-9999 -9999 -9999 -9999 -9999 -9999 -9999 -9999 -9999 -9999 -9999 -9999 -9999 -9999 -9999 -999 -9999 -9999 -9999 -9999 -9999 -9999 -9999 -9999 -9999 -9999 -9999 -9999 -9999 -9999 -9999 -9999 -9999 -9999 -9999 -9999 -9999 -9999 -9999 -9999 -9999 -9999 -9999 -9999 -9999 -9999

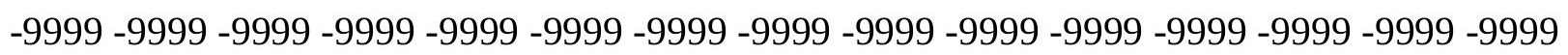
-9999 -9999 -9999 -9999 -9999 -9999 -9999 -9999 -9999 -9999 -9999 -9999 -9999 -9999 -9999

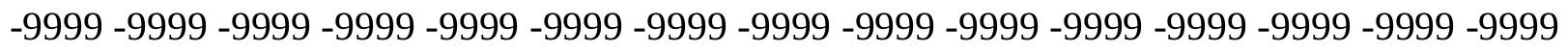
-9999 -9999 -9999 -9999 -9999-9999 76.50106811523 75.89148712158 75.89148712158 76.1962814331176 .8058471679777 .110626220777 .4154205322377 .72020721436 77.4154205322376 .5010681152375 .2819290161173 .7580032348672 .53885650635 71.6244964599671 .3197174072371 .014930725171 .3197174072371 .92929077148 72.5388565063573 .4532165527374 .6723632812576 .1962814331177 .72020721436 79.2441329956180 .7680587768682 .5967712402385 .9494018554790 .82597351074 92.349891662693 .8738174438594 .7881774902395 .7025299072396 .61688232422 97.2264633178797 .8360290527398 .1408081054798 .445587158298 .4455871582 95.397743225195 .397743225195 .397743225194 .7881774902394 .48339080811 93.5690307617292 .9594726562592 .0450973510791 .1307525634890 .52117919922 89.9116134643689 .302040100188 .6924667358488 .0829010009887 .47332763672 86.8637619018686 .254188537685 .6446228027384 .7302627563584 .42548370361 83.81591033936 83.2063369751 82.59677124023 82.29197692871 81.98719787598 81.6824111938581 .3776321411181 .0728530883880 .7680587768680 .46327209473 80.1584930419979 .8537063598679 .5489196777379 .2441329956178 .63455963135 78.0249862670977 .4154205322376 .8058471679776 .1962814331175 .58670806885 74.9771423339874 .062782287673 .4532165527372 .5388565063571 .92929077148 71.3197174072370 .4053573608469 .7957916259869 .1862335205168 .57665252686 67.9670867919967 .3575134277367 .0527267456166 .4431610107465 .52880096436 64.9192428588964 .3096618652363 .3953094482462 .4809494018661 .26181030273 60.6522407531749 .0704002380444 .4986305236840 .5364189147937 .48857116699 34.7455101013232 .9167900085431 .3928699493430 .1737308502228 .95458984375 27.7354507446326 .8210906982425 .906740188625 .2971591949524 .38281059265 23.7732391357422 .8588790893621 .9445304870621 .0301704406720 .11581993103 19.2014598846418 .5918903350818 .5918903350818 .8966808319119 .20145988464 19.811029434220 .4206008911121 .334960937521 .9445304870622 .55410003662 23.1636695861823 .7732391357424 .3828105926524 .9923801422125 .60194969177 26.5163097381627 .1258792877227 .7354507446328 .3450202941928 .95458984375 29.5641593933129 .8689403533929 .8689403533930 .1737308502230 .47850990295 30.7833003997831 .6976509094233 .2215805053734 .7455101013236 .26942825317 
38.4029312133840 .5364189147942 .66992187544 .4986305236846 .63212966919 48.4608306884850 .2895507812551 .8134689331153 .0326118469253 .94697189331 54.8613204956155 .7756805419956 .3852500915556 .6900291442957 .29959869385 57.6043891906757 .909179687557 .909179687558 .2139587402358 .51874923706 58.5187492370658 .8235282897959 .4331016540559 .7378807067960 .34745025635 60.9570198059161 .5666007995662 .4809494018663 .0905189514263 .70008850098 64.3096618652364 .6144485473664 .9192428588965 .2240066528365 .52880096436 65.5288009643665 .5288009643662 .4809494018662 .4809494018662 .17617034912 62.1761703491262 .1761703491261 .8713798522961 .8713798522961 .87137985229 61.8713798522961 .8713798522961 .8713798522961 .8713798522961 .87137985229 61.8713798522961 .8713798522961 .8713798522962 .1761703491262 .17617034912 62.1761703491262 .4809494018662 .48094940186 -9999 -9999 -9999 -9999 -9999 -9999 -9999 -9999 -9999 -9999 -9999 -9999 -9999 -9999 -9999 -9999 -9999 -9999 -9999 -9999 -9999 -9999 -9999 -9999 -9999 -9999 -9999 -9999 -9999 -9999 -9999 -9999 -9999 -9999 -9999 -9999 -9999 -9999 -9999 -9999 -9999 -9999 -9999 -9999 -9999 -9999 -9999 -9999 -9999 -9999 -9999 -9999 -9999 -9999 -9999 -9999 -9999

-9999 -9999 -9999 -9999 -9999 -9999 -9999 -9999 -9999 -9999 -9999 -9999 -9999 -9999 -9999 -9999 -9999 -9999 -9999 -9999 -9999 -9999 -9999 -9999 -9999 -9999 -9999 -9999 -9999 -9999 -9999 -9999 -9999 -9999 -9999 -9999 -9999 -9999 -9999 -9999 -9999 -9999 -9999 -9999 -9999 -9999 -9999 -9999 -9999 -9999 -9999 -9999 -9999 -9999 -9999 -9999 -9999 -9999 -9999 -9999 -9999 -9999 -9999 -9999 -9999 -9999 -9999 -9999 -9999 -9999 -9999 -9999 -9999 -9999 -9999

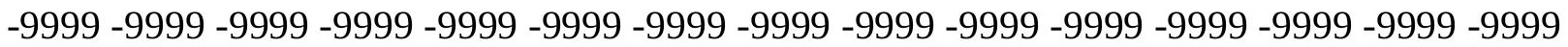
-9999 -9999 -9999 -9999 -9999 -9999 -9999 -9999 -9999 -9999 -9999 -9999 -9999 -9999 -9999 -9999 -9999 -9999 -9999 -9999 -9999 -9999 -9999 -9999 -9999 -9999 -9999 -9999 -9999 -9999 -9999 -9999 -9999 -9999 -9999 -9999 82.59677124023 81.9871978759881 .98719787598 82.9015579223683 .5111236572383 .206336975183 .5111236572383 .81591033936 83.81591033936 82.90155792236 81.37763214111 79.24413299561 77.72020721436 76.5010681152375 .5867080688574 .9771423339874 .9771423339874 .97714233398 75.2819290161175 .8914871215876 .8058471679777 .7202072143678 .93934631348 80.1584930419981 .3776321411182 .9015579223685 .9494018554790 .21640014648 91.7403335571392 .9594726562593 .8738174438595 .0929565429796 .00731658936 96.9216690063597 .8360290527398 .445587158298 .7503814697399 .05516815186 99.0551681518696 .0073165893696 .0073165893695 .7025299072395 .09295654297 94.1785964965893 .5690307617292 .349891662691 .4355392456190 .52117919922 89.9116134643689 .302040100188 .3876876831187 .7781066894587 .16854858398 86.5589828491285 .9494018554785 .3398437584 .7302627563584 .12069702148 83.81591033936 83.2063369751 82.90155792236 82.29197692871 81.98719787598 81.6824111938581 .3776321411180 .7680587768680 .4632720947380 .15849304199 79.8537063598679 .5489196777378 .9393463134878 .6345596313578 .02498626709 77.4154205322376 .8058471679776 .1962814331175 .5867080688574 .67236328125 74.062782287673 .1484298706172 .5388565063571 .6244964599671 .0149307251 70.1005783081169 .1862335205168 .5766525268667 .9670867919967 .35751342773 66.7479400634866 .1383666992265 .5288009643664 .6144485473664 .0048828125 63.0905189514262 .1761703491260 .9570198059159 .7378807067958 .21395874023 55.4708900451750 .5943298339845 .717769622841 .7555618286138 .40293121338 35.9646492004433 .8311500549332 .3072204589831 .0880794525129 .86894035339 
28.6497993469227 .7354507446326 .8210906982426 .2115192413325 .29715919495 24.6875991821323 .7732391357422 .8588790893621 .9445304870621 .3349609375 20.4206008911119 .811029434219 .5062503814719 .5062503814719 .8110294342 20.4206008911120 .7253894805921 .334960937521 .9445304870622 .55410003662 22.8588790893623 .4684505462624 .0780296325724 .6875991821325 .60194969177 26.2115192413326 .8210906982427 .7354507446328 .3450202941928 .95458984375 29.2593708038329 .5641593933129 .5641593933129 .5641593933129 .56415939331 29.8689403533930 .7833003997832 .0024414062533 .2215805053735 .05028915405 36.5742111206138 .7077102661140 .5364189147942 .66992187544 .49863052368 46.3273391723648 .1560516357449 .6799812316951 .2038993835452 .42303848267 53.3373985290554 .2517509460455 .1661109924355 .7756805419956 .38525009155 56.9948196411157 .2995986938557 .6043891906757 .909179687558 .21395874023 58.2139587402358 .8235282897959 .1283111572359 .7378807067960 .04267120361 60.9570198059161 .5666007995662 .4809494018663 .3953094482464 .0048828125 64.3096618652364 .6144485473665 .2240066528365 .5288009643665 .52880096436 65.8335876464865 .8335876464862 .4809494018662 .4809494018662 .17617034912 62.1761703491261 .8713798522961 .8713798522961 .5666007995661 .56660079956 61.5666007995661 .5666007995661 .5666007995661 .5666007995661 .56660079956 61.5666007995661 .5666007995661 .5666007995661 .8713798522961 .87137985229 61.8713798522962 .1761703491262 .1761703491262 .48094940186 -9999 -9999 -9999 -9999 -9999 -9999 -9999 -9999 -9999 -9999 -9999 -9999 -9999 -9999 -9999 -9999 -9999 -9999 -9999 -9999 -9999 -9999 -9999 -9999 -9999 -9999 -9999 -9999 -9999 -9999 -9999 -9999 -9999 -9999 -

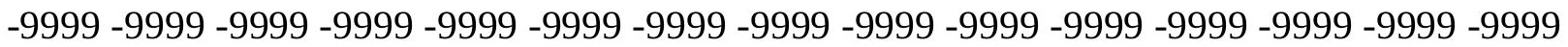
-9999 -9999 -9999 -9999-9999-9999-9999

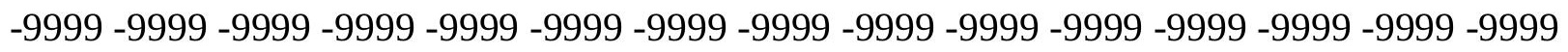
-9999 -9999 -9999 -9999 -9999 -9999 -9999 -9999 -9999 -9999 -9999 -9999 -9999 -9999 -9999 -9999 -9999 -9999 -9999 -9999 -9999 -9999 -9999 -9999 -9999 -9999 -9999 -9999 -9999 -9999

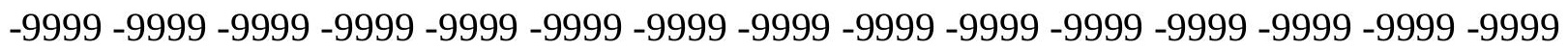
-9999 -9999 -9999 -9999 -9999 -9999 -9999 -9999 -9999 -9999 -9999 -9999 -9999 -9999 -9999 -9999 -9999 -9999 -9999 -9999 -9999 -9999 -9999 -9999 -9999 -9999 -9999 -9999 -9999 -9999 -9999 -9999 -9999 -9999 -9999 -9999 -9999 -9999 -9999 -9999 -9999 -9999 -9999 -9999 -9999 -9999 -9999 -9999 -9999 -9999 -9999 -9999 -9999 -9999 -9999 -9999 -9999 -9999 -9999 -9999 -999 -9999 -9999-9999 -9999 -9999-9999-9999 93.26425170898 90.82597351074 96.61688232422 92.349891662690 .5211791992289 .9116134643690 .5211791992291 .43553924561 90.5211791992288 .3876876831185 .9494018554784 .1206970214882 .59677124023 81.0728530883880 .4632720947379 .8537063598678 .9393463134878 .63455963135 78.9393463134879 .5489196777380 .1584930419981 .0728530883881 .68241119385 82.5967712402383 .5111236572384 .4254837036190 .2164001464891 .13075256348 92.349891662693 .2642517089894 .7881774902396 .0073165893696 .92166900635 97.8360290527398 .7503814697399 .3599472045999 .6647262573299 .66472625732 96.9216690063596 .9216690063596 .6168823242296 .0073165893695 .09295654297 94.1785964965893 .2642517089892 .0450973510791 .1307525634890 .21640014648 89.3020401001 88.3876876831187.77810668945 87.16854858398 86.55898284912 85.9494018554785 .3398437585 .0350494384884 .4254837036183 .81591033936 83.5111236572382 .9015579223682 .5967712402381 .9871978759881 .68241119385 81.3776321411180 .7680587768680 .4632720947380 .1584930419979 .54891967773 
79.2441329956178 .6345596313578 .3297805786177 .7202072143677 .1106262207 76.1962814331175 .5867080688574 .9771423339874 .062782287673 .14842987061 72.5388565063571 .6244964599670 .7101516723669 .7957916259869 .18623352051 68.2718734741267 .3575134277366 .4431610107465 .8335876464865 .22400665283 64.6144485473664 .004882812563 .0905189514262 .4809494018661 .56660079956 60.3474502563559 .1283111572357 .6043891906755 .7756805419953 .03261184692 49.6799812316945 .717769622842 .3651313781739 .3172798156736 .87900161743 34.7455101013233 .2215805053731 .6976509094230 .4785099029529 .56415939331 28.6497993469227 .7354507446327 .1258792877226 .5163097381625 .60194969177 24.9923801422124 .3828105926523 .4684505462622 .8588790893621 .94453048706 21.334960937521 .0301704406721 .0301704406721 .0301704406721 .3349609375 21.6397399902321 .9445304870622 .2493095397922 .5541000366223 .16366958618 23.4684505462624 .0780296325724 .6875991821325 .2971591949525 .9067401886 26.8210906982427 .430660247828 .3450202941928 .9545898437529 .25937080383 29.2593708038329 .2593708038329 .2593708038329 .2593708038329 .56415939331 30.1737308502231 .0880794525132 .3072204589833 .5263595581135 .05028915405 36.8790016174338 .7077102661140 .8412094116242 .66992187544 .49863052368 46.3273391723647 .8512611389249 .3751907348650 .8991203308152 .11825942993 53.0326118469253 .9469718933154 .8613204956155 .7756805419956 .08045959473 56.6900291442956 .9948196411157 .2995986938557 .6043891906758 .21395874023 58.5187492370658 .8235282897959 .4331016540560 .0426712036160 .65224075317 61.5666007995662 .1761703491263 .0905189514264 .004882812564 .30966186523 64.6144485473665 .2240066528365 .5288009643665 .8335876464865 .83358764648 65.8335876464862 .4809494018662 .4809494018662 .1761703491262 .17617034912 61.8713798522961 .5666007995661 .5666007995661 .2618103027361 .26181030273 61.2618103027361 .2618103027361 .2618103027361 .2618103027361 .26181030273 61.2618103027361 .2618103027361 .5666007995661 .5666007995661 .87137985229 61.8713798522961 .8713798522962 .17617034912 -9999 -9999 -9999 -9999 -9999 -9999 -9999 -9999 -9999 -9999 -9999 -9999 -9999 -9999 -9999 -9999 -9999 -9999 -9999 -9999 -9999 -9999 -9999 -9999 -9999 -9999 -9999 -9999 -9999 -9999 -9999 -9999 -9999 -9999 -9999 -9999 -999 -

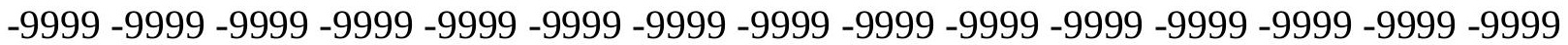
-9999 -9999-9999-9999 -9999 -9999 -9999 -9999 -9999 -9999 -9999 -9999 -9999 -9999 -9999 -9999 -9999 -9999 -9999 -9999 -9999 -9999 -9999 -9999 -9999 -9999 -9999 -9999 -9999 -9999 -9999 -9999 -9999 -9999 -9999 -9999 -9999 -9999 -9999 -9999 -9999 -9999 -9999 -9999 -9999 -9999 -9999 -9999 -9999 -9999 -9999 -9999 -9999 -9999 -9999 -9999 -9999 -9999 -9999 -9999 -9999 -9999 -9999 -9999

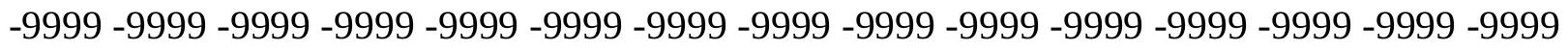

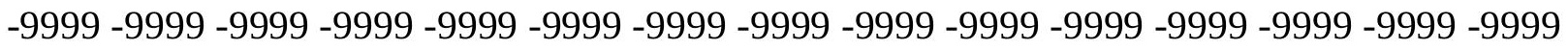
-9999 -9999 -9999 -9999 -9999 -9999 -9999 -9999 -9999 -9999 -9999 -9999 -9999 -9999 -9999 -9999 -9999 -9999 -9999 -9999 -9999 -9999 -9999 -9999 -9999 -9999 -9999 -9999 -9999 -9999 -9999 -9999-9999-9999-9999-9999-9999 107.8938980103 109.4179000854 118.8662033081 103.6268997192 97.2264633178796.0073165893697.2264633178798.4455871582 98.4455871582 97.2264633178793.5690307617293.2642517089891.43553924561 88.38768768311 87.77810668945 86.2541885376 84.42548370361 82.90155792236 82.9015579223683 .206336975183 .5111236572383 .5111236572383 .51112365723 83.8159103393684 .4254837036185 .3398437585 .9494018554791 .13075256348 
92.0450973510792 .9594726562594 .4833908081196 .0073165893697 .22646331787 98.445587158299 .35994720459100 .2742996216100 .5791015625100 .8839035034 98.1408081054798.1408081054797.83602905273 97.2264633178796.31210327148 95.397743225194 .1785964965892 .9594726562591 .7403335571390 .52117919922 89.60682678223 88.9972534179788.08290100098 87.47332763672 86.86376190186 86.254188537685 .6446228027385 .3398437584 .7302627563584 .12069702148 83.8159103393683 .206336975182 .9015579223682 .2919769287181 .98719787598 81.3776321411181.07285308838 80.46327209473 80.15849304199 79.54891967773 78.9393463134878 .6345596313578 .0249862670977 .4154205322376 .50106811523 75.8914871215875 .2819290161174 .3675689697373 .4532165527372 .53885650635 71.9292907714871 .014930725170 .1005783081169 .1862335205168 .27187347412 67.0527267456166 .1383666992265 .2240066528364 .3096618652363 .70008850098 63.0905189514262 .4809494018661 .8713798522960 .9570198059159 .73788070679 58.5187492370657 .2995986938555 .7756805419953 .6421813964851 .20389938354 48.4608306884845 .4129791259842 .3651313781739 .622070312537 .18378067017 35.3550796508833 .5263595581132 .3072204589831 .0880794525130 .17373085022 29.2593708038328 .6497993469228 .0402297973627 .430660247827 .12587928772 26.5163097381625 .906740188625 .2971591949524 .6875991821323 .77323913574 23.4684505462622 .8588790893622 .5541000366222 .2493095397922 .24930953979 22.5541000366222 .5541000366222 .8588790893622 .8588790893623 .16366958618 23.4684505462624 .0780296325724 .3828105926524 .9923801422125 .9067401886 26.5163097381627 .430660247828 .3450202941928 .9545898437528 .95458984375 28.9545898437528 .9545898437528 .9545898437528 .9545898437528 .95458984375 29.5641593933130 .1737308502231 .0880794525132 .3072204589833 .83115005493 35.3550796508837 .1837806701739 .0125007629440 .8412094116242 .669921875 44.4986305236846 .3273391723647 .8512611389249 .3751907348650 .89912033081 52.1182594299353 .0326118469253 .9469718933154 .8613204956155 .77568054199 56.0804595947356 .6900291442956 .9948196411157 .2995986938557 .60438919067 58.2139587402358 .5187492370659 .1283111572359 .4331016540560 .34745025635 60.9570198059161 .8713798522962 .7857398986863 .7000885009864 .30966186523 64.6144485473665 .2240066528365 .5288009643665 .8335876464865 .83358764648 65.8335876464862 .4809494018662 .4809494018662 .1761703491261 .87137985229 61.5666007995661 .5666007995661 .2618103027361 .2618103027360 .95701980591 60.9570198059160 .9570198059160 .9570198059160 .9570198059160 .95701980591 60.9570198059160 .9570198059161 .2618103027361 .2618103027361 .56660079956 61.5666007995661 .5666007995661 .87137985229 -9999 -9999 -9999 -9999 -9999 -9999 -9999 -9999 -9999 -9999 -9999 -9999 -9999 -9999 -9999 -9999-9999 -9999 -9999 -9999 -9999 - -9999 -

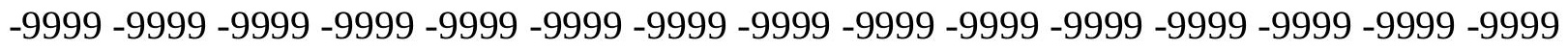

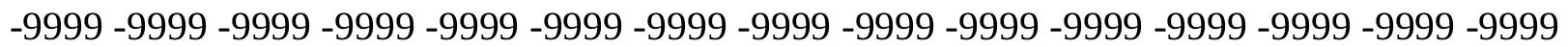
-9999 -9999 -9999-9999 -9999 -9999 -9999 -9999 -9999 -9999 -9999 -9999 -9999 -9999 -9999 -9999 -9999 -9999 -9999

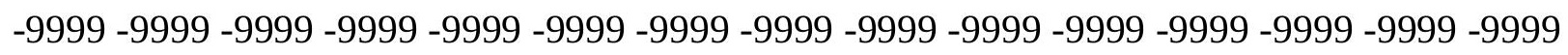
-9999 -9999 -9999 -9999 -9999 -9999 -9999 -9999 -9999 -9999 -9999 -9999 -9999 -9999 -9999 -9999 -9999 -9999 -9999 -9999 -9999 -9999 -9999 -9999 -9999 -9999 -9999 -9999 -9999 -9999 -9999 -9999 -9999 -9999 -9999 -9999 -9999 -9999 -9999 -9999 -9999 -9999 -9999 -9999 -9999 -

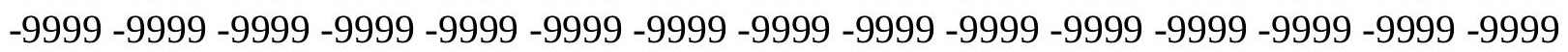


-9999 -9999 -9999 -9999 -9999 -9999 -9999 -9999 -9999 -9999 -9999 -9999 -9999 -9999 -9999 -9999 -9999 -9999 -9999 -9999 -9999 -9999 -9999 -9999 -9999 -9999 -9999 -9999 -9999 -9999 -9999 -9999 -9999 -9999 -9999 -9999 -9999 -9999 116.4279022217 114.2944030762 109.1130981445112 .4656982422115 .2088012695113 .075302124110 .0273971558 108.8082962036107 .5891036987106 .0652008057104 .5412979126102 .4077987671 99.6647262573297 .2264633178794 .4833908081191 .1307525634888 .08290100098 88.08290100098 88.38768768311 87.77810668945 86.86376190186 86.2541885376 85.9494018554786 .5589828491286 .8637619018686 .8637619018687 .16854858398 92.349891662693 .2642517089894 .4833908081195 .7025299072397 .53124237061 99.05516815186100 .5791015625101 .4934005737102 .102996826299 .66472625732 99.9695205688599 .6647262573299 .3599472045998 .7503814697397 .83602905273 96.9216690063595 .7025299072394 .1785964965892 .9594726562591 .43553924561 90.5211791992289 .6068267822388 .6924667358488 .0829010009887 .16854858398 86.5589828491286 .254188537685 .6446228027385 .0350494384884 .73026275635 84.1206970214883 .8159103393683 .206336975182 .5967712402382 .29197692871 81.6824111938581 .0728530883880 .7680587768680 .1584930419979 .54891967773 78.9393463134878 .3297805786177 .7202072143677 .110626220776 .50106811523 75.5867080688574 .9771423339874 .062782287673 .1484298706172 .23407745361 71.3197174072370 .4053573608469 .1862335205168 .2718734741267 .35751342773 66.4431610107465 .2240066528364 .3096618652363 .0905189514262 .17617034912 61.8713798522961 .2618103027360 .3474502563559 .4331016540558 .51874923706 56.9948196411155 .7756805419953 .9469718933152 .1182594299349 .67998123169 47.24169921875 44.4986305236841.75556182861 39.31727981567 37.18378067017 35.3550796508833 .8311500549332 .6120109558131 .6976509094230 .78330039978 30.1737308502229 .5641593933129 .2593708038328 .6497993469228 .34502029419 28.0402297973627 .7354507446327 .1258792877226 .5163097381625 .9067401886 25.6019496917724 .9923801422124 .3828105926524 .0780296325723 .77323913574 23.7732391357423 .4684505462623 .4684505462623 .4684505462623 .77323913574 23.7732391357424 .0780296325724 .3828105926524 .9923801422125 .60194969177 26.5163097381627 .1258792877228 .0402297973628 .9545898437528 .95458984375 28.9545898437528 .6497993469228 .6497993469228 .6497993469228 .64979934692 28.9545898437529 .5641593933130 .1737308502231 .3928699493432 .61201095581 34.1359291076735 .6598587036137 .4885711669939 .3172798156741 .14598846436 42.9747009277344 .8034095764246 .6321296691948 .1560516357449 .67998123169 50.8991203308152 .1182594299353 .3373985290554 .2517509460455 .16611099243 55.7756805419956 .3852500915556 .6900291442956 .9948196411157 .29959869385 57.6043891906757 .909179687558 .5187492370659 .1283111572359 .73788070679 60.3474502563561 .2618103027361 .8713798522962 .7857398986863 .39530944824 64.3096618652364 .9192428588965 .5288009643665 .5288009643665 .83358764648 65.8335876464862 .4809494018662 .1761703491262 .1761703491261 .87137985229 61.5666007995661 .2618103027360 .9570198059160 .6522407531760 .65224075317 60.6522407531760 .3474502563560 .3474502563560 .6522407531760 .65224075317 60.6522407531760 .6522407531760 .9570198059160 .9570198059161 .26181030273 61.2618103027361 .2618103027361 .56660079956 -9999 -9999 -9999 -9999 -9999 -9999 -9999 -9999 -9999 -9999 -9999 -9999 -9999 -9999 -9999 -9999 -9999 -9999 -9999 -9999 -9999 -9999 -

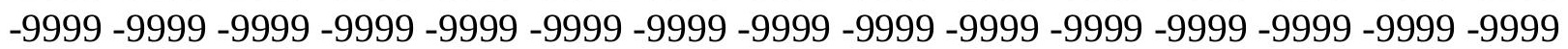


-9999 -9999 -9999 -9999 -9999 -9999 -9999 -9999 -9999 -9999 -9999 -9999 -9999 -9999 -9999 -9999 -9999 -9999-9999

-9999 -9999 -9999 -9999 -9999 -9999 -9999 -9999 -9999 -9999 -9999 -9999 -9999 -9999 -9999 -9999 -9999 -9999 -9999 -9999 -9999 -9999 -9999 -9999 -9999 -9999 -9999 -9999 -9999 -9999 - -999 -9999 -9999 -9999 -9999 -9999 -9999 -9999 -9999 -9999 -9999 -9999 -9999 -9999 - -9999 - -9999 -

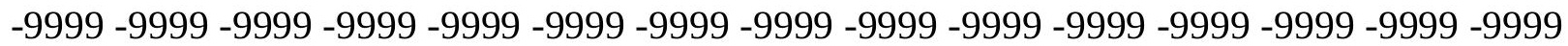

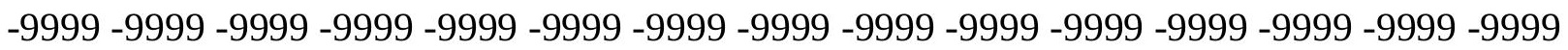
-9999 -9999 -9999 -9999 -9999 -9999 -9999 -9999 -9999 -9999 -9999 -9999 -9999 -9999 -9999

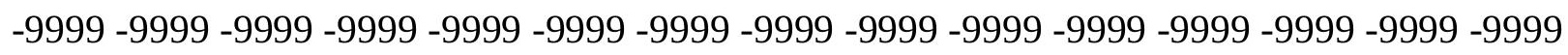

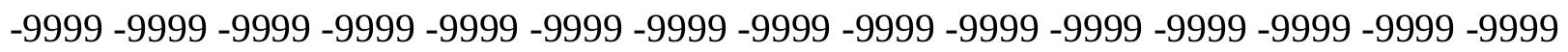
-9999 -9999-9999 -9999 -9999-9999-9999-9999-9999 143.8585968018145 .9920959473 146.2969055176144 .4682006836140 .8106994629136 .5437011719134 .1054992676 131.6672058105128 .0097961426123 .1332015991117 .0374984741110 .6370010376 106.3700027466 103.322196960499.0551681518696.3121032714895.3977432251 95.0929565429793 .8738174438591 .1307525634888 .9972534179788 .99725341797 89.6068267822389 .6068267822389 .302040100188 .6924667358488 .69246673584 94.1785964965895 .0929565429796 .6168823242298 .75038146973100 .5791015625 102.1029968262103 .0174026489103 .9317016602101 .4934005737101 .4934005737 101.4934005737100 .8839035034100 .274299621699 .6647262573298 .4455871582 97.2264633178796 .0073165893694 .4833908081192 .9594726562591 .74033355713 90.8259735107489 .6068267822388 .6924667358488 .0829010009887 .47332763672 86.8637619018686 .254188537685 .9494018554785 .3398437584 .73026275635 84.1206970214883 .8159103393683 .206336975182 .5967712402381 .98719787598 81.3776321411180 .7680587768680 .1584930419979 .8537063598678 .93934631348 78.3297805786177 .7202072143677 .110626220776 .1962814331175 .58670806885 74.6723632812573 .7580032348672 .8436431884871 .9292907714870 .71015167236 69.7957916259868 .8814392089867 .6623001098666 .7479400634865 .52880096436 64.3096618652363 .3953094482462 .1761703491260 .9570198059160 .65224075317 60.0426712036159 .1283111572358 .2139587402356 .9948196411155 .77568054199 54.2517509460452 .4230384826750 .5943298339848 .4608306884846 .02254867554 43.5842704772941 .1459884643639 .0125007629437 .1837806701735 .35507965088 34.1359291076732 .9167900085432 .0024414062531 .3928699493430 .78330039978 30.4785099029530 .1737308502229 .8689403533929 .8689403533929 .86894035339 29.5641593933128 .9545898437528 .6497993469228 .3450202941927 .73545074463 27.1258792877226 .5163097381625 .906740188625 .2971591949524 .99238014221 24.9923801422124 .6875991821324 .3828105926524 .3828105926524 .38281059265 24.3828105926524 .6875991821324 .9923801422125 .6019496917726 .21151924133 27.1258792877227 .7354507446328 .3450202941928 .6497993469228 .34502029419 28.3450202941928 .3450202941928 .0402297973628 .3450202941928 .34502029419 28.9545898437529 .5641593933130 .1737308502231 .3928699493432 .91679000854 34.4407196044936 .2694282531738 .0981407165539 .9268493652341 .75556182861 43.5842704772945 .1082000732446 .9369087219248 .4608306884849 .98476028442 51.2038993835452 .7278289794953 .6421813964854 .5565414428755 .47089004517 55.7756805419956 .3852500915556 .6900291442956 .6900291442956 .99481964111 57.6043891906757 .909179687558 .5187492370659 .1283111572359 .73788070679 60.0426712036160 .6522407531762 .7857398986862 .7857398986863 .70008850098 
64.6144485473665 .2240066528365 .5288009643665 .5288009643665 .52880096436 62.4809494018662 .1761703491261 .8713798522961 .5666007995661 .26181030273 60.9570198059160 .6522407531760 .3474502563560 .3474502563560 .04267120361 60.0426712036160 .0426712036160 .0426712036160 .0426712036160 .34745025635 60.3474502563560 .6522407531760 .6522407531760 .9570198059160 .95701980591 61.2618103027361 .2618103027361 .56660079956 -9999 -9999 -9999 -9999 -9999 -9999 -9999 -9999 -9999 -9999 -9999 -9999 -9999 -9999 -9999 -9999 -9999 -9999 -9999 -9999 -9999 -9999

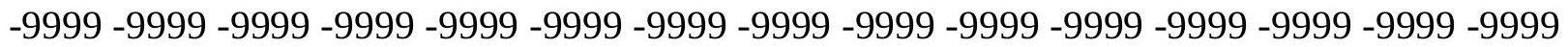

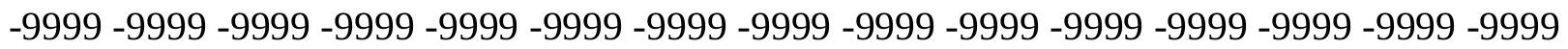
-9999-9999-9999

-9999 -9999 -9999 -9999 -9999 -9999 -9999 -9999 -9999 -9999 -9999 -9999 -9999 -9999 -9999 -9999 -9999 -9999 -9999 -9999 -9999 -9999 -9999 -9999 -9999 -9999 -9999 -9999 -9999 -9999 -9999 -9999 -9999 -9999 -9999 -9999 -9999 -9999 -9999 -9999 -9999 -9999 -9999 -9999 -9999 -9999 -9999 -9999 -9999 -9999 -9999 -9999 -9999 -9999 -9999 -9999 -9999 -9999 -9999 -9999 -9999 -9999 -9999 -9999 -9999 -9999 -9999 -9999 -9999 -9999 -9999 -9999 -9999 -9999 -9999

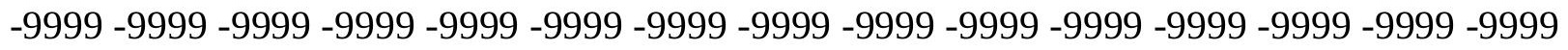

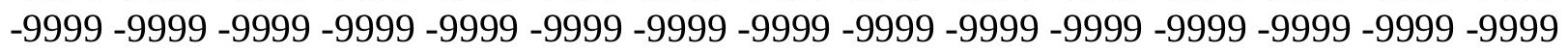

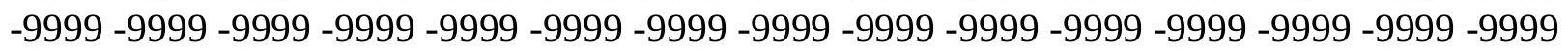
-9999 -9999 -9999 -9999 -9999 -9999 -9999 -9999 -9999 168.6976165771 168.3036499023 167.8045806885167 .2122650146164 .8056488037161 .2312927246157 .878692627 154.5260925293150 .5639038086145 .6873016357139 .5915985107132 .5814971924 125.2667007446117 .647102356109 .4179000854104 .2365036011103 .0174026489 103.9317016602101 .493400573796 .9216690063592 .349891662693 .56903076172 94.7881774902394 .4833908081192 .9594726562591 .1307525634891 .13075256348 93.2642517089896 .9216690063598 .75038146973100 .8839035034102 .712600708 104.2365036011105 .4557037354103 .0174026489103 .3221969604103 .6268997192 103.3221969604102 .712600708102 .4077987671101 .4934005737100 .5791015625 99.3599472045997 .8360290527396 .6168823242295 .0929565429793 .56903076172 92.349891662691 .1307525634889 .9116134643688 .9972534179788 .38768768311 87.7781066894587 .4733276367286 .8637619018686 .254188537685 .64462280273 85.0350494384884 .4254837036183 .8159103393683 .206336975182 .59677124023 81.9871978759881 .3776321411180 .4632720947379 .8537063598679 .24413299561 78.6345596313577 .7202072143677 .110626220776 .5010681152375 .58670806885 74.6723632812573 .4532165527372 .5388565063571 .6244964599670 .40535736084 69.4910125732468 .2718734741267 .3575134277366 .1383666992264 .91924285889 63.7000885009862 .7857398986861 .5666007995660 .6522407531759 .73788070679 59.1283111572358 .2139587402356 .9948196411155 .7756805419954 .55654144287 53.0326118469251 .2038993835449 .3751907348647 .2416992187545 .10820007324 42.66992187540 .5364189147938 .4029312133836 .5742111206135 .05028915405 33.8311500549332 .9167900085432 .3072204589831 .6976509094231 .39286994934 31.0880794525131 .0880794525131 .0880794525131 .0880794525131 .08807945251 31.0880794525131 .0880794525130 .7833003997830 .4785099029530 .17373085022 29.5641593933128 .6497993469227 .7354507446327 .1258792877226 .82109069824 26.2115192413325 .906740188625 .6019496917724 .9923801422124 .99238014221 24.9923801422124 .9923801422125 .2971591949525 .906740188626 .21151924133 26.8210906982427 .430660247827 .7354507446328 .0402297973628 .04022979736 
28.0402297973627 .7354507446327 .7354507446327 .7354507446328 .04022979736 28.3450202941928 .9545898437529 .5641593933130 .4785099029531 .69765090942 33.5263595581135 .0502891540536 .8790016174338 .7077102661140 .53641891479 42.3651313781744 .1938400268645 .717769622847 .5464782714849 .07040023804 50.5943298339851 .8134689331153 .0326118469254 .2517509460454 .86132049561 55.4708900451755 .7756805419956 .0804595947356 .0804595947356 .38525009155 56.6900291442957 .2995986938557 .6043891906758 .2139587402358 .82352828979 59.1283111572359 .4331016540559 .4331016540558 .8235282897963 .09051895142 64.004882812564 .6144485473665 .2240066528365 .2240066528365 .52880096436 62.1761703491261 .8713798522961 .5666007995661 .2618103027360 .95701980591 60.3474502563560 .0426712036160 .0426712036159 .7378807067959 .73788070679 59.7378807067959 .7378807067959 .7378807067959 .7378807067960 .04267120361 60.0426712036160 .3474502563560 .3474502563560 .6522407531760 .65224075317 60.9570198059160 .9570198059161 .26181030273 -9999 -9999 -9999 -9999 -9999 -9999 -9999 -9999 -9999 -9999 -9999 -9999 -9999 -9999 -9999 -9999 -9999 -9999 -9999 -9999 -9999 -9999

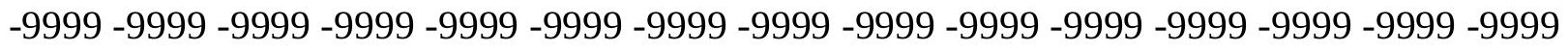
-9999 -9999 -9999 -9999 -9999 -9999 -9999 -9999 -9999 -9999 -9999 -9999 -9999 -9999 -9999 -9999-9999-9999

-9999 -9999 -9999 -9999 -9999 -9999 -9999 -9999 -9999 -9999 -9999 -9999 -9999 -9999 -9999

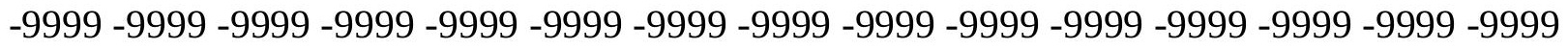

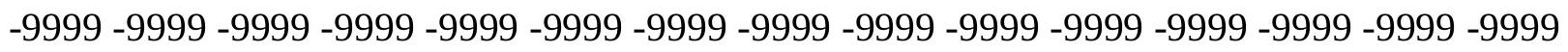
-9999 -9999 -9999 -9999 -9999 -9999 -9999 -9999 -9999 -9999 -9999 -9999 -9999 -9999 -9999 -9999 -9999 -9999 -9999 -9999 -9999 -9999 -9999 -9999 -9999 -9999 -9999 -9999 -9999 -9999 -

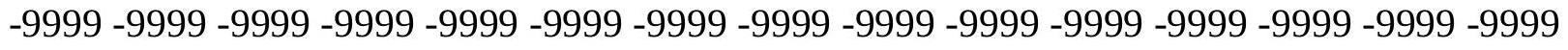

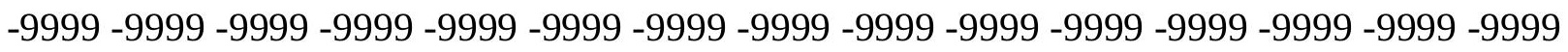
-9999 -9999 -9999 -9999 -9999 -9999 -9999 -9999 -9999 -9999 -9999 -9999 -9999 -9999 -9999 -9999 -9999 -9999 -9999 -9999 -9999 -9999 -9999 -9999 -9999 168.9797210693 168.5334014893167 .993057251167 .3788299561166 .7073822021165 .9880371094 165.2301940918164 .4424438477163 .6333618164159 .0977935791151 .1734008789 144.4682006836137 .7628936768129 .8385009766123 .43800354121 .3044967651 117.9517974854109 .1130981445103 .6268997192100 .5791015625101 .1886978149 101.4934005737100 .579101562598 .445587158296 .6168823242295 .3977432251 94.7881774902396 .92166900635101 .4934005737103 .6268997192105 .7603988647 107.2844009399 104.8460998535105.4557037354105.4557037354105.4557037354 105.1509017944104 .8460998535104 .2365036011103 .6268997192102 .712600708 101.4934005737100 .274299621698 .7503814697397 .2264633178795 .70252990723 94.1785964965892 .6546783447391 .4355392456190 .5211791992289 .91161346436 89.3020401001 88.38768768311 87.77810668945 87.16854858398 86.55898284912 85.6446228027385 .0350494384884 .4254837036183 .8159103393683 .2063369751 82.2919769287181 .6824111938581 .0728530883880 .1584930419979 .54891967773 78.6345596313578 .0249862670977 .4154205322376 .5010681152375 .58670806885 74.6723632812573 .4532165527372 .5388565063571 .3197174072370 .40535736084 69.1862335205167 .9670867919966 .7479400634865 .8335876464864 .61444854736 63.3953094482462 .1761703491261 .2618103027360 .0426712036159 .12831115723 58.2139587402357 .2995986938556 .0804595947354 .8613204956153 .64218139648 52.1182594299350 .2895507812548 .1560516357446 .3273391723643 .88906097412 
41.7555618286139 .622070312537 .7933502197335 .9646492004434 .44071960449 33.5263595581132 .6120109558132 .0024414062531 .6976509094231 .69765090942 31.6976509094231 .6976509094231 .6976509094232 .0024414062532 .30722045898 32.6120109558132 .9167900085432 .9167900085432 .9167900085432 .61201095581 32.0024414062531 .0880794525129 .8689403533929 .5641593933128 .64979934692 28.0402297973627 .430660247826 .8210906982426 .2115192413325 .60194969177 25.6019496917725 .6019496917725 .906740188626 .2115192413326 .51630973816 26.8210906982427 .430660247827 .430660247827 .7354507446327 .73545074463 27.7354507446327 .430660247827 .430660247827 .430660247827 .73545074463 28.0402297973628 .3450202941928 .9545898437529 .8689403533931 .08807945251 32.6120109558134 .1359291076735 .9646492004437 .7933502197339 .6220703125 41.1459884643642 .9747009277344 .8034095764246 .6321296691948 .15605163574 49.6799812316951.2038993835452.4230384826753.6421813964854.55654144287 55.1661109924355 .1661109924355 .1661109924355 .4708900451755 .77568054199 56.0804595947356 .3852500915556 .9948196411157 .2995986938557 .9091796875 58.5187492370658 .5187492370658 .5187492370659 .1283111572360 .04267120361 60.6522407531764 .3096618652364 .9192428588965 .2240066528365 .22400665283 61.8713798522961 .5666007995661 .2618103027360 .9570198059160 .34745025635 60.0426712036159 .7378807067959 .4331016540559 .1283111572359 .12831115723 59.1283111572359 .1283111572359 .1283111572359 .4331016540559 .43310165405 59.7378807067960 .0426712036160 .0426712036160 .3474502563560 .34745025635 60.6522407531760 .6522407531760 .95701980591 -9999 -9999 -9999 -9999 -9999 -9999 -9999 -9999 -9999 -9999 -9999 -9999 -9999 -9999 -9999 -9999 -9999 -9999 -9999 -9999 -9999 -9999 -9999 -9999 -9999 -9999 -9999 -9999 -9999 -9999 -9999 -9999 -9999 -9999 -9999 -9999 -9999 -

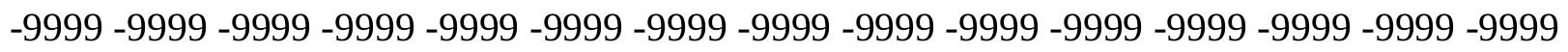
-9999 -9999-9999

-9999 -9999 -9999 -9999 -9999 -9999 -9999 -9999 -9999 -9999 -9999 -9999 -9999 -9999 -9999

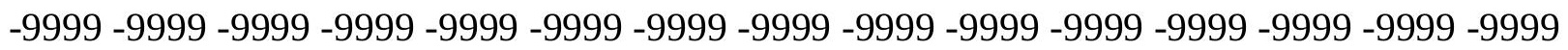
-9999 -9999 -9999 -9999 -9999 -9999 -9999 -9999 -9999 -9999 -9999 -9999 -9999 -9999 -9999 -9999 -9999 -9999 -9999 -9999 -9999 -9999 -9999 -9999 -9999 -9999 -9999 -9999 -9999 -9999 -9999 -9999 -9999 -9999 -9999 -9999 -9999 -9999 -9999 -9999 -9999 -9999 -9999 -9999 -9999 -9999 -9999 -9999 -9999 -9999 -9999 -9999 -9999 -9999 -9999 -9999 -9999 -9999 -9999 -9999 -

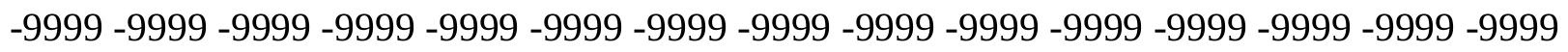

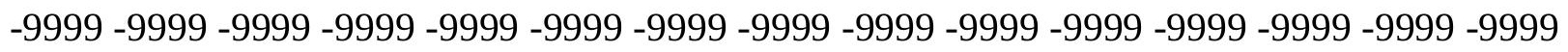
-9999 -9999 -9999 -9999-9999-9999 -9999 -9999 -9999 -9999-9999 178.143157959 177.3613433838176 .2783813477175 .5510559082175 .4417877197175 .4270935059 174.8757781982173 .404586792170 .9523468018165 .1934967041159 .4026031494 153.9165039062147 .5160064697142 .3347015381141 .1154937744138 .0677032471 126.4858016968114 .9039993286111 .551399231109 .7226028442108 .8082962036 106.6747970581104 .2365036011102 .102996826299 .9695205688598 .4455871582 98.75038146973101 .7982025146104 .2365036011105 .1509017944106 .979598999 107.8938980103107 .8938980103107 .5891036987107 .2844009399106 .979598999 106.6747970581 106.3700027466105.7603988647104.8460998535103.9317016602 102.712600708101 .188697814999 .6647262573298 .1408081054796 .31210327148 94.7881774902393 .5690307617292 .349891662691 .4355392456190 .52117919922 89.91161346436 88.99725341797 88.08290100098 87.47332763672 86.55898284912 
85.9494018554785 .3398437584 .4254837036183 .8159103393682 .90155792236 82.2919769287181 .3776321411180 .7680587768679 .8537063598678 .93934631348 78.3297805786177 .4154205322376 .5010681152375 .5867080688574 .67236328125 73.4532165527372 .5388565063571 .3197174072370 .1005783081168 .88143920898 67.9670867919966 .7479400634865 .5288009643664 .3096618652363 .09051895142 61.8713798522960 .6522407531759 .7378807067958 .8235282897957 .60438919067 56.6900291442955 .4708900451754 .2517509460453 .0326118469251 .20389938354 49.3751907348647 .5464782714845 .4129791259842 .9747009277340 .84120941162 38.7077102661136 .8790016174335 .0502891540533 .8311500549332 .91679000854 32.3072204589831 .6976509094231 .6976509094231 .6976509094232 .00244140625 32.0024414062532 .3072204589832 .9167900085433 .2215805053733 .83115005493 34.4407196044934 .7455101013235 .0502891540535 .0502891540535 .05028915405 34.1359291076733 .2215805053732 .0024414062531 .0880794525130 .17373085022 29.2593708038328 .3450202941927 .430660247826 .8210906982426 .51630973816 26.2115192413326 .5163097381626 .8210906982427 .1258792877227 .12587928772 27.430660247827 .430660247827 .430660247827 .430660247827 .430660247827 .4306602478 27.430660247827 .430660247827 .430660247827 .7354507446328 .04022979736 28.6497993469229 .5641593933130 .7833003997832 .0024414062533 .52635955811 35.0502891540536 .8790016174338 .7077102661140 .2316398620642 .06034851074 43.8890609741245 .717769622847 .2416992187548 .765621185350 .28955078125 51.8134689331153 .0326118469254 .2517509460454 .2517509460454 .25175094604 54.5565414428754 .5565414428754 .5565414428754 .8613204956155 .47089004517 56.0804595947356 .6900291442957 .2995986938557 .909179687558 .21395874023 58.5187492370659 .1283111572360 .0426712036160 .6522407531761 .26181030273 61.5666007995664 .9192428588961 .8713798522961 .8713798522961 .26181030273 60.9570198059160 .3474502563560 .0426712036159 .4331016540559 .12831115723 58.8235282897958 .5187492370658 .5187492370658 .5187492370658 .51874923706 58.8235282897958 .8235282897959 .1283111572359 .4331016540559 .43310165405 59.7378807067960 .0426712036160 .0426712036160 .3474502563560 .65224075317 60.6522407531760 .95701980591 -9999 -9999 -9999 -9999 -9999-9999 -9999 -9999 -9999 -9999 -9999 -9999 -9999 -9999 -9999 -9999 -9999 -9999 -9999 -9999 -9999 -9999 -9999 -9999

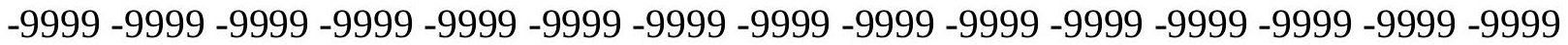

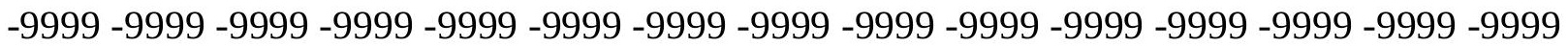

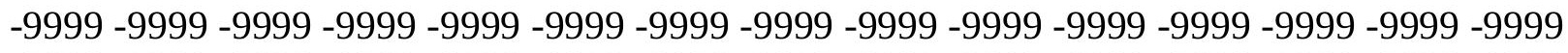
-9999 -9999 -9999 -9999 -9999 -9999 -9999 -9999 -9999 -9999 -9999 -9999 -9999 -9999 -9999 -9999 -9999 -9999 -9999 -9999 -9999 -9999 -9999 -9999 -9999 -9999 -9999 -9999 -9999 -9999

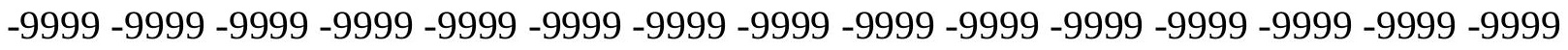

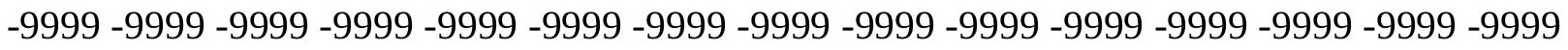
-9999 -9999 -9999 -9999 -9999 -9999 -9999 -9999 -9999 -9999 -9999 -9999 -9999 - 9999 - -999 -9999 -9999 -9999 -9999 -9999 -9999 -9999 -9999 -9999 -9999 -9999 -9999 -9999 -9999 -9999 -

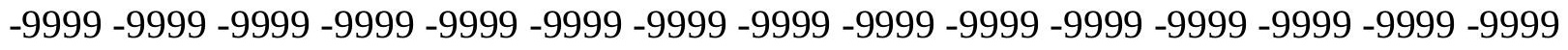
-9999 -9999 -9999 -9999 -9999 -9999-9999 -9999-9999-9999-9999 180.0388336182 180.0603637695179 .6439971924179 .0748596191178 .5398712158177 .8582000732 176.6766204834174 .6616973877171 .8142547607168 .3633270264164 .6878967285 161.1785430908157 .5738983154154 .2212982178153 .0021057129150 .8686065674 144.4682006836137 .4580993652132 .8863067627128 .3144989014120 .0852966309 
112.1608963013107 .8938980103107 .5891036987103 .3221969604101 .1886978149 101.4934005737103 .9317016602108 .1986999512110 .6370010376114 .5991973877 110.6370010376110 .3321990967113 .6848983765112 .7705001831108 .1986999512 108.1986999512108 .1986999512107 .8938980103107 .2844009399106 .3700027466 105.1509017944103 .6268997192102 .1029968262100 .579101562598 .75038146973 97.2264633178795 .7025299072394 .4833908081193 .2642517089892 .3498916626 91.4355392456190 .2164001464889 .302040100188 .6924667358487 .77810668945 86.86376190186 85.9494018554785.33984375 84.42548370361 83.81591033936 82.9015579223681 .9871978759881 .3776321411180 .4632720947379 .54891967773 78.6345596313577 .7202072143676 .8058471679775 .5867080688574 .67236328125 73.4532165527372 .5388565063571 .3197174072370 .1005783081169 .18623352051 67.9670867919966 .7479400634865 .5288009643664 .3096618652363 .09051895142 61.8713798522960 .6522407531759 .4331016540558 .5187492370657 .29959869385 56.3852500915555 .1661109924353 .9469718933152 .4230384826750 .89912033081 49.0704002380446 .9369087219244 .4986305236842 .3651313781739 .92684936523 37.7933502197335 .6598587036133 .8311500549332 .6120109558132 .00244140625 31.3928699493431 .3928699493431 .3928699493431 .6976509094231 .69765090942 32.3072204589832 .6120109558133 .5263595581134 .1359291076734 .74551010132 35.6598587036136 .2694282531736 .8790016174337 .4885711669937 .48857116699 37.1837806701736 .2694282531734 .7455101013233 .5263595581132 .30722045898 31.0880794525129 .8689403533928 .9545898437528 .0402297973627 .73545074463 27.430660247827 .7354507446328 .0402297973628 .0402297973628 .04022979736 27.7354507446327 .7354507446327 .430660247827 .430660247827 .4306602478 27.1258792877227 .1258792877227 .1258792877227 .430660247827 .73545074463 28.0402297973628 .6497993469229 .2593708038330 .4785099029531 .69765090942 32.9167900085434 .4407196044936 .2694282531737 .7933502197339 .6220703125 41.4507789611842 .9747009277344 .8034095764246 .3273391723647 .85126113892 49.3751907348650 .5943298339851 .8134689331152 .7278289794953 .33739852905 53.3373985290553 .3373985290553 .6421813964853 .6421813964853 .94697189331 54.2517509460454 .8613204956155 .7756805419956 .3852500915557 .29959869385 58.2139587402358 .8235282897959 .4331016540560 .3474502563560 .95701980591 61.2618103027361 .5666007995661 .8713798522961 .8713798522961 .56660079956 61.2618103027360 .6522407531760 .0426712036159 .4331016540559 .12831115723 58.5187492370658 .2139587402357 .909179687557 .909179687557 .9091796875 58.2139587402358 .2139587402358 .5187492370658 .8235282897959 .12831115723 59.4331016540559 .4331016540559 .7378807067960 .0426712036160 .04267120361 60.3474502563560 .3474502563560 .65224075317 -9999 -9999 -9999 -9999 -9999 -9999 -9999

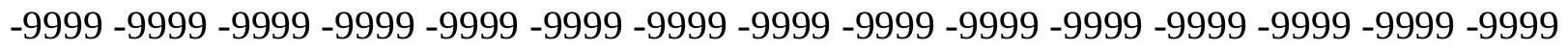
-9999 -9999 -9999 -9999 -9999 -9999 -9999 -9999 -9999 -9999 -9999 -9999 -9999 -9999 -9999 -

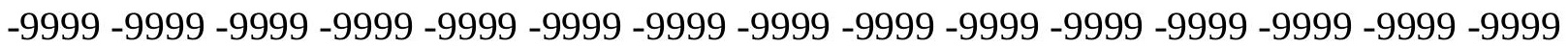
-9999-9999

-9999 -9999 -9999 -9999 -9999 -9999 -9999 -9999 -9999 -9999 -9999 -9999 -9999 -9999 -9999 -9999 -9999 -9999 -9999 -9999 -9999 -9999 -9999 -9999 -9999 -9999 -9999 -9999 -9999 -9999 -9999 -9999 -9999 -9999 -9999 -9999 -9999 -9999 -9999 -9999 -9999 -9999 -9999 -9999 -9999 -9999 -9999 -9999 -9999 -9999 -9999 -9999 -9999 -9999 -9999 -9999 -9999 -9999 -9999 -9999 -

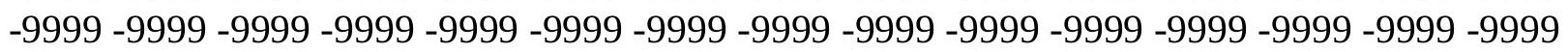


-9999 -9999 -9999 -9999 -9999 -9999 -9999 -9999 -9999 -9999 -9999 -9999 -9999 -9999 -9999 -9999 -9999 -9999 -9999 -9999 -9999 -9999 -9999 -9999 -9999 -9999 -9999 -9999 -9999 -9999

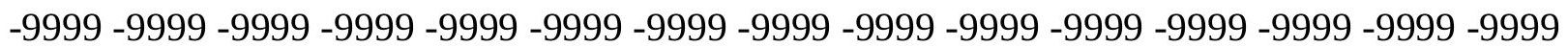
-9999 -9999 -9999 -9999 -9999 -9999 -9999 -9999 -9999 -9999 -9999 -9999 178.9089050293 180.7375946045181 .3347167969180 .4941101074179 .5534820557177 .9476776123 175.5266876221172 .311126709168 .6030883789164 .9046936035161 .6597900391 159.1217041016157 .3205718994156 .1999359131155 .6663970947155 .5440673828 155.6291809082153 .0021057129146 .2969055176135 .9342041016126 .1809997559 122.2188034058118 .5614013672110 .3321990967103 .3221969604104 .5412979126 107.5891036987110 .6370010376113 .3800964355115 .5136032104115 .2088012695 113.9896011353115 .5136032104114 .5991973877113 .9896011353110 .0273971558 110.3321990967110 .3321990967109 .7226028442108 .8082962036107 .5891036987 106.0652008057104 .5412979126103 .0174026489101 .188697814999 .66472625732 98.1408081054796 .6168823242295 .0929565429793 .8738174438592 .95947265625 91.7403335571390 .8259735107489 .6068267822388 .6924667358487 .77810668945 86.8637619018686 .254188537685 .3398437584 .4254837036183 .81591033936 82.9015579223681 .9871978759881 .0728530883880 .1584930419978 .93934631348 78.0249862670976 .8058471679775 .8914871215874 .6723632812573 .75800323486 72.5388565063571 .6244964599670 .4053573608469 .1862335205167 .96708679199 66.7479400634865 .5288009643664 .3096618652363 .0905189514261 .87137985229 60.6522407531759 .4331016540558 .5187492370657 .2995986938556 .08045959473 55.1661109924353 .6421813964852 .4230384826750 .5943298339848 .7656211853 46.6321296691944 .1938400268641 .4507789611839 .0125007629436 .57421112061 34.4407196044932 .6120109558131 .3928699493430 .7833003997830 .47850990295 30.4785099029530 .7833003997831 .0880794525131 .3928699493432 .00244140625 32.9167900085433 .5263595581134 .4407196044935 .3550796508836 .26942825317 37.1837806701738 .0981407165539 .0125007629439 .622070312539 .92684936523 38.4029312133836 .8790016174335 .6598587036134 .4407196044933 .22158050537 32.0024414062531 .0880794525129 .8689403533929 .2593708038329 .25937080383 29.5641593933129 .5641593933129 .5641593933128 .9545898437528 .64979934692 28.0402297973627 .7354507446327 .430660247827 .430660247827 .4306602478 27.430660247827 .430660247827 .430660247827 .7354507446328 .04022979736 28.6497993469229 .2593708038330 .1737308502231 .3928699493432 .61201095581 34.1359291076735 .6598587036137 .1837806701739 .0125007629440 .53641891479 42.3651313781743 .8890609741245 .4129791259846 .9369087219248 .46083068848 49.6799812316950 .8991203308151 .5086898803752 .1182594299352 .11825942993 52.4230384826752 .4230384826752 .4230384826752 .7278289794953 .33739852905 53.9469718933154 .8613204956155 .7756805419956 .9948196411157 .9091796875 58.8235282897959 .4331016540560 .3474502563560 .9570198059161 .56660079956 61.5666007995661 .5666007995661 .5666007995661 .2618103027360 .95701980591 60.3474502563559 .7378807067959 .1283111572358 .5187492370657 .9091796875 57.6043891906757 .2995986938557 .2995986938557 .6043891906757 .60438919067 57.909179687558 .2139587402358 .5187492370658 .8235282897959 .12831115723 59.4331016540559 .4331016540559 .7378807067960 .0426712036160 .04267120361 60.3474502563560 .34745025635 -9999 -9999 -9999 -9999 -9999 -9999 -9999 -9999 -9999 -9999 -9999 -9999 -9999 -9999 -9999 -9999 -9999 -9999 -9999 -9999 -9999 -9999 -9999 -9999 
-9999 -9999 -9999 -9999 -9999 -9999 -9999 -9999 -9999 -9999 -9999 -9999 -9999 -9999 -9999 -9999 -9999 -9999 -9999 -9999 -9999 -9999 -9999 -9999 -9999 -9999 -9999 -9999 -9999 -9999 -9999 -9999 -9999 -9999 -9999 -9999 -9999 -9999 -9999 -9999 -9999 -9999 -9999 -9999 -9999 -9999 -9999 -9999 -9999 -9999 -9999 -9999 -9999 -9999 -9999 -9999 -9999 -9999 -9999 -9999 -9999 -9999 -9999 -9999 -9999 -9999 -9999 -9999 -9999 -9999 -9999 -9999 -9999 -9999 -9999 -9999 -9999 -9999 -9999 -9999 -9999 -9999 -9999 -9999 -9999 -9999 -9999 -9999 -9999 -9999 -9999 -9999 -9999 -9999 -9999 -9999 -9999 -9999 -9999 -9999 -9999 -9999 -9999 -9999 -9999

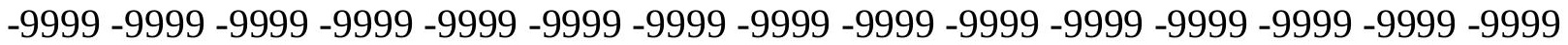
-9999 -9999 -9999 -9999 -9999 -9999 -9999 -9999 -9999 -9999 -9999 -9999 -9999 -9999 -9999 -9999 -9999 -9999 -9999 -9999 -9999 -9999 -9999 -9999 -9999 -9999 -9999 -9999 -9999 -9999 -9999 -9999 -9999 -9999 -9999 -9999 -9999 -9999 -9999 -9999 -9999 -9999 163.6696014404 165.1934967041165 .8031005859166 .1078948975166 .4127044678167 .3269958496 167.9365997314167 .0222015381165 .1934967041163 .0599975586161 .8283996582 159.8454284668158 .6937255859158 .2498321533158 .4440765381159 .0599060059 159.8301544189160 .461730957160 .7044677734154 .5260925293148 .1255950928 143.2489929199137 .4580993652129 .8385009766123 .43800354119 .7806015015 118.2565994263117 .0374984741117 .0374984741117 .342300415116 .4279022217 115.818397522113 .6848983765115 .818397522115 .818397522113 .3800964355 112.4656982422112 .7705001831112 .4656982422111 .24659729110 .0273971558 108.5035018921106 .6747970581105 .1509017944103 .3221969604101 .7982025146 100.274299621698 .445587158297 .2264633178795 .7025299072394 .48339080811 93.2642517089892 .0450973510790 .8259735107489 .9116134643688 .99725341797 88.0829010009887 .1685485839886 .254188537685 .6446228027384 .73026275635 83.8159103393682 .9015579223681 .6824111938580 .7680587768679 .54891967773 78.3297805786177 .4154205322376 .1962814331174 .9771423339874 .0627822876 72.8436431884871 .6244964599670 .7101516723669 .4910125732468 .27187347412 67.0527267456165 .8335876464864 .6144485473663 .0905189514261 .87137985229 60.6522407531759 .7378807067958 .5187492370657 .2995986938556 .38525009155 55.1661109924353 .9469718933152 .4230384826750 .5943298339848 .7656211853 46.3273391723643 .8890609741241 .1459884643638 .0981407165535 .35507965088 32.9167900085431 .0880794525129 .8689403533928 .9545898437528 .95458984375 29.2593708038329 .8689403533930 .1737308502230 .7833003997831 .69765090942 32.6120109558133 .5263595581134 .7455101013235 .6598587036136 .87900161743 37.7933502197338 .7077102661139 .622070312540 .2316398620640 .23163986206 39.622070312538 .4029312133837 .4885711669936 .2694282531735 .35507965088 34.4407196044933 .5263595581132 .6120109558131 .3928699493432 .00244140625 32.3072204589832 .0024414062531 .6976509094230 .4785099029529 .56415939331 28.6497993469228 .0402297973627 .7354507446327 .7354507446327 .4306602478 27.430660247827 .430660247827 .7354507446327 .7354507446328 .04022979736 28.6497993469229 .2593708038330 .1737308502231 .0880794525132 .30722045898 33.8311500549335 .3550796508836 .8790016174338 .4029312133839 .92684936523 41.7555618286143 .2794914245644 .8034095764246 .0225486755447 .54647827148 48.765621185349 .6799812316950 .2895507812550 .8991203308151 .20389938354 51.2038993835451 .2038993835451 .5086898803751 .8134689331152 .11825942993 53.0326118469253 .9469718933155 .1661109924356 .6900291442957 .9091796875 59.1283111572359 .7378807067960 .6522407531761 .2618103027361 .56660079956 
61.5666007995661 .5666007995661 .5666007995660 .9570198059160 .65224075317 60.0426712036159 .1283111572358 .5187492370657 .909179687557 .29959869385 56.9948196411156 .6900291442956 .6900291442956 .9948196411157 .29959869385 57.6043891906757 .909179687558 .2139587402358 .5187492370658 .82352828979 59.1283111572359 .4331016540559 .4331016540559 .7378807067960 .04267120361 60.0426712036160 .34745025635 -9999 -9999 -9999 -9999 -9999 -9999 -9999 -9999 -9999 -9999 -9999 -9999 -9999 -9999 -9999 -9999 -9999 -9999 -9999 -9999 -9999 -9999 -9999 -9999

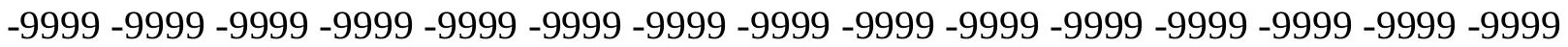

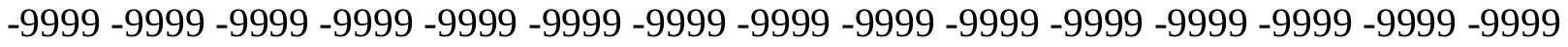
-9999 -9999 -9999 -9999 -9999 -9999 -9999 -9999 -9999 -9999 -9999 -9999 -9999 -9999 -9999

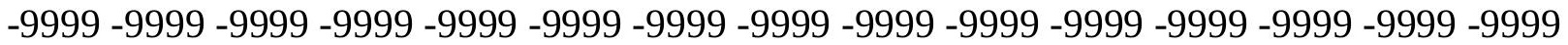
-9999 -9999 -9999 -9999 -9999 -9999 -9999 -9999 -9999 -9999 -9999 -9999 -9999 -9999 -9999 -9999 -9999 -9999 -9999 -9999 -9999 -9999 -9999 -9999 -9999 -9999 -9999 -9999 -9999 -9999 -9999 -9999 -9999 -9999 -9999 -9999 -9999 -9999 -9999 -9999 -9999 -9999 -9999 -9999 -9999 -9999 -9999 -9999 -9999 -9999 -9999 -9999 -9999 -9999 -9999 -9999 -9999 -9999 -9999 -9999

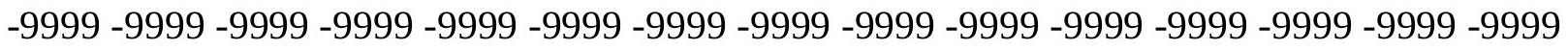
-9999 -9999 -9999 -9999 -9999 -9999 -9999 -9999 -9999 -9999 -9999 -9999 -9999 -9999 -9999 -9999 -9999 -9999 -9999 -9999 -9999 -9999 -9999 -9999 -9999 -9999 -9999 -9999 145.6873016357146 .2969055176147 .5160064697148 .4304046631147 .8208007812 147.8208007812150 .5639038086153 .3069000244153 .9165039062154 .5260925293 156.3547973633158 .4882965088159 .7073974609161 .075088501162 .4723358154 164.0384979248165 .3240661621165 .8265686035165 .4408416748164 .449798584 161.5361022949155 .4403991699150 .5639038086145 .9920959473141 .4203033447 137.4580993652135 .9342041016133 .8007049561128 .6192932129121 .9140014648 115.5136032104112 .4656982422113 .3800964355114 .2944030762115 .5136032104 115.2088012695115 .2088012695114 .5991973877113 .3800964355111 .8561019897 110.3321990967108 .8082962036107 .2844009399105 .4557037354103 .9317016602 102.1029968262100 .274299621698 .7503814697397 .2264633178795 .70252990723 94.4833908081193 .2642517089892 .0450973510791 .1307525634889 .91161346436 88.9972534179788 .0829010009887 .4733276367286 .5589828491285 .64462280273 84.7302627563583 .8159103393682 .9015579223681 .6824111938580 .46327209473 78.9393463134877 .7202072143676 .5010681152375 .5867080688574 .36756896973 73.1484298706172 .2340774536171 .014930725169 .7957916259868 .57665252686 67.3575134277366 .1383666992264 .9192428588963 .3953094482462 .17617034912 60.9570198059159 .7378807067958 .8235282897957 .6043891906756 .38525009155 55.4708900451753 .9469718933152 .7278289794950 .8991203308149 .07040023804 46.6321296691943 .8890609741240 .8412094116237 .4885711669934 .44071960449 31.3928699493429 .2593708038328 .0402297973627 .1258792877227 .12587928772 27.430660247828 .3450202941928 .9545898437529 .8689403533930 .78330039978 32.0024414062533 .2215805053734 .4407196044935 .6598587036136 .87900161743 37.7933502197338 .7077102661139 .622070312539 .9268493652340 .23163986206 39.9268493652339 .3172798156738 .7077102661138 .0981407165537 .79335021973 37.1837806701736 .5742111206135 .9646492004435 .6598587036135 .65985870361 35.6598587036135 .3550796508834 .1359291076732 .6120109558130 .78330039978 29.5641593933128 .6497993469228 .3450202941928 .0402297973628 .04022979736 28.0402297973628 .0402297973628 .0402297973628 .0402297973628 .34502029419 
28.6497993469229 .2593708038330 .1737308502231 .0880794525132 .30722045898 33.5263595581135 .0502891540536 .5742111206138 .0981407165539 .6220703125 41.1459884643642 .66992187544 .1938400268645 .4129791259846 .63212966919 47.5464782714848 .4608306884849 .3751907348649 .6799812316949 .98476028442 50.2895507812550 .2895507812550 .2895507812550 .5943298339851 .20389938354 52.1182594299353 .3373985290554 .8613204956156 .3852500915557 .9091796875 59.1283111572359 .7378807067960 .6522407531761 .2618103027361 .26181030273 61.2618103027361 .5666007995661 .2618103027360 .9570198059160 .34745025635 59.7378807067958 .8235282897957 .909179687557 .2995986938556 .69002914429 56.3852500915556 .3852500915556 .3852500915556 .6900291442956 .99481964111 57.2995986938557 .6043891906757 .909179687558 .2139587402358 .51874923706 58.8235282897959 .1283111572359 .4331016540559 .7378807067959 .73788070679 60.0426712036160 .0426712036160 .04267120361 -9999 -9999 -9999 -9999 -9999 -9999 -9999 -9999 -9999 -9999 -9999 -9999 -9999 -9999 -9999 -9999 -9999 -9999 -9999 -9999 -9999 -9999 -9999 -9999 -9999 -9999 -9999 -9999 -9999 -9999 -9999 -9999 -9999 -9999 -9999 -9999 -9999 -9999 -9999 -9999 -9999 -9999 -9999 -9999 -9999 -9999 -9999 -9999 -9999 -9999 -999 - -999 $-9999$

-9999 -9999 -9999 -9999 -9999 -9999 -9999 -9999 -9999 -9999 -9999 -9999 -9999 -9999 -9999 -9999 -9999 -9999 -9999 -9999 -9999 -9999 -9999 -9999 -9999 -9999 -9999 -9999 -9999 -9999 -

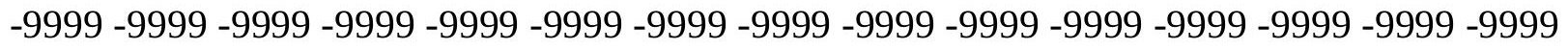

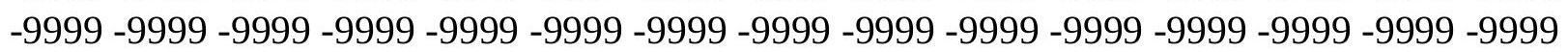

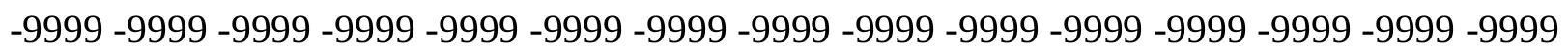
-9999 -9999 -9999 -9999 -9999 -9999 -9999 -9999 -9999 -9999 -9999 -9999 -9999 -9999 -9999 -9999 -9999 -9999 -9999 -9999 -9999 -9999 -9999 -9999 -9999 -9999 -9999 -9999 -9999 -9999 -

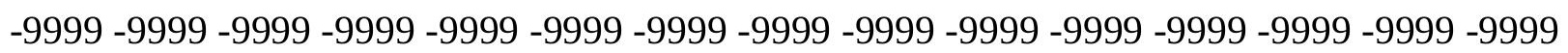
-9999 -9999 -9999 -9999 -9999 -9999 -9999 -9999 -9999 -9999 -9999 -9999 -9999 -9999 124.3523025513127 .0953979492130 .1432037354130 .4479980469131 .0576019287 133.8007049561137 .7628936768140 .8106994629143 .8585968018146 .6015930176 149.6495056152151 .7830047607154 .8307952881159 .4026031494165 .8031005859 170.0283966064170 .8007965088170 .0501251221168 .3008728027166 .4525756836 165.3037872314165 .0207977295165 .3170623779165 .8017272949161 .8408966064 157.5738983154152 .6972961426146 .2969055176138 .0677032471127 .7050018311 118.2565994263112 .7705001831114 .5991973877116 .4279022217117 .342300415 117.342300415116 .4279022217114 .9039993286113 .6848983765112 .1608963013 110.6370010376108 .8082962036107 .2844009399105 .4557037354103 .9317016602 102.1029968262100 .274299621698 .7503814697397 .2264633178795 .70252990723 94.4833908081193 .2642517089892 .349891662691 .1307525634890 .21640014648 89.3020401001 88.38768768311 87.77810668945 86.86376190186 86.2541885376 85.33984375 84.12069702148 82.90155792236 81.37763214111 79.85370635986 78.6345596313577 .110626220775 .8914871215874 .9771423339873 .75800323486 72.8436431884871 .6244964599670 .4053573608469 .1862335205167 .96708679199 66.7479400634865 .2240066528364 .004882812562 .7857398986861 .26181030273 60.0426712036158 .8235282897957 .909179687556 .6900291442955 .77568054199 54.5565414428753 .3373985290551 .5086898803749 .6799812316947 .24169921875 44.4986305236841 .1459884643637 .4885711669933 .5263595581130 .17373085022 28.0402297973626 .5163097381625 .6019496917724 .9923801422125 .60194969177 
26.5163097381627 .7354507446328 .9545898437530 .1737308502231 .39286994934 32.6120109558134 .1359291076735 .3550796508836 .2694282531737 .48857116699 38.0981407165539 .0125007629439 .3172798156739 .622070312539 .6220703125 39.622070312539 .622070312539 .622070312539 .622070312539 .92684936523 39.9268493652339 .9268493652339 .9268493652339 .9268493652339 .6220703125 38.7077102661136 .8790016174334 .7455101013232 .3072204589830 .47850990295 29.5641593933128 .9545898437528 .6497993469228 .6497993469228 .34502029419 28.3450202941928 .3450202941928 .6497993469228 .6497993469229 .25937080383 29.5641593933130 .1737308502231 .0880794525132 .3072204589833 .52635955811 34.7455101013236 .2694282531737 .7933502197339 .3172798156740 .84120941162 42.0603485107443 .5842704772944 .8034095764246 .0225486755446 .93690872192 47.8512611389248 .4608306884848 .765621185349 .0704002380449 .37519073486 49.3751907348649 .6799812316949 .6799812316950 .2895507812551 .20389938354 52.4230384826754 .2517509460456 .3852500915557 .909179687559 .43310165405 60.0426712036160 .9570198059161 .2618103027361 .2618103027361 .56660079956 61.5666007995661 .2618103027360 .6522407531760 .0426712036159 .12831115723 58.5187492370657 .6043891906756 .6900291442956 .0804595947355 .77568054199 55.7756805419956 .0804595947356 .3852500915556 .6900291442956 .99481964111 57.2995986938557 .909179687558 .2139587402358 .5187492370658 .82352828979 59.1283111572359 .1283111572359 .4331016540559 .7378807067959 .73788070679 60.0426712036160 .04267120361 -9999 -9999 -9999 -9999 -9999 -9999 -9999 -9999 -9999 -9999 -9999 -9999 -9999 -9999 -9999 -9999 -9999 -9999 -9999 -9999 -9999 -9999 -9999 -9999 -9999 -9999 -9999 -9999 -9999 -9999 -9999 -9999 -9999 -9999 -9999 -9999 -9999 -9999 -9999 -

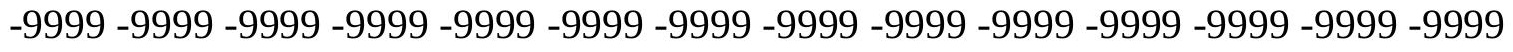

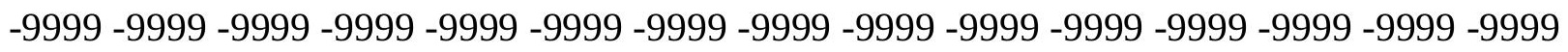
-9999 -9999 -9999 -9999 -9999 -9999 -9999 -9999 -9999 -9999 -9999 -9999 -9999 -9999 -9999 -9999 -9999 -9999 -9999 -9999 -9999 -9999 -9999 -9999 -9999 -9999 -9999 -9999 -9999 -9999

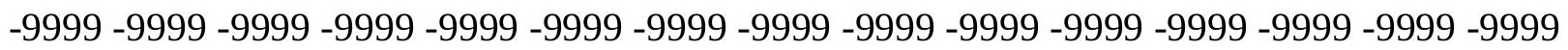
-9999 -9999 -9999 -9999 -9999 -9999 -9999 -9999 -9999 -9999 -9999 -9999 -9999 -9999 -9999 -9999 -9999 -9999 -9999 -9999 -9999 -9999 -9999 -9999 -9999 -9999 -9999 -9999 -9999 -9999 -9999 -9999 -9999 -9999 -9999 -9999 -9999 -9999 -9999 -9999 -9999 -9999 -9999 -9999 -9999 -9999 -9999 -9999 -9999 -9999 -9999 -9999 -9999 -9999 -9999 -9999 -9999 -9999 -9999 -9999 -9999 -9999 -9999 -9999-9999 -9999 -9999 -9999 -9999 -9999 -9999 -9999 -9999 -9999 123.43800354122 .8283996582122 .8283996582123 .1332015991123 .43800354 124.3523025513125 .8762969971126 .7906036377131 .6672058105135 .0198059082 137.7628936768140 .5059967041143 .8585968018149 .0399017334156 .9642944336 169.7653045654175 .0610351562173 .7629241943170 .7901763916168 .1548461914 166.8993225098166 .9664001465167 .6930541992168 .4541015625168 .8588409424 168.759475708168 .2787628174161 .2312927246152 .0877990723140 .5059967041 130.1432037354125 .8762969971123 .1332015991119 .7806015015120 .0852966309 119.4757995605117 .647102356116 .1231002808114 .5991973877113 .075302124 111.8561019897110 .3321990967108 .8082962036106 .979598999105 .1509017944 103.3221969604101 .798202514699 .9695205688598 .445587158296 .92166900635 95.7025299072394 .4833908081193 .2642517089892 .349891662691 .43553924561 90.5211791992289 .6068267822388 .9972534179788 .3876876831187 .77810668945 86.8637619018685 .6446228027384 .1206970214882 .5967712402381 .07285308838 
79.5489196777378 .0249862670976 .8058471679775 .5867080688574 .67236328125 73.4532165527372 .5388565063571 .3197174072370 .1005783081168 .88143920898 67.3575134277365 .8335876464864 .6144485473663 .0905189514261 .87137985229 60.3474502563559 .4331016540558 .2139587402357 .2995986938556 .08045959473 55.1661109924353 .9469718933152 .4230384826750 .5943298339848 .46083068848 45.4129791259841 .7555618286137 .7933502197333 .5263595581129 .86894035339 27.1258792877225 .2971591949524 .0780296325723 .7732391357424 .07802963257 24.9923801422126 .5163097381627 .7354507446329 .2593708038330 .47850990295 32.3072204589833 .5263595581134 .7455101013235 .6598587036136 .57421112061 37.4885711669938 .0981407165538 .4029312133838 .7077102661139 .31727981567 39.622070312539 .9268493652340 .5364189147941 .4507789611842 .36513137817 43.2794914245643 .8890609741243 .8890609741243 .5842704772942 .97470092773 42.0603485107439 .622070312536 .8790016174334 .1359291076732 .30722045898 30.7833003997830 .1737308502229 .5641593933129 .2593708038328 .95458984375 28.9545898437528 .9545898437528 .9545898437529 .2593708038329 .56415939331 29.8689403533930 .7833003997831 .3928699493432 .6120109558133 .52635955811 35.0502891540536 .2694282531737 .4885711669939 .0125007629440 .53641891479 41.7555618286142 .9747009277344 .1938400268645 .4129791259846 .32733917236 46.9369087219247 .8512611389248 .1560516357448 .4608306884848 .7656211853 48.765621185349 .0704002380449 .0704002380449 .3751907348650 .28955078125 52.1182594299354 .2517509460456 .3852500915558 .2139587402359 .43310165405 60.0426712036160 .9570198059161 .2618103027361 .2618103027361 .56660079956 61.2618103027360 .9570198059160 .3474502563559 .7378807067958 .82352828979 58.2139587402357 .2995986938556 .3852500915555 .7756805419955 .47089004517 55.4708900451755 .7756805419956 .0804595947356 .3852500915556 .99481964111 57.2995986938557 .6043891906758 .2139587402358 .5187492370658 .82352828979 58.8235282897959 .1283111572359 .4331016540559 .4331016540559 .73788070679 59.7378807067960 .04267120361 -9999 -9999 -9999 -9999 -9999 -9999 -9999 -9999 -9999 -9999 -9999 -9999 -9999 -9999 -9999 -9999 -9999 -9999 -9999 -9999 -9999 -9999 -9999 -9999 -

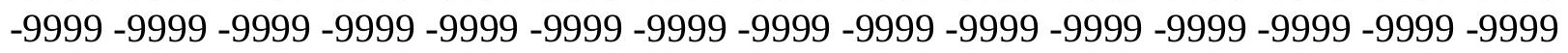
-9999 -9999 -9999 -9999 -9999 -9999 -9999 -9999 -9999 -9999 -9999 -9999 -9999 -9999 -

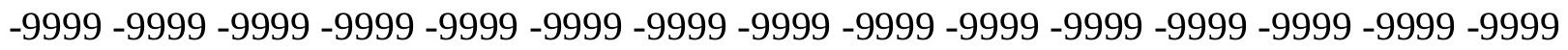

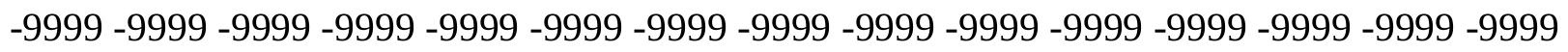

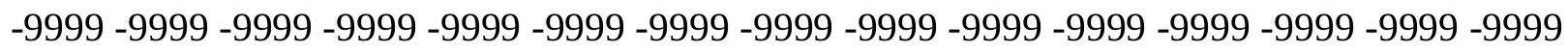
-9999 -9999 -9999 -9999 -9999 -9999 -9999 -9999 -9999 -9999 -9999 -9999 -9999 -9999 -9999

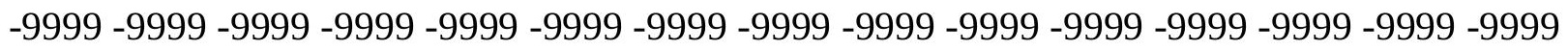

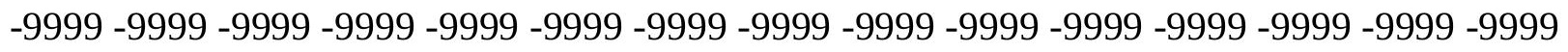

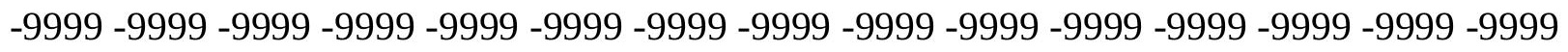

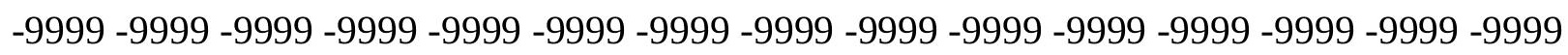
-9999 -9999 -9999 -9999 -9999 -9999 -9999 -9999 -9999 -9999 -9999 -9999 -9999 -9999 -9999 123.7427978516123 .7427978516124 .0475006104124 .6570968628125 .5715026855 127.0953979492128 .3144989014128 .9241027832128 .9241027832128 .3144989014 130.4479980469129 .533706665133 .4958953857140 .2012023926151 .7830047607 161.5361022949163 .0599975586162 .1457061768163 .974395752167 .1504516602 168.0281219482169 .5756530762170 .8349761963171 .3155517578170 .9410705566 170.1496734619169 .1773376465162 .1457061768154 .5260925293148 .1255950928 
143.8585968018139 .5915985107134 .7149963379129 .2288970947122 .2188034058 118.8662033081117 .342300415116 .1231002808114 .5991973877112 .4656982422 111.24659729109 .7226028442108 .1986999512106 .3700027466104 .5412979126 102.712600708100 .883903503499 .3599472045998 .1408081054796 .92166900635 95.7025299072394 .4833908081193 .5690307617292 .6546783447392 .04509735107 91.1307525634890 .5211791992290 .2164001464889 .6068267822388 .69246673584 87.1685485839885 .6446228027384 .1206970214882 .2919769287180 .76805877686 79.2441329956178 .0249862670976 .8058471679775 .8914871215874 .67236328125 73.4532165527372 .2340774536171 .014930725169 .7957916259868 .27187347412 66.7479400634865 .2240066528363 .7000885009862 .1761703491260 .95701980591 59.7378807067958 .5187492370657 .6043891906756 .6900291442955 .77568054199 54.8613204956153 .6421813964852 .1182594299349 .6799812316946 .63212966919 42.9747009277338 .4029312133833 .8311500549329 .8689403533926 .51630973816 24.3828105926522 .8588790893622 .2493095397922 .5541000366223 .77323913574 25.2971591949526 .8210906982428 .6497993469230 .1737308502231 .69765090942 33.2215805053734 .1359291076735 .0502891540535 .9646492004436 .57421112061 36.8790016174337 .4885711669937 .7933502197338 .4029312133839 .01250076294 39.9268493652341 .1459884643642 .66992187544 .1938400268645 .7177696228 46.9369087219246 .9369087219246 .3273391723645 .1082000732443 .58427047729 41.1459884643638 .4029312133835 .9646492004433 .8311500549332 .30722045898 31.3928699493430 .4785099029530 .1737308502229 .8689403533929 .56415939331 29.5641593933129 .5641593933129 .8689403533930 .1737308502230 .47850990295 31.0880794525132 .0024414062532 .9167900085433 .8311500549335 .05028915405 36.2694282531737 .4885711669939 .0125007629440 .2316398620641 .45077896118 42.66992187543 .8890609741244 .8034095764245 .717769622846 .63212966919 47.24169921875 47.8512611389248.15605163574 48.4608306884848.46083068848 48.765621185348 .765621185349 .0704002380449 .6799812316952 .11825942993 54.2517509460456 .3852500915558 .2139587402359 .4331016540560 .04267120361 60.6522407531761 .2618103027361 .5666007995661 .5666007995661 .26181030273 60.6522407531760 .0426712036159 .4331016540558 .5187492370657 .9091796875 56.9948196411156 .0804595947355 .1661109924355 .4708900451755 .47089004517 55.7756805419956 .0804595947356 .6900291442956 .9948196411157 .29959869385 57.6043891906758 .2139587402358 .5187492370658 .5187492370658 .82352828979 59.1283111572359 .1283111572359 .4331016540559 .4331016540559 .73788070679 59.73788070679 -9999 -9999 -9999 -9999 -9999 -9999 -9999 -9999 -9999 -9999 -9999 -9999 -9999 -9999 -9999 -9999 -9999 -9999 -9999 -9999 -9999 -9999 -9999 -9999 -9999 -9999 - -9999 - -999 -

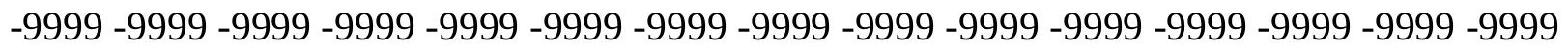
-9999 -9999 -9999 -9999-9999 -9999 -9999 -9999 -9999-9999-9999 -9999 -9999 -9999 -9999 -9999 -9999 -9999 -9999 -9999 -9999 -9999 -9999 -9999 -9999 -9999 -9999 -9999 -9999 -9999 -9999 -9999 -9999 -9999 -9999 -9999 -9999 -9999 -9999 -9999 -9999 -

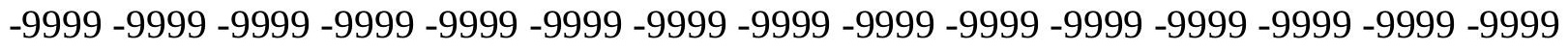

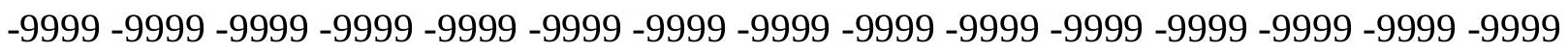
-9999 -9999 -9999 -9999 -9999 -9999 -9999 -9999 -9999 -9999 -9999 -9999 -9999 -9999 -9999 -9999 -9999 -9999 -9999 -9999 -9999 -9999 -9999 -9999 -9999 -9999 -9999 -9999 -9999 -9999 -9999 -9999 -9999 -9999 -9999 -9999 -9999 -9999 -9999 -9999 -9999 -9999 -9999 -9999 -9999 -

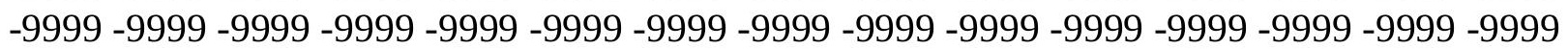


-9999 -9999 -9999 -9999 -9999 -9999 -9999 -9999 -9999 -9999 -9999 -9999 -9999 -9999 -9999 -9999 124.6570968628124.9618988037125.8762969971 126.7906036377127 .7050018311 128.6192932129129 .2288970947129 .533706665128 .9241027832128 .3144989014 127.4001998901126 .7906036377126 .1809997559128 .9241027832136 .5437011719 142.0299072266146 .6015930176151 .1734008789157 .2691040039167 .6318054199 170.692199707172 .8344421387173 .1168670654172 .3920288086171 .3820800781 170.2881011963167 .0222015381164 .2792053223162 .4505004883158 .4882965088 153.6116943359147 .8208007812141 .1154937744132 .5814971924124 .3523025513 119.1709976196117 .9517974854116 .7326965332114 .9039993286113 .075302124 111.24659729110 .3321990967106 .979598999105 .1509017944103 .3221969604 101.7982025146100 .274299621699 .0551681518697 .8360290527396 .61688232422 95.7025299072395 .0929565429794 .1785964965893 .5690307617292 .95947265625 92.6546783447392 .349891662691 .7403335571390 .8259735107489 .3020401001 87.4733276367285 .6446228027383 .8159103393682 .2919769287181 .07285308838 79.5489196777378 .3297805786177 .110626220775 .8914871215874 .97714233398 73.7580032348672 .2340774536170 .7101516723669 .1862335205167 .66230010986 66.1383666992264 .3096618652362 .7857398986861 .2618103027360 .04267120361 58.8235282897957 .909179687556 .9948196411156 .3852500915555 .47089004517 54.5565414428753 .3373985290551 .5086898803748 .4608306884844 .19384002686 39.0125007629434 .1359291076729 .5641593933125 .6019496917723 .16366958618 21.3349609375 20.7253894805921.03017044067 22.24930953979 23.77323913574 25.906740188628 .0402297973629 .8689403533931 .3928699493432 .61201095581 33.5263595581134 .4407196044935 .0502891540535 .3550796508835 .96464920044 36.2694282531736 .8790016174337 .4885711669938 .4029312133839 .6220703125 41.1459884643642 .9747009277345 .1082000732447 .2416992187549 .07040023804 48.4608306884847 .5464782714846 .3273391723644 .4986305236842 .06034851074 39.622070312537 .1837806701735 .0502891540533 .5263595581132 .30722045898 31.3928699493430 .7833003997830 .4785099029530 .1737308502230 .17373085022 30.1737308502230 .4785099029530 .7833003997831 .0880794525131 .69765090942 32.3072204589833 .2215805053734 .1359291076735 .3550796508836 .57421112061 37.7933502197339 .0125007629440 .2316398620641 .4507789611842 .669921875 43.5842704772944 .4986305236845 .4129791259846 .3273391723646 .93690872192 47.5464782714847 .8512611389248 .4608306884848 .765621185349 .07040023804 49.3751907348649 .9847602844251 .2038993835453 .0326118469255 .16611099243 56.9948196411158 .2139587402358 .8235282897959 .7378807067960 .65224075317 61.2618103027361 .2618103027361 .2618103027360 .9570198059160 .34745025635 59.7378807067959 .1283111572358 .5187492370657 .6043891906756 .99481964111 56.0804595947355 .7756805419955 .7756805419955 .7756805419956 .08045959473 56.3852500915556 .6900291442957 .2995986938557 .6043891906757 .9091796875 58.2139587402358 .5187492370658 .5187492370658 .8235282897959 .12831115723 59.1283111572359 .4331016540559 .4331016540559 .4331016540559 .73788070679 59.58876037598 -9999 -9999 -9999 -9999 -9999 -9999 -9999 -9999 -9999 -9999 -9999 -9999

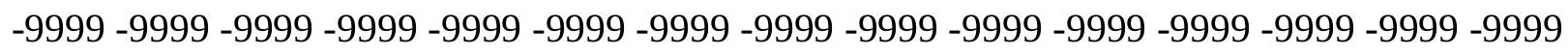
-9999 -9999 -9999 -9999 -9999 -9999 -9999 -9999 -9999-9999 -9999 -9999 -9999 -9999 -9999 -9999 -9999 -9999 -9999 -9999 -9999 -9999 -9999 -9999 -9999

-9999 -9999-9999 -9999 -9999 -9999 -9999 -9999 -9999 -9999 -9999 -9999 -9999 -9999 - 
-9999 -9999 -9999 -9999 -9999 -9999 -9999 -9999 -9999 -9999 -9999 -9999 -9999 -9999 -9999 -9999 -9999 -9999 -9999 -9999 -9999 -9999 -9999 -9999 -9999 -9999 -9999 -9999 -9999 -9999

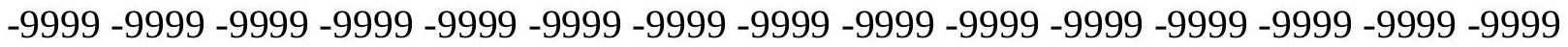
-9999 -9999 -9999 -9999 -9999 -9999 -9999 -9999 -9999 -9999 -9999 -9999 -9999 -9999 -9999 -9999 -9999 -9999 -9999 -9999 -9999 -9999 -9999 -9999 -9999 -9999 -9999-9999 -9999 -9999 -9999 -9999 -9999 -9999 -9999 -9999 -9999 -9999 -9999 -9999 -9999 -9999 -9999 -9999 -9999

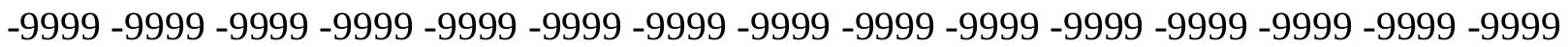
-9999 -9999 -9999 -9999 -9999 -9999 -9999 -9999 -9999 -9999 -9999 -9999 -9999 -9999 -9999 -9999 124.9618988037125.5715026855 126.4858016968 127.4001998901 128.3144989014 128.9241027832129 .533706665129 .533706665129 .2288970947128 .9241027832 128.3144989014127 .7050018311127 .7050018311128 .3144989014129 .2288970947 129.8385009766130 .1432037354132 .5814971924137 .4580993652145 .6873016357 156.0500030518166 .4127044678173 .3153076172172 .5039978027171 .7181549072 168.241394043163 .6696014404162 .7552947998162 .7552947998161 .5361022949 159.0977935791156 .9642944336152 .3925933838142 .9441986084132 .8863067627 126.4858016968121 .3044967651118 .5614013672116 .4279022217115 .5136032104 113.9896011353111 .8561019897109 .1130981445106 .3700027466103 .6268997192 102.4077987671101 .188697814999 .9695205688598 .7503814697397 .83602905273 96.9216690063596 .3121032714895 .7025299072395 .397743225195 .09295654297 94.7881774902394 .4833908081194 .1785964965893 .2642517089891 .74033355713 89.6068267822387 .7781066894585 .9494018554784 .7302627563584 .73026275635 81.6824111938580 .4632720947378 .9393463134877 .7202072143676 .50106811523 74.9771423339873 .7580032348672 .2340774536170 .4053573608468 .57665252686 67.0527267456165 .2240066528363 .3953094482461 .8713798522960 .34745025635 59.1283111572358 .2139587402357 .2995986938556 .6900291442956 .08045959473 55.4708900451754 .5565414428753 .0326118469249 .9847602844245 .41297912598 39.622070312533 .8311500549328 .6497993469224 .3828105926521 .3349609375 19.5062503814718 .8966808319119 .2014598846420 .4206008911122 .24930953979 24.6875991821327 .1258792877229 .5641593933130 .4785099029531 .69765090942 32.9167900085433 .8311500549334 .4407196044934 .7455101013234 .74551010132 35.0502891540535 .6598587036136 .5742111206137 .4885711669939 .01250076294 40.5364189147942 .66992187544 .8034095764246 .9369087219248 .46083068848 48.4608306884847 .5464782714846 .3273391723644 .4986305236842 .36513137817 40.2316398620638 .0981407165535 .9646492004434 .4407196044933 .22158050537 32.3072204589831 .6976509094231 .0880794525130 .7833003997830 .78330039978 30.7833003997831 .0880794525131 .0880794525131 .6976509094232 .30722045898 32.9167900085433 .5263595581134 .7455101013235 .6598587036136 .87900161743 37.7933502197339 .0125007629440 .2316398620641 .4507789611842 .669921875 43.5842704772944 .4986305236845 .4129791259846 .3273391723646 .93690872192 47.5464782714848 .1560516357448 .4608306884849 .0704002380449 .37519073486 50.2895507812551 .2038993835452 .7278289794954 .5565414428756 .38525009155 57.6043891906757 .909179687557 .6043891906759 .7378807067960 .65224075317 61.2618103027360 .9570198059160 .6522407531760 .3474502563559 .73788070679 59.1283111572358 .5187492370657 .909179687557 .6043891906756 .99481964111 56.3852500915556 .0804595947356 .0804595947356 .3852500915556 .38525009155 56.6900291442956 .9948196411157 .2995986938557 .6043891906757 .9091796875 
58.2139587402358 .5187492370658 .8235282897958 .8235282897959 .12831115723 59.1283111572359 .1283111572359 .4331016540559 .4331016540559 .43310165405 59.40697479248 -9999 -9999 -9999 -9999 -9999 -9999 -9999 -9999 -9999 -9999 -9999 -9999 -9999 -9999 -9999 -9999 -9999 -9999 -9999 -9999 -9999 -9999 -9999 -9999 -9999 -9999 -9999 -9999 -9999 -9999 -9999 -9999 -9999 -9999 -9999 -9999 -9999 -9999 -9999 -9999 -9999 - -9999 -9999 -9999 -9999 -9999 -9999 -9999 -9999 -9999 -9999 -9999

-9999 -9999 -9999 -9999 -9999 -9999 -9999 -9999 -9999 -9999 -9999 -9999 -9999 -9999 -9999

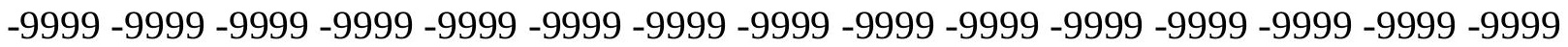

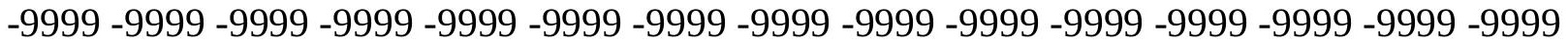
-9999 -9999 -9999 -9999 -9999 -9999 -9999 -9999 -9999 -9999 -9999 -9999 -9999 - -9999 - -9999 -

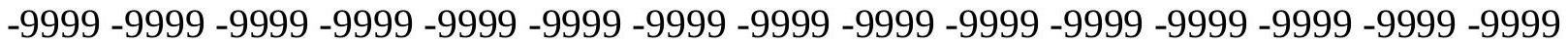
-9999 -9999 -9999 -9999 -9999 -9999 -9999 -9999 -9999 -9999 -9999 -9999 -9999 -9999 -9999 -9999 -9999 -9999 -9999 -9999 -9999 -9999 -9999 -9999 -9999 -9999 -9999 -9999 -9999 -9999 -9999 -9999 -9999 -9999 -9999 -9999 -9999 -9999 -9999 -9999 -9999 -9999 -9999 -9999 -9999 -9999 -9999 -9999 -9999 -9999 -9999 -9999 -9999 -9999 -9999 -9999 -9999 -9999 -9999 -9999 -9999-9999 125.8762969971 126.7906036377 127.4001998901 128.3144989014 128.9241027832129 .533706665129 .8385009766129 .8385009766129 .533706665 129.2288970947128 .6192932129128 .6192932129129 .2288970947129 .533706665 130.1432037354129 .8385009766128 .9241027832127 .7050018311126 .4858016968 132.2767028809142 .6394042969151 .4781951904154 .8307952881155 .1356048584 154.8307952881154 .2212982178154 .8307952881156 .0500030518157 .2691040039 158.1835021973160 .3170013428159 .0977935791149 .6495056152138 .3724975586 130.7528076172125 .2667007446121 .6092987061118 .8662033081117 .9517974854 116.4279022217113 .9896011353111 .24659729108 .5035018921106 .0652008057 103.6268997192101 .7982025146100 .579101562599 .6647262573298 .75038146973 98.1408081054797 .5312423706197 .2264633178796 .9216690063596 .61688232422 96.6168823242296 .6168823242296 .3121032714895 .7025299072394 .48339080811 92.349891662690 .2164001464888 .9972534179787 .7781066894585 .94940185547 84.4254837036182 .5967712402381 .0728530883879 .5489196777378 .32978057861 76.8058471679775 .2819290161173 .4532165527371 .9292907714870 .10057830811 67.9670867919966 .1383666992264 .3096618652362 .4809494018660 .95701980591 59.4331016540558 .5187492370657 .6043891906757 .2995986938556 .69002914429 56.0804595947355 .1661109924353 .6421813964851 .5086898803745 .7177696228 39.0125007629432 .9167900085427 .1258792877222 .5541000366219 .20145988464 17.0679702758816 .1536102294916 .7631797790518 .28710937520 .42060089111 22.8588790893625 .6019496917727 .7354507446329 .2593708038330 .78330039978 32.0024414062532 .9167900085433 .5263595581134 .1359291076734 .13592910767 34.4407196044934 .7455101013235 .6598587036136 .5742111206137 .79335021973 39.622070312541 .7555618286143 .8890609741245 .717769622846 .93690872192 47.24169921875 46.9369087219245.717769622844.1938400268642.06034851074 40.2316398620638 .4029312133836 .5742111206135 .0502891540533 .83115005493 32.9167900085432 .3072204589831 .6976509094231 .3928699493431 .39286994934 31.3928699493431 .3928699493431 .6976509094232 .3072204589832 .61201095581 33.5263595581134 .1359291076735 .0502891540535 .9646492004437 .18378067017 38.0981407165539 .3172798156740 .5364189147941 .4507789611842 .669921875 43.5842704772944 .4986305236845 .4129791259846 .3273391723646 .93690872192 
47.5464782714848 .4608306884849 .0704002380449 .6799812316950 .28955078125 51.5086898803752 .7278289794954 .5565414428756 .3852500915557 .9091796875 58.2139587402357 .2995986938557 .6043891906759 .4331016540560 .34745025635 60.6522407531760 .3474502563560 .0426712036159 .4331016540559 .12831115723 58.5187492370658 .2139587402357 .6043891906757 .2995986938556 .99481964111 56.6900291442956 .6900291442956 .6900291442956 .6900291442956 .99481964111 57.2995986938557 .6043891906757 .6043891906757 .909179687558 .21395874023 58.5187492370658 .5187492370658 .8235282897958 .8235282897959 .12831115723 59.1283111572359 .1283111572359 .1283111572359 .4331016540559 .43310165405 59.25965881348 -9999 -9999 -9999 -9999 -9999 -9999 -9999 -9999 -9999 -9999 -9999 -9999 -9999 -9999 -9999 -9999 -9999 -9999 -9999 -9999 -9999 -9999 -9999 -9999 -9999 -9999 -9999 -9999 -9999 -9999 -9999 -9999 -9999 -9999 -9999 -9999 -9999 -9999 -9999 -9999 -9999 -9999 -9999 -9999 -9999 -9999 -9999 -9999 -9999 -9999 -9999 -9999

-9999 -9999 -9999 -9999 -9999 -9999 -9999 -9999 -9999 -9999 -9999 -9999 -9999 -9999 - -999 -9999 -9999 -9999 -9999 -9999 -9999 -9999 -9999 -9999 -9999 -9999 -9999 -9999 -9999 -9999

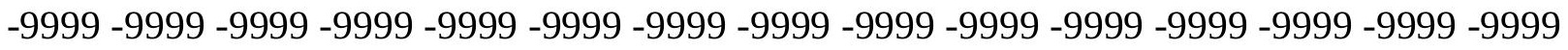
-9999 -9999 -9999 -9999 -9999 -9999 -9999 -9999 -9999 -9999 -9999 -9999 -9999 -9999 -9999 -9999 -9999 -9999 -9999 -9999 -9999 -9999 -9999 -9999 -9999 -9999 -9999 -9999 -9999 -9999 -9999 -9999 -9999 -9999 -9999 -9999 -9999 -9999 -9999 -9999 -9999 -9999 -9999 -9999 -9999 -

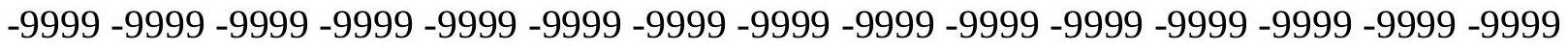

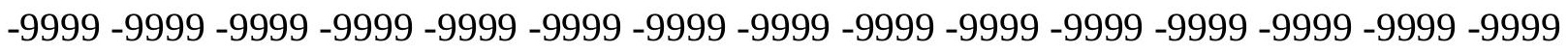
-9999 -9999 -9999 -9999 -9999 -9999 -9999 -9999 -9999 -9999 -9999 -9999 -9999 -9999 -9999 -9999 -9999 125.5715026855126 .4858016968127 .4001998901129 .8385009766 128.9241027832129 .533706665130 .1432037354130 .1432037354130 .1432037354 129.8385009766129 .8385009766130 .4479980469130 .7528076172131 .3623962402 131.0576019287130 .1432037354130 .1432037354128 .0097961426128 .3144989014 130.4479980469133 .1911010742134 .4102020264134 .7149963379134 .1054992676 137.1533050537140 .2012023926142 .9441986084145 .3825073242148 .7351074219 152.3925933838155 .7451934814155 .1356048584146 .9064025879136 .2389984131 129.8385009766125 .5715026855123 .43800354121 .6092987061119 .4757995605 117.647102356115 .2088012695112 .4656982422110 .0273971558107 .5891036987 105.4557037354103 .3221969604101 .7982025146100 .579101562599 .96952056885 99.0551681518698 .7503814697398 .445587158298 .1408081054798 .14080810547 98.1408081054798.445587158298.445587158298.445587158298.14080810547 96.6168823242293 .2642517089893 .2642517089891 .7403335571389 .60682678223 87.4733276367286 .8637619018683 .5111236572381 .9871978759880 .15849304199 78.6345596313577 .110626220775 .2819290161173 .4532165527371 .31971740723 69.4910125732467 .3575134277365 .2240066528363 .3953094482461 .26181030273 59.7378807067958 .8235282897957 .909179687557 .2995986938556 .69002914429 56.0804595947354 .8613204956153 .0326118469249 .9847602844244 .49863052368 38.0981407165531 .3928699493425 .2971591949520 .1158199310316 .45840072632 14.0201196670513 .1057596206714 .0201196670515 .5440397262618 .287109375 21.0301704406723 .4684505462625 .906740188628 .0402297973629 .86894035339 31.3928699493432 .3072204589833 .2215805053733 .5263595581133 .83115005493 33.8311500549334 .1359291076734 .7455101013235 .3550796508836 .26942825317 38.0981407165540 .2316398620642 .3651313781744 .1938400268645 .10820007324 
45.717769622845 .4129791259844 .4986305236843 .2794914245641 .75556182861 39.9268493652338 .0981407165536 .5742111206135 .3550796508834 .13592910767 33.5263595581132 .6120109558132 .3072204589832 .0024414062532 .00244140625 32.0024414062532 .0024414062532 .3072204589832 .9167900085433 .22158050537 33.8311500549334 .7455101013235 .6598587036136 .5742111206137 .48857116699 38.7077102661139 .622070312540 .8412094116241 .7555618286142 .97470092773 43.8890609741244 .8034095764245 .717769622846 .3273391723647 .24169921875 47.8512611389248 .765621185349 .3751907348650 .2895507812551 .20389938354 52.4230384826754 .2517509460456 .0804595947358 .2139587402359 .73788070679 59.4331016540555 .7756805419957 .6043891906759 .1283111572359 .73788070679 60.0426712036159 .4331016540559 .1283111572358 .5187492370658 .21395874023 57.6043891906757 .2995986938557 .2995986938556 .9948196411156 .99481964111 56.9948196411156 .9948196411156 .9948196411157 .2995986938557 .60438919067 57.6043891906757 .909179687558 .2139587402358 .2139587402358 .51874923706 58.5187492370658 .5187492370658 .8235282897958 .8235282897958 .82352828979 59.1283111572359 .1283111572359 .1283111572359 .1283111572359 .12831115723 59.1408767700258 .95357131958 -9999 -9999 -9999 -9999 -9999 -9999 -9999 -9999 -9999 -9999 -9999 -9999 -9999 -9999 -9999 -9999 -9999 -9999 -9999 -9999 -9999 -9999 -9999 -9999 -9999 -9999 -9999 -9999 -9999 -9999 -9999 -9999 -9999 -9999 -9999 -9999 -9999 -9999 -9999 -9999 -9999 -9999 -9999 -9999 -9999 -9999 -9999 -9999 -9999 -9999 -9999 -

-9999 -9999 -9999 -9999 -9999 -9999 -9999 -9999 -9999 -9999 -9999 -9999 -9999 -9999 -9999

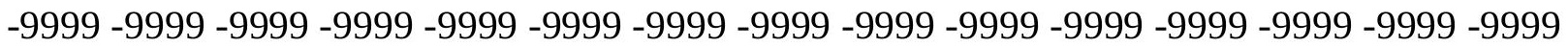
-9999 -9999 -9999 -9999 -9999 -9999 -9999 -9999 -9999 -9999 -9999 -9999 -9999 -9999 -9999 -9999 -9999 -9999 -9999 -9999 -9999 -9999 -9999 -9999 -9999 -9999 -9999 -9999 -9999 -9999 -9999 -9999 -9999 -9999 -9999 -9999 -9999 -9999 -9999 -9999 -9999 -9999 -9999 -9999 -9999 -9999 -9999 -9999 -9999 -9999 -9999 -9999 -9999 -9999 -9999 -9999 -9999 -9999 -9999 -9999 -9999 -9999 -9999 -9999 -9999 -9999 -9999 -9999 -9999 -9999 -9999 -9999 -9999 -9999 -9999

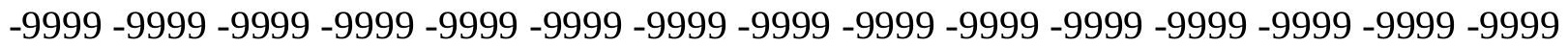
-9999 -9999 -9999 -9999 -9999 -9999 -9999 -9999 -9999 -9999 -9999 -9999 -9999 -9999 -9999 -9999 -9999-9999 126.4858016968 127.4001998901129 .533706665130 .1432037354 129.2288970947 129.8385009766 130.1432037354130.1432037354 130.1432037354 130.4479980469131 .3623962402131 .9720001221132 .8863067627132 .8863067627 131.9720001221130 .7528076172129 .8385009766129 .8385009766131 .0576019287 132.2767028809133 .1911010742132 .5814971924129 .8385009766126 .1809997559 125.8762969971129 .8385009766133 .4958953857138 .3724975586142 .6394042969 145.3825073242145 .0776977539138 .0677032471129 .8385009766125 .2667007446 122.8283996582122 .5235977173122 .2188034058119 .1709976196117 .342300415 114.9039993286112 .7705001831110 .6370010376108 .5035018921106 .6747970581 104.8460998535103 .3221969604102 .1029968262101 .1886978149100 .5791015625 99.9695205688599 .3599472045999 .3599472045999 .0551681518699 .35994720459 99.6647262573299 .96952056885100 .5791015625101 .4934005737102 .1029968262 101.798202514699 .6647262573296 .6168823242293 .5690307617290 .82597351074 88.38768768311 86.2541885376 84.42548370361 82.59677124023 80.76805877686 78.9393463134877 .110626220774 .9771423339873 .1484298706171 .0149307251 68.8814392089866 .4431610107464 .3096618652362 .1761703491260 .34745025635 59.4331016540558 .5187492370657 .6043891906756 .9948196411155 .77568054199 
54.2517509460452 .1182594299348 .1560516357443 .2794914245636 .87900161743 29.8689403533923 .4684505462617 .6775398254413 .1057596206710 .36268997192 9.75312423706110 .6674804687513 .1057596206715 .8488302230818 .89668083191 21.6397399902324 .3828105926526 .8210906982428 .9545898437530 .47850990295 32.0024414062532 .6120109558132 .9167900085433 .2215805053733 .52635955811 33.5263595581133 .8311500549334 .4407196044935 .0502891540536 .87900161743 39.0125007629440 .8412094116242 .3651313781743 .2794914245643 .88906097412 43.8890609741243 .2794914245642 .0603485107440 .8412094116239 .31727981567 37.7933502197336 .5742111206135 .3550796508834 .4407196044933 .83115005493 33.2215805053732 .9167900085432 .6120109558132 .3072204589832 .61201095581 32.6120109558132 .9167900085433 .2215805053733 .8311500549334 .44071960449 35.3550796508835 .9646492004436 .8790016174338 .0981407165539 .01250076294 40.2316398620641 .1459884643642 .0603485107443 .2794914245644 .19384002686 45.1082000732446 .0225486755446 .9369087219247 .5464782714848 .46083068848 49.3751907348650 .2895507812551 .2038993835452 .4230384826753 .64218139648 55.4708900451757 .2995986938559 .1283111572360 .6522407531761 .56660079956 54.2517509460456 .9948196411158 .5187492370658 .8235282897958 .82352828979 58.5187492370657 .909179687557 .2995986938556 .9948196411156 .69002914429 56.6900291442956 .3852500915556 .6900291442956 .6900291442956 .99481964111 56.9948196411157 .6043891906757 .909179687557 .909179687558 .21395874023 58.2139587402358 .5187492370658 .5187492370658 .5187492370658 .51874923706 58.8235282897958 .8235282897958 .8235282897958 .8235282897959 .12831115723 59.1283111572359 .1283111572359 .1283111572359 .1283111572359 .12831115723 58.87155914307 -9999 -9999 -9999 -9999 -9999 -9999 -9999 -9999 -9999 -9999 -9999 -9999 -9999 -9999 -9999 -9999 -9999 -9999 -9999 -9999 -9999 -9999 -9999 -9999 -9999 -9999 -9999 -9999 -9999 -9999 -9999 -9999 -9999 -9999 -9999 -9999 -9999 -9999 -9999 -9999 -9999 -9999 -9999 -9999 -9999 -9999 -9999 -9999-9999 -9999 -9999

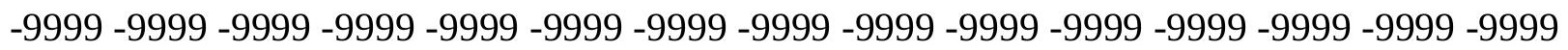
-9999 -9999 -9999 -9999 -9999 -9999 -9999 -9999 -9999 -9999 -9999 -9999 -9999 -9999 -9999 -9999 -9999 -9999 -9999 -9999 -9999 -9999 -9999 -9999 -9999 -9999 -9999 -9999 -9999 -9999 -9999 -9999 -9999 -9999 -9999 -9999 -9999 -9999 -9999 -9999 -9999 -9999-9999 -9999 -9999 -9999 -9999 -9999 -9999 -9999 -9999 -9999 -9999 -9999 -9999 -9999 -9999 -9999 -9999 -9999 -

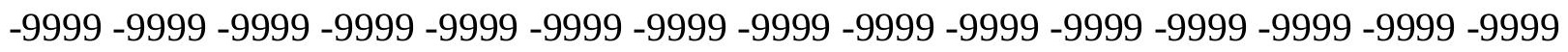
-9999 -9999 -9999 -9999 -9999 -9999 -9999 -9999 -9999 -9999 -9999 -9999 -9999 -9999 -9999 -9999 -9999 -9999 -9999 -9999 -9999 -9999 -9999 -9999 -9999 -9999 -9999 -9999 -9999 -9999 -9999 -9999 -9999 -9999 -9999 -9999 -9999 -9999 -9999 -9999 -9999 -9999 -9999 -9999 -9999 -9999 -9999 -9999 -9999 127.0953979492 128.0097961426130 .1432037354128 .9241027832 129.2288970947129 .533706665129 .8385009766129 .8385009766130 .4479980469 131.3623962402132 .2767028809133 .4958953857134 .1054992676133 .1911010742 131.6672058105130 .7528076172130 .7528076172131 .0576019287131 .9720001221 131.9720001221131 .0576019287129 .2288970947127 .7050018311127 .0953979492 127.4001998901128 .0097961426128 .0097961426130 .7528076172132 .2767028809 131.0576019287126 .1809997559120 .6949005127117 .9517974854116 .7326965332 117.0374984741117 .647102356116 .1231002808114 .9039993286113 .6848983765 112.1608963013110 .3321990967108 .8082962036107 .2844009399105 .7603988647 104.5412979126103 .3221969604102 .4077987671101 .7982025146101 .1886978149 
100.5791015625100 .274299621699 .6647262573299 .6647262573299 .96952056885 100.5791015625101 .7982025146103 .6268997192106 .3700027466109 .4179000854 104.8460998535100 .579101562596 .9216690063593 .8738174438591 .13075256348 88.9972534179786 .8637619018685 .0350494384882 .9015579223681 .07285308838 78.9393463134876 .8058471679774 .6723632812572 .5388565063570 .40535736084 68.2718734741265 .8335876464863 .7000885009861 .8713798522960 .34745025635 59.4331016540558 .2139587402356 .9948196411155 .7756805419953 .64218139648 50.8991203308147 .2416992187542 .3651313781736 .2694282531729 .56415939331 22.5541000366215 .8488302230810 .362689971927 .0100579261786 .095703125 7.92441320419310 .6674804687514 .0201196670517 .3727493286120 .11581993103 22.8588790893625 .2971591949527 .1258792877229 .2593708038331 .39286994934 32.0024414062532 .3072204589832 .6120109558132 .9167900085433 .22158050537 33.2215805053733 .8311500549334 .7455101013235 .9646492004437 .79335021973 39.3172798156740 .8412094116241 .7555618286142 .0603485107442 .06034851074 41.7555618286140 .8412094116239 .622070312538 .4029312133837 .18378067017 36.2694282531735 .3550796508834 .7455101013234 .1359291076733 .52635955811 33.2215805053732 .9167900085432 .9167900085433 .2215805053733 .22158050537 33.5263595581133 .8311500549334 .4407196044935 .0502891540535 .96464920044 36.5742111206137 .4885711669938 .4029312133839 .622070312540 .53641891479 41.7555618286142 .66992187543 .5842704772944 .4986305236845 .7177696228 46.6321296691947 .2416992187548 .1560516357449 .0704002380449 .98476028442 50.8991203308152 .1182594299353 .3373985290555 .1661109924356 .69002914429 58.2139587402359 .4331016540560 .0426712036156 .9948196411153 .64218139648 56.3852500915557 .6043891906757 .6043891906757 .2995986938556 .99481964111 56.6900291442956 .0804595947355 .7756805419955 .7756805419955 .77568054199 55.7756805419956 .0804595947356 .3852500915556 .6900291442957 .29959869385 57.6043891906758 .2139587402358 .5187492370658 .5187492370658 .82352828979 58.8235282897958 .8235282897958 .8235282897958 .8235282897958 .82352828979 58.8235282897958 .8235282897958 .8235282897958 .8235282897958 .82352828979 $58.8235282897959 .1283111572359 .1283111572359 .1283111572358 .76265335083-9999$ -9999 -9999 -9999 -9999 -9999 -9999 -9999 -9999 -9999 -9999 -9999 -9999 -9999 -9999 -

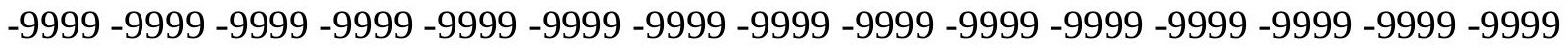

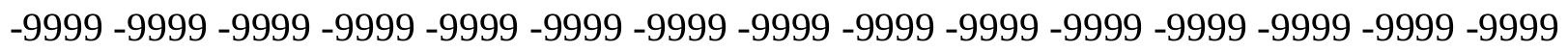
-9999-9999 -9999 -9999-9999

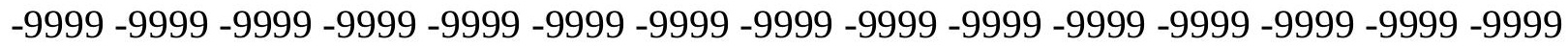

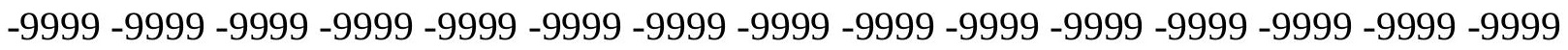

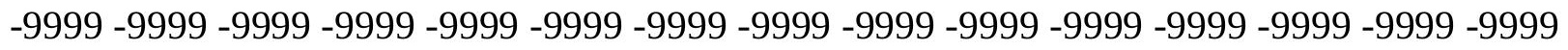

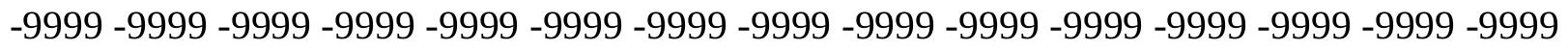

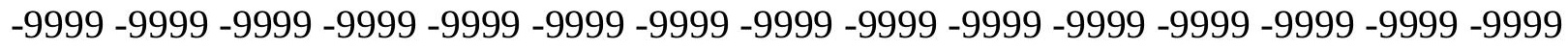

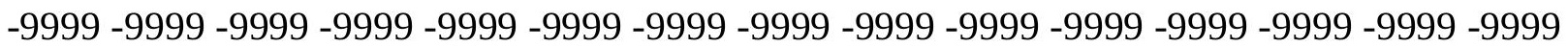

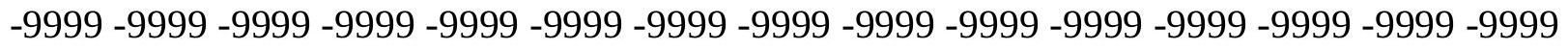

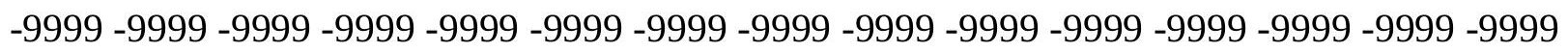

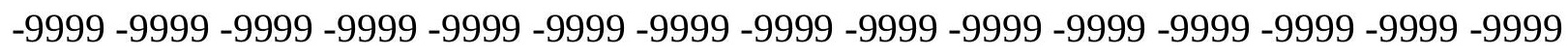
-9999 -9999 -9999 -9999 126.7906036377 127.7050018311 128.0097961426128 .6192932129 128.6192932129128 .9241027832128 .9241027832129 .2288970947129 .533706665 130.4479980469131 .3623962402133 .1911010742135 .0198059082133 .1911010742 
131.6672058105130 .4479980469130 .1432037354130 .4479980469130 .7528076172 130.7528076172130 .1432037354129 .533706665130 .4479980469128 .9241027832 130.7528076172129 .533706665129 .2288970947127 .4001998901124 .3523025513 117.342300415112 .7705001831109 .7226028442108 .5035018921108 .8082962036 110.0273971558111 .24659729111 .551399231111 .24659729111 .24659729110 .6370010376 109.7226028442108 .8082962036107 .5891036987106 .3700027466105 .1509017944 104.2365036011103 .3221969604102 .712600708102 .4077987671101 .7982025146 101.4934005737100 .8839035034100 .274299621699 .96952056885100 .2742996216 101.4934005737103 .6268997192106 .0652008057107 .5891036987105 .7603988647 102.71260070899 .3599472045996 .6168823242294 .1785964965891 .74033355713 89.6068267822387 .4733276367285 .0350494384882 .9015579223681 .07285308838 78.9393463134876 .8058471679774 .6723632812572 .2340774536170 .10057830811 67.6623001098665 .5288009643663 .7000885009861 .8713798522960 .34745025635 58.8235282897957 .2995986938555 .7756805419953 .3373985290550 .59432983398 46.9369087219242 .3651313781736 .5742111206130 .1737308502223 .16366958618 15.544039726268 .5339832305913 .6574220657353 .3526360988625 .790916919708 9.4483394622812 .8009700775116 .1536102294919 .2014598846421 .63973999023 24.0780296325726 .2115192413328 .0402297973629 .8689403533930 .78330039978 31.3928699493432 .0024414062532 .3072204589832 .6120109558132 .91679000854 33.5263595581134 .4407196044935 .3550796508836 .8790016174338 .09814071655 39.3172798156740 .2316398620640 .5364189147940 .8412094116240 .53641891479 39.622070312538 .7077102661137 .7933502197336 .5742111206135 .96464920044 35.3550796508834 .7455101013234 .1359291076733 .8311500549333 .52635955811 33.5263595581133 .5263595581133 .5263595581133 .8311500549334 .13592910767 34.7455101013235 .0502891540535 .6598587036136 .5742111206137 .18378067017 38.0981407165539 .0125007629440 .2316398620641 .1459884643642 .06034851074 43.2794914245644 .1938400268645 .1082000732446 .0225486755446 .93690872192 47.8512611389248 .765621185349 .6799812316950 .5943298339851 .81346893311 53.0326118469254 .5565414428756 .3852500915558 .5187492370660 .04267120361 60.3474502563560 .9570198059156 .6900291442952 .7278289794955 .47089004517 56.3852500915556 .0804595947355 .7756805419955 .4708900451755 .16611099243 54.8613204956154 .5565414428754 .5565414428754 .8613204956154 .86132049561 55.1661109924355 .4708900451756 .0804595947356 .9948196411157 .9091796875 58.5187492370658 .8235282897960 .6522407531760 .6522407531761 .87137985229 62.1761703491262 .1761703491261 .5666007995661 .2618103027361 .26181030273 60.9570198059160 .6522407531759 .7378807067958 .8235282897958 .82352828979 58.8235282897958 .8235282897958 .8235282897958 .5846824646 -9999 -9999 -9999 -9999 -9999 -9999 -9999 -9999 -9999 -9999 -9999 -9999 -9999 -9999 -9999 -9999-9999-9999 -9999 - -999 -9999 -9999 -9999 -9999 -9999 -9999 -9999 -9999 -9999 -9999 -9999 -9999 -9999 -9999 -9999 -

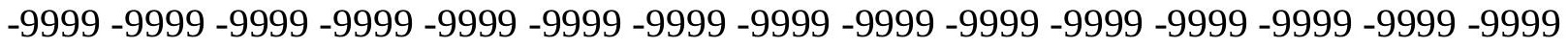
-9999-9999

-9999 -9999 -9999 -9999 -9999 -9999 -9999 -9999 -9999 -9999 -9999 -9999 -9999 -9999 -9999 -9999 -9999 -9999 -9999 -9999 -9999 -9999 -9999 -9999 -9999 -9999 -9999 -9999 -9999 -9999 -9999 -9999 -9999 -9999 -9999 -9999 -9999 -9999 -9999 -9999 -9999 -9999 -9999 -9999 -9999 -

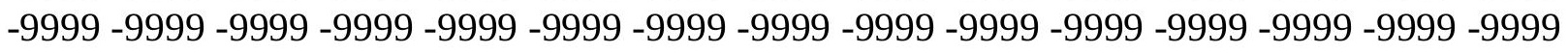

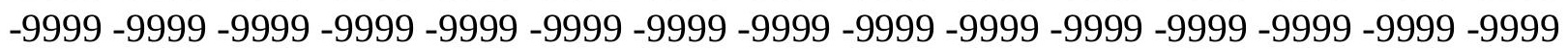


-9999 -9999 -9999 -9999 -9999 -9999 -9999 -9999 -9999 -9999 -9999 -9999 -9999 -9999 -9999 -9999 -9999 -9999 -9999 -9999 -9999 -9999 -9999 -9999 -9999 -9999 -9999 -9999 -9999 -9999

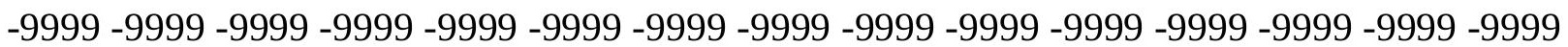
-9999 -9999 -9999 -9999 -9999 -9999 -9999 -9999 -9999 -9999 -9999 -9999 -9999 -9999 -9999 -9999 -9999 -9999 -9999-9999-9999 127.7050018311 128.0097961426128 .3144989014 128.3144989014128 .0097961426128 .0097961426128 .3144989014128 .6192932129 129.533706665130 .4479980469131 .3623962402131 .0576019287130 .1432037354 129.2288970947129 .2288970947129 .2288970947129 .533706665129 .533706665 131.0576019287131 .3623962402131 .3623962402131 .6672058105132 .2767028809 130.7528076172130 .1432037354128 .0097961426124 .6570968628116 .4279022217 108.5035018921100 .579101562599 .35994720459100 .5791015625103 .0174026489 106.0652008057107 .8938980103108 .8082962036109 .1130981445109 .1130981445 108.8082962036108 .1986999512107 .2844009399106 .3700027466105 .4557037354 104.8460998535103 .9317016602103 .6268997192103 .0174026489102 .712600708 102.4077987671102 .1029968262101 .4934005737100 .8839035034100 .2742996216 99.96952056885101 .4934005737103 .6268997192104 .5412979126104 .5412979126 103.3221969604101 .188697814999 .0551681518696 .6168823242294 .48339080811 92.349891662689 .9116134643688 .9972534179786 .8637619018682 .90155792236 81.0728530883878 .9393463134876 .8058471679774 .3675689697372 .23407745361 69.7957916259867 .6623001098665 .5288009643663 .7000885009861 .56660079956 60.0426712036158 .2139587402356 .0804595947353 .6421813964850 .89912033081 47.5464782714843 .2794914245638 .0981407165532 .3072204589825 .60194969177 17.677539825449 .448339462283 .0478510856633 .6574220657356 .400486946106 9.4483394622812 .8009700775115 .8488302230818 .5918903350820 .72538948059 23.1636695861824 .9923801422126 .8210906982428 .3450202941929 .56415939331 30.4785099029531 .0880794525131 .6976509094232 .0024414062532 .61201095581 33.2215805053733 .8311500549335 .0502891540535 .9646492004437 .18378067017 38.0981407165538 .7077102661139 .3172798156739 .3172798156739 .01250076294 38.7077102661137 .7933502197337 .1837806701736 .2694282531735 .65985870361 35.0502891540534 .7455101013234 .4407196044934 .1359291076734 .13592910767 34.1359291076734 .1359291076734 .1359291076734 .4407196044934 .74551010132 35.3550796508835 .6598587036136 .2694282531737 .1837806701737 .79335021973 38.7077102661139 .622070312540 .8412094116241 .7555618286142 .669921875 43.8890609741244 .8034095764245 .717769622846 .9369087219247 .85126113892 48.765621185349 .6799812316950 .5943298339851 .5086898803752 .42303848267 53.9469718933155 .4708900451757 .6043891906760 .3474502563563 .39530944824 66.4431610107466 .1383666992259 .7378807067954 .2517509460453 .64218139648 54.5565414428754 .5565414428753 .9469718933153 .9469718933153 .94697189331 53.6421813964853 .6421813964853 .6421813964853 .6421813964853 .94697189331 54.2517509460454 .8613204956155 .4708900451758 .5187492370661 .87137985229 64.004882812567 .3575134277367 .9670867919967 .3575134277366 .74794006348 66.1383666992265 .5288009643664 .9192428588964 .3096618652364 .0048828125 63.3953094482462 .4809494018661 .5666007995660 .3474502563559 .12831115723 $58.8235282897958 .8235282897958 .8235282897958 .3729438781757 .94683837891-9999$ -9999 -9999 -9999 -9999 -9999 -9999 -9999 -9999 -9999 -9999 -9999 -9999 -9999 -9999 -9999

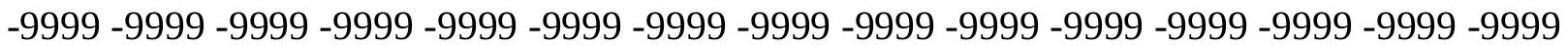


-9999 -9999 -9999 -9999 -9999 -9999 -9999 -9999 -9999 -9999 -9999 -9999 -9999 -9999 -9999 -9999 -9999 -9999-9999

-9999 -9999 -9999 -9999 -9999 -9999 -9999 -9999 -9999 -9999 -9999 -9999 -9999 -9999 -9999 -9999 -9999 -9999 -9999 -9999 -9999 -9999 -9999 -9999 -9999 -9999 -9999 -9999 -9999 -9999 - -999 -9999 -9999 -9999 -9999 -9999 -9999 -9999 -9999 -9999 -9999 -9999 -9999 -9999 - -9999 - -9999 -

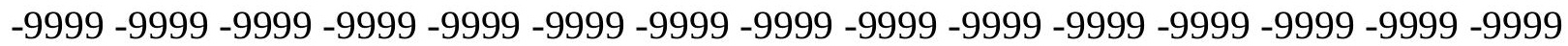

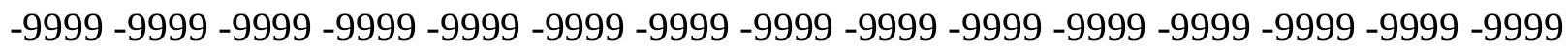
-9999 -9999 -9999 -9999 -9999 -9999 -9999 -9999 -9999 -9999 -9999 -9999 -9999 -9999 -9999

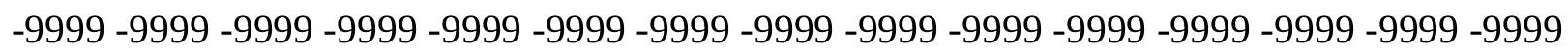

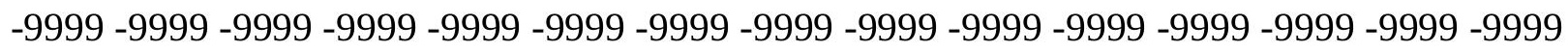

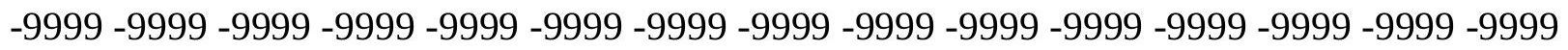
-9999 -9999 -9999 -9999-9999 -9999 -9999 -9999 127.7050018311127 .7050018311 127.4001998901127 .4001998901127 .0953979492126 .7906036377127 .0953979492 127.0953979492127 .7050018311128 .0097961426127 .7050018311127 .7050018311 127.7050018311127 .7050018311128 .0097961426130 .1432037354130 .7528076172 131.3623962402132 .2767028809132 .8863067627131 .9720001221131 .9720001221 130.7528076172127 .7050018311124 .0475006104117 .647102356110 .6370010376 104.8460998535100 .8839035034100 .5791015625101 .7982025146103 .9317016602 105.4557037354106 .6747970581107 .5891036987107 .8938980103107 .8938980103 107.5891036987106 .979598999106 .3700027466105 .4557037354104 .8460998535 104.2365036011103 .9317016602103 .6268997192103 .3221969604103 .0174026489 102.712600708102 .4077987671101 .7982025146101 .1886978149101 .1886978149 101.1886978149101 .1886978149102 .1029968262103 .3221969604103 .3221969604 102.4077987671100 .883903503499 .3599472045997 .2264633178795 .09295654297 94.1785964965892 .0450973510789 .9116134643687 .4733276367285 .03504943848 81.0728530883878 .9393463134876 .8058471679774 .3675689697372 .23407745361 69.7957916259867 .6623001098665 .5288009643663 .3953094482461 .26181030273 59.1283111572356 .9948196411154 .5565414428752 .1182594299348 .7656211853 45.1082000732440 .8412094116235 .6598587036130 .1737308502222 .55410003662 15.239259719859 .7531242370618 .2291984558119 .14355373382611 .27705001831 13.715330123916 .1536102294918 .28710937520 .4206008911122 .24930953979 24.0780296325725 .6019496917727 .1258792877228 .3450202941929 .25937080383 30.1737308502231 .0880794525131 .3928699493432 .0024414062532 .61201095581 33.5263595581134 .4407196044935 .3550796508836 .2694282531737 .18378067017 37.7933502197338 .0981407165538 .0981407165538 .0981407165537 .79335021973 37.1837806701736 .5742111206135 .9646492004435 .3550796508835 .05028915405 34.7455101013234 .7455101013234 .4407196044934 .4407196044934 .44071960449 34.4407196044934 .7455101013235 .0502891540535 .3550796508835 .96464920044 36.2694282531737 .1837806701737 .7933502197338 .7077102661139 .31727981567 40.5364189147941 .4507789611842 .3651313781743 .5842704772944 .49863052368 45.4129791259846 .6321296691947 .5464782714848 .4608306884849 .37519073486 50.2895507812551 .2038993835452 .4230384826753 .3373985290554 .86132049561 56.3852500915558 .2139587402361 .2618103027365 .8335876464871 .0149307251 74.6723632812562 .7857398986850 .2895507812552 .1182594299353 .03261184692 53.0326118469252 .7278289794952 .7278289794952 .7278289794952 .72782897949 52.4230384826752 .7278289794952 .7278289794953 .0326118469253 .33739852905 
54.8613204956158 .8235282897966 .1383666992274 .3675689697379 .85370635986 80.1584930419977 .7202072143674 .6723632812572 .5388565063570 .71015167236 69.1862335205168 .2718734741267 .3575134277366 .7479400634865 .83358764648 64.9192428588963 .7000885009862 .1761703491260 .6522407531759 .12831115723 58.51874923706 58.51874923706 58.1772117614757 .77972412109 -9999 -9999 -9999 -9999 -9999 -9999 -9999 -9999 -9999 -9999 -9999 -9999 -9999 -9999 -9999 -9999 -9999 -9999 -9999 -9999 -9999 -9999 -9999 -9999 -9999 -9999 -9999 -9999 -9999 -9999 -9999 -9999 -9999 -9999 -

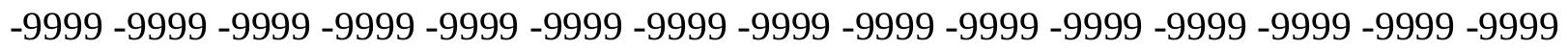
$-9999$

-9999 -9999 -9999 -9999 -9999 -9999 -9999 -9999 -9999 -9999 -9999 -9999 -9999 -9999 -9999 -9999 -9999 -9999 -9999 -9999 -9999 -9999 -9999 -9999 -9999 -9999 -9999 -9999 -9999 -9999 -999 -9999 -9999 -9999 -9999 -9999 -9999 -9999 -9999 -9999 -9999 -9999 -9999 -9999 -9999 -9999 -9999 -9999 -9999 -9999 -9999 -9999 -9999 -9999 -9999 -9999 -9999 -9999 -9999 -9999 -9999

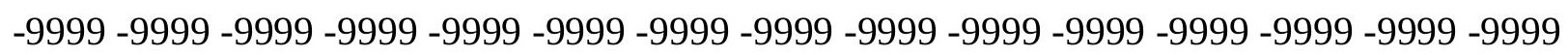
-9999 -9999 -9999 -9999 -9999 -9999 -9999 -9999 -9999 -9999 -9999 -9999 -9999 -9999 -9999

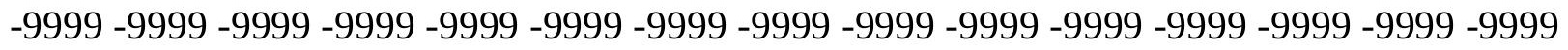

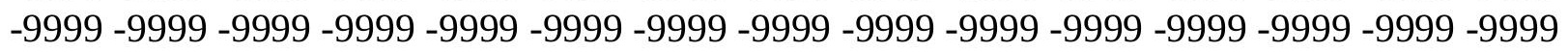

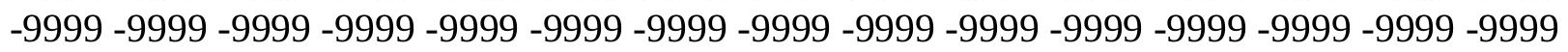
-9999 -9999 -9999 -9999 -9999 -9999 -9999 -9999-9999-9999-9999 126.4858016968 126.1809997559126 .1809997559125 .8762969971125 .8762969971125 .8762969971 125.8762969971125 .8762969971125 .8762969971126 .1809997559126 .4858016968 128.6192932129129 .533706665130 .4479980469131 .6672058105132 .8863067627 132.2767028809133 .1911010742133 .1911010742131 .3623962402127 .7050018311 124.3523025513118 .5614013672112 .7705001831107 .8938980103105 .1509017944 104.5412979126105 .1509017944106 .3700027466105 .7603988647106 .3700027466 106.6747970581 106.979598999 106.979598999 106.979598999 106.3700027466 106.0652008057105 .4557037354104 .8460998535104 .5412979126103 .9317016602 103.6268997192103 .3221969604103 .3221969604103 .0174026489102 .712600708 102.4077987671102 .1029968262102 .1029968262102 .1029968262102 .4077987671 102.712600708103 .0174026489103 .6268997192103 .6268997192103 .0174026489 101.7982025146100 .2742996216101 .798202514696 .9216690063595 .09295654297 92.9594726562590 .5211791992288 .0829010009885 .3398437581 .37763214111 79.2441329956176 .8058471679774 .6723632812572 .2340774536169 .79579162598 67.3575134277365 .2240066528362 .7857398986860 .3474502563558 .21395874023 56.0804595947353 .6421813964850 .8991203308147 .5464782714843 .88906097412 39.622070312534 .7455101013229 .2593708038323 .4684505462618 .287109375 14.934470176714 .0201196670514 .6296901702915 .8488302230817 .37274932861 18.8966808319120 .4206008911121 .9445304870623 .4684505462624 .68759918213 26.2115192413327 .1258792877228 .3450202941929 .2593708038330 .17373085022 30.7833003997831 .3928699493432 .3072204589832 .9167900085433 .83115005493 34.7455101013235 .3550796508835 .9646492004436 .5742111206136 .87900161743 37.1837806701737 .1837806701736 .8790016174336 .5742111206136 .26942825317 35.6598587036135 .3550796508835 .0502891540535 .0502891540534 .74551010132 34.7455101013234 .7455101013234 .7455101013235 .0502891540535 .35507965088 35.6598587036135 .9646492004436 .5742111206137 .1837806701737 .79335021973 38.4029312133839 .3172798156740 .2316398620641 .1459884643642 .06034851074 
42.9747009277344 .1938400268645 .1082000732446 .3273391723647 .24169921875 48.4608306884849 .3751907348650 .2895507812551 .2038993835452 .11825942993 53.3373985290554 .2517509460455 .7756805419956 .9948196411158 .82352828979 61.2618103027366 .4431610107470 .7101516723670 .4053573608463 .70008850098 55.4708900451750 .8991203308151 .2038993835451 .5086898803751 .81346893311 51.5086898803751 .5086898803751 .8134689331152 .1182594299352 .42303848267 52.7278289794953 .9469718933156 .3852500915560 .3474502563566 .44316101074 74.9771423339885 .3398437595 .7025299072390 .8259735107485 .3398437581 .07285308838 77.4154205322374 .6723632812572 .8436431884871 .6244964599670 .40535736084 69.4910125732468 .2718734741267 .0527267456165 .8335876464864 .30966186523 62.4809494018660 .9570198059159 .4331016540558 .2139587402358 .21395874023 57.74991607666 -9999 -9999 -9999 -9999 -9999 -9999 -9999 -9999 -9999 -9999 -9999 -9999 -9999 -9999 -9999 -9999 -9999 -9999 -9999 -9999 -9999 -9999 -9999 -9999 -9999 -9999 -9999

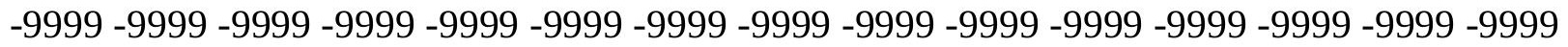
-9999 -9999 -9999 -9999 -9999 -9999 -9999 -9999

-9999 -9999 -9999 -9999 -9999 -9999 -9999 -9999 -9999 -9999 -9999 -9999 -9999 -9999 -9999 -9999 -9999 -9999 -9999 -9999 -9999 -9999 -9999 -9999 -9999 -9999 -9999 -9999 -9999 -9999 -9999 -9999 -9999 -9999 -9999 -9999 -9999 -9999 -9999 -9999 -9999 -9999 -9999 -9999 -9999 -9999 -9999 -9999 -9999 -9999 -9999 -9999 -9999 -9999 -9999 -9999 -9999 -9999 -9999 -9999 -

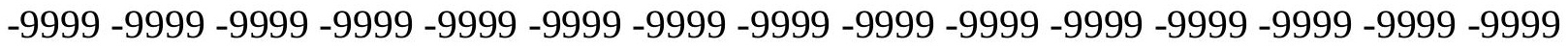

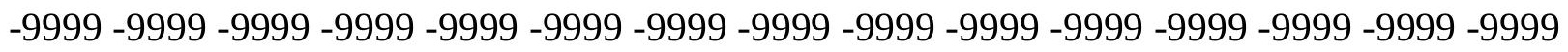
-9999 -9999 -9999 -9999 -9999 -9999 -9999 -9999 -9999 -9999 -9999 -9999 -9999 -9999 -9999 -9999 -9999 -9999 -9999 -9999 -9999 -9999 -9999 -9999 -9999 -9999 -9999 -9999 -9999 -9999 -9999 -9999 -9999 -9999 -9999 -9999 -9999 -9999 -9999 -9999 -9999 -9999 -9999 -9999 -9999 -

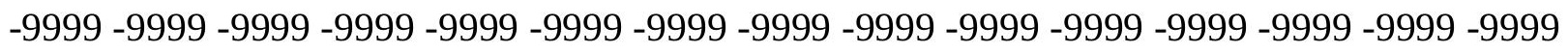
125.2667007446125 .2667007446125 .2667007446125 .2667007446125 .2667007446 125.2667007446125 .5715026855126 .1809997559127 .0953979492128 .3144989014 131.6672058105131 .6672058105133 .1911010742134 .4102020264134 .4102020264 132.2767028809128 .3144989014125 .2667007446120 .0852966309114 .9039993286 110.9418029785108 .1986999512107 .2844009399106 .979598999107 .5891036987 108.1986999512107 .2844009399107 .5891036987107 .2844009399107 .2844009399 106.6747970581106 .0652008057105 .7603988647105 .1509017944104 .5412979126 104.2365036011103 .9317016602103 .6268997192103 .3221969604103 .3221969604 103.3221969604103 .0174026489103 .0174026489103 .0174026489103 .0174026489 103.0174026489103 .6268997192103 .9317016602104 .2365036011104 .2365036011 104.8460998535105 .1509017944107 .2844009399106 .3700027466104 .8460998535 103.0174026489100 .579101562595 .397743225193 .2642517089890 .82597351074 88.0829010009884 .1206970214881 .6824111938579 .5489196777377 .1106262207 74.6723632812572 .2340774536169 .7957916259867 .3575134277364 .61444854736 62.1761703491260 .3474502563558 .2139587402355 .7756805419953 .33739852905 50.5943298339847 .2416992187543 .5842704772939 .9268493652335 .96464920044 32.0024414062526 .2115192413321 .9445304870619 .811029434218 .89668083191 18.5918903350819 .2014598846419 .811029434220 .7253894805921 .63973999023 22.8588790893624 .0780296325724 .9923801422126 .2115192413327 .4306602478 28.3450202941929 .2593708038330 .1737308502230 .7833003997831 .69765090942 32.3072204589833 .2215805053733 .8311500549334 .7455101013235 .35507965088 
35.6598587036135 .9646492004436 .2694282531736 .2694282531736 .26942825317 35.9646492004435 .6598587036135 .6598587036135 .3550796508835 .05028915405 35.0502891540535 .0502891540535 .0502891540535 .0502891540535 .35507965088 35.6598587036135 .9646492004436 .2694282531736 .5742111206137 .18378067017 37.7933502197338 .4029312133839 .0125007629439 .9268493652340 .84120941162 41.7555618286142 .66992187543 .8890609741244 .8034095764246 .02254867554 46.9369087219248 .1560516357449 .0704002380450 .2895507812551 .20389938354 52.1182594299353 .3373985290554 .2517509460455 .4708900451756 .69002914429 57.909179687559 .7378807067962 .1761703491265 .5288009643667 .96708679199 67.3575134277363 .7000885009858 .5187492370654 .5565414428753 .03261184692 53.3373985290553 .3373985290553 .3373985290553 .6421813964853 .64218139648 54.2517509460454 .8613204956156 .0804595947358 .2139587402361 .26181030273 65.8335876464872 .2340774536180 .7680587768689 .6068267822395 .09295654297 94.1785964965889 .9116134643685 .3398437581 .3776321411178 .32978057861 76.1962814331174 .6723632812573 .4532165527372 .2340774536171 .0149307251 69.4910125732467 .9670867919966 .1383666992264 .6144485473662 .78573989868 $61.2618103027359 .7378807067958 .2139587402357 .9807624816958 .21395874023-9999$ -9999 -9999 -9999 -9999 -9999 -9999 -9999 -9999 -9999 -9999 -9999 -9999 -9999 -9999 -9999

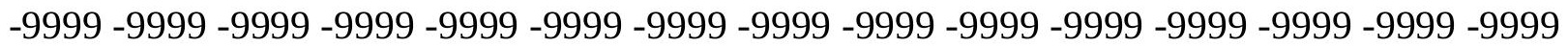

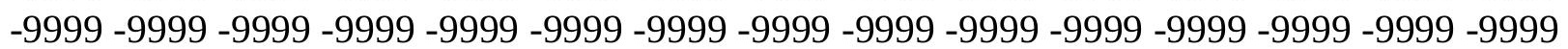
$-9999-9999-9999$

-9999 -9999 -9999 -9999 -9999 -9999 -9999 -9999 -9999 -9999 -9999 -9999 -9999 -9999 -9999 -9999 -9999 -9999 -9999 -9999 -9999 -9999 -9999 -9999 -9999 -9999 -9999 -9999 -9999 -9999 -9999 -9999 -9999 -9999 -9999 -9999 -9999 -9999 -9999 -9999 -9999 -9999 -9999 -9999 -9999 -

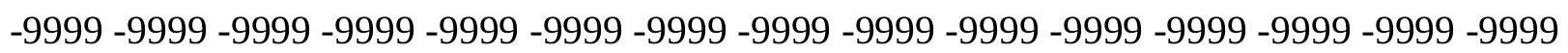

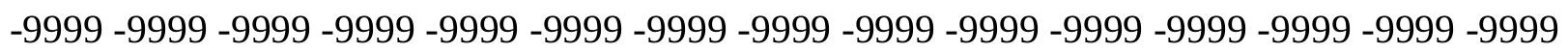
-9999 -9999 -9999 -9999 -9999 -9999 -9999 -9999 -9999 -9999 -9999 -9999 -9999 - -9999 - -9999 -

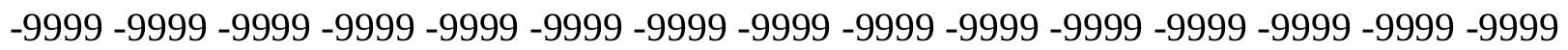

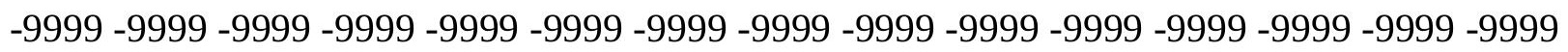

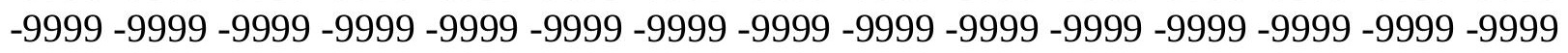
-9999 -9999 -9999 -9999 -9999 -9999 -9999 -9999 -9999 -9999 -9999 -9999 -9999 -9999 -9999 -9999 -9999 -9999 -9999 124.6570968628 124.6570968628124 .9618988037125 .2667007446 126.1809997559127 .7050018311129 .8385009766132 .2767028809134 .1054992676 135.3246002197135 .9342041016133 .1911010742128 .9241027832125 .8762969971 121.3044967651117 .0374984741113 .3800964355110 .9418029785109 .7226028442 109.1130981445109 .4179000854107 .8938980103108 .5035018921108 .5035018921 108.1986999512107 .8938980103107 .2844009399106 .6747970581105 .7603988647 105.1509017944107 .2844009399103 .9317016602103 .6268997192103 .3221969604 103.3221969604103 .3221969604103 .3221969604103 .3221969604103 .3221969604 103.3221969604103 .6268997192103 .9317016602104 .5412979126105 .1509017944 105.7603988647105 .7603988647105 .7603988647110 .0273971558109 .4179000854 108.5035018921107 .2844009399105 .4557037354103 .017402648997 .83602905273 95.397743225192 .9594726562590 .2164001464886 .5589828491284 .42548370361 82.2919769287179 .8537063598677 .4154205322374 .9771423339872 .23407745361 69.7957916259867 .3575134277364 .9192428588962 .7857398986860 .65224075317 58.5187492370656 .3852500915553 .6421813964850 .8991203308147 .85126113892 
44.4986305236841 .1459884643637 .1837806701732 .6120109558128 .34502029419 24.9923801422122 .8588790893621 .6397399902321 .0301704406721 .03017044067 21.334960937521 .6397399902322 .5541000366223 .4684505462624 .38281059265 25.2971591949526 .2115192413327 .430660247828 .3450202941929 .25937080383 30.1737308502231 .0880794525131 .6976509094232 .6120109558133 .22158050537 33.8311500549334 .4407196044935 .0502891540535 .3550796508835 .35507965088 35.6598587036135 .6598587036135 .6598587036135 .3550796508835 .35507965088 35.3550796508835 .0502891540535 .0502891540535 .3550796508835 .35507965088 35.6598587036135 .6598587036135 .9646492004436 .2694282531736 .87900161743 37.1837806701737 .7933502197338 .4029312133839 .0125007629439 .6220703125 40.5364189147941 .4507789611842 .3651313781743 .2794914245644 .49863052368 45.717769622846 .6321296691947 .8512611389249 .0704002380449 .98476028442 51.2038993835452 .1182594299353 .0326118469254 .2517509460455 .16611099243 56.3852500915557 .2995986938558 .8235282897960 .3474502563562 .48094940186 64.6144485473665 .8335876464865 .2240066528363 .0905189514260 .04267120361 57.6043891906756 .0804595947356 .0804595947356 .0804595947356 .08045959473 56.3852500915556 .9948196411157 .6043891906758 .5187492370660 .04267120361 62.4809494018665 .5288009643670 .1005783081176 .1962814331182 .90155792236 89.302040100193 .2642517089893 .5690307617290 .8259735107487 .47332763672 84.1206970214881 .3776321411179 .2441329956177 .7202072143676 .19628143311 74.9771423339873 .4532165527371 .9292907714870 .1005783081168 .27187347412 66.4431610107464 .6144485473662 .7857398986861 .2618103027359 .73788070679 58.5187492370657 .909179687557 .9091796875 -9999 -9999 -9999 -9999 -9999 -9999 -9999 -9999 -9999 -9999 -9999 -9999 -9999 -9999 -9999 -9999 -9999 -9999 -9999 -9999 -9999 -9999

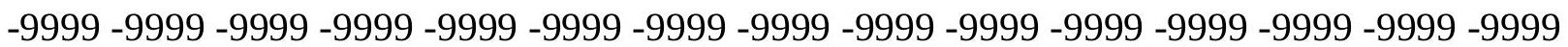
-9999 -9999 -9999 -9999 -9999 -9999 -9999 -9999 -9999 -9999 -9999 -9999 -9999 -9999 -9999 -9999 -9999 -9999 -9999 -9999 -9999 -9999 -9999 -9999 -9999 -9999 -9999 -9999 -9999 -9999 -9999 -9999 -9999 -9999 -9999 -9999 -9999 -9999 -9999 -9999 -9999 -9999 -9999 -9999 -9999 -9999 -9999 -9999 -9999 -9999 -9999 -9999 -9999 -9999 -9999 -9999 -9999 -9999 -9999 -9999 -9999 -9999 -9999 -9999 -9999 -9999 -9999 -9999 -9999 -9999 -9999 -9999 -9999 -9999 -9999 -9999 -9999 -9999 -9999 -9999 -9999 -9999 -9999 -9999 -9999 -9999 -9999 -9999 -9999 -9999 -9999 -9999 -9999 -9999 -9999 -9999 -9999 -9999 -9999 -9999 -9999 -9999 -9999 -9999 -9999 -9999 -9999 -9999 -9999 -9999 -9999 -9999 -9999 -9999 -9999 -9999 -9999 -9999 -9999 -9999 -9999 -9999 -9999 -9999 -9999 -9999 -9999 -9999 -9999 -9999 -9999

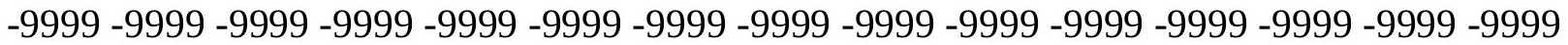
-9999 -9999 -9999 -9999 -9999 -9999 -9999 -9999 -9999 -9999 -9999 -9999 -9999 -9999 -9999 -9999 -9999 -9999 -9999 -9999 -9999 -9999 -9999 125.5715026855128 .3144989014 132.2767028809136 .2389984131139 .2868041992140 .2012023926138 .3724975586 133.4958953857129 .2288970947126 .4858016968122 .2188034058118 .5614013672 115.5136032104113 .075302124111 .8561019897111 .24659729110 .9418029785 109.7226028442109 .7226028442109 .4179000854109 .1130981445108 .5035018921 107.8938980103107 .2844009399106 .3700027466105 .4557037354104 .8460998535 103.9317016602103 .3221969604103 .0174026489103 .0174026489103 .0174026489 103.0174026489103 .0174026489103 .3221969604103 .6268997192103 .9317016602 104.5412979126105 .1509017944105 .7603988647106 .6747970581107 .2844009399 107.2844009399110 .0273971558110 .3321990967110 .3321990967108 .8082962036 
106.979598999101 .493400573799 .6647262573297 .2264633178794 .78817749023 91.1307525634889 .302040100187 .1685485839885 .0350494384882 .59677124023 80.1584930419977 .7202072143674 .9771423339872 .5388565063570 .10057830811 67.9670867919965 .8335876464863 .7000885009861 .5666007995659 .43310165405 56.9948196411154 .5565414428751 .8134689331149 .0704002380445 .7177696228 41.7555618286137 .7933502197333 .5263595581129 .8689403533926 .82109069824 24.6875991821323 .4684505462622 .5541000366221 .9445304870621 .94453048706 22.2493095397922 .8588790893623 .7732391357424 .6875991821325 .60194969177 26.5163097381627 .430660247828 .3450202941929 .2593708038330 .17373085022 31.0880794525132 .0024414062532 .6120109558133 .2215805053733 .83115005493 34.1359291076734 .7455101013234 .7455101013235 .0502891540535 .05028915405 35.0502891540535 .0502891540535 .0502891540535 .0502891540535 .35507965088 35.3550796508835 .6598587036135 .6598587036135 .9646492004436 .26942825317 36.5742111206136 .8790016174337 .4885711669937 .7933502197338 .40293121338 39.0125007629439 .622070312540 .5364189147941 .1459884643642 .06034851074 42.9747009277344 .1938400268645 .1082000732446 .3273391723647 .54647827148 48.765621185349 .6799812316950 .8991203308152 .1182594299353 .03261184692 54.2517509460455 .1661109924356 .0804595947356 .9948196411158 .21395874023 59.4331016540560 .9570198059162 .1761703491263 .7000885009864 .30966186523 64.004882812562 .4809494018660 .9570198059159 .4331016540558 .51874923706 58.5187492370658 .5187492370659 .1283111572359 .4331016540560 .04267120361 60.9570198059162 .4809494018664 .004882812566 .4431610107469 .49101257324 73.4532165527378 .3297805786183 .5111236572388 .0829010009891 .13075256348 91.7403335571390 .5211791992288 .0829010009885 .6446228027383 .51112365723 81.6824111938580 .1584930419978 .6345596313577 .4154205322375 .58670806885 74.062782287672 .2340774536170 .4053573608468 .2718734741266 .44316101074 64.6144485473662 .7857398986861 .2618103027360 .0426712036158 .82352828979 57.6043891906757 .60438919067 -9999 -9999 -9999 -9999 -9999 -9999 -9999 -9999 -9999 -9999 -9999 -9999 -9999 -9999 -9999 -9999 -9999 -9999 -9999 -9999 -9999 -9999 -9999 -9999 -

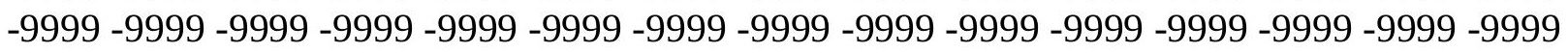
-9999 -9999 -9999 -9999-9999-9999-9999-9999

-9999 -9999 -9999 -9999 -9999 -9999 -9999 -9999 -9999 -9999 -9999 -9999 -9999 -9999 -9999

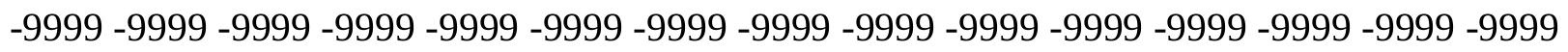
-9999 -9999 -9999 -9999 -9999 -9999 -9999 -9999 -9999 -9999 -9999 -9999 -9999 -9999 -9999 -9999 -9999 -9999 -9999 -9999 -9999 -9999 -9999 -9999 -9999 -9999 -9999 -9999 -9999 -9999 -

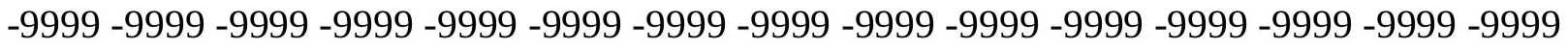

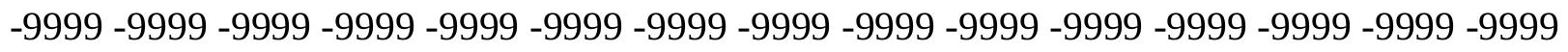

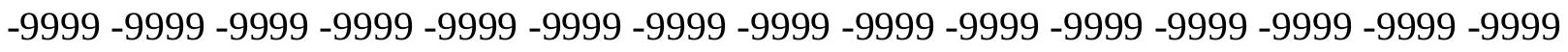
-9999 -9999 -9999 -9999 -9999 -9999 -9999 -9999 -9999 -9999 -9999 -9999 -9999 -9999 -9999 -9999 -9999 -9999 -9999 -9999 -9999 -9999 -9999 -9999 -9999 -9999 -9999 -9999 -9999 -9999 -

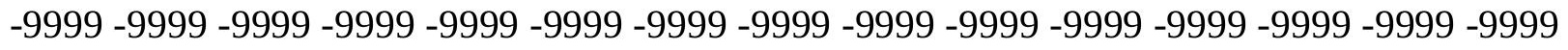
-9999 -9999 -9999 -9999 -9999-9999 -9999 -9999 -9999-9999 -9999-9999 141.5365447998 143.3910369873143 .8585968018138 .0677032471131 .0576019287125 .2667007446 121.3044967651119 .4757995605117 .0374984741115 .2088012695113 .9896011353 113.3800964355111 .24659729111 .24659729111 .24659729110 .9418029785110 .3321990967 109.7226028442108 .8082962036107 .8938980103106 .979598999107 .5891036987 
105.1509017944104 .5412979126103 .9317016602103 .3221969604102 .712600708 102.4077987671102 .712600708102 .712600708103 .0174026489103 .6268997192 104.2365036011104 .8460998535105 .4557037354106 .3700027466106 .979598999 107.8938980103108 .1986999512108 .1986999512110 .9418029785111 .24659729 106.6747970581104 .2365036011101 .7982025146101 .188697814998 .75038146973 95.0929565429793 .2642517089891 .7403335571389 .9116134643687 .47332763672 85.0350494384882 .9015579223680 .4632720947378 .0249862670975 .58670806885 73.1484298706171 .014930725168 .8814392089866 .7479400634864 .61444854736 62.4809494018660 .3474502563558 .2139587402355 .7756805419953 .03261184692 49.6799812316946 .3273391723642 .3651313781738 .0981407165534 .44071960449 30.7833003997827 .7354507446325 .6019496917724 .0780296325723 .16366958618 22.5541000366222 .5541000366222 .5541000366223 .1636695861824 .07802963257 24.6875991821325 .906740188626 .8210906982427 .7354507446328 .64979934692 29.5641593933130 .4785099029531 .3928699493432 .0024414062532 .61201095581 33.2215805053733 .5263595581134 .1359291076734 .4407196044934 .44071960449 34.7455101013234 .7455101013235 .0502891540535 .0502891540535 .35507965088 35.3550796508835 .6598587036135 .6598587036135 .9646492004436 .26942825317 36.5742111206137 .1837806701737 .4885711669938 .0981407165538 .40293121338 39.0125007629439 .622070312540 .2316398620641 .1459884643641 .75556182861 42.66992187543 .8890609741244 .8034095764245 .717769622846 .93690872192 48.1560516357449 .3751907348650 .5943298339851 .8134689331153 .03261184692 53.9469718933155 .1661109924356 .0804595947356 .9948196411157 .9091796875 58.8235282897959 .7378807067960 .9570198059161 .8713798522962 .78573989868 63.0905189514262 .7857398986862 .1761703491261 .5666007995660 .95701980591 60.6522407531762 .4809494018663 .3953094482463 .7000885009862 .78573989868 63.7000885009864 .6144485473666 .1383666992267 .9670867919970 .10057830811 72.8436431884876 .1962814331180 .1584930419983 .8159103393687 .16854858398 89.6068267822390 .2164001464889 .9116134643688 .6924667358486 .86376190186 85.33984375 83.81591033936 82.59677124023 81.07285308838 79.54891967773

77.7202072143676 .1962814331174 .062782287672 .2340774536170 .10057830811 68.2718734741266 .1383666992264 .3096618652362 .7857398986861 .26181030273 59.7378807067958 .5187492370657 .2995986938557 .60438919067 -9999 -9999 -9999 -9999 -9999 -9999 -9999 -9999 -9999 -9999 -9999 -9999 -9999 -9999 -9999 -9999-9999 -9999 -9999 -

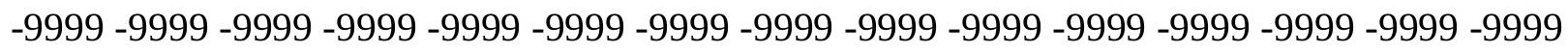
-9999 -9999 -9999 -9999 -9999 -9999 -9999 -9999 -9999 -9999 -9999 -9999

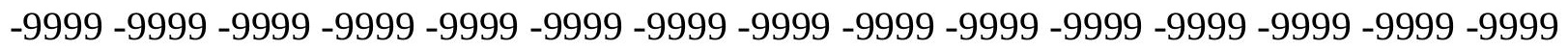

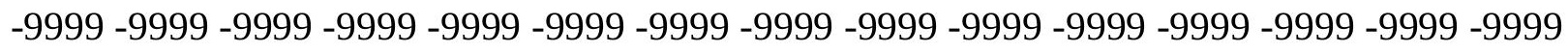

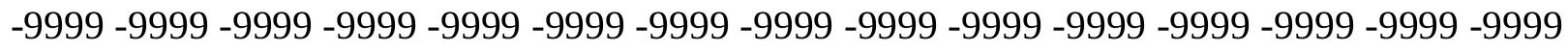
-9999 -9999 -9999 -9999 -9999 -9999 -9999 -9999 -9999 -9999 -9999 -9999 -9999 -9999 -9999 -

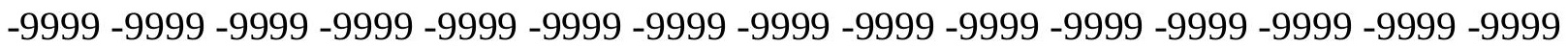

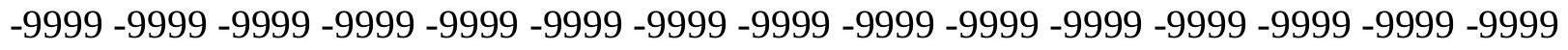

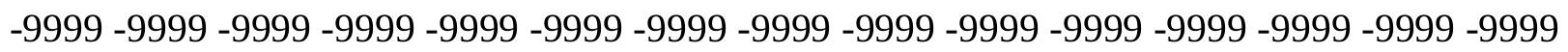

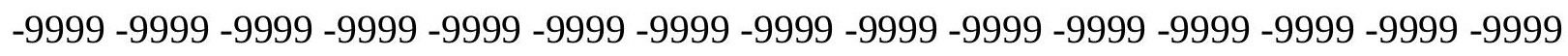
-9999 -9999 -9999 -9999 -9999 -9999 -9999 -9999 -9999 -9999 -9999 -9999 -9999 -9999 -9999 -

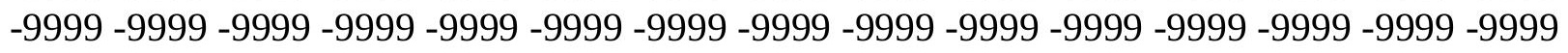

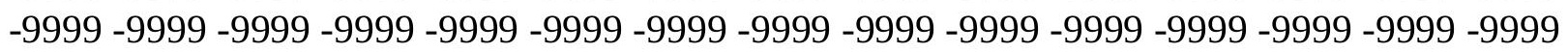


-9999 132.701385498 126.7906036377 121.9140014648 118.8662033081 116.4279022217 115.2088012695115 .818397522115 .2088012695113 .3800964355113 .075302124 112.7705001831112 .1608963013111 .551399231110 .6370010376109 .7226028442 108.8082962036107 .8938980103106 .979598999106 .0652008057105 .1509017944 104.5412979126103 .6268997192103 .0174026489102 .712600708102 .4077987671 102.4077987671102 .712600708103 .3221969604103 .9317016602104 .5412979126 105.4557037354106 .3700027466107 .2844009399108 .1986999512108 .8082962036 109.1130981445108 .5035018921107 .5891036987106 .6747970581104 .8460998535 103.0174026489100 .883903503499 .0551681518697 .2264633178795 .3977432251 93.5690307617291 .7403335571389 .9116134643687 .4733276367285 .33984375 83.206336975180 .7680587768678 .6345596313576 .1962814331174 .0627822876 71.9292907714869 .7957916259867 .6623001098665 .8335876464863 .70008850098 61.5666007995659 .4331016540556 .6900291442953 .9469718933150 .28955078125 46.6321296691942 .66992187538 .4029312133834 .4407196044930 .78330039978 28.0402297973625 .906740188624 .0780296325723 .1636695861822 .55410003662 22.5541000366222 .8588790893623 .4684505462624 .3828105926524 .99238014221 26.2115192413327 .1258792877228 .0402297973628 .9545898437529 .86894035339 30.7833003997831 .3928699493432 .0024414062532 .6120109558133 .22158050537 33.5263595581133 .8311500549334 .1359291076734 .4407196044934 .44071960449 34.7455101013235 .0502891540535 .3550796508835 .6598587036135 .96464920044 36.2694282531736 .5742111206136 .8790016174337 .1837806701737 .48857116699 38.0981407165538 .7077102661139 .0125007629439 .622070312540 .23163986206 40.8412094116241 .7555618286142 .66992187543 .5842704772944 .49863052368 45.4129791259846 .6321296691947 .5464782714848 .765621185349 .98476028442 51.2038993835452 .4230384826753 .9469718933154 .8613204956156 .08045959473 56.9948196411157 .6043891906758 .5187492370659 .1283111572360 .04267120361 60.9570198059161 .5666007995661 .8713798522962 .1761703491262 .17617034912 62.1761703491261 .8713798522962 .1761703491264 .3096618652365 .52880096436 66.7479400634867 .0527267456167 .3575134277367 .0527267456168 .27187347412 69.7957916259871 .3197174072373 .4532165527375 .8914871215878 .63455963135 81.6824111938584 .4254837036186 .8637619018688 .6924667358489 .60682678223 89.6068267822388 .9972534179788 .0829010009886 .8637619018685 .64462280273 84.4254837036182 .9015579223681 .3776321411179 .8537063598678 .02498626709 75.8914871215873 .7580032348671 .9292907714869 .7957916259867 .66230010986 65.8335876464864 .004882812562 .4673805236860 .6522407531759 .12831115723 57.6043891906757 .2995986938557 .29959869385 -9999 -9999 -9999 -9999 -9999 -9999 -9999

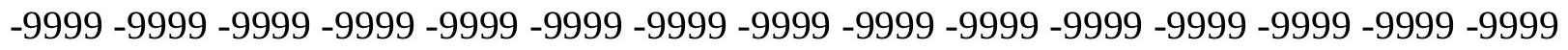

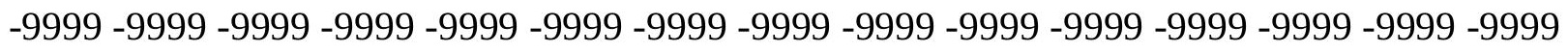
-9999 -9999 -9999 -9999 -9999 -9999 -9999 -9999 -9999 -9999 -9999 -9999 -9999 -9999 -9999 -9999 -9999 -9999 -9999 -9999 -9999 -9999 -9999

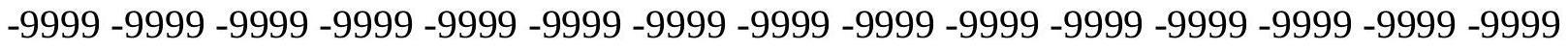

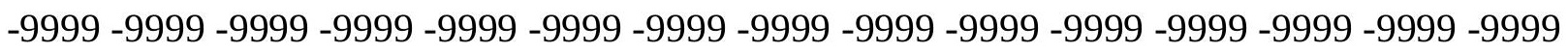
-9999 -9999 -9999 -9999 -9999 -9999 -9999 -9999 -9999 -9999 -9999 -9999 -9999 -9999 -9999 -9999 -9999 -9999 -9999 -9999 -9999 -9999 -9999 -9999-9999 -9999 -9999 -9999 -9999 -9999 -9999 -9999 -9999 -9999 -9999 -9999 -9999 -9999 -9999 -9999 -9999 -9999 -9999 -9999 -9999 -

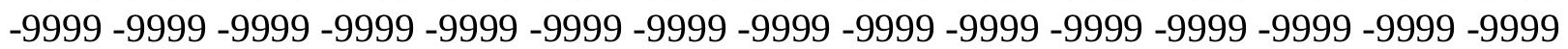


-9999 -9999 -9999 -9999 -9999 -9999 -9999 -9999 -9999 -9999 -9999 -9999 -9999 -9999 -9999 -9999 -9999 -9999 -9999 -9999 -9999 -9999 -9999 -9999 -9999 -9999 -9999 -9999 -9999 -9999

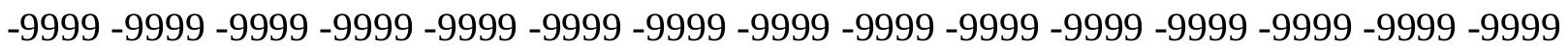
-9999 -9999 -9999 -9999 -9999 -9999 -9999 -9999 -9999 -9999 -9999 -9999 -9999 -9999 -9999 -9999 -9999-9999-9999 120.0504684448 117.80884552116 .7326965332116 .1231002808 115.818397522115 .2088012695114 .5991973877114 .2944030762113 .3800964355 112.4656982422111 .551399231110 .6370010376109 .4179000854108 .5035018921 107.5891036987106 .6747970581106 .0652008057105 .1509017944104 .5412979126 103.9317016602103 .3221969604102 .712600708102 .4077987671102 .4077987671 102.712600708103 .3221969604103 .9317016602104 .8460998535106 .0652008057 106.979598999108 .1986999512109 .1130981445109 .4179000854108 .8082962036 107.8938980103106 .6747970581105 .4557037354103 .6268997192102 .1029968262 100.274299621698 .7503814697397 .2264633178795 .397743225193 .87381744385 92.0450973510789 .9116134643687 .7781066894585 .6446228027383 .51112365723 81.3776321411179 .2441329956177 .110626220774 .9771423339872 .84364318848 70.7101516723668 .8814392089866 .7479400634864 .9192428588962 .78573989868 60.3474502563557 .6043891906754 .5565414428750 .8991203308146 .93690872192 42.66992187538 .0981407165534 .1359291076730 .4785099029527 .73545074463 25.6019496917724 .0780296325723 .1636695861822 .5541000366222 .85887908936 23.1636695861823 .7732391357424 .6875991821325 .6019496917726 .51630973816 27.430660247828 .3450202941929 .2593708038329 .8689403533930 .78330039978 31.3928699493432 .0024414062532 .6120109558132 .9167900085433 .52635955811 33.8311500549334 .1359291076734 .4407196044934 .7455101013235 .05028915405 35.3550796508835 .6598587036136 .2694282531736 .5742111206136 .87900161743 37.1837806701737 .7933502197338 .0981407165538 .7077102661139 .31727981567 39.622070312540 .2316398620640 .8412094116241 .7555618286142 .36513137817 43.2794914245644 .1938400268645 .1082000732446 .0225486755447 .24169921875 48.1560516357449 .3751907348650 .5943298339852 .1182594299353 .33739852905 54.5565414428755 .7756805419956 .9948196411157 .6043891906758 .51874923706 59.1283111572359 .7378807067960 .3474502563560 .6522407531761 .26181030273 61.5666007995661 .5666007995661 .8713798522961 .8713798522962 .48094940186 63.0905189514267 .0527267456168 .8814392089869 .7957916259870 .40535736084 70.7101516723670 .1005783081171 .6244964599673 .1484298706174 .67236328125 76.5010681152378 .3297805786180 .7680587768682 .9015579223685 .33984375 87.1685485839888 .6924667358489 .6068267822389 .9116134643689 .60682678223 88.9972534179788 .3876876831187 .1685485839885 .9494018554784 .73026275635 83.206336975181 .3776321411179 .5489196777377 .4154205322375 .28192901611 73.1484298706171 .3197174072369 .1862335205167 .0527267456165 .22400665283 63.3953094482461 .5666007995660 .0426712036158 .2139587402356 .99481964111 56.99481964111 -9999 -9999 -9999 -9999 -9999 -9999 -9999 -9999 -9999 -9999 -9999 -9999 -9999 -9999 -9999 -9999 -9999 -9999 -9999 -9999 -9999 -9999 -9999 -9999 -9999 -9999 -9999

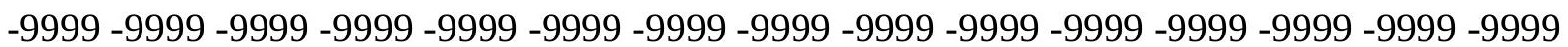
-9999 -9999-9999 -9999 -9999 -9999 -9999 -9999 -9999 -9999 -9999 -9999 -9999 -9999 -9999 -9999 -9999 -9999 -9999 -9999 -9999 -9999 -9999 -9999 -9999 -9999 -9999 -9999 -9999 -9999 -9999 -9999 -9999

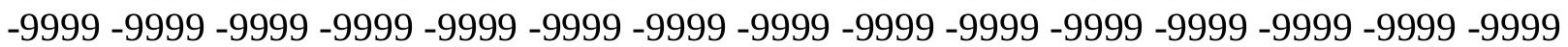


-9999 -9999 -9999 -9999 -9999 -9999 -9999 -9999 -9999 -9999 -9999 -9999 -9999 -9999 -9999 -9999 -9999 -9999 -9999 -9999 -9999 -9999 -9999 -9999 -9999 -9999 -9999 -9999 -9999 -9999 -9999 -9999 -9999 -9999 -9999 -9999 -9999 -9999 -9999 -9999 -9999 -9999 -9999 -9999 -9999 -9999 -9999 -9999 -9999 -9999 -9999 -9999 -9999 -9999 -9999 -9999 -9999 -9999 -9999 -9999 -9999 -9999 -9999 -9999 -9999 -9999 -9999 -9999 -9999 -9999 -9999 -9999 -9999 -9999 -9999 -9999 -9999 -9999 -9999 -9999 -9999 -9999 -9999 -9999 -9999 -9999 -9999 -9999 -9999 -9999 -9999 -9999 -9999 -9999 -9999 -9999 -9999 -9999 -9999 -9999 -9999 -9999 -9999 -9999 -9999 -9999 -9999 -9999 -9999 -9999 -9999 -9999 -9999 -9999 -9999 -9999 -9999 -9999 -9999 -9999 -9999 -9999 -9999 -9999-9999-9999-9999 117.4897537231 117.1555786133 117.0374984741 116.4279022217115 .5136032104114 .5991973877113 .6848983765112 .4656982422 111.551399231110 .3321990967109 .4179000854108 .5035018921107 .5891036987 106.979598999106 .3700027466105 .4557037354104 .8460998535104 .2365036011 103.6268997192103 .0174026489102 .4077987671102 .4077987671102 .4077987671 103.0174026489103 .9317016602105 .1509017944106 .3700027466107 .5891036987 108.8082962036109 .1130981445108 .8082962036107 .8938980103106 .6747970581 105.4557037354104 .2365036011102 .712600708101 .493400573799 .96952056885 98.445587158296 .9216690063595 .397743225193 .8738174438592 .04509735107 89.9116134643688.08290100098 86.2541885376 84.12069702148 81.98719787598 79.8537063598677 .7202072143675 .5867080688573 .4532165527371 .62449645996 69.4910125732467 .6623001098665 .5288009643663 .3953094482460 .95701980591 58.2139587402354 .8613204956150 .8991203308146 .6321296691941 .75556182861 37.4885711669933 .2215805053729 .8689403533926 .8210906982424 .99238014221 23.4684505462622 .8588790893622 .5541000366222 .8588790893623 .46845054626 24.0780296325724 .9923801422125 .906740188626 .5163097381627 .4306602478 28.3450202941929 .2593708038330 .1737308502231 .0880794525131 .69765090942 32.0024414062532 .6120109558132 .9167900085433 .5263595581133 .83115005493 34.4407196044934 .7455101013235 .0502891540535 .6598587036135 .96464920044 36.5742111206136 .8790016174337 .4885711669937 .7933502197338 .40293121338 38.7077102661139 .3172798156739 .9268493652340 .2316398620640 .84120941162 41.4507789611842 .3651313781742 .9747009277343 .8890609741244 .80340957642 45.717769622846 .6321296691947 .8512611389248 .765621185349 .98476028442 51.2038993835452 .4230384826753 .9469718933155 .1661109924356 .38525009155 57.6043891906758 .2139587402358 .8235282897959 .4331016540560 .04267120361 60.3474502563560 .9570198059161 .2618103027361 .2618103027361 .26181030273 61.5666007995662 .1761703491263 .0905189514266 .7479400634869 .79579162598 71.6244964599673 .1484298706173 .7580032348673 .7580032348673 .45321655273 74.6723632812576 .1962814331177 .4154205322378 .9393463134880 .76805877686 82.5967712402384 .4254837036186 .254188537688 .0829010009889 .3020401001 89.9116134643690 .5211791992290 .5211791992289 .9116134643689 .3020401001 88.6924667358487 .4733276367285 .9494018554784 .4254837036182 .59677124023 80.7680587768678 .9393463134876 .8058471679774 .6723632812572 .53885650635 70.4053573608468 .2718734741266 .4431610107464 .3096618652362 .48094940186 60.6522407531758 .8235282897957 .2995986938556 .6900291442956 .99481964111 -9999 -9999 -9999 -9999 -9999 -9999 -9999 -9999 -9999 -9999 -9999 -9999 -9999 -9999 -9999 -9999 -9999 -9999 -9999 -9999 -9999 -9999 -9999 -9999 -9999 -9999 -9999 -9999 -9999 -9999 -9999 -9999 -9999 -9999 -9999 -9999 -9999 -9999 -9999 -9999 -9999 -9999 -9999 -9999 
-9999 -9999 -9999 -9999 -9999 -9999 -9999 -9999 -9999 -9999 -9999 -9999 -9999 -9999 -9999 -9999 -9999 -9999 -9999 -9999 -9999 -9999 -9999 -9999 -9999 -9999 -9999 -9999 -9999 -9999

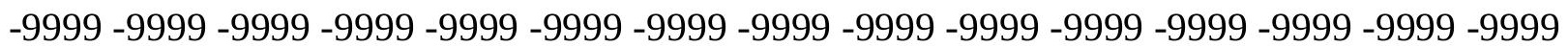
-9999 -9999 -9999 -9999 -9999 -9999 -9999 -9999 -9999 -9999 -9999 -9999 -9999 -9999 -9999

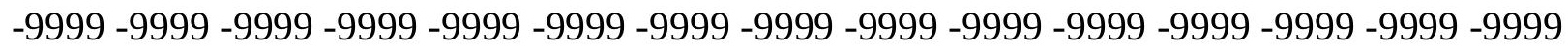
-9999 -9999 -9999 -9999 -9999 -9999 -9999 -9999 -9999 -9999 -9999 -9999 -9999 -9999 -9999 -9999 -9999 -9999 -9999 -9999 -9999 -9999 -9999 -9999 -9999 -9999 -9999 -9999 -9999 -9999 -9999 -9999 -9999 -9999 -9999 -9999 -9999 -9999 -9999 -9999 -9999 -9999 -9999 -9999 -9999 -999 -9999 -9999 -9999 -9999 -9999 -9999 -9999 -9999 -9999 -9999 -9999 -9999 -9999 -9999 -9999

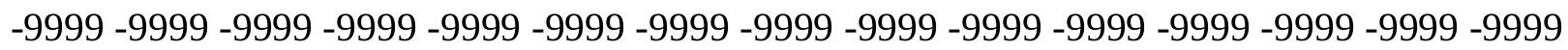
-9999 -9999 -9999 -9999 -9999 -9999 -9999 -9999 -9999 -9999 -9999 -9999 -9999 -9999 -9999 -9999 -9999 -9999 -9999 -9999 -9999 -9999 -9999 -9999 -9999 117.7243270874 117.0374984741115 .818397522114 .5991973877113 .3800964355112 .1608963013 112.7705001831111 .8561019897110 .9418029785108 .5035018921107 .8938980103 107.2844009399106 .6747970581106 .0652008057105 .4557037354104 .5412979126 103.9317016602103 .3221969604102 .712600708102 .4077987671102 .4077987671 102.712600708103 .6268997192104 .8460998535106 .3700027466107 .5891036987 108.5035018921108 .1986999512107 .2844009399106 .6747970581105 .7603988647 104.5412979126103 .3221969604102 .4077987671100 .883903503499 .66472625732 98.445587158296.9216690063595.397743225193.8738174438592.04509735107 90.2164001464888 .3876876831186 .5589828491284 .7302627563582 .59677124023 80.4632720947378 .3297805786176 .1962814331174 .062782287671 .92929077148 70.1005783081167 .9670867919965 .8335876464863 .7000885009861 .56660079956 58.8235282897954 .8613204956149 .9847602844245 .4129791259840 .53641891479 36.2694282531732 .0024414062528 .6497993469226 .2115192413324 .38281059265 23.1636695861822 .5541000366222 .5541000366223 .1636695861823 .77323913574 24.6875991821325 .2971591949525 .906740188626 .5163097381627 .4306602478 28.3450202941929 .5641593933130 .4785099029531 .0880794525131 .69765090942 32.3072204589832 .6120109558133 .2215805053733 .8311500549334 .44071960449 34.7455101013235 .3550796508835 .9646492004436 .5742111206136 .87900161743 37.4885711669937 .7933502197338 .4029312133839 .0125007629439 .31727981567 39.9268493652340 .5364189147941 .1459884643641 .7555618286142 .36513137817 42.9747009277343 .5842704772944 .4986305236845 .4129791259846 .32733917236 47.24169921875 48.15605163574 49.3751907348650.5943298339851.81346893311 53.0326118469254 .2517509460455 .4708900451756 .6900291442957 .9091796875 58.5187492370659 .1283111572359 .7378807067960 .3474502563560 .65224075317 61.2618103027361 .2618103027361 .2618103027361 .2618103027361 .56660079956 62.4809494018664 .004882812567 .9670867919971 .9292907714874 .36756896973 75.8914871215876 .1962814331176 .1962814331176 .1962814331177 .41542053223 78.6345596313579 .8537063598681 .3776321411182 .9015579223684 .42548370361 85.9494018554787 .4733276367288 .6924667358489 .9116134643690 .52117919922 91.1307525634891 .1307525634890 .8259735107490 .2164001464889 .60682678223 88.38768768311 87.16854858398 85.64462280273 83.81591033936 81.98719787598 79.8537063598677 .7202072143675 .8914871215873 .7580032348671 .62449645996 69.49101257324 67.3575134277365.2240066528363.39530944824 61.56660079956 $59.7378807067957 .909179687556 .6900291442956 .6900291442956 .69002914429-9999$ 
-9999 -9999 -9999 -9999 -9999 -9999 -9999 -9999 -9999 -9999 -9999 -9999 -9999 -9999 -9999 -9999 -9999 -9999 -9999 -9999 -9999 -9999 -9999 -9999 -9999 -9999 -9999 -9999 -9999 -9999 -9999 -9999 -9999 -9999 -9999 -9999 -9999 -9999 -9999 -9999 -9999 -9999

-9999 -9999 -9999 -9999 -9999 -9999 -9999 -9999 -9999 -9999 -9999 -9999 -9999 -9999 -9999 -9999 -9999 -9999 -9999 -9999 -9999 -9999 -9999 -9999 -9999 -9999 -9999 -9999 -9999 -9999 -9999 -9999 -9999 -9999 -9999 -9999 -9999 -9999 -9999 -9999 -9999 -9999 -9999 -9999 -9999 -9999 -9999 -9999 -9999 -9999 -9999 -9999 -9999 -9999 -9999 -9999 -9999 -9999 -9999 -9999

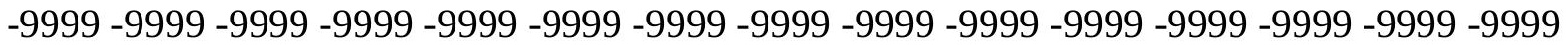
-9999 -9999 -9999 -9999 -9999 -9999 -9999 -9999 -9999 -9999 -9999 -9999 -9999 -9999 -9999 -9999 -9999 -9999 -9999 -9999 -9999 -9999 -9999 -9999 -9999 -9999 -9999 -9999 -9999 -9999 -9999 -9999 -9999 -9999 -9999 -9999 -9999 -9999 -9999 -9999 -9999 -9999 -9999 -9999 -9999 -9999 -9999 -9999 -9999 -9999 -9999 -9999 -9999 -9999 -9999 -9999 -9999 -9999 -9999 -9999

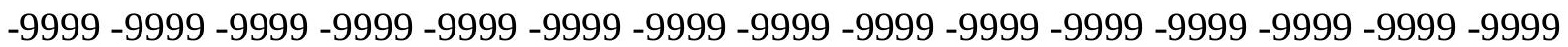
-9999 -9999 -9999 -9999 -9999 -9999 -9999 -9999 -9999 -9999 -9999 -9999 -9999 -9999 -9999 -9999 -9999 -9999 -9999 -9999 -9999 -9999 -9999 -9999 -9999 -9999 -9999 116.91771698 115.818397522114 .2944030762113 .075302124112 .1608963013110 .9418029785 110.3321990967110 .9418029785109 .1130981445108 .5035018921107 .8938980103 107.5891036987106 .6747970581106 .0652008057105 .1509017944104 .2365036011 103.3221969604104 .2365036011102 .712600708102 .712600708103 .0174026489 103.3221969604104 .2365036011105 .7603988647106 .6747970581110 .3321990967 106.6747970581106 .0652008057105 .4557037354104 .8460998535103 .9317016602 102.712600708101 .7982025146100 .579101562599 .6647262573298 .14080810547 96.9216690063595 .397743225193 .8738174438592 .349891662690 .52117919922 88.9972534179786 .8637619018685 .0350494384882 .9015579223680 .76805877686 78.6345596313576 .5010681152374 .3675689697372 .2340774536169 .79579162598 67.6623001098665 .8335876464864 .004882812562 .1761703491257 .60438919067 53.0326118469248 .4608306884843 .8890609741239 .3172798156735 .05028915405 31.0880794525127 .7354507446325 .2971591949523 .7732391357422 .85887908936 22.5541000366222 .8588790893623 .4684505462624 .3828105926524 .68759918213 25.2971591949525 .906740188626 .5163097381627 .430660247828 .64979934692 29.5641593933130 .4785099029531 .0880794525132 .0024414062532 .61201095581 33.2215805053733 .8311500549334 .4407196044935 .0502891540535 .65985870361 36.2694282531736 .8790016174337 .4885711669938 .0981407165538 .70771026611 39.0125007629439 .622070312540 .2316398620640 .5364189147941 .14598846436 41.7555618286142 .3651313781742 .9747009277343 .5842704772944 .19384002686 45.1082000732446 .0225486755446 .6321296691947 .8512611389248 .7656211853 49.6799812316950 .8991203308152 .1182594299353 .3373985290554 .55654144287 55.7756805419956 .9948196411157 .909179687558 .8235282897959 .43310165405 60.0426712036160 .6522407531761 .2618103027361 .8713798522962 .17617034912 62.1761703491261 .8713798522961 .5666007995663 .3953094482464 .91924285889 69.4910125732474 .062782287676 .8058471679778 .0249862670978 .02498626709 76.8058471679778 .6345596313579 .5489196777380 .7680587768681 .68241119385 82.9015579223684 .4254837036185 .6446228027387 .1685485839888 .38768768311 89.6068267822390 .5211791992291 .1307525634891 .4355392456191 .74033355713 91.4355392456190 .8259735107490 .2164001464888 .9972534179787 .77810668945 86.254188537684 .7302627563582 .9015579223680 .7680587768678 .63455963135 
76.8058471679774 .6723632812572 .5388565063570 .4053573608468 .27187347412 66.1383666992264 .3096618652362 .1761703491260 .3474502563558 .82352828979 56.9948196411156 .3852500915556 .69002914429 -9999 -9999 -9999 -9999 -9999 -9999 -9999 -9999 -9999 -9999 -9999 -9999 -9999 -9999 -9999 -9999 -9999 -9999 -9999 -9999 -9999 -9999 -9999 -9999 -9999 -9999 -9999 -9999 -9999 -9999 -9999-9999 -9999 -9999 -9999 -9999 - -9999 -9999 -9999 -9999-9999-9999-9999

-9999 -9999 -9999 -9999 -9999 -9999 -9999 -9999 -9999 -9999 -9999 -9999 -9999 -9999 -9999

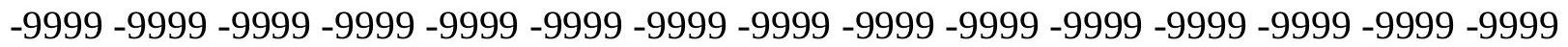
-9999 -9999 -9999 -9999 -9999 -9999 -9999 -9999 -9999 -9999 -9999 -9999 -9999 -9999 -9999 -9999 -9999 -9999 -9999 -9999 -9999 -9999 -9999 -9999 -9999 -9999 -9999 -9999 -9999 -9999 -9999 -9999 -9999 -9999 -9999 -9999 -9999 -9999 -9999 -9999 -9999 -9999 -9999 -9999 -9999 -999 -9999 -9999 -9999 -9999 -9999 -9999 -9999 -9999 -9999 -9999 -9999 -9999 -9999 -9999 -9999 -9999 -9999 -9999 -9999 -9999 -9999 -9999 -9999 -9999 -9999 -9999 -9999 -9999 -9999 -9999 -9999 -9999 -9999 -9999 -9999 -9999 -9999 -9999 -9999 -9999 -9999 -9999 -9999 -9999 -9999 -9999 -9999 -9999 -9999 -9999 -9999 -9999 -9999 -9999 -9999 -9999 -9999 -9999 -9999 -9999 -

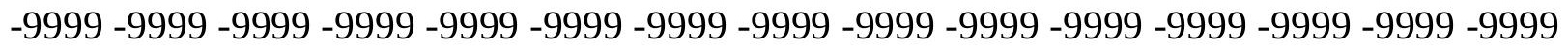

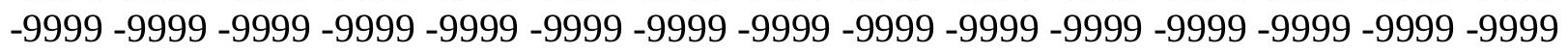

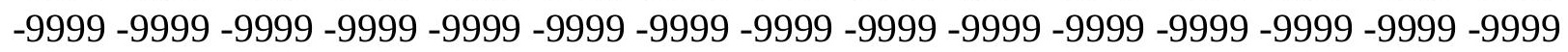
113.9896011353112 .7705001831111 .8561019897111 .24659729110 .6370010376 110.3321990967109 .7226028442109 .4179000854108 .8082962036108 .1986999512 107.2844009399 106.3700027466105.4557037354104.2365036011 103.6268997192 103.0174026489102.712600708102.712600708 103.0174026489103.6268997192 104.2365036011105 .1509017944105 .7603988647106 .0652008057105 .7603988647 105.1509017944104 .5412979126103 .9317016602103 .3221969604102 .4077987671 101.4934005737100 .579101562599 .3599472045998 .1408081054796 .92166900635 95.397743225194 .1785964965892 .6546783447391 .1307525634888 .99725341797 87.1685485839885 .0350494384882 .9015579223680 .7680587768678 .63455963135 76.5010681152374 .062782287671 .9292907714869 .4910125732467 .05272674561 64.6144485473661 .8713798522958 .8235282897955 .1661109924351 .20389938354 47.2416992187542 .66992187538 .0981407165533 .8311500549329 .86894035339 26.8210906982424 .3828105926523 .1636695861822 .5541000366222 .55410003662 23.1636695861824 .0780296325724 .0780296325724 .3828105926524 .99238014221 25.6019496917726 .8210906982427 .7354507446328 .9545898437529 .86894035339 30.7833003997831 .6976509094232 .3072204589833 .2215805053733 .83115005493 34.7455101013235 .3550796508835 .9646492004436 .8790016174337 .48857116699 38.0981407165538 .7077102661139 .3172798156739 .9268493652340 .23163986206 40.8412094116241 .4507789611842 .0603485107442 .3651313781742 .97470092773 43.5842704772944 .1938400268644 .8034095764245 .717769622846 .32733917236 47.2416992187548 .1560516357449 .0704002380450 .2895507812551 .20389938354 52.4230384826753 .6421813964854 .8613204956156 .0804595947356 .99481964111 58.2139587402358 .8235282897959 .7378807067960 .3474502563560 .95701980591 61.8713798522962 .7857398986863 .3953094482463 .3953094482463 .70008850098 64.004882812564 .9192428588966 .4431610107471 .9292907714876 .50106811523 78.6345596313579 .2441329956178 .9393463134878 .0249862670979 .85370635986 81.0728530883881 .9871978759882 .9015579223684 .1206970214885 .33984375 86.55898284912 88.08290100098 88.9972534179790.2164001464890.82597351074 
91.4355392456191.7403335571392.0450973510791.7403335571391.13075256348 90.5211791992289 .6068267822388 .3876876831186 .8637619018685 .03504943848 83.5111236572381 .3776321411179 .5489196777377 .4154205322375 .28192901611 73.1484298706171 .014930725168 .8814392089867 .0527267456164 .91924285889 63.0905189514261 .2618103027359 .4331016540557 .6043891906756 .38525009155 56.3852500915556 .38525009155 -9999 -9999 -9999 -9999 -9999 -9999 -9999 -9999 -9999 -9999 -9999 -9999 -9999 -9999 -9999 -9999 -9999 -9999 -9999 -9999 -9999 -9999 -9999 -9999

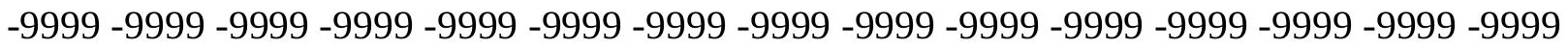
-9999 -9999-9999

-9999 -9999 -9999 -9999 -9999 -9999 -9999 -9999 -9999 -9999 -9999 -9999 -9999 -9999 -9999

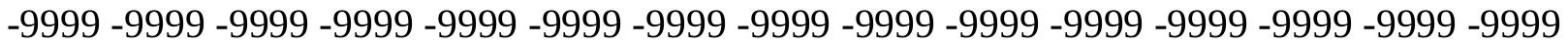
-9999 -9999 -9999 -9999 -9999 -9999 -9999 -9999 -9999 -9999 -9999 -9999 -9999 -9999 -9999 -999 -9999 -9999 -9999 -9999 -9999 -9999 -9999 -9999 -9999 -9999 -9999 -9999 -9999 -9999 -9999 -9999 -9999 -9999 -9999 -9999 -9999 -9999 -9999 -9999 -9999 -9999 -9999 -9999 -9999 -9999 -9999 -9999 -9999 -9999 -9999 -9999 -9999 -9999 -9999 -9999 -9999 -9999 -9999 -9999 -9999

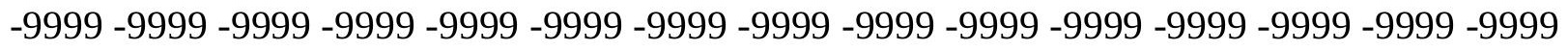
-9999 -9999 -9999 -9999 -9999 -9999 -9999 -9999 -9999 -9999 -9999 -9999 -9999 -9999 -9999 -

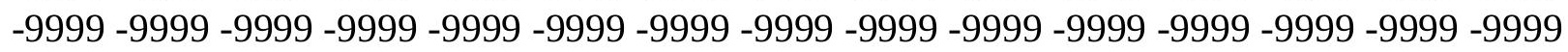

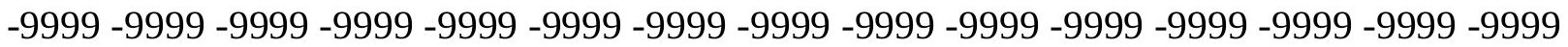

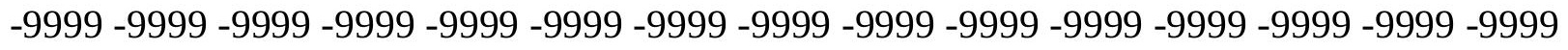

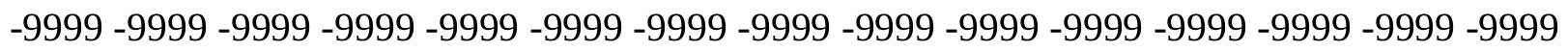
-9999 -9999-9999 111.8561019897 111.551399231 111.551399231 111.24659729 110.9418029785110 .3321990967109 .4179000854108 .5035018921107 .2844009399 106.3700027466105 .1509017944104 .2365036011103 .3221969604104 .2365036011 104.2365036011104 .2365036011103 .0174026489103 .6268997192104 .2365036011 104.8460998535105 .1509017944105 .1509017944104 .8460998535104 .5412979126 103.9317016602103 .3221969604102 .712600708102 .1029968262101 .1886978149 100.274299621699 .0551681518698 .1408081054796 .9216690063595 .3977432251 94.1785964965892 .6546783447390 .8259735107488 .9972534179787 .16854858398 85.0350494384882 .9015579223680 .7680587768678 .3297805786176 .19628143311 73.7580032348671 .014930725168 .2718734741265 .2240066528361 .56660079956 60.0426712036157 .6043891906754 .5565414428750 .5943298339846 .32733917236 41.7555618286136 .8790016174332 .6120109558128 .6497993469225 .60194969177 23.7732391357422 .8588790893622 .5541000366222 .8588790893623 .16366958618 23.4684505462623 .7732391357424 .0780296325724 .9923801422125 .9067401886 27.1258792877228 .3450202941929 .5641593933130 .7833003997831 .69765090942 32.3072204589833 .2215805053734 .1359291076735 .0502891540535 .96464920044 36.5742111206137 .4885711669938 .0981407165538 .7077102661139 .31727981567 39.9268493652340 .5364189147941 .1459884643641 .7555618286142 .06034851074 42.66992187543 .2794914245643 .8890609741244 .4986305236845 .10820007324 45.717769622846 .3273391723646 .9369087219247 .8512611389248 .7656211853 49.6799812316950 .5943298339851 .5086898803752 .7278289794953 .94697189331 54.8613204956156 .0804595947357 .2995986938558 .2139587402359 .12831115723 60.0426712036160 .6522407531761 .2618103027362 .7857398986864 .0048828125 64.9192428588965 .5288009643665 .8335876464866 .1383666992267 .05272674561 68.2718734741274 .6723632812578 .3297805786179 .5489196777379 .54891967773 
77.110626220778 .9393463134880 .4632720947381 .6824111938582 .90155792236 83.8159103393685 .0350494384885 .9494018554787 .1685485839888 .38768768311 89.302040100190 .2164001464891 .1307525634891 .4355392456191 .74033355713 92.0450973510791 .7403335571391 .1307525634890 .5211791992289 .60682678223 88.3876876831187 .1685485839885 .6446228027383 .8159103393681 .98719787598 80.1584930419978 .0249862670975 .8914871215873 .7580032348671 .92929077148 69.7957916259867 .6623001098665 .5288009643663 .7000885009861 .87137985229 60.0426712036158 .5187492370656 .9948196411156 .0804595947356 .38525009155 -9999 -9999 -9999 -9999 -9999 -9999 -9999 -9999 -9999 -9999 -9999 -9999 -9999 -9999 -9999 -9999 -9999 -9999 -9999 -9999 -9999 -9999 -9999 -9999 -9999 -9999 -9999 -9999 -9999 -9999 -9999 -9999 -9999 -9999 -9999 -9999 -9999 -9999 -9999 -9999 -9999 -9999 -9999 -9999 -9999 -9999 -9999 -9999 -9999 -9999 -9999 -9999 -9999 -9999 -9999 -9999 -9999

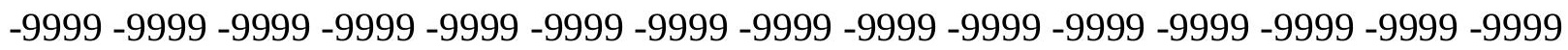
-9999 -9999 -9999 -9999 -9999 -9999 -9999 -9999 -9999 -9999 -9999 -9999 -9999 -9999 -9999 -9999 -9999 -9999 -9999 -9999 -9999 -9999 -9999 -9999 -9999 -9999 -9999 -9999 -9999 -9999 -9999 -9999 -9999 -9999 -9999 -9999 -9999 -9999 -9999 -9999 -9999 -9999 -9999 -9999 -9999 -

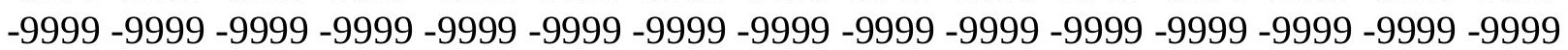
-9999 -9999 -9999 -9999 -9999 -9999 -9999 -9999 -9999 -9999 -9999 -9999 -9999 -9999 -9999 -9999 -9999 -9999 -9999 -9999 -9999 -9999 -9999 -9999 -9999 -9999 -9999 -9999 -9999 -9999 -9999 -9999 -9999 -9999 -9999 -9999 -9999 -9999 -9999 -9999 -9999 -9999 -9999 -9999 -9999 -

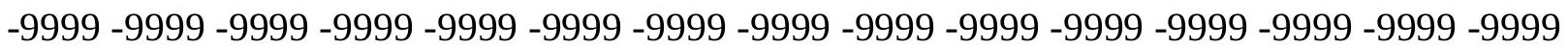
-9999 -9999 -9999 -9999 -9999 -9999 -9999 -9999 -9999 -9999 -9999 -9999 -9999 -9999 -9999 -9999 -9999 -9999 -9999 -9999 -9999 -9999 -9999 -9999 -9999 -9999 -9999 -9999 -9999 -9999 -9999 -9999 -9999 -9999 -9999 -9999 113.075302124112 .7705001831112 .1608963013 111.24659729110 .0273971558108 .5035018921107 .2844009399106 .0652008057 104.8460998535103 .6268997192104 .5412979126103 .9317016602103 .9317016602 104.2365036011 104.5412979126104.8460998535105.4557037354105.7603988647 104.2365036011104 .2365036011104 .2365036011103 .9317016602103 .6268997192 103.0174026489102 .4077987671101 .7982025146100 .883903503499 .96952056885 99.0551681518697 .8360290527396 .9216690063595 .397743225194 .17859649658 92.6546783447390 .8259735107488 .9972534179787 .1685485839885 .03504943848 82.9015579223680 .4632720947378 .0249862670975 .5867080688573 .14842987061 70.1005783081167 .3575134277364 .6144485473662 .4809494018660 .34745025635 57.909179687554 .5565414428750 .5943298339846 .0225486755440 .84120941162 35.6598587036130 .7833003997827 .1258792877224 .6875991821323 .46845054626 22.8588790893622 .5541000366222 .5541000366222 .8588790893623 .16366958618 23.7732391357424 .3828105926525 .2971591949526 .5163097381627 .73545074463 29.25937080383 30.7833003997831 .6976509094232 .6120109558133 .52635955811 34.4407196044935 .3550796508836 .5742111206137 .4885711669938 .09814071655 39.0125007629439 .622070312540 .2316398620640 .8412094116241 .45077896118 42.0603485107442 .3651313781742 .9747009277343 .5842704772943 .88906097412 44.4986305236845 .1082000732445 .717769622846 .3273391723646 .93690872192 47.5464782714848 .4608306884849 .0704002380449 .9847602844250 .89912033081 51.8134689331153 .0326118469253 .9469718933155 .1661109924356 .08045959473 57.2995986938558 .2139587402359 .4331016540560 .3474502563561 .26181030273 62.1761703491263 .7000885009865 .2240066528366 .7479400634867 .66230010986 
67.9670867919968 .2718734741268 .8814392089870 .1005783081177 .41542053223 78.9393463134878 .9393463134878 .3297805786177 .7202072143679 .24413299561 80.7680587768681 .9871978759883 .206336975184 .1206970214885 .33984375 86.254188537687 .4733276367288 .3876876831189 .302040100190 .21640014648 90.8259735107491 .4355392456191 .7403335571391 .7403335571391 .43553924561 91.1307525634890 .5211791992289 .6068267822388 .3876876831187 .16854858398 85.6446228027384 .1206970214882 .2919769287180 .4632720947378 .32978057861 76.5010681152374 .3675689697372 .2340774536170 .4053573608468 .27187347412 66.4431610107464 .3096618652362 .4809494018660 .6522407531759 .12831115723 57.6043891906756 .0804595947356 .0804595947356 .08045959473 -9999 -9999 -9999 -9999 -9999 -9999 -9999 -9999 -9999 -9999 -9999 -9999 -9999 -9999 -9999 -9999 -9999 -9999 -9999

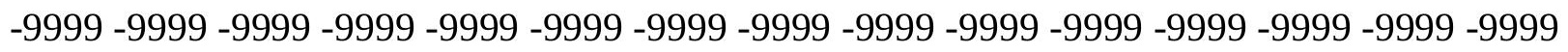
-9999 -9999 -9999 -9999-9999-9999 -9999

-9999 -9999 -9999 -9999 -9999 -9999 -9999 -9999 -9999 -9999 -9999 -9999 -9999 -9999 -9999 -9999 -9999 -9999 -9999 -9999 -9999 -9999 -9999 -9999 -9999 -9999 -9999 -9999 -9999 -9999 -

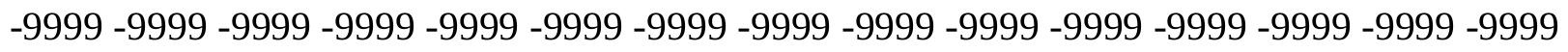
-9999 -9999 -9999 -9999 -9999 -9999 -9999 -9999 -9999 -9999 -9999 -9999 -9999 -9999 -9999 -9999 -9999 -9999 -9999 -9999 -9999 -9999 -9999 -9999 -9999 -9999 -9999 -9999 -9999 -9999 -

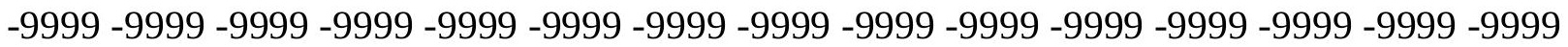

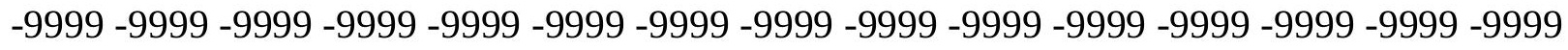

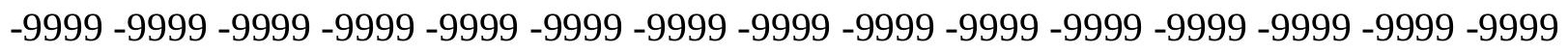

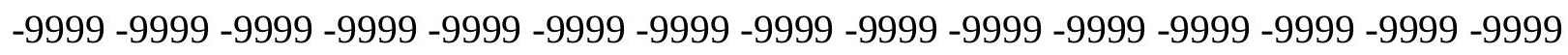
-9999 -9999 -9999 -9999 -9999 -9999 -9999 -9999 -9999 -9999 -9999 -9999 -9999 -9999 -9999 -

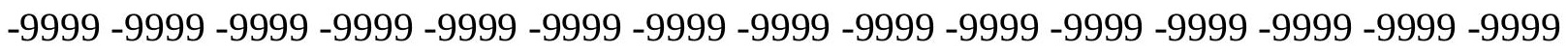

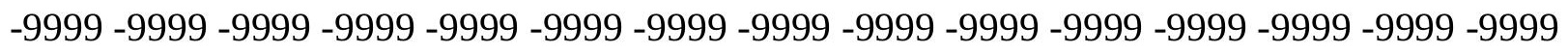
-9999 -9999 -9999 -9999-9999 -9999 -9999 -9999 -9999 113.075302124 111.551399231 110.0273971558108 .5035018921106 .6747970581105 .1509017944103 .9317016602 104.5412979126103 .9317016602103 .6268997192103 .6268997192103 .9317016602 104.2365036011104 .5412979126104 .8460998535105 .1509017944103 .6268997192 103.6268997192103 .6268997192103 .6268997192103 .3221969604102 .712600708 102.1029968262101 .4934005737100 .883903503499 .9695205688599 .05516815186 97.8360290527396 .6168823242295 .397743225193 .8738174438592 .3498916626 90.8259735107488 .9972534179786 .8637619018684 .7302627563582 .59677124023 80.4632720947378 .0249862670975 .2819290161172 .8436431884870 .10057830811 67.9670867919965 .8335876464864 .004882812561 .5666007995658 .82352828979 55.1661109924350 .5943298339845 .1082000732439 .3172798156734 .13592910767 29.2593708038327 .1258792877225 .2971591949524 .0780296325723 .16366958618 22.8588790893623 .1636695861823 .4684505462623 .7732391357424 .68759918213 25.2971591949526 .5163097381627 .7354507446328 .9545898437530 .47850990295 31.6976509094232 .9167900085434 .1359291076735 .0502891540536 .26942825317 37.1837806701738 .0981407165539 .0125007629439 .9268493652340 .53641891479 41.1459884643641 .7555618286142 .3651313781742 .9747009277343 .58427047729 43.8890609741244 .4986305236844 .8034095764245 .4129791259845 .7177696228 46.3273391723646 .9369087219247 .5464782714848 .1560516357448 .7656211853 49.6799812316950 .2895507812551 .2038993835452 .1182594299353 .03261184692 53.9469718933155 .1661109924356 .0804595947357 .2995986938558 .51874923706 
59.4331016540560 .6522407531761 .8713798522963 .0905189514264 .61444854736 66.1383666992267 .9670867919969 .4910125732469 .7957916259870 .10057830811 70.4053573608471 .3197174072372 .2340774536176 .1962814331174 .97714233398 76.5010681152378 .0249862670979 .5489196777380 .7680587768681 .98719787598 83.2063369751 84.12069702148 85.33984375 86.2541885376 87.16854858398 88.3876876831188 .9972534179789 .9116134643690 .5211791992290 .82597351074 91.1307525634891 .1307525634891 .1307525634890 .5211791992289 .91161346436 89.302040100188.08290100098 86.8637619018685.6446228027384.12069702148 82.2919769287180 .4632720947378 .6345596313576 .8058471679774 .67236328125 72.8436431884870 .7101516723668 .8814392089866 .7479400634864 .91924285889 63.0905189514261 .2618103027359 .7378807067958 .2139587402356 .69002914429 55.7756805419956 .08045959473 -9999 -9999 -9999 -9999 -9999 -9999 -9999 -9999 -9999 -9999 -9999 -9999 -9999 -9999 -9999 -9999 -9999 -9999 -9999 -9999 -9999 -9999 -9999 -9999 -9999 -9999 -9999 -9999 -9999 -9999 -9999 -9999 -9999 -9999 -9999 -9999 -9999 -9999 -9999 $-9999-9999$

-9999 -9999 -9999 -9999 -9999 -9999 -9999 -9999 -9999 -9999 -9999 -9999 -9999 -9999 -9999 -9999 -9999 -9999 -9999 -9999 -9999 -9999 -9999 -9999 -9999 -9999 -9999 -9999 -9999 -9999 -9999 -9999 -9999 -9999 -9999 -9999 -9999 -9999 -9999 -9999 -9999 -9999 -9999 -9999 -9999 -9999 -9999 -9999 -9999 -9999 -9999 -9999 -9999 -9999 -9999 -9999 -9999 -9999 -9999 -9999 -

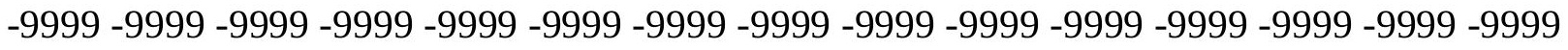

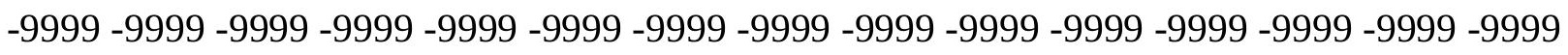
-9999 -9999 -9999 -9999 -9999 -9999 -9999 -9999 -9999 -9999 -9999 -9999 -9999 -9999 -9999 -9999 -9999 -9999 -9999 -9999 -9999 -9999 -9999 -9999 -9999 -9999 -9999 -9999 -9999 -9999 -9999 -9999 -9999 -9999 -9999 -9999 -9999 -9999 -9999 -9999 -9999 -9999 -9999 -9999 -9999 -

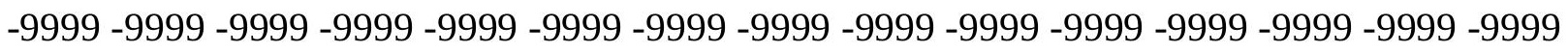
-9999 -9999 -9999 -9999 -9999 -9999 -9999 -9999 -9999 -9999 -9999 -9999 -9999 -9999 -9999 -9999 -9999 -9999 -9999 -9999-9999 -9999 -9999 -9999 -9999 -9999 -9999 -9999 -9999 - -9999 -9999 -9999 -9999 -9999 -9999 -9999 -9999 -9999 -9999 -9999 -9999 -9999 109.7226028442 107.5891036987105 .7603988647104 .2365036011103 .0174026489103 .6268997192 103.0174026489103 .0174026489103 .0174026489103 .3221969604103 .9317016602 104.2365036011104 .5412979126103 .0174026489103 .3221969604103 .3221969604 103.3221969604103 .3221969604103 .0174026489102 .712600708102 .1029968262 101.4934005737100 .883903503499 .9695205688599 .0551681518697 .83602905273 96.6168823242295 .397743225193 .8738174438592 .349891662690 .82597351074 88.9972534179786 .8637619018684 .7302627563582 .5967712402380 .46327209473 78.0249862670975 .5867080688573 .4532165527371 .3197174072369 .49101257324 67.6623001098665 .5288009643663 .0905189514260 .0426712036155 .16611099243 49.3751907348643 .8890609741238 .7077102661134 .4407196044931 .08807945251 28.3450202941926 .5163097381624 .9923801422124 .3828105926524 .07802963257 24.3828105926524 .6875991821325 .2971591949525 .906740188626 .82109069824 27.7354507446329 .2593708038330 .7833003997832 .0024414062533 .52635955811 34.7455101013235 .9646492004437 .1837806701738 .4029312133839 .31727981567 40.2316398620641 .1459884643641 .7555618286142 .3651313781742 .97470092773 43.5842704772943 .8890609741244 .4986305236844 .8034095764245 .41297912598 45.717769622846 .3273391723646 .6321296691947 .2416992187547 .54647827148 48.1560516357448 .765621185349 .3751907348649 .9847602844250 .89912033081 
51.5086898803752 .4230384826753 .3373985290554 .2517509460455 .16611099243 56.0804595947357 .2995986938558 .5187492370659 .7378807067960 .95701980591 62.1761703491263 .3953094482464 .9192428588966 .7479400634868 .57665252686 69.7957916259870 .4053573608471 .014930725171 .3197174072372 .23407745361 73.1484298706174 .062782287675 .5867080688576 .8058471679778 .02498626709 79.5489196777380 .7680587768681 .9871978759882 .9015579223684 .12069702148 85.0350494384885 .9494018554786 .8637619018687 .7781066894588 .69246673584 89.302040100189 .9116134643690 .2164001464890 .5211791992290 .52117919922 90.2164001464889 .9116134643689 .6068267822388 .6924667358487 .77810668945 86.5589828491285 .3398437583 .8159103393682 .2919769287180 .76805877686 78.9393463134877 .110626220774 .9771423339873 .1484298706171 .31971740723 69.1862335205167 .3575134277365 .5288009643663 .7000885009861 .87137985229 $60.3474502563558 .8235282897957 .2995986938555 .7756805419955 .77568054199-9999$ -9999 -9999 -9999 -9999 -9999 -9999 -9999 -9999 -9999 -9999 -9999 -9999 -9999 -9999 -9999 -9999 -9999 -9999 -9999 -9999 -9999 -9999 -9999 -9999 -9999 -9999 -9999 -9999 -9999 -9999 -9999 -9999 -9999-9999-9999-9999-9999 -9999 -9999-9999

-9999 -9999 -9999 -9999 -9999 -9999 -9999 -9999 -9999 -9999 -9999 -9999 -9999 -9999 -9999 -9999 -9999 -9999 -9999 -9999 -9999 -9999 -9999 -9999 -9999 -9999 -9999 -9999 -9999 -9999 -9999 -9999 -9999 -9999 -9999 -9999 -9999 -9999 -9999 -9999 -9999 -9999 -9999 -9999 -9999 -

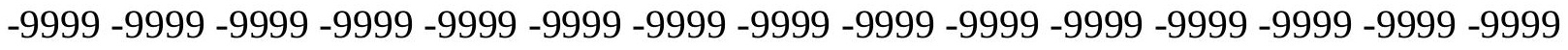

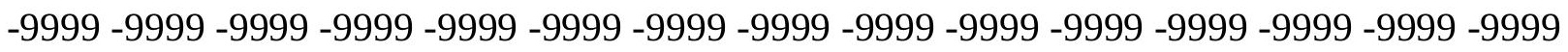
-9999 -9999 -9999 -9999 -9999 -9999 -9999 -9999 -9999 -9999 -9999 -9999 -9999 -9999 -9999 -9999 -9999 -9999 -9999 -9999 -9999 -9999 -9999 -9999 -9999 -9999 -9999 -9999 -9999 -9999 -

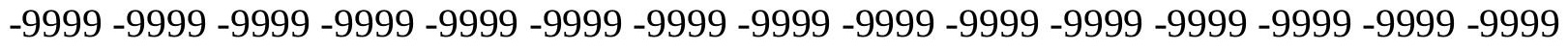

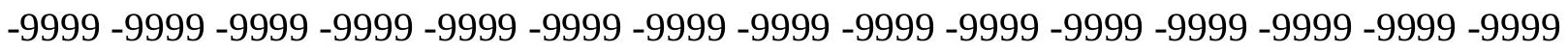
-9999 -9999 -9999 -9999 -9999 -9999 -9999 -9999 -9999 -9999 -9999 -9999 -9999 -9999 -9999 -9999 -9999 -9999 -9999 -9999 -9999 -9999 -9999 -9999 -9999 -9999 -9999 -9999 -9999 -9999

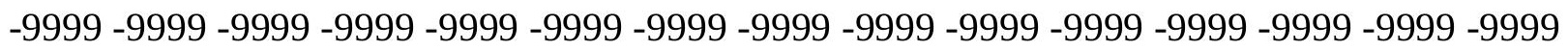
-9999 -9999 -9999 -9999 -9999 -9999 -9999 -9999 -9999 -9999 -9999 -9999 -9999 -9999 106.3700027466104 .5412979126102 .712600708101 .7982025146100 .8839035034 100.8839035034102 .4077987671102 .712600708103 .3221969604103 .6268997192 103.9317016602102 .712600708103 .0174026489103 .3221969604103 .3221969604 103.3221969604103 .3221969604103 .0174026489102 .712600708102 .1029968262 101.4934005737100 .579101562599 .6647262573298 .7503814697397 .83602905273 96.6168823242295 .397743225193 .8738174438592 .349891662690 .82597351074 88.9972534179786 .8637619018685 .0350494384882 .9015579223680 .76805877686 78.6345596313576 .8058471679774 .6723632812572 .8436431884871 .0149307251 69.1862335205166 .7479400634863 .3953094482459 .1283111572354 .25175094604 49.0704002380444 .4986305236840 .2316398620636 .5742111206133 .22158050537 30.1737308502229 .5641593933128 .3450202941926 .5163097381626 .51630973816 26.8210906982427 .1258792877227 .430660247827 .7354507446328 .64979934692 29.8689403533931 .3928699493432 .9167900085434 .7455101013235 .96464920044 37.4885711669938 .7077102661139 .622070312540 .8412094116241 .45077896118 42.3651313781742 .9747009277343 .5842704772944 .1938400268644 .49863052368 45.1082000732445 .4129791259845 .717769622846 .3273391723646 .63212966919 46.9369087219247 .5464782714847 .8512611389248 .4608306884848 .7656211853 
49.3751907348649 .9847602844250 .5943298339851 .2038993835451 .81346893311 52.4230384826753 .3373985290554 .2517509460455 .1661109924356 .08045959473 57.2995986938558 .2139587402359 .4331016540560 .9570198059162 .17617034912 63.7000885009865 .2240066528366 .7479400634868 .2718734741269 .49101257324 70.4053573608471 .3197174072371 .9292907714872 .5388565063573 .45321655273 74.3675689697375 .5867080688576 .8058471679778 .0249862670979 .24413299561 80.4632720947381 .6824111938582 .5967712402383 .5111236572384 .73026275635 85.3398437586 .254188537687 .1685485839887 .7781066894588 .38768768311 88.9972534179789 .302040100189 .6068267822389 .6068267822389 .60682678223 89.3020401001 88.69246673584 88.08290100098 87.16854858398 86.2541885376 85.0350494384883 .5111236572382 .2919769287180 .4632720947378 .93934631348 77.110626220775 .2819290161173 .4532165527371 .6244964599669 .79579162598 67.9670867919966 .1383666992264 .3096618652362 .4809494018660 .95701980591 $59.1283111572357 .6043891906756 .0804595947355 .7756805419955 .77568054199-9999$ -9999 -9999 -9999 -9999 -9999 -9999 -9999 -9999 -9999 -9999 -9999 -9999 -9999 -9999 -9999 -9999 -9999 -9999 -9999 -9999 -9999 -9999 -9999 -9999 -9999 -9999 -9999 -9999 -9999 -9999 -9999 -9999 -9999 -9999 -9999 -9999 -9999 -9999 -9999 -9999 -9999 -9999 -9999 -9999 -9999 -9999 -9999 -9999 -9999 -9999 -9999 -9999 -9999 -9999 -9999 -9999 -9999 -9999 -9999 -9999 -9999 -9999 -9999 -9999 -9999 -9999 -9999 -9999 -9999 -9999 -9999 -9999 -9999 -9999 -9999 -9999 -9999 -9999 -9999 -9999 -9999 -9999 -9999 -9999

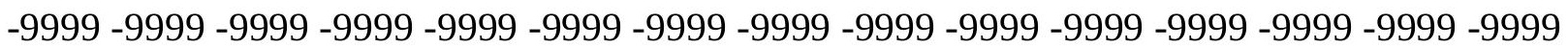
-9999 -9999 -9999 -9999 -9999 -9999 -9999 -9999 -9999 -9999 -9999 -9999 -9999 -9999 -9999 -9999 -9999 -9999 -9999 -9999 -9999 -9999 -9999 -9999 -9999 -9999 -9999 -9999 -9999 -9999 -9999 -9999 -9999 -9999 -9999 -9999 -9999 -9999 -9999 -9999 -9999 -9999 -9999 -9999 -9999

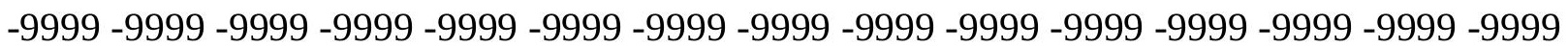
-9999 -9999 -9999 -9999 -9999 -9999 -9999 -9999 -9999 -9999 -9999 -9999 -9999 -9999 -9999 -9999 -9999 -9999 -9999 -9999 -9999 -9999 -9999 -9999 -9999 -9999 -9999 -9999 -9999 -9999 -9999 -9999 -9999 -9999 -9999 -9999 -9999 -9999 -9999 -9999 -9999 -9999 -9999 -9999 -9999 -9999 -9999 -9999 -9999 -9999 -9999 -9999 -9999 -9999 -9999 -9999 -9999 -9999 -9999 -9999

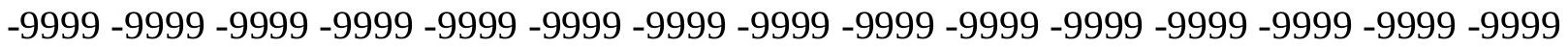
-9999 -9999 101.1886978149 100.274299621699.96952056885100.2742996216 100.5791015625102 .712600708103 .3221969604103 .6268997192102 .4077987671 102.712600708103 .0174026489103 .3221969604103 .6268997192103 .3221969604 103.3221969604103 .0174026489102 .4077987671102 .1029968262101 .4934005737 100.579101562599 .6647262573298 .7503814697397 .8360290527396 .61688232422 95.397743225193 .8738174438592 .349891662690 .8259735107488 .99725341797 87.1685485839885 .3398437583 .5111236572381 .6824111938579 .85370635986 78.0249862670976 .1962814331174 .3675689697372 .5388565063570 .10057830811 66.7479400634863 .0905189514258 .8235282897954 .5565414428750 .59432983398 46.9369087219243 .2794914245639 .622070312535 .6598587036134 .44071960449 32.9167900085430 .4785099029530 .1737308502229 .8689403533929 .86894035339 29.8689403533929 .8689403533930 .1737308502231 .3928699493433 .22158050537 34.7455101013236 .2694282531737 .7933502197339 .0125007629440 .23163986206 41.4507789611842 .3651313781742 .9747009277343 .8890609741244 .49863052368 44.8034095764245 .4129791259845 .717769622846 .3273391723646 .63212966919 46.9369087219247 .2416992187547 .5464782714847 .8512611389248 .46083068848 
48.765621185349 .0704002380449 .6799812316949 .9847602844250 .59432983398 50.8991203308151 .5086898803752 .1182594299352 .7278289794953 .33739852905 54.2517509460455 .1661109924356 .0804595947356 .9948196411158 .21395874023 59.4331016540560 .6522407531762 .1761703491263 .3953094482464 .91924285889 66.4431610107467 .9670867919969 .1862335205170 .1005783081171 .0149307251 71.9292907714872 .5388565063573 .4532165527374 .3675689697375 .58670806885 76.8058471679777 .7202072143678 .9393463134880 .1584930419981 .07285308838 81.9871978759882 .9015579223683 .8159103393684 .7302627563585 .64462280273 86.254188537686 .8637619018687 .4733276367288 .0829010009888 .38768768311 88.6924667358488 .6924667358488 .6924667358488 .3876876831188 .08290100098 87.4733276367286 .5589828491285 .6446228027384 .4254837036183 .2063369751 81.9871978759880 .4632720947378 .9393463134877 .110626220775 .28192901611 73.7580032348671 .9292907714870 .1005783081168 .2718734741266 .44316101074 64.6144485473663 .0905189514261 .2618103027359 .7378807067958 .21395874023 56.6900291442955 .4708900451755 .77568054199 -9999 -9999 -9999 -9999 -9999 -9999 -9999 -9999 -9999 -9999 -9999 -9999 -9999 -9999 -9999 -9999 -9999 -9999 -9999 -9999 -9999 -9999 -9999 -9999 -9999 -9999 -9999 -9999 -9999 -9999 -9999 -9999 -9999 -9999 -9999 -9999 -9999 -9999 -9999-9999

-9999 -9999 -9999 -9999 -9999 -9999 -9999 -9999 -9999 -9999 -9999 -9999 -9999 -9999 -9999

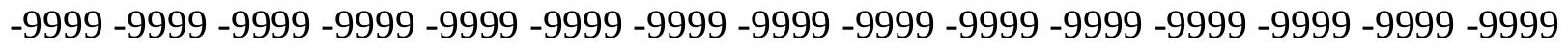

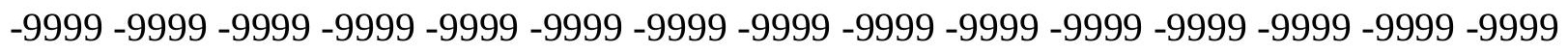
-9999 -9999 -9999 -9999 -9999 -9999 -9999 -9999 -9999 -9999 -9999 -9999 -9999 -9999 -9999 -9999 -9999 -9999 -9999 -9999 -9999 -9999 -9999 -9999 -9999 -9999 -9999 -9999 -9999 -9999 -

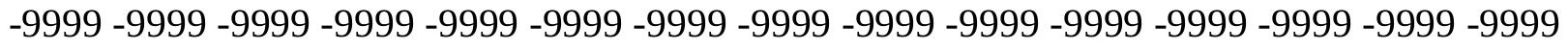

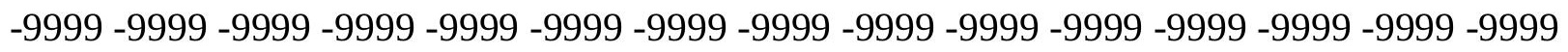
-9999 -9999 -9999 -9999 -9999 -9999 -9999 -9999 -9999 -9999 -9999 -9999 -9999 -9999 -9999

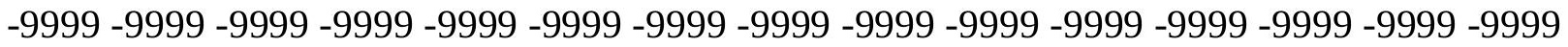

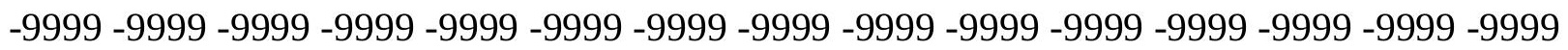
-9999 -9999 -9999 -9999 -9999 -9999 -9999 -9999 -9999 -9999 -9999 -9999 -9999 -9999 -9999 -9999 -9999 -9999 -9999 -9999 -9999 -9999 -9999 -9999 -9999 -9999 -9999 -9999 -9999 -9999 -9999 -9999 -9999 -9999 -9999 -9999 -9999 -9999 -9999 -9999 -9999 -9999 -9999 -9999 -9999 -9999 -9999 -9999 -9999 99.35994720459 99.66472625732 100.2742996216100.8839035034 103.0174026489103 .3221969604102 .4077987671102 .712600708103 .0174026489 103.3221969604103 .6268997192103 .6268997192103 .6268997192103 .3221969604 103.0174026489102 .4077987671102 .1029968262101 .1886978149100 .5791015625 99.6647262573298 .7503814697397 .8360290527396 .6168823242295 .3977432251 94.1785964965892 .6546783447391 .1307525634889 .6068267822387 .77810668945 86.2541885376 84.42548370361 82.90155792236 81.07285308838 79.24413299561 77.4154205322375 .5867080688573 .1484298706170 .1005783081167 .05272674561 63.3953094482460 .0426712036156 .6900291442953 .6421813964850 .59432983398 46.9369087219243 .2794914245639 .622070312537 .1837806701735 .65985870361 34.7455101013234 .1359291076733 .5263595581133 .2215805053733 .22158050537 33.5263595581134 .4407196044935 .6598587036137 .1837806701738 .70771026611 39.9268493652341 .1459884643642 .3651313781743 .2794914245644 .19384002686 44.8034095764245 .4129791259846 .0225486755446 .3273391723646 .63212966919 46.9369087219247 .5464782714847 .5464782714847 .8512611389248 .15605163574 
48.4608306884848 .765621185349 .0704002380449 .6799812316949 .98476028442 50.2895507812550 .5943298339851 .2038993835451 .5086898803752 .11825942993 52.4230384826753 .0326118469253 .6421813964854 .2517509460455 .16611099243 55.7756805419956 .6900291442957 .909179687559 .1283111572360 .34745025635 61.8713798522963 .0905189514264 .6144485473666 .1383666992267 .35751342773 68.5766525268669 .7957916259870 .7101516723671 .6244964599672 .53885650635 73.4532165527374 .3675689697375 .2819290161176 .1962814331177 .41542053223 78.3297805786179 .5489196777380 .4632720947381 .3776321411182 .29197692871 83.2063369751 83.81591033936 84.73026275635 85.33984375 85.94940185547 86.5589828491286 .8637619018687 .4733276367287 .4733276367287 .77810668945 87.7781066894587 .4733276367287 .1685485839886 .5589828491285 .94940185547 85.03504943848 84.12069702148 82.90155792236 81.6824111938580.15849304199 78.6345596313577 .110626220775 .5867080688573 .7580032348671 .92929077148 70.4053573608468 .5766525268666 .7479400634864 .9192428588963 .39530944824 61.5666007995660 .0426712036158 .5187492370656 .9948196411155 .47089004517 55.47089004517 -9999 -9999 -9999 -9999 -9999 -9999 -9999 -9999 -9999 -9999 -9999 -9999 -9999 -9999 -9999 -9999 -9999 -9999 -9999 -9999 -9999 -9999 -9999 -9999 -9999 -9999 -9999 -9999 -9999 -9999 -9999 -9999 -9999 -9999 -9999 -9999 -9999 -9999 -9999 -9999 -9999 -9999 -9999 -9999 -9999 -9999 -9999 -9999 -9999 -9999 -9999 -9999 -9999 -9999 -9999 -

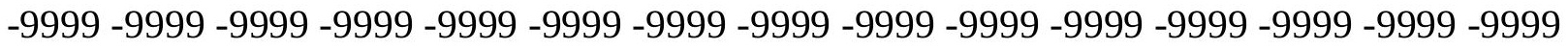

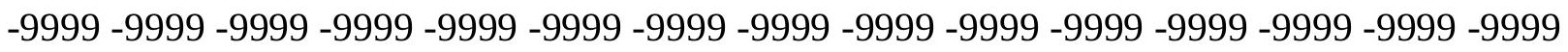
-9999 -9999 -9999 -9999 -9999 -9999 -9999 -9999 -9999 -9999 -9999 -9999 -9999 -9999 -9999 -9999 -9999 -9999 -9999 -9999 -9999 -9999 -9999 -9999 -9999 -9999 -9999 -9999 -9999 -9999 -

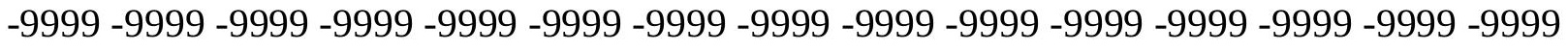

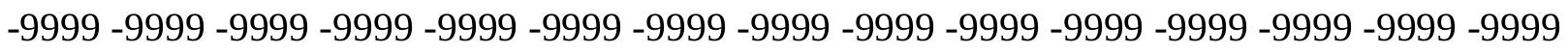
-9999 -9999 -9999 -9999 -9999 -9999 -9999 -9999 -9999 -9999 -9999 -9999 -9999 -9999 -9999 -9999 -9999 -9999 -9999 -9999 -9999 -9999 -9999 -9999 -9999 -9999 -9999 -9999 -9999 -9999 -

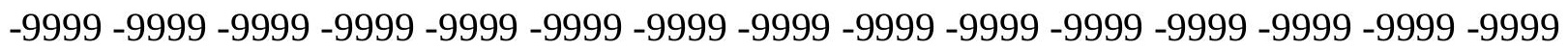
-9999 -9999 -9999 -9999 -9999 -9999 -9999 -9999 -9999 -9999 -9999 -9999 -9999 -9999 -9999 -9999 -9999 -9999 -9999 -9999 -9999 -9999 -9999 -9999 -9999 -9999 -9999 -9999 -9999 -999 -9999 -9999 -9999 -9999 -9999 -9999 -9999 -9999 -9999 -9999 -9999 -9999 -9999 -9999 -9999 -9999 -9999 -9999 -9999 -9999 99.66472625732 100.2742996216100.8839035034 101.4934005737101 .7982025146103 .9317016602102 .712600708103 .3221969604 103.6268997192103 .6268997192103 .9317016602103 .9317016602103 .6268997192 103.3221969604103 .0174026489102 .4077987671101 .7982025146101 .1886978149 100.579101562599 .6647262573298 .7503814697397 .8360290527396 .92166900635 95.7025299072394 .4833908081193 .2642517089891 .7403335571390 .21640014648 88.69246673584 87.16854858398 85.33984375 83.81591033936 81.98719787598 80.1584930419978 .3297805786175 .8914871215873 .4532165527370 .71015167236 67.6623001098664 .9192428588962 .4809494018660 .3474502563558 .21395874023 55.4708900451751 .5086898803747 .5464782714844 .1938400268641 .75556182861 40.2316398620639 .0125007629438 .0981407165537 .4885711669937 .18378067017 37.4885711669938 .0981407165539 .3172798156740 .5364189147941 .75556182861 42.66992187543 .8890609741244 .8034095764245 .4129791259846 .02254867554 46.6321296691947 .2416992187547 .5464782714847 .8512611389248 .15605163574 48.4608306884848 .765621185348 .765621185349 .0704002380449 .37519073486 
49.6799812316949 .9847602844249 .9847602844250 .2895507812550 .59432983398 51.2038993835451 .5086898803751 .8134689331152 .1182594299352 .42303848267 53.0326118469253 .3373985290553 .9469718933154 .5565414428755 .16611099243 55.7756805419956 .6900291442957 .6043891906758 .8235282897960 .04267120361 61.2618103027362 .7857398986864 .004882812565 .5288009643666 .74794006348 67.9670867919969 .1862335205170 .1005783081171 .014930725171 .92929077148 72.8436431884873 .7580032348674 .6723632812575 .8914871215876 .80584716797 77.7202072143678 .6345596313579 .5489196777380 .4632720947381 .37763214111 82.29197692871 82.9015579223683.51112365723 84.42548370361 85.03504943848 85.3398437585 .9494018554786 .254188537686 .5589828491286 .55898284912 86.5589828491286 .5589828491286 .254188537685 .6446228027385 .03504943848 84.4254837036183 .5111236572382 .2919769287181 .3776321411179 .85370635986 78.6345596313577 .110626220775 .5867080688573 .7580032348672 .23407745361 70.4053573608468 .8814392089867 .0527267456165 .5288009643663 .70008850098 62.1761703491260 .6522407531758 .8235282897957 .2995986938556 .08045959473 55.4708900451755 .47089004517 -9999 -9999 -9999 -9999 -9999 -9999 -9999 -9999 -9999 -9999 -9999 -9999 -9999 -9999 -9999 -9999 -9999 -9999 -9999 -9999 -9999 -9999 -9999 -9999 -9999 -9999 -9999 -9999 -9999 -9999 -9999 -9999 -9999 -9999 -9999 -9999 -9999 -9999 -9999 -

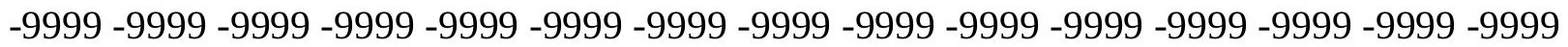

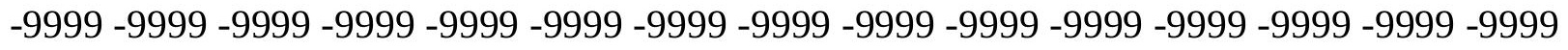

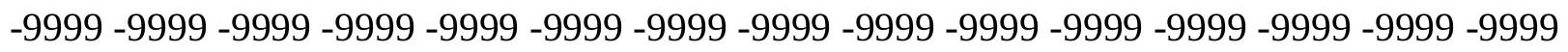

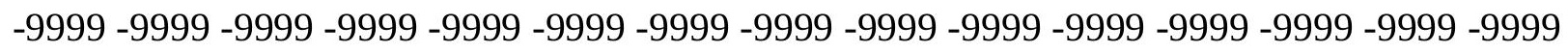
-9999 -9999 -9999 -9999 -9999 -9999 -9999 -9999 -9999 -9999 -9999 -9999 -9999 -9999 -9999 -

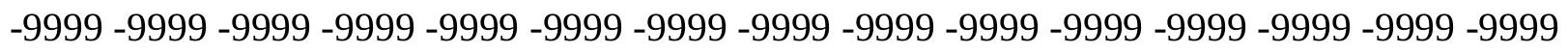

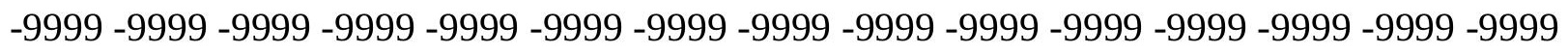
-9999 -9999 -9999 -9999 -9999 -9999 -9999 -9999 -9999 -9999 -9999 -9999 -9999 -9999 -9999 -9999 -9999 -9999 -9999 -9999 -9999 -9999 -9999 -9999 -9999 -9999 -9999 -9999 -9999 - -9999 -

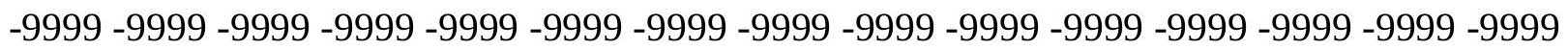

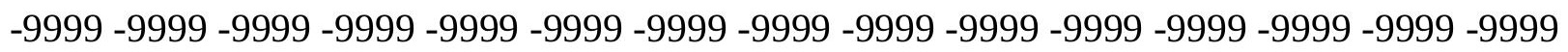

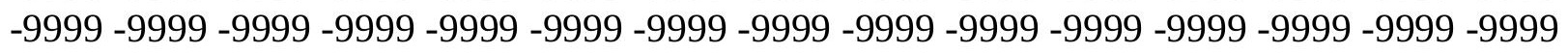
-9999 -9999 -9999 -9999 -9999 -9999 -9999 -9999 -9999 -9999 -9999 -9999 -9999 -9999 -9999 -9999 -9999-9999 -9999 -9999-9999-9999 101.1886978149 101.4934005737 102.1029968262 102.712600708103 .0174026489103 .3221969604103 .6268997192103 .9317016602 104.2365036011 104.2365036011 103.9317016602103 .6268997192103 .3221969604 103.0174026489102 .4077987671101 .7982025146101 .1886978149100 .5791015625 99.6647262573299 .0551681518698 .1408081054797 .2264633178796 .00731658936 95.0929565429793 .8738174438592 .349891662690 .8259735107489 .3020401001 87.7781066894586 .254188537684 .7302627563582 .9015579223680 .76805877686 78.6345596313576 .5010681152374 .062782287671 .9292907714869 .79579162598 67.6623001098666 .1383666992264 .9192428588963 .7000885009858 .82352828979 54.5565414428750 .8991203308148 .1560516357446 .0225486755444 .19384002686 42.9747009277342 .3651313781742 .0603485107442 .0603485107442 .36513137817 43.2794914245644 .1938400268645 .1082000732446 .0225486755446 .63212966919 47.2416992187547 .8512611389248 .4608306884848 .765621185349 .07040023804 49.3751907348649 .3751907348649 .6799812316949 .6799812316949 .98476028442 49.9847602844250 .2895507812550 .5943298339850 .5943298339850 .89912033081 
51.2038993835451 .2038993835451 .5086898803751 .8134689331152 .11825942993 52.4230384826752 .7278289794953 .0326118469253 .3373985290553 .64218139648 54.2517509460454 .5565414428755 .1661109924355 .7756805419956 .38525009155 57.6043891906758 .5187492370659 .7378807067960 .9570198059162 .17617034912 63.3953094482464 .9192428588966 .1383666992267 .3575134277368 .27187347412 69.4910125732470 .4053573608471 .3197174072372 .2340774536173 .14842987061 74.062782287675 .2819290161176 .1962814331177 .110626220778 .02498626709 78.9393463134879 .5489196777380 .4632720947381 .0728530883881 .98719787598 82.5967712402383 .206336975183 .8159103393684 .1206970214884 .73026275635 85.0350494384885 .3398437585 .3398437585 .3398437585 .3398437585 .03504943848 84.7302627563584 .4254837036183 .8159103393682 .9015579223681 .98719787598 80.7680587768679 .5489196777378 .3297805786176 .8058471679775 .58670806885 73.7580032348672 .2340774536170 .7101516723668 .8814392089867 .35751342773 65.8335876464864 .004882812562 .4809494018660 .9570198059159 .43310165405 57.909179687556 .3852500915555 .4708900451755 .47089004517 -9999 -9999 -9999 -9999 -9999 -9999 -9999 -9999 -9999 -9999 -9999 -9999 -9999 -9999 -9999 -9999 -9999 -9999 -9999 -9999 -9999 -9999 -9999 -9999 -9999 -9999 -9999 -9999 -9999 -9999 -9999 -9999 -9999 -9999 -9999 -9999-9999-9999-9999

-9999 -9999 -9999 -9999 -9999 -9999 -9999 -9999 -9999 -9999 -9999 -9999 -9999 -9999 -9999 -9999 -9999 -9999 -9999 -9999 -9999 -9999 -9999 -9999 -9999 -9999 -9999 -9999 -9999 -9999 -9999 -9999 -9999 -9999 -9999 -9999 -9999 -9999 -9999 -9999 -9999 -9999 -9999 -9999 -9999 -9999 -9999 -9999 -9999 -9999 -9999 -9999 -9999 -9999 -9999 -9999 -9999 -9999 -9999 -9999 -9999 -9999 -9999 -9999 -9999 -9999 -9999 -9999 -9999 -9999 -9999 -9999 -9999 -9999 -9999 -9999 -9999 -9999 -9999 -9999 -9999 -9999 -9999 -9999 -9999 -9999 -9999 -9999 -9999 -9999 -9999 -9999 -9999 -9999 -9999 -9999 -9999 -9999 -9999 -9999 -9999 -9999 -9999 -9999 -9999 -9999 -9999 -9999 -9999 -9999 -9999 -9999 -9999 -9999 -9999 -9999 -9999 -9999 -9999 -9999 -9999 -9999 -9999 -9999 -9999 -9999 -9999 -9999 -9999 -9999 -9999 -9999 -9999 -9999 -9999

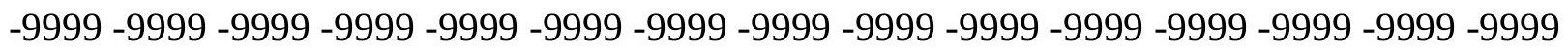

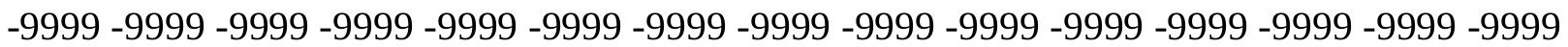

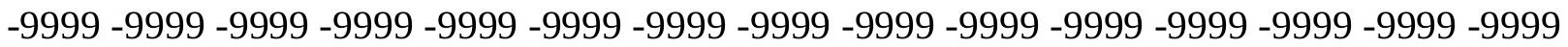
-9999 -9999 -9999 -9999 -9999 -9999 -9999 -9999 -9999 -9999 -9999 -9999 -9999 -9999 -9999 -9999 -9999 -9999 -9999 -9999 -9999 -9999 -9999 -9999 102.4077987671103 .0174026489 103.3221969604103 .6268997192103 .9317016602104 .2365036011104 .2365036011 104.2365036011104 .2365036011103 .9317016602103 .6268997192103 .3221969604 102.712600708102 .1029968262101 .7982025146101 .1886978149100 .5791015625 99.9695205688599 .3599472045998 .445587158297 .5312423706196 .61688232422 95.7025299072394 .4833908081192 .9594726562591 .7403335571390 .21640014648 88.69246673584 86.86376190186 85.03504943848 83.206336975181.37763214111 79.2441329956177 .4154205322375 .2819290161173 .7580032348672 .23407745361 71.014930725169 .7957916259867 .6623001098664 .3096618652360 .65224075317 56.9948196411153 .9469718933151 .5086898803749 .6799812316948 .15605163574 47.2416992187546 .9369087219246 .6321296691946 .9369087219247 .54647827148 48.4608306884849 .0704002380449 .3751907348649 .9847602844250 .28955078125 50.5943298339850 .8991203308150 .8991203308150 .8991203308151 .20389938354 51.2038993835451 .2038993835451 .2038993835451 .2038993835451 .50868988037 51.5086898803751 .5086898803751 .8134689331151 .8134689331152 .11825942993 
52.1182594299352 .4230384826752 .7278289794953 .0326118469253 .03261184692 53.3373985290553 .6421813964853 .9469718933154 .2517509460454 .55654144287 54.8613204956155 .1661109924355 .7756805419956 .3852500915557 .29959869385 58.2139587402359 .4331016540560 .6522407531761 .8713798522963 .09051895142 64.3096618652365 .2240066528366 .4431610107467 .6623001098668 .57665252686 69.7957916259870 .7101516723671 .6244964599672 .5388565063573 .45321655273 74.3675689697375 .2819290161176 .1962814331177 .110626220778 .02498626709 78.6345596313579 .5489196777380 .1584930419980 .7680587768681 .37763214111 81.9871978759882 .5967712402382 .9015579223683 .5111236572383 .81591033936 84.1206970214884 .1206970214884 .4254837036184 .4254837036184 .12069702148 83.81591033936 83.51112365723 82.90155792236 82.29197692871 81.37763214111 80.46327209473 79.24413299561 78.02498626709 76.80584716797 75.28192901611 74.062782287672 .2340774536170 .7101516723669 .1862335205167 .66230010986 65.8335876464864 .3096618652362 .7857398986861 .2618103027359 .73788070679 58.2139587402356 .6900291442955 .4708900451755 .47089004517 -9999 -9999 -9999 -9999 -9999 -9999 -9999 -9999 -9999 -9999 -9999 -9999 -9999 -9999 -9999 -9999 -9999 -9999 -9999 -9999 -9999 -9999 -9999 -9999 -9999 -9999 -9999 -9999 -9999 -9999 -9999 -9999 -9999 -9999 -9999 -9999 -9999 -9999-9999

-9999 -9999 -9999 -9999 -9999 -9999 -9999 -9999 -9999 -9999 -9999 -9999 -9999 -9999 -9999

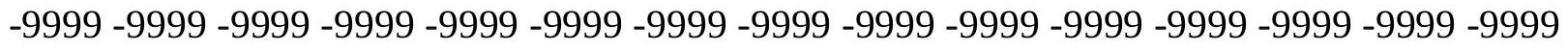

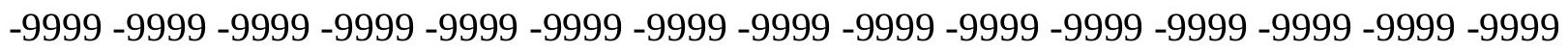
-9999 -9999 -9999 -9999 -9999 -9999 -9999 -9999 -9999 -9999 -9999 -9999 -9999 -9999 -9999 -9999 -9999 -9999 -9999 -9999 -9999 -9999 -9999 -9999 -9999 -9999 -9999 -9999 -9999 -9999 -

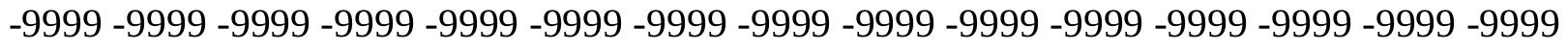

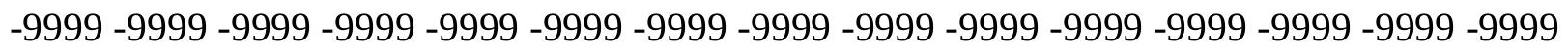
-9999 -9999 -9999 -9999 -9999 -9999 -9999 -9999 -9999 -9999 -9999 -9999 -9999 -9999 -9999

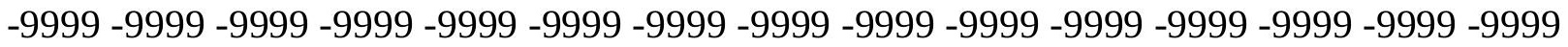

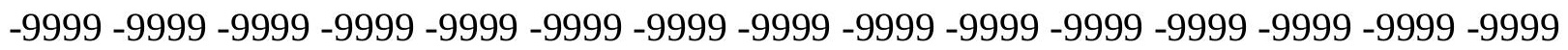
-9999 -9999 -9999 -9999 -9999 -9999 -9999 -9999 -9999 -9999 -9999 -9999 -9999 -9999 -9999 -9999 -9999 -9999 -9999 -9999 -9999 -9999 -9999 -9999 -9999 -9999 -9999 -9999 -9999 -9999 -9999 -9999 -9999 -9999 -9999 -9999 -9999 -9999 -9999 -9999 -9999 -9999 -9999 -9999 -9999 -9999 -9999 -9999 -9999 -9999 -9999 -9999 -9999 -9999 -9999 -9999 104.2365036011 104.5412979126104 .5412979126104 .5412979126104 .5412979126104 .5412979126 104.5412979126104 .2365036011103 .9317016602103 .6268997192103 .0174026489 102.712600708102 .1029968262101 .4934005737101 .1886978149100 .5791015625 100.274299621699 .6647262573299 .0551681518698 .445587158297 .53124237061 96.3121032714895 .0929565429793 .5690307617292 .349891662690 .52117919922 88.9972534179787 .1685485839885 .3398437583 .5111236572381 .98719787598 80.1584930419978 .3297805786177 .110626220775 .5867080688574 .36756896973 73.1484298706171 .014930725168 .5766525268665 .2240066528362 .17617034912 59.1283111572356 .6900291442954 .8613204956153 .3373985290552 .42303848267 51.8134689331151 .5086898803751 .8134689331152 .4230384826752 .72782897949 53.0326118469253 .0326118469253 .0326118469253 .3373985290553 .33739852905 53.3373985290553 .0326118469253 .0326118469253 .0326118469253 .03261184692 52.7278289794952 .7278289794952 .7278289794952 .7278289794952 .72782897949 52.7278289794952 .7278289794953 .0326118469253 .0326118469253 .33739852905 
53.3373985290553 .6421813964853 .6421813964853 .9469718933153 .94697189331 54.2517509460454 .5565414428754 .5565414428754 .8613204956155 .16611099243 55.4708900451756 .0804595947356 .6900291442957 .2995986938558 .21395874023 59.1283111572360 .3474502563561 .2618103027362 .4809494018663 .39530944824 64.6144485473665 .8335876464866 .7479400634867 .9670867919968 .88143920898 69.7957916259870 .7101516723671 .6244964599672 .5388565063573 .45321655273 74.3675689697375 .2819290161176 .1962814331177 .110626220777 .72020721436 78.3297805786179 .2441329956179 .8537063598680 .1584930419980 .76805877686 81.3776321411181 .6824111938581 .9871978759882 .2919769287182 .59677124023 82.9015579223683 .206336975183 .206336975183 .206336975183 .2063369751 82.9015579223682 .2919769287181 .6824111938581 .0728530883880 .15849304199 78.9393463134878 .0249862670976 .8058471679775 .2819290161174 .0627822876 72.5388565063571 .014930725169 .4910125732467 .6623001098666 .13836669922 64.6144485473663 .0905189514261 .5666007995660 .0426712036158 .51874923706 57.2995986938555 .7756805419955 .16611099243 -9999 -9999 -9999 -9999 -9999 -9999 -9999 -9999 -9999 -9999 -9999 -9999 -9999 -9999 -9999 -9999 -9999 -9999 -9999 -9999 -9999 -9999

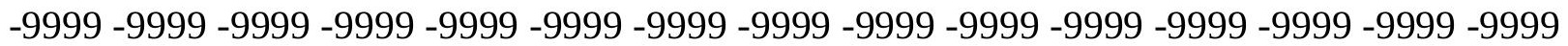
$-9999-9999$

-9999 -9999 -9999 -9999 -9999 -9999 -9999 -9999 -9999 -9999 -9999 -9999 -9999 -9999 -9999 -9999 -9999 -9999 -9999 -9999 -9999 -9999 -9999 -9999 -9999 -9999 -9999 -9999 -9999 -9999

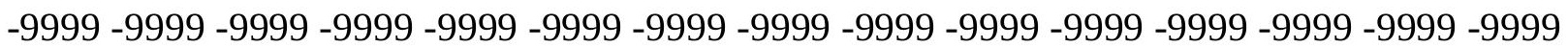
-9999 -9999 -9999 -9999 -9999 -9999 -9999 -9999 -9999 -9999 -9999 -9999 -9999 -9999 -9999 -9999 -9999 -9999 -9999 -9999 -9999 -9999 -9999 -9999 -9999 -9999 -9999 -9999 -9999 -9999 -999 -9999 -9999 -9999 -9999 -9999 -9999 -9999 -9999 -9999 -9999 -9999 -9999 -9999 -9999 -9999

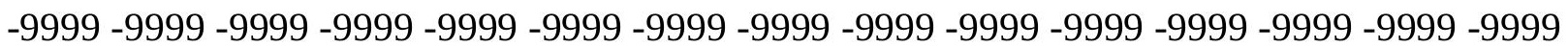
-9999 -9999 -9999 -9999 -9999 -9999 -9999 -9999 -9999 -9999 -9999 -9999 -9999 -9999 -9999 -9999 -9999 -9999 -9999 -9999 -9999 -9999 -9999 -9999 -9999 -9999 -9999 -9999 -9999 -9999 -9999 -9999 -9999 -9999 -9999 -9999 -9999 -9999 -9999 -9999 -9999 -9999 -9999 -9999 -9999 -9999 -9999 -9999 -9999 -9999 -9999 -9999 -9999 -9999 -9999 -9999 -9999 -9999 -9999 -9999

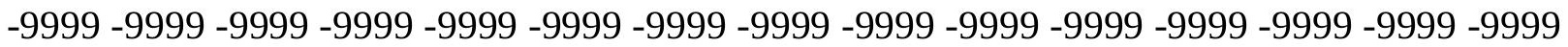
-9999 -9999 -9999 -9999 -9999 -9999 -9999 -9999 -9999 -9999 -9999 -9999 -9999 -9999 -9999 -9999 -9999 -9999 -9999 -9999 -9999 -9999 -9999 -9999 -9999 -9999 -9999 105.1509017944 105.4557037354105 .4557037354105 .1509017944104 .8460998535104 .5412979126 104.2365036011103 .9317016602103 .6268997192103 .3221969604102 .712600708 102.4077987671101 .7982025146101 .4934005737101 .1886978149100 .8839035034 100.5791015625100 .274299621699 .6647262573299 .0551681518698 .14080810547 96.9216690063595 .7025299072394 .1785964965892 .349891662690 .82597351074 88.99725341797 87.47332763672 85.64462280273 84.12069702148 82.59677124023 81.0728530883879 .8537063598678 .6345596313577 .4154205322375 .89148712158 74.062782287671 .6244964599669 .1862335205166 .4431610107463 .70008850098 61.5666007995659 .4331016540558 .2139587402356 .9948196411156 .38525009155 56.3852500915556 .3852500915556 .9948196411157 .2995986938556 .99481964111 56.6900291442956 .3852500915556 .0804595947356 .0804595947355 .77568054199 55.4708900451755 .1661109924354 .8613204956154 .5565414428754 .55654144287 54.2517509460453 .9469718933153 .9469718933153 .9469718933153 .94697189331 53.9469718933153 .9469718933154 .2517509460454 .2517509460454 .25175094604 
54.5565414428754 .5565414428754 .8613204956154 .8613204956154 .86132049561 55.1661109924355 .1661109924355 .4708900451755 .4708900451755 .77568054199 56.3852500915556 .6900291442957 .2995986938558 .2139587402359 .12831115723 59.7378807067960 .9570198059161 .8713798522962 .7857398986864 .0048828125 64.9192428588966 .1383666992267 .0527267456167 .9670867919968 .88143920898 69.7957916259871 .014930725171 .9292907714872 .8436431884873 .45321655273 74.3675689697375 .2819290161175 .8914871215876 .8058471679777 .41542053223 78.0249862670978 .6345596313579 .2441329956179 .5489196777380 .15849304199 80.4632720947380 .7680587768681 .0728530883881 .3776321411181 .68241119385 81.9871978759882 .2919769287182 .2919769287182 .2919769287181 .98719787598 81.6824111938581 .0728530883880 .4632720947379 .8537063598678 .93934631348 77.7202072143676 .5010681152375 .2819290161174 .062782287672 .53885650635 71.014930725169 .4910125732467 .9670867919966 .4431610107464 .91924285889 63.3953094482461 .8713798522960 .3474502563558 .8235282897957 .29959869385 56.0804595947355 .16611099243 -9999 -9999 -9999 -9999 -9999 -9999 -9999 -9999 -9999

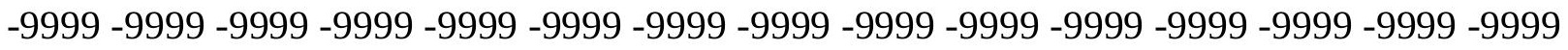
-9999 -9999 -9999 -9999 -9999 -9999 -9999 -9999 -9999 -9999 -9999 -9999 -9999 -9999 -9999 -9999 -9999 -9999 -9999 -9999 -9999 -9999 -9999 -9999 -9999 -9999 -9999 -9999 -9999 -9999 -9999 -9999 -9999 -9999 -9999 -9999 -9999 -9999 -9999 -9999 -9999 -9999 -9999 -9999 -9999 -

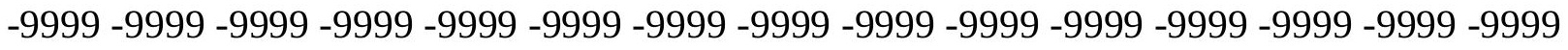
-9999 -9999 -9999 -9999 -9999 -9999 -9999 -9999 -9999 -9999 -9999 -9999 -9999 -9999 -9999

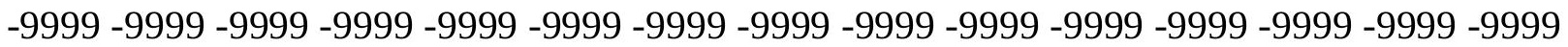
-9999 -9999 -9999 -9999 -9999 -9999 -9999 -9999 -9999 -9999 -9999 -9999 -9999 -9999 -9999 -9999 -9999 -9999 -9999 -9999 -9999 -9999 -9999 -9999 -9999 -9999 -9999 -9999 -9999 -9999 -9999 -9999 -9999 -9999 -9999 -9999 -9999 -9999 -9999 -9999 -9999 -9999 -9999 -9999 -9999 -9999 -9999 -9999 -9999 -9999 -9999 -9999 -9999 -9999 -9999 -9999 -9999 -9999 -9999 -9999 -9999 -9999 -9999 -9999 -9999 -9999 -9999 -9999 -9999 -9999 -9999 -9999 -9999 -9999 -9999 -9999 -9999 -9999 -9999 -9999 -9999 -9999 -9999 -9999 -9999 -9999 -9999 -9999 -9999 -9999 -9999 -9999 -9999 -9999 -9999 -9999 -9999 -9999 -9999 -9999 -9999 -9999 -9999 -9999 -9999 -9999 -9999 -9999 -9999 -9999 -9999 -9999 -9999 -9999 -9999 -9999 -9999 -9999 -9999 -9999 -9999 -9999 -9999 -9999 -9999 -9999 -9999 -9999 -9999 -9999 -9999 -9999 -9999 -9999 106.0652008057106 .0652008057105 .4557037354105 .1509017944104 .5412979126 104.2365036011103 .6268997192103 .3221969604102 .712600708102 .4077987671 102.1029968262101 .7982025146101 .7982025146101 .4934005737101 .4934005737 101.4934005737101 .1886978149100 .579101562599 .6647262573298 .4455871582 97.2264633178795 .7025299072393 .8738174438592 .349891662690 .52117919922 88.99725341797 87.47332763672 85.94940185547 84.73026275635 83.51112365723 82.2919769287181 .0728530883879 .8537063598678 .3297805786176 .50106811523 74.6723632812572 .2340774536170 .1005783081167 .6623001098665 .83358764648 64.004882812562 .4809494018661 .5666007995660 .6522407531760 .65224075317 60.6522407531760 .9570198059161 .5666007995660 .9570198059160 .34745025635 59.7378807067959 .1283111572358 .5187492370658 .2139587402357 .60438919067 57.2995986938556 .6900291442956 .3852500915556 .0804595947355 .77568054199 55.4708900451755 .1661109924355 .1661109924355 .1661109924355 .16611099243 55.1661109924355 .1661109924355 .1661109924355 .4708900451755 .47089004517 55.4708900451755 .4708900451755 .7756805419955 .7756805419955 .77568054199 
55.7756805419956 .0804595947356 .0804595947356 .3852500915556 .69002914429 56.9948196411157 .6043891906758 .2139587402358 .8235282897959 .43310165405 60.3474502563561 .2618103027362 .1761703491263 .3953094482464 .30966186523 65.2240066528366 .1383666992267 .0527267456168 .2718734741269 .18623352051 70.1005783081171 .014930725171 .9292907714872 .8436431884873 .45321655273 74.3675689697374 .9771423339875 .8914871215876 .5010681152377 .1106262207 77.4154205322378 .0249862670978 .3297805786178 .9393463134879 .24413299561 79.5489196777379 .8537063598680 .1584930419980 .7680587768681 .07285308838 81.37763214111 81.37763214111 81.37763214111 81.3776321411181.07285308838 80.7680587768680 .1584930419979 .5489196777378 .6345596313577 .72020721436 76.5010681152375 .2819290161174 .062782287672 .5388565063571 .0149307251 69.4910125732467 .9670867919966 .4431610107464 .9192428588963 .39530944824 61.8713798522960 .3474502563558 .8235282897957 .6043891906756 .08045959473 55.16611099243 -9999 -9999 -9999 -9999 -9999 -9999 -9999 -9999 -9999 -9999 -9999 -9999 -9999 -9999 -9999 -9999 -9999 -9999 -9999 -9999 -9999 -9999 -9999 -9999 -9999 -9999 -9999 -9999 -9999 -9999 -9999 -9999 -9999 -9999 -9999 -9999 -9999 -9999 -9999 -

-9999 -9999 -9999 -9999 -9999 -9999 -9999 -9999 -9999 -9999 -9999 -9999 -9999 -9999 -9999 -9999 -9999 -9999 -9999 -9999 -9999 -9999 -9999 -9999 -9999 -9999 -9999 -9999 -9999 -9999 -9999 -9999 -9999 -9999 -9999 -9999 -9999 -9999 -9999 -9999 -9999 -9999 -9999 -9999 -9999 -

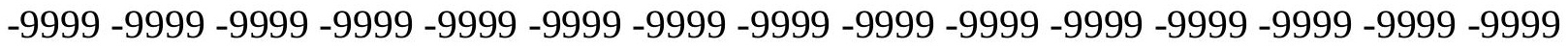

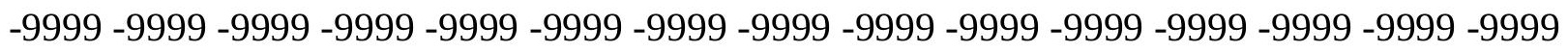
-9999 -9999 -9999 -9999 -9999 -9999 -9999 -9999 -9999 -9999 -9999 -9999 -9999 -9999 -9999 -9999 -9999 -9999 -9999 -9999 -9999 -9999 -9999 -9999 -9999 -9999 -9999 -9999 -9999 -9999 -

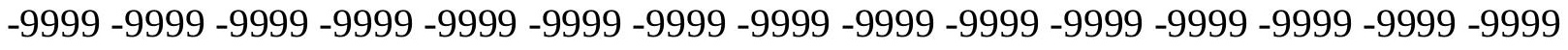

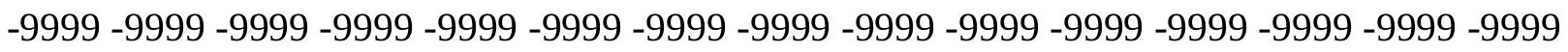
-9999 -9999 -9999 -9999 -9999 -9999 -9999 -9999 -9999 -9999 -9999 -9999 -9999 -9999 -9999 -

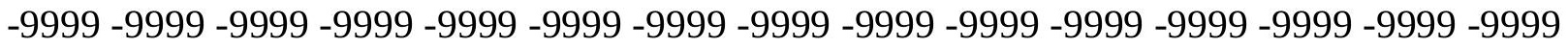

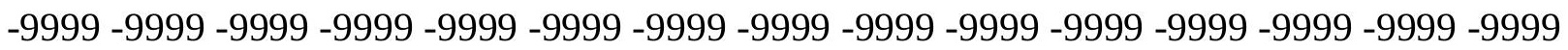
-9999 -9999 -9999 -9999 -9999 -9999 -9999 -9999 -9999 -9999 -9999 -9999 -9999 -9999 -9999 -9999 -9999 -9999 -9999 -9999 -9999 -9999 -9999 -9999 -9999 -9999 -9999 -9999 -9999 -9999 -9999 106.3700027466105.7603988647 105.1509017944104.2365036011 103.6268997192 103.3221969604102 .712600708102 .4077987671102 .1029968262101 .7982025146 101.7982025146101 .7982025146102 .1029968262102 .4077987671102 .4077987671 102.1029968262101 .188697814999 .9695205688598 .7503814697396 .92166900635 95.397743225193 .5690307617292 .0450973510790 .5211791992288 .99725341797 87.7781066894586 .5589828491285 .3398437584 .4254837036183 .2063369751 81.9871978759880 .4632720947378 .9393463134877 .110626220775 .28192901611 73.1484298706171 .3197174072369 .4910125732467 .6623001098666 .44316101074 65.5288009643664 .9192428588964 .6144485473664 .3096618652364 .61444854736 64.6144485473664 .004882812563 .3953094482462 .4809494018661 .87137985229 61.2618103027360 .6522407531760 .0426712036159 .4331016540558 .82352828979 58.2139587402357 .6043891906757 .2995986938556 .9948196411156 .69002914429 56.3852500915556 .3852500915556 .3852500915556 .3852500915556 .38525009155 56.3852500915556 .3852500915556 .3852500915556 .3852500915556 .69002914429 56.6900291442956 .6900291442956 .3852500915556 .3852500915556 .38525009155 56.6900291442956 .6900291442956 .9948196411157 .2995986938557 .60438919067 
57.909179687558 .5187492370659 .1283111572360 .0426712036160 .95701980591 61.5666007995662 .4809494018663 .3953094482464 .3096618652365 .52880096436 66.4431610107467 .3575134277368 .2718734741269 .1862335205170 .10057830811 71.014930725171 .9292907714872 .5388565063573 .4532165527374 .0627822876 74.9771423339875 .5867080688576 .1962814331176 .5010681152377 .1106262207 77.4154205322377 .7202072143678 .0249862670978 .3297805786178 .63455963135 79.2441329956179 .5489196777380 .1584930419980 .4632720947380 .76805877686 80.7680587768680 .7680587768680 .7680587768680 .4632720947379 .85370635986 79.2441329956178 .3297805786177 .4154205322376 .5010681152375 .28192901611 74.062782287672 .5388565063571 .014930725169 .7957916259868 .27187347412 66.7479400634865 .2240066528363 .7000885009862 .1761703491260 .65224075317 59.1283111572357 .6043891906756 .0804595947355 .16611099243 -9999 -9999 -9999 -9999 -9999 -9999 -9999 -9999 -9999 -9999 -9999 -9999 -9999 -9999 -9999 -9999 -9999 -9999 -9999

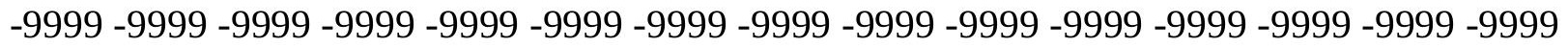
-9999 -9999 -9999-9999-9999

-9999 -9999 -9999 -9999 -9999 -9999 -9999 -9999 -9999-9999 -9999 -9999 -9999 -9999 -9999 -9999 -9999 -9999 -9999 -9999 -9999 -9999 -9999 -9999 -9999 -9999 -9999 -9999 -9999 -9999 -9999 -9999 -9999 -9999 -9999 -9999 -9999 -9999 -9999 -9999 -9999 -9999 -9999 -9999 -9999 -9999 -9999 -9999 -9999 -9999 -9999 -9999 -9999 -9999 -9999 -9999 -9999 -9999 -9999 -9999 -

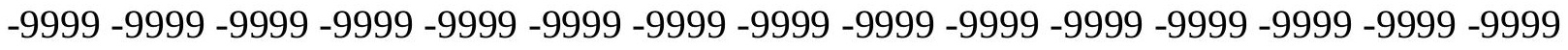

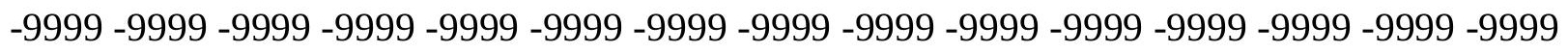
-9999 -9999 -9999 -9999 -9999 -9999 -9999 -9999 -9999 -9999 -9999 -9999 -9999 -9999 -9999 -9999 -9999 -9999 -9999 -9999 -9999 -9999 -9999 -9999 -9999 -9999 -9999 -9999 -9999 -9999 -

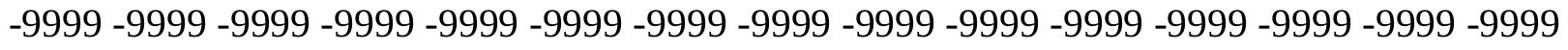

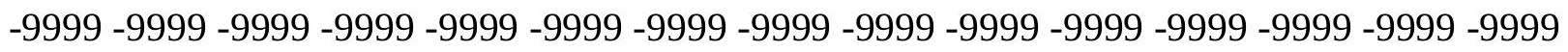
-9999 -9999 -9999 -9999 -9999 -9999 -9999 -9999 -9999 -9999 -9999 -9999 -9999 -9999 -9999 -9999 -9999 -9999 -9999 -9999 -9999 -9999 -9999 -9999 -9999 -9999 -9999 -9999 -9999 -9999 -

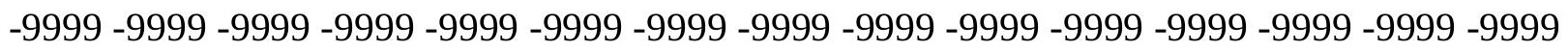

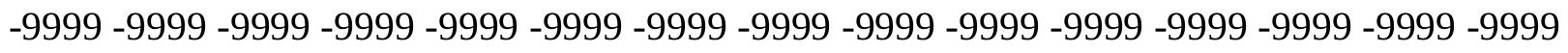
-9999 -9999 -9999 105.7603988647104.8460998535103.9317016602 103.3221969604 102.4077987671102 .1029968262101 .7982025146101 .7982025146101 .7982025146 102.1029968262102 .4077987671103 .0174026489103 .3221969604103 .3221969604 102.4077987671101 .188697814999 .6647262573298 .1408081054796 .31210327148 94.7881774902392 .9594726562591 .4355392456190 .5211791992289 .3020401001 88.38768768311 87.16854858398 86.2541885376 85.03504943848 83.81591033936 82.5967712402381 .0728530883879 .5489196777378 .0249862670976 .19628143311 74.3675689697372 .8436431884871 .3197174072370 .1005783081169 .18623352051 68.2718734741267 .9670867919967 .6623001098667 .6623001098667 .35751342773 66.7479400634866 .1383666992265 .2240066528364 .3096618652363 .70008850098 62.7857398986862 .1761703491261 .2618103027360 .6522407531760 .04267120361 59.4331016540558 .8235282897958 .2139587402357 .909179687557 .60438919067 57.6043891906757 .6043891906757 .6043891906757 .6043891906757 .60438919067 57.6043891906757 .6043891906757 .6043891906757 .6043891906757 .60438919067 57.2995986938557 .2995986938557 .2995986938556 .9948196411156 .99481964111 56.9948196411157 .2995986938557 .2995986938557 .6043891906757 .9091796875 58.5187492370659 .1283111572359 .7378807067960 .3474502563561 .26181030273 
61.8713798522962 .7857398986863 .7000885009864 .6144485473665 .52880096436 66.4431610107467 .3575134277368 .2718734741269 .1862335205170 .10057830811 71.014930725171 .9292907714872 .5388565063573 .4532165527374 .0627822876 74.6723632812575 .2819290161175 .5867080688576 .1962814331176 .50106811523 76.8058471679776 .8058471679777 .110626220777 .4154205322378 .02498626709 78.6345596313579 .2441329956179 .5489196777380 .1584930419980 .15849304199 80.4632720947380 .1584930419980 .1584930419979 .5489196777378 .93934631348 78.3297805786177 .4154205322376 .1962814331175 .2819290161174 .0627822876 72.5388565063571 .3197174072369 .7957916259868 .2718734741266 .74794006348 65.2240066528363 .7000885009862 .1761703491260 .6522407531759 .12831115723 57.6043891906756 .0804595947355 .16611099243 -9999 -9999 -9999 -9999 -9999 -9999 -9999 -9999 -9999 -9999 -9999 -9999 -9999 -9999 -9999 -9999 -9999 -9999 -9999 -9999 -9999 -9999

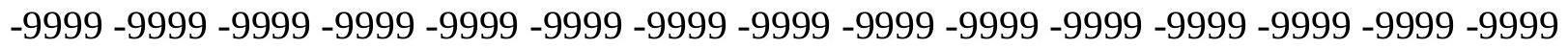
$-9999-9999$

-9999 -9999 -9999 -9999 -9999 -9999 -9999 -9999 -9999 -9999 -9999 -9999 -9999 -9999 -9999

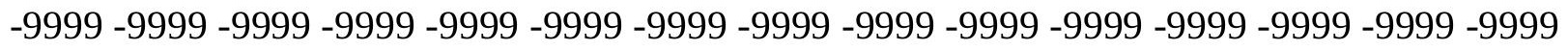
-9999 -9999 -9999 -9999 -9999 -9999 -9999 -9999 -9999 -9999 -9999 -9999 -9999 -9999 -9999 -9999 -9999 -9999 -9999 -9999 -9999 -9999 -9999 -9999 -9999 -9999 -9999 -9999 -9999 -9999 -

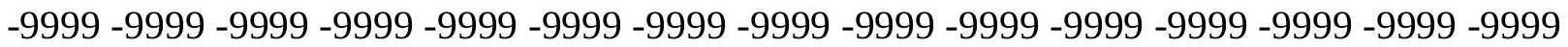

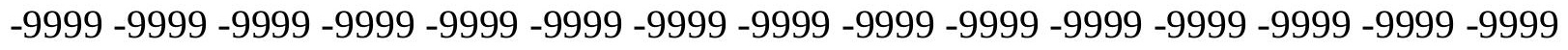

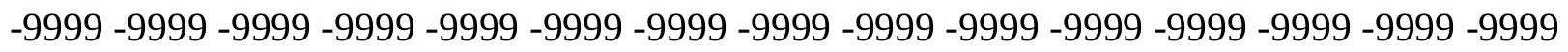

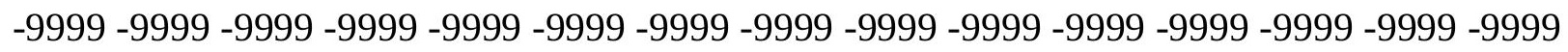
-9999 -9999 -9999 -9999 -9999 -9999 -9999 -9999 -9999 -9999 -9999 -9999 -9999 -9999 -9999 -

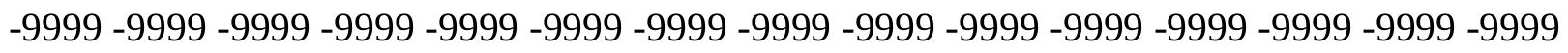

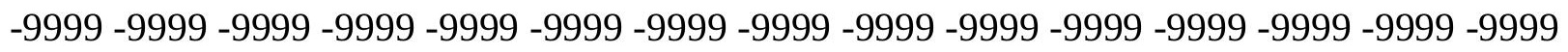
-9999 -9999 -9999 -9999 -9999 -9999 -9999 -9999 -9999 -9999 -9999 -9999 -9999 -9999 -9999 -9999 -9999 -9999 -9999 -9999 -9999 -9999 -9999 -9999 -9999 -9999 -9999 -9999 -9999 - -9999 -

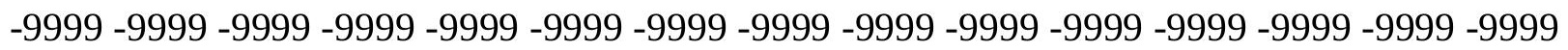
-9999 -9999 -9999-9999-9999 104.5412979126103.6268997192102.712600708 101.7982025146101 .4934005737101 .1886978149101 .1886978149101 .7982025146 102.4077987671103 .0174026489103 .9317016602104 .2365036011103 .3221969604 102.1029968262100 .274299621698 .7503814697397 .2264633178795 .3977432251 94.1785964965892 .6546783447391 .7403335571390 .8259735107489 .91161346436 88.9972534179787 .7781066894586 .8637619018685 .9494018554784 .73026275635 83.2063369751 81.98719787598 80.46327209473 78.63455963135 77.1106262207 75.8914871215874 .3675689697373 .4532165527372 .2340774536171 .62449645996 71.014930725170 .7101516723670 .4053573608469 .7957916259869 .18623352051 68.5766525268667 .6623001098666 .7479400634865 .8335876464865 .22400665283 64.3096618652363 .3953094482462 .4809494018661 .8713798522960 .95701980591 60.3474502563559 .7378807067959 .4331016540559 .1283111572358 .82352828979 58.8235282897958 .8235282897958 .8235282897958 .8235282897958 .82352828979 58.5187492370658 .5187492370658 .5187492370658 .5187492370658 .51874923706 58.2139587402357 .909179687557 .6043891906757 .6043891906757 .60438919067 57.2995986938557 .6043891906757 .6043891906757 .909179687558 .21395874023 58.8235282897959 .1283111572360 .0426712036160 .6522407531761 .26181030273 62.1761703491263 .0905189514264 .004882812564 .9192428588965 .83358764648 
66.7479400634867 .6623001098668 .5766525268669 .4910125732470 .10057830811 71.014930725171 .9292907714872 .5388565063573 .1484298706173 .75800323486 74.3675689697374 .9771423339875 .2819290161175 .5867080688575 .89148712158 75.8914871215876 .1962814331176 .5010681152377 .110626220777 .72020721436 78.6345596313579 .2441329956179 .5489196777379 .8537063598680 .15849304199 80.1584930419979 .8537063598679 .5489196777378 .9393463134878 .32978057861 77.4154205322376 .1962814331175 .2819290161174 .062782287672 .53885650635 71.3197174072369 .7957916259868 .2718734741266 .7479400634865 .22400665283 63.7000885009862 .1761703491260 .6522407531759 .1283111572357 .60438919067 56.0804595947355 .16611099243 -9999 -9999 -9999 -9999 -9999 -9999 -9999 -9999 -9999 -9999 -9999 -9999 -9999 -9999 -9999 -9999 -9999 -9999 -9999 -9999 -9999 -9999 -9999 -9999 -9999 -9999 -9999 -9999 -9999 -9999 -9999 -9999 -9999 -9999 -9999 -9999 -9999 -9999 -9999 -9999 -9999 -9999 -9999 -9999 -9999 -9999 -9999 -9999 -9999 -9999 -9999 -9999 -9999 -9999 -9999 -9999 -9999 -9999 -9999 -9999 -9999 -9999 -9999 -9999 -9999 -9999 -9999 -9999 - -9999 -9999 -9999 -9999 -9999 -9999 -9999 -9999 -9999 -9999 -9999 -9999 -9999 -9999 -9999 -9999

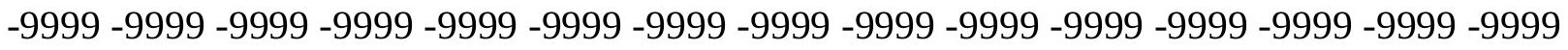

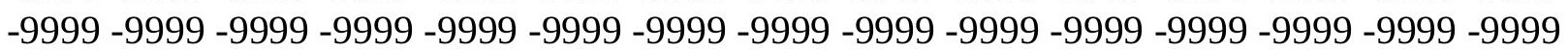

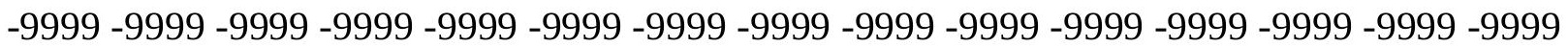
-9999 -9999 -9999 -9999 -9999 -9999 -9999 -9999 -9999 -9999 -9999 -9999 -9999 -9999 -9999 -9999 -9999 -9999 -9999 -9999 -9999 -9999 -9999 -9999 -9999 -9999 -9999 -9999 -9999 -9999 -9999 -9999 -9999 -9999 -9999 -9999 -9999 -9999 -9999 -9999 -9999 -9999 -9999 -9999 -9999 -9999 -9999 -9999 -9999 -9999 -9999 -9999 -9999 -9999 -9999 -9999 -9999 -9999 -9999 -9999 -9999 -9999 -9999 -9999 -9999 -9999 -9999 -9999 -9999 -9999 -9999 -9999 -9999 -9999 -9999 -9999 -9999 -9999 -9999 -9999 -9999 -9999 -9999 -9999 -9999 -9999 -9999 -9999 -9999 -9999 -9999 -9999 -9999 -9999 -9999 -9999 -9999 -9999 -9999 -9999 -9999 -9999 -9999 -9999 -9999 -9999 -9999 -9999 -9999 -9999 -9999 -9999 -9999 -9999 -9999 -9999 -9999 -9999 -9999 -9999 -9999 -9999 -9999 -9999 -9999 -9999 104.2365036011 103.3221969604 102.4077987671 101.4934005737100 .8839035034100 .5791015625100 .8839035034101 .4934005737 102.4077987671103 .6268997192104 .5412979126103 .3221969604102 .1029968262 100.579101562599 .0551681518697 .5312423706196 .0073165893694 .78817749023 93.8738174438592 .6546783447391 .7403335571391 .1307525634890 .21640014648 89.302040100188.38768768311 87.47332763672 86.2541885376 85.33984375 83.81591033936 82.59677124023 81.0728530883879.85370635986 78.63455963135 77.4154205322376 .1962814331175 .2819290161174 .6723632812574 .0627822876 73.4532165527372 .8436431884872 .2340774536171 .6244964599670 .71015167236 69.7957916259869 .1862335205168 .2718734741267 .3575134277366 .44316101074 65.5288009643664 .6144485473663 .7000885009862 .7857398986862 .17617034912 61.2618103027360 .6522407531760 .3474502563560 .3474502563560 .34745025635 60.0426712036160 .0426712036160 .0426712036159 .7378807067959 .73788070679 59.7378807067959 .7378807067959 .4331016540559 .4331016540559 .12831115723 58.8235282897958 .2139587402358 .2139587402357 .909179687557 .60438919067 57.6043891906757 .6043891906757 .909179687558 .2139587402358 .51874923706 58.8235282897959 .4331016540560 .0426712036160 .9570198059161 .56660079956 62.4809494018663 .0905189514264 .004882812564 .9192428588965 .83358764648 66.7479400634867 .6623001098668 .5766525268669 .4910125732470 .40535736084 71.3197174072371 .9292907714872 .5388565063573 .1484298706173 .75800323486 
74.3675689697374 .6723632812574 .9771423339875 .2819290161175 .28192901611 75.5867080688575 .5867080688576 .5010681152377 .4154205322378 .02498626709 78.6345596313579 .2441329956179 .5489196777379 .8537063598679 .85370635986 79.5489196777379 .2441329956178 .9393463134878 .0249862670977 .41542053223 76.1962814331175 .2819290161174 .062782287672 .8436431884871 .31971740723 69.7957916259868 .2718734741266 .7479400634865 .2240066528363 .70008850098 62.1761703491260 .6522407531759 .1283111572357 .6043891906756 .08045959473 55.16611099243 -9999 -9999 -9999 -9999 -9999 -9999 -9999 -9999 -9999 -9999 -9999 -9999 -9999 -9999 -9999 -9999 -9999 -9999 -9999 -9999 -9999 -9999 -9999 -9999 -9999 -9999 -9999 -9999 -9999 -9999 -9999 -9999 -9999 -9999 -9999 -9999 -9999 -9999 -9999 -

-9999 -9999 -9999 -9999 -9999 -9999 -9999 -9999 -9999 -9999 -9999 -9999 -9999 -9999 -9999 -9999 -9999 -9999 -9999 -9999 -9999 -9999 -9999 -9999 -9999 -9999 -9999 -9999 -9999 -9999 -9999 -9999 -9999 -9999 -9999 -9999 -9999 -9999 -9999 -9999 -9999 -9999 -9999 -9999 -9999 -9999 -9999 -9999 -9999 -9999 -9999 -9999 -9999 -9999 -9999 -9999 -9999 -9999 -9999 - -9999 -9999 -9999 -9999 -9999 -9999 -9999 -9999 -9999 -9999 -9999 -9999 -9999 -9999 -9999 -9999

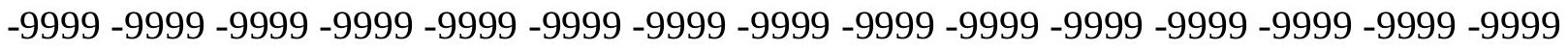

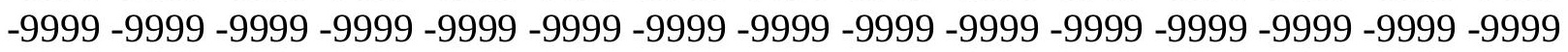
-9999 -9999 -9999 -9999 -9999 -9999 -9999 -9999 -9999 -9999 -9999 -9999 -9999 -9999 -9999 -999 -9999 -9999 -9999 -9999 -9999 -9999 -9999 -9999 -9999 -9999 -9999 -9999 -9999 -9999 -9999 -9999 -9999 -9999 -9999 -9999 -9999 -9999 -9999 -9999 -9999 -9999 -9999 -9999 -9999 -9999 -9999 -9999 -9999 -9999 -9999 -9999 -9999 -9999 -9999 -9999 -9999 -9999 -9999 -9999 -9999 -9999 -9999 -9999 -9999 -9999 -9999 -9999 -9999 -9999 -9999 -9999 -9999 -9999 -9999 -9999 -9999 -9999 -9999 -9999 -9999 -9999 -9999 -9999 -9999 -9999 -9999 -9999 -9999 -9999 -9999 -9999 -9999 -9999 -9999 -9999 -9999 -9999 -9999 -9999 -9999 -9999 -9999 -9999 -9999 -9999 -9999 -9999 -9999 -9999 -9999 -9999 -9999 -9999 102.712600708101 .7982025146 100.8839035034100 .274299621699 .96952056885100 .5791015625101 .1886978149 102.1029968262102 .712600708102 .1029968262101 .188697814999 .96952056885 98.7503814697397 .5312423706196 .6168823242295 .397743225194 .48339080811 93.5690307617292 .9594726562592 .0450973510791 .4355392456190 .82597351074 89.9116134643688 .9972534179788 .0829010009886 .8637619018685 .64462280273 84.7302627563583 .5111236572382 .2919769287181 .0728530883879 .85370635986 78.9393463134878 .0249862670977 .110626220776 .5010681152375 .89148712158 75.2819290161174 .3675689697373 .7580032348672 .8436431884872 .23407745361 71.3197174072370 .4053573608469 .1862335205168 .2718734741267 .35751342773 66.4431610107465 .5288009643664 .6144485473663 .7000885009863 .09051895142 62.4809494018662 .1761703491261 .8713798522961 .5666007995661 .56660079956 61.2618103027361 .2618103027360 .9570198059160 .9570198059160 .95701980591 60.6522407531760 .6522407531760 .3474502563560 .0426712036159 .43310165405 58.8235282897958 .5187492370658 .2139587402357 .909179687557 .9091796875 57.6043891906757 .909179687557 .909179687558 .2139587402358 .51874923706 59.1283111572359 .7378807067960 .3474502563560 .9570198059161 .87137985229 62.4809494018663 .3953094482464 .3096618652365 .2240066528366 .13836669922 67.0527267456167 .9670867919968 .8814392089869 .7957916259870 .71015167236 71.3197174072371 .9292907714872 .5388565063573 .1484298706173 .75800323486 74.062782287674 .3675689697374 .6723632812574 .9771423339875 .28192901611 75.5867080688576 .1962814331177 .110626220778 .0249862670978 .63455963135 
79.2441329956179 .5489196777379 .8537063598679 .8537063598679 .54891967773 79.2441329956178 .9393463134878 .0249862670977 .4154205322376 .50106811523 75.2819290161174 .062782287672 .8436431884871 .3197174072369 .79579162598 68.2718734741266 .7479400634865 .2240066528363 .7000885009862 .17617034912 $60.6522407531759 .1283111572357 .6043891906756 .0804595947355 .16611099243-9999$ -9999 -9999 -9999 -9999 -9999 -9999 -9999 -9999 -9999 -9999 -9999 -9999 -9999 -9999 -9999

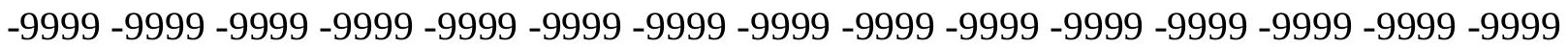
-9999 -9999 -9999 -9999 -9999 -9999 -9999 -9999

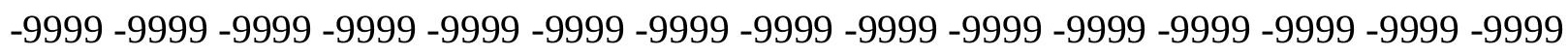
-9999 -9999 -9999 -9999 -9999 -9999 -9999 -9999 -9999 -9999 -9999 -9999 -9999 -9999 -9999 -

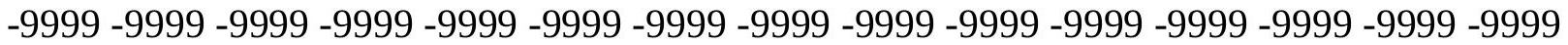
-9999 -9999 -9999 -9999 -9999 -9999 -9999 -9999 -9999 -9999 -9999 -9999 -9999 -9999 -9999 -9999 -9999 -9999 -9999 -9999 -9999 -9999 -9999 -9999 -9999 -9999 -9999 -9999 -9999 -9999 -9999 -9999 -9999 -9999 -9999 -9999 -9999 -9999 -9999 -9999 -9999 -9999 -9999 -9999 -9999 -9999 -9999 -9999 -9999 -9999 -9999 -9999 -9999 -9999 -9999 -9999 -9999 -9999 -9999 -9999

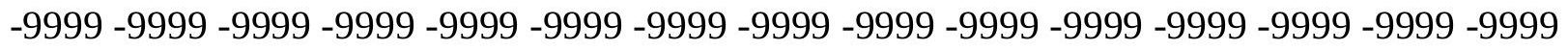

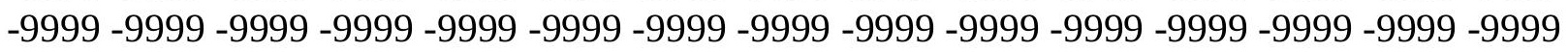

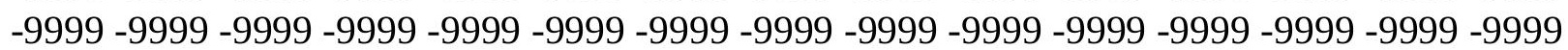

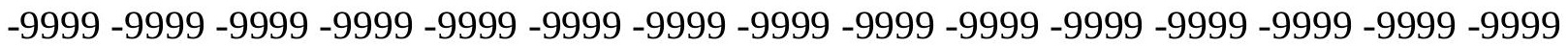

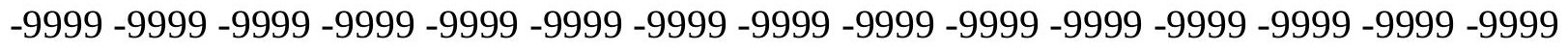

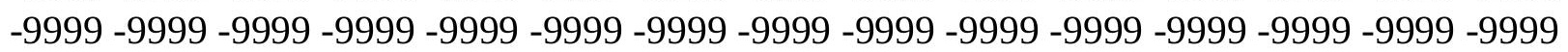

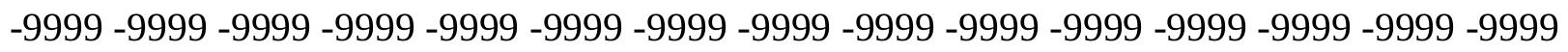
-9999 -9999 -9999 -9999 -9999 -9999 -9999 -9999 -9999 -9999 101.4934005737 100.579101562599 .6647262573299 .0551681518699 .66472625732100 .2742996216 100.5791015625100 .579101562599 .9695205688599 .0551681518698 .14080810547 97.5312423706196 .6168823242295 .7025299072395 .0929565429794 .17859649658 93.5690307617292 .9594726562592 .349891662691 .7403335571391 .13075256348 90.5211791992289 .6068267822388 .3876876831187 .4733276367286 .55898284912 85.3398437584 .1206970214883 .206336975182 .2919769287181 .37763214111 80.4632720947379 .5489196777378 .9393463134878 .0249862670977 .41542053223 76.5010681152375 .8914871215874 .9771423339874 .062782287673 .14842987061 72.2340774536171 .3197174072370 .4053573608469 .4910125732468 .27187347412 67.3575134277366 .4431610107465 .8335876464864 .9192428588964 .30966186523 64.004882812563 .3953094482463 .3953094482463 .0905189514262 .78573989868 62.4809494018662 .4809494018662 .1761703491261 .8713798522961 .87137985229 61.5666007995661 .2618103027360 .6522407531760 .0426712036159 .43310165405 59.1283111572358 .5187492370658 .2139587402357 .909179687557 .9091796875 57.909179687557 .909179687558 .2139587402358 .5187492370658 .82352828979 59.4331016540559 .7378807067960 .6522407531761 .2618103027362 .17617034912 63.0905189514263 .7000885009864 .6144485473665 .5288009643666 .74794006348 67.6623001098668 .5766525268669 .1862335205170 .1005783081171 .0149307251 71.6244964599672 .2340774536172 .8436431884873 .4532165527373 .75800323486 74.062782287674 .6723632812574 .9771423339875 .2819290161175 .89148712158 76.5010681152377 .110626220778 .0249862670978 .6345596313579 .24413299561 79.5489196777379 .8537063598679 .8537063598679 .5489196777379 .24413299561 78.9393463134878 .3297805786177 .4154205322376 .5010681152375 .28192901611 
74.062782287672 .8436431884871 .3197174072369 .7957916259868 .27187347412 66.7479400634865 .2240066528363 .7000885009862 .1761703491260 .65224075317 59.1283111572357 .6043891906756 .0804595947355 .16611099243 -9999 -9999 -9999 -9999 -9999 -9999 -9999 -9999 -9999 -9999 -9999 -9999 -9999 -9999 -9999 -9999 -9999 -9999 -9999

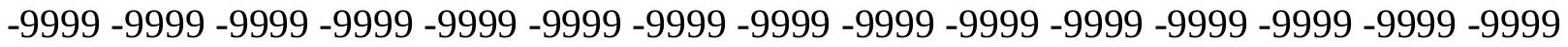
-9999 -9999 -9999-9999-9999

-9999 -9999 -9999 -9999 -9999 -9999 -9999 -9999 -9999 -9999 -9999 -9999 -9999 -9999 -9999

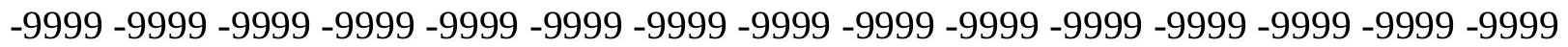

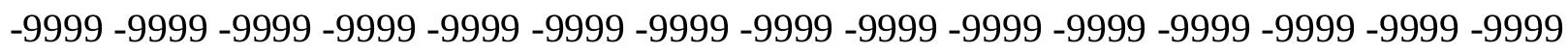
-9999 -9999 -9999 -9999 -9999 -9999 -9999 -9999 -9999 -9999 -9999 -9999 -9999 -9999 -9999

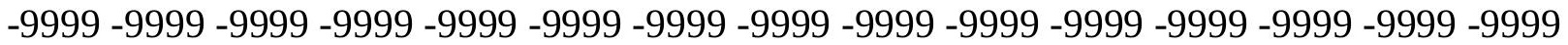
-9999 -9999 -9999 -9999 -9999 -9999 -9999 -9999 -9999 -9999 -9999 -9999 -9999 -9999 -9999 -9999 -9999 -9999 -9999 -9999 -9999 -9999 -9999 -9999 -9999 -9999 -9999 -9999 -9999 -9999 -9999 -9999 -9999 -9999 -9999 -9999 -9999 -9999 -9999 -9999 -9999 -9999 -9999 -9999 -9999 -9999 -9999 -9999 -9999 -9999 -9999 -9999 -9999 -9999 -9999 -9999 -9999 -9999 -9999 -9999 -9999 -9999 -9999 -9999 -9999 -9999 -9999 -9999 -9999 -9999 -9999 -9999 -9999 - -9999 - -9999 -9999 -9999 -9999 -9999 -9999 -9999 -9999 -9999 -9999 -9999 -9999 -9999 -9999 -9999 -9999 -9999 -9999 -9999 -9999 -9999 -9999 -9999 -9999 -9999 -9999 -9999 -9999 -9999 -9999 -9999 -9999 -9999 -9999 -9999 -9999 -9999 -9999 -9999 -9999 -9999 -9999 -9999 -9999 -9999 -9999 -

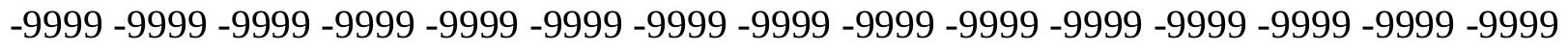
-9999 -9999-9999 -9999-9999-9999-9999-9999-9999-9999-9999 100.8839035034 99.9695205688599 .3599472045998 .445587158298 .1408081054798 .4455871582 98.7503814697398 .445587158298 .1408081054797 .5312423706196 .92166900635 96.3121032714895 .7025299072395 .0929565429794 .7881774902394 .17859649658 93.5690307617293 .2642517089892 .6546783447392 .0450973510791 .43553924561 90.8259735107489 .9116134643688 .9972534179788 .0829010009887 .16854858398 86.254188537685 .3398437584 .4254837036183 .5111236572382 .59677124023 81.6824111938581 .0728530883880 .1584930419979 .5489196777378 .63455963135 78.0249862670977 .110626220776 .1962814331175 .2819290161174 .36756896973 73.4532165527372 .2340774536171 .3197174072370 .4053573608469 .49101257324 68.5766525268667 .6623001098666 .7479400634866 .1383666992265 .52880096436 65.2240066528364 .9192428588964 .6144485473664 .3096618652364 .0048828125 63.7000885009863 .3953094482463 .0905189514262 .7857398986862 .48094940186 61.8713798522961 .2618103027360 .6522407531760 .0426712036159 .43310165405 58.8235282897958 .5187492370658 .2139587402357 .909179687557 .9091796875 57.909179687557 .909179687558 .2139587402358 .5187492370659 .12831115723 59.4331016540560 .0426712036160 .9570198059161 .5666007995662 .48094940186 63.3953094482464 .3096618652365 .2240066528366 .1383666992267 .05272674561 67.9670867919968 .8814392089869 .7957916259870 .4053573608471 .31971740723 71.9292907714872 .5388565063573 .1484298706173 .7580032348674 .0627822876 74.6723632812574 .9771423339875 .5867080688576 .1962814331176 .80584716797 77.4154205322378 .0249862670978 .6345596313579 .2441329956179 .54891967773 79.8537063598679 .8537063598679 .8537063598679 .5489196777378 .93934631348 78.3297805786177 .4154205322376 .5010681152375 .2819290161174 .0627822876 72.8436431884871 .3197174072369 .7957916259868 .2718734741266 .74794006348 65.2240066528363 .7000885009862 .1761703491260 .6522407531759 .12831115723 
57.6043891906756 .0804595947355 .16611099243 -9999 -9999 -9999 -9999 -9999 -9999 -9999 -9999 -9999 -9999 -9999 -9999 -9999 -9999 -9999 -9999 -9999 -9999 -9999 -9999 -9999 -9999 -9999 -9999 -9999 -9999 -9999 -9999 -9999 -9999 -9999 -9999 -9999 -9999 -9999 -9999 -9999 $-9999-9999$

-9999 -9999 -9999 -9999 -9999 -9999 -9999 -9999 -9999 -9999 -9999 -9999 -9999 -9999 -9999 -9999 -9999 -9999 -9999 -9999 -9999 -9999 -9999 -9999 -9999 -9999 -9999 -9999 -9999 -9999 -9999 -9999 -9999 -9999 -9999 -9999 -9999 -9999 -9999 -9999 -9999 -9999 -9999 -9999 -9999 -9999 -9999 -9999 -9999 -9999 -9999 -9999 -9999 -9999 -9999 -9999 -9999 -9999 -9999 -9999 -9999 -9999 -9999 -9999 -9999 -9999 -9999 -9999 -9999 -9999 -9999 -9999 -9999 -9999 -9999 -9999 -9999 -9999 -9999 -9999 -9999 -9999 -9999 -9999 -9999 -9999 -9999 -9999 -9999 -9999

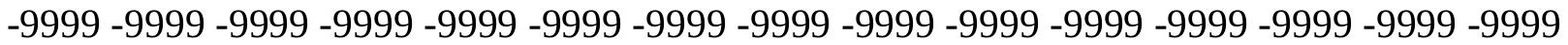
-9999 -9999 -9999 -9999 -9999 -9999-9999 -9999 -9999 -9999 -9999 -9999-9999-9999-999 -9999 -9999 -9999 -9999 -9999 -9999 -9999 -9999 -9999 -9999 -9999 -9999 -9999 -9999 -9999 -9999 -9999 -9999 -9999 -9999 -9999 -9999 -9999 -9999 -9999 -9999 -9999 -9999 -9999 -9999 -9999 -9999 -9999 -9999 -9999 -9999 -9999 -9999 -9999 -9999 -9999 -9999 -9999 -9999 -9999 -9999 -9999 -9999 -9999 -9999 -9999 -9999 -9999 -9999 -9999 -9999 -9999 -9999 -9999 -9999

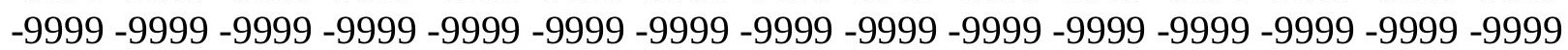

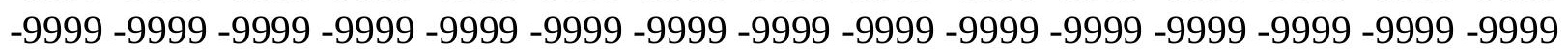
-9999 -9999 -9999 -9999 -9999 -9999 -9999 -9999 -9999 -9999 -9999 -9999 100.2742996216 99.6647262573298 .445587158297 .5312423706196 .9216690063596 .92166900635 96.9216690063596 .9216690063596 .6168823242296 .3121032714896 .00731658936 95.7025299072395 .397743225195 .0929565429794 .4833908081194 .17859649658 93.8738174438593 .2642517089892 .9594726562592 .349891662691 .74033355713 91.1307525634890 .2164001464889 .6068267822388 .6924667358487 .77810668945 86.8637619018686 .254188537685 .3398437584 .4254837036183 .81591033936 82.9015579223682 .2919769287181 .3776321411180 .7680587768679 .85370635986 78.9393463134878 .0249862670977 .110626220776 .1962814331175 .28192901611 74.3675689697373 .1484298706172 .2340774536173 .4532165527374 .0627822876 74.6723632812574 .062782287673 .1484298706172 .5388565063571 .62449645996 71.014930725169 .7957916259865 .8335876464865 .2240066528364 .91924285889 64.6144485473664 .004882812563 .7000885009863 .0905189514262 .78573989868 61.8713798522961 .2618103027360 .6522407531760 .0426712036159 .12831115723 58.8235282897958 .2139587402357 .909179687557 .909179687557 .60438919067 57.909179687557 .909179687558 .2139587402358 .8235282897959 .12831115723 59.7378807067960 .6522407531761 .2618103027362 .1761703491263 .09051895142 64.004882812564 .9192428588965 .8335876464866 .7479400634867 .66230010986 68.5766525268669 .4910125732470 .4053573608471 .014930725171 .62449645996 72.5388565063573 .1484298706173 .4532165527374 .062782287674 .67236328125 75.2819290161175 .8914871215876 .5010681152377 .110626220777 .72020721436 78.3297805786178 .9393463134879 .5489196777379 .8537063598680 .15849304199 80.1584930419980 .1584930419979 .5489196777379 .2441329956178 .32978057861 77.4154205322376 .5010681152375 .2819290161174 .062782287672 .84364318848 71.3197174072369 .7957916259868 .2718734741266 .7479400634865 .22400665283 63.7000885009862 .1761703491260 .3474502563558 .8235282897957 .29959869385 56.0804595947355 .16611099243 -9999 -9999 -9999 -9999 -9999 -9999 -9999 -9999 -9999 -9999 -9999 -9999 -9999 -9999 -9999 -9999 -9999 -9999 -9999 -9999 -9999 -9999 -9999 -9999 
-9999 -9999 -9999 -9999 -9999 -9999 -9999 -9999 -9999 -9999 -9999 -9999 -9999 -9999 -9999 -9999 -9999 -9999 -9999 -9999 -9999 -9999 -9999 -9999 -9999 -9999 -9999 -9999 -9999 -9999 -9999 -9999 -9999 -9999 -9999 -9999 -9999 -9999 -9999 -9999 -9999 -9999 -9999 -9999 -9999 -9999 -9999 -9999 -9999 -9999 -9999 -9999 -9999 -9999 -9999 -9999 -9999 -9999 -9999 -9999 -9999 -9999 -9999 -9999 -9999 -9999 -9999 -9999 -9999 -9999 -9999 -9999 -9999 -9999 -9999 -9999 -9999 -9999 -9999 -9999 -9999 -9999 -9999 -9999 -9999 -9999 -9999 -9999 -9999 -9999 -9999 -9999 -9999 -9999 -9999 -9999 -9999 -9999 -9999 -9999 -9999 -9999 -9999 -9999 -9999

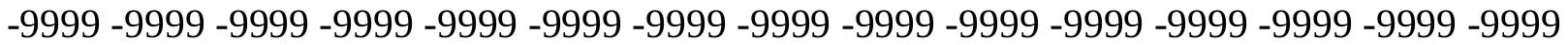
-9999 -9999 -9999 -9999 -9999 -9999 -9999 -9999 -9999 -9999 -9999 -9999 -9999 -9999 -9999 -9999 -9999 -9999 -9999 -9999 -9999 -9999 -9999 -9999 -9999 -9999 -9999 -9999 -9999 -9999 -9999 -9999 -9999 -9999 -9999 -9999 -9999 -9999 -9999 -9999 -9999 -9999 -9999 -9999 -9999 -9999 -9999 -9999 -9999 -9999 -9999 -9999 -9999 -9999 -9999 -9999 -9999 -9999 -9999 -9999

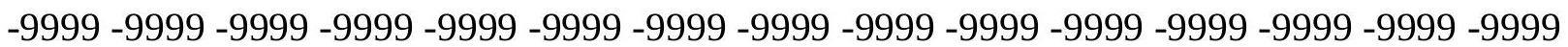
-9999 -9999 -9999 -9999 -9999 -9999 -9999 -9999 -9999 -9999 -9999 -9999 -9999 -9999 -9999 -9999 -9999 -9999 -9999 -9999 -9999 -9999 -9999 -9999 -9999 -9999 -9999 -9999 -9999 -9999 -9999 -9999 -9999 -9999 -9999 -9999 -9999 -9999 -9999 -9999 -9999 -9999 -9999 99.9695205688599 .0551681518697 .8360290527396 .9216690063597 .22646331787 96.0073165893696 .0073165893696 .0073165893696 .0073165893695 .70252990723 95.397743225195 .397743225195 .0929565429794 .7881774902394 .48339080811 94.1785964965893 .8738174438593 .5690307617293 .2642517089892 .65467834473 92.0450973510791 .4355392456190 .8259735107490 .2164001464889 .3020401001 88.6924667358487 .7781066894587 .1685485839886 .254188537685 .64462280273 84.7302627563584 .1206970214883 .206336975182 .5967712402381 .68241119385 80.7680587768679 .8537063598678 .9393463134878 .0249862670977 .1106262207 78.0249862670977 .7202072143677 .7202072143678 .3297805786178 .63455963135 78.9393463134878 .9393463134878 .3297805786177 .7202072143677 .1106262207 76.1962814331174 .9771423339873 .1484298706171 .6244964599670 .10057830811 65.8335876464865 .2240066528364 .6144485473664 .004882812563 .39530944824 62.7857398986861 .8713798522961 .2618103027360 .3474502563559 .73788070679 59.1283111572358 .5187492370658 .2139587402357 .909179687557 .60438919067 57.909179687557 .909179687558 .2139587402358 .5187492370659 .12831115723 59.7378807067960 .3474502563560 .9570198059161 .8713798522962 .78573989868 63.7000885009864 .6144485473665 .5288009643666 .4431610107467 .35751342773 68.2718734741269 .1862335205170 .1005783081171 .014930725171 .62449645996 72.2340774536173 .1484298706173 .7580032348674 .3675689697374 .97714233398 75.5867080688576 .1962814331176 .8058471679777 .4154205322378 .32978057861 78.9393463134879 .5489196777379 .8537063598680 .1584930419980 .46327209473 80.4632720947380 .1584930419979 .8537063598679 .2441329956178 .63455963135 77.7202072143676 .5010681152375 .2819290161174 .062782287672 .84364318848 71.3197174072369 .7957916259868 .2718734741266 .7479400634865 .22400665283 63.3953094482461 .8713798522960 .3474502563558 .8235282897957 .29959869385 55.7756805419955 .16611099243 -9999 -9999 -9999 -9999 -9999 -9999 -9999 -9999 -9999

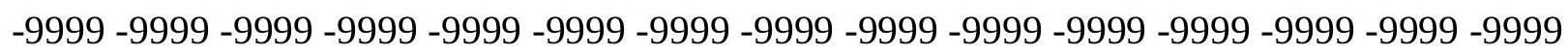
-9999 -9999 -9999 -9999 -9999 -9999 -9999 -9999 -9999 -9999 -9999 -9999 -9999 -9999 -9999 -9999 -9999 -9999 -9999 -9999 -9999 -9999 -9999 -9999 -9999 -9999 -9999 -9999 -9999 -9999

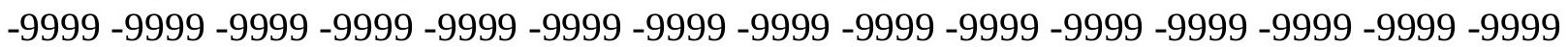


-9999 -9999 -9999 -9999 -9999 -9999 -9999 -9999 -9999 -9999 -9999 -9999 -9999 -9999 -9999 -9999 -9999 -9999 -9999 -9999 -9999 -9999 -9999 -9999 -9999 -9999 -9999 -9999 -9999 -9999

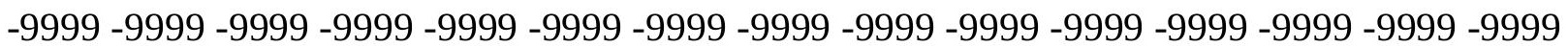
-9999 -9999 -9999 -9999 -9999 -9999 -9999 -9999 -9999 -9999 -9999 -9999 -9999 -9999 -9999 -9999 -9999 -9999 -9999 -9999 -9999 -9999 -9999 -9999 -9999 -9999 -9999 -9999 -9999 -9999 -9999 -9999 -9999 -9999 -9999 -9999 -9999 -9999 -9999 -9999 -9999 -9999 -9999 -9999 -9999 -9999 -9999 -9999 -9999 -9999 -9999 -9999 -9999 -9999 -9999 -9999 -9999 -9999 -9999 -9999

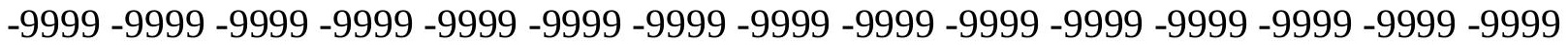
-9999 -9999 -9999 -9999 -9999 -9999 -9999 -9999 -9999 -9999 -9999 -9999 -9999 -9999 -9999 -9999 -9999 -9999 -9999 -9999 -9999 -9999 -9999 -9999 -9999 -9999 -9999 -9999 -9999 -9999 -9999 -9999 -9999 -9999 -9999 -9999 -9999 -9999 -9999 -9999 -9999 -9999 -9999 -9999 -9999 -9999 -9999 -9999 -9999 -9999 -9999 -9999 -9999 -9999 -9999 -9999 -9999 -9999 -9999 -9999 -9999 -9999 -9999 -9999 -9999 -9999 -9999 -9999 -9999 -9999 -9999 -9999 -9999 -9999 -9999 98.445587158297 .2264633178796 .3121032714895 .397743225195 .09295654297 95.397743225195 .397743225195 .397743225195 .397743225195 .09295654297 95.0929565429794.7881774902394.7881774902394.4833908081194.48339080811 94.1785964965893 .8738174438593 .2642517089892 .9594726562592 .3498916626 92.0450973510791 .4355392456190 .8259735107489 .9116134643689 .3020401001 88.6924667358487 .7781066894587 .1685485839886 .254188537685 .64462280273 85.0350494384884 .1206970214883 .5111236572382 .5967712402381 .68241119385 82.9015579223682 .2919769287181 .9871978759881 .6824111938581 .68241119385 81.6824111938581 .9871978759882 .2919769287182 .5967712402382 .59677124023 82.2919769287181 .6824111938581 .0728530883880 .1584930419978 .93934631348 77.4154205322375 .2819290161172 .8436431884867 .0527267456169 .49101257324 65.8335876464864 .9192428588964 .3096618652363 .3953094482462 .48094940186 61.8713798522960 .9570198059160 .0426712036159 .4331016540558 .82352828979 58.2139587402357 .909179687557 .909179687557 .909179687557 .9091796875 58.2139587402358 .5187492370659 .1283111572359 .4331016540560 .04267120361 60.9570198059161 .8713798522962 .4809494018663 .3953094482464 .61444854736 65.5288009643666 .4431610107467 .3575134277368 .2718734741269 .18623352051 70.1005783081170 .7101516723671 .6244964599672 .2340774536173 .14842987061 73.7580032348674 .3675689697375 .2819290161175 .8914871215876 .50106811523 77.4154205322378 .0249862670978 .6345596313579 .2441329956179 .85370635986 80.4632720947380 .7680587768680 .7680587768680 .7680587768680 .46327209473 80.1584930419979 .5489196777378 .6345596313577 .7202072143676 .50106811523 75.2819290161174 .062782287672 .8436431884871 .3197174072369 .79579162598 68.2718734741266 .7479400634864 .9192428588963 .3953094482461 .87137985229 $60.3474502563558 .5187492370656 .9948196411155 .4708900451755 .16611099243-9999$ -9999 -9999 -9999 -9999 -9999 -9999 -9999 -9999 -9999 -9999 -9999 -9999 -9999 -9999 -9999 -9999 -9999 -9999 -9999 -9999 -9999 -9999 -9999 -9999 -9999 -9999 -9999 -9999 -9999 -9999 -9999 -9999 -9999 -9999 -9999 -9999 -9999 -9999

-9999 -9999 -9999 -9999 -9999 -9999 -9999 -9999 -9999 -9999 -9999 -9999 -9999 -9999 -9999 -9999 -9999 -9999 -9999 -9999 -9999 -9999 -9999 -9999 -9999 -9999 -9999 -9999 -9999 -9999 -9999 -9999 -9999 -9999 -9999 -9999 -9999 -9999 -9999 -9999 -9999 -9999 -9999 -9999 -9999 -999 -9999 -9999 -9999 -9999 -9999 -9999 -9999 -9999 -9999 -9999 -9999 -9999 -9999 -9999 -9999

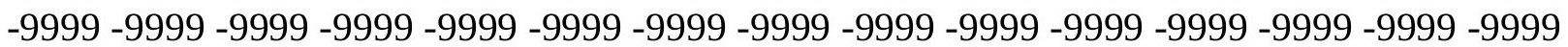


-9999 -9999 -9999 -9999 -9999 -9999 -9999 -9999 -9999 -9999 -9999 -9999 -9999 -9999 -9999 -9999 -9999 -9999 -9999 -9999 -9999 -9999 -9999 -9999 -9999 -9999 -9999 -9999 -9999 -9999 -9999 -9999 -9999 -9999 -9999 -9999 -9999 -9999 -9999 -9999 -9999 -9999 -9999 -9999 -9999 -9999 -9999 -9999 -9999 -9999 -9999 -9999 -9999 -9999 -9999 -9999 -9999 -9999 -9999 -9999 -9999 -9999 -9999 -9999 -9999 -9999 -9999 -9999 -9999 -9999 -9999 -9999 -9999 -9999 -9999 -9999 -9999 -9999 -9999 -9999 -9999 -9999 -9999 -9999 -9999 -9999 -9999 -9999 -9999 -9999 -9999 -9999 -9999 -9999 -9999 -9999 -9999 -9999 -9999 -9999 -9999 -9999 -9999 -9999 -9999

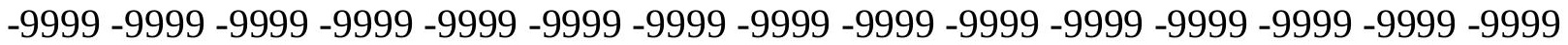
-9999 -9999 -9999 -9999 -9999 -9999 -9999 -9999 -9999 -9999 -9999 -9999 -9999 -9999 -9999 -9999 -9999 -9999 -9999 -9999 -9999 -9999 -9999 -9999 -9999 -9999 -9999 -9999 -9999 -9999 -999 -9999 97.8360290527396.9216690063596.0073165893695.397743225194.78817749023 94.7881774902394 .7881774902395 .0929565429795 .0929565429795 .09295654297 94.7881774902394 .7881774902394 .7881774902394 .4833908081194 .48339080811 94.1785964965893 .8738174438593 .5690307617293 .2642517089892 .65467834473 92.349891662691 .7403335571391 .1307525634890 .5211791992289 .91161346436 89.302040100188 .6924667358487 .7781066894587 .1685485839886 .55898284912 85.6446228027385 .0350494384884 .1206970214885 .0350494384885 .03504943848 84.7302627563584 .7302627563584 .7302627563584 .7302627563584 .73026275635 85.0350494384885 .3398437585 .3398437585 .3398437585 .3398437584 .73026275635 84.1206970214883 .206336975181 .9871978759880 .4632720947378 .32978057861 75.5867080688573 .4532165527371 .6244964599666 .7479400634866 .13836669922 65.2240066528364 .3096618652363 .3953094482462 .4809494018661 .56660079956 60.6522407531759 .7378807067959 .1283111572358 .5187492370658 .21395874023 58.2139587402357 .909179687558 .2139587402358 .2139587402358 .82352828979 59.1283111572359 .7378807067960 .0426712036160 .9570198059161 .56660079956 62.4809494018663 .3953094482464 .6144485473665 .5288009643666 .44316101074 67.3575134277368 .2718734741269 .1862335205170 .1005783081171 .0149307251 71.6244964599672 .5388565063573 .1484298706174 .062782287674 .67236328125 75.5867080688576 .1962814331177 .110626220777 .7202072143678 .63455963135 79.2441329956179 .8537063598680 .4632720947381 .0728530883881 .07285308838 81.3776321411181 .0728530883880 .7680587768680 .4632720947379 .54891967773 78.6345596313577 .7202072143676 .5010681152375 .2819290161174 .0627822876 72.5388565063571 .014930725169 .4910125732467 .9670867919966 .44316101074 64.9192428588963 .0905189514261 .5666007995660 .0426712036158 .51874923706 56.9948196411155 .4708900451755 .16611099243 -9999 -9999 -9999 -9999 -9999 -9999 -9999 -9999 -9999 -9999 -9999 -9999 -9999 -9999 -9999 -9999 -9999 -9999 -9999 -9999 -9999 -9999 -

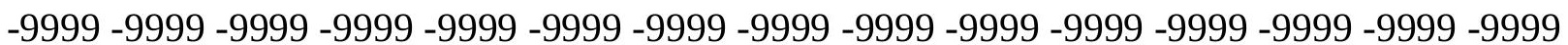
-9999-9999 -9999 -9999 -9999 -9999 -9999 -9999 -9999 -9999 -9999 -9999 -9999 -9999 -9999 -9999 -9999 -9999 -9999 -9999 -9999 -9999 -9999 -9999 -9999 -9999 -9999 -9999 -9999 -9999 -9999 -9999 -9999 -9999 -9999 -9999 -9999 -9999 -9999 -9999 -9999 -9999 -9999 -9999 -9999 -9999 -9999

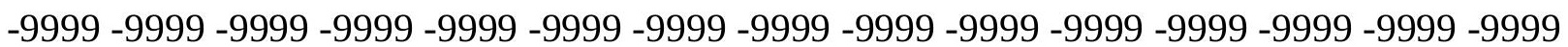
-9999 -9999 -9999 -9999 -9999 -9999 -9999 -9999 -9999 -9999 -9999 -9999 -9999 -9999 -9999 -9999 -9999 -9999 -9999 -9999 -9999 -9999 -9999 -9999 -9999 -9999 -9999 -9999 -9999 -9999 -9999 -9999 -9999 -9999 -9999 -9999 -9999 -9999 -9999 -9999 -9999 -9999 -9999 -9999 -9999

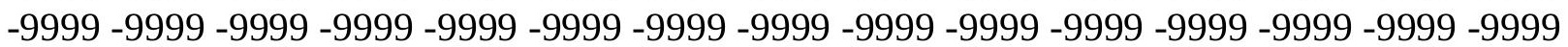


-9999 -9999 -9999 -9999 -9999 -9999 -9999 -9999 -9999 -9999 -9999 -9999 -9999 -9999 -9999 -9999 -9999 -9999 -9999 -9999 -9999 -9999 -9999 -9999 -9999 -9999 -9999 -9999 -9999 -9999 -9999 -9999 -9999 -9999 -9999 -9999 -9999 -9999 -9999 -9999 -9999 -9999 -9999 -9999 -9999 -9999 -9999 -9999 -9999 -9999 -9999 -9999 -9999 -9999 -9999 -9999 -9999 -9999 -9999 -9999 -9999 -9999 -9999 -9999 -9999 -9999 -9999 -9999 -9999 -9999 -9999 -9999 -9999 -9999 -9999 -9999 -9999 -9999 -9999 -9999 -9999 -9999 -9999 -9999 -9999 -9999 -9999 -9999 -9999 -9999 -9999 -9999 -9999 -9999 -9999 -9999 -9999 -9999 -9999 -9999 -9999 -9999 -9999 -9999 -9999 -9999 -9999 97.5312423706196.6168823242296.0073165893695.09295654297 96.0073165893694 .4833908081194 .7881774902394 .7881774902394 .78817749023 94.7881774902394 .7881774902394 .7881774902394 .7881774902394 .78817749023 94.4833908081194 .1785964965894 .1785964965893 .8738174438593 .56903076172 92.9594726562592 .6546783447392 .0450973510791 .4355392456191 .13075256348 90.5211791992289 .9116134643689 .302040100188 .6924667358488 .08290100098 87.1685485839886 .5589828491285 .6446228027385 .0350494384886 .55898284912 86.8637619018686 .8637619018686 .8637619018686 .8637619018687 .16854858398 87.47332763672 87.47332763672 87.77810668945 87.77810668945 87.47332763672 87.1685485839886 .5589828491285 .6446228027384 .4254837036182 .59677124023 80.4632720947378 .3297805786175 .8914871215873 .7580032348671 .31971740723 67.0527267456166 .1383666992265 .2240066528364 .3096618652363 .39530944824 62.1761703491261 .2618103027360 .3474502563559 .4331016540558 .82352828979 58.5187492370658 .5187492370658 .5187492370658 .5187492370658 .82352828979 58.8235282897959 .4331016540559 .7378807067960 .3474502563560 .95701980591 61.8713798522962 .7857398986863 .7000885009864 .6144485473665 .52880096436 66.4431610107467 .3575134277368 .2718734741269 .1862335205170 .10057830811 71.014930725171 .9292907714872 .5388565063573 .4532165527374 .36756896973 74.9771423339875 .8914871215876 .5010681152377 .4154205322378 .32978057861 78.9393463134879 .8537063598680 .4632720947381 .0728530883881 .37763214111 81.6824111938581 .6824111938581 .6824111938581 .0728530883880 .46327209473 79.8537063598678 .9393463134877 .7202072143676 .5010681152375 .28192901611 74.062782287672 .5388565063571 .014930725169 .4910125732467 .96708679199 66.1383666992264 .6144485473663 .0905189514261 .5666007995659 .73788070679 58.2139587402356 .9948196411155 .4708900451755 .16611099243 -9999 -9999 -9999 -9999 -9999 -9999 -9999 -9999 -9999 -9999 -9999 -9999 -9999 -9999 -9999 -9999 -9999 -9999 -9999 -9999 -9999 -9999 -9999 -9999 -9999 -9999 -9999 -9999 -9999 -9999 -9999 -9999 -9999 -9999 -9999 -9999-9999-9999-9999

-9999 -9999 -9999 -9999 -9999 -9999 -9999 -9999 -9999 -9999 -9999 -9999 -9999 -9999 -9999 -9999 -9999 -9999 -9999 -9999 -9999 -9999 -9999 -9999 -9999 -9999 -9999 -9999 -9999 -9999

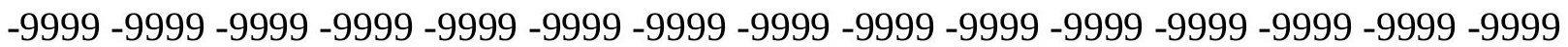
-9999 -9999 -9999 -9999 -9999 -9999 -9999 -9999 -9999 -9999 -9999 -9999 -9999 -9999 -9999 -9999 -9999 -9999 -9999 -9999 -9999 -9999 -9999 -9999 -9999 -9999 -9999 -9999 -9999 -9999 -9999 -9999 -9999 -9999 -9999 -9999 -9999 -9999 -9999 -9999 -9999 -9999 -9999 -9999 -9999

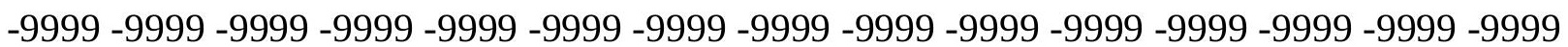
-9999 -9999 -9999 -9999 -9999 -9999 -9999 -9999 -9999 -9999 -9999 -9999 -9999 -9999 -9999 -9999 -9999 -9999 -9999 -9999 -9999 -9999 -9999 -9999 -9999 -9999 -9999 -9999 -9999 -9999 -9999 -9999 -9999 -9999 -9999 -9999 -9999 -9999 -9999 -9999 -9999 -9999 -9999 -9999 -9999

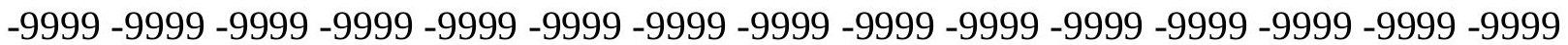


-9999 -9999 -9999 -9999 -9999 -9999 -9999 -9999 -9999 -9999 -9999 -9999 -9999 -9999 -9999 -9999 -9999 -9999 -9999 -9999 -9999 -9999 -9999 -9999 -9999 -9999 -9999 -9999 -9999 -9999 -9999 -9999 -9999 -9999 -9999 -9999 -9999 -9999 -9999 -9999 -9999 -9999 -9999 -9999 -9999 -9999 -9999 -9999 -9999 -9999 -9999 -9999 -9999 -9999 -9999 -9999 -9999 -9999 -9999 -9999 -9999 -9999 -9999 97.2264633178796.31210327148 95.70252990723 95.09295654297 94.4833908081194 .4833908081194 .4833908081194 .7881774902394 .78817749023 94.7881774902394 .7881774902394 .7881774902394 .7881774902394 .78817749023 94.4833908081194 .4833908081194 .1785964965893 .8738174438593 .56903076172 93.2642517089892 .9594726562592 .349891662692 .0450973510791 .43553924561 91.1307525634890 .5211791992289 .9116134643689 .302040100188 .69246673584 87.7781066894587 .1685485839886 .5589828491287 .7781066894588 .08290100098 88.3876876831188 .3876876831188 .6924667358488 .9972534179788 .99725341797 89.3020401001 89.302040100189.302040100189.302040100188.99725341797 88.3876876831187 .4733276367286 .254188537684 .4254837036182 .59677124023 80.1584930419978 .0249862670975 .5867080688573 .1484298706168 .57665252686 67.3575134277366 .4431610107465 .5288009643664 .3096618652363 .09051895142 62.1761703491260 .9570198059160 .0426712036159 .4331016540559 .12831115723 59.1283111572359 .1283111572359 .1283111572359 .1283111572359 .43310165405 59.7378807067960 .0426712036160 .6522407531761 .2618103027362 .17617034912 63.0905189514264 .004882812564 .9192428588965 .8335876464866 .74794006348 67.6623001098668 .5766525268669 .4910125732470 .4053573608471 .31971740723 71.9292907714872 .8436431884873 .7580032348674 .3675689697375 .28192901611 76.1962814331177 .110626220777 .7202072143678 .6345596313579 .54891967773 80.1584930419980 .7680587768681 .3776321411181 .9871978759882 .29197692871 82.2919769287181 .9871978759881 .3776321411180 .7680587768679 .85370635986 78.9393463134877 .7202072143676 .5010681152375 .2819290161173 .75800323486 72.2340774536170 .7101516723669 .1862335205167 .6623001098666 .13836669922 64.3096618652362 .7857398986861 .2618103027359 .7378807067958 .21395874023 56.6900291442955 .4708900451755 .16611099243 -9999 -9999 -9999 -9999 -9999 -9999 -9999 -9999 -9999 -9999 -9999 -9999 -9999 -9999 -9999 -9999 -9999 -9999 -9999 -9999 -9999 -9999 -9999 -9999 -9999 -9999 -9999 -9999 -9999 -9999 -9999 -9999 -9999 -9999 -9999 -9999 -9999 $-9999-9999$

-9999 -9999 -9999 -9999 -9999 -9999 -9999 -9999 -9999 -9999 -9999 -9999 -9999 -9999 -9999 -9999 -9999 -9999 -9999 -9999 -9999 -9999 -9999 -9999 -9999 -9999 -9999 -9999 -9999 -9999 -

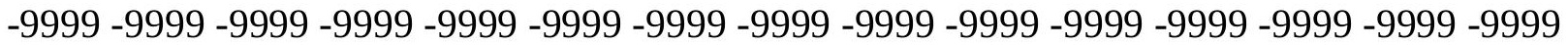
-9999 -9999 -9999 -9999 -9999 -9999 -9999 -9999 -9999 -9999 -9999 -9999 -9999 -9999 -9999 -9999 -9999 -9999 -9999 -9999 -9999 -9999 -9999 -9999 -9999 -9999 -9999 -9999 -9999 -9999

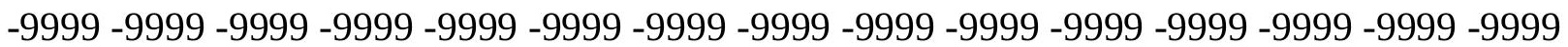
-9999 -9999 -9999 -9999 -9999 -9999 -9999 -9999 -9999 -9999 -9999 -9999 -9999 -9999 -9999 -9999 -9999 -9999 -9999 -9999 -9999 -9999 -9999 -9999 -9999 -9999 -9999 -9999 -9999 -9999 -9999 -9999 -9999 -9999 -9999 -9999 -9999 -9999 -9999 -9999 -9999 -9999 -9999 -9999 -9999

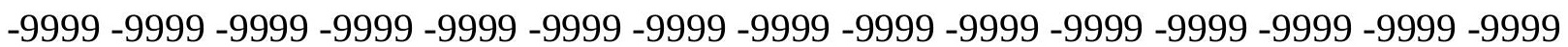
-9999 -9999 -9999 -9999 -9999 -9999 -9999 -9999 -9999 -9999 -9999 -9999 -9999 -9999 -9999 -9999 -9999 -9999 -9999 -9999 -9999 -9999 -9999 -9999 -9999 -9999 -9999 -9999 -9999 -9999 -999 -9999 -9999 -9999 -9999 -9999 -9999 -9999 -9999 -9999 -9999 -9999 -9999 -9999 -9999 -9999

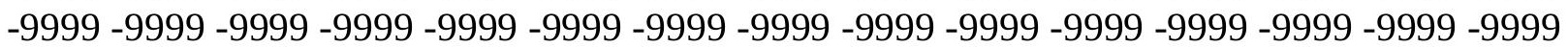


-9999 -9999 -9999 -9999 -9999 -9999 -9999 -9999 -9999 -9999 -9999 -9999 -9999 -9999 -9999 -9999 -9999 -9999 -9999 -9999 96.31210327148 95.70252990723 95.09295654297 94.4833908081194 .4833908081194 .4833908081194 .7881774902394 .78817749023 94.7881774902394 .7881774902394 .7881774902394 .7881774902394 .78817749023 94.4833908081194 .4833908081194 .1785964965893 .8738174438593 .87381744385 93.5690307617292 .9594726562592 .6546783447392 .349891662692 .04509735107 91.4355392456190 .8259735107490 .2164001464889 .6068267822388 .99725341797 88.3876876831187 .7781066894587 .1685485839888 .9972534179789 .3020401001 89.60682678223 89.9116134643690.21640014648 90.21640014648 90.52117919922 90.5211791992290 .5211791992290 .5211791992290 .2164001464889 .60682678223 88.6924667358487 .4733276367285 .6446228027383 .8159103393681 .68241119385 79.5489196777377 .110626220774 .6723632812571 .9292907714868 .88143920898 67.6623001098666 .7479400634865 .5288009643664 .3096618652363 .09051895142 61.8713798522960 .9570198059160 .3474502563560 .0426712036160 .04267120361 59.7378807067960 .0426712036160 .0426712036160 .0426712036160 .34745025635 60.6522407531761 .2618103027361 .8713798522962 .7857398986863 .39530944824 64.3096618652365 .2240066528366 .1383666992267 .0527267456167 .96708679199 68.8814392089869 .7957916259870 .7101516723671 .3197174072372 .23407745361 73.1484298706173 .7580032348674 .6723632812575 .5867080688576 .50106811523 77.4154205322378 .0249862670978 .9393463134879 .8537063598680 .46327209473 81.0728530883881 .9871978759882 .2919769287182 .5967712402382 .59677124023 82.2919769287181 .6824111938580 .7680587768679 .8537063598678 .63455963135 77.4154205322376 .1962814331174 .9771423339873 .4532165527371 .92929077148 70.4053573608468 .8814392089867 .3575134277365 .8335876464864 .0048828125 62.4809494018660 .9570198059159 .4331016540557 .909179687556 .38525009155 55.1661109924355 .47089004517 -9999 -9999 -9999 -9999 -9999 -9999 -9999 -9999 -9999 -9999 -9999 -9999 -9999 -9999 -9999 -9999 -9999 -9999 -9999 -9999 -9999 -9999 -9999 -9999 -9999 -9999 -9999 -9999 -9999 -9999 -9999 -9999 -9999 -9999 -9999 -9999 -9999 -9999 -9999

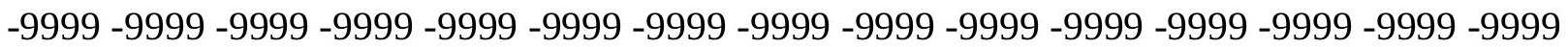

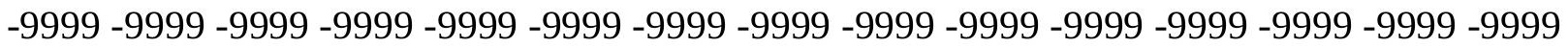
-9999 -9999 -9999 -9999 -9999 -9999 -9999 -9999 -9999 -9999 -9999 -9999 -9999 -9999 -9999 -

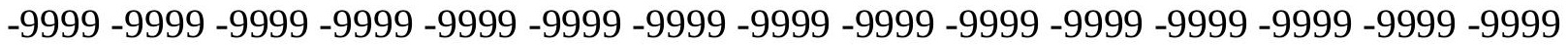
-9999 -9999 -9999 -9999 -9999 -9999 -9999 -9999 -9999 -9999 -9999 -9999 -9999 -9999 -9999 -9999 -9999 -9999 -9999 -9999 -9999 -9999 -9999 -9999 -9999 -9999 -9999 -9999 -9999 -9999 -

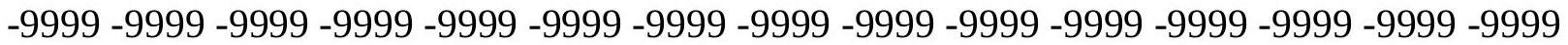
-9999 -9999 -9999 -9999 -9999 -9999 -9999 -9999 -9999 -9999 -9999 -9999 -9999 -9999 -9999 -9999 -9999 -9999 -9999 -9999 -9999 -9999 -9999 -9999 -9999 -9999 -9999 -9999 -9999 -9999

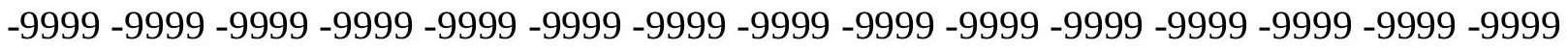
-9999 -9999 -9999 -9999 -9999 -9999 -9999 -9999 -9999 -9999 -9999 -9999 -9999 -9999 -9999 -9999 -9999 -9999 -9999 -9999 -9999 -9999 -9999 -9999 -9999 -9999 -9999 -9999 -9999 -9999 -

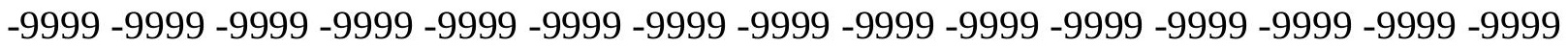
-9999 -9999 -9999 -9999 -9999 -9999 -9999 -9999 -9999 -9999 -9999 -9999 -9999 -9999 -9999 -9999 -9999 -9999 -9999 -9999 -9999 -9999 -9999 -9999 -9999 -9999 -9999 -9999 -9999 -9999 -999 -9999 -9999 -9999 -9999 -9999 -9999 96.31210327148 95.70252990723 95.09295654297 94.7881774902394 .4833908081194 .4833908081194 .7881774902394 .78817749023 94.7881774902394 .7881774902394 .7881774902394 .7881774902394 .78817749023 
94.4833908081194 .4833908081194 .1785964965894 .1785964965893 .87381744385 93.5690307617293 .2642517089892 .9594726562592 .6546783447392 .04509735107 91.7403335571391 .1307525634890 .8259735107490 .2164001464889 .60682678223 88.9972534179788 .3876876831189 .6068267822389 .9116134643690 .52117919922 90.8259735107491 .1307525634891 .1307525634891 .4355392456191 .43553924561 91.4355392456191 .1307525634890 .8259735107490 .2164001464889 .3020401001 88.0829010009886 .5589828491284 .7302627563582 .9015579223680 .76805877686 78.3297805786175 .8914871215873 .1484298706170 .1005783081169 .18623352051 67.9670867919966 .7479400634865 .5288009643664 .6144485473663 .39530944824 62.4809494018661 .8713798522961 .2618103027361 .2618103027360 .95701980591 60.9570198059160 .9570198059161 .2618103027361 .2618103027361 .56660079956 62.1761703491262 .7857398986863 .3953094482464 .004882812564 .91924285889 65.8335876464866 .7479400634867 .6623001098668 .2718734741269 .18623352051 70.1005783081171 .014930725171 .6244964599672 .5388565063573 .45321655273 74.062782287674 .9771423339875 .8914871215876 .5010681152377 .41542053223 78.3297805786178 .9393463134879 .8537063598680 .7680587768681 .37763214111 81.9871978759882 .5967712402382 .9015579223683 .206336975182 .59677124023 81.6824111938580 .7680587768679 .5489196777378 .6345596313577 .41542053223 76.1962814331174 .6723632812573 .1484298706171 .6244964599670 .10057830811 68.5766525268667 .0527267456165 .5288009643663 .7000885009862 .17617034912 60.6522407531759 .1283111572357 .6043891906756 .0804595947355 .47089004517 55.47089004517 -9999 -9999 -9999 -9999 -9999 -9999 -9999 -9999 -9999 -9999 -9999 -9999 -9999 -9999 -9999 -9999 -9999 -9999 -9999 -9999 -9999 -9999 -9999 -9999 -9999 -9999 -9999 -9999 -9999 -9999 -9999 -9999 -9999 -9999 -9999 -9999 -9999 -9999 -9999 -

-9999 -9999 -9999 -9999 -9999 -9999 -9999 -9999 -9999 -9999 -9999 -9999 -9999 -9999 -9999 -9999 -9999 -9999 -9999 -9999 -9999 -9999 -9999 -9999 -9999 -9999 -9999 -9999 -9999 -9999 -9999 -9999 -9999 -9999 -9999 -9999 -9999 -9999 -9999 -9999 -9999 -9999 -9999 -9999 -9999 -

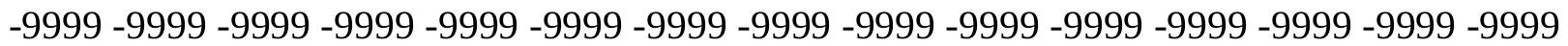
-9999 -9999 -9999 -9999 -9999 -9999 -9999 -9999 -9999 -9999 -9999 -9999 -9999 -9999 -9999 -9999 -9999 -9999 -9999 -9999 -9999 -9999 -9999 -9999 -9999 -9999 -9999 -9999 -9999 -9999 -9999 -9999 -9999 -9999 -9999 -9999 -9999 -9999 -9999 -9999 -9999 -9999 -9999 -9999 -9999

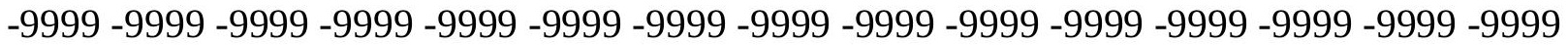

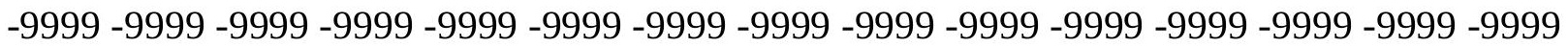
-9999 -9999 -9999 -9999 -9999 -9999 -9999 -9999 -9999 -9999 -9999 -9999 -9999 -9999 -9999 -9999 -9999 -9999 -9999 -9999 -9999 -9999 -9999 -9999 -9999 -9999 -9999 -9999 -9999 -9999 -9999 -9999 -9999 -9999 -9999 -9999 -9999 -9999 -9999 -9999 -9999 -9999 -9999 -9999 -9999

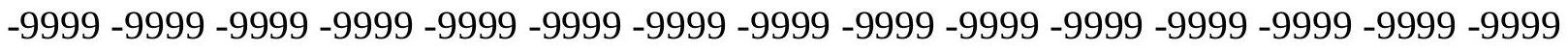

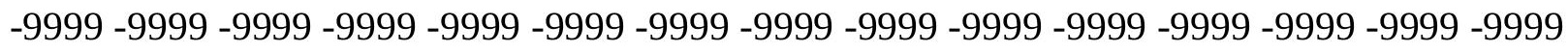
-9999 -9999 -9999 -9999 -9999 -9999 -9999 -9999 -9999 -9999 -9999 -9999 -9999 -9999 -9999 -9999 -9999 -9999 -9999 -9999 -9999-9999 96.31210327148 95.70252990723 95.09295654297 94.7881774902394 .4833908081194 .4833908081194 .7881774902394 .78817749023 94.7881774902394 .7881774902394 .7881774902394 .7881774902394 .78817749023 94.4833908081194 .4833908081194 .1785964965894 .1785964965893 .87381744385 93.5690307617293 .2642517089892 .9594726562592 .6546783447392 .3498916626 91.7403335571391 .4355392456191 .1307525634890 .5211791992290 .21640014648 89.6068267822388 .9972534179790 .5211791992290 .8259735107491 .13075256348 
91.4355392456191 .7403335571391 .7403335571391 .7403335571391 .74033355713 91.4355392456191 .1307525634890 .5211791992289 .6068267822388 .38768768311 87.16854858398 85.33984375 83.51112365723 81.37763214111 79.24413299561 76.8058471679774 .3675689697371 .6244964599670 .4053573608469 .49101257324 68.2718734741267 .0527267456166 .1383666992264 .9192428588964 .0048828125 63.3953094482463 .0905189514262 .4809494018662 .4809494018662 .17617034912 62.1761703491262 .1761703491262 .4809494018662 .7857398986863 .09051895142 63.7000885009864 .3096618652364 .9192428588965 .5288009643666 .44316101074 67.3575134277367 .9670867919968 .8814392089869 .7957916259870 .40535736084 71.3197174072371 .9292907714872 .8436431884873 .4532165527374 .36756896973 74.9771423339875 .8914871215876 .8058471679777 .4154205322378 .32978057861 79.2441329956179 .8537063598680 .7680587768681 .3776321411181 .98719787598 82.5967712402382 .9015579223682 .5967712402382 .2919769287181 .37763214111 80.4632720947379 .2441329956178 .3297805786177 .110626220775 .58670806885 74.3675689697372 .8436431884871 .3197174072369 .7957916259868 .27187347412 66.7479400634865 .2240066528363 .3953094482461 .8713798522960 .34745025635 58.8235282897957 .2995986938555 .7756805419955 .4708900451755 .47089004517 -9999 -9999 -9999 -9999 -9999 -9999 -9999 -9999 -9999 -9999 -9999 -9999 -9999 -9999 -9999 -9999 -9999 -9999 -9999 -9999 -9999 -9999 -9999 -9999 -9999 -9999 -9999 -9999 -9999 -9999 -9999 -9999 -9999-9999-9999-9999-9999-9999-9999

-9999 -9999-9999 -9999 -9999 -9999 -9999 -9999 -9999-9999 -9999 -9999 -9999 -9999 -9999 -9999 -9999 -9999 -9999 -9999 -9999 -9999 -9999 -9999 -9999 -9999 -9999 -9999 -9999 -9999 -9999 -9999 -9999 -9999 -9999 -9999 -9999 -9999 -9999 -9999 -9999 -9999 -9999 -9999 -9999 -

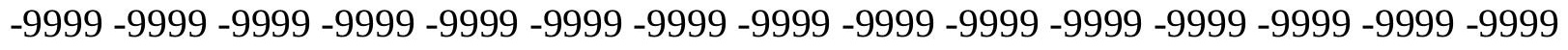

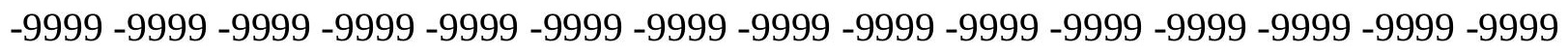
-9999 -9999 -9999 -9999 -9999 -9999 -9999 -9999 -9999 -9999 -9999 -9999 -9999 -9999 -9999

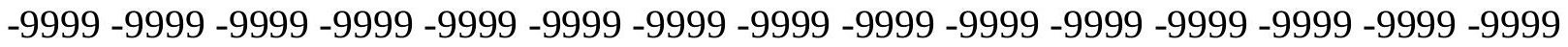

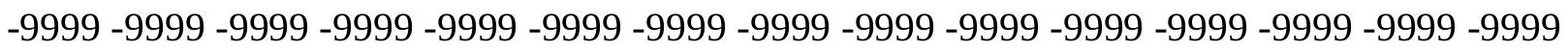
-9999 -9999 -9999 -9999 -9999 -9999 -9999 -9999 -9999 -9999 -9999 -9999 -9999 -9999 -9999 -9999 -9999 -9999 -9999 -9999 -9999 -9999 -9999 -9999 -9999 -9999 -9999 -9999 -9999 -9999 -9999 -9999 -9999 -9999 -9999 -9999 -9999 -9999 -9999 -9999 -9999 -9999-9999 -9999 -9999 -9999 -9999 -9999 -9999 -9999 -9999 -9999 -9999 -9999 -9999 -9999 -9999 -9999 -9999 -9999 -

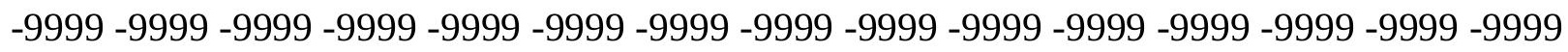

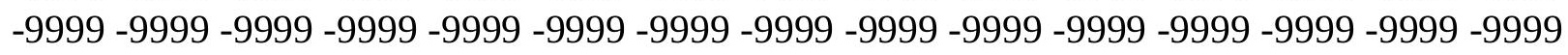

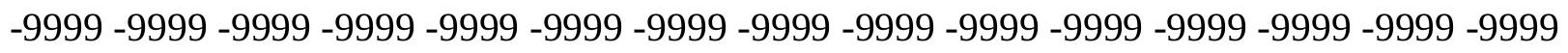
-9999 -9999 -9999-9999 -9999 -9999 -9999-9999 -9999 95.70252990723 95.3977432251 94.78817749023 94.4833908081194.4833908081194.4833908081194.48339080811 94.4833908081194 .4833908081194 .4833908081194 .4833908081194 .48339080811 94.4833908081194 .4833908081194 .1785964965894 .1785964965893 .87381744385 93.5690307617293 .2642517089892 .9594726562592 .6546783447392 .3498916626 92.0450973510791 .7403335571391 .4355392456191 .1307525634890 .52117919922 89.9116134643689 .302040100190 .8259735107491 .1307525634891 .43553924561 91.7403335571392 .0450973510792 .0450973510791 .7403335571391 .74033355713 91.1307525634890 .5211791992289 .6068267822388 .6924667358487 .47332763672 85.9494018554784 .1206970214881 .9871978759879 .8537063598677 .72020721436 74.3675689697373 .1484298706172 .2340774536171 .014930725170 .10057830811 
68.8814392089867 .9670867919966 .7479400634866 .1383666992265 .22400665283 64.6144485473664 .3096618652364 .004882812564 .004882812563 .70008850098 63.7000885009863 .7000885009864 .004882812564 .3096618652364 .61444854736 65.2240066528365 .8335876464866 .4431610107467 .3575134277367 .96708679199 68.8814392089869 .4910125732470 .4053573608471 .014930725171 .62449645996 72.5388565063573 .1484298706173 .7580032348674 .6723632812575 .28192901611 75.8914871215876 .8058471679777 .4154205322378 .3297805786178 .93934631348 79.8537063598680 .4632720947381 .0728530883881 .6824111938582 .29197692871 82.2919769287182 .2919769287181 .6824111938581 .0728530883880 .15849304199 78.9393463134877 .7202072143676 .5010681152375 .2819290161174 .0627822876 72.5388565063571 .014930725169 .4910125732467 .9670867919966 .44316101074 64.6144485473663 .0905189514261 .5666007995660 .0426712036158 .51874923706 56.9948196411155 .4708900451755 .47089004517 -9999 -9999 -9999 -9999 -9999 -9999 -9999 -9999 -9999 -9999 -9999 -9999 -9999 -9999 -9999 -9999 -9999 -9999 -9999 -9999 -9999 -9999

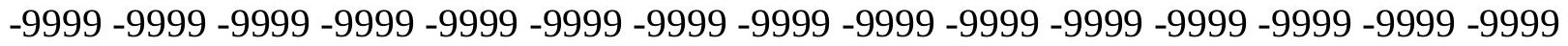
-9999 -9999 -9999

-9999 -9999 -9999 -9999 -9999 -9999 -9999 -9999 -9999 -9999 -9999 -9999 -9999 -9999 -9999 -9999 -9999 -9999 -9999 -9999 -9999 -9999 -9999 -9999 -9999 -9999 -9999 -9999 -9999 -9999 -9999 -9999 -9999 -9999 -9999 -9999 -9999 -9999 -9999 -9999 -9999 -9999 -9999 -9999 -9999 -

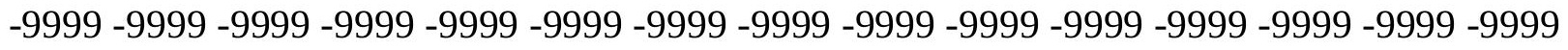

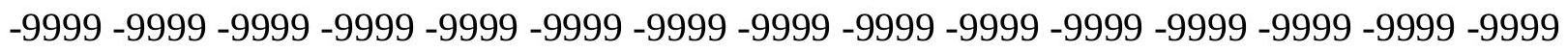
-9999 -9999 -9999 -9999 -9999 -9999 -9999 -9999 -9999 -9999 -9999 -9999 -9999 -9999 -9999 -9999 -9999 -9999 -9999 -9999 -9999 -9999 -9999 -9999 -9999 -9999 -9999 -9999 -9999 -9999 -9999 -9999 -9999 -9999 -9999 -9999 -9999 -9999 -9999 -9999 -9999 -9999 -9999 -9999 -9999 -9999 -9999 -9999 -9999 -9999 -9999 -9999 -9999 -9999 -9999 -9999 -9999 -9999 -9999 -9999 -9999 -9999 -9999 -9999 -9999 -9999 -9999 -9999 -9999 -9999 -9999 -9999 -9999 -9999 -9999 -9999 -9999 -9999 -9999 -9999 -9999 -9999 -9999 -9999 -9999 -9999 -9999 -9999 -9999 -9999

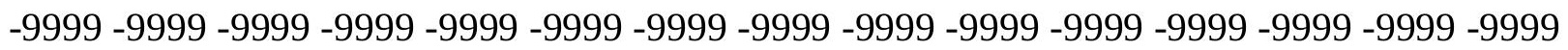
-9999 -9999 -9999 -9999 -9999 -9999 -9999 -9999 -9999 -9999 -9999 -9999 -9999 -9999 -9999 -9999 -9999 -9999 -9999 -9999 -9999 -9999 -9999 -9999 -9999 -9999 -9999 -9999 -9999 -9999

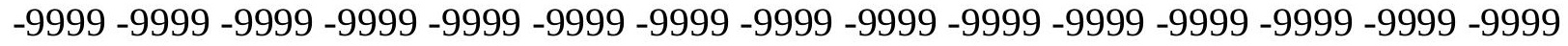
-9999 -9999 -9999 -9999 -9999 -9999 -9999 -9999 -9999 -9999 95.70252990723 95.397743225194 .7881774902394 .4833908081194 .4833908081194 .48339080811 94.4833908081194 .4833908081194 .4833908081194 .4833908081194 .48339080811 94.4833908081194 .1785964965894 .1785964965894 .1785964965893 .87381744385 93.5690307617293 .5690307617293 .2642517089892 .9594726562592 .65467834473 92.349891662692 .0450973510791 .7403335571391 .7403335571391 .13075256348 90.8259735107490 .2164001464889 .302040100191 .1307525634891 .43553924561 91.7403335571391 .7403335571391 .7403335571391 .7403335571391 .43553924561 91.1307525634890 .5211791992289 .6068267822388 .6924667358487 .47332763672 85.9494018554784 .4254837036182 .5967712402380 .4632720947376 .80584716797 75.8914871215874 .9771423339873 .7580032348672 .8436431884871 .62449645996 70.7101516723669 .7957916259868 .8814392089867 .9670867919967 .35751342773 66.7479400634866 .1383666992265 .8335876464865 .5288009643665 .52880096436 65.2240066528365 .2240066528365 .5288009643665 .5288009643665 .83358764648 66.4431610107467 .0527267456167 .6623001098668 .2718734741268 .88143920898 
69.4910125732470 .4053573608471 .014930725171 .6244964599672 .23407745361 72.8436431884873 .4532165527374 .062782287674 .6723632812575 .28192901611 76.1962814331176 .8058471679777 .4154205322378 .0249862670978 .93934631348 79.5489196777380 .1584930419980 .7680587768681 .3776321411181 .68241119385 81.6824111938581 .3776321411181 .0728530883880 .4632720947379 .54891967773 78.3297805786177 .4154205322376 .1962814331174 .6723632812573 .45321655273 71.9292907714870 .4053573608468 .8814392089867 .3575134277365 .83358764648 64.3096618652362 .7857398986861 .2618103027359 .7378807067958 .21395874023 56.6900291442955 .4708900451755 .47089004517 -9999 -9999 -9999 -9999 -9999 -9999 -9999 -9999 -9999 -9999 -9999 -9999 -9999 -9999 -9999 -9999 -9999 -9999 -9999 -9999 -9999 -9999

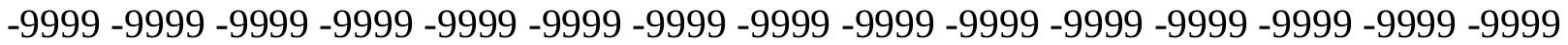
-9999 -9999-9999

-9999 -9999 -9999 -9999 -9999 -9999 -9999 -9999 -9999 -9999 -9999 -9999 -9999 -9999 -9999 -9999 -9999 -9999 -9999 -9999 -9999 -9999 -9999 -9999 -9999 -9999 -9999 -9999 -9999 - 9999 -9999 -9999 -9999 -9999 -9999 -9999 -9999 -9999 -9999 -9999 -9999 -9999 -9999 -9999 -9999

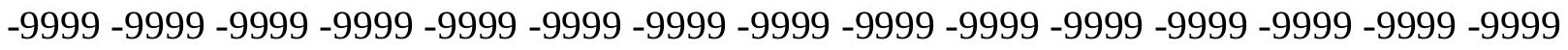
-9999 -9999 -9999 -9999 -9999 -9999 -9999 -9999 -9999 -9999 -9999 -9999 -9999 -9999 -9999 -9999 -9999 -9999 -9999 -9999 -9999 -9999 -9999 -9999 -9999 -9999 -9999 -9999 -9999 -9999 -999 -9999 -9999 -9999 -9999 -9999 -9999 -9999 -9999 -9999 -9999 -9999 -9999 -9999 -9999 -9999 -9999 -9999 -9999 -9999 -9999 -9999 -9999 -9999 -9999 -9999 -9999 -9999 -9999 -9999 -9999 -9999 -9999 -9999 -9999 -9999 -9999 -9999 -9999 -9999 -9999 -9999 -9999 -9999 -9999 -9999 -9999 -9999 -9999 -9999 -9999 -9999 -9999 -9999 -9999 -9999 -9999 -9999 -9999 -9999 -9999 -9999 -9999 -9999 -9999 -9999 -9999 -9999 -9999 -9999 -9999 -9999 -9999 -9999 -9999 -9999 -9999 -9999 -9999 -9999 -9999 -9999 -9999 -9999 -9999 -9999 -9999 -9999 -9999 -9999 -9999 -9999 -9999 -9999 -9999 -9999 -9999 -9999 -9999 -9999 -9999 -9999 -9999 -9999 -9999 -9999 -9999 -9999 -9999 -9999 -9999 -9999 -9999 -9999 -9999 -9999 -9999 -9999 -9999 -9999 -9999 -9999 -9999 -9999 -9999 -9999 -9999 -9999 -9999 -9999 -9999 -9999 -9999 -9999 -9999 -9999 -9999 -9999 -9999 -9999 -9999 -9999 -9999 -9999 -9999 -9999 -9999 95.70252990723 95.0929565429794 .7881774902394 .4833908081194 .1785964965894 .17859649658 94.1785964965894 .1785964965894 .1785964965894 .1785964965894 .17859649658 94.1785964965894 .1785964965893 .8738174438593 .8738174438593 .56903076172 93.5690307617293 .2642517089892 .9594726562592 .9594726562592 .65467834473 92.349891662692 .0450973510792 .0450973510791 .7403335571391 .13075256348 90.5211791992289 .9116134643689 .6068267822391 .1307525634891 .43553924561 91.4355392456191 .4355392456191 .4355392456191 .1307525634890 .82597351074 90.2164001464889 .302040100188 .3876876831187 .1685485839885 .94940185547 84.4254837036182 .5967712402379 .5489196777378 .6345596313577 .41542053223 76.5010681152375 .5867080688574 .6723632812573 .4532165527372 .53885650635 71.6244964599670 .7101516723670 .1005783081169 .1862335205168 .88143920898 68.2718734741267 .9670867919967 .6623001098667 .3575134277367 .05272674561 67.0527267456167 .0527267456167 .0527267456167 .3575134277367 .66230010986 68.2718734741268 .8814392089869 .4910125732470 .1005783081170 .71015167236 71.3197174072371 .6244964599672 .2340774536172 .8436431884873 .45321655273 73.7580032348674 .3675689697374 .9771423339875 .5867080688576 .19628143311 76.5010681152377 .110626220778 .0249862670978 .6345596313579 .24413299561 79.8537063598680 .1584930419980 .7680587768680 .7680587768681 .07285308838 
80.7680587768680 .1584930419979 .5489196777378 .6345596313577 .72020721436 76.8058471679775 .5867080688574 .3675689697372 .8436431884871 .31971740723 70.1005783081168 .5766525268667 .0527267456165 .5288009643663 .70008850098 62.1761703491260 .6522407531759 .1283111572357 .909179687556 .38525009155 55.7756805419955 .77568054199 -9999 -9999 -9999 -9999 -9999 -9999 -9999 -9999 -9999 -9999 -9999 -9999 -9999 -9999 -9999 -9999 -9999 -9999 -9999 -9999 -9999 -9999 -9999 -9999

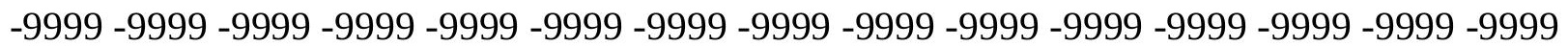
$-9999$

-9999 -9999 -9999 -9999 -9999 -9999 -9999 -9999 -9999 -9999 -9999 -9999 -9999 -9999 -9999 -9999 -9999 -9999 -9999 -9999 -9999 -9999 -9999 -9999 -9999 -9999 -9999 -9999 -9999 -9999 -9999 -9999 -9999 -9999 -9999 -9999 -9999 -9999 -9999 -9999 -9999 -9999 -9999 -9999-999 -9999 -9999 -9999 -9999 -9999 -9999 -9999 -9999 -9999 -9999 -9999 -9999 -9999 -9999 -9999 -9999 -9999 -9999 -9999 -9999 -9999 -9999 -9999 -9999 -9999 -9999 -9999 -9999 -9999 -9999 -9999 -9999 -9999 -9999 -9999 -9999 -9999 -9999 -9999 -9999 -9999 -9999 -9999 -9999 -9999 -9999 -9999 -9999 -9999 -9999 -9999 -9999 -9999 -9999 -9999 -9999 -9999 -9999 -9999 -9999

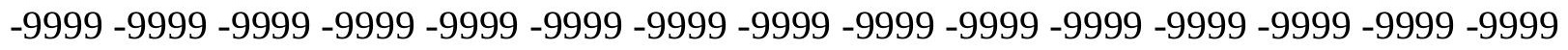

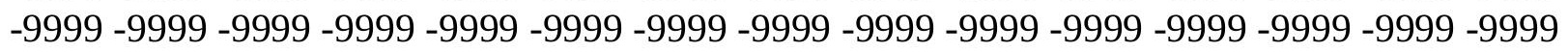

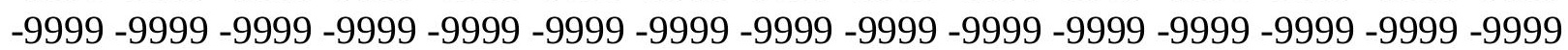

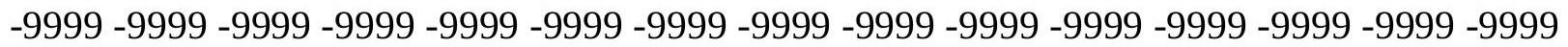

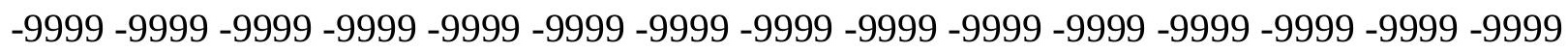

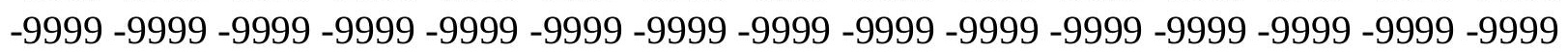

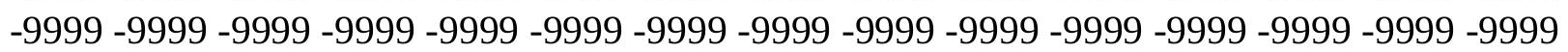
-9999 -9999 -9999 -9999 -9999 -9999 -9999 -9999 -9999 -9999 -9999 -9999 -9999 -9999 -9999 -9999 -9999-9999 -9999 -9999 -9999 -9999 -9999 -9999 -9999 -9999-9999 95.70252990723 95.0929565429794 .7881774902394 .1785964965894 .1785964965894 .17859649658 94.1785964965894 .1785964965894 .1785964965893 .8738174438593 .87381744385 93.8738174438593.8738174438593.5690307617293.5690307617293.26425170898 93.2642517089892 .9594726562592 .6546783447392 .6546783447392 .3498916626 92.349891662692 .0450973510791 .7403335571391 .4355392456190 .82597351074 90.5211791992289 .9116134643689 .6068267822390 .8259735107491 .13075256348 91.1307525634890 .8259735107490 .8259735107490 .2164001464889 .60682678223 88.9972534179788 .0829010009887 .1685485839885 .6446228027383 .2063369751 81.9871978759881 .0728530883880 .1584930419979 .2441329956178 .32978057861 77.4154205322376 .1962814331175 .2819290161174 .3675689697373 .75800323486 72.8436431884872 .2340774536171 .3197174072371 .014930725170 .40535736084 69.7957916259869 .4910125732469 .1862335205169 .1862335205168 .88143920898 68.8814392089868 .8814392089868 .8814392089868 .8814392089869 .49101257324 70.1005783081170 .7101516723671 .014930725171 .6244964599672 .23407745361 72.5388565063573 .1484298706173 .4532165527373 .7580032348674 .36756896973 74.6723632812575 .2819290161175 .5867080688575 .8914871215876 .50106811523 77.110626220777 .4154205322378 .0249862670978 .6345596313579 .24413299561 79.5489196777379 .8537063598680 .1584930419980 .1584930419979 .85370635986 79.5489196777378 .9393463134878 .0249862670977 .110626220775 .89148712158 74.6723632812573 .4532165527372 .2340774536170 .7101516723669 .49101257324 67.9670867919966 .4431610107464 .9192428588963 .3953094482461 .87137985229 60.3474502563558 .8235282897957 .6043891906756 .0804595947355 .77568054199 -9999 
-9999 -9999 -9999 -9999 -9999 -9999 -9999 -9999 -9999 -9999 -9999 -9999 -9999 -9999 -9999 -9999 -9999 -9999 -9999 -9999 -9999 -9999 -9999 -9999 -9999 -9999 -9999 -9999 -9999 -9999 -9999 -9999 -9999 -9999 -9999 -9999 -9999 -9999 -9999 -9999

-9999 -9999 -9999 -9999 -9999 -9999 -9999 -9999 -9999 -9999 -9999 -9999 -9999 -9999 -9999 -9999 -9999 -9999 -9999 -9999 -9999 -9999 -9999 -9999 -9999 -9999 -9999 -9999 -9999 -9999 -9999 -9999 -9999 -9999 -9999 -9999 -9999 -9999 -9999 -9999 -9999 -9999 -9999 -9999 -9999 -9999 -9999 -9999 -9999 -9999 -9999 -9999 -9999 -9999 -9999 -9999 -9999 -9999 -9999 -9999

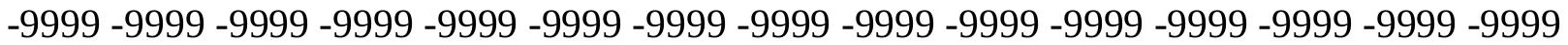
-9999 -9999 -9999 -9999 -9999 -9999 -9999 -9999 -9999 -9999 -9999 -9999 -9999 -9999 -9999 -9999 -9999 -9999 -9999 -9999 -9999 -9999 -9999 -9999 -9999 -9999 -9999 -9999 -9999 -9999 -9999 -9999 -9999 -9999 -9999 -9999 -9999 -9999 -9999 -9999 -9999 -9999 -9999 -9999 -9999 -9999 -9999 -9999 -9999 -9999 -9999 -9999 -9999 -9999 -9999 -9999 -9999 -9999 -9999 -9999

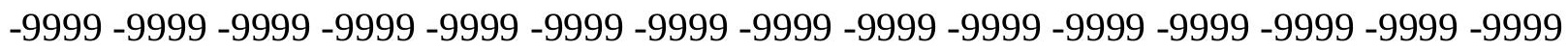
-9999 -9999 -9999 -9999 -9999 -9999 -9999 -9999 -9999 -9999 -9999 -9999 -9999 -9999 -9999 -9999 -9999 -9999 -9999 -9999 -9999 -9999 -9999 -9999 -9999 -9999 -9999 -9999 -9999 -9999

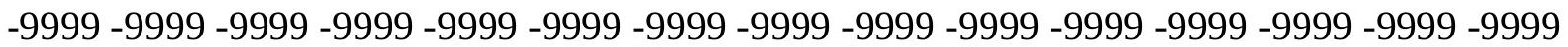

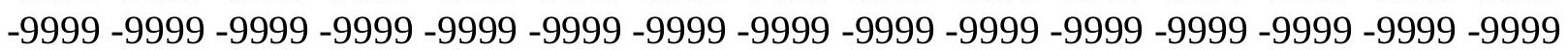
-9999 -9999 -9999 -9999 -9999 -9999 -9999 -9999 -9999 -9999 -9999 -9999 -9999 -9999 -9999 -9999 -9999 -9999 -9999 -9999 -9999 -9999 -9999 -9999 -9999 -9999 -9999 -9999 -9999 95.0929565429794 .4833908081194 .1785964965893 .8738174438593 .87381744385 93.8738174438593 .8738174438593 .8738174438593 .5690307617293 .56903076172 93.5690307617293 .2642517089893 .2642517089892 .9594726562592 .95947265625 92.6546783447392 .6546783447392 .349891662692 .349891662692 .04509735107 91.7403335571391 .7403335571391 .4355392456191 .1307525634890 .52117919922 90.2164001464889 .9116134643689 .9116134643689 .6068267822389 .3020401001 89.3020401001 88.9972534179788.6924667358488.3876876831187.77810668945 87.1685485839886 .254188537685 .3398437584 .4254837036183 .51112365723 82.5967712402381 .6824111938580 .7680587768679 .8537063598678 .93934631348 78.0249862670977 .4154205322376 .5010681152375 .5867080688574 .97714233398 74.3675689697373 .7580032348673 .1484298706172 .5388565063572 .23407745361 71.6244964599671 .3197174072371 .014930725171 .014930725170 .71015167236 70.7101516723670 .7101516723670 .7101516723671 .3197174072371 .62449645996 71.9292907714872 .5388565063572 .8436431884873 .1484298706173 .45321655273 73.7580032348674 .3675689697374 .3675689697374 .6723632812574 .97714233398 75.2819290161175 .5867080688575 .8914871215876 .1962814331176 .80584716797 77.110626220777 .7202072143678 .0249862670978 .3297805786178 .93934631348 78.9393463134879 .2441329956179 .2441329956178 .9393463134878 .63455963135 78.0249862670977 .110626220776 .1962814331175 .2819290161174 .0627822876 72.8436431884871 .6244964599670 .1005783081168 .8814392089867 .35751342773 65.8335876464864 .3096618652362 .7857398986861 .2618103027359 .73788070679 58.5187492370656 .9948196411155 .7756805419955 .77568054199 -9999 -9999 -9999 -9999 -9999 -9999 -9999 -9999 -9999 -9999 -9999 -9999 -9999 -9999 -9999 -9999 -9999 -9999 -9999

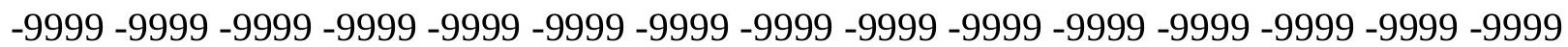
-9999 -9999 -9999 -9999 -9999 -9999 -9999 -9999 -9999 -9999 -9999 -9999 -9999 -9999 -9999 -9999 -9999 -9999 -9999 -9999 -9999 -9999

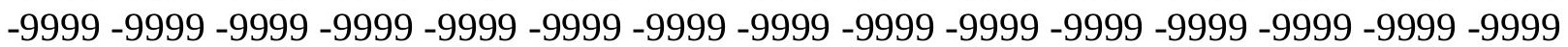


-9999 -9999 -9999 -9999 -9999 -9999 -9999 -9999 -9999 -9999 -9999 -9999 -9999 -9999 -9999 -9999 -9999 -9999 -9999 -9999 -9999 -9999 -9999 -9999 -9999 -9999 -9999 -9999 -9999 -9999 -9999 -9999 -9999 -9999 -9999 -9999 -9999 -9999 -9999 -9999 -9999 -9999 -9999 -9999 -9999 -9999 -9999 -9999 -9999 -9999 -9999 -9999 -9999 -9999 -9999 -9999 -9999 -9999 -9999 -9999 -9999 -9999 -9999 -9999 -9999 -9999 -9999 -9999 -9999 -9999 -9999 -9999 -9999 -9999 -9999 -9999 -9999 -9999 -9999 -9999 -9999 -9999 -9999 -9999 -9999 -9999 -9999 -9999 -9999 -9999 -9999 -9999 -9999 -9999 -9999 -9999 -9999 -9999 -9999 -9999 -9999 -9999 -9999 -9999 -9999

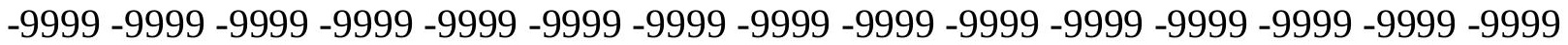
-9999 -9999 -9999 -9999 -9999 -9999 -9999 -9999 -9999 -9999 -9999 -9999 -9999 -9999 -9999 -9999 -9999 -9999 -9999 -9999 -9999 -9999 -9999 -9999 -9999 -9999 -9999 -9999 -9999 -9999 -9999 -9999 -9999 -9999 -9999 -9999 -9999 -9999 -9999 -9999 -9999 -9999 -9999 -9999 -9999 -9999 -9999 -9999 -9999 -9999 -9999 -9999 -9999 -9999 -9999 -9999 -9999 -9999 -9999 -9999

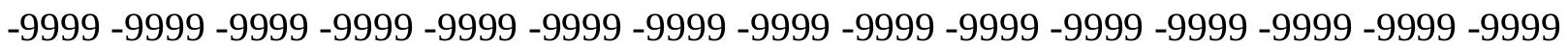
-9999 -9999 -9999 -9999 -9999 -9999 -9999 -9999 -9999 -9999 -9999 -9999 -9999 -9999 -9999 94.7881774902394 .4833908081194 .1785964965893 .8738174438593 .56903076172 93.5690307617293 .5690307617293 .5690307617293 .2642517089893 .26425170898 92.9594726562592 .9594726562592 .6546783447392 .6546783447392 .3498916626 92.349891662692 .0450973510792 .0450973510791 .7403335571391 .74033355713 91.4355392456191 .1307525634890 .8259735107490 .8259735107490 .52117919922 90.2164001464890 .2164001464890 .2164001464889 .9116134643689 .91161346436 89.9116134643689 .6068267822389 .302040100188 .9972534179788 .38768768311 87.4733276367286 .5589828491285 .9494018554785 .0350494384884 .12069702148 83.206336975182 .2919769287181 .6824111938580 .7680587768679 .85370635986 79.2441329956178 .3297805786177 .7202072143677 .110626220776 .50106811523 75.8914871215875 .2819290161174 .6723632812574 .3675689697374 .0627822876 73.4532165527373 .1484298706173 .1484298706172 .8436431884872 .84364318848 72.8436431884872 .8436431884872 .8436431884873 .1484298706173 .45321655273 73.7580032348674 .062782287674 .3675689697374 .6723632812574 .97714233398 74.9771423339875 .2819290161175 .2819290161175 .5867080688575 .58670806885 75.8914871215875 .8914871215876 .1962814331176 .5010681152376 .80584716797 77.110626220777 .4154205322377 .7202072143678 .0249862670978 .32978057861 78.3297805786178 .3297805786178 .0249862670977 .4154205322376 .80584716797 76.1962814331175 .2819290161174 .3675689697373 .1484298706172 .23407745361 70.7101516723669 .4910125732468 .2718734741266 .7479400634865 .22400665283 63.7000885009862 .1761703491260 .9570198059159 .4331016540557 .9091796875 56.6900291442956 .0804595947356 .08045959473 -9999 -9999 -9999 -9999 -9999 -9999 -9999 -9999 -9999 -9999 -9999 -9999 -9999 -9999 -9999 -9999 -9999 -9999 -9999 -9999 -9999 -9999

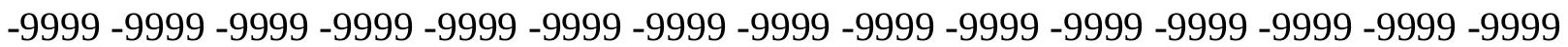
-9999 -9999-9999-9999

-9999 -9999 -9999 -9999 -9999 -9999 -9999 -9999 -9999 -9999 -9999 -9999 -9999 -9999 -9999 -9999 -9999 -9999 -9999 -9999 -9999 -9999 -9999 -9999 -9999 -9999 -9999 -9999 -9999 -9999

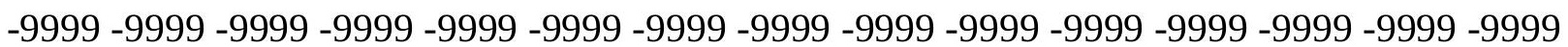
-9999 -9999 -9999 -9999 -9999 -9999 -9999 -9999 -9999 -9999 -9999 -9999 -9999 -9999 -9999 -9999 -9999 -9999 -9999 -9999 -9999 -9999 -9999 -9999 -9999 -9999 -9999 -9999 -9999 -9999 -9999 -9999 -9999 -9999 -9999 -9999 -9999 -9999 -9999 -9999 -9999 -9999 -9999 -9999 -9999

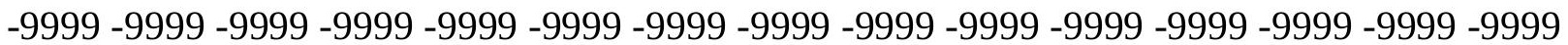


-9999 -9999 -9999 -9999 -9999 -9999 -9999 -9999 -9999 -9999 -9999 -9999 -9999 -9999 -9999 -9999 -9999 -9999 -9999 -9999 -9999 -9999 -9999 -9999 -9999 -9999 -9999 -9999 -9999 -9999 -9999 -9999 -9999 -9999 -9999 -9999 -9999 -9999 -9999 -9999 -9999 -9999 -9999 -9999 -9999 -9999 -9999 -9999 -9999 -9999 -9999 -9999 -9999 -9999 -9999 -9999 -9999 -9999 -9999 -9999 -9999 -9999 -9999 -9999 -9999 -9999 -9999 -9999 -9999 -9999 -9999 -9999 -9999 -9999 -9999 -9999 -9999 -9999 -9999 -9999 -9999 -9999 -9999 -9999 -9999 -9999 -9999 -9999 -9999 -9999 -9999 -9999 -9999 -9999 -9999 -9999 -9999 -9999 -9999 -9999 -9999 -9999 -9999 -9999 -9999

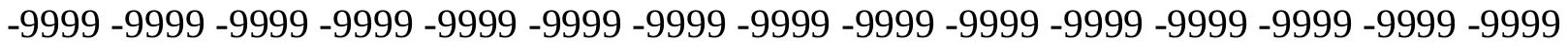
-9999 -9999 -9999 -9999 -9999-9999 -9999 -9999 -9999 -9999 -9999 -9999 -9999 -9999 -9999 -9999 -9999 94.4833908081194.1785964965893.8738174438593.56903076172 93.2642517089893 .2642517089892 .9594726562592 .9594726562592 .65467834473 92.6546783447392 .349891662692 .349891662692 .0450973510792 .04509735107 91.7403335571391 .7403335571391 .4355392456191 .1307525634891 .13075256348 90.8259735107490 .8259735107490 .5211791992290 .5211791992290 .21640014648 90.2164001464890 .2164001464890 .5211791992290 .5211791992290 .52117919922 90.5211791992290 .2164001464889 .9116134643689 .302040100188 .69246673584 87.7781066894586 .8637619018686 .254188537685 .3398437584 .73026275635 83.8159103393683 .206336975182 .2919769287181 .6824111938581 .07285308838 80.4632720947379 .8537063598679 .2441329956178 .6345596313578 .02498626709 77.4154205322377 .110626220776 .5010681152376 .1962814331175 .89148712158 75.5867080688575 .2819290161174 .9771423339874 .9771423339874 .67236328125 74.6723632812574 .9771423339874 .9771423339875 .2819290161175 .28192901611 75.5867080688575 .5867080688575 .8914871215875 .8914871215875 .89148712158 75.8914871215875 .8914871215875 .8914871215875 .8914871215875 .89148712158 75.8914871215875 .8914871215876 .1962814331176 .1962814331176 .50106811523 76.8058471679777 .110626220777 .110626220777 .4154205322377 .41542053223 77.110626220777 .110626220776 .5010681152375 .8914871215875 .28192901611 74.3675689697373 .4532165527372 .5388565063571 .3197174072370 .10057830811 68.8814392089867 .3575134277366 .1383666992264 .6144485473663 .09051895142 61.8713798522960 .3474502563558 .8235282897957 .6043891906756 .38525009155 56.08045959473 -9999 -9999 -9999 -9999 -9999 -9999 -9999 -9999 -9999 -9999 -9999 -9999 -9999 -9999 -9999 -9999 -9999 -9999 -9999 -9999 -9999 -9999 -9999 -9999 -9999 -9999 -9999 -9999 -9999 -9999 -9999 -9999 -9999 -9999 -9999 -9999 -9999 -9999 -9999 -9999 -9999 -9999 -9999 -9999 -9999 -9999 -9999 -9999 -9999 -9999 -9999 -9999 -9999 -9999 -9999 -9999 -9999

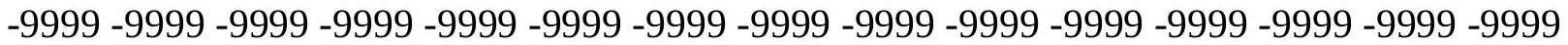
-9999 -9999 -9999 -9999 -9999 -9999 -9999 -9999 -9999 -9999 -9999 -9999 -9999 -9999 -9999

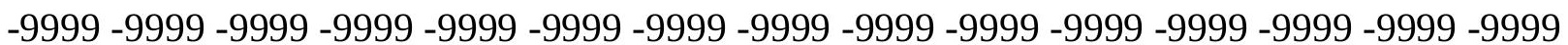

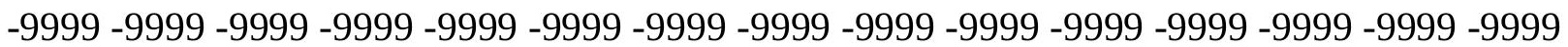
-9999 -9999 -9999 -9999 -9999 -9999 -9999 -9999 -9999 -9999 -9999 -9999 -9999 -9999 -9999 -9999 -9999 -9999 -9999 -9999 -9999 -9999 -9999 -9999 -9999 -9999 -9999 -9999 -9999 -9999 -9999 -9999 -9999 -9999 -9999 -9999 -9999 -9999 -9999 -9999 -9999 -9999 -9999 -9999 -9999

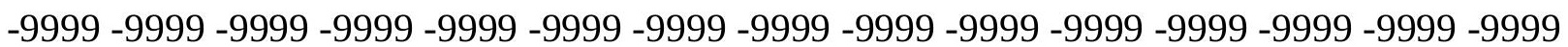
-9999 -9999 -9999 -9999 -9999 -9999 -9999 -9999 -9999 -9999 -9999 -9999 -9999 -9999 -9999 -9999 -9999 -9999 -9999 -9999 -9999 -9999 -9999 -9999 -9999 -9999 -9999 -9999 -9999 -9999 -9999 -9999 -9999 -9999 -9999 -9999 -9999 -9999 -9999 -9999 -9999 -9999 -9999 -9999 -9999

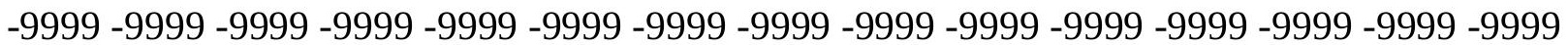


-9999 -9999 -9999 -9999 -9999 -9999 -9999 -9999 -9999 -9999 -9999 -9999 -9999 -9999 -9999 -9999 -9999 -9999 -9999 -9999 -9999 -9999 -9999 -9999 -9999 -9999 -9999 -9999 -9999 -9999 -9999 -9999 -9999 -9999 -9999 -9999 -9999 -9999 -9999 -9999 -9999 -9999 -9999 -9999 -9999 -9999 -9999 -9999 94.4833908081194.1785964965893.8738174438593.26425170898 92.9594726562592 .6546783447392 .6546783447392 .349891662692 .3498916626 92.0450973510791 .7403335571391 .7403335571391 .4355392456191 .43553924561 91.1307525634891 .1307525634890 .8259735107490 .5211791992290 .52117919922 90.2164001464890 .2164001464890 .2164001464890 .2164001464890 .21640014648 90.2164001464890 .5211791992290 .8259735107490 .8259735107491 .13075256348 90.8259735107490 .8259735107490 .2164001464889 .6068267822388 .69246673584 88.0829010009887 .1685485839886 .5589828491285 .9494018554785 .33984375 84.7302627563584 .1206970214883 .5111236572382 .9015579223682 .29197692871 81.6824111938581 .0728530883880 .7680587768680 .1584930419979 .85370635986 79.2441329956178 .9393463134878 .6345596313578 .0249862670977 .72020721436 77.4154205322377 .110626220777 .110626220776 .8058471679776 .80584716797 76.8058471679776 .8058471679776 .8058471679776 .8058471679777 .1106262207 77.110626220777 .110626220777 .110626220776 .8058471679776 .80584716797 76.5010681152376 .5010681152376 .1962814331176 .1962814331175 .89148712158 75.8914871215875 .8914871215875 .8914871215875 .8914871215876 .19628143311 76.1962814331176 .5010681152376 .5010681152376 .5010681152376 .19628143311 75.8914871215875 .5867080688574 .9771423339874 .3675689697373 .45321655273 72.5388565063571 .6244964599670 .4053573608469 .1862335205167 .96708679199 66.7479400634865 .5288009643664 .004882812562 .4809494018661 .26181030273 $59.7378807067958 .5187492370656 .9948196411156 .0804595947356 .08045959473-9999$ -9999 -9999 -9999 -9999 -9999 -9999 -9999 -9999 -9999 -9999 -9999 -9999 -9999 -9999 -9999 -9999 -9999 -9999 -9999 -9999 -9999 -9999 -9999 -9999 -9999 -9999 -9999 -9999 -9999 -9999 -9999 -9999 -9999 -9999 -9999 -9999 -9999 -9999 -9999 -9999 -9999

-9999 -9999 -9999 -9999 -9999 -9999 -9999 -9999 -9999 -9999 -9999 -9999 -9999 -9999 -9999 -9999 -9999 -9999 -9999 -9999 -9999 -9999 -9999 -9999 -9999 -9999 -9999 -9999 -9999 -9999 -9999 -9999 -9999 -9999 -9999 -9999 -9999 -9999 -9999 -9999 -9999 -9999 -9999 -9999 -9999 -9999 -9999 -9999 -9999 -9999 -9999 -9999 -9999 -9999 -9999 -9999 -9999 -9999 -9999 -9999 -9999 -9999 -9999 -9999 -9999 -9999 -9999 -9999 -9999 -9999 -9999 -9999 -9999 -9999 -9999 -9999 -9999 -9999 -9999 -9999 -9999 -9999 -9999 -9999 -9999 -9999 -9999 -9999 -9999 -9999 -9999 -9999 -9999 -9999 -9999 -9999 -9999 -9999 -9999 -9999 -9999 -9999 -9999 -9999 -9999 -

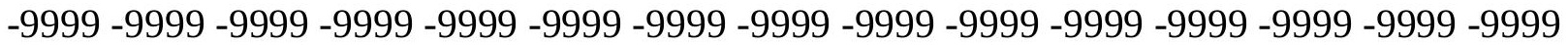
-9999 -9999 -9999 -9999 -9999 -9999 -9999 -9999 -9999 -9999 -9999 -9999 -9999 -9999 -9999 -9999 -9999 -9999 -9999 -9999 -9999 -9999 -9999 -9999 -9999 -9999 -9999 -9999 -9999 -9999

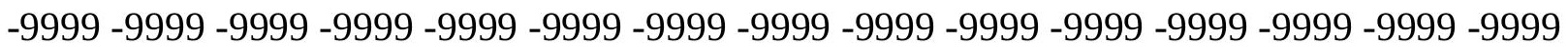
-9999 -9999 -9999 -9999 -9999 -9999 -9999 -9999 -9999 -9999 -9999 -9999 -9999 -9999 -9999 -9999 -9999 -9999 -9999 -9999 -9999 -9999 -9999 -9999 -9999 -9999 -9999 -9999 -9999 -9999 -9999 -9999 -9999 -9999 -9999 -9999 -9999 -9999 -9999 -9999 -9999 -9999 -9999 -9999 -9999 -9999 -9999 -9999 -9999 -9999 -9999 -9999 -9999 -9999 -9999 -9999 -9999 -9999 -9999 -9999 -9999 -9999 -9999 -9999 -9999 -9999 -9999 -9999 -9999 -9999 -9999 -9999 -9999 -9999 -9999 -999 -9999 -9999 -9999 -9999 94.4833908081194.17859649658 93.8738174438593.26425170898 92.9594726562592 .6546783447392 .0450973510791 .7403335571391 .74033355713 91.4355392456191 .1307525634891 .1307525634890 .8259735107490 .52117919922 
90.5211791992290 .2164001464890 .2164001464889 .9116134643689 .91161346436 89.9116134643689 .9116134643689 .9116134643689 .9116134643690 .21640014648 90.5211791992290 .8259735107490 .8259735107491 .1307525634891 .13075256348 91.1307525634890 .5211791992289 .9116134643689 .302040100188 .69246673584 88.08290100098 87.47332763672 87.16854858398 86.55898284912 85.94940185547 85.6446228027385 .0350494384884 .4254837036184 .1206970214883 .51112365723 83.206336975182 .9015579223682 .2919769287181 .9871978759881 .68241119385 81.0728530883880 .7680587768680 .4632720947379 .8537063598679 .54891967773 79.2441329956179 .2441329956178 .9393463134878 .6345596313578 .63455963135 78.6345596313578 .6345596313578 .6345596313578 .6345596313578 .63455963135 78.3297805786178 .3297805786178 .0249862670977 .7202072143677 .41542053223 77.110626220776 .8058471679776 .1962814331175 .8914871215875 .58670806885 75.5867080688575 .5867080688575 .5867080688575 .5867080688575 .58670806885 75.8914871215875 .5867080688575 .5867080688575 .2819290161174 .97714233398 74.6723632812574 .062782287673 .4532165527372 .5388565063571 .62449645996 70.7101516723669 .4910125732468 .5766525268667 .3575134277366 .13836669922 64.6144485473663 .3953094482462 .1761703491260 .6522407531759 .12831115723 57.909179687556 .6900291442956 .3852500915556 .38525009155 -9999 -9999 -9999 -9999 -9999 -9999 -9999 -9999 -9999 -9999 -9999 -9999 -9999 -9999 -9999 -9999 -9999 -9999 -9999

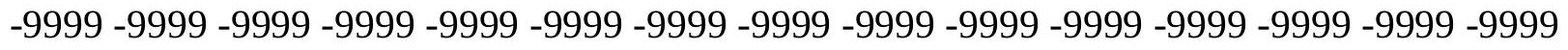
-9999 -9999-9999-9999-9999 -9999-9999-9999

-9999 -9999 -9999 -9999 -9999 -9999 -9999 -9999 -9999 -9999 -9999 -9999 -9999 -9999 -9999 -9999 -9999 -9999 -9999 -9999 -9999 -9999 -9999 -9999 -9999 -9999 -9999 -9999 -9999 -9999 -

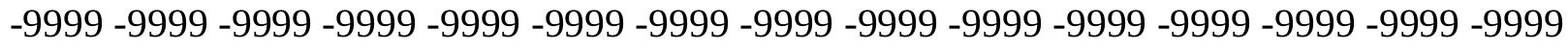

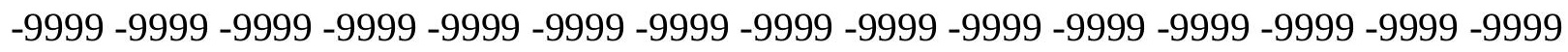
-9999 -9999 -9999 -9999 -9999 -9999 -9999 -9999 -9999 -9999 -9999 -9999 -9999 -9999 -9999 -

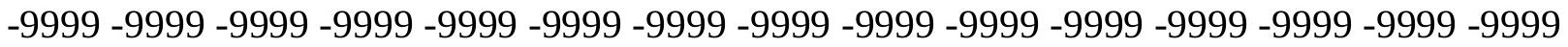

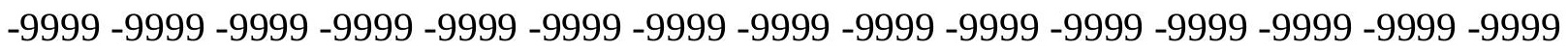
-9999 -9999 -9999 -9999 -9999 -9999 -9999 -9999 -9999 -9999 -9999 -9999 -9999 -9999 -9999 -9999 -9999 -9999 -9999 -9999 -9999 -9999 -9999 -9999 -9999 -9999 -9999 -9999 -9999 -9999 -9999 -9999 -9999 -9999 -9999 -9999 -9999 -9999 -9999-9999 -9999 -9999 -9999 -9999 -9999 -9999 -9999 -9999 -9999 -9999 -9999 -9999 -9999 -9999 -9999 -9999 -9999 -9999 -9999 -9999 -

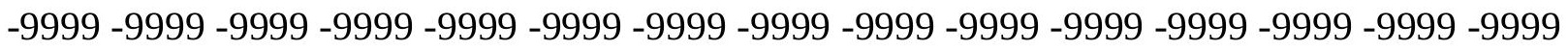
-9999 -9999 -9999 -9999 -9999 -9999 -9999 -9999 -9999 -9999 -9999 -9999 -9999 -9999 -9999 -9999 -9999 -9999 -9999 -9999 -9999 -9999 -9999 -9999 -9999 -9999 -9999 -9999 -9999 -9999

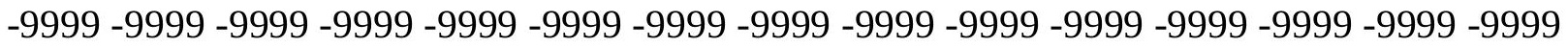

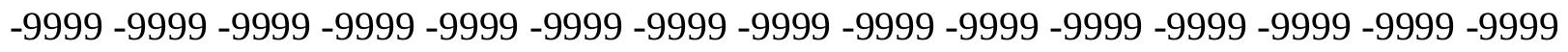
-9999 -9999-9999-9999-9999 94.48339080811 94.1785964965893.56903076172 93.2642517089892 .9594726562592 .349891662692 .0450973510791 .74033355713 91.1307525634890 .8259735107490 .5211791992290 .2164001464890 .21640014648 89.9116134643689 .9116134643689 .6068267822389 .6068267822389 .3020401001 89.3020401001 89.302040100189.3020401001 89.60682678223 89.91161346436 90.2164001464890 .5211791992290 .8259735107490 .8259735107491 .13075256348 91.1307525634890 .8259735107490 .2164001464889 .6068267822389 .3020401001 88.6924667358488 .3876876831188 .0829010009887 .7781066894587 .47332763672 86.8637619018686 .5589828491286 .254188537685 .6446228027385 .33984375 
85.0350494384884 .7302627563584 .4254837036184 .1206970214883 .81591033936 83.206336975182 .9015579223682 .5967712402381 .9871978759881 .68241119385 81.3776321411181 .0728530883881 .0728530883880 .7680587768680 .46327209473 80.4632720947380 .4632720947380 .1584930419980 .1584930419980 .15849304199 79.8537063598679 .5489196777379 .2441329956178 .9393463134878 .32978057861 77.7202072143677 .110626220776 .5010681152375 .8914871215875 .58670806885 75.2819290161174 .9771423339874 .9771423339874 .9771423339875 .28192901611 74.9771423339874 .9771423339874 .6723632812574 .3675689697374 .0627822876 73.4532165527373 .1484298706172 .2340774536171 .6244964599670 .71015167236 69.7957916259868 .8814392089867 .6623001098666 .4431610107465 .22400665283 64.004882812562 .7857398986861 .5666007995660 .0426712036158 .82352828979 57.6043891906756 .6900291442956 .69002914429 -9999 -9999 -9999 -9999 -9999 -9999 -9999

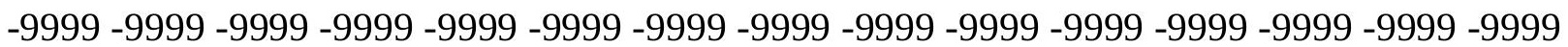
-9999 -9999 -9999 -9999 -9999 -9999 -9999 -9999 -9999 -9999 -9999 -9999 -9999 -9999 -9999 -9999 -9999 -9999 -9999-9999-9999

-9999 -9999 -9999 -9999 -9999 -9999 -9999 -9999 -9999 -9999 -9999 -9999 -9999 -9999 -9999 -9999 -9999 -9999 -9999 -9999 -9999 -9999 -9999 -9999 -9999 -9999 -9999 -9999 -9999 -9999 -9999 -9999 -9999 -9999 -9999 -9999 -9999 -9999 -9999 -9999 -9999 -9999 -9999 -9999 -9999 -9999 -9999 -9999 -9999 -9999 -9999 -9999 -9999 -9999 -9999 -9999 -9999 -9999 -9999 -9999 -9999 -9999 -9999 -9999 -9999 -9999 -9999 -9999 -9999 -9999 -9999 -9999 -9999 -9999 -9999

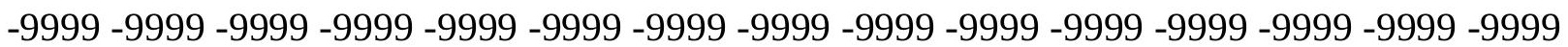
-9999 -9999 -9999 -9999 -9999 -9999 -9999 -9999 -9999 -9999 -9999 -9999 -9999 -9999 -9999 -9999 -9999 -9999 -9999 -9999 -9999 -9999 -9999 -9999 -9999 -9999 -9999 -9999 -9999 -9999 -9999 -9999 -9999 -9999 -9999 -9999 -9999 -9999 -9999 -9999 -9999 -9999 -9999 -9999 -9999

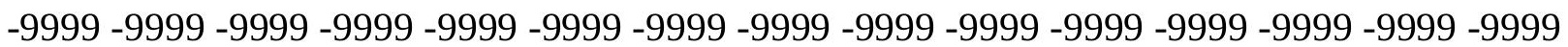
-9999 -9999 -9999 -9999 -9999 -9999 -9999 -9999 -9999 -9999 -9999 -9999 -9999 -9999 -9999 -9999 -9999 -9999 -9999 -9999 -9999 -9999 -9999 -9999 -9999 -9999 -9999 -9999 -9999 -9999 -9999 -9999 -9999 -9999 -9999 -9999 -9999 -9999 -9999 -9999 -9999 -9999 -9999 -9999 -9999 -9999 -9999 -9999 -9999 -9999 -9999 -9999 -9999 -9999 -9999 -9999 -9999 -9999 -9999 -9999 -9999 -9999 -9999 -9999 -9999 -9999 -9999 -9999 -9999 -9999 -9999 -9999 -9999 -9999 -9999 -9999 -9999 -9999 -9999 -9999 -9999 -9999 -9999 -9999 -9999 -9999 -9999 -9999 -9999 -9999 -9999 -9999 -9999 -9999 -9999 94.78817749023 94.4833908081194.17859649658 93.5690307617293 .2642517089892 .6546783447392 .349891662691 .74033355713 91.4355392456190 .8259735107490 .5211791992289 .9116134643689 .60682678223 89.6068267822389 .302040100188 .9972534179788 .9972534179788 .69246673584 88.6924667358488 .6924667358488 .6924667358488 .9972534179789 .3020401001 89.6068267822389 .9116134643690 .2164001464890 .5211791992290 .52117919922 90.5211791992290 .5211791992290 .2164001464889 .9116134643689 .60682678223 89.3020401001 88.9972534179788.69246673584 88.69246673584 88.38768768311 88.38768768311 88.08290100098 87.77810668945 87.16854858398 87.16854858398 86.8637619018686 .8637619018686 .5589828491286 .254188537685 .94940185547 85.6446228027385 .0350494384884 .7302627563584 .1206970214883 .81591033936 83.5111236572383 .206336975182 .9015579223682 .5967712402382 .59677124023 82.2919769287182 .2919769287181 .9871978759881 .6824111938581 .68241119385 81.3776321411181 .0728530883880 .4632720947380 .1584930419979 .54891967773 78.6345596313578 .0249862670977 .110626220776 .1962814331175 .58670806885 
74.9771423339874 .9771423339874 .6723632812574 .6723632812574 .67236328125 74.6723632812574 .3675689697374 .062782287673 .7580032348673 .14842987061 72.5388565063571 .9292907714871 .3197174072370 .7101516723669 .79579162598 68.8814392089867 .9670867919966 .7479400634865 .8335876464864 .61444854736 63.3953094482462 .1761703491260 .9570198059159 .4331016540558 .21395874023 56.9948196411156 .6900291442956 .69002914429 -9999 -9999 -9999 -9999 -9999 -9999 -9999 -9999 -9999 -9999 -9999 -9999 -9999 -9999 -9999 -9999 -9999 -9999 -9999 -9999 -9999 -9999

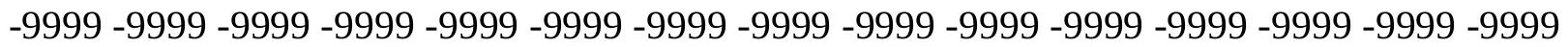
-9999-9999-9999-9999-9999-9999

-9999 -9999 -9999 -9999 -9999 -9999 -9999 -9999 -9999 -9999 -9999 -9999 -9999 -9999 -9999 -9999 -9999 -9999 -9999 -9999 -9999 -9999 -9999 -9999 -9999 -9999 -9999 -9999 -9999 -9999 -9999 -9999 -9999 -9999 -9999 -9999 -9999 -9999 -9999 -9999 -9999 -9999 -9999 -9999 -9999 -9999 -9999 -9999 -9999 -9999 -9999 -9999 -9999 -9999 -9999 -9999 -9999 -9999 -9999 -9999 -9999 -9999 -9999 -9999 -9999 -9999 -9999 -9999 -9999 -9999 -9999 -9999 -9999 -9999 - 9999 -9999 -9999 -9999 -9999 -9999 -9999 -9999 -9999 -9999 -9999 -9999 -9999 -9999 -9999 -9999 -9999 -9999 -9999 -9999 -9999 -9999 -9999 -9999 -9999 -9999 -9999 -9999 -9999 - -9999 - -9999 -

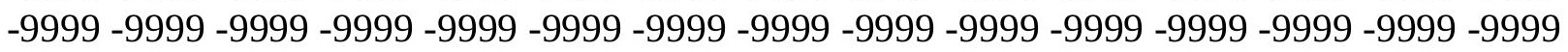
-9999 -9999 -9999 -9999 -9999 -9999 -9999 -9999 -9999 -9999 -9999 -9999 -9999 -9999 -9999 -999 -9999 -9999 -9999 -9999 -9999 -9999 -9999 -9999 -9999 -9999 -9999 -9999 -9999 -9999 -9999 -9999 -9999 -9999 -9999 -9999 -9999 -9999 -9999 -9999 -9999 -9999 -9999 -9999 -9999 -9999 -9999 -9999 -9999 -9999 -9999 -9999 -9999 -9999 -9999 -9999 -9999 -9999 -9999 -9999 -9999 -9999 -9999 -9999 -9999 -9999 -9999 -9999 -9999 -9999 -9999 -9999 -9999 -9999 -9999 -9999 -9999 -9999 -9999 -9999 -9999 -9999 -9999 -9999 -9999 -9999 -9999 -9999 -9999 -9999 -9999 -9999 -9999 -9999 -9999 -9999 -9999 -9999 -9999 -9999 -9999 -9999 -9999 -9999 -9999 -9999 -9999 -9999 -9999 -9999 -9999 -9999 -9999 -9999 -9999 -9999 -9999 -9999 -9999 -9999 -9999 -9999 -9999 -9999 -9999 -9999 -9999 94.78817749023 94.4833908081193.87381744385 93.5690307617292 .9594726562592 .349891662692 .0450973510791 .74033355713 91.1307525634890 .8259735107490 .2164001464889 .9116134643689 .60682678223 88.9972534179788 .6924667358488 .3876876831188 .0829010009888 .08290100098 88.0829010009888 .0829010009888 .3876876831188 .6924667358488 .99725341797 89.302040100189 .6068267822389 .9116134643689 .9116134643690 .21640014648 90.2164001464889 .9116134643689 .9116134643689 .6068267822389 .60682678223 89.6068267822389 .302040100189 .6068267822389 .6068267822389 .3020401001 89.302040100188 .9972534179788 .6924667358488 .6924667358488 .69246673584 88.6924667358488 .6924667358488 .3876876831188 .0829010009887 .47332763672 86.8637619018686 .5589828491285 .9494018554785 .6446228027385 .33984375 85.0350494384884 .7302627563584 .4254837036184 .1206970214884 .12069702148 83.8159103393683 .5111236572383 .5111236572383 .206336975182 .90155792236 82.5967712402381 .9871978759881 .3776321411180 .7680587768679 .85370635986 78.9393463134877 .7202072143676 .5010681152375 .5867080688574 .97714233398 74.9771423339874 .6723632812574 .6723632812574 .3675689697374 .36756896973 73.7580032348673 .4532165527372 .8436431884872 .2340774536171 .62449645996 71.014930725170 .4053573608469 .4910125732468 .8814392089867 .96708679199 67.0527267456166 .1383666992265 .2240066528364 .004882812562 .78573989868 61.5666007995660 .3474502563559 .1283111572357 .6043891906756 .99481964111 56.99481964111 -9999 -9999 -9999 -9999 -9999 -9999 -9999 -9999 -9999 -9999 -9999 -9999 
-9999 -9999 -9999 -9999 -9999 -9999 -9999 -9999 -9999 -9999 -9999 -9999 -9999 -9999 -9999 -9999 -9999 -9999 -9999 -9999 -9999 -9999 -9999 -9999 -9999 -9999 -9999 -9999 -9999 -9999 $-9999-9999$

-9999 -9999 -9999 -9999 -9999 -9999 -9999 -9999 -9999 -9999 -9999 -9999 -9999 -9999 -9999 -9999 -9999 -9999 -9999 -9999 -9999 -9999 -9999 -9999 -9999 -9999 -9999-9999 -9999 -9999 -9999 -9999 -9999 -9999 -9999 -9999 -9999 -9999 -9999 -9999 -9999 -9999 -9999 -9999 -9999 -9999 -9999 -9999 -9999 -9999 -9999 -9999 -9999 -9999 -9999 -9999 -9999 -9999 -9999 -9999 -9999 -9999 -9999 -9999 -9999 -9999 -9999 -9999 -9999 -9999 -9999 -9999 -9999 -9999 -9999

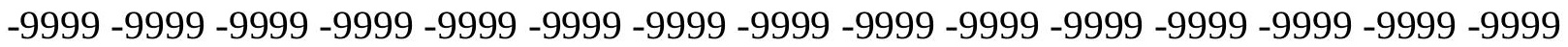
-9999 -9999 -9999 -9999 -9999 -9999 -9999 -9999 -9999 -9999 -9999 -9999 -9999 -9999 -9999 -9999 -9999 -9999 -9999 -9999 -9999 -9999 -9999 -9999 -9999 -9999 -9999 -9999 -9999 -9999 -9999 -9999 -9999 -9999 -9999 -9999 -9999 -9999 -9999 -9999 -9999 -9999 -9999 -9999 -9999 -9999 -9999 -9999 -9999 -9999 -9999 -9999 -9999 -9999 -9999 -9999 -9999 -9999 -9999 -9999 -9999 -9999 -9999 -9999 -9999 -9999 -9999 -9999 -9999 -9999 -9999 -9999 -9999 -9999 -9999 -9999 -9999 -9999 -9999 -9999 -9999 -9999 -9999 -9999 -9999 -9999 -9999 -9999 -9999 -9999 -9999 -9999 -9999 -9999 -9999 -9999 -9999 -9999 -9999 -9999 -9999 -9999 -9999 -9999 -9999

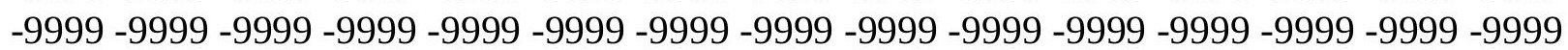
-9999 -9999 -9999 -9999 -9999 -9999 -9999 -9999 -9999 -9999 -9999 -9999 -9999 -9999 -9999 -999 -9999 -9999 -9999 -9999 -9999 -9999 -9999 -9999 -9999 -9999 -9999 -9999 -9999 -9999 -9999 -9999 -9999 -9999 -9999 -9999 -9999 95.397743225195.0929565429794.48339080811 93.5690307617293 .2642517089892 .6546783447392 .349891662692 .04509735107 91.7403335571391 .1307525634890 .8259735107490 .2164001464889 .91161346436 89.302040100188 .6924667358488 .3876876831187 .7781066894587 .47332763672 87.1685485839887 .4733276367287 .4733276367287 .7781066894588 .08290100098 88.6924667358488 .9972534179789 .302040100189 .302040100189 .60682678223 89.6068267822389 .6068267822389 .6068267822389 .6068267822389 .60682678223 89.6068267822389 .9116134643689 .9116134643690 .2164001464890 .52117919922 90.5211791992290 .5211791992290 .2164001464890 .2164001464890 .21640014648 90.5211791992290 .5211791992290 .2164001464889 .9116134643689 .3020401001 88.69246673584 88.08290100098 87.77810668945 87.16854858398 86.86376190186 86.5589828491286 .254188537686 .254188537685 .9494018554785 .64462280273 85.6446228027385 .3398437585 .0350494384884 .7302627563584 .42548370361 84.1206970214883 .5111236572382 .9015579223682 .2919769287181 .07285308838 79.8537063598678 .6345596313577 .110626220775 .8914871215875 .28192901611 75.2819290161174 .9771423339874 .6723632812574 .3675689697374 .0627822876 73.7580032348673 .1484298706172 .2340774536171 .6244964599670 .71015167236 70.1005783081169 .4910125732468 .5766525268667 .9670867919967 .05272674561 66.4431610107465 .5288009643664 .3096618652363 .3953094482462 .17617034912 60.9570198059159 .7378807067958 .5187492370657 .2995986938557 .29959869385 57.29959869385 -9999 -9999 -9999 -9999 -9999 -9999 -9999 -9999 -9999 -9999 -9999 -9999 -9999 -9999 -9999 -9999 -9999 -9999 -9999 -9999 -9999 -9999 -9999 -9999 -9999 -9999 -9999 -9999 -9999 -9999 -9999 -9999 -9999 -9999 -9999 -9999 -9999 -9999 -9999 -9999 -9999 -9999 $-9999-9999$

-9999 -9999 -9999 -9999 -9999 -9999 -9999 -9999 -9999 -9999 -9999 -9999 -9999 -9999 -9999 -9999 -9999 -9999 -9999 -9999 -9999 -9999 -9999 -9999 -9999 -9999 -9999 -9999 -9999 -9999

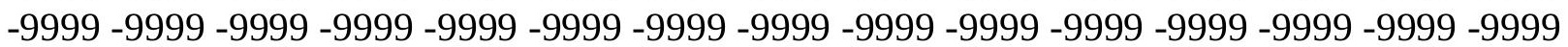


-9999 -9999 -9999 -9999 -9999 -9999 -9999 -9999 -9999 -9999 -9999 -9999 -9999 -9999 -9999 -9999 -9999 -9999 -9999 -9999 -9999 -9999 -9999 -9999 -9999 -9999 -9999 -9999 -9999 -9999 -9999 -9999 -9999 -9999 -9999 -9999 -9999 -9999 -9999 -9999 -9999 -9999 -9999 -9999 -9999 -9999 -9999 -9999 -9999 -9999 -9999 -9999 -9999 -9999 -9999 -9999 -9999 -9999 -9999 -9999 -9999 -9999 -9999 -9999 -9999 -9999 -9999 -9999 -9999 -9999 -9999 -9999 -9999 -9999 -9999 -9999 -9999 -9999 -9999 -9999 -9999 -9999 -9999 -9999 -9999 -9999 -9999 -9999 -9999 -9999 -9999 -9999 -9999 -9999 -9999 -9999 -9999 -9999 -9999 -9999 -9999 -9999 -9999 -9999 -9999

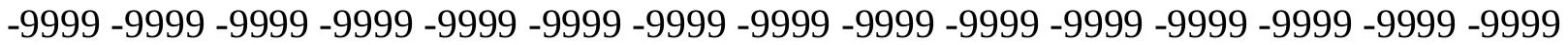
-9999 -9999 -9999 -9999 -9999 -9999 -9999 -9999 -9999 -9999 -9999 -9999 -9999 -9999 -9999 -9999 -9999 -9999 -9999 -9999 -9999 -9999 -9999 -9999 -9999 -9999 -9999 -9999 -9999 -9999 -9999 -9999 -9999 -9999 -9999 -9999 -9999 -9999 -9999 -9999 -9999 -9999 -9999 -9999 -9999 -9999 -9999 -9999 -9999 -9999 -9999 -9999 -9999 -9999 -9999 -9999 -9999 -9999 -9999 -9999 -9999 -9999 -9999 -9999 -9999 -9999 -9999 -9999 -9999 -9999 -9999 -9999 -9999 -9999 -9999 -9999 -9999-9999 -9999 -9999-9999-9999 95.3977432251 94.78817749023 94.17859649658 93.5690307617292 .9594726562592 .6546783447392 .6546783447392 .3498916626 91.7403335571391 .1307525634890 .8259735107490 .2164001464889 .60682678223 88.9972534179788 .6924667358488 .0829010009887 .7781066894587 .47332763672 86.8637619018686 .8637619018687 .1685485839887 .4733276367287 .77810668945 88.0829010009888 .3876876831188 .6924667358488 .6924667358488 .99725341797 88.9972534179789 .302040100189 .302040100189 .6068267822389 .60682678223 89.9116134643690 .5211791992290 .8259735107491 .4355392456191 .74033355713 92.0450973510792 .0450973510791 .7403335571392 .349891662692 .65467834473 92.6546783447392 .349891662691 .7403335571391 .1307525634890 .21640014648 89.6068267822388 .9972534179788 .6924667358488 .3876876831188 .08290100098 87.7781066894587 .7781066894587 .4733276367287 .4733276367287 .16854858398 86.8637619018686 .5589828491286 .254188537685 .9494018554785 .64462280273 85.0350494384884 .4254837036183 .8159103393682 .9015579223681 .68241119385 80.1584930419978 .3297805786176 .8058471679776 .1962814331176 .19628143311 75.5867080688575 .2819290161174 .9771423339874 .3675689697373 .75800323486 73.1484298706172 .2340774536171 .3197174072370 .1005783081169 .18623352051 68.5766525268667 .6623001098667 .0527267456166 .4431610107465 .52880096436 64.6144485473663 .7000885009862 .7857398986861 .5666007995660 .65224075317 59.4331016540558 .2139587402357 .6043891906757 .60438919067 -9999 -9999 -9999 -9999 -9999 -9999 -9999 -9999 -9999 -9999 -9999 -9999 -9999 -9999 -9999 -9999 -9999 -9999 -9999 -9999 -9999 -9999 -9999 -9999 -9999 -9999 -9999 -9999 -9999 -9999 -9999 -9999 -9999 -9999 -9999 -9999 -9999 -9999 -9999 -9999 -9999 -9999 -9999 -9999 -9999

-9999 -9999 -9999 -9999 -9999 -9999 -9999 -9999 -9999 -9999 -9999 -9999 -9999 -9999 -9999

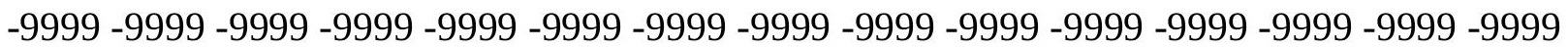
-9999 -9999 -9999 -9999 -9999 -9999 -9999 -9999 -9999 -9999 -9999 -9999 -9999 -9999 -9999 -9999 -9999 -9999 -9999 -9999 -9999 -9999 -9999 -9999 -9999 -9999 -9999 -9999 -9999 -9999 -9999 -9999 -9999 -9999 -9999 -9999 -9999 -9999 -9999 -9999 -9999 -9999 -9999 -9999 -9999

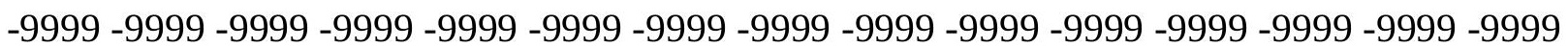
-9999 -9999 -9999 -9999 -9999 -9999 -9999 -9999 -9999 -9999 -9999 -9999 -9999 -9999 -9999 -9999 -9999 -9999 -9999 -9999 -9999 -9999 -9999 -9999 -9999 -9999 -9999 -9999 -9999 -9999 -9999 -9999 -9999 -9999 -9999 -9999 -9999 -9999 -9999 -9999 -9999 -9999 -9999 -9999 -9999

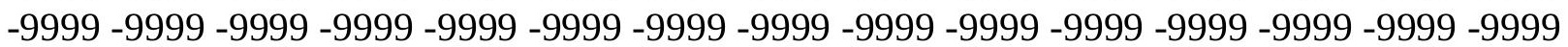


-9999 -9999 -9999 -9999 -9999 -9999 -9999 -9999 -9999 -9999 -9999 -9999 -9999 -9999 -9999 -9999 -9999 -9999 -9999 -9999 -9999 -9999 -9999 -9999 -9999 -9999 -9999 -9999 -9999 -9999 -9999 -9999 -9999 -9999 -9999 -9999 -9999 -9999 -9999 -9999 -9999 -9999 -9999 -9999 -9999 -9999 -9999 -9999 -9999 -9999 -9999 -9999 -9999 -9999 -9999 -9999 -9999 -9999 -9999 -9999 -9999 -9999 -9999 -9999 -9999 -9999 -9999 -9999 -9999 -9999 -9999 -9999 -9999 -9999 -9999 -9999 -9999 -9999 -9999 -9999 -9999 -9999 -9999 -9999 -9999 -9999 -9999 -9999 -9999 -9999 -9999 -9999 -9999 -9999 -9999 -9999 -9999 96.3121032714895.397743225194.48339080811 93.8738174438593 .5690307617293 .5690307617293 .2642517089893 .26425170898 92.6546783447392 .0450973510791 .4355392456190 .8259735107489 .91161346436 89.302040100188.9972534179788.3876876831188.08290100098 87.47332763672 87.1685485839886 .8637619018688 .0829010009886 .5589828491286 .86376190186 87.1685485839887 .4733276367287 .7781066894588 .0829010009888 .38768768311 88.3876876831188 .6924667358488 .6924667358488 .9972534179789 .3020401001 89.9116134643690.5211791992291.1307525634892.0450973510792.95947265625 93.5690307617294 .4833908081194 .7881774902395 .0929565429794 .78817749023 94.4833908081193 .8738174438592 .9594726562592 .349891662691 .43553924561 90.8259735107490 .2164001464889 .9116134643689 .6068267822389 .3020401001 89.3020401001 88.99725341797 88.99725341797 88.69246673584 88.38768768311 88.0829010009887 .7781066894587 .4733276367287 .1685485839886 .86376190186 86.5589828491286 .254188537685 .3398437584 .7302627563583 .51112365723 81.9871978759880 .4632720947378 .9393463134878 .0249862670977 .41542053223 77.110626220776 .5010681152375 .8914871215875 .2819290161174 .67236328125 73.7580032348672 .5388565063571 .3197174072369 .7957916259868 .57665252686 67.6623001098667 .0527267456166 .1383666992265 .5288009643664 .91924285889 64.004882812563 .0905189514262 .1761703491261 .2618103027360 .91326522827 60.6522407531759 .7378807067958 .21395874023 -9999 -9999 -9999 -9999 -9999 -9999 -9999 -9999 -9999 -9999 -9999 -9999 -9999 -9999 -9999 -9999 -9999 -9999 -9999 -9999 -9999 -9999 -9999 -9999 -9999 -9999 -9999 -9999 -9999 -9999 -9999 -9999 -9999 -9999 -9999 -9999 -9999 -999 -9999 -9999 -9999 -9999 -9999 -9999 -9999 -9999 -9999 -9999 -9999 -9999 -9999 -9999 -9999 -9999 -9999 -9999 -9999 -9999 -9999 -9999 -9999 -9999 -9999 -9999 -9999 -9999 -9999 -9999 -9999 -9999 -9999 -9999 -9999 -9999 -9999 -9999 -9999 -

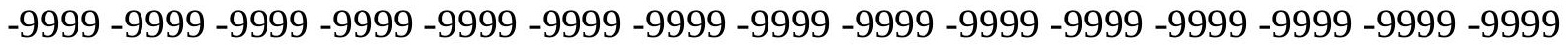
-9999 -9999 -9999 -9999 -9999 -9999 -9999 -9999 -9999 -9999 -9999 -9999 -9999 -9999 -9999 -9999 -9999 -9999 -9999 -9999 -9999 -9999 -9999 -9999 -9999 -9999 -9999 -9999 -9999 -9999 -9999 -9999 -9999 -9999 -9999 -9999 -9999 -9999 -9999 -9999 -9999 -9999 -9999 -9999 -9999 -9999 -9999 -9999 -9999 -9999 -9999 -9999 -9999 -9999 -9999 -9999 -9999 -9999 -9999 -9999 -9999 -9999 -9999 -9999 -9999 -9999 -9999 -9999 -9999 -9999 -9999 -9999 -9999 -9999 -9999

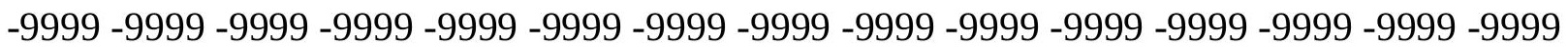
-9999 -9999 -9999 -9999 -9999 -9999 -9999 -9999 -9999 -9999 -9999 -9999 -9999 -9999 -9999 -9999 -9999 -9999 -9999 -9999 -9999 -9999 -9999 -9999 -9999 -9999 -9999 -9999 -9999 -9999 -

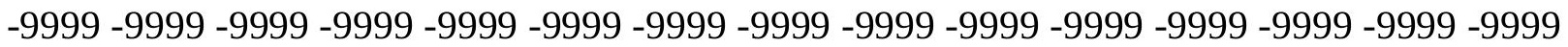
-9999 -9999 -9999 -9999 -9999 -9999 -9999 -9999 -9999 -9999 -9999 -9999 -9999 - -9999 - -9999 -9999 -9999 -9999 -9999 -9999 -9999 -9999 -9999 -9999 -9999 -9999 -9999 -9999 -9999 -9999 -9999 -9999 -9999 -9999 -9999 -9999 -9999 -9999 -9999 -9999 -9999 -9999 -9999 -9999 -9999 -9999 -9999 -9999 -9999 -9999 -9999 -9999 -9999 -9999 -9999 -9999 -9999 -9999 -9999 -9999 -9999 -9999 -9999 -9999 -9999 -9999 -9999 -9999 98.14080810547 96.00731658936 
94.1785964965893 .8738174438594 .1785964965894 .4833908081194 .17859649658 93.5690307617292 .9594726562592 .0450973510791 .1307525634890 .52117919922 89.6068267822389 .302040100188 .6924667358488 .3876876831187 .77810668945 87.4733276367287 .1685485839886 .8637619018686 .5589828491286 .2541885376 86.5589828491286 .8637619018687 .1685485839887 .1685485839887 .47332763672 87.7781066894587 .7781066894588 .0829010009888 .3876876831188 .99725341797 89.6068267822390 .2164001464891 .1307525634892 .349891662693 .56903076172 95.0929565429796 .6168823242297 .5312423706197 .2264633178796 .61688232422 95.7025299072394 .7881774902393 .8738174438592 .9594726562592 .3498916626 91.4355392456190 .8259735107490 .5211791992290 .2164001464890 .21640014648 90.2164001464890 .2164001464890 .2164001464889 .9116134643689 .60682678223 89.3020401001 88.9972534179788.69246673584 88.69246673584 88.38768768311 88.0829010009887 .7781066894587 .1685485839886 .5589828491285 .64462280273 84.4254837036183 .206336975181 .6824111938580 .4632720947379 .54891967773 78.6345596313578 .0249862670977 .4154205322376 .8058471679776 .19628143311 74.9771423339873 .4532165527371 .9292907714870 .1005783081168 .27187347412 67.0527267456166 .1383666992265 .5288009643664 .9192428588964 .30966186523 63.7000885009862 .7857398986861 .8713798522961 .5666007995661 .11140060425 60.3474502563560 .3474502563560 .04267120361 -9999 -9999 -9999 -9999 -9999 -9999 -9999 -9999 -9999 -9999 -9999 -9999 -9999 -9999 -9999 -9999 -9999 -9999 -9999 -9999 -9999 -9999 -9999 -9999 -9999 -9999 -9999 -9999 -9999 -9999 -9999 -9999 -9999 -9999 -9999 -9999 -9999 -9999 -9999 -9999 -9999 -9999 -9999 -9999 -9999 -9999 -9999 -9999 -9999 -9999 -9999 -9999 -9999 -9999 -9999 -9999 -9999 -9999 -9999 -9999 -9999 -9999 -9999 -9999 -9999 -9999 -9999 -9999 -9999 -9999 -9999 -9999 -9999 -9999 -9999 -9999 -9999 -9999 -9999 -9999 -9999 -9999 -9999 -9999 -9999 -9999 -9999 -9999 -9999 -9999 -9999 -9999 -9999 -9999 -9999 -9999 -9999 -9999 -9999 -9999 -9999 -9999 -9999 -9999 -9999 -9999 -9999 -9999 -9999 -9999 -9999 -9999 -9999 -9999 -9999 -9999 -9999 -9999 -9999 -9999 -9999 -

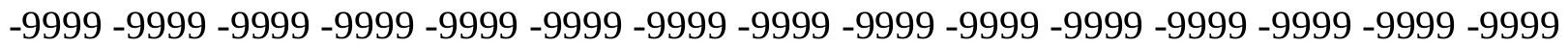
-9999 -9999 -9999 -9999 -9999 -9999 -9999 -9999 -9999 -9999 -9999 -9999 -9999 -9999 -9999 -9999 -9999 -9999 -9999 -9999 -9999 -9999 -9999 -9999 -9999 -9999 -9999 -9999 -9999 -9999 -9999 -9999 -9999 -9999 -9999 -9999 -9999 -9999 -9999 -9999 -9999 -9999 -9999 -9999 -9999

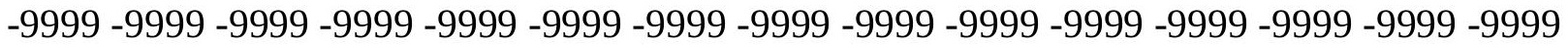

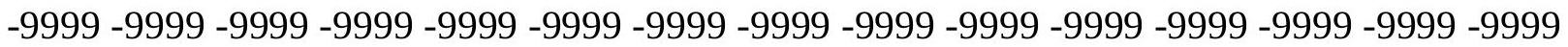
-9999 -9999 -9999 -9999 -9999 -9999 -9999 -9999 -9999 -9999 -9999 -9999 -9999 -9999 -9999 -9999 -9999 -9999 -9999 -9999 -9999 -9999 -9999 -9999 -9999 -9999 -9999 -9999 -9999 -9999 -9999 -9999 -9999 -9999 -9999 -9999 -9999 -9999 -9999 -9999 -9999 -9999 -9999 -9999 -9999

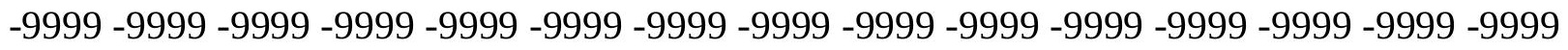

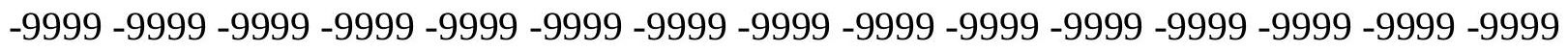
-9999 -9999 -9999 -9999 -9999 -9999 -9999 -9999 104.2365036011102 .4077987671 99.9695205688597 .5312423706195 .7025299072395 .7025299072395 .3977432251 94.7881774902393 .8738174438592 .6546783447391 .7403335571390 .82597351074 89.91161346436 89.3020401001 88.99725341797 88.6924667358488.38768768311 87.7781066894587 .4733276367287 .1685485839886 .8637619018686 .2541885376 85.9494018554785 .9494018554786 .254188537686 .5589828491286 .55898284912 86.8637619018687 .1685485839887 .4733276367287 .7781066894588 .38768768311 88.99725341797 89.6068267822390.8259735107492.0450973510793.87381744385 
95.7025299072397 .5312423706199 .6647262573298 .7503814697397 .53124237061 96.3121032714895 .397743225194 .1785964965893 .2642517089892 .65467834473 91.7403335571391 .4355392456191 .1307525634890 .8259735107490 .82597351074 90.8259735107491 .1307525634891 .1307525634890 .8259735107490 .52117919922 90.2164001464889 .9116134643689 .9116134643689 .6068267822389 .60682678223 89.3020401001 89.302040100188.9972534179788.38768768311 87.77810668945 87.1685485839885 .9494018554784 .4254837036183 .206336975181 .68241119385 80.4632720947379 .8537063598679 .2441329956178 .9393463134878 .63455963135 77.4154205322375 .5867080688573 .1484298706170 .4053573608468 .27187347412 66.7479400634865 .8335876464864 .9192428588964 .6144485473664 .0048828125 63.3953094482462 .4809494018662 .1761703491261 .8713798522961 .26181030273 60.9570198059160 .9570198059160 .65224075317 -9999 -9999 -9999 -9999 -9999 -9999 -9999 -9999 -9999 -9999 -9999 -9999 -9999 -9999 -9999 -9999 -9999 -9999 -9999 -9999 -9999 -9999

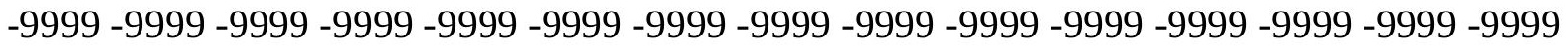
-9999 -9999 -9999 -9999 -9999 -9999 -9999 -9999 -9999

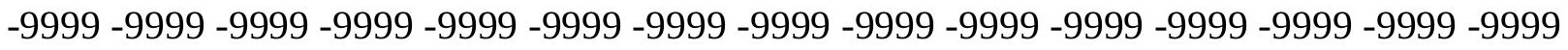
-9999 -9999 -9999 -9999 -9999 -9999 -9999 -9999 -9999 -9999 -9999 -9999 -9999 -9999 -9999 -9999 -9999 -9999 -9999 -9999 -9999 -9999 -9999 -9999 -9999 -9999 -9999 -9999 -9999 -9999 -9999 -9999 -9999 -9999 -9999 -9999 -9999 -9999 -9999 -9999 -9999 -9999 -9999 -9999 -9999 -9999 -9999 -9999 -9999 -9999 -9999 -9999 -9999 -9999 -9999 -9999 -9999 -9999 -9999 -9999 -9999 -9999 -9999 -9999 -9999 -9999 -9999 -9999 -9999 -9999 -9999 -9999 -9999 -9999 -9999 -9999 -9999 -9999 -9999 -9999 -9999 -9999 -9999 -9999 -9999 -9999 -9999 -9999 -9999 -9999 -9999 -9999 -9999 -9999 -9999 -9999 -9999 -9999 -9999 -9999 -9999 -9999 -9999 -9999 -9999 -9999 -9999 -9999 -9999 -9999 -9999 -9999 -9999 -9999 -9999 -9999 -9999 -9999 -9999 -9999 -9999 -9999 -9999 -9999 -9999 -9999 -9999 -9999 -9999 -9999 -9999 -9999 -9999 -9999 -9999 -9999 -9999 -9999 -9999 -9999 -9999 -9999 -9999 -9999 -9999 -9999 -9999 -9999 -9999 -9999 -9999 -9999 -9999 -9999 -9999 -9999 -9999 -9999 -9999 -9999 -9999 -9999 -9999 -9999 -9999 -

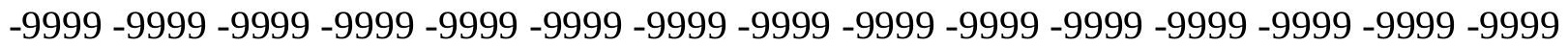
-9999 -9999 -9999 -9999 -9999 -9999 -9999 -9999 -9999 -9999 -9999 -9999 -9999 -9999 -9999 -9999 -9999 -9999 -9999 -9999 -9999 -9999 -9999 -9999 -9999 -9999 -9999 -9999 -9999 -999 -9999 -9999 -9999 -9999 -9999 -9999 -9999 -9999 -9999 -9999 -9999 -9999 -9999 -9999 -9999 -9999 -9999 -9999 -9999 -9999 -9999 -9999 -9999 111.24659729109 .7226028442 107.5891036987104 .8460998535102 .102996826299 .6647262573297 .53124237061 95.7025299072394 .4833908081193 .2642517089892 .0450973510791 .13075256348 90.2164001464889 .9116134643689 .302040100188 .9972534179788 .69246673584 88.38768768311 87.77810668945 87.47332763672 87.16854858398 86.86376190186 86.2541885376 85.9494018554785.33984375 85.64462280273 85.64462280273 85.94940185547 86.2541885376 86.2541885376 86.86376190186 87.16854858398 88.0829010009888 .6924667358489 .9116134643691 .4355392456192 .95947265625 94.7881774902396 .9216690063598 .1408081054797 .8360290527396 .92166900635 96.0073165893695 .0929565429793 .8738174438593 .2642517089892 .3498916626 91.7403335571391 .4355392456191 .1307525634891 .1307525634891 .13075256348 91.1307525634891 .4355392456191 .4355392456191 .4355392456191 .13075256348 90.8259735107490 .8259735107490 .5211791992290 .5211791992290 .52117919922 90.5211791992290 .5211791992290 .5211791992290 .2164001464889 .91161346436 89.302040100188 .3876876831187 .1685485839885 .6446228027383 .81591033936 
82.5967712402381 .6824111938581 .6824111938581 .6824111938581 .98719787598 81.0728530883878 .3297805786174 .6723632812570 .7101516723667 .96708679199 66.1383666992265 .2240066528364 .6144485473664 .004882812563 .70008850098 62.7857398986862 .1761703491262 .4809494018661 .8713798522961 .67150115967 61.5666007995661 .5666007995661 .26181030273 -9999 -9999 -9999 -9999 -9999 -9999 -9999 -9999 -9999 -9999 -9999 -9999 -9999 -9999 -9999 -9999 -9999 -9999 -9999 -9999 -9999 -9999

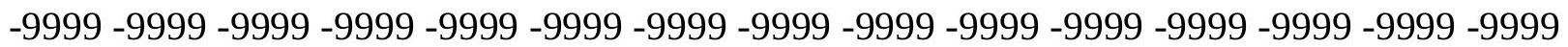
-9999 -9999 -9999 -9999 -9999 -9999 -9999 -9999 -9999

-9999 -9999 -9999 -9999 -9999 -9999 -9999 -9999 -9999 -9999 -9999 -9999 -9999 -9999 -9999 -9999 -9999 -9999 -9999 -9999 -9999 -9999 -9999 -9999 -9999 -9999 -9999 -9999 -9999 -9999

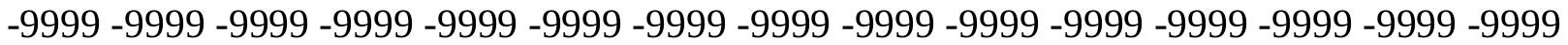
-9999 -9999 -9999 -9999 -9999 -9999 -9999 -9999 -9999 -9999 -9999 -9999 -9999 -9999 -9999 -9999 -9999 -9999 -9999 -9999 -9999 -9999 -9999 -9999 -9999 -9999 -9999 -9999 -9999 -9999 -9999 -9999 -9999 -9999 -9999 -9999 -9999 -9999 -9999 -9999 -9999 -9999 -9999 -9999 - 9999 -9999 -9999 -9999 -9999 -9999 -9999 -9999 -9999 -9999 -9999 -9999 -9999 -9999 -9999 -9999

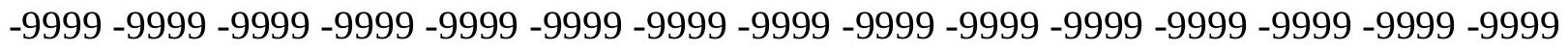
-9999 -9999 -9999 -9999 -9999 -9999 -9999 -9999 -9999 -9999 -9999 -9999 -9999 -9999 -9999 -9999 -9999 -9999 -9999 -9999 -9999 -9999 -9999 -9999 -9999 -9999 -9999 -9999 -9999 -9999 -9999 -9999 -9999 -9999 -9999 -9999 -9999 -9999 -9999 -9999 -9999 -9999 -9999 -9999 -9999 -

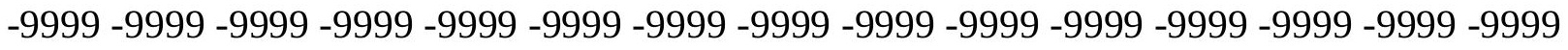
-9999 -9999 -9999 -9999 -9999 -9999 -9999 -9999 -9999 -9999 -9999 -9999 -9999 -9999 -9999 -9999 -9999 -9999 -9999 -9999 -9999 -9999 -9999 -9999 -9999 -9999 -9999 -9999 -9999 -9999 -9999 -9999 -9999 -9999 -9999 -9999 -9999 -9999 -9999 -9999 -9999 -9999 -9999 -9999 -9999 -

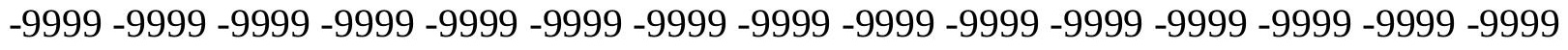
-9999 -9999-9999 -9999 -9999 -9999-9999-9999-9999 116.4459228516 115.5136032104 112.4656982422109 .1130981445105 .7603988647102 .71260070899 .66472625732 96.9216690063597 .2264633178792 .6546783447391 .4355392456190 .82597351074 90.2164001464889 .6068267822389 .302040100188 .9972534179788 .69246673584 88.38768768311 88.08290100098 87.47332763672 87.16854858398 86.55898284912 86.254188537685 .6446228027385 .3398437584 .7302627563585 .03504943848 85.0350494384885 .3398437585 .6446228027386 .254188537686 .86376190186 87.4733276367288 .6924667358489 .9116134643691 .4355392456193 .26425170898 94.7881774902395 .7025299072395 .7025299072395 .397743225194 .78817749023 93.8738174438592 .9594726562592 .349891662691 .7403335571391 .43553924561 91.1307525634890 .8259735107490 .8259735107490 .8259735107491 .13075256348 91.1307525634891 .4355392456191 .4355392456191 .4355392456191 .43553924561 91.1307525634891 .1307525634891 .1307525634891 .1307525634891 .43553924561 91.4355392456191 .7403335571391 .7403335571391 .4355392456191 .13075256348 90.5211791992289 .302040100187 .4733276367285 .6446228027384 .12069702148 83.2063369751 83.51112365723 84.42548370361 85.33984375 85.33984375 81.37763214111 76.1962814331170 .1005783081166 .7479400634865 .2240066528364 .91924285889 64.3096618652363 .7000885009863 .0905189514262 .4809494018661 .87137985229 61.2618103027362 .4809494018661 .9893760681262 .1761703491261 .87137985229 60.34745025635 -9999 -9999 -9999 -9999 -9999 -9999 -9999 -9999 -9999 -9999 -9999 -9999 -9999 -9999 -9999 -9999 -9999 -9999 -9999 -9999 -9999 -9999 -9999 -9999 -9999 -9999 -9999

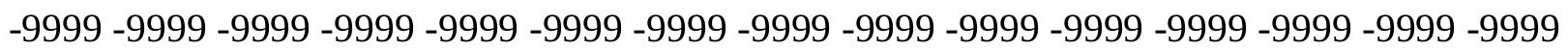


-9999 -9999 -9999 -9999

-9999 -9999 -9999 -9999 -9999 -9999 -9999 -9999 -9999 -9999 -9999 -9999 -9999 -9999 -9999

-9999 -9999 -9999 -9999 -9999 -9999 -9999 -9999 -9999 -9999 -9999 -9999 -9999 -9999 - 9999 -

-9999 -9999 -9999 -9999 -9999 -9999 -9999 -9999 -9999 -9999 -9999 -9999 -9999 -9999 -9999

-9999 -9999 -9999 -9999 -9999 -9999 -9999 -9999 -9999 -9999 -9999 -9999-9999 -9999 -9999 -

-9999 -9999 -9999 -9999 -9999 -9999 -9999 -9999 -9999 -9999 -9999 -9999 -9999 -9999 -9999

-9999 -9999 -9999 -9999 -9999 -9999 -9999 -9999 -9999 -9999 -9999 -9999 -9999 -9999 -9999 -999 -

-9999 -9999 -9999 -9999 -9999 -9999 -9999 -9999 -9999 -9999 -9999 -9999 -9999 -9999 -9999

-9999 -9999 -9999 -9999 -9999 -9999 -9999 -9999 -9999 -9999 -9999 -9999 -9999 -9999 -9999 -

-9999 -9999 -9999 -9999 -9999 -9999 -9999 -9999 -9999 -9999 -9999 -9999 -9999 -9999 -9999 -

-9999 -9999 -9999 -9999 -9999 -9999 -9999 -9999 -9999 -9999 -9999 -9999 -9999 -9999 -9999

-9999 -9999 -9999 -9999 -9999 -9999 -9999 -9999 -9999 -9999 -9999 -9999 -9999 -9999 -9999

-9999 -9999 -9999 -9999 -9999 -9999 -9999 -9999 -9999 -9999 -9999 -9999 -9999 -9999 -9999

-9999 -9999 -9999 -9999 -9999 -9999 -9999 -9999 -9999 -9999 -9999 -9999 -9999 -9999 -9999 -

-9999 -9999 -9999 -9999 -9999 -9999 -9999 -9999 -9999 -9999 -9999 -9999 -9999 -9999 -9999

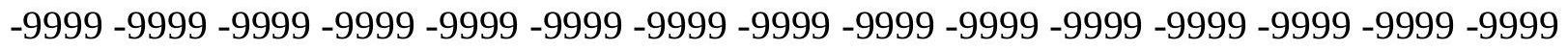

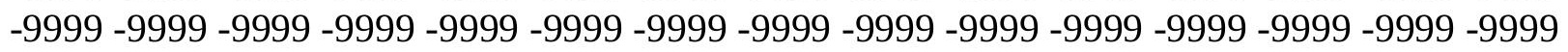

-9999 -9999-9999 -9999 -9999 -9999-9999-9999 -9999 121.7130279541 121.2111663818

119.7806015015115 .818397522111 .8561019897107 .8938980103104 .2365036011 100.883903503497 .5312423706194 .4833908081192 .349891662691 .13075256348 90.5211791992290 .2164001464889 .6068267822389 .302040100188 .99725341797 88.69246673584 88.38768768311 88.08290100098 87.47332763672 87.16854858398 86.5589828491286 .254188537685 .6446228027385 .0350494384884 .73026275635 84.1206970214884 .1206970214884 .4254837036185 .0350494384885 .33984375 86.254188537687 .1685485839888 .0829010009889 .302040100190 .82597351074 92.0450973510792 .9594726562593 .2642517089892 .9594726562592 .65467834473 92.0450973510791 .7403335571391 .1307525634890 .8259735107490 .52117919922 90.2164001464890 .2164001464890 .2164001464890 .2164001464890 .52117919922 90.8259735107491 .1307525634891 .1307525634891 .1307525634891 .43553924561 91.4355392456191 .4355392456191 .4355392456191 .7403335571392 .04509735107 92.349891662692 .349891662692 .6546783447392 .6546783447392 .3498916626 91.7403335571391 .1307525634888 .6924667358486 .254188537684 .73026275635 84.1206970214884 .4254837036185 .6446228027387 .1685485839888 .52935791016 85.6446228027374 .3675689697367 .6623001098664 .6144485473665 .83358764648 64.6144485473664 .004882812563 .7000885009863 .3953094482462 .78573989868 62.4809494018662 .1761703491261 .8713798522961 .5666007995661 .26181030273 61.2618103027360 .95701980591 -9999 -9999 -9999 -9999 -9999 -9999 -9999 -9999 -9999 -9999 -9999 -9999 -9999 -9999 -9999 -9999 -9999 -9999 -9999 -9999 -9999 -9999 -9999 -9999 -

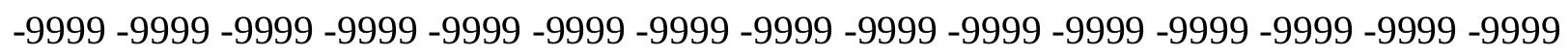
-9999 -9999 -9999 -9999 -9999 -9999-9999

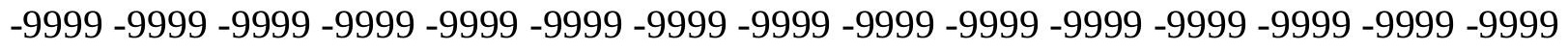

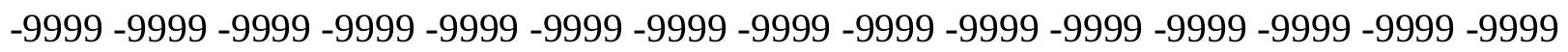

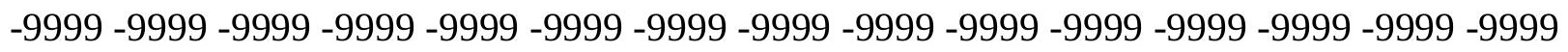
-9999 -9999 -9999 -9999 -9999 -9999 -9999 -9999 -9999 -9999 -9999 -9999 -9999 -9999 -9999 -

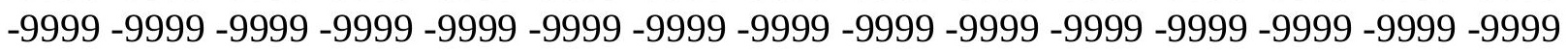

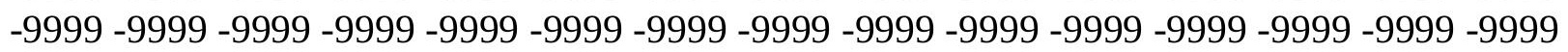


-9999 -9999 -9999 -9999 -9999 -9999 -9999 -9999 -9999 -9999 -9999 -9999 -9999 -9999 -9999 -9999 -9999 -9999 -9999 -9999 -9999 -9999 -9999 -9999 -9999 -9999 -9999 -9999 -9999 -9999 -9999 -9999 -9999 -9999 -9999 -9999 -9999 -9999 -9999 -9999 -9999 -9999 -9999 -9999 -9999 -9999 -9999 -9999 -9999 -9999 -9999 -9999 -9999 -9999 -9999 -9999 -9999 -9999 -9999 -9999 -9999 -9999 -9999 -9999 -9999 -9999 -9999 -9999 -9999 -9999 -9999 -9999 -9999 -9999 -9999 -9999 -9999 -9999 -9999 -9999 -9999 -9999 -9999 -9999 -9999 -9999 -9999 -9999 -9999 -9999 -9999 -9999 -9999 -9999 -9999 -9999 -9999 -9999 -9999 -9999 -9999 -9999 -9999 -9999 -9999

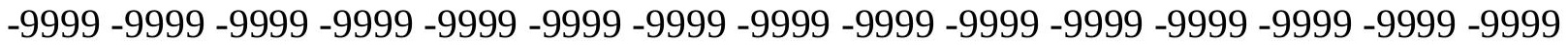

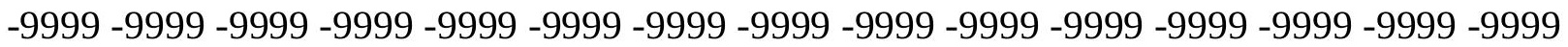
-9999 -9999 -9999 -9999 -9999 -9999 -9999 -9999 -9999 -9999 -9999 -9999 -9999 -9999 -9999 -9999 -9999 -9999 -9999 -9999 -9999 -9999 -9999 -9999 -9999 125.334197998 123.8538894653120 .9546356201117 .342300415113 .075302124108 .8082962036 104.8460998535100 .883903503497 .5312423706194 .4833908081192 .04509735107 90.8259735107490 .5211791992290 .2164001464889 .9116134643689 .60682678223 89.302040100188.69246673584 88.3876876831188.08290100098 87.47332763672 86.8637619018686 .5589828491285 .9494018554785 .6446228027385 .03504943848 84.4254837036183 .8159103393683 .5111236572383 .5111236572383 .81591033936 84.4254837036185 .3398437585 .9494018554787 .1685485839888 .08290100098 88.9972534179789 .9116134643690 .2164001464890 .2164001464890 .21640014648 89.9116134643689 .6068267822389 .302040100189 .302040100188 .99725341797 88.9972534179788 .9972534179789 .302040100189 .6068267822389 .91161346436 90.2164001464890 .5211791992290 .8259735107490 .8259735107491 .13075256348 91.4355392456191 .4355392456191 .7403335571392 .0450973510792 .3498916626 92.6546783447392 .9594726562592 .9594726562592 .6546783447392 .3498916626 91.7403335571390 .2164001464888 .0829010009885 .9494018554784 .12069702148 83.5111236572383 .8159103393684 .7302627563584 .7302627563585 .94940185547 86.6867599487367 .6623001098665 .8335876464865 .8335876464865 .52880096436 65.2240066528364 .9192428588964 .6144485473664 .3096618652364 .0048828125 63.3953094482463 .0905189514262 .7857398986862 .4809494018662 .17617034912 61.87137985229 -9999 -9999 -9999 -9999 -9999 -9999 -9999 -9999 -9999 -9999 -9999 -9999 -9999 -9999 -9999 -9999 -9999 -9999 -9999 -9999 -9999 -9999 -9999 -9999 -9999 -9999 -9999

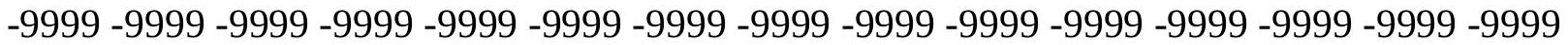
-9999 -9999-9999-9999-9999

-9999 -9999 -9999 -9999 -9999 -9999 -9999 -9999 -9999 -9999 -9999 -9999 -9999 -9999 -9999

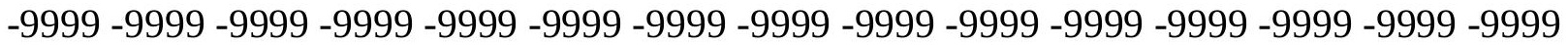
-9999 -9999 -9999 -9999 -9999 -9999 -9999 -9999 -9999 -9999 -9999 -9999 -9999 -9999 -9999 -9999 -9999 -9999 -9999 -9999 -9999 -9999 -9999 -9999 -9999 -9999 -9999 -9999 -9999 -9999

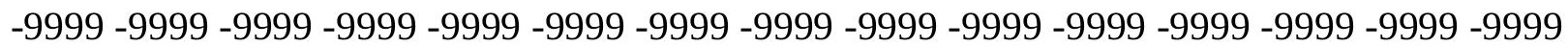
-9999 -9999 -9999 -9999 -9999 -9999 -9999 -9999 -9999 -9999 -9999 -9999 -9999 -9999 -9999 -9999 -9999 -9999 -9999 -9999 -9999 -9999 -9999 -9999 -9999 -9999 -9999 -9999 -9999 -9999 -9999 -9999 -9999 -9999 -9999 -9999 -9999 -9999 -9999 -9999 -9999 -9999 -9999 -9999 -9999 -999 -9999 -9999 -9999 -9999 -9999 -9999 -9999 -9999 -9999 -9999 -9999 -9999 -9999 -9999 -9999 -9999 -9999 -9999 -9999 -9999 -9999 -9999 -9999 -9999 -9999 -9999 -9999 -9999 -9999 -9999 -9999 -9999 -9999 -9999 -9999 -9999 -9999 -9999 -9999 -9999 -9999 -9999 -9999 -9999 -9999 -999 -9999 -9999 -9999 -9999 -9999 -9999 -9999 -9999 -9999 -9999 -9999 -9999 -9999 -9999 -9999

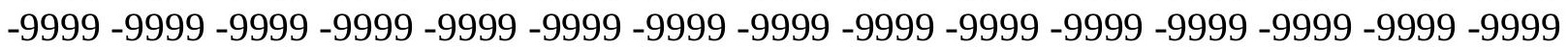


-9999 -9999 -9999 -9999 -9999 -9999 -9999 -9999 -9999 -9999 -9999 -9999 -9999 -9999 -9999 -9999 -9999 -9999 -9999 -9999 -9999 -9999 -9999 -9999 -9999 -9999 -9999 -9999 -9999 -9999

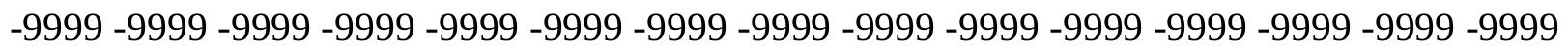
-9999 -9999 -9999 -9999 -9999 -9999 -9999 -9999 -9999 -9999 128.2546234131 126.9316711426124 .612953186121 .4244766235117 .647102356113 .075302124 108.5035018921104 .5412979126100 .883903503497 .5312423706194 .78817749023 92.349891662691 .1307525634890 .8259735107490 .5211791992289 .91161346436 89.60682678223 89.3020401001 88.69246673584 88.3876876831187.77810668945 87.4733276367286 .8637619018686 .254188537685 .9494018554785 .33984375 84.7302627563584 .4254837036183 .8159103393683 .206336975182 .59677124023 82.9015579223683 .206336975183 .8159103393684 .7302627563585 .33984375 86.254188537686 .8637619018687 .4733276367287 .4733276367287 .47332763672 87.4733276367287 .4733276367287 .4733276367287 .4733276367287 .47332763672 87.4733276367287 .7781066894588 .0829010009888 .3876876831188 .69246673584 88.9972534179789 .6068267822389 .9116134643690 .2164001464890 .82597351074 91.1307525634891 .4355392456191 .7403335571392 .0450973510792 .3498916626 92.6546783447392 .9594726562592 .6546783447392 .349891662691 .74033355713 90.8259735107488 .9972534179786 .8637619018684 .7302627563582 .90155792236 81.6824111938581 .0728530883881 .6824111938581 .9871978759869 .18623352051 67.6623001098667 .3575134277367 .3575134277367 .0527267456166 .74794006348 66.4431610107466 .1383666992265 .8335876464865 .5288009643664 .91924285889 64.6144485473664 .3096618652363 .7000885009863 .3953094482463 .09051895142 63.09051895142 -9999 -9999 -9999 -9999 -9999 -9999 -9999 -9999 -9999 -9999 -9999 -9999 -9999 -9999 -9999 -9999 -9999 -9999 -9999 -9999 -9999 -9999 -9999 -9999 -9999 -9999 -9999 -9999 -9999 -9999 -9999 -9999 -9999 -9999 -9999 -9999 -9999 -9999 -9999 -9999 -9999 -9999 -9999 -9999 -9999-9999-9999 -9999 -9999 -9999 -9999 -9999 -9999 -9999 -9999 -9999 -9999 -9999 -9999 -9999 -9999 -9999 -9999 -9999 -9999 -9999 -9999 -9999 -9999 -9999 -9999 -9999 -9999 -9999 -9999 -9999 -9999 -9999 -9999 -9999 -9999 -9999 -9999 -9999 -9999 -9999 -9999 -9999 -9999 -9999 -9999 -9999 -999 -9999 -9999 -9999 -9999 -9999 -9999 -9999 -9999 -9999 -9999 -9999 -9999 -9999 -9999 -9999 -9999 -9999 -9999 -9999 -9999 -9999 -9999 -9999 -9999 -9999 -9999 -9999 -9999 -9999 -9999 -9999 -9999 -9999 -9999 -9999 -9999 -9999 -9999 -9999 -9999 -9999 -9999 -9999 -9999 -9999 -9999 -9999 -9999 -9999 -9999 -9999 -9999 -9999 -9999 -9999 -9999 -9999 -9999 -9999 -9999 -9999 -9999 -9999 -9999 -9999 -9999 -9999 -9999 -9999 -9999 -9999 -9999 -9999 -9999 -9999 -9999 -9999 -9999 -9999 -9999 -9999 -9999 -9999 -9999 -9999 -9999 -9999 -9999 -9999 -9999 -9999 -9999 -9999 -9999 -9999 -9999 -9999 -9999 -9999 -9999 -9999 -9999 -9999 -9999 -9999 -9999 -9999 -9999 -9999 -9999 -9999 -9999 -9999 -9999 -9999 -9999 -9999 -9999 -9999 -9999 -9999 -9999 -9999 -9999 -9999 -9999 -9999 -9999 -9999 -9999 -9999 -9999 -9999 -9999 -9999 -9999 -9999 -9999 -9999 -9999 -9999 -9999 -9999 -9999 -9999 -9999 -9999 -9999 -9999 -9999 -9999 -9999 -9999 -9999 -9999 -9999 -9999 -9999 -9999 -9999 -9999 -9999 -9999 -9999 -9999 -9999 -9999 -9999 -9999 -9999 -9999 -9999 -9999 -9999 -9999 -9999 -9999 -9999 -9999 -9999

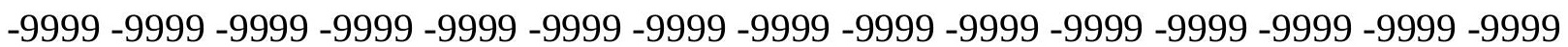
-9999 -9999 -9999 -9999 -9999 -9999 -9999 -9999 -9999 -9999 -9999 129.2579956055 127.2749481201 124.4770889282120.9415130615 116.7326965332112 .1608963013 107.8938980103103 .9317016602100 .274299621697 .2264633178794 .48339080811 92.349891662691 .4355392456191 .1307525634890 .5211791992290 .21640014648 
89.6068267822389 .302040100188 .6924667358488 .0829010009887 .77810668945 87.1685485839886 .8637619018686 .254188537685 .6446228027385 .33984375 84.7302627563584 .1206970214883 .8159103393683 .206336975182 .59677124023 81.9871978759881 .6824111938582 .2919769287182 .9015579223683 .51112365723 84.1206970214884 .4254837036184 .7302627563584 .7302627563585 .03504943848 85.0350494384885 .3398437585 .3398437585 .6446228027385 .9494018554786 .2541885376 86.5589828491287 .1685485839887 .4733276367288 .0829010009888 .38768768311 88.9972534179789 .6068267822390 .2164001464890 .5211791992291 .13075256348 91.7403335571392 .0450973510792 .349891662692 .6546783447392 .65467834473 92.349891662691 .7403335571390 .8259735107489 .302040100187 .47332763672 85.3398437583 .206336975181 .0728530883878 .9393463134877 .41542053223 75.5867080688569 .1862335205169 .1862335205169 .1862335205168 .88143920898 68.5766525268668 .2718734741267 .9670867919967 .6623001098667 .35751342773 67.0527267456166 .7479400634866 .1383666992265 .8335876464865 .22400665283 64.9192428588964 .5805435180764 .3096618652364 .0048828125 -9999 -9999 -9999 -9999 -9999 -9999 -9999 -9999 -9999 -9999 -9999 -9999 -9999 -9999 -9999 -9999 -9999 -9999 -9999

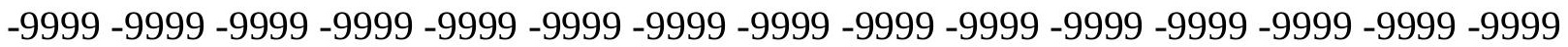
-9999 -9999 -9999 -9999 -9999 -9999 -9999 -9999 -9999 -9999 -9999 -9999 -9999 -9999 -9999 -9999 -9999 -9999 -9999 -9999 -9999 -9999 -9999 -9999 -9999 -9999 -9999 -9999 -9999 -9999 -9999 -9999 -9999 -9999 -9999 -9999 -9999 -9999 -9999 -9999 -9999 -9999 -9999

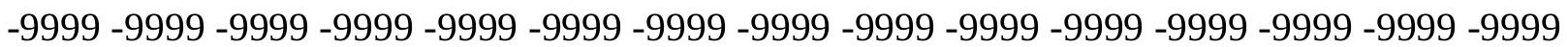
-9999 -9999 -9999 -9999 -9999 -9999 -9999 -9999 -9999 -9999 -9999 -9999 -9999 -9999 -9999 -9999 -9999 -9999 -9999 -9999 -9999 -9999 -9999 -9999 -9999 -9999 -9999 -9999 -9999 -9999 -9999 -9999 -9999 -9999 -9999 -9999 -9999 -9999 -9999 -9999 -9999 -9999 -9999 -9999 -9999

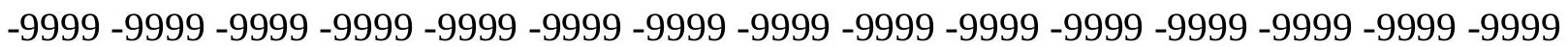
-9999 -9999 -9999 -9999 -9999 -9999 -9999 -9999 -9999 -9999 -9999 -9999 -9999 -9999 -9999 -9999 -9999 -9999 -9999 -9999 -9999 -9999 -9999 -9999 -9999 -9999 -9999 -9999 -9999 -9999 -9999 -9999 -9999 -9999 -9999 -9999 -9999 -9999 -9999 -9999 -9999 -9999 -9999 -9999 -9999 -9999 -9999 -9999 -9999 -9999 -9999 -9999 -9999 -9999 -9999 -9999 -9999 -9999 -9999 -9999

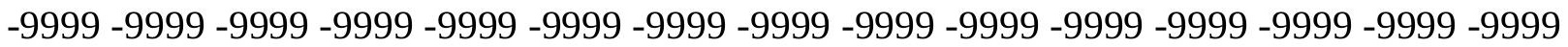
-9999 -9999 -9999 -9999 -9999 -9999 -9999 -9999 -9999 -9999 -9999 -9999 -9999 -9999 -9999 -

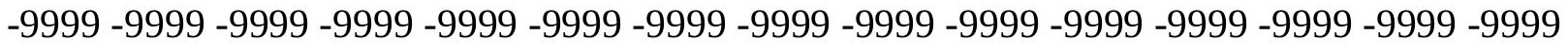
-9999 -9999 -9999 -9999 -9999 -9999 -9999 -9999 -9999 -9999 -9999 -9999 -9999 -9999 -9999 -9999 -9999 -9999 -9999 -9999 -9999 -9999 -9999 -9999 -9999 -9999 -9999 -9999 -9999 -9999 -9999 -9999 -9999 -9999 -9999 -9999 -9999 -9999 -9999 -9999 -9999 130.9423980713 129.1887054443126 .6932144165123 .5154190063119 .7806015015115 .2088012695 110.6370010376106 .6747970581103 .017402648999 .6647262573296 .92166900635 94.1785964965892 .0450973510791 .4355392456191 .1307525634890 .52117919922 89.91161346436 89.60682678223 88.9972534179788.69246673584 88.08290100098 87.4733276367287 .1685485839886 .5589828491286 .254188537685 .64462280273 85.0350494384884 .7302627563584 .1206970214883 .5111236572383 .2063369751 82.5967712402381 .9871978759881 .6824111938581 .0728530883881 .07285308838 81.6824111938581 .9871978759881 .9871978759882 .2919769287182 .29197692871 82.5967712402382 .9015579223683 .206336975183 .8159103393684 .12069702148 84.4254837036185 .0350494384885 .3398437585 .9494018554786 .55898284912 87.1685485839888 .0829010009888 .6924667358489 .302040100190 .21640014648 
90.8259735107491 .1307525634891 .7403335571392 .0450973510792 .04509735107 92.0450973510791 .7403335571390 .8259735107489 .6068267822388 .08290100098 85.9494018554783 .8159103393681 .3776321411178 .9393463134876 .50106811523 73.7580032348670 .7101516723670 .7101516723670 .7101516723670 .71015167236 70.4053573608470 .1005783081169 .7957916259869 .4910125732469 .18623352051 68.5766525268668 .2718734741267 .9670867919967 .3575134277367 .05272674561 $66.4431610107466 .1383666992265 .7354278564565 .2240066528364 .91924285889-9999$ -9999 -9999 -9999 -9999 -9999 -9999 -9999 -9999 -9999 -9999 -9999 -9999 -9999 -9999 -9999

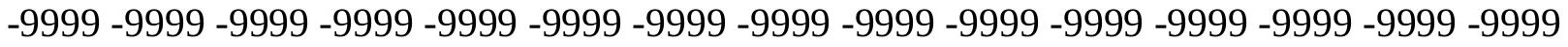

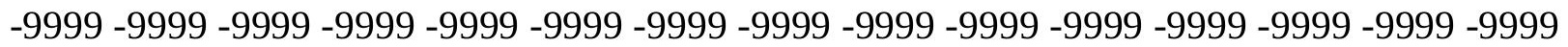
$-9999$

-9999 -9999 -9999 -9999 -9999 -9999 -9999 -9999 -9999 -9999 -9999 -9999 -9999 -9999 -9999 -9999 -9999 -9999 -9999 -9999 -9999 -9999 -9999 -9999 -9999 -9999 -9999 -9999 -9999 -9999 -9999 -9999 -9999 -9999 -9999 -9999 -9999 -9999 -9999 -9999 -9999 -9999 -9999 -9999 -9999 -9999 -9999 -9999 -9999 -9999 -9999 -9999 -9999 -9999 -9999 -9999 -9999 -9999 -9999 -9999

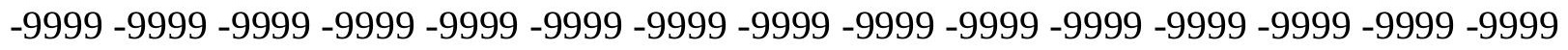
-9999 -9999 -9999 -9999 -9999 -9999 -9999 -9999 -9999 -9999 -9999 -9999 -9999 -9999 -9999 -9999 -9999 -9999 -9999 -9999 -9999 -9999 -9999 -9999 -9999 -9999 -9999 -9999 -9999 -9999 -9999 -9999 -9999 -9999 -9999 -9999 -9999 -9999 -9999 -9999 -9999 -9999 -9999 -9999 -9999 -999 -

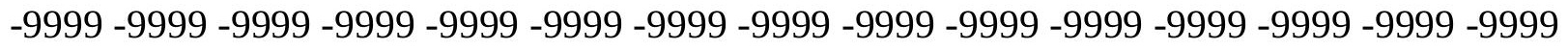

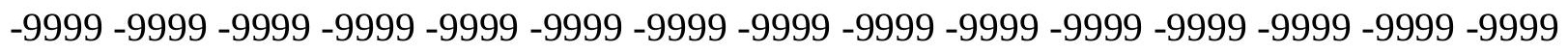

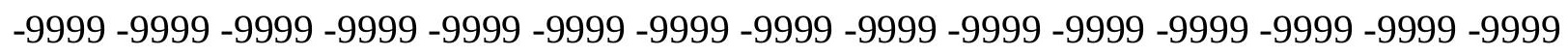
-9999 -9999 -9999 -9999 -9999 -9999 -9999 -9999 -9999 -9999 -9999 -9999 -9999 -9999 -9999 -

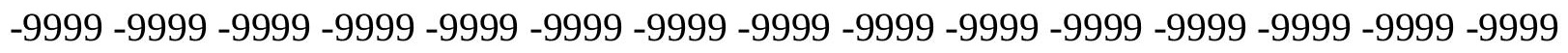

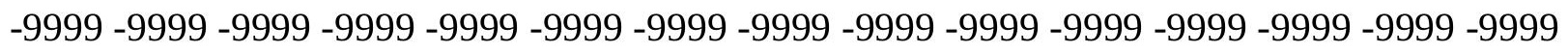
-9999 -9999 -9999 -9999 -9999 -9999 -9999 -9999 -9999 -9999 -9999 -9999 -9999 -9999 -9999 -9999 -9999 -9999 -9999 -9999 -9999 -9999 -9999 -9999 -9999 -9999 -9999 -9999 -9999 - -9999 -9999 -9999-9999 -9999 -9999 -9999-9999 -9999 -9999 -9999-9999-9999 130.520690918 128.2697296143125 .3738021851121 .8194122314117 .647102356113 .075302124 109.1130981445105 .1509017944101 .798202514698 .7503814697396 .00731658936 93.8738174438592 .0450973510791 .4355392456190 .8259735107490 .21640014648 89.91161346436 89.302040100188.9972534179788.3876876831188.08290100098 87.4733276367286 .8637619018686 .5589828491285 .9494018554785 .64462280273 85.0350494384884 .4254837036184 .1206970214883 .5111236572383 .2063369751 82.5967712402381 .9871978759881 .6824111938581 .0728530883880 .46327209473 79.8537063598679 .8537063598679 .5489196777379 .5489196777380 .15849304199 80.7680587768681 .3776321411181 .6824111938582 .2919769287182 .90155792236 83.2063369751 83.81591033936 84.42548370361 85.03504943848 85.94940185547 86.8637619018687 .7781066894588 .6924667358489 .302040100190 .21640014648 90.8259735107491 .4355392456191 .7403335571391 .7403335571391 .43553924561 90.8259735107489 .9116134643688 .6924667358486 .8637619018684 .73026275635 82.2919769287179 .8537063598677 .4154205322374 .9771423339873 .75800323486 72.2340774536172 .2340774536172 .2340774536172 .2340774536171 .92929077148 71.6244964599671 .3197174072370 .7101516723670 .4053573608470 .10057830811 69.4910125732469 .1862335205168 .5766525268668 .2718734741267 .66230010986 67.3575134277366 .7479400634866 .4431610107466 .13836669922 -9999-9999-9999 -9999 
-9999 -9999 -9999 -9999 -9999 -9999 -9999 -9999 -9999 -9999 -9999 -9999 -9999 -9999 -9999 -9999 -9999 -9999 -9999 -9999 -9999 -9999 -9999 -9999 -9999 -9999 -9999 -9999 -9999 -9999 -9999 -9999 -9999 -9999 -9999 -9999 -9999 -9999 -9999 -9999 -9999 -9999 -9999

-9999 -9999 -9999 -9999 -9999 -9999 -9999 -9999 -9999 -9999 -9999 -9999 -9999 -9999 -9999 -9999 -9999 -9999 -9999 -9999 -9999 -9999 -9999 -9999 -9999 -9999 -9999 -9999 -9999 -9999 -9999 -9999 -9999 -9999 -9999 -9999 -9999 -9999 -9999 -9999 -9999 -9999 -9999 -9999 -9999 -9999 -9999 -9999 -9999 -9999 -9999 -9999 -9999 -9999 -9999 -9999 -9999 -9999 -9999 -9999

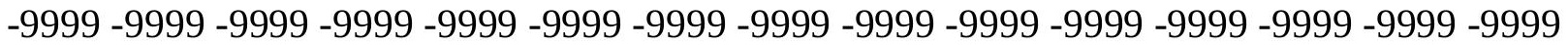
-9999 -9999 -9999 -9999 -9999 -9999 -9999 -9999 -9999 -9999 -9999 -9999 -9999 -9999 -9999 -9999 -9999 -9999 -9999 -9999 -9999 -9999 -9999 -9999 -9999 -9999 -9999 -9999 -9999 -9999 -9999 -9999 -9999 -9999 -9999 -9999 -9999 -9999 -9999 -9999 -9999 -9999 -9999 -9999 -9999 -9999 -9999 -9999 -9999 -9999 -9999 -9999 -9999 -9999 -9999 -9999 -9999 -9999 -9999 -9999

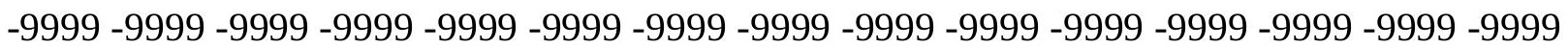
-9999 -9999 -9999 -9999 -9999 -9999 -9999 -9999 -9999 -9999 -9999 -9999 -9999 -9999 -9999 -9999 -9999 -9999 -9999 -9999 -9999 -9999 -9999 -9999 -9999 -9999 -9999 -9999 -9999 -9999

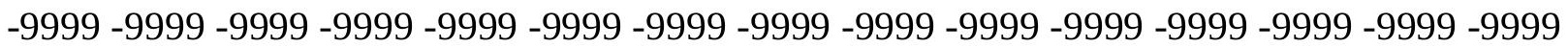

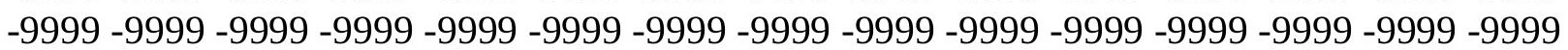
-9999 -9999 -9999 -9999 -9999 -9999 -9999 -9999 -9999 -9999 -9999 -9999 -9999 -9999 -9999 -9999 -9999 -9999 -9999 -9999 -9999 -9999 -9999 -9999 -9999 -9999 -9999 -9999 -9999 -9999 -9999 -9999 -9999 -9999 -9999 -9999 -9999 -9999 -9999 -9999 -9999 -9999 131.3740997314 129.3269958496126 .6760025024123 .3919067383119 .4757995605115 .2088012695 110.9418029785106 .979598999103 .6268997192100 .579101562597 .83602905273 95.0929565429792 .9594726562591 .7403335571391 .1307525634890 .52117919922 90.2164001464889 .6068267822389 .302040100188 .6924667358488 .38768768311 87.7781066894587 .1685485839886 .8637619018686 .254188537685 .94940185547 85.3398437585 .0350494384884 .4254837036184 .1206970214883 .51112365723 82.9015579223682 .5967712402381 .9871978759881 .3776321411181 .07285308838 80.4632720947380 .1584930419979 .5489196777378 .9393463134878 .63455963135 78.6345596313579 .2441329956179 .8537063598680 .4632720947381 .07285308838 81.37763214111 81.98719787598 82.59677124023 83.51112365723 84.42548370361 85.33984375 86.55898284912 87.77810668945 88.69246673584 89.60682678223 90.2164001464890 .8259735107491 .1307525634891 .1307525634890 .82597351074 90.2164001464889 .302040100187 .7781066894585 .6446228027383 .51112365723 81.0728530883878 .6345596313576 .1962814331174 .062782287674 .0627822876 74.062782287674 .062782287673 .7580032348673 .7580032348673 .45321655273 73.1484298706172 .5388565063572 .2340774536171 .6244964599671 .31971740723 70.7101516723670 .4053573608469 .7957916259869 .4910125732468 .88143920898 68.5766525268667 .9670867919967 .6623001098667 .05272674561 -9999 -9999 -9999 -9999 -9999 -9999 -9999 -9999 -9999 -9999 -9999 -9999 -9999 -9999 -9999 -9999 -9999 -9999 -9999 -9999 -9999 -9999 -9999 -9999 -9999 -9999 -9999 -9999 -9999 -9999 -9999 -9999 -9999 -9999 -9999 -9999 -9999 -9999 -9999 -9999 -9999 -9999 -9999 -9999 -9999 -9999 -9999

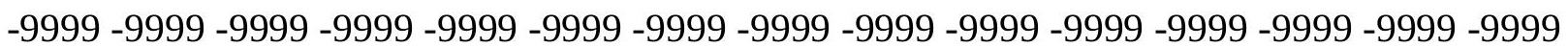
-9999 -9999 -9999 -9999 -9999 -9999 -9999 -9999 -9999 -9999 -9999 -9999 -9999 -9999 -9999 -9999 -9999 -9999 -9999 -9999 -9999 -9999 -9999 -9999 -9999 -9999 -9999 -9999 -9999 -9999 -9999 -9999 -9999 -9999 -9999 -9999 -9999 -9999 -9999 -9999 -9999 -9999 -9999 -9999 -9999

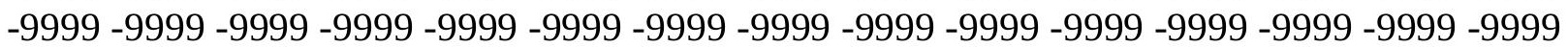


-9999 -9999 -9999 -9999 -9999 -9999 -9999 -9999 -9999 -9999 -9999 -9999 -9999 -9999 -9999 -9999 -9999 -9999 -9999 -9999 -9999 -9999 -9999 -9999 -9999 -9999 -9999 -9999 -9999 -9999 -9999 -9999 -9999 -9999 -9999 -9999 -9999 -9999 -9999 -9999 -9999 -9999 -9999 -9999 -9999 -9999 -9999 -9999 -9999 -9999 -9999 -9999 -9999 -9999 -9999 -9999 -9999 -9999 -9999 -9999 -9999 -9999 -9999 -9999 -9999 -9999 -9999 -9999 -9999 -9999 -9999 -9999 -9999 -9999 -9999 -9999 -9999 -9999 -9999 -9999 -9999 -9999 -9999 -9999 -9999 -9999 -9999 -9999 -9999 -9999 -9999 -9999 -9999 -9999 -9999 -9999 -9999 -9999 -9999 -9999 -9999 -9999 -9999 -9999 -9999

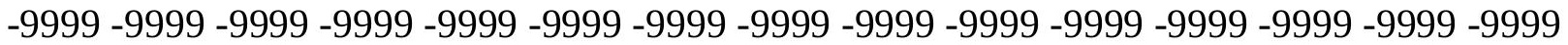

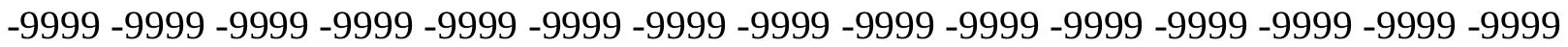
-9999 -9999 -9999 -9999 -9999 -9999 -9999 -9999 -9999 -9999 -9999 -9999 -9999 -9999 -9999 -

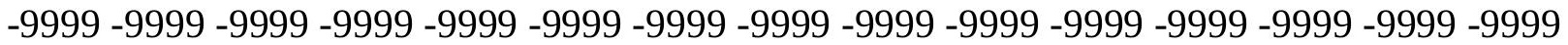
-9999 -9999 -9999 -9999 -9999 -9999 -9999 -9999 -9999 -9999 -9999 -9999 -9999 129.9523162842127 .5368270874124 .571685791120 .9997024536116 .4279022217 112.4656982422108 .8082962036105 .1509017944102 .102996826299 .05516815186 96.6168823242294 .1785964965892 .0450973510791 .4355392456190 .82597351074 90.5211791992289 .9116134643689 .6068267822388 .9972534179788 .69246673584 88.0829010009887 .4733276367287 .1685485839886 .5589828491286 .2541885376 85.6446228027385 .3398437584 .7302627563584 .4254837036183 .81591033936 83.5111236572382 .9015579223682 .5967712402381 .9871978759881 .68241119385 81.0728530883880 .4632720947380 .1584930419979 .5489196777379 .24413299561 78.6345596313578 .3297805786178 .0249862670978 .6345596313579 .24413299561 79.8537063598680 .1584930419980 .7680587768681 .6824111938582 .90155792236 84.1206970214885 .3398437586 .8637619018688 .0829010009888 .99725341797 89.9116134643690 .5211791992290 .8259735107490 .8259735107490 .52117919922 89.9116134643688 .6924667358486 .8637619018685 .0350494384882 .59677124023 80.1584930419977 .7202072143675 .5867080688575 .2819290161175 .58670806885 75.5867080688575 .5867080688575 .2819290161175 .2819290161174 .97714233398 74.3675689697374 .062782287673 .4532165527373 .1484298706172 .53885650635 72.2340774536171 .6244964599671 .014930725170 .7101516723670 .10057830811 69.4910125732469 .0421142578168 .5766525268668 .27187347412 -9999 -9999 -9999 -9999 -9999 -9999 -9999 -9999 -9999 -9999 -9999 -9999 -9999 -9999 -9999 -9999 -9999 -9999 -9999 -9999 -9999 -9999 -9999 -9999 -9999 -9999 -9999 -9999 -9999 -9999 -9999 -9999 -9999 -9999 -9999 -9999 -9999 -9999 -9999 -9999 -9999 -9999 -9999 -9999 -9999 -9999 -9999 -

-9999 -9999 -9999 -9999 -9999 -9999 -9999 -9999 -9999 -9999 -9999 -9999 -9999 -9999 -9999 -999 -

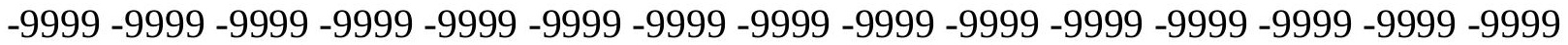
-9999 -9999 -9999 -9999 -9999 -9999 -9999 -9999 -9999 -9999 -9999 -9999 -9999 -9999 -9999 -9999 -9999 -9999 -9999 -9999 -9999 -9999 -9999 -9999 -9999 -9999 -9999 -9999 -9999 -9999

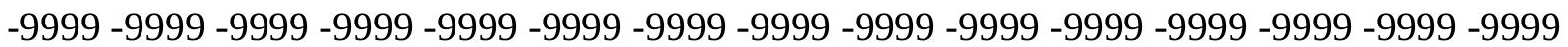
-9999 -9999 -9999 -9999 -9999 -9999 -9999 -9999 -9999 -9999 -9999 -9999 -9999 -9999 -9999 -9999 -9999 -9999 -9999 -9999 -9999 -9999 -9999 -9999 -9999 -9999 -9999 -9999 -9999 -9999 -

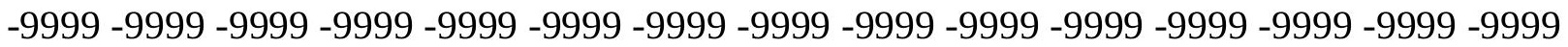
-9999 -9999 -9999 -9999 -9999 -9999 -9999 -9999 -9999 -9999 -9999 -9999 -9999 -9999 -9999 -9999 -9999 -9999 -9999 -9999 -9999 -9999 -9999 -9999 -9999 -9999 -9999 -9999 -9999 -9999 -9999 -9999 -9999 -9999 -9999 -9999 -9999 -9999 -9999 -9999 -9999 -9999 -9999 -9999 -9999 -9999 -9999 -9999 -9999 -9999 -9999 -9999 -9999 -9999 -9999 -9999 -9999 -9999 -9999 -9999

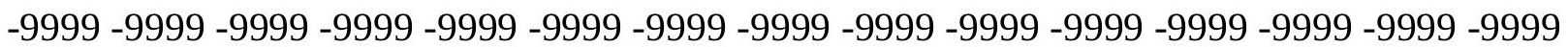


-9999 -9999 -9999 -9999 -9999 -9999 -9999 -9999 -9999 -9999 -9999 -9999 -9999 -9999 -9999 -9999 -9999 -9999 -9999 -9999 -9999 -9999 -9999 -9999 -9999 -9999 -9999 -9999 -9999 -9999

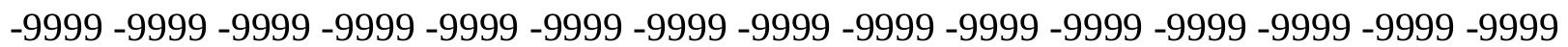
-9999 -9999 -9999 -9999 -9999 -9999 -9999 -9999 -9999 -9999 -9999 -9999 -9999 130.2109985352127 .9764709473125 .2370834351121 .9140014648117 .647102356 113.6848983765110 .0273971558106 .3700027466103 .3221969604100 .2742996216 97.8360290527395 .397743225193 .2642517089891 .7403335571391 .13075256348 90.8259735107490 .2164001464889 .6068267822389 .302040100188 .69246673584 88.38768768311 87.77810668945 87.47332763672 87.16854858398 86.55898284912 86.254188537685 .6446228027385 .3398437584 .7302627563584 .42548370361 83.8159103393683 .5111236572382 .9015579223682 .5967712402381 .98719787598 81.6824111938581 .0728530883880 .7680587768680 .1584930419979 .85370635986 79.2441329956178 .9393463134878 .6345596313578 .0249862670977 .72020721436 78.0249862670978 .6345596313578 .9393463134879 .8537063598681 .07285308838 82.5967712402384 .4254837036185 .9494018554787 .1685485839888 .38768768311 89.6068267822390 .2164001464890 .8259735107490 .8259735107490 .52117919922 89.6068267822388 .0829010009886 .5589828491284 .4254837036181 .98719787598 79.5489196777377 .110626220776 .5010681152376 .8058471679777 .1106262207 77.110626220777 .110626220777 .110626220776 .8058471679776 .19628143311 75.8914871215875 .2819290161174 .9771423339874 .3675689697373 .75800323486 73.4532165527372 .8436431884872 .2340774536171 .9292907714871 .31971740723 70.7101516723670 .1328201293969 .7957916259869 .49101257324 -9999 -9999 -9999 -9999 -9999 -9999 -9999 -9999 -9999 -9999 -9999 -9999 -9999 -9999 -9999 -9999 -9999 -9999 -9999 -9999 -9999 -9999 -9999 -9999 -9999 -9999 -9999 -9999 -9999 -9999 -9999 -9999 -9999 -9999 -9999 -9999 -9999 -9999 -9999 -9999 -9999 -9999 -9999 -9999 -9999 -9999 -9999 -9999 -9999 -9999 -9999 -9999 -9999 -9999 -9999 -9999 -9999 -9999 -9999 -9999 -9999 -9999 -9999 -9999 -9999 -9999 -9999 -9999 -9999 -9999 -9999 -9999 -9999 -9999 -9999 -9999 -9999 -9999 -9999 -9999 -9999 -9999 -9999 -9999 -9999 -9999 -9999 -9999 -9999 -9999 -9999 -9999 -9999 -9999 -9999 -9999 -9999 -9999 -9999 -9999 -9999 -9999 -9999 -9999 -9999 -9999 -9999 -9999 -9999 -9999 -9999 -9999 -9999 -9999 -9999 -9999 -9999 -9999 -9999 -9999 -9999 -9999 -9999 -9999 -9999 -9999 -9999 -9999 -9999 -9999 -9999 -9999 -9999 -9999 -9999 -9999 -9999 -9999 -9999 -9999 -9999 -9999 -9999 -9999 -9999 -9999 -9999 -9999 -9999 -9999 -9999 -9999 -9999 -9999 -9999 -9999 -9999 -9999 -9999 -9999 -9999 -9999 -9999 -9999 -9999 -9999 -9999 -9999 -9999 -9999 -9999 -9999 -9999 -9999 -9999 -9999 -9999 -9999 -9999 -9999 -9999 -9999 -

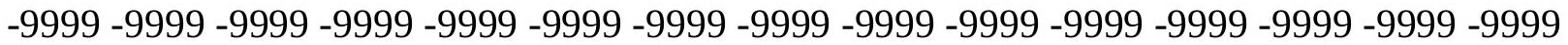
-9999 -9999 -9999 -9999 -9999 -9999 -9999 -9999 -9999 -9999 -9999 -9999 -9999 -9999 -9999 -9999 -9999 -9999 -9999 -9999 -9999 -9999 -9999 -9999 -9999 -9999 -9999 -9999 -9999 -9999

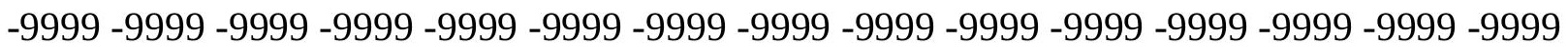
-9999 -9999 -9999 -9999 -9999 -9999 -9999 -9999 -9999 -9999 -9999 -9999 -9999 -9999 -9999 -9999 -9999 -9999 -9999 -9999 -9999 -9999 -9999 -9999 -9999 -9999 -9999 -9999 -9999 -9999 -9999 -9999 -9999 -9999 -9999 -9999 -9999 -9999 -9999 -9999 -9999 -9999 -9999 -9999 -9999 -9999 -9999 -9999 -9999 -9999 -9999 -9999 -9999 -9999 -9999 -9999 -9999 -9999 -9999 128.0438690186125 .4325408936122 .2188034058118 .2565994263114 .5991973877 110.9418029785107 .5891036987104 .2365036011101 .493400573798 .75038146973 96.3121032714894 .1785964965892 .349891662691 .4355392456190 .82597351074 90.5211791992289 .9116134643689 .6068267822388 .9972534179788 .69246673584 
88.0829010009887 .7781066894587 .4733276367286 .8637619018686 .55898284912 85.9494018554785 .6446228027385 .3398437584 .7302627563584 .42548370361 83.8159103393683 .5111236572382 .9015579223682 .5967712402381 .98719787598 81.6824111938581 .0728530883880 .7680587768680 .1584930419979 .85370635986 79.5489196777379 .2441329956178 .6345596313578 .3297805786178 .02498626709 77.7202072143677 .4154205322378 .0249862670979 .8537063598681 .68241119385 83.5111236572385 .0350494384886 .5589828491288 .0829010009889 .3020401001 90.2164001464890 .8259735107490 .8259735107490 .5211791992289 .60682678223 88.0829010009886 .254188537684 .1206970214881 .6824111938579 .24413299561 77.4154205322378 .0249862670978 .3297805786178 .6345596313578 .63455963135 78.6345596313578 .3297805786178 .0249862670977 .7202072143677 .1106262207 76.8058471679776 .1962814331175 .5867080688574 .9771423339874 .67236328125 74.062782287673 .4532165527372 .8436431884872 .5388565063571 .92929077148 71.2287063598671 .0149307251 -9999 -9999 -9999 -9999 -9999 -9999 -9999 -9999 -9999 -9999 -9999 -9999 -9999 -9999 -9999 -9999 -9999 -9999 -9999 -9999 -9999 -9999 -9999 -9999

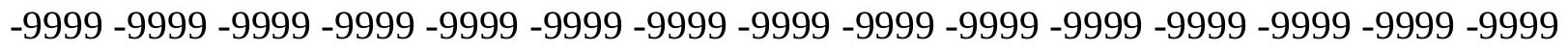
-9999 -9999 -9999 -9999 -9999 -9999-9999 -9999 -9999

-9999 -9999 -9999 -9999 -9999 -9999 -9999 -9999 -9999 -9999 -9999 -9999 -9999 -9999 -9999 -9999 -9999 -9999 -9999 -9999 -9999 -9999 -9999 -9999 -9999 -9999 -9999 -9999 -9999 -9999 -

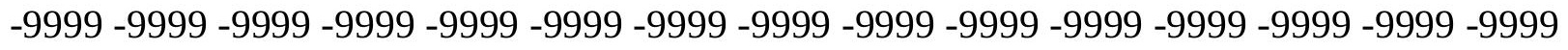

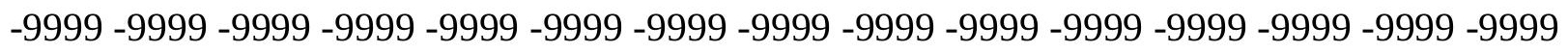
-9999 -9999 -9999 -9999 -9999 -9999 -9999 -9999 -9999 -9999 -9999 -9999 -9999 -9999 -9999 -9999 -9999 -9999 -9999 -9999 -9999 -9999 -9999 -9999 -9999 -9999 -9999 -9999 -9999 -9999 -

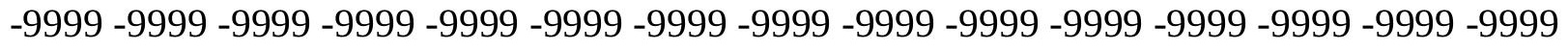

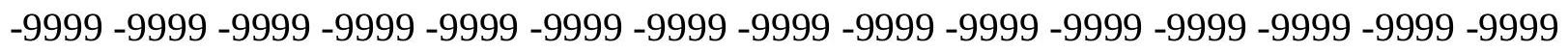
-9999 -9999 -9999 -9999 -9999 -9999 -9999 -9999 -9999 -9999 -9999 -9999 -9999 -9999 -9999 -9999 -9999 -9999 -9999 -9999 -9999 -9999 -9999 -9999 -9999 -9999 -9999 -9999 -9999 - -9999 -

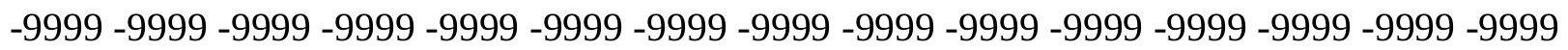
-9999 -9999 -9999 -9999 -9999 -9999 -9999 -9999 -9999 -9999 -9999 -9999 -9999 -9999 -9999 -9999 -9999 -9999 -9999 -9999 -9999 -9999 -9999 -9999 -9999 -9999 -9999 -9999 -9999 -9999 -9999 -9999 -9999 -9999 -9999 -9999 -9999 -9999 -9999 -9999 -9999 -9999-9999 -9999 -9999 -9999 -9999 -9999 -9999 -9999 -9999 -9999 -9999 -9999 -9999 -9999 -9999 -9999 -9999 -9999 -

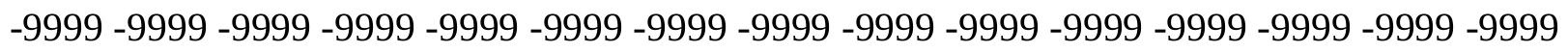
-9999 -9999 -9999 -9999 -9999 -9999 -9999 -9999 -9999 -9999 -9999 -9999 -9999 -9999 -999 127.8269195557125 .327255249122 .2188034058118 .5614013672114 .9039993286 111.551399231108 .1986999512105 .1509017944102 .407798767199 .66472625732 97.5312423706195 .0929565429793 .2642517089891 .7403335571391 .13075256348 90.5211791992290 .2164001464889 .9116134643689 .302040100188 .99725341797 88.38768768311 88.08290100098 87.77810668945 87.16854858398 86.86376190186 86.5589828491285 .9494018554785 .6446228027385 .0350494384884 .73026275635 84.4254837036183 .8159103393683 .5111236572382 .9015579223682 .59677124023 81.9871978759881 .6824111938581 .3776321411180 .7680587768680 .46327209473 80.1584930419979 .5489196777379 .2441329956178 .9393463134878 .63455963135 78.0249862670977 .7202072143677 .4154205322378 .9393463134880 .76805877686 82.5967712402384 .4254837036185 .9494018554787 .7781066894588 .99725341797 90.2164001464890 .8259735107491 .1307525634890 .8259735107489 .60682678223 
88.0829010009885 .9494018554783 .8159103393681 .3776321411178 .93934631348 78.6345596313579 .5489196777379 .8537063598680 .1584930419980 .15849304199 80.1584930419979 .8537063598679 .5489196777378 .9393463134878 .32978057861 78.0249862670977 .4154205322376 .8058471679776 .1962814331175 .58670806885 75.2819290161174 .6723632812574 .062782287673 .4532165527372 .84364318848 72.2871627807671 .92929077148 -9999 -9999 -9999 -9999 -9999 -9999 -9999 -9999 -9999 -9999 -9999 -9999 -9999 -9999 -9999 -9999 -9999 -9999 -9999 -9999 -9999 -9999 -9999 -9999 -9999 -9999 -9999 -9999 -9999 -9999 -9999 -9999 -9999 -9999 -9999 -9999 -9999 -9999 -9999 -9999 -9999 -9999 -9999 -9999 -9999 -9999 -9999 -9999

-9999 -9999 -9999 -9999 -9999 -9999 -9999 -9999 -9999 -9999 -9999 -9999 -9999 -9999 -9999 -9999 -9999 -9999 -9999 -9999 -9999 -9999 -9999 -9999 -9999 -9999 -9999 -9999 -9999 -9999 -

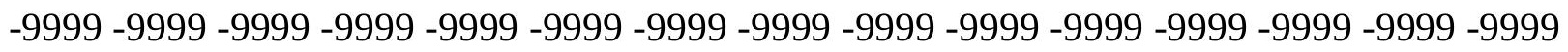

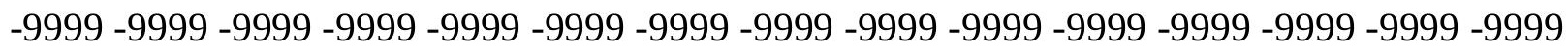
-9999 -9999 -9999 -9999 -9999 -9999 -9999 -9999 -9999 -9999 -9999 -9999 -9999 -9999 -9999 -9999 -9999 -9999 -9999 -9999 -9999 -9999 -9999 -9999 -9999 -9999 -9999 -9999 -9999 -9999

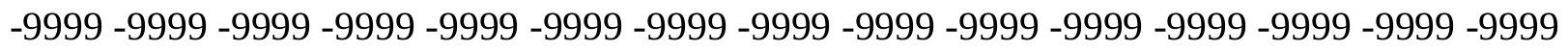
-9999 -9999 -9999 -9999 -9999 -9999 -9999 -9999 -9999 -9999 -9999 -9999 -9999 -9999 -9999 -9999 -9999 -9999 -9999 -9999 -9999 -9999 -9999 -9999 -9999 -9999 -9999 -9999 -9999 -9999 -

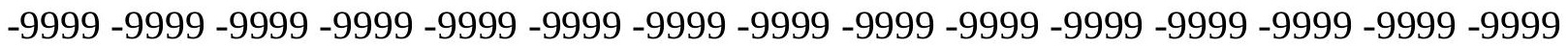

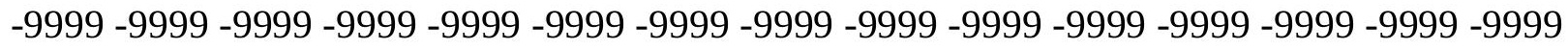

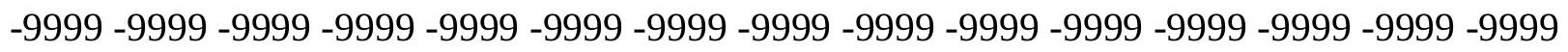
-9999 -9999 -9999 -9999 -9999 -9999 -9999 -9999 -9999 -9999 -9999 -9999 -9999 -9999 -9999 -9999 -9999 -9999 -9999 -9999 -9999 -9999 -9999 -9999 -9999 -9999 -9999 -9999 -9999 -9999 -

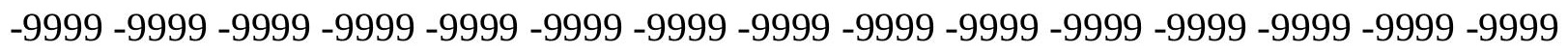

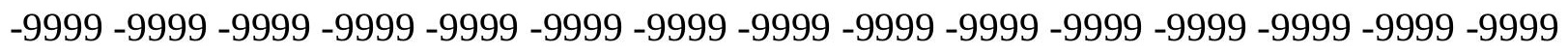
-9999 -9999 -9999 -9999 -9999 -9999 -9999 -9999 -9999 -9999 -9999 -9999 -9999 -9999 127.4121856689125 .0449981689122 .2188034058118 .8662033081115 .2088012695 112.1608963013108 .8082962036106 .0652008057103 .3221969604100 .5791015625 98.445587158296 .0073165893694 .1785964965892 .349891662691 .43553924561 90.8259735107490 .5211791992289 .9116134643689 .6068267822389 .3020401001 88.69246673584 88.38768768311 88.08290100098 87.47332763672 87.16854858398 86.8637619018686 .254188537685 .9494018554785 .6446228027385 .03504943848 84.7302627563584 .4254837036183 .8159103393683 .5111236572382 .90155792236 82.5967712402382 .2919769287181 .6824111938581 .3776321411181 .07285308838 80.4632720947380 .1584930419979 .8537063598679 .5489196777378 .93934631348 78.6345596313578 .3297805786178 .0249862670978 .0249862670979 .85370635986 81.6824111938583 .5111236572385 .6446228027387 .4733276367288 .99725341797 90.5211791992291 .4355392456191 .7403335571391 .4355392456190 .21640014648 88.6924667358486 .254188537683 .5111236572380 .7680587768678 .63455963135 80.1584930419980 .7680587768681 .3776321411181 .3776321411181 .37763214111 81.3776321411181 .0728530883880 .7680587768680 .1584930419979 .54891967773 78.9393463134878 .6345596313578 .0249862670977 .4154205322376 .80584716797 76.1962814331175 .5867080688574 .9771423339874 .6723632812574 .0627822876 73.3324279785272 .84364318848 -9999 -9999 -9999 -9999 -9999 -9999 -9999 -9999 -9999 -9999 -9999 -9999 -9999 -9999 -9999 -9999 -9999 -9999 -9999 -9999 -9999 -9999 -9999 -9999 -9999 -9999 -9999 -9999 -9999 -9999 -9999 -9999 -9999 -9999 -9999 -9999 -9999 -9999 -9999 
-9999 -9999 -9999 -9999 -9999 -9999 -9999 -9999 -9999

-9999 -9999 -9999 -9999 -9999 -9999 -9999 -9999 -9999 -9999 -9999 -9999 -9999 -9999 -9999

-9999 -9999 -9999 -9999 -9999 -9999 -9999 -9999 -9999 -9999 -9999 -9999 -9999 -9999 -9999

-9999 -9999 -9999 -9999 -9999 -9999 -9999 -9999 -9999 -9999 -9999 -9999 -9999 -9999 -9999

-9999 -9999 -9999 -9999 -9999 -9999 -9999 -9999 -9999 -9999 -9999 -9999 -9999 -9999 -9999 -

-9999 -9999 -9999 -9999 -9999 -9999 -9999 -9999 -9999 -9999 -9999 -9999 -9999 -9999 -9999 -

-9999 -9999 -9999 -9999 -9999 -9999 -9999 -9999 -9999 -9999 -9999 -9999 -9999 -9999 -9999 -

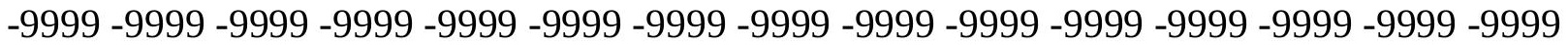

-9999 -9999 -9999 -9999 -9999 -9999 -9999 -9999 -9999 -9999 -9999 -9999 -9999 -9999 -9999

-9999 -9999 -9999 -9999 -9999 -9999 -9999 -9999 -9999 -9999 -9999 -9999 -9999 -9999 -9999 -

-9999 -9999 -9999 -9999 -9999 -9999 -9999 -9999 -9999 -9999 -9999 -9999 -9999 -9999 -9999 -

-9999 -9999 -9999 -9999 -9999 -9999 -9999 -9999 -9999 -9999 -9999 -9999 -9999 -9999 -9999

-9999 -9999 -9999 -9999 -9999 -9999 -9999 -9999 -9999 -9999 -9999 -9999 -9999 -9999 -9999 -

-9999 -9999 -9999 -9999 -9999 -9999 -9999 -9999 -9999 -9999 -9999 -9999 -9999 -9999 -9999 -

-9999 -9999 -9999 -9999 -9999 -9999 -9999 -9999 -9999 -9999 -9999 -9999 -9999 -9999 -9999

-9999 -9999 -9999 -9999 -9999 -9999 -9999 -9999 -9999 -9999 -9999 -9999 -9999 -9999 -9999

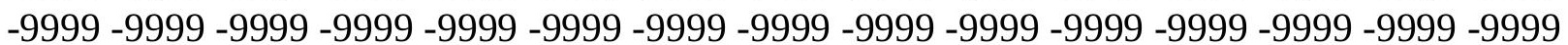

-9999 -9999 -9999 -9999 -9999 -9999 -9999 -9999 -9999 -9999 -9999 -9999 -9999 -9999 -9999

124.6310806274121 .9140014648118 .5614013672115 .5136032104112 .4656982422 109.4179000854106 .6747970581103 .9317016602101 .493400573799 .05516815186 96.9216690063595 .0929565429793 .2642517089891 .4355392456191 .13075256348 90.5211791992290 .2164001464889 .9116134643689 .302040100188 .99725341797 88.6924667358488 .3876876831187 .7781066894587 .4733276367287 .16854858398 86.5589828491286 .254188537685 .9494018554785 .6446228027385 .03504943848 84.7302627563584 .4254837036183 .8159103393683 .5111236572382 .90155792236 82.5967712402382 .2919769287181 .6824111938581 .3776321411181 .07285308838 80.7680587768680 .4632720947379 .8537063598679 .5489196777379 .24413299561 78.9393463134878 .3297805786178 .0249862670978 .9393463134880 .76805877686 82.9015579223685 .0350494384887 .1685485839888 .9972534179790 .82597351074 92.0450973510792 .6546783447392 .349891662691 .4355392456189 .3020401001 86.8637619018683 .8159103393680 .1584930419979 .5489196777381 .07285308838 81.9871978759882 .5967712402382 .5967712402382 .5967712402382 .29197692871 81.9871978759881 .6824111938581 .0728530883880 .7680587768680 .15849304199 79.5489196777378 .9393463134878 .3297805786177 .7202072143677 .1106262207 76.5010681152376 .1962814331175 .5867080688574 .9771423339874 .31840515137 74.0627822876 -9999 -9999 -9999 -9999 -9999 -9999 -9999 -9999 -9999 -9999 -9999 -9999 -9999 -9999 -9999 -9999 -9999 -9999 -9999 -9999 -9999 -9999 -9999 -9999 -9999 -9999-9999 -9999 -9999 -9999 -9999 -9999 -9999 -9999 -9999 -9999 -9999 -9999 -9999 -9999 -9999 -9999 -9999 -9999 -9999-9999-9999-9999

-9999 -9999 -9999 -9999 -9999 -9999 -9999 -9999 -9999 -9999 -9999 -9999 -9999 -9999 -9999 -9999 -9999 -9999 -9999 -9999 -9999 -9999 -9999 -9999 -9999 -9999 -9999 -9999 -9999 -9999 -9999 -9999 -9999 -9999 -9999 -9999 -9999 -9999 -9999 -9999 -9999 -9999-9999-9999-9999 -9999 -9999 -9999 -9999 -9999 -9999 -9999 -9999 -9999 -9999 -9999 -9999 -9999 -9999 -9999 -9999 -9999 -9999 -9999 -9999 -9999 -9999 -9999 -9999 -9999 -9999 -9999 -9999 -9999 -9999 -9999 -9999 -9999 -9999 -9999 -9999 -9999 -9999 -9999 -9999 -9999 -9999 -9999 -9999 -9999 -9999 -9999 -9999 -9999 -9999 -9999 -9999 -9999 -9999 -9999 -9999 -9999 -9999 -9999 -9999 
-9999 -9999 -9999 -9999 -9999 -9999 -9999 -9999 -9999 -9999 -9999 -9999 -9999 -9999 -9999 -9999 -9999 -9999 -9999 -9999 -9999 -9999 -9999 -9999 -9999 -9999 -9999 -9999 -9999 -9999 -9999 -9999 -9999 -9999 -9999 -9999 -9999 -9999 -9999 -9999 -9999 -9999 -9999 -9999 -9999 -9999 -9999 -9999 -9999 -9999 -9999 -9999 -9999 -9999 -9999 -9999 -9999 -9999 -9999 -9999 -9999 -9999 -9999 -9999 -9999 -9999 -9999 -9999 -9999 -9999 -9999 -9999 -9999 -9999 -9999 -9999 -9999 -9999 -9999 -9999 -9999 -9999 -9999 -9999 -9999 -9999 -9999 -9999 -9999 -9999 -9999 -9999 -9999 -9999 -9999 -9999 -9999 -9999 -9999 -9999 -9999 -9999 -9999 -9999 -9999

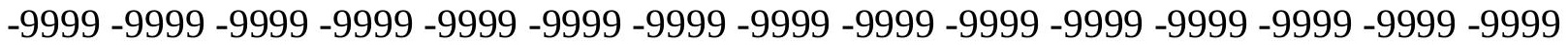

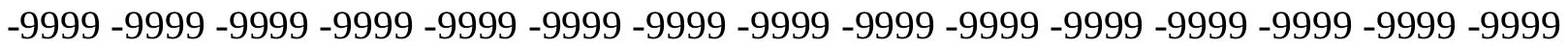
-9999 -9999 -9999 -9999 -9999 -9999 -9999 -9999 -9999 -9999 -9999 -9999 -9999 -9999 -9999 124.0656356812121 .6092987061118 .5614013672115 .5136032104112 .4656982422 109.7226028442106 .979598999104 .5412979126102 .102996826299 .96952056885 97.8360290527396 .0073165893694 .1785964965892 .349891662691 .13075256348 90.8259735107490 .5211791992289 .9116134643689 .6068267822389 .3020401001 88.9972534179788 .6924667358488 .0829010009887 .7781066894587 .47332763672 87.1685485839886 .5589828491286 .254188537685 .9494018554785 .33984375 85.0350494384884 .7302627563584 .4254837036183 .8159103393683 .51112365723 83.2063369751 82.59677124023 82.29197692871 81.98719787598 81.68241119385 81.0728530883880 .7680587768680 .4632720947380 .1584930419979 .54891967773 79.2441329956178 .9393463134878 .3297805786179 .5489196777379 .85370635986 81.9871978759884 .4254837036186 .5589828491288 .9972534179791 .13075256348 92.6546783447393 .5690307617293 .5690307617292 .6546783447390 .82597351074 88.0829010009884 .7302627563581 .0728530883880 .1584930419981 .98719787598 82.5967712402383 .206336975183 .206336975183 .206336975183 .2063369751 82.9015579223682 .5967712402381 .9871978759881 .3776321411181 .07285308838 80.4632720947379 .8537063598679 .2441329956178 .6345596313578 .02498626709 77.7202072143677 .110626220776 .5010681152375 .8914871215875 .24906158447 74.97714233398 -9999 -9999 -9999 -9999 -9999 -9999 -9999 -9999 -9999 -9999 -9999 -9999 -9999 -9999 -9999 -9999 -9999 -9999 -9999 -9999 -9999 -9999 -9999 -9999 -9999 -9999 -9999

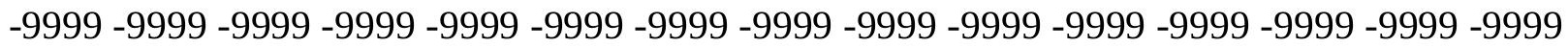
-9999 -9999-9999-9999-9999-9999

-9999 -9999 -9999 -9999 -9999 -9999 -9999 -9999 -9999 -9999 -9999 -9999 -9999 -9999 -9999 -9999 -9999 -9999 -9999 -9999 -9999 -9999 -9999 -9999 -9999 -9999 -9999 -9999 -9999 -9999 -9999 -9999 -9999 -9999 -9999 -9999 -9999 -9999 -9999 -9999 -9999 -9999 -9999 -9999 -9999 -

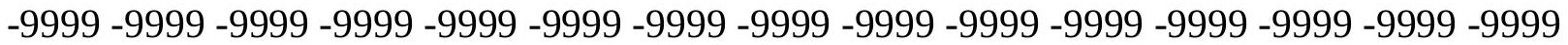
-9999 -9999 -9999 -9999 -9999 -9999 -9999 -9999 -9999 -9999 -9999 -9999 -9999 -9999 -9999 -9999 -9999 -9999 -9999 -9999 -9999 -9999 -9999 -9999 -9999 -9999 -9999 -9999 -9999 -9999

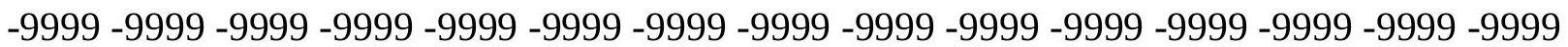
-9999 -9999 -9999 -9999 -9999 -9999 -9999 -9999 -9999 -9999 -9999 -9999 -9999 -9999 -9999 -9999 -9999 -9999 -9999 -9999 -9999 -9999 -9999 -9999 -9999 -9999 -9999 -9999 -9999 -9999 -

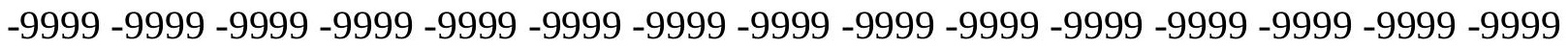
-9999 -9999 -9999 -9999 -9999 -9999 -9999 -9999 -9999 -9999 -9999 -9999 -9999 -9999 -9999 -9999 -9999 -9999 -9999 -9999 -9999 -9999 -9999 -9999 -9999 -9999 -9999 -9999 -9999 -9999 -9999 -9999 -9999 -9999 -9999 -9999 -9999 -9999 -9999 -9999 -9999 -9999 -9999 -9999 -9999 -9999 -9999 -9999 -9999 -9999 -9999 -9999 -9999 -9999 -9999 -9999 -9999 -9999 -9999 -9999

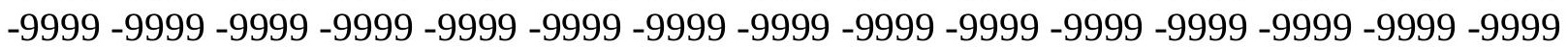


-9999 -9999 -9999 -9999 -9999 -9999 -9999 -9999 -9999 -9999 -9999 -9999 -9999 -9999 -9999 -9999 -9999 -9999 -9999 -9999 -9999 -9999 -9999 -9999 -9999 -9999 -9999 -9999 -9999 -9999 -9999 120.9997024536118.2565994263115.2088012695112.7705001831 110.0273971558 107.5891036987105 .1509017944103 .0174026489100 .883903503498 .75038146973 96.9216690063594 .7881774902393 .2642517089891 .7403335571390 .82597351074 90.5211791992290 .2164001464889 .9116134643689 .6068267822389 .3020401001 88.6924667358488 .3876876831188 .0829010009887 .7781066894587 .47332763672 86.8637619018686 .5589828491286 .254188537685 .9494018554785 .33984375 85.0350494384884 .7302627563584 .4254837036183 .8159103393683 .51112365723 83.206336975182.90155792236 82.29197692871 81.98719787598 81.68241119385 81.3776321411181 .0728530883880 .4632720947380 .1584930419979 .85370635986 79.2441329956178 .9393463134878 .6345596313578 .9393463134881 .07285308838 83.5111236572386 .254188537689 .302040100191 .7403335571393 .87381744385 94.7881774902395 .0929565429794 .4833908081192 .6546783447389 .91161346436 86.254188537681 .9871978759879 .5489196777381 .6824111938582 .59677124023 83.206336975183 .5111236572383 .8159103393683 .5111236572383 .51112365723 83.206336975182 .5967712402382 .2919769287181 .6824111938581 .07285308838 80.4632720947380 .1584930419979 .5489196777378 .9393463134878 .32978057861 78.0249862670977 .4154205322376 .8058471679776 .1690216064575 .89148712158 -9999 -9999 -9999 -9999 -9999 -9999 -9999 -9999 -9999 -9999 -9999 -9999 -9999 -9999 -9999 -9999

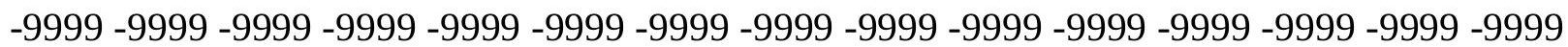

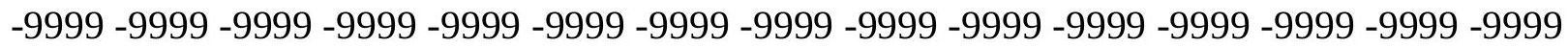
$-9999-9999$

-9999 -9999 -9999 -9999 -9999 -9999 -9999 -9999 -9999 -9999 -9999 -9999 -9999 -9999 -9999

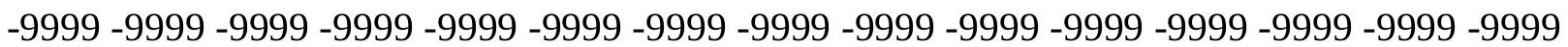
-9999 -9999 -9999 -9999 -9999 -9999 -9999 -9999 -9999 -9999 -9999 -9999 -9999 -9999 -9999 -9999 -9999 -9999 -9999 -9999 -9999 -9999 -9999 -9999 -9999 -9999 -9999 -9999 -9999 -9999 -9999 -9999 -9999 -9999 -9999 -9999 -9999 -9999 -9999 -9999 -9999 -9999 -9999 -9999 -9999 -9999 -9999 -9999 -9999 -9999 -9999 -9999 -9999 -9999 -9999 -9999 -9999 -9999 -9999 -9999 -9999 -9999 -9999 -9999 -9999 -9999 -9999 -9999 -9999 -9999 -9999 -9999 -9999 -9999 -9999 -9999 -9999 -9999 -9999 -9999 -9999 -9999 -9999 -9999 -9999 -9999 -9999 -9999 -9999 -9999 -9999 -9999 -9999 -9999 -9999 -9999 -9999 -9999 -9999 -9999 -9999 -9999 -9999 -9999 -9999 -9999 -9999 -9999 -9999 -9999 -9999 -9999 -9999 -9999 -9999 -9999 -9999 -9999 -9999 -9999 -9999 -9999 -9999 -9999 -9999 -9999 -9999 -9999 -9999 -9999 -9999 -9999 -9999 -9999 -9999 -

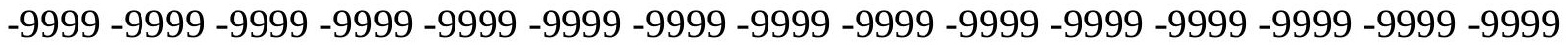
-9999 -9999 -9999 -9999 -9999 -9999 -9999 -9999 -9999 -9999 -9999 -9999 -9999 -9999 -9999 -9999 -9999 -9999 -9999 -9999 -9999 -9999 -9999 -9999 -9999 -9999 -9999 -9999 -9999 -9999

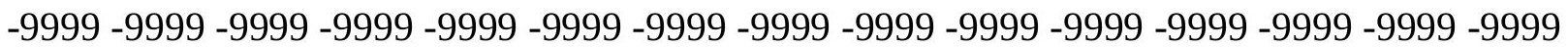
-9999 -9999 -9999 -9999 -9999 -9999 -9999 -9999 -9999 -9999 -9999 -9999 -9999 -9999 -9999 -9999 -9999 -9999 -9999 -9999 -9999 -9999 -9999 -9999 -9999 -9999 -9999 -9999 -9999 -9999 -9999120.3900985718117.647102356115.2088012695112.7705001831110.3321990967 108.1986999512106 .0652008057103 .6268997192101 .798202514699 .66472625732 97.8360290527396 .0073165893694 .1785964965892 .349891662691 .13075256348 90.8259735107490 .5211791992290 .2164001464889 .9116134643689 .3020401001 88.9972534179788 .6924667358488 .3876876831188 .0829010009887 .77810668945 87.1685485839886 .8637619018686 .5589828491286 .254188537685 .94940185547 
85.3398437585 .0350494384884 .7302627563584 .4254837036183 .81591033936 83.5111236572383 .206336975182 .9015579223682 .5967712402382 .29197692871 81.6824111938581 .3776321411181 .0728530883880 .7680587768680 .15849304199 79.8537063598679 .5489196777378 .9393463134878 .6345596313579 .85370635986 82.9015579223685 .9494018554789 .302040100192 .349891662694 .78817749023 96.3121032714896 .9216690063596 .3121032714894 .7881774902392 .3498916626 88.9972534179784 .1206970214878 .9393463134880 .7680587768682 .29197692871 83.2063369751 83.51112365723 83.81591033936 83.8159103393683.81591033936 83.5111236572383 .206336975182 .5967712402382 .2919769287181 .68241119385 81.3776321411180 .7680587768680 .1584930419979 .8537063598679 .24413299561 78.6345596313578 .3297805786177 .7202072143677 .074913024976 .80584716797 -9999 -9999 -9999 -9999 -9999 -9999 -9999 -9999 -9999 -9999 -9999 -9999 -9999 -9999 -9999 -9999 -9999 -9999 -9999 -9999 -9999 -9999 -9999 -9999 -9999 -9999 -9999 -9999 -9999 -9999 -9999 -9999 -9999 -9999 -9999 -9999 -9999 -9999 -9999 -9999 -9999 -9999 -9999 -9999 -9999 -9999 $-9999-9999$

-9999 -9999 -9999 -9999 -9999 -9999 -9999 -9999 -9999-9999 -9999 -9999 -9999 -9999 -9999 -9999 -9999 -9999 -9999 -9999 -9999 -9999 -9999 -9999 -9999 -9999 -9999 -9999 -9999 -9999 -9999 -9999 -9999 -9999 -9999 -9999 -9999 -9999 -9999 -9999 -9999 -9999 -9999 -9999 -9999 -

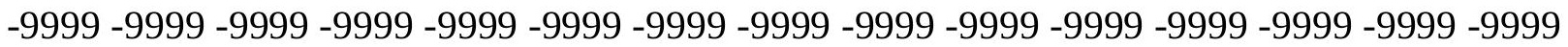

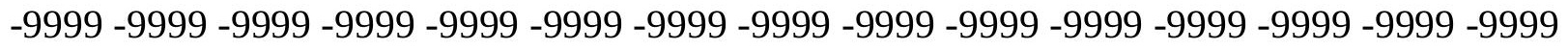

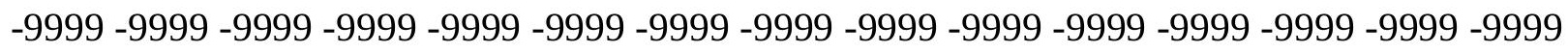
-9999 -9999 -9999 -9999 -9999 -9999 -9999 -9999 -9999 -9999 -9999 -9999 -9999 -9999 -9999 -9999 -9999 -9999 -9999 -9999 -9999 -9999 -9999 -9999 -9999 -9999 -9999 -9999 -9999 -9999 -

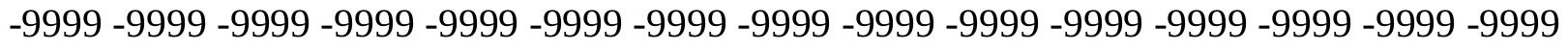

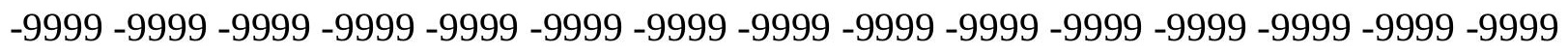
-9999 -9999 -9999 -9999 -9999 -9999 -9999 -9999 -9999 -9999 -9999 -9999 -9999 -9999 -9999 -9999 -9999 -9999 -9999 -9999 -9999 -9999 -9999 -9999 -9999 -9999 -9999 -9999 -9999 - -9999 -

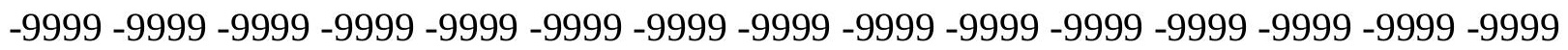
-9999 -9999 -9999 -9999 -9999 -9999 -9999 -9999 -9999 -9999 -9999 -9999 -9999 -9999 -9999 -9999 -9999 -9999 -9999 -9999 -9999 -9999 -9999 -9999 -9999 -9999 -9999 -9999 -9999 -9999 -9999 -9999 -9999 -9999 -9999 -9999 -9999 -9999 -9999-9999 -9999 -9999 -9999 -9999 -9999 -9999 -9999 -9999 -9999 -9999 -9999 -9999 -9999 -9999 -9999 -9999 -9999 -9999 -9999 -9999 -9999 -9999 117.342300415 115.2088012695 113.075302124110.9418029785108.8082962036 106.6747970581104 .5412979126102 .712600708100 .579101562598 .75038146973 96.9216690063595 .0929565429793 .5690307617291 .7403335571390 .82597351074 90.5211791992290 .2164001464889 .9116134643689 .6068267822389 .3020401001 88.9972534179788 .6924667358488 .3876876831188 .0829010009887 .47332763672 87.16854858398 86.86376190186 86.55898284912 86.2541885376 85.94940185547 85.33984375 85.03504943848 84.73026275635 84.42548370361 84.12069702148 83.5111236572383 .206336975182 .9015579223682 .5967712402382 .29197692871 81.9871978759881 .3776321411181 .0728530883880 .7680587768680 .46327209473 79.8537063598679 .5489196777378 .9393463134879 .5489196777382 .59677124023 85.9494018554789 .302040100192 .6546783447395 .7025299072397 .83602905273 98.445587158298 .1408081054796 .9216690063595 .0929565429792 .3498916626 88.3876876831182 .2919769287179 .8537063598681 .3776321411182 .59677124023 83.2063369751 83.51112365723 83.81591033936 83.8159103393683.51112365723 
83.5111236572383 .206336975182 .5967712402382 .2919769287181 .68241119385 81.3776321411180 .7680587768680 .4632720947379 .8537063598679 .54891967773 78.9393463134878 .6345596313577 .9320220947377 .41542053223 -9999 -9999 -9999 -9999 -9999 -9999 -9999 -9999 -9999 -9999 -9999 -9999 -9999 -9999 -9999 -9999 -9999 -9999 -9999 -9999 -9999 -9999 -9999 -9999 -9999 -9999 -9999 -9999 -9999 -9999 -9999-9999 -9999 -9999 -9999 -9999 -9999 -9999 -9999 -9999 -9999 -9999 -9999 -9999 -9999 -9999 -9999 -9999 -9999 -9999 -9999 -9999 -9999 -9999 -9999 -9999 -9999 -9999 -9999 -9999 -9999 -9999 -9999 -999 -

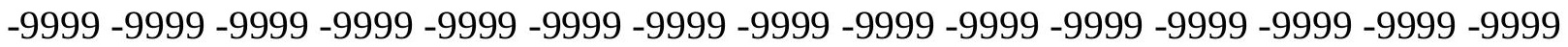

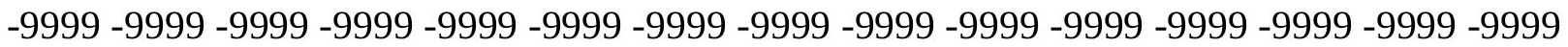
-9999 -9999 -9999 -9999 -9999 -9999 -9999 -9999 -9999 -9999 -9999 -9999 -9999 -9999 -9999 -

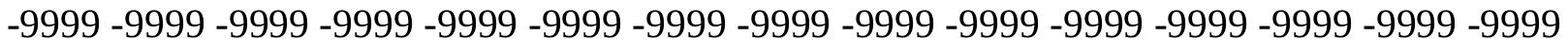
-9999 -9999 -9999 -9999 -9999 -9999 -9999 -9999 -9999 -9999 -9999 -9999 -9999 -9999 -9999 -9999 -9999 -9999 -9999 -9999 -9999 -9999 -9999 -9999 -9999 -9999 -9999 -9999 -9999 -9999 -9999 -9999 -9999 -9999 -9999 -9999 -9999 -9999 -9999 -9999 -9999 -9999 -9999 -9999 - 9999 -9999 -9999 -9999 -9999 -9999 -9999 -9999 -9999 -9999 -9999 -9999 -9999 -9999 -9999 -9999

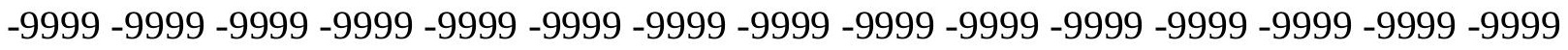

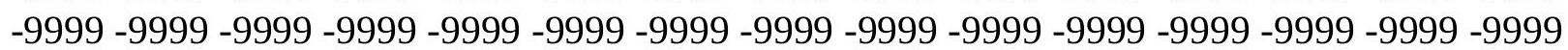
-9999 -9999 -9999 -9999 -9999 -9999 -9999 -9999 -9999 -9999 -9999 -9999 -9999 -9999 -9999 -9999 -9999 -9999 -9999 -9999 -9999 -9999 -9999 -9999 -9999 -9999 -9999 -9999 -9999 -9999 -9999 -9999 -9999 -9999 -9999 -9999 -9999 -9999 -9999 -9999 -9999 -9999 -9999 -9999 -9999 -9999 -9999 -9999 -9999 -9999 -9999 -9999 -9999 -9999 -9999 -9999 -9999 -9999 -9999 -9999 -9999 -9999 -9999 -9999 -9999 -9999 -9999 -9999 -9999 -9999 -9999 -9999 -9999 -9999 -9999 -9999 -9999 -9999 -9999 -9999 -9999 -9999 -9999 -9999 -9999 -9999 -9999 -9999 -9999 -9999 -9999 -9999 117.342300415 115.2088012695 113.3800964355111 .551399231109 .7226028442 107.5891036987105 .7603988647103 .6268997192101 .798202514699 .96952056885 97.8360290527396 .0073165893694 .4833908081192 .6546783447391 .43553924561 90.8259735107490 .5211791992290 .2164001464889 .9116134643689 .60682678223 89.3020401001 88.9972534179788.69246673584 88.38768768311 87.77810668945 87.4733276367287 .1685485839886 .8637619018686 .5589828491286 .2541885376 85.94940185547 85.33984375 85.03504943848 84.7302627563584.42548370361 84.1206970214883 .8159103393683 .5111236572383 .206336975182 .59677124023 82.2919769287181 .9871978759881 .6824111938581 .3776321411180 .76805877686 80.4632720947380 .1584930419979 .5489196777379 .2441329956182 .29197692871 85.6446228027389 .302040100192 .9594726562596 .3121032714899 .05516815186 99.6647262573299 .3599472045998 .7503814697397 .8360290527396 .00731658936 93.5690307617287 .7781066894578 .9393463134880 .4632720947381 .68241119385 82.5967712402382 .9015579223683 .5111236572383 .5111236572383 .51112365723 83.5111236572383 .206336975182 .9015579223682 .5967712402382 .29197692871 81.9871978759881 .3776321411181 .0728530883880 .4632720947380 .15849304199 79.5489196777379 .2441329956178 .6345596313578 .32978057861 -9999 -9999 -9999 -9999 -9999 -9999 -9999 -9999 -9999 -9999 -9999 -9999 -9999-9999 -9999 -9999 -9999-9999-9999 -

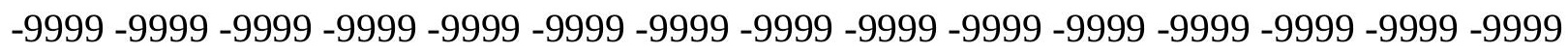
-9999 -9999 -9999 -9999 -9999 -9999 -9999 -9999 -9999 -9999 -9999 -9999 -9999 -9999 -9999 -9999 -9999 -9999 -9999 -9999 -9999 -9999 -9999 -9999 -9999 -9999 -9999 -9999 -9999 -9999 -9999 -9999 -9999 -9999 -9999 -9999 -9999 -9999 -9999 -9999 -9999 -9999 -9999 -9999 -

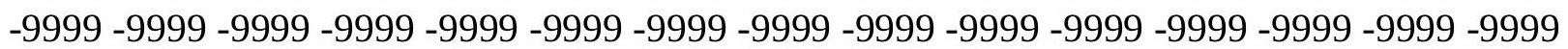


-9999 -9999 -9999 -9999 -9999 -9999 -9999 -9999 -9999 -9999 -9999 -9999 -9999 -9999 -9999 -9999 -9999 -9999 -9999 -9999 -9999 -9999 -9999 -9999 -9999 -9999 -9999 -9999 -9999 -9999 -9999 -9999 -9999 -9999 -9999 -9999 -9999 -9999 -9999 -9999 -9999 -9999 -9999 -9999 -9999 -9999 -9999 -9999 -9999 -9999 -9999 -9999 -9999 -9999 -9999 -9999 -9999 -9999 -9999 -9999 -9999 -9999 -9999 -9999 -9999 -9999 -9999 -9999 -9999 -9999 -9999 -9999 -9999 -9999 -9999 -9999 -9999 -9999 -9999 -9999 -9999 -9999 -9999 -9999 -9999 -9999 -9999 -9999 -9999 -9999 -9999 -9999 -9999 -9999 -9999 -9999 -9999 -9999 -9999 -9999 -9999 -9999 -9999 -9999 -9999

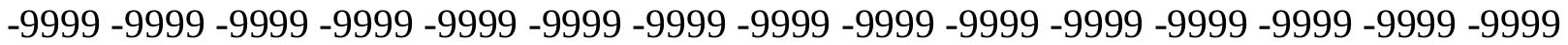
-9999 -9999 -9999 -9999 -9999 -9999 -9999 -9999 -9999 -9999 -9999 -9999 -9999 -9999 -9999 -9999 -9999 -9999 -9999 -9999 -9999 -9999 -9999 -9999 -9999 -9999 -9999 -9999 -9999 -9999 -9999 -9999 -9999 -9999 -9999 -9999 -9999 -9999 -9999 -9999 -9999 -9999 -9999 -9999 -9999 -9999 -9999 -9999 -9999 -9999 -9999 -9999 -9999 -9999 -9999 -9999 -9999 -9999 -9999 -9999

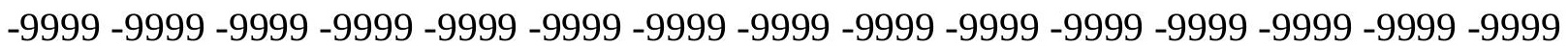
-9999 -9999 -9999 -9999 -9999 -9999 -9999 -9999 -9999 -9999 -9999 -9999 -9999 -9999 -9999 -9999 -9999-9999 115.5136032104 113.9896011353112.4656982422 110.6370010376 108.8082962036106 .979598999104 .8460998535103 .0174026489100 .8839035034 99.0551681518697 .2264633178795 .397743225193 .8738174438592 .3498916626 91.1307525634890 .8259735107490 .5211791992290 .2164001464889 .91161346436 89.6068267822389 .302040100188 .9972534179788 .3876876831188 .08290100098 87.7781066894587 .4733276367287 .1685485839886 .8637619018686 .55898284912 86.254188537685 .9494018554785 .3398437585 .0350494384884 .73026275635 84.4254837036184 .1206970214883 .8159103393683 .5111236572383 .2063369751 82.9015579223682 .5967712402381 .9871978759881 .6824111938581 .37763214111 81.0728530883880 .7680587768680 .1584930419979 .8537063598681 .98719787598 85.3398437588 .9972534179792 .6546783447396 .0073165893698 .4455871582 99.6647262573299 .9695205688599 .6647262573299 .3599472045998 .4455871582 97.5312423706194 .1785964965878 .3297805786179 .8537063598681 .07285308838 81.6824111938582 .2919769287182 .9015579223683 .206336975183 .51112365723 83.5111236572383 .5111236572383 .206336975182 .9015579223682 .59677124023 82.2919769287181 .9871978759881 .6824111938581 .0728530883880 .76805877686 80.1584930419979 .8537063598679 .24413299561 -9999 -9999 -9999 -9999 -9999 -9999 -9999 -9999 -9999 -9999 -9999 -9999 -9999 -9999 -9999 -9999 -9999 -9999 -9999 -9999 -9999 -9999 -9999 -9999 -9999 -9999 -9999 -9999 -9999 -9999 -9999 -9999 -9999 -9999 -9999 -9999 -9999 -9999 -9999 -9999 -9999 -9999 -9999 -9999 -9999 -9999 -9999 -9999 -9999 -9999 -9999 -9999 -9999 -9999 -9999 -9999 -9999 -9999 -9999 -9999 -9999 -9999 -9999 -9999 -9999 -9999 -9999 -9999 -9999 -9999 -9999 -9999 -9999 -9999 -9999 -9999 -9999 -9999 -9999 -9999 -9999 -9999 -9999 -9999 -9999 -9999 -9999 -9999 -9999 -9999 -9999 -9999 -9999 -9999

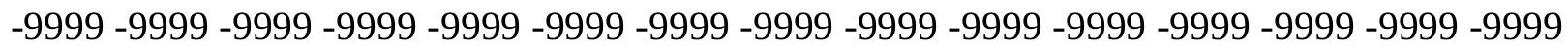
-9999 -9999 -9999 -9999 -9999 -9999 -9999 -9999 -9999 -9999 -9999 -9999 -9999 -9999 -9999 -9999 -9999 -9999 -9999 -9999 -9999 -9999 -9999 -9999 -9999 -9999 -9999 -9999 -9999 -9999 -9999 -9999 -9999 -9999 -9999 -9999 -9999 -9999 -9999 -9999 -9999 -9999 -9999 -9999 -9999 -999 -9999 -9999 -9999 -9999 -9999 -9999 -9999 -9999 -9999 -9999 -9999 -9999 -9999 -9999 -9999 -9999 -9999 -9999 -9999 -9999 -9999 -9999 -9999 -9999 -9999 -9999 -9999 -9999 -9999 -9999 -9999 -9999 -9999 -9999 -9999 -9999 -9999 -9999 -9999 -9999 -9999 -9999 -9999 -9999 -9999 -9999 -9999 -9999 -9999 -9999 -9999 -9999 -9999 -9999 -9999 -9999 -9999 -9999 -9999 -9999

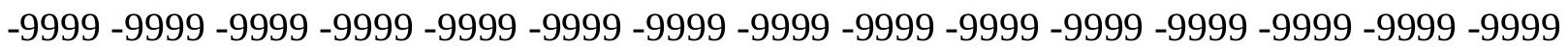


-9999 -9999 -9999 -9999 -9999 -9999 -9999 -9999 -9999 -9999 -9999 -9999 -9999 -9999 -9999 -9999 -9999 -9999 -9999 -9999 -9999 -9999 -9999 -9999 -9999 -9999 -9999 -9999 -9999 -9999 -9999 -9999 -9999 -9999 -9999 -9999 -9999 -9999 -9999 -9999 -9999 -9999 -9999 -9999 -9999 -9999 -9999 -9999 -9999 -9999 -9999 -9999 -9999 -9999 -9999 -9999 -9999 -9999 -9999 -9999 -9999 -9999 -9999 -9999 -9999 -9999 -9999 -9999 -9999 -9999 -9999 -9999 -9999 -9999 -9999 -9999 -9999-9999 116.1231002808114.9039993286113.6848983765 111.8561019897 110.3321990967108 .1986999512106 .3700027466104 .2365036011102 .4077987671 100.274299621698 .445587158296 .6168823242295 .0929565429793 .26425170898 91.7403335571390 .8259735107490 .5211791992290 .5211791992290 .21640014648 89.91161346436 89.3020401001 88.99725341797 88.69246673584 88.38768768311 88.0829010009887 .7781066894587 .4733276367287 .1685485839886 .86376190186 86.5589828491286 .254188537685 .9494018554785 .6446228027385 .33984375 84.7302627563584 .4254837036184 .1206970214883 .8159103393683 .51112365723 83.206336975182 .9015579223682 .5967712402382 .2919769287181 .98719787598 81.6824111938581 .3776321411181 .0728530883880 .7680587768681 .68241119385 85.0350494384888 .6924667358492 .0450973510795 .397743225197 .53124237061 99.3599472045999 .9695205688599 .9695205688599 .6647262573299 .66472625732 98.1408081054792 .349891662681 .0728530883878 .9393463134881 .07285308838 80.4632720947381 .9871978759882 .5967712402383 .206336975183 .2063369751 83.5111236572383 .5111236572383 .206336975183 .206336975182 .90155792236 82.5967712402382 .2919769287181 .9871978759881 .6824111938581 .37763214111 80.7680587768680 .4632720947379 .85370635986 -9999 -9999 -9999 -9999 -9999 -9999 -9999 -9999 -9999 -9999 -9999 -9999 -9999 -9999 -9999 -9999 -9999 -9999 -9999 -9999 -9999 -9999 -9999 -9999 -9999 -9999 -9999 -9999 -9999 -9999 -9999 -9999 -9999 -9999 -9999 -9999 -9999 -9999 -9999 -9999 -9999 -9999 -9999 -9999 -9999 -9999 -9999 -9999 -9999 -9999 -9999 -9999 -9999 -9999 -9999 -9999 -9999 -9999 -9999 -9999 -9999 -9999 -9999 -9999 -9999 -9999 -9999 -9999 -9999 -9999 -9999 -9999 -9999 -9999 -9999 -9999 -9999 -9999 -9999 -9999 -9999 -9999 -9999 -9999 -9999 -9999 -9999 -9999 -9999 -9999 -9999 -9999 -9999 -9999 -9999 -9999 -9999 -9999 -9999 -9999 -9999 -9999 -9999 -9999 -9999 -9999 -9999 -9999 -9999 -9999 -9999 -9999 -9999 -9999 -9999 -9999 -9999 -9999 -9999 -9999 -9999 -9999 -9999 -9999 -9999 -9999 -9999 -9999 -9999 -9999 -9999 -9999 -9999 -9999 -9999 -9999 -9999 -9999 -9999 -

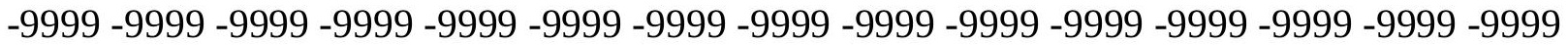
-9999 -9999 -9999 -9999 -9999 -9999 -9999 -9999 -9999 -9999 -9999 -9999 -9999 -9999 -9999 -9999 -9999 -9999 -9999 -9999 -9999 -9999 -9999 -9999 -9999 -9999 -9999 -9999 -9999 -9999 -9999 -9999 -9999 -9999 -9999 -9999 -9999 -9999 -9999 -9999 -9999 -9999 -9999 -9999 -9999 -9999 -9999 -9999 -9999 -9999 -9999 -9999 -9999 -9999 -9999 -9999 -9999 -9999 -9999 -9999 -9999 -9999 -9999 -9999 -9999 -9999 -9999 -9999 -9999 -9999 -9999 -9999 -9999 -9999 -9999

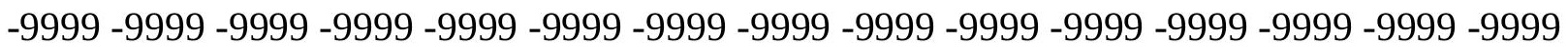
-9999 -9999 -9999 -9999 -9999 -9999 -9999 -9999 -9999 -9999 -9999 -9999 -9999 -9999 -9999 -9999 -9999 -9999 -9999 -9999 -9999 -9999 -9999 -9999 -9999 -9999 -9999 -9999 -9999 -9999 -9999 -9999 -9999 -9999 -9999 -9999 -9999 -9999 -9999 -9999 -9999 -9999 -9999 -9999 -9999 -9999 -9999 -9999 -9999 -9999 -9999 -9999 -9999 -9999 -9999 -9999 -9999 -9999 -9999 -9999 -9999 -9999 -9999 -9999 116.4279022217 115.2088012695113.6848983765 111.8561019897 109.7226028442107 .8938980103105 .7603988647103 .6268997192101 .7982025146 99.6647262573297 .8360290527396 .0073165893694 .4833908081192 .95947265625 91.7403335571390 .8259735107490 .5211791992290 .2164001464889 .91161346436 
89.6068267822389 .302040100188 .9972534179788 .6924667358488 .38768768311 88.0829010009887 .7781066894587 .4733276367287 .1685485839886 .86376190186 86.5589828491286 .254188537685 .9494018554785 .6446228027385 .33984375 85.0350494384884 .7302627563584 .4254837036184 .1206970214883 .81591033936 83.5111236572383 .206336975182 .9015579223682 .5967712402382 .29197692871 81.9871978759881 .6824111938581 .3776321411181 .6824111938584 .73026275635 88.3876876831191.4355392456194.4833908081196.9216690063598.75038146973 99.6647262573299 .6647262573299 .3599472045999 .3599472045997 .83602905273 93.2642517089884 .7302627563578 .6345596313579 .8537063598681 .37763214111 81.9871978759882 .2919769287182 .9015579223683 .206336975183 .2063369751 83.5111236572383 .5111236572383 .206336975183 .206336975182 .90155792236 82.59677124023 82.29197692871 81.98719787598 81.6824111938581.37763214111 81.0728530883880 .40683746338 -9999 -9999 -9999 -9999 -9999 -9999 -9999 -9999 -9999 -9999 -9999 -9999 -9999 -9999 -9999 -9999 -9999 -9999 -9999 -9999 -9999 -9999 -9999 -9999 -9999 -9999 -9999 -9999 -9999 -9999 -9999 -9999 -9999 -9999 -9999 -9999 -9999 -9999 - -9999 -9999 -9999 -9999-9999-9999-9999-9999-9999 -9999-9999

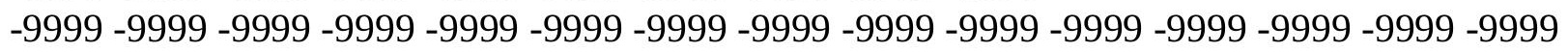
-9999 -9999 -9999 -9999 -9999 -9999 -9999 -9999 -9999 -9999 -9999 -9999 -9999 -9999 -9999 -9999 -9999 -9999 -9999 -9999 -9999 -9999 -9999 -9999 -9999 -9999 -9999 -9999 -9999 -9999

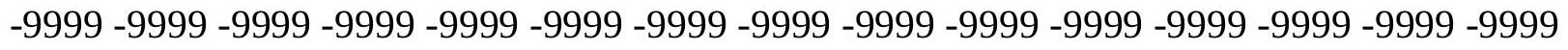

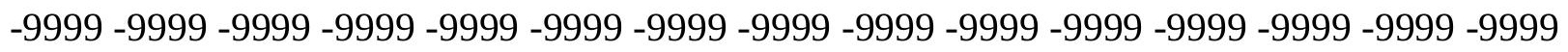

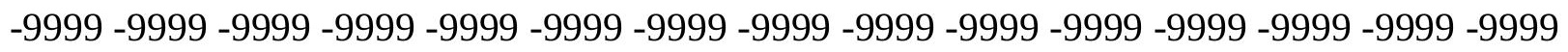
-9999 -9999 -9999 -9999 -9999 -9999 -9999 -9999 -9999 -9999 -9999 -9999 -9999 -9999 -9999 -

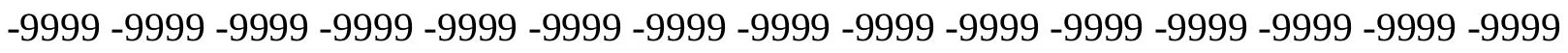

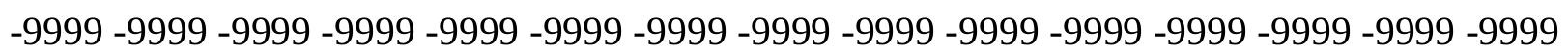
-9999 -9999 -9999 -9999 -9999 -9999 -9999 -9999 -9999 -9999 -9999 -9999 -9999 -9999 -9999 -9999 -9999 -9999 -9999 -9999 -9999 -9999 -9999 -9999 -9999 -9999 -9999 -9999 -9999 - -9999 -

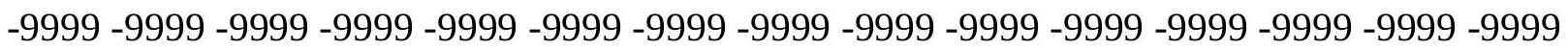

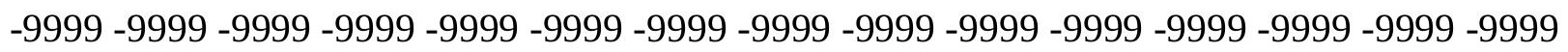

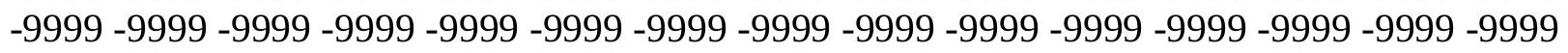
-9999 -9999 -9999 -9999 -9999 -9999 -9999 -9999 -9999 -9999 -9999 -9999 -9999 -9999 -9999

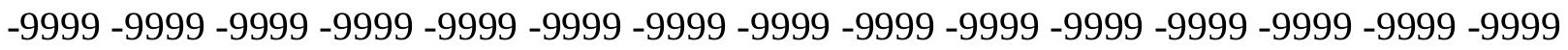

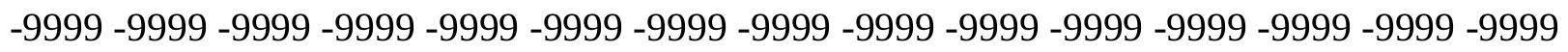
-9999-9999-9999-9999 118.2565994263117.0374984741 115.5136032104113.6848983765 111.551399231109 .4179000854107 .2844009399105 .1509017944103 .0174026489 101.188697814999.0551681518697.5312423706195.7025299072394.17859649658 92.6546783447391 .4355392456190 .8259735107490 .5211791992290 .21640014648 89.9116134643689 .6068267822389 .302040100188 .9972534179788 .69246673584 88.3876876831188 .0829010009887 .7781066894587 .4733276367287 .16854858398 86.8637619018686 .5589828491286 .254188537685 .9494018554785 .64462280273 85.3398437585 .0350494384884 .7302627563584 .4254837036184 .12069702148 83.81591033936 83.51112365723 83.2063369751 82.9015579223682.90155792236 82.59677124023 82.29197692871 82.29197692871 82.29197692871 84.73026275635 88.0829010009891 .1307525634893 .8738174438596 .3121032714898 .14080810547 99.3599472045999 .6647262573299 .6647262573299 .0551681518697 .22646331787 92.9594726562586 .8637619018680 .1584930419978 .6345596313580 .46327209473 
81.37763214111 81.98719787598 82.29197692871 82.9015579223683.2063369751 83.206336975183 .5111236572383 .5111236572383 .5111236572383 .2063369751 83.206336975182 .9015579223682 .5967712402381 .9871978759881 .68241119385 81.3776321411180 .81609344482 -9999 -9999 -9999 -9999 -9999 -9999 -9999 -9999 -9999 -9999 -9999 -9999 -9999 -9999 -9999 -9999 -9999 -9999 -9999 -9999 -9999 -9999 -9999 -9999 -9999 -9999 -9999 -9999 -9999 -9999 -9999 -9999 -9999 -9999 -9999 -9999 -9999 -9999 -9999 -9999 -9999 -9999 -9999 -9999 -9999 -9999 -9999 -9999 -9999

-9999 -9999 -9999 -9999 -9999 -9999 -9999 -9999 -9999 -9999 -9999 -9999 -9999 -9999 -9999 -9999 -9999 -9999 -9999 -9999 -9999 -9999 -9999 -9999 -9999 -9999 -9999 -9999 -9999 -9999 -9999 -9999 -9999 -9999 -9999 -9999 -9999 -9999 -9999 -9999 -9999 -9999 -9999 -9999 -9999 -

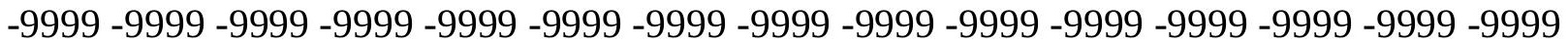
-9999 -9999 -9999 -9999 -9999 -9999 -9999 -9999 -9999 -9999 -9999 -9999 -9999 -9999 -9999 -9999 -9999 -9999 -9999 -9999 -9999 -9999 -9999 -9999 -9999 -9999 -9999 -9999 -9999 -9999 -9999 -9999 -9999 -9999 -9999 -9999 -9999 -9999 -9999 -9999 -9999 -9999 -9999 -9999 -9999 -9999 -9999 -9999 -9999 -9999 -9999 -9999 -9999 -9999 -9999 -9999 -9999 -9999 -9999 -9999

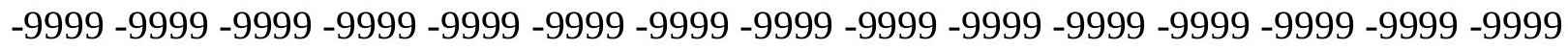
-9999 -9999 -9999 -9999 -9999 -9999 -9999 -9999 -9999 -9999 -9999 -9999 -9999 -9999 -9999 -9999 -9999 -9999 -9999 -9999 -9999 -9999 -9999 -9999 -9999 -9999 -9999 -9999 -9999 -9999 -

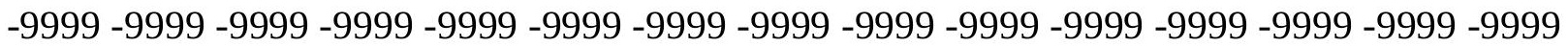

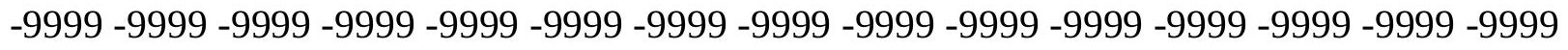

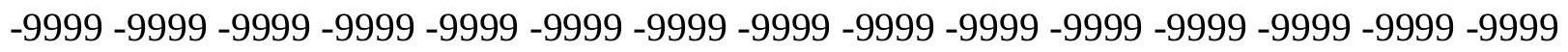

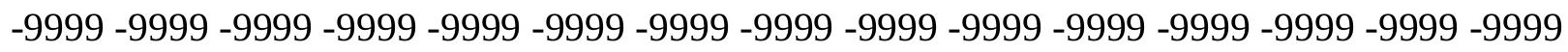
-9999 -9999 -9999 -9999 -9999 -9999 -9999 -9999 -9999 -9999 -9999 -9999 -9999 -9999 -9999 -

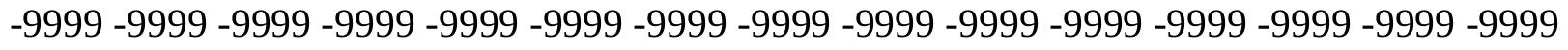
-9999 -9999 -9999 -9999 -9999 119.4757995605 117.647102356115 .5136032104 113.3800964355111 .24659729108 .8082962036106 .6747970581104 .5412979126 102.4077987671100 .579101562598 .7503814697396 .9216690063595 .3977432251 93.8738174438592 .6546783447391 .4355392456190 .8259735107490 .52117919922 89.9116134643689 .6068267822389 .302040100188 .9972534179788 .69246673584 88.38768768311 88.08290100098 87.77810668945 87.77810668945 87.47332763672 87.1685485839886 .8637619018686 .5589828491286 .254188537685 .94940185547 85.6446228027385 .3398437585 .0350494384885 .0350494384884 .73026275635 84.4254837036184 .1206970214883 .8159103393683 .5111236572383 .2063369751 83.206336975183 .206336975183 .206336975182 .9015579223684 .73026275635 87.7781066894590 .8259735107493 .5690307617296 .0073165893697 .83602905273 99.0551681518699 .9695205688599 .9695205688599 .3599472045997 .22646331787 93.8738174438588 .9972534179784 .4254837036179 .5489196777379 .54891967773 80.7680587768681 .3776321411181 .9871978759882 .2919769287182 .90155792236 83.206336975183 .5111236572383 .5111236572383 .5111236572383 .51112365723 83.206336975183 .206336975182 .9015579223682 .5967712402382 .29197692871 81.6824111938581 .18845367432 -9999 -9999-9999 -9999 -9999 -9999 -9999 -9999 -9999 -9999 -9999 -9999 -9999 -9999 -9999 -9999 -9999 -9999 -9999 -9999 -9999 -9999 -9999 -9999 -

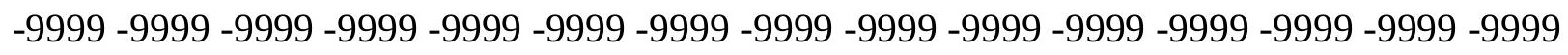
-9999 -9999 -9999 -9999-9999 -9999-9999 -9999 -9999 -9999

-9999 -9999 -9999 -9999 -9999 -9999 -9999 -9999 -9999 -9999 -9999 -9999 -9999 -9999 -9999

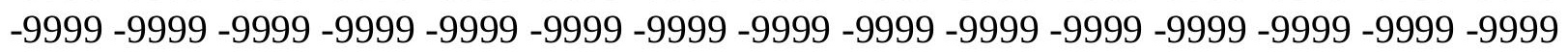


-9999 -9999 -9999 -9999 -9999 -9999 -9999 -9999 -9999 -9999 -9999 -9999 -9999 -9999 -9999 -9999 -9999 -9999 -9999 -9999 -9999 -9999 -9999 -9999 -9999 -9999 -9999 -9999 -9999 -9999 -9999 -9999 -9999 -9999 -9999 -9999 -9999 -9999 -9999 -9999 -9999 -9999 -9999 -9999 -9999 -9999 -9999 -9999 -9999 -9999 -9999 -9999 -9999 -9999 -9999 -9999 -9999 -9999 -9999 -9999 -9999 -9999 -9999 -9999 -9999 -9999 -9999 -9999 -9999 -9999 -9999 -9999 -9999 -9999 -9999 -9999 -9999 -9999 -9999 -9999 -9999 -9999 -9999 -9999 -9999 -9999 -9999 -9999 -9999 -9999 -9999 -9999 -9999 -9999 -9999 -9999 -9999 -9999 -9999 -9999 -9999 -9999 -9999 -9999 -9999

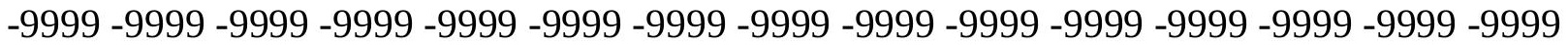
-9999 -9999 -9999 -9999 -9999 -9999 -9999 -9999 -9999 -9999 -9999 -9999 -9999 -9999 -9999 -9999 -9999 -9999 -9999 -9999 -9999 -9999 -9999 -9999 -9999 -9999 -9999 -9999 -9999 -9999 -

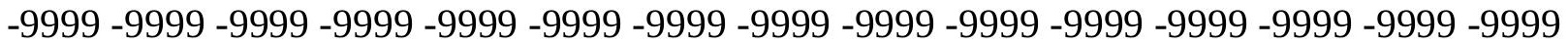
-9999 -9999 -9999 -9999 -9999 -9999 -9999 -9999 -9999 -9999 -9999 -9999 -9999 -9999 -9999

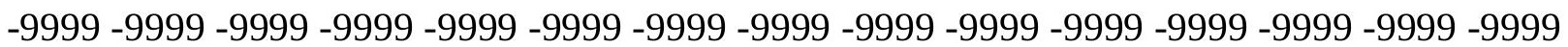
-9999 -9999 -9999 -9999 -9999 -9999 -9999 -9999 -9999 -9999 -9999 -9999 -9999 -9999 -9999 -9999 -9999 -9999 -9999 -9999 -9999 -9999 -9999 -9999 -9999 -9999 -9999 -9999 -9999 -9999 -9999 -9999 -9999 -9999 -9999 121.9140014648 120.0852966309117 .647102356 115.2088012695112 .7705001831110 .3321990967108 .1986999512105 .7603988647 103.9317016602101 .798202514699 .9695205688598 .1408081054796 .61688232422 95.0929565429793 .5690307617292 .349891662691 .1307525634890 .52117919922 90.2164001464889 .9116134643689 .302040100189 .302040100188 .99725341797 88.6924667358488 .3876876831188 .0829010009887 .7781066894587 .77810668945 87.4733276367287 .1685485839886 .8637619018686 .5589828491286 .2541885376 86.254188537685 .9494018554785 .6446228027385 .3398437585 .03504943848 84.7302627563584 .4254837036184 .4254837036184 .1206970214883 .81591033936 83.81591033936 83.81591033936 83.81591033936 83.51112365723 85.03504943848 87.7781066894590 .5211791992293 .2642517089895 .7025299072397 .53124237061 99.05516815186100 .2742996216100 .274299621699 .9695205688598 .14080810547 95.397743225192 .0450973510788 .9972534179786 .5589828491282 .29197692871 80.4632720947380 .7680587768681 .3776321411181 .9871978759882 .59677124023 83.206336975183.51112365723 83.8159103393683.8159103393683.81591033936 83.5111236572383 .5111236572383 .206336975182 .9015579223682 .59677124023 82.2919769287181 .61303710938 -9999 -9999 -9999 -9999 -9999 -9999 -9999 -9999 -9999 -9999 -9999 -9999 -9999 -9999 -9999 -9999 -9999 -9999 -9999 -9999 -9999 -9999 -9999 -9999 -9999 -9999 -9999 -9999 -9999 -9999 -9999 -9999 -9999 -9999 -9999 -9999 -9999 -9999 -9999 -9999 -9999 -9999 -9999 -9999 -9999 -9999 -9999 -9999 -9999

-9999 -9999 -9999 -9999 -9999 -9999 -9999 -9999 -9999 -9999 -9999 -9999 -9999 -9999 -9999 -9999 -9999 -9999 -9999 -9999 -9999 -9999 -9999 -9999 -9999 -9999 -9999 -9999 -9999 -9999

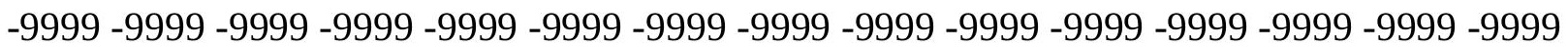
-9999 -9999 -9999 -9999 -9999 -9999 -9999 -9999 -9999 -9999 -9999 -9999 -9999 -9999 -9999 -9999 -9999 -9999 -9999 -9999 -9999 -9999 -9999 -9999 -9999 -9999 -9999 -9999 -9999 -9999 -9999 -9999 -9999 -9999 -9999 -9999 -9999 -9999 -9999 -9999 -9999 -9999 -9999 -9999 -9999

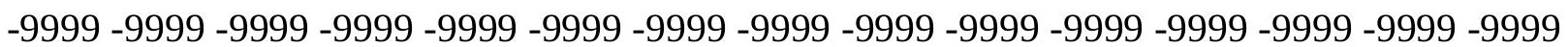
-9999 -9999 -9999 -9999 -9999 -9999 -9999 -9999 -9999 -9999 -9999 -9999 -9999 -9999 -9999 -999 -9999 -9999 -9999 -9999 -9999 -9999 -9999 -9999 -9999 -9999 -9999 -9999 -9999 -9999 -9999 -9999 -9999 -9999 -9999 -9999 -9999 -9999 -9999 -9999 -9999 -9999 -9999 -9999 -9999 -9999 -9999 -9999 -9999 -9999 -9999 -9999 -9999 -9999 -9999 -9999 -9999 -9999 -9999 -9999 -9999 
-9999 -9999 -9999 -9999 -9999 -9999 -9999 -9999 -9999 -9999 -9999 -9999 -9999 -9999 -9999 -9999 -9999 -9999 -9999 -9999 -9999 -9999 -9999 -9999 -9999 -9999 -9999 -9999 -9999 -9999 -9999 -9999 -9999 -9999 -9999 -9999 -9999 -9999 -9999 -9999 -9999 -9999 -9999 -9999 -9999 -9999 -9999 -9999 -9999 -9999 -9999 -9999 -9999 -9999 -9999 -9999 -9999 -9999 -9999 -9999 -9999 -9999 -9999 -9999 -9999 -9999 -9999 -9999 -9999 -9999 -9999 -9999 -9999 -9999 -9999 -9999 -9999 -9999 -9999 -9999 -9999 -9999 -9999 -9999 -9999 -9999 -9999 -9999 -9999 -9999 -9999 -9999 -9999 -9999 -9999 124.6570968628 122.2188034058119 .7806015015 117.0374984741114 .5991973877111 .8561019897109 .7226028442107 .2844009399 105.1509017944103 .0174026489101 .188697814999 .3599472045997 .83602905273 96.0073165893694 .7881774902393 .2642517089892 .0450973510790 .82597351074 90.2164001464889 .9116134643689 .6068267822389 .302040100188 .99725341797 88.6924667358488 .6924667358488 .3876876831188 .0829010009888 .08290100098 87.7781066894587 .4733276367287 .1685485839886 .8637619018686 .86376190186 86.5589828491286 .254188537685 .9494018554785 .6446228027385 .3398437585 .33984375 85.0350494384884 .7302627563584 .7302627563584 .4254837036184 .42548370361 84.4254837036184 .4254837036184 .1206970214884 .7302627563587 .47332763672 90.2164001464892 .9594726562595 .397743225197 .5312423706199 .35994720459 100.5791015625100 .8839035034100 .579101562599 .6647262573297 .53124237061 95.0929565429792.3498916626 93.8738174438593.87381744385 79.85370635986 79.8537063598680 .7680587768681 .6824111938582 .5967712402383 .2063369751 83.8159103393683 .8159103393684 .1206970214884 .1206970214883 .81591033936 83.5111236572383 .5111236572383 .206336975182 .9015579223682 .59677124023 81.90462493896 -9999 -9999 -9999 -9999 -9999 -9999 -9999 -9999 -9999 -9999 -9999 -9999 -9999 -9999 -9999 -9999 -9999 -9999 -9999 -9999 -9999 -9999 -9999 -9999 -9999 -9999 -9999

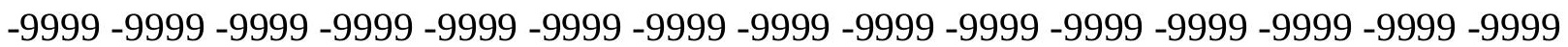
-9999 -9999 -9999 -9999-9999 -9999-9999 -9999 -9999 -9999 -9999 -9999 -9999 -9999 -9999 -9999 -9999 -9999 -9999 -9999 -9999 -9999 -9999 -9999 -9999 -9999 -9999 -9999 -9999 -9999 -9999 -9999 -9999 -9999 -9999 -9999 -9999 -9999 -9999 -9999 -9999 -9999 -9999 -9999 -9999 -9999 -9999 -9999 -9999 -9999 -9999 -9999 -9999 -9999 -9999 -9999 -9999 -9999 -9999 -9999 -9999 -9999 -9999 -9999 -9999 -9999 -9999 -9999 -9999 -9999 -9999 -9999 -9999 -9999 -9999 -9999 -9999 -9999 -9999 -9999 -9999 -9999 -

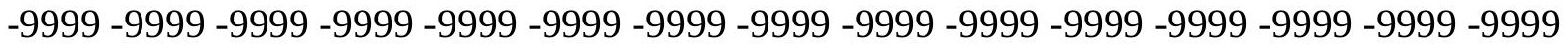
-9999 -9999 -9999 -9999 -9999 -9999 -9999 -9999 -9999 -9999 -9999 -9999 -9999 -9999 -9999 -9999 -9999 -9999 -9999 -9999 -9999 -9999 -9999 -9999 -9999 -9999 -9999 -9999 -9999 -9999 -9999 -9999 -9999 -9999 -9999 -9999 -9999 -9999 -9999 -9999 -9999 -9999 -9999 -9999 -9999 -9999 -9999 -9999 -9999 -9999 -9999 -9999 -9999 -9999 -9999 -9999 -9999 -9999 -9999 -9999 -9999 -9999 -9999 -9999 -9999 -9999 -9999 -9999 -9999 -9999 -9999 -9999 -9999 -9999 -9999

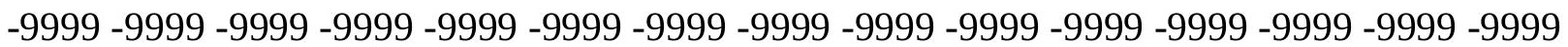
-9999 -9999 -9999 -9999 -9999 -9999 -9999 -9999 -9999 -9999 -9999 -9999 -9999 -9999 -9999 -9999 -9999 -9999 -9999 -9999 -9999 -9999 -9999 -9999 -9999 -9999 -9999 -9999 -9999 -9999 -9999 -9999 -9999 -9999 -9999 -9999 -9999 -9999 -9999 -9999 -9999 -9999 -9999 -9999 -9999 -9999 -9999 -9999 -9999 -9999 -9999 -9999 -9999 -9999 -9999 -9999 -9999 -9999 - -9999 - -9999 -9999 -9999 -9999 -9999 -9999 -9999 -9999 -9999 -9999 -9999 -9999 -9999 -9999 -9999 -9999 -9999 -9999 -9999 -9999 -9999 -9999 124.3523025513121 .6092987061118 .8662033081 116.1231002808113 .3800964355110 .9418029785108 .5035018921106 .3700027466 104.2365036011102 .4077987671100 .579101562598 .7503814697397 .22646331787 
95.7025299072394 .4833908081192 .9594726562591 .7403335571390 .82597351074 89.9116134643689 .6068267822389 .302040100188 .9972534179788 .99725341797 88.6924667358488 .6924667358488 .3876876831188 .0829010009888 .08290100098 87.7781066894587 .4733276367287 .1685485839887 .1685485839886 .86376190186 86.5589828491286 .254188537685 .9494018554785 .9494018554785 .64462280273 85.3398437585 .3398437585 .0350494384885 .0350494384885 .0350494384885 .03504943848 84.7302627563584 .1206970214884 .7302627563587 .1685485839889 .91161346436 92.349891662695 .0929565429797 .5312423706199 .66472625732100 .8839035034 101.7982025146101 .7982025146101 .188697814999 .9695205688598 .14080810547 96.6168823242294 .7881774902388 .6924667358479 .5489196777378 .93934631348 80.4632720947381 .6824111938582 .5967712402383 .5111236572383 .81591033936 84.12069702148 84.12069702148 84.12069702148 84.12069702148 83.81591033936 83.51112365723 83.206336975182.90155792236 82.59677124023 82.04577636719-9999 -9999 -9999 -9999 -9999 -9999 -9999 -9999 -9999 -9999 -9999 -9999 -9999 -9999 -9999 -9999 -9999 -9999 -9999 -9999 -9999 -9999 -9999 -9999 -9999 -9999 -9999 -9999 -9999 -9999 -9999

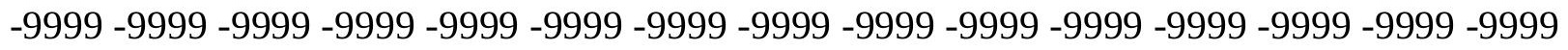
-9999 -9999-9999

-9999 -9999 -9999 -9999 -9999 -9999 -9999 -9999 -9999 -9999 -9999 -9999 -9999 -9999 -9999 -9999 -9999 -9999 -9999 -9999 -9999 -9999 -9999 -9999 -9999 -9999 -9999 -9999 -9999 -9999 -

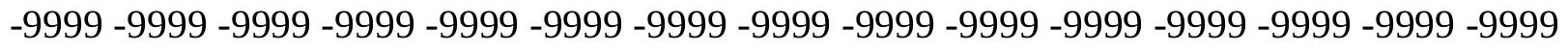

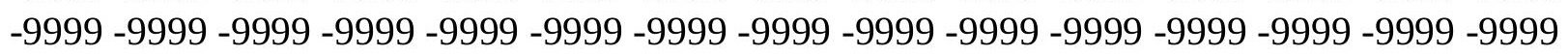

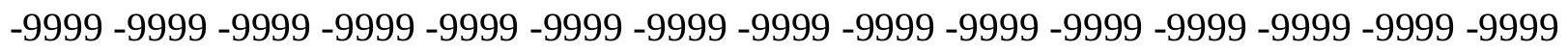
-9999 -9999 -9999 -9999 -9999 -9999 -9999 -9999 -9999 -9999 -9999 -9999 -9999 -9999 -9999 -

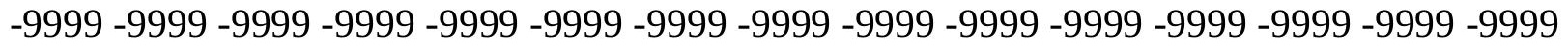

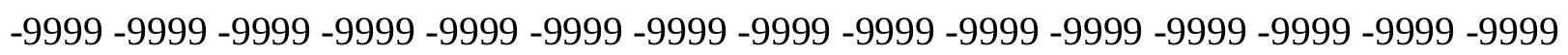
-9999 -9999 -9999 -9999 -9999 -9999 -9999 -9999 -9999 -9999 -9999 -9999 -9999 -9999 -9999 -9999 -9999 -9999 -9999 -9999 -9999 -9999 -9999 -9999 -9999 -9999 -9999 -9999 -9999 - -9999 -

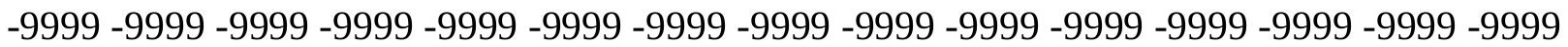

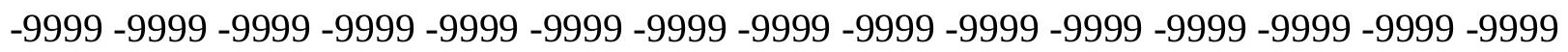

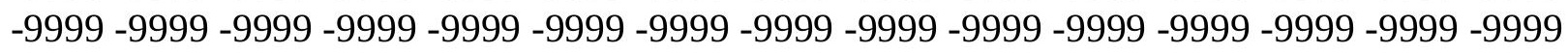
-9999 -9999 -9999 -9999 -9999 -9999 -9999 -9999 -9999 -9999 -9999 -9999 -9999 -9999 -9999 -9999 -9999 -9999 -9999 -9999 -9999 -9999 -9999 -9999 -9999 -9999 -9999 -9999 -9999 -9999 -

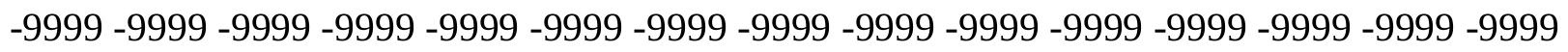

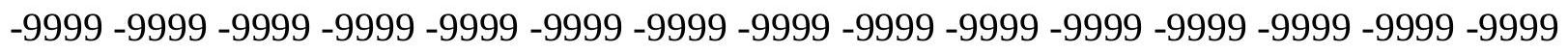
-9999 -9999-9999-9999-9999-9999 126.1809997559 123.1332015991 120.3900985718 117.342300415114 .5991973877112 .1608963013109 .7226028442107 .5891036987 105.4557037354103 .6268997192101 .798202514699 .9695205688598 .4455871582 96.9216690063595 .397743225193 .8738174438592 .6546783447391 .43553924561 90.5211791992289 .6068267822389 .302040100189 .302040100188 .99725341797 88.99725341797 88.69246673584 88.69246673584 88.38768768311 88.38768768311 88.0829010009887 .7781066894587 .4733276367287 .4733276367287 .16854858398 86.8637619018686 .5589828491286 .5589828491286 .254188537685 .94940185547 85.9494018554785 .6446228027385 .6446228027385 .6446228027385 .64462280273 85.3398437585 .0350494384884 .4254837036184 .4254837036186 .86376190186 89.302040100192.0450973510794.7881774902397.8360290527399.66472625732 101.1886978149102 .4077987671102 .712600708102 .4077987671101 .7982025146 
100.579101562598 .445587158294 .1785964965886 .254188537678 .63455963135 79.2441329956180 .7680587768681 .9871978759883 .206336975183 .81591033936 84.1206970214884 .4254837036184 .4254837036184 .4254837036184 .12069702148 84.1206970214883 .8159103393683 .5111236572383 .206336975182 .69612121582 82.12335205078 -9999 -9999 -9999 -9999 -9999 -9999 -9999 -9999 -9999 -9999 -9999 -9999 -9999 -9999 -9999 -9999 -9999 -9999 -9999 -9999 -9999 -9999 -9999 -9999 -9999 -9999 -9999

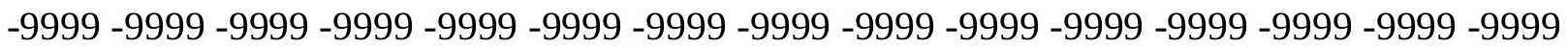
-9999 -9999 -9999 -9999-9999-9999-9999

-9999 -9999 -9999 -9999 -9999 -9999 -9999 -9999 -9999 -9999 -9999 -9999 -9999 -9999 -9999 -9999 -9999 -9999 -9999 -9999 -9999 -9999 -9999 -9999 -9999 -9999 -9999 -9999 -9999 -9999 -9999 -9999 -9999 -9999 -9999 -9999 -9999 -9999 -9999 -9999 -9999 -9999 -9999 -9999 -9999 -999 -9999 -9999 -9999 -9999 -9999 -9999 -9999 -9999 -9999 -9999 -9999 -9999 -9999 -9999 -9999 -9999 -9999 -9999 -9999 -9999 -9999 -9999 -9999 -9999 -9999 -9999 -9999 -9999 -9999 -9999 -9999 -9999 -9999 -9999 -9999 -9999 -9999 -9999 -9999 -9999 -9999 -9999 -9999 -9999 -9999 -9999 -9999 -9999 -9999 -9999 -9999 -9999 -9999 -9999 -9999 -9999 -9999 -9999 -9999 -9999 -9999 -9999 -9999 -9999 -9999 -9999 -9999 -9999 -9999 -9999 -9999 -9999 -9999 - -9999 - -9999 -

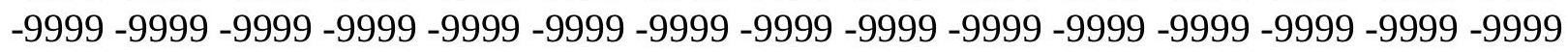

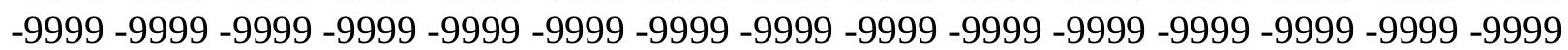

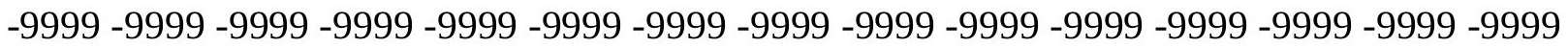

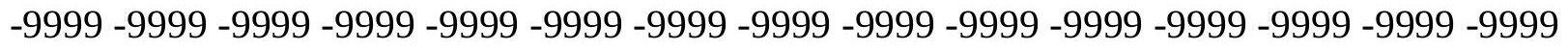

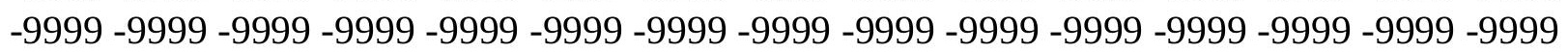

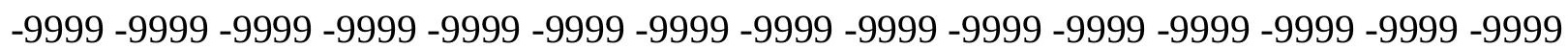

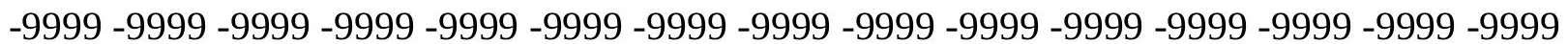

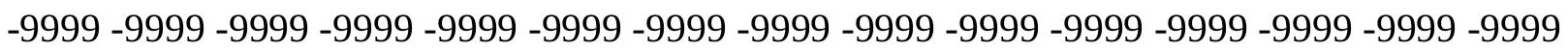

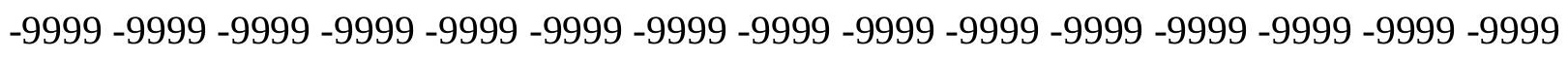
-9999 -9999-9999 -9999 -9999-9999-9999 124.3523025513121 .3044967651118 .5614013672 115.818397522113 .3800964355110 .9418029785108 .8082962036106 .6747970581 104.5412979126102 .712600708101 .188697814999 .3599472045997 .83602905273 96.3121032714895 .0929565429793 .5690307617292 .349891662691 .13075256348 90.2164001464889 .6068267822389 .302040100189 .302040100189 .3020401001 88.99725341797 88.99725341797 88.69246673584 88.38768768311 88.38768768311 88.0829010009887 .7781066894587 .7781066894587 .4733276367287 .16854858398 87.1685485839886 .8637619018686 .5589828491286 .254188537686 .2541885376 85.9494018554785 .9494018554785 .9494018554785 .9494018554785 .94940185547 85.6446228027384 .7302627563584 .1206970214886 .5589828491289 .3020401001 91.7403335571394 .1785964965897 .2264633178799 .66472625732101 .4934005737 102.712600708103 .3221969604103 .6268997192103 .0174026489101 .7982025146 99.6647262573295 .0929565429786 .5589828491277 .7202072143679 .54891967773 81.3776321411182 .9015579223683 .8159103393684 .1206970214884 .42548370361 84.4254837036184 .4254837036184 .4254837036184 .1206970214884 .12069702148 83.8159103393683 .5111236572383 .206336975182 .81823730469 -9999 -9999 -9999 -9999 -9999 -9999 -9999 -9999 -9999 -9999 -9999 -9999 -9999 -9999 -9999 -9999 -9999 - -9999 -9999 -9999 -9999 -9999 -9999 -9999 -9999 -9999 -9999 -9999 -9999 -9999 -9999 -9999 -9999

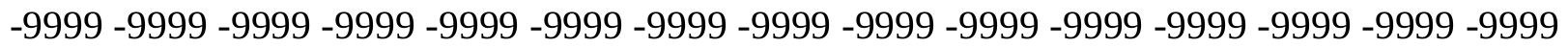
$-9999$

-9999 -9999 -9999 -9999 -9999 -9999 -9999 -9999 -9999 -9999 -9999 -9999 -9999 -9999 -9999 
-9999 -9999 -9999 -9999 -9999 -9999 -9999 -9999 -9999 -9999 -9999 -9999 -9999 -9999 -9999 -9999 -9999 -9999 -9999 -9999 -9999 -9999 -9999 -9999 -9999 -9999 -9999 -9999 -9999 -9999 -9999 -9999 -9999 -9999 -9999 -9999 -9999 -9999 -9999 -9999 -9999 -9999 -9999 -9999 -9999 -9999 -9999 -9999 -9999 -9999 -9999 -9999 -9999 -9999 -9999 -9999 -9999 -9999 -9999 -9999 -9999 -9999 -9999 -9999 -9999 -9999 -9999 -9999 -9999 -9999 -9999 -9999 -9999 -9999 -9999 -9999 -9999 -9999 -9999 -9999 -9999 -9999 -9999 -9999 -9999 -9999 -9999 -9999 -9999 -9999 -9999 -9999 -9999 -9999 -9999 -9999 -9999 -9999 -9999 -9999 -9999 -9999 -9999 -9999 -9999 -9999 -9999 -9999 -9999 -9999 -9999 -9999 -9999 -9999 -9999 -9999 -9999 -9999 -9999 -9999 -9999 -9999 -9999 -9999 -9999 -9999 -9999 -9999 -9999 -9999 -9999 -9999 -9999 -9999 -9999 -9999 -9999 -9999 -9999 -9999 -9999 -9999 -9999 -9999 -9999 -9999 -9999 -9999 -9999 -9999 -

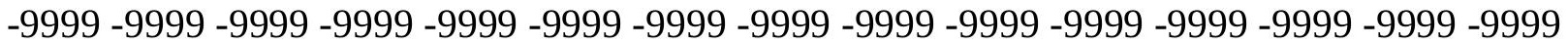
-9999 -9999 -9999 -9999 -9999 -9999 -9999 -9999 -9999 -9999 -9999 -9999 -9999 -9999 -9999

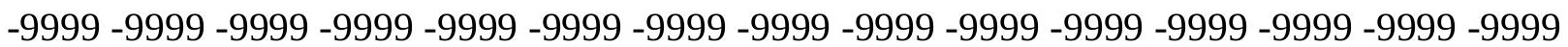
-9999 -9999 -9999 -9999 -9999 -9999 -9999 -9999 -9999 -9999 -9999 -9999 -9999 -9999 -9999 -9999 -9999 -9999 -9999 -9999 -9999 -9999 -9999 -9999 -9999 -9999 -9999 -9999 -9999 -9999 -9999 -9999 -9999 -9999 -9999 -9999 -9999 -9999 -9999 -9999 -9999 -9999 -9999 -9999 -9999 -9999 -9999 -9999 -9999-9999 -9999 -9999 125.2667007446 122.2188034058 119.4757995605 116.7326965332114 .2944030762112 .1608963013109 .7226028442107 .8938980103 105.7603988647103 .9317016602102 .1029968262100 .579101562598 .75038146973 97.2264633178796 .0073165893694 .4833908081193 .2642517089892 .04509735107 90.8259735107489 .9116134643689 .6068267822389 .6068267822389 .3020401001 89.3020401001 88.99725341797 88.99725341797 88.69246673584 88.69246673584 88.38768768311 88.08290100098 88.08290100098 87.77810668945 87.47332763672 87.4733276367287 .1685485839886 .8637619018686 .8637619018686 .55898284912 86.5589828491286 .5589828491286 .5589828491286 .5589828491286 .2541885376 85.9494018554785 .0350494384884 .4254837036186 .8637619018689 .3020401001 91.7403335571394 .4833908081196 .9216690063599 .35994720459101 .4934005737 103.0174026489103 .6268997192103 .9317016602103 .6268997192102 .4077987671 99.9695205688595 .7025299072388 .9972534179779 .5489196777380 .46327209473 82.5967712402383 .8159103393684 .4254837036184 .7302627563584 .73026275635 84.7302627563584 .7302627563584 .4254837036184 .4254837036184 .12069702148 83.8159103393683 .8159103393683 .5111236572382 .94596862793 -9999 -9999 -9999 -9999 -9999 -9999 -9999 -9999 -9999 -9999 -9999 -9999 -9999 -9999 -9999 -9999 -9999 -9999 -9999 -9999 -9999 -9999 -9999 -9999 -9999 -9999 -9999 -9999 -9999 -9999 -9999 -9999 -9999 -9999

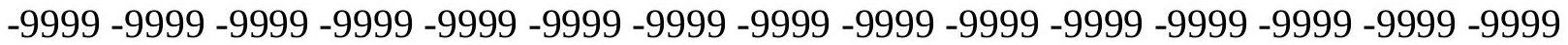
$-9999$

-9999 -9999 -9999 -9999 -9999 -9999 -9999 -9999 -9999 -9999 -9999 -9999 -9999 -9999 -9999

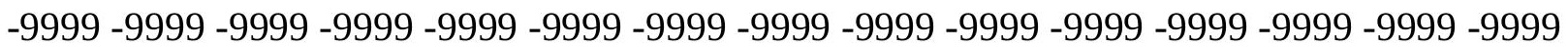
-9999 -9999 -9999 -9999 -9999 -9999 -9999 -9999 -9999 -9999 -9999 -9999 -9999 -9999 -9999 -9999 -9999 -9999 -9999 -9999 -9999 -9999 -9999 -9999 -9999 -9999 -9999 -9999 -9999 -9999 -9999 -9999 -9999 -9999 -9999 -9999 -9999 -9999 -9999 -9999 -9999 -9999 -9999 -9999 -9999

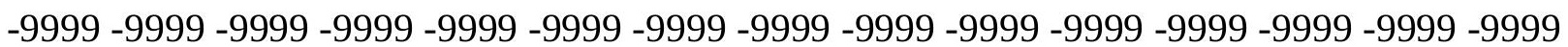
-9999 -9999 -9999 -9999 -9999 -9999 -9999 -9999 -9999 -9999 -9999 -9999 -9999 -9999 -9999 -999 -9999 -9999 -9999 -9999 -9999 -9999 -9999 -9999 -9999 -9999 -9999 -9999 -9999 -9999 -9999 -9999 -9999 -9999 -9999 -9999 -9999 -9999 -9999 -9999 -9999 -9999 -9999 -9999 -9999 -9999

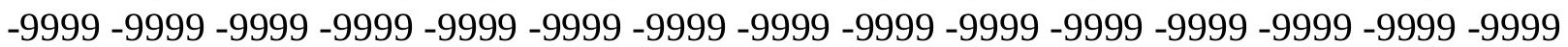


-9999 -9999 -9999 -9999 -9999 -9999 -9999 -9999 -9999 -9999 -9999 -9999 -9999 -9999 -9999 -9999 -9999 -9999 -9999 -9999 -9999 -9999 -9999 -9999 -9999 -9999 -9999 -9999 -9999 -9999 -9999 -9999 -9999 -9999 -9999 -9999 -9999 -9999 -9999 -9999 -9999 -9999 -9999 -9999 -9999 -9999 -9999 -9999 -9999 -9999 -9999 -9999 -9999 -9999 -9999 -9999 -9999 -9999 -9999 -9999 -9999 -9999 -9999 -9999 -9999 -9999 -9999 -9999 -9999 -9999 -9999 -9999 -9999 -9999 -9999 -9999 -9999 -9999 -9999 -9999 -9999 -9999 -9999 -9999 -9999 -9999 -9999 -9999 -9999 -9999 -9999 -9999 -9999 -9999 -9999 -9999 -9999 -9999 -9999 -9999 -9999 -9999 -9999 -9999 -9999 -9999 -9999 -9999 -9999 -9999 -9999 -9999 -9999 122.8283996582120 .0852966309 117.647102356115 .2088012695113 .075302124110 .9418029785108 .8082962036 106.6747970581104 .8460998535103 .0174026489101 .493400573799 .96952056885 98.445587158296 .9216690063595 .397743225194 .1785964965892 .95947265625 91.7403335571390 .8259735107489 .9116134643689 .6068267822389 .60682678223 89.6068267822389 .302040100189 .302040100188 .9972534179788 .69246673584 88.6924667358488 .3876876831188 .3876876831188 .0829010009887 .77810668945 87.7781066894587 .4733276367287 .1685485839887 .1685485839886 .86376190186 86.8637619018686 .8637619018686 .8637619018686 .8637619018686 .86376190186 86.5589828491285 .6446228027385 .0350494384887 .1685485839889 .91161346436 92.349891662694 .7881774902397 .2264633178799 .35994720459101 .4934005737 102.712600708103 .6268997192103 .9317016602103 .6268997192102 .4077987671 100.274299621696 .6168823242292 .9594726562590 .2164001464881 .37763214111 83.8159103393685 .0350494384885 .0350494384885 .0350494384885 .03504943848 84.7302627563584 .4254837036184 .4254837036184 .1206970214884 .12069702148 83.8159103393683 .8159103393683 .5111236572383 .02568817139 -9999 -9999 -9999 -9999 -9999 -9999 -9999 -9999 -9999 -9999 -9999 -9999 -9999 -9999 -9999 -9999 -9999 -9999 -9999 -9999 -9999 -9999 -9999 -9999 -9999 -9999 -9999 -9999 -9999 -9999 -9999 -9999 -9999 -9999 -9999 -9999 -9999 -9999 -9999 -9999 -9999 -9999 -9999 -9999 -9999 -9999 -9999 -9999 -9999 $-9999$

-9999 -9999 -9999 -9999 -9999 -9999 -9999 -9999 -9999 -9999 -9999 -9999 -9999 -9999 -9999 -9999 -9999 -9999 -9999 -9999 -9999 -9999 -9999 -9999 -9999 -9999 -9999 -9999 -9999 -9999 -9999 -9999 -9999 -9999 -9999 -9999 -9999 -9999 -9999 -9999 -9999 -9999 -9999 -9999 -9999 -9999 -9999 -9999 -9999 -9999 -9999 -9999 -9999 -9999 -9999 -9999 -9999 -9999 -9999 -9999 -9999 -9999 -9999 -9999 -9999 -9999 -9999 -9999 -9999 -9999 -9999 -9999 -9999 -9999 -9999 -9999 -9999 -9999 -9999 -9999 -9999 -9999 -9999 -9999 -9999 -9999 -9999 -9999 -9999 -9999 -9999 -9999 -9999 -9999 -9999 -9999 -9999 -9999 -9999 -9999 -9999 -9999 -9999 -9999 -9999 -

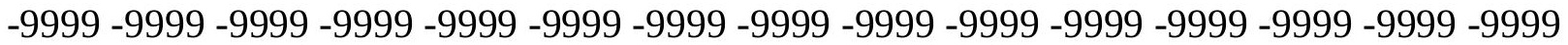
-9999 -9999 -9999 -9999 -9999 -9999 -9999 -9999 -9999 -9999 -9999 -9999 -9999 -9999 -9999 -9999 -9999 -9999 -9999 -9999 -9999 -9999 -9999 -9999 -9999 -9999 -9999 -9999 -9999 -9999

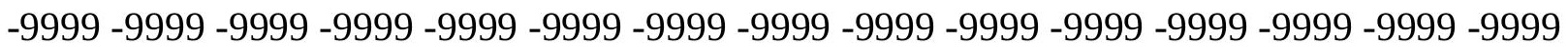
-9999 -9999 -9999 -9999 -9999 -9999 -9999 -9999 -9999 -9999 -9999 -9999 -9999 -9999 -9999 -9999 -9999 -9999 -9999 -9999 -9999 -9999 -9999 -9999 -9999 -9999 -9999 -9999 -9999 -9999 -9999 -9999 -9999 -9999 -9999 -9999 -9999 -9999 -9999 -9999 -9999 -9999 -9999 -9999 -9999

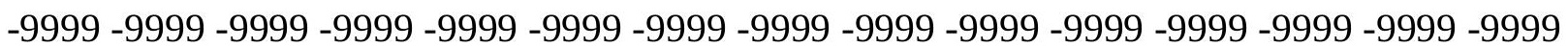
-9999 -9999 -9999 -9999 -9999 -9999 -9999 -9999 -9999 -9999 -9999 -9999 -9999 -9999 -9999 -9999 -9999 -9999 -9999 -9999 -9999 -9999 -9999 -9999 -9999 -9999 -9999 -9999 -9999 -9999 -9999 -9999 -9999 -9999 -9999 -9999 -9999 -9999 123.1332015991120 .6949005127 118.5614013672116 .1231002808113 .9896011353111 .8561019897109 .7226028442 
107.8938980103106 .0652008057104 .2365036011102 .4077987671100 .8839035034 99.3599472045997 .8360290527396 .3121032714895 .0929565429793 .87381744385 92.6546783447391 .4355392456190 .5211791992290 .2164001464889 .91161346436 89.6068267822389 .6068267822389 .302040100189 .302040100188 .99725341797 88.99725341797 88.6924667358488.38768768311 88.3876876831188.08290100098 88.0829010009887 .7781066894587 .4733276367287 .4733276367287 .16854858398 87.1685485839887 .1685485839887 .1685485839887 .1685485839887 .16854858398 86.86376190186 86.5589828491285.9494018554788.0829010009890.52117919922 92.6546783447395 .0929565429797 .2264633178799 .35994720459101 .1886978149 102.4077987671103 .3221969604103 .6268997192103 .0174026489101 .7982025146 99.6647262573296 .9216690063593 .8738174438590 .2164001464881 .68241119385 84.7302627563585 .0350494384885 .0350494384885 .0350494384884 .73026275635 84.42548370361 84.42548370361 84.12069702148 84.12069702148 84.12069702148 83.8159103393683 .8159103393683 .5111236572383 .05413818359 -9999 -9999 -9999 -9999 -9999 -9999 -9999 -9999 -9999 -9999 -9999 -9999 -9999 -9999 -9999 -9999 -9999 -9999 -9999

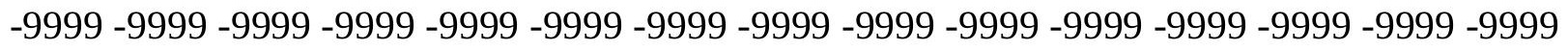
-9999 -9999 -9999 -9999 -9999 -9999 -9999 -9999 -9999 -9999 -9999 -9999 -9999 -9999 -9999 $-9999$

-9999 -9999 -9999 -9999 -9999 -9999 -9999 -9999 -9999 -9999 -9999 -9999 -9999 -9999 -9999

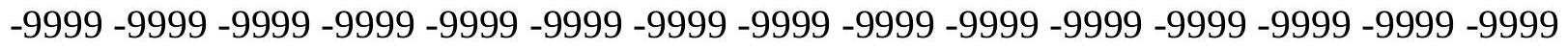

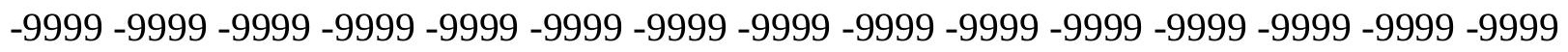
-9999 -9999 -9999 -9999 -9999 -9999 -9999 -9999 -9999 -9999 -9999 -9999 -9999 -9999 -9999 -9999 -9999 -9999 -9999 -9999 -9999 -9999 -9999 -9999 -9999 -9999 -9999 -9999 -9999 -9999 -

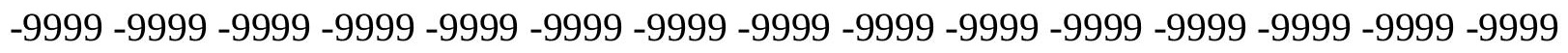

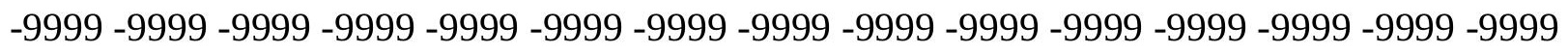
-9999 -9999 -9999 -9999 -9999 -9999 -9999 -9999 -9999 -9999 -9999 -9999 -9999 -9999 -9999 -9999 -9999 -9999 -9999 -9999 -9999 -9999 -9999 -9999 -9999 -9999 -9999 -9999 -9999 - -9999 -

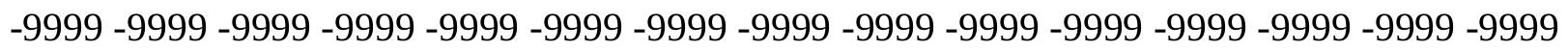
-9999 -9999 -9999 -9999 -9999 -9999 -9999 -9999 -9999 -9999 -9999 -9999 -9999 -9999 -9999 -9999 -9999 -9999 -9999 -9999 -9999 -9999 -9999 -9999 -9999 -9999 -9999 -9999 -9999 -9999 -9999 -9999 -9999 -9999 -9999 -9999 -9999 -9999 -9999-9999 -9999 -9999 -9999 -9999 -9999 -9999 -9999 -9999 -9999 -9999 -9999 -9999 -9999 -9999 -9999 -9999 -9999 -9999 -9999 -9999 -

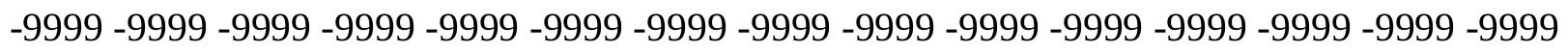
-9999 -9999 -9999 -9999 -9999 -9999 -9999 -9999 -9999 -9999 -9999 -9999 -9999 -9999 -9999 -9999 -9999 -9999 -9999 -9999 -9999 -9999 -9999 -9999 -9999 -9999 -9999 -9999 -9999 -9999 -9999 -9999 -9999 -9999 -9999 -9999 -9999 -9999 -9999 121.3044967651 119.1709976196 117.0374984741114 .9039993286112 .7705001831110 .6370010376108 .8082962036 106.979598999105 .1509017944103 .3221969604101 .7982025146100 .2742996216 98.7503814697397 .2264633178796 .0073165893694 .7881774902393 .56903076172 92.349891662691 .4355392456190 .5211791992289 .9116134643689 .91161346436 89.6068267822389 .6068267822389 .302040100189 .302040100188 .99725341797 88.9972534179788 .6924667358488 .3876876831188 .3876876831188 .08290100098 88.0829010009887 .7781066894587 .7781066894587 .4733276367287 .47332763672 87.4733276367287 .4733276367287 .4733276367287 .4733276367287 .47332763672 87.1685485839887 .4733276367289 .302040100191 .1307525634893 .26425170898 95.397743225197 .5312423706199 .35994720459100 .8839035034102 .1029968262 
102.712600708102 .712600708102 .1029968262100 .883903503498 .75038146973 95.7025299072391 .7403335571385 .9494018554780 .4632720947383 .2063369751 84.1206970214884 .4254837036184 .4254837036184 .4254837036184 .12069702148 84.1206970214884 .1206970214883 .8159103393683 .8159103393683 .81591033936 83.5111236572383 .5111236572383 .06890869141 -9999 -9999 -9999 -9999 -9999 -9999-9999 -9999 -9999 -9999 -9999 -9999 -9999 -9999 -9999 -9999 -9999 -9999 -9999 -9999 -9999 -9999

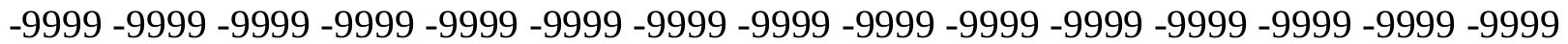
-9999 -9999 -9999 -9999 -9999 -9999 -9999 -9999 -9999 -9999 -9999 -9999 -9999 -9999 -9999 -9999 -9999 -9999 -9999 -9999 -9999 -9999 -9999 -9999 -9999 -9999 -9999 -9999 -9999 -9999 -9999 -9999 -9999 -9999 -9999 -9999 -9999 -9999 -9999 -9999 -9999 -9999 -9999 -

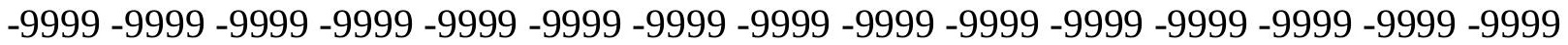
-9999 -9999 -9999 -9999 -9999 -9999 -9999 -9999 -9999 -9999 -9999 -9999 -9999 -9999 -9999 -9999 -9999 -9999 -9999 -9999 -9999 -9999 -9999 -9999 -9999 -9999 -9999 -9999 -9999 -9999 -9999 -9999 -9999 -9999 -9999 -9999 -9999 -9999 -9999 -9999 -9999 -9999 -9999 -9999 -9999 -9999 -9999 -9999 -9999 -9999 -9999 -9999 -9999 -9999 -9999 -9999 -9999 -9999 -9999 -9999

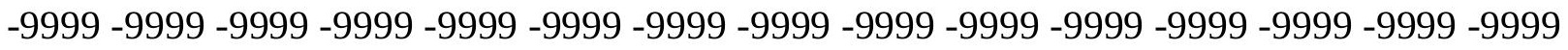

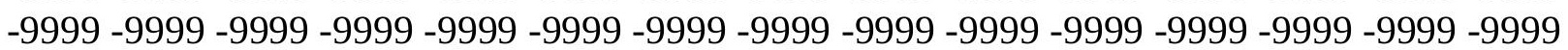
-9999 -9999 -9999 -9999 -9999 -9999 -9999 -9999 -9999 -9999 -9999 -9999 -9999 -9999 -9999 -9999 -9999 -9999 -9999 -9999 -9999 -9999 -9999 -9999 -9999 -9999 -9999 -9999 -9999 -9999 -9999 -9999 -9999 -9999 -9999 -9999 -9999 -9999 -9999 -9999 -9999 -9999 -9999 -9999 -9999 -9999 -9999 -9999 -9999 -9999 -9999 -9999 -9999 -9999 -9999 -9999 -9999 -9999 -9999 -9999 -9999 -9999 -9999 -9999 -9999 -9999 -9999 -9999 -9999 -9999 -9999 -9999 -9999 -9999 -9999 -9999 -9999 -9999 -9999 -9999 -9999 -9999 -9999 -9999 -9999 -9999 -9999 -9999 -9999 -9999 -9999 -9999 -9999 -9999 -9999 -9999 -9999 -9999 -9999 -9999 -9999 -9999 -9999 -9999 -9999 -9999 -9999 -9999 -9999 -9999 -9999 -9999 -9999 -9999 -9999 -9999 -9999 -9999 -9999 -9999 -9999 -9999 -9999 -9999 -9999 -9999 -9999 -9999 -9999 121.9140014648 119.7806015015 117.647102356115 .5136032104113 .6848983765111 .551399231109 .7226028442 107.8938980103106 .0652008057104 .5412979126102 .712600708101 .1886978149 99.6647262573298 .1408081054796 .9216690063595 .7025299072394 .48339080811 93.2642517089892.0450973510791.1307525634890.21640014648 89.91161346436 89.9116134643689 .9116134643689 .6068267822389 .6068267822389 .3020401001 88.9972534179788 .9972534179788 .6924667358488 .6924667358488 .38768768311 88.38768768311 88.08290100098 88.08290100098 87.77810668945 87.77810668945 87.7781066894587 .7781066894587 .7781066894587 .7781066894587 .77810668945 87.4733276367288 .3876876831189 .9116134643691 .7403335571393 .87381744385 95.7025299072397 .5312423706199 .05516815186100 .2742996216101 .1886978149 101.7982025146101 .7982025146101 .188697814999 .6647262573297 .22646331787 93.8738174438589 .302040100183 .8159103393680 .7680587768681 .07285308838 82.5967712402383 .206336975183 .5111236572383 .8159103393683 .81591033936 83.81591033936 83.8159103393683.81591033936 83.81591033936 83.51112365723 83.5111236572383 .5111236572383 .01290130615 -9999 -9999 -9999 -9999 -9999 -9999 -9999

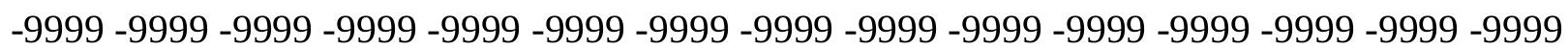
-9999 -9999 -9999 -9999 -9999 -9999 -9999 -9999 -9999 -9999 -9999 -9999 -9999 -9999 -9999 -9999 -9999 -9999 -9999 -9999 -9999 -9999 -9999 -9999 -9999 -9999 -9999 -9999 -9999 -9999 -9999 -9999 -9999 -9999 -9999 -9999 -9999 -9999 -9999 -9999 -9999 -9999 -9999

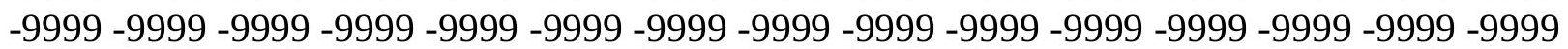


-9999 -9999 -9999 -9999 -9999 -9999 -9999 -9999 -9999 -9999 -9999 -9999 -9999 -9999 -9999 -9999 -9999 -9999 -9999 -9999 -9999 -9999 -9999 -9999 -9999 -9999 -9999 -9999 -9999 -9999 -9999 -9999 -9999 -9999 -9999 -9999 -9999 -9999 -9999 -9999 -9999 -9999 -9999 -9999 -9999 -9999 -9999 -9999 -9999 -9999 -9999 -9999 -9999 -9999 -9999 -9999 -9999 -9999 -9999 -9999 -9999 -9999 -9999 -9999 -9999 -9999 -9999 -9999 -9999 -9999 -9999 -9999 -9999 -9999 -9999 -9999 -9999 -9999 -9999 -9999 -9999 -9999 -9999 -9999 -9999 -9999 -9999 -9999 -9999 -9999 -9999 -9999 -9999 -9999 -9999 -9999 -9999 -9999 -9999 -9999 -9999 -9999 -9999 -9999 -9999

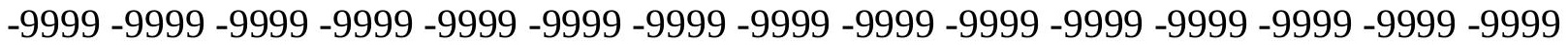
-9999 -9999 -9999 -9999 -9999 -9999 -9999 -9999 -9999 -9999 -9999 -9999 -9999 -9999 -9999 -9999 -9999 -9999 -9999 -9999 -9999 -9999 -9999 -9999 -9999 -9999 -9999 -9999 -9999 -9999 -

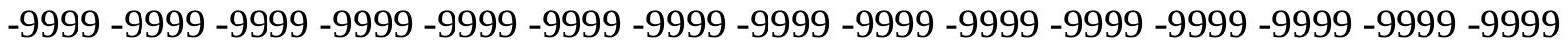
-9999 -9999 -9999 -9999 -9999 -9999 -9999 -9999 -9999 -9999 -9999 -9999 -9999 -9999 -9999

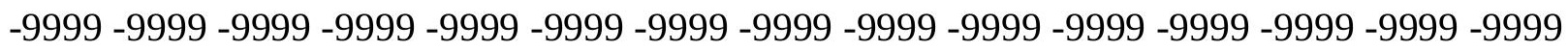
-9999 -9999 -9999 -9999 -9999 -9999 -9999 -9999 -9999 -9999 -9999 -9999 -9999 -9999 -9999 -9999 -9999 -9999 -9999 -9999 -9999 -9999 -9999 -9999 -9999 -9999 -9999 -9999 -9999 -9999 -9999 -9999 -9999 -9999 -9999 -9999 -9999 -9999 -9999 -9999 120.3900985718 118.5614013672116 .4279022217114 .5991973877112 .4656982422110 .6370010376 108.8082962036106 .979598999105 .4557037354103 .6268997192102 .1029968262 100.579101562599 .0551681518697 .8360290527396 .3121032714895 .09295654297 93.8738174438592 .6546783447391 .4355392456190 .5211791992290 .21640014648 90.2164001464889 .9116134643689 .9116134643689 .6068267822389 .3020401001 89.3020401001 88.99725341797 88.99725341797 88.69246673584 88.69246673584 88.3876876831188 .3876876831188 .0829010009888 .0829010009888 .08290100098 88.0829010009887 .7781066894587 .7781066894587 .7781066894587 .77810668945 87.7781066894588 .9972534179790 .5211791992292 .349891662694 .17859649658 95.7025299072397 .2264633178798 .7503814697399 .96952056885100 .5791015625 101.1886978149100 .8839035034100 .274299621698 .7503814697396 .31210327148 92.6546783447387 .7781066894583 .5111236572380 .7680587768679 .24413299561 80.7680587768681 .9871978759882 .5967712402382 .9015579223683 .2063369751 83.206336975183.51112365723 83.51112365723 83.51112365723 83.51112365723 83.5111236572383 .206336975182 .88823699951 -9999 -9999 -9999 -9999 -9999 -9999 -9999 -9999 -9999 -9999 -9999 -9999 -9999 -9999 -9999 -9999 -9999 -9999 -9999 -9999 -9999 -9999 -9999 -9999 -9999 -9999 -9999 -9999 -9999 -9999 -9999 -9999 -9999 -9999 -9999 -9999 -9999 -9999 -9999 -9999 -9999 -9999 -9999 -9999 -9999 -9999 -9999 -9999 -9999 -9999 -9999 -9999 -9999 -9999 -9999 -9999 -9999 -9999 -9999 -9999 -9999 -9999 -9999 -9999 -9999 -9999 -9999 -9999 -9999 -9999 -9999 -9999 -9999 -9999 -9999 -9999 -9999 -9999 -9999 -9999 -9999 -9999 -9999 -9999 -9999 -9999 -9999 -9999 -9999 -9999 -9999 -9999 -9999 -9999 -9999

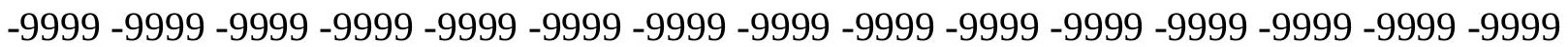
-9999 -9999 -9999 -9999 -9999 -9999 -9999 -9999 -9999 -9999 -9999 -9999 -9999 -9999 -9999 -9999 -9999 -9999 -9999 -9999 -9999 -9999 -9999 -9999 -9999 -9999 -9999 -9999 -9999 -9999 -9999 -9999 -9999 -9999 -9999 -9999 -9999 -9999 -9999 -9999 -9999 -9999 -9999 -9999 -9999

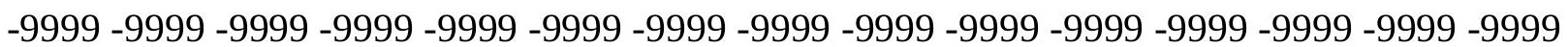
-9999 -9999 -9999 -9999 -9999 -9999 -9999 -9999 -9999 -9999 -9999 -9999 -9999 -9999 -9999 -999 -9999 -9999 -9999 -9999 -9999 -9999 -9999 -9999 -9999 -9999 -9999 -9999 -9999 -9999 -9999 -9999 -9999 -9999 -9999 -9999 -9999 -9999 -9999 -9999 -9999 -9999 -9999 -9999 -9999 -9999

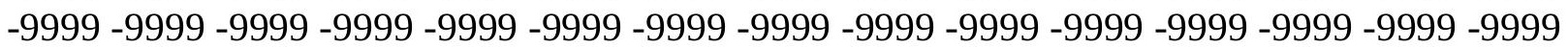


-9999 -9999 -9999 -9999 -9999 -9999 -9999 -9999 -9999 -9999 -9999 -9999 -9999 -9999 -9999 -9999 -9999 -9999 -9999 -9999 -9999 -9999 -9999 -9999 -9999 -9999 -9999 -9999 -9999 -9999 -9999 -9999 -9999 -9999 -9999 -9999 -9999 -9999 -9999 -9999 -9999 -9999 -9999 -9999 -9999 -9999 -9999 -9999 -9999 -9999 -9999 -9999 -9999 -9999 -9999 -9999 -9999 -9999 -9999 -9999 -9999 -9999 -9999 -9999 -9999 -9999 -9999 -9999 -9999 -9999 -9999 -9999 -9999 -9999 -9999 -9999 -9999 -9999 -9999 -9999 -9999 -9999 -9999 -9999 -9999 120.9997024536 119.1709976196117 .342300415115 .2088012695113 .3800964355111 .551399231 109.7226028442107 .8938980103106 .0652008057104 .5412979126103 .0174026489 101.493400573799 .9695205688598 .445587158297 .2264633178796 .00731658936 94.7881774902393 .2642517089892 .0450973510790 .8259735107490 .52117919922 90.2164001464890 .2164001464889 .9116134643689 .6068267822389 .60682678223 89.3020401001 89.3020401001 88.99725341797 88.99725341797 88.69246673584 88.69246673584 88.69246673584 88.38768768311 88.38768768311 88.38768768311 88.0829010009888 .0829010009888 .0829010009888 .0829010009888 .08290100098 88.0829010009889 .302040100191 .1307525634892 .6546783447394 .17859649658 95.7025299072397 .2264633178798 .445587158299 .3599472045999 .96952056885 100.2742996216100 .274299621699 .3599472045997 .8360290527396 .00731658936 92.9594726562586 .5589828491284 .4254837036182 .5967712402380 .76805877686 79.5489196777380 .7680587768681 .3776321411181 .9871978759882 .59677124023 82.9015579223682 .9015579223683 .206336975183 .206336975183 .2063369751 83.206336975183 .206336975182 .82453155518 -9999 -9999 -9999 -9999 -9999 -9999 -9999 -9999 -9999 -9999 -9999 -9999 -9999 -9999 -9999 -9999 -9999 -9999 -9999 -9999 -9999 -9999 -9999 -9999 -9999 -9999 -9999 -9999 -9999 -9999 -9999 -9999 -9999 -9999 -9999 -9999 -9999 -9999 -9999 -9999 -9999 -9999 -9999 -9999 -9999 -9999 -9999 -9999 -9999 -9999 -9999 -9999 -9999 -9999 -9999 -9999 -9999 -9999 -9999 -9999 -9999 -9999 -9999 -9999 -9999 -9999 -9999 -9999 -9999 -9999 -9999 -9999 -9999 -9999 -9999 -9999 -9999 -9999 -9999 -9999 -9999 -9999 -9999 -9999 -9999 -9999 -9999 -9999 -9999 -9999 -9999 -9999 -9999 -9999 -9999 -9999 -9999 -9999 -9999 -9999 -9999 -9999 -9999 -9999 -9999 -9999 -9999 -9999 -9999 -9999 -9999 -9999 -9999 -9999 -9999 -9999 -9999 -9999 -9999 -9999 -9999 -9999 -9999 -9999 -9999 -9999 -9999 -9999 -9999 -9999 -9999 -9999 -9999 -9999 -9999 -9999 -9999 -9999 -9999 -9999 -9999 -9999 -9999 -9999 -9999 -9999 -9999 -9999 -9999 -9999 -9999 -9999 -9999 -9999 -9999 -

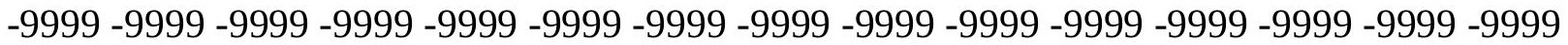
-9999 -9999 -9999 -9999 -9999 -9999 -9999 -9999 -9999 -9999 -9999 -9999 -9999 -9999 -9999 -9999 -9999 -9999 -9999 -9999 -9999 -9999 -9999 -9999 -9999 -9999 -9999 -9999 -9999 -9999 -

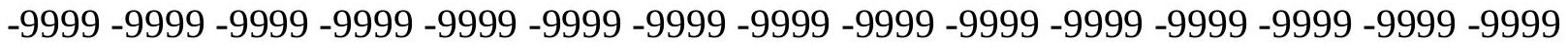
-9999 -9999 -9999 -9999 -9999 -9999 -9999 -9999 -9999 -9999 -9999 -9999 -9999 -9999 -9999 -9999 -9999 -9999 -9999 -9999 -9999 -9999 -9999 -9999 -9999 -9999 -9999 -9999 -9999 -9999

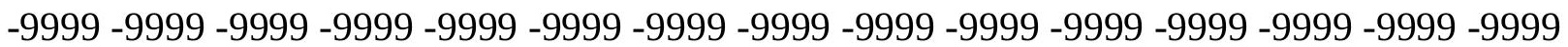
-9999 -9999 -9999 -9999 -9999 -9999 -9999 -9999 -9999 -9999 -9999 -9999 -9999 -9999 -9999 -9999 -9999 -9999 -9999 -9999 -9999 -9999 -9999 -9999 -9999 -9999 -9999 -9999 -9999 -9999 -9999 -9999 -9999 -9999 -9999 -9999 -9999 -9999 -9999 -9999 -9999 -9999 -9999 -9999 -9999 -9999 -9999 -9999 -9999 -9999 -9999 -9999 -9999 -9999 -9999 -9999 120.0852966309 117.9517974854116 .1231002808114 .2944030762112 .4656982422110 .6370010376 108.8082962036106 .979598999105 .4557037354103 .6268997192102 .1029968262 100.579101562599 .0551681518697 .8360290527396 .6168823242295 .3977432251 93.8738174438592 .6546783447391 .7403335571390 .8259735107490 .52117919922 
90.2164001464889 .9116134643689 .6068267822389 .6068267822389 .3020401001 89.302040100188 .9972534179788 .9972534179788 .9972534179788 .69246673584 88.69246673584 88.69246673584 88.38768768311 88.38768768311 88.38768768311 88.3876876831188 .3876876831188 .0829010009888 .0829010009888 .38768768311 89.91161346436 91.4355392456192.95947265625 94.4833908081195.70252990723 97.2264633178798 .1408081054799 .0551681518699 .6647262573299 .66472625732 99.3599472045998 .7503814697397 .5312423706195 .7025299072392 .65467834473 89.302040100186 .8637619018685 .0350494384883 .206336975181 .07285308838 79.5489196777380 .4632720947381 .3776321411181 .9871978759882 .29197692871 82.5967712402382 .9015579223682 .9015579223683 .206336975183 .2063369751 83.2063369751 -9999 -9999 -9999 -9999 -9999 -9999 -9999 -9999 -9999 -9999 -9999 -9999 -9999 -9999 -9999 -9999 -9999 -9999 -9999 -9999 -9999 -9999 -9999 -9999 -9999 -9999 -9999 -9999 -9999 -9999 -9999 -9999 -9999 -9999 -9999 -9999 -9999 -9999 -9999 -9999 -9999 -9999 -9999 -9999 -9999-9999 -9999 -9999 -9999 -9999 -9999

-9999 -9999 -9999 -9999 -9999 -9999 -9999 -9999 -9999 -9999 -9999 -9999 -9999 -9999 -9999

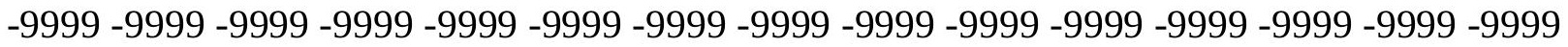
-9999 -9999 -9999 -9999 -9999 -9999 -9999 -9999 -9999 -9999 -9999 -9999 -9999 -9999 -9999 -9999 -9999 -9999 -9999 -9999 -9999 -9999 -9999 -9999 -9999 -9999 -9999 -9999 -9999 -9999 -9999 -9999 -9999 -9999 -9999 -9999 -9999 -9999 -9999 -9999 -9999 -9999 -9999 -9999 -9999 -

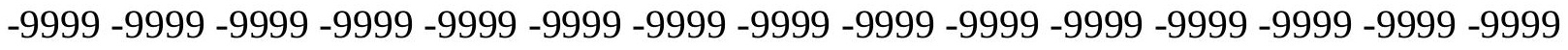
-9999 -9999 -9999 -9999 -9999 -9999 -9999 -9999 -9999 -9999 -9999 -9999 -9999 -9999 -9999 -9999 -9999 -9999 -9999 -9999 -9999 -9999 -9999 -9999 -9999 -9999 -9999 -9999 -9999 -9999 -9999 -9999 -9999 -9999 -9999 -9999 -9999 -9999 -9999 -9999 -9999 -9999 -9999 -9999 -9999 -9999 -9999 -9999 -9999 -9999 -9999 -9999 -9999 -9999 -9999 -9999 -9999 -9999 -9999 -9999 -9999 -9999 -9999 -9999 -9999 -9999 -9999 -9999 -9999 -9999 -9999 -9999 -9999 -9999 -9999 -9999 -9999 -9999 -9999 -9999 -9999 -9999 -9999 -9999 -9999 -9999 -9999 -9999 -9999 -9999 -9999 -9999 -9999 -9999 -9999 -9999 -9999 -9999 -9999 -9999 -9999 -9999 -9999 -9999 -9999 -

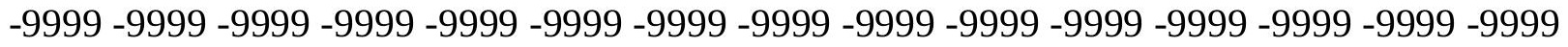
-9999 -9999 -9999 -9999 -9999 -9999 -9999 -9999 -9999 -9999 -9999 -9999 -9999 -9999 -9999 -9999 -9999 -9999 -9999 -9999 -9999 -9999 -9999 -9999 -9999 -9999 -9999 -9999 -9999 -999 -9999 -9999 -9999 -9999 -9999 -9999 -9999 -9999 -9999 -9999 -9999 -9999 -9999 -9999 -9999 -9999 -9999 -9999 -9999 -9999 -9999-9999 -9999 -9999-9999 -9999 120.9997024536 118.8662033081117 .0374984741115 .2088012695113 .3800964355111 .551399231 109.7226028442107 .8938980103106 .0652008057104 .5412979126102 .712600708 101.188697814999 .6647262573298 .445587158297 .2264633178796 .00731658936 94.4833908081193 .2642517089892 .0450973510791 .1307525634890 .21640014648 90.2164001464889 .9116134643689 .6068267822389 .6068267822389 .3020401001 89.3020401001 89.3020401001 88.9972534179788.9972534179788.99725341797 88.9972534179788 .6924667358488 .6924667358488 .6924667358488 .69246673584 88.38768768311 88.38768768311 88.38768768311 88.38768768311 88.69246673584 90.2164001464891 .4355392456192 .9594726562594 .4833908081195 .70252990723 96.9216690063597 .8360290527398 .7503814697399 .0551681518699 .35994720459 99.0551681518698.445587158297.5312423706196.0073165893693.87381744385 91.7403335571390 .2164001464888 .3876876831186 .254188537683 .81591033936 81.0728530883879 .8537063598680 .7680587768681 .3776321411181 .98719787598 82.2919769287182 .5967712402382 .5967712402382 .9015579223682 .90155792236 
82.90155792236 -9999 -9999 -9999 -9999 -9999 -9999 -9999 -9999 -9999 -9999 -9999 -9999 -9999 -9999 -9999 -9999 -9999 -9999 -9999 -9999 -9999 -9999 -9999 -9999 -9999 -9999 -9999

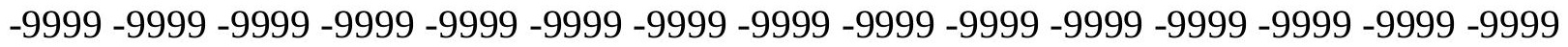
-9999 -9999 -9999 -9999 -9999 -9999 -9999 -9999 -9999

-9999 -9999 -9999 -9999 -9999 -9999 -9999 -9999 -9999 -9999 -9999 -9999 -9999 -9999 -9999 -9999 -9999 -9999 -9999 -9999 -9999 -9999 -9999 -9999 -9999 -9999 -9999 -9999 -9999 -9999 -

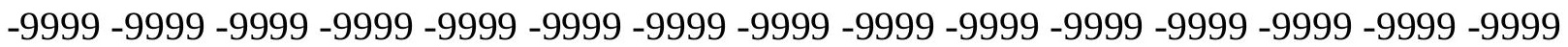

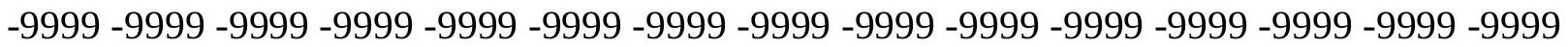
-9999 -9999 -9999 -9999 -9999 -9999 -9999 -9999 -9999 -9999 -9999 -9999 -9999 -9999 -9999 -9999 -9999 -9999 -9999 -9999 -9999 -9999 -9999 -9999 -9999 -9999 -9999 -9999 -9999 -9999

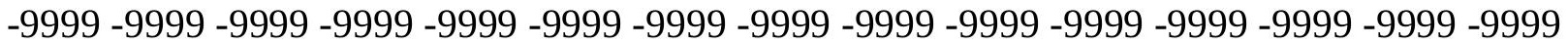
-9999 -9999 -9999 -9999 -9999 -9999 -9999 -9999 -9999 -9999 -9999 -9999 -9999 -9999 -9999 -9999 -9999 -9999 -9999 -9999 -9999 -9999 -9999 -9999 -9999 -9999 -9999 -9999 -9999 -9999 -9999 -9999 -9999 -9999 -9999 -9999 -9999 -9999 -9999 -9999 -9999 -9999 -9999 -9999 - 9999 -9999 -9999 -9999 -9999 -9999 -9999 -9999 -9999 -9999 -9999 -9999 -9999 -9999 -9999 -9999

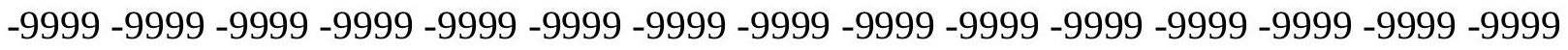
-9999 -9999 -9999 -9999 -9999 -9999 -9999 -9999 -9999 -9999 -9999 -9999 -9999 -9999 -9999 -9999 -9999 -9999 -9999 -9999 -9999 -9999 -9999 -9999 -9999 -9999 -9999 -9999 -9999 -9999 -9999 -9999 -9999 -9999 -9999 -9999 -9999 -9999 -9999 -9999 -9999 -9999 -9999 -9999 -9999 -9999 -9999 -9999 -9999 -9999 -9999 -9999 -9999 -9999 -9999 -9999 -9999 -9999 -9999 -9999 -9999 -9999 -9999 -9999 -9999 -9999 -9999 -9999 -9999 -9999 -9999 -9999 -9999 -9999 -9999 -9999 -9999 -9999 -9999 -9999 -9999 -9999 -9999 -9999 -9999 -9999 121.9140014648 119.7806015015117 .9517974854116 .1231002808114 .2944030762112 .4656982422 110.6370010376108 .8082962036106 .979598999105 .1509017944103 .3221969604 101.7982025146100 .274299621698 .7503814697397 .5312423706196 .00731658936 94.7881774902393 .5690307617292 .349891662690 .8259735107489 .91161346436 89.9116134643689 .9116134643689 .6068267822389 .6068267822389 .3020401001 89.3020401001 89.3020401001 89.3020401001 88.9972534179788.99725341797 88.99725341797 88.9972534179788.99725341797 88.69246673584 88.69246673584 88.69246673584 88.69246673584 88.38768768311 88.38768768311 88.99725341797 90.5211791992291 .7403335571393 .2642517089894 .4833908081195 .70252990723 96.9216690063597 .8360290527398 .445587158299 .0551681518699 .05516815186 99.0551681518698 .445587158297 .5312423706196 .6168823242295 .09295654297 93.8738174438592 .9594726562592 .0450973510789 .6068267822386 .86376190186 83.8159103393681 .0728530883880 .4632720947381 .0728530883881 .68241119385 81.9871978759882 .2919769287182 .5967712402382 .5967712402382 .90155792236 82.90155792236 -9999 -9999 -9999 -9999 -9999 -9999 -9999 -9999 -9999 -9999 -9999 -9999

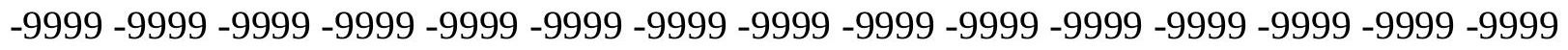
-9999 -9999 -9999 -9999 -9999 -9999 -9999 -9999 -9999 -9999 -9999 -9999 -9999 -9999 -9999 -9999 -9999 -9999 -9999 -9999 -9999 -9999 -9999 -9999

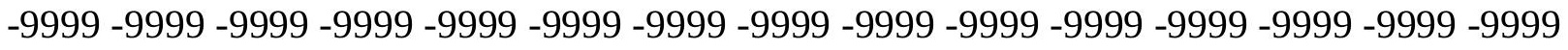

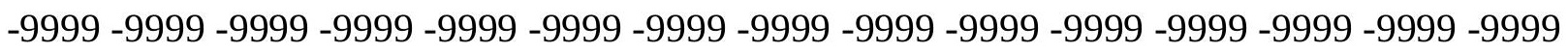
-9999 -9999 -9999 -9999 -9999 -9999 -9999 -9999 -9999 -9999 -9999 -9999 -9999 -9999 -9999 -9999 -9999 -9999 -9999 -9999 -9999 -9999 -9999 -9999 -9999 -9999 -9999 -9999 -9999 -9999 -9999 -9999 -9999 -9999 -9999 -9999 -9999 -9999 -9999 -9999 -9999 -9999 -9999 -9999 -9999 -9999 -9999 -9999 -9999 -9999 -9999 -9999 -9999 -9999 -9999 -9999 -9999 -9999 -9999 -9999 
-9999 -9999 -9999 -9999 -9999 -9999 -9999 -9999 -9999 -9999 -9999 -9999 -9999 -9999 -9999 -9999 -9999 -9999 -9999 -9999 -9999 -9999 -9999 -9999 -9999 -9999 -9999 -9999 -9999 -9999 -9999 -9999 -9999 -9999 -9999 -9999 -9999 -9999 -9999 -9999 -9999 -9999 -9999 -9999 -9999 -9999 -9999 -9999 -9999 -9999 -9999 -9999 -9999 -9999 -9999 -9999 -9999 -9999 -9999 -9999 -9999 -9999 -9999 -9999 -9999 -9999 -9999 -9999 -9999 -9999 -9999 -9999 -9999 -9999 -9999 -9999 -9999 -9999 -9999 -9999 -9999 -9999 -9999 -9999 -9999 -9999 -9999 -9999 -9999 -9999 -9999 -9999 -9999 -9999 -9999 -9999 -9999 -9999 -9999 -9999 -9999 -9999 -9999 -9999 -9999

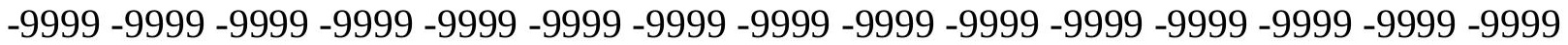
-9999 -9999 -9999 -9999 -9999 -9999 -9999 -9999 -9999 -9999 -9999 -9999 -9999 -9999 -9999 -9999 -9999 -9999 -9999 -9999 -9999 -9999 -9999 -9999 -9999 -9999 -9999 -9999 -9999 -9999 -

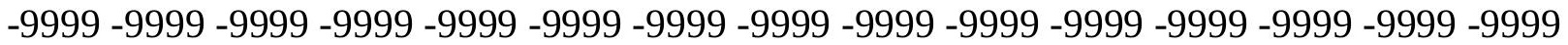
-9999 -9999 -9999 -9999 -9999 -9999 -9999 -9999 -9999 -9999 -9999 -9999 120.9997024536 118.8662033081117 .0374984741115 .2088012695113 .3800964355111 .24659729 109.4179000854107 .5891036987105 .7603988647103 .9317016602102 .4077987671 100.579101562599 .0551681518697 .5312423706196 .0073165893694 .78817749023 93.2642517089892 .0450973510790 .5211791992289 .9116134643689 .91161346436 89.6068267822389 .6068267822389 .6068267822389 .302040100189 .3020401001 89.3020401001 89.302040100189.3020401001 88.9972534179788.99725341797 88.9972534179788 .9972534179788 .9972534179788 .9972534179788 .69246673584 88.6924667358488 .6924667358488 .6924667358489 .302040100190 .82597351074 92.0450973510793 .2642517089894 .7881774902395 .7025299072396 .92166900635 97.8360290527398 .445587158298 .7503814697399 .0551681518699 .05516815186 98.7503814697398 .1408081054797 .2264633178796 .6168823242295 .70252990723 95.0929565429793 .8738174438592 .0450973510789 .9116134643686 .86376190186 83.81591033936 81.3776321411180.76805877686 81.3776321411181.68241119385 81.9871978759882 .2919769287182 .5967712402382 .9015579223682 .90155792236 -9999 -9999 -9999 -9999 -9999 -9999 -9999 -9999 -9999 -9999 -9999 -9999 -9999 -9999 -9999 -9999 -9999 -9999 -9999 -9999 -9999 -9999 -9999 -9999 -9999 -9999 -9999 -9999 -9999 -9999 -9999

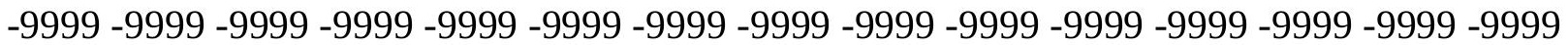
-9999 -9999 -9999-9999-9999 -9999 -9999 -9999 -9999 -9999 -9999 -9999 -9999 -9999 -9999 -9999 -9999 -9999 -9999 -9999

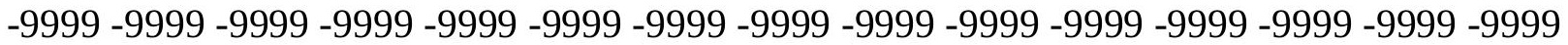
-9999 -9999 -9999 -9999 -9999 -9999 -9999 -9999 -9999 -9999 -9999 -9999 -9999 -9999 -9999 -9999 -9999 -9999 -9999 -9999 -9999 -9999 -9999 -9999 -9999 -9999 -9999 -9999 -9999 -9999 -

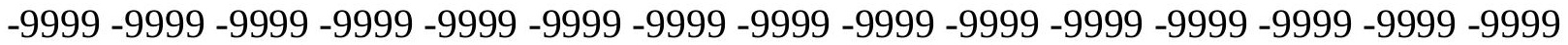
-9999 -9999 -9999 -9999 -9999 -9999 -9999 -9999 -9999 -9999 -9999 -9999 -9999 -9999 -9999 -9999 -9999 -9999 -9999 -9999 -9999 -9999 -9999 -9999 -9999 -9999 -9999 -9999 -9999 -9999

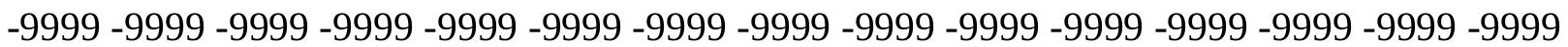
-9999 -9999 -9999 -9999 -9999 -9999 -9999 -9999 -9999 -9999 -9999 -9999 -9999 -9999 -9999 -9999 -9999 -9999 -9999 -9999 -9999 -9999 -9999 -9999 -9999 -9999 -9999 -9999 -9999 -9999 -

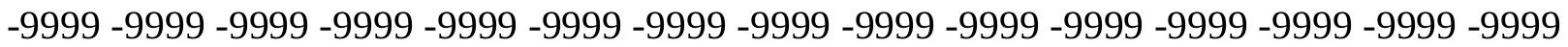
-9999 -9999 -9999 -9999 -9999 -9999 -9999 -9999 -9999 -9999 -9999 -9999 -9999 -9999 -9999 -9999 -9999 -9999 -9999 -9999 -9999 -9999 -9999 -9999 -9999 -9999 -9999 -9999 -9999 -9999 -9999 -9999 -9999 -9999 -9999 -9999 -9999 -9999 -9999 -9999 -9999 -9999 -9999 -9999 -9999 -9999 -9999 -9999 -9999 -9999 -9999 -9999 -9999 -9999 -9999 -9999 -9999 -9999 -9999 -9999

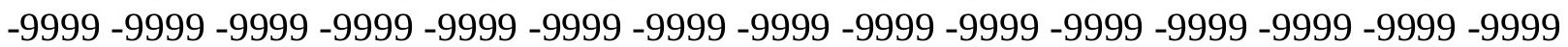


-9999 -9999 -9999 -9999 -9999 -9999 -9999 -9999 -9999 -9999 -9999 -9999 -9999 -9999 -9999 -9999 -9999 -9999 -9999 -9999 -9999 -9999 -9999 -9999 -9999 -9999 -9999 121.9140014648 120.0852966309117 .9517974854116 .1231002808114 .2944030762112 .1608963013 110.3321990967108 .1986999512106 .3700027466104 .5412979126102 .712600708 100.883903503499 .0551681518697 .5312423706196 .0073165893694 .17859649658 92.9594726562591 .4355392456189 .9116134643689 .6068267822389 .60682678223 89.60682678223 89.302040100189.302040100189.302040100189.3020401001 89.3020401001 89.302040100189.302040100189.302040100188.99725341797 88.9972534179788 .9972534179788 .9972534179788 .9972534179788 .99725341797 88.9972534179788 .6924667358488 .6924667358489 .9116134643691 .13075256348 92.349891662693 .5690307617294 .7881774902396 .0073165893696 .92166900635 97.8360290527398 .445587158298 .7503814697399 .0551681518699 .05516815186 99.0551681518698 .7503814697398 .1408081054797 .5312423706197 .22646331787 96.3121032714895 .397743225194 .1785964965892 .349891662689 .60682678223 86.5589828491283 .8159103393681 .6824111938581 .0728530883881 .68241119385 81.9871978759882 .2919769287182 .5967712402382 .5967712402382 .90155792236 -9999 -9999 -9999 -9999 -9999 -9999 -9999 -9999 -9999 -9999 -9999 -9999 -9999 -9999 -9999 -9999 -9999 -9999 -9999 -9999 -9999 -9999 -9999 -9999 -9999 -9999 -9999 -9999 -9999 -9999 -9999 -

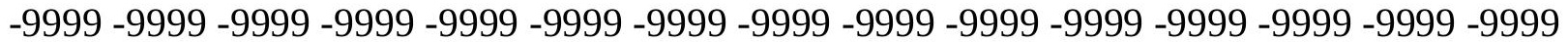
$-9999-9999-9999-9999-9999$

-9999 -9999 -9999 -9999 -9999 -9999 -9999 -9999 -9999 -9999 -9999 -9999 -9999 -9999 -9999 -9999 -9999 -9999 -9999 -9999 -9999 -9999 -9999 -9999 -9999 -9999 -9999 -9999 -9999 -9999 -9999 -9999 -9999 -9999 -9999 -9999 -9999 -9999 -9999 -9999 -9999 -9999 -9999 -9999 -9999 -9999 -9999 -9999 -9999 -9999 -9999 -9999 -9999 -9999 -9999 -9999 -9999 -9999 -9999 -9999

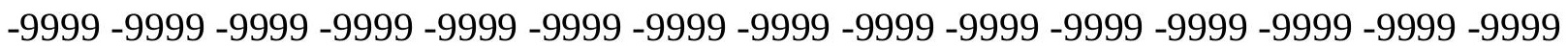
-9999 -9999 -9999 -9999 -9999 -9999 -9999 -9999 -9999 -9999 -9999 -9999 -9999 -9999 -9999 -9999 -9999 -9999 -9999 -9999 -9999 -9999 -9999 -9999 -9999 -9999 -9999 -9999 -9999 -9999 -9999 -9999 -9999 -9999 -9999 -9999 -9999 -9999 -9999 -9999 -9999 -9999 -9999 -9999 -9999 -9999 -9999 -9999 -9999 -9999 -9999 -9999 -9999 -9999 -9999 -9999 -9999 -9999 -9999 -9999 -9999 -9999 -9999 -9999 -9999 -9999 -9999 -9999 -9999 -9999 -9999 -9999 -9999 -9999 -9999 -9999 -9999 -9999 -9999 -9999 -9999 -9999 -9999 -9999 -9999 -9999 -9999 -9999 -9999 -9999 -

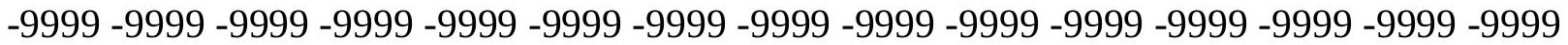
-9999 -9999 -9999 -9999 -9999 -9999 -9999 -9999 -9999 -9999 -9999 -9999 -9999 -9999 -9999 -9999 -9999 -9999 -9999 -9999 -9999 -9999 -9999 -9999 -9999 -9999 -9999 -9999 -9999 -9999 -

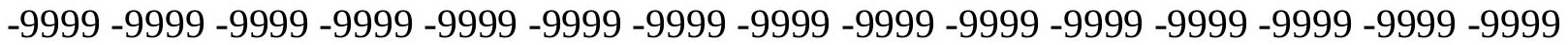
-9999 -9999 -9999 -9999 -9999 -9999 -9999 -9999 -9999 -9999 -9999 -9999 -9999 -9999 -9999 -9999 -9999 -9999 -9999 -9999 -9999 -9999 -9999 -9999 -9999 -9999 -9999 -9999 -9999 -9999 -9999 -9999 -9999 -9999 -9999 -9999 -9999 -9999 -9999 -9999 -9999 -9999 120.9997024536119 .1709976196117 .0374984741115 .2088012695113 .075302124 110.9418029785109 .1130981445106 .979598999105 .1509017944103 .0174026489 101.188697814999 .3599472045997 .5312423706195 .397743225193 .56903076172 91.7403335571389 .9116134643689 .302040100189 .302040100189 .3020401001 89.302040100189.302040100189.302040100189.302040100189.302040100189.3020401001 89.3020401001 89.302040100189.302040100189.3020401001 89.302040100189.3020401001 88.9972534179788 .9972534179788 .9972534179788 .9972534179788 .99725341797 88.9972534179790.21640014648 91.4355392456192.6546783447393.87381744385 
94.7881774902396 .0073165893696 .9216690063597 .8360290527398 .4455871582 98.7503814697399 .3599472045999 .3599472045999 .3599472045999 .05516815186 99.0551681518698 .445587158298 .1408081054797 .5312423706196 .61688232422 95.397743225193 .8738174438591 .4355392456188 .6924667358486 .2541885376 83.8159103393681 .9871978759881 .6824111938581 .9871978759882 .29197692871 82.5967712402382 .5967712402382 .90155792236 -9999 -9999 -9999 -9999 -9999 -9999-9999 -9999 -9999 -9999 -9999 -9999 -9999 -9999 -9999 -9999 -9999 -9999 -9999 -9999 -9999 -9999 -9999 -9999 -9999 -9999 -9999 -9999 -9999 -9999 -9999 -9999 -9999 -9999 -9999 -999 -999 -9999 -9999 -9999 -9999 -9999 -9999 -9999 -9999 -9999 -9999 -9999 -9999 -9999 -9999 -9999 -9999 -9999 -9999 -9999 -9999 -9999 -9999 -9999 -9999 -9999 -9999 -9999 -9999 -9999

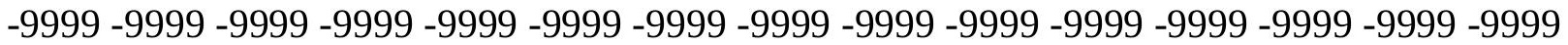
-9999 -9999 -9999 -9999 -9999 -9999 -9999 -9999 -9999 -9999 -9999 -9999 -9999 -9999 -9999 -9999 -9999 -9999 -9999 -9999 -9999 -9999 -9999 -9999 -9999 -9999 -9999 -9999 -9999 -9999 -9999 -9999 -9999 -9999 -9999 -9999 -9999 -9999 -9999 -9999 -9999 -9999 -9999 -9999 -9999 -9999 -9999 -9999 -9999 -9999 -9999 -9999 -9999 -9999 -9999 -9999 -9999 -9999 -9999 -9999

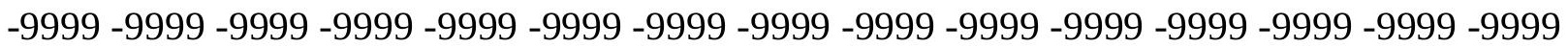
-9999 -9999 -9999 -9999 -9999 -9999 -9999 -9999 -9999 -9999 -9999 -9999 -9999 -9999 -9999 -9999 -9999 -9999 -9999 -9999 -9999 -9999 -9999 -9999 -9999 -9999 -9999 -9999 -9999 -9999 -9999 -9999 -9999 -9999 -9999 -9999 -9999 -9999 -9999 -9999 -9999 -9999 -9999 -9999 -9999 -9999 -9999 -9999 -9999 -9999 -9999 -9999 -9999 -9999 -9999 -9999 -9999 -9999 -9999 -9999 -9999 -9999 -9999 -9999 -9999 -9999 -9999 -9999 -9999 -9999 -9999 -9999 -9999 -9999 -9999 -9999 -9999 -9999 -9999 -9999 -9999 -9999 -9999 -9999 -9999 -9999 -9999 -9999 -9999 -9999 -9999 -9999 -9999 -9999 -9999 -9999 -9999 -9999 -9999 -9999 -9999 -9999 -9999 -9999 -9999 -9999 -9999 -9999 -9999 -9999 -9999 -9999 -9999 -9999 -9999 -9999 -9999 -9999 -9999 -9999 -9999 -9999 -9999 -9999 -9999 -9999 -9999 -9999 -9999 -9999 -9999 -9999 -9999 -9999 -9999 -9999 -9999 -9999 -9999 -9999 -9999 -9999 -9999 -9999 -9999 -9999 -9999 -9999 -9999 -9999 -9999 -9999 -9999 -9999 -9999 -9999 -9999 -9999 -9999 -9999 -9999 -9999 -9999 122.2188034058120 .0852966309117 .9517974854116 .1231002808113 .9896011353 111.8561019897109 .7226028442107 .5891036987105 .4557037354103 .3221969604 101.188697814999.3599472045997.2264633178795.0929565429792.95947265625 90.5211791992288 .3876876831188 .3876876831188 .6924667358488 .69246673584 88.9972534179788 .9972534179788 .9972534179788 .9972534179788 .99725341797 89.3020401001 89.302040100189.302040100189.302040100189.302040100189.3020401001 89.302040100189.302040100189.302040100189.302040100188.99725341797 88.9972534179789 .6068267822390 .5211791992291 .7403335571392 .95947265625 93.8738174438595 .0929565429796 .0073165893696 .9216690063597 .83602905273 98.445587158299 .0551681518699 .3599472045999 .6647262573299 .66472625732 99.6647262573299 .6647262573299 .3599472045999 .0551681518698 .4455871582 97.5312423706196 .3121032714894 .7881774902392 .9594726562590 .52117919922 88.3876876831185 .9494018554784 .1206970214882 .2919769287181 .98719787598 82.2919769287182 .5967712402382 .5967712402382 .90155792236 -9999 -9999 -9999 -9999 -9999 -9999 -9999 -9999 -9999 -9999 -9999 -9999 -9999 -9999 -9999 -9999 -9999 -9999 -9999 -9999 -9999 -9999 -9999 -9999 -9999 -9999 -9999 -9999 -9999 -9999 -9999 -9999 -9999 -9999 -

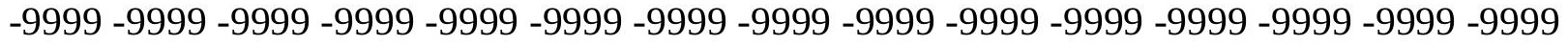
$-9999-9999$

-9999 -9999 -9999 -9999 -9999 -9999 -9999 -9999 -9999 -9999 -9999 -9999 -9999 -9999 -9999 
-9999 -9999 -9999 -9999 -9999 -9999 -9999 -9999 -9999 -9999 -9999 -9999 -9999 -9999 -9999 -9999 -9999 -9999 -9999 -9999 -9999 -9999 -9999 -9999 -9999 -9999 -9999 -9999 -9999 -9999 -9999 -9999 -9999 -9999 -9999 -9999 -9999 -9999 -9999 -9999 -9999 -9999 -9999 -9999 -9999 -9999 -9999 -9999 -9999 -9999 -9999 -9999 -9999 -9999 -9999 -9999 -9999 -9999 -9999 -9999 -9999 -9999 -9999 -9999 -9999 -9999 -9999 -9999 -9999 -9999 -9999 -9999 -9999 -9999 -9999 -9999 -9999 -9999 -9999 -9999 -9999 -9999 -9999 -9999 -9999 -9999 -9999 -9999 -9999 -9999 -9999 -9999 -9999 -9999 -9999 -9999 -9999 -9999 -9999 -9999 -9999 -9999 -9999 -9999 -9999 -9999 -9999 -9999 -9999 -9999 -9999 -9999 -9999 -9999 -9999 -9999 -9999 -9999 -9999 -9999 -9999 -9999 -9999 -9999 -9999 -9999 -9999 -9999 -9999 -9999 -9999 -9999 -9999 -9999 -9999 -9999 -9999 -9999 -9999 -9999 -9999 -9999 -9999 -9999 -9999 -9999 -9999 -9999 -9999 -9999 -

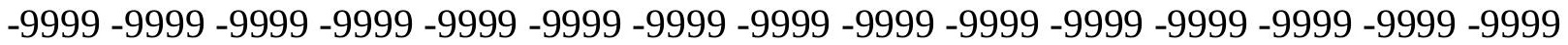
-9999 -9999 -9999 -9999 -9999 -9999 -9999 -9999 -9999 -9999 -9999 -9999 -9999 -9999 -9999

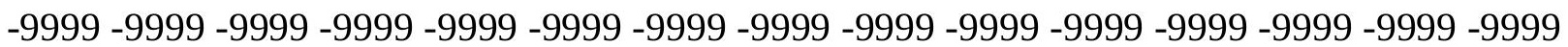
-9999 -9999 -9999 -9999 -9999 -9999 -9999 -9999 -9999 -9999 -9999 -9999 -9999 -9999 -9999 -9999 -9999 -9999 -9999 -9999 -9999 -9999 -9999 -9999 -9999 -9999 -9999 -9999 -9999 -9999 -9999 -9999 -9999 -9999 -9999 -9999 -9999 -9999 -9999 -9999 -9999 -9999 -9999 -9999 -9999 -9999 -9999 -9999 -9999 -9999 -9999 -9999 -9999 -9999 -9999 -9999 -9999 -9999 -9999 121.3044967651119 .1709976196117 .0374984741114 .9039993286112 .7705001831 110.6370010376108 .1986999512106 .0652008057103 .6268997192101 .4934005737 99.3599472045997 .2264633178794 .7881774902392 .349891662689 .3020401001 87.4733276367287 .7781066894588 .0829010009888 .3876876831188 .69246673584 88.6924667358488 .9972534179788 .9972534179788 .9972534179788 .99725341797 89.3020401001 89.302040100189.302040100189.302040100189.302040100189.3020401001 89.302040100189.302040100189.302040100189.302040100188.99725341797 89.9116134643691.1307525634892.0450973510793.2642517089894.17859649658 95.397743225196 .3121032714897 .2264633178797 .8360290527398 .75038146973 99.0551681518699 .6647262573299 .96952056885100 .2742996216100 .2742996216 100.274299621699 .9695205688599 .6647262573299 .0551681518698 .4455871582 97.2264633178795 .7025299072394 .1785964965892 .0450973510789 .91161346436 88.0829010009885 .9494018554784 .1206970214883 .5111236572382 .29197692871 82.5967712402382 .9015579223682 .90155792236 -9999 -9999 -9999 -9999 -9999 -9999 -9999 -9999 -9999 -9999 -9999 -9999 -9999 -9999 -9999 -9999 -9999 -9999 -9999 -9999 -9999 -9999 -9999 -9999 -9999 -9999 -9999 -9999 -9999 -9999 -9999 -9999 -9999 -9999 -9999 -9999 -9999 -9999 -9999 -9999 -9999 -9999 -9999 -9999 -9999 -9999 -9999 -9999 -9999 -9999 -9999 -9999 -9999 -9999 -9999 -9999 -9999 -9999 -9999 -9999 -9999 -9999 -9999 -9999 -9999 -9999 -9999 -9999 -9999 -9999 -9999 -9999 -9999 -9999 -9999 -9999 -9999 -9999 -9999 -9999 -9999 -9999 -9999 -9999 -9999 -9999 -9999 -9999 -9999 -9999 -9999 -9999 -9999 -9999 -9999 -9999

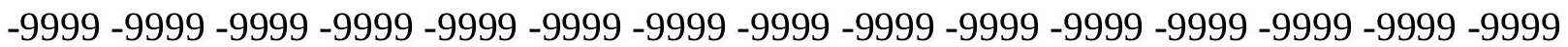
-9999 -9999 -9999 -9999 -9999 -9999 -9999 -9999 -9999 -9999 -9999 -9999 -9999 -9999 -9999 -9999 -9999 -9999 -9999 -9999 -9999 -9999 -9999 -9999 -9999 -9999 -9999 -9999 -9999 -9999 -9999 -9999 -9999 -9999 -9999 -9999 -9999 -9999 -9999 -9999 -9999 -9999 -9999 -9999 -9999 -9999 -9999 -9999 -9999 -9999 -9999 -9999 -9999 -9999 -9999 -9999 -9999 -9999 -9999 -9999 -9999 -9999 -9999 -9999 -9999 -9999 -9999 -9999 -9999 -9999 -9999 -9999 -9999 -9999 -9999 -9999 -9999 -9999 -9999 -9999 -9999 -9999 -9999 -9999 -9999 -9999 -9999 -9999 -9999 -9999 -9999 -9999 -9999 -9999 -9999 -9999 -9999 -9999 -9999 -9999 -9999 -9999 -9999 -9999 -9999

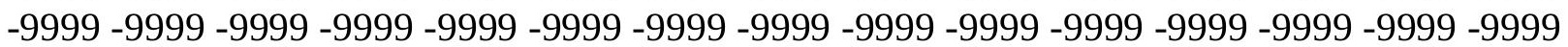


-9999 -9999 -9999 -9999 -9999 -9999 -9999 -9999 -9999 -9999 -9999 -9999 -9999 -9999 -9999 -9999 -9999 -9999 -9999 -9999 -9999 -9999 -9999 -9999 -9999 -9999 -9999 -9999 -9999 -9999 -9999 -9999 -9999 -9999 -9999 -9999 -9999 -9999 -9999 -9999 -9999 -9999 -9999 -9999 -9999 -9999 -9999 -9999 -9999 -9999 -9999 -9999 -9999 -9999 -9999 -9999 -9999 -9999 -9999 -9999 -9999 -9999 -9999 -9999 -9999 -9999 -9999 -9999 -9999 -9999 -9999 -9999 -9999 -9999 -9999 -9999 -9999 -9999 -9999 -9999 -9999 -9999 -9999 -9999 -9999 -9999 -9999 -9999 -9999 122.5235977173120 .3900985718118 .2565994263116 .1231002808113 .6848983765 111.551399231109 .1130981445106 .6747970581104 .2365036011101 .7982025146 99.3599472045996 .9216690063594 .4833908081192 .0450973510788 .69246673584 87.4733276367287 .7781066894587 .7781066894588 .0829010009888 .38768768311 88.6924667358488 .6924667358488 .6924667358488 .9972534179788 .99725341797 88.9972534179789.3020401001 89.302040100189.302040100189.3020401001 89.302040100189.302040100189.302040100189.302040100189.3020401001 89.6068267822390 .5211791992291 .4355392456192 .349891662693 .56903076172 94.4833908081195 .397743225196 .3121032714897 .2264633178798 .14080810547 98.7503814697399 .3599472045999 .96952056885100 .2742996216100 .5791015625 100.5791015625100 .5791015625100 .5791015625100 .274299621699 .66472625732 99.0551681518697 .8360290527396 .6168823242295 .0929565429793 .56903076172 91.7403335571389 .9116134643688 .0829010009885 .9494018554784 .12069702148 82.5967712402382 .5967712402382 .9015579223682 .90155792236 -9999 -9999 -9999 -9999 -9999 -9999 -9999 -9999 -9999 -9999 -9999 -9999 -9999 -9999 -9999 -9999 -9999 -9999 -9999 -9999 -9999 -9999 -9999 -9999 -9999 -9999 -9999 -9999 -9999 -9999 -9999 -9999 -9999 -9999 -9999 -9999 -9999 -9999 -9999 -9999 -9999 -9999 -9999 -9999 -9999 -9999 -9999 -9999 -9999 $-9999-9999$

-9999 -9999 -9999 -9999 -9999 -9999 -9999 -9999 -9999 -9999 -9999 -9999 -9999 -9999 -9999 -9999 -9999 -9999 -9999 -9999 -9999 -9999 -9999 -9999 -9999 -9999 -9999 -9999 -9999 -9999 -9999 -9999 -9999 -9999 -9999 -9999 -9999 -9999 -9999 -9999 -9999 -9999 -9999 -9999 -9999 -9999 -9999 -9999 -9999 -9999 -9999 -9999 -9999 -9999 -9999 -9999 -9999 -9999 -9999 -9999 -9999 -9999 -9999 -9999 -9999 -9999 -9999 -9999 -9999 -9999 -9999 -9999 -9999-999 -999 -9999 -9999 -9999 -9999 -9999 -9999 -9999 -9999 -9999 -9999 -9999 -9999 -9999 -9999 -9999 -9999 -9999 -9999 -9999 -9999 -9999 -9999 -9999 -9999 -9999 -9999 -9999 -9999 -9999 -9999 -9999 -9999 -9999 -9999 -9999 -9999 -9999 -9999 -9999 -9999 -9999 -9999 -9999 -9999 -9999 -9999 -9999 -9999 -9999 -9999 -9999 -9999 -9999 -9999 -9999 -9999 -9999 -9999 -9999 -9999 -9999 -9999 -9999 -9999 -9999 -9999 -9999 -9999 -9999 -9999 -9999 -9999 -9999 -9999 -9999 -

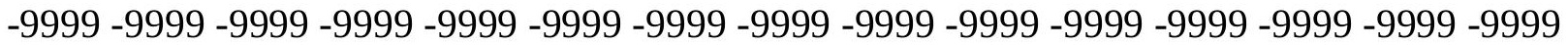
-9999 -9999 -9999 -9999 -9999 -9999 -9999 -9999 -9999 -9999 -9999 -9999 -9999 -9999 -9999 -9999 -9999 -9999 -9999 -9999 -9999 -9999 -9999 -9999 -9999 -9999 -9999 -9999 -9999 -9999

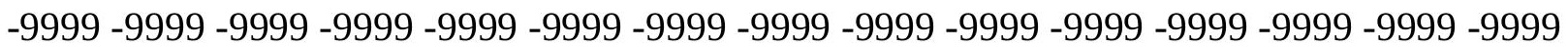
-9999 -9999 -9999 -9999 -9999 -9999 -9999 -9999 -9999 -9999 -9999 -9999 -9999 -9999 -9999 -9999 -9999 -9999 -9999 -9999 -9999 -9999 -9999 -9999 -9999 -9999 -9999 -9999 -9999 -9999 -9999 -9999 -9999 -9999 -9999 -9999 -9999 -9999 -9999 -9999 -9999 -9999 -9999 -9999 -9999 -9999 -9999 -9999 -9999 -9999 -9999 -9999 -9999 -9999 -9999 -9999 -9999 -9999 -9999 -9999 121.6092987061119 .4757995605117 .342300415114 .9039993286112 .4656982422 109.7226028442107 .2844009399104 .5412979126101 .798202514699 .35994720459 96.6168823242294 .1785964965891 .1307525634888 .0829010009887 .47332763672 87.47332763672 87.77810668945 88.08290100098 88.08290100098 88.38768768311 
88.69246673584 88.6924667358488.9972534179788.9972534179788.99725341797 89.302040100189.302040100189.302040100189.302040100189.3020401001 89.6068267822389 .6068267822389 .302040100189 .302040100189 .91161346436 90.8259735107491 .7403335571392 .6546783447393 .5690307617294 .78817749023 95.7025299072396 .6168823242297 .2264633178798 .1408081054798 .75038146973 99.3599472045999 .96952056885100 .2742996216100 .8839035034100 .8839035034 100.8839035034100 .8839035034100 .5791015625100 .274299621699 .66472625732 98.7503814697397 .5312423706196 .3121032714894 .7881774902393 .26425170898 91.4355392456189 .6068267822387 .7781066894585 .9494018554783 .81591033936 82.9015579223682 .90155792236 -9999 -9999 -9999 -9999 -9999 -9999 -9999 -9999 -9999 -9999 -9999 -9999 -9999 -9999 -9999 -9999 -9999 -9999 -9999 -9999 -9999 -9999 -9999 -9999 -9999 -9999 -9999 -9999 -9999 -9999 -9999 -9999 -9999 -9999 -9999 -9999 -9999 -9999 -9999 -9999 -9999 -9999 -9999 -9999 -9999 -9999 -9999 -9999 -9999 -9999 -9999 -9999 -9999 -9999 -9999 -9999 -9999 -9999 -9999 -9999 -9999 -9999 -9999 -9999 -9999 -9999 - -999 -9999 -9999 -9999 -9999 -9999 -9999 -9999 -9999 -9999 -9999 -9999 -9999 -9999 -9999 -9999

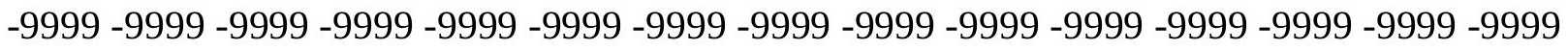
-9999 -9999 -9999 -9999 -9999 -9999 -9999 -9999 -9999 -9999 -9999 -9999 -9999 -9999 -9999 -9999 -9999 -9999 -9999 -9999 -9999 -9999 -9999 -9999 -9999 -9999 -9999 -9999 -9999 -9999 -999 -9999 -9999 -9999 -9999 -9999 -9999 -9999 -9999 -9999 -9999 -9999 -9999 -9999 -9999 -9999 -9999 -9999 -9999 -9999 -9999 -9999 -9999 -9999 -9999 -9999 -9999 -9999 -9999 -9999 -9999 -9999 -9999 -9999 -9999 -9999 -9999 -9999 -9999 -9999 -9999 -9999 -9999 -9999 -9999 -9999 -9999 -9999 -9999 -9999 -9999 -9999 -9999 -9999 -9999 -9999 -9999 -9999 -9999 -9999 -9999 -9999 -9999 -9999 -9999 -9999 -9999 -9999 -9999 -9999 -9999 -9999 -9999 -9999 -9999 -9999 -9999 -9999 -9999 -9999 -9999 -9999 -9999 -9999 -9999 -9999 -9999 -9999 -9999 -9999 -9999 -9999 -9999 -9999 -9999 -9999 -9999 -9999 -9999 -9999 -9999 -9999 -9999 -9999 -9999 -9999 -9999 -9999 -9999 -9999 -9999 -9999 -9999 -9999 -9999 -9999 -9999 -9999 -9999 -9999 -9999 -9999 -9999 -9999 -9999 -9999 -9999 -9999 -9999 -9999 -9999 -9999 -9999 -9999 -9999 -9999 -

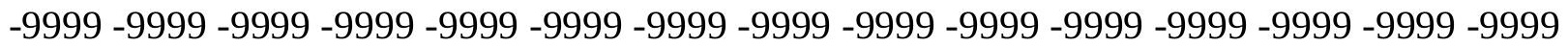

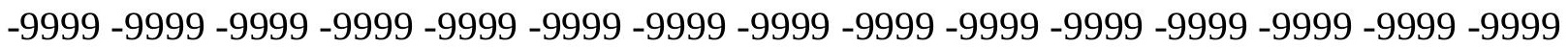
-9999 -9999 -9999 -9999 -9999 -9999 -9999 -9999 -9999 -9999 -9999 -9999 -9999 -9999 -9999 -9999 -9999 -9999 -9999 -9999 -9999 -9999 -9999 -9999 -9999 -9999 -9999 -9999 -9999 -9999 123.1332015991120 .9997024536118 .5614013672116 .1231002808113 .3800964355 110.6370010376107 .8938980103105 .1509017944102 .102996826299 .35994720459 96.3121032714893 .5690307617290 .5211791992287 .7781066894587 .47332763672 87.4733276367287 .7781066894587 .7781066894588 .0829010009888 .38768768311 88.3876876831188 .6924667358488 .6924667358488 .9972534179788 .99725341797 89.302040100189.302040100189.302040100189.60682678223 89.60682678223 89.6068267822389 .6068267822389 .6068267822389 .6068267822390 .21640014648 91.1307525634892 .0450973510792 .9594726562593 .8738174438594 .78817749023 95.7025299072396 .6168823242297 .5312423706198 .1408081054798 .75038146973 99.3599472045999 .96952056885100 .5791015625100 .8839035034101 .1886978149 101.1886978149101 .1886978149100 .8839035034100 .579101562599 .96952056885 99.3599472045998.1408081054797.2264633178795.7025299072394.48339080811 92.9594726562591 .4355392456189 .6068267822387 .4733276367285 .33984375 82.9015579223683 .2063369751 -9999 -9999 -9999 -9999 -9999 -9999 -9999 -9999 -9999 -9999 -9999 -9999 -9999 -9999 -9999 -9999 -9999 -9999 -9999 -9999 -9999 -9999 -9999 -9999 
-9999 -9999 -9999 -9999 -9999 -9999 -9999 -9999 -9999 -9999 -9999 -9999 -9999 -9999 -9999 -9999 -9999 -9999 -9999 -9999 -9999 -9999 -9999 -9999 -9999 -9999 -9999 -9999 -

-9999 -9999 -9999 -9999 -9999 -9999 -9999 -9999 -9999 -9999 -9999 -9999 -9999 -9999 - -999 -9999 -9999 -9999 -9999 -9999 -9999 -9999 -9999 -9999 -9999 -9999 -9999 -9999 -9999 -9999 -9999 -9999 -9999 -9999 -9999 -9999 -9999 -9999 -9999-9999 -9999 -9999 -9999 -9999 -9999 -9999 -9999 -9999 -9999 -9999 -9999 -9999 -9999 -9999 -9999 -9999 -9999 -9999 -9999 -9999 -

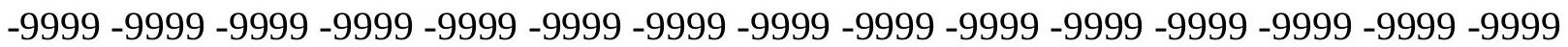

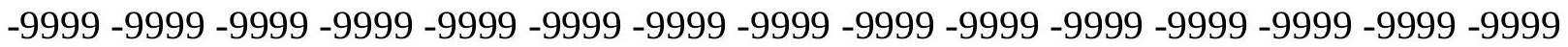

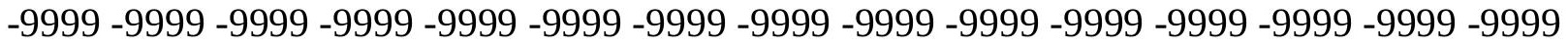
-9999 -9999 -9999 -9999 -9999 -9999 -9999 -9999 -9999 -9999 -9999 -9999 -9999 -9999 -9999 -9999 -9999 -9999 -9999 -9999 -9999 -9999 -9999 -9999 -9999 -9999 -9999 -9999 -9999 -9999 -9999 -9999 -9999 -9999 -9999 -9999 -9999 -9999 -9999 -9999 -9999 -9999 -9999 -9999 -9999 -9999 -9999 -9999 -9999 -9999 -9999 -9999 -9999 -9999 -9999 -9999 -9999 -9999 -9999 -9999 -9999 -9999 -9999 -9999 -9999 -9999 -9999 -9999 -9999 -9999 -9999 -9999 -9999 -9999 - 9999 -9999 -9999 -9999 -9999 -9999 -9999 -9999 -9999 -9999 -9999 -9999 -9999 -9999 -9999 -9999

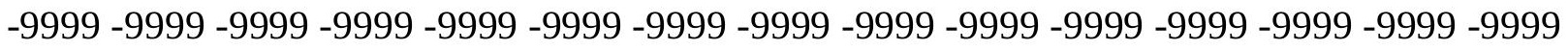
-9999 -9999 -9999 -9999 -9999 -9999 -9999 -9999 -9999 -9999 -9999 -9999 -9999 -9999 -9999 -9999 -9999 -9999 -9999 -9999 -9999 -9999 -9999 -9999 -9999 -9999 -9999 -9999 -9999 -9999 -9999 -9999 -9999 -9999 -9999 -9999 -9999 -9999 -9999 -9999 -9999 -9999 -9999 -9999 -9999 -

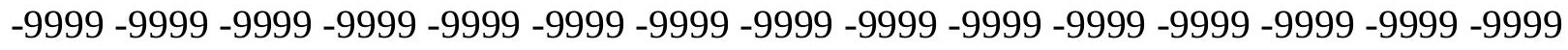
-9999 122.5235977173120.0852966309 117.342300415114.5991973877 111.8561019897 108.8082962036105 .7603988647102 .407798767199 .3599472045996 .31210327148 93.2642517089890 .2164001464887 .4733276367287 .4733276367287 .47332763672 87.4733276367287 .7781066894588 .0829010009888 .0829010009888 .38768768311 88.69246673584 88.69246673584 88.9972534179788.9972534179789.3020401001 89.302040100189 .302040100189 .6068267822389 .6068267822389 .60682678223 89.6068267822389 .6068267822389 .9116134643690 .8259735107491 .43553924561 92.349891662693 .2642517089894 .1785964965895 .0929565429796 .00731658936 96.6168823242297 .5312423706198 .1408081054798 .7503814697399 .35994720459 99.96952056885100 .5791015625100 .8839035034101 .1886978149101 .4934005737 101.4934005737101 .1886978149100 .8839035034100 .579101562599 .66472625732 98.7503814697397 .8360290527396 .9216690063595 .397743225194 .17859649658 92.6546783447391 .1307525634888 .9972534179786 .5589828491283 .51112365723 83.2063369751 -9999 -9999 -9999 -9999 -9999 -9999 -9999 -9999 -9999 -9999 -9999 -9999 -9999 -9999 -9999 -9999 -9999 -9999 -9999 -9999 -9999 -9999 -9999 -9999 -9999 -9999 -9999

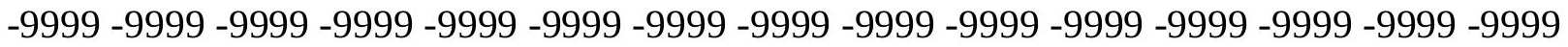
-9999 -9999 -9999-9999-9999-9999-9999-9999-9999-9999

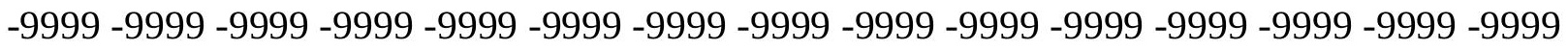
-9999 -9999 -9999 -9999 -9999 -9999 -9999 -9999 -9999 -9999 -9999 -9999 -9999 - 9999 - -999 -9999 -9999 -9999 -9999 -9999 -9999 -9999 -9999 -9999 -9999 -9999 -9999 -9999 -9999 -9999 -

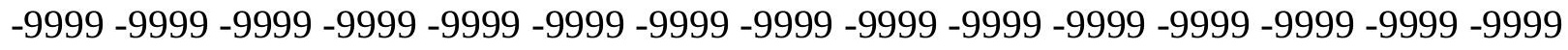

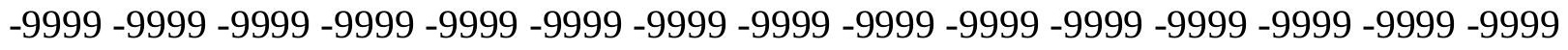
-9999 -9999 -9999 -9999 -9999 -9999 -9999 -9999 -9999 -9999 -9999 -9999 -9999 -9999 -9999 -9999 -9999 -9999 -9999 -9999 -9999 -9999 -9999 -9999-9999 -9999 -9999 -9999 -9999 -9999 -9999 -9999 -9999 -9999 -9999 -9999 -9999 -9999 -9999 -9999 -9999 -9999 -9999 -9999 -9999 -

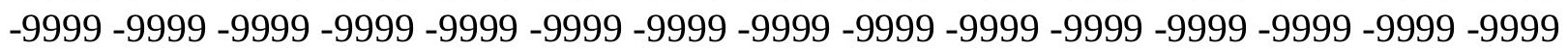


-9999 -9999 -9999 -9999 -9999 -9999 -9999 -9999 -9999 -9999 -9999 -9999 -9999 -9999 -9999 -9999 -9999 -9999 -9999 -9999 -9999 -9999 -9999 -9999 -9999 -9999 -9999 -9999 -9999 -9999 -9999 -9999 -9999 -9999 -9999 -9999 -9999 -9999 -9999 -9999 -9999 -9999 -9999 -9999 -9999 -9999 -9999 -9999 -9999 -9999 -9999 -9999 -9999 -9999 -9999 -9999 -9999 -9999 -9999 -9999 -9999 -9999 -9999 -9999 -9999 -9999 -9999 -9999 -9999 -9999 -9999 -9999 -9999 -9999 -9999 -9999 -9999 -9999 -9999 -9999 -9999 -9999 -9999 -9999 -9999 -9999 -9999 -9999 -9999 -9999 -9999 -9999 -9999 -9999 -9999 -9999 -9999 -9999 -9999 -9999 -9999 -9999 -9999 -9999 -9999

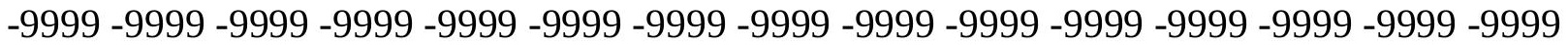
-9999 -9999 -9999 -9999 -9999 -9999 -9999 -9999 -9999 -9999 -9999 -9999 -9999 -9999 -9999 -9999 124.0475006104121.6092987061 118.8662033081 116.1231002808 112.7705001831 109.7226028442106 .3700027466103 .017402648999 .6647262573296 .31210327148 93.2642517089889 .9116134643687 .1685485839887 .1685485839887 .47332763672 87.47332763672 87.77810668945 87.77810668945 88.08290100098 88.38768768311 88.3876876831188 .6924667358488 .9972534179788 .9972534179789 .3020401001 89.302040100189 .6068267822389 .6068267822389 .6068267822389 .60682678223 89.6068267822389 .6068267822390 .2164001464891 .1307525634891 .74033355713 92.6546783447393 .5690307617294 .4833908081195 .0929565429796 .00731658936 96.6168823242297 .5312423706198 .1408081054798 .7503814697399 .35994720459 99.96952056885100 .5791015625100 .8839035034101 .1886978149101 .4934005737 101.4934005737101 .4934005737101 .1886978149100 .8839035034100 .2742996216 99.3599472045998 .445587158297 .5312423706196 .3121032714895 .09295654297 93.8738174438592 .349891662690 .5211791992288 .0829010009884 .73026275635 83.2063369751 -9999 -9999 -9999 -9999 -9999 -9999 -9999 -9999 -9999 -9999 -9999 -9999 -9999 -9999 -9999 -9999 -9999 -9999 -9999 -9999 -9999 -9999 -9999 -9999 -9999 -9999 -9999 -9999 -9999 -9999 -9999 -9999 -9999 -9999 -9999 -9999 -9999 -9999 -9999 -9999 -9999 -9999 -9999 -9999 -9999 -9999 -9999 -9999 -9999 -9999 -9999 -9999 -9999 -9999 -9999 -9999 -9999 -9999 -9999 -9999 -9999 -9999 -9999 -9999 -9999 -9999 -9999 -9999 -9999 -9999 -9999 -9999 -9999 -9999 -9999 -9999 -9999 -9999 -9999 -9999 -9999 -9999 -9999 -9999 -9999 -9999 -9999 -9999 -9999 -9999 -9999 -9999 -9999 -9999 -9999-999 -999 -9999 -9999 -9999 -9999 -9999 -9999 -9999 -9999 -9999 -9999 -9999 -9999 -9999 -9999 -9999 -9999 -9999 -9999 -9999 -9999 -9999 -9999 -9999 -9999 -9999 -9999 -9999 -9999 -9999 -9999 -

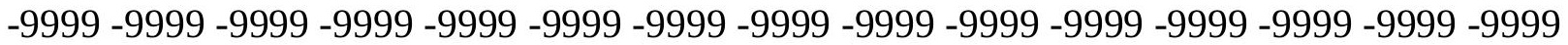
-9999 -9999 -9999 -9999 -9999 -9999 -9999 -9999 -9999 -9999 -9999 -9999 -9999 -9999 -9999 -9999 -9999 -9999 -9999 -9999 -9999 -9999 -9999 -9999 -9999 -9999 -9999 -9999 -9999 -9999 -9999 -9999 -9999 -9999 -9999 -9999 -9999 -9999 -9999 -9999 -9999 -9999 -9999 -9999 -9999 -9999 -9999 -9999 -9999 -9999 -9999 -9999 -9999 -9999 -9999 -9999 -9999 -9999 -9999 -9999 -9999 -9999 -9999 -9999 -9999 -9999 -9999 -9999 -9999 -9999 -9999 -9999 -9999 -9999 -9999

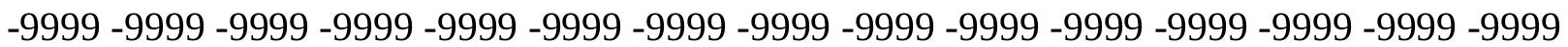
-9999 -9999 -9999 -9999 -9999 -9999 -9999 -9999 -9999 -9999 -9999 -9999 -9999 -9999 -9999 -9999 -9999 -9999 -9999 -9999 -9999 -9999 -9999 -9999 -9999 -9999 -9999 -9999 -9999 -9999 -9999 -9999 -9999 -9999 -9999 -9999 -9999 -9999 -9999 -9999 -9999 -9999 -9999 -9999 -9999

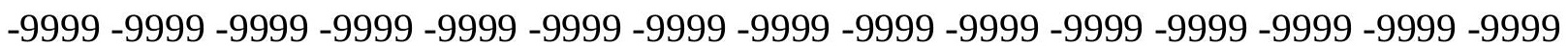
-9999 -9999 -9999 -9999 -9999 -9999 -9999 -9999 -9999 -9999 -9999 -9999 -9999 -9999 -9999 -9999 -9999 -9999 -9999 -9999 -9999 -9999 -9999 -9999 -9999 -9999 -9999 -9999 -9999 -9999 -9999 -9999 123.43800354120.6949005127 117.647102356114.2944030762 110.9418029785 107.2844009399 103.626899719299.9695205688596.6168823242293.26425170898 
89.91161346436 87.16854858398 87.47332763672 87.47332763672 87.47332763672 87.7781066894587 .7781066894588 .0829010009888 .0829010009888 .38768768311 88.6924667358488 .9972534179788 .9972534179789 .302040100189 .3020401001 89.6068267822389 .6068267822389 .6068267822389 .9116134643689 .91161346436 89.9116134643690 .8259735107491 .4355392456192 .0450973510792 .95947265625 93.5690307617294 .4833908081195 .397743225196 .0073165893696 .61688232422 97.5312423706198 .1408081054798 .7503814697399 .3599472045999 .66472625732 100.2742996216100 .5791015625100 .8839035034101 .1886978149101 .4934005737 101.4934005737101 .4934005737100 .8839035034100 .274299621699 .66472625732 98.7503814697397 .8360290527396 .9216690063596 .0073165893694 .78817749023 93.5690307617291 .7403335571389 .9116134643685 .3398437583 .51112365723 83.2063369751 -9999 -9999 -9999 -9999 -9999 -9999 -9999 -9999 -9999 -9999 -9999 -9999 -9999 -9999 -9999 -9999 -9999 -9999 -9999 -9999 -9999 -9999 -9999 -9999 -9999 -9999 -9999

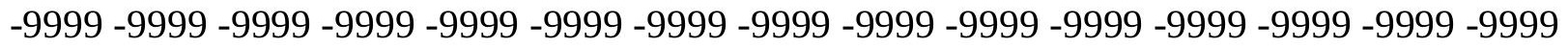
-9999 -9999 -9999 -9999 -9999 -9999 -9999 -9999 -9999

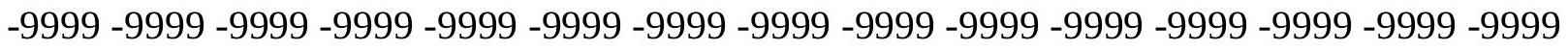
-9999 -9999 -9999 -9999 -9999 -9999 -9999 -9999 -9999 -9999 -9999 -9999 -9999 -9999 -9999 -9999 -9999 -9999 -9999 -9999 -9999 -9999 -9999 -9999 -9999 -9999 -9999 -9999 -9999 -9999 -9999 -9999 -9999 -9999 -9999 -9999 -9999 -9999 -9999 -9999 -9999 -9999 -9999 -9999 -9999 -

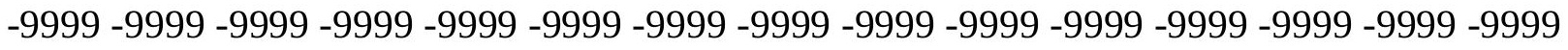
-9999 -9999 -9999 -9999 -9999 -9999 -9999 -9999 -9999 -9999 -9999 -9999 -9999 -9999 -9999 -9999 -9999 -9999 -9999 -9999 -9999 -9999 -9999 -9999 -9999 -9999 -9999 -9999 -9999 -9999 -9999 -9999 -9999 -9999 -9999 -9999 -9999 -9999 -9999 -9999 -9999 -9999 -9999 -9999 -9999 -9999 -9999 -9999 -9999 -9999 -9999 -9999 -9999 -9999 -9999 -9999 -9999 -9999 -9999 -9999 -

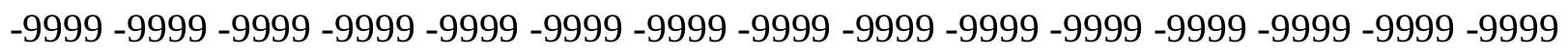
-9999 -9999 -9999 -9999 -9999 -9999 -9999 -9999 -9999 -9999 -9999 -9999 -9999 -9999 -9999 -9999 -9999 -9999 -9999 -9999 -9999 -9999 -9999 -9999 -9999 -9999 -9999 -9999 -9999 -9999 -

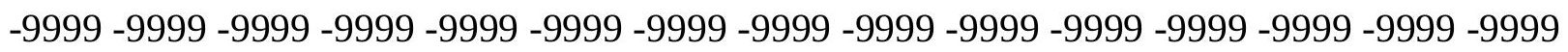
-9999 -9999 -9999 -9999 -9999 -9999 -9999 -9999 -9999 -9999 -9999 -9999 -9999 -9999 -9999 -9999 -9999 -9999 -9999 -9999 -9999 -9999 -9999 -9999 -9999 -9999 -9999 -9999 -9999 -999 -9999 -9999 -9999 -9999 -9999 -9999 -9999 -9999 -9999 -9999 -9999 -9999 -9999 -9999 -9999

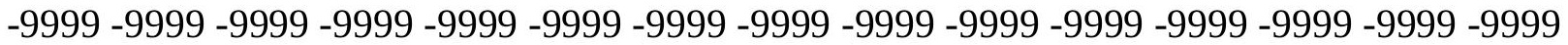

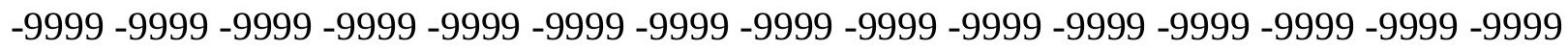
-9999-9999 125.5715026855122 .5235977173119 .1709976196115 .818397522 112.1608963013108 .1986999512104 .5412979126100 .579101562596 .92166900635 93.2642517089889 .9116134643687 .7781066894587 .4733276367287 .47332763672 87.4733276367287 .4733276367287 .7781066894588 .0829010009888 .08290100098 88.3876876831188 .6924667358488 .9972534179788 .9972534179789 .3020401001 89.6068267822389 .6068267822389 .6068267822389 .9116134643689 .91161346436 89.9116134643690 .5211791992291 .1307525634891 .7403335571392 .3498916626 93.2642517089893.8738174438594.4833908081195.397743225196.00731658936 96.6168823242297 .2264633178797 .8360290527398 .445587158299 .05516815186 99.3599472045999 .96952056885100 .2742996216100 .5791015625100 .8839035034 101.1886978149101 .4934005737101 .1886978149100 .8839035034100 .5791015625 99.6647262573299 .0551681518698 .1408081054797 .2264633178796 .31210327148 95.397743225194 .1785964965892 .349891662689 .9116134643686 .2541885376 
83.5111236572383 .2063369751 -9999 -9999 -9999 -9999 -9999 -9999 -9999 -9999 -9999 -9999 -9999 -9999 -9999 -9999 -9999 -9999 -9999 -9999 -9999 -9999 -9999 -9999 -9999 -9999

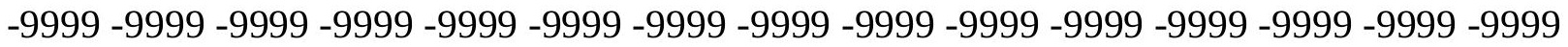
-9999 -9999 -9999 -9999 -9999 -9999 -9999 -9999 -9999 -9999 -9999 -9999

-9999 -9999 -9999 -9999 -9999 -9999 -9999 -9999 -9999 -9999 -9999 -9999 -9999 -9999 -9999 -9999 -9999 -9999 -9999 -9999 -9999 -9999 -9999 -9999 -9999 -9999 -9999 -9999 -9999 -9999 -9999 -9999 -9999 -9999 -9999 -9999 -9999 -9999 -9999 -9999 -9999 -9999 -9999 -9999 -9999 -999 -

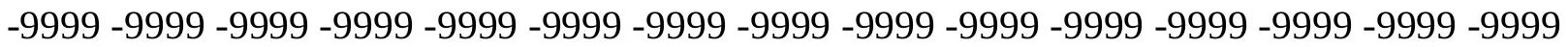
-9999 -9999 -9999 -9999 -9999 -9999 -9999 -9999 -9999 -9999 -9999 -9999 -9999 -9999 -9999 -9999 -9999 -9999 -9999 -9999 -9999 -9999 -9999 -9999 -9999 -9999 -9999 -9999 -9999 -9999 -9999 -9999 -9999 -9999 -9999 -9999 -9999 -9999 -9999 -9999 -9999 -9999 -9999 -9999 -9999 -9999 -9999 -9999 -9999 -9999 -9999 -9999 -9999 -9999 -9999 -9999 -9999 -9999 -9999 -9999 -9999 -9999 -9999 -9999 -9999 -9999 -9999 -9999 -9999 -9999 -9999 -9999 -9999 -9999 -9999 -9999 -9999 -9999 -9999 -9999 -9999 -9999 -9999 -9999 -9999 -9999 -9999 -9999 -9999 -9999 -9999 -9999 -9999 -9999 -9999 -9999 -9999 -9999 -9999 -9999 -9999 -9999 -9999 -9999 -9999 -9999 -9999 -9999 -9999 -9999 -9999 -9999 -9999 -9999 -9999 -9999 -9999 -9999 -9999 -9999 -9999 -9999 -9999 -9999 -9999 -9999 -9999 -9999 -9999 -9999 -9999 -9999 -9999 -9999 -9999 -9999 -9999 -9999 -9999 -9999 -9999 -9999 -9999 -9999 -9999 -9999 -9999 -9999 -9999 -9999 -9999 -9999 -9999 -9999 -9999 -9999 -9999 -9999 -9999 -9999 -9999 -9999 -9999 -9999 -9999 -9999 -9999 -9999 -9999 -9999 -9999 -9999 -9999 -9999 -9999 -9999 -9999 -9999 -9999 -9999 -9999 -9999 -9999 -9999 -9999 -9999 -9999 -9999 -9999 -9999 -9999 -9999 -9999 -9999 -9999 -9999 -9999 -9999 -9999 -9999 -9999 -9999 -9999 -9999 -9999 -9999 -9999 -9999 -9999 -9999 -9999 -9999 -9999 124.6570968628 121.3044967651 117.342300415113.6848983765 109.4179000854105 .1509017944101 .188697814997 .2264633178793 .56903076172 89.9116134643688 .0829010009887 .7781066894587 .4733276367287 .47332763672 87.4733276367287 .7781066894587 .7781066894588 .0829010009888 .38768768311 88.6924667358488 .9972534179789 .302040100189 .302040100189 .60682678223 89.6068267822389 .9116134643689 .9116134643689 .9116134643690 .21640014648 90.8259735107491 .4355392456192 .0450973510792 .6546783447393 .26425170898 94.1785964965894 .7881774902395 .397743225196 .0073165893696 .61688232422 97.2264633178797 .8360290527398 .1408081054798 .7503814697399 .05516815186 99.3599472045999 .6647262573299 .96952056885100 .2742996216100 .5791015625 100.8839035034101 .1886978149100 .8839035034100 .274299621699 .66472625732 99.0551681518698 .1408081054797 .5312423706196 .6168823242295 .70252990723 94.4833908081192 .9594726562590 .2164001464886 .8637619018683 .51112365723 83.51112365723 -9999 -9999 -9999 -9999 -9999 -9999 -9999 -9999 -9999 -9999 -9999 -9999

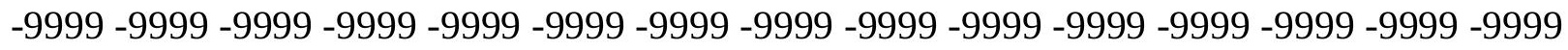

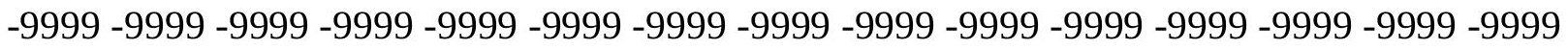
-9999 -9999 -9999 -9999 -9999 -9999 -9999 -9999 -9999

-9999 -9999 -9999 -9999 -9999 -9999 -9999 -9999 -9999 -9999 -9999 -9999 -9999 -9999 -9999 -9999 -9999 -9999 -9999 -9999 -9999 -9999 -9999 -9999 -9999 -9999 -9999 -9999 -9999 -9999 -999 -9999 -9999 -9999 -9999 -9999 -9999 -9999 -9999 -9999 -9999 -9999 -9999 -9999 -9999 -9999 -9999 -9999 -9999 -9999 -9999 -9999 -9999 -9999 -9999 -9999 -9999 -9999 -9999 -9999 -9999 -9999 -9999 -9999 -9999 -9999 -9999 -9999 -9999 -9999 -9999 -9999 -9999 -9999 -9999 -9999 -9999 -9999 -9999 -9999 -9999 -9999 -9999 -9999 -9999 -9999 -9999 -9999 -9999 -9999 -9999 -9999 -9999 -9999 -9999 -9999 -9999 -9999 -9999 -9999 -9999 -9999 -9999 -9999 -9999 -9999 
-9999 -9999 -9999 -9999 -9999 -9999 -9999 -9999 -9999 -9999 -9999 -9999 -9999 -9999 -9999 -9999 -9999 -9999 -9999 -9999 -9999 -9999 -9999 -9999 -9999 -9999 -9999 -9999 -9999 -9999 -9999 -9999 -9999 -9999 -9999 -9999 -9999 -9999 -9999 -9999 -9999 -9999 -9999 -9999 -9999 -9999 -9999 -9999 -9999 -9999 -9999 -9999 -9999 -9999 -9999 -9999 -9999 -9999 -9999 -9999 -9999 -9999 -9999 -9999 -9999 -9999 -9999 -9999 -9999 -9999 -9999 -9999 -9999 -9999 -9999 -9999 -9999 -9999 -9999 -9999 -9999 -9999 -9999 -9999 -9999 -9999 -9999 -9999 -9999 -9999 -9999 -9999 -9999 -9999 -9999 -9999 -9999 -9999 -9999 -9999 -9999 -9999 -9999 -9999 -9999

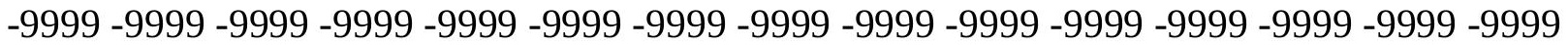
-9999 -9999 -9999 -9999 -9999 -9999 -9999 -9999 -9999 -9999 -9999 -9999 -9999 -9999 -9999 -9999 -9999 -9999 -9999 -9999 -9999 -9999 -9999 -9999 -9999 -9999 -9999 -9999 -9999 -9999 -9999 -9999 -9999 -9999 -9999 -9999 -9999 -9999 -9999 -9999 -9999 -9999 -9999 -9999 -9999 -9999 -9999 -9999 127.0953979492 123.43800354119 .4757995605115 .2088012695 110.6370010376106 .3700027466101 .798202514697 .5312423706193 .56903076172 89.91161346436 88.08290100098 87.77810668945 87.47332763672 87.47332763672 87.4733276367287 .4733276367287 .7781066894588 .0829010009888 .38768768311 88.6924667358488 .9972534179789 .302040100189 .6068267822389 .60682678223 89.9116134643689 .9116134643689 .9116134643690 .2164001464890 .52117919922 91.1307525634891 .7403335571392 .349891662692 .9594726562593 .56903076172 94.1785964965894 .7881774902395 .397743225196 .0073165893696 .61688232422 96.9216690063597 .5312423706197 .8360290527398 .1408081054798 .4455871582 98.7503814697398 .7503814697399 .0551681518699 .3599472045999 .66472625732 100.2742996216100 .5791015625100 .579101562599 .9695205688599 .35994720459 98.7503814697398 .1408081054797 .2264633178796 .6168823242296 .00731658936 95.0929565429793 .5690307617291 .1307525634888 .0829010009884 .12069702148 83.2063369751 -9999 -9999 -9999 -9999 -9999 -9999 -9999 -9999 -9999 -9999 -9999 -9999 -9999 -9999 -9999 -9999 -9999 -9999 -9999 -9999 -9999 -9999 -9999 -9999 -9999 -9999 -9999 -9999 -9999 -9999 -9999 -9999 -9999 -9999 -9999 -9999 -9999 -9999 -9999 -9999 -9999 -9999 -9999 -9999 -9999 -9999 -9999 -9999 -9999 -9999 -9999

-9999 -9999 -9999 -9999 -9999 -9999 -9999 -9999 -9999 -9999 -9999 -9999 -9999 -9999 -9999 -9999 -9999 -9999 -9999 -9999 -9999 -9999 -9999 -9999 -9999 -9999 -9999 -9999 -9999 -9999 -9999 -9999 -9999 -9999 -9999 -9999 -9999 -9999 -9999 -9999 -9999 -9999 -9999 -9999 -9999 -9999 -9999 -9999 -9999 -9999 -9999 -9999 -9999 -9999 -9999 -9999 -9999 -9999 -9999 -9999 -9999 -9999 -9999 -9999 -9999 -9999 -9999 -9999 -9999 -9999 -9999 -9999 -9999 -9999 -9999 -9999 -9999 -9999 -9999 -9999 -9999 -9999 -9999 -9999 -9999 -9999 -9999 -9999 -9999 -9999 -

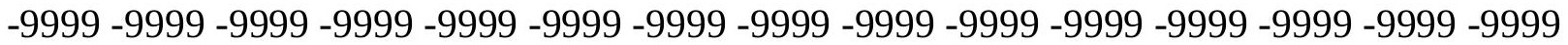
-9999 -9999 -9999 -9999 -9999 -9999 -9999 -9999 -9999 -9999 -9999 -9999 -9999 -9999 -9999 -9999 -9999 -9999 -9999 -9999 -9999 -9999 -9999 -9999 -9999 -9999 -9999 -9999 -9999 -9999

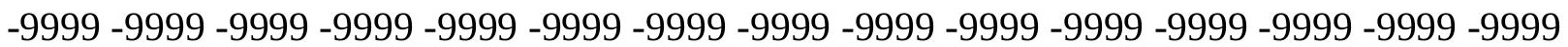
-9999 -9999 -9999 -9999 -9999 -9999 -9999 -9999 -9999 -9999 -9999 -9999 -9999 -9999 -9999 -9999 -9999 -9999 -9999 -9999 -9999 -9999 -9999 -9999 -9999 -9999 -9999 -9999 -9999 -9999 -9999 -9999 -9999 -9999 -9999 -9999 -9999 -9999 -9999 -9999 -9999 -9999 -9999 -9999 -9999 -9999 -9999 -9999 -9999 -9999 -9999 -9999 -9999 -9999 -9999 -9999 -9999 -9999 -9999 -9999 -9999 -9999 -9999 -9999 -9999 -9999 -9999 -9999 -9999 -9999 -9999 -9999 -9999 -9999 -9999 -9999 -9999 -9999 -9999 -9999 -9999 -9999 -9999 -9999 -9999 -9999 -9999 -9999 -9999 -9999 -9999 -9999 -9999 -9999 -9999 -9999 -9999 -9999 -9999 -9999 -9999 -9999 -9999 -9999 -9999

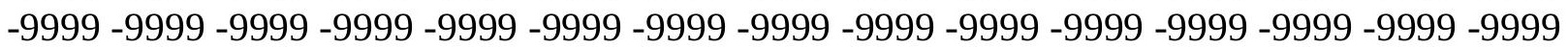


-9999 -9999 -9999 129.533706665125.5715026855 121.3044967651 116.7326965332 112.1608963013107 .2844009399102 .71260070898 .1408081054793 .87381744385 89.91161346436 87.47332763672 87.16854858398 87.16854858398 87.16854858398 87.1685485839887 .4733276367287 .7781066894588 .0829010009888 .38768768311 88.6924667358488 .9972534179789 .302040100189 .6068267822389 .60682678223 89.9116134643689 .9116134643690 .2164001464890 .5211791992290 .82597351074 91.4355392456192 .0450973510792 .6546783447393 .2642517089893 .87381744385 94.1785964965894 .7881774902395 .397743225196 .0073165893696 .31210327148 96.9216690063597 .2264633178797 .5312423706197 .8360290527397 .83602905273 98.1408081054797 .8360290527397 .8360290527397 .8360290527398 .14080810547 98.7503814697399 .9695205688599 .3599472045999 .0551681518698 .75038146973 98.1408081054797 .5312423706197 .2264633178796 .6168823242296 .00731658936 95.397743225194 .1785964965892 .6546783447389 .6068267822385 .03504943848 83.2063369751 -9999 -9999 -9999 -9999 -9999 -9999 -9999 -9999 -9999 -9999 -9999 -9999 -9999 -9999 -9999 -9999 -9999 -9999 -9999 -9999 -9999 -9999 -9999 -9999 -9999 -9999 -9999

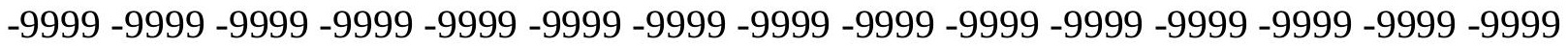
-9999 -9999 -9999 -9999 -9999 -9999-9999 -9999 -9999 -9999 -9999 -9999 -9999 -9999 -9999 -9999 -9999 -9999 -9999 -9999 -9999 -9999 -9999 -9999 -9999 -9999 -9999 -9999 -9999 -9999 -9999 -9999 -9999 -9999 -9999 -9999 -9999 -9999 -9999 -9999 -9999 -9999 -9999 -9999 -9999 -9999 -9999 -9999 -9999 -9999 -9999 -9999 -9999 -9999 -9999 -9999 -9999 -9999 -9999 -9999 -9999 -9999 -9999 -9999 -9999 -9999 -9999 -9999 -9999 -9999 -9999 -9999 -9999 -9999 -9999 -9999 -9999 -9999 -9999 -9999 -9999 -9999 -9999 -9999 -9999 -9999 -9999 -9999 -9999 -9999 -9999 -9999 -9999 -9999 -9999 -9999 -9999 -9999 -9999 -9999 -9999 -9999 -9999 -9999 -9999 -9999 -9999 -9999 -9999 -9999 -9999 -9999 -9999 -9999 -9999 -9999 -9999 -9999 -9999 -9999 -9999 -9999 -9999 -9999 -9999 -9999 -9999 -9999 -9999 -9999 -9999 -9999 -9999 -9999 -9999 -9999 -9999 -9999 -9999 -9999 -9999 -9999 -9999 -9999 -9999 -9999 -9999 -9999 -9999 -9999 -9999 -9999 -9999 -9999 -9999 -9999 -9999 -9999 -9999 -

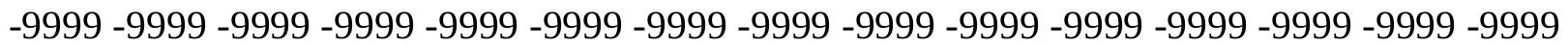

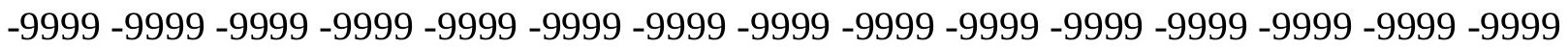
-9999 -9999 -9999 -9999 -9999 -9999 -9999 -9999 -9999 -9999 -9999 -9999 -9999 -9999 -999 -9999 -9999 -9999 -9999 -9999 -9999 -9999 -9999 -9999 -9999 -9999 -9999 -9999 -9999 -9999

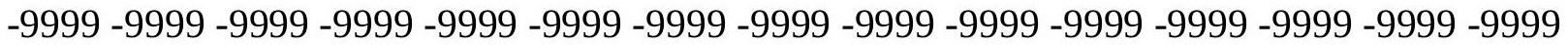

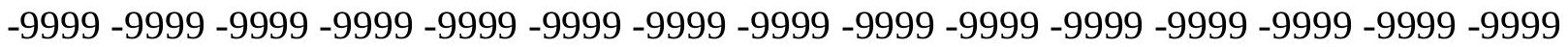
-9999 -9999 -9999 -9999 -9999 -9999 -9999 -9999 -9999 -9999 -9999 -9999 -9999 -9999 -9999 -9999 -9999 -9999 -9999 -9999 -9999 -9999 -9999 -9999 -9999 -9999 -9999 -9999 -9999 -9999 -9999 -9999 -9999 -9999 128.0097961426123.43800354 118.5614013672113 .6848983765 108.5035018921103 .626899719298 .7503814697394 .1785964965889 .91161346436 86.8637619018686 .5589828491286 .5589828491286 .8637619018686 .86376190186 87.4733276367287 .7781066894588 .0829010009888 .3876876831188 .99725341797 89.302040100189 .6068267822389 .6068267822389 .9116134643689 .91161346436 90.2164001464890 .2164001464890 .8259735107491 .1307525634891 .74033355713 92.349891662692 .9594726562593 .2642517089893 .8738174438594 .48339080811 94.7881774902395 .397743225196 .0073165893696 .3121032714896 .61688232422 96.9216690063597 .2264633178797 .2264633178797 .2264633178797 .22646331787 96.9216690063596 .6168823242296 .3121032714896 .0073165893696 .31210327148 97.2264633178797 .8360290527397 .8360290527397 .8360290527397 .53124237061 
97.2264633178796.9216690063596.3121032714896.0073165893695.3977432251 94.7881774902393 .5690307617291 .7403335571386 .5589828491283 .2063369751 -9999 -9999 -9999 -9999 -9999 -9999 -9999 -9999 -9999 -9999 -9999 -9999 -9999 -9999 -9999 -9999 -9999 -9999 -9999 -9999 -9999 -9999 -9999 -9999 -9999 -9999 -9999 -9999 -9999 -9999 -9999

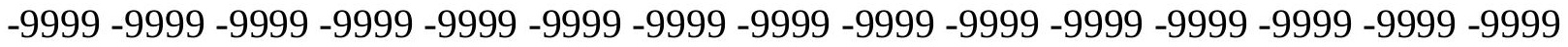
-9999 -9999-9999-9999-9999

-9999 -9999 -9999 -9999 -9999 -9999 -9999 -9999 -9999 -9999 -9999 -9999 -9999 -9999 -9999

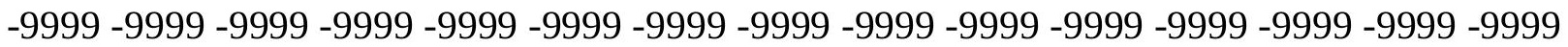

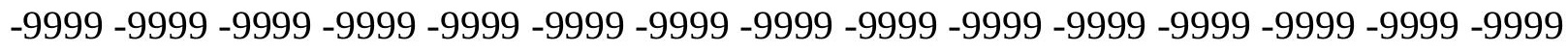
-9999 -9999 -9999 -9999 -9999 -9999 -9999 -9999 -9999 -9999 -9999 -9999 -9999 -9999 -9999 -

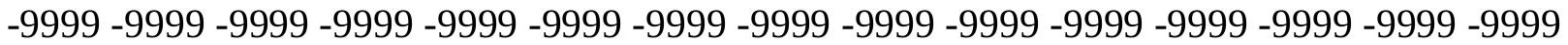
-9999 -9999 -9999 -9999 -9999 -9999 -9999 -9999 -9999 -9999 -9999 -9999 -9999 -9999 -9999 -9999 -9999 -9999 -9999 -9999 -9999 -9999 -9999 -9999 -9999 -9999 -9999 -9999 -9999 -9999 -9999 -9999 -9999 -9999 -9999 -9999 -9999 -9999 -9999 -9999 -9999 -9999 -9999 -9999 -9999 -9999 -9999 -9999 -9999 -9999 -9999 -9999 -9999 -9999 -9999 -9999 -9999 -9999 -9999 -9999

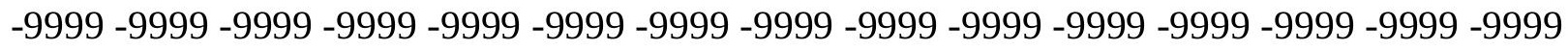
-9999 -9999 -9999 -9999 -9999 -9999 -9999 -9999 -9999 -9999 -9999 -9999 -9999 -9999 -9999 -9999 -9999 -9999 -9999 -9999 -9999 -9999 -9999 -9999 -9999 -9999 -9999 -9999 -9999 -9999 -

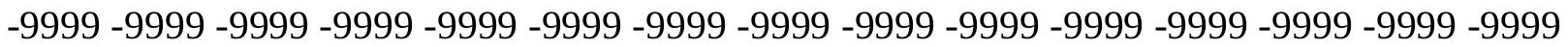

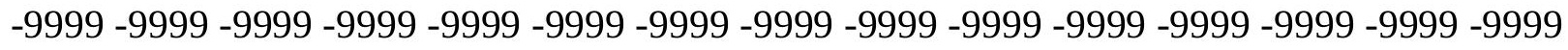

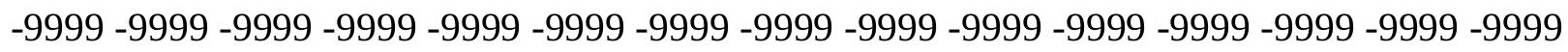
-9999 -9999 -9999 -9999 -9999 -9999 -9999 -9999 -9999 -9999 -9999 -9999 -9999 -9999 -9999 -9999 -9999 -9999 -9999 -9999 -9999 -9999 -9999 -9999 -9999 -9999 -9999 -9999 -9999 -9999 -

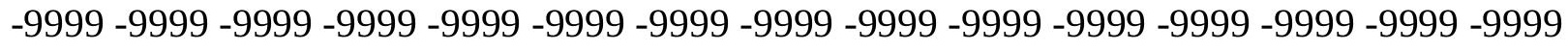
-9999 -9999-9999-9999 130.4479980469 125.5715026855120 .6949005127115 .2088012695 110.0273971558104 .541297912699 .3599472045994 .4833908081190 .21640014648 86.5589828491285 .9494018554786 .254188537686 .5589828491286 .86376190186 87.1685485839887 .7781066894588 .3876876831188 .6924667358488 .99725341797 89.302040100189 .6068267822389 .9116134643690 .2164001464890 .21640014648 90.2164001464890 .5211791992291 .1307525634891 .4355392456192 .04509735107 92.6546783447392 .9594726562593 .5690307617294 .1785964965894 .48339080811 95.0929565429795 .397743225195 .7025299072396 .3121032714896 .31210327148 96.6168823242296 .9216690063596 .9216690063596 .9216690063596 .61688232422 96.3121032714895 .7025299072395 .0929565429794 .4833908081193 .56903076172 95.0929565429796 .0073165893696 .6168823242296 .9216690063596 .92166900635 96.9216690063596 .6168823242296 .3121032714895 .7025299072395 .3977432251 94.4833908081193 .5690307617291 .1307525634887 .7781066894582 .90155792236 80.20375823975 -9999 -9999 -9999 -9999 -9999 -9999 -9999 -9999 -9999 -9999 -9999 -9999 -9999 -9999 -9999 -9999 -9999-9999 -9999 -9999 -9999 -9999 -9999 -9999 -9999 -9999 - -999 -

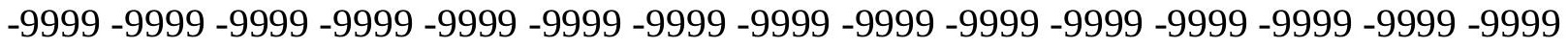
-9999 -9999 -9999-9999-9999-9999-9999-9999

-9999 -9999 -9999 -9999 -9999 -9999 -9999 -9999 -9999 -9999 -9999 -9999 -9999 -9999 -9999 -9999 -9999 -9999 -9999 -9999 -9999 -9999 -9999 -9999 -9999 -9999 -9999 -9999 -9999 -9999 -9999 -9999 -9999 -9999 -9999 -9999 -9999 -9999 -9999 -9999 -9999 -9999 -9999 -9999 -9999 -

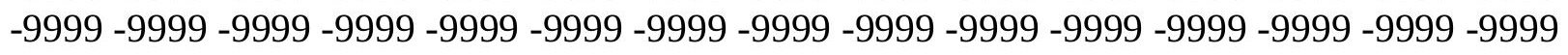

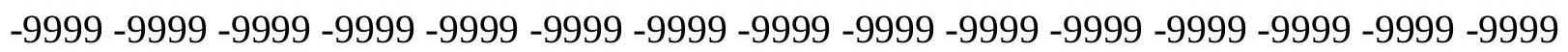


-9999 -9999 -9999 -9999 -9999 -9999 -9999 -9999 -9999 -9999 -9999 -9999 -9999 -9999 -9999 -9999 -9999 -9999 -9999 -9999 -9999 -9999 -9999 -9999 -9999 -9999 -9999 -9999 -9999 -9999 -9999 -9999 -9999 -9999 -9999 -9999 -9999 -9999 -9999 -9999 -9999 -9999 -9999 -9999 -9999 -9999 -9999 -9999 -9999 -9999 -9999 -9999 -9999 -9999 -9999 -9999 -9999 -9999 -9999 -9999 -9999 -9999 -9999 -9999 -9999 -9999 -9999 -9999 -9999 -9999 -9999 -9999 -9999 -9999 -9999 -9999 -9999 -9999 -9999 -9999 -9999 -9999 -9999 -9999 -9999 -9999 -9999 -9999 -9999 -9999 -9999 -9999 -9999 -9999 -9999 -9999 -9999 -9999 -9999 -9999 -9999 -9999 -9999 -9999 -9999

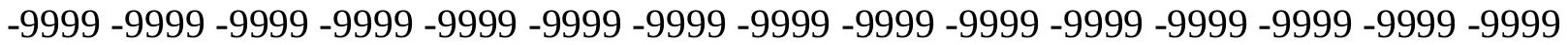
-9999 -9999 -9999 -9999 -9999 -9999 -9999 -9999 -9999 -9999 -9999 -9999 -9999 -9999 -9999 -9999 -9999 -9999 -9999 -9999 -9999 -9999 -9999 -9999 -9999 -9999 -9999 -9999 -9999 -9999 -

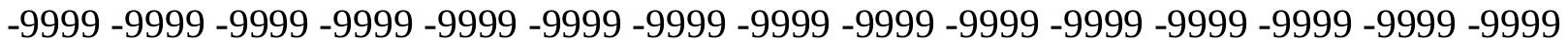
-9999 -9999 -9999 -9999 -9999 -9999 -9999 -9999 -9999 -9999 -9999 -9999 -9999 -9999 -9999

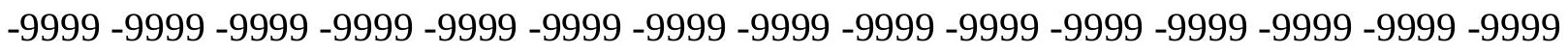
-9999 -9999 -9999 -9999 -9999 127.2545700073 122.5235977173117 .0374984741 111.551399231105 .7603988647100 .274299621695 .0929565429790 .21640014648 86.8637619018685 .6446228027385 .9494018554786 .254188537686 .86376190186 87.4733276367287 .7781066894588 .3876876831188 .9972534179789 .3020401001 89.60682678223 89.9116134643690.2164001464890.2164001464890.52117919922 90.5211791992291 .1307525634891 .4355392456191 .7403335571392 .3498916626 92.6546783447393 .2642517089893 .5690307617294 .1785964965894 .78817749023 95.0929565429795 .397743225195 .7025299072396 .0073165893696 .31210327148 96.6168823242296 .6168823242296 .6168823242296 .3121032714896 .00731658936 95.7025299072395 .0929565429794 .4833908081193 .8738174438593 .56903076172 94.1785964965895 .0929565429795 .7025299072396 .3121032714896 .31210327148 96.3121032714896 .3121032714896 .0073165893695 .397743225194 .78817749023 93.8738174438592 .6546783447390 .5211791992287 .7781066894582 .90155792236 79.93711853027 -9999 -9999 -9999 -9999 -9999 -9999 -9999 -9999 -9999 -9999 -9999 -9999 -9999 -9999 -9999 -9999 -9999 -9999 -9999 -9999 -9999 -9999 -9999 -9999 -9999 -9999 -9999

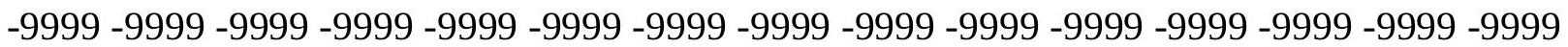
-9999 -9999 -9999 -9999-9999-9999-9999-9999 -9999 -9999 -9999 -9999 -9999 -9999 -9999 -9999 -9999 -9999 -9999 -9999 -9999 -9999 -9999

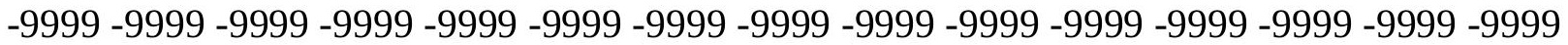
-9999 -9999 -9999 -9999 -9999 -9999 -9999 -9999 -9999 -9999 -9999 -9999 -9999 -9999 -9999 -9999 -9999 -9999 -9999 -9999 -9999 -9999 -9999 -9999 -9999 -9999 -9999 -9999 -9999 -9999 -

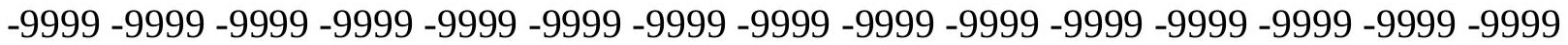
-9999 -9999 -9999 -9999 -9999 -9999 -9999 -9999 -9999 -9999 -9999 -9999 -9999 -9999 -9999 -9999 -9999 -9999 -9999 -9999 -9999 -9999 -9999 -9999 -9999 -9999 -9999 -9999 -9999 -9999

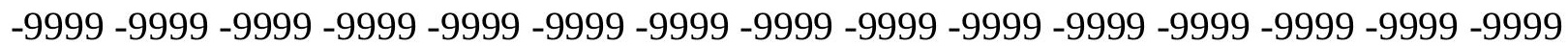
-9999 -9999 -9999 -9999 -9999 -9999 -9999 -9999 -9999 -9999 -9999 -9999 -9999 -9999 -9999 -9999 -9999 -9999 -9999 -9999 -9999 -9999 -9999 -9999 -9999 -9999 -9999 -9999 -9999 -9999 -9999 -9999 -9999 -9999 -9999 -9999 -9999 -9999 -9999 -9999 -9999 -9999 -9999 -9999 -9999 -999 -9999 -9999 -9999 -9999 -9999 -9999 -9999 -9999 -9999 -9999 -9999 -9999 -9999 -9999 -9999 -9999 -9999 -9999 -9999 -9999 -9999 -9999 -9999 -9999 -9999 -9999 -9999 -9999 -9999 -9999 -9999 -9999 -9999 -9999 -9999 -9999 -9999 -9999 -9999 -9999 -9999 -9999 -9999 -9999 -9999 -9999 -9999 -9999 -9999 -9999 -9999 -9999 -9999 -9999 -9999 -9999 -9999 -9999 -9999 -9999

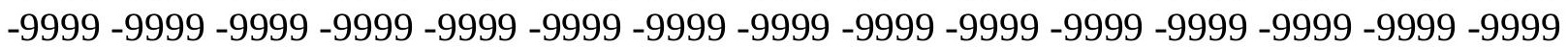


-9999 -9999 -9999 -9999 -9999 -9999 -9999 -9999 -9999 -9999 -9999 -9999 -9999 -9999 -9999 -9999 -9999 -9999 -9999 -9999 -9999 -9999 -9999 -9999 -9999 -9999 -9999 -9999 -9999 -9999 -9999 -9999 -9999 -9999-9999 128.2164916992 123.741973877 118.8662033081 113.075302124107 .2844009399101 .493400573796 .0073165893690 .82597351074 87.4733276367285 .3398437585 .9494018554786 .254188537686 .86376190186 87.4733276367288 .0829010009888 .6924667358488 .9972534179789 .60682678223 89.9116134643690 .2164001464890 .2164001464890 .5211791992290 .52117919922 90.8259735107491 .4355392456191 .7403335571392 .0450973510792 .65467834473 92.9594726562593 .5690307617293 .8738174438594 .4833908081194 .78817749023 95.0929565429795 .397743225195 .7025299072396 .0073165893696 .31210327148 96.3121032714896 .3121032714896 .3121032714896 .0073165893696 .00731658936 95.397743225194 .7881774902394 .1785964965893 .8738174438593 .87381744385 94.1785964965894 .7881774902395 .397743225196 .0073165893696 .00731658936 96.0073165893696 .0073165893695 .397743225195 .0929565429794 .17859649658 92.9594726562591 .4355392456189 .302040100186 .8637619018682 .59677124023 79.79127502441 -9999 -9999 -9999 -9999 -9999 -9999 -9999 -9999 -9999 -9999 -9999 -9999 -9999 -9999 -9999 -9999 -9999 -9999 -9999 -9999 -9999 -9999 -9999 -9999 -9999 -9999 -9999 -9999 -9999 -9999 -9999 -9999 -9999 -9999 -9999 -9999 -9999 -9999 -9999 -9999 -9999 -9999 -9999 -9999 -9999 -9999 -9999 -9999 -9999 -9999

-9999 -9999 -9999 -9999 -9999 -9999 -9999 -9999 -9999 -9999 -9999 -9999 -9999 -9999 -9999

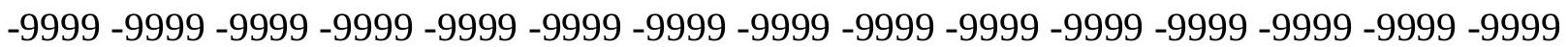
-9999 -9999 -9999 -9999 -9999 -9999 -9999 -9999 -9999 -9999 -9999 -9999 -9999 -9999 -9999 -9999 -9999 -9999 -9999 -9999 -9999 -9999 -9999 -9999 -9999 -9999 -9999 -9999 -9999 -9999 -9999 -9999 -9999 -9999 -9999 -9999 -9999 -9999 -9999 -9999 -9999 -9999 -9999 -9999 -9999

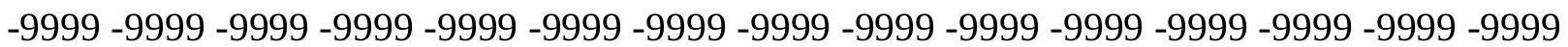
-9999 -9999 -9999 -9999 -9999 -9999 -9999 -9999 -9999 -9999 -9999 -9999 -9999 -9999 -9999 -9999 -9999 -9999 -9999 -9999 -9999 -9999 -9999 -9999 -9999 -9999 -9999 -9999 -9999 -9999 -9999 -9999 -9999 -9999 -9999 -9999 -9999 -9999 -9999 -9999 -9999 -9999 -9999 -9999 -9999 -9999 -9999 -9999 -9999 -9999 -9999 -9999 -9999 -9999 -9999 -9999 -9999 -9999 -9999 -9999 -9999 -9999 -9999 -9999 -9999 -9999 -9999 -9999 -9999 -9999 -9999 -9999 -9999 -9999 -9999 -9999 -9999 -9999 -9999 -9999 -9999 -9999 -9999 -9999 -9999 -9999 -9999 -9999 -9999 -9999 -9999 -9999 -9999 -9999 -9999 -9999 -9999 -9999 -9999 -9999 -9999 -9999 -9999 -9999 -9999 -9999 -9999 -9999 -9999 -9999 -9999 -9999 -9999 -9999 -9999 -9999 -9999 -9999 -9999 -9999 -9999 -9999 -9999 -9999 -9999 -9999 -9999 -9999 -9999 -9999 -9999 -9999 -9999 -9999 -9999 -

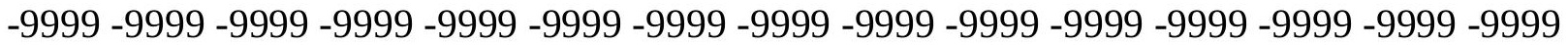
-9999 -9999 -9999 -9999 -9999 -9999 -9999 -9999 -9999 -9999 -9999 -9999 -9999 -9999 -9999 -9999 -9999 -9999 -9999 -9999 -9999 -9999 -9999 -9999 -9999 -9999 -9999 -9999 -9999 -9999 -9999 -9999-9999-9999-9999-9999 124.4780960083 119.744720459 114.5091171265 109.1130981445103 .322196960497 .8360290527392 .9594726562588 .99725341797 85.9494018554785 .9494018554786 .5589828491287 .1685485839887 .77810668945 88.3876876831188 .9972534179789 .6068267822389 .9116134643690 .21640014648 90.5211791992290 .5211791992290 .8259735107490 .8259735107491 .43553924561 91.7403335571392 .0450973510792 .349891662692 .9594726562593 .26425170898 93.5690307617294 .1785964965894 .4833908081194 .7881774902395 .09295654297 95.397743225195 .7025299072396 .0073165893696 .0073165893696 .31210327148 96.3121032714896 .0073165893696 .0073165893695 .7025299072395 .3977432251 
95.0929565429794 .4833908081194 .1785964965894 .1785964965894 .48339080811 95.0929565429795 .397743225195 .7025299072396 .0073165893696 .00731658936 95.7025299072395 .0929565429794 .4833908081193 .5690307617292 .04509735107 $90.5211791992288 .0829010009885 .3398437582 .2919769287179 .71612548828-9999-9999$ -9999 -9999 -9999 -9999 -9999 -9999 -9999 -9999 -9999 -9999 -9999 -9999-9999 -9999 -9999 -9999 -9999 -9999 -9999 -9999 -9999 -9999 -9999 -9999 -9999 -9999 -9999 -9999 -9999 -9999

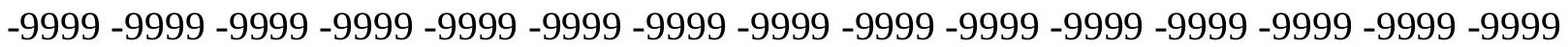
-9999 -9999-9999

-9999 -9999 -9999 -9999 -9999 -9999 -9999 -9999 -9999 -9999 -9999 -9999 -9999 -9999 -9999 -9999 -9999 -9999 -9999 -9999 -9999 -9999 -9999 -9999 -9999 -9999 -9999 -9999 -9999 -9999 -

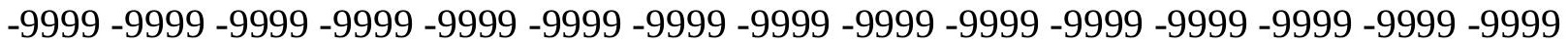
-9999 -9999 -9999 -9999 -9999 -9999 -9999 -9999 -9999 -9999 -9999 -9999 -9999 -9999 -9999 -9999 -9999 -9999 -9999 -9999 -9999 -9999 -9999 -9999 -9999 -9999 -9999 -9999 -9999 -9999 -9999 -9999 -9999 -9999 -9999 -9999 -9999 -9999 -9999 -9999 -9999 -9999 -9999 -9999 -9999 -9999 -9999 -9999 -9999 -9999 -9999 -9999 -9999 -9999 -9999 -9999 -9999 -9999 -9999 -9999

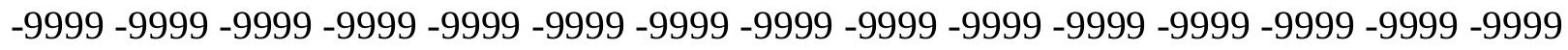
-9999 -9999 -9999 -9999 -9999 -9999 -9999 -9999 -9999 -9999 -9999 -9999 -9999 -9999 -9999 -

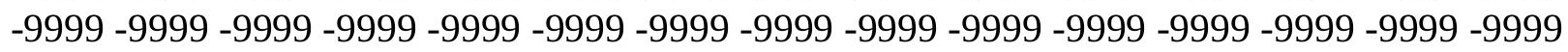

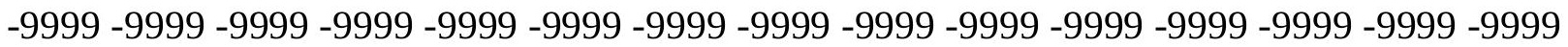

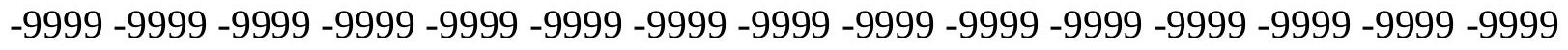

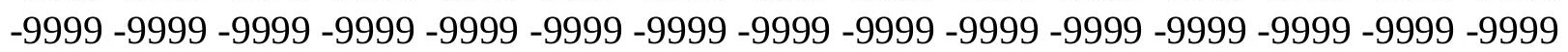

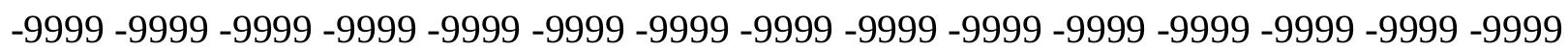
-9999 -9999 -9999 -9999 -9999 -9999 -9999 -9999 -9999 -9999 -9999 -9999 -9999 -9999 -9999 -9999 -9999 -9999 -9999 -9999 -9999 -9999 -9999 -9999 -9999 -9999 -9999 -9999 -9999 -9999 -

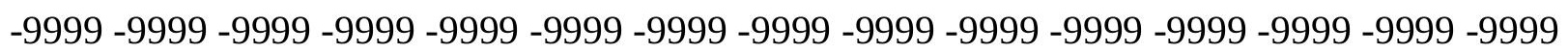
-9999 -9999 -9999 -9999 -9999 -9999 -9999 -9999 -9999 -9999 -9999 -9999 -9999 -9999 -9999 -9999 -9999 -9999 -9999 -9999 -9999 128.0097961426120 .4090957642115 .5939331055 110.4764022827105 .150901794499 .9695205688595 .0929565429791 .13075256348 87.7781066894586 .5589828491287 .1685485839887 .7781066894588 .38768768311 88.9972534179789 .302040100189 .9116134643690 .2164001464890 .52117919922 90.8259735107490 .8259735107491 .4355392456191 .4355392456191 .74033355713 92.0450973510792 .349891662692 .6546783447392 .9594726562593 .56903076172 93.8738174438594.1785964965894.4833908081195.0929565429795.3977432251 95.7025299072395 .7025299072396 .0073165893696 .0073165893696 .00731658936 96.0073165893696 .0073165893696 .0073165893695 .7025299072395 .3977432251 95.397743225195 .0929565429794 .7881774902394 .7881774902395 .09295654297 95.397743225195 .7025299072396 .0073165893696 .0073165893695 .70252990723 95.397743225194 .7881774902394 .1785964965892 .9594726562591 .43553924561 89.6068267822387 .1685485839884 .4254837036181 .9871978759879 .59954071045 -9999 -9999 -9999 -9999 -9999 -9999 -9999 -9999 -9999 -9999 -9999 -9999 -9999 -9999 -9999 -9999

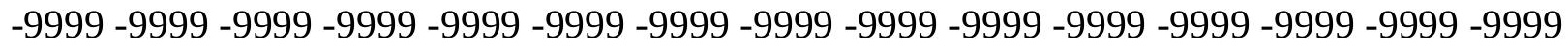

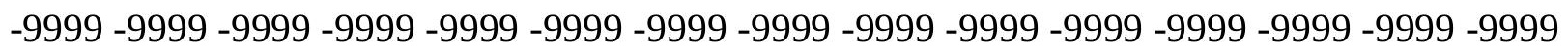
-9999 -9999 -9999-9999

-9999 -9999 -9999 -9999 -9999 -9999 -9999 -9999 -9999 -9999 -9999 -9999 -9999 -9999 -9999 -9999 -9999 -9999 -9999 -9999 -9999 -9999 -9999 -9999 -9999 -9999 -9999 -9999 -9999 -9999 -

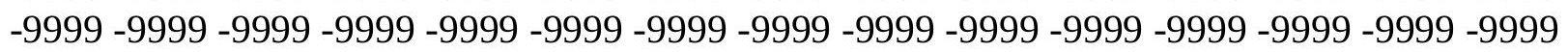


-9999 -9999 -9999 -9999 -9999 -9999 -9999 -9999 -9999 -9999 -9999 -9999 -9999 -9999 -9999 -9999 -9999 -9999 -9999 -9999 -9999 -9999 -9999 -9999 -9999 -9999 -9999 -9999 -9999 -9999 -9999 -9999 -9999 -9999 -9999 -9999 -9999 -9999 -9999 -9999 -9999 -9999 -9999 -9999 -9999 -9999 -9999 -9999 -9999 -9999 -9999 -9999 -9999 -9999 -9999 -9999 -9999 -9999 -9999 -9999 -9999 -9999 -9999 -9999 -9999 -9999 -9999 -9999 -9999 -9999 -9999 -9999 -9999 -9999 -9999 -9999 -9999 -9999 -9999 -9999 -9999 -9999 -9999 -9999 -9999 -9999 -9999 -9999 -9999 -9999 -9999 -9999 -9999 -9999 -9999 -9999 -9999 -9999 -9999 -9999 -9999 -9999 -9999 -9999 -9999

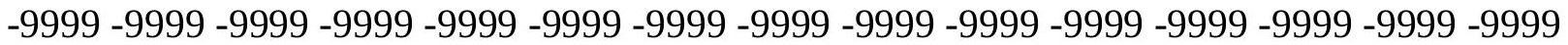
-9999 -9999 -9999 -9999 -9999 -9999 -9999 -9999 -9999 -9999 -9999 -9999 -9999 -9999 -9999 -9999 -9999 -9999 -9999 -9999 -9999 -9999 -9999 -9999 -9999 -9999 -9999 -9999 -9999 -9999 -

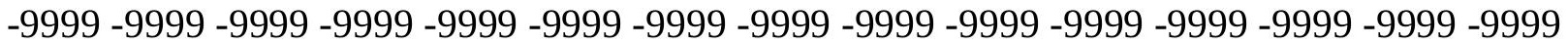
-9999 -9999 -9999 -9999 -9999 -9999 -9999 -9999 -9999 -9999 -9999 -9999 -9999 -9999 -9999

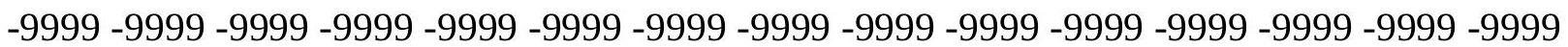
-9999 -9999 -9999 -9999 -9999 -9999 -9999 -9999 -9999 -9999 -9999 -9999 -9999 -9999 -9999 -9999 -9999 -9999 -9999 -9999 -9999 -9999 -9999 -9999 -9999 -9999 -9999 -9999 -9999 -9999 -9999 -9999 -9999 -9999 -9999 -9999 -9999 124.0475006104116 .4211425781111 .7344589233 107.0058441162102 .407798767197 .5312423706193 .2642517089889 .60682678223 86.8637619018687 .4733276367288 .0829010009888 .6924667358489 .3020401001 89.9116134643690 .2164001464890 .8259735107490 .8259735107491 .13075256348 91.1307525634891 .4355392456191 .7403335571392 .0450973510792 .3498916626 92.6546783447392 .9594726562593 .2642517089893 .8738174438594 .17859649658 94.4833908081194 .7881774902395 .0929565429795 .397743225195 .70252990723 95.7025299072396 .0073165893696 .0073165893696 .3121032714896 .31210327148 96.0073165893696 .0073165893696 .0073165893695 .7025299072395 .70252990723 95.397743225195 .397743225195 .7025299072395 .7025299072396 .00731658936 96.0073165893696 .3121032714896 .0073165893695 .7025299072395 .3977432251 94.4833908081193 .5690307617292 .349891662690 .8259735107488 .69246673584 86.5589828491284 .1206970214881 .6824111938579 .35852813721 -9999 -9999 -9999 -9999 -9999 -9999 -9999 -9999 -9999 -9999 -9999 -9999 -9999 -9999 -9999 -9999 -9999 -9999 -9999 -9999 -9999 -9999 -9999 -9999 -9999 -9999 -9999 -9999 -9999 -9999 -9999 -9999 -9999 -9999 -999 -9999 -9999 -9999 -9999 -9999 -9999 -9999 -9999 -9999 -9999 -9999 -9999 -9999 -9999 -9999 $-9999$

-9999 -9999 -9999 -9999 -9999 -9999 -9999 -9999 -9999 -9999 -9999 -9999 -9999 -9999 -9999 -9999 -9999 -9999 -9999 -9999 -9999 -9999 -9999 -9999 -9999 -9999 -9999 -9999 -9999 -9999 -

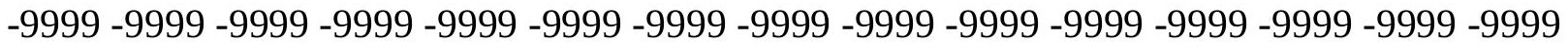
-9999 -9999 -9999 -9999 -9999 -9999 -9999 -9999 -9999 -9999 -9999 -9999 -9999 -9999 -9999 -9999 -9999 -9999 -9999 -9999 -9999 -9999 -9999 -9999 -9999 -9999 -9999 -9999 -9999 -9999

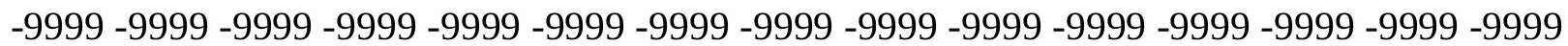
-9999 -9999 -9999 -9999 -9999 -9999 -9999 -9999 -9999 -9999 -9999 -9999 -9999 -9999 -9999 -9999 -9999 -9999 -9999 -9999 -9999 -9999 -9999 -9999 -9999 -9999 -9999 -9999 -9999 -9999 -9999 -9999 -9999 -9999 -9999 -9999 -9999 -9999 -9999 -9999 -9999 -9999 -9999 -9999 -9999 -999 -9999 -9999 -9999 -9999 -9999 -9999 -9999 -9999 -9999 -9999 -9999 -9999 -9999 -9999 -9999 -9999 -9999 -9999 -9999 -9999 -9999 -9999 -9999 -9999 -9999 -9999 -9999 -9999 -9999 -9999 -9999 -9999 -9999 -9999 -9999 -9999 -9999 -9999 -9999 -9999 -9999 -9999 -9999 -9999 -9999 -9999 -9999 -9999 -9999 -9999 -9999 -9999 -9999 -9999 -9999 -9999 -9999 -9999 -9999 -9999

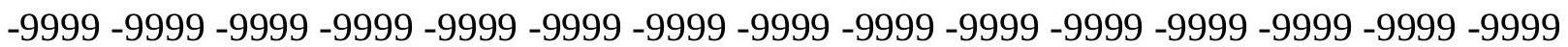


-9999 -9999 -9999 -9999 -9999 -9999 -9999 -9999 -9999 -9999 -9999 -9999 -9999 -9999 -9999 -9999 -9999 -9999 -9999 -9999 -9999 -9999 -9999 -9999 -9999 -9999 -9999 -9999 -9999 -9999

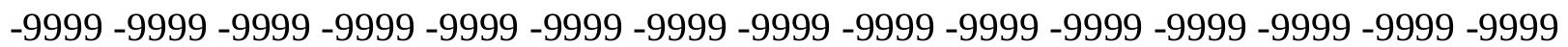
-9999 -9999 -9999 -9999 -9999 -9999 -9999 -9999 -9999 -9999 -9999 -9999 -9999 -9999 -9999 -9999 -9999 -9999 -9999 -9999 -9999-9999 125.5715026855120 .3900985718112 .7727661133 108.4751739502104 .204299926899 .9695205688595 .397743225191 .74033355713 88.0829010009888 .0829010009888 .6924667358489 .302040100189 .91161346436 90.5211791992290 .8259735107491 .1307525634891 .4355392456191 .43553924561 91.7403335571391 .7403335571392 .0450973510792 .349891662692 .65467834473 92.9594726562593 .2642517089893 .5690307617293 .8738174438594 .17859649658 94.7881774902395 .0929565429795 .397743225195 .397743225195 .70252990723 96.0073165893696 .0073165893696 .3121032714896 .3121032714896 .31210327148 96.3121032714896 .3121032714896 .0073165893696 .0073165893696 .00731658936 96.0073165893696 .0073165893696 .3121032714896 .3121032714896 .61688232422 96.6168823242296 .6168823242296 .3121032714896 .0073165893695 .3977432251 94.4833908081193 .2642517089891 .7403335571390 .2164001464888 .08290100098 85.9494018554783 .5111236572381 .0728530883879 .01314544678 -9999 -9999 -9999-9999 -9999 -9999 -9999 -9999 -9999 -9999 -9999 -9999 -9999 -9999 -9999 -9999 -9999 -9999 -9999 -9999 -9999 -9999 -9999 -9999 -9999 -9999 -9999 -9999 -9999 -9999 -9999 -9999 -9999 -9999

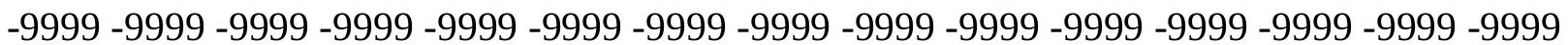
$-9999$

-9999 -9999 -9999 -9999 -9999 -9999 -9999 -9999 -9999 -9999 -9999 -9999 -9999 -9999 -9999 -9999 -9999 -9999 -9999 -9999 -9999 -9999 -9999 -9999 -9999 -9999 -9999 -9999 -9999 -9999 -9999 -9999 -9999 -9999 -9999 -9999 -9999 -9999 -9999 -9999 -9999 -9999 -9999 -9999 -9999 -9999 -9999 -9999 -9999 -9999 -9999 -9999 -9999 -9999 -9999 -9999 -9999 -9999 -9999 -9999 -9999 -9999 -9999 -9999 -9999 -9999 -9999 -9999 -9999 -9999 -9999 -9999 -9999 -9999 -9999 -9999 -9999 -9999 -9999 -9999 -9999 -9999 -9999 -9999 -9999 -9999 -9999 -9999 -9999 -9999 -

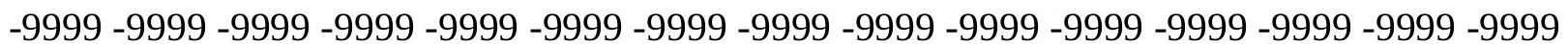
-9999 -9999 -9999 -9999 -9999 -9999 -9999 -9999 -9999 -9999 -9999 -9999 -9999 -9999 -9999 -9999 -9999 -9999 -9999 -9999 -9999 -9999 -9999 -9999 -9999 -9999 -9999 -9999 -9999 -9999 -9999 -9999 -9999 -9999 -9999 -9999 -9999 -9999 -9999 -9999 -9999 -9999 -9999 -9999 -9999 -9999 -9999 -9999 -9999 -9999 -9999 -9999 -9999 -9999 -9999 -9999 -9999 -9999 -9999 -9999 -9999 -9999 -9999 -9999 -9999 -9999 -9999 -9999 -9999 -9999 -9999 -9999 -9999 -9999 -9999 -9999 -9999 -9999 -9999 -9999 -9999 -9999 -9999 -9999 -9999 -9999 -9999 -9999 -9999 -9999 -

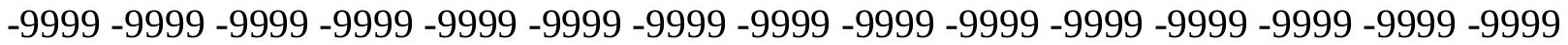
-9999 -9999 -9999 -9999 -9999 -9999 -9999 -9999 -9999 -9999 -9999 -9999 -9999 -9999 -9999 -9999 -9999 -9999 -9999 -9999 -9999 -9999 -9999 -9999 -9999 -9999 -9999 -9999 -9999 -9999

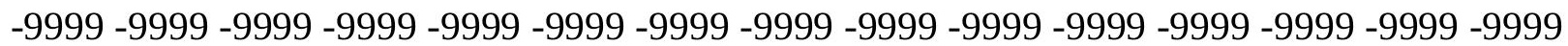
-9999 -9999 -9999 -9999 -9999 -9999 -9999 -9999 -9999 -9999 -9999 -9999 -9999 -9999 -9999 -9999 -9999 -9999 -9999 -9999 -9999 -9999 -9999 121.9140014648116 .7326965332 109.5040893555105 .5389251709101 .646949768197 .8360290527393 .56903076172 89.9116134643688 .6924667358489 .302040100189 .9116134643690 .52117919922 91.1307525634891 .4355392456191 .7403335571391 .7403335571392 .04509735107 92.0450973510792 .349891662692 .6546783447392 .6546783447392 .95947265625 93.2642517089893 .5690307617293 .8738174438594 .1785964965894 .48339080811 94.7881774902395 .0929565429795 .397743225195 .7025299072396 .00731658936 
96.0073165893696 .3121032714896 .3121032714896 .3121032714896 .31210327148 96.3121032714896 .3121032714896 .3121032714896 .3121032714896 .31210327148 96.6168823242296 .6168823242296 .9216690063596 .9216690063597 .22646331787 97.2264633178796 .9216690063596 .6168823242296 .0073165893695 .09295654297 94.1785964965892 .9594726562591 .4355392456189 .6068267822387 .47332763672 85.3398437583 .206336975180 .7680587768678 .64893341064 -9999 -9999 -9999 -9999 -9999 -9999 -9999 -9999 -9999 -9999 -9999 -9999 -9999 -9999 -9999 -9999 -9999 -9999 -9999 -9999

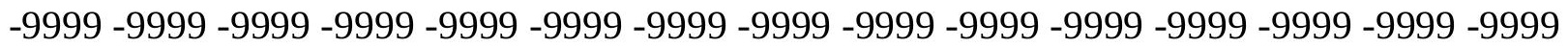
-9999 -9999 -9999 -9999 -9999 -9999 -9999 -9999 -9999 -9999 -9999 -9999 -9999 -9999 -9999 -9999 -9999 -9999 -9999 -9999 -9999 -9999 -9999 -9999 -9999 -9999 -9999 -9999 -9999 -9999 -

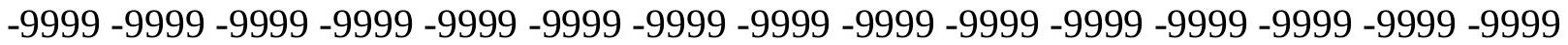
-9999 -9999 -9999 -9999 -9999 -9999 -9999 -9999 -9999 -9999 -9999 -9999 -9999 -9999 -9999 -9999 -9999 -9999 -9999 -9999 -9999 -9999 -9999 -9999 -9999 -9999 -9999 -9999 -9999 -9999 -9999 -9999 -9999 -9999 -9999 -9999 -9999 -9999 -9999 -9999 -9999 -9999 -9999 -9999 -9999 -9999 -9999 -9999 -9999 -9999 -9999 -9999 -9999 -9999 -9999 -9999 -9999 -9999 -9999 -9999

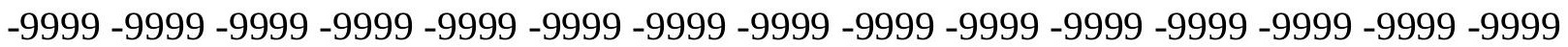

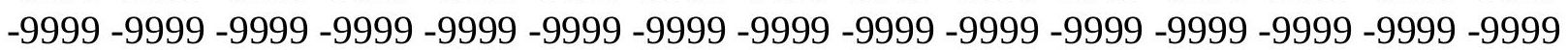
-9999 -9999 -9999 -9999 -9999 -9999 -9999 -9999 -9999 -9999 -9999 -9999 -9999 -9999 -9999 -999 -9999 -9999 -9999 -9999 -9999 -9999 -9999 -9999 -9999 -9999 -9999 -9999 -9999 -9999 -9999 -9999 -9999 -9999 -9999 -9999 -9999 -9999 -9999 -9999 -9999 -9999 -9999 -9999 -9999 -9999 -9999 -9999 -9999 -9999 -9999 -9999 -9999 -9999 -9999 -9999 -9999 -9999 -9999 -9999 -9999 -999 -9999 -9999 -9999 -9999 -9999 -9999 -9999 -9999 -9999 -9999 -9999 -9999 -9999 -9999 -9999 -9999 -9999 -9999 -9999 -9999 -9999 -9999 -9999 -9999 -9999 -9999 -9999 -9999 -9999 -9999 -9999 -9999 -9999 -9999 -9999 -9999 -9999 -9999 -9999 -9999 -9999 -9999 -9999 -9999 -9999 -9999 -9999 -9999 -9999 -9999 -9999 -9999 -9999 -9999 -9999 -9999 -9999 -9999 -9999 -9999 -9999 -9999 -9999 -9999 -9999 -9999 -9999 -9999 -9999 -9999 -9999 -9999 -9999 -9999 -9999 -9999 -9999 -9999 -9999 -9999-9999 -9999 -9999 -9999 -9999 -9999 -9999 -9999 -9999 - -9999 -9999 -9999 -9999 -9999 -9999 -9999 -9999 -9999 123.1332015991118 .5614013672 113.6848983765106 .3972396851102 .724388122699 .1709060668995 .70252990723 91.4355392456189 .302040100189 .9116134643690 .5211791992291 .13075256348 91.4355392456192 .0450973510792 .0450973510792 .349891662692 .3498916626 92.6546783447392 .6546783447392 .9594726562593 .2642517089893 .26425170898 93.5690307617293 .8738174438594 .1785964965894 .4833908081194 .78817749023 95.0929565429795 .397743225195 .7025299072395 .7025299072396 .00731658936 96.3121032714896 .3121032714896 .3121032714896 .3121032714896 .61688232422 96.6168823242296 .6168823242296 .6168823242296 .6168823242296 .92166900635 96.9216690063597 .2264633178797 .5312423706197 .5312423706197 .53124237061 97.5312423706197 .2264633178796 .9216690063596 .3121032714895 .09295654297 93.8738174438592 .6546783447390 .8259735107488 .9972534179787 .16854858398 85.0350494384882 .5967712402380 .3569488525478 .25050354004 -9999 -9999 -9999 -9999 -9999 -9999 -9999 -9999 -9999 -9999 -9999 -9999 -9999 -9999 -9999 -9999 -9999 -9999 -9999 -9999 -9999 -9999 -9999 -9999 -9999 -9999 -9999 -9999 -9999 -9999 -9999 -9999 -9999 -9999 -

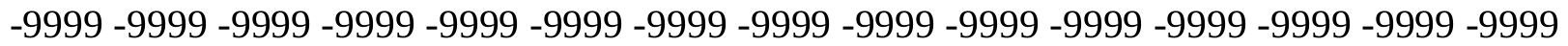
$-9999$

-9999 -9999 -9999 -9999 -9999 -9999 -9999 -9999 -9999 -9999 -9999 -9999 -9999 -9999 -9999

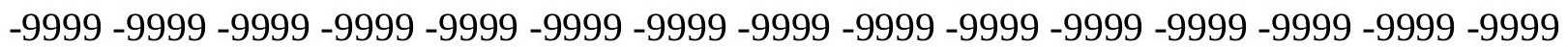


-9999 -9999 -9999 -9999 -9999 -9999 -9999 -9999 -9999 -9999 -9999 -9999 -9999 -9999 -9999 -9999 -9999 -9999 -9999 -9999 -9999 -9999 -9999 -9999 -9999 -9999 -9999 -9999 -9999 -9999 -9999 -9999 -9999 -9999 -9999 -9999 -9999 -9999 -9999 -9999 -9999 -9999 -9999 -9999 -9999 -9999 -9999 -9999 -9999 -9999 -9999 -9999 -9999 -9999 -9999 -9999 -9999 -9999 -9999 -9999 -9999 -9999 -9999 -9999 -9999 -9999 -9999 -9999 -9999 -9999 -9999 -9999 -9999 -9999 -9999 -9999 -9999 -9999 -9999 -9999 -9999 -9999 -9999 -9999 -9999 -9999 -9999 -9999 -9999 -9999 -9999 -9999 -9999 -9999 -9999 -9999 -9999 -9999 -9999 -9999 -9999 -9999 -9999 -9999 -9999

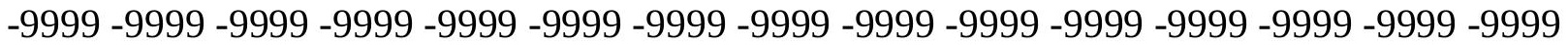
-9999 -9999 -9999 -9999 -9999 -9999 -9999 -9999 -9999 -9999 -9999 -9999 -9999 -9999 -9999 -9999 -9999 -9999 -9999 -9999 -9999 -9999 -9999 -9999 -9999 -9999 -9999 -9999 -9999 -9999 -

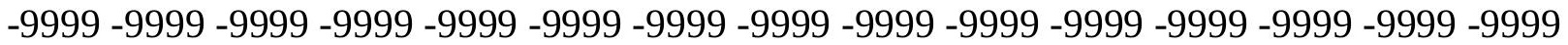
-9999 -9999 -9999 -9999 -9999 -9999 -9999 -9999 -9999 -9999 -9999 -9999 -9999 -9999 -9999

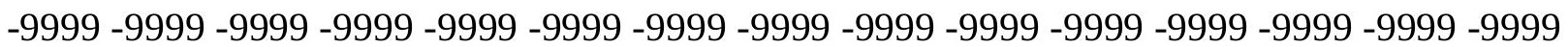
-9999 -9999 -9999 -9999 -9999 -9999 -9999 -9999 -9999 -9999 -9999 -9999 -9999 -9999 -9999 -9999 -9999 -9999 -9999 -9999 -9999 -9999 -9999 -9999 -9999 -9999 -9999 -9999 -9999 -9999 -9999 -9999 -9999 -9999 -9999 -9999 -9999 -9999 -9999 -9999 -9999 -9999 -9999 -9999 -9999 -9999 -9999 -9999 -9999 -9999 -9999 -9999 -9999 -9999 120.0852966309115 .5136032104 111.24659729103 .298332214499 .7998199462996 .3641738891693 .26425170898 90.2164001464890 .5211791992291 .1307525634891 .7403335571392 .3498916626 92.349891662692 .6546783447392 .6546783447392 .9594726562592 .95947265625 93.2642517089893 .2642517089893 .5690307617293 .8738174438593 .87381744385 94.1785964965894 .4833908081194 .7881774902395 .0929565429795 .09295654297 95.397743225195 .7025299072396 .0073165893696 .0073165893696 .31210327148 96.3121032714896 .6168823242296 .6168823242296 .6168823242296 .61688232422 96.6168823242296 .9216690063596 .9216690063597 .2264633178797 .53124237061 97.5312423706197.83602905273 98.1408081054798.1408081054798.14080810547 97.8360290527397 .2264633178796 .3121032714895 .0929565429793 .87381744385 92.0450973510790 .5211791992288 .3876876831186 .254188537684 .12069702148 81.9871978759879 .8252792358477 .72682189941 -9999 -9999 -9999 -9999 -9999 -9999 -9999 -9999 -9999 -9999 -9999 -9999 -9999 -9999 -9999 -9999 -9999 -9999 -9999 -9999 -9999 -9999 -9999 -9999 -9999 -9999 -9999 -9999 -9999 -9999 -9999 -9999 -9999 -9999 -9999 -9999 -9999 -9999 -9999 -9999 -9999 -9999 -9999 -9999 -9999 -9999 -9999 -9999 -9999 -9999 -9999 -9999 -9999 -9999 -9999 -9999 -9999 -9999 -9999 -9999 -9999 -9999 -9999 -9999 -9999 -9999 -9999 -9999 -9999 -9999 -9999 -9999 -9999 -9999 -9999 -9999 -9999 -9999 -9999 -9999 -

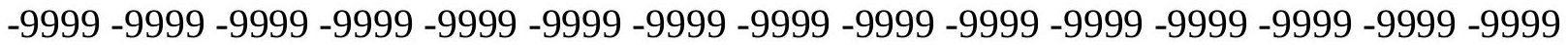
-9999 -9999 -9999 -9999 -9999 -9999 -9999 -9999 -9999 -9999 -9999 -9999 -9999 -9999 -9999 -9999 -9999 -9999 -9999 -9999 -9999 -9999 -9999 -9999 -9999 -9999 -9999 -9999 -9999 -9999

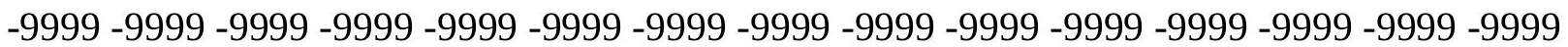
-9999 -9999 -9999 -9999 -9999 -9999 -9999 -9999 -9999 -9999 -9999 -9999 -9999 -9999 -9999 -9999 -9999 -9999 -9999 -9999 -9999 -9999 -9999 -9999 -9999 -9999 -9999 -9999 -9999 -9999 -9999 -9999 -9999 -9999 -9999 -9999 -9999 -9999 -9999 -9999 -9999 -9999 -9999 -9999 -9999 -999 -9999 -9999 -9999 -9999 -9999 -9999 -9999 -9999 -9999 -9999 -9999 -9999 -9999 -9999 -9999 -9999 -9999 -9999 -9999 -9999 -9999 -9999 -9999 -9999 -9999 -9999 -9999 -9999 -9999 -9999 -9999 -9999 -9999 -9999 -9999 -9999 -9999 -9999 -9999 -9999 -9999 -9999 -9999 -9999 -9999 -9999 -9999 -9999 -9999 -9999 -9999 -9999 -9999 -9999 -9999 -9999 -9999 -9999 -9999 -9999

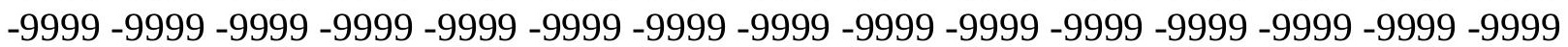


-9999 -9999 -9999 -9999 -9999 -9999 -9999 -9999 -9999 -9999 -9999 -9999 -9999 -9999 -9999 -9999 -9999 -9999 -9999 -9999 -9999 -9999 -9999 -9999 -9999 -9999 -9999 -9999 -9999 -9999 -9999 -9999 -9999 -9999 -9999 -9999 -9999 -9999 -9999 -9999 -9999 -9999 -9999 -9999 -9999 -9999 -9999 -9999 -9999 -9999 -9999 -9999 -9999 -9999 -9999 -9999 -9999 -9999 -9999 -9999 -9999 -9999 -9999 -9999 -9999 -9999 -9999-9999 -9999 121.6092987061117 .342300415 113.075302124108 .8082962036100 .128738403396 .7666778564593 .55889129639 90.8259735107491 .1307525634891 .7403335571392 .349891662692 .95947265625 92.9594726562593 .2642517089893 .2642517089893 .2642517089893 .56903076172 93.5690307617293 .8738174438593 .8738174438594 .1785964965894 .17859649658 94.4833908081194 .7881774902395 .0929565429795 .0929565429795 .3977432251 95.7025299072396 .0073165893696 .0073165893696 .3121032714896 .31210327148 96.6168823242296 .6168823242296 .9216690063596 .9216690063596 .92166900635 96.9216690063596 .9216690063597 .2264633178797 .5312423706197 .83602905273 98.1408081054798 .445587158298 .445587158298 .7503814697398 .4455871582 98.1408081054797 .5312423706196 .6168823242295 .0929565429793 .56903076172 91.7403335571389 .9116134643687 .7781066894585 .6446228027383 .51112365723 81.3776321411179 .1509323120177 .06860351562 -9999 -9999 -9999 -9999 -9999 -9999-9999 -9999 -9999 -9999 -9999 -9999 -9999 -9999 -9999 -9999 -9999 -9999 -9999 -9999 -9999 -9999 -9999 -9999 -9999 -9999 -9999 -9999 -9999 -9999 -9999 -9999 -9999 -9999 -9999 -9999 -9999 -9999 -9999 -9999 -9999 -9999 -9999 -9999 -9999 -9999 -9999 -9999 -9999 -9999 -

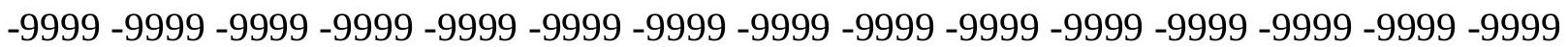
-9999 -9999 -9999 -9999 -9999 -9999 -9999 -9999 -9999 -9999 -9999 -9999 -9999 -9999 -9999 -9999 -9999 -9999 -9999 -9999 -9999 -9999 -9999 -9999 -9999 -9999 -9999 -9999 -9999 -9999 -9999 -9999 -9999 -9999 -9999 -9999 -9999 -9999 -9999 -9999 -9999 -9999 -9999 -9999 -9999

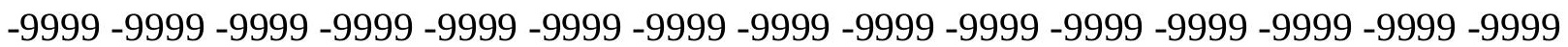
-9999 -9999 -9999 -9999 -9999 -9999 -9999 -9999 -9999 -9999 -9999 -9999 -9999 -9999 -9999 -9999 -9999 -9999 -9999 -9999 -9999 -9999 -9999 -9999 -9999 -9999 -9999 -9999 -9999 -9999 -9999 -9999 -9999 -9999 -9999 -9999 -9999 -9999 -9999 -9999 -9999 -9999 -9999 -9999 -9999 -9999 -9999 -9999 -9999 -9999 -9999 -9999 -9999 -9999 -9999 -9999 -9999 -9999 -9999 -9999 -9999 -9999 -9999 -9999 -9999 -9999 -9999 -9999 -9999 -9999 -9999 -9999 -9999 -9999 -9999 -9999 -9999 -9999 -9999 -9999 -9999 -9999 -9999 -9999 -9999 -9999 -9999 -9999 -9999 -9999 -9999 -9999 -9999 -9999 -9999 -9999 -9999 -9999 -9999 -9999 -9999 -9999 -9999 -9999 -9999 -9999 -9999 -9999 -9999 -9999 -9999 -9999 -9999 -9999 -9999 -9999 -9999 -9999 -9999 -9999 -9999 -9999 -9999 -9999 -9999 -9999 -9999 -9999 -9999 -9999 -9999 -9999 -9999 -9999 -9999 -9999 -9999 -9999 -9999 -9999 -9999 -9999 -9999 -9999 -9999 -9999 -9999 -9999 -9999 -9999 -9999 -9999 -9999 -9999 -9999 -9999 -9999 -9999 -9999 -9999 -9999 -9999 -9999 -9999 -9999 -9999 -9999 -9999 -9999 -9999 -9999 -9999 -9999 -9999 -9999 -9999 -9999 -9999 -9999 -9999 -9999 -9999 -9999 -9999 -9999 -9999 -9999 -9999 -9999 -9999 -9999 -9999 -9999 -9999 -9999 -9999 -9999 -9999 -9999 -9999 -9999 -9999 -9999 -9999 122.8283996582119 .1709976196 115.2088012695110 .6370010376106 .065200805797 .233818054294 .41316223145 92.5508270263792 .0450973510792 .6546783447393 .2642517089893 .26425170898 93.5690307617293 .5690307617293 .8738174438593 .8738174438593 .87381744385 94.1785964965894 .1785964965894 .4833908081194 .4833908081194 .78817749023 94.7881774902395 .0929565429795 .0929565429795 .397743225195 .70252990723 96.0073165893696 .0073165893696 .3121032714896 .6168823242296 .61688232422 96.6168823242296 .9216690063596 .9216690063596 .9216690063597 .22646331787 
97.2264633178797.2264633178797.5312423706197.8360290527398.14080810547 98.445587158298 .445587158298 .7503814697398 .7503814697398 .75038146973 98.445587158297 .8360290527396 .6168823242294 .7881774902392 .95947265625 91.1307525634889 .302040100187 .1685485839885 .0350494384882 .90155792236 80.4632720947378 .3181228637776 .30086517334 -9999 -9999 -9999 -9999 -9999 -9999 -9999 -9999 -9999 -9999 -9999 -9999 -9999 -9999 -9999 -9999 -9999 -9999 -9999 -9999 -9999 -9999

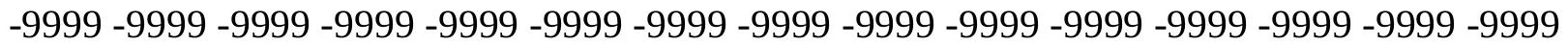
-9999 -9999 -9999 -9999 -9999 -9999 -9999 -9999 -9999 -9999 -9999 -9999 -9999 -9999 -9999 -9999 -9999 -9999 -9999 -9999 -9999 -9999 -9999 -9999 -9999 -9999 -9999 -9999 -9999 -9999 -9999 -9999 -9999 -9999 -9999 -9999 -9999 -9999 -9999 -9999 -9999 -9999 -9999 -

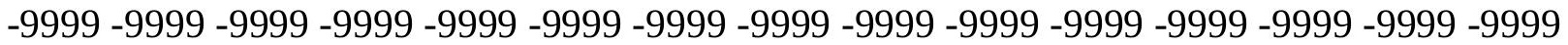
-9999 -9999 -9999 -9999 -9999 -9999 -9999 -9999 -9999 -9999 -9999 -9999 -9999 -9999 -9999 -9999 -9999 -9999 -9999 -9999 -9999 -9999 -9999 -9999 -9999 -9999 -9999 -9999 -9999 -9999 -9999 -9999 -9999 -9999 -9999 -9999 -9999 -9999 -9999 -9999 -9999 -9999 -9999 -9999 -9999 -9999 -9999 -9999 -9999 -9999 -9999 -9999 -9999 -9999 -9999 -9999 -9999 -9999 -9999 -9999

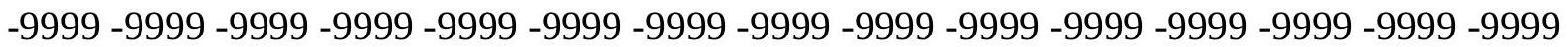

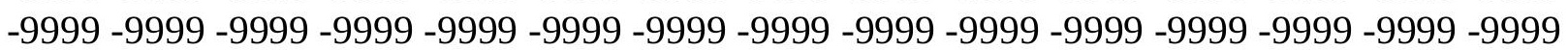
-9999 -9999 -9999 -9999 -9999 -9999 -9999 -9999 -9999 -9999 -9999 -9999 -9999 -9999 -9999 -9999 -9999 -9999 -9999 -9999 -9999 -9999 -9999 -9999 -9999 -9999 -9999 -9999 -9999 -9999 -9999 -9999 -9999 -9999 -9999 -9999 -9999 -9999 -9999 -9999 -9999 -9999 -9999 -9999 -9999 -9999 -9999 -9999 -9999 -9999 -9999 -9999 -9999 -9999 -9999 -9999 -9999 -9999 -9999 -9999 -9999 -9999 -9999 -9999 -9999 -9999 -9999 -9999 -9999 -9999 -9999 -9999 -9999 -9999 -9999 -9999 -9999 -9999 -9999 -9999 -9999 -9999 -9999 -9999 -9999 -9999 -9999 -9999 -9999 -9999 -9999 -9999 -9999 -9999 -9999 -9999 -9999 -9999 -9999 -9999 -9999 -9999 -9999 -9999 -9999

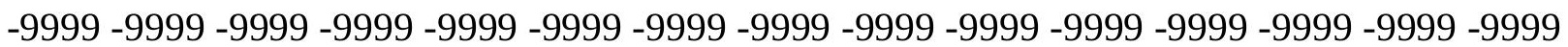
-9999 -9999 -9999 -9999 -9999 -9999 -9999 -9999 -9999 -9999 -9999 -9999 -9999 -9999 -9999 -9999 -9999 -9999 -9999 -9999 -9999 -9999 -9999 -9999 -9999 120.6949005127 117.0374984741112 .4656982422107 .5891036987102 .71260070895 .55541992188 93.9932861328192 .9594726562593 .5690307617293 .8738174438593 .87381744385 93.8738174438594 .1785964965894 .1785964965894 .4833908081194 .48339080811 94.4833908081194 .7881774902394 .7881774902394 .7881774902395 .09295654297 95.0929565429795 .397743225195 .397743225195 .7025299072396 .00731658936 96.0073165893696 .3121032714896 .6168823242296 .6168823242296 .92166900635 96.9216690063596 .9216690063597 .2264633178797 .2264633178797 .22646331787 97.5312423706197 .5312423706197 .8360290527397 .8360290527398 .14080810547 98.445587158298 .7503814697398 .7503814697398 .7503814697398 .75038146973 98.445587158297 .8360290527396 .3121032714894 .4833908081192 .65467834473 90.5211791992288 .3876876831186 .254188537684 .1206970214881 .98719787598 79.5489196777377 .4154205322375 .45218658447 -9999 -9999 -9999 -9999 -9999 -9999 -9999 -9999 -9999 -9999 -9999 -9999 -9999 -9999 -9999 -9999 -9999 -9999 -9999 -9999 -9999 -9999

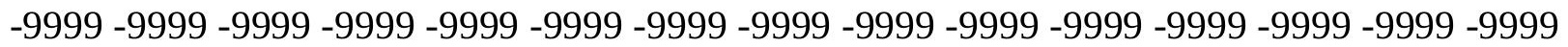
-9999 -9999 -9999 -9999 -9999 -9999 -9999 -9999 -9999 -9999 -9999 -9999 -9999 -9999 -9999 -9999 -9999 -9999 -9999 -9999 -9999 -9999 -9999 -9999 -9999 -9999 -9999 -9999 -9999 -9999 -9999 -9999 -9999 -9999 -9999 -9999 -9999 -9999 -9999 -9999 -9999 -9999 -9999 -9999 -9999 -9999 -9999 -9999 -9999 -9999 -9999 -9999 -9999 -9999 -9999 -9999 -9999 -9999

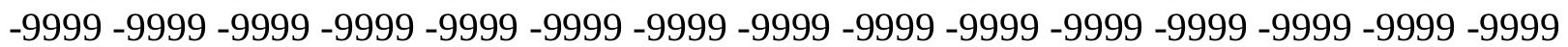


-9999 -9999 -9999 -9999 -9999 -9999 -9999 -9999 -9999 -9999 -9999 -9999 -9999 -9999 -9999 -9999 -9999 -9999 -9999 -9999 -9999 -9999 -9999 -9999 -9999 -9999 -9999 -9999 -9999 -9999 -9999 -9999 -9999 -9999 -9999 -9999 -9999 -9999 -9999 -9999 -9999 -9999 -9999 -9999 -9999 -9999 -9999 -9999 -9999 -9999 -9999 -9999 -9999 -9999 -9999 -9999 -9999 -9999 -9999 -9999 -9999 -9999 -9999 -9999 -9999 -9999 -9999 -9999 -9999 -9999 -9999 -9999 -9999 -9999 -9999 -9999 -9999 -9999 -9999 -9999 -9999 -9999 -9999 -9999 -9999 -9999 -9999 -9999 -9999 -9999 -9999 -9999 -9999 -9999 -9999 -9999 -9999 -9999 -9999 -9999 -9999 -9999 -9999 -9999 -9999

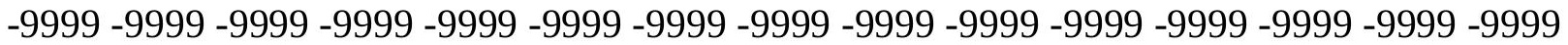
-9999 -9999 -9999 -9999 -9999 -9999 -9999 -9999 -9999 -9999 -9999 -9999 -9999 -9999 -9999 -9999 -9999 -9999 -9999 -9999 -9999 -9999 -9999 -9999 -9999 -9999 -9999 -9999 -9999 -9999 -

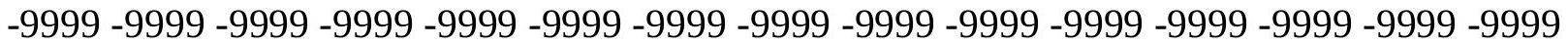
-9999 -9999 -9999 -9999 -9999 -9999 -9999 -9999 -9999 -9999 -9999 -9999 -9999 -9999 -9999

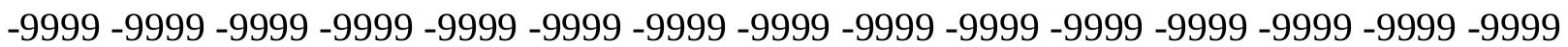
-9999 -9999 -9999 -9999 -9999 -9999 -9999 -9999 -9999 -9999 -9999 -9999 -9999 -9999 -9999 -9999 -9999 -9999 -9999 -9999 -9999 -9999 -9999 -9999 -9999 122.8283996582 118.2565994263113 .6848983765108 .8082962036103 .931701660299 .35994720459 95.0929565429793 .8738174438594 .1785964965894 .1785964965894 .48339080811 94.4833908081194 .7881774902394 .7881774902395 .0929565429795 .09295654297 95.0929565429795 .0929565429795 .0929565429795 .397743225195 .3977432251 95.397743225195 .7025299072395 .7025299072396 .0073165893696 .00731658936 96.3121032714896 .6168823242296 .6168823242296 .9216690063596 .92166900635 97.22646331787 97.2264633178797.22646331787 97.5312423706197.53124237061 97.5312423706197 .8360290527397 .8360290527398 .1408081054798 .14080810547 98.445587158298 .7503814697398 .7503814697398 .7503814697398 .4455871582 97.8360290527396 .9216690063595 .7025299072393 .8738174438591 .74033355713 89.91161346436 87.77810668945 85.33984375 83.206336975181.07285308838 78.6345596313576 .5010681152374 .57447814941 -9999 -9999 -9999 -9999 -9999 -9999-9999 -9999 -9999 -9999 -9999 -9999 -9999 -9999 -9999 -9999 -9999 -9999 -9999 -9999 -9999 -9999 -9999 -9999 -9999 -9999 -9999 -9999 -9999 -9999 -9999 -9999 -9999 -9999 -9999 -9999 -999 -9999 -9999 -9999 -9999 -9999 -9999 -9999 -9999 -9999 -9999 -9999 -9999 -9999 - 9999 -9999 -9999 -9999 -9999 -9999 -9999 -9999 -9999 -9999 -9999 -9999 -9999 -9999 -9999 -9999

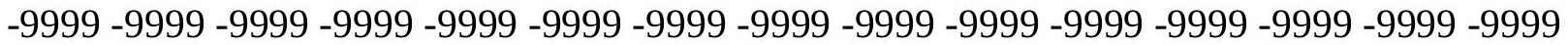

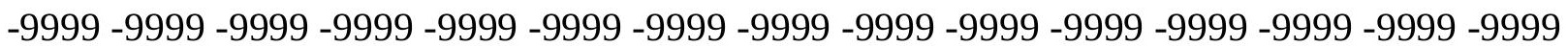
-9999 -9999 -9999 -9999 -9999 -9999 -9999 -9999 -9999 -9999 -9999 -9999 -9999 -9999 -9999 -

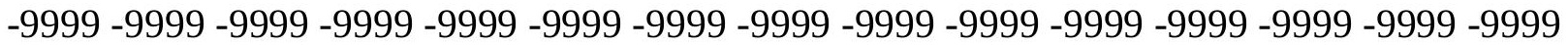
-9999 -9999 -9999 -9999 -9999 -9999 -9999 -9999 -9999 -9999 -9999 -9999 -9999 -9999 -9999 -9999 -9999 -9999 -9999 -9999 -9999 -9999 -9999 -9999 -9999 -9999 -9999 -9999 -9999 -9999

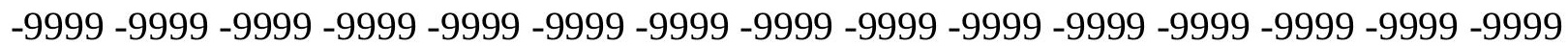
-9999 -9999 -9999 -9999 -9999 -9999 -9999 -9999 -9999 -9999 -9999 -9999 -9999 -9999 -9999 -9999 -9999 -9999 -9999 -9999 -9999 -9999 -9999 -9999 -9999 -9999 -9999 -9999 -9999 -9999 -9999 -9999 -9999 -9999 -9999 -9999 -9999 -9999 -9999 -9999 -9999 -9999 -9999 -9999 -9999 -999 -9999 -9999 -9999 -9999 -9999 -9999 -9999 -9999 -9999 -9999 -9999 -9999 -9999 -9999 -9999 -9999 -9999 -9999 -9999 -9999 -9999 -9999 -9999 -9999 -9999 -9999 -9999 -9999 -9999 -9999 -9999 -9999 -9999 -9999 -9999 -9999 -9999 -9999 -9999 -9999 -9999 -9999 -9999 -9999 -9999 -9999 -9999 -9999 -9999 -9999 -9999 -9999 -9999 -9999 -9999 -9999 -9999 -9999 -9999 -9999

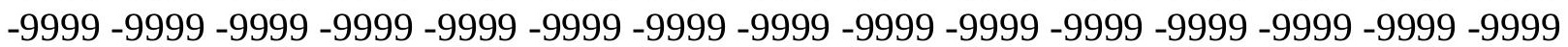


-9999 -9999 -9999 -9999 -9999 -9999 -9999 -9999 -9999 -9999 -9999 -9999 -9999 -9999 -9999 -9999 -9999 -9999 -9999 -9999 -9999 -9999 -9999 -9999 -9999 -9999 -9999 -9999 -9999 -9999 -9999 -9999 -9999 -9999 -9999 -9999 -9999 -9999 -9999 -9999 -9999 118.5614013672 113.6848983765108 .8082962036104 .236503601199 .6647262573295 .70252990723 94.1785964965894 .4833908081194 .4833908081194 .7881774902395 .09295654297 95.397743225195 .397743225195 .397743225195 .397743225195 .70252990723 95.7025299072395 .7025299072395 .7025299072395 .7025299072395 .70252990723 96.0073165893696 .0073165893696 .3121032714896 .3121032714896 .61688232422 96.6168823242296 .9216690063596 .9216690063597 .2264633178797 .22646331787 97.2264633178797 .5312423706197 .5312423706197 .5312423706197 .83602905273 97.8360290527397 .8360290527398 .1408081054798 .1408081054798 .4455871582 98.445587158298 .445587158298 .1408081054797 .8360290527396 .92166900635 96.0073165893694 .4833908081192 .9594726562590 .8259735107488 .99725341797 86.8637619018684 .4254837036182 .2919769287180 .1584930419977 .72020721436 75.6141586303773 .68682861328 -9999 -9999 -9999 -9999 -9999 -9999 -9999 -9999 -9999 -9999 -9999 -9999 -9999 -9999 -9999 -9999 -9999 -9999 -9999 -9999 -9999 -9999 -9999 -9999

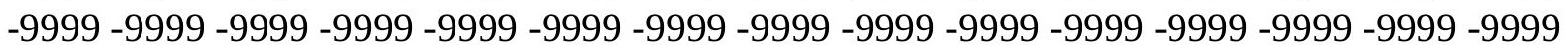
-9999 -9999 -9999 -9999 -9999 -9999 -9999 -9999 -9999 -9999 -9999 -9999 -9999 -9999 -9999 -9999 -9999 -9999 -9999 -9999 -9999 -9999 -9999 -9999 -9999 -9999 -9999 -9999 -9999 -9999 -9999 -9999 -9999 -9999 -9999 -9999 -9999 -9999 -9999 -9999 -9999

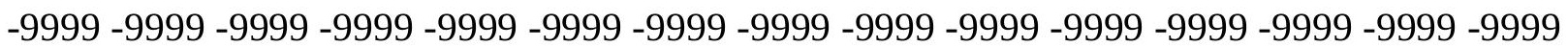
-9999 -9999 -9999 -9999 -9999 -9999 -9999 -9999 -9999 -9999 -9999 -9999 -9999 -9999 -9999 -9999 -9999 -9999 -9999 -9999 -9999 -9999 -9999 -9999 -9999 -9999 -9999 -9999 -9999 -9999 -9999 -9999 -9999 -9999 -9999 -9999 -9999 -9999 -9999 -9999 -9999 -9999 -9999 -9999 -9999

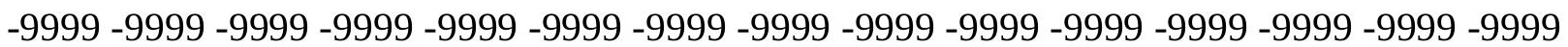
-9999 -9999 -9999 -9999 -9999 -9999 -9999 -9999 -9999 -9999 -9999 -9999 -9999 -9999 -9999 -9999 -9999 -9999 -9999 -9999 -9999 -9999 -9999 -9999 -9999 -9999 -9999 -9999 -9999 -9999 -9999 -9999 -9999 -9999 -9999 -9999 -9999 -9999 -9999 -9999 -9999 -9999 -9999 -9999 -9999 -9999 -9999 -9999 -9999 -9999 -9999 -9999 -9999 -9999 -9999 -9999 -9999 -9999 -9999 -9999 -9999 -9999 -9999 -9999 -9999 -9999 -9999 -9999 -9999 -9999 -9999 -9999 -9999 -9999 -9999 -9999 -9999 -9999 -9999 -9999 -9999 -9999 -9999 -9999 -9999 -9999 -9999 -9999 -9999 -9999 -9999 -9999 -9999 -9999 -9999 -9999 -9999 -9999 -9999 -9999 -9999 -9999 -9999 -9999 -9999 -9999 -9999 -9999 -9999 -9999 -9999 -9999 -9999 -9999 -9999 -9999 -9999 -9999 -9999 -9999 -9999 -9999 -9999 -9999 -9999 -9999 -9999 -9999 -9999 -9999 -9999 -9999 -9999 -9999 -9999 -9999 -9999 -9999 -9999 -9999 -9999 -9999 -9999 -9999 -9999 -9999 -9999 -9999 -9999 -9999 -9999 -9999 -9999 -9999 -9999 -9999 -9999 -9999 -9999 -9999 -9999 -9999 -9999 -9999 -9999 -9999 -9999 -9999 -9999 -9999 -9999 -9999 -9999 -9999 -9999 -9999 118.2565994263 112.4656982422107 .8938980103103 .322196960499 .0551681518695 .09295654297 94.1785964965894 .7881774902394 .7881774902395 .397743225195 .70252990723 96.0073165893696 .0073165893696 .0073165893696 .0073165893696 .00731658936 96.0073165893696 .0073165893696 .0073165893696 .0073165893696 .00731658936 96.3121032714896 .3121032714896 .3121032714896 .6168823242296 .61688232422 96.9216690063596 .9216690063597 .2264633178797 .2264633178797 .53124237061 97.5312423706197 .5312423706197 .5312423706197 .8360290527397 .83602905273 97.8360290527397 .8360290527398 .1408081054798 .1408081054798 .14080810547 97.8360290527397 .8360290527397 .5312423706196 .9216690063596 .00731658936 
94.7881774902393 .5690307617291 .7403335571389 .9116134643687 .77810668945 85.6446228027383 .5111236572381 .3776321411179 .2441329956176 .80584716797 74.7174835205174 .36756896973 -9999 -9999 -9999 -9999 -9999 -9999 -9999 -9999 -9999 -9999 -9999 -9999 -9999 -9999 -9999 -9999 -9999 -9999 -9999 -9999 -9999 -9999 -9999 -9999

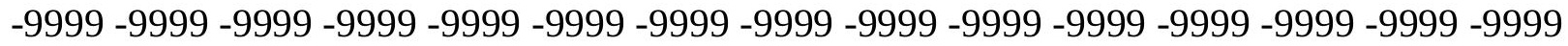
-9999 -9999 -9999 -9999 -9999 -9999 -9999 -9999 -9999 -9999 -9999

-9999 -9999 -9999 -9999 -9999 -9999 -9999 -9999 -9999 -9999 -9999 -9999 -9999 -9999 -9999 -9999 -9999 -9999 -9999 -9999 -9999 -9999 -9999 -9999 -9999 -9999 -9999 -9999 -9999 -9999 -9999 -9999 -9999 -9999 -9999 -9999 -9999 -9999 -9999 -9999 -9999 -9999 -9999 -9999 -9999 -9999 -9999 -9999 -9999 -9999 -9999 -9999 -9999 -9999 -9999 -9999 -9999 -9999 -9999 -9999 -9999 -9999 -9999 -9999 -9999 -9999 -9999 -9999 -9999 -9999 -9999 -9999 -9999 -9999 -9999 -999 -9999 -9999 -9999 -9999 -9999 -9999 -9999 -9999 -9999 -9999 -9999 -9999 -9999 -9999 -9999 -9999 -9999 -9999 -9999 -9999 -9999 -9999 -9999 -9999 -9999 -9999 -9999 -9999 -9999 -9999 -9999 -9999 -9999 -9999 -9999 -9999 -9999 -9999 -9999 -9999 -9999 -9999 -9999 -9999 -9999 -9999 -9999 -9999 -9999 -9999 -9999 -9999 -9999 -9999 -9999 -9999 -9999 -9999 -9999 -9999

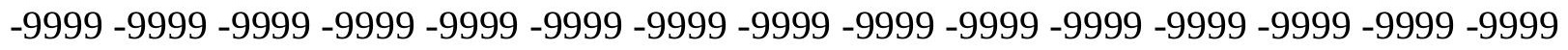
-9999 -9999 -9999 -9999 -9999 -9999 -9999 -9999 -9999 -9999 -9999 -9999 -9999 -9999 -9999 -

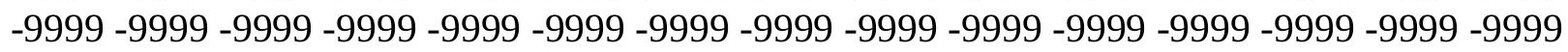

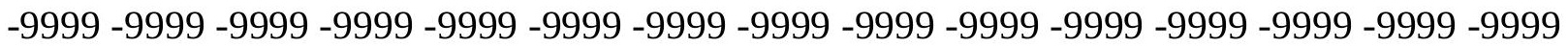

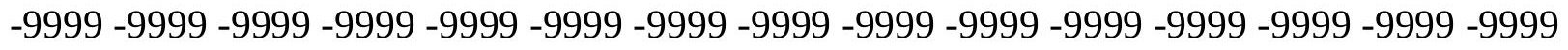

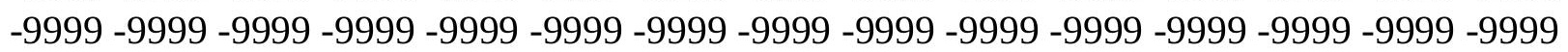

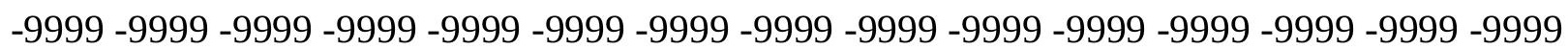
-9999 -9999 -9999 -9999 -9999 -9999 -9999 -9999 -9999 -9999 -9999 -9999 -9999 -9999 -9999 -9999 -9999 -9999 -9999 -9999 -9999 -9999 -9999 -9999 -9999 -9999 -9999 -9999 -9999 -9999 -9999 -9999 -9999 -9999 -9999 -9999 -9999 -9999 -9999 -9999-9999 -9999 110.9418029785 106.0652008057 101.493400573797.5312423706193.8738174438593.87381744385 94.4833908081195 .0929565429796 .0073165893696 .3121032714896 .61688232422 96.6168823242296 .6168823242296 .6168823242296 .3121032714896 .31210327148 96.3121032714896 .3121032714896 .3121032714896 .3121032714896 .61688232422 96.6168823242296 .6168823242296 .9216690063596 .9216690063597 .22646331787 97.22646331787 97.2264633178797.5312423706197.5312423706197.53124237061 97.8360290527397 .8360290527397 .8360290527397 .8360290527397 .83602905273 97.8360290527397 .8360290527397 .8360290527397 .8360290527397 .53124237061 97.2264633178796 .6168823242296 .0073165893695 .0929565429793 .87381744385 92.349891662690 .5211791992288 .6924667358486 .8637619018684 .73026275635 82.5967712402380 .4632720947378 .0249862670975 .8914871215873 .8264465332 73.45321655273 -9999 -9999 -9999 -9999 -9999 -9999 -9999 -9999 -9999 -9999 -9999 -9999

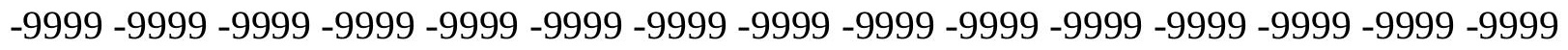

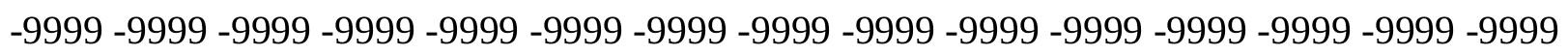
-9999 -9999 -9999 -9999 -9999 -9999 -9999 -9999

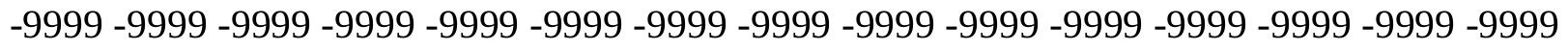

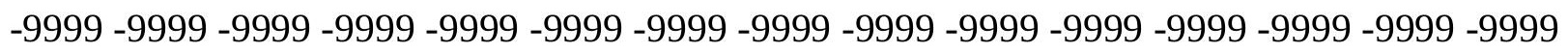

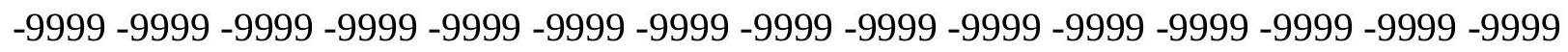
-9999 -9999 -9999 -9999 -9999 -9999 -9999 -9999 -9999 -9999 -9999 -9999 -9999 -9999 -9999 -

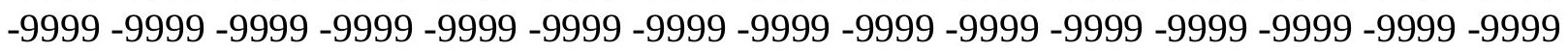

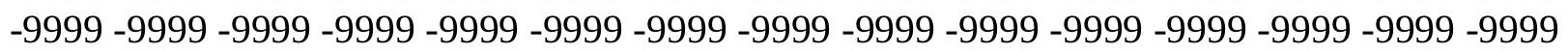


-9999 -9999 -9999 -9999 -9999 -9999 -9999 -9999 -9999 -9999 -9999 -9999 -9999 -9999 -9999 -9999 -9999 -9999 -9999 -9999 -9999 -9999 -9999 -9999 -9999 -9999 -9999 -9999 -9999 -9999 -9999 -9999 -9999 -9999 -9999 -9999 -9999 -9999 -9999 -9999 -9999 -9999 -9999 -9999 -9999 -9999 -9999 -9999 -9999 -9999 -9999 -9999 -9999 -9999 -9999 -9999 -9999 -9999 -9999 -9999 -9999 -9999 -9999 -9999 -9999 -9999 -9999 -9999 -9999 -9999 -9999 -9999 -9999 -9999 -9999 -9999 -9999 -9999 -9999 -9999 -9999 -9999 -9999 -9999 -9999 -9999 -9999 -9999 -9999 -9999 -9999 -9999 -9999 -9999 -9999 -9999 -9999 -9999 -9999 -9999 -9999 -9999 -9999 -9999 -9999

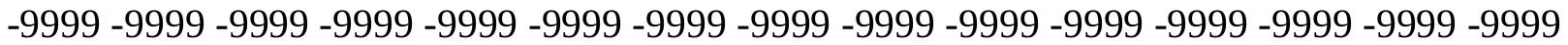
-9999 -9999 -9999 -9999 -9999 -9999 -9999 -9999 -9999 -9999 -9999 -9999 -9999 -9999 -9999 -9999 -9999 -9999 -9999 -9999 -9999 -9999 -9999 -9999 -9999 -9999 -9999 -9999 -9999 -9999 -

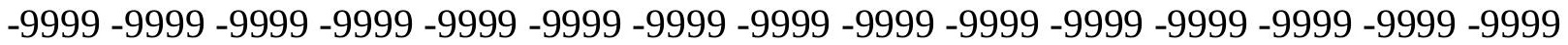
-9999 -9999 -9999 -9999 -9999 -9999 -9999 -9999 -9999 -9999 -9999 -9999 -9999 -9999 -9999 -9999 -9999 -9999 -9999 -9999 -9999 -9999 -9999 -9999 -9999 -9999 -9999 109.1130981445 103.322196960498 .7503814697395 .0929565429792 .349891662692 .95947265625 93.8738174438595 .397743225196 .6168823242297 .2264633178797 .22646331787 97.2264633178796 .9216690063596 .9216690063596 .9216690063596 .92166900635 96.9216690063596 .6168823242296 .6168823242296 .6168823242296 .92166900635 96.9216690063596 .9216690063596 .9216690063597 .2264633178797 .22646331787 97.5312423706197 .5312423706197 .5312423706197 .8360290527397 .83602905273 97.8360290527397 .8360290527397 .8360290527397 .8360290527397 .83602905273 97.8360290527397 .5312423706197 .5312423706197 .2264633178796 .92166900635 96.6168823242296 .0073165893695 .0929565429793 .8738174438592 .65467834473 91.1307525634889 .6068267822387 .7781066894585 .6446228027383 .51112365723 $81.3776321411179 .2441329956177 .110626220774 .9771423339872 .86014556885-9999$ -9999 -9999 -9999 -9999 -9999 -9999 -9999 -9999 -9999 -9999 -9999 -9999 -9999 -9999 -9999 -9999 -9999 -9999 -9999 -9999 -9999 -9999 -9999 -9999 -9999 -9999 -9999 -9999 -9999 -9999 -9999 -9999 -9999 -9999 -9999 -9999 -9999 -9999 -9999 -9999 -9999 -9999 -9999 -9999 -9999 -9999 -9999-9999-9999-9999

-9999 -9999 -9999 -9999 -9999 -9999 -9999 -9999 -9999 -9999 -9999 -9999 -9999 -9999 -9999 -9999 -9999 -9999 -9999 -9999 -9999 -9999 -9999 -9999 -9999 -9999 -9999 -9999 -9999 -9999 -9999 -9999 -9999 -9999 -9999 -9999 -9999 -9999 -9999 -9999 -9999 -9999 -9999 -9999 -9999 -

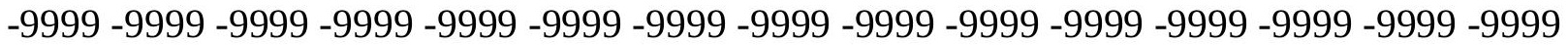
-9999 -9999 -9999 -9999 -9999 -9999 -9999 -9999 -9999 -9999 -9999 -9999 -9999 -9999 -9999 -9999 -9999 -9999 -9999 -9999 -9999 -9999 -9999 -9999 -9999 -9999 -9999 -9999 -9999 -9999 -

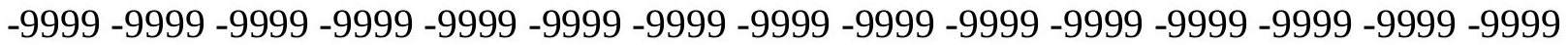
-9999 -9999 -9999 -9999 -9999 -9999 -9999 -9999 -9999 -9999 -9999 -9999 -9999 -9999 -9999 -9999 -9999 -9999 -9999 -9999 -9999 -9999 -9999 -9999 -9999 -9999 -9999 -9999 -9999 -9999

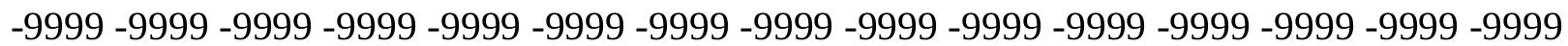
-9999 -9999 -9999 -9999 -9999 -9999 -9999 -9999 -9999 -9999 -9999 -9999 -9999 -9999 -9999 -9999 -9999 -9999 -9999 -9999 -9999 -9999 -9999 -9999 -9999 -9999 -9999 -9999 -9999 -9999 -9999 -9999 -9999 -9999 -9999 -9999 -9999 -9999 -9999 -9999 -9999 -9999 -9999 -9999 -9999 -999 -9999 -9999 -9999 -9999 -9999 -9999 -9999 -9999 -9999 -9999 -9999 -9999 -9999 -9999 -9999 -9999 -9999 -9999 -9999 -9999 -9999 -9999 -9999 -9999 -9999 -9999 -9999 -9999 -9999 -9999 -9999 -9999 -9999 -9999 -9999 -9999 -9999 -9999 -9999 -9999 -9999 -9999 -9999 -9999 -9999 -9999 -9999 -9999 -9999 -9999 -9999 -9999 -9999 -9999 -9999 -9999 -9999 -9999 -9999 -9999

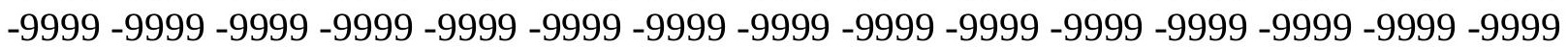


-9999 -9999 -9999 -9999 -9999 -9999 -9999 -9999 -9999 -9999 -9999 -9999 -9999 100.579101562594 .7881774902392 .349891662693 .2642517089891 .43553924561 93.5690307617296 .3121032714897 .5312423706198 .0543594360498 .14080810547 97.8360290527397 .5312423706197 .2264633178797 .2264633178797 .22646331787 97.22646331787 97.2264633178796.9216690063596.92166900635 97.22646331787 97.2264633178797 .2264633178797 .2264633178797 .5312423706197 .53124237061 97.5312423706197 .8360290527397 .8360290527397 .8360290527397 .83602905273 97.8360290527397 .8360290527397 .8360290527397 .8360290527397 .83602905273 97.5312423706197 .5312423706197 .2264633178796 .9216690063596 .31210327148 95.7025299072395 .0929565429794 .1785964965892 .9594726562591 .74033355713 90.2164001464888 .3876876831186 .5589828491284 .4254837036182 .29197692871 80.4632720947378 .0249862670975 .8914871215873 .7580032348671 .79763031006 -9999 -9999 -9999 -9999 -9999 -9999 -9999 -9999 -9999 -9999 -9999 -9999 -9999 -9999 -9999 -9999 -9999 -9999 -9999 -9999 -9999 -9999 -9999 -9999 -9999 -9999 -9999 -9999 -9999 -9999 - 9999 -9999 -9999 -9999 -9999 -9999 -9999 -9999 -9999 -9999 -9999 -9999 -9999 -9999 -9999 - -9999 -9999 -9999 -9999 -9999-9999

-9999 -9999 -9999 -9999 -9999 -9999 -9999 -9999 -9999 -9999 -9999 -9999 -9999 -9999 -9999 -9999 -9999 -9999 -9999 -9999 -9999 -9999 -9999 -9999 -9999 -9999 -9999 -9999 -9999 -9999 -9999 -9999 -9999 -9999 -9999 -9999 -9999 -9999 -9999 -9999 -9999 -9999 -9999 -9999 -9999 -

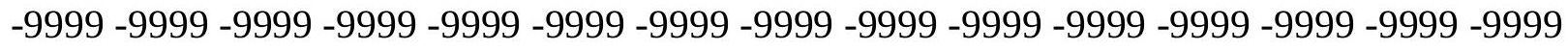

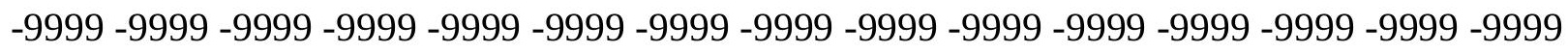
-9999 -9999 -9999 -9999 -9999 -9999 -9999 -9999 -9999 -9999 -9999 -9999 -9999 -9999 -9999 -9999 -9999 -9999 -9999 -9999 -9999 -9999 -9999 -9999 -9999 -9999 -9999 -9999 -9999 -9999 -

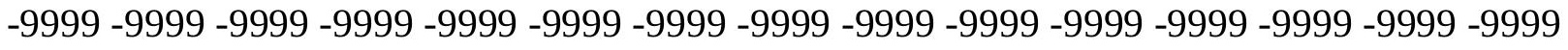

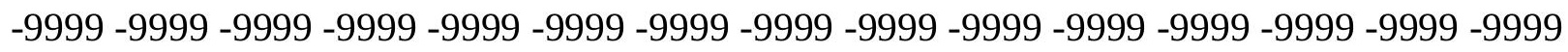
-9999 -9999 -9999 -9999 -9999 -9999 -9999 -9999 -9999 -9999 -9999 -9999 -9999 -9999 -9999 -

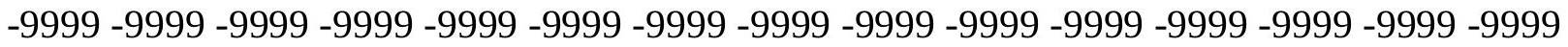

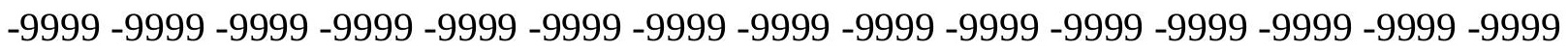
-9999 -9999 -9999 -9999 -9999 -9999 -9999 -9999 -9999 -9999 -9999 -9999 -9999 -9999 -9999 -9999 -9999 -9999 -9999 -9999 -9999 -9999 -9999 -9999 -9999 -9999 -9999 -9999 -9999 -9999 -9999 -9999 -9999 -9999 -9999 -9999 -9999 -9999 -9999-9999 -9999 -9999 -9999 -9999 -9999 -9999 -9999 -9999 -9999 -9999 -9999 -9999 -9999 -9999 -9999 -9999 -9999 -9999 -9999 -9999 -

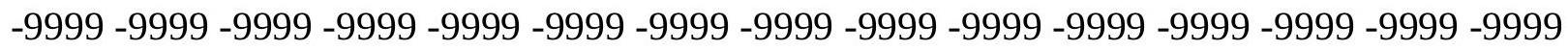
-9999 -9999 -9999 -9999 -9999 -9999 -9999 -9999 -9999 -9999 -9999 -9999 -9999 -9999 -9999 -9999 -9999 -9999 -9999 -9999 -9999 -9999 -9999 -9999 -9999 -9999 -9999 -9999 98.1408081054792.04509735107 89.3020401001 87.16854858398 89.91161346436 94.1785964965897 .5312423706198 .8338623046998 .6980590820398 .54981231689 98.1408081054797.83602905273 97.8360290527397.5312423706197.53124237061 97.5312423706197 .5312423706197 .5312423706197 .2264633178797 .53124237061 97.5312423706197 .5312423706197 .5312423706197 .5312423706197 .53124237061 97.8360290527397 .8360290527397 .8360290527397 .8360290527397 .83602905273 97.8360290527397 .8360290527397 .8360290527397 .8360290527397 .53124237061 97.5312423706197 .2264633178796 .9216690063596 .3121032714895 .70252990723 95.0929565429794 .1785964965893 .2642517089892 .0450973510790 .52117919922 88.9972534179787 .1685485839885 .3398437583 .206336975181 .37763214111 79.2441329956176 .8058471679774 .6723632812572 .5388565063570 .6990737915 -9999 
-9999 -9999 -9999 -9999 -9999 -9999 -9999 -9999 -9999 -9999 -9999 -9999 -9999 -9999 -9999 -9999 -9999 -9999 -9999 -9999 -9999 -9999 -9999 -9999 -9999 -9999 -9999 -9999 -9999 -9999 -9999 -9999 -9999 -9999 -9999 -9999 -9999 -9999 -9999 -9999 -9999 -9999 -9999 -9999 -9999 -9999 -9999-9999-9999-9999

-9999 -9999 -9999 -9999 -9999 -9999 -9999 -9999 -9999 -9999 -9999 -9999 -9999 -9999 -9999 -9999 -9999 -9999 -9999 -9999 -9999 -9999 -9999 -9999 -9999 -9999 -9999 -9999 -9999 -9999 -9999 -9999 -9999 -9999 -9999 -9999 -9999 -9999 -9999 -9999 -9999 -9999 -9999 -9999 -9999

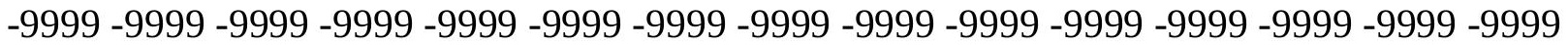

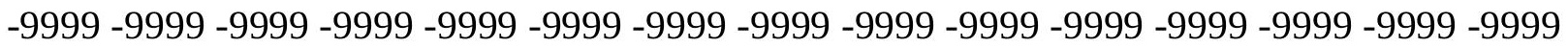
-9999 -9999 -9999 -9999 -9999 -9999 -9999 -9999 -9999 -9999 -9999 -9999 -9999 -9999 -9999 -

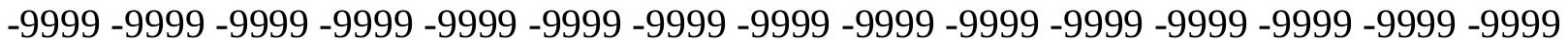
-9999 -9999 -9999 -9999 -9999 -9999 -9999 -9999 -9999 -9999 -9999 -9999 -9999 -9999 -9999 -9999 -9999 -9999 -9999 -9999 -9999 -9999 -9999 -9999 -9999 -9999 -9999 -9999 -9999 -9999 -9999 -9999 -9999 -9999 -9999 -9999 -9999 -9999 -9999 -9999 -9999 -9999 -9999 -9999 -9999 -9999 -9999 -9999 -9999 -9999 -9999 -9999 -9999 -9999 -9999 -9999 -9999 -9999 -9999 -9999

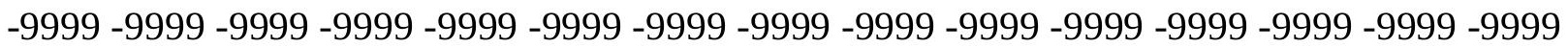

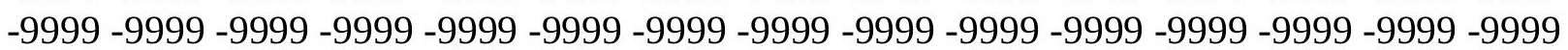
-9999 -9999 -9999 -9999 -9999 -9999 -9999 -9999 -9999 -9999 -9999 -9999 -9999 -9999 -9999 -9999 -9999 -9999 -9999 -9999 -9999 -9999 -9999 -9999 -9999 -9999 -9999 -9999 -9999 -9999 -9999 -9999 -9999 -9999 -9999 -9999 -9999 -9999 -9999 -9999 -9999 -9999 -9999 -9999 -9999

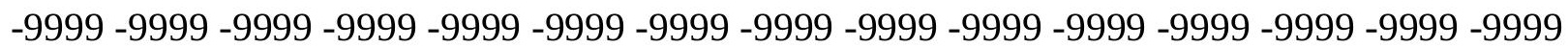

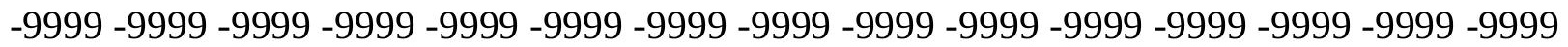
-9999 -9999 -9999 -9999 -9999 -9999 -9999 -9999 -9999 -9999 -9999 -9999 -9999 -9999 89.6068267822383 .5111236572383 .8159103393688 .6924667358496 .00731658936 99.66472625732100 .274299621699 .1826782226698 .9472274780398 .75038146973 98.1408081054798 .1408081054797 .8360290527397 .8360290527397 .83602905273 97.8360290527397 .8360290527397 .8360290527397 .8360290527397 .83602905273 97.8360290527397 .8360290527397 .8360290527397 .8360290527397 .83602905273 97.83602905273 98.1408081054798.1408081054798.1408081054797.83602905273 97.8360290527397 .8360290527397 .5312423706197 .5312423706197 .22646331787 96.9216690063596 .6168823242296 .0073165893695 .397743225194 .48339080811 93.5690307617292 .349891662691 .1307525634889 .6068267822387 .77810668945 85.9494018554784 .1206970214882 .2919769287180 .1584930419977 .72020721436 75.5867080688573 .4532165527371 .4637908935569 .5968170166 -9999 -9999 -9999 -9999 -9999 -9999 -9999 -9999 -9999 -9999 -9999 -9999 -9999 -9999 -9999 -9999 -9999 -9999 -9999 -9999 -9999 -9999 -9999 -9999 -9999 -9999 -9999 -9999 -9999 -9999 -9999 -9999 -9999 -9999

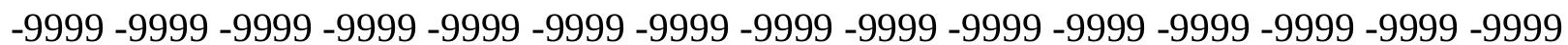
$-9999-9999$ -9999 -9999 -9999 -9999 -9999 -9999 -9999 -9999 -9999 -9999 -9999 -9999 -9999 -9999 -9999 -9999 -9999 -9999 -9999 -9999 -9999 -9999 -9999 -9999 -9999 -9999 -9999 -9999 -9999 -9999 -9999 -9999 -9999 -9999 -9999 -9999 -9999 -9999 -9999 -9999 -9999 -9999 -9999 -9999 -9999 -9999 -9999 -9999 -9999 -9999 -9999 -9999 -9999 -9999 -9999 -9999 -9999 -9999 -9999 -9999 -9999 -9999 -9999 -9999 -9999 -9999 -9999 -9999 -9999 -9999 -9999 -9999 -9999 -9999 -9999 -9999 -9999 -9999 -9999 -9999 -9999 -9999 -9999 -9999 -9999 -9999 -9999 -9999 -9999 -9999 -9999 -9999 -9999 -9999 -9999 -9999 -9999 -9999 -9999 -9999 -9999 -9999 -9999 -9999 -9999

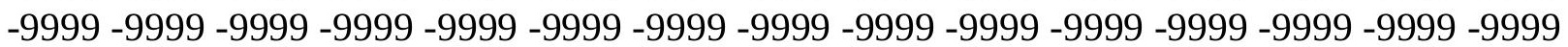


-9999 -9999 -9999 -9999 -9999 -9999 -9999 -9999 -9999 -9999 -9999 -9999 -9999 -9999 -9999 -9999 -9999 -9999 -9999 -9999 -9999 -9999 -9999 -9999 -9999 -9999 -9999 -9999 -9999 -9999 -9999 -9999 -9999 -9999 -9999 -9999 -9999 -9999 -9999 -9999 -9999 -9999 -9999 -9999 -9999 -9999 -9999 -9999 -9999 -9999 -9999 -9999 -9999 -9999 -9999 -9999 -9999 -9999 -9999 -9999 -9999 -9999 -9999 -9999 -9999 -9999 -9999 -9999 -9999 -9999 -9999 -9999 -9999 -9999 -9999 -9999 -9999 -9999 -9999 -9999 -9999 -9999 -9999 -9999 -9999 -9999 -9999 -9999 -9999 -9999 -9999 -9999 -9999 -9999 -9999 -9999 -9999 -9999 -9999 -9999 -9999 -9999 -9999 -9999 -9999

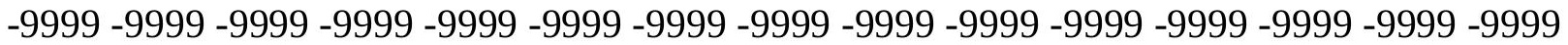
-9999 -9999 -9999 -9999 -9999 -9999 -9999 -9999 -9999 -9999 -9999 -9999 -9999 -9999 -9999 -9999 -9999 -9999 -9999 -9999 -9999 -9999 -9999 -9999 -9999 -9999 -9999 -9999 -9999 -9999 -9999 -9999 -9999 -9999 -9999 -9999 -9999 -9999 -9999 -9999 -9999 -9999 -9999 -9999 -999 87.7781066894581 .6824111938582 .5967712402386 .8637619018699 .96952056885 100.5791015625100 .274299621699 .9695205688599 .2341384887798 .75038146973 98.445587158298 .1408081054798 .1408081054798 .1408081054798 .14080810547 98.1408081054798.1408081054798.1408081054798.1408081054797.83602905273 97.83602905273 97.83602905273 98.1408081054798.1408081054798.14080810547 98.1408081054798.1408081054798.1408081054798.1408081054797.83602905273 97.8360290527397 .8360290527397 .5312423706197 .2264633178796 .92166900635 96.6168823242296 .3121032714895 .7025299072394 .7881774902393 .87381744385 92.9594726562591 .7403335571390 .2164001464888 .6924667358486 .86376190186 85.0350494384883 .206336975181 .0728530883878 .9393463134876 .50106811523

74.3675689697372 .2340774536170 .29719543457 -9999 -9999 -9999 -9999 -9999 -9999 -9999 -9999 -9999 -9999 -9999 -9999 -9999 -9999 -9999 -9999 -9999 -9999 -9999 -9999 -9999 -9999 -9999 -9999 -9999 -9999 -9999 -9999 -9999 -9999 -9999 -9999 -9999 -9999 -9999 -9999 -9999

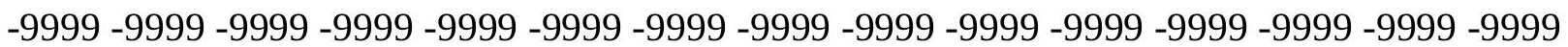
-9999 -9999 -9999 -9999 -9999 -9999 -9999 -9999 -9999 -9999 -9999 -9999 -9999 -9999 -9999 -9999 -9999 -9999 -9999 -9999 -9999 -9999 -9999 -9999 -9999 -9999 -9999 -9999 -9999 -9999 -9999 -9999 -9999 -9999 -9999 -9999 -9999 -9999 -9999 -9999 -9999 -9999 -9999 -9999 -9999 -9999 -9999 -9999 -9999 -9999 -9999 -9999 -9999 -9999 -9999 -9999 -9999 -9999 -9999 -9999

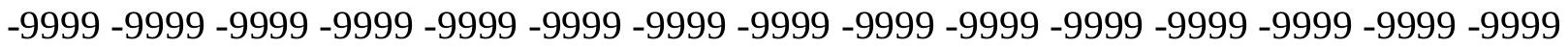
-9999 -9999 -9999 -9999 -9999 -9999 -9999 -9999 -9999 -9999 -9999 -9999 -9999 -9999 -9999 -

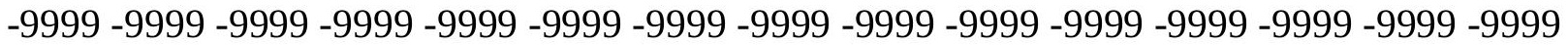
-9999 -9999 -9999 -9999 -9999 -9999 -9999 -9999 -9999 -9999 -9999 -9999 -9999 -9999 -9999 -9999 -9999 -9999 -9999 -9999 -9999 -9999 -9999 -9999 -9999 -9999 -9999 -9999 -9999 -9999 -

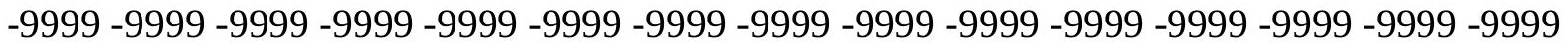
-9999 -9999 -9999 -9999 -9999 -9999 -9999 -9999 -9999 -9999 -9999 -9999 -9999 -9999 -9999 -9999 -9999 -9999 -9999 -9999 -9999 -9999 -9999 -9999 -9999 -9999 -9999 -9999 -9999 -9999

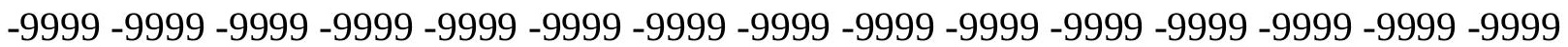
-9999 -9999 -9999 -9999 -9999 -9999 -9999 -9999 -9999 -9999 -9999 -9999 -9999 -9999 -9999 -9999 -9999 -9999 -9999 -9999 -9999 -9999 -9999 -9999 -9999 -9999 -9999 -9999 -9999 -9999 -9999 -9999 -9999 -9999 -9999 -9999 -9999 -9999 -9999 -9999 -9999 -9999 -9999 -9999 -9999 -999 -9999 -9999 -9999 -9999 -9999 -9999 -9999 -9999 -9999 -9999 -9999 -9999 -9999 -9999 -9999 -9999 -9999 -9999 -9999 -9999 -9999 -9999 -9999 -9999 -9999 -9999 -9999 -9999 -9999 -9999 -9999 -9999 -9999 -9999 -9999 -9999 -9999 -9999 -9999 -9999 -9999 -9999 -9999 -9999 -9999 81.0728530883882 .2919769287185 .6446228027393 .8738174438597 .83602905273 99.0551681518699 .0551681518698 .7503814697398 .445587158298 .4455871582 
98.445587158298 .445587158298 .445587158298 .445587158298 .445587158298 .4455871582 98.445587158298 .445587158298 .1408081054798 .1408081054798 .14080810547 98.1408081054798.1408081054798.1408081054798.1408081054798.14080810547 98.1408081054798 .1408081054797 .8360290527397 .8360290527397 .83602905273 97.5312423706197 .2264633178796 .9216690063596 .3121032714896 .00731658936 95.0929565429794 .4833908081193 .5690307617292 .349891662690 .82597351074 89.60682678223 87.7781066894585.9494018554784.12069702148 81.98719787598 79.8537063598677 .7202072143675 .2819290161173 .1484298706171 .0149307251 69.16086578369 -9999 -9999 -9999 -9999 -9999 -9999 -9999 -9999 -9999 -9999 -9999 -9999 -9999 -9999 -9999 -9999 -9999 -9999 -9999 -9999 -9999 -9999 -9999 -9999 -9999 -9999 -9999

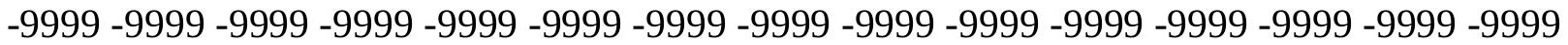
-9999 -9999 -9999 -9999 -9999 -9999 -9999 -9999 -9999-9999

-9999 -9999 -9999 -9999 -9999 -9999 -9999 -9999 -9999 -9999 -9999 -9999 -9999 -9999 -9999 -9999 -9999 -9999 -9999 -9999 -9999 -9999 -9999 -9999 -9999 -9999 -9999 -9999 -9999 -9999 -9999 -9999 -9999 -9999 -9999 -9999 -9999 -9999 -9999 -9999 -9999 -9999 -9999 -9999 -9999

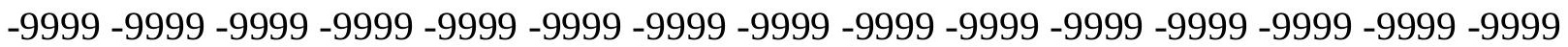

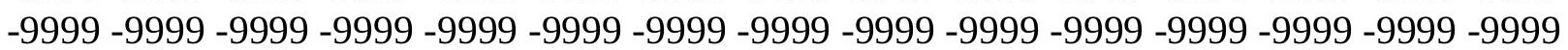
-9999 -9999 -9999 -9999 -9999 -9999 -9999 -9999 -9999 -9999 -9999 -9999 -9999 -9999 -9999 -999 -9999 -9999 -9999 -9999 -9999 -9999 -9999 -9999 -9999 -9999 -9999 -9999 -9999 -9999 -9999 -9999 -9999 -9999 -9999 -9999 -9999 -9999 -9999 -9999 -9999 -9999 -9999 -9999 -9999 -9999

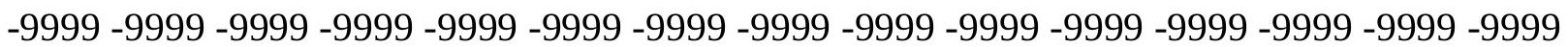
-9999 -9999 -9999 -9999 -9999 -9999 -9999 -9999 -9999 -9999 -9999 -9999 -9999 -9999 -9999 -9999 -9999 -9999 -9999 -9999 -9999 -9999 -9999 -9999 -9999 -9999 -9999 -9999 -9999 -9999 -9999 -9999 -9999 -9999 -9999 -9999 -9999 -9999 -9999 -9999 -9999 -9999 -9999 -9999 -9999

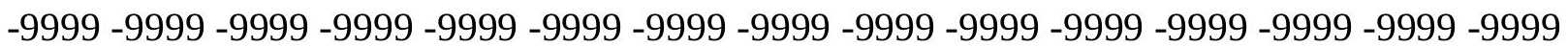
-9999 -9999 -9999 -9999 -9999 -9999 -9999 -9999 -9999 -9999 -9999 -9999 -9999 -9999 -9999 -9999 -9999 -9999 -9999 -9999 -9999 -9999 -9999 -9999 -9999 -9999 -9999 -9999 -9999 -9999 -9999 -9999 -9999 -9999 -9999 -9999 -9999 -9999 -9999 -9999 -9999 -9999 -9999 -9999 -9999 -9999 -9999 -9999 -9999 -9999 -9999 -9999 -9999 -9999 -9999 -9999 -9999 -9999 -9999 -9999

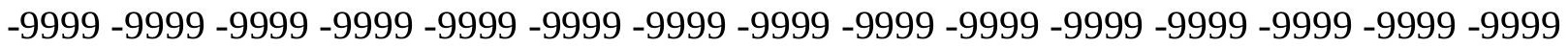
-9999 -9999 -9999 -9999 -9999 -9999 -9999 -9999 -9999 -9999 -9999 -9999 -9999 -9999 -9999 81.6824111938582 .2919769287185 .0350494384889 .9116134643694 .48339080811 96.6168823242297 .5312423706198 .1408081054798 .1408081054798 .4455871582 98.445587158298 .7503814697398 .7503814697398 .7503814697398 .75038146973 98.7503814697398 .7503814697398 .7503814697398 .445587158298 .4455871582 98.445587158298 .445587158298 .445587158298 .1408081054798 .14080810547 98.1408081054798.1408081054798.1408081054797.8360290527397.83602905273 97.5312423706197 .5312423706197 .2264633178796 .6168823242296 .31210327148 95.7025299072395 .0929565429794 .1785964965892 .9594726562591 .74033355713 90.5211791992288 .9972534179787 .1685485839885 .3398437583 .2063369751 81.0728530883878 .9393463134876 .5010681152374 .062782287671 .92929077148 69.9064407348668 .09610748291 -9999 -9999 -9999 -9999 -9999 -9999 -9999 -9999 -9999 -9999 -9999 -9999 -9999 -9999 -9999 -9999 -9999 -9999 -9999 -9999 -9999 -9999 -9999 -9999 -9999 -9999 -9999 -9999 -9999 -9999 -9999 -9999 -9999 -9999 -9999 -9999 -9999 -9999 -9999 -9999 -9999 -9999 -9999 -9999 -9999 -9999 -9999 -9999 -9999 -9999 -9999 -9999 -

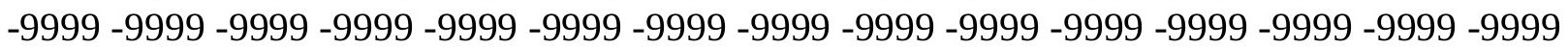


-9999 -9999 -9999 -9999 -9999 -9999 -9999 -9999 -9999 -9999 -9999 -9999 -9999 -9999 -9999 -9999 -9999 -9999 -9999 -9999 -9999 -9999 -9999 -9999 -9999 -9999 -9999 -9999 -9999 -9999 -

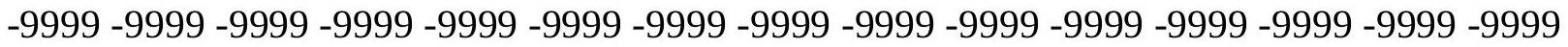
-9999 -9999 -9999 -9999 -9999 -9999 -9999 -9999 -9999 -9999 -9999 -9999 -9999 -9999 -9999 -9999 -9999 -9999 -9999 -9999 -9999 -9999 -9999 -9999-9999 -9999 -9999 -9999 -9999 -9999 -9999 -9999 -9999 -9999 -9999 -9999 -9999 -9999 -9999 -9999 -9999 -9999 -9999 -9999 -9999 -

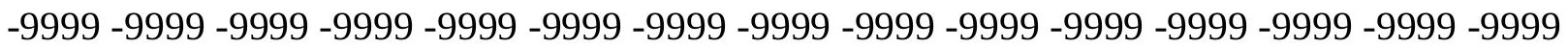

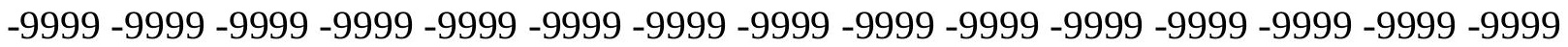

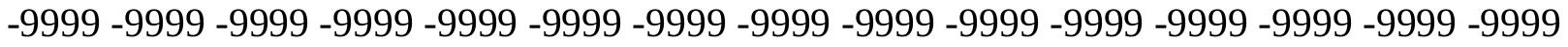
-9999 -9999 -9999 -9999 -9999 -9999 -9999 -9999 -9999 -9999 -9999 -9999 -9999 -9999 -9999

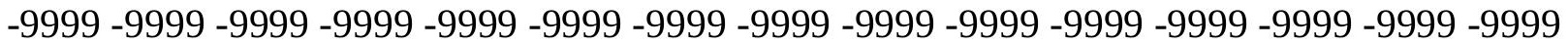
-9999 -9999 -9999 -9999 -9999 -9999 -9999 -9999 -9999 -9999 -9999 -9999 -9999 -9999 -9999 -9999 -9999 -9999 -9999 -9999 -9999 -9999 -9999 -9999 -9999 -9999 -9999 -9999 -9999 -9999 -

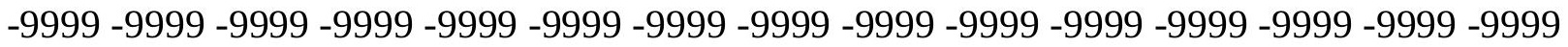
-9999 -9999 -9999 -9999 -9999 -9999 -9999 -9999 -9999 -9999 -9999 -9999 -9999 -9999 -9999

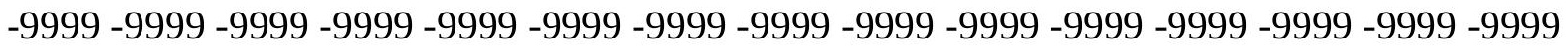
-9999 -9999 -9999 -9999 -9999 -9999 -9999 -9999 -9999 -9999 -9999 -9999 -9999 -9999 -9999 -9999 -9999 -9999 -9999 -9999 -9999 -9999 -9999 -9999 -9999 -9999 -9999 -9999 -9999 -999 82.9015579223682 .2919769287185 .0350494384888 .0829010009892 .04509735107 94.7881774902396 .3121032714897 .5312423706198 .1408081054798 .4455871582 98.7503814697399 .0551681518699 .3599472045999 .3599472045999 .35994720459 99.3599472045999 .0551681518699 .0551681518699 .0551681518698 .75038146973 98.7503814697398 .445587158298 .445587158298 .445587158298 .14080810547 98.1408081054798.1408081054797.8360290527397.8360290527397.83602905273 97.5312423706197 .2264633178796 .9216690063596 .6168823242296 .31210327148 95.7025299072394 .7881774902393 .8738174438592 .6546783447391 .43553924561 89.9116134643688 .3876876831186 .5589828491284 .4254837036182 .29197692871 80.1584930419977 .7202072143675 .2819290161173 .1484298706170 .71015167236 68.8280258178767 .11304473877 -9999 -9999 -9999 -9999 -9999 -9999 -9999 -9999 -9999 -9999 -9999 -9999 -9999 -9999 -9999 -9999 -9999 -9999 -9999 -9999 -9999 -9999 -9999 -9999 -9999 -9999 -9999 -9999 -9999 -9999 -9999 -9999 -9999 -9999 -9999 -9999 -9999 -9999 -9999 -9999 -9999 -9999 -9999 -9999 -9999 -9999 -9999 -9999 -9999 -9999 -9999 -9999 -

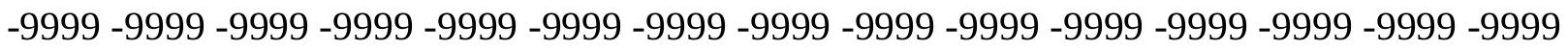

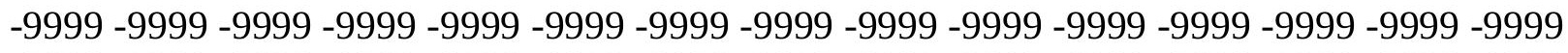
-9999 -9999 -9999 -9999 -9999 -9999 -9999 -9999 -9999 -9999 -9999 -9999 -9999 -9999 -9999 -

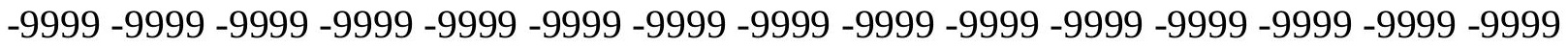

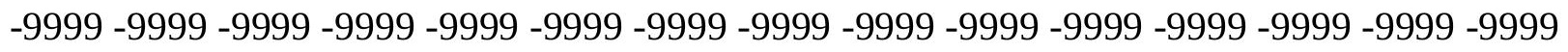

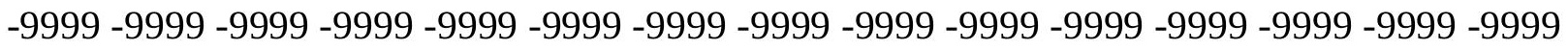

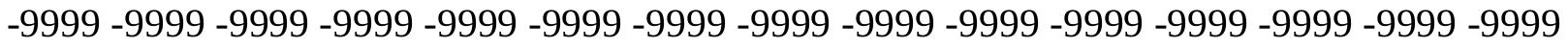
-9999 -9999 -9999 -9999 -9999 -9999 -9999 -9999 -9999 -9999 -9999 -9999 -9999 -9999 - -999 -

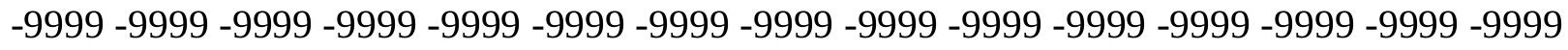

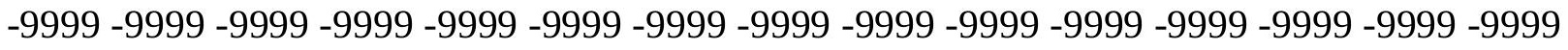
-9999 -9999 -9999 -9999 -9999 -9999 -9999 -9999 -9999 -9999 -9999 -9999 -9999 -9999 -9999 -9999 -9999 -9999 -9999 -9999 -9999 -9999 -9999 -9999-9999 -9999 -9999 -9999 -9999 -9999 -9999 -9999 -9999 -9999 -9999 -9999 -9999 -9999 -9999 -9999 -9999 -9999 -9999 -9999 -9999 -

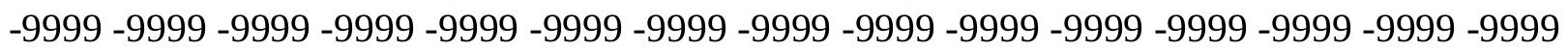


-9999 -9999 -9999 -9999 -9999 -9999 -9999 -9999 -9999 -9999 -9999 -9999 -9999 -9999 -9999 -9999 -9999 -9999 -9999 -9999 -9999 -9999 -9999 -9999 -9999 -9999 -9999 -9999 -9999 -9999

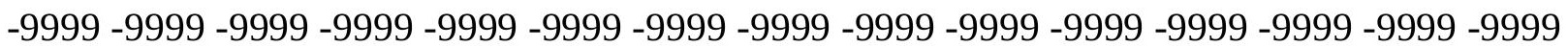
-9999 -9999 -9999 -9999 -9999 -9999 -9999 -9999 -9999 -9999 -9999 -9999 -9999 -9999 -9999 -9999 -9999 -9999 -9999 -9999 -9999 -9999 -9999 -9999 -9999 -9999 -9999 -9999 -9999 -9999 -9999 83.81591033936 85.9494018554788.0829010009891.1307525634893.87381744385 95.7025299072396 .9216690063598 .1408081054798 .7503814697399 .05516815186 99.3599472045999 .6647262573299 .6647262573299 .6647262573299 .66472625732 99.6647262573299 .3599472045999 .3599472045999 .0551681518699 .05516815186 98.7503814697398 .7503814697398 .445587158298 .445587158298 .14080810547 98.1408081054797 .8360290527397 .8360290527397 .5312423706197 .53124237061 97.2264633178796 .9216690063596 .6168823242296 .0073165893695 .3977432251 94.7881774902393 .8738174438592 .6546783447391 .4355392456189 .91161346436 88.0829010009886 .254188537684 .1206970214881 .6824111938579 .24413299561 76.8058471679774 .3675689697371 .9292907714869 .7957916259867 .8876953125 67.66230010986 -9999 -9999 -9999 -9999 -9999 -9999 -9999 -9999 -9999 -9999 -9999 -9999

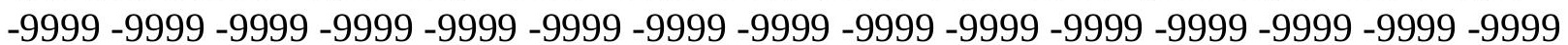
-9999 -9999 -9999 -9999 -9999 -9999 -9999 -9999 -9999 -9999 -9999 -9999 -9999 -9999 -9999 -9999 -9999 -9999 -9999 -9999 -9999 -9999 -9999 -9999 -9999

-9999 -9999 -9999 -9999 -9999 -9999 -9999 -9999 -9999 -9999 -9999 -9999 -9999 -9999 -9999

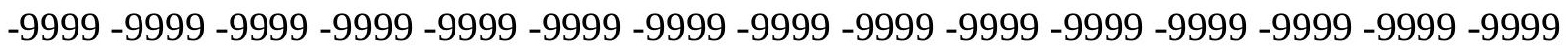
-9999 -9999 -9999 -9999 -9999 -9999 -9999 -9999 -9999 -9999 -9999 -9999 -9999 -9999 -9999 -9999 -9999 -9999 -9999 -9999 -9999 -9999 -9999 -9999 -9999 -9999 -9999 -9999 -9999 -9999 -9999 -9999 -9999 -9999 -9999 -9999 -9999 -9999 -9999 -9999 -9999 -9999 -9999 -9999 -9999

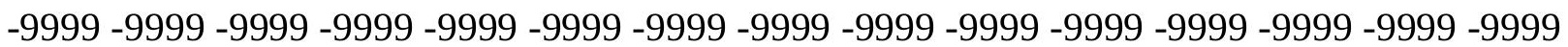
-9999 -9999 -9999 -9999 -9999 -9999 -9999 -9999 -9999 -9999 -9999 -9999 -9999 -9999 -9999 -9999 -9999 -9999 -9999 -9999 -9999 -9999 -9999 -9999 -9999 -9999 -9999 -9999 -9999 -9999 -9999 -9999 -9999 -9999 -9999 -9999 -9999 -9999 -9999 -9999 -9999 -9999 -9999 -9999 -9999 -9999 -9999 -9999 -9999 -9999 -9999 -9999 -9999 -9999 -9999 -9999 -9999 -9999 -9999 -9999 -9999 -9999 -9999 -9999 -9999 -9999 -9999 -9999 -9999 -9999 -9999 -9999 -9999 -9999 -9999 -9999 -9999 -9999 -9999 -9999 -9999 -9999 -9999 -9999 -9999 -9999 -9999 -9999 -9999 -9999

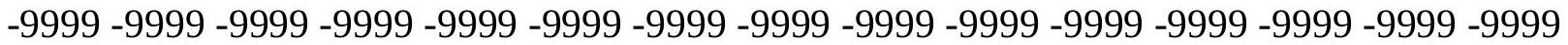
-9999 -9999 -9999 -9999 -9999 -9999 -9999 -9999 -9999 -9999 -9999 -9999 -9999 -9999 -9999 -9999 -9999 -9999 -9999 -9999 -9999 -9999 -9999 -9999 -9999 -9999 -9999 -9999 -9999 -9999 -9999 -9999 -9999 -9999 -9999 -9999 -9999 -9999 -9999 -9999 -9999 -9999 -9999 -9999 -9999 -9999 -9999 -9999 -9999 -9999 -9999 -9999 -9999 -9999 -9999 -9999 -9999 -9999 -9999 -9999 -9999 -9999 -9999 -9999 -9999 -9999 -9999 -9999 -9999 -9999 -9999 -9999 -9999 -9999 -9999 -9999 -9999 -9999 -9999 -9999 -9999 -9999 -9999 -9999 -9999 -9999 -9999 -9999 -9999 -9999 -9999 86.2541885376 87.7781066894590.52117919922 91.4355392456193.87381744385 95.7025299072397 .2264633178798 .445587158299 .0551681518699 .66472625732 99.96952056885100 .2390365601100 .2742996216100 .2742996216100 .2742996216 99.9695205688599 .6647262573299 .6647262573299 .3599472045999 .05516815186 99.0551681518698 .7503814697398 .445587158298 .445587158298 .14080810547 98.1408081054797 .8360290527397 .8360290527397 .5312423706197 .53124237061 97.2264633178796 .9216690063596 .6168823242296 .0073165893695 .70252990723 94.7881774902393 .8738174438592 .6546783447391 .1307525634889 .60682678223 
87.7781066894585 .9494018554783 .5111236572381 .3776321411178 .63455963135 76.1962814331173 .4532165527370 .7101516723668 .7952880859467 .07371520996 66.74794006348 -9999 -9999 -9999 -9999 -9999 -9999 -9999 -9999 -9999 -9999 -9999 -9999 -9999 -9999 -9999 -9999 -9999 -9999 -9999 -9999 -9999 -9999 -9999 -9999 -9999 -9999 -9999 -9999 -9999 -9999 -9999 -9999 -9999 -9999 -9999 -9999 -9999 -9999 -9999 -9999 -9999 - -9999 -9999 -9999 -9999 -9999 -9999 -9999 -9999 -9999 -9999 -9999

-9999 -9999 -9999 -9999 -9999 -9999 -9999 -9999 -9999 -9999 -9999 -9999 -9999 -9999 -9999

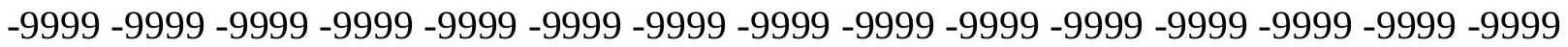
-9999 -9999 -9999 -9999 -9999 -9999 -9999 -9999 -9999 -9999 -9999 -9999 -9999 -9999 -9999 -9999 -9999 -9999 -9999 -9999 -9999 -9999 -9999 -9999 -9999 -9999 -9999 -9999 -9999 -9999 -

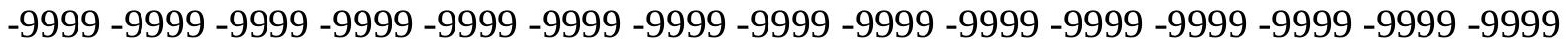
-9999 -9999 -9999 -9999 -9999 -9999 -9999 -9999 -9999 -9999 -9999 -9999 -9999 -9999 -9999 -9999 -9999 -9999 -9999 -9999 -9999 -9999 -9999 -9999 -9999 -9999 -9999 -9999 -9999 -9999 -9999 -9999 -9999 -9999 -9999 -9999 -9999 -9999 -9999 -9999 -9999 -9999 -9999 -9999 -9999 -9999 -9999 -9999 -9999 -9999 -9999 -9999 -9999 -9999 -9999 -9999 -9999 -9999 -9999 -9999

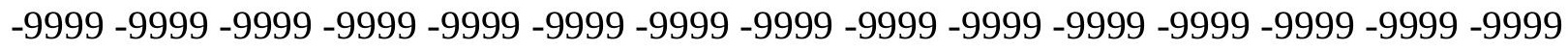
-9999 -9999 -9999 -9999 -9999 -9999 -9999 -9999 -9999 -9999 -9999 -9999 -9999 -9999 -9999 -9999 -9999 -9999 -9999 -9999 -9999 -9999 -9999 -9999 -9999 -9999 -9999 -9999 -9999 -9999 -9999 -9999 -9999 -9999 -9999 -9999 -9999 -9999 -9999 -9999 -9999 -9999 -9999 -9999 -9999 -

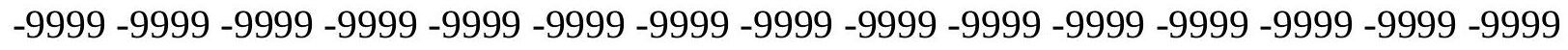

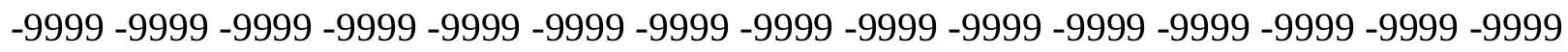
-9999 -9999 -9999 -9999 -9999 -9999 -9999 -9999 -9999 -9999 -9999 -9999 -9999 -9999 -9999 -9999 -9999 -9999 -9999 -9999 -9999 -9999 -9999 -9999 -9999 -9999 -9999 -9999 -9999 -9999 -

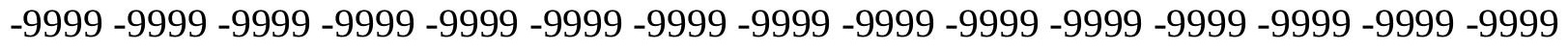

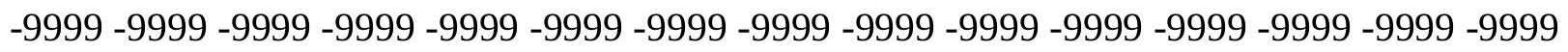
-9999 -9999 90.2164001464891.13075256348 92.6546783447394.48339080811 96.3121032714897 .8360290527399 .0551681518699 .96952056885100 .5791015625 100.8839035034100 .8839035034100 .8839035034100 .8839035034100 .5791015625 100.5791015625100 .274299621699 .9695205688599 .6647262573299 .35994720459 99.0551681518698 .7503814697398 .445587158298 .445587158298 .14080810547 97.8360290527397 .8360290527397 .5312423706197 .5312423706197 .22646331787 97.2264633178796.9216690063596.61688232422 96.3121032714895.70252990723 95.0929565429793.8738174438592.9594726562591.43553924561 89.60682678223 87.7781066894585 .6446228027383 .5111236572380 .7680587768678 .32978057861 75.5867080688572 .8436431884870 .1005783081168 .1065216064566 .4541015625 65.8335876464864 .61444854736 -9999 -9999 -9999 -9999 -9999 -9999 -9999 -9999 -9999

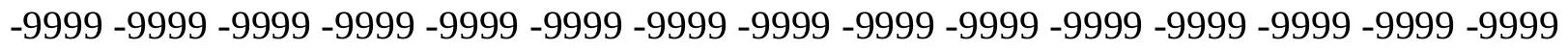

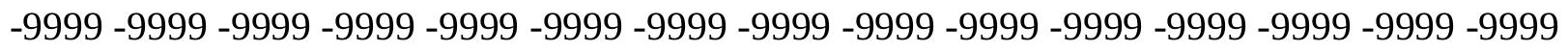
-9999 -9999 -9999 -9999 -9999 -9999 -9999 -9999 -9999 -9999 -9999 -9999 -

-9999 -9999 -9999 -9999 -9999 -9999 -9999 -9999 -9999 -9999 -9999 -9999 -9999 -9999 -9999

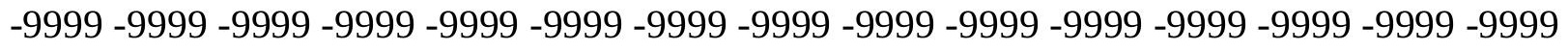

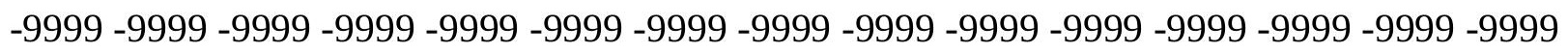
-9999 -9999 -9999 -9999 -9999 -9999 -9999 -9999 -9999 -9999 -9999 -9999 -9999 -9999 -9999 -9999 -9999 -9999 -9999 -9999 -9999 -9999 -9999 -9999 -9999 -9999 -9999 -9999 -9999 -9999 -9999 -9999 -9999 -9999 -9999 -9999 -9999 -9999 -9999 -9999 -9999 -9999 -9999 -9999 -9999 -

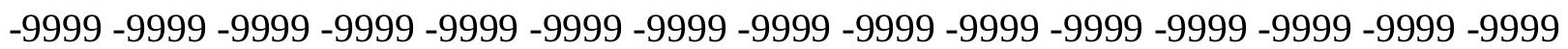


-9999 -9999 -9999 -9999 -9999 -9999 -9999 -9999 -9999 -9999 -9999 -9999 -9999 -9999 -9999 -9999 -9999 -9999 -9999 -9999 -9999 -9999 -9999 -9999 -9999 -9999 -9999 -9999 -9999 -9999 -9999 -9999 -9999 -9999 -9999 -9999 -9999 -9999 -9999 -9999 -9999 -9999 -9999 -9999 -9999 -9999 -9999 -9999 -9999 -9999 -9999 -9999 -9999 -9999 -9999 -9999 -9999 -9999 -9999 -9999 -9999 -9999 -9999 -9999 -9999 -9999 -9999 -9999 -9999 -9999 -9999 -9999 -9999 -9999 -9999 -9999 -9999 -9999 -9999 -9999 -9999 -9999 -9999 -9999 -9999 -9999 -9999 -9999 -9999 -9999 -9999 -9999 -9999 -9999 -9999 -9999 -9999 -9999 -9999 -9999 -9999 -9999 -9999 -9999 -9999

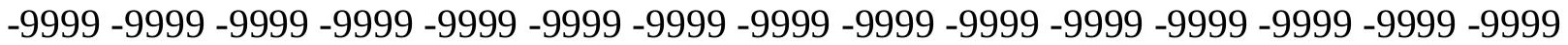
-9999 -9999 -9999 -9999 -9999 -9999 -9999 -9999 -9999 -9999 -9999 -9999 -9999 -9999 -9999 -9999 -9999 -9999 -9999 -9999 -9999 -9999 -9999 -9999 -9999 -9999 -9999 -9999 -9999 -9999 -9999 -9999 -9999 -9999 -9999 -9999 -9999 -9999 -9999 -9999 -9999 -9999 -9999 -9999 -9999 -9999 -9999 -9999 -9999 -9999 -9999 -9999 -9999 -9999 -9999 -9999 -9999 -9999 -9999 -9999 -9999 -9999 92.6546783447393.2642517089894.1785964965896.00731658936 97.5312423706199 .05516815186100 .2742996216100 .8839035034101 .4934005737 101.4934005737101 .4934005737101 .4651870728101 .3502731323101 .1886978149 100.8839035034100 .5791015625100 .274299621699 .9695205688599 .66472625732 99.3599472045999 .0551681518698 .7503814697398 .445587158298 .14080810547 97.8360290527397 .8360290527397 .5312423706197 .5312423706197 .22646331787 97.2264633178797 .2264633178796 .9216690063596 .6168823242296 .00731658936 95.397743225194 .4833908081193 .2642517089891 .7403335571389 .91161346436 88.0829010009885 .6446228027383 .206336975180 .7680587768678 .02498626709 74.9771423339872 .2340774536169 .4910125732467 .6623001098666 .13836669922 64.9192428588963 .70008850098 -9999 -9999 -9999 -9999 -9999 -9999 -9999 -9999 -9999 -9999 -9999 -9999 -9999 -9999 -9999 -9999 -9999 -9999 -9999 -9999 -9999 -9999 -9999 -9999

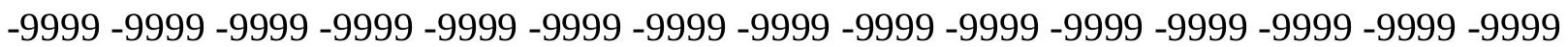
-9999 -9999 -9999 -9999 -9999 -9999 -9999 -9999 -9999 -9999 -9999 -9999 -9999 -9999 -9999 -9999 -9999 -9999 -9999 -9999 -9999 -9999 -9999 -9999 -9999 -9999 -9999 -9999 -9999 -9999 -9999 -9999 -9999 -9999 -9999 -9999 -9999 -9999 -9999 -9999 -9999 -9999 -9999 -9999 -9999 -9999 -9999 -9999 -9999 -9999 -9999 -9999 -9999 -9999 -9999 -9999 -9999

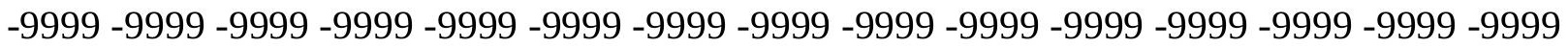
-9999 -9999 -9999 -9999 -9999 -9999 -9999 -9999 -9999 -9999 -9999 -9999 -9999 -9999 -9999 -

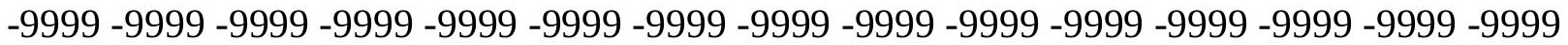
-9999 -9999 -9999 -9999 -9999 -9999 -9999 -9999 -9999 -9999 -9999 -9999 -9999 -9999 -9999 -9999 -9999 -9999 -9999 -9999 -9999 -9999 -9999 -9999 -9999 -9999 -9999 -9999 -9999 -9999 -

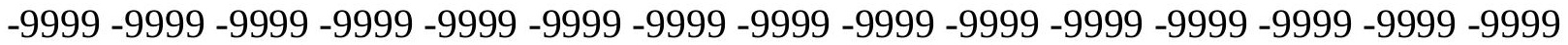
-9999 -9999 -9999 -9999 -9999 -9999 -9999 -9999 -9999 -9999 -9999 -9999 -9999 -9999 -9999 -9999 -9999 -9999 -9999 -9999 -9999 -9999 -9999 -9999 -9999 -9999 -9999 -9999 -9999 -9999

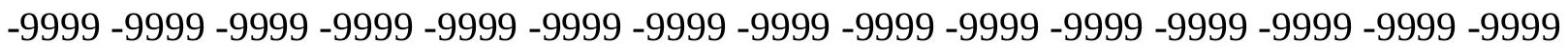
-9999 -9999 -9999 -9999 -9999 -9999 -9999 -9999 -9999 -9999 -9999 -9999 -9999 -9999 -9999 -9999 -9999 -9999 -9999 -9999 -9999 -9999 -9999 -9999 -9999 -9999 -9999 -9999 -9999 -9999 -

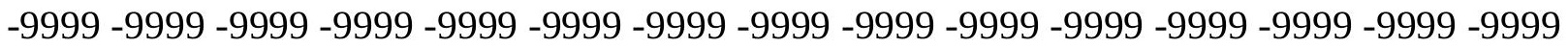
-9999 -9999 -9999 -9999 -9999 -9999 -9999 -9999 -9999 -9999 -9999 -9999 -9999 -9999 -9999 -9999 -9999 -9999 -9999 -9999 -9999 -9999 -9999 -9999 -9999 -9999 -9999 -9999 -9999 -9999 -9999 -9999 -9999 -9999 -9999 -9999 -9999 -9999 -9999 -9999 -9999 -9999 -9999 -9999 -9999 -9999 -9999 -9999 -9999 -9999 -9999 -9999 -9999 -9999 -9999 -9999 -9999 -9999 -9999 -9999 -9999 -9999-9999 95.397743225195.70252990723 97.2264633178799.05516815186 
100.5791015625101 .4934005737102 .1029968262102 .4077987671102 .4077987671 102.4077987671101 .9907150269101 .7875976562101 .5375671387101 .1886978149 100.8839035034100 .5791015625100 .274299621699 .6647262573299 .35994720459 99.0551681518698 .7503814697398 .445587158298 .1408081054797 .83602905273 97.5312423706197 .5312423706197 .2264633178797 .2264633178797 .22646331787 97.22646331787 97.2264633178796.92166900635 96.3121032714895.70252990723 94.7881774902393 .5690307617292 .0450973510790 .5211791992288 .38768768311 85.9494018554783 .5111236572380 .7680587768677 .7202072143674 .67236328125 71.6244964599668 .8814392089866 .7479400634865 .5288009643664 .0048828125 62.78573989868 -9999 -9999 -9999 -9999 -9999 -9999 -9999 -9999 -9999 -9999 -9999 -9999 -9999 -9999 -9999 -9999 -9999 -9999 -9999 -9999 -9999 -9999 -9999 -9999 -9999 -9999 -9999 - 999 -

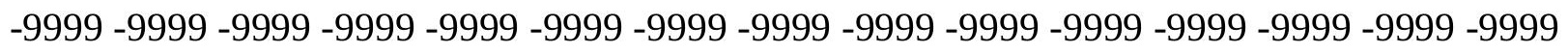
-9999 -9999 -9999 -9999 -9999 -9999 -9999 -9999 -9999

-9999 -9999 -9999 -9999 -9999 -9999 -9999 -9999 -9999 -9999 -9999 -9999 -9999 -9999 -9999 -9999 -9999 -9999 -9999 -9999 -9999 -9999 -9999 -9999 -9999 -9999 -9999 -9999 -9999 -9999

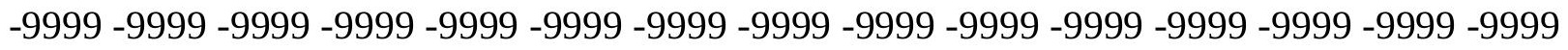
-9999 -9999 -9999 -9999 -9999 -9999 -9999 -9999 -9999 -9999 -9999 -9999 -9999 -9999 -9999 -9999 -9999 -9999 -9999 -9999 -9999 -9999 -9999 -9999 -9999 -9999 -9999 -9999 -9999 -9999 -

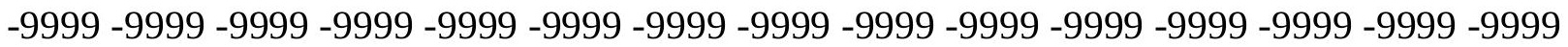

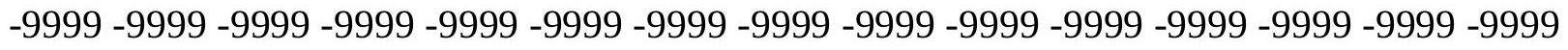

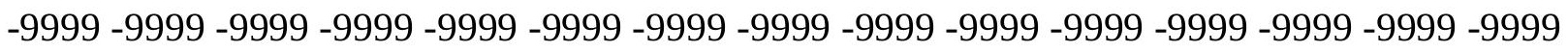
-9999 -9999 -9999 -9999 -9999 -9999 -9999 -9999 -9999 -9999 -9999 -9999 -9999 -9999 -9999 -9999 -9999 -9999 -9999 -9999 -9999 -9999 -9999 -9999 -9999 -9999 -9999 -9999 -9999 -9999 -

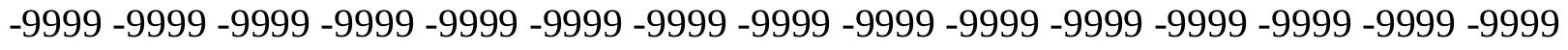

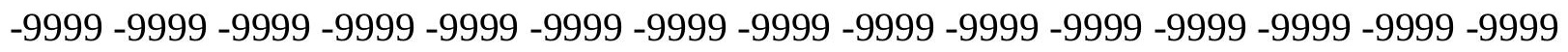
-9999 -9999 -9999 -9999 -9999 -9999 -9999 -9999 -9999 -9999 -9999 -9999 -9999 -9999 -9999

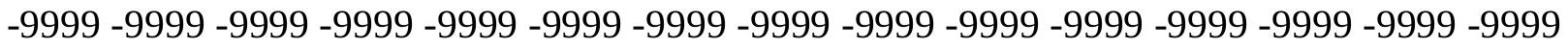

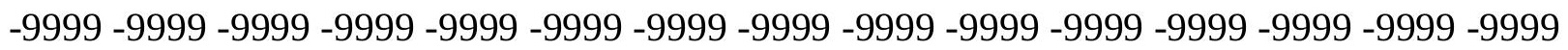
-9999 -9999 -9999 -9999 -9999 -9999 -9999 -9999 -9999 -9999 -9999 -9999 -9999 -9999 -9999 -9999 -9999 -9999 -9999 -9999 -9999 -9999 -9999 -9999 -9999 -9999 -9999 -9999 -9999 -9999 -9999 -9999 -9999 -9999 -9999 -9999 -9999 -9999 -9999 -9999 -9999 -9999-9999 -9999 -9999 -9999 -9999 -9999 -9999 -9999 -9999 -9999 -9999 -9999 -9999 -9999 -9999 -9999 -9999 -9999 -9999 -9999-9999 97.5312423706197.5312423706197.53124237061 100.8839035034 102.1029968262103 .0174026489103 .3221969604103 .3221969604103 .3221969604 103.0174026489103 .0174026489102 .2009506226101 .8865585327101 .5363922119 101.1886978149100 .8839035034100 .274299621699 .9695205688599 .66472625732 99.0551681518698 .7503814697398 .445587158298 .1408081054797 .83602905273 97.53124237061 97.22646331787 97.22646331787 97.22646331787 97.53124237061 97.5312423706197 .5312423706197 .2264633178796 .9216690063596 .31210327148 95.397743225194 .4833908081192 .9594726562591 .1307525634888 .99725341797 86.254188537683 .8159103393680 .7680587768677 .7202072143674 .36756896973 71.014930725167 .9670867919966 .1383666992264 .6144485473663 .09051895142 61.87137985229 -9999 -9999 -9999 -9999 -9999 -9999 -9999 -9999 -9999 -9999 -9999 -9999 -9999 -9999 -9999 -9999 -9999 -9999 -9999 -9999 -9999 -9999 -9999 -9999 -9999 -9999 -9999 -9999 -9999 -9999 -9999 -9999 -9999 -9999 -9999 -9999 -9999 -9999 -9999 -9999 -9999 -9999 -9999 -9999 -9999 -9999 -9999 -9999 -9999 -9999 -9999 
-9999 -9999 -9999 -9999 -9999 -9999 -9999 -9999 -9999 -9999 -9999 -9999 -9999 -9999 -9999 -9999 -9999 -9999 -9999 -9999 -9999 -9999 -9999 -9999 -9999 -9999 -9999 -9999 -9999 -9999 -9999 -9999 -9999 -9999 -9999 -9999 -9999 -9999 -9999 -9999 -9999 -9999 -9999 -9999 -9999 -9999 -9999 -9999 -9999 -9999 -9999 -9999 -9999 -9999 -9999 -9999 -9999 -9999 -9999 -9999 -9999 -9999 -9999 -9999 -9999 -9999 -9999 -9999 -9999 -9999 -9999 -9999 -9999 -9999 -9999 -9999 -9999 -9999 -9999 -9999 -9999 -9999 -9999 -9999 -9999 -9999 -9999 -9999 -9999 -9999 -9999 -9999 -9999 -9999 -9999 -9999 -9999 -9999 -9999 -9999 -9999 -9999 -9999 -9999 -9999

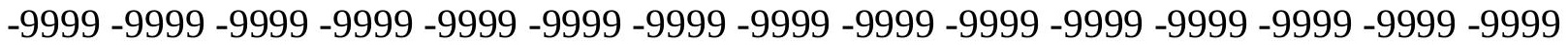
-9999 -9999 -9999 -9999 -9999 -9999 -9999 -9999 -9999 -9999 -9999 -9999 -9999 -9999 -9999 -9999 -9999 -9999 -9999 -9999 -9999 -9999 -9999 -9999 -9999 -9999 -9999 -9999 -9999 -9999 -

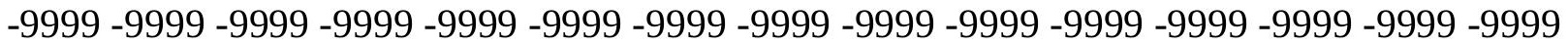
-9999 -9999 -9999 -9999 -9999 -9999 -9999 -9999 -9999 -9999 -9999 -9999 -9999 -9999 -9999

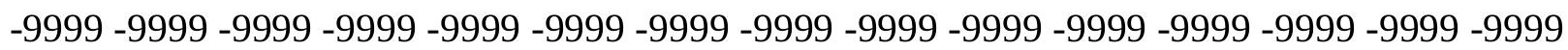
-9999 -9999 -9999 -9999 -9999 -9999 -9999 -9999 -9999 -9999 -9999 -9999 -9999 -9999 -9999 -9999 -9999 -9999 -9999 -9999 -9999 -9999 -9999 -9999 -9999 -9999 -9999 -9999 -9999 -9999

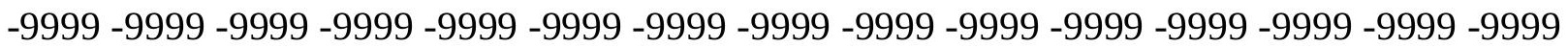
-9999 -9999 -9999 -9999 -9999 -9999 -9999 -9999 -9999 -9999 -9999 -9999 -9999 -9999 -9999 -9999 -9999 -9999 -9999 -9999 -9999 -9999 -9999 -9999 -9999 -9999 -9999 -9999 -9999 -9999 -9999 -9999 -9999 -9999 -9999 -9999 -9999 -9999 -9999 -9999 -9999 -9999 -9999 -9999 -9999 -999 -9999 -9999 -9999 -9999 99.6647262573299.35994720459102.4077987671 103.3221969604 103.9317016602104 .2365036011104 .2365036011103 .9317016602103 .9317016602 103.6268997192103 .0174026489102 .2572174072101 .8851776123101 .4934005737 101.1886978149100 .5791015625100 .274299621699 .6647262573299 .05516815186 98.7503814697398 .445587158297 .8360290527397 .5312423706197 .53124237061 97.2264633178797 .2264633178797 .2264633178797 .5312423706197 .83602905273 97.8360290527397 .8360290527397 .5312423706197 .2264633178796 .31210327148 95.0929565429793 .5690307617291 .7403335571389 .6068267822386 .86376190186 84.1206970214881 .0728530883877 .7202072143674 .3675689697370 .71015167236 $67.3575134277365 .2240066528363 .7000885009862 .1761703491260 .95701980591-9999$ -9999 -9999 -9999 -9999 -9999 -9999 -9999 -9999 -9999 -9999 -9999 -9999 -9999 -9999 -9999 -9999 -9999 -9999 -9999 -9999 -9999 -9999 -9999 -9999 -9999 -9999 -9999 -9999 -9999 -9999 -

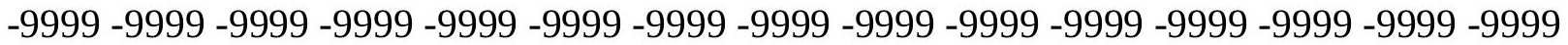
-9999 -9999-9999-9999-9999

-9999 -9999 -9999 -9999 -9999 -9999 -9999 -9999 -9999 -9999 -9999 -9999 -9999 -9999 -9999

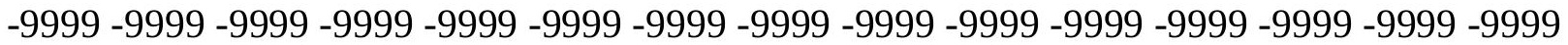
-9999 -9999 -9999 -9999 -9999 -9999 -9999 -9999 -9999 -9999 -9999 -9999 -9999 -9999 -9999 -9999 -9999 -9999 -9999 -9999 -9999 -9999 -9999 -9999 -9999 -9999 -9999 -9999 -9999 -9999

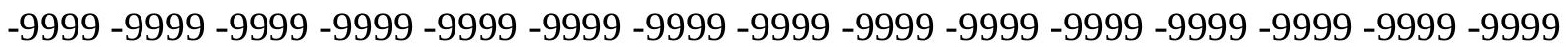
-9999 -9999 -9999 -9999 -9999 -9999 -9999 -9999 -9999 -9999 -9999 -9999 -9999 -9999 -9999 -9999 -9999 -9999 -9999 -9999 -9999 -9999 -9999 -9999 -9999 -9999 -9999 -9999 -9999 -9999 -9999 -9999 -9999 -9999 -9999 -9999 -9999 -9999 -9999 -9999 -9999 -9999 -9999 -9999 -9999 -999 -9999 -9999 -9999 -9999 -9999 -9999 -9999 -9999 -9999 -9999 -9999 -9999 -9999 -9999 -9999 -9999 -9999 -9999 -9999 -9999 -9999 -9999 -9999 -9999 -9999 -9999 -9999 -9999 -9999 -9999 -9999 -9999 -9999 -9999 -9999 -9999 -9999 -9999 -9999 -9999 -9999 -9999 -9999 -9999 -9999 -9999 -9999 -9999 -9999 -9999 -9999 -9999 -9999 -9999 -9999 -9999 -9999 -9999 -9999 -9999

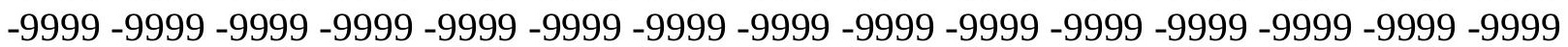


-9999 -9999 -9999 -9999 -9999 -9999 -9999 -9999 -9999 -9999 -9999 -9999 -9999 -9999 -9999 -9999 -9999 -9999 -9999 -9999 -9999 -9999 -9999 -9999 -9999 -9999 -9999 -9999 -9999 -9999 -9999 -9999 -9999 -9999 -9999 -9999 -9999 -9999 -9999 -9999 -9999 -9999 -9999 -9999 -9999 -9999 -9999 -9999 -9999 -9999 -9999 -9999 -9999 -9999 -9999 -9999 -9999 -9999 -9999 -9999 -9999 -9999 -9999 -9999 -9999 -9999 -9999 -9999 -9999 -9999 -9999 -9999 -9999 -9999 -9999 -9999 -9999 -9999 -9999 -9999 -9999 -9999 -9999 -9999 -9999 -9999 -9999 -9999 -9999 -9999 -9999 -9999 -9999 -9999 -9999 101.1886978149 104.2365036011 104.2365036011 104.5412979126104 .8460998535104 .8460998535104 .5412979126104 .5412979126 103.9317016602103 .6268997192103 .0174026489102 .2374649048101 .7982025146 101.4934005737100 .8839035034100 .274299621699 .6647262573299 .35994720459 98.7503814697398 .445587158297 .8360290527397 .5312423706197 .22646331787 97.2264633178797 .2264633178797 .5312423706197 .8360290527398 .14080810547 98.445587158298 .445587158298 .445587158298 .1408081054797 .22646331787 96.3121032714894 .7881774902392 .6546783447390 .5211791992287 .77810668945 84.7302627563581 .3776321411178 .0249862670974 .3675689697370 .71015167236 $67.3575134277364 .6144485473662 .7857398986861 .2618103027359 .73788070679-9999$ -9999 -9999 -9999 -9999 -9999 -9999 -9999 -9999 -9999 -9999 -9999 -9999 -9999-9999-9999 -9999 -9999 -9999 -9999 -9999 -9999 -9999 -9999 -9999 -9999 -9999 -9999 -9999 -9999 -9999 -9999 -9999 -9999 -9999 -9999 -9999 -9999 -9999 -9999 -9999 -9999 -9999 -9999 -9999 -9999 $-9999-9999-9999-9999-9999$

-9999 -9999 -9999 -9999 -9999 -9999 -9999 -9999 -9999 -9999 -9999 -9999 -9999 -9999 -9999 -9999 -9999 -9999 -9999 -9999 -9999 -9999 -9999 -9999 -9999 -9999 -9999 -9999 -9999 -9999 -9999 -9999 -9999 -9999 -9999 -9999 -9999 -9999 -9999 -9999 -9999 -9999 -9999 -9999 -9999 -9999 -9999 -9999 -9999 -9999 -9999 -9999 -9999 -9999 -9999 -9999 -9999 -9999 -9999 -9999

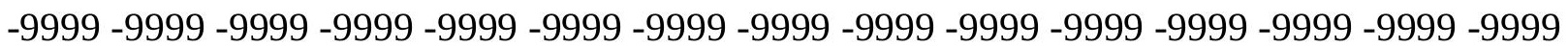
-9999 -9999 -9999 -9999 -9999 -9999 -9999 -9999 -9999 -9999 -9999 -9999 -9999 -9999 -9999 -9999 -9999 -9999 -9999 -9999 -9999 -9999 -9999 -9999 -9999 -9999 -9999 -9999 -9999 -9999 -9999 -9999 -9999 -9999 -9999 -9999 -9999 -9999 -9999 -9999 -9999 -9999 -9999 -9999 -9999 -9999 -9999 -9999 -9999 -9999 -9999 -9999 -9999 -9999 -9999 -9999 -9999 -9999 -9999 -9999 -9999 -9999 -9999 -9999 -9999 -9999 -9999 -9999 -9999 -9999 -9999 -9999 -9999 -9999 -9999 -9999 -9999 -9999 -9999 -9999 -9999 -9999 -9999 -9999 -9999 -9999 -9999 -9999 -9999 -9999 -

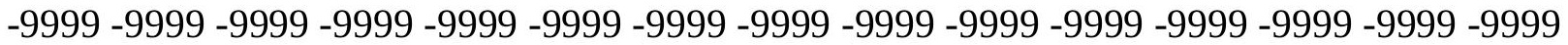
-9999 -9999 -9999 -9999 -9999 -9999 -9999 -9999 -9999 -9999 -9999 -9999 -9999 -9999 -9999 -9999 -9999 -9999 -9999 -9999 -9999 -9999 -9999 -9999 -9999 -9999 -9999 -9999 -9999 -9999 -9999 -9999 -9999 -9999 -9999 -9999 -9999 -9999 -9999 -9999 -9999 -9999 -9999 -9999 -9999 -9999 -9999 -9999 -9999 -9999 -9999 -9999 -9999 -9999 -9999 -9999 -9999 -9999 -9999 -9999 -9999 -9999 -9999 -9999 -9999 -9999 -9999 -9999 -9999 -9999 -9999 -9999 -9999 -9999 -9999

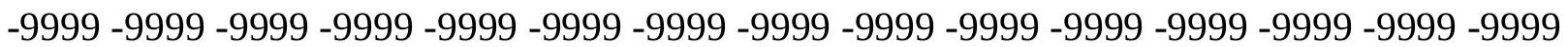
-9999 -9999 -9999 -9999 -9999 -9999 -9999 -9999 -9999 -9999 -9999 -9999 -9999 -9999 -9999 -9999 -9999 -9999 -9999 -9999 -9999 102.4077987671 105.4557037354 105.1509017944 105.4557037354105 .4557037354105 .1509017944104 .8460998535104 .2365036011 103.9317016602103 .3221969604102 .712600708102 .1029968262101 .4934005737 100.8839035034100 .579101562599 .9695205688599 .3599472045999 .05516815186 98.445587158298 .1408081054797 .5312423706197 .2264633178797 .22646331787 97.2264633178797.5312423706198.1408081054798.445587158299.05516815186 99.3599472045999 .3599472045999 .0551681518698 .445587158297 .53124237061 
95.7025299072393 .8738174438591 .4355392456188 .3876876831185 .33984375 81.9871978759878 .3297805786174 .6723632812571 .014930725167 .35751342773 64.3096618652362 .1761703491260 .3474502563558 .82352828979 -9999 -9999 -9999 -9999 -9999 -9999 -9999 -9999 -9999 -9999 -9999 -9999 -9999 -9999 -9999 -9999 -9999 -9999 -9999 -9999 -9999 -9999 -9999 -9999 -9999 -9999 -9999 -9999 -9999 -9999 -9999-9999 -9999 -9999 -

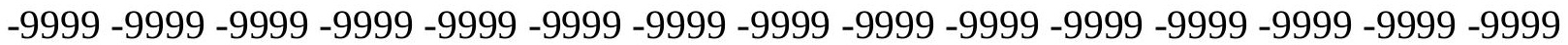
$-9999-9999$

-9999 -9999 -9999 -9999 -9999 -9999 -9999 -9999 -9999 -9999 -9999 -9999 -9999 -9999 -9999 -9999 -9999 -9999 -9999 -9999 -9999 -9999 -9999 -9999 -9999 -9999 -9999 -9999 -9999 -9999 -9999 -9999 -9999 -9999 -9999 -9999 -9999 -9999 -9999 -9999 -9999 -9999 -9999 -9999 -9999

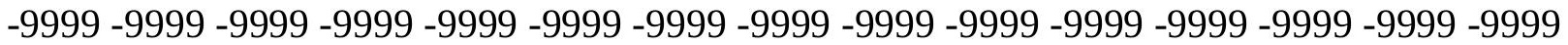
-9999 -9999 -9999 -9999 -9999 -9999 -9999 -9999 -9999 -9999 -9999 -9999 -9999 -9999 -9999 -9999 -9999 -9999 -9999 -9999 -9999 -9999 -9999 -9999 -9999 -9999 -9999 -9999 -9999 -9999 -9999 -9999 -9999 -9999 -9999 -9999 -9999 -9999 -9999 -9999 -9999 -9999 -9999 -9999 - 9999 -9999 -9999 -9999 -9999 -9999 -9999 -9999 -9999 -9999 -9999 -9999 -9999 -9999 -9999 -9999

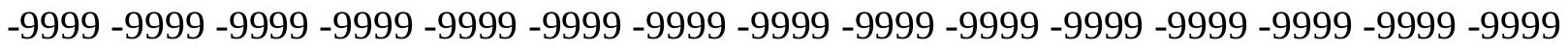
-9999 -9999 -9999 -9999 -9999 -9999 -9999 -9999 -9999 -9999 -9999 -9999 -9999 -9999 -9999 -

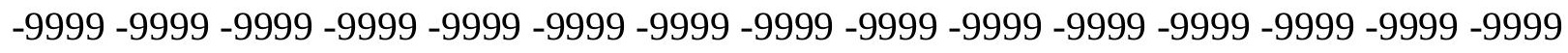
-9999 -9999 -9999 -9999 -9999 -9999 -9999 -9999 -9999 -9999 -9999 -9999 -9999 -9999 -9999 -

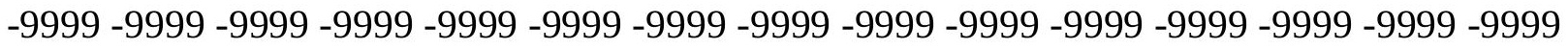
-9999 -9999 -9999 -9999 -9999 -9999 -9999 -9999 -9999 -9999 -9999 -9999 -9999 -9999 -9999 -9999 -9999 -9999 -9999 -9999 -9999 -9999 -9999 -9999 -9999 -9999 -9999 -9999 -9999 -9999 -9999 -9999 -9999 -9999 -9999 -9999 -9999 -9999 -9999 -9999 -9999 -9999 -9999 -9999 -9999 -9999 -9999 -9999 -9999 -9999 -9999 -9999 -9999 -9999 -9999 -9999 -9999 -9999 -9999 -9999 -9999 -9999 -9999 -9999 -9999 -9999 -9999 -9999 -9999 -9999 -9999 -9999 -9999 -9999 -9999 -9999 -9999 -9999 -9999 -9999 -9999 -9999 -9999 -9999 -9999 -9999 -9999 -9999 -9999 -9999 -9999 -9999 -9999 -9999 -9999 -9999 103.6268997192106 .3700027466106 .0652008057 105.7603988647105 .7603988647105 .4557037354105 .1509017944104 .5412979126 103.9317016602103 .3221969604103 .0174026489102 .4077987671101 .7982025146 101.1886978149100 .579101562599 .9695205688599 .6647262573299 .05516815186 98.445587158298 .1408081054797 .8360290527397 .5312423706197 .22646331787 97.2264633178797 .8360290527398 .445587158299 .0551681518699 .66472625732 100.2742996216100 .2742996216100 .274299621699 .6647262573298 .75038146973 96.9216690063595 .0929565429792 .349891662689 .302040100185 .94940185547 82.2919769287178 .6345596313574 .9771423339871 .014930725167 .66230010986 64.004882812561 .2618103027359 .4331016540557 .9091796875 -9999 -9999 -9999 -9999 -9999 -9999 -9999 -9999 -9999 -9999 -9999 -9999 -9999 -9999 -9999 -9999 -9999-999 - 9999 -

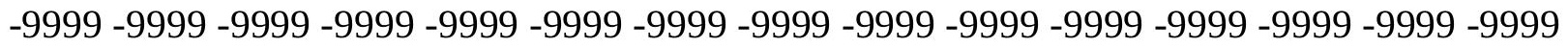

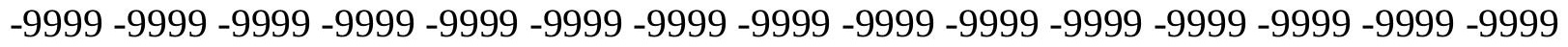
$-9999-9999$

-9999 -9999 -9999 -9999 -9999-9999 -9999 -9999 -9999 -9999 -9999 -9999 -9999 -9999 -9999 -

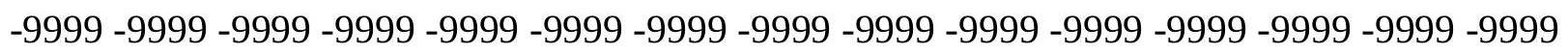
-9999 -9999 -9999 -9999 -9999 -9999 -9999 -9999 -9999 -9999 -9999 -9999 -9999 -9999 -9999 -9999 -9999 -9999 -9999 -9999 -9999 -9999 -9999 -9999-9999 -9999 -9999 -9999 -9999 -9999 -9999 -9999 -9999 -9999 -9999 -9999 -9999 -9999 -9999 -9999 -9999 -9999 -9999 -9999 -9999 -

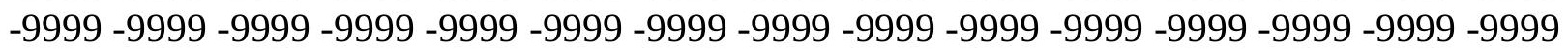


-9999 -9999 -9999 -9999 -9999 -9999 -9999 -9999 -9999 -9999 -9999 -9999 -9999 -9999 -9999 -9999 -9999 -9999 -9999 -9999 -9999 -9999 -9999 -9999 -9999 -9999 -9999 -9999 -9999 -9999 -9999 -9999 -9999 -9999 -9999 -9999 -9999 -9999 -9999 -9999 -9999 -9999 -9999 -9999 -9999 -9999 -9999 -9999 -9999 -9999 -9999 -9999 -9999 -9999 -9999 -9999 -9999 -9999 -9999 -9999 -9999 -9999 -9999 -9999 -9999 -9999 -9999 -9999 -9999 -9999 -9999 -9999 -9999 -9999 -9999 -9999 -9999 -9999 -9999 -9999 -9999 -9999 -9999 -9999 -9999 -9999 -9999 -9999 -9999 -9999 -9999 -9999 -9999 -9999 -9999 -9999 -9999 -9999 -9999 -9999 -9999 -9999 -9999 -9999 -9999

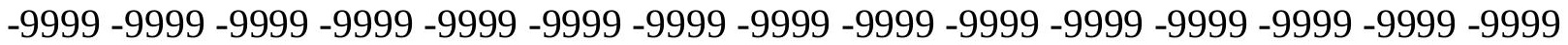
-9999 -9999 -9999 -9999 -9999 -9999 -9999 -9999 -9999 -9999 -9999 -9999 -9999 -9999 -9999 -9999 -9999 -9999 -9999 -9999 -9999 -9999 -9999 -9999 -9999 -9999 -9999 -9999 -9999 -9999 -

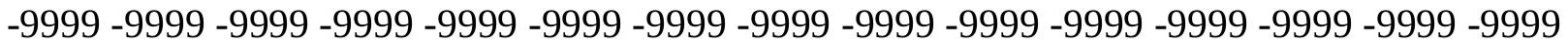
-9999 -9999 -9999 -9999 -9999 -9999 -9999 -9999 -9999 -9999 -9999 -9999 -9999 -9999 -9999 -9999 -9999 -9999 -9999 -9999 -9999 -9999 -9999 -9999 -9999 -9999 -9999 -9999 -9999 -9999 -9999 -9999 -9999 -9999 -9999 -9999 -9999 107.5891036987 107.2844009399 106.6747970581 106.0652008057105 .7603988647104 .8460998535104 .2365036011103 .9317016602 103.3221969604103 .0174026489102 .4077987671101 .7982025146101 .4707336426 100.8307952881100 .213653564599 .6647262573299 .0551681518698 .75038146973 98.445587158298 .1408081054797 .8360290527397 .5312423706197 .53124237061 98.1408081054799 .0551681518699 .66472625732100 .5791015625100 .8839035034 101.1886978149101 .1886978149100 .883903503499 .9695205688598 .4455871582 96.0073165893693 .5690307617290 .2164001464886 .5589828491282 .90155792236 78.9393463134874 .9771423339871 .3197174072367 .6623001098664 .0048828125 60.9570198059158 .5187492370656 .99481964111 -9999 -9999 -9999 -9999 -9999 -9999 -9999 -9999 -9999 -9999 -9999 -9999 -9999 -9999 -9999 -9999 -9999 -9999 -9999 -9999 -9999 -9999

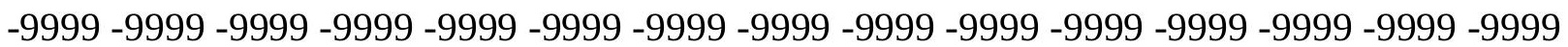
-9999 -9999 -9999 -9999 -9999 -9999 -9999 -9999 -9999 -9999 -9999 -9999 -9999 -9999 -9999 -9999 -9999 -9999 -9999 -9999 -9999 -9999 -9999 -9999 -9999 -9999 -9999 -9999 -9999 -9999 -9999 -9999 -9999 -9999 -9999 -9999 -9999 -9999 -9999 -9999 -9999 -9999 -9999 -9999 -9999 -9999 -9999 -9999 -9999 -9999 -9999 -9999 -9999 -9999 -9999 -9999 -9999 -9999 -9999 -9999 -9999 -9999 -9999 -9999 -9999 -9999 -9999 -9999 -9999 -9999 -9999 -9999 -9999 -9999 -9999 -9999 -9999 -9999 -9999 -9999 -9999 -9999 -9999 -9999 -9999 -9999 -9999 -9999 -9999 -9999 -9999 -9999 -9999 -9999 -9999 -9999 -9999 -9999 -9999 -9999 -9999 -9999 -9999 -9999 -9999 -9999 -9999 -9999 -9999 -9999 -9999 -9999 -9999 -9999 -9999 -9999 -9999 -9999 -9999 -9999 -9999 -9999 -9999 -9999 -9999 -9999 -9999 -9999 -9999 -9999 -9999 -9999 -9999 -9999 -

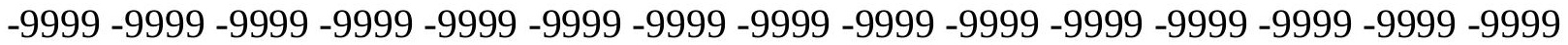
-9999 -9999 -9999 -9999 -9999 -9999 -9999 -9999 -9999 -9999 -9999 -9999 -9999 -9999 -9999 -9999 -9999 -9999 -9999 -9999 -9999 -9999 -9999 -9999 -9999 -9999 -9999 -9999 -9999 -9999

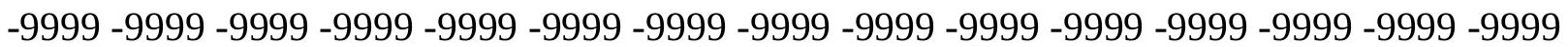
-9999 -9999 -9999 -9999 -9999 -9999 -9999 -9999 -9999 -9999 -9999 -9999 -9999 -9999 -9999 -9999 -9999 -9999 -9999 -9999 -9999 -9999 -9999 -9999 -9999 -9999 -9999 -9999 -9999 -9999 -9999 -9999 -9999 -9999 -9999 -9999 -9999 -9999 -9999 -9999 -9999 -9999 -9999 -9999 -9999 -9999 -9999 -9999 -9999 -9999 -9999 -9999 -9999 -9999 -9999 -9999 -9999 -9999 -9999 -9999 -9999 -9999 -9999 -9999 -9999 -9999 -9999 -9999 -9999 -9999 -9999 -9999 -9999 -9999 -9999 -9999 -9999 -9999 -9999 -9999 -9999 -9999 -9999 -9999 -9999 -9999 -9999 -9999 -9999 -9999 -9999 -9999 -9999 -9999 -9999 -9999 -9999 -9999 -9999 -9999 -9999 -9999 -9999 -9999 -9999 -9999 -9999 -9999 -9999 -9999 -9999 -9999 -9999 107.8938980103107 .5891036987 
106.979598999106 .3700027466104 .5412979126103 .9317016602103 .6268997192 103.6268997192103 .0174026489102 .712600708102 .1029968262101 .4934005737 100.8839035034100 .274299621699 .8548812866299 .3599472045999 .05516815186 98.7503814697398 .445587158298 .1408081054798 .1408081054798 .14080810547 98.7503814697399 .66472625732100 .5791015625101 .1886978149101 .7982025146 102.1029968262102 .4077987671101 .7982025146100 .883903503499 .35994720459 97.22646331787 94.4176559448291.13075256348 87.16854858398 83.2063369751 79.2441329956175 .2819290161171 .3197174072367 .3575134277364 .0048828125 60.6522407531757 .6043891906756 .08045959473 -9999 -9999 -9999 -9999 -9999 -9999 -9999 -9999 -9999 -9999 -9999 -9999 -9999 -9999 -9999 -9999 -9999 -9999 -9999 -9999 -9999 -9999 -9999 -9999 -9999 -9999 -9999 -9999 -9999 -9999 -9999 -9999 -9999 -9999 -9999 -9999 -9999 -9999 -9999 -9999 -9999 -9999 -9999 -9999 -9999 -9999 -9999 -9999 -9999 -9999 -9999 -9999 -9999 -9999 -9999 -9999 -9999 -9999 -9999 -9999 -9999 -9999 -9999 -9999 -9999 -9999 -9999 -9999 -9999 -9999 -9999 -9999 -9999 -9999 -9999 -9999 -9999 -9999 -9999 -9999 -9999 -9999 -9999 -9999 -9999 -9999 -9999 -9999 -9999 -9999 -9999 -9999 -9999 -9999 -9999 -9999

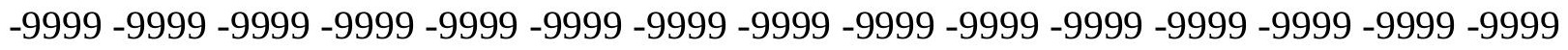
-9999 -9999 -9999 -9999 -9999 -9999 -9999 -9999 -9999 -9999 -9999 -9999 -9999 -9999 -9999 -9999 -9999 -9999 -9999 -9999 -9999 -9999 -9999 -9999 -9999 -9999 -9999 -9999 -9999 -9999 -

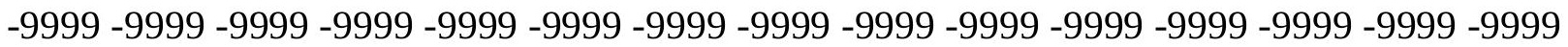

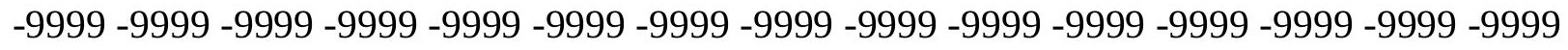

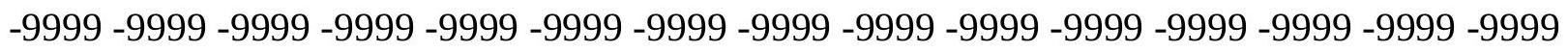
-9999 -9999 -9999 -9999 -9999 -9999 -9999 -9999 -9999 -9999 -9999 -9999 -9999 -9999 -9999 -9999 -9999 -9999 -9999 -9999 -9999 -9999 -9999 -9999 -9999 -9999 -9999 -9999 -9999 -9999 -

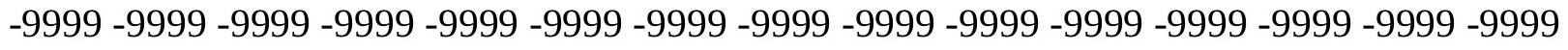

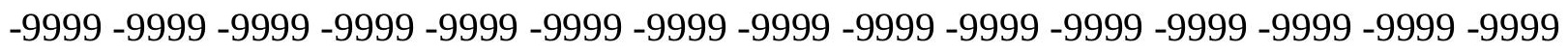
-9999 -9999 -9999 -9999 -9999 -9999 -9999 -9999 -9999 -9999 -9999 -9999 -9999 -9999 -9999

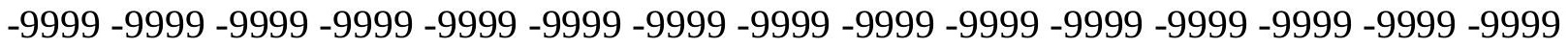

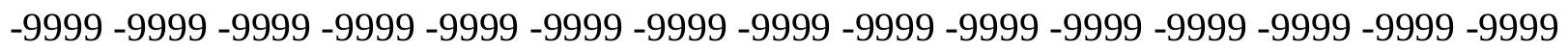
-9999 -9999 -9999 -9999 -9999 -9999 -9999 -9999 -9999 -9999 -9999 -9999 -9999 -9999 -9999 -9999 -9999 -9999 -9999 -9999 -9999 -9999 -9999 -9999 -9999 -9999 -9999 -9999 -9999 -9999 -9999 -9999 -9999 -9999 -9999 -9999 -9999 -9999 -9999 -9999 -9999 -9999 -9999 -9999 -9999 -9999 -9999 -9999 -9999 -9999 -9999 -9999 -9999 -9999 108.1986999512107 .8938980103 104.2365036011103 .6268997192103 .6268997192103 .6268997192103 .6268997192 103.3221969604102 .712600708102 .1029968262101 .7982025146101 .1886978149 100.579101562599 .9695205688599 .6647262573299 .0551681518698 .75038146973 98.7503814697398 .7503814697398 .7503814697399 .0551681518699 .66472625732 100.2742996216101 .1886978149101 .7982025146102 .712600708103 .0174026489 103.0174026489102 .712600708102 .1029968262100 .156723022597 .83642578125 95.1030807495191 .7403335571387 .7781066894583 .5111236572379 .24413299561 75.2819290161171 .014930725167 .3575134277363 .7000885009860 .04267120361 56.9948196411155 .16611099243 -9999 -9999 -9999 -9999 -9999 -9999 -9999 -9999 -9999 -9999 -9999 -9999 -9999 -9999 -9999 -9999 -9999 -9999 -9999 -9999 -9999 -9999 -9999 -9999 -9999 -9999 -9999 -9999 -9999 -9999 -9999 -9999 -9999 -9999 -9999 -9999 -9999 -9999 -9999 -9999 -9999 -9999 -9999 -9999 -9999 -9999 -9999 -9999 -9999 -9999 -9999 -9999 -9999 -9999 -9999 -9999 -9999 -9999 -9999 -9999 -9999 -9999 -9999 -9999 -9999 -9999 -9999 -9999 -9999 -9999 -9999 -9999 -9999 -9999 -9999 -9999 -9999 -9999 -9999 -9999 -9999 
-9999 -9999 -9999 -9999 -9999 -9999 -9999 -9999 -9999 -9999 -9999 -9999 -9999 -9999 -9999 -9999 -9999 -9999 -9999 -9999 -9999 -9999 -9999 -9999 -9999 -9999 -9999 -9999 -9999 -9999 -9999 -9999 -9999 -9999 -9999 -9999 -9999 -9999 -9999 -9999 -9999 -9999 -9999 -9999 -9999 -9999 -9999 -9999 -9999 -9999 -9999 -9999 -9999 -9999 -9999 -9999 -9999 -9999 -9999 -9999 -9999 -9999 -9999 -9999 -9999 -9999 -9999 -9999 -9999 -9999 -9999 -9999 -9999 -9999 -9999 -9999 -9999 -9999 -9999 -9999 -9999 -9999 -9999 -9999 -9999 -9999 -9999 -9999 -9999 -9999 -9999 -9999 -9999 -9999 -9999 -9999 -9999 -9999 -9999 -9999 -9999 -9999 -9999 -9999 -9999

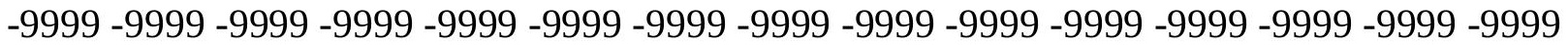
-9999 -9999 -9999 -9999 -9999 -9999 -9999 -9999 -9999 -9999 -9999 -9999 -9999 -9999 -9999 -9999 -9999 -9999 -9999 -9999 -9999 -9999 -9999 -9999 -9999 -9999 -9999 -9999 -9999 -9999 -

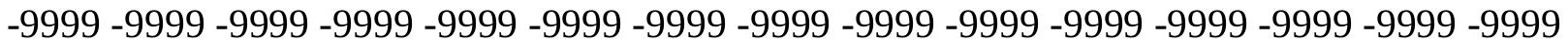
-9999 -9999 -9999 -9999 -9999 -9999 -9999 -9999 -9999 -9999 -9999 -9999 -9999 -9999 -9999

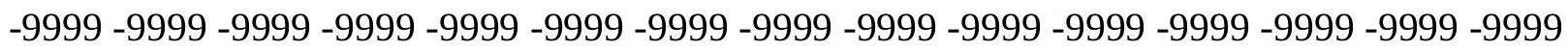
-9999 -9999 -9999 -9999 -9999 -9999 -9999 -9999 -9999 -9999 -9999 -9999 -9999 -9999 -9999 -9999 -9999 -9999 -9999 -9999 -9999 -9999 -9999 -9999 -9999 -9999 -9999 -9999 -9999 -9999 -9999 -9999 -9999 -9999 -9999 -9999 -9999 -9999 -9999 -9999 -9999 -9999 -9999 -9999 -9999 -

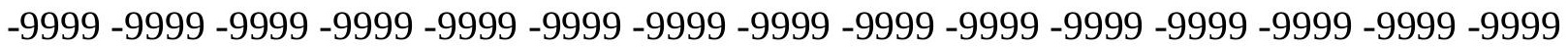
-9999 -9999 -9999 -9999 -9999 -9999 -9999 -9999 -9999 -9999 105.4557037354 104.8460998535104 .2365036011103 .9317016602103 .9317016602103 .6268997192 103.3221969604103 .0174026489102 .4077987671101 .7982025146101 .1886978149 100.5791015625100 .274299621699 .6647262573299 .3599472045999 .05516815186 99.0551681518699 .0551681518699 .3599472045999 .66472625732100 .2742996216 100.8839035034101 .7347106934102 .4077987671103 .0174026489103 .4490890503 103.4251861572103 .0398406982102 .101272583100 .409561157298 .15348052979 96.0073165893692 .0450973510787 .7781066894583 .5111236572379 .24413299561 74.9771423339870 .7101516723666 .7479400634863 .0905189514259 .43310165405 56.0804595947354 .25175094604 -9999 -9999 -9999 -9999 -9999 -9999 -9999 -9999 -9999 -9999 -9999 -9999 -9999 -9999 -9999 -9999 -9999 -9999 -9999 -9999 -9999 -9999 -9999 -9999

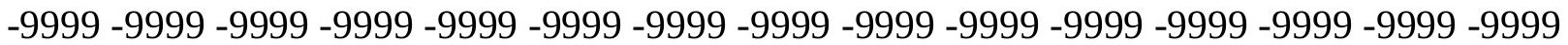
-9999 -9999 -9999 -9999 -9999 -9999 -9999 -9999 -9999 -9999 -9999 -9999 -9999 -9999 -9999 -9999 -9999 -9999 -9999 -9999 -9999 -9999 -9999 -9999 -9999 -9999 -9999

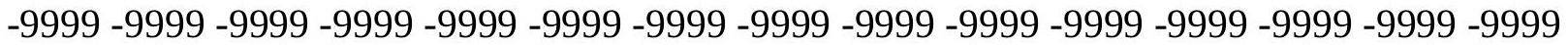
-9999 -9999 -9999 -9999 -9999 -9999 -9999 -9999 -9999 -9999 -9999 -9999 -9999 -9999 -9999 -9999 -9999 -9999 -9999 -9999 -9999 -9999 -9999 -9999 -9999 -9999 -9999 -9999 -9999 -9999 -

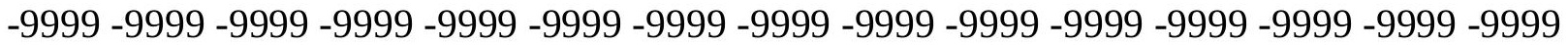
-9999 -9999 -9999 -9999 -9999 -9999 -9999 -9999 -9999 -9999 -9999 -9999 -9999 -9999 -9999 -9999 -9999 -9999 -9999 -9999 -9999 -9999 -9999 -9999 -9999 -9999 -9999 -9999 -9999 -9999

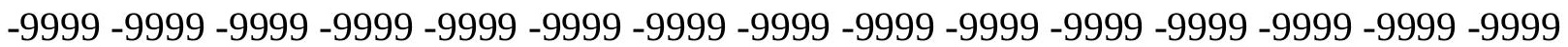
-9999 -9999 -9999 -9999 -9999 -9999 -9999 -9999 -9999 -9999 -9999 -9999 -9999 -9999 -9999 -9999 -9999 -9999 -9999 -9999 -9999 -9999 -9999 -9999 -9999 -9999 -9999 -9999 -9999 -9999 -9999 -9999 -9999 -9999 -9999 -9999 -9999 -9999 -9999 -9999 -9999 -9999 -9999 -9999 -9999 -9999 -9999 -9999 -9999 -9999 -9999 -9999 -9999 -9999 -9999 -9999 -9999 -9999 -9999 -9999 -9999 -9999 -9999 -9999 -9999 -9999 -9999 -9999 -9999 -9999 -9999 -9999 -9999 -9999 -9999 -9999 -9999 -9999 -9999 -9999 -9999 -9999 -9999 -9999 -9999 -9999 -9999 -9999 -9999 -9999 -9999 -9999 -9999 -9999 -9999 -9999 -9999 -9999 -9999 -9999 -9999 -9999 -9999 -9999 -9999

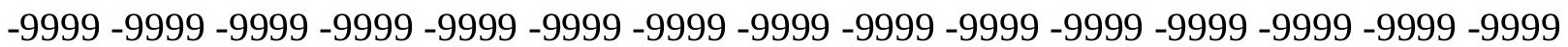


-9999 -9999 -9999 -9999 -9999 -9999 -9999 -9999 -9999 -9999 -9999 -9999 -9999 -9999 -9999 -9999 -9999 -9999 -9999 -9999 -9999 -9999 -9999 -9999 -9999 -9999 -9999 -9999 -9999 -9999

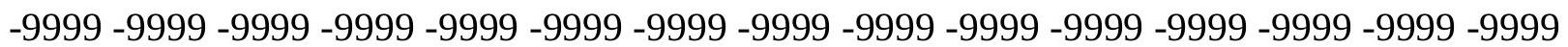
-9999 -9999 -9999 -9999 -9999 -9999 -9999 -9999 -9999 -9999 106.3700027466 105.7603988647105 .1509017944105 .7603988647104 .2365036011103 .9317016602 103.6268997192103 .0174026489102 .712600708102 .1029968262101 .4934005737 100.8839035034100 .274299621699 .9695205688599 .6647262573299 .35994720459 99.3599472045999 .3599472045999 .66472625732100 .2742996216100 .8839035034 101.4934005737102 .1029968262103 .0174026489103 .6268997192103 .9317016602 103.9317016602103 .6268997192102 .712600708101 .493400573799 .66472625732 96.0073165893691 .7403335571387 .4733276367283 .206336975178 .63455963135 74.3675689697370 .1005783081166 .1383666992262 .1761703491258 .82352828979 55.4708900451753 .33739852905 -9999 -9999 -9999 -9999 -9999 -9999 -9999 -9999 -9999 -9999 -9999 -9999 -9999 -9999 -9999 -9999 -9999 -9999 -9999 -9999 -9999 -9999 -9999 -9999 -9999 -9999 -9999 -9999 -9999 -9999 -9999 -9999 -9999 -9999 -9999 -9999 -9999 -9999 -9999 -9999 -9999 -9999 -9999 -9999 -9999 -9999 -9999 -9999 -9999 -9999 -9999

-9999 -9999 -9999 -9999 -9999 -9999 -9999 -9999 -9999 -9999 -9999 -9999 -9999 -9999 -9999 -9999 -9999 -9999 -9999 -9999 -9999 -9999 -9999 -9999 -9999 -9999 -9999 -9999 -9999 -9999 -9999 -9999 -9999 -9999 -9999 -9999 -9999 -9999 -9999 -9999 -9999 -9999 -9999 -9999 -9999 -9999 -9999 -9999 -9999 -9999 -9999 -9999 -9999 -9999 -9999 -9999 -9999 -9999 -9999 -9999

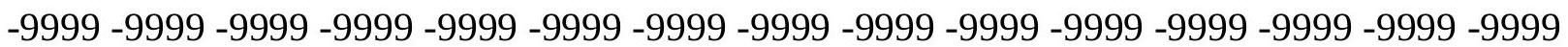
-9999 -9999 -9999 -9999 -9999 -9999 -9999 -9999 -9999 -9999 -9999 -9999 -9999 -9999 -9999 -9999 -9999 -9999 -9999 -9999 -9999 -9999 -9999 -9999 -9999 -9999 -9999 -9999 -9999 -9999 -9999 -9999 -9999 -9999 -9999 -9999 -9999 -9999 -9999 -9999 -9999 -9999 -9999 -9999 -9999

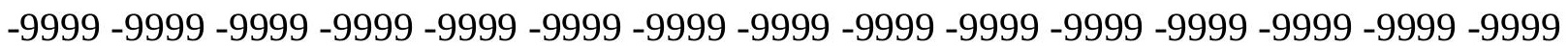
-9999 -9999 -9999 -9999 -9999 -9999 -9999 -9999 -9999 -9999 -9999 -9999 -9999 -9999 -9999 -9999 -9999 -9999 -9999 -9999 -9999 -9999 -9999 -9999 -9999 -9999 -9999 -9999 -9999 -9999 -9999 -9999 -9999 -9999 -9999 -9999 -9999 -9999 -9999 -9999 -9999 -9999 -9999 -9999 -9999 -9999 -9999 -9999 -9999 -9999 -9999 -9999 -9999 -9999 -9999 -9999 -9999 -9999 -9999 -9999 -9999 -9999 -9999 -9999 -9999 -9999 -9999 -9999 -9999 -9999 -9999 -9999 -9999 -9999 -9999 -9999 -9999 -9999 -9999 -9999 -9999 -9999 -9999 -9999 -9999 -9999 -9999 -9999 -9999 -9999 -

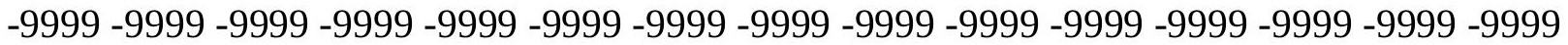
-9999 -9999 -9999 -9999 -9999 -9999 -9999 -9999 -9999 -9999 -9999 -9999 -9999 -9999 -9999 -9999 -9999 -9999 -9999 -9999 -9999 -9999 -9999 -9999 -9999 -9999 -9999 -9999 -9999 -9999

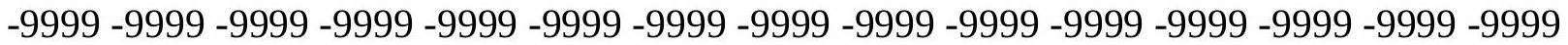
-9999 -9999 -9999 -9999 -9999 -9999 -9999 -9999 -9999 -9999 -9999 106.3700027466 105.7603988647105 .1509017944104 .5412979126104 .2365036011103 .9317016602 103.3221969604102 .712600708102 .1029968262101 .4934005737100 .8839035034 100.5791015625100 .274299621699 .9695205688599 .6647262573299 .66472625732 99.6647262573299 .96952056885100 .5791015625101 .1886978149101 .7982025146 102.4077987671103 .0174026489103 .6268997192103 .9317016602103 .9317016602 103.3221969604102 .4077987671100 .883903503498 .445587158295 .09295654297 91.1307525634886 .8637619018682 .5967712402378 .0249862670973 .75800323486 69.1862335205165 .2240066528361 .2618103027357 .909179687554 .55654144287 52.42303848267 -9999 -9999 -9999 -9999 -9999 -9999 -9999 -9999 -9999 -9999 -9999 -9999 -9999 -9999 -9999 -9999 -9999 -9999 -9999 -9999 -9999 -9999 -9999 -9999 -9999 -9999 -9999 
-9999 -9999 -9999 -9999 -9999 -9999 -9999 -9999 -9999 -9999 -9999 -9999 -9999 -9999 -9999 -9999 -9999 -9999 -9999 -9999 -9999 -9999 -9999 -9999

-9999 -9999 -9999 -9999 -9999 -9999 -9999 -9999 -9999 -9999 -9999 -9999 -9999 -9999 -9999 -9999 -9999 -9999 -9999 -9999 -9999 -9999 -9999 -9999 -9999 -9999 -9999 -9999 -9999 -9999 -9999 -9999 -9999 -9999 -9999 -9999 -9999 -9999 -9999-9999 -9999 -9999 -9999 -9999 -9999 -9999 -9999 -9999 -9999 -9999 -9999 -9999 -9999 -9999 -9999 -9999 -9999 -9999 -9999 -9999 -

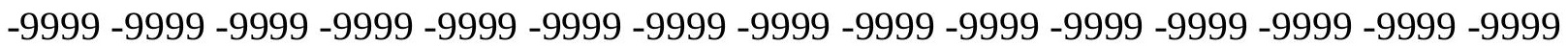

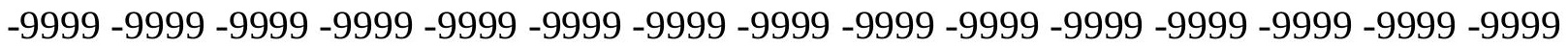

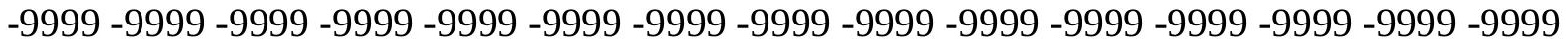
-9999 -9999 -9999 -9999 -9999 -9999 -9999 -9999 -9999 -9999 -9999 -9999 -9999 -9999 -9999

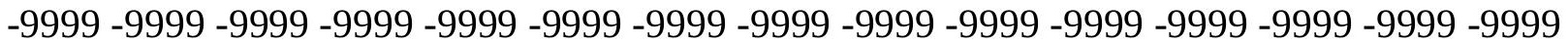
-9999 -9999 -9999 -9999 -9999 -9999 -9999 -9999 -9999 -9999 -9999 -9999 -9999 -9999 -9999 -9999 -9999 -9999 -9999 -9999 -9999 -9999 -9999 -9999 -9999 -9999 -9999 -9999 -9999 -9999 -9999 -9999 -9999 -9999 -9999 -9999 -9999 -9999 -9999 -9999 -9999 -9999 -9999 -9999 - 9999 -9999 -9999 -9999 -9999 -9999 -9999 -9999 -9999 -9999 -9999 -9999 -9999 -9999 -9999 -9999

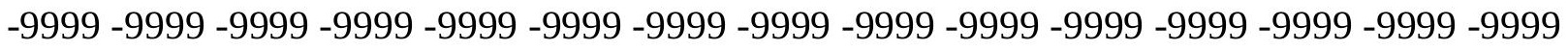
-9999 -9999 -9999 -9999 -9999 -9999 -9999 -9999 -9999 -9999 -9999 -9999 -9999 -9999 -9999 -9999 -9999 -9999 -9999 -9999 -9999 -9999 -9999 -9999 -9999 -9999 -9999 -9999 -9999 -9999 -9999 -9999 -9999 -9999 -9999 -9999 -9999 -9999 -9999 -9999 -9999 -9999 -9999 -9999 -9999 -

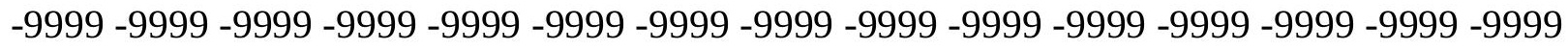

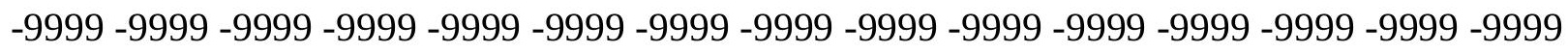
-9999 -9999 -9999 -9999 -9999 -9999 -9999 -9999 -9999 -9999 -9999 -9999 106.3700027466 105.7603988647105 .1509017944104 .8460998535104 .2365036011103 .6268997192 103.0174026489102 .4077987671101 .7982025146101 .1886978149100 .5791015625 100.274299621699 .9695205688599 .9695205688599 .9695205688599 .96952056885 100.2742996216100 .5791015625101 .1886978149101 .7982025146102 .4077987671 103.0174026489103 .6268997192103 .6268997192103 .6268997192103 .0174026489 101.798202514699 .9695205688597 .2264633178793 .8738174438589 .91161346436 85.9494018554781 .6824111938577 .110626220772 .8436431884868 .57665252686 65.8335876464860 .0426712036156 .6900291442953 .9469718933151 .50868988037 -9999 -9999 -9999 -9999 -9999 -9999 -9999 -9999 -9999 -9999 -9999 -9999 -9999 -9999 -9999 -9999 -9999 -9999 -9999 -9999 -9999 -9999 -9999 -9999 -9999 -9999 -9999 -9999 -9999 -9999 -9999 -

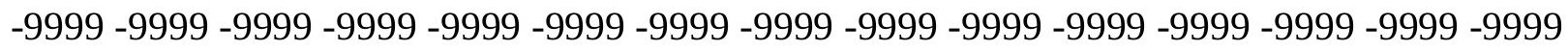
-9999 -9999-9999-9999-9999

-9999 -9999 -9999 -9999 -9999 -9999 -9999 -9999 -9999 -9999 -9999 -9999 -9999 -9999 -9999

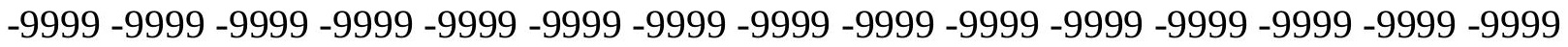

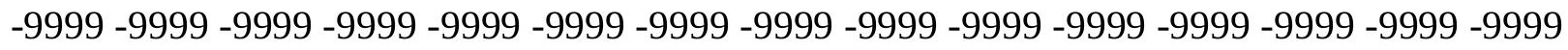

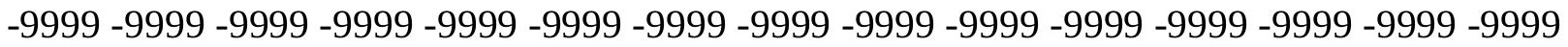
-9999 -9999 -9999 -9999 -9999 -9999 -9999 -9999 -9999 -9999 -9999 -9999 -9999 - 9999 - -999 -9999 -9999 -9999 -9999 -9999 -9999 -9999 -9999 -9999 -9999 -9999 -9999 -9999 -9999 -9999 -

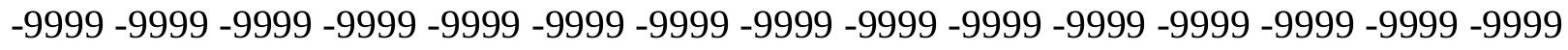

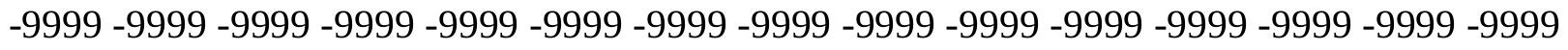
-9999 -9999 -9999 -9999 -9999 -9999 -9999 -9999 -9999 -9999 -9999 -9999 -9999 -9999 -9999 -9999 -9999 -9999 -9999 -9999 -9999 -9999 -9999 -9999-9999 -9999 -9999 -9999 -9999 -9999 -9999 -9999 -9999 -9999 -9999 -9999 -9999 -9999 -9999 -9999 -9999 -9999 -9999 -9999 -9999 -

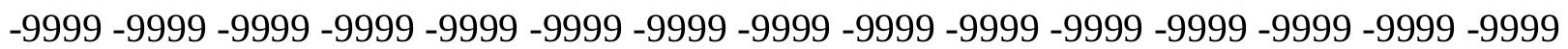


-9999 -9999 -9999 -9999 -9999 -9999 -9999 -9999 -9999 -9999 -9999 -9999 -9999 -9999 -9999 -9999 -9999 -9999 -9999 -9999 -9999 -9999 -9999 -9999 -9999 -9999 -9999 -9999 -9999 -9999 -9999 -9999 -9999 -9999 -9999 -9999 -9999 -9999 -9999 -9999 -9999 -9999 -9999 -9999 -9999 -9999 -9999 -9999 -9999 -9999 -9999 -9999 -9999 -9999 -9999 -9999 -9999 -9999 -9999 -9999 -9999 -9999 -9999 -9999 -9999 -9999 -9999 -9999 -9999 -9999 -9999 -9999 -9999 -9999 -9999 -9999 -9999 -9999 -9999 -9999 -9999 -9999 -9999 -9999 -9999 -9999 -9999 -9999 -9999 -9999 -

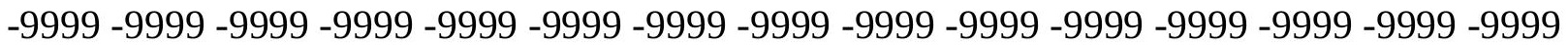
-9999 -9999 -9999 -9999 -9999 -9999 -9999 -9999 -9999 -9999 -9999 -9999 -9999 106.3700027466105 .7603988647105 .1509017944104 .5412979126103 .9317016602 103.3221969604102 .4077987671101 .7982025146101 .1886978149100 .8839035034 100.274299621699.9695205688599.9695205688599.9695205688599.96952056885 100.2742996216100 .5791015625101 .1886978149101 .7982025146102 .4077987671 102.712600708103 .0174026489103 .3221969604103 .0174026489102 .1029968262 100.579101562598 .445587158295 .7025299072392 .349891662688 .69246673584 84.7302627563580 .4632720947376 .1962814331171 .9292907714867 .66230010986 $65.5288009643658 .8235282897955 .4708900451752 .7278289794950 .59432983398-9999$ -9999 -9999 -9999 -9999 -9999 -9999 -9999 -9999 -9999 -9999 -9999 -9999 -9999-9999-9999 -9999 -9999 -9999 -9999 -9999 -9999 -9999 -9999 -9999 -9999 -9999 -9999 -9999 -9999 -9999 -9999 -9999 -9999 -9999 -9999 -9999 -9999 -9999 -9999 -9999 -9999 -9999 -9999 -9999 -9999 $-9999-9999-9999-9999-9999$

-9999 -9999 -9999 -9999 -9999 -9999 -9999 -9999 -9999 -9999 -9999 -9999 -9999 -9999 -9999 -9999 -9999 -9999 -9999 -9999 -9999 -9999 -9999 -9999 -9999 -9999 -9999 -9999 -9999 -9999 -9999 -9999 -9999 -9999 -9999 -9999 -9999 -9999 -9999 -9999 -9999 -9999 -9999 -9999 -9999 -9999 -9999 -9999 -9999 -9999 -9999 -9999 -9999 -9999 -9999 -9999 -9999 -9999 -9999 -9999

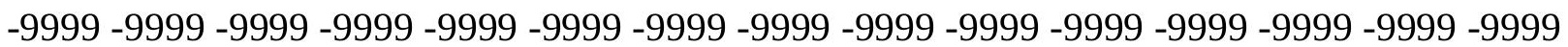
-9999 -9999 -9999 -9999 -9999 -9999 -9999 -9999 -9999 -9999 -9999 -9999 -9999 -9999 -9999 -9999 -9999 -9999 -9999 -9999 -9999 -9999 -9999 -9999 -9999 -9999 -9999 -9999 -9999 -9999 -9999 -9999 -9999 -9999 -9999 -9999 -9999 -9999 -9999 -9999 -9999 -9999 -9999 -9999 -9999 -9999 -9999 -9999 -9999 -9999 -9999 -9999 -9999 -9999 -9999 -9999 -9999 -9999 -9999 -9999 -9999 -9999 -9999 -9999 -9999 -9999 -9999 -9999 -9999 -9999 -9999 -9999 -9999 -9999 -9999 -9999 -9999 -9999 -9999 -9999 -9999 -9999 -9999 -9999 -9999 -9999 -9999 -9999 -9999 -9999 -9999 -9999 -9999 -9999 -9999 -9999 -9999 -9999 -9999 -9999 -9999 -9999 -9999 -9999 -9999 -9999 -9999 -9999 -9999 -9999 -9999 -9999 -9999 -9999 -9999 -9999 -9999 -9999 -9999 -9999 -9999 -9999 -9999 -9999 -9999 -9999 -9999 -9999 -9999 -9999 -9999 -9999 -9999 -9999 -9999 -

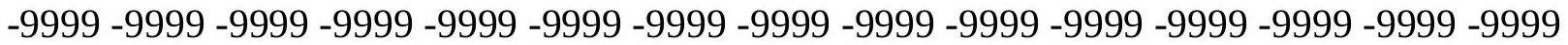
-9999 -9999 -9999 -9999 -9999 -9999 -9999 -9999 -9999 -9999 -9999 -9999 -9999 -9999 -9999 -9999 -9999 -9999 -9999 -9999 -9999 -9999 -9999 -9999 -9999 -9999 -9999 -9999 -9999 -9999

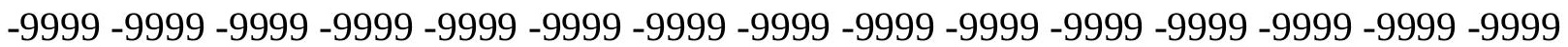
-9999 -9999 -9999 -9999 -9999 -9999 -9999 -9999 -9999 -9999 -9999 -9999 -9999 -9999 -9999 -9999 -9999 -9999 -9999 -9999 -9999 -9999 -9999 -9999 -9999 -9999 -9999 -9999 106.979598999106 .3700027466105 .4557037354104 .8460998535104 .2365036011 103.3221969604102 .712600708101 .7982025146101 .1886978149100 .8839035034 100.2742996216100 .274299621699 .9695205688599 .9695205688599 .96952056885 100.2742996216100 .5791015625100 .8839035034101 .4934005737101 .7982025146 102.4077987671102 .712600708102 .4077987671102 .1029968262101 .1886978149 99.6647262573297 .2264633178794 .1785964965890 .8259735107487 .16854858398 
83.2063369751 79.24413299561 75.2819290161171.3197174072367.35751342773 65.5288009643659 .4331016540554 .8613204956152 .11825942993 -9999 -9999 -9999 -9999 -9999 -9999 -9999 -9999 -9999 -9999 -9999 -9999 -9999 -9999 -9999 -9999 -9999 -9999 -9999 -9999 -9999 -9999 -9999 -9999 -9999 -9999 -9999 -9999 -9999 -9999 -9999 -9999 -9999 -9999

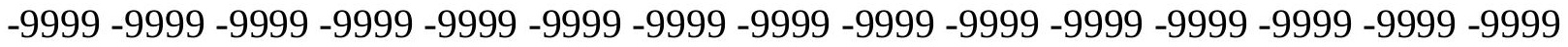
-9999 -9999-9999

-9999 -9999 -9999 -9999 -9999 -9999 -9999 -9999 -9999 -9999 -9999 -9999 -9999 -9999 -9999 -9999 -9999 -9999 -9999 -9999 -9999 -9999 -9999 -9999 -9999 -9999 -9999 -9999 -9999 -9999 -9999 -9999 -9999 -9999 -9999 -9999 -9999 -9999 -9999 -9999 -9999 -9999 -9999 -9999 -9999 -9999 -9999 -9999 -9999 -9999 -9999 -9999 -9999 -9999 -9999 -9999 -9999 -9999 -9999 -9999 -9999 -9999 -9999 -9999 -9999 -9999 -9999 -9999 -9999 -9999 -9999 -9999 -9999 -9999 -9999 -9999 -9999 -9999 -9999 -9999 -9999 -9999 -9999 -9999 -9999 -9999 -9999 -9999 -9999 -9999 -9999 -9999 -9999 -9999 -9999 -9999 -9999 -9999 -9999 -9999 -9999 -9999 -9999 -9999 -9999 -9999 -9999 -9999 -9999 -9999 -9999 -9999 -9999 -9999 -9999 -9999 -9999 -9999 -9999 -9999 -9999 -9999 -9999 -9999 -9999 -9999 -9999 -9999 -9999 -9999 -9999 -9999 -9999 -9999 -9999

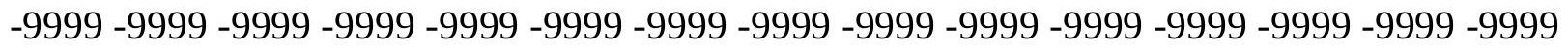
-9999 -9999 -9999 -9999 -9999 -9999 -9999 -9999 -9999 -9999 -9999 -9999 -9999 -9999 -9999 -9999 -9999 -9999 -9999 -9999 -9999 -9999 -9999 -9999 -9999 -9999 -9999 -9999 -9999 -9999 -

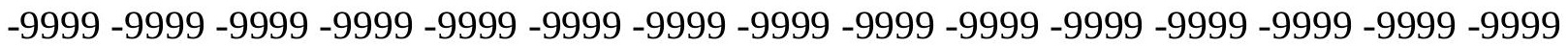

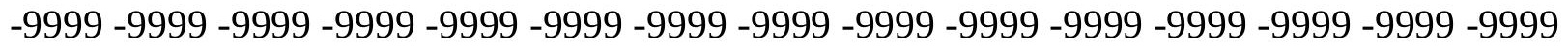

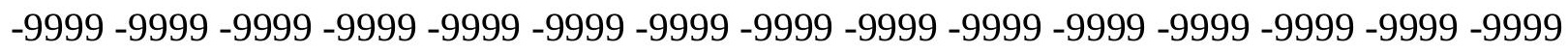
-9999 -9999 -9999 -9999 -9999 -9999 -9999 -9999 -9999 -9999 -9999 -9999 -9999 -9999 -9999 -9999 -9999 -9999 -9999 -9999 -9999 -9999 -9999 -9999 -9999 -9999 -9999 -9999 -9999 -9999 -

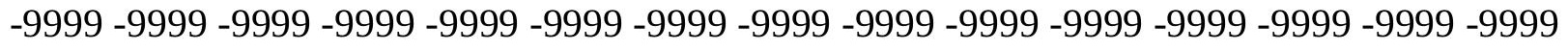

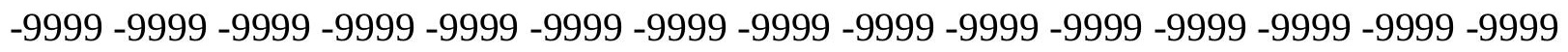
-9999 -9999 -9999 -9999 -9999 -9999 -9999 -9999 -9999 -9999 -9999 -9999 -9999 -9999 106.979598999106 .0652008057105 .1509017944104 .5412979126103 .6268997192 102.712600708102 .1029968262101 .1886978149100 .5791015625100 .2742996216 100.2742996216100 .2742996216100 .274299621699 .9695205688599 .96952056885 99.96952056885100 .5791015625100 .8839035034101 .4934005737101 .7982025146 101.7982025146101 .4934005737101 .188697814999 .9695205688598 .4455871582 96.0073165893692 .6546783447388 .9972534179785 .3398437581 .68241119385 78.0249862670974 .3675689697371 .014930725167 .3575134277365 .52880096436 57.6043891906754 .86132049561 -9999 -9999 -9999 -9999 -9999-9999 -9999 -9999 -9999 -9999 -9999 -9999 -9999 -9999 -9999 -9999 -9999 -9999 -9999 -9999 -9999 -9999 -9999 -9999

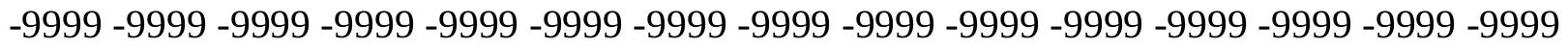

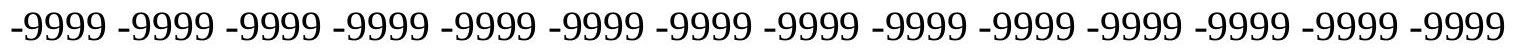

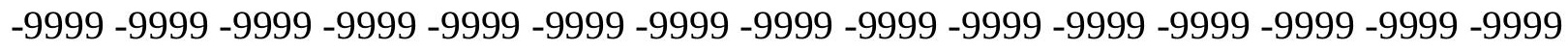
-9999 -9999 -9999 -9999 -9999 -9999 -9999 -9999 -9999 -9999 -9999 -9999 -9999 -9999 -9999 -9999 -9999 -9999 -9999 -9999 -9999 -9999 -9999 -9999 -9999 -9999 -9999 -9999 -9999 -9999 -

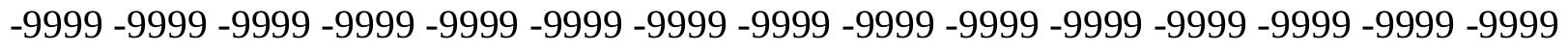

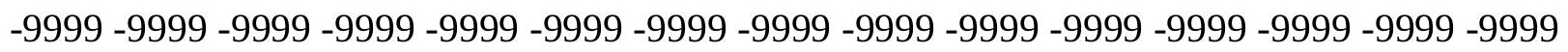

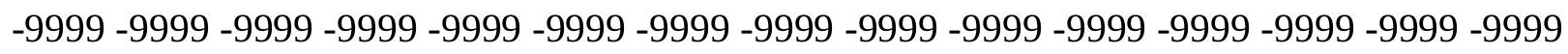
-9999 -9999 -9999 -9999 -9999 -9999 -9999 -9999 -9999 -9999 -9999 -9999 -9999 -9999 -9999 -9999 -9999 -9999 -9999 -9999 -9999 -9999 -9999 -9999 -9999 -9999 -9999 -9999 -9999 -9999 -

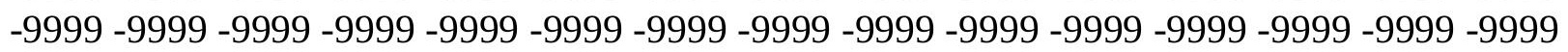


-9999 -9999 -9999 -9999 -9999 -9999 -9999 -9999 -9999 -9999 -9999 -9999 -9999 -9999 -9999 -9999 -9999 -9999 -9999 -9999 -9999 -9999 -9999 -9999 -9999 -9999 -9999 -9999 -9999 -9999 -9999 -9999 -9999 -9999 -9999 -9999 -9999 -9999 -9999 -9999 -9999 -9999 -9999 -9999 - 9999 -9999 -9999 -9999 -9999 -9999 -9999 -9999 -9999 -9999 -9999 -9999 -9999 -9999 -9999 -9999 -9999 -9999 -9999 -9999 -9999 -9999 -9999 -9999 -9999-9999 -9999 -9999 -9999 -9999 -9999 -9999 -9999 -9999 -9999 -9999 -9999 -9999 -9999 -9999 -9999 -9999 -9999 -9999 -9999 -9999 -9999 -9999 -9999 -9999 -9999 -9999 -9999 -9999 -9999 -9999 -9999 -9999 -9999 -9999 -9999 -999 -

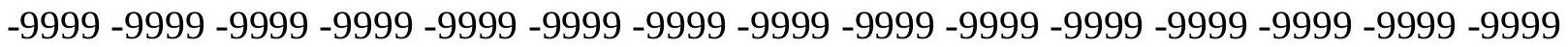
-9999 -9999 -9999 -9999 -9999 -9999 -9999 -9999 -9999 -9999 -9999 -9999 -9999 -9999 -9999 -9999 -9999 -9999 -9999 -9999 -9999 -9999 -9999 -9999 -9999 -9999 -9999 -9999 -9999 -9999 -9999 -9999 -9999 -9999 -9999 -9999 -9999 -9999 -9999 -9999 -9999 -9999 -9999 -9999 -9999 -999 106.979598999106 .0652008057104 .8460998535103 .9317016602103 .0174026489 102.1029968262101 .1886978149100 .5791015625100 .2742996216100 .5791015625 100.5791015625100 .2742996216101 .493400573799 .6647262573299 .66472625732 99.96952056885100 .2742996216100 .8839035034100 .8839035034100 .8839035034 100.579101562599 .9695205688599 .0551681518697 .5312423706194 .78817749023 91.1307525634887 .1685485839883 .8159103393680 .1584930419976 .50106811523 73.1484298706170 .4053573608468 .8814392089864 .004882812557 .9091796875 -9999-9999 -9999 -9999 -9999 -9999 -9999 -9999 -9999 -9999 -9999 -9999 -9999 -9999 -9999 -9999 -9999 -9999 -9999 -9999 -9999 -9999 -9999 -9999 -9999 -9999 -9999 -9999 -9999 -9999 -9999 -9999 -9999 -9999 -9999 -9999 -9999 -9999 -9999 -9999 -9999 -9999 -9999 -9999 -9999 -9999 -9999 -999 -9999 -9999 -9999 -9999-9999-9999-9999 -9999 -9999 -9999 -9999 -9999 -9999 -9999 -9999 -9999 -9999 -9999 -9999 -9999 -9999 -9999 -9999 -9999 -9999 -9999 -9999 -9999 -9999 -9999 -9999 -9999 -9999 -9999 -9999 -9999 -9999 -9999 -9999 -9999 -9999 -9999 -9999 -9999 -9999 -9999 -9999 -9999 -9999 -9999 -9999 -9999 -9999 -9999 -9999 -9999 -9999 -9999 -9999 -9999 -9999 -9999 -9999 -9999 -9999 -9999 -9999 -9999 -9999 -9999 -9999 -9999 -9999 -9999 -9999 -9999 -9999 -9999 -9999 -9999 -9999 -9999 -9999 -9999 -9999 -9999 -9999 -9999 -9999 -9999 -9999 -9999 -9999 -9999 -9999 -9999 -9999 -9999 -9999 -9999 -9999 -9999 -9999 -9999 -9999 -9999 -9999 -9999 -9999 -9999 -9999 -9999 -9999 -9999 -9999 -9999 -9999 -9999 -9999 -9999 -9999 -9999 -9999 -9999 -9999 -9999 -999 -9999 -9999 -9999 -9999 -9999 -9999 -9999 -9999 -9999 -9999 -9999 -9999 -9999 -9999 -9999 -9999 -9999 -9999 -9999 -9999 -9999 -9999 -9999 -9999 -9999 -9999 -9999 -9999 -9999 -9999 -

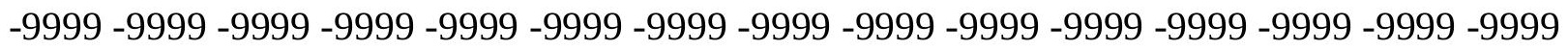

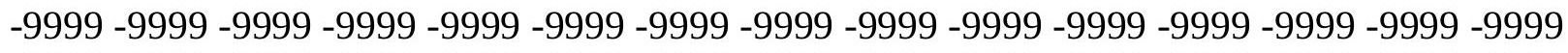
-9999 -9999 -9999 -9999 -9999 -9999 -9999 -9999 -9999 -9999 -9999 -9999 -9999 -9999 -9999 -9999 -9999 -9999 -9999 -9999 -9999 -9999 -9999 -9999 -9999 -9999 -9999 -9999 -9999 -9999

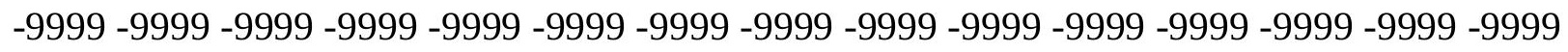

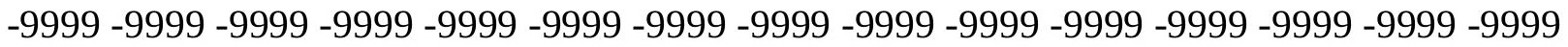
-9999 -9999 -9999 -9999 -9999 -9999 -9999 -9999 -9999 -9999 -9999 -9999 -9999 - 9999 - -999 -9999 -9999 -9999 -9999 -9999 -9999 -9999 -9999 -9999 -9999 -9999 -9999 -9999 -9999 -9999 -

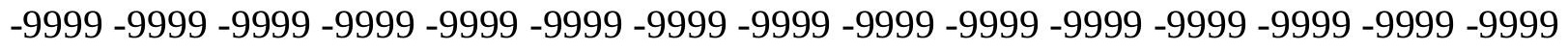

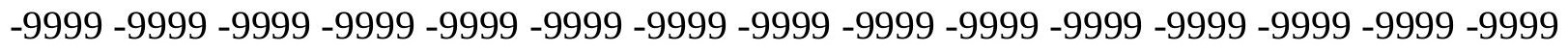
-9999 -9999 105.7603988647104.5412979126103.6268997192102.4077987671 101.1886978149100 .2742996216100 .2742996216103 .3221969604102 .712600708 102.1029968262101 .7982025146101 .7982025146101 .7982025146101 .7982025146 99.66472625732100 .274299621699 .9695205688599 .6647262573299 .05516815186 
98.445587158297 .8360290527396 .6168823242293 .8738174438589 .91161346436 85.3398437582 .2919769287179 .2441329956177 .110626220772 .23407745361

68.5766525268667 .9670867919961 .56660079956 -9999 -9999 -9999 -9999 -9999 -9999 -9999 -9999 -9999 -9999 -9999 -9999 -9999 -9999 -9999 -9999 -9999 -9999 -9999 -9999 -9999 -9999 -9999 -9999 -9999 -9999 -9999 -9999 -9999 -9999 -9999 -9999 -9999 -9999-9999 -9999 -9999 -

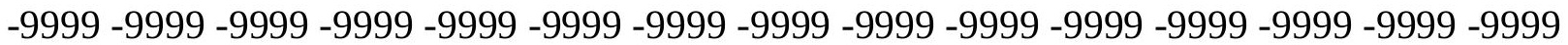
-9999 -9999 -9999

-9999 -9999 -9999 -9999 -9999 -9999 -9999 -9999 -9999 -9999 -9999 -9999 -9999 -9999 -9999

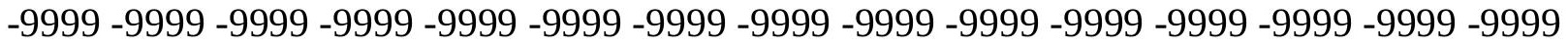
-9999 -9999 -9999 -9999 -9999 -9999 -9999 -9999 -9999 -9999 -9999 -9999 -9999 -9999 -9999

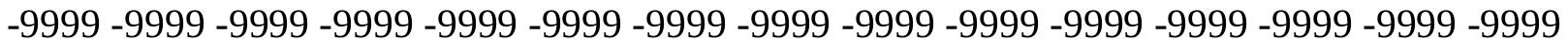
-9999 -9999 -9999 -9999 -9999 -9999 -9999 -9999 -9999 -9999 -9999 -9999 -9999 -9999 -9999 -999 -9999 -9999 -9999 -9999 -9999 -9999 -9999 -9999 -9999 -9999 -9999 -9999 -9999 -9999 -9999 -9999 -9999 -9999 -9999 -9999 -9999 -9999 -9999 -9999 -9999 -9999 -9999 -9999 -9999 - 9999 -9999 -9999 -9999 -9999 -9999 -9999 -9999 -9999 -9999 -9999 -9999 -9999 -9999 -9999 -9999

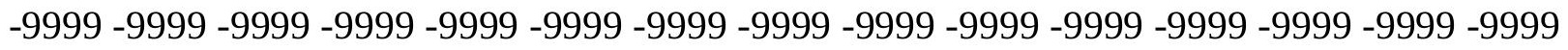
-9999 -9999 -9999 -9999 -9999 -9999 -9999 -9999 -9999 -9999 -9999 -9999 -9999 -9999 -9999 -9999 -9999 -9999 -9999 -9999 -9999 -9999 -9999 -9999 -9999 -9999 -9999 -9999 -9999 -9999 -9999 -9999 -9999 -9999 -9999 -9999 -9999 -9999 -9999 -9999 -9999 -9999 -9999 -9999 -9999 -

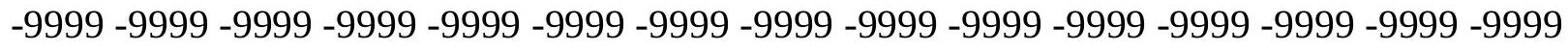

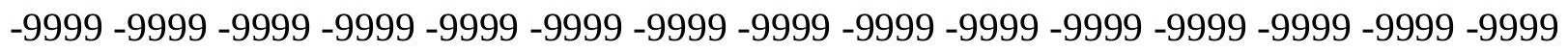
-9999 -9999 -9999 -9999 -9999 -9999 -9999 -9999 -9999 -9999 -9999 -9999 -9999 -9999 -9999 -9999 -9999 -9999 -9999 -9999 -9999 -9999 -9999 -9999 -9999 -9999 -9999 -9999 -9999 -9999 -9999 -9999 -9999 -9999 -9999 -9999 -9999 -9999 -9999 -9999 -9999 -9999 -9999 -9999 -9999 -

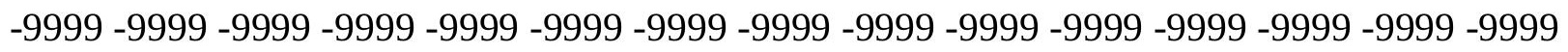
-9999 -9999 -9999 -9999 -9999 -9999 -9999 -9999 -9999 -9999 -9999 -9999 -9999 -9999 -9999 -9999 -9999 -9999 -9999 -9999 -9999 -9999 -9999 -9999 -9999 -9999 -9999 -9999 -9999 -9999 -9999 -9999 -9999 -9999 104.5412979126103.3221969604 102.1029968262100 .5791015625 99.6647262573299 .0551681518698 .445587158297 .8360290527397 .53124237061 97.22646331787 97.2264633178797.5312423706197.83602905273 101.4934005737 98.75038146973100 .274299621699 .3599472045996 .9216690063597 .53124237061 95.397743225192 .9594726562590 .5211791992285 .0350494384882 .29197692871 79.5489196777376 .1962814331172 .8436431884872 .2340774536165 .52880096436 -9999 -9999 -9999 -9999 -9999 -9999 -9999 -9999 -9999 -9999 -9999 -9999 -9999 -9999 -9999 -9999

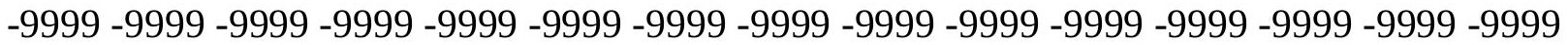

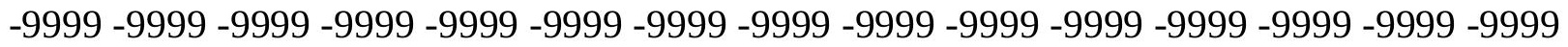
-9999 -9999-9999-9999-9999-9999-9999-9999-9999-9999 - -999 -

-9999 -9999 -9999 -9999 -9999 -9999 -9999 -9999 -9999 -9999 -9999 -9999 -9999 -9999 - 9999 -9999 -9999 -9999 -9999 -9999 -9999 -9999 -9999 -9999 -9999 -9999 -9999 -9999 - 9999 - -999 -9999 -9999 -9999 -9999 -9999 -9999 -9999 -9999 -9999 -9999 -9999 -9999 -9999 -9999 -9999 -

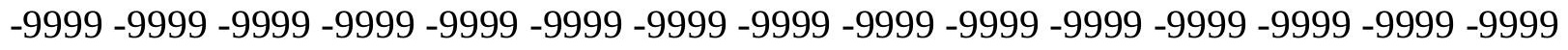

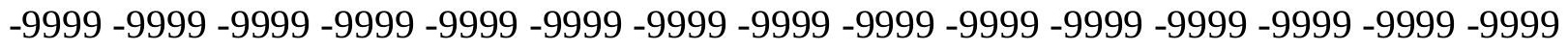

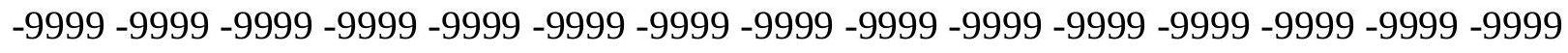
-9999 -9999 -9999 -9999 -9999 -9999 -9999 -9999 -9999-9999 -9999 -9999 -9999 -9999 -9999 -9999 -9999 -9999 -9999 -9999 -9999 -9999 -9999 -9999 -9999 -9999 -9999 -9999 -9999 -9999 -

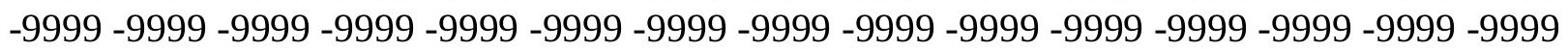


-9999 -9999 -9999 -9999 -9999 -9999 -9999 -9999 -9999 -9999 -9999 -9999 -9999 -9999 -9999 -9999 -9999 -9999 -9999 -9999 -9999 -9999 -9999 -9999 -9999 -9999 -9999 -9999 -9999 -9999 -9999 -9999 -9999 -9999 -9999 -9999 -9999 -9999 -9999 -9999 -9999 -9999 -9999 -9999 - 9999 -9999 -9999 -9999 -9999 -9999 -9999 -9999 -9999 -9999 -9999 -9999 -9999 -9999 -9999 -9999 -9999 -9999 -9999 -9999 -9999 -9999 -9999 -9999 -9999 -9999 -9999 -9999-9999 -9999 -9999 -9999 -9999 -9999 -9999 -9999 -9999 -9999 -9999 -9999 -9999 -9999 -9999 -9999 -9999 -9999 -9999 -9999 -9999 -9999 -9999 -9999 -9999 -9999 -9999 -9999 -9999 -9999 -9999 -9999 -9999

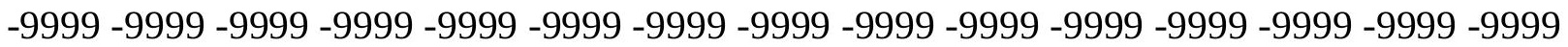
-9999 -9999 -9999 -9999 -9999 -9999 -9999 -9999 -9999 -9999 -9999 -9999 -9999 -9999 -9999 -9999 -9999 -9999 -9999 -9999 -9999 -9999 -9999 -9999 -9999 -9999 -9999 -9999 -9999 -9999

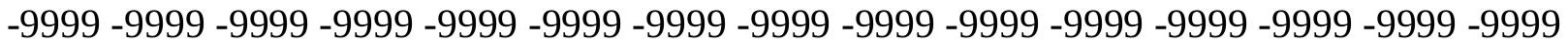
-9999 -9999 -9999 -9999 -9999-9999 -9999 -9999 -9999-9999 98.4455871582 98.14080810547 97.5312423706197.22646331787 97.2264633178797.53124237061 97.8360290527398 .7503814697399 .3599472045999 .3599472045998 .4455871582 96.9216690063594 .7881774902392 .349891662690 .2164001464887 .77810668945 85.3398437582 .9015579223680 .15849304199 -9999 -9999 -9999 -9999 -9999 -9999 -9999 -9999 -9999 -9999 -9999 -9999 -9999 -9999 -9999 -9999 -9999 -9999 -9999 -9999 -9999 -9999 -9999 -9999 -9999 -9999 -9999 -9999 -9999 -9999 -9999 -9999 -9999 -9999 -9999 -9999 -9999 -9999 -9999 -9999 -9999 -9999 -9999 -9999 -9999 -9999 -9999 -9999 -9999 -9999 -9999 -9999 -9999 -9999 -9999 -9999-9999-9999-9999-9999

-9999 -9999 -9999 -9999 -9999 -9999 -9999 -9999 -9999 -9999 -9999 -9999 -9999 -9999 -9999 -9999 -9999 -9999 -9999 -9999 -9999 -9999 -9999 -9999 -9999 -9999 -9999 -9999 -9999 -9999 -9999 -9999 -9999 -9999 -9999 -9999 -9999 -9999 -9999 -9999 -9999 -9999 -9999 -9999 -9999 -9999 -9999 -9999 -9999 -9999 -9999 -9999 -9999 -9999 -9999 -9999 -9999 -9999 -9999 -9999 -9999 -9999 -9999 -9999 -9999 -9999 -9999 -9999 -9999 -9999 -9999 -9999 -9999 -9999 -9999 -9999 -9999 -9999 -9999 -9999 -9999 -9999 -9999 -9999 -9999 -9999 -9999 -9999 -9999 -9999 -9999 -9999 -9999 -9999 -9999 -9999 -9999 -9999 -9999 -9999 -9999 -9999 -9999 -9999 -9999 -9999 -9999 -9999 -9999 -9999 -9999 -9999 -9999 -9999 -9999 -9999 -9999 -9999 -9999 -9999 -9999 -9999 -9999 -9999 -9999 -9999 -9999 -9999 -9999 -9999 -9999 -9999 -9999 -9999 -9999 -9999 -9999 -9999 -9999 -9999 -9999 -9999 -9999 -9999 -9999 -9999 -9999 -9999 -9999 -999 -9999 -9999 -9999 -9999 -9999 -9999 -9999 -9999 -9999 -9999 -9999 -9999 -9999 -9999 -9999 -9999 -9999 -9999 -9999 -9999 -9999 -9999 -9999 -9999 -9999 -9999 -9999 -9999 -9999 -9999

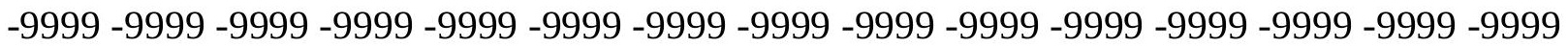

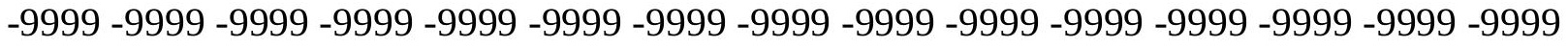

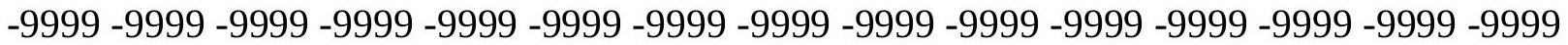
-9999 -9999 -9999 -9999 -9999 -9999 -9999 -9999 -9999 -9999 -9999 -9999 -9999 -9999 -9999

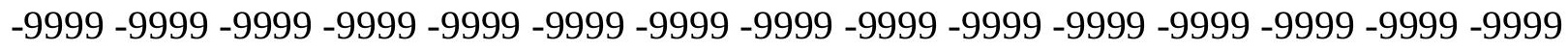

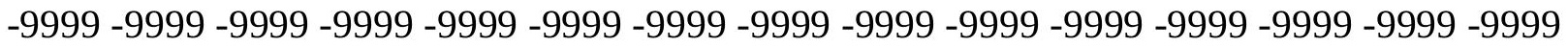
-9999 -9999 -9999 -9999 -9999 -9999 -9999 -9999 -9999 -9999 -9999 -9999 -9999 - 9999 - -999 -9999 -9999 -9999 -9999 -9999 -9999 -9999 -9999 -9999 -9999 -9999 -9999 -9999 -9999 -9999 -

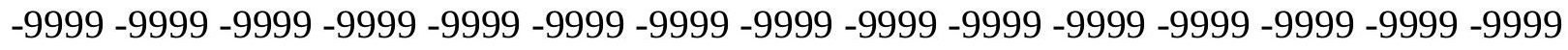

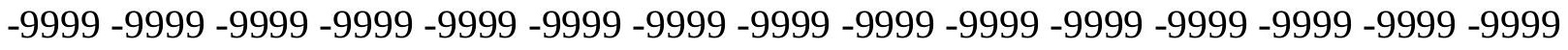
-9999 -9999 -9999 -9999 -9999 -9999 -9999 -9999 -9999 -9999 -9999 -9999 -9999 -9999 -9999 -9999 -9999 -9999 -9999 -9999 -9999 -9999 -9999 -9999-9999 -9999 -9999 -9999 -9999 -9999 -9999 -9999 -9999 -9999 -9999 -9999 -9999 -9999 -9999 -9999 -9999 -9999 -9999 -9999 -9999 -9999 -9999 -9999 -9999 -9999 -9999 -9999 -9999 -9999 -9999 -9999 -9999 -9999 -9999 
-9999 -9999 -9999 -9999 -9999 -9999 -9999 -9999 -9999 -9999 -9999 -9999 -9999 -9999 -9999 -9999 -9999 -9999 -9999 -9999 -9999 -9999 -9999 -9999 -9999 -9999 -9999 -9999 -9999 -9999 -

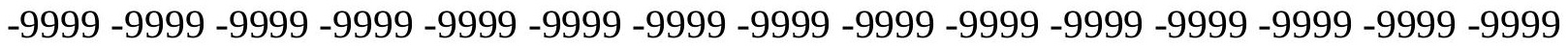
-9999 -9999 -9999 -9999 -9999 -9999 -9999 -9999 -9999 -9999 -9999 -9999 -9999 -9999 -9999 -9999 -9999 -9999 -9999 -9999 -9999 -9999 -9999 -9999-9999 -9999 -9999 -9999 -9999 -9999 -9999 -9999 -9999 -9999 -9999 -9999 -9999 -9999 -9999 -9999 -9999 -9999 -9999 -9999 -9999 -9999 -9999 -9999 -9999 -9999 -9999 -9999 -9999 -9999 -9999 -9999 -9999 -9999 -9999 -9999

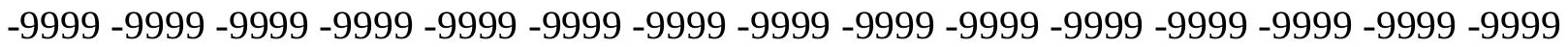

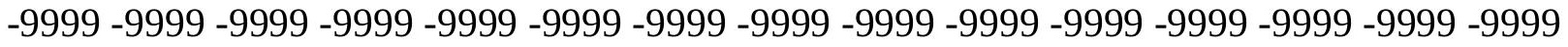
-9999 -9999 -9999 -9999 -9999 -9999 -9999 -9999 -9999 -9999 -9999 -9999 -9999 -9999 -9999 -9999 -9999 -9999 -9999 -9999 -9999 -9999 -9999 -9999 -9999 -9999 -9999 -9999 -9999 -9999 -9999 -9999 -9999 -9999 -9999 -9999 -9999 -9999 -9999 -9999 -9999 -9999 -9999 -9999 -9999 -9999 -9999 -9999 -9999 -9999 -9999 -9999 -9999 -9999 -9999 -9999 -9999 -9999 -9999 -9999 -

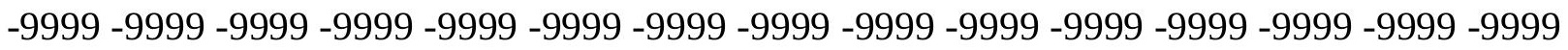
-9999 -9999 -9999 -9999 -9999 -9999 -9999 -9999 -9999 -9999 -9999 -9999 -9999 -9999 -9999 -

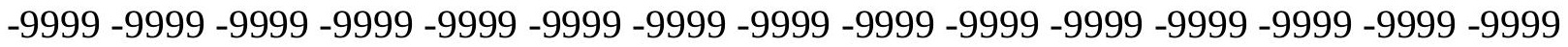
-9999 -9999 -9999 -9999 -9999 -9999 -9999 -9999 -9999 -9999 -9999 -9999 -9999 -9999 -9999 -9999 -9999 -9999 -9999 -9999 -9999 -9999 -9999 -9999 -9999 -9999 -9999 -9999 -9999 -9999 -9999 -9999 -9999 -9999 -9999 -9999 -9999 -9999 -9999 -9999 -9999 -9999 -9999 -9999 -9999 -

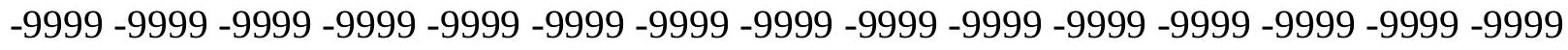

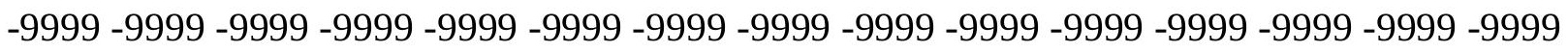

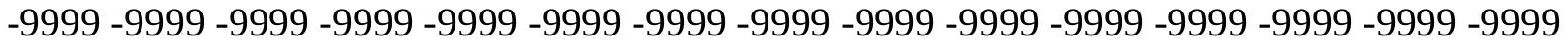
-9999 -9999 -9999 -9999 -9999 -9999 -9999 -9999 -9999 -9999 -9999 -9999 -9999 -9999 -9999 -9999 -9999 -9999 -9999 -9999 -9999 -9999 -9999 -9999 -9999 -9999 -9999 -9999 -9999 -9999 -

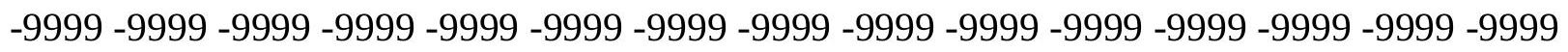
-9999 -9999 -9999 -9999 -9999 -9999 -9999 -9999 -9999 -9999 -9999 -9999 -9999 -9999 -9999 -9999 -9999 -9999 -9999 -9999 -9999 -9999 -9999 -9999 -9999 -9999 -9999 -9999 -9999 -

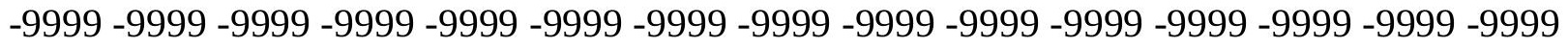
-9999 -9999 -9999 -9999 -9999 -9999 -9999 -9999 -9999 -9999 -9999 -9999 -9999 -9999 -9999 -9999 -9999 -9999 -9999 -9999 -9999 -9999 -9999 -9999 -9999 -9999 -9999 -9999 -9999 -999 -

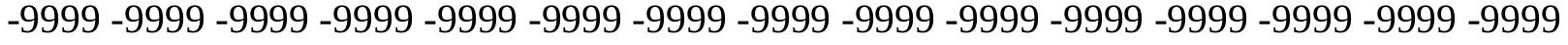
-9999 -9999 -9999 -9999 -9999 -9999 -9999 -9999 -9999 -9999 -9999 -9999 -9999 -9999 -9999 -

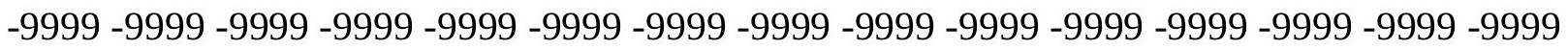

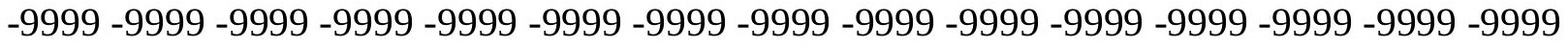

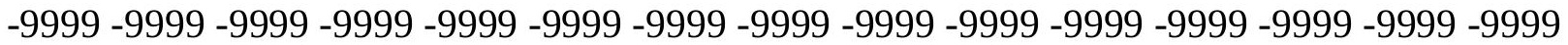
-9999 -9999 -9999 -9999 -9999 -9999 -9999 -9999 -9999 -9999 -9999 -9999 -9999 -9999 -9999

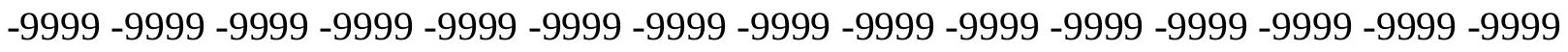

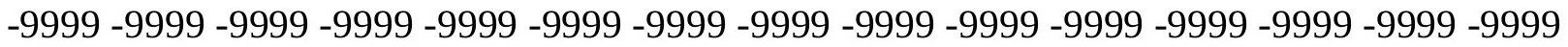
-9999 -9999 -9999 -9999 -9999 -9999 -9999 -9999 -9999 -9999 -9999 -9999 -9999 - 9999 - -999 -9999 -9999 -9999 -9999 -9999 -9999 -9999 -9999 -9999 -9999 -9999 -9999 -9999 -9999 -9999 -

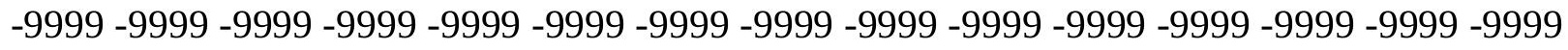

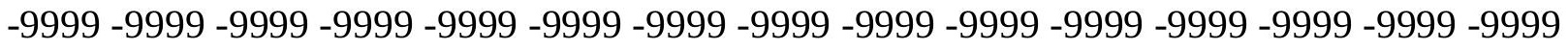
-9999 -9999 -9999 -9999 -9999 -9999 -9999 -9999 -9999 -9999 -9999 -9999 -9999 -9999 -9999 -9999 -9999 -9999 -9999 -9999 -9999 -9999 -9999 -9999-9999 -9999 -9999 -9999 -9999 -9999 -9999 -9999 -9999 -9999 -9999 -9999 -9999 -9999 -9999 -9999 -9999 -9999 -9999 -9999 -9999 -

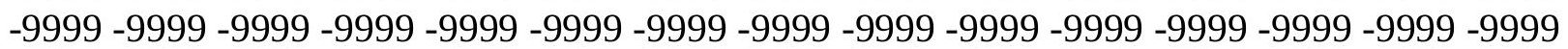


-9999 -9999 -9999 -9999 -9999 -9999 -9999 -9999 -9999 -9999 -9999 -9999 -9999 -9999 -9999 -9999 -9999 -9999 -9999 -9999 -9999 -9999 -9999 -9999 -9999 -9999 -9999 -9999 -9999 -9999 -9999 -9999 -9999 -9999 -9999 -9999 -9999 -9999 -9999 -9999 -9999 -9999 -9999 -9999 - 9999 -9999 -9999 -9999 -9999 -9999 -9999 -9999 -9999 -9999 -9999 -9999 -9999 -9999 -9999 -9999 -9999 -9999 -9999 -9999 -9999 -9999 -9999 -9999 -9999 -9999 -9999 -9999 -9999 -9999 - -9999 -9999 -9999 -9999 -9999 -9999 -9999 -9999 -9999 -9999 -9999 -9999 -9999 -9999 -9999 -9999 -9999 -9999 -9999 -9999 -9999 -9999 -9999 -9999 -9999 -9999 -9999 -9999 -9999 -9999

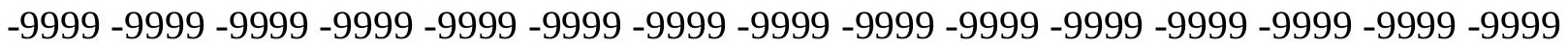

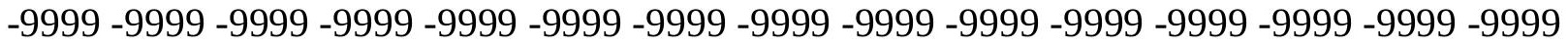
-9999 -9999 -9999 -9999 -9999 -9999 -9999 -9999 -9999 -9999 -9999 -9999 -9999 -9999 -9999

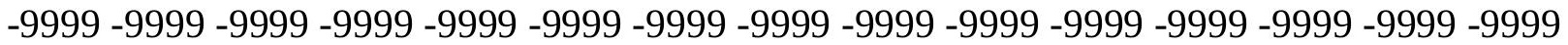
-9999 -9999 -9999 -9999 -9999 -9999 -9999 -9999 -9999 -9999 -9999 -9999 -9999 -9999 -9999 -9999 -9999 -9999 -9999 -9999 -9999 -9999 -9999 -9999 -9999 -9999 -9999 -9999 -9999 -9999 -9999 -9999 -9999 -9999 -9999 -9999 -9999 -9999 -9999 -9999 -9999 -9999 -9999 -9999 - -9999 -9999 -9999 -9999 -9999 -9999 -9999 -9999 -9999 -9999 -9999 -9999 -9999 -9999 -9999 -9999

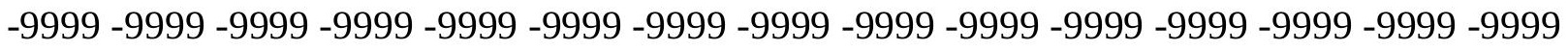
-9999 -9999 -9999 -9999 -9999 -9999 -9999 -9999 -9999 -9999 -9999 -9999 -9999 -9999 -9999 -9999 -9999 -9999 -9999 -9999 -9999 -9999 -9999 -9999 -9999 -9999 -9999 -9999 -9999 -9999 -9999 -9999 -9999 -9999 -9999 -9999 -9999 -9999 -9999 -9999 -9999 -9999 -9999 -9999 -9999 -

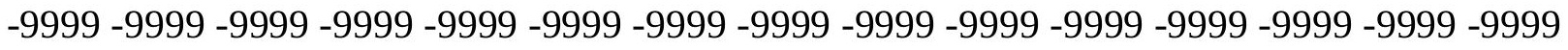
-9999 -9999 -9999 -9999 -9999 -9999 -9999 -9999 -9999 -9999 -9999 -9999 -9999 -9999 -9999 -999 -9999 -9999 -9999 -9999 -9999 -9999 -9999 -9999 -9999 -9999 -9999 -9999 -9999 -9999 -9999 -9999 -9999 -9999 -9999 -9999 -9999 -9999 -9999 -9999 -9999 -9999 -9999 -9999 -9999 -9999 -9999 -9999 -9999 -9999 -9999 -9999 -9999 -9999 -9999 -9999 -9999 -9999 -9999 -9999 -9999 -9999 -9999 -9999 -9999 -9999 -9999 -9999 -9999 -9999 -9999 -9999 -9999 -9999 -9999 -9999 -9999 -9999 -9999 -9999 -9999 -9999 -9999 -9999 -9999 -9999 -9999 -9999 -9999 -9999 -9999 -9999 -9999 -9999 -9999 -9999 -9999 -9999 -9999 -9999 -9999 -9999 -9999 -9999 -9999 -9999 -9999 -9999 -9999 -9999 -9999 -9999 -9999 -9999 -9999 -9999 -9999 -9999 -9999 -9999 -9999 -9999 -9999 -9999 -9999 -9999 -9999 -9999 -9999 -9999 -9999 -9999 -9999 -9999 -9999 -9999 -9999 -9999 -9999 -9999 -9999 -9999 -9999 -9999 -9999 -9999 -9999 -9999 -9999 -9999 -999 -9999 -9999 -9999 -9999 -9999 -9999 -9999 -9999 -9999 -9999 -9999 -9999 -9999 -9999 -9999 -9999 -9999 -9999 -9999 -9999 -9999 -9999 -9999 -9999 -9999 -9999 -9999 -9999 -9999 -

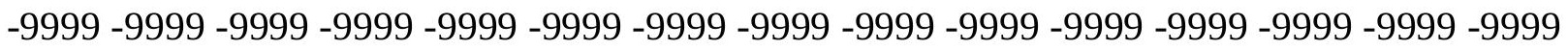

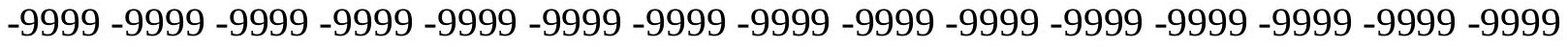

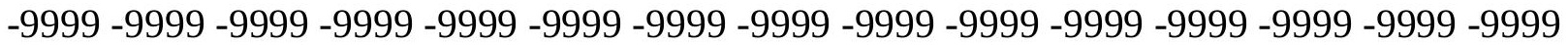
-9999 -9999 -9999 -9999 -9999 -9999 -9999 -9999 -9999 -9999 -9999 -9999 -9999 -9999 -9999 -

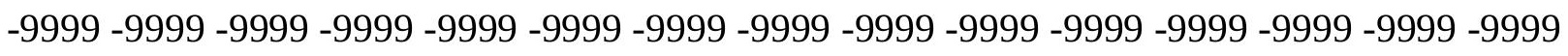

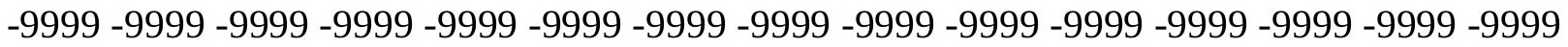

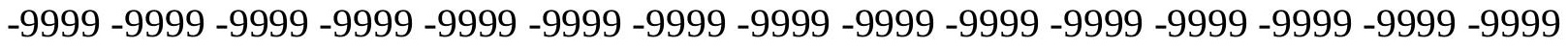
-9999 -9999 -9999 -9999 -9999 -9999 -9999 -9999 -9999 -9999 -9999 -9999 -9999 -9999 -9999 -

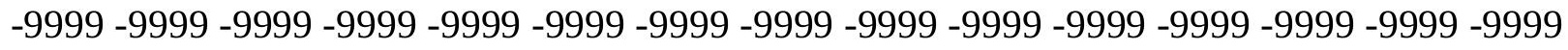

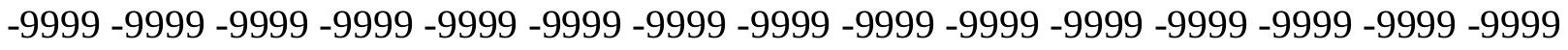
-9999 -9999 -9999 -9999 -9999 -9999 -9999 -9999 -9999 -9999 -9999 -9999 -9999 -9999 -9999 -9999 -9999 -9999 -9999 -9999 -9999 -9999 -9999 -9999-9999 -9999 -9999 -9999 -9999 -9999 -9999 -9999 -9999 -9999 -9999 -9999 -9999 -9999 -9999 -9999 -9999 -9999 -9999 -9999 -9999 -

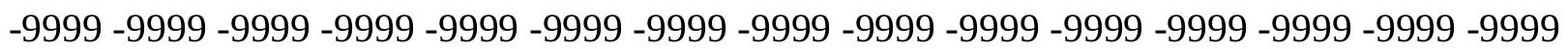


-9999 -9999 -9999 -9999 -9999 -9999 -9999 -9999 -9999 -9999 -9999 -9999 -9999 -9999 -9999 -9999 -9999 -9999 -9999 -9999 -9999 -9999 -9999 -9999 -9999 -9999 -9999 -9999 -9999 -9999 -

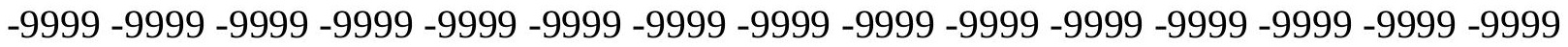
-9999 -9999 -9999 -9999 -9999 -9999 -9999 -9999 -9999 -9999 -9999 -9999 -9999 -9999 -9999 -9999 -9999 -9999 -9999 -9999 -9999 -9999 -9999 -9999-9999 -9999 -9999 -9999 -9999 -9999 -9999 -9999 -9999 -9999 -9999 -9999 -9999 -9999 -9999 -9999 -9999 -9999 -9999 -9999 -9999 -9999 -9999 -9999 -9999 -9999 -9999 -9999 -9999 -9999 -9999 -9999 -9999 -9999 -9999 -9999

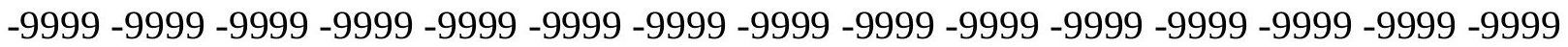

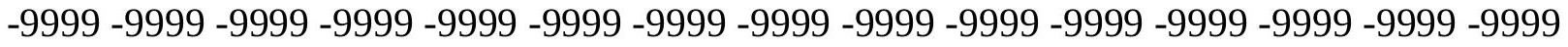
-9999 -9999 -9999 -9999 -9999 -9999 -9999 -9999 -9999 -9999 -9999 -9999 -9999 -9999 -9999 -9999 -9999 -9999 -9999 -9999 -9999 -9999 -9999 -9999 -9999 -9999 -9999 -9999 -9999 -9999 -9999 -9999 -9999 -9999 -9999 -9999 -9999 -9999 -9999 -9999 -9999 -9999 -9999 -9999 -9999 -9999 -9999 -9999 -9999 -9999 -9999 -9999 -9999 -9999 -9999 -9999 -9999 -9999 -9999 -9999 -9999 -9999 -9999 -9999 -9999 -9999 -9999 -9999 -9999 -9999 -9999 -9999 -9999 - 9999 -9999 -9999 -9999 -9999 -9999 -9999 -9999 -9999 -9999 -9999 -9999 -9999 -9999 -9999 -9999

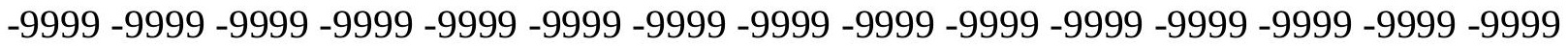
-9999 -9999 -9999 -9999 -9999 -9999 -9999 -9999 -9999 -9999 -9999 -9999 -9999 -9999 -9999 -9999 -9999 -9999 -9999 -9999 -9999 -9999 -9999 -9999 -9999 -9999 -9999 -9999 -9999 -9999 -9999 -9999 -9999 -9999 -9999 -9999 -9999 -9999 -9999 -9999 -9999 -9999 -9999 -9999 -9999 -

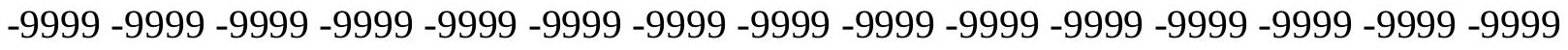

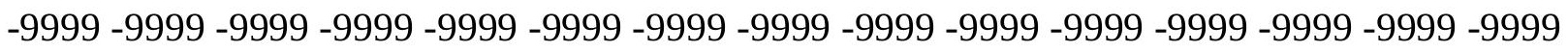
-9999 -9999 -9999 -9999 -9999 -9999 -9999 -9999 -9999 -9999 -9999 -9999 -9999 -9999 -9999 -9999 -9999 -9999 -9999 -9999 -9999 -9999 -9999 -9999 -9999 -9999 -9999 -9999 -9999 -9999 -9999 -9999 -9999 -9999 -9999 -9999 -9999 -9999 -9999 -9999 -9999 -9999 -9999 -9999 -9999 -

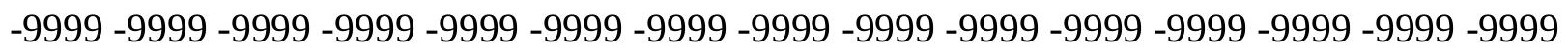
-9999 -9999 -9999 -9999 -9999 -9999 -9999 -9999 -9999 -9999 -9999 -9999 -9999 -9999 -9999 -9999 -9999 -9999 -9999 -9999 -9999 -9999 -9999 -9999 -9999 -9999 -9999 -9999 -9999 -9999 -

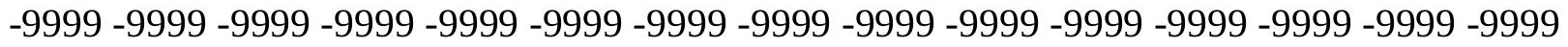
-9999 -9999 -9999 -9999 -9999 -9999 -9999 -9999 -9999 -9999 -9999 -9999 -9999 -9999 -9999 -9999 -9999 -9999 -9999 -9999 -9999 -9999 -9999 -9999 -9999 -9999 -9999 -9999 -9999 -999 -9999 -9999 -9999 -9999 -9999 -9999 -9999 -9999 -9999 -9999 -9999 -9999 -9999 -9999 -9999 -9999 -9999 -9999 -9999 -9999 -9999 -9999 -9999 -9999 -9999 -9999 -9999 -9999 -9999 -9999 -

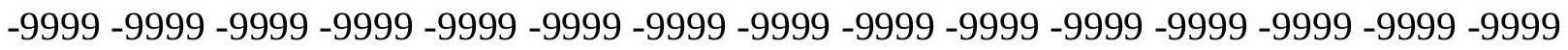

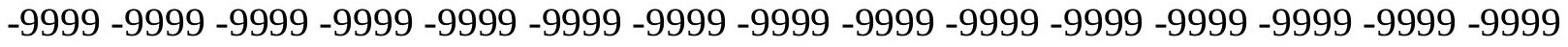

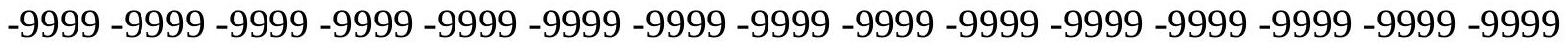

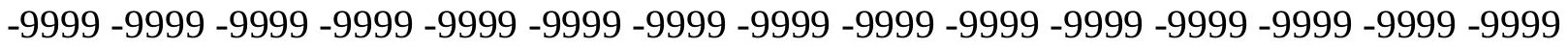

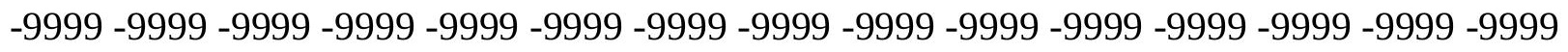

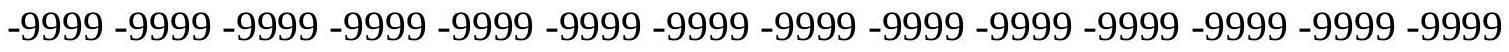
-9999 -9999 -9999 -9999 -9999 -9999 -9999 -9999 -9999 -9999 -9999 -9999 -9999 -9999 -9999 -9999 -9999 -9999 -9999 -9999 -9999 -9999 -9999 -9999 -9999 -9999 -9999 -9999 -9999 -9999 -

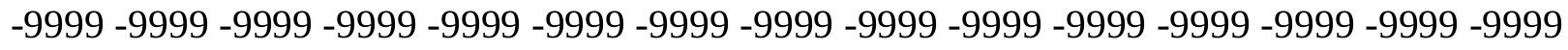

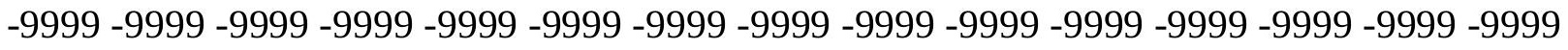
-9999 -9999 -9999 -9999 -9999 -9999 -9999 -9999 -9999 -9999 -9999 -9999 -9999 -9999 -9999 -9999 -9999 -9999 -9999 -9999 -9999 -9999 -9999 -9999-9999 -9999 -9999 -9999 -9999 -9999 -9999 -9999 -9999 -9999 -9999 -9999 -9999 -9999 -9999 -9999 -9999 -9999 -9999 -9999 -9999 -

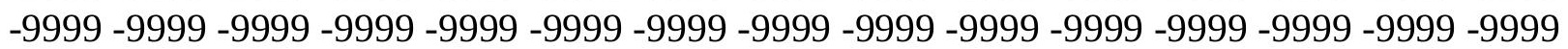


-9999 -9999 -9999 -9999 -9999 -9999 -9999 -9999 -9999 -9999 -9999 -9999 -9999 -9999 -9999 -9999 -9999 -9999 -9999 -9999 -9999 -9999 -9999 -9999 -9999 -9999 -9999 -9999 -9999 -9999 -9999 -9999 -9999 -9999 -9999 -9999 -9999 -9999 -9999 -9999 -9999 -9999 -9999 -9999 - 9999 -9999 -9999 -9999 -9999 -9999 -9999 -9999 -9999 -9999 -9999 -9999 -9999 -9999 -9999 -9999 -9999 -9999 -9999 -9999 -9999 -9999 -9999 -9999 -9999 -9999 -9999 -9999 -9999 -9999 -9999 -9999 -9999 -9999 -9999 -9999 -9999 -9999 -9999 -9999 -9999 -9999 -9999 -9999 -9999 -9999 -9999 -9999 -9999 -9999 -9999 -9999 -9999 -9999 -9999 -9999 -9999 -9999 -9999 -9999 -9999

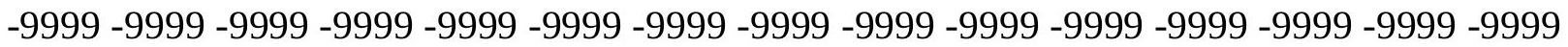
-9999 -9999 -9999 -9999 -9999 -9999 -9999 -9999 -9999 -9999 -9999 -9999 -9999 -9999 -9999 -9999 -9999 -9999 -9999 -9999 -9999 -9999 -9999 -9999 -9999 -9999 -9999 -9999 -9999 -9999

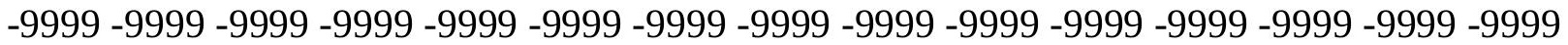
-9999 -9999 -9999 -9999 -9999 -9999 -9999 -9999 -9999 -9999 -9999 -9999 -9999 -9999 -9999 -9999 -9999 -9999 -9999 -9999 -9999 -9999 -9999 -9999 -9999 -9999 -9999 -9999 -9999 -9999 -

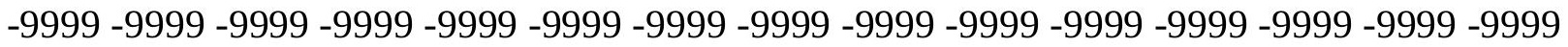
-9999 -9999 -9999 -9999 -9999 -9999 -9999 -9999 -9999 -9999 -9999 -9999 -9999 -9999 -9999

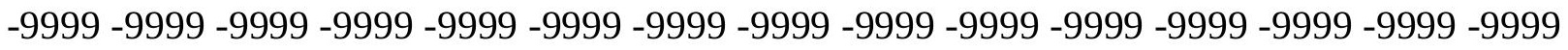
-9999 -9999 -9999 -9999 -9999 -9999 -9999 -9999 -9999 -9999 -9999 -9999 -9999 -9999 -9999 -9999 -9999 -9999 -9999 -9999 -9999 -9999 -9999 -9999 -9999 -9999 -9999 -9999 -9999 - -999 -9999 -9999 -9999 -9999 -9999 -9999 -9999 -9999 -9999 -9999 -9999 -9999 -9999 -9999 -9999 -9999 -9999 -9999 -9999 -9999 -9999 -9999 -9999 -9999 -9999 -9999 -9999 -9999 -9999 -9999 -9999 -9999 -9999 -9999 -9999 -9999 -9999 -9999 -9999 -9999 -9999 -9999 -9999 -9999 -9999 -999 -9999 -9999 -9999 -9999 -9999 -9999 -9999 -9999 -9999 -9999 -9999 -9999 -9999 -9999 -9999 -9999 -9999 -9999 -9999 -9999 -9999 -9999 -9999 -9999 -9999 -9999 -9999 -9999 -9999 -9999 -9999 -9999 -9999 -9999 -9999 -9999 -9999 -9999 -9999 -9999 -9999 -9999 -9999 -9999 -9999 -9999 -9999 -9999 -9999 -9999 -9999 -9999 -9999 -9999 -9999 -9999 -9999 -9999 -9999 -9999 -9999 -9999 -9999 -9999 -9999 -9999 -9999 -9999 -9999 -9999 -9999 -9999 -9999 -9999 -9999 -9999 -9999 -9999 -9999 -9999 -9999 -9999 -9999 -9999 -9999 -9999 -9999 -9999 -9999 -9999 -9999 -9999 -9999 -9999 -9999 -9999 -9999 -9999 -9999 -9999 -9999 -9999 -9999 -9999 -9999 -9999 -9999 -9999 -9999 -9999 -9999 -9999 -9999 -9999 -9999 -9999 -9999 -9999 -9999 -9999 -9999 -9999 -9999 -9999 -9999 -9999 -9999 -9999 -9999 -9999 -9999 -9999 -9999 -9999 -999 -9999 -9999 -9999 -9999 -9999 -9999 -9999 -9999 -9999 -9999 -9999 -9999 -9999 -9999 -9999 -9999 -9999 -9999 -9999 -9999 -9999 -9999 -9999 -9999 -9999 -9999 -9999 -9999 -9999 -9999 -

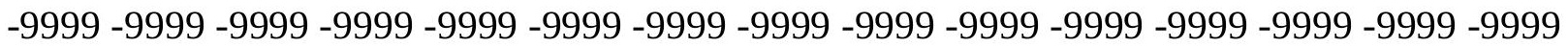

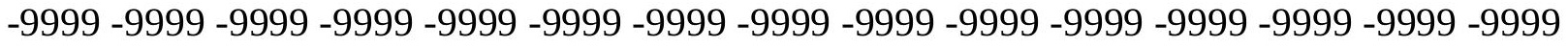

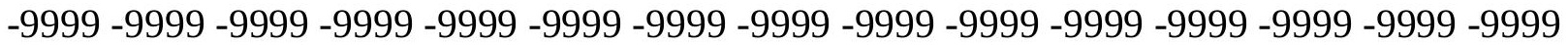
-9999 -9999 -9999 -9999 -9999 -9999 -9999 -9999 -9999 -9999 -9999 -9999 -9999 -9999 -9999

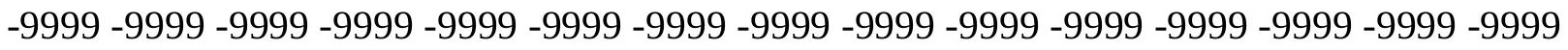

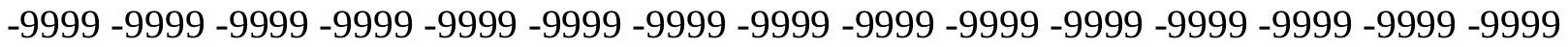

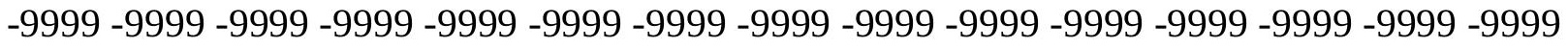
-9999 -9999 -9999 -9999 -9999 -9999 -9999 -9999 -9999 -9999 -9999 -9999 -9999 -9999 -9999 -

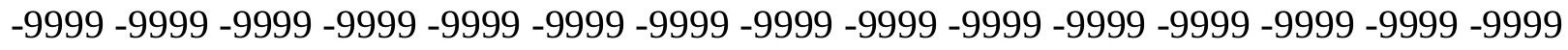

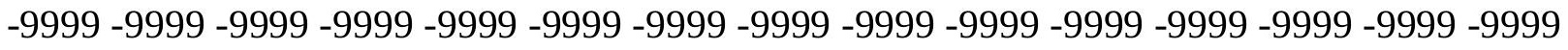
-9999 -9999 -9999 -9999 -9999 -9999 -9999 -9999 -9999 -9999 -9999 -9999 -9999 -9999 -9999 -9999 -9999 -9999 -9999 -9999 -9999 -9999 -9999 -9999 -9999 -9999 -9999 -9999 - -9999 -9999 -9999 -9999 -9999 -9999 -9999 -9999 -9999 -9999 -9999 -9999 -9999 -9999 -9999 -9999 -

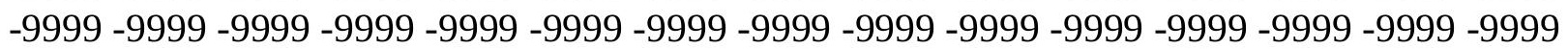


-9999 -9999 -9999 -9999 -9999 -9999 -9999 -9999 -9999 -9999 -9999 -9999 -9999 -9999 -9999 -9999 -9999 -9999 -9999 -9999 -9999 -9999 -9999 -9999 -9999 -9999 -9999 -9999 -9999 -9999 -9999 -9999 -9999 -9999 -9999 -9999 -9999 -9999 -9999 -9999 -9999 -9999 -9999 -9999 - 9999 -9999 -9999 -9999 -9999 -9999 -9999 -9999 -9999 -9999 -9999 -9999 -9999 -9999 -9999 -9999 -9999 -9999 -9999 -9999 -9999 -9999 -9999 -9999 -9999-9999 -9999 -9999 -9999 -9999 -9999 -9999 -9999 -9999 -9999 -9999 -9999 -9999 -9999 -9999 -9999 -9999 -9999 -9999 -9999 -9999 -9999 -9999 -9999 -9999 -9999 -9999 -9999 -9999 -9999 -9999 -9999 -9999 -9999 -9999 -9999

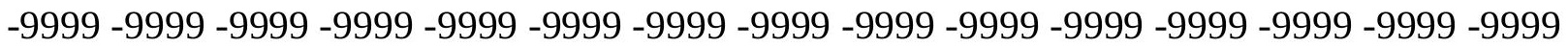

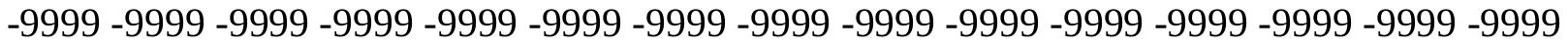
-9999 -9999 -9999 -9999 -9999 -9999 -9999 -9999 -9999 -9999 -9999 -9999 -9999 -9999 -9999

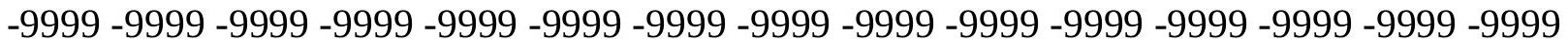
-9999 -9999 -9999 -9999 -9999 -9999 -9999 -9999 -9999 -9999 -9999 -9999 -9999 -9999 -9999 -9999 -9999 -9999 -9999 -9999 -9999 -9999 -9999 -9999 -9999 -9999 -9999 -9999 -9999 -9999 -

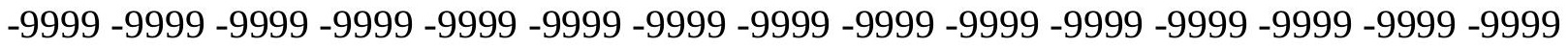
-9999 -9999 -9999 -9999 -9999 -9999 -9999 -9999 -9999 -9999 -9999 -9999 -9999 -9999 -9999

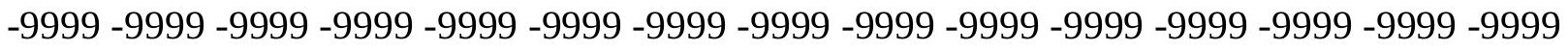
-9999 -9999 -9999 -9999 -9999 -9999 -9999 -9999 -9999 -9999 -9999 -9999 -9999 -9999 -9999 -9999 -9999 -9999 -9999 -9999 -9999 -9999 -9999 -9999 -9999 -9999 -9999 -9999 -9999 -9999 -9999 -9999 -9999 -9999 -9999 -9999 -9999 -9999 -9999 -9999 -9999 -9999 -9999 -9999 -9999 -9999 -9999 -9999 -9999 -9999 -9999 -9999 -9999 -9999 -9999 -9999 -9999 -9999 -9999 -9999 -9999 -9999 -9999 -9999 -9999 -9999 -9999 -9999 -9999 -9999 -9999 -9999 -9999 -9999 -9999 -999 -9999 -9999 -9999 -9999 -9999 -9999 -9999 -9999 -9999 -9999 -9999 -9999 -9999 -9999 -9999 -9999 -9999 -9999 -9999 -9999 -9999 -9999 -9999 -9999 -9999 -9999 -9999 -9999 -9999 -9999 -9999 -9999 -9999 -9999 -9999 -9999 -9999 -9999 -9999 -9999 -9999 -9999 -9999 -9999 -9999 -9999 -9999 -9999 -9999 -9999 -9999 -9999 -9999 -9999 -9999 -9999 -9999 -9999 -9999 -9999 -9999 -9999 -9999 -9999 -9999 -9999 -9999 -9999 -9999 -9999 -9999 -9999 -9999 -9999 -9999 -9999 -9999 -9999 -9999 -9999 -9999 -9999 -9999 -9999 -9999 -9999 -9999 -9999 -9999 -9999 -9999 -9999 -9999 -9999 -9999 -9999 -9999 -9999 -9999 -9999 -9999 -9999 -9999 -9999 -9999 -9999 -9999 -9999 -9999 -9999 -9999 -9999 -9999 -9999 -9999 -9999 -9999 -9999 -9999 -9999 -9999 -9999 -9999 -9999 -9999 -9999 -9999 -9999 -9999 -9999 -9999 -9999 -9999 -999 -9999 -9999 -9999 -9999 -9999 -9999 -9999 -9999 -9999 -9999 -9999 -9999 -9999 -9999 -9999 -9999 -9999 -9999 -9999 -9999 -9999 -9999 -9999 -9999 -9999 -9999 -9999 -9999 -9999 -9999 -

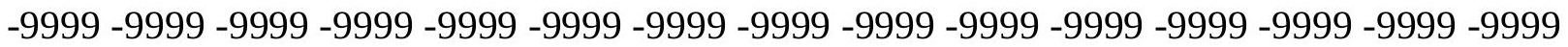

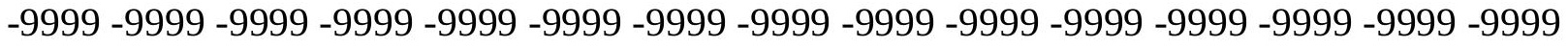

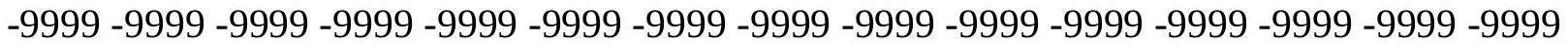
-9999 -9999 -9999 -9999 -9999 -9999 -9999 -9999 -9999 -9999 -9999 -9999 -9999 -9999 -9999

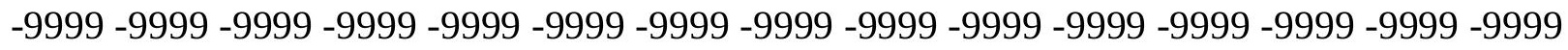

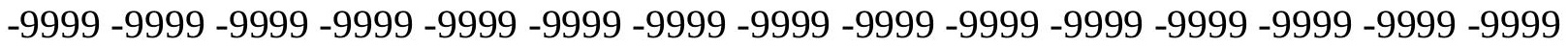
-9999 -9999 -9999 -9999 -9999 -9999 -9999 -9999 -9999 -9999 -9999 -9999 -9999 -9999 -9999 -9999 -9999 -9999 -9999 -9999 -9999 -9999 -9999 -9999 -9999 -9999 -9999 -9999 -9999 -9999 -

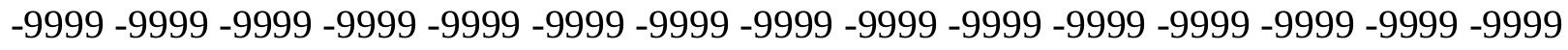

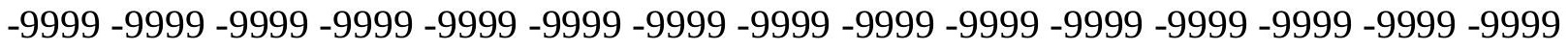
-9999 -9999 -9999 -9999 -9999 -9999 -9999 -9999 -9999 -9999 -9999 -9999 -9999 -9999 -9999 -9999 -9999 -9999 -9999 -9999 -9999 -9999 -9999 -9999-9999 -9999 -9999 -9999 -9999 -9999 -9999 -9999 -9999 -9999 -9999 -9999 -9999 -9999 -9999 -9999 -9999 -9999 -9999 -9999 -9999 -

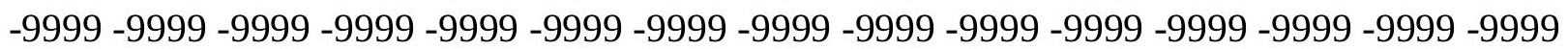


-9999 -9999 -9999 -9999 -9999 -9999 -9999 -9999 -9999 -9999 -9999 -9999 -9999 -9999 -9999 -9999 -9999 -9999 -9999 -9999 -9999 -9999 -9999 -9999 -9999 -9999 -9999 -9999 -9999 -9999 -9999 -9999 -9999 -9999 -9999 -9999 -9999 -9999 -9999 -9999 -9999 -9999 -9999 -9999 - 9999 -9999 -9999 -9999 -9999 -9999 -9999 -9999 -9999 -9999 -9999 -9999 -9999 -9999 -9999

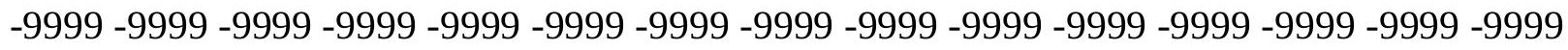
-9999 -9999 -9999 -9999 -9999 -9999 -9999 -9999 -9999 -9999 -9999 -9999 -9999 -9999 -9999 -9999 -9999 -9999 -9999 -9999 -9999 -9999 -9999 -9999 -9999 -9999 -9999 -9999 -9999 -9999

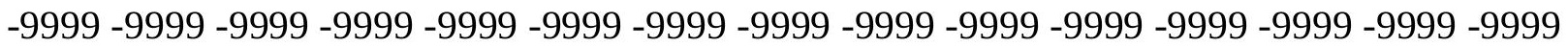

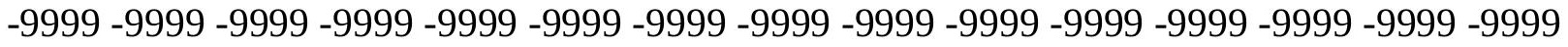
-9999 -9999 -9999 -9999 -9999 -9999 -9999 -9999 -9999 -9999 -9999 -9999 -9999 -9999 -9999 -9999 -9999 -9999 -9999 -9999 -9999 -9999 -9999 -9999 -9999 -9999 -9999 -9999 -9999 -9999 -9999 -9999 -9999 -9999 -9999 -9999 -9999 -9999 -9999 -9999 -9999 -9999 -9999 -9999 -9999 -9999 -9999 -9999 -9999 -9999 -9999 -9999 -9999 -9999 -9999 -9999 -9999 -9999 -9999 -9999 -

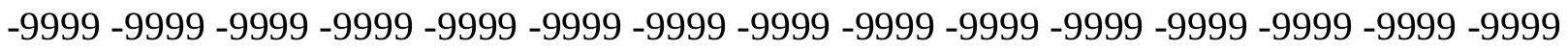
-9999 -9999 -9999 -9999 -9999 -9999 -9999 -9999 -9999 -9999 -9999 -9999 -9999 -9999 -9999 -

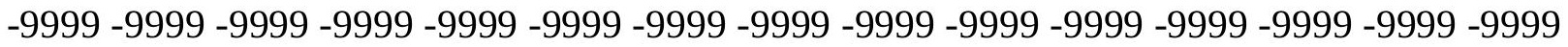
-9999 -9999 -9999 -9999 -9999 -9999 -9999 -9999 -9999 -9999 -9999 -9999 -9999 -9999 -9999 -9999 -9999 -9999 -9999 -9999 -9999 -9999 -9999 -9999 -9999 -9999 -9999 -9999 -9999 -9999 -9999 -9999 -9999 -9999 -9999 -9999 -9999 -9999 -9999 -9999 -9999 -9999 -9999 -9999 -9999 -

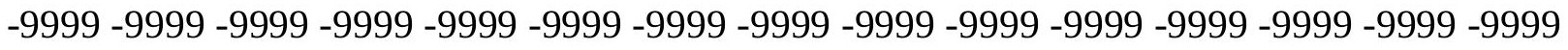
-9999 -9999 -9999 -9999 -9999 -9999 -9999 -9999 -9999 -9999 -9999 -9999 -9999 -9999 -9999

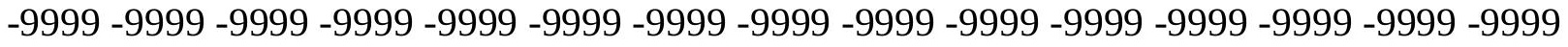
-9999 -9999 -9999 -9999 -9999 -9999 -9999 -9999 -9999 -9999 -9999 -9999 -9999 -9999 -9999 -9999 -9999 -9999 -9999 -9999 -9999 -9999 -9999 -9999 -9999 -9999 -9999 -9999 -9999 -9999 -9999 -9999 -9999 -9999 -9999 -9999 -9999 -9999 -9999 -9999 -9999 -9999 -9999 -9999 -9999 -9999 -9999 -9999 -9999 -9999 -9999 -9999 -9999 -9999 -9999 -9999 -9999 -9999 -9999 -9999 -9999 -9999 -9999 -9999 -9999 -9999 -9999 -9999 -9999 -9999 -9999 -9999 -9999 -9999 -9999 -9999 -9999 -9999 -9999 -9999 -9999 -9999 -9999 -9999 -9999 -9999 -9999 -9999 -9999 -9999 -9999 -9999 -9999 -9999 -9999 -9999 -9999 -9999 -9999 -9999 -9999 -9999 -9999 -9999 -9999 -9999 -9999 -9999 -9999 -9999 -9999 -9999 -9999 -9999 -9999 -9999 -9999 -9999 -9999 -9999 -9999 -9999 -9999 -9999 -9999 -9999 -9999 -9999 -9999 -9999 -9999 -9999 -9999 -9999 -9999 -9999 -9999 -9999 -9999 -9999 -9999 -9999 -9999 -9999 -9999 -9999 -9999 -9999 -9999 -

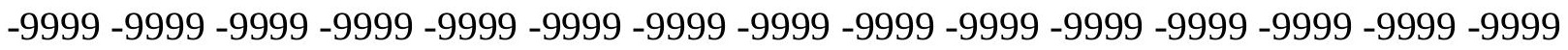

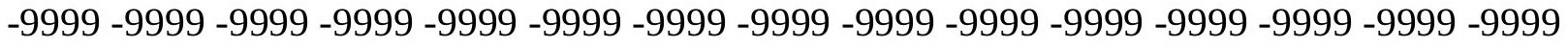
-9999 -9999 -9999 -9999 -9999 -9999 -9999 -9999 -9999 -9999 -9999 -9999 -9999 -9999 -9999 -

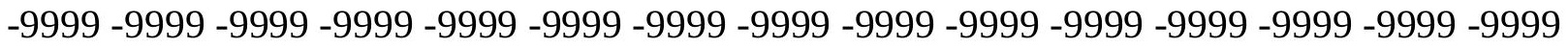

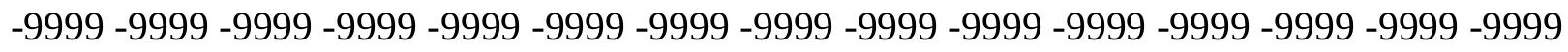

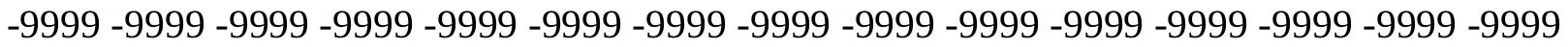

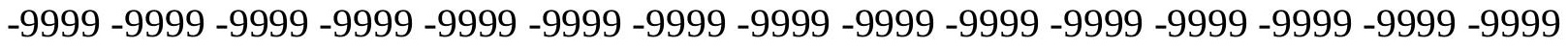
-9999 -9999 -9999 -9999 -9999 -9999 -9999 -9999 -9999 -9999 -9999 -9999 -9999 -9999 -9999 -

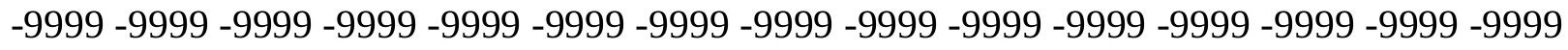

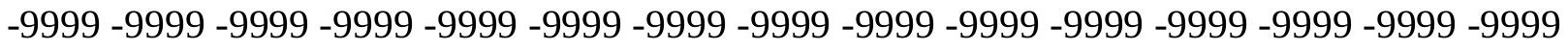
-9999 -9999 -9999 -9999 -9999 -9999 -9999 -9999 -9999 -9999 -9999 -9999 -9999 -9999 -9999 -9999 -9999 -9999 -9999 -9999 -9999 -9999 -9999 -9999-9999 -9999 -9999 -9999 -9999 -9999 -9999 -9999 -9999 -9999 -9999 -9999 -9999 -9999 -9999 -9999 -9999 -9999 -9999 -9999 -9999 -

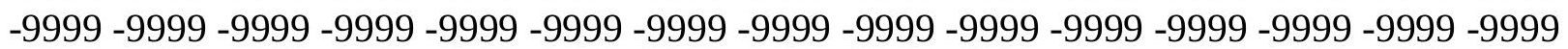


-9999 -9999 -9999 -9999 -9999 -9999 -9999 -9999 -9999 -9999 -9999 -9999 -9999 -9999 -9999 -9999 -9999 -9999 -9999 -9999 -9999 -9999 -9999 -9999 -9999 -9999 -9999 -9999 -9999 -9999 -9999 -9999 -9999 -9999 -9999 -9999 -9999 -9999 -9999 -9999 -9999 -9999 -9999 -9999 - 9999 -9999 -9999 -9999 -9999 -9999 -9999 -9999 -9999 -9999 -9999 -9999 -9999 -9999 -9999 -9999 -9999 -9999 -9999 -9999 -9999 -9999 -9999 -9999 -9999 -9999 -9999 -9999 -9999 -9999 -9999 -9999 -9999 -9999 -9999 -9999 -9999 -9999 -9999 -9999 -9999 -9999 -9999 -9999 -9999 -9999 -9999 -9999 -9999 -9999 -9999 -9999 -9999 -9999 -9999 -9999 -9999 -9999 -9999 -9999 -9999

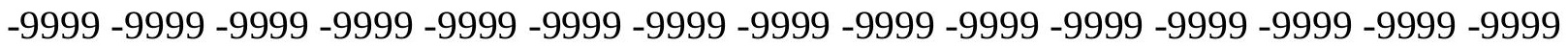

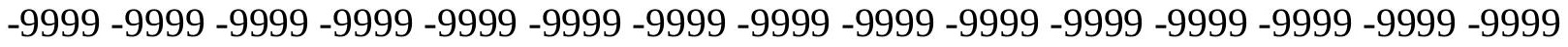
-9999 -9999 -9999 -9999 -9999 -9999 -9999 -9999 -9999 -9999 -9999 -9999 -9999 -9999 -9999 -9999 -9999 -9999 -9999 -9999 -9999 -9999 -9999 -9999 -9999 -9999 -9999 -9999 -9999 -9999 -9999 -9999 -9999 -9999 -9999 -9999 -9999 -9999 -9999 -9999 -9999 -9999 -9999 -9999 -9999 -9999 -9999 -9999 -9999 -9999 -9999 -9999 -9999 -9999 -9999 -9999 -9999 -9999 -9999 -9999 -9999 -9999 -9999 -9999 -9999 -9999 -9999 -9999 -9999 -9999 -9999 -9999 -9999 -9999 -9999 -9999 -9999 -9999 -9999 -9999 -9999 -9999 -9999 -9999 -9999 -9999 -9999 -9999 -9999 -

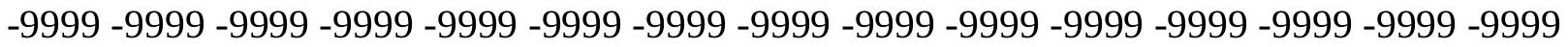
-9999 -9999 -9999 -9999 -9999 -9999 -9999 -9999 -9999 -9999 -9999 -9999 -9999 -9999 -9999 -9999 -9999 -9999 -9999 -9999 -9999 -9999 -9999 -9999 -9999 -9999 -9999 -9999 -9999 -9999 -9999 -9999 -9999 -9999 -9999 -9999 -9999 -9999 -9999 -9999 -9999 -9999 -9999 -9999 -9999 -9999 -9999 -9999 -9999 -9999 -9999 -9999 -9999 -9999 -9999 -9999 -9999 -9999 -9999 -9999 -9999 -9999 -9999 -9999 -9999 -9999 -9999 -9999 -9999 -9999 -9999 -9999 -9999 -9999 -9999 -999 -9999 -9999 -9999 -9999 -9999 -9999 -9999 -9999 -9999 -9999 -9999 -9999 -9999 -9999 -9999 -9999 -9999 -9999 -9999 -9999 -9999 -9999 -9999 -9999 -9999 -9999 -9999 -9999 -9999 -9999 -9999 -9999 -9999 -9999 -9999 -9999 -9999 -9999 -9999 -9999 -9999 -9999 -9999 -9999 -9999 -9999 -9999 -9999 -9999 -9999 -9999 -9999 -9999 -9999 -9999 -9999 -9999 -9999 -9999 -9999 -9999 -9999 -9999 -9999 -9999 -9999 -9999 -9999 -9999 -9999 -9999 -9999 -9999 -9999 -9999 -9999 -9999 -9999 -9999 -9999 -9999 -9999 -9999 -9999 -9999 -9999 -9999 -9999 -9999 -9999 -9999 -9999 -9999 -9999 -9999 -9999 -9999 -9999 -9999 -9999 -9999 -9999 -9999 -9999 -9999 -9999 -9999 -9999 -9999 -9999 -9999 -9999 -9999 -9999 -9999 -9999 -9999 -9999 -9999 -9999 -9999 -9999 -9999 -9999 -9999 -9999 -9999 -9999 -9999 -9999 -9999 -9999 -9999 -9999 -999 -9999 -9999 -9999 -9999 -9999 -9999 -9999 -9999 -9999 -9999 -9999 -9999 -9999 -9999 -9999 -9999 -9999 -9999 -9999 -9999 -9999 -9999 -9999 -9999 -9999 -9999 -9999 -9999 -9999 -9999 -

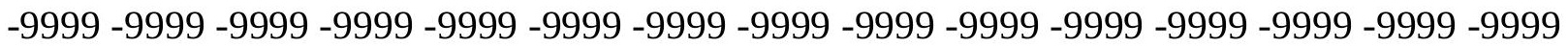

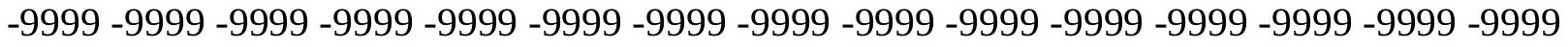

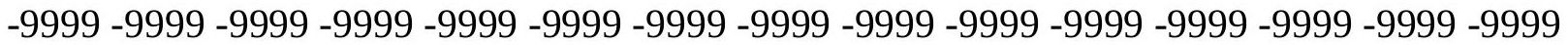
-9999 -9999 -9999 -9999 -9999 -9999 -9999 -9999 -9999 -9999 -9999 -9999 -9999 -9999 -9999 -9999 -9999 -9999 -9999 -9999 -9999 -9999 -9999 -9999 -9999 -9999 -9999 -9999 -9999 -

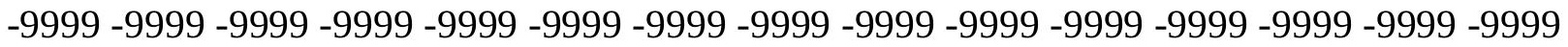
-9999 -9999 -9999 -9999 -9999 -9999 -9999 -9999 -9999 -9999 -9999 -9999 -9999 -9999 -9999 -9999 -9999 -9999 -9999 -9999 -9999 -9999 -9999 -9999 -9999 -9999 -9999 -9999 -9999 -9999 -

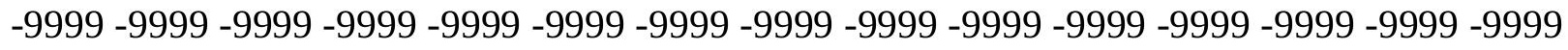

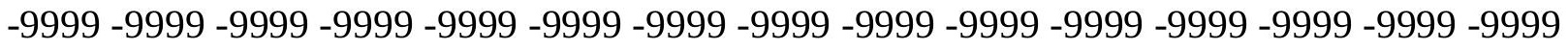
-9999 -9999 -9999 -9999 -9999 -9999 -9999 -9999 -9999 -9999 -9999 -9999 -9999 -9999 -9999 -9999 -9999 -9999 -9999 -9999 -9999 -9999 -9999 -9999-9999 -9999 -9999 -9999 -9999 -9999 -9999 -9999 -9999 -9999 -9999 -9999 -9999 -9999 -9999 -9999 -9999 -9999 -9999 -9999 -9999 -

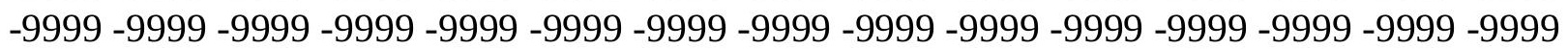


-9999 -9999 -9999 -9999 -9999 -9999 -9999 -9999 -9999 -9999 -9999 -9999 -9999 -9999 -9999 -9999 -9999 -9999 -9999 -9999 -9999 -9999 -9999 -9999 -9999 -9999 -9999 -9999 -9999 -9999 -

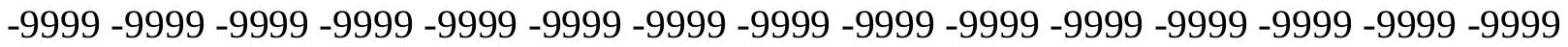
-9999 -9999 -9999 -9999 -9999 -9999 -9999 -9999 -9999 -9999 -9999 -9999 -9999 -9999 -9999 -9999 -9999 -9999 -9999 -9999 -9999 -9999 -9999 -9999-9999 -9999 -9999 -9999 -9999 -9999 -9999 -9999 -9999 -9999 -9999 -9999 -9999 -9999 -9999 -9999 -9999 -9999 -9999 -9999 -9999 -9999 -9999 -9999 -9999 -9999 -9999 -9999 -9999 -9999 -9999 -9999 -9999 -9999 -9999 -9999

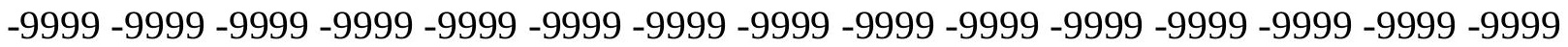

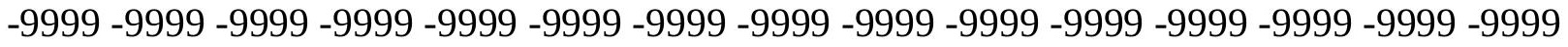
-9999 -9999 -9999 -9999 -9999 -9999 -9999 -9999 -9999 -9999 -9999 -9999 -9999 -9999 -9999 -9999 -9999 -9999 -9999 -9999 -9999 -9999 -9999 -9999 -9999 -9999 -9999 -9999 -9999 -9999 -9999 -9999 -9999 -9999 -9999 -9999 -9999 -9999 -9999 -9999 -9999 -9999 -9999 -9999 -9999 -9999 -9999 -9999 -9999 -9999 -9999 -9999 -9999 -9999 -9999 -9999 -9999 -9999 -9999 -9999 -9999 -9999 -9999 -9999 -9999 -9999 -9999 -9999 -9999 -9999 -9999 -9999 -9999 -9999 -9999 -9999 -9999 -9999 -9999 -9999 -9999 -9999 -9999 -9999 -9999 -9999 -9999 -9999 -9999 -9999 -

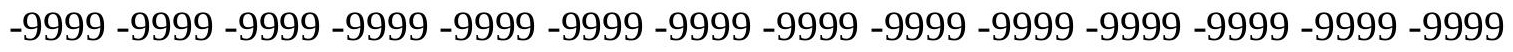
-9999 -9999 -9999 -9999 -9999 -9999 -9999 -9999 -9999 -9999 -9999 -9999 -9999 -9999 -9999 -9999 -9999 -9999 -9999 -9999 -9999 -9999 -9999 -9999 -9999 -9999 -9999 -9999 -9999 -9999 -9999 -9999 -9999 -9999 -9999 -9999 -9999 -9999 -9999 -9999 -9999 -9999 -9999 -9999 -9999 -

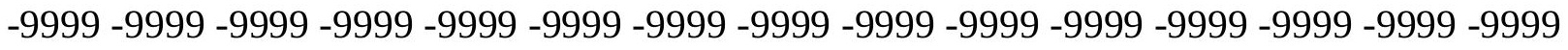

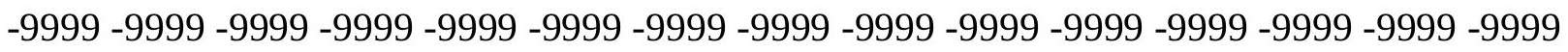
-9999 -9999 -9999 -9999 -9999 -9999 -9999 -9999 -9999 -9999 -9999 -9999 -9999 -9999 - 9999 -9999 -9999 -9999 -9999 -9999 -9999 -9999 -9999 -9999 -9999 -9999 -9999 -9999 -9999 -9999 -9999 -9999 -9999 -9999 -9999 -9999 -9999 -9999 -9999 -9999 -9999 -9999 -9999 -9999 -9999 -

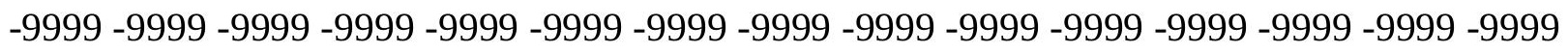
-9999 -9999 -9999 -9999 -9999 -9999 -9999 -9999 -9999 -9999 -9999 -9999 -9999 -9999 -9999 -9999 -9999 -9999 -9999 -9999 -9999 -9999 -9999 -9999 -9999 -9999 -9999 -9999 -9999 -9999 -

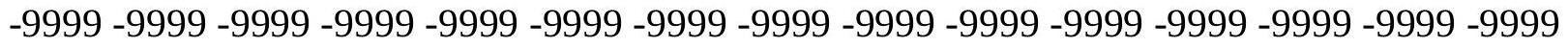
-9999 -9999 -9999 -9999 -9999 -9999 -9999 -9999 -9999 -9999 -9999 -9999 -9999 -9999 -9999 -9999 -9999 -9999 -9999 -9999 -9999 -9999 -9999 -9999 -9999 -9999 -9999 -9999 -9999 -999 -

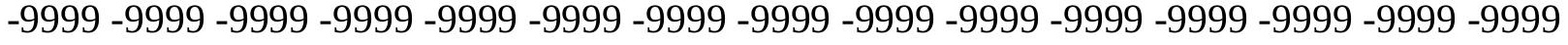
-9999 -9999 -9999 -9999 -9999 -9999 -9999 -9999 -9999 -9999 -9999 -9999 -9999 -9999 -9999 -

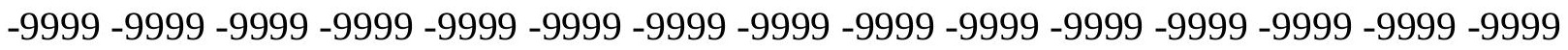

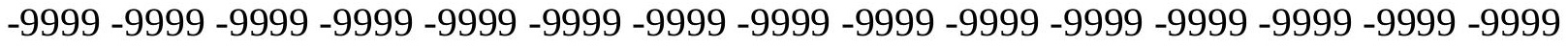

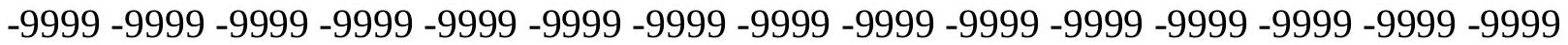
-9999 -9999 -9999 -9999 -9999 -9999 -9999 -9999 -9999 -9999 -9999 -9999 -9999 -9999 -9999 -

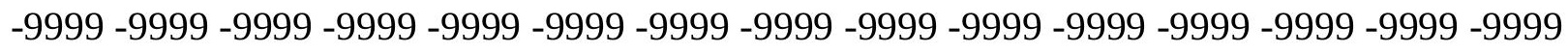

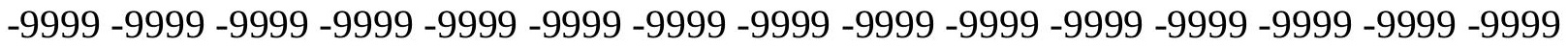
-9999 -9999 -9999 -9999 -9999 -9999 -9999 -9999 -9999 -9999 -9999 -9999 -9999 - 9999 - -999 -9999 -9999 -9999 -9999 -9999 -9999 -9999 -9999 -9999 -9999 -9999 -9999 -9999 -9999 -9999 -

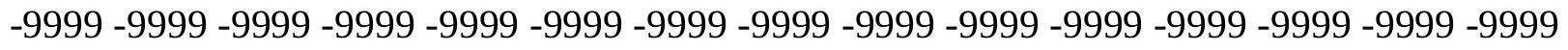

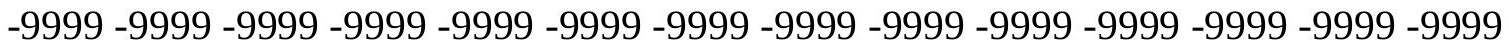
-9999 -9999 -9999 -9999 -9999 -9999 -9999 -9999 -9999 -9999 -9999 -9999 -9999 -9999 -9999 -9999 -9999 -9999 -9999 -9999 -9999 -9999 -9999 -9999-9999 -9999 -9999 -9999 -9999 -9999 -9999 -9999 -9999 -9999 -9999 -9999 -9999 -9999 -9999 -9999 -9999 -9999 -9999 -9999 -9999 -

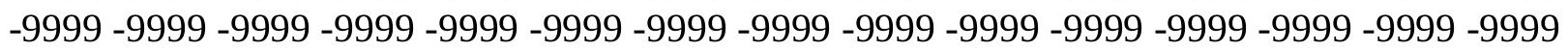


-9999 -9999 -9999 -9999 -9999 -9999 -9999 -9999 -9999 -9999 -9999 -9999 -9999 -9999 -9999 -9999 -9999 -9999 -9999 -9999 -9999 -9999 -9999 -9999 -9999 -9999 -9999 -9999 -9999 -9999 -

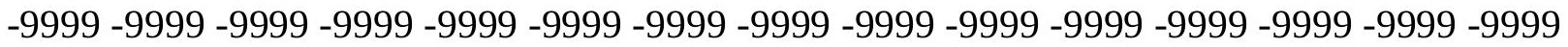
-9999 -9999 -9999 -9999 -9999 -9999 -9999 -9999 -9999 -9999 -9999 -9999 -9999 -9999 -9999 -9999 -9999 -9999 -9999 -9999 -9999 -9999 -9999 -9999-9999 -9999 -9999 -9999 -9999 -9999 -9999 -9999 -9999 -9999 -9999 -9999 -9999 -9999 -9999 -9999 -9999 -9999 -9999 -9999 -9999 -9999 -9999 -9999 -9999 -9999 -9999 -9999 -9999 -9999 -9999 -9999 -9999 -9999 -9999 -9999

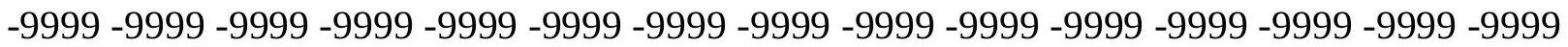

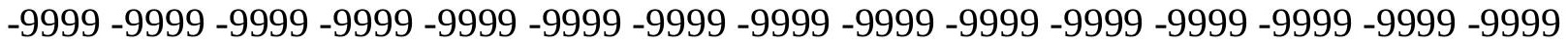
-9999 -9999 -9999 -9999 -9999 -9999 -9999 -9999 -9999 -9999 -9999 -9999 -9999 -9999 -9999 -9999 -9999 -9999 -9999 -9999 -9999 -9999 -9999 -9999 -9999 -9999 -9999 -9999 -9999 -9999 -9999 -9999 -9999 -9999 -9999 -9999 -9999 -9999 -9999 -9999 -9999 -9999 -9999 -9999 -9999 -9999 -9999 -9999 -9999 -9999 -9999 -9999 -9999 -9999 -9999 -9999 -9999 -9999 -9999 -9999 -

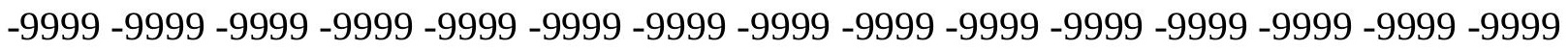
-9999 -9999 -9999 -9999 -9999 -9999 -9999 -9999 -9999 -9999 -9999 -9999 -9999 -9999 -9999 -

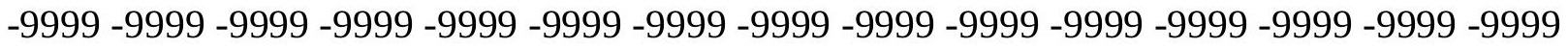
-9999 -9999 -9999 -9999 -9999 -9999 -9999 -9999 -9999 -9999 -9999 -9999 -9999 -9999 -9999 -9999 -9999 -9999 -9999 -9999 -9999 -9999 -9999 -9999 -9999 -9999 -9999 -9999 -9999 -9999 -9999 -9999 -9999 -9999 -9999 -9999 -9999 -9999 -9999 -9999 -9999 -9999 -9999 -9999 -9999 -

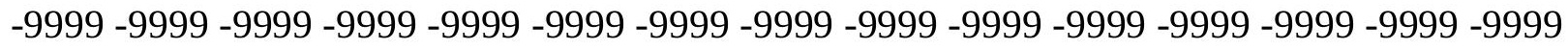

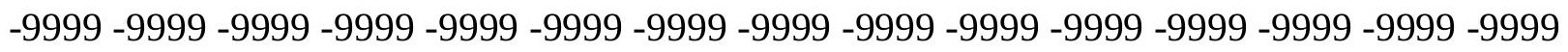
-9999 -9999 -9999 -9999 -9999 -9999 -9999 -9999 -9999 -9999 -9999 -9999 -9999 -9999 -9999 -9999 -9999 -9999 -9999 -9999 -9999 -9999 -9999 -9999 -9999 -9999 -9999 -9999 -9999 -9999 -9999 -9999 -9999 -9999 -9999 -9999 -9999 -9999 -9999 -9999 -9999 -9999 -9999 -9999 -

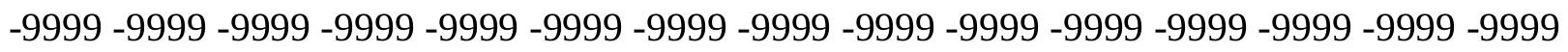
-9999 -9999 -9999 -9999 -9999 -9999 -9999 -9999 -9999 -9999 -9999 -9999 -9999 -9999 -9999 -9999 -9999 -9999 -9999 -9999 -9999 -9999 -9999 -9999 -9999 -9999 -9999 -9999 -9999 -9999 -

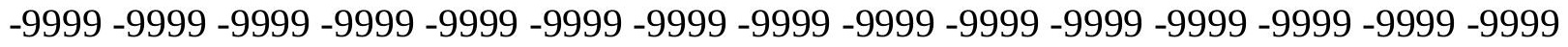
-9999 -9999 -9999 -9999 -9999 -9999 -9999 -9999 -9999 -9999 -9999 -9999 -9999 -9999 -9999 -9999 -9999 -9999 -9999 -9999 -9999 -9999 -9999 -9999 -9999 -9999 -9999 -9999 -9999 -999 -

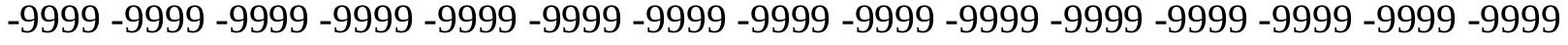
-9999 -9999 -9999 -9999 -9999 -9999 -9999 -9999 -9999 -9999 -9999 -9999 -9999 -9999 -9999 -

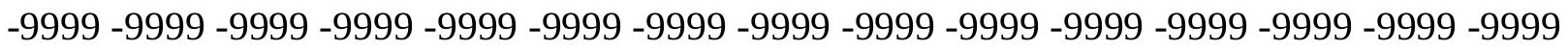

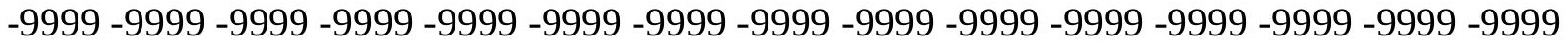

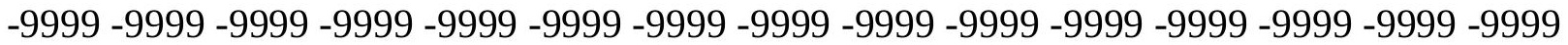

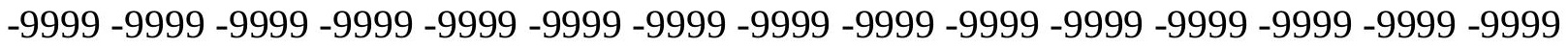

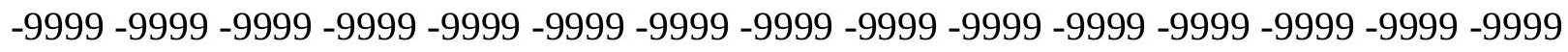

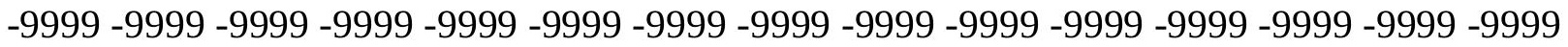

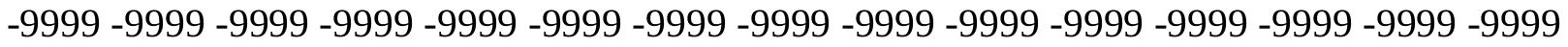
-9999 -9999 -9999 -9999 -9999 -9999 -9999 -9999 -9999 -9999 -9999 -9999 -9999 -9999 -9999 -

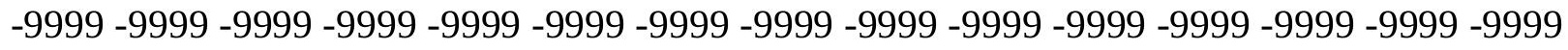

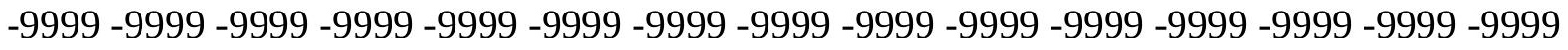
-9999 -9999 -9999 -9999 -9999 -9999 -9999 -9999 -9999 -9999 -9999 -9999 -9999 -9999 -9999 -9999 -9999 -9999 -9999 -9999 -9999 -9999 -9999 -9999-9999 -9999 -9999 -9999 -9999 -9999 -9999 -9999 -9999 -9999 -9999 -9999 -9999 -9999 -9999 -9999 -9999 -9999 -9999 -9999 -9999 -

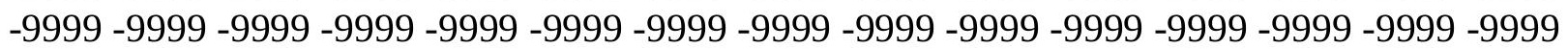


-9999 -9999 -9999 -9999 -9999 -9999 -9999 -9999 -9999 -9999 -9999 -9999 -9999 -9999 -9999 -9999 -9999 -9999 -9999 -9999 -9999 -9999 -9999 -9999 -9999 -9999 -9999 -9999 -9999 -

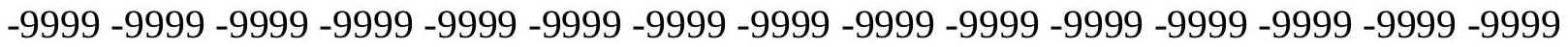
-9999 -9999 -9999 -9999 -9999 -9999 -9999 -9999 -9999 -9999 -9999 -9999 -9999 -9999 -9999 -9999 -9999 -9999 -9999 -9999 -9999 -9999 -9999 -9999 -9999 -9999 -9999 -9999 -9999 -9999 -9999 -9999 -9999 -9999 -9999 -9999 -9999 -9999 -9999 -9999 -9999 -9999 -9999 -9999 -9999 -9999 -9999 -9999 -9999 -9999 -9999 -9999 -9999 -9999 -9999 -9999 -9999 -9999 -9999 -9999

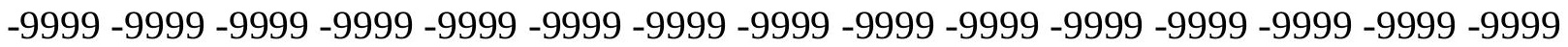

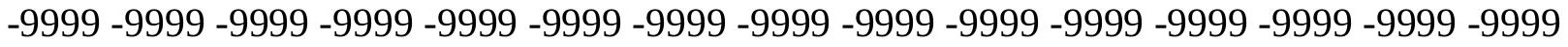
-9999 -9999 -9999 -9999 -9999 -9999 -9999 -9999 -9999 -9999 -9999 -9999 -9999 -9999 -9999 -9999 -9999 -9999 -9999 -9999 -9999 -9999 -9999 -9999 -9999 -9999 -9999 -9999 -9999 -9999 -9999 -9999 -9999 -9999 -9999 -9999 -9999 -9999 -9999 -9999 -9999 -9999 -9999 -9999 -9999 -9999 -9999 -9999 -9999 -9999 -9999 -9999 -9999 -9999 -9999 -9999 -9999 -9999 -9999 -9999 -9999 -9999 -9999 -9999 -9999 -9999 -9999 -9999 -9999 -9999 -9999 -9999 -9999 -9999 -9999 -9999 -9999 -9999 -9999 -9999 -9999 -9999 -9999 -9999 -9999 -9999 -9999 -9999 -9999 -9999 -

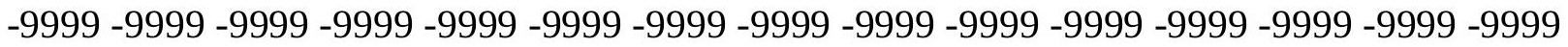
-9999 -9999 -9999 -9999 -9999 -9999 -9999 -9999 -9999 -9999 -9999 -9999 -9999 -9999 -9999 -9999 -9999 -9999 -9999 -9999 -9999 -9999 -9999 -9999 -9999 -9999 -9999 -9999 -9999 - 9999 -9999 -9999 -9999 -9999 -9999 -9999 -9999 -9999 -9999 -9999 -9999 -9999 -9999 -9999 -9999 -

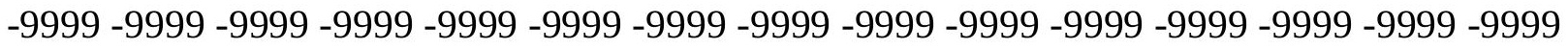

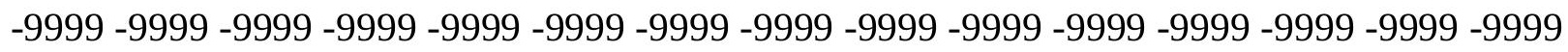

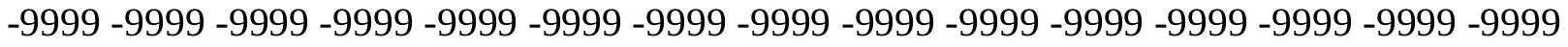
-9999 -9999 -9999 -9999 -9999 -9999 -9999 -9999 -9999 -9999 -9999 -9999 -9999 -9999 -9999 -9999 -9999 -9999 -9999 -9999 -9999 -9999 -9999 -9999 -9999 -9999 -9999 -9999 -9999 -9999 -

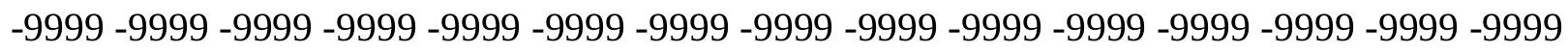
-9999 -9999 -9999 -9999 -9999 -9999 -9999 -9999 -9999 -9999 -9999 -9999 -9999 -9999 -9999 -9999 -9999 -9999 -9999 -9999 -9999 -9999 -9999 -9999 -9999 -9999 -9999 -9999 -9999 -9999 -9999 -9999 -9999 -9999 -9999 -9999 -9999 -9999 -9999 -9999 -9999 -9999 -9999 -9999 -9999 -9999 -9999 -9999 -9999 -9999 -9999 -9999 -9999 -9999 -9999 -9999 -9999 -9999 -9999 -9999 -9999 -9999 -9999 -9999 -9999 -9999 -9999 -9999 -9999 -9999 -9999 -9999 -9999 -999 -

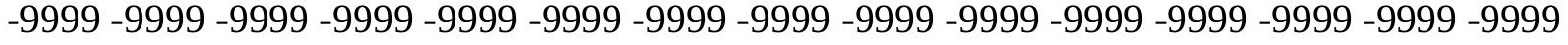
-9999 -9999 -9999 -9999 -9999 -9999 -9999 -9999 -9999 -9999 -9999 -9999 -9999 -9999 -9999 -

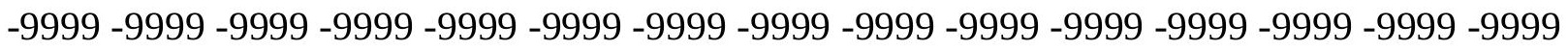

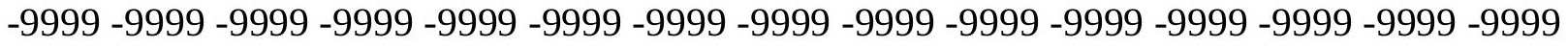

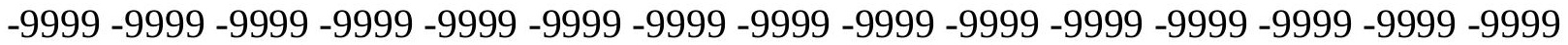

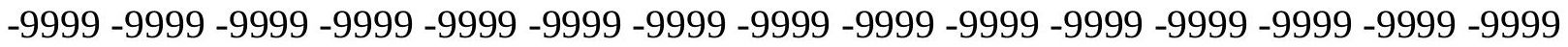

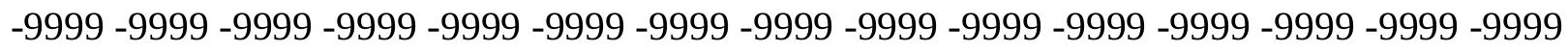

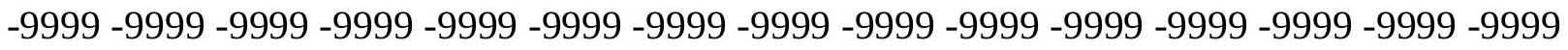

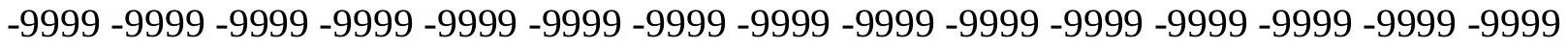
-9999 -9999 -9999 -9999 -9999 -9999 -9999 -9999 -9999 -9999 -9999 -9999 -9999 -9999 -9999 -

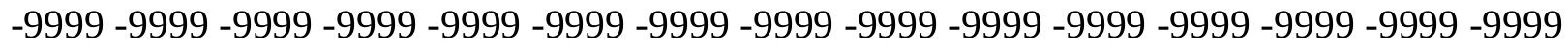

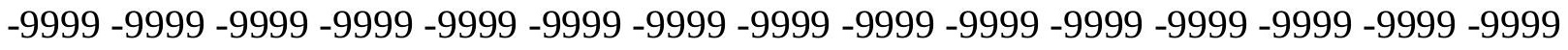
-9999 -9999 -9999 -9999 -9999 -9999 -9999 -9999 -9999 -9999 -9999 -9999 -9999 -9999 -9999 -9999 -9999 -9999 -9999 -9999 -9999 -9999 -9999 -9999-9999 -9999 -9999 -9999 -9999 -9999 -9999 -9999 -9999 -9999 -9999 -9999 -9999 -9999 -9999 -9999 -9999 -9999 -9999 -9999 -9999 -

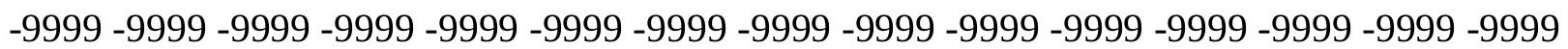


-9999 -9999 -9999 -9999 -9999 -9999 -9999 -9999 -9999 -9999 -9999 -9999 -9999 -9999 -9999 -9999 -9999 -9999 -9999 -9999 -9999 -9999 -9999 -9999 -9999 -9999 -9999 -9999 -9999 -9999 -9999 -9999 -9999 -9999 -9999 -9999 -9999 -9999 -9999 -9999 -9999 -9999 -9999 -9999 -9999 -9999 -9999 -9999 -9999 -9999 -9999 -9999 -9999 -9999 -9999 -9999 -9999 -9999 -9999 -9999 -9999 -9999 -9999 -9999 -9999 -9999 -9999 -9999 -9999 -9999 -9999 -9999-9999 -9999 -9999 -9999 -9999 -9999 -9999 -9999 -9999 -9999 -9999 -9999 -9999 -9999 -9999 -9999 -9999 -9999 -

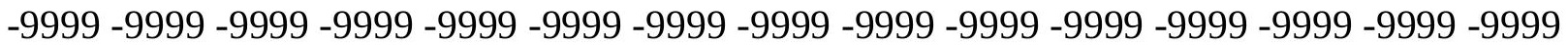
-9999 -9999 -9999 -9999 -9999 -9999 -9999 -9999 -9999 -9999 -9999 -9999 -9999 -9999 -9999 -9999 -9999 -9999 -9999 -9999 -9999 -9999 -9999 -9999 -9999 -9999 -9999 -9999 -9999 -9999 -9999 -9999 -9999 -9999 -9999 -9999 -9999 -9999 -9999 -9999 -9999 -9999 -9999 -9999 -

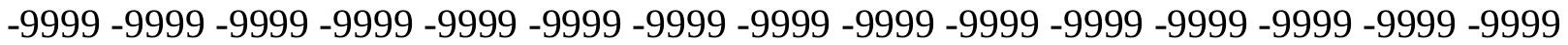
-9999 -9999 -9999 -9999 -9999 -9999 -9999 -9999 -9999 -9999 -9999 -9999 -9999 -9999 -9999 -9999 -9999 -9999 -9999 -9999 -9999 -9999 -9999 -9999 -9999 -9999 -9999 -9999 -9999 -9999 -9999 -9999 -9999 -9999 -9999 -9999 -9999 -9999 -9999 -9999 -9999 -9999 -9999 -9999 -9999 -9999 -9999 -9999 -9999 -9999 -9999 -9999 -9999 -9999 -9999 -9999 -9999 -9999 -9999 -9999 -

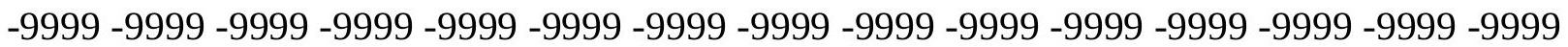
-9999 -9999 -9999 -9999 -9999 -9999 -9999 -9999 -9999 -9999 -9999 -9999 -9999 -9999 -9999 -9999 -9999 -9999 -9999 -9999 -9999 -9999 -9999 -9999 -9999 -9999 -9999 -9999 -9999 -9999 -9999 -9999 -9999 -9999 -9999 -9999 -9999 -9999 -9999 -9999 -9999 -9999 -9999 -9999 -9999 -9999 -9999 -9999 -9999 -9999 -9999 -9999 -9999 -9999 -9999 -9999 -9999 -9999 -9999 -9999

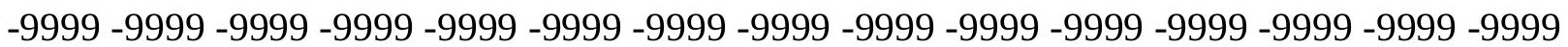
-9999 -9999 -9999 -9999 -9999 -9999 -9999 -9999 -9999 -9999 -9999 -9999 -9999 -9999 -9999 -9999 -9999 -9999 -9999 -9999 -9999 -9999 -9999 -9999 -9999 -9999 -9999 -9999 -9999 -9999 -9999 -9999 -9999 -9999 -9999 -9999 -9999 -9999 -9999 -9999 -9999 -9999 -9999 -9999 -9999

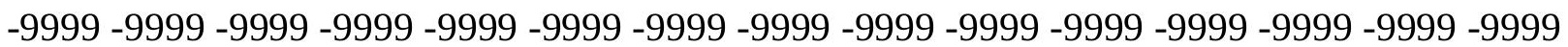
-9999 -9999 -9999 -9999 -9999 -9999 -9999 -9999 -9999 -9999 -9999 -9999 -9999 -9999 -9999 -9999 -9999 -9999 -9999 -9999 -9999 -9999 -9999 -9999 -9999 -9999 -9999 -9999 -9999 -9999 -9999 -9999 -9999 -9999 -9999 -9999 -9999 -9999 -9999 -9999 -9999 -9999 -9999 -9999 -9999

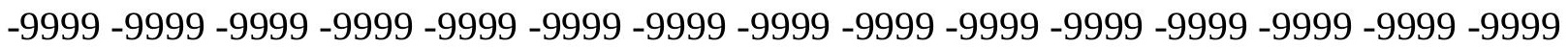
-9999 -9999 -9999 -9999 -9999 -9999 -9999 -9999 -9999 -9999 -9999 -9999 -9999 -9999 -9999 -9999 -9999 -9999 -9999 -9999 -9999 -9999 -9999 -9999 -9999 -9999 -9999 -9999 -9999 -9999 -9999 -9999 -9999 -9999 -9999 -9999 -9999 -9999 -9999 -9999 -9999 -9999 -9999 -9999 -9999 -9999 -9999 -9999 -9999 -9999 -9999 -9999 -9999 -9999 -9999 -9999 -9999 -9999 -9999 -9999 -9999 -9999 -9999 -9999 -9999 -9999 -9999 -9999 -9999 -9999 -9999 -9999 -9999 -9999 - 
u7top_elev 


$\begin{array}{ll}\text { ncols } & 389 \\ \text { nrows } & 437 \\ \text { xllcorner } & 545925 \\ \text { yllcorner } & 100925 \\ \text { cellsize } & 150\end{array}$

NODATA_value -9999

-9999 -9999 -9999 -9999 -9999 -9999 -9999 -9999 -9999 -9999 -9999 -9999 -9999 -9999 -9999 -9999 -9999 -9999 -9999 -9999 -9999 -9999 -9999 -9999 -9999 -9999 -9999 -9999 -9999 -9999 -999 -9999 -9999 -9999 -9999 -9999 -9999 -9999 -9999 -9999 -9999 -9999 -9999 -9999 -9999 -9999 -9999 -9999 -9999 -9999 -9999 -9999 -9999 -9999 -9999 -9999 -9999 -9999 -9999 -9999 -9999

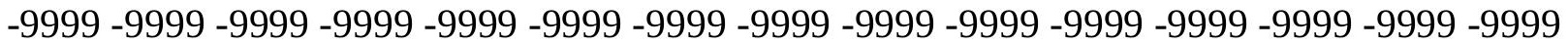
-9999 -9999 -9999 -9999 -9999 -9999 -9999 -9999 -9999 -9999 -9999 -9999 -9999 -9999 -9999 -9999 -9999 -9999 -9999 -9999 -9999 -9999 -9999 -9999 -9999 -9999 -9999 -9999 -9999 -9999 -9999 -9999 -9999 -9999 -9999 -9999 -9999 -9999 -9999 -9999 -9999 -9999 -9999 -9999 - 9999 -9999 -9999 -9999 -9999 -9999 -9999 -9999 -9999 -9999 -9999 -9999 -9999 -9999 -9999 -9999

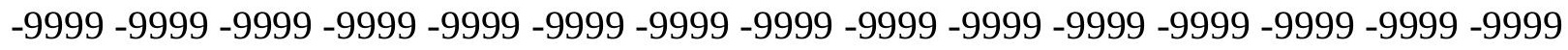
-9999 -9999 -9999 -9999 -9999 -9999 -9999 -9999 -9999 -9999 -9999 -9999 -9999 -9999 -9999 -9999 -9999 -9999 -9999 -9999 -9999 -9999 -9999 -9999 -9999 -9999 -9999 -9999 -9999 -9999 -999 -9999 -9999 -9999 -9999 -9999 -9999 -9999 -9999 -9999 -9999 -9999 -9999 -9999 -9999 -9999 -9999 -9999 -9999 -9999 -9999 -9999 -9999 -9999 -9999 -9999 -9999 -9999 -9999 -9999 -9999 -9999 -9999 -9999 -9999 -9999 -9999 -9999 -9999 -9999 -9999 -9999 -9999 -9999 -9999 -9999 -9999 -9999 -9999 -9999 -9999 -9999 -9999 -9999 -9999 -9999 -9999 -9999 -9999 -9999 -9999 -9999 -9999 -9999 -9999 -9999 -9999 -9999 -9999 -9999 -9999 -9999 -9999 -9999 -9999 -9999 -9999 -9999 -9999 -9999 -9999 -9999 -9999 -9999 -9999 -9999 -9999 -9999 -9999 -9999 -9999 -9999 -9999 -9999 -9999 -9999 -9999 -9999 -9999 -9999 -9999 -9999 -9999 -9999 -9999 -9999 -9999 -9999 -9999 -9999 -9999 -9999 -9999 -9999 -9999 -9999 -9999 -9999 -9999 -9999 -9999 -9999 -9999 -9999 -9999 -9999 -9999 -9999 -9999 -9999 -9999 -9999 -9999 -9999 -9999 -9999 -9999 -9999 -9999 -9999 -9999 -9999 -9999 -9999 -9999 -9999 -9999 -9999 -9999 -9999 -9999 -9999 -9999 -9999 -9999 -9999 -9999 -9999 -9999 -9999 -9999 -9999 -9999 -9999 -9999 -9999 -9999 -9999 -9999 -9999 -9999 -9999 -9999 -9999 -9999 -9999 -9999 -9999 -9999 -9999 -999 -9999 -9999 -9999 -9999 -9999 -9999 -9999 -9999 -9999 -9999 -9999 -9999 -9999 -9999 -9999 -9999 -9999 -9999 -9999 -9999 -9999 -9999 -9999 -9999 -9999 -9999 -9999 -9999 -9999 -

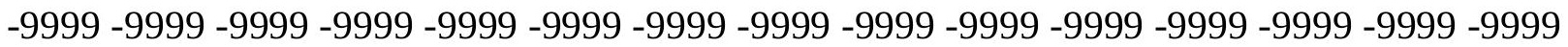
-9999 -9999 -9999 -9999 -9999 -9999 -9999 -9999 -9999 -9999 -9999 -9999 -9999 -9999 -9999 -9999 -9999 -9999 -9999 -9999 -9999 -9999 -9999 -9999 -9999 -9999 -9999 -9999 -9999 -9999 -

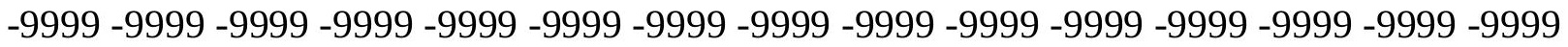

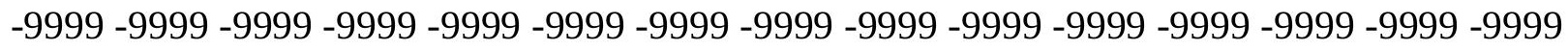
-9999 -9999 -9999 -9999 -9999 -9999 -9999 -9999 -9999 -9999 -9999 -9999 -9999 - 9999 - -9999 -9999 -9999 -9999 -9999 -9999 -9999 -9999 -9999 -9999 -9999 -9999 -9999 -9999 - 9999 - -999 -9999 -9999 -9999 -9999 -9999 -9999 -9999 -9999 -9999 -9999 -9999 -9999 -9999 -9999 -9999 -

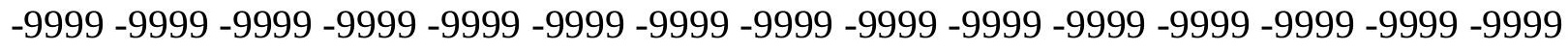

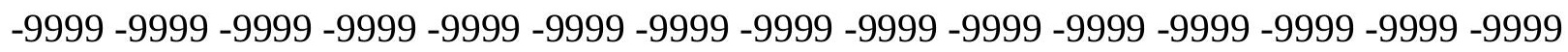
-9999 -9999 -9999 -9999 -9999 -9999 -9999 -9999 -9999 -9999 -9999 -9999 -9999 -9999 -9999 -9999 -9999 -9999 -9999 -9999 -9999 -9999 -9999 -9999-9999 -9999 -9999 -9999 -9999 -9999 -9999 -9999 -9999 -9999 -9999 -9999 -9999 -9999 -9999 -9999 -9999 -9999 -9999 -9999 -9999 -

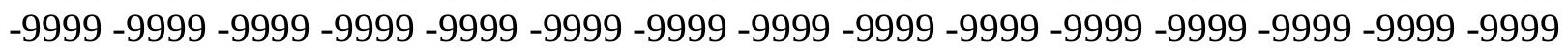


-9999 -9999 -9999 -9999 -9999 -9999 -9999 -9999 -9999 -9999 -9999 -9999 -9999 -9999 -9999 -9999 -9999 -9999 -9999 -9999 -9999 -9999 -9999 -9999 -9999 -9999 -9999 -9999 -9999 -9999 -

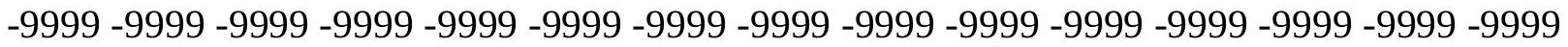
-9999 -9999 -9999 -9999 -9999 -9999 -9999 -9999 -9999 -9999 -9999 -9999 -9999 -9999 -9999 -9999 -9999 -9999 -9999 -9999 -9999 -9999 -9999 -9999-9999 -9999 -9999 -9999 -9999 -9999 -9999 -9999 -9999 -9999 -9999 -9999 -9999 -9999 -9999 -9999 -9999 -9999 -9999 -9999 -9999 -9999 -9999 -9999 -9999 -9999 -9999 -9999 -9999 -9999 -9999 -9999 -9999 -9999 -9999 -9999

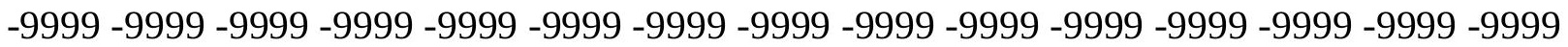

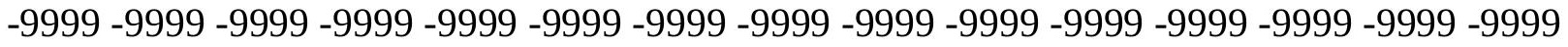
-9999 -9999 -9999 -9999 -9999 -9999 -9999 -9999 -9999 -9999 -9999 -9999 -9999 -9999 -9999 -9999 -9999 -9999 -9999 -9999 -9999 -9999 -9999 -9999 -9999 -9999 -9999 -9999 -9999 -9999 -9999 -9999 -9999 -9999 -9999 -9999 -9999 -9999 -9999 -9999 -9999 -9999 -9999 -9999 -9999 -9999 -9999 -9999 -9999 -9999 -9999 -9999 -9999 -9999 -9999 -9999 -9999 -9999 -9999 -9999 -9999 -9999 -9999 -9999 -9999 -9999 -9999 -9999 -9999 -9999 -9999 -9999 -9999 - 9999 -9999 -9999 -9999 -9999 -9999 -9999 -9999 -9999 -9999 -9999 -9999 -9999 -9999 -9999 -9999

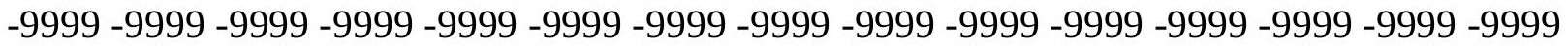
-9999 -9999 -9999 -9999 -9999 -9999 -9999 -9999 -9999 -9999 -9999 -9999 -9999 -9999 -9999 -9999 -9999 -9999 -9999 -9999 -9999 -9999 -9999 -9999 -9999 -9999 -9999 -9999 -9999 -9999 -9999 -9999 -9999 -9999 -9999 -9999 -9999 -9999 -9999 -9999 -9999 -9999 -9999 -9999 -9999 -

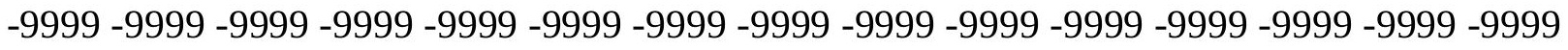

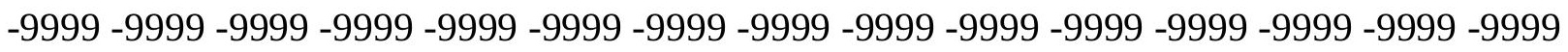
-9999 -9999 -9999 -9999 -9999 -9999 -9999 -9999 -9999 -9999 -9999 -9999 -9999 -9999 -9999 -9999 -9999 -9999 -9999 -9999 -9999 -9999 -9999 -9999 -9999 -9999 -9999 -9999 -9999 -9999 -9999 -9999 -9999 -9999 -9999 -9999 -9999 -9999 -9999 -9999 -9999 -9999 -9999 -9999 -9999 -

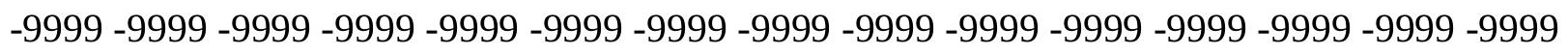
-9999 -9999 -9999 -9999 -9999 -9999 -9999 -9999 -9999 -9999 -9999 -9999 -9999 -9999 -9999 -9999 -9999 -9999 -9999 -9999 -9999 -9999 -9999 -9999 -9999 -9999 -9999 -9999 -9999 -9999 -

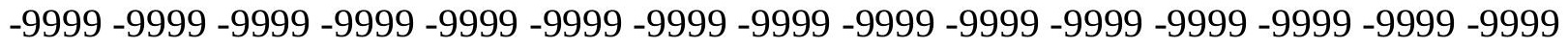
-9999 -9999 -9999 -9999 -9999 -9999 -9999 -9999 -9999 -9999 -9999 -9999 -9999 -9999 -9999 -9999 -9999 -9999 -9999 -9999 -9999 -9999 -9999 -9999 -9999 -9999 -9999 -9999 -9999 -999 -9999 -9999 -9999 -9999 -9999 -9999 -9999 -9999 -9999 -9999 -9999 -9999 -9999 -9999 -9999 -9999 -9999 -9999 -9999 -9999 -9999 -9999 -9999 -9999 -9999 -9999 -9999 -9999 -9999 -9999 -

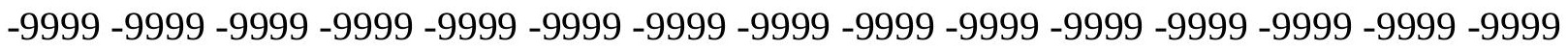

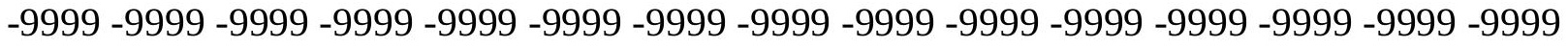

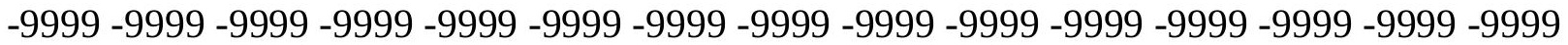

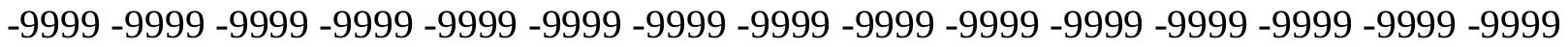

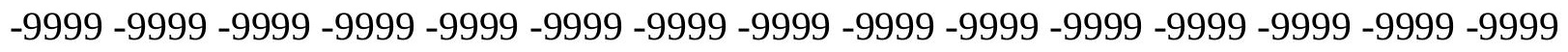

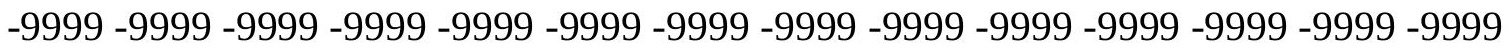
-9999 -9999 -9999 -9999 -9999 -9999 -9999 -9999 -9999 -9999 -9999 -9999 -9999 -9999 -9999 -9999 -9999 -9999 -9999 -9999 -9999 -9999 -9999 -9999 -9999 -9999 -9999 -9999 -9999 -9999 -

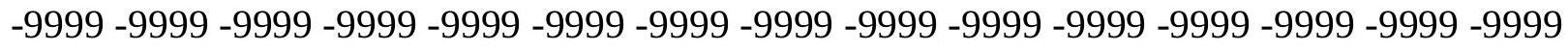

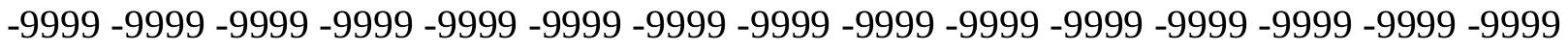
-9999 -9999 -9999 -9999 -9999 -9999 -9999 -9999 -9999 -9999 -9999 -9999 -9999 -9999 -9999 -9999 -9999 -9999 -9999 -9999 -9999 -9999 -9999 -9999-9999 -9999 -9999 -9999 -9999 -9999 -9999 -9999 -9999 -9999 -9999 -9999 -9999 -9999 -9999 -9999 -9999 -9999 -9999 -9999 -9999 -

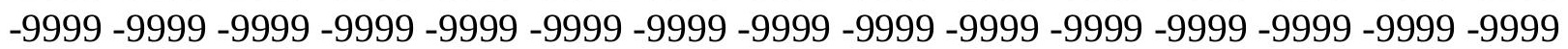


-9999 -9999 -9999 -9999 -9999 -9999 -9999 -9999 -9999 -9999 -9999 -9999 -9999 -9999 -9999 -9999 -9999 -9999 -9999 -9999 -9999 -9999 -9999 -9999 -9999 -9999 -9999 -9999 -9999 -9999 -9999 -9999 -9999 -9999 -9999 -9999 -9999 -9999 -9999 -9999 -9999 -9999 -9999 -9999 - 9999 -9999 -9999 -9999 -9999 -9999 -9999 -9999 -9999 -9999 -9999 -9999 -9999 -9999 -9999 -9999 -9999 -9999 -9999 -9999 -9999 -9999 -9999 -9999 -9999 -9999 -9999 -9999 -9999 -9999 -9999 -9999 -9999 -9999 -9999 -9999 -9999 -9999 -9999 -9999 -9999 -9999 -9999 -9999 -9999 -9999 -9999 -9999 -9999 -9999 -9999 -9999 -9999 -9999 -9999 -9999 -9999 -9999 -9999 -9999 -9999

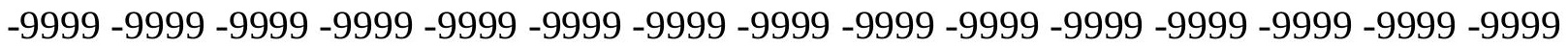
-9999 -9999 -9999 -9999 -9999 -9999 -9999 -9999 -9999 -9999 -9999 -9999 -9999 -9999 -9999 -9999 -9999 -9999 -9999 -9999 -9999 -9999 -9999 -9999 -9999 -9999 -9999 -9999 -9999 -9999

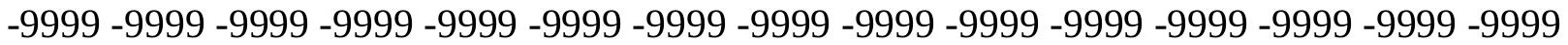
-9999 -9999 -9999 -9999 -9999 -9999 -9999 -9999 -9999 -9999 -9999 -9999 -9999 -9999 -9999 -9999 -9999 -9999 -9999 -9999 -9999 -9999 -9999 -9999 -9999 -9999 -9999 -9999 -9999 -9999 -

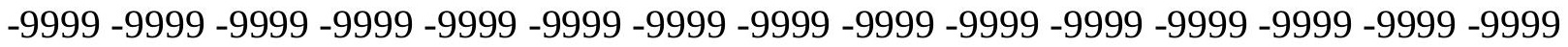
-9999 -9999 -9999 -9999 -9999 -9999 -9999 -9999 -9999 -9999 -9999 -9999 -9999 -9999 -9999

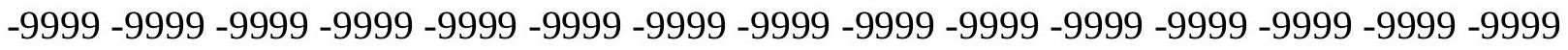
-9999 -9999 -9999 -9999 -9999 -9999 -9999 -9999 -9999 -9999 -9999 -9999 -9999 -9999 -9999 -9999 -9999 -9999 -9999 -9999 -9999 -9999 -9999 -9999 -9999 -9999 -9999 -9999 -9999 - -999 -9999 -9999 -9999 -9999 -9999 -9999 -9999 -9999 -9999 -9999 -9999 -9999 -9999 -9999 -9999 -9999 -9999 -9999 -9999 -9999 -9999 -9999 -9999 -9999 -9999 -9999 -9999 -9999 -9999 -9999 -9999 -9999 -9999 -9999 -9999 -9999 -9999 -9999 -9999 -9999 -9999 -9999 -9999 -9999 -9999 -999 -9999 -9999 -9999 -9999 -9999 -9999 -9999 -9999 -9999 -9999 -9999 -9999 -9999 -9999 -9999 -9999 -9999 -9999 -9999 -9999 -9999 -9999 -9999 -9999 -9999 -9999 -9999 -9999 -9999 -9999 -9999 -9999 -9999 -9999 -9999 -9999 -9999 -9999 -9999 -9999 -9999 -9999 -9999 -9999 -9999 -9999 -9999 -9999 -9999 -9999 -9999 -9999 -9999 -9999 -9999 -9999 -9999 -9999 -9999 -9999 -9999 -9999 -9999 -9999 -9999 -9999 -9999 -9999 -9999 -9999 -9999 -9999 -9999 -9999 -9999 -9999 -9999 -9999 -9999 -9999 -9999 -9999 -9999 -9999 -9999 -9999 -9999 -9999 -9999 -9999 -9999 -9999 -9999 -9999 -9999 -9999 -9999 -9999 -9999 -9999 -9999 -9999 -9999 -9999 -9999 -9999 -9999 -9999 -9999 -9999 -9999 -9999 -9999 -9999 -9999 -9999 -9999 -9999 -9999 -9999 -9999 -9999 -9999 -9999 -9999 -9999 -9999 -9999 -9999 -9999 -9999 -9999 -9999 -9999 -999 -9999 -9999 -9999 -9999 -9999 -9999 -9999 -9999 -9999 -9999 -9999 -9999 -9999 -9999 -9999 -9999 -9999 -9999 -9999 -9999 -9999 -9999 -9999 -9999 -9999 -9999 -9999 -9999 -9999 -9999 -

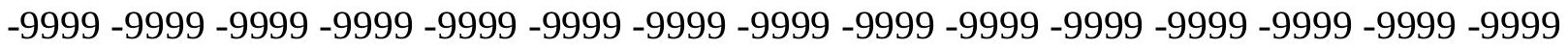

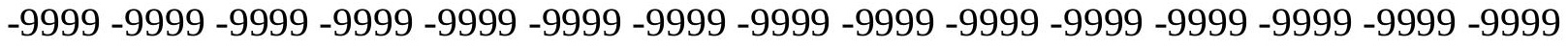

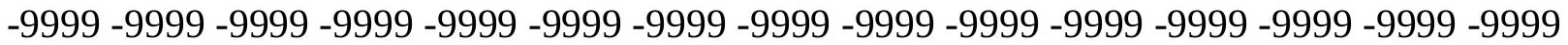
-9999 -9999 -9999 -9999 -9999 -9999 -9999 -9999 -9999 -9999 -9999 -9999 -9999 -9999 -9999

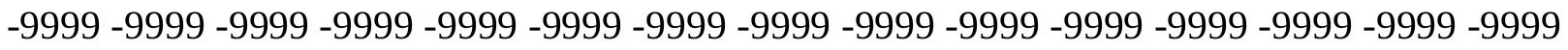

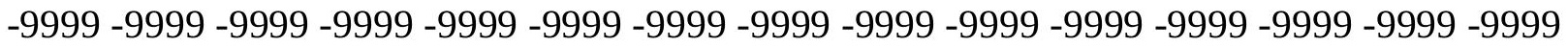

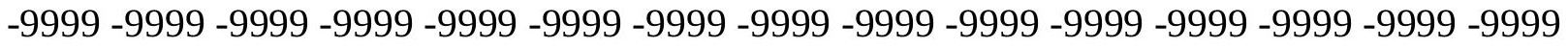
-9999 -9999 -9999 -9999 -9999 -9999 -9999 -9999 -9999 -9999 -9999 -9999 -9999 -9999 -9999 -

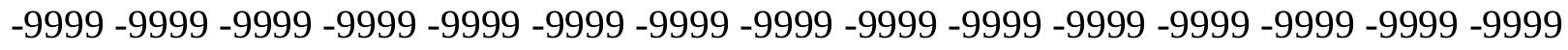

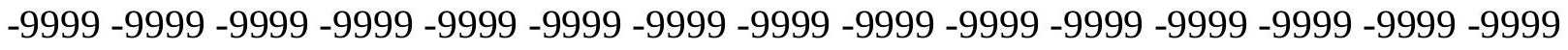
-9999 -9999 -9999 -9999 -9999 -9999 -9999 -9999 -9999 -9999 -9999 -9999 -9999 -9999 -9999 -9999 -9999 -9999 -9999 -9999 -9999 -9999 -9999 -9999 -9999 -9999 -9999 -9999 - -9999 -9999 -9999 -9999 -9999 -9999 -9999 -9999 -9999 -9999 -9999 -9999 -9999 -9999 -9999 -9999 -

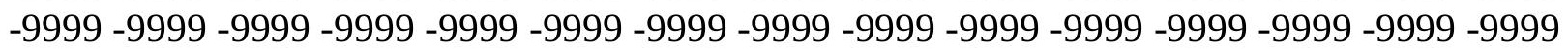


-9999 -9999 -9999 -9999 -9999 -9999 -9999 -9999 -9999 -9999 -9999 -9999 -9999 -9999 -9999 -9999 -9999 -9999 -9999 -9999 -9999 -9999 -9999 -9999 -9999 -9999 -9999 -9999 -9999 -9999 -9999 -9999 -9999 -9999 -9999 -9999 -9999 -9999 -9999 -9999 -9999 -9999 -9999 -9999 - 9999 -9999 -9999 -9999 -9999 -9999 -9999 -9999 -9999 -9999 -9999 -9999 -9999 -9999 -9999 -9999 -9999 -9999 -9999 -9999 -9999 -9999 -9999 -9999 -9999-9999 -9999 -9999 -9999 -9999 -9999 -9999 -9999 -9999 -9999 -9999 -9999 -9999 -9999 -9999 -9999 -9999 -9999 -9999 -9999 -9999 -9999 -9999 -9999 -9999 -9999 -9999 -9999 -9999 -9999 -9999 -9999 -9999 -9999 -9999 -9999

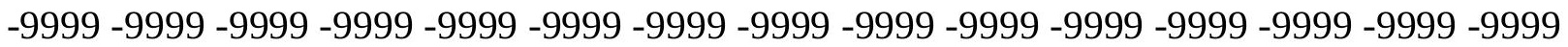

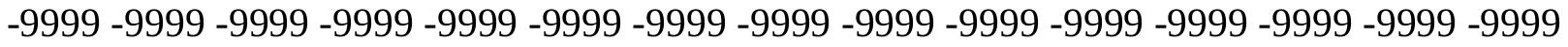
-9999 -9999 -9999 -9999 -9999 -9999 -9999 -9999 -9999 -9999 -9999 -9999 -9999 -9999 -9999

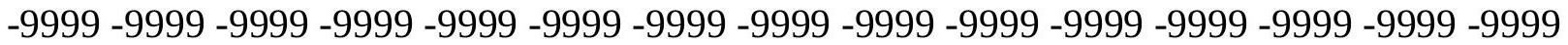
-9999 -9999 -9999 -9999 -9999 -9999 -9999 -9999 -9999 -9999 -9999 -9999 -9999 -9999 -9999 -9999 -9999 -9999 -9999 -9999 -9999 -9999 -9999 -9999 -9999 -9999 -9999 -9999 -9999 -9999 -

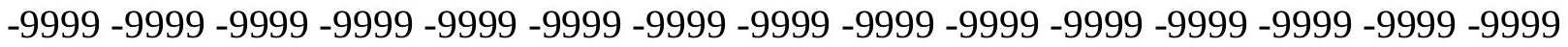
-9999 -9999 -9999 -9999 -9999 -9999 -9999 -9999 -9999 -9999 -9999 -9999 -9999 -9999 -9999

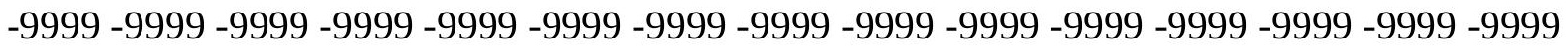
-9999 -9999 -9999 -9999 -9999 -9999 -9999 -9999 -9999 -9999 -9999 -9999 -9999 -9999 -9999 -9999 -9999 -9999 -9999 -9999 -9999 -9999 -9999 -9999 -9999 -9999 -9999 -9999 -9999 -9999 -9999 -9999 -9999 -9999 -9999 -9999 -9999 -9999 -9999 -9999 -9999 -9999 -9999 -9999 -9999 -9999 -9999 -9999 -9999 -9999 -9999 -9999 -9999 -9999 -9999 -9999 -9999 -9999 -9999 -9999 -9999 -9999 -9999 -9999 -9999 -9999 -9999 -9999 -9999 -9999 -9999 -9999 -9999 -9999 -9999 -999 -9999 -9999 -9999 -9999 -9999 -9999 -9999 -9999 -9999 -9999 -9999 -9999 -9999 -9999 -9999 -9999 -9999 -9999 -9999 -9999 -9999 -9999 -9999 -9999 -9999 -9999 -9999 -9999 -9999 -9999 -9999 -9999 -9999 -9999 -9999 -9999 -9999 -9999 -9999 -9999 -9999 -9999 -9999 -9999 -9999 -9999 -9999 -9999 -9999 -9999 -9999 -9999 -9999 -9999 -9999 -9999 -9999 -9999 -9999 -9999 -9999 -9999 -9999 -9999 -9999 -9999 -9999 -9999 -9999 -9999 -9999 -9999 -9999 -9999 -9999 -9999 -9999 -9999 -9999 -9999 -9999 -9999 -9999 -9999 -9999 -9999 -9999 -9999 -9999 -9999 -9999 -9999 -9999 -9999 -9999 -9999 -9999 -9999 -9999 -9999 -9999 -9999 -9999 -9999 -9999 -9999 -9999 -9999 -9999 -9999 -9999 -9999 -9999 -9999 -9999 -9999 -9999 -9999 -9999 -9999 -9999 -9999 -9999 -9999 -9999 -9999 -9999 -9999 -9999 -9999 -9999 -9999 -9999 -999 -9999 -9999 -9999 -9999 -9999 -9999 -9999 -9999 -9999 -9999 -9999 -9999 -9999 -9999 -9999 -9999 -9999 -9999 -9999 -9999 -9999 -9999 -9999 -9999 -9999 -9999 -9999 -9999 -9999 -9999 -

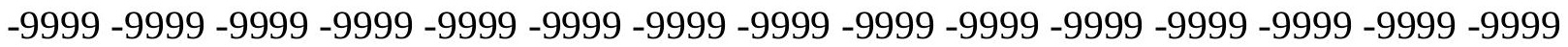

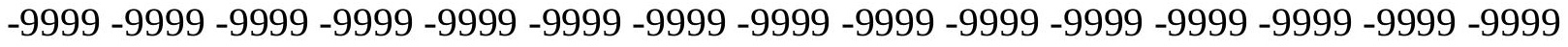

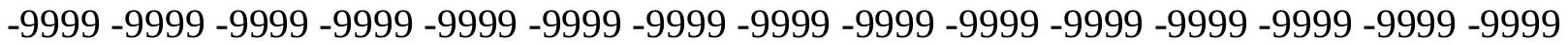
-9999 -9999 -9999 -9999 -9999 -9999 -9999 -9999 -9999 -9999 -9999 -9999 -9999 -9999 -9999

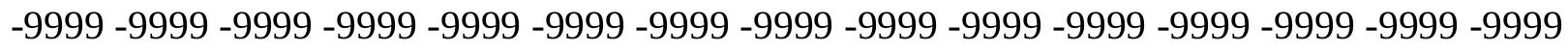

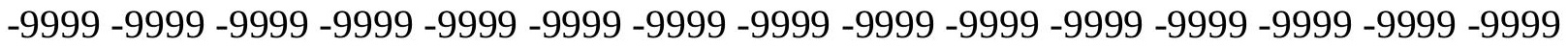
-9999 -9999 -9999 -9999 -9999 -9999 -9999 -9999 -9999 -9999 -9999 -9999 -9999 -9999 -9999 -9999 -9999 -9999 -9999 -9999 -9999 -9999 -9999 -9999 -9999 -9999 -9999 -9999 -9999 -9999 -

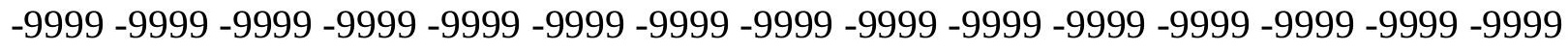

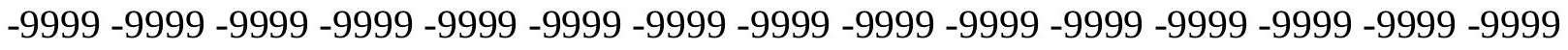
-9999 -9999 -9999 -9999 -9999 -9999 -9999 -9999 -9999 -9999 -9999 -9999 -9999 -9999 -9999 -9999 -9999 -9999 -9999 -9999 -9999 -9999 -9999 -9999-9999 -9999 -9999 -9999 -9999 -9999 -9999 -9999 -9999 -9999 -9999 -9999 -9999 -9999 -9999 -9999 -9999 -9999 -9999 -9999 -9999 -

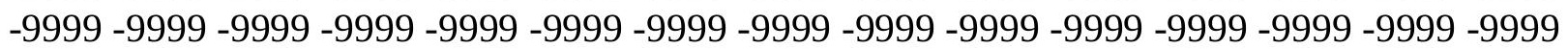


-9999 -9999 -9999 -9999 -9999 -9999 -9999 -9999 -9999 -9999 -9999 -9999 -9999 -9999 -9999 -9999 -9999 -9999 -9999 -9999 -9999 -9999 -9999 -9999 -9999 -9999 -9999 -9999 -9999 -9999 -9999 -9999 -9999 -9999 -9999 -9999 -9999 -9999 -9999 -9999 -9999 -9999 -9999 -9999 - 9999 -9999 -9999 -9999 -9999 -9999 -9999 -9999 -9999 -9999 -9999 -9999 -9999 -9999 -9999

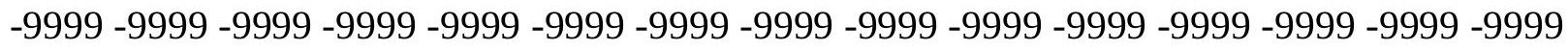
-9999 -9999 -9999 -9999 -9999 -9999 -9999 -9999 -9999 -9999 -9999 -9999 -9999 -9999 -9999 -9999 -9999 -9999 -9999 -9999 -9999 -9999 -9999 -9999 -9999 -9999 -9999 -9999 -9999 -9999

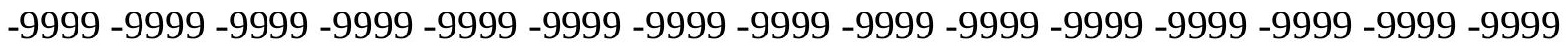

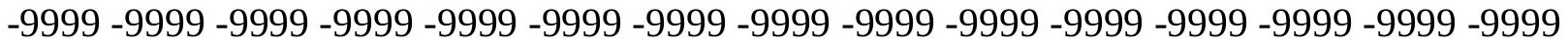
-9999 -9999 -9999 -9999 -9999 -9999 -9999 -9999 -9999 -9999 -9999 -9999 -9999 -9999 -9999 -9999 -9999 -9999 -9999 -9999 -9999 -9999 -9999 -9999 -9999 -9999 -9999 -9999 -9999 -9999 -9999 -9999 -9999 -9999 -9999 -9999 -9999 -9999 -9999 -9999 -9999 -9999 -9999 -9999 -9999 -9999 -9999 -9999 -9999 -9999 -9999 -9999 -9999 -9999 -9999 -9999 -9999 -9999 -9999 -9999 -

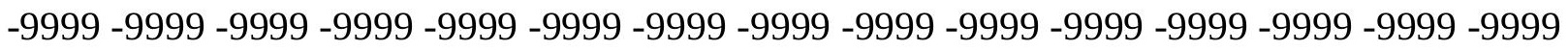
-9999 -9999 -9999 -9999 -9999 -9999 -9999 -9999 -9999 -9999 -9999 -9999 -9999 -9999 -9999 -

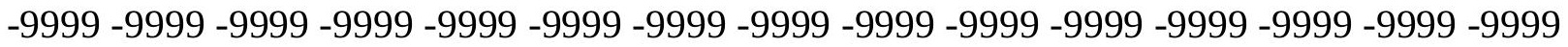
-9999 -9999 -9999 -9999 -9999 -9999 -9999 -9999 -9999 -9999 -9999 -9999 -9999 -9999 -9999 -9999 -9999 -9999 -9999 -9999 -9999 -9999 -9999 -9999 -9999 -9999 -9999 -9999 -9999 -9999 -9999 -9999 -9999 -9999 -9999 -9999 -9999 -9999 -9999 -9999 -9999 -9999 -9999 -9999 -9999 -

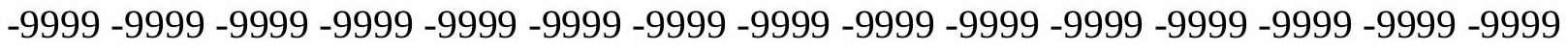
-9999 -9999 -9999 -9999 -9999 -9999 -9999 -9999 -9999 -9999 -9999 -9999 -9999 -9999 -9999

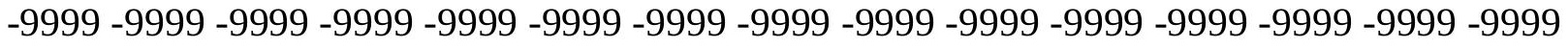
-9999 -9999 -9999 -9999 -9999 -9999 -9999 -9999 -9999 -9999 -9999 -9999 -9999 -9999 -9999 -9999 -9999 -9999 -9999 -9999 -9999 -9999 -9999 -9999 -9999 -9999 -9999 -9999 -9999 -9999 -9999 -9999 -9999 -9999 -9999 -9999 -9999 -9999 -9999 -9999 -9999 -9999 -9999 -9999 -9999 -9999 -9999 -9999 -9999 -9999 -9999 -9999 -9999 -9999 -9999 -9999 -9999 -9999 -9999 -9999 -9999 -9999 -9999 -9999 -9999 -9999 -9999 -9999 -9999 -9999 -9999 -9999 -9999 -9999 -9999 -9999 -9999 -9999 -9999 -9999 -9999 -9999 -9999 -9999 -9999 -9999 -9999 -9999 -9999 -9999 -9999 -9999 -9999 -9999 -9999 -9999 -9999 -9999 -9999 -9999 -9999 -9999 -9999 -9999 -9999 -9999 -9999 -9999 -9999 -9999 -9999 -9999 -9999 -9999 -9999 -9999 -9999 -9999 -9999 -9999 -9999 -9999 -9999 -9999 -9999 -9999 -9999 -9999 -9999 -9999 -9999 -9999 -9999 -9999 -9999 -9999 -9999 -9999 -9999 -9999 -9999 -9999 -9999 -9999 -9999 -9999 -9999 -9999 -9999 -

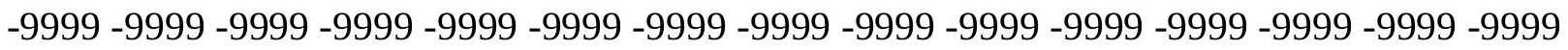

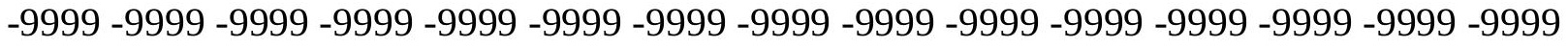
-9999 -9999 -9999 -9999 -9999 -9999 -9999 -9999 -9999 -9999 -9999 -9999 -9999 -9999 -9999 -

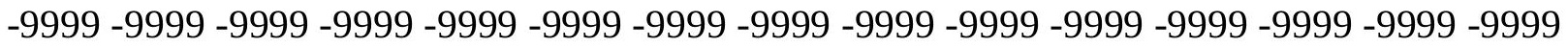

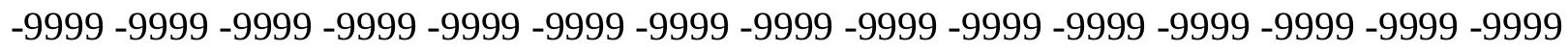

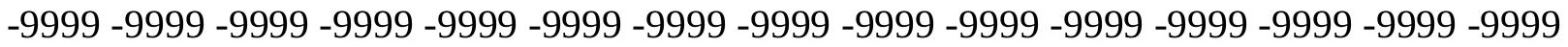

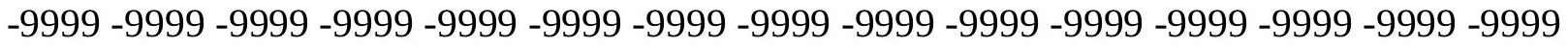
-9999 -9999 -9999 -9999 -9999 -9999 -9999 -9999 -9999 -9999 -9999 -9999 -9999 -9999 -9999 -

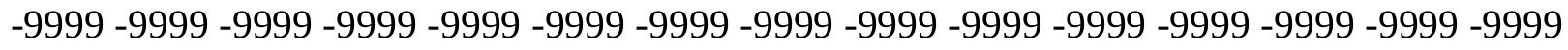

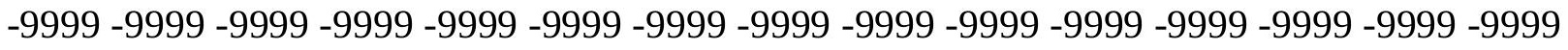
-9999 -9999 -9999 -9999 -9999 -9999 -9999 -9999 -9999 -9999 -9999 -9999 -9999 -9999 -9999 -9999 -9999 -9999 -9999 -9999 -9999 -9999 -9999 -9999-9999 -9999 -9999 -9999 -9999 -9999 -9999 -9999 -9999 -9999 -9999 -9999 -9999 -9999 -9999 -9999 -9999 -9999 -9999 -9999 -9999 -

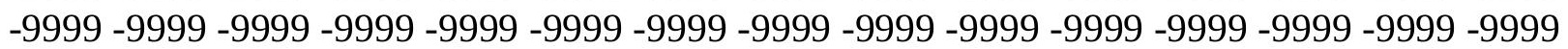


-9999 -9999 -9999 -9999 -9999 -9999 -9999 -9999 -9999 -9999 -9999 -9999 -9999 -9999 -9999 -9999 -9999 -9999 -9999 -9999 -9999 -9999 -9999 -9999 -9999 -9999 -9999 -9999 -9999 -9999 -9999 -9999 -9999 -9999 -9999 -9999 -9999 -9999 -9999 -9999 -9999 -9999 -9999 -9999 - 9999 -9999 -9999 -9999 -9999 -9999 -9999 -9999 -9999 -9999 -9999 -9999 -9999 -9999 -9999 -9999 -9999 -9999 -9999 -9999 -9999 -9999 -9999 -9999 -9999 -9999 -9999 -9999 -9999 -9999 -9999 -9999 -9999 -9999 -9999 -9999 -9999 -9999 -9999 -9999 -9999 -9999 -9999 -9999 -9999 -9999 -9999 -9999 -9999 -9999 -9999 -9999 -9999 -9999 -9999 -9999 -9999 -9999 -9999 -9999 -9999

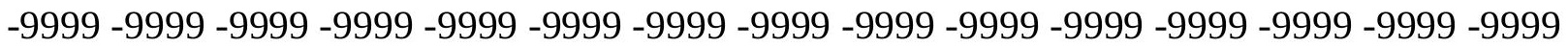

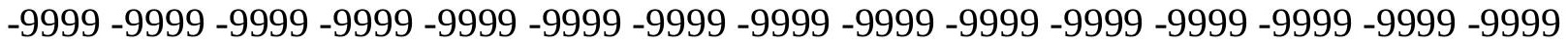
-9999 -9999 -9999 -9999 -9999 -9999 -9999 -9999 -9999 -9999 -9999 -9999 -9999 -9999 -9999 -9999 -9999 -9999 -9999 -9999 -9999 -9999 -9999 -9999 -9999 -9999 -9999 -9999 -9999 -9999 -9999 -9999 -9999 -9999 -9999 -9999 -9999 -9999 -9999 -9999 -9999 -9999 -9999 -9999 -9999 -9999 -9999 -9999 -9999 -9999 -9999 -9999 -9999 -9999 -9999 -9999 -9999 -9999 -9999 -9999 -9999 -9999 -9999 -9999 -9999 -9999 -9999 -9999 -9999 -9999 -9999 -9999 -9999 -9999 -9999 -9999 -9999 -9999 -9999 -9999 -9999 -9999 -9999 -9999 -9999 -9999 -9999 -9999 -9999 -

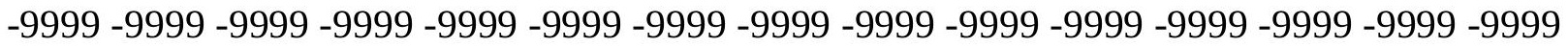
-9999 -9999 -9999 -9999 -9999 -9999 -9999 -9999 -9999 -9999 -9999 -9999 -9999 -9999 -9999 -9999 -9999 -9999 -9999 -9999 -9999 -9999 -9999 -9999 -9999 -9999 -9999 -9999 -9999 -9999 -9999 -9999 -9999 -9999 -9999 -9999 -9999 -9999 -9999 -9999 -9999 -9999 -9999 -9999 -9999 -9999 -9999 -9999 -9999 -9999 -9999 -9999 -9999 -9999 -9999 -9999 -9999 -9999 -9999 -9999 -9999 -9999 -9999 -9999 -9999 -9999 -9999 -9999 -9999 -9999 -9999 -9999 -9999 -9999 -9999 -999 -9999 -9999 -9999 -9999 -9999 -9999 -9999 -9999 -9999 -9999 -9999 -9999 -9999 -9999 -9999 -9999 -9999 -9999 -9999 -9999 -9999 -9999 -9999 -9999 -9999 -9999 -9999 -9999 -9999 -9999 -9999 -9999 -9999 -9999 -9999 -9999 -9999 -9999 -9999 -9999 -9999 -9999 -9999 -9999 -9999 -9999 -9999 -9999 -9999 -9999 -9999 -9999 -9999 -9999 -9999 -9999 -9999 -9999 -9999 -9999 -9999 -9999 -9999 -9999 -9999 -9999 -9999 -9999 -9999 -9999 -9999 -9999 -9999 -9999 -9999 -9999 -9999 -9999 -9999 -9999 -9999 -9999 -9999 -9999 -9999 -9999 -9999 -9999 -9999 -9999 -9999 -9999 -9999 -9999 -9999 -9999 -9999 -9999 -9999 -9999 -9999 -9999 -9999 -9999 -9999 -9999 -9999 -9999 -9999 -9999 -9999 -9999 -9999 -9999 -9999 -9999 -9999 -9999 -9999 -9999 -9999 -9999 -9999 -9999 -9999 -9999 -9999 -9999 -9999 -9999 -9999 -9999 -9999 -9999 -999 -9999 -9999 -9999 -9999 -9999 -9999 -9999 -9999 -9999 -9999 -9999 -9999 -9999 -9999 -9999 -9999 -9999 -9999 -9999 -9999 -9999 -9999 -9999 -9999 -9999 -9999 -9999 -9999 -9999 -9999 -

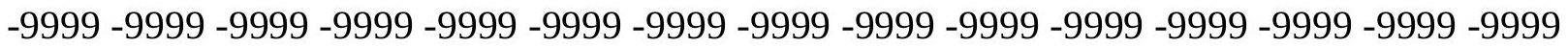

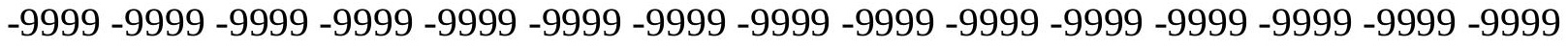

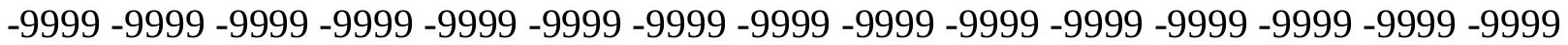
-9999 -9999 -9999 -9999 -9999 -9999 -9999 -9999 -9999 -9999 -9999 -9999 -9999 -9999 -9999 -9999 -9999 -9999 -9999 -9999 -9999 -9999 -9999 -9999 -9999 -9999 -9999 -9999 -9999 -

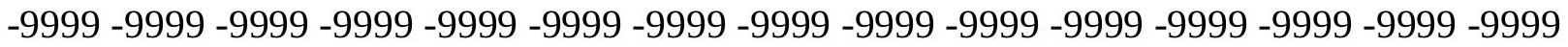
-9999 -9999 -9999 -9999 -9999 -9999 -9999 -9999 -9999 -9999 -9999 -9999 -9999 -9999 -9999 -9999 -9999 -9999 -9999 -9999 -9999 -9999 -9999 -9999 -9999 -9999 -9999 -9999 -9999 -9999 -

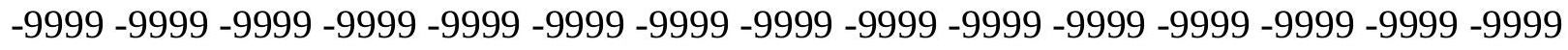

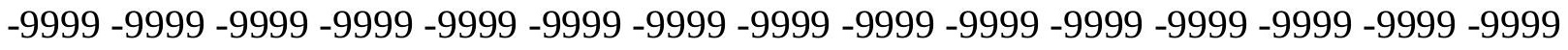
-9999 -9999 -9999 -9999 -9999 -9999 -9999 -9999 -9999 -9999 -9999 -9999 -9999 -9999 -9999 -9999 -9999 -9999 -9999 -9999 -9999 -9999 -9999 -9999-9999 -9999 -9999 -9999 -9999 -9999 -9999 -9999 -9999 -9999 -9999 -9999 -9999 -9999 -9999 -9999 -9999 -9999 -9999 -9999 -9999 -

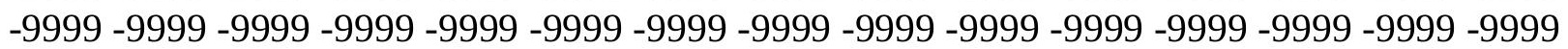


-9999 -9999 -9999 -9999 -9999 -9999 -9999 -9999 -9999 -9999 -9999 -9999 -9999 -9999 -9999 -9999 -9999 -9999 -9999 -9999 -9999 -9999 -9999 -9999 -9999 -9999 -9999 -9999 -9999 -9999 -

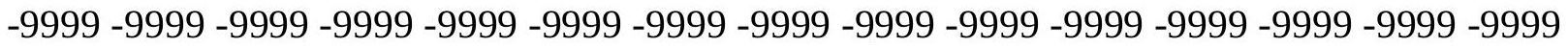
-9999 -9999 -9999 -9999 -9999 -9999 -9999 -9999 -9999 -9999 -9999 -9999 -9999 -9999 -9999 -9999 -9999 -9999 -9999 -9999 -9999 -9999 -9999 -9999-9999 -9999 -9999 -9999 -9999 -9999 -9999 -9999 -9999 -9999 -9999 -9999 -9999 -9999 -9999 -9999 -9999 -9999 -9999 -9999 -9999 -9999 -9999 -9999 -9999 -9999 -9999 -9999 -9999 -9999 -9999 -9999 -9999 -9999 -9999 -9999

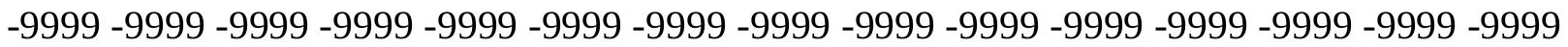

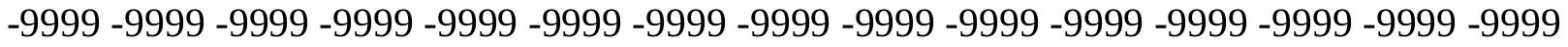
-9999 -9999 -9999 -9999 -9999 -9999 -9999 -9999 -9999 -9999 -9999 -9999 -9999 -9999 -9999 -9999 -9999 -9999 -9999 -9999 -9999 -9999 -9999 -9999 -9999 -9999 -9999 -9999 -9999 -9999 -9999 -9999 -9999 -9999 -9999 -9999 -9999 -9999 -9999 -9999 -9999 -9999 -9999 -9999 -9999 -9999 -9999 -9999 -9999 -9999 -9999 -9999 -9999 -9999 -9999 -9999 -9999 -9999 -9999 -9999 -9999 -9999 -9999 -9999 -9999 -9999 -9999 -9999 -9999 -9999 -9999 -9999 -9999 -9999 -9999 -9999 -9999 -9999 -9999 -9999 -9999 -9999 -9999 -9999 -9999 -9999 -9999 -9999 -9999 -9999 -

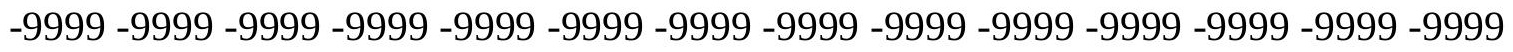
-9999 -9999 -9999 -9999 -9999 -9999 -9999 -9999 -9999 -9999 -9999 -9999 -9999 -9999 -9999 -9999 -9999 -9999 -9999 -9999 -9999 -9999 -9999 -9999 -9999 -9999 -9999 -9999 -9999 -9999 -9999 -9999 -9999 -9999 -9999 -9999 -9999 -9999 -9999 -9999 -9999 -9999 -9999 -9999 -9999 -

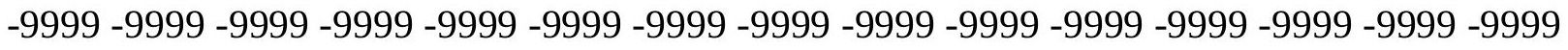

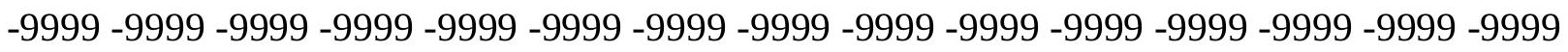
-9999 -9999 -9999 -9999 -9999 -9999 -9999 -9999 -9999 -9999 -9999 -9999 -9999 -9999 - 9999 -9999 -9999 -9999 -9999 -9999 -9999 -9999 -9999 -9999 -9999 -9999 -9999 -9999 -9999 -9999 -9999 -9999 -9999 -9999 -9999 -9999 -9999 -9999 -9999 -9999 -9999 -9999 -9999 -9999 -9999 -

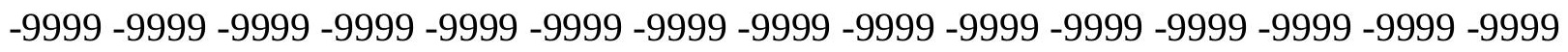
-9999 -9999 -9999 -9999 -9999 -9999 -9999 -9999 -9999 -9999 -9999 -9999 -9999 -9999 -9999 -9999 -9999 -9999 -9999 -9999 -9999 -9999 -9999 -9999 -9999 -9999 -9999 -9999 -9999 -9999 -

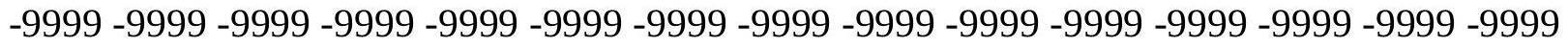
-9999 -9999 -9999 -9999 -9999 -9999 -9999 -9999 -9999 -9999 -9999 -9999 -9999 -9999 -9999 -9999 -9999 -9999 -9999 -9999 -9999 -9999 -9999 -9999 -9999 -9999 -9999 -9999 -9999 -999 -

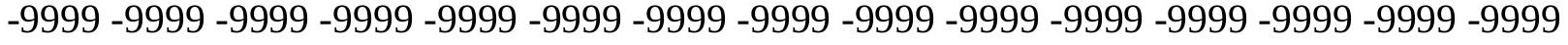
-9999 -9999 -9999 -9999 -9999 -9999 -9999 -9999 -9999 -9999 -9999 -9999 -9999 -9999 -9999 -

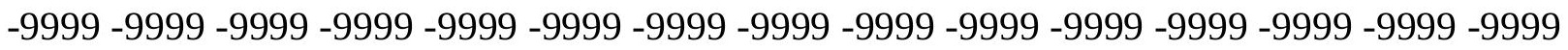

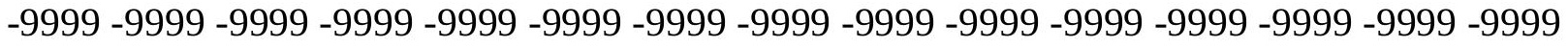

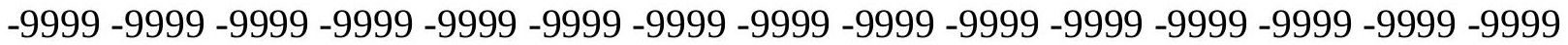
-9999 -9999 -9999 -9999 -9999 -9999 -9999 -9999 -9999 -9999 -9999 -9999 -9999 -9999 -9999 -

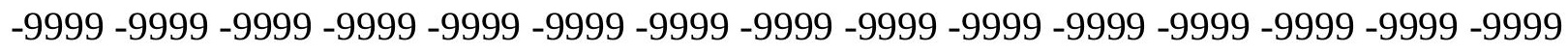

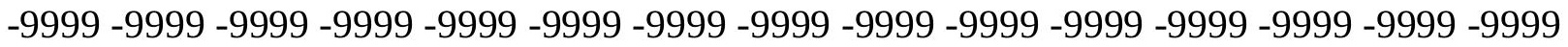
-9999 -9999 -9999 -9999 -9999 -9999 -9999 -9999 -9999 -9999 -9999 -9999 -9999 - 9999 - -999 -9999 -9999 -9999 -9999 -9999 -9999 -9999 -9999 -9999 -9999 -9999 -9999 -9999 -9999 -9999 -

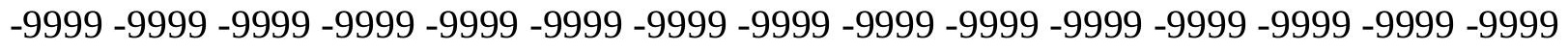

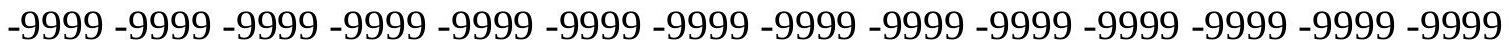
-9999 -9999 -9999 -9999 -9999 -9999 -9999 -9999 -9999 -9999 -9999 -9999 -9999 -9999 -9999 -9999 -9999 -9999 -9999 -9999 -9999 -9999 -9999 -9999-9999 -9999 -9999 -9999 -9999 -9999 -9999 -9999 -9999 -9999 -9999 -9999 -9999 -9999 -9999 -9999 -9999 -9999 -9999 -9999 -9999 -

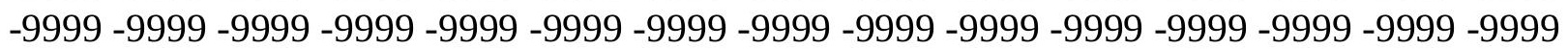


-9999 -9999 -9999 -9999 -9999 -9999 -9999 -9999 -9999 -9999 -9999 -9999 -9999 -9999 -9999 -9999 -9999 -9999 -9999 -9999 -9999 -9999 -9999 -9999 -9999 -9999 -9999 -9999 -9999 -9999 -

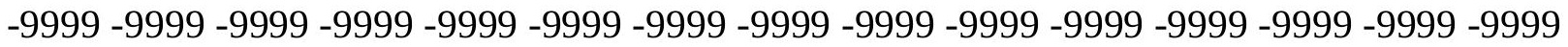
-9999 -9999 -9999 -9999 -9999 -9999 -9999 -9999 -9999 -9999 -9999 -9999 -9999 -9999 -9999 -9999 -9999 -9999 -9999 -9999 -9999 -9999 -9999 -9999-9999 -9999 -9999 -9999 -9999 -9999 -9999 -9999 -9999 -9999 -9999 -9999 -9999 -9999 -9999 -9999 -9999 -9999 -9999 -9999 -9999 -9999 -9999 -9999 -9999 -9999 -9999 -9999 -9999 -9999 -9999 -9999 -9999 -9999 -9999 -9999

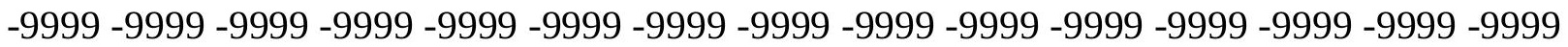

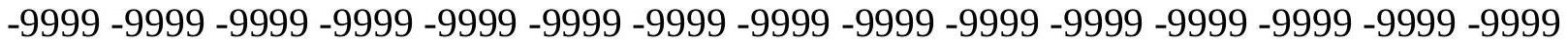
-9999 -9999 -9999 -9999 -9999 -9999 -9999 -9999 -9999 -9999 -9999 -9999 -9999 -9999 -9999 -9999 -9999 -9999 -9999 -9999 -9999 -9999 -9999 -9999 -9999 -9999 -9999 -9999 -9999 -9999 -9999 -9999 -9999 -9999 -9999 -9999 -9999 -9999 -9999 -9999 -9999 -9999 -9999 -9999 -9999 -9999 -9999 -9999 -9999 -9999 -9999 -9999 -9999 -9999 -9999 -9999 -9999 -9999 -9999 -9999 -

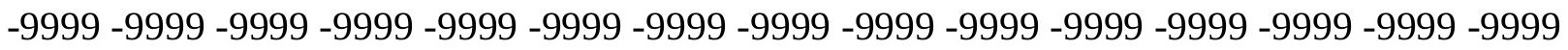
-9999 -9999 -9999 -9999 -9999 -9999 -9999 -9999 -9999 -9999 -9999 -9999 -9999 -9999 -9999 -

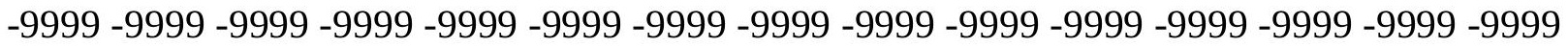
-9999 -9999 -9999 -9999 -9999 -9999 -9999 -9999 -9999 -9999 -9999 -9999 -9999 -9999 -9999 -9999 -9999 -9999 -9999 -9999 -9999 -9999 -9999 -9999 -9999 -9999 -9999 -9999 -9999 -9999 -9999 -9999 -9999 -9999 -9999 -9999 -9999 -9999 -9999 -9999 -9999 -9999 -9999 -9999 -9999 -

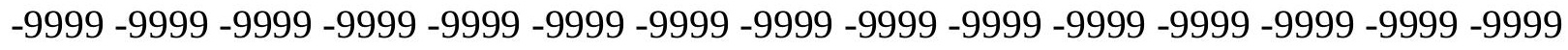

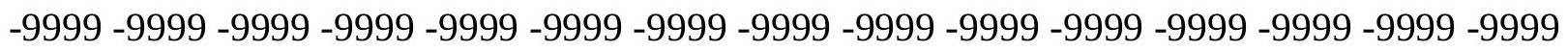
-9999 -9999 -9999 -9999 -9999 -9999 -9999 -9999 -9999 -9999 -9999 -9999 -9999 -9999 -9999 -9999 -9999 -9999 -9999 -9999 -9999 -9999 -9999 -9999 -9999 -9999 -9999 -9999 -9999 -9999 -9999 -9999 -9999 -9999 -9999 -9999 -9999 -9999 -9999 -9999 -9999 -9999 -9999 -9999 -

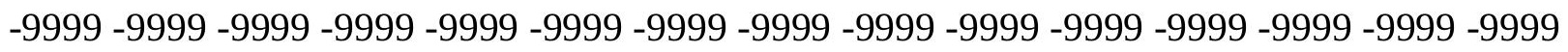
-9999 -9999 -9999 -9999 -9999 -9999 -9999 -9999 -9999 -9999 -9999 -9999 -9999 -9999 -9999 -9999 -9999 -9999 -9999 -9999 -9999 -9999 -9999 -9999 -9999 -9999 -9999 -9999 -9999 -9999 -

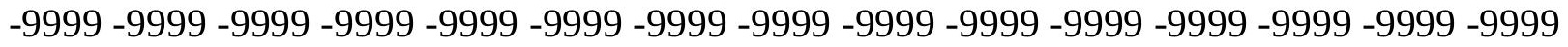
-9999 -9999 -9999 -9999 -9999 -9999 -9999 -9999 -9999 -9999 -9999 -9999 -9999 -9999 -9999 -9999 -9999 -9999 -9999 -9999 -9999 -9999 -9999 -9999 -9999 -9999 -9999 -9999 -9999 -999 -

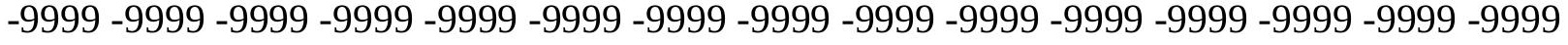
-9999 -9999 -9999 -9999 -9999 -9999 -9999 -9999 -9999 -9999 -9999 -9999 -9999 -9999 -9999 -

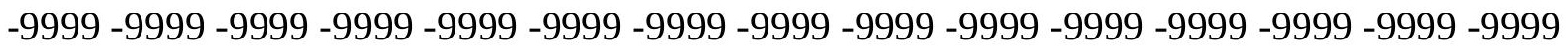

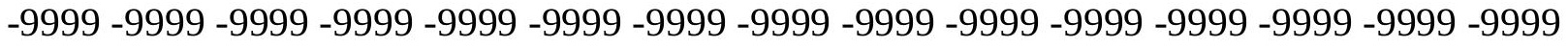

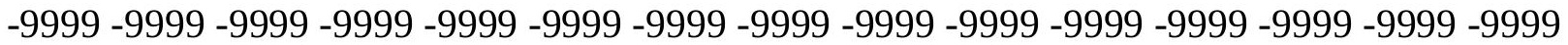

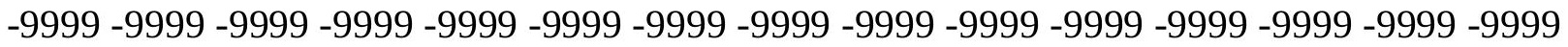

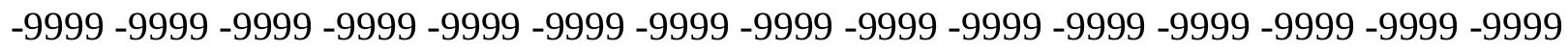

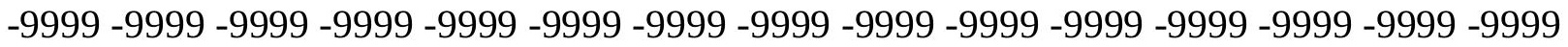

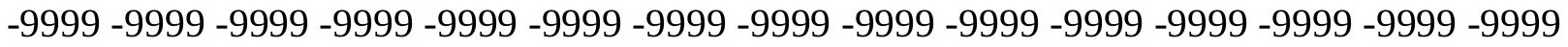
-9999 -9999 -9999 -9999 -9999 -9999 -9999 -9999 -9999 -9999 -9999 -9999 -9999 -9999 -9999 -

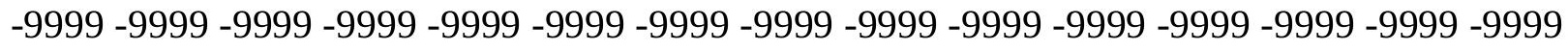

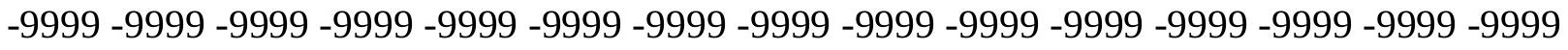
-9999 -9999 -9999 -9999 -9999 -9999 -9999 -9999 -9999 -9999 -9999 -9999 -9999 -9999 -9999 -9999 -9999 -9999 -9999 -9999 -9999 -9999 -9999 -9999-9999 -9999 -9999 -9999 -9999 -9999 -9999 -9999 -9999 -9999 -9999 -9999 -9999 -9999 -9999 -9999 -9999 -9999 -9999 -9999 -9999 -

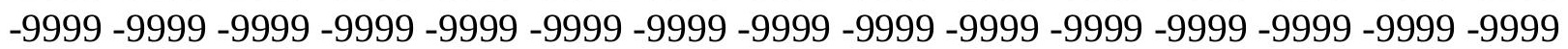


-9999 -9999 -9999 -9999 -9999 -9999 -9999 -9999 -9999 -9999 -9999 -9999 -9999 -9999 -9999 -9999 -9999 -9999 -9999 -9999 -9999 -9999 -9999 -9999 -9999 -9999 -9999 -9999 -9999 -

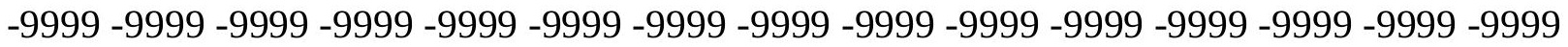
-9999 -9999 -9999 -9999 -9999 -9999 -9999 -9999 -9999 -9999 -9999 -9999 -9999 -9999 -9999 -9999 -9999 -9999 -9999 -9999 -9999 -9999 -9999 -9999 -9999 -9999 -9999 -9999 -9999 -9999 -9999 -9999 -9999 -9999 -9999 -9999 -9999 -9999 -9999 -9999 -9999 -9999 -9999 -9999 -9999 -9999 -9999 -9999 -9999 -9999 -9999 -9999 -9999 -9999 -9999 -9999 -9999 -9999 -9999 -9999

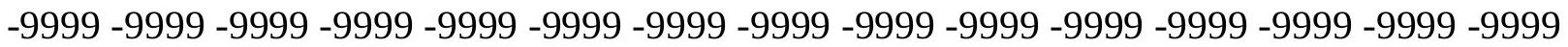

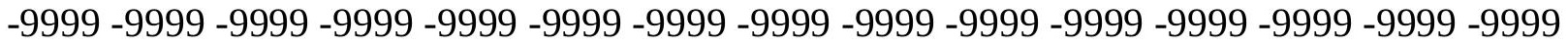
-9999 -9999 -9999 -9999 -9999 -9999 -9999 -9999 -9999 -9999 -9999 -9999 -9999 -9999 -9999 -9999 -9999 -9999 -9999 -9999 -9999 -9999 -9999 -9999 -9999 -9999 -9999 -9999 -9999 -9999 -9999 -9999 -9999 -9999 -9999 -9999 -9999 -9999 -9999 -9999 -9999 -9999 -9999 -9999 -9999 -9999 -9999 -9999 -9999 -9999 -9999 -9999 -9999 -9999 -9999 -9999 -9999 -9999 -9999 -9999 -9999 -9999 -9999 -9999 -9999 -9999 -9999 -9999 -9999 -9999 -9999 -9999 -9999 -9999 -9999 -9999 -9999 -9999 -9999 -9999 -9999 -9999 -9999 -9999 -9999 -9999 -9999 -9999 -9999 -9999 -

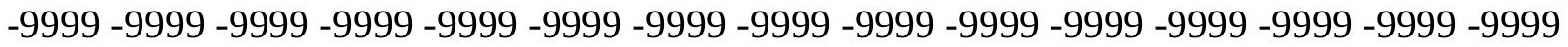
-9999 -9999 -9999 -9999 -9999 -9999 -9999 -9999 -9999 -9999 -9999 -9999 -9999 -9999 -9999 -9999 -9999 -9999 -9999 -9999 -9999 -9999 -9999 -9999 -9999 -9999 -9999 -9999 -9999 - 9999 -9999 -9999 -9999 -9999 -9999 -9999 -9999 -9999 -9999 -9999 -9999 -9999 -9999 -9999 -9999 -

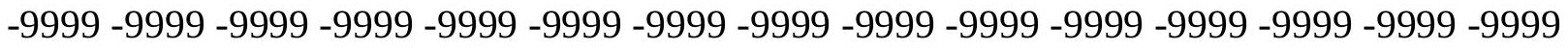

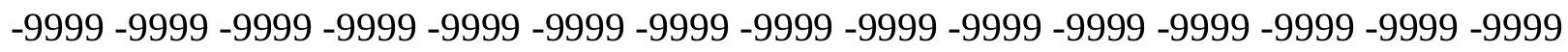

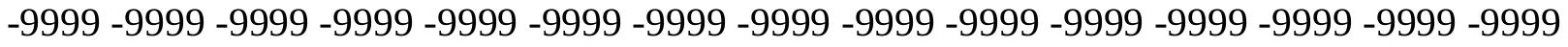
-9999 -9999 -9999 -9999 -9999 -9999 -9999 -9999 -9999 -9999 -9999 -9999 -9999 -9999 -9999 -9999 -9999 -9999 -9999 -9999 -9999 -9999 -9999 -9999 -9999 -9999 -9999 -9999 -9999 -9999 -

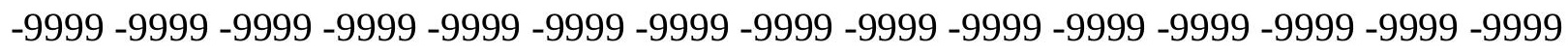
-9999 -9999 -9999 -9999 -9999 -9999 -9999 -9999 -9999 -9999 -9999 -9999 -9999 -9999 -9999 -9999 -9999 -9999 -9999 -9999 -9999 -9999 -9999 -9999 -9999 -9999 -9999 -9999 -9999 -9999 -9999 -9999 -9999 -9999 -9999 -9999 -9999 -9999 -9999 -9999 -9999 -9999 -9999 -9999 -9999 -9999 -9999 -9999 -9999 -9999 -9999 -9999 -9999 -9999 -9999 -9999 -9999 -9999 -9999 -9999 -9999 -9999 -9999 -9999 -9999 -9999 -9999 -9999 -9999 -9999 -9999 -9999 -9999 -999 -

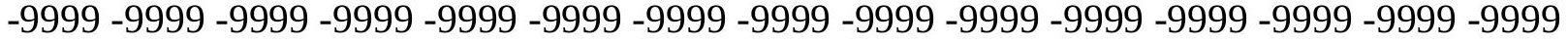
-9999 -9999 -9999 -9999 -9999 -9999 -9999 -9999 -9999 -9999 -9999 -9999 -9999 -9999 -9999 -

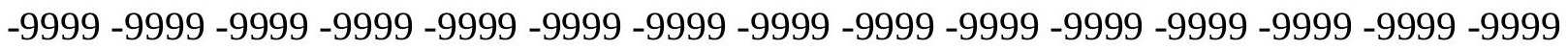

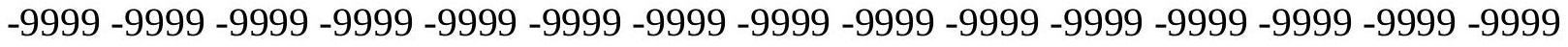

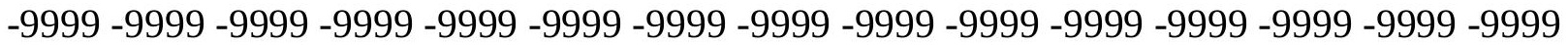

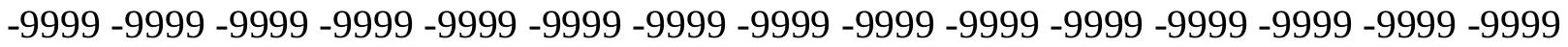

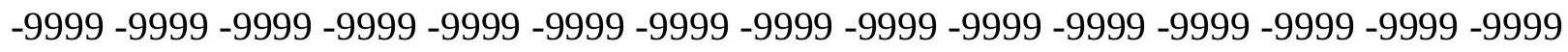

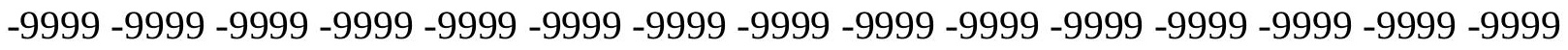

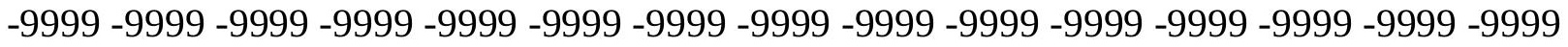
-9999 -9999 -9999 -9999 -9999 -9999 -9999 -9999 -9999 -9999 -9999 -9999 -9999 -9999 -9999 -

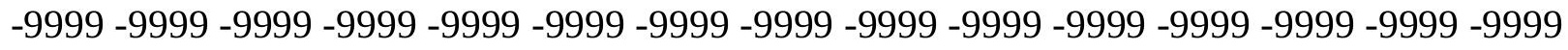

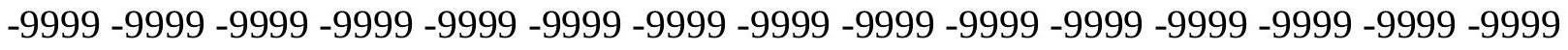
-9999 -9999 -9999 -9999 -9999 -9999 -9999 -9999 -9999 -9999 -9999 -9999 -9999 -9999 -9999 -9999 -9999 -9999 -9999 -9999 -9999 -9999 -9999 -9999-9999 -9999 -9999 -9999 -9999 -9999 -9999 -9999 -9999 -9999 -9999 -9999 -9999 -9999 -9999 -9999 -9999 -9999 -9999 -9999 -9999 -

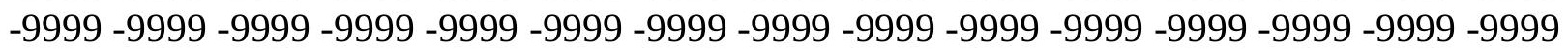


-9999 -9999 -9999 -9999 -9999 -9999 -9999 -9999 -9999 -9999 -9999 -9999 -9999 -9999 -9999 -9999 -9999 -9999 -9999 -9999 -9999 -9999 -9999 -9999 -9999 -9999 -9999 -9999 -9999 -9999 -

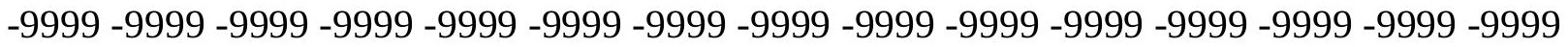
-9999 -9999 -9999 -9999 -9999 -9999 -9999 -9999 -9999 -9999 -9999 -9999 -9999 -9999 -9999 -9999 -9999 -9999 -9999 -9999 -9999 -9999 -9999 -9999-9999 -9999 -9999 -9999 -9999 -9999 -9999 -9999 -9999 -9999 -9999 -9999 -9999 -9999 -9999 -9999 -9999 -9999 -9999 -9999 -9999 -

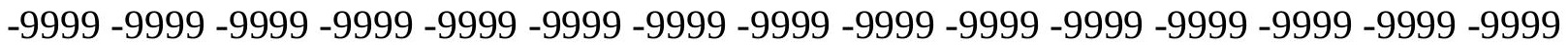
-9999 -9999 -9999 -9999 -9999 -9999 -9999 -9999 -9999 -9999 -9999 -9999 -9999 -9999 -9999 -9999 -9999 -9999 -9999 -9999 -9999 -9999 -9999 -9999 -9999 -9999 -9999 -9999 -9999 -9999 -9999 -9999 -9999 -9999 -9999 -9999 -9999 -9999 -9999 -9999 -9999 -9999 -9999 -9999 -9999 -9999 -9999 -9999 -9999 -9999 -9999 -9999 -9999 -9999 -9999 -9999 -9999 -9999 -9999 -9999 -9999 -9999 -9999 -9999 -9999 -9999 -9999 -9999 -9999 -9999 -9999 -9999 -9999 -9999 -9999 -9999 -9999 -9999 -9999 -9999 -9999 -9999 -9999 -9999 -9999 -9999 -9999 -9999 -9999 -9999 -9999 -9999 -9999 -9999 -9999 -9999 -9999 -9999 -9999 -9999 -9999 -9999 -9999 -9999 -9999 -9999 -9999 -9999 -9999 -9999 -9999 -9999 -9999 -9999 -9999 -9999 -9999 -9999 -9999 -

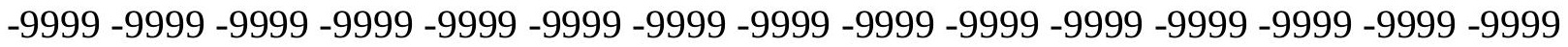
-9999 -9999 -9999 -9999 -9999 -9999 -9999 -9999 -9999 -9999 -9999 -9999 -9999 -9999 -9999 -9999 -9999 -9999 -9999 -9999 -9999 -9999 -9999 -9999 -9999 -9999 -9999 -9999 -9999 -9999 -9999 -9999 -9999 -9999 -9999 -9999 -9999 -9999 -9999 -9999 -9999 -9999 -9999 -9999 -9999 -

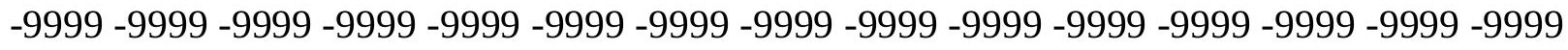

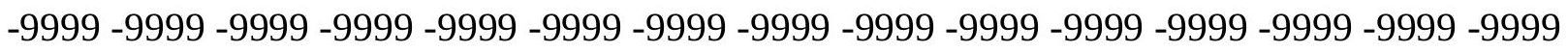
-9999 -9999 -9999 -9999 -9999 -9999 -9999 -9999 -9999 -9999 -9999 -9999 -9999 -9999 - 9999 -9999 -9999 -9999 -9999 -9999 -9999 -9999 -9999 -9999 -9999 -9999 -9999 -9999 -9999 -9999 -9999 -9999 -9999 -9999 -9999 -9999 -9999 -9999 -9999 -9999 -9999 -9999 -9999 -9999 -9999 -

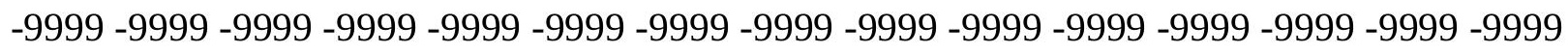
-9999 -9999 -9999 -9999 -9999 -9999 -9999 -9999 -9999 -9999 -9999 -9999 -9999 -9999 -9999 -9999 -9999 -9999 -9999 -9999 -9999 -9999 -9999 -9999 -9999 -9999 -9999 -9999 -9999 -9999 -

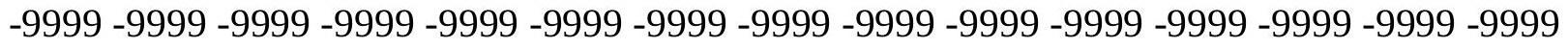
-9999 -9999 -9999 -9999 -9999 -9999 -9999 -9999 -9999 -9999 -9999 -9999 -9999 -9999 -9999 -9999 -9999 -9999 -9999 -9999 -9999 -9999 -9999 -9999 -9999 -9999 -9999 -9999 -9999 -999 -9999 -9999 -9999 -9999 -9999 -9999 -9999 -9999 -9999 -9999 -9999 -9999 -9999 -9999 -9999 -9999 -9999 -9999 -9999 -9999 -9999 -9999 -9999 -9999 -9999 -9999 -9999 -9999 -9999 -9999 -

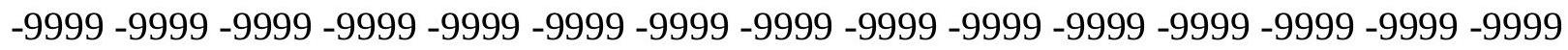

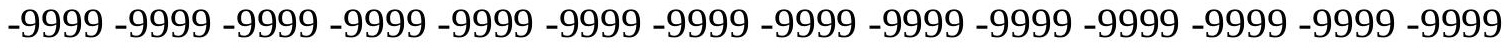
-9999 -9999 -9999 -9999 -9999 -9999 -9999 -9999 -9999 -9999 -9999 -9999 -9999 -9999 -9999

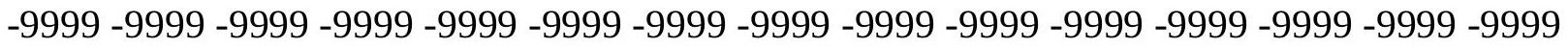

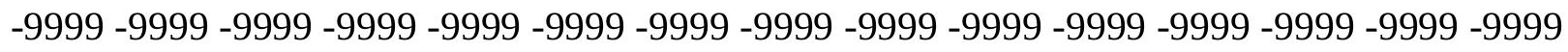

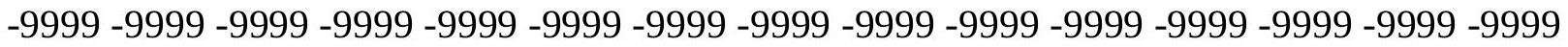

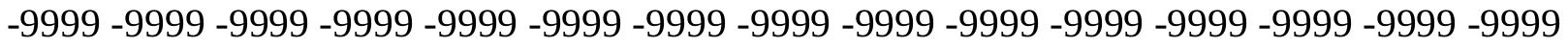
-9999 -9999 -9999 -9999 -9999 -9999 -9999 -9999 -9999 -9999 -9999 -9999 -9999 -9999 -9999 -

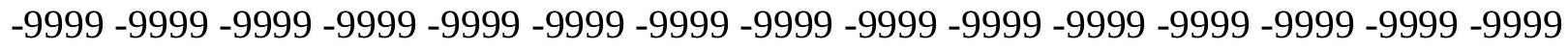

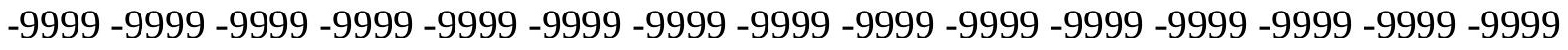
-9999 -9999 -9999 -9999 -9999 -9999 -9999 -9999 -9999 -9999 -9999 -9999 -9999 -9999 -9999 -9999 -9999 -9999 -9999 -9999 -9999 -9999 -9999 -9999-9999 -9999 -9999 -9999 -9999 -9999 -9999 -9999 -9999 -9999 -9999 -9999 -9999 -9999 -9999 -9999 -9999 -9999 -9999 -9999 -9999 -

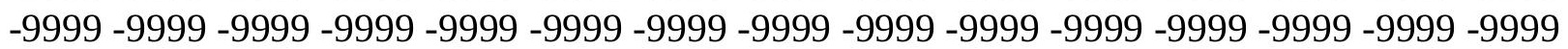


-9999 -9999 -9999 -9999 -9999 -9999 -9999 -9999 -9999 -9999 -9999 -9999 -9999 -9999 -9999 -9999 -9999 -9999 -9999 -9999 -9999 -9999 -9999 -9999 -9999 -9999 -9999 -9999 -9999 -9999 -

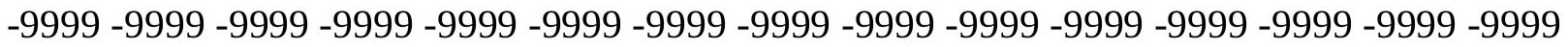
-9999 -9999 -9999 -9999 -9999 -9999 -9999 -9999 -9999 -9999 -9999 -9999 -9999 -9999 -9999 -9999 -9999 -9999 -9999 -9999 -9999 -9999 -9999 -9999-9999 -9999 -9999 -9999 -9999 -9999 -9999 -9999 -9999 -9999 -9999 -9999 -9999 -9999 -9999 -9999 -9999 -9999 -9999 -9999 -9999 -9999 -9999 -9999 -9999 -9999 -9999 -9999 -9999 -9999 -9999 -9999 -9999 -9999 -9999 -9999

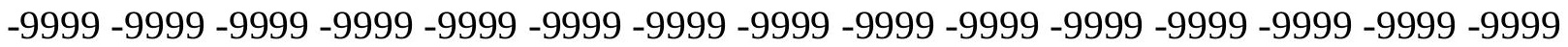

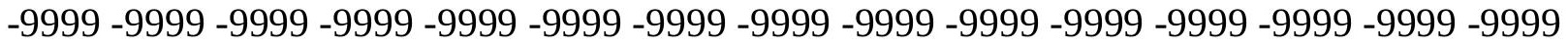
-9999 -9999 -9999 -9999 -9999 -9999 -9999 -9999 -9999 -9999 -9999 -9999 -9999 -9999 -9999 -9999 -9999 -9999 -9999 -9999 -9999 -9999 -9999 -9999 -9999 -9999 -9999 -9999 -9999 -9999 -9999 -9999 -9999 -9999 -9999 -9999 -9999 -9999 -9999 -9999 -9999 -9999 -9999 -9999 -9999 -9999 -9999 -9999 -9999 -9999 -9999 -9999 -9999 -9999 -9999 -9999 -9999 -9999 -9999 -9999 -9999 -9999 -9999 -9999 -9999 -9999 -9999 -9999 -9999 -9999 -9999 -9999 -9999 -9999 -9999 -9999 -9999 -9999 -9999 -9999 -9999 -9999 -9999 -9999 -9999 -9999 -9999 -9999 -9999

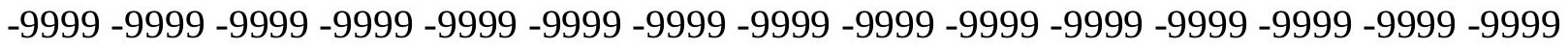
-9999 -9999 -9999 -9999 -9999 -9999 -9999 -9999 -9999 -9999 -9999 -9999 -9999 -9999 -9999 -9999 -9999 -9999 -9999 -9999 -9999 -9999 -9999 -9999 -9999 -9999 -9999 -9999 -9999 -9999 -9999 -9999 -9999 -9999 -9999 -9999 -9999 -9999 -9999 -9999 -9999 -9999 -9999 -9999 -9999 -

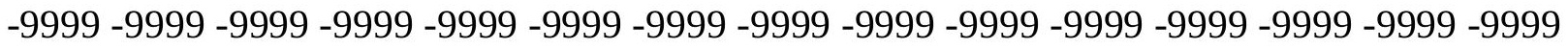

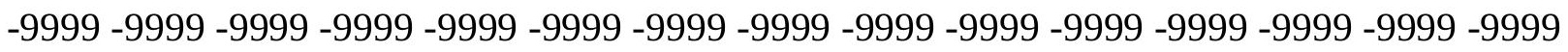
-9999 -9999 -9999 -9999 -9999 -9999 -9999 -9999 -9999 -9999 -9999 -9999 -9999 -9999 -9999 -9999 -9999 -9999 -9999 -9999 -9999 -9999 -9999 -9999 -9999 -9999 -9999 -9999 -9999 -9999 -9999 -9999 -9999 -9999 -9999 -9999 -9999 -9999 -9999 -9999 -9999 -9999 -9999 -9999 -9999 -

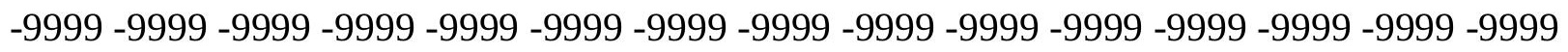
-9999 -9999 -9999 -9999 -9999 -9999 -9999 -9999 -9999 -9999 -9999 -9999 -9999 -9999 -9999 -9999 -9999 -9999 -9999 -9999 -9999 -9999 -9999 -9999 -9999 -9999 -9999 -9999 -9999 -9999 -

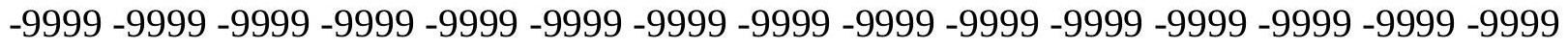
-9999 -9999 -9999 -9999 -9999 -9999 -9999 -9999 -9999 -9999 -9999 -9999 -9999 -9999 -9999 -9999 -9999 -9999 -9999 -9999 -9999 -9999 -9999 -9999 -9999 -9999 -9999 -9999 -9999 -999 -9999 -9999 -9999 -9999 -9999 -9999 -9999 -9999 -9999 -9999 -9999 -9999 -9999 -9999 -9999 -9999 -9999 -9999 -9999 -9999 -9999 -9999 -9999 -9999 -9999 -9999 -9999 -9999 -9999 -9999 -

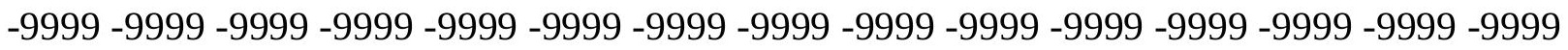

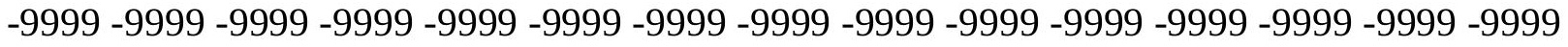

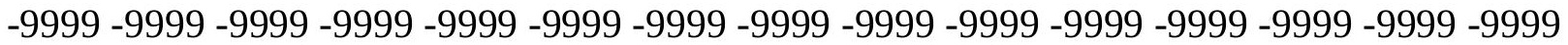

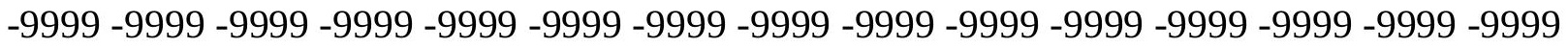

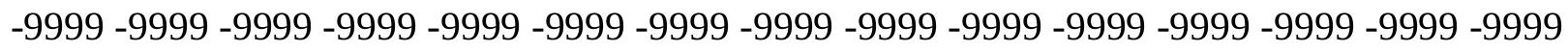

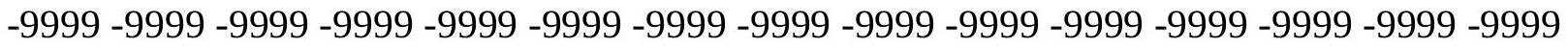
-9999 -9999 -9999 -9999 -9999 -9999 -9999 -9999 -9999 -9999 -9999 -9999 -9999 - 9999 - -999 -9999 -9999 -9999 -9999 -9999 -9999 -9999 -9999 -9999 -9999 -9999 -9999 -9999 -9999 - -999 -

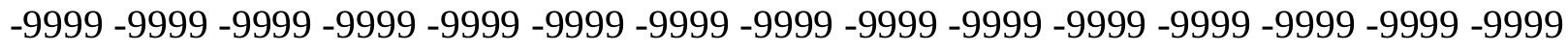

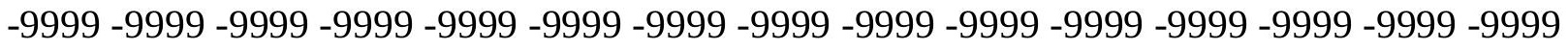
-9999 -9999 -9999 -9999 -9999 -9999 -9999 -9999 -9999 -9999 -9999 -9999 -9999 -9999 -9999 -9999 -9999 -9999 -9999 -9999 -9999 -9999 -9999 -9999-9999 -9999 -9999 -9999 -9999 -9999 -9999 -9999 -9999 -9999 -9999 -9999 -9999 -9999 -9999 -9999 -9999 -9999 -9999 -9999 -9999 -

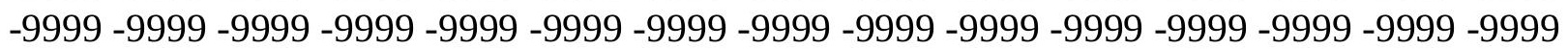


-9999 -9999 -9999 -9999 -9999 -9999 -9999 -9999 -9999 -9999 -9999 -9999 -9999 -9999 -9999 -9999 -9999 -9999 -9999 -9999 -9999 -9999 -9999 -9999 -9999 -9999 -9999 -9999 -9999 -9999 -9999 -9999 -9999 -9999 -9999 -9999 -9999 -9999 -9999 -9999 -9999 -9999 -9999 -9999 -9999 -9999 -9999 -9999 -9999 -9999 -9999 -9999 -9999 -9999 -9999 -9999 -9999 -9999 -9999 -9999 -9999 -9999 -9999 -9999 -9999 -9999 -9999 -9999 -9999 -9999 -9999 -9999 -9999 -9999 -9999 -9999 -9999 -9999 -9999 -9999 -9999 -9999 -9999 -9999 -9999 -9999 -9999 -9999 -9999 -9999 -9999 -9999 -9999 -9999 -9999 -9999 -9999 -9999 -9999 -9999 -9999 -9999 -9999 -9999 -9999 -

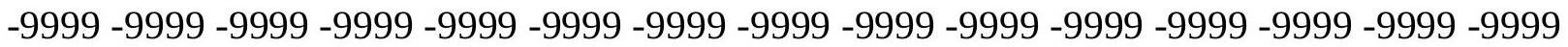
-9999 -9999 -9999 -9999 -9999 -9999 -9999 -9999 -9999 -9999 -9999 -9999 -9999 -9999 -9999 -9999 -9999 -9999 -9999 -9999 -9999 -9999 -9999 -9999 -9999 -9999 -9999 -9999 -9999 -9999 -

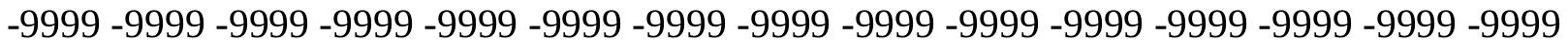
-9999 -9999 -9999 -9999 -9999 -9999 -9999 -9999 -9999 -9999 -9999 -9999 -9999 -9999 -9999 -9999 -9999 -9999 -9999 -9999 -9999 -9999 -9999 -9999 -9999 -9999 -9999 -9999 -9999 -9999 -9999 -9999 -9999 -9999 -9999 -9999 -9999 -9999 -9999 -9999 -9999 -9999 -9999 -9999 -9999 -9999 -9999 -9999 -9999 -9999 -9999 -9999 -9999 -9999 -9999 -9999 -9999 -9999 -9999 -9999

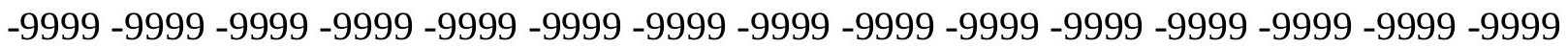
-9999 -9999 -9999 -9999 -9999 -9999 -9999 -9999 -9999 -9999 -9999 -9999 -9999 -9999 -9999 -9999 -9999 -9999 -9999 -9999 -9999 -9999 -9999 -9999 -9999 -9999 -9999 -9999 -9999 -9999 -9999 -9999 -9999 -9999 -9999 -9999 -9999 -9999 -9999 -9999 -9999 -9999 -9999 -9999 -9999 -9999 -9999 -9999 -9999 -9999 -9999 -9999 -9999 -9999 -9999 -9999 -9999 -9999 -9999 -9999 -9999 -9999 -9999 -9999 -9999 -9999 -9999 -9999 -9999 -9999 -9999 -9999 -9999 -9999 -9999 -9999 -9999 -9999 -9999 -9999 -9999 -9999 -9999 -9999 -9999 -9999 -9999 -9999 -9999 -9999 -9999 -9999 -9999 -9999 -9999 -9999 -9999 -9999 -9999 -9999 -9999 -9999 -9999 -9999 -9999 -9999 -9999 -9999 -9999 -9999 -9999 -9999 -9999 -9999 -9999 -9999 -9999 -9999 -9999 -9999 -9999 -9999 -9999 -9999 -9999 -9999 -9999 -9999 -9999 -9999 -9999 -9999 -9999 -9999 -9999 -9999 -9999 -9999 -9999 -9999 -9999 -9999 -9999 -9999 -9999 -9999 -9999 -9999 -9999 -9999 -9999 -9999 -9999 -9999 -9999 -9999 -9999 -9999 -9999 -9999 -9999 -9999 -9999 -9999 -9999 -9999 -9999 -9999 -9999 -9999 -9999 -9999 -9999 -9999 -9999 -9999 -9999 -9999 -9999

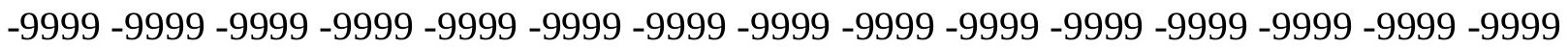
-9999 -9999 -9999 -9999 -9999 -9999 -9999 -9999 -9999 -9999 -9999 -9999 -9999 -9999 -9999 -9999 -9999 -9999 -9999 -9999 -9999 -9999 -9999 -9999 -9999 -9999 -9999 -9999 -9999 -9999 -

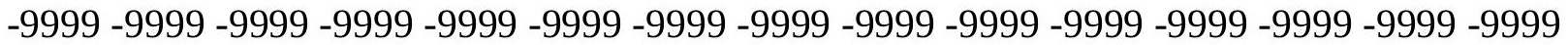
-9999 -9999 -9999 -9999 -9999 -9999 -9999 -9999 -9999 -9999 -9999 -9999 -9999 -9999 -9999 -9999 -9999 -9999 -9999 -9999 -9999 -9999 -9999 -9999 -9999 -9999 -9999 -9999 -9999 -9999 -9999 -9999 -9999 -9999 -9999 -9999 -9999 -9999 -9999 -9999 -9999 -9999 -9999 -9999 -9999 -9999 -9999 -9999 -9999 -9999 -9999 -9999 -9999 -9999 -9999 -9999 -9999 -9999 -9999 -9999 -9999 -9999 -9999 -9999 -9999 -9999 -9999 -9999 -9999 -9999 -9999 -9999 -9999 -9999 -9999

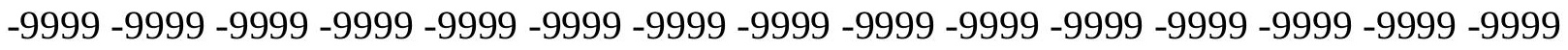
-9999 -9999 -9999 -9999 -9999 -9999 -9999 -9999 -9999 -9999 -9999 -9999 -9999 -9999 -9999 -9999 -9999 -9999 -9999 -9999 -9999 -9999 -9999 -9999 -9999 -9999 -9999 -9999 -9999 -9999 -9999 -9999 -9999 -9999 -9999 -9999 -9999 -9999 -9999 -9999 -9999 -9999 -9999 -9999 -9999 -999 -9999 -9999 -9999 -9999 -9999 -9999 -9999 -9999 -9999 -9999 -9999 -9999 -9999 -9999 -9999 -9999 -9999 -9999 -9999 -9999 -9999 -9999 -9999 -9999 -9999 -9999 -9999 -9999 -9999 -9999 -9999 -9999 -9999 -9999 -9999 -9999 -9999 -9999 -9999 -9999 -9999 -9999 -9999 -9999 -9999 -9999 -9999 -9999 -9999 -9999 -9999 -9999 -9999 -9999 -9999 -9999 -9999 -9999 -9999 -9999 -9999 -9999 -9999 -9999 -9999 -9999 -9999 -9999 -9999 -9999 -9999 -9999 -9999 -9999 
-9999 -9999 -9999 -9999 -9999 -9999 -9999 -9999 -9999 -9999 -9999 -9999 -9999 -9999 -9999 -9999 -9999 -9999 -9999 -9999 -9999 -9999 -9999 -9999 -9999 -9999 -9999 -9999 -9999 -9999 -

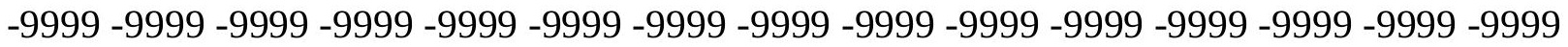
-9999 -9999 -9999 -9999 -9999 -9999 -9999 -9999 -9999 -9999 -9999 -9999 -9999 -9999 -9999 -9999 -9999 -9999 -9999 -9999 -9999 -9999 -9999 -9999-9999 -9999 -9999 -9999 -9999 -9999 -9999 -9999 -9999 -9999 -9999 -9999 -9999 -9999 -9999 -9999 -9999 -9999 -9999 -9999 -9999 -9999 -9999 -9999 -9999 -9999 -9999 -9999 -9999 -9999 -9999 -9999 -9999 -9999 -9999 -9999

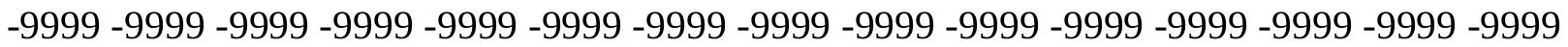

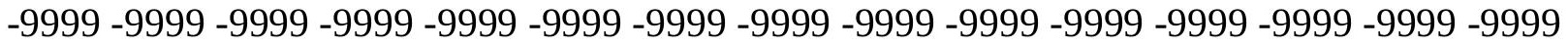
-9999 -9999 -9999 -9999 -9999 -9999 -9999 -9999 -9999 -9999 -9999 -9999 -9999 -9999 -9999 -9999 -9999 -9999 -9999 -9999 -9999 -9999 -9999 -9999 -9999 -9999 -9999 -9999 -9999 -9999 -9999 -9999 -9999 -9999 -9999 -9999 -9999 -9999 -9999 -9999 -9999 -9999 -9999 -9999 -9999 -9999 -9999 -9999 -9999 -9999 -9999 -9999 -9999 -9999 -9999 -9999 -9999 -9999 -9999 -9999 -

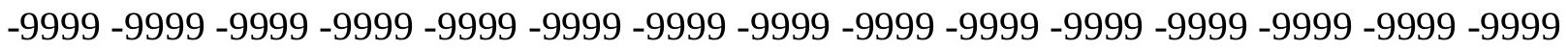
-9999 -9999 -9999 -9999 -9999 -9999 -9999 -9999 -9999 -9999 -9999 -9999 -9999 -9999 -9999 -

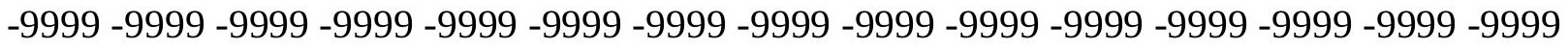
-9999 -9999 -9999 -9999 -9999 -9999 -9999 -9999 -9999 -9999 -9999 -9999 -9999 -9999 -9999 -9999 -9999 -9999 -9999 -9999 -9999 -9999 -9999 -9999 -9999 -9999 -9999 -9999 -9999 -9999 -9999 -9999 -9999 -9999 -9999 -9999 -9999 -9999 -9999 -9999 -9999 -9999 -9999 -9999 -9999 -

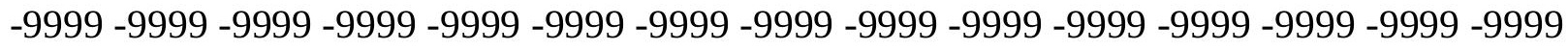

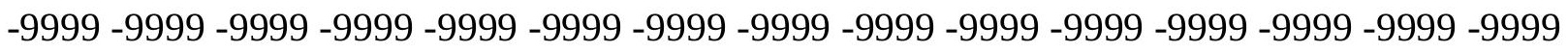

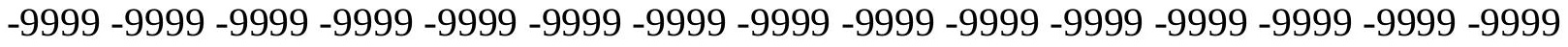
-9999 -9999 -9999 -9999 -9999 -9999 -9999 -9999 -9999 -9999 -9999 -9999 -9999 -9999 -9999 -9999 -9999 -9999 -9999 -9999 -9999 -9999 -9999 -9999 -9999 -9999 -9999 -9999 -9999 -9999 -

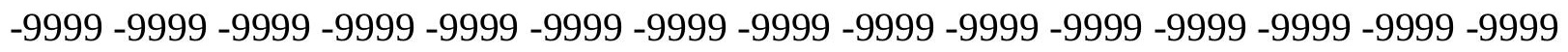
-9999 -9999 -9999 -9999 -9999 -9999 -9999 -9999 -9999 -9999 -9999 -9999 -9999 -9999 -9999 -9999 -9999 -9999 -9999 -9999 -9999 -9999 -9999 -9999 -9999 -9999 -9999 -9999 -9999 -

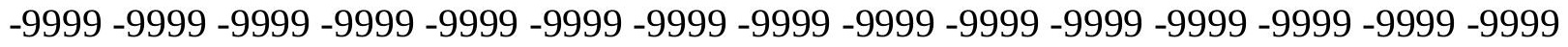
-9999 -9999 -9999 -9999 -9999 -9999 -9999 -9999 -9999 -9999 -9999 -9999 -9999 -9999 -9999 -9999 -9999 -9999 -9999 -9999 -9999 -9999 -9999 -9999 -9999 -9999 -9999 -9999 -9999 -999 -

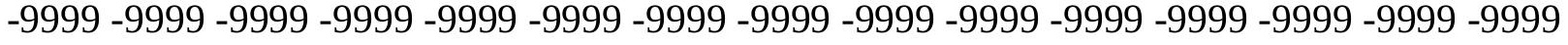
-9999 -9999 -9999 -9999 -9999 -9999 -9999 -9999 -9999 -9999 -9999 -9999 -9999 -9999 -9999 -

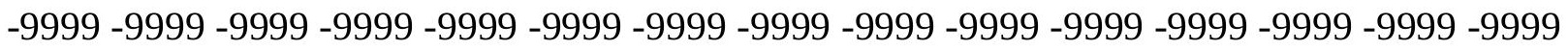

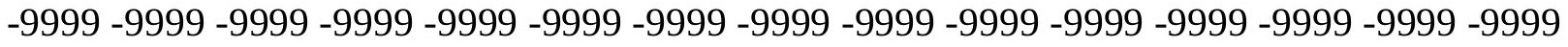

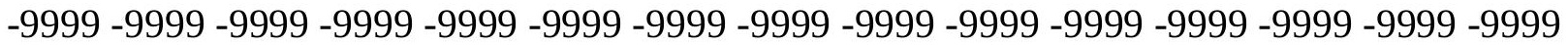
-9999 -9999 -9999 -9999 -9999 -9999 -9999 -9999 -9999 -9999 -9999 -9999 -9999 -9999 -9999

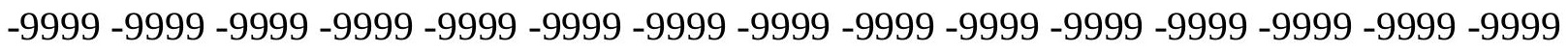

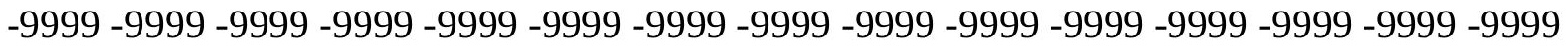
-9999 -9999 -9999 -9999 -9999 -9999 -9999 -9999 -9999 -9999 -9999 -9999 -9999 - 9999 - -999 -9999 -9999 -9999 -9999 -9999 -9999 -9999 -9999 -9999 -9999 -9999 -9999 -9999 -9999 -9999 -

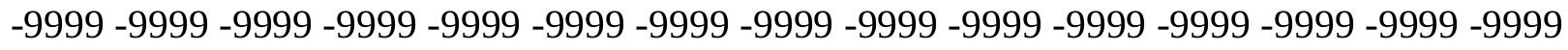

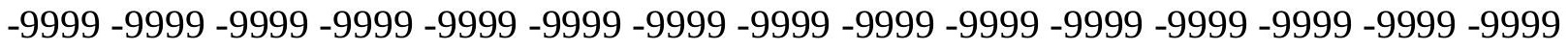
-9999 -9999 -9999 -9999 -9999 -9999 -9999 -9999 -9999 -9999 -9999 -9999 -9999 -9999 -9999 -9999 -9999 -9999 -9999 -9999 -9999 -9999 -9999 -9999-9999 -9999 -9999 -9999 -9999 -9999 -9999 -9999 -9999 -9999 -9999 -9999 -9999 -9999 -9999 -9999 -9999 -9999 -9999 -9999 -9999 -

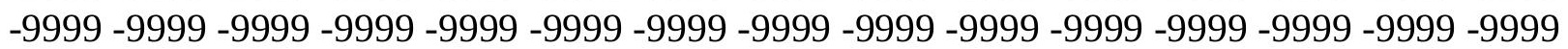


-9999 -9999 -9999 -9999 -9999 -9999 -9999 -9999 -9999 -9999 -9999 -9999 -9999 -9999 -9999 -9999 -9999 -9999 -9999 -9999 -9999 -9999 -9999 -9999 -9999 -9999 -9999 -9999 -9999 -9999 -9999 -9999 -9999 -9999 -9999 -9999 -9999 -9999 -9999 -9999 -9999 -9999 -9999 -9999 - 9999 -9999 -9999 -9999 -9999 -9999 -9999 -9999 -9999 -9999 -9999 -9999 -9999 -9999 -9999 -9999 -9999 -9999 -9999 -9999 -9999 -9999 -9999 -9999 -9999 -9999 -9999 -9999 -9999 -9999 - -9999 -9999 -9999 -9999 -9999 -9999 -9999 -9999 -9999 -9999 -9999 -9999 -9999 -9999 -9999 -9999 -9999 -9999 -9999 -9999 -9999 -9999 -9999 -9999 -9999 -9999 -9999 -9999 -9999 -9999

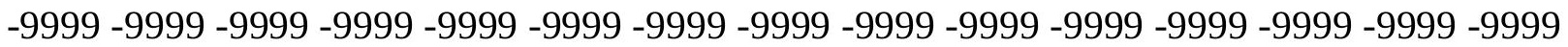

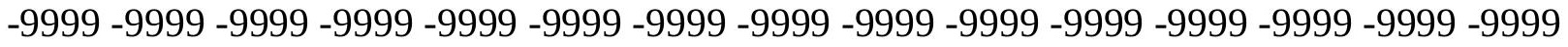
-9999 -9999 -9999 -9999 -9999 -9999 -9999 -9999 -9999 -9999 -9999 -9999 -9999 -9999 -9999

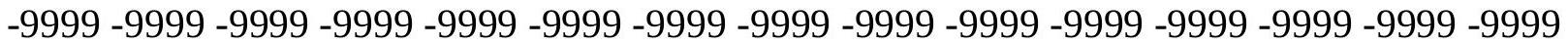
-9999 -9999 -9999 -9999 -9999 -9999 -9999 -9999 -9999 -9999 -9999 -9999 -9999 -9999 -9999 -9999 -9999 -9999 -9999 -9999 -9999 -9999 -9999 -9999 -9999 -9999 -9999 -9999 -9999 -9999 -9999 -9999 -9999 -9999 -9999 -9999 -9999 -9999 -9999 -9999 -9999 -9999 -9999 -9999 - -9999 -9999 -9999 -9999 -9999 -9999 -9999 -9999 -9999 -9999 -9999 -9999 -9999 -9999 -9999 -9999

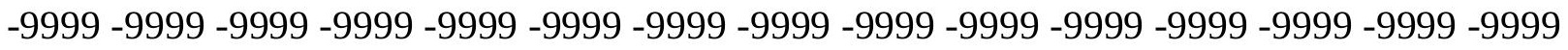
-9999 -9999 -9999 -9999 -9999 -9999 -9999 -9999 -9999 -9999 -9999 -9999 -9999 -9999 -9999 -9999 -9999 -9999 -9999 -9999 -9999 -9999 -9999 -9999 -9999 -9999 -9999 -9999 -9999 -9999 -9999 -9999 -9999 -9999 -9999 -9999 -9999 -9999 -9999 -9999 -9999 -9999 -9999 -9999 -9999 -

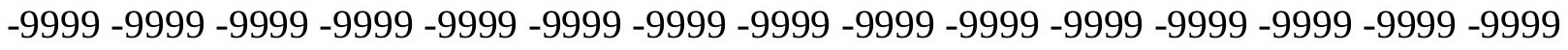
-9999 -9999 -9999 -9999 -9999 -9999 -9999 -9999 -9999 -9999 -9999 -9999 -9999 -9999 -9999 -999 -9999 -9999 -9999 -9999 -9999 -9999 -9999 -9999 -9999 -9999 -9999 -9999 -9999 -9999 -9999 -9999 -9999 -9999 -9999 -9999 -9999 -9999 -9999 -9999 -9999 -9999 -9999 -9999 -9999 -9999 -9999 -9999 -9999 -9999 -9999 -9999 -9999 -9999 -9999 -9999 -9999 -9999 -9999 -9999 -9999 -9999 -9999 -9999 -9999 -9999 -9999 -9999 -9999 -9999 -9999 -9999 -9999 -9999 -9999 -9999 -9999 -9999 -9999 -9999 -9999 -9999 -9999 -9999 -9999 -9999 -9999 -9999 -9999 -9999 -9999 -9999 -9999 -9999 -9999 -9999 -9999 -9999 -9999 -9999 -9999 -9999 -9999 -9999 -9999 -9999 -9999 -9999 -9999 -9999 -9999 -9999 -9999 -9999 -9999 -9999 -9999 -9999 -9999 -9999 -9999 -9999 -9999 -9999 -9999 -9999 -9999 -9999 -9999 -9999 -9999 -9999 -9999 -9999 -9999 -9999 -9999 -9999 -9999 -9999 -9999 -9999 -9999 -9999 -9999 -9999 -9999 -9999 -9999 -9999 -999 -9999 -9999 -9999 -9999 -9999 -9999 -9999 -9999 -9999 -9999 -9999 -9999 -9999 -9999 -9999 -9999 -9999 -9999 -9999 -9999 -9999 -9999 -9999 -9999 -9999 -9999 -9999 -9999 -9999 -

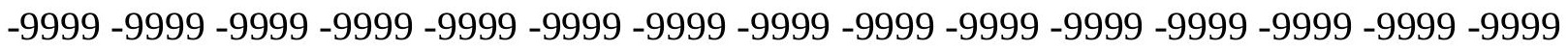

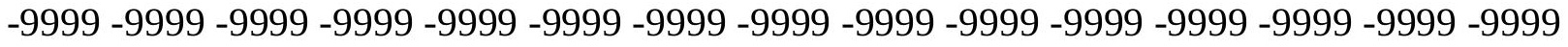

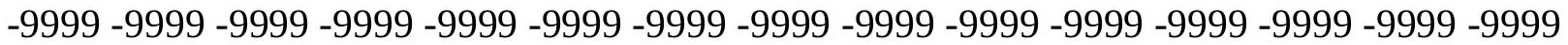
-9999 -9999 -9999 -9999 -9999 -9999 -9999 -9999 -9999 -9999 -9999 -9999 -9999 -9999 -9999 -

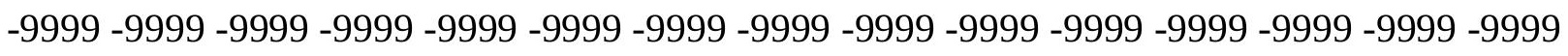

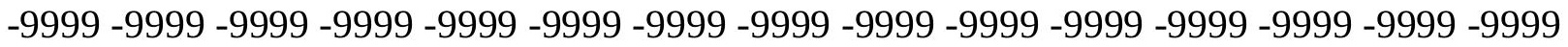

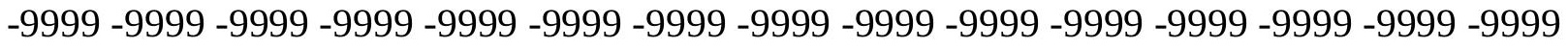
-9999 -9999 -9999 -9999 -9999 -9999 -9999 -9999 -9999 -9999 -9999 -9999 -9999 -9999 -9999 -

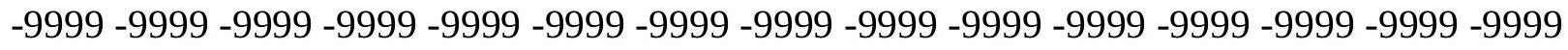

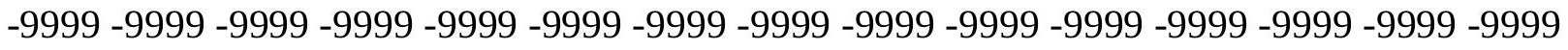
-9999 -9999 -9999 -9999 -9999 -9999 -9999 -9999 -9999 -9999 -9999 -9999 -9999 -9999 -9999 -9999 -9999 -9999 -9999 -9999 -9999 -9999 -9999 -9999-9999 -9999 -9999 -9999 -9999 -9999 -9999 -9999 -9999 -9999 -9999 -9999 -9999 -9999 -9999 -9999 -9999 -9999 -9999 -9999 -9999 -

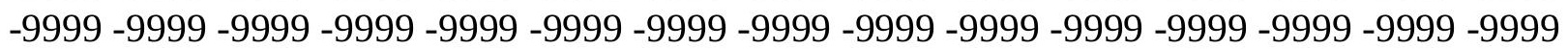


-9999 -9999 -9999 -9999 -9999 -9999 -9999 -9999 -9999 -9999 -9999 -9999 -9999 -9999 -9999 -9999 -9999 -9999 -9999 -9999 -9999 -9999 -9999 -9999 -9999 -9999 -9999 -9999 -9999 -9999 -

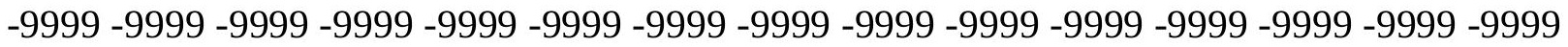
-9999 -9999 -9999 -9999 -9999 -9999 -9999 -9999 -9999 -9999 -9999 -9999 -9999 -9999 -9999 -9999 -9999 -9999 -9999 -9999 -9999 -9999 -9999 -9999-9999 -9999 -9999 -9999 -9999 -9999 -9999 -9999 -9999 -9999 -9999 -9999 -9999 -9999 -9999 -9999 -9999 -9999 -9999 -9999 -9999 -9999 -9999 -9999 -9999 -9999 -9999 -9999 -9999 -9999 -9999 -9999 -9999 -9999 -9999 -9999

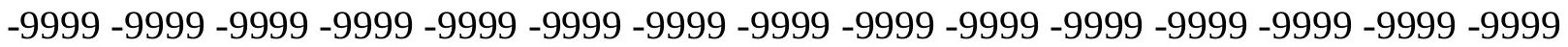

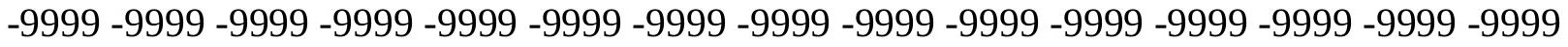
-9999 -9999 -9999 -9999 -9999 -9999 -9999 -9999 -9999 -9999 -9999 -9999 -9999 -9999 -9999 -9999 -9999 -9999 -9999 -9999 -9999 -9999 -9999 -9999 -9999 -9999 -9999 -9999 -9999 -9999 -9999 -9999 -9999 -9999 -9999 -9999 -9999 -9999 -9999 -9999 -9999 -9999 -9999 -9999 -9999 -9999 -9999 -9999 -9999 -9999 -9999 -9999 -9999 -9999 -9999 -9999 -9999 -9999 -9999 -9999 -9999 -9999 -9999 -9999 -9999 -9999 -9999 -9999 -9999 -9999 -9999 -9999 -9999 - 9999 -9999 -9999 -9999 -9999 -9999 -9999 -9999 -9999 -9999 -9999 -9999 -9999 -9999 -9999 -9999

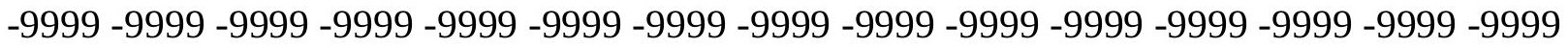
-9999 -9999 -9999 -9999 -9999 -9999 -9999 -9999 -9999 -9999 -9999 -9999 -9999 -9999 -9999 -9999 -9999 -9999 -9999 -9999 -9999 -9999 -9999 -9999 -9999 -9999 -9999 -9999 -9999 -9999 -9999 -9999 -9999 -9999 -9999 -9999 -9999 -9999 -9999 -9999 -9999 -9999 -9999 -9999 -9999 -

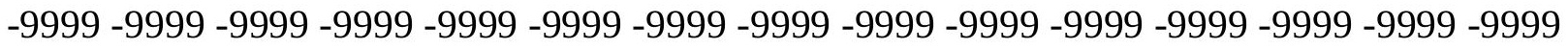

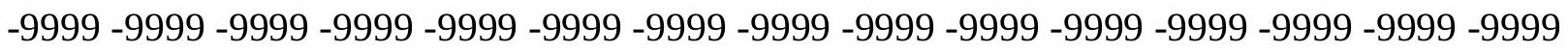
-9999 -9999 -9999 -9999 -9999 -9999 -9999 -9999 -9999 -9999 -9999 -9999 -9999 -9999 -9999 -9999 -9999 -9999 -9999 -9999 -9999 -9999 -9999 -9999 -9999 -9999 -9999 -9999 -9999 -9999 -9999 -9999 -9999 -9999 -9999 -9999 -9999 -9999 -9999 -9999 -9999 -9999 -9999 -9999 -9999 -

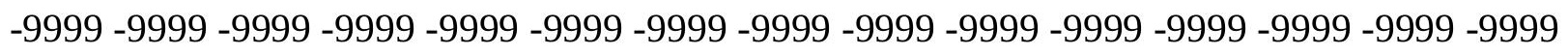
-9999 -9999 -9999 -9999 -9999 -9999 -9999 -9999 -9999 -9999 -9999 -9999 -9999 -9999 -9999 -9999 -9999 -9999 -9999 -9999 -9999 -9999 -9999 -9999 -9999 -9999 -9999 -9999 -9999 -9999 -

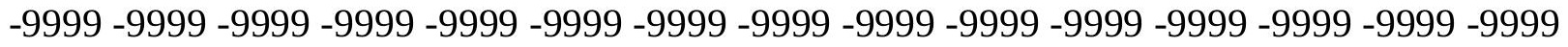
-9999 -9999 -9999 -9999 -9999 -9999 -9999 -9999 -9999 -9999 -9999 -9999 -9999 -9999 -9999 -9999 -9999 -9999 -9999 -9999 -9999 -9999 -9999 -9999 -9999 -9999 -9999 -9999 -9999 -999 -9999 -9999 -9999 -9999 -9999 -9999 -9999 -9999 -9999 -9999 -9999 -9999 -9999 -9999 -9999 -9999 -9999 -9999 -9999 -9999 -9999 -9999 -9999 -9999 -9999 -9999 -9999 -9999 -9999 -9999 -

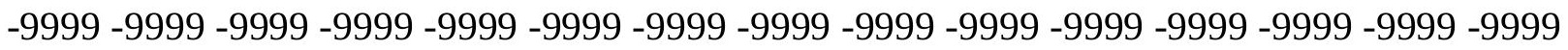

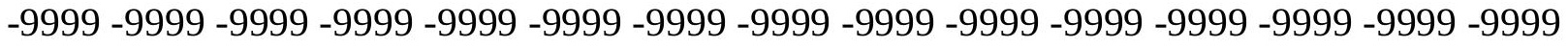

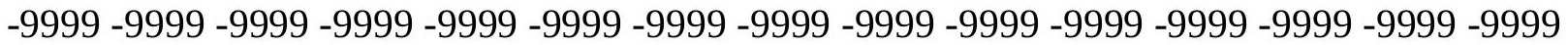

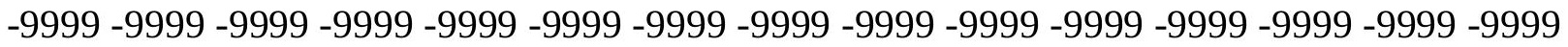

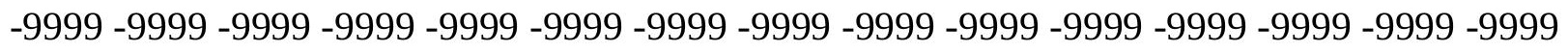

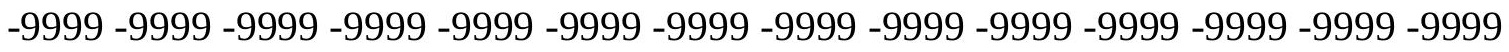
-9999 -9999 -9999 -9999 -9999 -9999 -9999 -9999 -9999 -9999 -9999 -9999 -9999 -9999 -9999 -9999 -9999 -9999 -9999 -9999 -9999 -9999 -9999 -9999 -9999 -9999 -9999 -9999 -9999 -9999 -

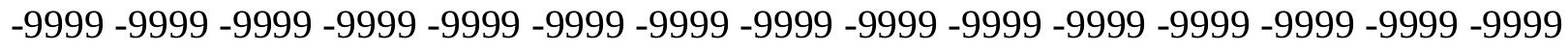

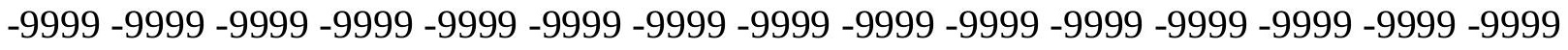
-9999 -9999 -9999 -9999 -9999 -9999 -9999 -9999 -9999 -9999 -9999 -9999 -9999 -9999 -9999 -9999 -9999 -9999 -9999 -9999 -9999 -9999 -9999 -9999-9999 -9999 -9999 -9999 -9999 -9999 -9999 -9999 -9999 -9999 -9999 -9999 -9999 -9999 -9999 -9999 -9999 -9999 -9999 -9999 -9999 -

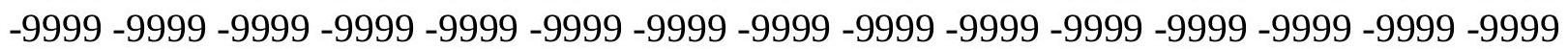


-9999 -9999 -9999 -9999 -9999 -9999 -9999 -9999 -9999 -9999 -9999 -9999 -9999 -9999 -9999 -9999 -9999 -9999 -9999 -9999 -9999 -9999 -9999 -9999 -9999 -9999 -9999 -9999 -9999 -9999 -9999 -9999 -9999 -9999 -9999 -9999 -9999 -9999 -9999 -9999 -9999 -9999 -9999 -9999 - 9999 -9999 -9999 -9999 -9999 -9999 -9999 -9999 -9999 -9999 -9999 -9999 -9999 -9999 -9999 -9999 -9999 -9999 -9999 -9999 -9999 -9999 -9999 -9999 -9999 -9999 -9999 -9999 -9999 -9999 -9999 -9999 -9999 -9999 -9999 -9999 -9999 -9999 -9999 -9999 -9999 -9999 -9999 -9999 -9999 -9999 -9999 -9999 -9999 -9999 -9999 -9999 -9999 -9999 -9999 -9999 -9999 -9999 -9999 -9999 -9999

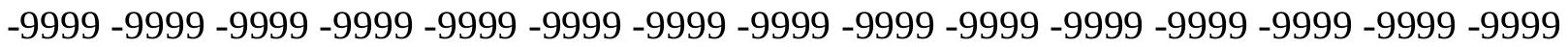
-9999 -9999 -9999 -9999 -9999 -9999 -9999 -9999 -9999 -9999 -9999 -9999 -9999 -9999 -9999 -9999 -9999 -9999 -9999 -9999 -9999 -9999 -9999 -9999 -9999 -9999 -9999 -9999 -9999 -9999

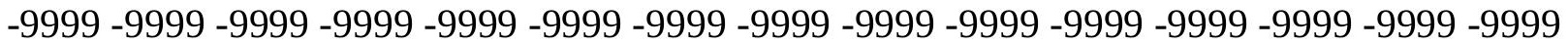
-9999 -9999 -9999 -9999 -9999 -9999 -9999 -9999 -9999 -9999 -9999 -9999 -9999 -9999 -9999 -9999 -9999 -9999 -9999 -9999 -9999 -9999 -9999 -9999 -9999 -9999 -9999 -9999 -9999 -9999 -

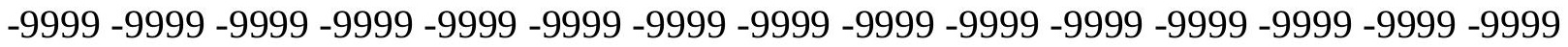
-9999 -9999 -9999 -9999 -9999 -9999 -9999 -9999 -9999 -9999 -9999 -9999 -9999 -9999 -9999

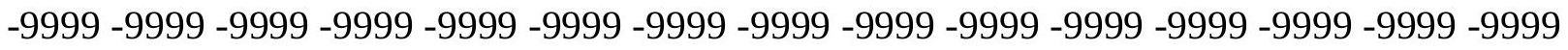
-9999 -9999 -9999 -9999 -9999 -9999 -9999 -9999 -9999 -9999 -9999 -9999 -9999 -9999 -9999 -9999 -9999 -9999 -9999 -9999 -9999 -9999 -9999 -9999 -9999 -9999 -9999 -9999 -9999 - -999 -9999 -9999 -9999 -9999 -9999 -9999 -9999 -9999 -9999 -9999 -9999 -9999 -9999 -9999 -9999 -9999 -9999 -9999 -9999 -9999 -9999 -9999 -9999 -9999 -9999 -9999 -9999 -9999 -9999 -9999 -9999 -9999 -9999 -9999 -9999 -9999 -9999 -9999 -9999 -9999 -9999 -9999 -9999 -9999 -9999 -999 -9999 -9999 -9999 -9999 -9999 -9999 -9999 -9999 -9999 -9999 -9999 -9999 -9999 -9999 -9999 -9999 -9999 -9999 -9999 -9999 -9999 -9999 -9999 -9999 -9999 -9999 -9999 -9999 -9999 -9999 -9999 -9999 -9999 -9999 -9999 -9999 -9999 -9999 -9999 -9999 -9999 -9999 -9999 -9999 -9999 -9999 -9999 -9999 -9999 -9999 -9999 -9999 -9999 -9999 -9999 -9999 -9999 -9999 -9999 -9999 -9999 -9999 -9999 -9999 -9999 -9999 -9999 -9999 -9999 -9999 -9999 -9999 -9999 -9999 -9999 -9999 -9999 -9999 -9999 -9999 -9999 -9999 -9999 -9999 -9999 -9999 -9999 -9999 -9999 -9999 -9999 -9999 -9999 -9999 -9999 -9999 -9999 -9999 -9999 -9999 -9999 -9999 -9999 -9999 -9999 -9999 -9999 -9999 -9999 -9999 -9999 -9999 -9999 -9999 -9999 -9999 -9999 -9999 -9999 -9999 -9999 -9999 -9999 -9999 -9999 -9999 -9999 -9999 -9999 -9999 -9999 -9999 -9999 -9999 -999 -9999 -9999 -9999 -9999 -9999 -9999 -9999 -9999 -9999 -9999 -9999 -9999 -9999 -9999 -9999 -9999 -9999 -9999 -9999 -9999 -9999 -9999 -9999 -9999 -9999 -9999 -9999 -9999 -9999 -9999 -

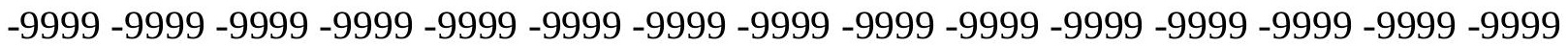

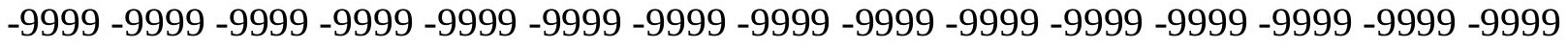

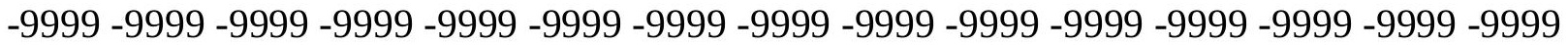
-9999 -9999 -9999 -9999 -9999 -9999 -9999 -9999 -9999 -9999 -9999 -9999 -9999 -9999 -9999

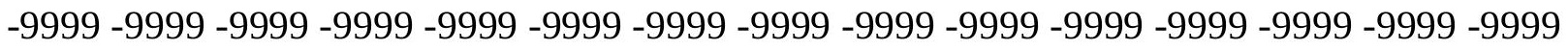

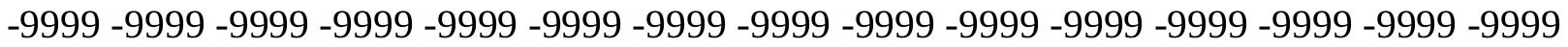

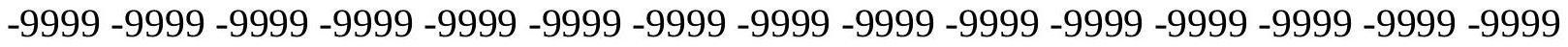
-9999 -9999 -9999 -9999 -9999 -9999 -9999 -9999 -9999 -9999 -9999 -9999 -9999 -9999 -9999 -

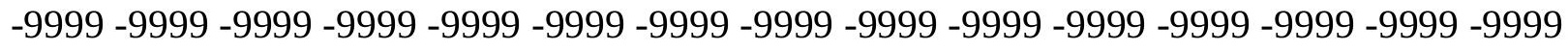

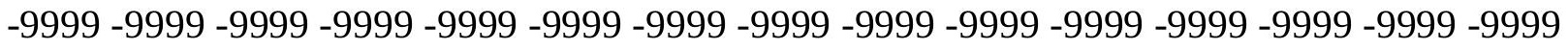
-9999 -9999 -9999 -9999 -9999 -9999 -9999 -9999 -9999 -9999 -9999 -9999 -9999 -9999 -9999 -9999 -9999 -9999 -9999 -9999 -9999 -9999 -9999 -9999 -9999 -9999 -9999 -9999 - -9999 -9999 -9999 -9999 -9999 -9999 -9999 -9999 -9999 -9999 -9999 -9999 -9999 -9999 -9999 -9999 -

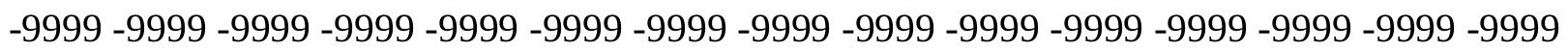


-9999 -9999 -9999 -9999 -9999 -9999 -9999 -9999 -9999 -9999 -9999 -9999 -9999 -9999 -9999 -9999 -9999 -9999 -9999 -9999 -9999 -9999 -9999 -9999 -9999 -9999 -9999 -9999 -9999 -9999 -9999 -9999 -9999 -9999 -9999 -9999 -9999 -9999 -9999 -9999 -9999 -9999 -9999 -9999 - 9999 -9999 -9999 -9999 -9999 -9999 -9999 -9999 -9999 -9999 -9999 -9999 -9999 -9999 -9999 -9999 -9999 -9999 -9999 -9999 -9999 -9999 -9999 -9999 -9999-9999 -9999 -9999 -9999 -9999 -9999 -9999 -9999 -9999 -9999 -9999 -9999 -9999 -9999 -9999 -9999 -9999 -9999 -9999 -9999 -9999 -9999 -9999 -9999 -9999 -9999 -9999 -9999 -9999 -9999 -9999 -9999 -9999 -9999 -9999 -9999

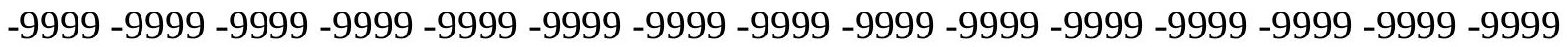

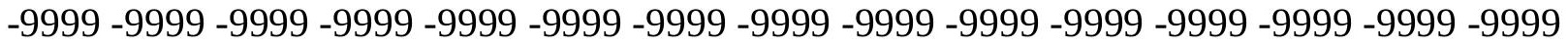
-9999 -9999 -9999 -9999 -9999 -9999 -9999 -9999 -9999 -9999 -9999 -9999 -9999 -9999 -9999

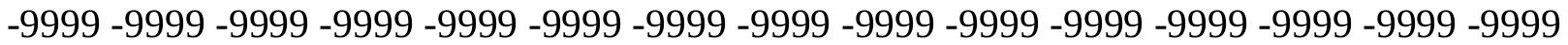
-9999 -9999 -9999 -9999 -9999 -9999 -9999 -9999 -9999 -9999 -9999 -9999 -9999 -9999 -9999 -9999 -9999 -9999 -9999 -9999 -9999 -9999 -9999 -9999 -9999 -9999 -9999 -9999 -9999 -9999 -

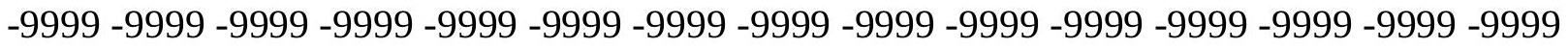
-9999 -9999 -9999 -9999 -9999 -9999 -9999 -9999 -9999 -9999 -9999 -9999 -9999 -9999 -9999

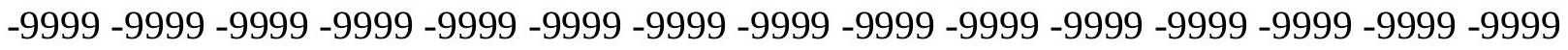
-9999 -9999 -9999 -9999 -9999 -9999 -9999 -9999 -9999 -9999 -9999 -9999 -9999 -9999 -9999 -9999 -9999 -9999 -9999 -9999 -9999 -9999 -9999 -9999 -9999 -9999 -9999 -9999 -9999 -9999 -9999 -9999 -9999 -9999 -9999 -9999 -9999 -9999 -9999 -9999 -9999 -9999 -9999 -9999 -9999 -9999 -9999 -9999 -9999 -9999 -9999 -9999 -9999 -9999 -9999 -9999 -9999 -9999 -9999 -9999 -9999 -9999 -9999 -9999 -9999 -9999 -9999 -9999 -9999 -9999 -9999 -9999 -9999 -9999 -9999 -999 -9999 -9999 -9999 -9999 -9999 -9999 -9999 -9999 -9999 -9999 -9999 -9999 -9999 -9999 -9999 -9999 -9999 -9999 -9999 -9999 -9999 -9999 -9999 -9999 -9999 -9999 -9999 -9999 -9999 -9999 -9999 -9999 -9999 -9999 -9999 -9999 -9999 -9999 -9999 -9999 -9999 -9999 -9999 -9999 -9999 -9999 -9999 -9999 -9999 -9999 -9999 -9999 -9999 -9999 -9999 -9999 -9999 -9999 -9999 -9999 -9999 -9999 -9999 -9999 -9999 -9999 -9999 -9999 -9999 -9999 -9999 -9999 -9999 -9999 -9999 -9999 -9999 -9999 -9999 -9999 -9999 -9999 -9999 -9999 -9999 -9999 -9999 -9999 -9999 -9999 -9999 -9999 -9999 -9999 -9999 -9999 -9999 -9999 -9999 -9999 -9999 -9999 -9999 -9999 -9999 -9999 -9999 -9999 -9999 -9999 -9999 -9999 -9999 -9999 -9999 -9999 -9999 -9999 -9999 -9999 -9999 -9999 -9999 -9999 -9999 -9999 -9999 -9999 -9999 -9999 -9999 -9999 -9999 -999 -9999 -9999 -9999 -9999 -9999 -9999 -9999 -9999 -9999 -9999 -9999 -9999 -9999 -9999 -9999 -9999 -9999 -9999 -9999 -9999 -9999 -9999 -9999 -9999 -9999 -9999 -9999 -9999 -9999 -9999 -

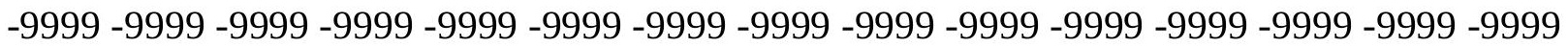

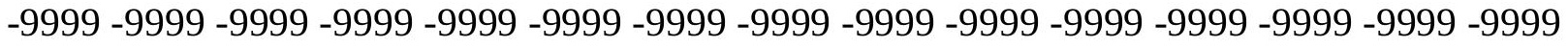

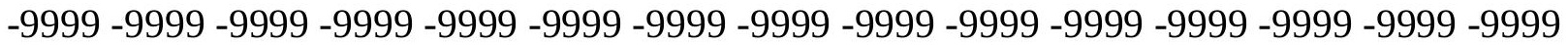
-9999 -9999 -9999 -9999 -9999 -9999 -9999 -9999 -9999 -9999 -9999 -9999 -9999 -9999 -9999

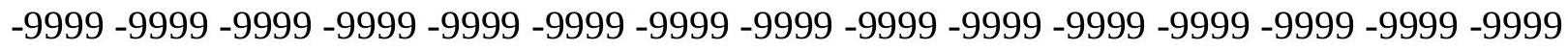

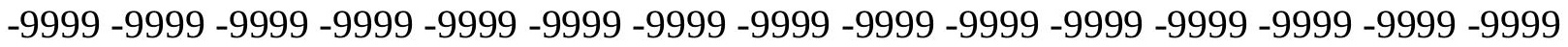
-9999 -9999 -9999 -9999 -9999 -9999 -9999 -9999 -9999 -9999 -9999 -9999 -9999 -9999 -9999 -9999 -9999 -9999 -9999 -9999 -9999 -9999 -9999 -9999 -9999 -9999 -9999 -9999 -9999 -9999 -

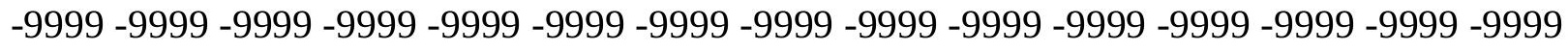

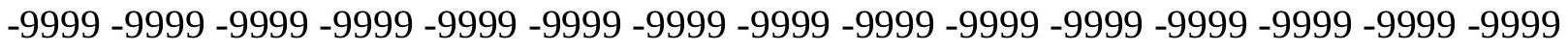
-9999 -9999 -9999 -9999 -9999 -9999 -9999 -9999 -9999 -9999 -9999 -9999 -9999 -9999 -9999 -9999 -9999 -9999 -9999 -9999 -9999 -9999 -9999 -9999-9999 -9999 -9999 -9999 -9999 -9999 -9999 -9999 -9999 -9999 -9999 -9999 -9999 -9999 -9999 -9999 -9999 -9999 -9999 -9999 -9999 -

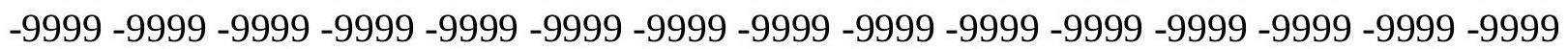


-9999 -9999 -9999 -9999 -9999 -9999 -9999 -9999 -9999 -9999 -9999 -9999 -9999 -9999 -9999 -9999 -9999 -9999 -9999 -9999 -9999 -9999 -9999 -9999 -9999 -9999 -9999 -9999 -9999 -9999 -9999 -9999 -9999 -9999 -9999 -9999 -9999 -9999 -9999 -9999 -9999 -9999 -9999 -9999 - 9999 -9999 -9999 -9999 -9999 -9999 -9999 -9999 -9999 -9999 -9999 -9999 -9999 -9999 -9999

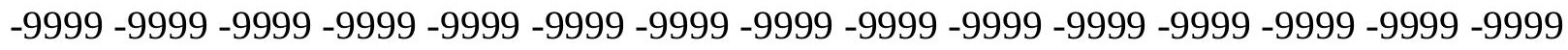
-9999 -9999 -9999 -9999 -9999 -9999 -9999 -9999 -9999 -9999 -9999 -9999 -9999 -9999 -9999 -9999 -9999 -9999 -9999 -9999 -9999 -9999 -9999 -9999 -9999 -9999 -9999 -9999 -9999 -9999

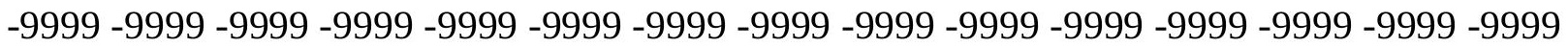

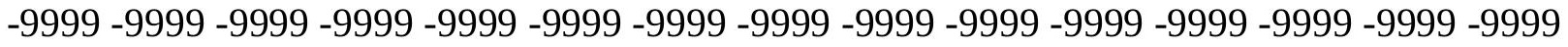
-9999 -9999 -9999 -9999 -9999 -9999 -9999 -9999 -9999 -9999 -9999 -9999 -9999 -9999 -9999 -9999 -9999 -9999 -9999 -9999 -9999 -9999 -9999 -9999 -9999 -9999 -9999 -9999 -9999 -9999 -9999 -9999 -9999 -9999 -9999 -9999 -9999 -9999 -9999 -9999 -9999 -9999 -9999 -9999 -9999 -9999 -9999 -9999 -9999 -9999 -9999 -9999 -9999 -9999 -9999 -9999 -9999 -9999 -9999 -9999 -

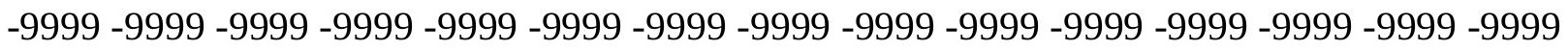
-9999 -9999 -9999 -9999 -9999 -9999 -9999 -9999 -9999 -9999 -9999 -9999 -9999 -9999 -9999 -

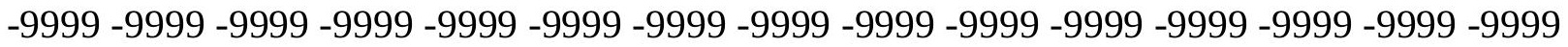
-9999 -9999 -9999 -9999 -9999 -9999 -9999 -9999 -9999 -9999 -9999 -9999 -9999 -9999 -9999 -9999 -9999 -9999 -9999 -9999 -9999 -9999 -9999 -9999 -9999 -9999 -9999 -9999 -9999 -9999 -9999 -9999 -9999 -9999 -9999 -9999 -9999 -9999 -9999 -9999 -9999 -9999 -9999 -9999 -9999 -

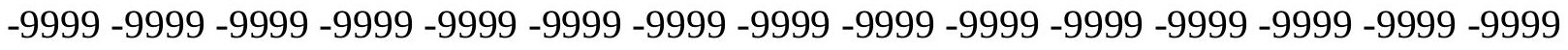
-9999 -9999 -9999 -9999 -9999 -9999 -9999 -9999 -9999 -9999 -9999 -9999 -9999 -9999 -9999

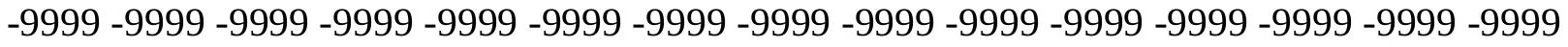
-9999 -9999 -9999 -9999 -9999 -9999 -9999 -9999 -9999 -9999 -9999 -9999 -9999 -9999 -9999 -9999 -9999 -9999 -9999 -9999 -9999 -9999 -9999 -9999 -9999 -9999 -9999 -9999 -9999 -9999 -9999 -9999 -9999 -9999 -9999 -9999 -9999 -9999 -9999 -9999 -9999 -9999 -9999 -9999 -9999 -9999 -9999 -9999 -9999 -9999 -9999 -9999 -9999 -9999 -9999 -9999 -9999 -9999 -9999 -9999 -9999 -9999 -9999 -9999 -9999 -9999 -9999 -9999 -9999 -9999 -9999 -9999 -9999 -9999 -9999 -9999 -9999 -9999 -9999 -9999 -9999 -9999 -9999 -9999 -9999 -9999 -9999 -9999 -9999 -9999 -9999 -9999 -9999 -9999 -9999 -9999 -9999 -9999 -9999 -9999 -9999 -9999 -9999 -9999 -9999 -9999 -9999 -9999 -9999 -9999 -9999 -9999 -9999 -9999 -9999 -9999 -9999 -9999 -9999 -9999 -9999 -9999 -9999 -9999 -9999 -9999 -9999 -9999 -9999 -9999 -9999 -9999 -9999 -9999 -9999 -9999 -9999 -9999 -9999 -9999 -9999 -9999 -9999 -9999 -9999 -9999 -9999 -9999 -9999 -

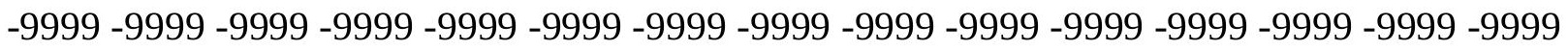

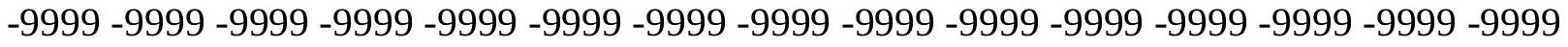
-9999 -9999 -9999 -9999 -9999 -9999 -9999 -9999 -9999 -9999 -9999 -9999 -9999 -9999 -9999 -

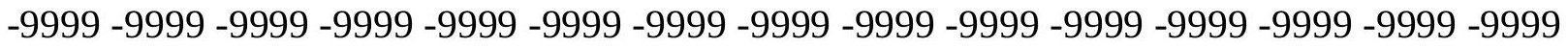

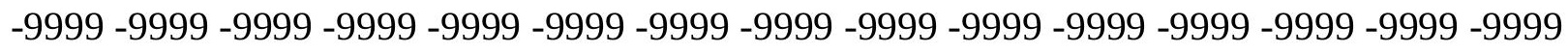

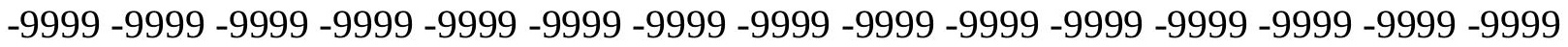

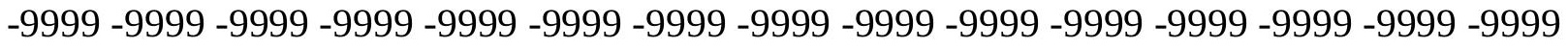
-9999 -9999 -9999 -9999 -9999 -9999 -9999 -9999 -9999 -9999 -9999 -9999 -9999 -9999 -9999 -

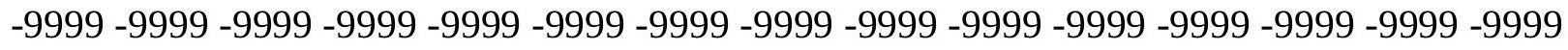

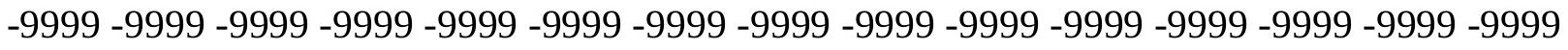
-9999 -9999 -9999 -9999 -9999 -9999 -9999 -9999 -9999 -9999 -9999 -9999 -9999 -9999 -9999 -9999 -9999 -9999 -9999 -9999 -9999 -9999 -9999 -9999-9999 -9999 -9999 -9999 -9999 -9999 -9999 -9999 -9999 -9999 -9999 -9999 -9999 -9999 -9999 -9999 -9999 -9999 -9999 -9999 -9999 -

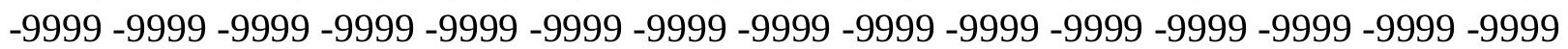


-9999 -9999 -9999 -9999 -9999 -9999 -9999 -9999 -9999 -9999 -9999 -9999 -9999 -9999 -9999 -9999 -9999 -9999 -9999 -9999 -9999 -9999 -9999 -9999 -9999 -9999 -9999 -9999 -9999 -9999 -9999 -9999 -9999 -9999 -9999 -9999 -9999 -9999 -9999 -9999 -9999 -9999 -9999 -9999 - 9999 -9999 -9999 -9999 -9999 -9999 -9999 -9999 -9999 -9999 -9999 -9999 -9999 -9999 -9999 -9999 -9999 -9999 -9999 -9999 -9999 -9999 -9999 -9999 -9999 -9999 -9999 -9999 -9999 -9999 -9999 -9999 -9999 -9999 -9999 -9999 -9999 -9999 -9999 -9999 -9999 -9999 -9999 -9999 -9999 -9999 -9999 -9999 -9999 -9999 -9999 -9999 -9999 -9999 -9999 -9999 -9999 -9999 -9999 -9999 -9999

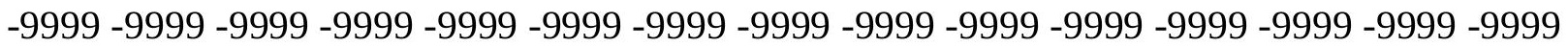

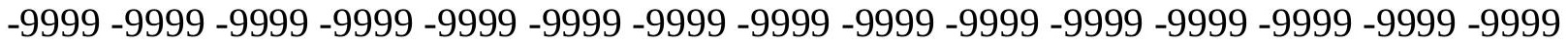
-9999 -9999 -9999 -9999 -9999 -9999 -9999 -9999 -9999 -9999 -9999 -9999 -9999 -9999 -9999 -9999 -9999 -9999 -9999 -9999 -9999 -9999 -9999 -9999 -9999 -9999 -9999 -9999 -9999 -9999 -9999 -9999 -9999 -9999 -9999 -9999 -9999 -9999 -9999 -9999 -9999 -9999 -9999 -9999 -9999 -9999 -9999 -9999 -9999 -9999 -9999 -9999 -9999 -9999 -9999 -9999 -9999 -9999 -9999 -9999 -9999 -9999 -9999 -9999 -9999 -9999 -9999 -9999 -9999 -9999 -9999 -9999 -9999 -9999 -9999 -9999 -9999 -9999 -9999 -9999 -9999 -9999 -9999 -9999 -9999 -9999 -9999 -9999 -9999 -

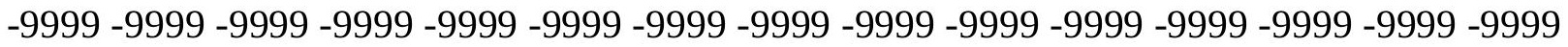
-9999 -9999 -9999 -9999 -9999 -9999 -9999 -9999 -9999 -9999 -9999 -9999 -9999 -9999 -9999 -9999 -9999 -9999 -9999 -9999 -9999 -9999 -9999 -9999 -9999 -9999 -9999 -9999 -9999 -9999 -9999 -9999 -9999 -9999 -9999 -9999 -9999 -9999 -9999 -9999 -9999 -9999 -9999 -9999 -9999 -9999 -9999 -9999 -9999 -9999 -9999 -9999 -9999 -9999 -9999 -9999 -9999 -9999 -9999 -9999 -9999 -9999 -9999 -9999 -9999 -9999 -9999 -9999 -9999 -9999 -9999 -9999 -9999 -9999 -9999 -999 -9999 -9999 -9999 -9999 -9999 -9999 -9999 -9999 -9999 -9999 -9999 -9999 -9999 -9999 -9999 -9999 -9999 -9999 -9999 -9999 -9999 -9999 -9999 -9999 -9999 -9999 -9999 -9999 -9999 -9999 -9999 -9999 -9999 -9999 -9999 -9999 -9999 -9999 -9999 -9999 -9999 -9999 -9999 -9999 -9999 -9999 -9999 -9999 -9999 -9999 -9999 -9999 -9999 -9999 -9999 -9999 -9999 -9999 -9999 -9999 -9999 -9999 -9999 -9999 -9999 -9999 -9999 -9999 -9999 -9999 -9999 -9999 -9999 -9999 -9999 -9999 -9999 -9999 -9999 -9999 -9999 -9999 -9999 -9999 -9999 -9999 -9999 -9999 -9999 -9999 -9999 -9999 -9999 -9999 -9999 -9999 -9999 -9999 -9999 -9999 -9999 -9999 -9999 -9999 -9999 -9999 -9999 -9999 -9999 -9999 -9999 -9999 -9999 -9999 -9999 -9999 -9999 -9999 -9999 -9999 -9999 -9999 -9999 -9999 -9999 -9999 -9999 -9999 -9999 -9999 -9999 -9999 -9999 -9999 -999 -9999 -9999 -9999 -9999 -9999 -9999 -9999 -9999 -9999 -9999 -9999 -9999 -9999 -9999 -9999 -9999 -9999 -9999 -9999 -9999 -9999 -9999 -9999 -9999 -9999 -9999 -9999 -9999 -9999 -9999 -

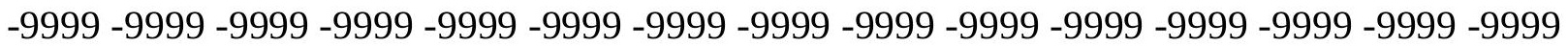

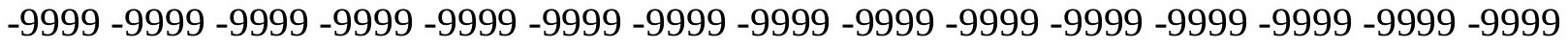

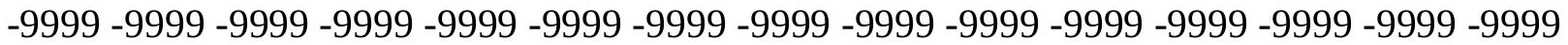
-9999 -9999 -9999 -9999 -9999 -9999 -9999 -9999 -9999 -9999 -9999 -9999 -9999 -9999 -9999 -9999 -9999 -9999 -9999 -9999 -9999 -9999 -9999 -9999 -9999 -9999 -9999 -9999 -9999 -

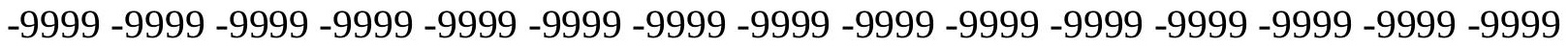
-9999 -9999 -9999 -9999 -9999 -9999 -9999 -9999 -9999 -9999 -9999 -9999 -9999 -9999 -9999 -9999 -9999 -9999 -9999 -9999 -9999 -9999 -9999 -9999 -9999 -9999 -9999 -9999 -9999 -9999 -

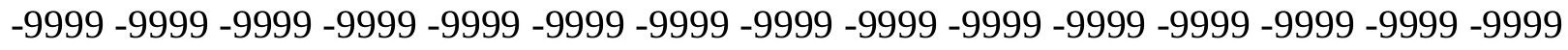

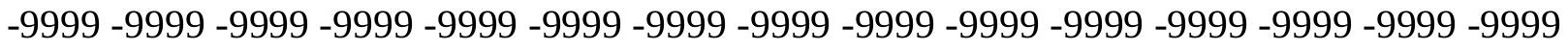
-9999 -9999 -9999 -9999 -9999 -9999 -9999 -9999 -9999 -9999 -9999 -9999 -9999 -9999 -9999 -9999 -9999 -9999 -9999 -9999 -9999 -9999 -9999 -9999-9999 -9999 -9999 -9999 -9999 -9999 -9999 -9999 -9999 -9999 -9999 -9999 -9999 -9999 -9999 -9999 -9999 -9999 -9999 -9999 -9999 -

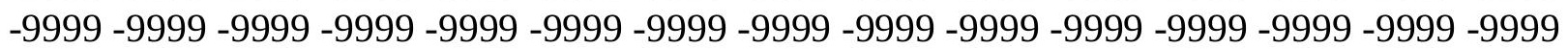


-9999 -9999 -9999 -9999 -9999 -9999 -9999 -9999 -9999 -9999 -9999 -9999 -9999 -9999 -9999 -9999 -9999 -9999 -9999 -9999 -9999 -9999 -9999 -9999 -9999 -9999 -9999 -9999 -9999 -9999 -

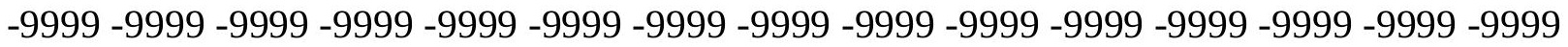
-9999 -9999 -9999 -9999 -9999 -9999 -9999 -9999 -9999 -9999 -9999 -9999 -9999 -9999 -9999 -9999 -9999 -9999 -9999 -9999 -9999 -9999 -9999 -9999-9999 -9999 -9999 -9999 -9999 -9999 -9999 -9999 -9999 -9999 -9999 -9999 -9999 -9999 -9999 -9999 -9999 -9999 -9999 -9999 -9999 -9999 -9999 -9999 -9999 -9999 -9999 -9999 -9999 -9999 -9999 -9999 -9999 -9999 -9999 -9999

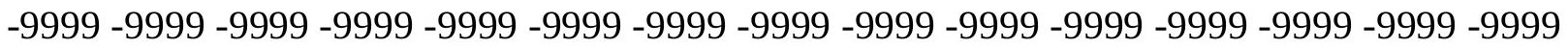

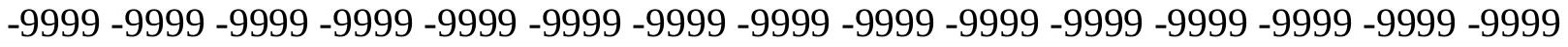
-9999 -9999 -9999 -9999 -9999 -9999 -9999 -9999 -9999 -9999 -9999 -9999 -9999 -9999 -9999 -9999 -9999 -9999 -9999 -9999 -9999 -9999 -9999 -9999 -9999 -9999 -9999 -9999 -9999 -9999 -9999 -9999 -9999 -9999 -9999 -9999 -9999 -9999 -9999 -9999 -9999 -9999 -9999 -9999 -9999 -9999 -9999 -9999 -9999 -9999 -9999 -9999 -9999 -9999 -9999 -9999 -9999 -9999 -9999 -9999 -9999 -9999 -9999 -9999 -9999 -9999 -9999 -9999 -9999 -9999 -9999 -9999 -9999 -9999 -9999 -9999 -9999 -9999 -9999 -9999 -9999 -9999 -9999 -9999 -9999 -9999 -9999 -9999 -9999 -9999 -

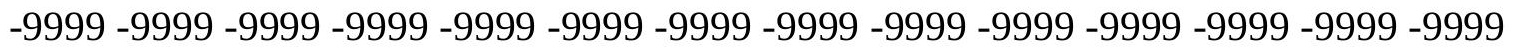
-9999 -9999 -9999 -9999 -9999 -9999 -9999 -9999 -9999 -9999 -9999 -9999 -9999 -9999 -9999 -9999 -9999 -9999 -9999 -9999 -9999 -9999 -9999 -9999 -9999 -9999 -9999 -9999 -9999 -9999 -9999 -9999 -9999 -9999 -9999 -9999 -9999 -9999 -9999 -9999 -9999 -9999 -9999 -9999 -9999 -

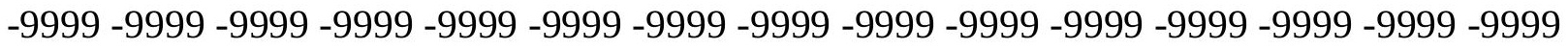

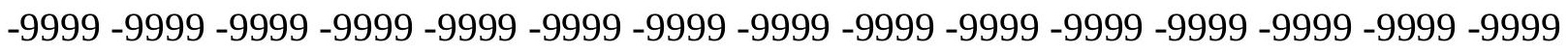
-9999 -9999 -9999 -9999 -9999 -9999 -9999 -9999 -9999 -9999 -9999 -9999 -9999 -9999 - 9999 -9999 -9999 -9999 -9999 -9999 -9999 -9999 -9999 -9999 -9999 -9999 -9999 -9999 -9999 -9999 -9999 -9999 -9999 -9999 -9999 -9999 -9999 -9999 -9999 -9999 -9999 -9999 -9999 -9999 -9999 -

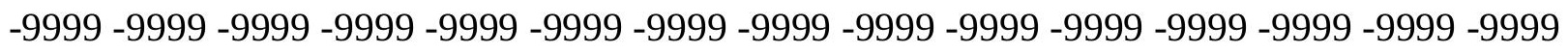
-9999 -9999 -9999 -9999 -9999 -9999 -9999 -9999 -9999 -9999 -9999 -9999 -9999 -9999 -9999 -9999 -9999 -9999 -9999 -9999 -9999 -9999 -9999 -9999 -9999 -9999 -9999 -9999 -9999 -9999 -

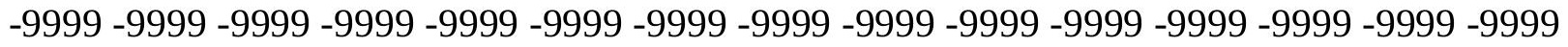
-9999 -9999 -9999 -9999 -9999 -9999 -9999 -9999 -9999 -9999 -9999 -9999 -9999 -9999 -9999 -9999 -9999 -9999 -9999 -9999 -9999 -9999 -9999 -9999 -9999 -9999 -9999 -9999 -9999 -999 -

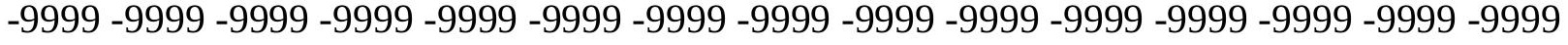
-9999 -9999 -9999 -9999 -9999 -9999 -9999 -9999 -9999 -9999 -9999 -9999 -9999 -9999 -9999 -

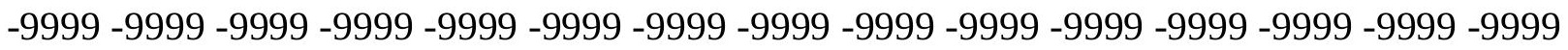

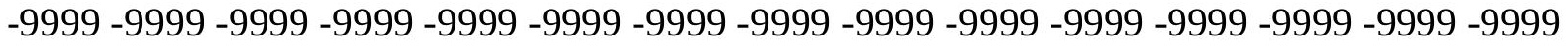

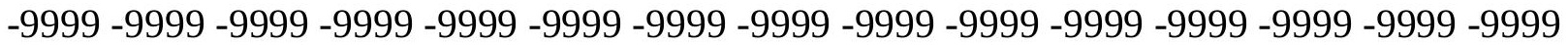
-9999 -9999 -9999 -9999 -9999 -9999 -9999 -9999 -9999 -9999 -9999 -9999 -9999 -9999 -9999 -

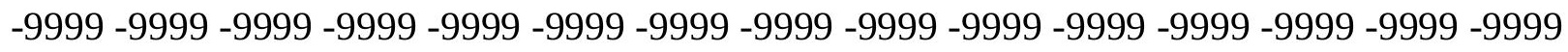

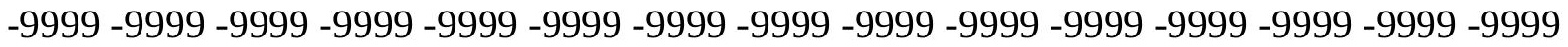
-9999 -9999 -9999 -9999 -9999 -9999 -9999 -9999 -9999 -9999 -9999 -9999 -9999 - 9999 - -999 -9999 -9999 -9999 -9999 -9999 -9999 -9999 -9999 -9999 -9999 -9999 -9999 -9999 -9999 -9999 -

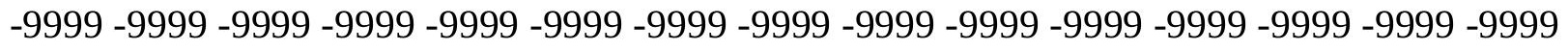

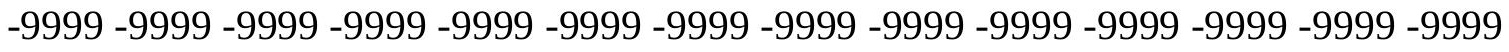
-9999 -9999 -9999 -9999 -9999 -9999 -9999 -9999 -9999 -9999 -9999 -9999 -9999 -9999 -9999 -9999 -9999 -9999 -9999 -9999 -9999 -9999 -9999 -9999-9999 -9999 -9999 -9999 -9999 -9999 -9999 -9999 -9999 -9999 -9999 -9999 -9999 -9999 -9999 -9999 -9999 -9999 -9999 -9999 -9999 -

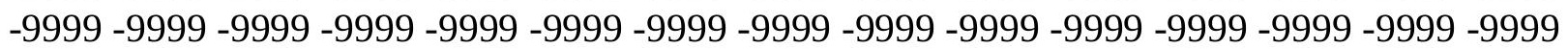


-9999 -9999 -9999 -9999 -9999 -9999 -9999 -9999 -9999 -9999 -9999 -9999 -9999 -9999 -9999 -9999 -9999 -9999 -9999 -9999 -9999 -9999 -9999 -9999 -9999 -9999 -9999 -9999 -9999 -9999 -

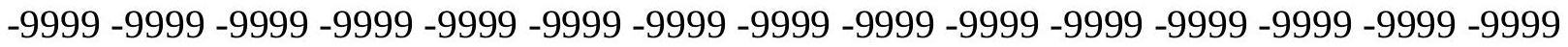
-9999 -9999 -9999 -9999 -9999 -9999 -9999 -9999 -9999 -9999 -9999 -9999 -9999 -9999 -9999 -9999 -9999 -9999 -9999 -9999 -9999 -9999 -9999 -9999-9999 -9999 -9999 -9999 -9999 -9999 -9999 -9999 -9999 -9999 -9999 -9999 -9999 -9999 -9999 -9999 -9999 -9999 -9999 -9999 -9999 -9999 -9999 -9999 -9999 -9999 -9999 -9999 -9999 -9999 -9999 -9999 -9999 -9999 -9999 -9999

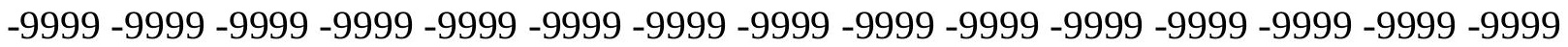

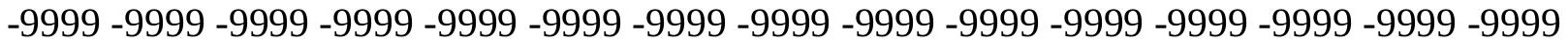
-9999 -9999 -9999 -9999 -9999 -9999 -9999 -9999 -9999 -9999 -9999 -9999 -9999 -9999 -9999 -9999 -9999 -9999 -9999 -9999 -9999 -9999 -9999 -9999 -9999 -9999 -9999 -9999 -9999 -9999 -9999 -9999 -9999 -9999 -9999 -9999 -9999 -9999 -9999 -9999 -9999 -9999 -9999 -9999 -9999 -9999 -9999 -9999 -9999 -9999 -9999 -9999 -9999 -9999 -9999 -9999 -9999 -9999 -9999 -9999 -

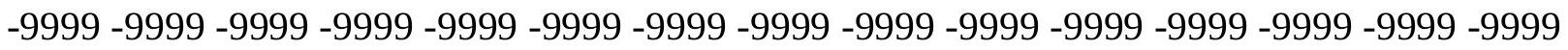
-9999 -9999 -9999 -9999 -9999 -9999 -9999 -9999 -9999 -9999 -9999 -9999 -9999 -9999 -9999 -

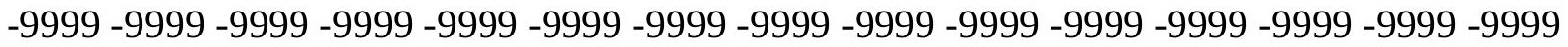
-9999 -9999 -9999 -9999 -9999 -9999 -9999 -9999 -9999 -9999 -9999 -9999 -9999 -9999 -9999 -9999 -9999 -9999 -9999 -9999 -9999 -9999 -9999 -9999 -9999 -9999 -9999 -9999 -9999 -9999 -9999 -9999 -9999 -9999 -9999 -9999 -9999 -9999 -9999 -9999 -9999 -9999 -9999 -9999 -9999 -

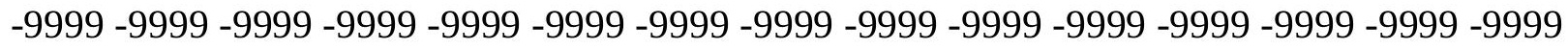

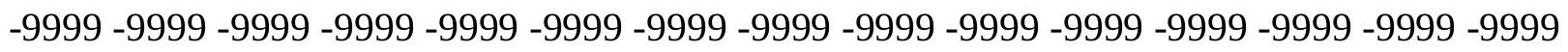
-9999 -9999 -9999 -9999 -9999 -9999 -9999 -9999 -9999 -9999 -9999 -9999 -9999 -9999 -9999 -9999 -9999 -9999 -9999 -9999 -9999 -9999 -9999 -9999 -9999 -9999 -9999 -9999 -9999 -9999 -9999 -9999 -9999 -9999 -9999 -9999 -9999 -9999 -9999 -9999 -9999 -9999 -9999 -9999 -

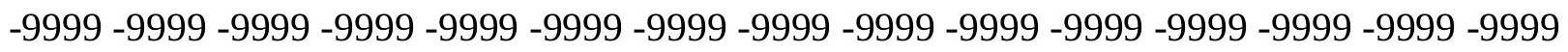
-9999 -9999 -9999 -9999 -9999 -9999 -9999 -9999 -9999 -9999 -9999 -9999 -9999 -9999 -9999 -9999 -9999 -9999 -9999 -9999 -9999 -9999 -9999 -9999 -9999 -9999 -9999 -9999 -9999 -9999 -

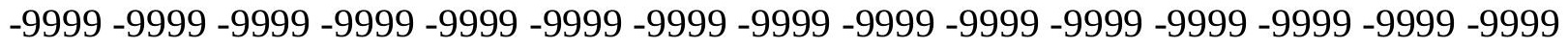
-9999 -9999 -9999 -9999 -9999 -9999 -9999 -9999 -9999 -9999 -9999 -9999 -9999 -9999 -9999 -9999 -9999 -9999 -9999 -9999 -9999 -9999 -9999 -9999 -9999 -9999 -9999 -9999 -9999 -999 -

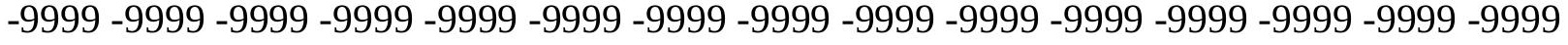
-9999 -9999 -9999 -9999 -9999 -9999 -9999 -9999 -9999 -9999 -9999 -9999 -9999 -9999 -9999 -

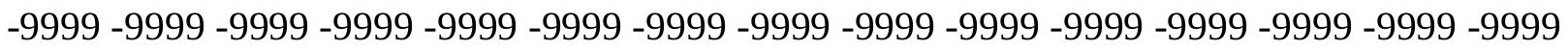

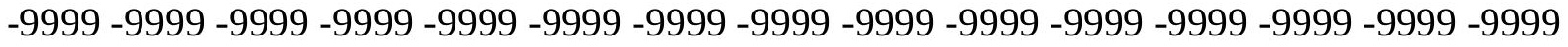

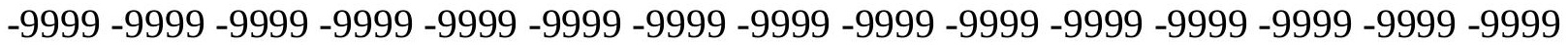

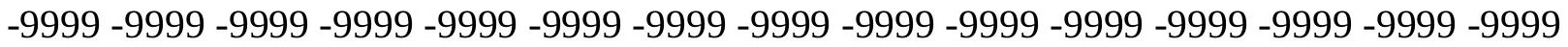

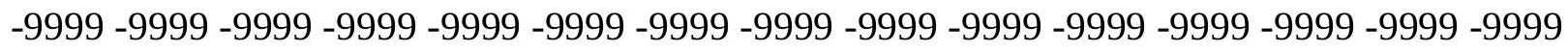

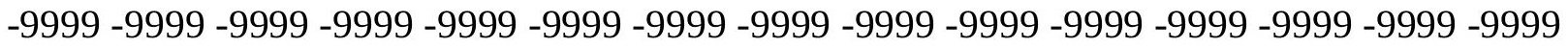

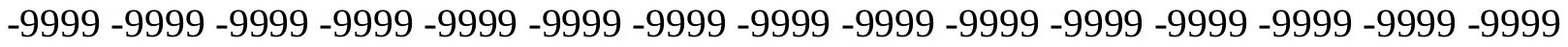
-9999 -9999 -9999 -9999 -9999 -9999 -9999 -9999 -9999 -9999 -9999 -9999 -9999 -9999 -9999 -

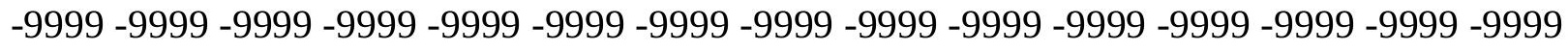

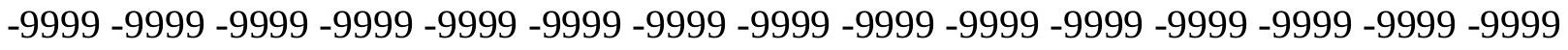
-9999 -9999 -9999 -9999 -9999 -9999 -9999 -9999 -9999 -9999 -9999 -9999 -9999 -9999 -9999 -9999 -9999 -9999 -9999 -9999 -9999 -9999 -9999 -9999-9999 -9999 -9999 -9999 -9999 -9999 -9999 -9999 -9999 -9999 -9999 -9999 -9999 -9999 -9999 -9999 -9999 -9999 -9999 -9999 -9999 -

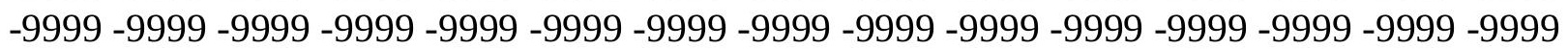


-9999 -9999 -9999 -9999 -9999 -9999 -9999 -9999 -9999 -9999 -9999 -9999 -9999 -9999 -9999 -9999 -9999 -9999 -9999 -9999 -9999 -9999 -9999 -9999 -9999 -9999 -9999 -9999 -9999 -

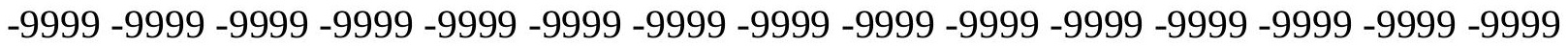
-9999 -9999 -9999 -9999 -9999 -9999 -9999 -9999 -9999 -9999 -9999 -9999 -9999 -9999 -9999 -9999 -9999 -9999 -9999 -9999 -9999 -9999 -9999 -9999 -9999 -9999 -9999 -9999 -9999 -9999 -9999 -9999 -9999 -9999 -9999 -9999 -9999 -9999 -9999 -9999 -9999 -9999 -9999 -9999 -9999 -9999 -9999 -9999 -9999 -9999 -9999 -9999 -9999 -9999 -9999 -9999 -9999 -9999 -9999 -9999

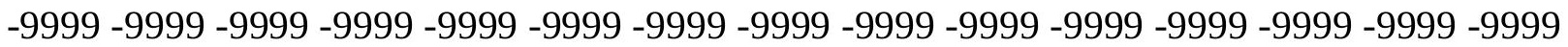

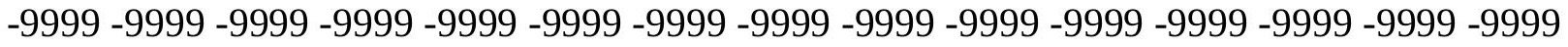
-9999 -9999 -9999 -9999 -9999 -9999 -9999 -9999 -9999 -9999 -9999 -9999 -9999 -9999 -9999 -9999 -9999 -9999 -9999 -9999 -9999 -9999 -9999 -9999 -9999 -9999 -9999 -9999 -9999 -9999 -9999 -9999 -9999 -9999 -9999 -9999 -9999 -9999 -9999 -9999 -9999 -9999 -9999 -9999 -9999 -9999 -9999 -9999 -9999 -9999 -9999 -9999 -9999 -9999 -9999 -9999 -9999 -9999 -9999 -9999 -9999 -9999 -9999 -9999 -9999 -9999 -9999 -9999 -9999 -9999 -9999 -9999 -9999 -9999 -9999 -9999 -9999 -9999 -9999 -9999 -9999 -9999 -9999 -9999 -9999 -9999 -9999 -9999 -9999 -9999 -

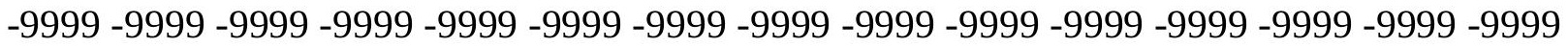
-9999 -9999 -9999 -9999 -9999 -9999 -9999 -9999 -9999 -9999 -9999 -9999 -9999 -9999 -9999 -9999 -9999 -9999 -9999 -9999 -9999 -9999 -9999 -9999 -9999 -9999 -9999 -9999 -9999 - 9999 -9999 -9999 -9999 -9999 -9999 -9999 -9999 -9999 -9999 -9999 -9999 -9999 -9999 -9999 -9999 -

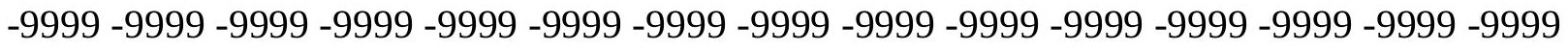

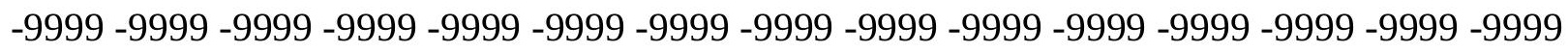

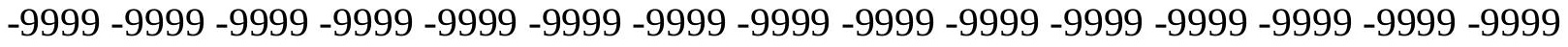
-9999 -9999 -9999 -9999 -9999 -9999 -9999 -9999 -9999 -9999 -9999 -9999 -9999 -9999 -9999 -9999 -9999 -9999 -9999 -9999 -9999 -9999 -9999 -9999 -9999 -9999 -9999 -9999 -9999 -9999 -

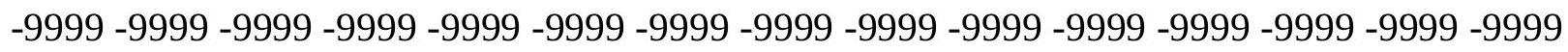
-9999 -9999 -9999 -9999 -9999 -9999 -9999 -9999 -9999 -9999 -9999 -9999 -9999 -9999 -9999 -9999 -9999 -9999 -9999 -9999 -9999 -9999 -9999 -9999 -9999 -9999 -9999 -9999 -9999 -9999 -9999 -9999 -9999 -9999 -9999 -9999 -9999 -9999 -9999 -9999 -9999 -9999 -9999 -9999 -9999 -9999 -9999 -9999 -9999 -9999 -9999 -9999 -9999 -9999 -9999 -9999 -9999 -9999 -9999 -9999 -9999 -9999 -9999 -9999 -9999 -9999 -9999 -9999 -9999 -9999 -9999 -9999 -9999 -999 -

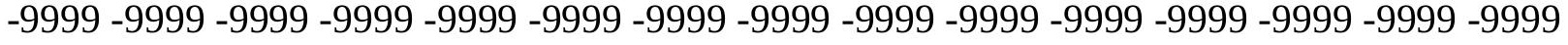
-9999 -9999 -9999 -9999 -9999 -9999 -9999 -9999 -9999 -9999 -9999 -9999 -9999 -9999 -9999 -

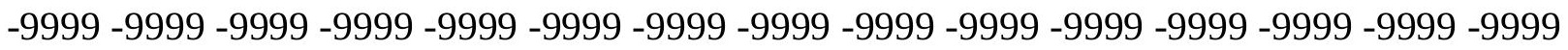

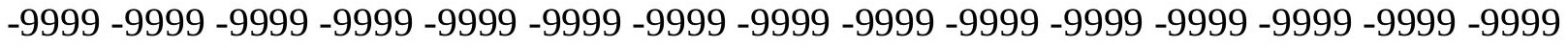

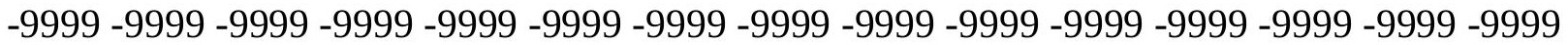

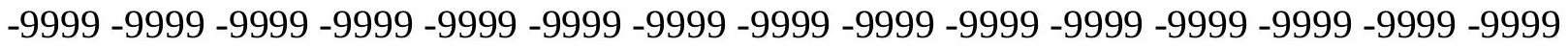

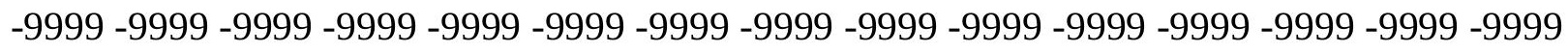

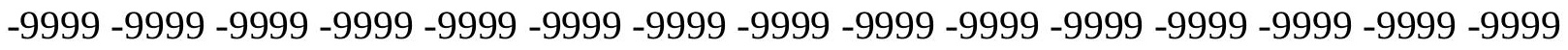

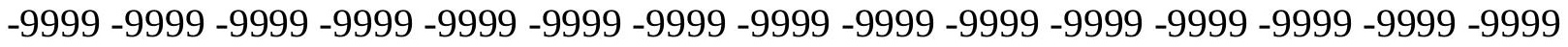
-9999 -9999 -9999 -9999 -9999 -9999 -9999 -9999 -9999 -9999 -9999 -9999 -9999 -9999 -9999 -

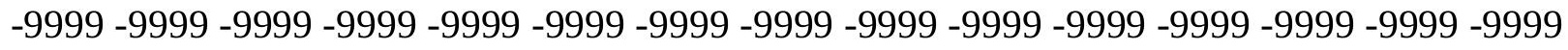

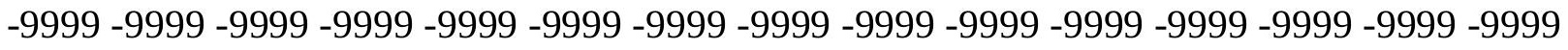
-9999 -9999 -9999 -9999 -9999 -9999 -9999 -9999 -9999 -9999 -9999 -9999 -9999 -9999 -9999 -9999 -9999 -9999 -9999 -9999 -9999 -9999 -9999 -9999-9999 -9999 -9999 -9999 -9999 -9999 -9999 -9999 -9999 -9999 -9999 -9999 -9999 -9999 -9999 -9999 -9999 -9999 -9999 -9999 -9999 -

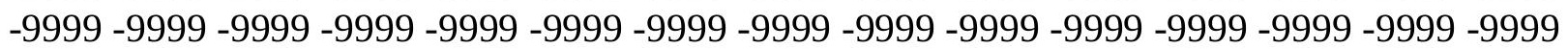


-9999 -9999 -9999 -9999 -9999 -9999 -9999 -9999 -9999 -9999 -9999 -9999 -9999 -9999 -9999 -9999 -9999 -9999 -9999 -9999 -9999 -9999 -9999 -9999 -9999 -9999 -9999 -9999 -9999 -9999 -

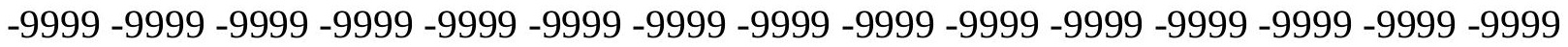
-9999 -9999 -9999 -9999 -9999 -9999 -9999 -9999 -9999 -9999 -9999 -9999 -9999 -9999 -9999 -9999 -9999 -9999 -9999 -9999 -9999 -9999 -9999 -9999-9999 -9999 -9999 -9999 -9999 -9999 -9999 -9999 -9999 -9999 -9999 -9999 -9999 -9999 -9999 -9999 -9999 -9999 -9999 -9999 -9999 -

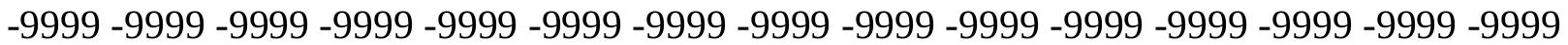
-9999 -9999 -9999 -9999 -9999 -9999 -9999 -9999 -9999 -9999 -9999 -9999 -9999 -9999 -9999 -9999 -9999 -9999 -9999 -9999 -9999 -9999 -9999 -9999 -9999 -9999 -9999 -9999 -9999 -9999 -9999 -9999 -9999 -9999 -9999 -9999 -9999 -9999 -9999 -9999 -9999 -9999 -9999 -9999 -9999 -9999 -9999 -9999 -9999 -9999 -9999 -9999 -9999 -9999 -9999 -9999 -9999 -9999 -9999 -9999 -9999 -9999 -9999 -9999 -9999 -9999 -9999 -9999 -9999 -9999 -9999 -9999 -9999 -9999 -9999 -9999 -9999 -9999 -9999 -9999 -9999 -9999 -9999 -9999 -9999 -9999 -9999 -9999 -9999 -9999 -9999 -9999 -9999 -9999 -9999 -9999 -9999 -9999 -9999 -9999 -9999 -9999 -9999 -9999 -9999 -9999 -9999 -9999 -9999 -9999 -9999 -9999 -9999 -9999 -9999 -9999 -9999 -9999 -9999 -

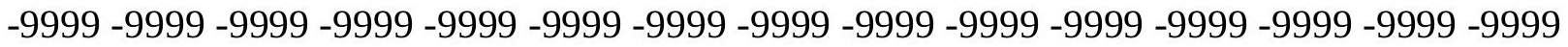
-9999 -9999 -9999 -9999 -9999 -9999 -9999 -9999 -9999 -9999 -9999 -9999 -9999 -9999 -9999 -9999 -9999 -9999 -9999 -9999 -9999 -9999 -9999 -9999 -9999 -9999 -9999 -9999 -9999 -9999 -9999 -9999 -9999 -9999 -9999 -9999 -9999 -9999 -9999 -9999 -9999 -9999 -9999 -9999 -9999 -

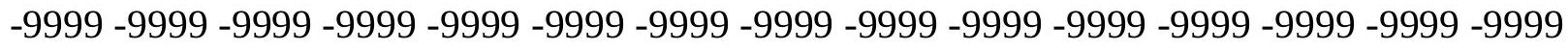

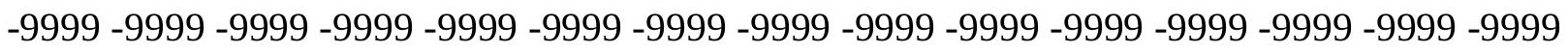
-9999 -9999 -9999 -9999 -9999 -9999 -9999 -9999 -9999 -9999 -9999 -9999 -9999 -9999 - 9999 -9999 -9999 -9999 -9999 -9999 -9999 -9999 -9999 -9999 -9999 -9999 -9999 -9999 -9999 -9999 -9999 -9999 -9999 -9999 -9999 -9999 -9999 -9999 -9999 -9999 -9999 -9999 -9999 -9999 -9999 -

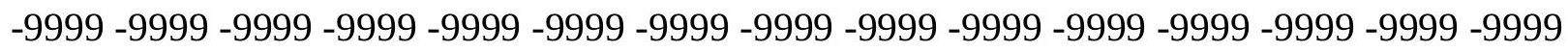
-9999 -9999 -9999 -9999 -9999 -9999 -9999 -9999 -9999 -9999 -9999 -9999 -9999 -9999 -9999 -9999 -9999 -9999 -9999 -9999 -9999 -9999 -9999 -9999 -9999 -9999 -9999 -9999 -9999 -9999 -

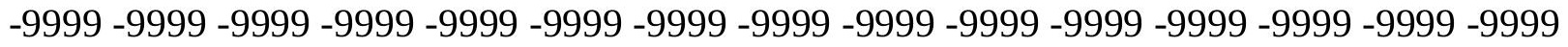
-9999 -9999 -9999 -9999 -9999 -9999 -9999 -9999 -9999 -9999 -9999 -9999 -9999 -9999 -9999 -9999 -9999 -9999 -9999 -9999 -9999 -9999 -9999 -9999 -9999 -9999 -9999 -9999 -9999 -999 -9999 -9999 -9999 -9999 -9999 -9999 -9999 -9999 -9999 -9999 -9999 -9999 -9999 -9999 -9999 -9999 -9999 -9999 -9999 -9999 -9999 -9999 -9999 -9999 -9999 -9999 -9999 -9999 -9999 -9999 -

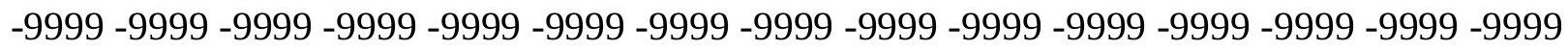

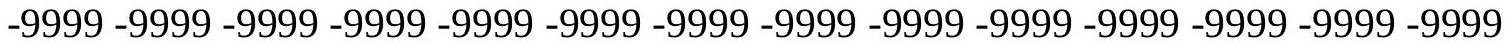
-9999 -9999 -9999 -9999 -9999 -9999 -9999 -9999 -9999 -9999 -9999 -9999 -9999 -9999 -9999

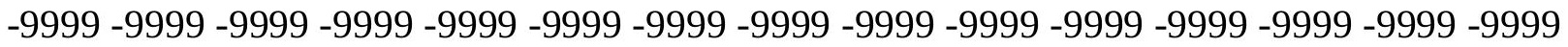

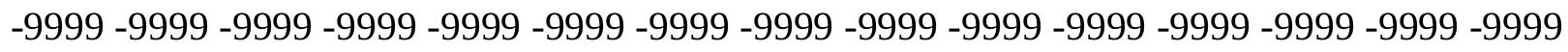

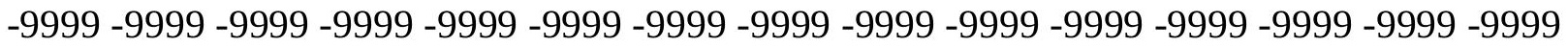

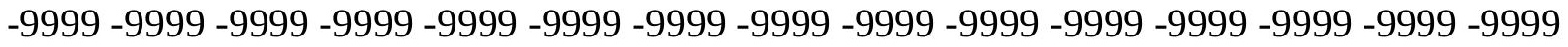
-9999 -9999 -9999 -9999 -9999 -9999 -9999 -9999 -9999 -9999 -9999 -9999 -9999 -9999 -9999 -

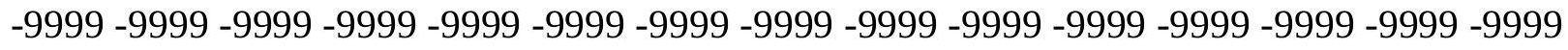

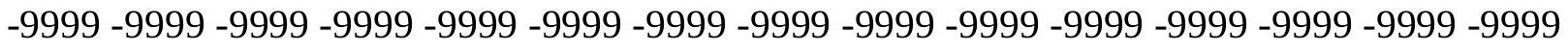
-9999 -9999 -9999 -9999 -9999 -9999 -9999 -9999 -9999 -9999 -9999 -9999 -9999 -9999 -9999 -9999 -9999 -9999 -9999 -9999 -9999 -9999 -9999 -9999-9999 -9999 -9999 -9999 -9999 -9999 -9999 -9999 -9999 -9999 -9999 -9999 -9999 -9999 -9999 -9999 -9999 -9999 -9999 -9999 -9999 -

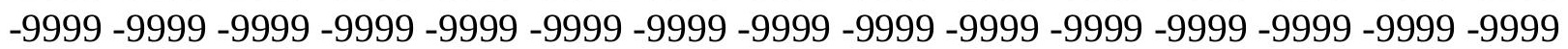


-9999 -9999 -9999 -9999 -9999 -9999 -9999 -9999 -9999 -9999 -9999 -9999 -9999 -9999 -9999 -9999 -9999 -9999 -9999 -9999 -9999 -9999 -9999 -9999 -9999 -9999 -9999 -9999 -9999 -9999 -

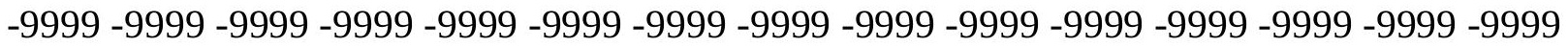
-9999 -9999 -9999 -9999 -9999 -9999 -9999 -9999 -9999 -9999 -9999 -9999 -9999 -9999 -9999 -9999 -9999 -9999 -9999 -9999 -9999 -9999 -9999 -9999-9999 -9999 -9999 -9999 -9999 -9999 -9999 -9999 -9999 -9999 -9999 -9999 -9999 -9999 -9999 -9999 -9999 -9999 -9999 -9999 -9999 -9999 -9999 -9999 -9999 -9999 -9999 -9999 -9999 -9999 -9999 -9999 -9999 -9999 -9999 -9999

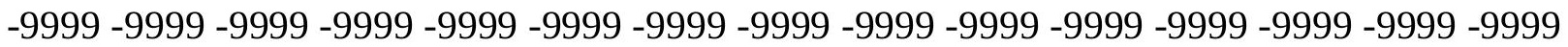

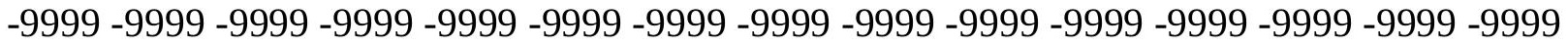
-9999 -9999 -9999 -9999 -9999 -9999 -9999 -9999 -9999 -9999 -9999 -9999 -9999 -9999 -9999 -9999 -9999 -9999 -9999 -9999 -9999 -9999 -9999 -9999 -9999 -9999 -9999 -9999 -9999 -9999 -9999 -9999 -9999 -9999 -9999 -9999 -9999 -9999 -9999 -9999 -9999 -9999 -9999 -9999 -9999 -9999 -9999 -9999 -9999 -9999 -9999 -9999 -9999 -9999 -9999 -9999 -9999 -9999 -9999 -9999 -9999 -9999 -9999 -9999 -9999 -9999 -9999 -9999 -9999 -9999 -9999 -9999 -9999 -9999 -9999 -9999 -9999 -9999 -9999 -9999 -9999 -9999 -9999 -9999 -9999 -9999 -9999 -9999 -9999

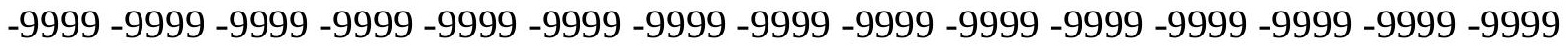
-9999 -9999 -9999 -9999 -9999 -9999 -9999 -9999 -9999 -9999 -9999 -9999 -9999 -9999 -9999 -9999 -9999 -9999 -9999 -9999 -9999 -9999 -9999 -9999 -9999 -9999 -9999 -9999 -9999 -9999 -9999 -9999 -9999 -9999 -9999 -9999 -9999 -9999 -9999 -9999 -9999 -9999 -9999 -9999 -9999 -

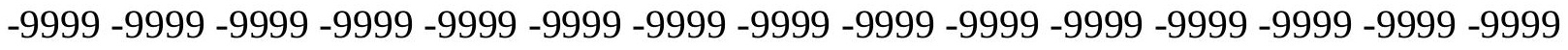

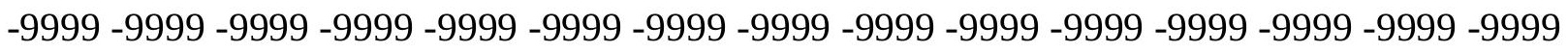
-9999 -9999 -9999 -9999 -9999 -9999 -9999 -9999 -9999 -9999 -9999 -9999 -9999 -9999 -9999 -9999 -9999 -9999 -9999 -9999 -9999 -9999 -9999 -9999 -9999 -9999 -9999 -9999 -9999 -9999 -9999 -9999 -9999 -9999 -9999 -9999 -9999 -9999 -9999 -9999 -9999 -9999 -9999 -9999 -9999 -

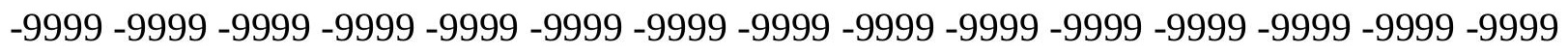
-9999 -9999 -9999 -9999 -9999 -9999 -9999 -9999 -9999 -9999 -9999 -9999 -9999 -9999 -9999 -9999 -9999 -9999 -9999 -9999 -9999 -9999 -9999 -9999 -9999 -9999 -9999 -9999 -9999 -9999 -

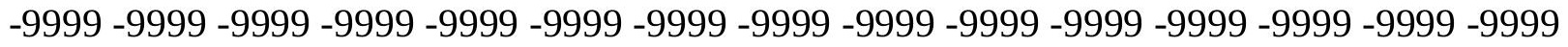
-9999 -9999 -9999 -9999 -9999 -9999 -9999 -9999 -9999 -9999 -9999 -9999 -9999 -9999 -9999 -9999 -9999 -9999 -9999 -9999 -9999 -9999 -9999 -9999 -9999 -9999 -9999 -9999 -9999 -999 -9999 -9999 -9999 -9999 -9999 -9999 -9999 -9999 -9999 -9999 -9999 -9999 -9999 -9999 -9999 -9999 -9999 -9999 -9999 -9999 -9999 -9999 -9999 -9999 -9999 -9999 -9999 -9999 -9999 -9999 -

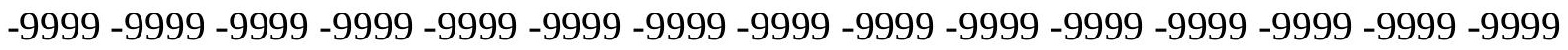

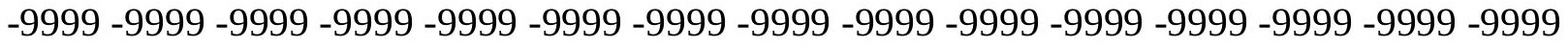

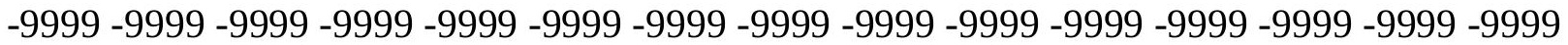

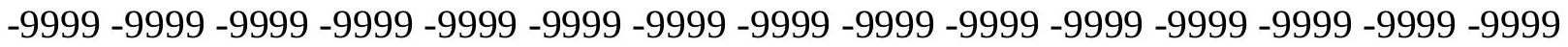

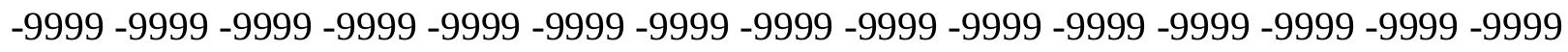

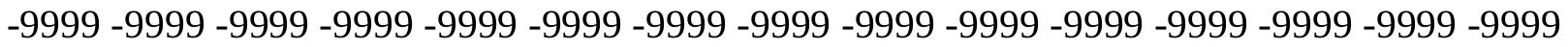
-9999 -9999 -9999 -9999 -9999 -9999 -9999 -9999 -9999 -9999 -9999 -9999 -9999 - 9999 - -999 -9999 -9999 -9999 -9999 -9999 -9999 -9999 -9999 -9999 -9999 -9999 -9999 -9999 -9999 - -999 -

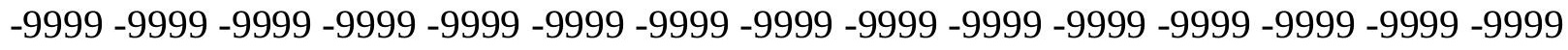

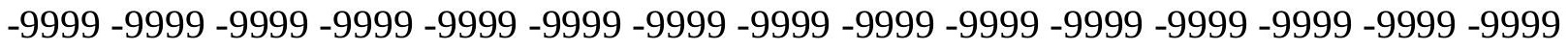
-9999 -9999 -9999 -9999 -9999 -9999 -9999 -9999 -9999 -9999 -9999 -9999 -9999 -9999 -9999 -9999 -9999 -9999 -9999 -9999 -9999 -9999 -9999 -9999-9999 -9999 -9999 -9999 -9999 -9999 -9999 -9999 -9999 -9999 -9999 -9999 -9999 -9999 -9999 -9999 -9999 -9999 -9999 -9999 -9999 -

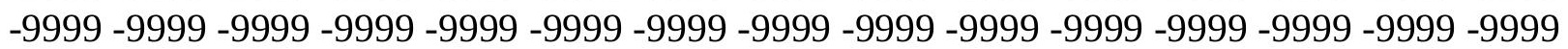


-9999 -9999 -9999 -9999 -9999 -9999 -9999 -9999 -9999 -9999 -9999 -9999 -9999 -9999 -9999 -9999 -9999 -9999 -9999 -9999 -9999 -9999 -9999 -9999 -9999 -9999 -9999 -9999 -9999 -9999 -9999 -9999 -9999 -9999 -9999 -9999 -9999 -9999 -9999 -9999 -9999 -9999 -9999 -9999 -9999 -9999 -9999 -9999 -9999 -9999 -9999 -9999 -9999 -9999 -9999 -9999 -9999 -9999 -9999 -9999 -9999 -9999 -9999 -9999 -9999 -9999 -9999 -9999 -9999 -9999 -9999 -9999 -9999 -9999 -9999 -9999 -9999 -9999 -9999 -9999 -9999 -9999 -9999 -9999 -9999 -9999 -9999 -9999 -9999 -9999 -9999 -9999 -9999 -9999 -9999 -9999 -9999 -9999 -9999 -9999 -9999 -9999 -9999 -9999 -9999 -

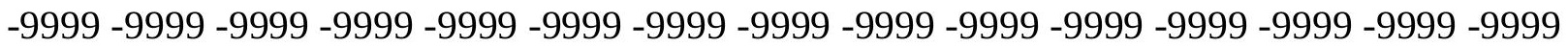
-9999 -9999 -9999 -9999 -9999 -9999 -9999 -9999 -9999 -9999 -9999 -9999 -9999 -9999 -9999 -9999 -9999 -9999 -9999 -9999 -9999 -9999 -9999 -9999 -9999 -9999 -9999 -9999 -9999 -9999 -

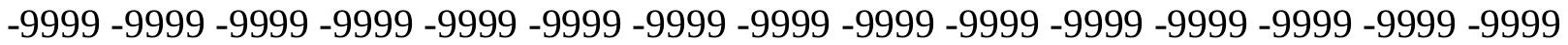
-9999 -9999 -9999 -9999 -9999 -9999 -9999 -9999 -9999 -9999 -9999 -9999 -9999 -9999 -9999 -9999 -9999 -9999 -9999 -9999 -9999 -9999 -9999 -9999 -9999 -9999 -9999 -9999 -9999 -9999 -9999 -9999 -9999 -9999 -9999 -9999 -9999 -9999 -9999 -9999 -9999 -9999 -9999 -9999 -9999 -9999 -9999 -9999 -9999 -9999 -9999 -9999 -9999 -9999 -9999 -9999 -9999 -9999 -9999 -9999

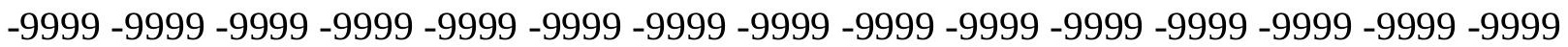
-9999 -9999 -9999 -9999 -9999 -9999 -9999 -9999 -9999 -9999 -9999 -9999 -9999 -9999 -9999 -9999 -9999 -9999 -9999 -9999 -9999 -9999 -9999 -9999 -9999 -9999 -9999 -9999 -9999 -9999 -9999 -9999 -9999 -9999 -9999 -9999 -9999 -9999 -9999 -9999 -9999 -9999 -9999 -9999 -9999 -9999 -9999 -9999 -9999 -9999 -9999 -9999 -9999 -9999 -9999 -9999 -9999 -9999 -9999 -9999 -9999 -9999 -9999 -9999 -9999 -9999 -9999 -9999 -9999 -9999 -9999 -9999 -9999 -9999 -9999 -9999 -9999 -9999 -9999 -9999 -9999 -9999 -9999 -9999 -9999 -9999 -9999 -9999 -9999 -9999 -9999 -9999 -9999 -9999 -9999 -9999 -9999 -9999 -9999 -9999 -9999 -9999 -9999 -9999 -9999 -9999 -9999 -9999 -9999 -9999 -9999 -9999 -9999 -9999 -9999 -9999 -9999 -9999 -9999 -9999 -9999 -9999 -9999 -9999 -9999 -9999 -9999 -9999 -9999 -9999 -9999 -9999 -9999 -9999 -9999 -9999 -9999 -9999 -9999 -9999 -9999 -9999 -9999 -9999 -9999 -9999 -9999 -9999 -9999 -9999 -9999 -9999 -9999 -9999 -9999 -9999 -9999 -9999 -9999 -9999 -9999 -9999 -9999 -9999 -9999 -9999 -9999 -9999 -9999 -9999 -9999 -9999 -9999 -9999 -9999 -9999 -9999 -9999 -9999

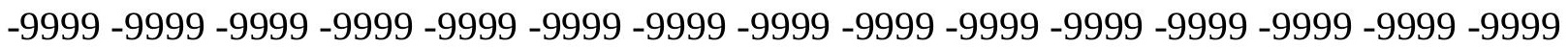
-9999 -9999 -9999 -9999 -9999 -9999 -9999 -9999 -9999 -9999 -9999 -9999 -9999 -9999 -9999 -9999 -9999 -9999 -9999 -9999 -9999 -9999 -9999 -9999 -9999 -9999 -9999 -9999 -9999 -9999 -

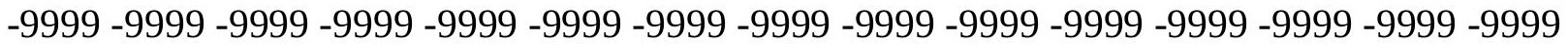
-9999 -9999 -9999 -9999 -9999 -9999 -9999 -9999 -9999 -9999 -9999 -9999 -9999 -9999 -9999 -9999 -9999 -9999 -9999 -9999 -9999 -9999 -9999 -9999 -9999 -9999 -9999 -9999 -9999 -9999 -9999 -9999 -9999 -9999 -9999 -9999 -9999 -9999 -9999 -9999 -9999 -9999 -9999 -9999 -9999 -9999 -9999 -9999 -9999 -9999 -9999 -9999 -9999 -9999 -9999 -9999 -9999 -9999 -9999 -9999 -9999 -9999 -9999 -9999 -9999 -9999 -9999 -9999 -9999 -9999 -9999 -9999 -9999 -9999 -9999

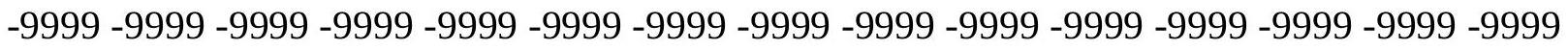
-9999 -9999 -9999 -9999 -9999 -9999 -9999 -9999 -9999 -9999 -9999 -9999 -9999 -9999 -9999 -9999 -9999 -9999 -9999 -9999 -9999 -9999 -9999 -9999 -9999 -9999 -9999 -9999 -9999 -9999 -9999 -9999 -9999 -9999 -9999 -9999 -9999 -9999 -9999 -9999 -9999 -9999 -9999 -9999 -9999 -999 -9999 -9999 -9999 -9999 -9999 -9999 -9999 -9999 -9999 -9999 -9999 -9999 -9999 -9999 -9999 -9999 -9999 -9999 -9999 -9999 -9999 -9999 -9999 -9999 -9999 -9999 -9999 -9999 -9999 -9999 -9999 -9999 -9999 -9999 -9999 -9999 -9999 -9999 -9999 -9999 -9999 -9999 -9999 -9999 -9999 -9999 -9999 -9999 -9999 -9999 -9999 -9999 -9999 -9999 -9999 -9999 -9999 -9999 -9999 -9999 -9999 -9999 -9999 -9999 -9999 -9999 -9999 -9999 -9999 -9999 -9999 -9999 -9999 -9999 
-9999 -9999 -9999 -9999 -9999 -9999 -9999 -9999 -9999 -9999 -9999 -9999 -9999 -9999 -9999 -9999 -9999 -9999 -9999 -9999 -9999 -9999 -9999 -9999 -9999 -9999 -9999 -9999 -9999 -9999 -

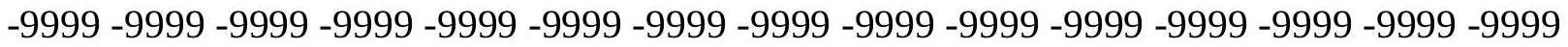
-9999 -9999 -9999 -9999 -9999 -9999 -9999 -9999 -9999 -9999 -9999 -9999 -9999 -9999 -9999 -9999 -9999 -9999 -9999 -9999 -9999 -9999 -9999 -9999-9999 -9999 -9999 -9999 -9999 -9999 -9999 -9999 -9999 -9999 -9999 -9999 -9999 -9999 -9999 -9999 -9999 -9999 -9999 -9999 -9999 -9999 -9999 -9999 -9999 -9999 -9999 -9999 -9999 -9999 -9999 -9999 -9999 -9999 -9999 -9999

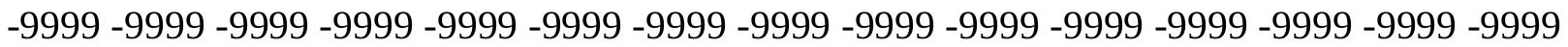

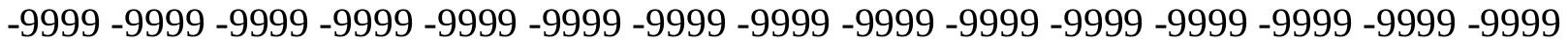
-9999 -9999 -9999 -9999 -9999 -9999 -9999 -9999 -9999 -9999 -9999 -9999 -9999 -9999 -9999 -9999 -9999 -9999 -9999 -9999 -9999 -9999 -9999 -9999 -9999 -9999 -9999 -9999 -9999 -9999 -9999 -9999 -9999 -9999 -9999 -9999 -9999 -9999 -9999 -9999 -9999 -9999 -9999 -9999 -9999 -9999 -9999 -9999 -9999 -9999 -9999 -9999 -9999 -9999 -9999 -9999 -9999 -9999 -9999 -9999 -

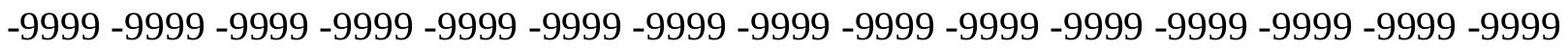
-9999 -9999 -9999 -9999 -9999 -9999 -9999 -9999 -9999 -9999 -9999 -9999 -9999 -9999 -9999 -

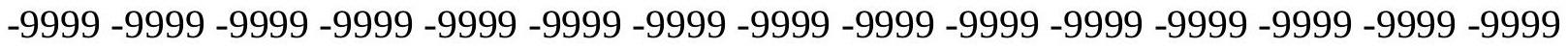
-9999 -9999 -9999 -9999 -9999 -9999 -9999 -9999 -9999 -9999 -9999 -9999 -9999 -9999 -9999 -9999 -9999 -9999 -9999 -9999 -9999 -9999 -9999 -9999 -9999 -9999 -9999 -9999 -9999 -9999 -9999 -9999 -9999 -9999 -9999 -9999 -9999 -9999 -9999 -9999 -9999 -9999 -9999 -9999 -9999 -

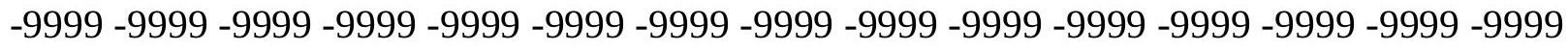

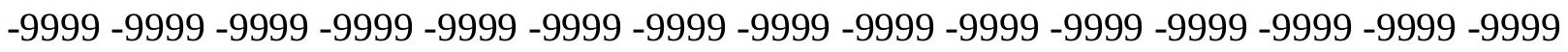

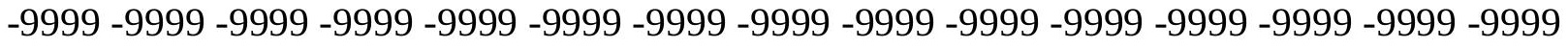
-9999 -9999 -9999 -9999 -9999 -9999 -9999 -9999 -9999 -9999 -9999 -9999 -9999 -9999 -9999 -9999 -9999 -9999 -9999 -9999 -9999 -9999 -9999 -9999 -9999 -9999 -9999 -9999 -9999 -9999 -

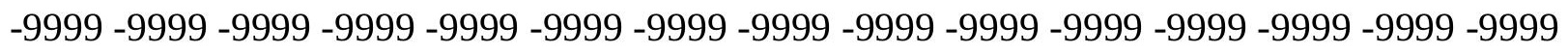
-9999 -9999 -9999 -9999 -9999 -9999 -9999 -9999 -9999 -9999 -9999 -9999 -9999 -9999 -9999 -9999 -9999 -9999 -9999 -9999 -9999 -9999 -9999 -9999 -9999 -9999 -9999 -9999 -9999 -

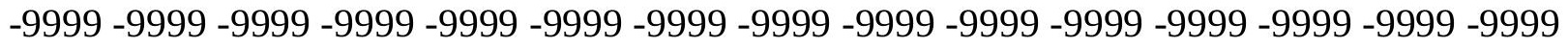
-9999 -9999 -9999 -9999 -9999 -9999 -9999 -9999 -9999 -9999 -9999 -9999 -9999 -9999 -9999 -9999 -9999 -9999 -9999 -9999 -9999 -9999 -9999 -9999 -9999 -9999 -9999 -9999 -9999 -999 -

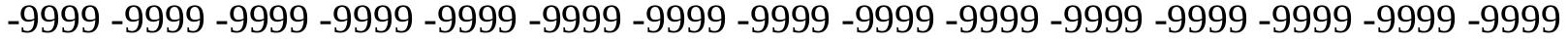
-9999 -9999 -9999 -9999 -9999 -9999 -9999 -9999 -9999 -9999 -9999 -9999 -9999 -9999 -9999 -

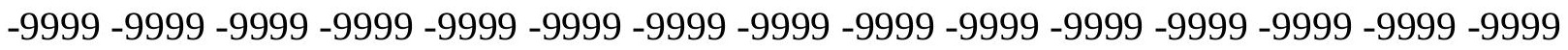

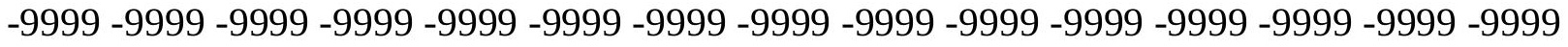

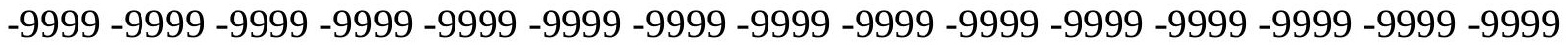
-9999 -9999 -9999 -9999 -9999 -9999 -9999 -9999 -9999 -9999 -9999 -9999 -9999 -9999 -9999

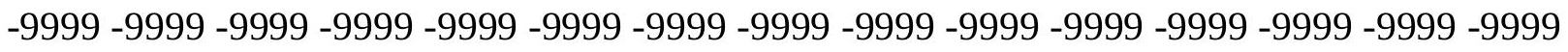

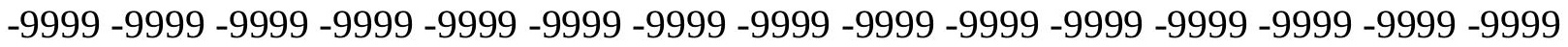
-9999 -9999 -9999 -9999 -9999 -9999 -9999 -9999 -9999 -9999 -9999 -9999 -9999 - 9999 - -999 -9999 -9999 -9999 -9999 -9999 -9999 -9999 -9999 -9999 -9999 -9999 -9999 -9999 -9999 -9999 -

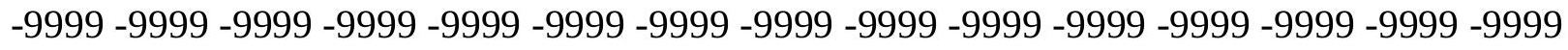

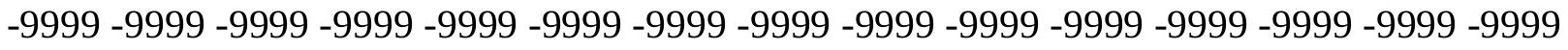
-9999 -9999 -9999 -9999 -9999 -9999 -9999 -9999 -9999 -9999 -9999 -9999 -9999 -9999 -9999 -9999 -9999 -9999 -9999 -9999 -9999 -9999 -9999 -9999-9999 -9999 -9999 -9999 -9999 -9999 -9999 -9999 -9999 -9999 -9999 -9999 -9999 -9999 -9999 -9999 -9999 -9999 -9999 -9999 -9999 -

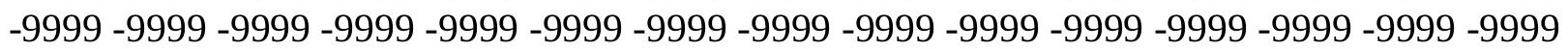


-9999 -9999 -9999 -9999 -9999 -9999 -9999 -9999 -9999 -9999 -9999 -9999 -9999 -9999 -9999 -9999 -9999 -9999 -9999 -9999 -9999 -9999 -9999 -9999 -9999 -9999 -9999 -9999 -9999 -9999 -9999 -9999 -9999 -9999 -9999 -9999 -9999 -9999 -9999 -9999 -9999 -9999 -9999 -9999 - 9999 -9999 -9999 -9999 -9999 -9999 -9999 -9999 -9999 -9999 -9999 -9999 -9999 -9999 -9999 -9999 -9999 -9999 -9999 -9999 -9999 -9999 -9999 -9999 -9999 -9999 -9999 -9999 -9999 -9999 - -9999 -9999 -9999 -9999 -9999 -9999 -9999 -9999 -9999 -9999 -9999 -9999 -9999 -9999 -9999 -9999 -9999 -9999 -9999 -9999 -9999 -9999 -9999 -9999 -9999 -9999 -9999 -9999 -9999 -9999

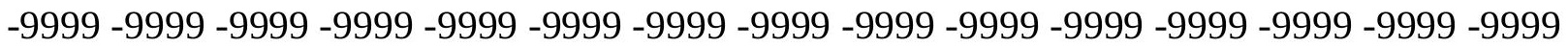

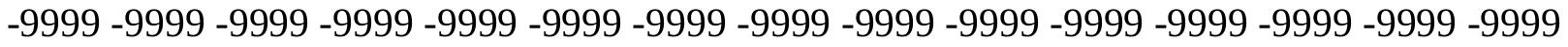
-9999 -9999 -9999 -9999 -9999 -9999 -9999 -9999 -9999 -9999 -9999 -9999 -9999 -9999 -9999

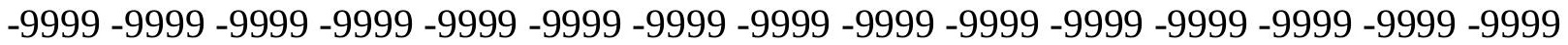
-9999 -9999 -9999 -9999 -9999 -9999 -9999 -9999 -9999 -9999 -9999 -9999 -9999 -9999 -9999 -9999 -9999 -9999 -9999 -9999 -9999 -9999 -9999 -9999 -9999 -9999 -9999 -9999 -9999 -9999 -9999 -9999 -9999 -9999 -9999 -9999 -9999 -9999 -9999 -9999 -9999 -9999 -9999 -9999 - -9999 -9999 -9999 -9999 -9999 -9999 -9999 -9999 -9999 -9999 -9999 -9999 -9999 -9999 -9999 -9999

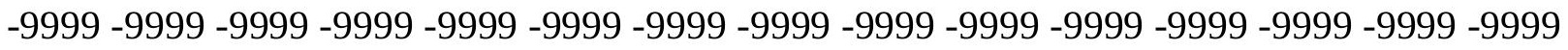
-9999 -9999 -9999 -9999 -9999 -9999 -9999 -9999 -9999 -9999 -9999 -9999 -9999 -9999 -9999 -9999 -9999 -9999 -9999 -9999 -9999 -9999 -9999 -9999 -9999 -9999 -9999 -9999 -9999 -9999 -9999 -9999 -9999 -9999 -9999 -9999 -9999 -9999 -9999 -9999 -9999 -9999 -9999 -9999 -9999 -

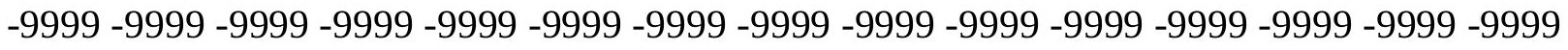
-9999 -9999 -9999 -9999 -9999 -9999 -9999 -9999 -9999 -9999 -9999 -9999 -9999 -9999 -9999 -999 -9999 -9999 -9999 -9999 -9999 -9999 -9999 -9999 -9999 -9999 -9999 -9999 -9999 -9999 -9999 -9999 -9999 -9999 -9999 -9999 -9999 -9999 -9999 -9999 -9999 -9999 -9999 -9999 -9999 -9999 -9999 -9999 -9999 -9999 -9999 -9999 -9999 -9999 -9999 -9999 -9999 -9999 -9999 -9999 -9999 -9999 -9999 -9999 -9999 -9999 -9999 -9999 -9999 -9999 -9999 -9999 -9999 -9999 -9999 -9999 -9999 -9999 -9999 -9999 -9999 -9999 -9999 -9999 -9999 -9999 -9999 -9999 -9999 -9999 -9999 -9999 -9999 -9999 -9999 -9999 -9999 -9999 -9999 -9999 -9999 -9999 -9999 -9999 -9999 -9999 -9999 -9999 -9999 -9999 -9999 -9999 -9999 -9999 -9999 -9999 -9999 -9999 -9999 -9999 -9999 -9999 -9999 -9999 -9999 -9999 -9999 -9999 -9999 -9999 -9999 -9999 -9999 -9999 -9999 -9999 -9999 -9999 -9999 -9999 -9999 -9999 -9999 -9999 -9999 -9999 -9999 -9999 -9999 -9999 -999 -9999 -9999 -9999 -9999 -9999 -9999 -9999 -9999 -9999 -9999 -9999 -9999 -9999 -9999 -9999 -9999 -9999 -9999 -9999 -9999 -9999 -9999 -9999 -9999 -9999 -9999 -9999 -9999 -9999 -

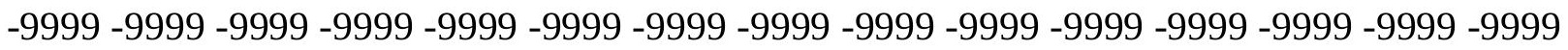

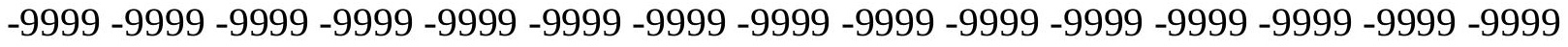

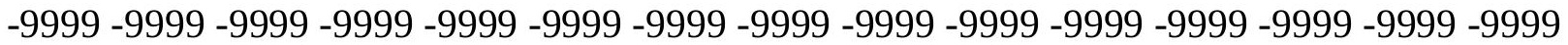
-9999 -9999 -9999 -9999 -9999 -9999 -9999 -9999 -9999 -9999 -9999 -9999 -9999 -9999 -9999 -

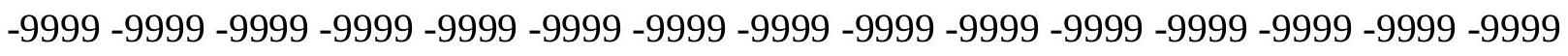

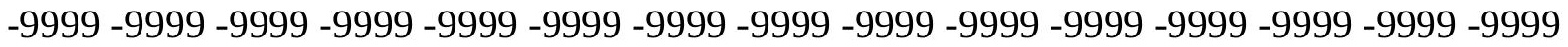

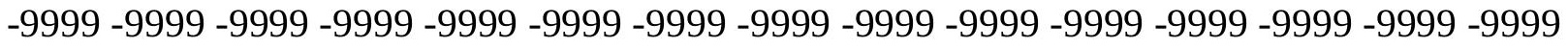
-9999 -9999 -9999 -9999 -9999 -9999 -9999 -9999 -9999 -9999 -9999 -9999 -9999 -9999 -9999 -

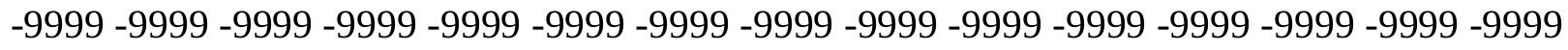

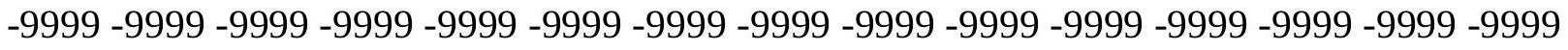
-9999 -9999 -9999 -9999 -9999 -9999 -9999 -9999 -9999 -9999 -9999 -9999 -9999 -9999 -9999 -9999 -9999 -9999 -9999 -9999 -9999 -9999 -9999 -9999-9999 -9999 -9999 -9999 -9999 -9999 -9999 -9999 -9999 -9999 -9999 -9999 -9999 -9999 -9999 -9999 -9999 -9999 -9999 -9999 -9999 -

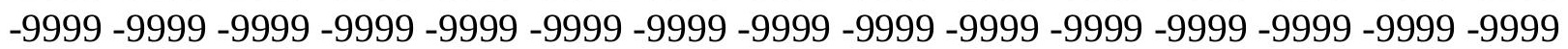


-9999 -9999 -9999 -9999 -9999 -9999 -9999 -9999 -9999 -9999 -9999 -9999 -9999 -9999 -9999 -9999 -9999 -9999 -9999 -9999 -9999 -9999 -9999 -9999 -9999 -9999 -9999 -9999 -9999 -9999 -9999 -9999 -9999 -9999 -9999 -9999 -9999 -9999 -9999 -9999 -9999 -9999 -9999 -9999 -9999 -9999 -9999 -9999 -9999 -9999 -9999 -9999 -9999 -9999 -9999 -9999 -9999 -9999 -9999 -9999 -9999 -9999 -9999 -9999 -9999 -9999 -9999 -9999 -9999 -9999 -9999 -9999 -9999 -9999 -9999 -9999 -9999 -9999 -9999 -9999 -9999 -9999 -9999 -9999 -9999 -9999 -9999 -9999 -9999 -9999 -9999 -9999 -9999 -9999 -9999 -9999 -9999 -9999 -9999 -9999 -9999 -9999 -9999 -9999 -9999

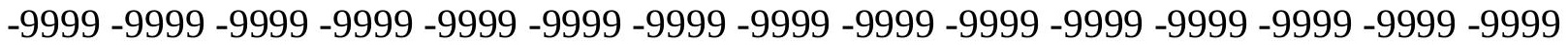
-9999 -9999 -9999 -9999 -9999 -9999 -9999 -9999 -9999 -9999 -9999 -9999 -9999 -9999 -9999 -9999 -9999 -9999 -9999 -9999 -9999 -9999 -9999 -9999 -9999 -9999 -9999 -9999 -9999 -9999 -9999 -9999 -9999 -9999 -9999 -9999 -9999 -9999 -9999 -9999 -9999 -9999 -9999 -9999 -9999 -9999 -9999 -9999 -9999 -9999 -9999 -9999 -9999 -9999 -9999 -9999 -9999 -9999 -9999 -

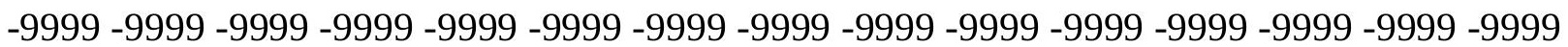
-9999 -9999 -9999 -9999 -9999 -9999 -9999 -9999 -9999 -9999 -9999 -9999 -9999 -9999 -9999 -9999 -9999 -9999 -9999 -9999 -9999 -9999 -9999 -9999 -9999 -9999 -9999 -9999 -9999 -9999 -9999 -9999 -9999 -9999 -9999 -9999 -9999 -9999 -9999 -9999 -9999 -9999 -9999 -9999 -9999 -9999 -9999 -9999 -9999 -9999 -9999 -9999 -9999 -9999 -9999 -9999 -9999 -9999 -9999 -9999 -9999 -9999 -9999 -9999 -9999 -9999 -9999 -9999 -9999 -9999 -9999 -9999 -9999 -9999 -9999 -9999 -9999 -9999 -9999 -9999 -9999 -9999 -9999 -9999 -9999 -9999 -9999 -9999 -9999 -9999 -9999 -9999 -9999 -9999 -9999 -9999 -9999 208.7778015137 203.4349822998203.38621521 203.2493591309203 .0497436523202 .8299407959202 .62159729202 .4010162354 202.1306762695 201.7364196777201.2111663818200.5980987549200.0307006836 199.6294250488199 .3593597412199 .0081787109198 .2435302734197 .1839141846 196.1680450439195 .7426147461196 .0354003906197 .107635498198 .3799285889 199.135635376199 .1737670898198 .2907562256196 .8201751709195 .3364562988 194.4528961182193 .233795166192 .624206543192 .3193969727192 .3193969727 192.624206543192 .9290008545193 .8433074951194 .4528961182195 .0625195 .6721038818 195.6721038818195 .6721038818195 .0625194 .7577056885194 .7577056885195 .0625 195.6721038818196 .2816009521196 .891204834197 .1959991455197 .8054962158 198.1103057861198 .4151000977198 .4151000977198 .1103057861197 .8054962158 197.500793457196 .891204834196 .891204834196 .5863952637196 .5863952637 196.2816009521 196.2816009521 195.9768066406195.6721038818195.0625194.4528961182 193.8433074951193 .5386047363193 .233795166193 .233795166193 .5386047363 193.8433074951194 .1481018066194 .1481018066194 .1481018066193 .8433074951 193.8433074951193 .5386047363192 .9290008545192 .624206543192 .3193969727 191.7097930908190 .795501709189 .8811035156188 .966796875187 .5232696533 186.5915985107185 .9365081787185 .3950500488185 .0375061035184 .8466033936 184.6914672852184 .6251373291184 .6822814941184 .8548126221185 .0461730957 185.1000061035184 .9903717041184 .6705474854184 .2562713623183 .9086303711 183.8553314209184 .200958252184 .9241638184185 .8515319824186 .7998657227 187.64453125188 .3740997314195 .0625195 .0625195 .3672943115195 .9768066406 196.5863952637197 .1959991455198 .1103057861199 .0247039795199 .9389953613 200.8533935547202 .0724945068202 .9868927002 -9999 -9999 -9999 -9999 -9999 -9999 -9999 -9999 -9999 -9999 -9999 -9999 -9999 -9999 -9999 -9999 -9999 -9999 -9999 -9999 -9999 -9999 -9999 -9999 -9999 -9999 -9999 -9999 -9999 -9999 -9999 -9999 -9999 -9999 -9999 -9999 -9999

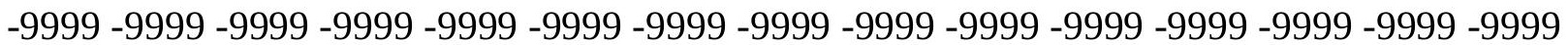


-9999 -9999 -9999 -9999 -9999 -9999 -9999 -9999 -9999 -9999 -9999 -9999 -9999 -9999 -9999 -9999 -9999 -9999 -9999 -9999 -9999 -9999 -9999 -9999 -9999 -9999 -9999 -9999 -9999 -9999 -9999 -9999 -9999 -9999 -9999 -9999 -9999 -9999 -9999 -9999 -9999 -9999 -9999 -9999 -9999 -9999 -9999 -9999 -9999 -9999 -9999 -9999 -9999 -9999 -9999 -9999 -9999 -9999 -9999 -9999 -9999 -9999 -9999 -9999 -9999 -9999 -9999 -9999 -9999 -9999 -9999 -9999 -9999 -9999 -9999 -9999 -9999 -9999 -9999 -9999 -9999 -9999 -9999 -9999 -9999 -9999 -9999 -9999 -9999 -9999 -9999 -9999 -9999 -9999 -9999 -9999 -9999 -9999 -9999 -9999 -9999 -9999 -9999 -9999 -9999

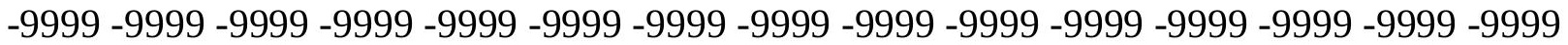
-9999 -9999 -9999 -9999 -9999 -9999 -9999 -9999 -9999 -9999 -9999 -9999 -9999 -9999 -9999 -9999 -9999 -9999 -9999 -9999 -9999 -9999 -9999 -9999 -9999 -9999 -9999 -9999 -9999 -9999 -9999 -9999 -9999 -9999 -9999 -9999 -9999 -9999 -9999 -9999 -9999 -9999 -9999 -9999 -9999 -9999 -9999 -9999 -9999 -9999 -9999 -9999 -9999 -9999 -9999 -9999 -9999 -9999 -9999 -9999 -9999 -9999 -9999 -9999 -9999 -9999 -9999 -9999 -9999 -9999 -9999 -9999 -9999 -9999 -9999 -9999 188.0523986816 189.2716064453 190.1858978271 191.4051055908192 .3193969727 193.5386047363194 .4528961182195 .3672943115193 .6015319824194 .4815368652 195.3317108154196 .1541900635196 .9399108887197 .6631317139198 .3015136719 198.848815918199 .3070983887199 .684463501199 .9988250732200 .2445983887 200.4106140137200 .50050354200 .5273590088200 .4658355713200 .2501678467 199.9850006104199 .7172698975199 .5025634766199 .3488006592199 .1084289551 198.7202758789198 .1280059814197 .3539276123196 .6304931641196 .1710662842 196.0440979004195 .9768066406195 .0625193 .8433074951192 .3193969727192 .0146026611 192.0146026611193 .5386047363195 .3672943115195 .9768066406196 .2816009521195 .0625 193.233795166191 .1002960205189 .5764007568188 .6620025635188 .0523986816 188.0523986816188 .3571929932188 .3571929932188 .966796875189 .5764007568 190.1858978271190 .4907073975190 .795501709190 .795501709190 .4907073975 189.8811035156189 .2716064453189 .2716064453189 .2716064453189 .5764007568 189.8811035156190 .4907073975191 .1002960205191 .4051055908191 .7097930908 192.0146026611192 .0146026611191 .4051055908190 .795501709190 .1858978271 189.2716064453189 .2716064453188 .966796875189 .2716064453189 .5764007568 189.5764007568189 .8811035156189 .8811035156189 .5764007568189 .2716064453 188.966796875188 .966796875188 .966796875189 .2716064453189 .5764007568 189.5764007568189 .8811035156189 .8811035156189 .8811035156189 .8811035156 189.5764007568189 .2716064453188 .6620025635188 .3571929932187 .7476043701 187.1381072998185 .9188995361185 .0045928955183 .7854003906183 .4806976318 182.87109375182 .5662994385181 .9566955566181 .6519012451181 .6519012451 181.3471984863181 .3471984863181 .3471984863181 .6519012451181 .9566955566 181.9566955566181 .7910766602181 .3979949951180 .9319152832180 .3815155029 180.1336669922180 .432800293181 .1337738037182 .2268829346183 .4163513184 184.3982086182 185.1516265869 185.6980133057 186.2428131104 186.8417816162 187.4827880859188 .1913299561188 .8799743652189 .1785125732189 .2524719238 189.8273773193189 .6794891357189 .3692474365188 .8888702393188 .3182373047 187.8165740967187 .7580108643 -9999 -9999 -9999 -9999 -9999 -9999 -9999 -9999 -9999 -9999 -9999 -9999 -9999 -9999 -9999 -9999 -9999 -9999 -9999 -9999 -9999 -9999 -9999 -9999 -9999 -9999 -9999 -9999 -9999 -9999 -9999 -9999 -9999 -9999 -9999 -9999 -9999 -9999 -9999 -9999 -9999 -9999 -9999 -9999 -9999 -9999 -9999 -9999 -9999 -9999 -9999 -9999 -9999 -9999

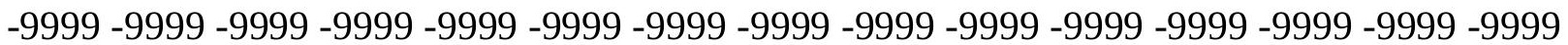


-9999 -9999 -9999 -9999 -9999 -9999 -9999 -9999 -9999 -9999 -9999 -9999 -9999 -9999 -9999 -9999 -9999 -9999 -9999 -9999 -9999 -9999 -9999 -9999 -9999 -9999 -9999 -9999 -9999 -9999 -9999 -9999 -9999 -9999 -9999 -9999 -9999 -9999 -9999 -9999 -9999 -9999 -9999 -9999 -9999 -9999 -9999 -9999 -9999 -9999 -9999 -9999 -9999 -9999 -9999 -9999 -9999 -9999 -9999 -9999

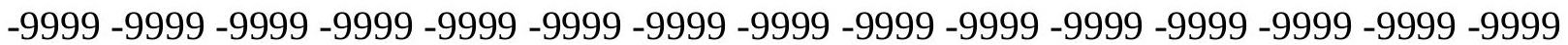
-9999 -9999 -9999 -9999 -9999 -9999 -9999 -9999 -9999 -9999

-9999 -9999 -9999 -9999 -9999 -9999 -9999 -9999 -9999 -9999 -9999 -9999 -9999 -9999 -9999

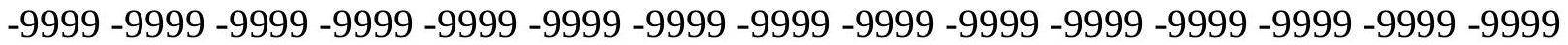

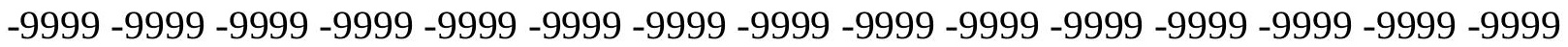
-9999 -9999 -9999 -9999 -9999 -9999 -9999 -9999 -9999 -9999 -9999 -9999 -9999 -9999 -9999 -

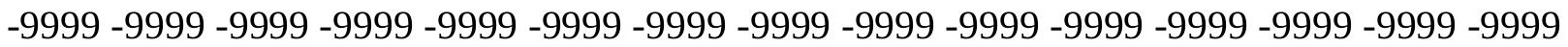
-9999 -9999 -9999 -9999 -9999-9999-9999 172.8132019043174 .0323028564175 .5561981201 176.7754058838177 .9945068359178 .9089050293180 .1280059814181 .3471984863 182.5662994385183 .4806976318184 .699798584184 .7381286621185 .7890625 186.8190917969187 .8618469238188 .9452667236189 .9506225586190 .8793487549 191.7097930908192 .5207214355193 .3697814941194 .1481018066194 .904586792 195.5305938721196 .0842437744196 .4831390381196 .8231048584197 .1246643066 197.3764953613 197.4806365967 197.500793457 197.500793457 197.500793457 197.1959991455196 .891204834196 .5863952637196 .2816009521196 .2816009521 195.9768066406195 .6721038818195 .0625194 .1481018066193 .233795166192 .624206543 192.624206543192 .3193969727191 .7097930908190 .4907073975189 .5764007568 188.966796875189 .2716064453190 .1858978271191 .4051055908192 .3193969727 192.0146026611191 .1002960205189 .5764007568188 .0523986816186 .528503418 185.6141052246185 .3094024658185 .0045928955185 .0045928955185 .3094024658 185.6141052246186 .2236938477186 .528503418186 .8332977295187 .1381072998 187.1381072998186 .8332977295186 .528503418186 .2236938477185 .9188995361 186.2236938477186 .2236938477186 .8332977295187 .1381072998187 .4429016113 188.0523986816188 .3571929932188 .3571929932188 .3571929932188 .0523986816 187.4429016113186 .8332977295186 .2236938477186 .2236938477185 .9188995361 186.2236938477186 .2236938477186 .528503418186 .528503418186 .528503418 186.2236938477186 .2236938477185 .9188995361185 .9188995361185 .9188995361 186.2236938477186 .2236938477186 .528503418186 .528503418186 .528503418 186.528503418186 .528503418186 .2236938477185 .9188995361185 .6141052246 185.0045928955184 .3950042725183 .7854003906182 .87109375181 .9566955566 181.0424041748180 .432800293179 .8231964111179 .5184020996179 .2136993408 178.9089050293178 .604095459178 .2993011475178 .2993011475178 .2993011475 178.604095459178 .604095459178 .604095459178 .604095459178 .2993011475 177.6896972656177 .0802001953176 .4705963135177 .0802001953178 .2993011475 179.5184020996180 .7375946045181 .9566955566182 .5662994385183 .1759033203 183.7854003906184 .373046875185 .0045928955185 .6141052246186 .3059234619 186.6651763916186 .802154541186 .7008209229186 .3913116455185 .7901611328 $184.9026641846183 .7522583008182 .3253173828180 .7059020996183 .7860412598-9999$ -9999 -9999 -9999 -9999 -9999 -9999 -9999 -9999 -9999 -9999 -9999 -9999 -9999 -9999 -9999 -9999 -9999 -9999 -9999 -9999 -9999 -9999 -9999 -9999 -9999 -9999 -9999 -9999 -9999 -9999 -999 -9999 -9999 -9999 -9999 -9999 -9999 -9999 -9999 -9999 -9999 -9999 -9999 -9999 -9999 -9999

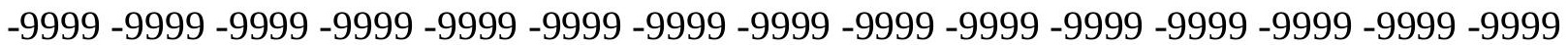


-9999 -9999 -9999 -9999 -9999 -9999 -9999 -9999 -9999 -9999 -9999 -9999 -9999 -9999 -9999 -9999 -9999 -9999 -9999 -9999 -9999 -9999 -9999 -9999 -9999 -9999 -9999 -9999 -9999 -9999

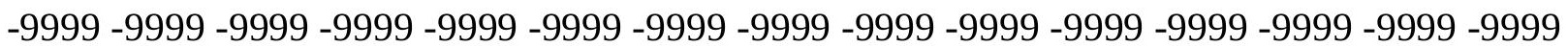
-9999 -9999 -9999 -9999 -9999 -9999 -9999 -9999 -9999 -9999 -9999 -9999 -9999 -9999 -9999 -9999 -9999 -9999 -9999 -9999 -9999 -9999 -9999 -9999 -9999 -9999 -9999 -9999 -9999 -9999

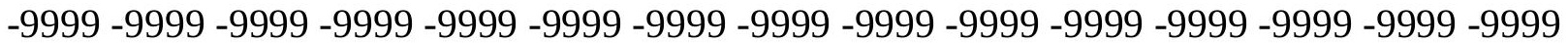
$-9999-9999$

-9999 -9999 -9999 -9999 -9999 -9999 -9999 -9999 -9999 -9999 -9999 -9999 -9999 -9999 -9999 -9999 -9999 -9999 -9999 -9999 -9999 -9999 -9999 -9999 -9999 -9999 -9999 -9999 -9999 -9999 -9999 -9999 -9999 -9999 -9999 -9999 -9999 -9999 -9999 -9999 -9999 -9999 -9999 -9999 -9999 -9999 -9999 -9999 -9999 -9999 -9999 -9999 -9999 -9999 -9999 -9999 -9999 -9999 -9999 -9999 -9999 -9999 -9999 -9999 -9999 -9999 -9999 -9999 -9999 -9999 -9999 -9999 -9999 -9999 -9999 -9999-9999 162.4505004883163.6696014404165.1934967041 166.4127044678 167.6318054199168 .8509979248170 .070098877171 .2891998291172 .5084075928 173.7274932861174 .9467010498176 .165802002177 .4847259521178 .604095459 179.8231964111180 .9573516846181 .9566955566183 .0835113525184 .0652160645 185.0045928955186 .2236938477187 .1381072998188 .0523986816188 .966796875 189.5764007568190 .4907073975191 .4051055908192 .0146026611192 .624206543 193.233795166193 .5386047363193 .8433074951194 .1481018066194 .4528961182 194.4528961182194 .4528961182194 .4528961182194 .1481018066194 .1481018066 193.8433074951193 .5386047363193 .233795166192 .9290008545192 .624206543 192.3193969727191 .7097930908191 .1002960205190 .1858978271189 .5764007568 189.2716064453188 .966796875188 .3571929932187 .4429016113186 .8332977295 186.528503418186 .528503418187 .1381072998187 .7476043701188 .0523986816 188.0523986816187 .1381072998186 .2236938477184 .699798584183 .7854003906 182.87109375182 .261505127181 .9566955566181 .9566955566182 .261505127 182.261505127182 .87109375183 .1759033203183 .1759033203183 .4806976318 183.4806976318183 .1759033203183 .1759033203182 .87109375182 .87109375182 .87109375 183.1759033203183 .4806976318183 .7854003906184 .0901947021184 .3950042725 184.699798584184 .699798584184 .699798584184 .3950042725184 .0901947021 183.7854003906183 .1759033203183 .1759033203182 .87109375183 .1759033203 183.1759033203183 .1759033203183 .1759033203183 .1759033203183 .1759033203 182.87109375182 .87109375182 .87109375182 .87109375182 .87109375183 .1759033203 183.1759033203183 .1759033203183 .1759033203183 .1759033203183 .1759033203 182.87109375182 .5662994385182 .261505127181 .6519012451181 .0424041748 180.432800293179 .5184020996178 .9089050293177 .9945068359177 .3849029541 177.0802001953176 .4705963135176 .165802002175 .8609924316175 .5561981201 175.5561981201175 .2514038086175 .2514038086175 .2514038086175 .5561981201 175.2514038086175 .2514038086174 .9467010498174 .337097168174 .0323028564 174.0323028564174 .337097168175 .2514038086176 .165802002177 .3849029541 178.604095459179 .5184020996180 .1280059814180 .7375946045181 .3471984863 181.9566955566182 .87109375183 .4806976318183 .7854003906184 .0901947021 183.7854003906183 .7854003906183 .0855865479182 .2673950195181 .1754760742 $179.673614502177 .8490142822176 .0208129883174 .3470153809172 .8667907715-9999$ -9999 -9999 -9999 -9999 -9999 -9999 -9999 -9999 -9999 -9999 -9999 -9999 -9999 -9999 -9999

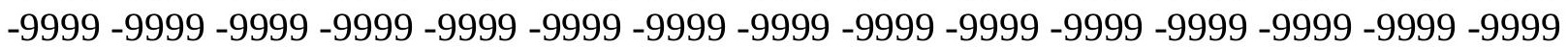


-9999 -9999 -9999 -9999 -9999 -9999 -9999 -9999 -9999 -9999 -9999 -9999 -9999 -9999 -9999 -9999 -9999 -9999 -9999 -9999 -9999 -9999 -9999 -9999 -9999 -9999 -9999 -9999 -9999 -9999 -9999 -9999 -9999 -9999 -9999 -9999 -9999 -9999 -9999 -9999 -9999 -9999 -9999 -9999 - 9999 -9999 -9999 -9999 -9999 -9999 -9999 -9999 -9999 -9999 -9999 -9999 -9999 -9999 -9999 -9999 -9999 -9999 -9999 -9999 -9999 -9999 -9999 -9999 -9999 -9999 -9999 -9999-9999 -9999 -9999 -9999 -9999 -9999 -9999 -9999 -9999 -9999 -9999 -9999 -9999 -9999 -9999 -9999 -9999 -9999

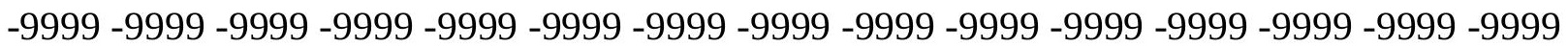

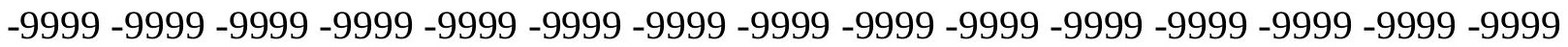

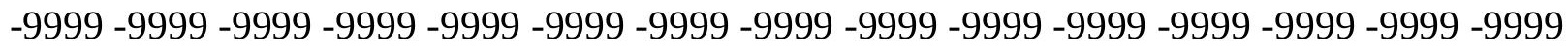
-9999 -9999 -9999 -9999 -9999 -9999 -9999 -9999 -9999 -9999 -9999 -9999 -9999 -9999 -9999

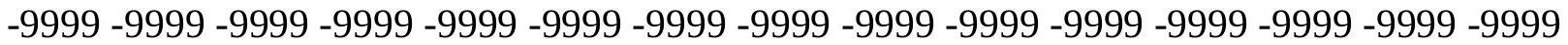
-9999 -9999 -9999 -9999 -9999 -9999 -9999 -9999 -9999 -9999 -9999 -9999 -9999 -9999 -9999 -9999 -9999 -9999 -9999 -9999 -9999 -9999 -9999 -9999 -9999 -9999 -9999 152.0877990723 153.3069000244154 .8307952881156 .3547973633157 .5738983154158 .7929992676 160.3170013428161 .5361022949162 .7552947998163 .974395752165 .1934967041 166.7174987793167 .9365997314169 .4604949951170 .6797027588172 .2035980225 173.4226989746174 .8582763672176 .0395965576177 .0802001953178 .2993011475 179.2136993408180 .432800293181 .3471984863182 .261505127183 .1759033203 184.0901947021185 .0045928955185 .9188995361186 .8332977295187 .4429016113 188.3571929932188 .966796875189 .5764007568189 .8811035156190 .4907073975 190.795501709191 .1002960205191 .1002960205191 .4051055908191 .4051055908 191.1002960205191 .1002960205190 .795501709190 .4907073975190 .4907073975 190.1858978271189 .8811035156189 .5764007568188 .966796875188 .3571929932 187.7476043701 187.1381072998 186.528503418185.9188995361 185.6141052246 185.0045928955184 .3950042725183 .7854003906183 .4806976318183 .4806976318 183.7854003906184 .0901947021184 .0901947021183 .7854003906183 .4806976318 182.5662994385181 .3471984863180 .432800293179 .8231964111179 .2136993408 179.2136993408178 .9089050293178 .9089050293179 .2136993408179 .5184020996 179.5184020996179 .8231964111179 .8231964111179 .8231964111179 .8231964111 179.8231964111179 .8231964111179 .8231964111179 .8231964111179 .8231964111 180.1280059814180 .432800293180 .7375946045181 .0424041748181 .0424041748 181.3471984863181 .0424041748181 .0424041748180 .7375946045180 .432800293 180.1280059814180 .1280059814179 .8231964111179 .8231964111179 .8231964111 179.8231964111179 .8231964111179 .8231964111179 .8231964111179 .8231964111 179.8231964111179 .8231964111179 .8231964111179 .8231964111179 .8231964111 179.8231964111180 .1280059814180 .1280059814179 .8231964111179 .8231964111 179.5184020996179 .2136993408178 .9089050293178 .2993011475177 .6896972656 177.0802001953176 .4705963135175 .8609924316175 .2514038086174 .6419067383 174.0323028564173 .7274932861173 .1179962158172 .8132019043172 .8132019043 172.5084075928172 .5084075928172 .2035980225172 .2035980225172 .2035980225 172.2035980225171 .8988037109171 .5939941406171 .2891998291170 .9844970703 171.2891998291171 .5939941406172 .2035980225173 .1179962158174 .337097168 175.2514038086176 .165802002177 .0802001953177 .6896972656178 .2993011475 178.9089050293179 .5184020996180 .1280059814180 .432800293180 .7375946045 180.432800293180 .432800293179 .8231964111179 .2136993408178 .2993011475 176.7754058838174 .6419067383172 .8132019043171 .0631256104169 .6179656982 
168.4301300049 -9999 -9999 -9999 -9999 -9999 -9999 -9999 -9999 -9999 -9999 -9999 -9999 -9999 -9999 -9999 -9999 -9999 -9999 -9999 -9999 -9999 -9999 -9999 -9999 -9999 -9999 -9999 -9999 -9999 -9999 -9999 -9999 -9999 -9999 -9999 -9999 -9999 -9999 -9999 -9999 -9999 -9999 -9999 -9999 -9999 -9999 -9999 -9999 -9999 -9999 -9999 -9999 -9999 -9999 -9999 -9999 -9999 -9999 -9999 -9999 -9999 -9999 -9999 -9999 -9999 -9999 -9999 -9999 -9999-9999 -9999 -9999 -9999 -9999 -9999 -9999 -9999 -9999 -9999 -9999 -9999 -9999 -9999 -9999 -9999 -9999 -9999

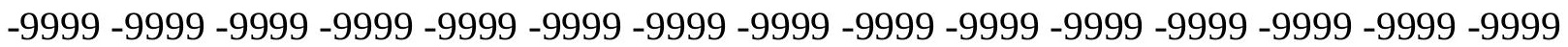
-9999 -9999 -9999 -9999 -9999 -9999 -9999 -9999 -9999 -9999 -9999 -9999 -9999 -9999 -9999 -999 -9999 -9999 -9999 -9999 -9999 -9999 -9999 -9999 -9999 -9999 -9999 -9999 -9999 -9999 -9999 -9999 -9999 -9999 -9999 -9999 -9999 -9999 -9999 -9999 -9999 -9999 -9999 -9999 -9999 -999 -9999 -9999 -9999

-9999 -9999 -9999 -9999 -9999 -9999 -9999 -9999 -9999 -9999 -9999 -9999 -9999 -9999 -9999 -9999 -9999 -9999 -9999 -9999 -9999 -9999 -9999 -9999 -9999 -9999 -9999 -9999 -9999 -9999 -9999 -9999 -9999 -9999 -9999 -9999 -9999 -9999 -9999 -9999 -9999 -9999 -9999 -9999 -9999 -9999 -9999 -9999 -9999 -9999 -9999 -9999 -9999 -9999 -9999 -9999 -9999 -9999 -9999 -9999 -9999 -9999 -9999 -9999-9999 -9999 -9999 -9999 142.9441986084144 .4682006836 145.9920959473147 .5160064697148 .7351074219150 .2590942383151 .4781951904 152.6972961426154 .2212982178155 .7451934814156 .9642944336158 .4882965088 160.0122070312161 .2312927246162 .7552947998163 .974395752165 .4983062744 166.7174987793168 .241394043169 .4604949951170 .950378418172 .2035980225 173.4226989746174 .337097168175 .5561981201176 .4705963135177 .6896972656 178.604095459179 .5184020996180 .432800293181 .3471984863182 .261505127 183.1759033203183 .7854003906184 .3950042725185 .3094024658185 .9188995361 186.528503418186 .8332977295187 .1381072998187 .4429016113187 .7476043701 188.0523986816188 .0523986816188 .0523986816188 .0523986816187 .7476043701 187.7476043701187 .4429016113187 .1381072998186 .8332977295186 .528503418 186.2236938477185 .6141052246185 .0045928955184 .3950042725184 .0901947021 183.4806976318182 .87109375182 .261505127181 .9566955566181 .3471984863 181.0424041748180 .7375946045180 .432800293180 .432800293180 .432800293 180.432800293180 .1280059814179 .5184020996178 .9089050293177 .9945068359 177.3849029541176 .7754058838176 .4705963135176 .165802002175 .8609924316 175.8609924316175 .8609924316176 .165802002176 .165802002176 .165802002 176.4705963135176 .4705963135176 .4705963135176 .4705963135176 .4705963135 176.4705963135176 .4705963135176 .7754058838176 .7754058838177 .0802001953 177.3849029541 177.3849029541 177.6896972656177.6896972656 177.6896972656 177.6896972656177 .3849029541177 .0802001953177 .0802001953176 .7754058838 176.7754058838176 .7754058838176 .7754058838176 .7754058838176 .7754058838 176.7754058838176 .7754058838176 .7754058838176 .7754058838176 .7754058838 176.7754058838176 .7754058838176 .7754058838176 .7754058838176 .7754058838 176.7754058838176 .4705963135176 .4705963135176 .165802002175 .8609924316 175.5561981201174 .9467010498174 .6419067383174 .0323028564173 .4226989746 172.8132019043172 .2035980225171 .5939941406170 .9844970703170 .6797027588 170.3748931885170 .070098877169 .7653045654169 .4604949951169 .4604949951 169.1557006836169 .1557006836169 .1557006836168 .8509979248168 .8509979248 168.5462036133168 .241394043168 .241394043168 .5462036133168 .8509979248 169.4604949951170 .3748931885171 .2891998291172 .2035980225172 .8132019043 
173.7274932861174 .6419067383175 .2514038086175 .8609924316176 .4705963135 176.7754058838177 .0802001953177 .0802001953177 .0802001953176 .7754058838 176.4705963135175 .5561981201174 .6419067383173 .1179962158171 .2891998291 $169.4604949951167 .6318054199166 .3842315674165 .2320251465164 .2686462402-9999$ -9999 -9999 -9999 -9999 -9999 -9999 -9999 -9999 -9999 -9999 -9999 -9999 -9999 -9999 -9999 -9999 -9999 -9999 -9999 -9999 -9999 -9999 -9999 -9999 -9999 -9999 -9999 -9999 -9999 -9999

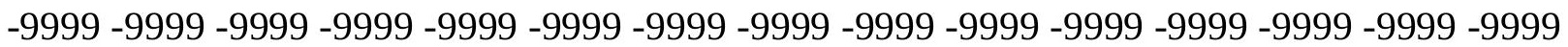

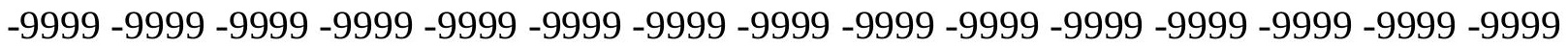
-9999 -9999 -9999 -9999 -9999 -9999 -9999 -9999 -9999 -9999 -9999 -9999 -9999 -9999 -9999 -9999 -9999 -9999 -9999 -9999 -9999 -9999 -9999 -9999 -9999 -9999 -9999 -9999 -9999 -9999 -

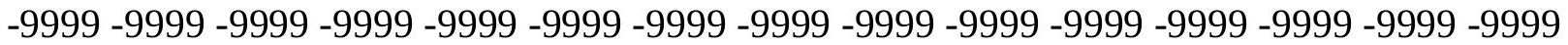
-9999 -9999 -9999 -9999 -9999 -9999 -9999 -9999 -9999 -9999 -9999 -9999 -9999 -9999 -9999

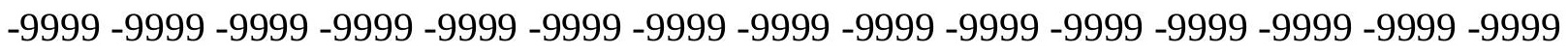
-9999 -9999 -9999 -9999 -9999 -9999 -9999 -9999 -9999 -9999 -9999 -9999 -9999 -9999 -9999 -9999 -9999 -9999 -9999 -9999 -9999 -9999 -9999 -9999 -9999 -9999 -9999 -9999

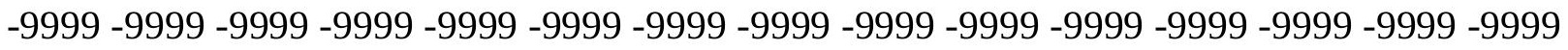

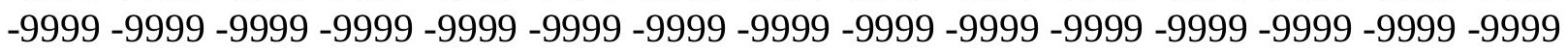
-9999 -9999 -9999 -9999 -9999 -9999 -9999 -9999 -9999 -9999 -9999 -9999 -9999 -9999 -9999 -9999 -9999-9999-9999 133.8007049561 135.6293945312 137.1533050537138.3724975586 139.8963928223141 .4203033447142 .9441986084144 .1634063721145 .9920959473 147.5160064697148 .7351074219150 .2590942383151 .7830047607153 .3069000244 154.5260925293156 .0500030518157 .5738983154158 .7929992676160 .3170013428 161.5361022949163 .0599975586164 .2792053223165 .4983062744167 .0222015381 168.241394043169 .4604949951170 .6797027588171 .5939941406172 .8132019043 173.7274932861174 .9467010498175 .8609924316176 .7754058838177 .6896972656 178.604095459179 .2136993408180 .1280059814180 .7375946045181 .6519012451 182.261505127182 .5662994385183 .1759033203183 .7854003906184 .0901947021 184.3950042725184 .699798584184 .699798584184 .699798584184 .699798584 184.699798584184 .3950042725184 .3950042725184 .0901947021183 .7854003906 183.4806976318183 .1759033203182 .87109375182 .261505127181 .9566955566 181.3471984863180 .7375946045180 .1280059814179 .5184020996179 .2136993408 178.604095459178 .2993011475177 .9945068359177 .3849029541177 .3849029541 177.0802001953176 .7754058838176 .7754058838176 .4705963135175 .8609924316 175.2514038086174 .6419067383174 .0323028564173 .7274932861173 .1179962158 172.8132019043172 .8132019043172 .8132019043172 .8132019043172 .8132019043 172.8132019043172 .8132019043173 .1179962158173 .1179962158173 .1179962158 173.1179962158173 .1179962158173 .1179962158173 .1179962158173 .4226989746 173.4226989746173 .7274932861174 .0323028564174 .0323028564174 .0323028564 174.0323028564174 .0323028564174 .0323028564174 .0323028564174 .0323028564 173.7274932861173 .7274932861173 .7274932861173 .7274932861173 .4226989746 173.4226989746173 .4226989746173 .4226989746173 .4226989746173 .4226989746 173.4226989746173 .4226989746173 .4226989746173 .4226989746173 .4226989746 173.4226989746173 .4226989746173 .4226989746173 .1179962158173 .1179962158 172.8132019043172 .5084075928172 .2035980225171 .5939941406171 .2891998291 170.6797027588170 .070098877169 .4604949951169 .1557006836168 .5462036133 167.9365997314167 .6318054199167 .3269958496167 .0222015381166 .7174987793 
166.7174987793166 .4127044678166 .4127044678166 .1078948975166 .1078948975 165.8031005859165 .8031005859165 .4983062744165 .4983062744165 .4983062744 165.8031005859166 .1078948975166 .7174987793167 .3269958496168 .241394043 168.8509979248169 .7653045654170 .6797027588171 .2891998291172 .2035980225 172.5084075928173 .1179962158173 .4226989746173 .7274932861173 .7274932861 173.7274932861173 .4226989746172 .8132019043171 .8988037109170 .9844970703 169.4604949951167 .9365997314166 .1078948975164 .5839996338163 .3648071289 162.0869598389161 .0643310547160 .4539794922 -9999 -9999 -9999 -9999 -9999 -9999 -9999

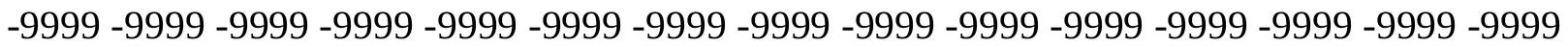
-9999 -9999 -9999 -9999 -9999 -9999 -9999 -9999 -9999 -9999 -9999 -9999 -9999 -9999 -9999 -

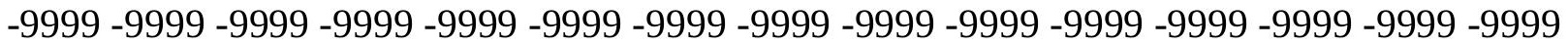
-9999 -9999 -9999 -9999 -9999 -9999 -9999 -9999 -9999 -9999 -9999 -9999 -9999 -9999 -9999 -9999 -9999 -9999 -9999 -9999 -9999 -9999 -9999 -9999 -9999 -9999 -9999 -9999 -9999 -9999 -9999 -9999 -9999 -9999 -9999 -9999 -9999 -9999 -9999 -9999 -9999 -9999 -9999 -9999 - 9999 -9999 -9999 -9999 -9999 -9999 -9999 -9999 -9999 -9999 -9999 -9999 -9999 -9999 -9999 -9999

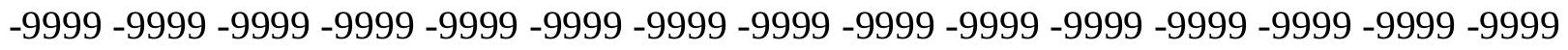
-9999 -9999 -9999 -9999 -9999 -9999 -9999 -9999 -9999 -9999 -9999 -9999 -9999 -9999 -9999 -9999 -9999 -9999 -9999-9999-9999

-9999 -9999 -9999 -9999 -9999 -9999 -9999 -9999 -9999 -9999 -9999 -9999 -9999 -9999 -9999

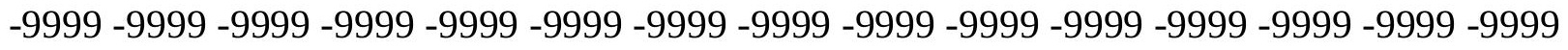

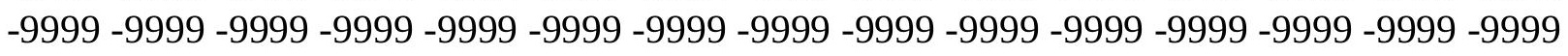
-9999 -9999 -9999 -9999 -9999 -9999 -9999 -9999 -9999 -9999 -9999 -9999 -9999 -9999 -9999 124.6570968628126 .4858016968128 .0097961426129 .533706665131 .0576019287 132.5814971924134 .1054992676135 .6293945312137 .1533050537138 .6772003174 140.5059967041142 .0299072266143 .5538024902145 .0776977539146 .6015930176 148.1255950928149 .3446960449150 .8686065674152 .3925933838153 .6116943359 155.1356048584156 .3547973633157 .8652801514159 .0977935791160 .3170013428 161.7424316406163 .0599975586164 .2792053223165 .4983062744166 .7174987793 167.9365997314168 .8509979248170 .070098877170 .9844970703171 .8988037109 172.8132019043173 .7274932861174 .6419067383175 .5561981201176 .4705963135 177.0802001953177 .6896972656178 .604095459178 .9089050293179 .5184020996 180.1280059814180 .432800293180 .7375946045181 .0424041748181 .3471984863 181.3471984863181 .3471984863181 .3471984863181 .3471984863181 .3471984863 181.0424041748180 .7375946045180 .432800293180 .1280059814179 .8231964111 179.5184020996178 .9089050293178 .604095459177 .9945068359177 .3849029541 177.0802001953176 .4705963135175 .8609924316175 .5561981201174 .9467010498 174.6419067383174 .337097168174 .0323028564173 .7274932861173 .4226989746 173.1179962158172 .8132019043172 .2035980225171 .8988037109171 .2891998291 170.9844970703170 .3748931885170 .070098877169 .7653045654169 .4604949951 169.4604949951169 .4604949951169 .4604949951169 .4604949951169 .4604949951 169.4604949951169 .7653045654169 .7653045654169 .7653045654169 .7653045654 169.7653045654170 .070098877170 .070098877170 .070098877170 .3748931885 170.3748931885170 .6797027588170 .6797027588170 .6797027588170 .6797027588 170.6797027588170 .6797027588170 .6797027588170 .6797027588170 .3748931885 170.3748931885170 .3748931885170 .3748931885170 .3748931885170 .3748931885 170.3748931885170 .3748931885170 .3748931885170 .3748931885170 .3748931885 
170.3748931885170 .3748931885170 .3748931885170 .070098877170 .070098877 170.070098877170 .070098877169 .7653045654169 .4604949951169 .1557006836 168.8509979248168 .5462036133167 .9365997314167 .6318054199167 .0222015381 166.4127044678166 .1078948975165 .4983062744165 .1934967041164 .5839996338 164.2792053223163 .974395752163 .6696014404163 .6696014404163 .3648071289 163.3648071289163 .0599975586163 .0599975586162 .7552947998162 .7552947998 162.7552947998162 .7552947998162 .7552947998163 .0599975586163 .3648071289 163.974395752164 .5839996338165 .1934967041166 .1078948975166 .7174987793 167.6318054199168 .241394043168 .8509979248169 .4604949951169 .7653045654 170.070098877170 .3748931885170 .3748931885170 .070098877169 .7653045654 169.1557006836168 .241394043167 .3269958496166 .1078948975164 .5839996338 163.0599975586161 .8408966064160 .3170013428159 .0977935791157 .878692627 157.4242401123157 .3602600098 -9999 -9999 -9999 -9999 -9999 -9999 -9999 -9999 -9999 -9999 -9999 -9999 -9999 -9999 -9999 -9999 -9999 -9999 -9999 -9999 -9999 -9999 -9999 -9999 -9999 -9999 -9999 -9999 -9999 -9999 -9999 -9999 -9999 -9999 -9999 -9999 -9999 -9999 -9999

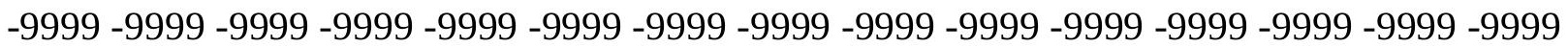

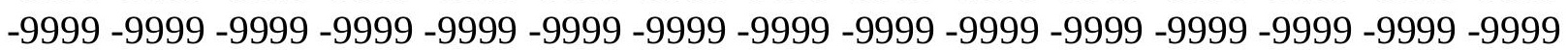
-9999 -9999 -9999 -9999 -9999 -9999 -9999 -9999 -9999 -9999 -9999 -9999 -9999 -9999 -9999 -999 -9999 -9999 -9999 -9999 -9999 -9999 -9999 -9999 -9999 -9999 -9999 -9999 -9999 -9999 -9999 -9999 -9999 -9999 -9999 -9999 -9999 -9999 -9999 -9999 -9999 -9999 -9999 -9999 -9999 -9999

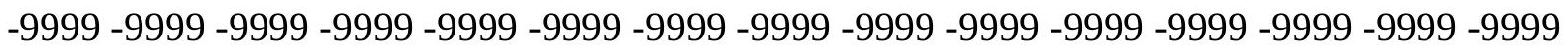

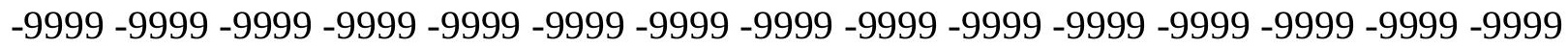
$-9999-9999-9999$

-9999 -9999 -9999 -9999 -9999 -9999 -9999 -9999 -9999 -9999 -9999 -9999 -9999 -9999 -9999 -9999 -9999 -9999 -9999 -9999 -9999 -9999 -9999 -9999 -9999 -9999 -9999 -9999 -9999 -9999 -9999 -9999 -9999 -9999 -9999 -9999 -9999 -9999 -9999 -9999 -9999 -9999 -9999 -9999 -9999 -9999 -9999 -9999 -9999 -9999 -9999 -9999 -9999 -9999 -9999 -9999 -9999 117.342300415 118.8662033081120 .6949005127122 .2188034058123 .7427978516125 .2667007446 126.7906036377128 .3144989014130 .1432037354131 .6672058105133 .4958953857 135.0198059082136 .5437011719138 .0677032471139 .5915985107141 .1154937744 142.6394042969144 .1634063721145 .6873016357146 .9064025879148 .4304046631 149.9542999268151 .1734008789152 .6363983154153 .9165039062155 .1356048584 156.6588897705157 .878692627159 .0977935791160 .3170013428161 .5361022949 162.7552947998163 .974395752165 .1934967041166 .1078948975167 .3269958496 168.241394043169 .1557006836170 .070098877170 .9844970703171 .8988037109 172.5084075928173 .4226989746174 .0323028564174 .6419067383175 .2514038086 175.8609924316176 .4705963135176 .7754058838177 .3849029541177 .6896972656 177.6896972656177 .9945068359177 .9945068359178 .2993011475177 .9945068359 177.9945068359177 .9945068359177 .6896972656177 .3849029541177 .0802001953 176.7754058838176 .4705963135176 .165802002175 .5561981201175 .2514038086 174.6419067383174 .337097168173 .7274932861173 .1179962158172 .8132019043 172.2035980225171 .8988037109171 .2891998291170 .9844970703170 .6797027588 170.3748931885170 .070098877169 .7653045654169 .1557006836168 .8509979248 168.5462036133167 .9365997314167 .6318054199167 .3269958496166 .7174987793 166.7174987793166 .4127044678166 .4127044678166 .1078948975166 .1078948975 166.1078948975166 .1078948975166 .1078948975166 .1078948975166 .4127044678 
166.4127044678166 .4127044678166 .4127044678166 .7174987793166 .7174987793 166.7174987793167 .0222015381167 .0222015381167 .3269958496167 .3269958496 167.3269958496167 .3269958496167 .3269958496167 .3269958496167 .3269958496 167.3269958496167 .3269958496167 .3269958496167 .3269958496167 .3269958496 167.0222015381167 .0222015381167 .0222015381167 .0222015381167 .0222015381 167.0222015381167 .0222015381167 .0222015381167 .0222015381167 .0222015381 167.0222015381167 .0222015381166 .7174987793166 .7174987793166 .4127044678 166.1078948975165 .8031005859165 .4983062744165 .1934967041164 .8887023926 164.2792053223163 .974395752163 .3648071289163 .0599975586162 .4505004883 162.1457061768161 .5361022949161 .2312927246160 .9264984131160 .9264984131 160.6217956543160 .3170013428160 .3170013428160 .0122070312160 .0122070312 160.0122070312159 .7073974609159 .7073974609159 .7073974609160 .0122070312 160.3170013428160 .6217956543160 .9264984131161 .5361022949162 .1457061768 163.0599975586163 .6696014404164 .2792053223164 .8887023926165 .4983062744 166.1078948975166 .4127044678166 .7174987793167 .0222015381166 .7174987793 166.7174987793166 .4127044678165 .8031005859164 .8887023926163 .974395752 162.7552947998161 .5361022949160 .3170013428158 .7929992676157 .5738983154 156.3547973633155 .1356048584154 .5260925293154 .7313842773155 .1148223877 -9999 -9999 -9999 -9999 -9999 -9999 -9999 -9999 -9999 -9999 -9999 -9999 -9999 -9999 -9999 -9999

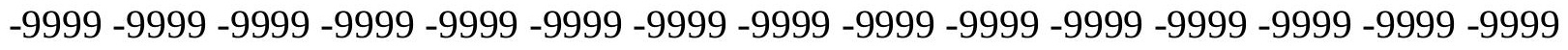

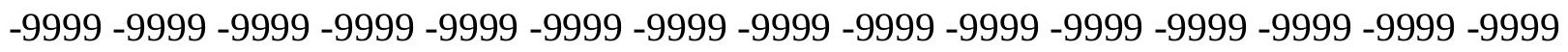
-9999 -9999 -9999 -9999 -9999 -9999 -9999 -9999 -9999 -9999 -9999 -9999 -9999 -9999 -9999 -9999 -9999 -9999 -9999 -9999 -9999 -9999 -9999 -9999 -9999 -9999 -9999 -9999 -9999 -9999 -

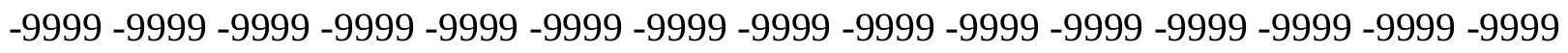

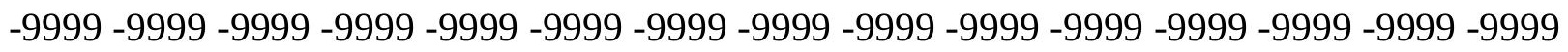
-9999 -9999 -9999 -9999 -9999 -9999 -9999 -9999 -9999 -9999 -9999 -9999 -9999 -9999 -9999

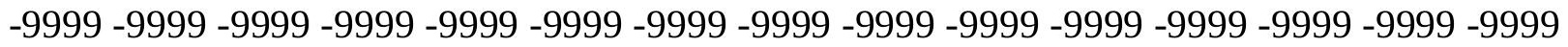
-9999 -9999 -9999 -9999 -9999 -9999-9999 -9999 -9999 -9999

-9999 -9999 -9999 -9999 -9999 -9999 -9999 -9999 -9999 -9999 -9999 -9999 -9999 -9999 -9999

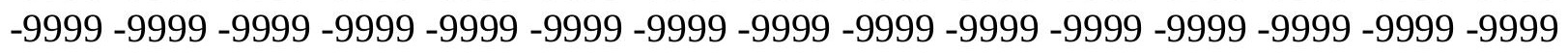
-9999 -9999 -9999 -9999 -9999 -9999 -9999 -9999 -9999 -9999 -9999 -9999 -9999 -9999 -9999 -9999 -9999 -9999 -9999 -9999 -9999 -9999 -9999 -9999 109.7226028442 111.24659729 113.075302124114 .9039993286116 .4279022217117 .9517974854122 .8283996582 121.3044967651123 .1332015991124 .6570968628126 .1809997559128 .0097961426 129.533706665131 .0576019287132 .8863067627134 .4102020264135 .9342041016 137.4580993652138 .9819946289140 .5059967041141 .7250976562143 .2489929199 144.7729034424145 .9920959473147 .4189605713148 .7351074219150 .1709899902 151.4604187012152 .6972961426154 .2212982178155 .4403991699156 .6596069336 157.878692627159 .0977935791160 .3170013428161 .2312927246162 .4505004883 163.3648071289164 .5839996338165 .4983062744166 .4127044678167 .3269958496 168.241394043168 .8509979248169 .7653045654170 .3748931885170 .9844970703 171.5939941406172 .2035980225172 .8132019043173 .4226989746173 .7274932861 174.0323028564174 .337097168174 .6419067383174 .6419067383174 .9467010498 174.9467010498174 .9467010498174 .6419067383174 .6419067383174 .337097168 174.0323028564173 .7274932861173 .4226989746173 .1179962158172 .8132019043 172.2035980225171 .8988037109171 .2891998291170 .9844970703170 .3748931885 
170.070098877169 .4604949951169 .1557006836168 .5462036133168 .241394043 167.6318054199167 .3269958496167 .0222015381166 .7174987793166 .4127044678 165.8031005859165 .4983062744165 .1934967041164 .5839996338164 .2792053223 163.974395752163 .6696014404163 .3648071289163 .0599975586163 .0599975586 163.0599975586162 .7552947998162 .7552947998162 .7552947998162 .7552947998 163.0599975586163 .0599975586163 .0599975586163 .0599975586163 .0599975586 163.3648071289163 .3648071289163 .3648071289163 .6696014404163 .6696014404 163.974395752163 .974395752163 .974395752163 .974395752163 .974395752163 .974395752 163.974395752163 .974395752163 .974395752163 .974395752163 .974395752163 .974395752 163.974395752163 .974395752163 .974395752163 .974395752163 .974395752163 .974395752 163.974395752163 .974395752163 .974395752163 .974395752163 .6696014404 163.6696014404163 .6696014404163 .3648071289163 .0599975586163 .0599975586 162.7552947998162 .4505004883161 .8408966064161 .5361022949161 .2312927246 160.6217956543160 .3170013428159 .7073974609159 .4026031494159 .0977935791 158.7929992676158 .4882965088158 .1835021973157 .878692627157 .5738983154 157.5738983154157 .2691040039157 .2691040039156 .9642944336156 .9642944336 156.9642944336156 .9642944336156 .9642944336157 .2691040039157 .2691040039 157.878692627158 .1835021973158 .7929992676159 .4026031494160 .0122070312 160.6217956543161 .2312927246161 .8408966064162 .4505004883162 .7552947998 163.0599975586163 .3648071289163 .3648071289163 .3648071289163 .0599975586 162.7552947998162 .1457061768161 .5361022949160 .6217956543159 .7073974609 158.4882965088157 .2691040039156 .0500030518154 .8307952881153 .6116943359 $152.6972961426151 .7830047607152 .3925933838152 .7766571045153 .5051422119-9999$ -9999 -9999 -9999 -9999 -9999 -9999 -9999 -9999 -9999 -9999 -9999 -9999 -9999 -9999 -9999 -9999 -9999 -9999 -9999 -9999 -9999 -9999 -9999 -9999 -9999 -9999 -9999 -9999 -9999 -9999 -9999 -9999 -9999 -9999 -9999 -9999 -9999 -9999 -9999 -9999 -9999 -9999 -9999 -9999 -9999 -9999 -9999 -9999 -9999 -9999 -9999 -9999 -9999 -9999 -9999 -9999 -9999 -9999 -9999 -9999

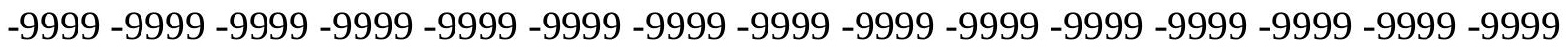
-9999 -9999 -9999 -9999 -9999 -9999 -9999 -9999 -9999 -9999 -9999 -9999 -9999 -9999 -9999

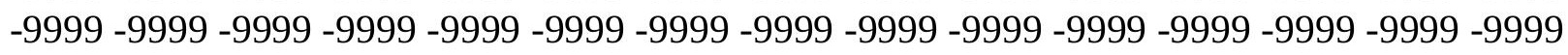
-9999 -9999 -9999 -9999 -9999 -9999 -9999 -9999 -9999 -9999 -9999 -9999 -9999 -9999 -9999 -9999 -9999 -9999 -9999 -9999 -9999 -9999 -9999 -9999 -9999 -9999 -9999 -9999 -9999 -9999 -9999-9999 -9999-9999-9999-9999-9999-9999-9999

-9999 -9999 -9999 -9999 -9999 -9999 -9999 -9999 -9999 -9999 -9999 -9999 -9999 -9999 -9999 -9999 -9999 -9999 -9999 -9999 -9999 -9999 -9999 -9999 -9999 -9999 -9999 -9999 -9999 -9999 -9999 -9999 -9999 -9999 -9999-9999 -9999 -9999 -9999 -9999 -9999 -9999 -9999 -9999 - -9999 -9999 -9999 -9999-9999-9999 100.2742996216102.1029968262 103.6268997192 105.4557037354107 .2844009399109 .1130981445110 .6370010376112 .4656982422 113.9896011353115 .818397522117 .647102356119 .1709976196120 .9997024536 122.5235977173124 .3523025513125 .8762969971127 .4001998901128 .9241027832 130.4479980469132 .2767028809133 .8007049561135 .3246002197136 .5437011719 138.0677032471139 .5915985107141 .1154937744142 .3277435303143 .6562194824 144.9795074463146 .2969055176147 .8208007812149 .0399017334150 .2590942383 151.4781951904152 .6972961426153 .9165039062155 .1356048584156 .3547973633 157.5738983154158 .7929992676159 .7073974609160 .6217956543161 .8408966064 162.7552947998163 .6696014404164 .2792053223165 .1934967041166 .1078948975 
166.7174987793167 .3269958496167 .9365997314168 .5462036133169 .1557006836 169.7653045654170 .070098877170 .6797027588170 .9844970703170 .9844970703 171.2891998291171 .5939941406171 .5939941406171 .5939941406171 .5939941406 171.2891998291171 .2891998291170 .9844970703170 .6797027588170 .3748931885 170.070098877169 .7653045654169 .4604949951169 .1557006836168 .5462036133 168.241394043167 .6318054199167 .0222015381166 .7174987793166 .1078948975 165.8031005859165 .1934967041164 .8887023926164 .5839996338163 .974395752 163.6696014404163 .3648071289162 .7552947998162 .4505004883162 .1457061768 161.8408966064161 .2312927246160 .9264984131160 .6217956543160 .3170013428 160.0122070312160 .0122070312159 .7073974609159 .7073974609159 .7073974609 159.7073974609159 .4026031494159 .4026031494159 .7073974609159 .7073974609 159.7073974609159 .7073974609159 .7073974609160 .0122070312160 .0122070312 160.0122070312160 .3170013428160 .3170013428160 .3170013428160 .6217956543 160.6217956543160 .6217956543160 .6217956543160 .6217956543160 .6217956543 160.6217956543160 .6217956543160 .9264984131160 .9264984131160 .9264984131 160.9264984131160 .9264984131160 .9264984131160 .9264984131160 .9264984131 160.6217956543160 .6217956543160 .6217956543160 .6217956543160 .6217956543 160.6217956543160 .3170013428160 .3170013428160 .0122070312160 .0122070312 159.7073974609159 .4026031494159 .0977935791158 .7929992676158 .4882965088 157.878692627157 .5738983154157 .2691040039156 .6596069336156 .3547973633 156.0500030518155 .7451934814155 .4403991699155 .1356048584154 .8307952881 154.5260925293154 .5260925293154 .2212982178154 .2212982178154 .2212982178 153.9165039062153 .9165039062153 .9165039062154 .2212982178154 .2212982178 154.5260925293154 .8307952881155 .4403991699155 .7451934814156 .3547973633 156.9642944336157 .5738983154157 .878692627158 .4882965088159 .0977935791 159.4026031494159 .7073974609160 .0122070312160 .0122070312160 .0122070312 159.7073974609159 .4026031494158 .7929992676158 .1835021973157 .2691040039 156.3547973633155 .4403991699154 .5260925293153 .3069000244152 .3925933838 151.1734008789150 .5639038086149 .6495056152149 .3446960449150 .5639038086 151.4781951904152 .6972961426 -9999 -9999 -9999 -9999 -9999 -9999 -9999 -9999 -9999 -9999 -9999 -9999 -9999 -9999 -9999 -9999 -9999 -9999 -9999 -9999 -9999 -9999 -9999 -9999 -9999 -9999 -9999 -9999 -9999 -9999 -9999 -9999 -9999 -9999 -9999 -9999 -9999 -9999 -9999 -

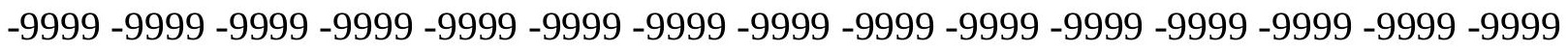
-9999 -9999 -9999 -9999 -9999 -9999 -9999 -9999 -9999 -9999 -9999 -9999 -9999 -9999 -9999 -9999 -9999 -9999 -9999 -9999 -9999 -9999 -9999 -9999 -9999 -9999 -9999 -9999 -9999 -9999 -9999 -9999 -9999 -9999 -9999 -9999 -9999 -9999 -9999 -9999 -9999 -9999 -9999 -9999 - -9999 -

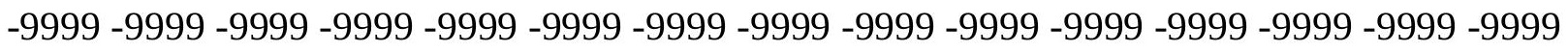

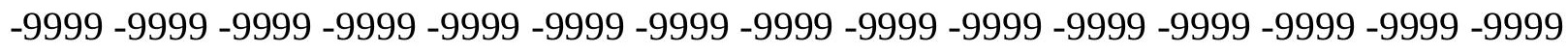
-9999 -9999 -9999 -9999 -9999 -9999 -9999 -9999 -9999 -9999 -9999 -9999 -9999 -9999 -9999 -9999 -9999 -9999 -9999 -9999 -9999 -9999 -9999 -9999 -9999 -9999 -9999 -9999 -9999 -9999 -

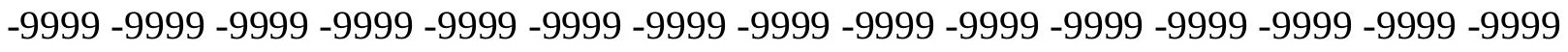

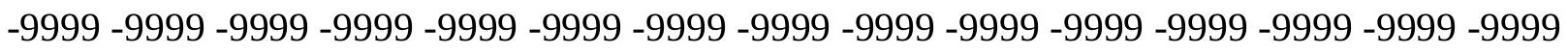
-9999 -9999 92.349891662694.1785964965896.0073165893697.83602905273 99.66472625732101 .4934005737103 .3221969604105 .1509017944106 .979598999 108.5035018921110 .3321990967112 .1608963013113 .9896011353115 .5136032104 117.342300415 118.8662033081 120.3900985718 122.2188034058 123.7427978516 
125.2667007446126 .7906036377128 .3144989014129 .8385009766131 .3623962402 132.8863067627134 .4102020264135 .9342041016137 .1533050537138 .6373748779 139.9612121582141 .286315918142 .6394042969144 .1634063721145 .3825073242 146.6015930176147 .8208007812149 .0399017334150 .2590942383151 .4781951904 152.6972961426153 .9165039062154 .8307952881156 .0500030518156 .9642944336 157.878692627158 .7929992676159 .7073974609160 .6217956543161 .5361022949 162.4505004883163 .0599975586163 .6696014404164 .5839996338165 .1934967041 165.4983062744166 .1078948975166 .7174987793167 .0222015381167 .3269958496 167.6318054199167 .9365997314167 .9365997314168 .241394043168 .241394043 168.241394043168 .241394043167 .9365997314167 .9365997314167 .6318054199 167.3269958496167 .3269958496166 .7174987793166 .4127044678166 .1078948975 165.8031005859165 .1934967041164 .8887023926164 .2792053223163 .974395752 163.3648071289163 .0599975586162 .4505004883162 .1457061768161 .5361022949 161.2312927246160 .6217956543160 .3170013428160 .0122070312159 .4026031494 159.0977935791158 .7929992676158 .4882965088158 .1835021973157 .5738983154 157.2691040039 157.2691040039156.9642944336156.6596069336156.6596069336 156.3547973633156 .3547973633156 .3547973633156 .3547973633156 .3547973633 156.3547973633156 .3547973633156 .3547973633156 .3547973633156 .6596069336 156.6596069336156 .6596069336156 .9642944336156 .9642944336156 .9642944336 157.2691040039 157.2691040039 157.2691040039 157.2691040039 157.2691040039 157.5738983154157 .5738983154157 .5738983154157 .5738983154157 .5738983154 157.5738983154157 .5738983154157 .5738983154157 .5738983154157 .5738983154 157.5738983154157 .5738983154157 .5738983154157 .5738983154157 .5738983154 157.5738983154157 .5738983154157 .2691040039157 .2691040039156 .9642944336 156.9642944336156 .6596069336156 .3547973633156 .0500030518155 .7451934814 155.4403991699155 .1356048584154 .8307952881154 .5260925293153 .9165039062 153.6116943359153 .3069000244153 .0021057129152 .6972961426152 .3925933838 152.0877990723151 .7830047607151 .4781951904151 .4781951904151 .1734008789 151.1734008789151 .1734008789151 .1734008789151 .1734008789151 .1734008789 151.1734008789151 .4781951904151 .7830047607152 .0877990723152 .3925933838 152.6972961426153 .3069000244153 .9165039062154 .2212982178154 .8307952881 155.4403991699155 .7451934814156 .0500030518156 .3547973633156 .6596069336 156.6596069336156 .6596069336156 .3547973633156 .0500030518155 .4403991699 154.8307952881154 .2212982178153 .3069000244152 .6972961426151 .7830047607 150.8686065674149 .9542999268149 .0399017334148 .4304046631148 .1255950928 148.1255950928148 .1255950928149 .9542999268152 .0877990723 -9999 -9999 -9999-9999 -9999 -9999 -9999 -9999 -9999 -9999 -9999 -9999 -9999-9999 -9999 -9999 -9999-9999 -9999 -

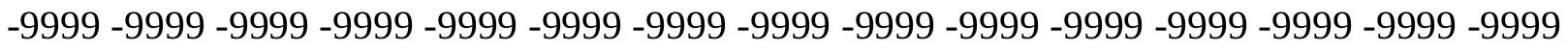
-9999 -9999 -9999 -9999 -9999 -9999 -9999 -9999 -9999 -9999 -9999 -9999 -9999 -9999 -9999

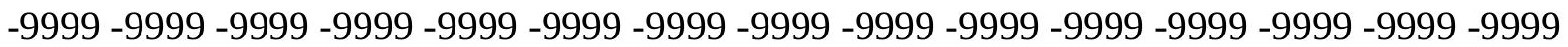

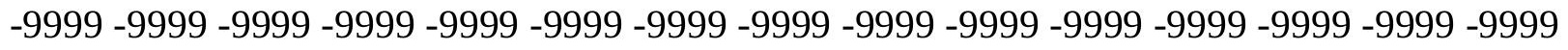

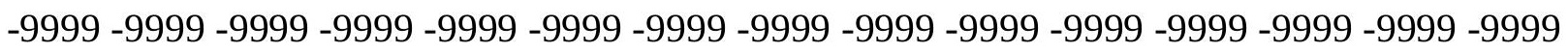
-9999 -9999 -9999 -9999 -9999 -9999 -9999 -9999 -9999 -9999 -9999 -9999 -9999 -9999 -9999 -9999 -9999 -9999 -9999 -9999 -9999 -9999 -9999 -9999 -9999 -9999 -9999 -9999 -9999 -9999 -

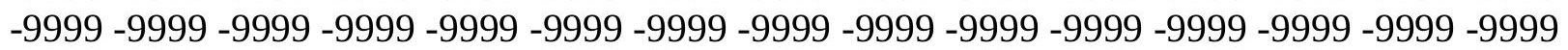
-9999 -9999 -9999-9999-9999 
-9999 -9999 -9999 -9999 -9999 -9999 -9999 -9999 -9999 -9999 -9999 -9999 -9999 -9999 -9999

-9999 -9999 -9999 -9999 -9999 -9999 -9999 -9999 -9999 -9999 -9999 -9999 -9999 -9999 -9999 -

-9999 -9999 -9999 -9999 -9999 -9999 -9999 -9999 -9999 -9999 -9999 -9999 -9999 -9999

84.4254837036186 .5589828491288 .3876876831190 .2164001464892 .04509735107

93.8738174438595 .7025299072397 .5312423706199 .35994720459101 .1886978149

103.0174026489104 .8460998535106 .6747970581108 .5035018921110 .0273971558 111.8561019897113 .3800964355115 .2088012695116 .7326965332118 .5614013672 120.0852966309121 .6092987061123 .1332015991124 .6570968628126 .1809997559 127.7050018311129 .2288970947130 .7528076172132 .2767028809133 .4958953857 135.0198059082136 .2389984131137 .6350860596138 .9819946289140 .5059967041 141.7250976562142 .9441986084144 .1634063721145 .3825073242146 .6015930176 147.8208007812149 .0399017334149 .9542999268151 .1734008789152 .3925933838 153.3069000244154 .2212982178155 .1356048584156 .0500030518156 .9642944336 157.878692627158 .7929992676159 .4026031494160 .0122070312160 .9264984131 161.5361022949162 .1457061768162 .4505004883163 .0599975586163 .3648071289 163.974395752164 .2792053223164 .5839996338164 .5839996338164 .8887023926 164.8887023926164 .8887023926164 .8887023926164 .8887023926164 .8887023926 164.5839996338164 .2792053223164 .2792053223163 .974395752163 .3648071289 163.0599975586162 .7552947998162 .4505004883161 .8408966064161 .5361022949 160.9264984131160 .6217956543160 .0122070312159 .7073974609159 .0977935791 158.7929992676158 .1835021973157 .878692627157 .2691040039156 .9642944336 156.6596069336156 .0500030518155 .7451934814155 .4403991699155 .1356048584 154.8307952881154 .5260925293154 .2212982178153 .9165039062153 .6116943359 153.3069000244153 .3069000244153 .0021057129153 .0021057129153 .0021057129 153.0021057129153 .0021057129153 .0021057129153 .0021057129153 .0021057129 153.0021057129153 .3069000244153 .3069000244153 .3069000244153 .6116943359 153.6116943359153 .6116943359153 .9165039062153 .9165039062153 .9165039062 153.9165039062154 .2212982178154 .2212982178154 .2212982178154 .2212982178 154.2212982178154 .2212982178154 .2212982178154 .5260925293154 .5260925293 154.5260925293154 .5260925293154 .5260925293154 .5260925293154 .5260925293 154.5260925293154 .5260925293154 .2212982178154 .2212982178154 .2212982178 153.9165039062153 .9165039062153 .6116943359153 .6116943359153 .3069000244 153.0021057129152 .6972961426152 .3925933838152 .0877990723151 .7830047607 151.1734008789150 .8686065674150 .5639038086150 .2590942383149 .9542999268 149.6495056152149 .3446960449149 .0399017334148 .7351074219148 .4304046631 148.4304046631148 .1255950928148 .1255950928148 .1255950928148 .1255950928 148.1255950928148 .1255950928148 .4304046631148 .4304046631148 .7351074219 149.0399017334149 .3446960449149 .6495056152150 .2590942383150 .5639038086 151.1734008789151 .7830047607152 .0877990723152 .3925933838152 .6972961426 153.0021057129153 .3069000244153 .3069000244153 .3069000244153 .0021057129 152.6972961426152 .3925933838151 .7830047607151 .1734008789150 .5639038086 149.6495056152149 .0399017334148 .1255950928147 .5160064697146 .9064025879 146.6015930176146 .6015930176146 .9064025879147 .5160064697148 .4304046631 151.1734008789151 .4781951904 -9999 -9999 -9999 -9999 -9999 -9999 -9999 -9999 -9999 -9999 -9999 -9999 -9999 -9999 -9999 -9999 -9999 -9999 -9999 -9999 -9999 -9999 -9999 -9999

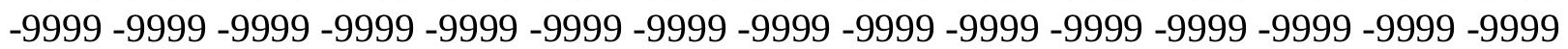


-9999 -9999 -9999 -9999 -9999 -9999 -9999 -9999 -9999 -9999 -9999 -9999 -9999 -9999 -9999 -9999 -9999 -9999 -9999 -9999 -9999 -9999 -9999 -9999 -9999 -9999 -9999 -9999 -9999 -9999

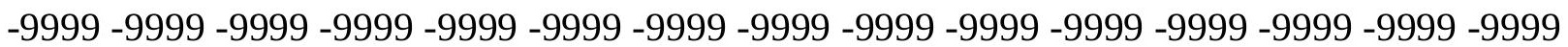
-9999 -9999 -9999 -9999 -9999 -9999 -9999 -9999 -9999 -9999 -9999 -9999 -9999 -9999 -9999 -9999 -9999 -9999 -9999 -9999 -9999 -9999 -9999 -9999 -9999 -9999 -9999 -9999 -9999 -9999 -9999 -9999 -9999 -9999 -9999 -9999 -9999 -9999 -9999 -9999 -9999 -9999 -9999 -9999 -9999 -999 -9999 -9999 -9999 -9999 -9999 -9999 -9999 -9999 -9999 -9999 -9999 -9999 -9999 -9999 -9999 -9999 -9999 -9999 -9999 -9999 -9999 -9999 -9999 -9999 -9999 -9999 -9999 -9999 -9999 -9999 -9999 -9999 -9999 -9999 -9999 -9999 -9999 -9999 -9999 -9999 -9999 -9999 -9999 -9999 -9999 -9999 -9999 -9999 -9999 -9999 -9999 -9999 -9999 -9999 -9999 -9999 78.63455963135 80.4632720947382 .5967712402384 .4254837036186 .254188537688 .08290100098 90.2164001464892 .0450973510793 .8738174438595 .7025299072397 .53124237061 99.35994720459101 .1886978149103 .0174026489104 .8460998535106 .3700027466 108.1986999512109 .7226028442111 .551399231113 .075302124114 .9039993286 116.4279022217117 .9517974854119 .4757995605120 .9997024536122 .5235977173 124.0475006104125 .5715026855127 .0953979492128 .6192932129129 .8385009766 131.3623962402132 .7499847412134 .1054992676135 .3246002197136 .8484954834 138.0677032471139 .2868041992140 .5059967041141 .7250976562142 .9441986084 144.1634063721145 .3825073242146 .2969055176147 .5160064697148 .4304046631 149.6495056152150 .5639038086151 .4781951904152 .3925933838153 .3069000244 154.2212982178155 .1356048584155 .7451934814156 .6596069336157 .2691040039 157.878692627158 .4882965088159 .0977935791159 .4026031494160 .0122070312 160.3170013428160 .6217956543160 .9264984131161 .2312927246161 .5361022949 161.5361022949161 .5361022949161 .5361022949161 .5361022949161 .5361022949 161.5361022949161 .2312927246160 .9264984131160 .9264984131160 .6217956543 160.3170013428159 .7073974609159 .4026031494159 .0977935791158 .4882965088 158.1835021973157 .5738983154157 .2691040039156 .6596069336156 .3547973633 155.7451934814155 .4403991699154 .8307952881154 .5260925293154 .2212982178 153.6116943359153 .3069000244153 .0021057129152 .3925933838152 .0877990723 151.7830047607151 .4781951904151 .1734008789150 .8686065674150 .5639038086 150.2590942383150 .2590942383149 .9542999268149 .9542999268149 .6495056152 149.6495056152149 .6495056152149 .6495056152149 .6495056152149 .6495056152 149.6495056152149 .9542999268149 .9542999268149 .9542999268149 .9542999268 150.2590942383150 .2590942383150 .2590942383150 .5639038086150 .5639038086 150.5639038086150 .8686065674150 .8686065674150 .8686065674150 .8686065674 151.1734008789151 .1734008789151 .1734008789151 .1734008789151 .1734008789 151.1734008789151 .1734008789151 .1734008789151 .1734008789151 .1734008789 151.1734008789151 .1734008789151 .1734008789151 .1734008789151 .1734008789 150.8686065674150 .8686065674150 .8686065674150 .5639038086150 .2590942383 149.9542999268149 .9542999268149 .6495056152149 .3446960449148 .7351074219 148.4304046631148 .1255950928147 .8208007812147 .5160064697147 .2111968994 146.9064025879146 .6015930176146 .2969055176145 .9920959473145 .6873016357 145.3825073242145 .3825073242145 .0776977539145 .0776977539145 .0776977539 145.0776977539145 .0776977539145 .0776977539145 .3825073242145 .3825073242 145.6873016357145 .9920959473146 .2969055176146 .6015930176147 .2111968994 147.5160064697148 .1255950928148 .4304046631148 .7351074219149 .0399017334 
149.3446960449149 .6495056152149 .9542999268149 .9542999268149 .9542999268 149.6495056152149 .3446960449149 .0399017334148 .7351074219148 .1255950928 147.5160064697146 .9064025879146 .2969055176145 .6873016357145 .0776977539 144.7729034424144 .7729034424144 .7729034424145 .3825073242146 .2969055176 147.2111968994147 .2111968994147 .8208007812147 .5950164795 -9999 -9999 -9999 -9999 -9999 -9999 -9999 -9999 -9999 -9999 -9999 -9999 -9999 -9999 -9999 -9999 -9999 -9999 -9999

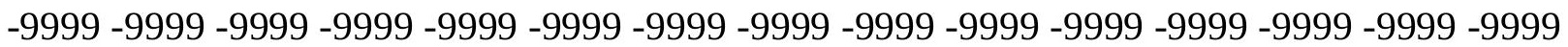

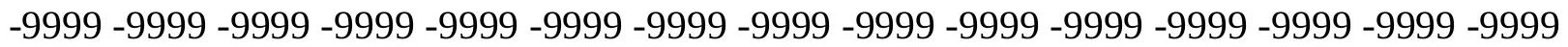

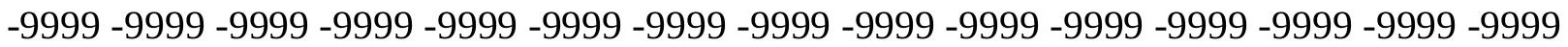
-9999 -9999 -9999 -9999 -9999 -9999 -9999 -9999 -9999 -9999 -9999 -9999 -9999 -9999 -9999 -9999 -9999 -9999 -9999 -9999 -9999 -9999 -9999 -9999 -9999 -9999 -9999 -9999 -9999 -9999 -9999 -9999 -9999 -9999 -9999 -9999 -9999 -9999 -9999 -9999 -9999 -9999 -9999 -9999 -9999 -999 -9999 -9999 -9999 -9999 -9999 -9999 -9999 -9999 -9999 -9999 -9999 -9999 -9999 -9999 -9999 -

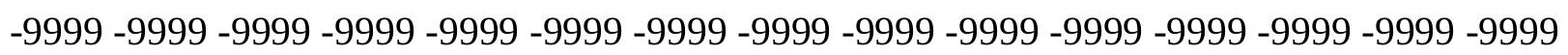
-9999 -9999 -9999

-9999 -9999 -9999 -9999 -9999 -9999 -9999 -9999 -9999-9999 -9999 -9999 -9999 -9999 -9999 -

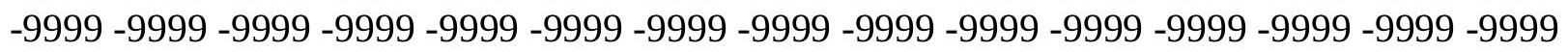
-9999 -9999 -9999-9999 -9999 -9999 -9999 -9999 -9999-9999 72.84364318848 74.6723632812576 .8058471679778 .6345596313580 .4632720947382 .59677124023 84.4254837036186 .254188537688 .3876876831190 .2164001464892 .04509735107 93.8738174438595 .7025299072397 .5312423706199 .35994720459101 .1886978149 102.712600708104 .5412979126106 .3700027466107 .8938980103109 .4179000854 111.24659729112 .7705001831114 .2944030762116 .1231002808117 .647102356 119.1709976196120 .6949005127122 .2188034058123 .43800354124 .9618988037 126.4858016968127 .7050018311129 .1944274902130 .4479980469131 .9720001221 133.1911010742134 .4102020264135 .6293945312136 .8484954834138 .0677032471 139.2868041992140 .5059967041141 .7250976562142 .9441986084143 .8585968018 145.0776977539145 .9920959473146 .9064025879147 .8208007812148 .7351074219 149.6495056152150 .5639038086151 .4781951904152 .0877990723153 .0021057129 153.6116943359154 .2212982178154 .8307952881155 .4403991699156 .0500030518 156.3547973633156 .9642944336157 .2691040039157 .5738983154157 .878692627 158.1835021973158 .1835021973158 .1835021973158 .4882965088158 .4882965088 158.4882965088158 .1835021973158 .1835021973157 .878692627157 .5738983154 157.5738983154157 .2691040039156 .9642944336156 .3547973633156 .0500030518 155.7451934814155 .1356048584154 .8307952881154 .2212982178153 .9165039062 153.3069000244153 .0021057129152 .3925933838152 .0877990723151 .7830047607 151.1734008789150 .8686065674150 .2590942383149 .9542999268149 .6495056152 149.0399017334148 .7351074219148 .4304046631148 .1255950928147 .8208007812 147.5160064697147 .2111968994147 .2111968994146 .9064025879146 .6015930176 146.6015930176146 .6015930176146 .2969055176146 .2969055176146 .2969055176 146.2969055176146 .2969055176146 .6015930176146 .6015930176146 .6015930176 146.6015930176146 .9064025879146 .9064025879146 .9064025879147 .2111968994 147.2111968994147 .2111968994147 .5160064697147 .5160064697147 .5160064697 147.8208007812147 .8208007812147 .8208007812147 .8208007812147 .8208007812 148.1255950928148 .1255950928148 .1255950928148 .1255950928148 .1255950928 148.1255950928148 .1255950928148 .1255950928148 .1255950928148 .1255950928 
148.1255950928148 .1255950928147 .8208007812147 .8208007812147 .5160064697 147.5160064697147 .2111968994146 .9064025879146 .6015930176146 .2969055176 145.9920959473145 .6873016357145 .3825073242145 .0776977539144 .7729034424 144.4682006836144 .1634063721143 .5538024902143 .2489929199143 .2489929199 142.9441986084142 .6394042969142 .3347015381142 .3347015381142 .0299072266 142.0299072266142 .0299072266142 .0299072266142 .0299072266142 .0299072266 142.3347015381142 .3347015381142 .6394042969142 .9441986084143 .2489929199 143.5538024902144 .1634063721144 .4682006836144 .7729034424145 .0776977539 145.6873016357145 .9920959473146 .2969055176146 .2969055176146 .6015930176 146.6015930176146 .6015930176146 .2969055176146 .2969055176145 .9920959473 145.6873016357145 .0776977539144 .7729034424144 .1634063721143 .8585968018 143.2489929199142 .9441986084142 .6394042969142 .6394042969142 .9441986084 143.2489929199143 .8585968018144 .1634063721143 .8585968018143 .5538024902 143.8585968018143 .8444061279 -9999 -9999 -9999 -9999 -9999 -9999 -9999 -9999 -9999 -9999 -9999 -9999 -9999 -9999 -9999 -9999 -9999 -9999 -9999 -9999 -9999 -9999 -9999 -9999

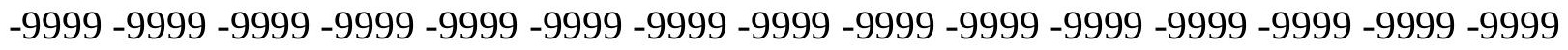
-9999 -9999 -9999 -9999 -9999 -9999 -9999 -9999 -9999 -9999 -9999 -9999 -9999 -9999 -9999 -9999 -9999 -9999 -9999 -9999 -9999 -9999 -9999 -9999 -9999 -9999 -9999 -9999 -9999 -9999 -9999 -9999 -9999 -9999 -9999 -9999 -9999 -9999 -9999 -9999 -9999 -9999 -9999 -9999 -9999 -

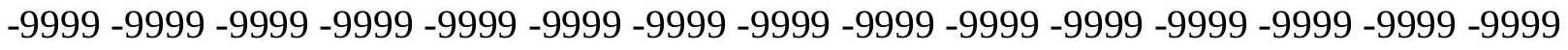

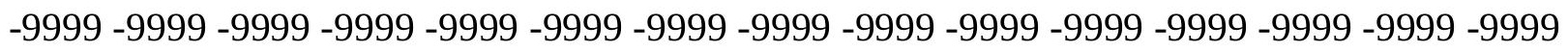
-9999 -9999 -9999 -9999 -9999 -9999 -9999 -9999 -9999 -9999 -9999 -9999 -9999 -9999 -9999 -9999 -9999 -9999 -9999 -9999 -9999 -9999 -9999 -9999 -9999 -9999 -9999 -

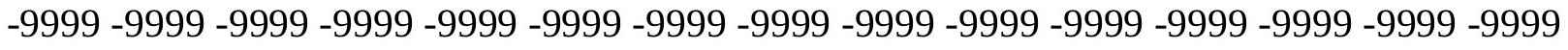

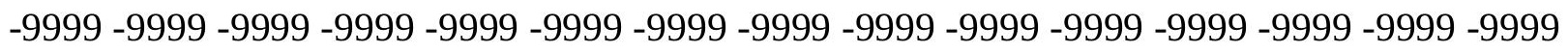
-9999 -9999 -9999 -9999-9999 -9999 -9999 -9999 66.74794006348 68.88143920898 70.7101516723672 .8436431884874 .9771423339876 .8058471679778 .93934631348 80.7680587768682 .5967712402384 .4254837036186 .5589828491288 .38768768311 90.2164001464892 .0450973510793 .8738174438595 .7025299072397 .53124237061 99.05516815186100 .8839035034102 .712600708104 .2365036011106 .0652008057 107.5891036987109 .1130981445110 .9418029785112 .4656982422113 .9896011353 115.5136032104117 .0374984741118 .5614013672120 .0852966309121 .3044967651 122.8283996582124 .3476791382125 .5715026855127 .0953979492128 .3144989014 129.533706665131 .0576019287132 .2767028809133 .4958953857134 .7149963379 135.9342041016136 .8484954834138 .0677032471139 .2868041992140 .2012023926 141.4203033447142 .3347015381143 .2489929199144 .4682006836145 .3825073242 146.2969055176146 .9064025879147 .8208007812148 .7351074219149 .3446960449 149.9542999268150 .8686065674151 .4781951904151 .7830047607152 .3925933838 153.0021057129153 .3069000244153 .9165039062154 .2212982178154 .5260925293 154.5260925293154 .8307952881154 .8307952881155 .1356048584155 .1356048584 155.1356048584155 .1356048584154 .8307952881154 .8307952881154 .5260925293 154.5260925293154 .2212982178153 .9165039062153 .6116943359153 .0021057129 152.6972961426152 .3925933838151 .7830047607151 .4781951904151 .1734008789 150.5639038086150 .2590942383149 .6495056152149 .3446960449148 .7351074219 148.4304046631147 .8208007812147 .5160064697146 .9064025879146 .6015930176 146.2969055176145 .9920959473145 .3825073242145 .0776977539144 .7729034424 
144.4682006836144 .1634063721144 .1634063721143 .8585968018143 .5538024902 143.5538024902143 .2489929199143 .2489929199143 .2489929199143 .2489929199 143.2489929199143 .2489929199143 .2489929199143 .2489929199143 .2489929199 143.2489929199143 .5538024902143 .5538024902143 .5538024902143 .8585968018 143.8585968018143 .8585968018144 .1634063721144 .1634063721144 .1634063721 144.4682006836144 .4682006836144 .4682006836144 .7729034424144 .7729034424 144.7729034424144 .7729034424144 .7729034424145 .0776977539145 .0776977539 145.0776977539145 .0776977539145 .0776977539145 .0776977539145 .0776977539 145.0776977539145 .0776977539144 .7729034424144 .7729034424144 .7729034424 144.4682006836144 .1634063721144 .1634063721143 .8585968018143 .5538024902 143.2489929199142 .9441986084142 .6394042969142 .3347015381142 .0299072266 141.7250976562141 .4203033447141 .1154937744140 .5059967041140 .2012023926 140.2012023926139 .8963928223139 .5915985107139 .2868041992139 .2868041992 138.9819946289138 .9819946289138 .9819946289138 .9819946289138 .9819946289 138.9819946289139 .2868041992139 .2868041992139 .5915985107139 .8963928223 140.2012023926140 .5059967041140 .8106994629141 .1154937744141 .7250976562 142.0299072266142 .3347015381142 .6394042969142 .9441986084142 .9441986084 143.2489929199143 .2489929199143 .2489929199143 .2489929199142 .9441986084 142.9441986084142 .6394042969142 .3347015381142 .0299072266141 .4203033447 141.1154937744140 .8106994629140 .5059967041140 .2012023926140 .5059967041 140.5059967041140 .8106994629141 .1154937744141 .1154937744140 .8106994629 140.2012023926139 .8963928223140 .5059967041140 .5850982666 -9999 -9999 -9999-9999 -9999 -9999 -9999 -9999 -9999 -9999 -9999 -9999 -9999 -9999 -9999 -9999 -9999 -9999 -9999

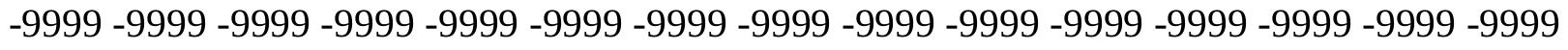

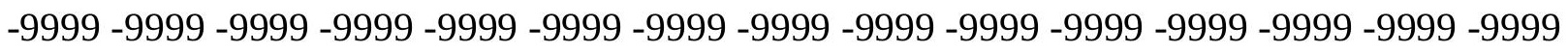
-9999 -9999 -9999 -9999 -9999 -9999 -9999 -9999 -9999 -9999 -9999 -9999 -9999 -9999 -9999 -

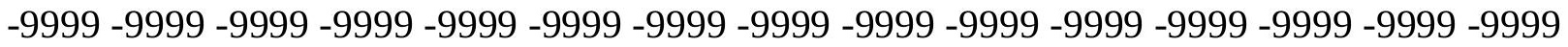

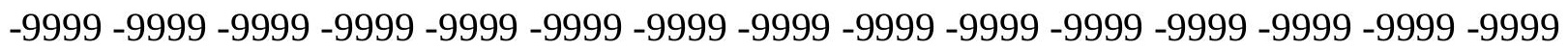
-9999 -9999 -9999 -9999 -9999 -9999 -9999 -9999 -9999 -9999 -9999 -9999 -9999 -9999 -9999 -9999 -9999 -9999 -9999 -9999 -9999 -9999 -9999 -9999 -9999 -9999 -9999 -9999 -9999 -9999

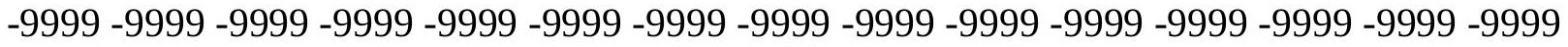
$-9999$

-9999 -9999 -9999 -9999 -9999 -9999 -9999 -9999 -9999 -9999 -9999 -9999 -9999 -9999 -9999 -9999 -9999 -9999 -9999 -9999 -9999 -9999 -9999 -9999 -9999 -9999 -9999 -9999 -9999 -9999 -9999 -9999 -9999 -9999 -9999 -9999 -9999 63.09051895142 64.9192428588967.05272674561 69.1862335205171 .014930725173 .1484298706174 .9771423339877 .1106262207 78.9393463134880 .7680587768682 .9015579223684 .7302627563586 .55898284912 88.3876876831190.2164001464892.0450973510793.87381744385 95.70252990723 97.2264633178799 .05516815186100 .5791015625102 .4077987671103 .9317016602 105.7603988647107 .2844009399108 .8082962036110 .3321990967111 .8561019897 113.3800964355114 .9039993286116 .4279022217117 .9517974854119 .4110412598 120.6949005127122 .2188034058123 .43800354124 .9618988037126 .1809997559 127.4001998901128 .6192932129129 .8385009766131 .0576019287132 .2767028809 133.4958953857134 .7149963379135 .6293945312136 .8484954834137 .7628936768 138.9819946289139 .8963928223140 .8106994629141 .7250976562142 .6394042969 143.5538024902144 .4682006836145 .0776977539145 .9920959473146 .6015930176 
147.2111968994147 .8208007812148 .4304046631149 .0399017334149 .3446960449 149.9542999268150 .2590942383150 .5639038086150 .8686065674151 .1734008789 151.4781951904151 .7830047607151 .7830047607151 .7830047607151 .7830047607 151.7830047607151 .7830047607151 .7830047607151 .4781951904151 .1734008789 151.1734008789150 .8686065674150 .5639038086150 .2590942383149 .6495056152 149.3446960449149 .0399017334148 .4304046631148 .1255950928147 .8208007812 147.2111968994146 .9064025879146 .2969055176145 .9920959473145 .3825073242 145.0776977539144 .4682006836144 .1634063721143 .8585968018143 .2489929199 142.9441986084142 .6394042969142 .3347015381142 .0299072266141 .7250976562 141.4203033447141 .1154937744140 .8106994629140 .5059967041140 .5059967041 140.2012023926140 .2012023926139 .8963928223139 .8963928223139 .8963928223 139.8963928223139 .8963928223139 .8963928223139 .8963928223139 .8963928223 140.2012023926140 .2012023926140 .2012023926140 .5059967041140 .5059967041 140.5059967041140 .8106994629140 .8106994629140 .8106994629141 .1154937744 141.1154937744141 .4203033447141 .4203033447141 .4203033447141 .4203033447 141.7250976562141 .7250976562141 .7250976562141 .7250976562142 .0299072266 142.0299072266142 .0299072266142 .0299072266142 .0299072266142 .0299072266 142.0299072266142 .0299072266141 .7250976562141 .7250976562141 .4203033447 141.4203033447141 .1154937744141 .1154937744140 .8106994629140 .5059967041 140.2012023926139 .8963928223139 .5915985107139 .2868041992138 .9819946289 138.6772003174138 .3724975586138 .0677032471137 .4580993652137 .1533050537 137.1533050537136 .8484954834136 .5437011719136 .2389984131136 .2389984131 135.9342041016135 .9342041016135 .9342041016135 .9342041016135 .9342041016 135.9342041016136 .2389984131136 .2389984131136 .5437011719136 .8484954834 137.1533050537137 .4580993652137 .7628936768138 .0677032471138 .3724975586 138.6772003174138 .9819946289139 .2868041992139 .5915985107139 .8963928223 139.8963928223140 .2012023926140 .2012023926140 .2012023926139 .8963928223 139.8963928223139 .5915985107139 .2868041992138 .9819946289138 .6772003174 138.6772003174138 .3724975586138 .0677032471138 .0677032471138 .0677032471 138.0677032471138 .3724975586138 .3724975586138 .3724975586137 .7628936768 137.1533050537136 .5437011719136 .8484954834137 .4580993652137 .4612579346 -9999 -9999 -9999 -9999 -9999 -9999 -9999 -9999 -9999 -9999 -9999 -9999 -9999 -9999 -9999 -9999

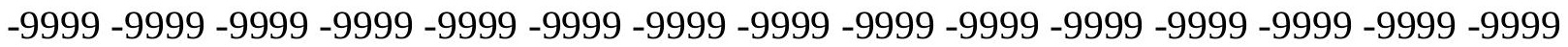

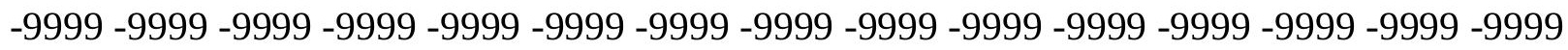
-9999 -9999 -9999 -9999 -9999 -9999 -9999 -9999 -9999 -9999 -9999 -9999 -9999 -9999 -9999 -9999 -9999 -9999 -9999 -9999 -9999 -9999 -9999 -9999 -9999 -9999 -9999 -9999 -9999 -9999

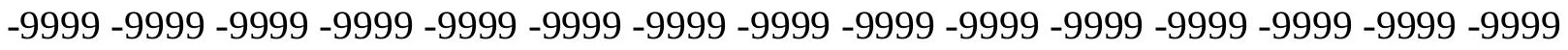

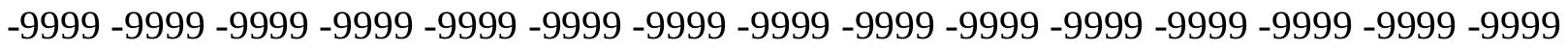
-9999 -9999 -9999 -9999 -9999 -9999 -9999 -9999 -9999 -9999 -9999 -9999 -9999 - 9999 - -999 -9999 -9999 -9999 -9999 -9999 -9999 -9999 -9999 -9999 -9999 -9999 -9999 -9999 -9999 -9999 -9999-9999-9999

-9999 -9999 -9999 -9999 -9999 -9999 -9999 -9999 -9999 -9999 -9999 -9999 -9999 -9999 -9999 -9999 -9999 -9999 -9999 -9999 -9999 -9999 -9999 -9999 -9999 -9999 -9999 -9999 -9999 -9999 -9999 -9999 -9999 -9999 -9999 57.29959869385 59.12831115723 61.26181030273 63.3953094482465 .2240066528367 .3575134277369 .4910125732471 .31971740723 73.4532165527375 .2819290161177 .110626220779 .2441329956181 .07285308838 
82.9015579223684 .7302627563586 .5589828491288 .3876876831190 .21640014648 92.0450973510793 .8738174438595 .397743225197 .2264633178798 .75038146973 100.5791015625102 .1029968262103 .9317016602105 .4557037354106 .979598999 108.5035018921110 .0273971558111 .551399231113 .075302124114 .5969467163 115.818397522117 .256439209118 .5614013672120 .0852966309121 .3044967651 122.8283996582124 .0475006104125 .2667007446126 .4858016968127 .7050018311 128.9241027832130 .1432037354131 .0576019287132 .2767028809133 .1911010742 134.4102020264135 .3246002197136 .2389984131137 .4580993652138 .3724975586 139.2868041992139 .8963928223140 .8106994629141 .7250976562142 .3347015381 142.9441986084143 .8585968018144 .4682006836145 .0776977539145 .6873016357 145.9920959473146 .6015930176146 .9064025879147 .2111968994147 .5160064697 147.8208007812148 .1255950928148 .4304046631148 .4304046631148 .4304046631 148.7351074219148 .7351074219148 .4304046631148 .4304046631148 .4304046631 148.1255950928148 .1255950928147 .8208007812147 .5160064697147 .2111968994 146.9064025879146 .6015930176145 .9920959473145 .6873016357145 .3825073242 144.7729034424144 .4682006836143 .8585968018143 .5538024902142 .9441986084 142.6394042969142 .0299072266141 .7250976562141 .1154937744140 .8106994629 140.5059967041139 .8963928223139 .5915985107139 .2868041992138 .9819946289 138.6772003174138 .3724975586138 .0677032471137 .7628936768137 .4580993652 137.4580993652137 .1533050537137 .1533050537136 .8484954834136 .8484954834 136.8484954834136 .5437011719136 .5437011719136 .5437011719136 .5437011719 136.8484954834136 .8484954834136 .8484954834136 .8484954834137 .1533050537 137.1533050537137 .1533050537137 .4580993652137 .4580993652137 .7628936768 137.7628936768137 .7628936768138 .0677032471138 .0677032471138 .3724975586 138.3724975586138 .3724975586138 .3724975586138 .6772003174138 .6772003174 138.6772003174138 .6772003174138 .9819946289138 .9819946289138 .9819946289 138.9819946289138 .9819946289138 .9819946289138 .9819946289138 .6772003174 138.6772003174138 .6772003174138 .3724975586138 .0677032471138 .0677032471 137.7628936768137 .4580993652137 .1533050537136 .8484954834136 .5437011719 136.2389984131135 .9342041016135 .6293945312135 .3246002197135 .0198059082 134.4102020264134 .1054992676134 .1054992676133 .8007049561133 .4958953857 133.1911010742133 .1911010742132 .8863067627132 .8863067627132 .8863067627 132.8863067627132 .8863067627132 .8863067627133 .1911010742133 .1911010742 133.4958953857133 .8007049561134 .1054992676134 .1054992676134 .7149963379 135.0198059082135 .3246002197135 .6293945312135 .9342041016136 .2389984131 136.5437011719136 .5437011719136 .8484954834136 .8484954834136 .8484954834 136.8484954834136 .8484954834136 .8484954834136 .8484954834136 .5437011719 136.2389984131136 .2389984131135 .9342041016135 .9342041016135 .6293945312 135.6293945312135 .6293945312135 .6293945312135 .6293945312135 .6293945312 135.3246002197135 .0198059082134 .4102020264133 .8007049561133 .1911010742 133.8007049561134 .4102020264 -9999 -9999 -9999 -9999 -9999 -9999 -9999 -9999 -9999 -9999 -9999 -9999 -9999 -9999 -9999 -9999 -9999 -9999 -9999 -9999 -9999 -9999 -9999 -9999 -9999 -9999 -9999 -9999 -9999 -9999 -9999 -9999 -9999 -9999 -9999 -9999 -9999 -9999 -9999 -9999 -9999 -9999 -9999 -9999 -9999 -9999 -9999 -9999 -9999 -9999 -9999 -9999 -9999 -9999 -9999 -9999 -9999 -9999 -9999 -9999 -9999 -9999 -9999 -9999 -9999 -9999 -9999 -9999 -9999 -

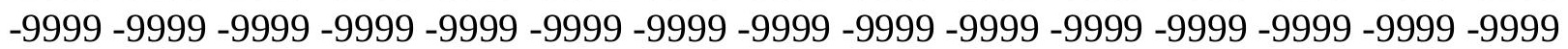


-9999 -9999 -9999 -9999 -9999 -9999 -9999 -9999 -9999 -9999 -9999 -9999 -9999 -9999 -9999 -9999 -9999 -9999 -9999 -9999 -9999 -9999 -9999 -9999 -9999 -9999 -9999 -9999 -9999 -9999 -9999 -9999 -9999 -9999 -9999 -9999 -9999 -9999 -9999 -9999 -9999 -9999 -9999 -9999 -9999 -9999 -9999 -9999 -9999 -9999 -9999 -9999 -9999 -9999 -9999

-9999 -9999 -9999 -9999 -9999 -9999 -9999 -9999 -9999 -9999 -9999 -9999 -9999 -9999 -9999 -9999 -9999 -9999 -9999 -9999 -9999 -9999 -9999 -9999 -9999 -9999 -9999 -9999 -9999 -9999 -9999 -9999 -9999 -9999 53.33739852905 55.47089004517 57.6043891906759 .43310165405 61.5666007995663 .7000885009865 .5288009643667 .6623001098669 .79579162598 71.6244964599673 .4532165527375 .5867080688577 .4154205322379 .24413299561 81.0728530883882 .9015579223684 .7302627563586 .5589828491288 .38768768311 90.2164001464892 .0450973510793 .5690307617295 .397743225196 .92166900635 98.75038146973100 .2742996216101 .7982025146103 .6268997192105 .1509017944 106.6747970581108 .1986999512109 .7226028442110 .9418029785112 .4656982422 113.8487854004115 .2088012695116 .7326965332117 .9517974854119 .1709976196 120.6949005127121 .9140014648123 .1332015991124 .3523025513125 .5715026855 126.4858016968127 .7050018311128 .9241027832129 .8385009766131 .0576019287 131.9720001221132 .8863067627133 .8007049561134 .7149963379135 .6293945312 136.5437011719137 .4580993652138 .0677032471138 .9819946289139 .5915985107 140.2012023926141 .1154937744141 .7250976562142 .0299072266142 .6394042969 143.2489929199143 .5538024902143 .8585968018144 .1634063721144 .4682006836 144.7729034424145 .0776977539145 .0776977539145 .3825073242145 .3825073242 145.3825073242145 .3825073242145 .3825073242145 .3825073242145 .0776977539 144.7729034424144 .7729034424144 .4682006836144 .1634063721143 .8585968018 143.5538024902143 .2489929199142 .6394042969142 .3347015381142 .0299072266 141.4203033447141 .1154937744140 .5059967041140 .2012023926139 .5915985107 139.2868041992 138.9819946289 138.3724975586138.0677032471 137.4580993652 137.1533050537136 .8484954834136 .2389984131135 .9342041016135 .6293945312 135.3246002197135 .0198059082134 .7149963379134 .4102020264134 .4102020264 134.1054992676133 .8007049561133 .8007049561133 .8007049561133 .4958953857 133.4958953857133 .4958953857133 .4958953857133 .4958953857133 .4958953857 133.4958953857133 .4958953857133 .4958953857133 .8007049561133 .8007049561 133.8007049561134 .1054992676134 .1054992676134 .4102020264134 .4102020264 134.7149963379134 .7149963379134 .7149963379135 .0198059082135 .0198059082 135.3246002197135 .3246002197135 .3246002197135 .6293945312135 .6293945312 135.6293945312135 .6293945312135 .9342041016135 .9342041016135 .9342041016 135.9342041016135 .9342041016135 .9342041016135 .9342041016135 .6293945312 135.6293945312135 .6293945312135 .3246002197135 .3246002197135 .0198059082 134.7149963379134 .4102020264134 .1054992676133 .8007049561133 .4958953857 133.1911010742132 .8863067627132 .5814971924132 .2767028809131 .9720001221 131.6672058105131 .3623962402131 .0576019287130 .7528076172130 .4479980469 130.1432037354130 .1432037354129 .8385009766129 .8385009766129 .8385009766 129.8385009766129 .8385009766129 .8385009766129 .8385009766130 .1432037354 130.4479980469130 .4479980469130 .7528076172131 .0576019287131 .3623962402 131.6672058105131 .9720001221132 .2767028809132 .5814971924132 .8863067627 133.1911010742133 .4958953857133 .4958953857133 .8007049561133 .8007049561 133.8007049561134 .1054992676133 .8007049561133 .8007049561133 .8007049561 
133.8007049561 133.4958953857 133.4958953857133 .1911010742133 .1911010742 133.1911010742133 .1911010742133 .1911010742133 .1911010742132 .8863067627 132.5814971924132 .2767028809131 .9720001221131 .3623962402131 .0576019287 130.7528076172131 .3623962402131 .9720001221 -9999 -9999 -9999 -9999 -9999 -9999 -9999 -9999 -9999 -9999 -9999 -9999 -9999 -9999 -9999 -9999 -9999 -9999 -9999 -9999 -9999 -9999 -9999 -9999 -9999 -9999 -9999 -9999 -9999 -9999 -9999 -9999 -9999 -9999 -9999 -9999 -9999 -9999 -9999 -9999 -9999 -9999 -9999 -9999 -9999 -9999 -9999 -9999 -9999 -9999 -9999 -9999 -

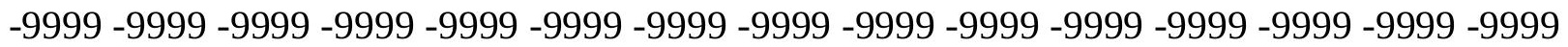

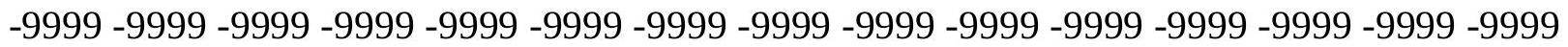
-9999 -9999 -9999 -9999 -9999 -9999 -9999 -9999 -9999 -9999 -9999 -9999 -9999 -9999 -9999 -9999 -9999 -9999 -9999 -9999 -9999 -9999 -9999 -9999 -9999 -9999 -9999 -9999 -9999 -9999 -999 -

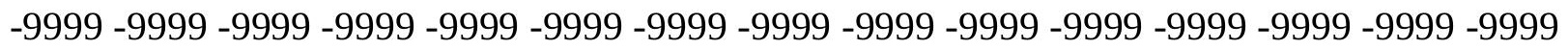
-9999 -9999 -9999 -9999 -9999 -9999 -9999 -9999 -9999 -9999 -9999

-9999 -9999 -9999 -9999 -9999 -9999 -9999 -9999 -9999 -9999 -9999 -9999 -9999 -9999 -9999 -9999 -9999 -9999 -9999 -9999 -9999 -9999 -9999 -9999 -9999 -9999 -9999 -9999 -9999 -9999 -9999 -9999 47.54647827148 49.6799812316951.8134689331153.94697189331 55.7756805419957 .909179687560 .0426712036161 .8713798522964 .0048828125 66.1383666992267 .9670867919970 .1005783081171 .9292907714873 .75800323486 75.5867080688577 .7202072143679 .5489196777381 .3776321411183 .2063369751 85.03504943848 86.8637619018688.3876876831190.2164001464892.04509735107 93.5690307617295 .0929565429796 .9216690063598 .445587158299 .96952056885 101.7982025146103 .3221969604104 .8460998535106 .0652008057107 .5891036987 109.1130981445110 .4917449951111 .8561019897113 .3800964355114 .5991973877 115.818397522117 .342300415118 .5614013672119 .7806015015120 .9997024536 122.2188034058123 .1332015991124 .3523025513125 .5715026855126 .4858016968 127.7050018311128 .6192932129129 .533706665130 .4479980469131 .3623962402 132.2767028809133 .1911010742134 .1054992676134 .7149963379135 .6293945312 136.2389984131136 .8484954834137 .4580993652138 .0677032471138 .6772003174 139.2868041992139 .8963928223140 .2012023926140 .5059967041141 .1154937744 141.4203033447141 .4203033447141 .7250976562142 .0299072266142 .0299072266 142.0299072266142 .3347015381142 .3347015381142 .3347015381142 .0299072266 142.0299072266141 .7250976562141 .7250976562141 .4203033447141 .1154937744 140.8106994629140 .5059967041140 .2012023926139 .8963928223139 .5915985107 138.9819946289138 .6772003174138 .0677032471137 .7628936768137 .4580993652 136.8484954834136 .5437011719135 .9342041016135 .6293945312135 .0198059082 134.7149963379134 .4102020264133 .8007049561133 .4958953857133 .1911010742 132.8863067627132 .2767028809131 .9720001221131 .6672058105131 .6672058105 131.3623962402131 .0576019287130 .7528076172130 .7528076172130 .4479980469 130.4479980469130 .4479980469130 .1432037354130 .1432037354130 .1432037354 130.1432037354130 .1432037354130 .4479980469130 .4479980469130 .4479980469 130.4479980469130 .7528076172130 .7528076172130 .7528076172131 .0576019287 131.0576019287131 .3623962402131 .3623962402131 .6672058105131 .6672058105 131.9720001221131 .9720001221131 .9720001221132 .2767028809132 .2767028809 132.5814971924132 .5814971924132 .5814971924132 .8863067627132 .8863067627 132.8863067627132 .8863067627132 .8863067627132 .8863067627132 .8863067627 132.8863067627132 .8863067627132 .5814971924132 .5814971924132 .2767028809 
132.2767028809 131.9720001221 131.6672058105 131.3623962402 131.0576019287 130.7528076172130 .4479980469130 .1432037354129 .8385009766129 .533706665 129.2288970947128 .9241027832128 .6192932129128 .3144989014128 .0097961426 127.7050018311127 .4001998901127 .0953979492127 .0953979492126 .7906036377 126.7906036377126 .7906036377126 .7906036377126 .7906036377126 .7906036377 126.7906036377127 .0953979492127 .0953979492127 .4001998901127 .7050018311 128.0097961426128 .3144989014128 .6192932129128 .9241027832129 .2288970947 129.533706665129 .8385009766130 .1432037354130 .4479980469130 .4479980469 130.7528076172130 .7528076172131 .0576019287131 .0576019287131 .0576019287 131.0576019287131 .0576019287131 .0576019287131 .0576019287130 .7528076172 130.7528076172130 .7528076172130 .7528076172130 .7528076172130 .7528076172 130.4479980469130 .4479980469130 .1432037354129 .8385009766129 .533706665 129.2288970947 128.6192932129 128.3144989014128.0097961426128.9241027832 129.3573455811 -9999 -9999 -9999 -9999 -9999 -9999 -9999 -9999 -9999 -9999 -9999 -9999 -9999 -9999 -9999 -9999 -9999 -9999 -9999 -9999 -9999 -9999 -9999 -9999 -9999 -9999 -9999

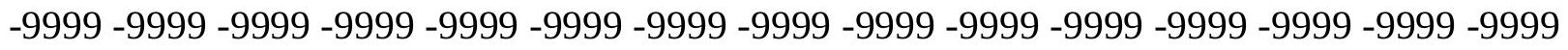
-9999 -9999 -9999 -9999 -9999 -9999 -9999 -9999 -9999 -9999 -9999 -9999 -9999 -9999 -9999 -9999 -9999 -9999 -9999 -9999 -9999 -9999 -9999 -9999 -9999 -9999 -9999 -9999 -9999 -9999 -

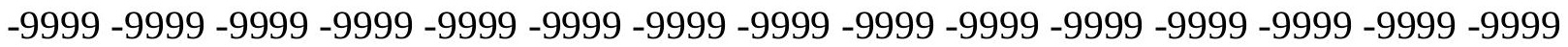

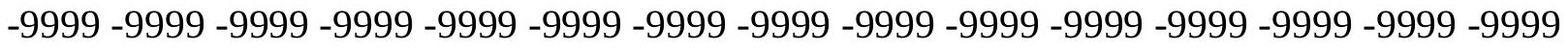

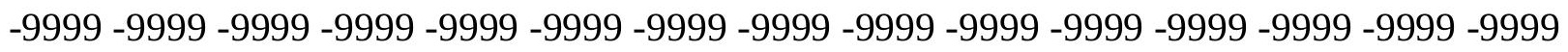

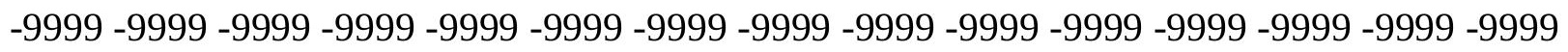
-9999 -9999 -9999-9999-9999

-9999 -9999 -9999 -9999 -9999-9999 -9999 -9999 -9999 -9999 -9999 -9999 -9999 -9999 -9999 -

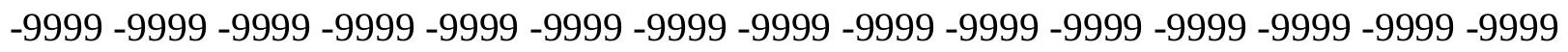
-9999 43.8890609741246.02254867554 48.15605163574 49.9847602844252.11825942993 54.2517509460456 .3852500915558 .2139587402360 .3474502563562 .48094940186 64.3096618652366 .4431610107468 .2718734741270 .4053573608472 .23407745361 74.062782287675 .8914871215877 .7202072143679 .5489196777381 .37763214111 83.2063369751 85.03504943848 86.86376190186 88.3876876831190.21640014648 91.7403335571393 .5690307617295 .0929565429796 .6168823242298 .14080810547 99.96952056885101 .4934005737102 .712600708104 .2365036011105 .7603988647 107.2603302002108 .5035018921110 .0273971558111 .24659729112 .7705001831 113.9896011353115 .2088012695116 .4279022217117 .647102356118 .8662033081 120.0852966309120 .9997024536122 .2188034058123 .1332015991124 .3523025513 125.2667007446126 .1809997559127 .0953979492128 .0097961426128 .9241027832 129.8385009766130 .7528076172131 .3623962402132 .2767028809132 .8863067627 133.4958953857134 .4102020264135 .0198059082135 .3246002197135 .9342041016 136.5437011719136 .8484954834137 .4580993652137 .7628936768138 .0677032471 138.3724975586138 .6772003174138 .6772003174138 .9819946289138 .9819946289 138.9819946289138 .9819946289138 .9819946289138 .9819946289138 .9819946289 138.6772003174138 .6772003174138 .3724975586138 .0677032471137 .7628936768 137.4580993652137 .1533050537136 .8484954834136 .5437011719136 .2389984131 135.6293945312135 .3246002197135 .0198059082134 .4102020264134 .1054992676 133.4958953857133 .1911010742132 .5814971924132 .2767028809131 .9720001221 131.3623962402131 .0576019287130 .4479980469130 .1432037354129 .8385009766 
129.533706665129 .2288970947128 .9241027832128 .6192932129128 .3144989014 128.0097961426127 .7050018311127 .7050018311127 .4001998901127 .4001998901 127.0953979492127 .0953979492127 .0953979492127 .0953979492127 .0953979492 127.0953979492127 .0953979492127 .0953979492127 .0953979492127 .4001998901 127.4001998901127 .4001998901127 .7050018311127 .7050018311128 .0097961426 128.0097961426128 .3144989014128 .3144989014128 .6192932129128 .6192932129 128.9241027832128 .9241027832128 .9241027832129 .2288970947129 .2288970947 129.533706665129 .533706665129 .533706665129 .8385009766129 .8385009766 129.8385009766129 .8385009766129 .8385009766129 .8385009766129 .8385009766 129.8385009766129 .8385009766129 .8385009766129 .533706665129 .533706665 129.2288970947128 .9241027832128 .9241027832128 .6192932129128 .3144989014 128.0097961426127 .7050018311127 .4001998901127 .0953979492126 .4858016968 126.1809997559125 .8762969971125 .5715026855125 .2667007446124 .9618988037 124.6570968628124 .3523025513124 .0475006104124 .0475006104123 .7427978516 123.7427978516123 .7427978516123 .7427978516123 .7427978516123 .7427978516 123.7427978516123 .7427978516124 .0475006104124 .3523025513124 .6570968628 124.6570968628124 .9618988037125 .2667007446125 .5715026855126 .1809997559 126.4858016968126 .7906036377127 .0953979492127 .0953979492127 .4001998901 127.7050018311128 .0097961426128 .0097961426128 .0097961426128 .3144989014 128.3144989014128 .3144989014128 .3144989014128 .3144989014128 .3144989014 128.3144989014128 .3144989014128 .3144989014128 .3144989014128 .3144989014 128.0097961426128 .0097961426127 .7050018311127 .7050018311127 .4001998901 126.7906036377126 .4858016968126 .1809997559126 .1809997559126 .1809997559 126.8020477295 -9999 -9999 -9999 -9999 -9999 -9999 -9999 -9999 -9999 -9999 -9999 -9999

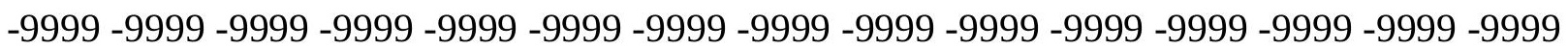

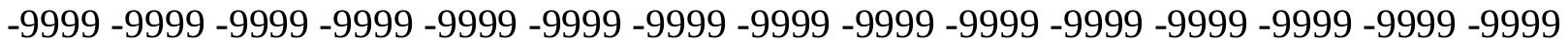

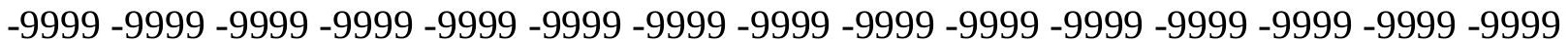

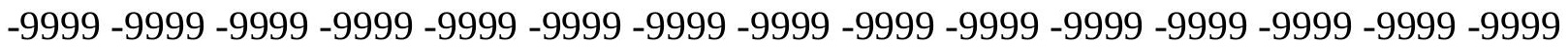

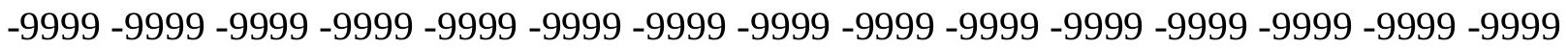

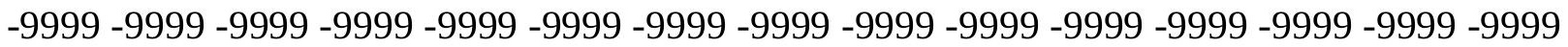

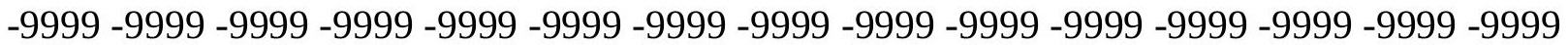

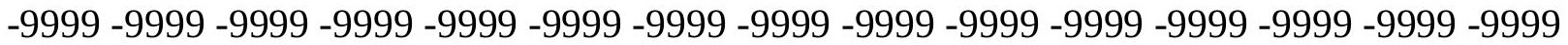
-9999-9999 -9999 -9999-9999

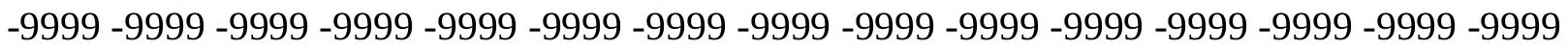
-9999 -9999 -9999 -9999 -9999 -9999 -9999 -9999 -9999 -9999 -9999 -9999 -9999 -9999 38.0981407165540 .2316398620642 .3651313781744 .4986305236846 .63212966919 48.4608306884850 .5943298339852 .7278289794954 .8613204956156 .69002914429 58.8235282897960 .6522407531762 .7857398986864 .6144485473666 .74794006348 68.5766525268670 .4053573608472 .5388565063574 .3675689697376 .19628143311 78.0249862670979 .8537063598681 .6824111938583 .206336975185 .03504943848 86.8637619018688 .3876876831190 .2164001464891 .7403335571393 .26425170898 94.7881774902396 .6168823242298 .1408081054799 .66472625732100 .8839035034 102.4077987671103 .9317016602105 .4557037354106 .6747970581107 .8938980103 109.4179000854110 .6370010376111 .8561019897113 .075302124114 .2944030762 115.5136032104116 .7326965332117 .9517974854118 .8662033081120 .0852966309 120.9997024536121 .9140014648123 .1332015991124 .0475006104124 .9618988037 
125.8762969971126 .4858016968127 .4001998901128 .3144989014128 .9241027832 129.533706665130 .4479980469131 .0576019287131 .6672058105132 .2767028809 132.5814971924133 .1911010742133 .8007049561134 .1054992676134 .4102020264 134.7149963379135 .0198059082135 .3246002197135 .6293945312135 .6293945312 135.9342041016135 .9342041016135 .9342041016135 .9342041016135 .9342041016 135.9342041016135 .6293945312135 .6293945312135 .3246002197135 .3246002197 135.0198059082134 .7149963379134 .4102020264134 .1054992676133 .8007049561 133.1911010742132 .8863067627132 .5814971924131 .9720001221131 .6672058105 131.0576019287130 .7528076172130 .4479980469129 .8385009766129 .533706665 128.9241027832128 .6192932129128 .0097961426127 .7050018311127 .4001998901 127.0953979492126 .4858016968126 .1809997559125 .8762969971125 .5715026855 125.2667007446124 .9618988037124 .9618988037124 .6570968628124 .3523025513 124.3523025513124 .0475006104124 .0475006104124 .0475006104124 .0475006104 123.7427978516123 .7427978516123 .7427978516124 .0475006104124 .0475006104 124.0475006104124 .0475006104124 .3523025513124 .3523025513124 .3523025513 124.6570968628124 .6570968628124 .9618988037124 .9618988037125 .2667007446 125.2667007446125 .5715026855125 .8762969971125 .8762969971126 .1809997559 126.1809997559126 .4858016968126 .4858016968126 .4858016968126 .7906036377 126.7906036377126 .7906036377127 .0953979492127 .0953979492127 .0953979492 127.0953979492127 .0953979492127 .0953979492127 .0953979492126 .7906036377 126.7906036377126 .4858016968126 .4858016968126 .1809997559125 .8762969971 125.5715026855125 .2667007446124 .9618988037124 .6570968628124 .3523025513 124.0475006104123 .7427978516123 .43800354123 .1332015991122 .5235977173 122.2188034058121 .9140014648121 .6092987061121 .3044967651121 .3044967651 120.9997024536120 .6949005127120 .6949005127120 .6949005127120 .3900985718 120.3900985718120 .6949005127120 .6949005127120 .6949005127120 .9997024536 121.3044967651121 .3044967651121 .6092987061121 .9140014648122 .2188034058 122.5235977173122 .8283996582123 .1332015991123 .43800354124 .0475006104 124.3523025513124 .3523025513124 .6570968628124 .9618988037125 .2667007446 125.2667007446125 .5715026855125 .5715026855125 .5715026855125 .8762969971 125.8762969971125 .8762969971125 .8762969971125 .8762969971125 .8762969971 125.8762969971125 .8762969971125 .8762969971125 .8762969971125 .5715026855 125.2667007446124 .9618988037124 .9618988037124 .6570968628124 .3523025513 124.0475006104124 .0475006104124 .6570968628124 .9553375244 -9999 -9999 -9999-9999 -9999 -9999 -9999 -9999 -9999 -9999 -9999 -9999 -9999 -9999 -9999 -9999 -9999 -9999 -9999

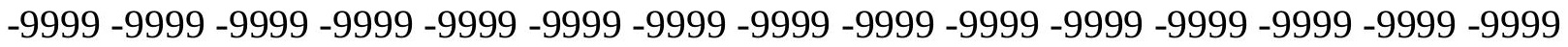

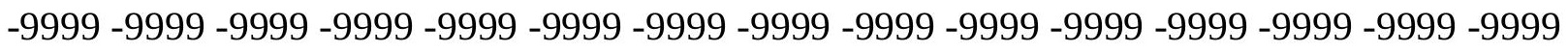

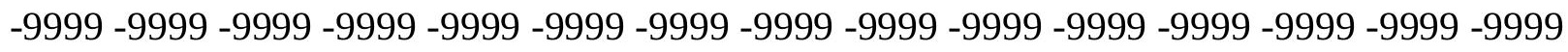
-9999 -9999 -9999 -9999 -9999 -9999 -9999 -9999 -9999 -9999 -9999 -9999 -9999 -9999 -9999 -9999 -9999 -9999 -9999 -9999 -9999 -9999 -9999 -9999 -9999 -9999 -9999 -9999 -9999 -9999 -

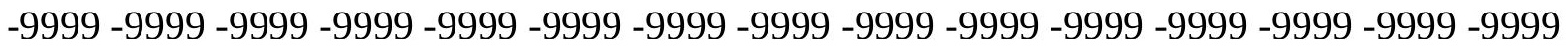

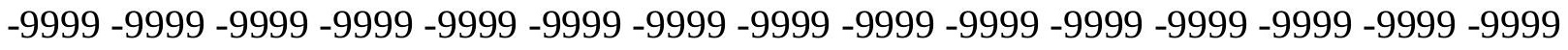
-9999 -9999 -9999 -9999 -9999 -9999 -9999 -9999 -9999 -9999 -9999 -9999 -9999 -9999 -9999 -9999 -9999 -9999 -9999 -9999 -9999 -9999 -9999 -9999 -9999 -9999 -9999 -9999 -9999 -9999 -9999 -9999 -9999 -9999 -9999 -9999 -9999 -9999 -9999 -9999 34.4407196044936 .5742111206138 .7077102661140 .8412094116242 .97470092773 
44.8034095764246 .9369087219249 .0704002380451 .2038993835453 .33739852905 55.1661109924357 .2995986938559 .1283111572361 .2618103027363 .09051895142 65.2240066528367 .0527267456168 .8814392089870 .7101516723672 .84364318848 74.6723632812576 .5010681152378 .0249862670979 .8537063598681 .68241119385 83.5111236572385 .0350494384886 .8637619018688 .3876876831189 .91161346436 91.7403335571393 .2642517089894 .7881774902396 .3121032714897 .83602905273 99.35994720459100 .5791015625102 .0987167358103 .3221969604104 .8460998535 106.0652008057 107.2844009399 108.8082962036110.0273971558 111.24659729 112.4656982422113 .3800964355114 .5991973877115 .818397522116 .7326965332 117.9517974854118 .8662033081119 .7806015015120 .6949005127121 .6092987061 122.5235977173123 .43800354124 .3523025513124 .9618988037125 .8762969971 126.4858016968127 .0953979492127 .7050018311128 .3144989014128 .9241027832 129.533706665130 .1432037354130 .4479980469130 .7528076172131 .3623962402 131.6672058105131 .9720001221132 .2767028809132 .2767028809132 .5814971924 132.5814971924132 .8863067627132 .8863067627132 .8863067627132 .8863067627 132.8863067627132 .5814971924132 .5814971924132 .2767028809132 .2767028809 131.9720001221131 .6672058105131 .3623962402131 .0576019287130 .7528076172 130.4479980469130 .1432037354129 .533706665129 .2288970947128 .9241027832 128.3144989014128 .0097961426127 .4001998901127 .0953979492126 .4858016968 126.1809997559125 .8762969971125 .2667007446124 .9618988037124 .3523025513 124.0475006104123 .7427978516123 .43800354123 .1332015991122 .8283996582 122.5235977173122 .2188034058121 .9140014648121 .6092987061121 .6092987061 121.3044967651120 .9997024536120 .9997024536120 .9997024536120 .6949005127 120.6949005127120 .6949005127120 .6949005127120 .6949005127120 .6949005127 120.9997024536120 .9997024536120 .9997024536120 .9997024536121 .3044967651 121.3044967651121 .6092987061121 .6092987061121 .9140014648121 .9140014648 122.2188034058122 .5235977173122 .5235977173122 .8283996582122 .8283996582 123.1332015991123 .1332015991123 .43800354123 .43800354123 .7427978516 123.7427978516124 .0475006104124 .0475006104124 .0475006104124 .0475006104 124.3523025513124 .3523025513124 .3523025513124 .0475006104124 .0475006104 124.0475006104124 .0475006104123 .7427978516123 .43800354123 .43800354 123.1332015991122 .8283996582122 .5235977173122 .2188034058121 .9140014648 121.6092987061121 .3044967651120 .6949005127120 .3900985718120 .0852966309 119.7806015015119 .4757995605119 .1709976196118 .8662033081118 .5614013672 118.2565994263117 .9517974854117 .9517974854117 .647102356117 .647102356 117.342300415117 .342300415117 .647102356117 .647102356117 .647102356 117.9517974854117 .9517974854118 .2565994263118 .5614013672118 .8662033081 119.1709976196119 .4757995605119 .7806015015120 .0852966309120 .6949005127 120.9997024536121 .3044967651121 .6092987061121 .9140014648122 .2188034058 122.2188034058122 .5235977173122 .8283996582122 .8283996582123 .1332015991 123.1332015991123 .43800354123 .43800354123 .43800354123 .7427978516123 .7427978516 123.7427978516123 .7427978516123 .7427978516123 .43800354123 .43800354 123.1332015991123 .1332015991122 .8283996582122 .5235977173122 .5235977173 $122.2188034058122 .2188034058122 .2188034058122 .7096328735123 .5216827393-9999$ -9999 -9999 -9999 -9999 -9999 -9999 -9999 -9999 -9999 -9999 -9999 -9999 -9999 -9999 -9999

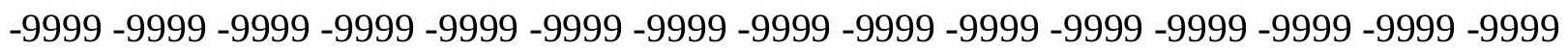


-9999 -9999 -9999 -9999 -9999 -9999 -9999 -9999 -9999 -9999 -9999 -9999 -9999 -9999 -9999 -9999 -9999 -9999 -9999 -9999 -9999 -9999 -9999 -9999 -9999 -9999 -9999 -9999 -9999 -9999

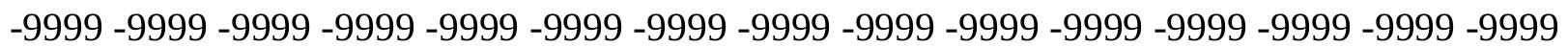
-9999 -9999 -9999 -9999 -9999 -9999 -9999 -9999 -9999 -9999 -9999 -9999 -9999 -9999 -9999

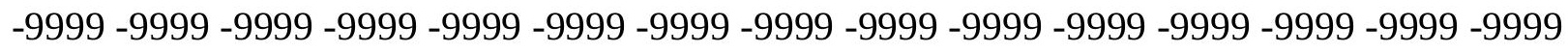

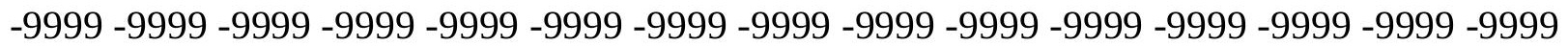
-9999 -9999 -9999 -9999 -9999 -9999 -9999 -9999 -9999 -9999 -9999 -9999 -9999 -9999 -9999 -9999 -9999 -9999 -9999 -9999 -9999 -9999 -9999 -9999 -9999 -9999 -9999 -9999 -9999 -9999 -9999 -9999 -9999 -9999 -9999 -9999 -9999 -9999 -9999 -9999 -9999 30.78330039978 32.9167900085435 .0502891540537 .1837806701739 .3172798156741 .45077896118 43.5842704772945 .4129791259847 .5464782714849 .6799812316951 .81346893311 53.6421813964855 .7756805419957 .6043891906759 .7378807067961 .56660079956 63.7000885009865 .5288009643667 .3575134277369 .1862335205171 .0149307251 72.8436431884874 .6723632812576 .5010681152378 .3297805786180 .15849304199 81.6824111938583 .5111236572385 .0350494384886 .8637619018688 .38768768311 89.91161346436 91.4355392456192.95947265625 94.4833908081196.00731658936 97.5312423706198 .75038146973100 .2742996216101 .4934005737103 .0174026489 104.2365036011105 .4557037354106 .6747970581107 .8938980103109 .1130981445 110.3321990967111 .551399231112 .4656982422113 .6848983765114 .5991973877 115.818397522116 .7326965332117 .647102356118 .5614013672119 .4757995605 120.3900985718120 .9997024536121 .9140014648122 .5235977173123 .43800354 124.0475006104124 .6570968628125 .2667007446125 .8762969971126 .4858016968 126.7906036377127 .4001998901127 .7050018311128 .0097961426128 .6192932129 128.9241027832128 .9241027832129 .2288970947129 .533706665129 .533706665 129.8385009766129 .8385009766129 .8385009766129 .8385009766129 .8385009766 129.8385009766129 .533706665129 .533706665129 .2288970947128 .9241027832 128.9241027832128 .6192932129128 .3144989014128 .0097961426127 .7050018311 127.0953979492126 .7906036377126 .4858016968125 .8762969971125 .5715026855 125.2667007446124 .6570968628124 .3523025513123 .7427978516123 .43800354 122.8283996582122 .5235977173122 .2188034058121 .6092987061121 .3044967651 120.9997024536120 .3900985718120 .0852966309119 .7806015015119 .4757995605 119.1709976196118 .8662033081118 .5614013672118 .5614013672118 .2565994263 118.2565994263117 .9517974854117 .9517974854117 .647102356117 .647102356 117.647102356117 .647102356117 .647102356117 .647102356117 .647102356117 .647102356 117.9517974854117 .9517974854117 .9517974854118 .2565994263118 .2565994263 118.5614013672118 .5614013672118 .8662033081118 .8662033081119 .1709976196 119.4757995605119 .4757995605119 .7806015015120 .0852966309120 .0852966309 120.3900985718120 .3900985718120 .6949005127120 .6949005127120 .9997024536 120.9997024536121 .3044967651121 .3044967651121 .3044967651121 .3044967651 121.3044967651121 .3044967651121 .3044967651121 .3044967651121 .3044967651 120.9997024536120 .9997024536120 .6949005127120 .6949005127120 .3900985718 120.0852966309119 .7806015015119 .4757995605119 .1709976196118 .8662033081 118.2565994263117 .9517974854117 .647102356117 .342300415117 .0374984741 116.4279022217116 .1231002808115 .818397522115 .5136032104115 .2088012695 114.9039993286114 .9039993286114 .5991973877114 .5991973877114 .5991973877 114.5991973877114 .5991973877114 .5991973877114 .5991973877114 .9039993286 
114.9039993286115 .2088012695115 .5136032104115 .818397522116 .1231002808 116.4279022217116 .7326965332117 .342300415117 .647102356117 .9517974854 118.2565994263118 .5614013672118 .8662033081119 .1709976196119 .4757995605 119.7806015015120 .0852966309120 .3900985718120 .6949005127120 .6949005127 120.9997024536120 .9997024536121 .3044967651121 .3044967651121 .3044967651 121.3044967651 121.3044967651 121.3044967651 121.3044967651 121.3044967651 121.3044967651120 .9997024536120 .9997024536120 .6949005127120 .6949005127 120.3900985718120 .3900985718120 .3900985718120 .9997024536122 .0973510742 -9999 -9999 -9999 -9999 -9999 -9999 -9999 -9999 -9999 -9999 -9999 -9999 -9999 -9999 -9999 -9999 -9999 -9999 -9999 -9999 -9999 -9999 -9999 -9999 -9999 -9999 -9999 -9999 -9999 -9999 -9999 -

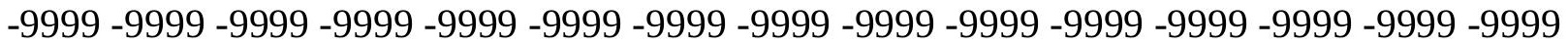
-9999 -9999 -9999 -9999 -9999 -9999 -9999 -9999 -9999 -9999 -9999 -9999 -9999 -9999 -9999 -9999 -9999 -9999 -9999 -9999 -9999 -9999 -9999 -9999 -9999 -9999 -9999 -9999 -9999 -9999 -9999 -9999 -9999 -9999 -9999 -9999 -9999 -9999 -9999 -9999 -9999 -9999 -9999 -9999 -9999 -9999 -9999 -9999 -9999 -9999 -9999 -9999 -9999 -9999 -9999 -9999 -9999 -9999 -9999 -9999

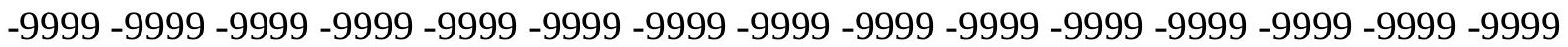
-9999 -9999 -9999 -9999 -9999 -9999 -9999 -9999 -9999 -9999 -9999 -9999 -9999 -9999 -9999 -9999 -9999 -9999 -9999 -9999 -9999 -9999 -9999 -9999 -9999 -9999 -9999 -9999 -9999 -9999 -9999 -9999 -9999 -9999 -9999 -9999 -9999 -9999 -9999 -9999 27.4306602478 29.5641593933131 .3928699493433 .5263595581135 .6598587036137 .79335021973 39.9268493652342 .0603485107444 .1938400268646 .0225486755448 .15605163574 50.2895507812552 .1182594299354 .2517509460456 .3852500915558 .21395874023 60.0426712036162 .1761703491264 .004882812565 .8335876464867 .66230010986 69.4910125732471 .3197174072373 .1484298706174 .9771423339876 .80584716797 78.3297805786180 .1584930419981 .6824111938583 .5111236572385 .03504943848 86.5589828491288 .3876876831189 .9116134643691 .4355392456192 .65467834473 94.1785964965895 .7025299072397 .2264633178798 .445587158299 .66472625732 101.1886978149102 .4077987671103 .6268997192104 .8460998535106 .0652008057 107.2844009399108 .5035018921109 .4179000854110 .6370010376111 .551399231 112.7705001831113 .6848983765114 .5991973877115 .5136032104116 .4279022217 117.342300415117 .9517974854118 .8662033081119 .4757995605120 .3900985718 120.9997024536121 .6092987061122 .2188034058122 .8283996582123 .43800354 123.7427978516124 .3523025513124 .6570968628124 .9618988037125 .5715026855 125.8762969971125 .8762969971126 .1809997559126 .4858016968126 .4858016968 126.7906036377126 .7906036377126 .7906036377126 .7906036377126 .7906036377 126.7906036377126 .7906036377126 .4858016968126 .4858016968126 .1809997559 125.8762969971125 .5715026855125 .2667007446124 .9618988037124 .6570968628 124.3523025513124 .0475006104123 .7427978516123 .1332015991122 .8283996582 122.2188034058121 .9140014648121 .6092987061120 .9997024536120 .6949005127 120.0852966309119 .7806015015119 .1709976196118 .8662033081118 .5614013672 117.9517974854117 .647102356117 .342300415117 .0374984741116 .7326965332 116.4279022217116 .1231002808115 .818397522115 .5136032104115 .2088012695 115.2088012695114 .9039993286114 .9039993286114 .5991973877114 .5991973877 114.5991973877114 .5991973877114 .5991973877114 .5991973877114 .5991973877 114.5991973877114 .5991973877114 .9039993286114 .9039993286114 .9039993286 115.2088012695115 .2088012695115 .5136032104115 .5136032104115 .818397522 
116.1231002808116 .1231002808116 .4279022217116 .7326965332116 .7326965332 117.0374984741117 .342300415117 .342300415117 .647102356117 .647102356 117.9517974854117 .9517974854118 .2565994263118 .2565994263118 .5614013672 118.5614013672118 .5614013672118 .5614013672118 .5614013672118 .5614013672 118.5614013672118 .5614013672118 .2565994263118 .2565994263117 .9517974854 117.9517974854117 .647102356117 .342300415117 .0374984741116 .7326965332 116.4279022217116 .1231002808115 .5136032104115 .2088012695114 .9039993286 114.5991973877113 .9896011353113 .6848983765113 .3800964355113 .075302124 112.7705001831112 .4656982422112 .1608963013111 .8561019897111 .8561019897 111.551399231111 .551399231111 .551399231111 .551399231111 .551399231111 .551399231 111.8561019897111 .8561019897112 .1608963013112 .4656982422112 .7705001831 113.075302124113 .3800964355113 .9896011353114 .2944030762114 .5991973877 115.2088012695115 .5136032104115 .818397522116 .1231002808116 .4279022217 117.0374984741117 .342300415117 .647102356117 .9517974854117 .9517974854 118.2565994263118 .5614013672118 .5614013672118 .8662033081118 .8662033081 119.1709976196119 .1709976196119 .1709976196119 .1709976196119 .1709976196 119.1709976196119 .1709976196119 .1709976196119 .1709976196118 .8662033081 118.8662033081118 .8662033081118 .8662033081118 .8662033081121 .9140014648 120.0852966309120 .4172210693 -9999 -9999 -9999 -9999 -9999 -9999 -9999 -9999 -9999

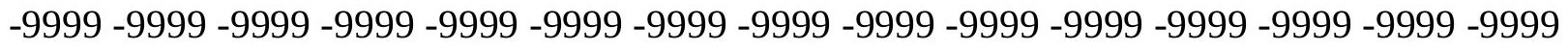
-9999 -9999 -9999 -9999 -9999 -9999 -9999 -9999 -9999 -9999 -9999 -9999 -9999 -9999 -9999 -9999 -9999 -9999 -9999 -9999 -9999 -9999 -9999 -9999 -9999 -9999 -9999 -9999 -9999 -9999 -9999 -9999 -9999 -9999 -9999 -9999 -9999 -9999 -9999 -9999 -9999 -9999 -9999 -9999 -9999 -9999 -9999 -9999 -9999 -9999 -9999 -9999 -9999 -9999 -9999 -9999 -9999 -9999 -9999 -9999 -9999 -9999 -9999 -9999 -9999 -9999 -9999 -9999 -9999 -9999 -9999 -9999 -9999 -9999 -9999 -9999 -9999 -9999 -9999 -9999 -9999 -9999 -9999 -9999 -9999 -9999 -9999 -9999 -9999 -9999 -

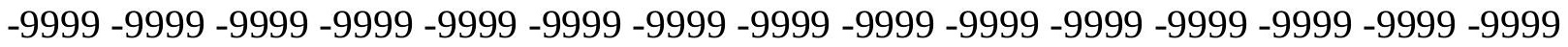
-9999 -9999-9999-9999-9999

-9999 -9999 -9999 -9999 -9999 -9999 -9999 -9999 -9999 -9999 -9999 -9999 -9999 -9999 -9999 -9999 -9999 -9999 -9999-9999 -9999 -9999 -9999-9999 -9999 23.77323913574 25.906740188628 .0402297973630 .1737308502232 .3072204589834 .44071960449 36.2694282531738 .4029312133840 .5364189147942 .66992187544 .80340957642 46.6321296691948 .765621185350 .8991203308152 .7278289794954 .86132049561 56.6900291442958 .8235282897960 .6522407531762 .4809494018664 .30966186523 66.1383666992267 .9670867919969 .7957916259871 .6244964599673 .45321655273 75.2819290161176 .8058471679778 .6345596313580 .1584930419981 .98719787598 83.5111236572385 .0350494384886 .5589828491288 .0829010009889 .60682678223 91.1307525634892 .5584640502993 .8738174438595 .397743225196 .61688232422 98.1408081054799 .35994720459100 .5791015625101 .7982025146103 .0174026489 104.2365036011105 .4557037354106 .3700027466107 .5891036987108 .5035018921 109.7226028442110 .6370010376111 .551399231112 .4656982422113 .3800964355 114.2944030762114 .9039993286115 .818397522116 .4279022217117 .342300415 117.9517974854118 .5614013672119 .1709976196119 .7806015015120 .3900985718 120.6949005127121 .3044967651121 .6092987061122 .2188034058122 .5235977173 122.8283996582123 .1332015991123 .1332015991123 .43800354123 .7427978516 123.7427978516123 .7427978516123 .7427978516124 .0475006104123 .7427978516 
123.7427978516123 .7427978516123 .7427978516123 .43800354123 .1332015991 123.1332015991122 .8283996582122 .5235977173122 .2188034058121 .9140014648 121.6092987061121 .3044967651120 .6949005127120 .3900985718120 .0852966309 119.4757995605119 .1709976196118 .8662033081118 .2565994263117 .9517974854 117.342300415117 .0374984741116 .4279022217116 .1231002808115 .818397522 115.2088012695114 .9039993286114 .5991973877114 .2944030762113 .6848983765 113.3800964355113 .075302124112 .7705001831112 .7705001831112 .4656982422 112.1608963013112 .1608963013111 .8561019897111 .8561019897111 .551399231 111.551399231111 .551399231111 .551399231111 .551399231111 .551399231111 .551399231 111.551399231111 .551399231111 .8561019897111 .8561019897111 .8561019897 112.1608963013112 .4656982422112 .4656982422112 .7705001831112 .7705001831 113.075302124113 .3800964355113 .3800964355113 .6848983765113 .9896011353 113.9896011353114 .2944030762114 .5991973877114 .9039993286114 .9039993286 115.2088012695115 .2088012695115 .5136032104115 .5136032104115 .818397522 115.818397522115 .818397522115 .818397522115 .818397522115 .818397522115 .818397522 115.818397522115 .818397522115 .5136032104115 .5136032104115 .2088012695 114.9039993286114 .5991973877114 .2944030762113 .9896011353113 .6848983765 113.3800964355112 .7705001831112 .4656982422112 .1608963013111 .8561019897 111.24659729110 .9418029785110 .6370010376110 .3321990967109 .7226028442 109.4179000854109.1130981445109.1130981445108.8082962036108.5035018921 108.5035018921108 .5035018921108 .5035018921108 .5035018921108 .5035018921 108.8082962036109 .1130981445109 .1130981445109 .4179000854109 .7226028442 110.0273971558110 .6370010376110 .9418029785111 .24659729111 .8561019897 112.1608963013112 .7705001831113 .075302124113 .3800964355113 .9896011353 114.2944030762114 .5991973877114 .9039993286115 .2088012695115 .5136032104 115.818397522116 .1231002808116 .4279022217116 .7326965332116 .7326965332 117.0374984741117 .0374984741117 .0374984741117 .342300415117 .342300415 117.342300415 117.342300415 117.342300415 117.342300415 117.342300415 117.0374984741117 .0374984741117 .0374984741117 .0374984741117 .342300415 117.9517974854118 .4417800903 -9999 -9999 -9999 -9999 -9999 -9999 -9999 -9999 -9999 -9999 -9999 -9999 -9999 -9999 -9999 -9999 -9999 -9999 -9999 -9999 -9999 -9999 -9999 -9999 -9999 -9999 -9999 -9999 -9999 -9999 -9999 -9999 -9999 -9999 -9999 -9999 -9999 -9999 -9999 -

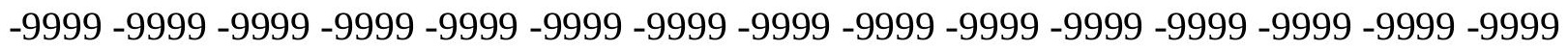

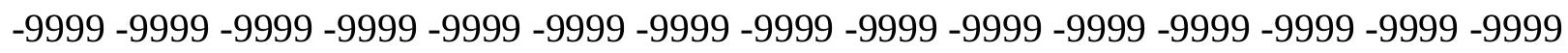
-9999 -9999 -9999 -9999 -9999 -9999 -9999 -9999 -9999 -9999 -9999 -9999 -9999 -9999 -9999 -999 -

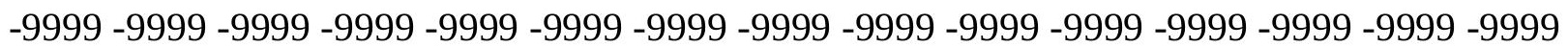

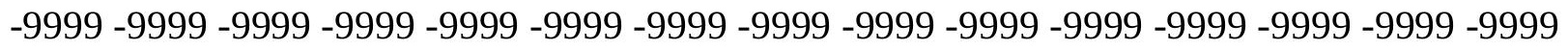

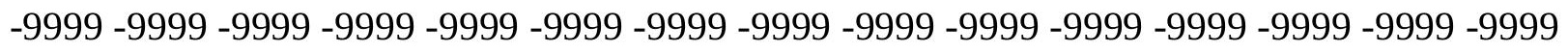
-9999 -9999-9999-9999-9999

-9999 -9999 -9999 -9999 -9999 -9999 -9999 -9999 -9999 -9999 -9999 -9999 -9999 -9999 -9999 -9999 -9999-9999 -9999 -9999 -9999-9999-9999 -9999 20.11581993103 22.24930953979 24.3828105926526 .5163097381628 .6497993469230 .7833003997832 .91679000854 35.0502891540537 .1837806701739 .3172798156741 .1459884643643 .27949142456 45.4129791259847 .5464782714849 .3751907348651 .5086898803753 .33739852905 55.4708900451757 .2995986938559 .1283111572360 .9570198059163 .09051895142 64.9192428588966 .7479400634868 .2718734741270 .1005783081171 .92929077148 
73.7580032348675 .2819290161177 .110626220778 .6345596313580 .46327209473 81.9871978759883 .5111236572385 .0350494384886 .5589828491288 .08290100098 89.4658813476690 .8259735107492 .349891662693 .5690307617295 .09295654297 96.3121032714897 .5312423706198 .7503814697399 .96952056885101 .1886978149 102.4077987671103 .3221969604104 .5412979126105 .4557037354106 .6747970581 107.5891036987108 .5035018921109 .4179000854110 .3321990967111 .24659729 112.1608963013112 .7705001831113 .6848983765114 .2944030762114 .9039993286 115.5136032104116 .1231002808116 .7326965332117 .342300415117 .9517974854 118.2565994263118 .8662033081119 .1709976196119 .4757995605119 .7806015015 120.0852966309120 .3900985718120 .3900985718120 .6949005127120 .6949005127 120.9997024536120 .9997024536120 .9997024536120 .9997024536120 .9997024536 120.9997024536120 .6949005127120 .6949005127120 .3900985718120 .3900985718 120.0852966309119 .7806015015119 .4757995605119 .1709976196118 .8662033081 118.5614013672117 .9517974854117 .647102356117 .342300415117 .0374984741 116.4279022217116 .1231002808115 .5136032104115 .2088012695114 .5991973877 114.2944030762113 .6848983765113 .3800964355113 .075302124112 .4656982422 112.1608963013111 .8561019897111 .24659729110 .9418029785110 .6370010376 110.3321990967110 .0273971558109 .7226028442109 .4179000854109 .4179000854 109.1130981445108 .8082962036108 .8082962036108 .8082962036108 .5035018921 108.5035018921108 .5035018921108 .5035018921108 .5035018921108 .5035018921 108.5035018921108 .5035018921108 .5035018921108 .8082962036108 .8082962036 109.1130981445109 .1130981445109 .4179000854109 .4179000854109 .7226028442 110.0273971558110 .0273971558110 .3321990967110 .6370010376110 .9418029785 110.9418029785111 .24659729111 .551399231111 .8561019897111 .8561019897 112.1608963013112 .4656982422112 .4656982422112 .7705001831112 .7705001831 113.075302124113 .075302124113 .3800964355113 .3800964355113 .3800964355 113.3800964355113 .3800964355113 .075302124113 .075302124113 .075302124 112.7705001831112 .4656982422112 .1608963013112 .1608963013111 .8561019897 111.24659729110 .9418029785110 .6370010376110 .3321990967109 .7226028442 109.4179000854109 .1130981445108 .5035018921108 .1986999512107 .8938980103 107.2844009399106 .979598999106 .6747970581106 .3700027466106 .0652008057 106.0652008057105 .7603988647105 .7603988647105 .4557037354105 .4557037354 105.4557037354105 .7603988647105 .7603988647106 .0652008057106 .3700027466 106.6747970581106 .979598999107 .2844009399107 .5891036987108 .1986999512 108.5035018921109 .1130981445109 .4179000854110 .0273971558110 .3321990967 110.9418029785111 .24659729111 .8561019897112 .1608963013112 .4656982422 112.7705001831113 .3800964355113 .6848983765113 .9896011353114 .2944030762 114.2944030762114 .5991973877114 .9039993286114 .9039993286115 .2088012695 115.2088012695115 .2088012695115 .5136032104115 .5136032104115 .5136032104 115.5136032104115 .5136032104115 .5136032104115 .5136032104115 .5136032104 $115.818397522115 .818397522115 .818397522116 .5578384399117 .0131607056-9999-9999$ -9999 -9999 -9999 -9999 -9999 -9999 -9999 -9999 -9999 -9999 -9999 -9999 -9999 -9999 -9999 -9999 -9999 -9999 -9999 -9999 -9999 -9999 -9999 -9999 -9999 -9999 -9999 -9999 -9999 -9999 -9999 -9999 -9999 -9999 -9999 -9999 -9999 -9999 -9999 -9999 -9999 -9999 -9999 -9999 -9999 -9999 -9999 -9999 -9999 -9999 -9999 -9999 -9999 -9999 -9999 -9999 -9999 -9999 -9999 -9999 -

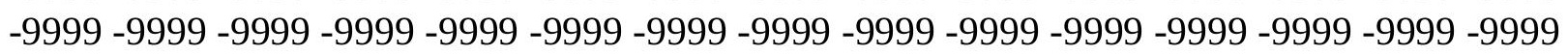


-9999 -9999 -9999 -9999 -9999 -9999 -9999 -9999 -9999 -9999 -9999 -9999 -9999 -9999 -9999 -9999 -9999 -9999 -9999 -9999 -9999 -9999 -9999 -9999 -9999 -9999 -9999 -9999 -9999 -9999

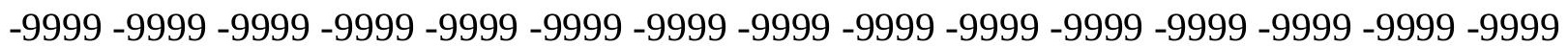
-9999 -9999 -9999 -9999 -9999 -9999 -9999 -9999 -9999 -9999 -9999

-9999 -9999 -9999 -9999 -9999 -9999 -9999 -9999 -9999 -9999 -9999 -9999 -9999 -9999 -9999 -9999 -9999 -9999 -9999 -9999 -9999-9999 -9999 16.7631797790518 .89668083191 21.0301704406723 .1636695861825 .2971591949527 .430660247829 .56415939331 31.6976509094233 .5263595581135 .6598587036137 .7933502197339 .92684936523 42.0603485107443 .8890609741246 .0225486755448 .1560516357449 .98476028442 52.1182594299353 .9469718933155 .7756805419957 .909179687559 .73788070679 61.5666007995663 .3953094482465 .2240066528367 .0527267456168 .88143920898 70.4053573608472 .2340774536173 .7580032348675 .5867080688577 .1106262207 78.9393463134880 .4632720947381 .9871978759883 .5111236572385 .03504943848 86.4123992919987 .7781066894589 .302040100190 .5211791992292 .04509735107 93.26425170898 94.4833908081195.7025299072396.9216690063598.14080810547 99.35994720459100 .5791015625101 .4934005737102 .712600708103 .6268997192 104.8460998535105 .7603988647106 .6747970581107 .5891036987108 .1986999512 109.1130981445110 .0273971558110 .6370010376111 .551399231112 .1608963013 112.7705001831113 .3800964355113 .9896011353114 .5991973877114 .9039993286 115.5136032104115 .818397522116 .1231002808116 .7326965332117 .0374984741 117.342300415117 .342300415117 .647102356117 .9517974854117 .9517974854 117.9517974854118 .2565994263118 .2565994263118 .2565994263118 .2565994263 117.9517974854117 .9517974854117 .9517974854117 .647102356117 .342300415 117.342300415117 .0374984741116 .7326965332116 .4279022217116 .1231002808 115.818397522115 .5136032104114 .9039993286114 .5991973877114 .2944030762 113.6848983765113 .3800964355112 .7705001831112 .4656982422112 .1608963013 111.551399231111 .24659729110 .6370010376110 .3321990967109 .7226028442 109.4179000854109 .1130981445108 .5035018921108 .1986999512107 .8938980103 107.5891036987107 .2844009399106 .979598999106 .6747970581106 .3700027466 106.3700027466106 .0652008057105 .7603988647105 .7603988647105 .7603988647 105.4557037354105 .4557037354105 .4557037354105 .4557037354105 .4557037354 105.4557037354105 .4557037354105 .4557037354105 .7603988647105 .7603988647 106.0652008057 106.0652008057 106.3700027466 106.3700027466 106.6747970581 106.979598999 106.979598999 107.2844009399107.5891036987107.8938980103 107.8938980103108 .1986999512108 .5035018921108 .8082962036109 .1130981445 109.1130981445109 .4179000854109 .7226028442110 .0273971558110 .0273971558 110.3321990967110 .3321990967110 .6370010376110 .6370010376110 .6370010376 110.6370010376110 .6370010376110 .6370010376110 .6370010376110 .6370010376 110.3321990967110 .3321990967110 .0273971558109 .7226028442109 .4179000854 109.1130981445108 .8082962036108 .5035018921108 .1986999512107 .5891036987 107.2844009399106 .979598999106 .3700027466106 .0652008057105 .4557037354 105.1509017944104 .8460998535104 .2365036011103 .9317016602103 .6268997192 103.3221969604103 .0174026489103 .0174026489102 .712600708102 .712600708 102.712600708102 .712600708102 .712600708103 .0174026489103 .0174026489 103.3221969604103 .6268997192103 .9317016602104 .5412979126104 .8460998535 105.4557037354105 .7603988647106 .3700027466106 .6747970581107 .2844009399 
107.8938980103108.1986999512108.8082962036109.1130981445 109.7226028442 110.0273971558110 .6370010376110 .9418029785111 .24659729111 .551399231 111.8561019897112 .1608963013112 .4656982422112 .7705001831113 .075302124 113.075302124113 .3800964355113 .3800964355113 .6848983765113 .6848983765 113.6848983765113 .6848983765113 .9896011353113 .9896011353113 .9896011353 113.9896011353114 .2944030762114 .2944030762114 .5991973877115 .2088012695 115.3771743774 -9999 -9999 -9999 -9999 -9999 -9999 -9999 -9999 -9999 -9999 -9999 -9999 -9999 -9999 -9999 -9999 -9999 -9999 -9999 -9999 -9999 -9999 -9999 -9999 -9999 -9999 -9999

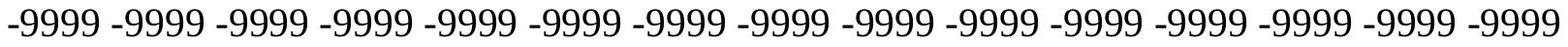
-9999 -9999 -9999 -9999 -9999 -9999 -9999 -9999 -9999 -9999 -9999 -9999 -9999 -9999 -9999 -9999 -9999 -9999 -9999 -9999 -9999 -9999 -9999 -9999 -9999 -9999 -9999 -9999 -9999 -9999 -9999 -9999 -9999 -9999 -9999 -9999 -9999 -9999 -9999 -9999 -9999 -9999 -9999 -9999 -9999 -999 -9999 -9999 -9999 -9999 -9999 -9999 -9999 -9999 -9999 -9999 -9999 -9999 -9999 -9999 -9999 -9999 -9999 -9999 -9999 -9999 -9999 -9999 -9999 -9999 -9999 -9999 -9999 -9999 -9999 -9999 -9999 -9999 -9999 -9999 -9999 -9999 -9999 -9999 -9999 -9999 -9999 -9999 -9999 -9999 -9999 $-9999$

-9999 -9999 -9999 -9999 -9999 -9999 -9999 -9999 -9999 -9999 -9999 -9999 -9999 -9999 -9999 -9999 -9999 -9999 -9999 -9999 -9999 -9999 13.41055011749 15.23925971985 17.37274932861 19.5062503814721 .6397399902323 .7732391357425 .906740188628 .04022979736 30.1737308502232 .3072204589834 .4407196044936 .5742111206138 .70771026611 40.5364189147942 .66992187544 .8034095764246 .6321296691948 .7656211853 50.5943298339852 .7278289794954 .5565414428756 .3852500915558 .21395874023 60.0426712036161 .8713798522963 .7000885009865 .5288009643667 .35751342773 69.1862335205170 .7101516723672 .5388565063574 .062782287675 .58670806885 77.4154205322378 .9393463134880 .4632720947381 .9871978759883 .44602203369 84.7302627563586 .254188537687 .7781066894588 .9972534179790 .21640014648 91.7403335571392 .9594726562594 .1785964965895 .397743225196 .61688232422 97.5312423706198 .7503814697399 .66472625732100 .8839035034101 .7982025146 102.712600708103 .6268997192104 .5412979126105 .4557037354106 .3700027466 106.979598999107 .8938980103108 .5035018921109 .4179000854110 .0273971558 110.6370010376111 .24659729111 .551399231112 .1608963013112 .7705001831 113.075302124113 .3800964355113 .6848983765113 .9896011353114 .2944030762 114.5991973877114 .9039993286115 .2088012695115 .2088012695115 .2088012695 115.5136032104115 .5136032104115 .5136032104115 .5136032104115 .2088012695 115.2088012695115 .2088012695114 .9039993286114 .9039993286114 .5991973877 114.2944030762113 .9896011353113 .6848983765113 .3800964355113 .075302124 112.7705001831112 .4656982422111 .8561019897111 .551399231111 .24659729 110.6370010376110 .3321990967109 .7226028442109 .4179000854108 .8082962036 108.5035018921107 .8938980103107 .5891036987107 .2844009399106 .6747970581 106.3700027466105 .7603988647105 .4557037354105 .1509017944104 .8460998535 104.5412979126104 .2365036011103 .9317016602103 .6268997192103 .3221969604 103.3221969604103 .0174026489102 .712600708102 .712600708102 .712600708 102.4077987671102 .4077987671102 .4077987671102 .4077987671102 .4077987671 102.4077987671102 .712600708102 .712600708102 .712600708103 .0174026489 103.0174026489103 .3221969604103 .3221969604103 .6268997192103 .9317016602 103.9317016602104 .2365036011104 .5412979126104 .8460998535104 .8460998535 
105.1509017944105 .4557037354105 .7603988647106 .0652008057106 .3700027466 106.6747970581106 .6747970581106 .979598999107 .2844009399107 .5891036987 107.5891036987107 .8938980103107 .8938980103108 .1986999512108 .1986999512 108.1986999512108 .1986999512108 .1986999512108 .1986999512107 .8938980103 107.8938980103 107.5891036987 107.5891036987 107.2844009399106.979598999 106.6747970581106 .3700027466106 .0652008057105 .4557037354105 .1509017944 104.8460998535104 .2365036011103 .9317016602103 .3221969604103 .0174026489 102.4077987671102 .1029968262101 .7982025146101 .1886978149100 .8839035034 100.5791015625100 .2742996216100 .274299621699 .9695205688599 .96952056885 99.6647262573299 .9695205688599 .9695205688599 .96952056885100 .2742996216 100.5791015625100 .8839035034101 .1886978149101 .7982025146102 .1029968262 102.712600708103 .0174026489103 .6268997192104 .2365036011104 .8460998535 105.1509017944105 .7603988647106 .3700027466106 .979598999107 .2844009399 107.8938980103108 .1986999512108 .8082962036109 .1130981445109 .4179000854 109.7226028442110 .0273971558110 .3321990967110 .6370010376110 .9418029785 111.24659729111 .551399231111 .551399231111 .8561019897111 .8561019897 112.1608963013112 .1608963013112 .1608963013112 .4656982422112 .4656982422 112.7705001831112 .7705001831113 .075302124113 .075302124113 .3800964355 113.7733535767113 .9618911743 -9999 -9999 -9999 -9999 -9999 -9999 -9999 -9999 -9999

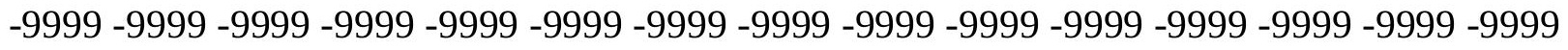

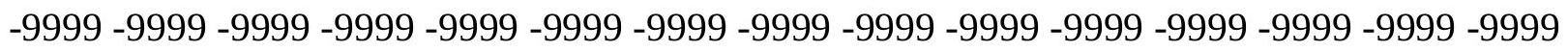
-9999 -9999 -9999 -9999 -9999 -9999 -9999 -9999 -9999 -9999 -9999 -9999 -9999 -9999 -9999 -9999 -9999 -9999 -9999 -9999 -9999 -9999 -9999 -9999 -9999 -9999 -9999 -9999 -9999 -9999 -

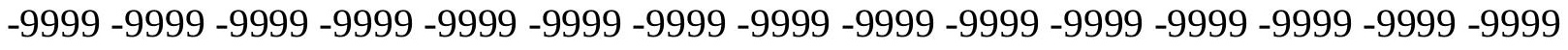

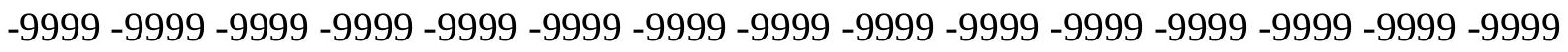
-9999 -9999 -9999 -9999 -9999 -9999 -9999 -9999 -9999 -9999 -9999 -9999 -9999 -9999 -9999 -

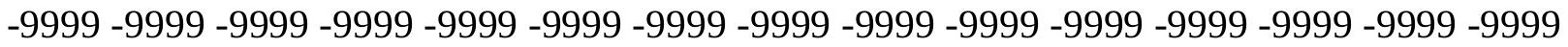
$-9999-9999-9999$

-9999 -9999 -9999 -9999 -9999 -9999 -9999 -9999 -9999 -9999 -9999 -9999 -9999 -9999 -9999 -9999 -9999 -9999 -9999 -9999 -9999 9.753124237061 11.8866195678714 .02011966705 16.1536102294918 .28710937520 .4206008911122 .5541000366224 .68759918213 26.8210906982428 .9545898437531 .0880794525133 .2215805053735 .35507965088 37.1837806701739 .3172798156741 .4507789611843 .2794914245645 .41297912598 47.2416992187549 .3751907348651 .2038993835453 .0326118469255 .16611099243 56.9948196411158 .8235282897960 .6522407531762 .4809494018664 .30966186523 65.8335876464867 .6623001098669 .1862335205171 .014930725172 .53885650635 74.3675689697375 .8914871215877 .4154205322378 .9393463134880 .46327209473 81.89932250977 83.2063369751 84.73026275635 85.94940185547 87.47332763672 88.6924667358489 .9116134643691 .1307525634892 .349891662693 .56903076172 94.7881774902396 .0073165893696 .9216690063598 .1408081054799 .05516815186 99.96952056885100 .8839035034101 .7982025146102 .712600708103 .6268997192 104.2365036011105 .1509017944105 .7603988647106 .6747970581107 .2844009399 107.8938980103108 .5035018921108 .8082962036109 .4179000854110 .0273971558 110.3321990967110 .6370010376110 .9418029785111 .551399231111 .551399231 111.8561019897112 .1608963013112 .4656982422112 .4656982422112 .4656982422 112.7705001831112 .7705001831112 .7705001831112 .7705001831112 .7705001831 
112.4656982422112 .4656982422112 .1608963013112 .1608963013111 .8561019897 111.551399231111 .24659729111 .24659729110 .9418029785110 .3321990967 110.0273971558109 .7226028442109 .4179000854109 .1130981445108 .5035018921 108.1986999512107 .5891036987107 .2844009399106 .6747970581106 .3700027466 105.7603988647105 .4557037354104 .8460998535104 .5412979126104 .2365036011 103.6268997192103 .3221969604102 .712600708102 .4077987671102 .1029968262 101.7982025146101 .4934005737101 .1886978149100 .8839035034100 .5791015625 100.2742996216100 .274299621699 .9695205688599 .9695205688599 .66472625732 99.6647262573299 .6647262573299 .6647262573299 .3599472045999 .35994720459 99.6647262573299 .6647262573299 .6647262573299 .6647262573299 .96952056885 99.96952056885100 .2742996216100 .2742996216100 .5791015625100 .8839035034 100.8839035034101 .1886978149101 .4934005737101 .7982025146102 .1029968262 102.4077987671102 .4077987671102 .712600708103 .0174026489103 .3221969604 103.6268997192103 .9317016602104 .2365036011104 .5412979126104 .8460998535 104.8460998535105 .1509017944105 .4557037354105 .4557037354105 .4557037354 105.7603988647105 .7603988647105 .7603988647105 .7603988647105 .7603988647 105.4557037354105 .4557037354105 .1509017944105 .1509017944104 .8460998535 104.5412979126104 .2365036011103 .9317016602103 .6268997192103 .0174026489 102.712600708102 .4077987671101 .7982025146101 .4934005737100 .8839035034 100.274299621699 .9695205688599 .3599472045999 .0551681518698 .75038146973 98.1408081054797 .8360290527397 .5312423706197 .5312423706197 .22646331787 97.2264633178796.9216690063596.92166900635 97.22646331787 97.22646331787 97.5312423706197 .8360290527398 .1408081054798 .445587158299 .05516815186 99.3599472045999 .96952056885100 .5791015625101 .1886978149101 .4934005737 102.1029968262102 .712600708103 .3221969604103 .9317016602104 .5412979126 105.1509017944105 .4557037354106 .0652008057106 .6747970581106 .979598999 107.2844009399107 .8938980103108 .1986999512108 .5035018921108 .8082962036 109.1130981445109 .4179000854109 .7226028442109 .7226028442110 .0273971558 110.3321990967110 .3321990967110 .6370010376110 .6370010376110 .9418029785 110.9418029785111 .24659729111 .551399231111 .551399231111 .8561019897 112.1608963013 112.2827911377 112.4295272827 -9999 -9999 -9999 -9999 -9999 -9999 -9999 -9999 -9999 -9999 -9999 -9999 -9999 -9999 -9999 -9999 -9999 -9999 -9999 -9999 -9999 -9999

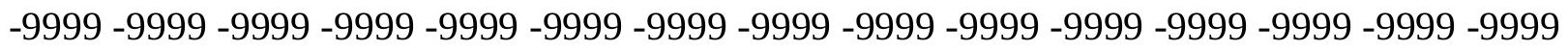
-9999 -9999 -9999 -9999 -9999 -9999 -9999 -9999 -9999 -9999 -9999 -9999 -9999 -9999 -9999 -9999 -9999 -9999 -9999 -9999 -9999 -9999 -9999 -9999 -9999 -9999 -9999 -9999 -9999 -9999 -9999 -9999 -9999 -9999 -9999 -9999 -9999 -9999 -9999 -9999 -9999 -9999 -9999 -9999 -9999

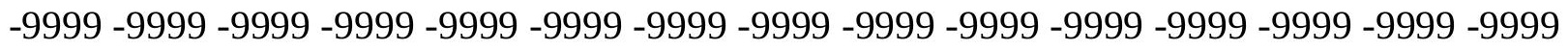

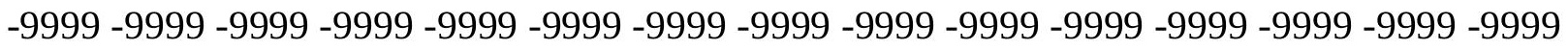
-9999 -9999 -9999 -9999 -9999 -9999 -9999 -9999 -9999 -9999 -9999 -9999 -9999 -9999 -9999 -9999 -9999-9999-9999-9999

-9999 -9999 -9999 -9999 -9999 -9999 -9999 -9999 -9999 -9999 -9999 -9999 -9999 -9999 -9999 -9999 -9999 -9999-9999-9999 6.400486946106 8.533983230591 10.66748046875 12.4961900711114 .934470176717 .0679702758819 .2014598846421 .3349609375 23.4684505462625 .6019496917727 .7354507446329 .8689403533932 .00244140625 34.1359291076735 .9646492004438 .0981407165540 .2316398620642 .06034851074 44.1938400268646 .0225486755448 .1560516357449 .9847602844251 .81346893311 
53.6421813964855 .4708900451757 .6043891906759 .1283111572360 .95701980591 62.7857398986864 .6144485473666 .1383666992267 .9670867919969 .49101257324 71.3197174072372 .8436431884874 .3675689697375 .8914871215877 .41542053223 78.9393463134880 .4632720947381 .6824111938583 .206336975184 .42548370361 85.94940185547 87.16854858398 88.38768768311 89.6068267822390.82597351074 92.0450973510793 .2642517089894 .1785964965895 .397743225196 .31210327148 97.2264633178798.1408081054799.0551681518699.96952056885 100.8839035034 101.7982025146102 .4077987671103 .0174026489103 .9317016602104 .5412979126 105.1509017944 105.7603988647 106.3700027466 106.6747970581 107.2844009399 107.5891036987 108.1986999512108.5035018921 108.8082962036109.1130981445 109.4179000854109 .4179000854109 .7226028442109 .7226028442110 .0273971558 110.0273971558110 .0273971558110 .0273971558110 .0273971558110 .0273971558 110.0273971558109 .7226028442109 .7226028442109 .4179000854109 .4179000854 109.1130981445108 .8082962036108 .5035018921108 .1986999512107 .8938980103 107.5891036987 107.2844009399 106.6747970581 106.3700027466 106.0652008057 105.4557037354105 .1509017944104 .8460998535104 .2365036011103 .9317016602 103.3221969604102 .712600708102 .4077987671101 .7982025146101 .4934005737 101.1886978149100 .5791015625100 .274299621699 .6647262573299 .35994720459 99.0551681518698 .7503814697398 .445587158298 .1408081054797 .83602905273 97.5312423706197 .2264633178797 .2264633178796 .9216690063596 .92166900635 96.9216690063596 .6168823242296 .6168823242296 .6168823242296 .61688232422 96.6168823242296 .6168823242296 .6168823242296 .9216690063596 .92166900635 96.9216690063597 .2264633178797 .2264633178797 .5312423706197 .83602905273 97.8360290527398 .1408081054798 .445587158298 .7503814697399 .05516815186 99.3599472045999 .6647262573299 .96952056885100 .2742996216100 .5791015625 100.8839035034101 .1886978149101 .4934005737101 .7982025146101 .7982025146 102.1029968262102 .4077987671102 .712600708102 .712600708103 .0174026489 103.0174026489103 .3221969604103 .3221969604103 .3221969604103 .3221969604 103.3221969604103 .3221969604103 .0174026489103 .0174026489102 .712600708 102.4077987671102 .1029968262101 .7982025146101 .4934005737101 .1886978149 100.8839035034100 .274299621699 .9695205688599 .3599472045999 .05516815186 98.445587158297 .8360290527397 .5312423706196 .9216690063596 .61688232422 96.0073165893695 .7025299072395 .397743225195 .0929565429794 .78817749023 94.4833908081194 .4833908081194 .1785964965894 .1785964965894 .48339080811 94.4833908081194 .7881774902395 .0929565429795 .397743225195 .70252990723 96.3121032714896 .9216690063597 .5312423706197 .8360290527398 .4455871582 99.0551681518699 .66472625732100 .5791015625101 .1886978149101 .7982025146 102.4077987671102 .712600708103 .3221969604103 .9317016602104 .5412979126 104.8460998535105 .4557037354105 .7603988647106 .3700027466106 .6747970581 106.979598999 107.2844009399 107.5891036987 107.8938980103108.1986999512 108.1986999512108 .5035018921108 .8082962036109 .1130981445109 .1130981445 109.4179000854 109.7226028442 109.7226028442 110.0273971558 110.3321990967 $110.6370010376110 .6370010376110 .8548736572111 .0057449341111 .107711792-9999$

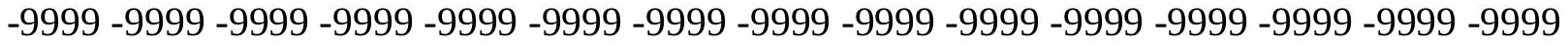

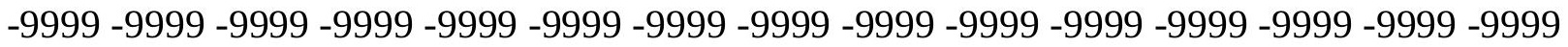

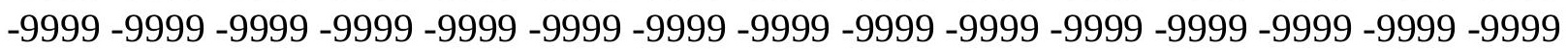


-9999 -9999 -9999 -9999 -9999 -9999 -9999 -9999 -9999 -9999 -9999 -9999 -9999 -9999 -9999 -9999 -9999 -9999 -9999 -9999 -9999 -9999 -9999 -9999 -9999 -9999 -9999 -9999 -9999 -9999 -9999 -9999 -9999 -9999 -9999 -9999 -9999 -9999 -9999 -9999 -9999 -9999 -9999 -9999 -9999 -9999 -9999 -9999 -9999 -9999 -9999 -9999 -9999 -9999 -9999 -9999 -9999 -9999 -9999 -9999 -9999 -9999 -9999 -9999 -9999 -9999 -9999 -9999 -9999 -9999 -9999 -9999-9999 -9999 -9999 -9999 -9999 -9999 -9999 -9999 -9999 -9999 -9999 -9999 -9999

-9999 -9999 -9999 -9999 -9999 -9999 -9999 -9999 -9999 -9999 -9999 -9999 -9999 -9999 -9999 -9999 -9999 -9999 -9999-9999 5.181346893311 7.010057926178 9.143553733826 11.2770500183113 .715330123915 .8488302230817 .9823207855220 .11581993103 22.2493095397924 .3828105926526 .5163097381628 .6497993469230 .78330039978 32.9167900085434 .7455101013236 .8790016174339 .0125007629440 .84120941162 42.9747009277344 .8034095764246 .9369087219248 .765621185350 .59432983398 52.4230384826754 .2517509460456 .0804595947357 .909179687559 .73788070679 61.5666007995663 .0905189514264 .9192428588966 .7479400634868 .27187347412 69.7957916259871 .3197174072373 .1484298706174 .6723632812576 .19628143311 77.4154205322378 .9393463134880 .4632720947381 .6824111938583 .2063369751 84.4254837036185 .6446228027386 .8637619018688 .0829010009889 .3020401001 90.5211791992291 .4355392456192 .6546783447393 .5690307617294 .48339080811 95.7025299072396 .6168823242297 .2264633178798 .1408081054799 .05516815186 99.66472625732100 .5791015625101 .1886978149101 .7982025146102 .4077987671 103.0174026489103 .6268997192104 .2365036011104 .5412979126105 .1509017944 105.4557037354105 .7603988647106 .0652008057106 .3700027466106 .6747970581 106.979598999107 .2844009399107 .2844009399107 .2844009399107 .5891036987 107.5891036987 107.5891036987 107.5891036987 107.5891036987 107.2844009399 107.2844009399 106.979598999106.979598999 106.6747970581 106.3700027466 106.3700027466 106.0652008057 105.7603988647 105.4557037354105.1509017944 104.5412979126104 .2365036011103 .9317016602103 .6268997192103 .0174026489 102.712600708102 .1029968262101 .7982025146101 .1886978149100 .8839035034 100.274299621699 .9695205688599 .3599472045999 .0551681518698 .4455871582 98.1408081054797 .5312423706197 .2264633178796 .9216690063596 .31210327148 96.0073165893695 .7025299072395 .397743225195 .0929565429794 .78817749023 94.4833908081194 .4833908081194 .1785964965894 .1785964965893 .87381744385 93.87381744385 93.8738174438593.8738174438593.87381744385 93.87381744385 93.8738174438593 .8738174438593 .8738174438593 .8738174438594 .17859649658 94.1785964965894 .4833908081194 .4833908081194 .7881774902395 .09295654297 95.0929565429795 .397743225195 .7025299072396 .0073165893696 .31210327148 96.6168823242296 .9216690063597 .2264633178797 .5312423706197 .83602905273 98.1408081054798 .445587158298 .7503814697399 .0551681518699 .35994720459 99.6647262573299 .96952056885100 .2742996216100 .5791015625100 .5791015625 100.8839035034100 .8839035034100 .8839035034100 .8839035034101 .1886978149 100.8839035034100 .8839035034100 .8839035034100 .5791015625100 .5791015625 100.274299621699 .9695205688599 .6647262573299 .3599472045999 .05516815186 98.4455871582 98.1408081054797.5312423706197.2264633178796.61688232422 96.0073165893695 .7025299072395 .0929565429794 .4833908081194 .17859649658 93.5690307617293 .2642517089892 .9594726562592 .349891662692 .04509735107 92.0450973510791 .7403335571391 .7403335571391 .7403335571391 .74033355713 
91.7403335571392 .0450973510792 .349891662692 .9594726562593 .26425170898 93.8738174438594 .1785964965894 .7881774902395 .397743225196 .31210327148 96.9216690063597 .5312423706198 .1408081054798 .7503814697399 .35994720459 99.96952056885100 .8839035034101 .1886978149101 .7982025146102 .4077987671 103.0174026489103 .3221969604103 .9317016602104 .2365036011104 .8460998535 105.1509017944105 .4557037354105 .7603988647106 .0652008057106 .3700027466 106.6747970581106 .979598999107 .2844009399107 .5891036987107 .5891036987 107.8938980103108 .1986999512108 .5035018921108 .8082962036108 .8082962036 $109.1130981445109 .4179000854109 .5168991089109 .636100769109 .7231292725-9999$ -9999 -9999 -9999 -9999 -9999 -9999 -9999 -9999 -9999 -9999 -9999 -9999 -9999 -9999 -9999 -9999 -9999 -9999 -9999 -9999 -9999 -9999 -9999 -9999 -9999 -9999 -9999 -9999 -9999 -9999 -9999 -9999 -9999 -9999 -9999 -9999 -9999 -9999 -9999 -9999 -9999 -9999 -9999 -9999 -9999 -9999 -9999 -9999 -9999 -9999 -9999 -9999 -9999 -9999 -9999 -9999 -9999 -9999 -9999 -9999 -

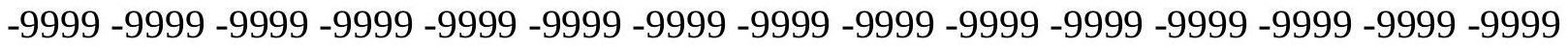
-9999 -9999 -9999 -9999 -9999 -9999 -9999 -9999 -9999 -9999 -9999 -9999 -9999 -9999 -9999

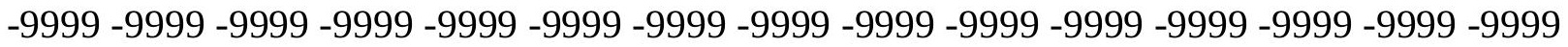

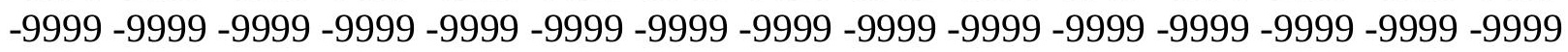
-9999 -9999 -9999 -9999 -9999 -9999 -9999 -9999 -9999 -9999 -9999 -9999 -9999 -9999 -9999 -9999 -9999 -9999 -9999 -9999 -9999 -9999 -9999 -9999 -9999 -9999 -9999 -9999 -9999 1.828711032867 3.6574220657355 .7909169197087 .924413204193 10.3626899719212 .4961900711114 .6296901702916 .7631797790518 .89668083191 21.0301704406723 .1636695861825 .2971591949527 .430660247829 .56415939331 31.6976509094233 .5263595581135 .6598587036137 .7933502197339 .6220703125 41.7555618286143 .5842704772945 .717769622847 .5464782714849 .37519073486 51.2038993835453 .0326118469254 .8613204956156 .6900291442958 .51874923706 60.3474502563561 .8713798522963 .7000885009865 .2240066528367 .05272674561 68.5766525268670 .1005783081170 .0709915161172 .1779479980574 .59617614746 76.1962814331177 .4154205322378 .9393463134880 .1584930419981 .68241119385 82.9015579223684 .1206970214885 .3398437586 .5589828491287 .77810668945 88.6924667358489 .9116134643690 .8259735107492 .0450973510792 .95947265625 93.8738174438594 .7881774902395 .7025299072396 .3121032714897 .22646331787 97.8360290527398 .7503814697399 .3599472045999 .96952056885100 .5791015625 101.1886978149101 .7982025146102 .1029968262102 .712600708103 .0174026489 103.3221969604103 .6268997192103 .9317016602104 .2365036011104 .5412979126 104.5412979126104 .8460998535104 .8460998535104 .8460998535105 .1509017944 105.1509017944105 .1509017944104 .8460998535104 .8460998535104 .8460998535 104.5412979126104 .5412979126104 .2365036011103 .9317016602103 .9317016602 103.6268997192103 .3221969604103 .0174026489102 .712600708102 .1029968262 101.7982025146101 .4934005737101 .1886978149100 .5791015625100 .2742996216 99.6647262573299 .3599472045998 .7503814697398 .445587158297 .83602905273 97.5312423706196 .9216690063596 .6168823242296 .0073165893695 .70252990723 95.0929565429794 .7881774902394 .1785964965893 .8738174438593 .56903076172 93.2642517089892 .6546783447392 .349891662692 .0450973510792 .04509735107 91.7403335571391 .4355392456191 .4355392456191 .1307525634891 .13075256348 91.1307525634890 .8259735107490 .8259735107490 .8259735107490 .82597351074 90.8259735107491 .1307525634891 .1307525634891 .1307525634891 .43553924561 
91.4355392456191 .7403335571391 .7403335571392 .0450973510792 .3498916626 92.6546783447392 .9594726562592 .9594726562593 .2642517089893 .56903076172 93.8738174438594 .4833908081194 .7881774902395 .0929565429795 .3977432251 95.7025299072396 .0073165893696 .3121032714896 .6168823242296 .92166900635 97.2264633178797 .5312423706197 .8360290527398 .1408081054798 .4455871582 98.445587158298 .7503814697398 .7503814697398 .7503814697398 .75038146973 98.7503814697398 .7503814697398 .7503814697398 .445587158298 .14080810547 98.1408081054797 .8360290527397 .5312423706197 .2264633178796 .61688232422 96.3121032714896 .0073165893695 .397743225194 .7881774902394 .48339080811 93.8738174438593 .2642517089892 .9594726562592 .349891662691 .74033355713 91.1307525634890 .8259735107490 .5211791992289 .9116134643689 .60682678223 89.302040100189.302040100188.9972534179788.9972534179789.3020401001 89.302040100189 .6068267822389 .9116134643690 .2164001464890 .82597351074 91.4355392456192 .0450973510792 .6546783447393 .2642517089893 .87381744385 94.4833908081195 .397743225196 .0073165893696 .6168823242297 .53124237061 98.1408081054798 .7503814697399 .3599472045999 .96952056885100 .5791015625 101.1886978149101 .4934005737102 .1029968262102 .712600708103 .0174026489 103.3221969604103 .9317016602104 .2365036011104 .5412979126104 .8460998535 105.1509017944105 .4557037354105 .7603988647106 .0652008057106 .3700027466 106.6747970581106 .6747970581106 .979598999107 .2844009399107 .5891036987 107.8938980103107 .8938980103108 .1986999512108 .3322372437108 .3760452271 110.9418029785 -9999 -9999 -9999 -9999 -9999 -9999 -9999 -9999 -9999 -9999 -9999 -9999 -9999 -9999 -9999 -9999 -9999 -9999 -9999 -9999 -9999 -9999 -9999 -9999 -9999 -9999 -9999 -9999 -9999 -9999 -9999 -9999 -9999 -9999 -9999 -9999 -9999 -9999 -9999 -9999 -9999 -9999 -9999 -9999 -9999 -9999 -9999 -9999 -9999 -9999 -9999 -9999 -9999 -9999 -9999 -9999 -9999 -9999 -9999 -9999 -9999 -9999 -9999 -9999 -9999 -9999 -9999 -9999 -9999 -9999 -9999 -9999 -9999 -9999 -9999 -9999 -9999 -9999 -9999 -9999 -9999 -9999 -9999 -9999 -9999 -9999 -9999 -

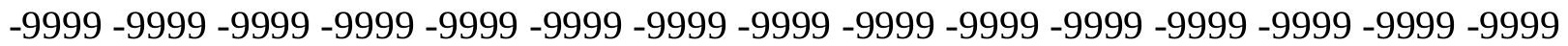
-9999 -9999 -9999 -9999 -9999 -9999 -9999 -9999 -9999 -9999 -9999 -9999 -9999 -9999 -9999 -9999 -9999 -9999 -9999 -9999 -9999 -9999 -9999 -9999 -9999 -9999 -9999 -9999 -9999 -9999 -9999 -9999 -9999 -9999 -9999 -9999 -9999 -9999 -9999 -9999 -9999 -9999 -9999 -9999 -9999-9999-1.43588280678 3047851026058 2.438281059265 4.571776866913 7.0100579261789 .14355373382611 .2770500183113 .4105501174915 .54403972626 17.6775398254419 .811029434221 .9445304870624 .0780296325726 .21151924133 28.3450202941930 .4785099029532 .6120109558134 .4407196044936 .57421112061 38.4029312133840 .5364189147942 .3651313781744 .4986305236846 .32733917236 48.1560516357449 .9847602844251 .8134689331153 .6421813964855 .47089004517 57.2995986938559 .1283111572360 .6522407531762 .4809494018664 .0048828125 64.0680541992265 .7722015380967 .4816513061569 .236892700271 .27305603027 73.4532165527374 .6723632812576 .1962814331177 .4154205322378 .93934631348 80.1584930419981 .3776321411182 .5967712402383 .8159103393685 .03504943848 86.254188537687 .1685485839888 .3876876831189 .302040100190 .21640014648 91.4355392456192 .349891662692 .9594726562593 .8738174438594 .78817749023 95.397743225196 .3121032714896 .9216690063597 .5312423706198 .14080810547 98.7503814697399 .3599472045999 .66472625732100 .2742996216100 .5791015625 100.8839035034101 .1886978149101 .4934005737101 .7982025146102 .1029968262 
102.1029968262102 .4077987671102 .4077987671102 .712600708102 .712600708 102.712600708102 .712600708102 .4077987671102 .4077987671102 .4077987671 102.1029968262102 .1029968262101 .7982025146101 .4934005737101 .4934005737 101.1886978149100 .8839035034100 .5791015625100 .274299621699 .96952056885 99.3599472045999 .0551681518698 .7503814697398 .1408081054797 .83602905273 97.5312423706196 .9216690063596 .6168823242296 .0073165893695 .3977432251 95.0929565429794 .4833908081194 .1785964965893 .5690307617293 .26425170898 92.6546783447392 .349891662691 .7403335571391 .4355392456190 .82597351074 90.5211791992290 .2164001464889 .9116134643689 .6068267822389 .3020401001 88.9972534179788 .6924667358488 .6924667358488 .3876876831188 .38768768311 88.3876876831188.08290100098 88.08290100098 88.08290100098 88.08290100098 88.08290100098 88.08290100098 88.38768768311 88.38768768311 88.38768768311 88.6924667358488 .6924667358488 .9972534179789 .302040100189 .3020401001 89.6068267822389 .9116134643690 .2164001464890 .5211791992290 .82597351074 91.1307525634891 .4355392456191 .7403335571392 .0450973510792 .65467834473 92.9594726562593 .2642517089893 .5690307617293 .8738174438594 .17859649658 94.7881774902395 .0929565429795 .397743225195 .7025299072395 .70252990723 96.0073165893696 .3121032714896 .3121032714896 .6168823242296 .61688232422 96.6168823242296 .6168823242296 .6168823242296 .6168823242296 .31210327148 96.0073165893696 .0073165893695 .7025299072395 .397743225195 .09295654297 94.7881774902394 .1785964965893 .8738174438593 .2642517089892 .95947265625 92.349891662691 .7403335571391 .1307525634890 .5211791992290 .21640014648 89.6068267822388 .9972534179788 .3876876831188 .0829010009887 .77810668945 87.1685485839886 .8637619018686 .8637619018686 .5589828491286 .55898284912 86.5589828491286 .8637619018687 .1685485839887 .4733276367287 .77810668945 88.38768768311 88.99725341797 89.60682678223 90.21640014648 91.13075256348 91.7403335571392 .349891662693 .2642517089893 .8738174438594 .78817749023 95.397743225196 .0073165893696 .9216690063597 .5312423706198 .14080810547 98.7503814697399 .3599472045999 .96952056885100 .2742996216100 .8839035034 101.1886978149101 .7982025146102 .1029968262102 .712600708103 .0174026489 103.3221969604103 .6268997192103 .9317016602104 .2365036011104 .5412979126 104.8460998535105 .1509017944105 .4557037354105 .7603988647106 .0652008057 106.0652008057 106.3700027466106.6747970581 106.979598999 106.979598999 107.0238800049107 .040763855 -9999 -9999 -9999 -9999 -9999 -9999 -9999 -9999 -9999 -9999 -9999 -9999 -9999 -9999 -9999 -9999 -9999 -9999 -9999 -9999 -9999 -9999 -9999 -9999

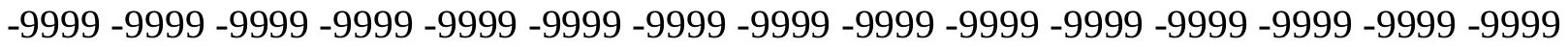

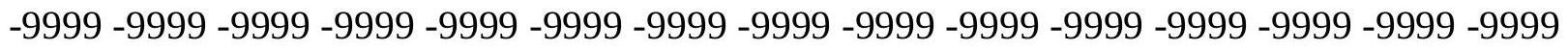

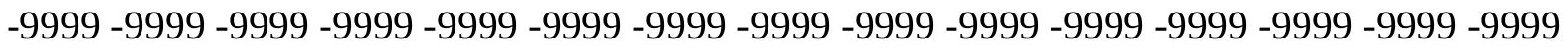
-9999 -9999 -9999 -9999 -9999 -9999 -9999 -9999 -9999 -9999 -9999 -9999 -9999 -9999 -9999 -

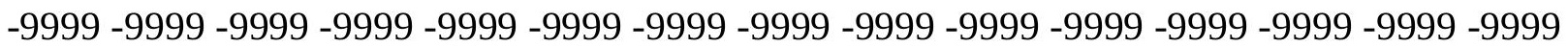

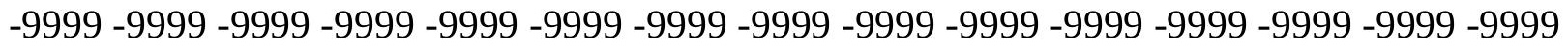
-9999 -9999 -9999 -9999 -9999 -9999 -9999 -9999 -9999 -9999 -9999 -9999 -9999 -9999 -9999 $-9999$

-9999 -9999 -9999 -9999 -9999 -9999 -9999 -9999 -9999 -9999 -9999 -9999 -9999 -9999 -9999 -9999 -9999-9999-2.43828105927-.609570324421 1.21914100647 3.657422065735 5.7909169197087 .92441320419310 .0579099655212 .4961900711114 .62969017029 
16.7631797790518 .8966808319121 .0301704406723 .1636695861825 .29715919495 27.430660247829 .2593708038331 .3928699493433 .5263595581135 .35507965088 37.4885711669939 .3172798156741 .4507789611843 .2794914245645 .10820007324 46.9369087219248 .765621185350 .5943298339852 .4230384826754 .25175094604 56.0804595947357 .909179687559 .4331016540560 .0107116699261 .75967788696 63.4893379211465 .1913146972766 .8696670532268 .5153350830170 .35820770264 71.9292907714873 .4532165527374 .9771423339876 .1962814331177 .41542053223 78.9393463134880 .1584930419981 .3776321411182 .5967712402383 .51112365723 84.7302627563585 .9494018554786 .8637619018687 .7781066894588 .69246673584 89.6068267822390 .5211791992291 .4355392456192 .349891662692 .95947265625 93.8738174438594 .4833908081195 .0929565429795 .7025299072396 .31210327148 96.9216690063597 .2264633178797 .8360290527398 .1408081054798 .4455871582 99.0551681518699 .3599472045999 .3599472045999 .6647262573299 .96952056885 99.96952056885100 .2742996216100 .2742996216100 .2742996216100 .2742996216 100.2742996216100 .2742996216100 .274299621699 .9695205688599 .96952056885 99.6647262573299 .6647262573299 .3599472045999 .0551681518698 .75038146973 98.445587158298 .1408081054797 .8360290527397 .5312423706197 .22646331787 96.9216690063596 .3121032714896 .0073165893695 .7025299072395 .09295654297 94.7881774902394 .1785964965893 .5690307617293 .2642517089892 .65467834473 92.349891662691 .7403335571391 .1307525634890 .8259735107490 .21640014648 89.91161346436 89.3020401001 88.9972534179788.3876876831188.08290100098 87.7781066894587 .4733276367287 .1685485839886 .8637619018686 .55898284912 86.254188537685 .9494018554785 .9494018554785 .6446228027385 .64462280273 85.3398437585 .3398437585 .3398437585 .3398437585 .3398437585 .3398437585 .33984375 85.6446228027385 .6446228027385 .9494018554785 .9494018554786 .2541885376 86.254188537686 .5589828491286 .8637619018687 .1685485839887 .47332763672 87.7781066894588 .0829010009888 .3876876831188 .6924667358488 .99725341797 89.302040100189 .6068267822390 .2164001464890 .5211791992290 .82597351074 91.1307525634891 .7403335571392 .0450973510792 .349891662692 .65467834473 92.9594726562593 .2642517089893 .5690307617293 .8738174438594 .17859649658 94.1785964965894 .4833908081194 .4833908081194 .4833908081194 .48339080811 94.4833908081194 .4833908081194 .1785964965894 .1785964965893 .87381744385 93.5690307617293 .2642517089892 .9594726562592 .6546783447392 .3498916626 91.7403335571391 .4355392456190 .8259735107490 .2164001464889 .60682678223 89.3020401001 88.6924667358488.08290100098 87.47332763672 86.86376190186 86.254188537685 .9494018554785 .3398437585 .0350494384884 .73026275635 84.4254837036184 .4254837036184 .1206970214884 .4254837036184 .42548370361 84.7302627563585 .0350494384885 .6446228027386 .254188537686 .86376190186 87.4733276367288 .0829010009888 .9972534179789 .6068267822390 .52117919922 91.1307525634892 .0450973510792 .6546783447393 .5690307617294 .17859649658 95.0929565429795.7025299072396.3121032714896.9216690063597.53124237061 98.1408081054798 .7503814697399 .3599472045999 .66472625732100 .2742996216 100.5791015625101 .1886978149101 .4934005737101 .7982025146102 .1029968262 102.4077987671102 .712600708103 .0174026489103 .3221969604103 .6268997192 103.9317016602104 .2365036011104 .5412979126104 .8460998535105 .1509017944 105.1509017944105 .4557037354105 .4557037354105 .6727828979105 .6829071045 
108.1986999512 -9999 -9999 -9999 -9999 -9999 -9999 -9999 -9999 -9999 -9999 -9999 -9999 -9999 -9999 -9999 -9999 -9999 -9999 -9999 -9999 -9999 -9999 -9999 -9999 -9999 -9999 -9999 -9999 -9999 -9999 -9999 -9999 -9999 -9999 -9999 -9999 -9999 -9999 -9999 -9999 -9999 -9999 -9999 -9999 -9999 -9999 -9999 -9999 -9999 -9999 -9999 -9999 -9999 -9999 -9999 -9999 -9999 -9999 -9999 -9999 -9999 -9999 -9999 -9999 -9999 -9999 -9999 -9999 -9999-9999 -9999 -9999 -9999 -9999 -9999 -9999 -9999 -9999 -9999 -9999 -9999 -9999 -9999 -9999 -9999 -9999 -9999

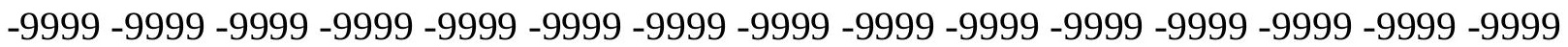
-9999 -9999 -9999 -9999 -9999 -9999 -9999 -9999 -9999 -9999 -9999 -9999 -9999 -9999 -9999 -9999 -9999 -9999 -9999 -9999 -9999 -9999 -9999 -9999 -9999 -9999 -9999 -9999 -9999 -9999 -9999 -9999 -9999 -9999 -9999 -9999 -9999 -9999 -9999 -9999 -9999 -9999 -9999 -9999 -5.89155101776 -3.96220707893 -1.82871103287 .3047851026058 2.4382810592654 .5717768669137 .0100579261789 .14355373382611 .27705001831 13.4105501174915 .5440397262617 .6775398254419 .811029434221 .94453048706 24.0780296325726 .2115192413328 .3450202941930 .1737308502232 .30722045898 34.4407196044936 .2694282531738 .4029312133840 .2316398620642 .06034851074 43.8890609741246 .0225486755447 .8512611389249 .6799812316951 .50868988037 53.0326118469254 .101428985655 .8712196350157 .6008300781259 .3635597229 61.1291999816962 .8848724365264 .5459518432666 .203262329167 .96708679199 69.1862335205170 .7101516723672 .2340774536173 .4532165527374 .97714233398 76.1962814331177 .4154205322378 .6345596313579 .8537063598681 .07285308838 82.29197692871 83.2063369751 84.42548370361 85.33984375 86.2541885376 87.1685485839888 .0829010009888 .9972534179789 .9116134643690 .52117919922 91.4355392456192 .0450973510792 .6546783447393 .2642517089893 .87381744385 94.4833908081195 .0929565429795 .397743225196 .0073165893696 .31210327148 96.6168823242296 .9216690063597 .2264633178797 .5312423706197 .53124237061 97.8360290527397 .8360290527397 .8360290527398 .1408081054798 .14080810547 98.1408081054797 .8360290527397 .8360290527397 .8360290527397 .53124237061 97.5312423706197 .2264633178796 .9216690063596 .9216690063596 .61688232422 96.3121032714896 .0073165893695 .7025299072395 .397743225194 .78817749023 94.4833908081194 .1785964965893 .8738174438593 .2642517089892 .95947265625 92.349891662692 .0450973510791 .4355392456191 .1307525634890 .52117919922 89.91161346436 89.60682678223 88.9972534179788.3876876831188.08290100098 87.47332763672 87.16854858398 86.55898284912 86.2541885376 85.64462280273 85.3398437585 .0350494384884 .4254837036184 .1206970214883 .81591033936 83.5111236572383 .5111236572383 .206336975182 .9015579223682 .90155792236 82.9015579223682 .5967712402382 .5967712402382 .5967712402382 .59677124023 82.5967712402382 .9015579223682 .9015579223682 .9015579223683 .2063369751 83.2063369751 83.51112365723 83.51112365723 83.81591033936 84.12069702148 84.1206970214884 .4254837036184 .7302627563585 .0350494384885 .33984375 85.9494018554786 .254188537686 .5589828491286 .8637619018687 .16854858398 87.7781066894588 .0829010009888 .3876876831188 .9972534179789 .3020401001 89.6068267822390 .2164001464890 .5211791992290 .8259735107491 .13075256348 91.4355392456191 .7403335571392 .0450973510792 .0450973510792 .3498916626 92.349891662692 .349891662692 .6546783447392 .349891662692 .3498916626 92.349891662692 .0450973510792 .0450973510791 .7403335571391 .43553924561 91.1307525634890 .8259735107490 .2164001464889 .9116134643689 .3020401001 
88.99725341797 88.38768768311 87.77810668945 87.16854858398 86.55898284912 85.9494018554785 .3398437584 .7302627563584 .4254837036183 .81591033936 83.206336975182.90155792236 82.59677124023 82.2919769287181.98719787598 81.9871978759881 .9871978759882 .2919769287182 .5967712402382 .90155792236 83.5111236572383 .8159103393684 .7302627563585 .3398437585 .94940185547 86.8637619018687 .7781066894588 .6924667358489 .302040100190 .21640014648 91.1307525634891 .7403335571392 .6546783447393 .2642517089893 .87381744385 94.7881774902395 .397743225196 .0073165893696 .6168823242297 .22646331787 97.8360290527398 .1408081054798 .7503814697399 .0551681518699 .66472625732 99.96952056885100 .2742996216100 .8839035034101 .1886978149101 .4934005737 101.7982025146102 .1029968262102 .4077987671102 .712600708103 .0174026489 103.3221969604103 .6268997192103 .6268997192103 .9317016602104 .2365036011 104.2365036011 104.2365036011 104.3250274658 106.0652008057 -9999 -9999 -9999 -9999 -9999 -9999 -9999 -9999 -9999 -9999 -9999 -9999 -9999 -9999 -9999 -9999 -9999 -9999 -9999 -9999 -9999 -9999 -9999 -9999 -9999 -9999 -9999 -9999 -9999 -9999 -9999 -9999 -9999 -9999 -

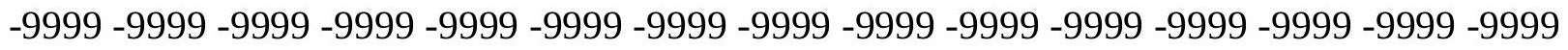
-9999 -9999 -9999 -9999 -9999 -9999 -9999 -9999 -9999 -9999 -9999 -9999 -9999 -9999 -9999 -9999 -9999 -9999 -9999 -9999 -9999 -9999 -9999 -9999 -9999 -9999 -9999 -9999 -9999 -9999 -

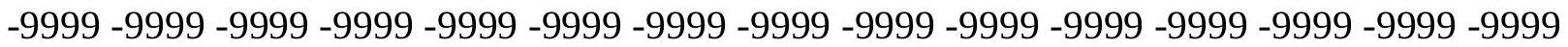

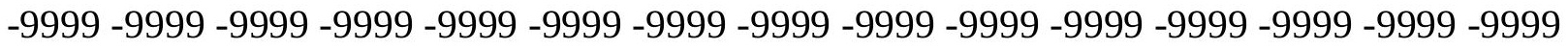

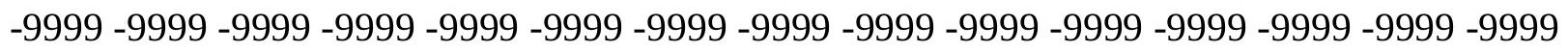
-9999 -9999-9999-9999-9999

-9999 -9999 -9999 -9999 -9999 -9999 -9999 -9999 -9999 -9999 -9999 -9999 -9999 -9999 -9999 -9999-9.16090869904-7.01005792618 -5.18134689331 - 2.74306607246-.609570324421 1.219141006473 .6574220657355 .7909169197087 .92441320419310 .36268997192 12.4961900711114 .6296901702916 .7631797790518 .8966808319121 .03017044067 23.1636695861825 .2971591949527 .1258792877229 .2593708038331 .39286994934 33.2215805053735 .3550796508837 .1837806701739 .0125007629441 .14598846436 42.9747009277344 .8034095764246 .6321296691947 .8471679687549 .75848770142 51.6343955993753 .4510726928755 .1567077636756 .886440277158 .58306884766 60.3474502563562 .1761703491263 .7000885009865 .2240066528366 .74794006348 67.9670867919969 .4910125732471 .014930725172 .2340774536173 .45321655273 74.9771423339876 .1962814331177 .4154205322378 .6345596313579 .85370635986 80.7680587768681 .9871978759882 .9015579223683 .8159103393684 .73026275635 85.6446228027386 .5589828491287 .4733276367288 .3876876831188 .99725341797 89.9116134643690 .5211791992291 .1307525634891 .7403335571392 .3498916626 92.65467834473 93.2642517089893.5690307617294.1785964965894.48339080811 94.7881774902395 .0929565429795 .397743225195 .397743225195 .70252990723 95.7025299072395 .7025299072395 .7025299072396 .0073165893695 .70252990723 95.7025299072395 .7025299072395 .7025299072395 .397743225195 .3977432251 95.0929565429794 .7881774902394 .4833908081194 .4833908081194 .17859649658 93.8738174438593 .5690307617292 .9594726562592 .6546783447392 .3498916626 92.0450973510791 .4355392456191 .1307525634890 .8259735107490 .21640014648 89.9116134643689 .302040100188 .6924667358488 .3876876831187 .77810668945 87.4733276367286 .8637619018686 .254188537685 .9494018554785 .33984375 84.7302627563584 .4254837036183 .8159103393683 .5111236572382 .90155792236 
82.5967712402382 .2919769287181 .6824111938581 .3776321411181 .07285308838 80.7680587768680 .7680587768680 .4632720947380 .1584930419980 .15849304199 80.1584930419980 .1584930419979 .8537063598679 .8537063598680 .15849304199 80.1584930419980 .1584930419980 .1584930419980 .4632720947380 .46327209473 80.7680587768680 .7680587768681 .0728530883881 .3776321411181 .37763214111 81.6824111938581 .9871978759882 .2919769287182 .5967712402382 .90155792236 83.5111236572383 .8159103393684 .1206970214884 .4254837036185 .03504943848 85.33984375 85.94940185547 86.2541885376 86.55898284912 87.16854858398 87.47332763672 88.08290100098 88.38768768311 88.69246673584 88.99725341797 89.302040100189 .6068267822389 .9116134643690 .2164001464890 .21640014648 90.5211791992290 .5211791992290 .5211791992290 .5211791992290 .52117919922 90.5211791992290 .2164001464890 .2164001464889 .9116134643689 .60682678223 89.302040100188 .9972534179788 .3876876831188 .0829010009887 .47332763672 87.1685485839886 .5589828491285 .9494018554785 .3398437584 .73026275635 84.1206970214883 .5111236572382 .9015579223682 .2919769287181 .68241119385 81.3776321411180 .7680587768680 .4632720947380 .1584930419979 .85370635986 79.8537063598679 .8537063598680 .1584930419980 .4632720947380 .76805877686 81.3776321411181 .9871978759882 .5967712402383 .5111236572384 .12069702148 85.0350494384885 .9494018554786 .8637619018687 .7781066894588 .38768768311 89.302040100190 .2164001464890 .8259735107491 .7403335571392 .3498916626 93.2642517089893.8738174438594.4833908081195.0929565429795.70252990723 96.3121032714896 .9216690063597 .2264633178797 .8360290527398 .14080810547 98.7503814697399 .0551681518699 .3599472045999 .66472625732100 .2742996216 100.5791015625100 .8839035034101 .1886978149101 .4934005737101 .7982025146 102.1029968262 102.1029968262 102.4077987671 102.712600708 102.712600708 $102.712600708102 .9301147461102 .9853668213103 .0227279663105 .4557037354-9999$ -9999 -9999 -9999 -9999 -9999 -9999 -9999 -9999 -9999 -9999 -9999 -9999 -9999 -9999 -9999

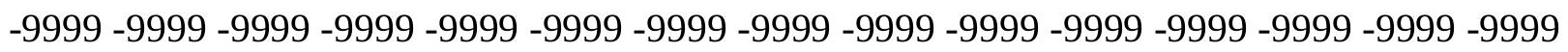
-9999 -9999 -9999 -9999 -9999 -9999 -9999 -9999 -9999 -9999 -9999 -9999 -9999 -9999 -9999 -9999 -9999 -9999 -9999 -9999 -9999 -9999 -9999 -9999 -9999 -9999 -9999 -9999 -9999 -9999 -9999 -9999 -9999 -9999 -9999 -9999 -9999 -9999 -9999 -9999 -9999 -9999 -9999 -9999 -9999

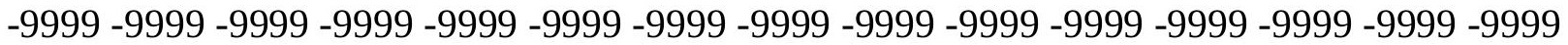
-9999 -9999 -9999 -9999 -9999 -9999 -9999 -9999 -9999 -9999 -9999 -9999 -9999 -9999 -9999 -

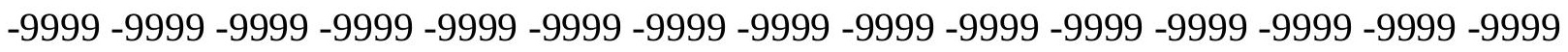
-9999 -9999 -9999 -9999-9999 -9999 -9999

-9999 -9999 -9999 -9999 -9999 -9999 -9999 -9999 -9999 -9999 -9999 -9999 -9999 -9999 -9999 -9999-10.3626899719-8.22919845581 -6.095703125 -3.96220707893-1.52392601967 .3047851026058 2.438281059265 4.87656211853 7.0100579261789.143553733826 11.2770500183113 .715330123915 .8488302230817 .9823207855220 .11581993103 21.9445304870624 .0780296325726 .2115192413328 .3450202941930 .17373085022 32.3072204589834 .1359291076736 .2694282531738 .0981407165539 .92684936523 41.7555618286143 .2523956298845 .1986083984447 .1233825683649 .01024246216 50.8863410949752 .7278289794954 .2517509460456 .0804595947357 .60438919067 59.4331016540560 .9570198059162 .4809494018664 .004882812565 .52880096436 67.0527267456168 .2718734741269 .7957916259871 .014930725172 .23407745361 73.7580032348674 .9771423339876 .1962814331177 .110626220778 .32978057861 
79.5489196777380 .4632720947381 .6824111938582 .5967712402383 .51112365723 84.42548370361 85.33984375 85.9494018554786.86376190186 87.47332763672 88.0829010009888 .9972534179789 .6068267822390 .2164001464890 .52117919922 91.1307525634891 .4355392456192 .0450973510792 .349891662692 .65467834473 92.9594726562593 .2642517089893 .2642517089893 .5690307617293 .56903076172 93.5690307617293 .8738174438593 .8738174438593 .8738174438593 .56903076172 93.5690307617293 .5690307617293 .2642517089893 .2642517089892 .95947265625 92.6546783447392 .6546783447392 .349891662692 .0450973510791 .74033355713 91.4355392456191 .1307525634890 .5211791992290 .2164001464889 .91161346436 89.6068267822388 .9972534179788 .6924667358488 .0829010009887 .77810668945 87.1685485839886 .8637619018686 .254188537685 .6446228027385 .33984375 84.7302627563584 .1206970214883 .8159103393683 .206336975182 .59677124023 81.9871978759881 .6824111938581 .0728530883880 .7680587768680 .15849304199 79.8537063598679 .5489196777378 .9393463134878 .6345596313578 .32978057861 78.3297805786178 .0249862670977 .7202072143677 .7202072143677 .41542053223 77.4154205322377 .4154205322377 .4154205322377 .4154205322377 .41542053223 77.4154205322377 .7202072143677 .7202072143677 .7202072143678 .02498626709 78.3297805786178 .3297805786178 .6345596313578 .9393463134878 .93934631348 79.2441329956179 .5489196777379 .8537063598680 .1584930419980 .76805877686 81.0728530883881 .3776321411181 .6824111938582 .2919769287182 .59677124023 83.206336975183 .5111236572384 .1206970214884 .4254837036185 .03504943848 85.3398437585 .9494018554786 .254188537686 .5589828491287 .16854858398 87.4733276367287 .7781066894588 .0829010009888 .0829010009888 .38768768311 88.6924667358488 .6924667358488 .6924667358488 .6924667358488 .69246673584 88.69246673584 88.38768768311 88.38768768311 88.08290100098 87.77810668945 87.4733276367287 .1685485839886 .8637619018686 .5589828491285 .94940185547 85.3398437585 .0350494384884 .4254837036183 .8159103393683 .2063369751 82.5967712402381 .9871978759881 .0728530883880 .4632720947380 .15849304199 79.5489196777378 .9393463134878 .6345596313578 .3297805786178 .02498626709 78.0249862670978 .0249862670978 .0249862670978 .3297805786178 .93934631348 79.2441329956180 .1584930419980 .7680587768681 .6824111938582 .59677124023 83.2063369751 84.12069702148 85.03504943848 85.9494018554786.86376190186 87.7781066894588 .6924667358489 .302040100190 .2164001464891 .13075256348 91.7403335571392 .349891662692 .9594726562593 .5690307617294 .17859649658 94.7881774902395 .397743225196 .0073165893696 .3121032714896 .92166900635 97.2264633178797.8360290527398.1408081054798.445587158298.75038146973 99.3599472045999 .6647262573299 .96952056885100 .2742996216100 .5791015625 100.5791015625100 .8839035034101 .1886978149101 .1886978149101 .4934005737 $101.4934005737101 .4934005737101 .4934005737101 .4934005737103 .3221969604-9999$ -9999 -9999 -9999 -9999 -9999 -9999 -9999 -9999 -9999 -9999 -9999 -9999 -9999 -9999 -9999

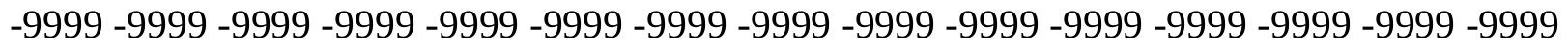

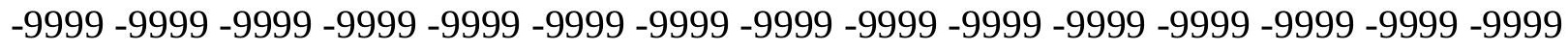
-9999 -9999 -9999 -9999 -9999 -9999 -9999 -9999 -9999 -9999 -9999 -9999 -9999 -9999 -9999 -9999 -9999 -9999 -9999 -9999 -9999 -9999 -9999 -9999 -9999 -9999 -9999 -9999 -9999 -9999 -

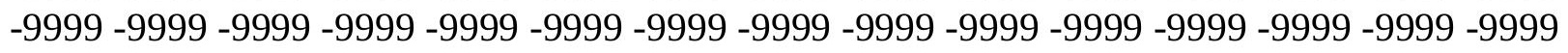

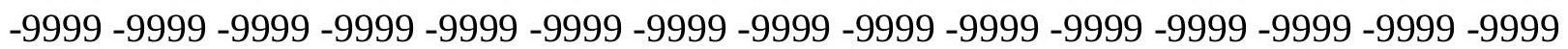


-9999 -9999 -9999 -9999 -9999 -9999 -9999 -9999 -9999 -9999 -9999 -9999 -9999 -9999 -9999 -9999 -9999 -9999 -9999 -9999 -9999 -9999

-9999 -9999 -9999 -9999 -9999 -9999 -9999 -9999 -9999 -9999 -9999 -9999 -9999 -9999 -9999 -13.6474218369-11.5818300247 -9.44833946228 -7.3148431778-4.87656211853 -2.74306607246 -.304785102606 1.523926019669 3.9622070789346 .095703125 8.22919845581110 .3626899719212 .4961900711114 .6296901702916 .76317977905 18.8966808319121 .0301704406723 .1636695861825 .2971591949527 .12587928772 29.2593708038331 .0880794525133 .2215805053735 .0502891540537 .18378067017 38.5620193481440 .5499877929742 .5015640258844 .424800872846 .32733917236 48.1560516357449 .9847602844251 .5086898803753 .3373985290554 .86132049561 56.6900291442958 .2139587402359 .7378807067961 .2618103027362 .78573989868 64.3096618652365 .8335876464867 .0527267456168 .5766525268669 .79579162598 71.3197174072372 .5388565063573 .7580032348674 .9771423339875 .89148712158 77.110626220778 .3297805786179 .2441329956180 .1584930419981 .07285308838 81.9871978759882 .9015579223683 .8159103393684 .7302627563585 .33984375 85.94940185547 86.86376190186 87.47332763672 88.08290100098 88.38768768311 88.9972534179789 .302040100189 .9116134643690 .2164001464890 .52117919922 90.8259735107491 .1307525634891 .4355392456191 .4355392456191 .74033355713 91.7403335571391 .7403335571391 .7403335571391 .7403335571391 .74033355713 91.7403335571391 .4355392456191 .4355392456191 .1307525634890 .82597351074 90.8259735107490 .5211791992290 .2164001464889 .9116134643689 .60682678223 89.3020401001 88.9972534179788.6924667358488.08290100098 87.77810668945 87.4733276367286 .8637619018686 .5589828491286 .254188537685 .64462280273 85.3398437584 .7302627563584 .1206970214883 .8159103393683 .2063369751 82.5967712402382 .2919769287181 .6824111938581 .0728530883880 .46327209473 80.1584930419979 .5489196777378 .9393463134878 .6345596313578 .02498626709 77.7202072143677 .110626220776 .8058471679776 .5010681152376 .19628143311 75.8914871215875 .5867080688575 .2819290161175 .2819290161174 .97714233398 74.9771423339874 .9771423339874 .6723632812574 .6723632812574 .97714233398 74.9771423339874 .9771423339874 .9771423339875 .2819290161175 .28192901611 75.5867080688575 .8914871215875 .8914871215876 .1962814331176 .50106811523 76.8058471679777 .110626220777 .4154205322377 .7202072143678 .02498626709 78.3297805786178 .6345596313579 .2441329956179 .5489196777379 .85370635986 80.4632720947381 .0728530883881 .3776321411181 .9871978759882 .29197692871 82.9015579223683 .206336975183 .8159103393684 .1206970214884 .73026275635 85.0350494384885 .3398437585 .6446228027385 .9494018554786 .2541885376 86.5589828491286 .8637619018686 .8637619018686 .8637619018686 .86376190186 86.8637619018686 .8637619018686 .8637619018686 .5589828491286 .55898284912 86.254188537685 .9494018554785 .6446228027385 .3398437584 .73026275635 84.4254837036183 .8159103393683 .206336975182 .9015579223682 .29197692871 81.6824111938580 .7680587768680 .1584930419979 .5489196777378 .93934631348 78.3297805786177 .7202072143677 .4154205322376 .8058471679776 .50106811523 76.1962814331176 .1962814331176 .1962814331176 .1962814331176 .50106811523 77.110626220777 .7202072143678 .3297805786178 .9393463134879 .85370635986 80.7680587768681 .6824111938582 .5967712402383 .8159103393684 .73026275635 85.6446228027386 .254188537687 .1685485839888 .0829010009888 .99725341797 
89.6068267822390.5211791992291.1307525634891.7403335571392.3498916626 92.9594726562593 .5690307617294 .1785964965894 .7881774902395 .09295654297 95.7025299072396 .0073165893696 .6168823242296 .9216690063597 .22646331787 97.5312423706198 .1408081054798 .445587158298 .7503814697399 .05516815186 99.0551681518699 .3599472045999 .6647262573299 .9695205688599 .96952056885 100.2742996216100 .2742996216100 .2742996216100 .2742996216100 .2742996216 101.1886978149103 .0174026489 -9999 -9999 -9999 -9999 -9999 -9999 -9999 -9999 -9999 -9999 -9999 -9999 -9999 -9999 -9999 -9999 -9999 -9999 -9999 -9999 -9999 -9999 -9999 -9999 -9999 -9999 -9999 -9999 -9999 -9999 -9999 -9999 -9999 -9999 -9999 -9999 -9999 -9999 -9999 -9999 -9999 -9999 -9999 -9999 -9999 -9999 -9999 -9999 -9999 -9999 -9999 -9999 -9999 -9999 -9999 -9999 -9999 -9999 -9999 -9999 -9999 -9999 -9999 -9999 -9999 -9999 -9999 -9999 -9999 -9999 -9999 -9999 -9999 -9999 -9999 -9999 -9999 -9999 -9999 -9999 -9999 -9999 -9999 -9999 -999 -9999 -9999 -9999 -9999 -9999 -9999 -9999 -9999 -9999 -9999 -9999 -9999 -9999 -9999 -9999 -9999 -9999 -9999 -9999 -9999 -9999 -9999 -9999 -9999 -9999 -9999 -9999 -9999 -9999 -9999 -9999 -9999 -9999 -9999 -9999 -9999 -9999 -9999 -9999 -9999 -9999 -9999 -9999 -9999 -9999 -9999 -9999 -9999 -9999 -9999 -9999 -9999 -9999 -9999 -9999 -9999 -9999 -9999 -14.6296901703 -12.8009700775 -10.6674804688 -8.22919845581 -5.79091691971 -3.65742206573 -1.21914100647.6095703244209 2.743066072464 5.181346893311 7.3148431777959 .4483394622811 .5818300247213 .715330123915 .84883022308 17.9823207855220 .1158199310322 .2493095397924 .3828105926526 .21151924133 28.34502029419 30.17373085022 32.30722045898 34.13592910767 35.78895950317 37.8165245056239 .7955894470241 .7044830322343 .5842704772945 .41297912598 47.2416992187548 .765621185350 .5943298339852 .4230384826753 .94697189331 55.4708900451757 .2995986938558 .8235282897960 .3474502563561 .86530303955 63.0905189514264 .6144485473666 .1383666992267 .3575134277368 .88143920898 70.1005783081171 .3197174072372 .5388565063573 .7580032348674 .67236328125 75.8914871215876 .8058471679778 .0249862670978 .9393463134879 .85370635986 80.7680587768681 .6824111938582 .2919769287183 .206336975183 .81591033936 84.7302627563585 .3398437585 .9494018554786 .5589828491286 .86376190186 87.4733276367287 .7781066894588 .3876876831188 .6924667358488 .99725341797 88.9972534179789 .302040100189 .6068267822389 .6068267822389 .91161346436 89.9116134643689 .9116134643689 .9116134643689 .9116134643689 .60682678223 89.6068267822389 .302040100189 .302040100188 .9972534179788 .69246673584 88.38768768311 88.38768768311 88.08290100098 87.77810668945 87.16854858398 86.8637619018686 .5589828491286 .254188537685 .9494018554785 .33984375 85.0350494384884 .7302627563584 .1206970214883 .8159103393683 .2063369751 82.9015579223682 .2919769287181 .6824111938581 .3776321411180 .76805877686 80.1584930419979 .5489196777379 .2441329956178 .6345596313578 .02498626709 77.4154205322377 .110626220776 .5010681152375 .8914871215875 .58670806885 74.9771423339874 .6723632812574 .062782287673 .7580032348673 .45321655273 73.1484298706172 .8436431884872 .8436431884872 .5388565063572 .53885650635 72.2340774536172 .2340774536172 .2340774536172 .2340774536172 .23407745361 72.5388565063572 .5388565063572 .8436431884872 .8436431884873 .14842987061 73.1484298706173 .4532165527373 .7580032348673 .7580032348674 .0627822876 74.3675689697374 .6723632812574 .9771423339875 .2819290161175 .58670806885 76.1962814331176 .5010681152376 .8058471679777 .4154205322377 .72020721436 
78.3297805786178 .9393463134879 .2441329956179 .8537063598680 .46327209473 80.7680587768681 .3776321411181 .6824111938582 .2919769287182 .59677124023 83.206336975183.51112365723 83.81591033936 84.12069702148 84.42548370361 84.7302627563585 .0350494384885 .0350494384885 .3398437585 .3398437585 .33984375 85.3398437585 .3398437585 .0350494384885 .0350494384884 .7302627563584 .42548370361 84.1206970214883 .8159103393683 .5111236572382 .9015579223682 .29197692871 81.9871978759881 .3776321411180 .7680587768680 .1584930419979 .54891967773 78.9393463134878 .3297805786177 .4154205322376 .8058471679776 .50106811523 75.8914871215875 .2819290161174 .9771423339874 .6723632812574 .36756896973 74.3675689697374 .6723632812574 .9771423339875 .2819290161175 .89148712158 76.8058471679777 .4154205322378 .3297805786179 .5489196777380 .46327209473 81.3776321411182 .2919769287183 .206336975184 .1206970214885 .03504943848 85.94940185547 86.86376190186 87.77810668945 88.3876876831189.3020401001 89.9116134643690 .5211791992291 .1307525634891 .7403335571392 .3498916626 92.9594726562593 .5690307617293 .8738174438594 .4833908081194 .78817749023 95.397743225195 .7025299072396 .0073165893696 .6168823242296 .92166900635 97.22646331787 97.5312423706197.83602905273 97.83602905273 98.14080810547 98.445587158298 .7503814697398 .7503814697398 .7503814697399 .05516815186 $99.0551681518699 .0551681518699 .0551681518699 .05516815186100 .8839035034-9999$ -9999 -9999 -9999 -9999 -9999 -9999 -9999 -9999 -9999 -9999 -9999 -9999 -9999 -9999 -9999 -9999 -9999 -9999 -9999 -9999 -9999 -9999 -9999 -9999 -9999 -9999 -9999 -9999 -9999 -9999 -9999 -9999 -9999 -9999 -9999 -9999 -9999 -9999 -9999 -9999 -9999 -9999 -9999 -9999 -9999 -9999 -9999 -9999 -9999 -9999 -9999 -9999 -9999 -9999 -9999 -9999 -9999-9999-9999-9999 -999 -9999 -9999 -9999 -9999 -9999 -9999 -9999 -9999 -9999 -9999 -9999 -9999 -9999 -9999 -9999 -

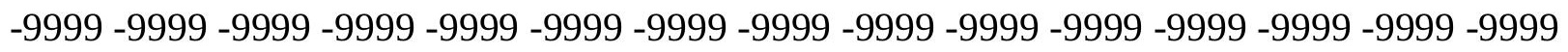
-9999 -9999 -9999 -9999 -9999 -9999 -9999 -9999 -9999 -9999 -9999 -9999 -9999 -9999 -9999 -9999 -9999 -9999 -9999 -9999 -9999 -9999 -9999 -9999 -9999 -9999 -9999 -9999 - 9999 - -9999 -9999 -9999 -9999 -9999-9999-9999

-9999 -9999 -9999 -9999 -9999 -9999 -9999 -9999 -9999 -9999 -9999 -9999 -9999 -9999 -9999 -15.8488302231 -13.7153301239-11.5818300247-9.14355373383 -6.7052731514 -4.57177686691 -2.13349604607-9999 1.828711032867 4.2669920921336.400486946106 8.53398323059110 .6674804687512 .8009700775114 .934470176717 .06797027588 19.2014598846421 .334960937523 .1636695861825 .2971591949527 .4306602478 29.2593708038330 .9131622314532 .9638404846234 .9919624328637 .04127883911 39.0125007629440 .8412094116242 .66992187544 .4986305236846 .32733917236 47.8512611389249 .6799812316951 .2038993835453 .0326118469254 .55654144287 56.0804595947357 .6043891906759 .1283111572360 .6522407531762 .17617034912 63.7000885009864 .9192428588966 .4431610107467 .6623001098668 .88143920898 70.1005783081171 .3197174072372 .5388565063573 .7580032348674 .67236328125 75.5867080688576 .8058471679777 .7202072143678 .6345596313579 .54891967773 80.1584930419981 .0728530883881 .9871978759882 .5967712402383 .2063369751 83.8159103393684 .4254837036185 .0350494384885 .3398437585 .94940185547 86.254188537686 .5589828491286 .8637619018687 .1685485839887 .47332763672 87.7781066894587 .7781066894587 .7781066894588 .0829010009888 .08290100098 88.0829010009888 .0829010009887 .7781066894587 .7781066894587 .47332763672 87.47332763672 87.16854858398 86.86376190186 86.55898284912 86.2541885376 
85.9494018554785 .6446228027385 .3398437585 .0350494384884 .73026275635 84.4254837036183 .8159103393683 .5111236572383 .206336975182 .59677124023 82.2919769287181 .6824111938581 .3776321411180 .7680587768680 .46327209473 79.8537063598679 .2441329956178 .9393463134878 .3297805786177 .72020721436 77.110626220776 .8058471679776 .1962814331175 .5867080688574 .97714233398 74.3675689697374 .062782287673 .4532165527372 .8436431884872 .53885650635 71.9292907714871 .6244964599671 .3197174072371 .014930725170 .71015167236 70.4053573608470 .4053573608470 .1005783081170 .1005783081169 .79579162598 69.7957916259869 .7957916259869 .7957916259869 .7957916259870 .10057830811 70.1005783081170 .4053573608470 .4053573608470 .7101516723671 .0149307251 71.014930725171 .3197174072371 .6244964599671 .9292907714872 .23407745361 72.5388565063572 .8436431884873 .1484298706173 .4532165527373 .75800323486 74.3675689697374 .6723632812575 .2819290161175 .5867080688576 .19628143311 76.8058471679777 .110626220777 .7202072143678 .3297805786178 .93934631348 79.2441329956179 .8537063598680 .4632720947380 .7680587768681 .37763214111 81.6824111938581 .9871978759882 .5967712402382 .9015579223683 .2063369751 83.206336975183 .5111236572383 .5111236572383 .8159103393683 .81591033936 83.8159103393683 .8159103393683 .5111236572383 .5111236572383 .2063369751 82.9015579223682 .5967712402382 .2919769287181 .9871978759881 .68241119385 81.0728530883880 .4632720947380 .1584930419979 .5489196777378 .93934631348 78.3297805786177 .7202072143676 .8058471679776 .1962814331175 .58670806885 74.9771423339874 .6723632812574 .062782287673 .7580032348673 .45321655273 73.1484298706172 .8436431884873 .1484298706173 .4532165527373 .75800323486 74.6723632812575 .2819290161176 .1962814331177 .110626220778 .32978057861 79.2441329956180 .1584930419981 .0728530883882 .2919769287183 .2063369751 84.1206970214885 .0350494384885 .6446228027386 .5589828491287 .16854858398 88.0829010009888 .6924667358489 .302040100190 .2164001464890 .82597351074 91.4355392456191 .7403335571392 .349891662692 .9594726562593 .26425170898 93.8738174438594 .1785964965894 .4833908081195 .0929565429795 .3977432251 95.7025299072396 .0073165893696 .3121032714896 .6168823242296 .92166900635 96.9216690063597 .2264633178797 .5312423706197 .5312423706197 .53124237061 97.8360290527397 .8360290527397 .8360290527397 .8360290527397 .83602905273 98.75038146973100 .5791015625 -9999 -9999-9999 -9999 -9999 -9999 -9999 -9999 -9999 -9999 -9999 -9999 -9999 -9999 -9999 -9999 -9999 -9999 -9999 -9999 -9999 -9999 -9999 -9999

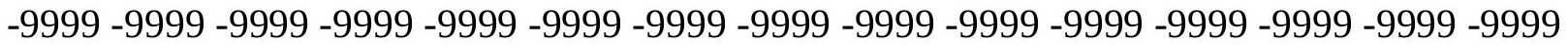
-9999 -9999 -9999 -9999 -9999 -9999 -9999 -9999 -9999 -9999 -9999 -9999 -9999 -9999 -9999 -9999 -9999 -9999 -9999 -9999 -9999 -9999 -9999 -9999 -9999 -9999 -9999 -9999 -9999 -9999

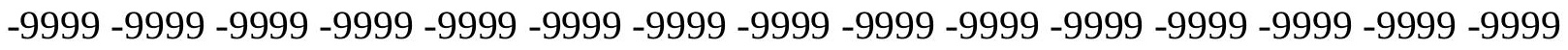
-9999 -9999 -9999 -9999 -9999 -9999 -9999 -9999 -9999 -9999 -9999 -9999 -9999 -9999 -9999 -9999 -9999 -9999 -9999 -9999 -9999 -9999 -9999 -9999 -9999 -9999 -9999 -9999 -9999 -9999 -9999 -9999 -9999 -9999 -9999 -9999 -9999 -9999 -9999 -9999 -9999 -9999 -9999 -9999 -9999 -9999 -9999 -9999 -9999 -9999 -9999 -9999 -9999 -9999 -9999 -9999 -19.1355056763 -17.0679702759-14.9344701767-12.4961900711-10.0579099655 -7.92441320419 -5.48613214493 -3.04785108566 -.914355397224 .9143553972244 3.3526360988625 .4861321449287 .6196279525769 .75312423706111 .88661956787 14.0201196670516 .1536102294918 .28710937520 .4206008911122 .24930953979 
24.3828105926526 .5163097381628 .1226558685330 .1804237365732 .1880569458 34.1359291076736 .2694282531738 .0981407165539 .9268493652341 .75556182861 43.5842704772945 .4129791259846 .9369087219248 .765621185350 .28955078125 52.1182594299353 .6421813964855 .1661109924356 .6900291442958 .21395874023 59.7378807067961 .2618103027362 .4809494018664 .004882812565 .22400665283 66.4431610107467 .9670867919969 .1862335205170 .1005783081171 .31971740723 72.5388565063573 .4532165527374 .6723632812575 .5867080688576 .50106811523 77.4154205322378 .3297805786178 .9393463134879 .8537063598680 .46327209473 81.3776321411181 .9871978759882 .5967712402382 .9015579223683 .51112365723 84.1206970214884 .4254837036184 .7302627563585 .0350494384885 .33984375 85.6446228027385 .9494018554785 .9494018554786 .254188537686 .2541885376 86.254188537686 .254188537686 .254188537686 .254188537685 .94940185547 85.9494018554785 .6446228027385 .3398437585 .0350494384885 .03504943848 84.7302627563584 .4254837036184 .1206970214883 .5111236572383 .2063369751 82.9015579223682 .5967712402381 .9871978759881 .6824111938581 .37763214111 80.7680587768680 .4632720947379 .8537063598679 .5489196777378 .93934631348 78.6345596313578 .0249862670977 .7202072143677 .110626220776 .50106811523 75.8914871215875 .5867080688574 .9771423339874 .3675689697373 .75800323486 73.1484298706172 .5388565063572 .2340774536171 .6244964599671 .0149307251 70.4053573608470 .1005783081169 .4910125732469 .1862335205168 .88143920898 68.5766525268668 .2718734741267 .9670867919967 .9670867919967 .66230010986 67.6623001098667 .3575134277367 .3575134277367 .3575134277367 .35751342773 67.6623001098667 .6623001098667 .9670867919967 .9670867919968 .27187347412 68.5766525268668 .5766525268668 .8814392089869 .1862335205169 .49101257324 69.7957916259869 .7957916259870 .1005783081170 .4053573608471 .0149307251 71.3197174072371 .6244964599672 .2340774536172 .5388565063573 .14842987061 73.7580032348674 .062782287674 .6723632812575 .2819290161175 .89148712158 76.5010681152376 .8058471679777 .4154205322378 .0249862670978 .63455963135 78.9393463134879 .5489196777379 .8537063598680 .4632720947380 .76805877686 81.0728530883881 .3776321411181 .6824111938581 .9871978759881 .98719787598 82.2919769287182 .2919769287182 .2919769287182 .2919769287182 .29197692871 81.9871978759881 .9871978759881 .6824111938581 .3776321411181 .07285308838 80.7680587768680 .4632720947379 .8537063598679 .5489196777378 .93934631348 78.3297805786177 .7202072143677 .110626220776 .5010681152375 .89148712158 75.2819290161174 .6723632812574 .062782287673 .4532165527372 .84364318848 72.5388565063572 .2340774536171 .9292907714871 .6244964599671 .62449645996 71.9292907714872 .5388565063573 .4532165527374 .062782287674 .97714233398 76.1962814331177 .110626220778 .0249862670979 .2441329956180 .15849304199 81.07285308838 81.98719787598 82.90155792236 83.81591033936 84.73026275635 85.64462280273 86.2541885376 87.16854858398 87.77810668945 88.38768768311 88.9972534179789 .6068267822390 .2164001464890 .8259735107491 .43553924561 91.7403335571392 .349891662692 .6546783447393 .2642517089893 .56903076172 93.8738174438594 .1785964965894 .4833908081194 .7881774902395 .09295654297 95.397743225195 .7025299072396 .0073165893696 .0073165893696 .31210327148 96.3121032714896 .3121032714896 .6168823242296 .6168823242296 .61688232422 96.6168823242296 .6168823242296 .6168823242298 .4455871582 -9999 -9999 -9999 -9999 
-9999 -9999 -9999 -9999 -9999 -9999 -9999 -9999 -9999 -9999 -9999 -9999 -9999 -9999 -9999 -9999 -9999 -9999 -9999 -9999 -9999 -9999 -9999 -9999 -9999 -9999 -9999 -9999 -9999 -9999

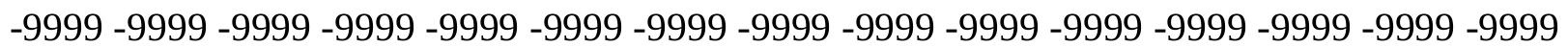
-9999 -9999 -9999 -9999 -9999 -9999 -9999 -9999 -9999 -9999 -9999 -9999 -9999 -9999 -9999

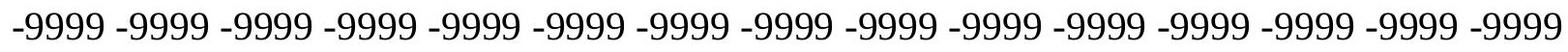
-9999 -9999 -9999 -9999 -9999 -9999 -9999 -9999 -9999 -9999 -9999 -9999 -9999 -9999 -9999 -9999 -9999 -9999 -9999 -9999 -9999 -9999 -9999 -9999 -9999 -9999 -9999 -9999 -9999 -9999

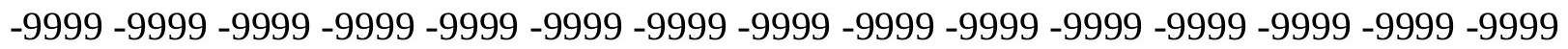
$-9999-9999$

-9999 -9999 -9999 -9999 -9999 -9999 -9999 -9999 -9999 -9999 -9999 -9999 -9999 -9999 $-20.115819931-18.287109375-15.8488302231-13.4105501175-10.9722604752$ -8.83876895905 -6.40048694611 -4.26699209213 -1.82871103287-9999 2.438281059265 4.5717768669136 .7052731513988 .83876895904510 .9722604751613 .10575962067 15.2392597198517 .3727493286119 .5062503814721 .6397399902323 .14079284668 25.3339309692427 .430660247829 .4328231811531 .3928699493433 .52635955811 35.3550796508837 .1837806701739 .0125007629440 .8412094116242 .669921875 44.4986305236846 .0225486755447 .8512611389249 .3751907348651 .20389938354 52.7278289794954 .2517509460455 .7756805419957 .2995986938558 .82352828979 60.3474502563561 .5666007995663 .0905189514264 .3096618652365 .52880096436 66.7479400634867 .9670867919969 .1862335205170 .4053573608471 .31971740723 72.5388565063573 .4532165527374 .3675689697375 .2819290161176 .19628143311 77.110626220777 .7202072143678 .6345596313579 .2441329956179 .85370635986 80.4632720947381 .0728530883881 .6824111938582 .2919769287182 .59677124023 82.9015579223683 .5111236572383 .8159103393683 .8159103393684 .12069702148 84.4254837036184 .4254837036184 .4254837036184 .7302627563584 .73026275635 84.4254837036184 .4254837036184 .4254837036184 .1206970214884 .12069702148 83.8159103393683 .5111236572383 .206336975182 .9015579223682 .59677124023 82.29197692871 81.98719787598 81.68241119385 81.07285308838 80.76805877686 80.4632720947379 .8537063598679 .5489196777379 .2441329956178 .63455963135 78.3297805786177 .7202072143677 .4154205322376 .8058471679776 .50106811523 75.8914871215875 .2819290161174 .6723632812574 .3675689697373 .75800323486 73.1484298706172 .5388565063571 .9292907714871 .3197174072371 .0149307251 70.4053573608469 .7957916259869 .1862335205168 .5766525268668 .27187347412 67.6623001098667 .3575134277366 .7479400634866 .4431610107466 .13836669922 65.8335876464865 .8335876464865 .5288009643665 .2240066528365 .22400665283 65.2240066528364 .9192428588965 .2240066528365 .2240066528365 .22400665283 65.5288009643665 .8335876464865 .8335876464866 .1383666992266 .44316101074 66.4431610107466 .7479400634867 .0527267456167 .3575134277367 .35751342773 67.6623001098667 .9670867919968 .5766525268668 .8814392089869 .18623352051 69.4910125732470 .1005783081170 .7101516723671 .014930725171 .62449645996 72.2340774536172 .8436431884873 .4532165527374 .062782287674 .36756896973 74.9771423339875 .5867080688576 .1962814331176 .8058471679777 .41542053223 77.7202072143678 .3297805786178 .6345596313579 .2441329956179 .54891967773 79.8537063598680 .1584930419980 .4632720947380 .4632720947380 .76805877686 80.7680587768680 .7680587768681 .0728530883880 .7680587768680 .76805877686 80.7680587768680 .4632720947380 .1584930419979 .8537063598679 .54891967773 
79.2441329956178 .9393463134878 .3297805786178 .0249862670977 .41542053223 76.8058471679776 .1962814331175 .5867080688574 .9771423339874 .36756896973 73.7580032348673 .1484298706172 .5388565063571 .9292907714871 .62449645996 71.3197174072371 .014930725170 .7101516723670 .7101516723671 .0149307251 71.6244964599672 .5388565063573 .1484298706174 .3675689697375 .28192901611 76.1962814331177 .4154205322378 .3297805786179 .2441329956180 .46327209473 81.37763214111 82.29197692871 83.2063369751 83.8159103393684.73026275635 85.3398437586 .254188537686 .8637619018687 .4733276367288 .08290100098 88.6924667358489 .302040100189 .9116134643690 .5211791992290 .82597351074 91.4355392456191 .7403335571392 .0450973510792 .6546783447392 .95947265625 93.2642517089893 .5690307617293 .8738174438594 .1785964965894 .48339080811 94.4833908081194.7881774902395.0929565429795.0929565429795.09295654297 95.397743225195.397743225195.397743225195.397743225195.397743225195.3977432251 95.3977432251 96.31210327148 98.4455871582 -9999 -9999 -9999 -9999 -9999 -9999 -9999 -9999 -9999 -9999 -9999 -9999 -9999 -9999 -9999 -9999 -9999 -9999 -9999 -9999 -9999 -9999

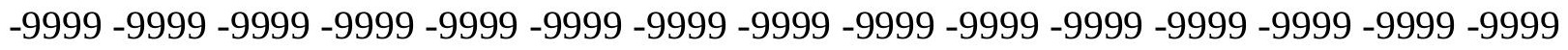
-9999 -9999 -9999 -9999 -9999 -9999 -9999 -9999 -9999 -9999 -9999 -9999 -9999 -9999 -9999 -9999 -9999 -9999 -9999 -9999 -9999 -9999 -9999 -9999 -9999 -9999 -9999 -9999 -9999 -9999 -9999 -9999 -9999 -9999 -9999 -9999 -9999 -9999 -9999 -9999 -9999 -9999 -9999 -9999 -9999 -

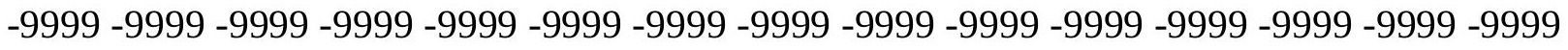

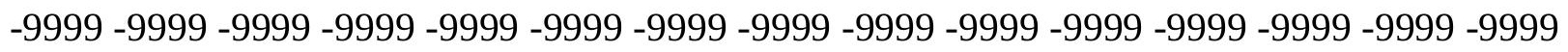
-9999 -9999 -9999 -9999 -9999 -9999 -9999 -9999 -9999 -9999 -9999 -9999 -9999 -9999 -9999 -9999 -9999 -9999 -9999 -9999 -9999 -9999 -9999 -9999 -9999 -9999 -9999 -21.0301704407 -19.2014598846 -16.7631797791 - 14.3248996735 -11.8866195679 -9.75312423706 -7.3148431778 -5.18134689331 -2.74306607246-.609570324421 1.5239260196693 .6574220657355 .7909169197087 .92441320419310 .05790996552 12.191410064714 .3248996734616 .4584007263218 .5918903350820 .26096153259 22.4351844787624 .6084270477326 .8210906982428 .6497993469230 .47850990295 32.6120109558134 .4407196044936 .2694282531738 .0981407165539 .92684936523 41.7555618286143 .5842704772945 .1082000732446 .9369087219248 .46083068848 50.2895507812551 .8134689331153 .3373985290554 .8613204956156 .38525009155 57.909179687559 .4331016540560 .6522407531761 .8713798522963 .39530944824 64.6144485473665 .8335876464867 .0527267456168 .2718734741269 .18623352051 70.4053573608471 .3197174072372 .2340774536173 .4532165527374 .0627822876 74.9771423339875 .8914871215876 .8058471679777 .4154205322378 .02498626709 78.6345596313579 .2441329956179 .8537063598680 .4632720947380 .76805877686 81.3776321411181 .6824111938581 .9871978759882 .2919769287182 .59677124023 82.5967712402382 .9015579223682 .9015579223682 .9015579223682 .90155792236 82.9015579223682 .9015579223682 .9015579223682 .5967712402382 .59677124023 82.2919769287181 .9871978759881 .6824111938581 .3776321411181 .07285308838 80.7680587768680 .1584930419979 .8537063598679 .5489196777379 .24413299561 78.6345596313578 .3297805786177 .7202072143677 .4154205322377 .1106262207 76.5010681152376 .1962814331175 .5867080688575 .2819290161174 .67236328125 74.3675689697373 .7580032348673 .1484298706172 .5388565063572 .23407745361 71.6244964599671 .014930725170 .4053573608469 .7957916259869 .18623352051 68.5766525268667 .9670867919967 .6623001098667 .0527267456166 .44316101074 
65.8335876464865 .5288009643664 .9192428588964 .6144485473664 .30966186523 64.004882812563 .7000885009863 .3953094482463 .3953094482463 .09051895142 63.0905189514262 .7857398986862 .7857398986862 .7857398986862 .78573989868 63.0905189514263 .3953094482463 .3953094482463 .7000885009864 .0048828125 64.3096618652364 .6144485473664 .6144485473664 .9192428588965 .22400665283 65.5288009643665 .8335876464866 .1383666992266 .4431610107466 .74794006348 67.0527267456167 .6623001098667 .9670867919968 .5766525268669 .18623352051 69.7957916259870 .4053573608471 .014930725171 .6244964599672 .23407745361 72.8436431884873 .4532165527373 .7580032348674 .3675689697374 .97714233398 75.5867080688576 .1962814331176 .8058471679777 .110626220777 .72020721436 78.0249862670978 .3297805786178 .6345596313578 .9393463134879 .24413299561 79.2441329956179 .5489196777379 .5489196777379 .5489196777379 .54891967773 79.5489196777379 .5489196777379 .2441329956179 .2441329956178 .93934631348 78.6345596313578 .3297805786178 .0249862670977 .4154205322377 .1106262207 76.5010681152375 .8914871215875 .2819290161174 .6723632812574 .36756896973 73.7580032348673 .1484298706172 .5388565063571 .9292907714871 .31971740723 71.014930725170 .7101516723670 .4053573608470 .1005783081170 .10057830811 70.4053573608471 .014930725171 .6244964599672 .5388565063573 .75800323486 74.6723632812575 .5867080688576 .8058471679777 .7202072143678 .63455963135 79.8537063598680 .7680587768681 .3776321411182 .2919769287183 .2063369751 84.12069702148 84.73026275635 85.33984375 86.2541885376 86.86376190186 87.4733276367288 .0829010009888 .3876876831188 .9972534179789 .60682678223 89.9116134643690 .5211791992290 .8259735107491 .4355392456191 .74033355713 92.0450973510792 .349891662692 .6546783447392 .9594726562593 .26425170898 93.2642517089893.5690307617293.8738174438593.8738174438593.87381744385 94.1785964965894 .1785964965894 .1785964965894 .1785964965894 .17859649658 $94.1785964965894 .1785964965894 .1785964965894 .4833908081196 .31210327148-9999$ -9999 -9999 -9999 -9999 -9999 -9999 -9999 -9999 -9999 -9999 -9999 -9999 -9999 -9999 -9999 -9999 -9999 -9999 -9999 -9999 -9999 -9999 -9999 -9999 -9999 -9999 -9999 -9999 -9999 -9999 -9999 -9999 -9999 -9999 -9999 -9999 -9999 -9999 -9999 -9999 -9999 -9999 -9999 -9999 -9999 -9999 -9999 -9999 -9999 -9999 -9999 -9999 -9999 -9999 -9999 -9999 -9999-9999 -9999 -9999 -9999 -9999 -9999 -9999 -9999 -9999 -9999 -9999 -9999 -9999 -9999 -9999 -9999 -9999 -9999 -

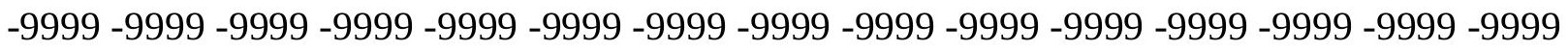
-9999 -9999 -9999 -9999 -9999 -9999 -9999 -9999 -9999 -9999 -9999 -9999 -9999 -9999 -9999

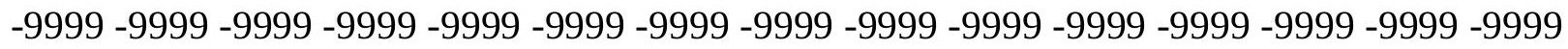
-9999 -9999-9999-9999

-9999 -9999 -9999 -9999 -9999 -9999 -9999 -9999 -9999 -9999 -9999 -9999 -9999 $-24.1298828125-22.2493095398-20.4206008911-17.9823207855-15.5440397263$ -13.1057596207 -10.6674804688 -8.22919845581 -6.095703125 -3.65742206573 -1.52392601967.6095703244209 2.743066072464 4.876562118537 .010057926178 9.14355373382611 .2770500183113 .4105501174915 .5440397262617 .41722488403 19.5926113128721 .7326526641823 .7732391357425 .906740188627 .73545074463 29.8689403533931 .6976509094233 .5263595581135 .6598587036137 .48857116699 39.3172798156740 .8412094116242 .66992187544 .4986305236846 .02254867554 47.8512611389249 .3751907348650 .8991203308152 .4230384826753 .94697189331 55.4708900451756 .9948196411158 .5187492370659 .7378807067961 .26181030273 
62.4809494018663 .7000885009864 .9192428588966 .1383666992267 .05272674561 68.2718734741269 .4910125732470 .4053573608471 .3197174072372 .23407745361 73.1484298706174 .062782287674 .6723632812575 .5867080688576 .19628143311 76.8058471679777 .4154205322378 .0249862670978 .6345596313579 .24413299561 79.5489196777379 .8537063598680 .4632720947380 .7680587768680 .76805877686 81.0728530883881 .3776321411181 .3776321411181 .3776321411181 .37763214111 81.3776321411181 .3776321411181 .3776321411181 .0728530883881 .07285308838 80.7680587768680 .4632720947380 .1584930419979 .8537063598679 .54891967773 79.2441329956178 .9393463134878 .3297805786178 .0249862670977 .41542053223 77.110626220776 .8058471679776 .1962814331175 .8914871215875 .28192901611 74.9771423339874 .3675689697374 .062782287673 .4532165527373 .14842987061 72.5388565063572 .2340774536171 .6244964599671 .014930725170 .71015167236 70.1005783081169 .4910125732468 .8814392089868 .2718734741267 .66230010986 67.0527267456166 .4431610107465 .8335876464865 .5288009643664 .91924285889 64.3096618652363 .7000885009863 .3953094482462 .7857398986862 .48094940186 62.1761703491261 .8713798522961 .5666007995661 .2618103027361 .26181030273 60.9570198059160 .9570198059160 .6522407531760 .6522407531760 .65224075317 60.6522407531760 .9570198059161 .2618103027361 .5666007995661 .87137985229 61.8713798522962 .1761703491262 .4809494018662 .7857398986862 .78573989868 63.0905189514263 .3953094482463 .7000885009864 .004882812564 .30966186523 64.6144485473665 .2240066528365 .5288009643666 .1383666992266 .74794006348 67.3575134277367 .9670867919968 .5766525268669 .1862335205169 .79579162598 70.4053573608471 .014930725171 .6244964599672 .2340774536172 .84364318848 73.4532165527374 .062782287674 .6723632812575 .2819290161175 .58670806885 76.1962814331176 .5010681152376 .8058471679777 .4154205322377 .72020721436 77.7202072143678 .0249862670978 .3297805786178 .3297805786178 .32978057861 78.6345596313578 .6345596313578 .3297805786178 .3297805786178 .02498626709 78.0249862670977 .7202072143677 .4154205322377 .110626220776 .80584716797 76.1962814331175 .8914871215875 .2819290161174 .6723632812574 .36756896973 73.7580032348673 .1484298706172 .5388565063571 .9292907714871 .62449645996 71.014930725170 .7101516723670 .4053573608470 .1005783081169 .79579162598 69.7957916259870 .1005783081170 .7101516723671 .3197174072372 .23407745361 73.1484298706174 .3675689697375 .2819290161176 .1962814331177 .41542053223 78.3297805786179 .2441329956180 .1584930419981 .0728530883881 .68241119385 82.5967712402383 .5111236572384 .1206970214884 .7302627563585 .33984375 85.94940185547 86.55898284912 87.16854858398 87.77810668945 88.38768768311 88.6924667358489 .302040100189 .6068267822389 .9116134643690 .52117919922 90.8259735107491 .1307525634891 .4355392456191 .7403335571392 .04509735107 92.0450973510792 .349891662692 .6546783447392 .6546783447392 .95947265625 92.9594726562592 .9594726562592 .9594726562592 .9594726562593 .26425170898 93.2642517089893.2642517089893.2642517089893.228515625 92.95947265625 94.1785964965896 .31210327148 -9999 -9999 -9999 -9999 -9999 -9999 -9999 -9999 -9999

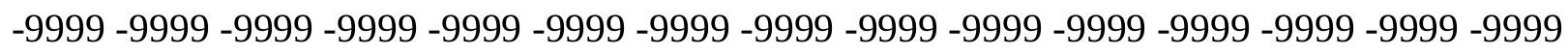
-9999 -9999 -9999 -9999 -9999 -9999 -9999 -9999 -9999-9999 -9999 -9999 -9999 -9999 -9999 -9999 -9999 -9999 -9999 -9999 -9999 -9999 -9999 -9999 -9999 -9999 -9999 -9999 -9999 -9999 -

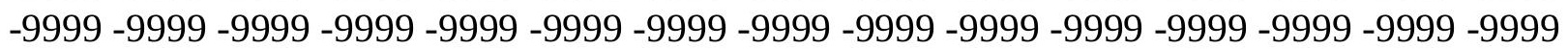


-9999 -9999 -9999 -9999 -9999 -9999 -9999 -9999 -9999 -9999 -9999 -9999 -9999 -9999 -9999 -9999 -9999 -9999 -9999 -9999 -9999 -9999 -9999 -9999 -9999 -9999 -9999 -9999 -9999 -9999 -9999 -9999 -9999 -9999 -9999 -9999 -9999 -9999 -9999 -9999 -9999 -9999 -9999 -9999 -9999 -9999 -9999 -9999 -9999 -9999 -9999 -9999 -9999 -9999 -9999

-9999 -9999 -9999 -9999 -9999 -9999 -9999 -9999 -9999 -9999 -9999 -9999 -9999 $-24.9923801422-23.4684505463-21.3349609375-18.8966808319-16.4584007263$ $-14.0201196671-11.5818300247-9.14355373383-7.01005792618-4.57177686691$ -2.43828105927-9999 1.828711032867 3.962207078934 6.095703125 8.533983230591 10.6674804687512 .8009700775114 .5515508651716 .7631797790518 .89668083191 21.0301704406723 .1636695861824 .9923801422127 .1258792877228 .95458984375 31.0880794525132 .9167900085434 .7455101013236 .5742111206138 .40293121338 40.2316398620642 .0603485107443 .5842704772945 .4129791259846 .93690872192 48.765621185350 .2895507812551 .8134689331153 .3373985290554 .80764389038 56.0804595947357 .6043891906758 .8235282897960 .3474502563561 .56660079956 62.7857398986864 .004882812565 .2240066528366 .1383666992267 .35751342773 68.2718734741269 .4910125732470 .4053573608471 .3197174072372 .23407745361 72.8436431884873 .7580032348674 .3675689697375 .2819290161175 .89148712158 76.5010681152377 .110626220777 .4154205322378 .0249862670978 .32978057861 78.6345596313578 .9393463134879 .2441329956179 .5489196777379 .85370635986 79.8537063598680 .1584930419980 .1584930419980 .1584930419980 .15849304199 79.8537063598679 .8537063598679 .5489196777379 .5489196777379 .24413299561 78.9393463134878 .6345596313578 .3297805786177 .7202072143677 .41542053223 77.110626220776 .5010681152376 .1962814331175 .5867080688575 .28192901611 74.6723632812574 .3675689697373 .7580032348673 .4532165527372 .84364318848 72.5388565063571 .9292907714871 .6244964599671 .014930725170 .71015167236 70.1005783081169 .4910125732469 .1862335205168 .5766525268667 .96708679199 67.3575134277366 .7479400634866 .1383666992265 .5288009643664 .91924285889 64.3096618652364 .004882812563 .3953094482462 .7857398986862 .17617034912 61.8713798522961 .2618103027360 .6522407531760 .3474502563560 .04267120361 59.7378807067959 .4331016540559 .1283111572359 .1283111572358 .82352828979 58.8235282897958 .8235282897958 .5187492370658 .8235282897958 .82352828979 59.1283111572359 .1283111572359 .4331016540559 .7378807067960 .04267120361 60.3474502563560 .3474502563560 .6522407531760 .9570198059161 .26181030273 61.5666007995661 .8713798522962 .1761703491262 .4809494018662 .78573989868 63.3953094482463 .7000885009864 .3096618652364 .9192428588965 .52880096436 66.1383666992266 .7479400634867 .3575134277367 .9670867919968 .57665252686 69.1862335205169 .7957916259870 .4053573608471 .3197174072371 .92929077148 72.5388565063573 .1484298706173 .7580032348674 .062782287674 .67236328125 75.2819290161175 .5867080688575 .8914871215876 .1962814331176 .50106811523 76.8058471679777 .110626220777 .110626220777 .4154205322377 .41542053223 77.4154205322377 .4154205322377 .4154205322377 .110626220777 .1106262207 76.8058471679776 .5010681152376 .5010681152375 .8914871215875 .58670806885 75.2819290161174 .6723632812574 .3675689697373 .7580032348673 .14842987061 72.8436431884872 .2340774536171 .6244964599671 .3197174072370 .71015167236 70.4053573608470 .1005783081170 .1005783081169 .7957916259869 .79579162598 70.1005783081170 .7101516723671 .3197174072372 .2340774536173 .14842987061 
74.062782287674 .9771423339876 .1962814331177 .110626220778 .02498626709 78.9393463134879 .8537063598680 .4632720947381 .3776321411182 .29197692871 82.9015579223683 .5111236572384 .1206970214885 .0350494384885 .64462280273 85.9494018554786 .5589828491287 .1685485839887 .4733276367288 .08290100098 88.38768768311 88.99725341797 89.3020401001 89.60682678223 89.91161346436 90.2164001464890 .5211791992290 .8259735107491 .1307525634891 .13075256348 91.4355392456191 .7403335571391 .7403335571391 .7403335571392 .04509735107 92.04509735107 92.0450973510792.0450973510792.0450973510792.04509735107 92.0450973510792 .0450973510792 .0450973510792 .0450973510792 .3498916626 94.17859649658 -9999 -9999 -9999 -9999 -9999 -9999 -9999 -9999 -9999 -9999 -9999 -9999 -9999 -9999 -9999 -9999 -9999 -9999 -9999 -9999 -9999 -9999 -9999 -9999 -9999 -9999 -9999 - 999 -9999 -9999 -9999 -9999 -9999 -9999 -9999 -9999 -9999 -9999 -9999 -9999 -9999 -9999 -9999

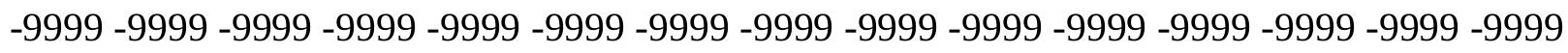

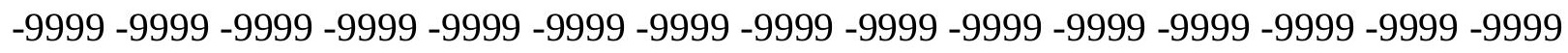
-9999 -9999 -9999 -9999 -9999 -9999 -9999 -9999 -9999 -9999 -9999 -9999 -9999 -9999 -9999

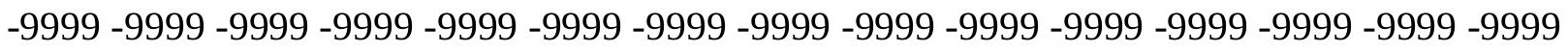

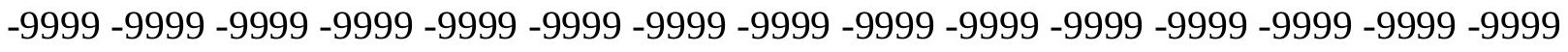
-9999 -9999 -9999 -9999 -9999-9999 -9999 -9999 -9999 -9999 -9999 -9999 -9999 -9999 -9999 -9999 -9999 -9999 -9999 -9999 -26.2115192413 -24.6875991821 -22.2493095398 -19.8110294342 -17.3727493286 $-14.9344701767-12.4961900711-10.0579099655-7.92441320419-5.48613214493$ -3.35263609886 -.914355397224 .9143553972244 3.0478510856635 .486132144928 7.6196279525769 .75312423706111 .5832338333113 .8827667236316 .15361022949 18.28710937520 .1158199310322 .2493095397924 .3828105926526 .21151924133 28.3450202941930 .1737308502232 .0024414062534 .1359291076735 .96464920044 37.7933502197339 .3172798156741 .1459884643642 .9747009277344 .49863052368 46.3273391723647 .8512611389249 .3751907348650 .8991203308152 .42303848267 53.9469718933155 .4708900451756 .6900291442958 .2139587402359 .43310165405 60.6522407531761 .8713798522963 .0905189514264 .3096618652365 .52880096436 66.4431610107467 .3575134277368 .5766525268669 .4910125732470 .40535736084 71.014930725171 .9292907714872 .8436431884873 .4532165527374 .0627822876 74.6723632812575 .2819290161175 .8914871215876 .5010681152376 .80584716797 77.110626220777 .7202072143678 .0249862670978 .0249862670978 .32978057861 78.6345596313578 .6345596313578 .6345596313578 .6345596313578 .63455963135 78.6345596313578 .6345596313578 .3297805786178 .0249862670978 .02498626709 77.7202072143677 .4154205322376 .8058471679776 .5010681152376 .19628143311 75.5867080688575 .2819290161174 .6723632812574 .3675689697373 .75800323486 73.4532165527372 .8436431884872 .5388565063571 .9292907714871 .62449645996 71.014930725170 .7101516723670 .1005783081169 .7957916259869 .18623352051 68.5766525268668 .2718734741267 .6623001098667 .0527267456166 .74794006348 66.1383666992265 .5288009643664 .9192428588964 .3096618652363 .70008850098 63.0905189514262 .4809494018661 .8713798522961 .2618103027360 .65224075317 60.3474502563559 .7378807067959 .4331016540558 .8235282897958 .51874923706 58.2139587402357 .909179687557 .6043891906757 .2995986938556 .99481964111 56.9948196411156 .9948196411156 .6900291442956 .6900291442956 .69002914429 56.9948196411156 .9948196411157 .2995986938557 .6043891906757 .9091796875 
57.909179687558 .2139587402358 .5187492370658 .8235282897959 .12831115723 59.4331016540559 .7378807067960 .0426712036160 .3474502563560 .65224075317 60.9570198059161 .5666007995661 .8713798522962 .4809494018663 .09051895142 63.7000885009864 .3096618652364 .9192428588965 .5288009643666 .13836669922 67.0527267456167 .6623001098668 .2718734741268 .8814392089869 .49101257324 70.4053573608471 .014930725171 .6244964599672 .2340774536172 .84364318848 73.4532165527373 .7580032348674 .3675689697374 .6723632812574 .97714233398 75.2819290161175 .5867080688575 .8914871215876 .1962814331176 .19628143311 76.5010681152376 .5010681152376 .5010681152376 .5010681152376 .50106811523 76.1962814331176 .1962814331175 .8914871215875 .5867080688575 .58670806885 74.9771423339874 .6723632812574 .3675689697374 .062782287673 .45321655273 73.1484298706172 .5388565063572 .2340774536171 .6244964599671 .31971740723 71.014930725170 .7101516723670 .4053573608470 .1005783081170 .10057830811 70.1005783081170 .4053573608471 .014930725171 .6244964599672 .53885650635 73.1484298706174 .062782287674 .9771423339875 .8914871215876 .80584716797 77.7202072143678 .6345596313579 .5489196777380 .4632720947381 .07285308838 81.6824111938582 .5967712402383 .206336975183 .8159103393684 .42548370361 85.0350494384885 .6446228027385 .9494018554786 .5589828491286 .86376190186 87.4733276367287 .7781066894588 .0829010009888 .6924667358488 .99725341797 89.302040100189 .6068267822389 .9116134643689 .9116134643690 .21640014648 90.5211791992290 .5211791992290 .8259735107490 .8259735107490 .82597351074 90.8259735107491 .1307525634891 .1307525634891 .1307525634891 .13075256348 91.1307525634891 .1307525634891 .1307525634890 .8259735107490 .82597351074 90.82597351074 92.04509735107 93.87381744385 -9999 -9999 -9999 -9999 -9999 -9999 -9999 -9999 -9999 -9999 -9999 -9999 -9999 -9999 -9999 -9999 -9999 -9999 -9999 -9999 -9999 -9999 -9999 -9999 -9999 -9999 -9999 -9999 -9999 -9999 -9999 -9999 -9999 -9999 -9999 -9999 -9999 -9999 -9999 -9999 -9999 -9999 -9999 -9999 -9999 -9999 -9999 -9999 -9999 -9999 -9999 -9999

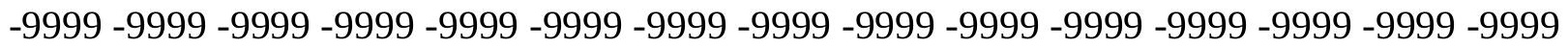
-9999 -9999 -9999 -9999 -9999 -9999 -9999 -9999 -9999 -9999 -9999 -9999 -9999 -9999 -9999 -9999 -9999 -9999 -9999 -9999 -9999 -9999 -9999 -9999 -9999 -9999 -9999 -9999 -9999 -9999 -9999 -9999 -9999 -9999 -9999 -9999 -9999 -9999 -9999 -9999 -9999 -9999 -9999 -9999 -9999 -9999 -9999 -9999 -9999 -9999 -9999 -9999 -9999 -9999 -9999 -9999

-9999 -9999 -9999 -9999 -9999 -9999 -9999 -9999 -9999 -9999 -9999 -9999 -9999 $-27.4306602478-25.6019496918-23.1636695862-20.7253894806-18.287109375$ -15.8488302231 -13.4105501175 -10.9722604752 -8.83876895905-6.40048694611 -4.26699209213 -1.82871103287-9999 2.438281059265 4.571776866913 6.705273151398 8.54831123352110 .9197301864613 .1057596206715 .2392597198517 .37274932861 19.5062503814721 .6397399902323 .4684505462625 .6019496917727 .4306602478 29.5641593933131 .3928699493433 .2215805053735 .0502891540536 .87900161743 38.7077102661140 .5364189147942 .3651313781743 .8890609741245 .7177696228 47.24169921875 48.7656211853 50.28955078125 51.81346893311 53.25506210327 54.5565414428756 .0804595947357 .2995986938558 .8235282897960 .04267120361 61.2618103027362 .4809494018663 .3953094482464 .6144485473665 .52880096436 66.7479400634867 .6623001098668 .5766525268669 .4910125732470 .10057830811 71.014930725171 .6244964599672 .5388565063573 .1484298706173 .75800323486 74.3675689697374 .6723632812575 .2819290161175 .5867080688576 .19628143311 
76.5010681152376 .8058471679777 .110626220777 .110626220777 .41542053223 77.4154205322377 .4154205322377 .4154205322377 .4154205322377 .41542053223 77.110626220777 .110626220776 .8058471679776 .5010681152376 .19628143311 75.8914871215875 .2819290161174 .9771423339874 .3675689697374 .0627822876 73.4532165527373 .1484298706172 .5388565063571 .9292907714871 .62449645996 71.014930725170 .7101516723670 .1005783081169 .4910125732469 .18623352051 68.5766525268668 .2718734741267 .6623001098667 .3575134277366 .74794006348 66.4431610107465 .8335876464865 .2240066528364 .6144485473664 .30966186523 63.7000885009863 .0905189514262 .4809494018661 .8713798522961 .26181030273 60.6522407531760 .0426712036159 .4331016540558 .8235282897958 .51874923706 57.909179687557 .2995986938556 .9948196411156 .6900291442956 .38525009155 56.0804595947355 .7756805419955 .4708900451755 .1661109924355 .16611099243 55.1661109924354 .8613204956154 .8613204956154 .8613204956155 .16611099243 55.1661109924355 .4708900451755 .7756805419955 .7756805419956 .08045959473 56.3852500915556 .6900291442956 .9948196411157 .2995986938557 .60438919067 57.909179687558 .2139587402358 .5187492370658 .8235282897959 .43310165405 59.7378807067960 .3474502563560 .6522407531761 .2618103027361 .87137985229 62.7857398986863 .3953094482464 .004882812564 .6144485473665 .22400665283 66.1383666992266 .7479400634867 .3575134277368 .2718734741268 .88143920898 69.4910125732470 .1005783081170 .7101516723671 .3197174072371 .92929077148 72.5388565063573 .1484298706173 .4532165527373 .7580032348674 .36756896973 74.6723632812574 .9771423339874 .9771423339875 .2819290161175 .58670806885 75.5867080688575 .5867080688575 .5867080688575 .5867080688575 .58670806885 75.5867080688575 .2819290161175 .2819290161174 .9771423339874 .67236328125 74.3675689697374 .062782287673 .7580032348673 .4532165527372 .84364318848 72.5388565063572 .2340774536171 .6244964599671 .3197174072371 .0149307251 70.7101516723670 .7101516723670 .7101516723670 .7101516723670 .71015167236 71.014930725171 .3197174072371 .9292907714872 .8436431884873 .45321655273 74.3675689697375 .2819290161176 .1962814331177 .110626220777 .72020721436 78.6345596313579 .5489196777380 .1584930419981 .0728530883881 .68241119385 82.2919769287182 .9015579223683 .5111236572384 .1206970214884 .73026275635 85.0350494384885 .6446228027385 .9494018554786 .5589828491286 .86376190186 87.16854858398 87.47332763672 88.08290100098 88.38768768311 88.38768768311 88.6924667358488 .9972534179789 .302040100189 .302040100189 .60682678223 89.6068267822389 .9116134643689 .9116134643689 .9116134643689 .91161346436 90.2164001464890 .2164001464890 .2164001464890 .2164001464889 .91161346436 89.91161346436 89.91161346436 89.91161346436 89.91161346436 89.91161346436 90.2164001464892 .04509735107 -9999 -9999 -9999 -9999 -9999 -9999 -9999 -9999 -9999 -9999 -9999 -9999 -9999 -9999 -9999 -9999 -9999 -9999 -9999 -9999 -9999 -9999 -9999 -9999

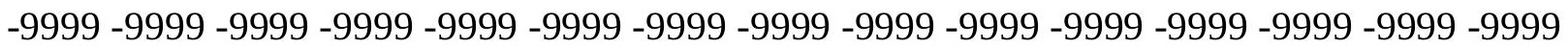

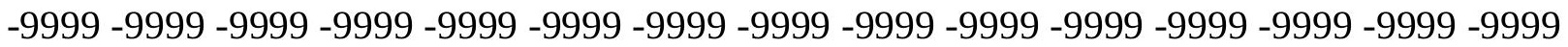
-9999 -9999 -9999 -9999 -9999 -9999 -9999 -9999 -9999 -9999 -9999 -9999 -9999 -9999 -9999 -9999 -9999 -9999 -9999 -9999 -9999 -9999 -9999 -9999 -9999 -9999 -9999 -9999 -9999 -9999 -9999 -9999 -9999 -9999 -9999 -9999 -9999 -9999 -9999 -9999 -9999 -9999 -9999 -9999 -9999 -9999 -9999 -9999 -9999 -9999 -9999 -9999 -9999 -9999 -9999 -9999 -9999 -9999 -9999 -9999 -9999 -9999 -9999 -9999 -9999 -9999 -9999 -9999 -9999 
-9999 -9999 -9999 -9999 -9999 -9999 -9999 -9999 -9999 -9999 -9999 -9999 -9999 -28.3450202942 -26.5163097382 -24.0780296326 -21.6397399902 -19.2014598846 -16.7631797791 -14.3248996735 -11.8866195679 -9.75312423706 -7.3148431778 $-4.87656211853-2.74306607246-.6095703244211 .5239260196693 .657422065735$ 5.7909169197087 .86152982711810 .1921434402512 .4961900711114 .62969017029 16.7631797790518 .8966808319120 .7253894805922 .8588790893624 .99238014221 26.8210906982428 .9545898437530 .7833003997832 .6120109558134 .44071960449 36.2694282531738 .0981407165539 .9268493652341 .7555618286143 .27949142456 44.8034095764246 .6321296691948 .1560516357449 .6799812316951 .18217086792 52.4230384826753 .9469718933155 .4708900451756 .6900291442957 .9091796875 59.1283111572360 .3474502563561 .5666007995662 .7857398986863 .70008850098 64.9192428588965 .8335876464866 .7479400634867 .6623001098668 .57665252686 69.1862335205170 .1005783081170 .7101516723671 .6244964599672 .23407745361 72.8436431884873 .4532165527373 .7580032348674 .3675689697374 .67236328125 74.9771423339875 .2819290161175 .5867080688575 .8914871215876 .19628143311 76.1962814331176 .1962814331176 .1962814331176 .1962814331176 .19628143311 76.1962814331175 .8914871215875 .5867080688575 .2819290161174 .97714233398 74.6723632812574 .3675689697373 .7580032348673 .4532165527372 .84364318848 72.5388565063571 .9292907714871 .3197174072371 .014930725170 .40535736084 69.7957916259869 .1862335205168 .8814392089868 .2718734741267 .96708679199 67.3575134277366 .7479400634866 .4431610107465 .8335876464865 .52880096436 64.9192428588964 .6144485473664 .004882812563 .3953094482463 .09051895142 62.4809494018661 .8713798522961 .2618103027360 .6522407531760 .04267120361 59.4331016540558 .8235282897958 .2139587402357 .6043891906756 .99481964111 56.6900291442956 .0804595947355 .7756805419955 .1661109924354 .86132049561 54.5565414428754 .2517509460453 .9469718933153 .6421813964853 .64218139648 53.3373985290553 .3373985290553 .3373985290553 .3373985290553 .33739852905 53.3373985290553 .6421813964853 .6421813964853 .9469718933153 .94697189331 54.2517509460454 .5565414428754 .8613204956155 .1661109924355 .47089004517 55.7756805419956 .0804595947356 .3852500915556 .6900291442957 .29959869385 57.6043891906758 .2139587402358 .5187492370659 .1283111572359 .73788070679 60.3474502563560 .9570198059161 .8713798522962 .4809494018663 .09051895142 63.7000885009864 .6144485473665 .2240066528365 .8335876464866 .74794006348 67.3575134277368 .2718734741268 .8814392089869 .4910125732470 .10057830811 70.7101516723671 .3197174072371 .9292907714872 .2340774536172 .84364318848 73.1484298706173 .4532165527373 .7580032348674 .062782287674 .36756896973 74.6723632812574 .6723632812574 .9771423339874 .9771423339874 .97714233398 74.9771423339874 .9771423339874 .9771423339874 .6723632812574 .67236328125 74.3675689697374 .062782287674 .062782287673 .7580032348673 .45321655273 72.8436431884872 .5388565063572 .2340774536171 .9292907714871 .62449645996 71.6244964599671 .3197174072371 .3197174072371 .014930725171 .31971740723 71.3197174072371 .6244964599672 .2340774536172 .8436431884873 .45321655273 74.062782287674 .9771423339875 .5867080688576 .5010681152377 .1106262207 78.0249862670978 .6345596313579 .5489196777380 .1584930419980 .76805877686 81.3776321411181 .9871978759882 .5967712402383 .206336975183 .81591033936 84.4254837036184 .7302627563585 .3398437585 .6446228027385 .94940185547 
86.254188537686 .8637619018687 .1685485839887 .4733276367287 .77810668945 87.7781066894588 .0829010009888 .3876876831188 .3876876831188 .69246673584 88.6924667358488 .9972534179788 .9972534179788 .9972534179789 .3020401001 89.302040100189.302040100189.302040100189.302040100188.99725341797 88.9972534179788.99725341797 88.9972534179788.9972534179788.9235458374 88.6924667358488 .6924667358489 .9116134643691 .74033355713 -9999 -9999 -9999 -9999 -9999 -9999 -9999 -9999 -9999 -9999 -9999 -9999 -9999 -9999 -9999 -9999 -9999 -9999 -9999 -9999 -9999 -9999 -9999 -9999 -9999 -9999 -9999 -9999 -9999 -9999 -9999 -9999 -9999 -9999 -9999 -9999 -9999 -9999 -9999 -9999 -9999 -9999 -9999 -9999 -9999 -9999 -9999 -9999 -9999 -9999 -9999 -9999 -9999 -9999 -9999 -9999 -9999 -9999 -9999 -9999 -9999 -9999 -9999 -9999 -9999 -9999 -9999 -9999 -9999 -9999 -9999 -9999 -9999 -9999 -9999 -9999 -9999 -9999 -9999 -

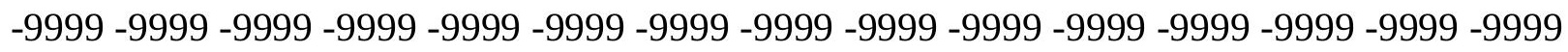

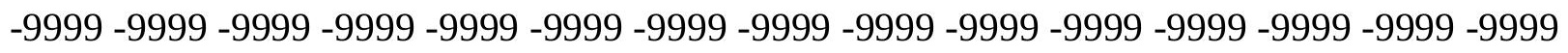
-9999 -9999 -9999 -9999 -9999 -9999 -9999 -9999 -9999 -9999 -9999 -9999 -9999 -9999 -9999 -9999 -9999 -9999 -9999 -9999 -9999 -9999 -9999 -9999 -9999 -9999 -29.2593708038 -27.4306602478 -24.9923801422 -22.5541000366 -20.115819931 $-17.6775398254-15.2392597198-12.8009700775-10.6674804688-8.22919845581$ -5.79091691971 -3.65742206573 -1.21914100647.6095703244209 2.743066072464 4.7861166000377 .1789073944099 .4483394622811 .5818300247213 .7153301239 15.8488302230817 .9823207855220 .1158199310322 .2493095397924 .38281059265 26.2115192413328 .3450202941930 .1737308502232 .0024414062533 .83115005493 35.6598587036137 .4885711669939 .3172798156741 .1459884643642 .669921875 44.1938400268646 .0225486755447 .5464782714849 .0704002380450 .48489761353 51.8134689331153 .3373985290554 .5565414428756 .0804595947357 .29959869385 58.5187492370659 .7378807067960 .9570198059161 .8713798522963 .09051895142 64.004882812564 .9192428588965 .8335876464866 .7479400634867 .66230010986 68.5766525268669 .1862335205170 .1005783081170 .7101516723671 .31971740723 71.9292907714872 .2340774536172 .8436431884873 .4532165527373 .75800323486 74.062782287674 .3675689697374 .6723632812574 .9771423339874 .97714233398 74.9771423339875 .2819290161175 .2819290161175 .2819290161174 .97714233398 74.9771423339874 .6723632812574 .3675689697374 .062782287673 .75800323486 73.4532165527372 .8436431884872 .5388565063571 .9292907714871 .62449645996 71.014930725170 .4053573608469 .7957916259869 .1862335205168 .57665252686 68.2718734741267 .6623001098667 .0527267456166 .7479400634866 .13836669922 65.5288009643665 .2240066528364 .6144485473664 .3096618652363 .70008850098 63.3953094482462 .7857398986862 .1761703491261 .8713798522961 .26181030273 60.6522407531760 .0426712036159 .4331016540558 .8235282897958 .21395874023 57.6043891906756 .9948196411156 .3852500915555 .7756805419955 .47089004517 54.8613204956154 .2517509460453 .9469718933153 .6421813964853 .03261184692 52.7278289794952 .4230384826752 .1182594299352 .1182594299351 .81346893311 51.8134689331151 .5086898803751 .5086898803751 .5086898803751 .50868988037 51.8134689331151 .8134689331151 .8134689331152 .1182594299352 .42303848267 52.7278289794952 .7278289794953 .0326118469253 .3373985290553 .64218139648 53.9469718933154 .2517509460454 .8613204956155 .1661109924355 .47089004517 56.0804595947356 .6900291442956 .9948196411157 .6043891906758 .21395874023 59.1283111572359 .7378807067960 .3474502563560 .9570198059161 .87137985229 
62.4809494018663 .0905189514263 .7000885009864 .6144485473665 .22400665283 66.1383666992266 .7479400634867 .6623001098668 .2718734741268 .88143920898 69.4910125732470 .1005783081170 .7101516723671 .3197174072371 .62449645996 72.2340774536172 .5388565063572 .8436431884873 .1484298706173 .45321655273 73.7580032348674 .062782287674 .062782287674 .3675689697374 .36756896973 74.3675689697374 .3675689697374 .3675689697374 .3675689697374 .36756896973 74.3675689697374 .062782287673 .7580032348673 .7580032348673 .45321655273 73.1484298706172 .8436431884872 .5388565063572 .5388565063572 .23407745361 71.9292907714871 .9292907714871 .9292907714871 .9292907714871 .92929077148 72.2340774536172 .5388565063572 .8436431884873 .4532165527374 .0627822876 74.6723632812575 .2819290161176 .1962814331176 .8058471679777 .72020721436 78.3297805786178 .9393463134879 .5489196777380 .1584930419981 .07285308838 81.3776321411181.98719787598 82.59677124023 83.2063369751 83.51112365723 84.1206970214884 .4254837036185 .0350494384885 .3398437585 .64462280273 85.9494018554786 .254188537686 .5589828491286 .8637619018687 .16854858398 87.16854858398 87.47332763672 87.77810668945 87.7781066894588.08290100098 88.08290100098 88.08290100098 88.38768768311 88.38768768311 88.38768768311 88.38768768311 88.38768768311 88.38768768311 88.38768768311 88.38768768311 88.0829010009888 .0829010009888 .0829010009888 .0829010009887 .77810668945 87.7781066894587 .7781066894588 .0829010009889 .91161346436 -9999 -9999 -9999-9999 -9999 -9999 -9999 -9999 -9999 -9999 -9999 -9999 -9999 -9999 -9999 -9999 -9999 -9999 -9999 -9999 -9999 -9999 -9999 -9999 -9999 -9999 -9999 -9999 -9999 -9999 -9999 -9999 -9999 -9999 -9999 -9999 -9999 -9999 -9999 -9999 -9999 -9999 -9999 -9999 -9999 -9999 -9999 -9999 -9999 -

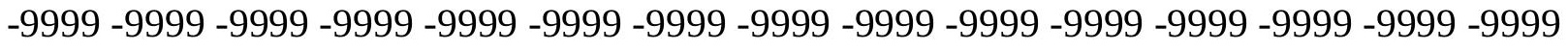

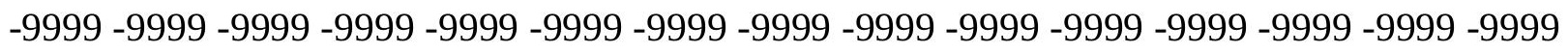
-9999 -9999 -9999 -9999 -9999 -9999 -9999 -9999 -9999 -9999 -9999 -9999 -9999 -9999 -9999

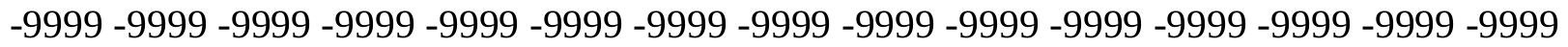

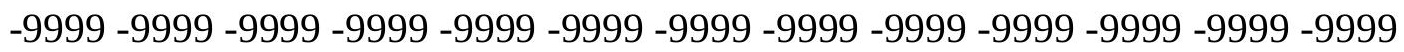
-9999 -9999 -9999 -9999 -9999 -9999 -9999 -9999 -9999 -9999 -9999 -9999 -9999 -30.478509903 -28.3450202942 -25.9067401886 -23.4684505463 -21.0301704407 -18.5918903351 -16.1536102295 -13.7153301239-11.5818300247-9.14355373383 $-6.7052731514-4.57177686691-2.13349604607-99992.1334960460664 .117168903351$ 6.4004869461068 .83876895904510 .9722604751613 .1057596206715 .23925971985 17.3727493286119 .5062503814721 .6397399902323 .4684505462625 .60194969177 27.7354507446329 .5641593933131 .3928699493433 .2215805053735 .05028915405 36.8790016174338 .7077102661140 .5364189147942 .0603485107443 .88906097412 45.4129791259846 .9369087219248 .4608306884849 .8973579406751 .20389938354 52.7278289794953 .9469718933155 .4708900451756 .6900291442957 .9091796875 59.1283111572360 .0426712036161 .2618103027362 .1761703491263 .39530944824 64.3096618652365 .2240066528366 .1383666992267 .0527267456167 .66230010986 68.5766525268669 .1862335205169 .7957916259870 .4053573608471 .0149307251 71.6244964599671 .9292907714872 .5388565063572 .8436431884873 .14842987061 73.4532165527373 .7580032348673 .7580032348674 .062782287674 .0627822876 74.062782287674 .062782287674 .062782287674 .062782287673 .75800323486 73.4532165527373 .1484298706172 .8436431884872 .5388565063572 .23407745361 71.6244964599671 .3197174072370 .7101516723670 .1005783081169 .49101257324 
68.8814392089868 .2718734741267 .6623001098667 .0527267456166 .44316101074 66.1383666992265 .5288009643664 .9192428588964 .6144485473664 .0048828125 63.3953094482463 .0905189514262 .4809494018662 .1761703491261 .56660079956 60.9570198059160 .6522407531760 .0426712036159 .4331016540558 .82352828979 58.2139587402357 .6043891906756 .9948196411156 .3852500915555 .77568054199 55.1661109924354 .8613204956154 .2517509460453 .6421813964853 .33739852905 52.7278289794952 .4230384826751 .8134689331151 .5086898803751 .20389938354 50.8991203308150 .5943298339850 .2895507812550 .2895507812549 .98476028442 49.9847602844249 .9847602844249 .9847602844249 .9847602844249 .98476028442 50.2895507812550 .2895507812550 .5943298339850 .5943298339850 .89912033081 51.2038993835451 .5086898803751 .8134689331152 .1182594299352 .42303848267 52.7278289794953 .0326118469253 .6421813964853 .9469718933154 .55654144287 55.1661109924355 .7756805419956 .3852500915556 .9948196411157 .60438919067 58.2139587402359 .1283111572359 .7378807067960 .3474502563560 .95701980591 61.8713798522962 .4809494018663 .3953094482464 .004882812564 .91924285889 65.5288009643666 .4431610107467 .0527267456167 .6623001098668 .27187347412 68.8814392089869 .4910125732470 .1005783081170 .7101516723671 .0149307251 71.6244964599671 .9292907714872 .2340774536172 .5388565063572 .84364318848 73.1484298706173 .4532165527373 .7580032348673 .7580032348674 .0627822876 74.062782287674 .062782287674 .062782287674 .062782287674 .062782287674 .0627822876 73.7580032348673 .7580032348673 .4532165527373 .4532165527373 .14842987061 73.1484298706172 .8436431884872 .8436431884872 .8436431884872 .53885650635 72.5388565063572 .8436431884872 .8436431884873 .1484298706173 .45321655273 73.7580032348674 .3675689697374 .9771423339875 .5867080688576 .19628143311 76.8058471679777 .4154205322378 .0249862670978 .6345596313579 .24413299561 79.8537063598680 .4632720947381 .0728530883881 .6824111938581 .98719787598 82.5967712402383 .206336975183 .5111236572383 .8159103393684 .42548370361 84.7302627563585 .0350494384885 .3398437585 .6446228027385 .94940185547 86.254188537686 .254188537686 .5589828491286 .8637619018686 .86376190186 87.16854858398 87.16854858398 87.47332763672 87.47332763672 87.47332763672 87.47332763672 87.47332763672 87.47332763672 87.47332763672 87.47332763672 87.47332763672 87.47332763672 87.47332763672 87.16854858398 87.16854858398 87.1685485839887 .1685485839886 .8637619018686 .8637619018686 .86376190186 86.8637619018688 .0829010009889 .60682678223 -9999 -9999 -9999 -9999 -9999 -9999 -9999 -9999 -9999 -9999 -9999 -9999 -9999 -9999 -9999 -9999 -9999 -9999 -9999 -9999 -9999 -9999

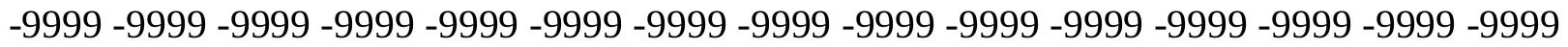

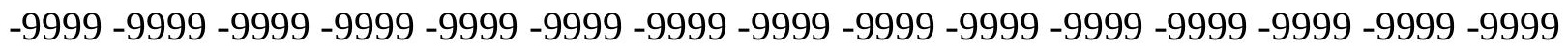

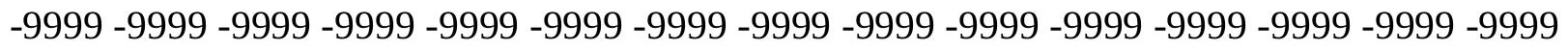
-9999 -9999 -9999 -9999 -9999 -9999 -9999 -9999 -9999 -9999 -9999 -9999 -9999 -9999 -9999 -9999 -9999 -9999 -9999 -9999 -9999 -9999 -9999 -9999 -9999 -9999 -9999 -9999 -9999 -9999 -

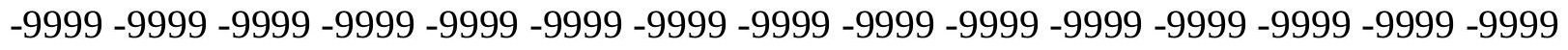
-9999-9999 -9999-9999-9999-9999-9999-9999 -9999 -9999 -9999 -9999 -9999 -9999 -9999 -9999 -9999 -9999 -9999-9999 -9999 -9999 -31.3928699493 -29.2593708038 -26.8210906982 -24.3828105927 -21.9445304871 $-19.5062503815-17.0679702759-14.6296901703-12.4961900711-10.0579099655$ $-7.61962795258-5.48613214493-3.04785108566-.6095703244211 .018710374832$ 
3.4678409099585 .7909169197087 .92441320419310 .3626899719212 .49619007111 14.6296901702916 .7631797790518 .8966808319121 .0301704406723 .16366958618 24.9923801422127 .1258792877228 .9545898437530 .7833003997832 .91679000854 34.7455101013236 .5742111206138 .0981407165539 .9268493652341 .75556182861 43.2794914245644 .8034095764246 .3273391723647 .8512611389249 .37519073486 50.8991203308152 .1182594299353 .6421813964854 .8613204956156 .08045959473 57.2995986938558 .5187492370659 .4331016540560 .6522407531761 .56660079956 62.7857398986863 .7000885009864 .6144485473665 .2240066528366 .13836669922 67.0527267456167 .6623001098668 .2718734741268 .8814392089869 .49101257324 70.1005783081170 .7101516723671 .014930725171 .6244964599671 .92929077148 72.2340774536172 .5388565063572 .8436431884872 .8436431884873 .14842987061 73.1484298706173 .1484298706173 .1484298706173 .1484298706172 .84364318848 72.8436431884872 .5388565063572 .2340774536171 .9292907714871 .31971740723 71.014930725170 .4053573608469 .7957916259869 .4910125732468 .88143920898 68.2718734741267 .3575134277366 .7479400634866 .1383666992265 .52880096436 64.9192428588964 .6144485473664 .004882812563 .3953094482462 .78573989868 62.4809494018661 .8713798522961 .2618103027360 .9570198059160 .34745025635 60.0426712036159 .4331016540558 .8235282897958 .5187492370657 .9091796875 57.2995986938556 .6900291442956 .0804595947355 .4708900451754 .86132049561 54.2517509460453 .6421813964853 .0326118469252 .7278289794952 .11825942993 51.5086898803751 .2038993835450 .8991203308150 .2895507812549 .98476028442 49.6799812316949 .3751907348649 .0704002380448 .765621185348 .7656211853 48.4608306884848 .4608306884848 .4608306884848 .4608306884848 .46083068848 48.4608306884848 .4608306884848 .765621185348 .765621185349 .07040023804 49.3751907348649 .6799812316949 .9847602844250 .2895507812550 .59432983398 50.8991203308151 .2038993835451 .5086898803752 .1182594299352 .42303848267 53.0326118469253 .6421813964854 .2517509460454 .8613204956155 .77568054199 56.3852500915556 .9948196411157 .909179687558 .5187492370659 .12831115723 60.0426712036160 .6522407531761 .2618103027362 .1761703491262 .78573989868 63.7000885009864 .3096618652365 .2240066528365 .8335876464866 .44316101074 67.3575134277367 .9670867919968 .5766525268668 .8814392089869 .49101257324 70.1005783081170 .4053573608471 .014930725171 .3197174072371 .92929077148 72.2340774536172 .5388565063572 .8436431884873 .1484298706173 .45321655273 73.4532165527373 .7580032348673 .7580032348674 .062782287674 .0627822876 74.062782287674 .062782287674 .062782287674 .062782287673 .75800323486 73.7580032348673 .7580032348673 .7580032348673 .4532165527373 .45321655273 73.4532165527373 .4532165527373 .4532165527373 .7580032348673 .75800323486 74.062782287674 .3675689697374 .6723632812575 .2819290161175 .89148712158 76.1962814331176 .8058471679777 .4154205322378 .0249862670978 .63455963135 79.2441329956179 .8537063598680 .1584930419980 .7680587768681 .37763214111 81.6824111938582 .2919769287182 .5967712402383 .206336975183 .51112365723 83.8159103393684 .1206970214884 .4254837036184 .7302627563585 .03504943848 85.3398437585 .6446228027385 .6446228027385 .9494018554786 .2541885376 86.254188537686 .5589828491286 .5589828491286 .5589828491286 .86376190186 86.8637619018686 .8637619018686 .8637619018686 .8637619018686 .86376190186 86.8637619018686 .8637619018686 .8637619018686 .5589828491286 .55898284912 
86.55898284912 86.55898284912 86.2541885376 86.2541885376 86.2541885376 85.9494018554785 .9494018554785 .9494018554786 .254188537687 .77810668945 -9999 -9999 -9999 -9999 -9999 -9999 -9999 -9999 -9999 -9999 -9999 -9999 -9999 -9999 -9999 -9999 -9999 -9999 -9999 -9999 -9999 -9999 -9999 -9999 -9999 -9999 -9999 -9999 -9999 -9999 -9999 -9999 -9999 -9999 -9999 -9999 -9999 -9999 -9999 -9999 -9999 -9999 -9999-9999 -9999 -9999 -9999 -9999 -9999 -9999 -9999 -9999 -9999 -9999 -9999 -9999 -9999 -9999 -9999 -9999 -9999

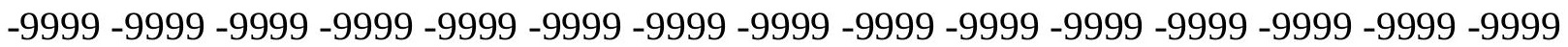
-9999 -9999 -9999 -9999 -9999 -9999 -9999 -9999 -9999 -9999 -9999 -9999 -9999 -9999 -9999 -999 -9999 -9999 -9999 -9999 -9999 -9999 -9999 -9999 -9999 -9999 -9999 -9999 -9999 -9999 -9999

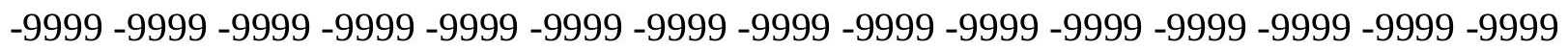
-9999 -9999 -9999 -9999 -9999 -9999 -9999 -9999 -9999 -9999 -9999 -9999 -9999 -32.307220459-30.1737308502 -27.7354507446 -25.2971591949-22.8588790894 $-20.4206008911-17.9823207855-15.5440397263-13.4105501175-10.9722604752$ -8.53398323059-6.095703125 -3.96220707893 -1.52392601967 .3733741939068 2.7430660724645 .1813468933117 .3148431777959 .4483394622811 .88661956787 14.0201196670516 .1536102294918 .28710937520 .4206008911122 .55410003662 24.6875991821326 .5163097381628 .6497993469230 .4785099029532 .30722045898 34.1359291076735 .9646492004437 .7933502197339 .622070312541 .14598846436 42.66992187544 .4986305236846 .0225486755447 .5464782714848 .7656211853 50.2895507812551 .8134689331153 .0326118469254 .2517509460455 .47089004517 56.6900291442957 .909179687559 .1283111572360 .0426712036160 .95701980591 62.1761703491263 .0905189514264 .004882812564 .6144485473665 .52880096436 66.1383666992267 .0527267456167 .6623001098668 .2718734741268 .88143920898 69.4910125732469 .7957916259870 .4053573608470 .7101516723671 .0149307251 71.3197174072371 .6244964599671 .9292907714871 .9292907714872 .23407745361 72.2340774536172 .2340774536172 .2340774536172 .2340774536171 .92929077148 71.6244964599671 .6244964599671 .3197174072370 .7101516723670 .40535736084 69.7957916259869 .4910125732468 .8814392089868 .2718734741267 .35751342773 66.7479400634866 .1383666992265 .5288009643664 .9192428588964 .30966186523 63.7000885009863 .0905189514262 .4809494018661 .8713798522961 .26181030273 60.9570198059160 .3474502563559 .7378807067959 .4331016540558 .82352828979 58.2139587402357 .909179687557 .2995986938556 .6900291442956 .08045959473 55.4708900451755 .1661109924354 .5565414428753 .9469718933153 .33739852905 52.7278289794952 .1182594299351 .5086898803751 .2038993835450 .59432983398 50.2895507812549 .6799812316949 .3751907348648 .765621185348 .46083068848 48.1560516357447 .8512611389247 .5464782714847 .5464782714847 .24169921875 47.2416992187546 .9369087219246 .9369087219246 .9369087219246 .93690872192 46.9369087219246 .9369087219247 .2416992187547 .2416992187547 .54647827148 47.8512611389248 .1560516357448 .4608306884848 .765621185349 .07040023804 49.3751907348649 .6799812316950 .2895507812550 .5943298339851 .20389938354 51.8134689331152 .4230384826753 .0326118469253 .6421813964854 .55654144287 58.2139587402359 .1283111572360 .0426712036160 .6522407531758 .21395874023 58.8235282897959 .7378807067960 .3474502563560 .9570198059161 .87137985229 62.4809494018663 .3953094482464 .004882812564 .6144485473665 .52880096436 66.1383666992266 .7479400634867 .3575134277367 .9670867919968 .57665252686 69.1862335205169 .4910125732470 .1005783081170 .7101516723671 .0149307251 
71.6244964599671 .9292907714872 .2340774536172 .5388565063572 .84364318848 73.1484298706173 .4532165527373 .7580032348673 .7580032348674 .0627822876 74.062782287674 .062782287674 .062782287674 .3675689697374 .36756896973 74.3675689697374 .3675689697374 .3675689697374 .3675689697374 .36756896973 74.3675689697374 .3675689697374 .6723632812574 .6723632812574 .97714233398 75.2819290161175 .5867080688575 .8914871215876 .1962814331176 .80584716797 77.110626220777 .7202072143678 .3297805786178 .6345596313579 .24413299561 79.8537063598680 .1584930419980 .7680587768681 .0728530883881 .68241119385 81.9871978759882 .5967712402382 .9015579223683 .206336975183 .51112365723 83.8159103393684 .1206970214884 .4254837036184 .7302627563584 .73026275635 85.0350494384885 .3398437585 .3398437585 .6446228027385 .6446228027385 .94940185547 85.94940185547 85.94940185547 86.2541885376 86.2541885376 86.2541885376 86.2541885376 86.2541885376 86.2541885376 86.2541885376 86.2541885376 85.9494018554785.9494018554785.9494018554785.9494018554785.64462280273 85.6446228027385 .6446228027385 .3398437585 .3398437585 .2791900634885 .03504943848 85.0350494384885 .0350494384886 .254188537688 .08290100098 -9999 -9999 -9999 -9999 -9999 -9999 -9999 -9999 -9999 -9999 -9999 -9999 -9999 -9999 -9999 -9999 -9999 -9999 -9999 -9999 -9999 -9999 -9999 -9999 -9999 -9999 -9999 -9999 -9999 -9999 -9999 -9999 -9999 -9999 -

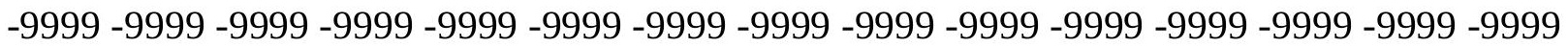

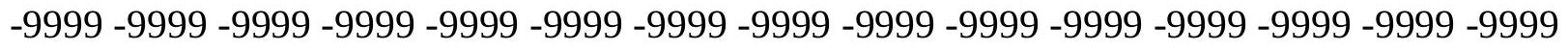

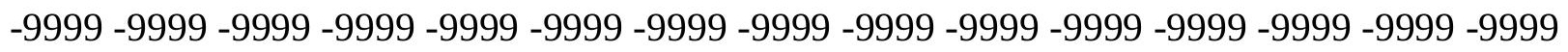

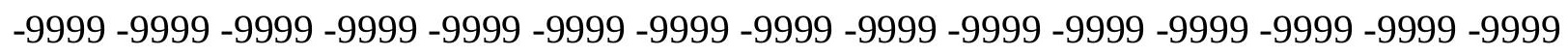
-9999 -9999 -9999 -9999 -9999 -9999 -9999 -9999 -9999 -9999 -9999 -9999 -9999 -9999 - -9999 -9999 -9999 -9999 -9999 -9999 -9999 -9999 -9999 -9999 -9999 -9999 -9999 -9999 -9999 -9999 -9999 -9999 -9999 -9999 -9999 -9999 -9999 -9999 -9999 -33.2215805054 -31.3928699493 -28.9545898438 -26.5163097382 -23.7732391357 $-21.3349609375-19.2014598846-16.7631797791-14.3248996735-11.8866195679$ $-9.44833946228-7.01005792618-4.57177686691-2.7799346447-.260856479406$ 2.1334960460664 .2669920921336 .7052731513988 .83876895904511 .27705001831 13.4105501174915 .5440397262617 .6775398254419 .811029434221 .94453048706 24.0780296325726 .2115192413328 .0402297973629 .8689403533932 .00244140625 33.8311500549335 .6598587036137 .4885711669939 .0125007629440 .84120941162 42.3651313781743 .8890609741245 .4129791259846 .9369087219248 .46083068848 49.9847602844251 .2038993835452 .4230384826753 .9469718933155 .16611099243 56.3852500915557 .2995986938558 .5187492370659 .4331016540560 .65224075317 61.5666007995662 .4809494018663 .3953094482464 .004882812564 .91924285889 65.5288009643666 .4431610107467 .0527267456167 .6623001098668 .27187347412 68.5766525268669 .1862335205169 .4910125732470 .1005783081170 .40535736084 70.7101516723671 .014930725171 .014930725171 .3197174072371 .31971740723 71.3197174072371 .3197174072371 .3197174072371 .3197174072371 .0149307251 70.7101516723670 .7101516723670 .1005783081169 .7957916259869 .49101257324 68.8814392089868 .2718734741267 .6623001098667 .0527267456166 .44316101074 65.5288009643664 .9192428588964 .3096618652363 .3953094482462 .78573989868 62.1761703491261 .5666007995660 .9570198059160 .3474502563560 .04267120361 59.4331016540558 .8235282897958 .5187492370657 .909179687557 .29959869385 56.6900291442956 .3852500915555 .7756805419955 .1661109924354 .55654144287 
53.9469718933153 .6421813964853 .0326118469252 .4230384826751 .81346893311 51.2038993835450 .5943298339850 .2895507812549 .6799812316949 .07040023804 48.765621185348 .1560516357447 .8512611389247 .5464782714847 .24169921875 46.9369087219246 .6321296691946 .3273391723646 .0225486755445 .7177696228 45.717769622845 .717769622845 .4129791259845 .4129791259845 .41297912598 45.4129791259845 .717769622845 .717769622846 .0225486755446 .02254867554 46.3273391723646 .6321296691946 .9369087219247 .2416992187547 .54647827148 47.8512611389248 .1560516357448 .765621185349 .0704002380449 .67998123169 50.2895507812550 .8991203308151 .8134689331152 .4230384826756 .38525009155 57.6043891906758 .2139587402359 .1283111572360 .0426712036160 .65224075317 58.2139587402358 .8235282897959 .4331016540560 .3474502563560 .95701980591 61.5666007995662 .1761703491262 .7857398986863 .7000885009864 .30966186523 64.9192428588965 .8335876464866 .4431610107467 .0527267456167 .66230010986 68.2718734741268 .5766525268669 .1862335205169 .7957916259870 .40535736084 70.7101516723671 .3197174072371 .6244964599671 .9292907714872 .53885650635 72.8436431884873 .1484298706173 .4532165527373 .7580032348673 .75800323486 74.062782287674 .3675689697374 .3675689697374 .6723632812574 .67236328125 74.6723632812574 .9771423339874 .9771423339874 .9771423339875 .28192901611 75.2819290161175 .2819290161175 .5867080688575 .8914871215875 .89148712158 76.1962814331176 .5010681152376 .8058471679777 .4154205322377 .72020721436 78.3297805786178 .6345596313579 .2441329956179 .5489196777379 .85370635986 80.4632720947380 .7680587768681 .3776321411181 .6824111938581 .98719787598 82.29197692871 82.59677124023 83.206336975183.2063369751 83.51112365723 83.8159103393684 .1206970214884 .4254837036184 .4254837036184 .73026275635 84.7302627563585 .0350494384885 .0350494384885 .3398437585 .3398437585 .33984375 85.6446228027385 .6446228027385 .6446228027385 .6446228027385 .64462280273 85.64462280273 85.64462280273 85.64462280273 85.64462280273 85.33984375 85.33984375 85.3398437585 .3398437585 .0350494384885 .0350494384885 .0350494384884 .73026275635 84.7302627563584 .7302627563584 .4254837036184 .4254837036184 .42548370361 84.4254837036184 .7302627563586 .55898284912 -9999 -9999 -9999 -9999 -9999 -9999 -9999

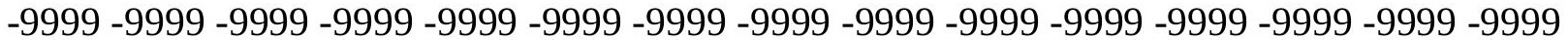

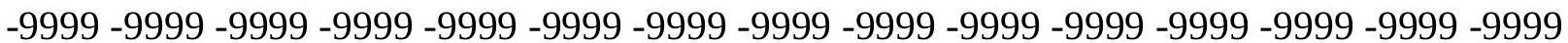

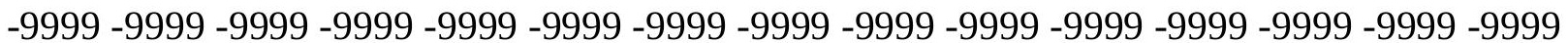

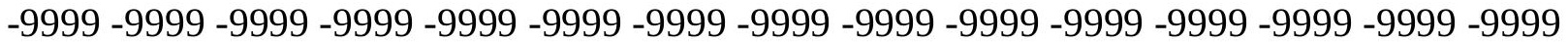

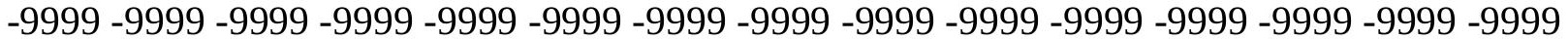

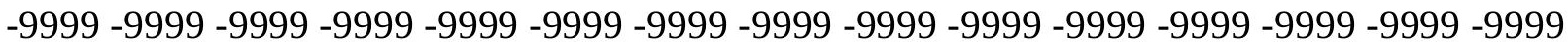
-9999 -9999 -9999 -9999 -9999 -9999 -9999 -9999-9999 -9999 -9999 -9999 -9999 -9999 -9999 -9999 -9999 -9999 -9999 -9999 -9999 -9999 -34.1359291077-32.6120109558 -29.8689403534-27.4306602478 -24.9923801422 $-22.5541000366-20.115819931-17.6775398254-15.2392597198-12.8009700775$ $-10.3626899719-7.92441320419-5.48613214493-3.41786050797-.933788597584$ 1.5239260196693 .6574220657356 .0957031258 .22919845581110 .66748046875 12.8009700775115 .2392597198517 .3727493286119 .5062503814721 .63973999023 23.7732391357425 .6019496917727 .7354507446329 .5641593933131 .69765090942 33.5263595581135 .3550796508836 .8790016174338 .7077102661140 .53641891479 
42.0603485107443 .5842704772945 .1082000732446 .6321296691948 .03126525879 49.3751907348650 .8991203308152 .1182594299353 .3373985290554 .55654144287 55.7756805419956 .9948196411157 .909179687559 .1283111572360 .04267120361 60.9570198059161 .8713798522962 .7857398986863 .3953094482464 .30966186523 64.9192428588965 .8335876464866 .4431610107467 .0527267456167 .35751342773 67.9670867919968 .5766525268668 .8814392089869 .1862335205169 .49101257324 69.7957916259870 .1005783081170 .4053573608470 .4053573608470 .71015167236 70.7101516723670 .7101516723670 .7101516723670 .4053573608470 .40535736084 70.1005783081169 .7957916259869 .4910125732468 .8814392089868 .57665252686 67.9670867919967 .3575134277366 .7479400634866 .1383666992265 .22400665283 64.6144485473663 .7000885009863 .0905189514262 .1761703491261 .56660079956 60.9570198059160 .3474502563559 .7378807067959 .1283111572358 .51874923706 58.2139587402357 .6043891906756 .9948196411156 .3852500915555 .77568054199 55.4708900451754 .8613204956154 .2517509460453 .6421813964853 .03261184692 52.7278289794952 .1182594299351 .5086898803750 .8991203308150 .28955078125 49.6799812316949 .3751907348648 .765621185348 .1560516357447 .85126113892 47.2416992187546 .9369087219246 .6321296691946 .0225486755445 .7177696228 45.4129791259845 .1082000732444 .8034095764244 .8034095764244 .49863052368 44.4986305236844 .1938400268644 .1938400268644 .1938400268644 .19384002686 44.1938400268644 .1938400268644 .4986305236844 .4986305236844 .80340957642 44.8034095764245 .1082000732445 .4129791259845 .717769622846 .02254867554 46.3273391723646 .9369087219247 .2416992187547 .8512611389248 .46083068848 49.0704002380449 .6799812316950 .5943298339854 .5565414428755 .47089004517 56.3852500915557 .6043891906758 .5187492370659 .1283111572359 .73788070679 57.2995986938558 .2139587402358 .8235282897959 .4331016540560 .04267120361 60.6522407531761 .2618103027361 .8713798522962 .4809494018663 .39530944824 64.004882812564 .6144485473665 .2240066528365 .8335876464866 .44316101074 67.3575134277367 .9670867919968 .5766525268668 .8814392089869 .49101257324 70.1005783081170 .7101516723671 .014930725171 .6244964599671 .92929077148 72.5388565063572 .8436431884873 .1484298706173 .4532165527374 .0627822876 74.062782287674 .3675689697374 .6723632812574 .9771423339875 .28192901611 75.2819290161175 .5867080688575 .5867080688575 .8914871215875 .89148712158 76.1962814331176 .5010681152376 .5010681152376 .8058471679777 .1106262207 77.4154205322377 .7202072143678 .0249862670978 .3297805786178 .93934631348 79.2441329956179 .5489196777380 .1584930419980 .4632720947380 .76805877686 81.0728530883881 .6824111938581 .9871978759882 .2919769287182 .59677124023 82.9015579223683 .206336975183 .206336975183 .5111236572383 .81591033936 83.8159103393684 .1206970214884 .4254837036184 .4254837036184 .42548370361 84.7302627563584 .7302627563584 .7302627563585 .0350494384885 .03504943848 85.0350494384885 .0350494384885 .0350494384885 .0350494384885 .03504943848 85.0350494384885 .0350494384885 .0350494384885 .0350494384885 .03504943848 84.7302627563584 .7302627563584 .7302627563584 .4254837036184 .42548370361 84.42548370361 84.12069702148 84.12069702148 84.12069702148 83.81591033936 83.8159103393683 .8159103393683 .8159103393683 .8159103393683 .81591033936 85.0350494384886 .86376190186 -9999 -9999 -9999 -9999 -9999 -9999 -9999 -9999 -9999 -9999 -9999 -9999 -9999 -9999 -9999 -9999 -9999 -9999 -9999 -9999 -9999 -9999 -9999 -9999 
-9999 -9999 -9999 -9999 -9999 -9999 -9999 -9999 -9999 -9999 -9999 -9999 -9999 -9999 -9999 -9999 -9999 -9999 -9999 -9999 -9999 -9999 -9999 -9999 -9999 -9999 -9999 -9999 -9999 -9999

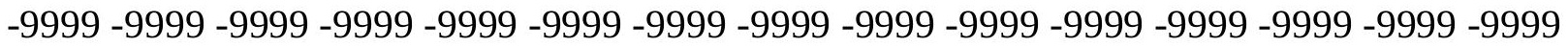
-9999 -9999 -9999 -9999 -9999 -9999 -9999 -9999 -9999 -9999 -9999 -9999 -9999 -9999 -9999 -9999 -9999 -9999 -9999 -9999 -9999 -9999 -9999 -9999 -9999 -9999 -9999-9999 -9999 -9999 -

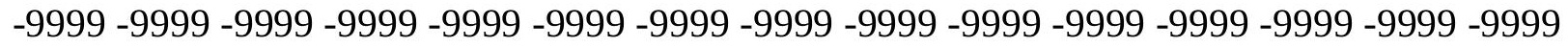
-9999 -9999 -9999 -9999-9999

-9999 -9999 -9999 -9999 -9999 -9999 -9999 -9999 -9999 -9999 -9999 -9999 -9999 -35.0502891541 -33.8311500549 -31.0880794525 -28.6497993469 -25.9067401886 $-23.4684505463-21.0301704407-18.5918903351-16.1536102295-13.7153301239$ $-10.9722604752-8.53398323059-6.095703125-4.03676700592-1.61843287945$ .60957032442093 .0478510856635 .4861321449287 .92441320419310 .05790996552 12.4961900711114 .6296901702916 .7631797790518 .8966808319121 .03017044067 23.1636695861825 .2971591949527 .430660247829 .2593708038331 .08807945251 33.2215805053735 .0502891540536 .5742111206138 .4029312133840 .23163986206 41.7555618286143 .2794914245644 .8034095764246 .301193237347 .66763687134 49.0704002380450 .5943298339851 .8134689331153 .0326118469254 .25175094604 55.4708900451756 .3852500915557 .6043891906758 .5187492370659 .43310165405 60.3474502563561 .2618103027362 .1761703491263 .0905189514263 .70008850098 64.3096618652365 .2240066528365 .8335876464866 .4431610107466 .74794006348 67.35751342773 67.9670867919968.27187347412 68.57665252686 68.88143920898 69.1862335205169 .4910125732469 .7957916259869 .7957916259869 .79579162598 69.7957916259869 .7957916259869 .7957916259869 .7957916259869 .49101257324 69.1862335205168 .8814392089868 .5766525268668 .2718734741267 .66230010986 67.0527267456166 .4431610107465 .8335876464864 .9192428588964 .30966186523 63.3953094482462 .4809494018661 .8713798522960 .9570198059160 .34745025635 59.7378807067959 .1283111572358 .5187492370657 .909179687557 .29959869385 56.6900291442956 .0804595947355 .4708900451755 .1661109924354 .55654144287 53.9469718933153 .3373985290552 .7278289794952 .4230384826751 .81346893311 51.2038993835450 .5943298339849 .9847602844249 .3751907348649 .07040023804 48.4608306884847 .8512611389247 .5464782714846 .9369087219246 .63212966919 46.0225486755445 .717769622845 .1082000732444 .8034095764244 .49863052368 44.1938400268643 .8890609741243 .5842704772943 .5842704772943 .27949142456 42.9747009277342 .9747009277342 .9747009277342 .9747009277342 .97470092773 42.9747009277342 .9747009277342 .9747009277343 .2794914245643 .27949142456 43.5842704772943 .8890609741244 .1938400268644 .4986305236844 .80340957642 45.1082000732445 .4129791259846 .0225486755446 .6321296691947 .24169921875 47.8512611389248 .4608306884849 .3751907348650 .2895507812554 .55654144287 55.4708900451756 .6900291442957 .6043891906758 .2139587402359 .12831115723 56.6900291442957 .2995986938558 .2139587402358 .8235282897959 .43310165405 59.7378807067960 .3474502563560 .9570198059161 .5666007995662 .17617034912 63.0905189514263 .7000885009864 .3096618652364 .9192428588965 .52880096436 66.1383666992267 .0527267456167 .6623001098668 .2718734741268 .88143920898 69.4910125732470 .1005783081170 .4053573608471 .014930725171 .62449645996 72.2340774536172 .5388565063573 .1484298706173 .4532165527374 .0627822876 74.3675689697374 .6723632812574 .9771423339875 .2819290161175 .58670806885 
75.8914871215876 .1962814331176 .5010681152376 .8058471679777 .1106262207 77.110626220777 .4154205322377 .7202072143678 .0249862670978 .32978057861 78.6345596313578 .9393463134879 .2441329956179 .5489196777379 .85370635986 80.1584930419980 .7680587768681 .0728530883881 .3776321411181 .68241119385 81.9871978759882 .2919769287182 .5967712402382 .9015579223682 .90155792236 83.2063369751 83.51112365723 83.51112365723 83.8159103393683.81591033936 84.1206970214884 .1206970214884 .4254837036184 .4254837036184 .42548370361 84.4254837036184 .7302627563584 .7302627563584 .7302627563584 .73026275635 84.7302627563584 .7302627563584 .7302627563584 .7302627563584 .73026275635 84.7302627563584 .4254837036184 .4254837036184 .4254837036184 .42548370361 84.1206970214884 .1206970214884 .1206970214883 .8159103393683 .81591033936 83.81591033936 83.51112365723 83.51112365723 83.5111236572383.2063369751 83.206336975183.206336975183.206336975183.206336975183.2063369751 83.5111236572385 .33984375 -9999 -9999 -9999 -9999 -9999-9999 -9999 -9999 -9999 -9999 -9999 -9999 -9999 -9999 -9999 -9999 -9999 -9999 -9999 -9999 -9999 -9999 -9999 -9999 -9999

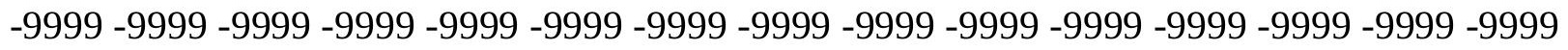
-9999 -9999 -9999 -9999 -9999 -9999 -9999 -9999 -9999 -9999 -9999 -9999 -9999 -9999 -9999 -9999 -9999 -9999 -9999 -9999 -9999 -9999 -9999 -9999 -9999 -9999 -9999 -9999 -9999 -9999 -

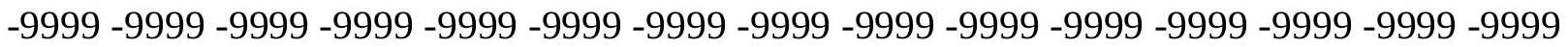

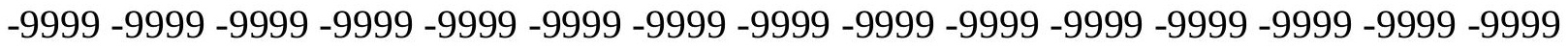

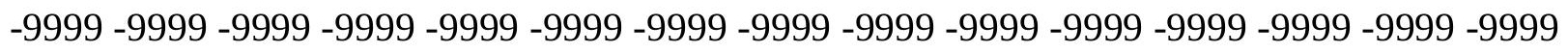
-9999 -9999 -9999 -9999

-9999 -9999 -9999 -9999 -9999 -9999 -9999 -9999 -9999 -9999 -9999 -9999 -9999 -35.9646492004 -34.7455101013 -32.307220459-29.5641593933 -27.1258792877 -24.3828105927 -21.9445304871 -19.5062503815 -17.0679702759-14.3248996735 -11.8866195679 -9.44833946228 -7.19626235962 -4.63433790207-2.13349604607 -9999 2.4382810592654 .876562118537 .3148431777959 .75312423706111 .88661956787 14.3248996734616 .4584007263218 .5918903350820 .7253894805922 .85887908936 24.9923801422127 .1258792877228 .9545898437531 .0880794525132 .91679000854 34.7455101013236 .5742111206138 .0981407165539 .9268493652341 .45077896118 42.9747009277344 .4986305236846 .0225486755447 .4200057983448 .7656211853 50.2895507812551 .5086898803752 .7278289794953 .9469718933155 .16611099243 56.0804595947357 .2995986938558 .2139587402359 .1283111572360 .04267120361 60.9570198059161 .8713798522962 .4809494018663 .0905189514264 .0048828125 64.6144485473665 .2240066528365 .8335876464866 .4431610107466 .74794006348 67.3575134277367 .6623001098667 .9670867919968 .2718734741268 .57665252686 68.8814392089868 .8814392089869 .1862335205169 .1862335205169 .18623352051 69.18623352051 69.1862335205168.8814392089868.88143920898 68.57665252686 68.2718734741267 .9670867919967 .3575134277367 .0527267456166 .44316101074 65.8335876464864 .9192428588964 .3096618652363 .3953094482462 .48094940186 61.5666007995660 .6522407531760 .0426712036159 .4331016540558 .51874923706 57.909179687557 .2995986938556 .6900291442956 .0804595947355 .47089004517 54.8613204956154 .2517509460453 .6421813964853 .0326118469252 .72782897949 52.1182594299351 .5086898803750 .8991203308150 .2895507812549 .67998123169 49.3751907348648 .765621185348 .1560516357447 .5464782714847 .24169921875 46.6321296691946 .0225486755445 .717769622845 .1082000732444 .80340957642 
44.4986305236843 .8890609741243 .5842704772943 .2794914245642 .97470092773 42.66992187542 .3651313781742 .3651313781742 .0603485107441 .75556182861 41.7555618286141 .7555618286141 .4507789611841 .4507789611841 .45077896118 41.7555618286141 .7555618286141 .7555618286142 .0603485107442 .36513137817 42.3651313781742 .66992187542 .9747009277343 .2794914245643 .88906097412 44.1938400268644 .8034095764245 .4129791259846 .0225486755446 .63212966919 47.5464782714848 .1560516357449 .0704002380450 .2895507812554 .25175094604 55.4708900451756 .3852500915557 .2995986938555 .1661109924356 .08045959473 56.6900291442957 .6043891906757 .909179687558 .5187492370659 .12831115723 59.4331016540560 .0426712036160 .6522407531761 .2618103027361 .87137985229 62.4809494018663 .0905189514264 .004882812564 .6144485473665 .22400665283 66.1383666992266 .7479400634867 .3575134277367 .9670867919968 .57665252686 69.4910125732470 .1005783081170 .7101516723671 .3197174072371 .62449645996 72.2340774536172 .8436431884873 .4532165527374 .062782287674 .36756896973 74.9771423339875 .2819290161175 .8914871215876 .1962814331176 .50106811523 76.8058471679777 .4154205322377 .7202072143678 .0249862670978 .32978057861 78.6345596313578 .9393463134879 .2441329956179 .5489196777379 .85370635986 80.1584930419980 .4632720947380 .7680587768681 .0728530883881 .37763214111 81.6824111938581 .9871978759882 .2919769287182 .5967712402382 .90155792236 82.9015579223683 .206336975183 .5111236572383 .5111236572383 .81591033936 83.81591033936 84.12069702148 84.12069702148 84.12069702148 84.12069702148 84.4254837036184 .4254837036184 .4254837036184 .4254837036184 .42548370361 84.4254837036184 .4254837036184 .4254837036184 .4254837036184 .42548370361 84.4254837036184 .4254837036184 .1206970214884 .1206970214884 .12069702148 84.12069702148 84.12069702148 83.8159103393683.8159103393683.81591033936 83.5111236572383 .5111236572383 .206336975183 .206336975183 .2063369751 82.9015579223682 .9015579223682 .9015579223682 .5967712402382 .59677124023 82.5967712402382 .5967712402382 .5967712402382 .5967712402382 .59677124023 83.8159103393685 .64462280273 -9999 -9999 -9999 -9999 -9999 -9999 -9999 -9999 -9999 -9999 -9999 -9999 -9999 -9999 -9999 -9999 -9999 -9999 -9999 -9999 -9999 -9999 -9999 -9999 -9999 -9999 -9999 -9999 -9999 -9999 -9999 -9999 -9999 -9999 -9999 -9999 -9999 -9999 -9999

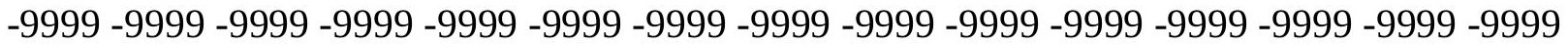

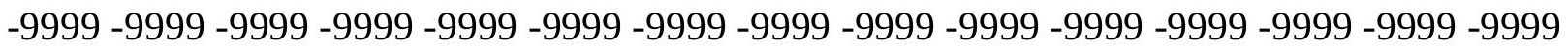

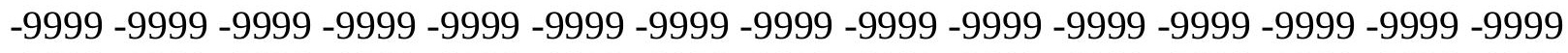
-9999 -9999 -9999 -9999 -9999 -9999 -9999 -9999 -9999 -9999 -9999 -9999 -9999 -9999 -9999 -

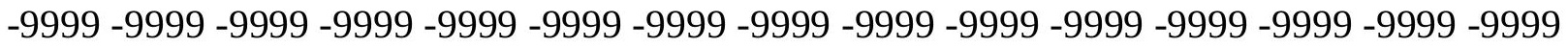
-9999-9999-9999-9999

-9999 -9999 -9999 -9999 -9999 -9999 -9999 -9999 -9999 -9999 -9999 -9999 -9999 -36.5742111206 -35.6598587036 -33.2215805054 -30.7833003998 -28.0402297974 -25.6019496918 -22.8588790894-20.4206008911 -17.6775398254-15.2392597198 -12.8009700775 -10.0579099655 -7.79123830795 -5.25190114975 -2.74306607246-9999 2.1334960460664 .5717768669137 .0100579261789 .14355373382611 .58183002472 14.0201196670516 .1536102294918 .28710937520 .4206008911122 .85887908936 24.6875991821326 .8210906982428 .9545898437530 .7833003997832 .61201095581 34.4407196044936 .2694282531738 .0981407165539 .622070312541 .45077896118 42.9747009277344 .4986305236845 .8245544433647 .2416992187548 .7656211853 
49.9847602844251 .2038993835452 .4230384826753 .6421813964854 .86132049561 55.7756805419960 .0426712036157 .909179687558 .8235282897959 .73788070679 60.3474502563561 .2618103027362 .1761703491262 .7857398986863 .39530944824 64.004882812564 .6144485473665 .2240066528365 .8335876464866 .13836669922 66.7479400634867 .0527267456167 .3575134277367 .6623001098667 .96708679199 68.2718734741268 .2718734741268 .5766525268668 .5766525268668 .57665252686 68.5766525268668 .5766525268668 .2718734741268 .2718734741267 .96708679199 67.6623001098667 .0527267456166 .7479400634866 .1383666992265 .52880096436 64.9192428588964 .3096618652363 .3953094482462 .4809494018661 .56660079956 60.6522407531759 .7378807067959 .1283111572358 .5187492370657 .60438919067 56.9948196411156 .3852500915555 .7756805419954 .8613204956154 .25175094604 53.6421813964853 .0326118469252 .4230384826751 .8134689331151 .20389938354 50.8991203308150 .2895507812549 .6799812316949 .0704002380448 .46083068848 47.8512611389247 .5464782714846 .9369087219246 .3273391723646 .02254867554 45.4129791259845 .1082000732444 .4986305236844 .1938400268643 .58427047729 43.2794914245642 .9747009277342 .3651313781742 .0603485107441 .75556182861 41.4507789611841 .1459884643641 .1459884643640 .8412094116240 .84120941162 40.5364189147940 .5364189147940 .5364189147940 .2316398620640 .53641891479 40.5364189147940 .5364189147940 .5364189147940 .8412094116240 .84120941162 41.1459884643641 .4507789611841 .7555618286142 .0603485107442 .36513137817 42.9747009277343 .5842704772944 .1938400268644 .8034095764245 .41297912598 46.3273391723647 .2416992187548 .1560516357449 .0704002380450 .28955078125 51.5086898803752 .4230384826753 .6421813964854 .5565414428755 .47089004517 56.0804595947356 .9948196411157 .2995986938557 .909179687558 .21395874023 58.5187492370659 .1283111572359 .4331016540560 .0426712036160 .65224075317 61.2618103027362 .1761703491262 .7857398986863 .3953094482464 .30966186523 64.9192428588965 .8335876464866 .4431610107467 .3575134277367 .96708679199 68.5766525268669 .4910125732470 .1005783081170 .7101516723671 .31971740723 71.9292907714872 .8436431884873 .4532165527374 .062782287674 .67236328125 75.2819290161175 .5867080688576 .1962814331176 .8058471679777 .1106262207 77.7202072143678 .0249862670978 .6345596313578 .9393463134879 .24413299561 79.5489196777379 .8537063598680 .4632720947380 .7680587768681 .07285308838 81.3776321411181 .6824111938581 .9871978759882 .2919769287182 .59677124023 82.5967712402382 .9015579223683 .206336975183 .5111236572383 .51112365723 83.8159103393683 .8159103393684 .1206970214884 .1206970214884 .12069702148 84.4254837036184 .4254837036184 .4254837036184 .4254837036184 .42548370361 84.4254837036184 .4254837036184 .4254837036184 .4254837036184 .42548370361 84.4254837036184 .1206970214884 .1206970214884 .1206970214884 .12069702148 84.12069702148 83.81591033936 83.8159103393683.81591033936 83.81591033936 83.5111236572383 .5111236572383 .5111236572383 .206336975183 .2063369751 82.9015579223682 .9015579223682 .9015579223682 .5967712402382 .59677124023 82.2919769287182 .2919769287182 .2919769287181 .9871978759881 .98719787598 81.9871978759881 .9871978759881 .9871978759881 .9871978759882 .29197692871 82.5967712402384 .42548370361 -9999 -9999 -9999 -9999 -9999 -9999 -9999 -9999 -9999 -9999 -9999 -9999 -9999 -9999 -9999 -9999 -9999 -9999 -9999 -9999 -9999 -9999 -9999 -9999 -9999 -9999 -9999 -9999 -9999 -9999 -9999 -9999 -9999 -9999 -9999 -9999 -9999 -9999 -9999 
-9999 -9999 -9999 -9999 -9999 -9999 -9999 -9999 -9999 -9999 -9999 -9999 -9999 -9999 -9999 -9999 -9999 -9999 -9999 -9999 -9999 -9999 -9999 -9999 -9999 -9999 -9999 -9999 -9999 -9999 -9999 -9999 -9999 -9999 -9999 -9999 -9999 -9999 -9999 -9999 -9999 -9999 -9999 -9999 -9999 -9999 -9999 -9999 -9999 -9999 -9999 -9999 -9999 -9999 -9999 -9999 -9999 -9999 -9999 -9999

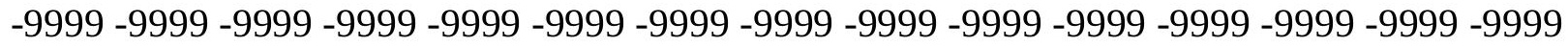
-9999 -9999 -9999-9999

-9999 -9999 -9999 -9999 -9999 -9999 -9999 -9999 -9999 -9999 -9999 -9999 -9999 -37.1837806702 -36.2694282532 -34.4407196045-31.6976509094-28.9545898438 $-26.5163097382-23.7732391357-21.3349609375-18.5918903351-15.8488302231$ $-13.4105501175-10.6674804688-8.34278583527-5.79091691971-3.04785108566$ -.609570324421 1.523926019669 3.9622070789346 .4004869461068 .838768959045 11.2770500183113 .715330123915 .8488302230818 .28710937520 .42060089111 22.5541000366224 .6875991821326 .8210906982428 .6497993469230 .78330039978 32.6120109558134 .4407196044936 .2694282531737 .7933502197339 .6220703125 41.1459884643642 .66992187544 .1938400268645 .6602210998547 .09888839722 48.4608306884849 .6799812316950 .8991203308152 .1182594299353 .33739852905 57.6043891906759 .1283111572360 .0426712036160 .9570198059161 .87137985229 62.4809494018660 .0426712036160 .9570198059161 .5666007995662 .48094940186 63.0905189514263 .7000885009864 .3096618652364 .9192428588965 .22400665283 65.8335876464866 .1383666992266 .4431610107467 .0527267456167 .35751342773 67.3575134277367 .6623001098667 .9670867919967 .9670867919967 .96708679199 67.9670867919967 .9670867919967 .9670867919967 .6623001098667 .66230010986 67.3575134277367 .0527267456166 .4431610107466 .1383666992265 .52880096436 64.9192428588964 .3096618652363 .7000885009862 .7857398986861 .87137985229 60.9570198059160 .0426712036159 .1283111572358 .2139587402357 .60438919067 56.6900291442956 .0804595947355 .1661109924354 .5565414428753 .94697189331 53.3373985290552 .7278289794951 .8134689331151 .2038993835450 .59432983398 49.9847602844249 .6799812316949 .0704002380448 .4608306884847 .85126113892 47.2416992187546 .9369087219246 .3273391723645 .717769622845 .10820007324 44.8034095764244 .1938400268643 .8890609741243 .2794914245642 .97470092773 42.66992187542 .0603485107441 .7555618286141 .4507789611841 .14598846436 40.8412094116240 .5364189147940 .2316398620639 .9268493652339 .92684936523 39.622070312539 .622070312539 .3172798156739 .3172798156739 .31727981567 39.3172798156739 .3172798156739 .3172798156739 .3172798156739 .6220703125 39.9268493652339 .9268493652340 .2316398620640 .5364189147940 .84120941162 41.1459884643641 .7555618286142 .3651313781742 .9747009277343 .58427047729 44.1938400268645 .1082000732446 .0225486755447 .2416992187548 .15605163574 49.3751907348650 .5943298339851 .8134689331152 .7278289794953 .94697189331 54.8613204956155 .7756805419956 .3852500915556 .6900291442956 .99481964111 57.2995986938557 .6043891906757 .909179687558 .5187492370658 .82352828979 59.4331016540560 .0426712036160 .9570198059161 .5666007995662 .48094940186 63.0905189514264 .004882812564 .9192428588965 .8335876464866 .44316101074 67.3575134277367 .9670867919968 .8814392089869 .4910125732470 .40535736084 71.014930725171 .9292907714872 .5388565063573 .1484298706174 .0627822876 74.6723632812575 .2819290161175 .8914871215876 .8058471679777 .41542053223 77.7202072143678 .3297805786178 .9393463134879 .2441329956179 .85370635986 
80.1584930419980 .7680587768681 .0728530883881 .3776321411181 .68241119385 82.2919769287182 .5967712402382 .9015579223683 .206336975183 .2063369751 83.5111236572383 .8159103393684 .1206970214884 .1206970214884 .42548370361 84.4254837036184 .4254837036184 .7302627563584 .7302627563584 .73026275635 84.7302627563584 .7302627563584 .7302627563584 .7302627563584 .73026275635 84.4254837036184 .4254837036184 .4254837036184 .4254837036184 .42548370361 84.12069702148 84.12069702148 84.12069702148 84.12069702148 83.81591033936 83.8159103393683 .8159103393683 .5111236572383 .5111236572383 .51112365723 83.206336975183 .206336975182 .9015579223682 .9015579223682 .90155792236 82.5967712402382 .5967712402382 .2919769287182 .2919769287181 .98719787598 81.9871978759881 .9871978759881 .6824111938581 .6824111938581 .68241119385 81.6824111938581 .6824111938581 .6824111938581 .6824111938581 .68241119385 81.6824111938581 .9871978759883 .206336975185 .03504943848 -9999 -9999 -9999 -9999 -9999 -9999 -9999 -9999 -9999 -9999 -9999 -9999 -9999 -9999 -9999 -9999 -9999 -9999 -9999 -9999 -9999 -9999 -9999 -9999 -9999 -9999 -9999 -9999 -9999 -9999 -9999 -9999 -9999 -9999

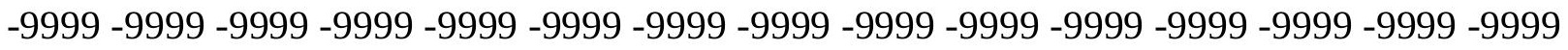
-9999 -9999 -9999 -9999 -9999 -9999 -9999 -9999 -9999 -9999 -9999 -9999 -9999 -9999 -9999 -9999 -9999 -9999 -9999 -9999 -9999 -9999 -9999 -9999 -9999 -9999 -9999 -9999 -9999 -9999 -9999 -9999 -9999 -9999 -9999 -9999 -9999 -9999 -9999 -9999 -9999 -9999 -9999 -9999 -9999 -

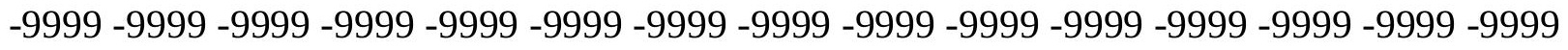
-9999 -9999 -9999 -9999-9999 -9999 -9999-9999

-9999 -9999 -9999 -9999 -9999 -9999 -9999 -9999 -9999 -9999 -9999 -9999 -9999 -37.7933502197 -36.8790016174 -35.3550796509 -32.6120109558 -29.8689403534 $-27.4306602478-24.6875991821-21.9445304871-19.2014598846-16.7631797791$ $-14.0201196671-11.5818300247-8.83876895905-6.095703125-3.65742206573$ -.9143553972241.219141006473.657422065735 6.0957031258.533983230591 10.9722604751613 .4105501174915 .8488302230817 .9823207855220 .11581993103 22.5541000366224 .6875991821326 .5163097381628 .6497993469230 .47850990295 32.6120109558134 .4407196044936 .2694282531737 .7933502197339 .6220703125 41.1459884643642 .66992187544 .1938400268645 .5150566101146 .93690872192 48.4608306884849 .6799812316950 .8991203308152 .1182594299356 .38525009155 57.909179687559 .4331016540560 .3474502563561 .2618103027362 .17617034912 62.7857398986863 .0905189514260 .6522407531761 .2618103027361 .87137985229 62.7857398986863 .3953094482463 .7000885009864 .3096618652364 .91924285889 65.2240066528365 .8335876464866 .1383666992266 .4431610107466 .74794006348 67.0527267456167 .0527267456167 .3575134277367 .3575134277367 .35751342773 67.35751342773 67.35751342773 67.35751342773 67.35751342773 67.05272674561 66.7479400634866 .4431610107466 .1383666992265 .5288009643664 .91924285889 64.3096618652363 .7000885009863 .0905189514262 .1761703491261 .26181030273 60.3474502563559 .4331016540558 .5187492370657 .6043891906756 .69002914429 55.7756805419955 .1661109924354 .2517509460453 .6421813964852 .72782897949 52.1182594299351 .5086898803750 .8991203308150 .2895507812549 .67998123169 49.0704002380448 .4608306884847 .8512611389247 .2416992187546 .63212966919 46.0225486755445 .717769622845 .1082000732444 .4986305236844 .19384002686 43.5842704772943 .2794914245642 .66992187542 .3651313781741 .75556182861 41.4507789611841 .1459884643640 .8412094116240 .2316398620639 .92684936523 
39.622070312539 .3172798156739 .3172798156739 .0125007629438 .70771026611 38.7077102661138 .4029312133838 .4029312133838 .0981407165538 .09814071655 38.0981407165538 .0981407165538 .0981407165538 .4029312133838 .40293121338 38.7077102661138 .7077102661139 .0125007629439 .3172798156739 .6220703125 40.2316398620640 .5364189147941 .1459884643641 .7555618286142 .36513137817 43.2794914245643 .8890609741245 .1082000732446 .0225486755447 .24169921875 48.4608306884849 .6799812316950 .8991203308152 .1182594299353 .33739852905 54.2517509460455 .1661109924355 .7756805419956 .0804595947356 .38525009155 56.3852500915556 .6900291442956 .6900291442956 .9948196411157 .29959869385 57.909179687558 .5187492370659 .4331016540560 .3474502563560 .95701980591 61.8713798522962 .7857398986864 .004882812564 .6144485473665 .52880096436 66.4431610107467 .3575134277367 .9670867919968 .8814392089869 .79579162598 70.7101516723671 .3197174072372 .2340774536173 .1484298706174 .0627822876 74.6723632812575 .5867080688576 .5010681152377 .110626220777 .72020721436 78.3297805786179 .2441329956179 .8537063598680 .1584930419980 .76805877686 81.3776321411181 .6824111938582 .2919769287182 .5967712402382 .90155792236 83.206336975183.8159103393683.81591033936 84.12069702148 84.42548370361 84.7302627563585 .0350494384885 .0350494384885 .0350494384885 .3398437585 .33984375 85.33984375 85.33984375 85.33984375 85.33984375 85.33984375 85.03504943848 85.0350494384885 .0350494384884 .7302627563584 .7302627563584 .73026275635 84.42548370361 84.4254837036184.42548370361 84.12069702148 84.12069702148 83.8159103393683 .8159103393683 .5111236572383 .5111236572383 .51112365723 83.206336975183.206336975182.90155792236 82.9015579223682.59677124023 82.5967712402382 .2919769287182 .2919769287181 .9871978759881 .98719787598 81.9871978759881 .6824111938581 .6824111938581 .3776321411181 .37763214111 81.3776321411181 .0728530883881 .0728530883881 .0728530883881 .07285308838 81.07285308838 81.07285308838 81.37763214111 81.37763214111 81.37763214111 81.9871978759883 .81591033936 -9999 -9999 -9999 -9999 -9999 -9999 -9999 -9999 -9999

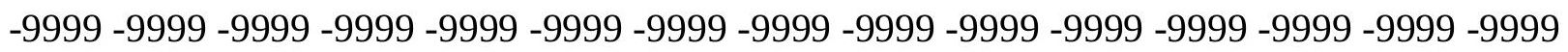

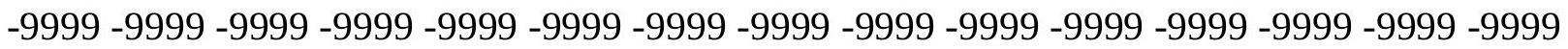

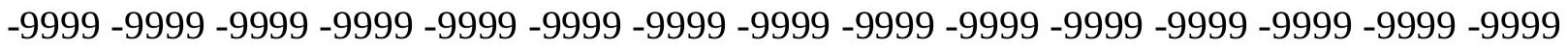

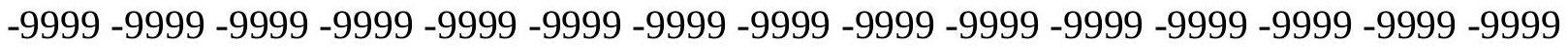

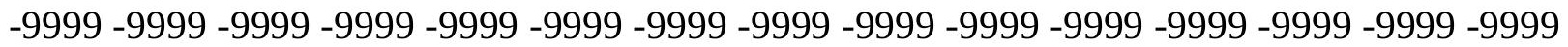

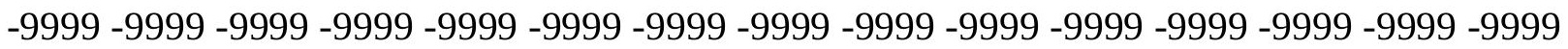

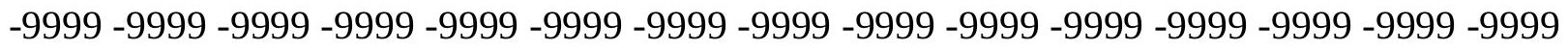
$-9999-9999-9999$

-9999 -9999 -9999 -9999 -9999 -9999 -9999 -9999 -9999 -9999 -9999 -9999 -9999 -9999 -37.488571167-36.2694282532 -33.5263595581 -30.7833003998 -28.0402297974 $-25.2971591949-22.8588790894-20.115819931-17.3727493286-14.6296901703$ $-11.9622364044-9.44833946228-6.7052731514-3.96220707893-1.52392601967$ .91435539722443 .3526360988625 .7909169197088 .53398323059110 .97226047516 13.4105501174915 .5440397262617 .9823207855220 .1158199310322 .55410003662 24.6875991821326 .5163097381628 .6497993469230 .7833003997832 .61201095581 34.4407196044936 .2694282531737 .7933502197339 .622070312541 .14598846436 42.66992187544 .1938400268645 .4496994018646 .9369087219248 .46083068848 49.6799812316950 .8991203308155 .1661109924356 .9948196411158 .51874923706 
59.7378807067960 .9570198059161 .8713798522962 .4809494018663 .09051895142 63.3953094482463 .7000885009860 .9570198059161 .5666007995662 .17617034912 62.7857398986863 .3953094482464 .004882812564 .6144485473664 .91924285889 65.2240066528365 .5288009643666 .1383666992266 .1383666992266 .44316101074 66.7479400634866 .7479400634867 .0527267456167 .0527267456167 .05272674561 67.0527267456166 .7479400634866 .7479400634866 .4431610107466 .13836669922 65.8335876464865 .5288009643664 .9192428588964 .6144485473664 .0048828125 63.0905189514262 .4809494018661 .5666007995660 .6522407531759 .73788070679 58.8235282897957 .909179687556 .6900291442955 .7756805419955 .16611099243 54.2517509460453 .3373985290552 .7278289794951 .8134689331151 .20389938354 50.2895507812549 .6799812316949 .0704002380448 .4608306884847 .85126113892 47.2416992187546 .6321296691946 .0225486755445 .717769622845 .10820007324 44.4986305236844 .1938400268643 .5842704772942 .9747009277342 .669921875 42.0603485107441 .7555618286141 .4507789611840 .8412094116240 .53641891479 40.2316398620639 .622070312539 .3172798156739 .0125007629438 .70771026611 38.4029312133838 .0981407165538 .0981407165537 .7933502197337 .48857116699 37.48857116699 37.18378067017 37.18378067017 37.18378067017 37.18378067017 37.1837806701737 .1837806701737 .1837806701737 .4885711669937 .48857116699 37.7933502197338 .0981407165538 .0981407165538 .7077102661139 .01250076294 39.3172798156739 .9268493652340 .5364189147941 .1459884643642 .06034851074 42.9747009277343 .8890609741244 .8034095764246 .0225486755447 .24169921875 48.765621185349 .9847602844251 .2038993835452 .4230384826753 .64218139648 54.5565414428755 .1661109924355 .4708900451755 .4708900451755 .47089004517 55.4708900451755 .4708900451755 .4708900451755 .7756805419956 .38525009155 56.9948196411157 .909179687558 .8235282897959 .7378807067960 .65224075317 61.8713798522962 .7857398986863 .7000885009864 .6144485473665 .52880096436 66.4431610107467 .3575134277368 .2718734741269 .1862335205170 .10057830811 71.014930725171 .9292907714872 .8436431884873 .7580032348674 .97714233398 75.8914871215876 .5010681152377 .4154205322378 .3297805786178 .93934631348 79.8537063598680 .4632720947381 .0728530883881 .6824111938582 .29197692871 82.9015579223683 .206336975183 .8159103393684 .1206970214884 .42548370361 84.7302627563585 .0350494384885 .3398437585 .6446228027385 .64462280273 85.9494018554785 .9494018554786 .254188537686 .254188537686 .2541885376 86.254188537685 .9494018554785 .9494018554785 .9494018554785 .64462280273 85.6446228027385 .3398437585 .3398437585 .0350494384885 .0350494384884 .73026275635 84.7302627563584 .4254837036184 .1206970214884 .1206970214883 .81591033936 83.81591033936 83.51112365723 83.51112365723 83.2063369751 83.2063369751 82.9015579223682 .9015579223682 .5967712402382 .2919769287182 .29197692871 81.9871978759881 .9871978759881 .6824111938581 .6824111938581 .37763214111 81.3776321411181 .0728530883881 .0728530883881 .0728530883880 .76805877686 80.7680587768680 .7680587768680 .7680587768680 .7680587768680 .76805877686 80.7680587768680 .7680587768680 .7680587768681 .0728530883881 .07285308838 81.2531585693482 .5967712402384 .42548370361 -9999 -9999 -9999 -9999 -9999 -9999 -9999 -9999 -9999 -9999 -9999 -9999 -9999 -9999 -9999 -9999 -9999 -9999 -9999 -9999 -9999 -9999 -9999 -9999 -9999 -9999 -9999 -9999 -9999 -9999 -9999 -9999 -9999 -9999 -9999 -9999 -9999 -

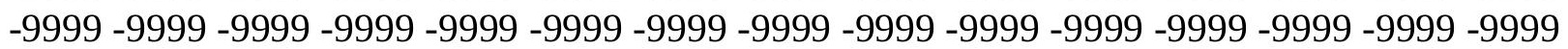


-9999 -9999 -9999 -9999 -9999 -9999 -9999 -9999 -9999 -9999 -9999 -9999 -9999 -9999 -9999 -9999 -9999 -9999 -9999 -9999 -9999 -9999 -9999 -9999 -9999 -9999 -9999 -9999 -9999 -9999 -9999 -9999 -9999 -9999 -9999 -9999 -9999 -9999 -9999 -9999 -9999 -9999 -9999 -9999 -9999 -9999 -9999 -9999 -9999 -9999 -9999 -9999 -9999 -9999 -9999 -9999 -9999 -9999 -9999 -9999 -9999-9999-9999-9999

-9999 -9999 -9999 -9999 -9999 -9999 -9999 -9999 -9999 -9999 -9999 -9999 -9999 -9999 -37.7933502197 -37.1837806702 -34.4407196045 -31.6976509094-28.9545898438 -26.2115192413 -23.4684505463 -20.7253894806 -17.9823207855 -15.2392597198 $-12.4961900711-9.75312423706-7.01005792618-4.26699209213-1.82871103287$ .6095703244209 3.3526360988625 .7909169197088 .22919845581110 .66748046875 13.1057596206715 .5440397262617 .9823207855220 .1158199310322 .55410003662 24.6875991821326 .8210906982428 .6497993469230 .7833003997832 .61201095581 34.4407196044936 .2694282531738 .0981407165539 .622070312541 .14598846436 42.66992187544 .1938400268645 .4674110412646 .9369087219248 .46083068848 49.6799812316950 .8991203308155 .4708900451757 .2995986938558 .82352828979 60.3474502563561 .2618103027362 .4809494018663 .0905189514263 .70008850098 64.004882812564 .004882812564 .004882812561 .2618103027361 .87137985229 62.4809494018663 .0905189514263 .7000885009864 .004882812564 .61444854736 64.9192428588965 .2240066528365 .5288009643665 .8335876464866 .13836669922 66.1383666992266 .4431610107466 .4431610107466 .4431610107466 .44316101074 66.4431610107466 .4431610107466 .1383666992266 .1383666992265 .83358764648 65.5288009643664 .9192428588964 .6144485473664 .004882812563 .39530944824 62.7857398986861 .8713798522961 .2618103027360 .0426712036159 .12831115723 58.2139587402356 .9948196411156 .0804595947355 .1661109924354 .25175094604 53.3373985290552 .4230384826751 .8134689331150 .8991203308150 .28955078125 49.3751907348648 .765621185348 .1560516357447 .5464782714846 .93690872192 46.3273391723645 .717769622845 .1082000732444 .4986305236843 .88906097412 43.5842704772942 .9747009277342 .66992187542 .0603485107441 .75556182861 41.1459884643640 .8412094116240 .2316398620639 .9268493652339 .6220703125 39.3172798156739 .0125007629438 .4029312133838 .0981407165537 .79335021973 37.4885711669937 .1837806701737 .1837806701736 .8790016174336 .57421112061 36.5742111206136 .2694282531736 .2694282531736 .2694282531736 .26942825317 36.26942825317 36.26942825317 36.26942825317 36.26942825317 36.57421112061 36.5742111206136 .8790016174337 .1837806701737 .4885711669937 .79335021973 38.4029312133838 .7077102661139 .3172798156739 .9268493652340 .84120941162 41.7555618286142 .66992187543 .8890609741245 .1082000732446 .32733917236 47.5464782714849 .0704002380450 .2895507812551 .5086898803752 .72782897949 53.6421813964854 .5565414428754 .5565414428754 .5565414428754 .25175094604 53.9469718933153 .6421813964853 .6421813964853 .9469718933154 .55654144287 55.4708900451756 .0804595947356 .9948196411158 .2139587402359 .12831115723 60.3474502563561 .5666007995662 .4809494018663 .7000885009864 .61444854736 65.5288009643666 .4431610107467 .3575134277368 .5766525268669 .49101257324 70.7101516723671 .6244964599672 .8436431884873 .7580032348674 .97714233398 75.8914871215876 .8058471679778 .0249862670978 .9393463134879 .54891967773 80.4632720947381 .3776321411181 .9871978759882 .5967712402383 .2063369751 83.8159103393684 .4254837036184 .7302627563585 .0350494384885 .64462280273 
85.94940185547 86.2541885376 86.55898284912 86.55898284912 86.86376190186 86.8637619018687 .1685485839887 .1685485839887 .1685485839886 .86376190186 86.8637619018686 .8637619018686 .5589828491286 .254188537686 .2541885376 85.9494018554785 .6446228027385 .6446228027385 .3398437585 .03504943848 84.7302627563584 .7302627563584 .4254837036184 .1206970214884 .12069702148 83.8159103393683 .5111236572383 .5111236572383 .206336975182 .90155792236 82.9015579223682 .5967712402382 .2919769287182 .2919769287181 .98719787598 81.9871978759881 .6824111938581 .3776321411181 .3776321411181 .07285308838 81.0728530883880 .7680587768680 .7680587768680 .4632720947380 .46327209473 80.4632720947380 .1584930419980 .1584930419980 .1584930419980 .15849304199 80.1584930419980 .1584930419980 .4632720947380 .4632720947380 .46327209473 80.6621017456180 .7965545654381 .3776321411183 .2063369751 -9999 -9999 -9999 -9999 -9999 -9999 -9999 -9999 -9999 -9999 -9999 -9999 -9999 -9999 -9999 -9999 -9999 -9999 -9999

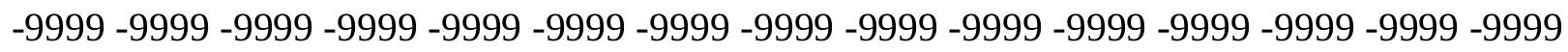
-9999 -9999 -9999 -9999 -9999 -9999 -9999 -9999 -9999 -9999 -9999 -9999 -9999 -9999 -9999

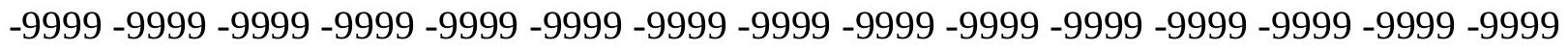
-9999 -9999 -9999 -9999 -9999 -9999 -9999 -9999 -9999 -9999 -9999 -9999 -9999 -9999 -9999 -9999 -9999 -9999 -9999 -9999 -9999 -9999 -9999 -9999 -9999 -9999 -9999 -9999 -9999 -9999 -

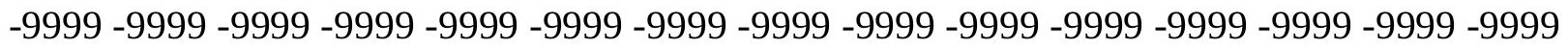
-9999 -9999-9999 -9999-9999-9999-9999

-9999 -9999 -9999 -9999 -9999 -9999 -9999 -9999 -9999 -9999 -9999 -9999 -9999 -9999 -38.4029312134 -37.488571167 -35.0502891541 -32.307220459 -29.5641593933 -26.8210906982 -24.0780296326 -21.3349609375 -18.5918903351 -15.8488302231 -12.8009700775 -10.0579099655 -7.3148431778 -4.57177686691 -1.82871103287 .30478510260583 .0478510856635 .7909169197088 .22919845581110 .97226047516 13.4105501174915 .8488302230817 .9823207855220 .4206008911122 .55410003662 24.6875991821326 .8210906982428 .9545898437531 .0880794525132 .91679000854 34.7455101013236 .5742111206138 .0981407165539 .9268493652341 .45077896118 42.9747009277344 .4986305236845 .5681381225647 .2416992187548 .46083068848 49.6799812316953 .9469718933156 .0804595947357 .909179687559 .43310165405 60.9570198059161 .8713798522963 .0905189514263 .7000885009864 .30966186523 64.6144485473664 .6144485473664 .3096618652361 .2618103027361 .87137985229 62.1761703491262 .7857398986863 .3953094482463 .7000885009864 .30966186523 64.6144485473664 .9192428588965 .2240066528365 .5288009643665 .83358764648 65.8335876464866 .1383666992266 .1383666992266 .1383666992266 .13836669922 66.1383666992265 .8335876464865 .8335876464865 .5288009643665 .22400665283 64.9192428588964 .6144485473664 .004882812563 .3953094482462 .78573989868 62.1761703491261 .5666007995660 .6522407531759 .7378807067958 .51874923706 57.6043891906756 .3852500915555 .4708900451754 .5565414428753 .33739852905 52.4230384826751 .5086898803750 .8991203308149 .9847602844249 .07040023804 48.4608306884847 .8512611389246 .9369087219246 .3273391723645 .7177696228 45.1082000732444 .4986305236844 .1938400268643 .5842704772942 .97470092773 42.66992187542 .0603485107441 .4507789611841 .1459884643640 .84120941162 40.2316398620639 .9268493652339 .622070312539 .0125007629438 .70771026611 38.4029312133838 .0981407165537 .7933502197337 .4885711669937 .18378067017 36.87900161743 36.57421112061 36.26942825317 35.96464920044 35.96464920044 
35.6598587036135 .6598587036135 .3550796508835 .3550796508835 .35507965088 35.3550796508835 .3550796508835 .3550796508835 .3550796508835 .65985870361 35.6598587036135 .9646492004436 .2694282531736 .5742111206136 .87900161743 37.1837806701737 .7933502197338 .0981407165539 .0125007629439 .6220703125 40.5364189147941 .4507789611842 .66992187543 .5842704772945 .10820007324 46.3273391723647 .8512611389249 .0704002380450 .5943298339851 .81346893311 52.7278289794953 .6421813964853 .6421813964853 .3373985290552 .72782897949 52.1182594299351 .8134689331151 .8134689331152 .1182594299352 .72782897949 53.3373985290554 .2517509460455 .4708900451756 .3852500915557 .60438919067 58.8235282897960 .0426712036161 .2618103027362 .4809494018663 .39530944824 64.3096618652365 .5288009643666 .4431610107467 .6623001098668 .88143920898 70.1005783081171 .3197174072372 .5388565063573 .7580032348674 .67236328125 75.8914871215877 .110626220778 .3297805786179 .2441329956180 .15849304199 81.0728530883881 .9871978759882 .9015579223683 .5111236572384 .12069702148 84.7302627563585 .3398437585 .6446228027386 .254188537686 .55898284912 86.8637619018687 .1685485839887 .4733276367287 .7781066894587 .77810668945 87.7781066894588 .0829010009888 .0829010009887 .7781066894587 .77810668945 87.4733276367287 .47332763672 87.16854858398 86.86376190186 86.55898284912 86.2541885376 85.9494018554785.64462280273 85.64462280273 85.33984375 85.0350494384884 .7302627563584 .4254837036184 .1206970214883 .81591033936 83.5111236572383 .5111236572383 .206336975182 .9015579223682 .59677124023 82.5967712402382 .2919769287181 .9871978759881 .9871978759881 .68241119385 81.3776321411181 .3776321411181 .0728530883880 .7680587768680 .76805877686 80.4632720947380 .4632720947380 .1584930419980 .1584930419980 .15849304199 79.8537063598679 .8537063598679 .8537063598679 .8537063598679 .85370635986 79.8537063598679 .8537063598679 .8537063598680 .1584930419980 .15849304199 80.2428359985480 .3610382080180 .465263366781 .9871978759883 .51112365723 -9999 -9999 -9999 -9999 -9999 -9999 -9999 -9999 -9999 -9999 -9999 -9999 -9999 -9999 -9999 -9999 -

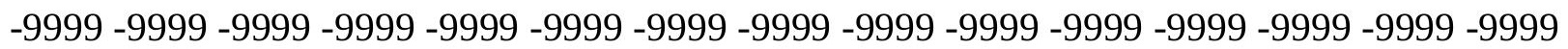

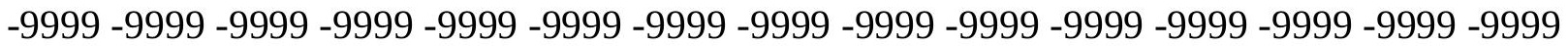

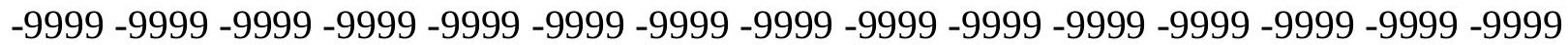
-9999 -

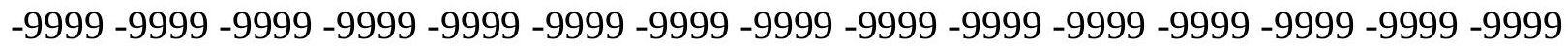

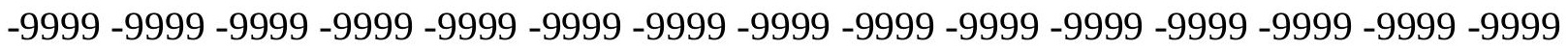
-9999 -9999 -9999 -9999 -9999 -9999 -9999 -9999 -9999 -9999 -9999 -9999 -9999 -9999 -9999 -9999 -9999 -9999 -9999 -9999 -9999 -9999 -9999 -38.4029312134-37.7933502197 -35.6598587036 -32.9167900085-30.1737308502 $-27.4306602478-24.6875991821-21.6397399902-18.8966808319-16.1536102295$ $-13.1318302155-10.3626899719-7.61962795258-4.87656211853-2.13349604607$ .30478510260583 .0478510856635 .7909169197088 .22919845581110 .97226047516 13.4105501174915 .8488302230818 .28710937520 .7253894805922 .85887908936 24.9923801422127 .1258792877229 .2593708038331 .3928699493433 .22158050537 35.0502891540536 .8790016174338 .4029312133840 .2316398620641 .75556182861 43.2794914245644 .4986305236845 .6408882141147 .2416992187548 .46083068848 49.6799812316954 .5565414428756 .3852500915558 .5187492370660 .04267120361 61.5666007995662 .7857398986863 .7000885009864 .3096618652364 .91924285889 
65.2240066528365 .2240066528364 .9192428588964 .6144485473661 .56660079956 62.1761703491262 .4809494018663 .0905189514263 .3953094482464 .0048828125 64.3096618652364 .6144485473664 .9192428588965 .2240066528365 .22400665283 65.5288009643665 .5288009643665 .8335876464865 .8335876464865 .83358764648 65.5288009643665 .5288009643665 .5288009643665 .2240066528364 .91924285889 64.6144485473664 .004882812563 .7000885009863 .0905189514262 .48094940186 61.5666007995660 .9570198059160 .0426712036159 .1283111572357 .9091796875 56.9948196411155 .7756805419954 .8613204956153 .6421813964852 .72782897949 51.8134689331150 .8991203308149 .9847602844249 .0704002380448 .15605163574 47.5464782714846 .6321296691946 .0225486755445 .4129791259844 .80340957642 44.1938400268643 .5842704772942 .9747009277342 .66992187542 .06034851074 41.4507789611841 .1459884643640 .8412094116240 .2316398620639 .92684936523 39.622070312539 .0125007629438 .7077102661138 .4029312133838 .09814071655 37.4885711669937 .1837806701736 .8790016174336 .5742111206136 .26942825317 35.9646492004435 .6598587036135 .3550796508835 .3550796508835 .05028915405 34.7455101013234 .7455101013234 .4407196044934 .4407196044934 .44071960449 34.4407196044934 .4407196044934 .4407196044934 .4407196044934 .74551010132 34.7455101013235 .0502891540535 .0502891540535 .3550796508835 .65985870361 36.2694282531736 .5742111206137 .1837806701737 .7933502197338 .40293121338 39.3172798156740 .2316398620641 .1459884643642 .3651313781743 .58427047729 44.8034095764246 .3273391723647 .5464782714849 .0704002380450 .28955078125 51.2038993835452 .1182594299352 .4230384826751 .8134689331150 .89912033081 49.9847602844249 .6799812316949 .6799812316949 .9847602844250 .59432983398 51.5086898803752 .4230384826753 .3373985290554 .5565414428755 .77568054199 57.2995986938558 .5187492370660 .0426712036160 .9570198059162 .17617034912 63.0905189514264 .3096618652365 .5288009643666 .7479400634867 .96708679199 69.4910125732470 .7101516723671 .9292907714873 .4532165527374 .67236328125 76.1962814331177 .4154205322378 .6345596313579 .8537063598680 .76805877686 81.9871978759882 .9015579223683 .5111236572384 .4254837036185 .03504943848 85.6446228027386 .254188537686 .8637619018687 .1685485839887 .47332763672 87.7781066894588 .0829010009888 .3876876831188 .6924667358488 .69246673584 88.6924667358488 .6924667358488 .6924667358488 .6924667358488 .38768768311 88.38768768311 88.08290100098 87.77810668945 87.47332763672 87.16854858398 86.5589828491286 .254188537685 .9494018554785 .6446228027385 .33984375 85.0350494384884 .7302627563584 .4254837036184 .1206970214883 .81591033936 83.5111236572383 .206336975182 .9015579223682 .5967712402382 .29197692871 82.29197692871 81.98719787598 81.68241119385 81.37763214111 81.37763214111 81.0728530883880 .7680587768680 .7680587768680 .4632720947380 .15849304199 80.1584930419979 .8537063598679 .8537063598679 .5489196777379 .54891967773 79.5489196777379 .2441329956179 .2441329956179 .2441329956179 .24413299561 79.2441329956179 .2441329956179 .5489196777379 .5489196777379 .85370635986 $79.8537063598679 .9706649780380 .0593490600681 .0728530883882 .29197692871-9999$ -9999 -9999 -9999 -9999 -9999 -9999 -9999 -9999 -9999 -9999 -9999 -9999 -9999 -9999 -9999 -9999 -9999 -9999 -9999 -9999 -9999 -9999 -9999 -9999 -9999 -9999 -9999 -9999 -9999 -9999 -9999 -9999 -9999 -9999 -9999 -9999 -9999 -9999 -9999 -9999 -9999 -9999 -9999 -9999 -9999 -

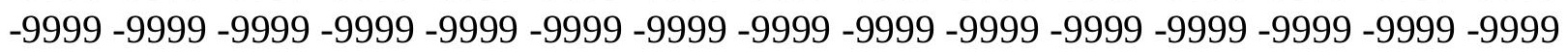


-9999 -9999 -9999 -9999 -9999 -9999 -9999 -9999 -9999 -9999 -9999 -9999 -9999 -9999 -9999

-9999 -9999 -9999 -9999 -9999 -9999 -9999 -9999 -9999 -9999 -9999 -9999 -9999 -9999 -9999 -

-9999 -9999 -9999 -9999 -9999 -9999 -9999 -9999 -9999 -9999 -9999 -9999 -9999 -9999 -9999

-9999 -9999 -9999 -9999 -9999 -9999 -9999 -9999 -9999

-9999 -9999 -9999 -9999 -9999 -9999 -9999 -9999 -9999 -9999 -9999 -9999 -9999 -9999

-38.4029312134 -38.0981407166 -36.2694282532 -33.5263595581 -30.7833003998

$-28.0402297974-24.9923801422-22.2493095398-19.2014598846-16.4584007263$

$-13.4105501175-10.6674804688-7.61962795258-4.87656211853-2.13349604607$

.30478510260583 .3526360988625 .7909169197088 .53398323059111 .27705001831

13.715330123916 .1536102294918 .5918903350821 .0301704406723 .16366958618

25.6019496917727 .7354507446329 .5641593933131 .6976509094233 .52635955811

35.3550796508837 .1837806701739 .0125007629440 .5364189147942 .06034851074

43.5842704772944 .8034095764245 .6746864318847 .5464782714848 .7656211853

49.9847602844254 .8613204956157 .2995986938559 .1283111572360 .65224075317

62.1761703491263 .3953094482464 .3096618652365 .2240066528365 .52880096436 65.8335876464865 .8335876464865 .5288009643665 .2240066528364 .30966186523 61.8713798522962 .4809494018662 .7857398986863 .0905189514263 .70008850098 64.004882812564 .3096618652364 .6144485473664 .9192428588964 .91924285889 65.2240066528365 .2240066528365 .5288009643665 .5288009643665 .52880096436 65.2240066528365 .2240066528364 .9192428588964 .6144485473664 .30966186523 64.004882812563 .7000885009863 .0905189514262 .4809494018661 .87137985229 61.2618103027360 .3474502563559 .4331016540558 .5187492370657 .29959869385 56.0804595947355 .1661109924353 .9469718933153 .0326118469251 .81346893311 50.8991203308149 .9847602844249 .0704002380448 .1560516357447 .24169921875 46.6321296691945 .717769622845 .1082000732444 .4986305236843 .88906097412 43.2794914245642 .66992187542 .0603485107441 .7555618286141 .14598846436 40.8412094116240 .2316398620639 .9268493652339 .3172798156739 .01250076294 38.7077102661138 .4029312133838 .0981407165537 .4885711669937 .18378067017 36.8790016174336 .5742111206136 .2694282531735 .9646492004435 .65985870361 35.3550796508835 .0502891540534 .7455101013234 .4407196044934 .44071960449 34.1359291076733 .8311500549333 .8311500549333 .8311500549333 .52635955811 33.5263595581133 .5263595581133 .5263595581133 .5263595581133 .83115005493 33.8311500549334 .1359291076734 .1359291076734 .4407196044934 .74551010132 35.0502891540535 .6598587036135 .9646492004436 .5742111206137 .18378067017 38.0981407165539 .0125007629439 .9268493652340 .8412094116242 .06034851074 43.2794914245644 .4986305236845 .717769622846 .9369087219248 .15605163574 49.0704002380449 .9847602844250 .5943298339849 .3751907348647 .85126113892 47.2416992187546 .9369087219247 .2416992187547 .5464782714848 .46083068848 49.3751907348650 .2895507812551 .5086898803752 .7278289794953 .94697189331 55.4708900451756 .6900291442958 .2139587402359 .4331016540560 .65224075317 61.8713798522963 .0905189514264 .3096618652365 .8335876464867 .05272674561 68.5766525268670 .1005783081171 .6244964599673 .1484298706174 .67236328125 76.1962814331177 .4154205322378 .9393463134880 .1584930419981 .37763214111 82.5967712402383 .5111236572384 .4254837036185 .3398437585 .94940185547 86.5589828491287 .1685485839887 .4733276367288 .0829010009888 .38768768311 88.69246673584 88.9972534179789.3020401001 89.302040100189.60682678223 
89.60682678223 89.60682678223 89.60682678223 89.302040100189.3020401001 88.9972534179788 .6924667358488 .0829010009887 .7781066894587 .47332763672 86.8637619018686 .5589828491286 .254188537685 .6446228027385 .33984375 85.0350494384884 .7302627563584 .4254837036184 .1206970214883 .81591033936 83.2063369751 82.90155792236 82.59677124023 82.29197692871 82.29197692871 81.9871978759881 .6824111938581 .3776321411181 .0728530883880 .76805877686 80.7680587768680 .4632720947380 .1584930419980 .1584930419979 .85370635986 79.5489196777379 .5489196777379 .2441329956179 .2441329956179 .24413299561 78.9393463134878 .9393463134878 .9393463134878 .9393463134878 .93934631348 78.9393463134878 .9393463134878 .9393463134879 .2441329956179 .24413299561 79.5489196777379 .5489196777379 .6638641357479 .6872482299881 .07285308838 82.59677124023 -9999 -9999 -9999 -9999 -9999 -9999 -9999 -9999 -9999 -9999 -9999 -9999 -9999 -9999 -9999 -9999 -9999 -9999 -9999 -9999 -9999 -9999 -9999 -9999 -9999 -9999 -9999 -9999 -9999 -9999 -9999 -9999 -9999 -9999 -9999 -9999 -9999 -9999 -9999 -9999 -9999 -9999 -9999 -9999 -9999 -9999 -9999 -9999 -9999 -9999 -9999 -9999 -9999 -9999 -9999 -9999 -9999

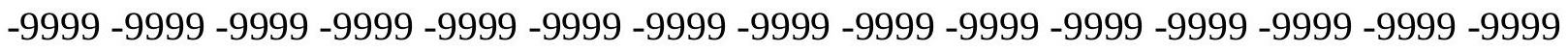
-9999 -9999 -9999 -9999 -9999 -9999 -9999 -9999 -9999 -9999 -9999 -9999 -9999 -9999 -9999 -9999 -9999 -9999 -9999 -9999 -9999 -9999 -9999 -9999 -9999 -9999 -9999 -9999 -9999 -9999 -9999 -9999 -9999 -9999 -9999 -9999 -9999 -9999 -9999 -9999 -9999 -9999 -9999 -9999 -9999 -9999 -9999 -9999 -9999 -9999 -9999 -9999 -9999 -9999 -9999 -9999 -38.4029312134 -38.0981407166 -36.8790016174 -33.8311500549-31.0880794525 $-28.3450202942-25.2971591949-22.5541000366-19.5062503815-16.4584007263$ $-13.7153301239-10.6674804688-7.61962795258-4.87656211853-1.82871103287$ .60957032442093 .3526360988626 .0957031258 .83876895904511 .58183002472 14.0201196670516 .7631797790519 .2014598846421 .334960937523 .77323913574 25.906740188628 .0402297973630 .1737308502232 .3072204589834 .13592910767 35.9646492004437 .7933502197339 .3172798156740 .8412094116242 .36513137817 43.8890609741245 .4129791259845 .4994964599647 .8512611389249 .07040023804 50.2895507812555 .4708900451757 .909179687559 .7378807067961 .56660079956 63.0905189514264 .3096618652365 .2240066528366 .1383666992266 .44316101074 66.7479400634866 .7479400634866 .4431610107465 .8335876464864 .91924285889 61.5666007995662 .1761703491262 .4809494018663 .0905189514263 .39530944824 63.7000885009864 .004882812564 .3096618652364 .6144485473664 .61444854736 64.9192428588964 .9192428588964 .9192428588965 .2240066528364 .91924285889 64.9192428588964 .9192428588964 .6144485473664 .3096618652364 .0048828125 63.7000885009863 .0905189514262 .7857398986862 .1761703491261 .56660079956 60.6522407531759 .7378807067958 .8235282897957 .6043891906756 .69002914429 55.4708900451754 .2517509460453 .3373985290552 .1182594299351 .20389938354 49.9847602844249 .0704002380448 .1560516357447 .2416992187546 .63212966919 45.717769622844 .8034095764244 .1938400268643 .5842704772942 .97470092773 42.3651313781741 .7555618286141 .1459884643640 .8412094116240 .23163986206 39.9268493652339 .3172798156739 .0125007629438 .7077102661138 .40293121338 38.0981407165537 .4885711669937 .1837806701736 .8790016174336 .57421112061 36.2694282531735 .9646492004435 .6598587036135 .3550796508835 .05028915405 34.7455101013234 .4407196044934 .1359291076733 .8311500549333 .83115005493 33.52635955811 33.2215805053733.2215805053732.91679000854 32.91679000854 
32.9167900085432 .9167900085432 .9167900085432 .9167900085432 .91679000854 32.9167900085433 .2215805053733 .2215805053733 .5263595581133 .83115005493 34.1359291076734 .4407196044935 .0502891540535 .3550796508835 .96464920044 36.8790016174337 .4885711669938 .4029312133839 .3172798156740 .23163986206 41.4507789611842 .66992187543 .8890609741244 .8034095764245 .7177696228 46.3273391723646 .3273391723646 .3273391723645 .4129791259844 .49863052368 43.8890609741244 .1938400268644 .4986305236845 .1082000732446 .02254867554 47.2416992187548 .1560516357449 .3751907348650 .5943298339852 .11825942993 53.3373985290554 .8613204956156 .0804595947357 .6043891906758 .82352828979 60.3474502563561 .5666007995663 .0905189514264 .6144485473666 .13836669922 67.6623001098669 .4910125732471 .014930725172 .8436431884874 .36756896973 75.8914871215877 .4154205322378 .9393463134880 .4632720947381 .68241119385 82.9015579223684 .1206970214885 .0350494384885 .9494018554786 .86376190186 87.4733276367287 .7781066894588 .3876876831188 .6924667358488 .99725341797 89.302040100189 .6068267822389 .9116134643689 .9116134643690 .21640014648 90.2164001464890 .2164001464890 .2164001464889 .9116134643689 .91161346436 89.302040100188 .9972534179788 .6924667358488 .0829010009887 .77810668945 87.1685485839886 .8637619018686 .254188537685 .9494018554785 .33984375 85.0350494384884 .7302627563584 .1206970214883 .8159103393683 .51112365723 83.2063369751 82.90155792236 82.59677124023 82.29197692871 81.98719787598 81.6824111938581 .3776321411181 .0728530883880 .7680587768680 .46327209473 80.1584930419980 .1584930419979 .8537063598679 .5489196777379 .54891967773 79.2441329956178 .9393463134878 .9393463134878 .9393463134878 .63455963135 78.6345596313578 .6345596313578 .3297805786178 .3297805786178 .32978057861 78.3297805786178 .6345596313578 .6345596313578 .6345596313578 .93934631348 78.9393463134879 .2441329956179 .2441329956179 .2510528564580 .15849304199 81.37763214111 -9999 -9999 -9999 -9999 -9999 -9999 -9999 -9999 -9999 -9999 -9999 -9999 -9999 -9999 -9999 -9999 -9999 -9999 -9999 -9999 -9999 -9999 -9999 -9999 -9999 -9999 -9999 -9999 -9999 -9999 -9999 -9999 -9999 -9999 -9999 -9999 -9999 -9999 -9999 -9999 -9999 -9999 -9999 -9999 -9999 -9999 -9999 -9999 -9999 -9999 -9999 -9999 -9999 -9999 -9999 -9999 -9999 -9999 -9999 -9999 -9999 -9999 -9999 -9999 -9999 -9999 -9999 -9999 -9999 -9999 -9999 -9999

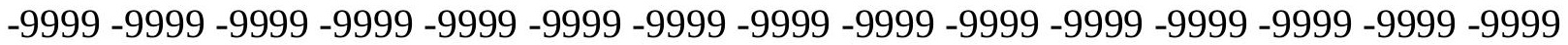

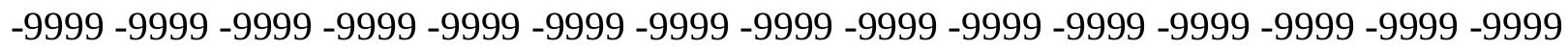
-9999 -9999 -9999 -9999 -9999 -9999 -9999 -9999 -9999 -9999 -9999 -9999 -9999 -9999 -9999 -9999 -9999 -9999 -9999 -9999 -9999 -9999 -9999 -9999 -9999 -9999 -9999 -37.7933502197 -37.1837806702 -34.4407196045 -31.3928699493 -28.6497993469 $-25.6019496918-22.5541000366-19.5062503815-16.4584007263-13.7153301239$ -10.6674804688 -7.61962795258 -4.57177686691 -1.82871103287.9143553972244 3.6574220657356 .7052731513989 .4483394622811 .8866195678714 .62969017029 17.0679702758819 .811029434221 .9445304870624 .3828105926526 .51630973816 28.64979934692 30.7833003997832 .9167900085434 .7455101013236 .57421112061 38.4029312133839 .9268493652341 .4507789611842 .9747009277344 .49863052368 45.717769622844 .9821014404347 .1283340454149 .3751907348653 .64218139648 56.3852500915558 .5187492370660 .6522407531762 .4809494018664 .0048828125 65.2240066528366 .1383666992267 .0527267456167 .3575134277367 .66230010986 67.3575134277367 .0527267456166 .4431610107465 .8335876464864 .61444854736 
61.8713798522962 .4809494018662 .7857398986863 .0905189514263 .39530944824 63.7000885009864 .004882812564 .3096618652364 .6144485473664 .61444854736 64.6144485473664 .9192428588964 .9192428588964 .6144485473664 .61444854736 64.6144485473664 .3096618652364 .004882812563 .7000885009863 .39530944824 62.7857398986862 .1761703491261 .5666007995660 .9570198059160 .04267120361 59.1283111572358 .2139587402356 .9948196411156 .0804595947354 .86132049561 53.6421813964852 .4230384826751 .5086898803750 .2895507812549 .37519073486 48.4608306884847 .2416992187546 .3273391723645 .717769622844 .80340957642 43.8890609741243 .2794914245642 .66992187542 .0603485107441 .45077896118 40.8412094116240 .2316398620639 .9268493652339 .622070312539 .01250076294 38.7077102661138 .4029312133838 .0981407165537 .7933502197337 .18378067017 36.8790016174336 .5742111206136 .2694282531735 .9646492004435 .65985870361 35.3550796508835 .0502891540534 .7455101013234 .4407196044934 .13592910767 33.8311500549333 .5263595581133 .2215805053733 .2215805053732 .91679000854 32.6120109558132 .6120109558132 .3072204589832 .3072204589832 .30722045898 32.3072204589832 .3072204589832 .3072204589832 .3072204589832 .30722045898 32.3072204589832 .6120109558132 .6120109558132 .9167900085433 .22158050537 33.5263595581133 .8311500549334 .4407196044935 .0502891540535 .35507965088 36.2694282531736 .8790016174337 .7933502197338 .7077102661139 .6220703125 40.5364189147941 .4507789611842 .0603485107442 .66992187542 .669921875 42.3651313781741 .4507789611840 .5364189147940 .2316398620640 .53641891479 41.1459884643642 .0603485107442 .9747009277343 .8890609741244 .80340957642 46.0225486755447 .2416992187548 .4608306884849 .9847602844251 .20389938354 52.7278289794954 .2517509460455 .4708900451756 .9948196411158 .51874923706 60.0426712036161 .8713798522963 .3953094482465 .2240066528366 .74794006348 68.5766525268670 .4053573608472 .2340774536174 .062782287675 .89148712158 77.4154205322379 .2441329956180 .7680587768682 .2919769287183 .51112365723 84.7302627563585 .6446228027386 .5589828491287 .4733276367288 .08290100098 88.6924667358488 .9972534179789 .302040100189 .6068267822389 .91161346436 90.2164001464890 .5211791992290 .5211791992290 .8259735107490 .82597351074 90.8259735107490 .8259735107490 .5211791992290 .2164001464889 .91161346436 89.3020401001 88.9972534179788.38768768311 87.77810668945 87.16854858398 86.8637619018686 .254188537685 .9494018554785 .3398437585 .03504943848 84.4254837036184 .1206970214883 .8159103393683 .206336975182 .90155792236 82.5967712402382 .2919769287181 .9871978759881 .6824111938581 .37763214111 81.0728530883880 .7680587768680 .4632720947380 .1584930419979 .85370635986 79.5489196777379 .5489196777379 .2441329956178 .9393463134878 .93934631348 78.6345596313578 .6345596313578 .3297805786178 .3297805786178 .02498626709 78.0249862670978 .0249862670978 .0249862670978 .0249862670978 .02498626709 78.0249862670978 .0249862670978 .3297805786178 .3297805786178 .63455963135 78.6345596313578 .6345596313578 .7984848022578 .7988052368280 .15849304199 81.68241119385 -9999 -9999 -9999 -9999 -9999 -9999 -9999 -9999 -9999 -9999 -9999 -9999 -9999 -9999 -9999 -9999 -9999 -9999 -9999 -9999 -9999 -9999 -9999 -9999 -9999 -9999 -9999 -9999 -9999 -9999 -9999 -9999 -9999 -9999 -9999 -9999 -9999 -9999 -9999 -9999 -9999 -9999 -

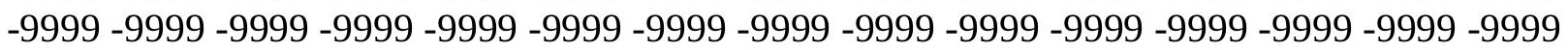

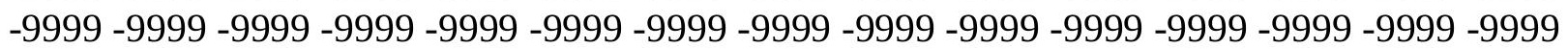


-9999 -9999 -9999 -9999 -9999 -9999 -9999 -9999 -9999 -9999 -9999 -9999 -9999 -9999 -9999 -9999 -9999 -9999 -9999 -9999 -9999 -9999 -9999 -9999 -9999 -9999 -9999 -9999 -9999 -9999 -9999 -9999 -9999 -9999 -9999 -9999 -9999 -9999 -9999 -9999 -9999

-9999 -9999 -9999 -9999 -9999 -9999 -9999 -9999 -9999 -9999 -9999 -9999 -9999 -9999 -9999 -37.488571167 -37.1837806702 -34.4407196045 -31.6976509094 -28.6497993469 $-25.6019496918-22.5541000366-19.5062503815-16.4584007263-13.4105501175$ $-10.3626899719-7.3148431778-4.26699209213-1.219141006471 .21914100647$ 4.2669920921337 .01005792617810 .0579099655212 .4961900711115 .23925971985 17.9823207855220 .4206008911122 .8588790893624 .9923801422127 .4306602478 29.5641593933131 .6976509094233 .5263595581135 .3550796508837 .18378067017 39.0125007629440 .5364189147942 .0603485107443 .5842704772945 .10820007324 46.3273391723644 .5020713806246 .9055404663149 .9847602844254 .25175094604 56.9948196411159 .4331016540561 .5666007995663 .3953094482464 .91924285889 66.1383666992267 .3575134277367 .9670867919968 .2718734741268 .57665252686 68.5766525268667 .9670867919967 .3575134277366 .4431610107465 .52880096436 61.8713798522962 .1761703491262 .4809494018663 .0905189514263 .39530944824 63.7000885009863 .7000885009864 .004882812564 .3096618652364 .30966186523 64.6144485473664 .6144485473664 .6144485473664 .3096618652364 .30966186523 64.3096618652364 .004882812563 .7000885009863 .3953094482462 .78573989868 62.4809494018661 .8713798522961 .2618103027360 .3474502563559 .43310165405 58.5187492370657 .6043891906756 .3852500915555 .4708900451754 .25175094604 53.0326118469251 .8134689331150 .5943298339849 .6799812316948 .46083068848 47.5464782714846 .6321296691945 .717769622844 .8034095764243 .88906097412 43.2794914245642 .3651313781741 .7555618286141 .1459884643640 .53641891479 39.9268493652339 .622070312539 .0125007629438 .7077102661138 .40293121338 38.0981407165537 .7933502197337 .1837806701737 .1837806701736 .87900161743 36.5742111206136 .2694282531735 .9646492004435 .6598587036135 .35507965088 35.0502891540534 .7455101013234 .4407196044934 .1359291076733 .83115005493 33.5263595581133.2215805053732.91679000854 32.6120109558132.30722045898 32.3072204589832 .0024414062531 .6976509094231 .6976509094231 .69765090942 31.6976509094231 .6976509094231 .6976509094231 .6976509094231 .69765090942 31.6976509094232 .0024414062532 .0024414062532 .3072204589832 .30722045898 32.6120109558132 .9167900085433 .2215805053733 .8311500549334 .13592910767 34.7455101013235 .3550796508835 .9646492004436 .8790016174337 .48857116699 38.4029312133839 .0125007629439 .622070312539 .622070312539 .6220703125 38.7077102661137 .4885711669935 .9646492004436 .8790016174337 .79335021973 38.7077102661139 .622070312540 .5364189147941 .7555618286142 .669921875 43.8890609741245 .1082000732446 .3273391723647 .8512611389249 .07040023804 50.5943298339852 .1182594299353 .6421813964855 .1661109924356 .99481964111 58.5187492370660 .3474502563562 .1761703491264 .004882812565 .83358764648 67.6623001098669 .4910125732471 .6244964599673 .7580032348675 .58670806885 77.4154205322379 .2441329956181 .0728530883882 .5967712402384 .12069702148 85.3398437586 .254188537687 .1685485839888 .0829010009888 .69246673584 89.302040100189 .6068267822389 .9116134643690 .2164001464890 .52117919922 90.5211791992290 .8259735107490 .8259735107491 .1307525634891 .13075256348 91.1307525634891 .4355392456190 .8259735107490 .5211791992290 .21640014648 
89.60682678223 88.9972534179788.38768768311 87.77810668945 87.47332763672 86.8637619018686 .254188537685 .9494018554785 .3398437584 .73026275635 84.4254837036184 .1206970214883 .5111236572383 .206336975182 .59677124023 82.2919769287181 .9871978759881 .6824111938581 .3776321411181 .07285308838 80.7680587768680 .4632720947380 .1584930419979 .8537063598679 .54891967773 79.2441329956178 .9393463134878 .9393463134878 .6345596313578 .32978057861 78.3297805786178 .0249862670978 .0249862670977 .7202072143677 .72020721436 77.7202072143677 .7202072143677 .7202072143677 .4154205322377 .72020721436 77.7202072143677 .7202072143677 .7202072143678 .0249862670978 .02498626709 78.0249862670978 .3297805786178 .309570312578 .2980499267678 .93934631348 80.46327209473 -9999 -9999 -9999 -9999 -9999 -9999 -9999 -9999 -9999 -9999 -9999 -9999 -9999 -9999 -9999 -9999 -9999 -9999 -9999 -9999 -9999 -9999 -9999 -9999 -9999 -9999 -9999 -9999 -9999 -9999 -9999 -9999 -9999 -9999 -9999 -9999 -9999 -9999 -9999 -9999 -9999 -9999 -9999 -9999 -9999 -9999 -9999 -9999 -9999 -9999 -9999 -9999 -9999 -9999 -9999 -9999 -9999 -9999 -9999 -9999 -9999 -9999 -9999 -9999 -9999 -9999 -9999 -9999 -9999 -9999 -9999 -9999

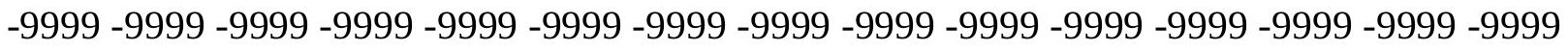
-9999 -9999 -9999 -9999 -9999 -9999 -9999 -9999 -9999 -9999 -9999 -9999 -9999 -9999 -9999 -9999 -9999 -9999 -9999 -9999 -9999 -9999 -9999 -9999 -9999 -9999 -9999 -9999 -9999 -9999 -9999 -9999 -9999 -9999 -9999 -9999 -9999 -9999 -9999 -9999 -9999 -36.8790016174 -36.5742111206 -34.7455101013 -31.6976509094-28.6497993469 $-25.6019496918-22.5541000366-19.5062503815-16.1536102295-13.1057596207$ $-10.0579099655-7.01005792618-3.96220707893-.9143553972241 .828711032867$ 4.876562118537 .92441320419310 .6674804687513 .4105501174916 .15361022949 18.5918903350821 .334960937523 .7732391357425 .906740188628 .34502029419 30.4785099029532 .3072204589834 .4407196044936 .2694282531738 .09814071655 39.622070312541 .4507789611842 .9747009277344 .1938400268645 .7177696228 46.9369087219244 .3093719482446 .9378128051850 .2895507812554 .86132049561 57.6043891906760 .3474502563562 .4809494018664 .3096618652365 .83358764648 67.3575134277368 .2718734741268 .8814392089869 .4910125732469 .49101257324 69.4910125732468 .8814392089868 .2718734741267 .3575134277366 .13836669922 64.9192428588962 .1761703491262 .4809494018662 .7857398986863 .09051895142 63.3953094482463 .7000885009863 .7000885009864 .004882812564 .0048828125 64.3096618652364 .3096618652364 .3096618652364 .3096618652364 .0048828125 64.004882812563 .7000885009863 .3953094482463 .0905189514262 .48094940186 61.8713798522961 .2618103027360 .6522407531759 .7378807067959 .12831115723 57.909179687556 .9948196411155 .7756805419954 .5565414428753 .33739852905 52.4230384826751 .2038993835449 .9847602844248 .765621185347 .85126113892 46.6321296691945 .717769622844 .8034095764243 .8890609741242 .97470092773 42.3651313781741 .4507789611840 .8412094116240 .2316398620639 .6220703125 39.3172798156738 .7077102661138 .4029312133838 .0981407165537 .48857116699 37.1837806701736 .8790016174336 .8790016174336 .5742111206136 .26942825317 35.9646492004435 .6598587036135 .3550796508835 .0502891540535 .05028915405 34.7455101013234 .4407196044934 .1359291076733 .8311500549333 .52635955811 33.2215805053732 .9167900085432 .6120109558132 .3072204589832 .00244140625 31.6976509094231 .3928699493431 .3928699493431 .0880794525131 .08807945251 31.0880794525131 .0880794525131 .0880794525131 .0880794525131 .08807945251 
31.0880794525131 .0880794525131 .3928699493431 .3928699493431 .69765090942 31.6976509094232 .0024414062532 .3072204589832 .6120109558132 .91679000854 33.5263595581133 .8311500549334 .4407196044935 .0502891540535 .65985870361 35.9646492004436 .5742111206136 .8790016174336 .8790016174336 .57421112061 35.9646492004435 .0502891540534 .1359291076734 .4407196044935 .35507965088 36.2694282531737 .4885711669938 .4029312133839 .622070312540 .53641891479 41.7555618286142 .9747009277344 .1938400268645 .4129791259846 .93690872192 48.4608306884849 .9847602844251 .5086898803753 .3373985290555 .16611099243 56.6900291442958 .8235282897960 .6522407531762 .4809494018664 .61444854736 66.7479400634868 .8814392089871 .014930725173 .1484298706175 .28192901611 77.4154205322379 .2441329956181 .0728530883882 .9015579223684 .42548370361 85.6446228027386 .8637619018687 .7781066894588 .3876876831188 .99725341797 89.6068267822389 .9116134643690 .2164001464890 .5211791992290 .82597351074 90.8259735107491 .1307525634891 .1307525634891 .1307525634891 .43553924561 91.4355392456191 .4355392456191 .1307525634890 .5211791992290 .21640014648 89.60682678223 88.9972534179788.38768768311 87.77810668945 87.16854858398 86.8637619018686 .254188537685 .6446228027385 .3398437584 .73026275635 84.1206970214883 .8159103393683 .206336975182 .9015579223682 .59677124023 81.9871978759881 .6824111938581 .3776321411181 .0728530883880 .46327209473 80.1584930419979 .8537063598679 .5489196777379 .2441329956179 .24413299561 78.9393463134878 .6345596313578 .3297805786178 .0249862670978 .02498626709 77.7202072143677 .7202072143677 .4154205322377 .4154205322377 .41542053223 77.1106262207 77.1106262207 77.1106262207 77.1106262207 77.1106262207 77.1106262207 77.110626220777 .4154205322377 .4154205322377 .4154205322377 .72020721436 77.7202072143677 .7202072143677 .7202072143677 .8547515869179 .24413299561 80.76805877686 -9999 -9999 -9999 -9999 -9999 -9999 -9999 -9999 -9999 -9999 -9999 -9999 -9999 -9999 -9999 -9999 -9999 -9999 -9999 -9999 -9999 -9999 -9999 -9999 -9999 -9999 -9999 -

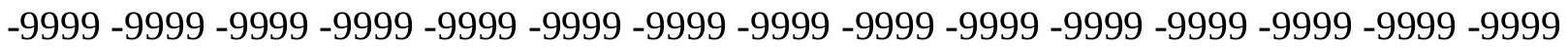

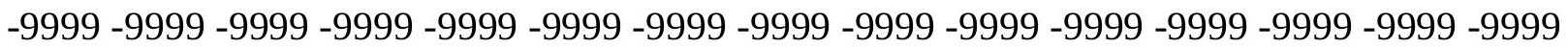

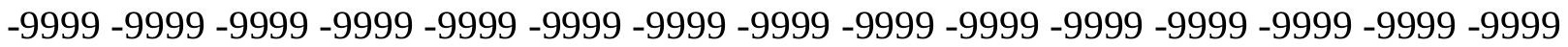
-9999 -9999 -9999 -9999 -9999 -9999 -9999 -9999 -9999 -9999 -9999 -9999 -9999 -9999 -9999 -9999 -9999 -9999 -9999 -9999 -9999 -9999 -9999 -9999 -9999 -9999 -9999 -9999 -9999 -9999 -9999 -9999-9999 -9999-9999-9999-9999-9999-9999-9999

-9999 -9999 -9999 -9999 -9999 -9999 -9999 -9999 -9999 -9999 -9999 -9999 -9999 -9999 -9999 -36.2694282532 -35.9646492004 -34.4407196045 -31.6976509094 -28.6497993469 -25.2971591949 -22.2493095398 -19.2014598846 -15.8488302231 -12.8009700775 $-9.44833946228-6.40048694611-3.04785108566-99992.7430660724645 .790916919708$ 8.53398323059111 .5818300247214 .3248996734617 .0679702758819 .50625038147 22.2493095397924 .6875991821326 .8210906982429 .2593708038331 .39286994934 33.5263595581135 .3550796508837 .1837806701739 .0125007629440 .53641891479 42.0603485107443 .5842704772945 .1082000732446 .3273391723647 .54647827148 44.4048118591347 .2337074279850 .8991203308155 .7756805419958 .51874923706 60.9570198059163 .3953094482465 .2240066528367 .0527267456168 .27187347412 69.1862335205170 .1005783081170 .4053573608470 .4053573608470 .40535736084 70.1005783081169 .1862335205168 .2718734741267 .0527267456165 .52880096436 61.8713798522962 .4809494018662 .7857398986863 .0905189514263 .09051895142 
63.3953094482463 .7000885009863 .7000885009864 .004882812564 .0048828125 64.004882812564 .004882812564 .004882812563 .7000885009863 .70008850098 63.3953094482463 .0905189514262 .4809494018662 .1761703491261 .56660079956 60.9570198059160 .0426712036159 .4331016540558 .5187492370657 .29959869385 56.3852500915555 .1661109924353 .9469718933152 .7278289794951 .50868988037 50.2895507812549 .3751907348648 .1560516357446 .9369087219246 .02254867554 44.8034095764243 .8890609741242 .9747009277342 .0603485107441 .45077896118 40.8412094116239 .9268493652339 .3172798156739 .0125007629438 .40293121338 38.0981407165537 .4885711669937 .1837806701736 .8790016174336 .57421112061 36.5742111206136 .2694282531735 .9646492004435 .6598587036135 .65985870361 35.3550796508835 .0502891540534 .7455101013234 .7455101013234 .44071960449 34.1359291076733 .8311500549333 .5263595581133 .2215805053732 .91679000854 32.6120109558132 .3072204589832 .0024414062531 .6976509094231 .39286994934 31.0880794525130 .7833003997830 .7833003997830 .7833003997830 .78330039978 30.4785099029530 .4785099029530 .4785099029530 .4785099029530 .47850990295 30.4785099029530 .7833003997830 .7833003997830 .7833003997831 .08807945251 31.0880794525131 .3928699493431 .6976509094232 .0024414062532 .30722045898 32.6120109558132 .9167900085433 .2215805053733 .5263595581133 .83115005493 34.4407196044934 .4407196044934 .4407196044934 .4407196044933 .83115005493 33.2215805053732 .9167900085432 .9167900085433 .5263595581134 .44071960449 35.6598587036136 .5742111206137 .4885711669938 .7077102661139 .6220703125 40.8412094116242 .0603485107443 .2794914245644 .8034095764246 .32733917236 47.8512611389249 .3751907348651 .2038993835453 .0326118469254 .86132049561 56.9948196411159 .1283111572360 .9570198059163 .0905189514265 .52880096436 67.6623001098670 .1005783081172 .5388565063574 .6723632812577 .1106262207 79.2441329956181 .3776321411183 .206336975184 .7302627563585 .94940185547 87.1685485839888 .0829010009888 .9972534179789 .302040100189 .91161346436 90.2164001464890 .5211791992290 .5211791992290 .8259735107490 .82597351074 91.1307525634891 .1307525634891 .1307525634891 .1307525634891 .13075256348 91.1307525634890 .8259735107490 .5211791992289 .9116134643689 .60682678223 88.9972534179788 .3876876831187 .7781066894587 .1685485839886 .55898284912 85.9494018554785 .6446228027385 .0350494384884 .4254837036184 .12069702148 83.5111236572383 .206336975182 .5967712402382 .2919769287181 .68241119385 81.3776321411181 .0728530883880 .4632720947380 .1584930419979 .85370635986 79.5489196777379 .2441329956178 .9393463134878 .6345596313578 .32978057861 78.3297805786178 .0249862670977 .7202072143677 .7202072143677 .41542053223 77.110626220777 .110626220777 .110626220776 .8058471679776 .80584716797 76.8058471679776 .8058471679776 .8058471679776 .8058471679776 .80584716797 76.8058471679776 .8058471679776 .8058471679777 .110626220777 .1106262207 77.110626220777 .110626220777 .2561874389677 .3954086303777 .51567840576 79.85370635986 -9999 -9999 -9999 -9999 -9999 -9999 -9999 -9999 -9999 -9999 -9999 -9999 -9999 -9999 -9999 -9999 -9999 -9999 -9999 -9999 -9999 -9999 -9999 -9999 -9999 -9999-9999 - -999 -9999 -9999 -9999 -9999 -9999 -9999 -9999 -9999 -9999 -9999 -9999 -9999 -9999 -9999 -9999 -9999 -9999 -9999 -9999 -9999 -9999 -9999 -9999 -9999-9999 -9999 -9999 -9999 -9999 -9999 -9999 -9999 -9999 -9999 -9999 -9999 -9999 -9999 -9999 -9999 -9999 -9999 -9999 -9999 -9999 -

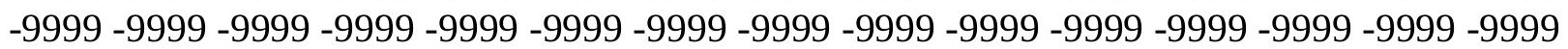


-9999 -9999 -9999 -9999 -9999 -9999 -9999 -9999 -9999 -9999 -9999 -9999 -9999 -9999 -9999 -9999 -9999 -9999 -9999 -9999 -9999 -9999 -9999 -9999 -9999

-9999 -9999 -9999 -9999 -9999 -9999 -9999 -9999 -9999 -9999 -9999 -9999 -9999 -9999 -9999 -9999 -35.0502891541 -34.1359291077 -31.0880794525 -28.0402297974 -24.9923801422 $-21.9445304871-18.5918903351-15.2392597198-12.1914100647-8.83876895905$ $-5.48613214493-2.43828105927 .60957032442093 .6574220657356 .705273151398$ 9.75312423706112 .4961900711115 .2392597198517 .9823207855220 .72538948059 23.1636695861825 .6019496917728 .0402297973630 .4785099029532 .61201095581 34.4407196044936 .5742111206138 .4029312133839 .9268493652341 .75556182861 43.2794914245644 .4986305236846 .0225486755447 .2416992187548 .46083068848 49.3751907348647 .7482948303251 .5086898803756 .3852500915559 .12831115723 61.8713798522964 .3096618652366 .1383666992267 .9670867919969 .18623352051 70.4053573608471 .014930725171 .3197174072371 .6244964599671 .31971740723 71.014930725170 .1005783081169 .1862335205167 .9670867919966 .44316101074 61.8713798522962 .1761703491262 .4809494018662 .7857398986863 .09051895142 63.3953094482463 .3953094482463 .7000885009863 .7000885009863 .70008850098 64.004882812564 .004882812563 .7000885009863 .7000885009863 .39530944824 63.0905189514262 .7857398986862 .1761703491261 .8713798522961 .26181030273 60.3474502563559 .7378807067958 .8235282897957 .909179687556 .99481964111 55.7756805419954 .5565414428753 .3373985290552 .1182594299350 .89912033081 49.6799812316948 .4608306884847 .2416992187546 .3273391723645 .10820007324 44.1938400268642 .9747009277342 .0603485107441 .4507789611840 .53641891479 39.9268493652339 .3172798156738 .7077102661138 .0981407165537 .79335021973 37.1837806701736 .8790016174336 .5742111206136 .2694282531735 .96464920044 35.9646492004435 .6598587036135 .6598587036135 .3550796508835 .05028915405 35.0502891540534 .7455101013234 .7455101013234 .4407196044934 .13592910767 33.8311500549333 .5263595581133 .2215805053732 .9167900085432 .61201095581 32.3072204589832 .0024414062531 .6976509094231 .3928699493431 .08807945251 30.7833003997830 .4785099029530 .4785099029530 .4785099029530 .17373085022 30.1737308502230 .1737308502230 .1737308502230 .1737308502230 .17373085022 30.1737308502230 .1737308502230 .1737308502230 .1737308502230 .47850990295 30.4785099029530 .4785099029530 .7833003997830 .7833003997831 .08807945251 31.0880794525131 .3928699493431 .6976509094231 .6976509094232 .00244140625 32.3072204589832 .3072204589832 .6120109558132 .3072204589832 .30722045898 32.0024414062531 .6976509094232 .0024414062532 .3072204589832 .91679000854 33.8311500549334 .7455101013235 .6598587036136 .5742111206137 .79335021973 38.7077102661139 .9268493652341 .1459884643642 .66992187544 .19384002686 45.717769622847 .2416992187549 .0704002380451 .2038993835453 .03261184692 55.1661109924357 .2995986938559 .4331016540561 .8713798522964 .0048828125 66.7479400634869 .1862335205171 .6244964599674 .062782287676 .80584716797 78.9393463134881 .0728530883883 .206336975184 .7302627563586 .2541885376 87.4733276367288 .3876876831188 .9972534179789 .6068267822389 .91161346436 90.2164001464890 .5211791992290 .5211791992290 .8259735107490 .82597351074 90.8259735107490 .8259735107490 .8259735107490 .8259735107490 .82597351074 90.8259735107490 .5211791992290 .2164001464889 .6068267822389 .3020401001 88.6924667358488 .0829010009887 .4733276367286 .8637619018686 .2541885376 
85.6446228027385 .3398437584 .7302627563584 .1206970214883 .81591033936 83.206336975182.90155792236 82.29197692871 81.98719787598 81.37763214111 81.0728530883880 .7680587768680 .1584930419979 .8537063598679 .54891967773 79.2441329956178 .9393463134878 .6345596313578 .3297805786178 .02498626709 77.7202072143677 .4154205322377 .4154205322377 .110626220777 .1106262207 76.8058471679776 .8058471679776 .5010681152376 .5010681152376 .50106811523 76.1962814331176 .1962814331176 .1962814331176 .1962814331176 .19628143311 76.1962814331176 .5010681152376 .5010681152376 .5010681152376 .50106811523 76.8058471679776 .8058471679776 .8058471679776 .9688415527377 .09966278076 78.6345596313580 .15849304199 -9999 -9999 -9999 -9999 -9999 -9999 -9999 -9999 -9999 -9999 -9999 -9999 -9999 -9999 -9999 -9999 -9999 -9999 -9999 -9999 -9999 -9999 -9999 -9999 -9999 -9999 -9999 -9999 -9999 -9999 -9999 -9999 -9999 -9999 -9999 -9999 -9999 -9999 -9999

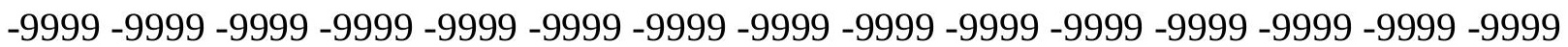
-9999 -9999 -9999 -9999 -9999 -9999 -9999 -9999 -9999 -9999 -9999 -9999 -9999 -9999 -9999 -9999 -9999 -9999 -9999 -9999 -9999 -9999 -9999 -9999 -9999 -9999 -9999 -9999 -9999 -9999 -9999 -9999 -9999 -9999 -9999 -9999 -9999 -9999 -9999 -9999 -9999 -9999 -9999 -9999 -9999 -9999 -9999 -9999 -9999 -9999 -9999 -9999 -9999 -9999 -9999 -9999 -9999 -9999 -9999 -9999 -9999 -9999 -9999 -9999 -9999 -9999 -9999 -9999 -9999 -9999 -9999 -9999 -9999 -33.8311500549 -33.8311500549 -30.7833003998 -27.7354507446 -24.3828105927 -21.0301704407 -17.9823207855 -14.6296901703 -11.2770500183 -7.92441320419 $-4.57177686691-1.523926019671 .5239260196694 .5717768669137 .619627952576$ 10.6674804687513 .715330123916 .4584007263219 .2014598846421 .94453048706 24.6875991821327 .1258792877229 .2593708038331 .6976509094233 .83115005493 35.6598587036137 .7933502197339 .3172798156741 .1459884643642 .669921875 44.1938400268645 .717769622846 .9369087219248 .1560516357449 .37519073486 50.2895507812548 .4195251464852 .1182594299356 .9948196411160 .04267120361 62.7857398986865 .2240066528367 .3575134277368 .8814392089870 .10057830811 71.3197174072371 .9292907714872 .2340774536172 .5388565063572 .23407745361 71.9292907714871 .3197174072370 .1005783081168 .8814392089867 .35751342773 65.5288009643662 .1761703491262 .4809494018662 .7857398986862 .78573989868 63.0905189514263 .3953094482463 .3953094482463 .7000885009863 .70008850098 63.7000885009863 .7000885009863 .7000885009863 .3953094482463 .09051895142 62.7857398986862 .4809494018662 .1761703491261 .5666007995660 .95701980591 60.0426712036159 .4331016540558 .5187492370657 .2995986938556 .38525009155 55.1661109924353 .9469718933152 .7278289794951 .5086898803750 .28955078125 49.0704002380447 .8512611389246 .6321296691945 .4129791259844 .49863052368 43.2794914245642 .3651313781741 .4507789611840 .5364189147939 .6220703125 39.0125007629438 .4029312133837 .7933502197337 .1837806701736 .87900161743 36.5742111206136 .2694282531735 .9646492004435 .6598587036135 .65985870361 35.3550796508835 .3550796508835 .0502891540535 .0502891540535 .05028915405 34.7455101013234 .7455101013234 .4407196044934 .4407196044934 .13592910767 33.8311500549333 .5263595581133 .2215805053732 .9167900085432 .61201095581 32.3072204589832 .0024414062531 .3928699493431 .0880794525130 .78330039978 30.4785099029530 .1737308502230 .1737308502229 .8689403533929 .86894035339 29.8689403533929 .8689403533929 .8689403533929 .5641593933129 .56415939331 29.5641593933129 .5641593933129 .8689403533929 .8689403533929 .86894035339 
29.8689403533929 .8689403533929 .8689403533929 .8689403533930 .17373085022 30.1737308502230 .1737308502230 .1737308502230 .1737308502230 .17373085022 30.4785099029530 .4785099029530 .7833003997830 .7833003997830 .78330039978 30.7833003997830 .7833003997830 .7833003997831 .0880794525131 .69765090942 32.6120109558133 .2215805053734 .1359291076735 .0502891540535 .96464920044 36.8790016174337 .7933502197339 .0125007629440 .5364189147941 .75556182861 43.5842704772945 .1082000732447 .2416992187549 .0704002380451 .20389938354 53.3373985290555 .4708900451757 .909179687560 .0426712036162 .78573989868 65.2240066528367 .9670867919970 .7101516723673 .4532165527376 .19628143311 78.6345596313581 .0728530883883 .206336975185 .0350494384886 .55898284912 87.4733276367288 .3876876831188 .9972534179789 .6068267822389 .91161346436 89.9116134643690 .2164001464890 .2164001464890 .5211791992290 .52117919922 90.5211791992290 .5211791992290 .5211791992290 .5211791992290 .52117919922 90.2164001464889 .9116134643689 .6068267822389 .302040100188 .69246673584 88.38768768311 87.77810668945 87.16854858398 86.55898284912 85.94940185547 85.3398437585 .0350494384884 .4254837036183 .8159103393683 .51112365723 82.9015579223682 .2919769287181 .9871978759881 .3776321411181 .07285308838 80.7680587768680 .1584930419979 .8537063598679 .5489196777379 .24413299561 78.9393463134878 .6345596313578 .3297805786178 .0249862670977 .72020721436 77.4154205322377 .110626220776 .8058471679776 .8058471679776 .50106811523 76.5010681152376 .1962814331176 .1962814331176 .1962814331175 .89148712158 75.8914871215875 .8914871215875 .8914871215875 .8914871215875 .89148712158 75.8914871215875 .8914871215875 .8914871215876 .1962814331176 .19628143311 76.1962814331176 .1962814331176 .5010681152376 .5010681152376 .68794250488 76.7637786865279 .24413299561 -9999 -9999 -9999 -9999 -9999 -9999 -9999 -9999 -9999 -9999 -9999 -9999 -9999 -9999 -9999 -9999 -9999 -9999 -9999 -9999 -9999 -9999 -9999 -9999 -9999 -9999 -9999 -9999 -9999 -9999 -9999 -9999 -9999 -9999 -9999 -9999 -9999 -9999 -9999

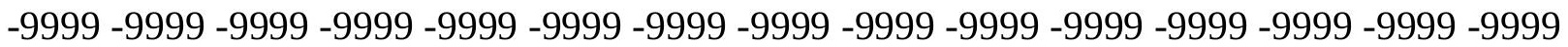

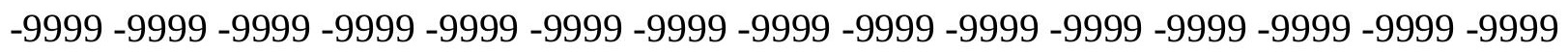

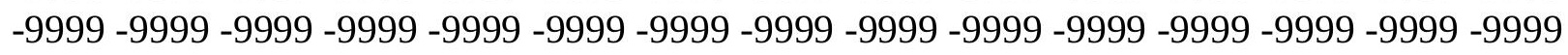

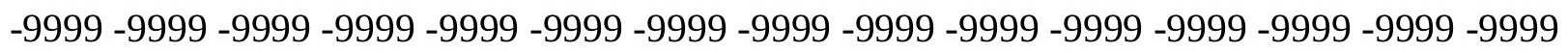
-9999 -9999 -9999 -9999 -9999 -9999 -9999 -9999 -9999 -9999 -9999 -9999 -9999 -9999-9999 -9999 -9999 -9999 -9999 -9999 -9999-9999 -9999 -9999 -9999 -9999 -9999 -9999 -32.307220459 -32.6120109558 -29.8689403534-26.8210906982 -23.4684505463 -20.4206008911 -17.0679702759-13.7153301239 -10.3626899719-6.7052731514 -3.65742206573 -.304785102606 2.743066072464 5.790916919708 9.143553733826 12.191410064714 .934470176717 .9823207855220 .7253894805923 .46845054626 25.906740188628 .3450202941930 .7833003997832 .9167900085435 .05028915405 37.1837806701739 .0125007629440 .8412094116242 .3651313781743 .88906097412 45.4129791259846 .6321296691947 .8512611389249 .0704002380450 .28955078125 51.2038993835449 .1246948242253 .0326118469257 .2995986938560 .65224075317 63.3953094482466 .1383666992267 .9670867919969 .7957916259871 .0149307251 72.2340774536172 .8436431884873 .1484298706173 .4532165527373 .14842987061 72.8436431884872 .2340774536171 .014930725169 .7957916259868 .27187347412 66.4431610107462 .1761703491262 .1761703491262 .4809494018662 .78573989868 63.0905189514263 .0905189514263 .3953094482463 .3953094482463 .39530944824 
63.7000885009863 .3953094482463 .3953094482463 .3953094482463 .09051895142 62.7857398986862 .4809494018661 .8713798522961 .2618103027360 .65224075317 59.7378807067958 .8235282897957 .909179687556 .9948196411155 .77568054199 54.5565414428753 .3373985290552 .1182594299350 .8991203308149 .67998123169 48.4608306884847 .2416992187546 .0225486755444 .8034095764243 .58427047729 42.3651313781741 .4507789611840 .5364189147939 .622070312539 .01250076294 38.0981407165537 .4885711669937 .1837806701736 .5742111206136 .26942825317 35.9646492004435 .6598587036135 .3550796508835 .0502891540535 .05028915405 35.0502891540534 .7455101013234 .7455101013234 .7455101013234 .74551010132 34.7455101013234 .4407196044934 .4407196044934 .4407196044934 .13592910767 33.8311500549333 .5263595581133 .2215805053732 .9167900085432 .61201095581 32.3072204589832 .0024414062531 .3928699493431 .0880794525130 .78330039978 30.4785099029530 .1737308502229 .8689403533929 .8689403533929 .56415939331 29.5641593933129 .5641593933129 .5641593933129 .5641593933129 .25937080383 29.2593708038329 .2593708038329 .2593708038329 .2593708038329 .25937080383 29.2593708038329 .2593708038329 .2593708038329 .2593708038329 .25937080383 28.9545898437528 .9545898437528 .9545898437528 .6497993469228 .64979934692 28.6497993469228 .9545898437529 .2593708038329 .2593708038329 .56415939331 29.5641593933129 .5641593933129 .8689403533930 .1737308502230 .78330039978 31.3928699493432 .0024414062532 .6120109558133 .2215805053734 .13592910767 35.0502891540535 .9646492004436 .8790016174338 .4029312133839 .6220703125 41.4507789611842 .9747009277345 .1082000732446 .9369087219249 .07040023804 51.5086898803753 .6421813964856 .0804595947358 .5187492370661 .26181030273 64.004882812566 .7479400634869 .4910125732472 .5388565063575 .28192901611 78.0249862670980 .4632720947382 .9015579223684 .7302627563586 .55898284912 87.47332763672 88.38768768311 88.99725341797 89.3020401001 89.3020401001 89.6068267822389 .6068267822389 .9116134643689 .9116134643689 .91161346436 89.9116134643689 .9116134643689 .9116134643689 .9116134643689 .60682678223 89.6068267822389 .302040100188 .9972534179788 .6924667358488 .08290100098 87.7781066894587 .1685485839886 .5589828491286 .254188537685 .64462280273 85.0350494384884 .4254837036184 .1206970214883 .5111236572382 .90155792236 82.5967712402381 .9871978759881 .6824111938581 .0728530883880 .76805877686 80.1584930419979 .8537063598679 .5489196777379 .2441329956178 .63455963135 78.3297805786178 .0249862670977 .7202072143677 .4154205322377 .1106262207 77.110626220776 .8058471679776 .5010681152376 .1962814331176 .19628143311 75.8914871215875 .8914871215875 .5867080688575 .5867080688575 .58670806885 75.5867080688575 .5867080688575 .2819290161175 .2819290161175 .28192901611 75.2819290161175 .5867080688575 .5867080688575 .5867080688575 .58670806885 75.8914871215875 .8914871215875 .8914871215876 .1962814331176 .19628143311 76.3195648193478 .0249862670979 .54891967773 -9999 -9999 -9999 -9999 -9999 -9999 -9999 -9999 -9999 -9999 -9999 -9999 -9999 -9999 -9999 -9999 -9999 -9999 -9999 -9999 -9999 -9999 -9999 -9999 -9999 -9999 -9999 -9999 -9999 -9999 -9999 -9999 -9999 -9999 -9999 -9999 -9999 -9999 -9999 -9999 -9999 -9999 -9999 -9999 -9999 -9999 -9999 -9999 -9999 -9999 -9999 -9999 -9999 -9999 -9999 -9999 -9999 -9999 -9999 -9999 -9999 -9999 -9999 -9999 -9999 -9999 -9999 -9999 -9999 -9999 -9999 -9999 -9999 -9999 -9999 -9999 -9999 -9999 -9999 -9999 -9999 -9999 -

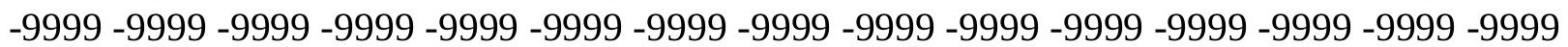


-9999 -9999 -9999 -9999 -9999 -9999 -9999 -9999 -9999 -9999 -9999 -9999 -9999

-9999 -9999 -9999 -9999 -9999 -9999 -9999 -9999 -9999 -9999 -9999 -9999 -9999 -9999 -9999

-9999 -30.7833003998 -30.7833003998 -28.9545898438 -25.9067401886 -22.5541000366

$-19.2014598846-15.8488302231-12.4961900711-8.83876895905-5.48613214493$

-2.17437958717.9143553972244 4.266992092133 7.314843177795 10.66748046875

13.715330123916 .4584007263219 .5062503814722 .2493095397924 .99238014221 27.430660247829 .8689403533932 .3072204589834 .4407196044936 .57421112061 38.7077102661140 .5364189147942 .0603485107443 .8890609741245 .10820007324 46.6321296691947 .8512611389249 .0704002380450 .2895507812551 .20389938354 52.1182594299349 .4348220825253 .1523590087957 .909179687561 .26181030273 64.3096618652366 .7479400634868 .8814392089870 .4053573608471 .92929077148 72.8436431884873 .4532165527374 .062782287674 .062782287674 .0627822876 73.7580032348673 .1484298706172 .2340774536170 .7101516723669 .18623352051 67.3575134277365 .2240066528362 .1761703491262 .4809494018662 .78573989868 62.7857398986863 .0905189514263 .0905189514263 .3953094482463 .39530944824 63.3953094482463 .3953094482463 .3953094482463 .0905189514262 .78573989868 62.4809494018662 .1761703491261 .5666007995660 .9570198059160 .34745025635 59.4331016540558 .8235282897957 .6043891906756 .6900291442955 .47089004517 54.2517509460453 .0326118469251 .8134689331150 .2895507812549 .07040023804 47.8512611389246 .3273391723645 .1082000732443 .8890609741242 .669921875 41.7555618286140 .5364189147939 .622070312539 .0125007629438 .09814071655 37.4885711669936 .8790016174336 .2694282531735 .9646492004435 .35507965088 35.0502891540535 .0502891540534 .7455101013234 .7455101013234 .74551010132 34.4407196044934 .4407196044934 .4407196044934 .4407196044934 .74551010132 34.4407196044934 .4407196044934 .4407196044934 .4407196044934 .13592910767 34.1359291076733 .8311500549333 .5263595581133 .2215805053732 .91679000854 32.6120109558132 .0024414062531 .6976509094231 .0880794525130 .78330039978 30.1737308502229 .8689403533929 .8689403533929 .5641593933129 .56415939331 29.5641593933129 .2593708038329 .2593708038329 .2593708038329 .25937080383 28.9545898437528 .9545898437528 .9545898437528 .9545898437528 .95458984375 28.9545898437528 .6497993469228 .6497993469228 .6497993469228 .34502029419 28.3450202941928 .0402297973628 .0402297973627 .7354507446327 .4306602478 27.430660247827 .430660247827 .7354507446328 .0402297973628 .34502029419 28.6497993469228 .6497993469228 .9545898437529 .2593708038329 .56415939331 30.1737308502230 .7833003997831 .3928699493431 .6976509094232 .61201095581 33.2215805053734 .1359291076735 .0502891540536 .2694282531737 .48857116699 39.3172798156741 .1459884643642 .9747009277345 .1082000732447 .24169921875 49.3751907348651 .8134689331154 .2517509460456 .6900291442959 .43310165405 62.4809494018665 .2240066528368 .2718734741271 .3197174072374 .0627822876 77.110626220779 .8537063598682 .2919769287184 .4254837036186 .2541885376 87.4733276367288 .0829010009888 .3876876831188 .6924667358488 .69246673584 88.9972534179788 .9972534179788 .9972534179788 .9972534179788 .99725341797 88.99725341797 88.99725341797 88.99725341797 88.99725341797 88.99725341797 88.6924667358488 .6924667358488 .3876876831187 .7781066894587 .47332763672 87.1685485839886 .5589828491285 .9494018554785 .6446228027385 .03504943848 84.4254837036184 .1206970214883 .5111236572382 .9015579223682 .59677124023 
81.9871978759881 .6824111938581 .0728530883880 .7680587768680 .15849304199 79.8537063598679 .5489196777378 .9393463134878 .6345596313578 .32978057861 78.0249862670977 .7202072143677 .4154205322377 .110626220776 .80584716797 76.5010681152376 .1962814331176 .1962814331175 .8914871215875 .89148712158 75.5867080688575 .5867080688575 .2819290161175 .2819290161175 .28192901611 74.9771423339874 .9771423339874 .9771423339874 .9771423339874 .97714233398 74.9771423339874 .9771423339874 .9771423339875 .2819290161175 .28192901611 75.2819290161175 .2819290161175 .5867080688575 .5867080688575 .74594116211 75.8698654174875 .9697952270578 .63455963135 -9999 -9999 -9999 -9999 -9999 -9999 -9999 -9999 -9999 -9999 -9999 -9999 -9999 -9999 -9999 -9999 -9999 -9999 -9999 -9999 -9999 -9999

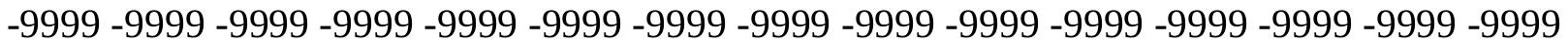
-9999 -9999 -9999 -9999 -9999 -9999 -9999 -9999 -9999 -9999 -9999 -9999 -9999 -9999 -9999 -9999 -9999 -9999 -9999 -9999 -9999 -9999 -9999 -9999 -9999 -9999 -9999 -9999 -9999 -9999 -9999 -9999 -9999 -9999 -9999 -9999 -9999 -9999 -9999 -9999 -9999 -9999 -9999 -9999 -9999 -9999 -9999 -9999 -9999 -9999 -9999 -9999 -9999 -9999 -9999 -9999 -9999 -9999 -9999 -9999 -

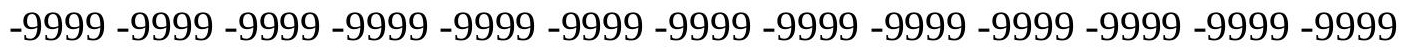
-9999 -9999-9999 -9999 -9999 -9999 -9999 -9999 -9999 -9999 -9999 -9999 -9999 -9999 -9999 -9999 -28.6497993469 -28.9545898438 -27.7354507446 -24.3828105927 -21.3349609375 -17.9823207855 -14.3248996735 -10.9722604752 -7.61962795258 -3.96220707893 -.609570324421 2.438281059265 5.790916919708 8.838768959045 12.1914100647 15.2392597198518 .28710937521 .334960937524 .0780296325726 .82109069824 29.2593708038331 .6976509094234 .1359291076736 .2694282531738 .40293121338 40.2316398620642 .0603485107443 .5842704772945 .1082000732446 .63212966919 47.8512611389249 .3751907348650 .2895507812551 .5086898803752 .42303848267 53.3373985290549 .6163368225152 .5756492614755 .4708900451761 .56660079956 64.61444854736 67.35751342773 69.18623352051 71.0149307251 72.23407745361 73.1484298706174 .062782287674 .3675689697374 .6723632812574 .67236328125 74.3675689697373 .7580032348673 .1484298706171 .9292907714870 .40535736084 68.5766525268666 .4431610107462 .1761703491262 .4809494018662 .48094940186 62.7857398986863 .0905189514263 .0905189514263 .0905189514263 .39530944824 63.3953094482463 .3953094482463 .0905189514263 .0905189514262 .78573989868 62.4809494018662 .1761703491261 .5666007995660 .9570198059160 .34745025635 59.4331016540558 .5187492370657 .2995986938556 .3852500915555 .16611099243 53.9469718933152 .4230384826751 .2038993835449 .6799812316948 .46083068848 47.2416992187545 .717769622844 .4986305236843 .2794914245642 .06034851074 40.8412094116239 .9268493652339 .0125007629438 .0981407165537 .18378067017 36.5742111206135 .9646492004435 .3550796508835 .0502891540534 .74551010132 34.4407196044934 .4407196044934 .1359291076734 .1359291076734 .13592910767 34.1359291076734 .4407196044934 .4407196044934 .4407196044934 .44071960449 34.7455101013234 .7455101013234 .7455101013234 .4407196044934 .44071960449 34.4407196044934 .1359291076733 .8311500549333 .5263595581133 .22158050537 32.9167900085432 .3072204589832 .0024414062531 .3928699493430 .78330039978 30.4785099029529 .8689403533929 .8689403533929 .5641593933129 .56415939331 29.2593708038329 .2593708038329 .2593708038328 .9545898437528 .95458984375 28.9545898437528 .9545898437528 .6497993469228 .6497993469228 .64979934692 28.6497993469228 .3450202941928 .3450202941928 .0402297973628 .04022979736 
27.7354507446327 .430660247827 .1258792877226 .8210906982426 .51630973816 26.2115192413326 .5163097381626 .8210906982427 .1258792877227 .4306602478 27.7354507446327 .7354507446328 .0402297973628 .3450202941928 .64979934692 29.2593708038329 .5641593933130 .1737308502230 .4785099029531 .08807945251 31.6976509094232 .3072204589833 .2215805053734 .1359291076735 .65985870361 37.1837806701739 .0125007629441 .1459884643642 .9747009277345 .41297912598 47.5464782714849 .9847602844252 .4230384826755 .1661109924357 .9091796875 60.6522407531763 .7000885009866 .7479400634869 .7957916259872 .84364318848 75.8914871215878 .6345596313581 .6824111938583 .8159103393685 .64462280273 86.8637619018687 .4733276367287 .7781066894587 .7781066894587 .77810668945 87.7781066894587 .7781066894588 .0829010009888 .0829010009888 .08290100098 88.0829010009888 .0829010009888 .0829010009888 .0829010009888 .08290100098 87.7781066894587 .7781066894587 .4733276367287 .1685485839886 .86376190186 86.254188537685 .9494018554785 .3398437585 .0350494384884 .42548370361 83.8159103393683 .5111236572382 .9015579223682 .5967712402381 .98719787598 81.6824111938581 .0728530883880 .7680587768680 .1584930419979 .85370635986 79.2441329956178 .9393463134878 .6345596313578 .3297805786177 .72020721436 77.4154205322377 .110626220776 .8058471679776 .5010681152376 .50106811523 76.1962814331175 .8914871215875 .5867080688575 .5867080688575 .28192901611 75.2819290161174 .9771423339874 .9771423339874 .6723632812574 .67236328125 74.6723632812574 .6723632812574 .6723632812574 .6723632812574 .67236328125 74.6723632812574 .6723632812574 .6723632812574 .6723632812574 .67236328125 74.9771423339874 .9771423339874 .9771423339875 .2819290161175 .28192901611 75.4231033325275 .5345001220775 .6553421020578 .93934631348 -9999 -9999 -9999 -9999 -9999 -9999 -9999 -9999 -9999 -9999 -9999 -9999 -9999 -9999 -9999 -9999 -9999 -9999 -9999 -9999 -9999 -9999 -9999 -9999 -9999 -9999 -9999 -9999 -9999 -9999 -9999 -9999 -9999 -9999 -9999 -9999 -9999 -9999 -9999 -9999 -9999 -9999 -9999 -9999 -9999 -9999 -9999 -9999 -9999

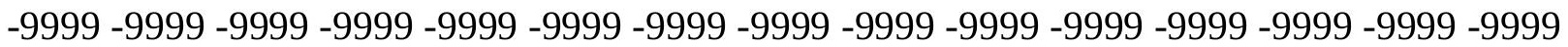

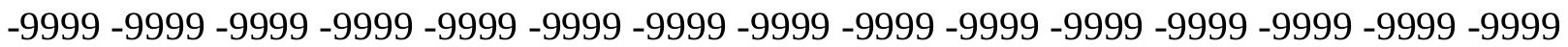

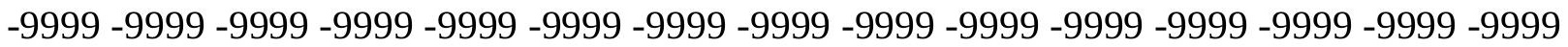
-9999 -9999 -9999 -9999 -9999 -9999 -9999 -9999 -9999 -9999 -9999 -9999 -9999 -9999 -9999 -9999 -9999 -9999 -9999 -9999 -9999 -9999 -9999 -9999 -9999 -9999 -9999 -9999 -9999 -9999 -9999 -9999-26.5163097382 -26.2115192413-22.8588790894-19.5062503815 -16.1536102295 -12.8009700775 -9.44833946228 -5.79091691971 -2.43828105927 .60957032442094 .2669920921337 .61962795257610 .6674804687514 .02011966705 17.0679702758820 .1158199310323 .1636695861825 .906740188628 .64979934692 31.0880794525133 .5263595581135 .9646492004438 .0981407165539 .92684936523 42.0603485107443 .5842704772945 .4129791259846 .9369087219248 .15605163574 49.3751907348650 .5943298339851 .8134689331152 .7278289794953 .64218139648 54.2517509460455 .1661109924352 .6265106201256 .3852500915561 .87137985229 65.2240066528367 .6623001098669 .4910125732471 .014930725172 .23407745361 73.4532165527374 .3675689697374 .9771423339875 .2819290161175 .28192901611 75.2819290161174 .6723632812573 .7580032348672 .8436431884871 .31971740723 69.4910125732467 .3575134277362 .1761703491262 .1761703491262 .48094940186 62.7857398986862 .7857398986863 .0905189514263 .0905189514263 .09051895142 63.3953094482463 .0905189514263 .0905189514263 .0905189514262 .78573989868 
62.4809494018662 .1761703491261 .5666007995660 .9570198059160 .04267120361 59.1283111572358 .2139587402357 .2995986938556 .0804595947354 .86132049561 53.3373985290552 .1182594299350 .5943298339849 .3751907348647 .85126113892 46.6321296691945 .1082000732443 .8890609741242 .3651313781741 .14598846436 40.2316398620639 .0125007629438 .0981407165537 .1837806701736 .57421112061 35.6598587036135 .0502891540534 .7455101013234 .4407196044934 .13592910767 33.8311500549333 .8311500549333 .8311500549333 .8311500549333 .83115005493 33.8311500549334 .1359291076734 .1359291076734 .4407196044934 .44071960449 34.7455101013234 .7455101013234 .7455101013234 .7455101013234 .74551010132 34.7455101013234 .4407196044934 .4407196044934 .1359291076733 .52635955811 33.2215805053732 .9167900085432 .3072204589831 .6976509094231 .08807945251 30.4785099029530 .1737308502229 .8689403533929 .8689403533929 .56415939331 29.5641593933129 .2593708038329 .2593708038328 .9545898437528 .95458984375 28.9545898437528 .6497993469228 .6497993469228 .6497993469228 .34502029419 28.3450202941928 .0402297973628 .0402297973627 .7354507446327 .4306602478 27.430660247827 .1258792877226 .8210906982426 .5163097381626 .21151924133 25.906740188625 .906740188626 .2115192413326 .5163097381626 .82109069824 26.8210906982427 .1258792877227 .430660247827 .7354507446328 .04022979736 28.3450202941928 .6497993469228 .9545898437529 .2593708038329 .86894035339 30.1737308502230 .7833003997831 .3928699493432 .3072204589833 .52635955811 35.3550796508837 .1837806701739 .3172798156741 .1459884643643 .58427047729 45.717769622848 .1560516357450 .5943298339853 .3373985290556 .08045959473 58.8235282897961 .5666007995664 .6144485473667 .6623001098671 .0149307251 74.062782287677 .110626220780 .1584930419982 .9015579223685 .03504943848 85.9494018554786 .254188537686 .5589828491286 .5589828491286 .55898284912 86.5589828491286 .5589828491286 .5589828491286 .8637619018686 .86376190186 86.8637619018686 .8637619018686 .8637619018686 .8637619018686 .86376190186 86.8637619018686 .5589828491286 .5589828491286 .254188537685 .94940185547 85.3398437585 .0350494384884 .7302627563584 .1206970214883 .81591033936 83.2063369751 82.9015579223682.29197692871 81.98719787598 81.37763214111 81.0728530883880 .4632720947380 .1584930419979 .5489196777379 .24413299561 78.9393463134878 .6345596313578 .0249862670977 .7202072143677 .41542053223 77.110626220776 .8058471679776 .5010681152376 .1962814331175 .89148712158 75.5867080688575 .5867080688575 .2819290161174 .9771423339874 .97714233398 74.6723632812574 .6723632812574 .3675689697374 .3675689697374 .36756896973 74.3675689697374 .062782287674 .062782287674 .062782287674 .0627822876 74.062782287674 .062782287674 .062782287674 .3675689697374 .36756896973 74.3675689697374 .3675689697374 .6723632812574 .6723632812574 .97714233398 74.9771423339875 .0967941284275 .2326354980578 .02498626709 -9999 -9999 -9999 -9999 -9999 -9999 -9999 -9999 -9999 -9999 -9999 -9999 -9999 -9999 -9999 -9999 -9999 -9999 -9999

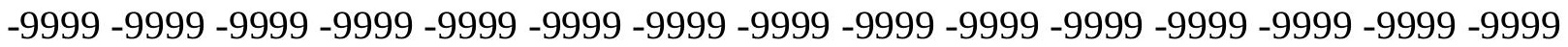
-9999 -9999 -9999 -9999 -9999 -9999 -9999 -9999 -9999 -9999 -9999 -9999 -9999 -9999 -9999 -9999 -9999 -9999 -9999 -9999 -9999 -9999 -9999 -9999 -9999 -9999 -9999 -9999 -9999 -9999 -9999 -9999 -9999 -9999 -9999 -9999 -9999 -9999 -9999 -9999 -9999 -9999 -9999 -9999 -9999 -9999 -9999 -9999 -9999 -9999 -9999 -9999 -9999 -9999 -9999 -9999 -9999 -9999 -9999 -9999 -

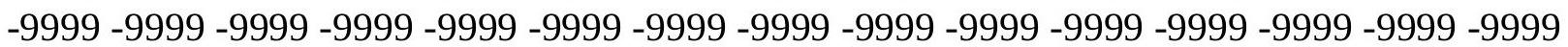


-9999 -9999 -9999 -9999 -9999 -9999 -9999 -9999 -9999 -9999 -9999 -9999 -9999 -9999 -9999 -9999 -9999 -24.0780296326 -24.3828105927 -21.0301704407-17.6775398254 $-14.3248996735-10.9722604752-7.3148431778-3.96220707893-.304785102606$ 2.7430660724646 .0957031259 .4483394622812 .8009700775116 .15361022949 19.2014598846422 .2493095397925 .2971591949528 .0402297973630 .78330039978 33.2215805053735 .6598587036137 .7933502197339 .9268493652342 .06034851074 43.8890609741245 .4129791259846 .9369087219248 .4608306884849 .67998123169 50.8991203308152 .1182594299353 .0326118469253 .9469718933154 .86132049561 55.4708900451756 .0804595947352 .9086837768656 .6309852600161 .26181030273 64.9192428588967 .3575134277368 .8814392089870 .4053573608471 .92929077148 73.1484298706174 .3675689697374 .9771423339875 .5867080688575 .89148712158 75.8914871215875 .5867080688574 .6723632812573 .7580032348672 .23407745361 70.4053573608468 .2718734741265 .8335876464862 .1761703491262 .48094940186 62.4809494018662 .7857398986862 .7857398986863 .0905189514263 .09051895142 63.0905189514263 .0905189514263 .0905189514263 .0905189514262 .78573989868 62.4809494018661 .8713798522961 .5666007995660 .9570198059160 .04267120361 59.1283111572358 .2139587402356 .9948196411155 .7756805419954 .55654144287 53.3373985290551 .8134689331150 .2895507812548 .765621185347 .54647827148 46.0225486755444 .4986305236843 .2794914245641 .7555618286140 .53641891479 39.3172798156738 .4029312133837 .1837806701736 .2694282531735 .65985870361 35.0502891540534 .4407196044933 .8311500549333 .5263595581133 .52635955811 33.2215805053733 .2215805053733 .2215805053733 .2215805053733 .52635955811 33.8311500549333 .8311500549334 .1359291076734 .4407196044934 .74551010132 34.7455101013235 .0502891540535 .0502891540535 .3550796508835 .35507965088 35.3550796508835 .0502891540535 .0502891540534 .7455101013234 .13592910767 33.8311500549333 .5263595581132 .9167900085432 .3072204589831 .69765090942 31.0880794525130 .4785099029530 .1737308502230 .1737308502229 .86894035339 29.8689403533929 .5641593933129 .2593708038329 .2593708038328 .95458984375 28.9545898437528 .6497993469228 .6497993469228 .3450202941928 .34502029419 28.0402297973628 .0402297973627 .7354507446327 .7354507446327 .4306602478 27.1258792877226 .8210906982426 .5163097381626 .2115192413325 .9067401886 25.906740188625 .906740188625 .906740188626 .2115192413326 .21151924133 26.5163097381626 .5163097381626 .8210906982427 .1258792877227 .4306602478 27.430660247827 .7354507446328 .0402297973628 .3450202941928 .64979934692 28.9545898437529 .2593708038329 .8689403533930 .4785099029532 .00244140625 33.8311500549335 .6598587036137 .4885711669939 .622070312541 .75556182861 43.8890609741246 .3273391723648 .765621185351 .5086898803753 .94697189331 56.6900291442959 .7378807067962 .4809494018665 .5288009643668 .57665252686 71.6244964599674 .9771423339878 .0249862670980 .7680587768683 .51112365723 84.1206970214884 .4254837036184 .7302627563584 .7302627563584 .73026275635 84.7302627563585 .0350494384885 .0350494384885 .3398437585 .3398437585 .64462280273 85.6446228027385 .6446228027385 .6446228027385 .6446228027385 .64462280273 85.6446228027385 .3398437585 .0350494384884 .7302627563584 .42548370361 84.1206970214883 .8159103393683 .5111236572382 .9015579223682 .59677124023 82.2919769287181 .6824111938581 .3776321411180 .7680587768680 .46327209473 79.8537063598679 .5489196777379 .2441329956178 .6345596313578 .32978057861 
78.0249862670977 .7202072143677 .4154205322376 .8058471679776 .50106811523 76.1962814331175 .8914871215875 .8914871215875 .5867080688575 .28192901611 74.9771423339874 .9771423339874 .6723632812574 .3675689697374 .36756896973 74.3675689697374 .062782287674 .062782287674 .062782287673 .75800323486 73.7580032348673 .7580032348673 .7580032348673 .7580032348673 .75800323486 73.7580032348673 .7580032348673 .7580032348673 .7580032348674 .0627822876 74.062782287674 .062782287674 .3675689697374 .3675689697374 .36756896973 74.6723632812574 .8119735717874 .98412322998 -9999 -9999 -9999 -9999 -9999 -9999 -9999 -9999 -9999 -9999 -9999 -9999 -9999 -9999 -9999 -9999 -9999 -9999 -9999 -9999 -9999 -9999 -9999 -9999 -9999 -9999 -9999 -9999 -9999 -9999 -9999 -9999 -9999 -9999 -9999 -9999 -9999 -9999 -9999 -9999 -9999 -9999 -9999 -9999 -9999 -9999 -9999 -9999 -9999 -9999 -9999 -9999 -999 -9999 -9999 -9999 -9999 -9999 -9999 -9999 -9999 -9999 -9999 -9999 -9999 -9999 -9999 -9999 -9999 -9999 -9999 -9999 -9999 -9999 -9999 -9999 -9999 -9999 -9999 -9999 -9999 -9999 -9999 -9999 -9999 -9999 -9999 -9999 -9999 -9999 -9999 -9999 -9999 -9999 -9999 -9999 -9999 -9999 -9999 -9999 -9999 -9999 -9999 -9999 -9999 -9999 -9999 -9999 -9999 -9999 -

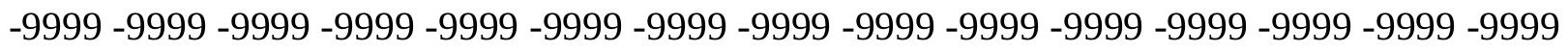
-9999 -9999 -21.0301704407 -21.3349609375 -18.8966808319 -15.5440397263 -12.1914100647-8.53398323059-5.18134689331 -1.82871103287 1.523926019669 4.876562118538 .22919845581111 .5818300247214 .934470176718 .287109375 21.3349609375 24.38281059265 27.4306602478 30.17373085022 32.91679000854 35.3550796508837 .7933502197339 .9268493652342 .0603485107443 .88906097412 45.717769622847 .5464782714849 .0704002380450 .2895507812551 .50868988037 52.7278289794953 .6421813964854 .5565414428755 .4708900451756 .08045959473 56.6900291442957 .2995986938553 .0161323547455 .8019409179758 .51874923706 63.0905189514265 .5288009643667 .6623001098669 .4910125732471 .0149307251 72.5388565063574 .062782287674 .9771423339875 .8914871215876 .19628143311 76.1962814331176 .1962814331175 .5867080688574 .6723632812573 .14842987061 71.6244964599669 .4910125732467 .0527267456162 .1761703491262 .17617034912 62.4809494018662 .7857398986862 .7857398986863 .0905189514263 .09051895142 63.0905189514263 .0905189514263 .0905189514262 .7857398986862 .78573989868 62.4809494018661 .8713798522961 .5666007995660 .9570198059160 .04267120361 59.1283111572358 .2139587402356 .9948196411155 .7756805419954 .25175094604 53.0326118469251 .5086898803749 .9847602844248 .4608306884846 .93690872192 45.4129791259843 .8890609741242 .66992187541 .1459884643639 .92684936523 38.7077102661137 .4885711669936 .5742111206135 .6598587036134 .74551010132 34.1359291076733 .5263595581133 .2215805053732 .9167900085432 .61201095581 32.6120109558132 .6120109558132 .9167900085432 .9167900085433 .22158050537 33.5263595581133 .8311500549334 .1359291076734 .4407196044934 .74551010132 35.0502891540535 .3550796508835 .6598587036135 .6598587036135 .96464920044 35.9646492004435 .6598587036135 .6598587036135 .3550796508835 .05028915405 34.7455101013234 .1359291076733 .5263595581132 .9167900085432 .30722045898 31.6976509094231 .3928699493430 .7833003997830 .4785099029530 .47850990295 30.1737308502229 .8689403533929 .5641593933129 .2593708038329 .25937080383 28.9545898437528 .6497993469228 .6497993469228 .3450202941928 .34502029419 28.0402297973628 .0402297973627 .7354507446327 .430660247827 .4306602478 27.1258792877226 .8210906982426 .5163097381626 .2115192413325 .9067401886 
25.9067401886 25.9067401886 25.9067401886 25.906740188625.9067401886 26.2115192413326 .2115192413326 .5163097381626 .5163097381626 .82109069824 27.12587928772 27.12587928772 27.4306602478 27.73545074463 27.73545074463 28.0402297973628 .3450202941928 .9545898437529 .5641593933130 .78330039978 32.3072204589834 .1359291076735 .9646492004438 .0981407165540 .23163986206 42.3651313781744 .8034095764246 .9369087219249 .6799812316952 .11825942993 54.8613204956157 .2995986938560 .0426712036163 .0905189514265 .83358764648 68.8814392089871 .9292907714874 .9771423339877 .7202072143680 .15849304199 81.3776321411181 .9871978759882 .2919769287182 .2919769287182 .59677124023 82.9015579223683 .206336975183 .206336975183 .5111236572383 .81591033936 84.1206970214884 .1206970214884 .1206970214884 .4254837036184 .42548370361 84.4254837036184 .4254837036184 .1206970214884 .1206970214883 .81591033936 83.51112365723 83.206336975182.9015579223682.5967712402382.29197692871 81.6824111938581 .3776321411181 .0728530883880 .4632720947380 .15849304199 79.8537063598679 .2441329956178 .9393463134878 .6345596313578 .32978057861 77.7202072143677 .4154205322377 .110626220776 .8058471679776 .50106811523 76.1962814331175 .8914871215875 .5867080688575 .2819290161174 .97714233398 74.9771423339874 .6723632812574 .3675689697374 .3675689697374 .0627822876 74.062782287673 .7580032348673 .7580032348673 .7580032348673 .45321655273 73.4532165527373 .4532165527373 .4532165527373 .4532165527373 .45321655273 73.4532165527373 .4532165527373 .4532165527373 .4532165527373 .45321655273 73.4532165527373 .7580032348673 .7580032348673 .7580032348673 .75800323486 74.062782287674 .062782287674 .3865356445374 .6052627563577 .72020721436 -9999 -9999 -9999 -9999 -9999 -9999 -9999 -9999 -9999 -9999 -9999 -9999 -9999 -9999 -9999 -9999 -9999 -999 -999 -999 -999 -999 -

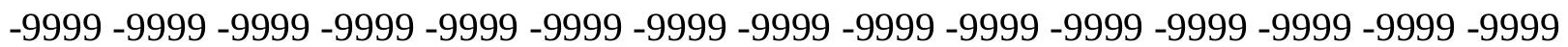

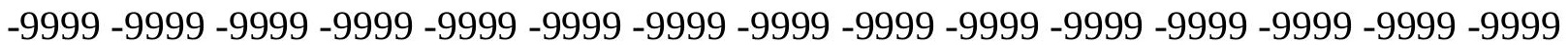

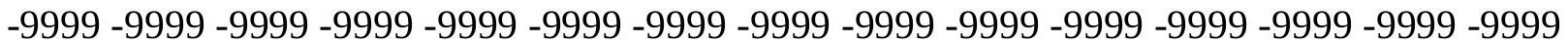
-9999 - 9999 -999 -

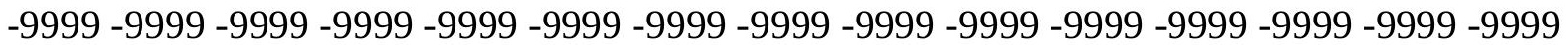

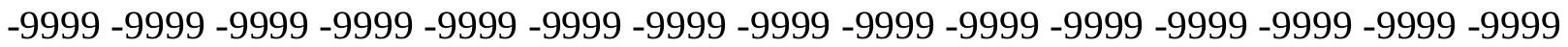
$-9999$

-9999 -9999 -9999 -9999 -9999 -9999 -9999 -9999 -9999 -9999 -9999 -9999 -9999 -9999 -9999 -9999-9999-17.6775398254-17.9823207855-16.4584007263-13.1057596207 $-9.75312423706-6.095703125-2.74306607246 .30478510260583 .657422065735$ 7.31484317779510 .6674804687514 .0201196670517 .3727493286120 .72538948059 23.7732391357426 .8210906982429 .8689403533932 .6120109558135 .35507965088 37.7933502197340 .2316398620642 .3651313781744 .1938400268646 .02254867554 47.8512611389249 .3751907348650 .8991203308152 .1182594299353 .33739852905 54.5565414428755 .4708900451756 .0804595947356 .9948196411157 .60438919067 58.2139587402358 .5187492370658 .8235282897955 .3179168701257 .56827545166 59.7378807067963 .0905189514265 .8335876464867 .9670867919969 .79579162598 71.6244964599673 .1484298706174 .6723632812575 .5867080688576 .19628143311 76.5010681152376 .5010681152376 .1962814331175 .2819290161174 .0627822876 72.5388565063570 .4053573608467 .9670867919965 .5288009643662 .17617034912 62.4809494018662 .4809494018662 .7857398986862 .7857398986863 .09051895142 63.0905189514263 .0905189514263 .0905189514262 .7857398986862 .78573989868 
62.4809494018662 .1761703491261 .5666007995660 .9570198059160 .04267120361 59.1283111572358 .2139587402356 .9948196411155 .7756805419954 .25175094604 52.7278289794951 .2038993835449 .6799812316948 .1560516357446 .63212966919 45.1082000732443 .2794914245642 .0603485107440 .5364189147939 .31727981567 37.7933502197336 .8790016174335 .6598587036134 .7455101013234 .13592910767 33.5263595581132 .9167900085432 .6120109558132 .3072204589832 .00244140625 32.0024414062532 .3072204589832 .3072204589832 .6120109558132 .91679000854 33.2215805053733 .8311500549334 .1359291076734 .4407196044935 .05028915405 35.3550796508835 .6598587036135 .9646492004436 .2694282531736 .57421112061 36.5742111206136 .5742111206136 .5742111206136 .2694282531735 .96464920044 35.6598587036135 .0502891540534 .4407196044933 .8311500549333 .22158050537 32.6120109558132 .3072204589831 .6976509094231 .3928699493431 .08807945251 30.7833003997830 .1737308502229 .8689403533929 .5641593933129 .25937080383 29.2593708038328 .9545898437528 .6497993469228 .6497993469228 .34502029419 28.0402297973628 .0402297973627 .7354507446327 .7354507446327 .4306602478 27.1258792877226 .8210906982426 .5163097381626 .2115192413326 .21151924133 25.906740188625 .906740188625 .906740188625 .906740188625 .9067401886 26.2115192413326 .2115192413326 .2115192413326 .5163097381626 .51630973816 26.8210906982426 .8210906982426 .8210906982427 .1258792877227 .12587928772 27.430660247827 .7354507446328 .3450202941928 .9545898437529 .86894035339 31.3928699493432 .9167900085434 .7455101013236 .5742111206138 .70771026611 40.8412094116242 .9747009277345 .4129791259847 .5464782714849 .98476028442 52.4230384826755 .1661109924357 .6043891906760 .3474502563562 .78573989868 65.5288009643668 .2718734741271 .014930725173 .7580032348675 .89148712158 77.7202072143678 .6345596313579 .2441329956179 .8537063598680 .15849304199 80.4632720947381 .0728530883881 .3776321411181 .6824111938581 .98719787598 82.2919769287182 .5967712402382 .5967712402382 .9015579223682 .90155792236 82.9015579223682 .9015579223682 .9015579223682 .9015579223682 .59677124023 82.2919769287182 .2919769287181 .9871978759881 .6824111938581 .37763214111 81.0728530883880 .4632720947380 .1584930419979 .8537063598679 .54891967773 78.9393463134878 .6345596313578 .3297805786178 .0249862670977 .72020721436 77.110626220776 .8058471679776 .5010681152376 .1962814331175 .89148712158 75.5867080688575 .2819290161174 .9771423339874 .9771423339874 .67236328125 74.3675689697374 .062782287674 .062782287673 .7580032348673 .75800323486 73.4532165527373 .4532165527373 .4532165527373 .1484298706173 .14842987061 73.1484298706173 .1484298706173 .1484298706173 .1484298706172 .84364318848 72.8436431884873 .1484298706173 .1484298706173 .1484298706173 .14842987061 73.1484298706173 .1484298706173 .4532165527373 .4532165527373 .45321655273 73.4532165527373 .7580032348674 .062782287674 .2234420776474 .45143890381 -9999 -9999 -9999 -9999 -9999 -9999 -9999 -9999 -9999 -9999 -9999 -9999 -9999 -9999 -9999 -9999

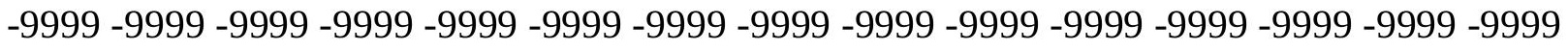

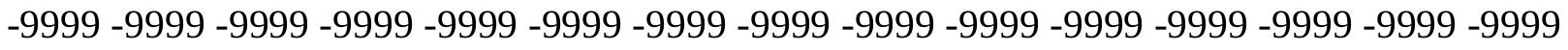
-9999 -9999 -9999 -9999 -9999 -9999 -9999 -9999 -9999 -9999 -9999 -9999 -9999 -9999 -9999 -9999 -9999 -9999 -9999 -9999 -9999 -9999 -9999 -9999 -9999 -9999 -9999 -9999 -9999 -9999 -

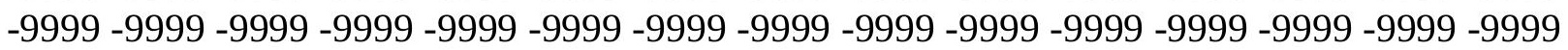

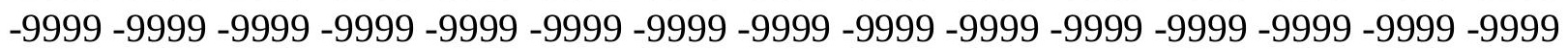


$-9999-9999$

-9999 -9999 -9999 -9999 -9999 -9999 -9999 -9999 -9999 -9999 -9999 -9999 -9999 -9999 -9999

-9999 -9999-14.7651109695-14.3248996735 -13.7153301239 -10.0579099655 -6.7052731514 -3.65742206573 -.304785102606 2.743066072464 6.400486946106 9.753124237061 13.1057596206716 .7631797790520 .1158199310323 .4684505462626 .51630973816 29.5641593933132 .6120109558135 .3550796508837 .7933502197340 .23163986206 42.66992187544 .8034095764246 .6321296691948 .4608306884849 .98476028442 51.5086898803753 .0326118469254 .2517509460455 .1661109924356 .38525009155 56.9948196411157 .909179687558 .5187492370659 .1283111572359 .43310165405 59.7378807067960 .0426712036155 .3621482849157 .4253540039159 .35673522949 60.6522407531760 .6522407531765 .8335876464867 .9670867919970 .10057830811 72.2340774536173 .7580032348675 .2819290161176 .1962814331176 .80584716797 76.8058471679776 .5010681152375 .8914871215874 .9771423339873 .45321655273 71.3197174072369 .1862335205166 .4431610107462 .1761703491262 .48094940186 62.4809494018662 .7857398986862 .7857398986863 .0905189514263 .09051895142 63.0905189514263 .0905189514263 .0905189514262 .7857398986862 .48094940186 62.1761703491261 .5666007995661 .2618103027360 .3474502563559 .43310165405 58.2139587402356 .9948196411155 .4708900451754 .2517509460452 .72782897949 51.2038993835449 .3751907348647 .8512611389246 .3273391723644 .49863052368 42.9747009277341 .4507789611839 .9268493652338 .4029312133837 .18378067017 35.9646492004435 .0502891540534 .1359291076733 .2215805053732 .61201095581 32.3072204589831 .6976509094231 .6976509094231 .3928699493431 .39286994934 31.6976509094232 .0024414062532 .3072204589832 .6120109558133 .22158050537 33.5263595581134 .1359291076734 .7455101013235 .3550796508835 .65985870361 36.2694282531736 .5742111206137 .1837806701737 .1837806701737 .48857116699 37.4885711669937 .4885711669937 .1837806701736 .8790016174336 .57421112061 36.2694282531735 .6598587036135 .0502891540534 .4407196044933 .83115005493 33.2215805053732 .6120109558132 .3072204589831 .6976509094231 .39286994934 30.7833003997830 .4785099029530 .1737308502229 .5641593933129 .25937080383 28.9545898437528 .9545898437528 .6497993469228 .6497993469228 .34502029419 28.0402297973628 .0402297973627 .7354507446327 .430660247827 .4306602478 27.1258792877226 .8210906982426 .5163097381626 .2115192413326 .21151924133 26.2115192413326 .2115192413326 .2115192413326 .2115192413326 .21151924133 26.2115192413326 .2115192413326 .5163097381626 .5163097381626 .51630973816 26.5163097381626 .8210906982426 .8210906982426 .8210906982427 .12587928772 27.430660247827 .7354507446328 .3450202941929 .2593708038330 .47850990295 32.0024414062533 .5263595581135 .3550796508837 .1837806701739 .31727981567 41.4507789611843 .5842704772945 .717769622848 .1560516357450 .28955078125 52.7278289794955 .1661109924357 .2995986938559 .4331016540561 .87137985229 64.3096618652367 .0527267456169 .4910125732471 .9292907714873 .75800323486 74.9771423339875 .8914871215876 .8058471679777 .4154205322378 .02498626709 78.6345596313579 .2441329956179 .5489196777380 .1584930419980 .46327209473 80.7680587768681 .0728530883881 .3776321411181 .3776321411181 .68241119385 81.6824111938581 .6824111938581 .6824111938581 .3776321411181 .37763214111 81.0728530883880 .7680587768680 .4632720947380 .4632720947380 .15849304199 79.8537063598679 .2441329956178 .9393463134878 .6345596313578 .32978057861 
78.0249862670977 .7202072143677 .4154205322376 .8058471679776 .50106811523 76.1962814331175 .8914871215875 .5867080688575 .2819290161174 .97714233398 74.9771423339874 .6723632812574 .3675689697374 .062782287674 .0627822876 73.7580032348673 .4532165527373 .4532165527373 .4532165527373 .14842987061 73.1484298706172 .8436431884872 .8436431884872 .8436431884872 .84364318848 72.8436431884872 .5388565063572 .5388565063572 .5388565063572 .53885650635 72.5388565063572 .5388565063572 .8436431884872 .8436431884872 .84364318848 72.8436431884872 .8436431884873 .1484298706173 .1484298706173 .14842987061 $73.4532165527373 .4532165527373 .8807678222774 .1699295043977 .41542053223-9999$ -9999 -9999 -9999 -9999 -9999 -9999 -9999 -9999 -9999 -9999 -9999 -9999 -9999 -9999 -9999

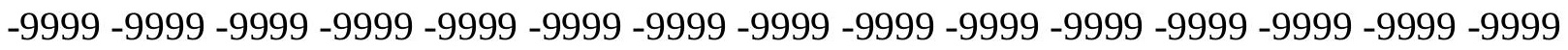
-9999 -9999 -9999 -9999 -9999 -9999 -9999 -9999 -9999 -9999 -9999 -9999 -9999 -9999 -9999

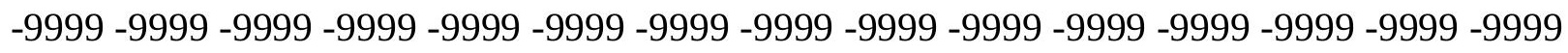
-9999 -9999 -9999 -9999 -9999 -9999 -9999 -9999 -9999 -9999 -9999 -9999 -9999 -9999 -9999 -

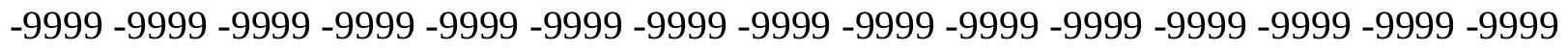
-9999 -9999 -9999 -9999 -9999 -9999 -9999 -9999 -9999 -9999 -9999 -9999 -9999 -999 - -999 $-9999$

-9999 -9999 -9999 -9999 -9999 -9999 -9999 -9999 -9999 -9999 -9999 -9999 -9999 -9999 -9999 -9999-9999-9999-10.3626899719-10.0579099655 -7.01005792618 -3.96220707893 -.609570324421 2.133496046066 5.4861321449289.14355373382612.49619007111 16.1536102294919 .5062503814722 .8588790893626 .2115192413329 .25937080383 32.3072204589835 .3550796508838 .0981407165540 .5364189147942 .97470092773 45.1082000732447 .2416992187549 .0704002380450 .8991203308152 .42303848267 53.9469718933155 .1661109924356 .3852500915557 .2995986938558 .21395874023 58.8235282897959 .4331016540560 .0426712036160 .6522407531760 .95701980591 61.2618103027361 .2618103027361 .5666007995657 .7930374145559 .73625946045 61.5666007995661 .5666007995661 .2618103027365 .8335876464868 .27187347412 70.7101516723672 .8436431884874 .3675689697375 .5867080688576 .50106811523 76.8058471679776 .8058471679776 .5010681152375 .5867080688574 .0627822876 72.2340774536170 .1005783081167 .6623001098662 .1761703491262 .17617034912 62.4809494018662 .7857398986862 .7857398986862 .7857398986863 .09051895142 63.0905189514263 .0905189514263 .0905189514262 .7857398986862 .48094940186 62.1761703491261 .8713798522961 .2618103027360 .3474502563559 .43310165405 58.2139587402356 .9948196411155 .7756805419954 .2517509460452 .72782897949 50.8991203308149 .3751907348647 .5464782714846 .0225486755444 .19384002686 42.66992187540 .8412094116239 .3172798156738 .0981407165536 .57421112061 35.3550796508834 .4407196044933 .5263595581132 .6120109558132 .00244140625 31.3928699493431 .0880794525131 .0880794525130 .7833003997831 .08807945251 31.0880794525131 .3928699493432 .0024414062532 .3072204589832 .91679000854 33.5263595581134 .1359291076735 .0502891540535 .6598587036136 .26942825317 36.8790016174337 .4885711669937 .7933502197338 .0981407165538 .40293121338 38.7077102661138 .7077102661138 .4029312133838 .0981407165537 .79335021973 37.4885711669936 .8790016174336 .2694282531735 .6598587036135 .05028915405 34.4407196044933 .8311500549333 .2215805053732 .6120109558132 .00244140625 31.3928699493431 .0880794525130 .4785099029530 .1737308502229 .56415939331 29.2593708038328 .9545898437528 .9545898437528 .6497993469228 .64979934692 
28.3450202941928 .3450202941928 .0402297973627 .7354507446327 .73545074463 27.430660247827 .1258792877226 .8210906982426 .8210906982426 .51630973816 26.5163097381626 .5163097381626 .5163097381626 .5163097381626 .51630973816 26.5163097381626 .5163097381626 .5163097381626 .5163097381626 .51630973816 26.8210906982426 .8210906982426 .8210906982426 .8210906982427 .12587928772 27.1258792877227 .7354507446328 .0402297973628 .9545898437529 .86894035339 31.0880794525132 .6120109558134 .4407196044936 .2694282531738 .09814071655 39.9268493652342 .0603485107444 .1938400268646 .0225486755448 .15605163574 50.2895507812552 .4230384826754 .5565414428756 .3852500915558 .21395874023 60.3474502563563 .0905189514265 .5288009643667 .9670867919969 .79579162598 71.3197174072372 .5388565063573 .7580032348674 .6723632812575 .58670806885 76.1962814331176 .8058471679777 .4154205322378 .0249862670978 .63455963135 78.9393463134879 .2441329956179 .5489196777379 .8537063598680 .15849304199 80.1584930419980 .1584930419980 .1584930419980 .1584930419980 .15849304199 79.8537063598679 .8537063598679 .5489196777379 .2441329956178 .93934631348 78.9393463134878 .6345596313578 .3297805786178 .0249862670977 .72020721436 77.110626220776 .8058471679776 .5010681152376 .1962814331175 .89148712158 75.5867080688575 .2819290161174 .9771423339874 .9771423339874 .67236328125 74.3675689697374 .062782287674 .062782287673 .7580032348673 .45321655273 73.4532165527373 .1484298706173 .1484298706172 .8436431884872 .84364318848 72.5388565063572 .5388565063572 .5388565063572 .5388565063572 .53885650635 72.2340774536172 .2340774536172 .2340774536172 .2340774536172 .23407745361 72.2340774536172 .2340774536172 .2340774536172 .5388565063572 .53885650635 72.5388565063572 .5388565063572 .5388565063572 .8436431884872 .84364318848 $73.1484298706173 .1484298706173 .7580032348673 .9142150878974 .03619384766-9999$ -9999 -9999 -9999 -9999 -9999 -9999 -9999 -9999 -9999 -9999 -9999 -9999 -9999 -9999 -9999 -9999 -9999 -9999 -9999 -9999 -9999 -9999 -9999 -9999 -9999 -9999 -9999 -9999 -9999 -9999 -

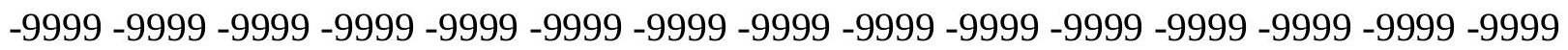
-9999 -9999 -9999 -9999 -9999 -9999 -9999 -9999 -9999 -9999 -9999 -9999 -9999 -9999 -9999 -9999 -9999 -9999 -9999 -9999 -9999 -9999 -9999 -9999 -9999 -9999 -9999 -9999 -9999 -9999 -9999 -9999 -9999 -9999 -9999 -9999 -9999 -9999 -9999 -9999 -9999 -9999 -9999 -9999 -9999

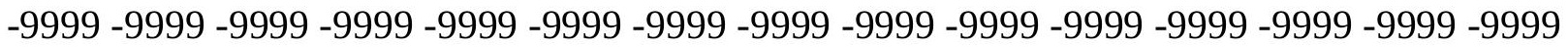
$-9999$

-9999 -9999 -9999 -9999 -9999 -9999 -9999 -9999 -9999 -9999 -9999 -9999 -9999 -9999 -9999 -9999 -9999-9999 -7.08704185486 -6.40048694611 -3.65742206573 -.914355397224 1.8287110328675 .1813468933118 .53398323059111 .8866195678715 .54403972626 18.8966808319122 .5541000366225 .906740188629 .2593708038332 .30722045898 35.3550796508838 .4029312133840 .8412094116243 .5842704772945 .7177696228 47.8512611389249 .9847602844251 .8134689331153 .3373985290554 .86132049561 56.0804595947357 .2995986938558 .5187492370659 .4331016540560 .04267120361 60.6522407531761 .2618103027361 .8713798522962 .1761703491262 .48094940186 62.4809494018662 .4809494018662 .4809494018662 .4809494018660 .28646469116 61.6344985961962 .1761703491262 .1761703491261 .8713798522966 .13836669922 68.8814392089871 .3197174072373 .1484298706174 .9771423339876 .19628143311 76.8058471679776 .8058471679776 .8058471679775 .8914871215874 .67236328125 73.1484298706171 .014930725168 .5766525268665 .8335876464862 .17617034912 
62.4809494018662 .4809494018662 .7857398986862 .7857398986863 .09051895142 63.0905189514263 .0905189514263 .0905189514262 .7857398986862 .48094940186 62.1761703491261 .8713798522961 .2618103027360 .3474502563559 .43310165405 58.5187492370657 .2995986938555 .7756805419954 .2517509460452 .72782897949 50.8991203308149 .3751907348647 .5464782714845 .717769622843 .88906097412 42.0603485107440 .5364189147939 .0125007629437 .4885711669935 .96464920044 34.7455101013233 .8311500549332 .9167900085432 .0024414062531 .39286994934 30.7833003997830 .4785099029530 .4785099029530 .4785099029530 .47850990295 30.7833003997831 .0880794525131 .6976509094232 .3072204589832 .91679000854 33.5263595581134 .4407196044935 .3550796508835 .9646492004436 .87900161743 37.4885711669938 .0981407165538 .7077102661139 .3172798156739 .6220703125 39.622070312539 .9268493652339 .622070312539 .622070312539 .31727981567 38.7077102661138 .0981407165537 .4885711669936 .8790016174336 .26942825317 35.6598587036134 .7455101013234 .1359291076733 .5263595581132 .91679000854 32.3072204589831 .6976509094231 .0880794525130 .4785099029530 .17373085022 29.5641593933129 .2593708038329 .2593708038328 .9545898437528 .95458984375 28.9545898437528 .6497993469228 .3450202941928 .3450202941928 .04022979736 27.7354507446327 .430660247827 .430660247827 .1258792877227 .12587928772 26.8210906982426 .8210906982426 .8210906982426 .8210906982426 .82109069824 26.8210906982426 .8210906982426 .8210906982426 .8210906982426 .82109069824 26.8210906982426 .8210906982426 .8210906982427 .1258792877227 .12587928772 27.430660247827 .7354507446328 .0402297973628 .6497993469229 .56415939331 30.7833003997832 .0024414062533 .5263595581135 .3550796508836 .87900161743 38.7077102661140 .5364189147942 .3651313781744 .1938400268646 .32733917236 48.1560516357449 .9847602844251 .8134689331153 .6421813964855 .47089004517 57.2995986938559 .7378807067962 .1761703491264 .3096618652366 .13836669922 67.6623001098669 .1862335205170 .4053573608471 .6244964599672 .84364318848 73.7580032348674 .3675689697375 .2819290161175 .8914871215876 .50106811523 77.110626220777 .4154205322378 .0249862670978 .3297805786178 .32978057861 78.6345596313578 .6345596313578 .9393463134878 .9393463134878 .63455963135 78.6345596313578 .6345596313578 .3297805786178 .3297805786178 .02498626709 77.7202072143677 .7202072143677 .4154205322377 .110626220776 .80584716797 76.5010681152376 .1962814331175 .8914871215875 .5867080688575 .28192901611 74.9771423339874 .6723632812574 .6723632812574 .3675689697374 .0627822876 73.7580032348673 .7580032348673 .4532165527373 .1484298706173 .14842987061 72.8436431884872 .8436431884872 .5388565063572 .5388565063572 .53885650635 72.2340774536172 .2340774536172 .2340774536172 .2340774536171 .92929077148 71.9292907714871 .9292907714871 .9292907714871 .9292907714871 .92929077148 71.9292907714871 .9292907714871 .9292907714872 .2340774536172 .23407745361 72.2340774536172 .2340774536172 .2340774536172 .5388565063572 .53885650635 72.8436431884873 .1484298706173 .4532165527373 .5737457275473 .69242858887 76.80584716797 -9999 -9999 -9999 -9999 -9999 -9999 -9999 -9999 -9999 -9999 -9999 -9999 -9999 -9999 -9999 -9999 -9999 -9999 -9999 -9999 -9999 -9999 -9999 -9999 -9999 -9999 -9999 -9999 -9999 -9999 -9999 -9999 -9999 -9999 -9999 -9999-9999 -9999 -9999 -9999 -9999 -9999 -9999 -9999 -9999 -9999 -9999 -9999 -9999 -9999 -9999 -9999 -9999 -9999 -9999 -9999 -9999 -

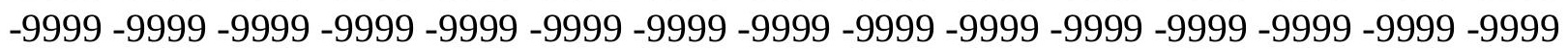


-9999 -9999 -9999 -9999 -9999 -9999 -9999 -9999 -9999 -9999 -9999 -9999 -9999 -9999 -9999 -9999 -9999 -9999 -9999 -9999 -9999 -9999 -9999 -9999 -9999 -9999 -9999 -9999 -9999 -9999 -9999 -9999-9999-9999

-9999 -9999 -9999 -9999 -9999 -9999 -9999 -9999 -9999 -9999 -9999 -9999 -9999 -9999 -9999 -9999 -9999 -9999-2.92282414436-1.52392601967-.609570324421 1.828711032867 4.876562118537 .92441320419311 .5818300247214 .934470176718 .59189033508 22.2493095397925 .6019496917729 .2593708038332 .3072204589835 .65985870361 38.7077102661141 .4507789611844 .1938400268646 .6321296691948 .7656211853 50.8991203308152 .7278289794954 .2517509460456 .0804595947357 .29959869385 58.5187492370659 .7378807067960 .6522407531761 .5666007995662 .17617034912 62.7857398986863 .0905189514263 .3953094482463 .7000885009864 .0048828125 64.004882812564 .004882812563 .7000885009863 .7000885009860 .69716262817 62.1080856323263 .0905189514262 .7857398986862 .4809494018662 .17617034912 66.1383666992269 .1862335205171 .6244964599673 .7580032348674 .97714233398 76.1962814331176 .5010681152376 .5010681152376 .1962814331174 .97714233398 73.7580032348671 .6244964599669 .4910125732466 .7479400634862 .17617034912 62.1761703491262 .4809494018662 .7857398986862 .7857398986863 .09051895142 63.0905189514263 .0905189514263 .0905189514263 .0905189514262 .78573989868 62.4809494018661 .8713798522961 .2618103027360 .6522407531759 .73788070679 58.5187492370657 .2995986938556 .0804595947354 .5565414428752 .72782897949 51.2038993835449 .3751907348647 .5464782714845 .4129791259843 .58427047729 42.0603485107440 .2316398620638 .7077102661137 .1837806701735 .65985870361 34.4407196044933 .2215805053732 .3072204589831 .3928699493430 .78330039978 30.4785099029530 .1737308502229 .8689403533929 .8689403533930 .17373085022 30.4785099029530 .7833003997831 .3928699493432 .0024414062532 .91679000854 33.8311500549334 .4407196044935 .3550796508836 .5742111206137 .18378067017 38.0981407165539 .0125007629439 .622070312540 .2316398620640 .53641891479 40.8412094116241 .1459884643641 .1459884643640 .8412094116240 .53641891479 40.2316398620639 .622070312539 .0125007629438 .4029312133837 .48857116699 36.8790016174335 .9646492004435 .3550796508834 .4407196044933 .83115005493 32.9167900085432 .3072204589831 .6976509094231 .0880794525130 .47850990295 29.8689403533929 .8689403533929 .5641593933129 .5641593933129 .25937080383 29.2593708038328 .9545898437528 .9545898437528 .6497993469228 .34502029419 28.0402297973628 .0402297973627 .7354507446327 .7354507446327 .4306602478 27.430660247827 .430660247827 .430660247827 .430660247827 .430660247827 .4306602478 27.430660247827 .430660247827 .430660247827 .430660247827 .430660247827 .4306602478 27.430660247827 .430660247827 .430660247827 .7354507446327 .73545074463 28.3450202941928 .6497993469229 .5641593933130 .4785099029531 .69765090942 32.9167900085434 .4407196044935 .9646492004437 .7933502197339 .31727981567 40.8412094116242 .66992187544 .1938400268646 .0225486755447 .85126113892 49.3751907348651 .2038993835452 .7278289794954 .5565414428756 .69002914429 58.8235282897960 .9570198059162 .7857398986864 .3096618652365 .83358764648 67.3575134277368 .5766525268669 .7957916259871 .014930725171 .92929077148 72.8436431884873 .7580032348674 .3675689697375 .2819290161175 .58670806885 76.1962814331176 .5010681152376 .8058471679777 .110626220777 .1106262207 77.4154205322377 .4154205322377 .4154205322377 .4154205322377 .41542053223 
77.4154205322377 .110626220777 .110626220776 .8058471679776 .50106811523 76.5010681152376 .1962814331175 .8914871215875 .5867080688575 .28192901611 75.2819290161174 .9771423339874 .6723632812574 .3675689697374 .0627822876 74.062782287673 .7580032348673 .4532165527373 .4532165527373 .14842987061 72.8436431884872 .8436431884872 .5388565063572 .5388565063572 .23407745361 72.2340774536172 .2340774536171 .9292907714871 .9292907714871 .92929077148 71.9292907714871 .9292907714871 .6244964599671 .6244964599671 .62449645996 71.6244964599671 .6244964599671 .6244964599671 .6244964599671 .62449645996 71.6244964599671 .9292907714871 .9292907714871 .9292907714871 .92929077148 72.2340774536172 .2340774536172 .5388565063572 .5388565063572 .84364318848 73.1484298706173 .1484298706173 .3318099975673 .55924224854 -9999 -9999 -9999 -9999 -9999 -9999 -9999 -9999 -9999 -9999 -9999 -9999 -9999 -9999 -9999 -9999 -9999 -9999 -9999 -9999 -9999 -9999 -9999 -9999 -9999 -9999 -9999 -9999 -9999 -9999 -9999 -9999 -9999 -9999 -9999 -9999 -9999 -9999 -9999 -9999 -9999 -9999 -9999 -9999 -9999 -9999 -9999 -9999 -9999 -9999 -9999 -9999 -9999 -9999 -9999 -9999 -9999 -9999 -9999 -9999 -9999 -9999 -9999 -9999 -9999 -9999 -9999 -9999 -9999 -9999 -9999 -9999 -9999 -9999 -9999 -9999 -9999 -9999 -9999 -9999 -9999 -9999 -9999 -9999 -9999 -9999 -9999 -9999 -9999 -9999 -9999 -9999 -9999 -9999 -9999 -9999 -9999 -9999 -9999 -9999 -9999 -9999 -9999 -9999 -9999 -9999 -9999 -9999 -9999 -9999 -9999 -9999 -9999 -9999 -9999 -9999 -9999 -9999 -9999 -9999 -9999 -9999 -9999 -9999 -9999 2.563822507858 3.0478510856634 .5717768669137 .924413204193 10.9722604751614 .6296901702918 .28710937521 .9445304870625 .60194969177 28.9545898437532 .6120109558135 .9646492004439 .0125007629442 .06034851074 44.8034095764247 .2416992187549 .6799812316951 .8134689331153 .64218139648 55.4708900451756 .9948196411158 .5187492370659 .7378807067960 .95701980591 61.8713798522962 .7857398986863 .7000885009864 .3096618652364 .61444854736 64.9192428588965 .2240066528365 .5288009643665 .5288009643665 .52880096436 65.2240066528365 .2240066528364 .9192428588964 .6144485473662 .38573074341 63.2425193786663 .3953094482463 .0905189514262 .7857398986862 .17617034912 66.7479400634869 .7957916259871 .9292907714873 .4532165527374 .97714233398 75.8914871215876 .1962814331175 .8914871215875 .2819290161174 .0627822876 72.2340774536169 .7957916259867 .3575134277362 .1761703491262 .17617034912 62.4809494018662 .7857398986862 .7857398986863 .0905189514263 .09051895142 63.0905189514263 .0905189514263 .0905189514262 .7857398986862 .48094940186 62.1761703491261 .5666007995660 .6522407531760 .0426712036158 .82352828979 57.6043891906756 .3852500915554 .8613204956153 .0326118469251 .20389938354 49.3751907348647.5464782714845.4129791259843.5842704772941.75556182861 39.9268493652338 .4029312133836 .8790016174335 .3550796508834 .13592910767 32.9167900085432 .0024414062531 .0880794525130 .4785099029529 .86894035339 29.5641593933129 .5641593933129 .5641593933129 .8689403533930 .17373085022 30.4785099029531 .0880794525132 .0024414062532 .9167900085433 .83115005493 34.7455101013235 .9646492004436 .8790016174337 .7933502197339 .01250076294 39.9268493652340 .5364189147941 .4507789611842 .0603485107442 .36513137817 42.66992187542 .66992187542 .3651313781742 .0603485107441 .75556182861 41.1459884643640 .5364189147939 .622070312539 .0125007629438 .09814071655 37.1837806701736 .2694282531735 .6598587036134 .7455101013233 .83115005493 33.2215805053732 .3072204589831 .6976509094231 .0880794525130 .47850990295 
30.1737308502230 .1737308502229 .8689403533929 .8689403533929 .56415939331 29.5641593933129 .2593708038329 .2593708038328 .9545898437528 .64979934692 28.3450202941928 .3450202941928 .0402297973628 .0402297973628 .04022979736 28.0402297973628 .0402297973628 .0402297973628 .0402297973628 .04022979736 28.0402297973628 .0402297973628 .0402297973628 .0402297973628 .04022979736 28.0402297973628 .0402297973628 .0402297973628 .0402297973628 .04022979736 28.3450202941928 .6497993469228 .9545898437529 .5641593933130 .47850990295 31.3928699493432 .6120109558133 .8311500549335 .3550796508836 .57421112061 38.0981407165539 .622070312541 .1459884643642 .66992187544 .19384002686 45.717769622847 .2416992187548 .765621185350 .2895507812552 .11825942993 53.9469718933155 .7756805419957 .6043891906759 .4331016540561 .26181030273 62.7857398986864 .3096618652365 .8335876464867 .0527267456168 .27187347412 69.4910125732470 .7101516723671 .6244964599672 .5388565063573 .14842987061 73.7580032348674 .3675689697374 .6723632812574 .9771423339875 .28192901611 75.5867080688575 .8914871215875 .8914871215876 .1962814331176 .19628143311 76.1962814331176 .1962814331175 .8914871215875 .8914871215875 .89148712158 75.5867080688575 .5867080688575 .2819290161174 .9771423339874 .97714233398 74.6723632812574 .3675689697374 .062782287674 .062782287673 .75800323486 73.4532165527373 .4532165527373 .1484298706172 .8436431884872 .84364318848 72.5388565063572 .5388565063572 .2340774536172 .2340774536171 .92929077148 71.9292907714871 .9292907714871 .6244964599671 .6244964599671 .62449645996 71.6244964599671 .6244964599671 .3197174072371 .3197174072371 .31971740723 71.3197174072371 .3197174072371 .3197174072371 .3197174072371 .31971740723 71.3197174072371 .6244964599671 .6244964599671 .6244964599671 .62449645996 71.6244964599671 .9292907714871 .9292907714872 .2340774536172 .23407745361 72.5388565063572 .8436431884872 .8436431884873 .0235519409273 .26914215088 75.89148712158 -9999 -9999 -9999 -9999 -9999 -9999 -9999 -9999 -9999 -9999 -9999 -9999 -9999 -9999 -9999 -9999 -9999 -9999 -9999 -9999 -9999 -9999 -9999 -9999 -9999 -9999 -9999

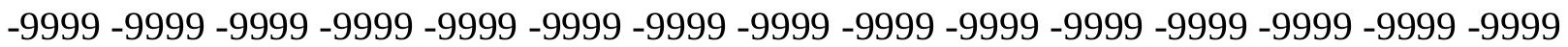
-9999 -9999 -9999 -9999 -9999 -9999 -9999 -9999 -9999 -9999 -9999 -9999 -9999 -9999 -9999 -9999 -9999 -9999 -9999 -9999 -9999 -9999 -9999 -9999 -9999 -9999 -9999 -9999 -9999 -9999 -

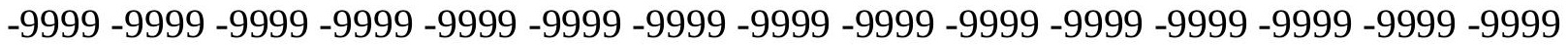

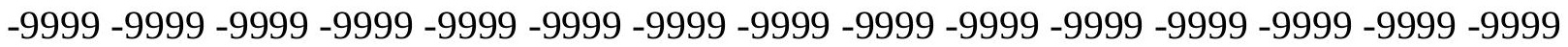
-9999-9999-9999

-9999 -9999 -9999 -9999 -9999 -9999 -9999 -9999 -9999 -9999 -9999 -9999 -9999 -9999 -9999 -9999 -9999 -9999 -9999 7.597989082336 8.533983230591 8.229198455811 10.97226047516 14.3248996734617 .9823207855221 .6397399902325 .2971591949528 .95458984375 32.6120109558136 .2694282531739 .622070312542 .66992187545 .41297912598 48.1560516357450 .5943298339852 .7278289794954 .8613204956156 .69002914429 58.5187492370659 .7378807067961 .2618103027362 .4809494018663 .39530944824 64.3096618652365 .2240066528365 .8335876464866 .4431610107466 .74794006348 67.0527267456167 .0527267456167 .0527267456167 .0527267456167 .05272674561 66.7479400634866 .4431610107466 .1383666992265 .5288009643662 .46248626709 63.373889923163 .8081169128463 .7000885009863 .0905189514262 .78573989868 62.1761703491266 .7479400634869 .4910125732471 .3197174072373 .14842987061 74.3675689697375 .2819290161175 .2819290161174 .9771423339874 .0627822876 
72.2340774536170 .1005783081167 .6623001098661 .8713798522962 .17617034912 62.4809494018662 .7857398986862 .7857398986863 .0905189514263 .09051895142 63.3953094482463 .3953094482463 .0905189514263 .0905189514262 .78573989868 62.4809494018661 .8713798522960 .9570198059160 .3474502563559 .43310165405 58.2139587402356 .6900291442955 .1661109924353 .3373985290551 .50868988037 49.6799812316947 .5464782714845 .717769622843 .5842704772941 .75556182861 39.9268493652338 .4029312133836 .5742111206135 .3550796508833 .83115005493 32.6120109558131 .6976509094230 .7833003997830 .1737308502229 .56415939331 29.2593708038329 .2593708038329 .2593708038329 .5641593933129 .86894035339 30.4785099029531 .0880794525132 .0024414062532 .9167900085433 .83115005493 35.0502891540536 .2694282531737 .4885711669938 .7077102661139 .6220703125 40.8412094116241 .7555618286142 .66992187543 .2794914245643 .88906097412 44.1938400268644 .1938400268644 .1938400268643 .8890609741243 .27949142456 42.66992187542 .0603485107441 .1459884643640 .2316398620639 .31727981567 38.4029312133837 .4885711669936 .5742111206135 .6598587036134 .74551010132 33.8311500549333 .2215805053732 .3072204589831 .6976509094231 .39286994934 30.7833003997830 .4785099029530 .4785099029530 .1737308502230 .17373085022 29.8689403533929 .8689403533929 .5641593933129 .2593708038329 .25937080383 28.9545898437528 .9545898437528 .6497993469228 .6497993469228 .64979934692 28.6497993469228 .6497993469228 .6497993469228 .6497993469228 .64979934692 28.6497993469228 .6497993469228 .6497993469228 .6497993469228 .64979934692 28.6497993469228 .6497993469228 .6497993469228 .6497993469228 .64979934692 28.9545898437528 .9545898437529 .2593708038329 .8689403533930 .47850990295 31.3928699493432 .3072204589833 .5263595581134 .7455101013235 .96464920044 37.1837806701738 .4029312133839 .622070312541 .1459884643642 .36513137817 43.5842704772945 .1082000732446 .6321296691948 .1560516357449 .67998123169 51.5086898803753 .0326118469254 .8613204956156 .3852500915558 .21395874023 59.7378807067961 .2618103027362 .7857398986864 .3096618652365 .83358764648 67.0527267456168 .2718734741269 .4910125732470 .4053573608471 .0149307251 71.9292907714872 .5388565063572 .8436431884873 .4532165527373 .75800323486 74.062782287674 .3675689697374 .3675689697374 .6723632812574 .67236328125 74.6723632812574 .6723632812574 .6723632812574 .6723632812574 .67236328125 74.6723632812574 .3675689697374 .3675689697374 .062782287674 .0627822876 73.7580032348673 .7580032348673 .4532165527373 .1484298706173 .14842987061 72.8436431884872 .8436431884872 .5388565063572 .5388565063572 .23407745361 72.2340774536171 .9292907714871 .9292907714871 .6244964599671 .62449645996 71.6244964599671 .6244964599671 .3197174072371 .3197174072371 .31971740723 71.3197174072371 .3197174072371 .3197174072371 .014930725171 .0149307251 71.014930725171 .014930725171 .014930725171 .014930725171 .31971740723 71.3197174072371 .3197174072371 .3197174072371 .3197174072371 .31971740723 71.6244964599671 .6244964599671 .9292907714871 .9292907714872 .23407745361 72.2340774536172 .5388565063572 .5388565063572 .7788543701273 .016746521 73.29527282715 -9999 -9999 -9999 -9999 -9999 -9999 -9999 -9999 -9999 -9999 -9999 -9999 -9999 -9999 -9999 -9999 -9999 -9999 -9999 -9999 -9999 -9999 -9999 -9999 -9999 -9999 -9999 -9999 -9999 -9999 -9999 -9999 -9999 -9999 -9999 -9999 -9999 -9999 -9999 -9999 -9999 -9999 -

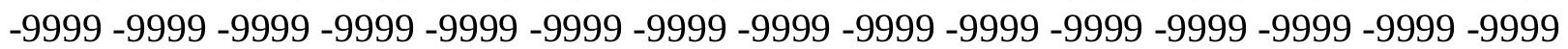


-9999 -9999 -9999 -9999 -9999 -9999 -9999 -9999 -9999 -9999 -9999 -9999 -9999 -9999 -9999 -9999 -9999 -9999 -9999 -9999 -9999 -9999 -9999 -9999 -9999 -9999 -9999 -9999 -9999 -9999

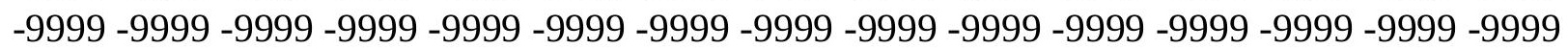
-9999 -9999-9999

-9999 -9999 -9999 -9999 -9999 -9999 -9999 -9999 -9999 -9999 -9999 -9999 -9999 -9999 -9999 -9999 -9999 -9999 -9999 -9999 13.9097566604614 .3248996734614 .32489967346 17.6775398254421 .334960937524 .9923801422128 .9545898437532 .91679000854 36.5742111206139 .9268493652343 .2794914245646 .3273391723649 .07040023804 51.8134689331153 .9469718933156 .0804595947357 .909179687559 .73788070679 61.2618103027362 .4809494018663 .7000885009864 .9192428588965 .83358764648 66.7479400634867 .3575134277367 .9670867919968 .5766525268668 .88143920898 68.8814392089868 .8814392089868 .8814392089868 .8814392089868 .57665252686 68.2718734741267 .6623001098667 .3575134277366 .7479400634866 .13836669922 63.3731460571364 .0158157348664 .3096618652363 .7000885009863 .09051895142 62.4809494018662 .1761703491265 .5288009643667 .9670867919970 .40535736084 72.2340774536173 .7580032348674 .3675689697374 .062782287673 .45321655273 71.9292907714869 .7957916259867 .6623001098665 .2240066528362 .17617034912 62.4809494018662 .7857398986863 .0905189514263 .0905189514263 .39530944824 63.3953094482463 .3953094482463 .3953094482463 .3953094482463 .09051895142 62.7857398986862 .1761703491261 .5666007995660 .6522407531759 .73788070679 58.8235282897957 .2995986938555 .7756805419953 .9469718933152 .11825942993 49.9847602844248 .1560516357446 .0225486755443 .8890609741242 .06034851074 40.2316398620638 .4029312133836 .8790016174335 .3550796508833 .83115005493 32.6120109558131 .6976509094230 .7833003997830 .1737308502229 .56415939331 29.2593708038328 .9545898437528 .9545898437529 .2593708038329 .56415939331 30.1737308502230 .7833003997831 .6976509094232 .9167900085434 .13592910767 35.3550796508836 .5742111206137 .7933502197339 .3172798156740 .53641891479 41.7555618286142 .9747009277343 .8890609741244 .8034095764245 .41297912598 45.717769622845 .717769622845 .717769622845 .4129791259844 .80340957642 44.1938400268643 .5842704772942 .66992187541 .7555618286140 .53641891479 39.622070312538 .7077102661137 .4885711669936 .5742111206135 .65985870361 34.7455101013233 .8311500549333 .2215805053732 .6120109558132 .00244140625 31.3928699493431 .0880794525130 .7833003997830 .7833003997830 .47850990295 30.4785099029530 .4785099029530 .1737308502229 .8689403533929 .56415939331 29.5641593933129 .2593708038329 .2593708038329 .2593708038329 .25937080383 29.2593708038329 .2593708038329 .2593708038329 .5641593933129 .56415939331 29.5641593933129 .5641593933129 .5641593933129 .5641593933129 .56415939331 29.5641593933129 .5641593933129 .5641593933129 .5641593933129 .56415939331 29.5641593933129 .8689403533929 .8689403533930 .4785099029530 .78330039978 31.6976509094232 .3072204589833 .2215805053734 .1359291076735 .35507965088 36.2694282531737 .1837806701738 .4029312133839 .622070312540 .84120941162 42.0603485107443 .2794914245644 .4986305236846 .0225486755447 .24169921875 48.765621185350 .5943298339852 .1182594299353 .6421813964855 .47089004517 56.9948196411158 .5187492370660 .0426712036161 .8713798522963 .09051895142 64.6144485473665 .8335876464867 .0527267456168 .2718734741269 .18623352051 69.7957916259870 .4053573608471 .014930725171 .6244964599671 .92929077148 
72.2340774536172 .5388565063572 .8436431884873 .1484298706173 .45321655273 73.4532165527373 .4532165527373 .4532165527373 .4532165527373 .45321655273 73.4532165527373 .4532165527373 .4532165527373 .1484298706173 .14842987061 72.8436431884872 .8436431884872 .5388565063572 .5388565063572 .23407745361 72.2340774536172 .2340774536171 .9292907714871 .9292907714871 .62449645996 71.6244964599671 .6244964599671 .3197174072371 .3197174072371 .31971740723 71.3197174072371 .014930725171 .014930725171 .014930725171 .0149307251

71.014930725171 .014930725171 .014930725171 .014930725171 .014930725171 .0149307251 71.014930725171 .014930725171 .014930725171 .014930725171 .014930725171 .0149307251 71.014930725171 .3197174072371 .3197174072371 .3197174072371 .62449645996 71.6244964599671 .6244964599671 .9292907714871 .9292907714872 .23407745361 72.5388565063572 .5388565063572 .7674484252973 .0670700073275 .28192901611 -9999 -9999 -9999 -9999 -9999 -9999 -9999 -9999 -9999 -9999 -9999 -9999 -9999 -9999 -9999 -9999 -9999 -9999 -9999 -9999 -9999 -9999 -9999 -9999 -9999 -9999 -9999 -9999 -9999 -9999 - 9999 -9999 -9999 -9999 -9999 -9999 -9999 -9999 -9999 -9999 -9999 -9999 -9999 -9999 -9999 -9999

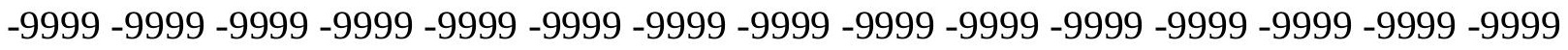
-9999 -9999 -9999 -9999 -9999 -9999 -9999 -9999 -9999 -9999 -9999 -9999 -9999 -9999 -9999 -9999 -9999 -9999 -9999 -9999 -9999 -9999 -9999 -9999 -9999 -9999 -9999 -9999 -9999 -9999 -9999 -9999 -9999 -9999 -9999 -9999 -9999 -9999 -9999 -9999 -9999 -9999 -9999 -

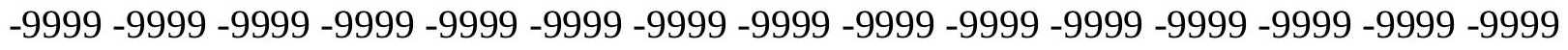
-9999 -9999-9999 -9999 -9999-9999 20.72538948059 20.11581993103 21.3349609375 24.9923801422128 .9545898437532 .9167900085436 .8790016174340 .53641891479 44.1938400268647 .2416992187550 .2518348693852 .9217224121155 .47089004517 57.6043891906759 .4331016540561 .2618103027362 .7857398986864 .0048828125 65.2240066528366 .4431610107467 .3575134277368 .2718734741268 .88143920898 69.7957916259870 .1005783081170 .4053573608470 .7101516723671 .0149307251 71.014930725170 .7101516723670 .4053573608470 .1005783081169 .79579162598 69.1862335205168 .5766525268667 .6623001098667 .0527267456166 .13836669922 63.8814888000564 .17465972964 .004882812563 .3953094482462 .78573989868 62.1761703491261 .8713798522961 .2618103027366 .7479400634869 .49101257324 71.6244964599672 .8436431884872 .8436431884872 .2340774536170 .71015167236 69.1862335205167 .0527267456161 .8713798522962 .1761703491262 .48094940186 62.7857398986863 .0905189514263 .3953094482463 .3953094482463 .70008850098 63.7000885009863 .7000885009863 .7000885009863 .3953094482463 .09051895142 62.7857398986862 .1761703491261 .2618103027360 .6522407531759 .43310165405 58.2139587402356 .3852500915554 .5565414428752 .7278289794950 .59432983398 48.4608306884846 .3273391723644 .4986305236842 .3651313781740 .53641891479 38.7077102661137 .1837806701735 .6598587036134 .1359291076732 .91679000854 31.6976509094230 .7833003997830 .1737308502229 .5641593933129 .25937080383 28.9545898437528 .9545898437529 .2593708038329 .5641593933130 .17373085022 30.7833003997831 .6976509094232 .9167900085434 .1359291076735 .35507965088 36.8790016174338 .4029312133839 .9268493652341 .4507789611842 .669921875 43.8890609741245 .1082000732446 .0225486755446 .6321296691947 .24169921875 47.5464782714847 .2416992187546 .9369087219246 .6321296691945 .7177696228 44.8034095764243 .8890609741242 .9747009277341 .7555618286140 .84120941162 39.622070312538 .7077102661137 .4885711669936 .5742111206135 .65985870361 
34.7455101013233 .8311500549333 .2215805053732 .6120109558132 .00244140625 31.6976509094231 .3928699493431 .0880794525130 .7833003997830 .78330039978 30.7833003997830 .4785099029530 .1737308502230 .1737308502230 .17373085022 29.8689403533929 .8689403533929 .8689403533930 .1737308502230 .17373085022 30.1737308502230 .1737308502230 .4785099029530 .4785099029530 .47850990295 30.7833003997830 .7833003997830 .7833003997830 .7833003997830 .78330039978 30.7833003997830 .4785099029530 .4785099029530 .4785099029530 .47850990295 30.4785099029530 .7833003997831 .0880794525131 .3928699493432 .00244140625 32.6120109558133 .2215805053733 .8311500549334 .7455101013235 .65985870361 36.2694282531737 .1837806701738 .4029312133839 .3172798156740 .23163986206 41.4507789611842 .66992187543 .8890609741245 .1082000732446 .63212966919 48.1560516357449 .6799812316951 .2038993835452 .7278289794954 .25175094604 55.7756805419957 .6043891906759 .1283111572360 .6522407531762 .17617034912 63.7000885009864 .9192428588966 .1383666992267 .0527267456167 .96708679199 68.5766525268669 .1862335205169 .7957916259870 .4053573608470 .71015167236 71.014930725171 .3197174072371 .6244964599671 .9292907714871 .92929077148 72.2340774536172 .2340774536172 .5388565063572 .5388565063572 .53885650635 72.5388565063572 .2340774536172 .2340774536172 .2340774536172 .23407745361 71.9292907714871 .9292907714871 .9292907714871 .6244964599671 .62449645996 71.6244964599671 .3197174072371 .3197174072371 .3197174072371 .0149307251 71.014930725171 .014930725171 .014930725170 .7101516723670 .71015167236 70.7101516723670 .7101516723670 .7101516723670 .7101516723670 .71015167236 70.7101516723670 .7101516723670 .7101516723670 .7101516723670 .71015167236 70.7101516723670 .7101516723670 .7101516723670 .7101516723670 .71015167236 71.014930725171 .014930725171 .014930725171 .014930725171 .31971740723 71.3197174072371 .3197174072371 .6244964599671 .6244964599671 .92929077148 71.9292907714872 .2340774536172 .2340774536172 .5388565063572 .88878631592 74.3675689697375 .89148712158 -9999 -9999 -9999 -9999 -9999 -9999 -9999 -9999 -9999 -9999 -9999 -9999 -9999 -9999 -9999 -9999 -9999 -9999 -9999 -9999 -9999 -9999 -9999 -9999

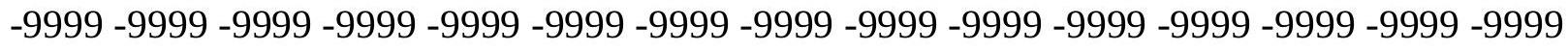
-9999 -9999 -9999 -9999 -9999 -9999 -9999 -9999 -9999 -9999 -9999 -9999 -9999 -9999 -9999

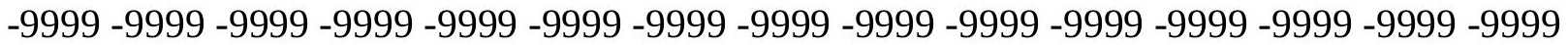

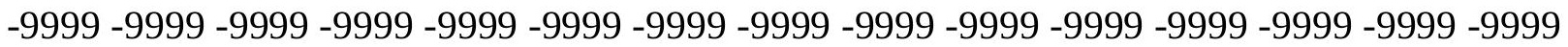

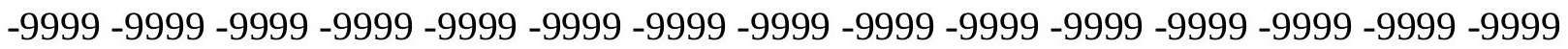
-9999 -9999-9999-9999

-9999 -9999 -9999 -9999 -9999 -9999 -9999 -9999 -9999 -9999 -9999 -9999 -9999 -9999 -9999 -9999 -9999 -9999 -9999 -9999 -9999 27.15194511414 27.12587928772 26.82109069824 28.9545898437532 .9167900085436 .8790016174340 .8412094116244 .80340957642 48.1560516357451 .5086898803754 .2517509460456 .4549102783258 .85159683228 60.9570198059162 .7857398986864 .3096618652365 .8335876464867 .05272674561 67.9670867919968 .8814392089869 .7957916259870 .7101516723671 .31971740723 71.9292907714872 .2340774536172 .5388565063572 .8436431884872 .84364318848 72.8436431884872 .5388565063572 .2340774536171 .9292907714871 .31971740723 70.4053573608469 .7957916259868 .8814392089867 .9670867919967 .05272674561 66.1383666992263 .8524627685563 .8502311706563 .540172576963 .09051895142 62.1761703491261 .8713798522961 .2618103027360 .9570198059165 .83358764648 
68.8814392089871 .014930725171 .014930725170 .1005783081168 .88143920898 67.3575134277365 .8335876464861 .8713798522962 .1761703491262 .48094940186 62.7857398986863 .0905189514263 .3953094482463 .7000885009863 .70008850098 64.004882812564 .004882812564 .004882812563 .7000885009863 .70008850098 63.0905189514262 .7857398986862 .1761703491261 .2618103027360 .34745025635 59.1283111572357 .2995986938555 .4708900451753 .3373985290551 .20389938354 49.0704002380447 .2416992187545 .1082000732443 .2794914245641 .14598846436 39.3172798156737 .7933502197336 .2694282531734 .7455101013233 .52635955811 32.3072204589831 .3928699493430 .4785099029529 .8689403533929 .25937080383 28.9545898437528 .9545898437529 .2593708038329 .5641593933130 .17373085022 30.7833003997831 .6976509094232 .9167900085434 .1359291076735 .65985870361 37.1837806701738 .7077102661140 .5364189147942 .0603485107443 .58427047729 45.1082000732446 .3273391723647 .5464782714848 .1560516357448 .7656211853 49.0704002380449 .0704002380448 .765621185348 .1560516357447 .24169921875 46.3273391723645 .4129791259844 .1938400268642 .9747009277342 .06034851074 40.8412094116239 .622070312538 .4029312133837 .4885711669936 .26942825317 35.3550796508834 .4407196044933 .8311500549333 .2215805053732 .61201095581 32.0024414062531 .6976509094231 .3928699493431 .3928699493431 .08807945251 31.0880794525130 .7833003997830 .7833003997830 .4785099029530 .47850990295 30.4785099029530 .7833003997830 .7833003997830 .7833003997831 .08807945251 31.0880794525131 .0880794525131 .3928699493431 .3928699493431 .69765090942 31.6976509094231 .6976509094232 .0024414062532 .0024414062531 .69765090942 31.6976509094231 .6976509094231 .6976509094231 .3928699493431 .39286994934 31.3928699493431 .6976509094231 .6976509094232 .0024414062532 .30722045898 32.6120109558133 .2215805053733 .5263595581134 .1359291076734 .74551010132 35.65985870361 36.2694282531737.1837806701737.79335021973 38.70771026611 39.622070312540 .8412094116241 .7555618286142 .9747009277344 .49863052368 45.717769622847 .2416992187548 .765621185350 .2895507812551 .81346893311 53.3373985290555 .1661109924356 .6900291442958 .2139587402359 .73788070679 61.2618103027362 .7857398986864 .004882812564 .9192428588965 .83358764648 66.7479400634867 .3575134277367 .9670867919968 .5766525268668 .88143920898 69.4910125732469 .7957916259870 .1005783081170 .4053573608470 .71015167236 71.014930725171 .014930725171 .3197174072371 .3197174072371 .31971740723 71.3197174072371 .3197174072371 .3197174072371 .3197174072371 .31971740723 71.014930725171 .014930725171 .014930725171 .014930725171 .0149307251 70.7101516723670 .7101516723670 .7101516723670 .7101516723670 .71015167236 70.7101516723670 .4053573608470 .4053573608470 .4053573608470 .40535736084 70.4053573608470 .4053573608470 .4053573608470 .4053573608470 .40535736084 70.4053573608470 .4053573608470 .4053573608470 .4053573608470 .40535736084 70.4053573608470 .4053573608470 .4053573608470 .7101516723670 .71015167236 70.7101516723670 .7101516723670 .7101516723671 .014930725171 .0149307251 71.3197174072371 .3197174072371 .3197174072371 .6244964599671 .62449645996 71.9292907714871 .9292907714872 .2340774536172 .4719314575272 .53885650635 73.0374679565474 .97714233398 -9999 -9999 -9999 -9999 -9999 -9999 -9999 -9999 -9999 -9999 -9999 -9999 -9999 -9999 -9999 -9999 -9999 -9999 -9999 -9999 -9999 -9999 -9999 -9999

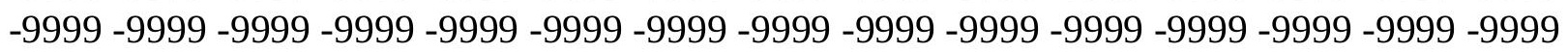


-9999 -9999 -9999 -9999 -9999 -9999 -9999 -9999 -9999 -9999 -9999 -9999 -9999 -9999 -9999 -9999 -9999 -9999 -9999 -9999 -9999 -9999 -9999 -9999 -9999 -9999 -9999 -9999 -9999 -9999

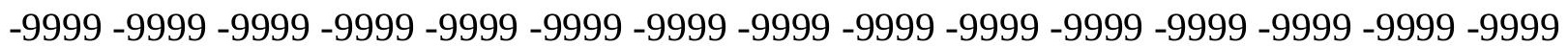
-9999 -9999 -9999 -9999 -9999 -9999 -9999 -9999 -9999 -9999 -9999 -9999 -9999 -9999 -9999 -9999 -9999-9999-9999

-9999 -9999 -9999 -9999 -9999 -9999 -9999 -9999 -9999 -9999 -9999 -9999 -9999 -9999 -9999 -9999 -9999 -9999 -9999 -9999 -9999 -9999 34.74551010132 34.13592910767 33.83115005493 37.1837806701741 .1459884643645 .4129791259849 .0704002380452 .42303848267 55.7756805419958 .2139587402360 .6522407531762 .0872993469264 .21740722656 66.1383666992267 .3575134277368 .5766525268669 .7957916259870 .71015167236 71.6244964599672 .2340774536172 .8436431884873 .4532165527374 .0627822876 74.3675689697374 .6723632812574 .9771423339874 .9771423339874 .67236328125 74.3675689697374 .062782287673 .4532165527372 .8436431884871 .92929077148 71.014930725170 .1005783081169 .1862335205167 .9670867919967 .05272674561 65.8335876464863 .516036987363 .3648681640662 .9853324890162 .48094940186 61.8713798522961 .2618103027360 .9570198059160 .6522407531764 .91924285889 67.9670867919967 .9670867919967 .0527267456166 .1383666992265 .22400665283 61.5666007995661 .8713798522962 .1761703491262 .4809494018662 .78573989868 63.3953094482463 .7000885009864 .004882812564 .004882812564 .30966186523 64.3096618652364 .3096618652364 .3096618652364 .004882812563 .70008850098 63.3953094482462 .7857398986862 .1761703491261 .2618103027360 .04267120361 58.5187492370656 .3852500915554 .2517509460452 .1182594299350 .28955078125 48.1560516357446 .0225486755444 .1938400268642 .3651313781740 .53641891479 38.7077102661137 .1837806701735 .6598587036134 .1359291076732 .91679000854 32.0024414062531 .0880794525130 .1737308502229 .8689403533929 .25937080383 29.2593708038329 .2593708038329 .5641593933130 .1737308502230 .78330039978 32.0024414062532 .9167900085434 .4407196044935 .9646492004437 .48857116699 39.3172798156741 .1459884643642 .66992187544 .4986305236846 .02254867554 47.5464782714848 .765621185349 .6799812316950 .2895507812550 .59432983398 50.5943298339850 .2895507812549 .6799812316948 .765621185347 .85126113892 46.6321296691945 .4129791259844 .1938400268642 .9747009277341 .75556182861 40.5364189147939 .3172798156738 .0981407165537 .1837806701735 .96464920044 35.0502891540534 .4407196044933 .5263595581132 .9167900085432 .61201095581 32.0024414062531 .6976509094231 .6976509094231 .3928699493431 .39286994934 31.0880794525131 .0880794525131 .0880794525131 .0880794525131 .08807945251 31.3928699493431 .3928699493431 .6976509094231 .6976509094232 .00244140625 32.3072204589832 .3072204589832 .6120109558132 .9167900085432 .91679000854 32.9167900085433 .2215805053733 .2215805053732 .9167900085432 .91679000854 32.9167900085432 .6120109558132 .6120109558132 .6120109558132 .30722045898 32.3072204589832 .3072204589832 .6120109558132 .6120109558132 .91679000854 33.2215805053733 .5263595581133 .8311500549334 .1359291076734 .74551010132 35.3550796508835 .9646492004436 .5742111206137 .1837806701738 .09814071655 39.0125007629439 .9268493652341 .1459884643642 .3651313781743 .58427047729 44.8034095764246 .3273391723647 .8512611389249 .3751907348650 .89912033081 52.4230384826754 .2517509460455 .7756805419957 .2995986938559 .12831115723 60.6522407531761 .8713798522962 .7857398986863 .7000885009864 .61444854736 
65.2240066528366 .1383666992266 .7479400634867 .3575134277367 .66230010986 68.2718734741268 .5766525268668 .8814392089869 .1862335205169 .49101257324 69.7957916259869 .7957916259870 .1005783081170 .1005783081170 .10057830811 70.4053573608470 .4053573608470 .4053573608470 .4053573608470 .40535736084 70.4053573608470 .4053573608470 .1005783081170 .1005783081170 .10057830811 70.1005783081170 .1005783081170 .1005783081170 .1005783081170 .10057830811 70.1005783081170 .1005783081170 .1005783081170 .1005783081170 .10057830811 70.1005783081170 .1005783081170 .1005783081170 .1005783081170 .10057830811 70.1005783081170 .1005783081170 .1005783081170 .1005783081170 .40535736084 70.4053573608470 .4053573608470 .4053573608470 .4053573608470 .40535736084 70.7101516723670 .7101516723670 .7101516723671 .014930725171 .0149307251 71.3197174072371 .3197174072371 .3197174072371 .6244964599671 .62449645996 71.9292907714872 .2340774536172 .2340774536172 .5388565063572 .84364318848 74.3675689697375 .58670806885 -9999 -9999 -9999 -9999 -9999 -9999 -9999 -9999 -9999 -9999 -9999 -9999 -9999 -9999 -9999 -9999 -9999 -9999 -9999 -9999 -9999-9999 -9999 -9999

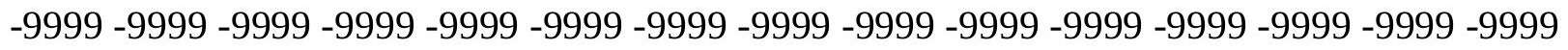
-9999 -9999 -9999 -9999 -9999 -9999 -9999 -9999 -9999 -9999 -9999 -9999 -9999 -9999 -9999 -9999 -9999 -9999 -9999 -9999 -9999 -9999 -9999 -9999 -9999 -9999 -9999 -9999 -9999 -9999 -

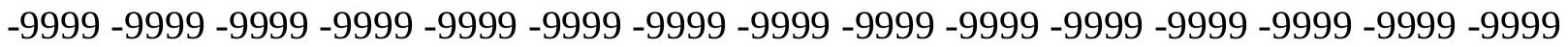

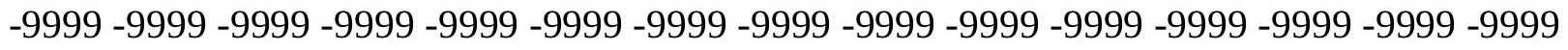
$-9999-9999-9999$

-9999 -9999 -9999 -9999 -9999 -9999 -9999 -9999 -9999 -9999 -9999 -9999 -9999 -9999 -9999 -9999 -9999 -9999 -9999-9999 -9999 -9999 -9999 42.06034851074 41.45077896118 41.4507789611845 .717769622849 .6799812316953 .6421813964856 .99481964111 59.7378807067962 .4809494018664 .6144485473666 .4431610107467 .17088317871 68.9546127319370 .4053573608471 .3197174072372 .2340774536173 .14842987061 73.7580032348674 .3675689697374 .9771423339875 .5867080688576 .19628143311 76.5010681152376 .8058471679776 .8058471679776 .8058471679776 .80584716797 76.5010681152375 .8914871215875 .2819290161174 .3675689697373 .45321655273 72.5388565063571 .3197174072370 .1005783081168 .8814392089867 .66230010986 66.4431610107465 .2240066528362 .9903182983462 .7297782897962 .34476852417 61.8713798522961 .2618103027360 .6522407531760 .3474502563560 .34745025635 60.3474502563560 .3474502563560 .3474502563560 .6522407531760 .95701980591 61.2618103027361 .8713798522962 .1761703491262 .4809494018663 .09051895142 63.3953094482463 .7000885009864 .004882812564 .3096618652364 .61444854736 64.9192428588964 .9192428588964 .9192428588964 .6144485473664 .61444854736 64.3096618652363 .7000885009863 .0905189514262 .1761703491261 .26181030273 59.4331016540557 .6043891906755 .4708900451753 .3373985290551 .50868988037 49.3751907348647 .5464782714845 .4129791259843 .5842704772941 .75556182861 39.9268493652338 .4029312133836 .8790016174335 .3550796508834 .13592910767 32.9167900085432 .0024414062531 .0880794525130 .4785099029529 .86894035339 29.5641593933129 .5641593933129 .8689403533930 .1737308502231 .08807945251 32.0024414062533 .2215805053734 .4407196044935 .9646492004437 .79335021973 39.622070312541 .4507789611843 .2794914245645 .4129791259847 .24169921875 48.765621185350 .2895507812551 .2038993835451 .8134689331152 .11825942993 52.1182594299351 .5086898803750 .8991203308149 .9847602844249 .07040023804 
47.8512611389246 .6321296691945 .4129791259843 .8890609741242 .669921875 41.4507789611840 .2316398620639 .0125007629437 .7933502197336 .87900161743 35.6598587036135 .0502891540534 .1359291076733 .5263595581132 .91679000854 32.6120109558132 .3072204589832 .0024414062531 .6976509094231 .69765090942 31.6976509094231 .6976509094231 .6976509094231 .6976509094232 .00244140625 32.0024414062532 .3072204589832 .6120109558132 .9167900085432 .91679000854 33.2215805053733 .5263595581133 .8311500549333 .8311500549334 .13592910767 34.1359291076734 .1359291076734 .1359291076734 .1359291076734 .13592910767 33.8311500549333 .8311500549333 .5263595581133 .5263595581133 .22158050537 33.2215805053732 .9167900085432 .9167900085432 .9167900085432 .91679000854 33.2215805053733 .2215805053733 .5263595581133 .8311500549334 .13592910767 34.4407196044934 .7455101013235 .3550796508835 .9646492004436 .57421112061 37.4885711669938 .0981407165539 .3172798156740 .2316398620641 .45077896118 42.66992187544 .1938400268645 .4129791259846 .9369087219248 .46083068848 50.2895507812551 .8134689331153 .3373985290555 .1661109924356 .69002914429 58.2139587402359 .4331016540560 .6522407531761 .5666007995662 .48094940186 63.3953094482464 .004882812564 .9192428588965 .5288009643666 .13836669922 66.7479400634867 .0527267456167 .3575134277367 .9670867919968 .27187347412 68.5766525268668 .5766525268668 .8814392089868 .8814392089869 .18623352051 69.1862335205169 .1862335205169 .4910125732469 .4910125732469 .49101257324 69.4910125732469 .4910125732469 .4910125732469 .4910125732469 .49101257324 69.4910125732469 .4910125732469 .4910125732469 .4910125732469 .49101257324 69.4910125732469 .7957916259869 .7957916259869 .7957916259869 .79579162598 69.7957916259869 .7957916259869 .7957916259869 .7957916259869 .79579162598 69.7957916259869 .7957916259870 .1005783081170 .1005783081170 .10057830811 70.1005783081170 .1005783081170 .4053573608470 .4053573608470 .40535736084 70.4053573608470 .7101516723670 .7101516723670 .7101516723671 .0149307251 71.014930725171 .3197174072371 .3197174072371 .6244964599671 .62449645996 71.9292907714871 .9292907714872 .2340774536172 .5388565063572 .53885650635 73.0661697387774 .9771423339876 .50106811523 -9999 -9999 -9999 -9999 -9999 -9999 -9999 -9999 -9999 -9999 -9999 -9999 -9999 -9999 -9999 -9999 -9999 -9999 -9999 -9999 -9999 -9999

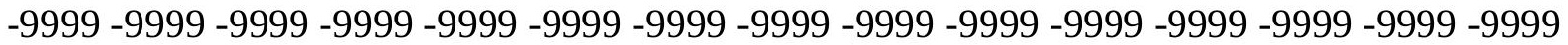
-9999 -9999 -9999 -9999 -9999 -9999 -9999 -9999 -9999 -9999 -9999 -9999 -9999 -9999 -9999 -9999 -9999 -9999 -9999 -9999 -9999 -9999 -9999 -9999 -9999 -9999 -9999 -9999 -9999 -9999 -

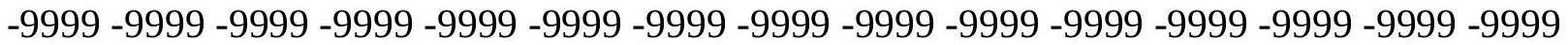
-9999 -9999 -9999 -9999 -9999 -9999 -9999 -9999 -9999 -9999 -9999 -9999 -9999 -9999 -9999 -9999 -9999 -9999-9999

-9999 -9999 -9999 -9999 -9999 -9999 -9999 -9999 -9999 -9999 -9999 -9999 -9999 -9999 -9999 -9999 -9999 -9999 -9999 -9999 -9999 -9999 -9999 -9999 49.6799812316949 .37519073486 50.2895507812554 .5565414428758 .2139587402361 .2618103027364 .0048828125 66.1383666992268 .2718734741269 .7957916259871 .014930725171 .53386688232 72.9350814819374 .062782287674 .6723632812575 .2819290161175 .89148712158 76.5010681152377 .110626220777 .7202072143678 .0249862670978 .63455963135 78.6345596313578 .9393463134878 .9393463134878 .6345596313578 .32978057861 77.7202072143677 .110626220776 .1962814331174 .9771423339873 .75800323486 72.5388565063571 .3197174072369 .7957916259868 .2718734741267 .05272674561 
65.8335876464864 .6144485473662 .3033905029361 .9764595031761 .51209640503 60.9570198059160 .6522407531760 .3474502563560 .0426712036160 .04267120361 60.0426712036160 .3474502563560 .6522407531760 .9570198059161 .26181030273 61.8713798522962 .1761703491262 .7857398986863 .0905189514263 .70008850098 64.004882812564 .3096618652364 .9192428588965 .2240066528365 .22400665283 65.5288009643665 .5288009643665 .5288009643665 .2240066528364 .91924285889 64.6144485473664 .004882812563 .0905189514262 .1761703491260 .65224075317 58.8235282897956 .6900291442954 .8613204956153 .0326118469251 .20389938354 49.0704002380447 .2416992187545 .4129791259843 .5842704772941 .75556182861 39.9268493652338 .4029312133836 .8790016174335 .6598587036134 .44071960449 33.2215805053732 .3072204589831 .3928699493430 .7833003997830 .17373085022 30.1737308502230 .1737308502230 .4785099029531 .0880794525132 .00244140625 33.2215805053734 .4407196044936 .2694282531737 .7933502197339 .92684936523 41.7555618286143 .8890609741245 .717769622847 .8512611389249 .67998123169 51.5086898803752 .7278289794953 .3373985290553 .6421813964853 .33739852905 52.7278289794952 .1182594299351 .2038993835449 .9847602844248 .7656211853 47.5464782714846 .3273391723644 .8034095764243 .5842704772942 .06034851074 40.8412094116239 .622070312538 .4029312133837 .4885711669936 .26942825317 35.3550796508834 .7455101013233 .8311500549333 .2215805053732 .91679000854 32.6120109558132 .3072204589832 .0024414062532 .0024414062532 .00244140625 32.0024414062532 .0024414062532 .3072204589832 .6120109558132 .91679000854 32.9167900085433 .5263595581133 .8311500549334 .1359291076734 .44071960449 34.7455101013234 .7455101013235 .0502891540535 .3550796508835 .35507965088 35.3550796508835 .3550796508835 .3550796508835 .3550796508835 .05028915405 34.7455101013234 .7455101013234 .4407196044934 .1359291076733 .83115005493 33.5263595581133 .2215805053733 .2215805053733 .2215805053732 .91679000854 32.9167900085432 .9167900085433 .2215805053733 .2215805053733 .52635955811 33.8311500549334 .1359291076734 .4407196044935 .0502891540535 .65985870361 36.5742111206137 .4885711669938 .4029312133839 .3172798156740 .53641891479 42.0603485107443 .2794914245644 .8034095764246 .3273391723647 .85126113892 49.3751907348651 .2038993835452 .7278289794954 .2517509460455 .77568054199 56.9948196411158 .2139587402359 .4331016540560 .3474502563561 .26181030273 62.1761703491263 .0905189514263 .7000885009864 .3096618652364 .91924285889 65.5288009643666 .1383666992266 .4431610107466 .7479400634867 .05272674561 67.3575134277367 .6623001098667 .9670867919967 .9670867919968 .27187347412 68.2718734741268 .2718734741268 .5766525268668 .5766525268668 .57665252686 68.8814392089868 .8814392089868 .8814392089868 .8814392089868 .88143920898 68.8814392089869 .1862335205169 .1862335205169 .1862335205169 .18623352051 69.1862335205169.1862335205169.1862335205169.49101257324 69.49101257324 69.4910125732469 .4910125732469 .4910125732469 .4910125732469 .79579162598 69.7957916259869 .7957916259869 .7957916259869 .7957916259870 .10057830811 70.1005783081170 .1005783081170 .1005783081170 .4053573608470 .40535736084 70.4053573608470 .7101516723670 .7101516723670 .7101516723671 .0149307251 71.014930725171 .3197174072371 .3197174072371 .6244964599671 .92929077148 71.9292907714872 .2340774536172 .5388565063572 .5388565063572 .84364318848 74.062782287675 .58670806885 -9999 -9999 -9999 -9999 -9999 -9999 -9999 -9999 -9999 
-9999 -9999 -9999 -9999 -9999 -9999 -9999 -9999 -9999 -9999 -9999 -9999 -9999 -9999 -9999 -9999 -9999 -9999 -9999 -9999 -9999 -9999 -9999 -9999 -9999 -9999 -9999 -9999 -9999 -9999 -9999 -9999 -9999 -9999 -9999 -9999 -9999 -9999 -9999 -9999 -9999 -9999 -9999 -9999 -9999 -9999 -9999 -9999 -9999 -9999 -9999 -9999 -9999 -9999 -9999 -9999 -9999 -9999 -9999 -9999 -9999 -9999 -9999 -9999 -9999 -9999 -9999 -9999 -9999 -9999 -9999 -9999-9999 -9999 -9999 -

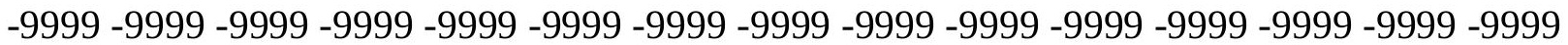
$-9999-9999$

-9999 -9999 -9999 -9999 -9999 -9999 -9999 -9999 -9999 -9999 -9999 -9999 -9999 -9999 -9999 -9999 -9999 -9999 -9999 -9999 -9999 -9999 -9999 -9999 58.5187492370657 .9091796875 57.2995986938559 .4331016540562 .7857398986865 .5288009643667 .96708679199 70.1005783081171 .6244964599673 .1484298706174 .062782287674 .97714233398 75.1920166015676 .15932464676 .8058471679777 .4154205322378 .02498626709 78.3297805786178 .9393463134879 .5489196777380 .1584930419980 .46327209473 80.7680587768680 .7680587768680 .7680587768680 .7680587768680 .15849304199 79.5489196777378 .9393463134877 .7202072143676 .5010681152375 .28192901611 73.7580032348672 .2340774536170 .7101516723669 .1862335205167 .66230010986 66.1383666992264 .9192428588963 .7000885009861 .4763717651461 .09018325806 60.6837654113860 .3474502563560 .0426712036159 .7378807067959 .73788070679 60.0426712036160 .0426712036160 .6522407531760 .9570198059161 .26181030273 61.8713798522962 .4809494018662 .7857398986863 .3953094482464 .0048828125 64.3096618652364 .9192428588965 .2240066528365 .5288009643665 .83358764648 66.1383666992266 .1383666992266 .1383666992266 .1383666992265 .83358764648 65.5288009643664 .9192428588964 .3096618652363 .0905189514261 .87137985229 60.3474502563558 .5187492370656 .6900291442954 .8613204956153 .33739852905 51.5086898803749 .6799812316947 .5464782714845 .717769622843 .58427047729 41.7555618286140 .2316398620638 .7077102661137 .1837806701735 .96464920044 34.7455101013233 .5263595581132 .6120109558131 .6976509094231 .08807945251 30.4785099029530 .4785099029530 .7833003997831 .3928699493432 .30722045898 33.2215805053734 .7455101013236 .2694282531738 .0981407165539 .92684936523 42.0603485107443 .8890609741246 .3273391723648 .4608306884850 .28955078125 52.4230384826753 .6421813964854 .5565414428754 .5565414428754 .25175094604 53.9469718933153 .0326118469252 .1182594299350 .8991203308149 .67998123169 48.4608306884846 .9369087219245 .717769622844 .1938400268642 .97470092773 41.4507789611840 .2316398620639 .0125007629437 .7933502197336 .87900161743 35.9646492004435 .0502891540534 .4407196044933 .8311500549333 .22158050537 32.9167900085432 .6120109558132 .3072204589832 .3072204589832 .30722045898 32.3072204589832 .6120109558132 .9167900085433 .2215805053733 .52635955811 33.8311500549334 .1359291076734 .7455101013235 .0502891540535 .35507965088 35.6598587036135 .9646492004436 .2694282531736 .2694282531736 .57421112061 36.5742111206136 .5742111206136 .2694282531736 .2694282531735 .96464920044 35.6598587036135 .3550796508835 .0502891540534 .7455101013234 .44071960449 33.8311500549333 .5263595581133 .2215805053732 .9167900085432 .91679000854 32.6120109558132 .6120109558132 .3072204589832 .3072204589832 .61201095581 32.6120109558132 .9167900085433 .2215805053733 .5263595581134 .13592910767 34.7455101013235 .6598587036136 .5742111206137 .4885711669938 .70771026611 39.9268493652341 .1459884643642 .66992187544 .1938400268645 .7177696228 
47.24169921875 48.765621185350.28955078125 51.8134689331153.33739852905 54.8613204956156 .0804595947357 .2995986938558 .2139587402359 .43310165405 60.3474502563560 .9570198059161 .8713798522962 .7857398986863 .39530944824 64.004882812564 .6144485473664 .9192428588965 .5288009643665 .83358764648 66.1383666992266 .4431610107466 .7479400634867 .0527267456167 .05272674561 67.3575134277367 .3575134277367 .6623001098667 .6623001098667 .96708679199 67.9670867919967 .9670867919968 .2718734741268 .2718734741268 .27187347412 68.5766525268668 .5766525268668 .5766525268668 .5766525268668 .88143920898 68.8814392089868 .8814392089868 .8814392089869 .1862335205169 .18623352051 69.1862335205169 .1862335205169 .1862335205169 .4910125732469 .49101257324 69.4910125732469 .4910125732469 .7957916259869 .7957916259869 .79579162598 69.7957916259870 .1005783081170 .1005783081170 .1005783081170 .40535736084 70.4053573608470 .4053573608470 .7101516723670 .7101516723671 .0149307251 71.014930725171 .3197174072371 .3197174072371 .6244964599671 .62449645996 71.9292907714872 .2340774536172 .2340774536172 .5388565063572 .84364318848 73.1662216186574 .9771423339876 .19628143311 -9999 -9999 -9999 -9999 -9999 -9999 -9999 -9999 -9999 -9999 -9999 -9999 -9999 -9999 -9999 -9999 -9999 -9999 -9999 -9999 -9999 -9999 -9999 -9999 -9999 -9999 -9999 -9999 -9999 -9999 -9999 -9999 -9999 -9999 -9999 -9999 -9999 -9999 -9999 -9999 -9999 -9999 -9999 -9999 -9999 -9999 -9999 -9999 -9999 -9999 -9999 -9999 -

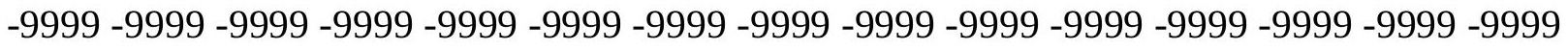
-9999 -9999 -9999 -9999 -9999 -9999 -9999 -9999 -9999 -9999 -9999 -9999 -9999 -9999 -9999 -9999 -9999 -9999 -9999 -9999 -9999 -9999 -9999 -9999 -9999 -9999 -9999 -9999 -9999 -9999 -9999 -9999-9999

-9999 -9999 -9999 -9999 -9999 -9999 -9999 -9999 -9999 -9999 -9999 -9999 -9999 -9999 -9999 -9999 -9999 -9999 -9999 -9999 -9999 -9999 -9999 -9999 -9999 66.74794006348 65.8335876464864 .9192428588966 .7479400634869 .1862335205171 .31971740723 73.4532165527374 .9771423339876 .1962814331177 .110626220777 .72020721436 78.0249862670978 .1521148681678 .7801589965879 .2281494140679 .54891967773 80.1584930419980 .7680587768681 .3776321411181 .6824111938582 .29197692871 82.5967712402382 .9015579223682 .9015579223682 .5967712402382 .29197692871 81.6824111938580 .7680587768679 .5489196777378 .3297805786176 .80584716797 75.2819290161173 .4532165527371 .6244964599669 .7957916259868 .27187347412 66.4431610107464 .9192428588963 .7000885009862 .4809494018660 .62353897095 60.2966270446859 .9820671081559 .7378807067959 .7378807067959 .73788070679 59.7378807067960 .0426712036160 .3474502563560 .9570198059161 .56660079956 61.8713798522962 .4809494018663 .0905189514263 .7000885009864 .30966186523 64.9192428588965 .2240066528365 .8335876464866 .1383666992266 .44316101074 66.7479400634867 .0527267456167 .0527267456167 .0527267456167 .05272674561 66.7479400634866 .1383666992265 .5288009643664 .6144485473663 .39530944824 61.8713798522960 .3474502563559 .1283111572357 .6043891906756 .38525009155 54.8613204956152 .7278289794950 .5943298339848 .1560516357446 .02254867554 43.8890609741242 .0603485107440 .5364189147939 .3172798156737 .79335021973 36.5742111206135 .0502891540533 .8311500549332 .9167900085435 .05028915405 34.7455101013234 .1359291076731 .0880794525131 .6976509094232 .30722045898 33.2215805053734 .7455101013236 .2694282531737 .7933502197339 .92684936523 41.7555618286143 .8890609741246 .3273391723648 .4608306884850 .59432983398 
52.7278289794954 .5565414428755 .1661109924355 .1661109924355 .16611099243 54.5565414428753 .9469718933152 .7278289794951 .8134689331150 .28955078125 49.0704002380447 .5464782714846 .3273391723644 .8034095764243 .58427047729 42.0603485107440 .8412094116239 .622070312538 .4029312133837 .48857116699 36.2694282531735 .3550796508834 .7455101013234 .1359291076733 .52635955811 33.2215805053732 .9167900085432 .6120109558132 .6120109558132 .61201095581 32.9167900085432 .9167900085433 .2215805053733 .8311500549334 .13592910767 34.7455101013235 .0502891540535 .6598587036135 .9646492004436 .26942825317 36.8790016174337 .1837806701737 .1837806701737 .4885711669937 .48857116699 37.4885711669937 .4885711669937 .4885711669937 .1837806701736 .87900161743 36.5742111206135 .9646492004435 .6598587036135 .0502891540534 .74551010132 34.1359291076733 .5263595581133 .2215805053732 .9167900085432 .30722045898 32.0024414062531 .6976509094231 .6976509094231 .3928699493431 .39286994934 31.3928699493431 .6976509094231 .6976509094232 .3072204589832 .61201095581 33.2215805053733 .8311500549334 .7455101013235 .6598587036136 .57421112061 37.7933502197339 .0125007629440 .5364189147941 .7555618286143 .27949142456 44.8034095764246 .6321296691948 .1560516357449 .6799812316951 .20389938354 52.4230384826753 .6421813964855 .1661109924356 .0804595947357 .29959869385 58.2139587402359 .1283111572360 .0426712036160 .9570198059161 .87137985229 62.4809494018663 .0905189514263 .7000885009864 .004882812564 .61444854736 64.9192428588965 .2240066528365 .5288009643665 .8335876464866 .13836669922 66.1383666992266 .4431610107466 .7479400634866 .7479400634867 .05272674561 67.3575134277367 .3575134277367 .6623001098667 .6623001098667 .66230010986 67.9670867919967 .9670867919968 .2718734741268 .2718734741268 .27187347412 68.5766525268668 .5766525268668 .5766525268668 .8814392089868 .88143920898 68.8814392089868 .8814392089869 .1862335205169 .1862335205169 .18623352051 69.4910125732469 .4910125732469 .4910125732469 .4910125732469 .79579162598 69.7957916259869 .7957916259870 .1005783081170 .1005783081170 .10057830811 70.4053573608470 .4053573608470 .7101516723670 .7101516723671 .0149307251 71.014930725171 .3197174072371 .3197174072371 .6244964599671 .62449645996 71.9292907714872 .2340774536172 .2340774536172 .5388565063572 .84030914307 73.131698608474 .062782287675 .5867080688577 .1106262207 -9999 -9999 -9999 -9999 -9999 -9999 -9999 -9999 -9999 -9999 -9999 -9999 -9999 -9999 -9999 -9999 -9999 -9999 -9999 -9999 -9999 -9999 -9999 -9999 -9999 -9999 -9999 -9999 -9999 -9999 -9999 -9999 -9999 -9999 -

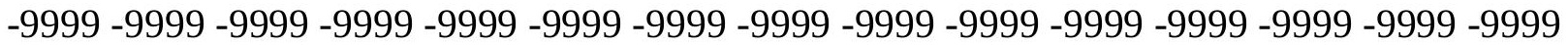
-9999 -9999 -9999 -9999 -9999 -9999 -9999 -9999 -9999 -9999 -9999 -9999 -9999 -9999 -9999 -9999 -9999 -9999 -9999 -9999 -9999 -9999 -9999 -9999 -9999 -9999 -9999 -9999 -9999 -9999 -

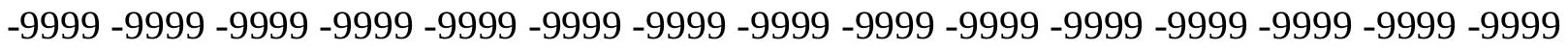
-9999 -9999-9999-9999-9999

-9999 -9999 -9999 -9999 -9999 -9999 -9999 -9999 -9999 -9999 -9999 -9999 -9999 -9999 -9999 -9999 -9999 -9999 -9999 -9999 -9999 -9999 -9999 -9999 -9999 -9999 74.97714233398 73.7580032348672 .5388565063572 .2340774536174 .6723632812576 .50106811523 78.0249862670978 .9393463134879 .5489196777379 .8537063598680 .15849304199 80.1124649047980 .4632720947380 .7680587768681 .0728530883881 .68241119385 82.2919769287182 .9015579223683 .5111236572384 .1206970214884 .42548370361 84.7302627563584 .7302627563584 .7302627563584 .1206970214883 .51112365723 
82.5967712402381 .3776321411179 .8537063598678 .3297805786176 .50106811523 74.6723632812572 .5388565063570 .7101516723668 .5766525268666 .74794006348 65.2240066528363 .7000885009862 .4809494018661 .2618103027359 .87979888916 59.6352691650459 .4331016540559 .4331016540559 .4331016540559 .73788070679 60.0426712036160 .3474502563560 .9570198059161 .5666007995662 .17617034912 62.7857398986863 .3953094482464 .004882812564 .6144485473665 .22400665283 65.8335876464866 .4431610107466 .7479400634867 .3575134277367 .66230010986 67.9670867919968 .2718734741268 .2718734741267 .9670867919967 .96708679199 67.6623001098667 .0527267456166 .1383666992265 .2240066528364 .30966186523 63.0905189514261 .8713798522961 .2618103027360 .3474502563558 .82352828979 56.6900291442954 .2517509460451 .5086898803748 .765621185346 .32733917236 44.4986305236842 .66992187541 .1459884643639 .9268493652338 .40293121338 37.1837806701735 .6598587036137 .4885711669936 .8790016174336 .26942825317 35.6598587036134 .7455101013232 .0024414062532 .6120109558133 .52635955811 34.7455101013235 .9646492004437 .7933502197339 .622070312541 .75556182861 43.8890609741246 .0225486755448 .1560516357450 .2895507812552 .42303848267 53.9469718933154 .8613204956155 .1661109924355 .4708900451755 .16611099243 54.2517509460453 .3373985290552 .1182594299350 .8991203308149 .37519073486 48.1560516357446 .6321296691945 .4129791259843 .8890609741242 .669921875 41.4507789611839 .9268493652338 .7077102661137 .7933502197336 .57421112061 35.6598587036135 .0502891540534 .4407196044933 .8311500549333 .22158050537 32.9167900085432 .9167900085432 .9167900085432 .9167900085433 .22158050537 33.5263595581133 .8311500549334 .4407196044934 .7455101013235 .35507965088 35.9646492004436 .2694282531736 .8790016174337 .4885711669937 .79335021973 38.0981407165538 .4029312133838 .4029312133838 .4029312133838 .40293121338 38.4029312133838 .0981407165537 .7933502197337 .4885711669936 .87900161743 36.2694282531735 .9646492004435 .3550796508834 .7455101013234 .13592910767 33.5263595581132 .9167900085432 .3072204589831 .6976509094231 .39286994934 31.0880794525130 .7833003997830 .4785099029530 .4785099029530 .17373085022 30.1737308502230 .4785099029530 .7833003997831 .0880794525131 .69765090942 32.3072204589832 .9167900085433 .8311500549334 .7455101013235 .96464920044 37.1837806701738 .4029312133839 .9268493652341 .1459884643642 .669921875 44.1938400268645 .717769622847 .2416992187548 .765621185350 .28955078125 51.5086898803752 .7278289794953 .9469718933155 .1661109924356 .38525009155 57.2995986938558 .2139587402359 .1283111572360 .0426712036160 .95701980591 61.5666007995662 .1761703491262 .7857398986863 .0905189514263 .70008850098 64.004882812564 .3096618652364 .6144485473664 .9192428588965 .22400665283 65.5288009643665 .8335876464866 .1383666992266 .1383666992266 .44316101074 66.7479400634866 .7479400634867 .0527267456167 .3575134277367 .35751342773 67.6623001098667 .6623001098667 .6623001098667 .9670867919967 .96708679199 68.2718734741268 .2718734741268 .5766525268668 .5766525268668 .57665252686 68.8814392089868 .8814392089868 .8814392089869 .1862335205169 .18623352051 69.1862335205169 .4910125732469 .4910125732469 .4910125732469 .79579162598 69.7957916259869 .7957916259870 .1005783081170 .1005783081170 .40535736084 70.4053573608470 .4053573608470 .7101516723670 .7101516723671 .0149307251 71.014930725171 .3197174072371 .6244964599671 .6244964599671 .92929077148 
72.2340774536172 .2340774536172 .5388565063572 .8436431884873 .12738037109 73.3969116210974 .9771423339876 .50106811523 -9999 -9999 -9999 -9999 -9999 -9999 -9999 -9999 -9999 -9999 -9999 -9999 -9999 -9999 -9999 -9999 -9999 -9999 -9999 -9999 -9999 -9999 -9999 -9999 -9999 -9999 -9999 -9999 -9999 -9999 -9999 -9999 -9999 -9999 -9999 -9999 -9999 -9999 -9999 -9999 -9999 -9999 -9999 -9999 -9999 -9999 -9999 -9999 -9999-9999 -9999 -9999 -9999 -9999 -9999 -9999 -9999 -9999 -9999 -9999 -9999 -9999 -9999 -9999 -9999 -9999 -9999

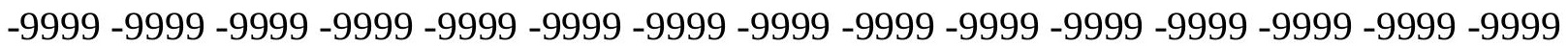

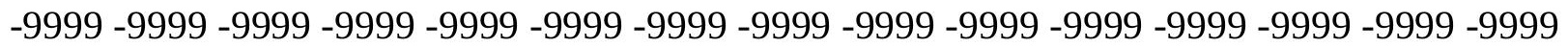
$-9999-9999$

-9999 -9999 -9999 -9999 -9999 -9999 -9999 -9999 -9999 -9999 -9999 -9999 -9999 -9999 -9999 -9999 -9999 -9999 -9999 -9999 -9999 -9999 -9999 -9999 -9999 -9999 -9999 82.59677124023 81.0728530883879 .2441329956177 .7202072143679 .2441329956180 .46327209473 81.3776321411181 .9871978759881 .9871978759881 .9871978759881 .98719787598 81.9871978759881 .9871978759882 .2919769287182 .9015579223683 .81591033936 84.4254837036185 .3398437585 .9494018554786 .254188537686 .86376190186 86.8637619018686 .8637619018686 .254188537685 .6446228027384 .73026275635 83.206336975181 .6824111938579 .8537063598678 .0249862670975 .89148712158 73.7580032348671 .3197174072369 .1862335205167 .0527267456165 .22400665283 63.7000885009862 .1761703491260 .9570198059160 .0426712036159 .31357192993 59.1283111572359 .1173629760759 .1283111572359 .4331016540560 .04267120361 60.3474502563560 .9570198059161 .5666007995662 .4809494018663 .09051895142 63.7000885009864 .3096618652365 .2240066528365 .8335876464866 .44316101074 67.0527267456167 .6623001098668 .2718734741268 .5766525268668 .88143920898 69.1862335205169 .4910125732469 .4910125732469 .1862335205169 .18623352051 68.5766525268668 .2718734741267 .6623001098667 .0527267456166 .44316101074 66.1383666992265 .8335876464865 .2240066528364 .004882812561 .87137985229 58.8235282897955 .4708900451752 .1182594299349 .3751907348646 .93690872192 45.1082000732443 .5842704772942 .0603485107440 .8412094116239 .31727981567 37.7933502197339 .9268493652339 .0125007629438 .0981407165537 .18378067017 35.9646492004432 .3072204589832 .6120109558133 .5263595581134 .44071960449 35.9646492004437 .4885711669939 .3172798156741 .4507789611843 .27949142456 45.4129791259847 .5464782714849 .6799812316951 .5086898803753 .03261184692 53.9469718933154 .8613204956155 .1661109924355 .1661109924354 .25175094604 53.3373985290552 .1182594299350 .8991203308149 .6799812316948 .46083068848 47.2416992187545 .717769622844 .4986305236842 .9747009277341 .75556182861 40.5364189147939 .3172798156738 .0981407165537 .1837806701735 .96464920044 35.3550796508834 .4407196044933 .8311500549333 .5263595581133 .22158050537 33.22158050537 33.2215805053733.2215805053733.5263595581133.83115005493 34.4407196044934 .7455101013235 .3550796508835 .9646492004436 .57421112061 37.1837806701737 .7933502197338 .0981407165538 .7077102661139 .01250076294 39.0125007629439 .3172798156739 .3172798156739 .0125007629439 .01250076294 38.7077102661138 .0981407165537 .7933502197337 .1837806701736 .57421112061 35.9646492004435 .0502891540534 .4407196044933 .8311500549332 .91679000854 32.3072204589831 .6976509094231 .0880794525130 .4785099029530 .17373085022 29.5641593933129 .2593708038329 .2593708038328 .9545898437528 .95458984375 28.9545898437529 .2593708038329 .5641593933129 .8689403533930 .47850990295 
31.0880794525132 .0024414062532 .9167900085434 .1359291076735 .05028915405 36.5742111206137 .7933502197339 .3172798156740 .8412094116242 .36513137817 43.5842704772945 .1082000732446 .6321296691948 .1560516357449 .37519073486 50.5943298339851 .8134689331153 .0326118469254 .2517509460455 .47089004517 56.3852500915557 .6043891906758 .5187492370659 .4331016540560 .04267120361 60.6522407531761 .2618103027361 .8713798522962 .1761703491262 .78573989868 63.0905189514263 .3953094482464 .004882812564 .3096618652364 .61444854736 64.9192428588965 .2240066528365 .5288009643665 .8335876464866 .13836669922 66.1383666992266 .4431610107466 .7479400634866 .7479400634867 .05272674561 67.0527267456167 .3575134277367 .6623001098667 .6623001098667 .96708679199 67.9670867919968 .2718734741268 .2718734741268 .2718734741268 .57665252686 68.5766525268668 .8814392089868 .8814392089869 .1862335205169 .18623352051 69.1862335205169 .4910125732469 .4910125732469 .4910125732469 .79579162598 69.7957916259870 .1005783081170 .1005783081170 .1005783081170 .40535736084 70.4053573608470 .7101516723670 .7101516723671 .014930725171 .0149307251 71.3197174072371 .6244964599671 .6244964599671 .9292907714872 .23407745361 72.2340774536172 .5388565063572 .8436431884873 .1387023925873 .4083480835 73.6482620239375 .5867080688577 .1106262207 -9999 -9999 -9999 -9999 -9999 -9999 -9999 -9999 -9999 -9999 -9999 -9999 -9999 -9999 -9999 -9999 -9999 -9999 -9999 -9999 -9999 -9999

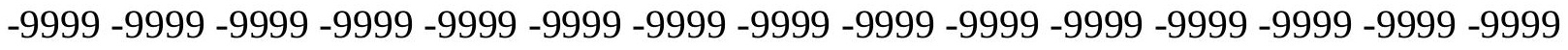

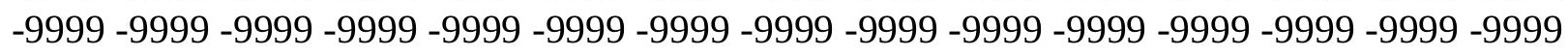
-9999 -9999 -9999 -9999 -9999 -9999 -9999 -9999 -9999 -9999 -9999 -9999 -9999 -9999 -9999 -9999 -9999 -9999 -9999 -9999 -9999 -9999 -9999 -9999 -9999 -9999 -9999 -9999 -9999 -9999

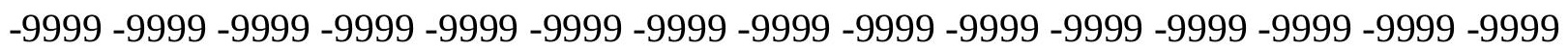
$-9999$

-9999 -9999 -9999 -9999 -9999 -9999 -9999 -9999 -9999 -9999 -9999 -9999 -9999 -9999 -9999 -9999 -9999 -9999 -9999 -9999 -9999 -9999 -9999 -9999 -9999 -9999 -9999 -9999 -9999 87.4733276367285 .3398437582 .9015579223682 .5967712402383 .51112365723 83.81591033936 83.81591033936 83.51112365723 86.8637619018684.6130065918 82.9015579223683 .5111236572384 .1206970214885 .0350494384885 .94940185547 86.8637619018687 .4733276367288 .3876876831188 .6924667358488 .99725341797 88.6924667358488 .3876876831187 .7781066894586 .8637619018685 .33984375 83.8159103393681 .6824111938579 .5489196777377 .110626220774 .67236328125 72.2340774536169 .7957916259867 .3575134277365 .2240066528363 .39530944824 61.8713798522960 .6522407531759 .7378807067959 .1283111572358 .82352828979 58.8235282897959 .0846939086959 .4331016540560 .0426712036160 .65224075317 61.2618103027361 .8713798522962 .7857398986863 .3953094482464 .0048828125 64.9192428588965 .5288009643666 .4431610107467 .0527267456167 .66230010986 68.5766525268669 .1862335205169 .7957916259870 .1005783081170 .40535736084 70.7101516723670 .7101516723670 .7101516723670 .7101516723670 .71015167236 70.4053573608470 .4053573608470 .1005783081170 .4053573608470 .71015167236 71.014930725171 .014930725170 .1005783081167 .9670867919964 .91924285889 60.6522407531756 .3852500915553 .0326118469250 .5943298339848 .15605163574 46.3273391723645 .1082000732443 .5842704772942 .0603485107443 .58427047729 42.66992187541 .1459884643639 .622070312538 .4029312133836 .87900161743 35.9646492004432 .9167900085433 .5263595581134 .4407196044935 .65985870361 
37.1837806701739 .0125007629440 .8412094116242 .66992187544 .80340957642 46.6321296691948 .4608306884850 .2895507812551 .8134689331153 .03261184692 53.6421813964854 .2517509460454 .2517509460453 .6421813964853 .03261184692 52.1182594299350 .8991203308149 .6799812316948 .4608306884847 .24169921875 46.0225486755444 .8034095764243 .2794914245642 .0603485107440 .84120941162 39.622070312538 .4029312133837 .1837806701736 .2694282531735 .35507965088 34.7455101013234 .1359291076733 .8311500549333 .5263595581133 .22158050537 33.2215805053733 .5263595581133 .8311500549334 .1359291076734 .74551010132 35.3550796508835 .9646492004436 .8790016174337 .4885711669938 .09814071655 38.7077102661139 .0125007629439 .3172798156739 .622070312539 .92684936523 39.9268493652339 .9268493652339 .622070312539 .3172798156739 .01250076294 38.4029312133837 .7933502197337 .1837806701736 .2694282531735 .65985870361 34.7455101013233 .8311500549332 .9167900085432 .3072204589831 .39286994934 30.7833003997829 .8689403533929 .2593708038328 .9545898437528 .34502029419 28.0402297973627 .7354507446327 .7354507446327 .7354507446327 .73545074463 27.7354507446328 .0402297973628 .3450202941928 .9545898437529 .56415939331 30.1737308502231 .0880794525132 .3072204589833 .5263595581134 .74551010132 35.9646492004437 .4885711669938 .7077102661140 .2316398620641 .75556182861 43.2794914245644 .4986305236846 .0225486755447 .2416992187548 .7656211853 49.9847602844251 .2038993835452 .4230384826753 .6421813964854 .55654144287 55.7756805419956 .6900291442957 .6043891906758 .5187492370659 .12831115723 59.7378807067960 .3474502563560 .9570198059161 .5666007995661 .87137985229 62.4809494018662 .7857398986863 .3953094482463 .7000885009864 .0048828125 64.3096618652364 .6144485473664 .9192428588965 .2240066528365 .52880096436 65.8335876464866 .1383666992266 .4431610107466 .4431610107466 .74794006348 67.0527267456167 .0527267456167 .3575134277367 .3575134277367 .66230010986 67.9670867919967 .9670867919968 .2718734741268 .2718734741268 .57665252686 68.5766525268668 .8814392089868 .8814392089868 .8814392089869 .18623352051 69.1862335205169 .4910125732469 .4910125732469 .7957916259869 .79579162598 69.7957916259870 .1005783081170 .1005783081170 .4053573608470 .40535736084 70.7101516723670 .7101516723671 .014930725171 .014930725171 .31971740723 71.3197174072371 .6244964599671 .9292907714872 .2340774536172 .23407745361 72.5388565063572 .8436431884873 .1484298706173 .4390029907273 .6459274292 73.8326339721776 .19628143311 -9999 -9999-9999 -9999 -9999 -9999-9999 -9999 -9999 -9999 -9999 -9999 -9999 -9999 -9999 -9999 -9999 -9999 -9999 -9999 -9999 -9999 -9999 -9999 -9999 -9999 -9999 -9999 -9999 -9999 -9999 -9999 -9999 -9999 -9999 -9999 -9999 -9999 -9999

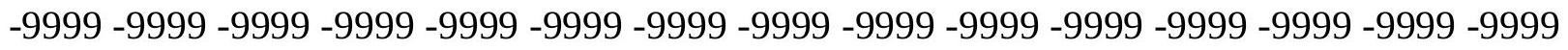

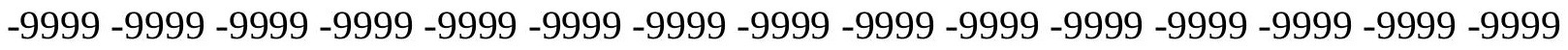
-9999 -9999 -9999 -9999 -9999 -9999 -9999 -9999 -9999 -9999 -9999 -9999 -9999 -9999 -9999 -9999 -9999 -9999 -9999 -9999 -9999 -9999 -9999 -9999 -9999 -9999 -9999 -9999 -9999 - -999 -

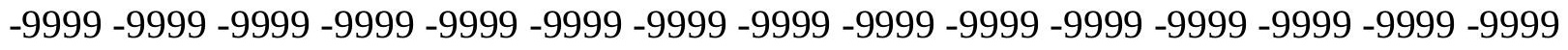

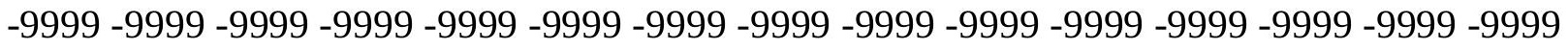
92.9594726562589 .9116134643687 .1685485839888 .0829010009885 .3398437585 .33984375 88.3876876831191.74033355713 86.71221923828 87.1085815429784.12069702148 85.0350494384886 .254188537687 .4733276367288 .3876876831189 .3020401001 90.2164001464890 .5211791992290 .8259735107490 .8259735107490 .52117919922 
89.9116134643688 .9972534179787 .4733276367285 .6446228027383 .51112365723 81.0728530883878 .3297805786175 .5867080688572 .8436431884870 .40535736084 67.6623001098665 .5288009643663 .3953094482461 .5666007995660 .34745025635 59.4331016540558 .8235282897958 .5187492370658 .5187492370658 .82352828979 59.4331016540560 .0426712036160 .6522407531761 .5666007995662 .17617034912 63.0905189514263 .7000885009864 .6144485473665 .2240066528366 .13836669922 67.0527267456167 .6623001098668 .5766525268669 .4910125732470 .10057830811 70.7101516723671 .3197174072371 .6244964599671 .9292907714872 .23407745361 72.5388565063572 .5388565063572 .8436431884872 .8436431884873 .14842987061 73.4532165527374 .3675689697375 .5867080688576 .8058471679777 .72020721436 77.4154205322375 .5867080688572 .5388565063567 .6623001098661 .87137985229 59.1283111572355 .4708900451752 .1182594299349 .6799812316948 .46083068848 47.2416992187548 .4608306884847 .2416992187545 .4129791259843 .27949142456 41.4507789611839 .622070312538 .0981407165536 .5742111206133 .22158050537 33.5263595581134 .4407196044935 .6598587036136 .8790016174338 .40293121338 40.2316398620641 .7555618286143 .5842704772945 .4129791259847 .24169921875 49.0704002380450 .2895507812551 .5086898803752 .4230384826753 .03261184692 53.0326118469252 .7278289794952 .4230384826751 .5086898803750 .59432983398 49.6799812316948 .765621185347 .5464782714846 .3273391723645 .10820007324 43.5842704772942 .3651313781741 .1459884643639 .9268493652338 .70771026611 37.4885711669936 .5742111206135 .6598587036134 .7455101013234 .13592910767 33.8311500549333 .5263595581133 .2215805053733 .5263595581133 .52635955811 34.1359291076734 .4407196044935 .0502891540535 .9646492004436 .57421112061 37.4885711669938 .0981407165538 .7077102661139 .3172798156739 .92684936523 40.2316398620640 .5364189147940 .5364189147940 .5364189147940 .23163986206 39.9268493652339 .622070312539 .0125007629438 .4029312133837 .48857116699 36.8790016174335 .9646492004435 .0502891540534 .1359291076733 .22158050537 32.0024414062531 .0880794525130 .1737308502229 .5641593933128 .64979934692 28.0402297973627 .430660247827 .1258792877226 .8210906982426 .51630973816 26.2115192413326 .2115192413326 .2115192413326 .2115192413326 .51630973816 26.8210906982427 .430660247828 .0402297973628 .6497993469229 .56415939331 30.4785099029531 .6976509094232 .9167900085434 .1359291076735 .65985870361 36.8790016174338 .4029312133839 .9268493652341 .1459884643642 .669921875 43.8890609741245 .4129791259846 .6321296691947 .8512611389249 .07040023804 50.2895507812551 .5086898803752 .7278289794953 .9469718933154 .86132049561 55.7756805419956 .6900291442957 .6043891906758 .5187492370659 .12831115723 59.7378807067960 .3474502563560 .9570198059161 .2618103027361 .87137985229 62.1761703491262 .7857398986863 .0905189514263 .7000885009864 .0048828125 64.3096618652364 .6144485473664 .9192428588965 .2240066528365 .52880096436 65.8335876464866 .1383666992266 .4431610107466 .4431610107466 .74794006348 67.0527267456167 .0527267456167 .3575134277367 .6623001098667 .66230010986 67.9670867919967 .9670867919968 .2718734741268 .5766525268668 .57665252686 68.8814392089868 .8814392089869 .1862335205169 .1862335205169 .18623352051 69.4910125732469 .4910125732469 .7957916259869 .7957916259870 .10057830811 70.1005783081170 .4053573608470 .4053573608470 .4053573608470 .71015167236 71.014930725171 .014930725171 .3197174072371 .3197174072371 .62449645996 
71.9292907714871 .9292907714872 .2340774536172 .5388565063572 .84364318848 73.1484298706173 .4532165527373 .5899963378973 .7868576049873 .97545623779 76.50106811523 -9999 -9999 -9999 -9999 -9999 -9999 -9999 -9999 -9999 -9999 -9999 -9999 -9999 -9999 -9999 -9999 -9999 -9999 -9999 -9999 -9999 -9999 -9999 -9999 -9999 -9999 -9999 -9999 -9999 -9999 -9999 -9999 -9999 -9999 -9999 -9999 -9999 -9999 -9999-9999 -9999 -9999 -

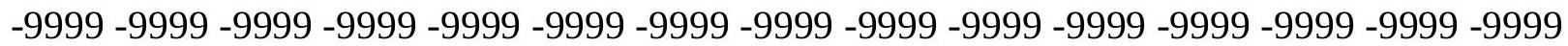

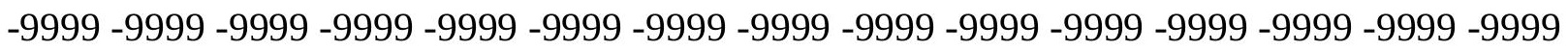

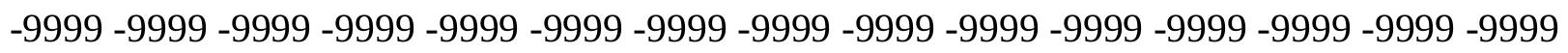
-9999 -9999 -9999 -9999 -9999 -9999 -9999 -9999 -9999 -9999

-9999 -9999 -9999 -9999 -9999 -9999 -9999 -9999 -9999 -9999 -9999 -9999 -9999 -9999 -9999 -9999 -9999 -9999 -9999 -9999 -9999 -9999 -9999 -9999 -9999 -9999 -9999 -9999 -9999 -9999 -9999 96.92166900635 92.95947265625 89.60682678223 87.16854858398 86.2541885376 89.6068267822391 .7403335571392 .349891662689 .3060455322385 .03504943848 86.254188537687 .7781066894588 .9972534179790 .2164001464891 .13075256348 92.0450973510792 .6546783447392 .9594726562593 .2642517089892 .95947265625 92.349891662691 .1307525634889 .6068267822387 .7781066894585 .33984375 82.5967712402379 .8537063598676 .8058471679773 .7580032348670 .71015167236 67.9670867919965 .2240066528363 .0905189514261 .2618103027359 .73788070679 58.8235282897958 .2139587402357 .909179687558 .2139587402358 .51874923706 59.4331016540560 .0426712036160 .9570198059161 .8713798522962 .78573989868 63.3953094482464 .3096618652364 .9192428588965 .8335876464866 .74794006348 67.6623001098668 .5766525268669 .4910125732470 .4053573608471 .31971740723 71.9292907714872 .5388565063573 .1484298706173 .4532165527373 .75800323486 74.3675689697374 .6723632812574 .9771423339875 .5867080688575 .89148712158 76.5010681152377 .7202072143679 .8537063598682 .2919769287184 .12069702148 84.7302627563583 .5111236572381 .0728530883877 .4154205322373 .45321655273 68.8814392089863 .3953094482456 .9948196411154 .8613204956153 .94697189331 52.1182594299353 .3373985290550 .8991203308148 .1560516357445 .41297912598 42.66992187540 .5364189147938 .7077102661137 .1837806701733 .22158050537 33.8311500549334 .4407196044935 .3550796508836 .5742111206137 .79335021973 39.3172798156740 .8412094116242 .3651313781744 .1938400268646 .02254867554 47.5464782714848 .765621185349 .9847602844250 .8991203308151 .50868988037 51.8134689331151 .8134689331151 .5086898803750 .8991203308150 .28955078125 49.3751907348648 .4608306884847 .5464782714846 .3273391723645 .10820007324 43.8890609741242 .66992187541 .4507789611840 .2316398620639 .01250076294 37.7933502197336 .8790016174335 .6598587036135 .0502891540534 .44071960449 33.8311500549333 .5263595581133 .5263595581133 .5263595581133 .83115005493 34.1359291076734 .7455101013235 .6598587036136 .2694282531737 .18378067017 38.0981407165538 .7077102661139 .622070312540 .2316398620640 .53641891479 40.8412094116240 .8412094116240 .8412094116240 .8412094116240 .53641891479 39.9268493652339 .622070312538 .7077102661138 .0981407165537 .18378067017 36.2694282531735 .3550796508834 .1359291076733 .2215805053732 .00244140625 31.0880794525129 .8689403533928 .9545898437528 .0402297973627 .4306602478 26.8210906982426 .2115192413325 .6019496917725 .2971591949524 .99238014221 24.9923801422124 .9923801422124 .9923801422124 .9923801422125 .29715919495 25.6019496917725 .906740188626 .5163097381627 .430660247828 .04022979736 
29.2593708038330 .1737308502231 .3928699493432 .9167900085434 .13592910767 35.3550796508836 .8790016174338 .0981407165539 .622070312540 .84120941162 42.0603485107443 .5842704772944 .8034095764246 .0225486755447 .24169921875 48.4608306884849 .6799812316950 .8991203308152 .1182594299353 .33739852905 54.2517509460455 .1661109924356 .0804595947356 .9948196411157 .60438919067 58.5187492370659 .1283111572359 .7378807067960 .3474502563560 .95701980591 61.2618103027361 .8713798522962 .4809494018662 .7857398986863 .39530944824 63.7000885009864 .004882812564 .6144485473664 .9192428588965 .22400665283 65.2240066528365 .5288009643665 .8335876464866 .1383666992266 .44316101074 66.4431610107466 .7479400634867 .0527267456167 .3575134277367 .35751342773 67.6623001098667 .9670867919967 .9670867919968 .2718734741268 .57665252686 68.5766525268668 .8814392089868 .8814392089869 .1862335205169 .18623352051 69.4910125732469 .4910125732469 .7957916259869 .7957916259869 .79579162598 70.1005783081170 .1005783081170 .4053573608470 .4053573608470 .71015167236 70.7101516723671 .014930725171 .3197174072371 .3197174072371 .62449645996 71.6244964599671 .9292907714872 .2340774536172 .5388565063572 .84364318848 73.1484298706173 .1484298706173 .4532165527373 .7580032348673 .93996429443 75.5867080688576 .80584716797 -9999 -9999 -9999 -9999 -9999 -9999 -9999 -9999 -9999 -9999 -9999 -9999 -9999 -9999 -9999 -9999 -9999 -9999 -9999 -9999 -9999 -9999 -9999 -9999

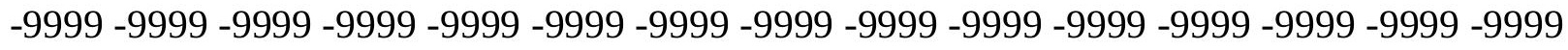

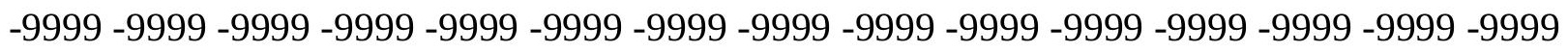
-9999 -9999 -9999 -9999 -9999 -9999 -9999 -9999 -9999 -9999 -9999 -9999 -9999 -9999 -9999 -9999 -9999 -9999 -9999 -9999 -9999 -9999 -9999 -9999 -9999 -9999 -9999 -9999 -9999 -9999 -9999 -9999 -9999 -9999 -9999 -9999 -9999 -9999 -9999 -9999 -9999 -9999 -

-9999 -9999 -9999 -9999 -9999 -9999 -9999 -9999 -9999 -9999 -9999 -9999 -9999 -9999 -9999

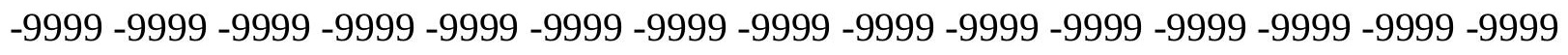
-9999 -9999-9999 94.4833908081190.21640014648 87.77810668945 89.60682678223 89.302040100189 .302040100188 .6924667358485 .6446228027387 .47332763672 89.302040100190 .8259735107492 .0450973510792 .9594726562593 .87381744385 94.4833908081195 .0929565429795 .3586654663195 .0929565429794 .51129150391 93.5690307617292 .0450973510789 .9116134643687 .4733276367284 .42548370361 81.0728530883877 .7202072143674 .3675689697371 .014930725167 .96708679199 65.2240066528362 .7857398986860 .9570198059159 .1283111572358 .21395874023 57.6043891906757 .6043891906757 .909179687558 .5187492370659 .43310165405 60.3474502563561 .5042152404862 .4115219116263 .3953094482464 .0048828125 64.9192428588965 .5288009643666 .4431610107467 .3575134277368 .27187347412 69.1862335205170 .4053573608471 .3197174072372 .5388565063573 .45321655273 74.062782287674 .6723632812574 .9771423339875 .5867080688575 .89148712158 76.8058471679777 .4154205322378 .3297805786178 .6345596313578 .93934631348 79.8537063598682 .9015579223686 .8637619018689 .9116134643691 .43553924561 90.5211791992289 .6068267822387 .1685485839884 .7302627563580 .76805877686 75.5867080688567 .3575134277363 .7000885009861 .5666007995657 .9091796875 58.2139587402354 .5565414428750 .5943298339846 .9369087219243 .88906097412 41.4507789611839 .3172798156737 .7933502197333 .8311500549334 .13592910767 34.4407196044935 .3550796508836 .2694282531737 .1837806701738 .40293121338 39.622070312541 .1459884643642 .66992187544 .4986305236846 .02254867554 
47.24169921875 48.46083068848 49.3751907348649.9847602844250.28955078125 50.5943298339850 .2895507812550 .2895507812549 .6799812316949 .07040023804 48.4608306884847 .5464782714846 .6321296691945 .4129791259844 .19384002686 42.9747009277341 .7555618286140 .5364189147939 .3172798156738 .09814071655 36.8790016174335 .9646492004435 .0502891540534 .4407196044933 .83115005493 33.5263595581133 .2215805053733 .5263595581133 .8311500549334 .44071960449 35.0502891540535 .9646492004436 .8790016174337 .7933502197338 .70771026611 39.622070312540 .2316398620640 .8412094116241 .1459884643641 .45077896118 41.4507789611841 .4507789611841 .1459884643640 .8412094116239 .92684936523 39.3172798156738 .4029312133837 .4885711669936 .5742111206135 .35507965088 34.4407196044933 .2215805053732 .0024414062530 .7833003997829 .56415939331 28.6497993469227 .430660247826 .5163097381625 .906740188625 .29715919495 24.6875991821324 .3828105926524 .0780296325723 .7732391357423 .77323913574 23.7732391357423 .7732391357423 .7732391357424 .0780296325724 .38281059265 24.6875991821325 .2971591949525 .906740188626 .8210906982428 .04022979736 28.9545898437530 .1737308502231 .3928699493432 .9167900085434 .13592910767 35.3550796508836 .5742111206138 .0981407165539 .3172798156740 .53641891479 41.7555618286142 .9747009277344 .1938400268645 .4129791259846 .63212966919 47.8512611389249 .3751907348650 .5943298339851 .5086898803752 .72782897949 53.6421813964854 .8613204956155 .7756805419956 .3852500915557 .29959869385 57.909179687558 .5187492370659 .1283111572359 .7378807067960 .34745025635 60.9570198059161 .5666007995662 .1761703491262 .4809494018663 .09051895142 63.3953094482464 .004882812564 .3096618652364 .6144485473664 .91924285889 65.2240066528365 .5288009643665 .8335876464865 .8335876464866 .13836669922 66.4431610107466 .7479400634867 .0527267456167 .0527267456167 .35751342773 67.6623001098667 .9670867919967 .9670867919968 .2718734741268 .57665252686 68.5766525268668 .8814392089868 .8814392089869 .1862335205169 .18623352051 69.4910125732469 .4910125732469 .7957916259869 .7957916259870 .10057830811 70.1005783081170 .4053573608470 .4053573608470 .7101516723670 .71015167236 71.014930725171 .014930725171 .3197174072371 .6244964599671 .62449645996 71.9292907714872 .2340774536172 .2340774536172 .5388565063572 .84364318848 73.1484298706173 .4532165527373 .7580032348673 .7580032348673 .9289855957 75.89148712158 -9999 -9999 -9999 -9999 -9999 -9999 -9999 -9999 -9999 -9999 -9999 -9999 -9999 -9999 -9999 -9999 -9999 -9999 -9999 -9999 -9999 -9999 -9999 -9999 -9999 -9999 -9999 -9999 -9999 -9999 -9999 -9999 -9999 -9999 -9999 -9999 -9999 -9999 -9999 -9999 -9999 -9999 -

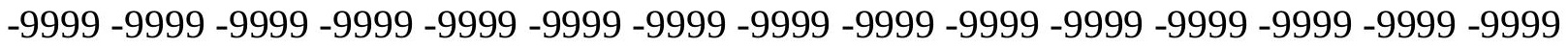

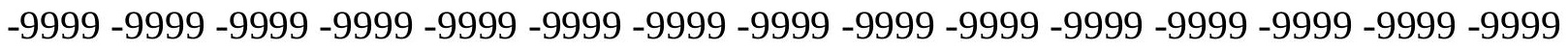

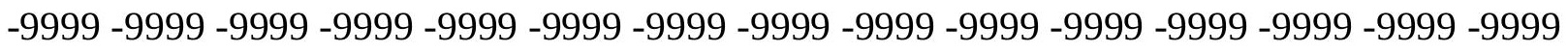
-9999 -9999 -9999 -9999 -9999 -9999 -9999 -9999 -9999

-9999 -9999 -9999 -9999 -9999 -9999 -9999 -9999 -9999 -9999 -9999 -9999 -9999 -9999 -9999

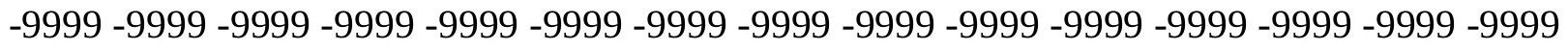
-9999 -9999 -9999 -9999 93.56903076172 88.99725341797 85.9494018554784.42548370361 84.1206970214884 .7302627563586 .8637619018689 .302040100191 .43553924561 92.6546783447393 .8738174438594 .7881774902395 .7025299072396 .31210327148 96.9216690063597 .2264633178797 .0225906372196 .3909606933695 .36889648438 93.8322906494191 .7815551757889 .302040100185 .9494018554782 .59677124023 
78.6345596313574 .9771423339871 .3197174072368 .2718734741265 .22400665283 62.4809494018660 .3474502563558 .5187492370657 .6043891906756 .99481964111 56.9948196411157 .6043891906758 .5187492370659 .7378807067960 .95701980591 62.1315917968862 .9942054748563 .8594093322864 .6525192260765 .407081604 66.1383666992267 .0527267456167 .6623001098668 .5766525268669 .79579162598 71.014930725172 .2340774536173 .4532165527374 .6723632812575 .58670806885 75.8914871215876 .5010681152376 .8058471679777 .7202072143678 .63455963135 79.8537063598681 .0728530883881 .6824111938581 .3776321411180 .15849304199 82.2919769287190 .2164001464896 .74346923828100 .6431808472101 .7982025146 104.2365036011104 .7792282104103 .6268997192100 .883903503499 .66472625732 95.7025299072385 .6446228027369 .4910125732463 .7000885009862 .17617034912 56.9948196411152 .1182594299347 .8512611389244 .4986305236842 .06034851074 39.9268493652338 .4029312133837 .1837806701734 .4407196044934 .74551010132 35.0502891540535 .6598587036136 .2694282531737 .1837806701738 .40293121338 39.622070312541 .4507789611842 .9747009277344 .4986305236845 .7177696228 46.9369087219247 .8512611389248 .4608306884848 .765621185349 .07040023804 49.3751907348649 .3751907348649 .0704002380448 .765621185348 .15605163574 47.5464782714846 .6321296691945 .4129791259844 .4986305236843 .27949142456 41.7555618286140 .5364189147939 .3172798156738 .0981407165537 .18378067017 35.9646492004435 .0502891540534 .4407196044933 .8311500549333 .22158050537 33.2215805053733 .2215805053733 .8311500549334 .4407196044935 .05028915405 36.2694282531737 .1837806701738 .4029312133839 .3172798156740 .23163986206 41.1459884643641 .7555618286142 .0603485107442 .0603485107442 .06034851074 41.7555618286141 .4507789611840 .8412094116239 .9268493652339 .01250076294 38.0981407165536 .8790016174335 .9646492004434 .7455101013233 .52635955811 32.3072204589830 .7833003997829 .5641593933128 .3450202941927 .12587928772 26.2115192413325 .2971591949524 .3828105926523 .7732391357423 .46845054626 23.1636695861822 .8588790893622 .8588790893622 .5541000366222 .55410003662 22.8588790893622 .8588790893623 .1636695861823 .4684505462623 .77323913574 24.3828105926524 .9923801422125 .906740188627 .1258792877228 .04022979736 29.2593708038330 .4785099029531 .6976509094233 .2215805053734 .44071960449 35.3550796508836 .5742111206137 .7933502197339 .0125007629440 .23163986206 41.4507789611842 .3651313781743 .8890609741245 .1082000732446 .32733917236 47.5464782714848 .765621185349 .9847602844251 .2038993835452 .42303848267 53.3373985290554 .2517509460455 .1661109924356 .0804595947356 .99481964111 57.6043891906758 .2139587402358 .8235282897959 .4331016540560 .04267120361 60.6522407531761 .2618103027361 .8713798522962 .4809494018663 .09051895142 63.3953094482463 .7000885009864 .004882812564 .3096618652364 .61444854736 64.9192428588965 .2240066528365 .5288009643665 .8335876464866 .13836669922 66.4431610107466 .7479400634866 .7479400634867 .0527267456167 .35751342773 67.6623001098667 .9670867919967 .9670867919968 .2718734741268 .57665252686 68.5766525268668 .8814392089869 .1862335205169 .1862335205169 .49101257324 69.4910125732469 .7957916259869 .7957916259870 .1005783081170 .10057830811 70.4053573608470 .4053573608470 .7101516723670 .7101516723671 .0149307251 71.014930725171 .3197174072371 .3197174072371 .6244964599671 .92929077148 71.9292907714872 .2340774536172 .5388565063572 .8436431884872 .84364318848 
73.1484298706173 .4532165527373 .4532165527373 .7580032348673 .82674407959 76.19628143311 -9999 -9999 -9999 -9999 -9999 -9999 -9999 -9999 -9999 -9999 -9999 -9999 -9999 -9999 -9999 -9999 -9999 -9999 -9999 -9999 -9999 -9999 -9999 -9999 -9999 -9999 -9999 -9999 -9999 -9999 -9999 -9999 -9999 -9999 -9999 -9999 -9999 -9999 -9999 -9999 -9999 -9999 -9999 -9999 -9999 -9999 -9999 -9999 -9999 -9999 -9999-9999 -9999 -9999 -9999 -9999 -9999 -9999 -9999 -9999 -9999 -9999 -9999 -9999 -9999 -9999 -9999 -9999 -9999 -9999 -9999 -9999

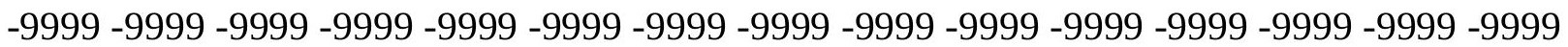
-9999 -9999-9999 -9999-9999-9999-9999-9999

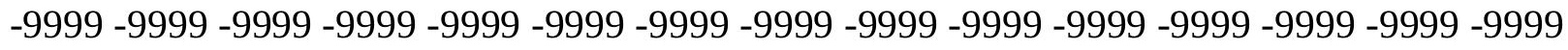
-9999 -9999 -9999 -9999 -9999 -9999 -9999 -9999 -9999 -9999 -9999 -9999 -9999 -9999 -9999 -9999 -9999 -9999 -9999 -9999 -9999 86.2541885376 84.12069702148 84.12069702148 88.69246673584 88.9972534179792.0450973510793.8738174438594.78817749023 95.70252990723 96.61688232422 97.2264633178798.1408081054798.75038146973 99.0976028442498 .709259033297 .9872970581196 .8722305297995 .28426361084 93.1800003051890 .5001983642687 .2402801513783 .5619277954179 .54891967773 75.5867080688571 .6244964599668 .2718734741264 .9192428588962 .17617034912 59.7378807067957 .909179687556 .6900291442956 .3852500915556 .38525009155 57.2995986938558 .5187492370660 .0426712036161 .5666007995662 .78573989868 63.6469459533764 .4748229980565 .2931365966866 .0653610229566 .74794006348 67.3575134277367 .9670867919968 .8814392089870 .1005783081171 .62449645996 73.1484298706174 .6723632812575 .8914871215876 .8058471679777 .41542053223 78.0249862670978 .3297805786178 .9393463134880 .1584930419981 .81304168701 83.1438980102583 .9327468872184 .2428054809680 .7680587768681 .37763214111 95.7407073974699 .52395629883102 .8746795654105 .3935394287106 .8535614014 107.3813171387 107.2715759277 106.982963562 106.8941574097 107.0583724976 104.817047119197 .5312423706173 .4532165527360 .6522407531757 .60438919067 52.4230384826748 .1560516357445 .1082000732442 .66992187540 .84120941162 39.3172798156738 .0981407165535 .0502891540535 .0502891540535 .05028915405 35.3550796508835 .3550796508835 .9646492004436 .5742111206138 .09814071655 39.9268493652341 .4507789611843 .2794914245644 .4986305236845 .41297912598 46.3273391723646 .9369087219247 .5464782714847 .8512611389248 .15605163574 48.4608306884848 .4608306884848 .4608306884847 .8512611389247 .24169921875 46.6321296691945 .4129791259844 .4986305236843 .2794914245642 .06034851074 40.8412094116239 .622070312538 .4029312133837 .1837806701736 .26942825317 35.0502891540534 .4407196044933 .5263595581133 .2215805053732 .91679000854 33.2215805053733 .5263595581134 .4407196044935 .3550796508836 .57421112061 37.7933502197339 .0125007629440 .2316398620641 .1459884643642 .06034851074 42.3651313781742 .66992187542 .9747009277342 .66992187542 .36513137817 41.7555618286140 .8412094116239 .9268493652339 .0125007629437 .79335021973 36.5742111206135 .3550796508833 .8311500549332 .6120109558131 .39286994934 29.8689403533928 .6497993469227 .1258792877225 .906740188624 .99238014221 23.7732391357423 .1636695861822 .5541000366222 .2493095397921 .94453048706 21.9445304870621 .9445304870621 .9445304870621 .9445304870622 .24930953979 22.2493095397922 .5541000366222 .8588790893623 .1636695861823 .77323913574 24.3828105926525 .2971591949526 .5163097381627 .430660247828 .64979934692 30.1737308502231 .3928699493432 .3072204589833 .5263595581134 .74551010132 
35.6598587036136 .5742111206137 .7933502197338 .7077102661139 .92684936523 41.1459884643642 .3651313781743 .5842704772944 .8034095764246 .02254867554 47.5464782714848 .765621185349 .9847602844251 .2038993835452 .11825942993 53.0326118469254 .2517509460454 .8613204956155 .7756805419956 .69002914429 57.2995986938557 .909179687558 .8235282897959 .4331016540560 .04267120361 60.6522407531761 .2618103027361 .8713798522962 .4809494018662 .78573989868 63.0905189514263 .7000885009864 .004882812564 .3096618652364 .61444854736 64.9192428588965 .2240066528365 .5288009643665 .8335876464866 .13836669922 66.4431610107466 .7479400634866 .7479400634867 .0527267456167 .35751342773 67.6623001098667 .9670867919968 .2718734741268 .2718734741268 .57665252686 68.8814392089868 .8814392089869 .1862335205169 .1862335205169 .49101257324 69.4910125732469 .7957916259869 .7957916259870 .1005783081170 .10057830811 70.4053573608470 .4053573608470 .7101516723670 .7101516723671 .0149307251 71.014930725171 .3197174072371 .6244964599671 .6244964599671 .92929077148 72.2340774536172 .2340774536172 .5388565063572 .8436431884872 .84364318848 73.1484298706173 .4532165527373 .4532165527373 .5835876464873 .69967651367 76.19628143311 -9999 -9999 -9999 -9999 -9999 -9999 -9999 -9999 -9999 -9999 -9999 -9999

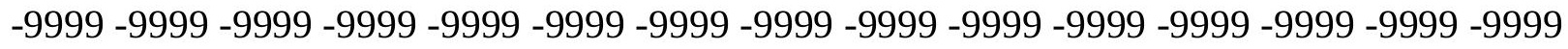

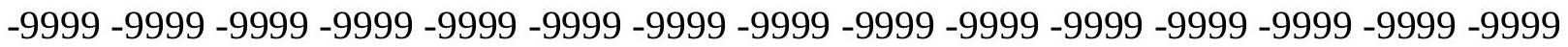

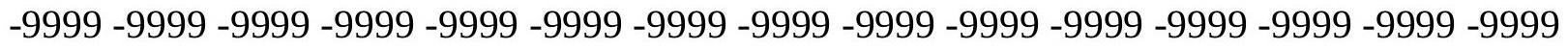

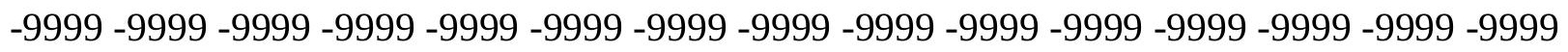

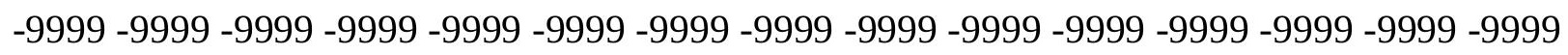
-9999 -9999 -9999 -9999 -9999 -9999 -9999

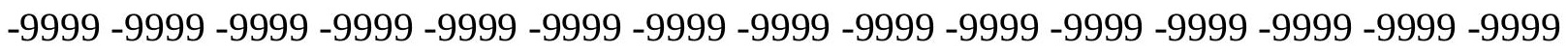

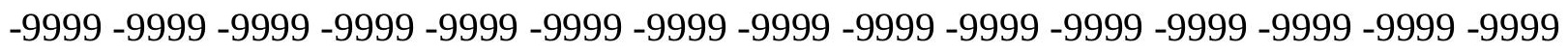
-9999 -9999 -9999 -9999 -9999 -9999 -9999 85.64462280273 87.4733276367289 .3020401001 92.0450973510795.397743225196.3121032714896.9216690063597.53124237061 98.1408081054798 .7503814697399 .66472625732100 .2742996216100 .7382888794 100.236915588499 .4108734130998 .1939315795996 .521072387794 .33436584473 91.5867309570388 .3247299194384 .6034698486380 .4632720947375 .89148712158 71.9292907714868 .2718734741264 .9192428588961 .8713798522959 .12831115723 56.9948196411155 .7756805419955 .4708900451755 .7756805419956 .99481964111 58.8235282897960 .6522407531762 .4809494018664 .004882812565 .22400665283 65.2388916015666 .0624694824266 .873458862367 .3575134277367 .66230010986 68.2718734741269 .1862335205170 .4053573608472 .2340774536174 .0627822876 75.7990646362377 .0949707031278 .1335906982478 .973632812579 .54891967773 79.5489196777380 .1584930419981 .3776321411183 .5111236572385 .53588104248 86.90336608887 88.4328079223691.0656967163195.175926208598.27857971191 101.4633102417104 .3147201538106 .5492935181108 .0105056763108 .7211761475 108.8865127563108 .753364563108 .4623947144107 .8649215698106 .3748245239 103.507591247688 .0829010009864 .9192428588954 .5565414428749 .37519073486 48.4608306884845 .4129791259843 .2794914245641 .4507789611840 .23163986206 39.3172798156735 .6598587036135 .6598587036135 .3550796508834 .74551010132 34.4407196044934 .4407196044935 .0502891540536 .2694282531738 .40293121338 40.2316398620642 .0603485107443 .2794914245644 .1938400268644 .80340957642 45.4129791259845 .717769622846 .3273391723646 .9369087219247 .54647827148 
47.8512611389247 .8512611389247 .5464782714847 .2416992187546 .32733917236 45.4129791259844 .1938400268642 .9747009277342 .0603485107440 .84120941162 39.622070312538 .4029312133837 .4885711669936 .2694282531735 .35507965088 34.4407196044933 .5263595581132 .9167900085432 .6120109558132 .91679000854 33.2215805053734 .1359291076735 .3550796508836 .8790016174338 .40293121338 39.622070312541 .1459884643642 .0603485107442 .66992187543 .27949142456 43.5842704772943 .5842704772943 .2794914245642 .9747009277342 .06034851074 41.1459884643639 .9268493652338 .7077102661137 .4885711669936 .26942825317 34.7455101013233 .5263595581132 .0024414062530 .4785099029529 .25937080383 27.7354507446326 .2115192413324 .9923801422123 .7732391357422 .85887908936 22.2493095397921 .6397399902321 .6397399902321 .334960937521 .63973999023 21.6397399902321 .9445304870621 .9445304870622 .2493095397922 .24930953979 22.5541000366222 .5541000366223 .1636695861823 .7732391357424 .38281059265 25.2971591949526 .2115192413327 .430660247828 .9545898437530 .17373085022 31.0880794525132 .3072204589833 .2215805053734 .1359291076735 .05028915405 35.9646492004436 .8790016174337 .7933502197338 .7077102661139 .6220703125 40.8412094116242 .0603485107443 .5842704772944 .8034095764246 .02254867554 47.5464782714848 .765621185349 .9847602844251 .2038993835452 .11825942993 53.0326118469253 .9469718933154 .8613204956155 .7756805419956 .38525009155 56.9948196411157 .909179687558 .5187492370659 .1283111572360 .04267120361 60.6522407531761 .2618103027361 .8713798522962 .1761703491262 .78573989868 63.0905189514263 .3953094482463 .7000885009864 .004882812564 .30966186523 64.6144485473665 .2240066528365 .5288009643665 .8335876464866 .13836669922 66.4431610107466 .7479400634866 .7479400634867 .0527267456167 .35751342773 67.6623001098667 .9670867919968 .2718734741268 .5766525268668 .57665252686 68.8814392089869 .1862335205169 .1862335205169 .4910125732469 .49101257324 69.7957916259869 .7957916259870 .1005783081170 .1005783081170 .40535736084 70.4053573608470 .7101516723670 .7101516723671 .014930725171 .0149307251 71.3197174072371 .3197174072371 .6244964599671 .9292907714871 .92929077148 72.2340774536172 .2340774536172 .5388565063572 .8436431884872 .84364318848 $73.1484298706173 .1484298706173 .2975997924873 .4607467651473 .59777069092-9999$ -9999 -9999 -9999 -9999 -9999 -9999 -9999 -9999 -9999 -9999 -9999 -9999 -9999 -9999 -9999

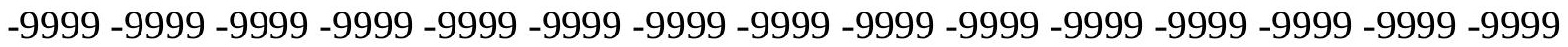
-9999 -9999 -9999 -9999 -9999 -9999 -9999 -9999 -9999 -9999 -9999 -9999 -9999 -9999 -9999 -9999 -9999 -9999 -9999 -9999 -9999 -9999 -9999 -9999 -9999 -9999 -9999 -9999 -9999 -9999 -9999 -9999 -9999 -9999 -9999 -9999 -9999 -9999 -9999 -9999 -9999 -9999 -9999 -9999 -9999

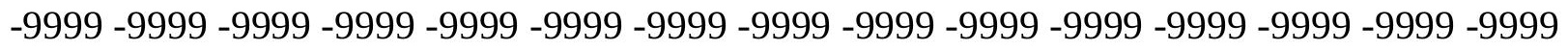
-9999-9999-9999

-9999 -9999 -9999 -9999 -9999 -9999 -9999 -9999 -9999 -9999 -9999 -9999 -9999 -9999 -9999 -9999 -9999 -9999 -9999 -9999 -9999 -9999 -9999 -9999 -9999 -9999 -9999 -9999 -9999 -9999 -9999 -9999-9999 -9999 -9999 -9999-9999-9999-9999 98.14080810547 98.75038146973 99.3599472045999 .3599472045998 .7503814697398 .7503814697399 .66472625732 100.2742996216100 .8839035034101 .7982025146102 .2783737183101 .6678390503 100.738838195899 .4282531738397 .6784896850695 .4393234252992 .68894958496 89.4549636840885 .6446228027380 .7680587768676 .1962814331171 .92929077148 68.2718734741264 .9192428588961 .5666007995658 .5187492370656 .08045959473 
54.5565414428754 .2517509460455 .1661109924356 .9948196411159 .12831115723 61.5666007995663 .7000885009865 .5288009643666 .7479400634867 .66230010986 66.9783935546967 .8317337036167 .9670867919967 .9670867919967 .96708679199 68.8814392089870 .1005783081172 .2340774536174 .6723632812576 .46012878418 78.0512313842879 .4094848632880 .6156158447381 .0728530883881 .07285308838 81.3776321411181 .9871978759885 .0350494384888 .5048599243290 .49864959717 92.980049133395 .1414260864397 .57564544678100 .1992340088102 .8078079224 105.1513824463107 .0257797241108 .3261871338109 .0376434326109 .2577056885 109.0938034058108 .560546875107 .4892196655105 .5747146606102 .6276016235 96.3121032714879 .5489196777364 .004882812549 .0704002380445 .41297912598 43.5842704772944 .8034095764242 .66992187541 .1459884643640 .84120941162 40.2316398620636 .2694282531735 .6598587036134 .7455101013233 .52635955811 32.9167900085432 .9167900085434 .4407196044936 .8790016174339 .6220703125 41.4507789611842 .66992187542 .9747009277343 .5842704772943 .88906097412 44.1938400268644 .8034095764245 .717769622846 .6321296691946 .93690872192 47.24169921875 47.24169921875 46.6321296691945.717769622844.80340957642 43.5842704772942 .66992187541 .7555618286140 .5364189147939 .6220703125 38.7077102661137 .4885711669936 .2694282531735 .3550796508834 .44071960449 33.5263595581132 .6120109558132 .3072204589832 .3072204589832 .91679000854 33.8311500549335 .3550796508837 .1837806701739 .0125007629440 .53641891479 42.0603485107442 .9747009277343 .5842704772943 .8890609741244 .19384002686 44.1938400268643 .8890609741243 .2794914245642 .66992187541 .45077896118 40.2316398620639 .0125007629437 .4885711669936 .2694282531734 .74551010132 33.5263595581132 .0024414062530 .4785099029528 .9545898437527 .4306602478 25.906740188624 .6875991821323 .4684505462622 .5541000366221 .94453048706 21.6397399902321 .6397399902321 .6397399902321 .9445304870622 .24930953979 22.5541000366222 .5541000366222 .8588790893622 .8588790893623 .16366958618 23.1636695861823 .4684505462624 .0780296325724 .6875991821325 .9067401886 26.8210906982428 .0402297973629 .5641593933130 .7833003997831 .69765090942 32.6120109558133 .5263595581134 .4407196044935 .0502891540535 .65985870361 36.2694282531736 .8790016174337 .7933502197338 .7077102661139 .92684936523 41.1459884643642 .3651313781743 .5842704772945 .1082000732446 .32733917236 47.8512611389249 .0704002380450 .2895507812551 .2038993835452 .42303848267 53.3373985290553 .9469718933154 .8613204956155 .4708900451756 .38525009155 56.9948196411157 .6043891906758 .5187492370659 .1283111572359 .73788070679 60.6522407531761 .2618103027361 .5666007995662 .1761703491262 .48094940186 62.7857398986863 .0905189514263 .7000885009864 .004882812564 .30966186523 64.6144485473664 .9192428588965 .2240066528365 .5288009643666 .13836669922 66.4431610107466 .7479400634867 .0527267456167 .3575134277367 .35751342773 67.6623001098667 .9670867919968 .2718734741268 .5766525268668 .88143920898 68.8814392089869 .1862335205169 .1862335205169 .4910125732469 .49101257324 69.7957916259869 .7957916259870 .1005783081170 .1005783081170 .40535736084 70.4053573608470 .7101516723670 .7101516723671 .014930725171 .0149307251 71.3197174072371 .3197174072371 .6244964599671 .9292907714871 .92929077148 72.2340774536172 .2340774536172 .5388565063572 .5388565063572 .84364318848 72.8436431884873 .0321044921973 .1484298706173 .3427047729573 .48438262939 -9999 
-9999 -9999 -9999 -9999 -9999 -9999 -9999 -9999 -9999 -9999 -9999 -9999 -9999 -9999 -9999 -9999 -9999 -9999 -9999 -9999 -9999 -9999 -9999 -9999 -9999 -9999 -9999 -9999 -9999 -9999 -9999 -9999 -9999 -9999 -9999 -9999 -9999 -9999 -9999 -9999 -9999 -9999 -9999 -9999 -9999 -9999 -9999 -9999 -9999 -9999 -9999 -9999 -9999 -9999 -9999 -9999 -9999 -9999 -9999 -9999 -9999 -9999 -9999 -9999 -9999 -9999 -9999 -9999 -9999 -9999 -9999 -9999-9999 -9999 -9999 -

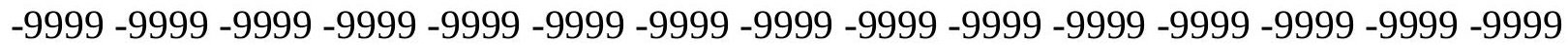
$-9999-9999$

-9999 -9999 -9999 -9999 -9999 -9999 -9999 -9999 -9999 -9999 -9999 -9999 -9999 -9999 -9999 -9999 -9999 -9999 -9999 -9999 -9999 -9999 -9999 -9999 -9999 -9999 -9999 -9999 -9999 -9999 -999 -9999 -9999 -9999 -9999 -9999 -9999-9999 -9999 -9999-9999-9999 103.4320755005 103.7659606934104 .0533370972104 .2862472534104 .4478530884101 .7982025146 102.1029968262103 .0174026489103 .7709197998103 .0642471313102 .0458068848 100.661178588998 .8628921508896 .6138687133893 .9038696289190 .75724029541 86.5589828491281 .0728530883876 .1962814331171 .9292907714868 .57665252686 65.2240066528361 .8713798522957 .909179687554 .8613204956153 .03261184692 52.7278289794954 .2517509460456 .9948196411160 .0426712036162 .78573989868 65.4744491577167 .292549133368 .6195373535269 .4821853637768 .02234649658 68.9285888671968 .5766525268667 .9670867919967 .9670867919968 .27187347412 69.7957916259871 .9292907714874 .9771423339877 .8084793090879 .46326446533 80.9519805908282 .3949279785282 .9015579223682 .9015579223682 .90155792236 84.7302627563587 .1685485839891 .7433319091893 .483963012795 .34674835205 97.3444976806699 .45556640625101 .6145095825103 .694442749105 .5316619873 106.9951019287108 .0145645142108 .5609436035108 .6798934937108 .4114685059 107.7360076904106 .5457458496104 .7110824585102 .215698242299 .33261108398 92.0450973510780 .1584930419967 .6623001098656 .3852500915546 .32733917236 44.4986305236840 .2316398620639 .9268493652339 .9268493652339 .01250076294 38.4029312133837 .1837806701737 .7933502197332 .6120109558131 .39286994934 31.0880794525132 .6120109558135 .9646492004439 .3172798156741 .14598846436 41.7555618286142 .0603485107442 .0603485107442 .3651313781742 .669921875 43.2794914245644 .4986305236845 .4129791259846 .3273391723646 .93690872192 46.6321296691946 .0225486755445 .1082000732443 .8890609741242 .669921875 41.7555618286140 .8412094116240 .2316398620639 .3172798156738 .40293121338 37.4885711669936 .5742111206135 .3550796508834 .1359291076733 .22158050537 32.3072204589831 .6976509094231 .3928699493432 .0024414062533 .22158050537 35.0502891540537 .1837806701739 .3172798156741 .4507789611842 .97470092773 43.8890609741244 .1938400268644 .4986305236844 .4986305236844 .49863052368 44.4986305236843 .8890609741243 .2794914245642 .0603485107440 .84120941162 39.622070312538 .4029312133836 .8790016174335 .6598587036134 .13592910767 32.6120109558130 .7833003997829 .2593708038327 .7354507446326 .21151924133 24.9923801422124 .0780296325723 .1636695861822 .5541000366222 .24930953979 22.5541000366222 .8588790893623 .1636695861823 .7732391357424 .07802963257 24.3828105926524 .3828105926524 .3828105926524 .6875991821324 .68759918213 24.9923801422125 .2971591949525 .906740188626 .8210906982428 .04022979736 29.5641593933130 .7833003997832 .0024414062532 .9167900085433 .83115005493 34.4407196044934 .7455101013235 .3550796508835 .6598587036135 .96464920044 36.5742111206137 .1837806701738 .0981407165539 .0125007629440 .23163986206 
41.4507789611842 .9747009277344 .4986305236845 .717769622847 .24169921875 48.4608306884849 .6799812316950 .5943298339851 .5086898803752 .42303848267 53.3373985290554 .2517509460454 .8613204956155 .4708900451756 .38525009155 56.9948196411157 .6043891906758 .2139587402359 .1283111572359 .73788070679 60.6522407531760 .9570198059161 .2618103027361 .8713798522962 .17617034912 62.7857398986863 .0905189514263 .3953094482464 .004882812564 .30966186523 64.6144485473664 .9192428588965 .2240066528365 .5288009643666 .13836669922 66.4431610107466 .7479400634867 .0527267456167 .3575134277367 .66230010986 67.9670867919967 .9670867919968 .2718734741268 .5766525268668 .88143920898 68.8814392089869 .1862335205169 .4910125732469 .4910125732469 .79579162598 69.7957916259870 .1005783081170 .1005783081170 .4053573608470 .40535736084 70.7101516723670 .7101516723670 .7101516723671 .014930725171 .0149307251 71.3197174072371 .3197174072371 .6244964599671 .6244964599671 .92929077148 71.9292907714872 .2340774536172 .2340774536172 .5388565063572 .53885650635 72.8436431884872 .8436431884873 .051200866773 .2187423706175 .89148712158 -9999 -9999 -9999 -9999 -9999 -9999 -9999 -9999 -9999 -9999 -9999 -9999 -9999 -9999 -9999 -9999 -9999 -9999 -9999 -9999 -9999 -9999 -9999 -9999 -9999 -9999 -9999 -9999 -9999 -9999 -9999 -

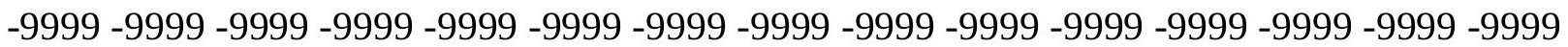
-9999 -9999 -9999 -9999 -9999 -9999 -9999 -9999 -9999 -9999 -9999 -9999 -9999 -9999 -9999 -9999 -9999 -9999 -9999 -9999 -9999 -9999 -9999 -9999 -9999 -9999 -9999 -9999 -9999 -9999 -

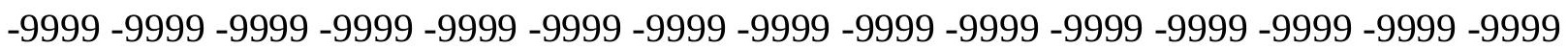
$-9999$

-9999 -9999 -9999 -9999 -9999 -9999 -9999 -9999 -9999 -9999 -9999 -9999 -9999 -9999 -9999 -9999 -9999 -9999 -9999 -9999 -9999 -9999 -9999 -9999 -9999 -9999 -9999 -9999 -9999 -9999 -9999 -9999 -9999 -9999 -9999 -9999 -9999 -9999 -9999 -9999 -9999 -9999 -9999 106.0160827637106 .1872634888106 .2758407593106 .2595367432106 .1080703735 105.7871322632105 .2560119629104 .4724502563103 .3897323608101 .9621429443 100.152565002497 .935966491795 .30942535492 .2979354858487 .16854858398 81.0728530883875 .5867080688571 .3197174072368 .8814392089866 .44316101074 62.7857398986857 .909179687553 .3373985290550 .8991203308151 .20389938354 53.6421813964857 .2995986938560 .9570198059164 .3096618652367 .35751342773 69.4910125732470 .7101516723671 .3197174072371 .3197174072370 .13761138916 69.1862335205168 .2718734741267 .6623001098667 .6623001098669 .18623352051 71.6244964599675 .2819290161178 .9393463134881 .6296310424883 .13019561768 84.5347595214884 .7302627563585 .9494018554787 .1685485839888 .69246673584 90.5211791992294 .014511108495 .6890258789197 .4104537963999 .17767333984 100.9421157837102 .6561737061104 .231842041105 .5732498169106 .5855636597 107.2391433716107.5117111206 107.436088562 107.0490570068 106.3547973633 105.3165664673103 .8947753906102 .1242218018100 .199150085498 .44416046143 93.2642517089883 .8159103393674 .9771423339867 .3575134277363 .70008850098 61.8713798522960 .3474502563559 .1283111572356 .0804595947352 .72782897949 50.8991203308149 .0704002380445 .1082000732441 .1459884643638 .09814071655 35.6598587036135 .0502891540539 .622070312540 .8412094116241 .14598846436 40.8412094116240 .5364189147940 .5364189147941 .1459884643641 .75556182861 42.9747009277344 .4986305236845 .717769622846 .3273391723646 .02254867554 45.1082000732443 .8890609741242 .3651313781741 .1459884643640 .23163986206 
39.9268493652339 .622070312539 .0125007629438 .4029312133837 .48857116699 36.5742111206135 .3550796508834 .1359291076733 .2215805053732 .00244140625 31.0880794525130 .4785099029531 .0880794525132 .3072204589834 .44071960449 37.1837806701740 .2316398620642 .3651313781743 .8890609741244 .49863052368 44.8034095764244 .8034095764244 .8034095764244 .8034095764244 .80340957642 44.8034095764244 .1938400268643 .2794914245642 .0603485107440 .84120941162 39.9268493652338 .7077102661137 .1837806701735 .9646492004434 .13592910767 32.3072204589830 .7833003997828 .9545898437527 .7354507446326 .51630973816 25.6019496917724 .9923801422124 .3828105926524 .3828105926524 .68759918213 24.9923801422125 .906740188626 .5163097381626 .8210906982427 .12587928772 27.12587928772 27.12587928772 27.12587928772 27.12587928772 27.12587928772 27.430660247828 .0402297973628 .9545898437530 .1737308502231 .69765090942 32.9167900085433 .8311500549334 .7455101013235 .3550796508835 .65985870361 35.9646492004436 .2694282531736 .2694282531736 .5742111206136 .87900161743 37.1837806701738 .0981407165538 .7077102661139 .9268493652341 .14598846436 42.66992187544 .1938400268645 .4129791259846 .9369087219248 .15605163574 49.0704002380450 .2895507812551 .2038993835452 .1182594299352 .72782897949 53.6421813964854 .2517509460454 .8613204956155 .4708900451756 .08045959473 56.9948196411157 .6043891906758 .2139587402358 .8235282897959 .43310165405 60.0426712036160 .6522407531760 .9570198059161 .5666007995662 .17617034912 62.4809494018662 .7857398986863 .3953094482463 .7000885009864 .0048828125 64.6144485473664 .9192428588965 .2240066528365 .5288009643666 .13836669922 66.4431610107466 .7479400634867 .0527267456167 .3575134277367 .66230010986 67.9670867919968 .2718734741268 .5766525268668 .5766525268668 .88143920898 69.1862335205169 .1862335205169 .4910125732469 .4910125732469 .79579162598 69.7957916259870 .1005783081170 .1005783081170 .4053573608470 .40535736084 70.7101516723670 .7101516723670 .7101516723671 .014930725171 .0149307251 71.3197174072371 .3197174072371 .6244964599671 .6244964599671 .92929077148 71.9292907714872 .2340774536172 .2340774536172 .2340774536172 .53885650635 72.5388565063572 .7560119628972 .9488601684673 .11164855957 -9999 -9999 -9999 -9999

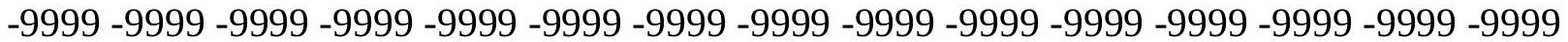

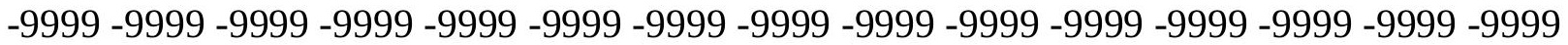

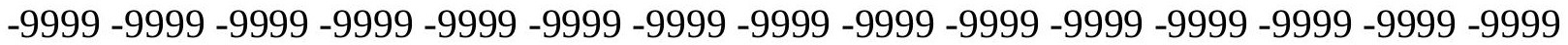

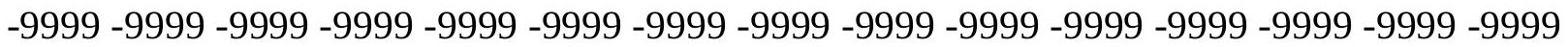

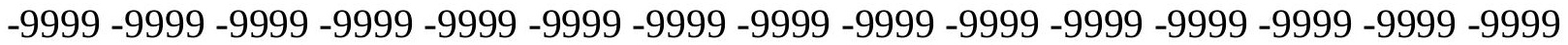

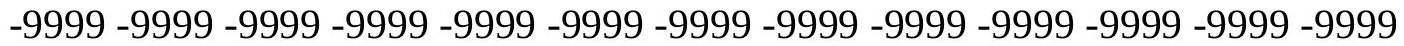

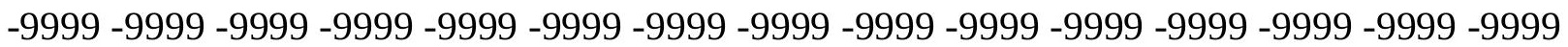

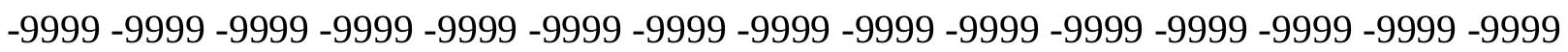

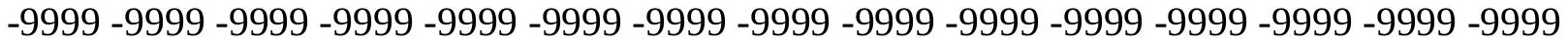
-9999 -9999 107.7519836426 107.3610153198 106.7663421631 105.9308776855 104.8150558472103 .3812942505101 .600784301899 .4576339721796 .95550537109 94.1192398071388 .3876876831181 .0728530883874 .3675689697370 .40535736084 69.1862335205168 .5766525268665 .2240066528358 .5187492370651 .50868988037 49.0704002380449 .9847602844253 .6421813964857 .909179687562 .17617034912 66.1383666992269 .1862335205171 .3197174072372 .8436431884873 .14842987061 72.8436431884871 .4298019409270 .1005783081168 .5766525268667 .66230010986 
67.3575134277368 .5766525268671 .6244964599675 .2819290161180 .15849304199 83.5479049682685 .0863342285286 .6447906494188 .2474975585989 .93466186523 91.1307525634892 .6546783447394 .7105865478596 .2164535522597 .73638916016 99.25390625100 .7373886108102 .1513977051103 .4349517822104 .5367584229 105.3897247314105 .937461853106 .165763855106 .0855178833105 .7522888184 105.2365036011104 .5981445312103 .8681869507103 .0503845215102 .145614624 101.2007141113100 .298896789699 .5416259765698 .9793777465895 .3977432251 92.349891662690 .8259735107490 .5211791992292 .0450973510792 .04509735107 88.6924667358484 .7302627563581 .9871978759879 .8537063598677 .1106262207 74.6723632812572 .2340774536169 .4910125732466 .7479400634862 .17617034912 54.2517509460446 .9369087219244 .4986305236842 .9747009277340 .84120941162 39.9268493652340 .2316398620641 .4507789611843 .8890609741245 .7177696228 46.0225486755445 .4129791259844 .1938400268642 .66992187540 .84120941162 39.3172798156738 .7077102661138 .7077102661139 .0125007629438 .70771026611 38.0981407165537 .4885711669936 .5742111206135 .6598587036134 .44071960449 33.2215805053731 .6976509094230 .1737308502229 .5641593933129 .56415939331 31.0880794525133 .8311500549337 .4885711669941 .1459884643643 .88906097412 45.4129791259845 .4129791259845 .1082000732444 .8034095764244 .80340957642 45.4129791259845 .717769622846 .3273391723646 .0225486755445 .41297912598 44.4986305236843 .5842704772942 .66992187541 .4507789611840 .23163986206 39.0125007629437 .1837806701735 .3550796508833 .5263595581131 .69765090942 30.4785099029529 .5641593933128 .9545898437528 .3450202941928 .04022979736 28.0402297973628 .3450202941929 .2593708038329 .8689403533930 .78330039978 31.0880794525131 .0880794525131 .0880794525131 .0880794525130 .78330039978 30.7833003997830 .4785099029530 .7833003997831 .0880794525132 .00244140625 33.2215805053734 .4407196044935 .9646492004436 .8790016174337 .48857116699 37.7933502197337 .7933502197337 .7933502197337 .4885711669937 .48857116699 37.4885711669937 .4885711669937 .7933502197338 .4029312133839 .31727981567 40.2316398620641 .4507789611842 .9747009277344 .1938400268645 .7177696228 46.9369087219248 .1560516357449 .0704002380450 .2895507812551 .20389938354 51.8134689331152 .4230384826753 .0326118469253 .6421813964854 .25175094604 54.8613204956155 .4708900451756 .0804595947356 .6900291442957 .29959869385 57.909179687558 .5187492370659 .1283111572359 .7378807067960 .34745025635 60.6522407531761 .2618103027361 .8713798522962 .4809494018662 .78573989868 63.0905189514263 .7000885009864 .004882812564 .6144485473664 .91924285889 65.2240066528365 .5288009643666 .1383666992266 .4431610107466 .74794006348 67.0527267456167 .3575134277367 .6623001098667 .9670867919968 .27187347412 68.5766525268668 .5766525268668 .8814392089869 .1862335205169 .18623352051 69.4910125732469 .4910125732469 .7957916259869 .7957916259870 .10057830811 70.1005783081170 .4053573608470 .4053573608470 .7101516723670 .71015167236 70.7101516723671 .014930725171 .014930725171 .3197174072371 .31971740723 71.3197174072371 .6244964599671 .6244964599671 .9292907714871 .92929077148 71.9292907714872 .2340774536172 .2340774536172 .5388565063572 .53885650635 72.7983398437573 .01694488525 -9999 -9999 -9999 -9999 -9999 -9999 -9999 -9999 -9999 -9999 -9999 -9999 -9999 -9999 -9999 -9999 -9999 -9999 -9999 -9999 -9999 -9999 -9999 -9999 -9999 -9999 -9999 -9999 -9999 -9999 -9999 -9999 -9999 -9999 -9999 -9999 -9999 -9999 -9999 
-9999 -9999 -9999 -9999 -9999 -9999 -9999 -9999 -9999 -9999 -9999 -9999 -9999 -9999 -9999 -9999 -9999 -9999 -9999 -9999 -9999 -9999 -9999 -9999 -9999 -9999 -9999 -9999 -9999 -9999

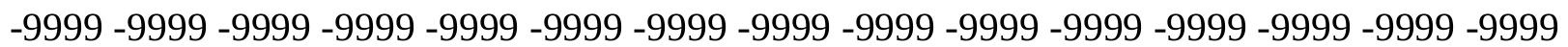
-9999 -9999 -9999 -9999 -9999-9999 -9999

-9999 -9999 -9999 -9999 -9999 -9999 -9999 -9999 -9999 -9999 -9999 -9999 -9999 -9999 -9999 -9999 -9999 -9999 -9999 -9999 -9999 -9999 -9999 -9999 -9999 -9999 -9999 -9999 -9999 -9999 -9999 -9999 -9999 -9999 -9999 -9999 -9999 -9999 -9999 -9999 -9999 -9999 -9999 -9999 -9999 -9999 -9999 -9999 -9999-9999 107.4691009521 106.352935791 104.9492416382 103.2368011475101 .206306457598 .8652496337996 .2382888793993 .36891937256 90.3184432983478 .3297805786168 .8814392089874 .9771423339878 .13455963135 69.4910125732456 .3852500915549 .9847602844248 .1560516357450 .59432983398 55.4708900451761 .2618103027366 .7479400634870 .7101516723673 .75800323486 76.8058471679778 .4278488159279 .2441329956178 .3297805786177 .72020721436 73.9408950805775 .1708221435574 .062782287673 .7580032348674 .97714233398 77.4154205322380 .7680587768683 .8615493774485 .4735260009887 .11996459961 88.811111450290 .5686264038192 .4232482910294 .4161911010795 .73745727539 97.0607147216898 .3810272216899 .68353271484100 .9433288574102 .1238861084 103.1797103882104 .0607681274104 .7145004272105 .0969696045105 .1772079468 104.9399642944104 .4506759644103 .7980651855103 .1041717529102 .5068054199 102.1203842163101 .9837112427102 .0359954834102 .1369781494102 .1616897583 102.0237045288101 .7533569336101 .4730072021101 .3864517212101 .6879806519 102.480796814103 .545135498104 .604385376105 .3378982544105 .6184082031 105.5886077881105 .8605651855105 .3779449463105 .0891265869106 .3700027466 103.931701660299 .6647262573293 .8738174438585 .3398437577 .41542053223 74.3675689697372 .2340774536169 .1862335205165 .2240066528359 .43310165405 53.6421813964849 .9847602844246 .3273391723646 .0225486755444 .49863052368 44.1938400268641 .7555618286138 .7077102661137 .1837806701736 .87900161743 37.7933502197338 .7077102661138 .7077102661138 .0981407165537 .18378067017 36.5742111206135 .6598587036135 .0502891540533 .5263595581131 .69765090942 29.8689403533928 .3450202941928 .0402297973629 .5641593933132 .91679000854 37.7933502197342 .66992187546 .3273391723647 .5464782714846 .93690872192 45.4129791259844 .4986305236845 .1082000732446 .3273391723647 .85126113892 49.0704002380449 .3751907348649 .0704002380448 .4608306884847 .54647827148 46.9369087219246 .0225486755445 .1082000732443 .5842704772942 .06034851074 39.9268493652338 .0981407165536 .5742111206135 .6598587036135 .05028915405 34.7455101013234 .4407196044934 .1359291076733 .8311500549334 .13592910767 35.0502891540535 .9646492004436 .5742111206136 .8790016174336 .87900161743 36.5742111206136 .2694282531735 .9646492004435 .9646492004435 .35507965088 35.3550796508835 .3550796508835 .9646492004437 .1837806701738 .70771026611 39.9268493652340 .8412094116241 .1459884643640 .8412094116240 .53641891479 40.2316398620639 .9268493652339 .3172798156739 .0125007629439 .01250076294 39.3172798156739 .622070312540 .2316398620641 .4507789611842 .36513137817 43.5842704772944 .8034095764246 .3273391723647 .5464782714848 .46083068848 49.6799812316950 .5943298339851 .2038993835451 .8134689331152 .42303848267 53.0326118469253 .3373985290553 .9469718933154 .2517509460454 .86132049561 55.4708900451756 .0804595947356 .3852500915556 .9948196411157 .60438919067 
58.2139587402358 .8235282897959 .4331016540560 .0426712036160 .65224075317 61.2618103027361 .8713798522962 .1761703491262 .7857398986863 .09051895142 63.3953094482464 .004882812564 .3096618652364 .9192428588965 .22400665283 65.5288009643666 .1383666992266 .4431610107466 .7479400634867 .05272674561 67.3575134277367 .6623001098667 .9670867919968 .2718734741268 .57665252686 68.8814392089868 .8814392089869 .1862335205169 .1862335205169 .49101257324 69.4910125732469 .7957916259869 .7957916259870 .1005783081170 .10057830811 70.4053573608470 .4053573608470 .4053573608470 .7101516723670 .71015167236 71.014930725171 .014930725171 .014930725171 .3197174072371 .31971740723 71.3197174072371 .6244964599671 .6244964599671 .9292907714871 .92929077148 71.9292907714872 .2340774536172 .2340774536172 .4763717651472 .72402191162 -9999 -9999 -9999 -9999 -9999 -9999 -9999 -9999 -9999 -9999 -9999 -9999 -9999 -9999 -9999 -9999 -9999 -9999 -9999 -9999 -9999 -9999 -9999 -9999 -9999 -9999 -9999 -9999 -9999 -9999 -9999 -9999 -9999 -9999 -9999 -9999 -9999 -9999 -9999 -9999 -9999 -9999 -9999 -9999 -9999 -9999 -9999 -9999 -9999 -9999 -9999 -9999 -9999 -9999 -9999 -9999 -9999 -9999 -9999 -9999 -9999 -

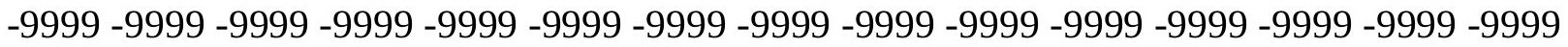
-9999 -9999 -9999 -9999 -9999 -9999 -9999 -9999 -9999 -9999 -9999 -9999 -9999 -9999 -9999 -9999 -9999 -9999 -9999 -9999 -9999 -9999 -9999 -9999 -9999 -9999 -9999 -9999 -9999 -9999 -9999 -9999 -9999 -9999 -9999 -9999 -9999 -9999 -9999 -9999 -9999 -9999 -9999 -9999 -9999 -9999 -9999 -9999 -9999 -9999 -9999 -9999 -9999 -9999 -9999 -9999 -9999 -9999 -9999 -9999 -9999 -9999 -9999 -9999 -9999 -9999 -9999 106.6810073853105 .0711746216103 .1863632202 101.036598205698 .6461486816496 .0560989379993 .3211593627990 .51415252686 87.7195739746185 .0340499877982 .5607299804780 .3935165405375 .58670806885 68.2718734741267 .0527267456171 .9292907714876 .3174667358477 .04718780518 78.1439208984479 .4536514282280 .82700347982 .1324768066483 .29452514648 84.2930297851685 .1075134277385 .745811462486 .2557601928776 .68784332275 78.0505599975679 .475448608480 .9600601196382 .5028991699284 .10005950928 85.7474212646587 .4423294067489 .1876907348690 .9932403564592 .8775177002 94.8667831420996 .9969711303798 .3399200439599 .44327545166100 .5335235596 101.5864334106102 .5687713623103 .4379882812104 .1455841064104 .6403503418 104.872795105104 .8029632568104 .4053421021103 .7010421753102 .7639694214 101.7154693604100 .7293548584100 .032554626599 .86881256104100 .3573074341 101.4230728149102 .6675415039103 .7596740723104 .3517990112104 .4262390137 104.0917663574103 .6926116943103 .5488586426103 .8283843994104 .4712142944 105.2901306152106 .0723800659106 .707359314107 .3734436035108 .2440414429 109.4540100098110 .8475265503111 .7106933594111 .1476745605108 .7906951904 106.6583786011104 .4417190552103 .040435791101 .7501754761100 .3515090942 100.274299621695 .0929565429789 .9116134643685 .3398437581 .68241119385 77.4154205322370 .1005783081161 .2618103027352 .7278289794943 .58427047729 36.8790016174335 .9646492004435 .6598587036138 .0981407165539 .01250076294 39.0125007629438 .4029312133837 .1837806701736 .2694282531736 .26942825317 35.9646492004434 .7455101013232 .3072204589829 .8689403533927 .73545074463 26.8210906982428 .0402297973632 .0024414062538 .4029312133845 .10820007324 49.9847602844251 .5086898803749 .3751907348646 .0225486755445 .10820007324 46.6321296691949 .3751907348652 .1182594299354 .5565414428756 .08045959473 55.4708900451754 .2517509460454 .2517509460453 .9469718933152 .42303848267 
50.8991203308150 .2895507812549 .0704002380446 .9369087219245 .41297912598 44.8034095764244 .1938400268643 .2794914245643 .5842704772944 .19384002686 43.5842704772942 .0603485107442 .66992187543 .2794914245644 .19384002686 44.8034095764244 .8034095764244 .1938400268643 .5842704772942 .97470092773 42.9747009277342 .9747009277342 .3651313781741 .7555618286141 .14598846436 41.4507789611842 .66992187544 .4986305236845 .717769622846 .02254867554 45.717769622845 .1082000732444 .4986305236843 .8890609741242 .97470092773 42.3651313781741 .7555618286141 .4507789611841 .4507789611841 .75556182861 42.3651313781742 .9747009277344 .1938400268645 .1082000732446 .32733917236 47.2416992187548 .4608306884849 .3751907348650 .2895507812551 .20389938354 51.8134689331152 .4230384826752 .7278289794953 .0326118469253 .33739852905 53.6421813964853 .9469718933154 .2517509460454 .8613204956155 .16611099243 55.7756805419956 .0804595947356 .6900291442957 .2995986938557 .9091796875 58.5187492370659 .1283111572359 .7378807067960 .3474502563560 .95701980591 61.5666007995661 .8713798522962 .4809494018662 .7857398986863 .39530944824 64.004882812564 .3096618652364 .9192428588965 .2240066528365 .52880096436 66.1383666992266 .4431610107466 .7479400634867 .0527267456167 .66230010986 67.9670867919967 .9670867919968 .2718734741268 .5766525268668 .88143920898 68.8814392089869 .1862335205169 .1862335205169 .4910125732469 .49101257324 69.7957916259869 .7957916259870 .1005783081170 .1005783081170 .10057830811 70.4053573608470 .4053573608470 .4053573608470 .7101516723670 .71015167236 71.014930725171 .014930725171 .014930725171 .3197174072371 .31971740723 71.3197174072371 .6244964599671 .6244964599671 .6244964599671 .92929077148 71.9292907714872 .2340774536172 .3950729370172 .66847991943 -9999 -9999 -9999 -9999

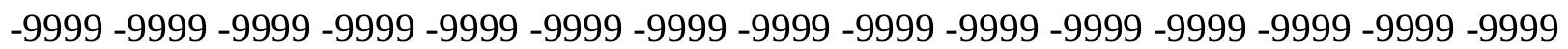

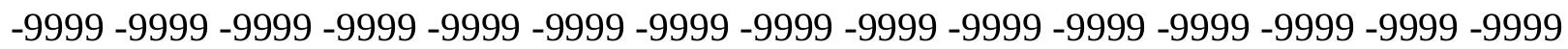

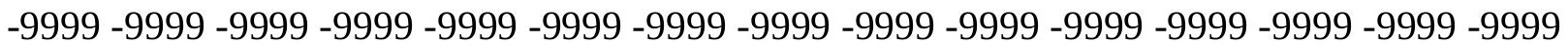

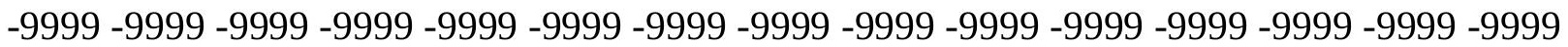

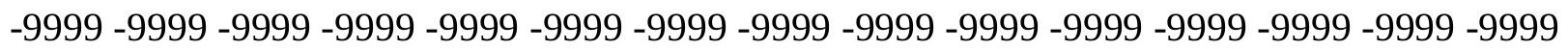
- l

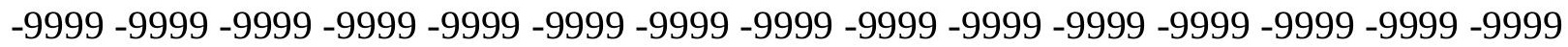

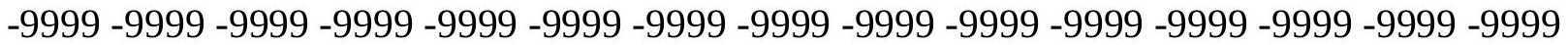

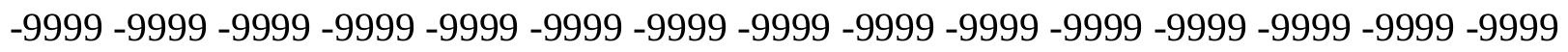
-9999 -9999 -9999 -9999 -9999 -9999-9999-9999 107.0963287354 105.3832015991 103.4478378296101 .314041137799 .0197219848696 .6158370971794 .1667175293 91.7470550537189 .4397811889687 .33119964685 .5042266845784 .01889801025 82.9330749511782 .2934265136782 .1239852905382 .4016342163183 .0834274292 84.0655822753985 .2480926513786 .5067291259887 .7397766113388 .89656066895 89.9213485717890 .7911834716891 .5116500854592 .1008377075278 .21246337891 79.6366577148481 .1215896606482 .6651458740284 .2676391601685 .9280090332 87.6451492309689 .4186477661191 .2525329589893 .1555023193495 .14347076416 97.2381515502999 .46934509277101 .0052947998101 .8506164551102 .6833190918 103.4714279175104 .174621582104 .7432785034105 .1247406006105 .2625656128 105.1066970825104 .6166381836103 .7679901123102 .6021270752101 .1916885376 99.6664505004998 .2183761596797 .135040283296 .823104858497 .66053009033 99.63524627686102 .1990280151104 .5153961182106 .0928497314106 .5848007202 
106.1499023438105 .3498153687104 .7076644897104 .5332946777104 .8563690186 105.5287857056106 .3731994629107 .2942581177108 .3302001953109 .5412597656 110.9244613647112 .2610092163112 .978477478112 .6305770874111 .2550582886 109.2632217407107 .4944000244106 .2222137451105 .7220993042105 .7991333008 106.0910568237106 .3592605591106 .5591506958106 .5815887451106 .2905426025 105.455703735499 .0551681518691 .7403335571383 .5111236572374 .36756896973 65.2240066528357 .2995986938551 .5086898803746 .3273391723639 .6220703125 38.7077102661139 .0125007629437 .4885711669935 .9646492004437 .48857116699 37.7933502197336 .2694282531733 .5263595581130 .4785099029527 .73545074463 26.2115192413327 .7354507446331 .0880794525139 .9268493652348 .46083068848 54.8613204956157 .2995986938553 .9469718933147 .5464782714847 .24169921875 50.5943298339854 .8613204956160 .9570198059162 .7857398986867 .66230010986 67.0527267456161 .8713798522966 .1383666992264 .3096618652359 .12831115723 57.2995986938559 .1283111572358 .2139587402357 .2995986938555 .47089004517 58.5187492370658 .2139587402354 .8613204956156 .9948196411157 .60438919067 56.9948196411155 .1661109924353 .9469718933153 .9469718933154 .25175094604 54.5565414428754 .5565414428753 .3373985290552 .1182594299351 .20389938354 51.8134689331153 .0326118469252 .4230384826750 .2895507812548 .7656211853 48.765621185349 .9847602844251 .8134689331153 .0326118469253 .03261184692 51.8134689331150 .2895507812549 .6799812316948 .765621185347 .54647827148 46.3273391723645 .717769622845 .4129791259845 .1082000732445 .41297912598 45.4129791259846 .0225486755446 .6321296691947 .2416992187548 .15605163574 48.765621185349 .9847602844250 .8991203308151 .8134689331152 .42303848267 52.7278289794953 .0326118469253 .0326118469253 .0326118469253 .33739852905 53.6421813964853 .6421813964853 .9469718933154 .2517509460454 .55654144287 54.8613204956155 .4708900451755 .7756805419956 .3852500915556 .69002914429 57.2995986938557 .909179687558 .8235282897959 .4331016540560 .04267120361 60.6522407531761 .2618103027361 .5666007995662 .1761703491262 .78573989868 63.3953094482463 .7000885009864 .3096618652364 .6144485473665 .22400665283 65.5288009643666 .1383666992266 .4431610107466 .7479400634867 .35751342773 67.6623001098667 .9670867919968 .2718734741268 .2718734741268 .57665252686 68.8814392089868 .8814392089869 .1862335205169 .1862335205169 .49101257324 69.4910125732469 .7957916259869 .7957916259869 .7957916259870 .10057830811 70.1005783081170 .1005783081170 .4053573608470 .4053573608470 .40535736084 70.7101516723670 .7101516723670 .7101516723671 .014930725171 .0149307251 71.014930725171 .3197174072371 .3197174072371 .3197174072371 .62449645996 $71.6244964599671 .9292907714871 .9292907714872 .4126434326272 .78970336914-9999$ -9999 -9999 -9999 -9999 -9999 -9999 -9999 -9999 -9999 -9999 -9999 -9999 -9999 -9999 -9999 -9999 -9999 -9999 -9999 -9999 -9999 -9999 -9999 -9999 -9999 -9999 -9999 -9999 -9999 -9999 -9999 -9999 -9999 -9999 -9999 -9999 -9999 -9999 -9999 -9999 -9999 -9999 -9999 -9999 -9999 -

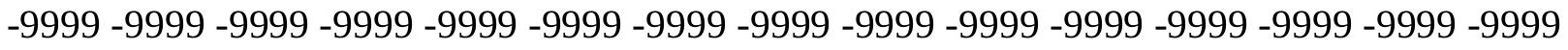

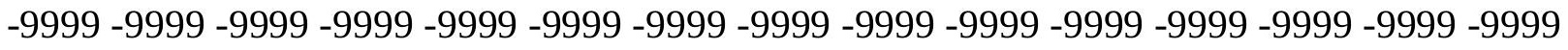
-9999 -9999 -9999 -9999 -9999 -9999 -9999 -9999 -9999 -9999 -9999 -9999 -9999 -9999 -9999 -9999 -9999 -9999 -9999 -9999 -9999 -9999 -9999 -9999 -9999 -9999 -9999 -9999 -999 -9999 -9999 -9999 -9999 -9999 -9999 -9999 -9999 -9999 -9999 -9999 -9999 -9999 -9999 -9999 -

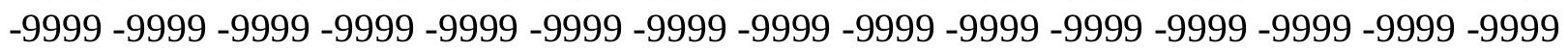


-9999 -9999 -9999 -9999 -9999 -9999-9999 -9999 -9999 107.7713394165106 .0660324097 104.2018356323102 .2126846313100 .145286560198 .055244445896 .0099105835 94.0777206420992 .3328170776490 .844589233489 .6719055175888 .85587310791 88.4319763183688 .4113082885788 .765068054289 .4565658569390 .40669250488 91.5393600463992 .7538375854593 .9839477539195 .1567001342896 .21983337402 97.1419067382897 .9129714965898 .5404357910299 .0445785522581 .21405792236 82.7568283081184 .3588714599686 .0211563110487 .7439422607489 .52758026123 91.37272644043 93.2833786010795.2669143676897.3362503051899.5085144043 101.8066711426103 .7041244507104 .2664489746104 .8286590576105 .3526535034 105.7902374268106 .0860214233106 .1775054932106 .0048370361105 .5116043091 104.6533737183103 .4008331299101 .801002502499 .9194946289197 .87442779541 95.8236694335993 .9862899780392 .811935424893 .2642517089895 .3977432251 99.66472625732103 .4047393799106 .6582870483107 .5895996094107 .106552124 105.8764038086104 .8319702148104 .3893508911104 .5821762085105 .2509078979 106.2049179077 107.3177032471 108.537689209 109.8450927734111.1635818481 112.2839508057112 .889465332112 .7440719604111 .8913345337110 .5609359741 109.2509918213 108.2547073364107.7123641968 107.5663299561 107.6287612915 107.721282959107 .7286224365107 .5262145996107 .014465332106 .1504821777 105.0079574585103 .6539840698102 .0657958984100 .133277893196 .00731658936 87.7781066894578 .9393463134870 .7101516723663 .0905189514256 .99481964111 54.5565414428752 .4230384826748 .1560516357445 .4129791259847 .24169921875 49.3751907348649 .0704002380448 .765621185350 .5943298339853 .33739852905 56.9948196411160 .3474502563562 .4809494018665 .5288009643671 .62449645996 75.2819290161171 .6244964599666 .4431610107465 .8335876464869 .18623352051 77.110626220785 .3398437588 .6924667358488 .6924667358486 .86376190186 86.254188537683 .8159103393677 .7202072143664 .004882812564 .91924285889 66.1383666992268 .2718734741271 .6244964599674 .6723632812578 .02498626709 78.3297805786175 .8914871215874 .6723632812573 .7580032348672 .84364318848 70.7101516723667 .0527267456167 .3575134277366 .1383666992266 .74794006348 66.1383666992264 .004882812562 .1761703491260 .9570198059161 .56660079956 66.4431610107467 .6623001098661 .2618103027360 .6522407531758 .21395874023 59.4331016540561 .2618103027362 .4809494018662 .1761703491260 .34745025635 56.6900291442956 .9948196411155 .4708900451753 .9469718933152 .42303848267 51.2038993835450 .8991203308150 .8991203308150 .2895507812549 .98476028442 49.9847602844249 .9847602844250 .2895507812550 .5943298339850 .89912033081 51.8134689331152 .7278289794953 .6421813964854 .2517509460454 .25175094604 53.9469718933153 .6421813964853 .6421813964853 .6421813964853 .64218139648 53.6421813964853 .9469718933153 .9469718933154 .2517509460454 .25175094604 54.5565414428754 .8613204956155 .1661109924355 .7756805419956 .38525009155 56.9948196411157 .6043891906758 .2139587402358 .8235282897959 .43310165405 60.0426712036160 .6522407531761 .2618103027361 .8713798522962 .48094940186 63.0905189514263 .7000885009864 .004882812564 .6144485473665 .22400665283 65.5288009643666 .1383666992266 .4431610107467 .0527267456167 .35751342773 67.6623001098667 .9670867919968 .2718734741268 .2718734741268 .57665252686 68.8814392089868 .8814392089869 .1862335205169 .1862335205169 .49101257324 69.49101257324 69.4910125732469.79579162598 69.7957916259869.79579162598 
70.1005783081170 .1005783081170 .1005783081170 .4053573608470 .40535736084 70.4053573608470 .7101516723670 .7101516723670 .7101516723670 .71015167236 71.014930725171 .014930725171 .014930725171 .3197174072371 .31971740723 71.3197174072371 .6244964599672 .2340774536172 .50940704346 -9999 -9999 -9999 -9999

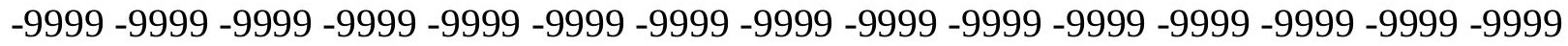

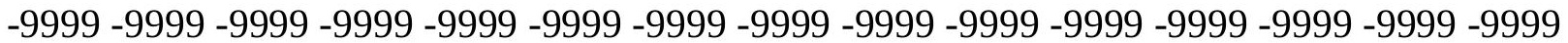

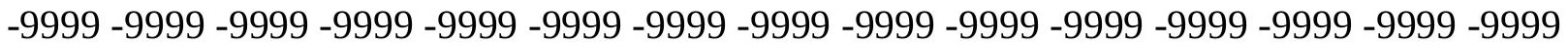

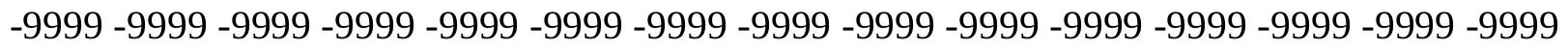

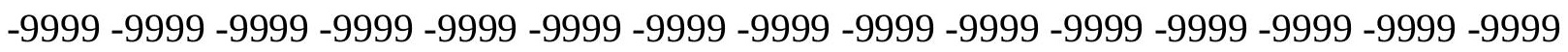
-9999 -9999 -9999 -9999 -9999 -9999 -9999 -9999 -9999 -9999

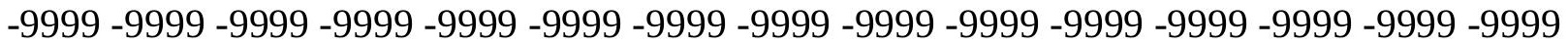

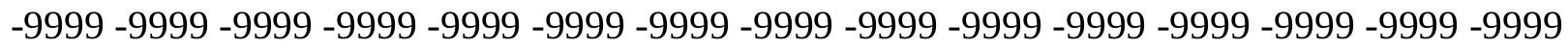

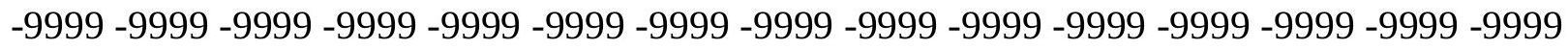
-9999 -9999 -9999 -9999 -9999-9999 -9999 -9999 -9999-9999 108.8526916504 107.2636871338 105.5822296143103.8498077393 102.1158370972 100.4365158081 98.8728103637797 .4845962524496 .3313140869195 .4636764526494 .91864013672 94.7183837890694 .8639678955195 .3370895385796 .0984725952197 .09315490723 98.2536087036199 .50636291504100 .7781219482102 .0020141602103 .1233062744 104.1020812988104 .9149169922105 .5531234741106 .0210571289106 .3322525024 84.37031555176 86.0279388427787.74722290039 89.52863311768 91.37300109863 93.2810592651495.2562332153397.3040771484499.43438720703 101.6595611572 103.9959716797 106.397857666106.6633987427 106.9553756714107.2296676636 107.4311523438 107.4940795898 107.3490219116 106.9267425537 106.1630783081 105.0068054199 103.4252624512 101.444137573299.133514404396.5908203125 93.9394378662191 .3056716918988 .755165100186 .5589828491286 .55898284912 92.0450973510799 .66472625732105 .1509017944106 .5627975464106 .1390151978 104.6946258545103 .5630950928103 .2085876465103 .5684127808104 .4271697998 105.5719299316106 .8497314453108 .1694793701109 .4702606201110 .6672286987 111.6180038452112 .1579055786112 .180229187111 .7115402222110 .9264831543 110.0771789551109 .3875808716108 .9521255493108 .7541275024108 .69115448 108.6472549438108 .4866256714108 .1193771362107 .4661483765106 .5055618286 105.2830123901103 .8308792114102 .1665267944100 .424263000598 .95516204834 98.0603103637797 .2072372436595 .397743225186 .8637619018679 .85370635986 74.6723632812571 .014930725167 .6623001098665 .5288009643664 .91924285889 64.9192428588966 .7479400634869 .4910125732471 .9292907714875 .58670806885 82.29197692871 88.08290100098 87.47332763672 86.8637619018692.65467834473 97.2264633178794 .7881774902391 .1307525634889 .6068267822391 .43553924561 99.96952056885109 .7226028442115 .2088012695117 .647102356118 .8662033081 117.342300415112 .7705001831105 .455703735491 .7403335571380 .46327209473 79.2441329956182 .5967712402389 .9116134643697 .83602905273101 .1886978149 101.798202514697 .8360290527393 .5690307617292 .349891662692 .3498916626 91.7403335571390 .2164001464887 .7781066894585 .9494018554788 .08290100098 88.9972534179782 .9015579223675 .8914871215872 .8436431884874 .0627822876 81.0728530883888 .6924667358484 .1206970214876 .8058471679772 .23407745361 70.7101516723671 .6244964599673 .1484298706173 .4532165527371 .31971740723 68.5766525268665 .8335876464863 .7000885009862 .1761703491260 .95701980591 
58.8235282897959 .7378807067959 .1283111572357 .6043891906755 .77568054199 55.4708900451755 .1661109924354 .2517509460453 .3373985290553 .03261184692 53.9469718933155 .1661109924356 .0804595947356 .6900291442956 .38525009155 55.4708900451754 .5565414428753 .9469718933153 .9469718933153 .94697189331 53.9469718933153 .9469718933153 .9469718933153 .9469718933153 .94697189331 53.9469718933154 .2517509460454 .2517509460454 .5565414428755 .16611099243 55.7756805419956 .3852500915556 .9948196411157 .6043891906758 .21395874023 58.8235282897959 .7378807067960 .3474502563561 .2618103027361 .87137985229 62.4809494018662 .7857398986863 .3953094482464 .004882812564 .61444854736 65.2240066528365 .5288009643666 .1383666992266 .4431610107467 .05272674561 67.3575134277367 .6623001098667 .9670867919968 .2718734741268 .27187347412 68.5766525268668 .8814392089868 .8814392089868 .8814392089869 .18623352051 69.1862335205169 .4910125732469 .4910125732469 .4910125732469 .79579162598 69.7957916259869 .7957916259870 .1005783081170 .1005783081170 .10057830811 70.1005783081170 .4053573608470 .4053573608470 .4053573608470 .71015167236 70.7101516723670 .7101516723670 .7101516723671 .014930725171 .0149307251 $71.014930725171 .3197174072371 .3197174072372 .1622848510772 .76258087158-9999$ -9999 -9999 -9999 -9999 -9999 -9999 -9999 -9999 -9999 -9999 -9999 -9999 -9999 -9999 -9999 -9999 -9999 -9999 -9999 -9999 -9999 -9999 -9999 -9999 -9999 -9999 -9999 -9999 -9999 -9999 -9999 -9999 -9999 -9999 -9999 -9999 -9999 -9999 -9999 -9999 -9999 -9999 -9999 -9999 -9999

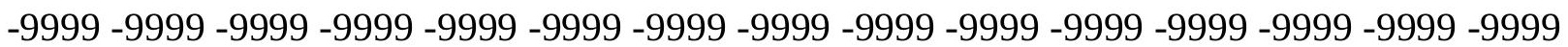

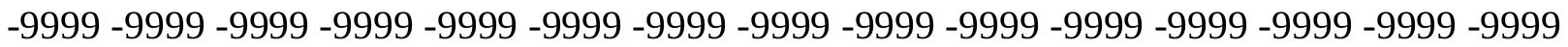
-9999 -9999 -9999 -9999 -9999 -9999 -9999 -9999 -9999 -9999 -9999 -9999

-9999 -9999 -9999 -9999 -9999 -9999 -9999 -9999 -9999 -9999 -9999 -9999 -9999 -9999 -9999

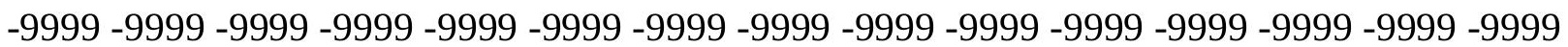
-9999 -9999 -9999 -9999 -9999 -9999 -9999 -9999 -9999 -9999 -9999 -9999 -9999 -9999 -9999 -9999 -9999 -9999 -9999 -9999 -9999 -9999 -9999 -9999 -9999 111.7666931152 110.4532089233109 .0762481689107 .6724243164106 .2848434448104 .9617919922 103.7543182373102 .7164535522101 .8938980103101 .3314666748101 .0575866699 101.0925216675101 .4348449707102 .0708694458102 .9658203125104 .0734100342 105.3338699341106 .6808547974108 .0453948975109 .3606414795110 .5673065186 111.6159057617112 .4701156616113 .1063919067113 .5152206421113 .699005127 85.95342254639 87.66152191162 89.4325256347791.2664337158293.16381835938 95.1249618530397 .1521682739399 .24900054932101 .4220046997103 .6791229248 106.0307388306108 .4864196777109 .0021743774109 .0352325439109 .085395813 109.092918396108 .9779434204108 .6626281738108 .0657653809107 .1132278442 105.744430542103 .9175338745101 .653297424398 .9959106445396 .04437255859 92.9278640747189 .6068267822386 .254188537683 .206336975182 .59677124023 86.254188537691 .7403335571396 .31210327148103 .3221969604102 .5341033936 101.2474441528100 .7195739746100 .9907531738101 .8662414551103 .1208496094 104.5553131104106 .0225143433107 .4290008545108 .7132797241109 .8153762817 110.660987854111 .1772460938111 .3292388916111 .1504440308110 .7538223267 110.2844238281109 .8763885498109 .5956344604109 .4353027344109 .3322219849 109.1955337524108 .9292831421108 .4613571167107 .7323303223106 .7361450195 105.5033340454104 .0777130127102 .5331878662101 .013954162699 .7400970459 98.6998901367297 .7898025512796 .8687896728595 .9063491821395 .02514648438 
93.1411590576288 .6924667358484 .7302627563581 .6824111938578 .93934631348 77.4154205322378 .3297805786181 .0728530883884 .4254837036188 .38768768311 91.7403335571394 .7881774902396 .0073165893697 .22646331787101 .7982025146 105.7603988647106 .0652008057105 .1509017944104 .8460998535106 .3700027466 110.6370010376115 .5136032104119 .4757995605122 .2188034058124 .0475006104 124.3523025513123 .7427978516120 .788230896118 .0581970215116 .1231002808 114.9039993286116 .1231002808120 .0852966309124 .9006729126126 .7168960571 127.400932312124 .0475006104118 .5614013672121 .9140014648125 .7626724243 124.8388595581123 .6114349365117 .647102356112 .4656982422112 .4656982422 113.075302124109 .4179000854104 .8460998535101 .1886978149100 .2742996216 104.8460998535108 .8082962036106 .3700027466101 .493400573797 .53124237061 94.1785964965892 .6546783447391 .7403335571390 .5211791992287 .77810668945 82.5967712402376 .1962814331172 .5388565063571 .6244964599672 .53885650635 73.1484298706172 .2340774536170 .1005783081167 .3575134277363 .09051895142 63.7000885009862 .4809494018659 .4331016540556 .3852500915555 .47089004517 56.3852500915558 .2139587402359 .7378807067959 .7378807067958 .82352828979 57.2995986938555 .7756805419954 .8613204956154 .5565414428754 .25175094604 54.5565414428754 .2517509460454 .2517509460453 .9469718933153 .64218139648 53.3373985290553 .3373985290553 .3373985290553 .6421813964853 .94697189331 54.5565414428755 .1661109924355 .7756805419956 .3852500915556 .99481964111 57.6043891906758 .5187492370659 .1283111572360 .0426712036160 .95701980591 61.2618103027361 .8713798522962 .4809494018663 .3953094482464 .0048828125 64.6144485473665 .2240066528365 .8335876464866 .1383666992266 .74794006348 67.0527267456167 .3575134277367 .6623001098667 .9670867919968 .27187347412 68.2718734741268 .5766525268668 .5766525268668 .8814392089868 .88143920898 68.8814392089869 .1862335205169 .1862335205169 .1862335205169 .49101257324 69.4910125732469 .4910125732469 .7957916259869 .7957916259869 .79579162598 70.1005783081170 .1005783081170 .1005783081170 .1005783081170 .40535736084 70.4053573608470 .4053573608470 .4053573608470 .7101516723670 .71015167236 70.7101516723671 .014930725171 .014930725171 .9292907714872 .5147857666 -9999 -9999 -9999 -9999 -9999 -9999 -9999 -9999 -9999 -9999 -9999 -9999 -9999 -9999 -9999 -9999 -9999 -9999 -9999 -9999 -9999 -9999 -9999 -9999 -9999 -9999 -9999 -9999 -9999 -9999 -9999 -9999 -

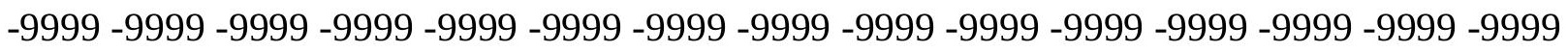

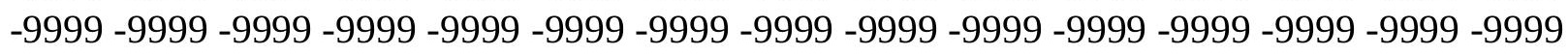

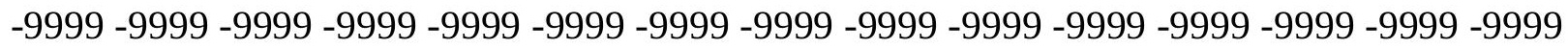
-9999 -9999 -9999 -9999 -9999 -9999 -9999 -9999 -9999 -9999 -9999 -

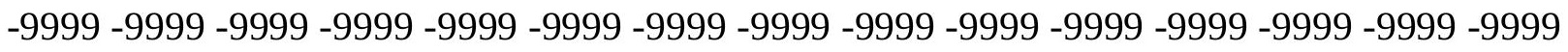

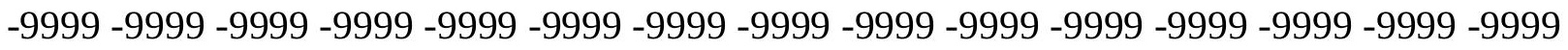
-9999 -9999 -9999 -9999 -9999 -9999 -9999 -9999 -9999 -9999 -9999 -9999 -9999 -9999 -9999 -9999 -9999 -9999 -9999 -9999 -9999 -9999 -9999 -9999 -9999 -9999 113.7223052979 112.6424789429111 .5572509766110 .5042419434109 .5249633789108 .6641082764 107.9651184082107 .470375061107 .2141799927107 .2244644165107 .5146255493 108.0873565674108 .927444458110 .0076141357111 .2841110229112 .7041549683 114.2037124634115 .7157821655117 .1675720215118 .4979629517119 .6354675293 120.5434417725121 .1708374023121 .5027160645121 .5288925171121 .2590560913 89.251258850191.0670852661192.9458923339894.8875732421996.89157867432 
98.95886230469101 .0908432007103 .2910232544105 .5633087158107 .9129333496 110.343788147111 .2303771973111 .0183639526110 .8821258545110 .7474136353 110.5290756226110 .1270141602109 .4542236328108 .4126358032106 .931968689 104.968460083102 .523101806699 .6272811889696 .3632812592 .90771484375 88.3876876831186 .5589828491281 .6824111938579 .8537063598681 .07285308838 84.4254837036188 .6924667358494 .4833908081195 .4669876098695 .85085296631 96.7383270263798 .071289062599 .7127456665101 .5049438477103 .3018875122 104.9904708862106 .4989852905107 .7886428833108 .8362579346109 .6226654053 110.1353683472110 .3822174072110 .4042892456110 .2758331299110 .0851821899 109.9075164795 109.7811126709 109.6968917847 109.6092910767 109.4370574951 109.1253662109108 .6217956543107 .8879318237106 .920791626105 .7583694458 104.4487304688103 .0789413452101 .7626647949100 .63064575299 .68581390381 98.9179382324298 .3029785156297 .839141845797 .5326004028397 .47554016113 98.5065307617298 .4525833129994 .3275070190490 .8259735107487 .47332763672 86.254188537687 .4733276367290 .8259735107494 .1785964965893 .56903076172 92.9594726562596 .0073165893699 .66472625732103 .0174026489106 .6747970581 109.4179000854111 .8561019897113 .9896011353115 .2088012695114 .5991973877 113.9896011353114 .9039993286116 .4279022217118 .2565994263120 .6949005127 123.43800354122 .7456817627120 .7927398682119 .7578659058120 .0246734619 121.5503768921123 .6818618774125 .7787628174127 .3503494263128 .2060241699 128.4468841553128 .1326599121127 .1856231689126 .2432327271125 .3056793213 124.3730545044 122.5447235107 120.2886886597 118.1594848633116 .3431625366 114.8945999146113 .8122406006113 .0937957764112 .6992492676112 .5119552612 112.3536529541112 .0320968628111 .4306259155110 .5720443726109 .5571975708 108.5023193359107 .4691467285106 .4538269043103 .9034042358101 .8657455444 102.71260070898 .445587158295 .0929565429796 .3121032714896 .92166900635 90.5211791992282 .5967712402379 .5489196777376 .8058471679774 .97714233398 71.6244964599664 .9192428588959 .1283111572356 .6900291442959 .12831115723 62.1761703491264 .004882812564 .004882812561 .8713798522959 .12831115723 56.9948196411155 .7756805419955 .4708900451755 .4708900451755 .47089004517 55.1661109924354 .8613204956154 .2517509460453 .6421813964853 .03261184692 52.7278289794952 .7278289794952 .7278289794953 .0326118469253 .33739852905 53.9469718933154 .2517509460454 .8613204956155 .7756805419956 .38525009155 56.9948196411157 .909179687558 .5187492370659 .4331016540560 .04267120361 60.9570198059161 .5666007995662 .4809494018663 .0905189514264 .0048828125 64.6144485473665 .2240066528365 .8335876464866 .1383666992266 .74794006348 67.0527267456167 .3575134277367 .6623001098667 .9670867919968 .27187347412 68.2718734741268 .5766525268668 .5766525268668 .5766525268668 .88143920898 68.8814392089868 .8814392089869 .1862335205169 .1862335205169 .18623352051 69.4910125732469 .4910125732469 .4910125732469 .4910125732469 .79579162598 69.7957916259869 .7957916259869 .7957916259870 .1005783081170 .10057830811 70.1005783081170 .4053573608470 .4053573608470 .4053573608470 .40535736084 70.7101516723670 .7101516723670 .7101516723672 .2340774536172 .78578186035 -9999 -9999 -9999 -9999 -9999 -9999 -9999 -9999 -9999 -9999 -9999 -9999 -9999 -9999 -9999 -9999 -9999 -9999 -9999 -9999 -9999 -9999 -9999 -9999 -9999 -9999 -9999 -9999 -9999 -9999 -9999 -

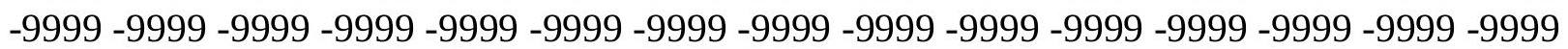


-9999 -9999 -9999 -9999 -9999 -9999 -9999 -9999 -9999 -9999 -9999 -9999 -9999 -9999 -9999 -9999 -9999 -9999 -9999 -9999 -9999 -9999 -9999 -9999 -9999 -9999 -9999 -9999 -9999 -9999 -9999 -9999 -9999 -9999 -9999 -9999 -9999 -9999 -9999 -9999 -9999

-9999 -9999 -9999 -9999 -9999 -9999 -9999 -9999 -9999 -9999 -9999 -9999 -9999 -9999 -9999 -9999 -9999 -9999 -9999 -9999 -9999 -9999 -9999 -9999 -9999 -9999 -9999-9999 -9999 -9999 -

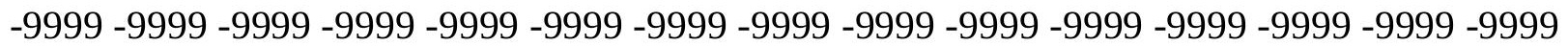
-9999 -9999 -9999 -9999 -9999 -9999 -9999 -9999 -9999 -9999 -9999 -9999 116.231803894 115.4524536133114 .7201080322114 .0707015991113 .5430831909113 .174697876 113.002456665113 .0560836792113 .3603591919113 .9271850586114 .7596130371 115.8442611694117 .1567687988118 .6563873291120 .2930221558122 .0017623901 123.718460083125 .3639297485126 .8554916382128 .1192779541129 .0871887207 129.7136383057129 .9514007568129 .7899780273129 .232055664190 .78991699219 92.6427001953194 .5579452514696 .5346603393698 .5712890625100 .6673126221 102.8221588135105 .0365371704107 .3109130859109 .6463241577112 .0422210693 113.2776565552112 .8503417969112 .5671920776112 .3568344116112 .12109375 111.7481002808111 .1074905396110 .0848846436108 .5972518921106 .5993804932 104.0858230591101 .087867736897 .680107116793 .2642517089887 .77810668945 86.8637619018685 .0350494384881 .0728530883879 .2441329956181 .98719787598 81.3776321411184 .7302627563587 .7446594238390 .1616363525492 .64511871338 95.1011810302797 .5090560913199 .83782196045102 .0009841919103 .9144363403 105.5300445557106 .837310791107 .8500061035108 .5929794312109 .0964508057 109.3975143433109.5434875488109.5899658203109.5924606323109.5922012329 109.605255127109 .6145095825109 .5753250122109 .4261703491109 .1354293823 108.6628417969107 .9847869873107 .1102981567106 .0714492798104 .923538208 103.7497634888102 .6320648193101 .6799316406100 .9260406494100 .4076156616 100.1695556641100 .283744812100 .8730316162102 .1408615112104 .3578796387 106.7792434692104 .672172546499 .9471130371195 .4625625610491 .43553924561 89.302040100192.0450973510795.0929565429794.4833908081193.26425170898 94.1785964965896 .3121032714899 .96952056885104 .2365036011108 .5035018921 112.4656982422115 .7057723999117 .7201919556116 .7326965332114 .5991973877 114.2944030762115 .2088012695116 .7326965332119 .7806015015123 .7427978516 124.0501174927122 .8981704712122 .2629318237122 .4596862793123 .4742126465 124.9742889404126 .5318145752127 .8078155518128 .6291503906128 .9874572754 128.6369476318127 .6768264771126 .7214126587125 .770866394124 .8252029419 123.3695907593121 .3460083008119 .3719863892117 .6080474854116 .130531311 114.9687271118114 .1128311157113 .5107498169113 .0661315918112 .6539077759 112.1485137939111 .479095459110 .6390533447109 .6770553589108 .6575241089 107.6375045776106 .6572418213105 .732635498104 .911315918104 .3285903931 104.1516571045104 .5035629272104 .0087432861103 .1424026489102 .28540802 101.438575744699 .0551681518692 .349891662689 .302040100183 .2063369751 69.1862335205162 .1761703491257 .2995986938561 .5666007995666 .74794006348 70.1005783081169 .1862335205165 .2240066528361 .2618103027358 .21395874023 57.2995986938557 .2995986938556 .9948196411156 .9948196411156 .38525009155 55.7756805419954 .8613204956153 .6421813964853 .0326118469252 .42303848267 51.8134689331151 .8134689331151 .8134689331152 .1182594299352 .72782897949 53.0326118469253 .6421813964854 .2517509460454 .8613204956155 .47089004517 
56.3852500915557 .2995986938557 .909179687558 .8235282897959 .73788070679 60.6522407531761 .5666007995662 .4809494018663 .0905189514264 .0048828125 64.6144485473665 .2240066528365 .8335876464866 .4431610107466 .74794006348 67.0527267456167 .3575134277367 .6623001098667 .9670867919967 .96708679199 68.2718734741268 .2718734741268 .5766525268668 .5766525268668 .57665252686 68.5766525268668 .8814392089868 .8814392089868 .8814392089869 .18623352051 69.1862335205169 .1862335205169 .1862335205169 .4910125732469 .49101257324 69.4910125732469 .4910125732469 .7957916259869 .7957916259869 .79579162598 70.1005783081170 .1005783081170 .1005783081170 .1005783081170 .40535736084 70.4053573608470 .4053573608471 .3197174072372 .22332763672 -9999 -9999 -9999 -9999 -9999 -9999 -9999 -9999 -9999 -9999 -9999 -9999 -9999 -9999 -9999 -9999 -9999 -9999 -9999 -9999 -9999 -9999 -9999 -9999 -9999 -9999 -9999 -9999 -9999 -9999 -9999 -9999 -9999 -9999 -9999 -9999 -9999 -9999 -9999 -9999 -9999 -9999 -9999 -9999 -9999 -9999 -9999 -9999 -9999 -9999 -9999 -9999 -9999 -9999 -9999 -9999 -9999 -9999 -9999 -9999 -9999 -9999 -9999 -9999 -

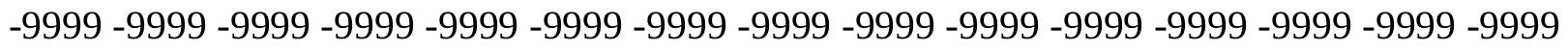
-9999 -9999-9999 -9999-9999-9999-9999-9999

-9999 -9999 -9999 -9999 -9999 -9999 -9999 -9999 -9999 -9999 -9999 -9999 -9999 -9999 -9999 -

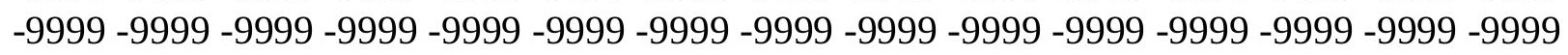

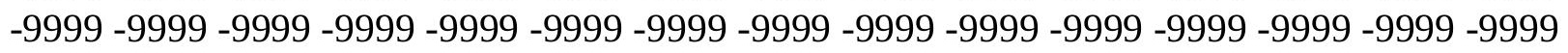
-9999 -9999 -9999 -9999 -9999 -9999 -9999 -9999 -9999 -9999 -9999 -9999 -9999 119.3100738525118 .8831787109118 .5489425659118 .3416519165118 .2943344116 118.4399032593118 .8051376343119 .4127960205120 .2743835449121 .3934326172 122.7583389282124 .346534729126 .120223999128 .0291748047130 .0116271973 131.9881744385133 .8726959229135 .5729980469136 .9976654053138 .0596313477 138.6831817627138 .8195343018138 .4561004639137 .5723419189136 .2232208252 94.1540908813596 .0971221923898 .09967041016100 .1591491699102 .2736434937 104.440788269106 .6588897705108 .9256210327111 .2386856079113 .5942840576 115.1353530884114 .502243042114 .1129150391113 .895614624113 .7387619019 113.5051269531113 .0128097534112 .1153335571110 .7135238647108 .7679901123 106.2865982056 103.31835937599.9413299560596.0073165893692.3498916626 89.6068267822386 .8637619018684 .7302627563583 .8159103393684 .42548370361 84.4254837036183 .5111236572382 .5967712402385 .0350494384889 .85102081299 92.8042144775495 .6759643554798 .40273284912100 .8604736328102 .9562072754 104.6508636475105 .9559783936106 .9173355103107 .5965881348108 .0582427979 108.36302948108 .5661849976108 .7155609131108 .8486175537108 .9859085083 109.1263656616109 .2487640381109 .2849121094109 .2163848877109 .0058288574 108.6220626831108 .0531692505107 .3116607666106 .4315872192105 .4680328369 104.4989852905103 .5897750854102 .8401031494102 .3091583252102 .067817688 102.2005462646102 .8110275269104 .0197296143105 .9342498779108 .4262008667 110.4982070923110 .8780288696108 .098487854103 .401702880996 .92166900635 91.1307525634892 .6546783447395 .0929565429794 .4833908081193 .26425170898 91.7403335571391 .7403335571394 .7881774902399 .66472625732104 .5412979126 109.4179000854113 .3800964355115 .818397522115 .2088012695113 .9896011353 113.075302124113 .3800964355114 .9039993286118 .2565994263122 .2188034058 124.9072113037124 .3282470703124 .0202941895124 .2149200439124 .9180603027 125.9613418579127 .0867385864128 .0653991699128 .751663208129 .0933074951 
129.0843505859 128.164352417 127.1966705322 126.2339019775 125.2760391235 123.8493499756122 .0472412109120 .2580108643118 .6016540527117 .1545562744 115.9550552368114 .9966659546114 .2367706299113 .6009140015113 .0023345947 112.3653488159111 .6350250244110 .8018035889109 .881942749108 .9143371582 107.9458999634107 .0305252075106 .20728302105 .5217514038105 .0752563477 104.9542617798104 .8986282349103 .9867630005103 .0796661377102 .1784973145 101.2835769653100 .394210815499 .509063720798 .6278381347796 .61688232422 87.16854858398 78.93934631348 74.36756896973 72.53885650635 74.97714233398 77.4154205322373 .4532165527368 .5766525268664 .3096618652360 .04267120361 60.3474502563560 .0426712036159 .7378807067959 .1283111572358 .21395874023 56.9948196411155 .7756805419954 .2517509460453 .0326118469252 .11825942993 51.5086898803751 .2038993835451 .2038993835451 .2038993835451 .50868988037 51.8134689331152 .4230384826753 .0326118469253 .3373985290554 .25175094604 54.8613204956155 .4708900451756 .3852500915557 .2995986938558 .21395874023 59.4331016540560 .3474502563561 .5666007995662 .4809494018663 .09051895142 64.004882812564 .6144485473665 .2240066528365 .8335876464866 .44316101074 66.7479400634867 .0527267456167 .3575134277367 .6623001098667 .66230010986 67.9670867919967 .9670867919968 .2718734741268 .2718734741268 .27187347412 68.2718734741268 .5766525268668 .5766525268668 .5766525268668 .88143920898 68.8814392089868 .8814392089869 .1862335205169 .1862335205169 .18623352051 69.1862335205169 .4910125732469 .4910125732469 .4910125732469 .49101257324 69.7957916259869 .7957916259869 .7957916259869 .7957916259870 .10057830811 70.1005783081170 .4053573608470 .4053573608471 .6244964599672 .64956665039 -9999 -9999 -9999 -9999 -9999 -9999 -9999 -9999 -9999 -9999 -9999 -9999 -9999 -9999 -9999 -9999 -9999 -9999 -9999 -9999 -9999 -9999 -9999 -9999 -9999 -9999 -9999 -9999 -9999 -9999 -9999 -9999 -9999 -9999 -9999 -9999 -9999 -9999 -9999 -9999 -9999 -9999 -9999 -9999 -9999 -9999 -9999 -9999 -9999 -9999 -9999 -9999 -9999 -9999 -9999 -9999 -9999 -9999 -9999 -9999 -9999

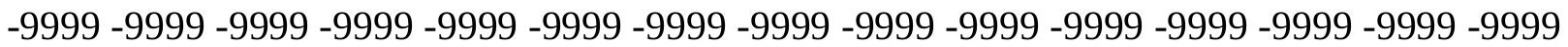
-9999 -9999 -9999 -9999 -9999 -9999 -9999 -9999 -9999 -9999

-9999 -9999 -9999 -9999 -9999 -9999 -9999 -9999 -9999 -9999 -9999 -9999 -9999 -9999 -9999 -9999 -9999 -9999 -9999 -9999 -9999 -9999 -9999 -9999 -9999 -9999 -9999 -9999 -9999 -9999

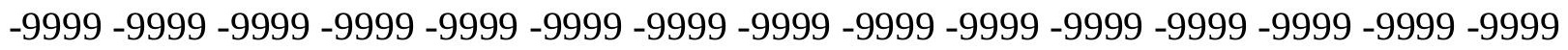
-9999 -9999 -9999 -9999 -9999 -9999 -9999 -9999 -9999 -9999 -9999 -9999 -9999 123.0858764648122 .948097229122 .9134750366123 .0129776001123 .2764205933 123.7342147827124 .4109573364125 .329574585126 .5009613037127 .9295730591 129.6068572998131 .5082244873133 .5997467041135 .8330993652138 .1459503174 140.4387969971142 .6169586182144 .5743865967146 .1984405518147 .3791656494 148.0283813477148 .0705871582147 .4730224609146 .2223968506144 .3650970459 141.977737426897 .5593109130999 .57875823975101 .6518936157103 .7755966187 105.9459686279108 .1593933105110 .4113311768112 .6970367432115 .010307312 116.7385482788115 .9118652344115 .4416503906115 .2876815796115 .3109664917 115.3547210693115 .1304321289114 .4514465332113 .195526123111 .353843689 108.9630050659106 .0987930298102 .890892028899 .5139236450296 .31210327148 93.2642517089890 .8259735107488 .9972534179788 .0829010009887 .47332763672 87.1685485839886 .8637619018686 .254188537685 .6446228027384 .73026275635 85.3398437591 .1307525634897 .46012878418100 .0832901001102 .2749176025 
103.9807662964105 .2232131958106 .0750045776106 .6320724487106 .9919128418 107.2390823364 107.4388961792 107.6362533569 107.859375 108.1161117554 108.3798904419108 .6213226318108 .7945556641108 .8607254028108 .7825317383 108.5352096558108 .1109161377107 .5263519287106 .8188095093106 .0461807251 105.2759780884104 .5768356323104 .026473999103 .7119827271103 .7161102295 104.1287078857105 .039932251106 .511177063108 .4940109253110 .6534042358 112.316986084112 .5205230713111 .0967254639107 .7021560669102 .8403549194 100.274299621698 .445587158298 .445587158295 .7025299072392 .65467834473 90.2164001464889 .6068267822391 .4355392456195 .3977432251100 .2742996216 105.1509017944108 .1986999512109 .7226028442109 .7226028442108 .8082962036 108.1986999512108 .1986999512109 .1130981445111 .551399231115 .5136032104 121.3044967651125 .2053375244125 .141456604125 .3595657349125 .873550415 126.6064758301127 .400970459128 .1170043945128 .6378173828128 .9085235596 128.8732910156128 .5137176514127 .6683654785126 .6942367554125 .5497817993 124.0651855469122 .4732513428120 .8693084717119 .342880249117 .9625244141 116.7650909424115 .749786377114 .8861999512114 .1243209839113 .4052658081 112.677734375111 .9060897827111 .0755691528110 .1938323975109 .2852478027 108.3869628906107 .5453186035106 .8165283203106 .2334136963105 .856590271 105.737449646104 .9427337646103 .9946517944103 .0481567383102 .1039123535 101.1618423462100 .220832824799 .2792816162198 .3368301391697 .39568328857 96.460655212495 .5382919311594 .6363372802792 .9594726562592 .92715454102 92.1386871337987 .1685485839872 .8436431884869 .7957916259868 .27187347412 65.8335876464864 .004882812562 .7857398986861 .8713798522960 .65224075317 59.1283111572356 .9948196411154 .8613204956153 .3373985290552 .11825942993 51.2038993835450 .8991203308150 .5943298339850 .5943298339850 .89912033081 50.8991203308151 .2038993835451 .8134689331152 .1182594299352 .72782897949 53.3373985290553 .9469718933154 .8613204956155 .7756805419956 .69002914429 57.909179687559 .1283111572360 .6522407531761 .5666007995662 .48094940186 63.0905189514264 .004882812564 .9192428588965 .5288009643666 .13836669922 66.4431610107466 .7479400634867 .0527267456167 .3575134277367 .66230010986 67.6623001098667 .6623001098667 .9670867919967 .9670867919967 .96708679199 67.9670867919968 .2718734741268 .2718734741268 .2718734741268 .57665252686 68.5766525268668 .5766525268668 .8814392089868 .8814392089868 .88143920898 68.8814392089869 .1862335205169 .1862335205169 .1862335205169 .18623352051 69.4910125732469 .4910125732469 .4910125732469 .7957916259869 .79579162598 $69.7957916259870 .1005783081170 .1005783081170 .7101516723672 .23407745361-9999$ -9999 -9999 -9999 -9999 -9999 -9999 -9999 -9999 -9999 -9999 -9999 -9999 -9999 -9999 -9999

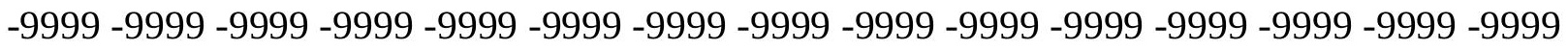
-9999 -9999 -9999 -9999 -9999 -9999 -9999 -9999 -9999 -9999 -9999 -9999 -9999 -9999 -9999 -9999 -9999 -9999 -9999 -9999 -9999 -9999 -9999 -9999 -9999 -9999 -9999 -9999 -9999 -9999 -

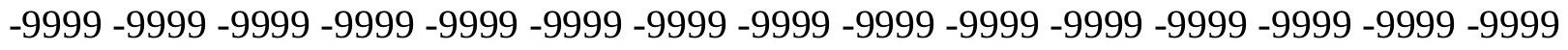

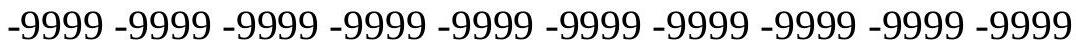

-9999 -9999 -9999 -9999 -9999 -9999 -9999 -9999 -9999 -9999 -9999 -9999 -9999 -9999 -9999 -9999 -9999 -9999 -9999 -9999 -9999 -9999 -9999 -9999-9999 -9999 -9999 -9999 -9999 -9999 -9999 -9999 -9999 -9999 -9999 -9999 -9999 -9999 -9999 -9999 -9999 -9999 -9999 -9999 -9999 -9999 -9999 -9999 -9999 -9999 -9999 -9999 -9999 -9999 -9999 -9999 -9999 -9999 -9999 
126.8743743896127 .1243515015127 .5146331787128 .0792388916128 .8404998779 129.82862854131 .0605773926132 .5526428223134 .3088226318136 .3220825195 138.5705413818141 .0220336914143 .6301574707146 .3157348633148 .9764404297 151.5014953613153 .7646026611155 .630645752156 .9661560059157 .6482696533 157.5940246582156 .7456359863155 .0891723633152 .6629333496149 .5617675781 98.94322967529100 .9712295532103 .0496749878105 .1744384766107 .3404312134 109.5425186157111 .7745819092114 .0300521851116 .3011779785118 .0315933228 116.9980926514116 .4389038086116 .4020385742116 .763168335117 .2174987793 117.4032821655116 .9943466187115 .8908157349114 .1501083374111 .856918335 109.0906143188106 .0713577271103 .017402648999 .6647262573296 .92166900635 94.4833908081192 .6546783447391 .4355392456190 .8259735107490 .52117919922 89.9116134643689 .6068267822388 .6924667358487 .7781066894586 .2541885376 84.4254837036187 .7781066894592 .349891662699 .35994720459103 .6343841553 104.7120132446105 .3528366089105 .6901397705105 .8605270386105 .978302002 106.1180267334 106.3243179321 106.6159744263106.9837799072107.3965530396 107.8050613403108 .1591644287108 .4072723389108 .5038070679108 .424659729 108.165977478107 .7486190796107 .2128677368106 .6165771484106 .0268173218 105.5136947632105 .1502685547105 .0222320557105 .2095870972105 .7872314453 106.8091201782108 .2715988159110 .047492981111 .8116836548113 .0666885376 113.2726669312112 .2250061035109 .7417755127106 .8383560181104 .2979049683 102.06058502299 .8816604614396 .949630737393 .7437744140691 .13075256348 89.9116134643690.2164001464892.0450973510796.31210327148 100.5791015625 102.1029968262102 .4077987671102 .712600708102 .4077987671102 .1029968262 102.1029968262102 .712600708104 .2365036011106 .979598999111 .551399231 116.4279022217125 .755859375125 .9994735718126 .4020309448126 .9225845337 127.4815444946127 .9854278564128 .3659362793128 .5425567627128 .4638519287 128.1000061035127 .4525756836126 .5410842896125 .4053497314124 .1005020142 122.6972808838121 .2659835815119 .8761291504118 .5833282471117 .4188537598 116.3883209229115 .4730224609114 .6405944824113 .8525238037113 .0742950439 112.2806777954111 .4602432251110 .6167678833109 .767791748108 .941986084 108.1770477295107 .5188140869106 .998008728106 .6503829956105 .9987869263 105.0184707642104 .0361251831103 .0520935059102 .0664901733101 .0788879395 100.087936401499 .0919647216898 .0905914306697 .0863113403396 .08431243896 95.0914611816494 .115516662693 .1642837524492 .2460250854591 .36889648438 90.5420532226689 .7813720703185 .0350494384876 .8058471679771 .31971740723 67.3575134277365 .8335876464865 .2240066528364 .004882812561 .56660079956 58.5187492370655 .7756805419953 .9469718933152 .4230384826751 .20389938354 50.5943298339850 .2895507812550 .2895507812550 .2895507812550 .28955078125 50.2895507812550 .5943298339850 .8991203308151 .2038993835451 .81346893311 52.4230384826753 .0326118469253 .9469718933155 .1661109924356 .38525009155 57.6043891906759 .1283111572360 .0426712036161 .2618103027362 .17617034912 63.3953094482464 .3096618652364 .9192428588965 .5288009643666 .13836669922 66.4431610107466 .7479400634867 .0527267456167 .0527267456167 .35751342773 67.3575134277367 .6623001098667 .6623001098667 .6623001098667 .66230010986 67.9670867919967 .9670867919967 .9670867919968 .2718734741268 .27187347412 68.2718734741268 .5766525268668 .5766525268668 .5766525268668 .57665252686 
68.8814392089868 .8814392089868 .8814392089868 .8814392089869 .18623352051 69.1862335205169 .1862335205169 .4910125732469 .4910125732469 .49101257324 $69.7957916259869 .7957916259869 .7957916259871 .3197174072372 .84364318848-9999$ -9999 -9999 -9999 -9999 -9999 -9999 -9999 -9999 -9999 -9999 -9999 -9999 -9999 -9999 -9999 -9999 -9999 -9999 -9999 -9999 -9999 -9999 -9999 -9999 -9999 -9999 -9999 -9999 -9999 -9999 -9999 -9999 -9999 -9999 -9999 -9999 -9999 -9999 -9999 -9999 -9999 -9999 -9999 -9999 -9999 -9999 -9999 -9999 -9999 -9999 -9999 -9999 -9999 -9999 -9999 -9999 -9999 -9999 -9999 -9999

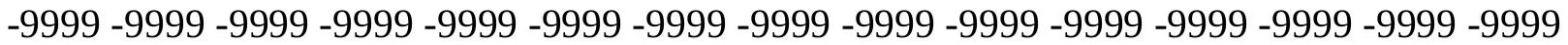
-9999 -9999 -9999 -9999 -9999 -9999 -9999 -9999 -9999

-9999 -9999 -9999 -9999 -9999 -9999 -9999 -9999 -9999 -9999 -9999 -9999 -9999 -9999 -9999

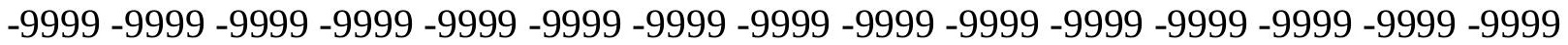
-9999 -9999 -9999 -9999 -9999 -9999 -9999 -9999 -9999 -9999 -9999 -9999 -9999 -9999 -9999 -9999 -9999 -9999 -9999 -9999 -9999 -9999 -9999 -9999 -9999 -9999 -9999 -9999 -9999 -9999 131.1436767578131 .8120574951132 .6619567871133 .7199401855135 .0116424561 136.5582275391138 .3753967285140 .4692993164142 .8361358643145 .4601135254 148.3041687012151 .3210754395154 .4140319824157 .4911193848160 .4067077637 163.0214538574165 .1675872803161 .7767791748162 .0913085938162 .3684539795 162.607635498162 .8082733154161 .0927429199157 .1807861328152 .600189209 102.2769699097104 .353187561106 .4718551636108 .6269989014110 .8124313354 113.0209121704115 .2447280884117 .475112915118 .9636077881117 .6661529541 116.9651412964116 .9991836548117 .950012207118 .9931182861119 .7928771973 119.5812988281118 .5693969727116 .8657684326114 .6305465698111 .9321670532 108.8566741943105 .7603988647102 .71260070899 .9695205688597 .83602905273 96.0073165893694 .7881774902394 .1785964965893 .5690307617292 .95947265625 92.6546783447392 .0450973510791 .1307525634889 .9116134643688 .08290100098 85.3398437581 .3776321411186 .5589828491298 .14080810547104 .4867858887 104.7726135254104 .7542495728104 .6188201904104 .5192337036104 .538444519 104.733833313105 .102973938105 .6157836914106 .2190628052106 .8484725952 107.4259643555107 .8973770142108 .2011108398108 .3115158081108 .2265472412 107.971496582107 .5909957886107 .1468276978106 .708946228106 .3507461548 106.1422958374106 .1568069458106 .4611358643107 .1068191528108 .1122436523 109.4335098267110 .9257354736112 .3242492676113 .2765426636113 .4632034302 112.6827545166110 .9978256226108 .8399581909106 .4409255981103 .9964523315 101.267082214498 .3710174560595 .5806198120193 .7017517089893 .42633056641 92.349891662692 .0450973510793 .5690307617295 .7025299072396 .92166900635 97.5312423706197 .8360290527397 .8360290527397 .5312423706196 .92166900635 96.9216690063597 .5312423706198 .75038146973101 .1886978149105 .1509017944 112.4656982422123 .7427978516126 .5840301514126 .9706878662127 .3737640381 127.7339782715127 .9851379395128 .0721740723127 .946647644127 .587059021 126.9882583618126 .1717300415125 .166343689124 .0202941895122 .7820281982 121.5089569092120 .2532119751119 .0581130981117 .9499893188116 .9374847412 116.0114364624115 .1525726318114 .3361358643113 .5392150879112 .7446289062 111.9445571899111 .1421966553110 .3507843018109 .5919036865108 .8937225342 108.2870941162107 .8014678955107 .1431884766106 .1386642456105 .1293029785 104.1150741577103 .0958709717102 .0713043213101 .0406188965100 .0023345947 98.9549026489397 .8981781005996 .8349838256895 .7709350585994 .71326446533 
93.6698913574292 .6484832763791 .6567535400490 .7016448974689 .78928375244 88.9320373535288 .1749343872187 .5158386230580 .1584930419969 .18623352051 69.4910125732469 .7957916259867 .9670867919964 .004882812560 .04267120361 56.9948196411154 .5565414428753 .0326118469251 .8134689331151 .20389938354 50.5943298339850 .2895507812549 .9847602844249 .6799812316949 .67998123169 49.6799812316949 .6799812316949 .9847602844250 .2895507812550 .59432983398 51.5086898803752 .1182594299353 .3373985290554 .5565414428756 .08045959473 57.2995986938558 .8235282897960 .0426712036161 .2618103027362 .48094940186 63.3953094482464 .3096618652365 .2240066528365 .5288009643666 .13836669922 66.4431610107466 .7479400634866 .7479400634867 .0527267456167 .05272674561 67.0527267456167 .3575134277367 .3575134277367 .3575134277367 .66230010986 67.6623001098667 .6623001098667 .9670867919967 .9670867919967 .96708679199 68.2718734741268 .2718734741268 .2718734741268 .2718734741268 .57665252686 68.5766525268668 .5766525268668 .5766525268668 .8814392089868 .88143920898 68.8814392089869 .1862335205169 .1862335205169 .1862335205169 .49101257324 69.4910125732469 .4910125732470 .1005783081171 .92929077148 -9999 -9999 -9999-9999 -9999 -9999 -9999 -9999 -9999 -9999 -9999 -9999 -9999 -9999 -9999 -9999 -9999 -9999 -9999 -9999 -9999 -9999 -9999 -9999 -9999 -9999 -9999 -9999 -9999 -9999 -9999 -9999 -9999 -9999 -999 -9999 -9999 -9999 -9999 -9999 -9999 -9999 -9999 -9999 -9999 -9999 -9999 -9999 -9999 -9999 -9999 -9999 -9999 -9999 -9999 -9999 -9999 -9999 -9999 -9999 -9999 -9999 -9999 -9999 -9999 -

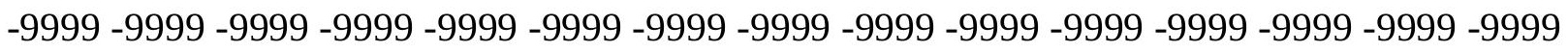
-9999 -9999 -9999-9999-9999-9999

-9999 -9999 -9999 -9999 -9999 -9999 -9999 -9999 -9999 -9999 -9999 -9999 -9999 -9999 -9999 -9999 -9999 -9999 -9999 -9999 -9999 -9999 -9999 -9999 -9999 -9999 -9999 -9999 -9999 -9999 -9999 -9999 -9999 -9999 -9999 -9999 -9999 -9999 -9999 -9999 -9999 -9999 -9999 -9999 -9999 -9999 -9999 -9999 -9999 -9999 -9999 -9999 -9999 -9999 -9999 -9999 -9999 -9999 -9999 -9999 -9999 135.8729095459 136.9944915771 138.3353118896139.9215698242141.7756652832 143.9151763916146 .3485412598149 .0732574463152 .0852508545155 .3432006836 158.7850952148162 .3242340088165 .8356628418169 .1841430664172 .1837463379 161.8780212402162 .252456665162 .5875701904162 .8818511963163 .1347808838 163.3459014893163 .5157318115163 .6446990967159 .1328582764152 .9428710938 105.565536499107 .6718978882109 .8107376099111 .9751815796114 .1573562622 116.3488388062118 .5403823853119 .481048584117 .841796875116 .8500061035 116.7862319946118 .5272064209120 .8722610474122 .1885528564121 .9644622803 120.9119415283119 .1452178955116 .8231506348114 .2944030762110 .9418029785 107.8938980103105 .1509017944102 .712600708100 .579101562598 .75038146973 97.5312423706196 .9216690063598 .7503814697399 .6647262573298 .4455871582 95.0929565429794 .4833908081193 .5690307617292 .0450973510789 .91161346436 87.7781066894585 .9494018554789 .91161346436100 .8839035034104 .3330993652 103.7852401733103 .2006378174102 .7891693115102 .654045105102 .8435516357 103.3239593506104 .0334243774104 .8795547485105 .7869720459106 .6479797363 107.3768386841 107.9096908569 108.2224197388 108.3030929565 108.1930007935 107.9412307739 107.6164016724 107.2942657471 107.0505142212 106.9563903809 107.0657272339107 .4315719604108 .0814590454109 .0074386597110 .1484832764 111.3714447021112 .471862793113 .2059249878113 .3574523926112 .7934341431 111.5593490601109 .7970352173107 .6549377441105 .2496490479102 .6314163208 
99.9944992065497 .6874160766696 .217491149995 .9900360107496 .00731658936 94.1785964965892 .9594726562592 .349891662692 .6546783447393 .26425170898 93.5690307617293 .5690307617293 .2642517089892 .9594726562592 .3498916626 92.349891662692 .349891662693 .2642517089896 .92166900635101 .4934005737 103.3221969604111 .24659729126 .8361358643127 .1353988647127 .383972168 127.5371246338127 .5508880615127 .3920059204127 .0400848389126 .4933624268 125.7638168335124 .8779754639123 .8696212769122 .7797164917121 .6504516602 120.5223999023119 .4289779663118 .3923492432117 .4222793579116 .516204834 115.6637268066114 .8496856689114 .0594940186113 .2819366455112 .5125732422 111.7545089722111 .0181350708110 .3190155029109 .6770782471109 .1131591797 108.3634338379107 .3420257568106 .313583374105 .2779769897104 .2347335815 103.1832885742102 .1228485107101 .052429199299 .9704360961998 .87552642822 97.7680358886796.65138244629 95.5316467285294.41650390625 93.31410217285 92.2322235107491 .1783828735490 .1589889526489 .179412841888 .25308990479 87.39563751221 86.59851837158 85.85660552979 85.17398071289 78.63455963135 75.5867080688571 .6244964599666 .4431610107461 .5666007995658 .21395874023 56.0804595947354 .2517509460453 .0326118469251 .8134689331151 .20389938354 50.5943298339849 .9847602844249 .6799812316949 .3751907348649 .07040023804 48.765621185348 .765621185348 .765621185349 .0704002380449 .67998123169 50.2895507812551 .5086898803752 .7278289794954 .2517509460455 .47089004517 56.9948196411158 .5187492370660 .0426712036161 .5666007995662 .78573989868 63.7000885009864 .6144485473665 .2240066528365 .5288009643665 .83358764648 66.1383666992266 .4431610107466 .4431610107466 .7479400634866 .74794006348 67.0527267456167 .0527267456167 .0527267456167 .3575134277367 .35751342773 67.3575134277367 .6623001098667 .6623001098667 .6623001098667 .96708679199 67.9670867919967 .9670867919967 .9670867919968 .2718734741268 .27187347412 68.2718734741268 .2718734741268 .5766525268668 .5766525268668 .57665252686 68.8814392089868 .8814392089868 .8814392089869 .1862335205169 .18623352051 69.1862335205169 .4910125732470 .7101516723672 .23407745361 -9999 -9999 -9999 -9999 -9999 -9999 -9999 -9999 -9999 -9999 -9999 -9999 -9999 -9999 -9999 -9999 -9999 -9999 -9999 -9999 -9999 -9999 -9999 -9999 -9999 -9999 -9999 -9999-9999 -9999 -9999 -9999 -9999 -9999 -9999 -9999 -9999 -9999 -9999 -9999 -9999 -9999 -9999 -9999 -9999 -9999 -9999 -9999 -9999 -

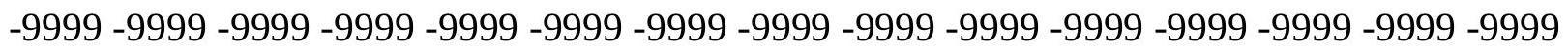

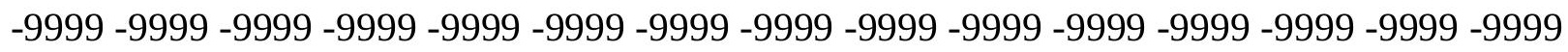
-9999 -9999-9999-9999-9999

-9999 -9999 -9999 -9999 -9999 -9999 -9999 -9999 -9999 -9999 -9999 -9999 -9999 -9999 -9999

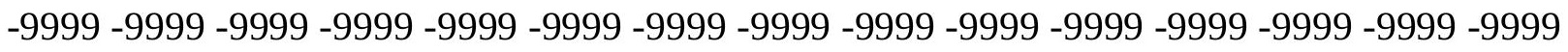

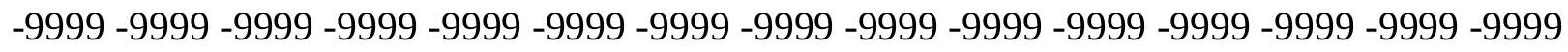
-9999 -9999 -9999 -9999 -9999 -9999 -9999 -9999 -9999 -9999 -9999 -9999 -9999 -9999 -9999 -9999 139.6708831787141.0469512939142.654586792 144.5207977295146.6694641113 149.1202697754151 .8860321045154 .9701538086158 .3622283936162 .026260376 165.8992614746169 .888092041173 .8618469238177 .657699585161 .9218444824 162.3620452881162 .7609405518163 .1167144775163 .4277648926163 .6936798096 163.9142456055164 .0902404785164 .2223358154164 .3120727539157 .8349914551 106.6896591187108 .7782669067110 .8960952759113 .0359344482115 .1896209717 117.3484573364119 .5030212402119 .4270629883117 .6074676514115 .7750473022 
115.818397522117 .342300415124 .0475006104124 .0475006104123 .7427978516 122.5235977173120 .6949005127117 .9517974854115 .2088012695112 .4656982422 109.4179000854106 .979598999104 .5412979126102 .712600708101 .1886978149 99.9695205688599 .05516815186100 .8839035034102 .712600708102 .712600708 101.188697814997 .8360290527397 .2264633178796 .6168823242295 .70252990723 94.7881774902394 .1785964965892 .9594726562590 .5211791992297 .83602905273 102.7040252686101 .5188751221100 .7072143555100 .3941574097100 .6105575562 101.2660293579102 .2493591309103 .4200363159104 .6522598267105 .825668335 106.8433227539107 .6244430542108 .1426391602108 .3883590698108 .4051971436 108.2537460327108 .0064926147107 .7584686279107 .5876922607107 .5609817505 107.7253417969108 .1146087646108 .7339019775109 .5618057251110 .5336227417 111.5355148315112 .4120483398112 .9903564453113 .1173706055112 .7015838623 111.7388763428110 .2813339233108 .4228439331106 .2681503296103 .9580917358 101.712417602599 .84458160498 .7038497924898 .5414886474699 .44528198242 96.9216690063594 .1785964965892 .0450973510790 .2164001464889 .3020401001 89.302040100189 .9116134643690 .2164001464890 .2164001464889 .91161346436 90.2164001464890 .2164001464890 .8259735107492 .0450973510792 .04509735107 89.9116134643692 .95947265625109 .7226028442126 .7977523804126 .9697723389 127.0531387329127 .0171051025126 .8380661011126 .5007095337126 .0034866333 125.3547515869124 .5747375488123 .6895675659122 .7311935425121 .7322006226 120.7238540649119 .7323074341118 .7759246826117 .8648223877117 .0002593994 116.177772522115 .3887786865114 .6245880127113 .8785095215113 .1484832764 112.4376144409111 .7538375854111 .1081466675110 .5138931274109 .6473770142 108.6156845093107 .5753250122106 .5260391235105 .4673919678104 .3985137939 103.318397522102 .2258911133101 .119857788199 .9987335205198 .86144256592 97.708839416596.5451660156295.3772048950294.2130966186593.06139373779 91.9301834106490 .8273162841889 .7581405639688 .7319641113387 .76127624512 86.839286804285 .944755554285 .0510864257884 .1342391967883 .18672943115 82.2136077880974 .062782287669 .1862335205162 .4809494018660 .34745025635 58.2139587402356 .3852500915554 .8613204956153 .3373985290552 .11825942993 51.5086898803750 .5943298339849 .9847602844249 .0704002380448 .46083068848 47.8512611389247 .5464782714847 .2416992187547 .5464782714847 .85126113892 48.4608306884849 .3751907348650 .5943298339852 .1182594299353 .64218139648 55.4708900451757 .2995986938558 .8235282897960 .3474502563561 .87137985229 63.0905189514264 .004882812564 .6144485473665 .2240066528365 .52880096436 65.8335876464865 .8335876464866 .1383666992266 .4431610107466 .44316101074 66.4431610107466 .7479400634866 .7479400634866 .7479400634867 .05272674561 67.0527267456167 .3575134277367 .3575134277367 .3575134277367 .66230010986 67.6623001098667 .6623001098667 .6623001098667 .9670867919967 .96708679199 67.9670867919968 .2718734741268 .2718734741268 .2718734741268 .27187347412 68.5766525268668 .5766525268668 .5766525268668 .8814392089868 .88143920898 68.8814392089869 .1862335205169 .4910125732471 .31971740723 -9999 -9999 -9999-9999 -9999 -9999 -9999 -9999 -9999 -9999 -9999 -9999 -9999 -9999 -9999 -9999 -9999 -9999 -9999 -9999 -9999 -9999 -9999 -9999 -9999 -9999 -9999 -9999 -9999 -9999 -9999 -9999 -9999 -9999 -

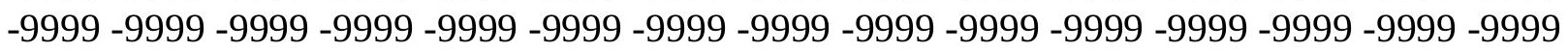

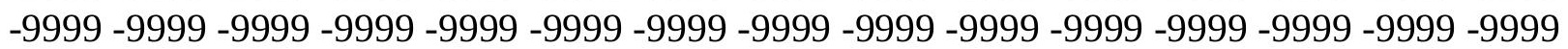


-9999 -9999 -9999 -9999 -9999 -9999 -9999 -9999 -9999 -9999 -9999 -9999 -9999 -9999 -9999 -9999 -9999 -9999 -9999-9999

-9999 -9999 -9999 -9999 -9999 -9999 -9999 -9999 -9999 -9999 -9999 -9999 -9999 -9999 -9999 -9999 -9999 -9999 -9999 -9999 -9999 -9999 -9999 -9999 -9999 -9999 -9999 -9999 -9999 -9999 -9999 -9999 -9999 -9999 -9999 -9999 -9999 -9999 -9999 -9999 -9999 -9999 -9999 - -9999 - -9999 -

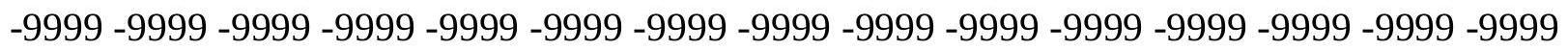
-9999-9999 144.7969818115146.6515197754148.7776031494151.2004394531 153.9418334961157 .0189971924160 .4363708496164 .1911773682168 .2444152832 172.5306091309176 .953414917181 .3742675781161 .8998565674162 .4113922119 162.8804931641163 .30418396163 .6805725098164 .0079040527164 .2858428955 164.5144348145164 .6948852539164 .8282470703164 .9164123535162 .0725250244 152.7353820801109 .7962417603111 .8889846802114 .0011062622116 .1244430542 118.2503051758120 .3694000244118 .4433135986117 .0374984741113 .075302124 114.2944030762115 .818397522127 .0953979492125 .5715026855124 .3523025513 122.8283996582120 .6949005127118 .2565994263115 .818397522113 .075302124 110.3321990967107 .8938980103105 .7603988647103 .9317016602102 .712600708 101.7982025146100 .8839035034100 .5791015625103 .6268997192104 .8460998535 104.2365036011100 .8839035034101 .1886978149101 .1886978149101 .4934005737 102.1029968262102 .1029968262101 .188697814997 .8360290527392 .04509735107 93.2642517089896.9216690063598.1419296264697.6761398315497.9916305542 98.92394256592100 .2752456665101 .8375396729103 .4494628906104 .9809570312 106.3112335205 107.3577270508 108.0759658813 108.4740142822 108.5899200439 108.5037307739108 .3012390137108 .0840148926107 .9451751709107 .9471740723 108.132774353108 .5225982666109 .0959854126109 .8328933716110 .668838501 111.5067977905112 .2279281616112 .7050323486112 .8274078369112 .5228652954 111.7668228149110 .5813674927109 .0283126831107 .2061004639105 .2726593018 103.4344558716101 .9520339966101 .0727233887100 .9647369385101 .6859893799 100.274299621696 .6168823242293 .2642517089889 .302040100186 .2541885376 86.254188537687 .1685485839888 .0829010009888 .9972534179789 .60682678223 90.2164001464891 .1307525634891 .1307525634889 .6068267822387 .47332763672 83.5111236572383 .8159103393696 .00731658936110 .3321990967118 .5614013672 121.6092987061113 .6848983765107 .5891036987115 .2088012695125 .5442123413 124.969291687124 .284034729123 .5085449219122 .6676330566121 .7864608765 120.8894348145119 .9971237183119 .1249923706118 .2826538086117 .4736328125 116.6970977783115 .9489517212115 .2246551514114 .520652771113 .836517334 113.1750106812112 .5420913696111 .9451446533110 .9824829102109 .9465332031 108.9006576538107 .8446044922106 .7778701782105 .6997375488104 .6089935303 103.5043029785102 .3841323853101 .247215271100 .092147827198 .91832733154 97.7271881103596 .5237731933695 .3156738281294 .1116790771592 .92087554932 91.7520446777390 .6138305664189 .5141677856488 .4638977050887 .47401428223 86.5261993408285 .5920257568484 .6337356567483 .6126861572382 .50255584717 81.3236465454180 .1720809936577 .7202072143667 .9670867919964 .30966186523 61.5666007995659 .1283111572356 .9948196411155 .1661109924353 .94697189331 52.7278289794951 .5086898803750 .2895507812549 .3751907348648 .15605163574 47.2416992187546 .6321296691946 .0225486755446 .0225486755446 .02254867554 46.6321296691947 .5464782714848 .765621185350 .2895507812551 .81346893311 
53.6421813964855 .7756805419957 .6043891906759 .4331016540560 .95701980591 62.1761703491263 .0905189514264 .004882812564 .3096618652364 .91924285889 65.2240066528365 .5288009643665 .5288009643665 .8335876464866 .13836669922 66.1383666992266 .1383666992266 .4431610107466 .4431610107466 .74794006348 66.7479400634866 .7479400634867 .0527267456167 .0527267456167 .35751342773 67.3575134277367 .3575134277367 .6623001098667 .6623001098667 .66230010986 67.6623001098667 .9670867919967 .9670867919967 .9670867919967 .96708679199 68.2718734741268 .2718734741268 .2718734741268 .5766525268668 .57665252686 $68.5766525268668 .8814392089868 .8814392089870 .1005783081171 .62449645996-9999$ -9999 -9999 -9999 -9999 -9999 -9999 -9999 -9999 -9999 -9999 -9999 -9999 -9999 -9999 -9999 -9999 -9999 -9999 -9999 -9999 -9999 -9999 -9999 -9999 -9999 -9999 -9999 -9999 -9999 -9999 -9999 -9999 -9999 -9999 -9999 -9999 -9999 -9999 -9999 -9999 -9999 -9999 -9999 -9999 -9999

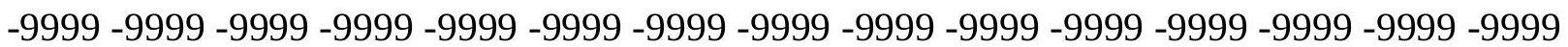
-9999 -9999 -9999 -9999 -9999 -9999 -9999 -9999 -9999 -9999 -9999 -9999 -9999 -9999 -9999 -9999 -9999 -9999 -9999 -9999 -9999 -9999

-9999 -9999 -9999 -9999 -9999 -9999 -9999 -9999 -9999 -9999 -9999 -9999 -9999 -9999 -9999

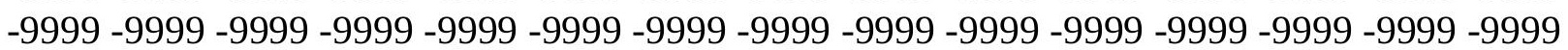
-9999 -9999 -9999 -9999 -9999 -9999 -9999 -9999 -9999 -9999 -9999 -9999 -9999 -9999 -9999 -9999 -9999 -9999 -9999 -9999 -9999 -9999 -9999 -9999 -9999 -9999 -9999 -9999 -9999 -9999 -9999 -9999-9999 150.3075714111 152.6677246094155.3364868164158.3373565674 161.6919708252165 .4124298096169 .4874572754173 .8795776367178 .5367431641 183.349899292188 .177520752162 .3899993896162 .9357910156163 .4347991943 163.8837585449164 .2807617188164 .6239624023164 .912979126165 .1480102539 165.330871582165 .4631958008165 .5473175049165 .2937774658153 .9412078857 110.7303695679112 .7944107056114 .8760528564116 .9673156738119 .0597229004 118.2919387817116 .1231002808111 .8561019897112 .1608963013113 .075302124 114.2944030762128 .9241027832126 .7906036377124 .9618988037122 .8283996582 120.3900985718118 .2565994263115 .5136032104113 .075302124110 .6370010376 108.1986999512106 .3700027466104 .8460998535103 .6268997192102 .712600708 102.4077987671102 .1029968262102 .4077987671105 .1509017944105 .1509017944 103.6268997192104 .2365036011105 .4557037354106 .6747970581107 .8938980103 109.1130981445108 .8452224731106 .065200805796 .3121032714885 .64462280273 90.2164001464893 .8738174438594 .430252075294 .9858856201296 .31210327148 97.5312423706199 .66472625732102 .2107849121104 .1353912354105 .8129959106 107.1331939697108 .0421142578108 .5518875122108 .7305450439108 .6714706421 108.4736022949108 .2585906982108 .1198196411108 .1212234497108 .299987793 108.6643371582109 .205406189109 .8707809448110 .6103897095111 .3416595459 111.9667358398112 .3924865723112 .5359725952112 .337310791111 .7689361572 110.8406295776109 .5949478149108 .1211624146106 .5702819824105 .12059021 103.96900177103 .2966079712103 .2360839844103 .8156661987103 .9317016602 98.7503814697393 .2642517089888 .6924667358485 .6446228027385 .33984375 86.254188537688 .0829010009889 .9116134643691 .7403335571392 .95947265625 93.8738174438593 .5690307617292 .0450973510789 .6068267822386 .55898284912 86.5589828491292 .95947265625100 .5791015625104 .8460998535104 .8460998535 97.2264633178790 .5211791992293 .2642517089899 .05516815186101 .7982025146 105.7603988647113 .9896011353120 .0852966309117 .9517974854120 .9997024536 
120.2448272705119 .4572982788118 .6886062622117 .9432983398117 .2228088379 116.525932312115 .8509216309115 .1963272095114 .5625610352113 .9519271851 113.3686294556112 .357093811111 .321975708110 .2763519287109 .2196121216 108.1513824463107 .0709228516105 .9772338867104 .8687973022103 .7440414429 102.6011734009101 .4387359619100 .255523681699 .05161285497 .82921600342 96.5940475463995 .3544235229594 .119842529392 .9001922607491 .70520782471 90.5448684692489 .4294357299888 .3752899169987 .3882675170986 .45199584961 85.5348205566484 .5990371704183 .6139373779382 .5761947631881 .54379272461 80.7897720336979 .9436187744175 .2047424316469 .7957916259865 .22400665283 62.7857398986860 .0426712036157 .909179687556 .0804595947354 .86132049561 53.0326118469251 .5086898803749 .6799812316948 .1560516357446 .93690872192 45.717769622845 .1082000732444 .4986305236844 .4986305236844 .80340957642 45.717769622846 .9369087219248 .4608306884850 .2895507812552 .11825942993 54.2517509460456 .3852500915558 .2139587402360 .0426712036161 .26181030273 62.1761703491263 .0905189514263 .7000885009864 .3096618652364 .61444854736 64.9192428588965 .2240066528365 .5288009643665 .5288009643665 .83358764648 65.8335876464866 .1383666992266 .1383666992266 .1383666992266 .44316101074 66.4431610107466 .7479400634866 .7479400634867 .0527267456167 .05272674561 67.0527267456167 .3575134277367 .3575134277367 .3575134277367 .35751342773 67.6623001098667 .6623001098667 .6623001098667 .6623001098667 .96708679199 67.9670867919967 .9670867919967 .9670867919968 .2718734741268 .27187347412 68.2718734741268 .5766525268668 .8814392089870 .40535736084 -9999 -9999 -9999 -9999 -9999 -9999 -9999 -9999 -9999 -9999 -9999 -9999 -9999 -9999 -9999 -9999 -9999 -9999 -9999

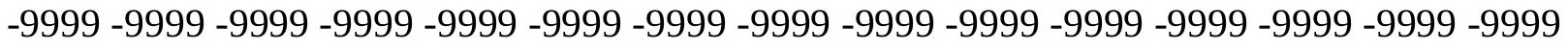

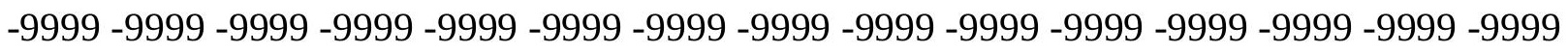
-9999 -9999 -9999 -9999 -9999 -9999 -9999 -9999 -9999 -9999 -9999 -9999 -9999 -9999 -9999 -

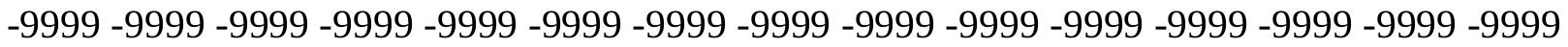
-9999-9999-9999-9999

-9999 -9999 -9999 -9999 -9999 -9999 -9999 -9999 -9999 -9999 -9999 -9999 -9999 -9999 -9999 -9999 -9999 -9999 -9999 -9999 -9999 -9999 -9999 -9999 -9999 -9999 -9999 -9999 -9999 -9999 -9999 -9999 -9999 -9999 -9999 -9999 -9999 -9999 -9999 -9999 -9999 -9999 -9999 -9999 -9999 -9999 -9999 -9999 -9999 -9999 -9999 -9999 -9999 -9999 -9999 -9999 -9999 -9999 -9999 -9999 -999 -9999 -9999-9999 -9999 156.1747894287 159.0534362793 162.2746124268 165.8611297607 169.8190002441174 .1549682617178 .821105957183 .7771148682188 .9099273682 162.2821960449162 .911529541163 .4934082031164 .0237579346164 .4989471436 164.9169464111165 .2758483887165 .5753173828165 .8155822754165 .9988555908 166.1275482178166 .2047424316166 .2331695557153 .1297607422141 .7313690186 113.6184692383115 .6671218872117 .724609375118 .5614013672114 .9039993286 111.24659729110 .9418029785111 .24659729111 .551399231131 .6725463867 129.8385009766127 .0953979492124 .6570968628122 .2188034058119 .7806015015 117.342300415114 .9039993286112 .4656982422110 .0273971558108 .1986999512 106.3700027466104 .8460998535103 .9317016602103 .3221969604103 .0174026489 103.0174026489103 .3221969604103 .9317016602104 .8460998535105 .7603988647 106.979598999108 .1986999512110 .0273971558111 .841545105112 .4366531372 110.6969833374106 .947547912699 .9695205688586 .254188537685 .64462280273 89.9116134643690 .6391601562591 .6670379638793 .2642517089894 .78817749023 
97.22646331787100 .2742996216103 .3410720825105 .3911895752106 .9908905029 108.0604705811108 .6394119263108 .8112182617108 .7180480957108 .4959335327 108.262008667108 .1113739014108 .1024856567108 .2607116699108 .6013336182 109.0990982056109 .7243881226110 .4050445557111 .0847549438111 .6622390747 112.0820007324112 .2766418457112 .1937103271111 .8105239868111 .1212844849 110.1701202393109 .042350769107 .8545074463106 .7488250732105 .8854217529 105.3851852417105 .3566207886105 .8227767944106 .674797058199 .66472625732 92.6546783447388 .3876876831185 .9494018554785 .6446228027386 .86376190186 89.6068267822392.95947265625 95.397743225197.2264633178797.83602905273 97.5312423706196 .3121032714894 .7881774902394 .4833908081194 .17859649658 96.0073165893697 .5312423706198 .1408081054797 .2264633178793 .26425170898 89.302040100188 .6924667358488 .3876876831183 .5111236572380 .76805877686 87.1685485839893.8738174438591.43553924561 89.9116134643692.3498916626 98.75038146973106 .6747970581118 .4125366211117 .7536239624117 .1141891479 116.4942398071115 .8936080933115 .3130569458114 .7542037964113 .7599716187 112.729850769111 .689163208110 .6371078491109 .5729675293108 .4962463379 107.4059906006106 .3009338379105 .1792755127104 .039276123102 .8789978027 101.6969223022100 .491996765199 .2649459838998 .0188446044996 .76011657715 95.4976425170994 .2415847778393 .0027160644591 .7919082641690 .62087249756 89.5035095214888 .4558944702187 .4904632568486 .5906600952185 .7294921875 84.8757247924884 .0101547241283 .1555938720782 .4305953979581 .46276092529 80.089149475179 .0504302978576 .0613708496173 .1484298706167 .05272674561 64.004882812560 .9570198059159 .7378807067957 .6043891906755 .16611099243 52.7278289794950 .2895507812548 .4608306884846 .6321296691945 .10820007324 44.1938400268643 .2794914245642 .9747009277343 .2794914245643 .88906097412 45.1082000732446 .6321296691948 .4608306884850 .5943298339852 .72782897949 54.8613204956156 .9948196411158 .8235282897960 .3474502563561 .26181030273 62.1761703491262 .7857398986863 .3953094482464 .004882812564 .30966186523 64.6144485473664 .9192428588965 .2240066528365 .2240066528365 .52880096436 65.5288009643665 .8335876464865 .8335876464866 .1383666992266 .13836669922 66.4431610107466 .4431610107466 .7479400634866 .7479400634866 .74794006348 67.0527267456167 .0527267456167 .0527267456167 .0527267456167 .35751342773 67.35751342773 67.35751342773 67.35751342773 67.66230010986 67.66230010986 67.6623001098667 .6623001098667 .6623001098667 .9670867919967 .96708679199 67.9670867919967 .9670867919969 .1862335205170 .71015167236 -9999 -9999 -9999 -9999 -9999 -9999 -9999 -9999 -9999 -9999 -9999 -9999 -9999 -9999 -9999 -9999 -9999 -9999 -9999

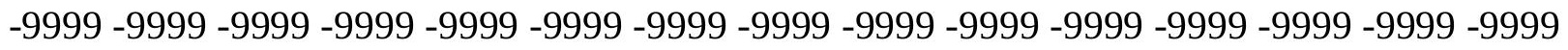

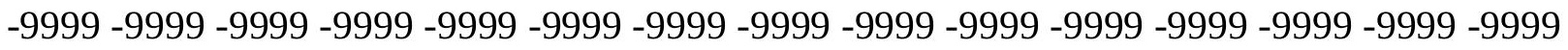
-9999 -9999 -9999 -9999 -9999 -9999 -9999 -9999 -9999 -9999 -9999 -9999 -9999 -9999 -9999 -9999 -9999 -9999 -9999 -9999 -9999 -9999 -9999 -9999 -9999 -9999 -9999 -9999 -9999 -9999 - -999 $-9999-9999-9999$

-9999 -9999 -9999 -9999 -9999 -9999 -9999 -9999 -9999 -9999 -9999 -9999 -9999 -9999 -9999 -9999 -9999 -9999 -9999 -9999 -9999 -9999 -9999 -9999 -9999 -9999 -9999 -9999 -9999 -9999 -9999 -9999 -9999 -9999 -9999 -9999 -9999 -9999 -9999 -9999 -9999 -9999 -9999 -9999 -9999 -9999 -9999 -9999 -9999 -9999 -9999 -9999 -9999 -9999 -9999 -9999 -9999 -9999 -9999 -9999 -9999 -9999-9999-9999 159.2933807373 162.3389892578 165.724105835 169.4836120605 
173.6193847656178 .1253051758182 .9789428711188 .1211242676162 .0711212158 162.789352417163 .4615936279164 .0817565918164 .6452941895165 .1481323242 165.5879516602165 .9627380371166 .272277832166 .5168457031166 .698928833 166.8214416504166 .8885345459166 .5880432129149 .0835418701136 .9479980469 129.8316497803116 .379699707118 .4017028809114 .9039993286110 .6370010376 110.3321990967110 .0273971558110 .0273971558113 .075302124132 .1414337158 129.533706665126 .7906036377124 .0475006104121 .3044967651118 .8662033081 116.1231002808113 .6848983765111 .24659729109 .1130981445107 .2844009399 105.7603988647104 .5412979126103 .6268997192103 .3221969604103 .0174026489 103.3221969604103 .9317016602104 .5412979126105 .7603988647106 .979598999 108.1986999512110 .0273971558111 .551399231113 .3800964355114 .5991973877 111.8014221191106 .897018432699 .9695205688587 .7781066894580 .46327209473 84.7302627563586 .4145736694388 .2586059570390 .8259735107492 .95947265625 95.7025299072398 .75038146973102 .1029968262105 .1205291748106 .9966506958 108.1781158447106 .979598999107 .2844009399108 .6216583252108 .3339614868 108.0804824829107 .9185943604107 .89868927108 .0433807373108 .3623733521 108.8417282104109 .4377975464110 .1018218994110 .763885498111 .3528442383 111.8073577881112 .0818939209112 .1286621094111 .9251785278111 .4718475342 110.8048706055109 .9918212891109 .1305923462108 .3302612305107 .705078125 107.3530654907 107.3432769775 107.7110748291 106.97959899998.75038146973 91.1307525634888 .0829010009886 .8637619018686 .254188537687 .77810668945 92.349891662697 .53124237061100 .8839035034102 .712600708102 .712600708 102.1029968262102 .4077987671102 .4077987671102 .4077987671101 .7982025146 101.4934005737100 .579101562599 .3599472045998 .7503814697396 .92166900635 94.7881774902394 .1785964965891 .1307525634883 .8159103393678 .32978057861 79.8537063598682 .9015579223681 .0728530883877 .7202072143675 .89148712158 77.110626220781 .0728530883892 .3498916626110 .0273971558117 .7073898315 117.145401001116 .6009902954116 .0749740601115 .1812362671114 .1592254639 113.1272888184112 .0842056274111 .0291061401109 .9611816406108 .8797988892 107.7838439941106 .6718139648105 .5416793823104 .3915786743103 .2195205688 102.0240478516100 .804336547999 .5616302490298 .2997131347797 .0256729126 95.7489013671994 .4801330566493 .2309570312592 .0133209228590 .84017181396 89.7281570434688 .6952590942487 .7559127807686 .9043045043986 .11386108398 85.360626220784.6314163208 83.93971252441 83.32410430908 82.07077789307 80.813758850179 .7936935424878 .1942520141676 .2625427246172 .49747467041 68.5766525268666 .7479400634864 .6144485473661 .5666007995657 .9091796875 54.2517509460451 .2038993835448 .765621185346 .6321296691944 .80340957642 43.2794914245642 .3651313781741 .4507789611841 .4507789611842 .36513137817 43.5842704772945 .1082000732447 .2416992187549 .3751907348651 .50868988037 53.6421813964855 .7756805419957 .6043891906759 .1283111572360 .34745025635 61.2618103027362 .1761703491262 .7857398986863 .3953094482463 .70008850098 64.004882812564 .3096618652364 .6144485473664 .9192428588965 .22400665283 65.2240066528365 .5288009643665 .5288009643665 .8335876464865 .83358764648 66.1383666992266 .1383666992266 .4431610107466 .4431610107466 .44316101074 66.7479400634866 .7479400634866 .7479400634866 .7479400634867 .05272674561 67.0527267456167 .0527267456167 .0527267456167 .3575134277367 .35751342773 
67.3575134277367 .3575134277367 .3575134277367 .3575134277367 .35751342773 67.3575134277367 .3575134277367 .9670867919969 .49101257324 -9999 -9999 -9999 -9999 -9999 -9999 -9999 -9999 -9999 -9999 -9999 -9999 -9999 -9999 -9999 -9999 -9999 -9999 -9999 -9999 -9999 -9999 -9999 -9999 -9999 -9999 -9999 -9999 -9999 -9999 -9999 -9999 -9999 -9999 -9999 -9999 -9999 -9999 -9999 -9999 -9999 -9999 -9999 -9999 -9999 -9999 -9999 -9999 -9999 -9999 -9999 -9999 -9999 -9999 -9999 -9999 -9999 -9999 -9999 -9999 -9999 -9999 -9999 -9999

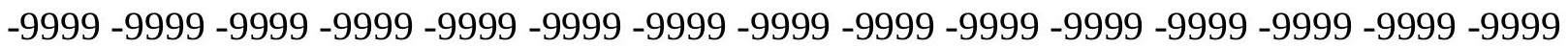
-9999-9999-9999

-9999 -9999 -9999 -9999 -9999 -9999 -9999 -9999 -9999 -9999 -9999 -9999 -9999 -9999 -9999 -9999 -9999 -9999 -9999 -9999 -9999 -9999 -9999 -9999 -9999 -9999 -9999 -9999 -9999 -9999 -9999 -9999 -9999 -9999 -9999 -9999 -9999 -9999 -9999 -9999 -9999 -9999 -9999 -9999 -9999 -9999 -9999 -9999 -9999 -9999 -9999 -9999 -9999 -9999 -9999 -9999 -9999 -9999 -9999 -9999 -9999 -9999 -9999 -9999 -9999 165.193069458 168.6951904297172 .5508728027 176.7692871094181 .3481903076186 .2667541504161 .7424316406162 .5528869629 163.3204650879164 .0379638672164 .6985626221165 .2971343994165 .8290557861 166.2916259766166 .6826324463167 .0019378662167 .2499542236167 .4293823242 167.5435028076167 .5973510742163 .974395752140 .2012023926130 .4479980469 125.8762969971117 .0201644897116 .1231002808111 .24659729110 .0273971558 109.4179000854108 .8082962036108 .5035018921108 .5035018921131 .3623962402 128.3144989014125 .2667007446122 .5235977173119 .7806015015117 .0374984741 114.2944030762111 .8561019897109 .4179000854107 .5891036987105 .7603988647 104.5412979126103 .6268997192103 .0174026489102 .712600708102 .712600708 103.0174026489103 .6268997192104 .5412979126105 .7603988647107 .2844009399 108.5035018921110 .0273971558111 .551399231112 .7705001831113 .075302124 111.24659729106 .065200805797 .8360290527389 .6068267822378 .32978057861 79.5489196777382 .1942749023485 .1418685913188 .3876876831191 .43553924561 94.7881774902398 .14080810547101 .4934005737104 .2365036011106 .3700027466 107.2844009399107 .2844009399107 .8938980103108 .323928833107 .9839782715 107.7172698975107 .555519104107 .5297317505107 .6628799438107 .974899292 108.447227478109 .0475921631109 .7233123779110 .4158477783111 .053314209 111.5859222412111 .9633026123112 .1505661011112 .1355056763111 .9137268066 111.513053894110 .9851608276110 .4034347534109 .8526687622109 .4173202515 109.1766662598109 .1870803833109 .4817886353107 .284400939998 .75038146973 90.8259735107488 .9972534179789 .302040100188 .6924667358490 .21640014648 96.31210327148103 .0174026489106 .6747970581108 .1986999512107 .5891036987 106.3700027466107 .2844009399107 .8938980103108 .1986999512107 .5891036987 106.6747970581105 .4557037354104 .5412979126104 .2365036011103 .9317016602 104.2365036011105 .1509017944101 .493400573792 .349891662686 .2541885376 84.1206970214883 .206336975181 .3776321411178 .9393463134875 .89148712158 74.6723632812576 .5010681152380 .7680587768681 .0728530883885 .03504943848 98.4455871582113 .3800964355116 .6116104126115 .6000823975114 .5796203613 113.5489120483112 .5066833496111 .4519729614110 .3839187622109 .3017807007 108.2042922974107 .0897598267105 .9560089111104 .801109314103 .623085022 102.4206314087101 .193183898999 .9424438476698 .6726989746197 .39151000977 96.1086883544994 .8354187011793 .5839233398492 .3669891357491 .1990814209 90.0966644287189 .079933166588 .1686019897587 .3574905395586 .63081359863 
85.9654541015685 .3405990600684 .7397766113384 .1350784301883 .10063171387 82.0468902587981 .0163497924879 .4767684936578 .3143692016677 .39571380615 74.7615356445373 .1484298706170 .1005783081166 .1383666992260 .95701980591 56.0804595947352 .4230384826749 .6799812316947 .2416992187545 .10820007324 42.9747009277341 .4507789611840 .5364189147940 .2316398620640 .84120941162 42.0603485107443 .8890609741246 .3273391723648 .4608306884850 .59432983398 52.7278289794954 .8613204956156 .3852500915557 .909179687559 .12831115723 60.3474502563561 .2618103027362 .1761703491262 .7857398986863 .09051895142 63.7000885009864 .004882812564 .3096618652364 .6144485473664 .61444854736 64.9192428588964 .9192428588965 .2240066528365 .5288009643665 .52880096436 65.8335876464865 .8335876464866 .1383666992266 .1383666992266 .13836669922 66.44316101074 66.44316101074 66.44316101074 66.74794006348 66.74794006348 66.7479400634866 .7479400634866 .7479400634867 .0527267456167 .05272674561 67.0527267456167 .0527267456167 .0527267456167 .0527267456167 .05272674561 67.0527267456166 .7479400634866 .7479400634868 .2718734741270 .10057830811 -9999 -9999 -9999 -9999 -9999 -9999 -9999 -9999 -9999 -9999 -9999 -9999 -9999 -9999 -9999 -9999 -9999 -9999 -9999 -9999 -9999 -9999 -9999 -9999 -9999 -9999 -9999 -9999 -9999 -9999 -9999 -9999 -9999 -9999 -9999 -9999 -9999 -9999 -9999 -9999 -9999 -9999 -9999 -9999 -9999 -9999 -9999 -9999 -9999 -9999 -9999 -9999 -9999 -9999 -9999 -9999 -9999 -9999 -9999 -9999 -9999 -

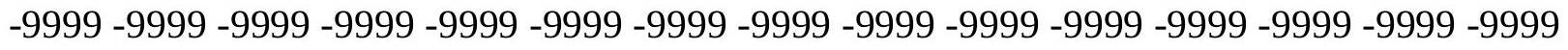
-9999 -9999 -9999-9999-9999

-9999 -9999 -9999 -9999 -9999-9999 -9999 -9999 -9999 -9999 -9999 -9999 -9999 -9999 -9999 -9999 -9999 -9999 -9999 -9999 -9999 -9999 -9999 -9999 -9999 -9999 -9999 -9999 -9999 -9999 -

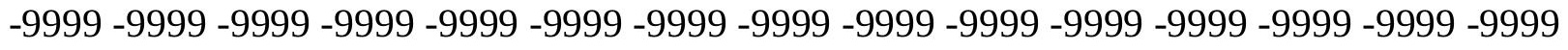

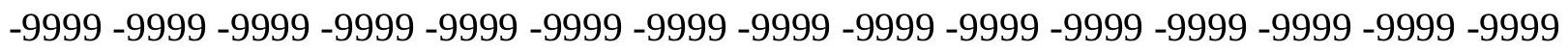
-9999 -9999 -9999 -9999 -9999 -9999 171.1826324463 175.057434082 179.2678070068 183.7965087891161 .2890777588162 .1908569336163 .0559082031163 .8748474121 164.6396026611165 .3424987793165 .9777069092166 .5399475098167 .0260925293 167.4336090088167 .7623443604168 .0128326416168 .1880340576168 .2915649414 168.3291931152150 .2590942383133 .8007049561127 .0953979492123 .1332015991 115.818397522110 .9418029785110 .0273971558108 .8082962036107 .8938980103 107.2844009399 106.979598999 106.6747970581 128.9241027832125.8762969971 123.1332015991120 .3900985718117 .342300415114 .2944030762111 .551399231 109.1130981445 106.979598999 105.4557037354103.9317016602 102.712600708 102.1029968262101 .7982025146101 .4934005737101 .7982025146102 .1029968262 103.0174026489103 .9317016602105 .1509017944106 .6747970581107 .8938980103 109.4179000854110 .3321990967110 .9418029785110 .3321990967107 .8938980103 103.017402648995.70252990723 87.16854858398 79.24413299561 75.28192901611 78.9393463134882 .5967712402386 .254188537689 .9116134643693 .56903076172 97.83602905273102 .1029968262105 .7603988647107 .5891036987108 .5035018921 108.1986999512107 .5891036987107 .8249664307107 .4750213623107 .2201004028 107.0780410767107 .0386428833107 .1620483398107 .4711608887107 .9543457031 108.5832672119109 .3007354736110 .0470199585110 .7717285156111 .4130020142 111.9203109741112 .2733078003112 .4562606812112 .4596557617112 .30078125 112.0187072754111 .6692047119111 .3183898926111 .0339431763110 .8798446655 110.9029464722111 .1367797852111 .24659729103 .322196960496 .31210327148 
93.5690307617293 .5690307617293 .8738174438596 .31210327148102 .1029968262 107.8938980103110 .9418029785111 .8561019897110 .3321990967108 .8082962036 108.1986999512107 .8938980103108 .8082962036109 .1130981445108 .5035018921 107.5891036987107 .2844009399107 .8938980103108 .1986999512108 .8082962036 113.9896011353121 .6092987061117 .647102356104 .2365036011111 .551399231 94.4833908081192 .349891662688 .6924667358483 .206336975178 .32978057861 77.110626220776 .5010681152374 .3675689697376 .1962814331186 .86376190186 99.05516815186104 .8460998535106 .979598999106 .0652008057113 .9941940308 112.9561157227111 .9053039551110 .8408355713109 .7619018555108 .6671066284 107.5546340942106 .422203064105 .2679138184104 .0898895264102 .8869781494 101.6589279175100 .407783508399 .1381988525497 .8580017089896 .57722473145 95.3072891235494 .0607223510792 .8508148193491 .6923141479590 .60182952881 89.59856414795 88.7021865844787.92382049561 87.24491119385 86.64319610596 86.0904235839885 .5516433715884 .9771423339884 .2913742065483 .41785430908 82.41210937581 .4864120483481 .006416320881 .2792053222779 .62343597412 77.8851623535275 .5867080688570 .7101516723664 .6144485473657 .9091796875 54.5565414428751 .5086898803748 .765621185346 .0225486755443 .27949142456 41.1459884643639 .622070312539 .3172798156739 .622070312541 .14598846436 43.2794914245645 .717769622847 .8512611389250 .2895507812552 .11825942993 53.9469718933155 .7756805419957 .2995986938558 .5187492370659 .43310165405 60.6522407531761 .2618103027362 .1761703491262 .7857398986863 .09051895142 63.3953094482463 .7000885009864 .004882812564 .3096618652364 .61444854736 64.6144485473664 .9192428588965 .2240066528365 .2240066528365 .52880096436 65.5288009643665 .8335876464865 .8335876464866 .1383666992266 .13836669922 66.1383666992266 .1383666992266 .4431610107466 .4431610107466 .44316101074 66.4431610107466 .4431610107466 .7479400634866 .7479400634866 .74794006348 66.7479400634866 .7479400634866 .7479400634866 .4431610107466 .44316101074 66.4431610107466 .1383666992267 .3575134277368 .88143920898 -9999 -9999 -9999 -9999 -9999 -9999 -9999 -9999 -9999 -9999 -9999 -9999 -9999 -9999 -9999 -9999 -9999 -9999 -9999 -9999 -9999 -9999 -9999 -9999 -9999 -9999 -9999 -9999 -9999 -9999 -9999 -9999 -9999 -9999 -9999 -9999 -9999 -9999 -9999 -9999 -9999 -9999 -9999-9999 -9999 -9999 -9999 -9999 -9999 -9999 -9999 -9999 -9999 -9999 -9999 -9999 -9999 -9999 -9999 -9999 -9999 -9999 -9999 -9999 -

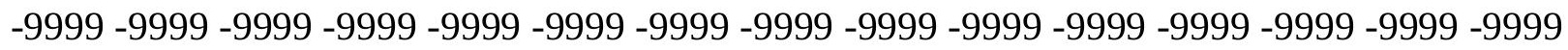
$-9999-9999$

-9999 -9999 -9999 -9999 -9999 -9999 -9999 -9999 -9999 -9999 -9999 -9999 -9999 -9999 -9999

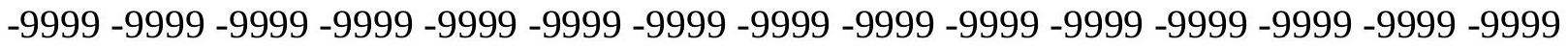

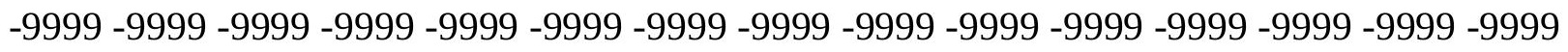

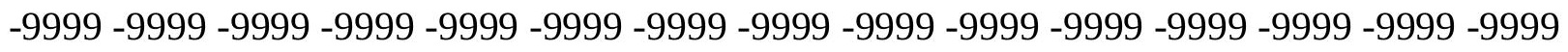
-9999 -9999-9999 -9999 -9999-9999-9999 177.0360870361 181.1257324219 185.4862823486 161.6987915039162 .6585998535163 .5796813965164 .4515686035165 .2651977539 166.011932373166 .6851501465167 .278793335167 .7891998291168 .2134399414 168.5512237549168 .8031005859168 .9722595215169 .0627441406152 .3925933838 137.4580993652128 .6192932129123 .43800354118 .8662033081111 .551399231 109.7226028442108 .1986999512106 .979598999106 .0652008057105 .1509017944 104.5412979126128 .9241027832125 .2667007446122 .5235977173120 .0852966309 117.342300415114 .2944030762110 .9418029785108 .1986999512106 .0652008057 
104.2365036011102 .712600708101 .4934005737100 .8839035034100 .2742996216 99.9695205688599 .96952056885100 .2742996216100 .8839035034101 .7982025146 102.712600708103 .9317016602105 .4557037354106 .6747970581107 .5891036987 108.5035018921108 .5035018921107 .5891036987104 .8460998535100 .5791015625 94.4833908081187 .1685485839879 .2441329956172 .5388565063575 .58670806885 79.8537063598684 .1206970214888 .0829010009892 .6546783447397 .22646331787 102.4077987671106 .6747970581109 .1130981445109 .7226028442109 .1130981445 107.5891036987107 .2844009399106 .9339065552106 .7095031738106 .5463790894 106.4992370605106 .608039856106 .9234390259107 .4208908081108 .0943069458 108.8690567017109 .688911438110 .5127563477111 .2862701416111 .9507522583 112.4889221191112 .8814849854113 .109664917113 .1746826172113 .1044082642 112.9428329468112 .7440032959112 .5655593872112 .4655227661112 .492980957 112.6707458496113 .0157394409109 .1130981445103 .017402648999 .66472625732 98.7503814697399 .96952056885103 .0174026489107 .5891036987112 .1608963013 113.9896011353114 .5991973877112 .7705001831109 .7226028442106 .3700027466 103.6268997192104 .8460998535106 .979598999107 .8938980103108 .8082962036 110.3321990967111 .8561019897112 .1608963013111 .24659729115 .818397522 118.5614013672113 .075302124123 .40990448115 .2088012695109 .1130981445 122.3340835571101 .798202514694 .1785964965886 .254188537681 .98719787598 79.8537063598680 .1584930419983 .206336975190 .2164001464895 .09295654297 85.03504943848 76.1962814331184.4254837036197.53124237061 108.8082962036 112.3878479004111 .3306503296110 .2588348389109 .1709060669108 .0649871826 106.9387817383105 .7904663086104 .6183395386103 .4214477539102 .199798584 100.955741882399 .6941604614398 .4229583740297 .1521148681695 .89296722412 94.6579971313593 .4604873657292 .3155364990291 .2376708984490 .24552154541 89.35375213623 88.59349060059 87.9447937011787.38648986816 86.8890838623 86.4146575927785 .9210586547985 .3690872192484 .7551422119184 .15644836426 83.7311096191483 .6855087280384 .1177215576283 .0236206054781 .29527282715 78.8352279663174 .9771423339869 .4910125732463 .3953094482458 .21395874023 54.2517509460450 .8991203308147 .5464782714844 .4986305236841 .45077896118 39.3172798156738 .7077102661139 .3172798156741 .1459884643643 .58427047729 45.717769622848 .1560516357450 .2895507812552 .1182594299353 .64218139648 55.1661109924356 .6900291442957 .909179687558 .8235282897959 .73788070679 60.6522407531761 .5666007995662 .1761703491262 .4809494018663 .09051895142 63.3953094482463 .7000885009864 .004882812564 .004882812564 .30966186523 64.6144485473664 .9192428588964 .9192428588965 .2240066528365 .22400665283 65.5288009643665 .5288009643665 .8335876464865 .8335876464865 .83358764648 66.1383666992266 .1383666992266 .1383666992266 .1383666992266 .13836669922 66.4431610107466 .4431610107466 .4431610107466 .4431610107466 .44316101074 66.4431610107466 .4431610107466 .1383666992266 .1383666992266 .13836669922 65.8335876464866 .1383666992267 .9670867919969 .79579162598 -9999 -9999 -9999 -9999 -9999 -9999 -9999 -9999 -9999 -9999 -9999 -9999 -9999-9999 -9999 -9999 -9999 -9999 -9999 -9999 -9999 -9999 -9999 -9999 -9999 -9999 -9999 -9999 -9999 -9999 -9999 -9999 -9999 -9999 -9999 -9999 -9999 -9999 -9999 -9999 -9999 -9999 -9999 -9999 -9999 -9999 -9999 -9999 -9999 -9999 -9999 -9999 -9999 -9999 -9999 -9999 -9999 -9999 -9999 -9999 -9999 -9999 -9999 -9999 -

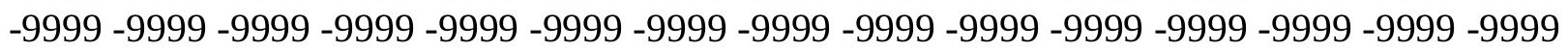


$-9999$

-9999 -9999 -9999 -9999 -9999 -9999 -9999 -9999 -9999 -9999 -9999 -9999 -9999 -9999 -9999

-9999 -9999 -9999 -9999 -9999 -9999 -9999 -9999 -9999 -9999 -9999 -9999 -9999 -9999 - 9999 -

-9999 -9999 -9999 -9999 -9999 -9999 -9999 -9999 -9999 -9999 -9999 -9999 -9999 -9999 -9999

-9999 -9999 -9999 -9999 -9999 -9999 -9999 -9999 -9999 -9999 -9999 -9999 -9999 -9999 -9999 -

-9999 -9999-9999 -9999 -9999-9999-9999 178.5319824219 182.4003601074 161.0799560547

162.1269989014163 .1455383301164 .1236877441165 .0497436523165 .9135437012 166.7054138184167 .4178314209168 .0438690186168 .5792388916169 .020401001 169.3668212891169 .6188812256169 .7800292969160 .6217956543140 .8106994629 127.4001998901118 .2565994263112 .7705001831111 .24659729110 .0273971558 108.1986999512106 .3700027466105 .1509017944103 .9317016602103 .0174026489 102.4077987671 123.43800354120.6949005127117.9517974854115.5136032104 113.3800964355110 .0273971558106 .6747970581104 .2365036011102 .4077987671 100.883903503499 .6647262573299 .0551681518698 .445587158298 .14080810547 97.83602905273 98.1408081054798.445587158299.0551681518699.96952056885 101.1886978149102 .4077987671103 .3221969604104 .5412979126105 .4557037354 106.0652008057106 .0652008057104 .8460998535103 .017402648999 .66472625732 97.2264633178788 .3876876831180 .4632720947372 .2340774536173 .14842987061 77.7202072143681 .9871978759886 .5589828491291 .1307525634895 .70252990723 100.5791015625104 .8460998535107 .2844009399108 .5035018921108 .1986999512 107.5891036987106 .979598999106 .3700027466106 .3700027466106 .0652008057 106.0191726685106 .0652008057106 .0652008057106 .6747970581107 .6742019653 108.4888305664109 .3727493286110 .304145813111 .2197265625112 .0492401123 112.7847137451113 .3893280029113 .8340072632114 .10181427114 .2168197632 114.2029876709114 .1186294556114 .0075302124113 .9356307983113 .9472045898 114.071395874114 .3208007812112 .1608963013107 .5891036987105 .1509017944 103.9317016602105 .1509017944107 .5891036987111 .24659729114 .2944030762 116.4279022217117 .0374984741115 .5136032104110 .6370010376102 .1029968262 95.0929565429795 .7025299072399 .96952056885104 .5412979126109 .1130981445 112.7705001831115 .2088012695116 .4279022217115 .818397522113 .3800964355 118.2565994263113 .9896011353121 .6092987061123 .1158294678119 .1709976196 122.4734420776122 .1241836548105 .455703735496 .3121032714890 .82597351074 88.3876876831188 .9972534179790 .8259735107493 .5690307617293 .56903076172 86.8637619018681 .3776321411184 .7302627563592 .0450973510799 .66472625732 106.979598999111 .8520431519110 .7911758423109 .7142181396108 .6192779541 107.5041351318106 .3671035767105 .2066726685104 .0221481323102 .8137893677 101.5841903687100 .338356018199 .0840606689597 .8309555053796 .58994293213 95.3729934692494 .1929016113393 .0639572143692 .0009078979591 .01964569092 90.1367492675889 .3684158325288 .7343902587988 .2069015502987 .75682830811 87.35440063477 86.97491455078 86.60652923584 86.267578125 86.01659393311 85.940849304286 .0962524414186 .3957214355585 .1448745727583 .50222015381 81.1698303222777 .9352264404373 .7580032348667 .9670867919962 .48094940186 57.909179687553 .9469718933149 .9847602844246 .6321296691942 .97470092773 40.2316398620639 .0125007629439 .9268493652342 .0603485107444 .49863052368 46.9369087219249 .0704002380450 .8991203308152 .4230384826753 .64218139648 54.8613204956156 .0804595947357 .2995986938558 .2139587402359 .12831115723 
60.0426712036160 .9570198059161 .5666007995662 .1761703491262 .48094940186 62.7857398986863 .0905189514263 .3953094482463 .7000885009864 .0048828125 64.3096618652364 .6144485473664 .6144485473664 .9192428588965 .22400665283 65.2240066528365 .5288009643665 .5288009643665 .8335876464865 .83358764648 65.8335876464865 .8335876464865 .8335876464866 .1383666992266 .13836669922 66.1383666992266 .1383666992266 .1383666992266 .1383666992266 .13836669922 66.1383666992266 .1383666992266 .1383666992265 .8335876464865 .83358764648 65.8335876464865 .8335876464866 .7479400634868 .88143920898 -9999 -9999 -9999 -9999 -9999 -9999 -9999 -9999 -9999 -9999 -9999 -9999 -9999 -9999 -9999 -9999 -9999 -9999 -9999 -9999 -9999 -9999 -9999 -9999 -9999 -9999 -9999 -9999 -9999 -9999 -9999 -9999 -9999 -9999 -

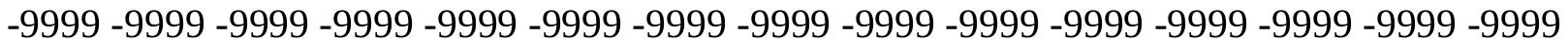
-9999 -9999 -9999 -9999 -9999 -9999 -9999 -9999 -9999 -9999 -9999 -9999 -9999 -9999 -9999 -9999 -9999 -9999 -9999 -9999 -9999 -9999 -9999 -9999 -9999 -9999 -9999 -9999 -9999 -999 -999 $-9999$

-9999 -9999 -9999 -9999 -9999 -9999 -9999 -9999 -9999 -9999 -9999 -9999 -9999 -9999 -9999

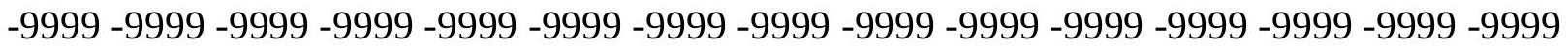

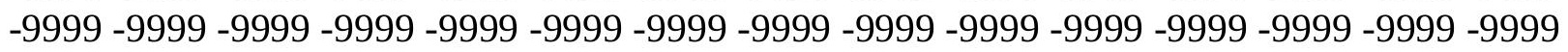

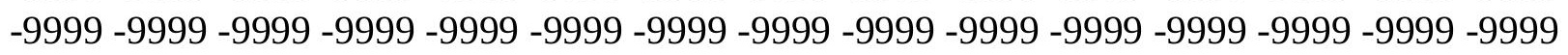
-9999 -9999 -9999 -9999 -9999 -9999 -9999 -9999 160.346862793161 .4674072266 162.5735321045163 .6511688232164 .6870269775165 .6680908203166 .5830841064 167.4211730957168 .1738891602168 .8332977295169 .394317627169 .8526763916 170.2073516846170 .4584197998157 .2691040039140 .5059967041128 .0097961426 115.5136032104122 .8283996582113 .3800964355109 .4179000854107 .5891036987 105.7603988647104 .2365036011103 .0174026489101 .7982025146100 .8839035034 99.96952056885117 .647102356115 .2088012695112 .4656982422110 .0273971558 107.2844009399 104.2365036011 101.493400573799.6647262573298.14080810547 97.2264633178796.61688232422 96.0073165893695.7025299072395.70252990723 95.7025299072396 .0073165893696 .3121032714896 .9216690063597 .83602905273 99.0551681518699 .96952056885101 .1886978149102 .1029968262103 .0174026489 103.6268997192103 .6268997192103 .0174026489101 .493400573799 .66472625732 98.7503814697394 .7881774902388 .9972534179781 .0728530883871 .62449645996 75.5867080688580 .1584930419984 .7302627563589 .302040100193 .87381744385 98.14080810547101 .7982025146104 .2365036011106 .0652008057106 .979598999 106.979598999106 .6747970581106 .3700027466106 .0652008057105 .7603988647 105.7603988647106 .0652008057106 .0652008057106 .6747970581107 .4782180786 108.1986999512109 .1130981445110 .0273971558111 .2110366821112 .1994400024 113.1217956543113 .9336090088114 .5850143433115 .0512695312115 .3190765381 115.4265441895115 .419342041115 .3516464233115 .2741241455115 .256362915 115.3199539185115 .4861984253114 .2944030762111 .551399231109 .7226028442 108.8082962036109 .7226028442111 .24659729113 .3800964355115 .5136032104 117.647102356117 .9517974854115 .5136032104109 .417900085496 .61688232422 86.2541885376 87.1685485839893.26425170898 101.7982025146110.3321990967 115.5136032104118 .5614013672120 .0852966309120 .3900985718119 .1709976196 117.9517974854117 .647102356119 .1709976196123 .1332015991121 .9140014648 122.6081390381122 .3078842163121 .9977340698121 .6820297241101 .7982025146 99.3599472045999 .6647262573299 .9695205688598 .445587158296 .31210327148 
96.3121032714896 .9216690063595 .7025299072396 .0073165893699 .05516815186 103.3221969604106 .3700027466108 .8082962036110 .2946166992109 .2148895264 108.1154251099106 .9947357178105 .8515548706104 .6854324341103 .496925354 102.2888565063101 .066246032799 .8365631103598 .6088714599697 .39328765869 96.2008743286195 .043380737393 .934013366792 .8864593505991 .91623687744 91.0370483398490 .2698516845789 .62416839689 .1180114746188 .70436096191 88.37088775635 88.11183929443 87.92975616455 87.84053039551 87.87049865723 88.03828430176 88.31162261963 87.41796112061 86.2388381958 84.72074890137 82.6137237548879 .7264404296975 .9394760131871 .3197174072365 .83358764648 61.2618103027357 .6043891906753 .6421813964849 .9847602844246 .32733917236 42.9747009277340 .2316398620642 .3651313781744 .8034095764247 .24169921875 49.0704002380450 .5943298339851 .8134689331153 .0326118469253 .94697189331 54.8613204956155 .7756805419956 .6900291442957 .6043891906758 .51874923706 59.4331016540560 .3474502563560 .9570198059161 .5666007995661 .87137985229 62.4809494018662 .7857398986863 .0905189514263 .3953094482463 .70008850098 64.004882812564 .3096618652364 .6144485473664 .6144485473664 .91924285889 65.2240066528365 .2240066528365 .5288009643665 .5288009643665 .52880096436 65.8335876464865 .8335876464865 .8335876464865 .8335876464865 .83358764648 65.8335876464865 .8335876464865 .8335876464865 .8335876464865 .83358764648 65.8335876464865 .8335876464865 .8335876464865 .8335876464865 .83358764648 $65.8335876464865 .8335876464866 .1383666992267 .6623001098669 .79579162598-9999$ -9999 -9999 -9999 -9999 -9999 -9999 -9999 -9999 -9999 -9999 -9999 -9999 -9999 -9999 -9999 -9999 -9999 -9999 -9999 -9999 -9999 -9999 -9999 -9999 -9999 -9999 -9999 -9999 -9999 -9999 -

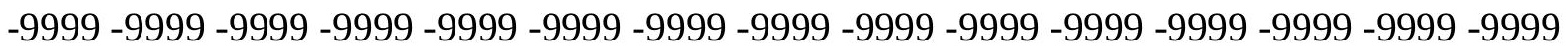

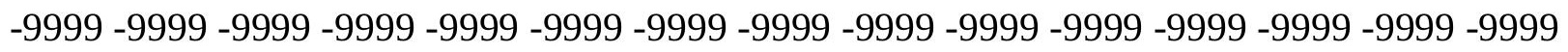

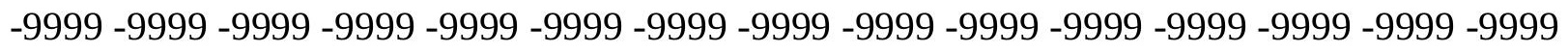
$-9999-9999-9999$

-9999 -9999 -9999 -9999 -9999 -9999 -9999 -9999 -9999 -9999 -9999 -9999 -9999 -9999 -9999 -9999 -9999 -9999 -9999 -9999 -9999 -9999 -9999 -9999 -9999 -9999 -9999 -9999 -9999 -9999

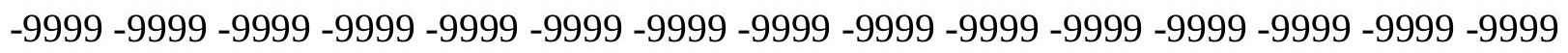

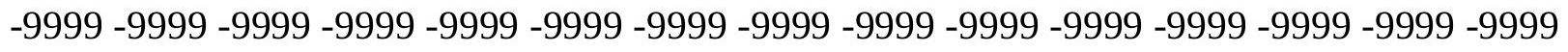
-9999 -9999-9999 -9999 -9999-9999-9999-9999-9999 161.8736724854 163.0386199951 164.1753997803165 .269241333166 .3058166504167 .272644043168 .1578216553 168.9517974854169 .6455688477170 .2330627441170 .7089996338171 .0716705322 149.6495056152126 .7906036377111 .24659729102 .4077987671103 .9317016602 110.3321990967110 .3321990967107 .5891036987105 .1509017944103 .3221969604 101.7982025146100 .883903503499 .6647262573298 .7503814697397 .83602905273 111.551399231109 .1130981445106 .6747970581103 .9317016602101 .1886978149 98.445587158296 .0073165893694 .4833908081193 .8738174438593 .56903076172 93.5690307617293 .2642517089893 .2642517089893 .2642517089893 .26425170898 93.5690307617294 .1785964965894 .7881774902395 .7025299072396 .61688232422 97.5312423706198 .445587158299 .66472625732100 .2742996216100 .8839035034 101.1886978149101 .1886978149100 .8839035034100 .274299621699 .66472625732 98.7503814697396 .9216690063591 .4355392456181 .3776321411175 .58670806885 78.0249862670982 .5967712402386 .8637619018691 .1307525634895 .09295654297 98.4455871582101 .1886978149103 .3221969604105 .1509017944106 .3700027466 
106.3700027466106 .0652008057105 .7603988647105 .7603988647106 .0652008057 106.0652008057106 .6747970581106 .979598999107 .5891036987108 .1986999512 109.1130981445110 .0273971558111 .24659729112 .3647537231113 .4350128174 114.4448394775115 .2960281372115 .9412918091116 .3408279419116 .5495147705 116.6079711914116 .5563354492116 .4680557251116 .4008789062116 .3988265991 116.4883956909115 .818397522114 .2944030762113 .075302124112 .4656982422 112.7705001831113 .9896011353114 .9039993286115 .818397522116 .4279022217 114.5991973877109 .4179000854101 .493400573790 .2164001464881 .68241119385 83.5111236572391 .43553924561103 .0174026489114 .2944030762119 .7806015015 121.9140014648123 .43800354123 .43800354122 .8283996582121 .9140014648 121.9140014648121 .9140014648122 .5235977173122 .8283996582122 .7273483276 122.4698562622122 .2038574219121 .9329681396121 .6605758667121 .3903198242 109.4179000854 107.5891036987104.5412979126103.0174026489103.3221969604 104.2365036011103 .9317016602102 .712600708102 .712600708103 .6268997192 105.1509017944106 .979598999108 .8082962036109 .8492050171108 .7697982788 107.6702270508106 .5494995117105 .4074783325104 .2450332642103 .0652008057 101.8730010986100 .675430297999 .4807662963998 .2980499267697 .13706970215 96.008094787694 .9226913452193 .8930740356492 .9332199096792 .06072235107 91.289337158290 .6463317871190 .1253967285289 .7238540649489 .44281005859 89.2904891967889 .2768707275489 .4081344604589 .6786575317489 .24212646484 88.37538909912 87.50927734375 86.48583984375 85.12287902832 83.23112487793 80.6673355102577 .3192138671973 .2027435302768 .5766525268665 .22400665283 61.8713798522958 .5187492370654 .8613204956151 .2038993835448 .46083068848 46.9369087219247 .8512611389249 .3751907348650 .8991203308152 .11825942993 52.7278289794953 .3373985290553 .6421813964854 .2517509460455 .16611099243 55.7756805419956 .3852500915557 .2995986938558 .2139587402358 .82352828979 59.7378807067960 .3474502563560 .9570198059161 .2618103027361 .87137985229 62.1761703491262 .4809494018663 .0905189514263 .3953094482463 .70008850098 64.004882812564 .3096618652364 .6144485473664 .9192428588964 .91924285889 65.2240066528365 .5288009643665 .5288009643665 .5288009643665 .52880096436 65.8335876464865 .8335876464865 .8335876464865 .8335876464865 .83358764648 65.8335876464865 .8335876464865 .8335876464865 .8335876464865 .83358764648 65.8335876464865 .8335876464865 .8335876464865 .8335876464865 .83358764648 66.1383666992269 .4910125732467 .0527267456168 .88143920898 -9999 -9999 -9999 -9999 -9999 -9999 -9999 -9999 -9999 -9999 -9999 -9999 -9999 -9999 -9999 -9999 -9999 -9999 -9999

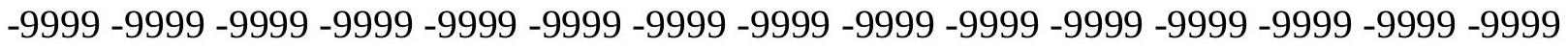

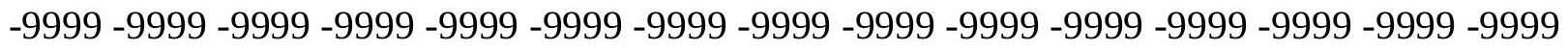

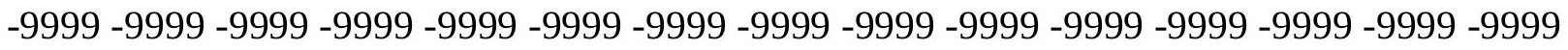
-9999 -9999 -9999 -9999 -9999 -9999 -9999 -9999 -9999 -9999 -9999 -9999 -9999 -9999 -9999 -

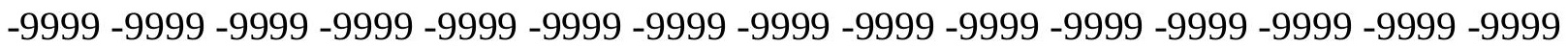

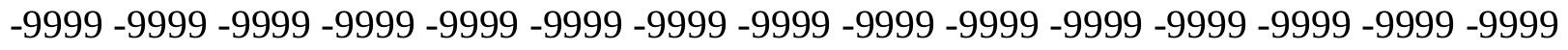

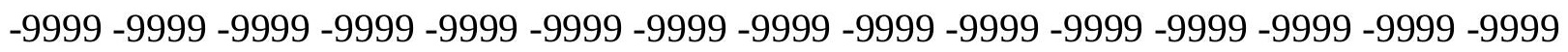
-9999 -9999 -9999 -9999 -9999 -9999 -9999 -9999 -9999 -9999 -9999 -9999 -9999 -9999 -9999 -9999 -9999 -9999 -9999 -9999 -9999 -9999 -9999 -9999 -9999 163.5228424072 164.7185668945165 .8702697754166 .9623260498167 .9812164307168 .9139556885169 .75 170.4791412354171 .0940704346167 .9365997314140 .2012023926117 .9517974854 
99.9695205688596 .3121032714897 .2264633178799 .96952056885103 .0174026489 104.5412979126103 .9317016602102 .4077987671100 .883903503499 .66472625732 98.7503814697398 .1408081054796 .9216690063596 .00731658936105 .1509017944 103.0174026489 100.579101562598.1408081054795.70252990723 92.95947265625 90.2164001464890 .2164001464890 .2164001464890 .2164001464890 .52117919922 90.5211791992290 .8259735107490 .8259735107490 .8259735107491 .43553924561 91.7403335571392 .349891662692 .9594726562593 .8738174438594 .78817749023 95.7025299072396 .6168823242297 .5312423706198 .445587158299 .05516815186 99.6647262573299 .96952056885100 .8839035034101 .7982025146103 .3221969604 105.4557037354107 .893898010391 .4355392456184 .7302627563579 .24413299561 80.1584930419984 .4254837036188 .3876876831192 .0450973510795 .09295654297 97.83602905273100 .5791015625102 .712600708104 .5412979126104 .8460998535 105.1509017944 105.4557037354106.0652008057 106.3700027466106.6747970581 106.979598999107 .5891036987107 .8938980103108 .8082962036109 .4179000854 110.3321990967111 .24659729112 .4656982422113 .5730361938114 .7459869385 115.8541488647116 .6301345825117 .1551589966117 .4712982178117 .6048049927 117.5713272095117 .4572525024117 .3489608765117 .2870635986117 .3063354492 117.342300415116 .1231002808115 .5136032104114 .9039993286115 .2088012695 115.5136032104116 .1231002808115 .818397522114 .2944030762110 .6370010376 103.3221969604 94.48339080811 85.94940185547 81.37763214111 84.42548370361 93.56903076172106 .3700027466118 .2565994263122 .8283996582123 .7293395996 123.7741775513123 .7759780884123 .7362213135123 .6576385498123 .5432128906 123.397102356123 .2241210938123 .0300369263119 .4757995605116 .1231002808 122.3717193604122 .1401138306121 .9076309204121 .6777496338121 .4545211792 121.2421951294121 .044921875110 .3321990967109 .7226028442109 .4179000854 110.0273971558110 .0273971558108 .1986999512106 .6747970581106 .979598999 108.1986999512110 .0273971558110 .5187225342109 .4633331299108 .389175415 107.2955780029 106.1827774048 105.0520324707 103.9066009521 102.751449585 101.5930557251100 .438796997199 .2964782714898 .1743392944397 .08083343506 96.0253753662195 .0180816650494 .0726928710993 .2056121826292 .43444061279 91.76479339691 .2129974365290 .7968826293990 .539482116790 .46726226807 90.5989608764689 .7518997192488 .9576644897588 .279434204187 .64022064209 86.9416046142686 .0625686645584 .8682785034283 .2297134399481 .04877471924 78.2902526855575 .0539321899471 .7693557739368 .8814392089866 .44316101074 63.7000885009860 .9570198059157 .909179687555 .4708900451754 .55654144287 54.8613204956155 .4708900451755 .7756805419955 .4708900451754 .86132049561 54.8613204956154 .8613204956154 .8613204956155 .1661109924355 .77568054199 56.0804595947356 .6900291442957 .6043891906758 .2139587402358 .82352828979 59.4331016540560 .0426712036160 .6522407531761 .2618103027361 .56660079956 62.1761703491262 .4809494018663 .0905189514263 .3953094482463 .70008850098 64.3096618652364 .6144485473664 .9192428588964 .9192428588965 .22400665283 65.5288009643665 .5288009643665 .5288009643665 .5288009643665 .52880096436 65.5288009643665 .5288009643665 .5288009643665 .5288009643665 .52880096436 65.5288009643665 .5288009643665 .5288009643665 .5288009643665 .52880096436 65.8335876464865 .8335876464865 .8335876464866 .1383666992266 .44316101074 66.7479400634867 .0527267456167 .9670867919969 .79579162598 -9999 -9999 -9999 -9999 
-9999 -9999 -9999 -9999 -9999 -9999 -9999 -9999 -9999 -9999 -9999 -9999 -9999 -9999 -9999 -9999 -9999 -9999 -9999 -9999 -9999 -9999 -9999 -9999 -9999 -9999 -9999 -9999 -9999 -9999 -9999 -9999 -9999 -9999 -9999 -9999 -9999 -9999 -9999 -9999 -9999 -9999 -9999 -9999 -9999 -9999 -9999 -9999 -9999 -9999 -9999 -9999 -9999 -9999 -9999 -9999 -9999 -9999 -9999 -9999 -9999 -9999 -9999 -9999 -9999 -9999 -9999 -9999 -9999 -9999 -9999 -9999 -9999 -9999 -9999 -9999 -9999 -9999 -9999 -9999 -9999 -9999 -9999 -9999 -9999 -9999 -9999 -9999 -9999 -9999 -9999 -9999 -9999 -9999 -9999 -9999 -9999 -9999 -9999 -9999 -9999 -9999 -9999 -9999 -9999 -9999 -9999 -9999 -9999 -9999 -9999 -9999 -9999 -9999 -9999 -9999 -9999 -9999 -9999 -999 -9999 -9999 -9999 -9999 -9999 -9999 -9999 -9999 -9999 -9999 -9999 -9999 -9999 -9999 -9999 -9999 -9999 -9999 -9999 -9999 -9999 -9999 -9999 -9999 -9999 164.0280303955 165.2822570801166 .4911499023167 .6379699707168 .708404541169 .6887054443 170.5673675537171 .3329162598170 .6797027588149 .9542999268125 .8762969971 105.455703735497 .2264633178794 .4833908081194 .7881774902396 .61688232422 98.445587158299 .6647262573299 .9695205688599 .3599472045998 .75038146973 98.1408081054797 .5312423706196 .6168823242296 .00731658936101 .1886978149 99.35994720459 97.2264633178795.0929565429792.9594726562590.82597351074 88.6924667358487 .1685485839886 .8637619018686 .8637619018687 .47332763672 87.7781066894588 .0829010009888 .3876876831188 .3876876831188 .69246673584 88.9972534179789 .6068267822390 .2164001464890 .5211791992291 .43553924561 92.349891662692 .9594726562593 .8738174438595 .0929565429796 .00731658936 97.2264633178797 .8360290527399 .05516815186100 .2742996216102 .4077987671 104.8460998535106 .3700027466103 .626899719293 .8738174438589 .3020401001 85.3398437582 .2919769287181 .6824111938585 .3398437588 .6924667358491 .74033355713 94.1785964965896 .9216690063599 .05516815186100 .8839035034102 .1029968262 103.0174026489104 .5412979126106 .0652008057106 .3700027466106 .3700027466 106.979598999 107.8938980103108.5035018921 109.1130981445110.0273971558 110.6370010376111 .24659729112 .1608963013113 .3800964355114 .5991973877 116.1231002808116 .8594360352117 .5526351929118 .075958252118 .298576355 118.2916107178118 .195098877118 .052772522117 .948387146117 .9241943359 117.9767913818117 .647102356117 .0374984741116 .7326965332116 .7326965332 116.7326965332116 .4279022217115 .2088012695113 .3800964355109 .4179000854 103.322196960496 .6168823242288 .3876876831184 .1206970214889 .3020401001 98.75038146973109 .7226028442119 .1709976196123 .4850921631123 .585647583 123.6446228027123 .6628799438123 .6416015625123 .5834732056123 .4914398193 123.3694839478123 .222366333123 .056060791122 .8760070801120 .9997024536 120.9997024536121 .9140014648122 .0973968506121 .904296875121 .7191772461 121.5467834473121 .392364502120 .783821106114 .9039993286113 .6848983765 114.2944030762113 .6848983765111 .8561019897110 .0273971558109 .7226028442 110.9418029785112 .2311019897111 .2198638916110 .1921005249109 .1471710205 108.0848083496107 .0056991577105 .9115905762104 .8060150146103 .6938781738 102.5811309814101 .4742736816100 .379837036199 .3044586181698 .25451660156 97.2368698120196 .2588500976695 .3301467895594 .4712371826293 .19206237793 91.9285507202192 .2953262329191 .2521362304789 .8104324340888 .90830230713 88.2820739746187 .7892761230587 .3540267944386 .9265747070386 .45664215088 85.8825836181685 .1296386718884 .1167449951282 .7716140747181 .05317687988 78.9888153076276 .7149734497174 .5237350463972 .5761184692470 .88259124756 
69.1862335205167 .6623001098665 .8335876464862 .7857398986862 .48094940186 62.4809494018662 .1761703491260 .3474502563558 .5187492370656 .99481964111 56.0804595947355 .7756805419955 .4708900451755 .4708900451755 .77568054199 56.0804595947356 .3852500915556 .9948196411157 .6043891906758 .21395874023 58.8235282897959 .4331016540560 .0426712036160 .6522407531761 .26181030273 61.8713798522962 .1761703491262 .7857398986863 .3953094482463 .70008850098 64.004882812564 .6144485473664 .9192428588964 .9192428588965 .22400665283 65.5288009643665 .5288009643665 .5288009643665 .8335876464865 .83358764648 65.5288009643665 .5288009643665 .5288009643665 .5288009643665 .52880096436 65.5288009643665 .5288009643665 .5288009643665 .5288009643665 .52880096436 65.5288009643665 .8335876464865 .8335876464866 .1383666992266 .44316101074 66.7479400634867 .0527267456167 .6623001098668 .88143920898 -9999 -9999 -9999 -9999 -9999 -9999 -9999 -9999 -9999 -9999 -9999 -9999 -9999 -9999 -9999 -9999 -9999 -9999 -9999 -9999 -9999 -9999 -9999 -9999 -9999 -9999 -9999 -9999 -9999 -9999 -9999 -9999 -9999 -9999 -9999 -9999 -9999 -9999 -9999 -9999 -9999 -9999 -9999 -9999 -9999 -9999 -9999 -9999 -9999

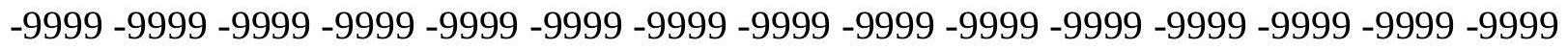
-9999 -9999 -9999 -9999 -9999 -9999 -9999 -9999 -9999 -9999 -9999 -9999 -9999 -9999 -9999 -9999 -9999 -9999 -9999 -9999 -9999 -9999 -9999 -9999 -9999 -9999 -9999 -9999 -9999 -

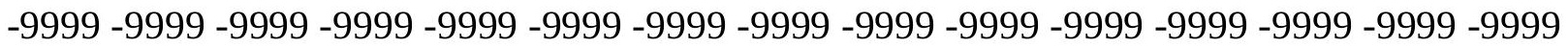

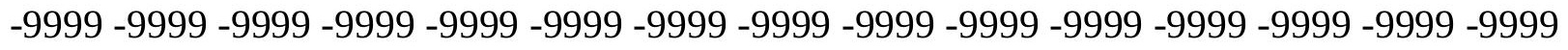

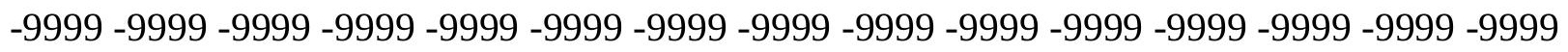
-9999 -9999 -9999 -9999 -9999 -9999-9999 -9999 -9999-9999 -9999 165.8695831299 167.1340484619168 .3337097168169 .4540863037170 .4811401367168 .4915924072 162.1457061768153 .0021057129138 .9819946289121 .3044967651102 .1029968262 93.8738174438593 .5690307617293 .8738174438594 .4833908081195 .3977432251 96.3121032714896 .6168823242296 .9216690063596 .9216690063596 .92166900635 96.6168823242296 .0073165893695 .397743225196 .0073165893694 .17859649658 92.0450973510789 .9116134643688 .3876876831186 .8637619018685 .33984375 84.4254837036184 .1206970214884 .4254837036185 .0350494384885 .33984375 85.9494018554786 .254188537686 .5589828491286 .8637619018687 .16854858398 87.47332763672 88.08290100098 88.38768768311 88.99725341797 89.91161346436 90.5211791992291 .1307525634892 .349891662693 .8738174438595 .09295654297 96.0073165893697 .2264633178798 .75038146973100 .8839035034102 .712600708 103.0174026489100 .274299621695 .397743225191 .4355392456189 .3020401001 86.55898284912 84.12069702148 82.29197692871 85.33984375 88.08290100098 90.5211791992292 .9594726562594 .7881774902396 .6168823242298 .14080810547 99.96952056885102 .4077987671104 .5412979126105 .1509017944105 .4557037354 106.6747970581107 .8938980103108 .8082962036109 .7226028442110 .3321990967 110.6370010376111 .24659729111 .8561019897112 .7705001831113 .9896011353 115.2088012695116 .4279022217117 .342300415118 .2565994263118 .4784698486 118.6201400757118 .5820999146118 .4574356079118 .3596572876118 .3153076172 118.3425674438118 .2565994263117 .9517974854117 .647102356117 .647102356 117.0374984741116 .4279022217114 .9039993286112 .7705001831109 .7226028442 106.0652008057101 .798202514694 .7881774902391 .1307525634896 .92166900635 105.7603988647113 .075302124119 .1709976196123 .3174057007123 .4276275635 123.4982757568123 .5300598145123 .523979187123 .4826812744123 .4092941284 
123.3078079224123 .1828384399123 .0403213501122 .8858566284122 .7238540649 122.5576629639122 .3904876709122 .2255401611122 .0661849976121 .9164810181 121.7814483643121 .6674041748121 .2530441284120 .3579406738118 .5614013672 117.0374984741116 .4279022217114 .9039993286113 .6848983765113 .075302124 113.8976593018112 .9301757812111 .9482879639110 .9512329102109 .9387969971 108.9111328125107 .8694076538106 .8159332275105 .7546081543104 .6903533936 103.628692627102 .5753326416101 .535736084100 .51504516699 .51763153076 98.5475234985497 .608535766696 .706748962495 .0745544433690 .33068084717 88.5394287109487 .7237472534286 .2804260253985 .8087081909285 .72905731201 85.7360000610485 .7027359008885 .5799789428785 .3457183837984 .98497772217 84.4819107055783.81910705566 82.97536468506 81.93257141113 80.69584655762 79.3212661743277 .9268493652376 .6888656616275 .7503814697375 .14026641846 74.7304916381874 .062782287675 .5867080688572 .5388565063569 .18623352051 67.6623001098667 .6623001098663 .7000885009860 .3474502563558 .51874923706 57.2995986938556 .3852500915556 .0804595947355 .7756805419955 .77568054199 55.7756805419956 .0804595947356 .3852500915556 .9948196411157 .60438919067 58.2139587402358 .8235282897959 .4331016540560 .0426712036160 .65224075317 61.2618103027361 .8713798522962 .4809494018663 .0905189514263 .70008850098 64.004882812564 .6144485473664 .9192428588965 .2240066528365 .52880096436 65.5288009643665 .8335876464865 .8335876464865 .8335876464865 .83358764648 65.8335876464865 .5288009643665 .5288009643665 .5288009643665 .52880096436 65.5288009643665 .5288009643665 .5288009643665 .5288009643665 .52880096436 65.5288009643665 .8335876464866 .1383666992266 .4431610107466 .74794006348 67.05272674561 67.35751342773 67.66230010986 68.2718734741269.79579162598-9999

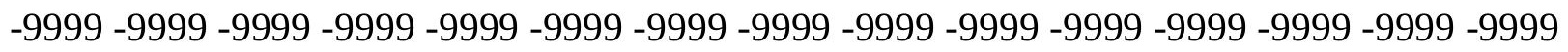

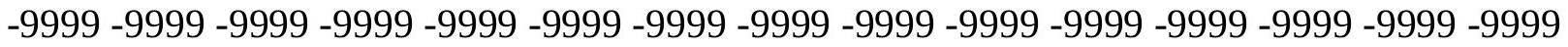

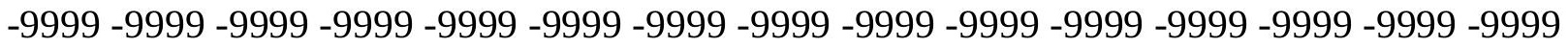

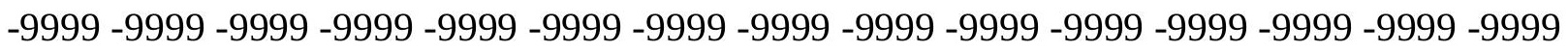

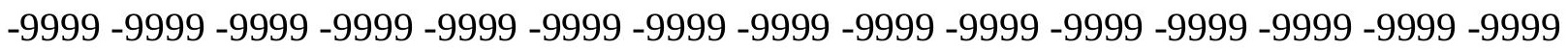
$-9999$

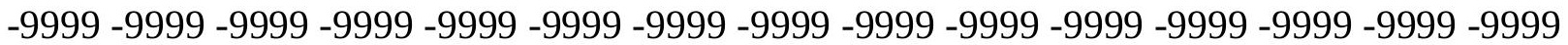

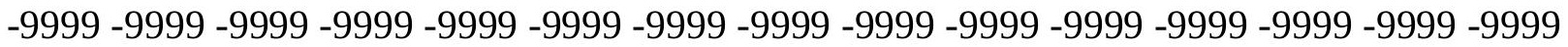

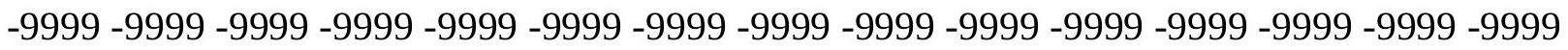

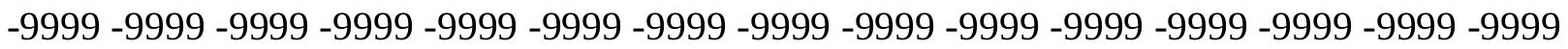
-9999 -9999 -9999 -9999 -9999 -9999 -9999 -9999 -9999 -9999 -9999 -9999 167.8022766113 169.0518341064170.2187957764166.7174987793158.1835021973 151.4781951904 144.1634063721132 .8863067627118 .8662033081102 .407798767195 .3977432251 94.1785964965893 .5690307617293 .5690307617293 .8738174438594 .48339080811 95.0929565429795 .7025299072396 .3121032714896 .6168823242296 .61688232422 96.0073165893695 .397743225190 .8259735107489 .302040100187 .77810668945 85.9494018554784 .7302627563583 .5111236572382 .5967712402382 .29197692871 82.29197692871 82.59677124023 82.90155792236 83.5111236572384.12069702148 84.4254837036184 .7302627563585 .0350494384885 .3398437585 .64462280273 85.94940185547 86.55898284912 86.86376190186 87.47332763672 88.08290100098 88.9972534179790 .2164001464892 .0450973510792 .6546783447393 .56903076172 94.7881774902396 .3121032714898 .1408081054799 .3599472045999 .35994720459 
97.8360290527395 .0929565429792 .6546783447391 .4355392456189 .91161346436 87.7781066894585 .6446228027382 .9015579223684 .4254837036186 .55898284912 88.6924667358490 .5211791992292 .349891662693 .8738174438595 .70252990723 97.8360290527399 .96952056885101 .4934005737103 .3221969604105 .7603988647 107.5891036987109 .1130981445109 .7226028442110 .0273971558110 .3321990967 110.6370010376111 .551399231112 .1608963013113 .3800964355114 .2944030762 115.5136032104116 .4279022217117 .342300415117 .9517974854118 .5614013672 118.5210723877118 .507598877118 .4898757935118 .486869812118 .5149307251 118.5892333984118 .5614013672118 .2565994263117 .9517974854117 .342300415 116.4279022217115 .2088012695113 .075302124110 .9418029785108 .5035018921 106.0652008057102 .712600708101 .7982025146107 .2844009399113 .6848983765 117.647102356120 .6949005127123 .1291503906123 .2472839355123 .3268966675 123.3688659668123 .3743972778123 .3462295532123 .2877349854123 .2031707764 123.097114563122 .9752197266122 .8430099487122 .7050170898122 .5645980835 122.424911499122 .2892456055122 .160987854122 .0441360474121 .9438247681 121.8671875121 .7197341919120 .8491897583119 .9759292603119 .09815979 118.2142105103117 .3224182129116 .4213790894115 .5096817017114 .586151123 113.6497268677112 .6997909546111 .7360229492110 .7587127686109 .7685241699 108.7670974731107 .7572631836106 .743347168105 .7304458618104 .723815918 103.7286758423102 .7496871948101 .7909698486100 .855186462499 .94378662109 99.0566635131898 .1938400268693 .2642517089884 .1206970214880 .76805877686 81.355323791581 .2155303955181 .8942413330182 .6359100341883 .22975158691 83.602119445883 .7454757690483 .6535720825283 .3417892456182 .84387207031 82.2145996093881 .4973373413180 .7249832153379 .9289245605579 .15937042236 78.5180358886778 .1056594848678 .0212249755978 .3453369140679 .2954788208 81.6809997558685 .6446228027378 .0249862670971 .9292907714868 .88143920898 67.3575134277364 .6144485473661 .2618103027359 .4331016540558 .21395874023 56.9948196411156 .3852500915555 .7756805419955 .7756805419955 .77568054199 55.7756805419956 .0804595947356 .3852500915556 .9948196411157 .60438919067 58.2139587402358 .8235282897959 .4331016540560 .3474502563560 .95701980591 61.5666007995662 .1761703491262 .7857398986863 .3953094482464 .0048828125 64.6144485473664 .9192428588965 .5288009643665 .8335876464865 .83358764648 66.1383666992266 .1383666992266 .1383666992266 .1383666992265 .83358764648 65.8335876464865 .5288009643665 .5288009643665 .5288009643665 .22400665283 65.2240066528365 .2240066528365 .5288009643665 .5288009643665 .52880096436 65.8335876464866 .1383666992266 .4431610107466 .7479400634867 .05272674561 67.3575134277367 .6623001098668 .2718734741268 .88143920898 -9999 -9999 -9999 -9999 -9999 -9999 -9999 -9999 -9999 -9999 -9999 -9999 -9999 -9999 -9999 -9999 -9999 -9999 -9999 -9999 -9999 -9999 -9999 -9999 -9999 -9999 -9999 -9999 -9999 -9999 -9999 -9999 -9999 -9999 -9999 -9999 -9999 -9999 -9999 -9999 -9999 -9999 -9999 -9999 -9999 -9999 -9999 -9999 -9999 -

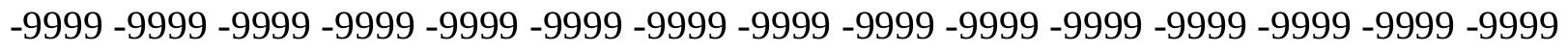

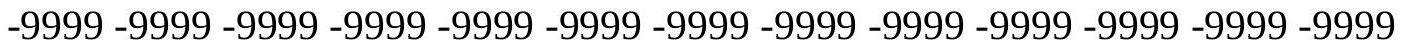

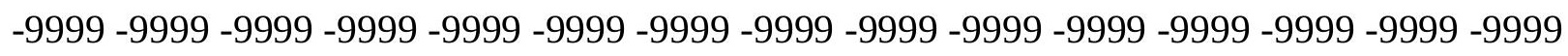
-9999 -9999 -9999 -9999 -9999 -9999 -9999 -9999 -9999 -9999 -9999 -9999 -9999 -9999 -9999 -

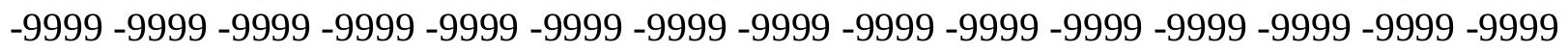

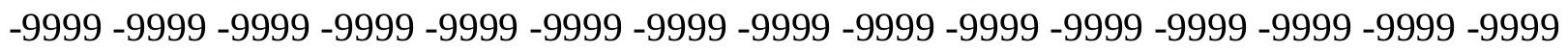


-9999 -9999 -9999 -9999 -9999 -9999 -9999 -9999 -9999 -9999 -9999 -9999 -9999 169.7953186035168 .8509979248161 .8408966064154 .5260925293148 .7351074219 142.3347015381131 .6672058105120 .6949005127112 .1608963013105 .1509017944 98.7503814697395 .0929565429794 .1785964965894 .1785964965893 .87381744385 94.4833908081195 .397743225196 .6168823242297 .2264633178797 .22646331787 96.9216690063587 .4733276367285 .9494018554784 .7302627563583 .51112365723 82.2919769287181 .3776321411180 .7680587768680 .4632720947380 .46327209473 80.4632720947380 .7680587768681 .3776321411181 .9871978759882 .29197692871 82.9015579223683 .206336975183 .5111236572383 .8159103393684 .12069702148 84.1206970214884 .4254837036184 .7302627563585 .3398437585 .64462280273 86.5589828491287 .7781066894588 .9972534179789 .9116134643690 .82597351074 92.0450973510793 .5690307617294 .7881774902396 .0073165893696 .31210327148 95.7025299072394 .4833908081192 .9594726562592 .6546783447392 .04509735107 90.8259735107489 .302040100186 .8637619018683 .8159103393682 .90155792236 84.7302627563586 .254188537687 .7781066894589 .6068267822391 .43553924561 92.6546783447394 .4833908081197 .22646331787100 .5791015625103 .6268997192 106.3700027466107 .8938980103108 .8082962036109 .1130981445109 .4179000854 110.0273971558110 .6370010376111 .551399231112 .4656982422113 .6848983765 114.5991973877115 .5136032104116 .4279022217117 .0374984741117 .647102356 117.9517974854118 .2565994263118 .3528747559118 .4226303101118 .4988327026 118.586227417118 .6860351562118 .5614013672118 .2565994263117 .647102356 117.0374984741115 .818397522114 .2944030762112 .4656982422110 .9418029785 110.0273971558110 .3321990967112 .1608963013116 .1231002808120 .0852966309 121.3044967651 122.2188034058 122.9175796509123 .0420074463123 .1281585693 123.1771240234123 .1906509399123 .1718521118123 .1244506836123 .0530853271 122.9624862671122 .8580322266122 .7449951172122 .6279830933122 .5105514526 122.3957672119122 .286819458122 .1870498657122 .1005172729122 .0324630737 121.9902877808121 .9825592041121 .3374099731120 .4919586182119 .6430664062 118.7889862061117 .927986145117 .0585403442116 .1791381836115 .288520813 114.385559082113 .4698181152112 .5413894653111 .6011657715110 .6504135132 109.6912384033108 .7268981934107 .7620697021106 .8021621704105 .8524475098 104.9179916382104 .0032272339103 .1120529175102 .2456207275101 .4030914307 100.582099914699 .7823486328186 .5589828491274 .9771423339869 .18623352051 72.5388565063576 .6197814941478 .3487930297979 .7184295654380 .75528717041 81.4628067016681 .8458938598681 .8763732910281 .5588531494180 .99806976318 80.3349914550879 .6829071044979 .1246185302778 .703964233478 .44957733154 78.4040069580178 .6029129028379 .1102905273480 .0136566162181 .37415313721 82.7958450317481 .8855819702176 .5010681152369 .7957916259867 .05272674561 65.8335876464864 .6144485473662 .4809494018660 .6522407531759 .12831115723 57.6043891906756 .6900291442956 .0804595947355 .7756805419955 .47089004517 55.4708900451755 .7756805419955 .7756805419956 .3852500915556 .99481964111 57.6043891906758 .2139587402358 .8235282897959 .7378807067960 .65224075317 61.2618103027362 .1761703491262 .7857398986863 .3953094482464 .0048828125 64.6144485473665 .2240066528365 .8335876464866 .1383666992266 .44316101074 66.4431610107466 .4431610107466 .4431610107466 .1383666992266 .13836669922 65.8335876464865 .8335876464865 .5288009643665 .5288009643665 .22400665283 
65.2240066528365 .2240066528365 .2240066528365 .5288009643665 .52880096436 65.8335876464866 .1383666992266 .4431610107466 .7479400634867 .05272674561 $67.3575134277367 .6623001098667 .9670867919968 .5766525268669 .18623352051-9999$ -9999 -9999 -9999 -9999 -9999 -9999 -9999 -9999 -9999 -9999 -9999 -9999 -9999 -9999 -9999 -9999 -9999 -9999 -9999 -9999 -9999 -9999 -9999 -9999-9999 -9999 -9999 -9999 -9999 - 9999 -

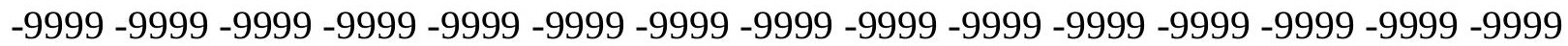

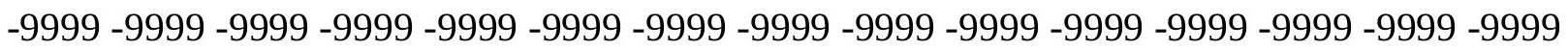

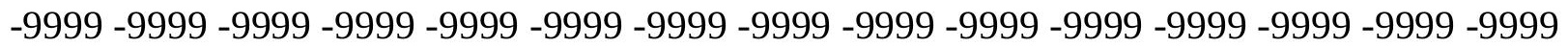
-9999 -9999 -9999 -9999 -9999 -9999 -9999 -9999 -9999 -9999 -9999 -9999 -9999 -9999 -9999 -

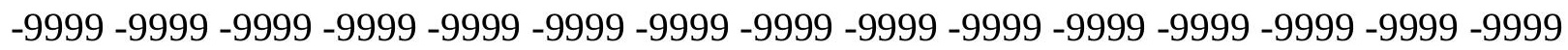
-9999 -9999 -9999 -9999 -9999 -9999 -9999 -9999 -9999 -9999 -9999 -9999 -9999 -9999 -9999 -999 -

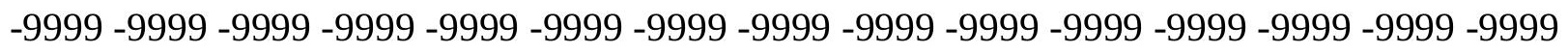
-9999 -9999 -9999 -9999 -9999 -9999 -9999 -9999 -9999 -9999 -9999 -9999 -9999 170.5453491211168 .241394043162 .1457061768156 .3547973633152 .0877990723 146.9064025879137 .4580993652128 .6192932129123 .1332015991118 .5614013672 113.6848983765108 .5035018921103 .9317016602100 .274299621696 .92166900635 95.7025299072396 .9216690063598 .1408081054798 .445587158298 .4455871582 98.1408081054781 .9871978759881 .0728530883880 .4632720947379 .85370635986 79.2441329956178 .6345596313578 .6345596313578 .6345596313578 .63455963135 79.2441329956179 .5489196777380 .1584930419980 .7680587768681 .07285308838 81.6824111938581 .9871978759881 .9871978759882 .2919769287182 .59677124023 82.5967712402382 .5967712402382 .9015579223683 .206336975183 .51112365723 84.1206970214885 .0350494384885 .9494018554786 .8637619018688 .08290100098 89.302040100190 .5211791992291 .7403335571392 .9594726562593 .56903076172 93.8738174438593 .5690307617293 .2642517089893 .2642517089893 .26425170898 92.9594726562592 .349891662690 .2164001464887 .4733276367283 .81591033936 80.7680587768681 .6824111938582 .9015579223685 .0350494384887 .47332763672 88.9972534179790.8259735107493.8738174438596.9216690063599.96952056885 102.712600708104 .8460998535106 .0652008057106 .979598999107 .5891036987 108.5035018921109 .4179000854110 .6370010376111 .551399231112 .7705001831 113.6848983765114 .5991973877115 .5136032104116 .1231002808116 .7326965332 117.342300415117 .647102356117 .9517974854118 .1427841187118 .3087921143 118.433883667118 .5327301025118 .5614013672118 .2565994263117 .9517974854 117.342300415116 .4279022217115 .2088012695114 .2944030762113 .3800964355 113.3800964355114 .9039993286117 .0374984741120 .0852966309121 .9140014648 122.2188034058122 .2188034058122 .5235977173122 .8131790161122 .9035949707 122.9565734863122 .9744644165122 .9610595703122 .9206314087122 .858291626 122.7790527344122 .6881408691122 .5905990601122 .4910507202122 .3932266235 122.3001251221122 .2147216797122 .1403045654122 .0810546875122 .0422744751 122.031211853122 .0562210083121 .8196487427121 .0041122437120 .1862945557 119.3643493652118 .5364532471117 .7009429932116 .8561782837116 .0007705688 115.1335067749114 .2539672852113 .3625793457112 .4608383179111 .5506668091 110.6346511841109 .7163696289108 .8007354736107 .8934173584106 .9999923706 106.1258468628105 .2757873535104 .4539718628103 .6612167358102 .8985671997 102.171333313101 .466140747173 .4532165527370 .4053573608468 .27187347412 69.7957916259873 .1484298706175 .1416168212976 .7952117919978 .02964782715 
79.0553970336979 .7174606323279 .9117202758879 .5434875488378 .88156890869 78.1265182495177 .4878311157277 .0939483642676 .9870071411177 .15406036377 77.5564346313578 .1610107421978 .937217712479 .8009948730580 .48392486572 80.2181777954177 .4259796142671 .7467498779364 .004882812564 .91924285889 65.8335876464865 .2240066528364 .004882812561 .8713798522960 .04267120361 58.2139587402356 .9948196411156 .0804595947355 .7756805419955 .47089004517 55.1661109924355 .1661109924355 .4708900451755 .7756805419956 .38525009155 56.9948196411157 .6043891906758 .5187492370659 .4331016540560 .04267120361 60.9570198059161 .8713798522962 .4809494018663 .3953094482464 .0048828125 64.9192428588965 .5288009643666 .1383666992266 .4431610107466 .74794006348 66.7479400634866 .7479400634866 .7479400634866 .7479400634866 .44316101074 66.1383666992265 .8335876464865 .5288009643665 .5288009643665 .22400665283 65.2240066528365 .2240066528365 .2240066528365 .2240066528365 .52880096436 65.8335876464866 .1383666992266 .4431610107466 .7479400634867 .05272674561 67.3575134277367 .6623001098667 .6623001098668 .2718734741268 .88143920898 -9999 -9999 -9999 -9999 -9999 -9999 -9999 -9999 -9999 -9999 -9999 -9999 -9999 -9999 -9999 -9999 -9999 -9999 -9999 -9999 -9999 -9999 -9999 -9999 -9999 -9999 -9999 -9999 -9999 -9999 -9999 -

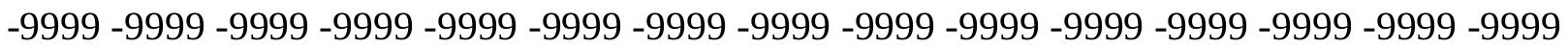
-9999 -9999 -9999 -9999 -9999 -9999 -9999 -9999 -9999 -9999 -9999 -9999 -9999 -9999 -9999 -

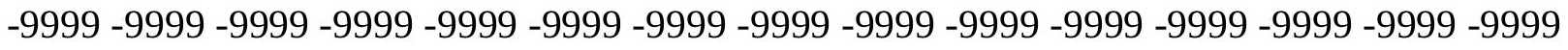
-9999 -9999 -9999 -9999 -9999 -9999 -9999 -9999 -9999 -9999 -9999 -9999 -9999 -9999 -9999

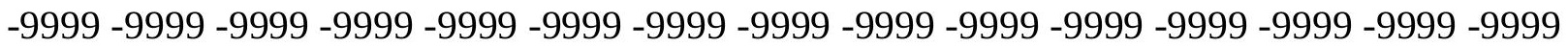
-9999 -9999 -9999 -9999 -9999 -9999 -9999 -9999 -9999 -9999 -9999 -9999 -9999 -9999 -9999 -9999 -9999 -9999 -9999 -9999 -9999 -9999 -9999 -9999 -9999 -9999 -9999 -9999 -9999 -9999 -

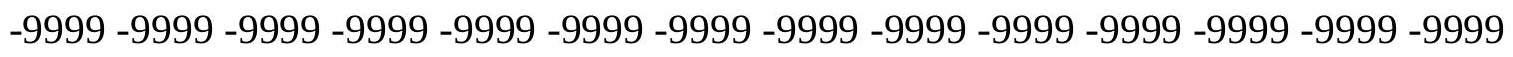
170.3748931885164 .5839996338160 .3170013428157 .2691040039153 .6116943359 145.3825073242137 .1533050537132 .5814971924128 .9241027832124 .9618988037 120.6949005127116 .1231002808111 .551399231108 .1986999512105 .1509017944 101.4934005737100 .5791015625100 .579101562599 .9695205688599 .35994720459 77.110626220776 .8058471679776 .5010681152376 .5010681152376 .19628143311 76.5010681152376 .5010681152376 .8058471679777 .4154205322378 .02498626709 78.6345596313579 .2441329956179 .5489196777380 .1584930419980 .46327209473 80.7680587768680 .7680587768681 .0728530883881 .0728530883881 .07285308838 81.0728530883881 .0728530883881 .3776321411181 .6824111938581 .98719787598 82.2919769287182 .9015579223683 .8159103393685 .0350494384886 .55898284912 87.7781066894589 .302040100190 .5211791992291 .4355392456192 .04509735107 92.65467834473 92.95947265625 93.2642517089893.8738174438594.17859649658 93.8738174438592 .6546783447390 .8259735107488 .0829010009884 .42548370361 78.9393463134878 .9393463134881 .3776321411184 .1206970214886 .2541885376 88.3876876831190.82597351074 93.2642517089895.70252990723 98.14080810547 100.2742996216102 .1029968262103 .9317016602105 .1509017944106 .6747970581 107.8938980103109 .1130981445110 .3321990967111 .551399231112 .4656982422 113.3800964355114 .2944030762115 .2088012695115 .818397522116 .4279022217 117.0374984741117 .342300415117 .647102356117 .9517974854118 .1360549927 118.2290267944118 .2565994263118 .2565994263117 .9517974854117 .647102356 117.0374984741116 .7326965332116 .1231002808115 .818397522116 .1231002808 
117.342300415118 .5614013672120 .6949005127121 .808380127122 .051574707 121.9140014648121 .9140014648121 .9140014648121 .3044967651120 .9997024536 119.7806015015119 .7806015015122 .2188034058122 .6207046509122 .5478897095 122.465675354122 .3789291382122 .2922744751122 .209602356122 .1339035034 122.0679397583122 .0148696899121 .9788513184121 .9650650024121 .9803314209 122.0322570801122 .1290740967121 .5091934204120 .7244873047119 .9367828369 119.1441421509118 .3447341919117 .5367660522116 .7186584473115 .8890609741 115.0475158691114 .1946334839113 .3323745728112 .4632492065111 .5902709961 110.7172241211109 .8490905762108 .9917602539108 .1511764526107 .3335113525 106.5445709229105 .789932251105 .0681533813104 .4017028809103 .7842559814 103.203697204666 .7479400634865 .5288009643665 .8335876464867 .35751342773 69.4910125732471 .6244964599673 .4532165527374 .4511489868275 .84947967529 77.0754623413177 .4500122070377 .0685424804776 .3435134887775 .47791290283 74.8497085571374 .6103134155374 .7836074829175 .3041839599676 .05372619629 76.8987045288177 .707450866778 .2812576293978 .268974304277 .03730010986 74.0299148559669 .6535568237366 .012977600165 .6659088134867 .05272674561 67.0527267456165 .5288009643663 .3953094482460 .9570198059158 .82352828979 57.2995986938556 .3852500915555 .7756805419955 .4708900451755 .16611099243 55.1661109924355 .1661109924355 .4708900451755 .7756805419956 .38525009155 57.2995986938557 .909179687558 .8235282897959 .7378807067960 .65224075317 61.5666007995662 .4809494018663 .3953094482464 .3096618652364 .91924285889 65.8335876464866 .4431610107467 .0527267456167 .3575134277367 .35751342773 67.3575134277367 .3575134277367 .0527267456166 .7479400634866 .13836669922 65.8335876464865 .5288009643665 .5288009643665 .2240066528365 .22400665283 65.2240066528365 .2240066528365 .2240066528365 .5288009643665 .83358764648 65.8335876464866 .4431610107466 .7479400634867 .0527267456167 .05272674561 67.3575134277367 .6623001098667 .9670867919968 .2718734741268 .88143920898 -9999 -9999 -9999 -9999 -9999 -9999 -9999 -9999 -9999 -9999 -9999 -9999 -9999 -9999 -9999 -9999 -9999 -9999 -9999 -9999 -9999 -9999 -9999 -9999 -9999 -9999 -9999 -9999 -9999 -9999 -9999 -9999 -9999 -9999 -9999 -9999 -9999 -9999 -9999 -9999 -9999 -9999 -9999 -9999 -9999 -9999 -9999 -9999 -9999 -9999 -9999 -9999 -9999 -9999 -9999 -9999 -9999 -9999 -9999 -9999 -9999 -9999 -9999 -9999 -9999 -9999 -9999 -9999 -9999 -9999 -9999 -9999 -9999 -9999 -9999 -

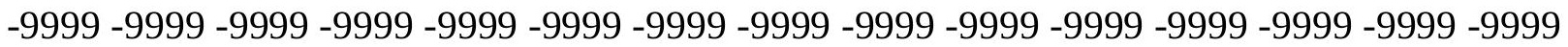
-9999 -9999 -9999 -9999 -9999 -9999 -9999 -9999 -9999 -9999 -9999 -9999 -9999 -9999 -9999 -9999 -9999 -9999 -9999 -9999 -9999 -9999 -9999 -9999 -9999 -9999 -9999 -9999 -9999 -9999 -9999 -9999 -9999 -9999 -9999 -9999 -9999 -9999 -9999 -9999 -9999 -9999 -9999 -9999 -9999

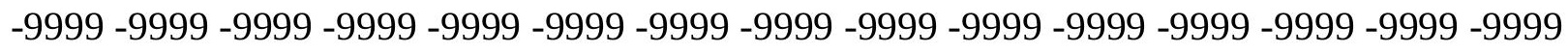
167.0222015381163 .0599975586160 .3170013428156 .6596069336149 .3446960449 141.7250976562137 .1533050537133 .1911010742129 .8385009766126 .4858016968 122.8283996582119 .4757995605117 .647102356115 .2088012695109 .7226028442 103.6268997192102 .4077987671103 .0174026489100 .883903503472 .53885650635 73.1484298706173 .1484298706173 .4532165527373 .7580032348674 .36756896973 74.9771423339875 .5867080688576 .1962814331176 .8058471679777 .72020721436 78.3297805786178 .9393463134879 .2441329956179 .5489196777379 .85370635986 79.8537063598679 .8537063598679 .8537063598679 .5489196777379 .54891967773 79.5489196777379 .5489196777379 .5489196777379 .8537063598680 .15849304199 
80.4632720947381 .0728530883882 .5967712402384 .1206970214885 .64462280273 87.1685485839888 .3876876831189 .6068267822390 .5211791992291 .43553924561 92.349891662693 .2642517089893 .8738174438594 .4833908081194 .48339080811 94.1785964965893 .2642517089892 .0450973510790 .5211791992285 .03504943848 82.2919769287181 .6824111938582 .5967712402383 .8159103393685 .94940185547 87.7781066894589 .9116134643691 .4355392456193 .2642517089895 .70252990723 98.4455871582100 .5791015625102 .712600708104 .2365036011106 .0652008057 107.5891036987108 .8082962036110 .0273971558111 .24659729112 .1608963013 113.075302124113 .9896011353114 .5991973877115 .5136032104116 .1231002808 116.7326965332117 .0374984741117 .342300415117 .647102356117 .7352294922 117.8359909058117 .9517974854117 .9517974854117 .647102356117 .647102356 117.647102356117 .647102356117 .647102356117 .647102356118 .2565994263 119.1709976196120 .6949005127121 .5234985352121 .7764282227121 .9936294556 122.1703033447120 .9997024536117 .9517974854114 .5991973877111 .24659729 110.9418029785116 .7326965332122 .2188034058122 .2678604126122 .1882858276 122.1064987183122 .0270614624121 .9539871216121 .890335083121 .8387756348 121.802154541121 .784324646121 .7899856567121 .8252410889121 .8968963623 122.0127716064122 .0037841797121 .2540817261120 .5025863647119 .747215271 118.9859542847118 .2168045044117 .4379348755116 .6478042603115 .8458480835 115.0327682495114 .2107543945113 .3826599121112 .5517501831111 .7218551636 110.8978805542110 .0857086182109 .2917404175108 .5230712891107 .7869720459 107.0906524658106 .4425964355105 .8671798706105 .364463806295 .3977432251 60.9570198059160 .9570198059163 .0905189514264 .9192428588966 .13836669922 67.3575134277368 .2718734741269 .4910125732471 .014930725173 .45321655273 73.7789916992273 .8815460205173 .1639938354572 .2908096313571 .75241088867 71.7193298339872 .1737060546973 .0311737060574 .0746841430775 .08743286133 75.8650131225676 .2027893066475 .8316268920974 .4894485473672 .1838684082 69.5098114013767 .7926330566467 .5283355712968 .2718734741269 .18623352051 67.6623001098665 .2240066528362 .4809494018659 .7378807067958 .21395874023 56.9948196411156 .3852500915555 .4708900451755 .1661109924354 .86132049561 54.8613204956155 .1661109924355 .7756805419956 .0804595947356 .99481964111 57.6043891906758 .5187492370659 .1283111572360 .0426712036160 .95701980591 62.1761703491263 .0905189514264 .3096618652365 .2240066528366 .13836669922 67.0527267456167 .6623001098667 .9670867919967 .9670867919967 .96708679199 67.6623001098667 .3575134277367 .0527267456166 .4431610107466 .13836669922 65.5288009643665 .2240066528365 .2240066528364 .9192428588964 .91924285889 64.9192428588965 .2240066528365 .2240066528365 .5288009643665 .83358764648 66.1383666992266 .4431610107466 .7479400634867 .0527267456167 .35751342773 67.3575134277367 .6623001098667 .9670867919968 .57665252686 -9999 -9999 -9999 -9999 -9999 -9999 -9999 -9999 -9999 -9999 -9999 -9999 -9999 -9999 -9999 -9999 -9999 -9999 -9999

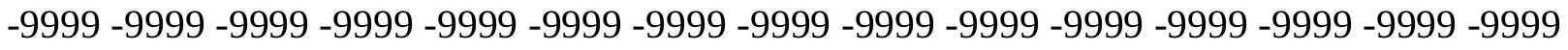

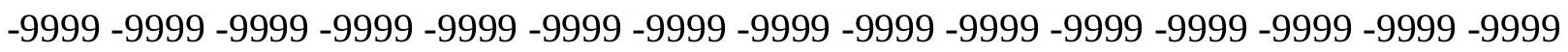
-9999 -9999 -9999 -9999 -9999 -9999 -9999 -9999 -9999 -9999 -9999 -9999 -9999 -9999 -9999 -9999 -9999 -9999 -9999 -9999 -9999 -9999 -9999 -9999 -9999 -9999

-9999 -9999 -9999 -9999 -9999 -9999 -9999 -9999 -9999 -9999 -9999 -9999 -9999 -9999 -9999

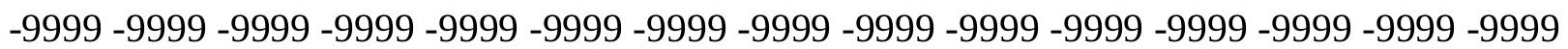


-9999 -9999 -9999 -9999 -9999 -9999 -9999 -9999 -9999 -9999 -9999 -9999 -9999 -9999 -9999 -9999 -9999 -9999 -9999 -9999 -9999 -9999 -9999 -9999 -9999 -9999 -9999 -9999 -9999 -9999 -9999 -9999 -9999 -9999 -9999 -9999 -9999 -9999 -9999 -9999 -9999 -9999 -9999 -9999 -9999 -9999 163.974395752160.6217956543156.3547973633149.6495056152142.9441986084 137.4580993652133 .4958953857130 .1432037354127 .7050018311124 .9618988037 122.8283996582122 .5235977173120 .6949005127113 .075302124105 .7603988647 102.712600708102 .4077987671102 .102996826268 .8814392089869 .79579162598 70.4053573608471 .014930725171 .6244964599672 .5388565063573 .45321655273 74.3675689697375 .2819290161176 .1962814331176 .8058471679777 .72020721436 78.3297805786178 .6345596313578 .9393463134878 .9393463134878 .93934631348 78.9393463134878 .6345596313578 .3297805786178 .3297805786178 .02498626709 78.0249862670978 .0249862670978 .0249862670978 .3297805786178 .63455963135 79.2441329956180 .4632720947381 .9871978759883 .5111236572385 .03504943848 86.5589828491287 .7781066894589 .302040100190 .5211791992291 .74033355713 92.6546783447392 .9594726562594 .1785964965894 .4833908081194 .78817749023 94.4833908081193 .5690307617291 .7403335571388 .9972534179786 .2541885376 85.0350494384885 .0350494384885 .3398437586 .254188537686 .86376190186 86.8637619018687 .4733276367288 .9972534179791 .7403335571394 .78817749023 97.2264633178799 .66472625732101 .7982025146103 .6268997192105 .4557037354 107.2844009399108 .5035018921109 .4179000854110 .6370010376111 .551399231 112.4656982422113 .3800964355114 .2944030762114 .9039993286115 .5136032104 116.1231002808116 .4279022217116 .7326965332117 .0374984741117 .1809692383 117.342300415117 .647102356117 .9517974854117 .9517974854118 .2565994263 118.5614013672118 .5614013672118 .5614013672118 .8662033081119 .1709976196 120.3900985718121 .2264938354121 .4934387207121 .7203979492121 .9016265869 120.3900985718115 .2088012695108 .8082962036102 .712600708100 .5791015625 107.8938980103116 .7326965332117 .9517974854117 .9517974854120 .0852966309 121.6886291504121 .6190643311121 .5616760254121 .5190353394121 .4935531616 121.4884033203121 .5074462891121 .555847168121 .6395263672121 .7659072876 121.9429168701121 .7715072632121 .0580291748120 .3417892456119 .6205825806 118.8921356201118 .1543502808117 .405380249116 .6444778442115 .8722915649 115.0910873413114 .3037261963113 .513343811112 .7236099243111 .9391403198 111.1656723022110 .4097518921109 .6793365479108 .9830551147108 .3284454346 107.7393798828107 .244010925396 .3121032714880 .4632720947358 .51874923706 60.3474502563562 .1761703491263 .7000885009864 .6144485473664 .91924285889 64.3096618652363 .3953094482463 .3953094482466 .1383666992268 .27187347412 70.1005783081169 .0658111572368 .5807189941465 .8335876464862 .17617034912 62.7857398986870 .5521850585971 .882118225173 .0364379882873 .80448150635 74.0367736816473 .626678466872 .5766754150471 .1007080078169 .69354248047 68.949363708569 .0960388183669 .8542785644570 .4447860717870 .10057830811 67.9670867919964 .6144485473660 .9570198059159 .7378807067958 .51874923706 57.2995986938556 .0804595947355 .4708900451755 .1661109924355 .16611099243 55.4708900451755 .7756805419956 .0804595947356 .6900291442957 .29959869385 57.909179687558 .8235282897959 .4331016540560 .6522407531761 .56660079956 62.7857398986864 .3096618652365 .5288009643666 .7479400634867 .96708679199 68.5766525268668 .8814392089868 .8814392089868 .5766525268668 .27187347412 
67.6623001098667 .0527267456166 .7479400634866 .1383666992265 .52880096436 65.2240066528364 .9192428588964 .9192428588964 .9192428588964 .91924285889 64.9192428588965 .2240066528365 .5288009643665 .8335876464866 .13836669922 66.4431610107466 .7479400634867 .0527267456167 .0527267456167 .35751342773 67.3575134277367 .6623001098667 .9670867919968 .27187347412 -9999 -9999 -9999 -9999 -9999 -9999 -9999 -9999 -9999 -9999 -9999 -9999 -9999 -9999 -9999 -9999 -9999 -9999 -9999

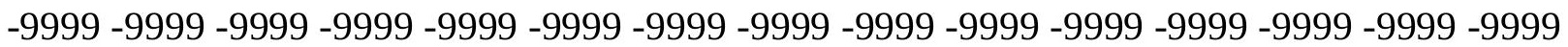

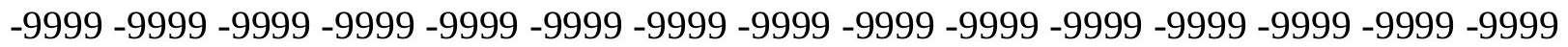

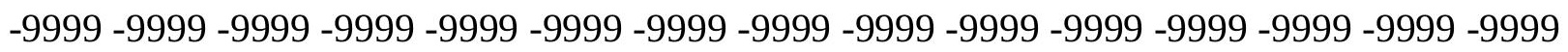
-9999 -9999 -9999 -9999 -9999 -9999 -9999 -9999 -9999 -9999

-9999 -9999 -9999 -9999 -9999 -9999 -9999 -9999 -9999 -9999 -9999 -9999 -9999 -9999 -9999 -9999 -9999 -9999 -9999 -9999 -9999 -9999 -9999 -9999 -9999 -9999 -9999 -9999 -9999 -9999 -9999 -9999 -9999 -9999 -9999 -9999 -9999 -9999 -9999 -9999 -9999 -9999 -9999 -9999 -9999 -9999 -9999 -9999 -9999 -9999 -9999 -9999 -9999 -9999 -9999 -9999 -9999 -9999 -9999 -9999 -9999 -9999 -9999 -9999 -9999 -9999 -9999 -9999 -9999 -9999 -9999 -9999 -9999 -9999 -9999 -9999 162.1457061768 156.9642944336151.4781951904 145.0776977539138.9819946289 133.8007049561129 .8385009766127 .0953979492124 .9618988037122 .2188034058 119.7806015015118 .2565994263115 .5136032104109 .4179000854106 .0652008057 104.2365036011103 .6268997192103 .017402648965 .8335876464867 .05272674561 67.9670867919968 .8814392089870 .1005783081171 .014930725172 .23407745361 73.1484298706174 .3675689697375 .2819290161176 .5010681152377 .41542053223 78.0249862670978 .3297805786178 .3297805786178 .3297805786178 .32978057861 78.0249862670977 .7202072143677 .4154205322377 .110626220776 .80584716797 76.5010681152376 .5010681152376 .5010681152376 .8058471679777 .1106262207 78.0249862670978 .9393463134880 .4632720947381 .9871978759883 .51112365723 85.0350494384886 .254188537687 .7781066894589 .302040100190 .52117919922 91.7403335571392 .6546783447393 .2642517089893 .8738174438594 .48339080811 94.4833908081193 .8738174438592 .349891662690 .5211791992288 .38768768311 87.1685485839886 .8637619018687 .1685485839887 .4733276367288 .08290100098 88.3876876831188 .3876876831188 .6924667358490 .2164001464892 .04509735107 94.1785964965896 .6168823242298 .75038146973100 .8839035034103 .0174026489 104.8460998535106 .3700027466107 .5891036987108 .8082962036110 .0273971558 110.9418029785112 .1608963013113 .075302124113 .6848983765114 .5991973877 114.9039993286115 .5136032104115 .818397522116 .1231002808116 .4279022217 116.7326965332117 .0374984741117 .5866012573117 .9517974854118 .4867935181 118.8653106689119 .1709976196119 .4757995605119 .4757995605119 .7806015015 120.6001663208120 .9236068726121 .2097167969121 .4483718872121 .6331100464 119.4757995605114 .2944030762106 .065200805795 .397743225188 .38768768311 91.4355392456199 .35994720459106 .979598999113 .9896011353118 .8662033081 121.2674407959121 .1949462891121 .1379547119121 .098739624121 .0790328979 121.0810852051121 .1075820923121 .1624984741121 .250793457121 .3793182373 121.5562210083121 .7919082642121 .5993041992120 .9239501953120 .2445755005 119.558631897118 .8636856079118 .1575469971117 .4391479492116 .7088928223 115.9689025879115 .2217483521114 .4701004028113 .7170333862112 .9667282104 112.2244567871111 .4966278076110 .7913589478110 .1182174683109 .4874420166 108.9338684082108 .482254028392 .6546783447374 .3675689697359 .12831115723 
60.6522407531762 .1761703491263 .0905189514263 .7000885009863 .70008850098 62.7857398986861 .2618103027359 .7378807067963 .0905189514261 .26181030273 62.4809494018664 .6144485473665 .2240066528363 .7000885009862 .48094940186 62.1761703491263 .3953094482466 .4431610107471 .037254333571 .78548431396 71.9765090942471 .6549301147570 .9686279296970 .1827774047969 .62238311768 69.5413665771570 .0347595214870 .8529357910271 .5063476562571 .46929931641 70.3877029418968 .5766525268665 .5288009643663 .0905189514260 .95701980591 58.8235282897956 .9948196411155 .7756805419955 .4708900451755 .47089004517 55.7756805419956 .0804595947356 .3852500915556 .6900291442956 .99481964111 57.6043891906758 .2139587402358 .8235282897959 .7378807067960 .95701980591 62.4809494018664 .3096618652365 .8335876464867 .3575134277368 .57665252686 69.49101257324 69.7957916259869.79579162598 69.1862335205168.57665252686 67.9670867919967 .3575134277366 .7479400634866 .1383666992265 .52880096436 65.2240066528364 .9192428588964 .6144485473664 .6144485473664 .61444854736 64.6144485473664 .9192428588965 .2240066528365 .5288009643665 .83358764648 66.1383666992266 .4431610107466 .7479400634867 .0527267456167 .35751342773 67.3575134277367 .3575134277367 .6623001098667 .96708679199 -9999 -9999 -9999-9999 -9999 -9999 -9999 -9999 -9999 -9999 -9999 -9999 -9999 -9999 -9999 -9999 -9999 -9999 -9999 -9999 -9999 -9999 -9999 -9999 -9999 -9999 -9999 -9999 -9999 -9999 -9999 -9999 -9999 -9999 -

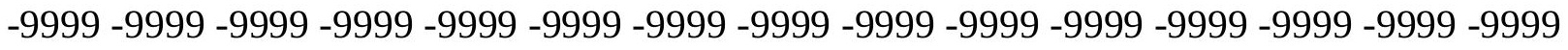

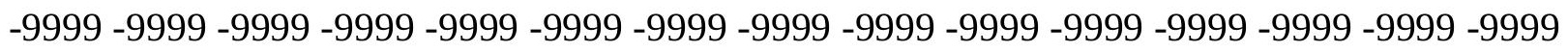
-9999 -9999-9999-9999-9999-9999-9999-9999-9999-9999 -9999 -9999 -9999 -9999 -9999 -9999 -9999 -9999 -9999 -9999 -9999 -9999 -9999 -9999 -9999

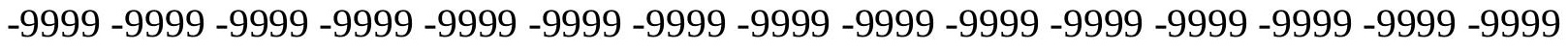

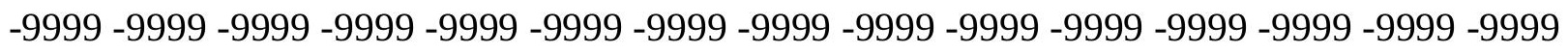
-9999 -9999 -9999 -9999 -9999 -9999 -9999 -9999 -9999 -9999 -9999 -9999 -9999 -9999 -9999 -9999 -9999 -9999 -9999 -9999 -9999 -9999 -9999 -9999 -9999 -9999 -9999 -9999 -9999 -9999 -9999-9999 149.9542999268 143.2489929199 137.1533050537131.9720001221 127.4001998901123 .43800354120 .9997024536118 .5614013672115 .5136032104 112.1608963013112 .1608963013110 .0273971558107 .2844009399105 .7603988647 105.1509017944103 .017402648961 .8713798522963 .3953094482464 .91924285889 66.1383666992267 .3575134277368 .5766525268669 .7957916259871 .0149307251 72.2340774536173 .4532165527374 .6723632812575 .8914871215877 .1106262207 77.7202072143678 .0249862670978 .0249862670977 .7202072143677 .41542053223 77.110626220776 .5010681152376 .1962814331175 .8914871215875 .58670806885 75.2819290161174 .9771423339875 .2819290161175 .2819290161175 .89148712158 76.5010681152377 .4154205322378 .6345596313580 .1584930419981 .68241119385 83.206336975184 .7302627563586 .254188537687 .7781066894589 .3020401001 90.5211791992291 .7403335571392 .6546783447393 .2642517089893 .26425170898 93.5690307617292 .9594726562592 .0450973510790 .5211791992289 .3020401001 88.0829010009887 .7781066894587 .7781066894588 .0829010009888 .69246673584 89.302040100189 .6068267822390 .5211791992291 .7403335571393 .56903076172 95.0929565429796 .3121032714897 .8360290527398 .75038146973100 .2742996216 102.4077987671104 .5412979126106 .6747970581108 .1986999512109 .7226028442 110.9418029785112 .1608963013113 .075302124113 .9896011353114 .5991973877 115.2088012695115 .5136032104115 .5136032104115 .5136032104115 .818397522 
115.818397522116 .4279022217117 .0259780884117 .6071166992118 .0924911499 118.4650650024118 .7950286865119 .1320266724119 .4927978516119 .8790512085 120.2656555176120 .6240692139120 .9350204468121 .1862716675121 .3044967651 118.5614013672113 .6848983765106 .674797058194 .1785964965883 .81591033936 82.2919769287186 .8637619018699 .05516815186112 .1608963013118 .2565994263 120.7539749146120 .6719360352120 .6095809937120 .5685806274120 .5497894287 120.5542297363120 .5831375122120 .6390457153120 .7256546021120 .8489532471 121.0168533325121 .2402648926121 .5317687988121 .4901351929120 .8542251587 120.2124404907119 .5619812012118 .9002838135118 .2258682251117 .5386428833 116.8402481079116 .1327209473115 .4179992676114 .6982345581113 .9767990112 111.551399231107 .5891036987111 .8547668457111 .1864776611110 .5539398193 109.9979095459109 .543273925896 .6168823242282 .2919769287160 .95701980591 61.8713798522962 .4809494018663 .0905189514263 .0905189514262 .78573989868 61.8713798522960 .6522407531759 .7378807067959 .4331016540559 .73788070679 60.3474502563561 .8713798522963 .0905189514263 .3953094482462 .78573989868 63.0905189514264 .6144485473667 .3575134277369 .2627716064569 .92751312256 70.0136184692469 .7502899169969 .3783645629969 .1304168701269 .16009521484 69.589569091870 .399978637771 .4113998413172 .2964782714872 .71884155273 72.4869613647571 .5773925781270 .1005783081167 .3575134277364 .30966186523 60.9570198059158 .2139587402356 .6900291442956 .3852500915556 .69002914429 56.9948196411156 .9948196411156 .9948196411156 .9948196411156 .99481964111 57.2995986938557 .6043891906758 .2139587402359 .1283111572360 .34745025635 62.1761703491264 .004882812566 .1383666992268 .2718734741269 .79579162598 70.4053573608470 .7101516723670 .4053573608469 .7957916259868 .88143920898 68.2718734741267 .3575134277366 .7479400634865 .8335876464865 .22400665283 64.9192428588964 .6144485473664 .3096618652364 .3096618652364 .30966186523 64.6144485473664 .6144485473664 .9192428588965 .5288009643665 .83358764648 66.1383666992266 .4431610107466 .7479400634867 .0527267456167 .05272674561 $67.0527267456167 .0527267456167 .0527267456167 .6623001098667 .96708679199-9999$ -9999 -9999 -9999 -9999 -9999 -9999 -9999 -9999 -9999 -9999 -9999 -9999 -9999 -9999 -9999 -9999 -9999 -9999 -9999 -9999 -9999 -9999 -9999 -9999 -9999 -9999 -9999 -9999 -9999 -9999 -

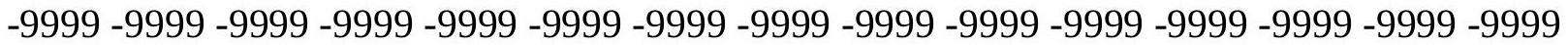

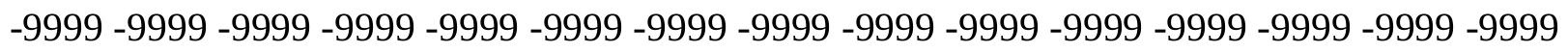
-9999 -9999 -9999 -9999 -9999 -9999 -9999 -9999 -9999 -9999 -9999 -9999 -9999 -9999 -9999 -9999 -9999 -9999 -9999 -9999 -9999 -9999 -9999 -9999 -9999 -9999 -9999

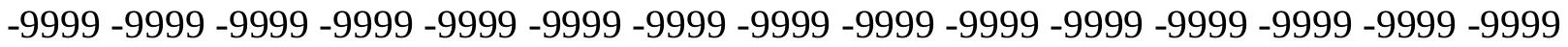

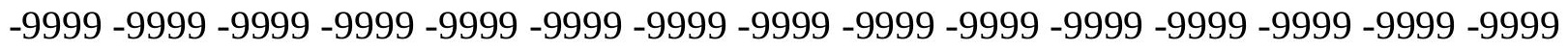

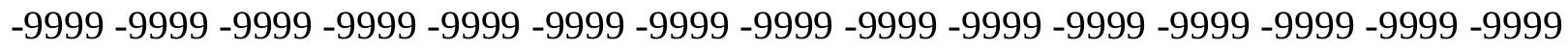

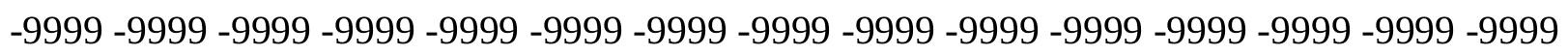
-9999 -9999-9999 131.9720001221 126.4858016968122 .2188034058117 .9517974854 114.2944030762110 .9418029785110 .0273971558110 .9418029785109 .4179000854 107.5891036987104 .5412979126101 .1886978149100 .5791015625104 .2365036011 97.8360290527360 .0426712036161 .5666007995663 .0905189514264 .61444854736 65.8335876464867 .3575134277368 .5766525268670 .1005783081171 .31971740723 72.8436431884874 .062782287675 .5867080688576 .8058471679777 .41542053223 77.7202072143677 .4154205322377 .110626220776 .5010681152376 .19628143311 
75.5867080688574 .9771423339874 .6723632812574 .3675689697374 .0627822876 73.7580032348673 .7580032348674 .062782287674 .3675689697374 .97714233398 75.8914871215877 .110626220778 .3297805786179 .8537063598681 .37763214111 82.9015579223684 .7302627563586 .254188537687 .7781066894588 .99725341797 90.5211791992291 .4355392456192 .0450973510792 .349891662692 .04509735107 91.7403335571391 .1307525634889 .9116134643688 .9972534179788 .08290100098 87.7781066894587 .7781066894588 .3876876831188 .9972534179789 .91161346436 90.8259735107493 .5690307617293 .2642517089894 .4833908081196 .00731658936 97.5312423706198 .7503814697399 .96952056885101 .4934005737103 .6268997192 105.7603988647107 .5891036987109 .4179000854110 .6370010376112 .1608963013 113.075302124113 .9896011353114 .9039993286115 .5136032104115 .5136032104 115.5136032104115 .2088012695114 .9039993286114 .5991973877114 .9039993286 115.5136032104116 .4279022217117 .1807098389117 .6797332764118 .0149536133 118.3167648315118 .6577529907119 .056602478119 .4914474487119 .9358596802 120.3409500122120 .6815109253120 .9442672729121 .1241760254119 .4757995605 115.5136032104110 .9418029785106 .3700027466102 .102996826298 .75038146973 99.05516815186105 .7603988647114 .5991973877119 .7806015015120 .1371612549 120.0388793945119 .9654846191119 .9179382324119 .8959274292119 .8990249634 119.9267272949119 .9797592163120 .0601501465120 .1725387573120 .3240585327 120.5254516602120 .7900924683121 .1346969604121 .44581604120 .8496704102 120.245223999119 .6295013428119 .0005264282118 .3575363159117 .7013244629 117.0330505371116 .3537368774115 .6643600464114 .9671401978113 .075302124 113.5641098022112 .8690872192112 .188079834111 .5297546387110 .9346694946 110.4152679443104 .846099853589 .302040100163 .0905189514263 .39530944824 63.3953094482463 .3953094482463 .0905189514262 .1761703491261 .56660079956 60.6522407531760 .0426712036159 .7378807067960 .0426712036160 .65224075317 61.5666007995662 .1761703491262 .7857398986862 .7857398986863 .39530944824 64.9192428588966 .5667495727567 .7933731079168 .2152023315468 .04871368408 67.7718124389667 .6565551757867 .8329238891668 .3277359008869 .15843200684 70.2942810058671 .5886917114372 .8217163085973 .7368774414174 .1612701416 73.9806671142673 .1839218139671 .6244964599668 .2718734741263 .70008850098 59.4331016540558 .2139587402358 .2139587402358 .8235282897958 .82352828979 58.5187492370658 .2139587402357 .6043891906756 .9948196411156 .69002914429 56.6900291442956 .9948196411157 .909179687559 .1283111572361 .26181030273 63.7000885009866 .1383666992268 .8814392089870 .7101516723671 .62449645996 71.6244964599671 .014930725170 .1005783081169 .1862335205167 .96708679199 67.3575134277366 .4431610107465 .5288009643664 .9192428588964 .61444854736 64.3096618652364 .004882812564 .004882812564 .004882812564 .30966186523 64.3096618652364 .9192428588965 .2240066528365 .5288009643666 .13836669922 66.4431610107466 .7479400634867 .0527267456167 .0527267456167 .05272674561 67.0527267456167 .0527267456167 .0527267456167 .66230010986 -9999 -9999 -9999 -9999 -9999 -9999 -9999 -9999 -9999 -9999 -9999 -9999 -9999 -9999 -9999 -9999 -9999 -9999 -9999 -

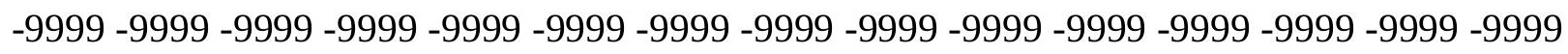
-9999 -9999 -9999 -9999 -9999 -9999 -9999 -9999 -9999 -9999 -9999 -9999 -9999 -9999 -9999 -

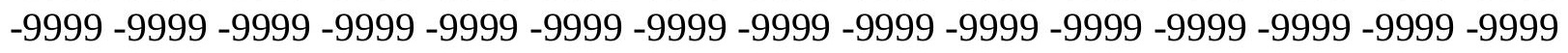
-9999 -9999 -9999 -9999 -9999 -9999 -9999 -9999 -9999 
-9999 -9999 -9999 -9999 -9999 -9999 -9999 -9999 -9999 -9999 -9999 -9999 -9999 -9999 -9999 -9999 -9999 -9999 -9999 -9999 -9999 -9999 -9999 -9999 -9999 -9999 -9999 -9999 -9999 -9999 -9999 -9999 -9999 -9999 -9999 -9999 -9999 -9999 -9999 -9999 -9999 -9999 -9999 -9999 -9999 -9999 -9999 -9999 -9999 -9999 -9999 -9999 -9999 -9999 -9999 -9999 -9999 -9999 -9999 -9999 -9999 -9999 -9999 -9999 -9999 -9999 -9999 -9999 -9999 -9999 -9999 -9999 -9999 -9999 -9999 -9999 -9999 -9999 -9999 114.9039993286112.7705001831 112.1608963013110 .9418029785 109.7226028442108 .5035018921107 .2844009399105 .4557037354102 .1029968262 98.1408081054793.56903076172 88.9972534179792.9594726562592.95947265625 58.5187492370660 .3474502563561 .8713798522963 .3953094482464 .61444854736 66.1383666992267 .6623001098669 .1862335205170 .7101516723671 .92929077148 73.4532165527374 .9771423339876 .1962814331177 .110626220777 .1106262207 76.8058471679776 .1962814331175 .5867080688575 .2819290161174 .67236328125 74.062782287673 .4532165527373 .1484298706172 .8436431884872 .53885650635 72.5388565063572 .8436431884873 .1484298706173 .7580032348674 .36756896973 75.2819290161176 .5010681152378 .0249862670979 .5489196777381 .07285308838 82.5967712402384 .4254837036185 .9494018554787 .4733276367288 .69246673584 89.9116134643690 .8259735107491 .1307525634891 .1307525634890 .82597351074 90.5211791992289 .9116134643690 .8259735107493 .2642517089890 .21640014648 89.302040100189 .6068267822390 .2164001464890 .8259735107491 .74033355713 92.6546783447393 .8738174438595 .0929565429796 .6168823242298 .14080810547 99.35994720459100 .8839035034102 .712600708104 .5412979126106 .3700027466 108.1986999512110 .0273971558111 .551399231112 .7705001831113 .6848983765 114.5991973877115 .2088012695115 .818397522115 .818397522115 .5136032104 114.9039993286113 .9896011353112 .7705001831113 .9896011353114 .9039993286 115.818397522116 .7326965332117 .1407165527117 .4483337402117 .7306518555 118.105506897118 .5794525146119 .1082305908119 .6306838989120 .092338562 120.4636077881120 .7323608398120 .8968963623120 .3900985718117 .647102356 115.818397522119 .4757995605120 .5481033325119 .4757995605116 .1231002808 116.7326965332118 .8662033081119 .5575561523119 .4066543579119 .2855377197 119.195854187119 .1377487183119 .1096038818119 .1092910767119 .1342544556 119.1829681396119 .2552719116119 .3538131714119 .4842300415119 .6564559937 119.8839569092120 .1845397949120 .5778045654121 .0853805542120 .9090042114 120.3407669067119 .7587509155119 .1613464355118 .5482788086117 .9195022583 117.274848938116 .6139373779115 .9374084473115 .2470703125114 .5460739136 113.8385772705113 .1298904419112 .4259796143111 .7526016235111 .1191177368 108.198699951289 .9116134643681 .6824111938565 .2240066528364 .61444854736 63.7000885009862 .7857398986862 .1761703491261 .2618103027360 .65224075317 60.3474502563560 .0426712036160 .3474502563560 .6522407531761 .26181030273 61.5666007995662 .1761703491262 .4809494018663 .0905189514264 .0048828125 65.2240066528366 .4431610107466 .4431610107465 .902198791564 .91924285889 65.8152465820366 .3840942382867 .2245864868268 .3567657470769 .79811859131 71.4604568481473 .1189804077174 .5136795043975 .457176208575 .83604431152 75.5097427368274 .2376632690471 .7176055908267 .9670867919960 .95701980591 61.5666007995661 .8713798522961 .8713798522961 .5666007995660 .65224075317 59.4331016540558 .2139587402356 .9948196411156 .0804595947355 .77568054199 55.7756805419956 .3852500915557 .6043891906759 .7378807067962 .48094940186 
65.8335876464869 .1862335205171 .6244964599672 .2340774536171 .62449645996 70.7101516723669 .7957916259868 .8814392089867 .6623001098666 .74794006348 65.8335876464865 .2240066528364 .6144485473664 .004882812563 .70008850098 63.7000885009863 .3953094482463 .7000885009863 .7000885009864 .0048828125 64.6144485473664 .9192428588965 .5288009643665 .8335876464866 .44316101074 66.7479400634867 .0527267456167 .0527267456167 .0527267456167 .05272674561 67.0527267456166 .7479400634867 .0527267456167 .66230010986 -9999 -9999 -9999 -9999 -9999 -9999 -9999 -9999 -9999 -9999 -9999 -9999 -9999 -9999 -9999 -9999 -9999 -9999 -9999 -9999 -9999 -9999 -9999 -9999 -9999 -9999 -9999 -9999 -9999 -9999 -9999 -9999 -9999 -9999 -9999 -9999 -9999 -9999 -9999 -9999 -9999 -9999 -9999 -9999 -9999 -9999 -9999 -9999 -9999 -

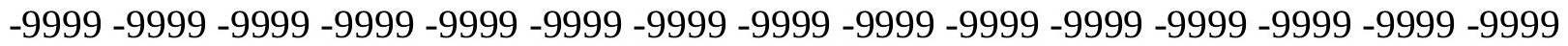
-9999 -9999-9999-9999-9999-9999-9999-9999

-9999 -9999 -9999 -9999 -9999 -9999 -9999 -9999 -9999 -9999 -9999 -9999 -9999 -9999 -9999 -9999 -9999 -9999 -9999 -9999 -9999 -9999 -9999 -9999 -9999 -9999 -9999 -9999 -9999 -9999 -9999 -9999 -9999 -9999 -9999 -9999 -9999 -9999 -9999 -9999 -9999 -9999 -9999 -9999 -9999 -

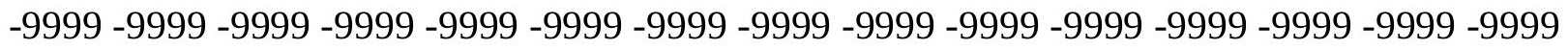

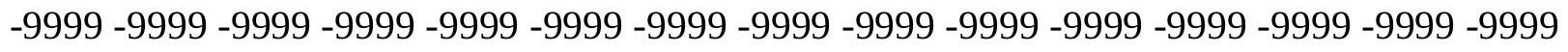
-9999 -9999 -9999 -9999 112.1608963013 111.24659729110 .3321990967109 .1130981445 107.8938980103106 .0652008057103 .9317016602100 .883903503496 .92166900635 92.349891662687 .7781066894584 .4254837036183 .8159103393683 .81591033936 57.2995986938559 .1283111572360 .6522407531762 .1761703491263 .70008850098 65.2240066528366 .7479400634868 .2718734741269 .7957916259871 .31971740723 72.5388565063574 .062782287675 .2819290161175 .8914871215875 .89148712158 75.8914871215875 .2819290161174 .6723632812574 .062782287673 .45321655273 72.8436431884872 .2340774536171 .9292907714871 .6244964599671 .31971740723 71.3197174072371 .3197174072371 .6244964599672 .2340774536172 .84364318848 73.7580032348674 .6723632812575 .8914871215877 .4154205322379 .24413299561 80.7680587768682 .5967712402384 .1206970214885 .6446228027387 .16854858398 88.0829010009888 .9972534179789 .6068267822389 .9116134643689 .91161346436 89.91161346436 90.2164001464890.8259735107491.7403335571391.13075256348 90.8259735107491 .1307525634891 .1307525634891 .4355392456192 .3498916626 92.9594726562594 .1785964965895 .397743225196 .9216690063598 .4455871582 99.96952056885101 .4934005737103 .3221969604105 .1509017944106 .979598999 108.8082962036110 .3321990967111 .8561019897113 .075302124114 .2944030762 114.9039993286115 .5136032104115 .818397522115 .5136032104115 .2088012695 114.5991973877113 .6848983765113 .075302124113 .6848983765114 .2944030762 114.5991973877115 .818397522116 .4044723511116 .6800918579116 .968711853 117.4360198975118 .0619506836118 .7390136719119 .3723526001119 .9008560181 120.2969207764120 .5595321655120 .6931762695120 .0852966309119 .7806015015 120.0852966309120 .2720031738120 .0247268677119 .7559127808119 .4806289673 119.2122573853118 .9620819092118 .7394180298118 .5507583618118 .4004364014 118.2897415161 118.2180786133118.1823959351 118.1786880493118.2019805908 118.2480392456118 .3138580322118 .399307251118 .5077438354118 .647354126 118.8310546875119 .0770721436119 .4068450928119 .8444366455120 .4118499756 121.0278167725120 .4946975708119 .9447860718119 .3765182495118 .7883987427 118.1788482666117 .5458602905116 .8882369995116 .2056274414115 .4991989136 
114.7706451416114 .0227584839113 .2584915161112 .4853439331111 .7110595703 104.846099853592 .9594726562578 .9393463134867 .0527267456165 .22400665283 64.004882812562 .7857398986861 .8713798522961 .2618103027360 .65224075317 60.3474502563560 .3474502563560 .6522407531760 .9570198059160 .95701980591 61.2618103027361 .5666007995661 .8713798522962 .1761703491262 .78573989868 63.7000885009864 .004882812564 .004882812563 .7000885009863 .39530944824 63.3953094482464 .6144485473665 .99916839667 .280693054269 .0075225830171 .125 73.2835388183675 .1380081176876 .5007705688577 .2985382080177 .43657684326 76.7012710571374 .89340972972 .0906600952169 .4910125732467 .35751342773 66.7479400634865 .8335876464864 .6144485473662 .7857398986860 .95701980591 58.8235282897956 .9948196411155 .1661109924354 .2517509460453 .94697189331 54.2517509460455 .7756805419957 .909179687560 .6522407531764 .30966186523 68.2718734741271 .9292907714871 .6244964599671 .014930725170 .10057830811 68.8814392089867 .9670867919967 .0527267456166 .1383666992265 .52880096436 64.6144485473664 .004882812563 .7000885009863 .3953094482463 .09051895142 63.0905189514263 .0905189514263 .3953094482463 .7000885009864 .30966186523 64.9192428588965 .2240066528365 .8335876464866 .4431610107466 .74794006348 67.0527267456167 .0527267456167 .3575134277367 .0527267456167 .05272674561 66.7479400634866 .7479400634867 .05272674561 -9999 -9999 -9999-9999 -9999 -9999 -9999

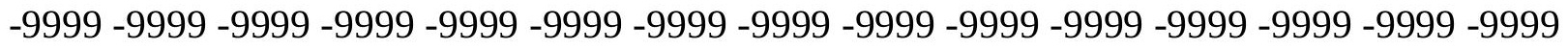

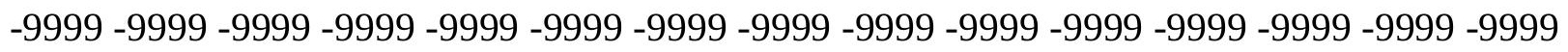
-9999 -9999 -9999 -9999 -9999 -9999 -9999 -9999 -9999 -9999 -9999 -9999 -9999 -9999 -9999 -

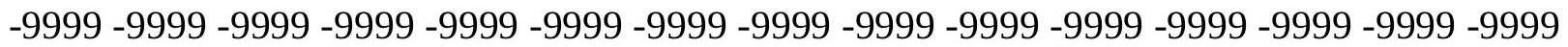
-9999 -9999 -9999-9999-9999

-9999 -9999 -9999 -9999 -9999 -9999 -9999 -9999 -9999-9999 -9999 -9999 -9999 -9999 -999 -9999 -9999 -9999 -9999 -9999 -9999 -9999 -9999 -9999 -9999 -9999 -9999 -9999 -9999 -9999

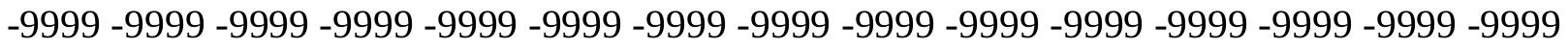

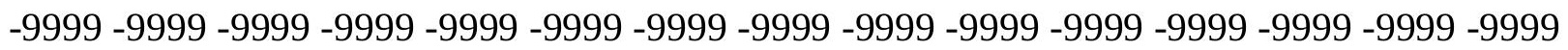

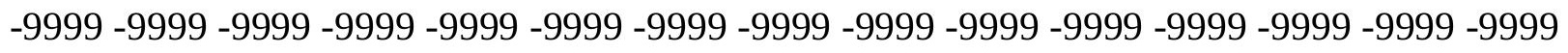
-9999 -9999 -9999 -9999 -9999 109.4179000854 108.5035018921 107.2844009399 105.7603988647103 .3221969604100 .579101562596 .9216690063592 .65467834473 88.0829010009883 .5111236572380 .1584930419977 .7202072143675 .58670806885 56.3852500915558 .2139587402359 .7378807067961 .2618103027362 .78573989868 64.3096618652365 .8335876464867 .3575134277368 .8814392089870 .40535736084 71.6244964599672 .8436431884873 .7580032348674 .3675689697374 .67236328125 74.6723632812574 .062782287673 .7580032348673 .1484298706172 .53885650635 71.9292907714871 .3197174072370 .7101516723670 .4053573608470 .10057830811 70.1005783081170 .1005783081170 .4053573608470 .7101516723671 .0149307251 71.6244964599672 .8436431884874 .062782287675 .5867080688577 .1106262207 78.6345596313580 .4632720947381 .9871978759883 .8159103393685 .03504943848 86.254188537687 .4733276367288 .0829010009888 .6924667358488 .99725341797 88.9972534179788 .9972534179788 .9972534179789 .302040100189 .91161346436 90.2164001464890 .8259735107491 .1307525634891 .7403335571392 .3498916626 93.26425170898 94.4833908081195.7025299072397.2264633178798.75038146973 100.2742996216102 .1029968262103 .9317016602105 .4557037354107 .2844009399 109.1130981445110 .6370010376112 .1608963013113 .3800964355114 .2944030762 
115.2088012695115 .5136032104115 .818397522115 .5136032104115 .2088012695 114.5991973877113 .6848983765113 .3800964355113 .3800964355113 .6848983765 113.9896011353114 .5991973877115 .5136032104115 .60987854115 .9373626709 116.6390914917117 .5556716919118 .4650726318119 .2362594604119 .82006073 120.2130661011120 .3900985718119 .7806015015119 .7806015015120 .3013305664 120.0620117188118 .2565994263114 .9039993286118 .8662033081118 .7264785767 118.3861846924118 .0718078613117 .7938766479117 .5597457886117 .3742752075 117.2387084961117 .151802063117 .1091308594117 .1046066284117 .1305389404 117.1794509888117 .2448043823117 .322807312117 .4135131836117 .5224075317 117.6608200073117 .8468170166118 .1033782959118 .4573974609118 .9337844849 119.5589141846120 .3670654297120 .7012634277120 .1806564331119 .6357040405 119.0631942749118 .4593963623117 .8211746216117 .1457061768116 .4315643311 115.6775817871114 .883682251114 .0502166748113 .1748657227108 .8507080078 97.5312423706187 .4733276367274 .062782287668 .2718734741265 .52880096436 63.7000885009862 .4809494018661 .5666007995660 .9570198059160 .65224075317 60.3474502563560 .6522407531760 .9570198059160 .6522407531760 .65224075317 60.6522407531760 .9570198059160 .9570198059161 .2618103027361 .56660079956 61.8713798522962 .1761703491262 .1761703491261 .8713798522962 .17617034912 62.7857398986864 .004882812564 .8413238525465 .9331283569368 .00155639648 70.7398986816473 .4741134643675 .7274856567477 .3683853149478 .52755737305 79.2094726562579 .2390594482478 .4047470092876 .7449493408274 .94366455078 73.0958786010771 .9292907714869 .7957916259867 .6623001098665 .22400665283 62.1761703491259 .4331016540556 .6900291442954 .2517509460452 .72782897949 51.8134689331152 .1182594299353 .3373985290555 .4708900451758 .21395874023 61.5666007995665 .5288009643668 .2718734741269 .1862335205169 .18623352051 68.2718734741267 .6623001098666 .7479400634866 .1383666992265 .22400665283 64.6144485473664 .004882812563 .3953094482463 .0905189514262 .78573989868 62.4809494018662 .4809494018662 .7857398986863 .0905189514263 .39530944824 64.004882812564 .6144485473665 .2240066528365 .8335876464866 .44316101074 66.7479400634867 .0527267456167 .3575134277367 .3575134277367 .35751342773 67.0527267456166 .7479400634866 .4431610107466 .7479400634867 .05272674561 -9999 -9999 -9999 -9999 -9999 -9999 -9999 -9999 -9999 -9999 -9999 -9999 -9999 -9999 -9999 -9999

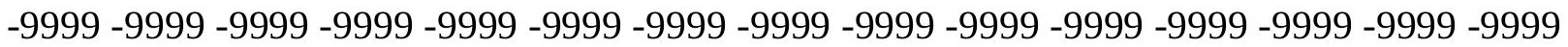
-9999 -9999 -9999 -9999 -9999 -9999 -9999 -9999 -9999 -9999 -9999 -9999 -9999 -9999 -9999 -9999 -9999 -9999 -9999 -9999 -9999 -9999 -9999 -9999 -9999 -9999 -9999 -9999 -9999 -9999 -9999 -9999 -9999 -9999 -9999 -9999 -9999 -9999 -9999-9999

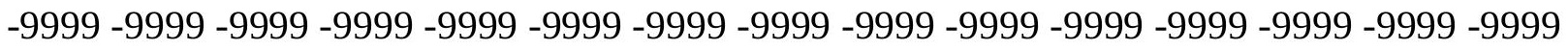

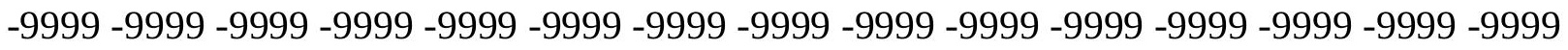
-9999 -9999 -9999 -9999 -9999 -9999 -9999 -9999 -9999 -9999 -9999 -9999 -9999 -9999 -9999 -9999 -9999 -9999 -9999 -9999 -9999 -9999 -9999 -9999 -9999 -9999 -9999 -9999 -9999 -9999 -

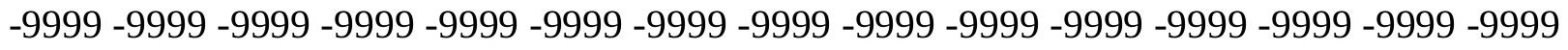
-9999 -9999 -9999 -9999-9999-9999 107.2844009399 105.7603988647 103.9317016602 101.188697814997 .8360290527393 .8738174438589 .6068267822385 .03504943848 80.7680587768676 .8058471679773 .1484298706169 .4910125732455 .77568054199 57.2995986938558 .8235282897960 .6522407531762 .1761703491263 .70008850098 65.2240066528366 .7479400634867 .9670867919969 .4910125732470 .71015167236 
71.6244964599672 .5388565063573 .1484298706173 .4532165527373 .14842987061 73.1484298706172 .5388565063571 .9292907714871 .3197174072370 .71015167236 70.1005783081169 .4910125732469 .1862335205168 .8814392089868 .57665252686 68.5766525268668 .8814392089868 .8814392089869 .1862335205169 .79579162598 70.7101516723671 .9292907714873 .4532165527374 .9771423339876 .80584716797 78.6345596313580 .1584930419981 .6824111938583 .206336975184 .42548370361 85.6446228027386 .5589828491287 .1685485839887 .4733276367287 .77810668945 87.4733276367287 .1685485839886 .254188537688 .0829010009889 .3020401001 90.2164001464890 .8259735107491 .4355392456192 .0450973510792 .95947265625 94.1785964965895 .7025299072397 .2264633178798 .75038146973100 .5791015625 102.1029968262103 .9317016602105 .7603988647107 .5891036987109 .4179000854 110.9418029785112 .1608963013113 .3800964355114 .2944030762115 .2088012695 115.5136032104115 .5136032104115 .5136032104115 .2088012695114 .5991973877 113.9896011353113 .6848983765113 .3800964355113 .3800964355113 .3800964355 114.5991973877113 .9896011353114 .0012207031114 .6590499878115 .8754882812 117.2267990112118 .2565994263118 .8662033081119 .1709976196119 .4757995605 119.4757995605119 .1709976196119 .4757995605119 .927482605119 .5911407471 118.5614013672116 .4279022217118 .3089675903117 .8651885986117 .4418029785 117.0529403687116 .7106781006116 .4235916138116 .1975860596116 .0341949463 115.9319152832115 .8849487305115 .8851547241115 .9217376709115 .983543396 116.059715271116 .1418762207116 .2256317139116 .3124313354116 .4109115601 116.5378799438116 .7178344727116 .983039856117 .3583755493117 .8840484619 118.6111907959119 .5668792725120 .7460021973120 .4558868408119 .9241027832 119.3528213501 118.7370605469118.0715789795 117.3520355225116.5738754272 115.73387146114 .8295593262113 .8610534668105 .218734741294 .48339080811 84.4254837036174 .3675689697366 .4431610107464 .6144485473663 .09051895142 61.8713798522960 .9570198059160 .3474502563560 .3474502563560 .34745025635 60.3474502563560 .3474502563560 .3474502563560 .3474502563560 .04267120361 60.0426712036160 .0426712036160 .3474502563560 .3474502563560 .65224075317 60.6522407531760 .6522407531760 .6522407531761 .2618103027362 .17617034912 63.0905189514264 .004882812564 .3096618652365 .5288009643670 .58207702637 73.8937683105576 .3121185302777 .9394149780379 .3863449096780 .80403900146 81.8267974853581 .9300460815480 .9892501831179 .2687377929777 .26910400391 75.2378768920973 .1484298706170 .7101516723667 .3575134277363 .70008850098 59.7378807067956 .3852500915553 .6421813964851 .2038993835449 .98476028442 49.6799812316950 .5943298339852 .7278289794955 .4708900451759 .12831115723 62.1761703491264 .6144485473665 .8335876464866 .1383666992266 .13836669922 65.8335876464865 .2240066528364 .6144485473664 .3096618652363 .70008850098 63.0905189514262 .7857398986862 .4809494018662 .1761703491261 .87137985229 61.8713798522962 .1761703491262 .4809494018663 .0905189514263 .70008850098 64.3096618652364 .9192428588965 .8335876464866 .4431610107467 .05272674561 67.3575134277367 .6623001098667 .6623001098667 .6623001098667 .35751342773 67.0527267456166 .4431610107466 .4431610107466 .74794006348 -9999 -9999 -9999 -9999 -9999 -9999 -9999 -9999 -9999 -9999 -9999 -9999 -9999 -9999 -9999 -9999 -9999 -9999 -9999 -9999 -9999 -9999 -9999 -9999 -9999 -9999 -9999 -9999 -9999 -9999 -9999 -9999 -9999 -9999 -

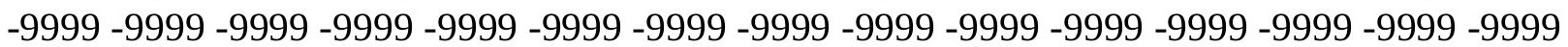


-9999 -9999 -9999 -9999 -9999 -9999 -9999 -9999 -9999 -9999 -9999 -9999 -9999 -9999 -9999 -9999 -9999 -9999 -9999-9999-9999-9999

-9999 -9999 -9999 -9999 -9999 -9999 -9999 -9999 -9999 -9999 -9999 -9999 -9999 -9999 -9999 -9999 -9999 -9999 -9999 -9999 -9999 -9999 -9999 -9999 -9999 -9999 -9999 -9999 -9999 -9999 -9999 -9999 -9999 -9999 -9999 -9999 -9999 -9999 -9999 -9999 -9999 -9999 -9999 - -9999 - -9999 -

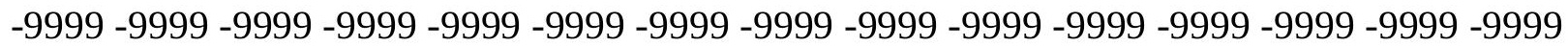

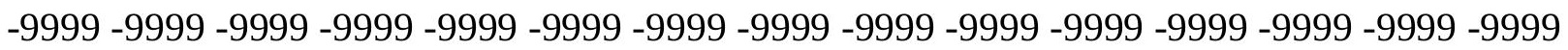
-9999 -9999-9999-9999-9999-9999-9999 105.4557037354 103.017402648999 .96952056885 96.3121032714892 .349891662688 .0829010009883 .5111236572378 .93934631348 74.6723632812570 .1005783081165 .2240066528355 .1661109924356 .69002914429 58.2139587402359 .7378807067961 .5666007995663 .0905189514264 .30966186523 65.8335876464867 .3575134277368 .5766525268669 .4910125732470 .71015167236 71.3197174072371 .9292907714871 .9292907714871 .9292907714871 .62449645996 71.3197174072371 .014930725170 .4053573608469 .4910125732468 .88143920898 68.2718734741267 .9670867919967 .3575134277367 .0527267456166 .74794006348 66.7479400634866 .7479400634867 .0527267456167 .6623001098668 .57665252686 70.1005783081171 .6244964599673 .1484298706174 .9771423339876 .50106811523 78.3297805786179 .8537063598681 .3776321411182 .5967712402383 .81591033936 84.7302627563585 .6446228027386 .254188537686 .5589828491286 .55898284912 86.254188537686 .5589828491287 .4733276367288 .6924667358489 .60682678223 90.2164001464890 .8259735107491 .4355392456192 .6546783447393 .87381744385 95.397743225197 .2264633178798 .75038146973100 .5791015625102 .4077987671 104.2365036011106 .0652008057107 .8938980103109 .4179000854110 .9418029785 112.1608963013113 .3800964355114 .2944030762114 .9039993286115 .2088012695 115.5136032104115 .5136032104115 .2088012695114 .5991973877114 .2944030762 113.6848983765113 .3800964355113 .075302124112 .4656982422112 .1608963013 112.1608963013112 .1259078979113 .4616241455114 .5991973877115 .5136032104 116.1231002808117 .0374984741117 .9517974854117 .9517974854118 .2565994263 118.5614013672118 .8662033081119 .1709976196119 .050163269118 .5336303711 117.9875793457117 .4328460693116 .8883209229116 .371673584115 .8986740112 115.4833984375115 .1363296509114 .8650512695114 .6720504761114 .5559005737 114.5097427368114 .5233154297114 .5826263428114 .6722946167114 .7764968872 114.8812866211114 .9765930176115 .0583496094115 .1307907104115 .2081832886 115.3167648315115 .4819717407115 .7482757568116 .1677093506116 .814491272 117.7241363525118 .8762359619120 .2141647339120 .7564544678120 .2231292725 119.6356506348118 .986618042118 .2689971924117 .4747085571116 .5969161987 115.6293945312113 .858795166104 .761695861890 .2164001464883 .2063369751 75.8914871215864 .004882812562 .7857398986861 .8713798522961 .26181030273 60.6522407531760 .0426712036160 .0426712036159 .7378807067959 .73788070679 59.7378807067959 .7378807067959 .4331016540559 .4331016540559 .43310165405 59.4331016540559 .4331016540559 .4331016540559 .4331016540559 .43310165405 59.4331016540559 .7378807067960 .3474502563561 .2618103027362 .17617034912 63.0905189514264 .004882812566 .1383666992270 .4053573608474 .79817199707 76.6249237060577 .7196502685579 .3456726074281 .9427032470784 .2839050293 85.4046936035284 .6568984985482 .5340957641679 .8822097778377 .20350646973 74.7095947265672 .1285781860469 .1862335205165 .2240066528360 .95701980591 
56.6900291442953 .6421813964850 .8991203308148 .4608306884847 .24169921875 47.8512611389249 .9847602844253 .0326118469256 .0804595947358 .82352828979 60.9570198059162 .4809494018663 .0905189514263 .3953094482463 .39530944824 63.3953094482463 .3953094482463 .0905189514262 .7857398986862 .48094940186 62.1761703491261 .5666007995661 .5666007995661 .2618103027361 .26181030273 61.5666007995661 .8713798522962 .4809494018663 .3953094482464 .0048828125 64.9192428588965 .8335876464866 .4431610107467 .3575134277367 .66230010986 67.9670867919967 .9670867919967 .9670867919967 .6623001098667 .05272674561 66.7479400634866 .1383666992266 .44316101074 -9999 -9999 -9999 -9999 -9999 -9999-9999 -9999 -9999 -9999 -9999 -9999 -9999 -9999 -9999 -9999 -9999 -9999 -9999 -9999 -9999 -9999 -9999 -9999 -9999 -9999 -9999 -9999 -9999 -9999 -9999 -9999 -9999 -9999 -9999 -9999 -9999 -9999 -9999 -9999 -9999 -9999 -9999 -9999 -9999 -9999 -9999 -9999 -9999 -9999 -9999 -9999 -9999 -9999-9999 -9999 -9999 -9999 -9999 -9999 -9999 -9999 -9999 -9999 -999 -999 -999 -999 -9999 -9999-9999-9999

-9999 -9999 -9999 -9999 -9999 -9999 -9999 -9999 -9999 -9999 -9999 -9999 -9999 -9999 -9999

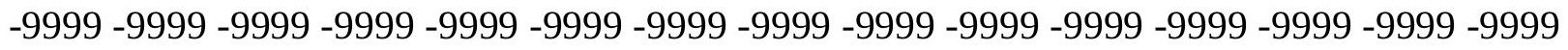
-9999 -9999 -9999 -9999 -9999 -9999 -9999 -9999 -9999 -9999 -9999 -9999 -9999 -9999 -9999 -9999 -9999 -9999 -9999 -9999 -9999 -9999 -9999 -9999 -9999 -9999 -9999 -9999 -9999 -9999 -9999 -9999 -9999 -9999 -9999 -9999 -9999 -9999 -9999 -9999 -9999 -9999 -9999 -9999 -9999 -9999 -9999 -9999 -9999-9999 -9999 -9999 -9999 103.322196960499 .96952056885 96.3121032714892 .0450973510787 .7781066894583 .206336975178 .32978057861 73.4532165527368 .5766525268663 .0905189514254 .5565414428756 .08045959473 57.909179687559 .4331016540560 .9570198059162 .4809494018663 .70008850098 65.2240066528366 .4431610107467 .6623001098668 .5766525268669 .49101257324 70.1005783081170 .4053573608470 .7101516723670 .7101516723670 .40535736084 70.1005783081169 .7957916259869 .1862335205168 .5766525268667 .96708679199 67.3575134277366 .7479400634866 .1383666992265 .5288009643664 .91924285889 64.6144485473664 .6144485473664 .9192428588965 .5288009643666 .74794006348 68.2718734741269 .7957916259871 .3197174072373 .1484298706174 .67236328125 76.5010681152378 .0249862670979 .5489196777380 .7680587768681 .98719787598 83.206336975184 .1206970214885 .0350494384885 .6446228027385 .94940185547 86.254188537686 .5589828491287 .4733276367288 .3876876831189 .3020401001 89.9116134643690 .5211791992291 .1307525634892 .0450973510793 .56903076172 95.0929565429796 .9216690063598 .4455871582100 .2742996216102 .4077987671 104.2365036011106 .0652008057107 .5891036987109 .4179000854110 .9418029785 112.1608963013113 .3800964355113 .9896011353114 .9039993286115 .2088012695 115.2088012695115 .2088012695114 .9039993286114 .5991973877114 .2944030762 113.6848983765113 .3800964355112 .7705001831112 .1608963013111 .551399231 110.3321990967110 .3321990967111 .24659729112 .1608963013113 .075302124 113.9896011353117 .647102356119 .4757995605117 .647102356116 .1231002808 116.7326965332117 .0374984741117 .342300415117 .647102356117 .647102356 117.110710144116 .4422607422115 .7889862061115 .1692352295114 .6030349731 114.1058807373113 .6929092407113 .3706817627113 .1496582031113 .0198974609 112.9850006104113 .0238800049113 .1220779419113 .2598190308113 .4155807495 113.5691375732113 .7035064697113 .807434082113 .8787002563113 .924697876 113.9741973877114 .0394363403114 .18334198114 .479888916115 .0411224365 
115.9179229736117 .0689086914118 .3647842407119 .7213821411120 .968536377 120.5141601562119 .8913879395119 .1875118 .3914108276117 .4925079346116 .4799346924 112.5879669189107 .589103698797 .8360290527385 .3398437578 .32978057861 62.1761703491261 .2618103027360 .9570198059160 .3474502563560 .04267120361 59.7378807067959 .4331016540559 .4331016540559 .1283111572359 .12831115723 59.1283111572358 .8235282897958 .8235282897958 .5187492370658 .51874923706 58.5187492370658 .5187492370658 .5187492370658 .5187492370658 .82352828979 59.1283111572359 .7378807067960 .6522407531761 .5666007995662 .48094940186 64.3096618652366 .7479400634870 .7101516723675 .8914871215876 .01540374756 75.6876983642677 .6050872802782 .183448791586 .5097427368288 .78126525879 87.5628509521584 .4972991943480 .8697280883877 .5847625732474 .92597961426 72.2871017456170 .1944274902367 .0527267456163 .3953094482458 .21395874023 56.0804595947352 .4230384826748 .4608306884846 .0225486755446 .32733917236 48.4608306884851 .2038993835454 .2517509460456 .3852500915558 .21395874023 59.1283111572360 .3474502563560 .9570198059161 .2618103027361 .56660079956 61.8713798522961 .8713798522961 .8713798522961 .5666007995661 .56660079956 60.9570198059160 .9570198059160 .6522407531760 .6522407531760 .95701980591 61.5666007995662 .1761703491262 .7857398986863 .7000885009864 .61444854736 65.8335876464866 .7479400634867 .6623001098667 .9670867919968 .57665252686 68.5766525268668 .2718734741267 .6623001098667 .3575134277366 .74794006348 66.1383666992266 .1383666992266 .74794006348 -9999 -9999-9999 -9999 -9999 -9999 -9999

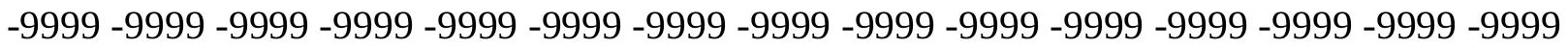
-9999 -9999 -9999 -9999 -9999 -9999 -9999 -9999 -9999 -9999 -9999 -9999 -9999 -9999 -9999 -9999 -9999 -9999 -9999 -9999 -9999 -9999 -9999 -9999 -9999 -9999 -9999 -9999 -9999 -9999

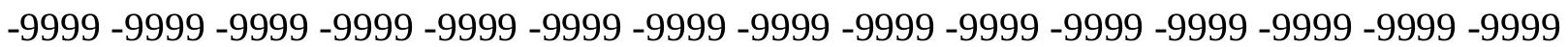
-9999-9999-9999

-9999 -9999 -9999 -9999 -9999 -9999 -9999 -9999 -9999 -9999 -9999 -9999 -9999 -9999 -9999 -9999 -9999 -9999 -9999 -9999 -9999 -9999 -9999 -9999 -9999 -9999 -9999 -9999 -9999 -9999

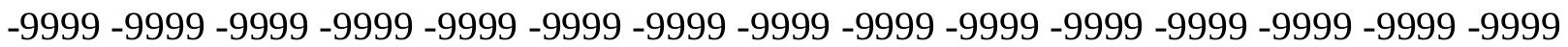

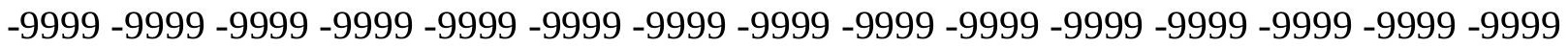
-9999 -9999 -9999 -9999 -9999 -9999 -9999 -9999 -9999 -9999 -9999 -9999 -9999 -9999 -9999 -9999 -9999 -9999 -9999 -9999 -9999 -9999 -9999 105.1509017944101 .1886978149 97.22646331787 93.26425170898 88.69246673584 84.12069702148 78.93934631348 73.7580032348668 .2718734741262 .1761703491254 .2517509460455 .77568054199 57.2995986938558 .8235282897960 .3474502563561 .8713798522963 .09051895142 64.3096618652365 .5288009643666 .7479400634867 .6623001098668 .27187347412 68.8814392089869 .1862335205169 .4910125732469 .4910125732469 .49101257324 69.1862335205168 .5766525268668 .2718734741267 .6623001098667 .05272674561 66.4431610107465 .8335876464864 .9192428588964 .004882812563 .39530944824 62.7857398986862 .4809494018662 .7857398986863 .7000885009865 .22400665283 66.4431610107468 .2718734741269 .7957916259871 .6244964599673 .14842987061 74.6723632812576 .1962814331177 .7202072143678 .9393463134880 .46327209473 81.6824111938582 .9015579223684 .1206970214885 .0350494384885 .64462280273 86.254188537686 .8637619018687 .4733276367288 .3876876831188 .99725341797 89.6068267822390 .2164001464890 .8259735107492 .0450973510793 .26425170898 94.7881774902396 .6168823242298 .4455871582100 .2742996216102 .1029968262 
103.9317016602105 .7603988647107 .5891036987109 .1130981445110 .6370010376 111.8561019897113 .075302124113 .9896011353114 .5991973877114 .9039993286 115.2088012695115 .2088012695114 .9039993286114 .5991973877114 .2944030762 113.9896011353113 .3800964355112 .7705001831112 .1608963013111 .8561019897 111.551399231111 .8561019897114 .5991973877117 .3522186279119 .2229003906 119.7806015015120 .6949005127121 .095451355119 .4757995605114 .9039993286 114.2944030762114 .9039993286115 .2088012695115 .5136032104115 .818397522 116.1145172119115 .3268280029114 .5591964722113 .8276672363113 .1585617065 112.5751342773112 .0876159668111 .7160720825111 .4651260376111 .334236145 111.3147583008111 .3932647705111 .5506820679111 .7617034912111 .9981460571 112.2375717163112 .4501037598112 .6237335205112 .7349624634112 .7911605835 112.7936477661112 .7679367065112 .7708587646112 .9071044922113 .3562011719 114.2053375244115 .397354126116 .6376037598117 .8437042236118 .821472168 119.4667358398119 .7328643799119 .2132339478118 .0300750732115 .9971847534 113.0210342407109 .4179000854101 .188697814994 .7881774902388 .38768768311 82.9015579223660 .9570198059160 .6522407531760 .0426712036159 .73788070679 59.4331016540559 .1283111572358 .8235282897958 .8235282897958 .51874923706 58.5187492370658 .2139587402358 .2139587402357 .909179687557 .9091796875 57.6043891906757 .6043891906757 .6043891906757 .6043891906757 .60438919067 57.909179687558 .2139587402359 .1283111572359 .7378807067960 .95701980591 62.1761703491264 .004882812566 .4431610107469 .4910125732472 .23407745361 74.3675689697371 .3197174072366 .1383666992280 .3807678222789 .05484771729 91.4115829467889 .084686279384 .694061279379 .9799346923876 .32621002197 73.9548797607472 .0016021728570 .6295928955169 .7957916259868 .27187347412 65.2240066528361 .8713798522957 .2995986938551 .8134689331146 .02254867554 46.9369087219248 .765621185350 .8991203308153 .3373985290555 .16611099243 56.6900291442957 .6043891906758 .2139587402358 .8235282897959 .43310165405 59.7378807067960 .3474502563560 .6522407531760 .9570198059160 .95701980591 60.9570198059160 .6522407531760 .3474502563560 .0426712036160 .34745025635 60.3474502563560 .9570198059161 .5666007995662 .4809494018663 .39530944824 64.6144485473665 .8335876464866 .7479400634867 .6623001098668 .57665252686 68.8814392089868 .8814392089868 .5766525268667 .9670867919967 .35751342773 66.7479400634866 .1383666992265 .8335876464866 .44316101074 -9999 -9999 -9999-9999 -9999 -9999 -9999 -9999 -9999 -9999 -9999 -9999 -9999 -9999 -9999 -9999 -9999 -9999 -9999 -9999 -9999 -9999 -9999 -9999 -9999 -9999 -9999 -9999 -9999 -9999 -9999 -9999 -9999 -9999 -

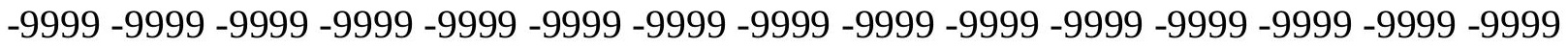

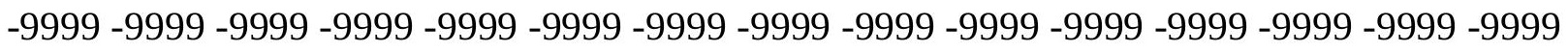
-9999 -9999-9999-9999-9999-9999

-9999 -9999 -9999 -9999 -9999 -9999 -9999 -9999 -9999 -9999 -9999 -9999 -9999 -9999 -9999 -9999 -9999 -9999 -9999 -9999 -9999 -9999 -9999 -9999 -9999 -9999 -9999 -9999 -9999 -9999 -

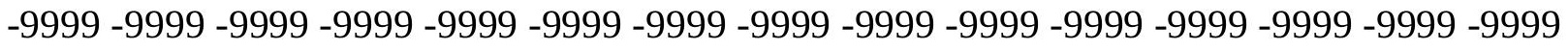

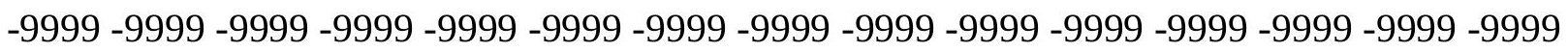
-9999 -9999 -9999 -9999 -9999 -9999 -9999 -9999 -9999 -9999 -9999 -9999 -9999 -9999 -9999 -9999 -9999 -9999 -9999 -9999 -9999 -9999 -9999 -9999 103.626899719299 .66472625732 95.397743225191 .1307525634885 .9494018554780 .4632720947374 .97714233398 69.18623352051 62.4809494018653.9469718933155.4708900451756.99481964111 
58.5187492370660 .0426712036161 .2618103027362 .4809494018663 .70008850098 64.9192428588965 .8335876464866 .7479400634867 .3575134277367 .96708679199 68.2718734741268 .2718734741268 .2718734741268 .2718734741267 .96708679199 67.6623001098667 .0527267456166 .7479400634866 .1383666992265 .52880096436 64.9192428588964 .004882812563 .0905189514262 .1761703491261 .26181030273 60.6522407531761 .2618103027362 .4809494018664 .004882812565 .52880096436 67.0527267456168 .5766525268670 .1005783081171 .6244964599673 .14842987061 74.6723632812575 .8914871215877 .4154205322378 .9393463134880 .46327209473 81.6824111938583 .206336975184 .1206970214885 .3398437586 .2541885376 86.8637619018687 .7781066894588 .3876876831188 .9972534179789 .3020401001 89.9116134643690.8259735107491.7403335571392.9594726562594.48339080811 96.3121032714898 .1408081054799 .96952056885102 .1029968262103 .9317016602 105.7603988647107 .5891036987109 .1130981445110 .6370010376111 .8561019897 112.7705001831113 .6848983765114 .2944030762114 .9039993286114 .9039993286 114.9039993286114 .9039993286114 .5991973877114 .2944030762113 .9896011353 113.6848983765113 .075302124112 .7705001831112 .7705001831113 .3800964355 114.5991973877116 .7326965332119 .1709976196120 .3661956787120 .3006591797 120.0453414917119 .7892837524119 .5335159302118 .8662033081117 .647102356 116.1231002808115 .2088012695114 .9039993286114 .5991973877114 .5991973877 114.0823059082113 .1909942627112 .3416061401111 .5659179688110 .885269165 110.3283615112109 .9100799561109 .640586853109 .5196533203109 .5330657959 109.6725006104109 .9172668457110 .2320327759110 .5849990845110 .9517822266 111.2945175171111 .5812759399111 .7901000977111 .8963012695111 .9002914429 111.7953262329111 .6435928345111 .5874252319111 .8575134277112 .664855957 113.9056930542114 .5477523804114 .7992095947115 .5143890381116 .1946868896 116.1027374268115 .224571228113 .5687561035111 .24659729106 .979598999 101.493400573796 .9216690063594 .4833908081190 .8259735107487 .47332763672 60.6522407531760 .0426712036159 .4331016540559 .1283111572358 .82352828979 58.5187492370658 .2139587402357 .909179687557 .909179687557 .60438919067 57.6043891906757 .2995986938557 .2995986938556 .9948196411156 .99481964111 56.6900291442956 .6900291442956 .6900291442956 .9948196411156 .99481964111 57.6043891906758 .2139587402359 .1283111572360 .0426712036161 .56660079956 63.3953094482465 .5288009643667 .6623001098669 .1862335205169 .79579162598 68.8814392089869 .1862335205174 .062782287692 .0450973510790 .85504150391 88.0403823852582 .6460189819377 .1621780395573 .6416091918972 .211769104 72.0448837280372 .4155883789173 .047714233473 .3717575073272 .84364318848 69.4910125732464 .9192428588958 .8235282897953 .6421813964851 .20389938354 51.2038993835452 .4230384826753 .9469718933155 .1661109924356 .08045959473 56.6900291442956 .9948196411157 .2995986938557 .6043891906758 .21395874023 59.1283111572359 .7378807067960 .3474502563560 .6522407531760 .34745025635 60.0426712036159 .7378807067959 .7378807067959 .7378807067960 .04267120361 60.3474502563560 .9570198059161 .8713798522963 .0905189514264 .30966186523 65.5288009643666 .7479400634867 .9670867919968 .8814392089869 .49101257324 69.4910125732468 .8814392089868 .2718734741267 .3575134277366 .74794006348 65.8335876464865 .5288009643666 .13836669922 -9999 -9999 -9999 -9999 -9999 -9999 -9999 -9999 -9999 -9999 -9999 -9999 -9999 -9999 -9999 -9999 -9999 -9999 -9999 -9999 -9999-9999 
-9999 -9999 -9999 -9999 -9999 -9999 -9999 -9999 -9999 -9999 -9999 -9999 -9999 -9999 -9999 -9999 -9999 -9999 -9999 -9999 -9999 -9999 -9999 -9999 -9999 -9999 -9999 -9999 -9999 -9999 -9999 -9999 -9999 -9999 -9999 -9999 -9999 -9999 -9999 -9999 -9999 -9999 -9999 -9999 -9999 -9999-9999-9999

-9999 -9999 -9999 -9999 -9999 -9999 -9999 -9999 -9999 -9999 -9999 -9999 -9999 -9999 -9999 -9999 -9999 -9999 -9999 -9999 -9999 -9999 -9999 -9999 -9999 -9999 -9999 -9999 -9999 -9999 -9999 -9999 -9999 -9999 -9999 -9999 -9999 -9999 -9999 -9999 -9999 -9999 -9999 -9999 -9999 -9999 -9999 -9999 -9999 -9999 -9999 -9999 -9999 -9999 -9999 -9999 -9999 -9999 -9999 -9999 -9999 -9999 -9999 -9999 -9999 -9999 -9999 -9999 -9999 -9999 -9999 -9999 -9999 -9999 -9999 -9999 -9999 -9999 -9999 -9999 -9999 -9999 -9999 -9999 -9999 103.0174026489 98.445587158293 .8738174438588 .6924667358483 .206336975177 .41542053223 71.3197174072352 .4230384826753 .9469718933155 .4708900451756 .99481964111 58.2139587402359 .7378807067960 .9570198059162 .1761703491263 .39530944824 64.3096618652365 .2240066528365 .8335876464866 .4431610107466 .74794006348 67.0527267456167 .3575134277367 .3575134277367 .0527267456167 .05272674561 66.7479400634866 .1383666992265 .8335876464865 .5288009643664 .91924285889 64.3096618652363 .3953094482462 .4809494018661 .5666007995660 .65224075317 59.7378807067960 .6522407531762 .1761703491263 .3953094482464 .91924285889 66.4431610107467 .6623001098669 .1862335205170 .7101516723671 .92929077148 73.1484298706174 .6723632812575 .8914871215877 .4154205322378 .93934631348 80.7680587768682 .2919769287183 .5111236572384 .7302627563585 .94940185547 86.8637619018687 .4733276367288 .0829010009888 .6924667358488 .99725341797 89.6068267822390 .5211791992291 .4355392456192 .9594726562594 .48339080811 96.0073165893697 .8360290527399 .96952056885101 .7982025146103 .6268997192 105.4557037354107 .2844009399108 .8082962036110 .3321990967111 .551399231 112.7705001831113 .3800964355113 .9896011353114 .5991973877114 .9039993286 114.9039993286114 .9039993286114 .5991973877114 .5991973877114 .2944030762 113.9896011353113 .6848983765113 .6848983765113 .9896011353114 .9039993286 116.4279022217117 .9517974854117 .906539917117 .6393890381117 .3711471558 117.0982055664116 .8187637329116 .5332870483116 .245010376115 .9599456787 115.6865005493115 .4352874756115 .2182846069114 .7594146729113 .7390594482 112.7164764404111 .7052230835110 .7344818115109 .8413696289109 .0625610352 108.4315490723107 .9716873169107 .695526123107 .6026763916107 .6814804077 107.9133300781108 .2714920044108 .7225494385109 .232460022109 .7664794922 110.2855148315110 .747543335111 .1125259399111 .3413848877111 .4044647217 111.2892456055111 .0359802246110 .7806167603110 .7835388184111 .3972854614 111.7768936157111 .259147644111 .548538208111 .9846038818113 .075302124 112.1608963013110 .9418029785108 .5035018921104 .846099853599 .96952056885 94.7881774902394 .7881774902394 .1785964965892 .6546783447391 .13075256348 60.6522407531759 .7378807067958 .8235282897958 .5187492370657 .9091796875 57.6043891906757 .2995986938557 .2995986938556 .9948196411156 .69002914429 56.6900291442956 .3852500915556 .3852500915556 .0804595947356 .08045959473 55.7756805419955 .7756805419955 .7756805419956 .0804595947356 .38525009155 56.6900291442957 .2995986938558 .2139587402359 .1283111572360 .65224075317 62.1761703491263 .7000885009865 .2240066528366 .7479400634867 .35751342773 67.9670867919969 .7957916259872 .2340774536174 .3675689697384 .73026275635 
85.64462280273 78.273017883373.0588836669970.5810089111370.88455200195 71.4867172241273 .1562576293975 .6716918945378 .0882492065479 .08673095703 77.7202072143673 .7580032348667 .6623001098661 .8713798522957 .29959869385 55.4708900451755 .1661109924355 .7756805419956 .6900291442956 .99481964111 56.9948196411156 .9948196411156 .6900291442956 .9948196411157 .60438919067 58.5187492370659 .1283111572359 .7378807067960 .0426712036160 .04267120361 59.7378807067959 .4331016540559 .1283111572359 .1283111572359 .43310165405 60.0426712036160 .3474502563561 .2618103027362 .4809494018663 .70008850098 65.2240066528366 .7479400634868 .2718734741269 .1862335205169 .79579162598 69.7957916259869 .1862335205168 .2718734741267 .3575134277366 .44316101074 65.8335876464865 .2240066528365 .83358764648 -9999 -9999 -9999 -9999 -9999 -9999 -9999 -9999 -9999 -9999 -9999 -9999 -9999 -9999 -9999 -9999 -9999 -9999 -9999 -9999 -9999 -9999 -9999 -9999 -9999 -9999 -9999 -9999 -9999 -9999 -9999 -9999 -9999 -9999 -9999 -9999 -9999 -9999 -9999 -9999 -9999 -9999 -9999 -9999 -9999 -9999 -9999 -9999 -9999 -9999 -9999 -9999 -

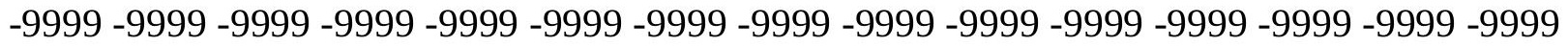
-9999 -9999 -9999

-9999 -9999 -9999 -9999 -9999 -9999 -9999 -9999 -9999 -9999 -9999 -9999 -9999 -9999 -9999 -9999 -9999 -9999 -9999 -9999 -9999 -9999 -9999 -9999 -9999 -9999 -9999 -9999 -9999 -9999 -9999 -9999 -9999 -9999 -9999 -9999 -9999 -9999 -9999 -9999 -9999 -9999 -9999 -9999 -9999

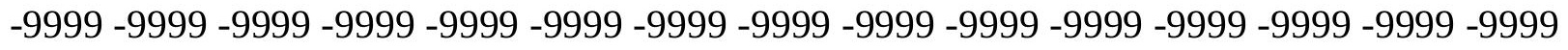

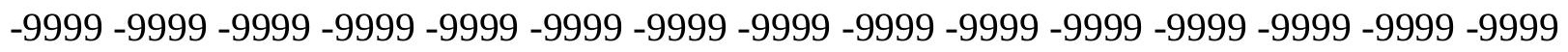
-9999 -9999 -9999 -9999 -9999 -9999 -9999 -9999 -9999 -9999 -9999 103.0174026489 97.5312423706191 .7403335571386 .254188537680 .1584930419974 .36756896973 52.4230384826753 .9469718933155 .4708900451756 .6900291442958 .21395874023 59.4331016540560 .6522407531761 .8713798522962 .7857398986863 .70008850098 64.6144485473665 .2240066528365 .5288009643665 .8335876464866 .13836669922 66.1383666992266 .1383666992266 .1383666992265 .8335876464865 .83358764648 65.5288009643665 .2240066528364 .9192428588964 .3096618652364 .0048828125 63.3953094482462 .7857398986861 .8713798522961 .2618103027360 .95701980591 61.5666007995662 .4809494018663 .7000885009864 .9192428588966 .13836669922 67.3575134277368 .5766525268669 .7957916259871 .014930725172 .23407745361 73.4532165527374 .6723632812576 .1962814331178 .0249862670979 .54891967773 81.0728530883882 .5967712402384 .1206970214885 .3398437586 .2541885376 86.86376190186 87.47332763672 88.08290100098 88.38768768311 89.3020401001 90.2164001464891 .1307525634892 .6546783447394 .1785964965896 .00731658936 97.8360290527399 .66472625732101 .4934005737103 .6268997192105 .4557037354 106.979598999108 .8082962036110 .0273971558111 .24659729112 .4656982422 113.3800964355113 .9896011353114 .2944030762114 .5991973877114 .5991973877 114.9039993286114 .5991973877114 .5991973877114 .5991973877114 .2944030762 114.2944030762114 .5991973877115 .2088012695116 .0342941284115 .7392959595 115.4593276978115 .1874160767114 .916519165114 .6401138306114 .352897644 114.0517578125113 .7362289429113 .4095916748113 .0786590576112 .753364563 112.4458084106112 .1705856323111 .94090271111 .7760238647111 .293762207 110.1681594849109 .0712509155108 .0519638062107 .1617126465106 .4453353882 105.9358520508105 .6503219604105 .5892333984105 .7385406494106 .0731811523 106.5620193481107 .1720275879107 .8694000244108 .616645813109 .3694839478 
110.0754241943110 .6774673462111 .1209487915111 .3605880737111 .3738327026 111.1726303101110 .8313598633110 .6073532104111 .1775512695109 .7063980103 109.5143432617110 .0273971558109 .4179000854108 .8082962036107 .8938980103 106.0652008057103 .3221969604100 .274299621697 .2264633178795 .09295654297 94.1785964965894 .1785964965894 .1785964965893 .8738174438560 .34745025635 59.1283111572358 .2139587402357 .6043891906756 .9948196411156 .69002914429 56.3852500915556 .0804595947356 .0804595947355 .7756805419955 .77568054199 55.4708900451755 .4708900451755 .1661109924355 .1661109924355 .16611099243 55.1661109924355 .1661109924355 .1661109924355 .4708900451755 .77568054199 56.3852500915556 .9948196411157 .909179687559 .1283111572360 .34745025635 61.8713798522963 .0905189514264 .3096618652365 .5288009643666 .74794006348 68.5766525268670 .7101516723674 .062782287677 .110626220776 .50106811523 73.1484298706171 .014930725171 .014930725171 .6244964599670 .7629699707 73.0093002319377 .4472885131882 .0688629150484 .7503280639684 .97757720947 81.9871978759876 .1962814331169 .1862335205163 .3953094482460 .04267120361 59.1283111572359 .1283111572359 .4331016540559 .1283111572358 .82352828979 58.2139587402357 .2995986938556 .9948196411157 .6043891906758 .51874923706 59.4331016540559 .7378807067959 .7378807067959 .7378807067959 .43310165405 59.1283111572359 .1283111572359 .1283111572359 .1283111572359 .43310165405 60.0426712036160 .6522407531761 .8713798522963 .3953094482464 .91924285889 66.7479400634868 .2718734741269 .4910125732470 .1005783081169 .79579162598 69.1862335205168 .2718734741267 .0527267456166 .1383666992265 .52880096436 64.9192428588965 .52880096436 -9999 -9999 -9999 -9999 -9999 -9999 -9999 -9999 -9999 -9999 -9999 -9999 -9999 -9999 -9999 -9999 -9999 -9999 -9999 -9999 -9999 -9999 -9999 -9999 -9999 -9999 -9999 -9999 -9999 -9999 -9999 -9999 -9999 -9999 -9999 -9999 -9999 -9999 -9999 -9999 -9999 -9999 -9999 -9999 -9999 -9999 -9999 -9999 -9999 -9999 -9999 -9999 -9999 -9999 -9999 -9999 -9999 -9999 -9999 -9999 -9999 -9999 -9999 -9999 -9999 -9999 -9999 -9999 -9999 $-9999$

-9999 -9999 -9999 -9999 -9999 -9999 -9999 -9999 -9999 -9999 -9999 -9999 -9999 -9999 -9999

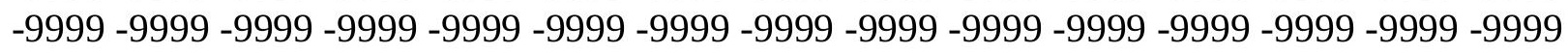
-9999 -9999 -9999 -9999 -9999 -9999 -9999 -9999 -9999 -9999 -9999 -9999 -9999 -9999 -9999

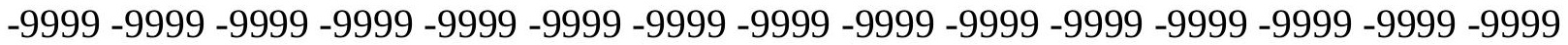

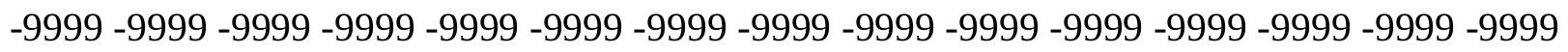
-9999 -9999 -9999 -9999 -9999 -9999 -9999 -9999 -9999 -9999 -9999 108.5035018921 101.798202514695 .7025299072389 .6068267822383 .206336975177 .1106262207 52.7278289794954 .2517509460455 .4708900451756 .9948196411158 .21395874023 59.4331016540560 .6522407531761 .5666007995662 .4809494018663 .39530944824 64.004882812564 .3096618652364 .9192428588965 .2240066528365 .22400665283 65.2240066528365 .2240066528365 .2240066528365 .2240066528364 .91924285889 64.6144485473664 .6144485473664 .3096618652364 .3096618652364 .0048828125 63.7000885009863 .3953094482463 .0905189514262 .7857398986862 .78573989868 63.3953094482464 .004882812564 .6144485473665 .5288009643666 .13836669922 67.0527267456167 .9670867919968 .8814392089870 .1005783081171 .31971740723 72.5388565063573 .7580032348675 .2819290161177 .110626220778 .63455963135 80.1584930419981 .6824111938583 .206336975184 .1206970214885 .03504943848 85.9494018554786 .5589828491287 .1685485839887 .7781066894588 .69246673584 
89.6068267822390.8259735107492.349891662693.8738174438595.70252990723 97.5312423706199 .35994720459101 .4934005737103 .3221969604105 .1509017944 106.979598999108 .5035018921110 .0273971558111 .24659729112 .1608963013 113.075302124113 .6848983765113 .9896011353114 .2944030762114 .5991973877 114.5991973877114 .5991973877114 .5991973877114 .5991973877114 .9039993286 114.5172195435114 .1381835938113 .7943572998113 .4808197021113 .191192627 112.9178848267112 .6519851685112 .3841781616112 .1056518555111 .8089447021 111.4891815186111 .1446990967110 .7785797119110 .3986206055110 .0176544189 109.645980835109 .3020553589108 .9976196289108 .7635498047108 .6211013794 108.5923614502107 .4321670532106 .2730407715105 .2499847412104 .424156189 103.8408660889103 .5246429443103 .4774856567103 .6821136475104 .1084747314 104.7235107422105 .4976806641106 .4034881592107 .4066619873108 .4567565918 109.4860687256110 .4173583984111 .1813354492111 .7291259766112 .0461578369 112.1617889404112 .1580276489112 .1111907959111 .5914535522109 .4179000854 111.551399231110 .0273971558110 .9418029785110 .6370010376109 .4179000854 106.979598999103 .6268997192100 .274299621697 .5312423706195 .70252990723 95.0929565429795 .0929565429795 .7025299072396 .3121032714859 .12831115723 57.909179687557 .2995986938556 .3852500915556 .0804595947355 .47089004517 55.1661109924355 .1661109924354 .8613204956154 .8613204956154 .55654144287 54.5565414428754 .5565414428754 .2517509460454 .2517509460454 .25175094604 54.2517509460454 .2517509460454 .2517509460454 .2517509460454 .55654144287 55.1661109924355 .7756805419956 .3852500915557 .6043891906758 .51874923706 59.7378807067960 .9570198059162 .1761703491263 .3953094482464 .61444854736 66.4431610107468 .5766525268671 .3197174072373 .1484298706174 .0627822876 74.6723632812578 .6345596313586 .8637619018673 .1484298706167 .96708679199 71.14145660478 .7339096069384 .824363708588 .68247222990 .32299041748 89.6068267822381 .9871978759873 .4532165527367 .9670867919965 .22400665283 64.004882812563 .3953094482463 .0905189514262 .4809494018662 .17617034912 61.5666007995660 .3474502563558 .5187492370659 .7378807067960 .34745025635 60.3474502563560 .3474502563560 .0426712036159 .7378807067959 .73788070679 59.4331016540559 .1283111572359 .1283111572359 .1283111572359 .43310165405 60.0426712036160 .6522407531761 .5666007995663 .0905189514264 .61444854736 66.1383666992267 .9670867919969 .1862335205170 .1005783081169 .49101257324 68.5766525268667 .6623001098666 .4431610107465 .8335876464865 .22400665283 64.6144485473664 .91924285889 -9999 -9999 -9999 -9999 -9999 -9999 -9999 -9999 -9999 -9999 -9999 -9999 -9999 -9999 -9999 -9999 -9999 -9999 -9999 -9999 -9999 -9999 -9999 -9999

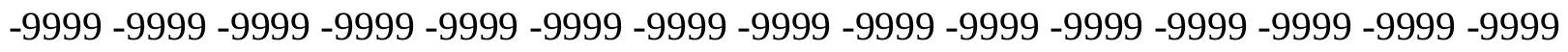

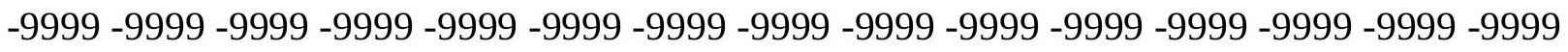
-9999 -9999 -9999 -9999 -9999 -9999 -9999 -9999 -9999 -9999 -9999 -9999 -9999 -9999 -9999 $-9999$

-9999 -9999 -9999 -9999 -9999 -9999 -9999 -9999 -9999 -9999 -9999 -9999 -9999 -9999 -9999 -

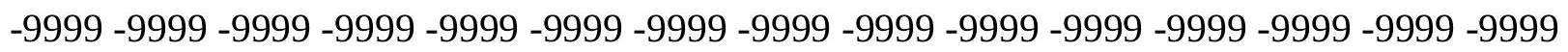

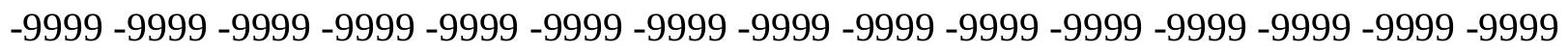
-9999 -9999 -9999 -9999 -9999 -9999 -9999 -9999 -9999 -9999 -9999 -9999 -9999 -9999 -9999 -9999 -9999 -9999 -9999 -9999 -9999 -9999 -9999 -9999 -9999 -9999 -9999 -9999 -9999 -9999 -999 -9999 -9999 -9999 -9999 -9999 -9999 -9999 -9999 -9999 -9999 -9999 -9999 107.2844009399 
99.3599472045992 .0450973510785 .6446228027379 .2441329956153 .03261184692 54.2517509460455 .7756805419956 .9948196411158 .2139587402359 .43310165405 60.6522407531761 .5666007995662 .1761703491263 .0905189514263 .39530944824 64.004882812564 .3096618652364 .3096618652364 .6144485473664 .61444854736 64.3096618652364 .3096618652364 .3096618652364 .3096618652364 .0048828125 64.004882812564 .004882812564 .004882812564 .004882812564 .0048828125 64.3096618652364 .3096618652364 .6144485473665 .2240066528365 .52880096436 65.8335876464866 .1383666992266 .4431610107466 .7479400634867 .05272674561 67.6623001098668 .2718734741269 .1862335205170 .4053573608471 .62449645996 73.1484298706174 .6723632812576 .5010681152378 .0249862670979 .24413299561 80.7680587768681 .9871978759882 .9015579223683 .8159103393684 .73026275635 85.3398437586 .254188537687 .1685485839888 .0829010009888 .99725341797 90.5211791992292 .0450973510793 .5690307617295 .397743225197 .22646331787 99.05516815186101 .1886978149103 .0174026489104 .8460998535106 .6747970581 108.1986999512109 .7226028442110 .9418029785111 .8561019897112 .7705001831 113.3800964355113 .9896011353114 .2944030762114 .2944030762114 .5991973877 114.1199111938113 .5419998169113 .0138473511112 .5375213623112 .1107254028 111.7295074463111 .3887329102111 .0830993652110 .8053207397110 .5462493896 110.2945861816110 .0381393433109 .7651824951109 .4654846191109 .1321029663 108.7618713379108 .3574752808107 .9272918701107 .4848937988107 .0424499512 106.6134872437106 .2239074707105 .9125442505105 .6922073364105 .6065826416 105.6648025513104 .588760376103 .4048233032102 .4331207275101 .7351303101 101.3473129272101 .2748413086101 .4981307983101 .9809265137102 .6903915405 103.6069564819104 .7219085693106 .0151596069107 .4297485352108 .8709335327 110.2264328003111 .4065475464112 .3722686768113 .146522522113 .8075408936 114.5064849854114 .4669418335113 .9896011353115 .5136032104120 .0852966309 116.1231002808114 .5991973877113 .6848983765111 .8561019897108 .8082962036 104.8460998535100 .579101562597 .5312423706196 .0073165893696 .00731658936 96.6168823242297 .5312423706198 .445587158257 .6043891906756 .69002914429 55.7756805419955 .1661109924354 .5565414428754 .2517509460453 .94697189331 53.6421813964853 .6421813964853 .6421813964853 .6421813964853 .33739852905 53.3373985290553 .3373985290553 .3373985290553 .3373985290553 .33739852905 53.3373985290553 .3373985290553 .3373985290553 .3373985290553 .64218139648 54.2517509460454 .8613204956155 .4708900451756 .3852500915557 .29959869385 58.5187492370659 .4331016540560 .6522407531762 .1761703491263 .70008850098 65.2240066528367 .0527267456168 .8814392089870 .7101516723673 .75800323486 77.7202072143679 .2441329956173 .7580032348667 .0527267456166 .44316101074 79.5489196777385 .2395629882889 .756973266691 .5910644531290 .31954193115 86.5589828491280 .7680587768672 .2340774536170 .4053573608469 .18623352051 68.2718734741267 .6623001098667 .0527267456166 .4431610107466 .74794006348 66.4431610107465 .5288009643664 .6144485473663 .7000885009862 .48094940186 61.2618103027360 .6522407531760 .6522407531760 .3474502563560 .04267120361 60.0426712036159 .7378807067959 .7378807067959 .7378807067960 .04267120361 60.6522407531761 .2618103027362 .4809494018664 .004882812565 .52880096436 67.0527267456168 .5766525268669 .7957916259868 .5766525268667 .35751342773 66.4431610107465 .5288009643664 .9192428588964 .6144485473664 .30966186523 
64.61444854736 -9999 -9999 -9999 -9999 -9999 -9999 -9999 -9999 -9999 -9999 -9999 -9999 -9999 -9999 -9999 -9999 -9999 -9999 -9999 -9999 -9999 -9999 -9999 -9999 -9999 -9999 -9999

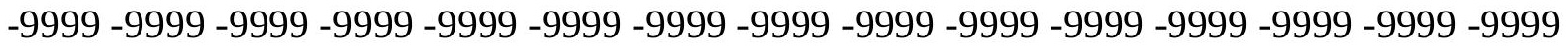
-9999 -9999 -9999 -9999 -9999 -9999 -9999 -9999 -9999 -9999 -9999 -9999 -9999 -9999 -9999 -9999 -9999 -9999 -9999 -9999 -9999 -9999 -9999 -9999 -9999 -9999 -9999 -9999 -9999 -9999 -9999 -9999 -9999 -9999 -9999 -9999 -9999 -9999 -9999 -9999 -9999 -9999 -9999

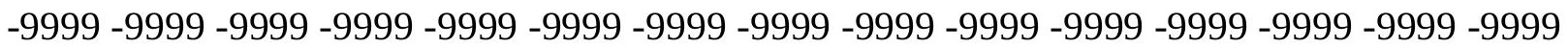
-9999 -9999 -9999 -9999 -9999 -9999 -9999 -9999 -9999 -9999 -9999 -9999 -9999 -9999 -9999 -999 -9999 -9999 -9999 -9999 -9999 -9999 -9999 -9999 -9999 -9999 -9999 -9999 -9999 -9999 -9999 -9999 -9999 -9999 -9999 -9999 -9999 -9999 -9999 -9999 -9999 -9999 -9999 -9999 -9999 -9999 -9999 -9999 -9999 -9999 -9999 -9999 -9999 -9999 -9999 -9999 -9999 -9999 -9999 103.626899719293 .5690307617287 .4733276367279 .2441329956153 .33739852905 54.8613204956156 .0804595947357 .2995986938558 .5187492370659 .73788070679 60.6522407531761 .5666007995662 .1761703491262 .7857398986863 .39530944824 63.3953094482463 .7000885009863 .7000885009863 .7000885009863 .70008850098 63.7000885009863 .7000885009863 .3953094482463 .3953094482463 .39530944824 63.7000885009863 .7000885009864 .004882812564 .3096618652364 .61444854736 65.2240066528365 .8335876464866 .7479400634867 .3575134277367 .96708679199 67.9670867919967 .6623001098667 .3575134277367 .0527267456167 .05272674561 67.3575134277367 .6623001098668 .5766525268669 .7957916259871 .0149307251 72.5388565063574 .3675689697375 .8914871215877 .110626220778 .32978057861 79.5489196777380 .4632720947381 .3776321411182 .2919769287183 .2063369751 84.1206970214885 .0350494384886 .254188537687 .1685485839888 .69246673584 89.9116134643691.4355392456193.2642517089895.0929565429796.92166900635 99.05516815186100 .8839035034102 .712600708104 .8460998535106 .3700027466 108.1986999512109 .4179000854110 .6370010376111 .8561019897112 .4656982422 113.075302124113 .6848983765113 .9383773804113 .2252502441112 .5417022705 111.8972549438111 .3005905151110 .7573623657110 .2702636719109 .8377151489 109.4564819336109.1218032837108.8284606934108.5686187744 108.3316268921 108.1034698486107 .8682937622107 .6104354858107 .3162689209106 .9764175415 106.5862121582106 .1477584839105 .6662063599105 .1656570435104 .6553878784 104.1527786255103 .6834793091103 .2773895264102 .9655914307102 .7843856812 102.7647171021102 .927482605101 .7019577026100 .544235229599 .68365478516 99.1722335815499 .0244750976699 .2150192260799 .69873809814100 .4406814575 101.4394454956102 .728515625104 .3284454346106 .1816940308108 .1348800659 110.0092773438111 .662322998113 .0851745605114 .1952438354114 .9467086792 115.3669586182115 .6896362305116 .4279022217117 .647102356118 .5614013672 117.647102356116 .1231002808115 .818397522114 .2944030762110 .3321990967 105.1509017944100 .274299621697 .2264633178796 .3121032714896 .92166900635 98.445587158299 .66472625732100 .883903503456 .0804595947355 .16611099243 54.5565414428753 .6421813964853 .3373985290552 .7278289794952 .42303848267 52.4230384826752 .1182594299352 .1182594299352 .1182594299352 .42303848267 52.4230384826752 .4230384826752 .4230384826752 .4230384826752 .42303848267 52.1182594299352 .1182594299352 .1182594299352 .1182594299352 .11825942993 52.4230384826752 .7278289794953 .3373985290553 .9469718933154 .86132049561 55.7756805419956 .6900291442957 .6043891906758 .8235282897960 .04267120361 
61.2618103027362 .4809494018663 .7000885009865 .5288009643667 .96708679199 70.4053573608471 .014930725169 .4910125732466 .7479400634866 .13836669922 68.8814392089881 .6824111938588 .4177932739390 .3251037597788 .43927001953 82.8426437377973 .1484298706176 .5010681152375 .2819290161174 .0627822876 73.1484298706172 .5388565063572 .2340774536172 .8436431884873 .75800323486 74.3675689697373 .4532165527371 .3197174072368 .2718734741265 .22400665283 62.7857398986861 .5666007995661 .5666007995661 .5666007995661 .56660079956 61.2618103027360 .6522407531760 .3474502563560 .3474502563560 .34745025635 60.6522407531761 .2618103027361 .8713798522963 .0905189514264 .30966186523 65.5288009643666 .7479400634867 .0527267456166 .7479400634865 .83358764648 64.9192428588964 .3096618652364 .004882812564 .004882812563 .70008850098 64.30966186523 -9999 -9999 -9999 -9999 -9999 -9999 -9999 -9999 -9999 -9999 -9999 -9999 -9999 -9999 -9999 -9999 -9999 -9999 -9999 -9999 -9999 -9999 -9999 -9999 -9999 -9999 -9999 -9999 -9999 -9999 -9999 -9999 -9999 -9999 -9999 -9999 -9999 -9999 -9999 -9999 -9999 - 9999 -9999 -9999 -9999 -9999 -9999 -9999 -9999 -9999 -9999 -9999 -9999 -9999 -9999 -9999 - -9999 -

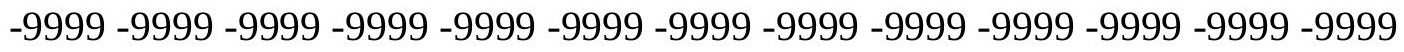
-9999 -9999 -9999 -9999 -9999 -9999 -9999 -9999 -9999 -9999 -9999 -9999 -9999 -9999 -9999

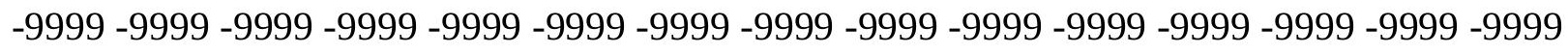
-9999 -9999 -9999 -9999 -9999 -9999 -9999 -9999 -9999 -9999 -9999 -9999 -9999 -9999 -9999 -

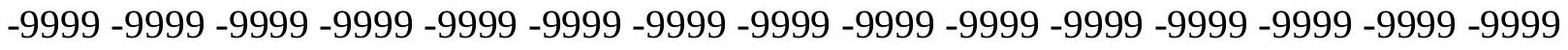

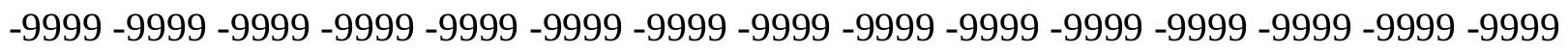
-9999 -9999 -9999 -9999 -9999 -9999 -9999 -9999 -9999 -9999 -9999 -9999 -9999 -9999 96.6168823242286 .5589828491276 .1962814331154 .2517509460455 .47089004517 56.6900291442957 .909179687559 .1283111572360 .0426712036160 .95701980591 61.5666007995662 .4809494018662 .7857398986863 .0905189514263 .39530944824 63.3953094482463 .3953094482463 .0905189514263 .0905189514263 .09051895142 62.7857398986862 .7857398986862 .7857398986862 .7857398986863 .09051895142 63.3953094482463 .7000885009864 .3096618652364 .9192428588965 .83358764648 67.0527267456168 .2718734741269 .4910125732470 .1005783081169 .79579162598 69.1862335205168 .2718734741267 .6623001098667 .0527267456167 .05272674561 67.0527267456167 .9670867919968 .8814392089870 .4053573608472 .23407745361 73.7580032348675 .2819290161176 .5010681152377 .4154205322378 .32978057861 79.2441329956180 .1584930419981 .0728530883881 .9871978759882 .90155792236 84.1206970214885 .3398437586 .5589828491288 .0829010009889 .3020401001 91.1307525634892 .6546783447394 .4833908081196 .6168823242298 .75038146973 100.5791015625102 .712600708104 .5412979126106 .3700027466107 .8938980103 109.4179000854110 .6370010376111 .551399231112 .4656982422113 .075302124 112.6606750488111 .9034729004111 .1658554077110 .4593048096109 .7945480347 109.1808319092108 .6239089966108 .1268463135107 .6889343262107 .3081512451 106.9808425903106 .7026138306106 .4656829834106 .2584838867106 .0640792847 105.8620300293105 .6313247681105 .3536300659105 .0168151855104 .6145553589 104.1445846558103 .6358413696103 .0922241211102 .5292358398101 .9638977051 101.4157028198100 .9085998535100 .4764633179100 .1619644165100 .0160980225 100.0839767456100 .194938659798 .8276672363397 .7757034301897 .10146331787 96.8462448120196 .9579849243297 .3855285644598 .0712585449299 .04137420654 100.409538269102 .2963027954104 .6787796021107 .2804412842108 .5470809937 
109.9229736328 111.3474960327 112.7891769409 114.1098022461 115.0591430664 115.5136032104115 .818397522115 .818397522115 .2088012695114 .5991973877 113.9896011353114 .5991973877115 .818397522110 .0273971558103 .9317016602 98.7503814697396 .0073165893696 .3121032714898 .4455871582100 .5791015625 102.1029968262103 .626899719254 .5565414428753 .6421813964852 .72782897949 52.1182594299351 .5086898803751 .2038993835450 .8991203308150 .59432983398 50.5943298339850 .5943298339850 .8991203308150 .8991203308151 .20389938354 51.5086898803751 .5086898803751 .5086898803751 .2038993835451 .20389938354 50.8991203308150 .5943298339850 .2895507812550 .2895507812550 .59432983398 50.5943298339851 .2038993835451 .5086898803752 .1182594299352 .72782897949 53.6421813964854 .2517509460455 .1661109924355 .7756805419956 .38525009155 56.9948196411157 .6043891906758 .5187492370659 .7378807067960 .95701980591 62.4809494018663 .7000885009863 .7000885009864 .6144485473667 .66230010986 71.9292907714885 .0350494384885 .7414703369184 .495948791581 .24822998047 78.7780914306681 .3776321411182 .2919769287177 .7202072143677 .41542053223 76.8058471679777 .110626220778 .3297805786180 .7680587768682 .29197692871 81.0728530883878 .0249862670973 .4532165527368 .5766525268664 .30966186523 63.0905189514263 .3953094482464 .004882812564 .004882812563 .70008850098 62.7857398986861 .8713798522961 .2618103027360 .6522407531760 .65224075317 60.9570198059161 .2618103027362 .1761703491263 .0905189514264 .0048828125 64.6144485473664 .6144485473664 .004882812563 .3953094482463 .09051895142 63.0905189514263 .0905189514263 .3953094482463 .3953094482464 .0048828125 -9999 -9999 -9999 -9999 -9999 -9999 -9999 -9999 -9999 -9999 -9999 -9999 -9999 -9999 -9999 -9999 -9999 -9999 -9999 -9999 -9999 -9999 -9999 -9999 -9999 -9999 -9999 -9999 -9999 -9999 -9999 -9999 -9999 -9999 -9999 -9999 -9999 -9999 -9999 -9999 -9999 -9999 -9999 -9999 -9999 -9999 -9999 -9999 -9999 -9999 -9999 -9999 -9999 -9999 -9999 -9999 -9999 -9999 -9999 -9999 -9999 -9999 -9999 -9999 -9999 -9999 -9999 -9999 -9999 -9999

-9999 -9999 -9999 -9999 -9999 -9999 -9999 -9999 -9999 -9999 -9999 -9999 -9999 -9999 -9999 -9999 -9999 -9999 -9999 -9999 -9999 -9999 -9999 -9999 -9999 -9999 -9999 -9999 -9999 -9999 -9999 -9999 -9999 -9999 -9999 -9999 -9999 -9999 -9999 -9999 -9999 -9999 -9999 -9999 -9999 -9999 -9999 -9999 -9999 -9999 -9999 -9999 -9999 -9999 -9999 -9999 -9999 -9999 -9999 -9999 -9999 -9999 -9999 -9999 -9999 -9999 -9999 -9999 -9999 -9999 -9999 -9999 -9999 -9999 -9999 -9999 -9999 -9999-9999 -9999 -9999 -9999 -9999 -9999 -9999 -9999 -9999 -9999 -9999 99.0551681518685 .3398437571 .6244964599654 .8613204956156 .38525009155 57.2995986938558 .5187492370659 .7378807067960 .6522407531761 .26181030273 62.1761703491262 .4809494018663 .0905189514263 .0905189514263 .09051895142 63.0905189514262 .7857398986862 .7857398986862 .4809494018662 .17617034912 62.1761703491262 .1761703491262 .1761703491262 .4809494018662 .78573989868 63.0905189514263 .7000885009864 .3096618652365 .2240066528366 .13836669922 67.6623001098668 .8814392089870 .7101516723671 .9292907714871 .0149307251 70.1005783081168 .8814392089867 .9670867919967 .0527267456166 .74794006348 66.4431610107467 .0527267456167 .9670867919969 .7957916259871 .62449645996 73.4532165527374 .6723632812575 .5867080688576 .5010681152377 .1106262207 77.7202072143678 .6345596313579 .5489196777380 .4632720947381 .68241119385 82.9015579223684 .4254837036185 .9494018554787 .4733276367288 .99725341797 90.5211791992292 .349891662694 .1785964965896 .3121032714898 .4455871582 
100.5791015625102 .4077987671104 .5412979126106 .0652008057107 .8938980103 109.1130981445110 .3321990967111 .551399231112 .1608963013111 .546913147 110.7599487305109 .9806976318109 .2203826904108 .4921722412107 .8078994751 107.1772766113106 .6061401367106 .0978622437105 .6527481079105 .2704925537 104.9492721558104 .6863708496104 .475151062104 .3041000366104 .1541290283 103.9992294312103 .8113479614103 .5659942627103 .2445907593102 .8414840698 102.37109375101 .8476638794101 .2831802368100 .692855835100 .0870513916 99.4722213745198 .8619079589898 .2842788696397 .7910995483497 .45739746094 97.3699645996197 .5948410034297 .3401336669996 .123329162695 .32452392578 94.9787597656295 .0183181762795 .3597259521595 .8856658935596 .65697479248 97.9142761230599 .98900604248103 .0018997192104 .3007888794105 .7513885498 107.3610305786109 .0409011841110 .7261657715112 .3296127319113 .6848983765 113.3800964355112 .7705001831111 .8561019897110 .6370010376109 .1130981445 108.5035018921109 .4179000854109 .7226028442106 .979598999102 .4077987671 97.5312423706193 .8738174438597 .53124237061101 .1886978149103 .3221969604 104.8460998535106 .370002746652 .7278289794952 .1182594299351 .20389938354 50.5943298339849 .9847602844249 .3751907348649 .0704002380449 .07040023804 49.0704002380449 .0704002380449 .3751907348649 .6799812316949 .98476028442 50.2895507812550 .2895507812550 .5943298339850 .2895507812549 .98476028442 49.3751907348649 .0704002380448 .765621185348 .4608306884848 .46083068848 48.4608306884848 .4608306884848 .765621185349 .3751907348649 .67998123169 50.2895507812550 .8991203308151 .2038993835451 .5086898803751 .50868988037 51.5086898803751 .2038993835450 .8991203308150 .5943298339850 .59432983398 52.1182594299356 .9948196411158 .8235282897961 .2618103027364 .30966186523 67.9670867919971 .3197174072378 .6608276367280 .8175506591880 .71675109863 81.2737731933682 .1137695312581 .3776321411180 .7680587768680 .76805877686 80.1584930419979 .8537063598681 .0728530883884 .4254837036188 .99725341797 85.9494018554782 .9015579223678 .9393463134872 .5388565063565 .83358764648 65.8335876464866 .7479400634867 .3575134277367 .3575134277366 .74794006348 65.2240066528363 .7000885009862 .4809494018661 .2618103027360 .65224075317 60.6522407531760 .9570198059161 .2618103027361 .8713798522962 .48094940186 62.4809494018662 .4809494018661 .8713798522961 .2618103027361 .56660079956 $62.1761703491262 .4809494018662 .7857398986863 .0905189514263 .70008850098-9999$ -9999 -9999 -9999 -9999 -9999 -9999 -9999 -9999 -9999 -9999 -9999 -9999 -9999 -9999 -9999 -9999 -9999 -9999 -9999 -9999 -9999 -9999 -9999 -9999 -9999 -9999 -9999 -9999 -9999 -9999 -

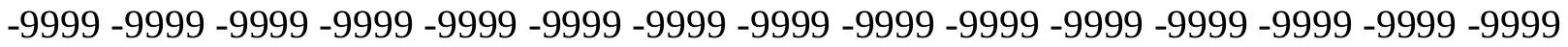

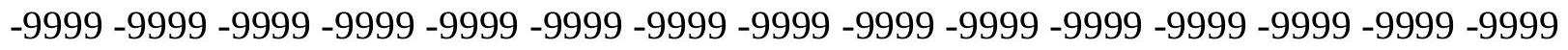
-9999-9999-9999-9999-9999-9999-9999-9999-9999 - -999 - -999 -

-9999 -9999 -9999 -9999 -9999 -9999 -9999 -9999 -9999 -9999 -9999 -9999 -9999 -9999 -9999 -9999 -9999 -9999 -9999 -9999 -9999 -9999 -9999 -9999 -9999 -9999 -9999 -9999 -9999 -9999 -

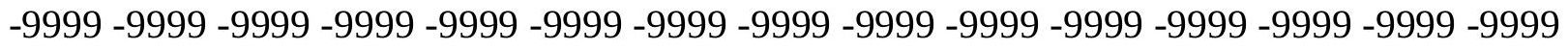

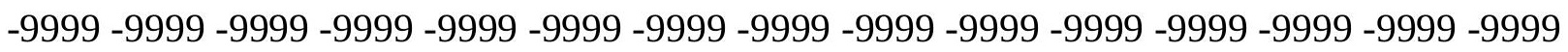
-9999 -9999 -9999 -9999 -9999 -9999 -9999 -9999 -9999 -9999 -9999 -9999 -9999 -9999 -9999 -9999 -9999 -9999 -9999 -9999 -9999 -9999 -9999 -9999 -9999 -9999 -9999 -9999 -9999 -9999 84.1206970214867 .0527267456156 .0804595947357 .2995986938558 .51874923706 59.4331016540560 .3474502563561 .2618103027362 .1761703491262 .78573989868 
63.0905189514263 .3953094482463 .3953094482463 .3953094482463 .09051895142 62.7857398986862 .1761703491261 .8713798522961 .5666007995661 .56660079956 61.5666007995661 .5666007995661 .8713798522962 .1761703491262 .78573989868 63.3953094482464 .004882812564 .9192428588966 .1383666992267 .66230010986 68.8814392089870 .4053573608471 .3197174072371 .014930725170 .10057830811 68.8814392089867 .9670867919967 .0527267456166 .1383666992265 .83358764648 66.1383666992267 .0527267456168 .8814392089871 .014930725173 .14842987061 73.7580032348674 .3675689697374 .9771423339875 .8914871215876 .19628143311 77.1106262207 78.02498626709 79.24413299561 80.46327209473 81.98719787598 83.5111236572385 .3398437586 .8637619018688 .6924667358490 .21640014648 91.7403335571393 .8738174438596 .0073165893698 .14080810547100 .2742996216 102.4077987671104 .2365036011106 .0652008057107 .8938980103109 .1130981445 110.3321990967111 .24659729110 .5748214722109 .7724685669108 .967628479 108.1684265137107 .387260437106 .6385574341105 .934928894105 .2862930298 104.6986236572104 .1757507324103 .7192001343103 .3307189941103 .0109634399 102.7598876953102 .5732879639102 .4418411255102 .3459472656102 .2545089722 102.1309661865101 .945022583101 .6633529663101 .2792129517100 .811630249 100.292572021599 .7330780029399 .150245666598 .5409393310597 .88803863525 97.1849670410296.448242187595.7346191406295.1437683105594.82247161865 94.9296798706195 .5317459106494 .8395004272594 .1918640136793 .80996704102 93.9450836181694 .1935195922994 .450752258394 .8030395507895 .64800262451 97.6482543945399 .93705749512101 .2073287964102 .7739334106104 .5043106079 106.0652008057 107.9162368774 109.305015564 110.0273971558 109.4179000854 108.5035018921107 .2844009399105 .4557037354103 .3221969604101 .1886978149 103.0174026489 103.9317016602 102.712600708 99.9695205688597.53124237061 96.6168823242299 .66472625732104 .5412979126105 .7603988647106 .979598999 108.503501892151 .2038993835450 .2895507812549 .3751907348648 .46083068848 47.8512611389247 .5464782714847 .2416992187546 .9369087219246 .93690872192 47.2416992187547 .5464782714847 .8512611389248 .4608306884849 .07040023804 49.3751907348649 .3751907348649 .0704002380448 .4608306884847 .85126113892 47.2416992187546 .6321296691946 .3273391723646 .0225486755446 .02254867554 46.0225486755446 .0225486755446 .3273391723646 .6321296691946 .93690872192 47.2416992187547 .5464782714847 .2416992187546 .9369087219246 .32733917236 45.4129791259844 .1938400268642 .9747009277341 .4507789611840 .23163986206 46.9369087219252 .1182594299356 .0804595947360 .0426712036163 .39530944824 67.0527267456173 .4532165527376 .285713195878 .4863128662180 .87000274658 82.7643508911184 .0459823608485 .0350494384886 .8637619018686 .55898284912 79.8537063598680 .7680587768683 .206336975185 .3398437585 .64462280273 85.0350494384884 .1206970214877 .4154205322372 .5388565063570 .71015167236 71.014930725171 .3197174072371 .3197174072369 .7957916259867 .96708679199 65.5288009643663 .7000885009862 .1761703491260 .9570198059160 .34745025635 60.3474502563560 .6522407531760 .6522407531760 .9570198059160 .95701980591 60.9570198059160 .6522407531760 .3474502563560 .6522407531761 .26181030273 61.8713798522962 .1761703491262 .78573989868 -9999 -9999 -9999 -9999 -9999 -9999 -9999

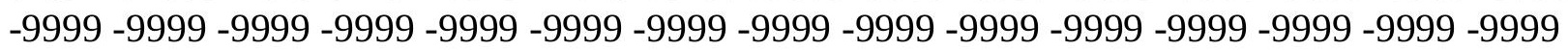

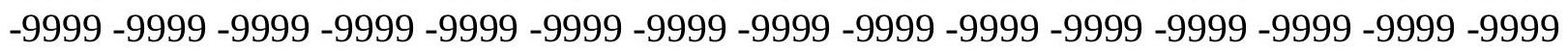


-9999 -9999 -9999 -9999 -9999 -9999 -9999 -9999 -9999 -9999 -9999 -9999 -9999 -9999 -9999 -9999 -9999 -9999 -9999 -9999 -9999 -9999 -9999 -9999 -9999 -9999 -9999 -9999 -9999 -9999 -9999 -9999 -9999-9999

-9999 -9999 -9999 -9999 -9999 -9999 -9999 -9999 -9999 -9999 -9999 -9999 -9999 -9999 -9999 -9999 -9999 -9999 -9999 -9999 -9999 -9999 -9999 -9999 -9999 -9999 -9999-9999 -9999 -9999 -

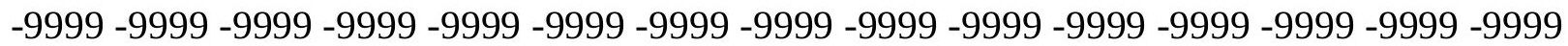

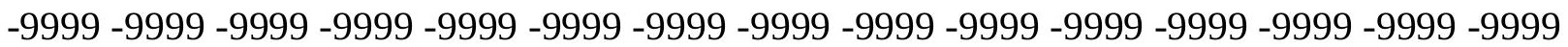
-9999 -9999 -9999 -9999 -9999 -9999 -9999 -9999 -9999 -9999 -9999 -9999 -9999 -9999 -9999 -999 -

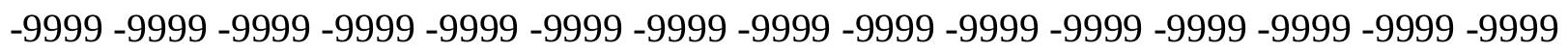
-9999 70.1005783081157.6043891906758.82352828979 59.73788070679 60.65224075317 61.2618103027362 .1761703491262 .7857398986863 .3953094482463 .70008850098 64.004882812564 .004882812563 .7000885009863 .0905189514262 .48094940186 61.8713798522961 .5666007995661 .2618103027360 .9570198059160 .95701980591 61.2618103027361 .5666007995661 .8713798522962 .4809494018663 .09051895142 63.7000885009864 .6144485473665 .8335876464867 .0527267456168 .27187347412 69.1862335205170 .1005783081170 .1005783081169 .4910125732468 .88143920898 67.9670867919967 .0527267456166 .1383666992265 .5288009643665 .22400665283 66.4431610107468 .2718734741269 .7957916259871 .3197174072372 .23407745361 72.8436431884873 .4532165527374 .3675689697374 .6723632812575 .28192901611 76.1962814331177 .7202072143679 .2441329956181 .0728530883883 .2063369751 84.7302627563586 .5589828491288 .3876876831189 .9116134643691 .74033355713 93.8738174438596 .0073165893698 .14080810547100 .2742996216102 .4077987671 104.2365036011106 .0652008057107 .5891036987109 .1130981445110 .3321990967 109.7232437134108.918182373 108.1028442383 107.2819595337 106.4644317627 105.6636734009104 .8950042725104 .1713867188103 .5027160645102 .8949813843 102.3526000977101 .8783798218101 .4762268066101 .1495132446100 .9016036987 100.7324523926100 .637878418100 .6003341675100 .5901260376100 .5612182617 100.4664154053100 .255615234499 .9017944335999 .4472885131898 .9274597168 98.391189575297 .8625564575297 .3002395629996 .657501220795 .88648986816 95.0035018920994 .0544204711993 .1497802734492 .5000915527392 .40577697754 93.1527786254994 .1076660156294 .1785964965893 .5690307617293 .87381744385 94.4833908081194 .1785964965894 .1785964965894 .3960952758895 .70252990723 96.3121032714897 .2264633178799 .66472625732101 .4934005737103 .0174026489 104.5412979126105 .4557037354105 .4557037354105 .1509017944103 .9317016602 102.712600708100 .883903503499 .0551681518698 .1408081054798 .75038146973 99.35994720459 99.3599472045998.1408081054797.5312423706198.14080810547 100.5791015625103 .9317016602106 .0652008057107 .8938980103110 .6370010376 49.6799812316948 .4608306884847 .5464782714846 .6321296691946 .02254867554 45.4129791259844 .8034095764244 .8034095764244 .8034095764245 .10820007324 45.4129791259846 .0225486755446 .6321296691947 .5464782714847 .85126113892 48.1560516357447 .8512611389246 .9369087219246 .0225486755445 .41297912598 44.4986305236843 .8890609741243 .5842704772943 .2794914245642 .97470092773 42.9747009277343 .2794914245643 .5842704772943 .8890609741243 .88906097412 43.8890609741243 .5842704772942 .9747009277342 .0603485107440 .53641891479 39.0125007629437 .1837806701735 .9646492004436 .8790016174340 .84120941162 46.0225486755450 .5943298339854 .8613204956158 .2139587402361 .56660079956 
64.9192428588970 .7101516723674 .6010437011778 .9284439086983 .10787963867 87.11830902189 .7808532714890 .8259735107487 .7781066894578 .32978057861 79.2441329956179 .8537063598680 .1584930419981 .9871978759883 .51112365723 83.5111236572380 .7680587768677 .7202072143675 .8914871215875 .28192901611 75.2819290161175 .2819290161172 .5388565063569 .7957916259867 .35751342773 64.9192428588962 .7857398986861 .2618103027360 .3474502563560 .04267120361 60.0426712036160 .0426712036160 .0426712036160 .0426712036160 .04267120361 59.7378807067960 .0426712036160 .3474502563560 .6522407531761 .26181030273 61.8713798522962 .4809494018663 .09051895142 -9999 -9999 -9999 -9999 -9999 -9999 -9999 -9999 -9999 -9999 -9999 -9999 -9999 -9999 -9999 -9999 -9999 -9999 -9999 -9999 -9999 -9999 -9999 -9999 -9999 -9999 -9999 -9999 -9999 -9999 -9999 -9999 -9999 -9999 -9999 -9999 -9999 -9999 -9999 -9999 -9999 -9999 -9999 -9999 -9999 -9999 -9999 -9999 -9999 -9999 -9999 -9999

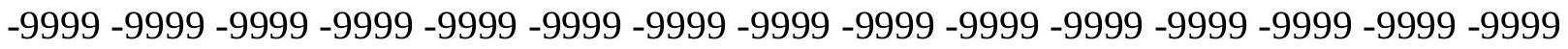
-9999 -9999-9999

-9999 -9999 -9999 -9999 -9999 -9999 -9999 -9999 -9999 -9999 -9999 -9999 -9999 -9999 -9999 -9999 -9999 -9999 -9999 -9999 -9999 -9999 -9999 -9999 -9999 -9999 -9999 -9999 -9999 -9999 -

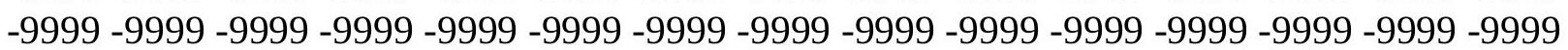

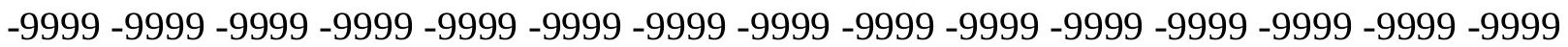
-9999 -9999 -9999 -9999 -9999 -9999 -9999 -9999 -9999 -9999 -9999 -9999 -9999 -9999 -9999 -9999 -9999 -9999 -9999 -9999 -9999 -9999 -9999 -9999 -9999 -9999 -9999 -9999 -9999 -9999 -9999 -9999 59.73788070679 60.65224075317 61.2618103027361.87137985229 62.7857398986863 .3953094482464 .004882812564 .6144485473664 .91924285889 64.9192428588964 .9192428588964 .3096618652363 .3953094482462 .48094940186 61.5666007995660 .9570198059160 .6522407531760 .3474502563560 .34745025635 60.6522407531760 .9570198059161 .5666007995662 .1761703491262 .78573989868 63.3953094482464 .3096618652365 .2240066528366 .1383666992267 .05272674561 67.9670867919968 .5766525268668 .8814392089868 .8814392089868 .57665252686 68.2718734741267 .3575134277366 .7479400634866 .1383666992265 .83358764648 66.4431610107467 .6623001098668 .5766525268669 .7957916259870 .40535736084 71.014930725171 .6244964599671 .9292907714872 .5388565063573 .45321655273 74.6723632812576 .5010681152378 .6345596313580 .7680587768682 .90155792236 84.7302627563586 .5589828491288 .0829010009889 .9116134643691 .74033355713 93.8738174438596 .0073165893698 .14080810547100 .2742996216102 .4077987671 104.2365036011106 .0652008057107 .5891036987109 .1130981445108 .9716110229 108.1764755249107 .3645324707106 .5384140015105 .7032852173104 .8687057495 104.0489425659103 .2598495483102 .5145721436101 .822883606101 .1907501221 100.6230545044100 .123725891199 .6983108520599 .3525314331199 .09281921387 98.9263916015698 .8606643676898 .8738098144598 .9481201171999 .03745269775 99.0759506225698 .9834442138798 .6860122680798 .2138061523497 .65591430664 97.1477890014696 .7324371337996 .2842483520595 .7043304443494 .89562225342 93.9228668212992 .7870712280391 .5757217407290 .5210876464890 .06934356689 90.8878021240293 .2929687595 .0929565429797 .5312423706197 .53124237061 96.3121032714895 .0929565429794 .1785964965893 .8738174438594 .17859649658 94.4833908081195 .397743225196 .9216690063598 .445587158299 .66472625732 100.8839035034101 .1886978149101 .1886978149100 .579101562599 .66472625732 98.445587158297 .2264633178796 .0073165893695 .7025299072395 .70252990723 
96.3121032714896 .6168823242296 .6168823242296 .9216690063598 .14080810547 100.2742996216102 .712600708105 .1509017944107 .589103698749 .37519073486 48.1560516357446 .9369087219245 .717769622844 .4986305236843 .58427047729 42.9747009277342 .66992187542 .3651313781742 .3651313781742 .669921875 43.2794914245643 .8890609741244 .8034095764245 .4129791259846 .32733917236 46.6321296691946 .0225486755445 .1082000732444 .1938400268643 .27949142456 42.3651313781741 .4507789611840 .8412094116240 .5364189147940 .23163986206 40.2316398620640 .2316398620640 .2316398620640 .5364189147940 .84120941162 40.8412094116240 .5364189147939 .9268493652338 .7077102661137 .18378067017 35.3550796508833 .8311500549333 .2215805053734 .4407196044937 .48857116699 41.7555618286146 .0225486755450 .2895507812553 .6421813964856 .99481964111 59.7378807067962 .1761703491269 .4910125732474 .668243408282 .55158996582 88.92375946045 92.86324310303 94.3270568847792.8950042724691.13075256348 83.206336975177 .7202072143674 .6723632812578 .3297805786181 .37763214111 82.2919769287182 .2919769287181 .0728530883879 .8537063598678 .63455963135 78.0249862670976 .5010681152374 .062782287671 .3197174072368 .27187347412 65.5288009643663 .3953094482461 .5666007995660 .3474502563559 .73788070679 59.4331016540559 .4331016540559 .4331016540559 .4331016540559 .43310165405 59.4331016540559 .7378807067963 .0905189514260 .3474502563560 .95701980591 61.5666007995662 .1761703491262 .78573989868 -9999 -9999 -9999 -9999 -9999 -9999 -9999 -9999 -9999 -9999 -9999 -9999 -9999 -9999 -9999 -9999 -9999 -9999 -9999 -9999 -9999 -9999 -9999 -9999 -9999 -9999 -9999 -9999 -9999 -9999 -9999 -9999 -9999 -9999 -9999 -9999 -9999 -9999 -9999 -9999 -9999 -9999 -9999 -9999 -9999 -9999 -9999 -9999 -9999 -9999 -9999 -9999 -

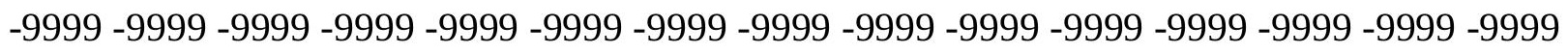
-9999 -9999-9999

-9999 -9999 -9999 -9999 -9999 -9999 -9999 -9999 -9999 -9999 -9999 -9999 -9999 -9999 -9999 -9999 -9999 -9999 -9999 -9999 -9999 -9999 -9999 -9999 -9999 -9999 -9999 -9999 -9999 - -9999 -

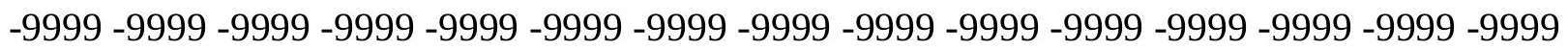
-9999 -9999 -9999 -9999 -9999 -9999 -9999 -9999 -9999 -9999 -9999 -9999 -9999 -9999 -9999 -9999 -9999 -9999 -9999 -9999 -9999 -9999 -9999 -9999 -9999 -9999 -9999 -9999 -9999 -9999 -9999 -9999 -9999 -9999 -9999 -9999 -9999 -9999 -9999 -9999 -9999 -9999 -9999 -9999 -9999 -9999 -999962.7857398986863.0905189514263.3953094482463.70008850098 64.3096618652364 .9192428588965 .2240066528365 .8335876464866 .13836669922 66.4431610107466 .1383666992265 .5288009643664 .3096618652362 .78573989868 61.5666007995660 .6522407531760 .0426712036159 .7378807067960 .04267120361 60.3474502563560 .6522407531761 .2618103027361 .8713798522962 .48094940186 63.0905189514263 .7000885009864 .3096618652365 .2240066528365 .83358764648 66.44316101074 67.05272674561 67.66230010986 68.27187347412 68.57665252686 68.5766525268667 .9670867919967 .3575134277367 .0527267456166 .74794006348 66.7479400634867 .3575134277367 .6623001098668 .2718734741268 .88143920898 69.1862335205169 .4910125732469 .7957916259870 .4053573608471 .31971740723 73.1484298706175 .2819290161178 .0249862670980 .4632720947382 .90155792236 85.0350494384886 .8637619018688 .3876876831190 .2164001464892 .04509735107 93.8738174438596 .0073165893698 .14080810547100 .2742996216102 .4077987671 104.2365036011106 .0652008057107 .5891036987108 .2959747314107 .5243148804 106.7295684814105 .913482666105 .0788574219104 .2312927246103 .3808288574 
102.5421600342101 .7314300537100 .9618453979100 .243209838999 .58171844482 98.9826507568498 .4505081176897 .9914627075297 .6170349121197 .34331512451 97.1715011596797 .1150817871197 .152755737397 .2830047607497 .47750854492 97.6798934936597 .7853546142697 .5651321411197 .040039062596 .336769104 95.8342971801895 .587615966895 .3919982910294 .8166732788194 .02791595459 93.0527801513791 .8867416381890 .5147247314589 .1089019775488 .24680328369 88.6924667358492 .0450973510797 .22646331787102 .712600708100 .5791015625 97.8360290527396 .0073165893694 .1785964965893 .2642517089892 .95947265625 92.9594726562593 .5690307617294 .4833908081195 .7025299072396 .61688232422 97.2264633178797 .5312423706197 .2264633178796 .6168823242295 .3977432251 94.7881774902394 .1785964965893 .8738174438593 .5690307617293 .56903076172 93.8738174438594 .4833908081195 .0929565429795 .7025299072396 .92166900635 99.05516815186101 .1886978149103 .6268997192106 .065200805748 .15605163574 46.6321296691945 .1082000732443 .5842704772942 .3651313781741 .45077896118 40.5364189147939 .9268493652339 .622070312539 .9268493652340 .23163986206 40.8412094116241 .4507789611842 .3651313781742 .9747009277343 .88906097412 43.8890609741243 .5842704772942 .66992187541 .7555618286140 .84120941162 39.9268493652339 .0125007629438 .4029312133837 .7933502197337 .18378067017 36.8790016174336 .8790016174337 .1837806701737 .4885711669938 .09814071655 38.4029312133838 .0981407165537 .4885711669936 .5742111206134 .74551010132 33.2215805053732 .0024414062532 .0024414062532 .9167900085435 .35507965088 39.0125007629442 .66992187546 .6321296691949 .9847602844253 .03261184692 55.7756805419958 .8235282897962 .1761703491266 .1383666992281 .37763214111 87.4509201049894 .0580902099696 .9118041992296 .8093719482494 .96179199219 91.1307525634885 .0350494384878 .9393463134877 .7202072143679 .85370635986 81.6824111938582 .9015579223683 .206336975182 .2919769287180 .76805877686 79.2441329956177 .110626220774 .6723632812571 .9292907714868 .88143920898 66.1383666992263 .7000885009861 .8713798522960 .3474502563559 .73788070679 59.1283111572358 .8235282897958 .8235282897958 .8235282897959 .12831115723 59.1283111572359 .4331016540559 .7378807067960 .3474502563560 .65224075317 61.2618103027361 .8713798522962 .48094940186 -9999 -9999 -9999 -9999 -9999 -9999 -9999 -9999 -9999 -9999 -9999 -9999 -9999 -9999 -9999 -9999 -9999 -9999 -9999 -9999 -9999 -9999 -9999 -9999 -9999 -9999 -9999 -9999 -9999 -9999 -9999-9999 -9999 -9999 -9999-9999-999 - -999 -9999 -9999 -9999 -9999 -9999 -9999 -9999 -9999 -9999 -9999 -9999 -9999 -9999 -9999 -9999

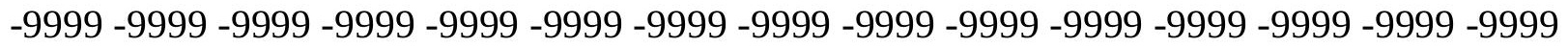
-9999 -9999-9999

-9999 -9999 -9999 -9999 -9999 -9999 -9999 -9999 -9999 -9999 -9999 -9999 -9999 -9999 - 9999-

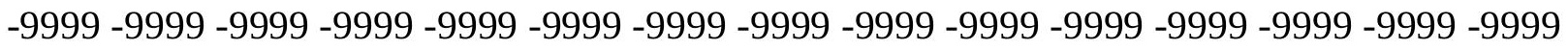
-9999 -9999 -9999 -9999 -9999 -9999 -9999 -9999 -9999 -9999 -9999 -9999 -9999 -9999 -9999 -9999 -9999 -9999 -9999 -9999 -9999 -9999 -9999 -9999 -9999 -9999 -9999 -9999 -9999 -9999 -

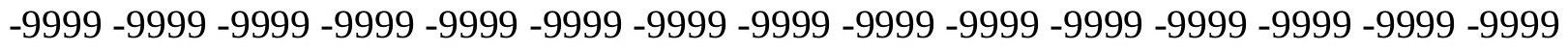
-9999 -9999-9999 -9999 -9999 -9999 -9999 -9999 -9999 -9999 -9999 -9999 -9999 -9999 -9999 -9999 -9999 -9999 66.13836669922 65.83358764648 65.83358764648 66.13836669922 66.4431610107467 .0527267456167 .6623001098667 .9670867919968 .27187347412 67.9670867919967 .0527267456165 .5288009643663 .7000885009861 .56660079956 60.3474502563559 .4331016540559 .4331016540559 .7378807067960 .04267120361 
60.3474502563560 .9570198059161 .5666007995662 .1761703491262 .78573989868 63.0905189514263 .7000885009864 .3096618652364 .6144485473665 .22400665283 65.8335876464866 .7479400634867 .9670867919968 .5766525268669 .18623352051 68.8814392089868 .5766525268667 .9670867919967 .6623001098667 .66230010986 67.6623001098667 .6623001098667 .3575134277367 .9670867919968 .27187347412 68.2718734741267 .9670867919968 .2718734741269 .4910125732471 .92929077148 74.9771423339878 .0249862670981 .0728530883883 .8159103393685 .64462280273 87.1685485839888 .6924667358490 .2164001464892 .0450973510794 .17859649658 96.3121032714898 .14080810547100 .2742996216102 .4077987671104 .2365036011 106.0652008057107 .5891036987106 .9363098145106 .1737594604105 .3831253052 104.5659713745103 .7252349854102 .8670043945102 .0016098022101 .1438446045 100.309730529899 .512557983498 .7623748779398 .0660400390697 .42948913574 96.8573379516696 .3544616699295 .9496002197395 .6482467651495 .46142578125 95.3816833496195 .4061889648495 .5286788940495 .7640304565496 .11520385742 96.4477920532296 .5344161987395 .7848358154394 .8498687744194 .26879119873 94.2369995117294 .4833908081193 .5690307617292 .9594726562592 .04509735107 91.1307525634889 .9116134643688 .3876876831187 .4733276367288 .08290100098 92.0450973510796 .92166900635100 .2742996216100 .274299621698 .14080810547 96.0073165893693 .8738174438592 .349891662691 .4355392456191 .43553924561 91.7403335571392 .349891662692 .9594726562593 .8738174438594 .17859649658 94.1785964965893 .8738174438592 .9594726562592 .0450973510791 .43553924561 91.7403335571391 .7403335571391 .7403335571391 .7403335571392 .04509735107 92.6546783447393 .2642517089893 .8738174438595 .397743225196 .92166900635 99.05516815186101 .4934005737104 .236503601147 .2416992187545 .10820007324 43.2794914245641 .7555618286140 .2316398620639 .0125007629437 .79335021973 37.1837806701736 .8790016174336 .8790016174337 .1837806701737 .79335021973 38.7077102661139 .622070312540 .2316398620640 .8412094116241 .14598846436 40.8412094116239 .9268493652339 .0125007629438 .0981407165537 .18378067017 36.2694282531735 .6598587036134 .7455101013234 .1359291076733 .83115005493 33.8311500549334 .1359291076734 .7455101013235 .3550796508835 .96464920044 36.2694282531736 .2694282531735 .0502891540533 .5263595581132 .30722045898 31.3928699493431 .3928699493432 .3072204589834 .4407196044937 .18378067017 40.5364189147943 .8890609741247 .2416992187549 .9847602844253 .03261184692 56.0804595947359 .4331016540563 .7000885009869 .4910125732479 .54891967773 93.2642517089895 .7025299072396 .9216690063596 .0073165893693 .87381744385 89.3020401001 85.33984375 78.6345596313579.24413299561 81.07285308838 82.90155792236 84.12069702148 82.59677124023 81.07285308838 79.24413299561 76.8058471679774 .3675689697371 .6244964599668 .8814392089866 .13836669922 63.7000885009861 .8713798522960 .3474502563559 .4331016540558 .82352828979 58.8235282897958 .5187492370658 .5187492370658 .8235282897958 .82352828979 59.1283111572359 .7378807067960 .0426712036160 .6522407531760 .95701980591 61.5666007995662 .17617034912 -9999 -9999 -9999 -9999 -9999 -9999 -9999 -9999 -9999 -9999 -9999 -9999 -9999 -9999 -9999 -9999 -9999 -9999 -9999 -9999 -9999 -9999 -9999 -9999 -9999 -9999 -9999 -9999 -9999 -9999 -9999 -9999 -9999-9999 -9999 -9999 -9999 -9999 -9999 -9999 -9999 -9999 -9999 -9999 -9999 -9999 -9999 -9999 -9999 -9999 -9999 -9999 -9999 -9999 -

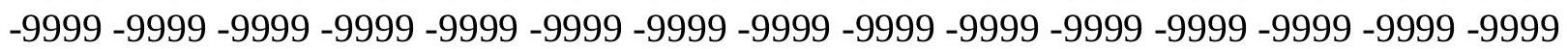


$-9999$

-9999 -9999 -9999 -9999 -9999 -9999 -9999 -9999 -9999 -9999 -9999 -9999 -9999 -9999 -9999 -

-9999 -9999 -9999 -9999 -9999 -9999 -9999 -9999 -9999 -9999 -9999 -9999 -9999 -9999 - 9999 -

-9999 -9999 -9999 -9999 -9999 -9999 -9999 -9999 -9999 -9999 -9999 -9999 -9999 -9999 -9999

-9999 -9999 -9999 -9999 -9999 -9999 -9999 -9999 -9999 -9999 -9999 -9999-9999 -9999 -9999 -

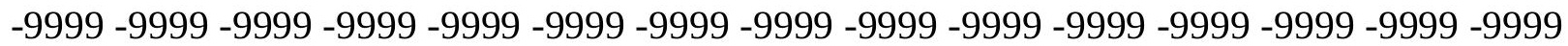

-9999 -9999 -9999 -9999 -9999 -9999 -9999 -9999 -9999 -9999 -9999 -9999 -9999 -9999 -9999

-9999-9999-9999-9999 68.88143920898 68.27187347412 68.27187347412 68.27187347412

68.8814392089869 .4910125732470 .1005783081170 .7101516723670 .71015167236

69.7957916259867 .6623001098664 .6144485473661 .8713798522959 .73788070679

59.1283111572359 .1283111572359 .4331016540560 .0426712036160 .34745025635

60.9570198059161 .5666007995661 .8713798522962 .4809494018662 .78573989868

63.0905189514263 .3953094482463 .7000885009864 .004882812564 .61444854736

66.1383666992267 .6623001098668 .8814392089869 .7957916259870 .10057830811 69.4910125732469 .1862335205168 .8814392089868 .5766525268668 .27187347412 68.2718734741267 .9670867919967 .9670867919967 .6623001098667 .35751342773 67.0527267456167 .0527267456167 .9670867919971 .014930725174 .97714233398 79.2441329956182 .5967712402385 .0350494384886 .8637619018688 .38768768311 89.6068267822390 .8259735107492 .6546783447394 .4833908081196 .61688232422 98.4455871582100 .5791015625102 .4077987671104 .2365036011105 .7603988647 106.3814926147105 .6664886475104 .9183197021104 .1363067627103 .321685791 102.4774932861101 .6102294922100 .730476379499 .8529281616298 .99333953857 98.1650314331197 .3785934448296 .6419296264695 .9620666503995 .34381866455 94.7952880859494 .3506698608494 .0141754150493 .7881011962993 .66064453125 93.6136627197393 .6447906494193 .7939605712994 .175498962494 .5641708374 95.397743225194 .1785964965893 .2642517089892 .6546783447392 .95947265625 92.349891662691 .7403335571391 .1307525634890 .5211791992289 .91161346436 88.99725341797 88.38768768311 88.38768768311 89.302040100192.04509735107 95.397743225197 .5312423706197 .8360290527396 .6168823242294 .78817749023 92.9594726562591 .4355392456190 .2164001464889 .6068267822389 .60682678223 90.2164001464890 .8259735107491 .4355392456191 .4355392456191 .43553924561 91.1307525634890 .5211791992289 .9116134643689 .6068267822389 .60682678223 89.91161346436 89.9116134643690.2164001464890.52117919922 90.82597351074 91.4355392456192 .0450973510793 .2642517089894 .7881774902396 .61688232422 98.7503814697348 .4608306884846 .0225486755443 .5842704772941 .45077896118 39.622070312537 .7933502197336 .2694282531735 .0502891540534 .13592910767 33.8311500549333 .8311500549334 .1359291076735 .0502891540535 .96464920044 36.5742111206137 .4885711669937 .7933502197338 .0981407165537 .79335021973 37.1837806701736 .2694282531735 .3550796508834 .4407196044933 .83115005493 32.9167900085432 .3072204589831 .3928699493430 .7833003997830 .47850990295 30.7833003997831 .6976509094232 .9167900085433 .8311500549334 .74551010132 35.0502891540534 .1359291076732 .9167900085432 .0024414062531 .08807945251 31.3928699493432 .3072204589833 .8311500549336 .2694282531739 .01250076294 42.0603485107445 .1082000732447 .8512611389250 .5943298339853 .64218139648 56.6900291442960 .3474502563565 .5288009643671 .9292907714879 .24413299561 89.6068267822392 .9594726562594 .4833908081195 .0929565429791 .74033355713 
87.47332763672 79.8537063598679 .2441329956180 .1584930419981 .37763214111 81.9871978759881 .3776321411179 .8537063598678 .0249862670975 .89148712158 73.4532165527371 .014930725168 .2718734741265 .8335876464863 .70008850098 61.8713798522960 .0426712036159 .4331016540558 .8235282897958 .51874923706 58.5187492370658 .5187492370658 .5187492370658 .8235282897959 .12831115723 59.4331016540559 .7378807067960 .3474502563560 .6522407531761 .26181030273 61.8713798522962 .48094940186 -9999 -9999 -9999 -9999 -9999 -9999 -9999 -9999 -9999

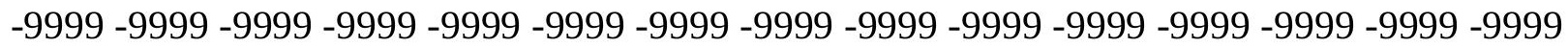

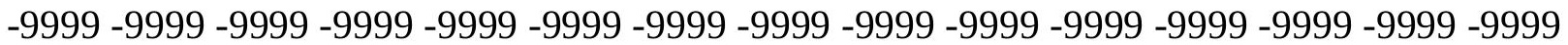

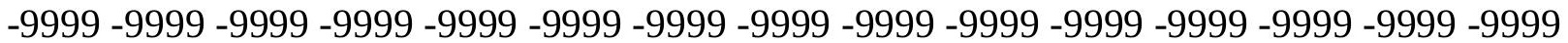

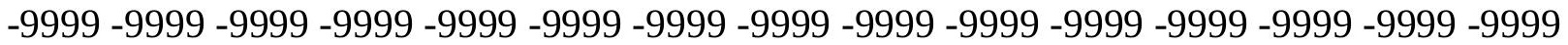

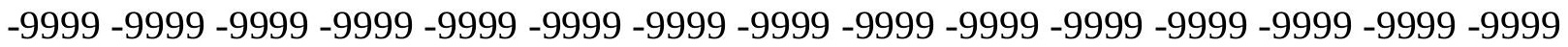

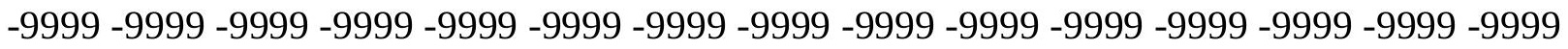

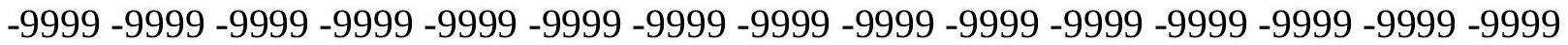

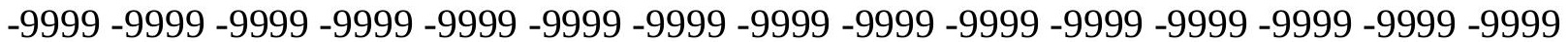

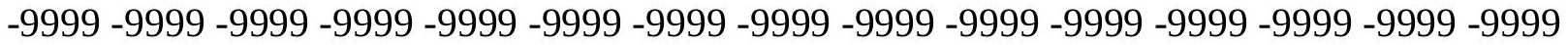

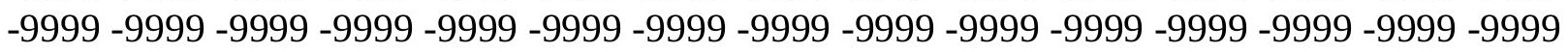
-9999 -9999 -9999 -9999 -9999 71.0149307251 70.40535736084 70.10057830811 70.7101516723671 .3197174072372 .2340774536173 .1484298706173 .75800323486 73.1484298706170 .4053573608466 .4431610107461 .8713798522959 .73788070679 59.1283111572359 .1283111572359 .4331016540560 .0426712036160 .65224075317 60.9570198059161 .5666007995661 .8713798522962 .4809494018662 .78573989868 63.0905189514263 .0905189514263 .3953094482463 .3953094482463 .70008850098 65.5288009643667 .6623001098669 .1862335205170 .7101516723670 .71015167236 70.4053573608470 .1005783081169 .7957916259869 .7957916259869 .49101257324 69.4910125732469 .1862335205168 .8814392089868 .2718734741267 .66230010986 67.0527267456166 .7479400634867 .0527267456171 .6244964599676 .50106811523 81.0728530883884 .7302627563587 .1685485839888 .3876876831189 .3020401001 90.5211791992291 .7403335571393 .5690307617295 .397743225197 .22646331787 99.05516815186100 .8839035034102 .4077987671104 .2365036011105 .4557037354 105.1733474731104 .4847869873103 .7572555542102 .9891967773102 .1814117432 101.3368453979100 .462341308699 .5685882568498 .6701889038197 .78263092041 96.9194564819396 .0919876098695 .3095397949294 .5805816650493 .91081237793 93.3095779418992 .8219757080192 .4389495849692 .1563720703191 .95255279541 91.7876892089891 .6032714843891 .5573577880991 .8799591064592 .3498916626 91.4355392456192 .0450973510792 .349891662692 .349891662692 .3498916626 92.0450973510791 .7403335571391 .4355392456191 .4355392456191 .43553924561 90.2164001464889 .302040100189 .302040100189 .9116134643691 .43553924561 93.5690307617295 .0929565429795 .397743225194 .7881774902393 .26425170898 91.7403335571390 .2164001464888 .6924667358487 .4733276367287 .77810668945 88.3876876831188 .6924667358489 .302040100189 .302040100189 .3020401001 88.9972534179788 .6924667358488 .0829010009888 .0829010009888 .08290100098 88.0829010009888 .3876876831188 .6924667358488 .9972534179789 .3020401001 89.9116134643690 .2164001464891 .1307525634892 .6546783447394 .17859649658 96.0073165893647 .5464782714844 .8034095764242 .0603485107439 .6220703125 37.4885711669935 .3550796508833 .5263595581132 .0024414062531 .08807945251 
30.4785099029530 .4785099029531 .0880794525132 .0024414062532 .91679000854 33.5263595581134 .4407196044934 .7455101013235 .0502891540534 .74551010132 34.4407196044933 .5263595581132 .6120109558132 .0024414062531 .39286994934 30.4785099029529 .5641593933128 .6497993469227 .7354507446327 .12587928772 27.430660247829 .2593708038330 .4785099029532 .0024414062532 .91679000854 33.5263595581133 .2215805053732 .3072204589831 .6976509094231 .39286994934 31.3928699493432 .3072204589833 .8311500549335 .9646492004438 .40293121338 40.8412094116243 .5842704772946 .3273391723648 .765621185351 .50868988037 53.9469718933156 .6900291442960 .0426712036164 .9192428588971 .62449645996 77.110626220786 .254188537688 .6924667358488 .3876876831186 .2541885376 81.6824111938579 .5489196777378 .3297805786178 .3297805786178 .93934631348 79.2441329956178 .6345596313577 .7202072143675 .8914871215874 .0627822876 71.9292907714869 .7957916259867 .6623001098665 .5288009643663 .39530944824 61.8713798522960 .3474502563559 .4331016540558 .8235282897958 .51874923706 58.5187492370658 .5187492370658 .5187492370658 .5187492370658 .82352828979 59.4331016540559 .7378807067960 .0426712036160 .6522407531761 .26181030273 61.5666007995662 .17617034912 -9999 -9999 -9999 -9999 -9999 -9999 -9999 -9999 -9999 -9999 -9999 -9999 -9999 -9999 -9999 -9999 -9999 -9999 -9999 -9999 -9999 -9999 -9999 -9999 -

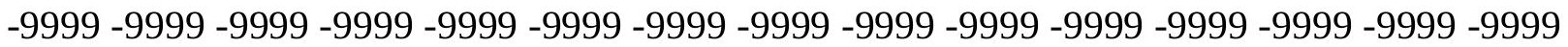

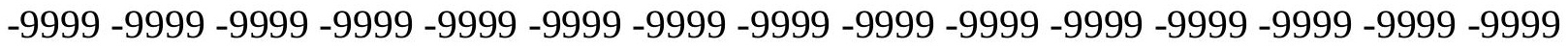

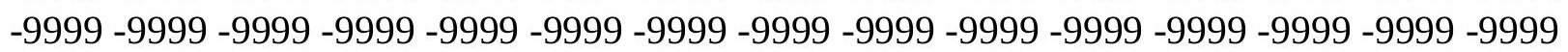

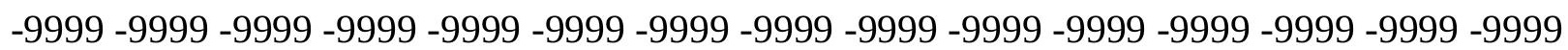
-9999 -9999 -9999 -9999 -9999 -9999 -9999 -9999 -9999 -9999 -9999 -9999 -9999 -9999 -9999 -

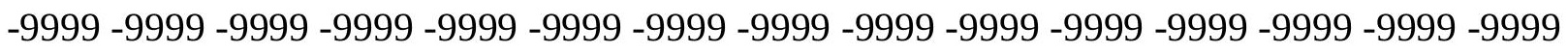

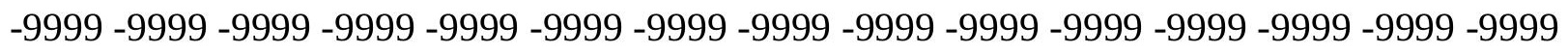
-9999 -9999 -9999 -9999 -9999 -9999 -9999 -9999 -9999 -9999 -9999 -9999 -9999 -9999 -9999 -9999 -9999 -9999 -9999 -9999 -9999 -9999 -9999 -9999 -9999 -9999 -9999 -9999 -9999 - 9999 -9999 -9999 -9999 -9999 -9999 73.45321655273 72.2340774536171 .92929077148 72.2340774536173 .1484298706174 .062782287675 .2819290161176 .50106811523 76.8058471679774 .6723632812569 .1862335205161 .8713798522960 .34745025635 59.7378807067959 .7378807067960 .0426712036160 .3474502563560 .95701980591 61.2618103027361 .8713798522962 .1761703491262 .4809494018662 .78573989868 63.0905189514263 .0905189514263 .3953094482463 .7000885009864 .30966186523 65.8335876464867 .6623001098669 .4910125732470 .7101516723671 .0149307251 71.014930725170 .7101516723670 .7101516723670 .7101516723670 .71015167236 70.7101516723670 .4053573608470 .1005783081169 .4910125732468 .57665252686 67.9670867919968 .2718734741269 .7957916259873 .4532165527378 .32978057861 83.5111236572387 .1685485839889 .302040100189 .9116134643690 .52117919922 91.4355392456192 .6546783447394 .1785964965896 .0073165893697 .83602905273 99.35994720459100 .8839035034102 .712600708103 .9317016602104 .6567687988 104.0442123413103 .3897018433102 .6895294189101 .9411621094101 .1448822021 100.303451538199 .4238510131898 .516738891697 .5964889526496 .67846679688 95.7766265869194 .9033126831194 .069473266693 .2855224609492 .55910491943 91.907646179291 .363143920990 .9199905395590 .5630493164190 .25798797607 89.9360046386789 .4916839599688 .9972534179788 .3876876831191 .43553924561 90.8259735107491 .7403335571391 .1307525634891 .1307525634891 .13075256348 
91.1307525634891 .1307525634891 .4355392456191 .4355392456191 .43553924561 90.8259735107490 .2164001464889 .9116134643690 .2164001464891 .13075256348 92.0450973510792 .9594726562593 .2642517089892 .6546783447391 .43553924561 90.2164001464888 .6924667358487 .4733276367286 .8637619018686 .55898284912 86.8637619018687 .1685485839887 .4733276367287 .4733276367287 .47332763672 87.1685485839886 .8637619018686 .8637619018686 .5589828491286 .86376190186 86.8637619018687 .1685485839887 .4733276367287 .7781066894588 .08290100098 88.3876876831188 .9972534179789 .6068267822390 .8259735107492 .04509735107 93.2642517089846 .6321296691943 .5842704772940 .5364189147937 .79335021973 35.3550796508832 .9167900085430 .7833003997829 .2593708038328 .04022979736 27.1258792877226 .8210906982427 .430660247828 .6497993469229 .56415939331 30.4785099029531 .3928699493432 .0024414062532 .0024414062532 .00244140625 31.6976509094230 .7833003997830 .1737308502229 .5641593933128 .95458984375 28.0402297973627 .1258792877226 .2115192413325 .2971591949524 .38281059265 24.0780296325726 .2115192413328 .3450202941930 .1737308502231 .39286994934 32.0024414062532 .3072204589832 .0024414062531 .6976509094231 .69765090942 32.0024414062532 .6120109558133 .8311500549335 .6598587036137 .79335021973 40.2316398620642 .66992187545 .1082000732447 .5464782714849 .67998123169 51.5086898803753 .3373985290555 .1661109924356 .9948196411164 .0048828125 69.7957916259873 .7580032348676 .8058471679778 .3297805786178 .63455963135 77.7202072143676 .8058471679775 .8914871215875 .5867080688575 .89148712158 75.5867080688575 .2819290161174 .6723632812573 .4532165527371 .92929077148 70.1005783081168 .2718734741266 .4431610107464 .9192428588963 .09051895142 61.5666007995660 .6522407531759 .7378807067959 .1283111572358 .51874923706 58.5187492370658 .2139587402358 .5187492370658 .5187492370658 .82352828979 59.1283111572359 .7378807067960 .0426712036160 .3474502563560 .95701980591 61.5666007995662 .17617034912 -9999 -9999 -9999 -9999 -9999 -9999 -9999 -9999 -9999 -9999 -9999 -9999 -9999 -9999 -9999 -9999 -9999 -9999 -9999 -9999 -9999 -9999 -9999 -999 -9999 -9999 -9999 -9999 -9999 -9999 -9999 -9999 -9999 -9999 -9999 -9999 -9999 -9999 -9999 -9999 -9999 -9999 -9999 -9999 -9999 -9999 -9999 -9999 -9999 -9999 -9999 -9999 -9999 -9999 -9999 -9999 -9999 -9999 -9999 -9999 -9999 -9999 -9999 -9999 -9999 -9999 -9999 -9999 -9999

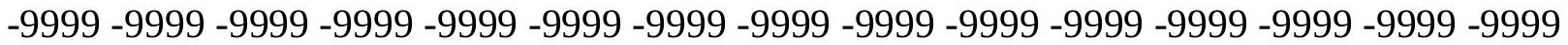

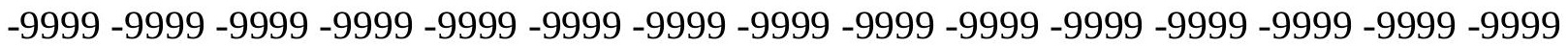
-9999 -9999 -9999 -9999 -9999 -9999 -9999 -9999 -9999 -9999 -9999 -9999 -9999 -9999 -9999 -9999 -9999 -9999 -9999 -9999 -9999 -9999 -9999 -9999 -9999 -9999 -9999 -9999 -9999 -9999 -9999 -9999 -9999 -9999 -9999 -9999 -9999 -9999 -9999 -9999 -9999 -9999 -9999 -9999 -9999

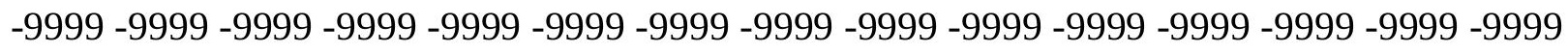
-9999 -9999 -9999 -9999-9999 -9999 73.75800323486 73.14842987061 73.45321655273 74.062782287675 .2819290161176 .8058471679778 .0249862670979 .24413299561 79.5489196777372 .2340774536165 .8335876464862 .4809494018660 .95701980591 60.6522407531760 .6522407531760 .9570198059161 .2618103027361 .87137985229 62.1761703491262 .4809494018662 .7857398986862 .7857398986863 .09051895142 63.3953094482463 .7000885009864 .004882812564 .9192428588966 .13836669922 67.6623001098669 .1862335205170 .4053573608471 .014930725171 .31971740723 71.3197174072371 .3197174072371 .3197174072371 .6244964599671 .92929077148 71.9292907714871 .6244964599670 .7101516723669 .7957916259869 .79579162598 
70.4053573608472 .2340774536175 .5867080688580 .1584930419985 .33984375 89.9116134643690 .8259735107490 .8259735107491 .1307525634892 .3498916626 93.5690307617295 .0929565429796 .6168823242298 .1408081054799 .66472625732 101.1886978149102 .712600708103 .9317016602103 .5591049194102 .9942474365 102.3815155029101 .7156448364100 .9929428101100 .213119506899 .3786239624 98.4964752197397 .5771179199296 .6346054077195 .6840896606494 .74019622803 93.8164138793992 .925636291592 .0808029174891 .2927932739390 .57740020752 89.9668884277389 .4513397216889 .0009078979588 .5502090454188 .03129577637 87.4733276367285 .6446228027385 .3398437587 .4733276367288 .38768768311 88.3876876831188 .6924667358488 .9972534179789 .6068267822389 .91161346436 90.5211791992290 .8259735107490 .8259735107490 .8259735107490 .82597351074 90.2164001464890 .2164001464890 .2164001464890 .5211791992291 .13075256348 91.4355392456191 .1307525634890 .8259735107489 .9116134643688 .69246673584 87.7781066894586 .5589828491285 .9494018554785 .6446228027385 .64462280273 85.6446228027385 .9494018554785 .9494018554785 .9494018554785 .64462280273 85.6446228027385 .6446228027385 .6446228027385 .6446228027385 .94940185547 85.9494018554786 .254188537686 .5589828491286 .8637619018687 .47332763672 87.7781066894588 .3876876831189 .302040100190 .2164001464849 .37519073486 45.717769622842 .3651313781739 .0125007629435 .9646492004432 .91679000854 30.4785099029528 .3450202941926 .5163097381624 .9923801422123 .77323913574 23.4684505462624 .3828105926525 .6019496917726 .5163097381627 .73545074463 28.3450202941928 .9545898437529 .2593708038329 .5641593933129 .25937080383 28.6497993469228 .0402297973627 .430660247826 .8210906982425 .9067401886 25.2971591949524 .3828105926523 .4684505462622 .8588790893623 .16366958618 24.3828105926526 .5163097381628 .3450202941929 .8689403533930 .78330039978 31.3928699493431 .6976509094231 .6976509094232 .0024414062532 .30722045898 32.9167900085434 .1359291076735 .6598587036137 .7933502197339 .92684936523 42.3651313781744 .4986305236846 .6321296691948 .4608306884849 .98476028442 51.5086898803752 .7278289794954 .8613204956158 .8235282897963 .09051895142 66.4431610107468 .8814392089871 .014930725172 .2340774536172 .53885650635 72.5388565063572 .2340774536171 .9292907714871 .9292907714871 .92929077148 71.6244964599671 .014930725170 .1005783081169 .1862335205167 .96708679199 66.7479400634865 .5288009643664 .004882812562 .7857398986861 .56660079956 60.6522407531759 .7378807067959 .1283111572358 .8235282897958 .51874923706 58.5187492370658 .5187492370658 .5187492370658 .8235282897959 .12831115723 59.7378807067960 .0426712036160 .3474502563560 .9570198059161 .56660079956 62.17617034912 -9999 -9999 -9999 -9999 -9999 -9999 -9999 -9999 -9999 -9999 -9999 -9999 -9999 -9999 -9999 -9999 -9999 -9999 -9999 -9999 -9999 -9999 -9999 -9999 -9999 -9999 -9999 -9999 -9999 -9999 -9999 -9999 -9999 -9999 -9999 -9999 -9999 -9999 -9999 -9999 -9999 -9999 -9999 -9999 -9999 -9999 -9999 -9999 -9999 -9999 -9999 -9999 -9999 -9999 -9999 -9999 -9999 -9999 -9999 -9999 -9999 -9999 -9999 -9999 -9999 -9999 -9999 -9999 -9999

-9999 -9999 -9999 -9999 -9999 -9999 -9999 -9999 -9999 -9999 -9999 -9999 -9999 -9999 -9999 -9999 -9999 -9999 -9999 -9999 -9999 -9999 -9999 -9999 -9999 -9999 -9999 -9999 -9999 -9999 -9999 -9999 -9999 -9999 -9999 -9999 -9999 -9999 -9999 -9999 -9999 -9999 -9999 -9999 -9999 -9999 -9999 -9999 -9999 -9999 -9999 -9999 -9999 -9999 -9999 -9999 -9999 -9999 -9999 -9999

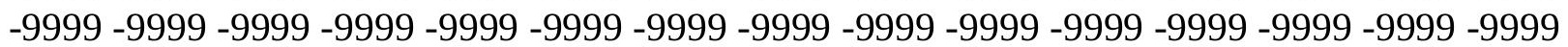


-9999 -9999 -9999 -9999 -9999 -9999 -9999 -9999 -9999 -9999 -9999 -9999 -9999 -9999 -9999 -9999 -9999 -9999 -9999 -9999-9999-9999 73.75800323486 73.7580032348674 .36756896973 75.2819290161176 .5010681152377 .7202072143678 .6345596313577 .41542053223 73.1484298706168 .2718734741264 .6144485473662 .4809494018661 .56660079956 61.2618103027361 .5666007995661 .8713798522962 .1761703491262 .48094940186 62.7857398986862 .7857398986863 .0905189514263 .3953094482463 .70008850098 64.004882812564 .6144485473665 .5288009643666 .7479400634867 .96708679199 69.1862335205170 .1005783081170 .7101516723671 .014930725171 .31971740723 71.6244964599671 .9292907714872 .2340774536172 .8436431884873 .45321655273 72.5388565063571 .6244964599671 .014930725171 .014930725171 .92929077148 74.062782287677 .110626220781 .0728530883885 .3398437588 .99725341797 90.5211791992291 .4355392456192 .0450973510792 .9594726562594 .48339080811 95.7025299072397 .2264633178798 .7503814697399 .96952056885101 .1886978149 102.4077987671102 .9957580566102 .5320205688102 .0230560303101 .4596633911 100.8350219727100 .144104003999 .3858489990298 .5623245239397 .68044281006 96.7504043579195 .7859573364394 .8020629882893 .8139648437592 .83638763428 91.8841247558690 .9731445312590 .1196823120189 .3247909545988 .62094116211 88.0137710571387 .482147216886 .8793029785286 .0362091064584 .73026275635 83.206336975183 .8159103393684 .4254837036184 .7302627563584 .42548370361 85.94940185547 87.16854858398 88.08290100098 88.69246673584 89.3020401001 89.9116134643690 .2164001464890 .2164001464890 .2164001464889 .91161346436 89.9116134643689 .9116134643689 .9116134643689 .9116134643689 .91161346436 89.6068267822388 .9972534179788 .3876876831187 .4733276367286 .55898284912 85.6446228027385 .0350494384884 .7302627563584 .7302627563584 .73026275635 84.7302627563584 .4254837036184 .4254837036184 .4254837036184 .42548370361 84.4254837036184 .4254837036184 .7302627563584 .7302627563585 .03504943848 85.3398437585 .6446228027385 .9494018554786 .5589828491286 .86376190186 87.4733276367288 .0829010009892 .349891662648 .765621185344 .49863052368 40.8412094116237 .1837806701733 .8311500549330 .7833003997828 .04022979736 25.6019496917723 .7732391357422 .2493095397921 .334960937521 .03017044067 21.6397399902322 .8588790893623 .7732391357424 .9923801422125 .9067401886 26.5163097381626 .8210906982427 .1258792877226 .8210906982426 .51630973816 26.2115192413325 .6019496917724 .9923801422124 .3828105926523 .46845054626 22.8588790893622 .2493095397921 .9445304870622 .5541000366223 .46845054626 25.2971591949527 .1258792877228 .6497993469229 .8689403533930 .78330039978 31.3928699493431 .6976509094232 .0024414062532 .6120109558133 .22158050537 34.4407196044935 .9646492004437 .7933502197339 .9268493652342 .06034851074 44.1938400268646 .3273391723648 .1560516357449 .3751907348650 .59432983398 52.1182594299353 .9469718933156 .0804595947358 .8235282897960 .65224075317 61.5666007995664 .6144485473666 .4431610107467 .3575134277367 .66230010986 67.9670867919967 .9670867919968 .2718734741268 .2718734741267 .96708679199 67.3575134277366 .7479400634866 .1383666992265 .5288009643664 .91924285889 64.004882812563 .0905189514262 .1761703491261 .2618103027360 .34745025635 59.7378807067959 .4331016540558 .8235282897958 .5187492370658 .51874923706 58.5187492370658 .5187492370658 .8235282897959 .4331016540559 .73788070679 60.0426712036160 .6522407531760 .9570198059161 .5666007995661 .87137985229 
62.48094940186 -9999 -9999 -9999 -9999 -9999 -9999 -9999 -9999 -9999 -9999 -9999 -9999 -9999 -9999 -9999 -9999 -9999 -9999 -9999 -9999 -9999 -9999 -9999 -9999 -9999 -9999 -9999 -9999 -9999 -9999 -9999 -9999 -9999 -9999 -9999 -9999 -9999 -9999 -9999 -9999 -9999 -9999 -9999 -9999 -9999 -9999 -9999 -9999 -9999 -9999 -9999 -9999 -9999 -9999 -9999 -9999 -9999 -9999 -9999 -9999-9999 -9999 -9999-9999 -9999 -9999-9999-9999

-9999 -9999 -9999 -9999 -9999 -9999 -9999 -9999 -9999 -9999 -9999 -9999 -9999 -9999 -9999

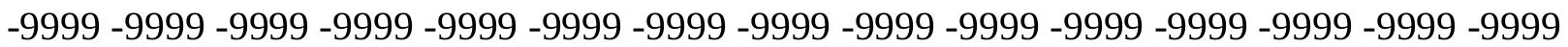
-9999 -9999 -9999 -9999 -9999 -9999 -9999 -9999 -9999 -9999 -9999 -9999 -9999 -9999 -9999 -999 -9999 -9999 -9999 -9999 -9999 -9999 -9999 -9999 -9999 -9999 -9999 -9999 -9999 -9999 -9999 -9999 -9999 -9999 -9999 -9999 -9999 -9999 -9999 -9999 -9999 -9999 -9999 -9999 -9999 -9999 -9999 -9999 -9999 -9999 -9999 -9999 -9999 -9999 -9999 -9999 -9999 -9999 -9999 -9999 -9999 -9999 -9999 -9999 -9999-9999 -9999-9999 -9999 73.4532165527373 .45321655273 74.062782287674 .9771423339875 .5867080688575 .8914871215874 .36756896973 71.6244964599668 .2718734741265 .2240066528363 .0905189514262 .17617034912 61.8713798522961 .8713798522962 .1761703491262 .4809494018662 .78573989868 63.0905189514263 .0905189514263 .3953094482463 .7000885009864 .0048828125 64.3096618652365 .2240066528365 .8335876464866 .7479400634867 .96708679199 68.8814392089869 .7957916259870 .4053573608470 .7101516723671 .0149307251 71.3197174072371 .6244964599672 .2340774536172 .5388565063572 .84364318848 72.5388565063571 .9292907714871 .6244964599671 .9292907714873 .14842987061 74.9771423339877 .7202072143681 .0728530883884 .4254837036187 .16854858398 89.302040100190.5211791992292.0450973510793.2642517089894.78817749023 96.3121032714897 .5312423706199 .05516815186100 .2742996216101 .4934005737 102.3265686035101 .9705581665101 .5762023926101 .1312332153100 .6246032715 100.048004150499 .3950271606498 .6636886596797 .8554458618296 .97705841064 96.0384445190495 .0532608032294 .0365142822393 .0041275024491 .97191619873 90.9561157226689 .9791183471789 .041290283288 .1468811035287 .3263092041 86.6023406982485 .9660644531285 .3043746948284 .4254837036182 .29197692871 82.2919769287182 .2919769287182 .5967712402382 .9015579223682 .90155792236 84.1206970214885 .3398437586 .5589828491287 .4733276367288 .38768768311 88.6924667358489 .302040100189 .302040100189 .302040100189 .3020401001 89.302040100188 .9972534179788 .9972534179788 .6924667358488 .69246673584 88.0829010009887 .7781066894587 .1685485839886 .254188537685 .64462280273 84.7302627563584 .4254837036183 .8159103393683 .5111236572383 .51112365723 83.5111236572383 .5111236572383 .5111236572383 .5111236572383 .51112365723 83.5111236572383 .5111236572383 .8159103393684 .1206970214884 .42548370361 84.73026275635 85.03504943848 85.33984375 85.9494018554786.2541885376 86.86376190186 87.16854858398 91.43553924561 47.85126113892 43.27949142456 39.0125007629435 .3550796508831 .6976509094228 .3450202941925 .60194969177 23.1636695861821 .334960937519 .811029434219 .2014598846418 .89668083191 19.5062503814720 .4206008911121 .6397399902322 .5541000366223 .46845054626 24.3828105926524 .6875991821324 .9923801422124 .9923801422124 .68759918213 24.3828105926524 .0780296325723 .4684505462622 .8588790893622 .24930953979 21.6397399902321 .334960937521 .334960937521 .9445304870622 .85887908936 24.3828105926525 .906740188627 .7354507446328 .9545898437530 .17373085022 31.0880794525131 .6976509094232 .0024414062532 .6120109558133 .52635955811 
34.4407196044935 .9646492004437 .7933502197339 .9268493652342 .06034851074 44.1938400268646 .3273391723648 .1560516357449 .6799812316950 .89912033081 52.1182594299353 .6421813964854 .8613204956156 .3852500915557 .29959869385 58.5187492370660 .0426712036161 .5666007995662 .4809494018663 .09051895142 63.7000885009864 .004882812564 .3096618652364 .3096618652364 .30966186523 63.7000885009863 .3953094482463 .3953094482463 .0905189514263 .09051895142 62.7857398986862 .1761703491261 .8713798522960 .9570198059160 .34745025635 59.7378807067959 .4331016540559 .1283111572358 .8235282897958 .51874923706 58.5187492370658 .5187492370659 .1283111572359 .4331016540559 .73788070679 60.0426712036160 .6522407531760 .9570198059161 .5666007995661 .87137985229 62.33870697021 -9999 -9999 -9999 -9999 -9999 -9999 -9999 -9999 -9999 -9999 -9999 -9999

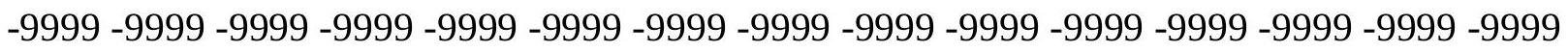
-9999 -9999 -9999 -9999 -9999 -9999 -9999 -9999 -9999 -9999 -9999 -9999 -9999 -9999 -9999 -9999 -9999 -9999 -9999 -9999 -9999 -9999 -9999 -9999 -9999 -9999 -9999 -9999 -9999 -9999 -9999 -9999 -9999 -9999 -9999 -9999 -9999 -9999 -9999 -9999 -9999

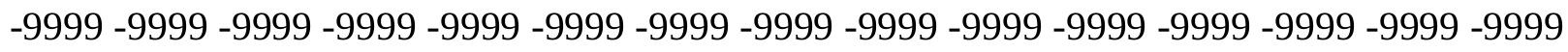
-9999 -9999 -9999 -9999 -9999 -9999 -9999 -9999 -9999 -9999 -9999 -9999 -9999 -9999 -9999 -9999 -9999 -9999 -9999 -9999 -9999 -9999 -9999 -9999 -9999 -9999 -9999 -9999 -9999 -9999 -9999 -9999 -9999 -9999 -9999 -9999 -9999 -9999 -9999 -9999 -9999 -9999 -9999 -9999 -9999 -

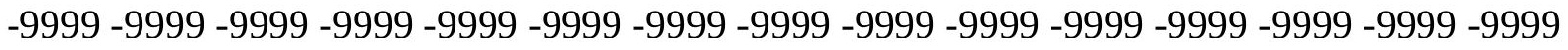

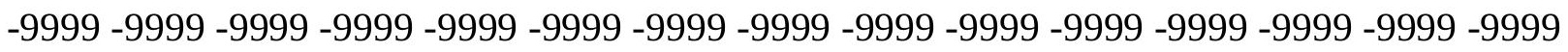
-9999 -9999 -9999 -9999 -9999 -9999 -9999 -9999 72.5388565063571 .92929077148 71.9292907714872 .2340774536172 .5388565063571 .9292907714871 .0149307251 69.1862335205166 .7479400634864 .6144485473663 .0905189514262 .17617034912 61.8713798522961 .8713798522962 .4809494018662 .7857398986863 .09051895142 63.0905189514263 .0905189514263 .3953094482463 .7000885009864 .30966186523 64.6144485473665 .5288009643666 .1383666992267 .0527267456167 .96708679199 68.8814392089869 .4910125732469 .7957916259870 .4053573608470 .40535736084 70.7101516723671 .014930725171 .3197174072371 .6244964599671 .62449645996 71.6244964599671 .6244964599671 .6244964599671 .9292907714873 .14842987061 74.9771423339877 .110626220779 .8537063598682 .5967712402385 .03504943848 87.16854858398 88.9972534179791.1307525634892.95947265625 94.78817749023 96.3121032714897 .8360290527399 .05516815186100 .2742996216101 .1886978149 101.2826843262101 .0082855225100 .6918029785100 .318580627499 .87570953369 99.3536071777398 .7445983886798 .0456008911197 .2572326660296 .38600158691 95.4416580200294 .4380187988393 .3906402587992 .3164672851691 .23212432861 90.1544876098689 .1046447753988 .0767135620187 .0727539062586 .10824584961 85.2257614135784 .4721450805783 .8159103393682 .2919769287181 .68241119385 81.6824111938581 .3776321411181 .6824111938581 .6824111938582 .29197692871 82.90155792236 84.12069702148 85.33984375 86.2541885376 87.16854858398 87.77810668945 88.08290100098 88.38768768311 88.38768768311 88.38768768311 88.38768768311 88.08290100098 88.08290100098 87.77810668945 87.47332763672 86.8637619018686 .254188537685 .6446228027385 .0350494384884 .42548370361 83.8159103393683 .206336975182 .9015579223682 .5967712402382 .59677124023 82.2919769287182 .2919769287182 .2919769287182 .2919769287182 .59677124023 82.5967712402382 .9015579223682 .9015579223683 .206336975183 .51112365723 
84.1206970214884 .4254837036184 .7302627563585 .3398437585 .64462280273 85.9494018554786 .5589828491252 .1182594299346 .6321296691941 .45077896118 36.8790016174332 .9167900085429 .2593708038325 .906740188622 .85887908936 20.7253894805918 .8966808319117 .6775398254417 .0679702758817 .06797027588 17.6775398254418 .5918903350819 .5062503814720 .4206008911121 .63973999023 22.2493095397922 .8588790893623 .1636695861823 .4684505462623 .16366958618 23.1636695861822 .5541000366222 .2493095397921 .6397399902321 .3349609375 20.7253894805920 .7253894805920 .7253894805921 .334960937522 .24930953979 23.7732391357425 .2971591949526 .8210906982428 .3450202941929 .56415939331 30.7833003997831 .3928699493431 .6976509094232 .6120109558133 .22158050537 34.4407196044935 .9646492004437 .7933502197339 .9268493652342 .06034851074 44.1938400268646 .6321296691948 .4608306884850 .2895507812551 .81346893311 53.0326118469253 .9469718933154 .8613204956155 .4708900451755 .77568054199 56.6900291442957 .2995986938558 .2139587402358 .8235282897959 .12831115723 60.0426712036160 .6522407531760 .9570198059161 .2618103027361 .26181030273 60.6522407531760 .3474502563560 .9570198059161 .2618103027361 .56660079956 61.5666007995661 .5666007995661 .2618103027360 .9570198059160 .34745025635 59.7378807067959 .4331016540559 .1283111572358 .8235282897958 .82352828979 58.8235282897958 .8235282897959 .1283111572359 .4331016540560 .04267120361 60.3474502563560 .6522407531760 .9570198059161 .5666007995661 .87137985229 62.27750778198 -9999 -9999 -9999 -9999 -9999 -9999 -9999 -9999 -9999 -9999 -9999 -9999 -9999 -9999 -9999 -9999 -9999 -9999 -9999 -9999 -9999 -9999 -9999 -9999 -9999 -9999 -9999 -9999 -9999 -9999 -9999 -9999 -9999 -9999 -9999 -9999 -9999 -9999 -9999 -9999 -9999 -9999 -9999 -9999 -9999 -9999 -9999 -9999 -9999 -9999 -9999 -9999 -9999 -9999 -9999 -9999 -9999 -9999 -9999 -9999 -9999 -9999 -9999 -9999 -9999 -9999 -9999 -9999

-9999 -9999 -9999 -9999 -9999 -9999 -9999 -9999 -9999 -9999 -9999 -9999 -9999 -9999 -9999 -9999 -9999 -9999 -9999 -9999 -9999 -9999 -9999 -9999 -9999 -9999 -9999 -9999 -9999 -9999 -

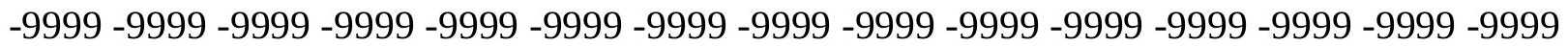
-9999 -9999 -9999 -9999 -9999 -9999 -9999 -9999 -9999 -9999 -9999 -9999 -9999 -9999 -9999 -9999 -9999 -9999 -9999 -9999 -9999 -9999 -9999 -9999 -9999 -9999 -9999 -9999 -9999 -999 -9999 -9999 -9999 -9999 -9999 -9999 -9999 -9999 -9999 -9999 -9999 -9999 -9999 -9999 -9999 -9999 -9999 -9999 -9999 -9999 -9999 -9999 -9999 -9999 70.10057830811 69.18623352051 68.8814392089868 .5766525268667 .9670867919967 .0527267456165 .83358764648 64.3096618652363 .0905189514262 .1761703491261 .5666007995661 .26181030273 61.5666007995661 .8713798522962 .4809494018662 .7857398986863 .09051895142 63.0905189514263 .3953094482464 .004882812564 .3096618652364 .91924285889 65.5288009643666 .4431610107467 .0527267456167 .9670867919968 .57665252686 68.8814392089869 .4910125732469 .7957916259869 .7957916259870 .10057830811 70.1005783081170 .4053573608470 .4053573608470 .4053573608470 .40535736084 70.4053573608470 .7101516723671 .3197174072372 .5388565063573 .75800323486 75.8914871215878 .0249862670980 .1584930419982 .2919769287184 .42548370361 86.5589828491289 .302040100192 .0450973510793 .8738174438595 .70252990723 97.5312423706198 .7503814697399 .96952056885100 .4523773193100 .2954406738 100.111412048399 .8771209716899 .5816726684699 .2092514038198 .74789428711 98.1892166137797 .529014587496 .7676620483495 .907501220794 .96064758301 93.9418945312592 .8677825927791 .7567291259890 .6259002685589 .49253082275 
88.36599731445 87.2439498901486.13333892822 85.0413360595784.00079345703 83.0068969726681 .9871978759881 .3776321411181 .3776321411181 .07285308838 81.0728530883881 .0728530883881 .3776321411181 .6824111938582 .29197692871 83.206336975184 .4254837036185 .3398437585 .9494018554786 .55898284912 87.1685485839887 .1685485839887 .4733276367287 .4733276367287 .16854858398 87.1685485839886 .8637619018686 .5589828491285 .9494018554785 .64462280273 85.0350494384884 .4254837036183 .8159103393683 .206336975182 .90155792236 82.29197692871 81.98719787598 81.68241119385 81.37763214111 81.37763214111 81.37763214111 81.37763214111 81.37763214111 81.68241119385 81.68241119385 81.9871978759882 .2919769287182 .5967712402382 .9015579223683 .51112365723 83.8159103393684 .1206970214884 .7302627563585 .0350494384885 .64462280273 85.9494018554750 .5943298339844 .8034095764239 .3172798156734 .44071960449 29.8689403533926 .2115192413322 .8588790893620 .1158199310317 .98232078552 16.4584007263215 .5440397262615 .2392597198515 .2392597198515 .84883022308 16.7631797790517 .6775398254418 .5918903350819 .811029434220 .42060089111 21.334960937521 .6397399902321 .9445304870621 .9445304870621 .63973999023 21.334960937521 .0301704406720 .7253894805920 .4206008911120 .11581993103 20.1158199310320 .4206008911120 .7253894805921 .6397399902322 .85887908936 24.3828105926525 .6019496917727 .1258792877228 .6497993469229 .86894035339 30.4785099029531 .3928699493432 .0024414062533 .2215805053734 .44071960449 35.9646492004437 .7933502197339 .9268493652342 .0603485107444 .49863052368 46.6321296691949 .0704002380451 .2038993835452 .7278289794953 .94697189331 54.8613204956155 .1661109924355 .1661109924355 .4708900451755 .47089004517 55.7756805419956 .0804595947356 .3852500915556 .6900291442957 .29959869385 57.909179687558 .2139587402358 .5187492370658 .5187492370658 .51874923706 58.5187492370659 .1283111572359 .4331016540560 .0426712036160 .34745025635 60.6522407531760 .9570198059160 .6522407531760 .0426712036159 .73788070679 59.4331016540559 .1283111572359 .1283111572358 .8235282897958 .82352828979 58.8235282897959 .4331016540559 .7378807067960 .0426712036160 .34745025635 $60.6522407531761 .2618103027361 .5666007995661 .8713798522962 .24111557007-9999$ -9999 -9999 -9999 -9999 -9999 -9999 -9999 -9999 -9999 -9999 -9999 -9999 -9999 -9999 -9999

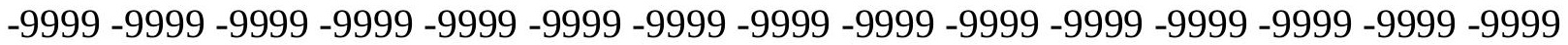

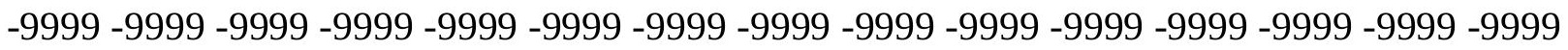

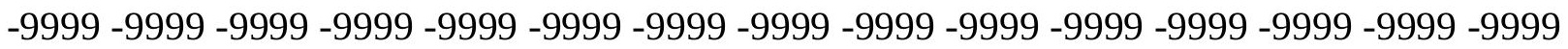
-9999 -9999 -9999 -9999-9999-9999-9999

-9999 -9999 -9999 -9999 -9999 -9999 -9999 -9999 -9999 -9999 -9999 -9999 -9999 -9999 -999 -

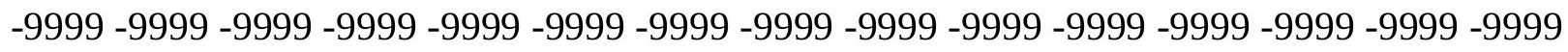

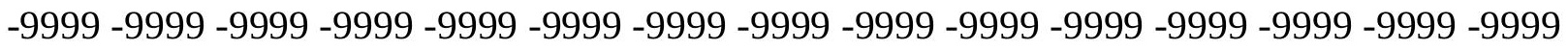
-9999 -9999 -9999 -9999 -9999 -9999 -9999 -9999 -9999 -9999 -9999 -9999 -9999 -9999 -9999 -9999 -9999 -9999 -9999 -9999 -9999 -9999 -9999 -9999 -9999 -9999 -9999 -9999 -9999 -9999 -

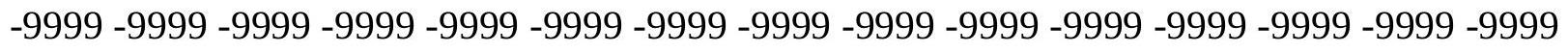
-9999 -9999-9999 -9999 -9999 -9999 -9999-9999 -9999-9999 66.44316101074 65.2240066528364 .6144485473663 .7000885009863 .0905189514262 .48094940186 61.5666007995660 .9570198059160 .6522407531760 .3474502563560 .65224075317 60.9570198059161 .2618103027361 .8713798522962 .1761703491262 .78573989868 63.0905189514263 .3953094482464 .004882812564 .6144485473665 .22400665283 
65.8335876464866 .4431610107467 .0527267456167 .6623001098668 .27187347412 68.5766525268668 .8814392089868 .8814392089869 .1862335205169 .18623352051 69.1862335205168 .8814392089868 .8814392089868 .8814392089868 .88143920898 69.1862335205169 .4910125732470 .1005783081171 .014930725172 .53885650635 74.062782287675 .5867080688577 .4154205322379 .2441329956181 .07285308838 83.5111236572386 .5589828491289 .9116134643692 .6546783447395 .09295654297 96.9216690063598 .445587158299 .4444122314599 .3912124633899 .34884643555 99.2797393798899 .1516189575298 .9522628784298 .6574630737398 .26499176025 97.7524871826297 .1282653808696 .3880462646595 .539764404394 .59259796143 93.561660766692 .4658660888791 .3250427246190 .1569213867288 .97737884521 87.7927703857486 .5961074829185 .4089279174884 .2140960693483 .05754089355 81.9871978759881 .3776321411181 .0728530883881 .0728530883880 .76805877686 80.7680587768680 .7680587768681 .0728530883881 .3776321411181 .98719787598 82.5967712402383 .5111236572384 .4254837036185 .0350494384885 .64462280273 85.9494018554786 .254188537686 .254188537686 .254188537686 .2541885376 85.9494018554785 .6446228027385 .3398437584 .7302627563584 .42548370361 83.8159103393683 .206336975182 .9015579223682 .2919769287181 .68241119385 81.3776321411181 .0728530883880 .7680587768680 .4632720947380 .46327209473 80.4632720947380 .4632720947380 .4632720947380 .7680587768681 .07285308838 81.3776321411181 .6824111938581 .9871978759882 .2919769287182 .90155792236 83.206336975183.81591033936 84.12069702148 84.7302627563585.03504943848 55.7756805419948 .765621185342 .3651313781736 .5742111206131 .08807945251 26.5163097381622 .5541000366219 .5062503814717 .0679702758815 .23925971985 14.0201196670513 .4105501174913 .1057596206713 .4105501174914 .02011966705 14.934470176716 .1536102294917 .0679702758817 .9823207855218 .89668083191 19.811029434220 .4206008911120 .7253894805920 .7253894805920 .72538948059 20.4206008911120 .1158199310319 .811029434219 .5062503814719 .20145988464 19.2014598846419 .5062503814720 .1158199310321 .0301704406721 .94453048706 23.1636695861824 .6875991821325 .906740188627 .1258792877228 .34502029419 29.5641593933130 .4785099029531 .3928699493432 .6120109558133 .83115005493 35.6598587036137 .4885711669939 .622070312541 .7555618286144 .19384002686 46.9369087219249 .3751907348651 .8134689331153 .9469718933155 .16611099243 55.7756805419955 .7756805419955 .4708900451755 .1661109924354 .86132049561 54.8613204956154 .8613204956154 .8613204956154 .8613204956155 .47089004517 55.7756805419956 .0804595947356 .3852500915556 .6900291442956 .69002914429 57.2995986938557 .6043891906758 .2139587402358 .8235282897959 .43310165405 60.0426712036160 .0426712036160 .0426712036160 .0426712036159 .73788070679 59.4331016540559 .1283111572359 .1283111572359 .1283111572359 .12831115723 59.1283111572359 .4331016540559 .7378807067960 .0426712036160 .65224075317 60.9570198059161 .2618103027361 .5666007995661 .8713798522962 .21542739868 62.48876953125 -9999 -9999 -9999 -9999 -9999 -9999 -9999 -9999 -9999 -9999 -9999 -9999 -9999 -9999 -9999 -9999 -9999 -9999 -9999 -9999 -9999 -9999 -9999 -9999 -9999 -9999 -9999 -9999 -9999 -9999 -9999 -9999 -9999 -9999 -9999 -9999 -9999 -9999 -9999 -9999 -9999 -9999 -9999 -9999 -9999 -9999 -9999 -9999 -9999 -9999 -9999 -9999 -9999 -9999 -9999 -9999 -9999 -9999 -9999 -9999 -9999 -9999 -9999 -9999 -9999 -9999-9999

-9999 -9999 -9999 -9999 -9999 -9999 -9999 -9999 -9999 -9999 -9999 -9999 -9999 -9999 -9999 
-9999 -9999 -9999 -9999 -9999 -9999 -9999 -9999 -9999 -9999 -9999 -9999 -9999 -9999 -9999 -9999 -9999 -9999 -9999 -9999 -9999 -9999 -9999 -9999 -9999 -9999 -9999 -9999 -9999 -9999 -9999 -9999 -9999 -9999 -9999 -9999 -9999 -9999 -9999 -9999 -9999 -9999 -9999 -9999 -9999 -9999 -9999 -9999 -9999 -9999 -9999 -9999 -9999 -9999 -9999 -9999 -9999 -9999 -9999 -9999 -9999 -9999 -9999 -9999 -9999 -9999 -9999 -9999 -9999 -9999 -9999 -9999-9999 -9999 -9999 -9999 -9999 -9999 -9999 -9999 -9999 -9999 -9999 -9999 -9999 -9999 61.87137985229 60.6522407531760 .0426712036159 .4331016540559 .1283111572358 .82352828979 58.8235282897958 .8235282897959 .1283111572359 .4331016540560 .04267120361 60.6522407531761 .2618103027361 .8713798522962 .4809494018662 .78573989868 63.3953094482464 .004882812564 .6144485473665 .2240066528366 .13836669922 66.7479400634867 .3575134277367 .6623001098668 .2718734741268 .27187347412 68.5766525268668 .2718734741268 .2718734741267 .9670867919967 .96708679199 67.6623001098667 .6623001098667 .3575134277367 .3575134277367 .66230010986 67.9670867919968 .5766525268669 .4910125732470 .7101516723671 .92929077148 73.1484298706174 .6723632812575 .8914871215877 .7202072143680 .15849304199 83.51112365723 87.47332763672 91.13075256348 93.8738174438596.31210327148 97.8360290527398 .2585983276498 .3354797363398 .4419860839898 .52547454834 98.5364761352598 .4472808837998 .2494201660297 .9175338745197 .45154571533 96.8502807617296 .1252670288195 .2849121093894 .333419799893 .28916168213 92.1765899658291 .0140533447389 .8209533691488 .6151504516687 .4021987915 86.16843414307 84.9532470703183.780418396 82.59677124023 81.68241119385 81.0728530883881 .0728530883880 .7680587768680 .4632720947380 .46327209473 80.4632720947380 .7680587768681 .0728530883881 .6824111938582 .29197692871 82.9015579223683 .5111236572384 .1206970214884 .4254837036185 .03504943848 85.0350494384885 .3398437585 .3398437585 .0350494384884 .7302627563584 .42548370361 84.12069702148 83.51112365723 83.2063369751 82.59677124023 81.98719787598 81.6824111938581 .0728530883880 .4632720947380 .1584930419979 .85370635986 79.5489196777379 .5489196777379 .2441329956179 .5489196777379 .54891967773 79.5489196777379 .8537063598680 .1584930419980 .4632720947380 .76805877686 81.0728530883881 .6824111938581 .9871978759882 .5967712402383 .2063369751 83.5111236572384 .1206970214884 .7302627563553 .3373985290546 .02254867554 39.3172798156732 .9167900085427 .1258792877221 .9445304870618 .287109375 15.5440397262613 .4105501174912 .191410064711 .5818300247211 .27705001831 11.2770500183111 .8866195678712 .4961900711113 .4105501174914 .62969017029 15.5440397262616 .7631797790517 .6775398254418 .5918903350819 .50625038147 19.811029434219 .811029434219 .811029434219 .5062503814719 .20145988464 18.8966808319118 .5918903350818 .5918903350818 .5918903350818 .89668083191 19.2014598846420 .1158199310321 .0301704406722 .2493095397923 .46845054626 24.6875991821325 .906740188627 .1258792877228 .0402297973629 .25937080383 30.4785099029531 .6976509094233 .2215805053735 .0502891540536 .87900161743 39.0125007629441 .4507789611843 .8890609741246 .6321296691949 .67998123169 52.4230384826754 .8613204956156 .3852500915556 .6900291442956 .38525009155 55.7756805419955 .1661109924354 .5565414428753 .9469718933153 .94697189331 53.6421813964853 .6421813964853 .9469718933154 .2517509460454 .55654144287 54.8613204956155 .1661109924355 .4708900451756 .0804595947356 .69002914429 57.2995986938557 .909179687558 .5187492370659 .1283111572359 .43310165405 
59.7378807067959 .7378807067959 .4331016540559 .4331016540559 .43310165405 59.1283111572359 .1283111572359 .1283111572359 .4331016540559 .73788070679 60.0426712036160 .3474502563560 .6522407531760 .9570198059161 .26181030273 61.5666007995661 .8713798522962 .2043228149462 .45101165771 -9999-9999-9999 -9999 -9999 -9999 -9999 -9999 -9999 -9999 -9999 -9999 -9999 -9999 -9999 -9999 -9999 -9999 -9999 -9999 -9999 -9999 -9999 -9999 -9999 -9999 -9999 -9999 -9999 -9999 -9999 -9999 -9999 -9999

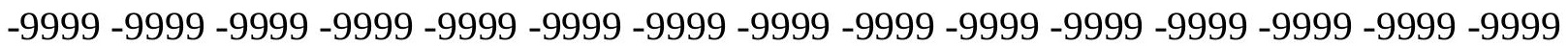

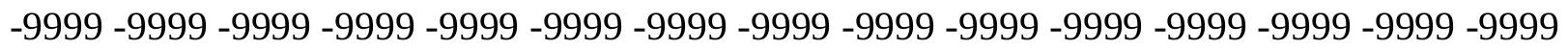
-9999-9999-9999

-9999 -9999 -9999 -9999 -9999 -9999 -9999 -9999 -9999 -9999 -9999 -9999 -9999 -9999 -9999 -9999 -9999 -9999 -9999 -9999 -9999 -9999 -9999 -9999 -9999 -9999 -9999 -9999 -9999 -9999 -999 -9999 -9999 -9999 -9999 -9999 -9999 -9999 -9999 -9999 -9999 -9999 -9999 -9999 -9999 -9999 -9999 -9999 -9999 -9999 -9999 -9999 -9999 -9999 -9999 -9999 -9999 -9999 -9999 -9999 -9999 -9999 -9999 -9999 -9999 -9999 -9999 -9999 -9999 -9999 -9999 -9999 -9999 -9999 -9999 -9999 -9999 -9999 -9999 -9999 -9999 -9999 -9999 -9999 -9999 -9999 -9999 -9999 -9999 -9999 -9999 -9999 -9999 -9999 -9999 -9999 -9999-9999-9999-9999-9999-9999 59.43310165405 57.6043891906756 .6900291442956 .3852500915556 .3852500915556 .38525009155 56.9948196411157 .2995986938557 .909179687558 .5187492370659 .43310165405 60.0426712036160 .6522407531761 .5666007995662 .1761703491262 .78573989868 63.3953094482464 .3096618652364 .9192428588965 .5288009643666 .44316101074 67.0527267456167 .6623001098667 .9670867919968 .2718734741268 .27187347412 67.9670867919967 .9670867919967 .3575134277367 .0527267456166 .74794006348 66.4431610107466 .1383666992265 .8335876464865 .8335876464866 .13836669922 66.4431610107467 .0527267456167 .6623001098668 .5766525268669 .79579162598 70.7101516723671 .9292907714873 .1484298706174 .6723632812576 .50106811523 80.7680587768685 .3398437589 .6068267822392 .9594726562595 .3977432251 96.9258728027397 .0561904907297 .2882843017697 .5851669311597 .86627197266 98.0447540283298 .0947875976697 .9864807128997 .7041549682697 .26942443848 96.6925811767695 .9788513183695 .1407775878994 .1755752563593 .10800933838 91.9792251586990 .8068923950289 .6127700805788 .407089233487 .21310424805 86.0348968505984 .7302627563583 .8159103393682 .5967712402381 .98719787598 81.3776321411181 .0728530883880 .7680587768680 .4632720947380 .46327209473 80.4632720947380 .4632720947380 .7680587768681 .3776321411181 .68241119385 82.2919769287182 .5967712402383 .206336975183 .5111236572383 .81591033936 84.1206970214884 .1206970214884 .1206970214883 .8159103393683 .81591033936 83.206336975182 .9015579223682 .2919769287181 .9871978759881 .37763214111 80.7680587768680 .4632720947379 .8537063598679 .5489196777378 .93934631348 78.6345596313578 .6345596313578 .3297805786178 .3297805786178 .32978057861 78.6345596313578 .6345596313578 .9393463134879 .2441329956179 .54891967773 79.8537063598680 .4632720947380 .7680587768681 .3776321411181 .98719787598 82.2919769287182 .9015579223683 .5111236572384 .1206970214850 .59432983398 42.66992187535 .0502891540528 .3450202941921 .6397399902316 .76317977905 13.4105501174911 .277050018319 .7531242370619 .1435537338268 .838768959045 9.1435537338269 .4483394622810 .0579099655210 .9722604751611 .88661956787 13.1057596206714 .3248996734615 .2392597198516 .4584007263217 .67753982544 18.28710937518 .8966808319119 .2014598846418 .8966808319118 .59189033508 
18.28710937517 .9823207855217 .6775398254417 .6775398254417 .67753982544 17.9823207855218 .28710937519 .2014598846419 .811029434221 .03017044067 21.9445304870623 .1636695861824 .3828105926525 .6019496917726 .82109069824 28.0402297973629 .2593708038330 .7833003997832 .3072204589834 .13592910767 35.9646492004438 .0981407165540 .5364189147943 .2794914245646 .02254867554 49.0704002380452 .1182594299354 .8613204956156 .9948196411156 .69002914429 56.0804595947355 .4708900451754 .5565414428753 .9469718933153 .33739852905 53.0326118469252 .7278289794952 .7278289794952 .7278289794953 .03261184692 53.3373985290553 .6421813964853 .9469718933154 .5565414428755 .16611099243 55.7756805419956 .3852500915557 .2995986938557 .909179687558 .51874923706 58.8235282897959 .1283111572359 .4331016540559 .4331016540559 .43310165405 59.4331016540559 .4331016540559 .4331016540559 .4331016540559 .43310165405 60.0426712036160 .3474502563560 .5992851257360 .8935966491761 .20404815674 61.4838676452661 .7456970214861 .9910087585462 .2234077453662 .43893432617 -9999 -9999 -9999 -9999 -9999 -9999 -9999 -9999 -9999 -9999 -9999 -9999 -9999 -9999 -9999 -9999 -9999 -9999 -9999 -9999 -9999 -9999 -9999 -9999 -9999 -9999 -9999 -9999 -9999 -9999 -9999 -9999 -9999 -9999 -9999 -9999 -9999 -9999 -9999 -9999 -9999 -9999 -9999 -9999 -9999 -9999

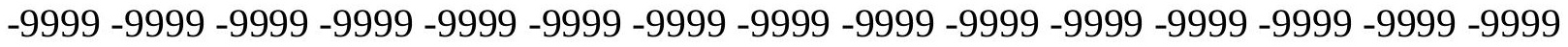
-9999 -9999-9999-9999-9999-9999

-9999 -9999 -9999 -9999 -9999 -9999 -9999 -9999 -9999 -9999 -9999 -9999 -9999 -9999 -9999 -9999 -9999 -9999 -9999 -9999 -9999 -9999 -9999 -9999 -9999 -9999 -9999 -9999 -9999 -9999 -9999 -9999 -9999 -9999 -9999 -9999 -9999 -9999 -9999 -9999 -9999 -9999 -9999 -9999 -9999 -9999 -9999 -9999 -9999 -9999 -9999 -9999 -9999 -9999 -9999 -9999 -9999 -9999 -9999 -9999 -9999 -9999 -9999 -9999 -9999 -9999 -9999 -9999 -9999 -9999 -9999 -9999 -9999 -9999 -9999 -9999 -9999 -9999 -9999 -9999 -9999 -9999 -9999 -9999 -9999 -9999 -9999 -9999 -9999 -9999 -9999 -9999 -9999 -9999 -9999 -9999 -9999 -9999 -9999 -9999 -9999 -9999 55.77568054199 54.2517509460453 .9469718933154 .2517509460454 .8613204956155 .47089004517 56.3852500915556 .9948196411157 .909179687558 .8235282897959 .73788070679 60.6522407531761 .2618103027362 .1761703491262 .7857398986863 .70008850098 64.3096618652365 .2240066528366 .1383666992266 .7479400634867 .35751342773 67.9670867919968 .2718734741268 .2718734741268 .2718734741267 .96708679199 67.3575134277366 .7479400634866 .1383666992265 .5288009643665 .22400665283 64.6144485473664 .3096618652364 .3096618652364 .3096618652364 .61444854736 65.2240066528365 .8335876464866 .7479400634867 .6623001098668 .88143920898 70.1005783081171 .3197174072372 .8436431884875 .2819290161178 .93934631348 83.5111236572388 .0829010009892 .0450973510794 .1785964965895 .57129669189 95.8471221923896 .2625198364396 .7856750488397 .3233642578197 .70043945312 97.9062881469797 .8494873046997 .5948333740297 .1742095947396 .60799407959 95.9117431640695 .0921630859494 .1216964721793 .0041503906291 .83920288086 90.7305831909289 .5382843017688 .3331680297987 .1685485839886 .2541885376 85.0350494384883 .8159103393682 .9015579223682 .2919769287181 .37763214111 81.0728530883880 .7680587768680 .4632720947380 .4632720947380 .15849304199 80.4632720947380 .4632720947380 .7680587768681 .3776321411181 .68241119385 81.9871978759882 .2919769287182 .5967712402382 .9015579223683 .2063369751 83.206336975182 .9015579223682 .9015579223682 .5967712402382 .29197692871 81.6824111938581 .3776321411180 .7680587768680 .1584930419979 .54891967773 
79.2441329956178 .6345596313578 .3297805786177 .7202072143677 .72020721436 77.4154205322377 .4154205322377 .110626220777 .4154205322377 .41542053223 77.7202072143678 .0249862670978 .3297805786178 .6345596313578 .93934631348 79.5489196777379 .8537063598680 .4632720947381 .0728530883881 .68241119385 82.2919769287182 .9015579223683 .5111236572347 .2416992187538 .09814071655 29.2593708038321 .334960937514 .6296901702910 .057909965527 .619627952576 6.7052731513986 .0957031256 .4004869461066 .7052731513987 .010057926178 7.9244132041938 .5339832305919 .4483394622810 .6674804687511 .58183002472 12.8009700775114 .0201196670515 .2392597198516 .4584007263217 .37274932861 18.28710937518 .28710937517 .9823207855217 .6775398254417 .37274932861 17.0679702758816 .7631797790516 .7631797790516 .7631797790517 .06797027588 17.3727493286117 .9823207855218 .8966808319119 .811029434220 .72538948059 21.9445304870622 .8588790893624 .0780296325725 .2971591949526 .82109069824 28.0402297973629 .5641593933131 .3928699493432 .9167900085435 .05028915405 37.1837806701739 .622070312542 .3651313781745 .1082000732448 .15605163574 50.8991203308153 .6421813964855 .1661109924355 .7756805419955 .16611099243 54.5565414428753 .9469718933153 .3373985290552 .7278289794952 .11825942993 52.1182594299351 .8134689331151 .8134689331152 .1182594299352 .42303848267 52.7278289794953 .3373985290553 .6421813964854 .5565414428755 .16611099243 55.7756805419956 .6900291442957 .2995986938557 .909179687558 .51874923706 58.8235282897959 .1283111572359 .1283111572359 .4331016540559 .43310165405 59.4331016540559 .7378807067959 .7378807067959 .7378807067960 .04267120361 60.3474502563560 .6522407531760 .9570198059161 .2618103027361 .56660079956 61.8536376953162 .0715484619162 .270931243962 .45216751099 -9999 -9999 -9999 -9999 -9999 -9999 -9999 -9999 -9999 -9999 -9999 -9999 -9999 -9999 -9999 -9999 -9999 -9999 -9999 -9999 -9999 -9999 -9999 -9999 -9999 -9999 -9999 -9999 -9999 -9999 -9999 -9999 -9999 -9999 -9999 -9999 -9999 -9999 -9999 -9999 -9999 -9999 -9999 -9999 -9999 -9999 -9999 -9999 -9999

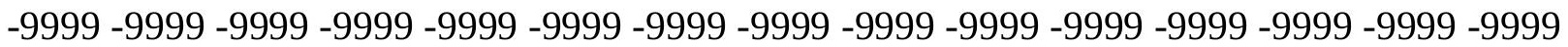
-9999-9999-9999

-9999 -9999 -9999 -9999 -9999 -9999 -9999 -9999 -9999 -9999 -9999 -9999 -9999 -9999 -9999 -9999 -9999 -9999 -9999 -9999 -9999 -9999 -9999 -9999 -9999 -9999 -9999 -9999 -9999 -9999 -

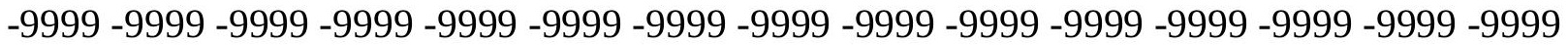

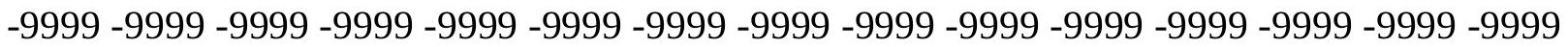
-9999 -9999 -9999 -9999 -9999 -9999 -9999 -9999 -9999 -9999 -9999 -9999 -9999 -9999 -9999 -9999 -9999 -9999 -9999 -9999 -9999 -9999 -9999 -9999 -9999 -9999 -9999 -9999 -9999 -9999 -9999 -9999 -9999 -9999 -9999 -9999 -9999 -9999 -9999 -9999 -9999 -9999 -9999 52.7278289794952 .4230384826753 .0326118469253 .6421813964854 .86132049561 55.7756805419956 .9948196411157 .909179687558 .8235282897959 .73788070679 60.6522407531761 .5666007995662 .1761703491263 .0905189514264 .0048828125 64.9192428588965 .5288009643666 .4431610107467 .3575134277367 .96708679199 68.5766525268668 .8814392089868 .8814392089868 .2718734741267 .96708679199 67.0527267456166 .4431610107465 .5288009643664 .9192428588964 .0048828125 63.7000885009863 .0905189514263 .0905189514263 .0905189514263 .39530944824 63.7000885009864 .3096618652365 .2240066528366 .1383666992267 .05272674561 68.2718734741269 .7957916259871 .6244964599674 .3675689697378 .02498626709 81.9871978759886 .254188537689 .9116134643692 .6546783447394 .18744659424 
94.685966491795 .3107604980596 .075897216896 .9608688354597 .52779388428 97.8965835571397 .7511596679797 .496650695897 .093475341896 .52317047119 95.8586044311595 .0929565429794 .1785964965892 .9594726562591 .74033355713 90.8259735107489 .6068267822388 .3876876831187 .4733276367286 .2541885376 85.3398437584 .1206970214883 .206336975182 .2919769287181 .68241119385 81.0728530883880 .7680587768680 .4632720947380 .1584930419980 .15849304199 80.1584930419980 .4632720947380 .7680587768680 .7680587768681 .07285308838 81.37763214111 81.6824111938581.98719787598 81.98719787598 82.29197692871 82.2919769287181 .9871978759881 .6824111938581 .3776321411181 .07285308838 80.4632720947380 .1584930419979 .5489196777378 .9393463134878 .32978057861 78.0249862670977 .4154205322377 .110626220776 .8058471679776 .50106811523 76.1962814331176 .1962814331176 .1962814331176 .1962814331176 .19628143311 76.5010681152376 .8058471679777 .110626220777 .4154205322378 .02498626709 78.3297805786178 .9393463134879 .2441329956179 .8537063598680 .46327209473 81.0728530883881 .9871978759852 .4230384826742 .66992187532 .91679000854 22.2493095397913 .105759620676 .4004869461062 .7430660724641 .828711032867 2.1334960460662 .7430660724643 .3526360988624 .2669920921335 .181346893311 6.0957031257 .0100579261788 .2291984558119 .14355373382610 .36268997192 11.5818300247212 .8009700775114 .0201196670515 .2392597198516 .15361022949 16.7631797790517 .0679702758816 .7631797790516 .7631797790516 .45840072632 16.1536102294915 .8488302230815 .8488302230815 .8488302230816 .15361022949 16.4584007263217 .0679702758817 .6775398254418 .5918903350819 .50625038147 20.4206008911121 .6397399902322 .5541000366224 .0780296325725 .29715919495 26.8210906982428 .3450202941930 .1737308502231 .6976509094233 .52635955811 35.6598587036138 .0981407165540 .8412094116243 .5842704772946 .32733917236 49.0704002380451 .5086898803753 .0326118469253 .6421813964853 .64218139648 53.3373985290552 .7278289794952 .1182594299351 .8134689331151 .50868988037 51.2038993835451 .2038993835451 .2038993835451 .2038993835451 .50868988037 52.1182594299352 .4230384826753 .0326118469253 .9469718933154 .55654144287 55.1661109924356 .0804595947356 .6900291442957 .2995986938557 .9091796875 58.5187492370658 .8235282897959 .1283111572359 .4331016540559 .43310165405 59.7378807067959 .7378807067960 .0426712036160 .0426712036160 .34745025635 60.6522407531760 .9570198059161 .2618103027361 .5666007995661 .56660079956 $61.8713798522962 .1761703491262 .3434219360462 .4809494018662 .61689758301-9999$ -9999 -9999 -9999 -9999 -9999 -9999 -9999 -9999 -9999 -9999 -9999 -9999 -9999 -9999 -9999 -9999 -9999 -9999 -9999 -9999 -9999 -9999 -9999 -9999 -9999 -9999 -9999 -9999 -9999 -9999

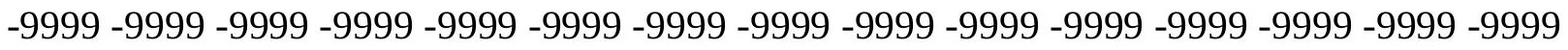

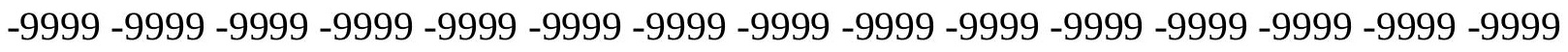
-9999 -9999-9999-9999-9999

-9999 -9999 -9999 -9999 -9999 -9999 -9999 -9999 -9999 -9999 -9999 -9999 -9999 -9999 -9999

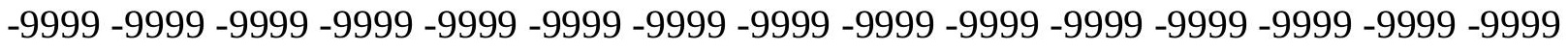

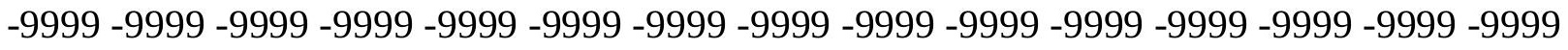
-9999 -9999 -9999 -9999 -9999 -9999 -9999 -9999 -9999 -9999 -9999 -9999 -9999 -9999 -9999 -9999 -9999 -9999 -9999 -9999 -9999 -9999 -9999 -9999-9999 -9999 -9999 -9999 -9999 -9999 -

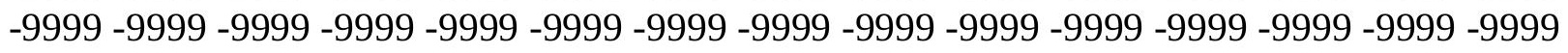
-9999 -9999 -9999 -9999 -9999 -9999 -9999 -9999 -9999 -9999 -9999 -9999 -9999 -9999 
52.1182594299352 .7278289794953 .6421813964854 .8613204956156 .08045959473 57.2995986938558 .2139587402359 .4331016540560 .3474502563561 .26181030273 61.8713798522962 .7857398986863 .7000885009864 .6144485473665 .52880096436 66.4431610107467 .3575134277368 .2718734741268 .8814392089869 .49101257324 69.4910125732469 .4910125732468 .8814392089867 .9670867919967 .05272674561 66.1383666992265 .2240066528364 .3096618652363 .3953094482462 .78573989868 62.1761703491261 .8713798522961 .8713798522962 .1761703491262 .48094940186 63.0905189514264 .004882812564 .9192428588965 .8335876464867 .35751342773 68.8814392089871 .014930725173 .7580032348676 .8058471679780 .46327209473 84.4254837036187 .7781066894590 .8259735107492 .7943344116293 .6834487915 94.6227874755995 .5913238525496 .6921615600697 .8360290527397 .83602905273 97.5312423706197 .2264633178796 .9216690063596 .3121032714895 .70252990723 95.0929565429794.1785964965892.9594726562592.0450973510790.82597351074 89.91161346436 88.69246673584 87.47332763672 86.55898284912 85.33984375 84.4254837036183 .5111236572382 .5967712402381 .9871978759881 .37763214111 81.0728530883880 .4632720947380 .4632720947380 .1584930419980 .15849304199 80.1584930419980 .4632720947380 .4632720947380 .7680587768681 .07285308838 81.0728530883881 .3776321411181 .3776321411181 .3776321411181 .37763214111 81.0728530883880 .7680587768680 .4632720947379 .8537063598679 .54891967773 78.9393463134878 .3297805786177 .7202072143677 .4154205322376 .80584716797 76.1962814331175 .8914871215875 .2819290161175 .2819290161174 .97714233398 74.6723632812574 .6723632812574 .9771423339874 .9771423339875 .28192901611 75.5867080688575 .8914871215876 .1962814331176 .5010681152377 .1106262207 77.4154205322378 .0249862670978 .6345596313579 .2441329956179 .85370635986 80.4632720947348 .765621185337 .7933502197326 .5163097381615 .23925971985 $5.181346893311-2.13349604607$-4.26699209213 -3.65742206573 -1.52392601967 -.304785102606.91435539722442.133496046066 3.6574220657354 .571776866913 5.4861321449286 .7052731513987 .9244132041939 .14355373382610 .36268997192 11.5818300247212 .8009700775113 .715330123914 .6296901702915 .23925971985 15.5440397262615 .5440397262615 .5440397262615 .2392597198514 .9344701767 14.934470176714 .934470176714 .934470176715 .2392597198515 .54403972626 15.8488302230816 .4584007263217 .0679702758817 .9823207855218 .89668083191 20.1158199310321 .334960937522 .5541000366223 .7732391357425 .29715919495 26.8210906982428 .3450202941930 .1737308502232 .0024414062534 .13592910767 36.5742111206139 .0125007629441 .7555618286144 .4986305236846 .93690872192 49.0704002380450 .5943298339851 .5086898803751 .8134689331151 .50868988037 51.5086898803750 .8991203308150 .5943298339850 .5943298339850 .28955078125 50.2895507812550 .2895507812550 .5943298339850 .8991203308151 .50868988037 52.1182594299352 .7278289794953 .3373985290553 .9469718933154 .86132049561 55.4708900451756 .3852500915556 .9948196411157 .6043891906758 .21395874023 58.5187492370659 .1283111572359 .4331016540559 .7378807067959 .73788070679 60.0426712036160 .3474502563560 .3474502563560 .6522407531760 .95701980591 61.2618103027361 .2618103027361 .5666007995661 .8713798522961 .87137985229 62.1761703491262 .1761703491262 .4809494018662 .63276290894 -9999 -9999 -9999 -9999 -9999 -9999 -9999 -9999 -9999 -9999 -9999 -9999 -9999 -9999 -9999 -9999 -9999 -9999 -9999

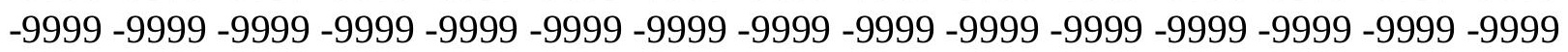


-9999 -9999 -9999 -9999 -9999 -9999 -9999 -9999 -9999 -9999 -9999 -9999 -9999 -9999 -9999 -9999 -9999 -9999 -9999 -9999 -9999 -9999 -9999 -9999 -9999 -9999 -9999 -9999 -9999 -9999 $-9999-9999$

-9999 -9999 -9999 -9999 -9999 -9999 -9999 -9999 -9999 -9999 -9999 -9999 -9999 -9999 -9999 -9999 -9999 -9999 -9999 -9999 -9999 -9999 -9999 -9999 -9999 -9999 -9999-9999 -9999 -9999 -9999 -9999 -9999 -9999 -9999 -9999 -9999 -9999 -9999 -9999 -9999 -9999 -9999 -9999 -9999 -9999 -9999 -9999 -9999 -9999 -9999 -9999 -9999 -9999 -9999 -9999 -9999 -9999 -9999 -9999 -9999 -9999 -9999 -9999 -9999 -9999 -9999 -9999 -9999 -9999 -9999 -9999 -9999 -9999 -9999 -999 -

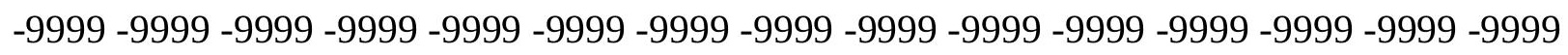
-9999 -9999 -9999 -9999 -9999 -9999 -9999 -9999 -9999 -9999 -9999 -9999 -9999 -9999 53.0326118469253 .6421813964854 .5565414428756 .0804595947357 .29959869385 58.5187492370659 .4331016540560 .3474502563561 .2618103027362 .17617034912 63.0905189514263 .7000885009864 .6144485473665 .5288009643666 .44316101074 67.3575134277368 .2718734741269 .4910125732470 .1005783081170 .71015167236 70.7101516723670 .1005783081169 .4910125732468 .5766525268667 .35751342773 66.1383666992265 .2240066528364 .3096618652363 .0905189514262 .48094940186 61.8713798522961 .2618103027361 .2618103027361 .5666007995661 .87137985229 62.4809494018663 .0905189514264 .004882812565 .2240066528366 .44316101074 68.2718734741270 .4053573608472 .8436431884875 .8914871215879 .24413299561 82.5967712402385 .9494018554788 .9972534179791 .4355392456192 .83071899414 94.7881774902395 .7025299072396 .3121032714899 .6647262573296 .92166900635 96.9216690063596 .6168823242296 .3121032714896 .0073165893695 .3977432251 94.7881774902394 .1785964965893 .2642517089892 .0450973510791 .13075256348 89.9116134643688 .9972534179787 .7781066894586 .8637619018685 .64462280273 84.7302627563583 .8159103393682 .9015579223682 .2919769287181 .68241119385 81.0728530883880 .7680587768680 .4632720947380 .1584930419980 .15849304199 80.1584930419980 .1584930419980 .1584930419980 .4632720947380 .46327209473 80.4632720947380 .7680587768680 .4632720947380 .4632720947380 .46327209473 80.1584930419979 .8537063598679 .5489196777378 .9393463134878 .32978057861 77.7202072143677 .110626220776 .8058471679776 .1962814331175 .58670806885 74.9771423339874 .6723632812574 .062782287673 .7580032348673 .75800323486 73.4532165527373 .4532165527373 .4532165527373 .4532165527373 .75800323486 74.062782287674 .3675689697374 .6723632812574 .9771423339875 .58670806885 75.8914871215876 .5010681152376 .8058471679777 .4154205322378 .32978057861 79.2441329956146 .0225486755433 .5263595581121 .030170440679 .143553733826 -.609570324421 -8.83876895905 -9.75312423706 -8.22919845581 -5.79091691971 -3.35263609886-1.21914100647.6095703244209 2.133496046066 3.047851085663 4.2669920921335 .1813468933116 .4004869461067 .6196279525768 .838768959045 10.3626899719211 .2770500183112 .4961900711113 .4105501174914 .02011966705 14.3248996734614 .3248996734614 .3248996734614 .0201196670514 .02011966705 14.0201196670513 .715330123914 .0201196670514 .0201196670514 .32489967346 14.6296901702915 .2392597198515 .8488302230816 .7631797790517 .67753982544 18.5918903350819 .811029434221 .0301704406722 .2493095397923 .77323913574 24.9923801422126 .8210906982428 .3450202941930 .1737308502232 .30722045898 34.4407196044937 .1837806701739 .622070312542 .3651313781744 .49863052368 46.3273391723647 .8512611389249 .0704002380449 .6799812316949 .67998123169 
49.9847602844249 .6799812316949 .6799812316949 .6799812316949 .67998123169 49.6799812316949 .6799812316949 .9847602844250 .2895507812550 .89912033081 51.5086898803752 .1182594299353 .0326118469253 .6421813964854 .55654144287 55.1661109924356 .0804595947356 .6900291442957 .2995986938557 .9091796875 58.5187492370658 .8235282897959 .4331016540559 .7378807067960 .04267120361 60.3474502563560 .6522407531760 .6522407531760 .9570198059161 .26181030273 61.2618103027361 .5666007995661 .5666007995661 .8713798522961 .87137985229 62.1761703491262 .1761703491262 .4809494018662 .65939331055 -9999 -9999 -9999 -9999 -9999 -9999 -9999 -9999 -9999 -9999 -9999 -9999 -9999 -9999 -9999 -9999 -9999 -9999 -9999 -9999 -9999 -9999 -9999 -9999 -9999 -9999 -9999 -9999 -9999 -9999 -9999 -9999 -9999 -9999 -9999 -9999 -9999 -9999 -9999 -9999 -9999 -9999 -9999 -9999 -9999 -9999 -9999 -9999 -9999 -

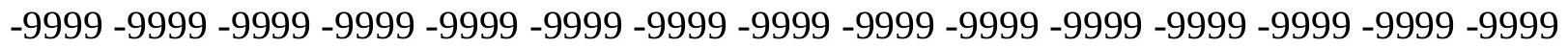
-9999 -9999

-9999 -9999 -9999 -9999 -9999 -9999 -9999 -9999 -9999 -9999 -9999 -9999 -9999 -9999 -9999 -9999 -9999 -9999 -9999 -9999 -9999 -9999 -9999 -9999 -9999 -9999 -9999 -9999 -9999 -9999 -

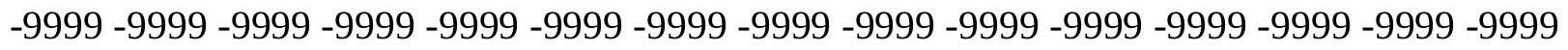
-9999 -9999 -9999 -9999 -9999 -9999 -9999 -9999 -9999 -9999 -9999 -9999 -9999 -9999 -9999 -9999 -9999 -9999 -9999 -9999 -9999 -9999 -9999 -9999 -9999 -9999 -9999 -9999 -9999 -9999 -

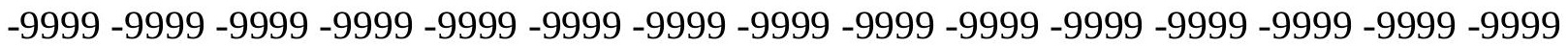

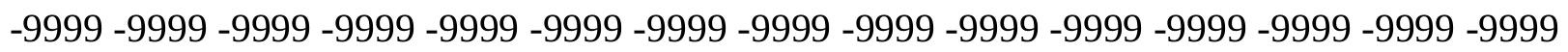
55.4708900451756 .6900291442957 .909179687559 .1283111572360 .34745025635 61.2618103027362 .1761703491263 .0905189514263 .7000885009864 .30966186523 65.2240066528365 .8335876464866 .4431610107467 .3575134277368 .27187347412 69.4910125732470 .7101516723671 .6244964599672 .2340774536171 .92929077148 71.3197174072370 .1005783081168 .8814392089867 .6623001098666 .74794006348 65.5288009643664 .6144485473663 .3953094482462 .4809494018661 .87137985229 61.2618103027361 .2618103027361 .2618103027361 .5666007995662 .17617034912 62.7857398986863 .7000885009864 .9192428588966 .1383666992267 .96708679199 69.7957916259872 .2340774536174 .9771423339878 .0249862670981 .07285308838 84.1206970214887 .1685485839889 .6068267822391 .7403335571396 .31210327148 97.5312423706198 .445587158298 .7503814697399 .0551681518696 .00731658936 96.0073165893696 .0073165893695 .7025299072395 .0929565429794 .48339080811 93.8738174438592 .9594726562592 .0450973510791 .1307525634890 .21640014648 88.9972534179788 .0829010009886 .8637619018685 .9494018554785 .03504943848 84.1206970214883 .206336975182 .2919769287181 .6824111938581 .37763214111 80.7680587768680 .4632720947380 .1584930419980 .1584930419980 .15849304199 79.8537063598680 .1584930419980 .1584930419980 .1584930419980 .15849304199 80.1584930419979 .8537063598679 .8537063598679 .5489196777379 .24413299561 78.9393463134878 .3297805786178 .0249862670977 .4154205322376 .80584716797 76.1962814331175 .5867080688574 .9771423339874 .3675689697373 .75800323486 73.1484298706172 .8436431884872 .5388565063572 .2340774536171 .92929077148 71.9292907714871 .9292907714871 .9292907714872 .2340774536172 .53885650635 72.8436431884873 .1484298706173 .4532165527373 .7580032348674 .0627822876 74.3675689697374 .9771423339875 .5867080688576 .5010681152377 .41542053223 $44.4986305236831 .0880794525117 .372749328614 .571776866913-4.57177686691$ $-10.3626899719-11.8866195679-10.9722604752-8.53398323059-5.79091691971$ 
-3.04785108566 -.609570324421.6095703244209 1.828711032867 2.743066072464 3.9622070789345 .1813468933116 .4004869461067 .6196279525768 .838768959045 10.0579099655211 .2770500183111 .8866195678712 .4961900711112 .80097007751 13.1057596206713 .1057596206713 .1057596206712 .8009700775112 .80097007751 12.8009700775112 .8009700775113 .1057596206713 .4105501174913 .7153301239 14.3248996734614 .934470176715 .5440397262616 .4584007263217 .37274932861 18.28710937519 .5062503814720 .7253894805922 .2493095397923 .46845054626 24.9923801422126 .8210906982428 .3450202941930 .1737308502232 .61201095581 35.0502891540537 .7933502197339 .9268493652342 .0603485107443 .88906097412 45.4129791259846 .6321296691947 .5464782714847 .8512611389248 .15605163574 48.4608306884848 .4608306884848 .4608306884848 .765621185348 .7656211853 49.0704002380449 .3751907348649 .9847602844250 .5943298339851 .20389938354 51.8134689331152 .7278289794953 .3373985290554 .2517509460454 .86132049561 55.7756805419956 .3852500915557 .2995986938557 .909179687558 .51874923706 59.1283111572359 .4331016540560 .0426712036163 .3953094482462 .56463623047 62.249996185360 .9570198059161 .2618103027361 .5666007995661 .56660079956 61.5666007995661 .8713798522961 .8713798522961 .8713798522962 .17617034912 62.1761703491262 .4809494018662 .48094940186 -9999 -9999 -9999 -9999 -9999 -9999-9999 -9999 -9999 -9999 -9999 -9999 -9999 -9999 -9999 -9999 -9999 -9999 -9999 -9999 -9999 -9999 -9999 -9999 -9999 -9999 -9999 -9999 -9999 -9999 -9999 -9999 -9999 -9999 -9999 -9999 -9999 -9999 -9999 -9999 -9999 -9999 -9999 -9999 -9999 -9999 -9999 -9999 -9999 -9999 -9999 -9999 -9999 -9999 -9999 -9999 -9999 -9999 -9999 -9999 -9999 -9999 -9999 -9999 -9999 -9999 -9999 -9999 -9999 -9999 -9999 -9999 -9999 -9999 -9999 -9999 -9999 -9999 -9999-9999 -9999 -9999 -9999 -9999 -9999 -9999 -9999 -9999 -9999 -9999 -9999 -9999 -9999 -9999 -9999 -9999 -9999 -9999 -9999 -9999 -9999 -9999 -9999 -9999 -9999 -9999 -9999 -9999 -9999 -9999 -9999 -9999 -9999 -9999 -9999 -9999 -9999 -9999 -9999 -9999 -9999 -9999 -9999 -9999 -9999 -9999 -9999 -9999 -9999 -9999 -9999 -9999 -9999 -9999 -9999 -9999 -9999 -9999 -9999 -9999 -9999 -9999 -9999 -9999 -9999 -9999 -9999 -9999 -9999 -9999 -9999 -9999 -9999 -9999 -9999 -9999 -9999 -9999 -9999 -9999 -9999 -9999 -9999 -9999 -9999 -9999 -9999 -9999 -9999 -9999 -9999 -999959.1283111572360.6522407531761.8713798522963.0905189514264.0048828125 64.6144485473665 .2240066528365 .8335876464866 .4431610107466 .74794006348 67.3575134277367 .9670867919968 .8814392089869 .7957916259870 .71015167236 71.9292907714873 .1484298706173 .7580032348673 .4532165527372 .23407745361 70.7101516723669 .4910125732468 .2718734741267 .3575134277366 .13836669922 65.2240066528364 .3096618652363 .3953094482462 .7857398986861 .87137985229 61.8713798522961 .8713798522962 .1761703491262 .4809494018663 .09051895142 64.004882812564 .9192428588966 .1383666992267 .9670867919969 .79579162598 71.9292907714874 .3675689697377 .110626220779 .8537063598682 .59677124023 85.3398437588 .0829010009893 .5690307617295 .397743225196 .61688232422 97.22646331787 97.83602905273 98.1408081054798.1408081054798.14080810547 95.0929565429795 .0929565429794 .7881774902394 .1785964965893 .87381744385 92.9594726562592 .349891662691 .4355392456190 .5211791992289 .3020401001 88.3876876831187 .1685485839886 .254188537685 .3398437584 .42548370361 83.5111236572382 .5967712402381 .9871978759881 .3776321411181 .07285308838 80.4632720947380 .1584930419980 .1584930419979 .8537063598679 .85370635986 79.8537063598679 .8537063598679 .8537063598679 .5489196777379 .54891967773 
79.2441329956179 .2441329956178 .9393463134878 .6345596313578 .02498626709 77.7202072143677 .110626220776 .5010681152375 .8914871215874 .97714233398 74.3675689697373 .7580032348673 .1484298706172 .5388565063571 .92929077148 71.3197174072371 .014930725170 .7101516723670 .4053573608470 .40535736084 70.4053573608470 .4053573608470 .4053573608470 .7101516723671 .0149307251 71.014930725171 .3197174072371 .6244964599671 .9292907714872 .23407745361 72.8436431884873 .1484298706174 .062782287674 .9771423339844 .80340957642 $30.7833003997816 .153610229492 .133496046066-5.18134689331$-9.75312423706 -11.8866195679 -11.5818300247 -9.75312423706 -7.3148431778-4.87656211853 $-2.43828105927-.914355397224 .30478510260581 .5239260196692 .438281059265$ 3.6574220657354 .876562118536 .4004869461067 .6196279525768 .838768959045 10.0579099655210 .6674804687511 .2770500183111 .5818300247211 .58183002472 11.8866195678711 .8866195678711 .8866195678711 .8866195678711 .88661956787 11.8866195678712 .191410064712 .4961900711112 .8009700775113 .10575962067 13.715330123914 .3248996734615 .2392597198516 .1536102294917 .06797027588 18.28710937519 .5062503814720 .7253894805922 .2493095397923 .77323913574 25.2971591949526 .8210906982428 .9545898437531 .0880794525133 .22158050537 35.6598587036137 .7933502197339 .9268493652341 .7555618286143 .27949142456 44.4986305236845 .4129791259846 .0225486755446 .6321296691946 .93690872192 47.2416992187547 .5464782714847 .8512611389248 .1560516357448 .46083068848 49.0704002380449 .3751907348649 .9847602844250 .8991203308151 .50868988037 52.4230384826753 .0326118469253 .9469718933154 .8613204956155 .47089004517 56.3852500915556 .9948196411157 .909179687561 .5666007995662 .17617034912 62.7857398986863 .3953094482463 .7000885009863 .8268508911163 .53799819946 61.5666007995661 .5666007995661 .5666007995661 .8713798522961 .87137985229 61.8713798522961 .8713798522961 .8713798522962 .1761703491262 .17617034912 62.1761703491262 .48094940186 -9999 -9999 -9999 -9999 -9999 -9999 -9999 -9999 -9999 -9999 -9999 -9999 -9999 -9999 -9999 -9999 -9999 -9999 -9999 -9999 -9999 -9999 -9999 -9999 -9999 -9999 -9999 -9999 -9999 -9999 -9999 -9999 -9999 -9999 -9999 -9999 -9999 -9999 -9999 -9999 -9999 -9999 -9999 -9999 -9999 -9999 -9999 -9999 -9999 -9999 -9999 -9999 -9999 -9999 -9999 -9999 -9999 -9999 -9999 -9999 -9999 -9999 -9999 -9999 -9999 -9999 -

-9999 -9999 -9999 -9999 -9999 -9999 -9999 -9999 -9999 -9999 -9999 -9999 -9999 -9999 -9999 -9999 -9999 -9999 -9999 -9999 -9999 -9999 -9999 -9999 -9999 -9999 -9999 -9999 -9999 -9999 -9999 -9999 -9999 -9999 -9999 -9999 -9999 -9999 -9999 -9999 -9999 -9999 -9999 -9999 -9999

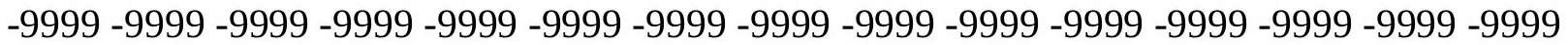
-9999 -9999 -9999 -9999 -9999 -9999 -9999 -9999 -9999 -9999 -9999 -9999 -9999 -9999 -9999 -9999 -9999 -9999 -9999 -9999 -9999 -9999 -9999 -9999 -9999 -9999 -9999 -9999 -9999 -9999

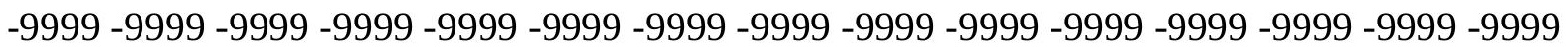
-9999 -9999 64.0048828125 65.52880096436 66.4431610107467.35751342773 67.6623001098668 .2718734741268 .2718734741268 .5766525268668 .88143920898 69.1862335205169 .7957916259870 .4053573608471 .014930725172 .23407745361 73.1484298706174 .6723632812575 .8914871215874 .3675689697372 .84364318848 71.3197174072370 .1005783081169 .1862335205168 .2718734741267 .66230010986 66.7479400634866 .1383666992265 .5288009643664 .6144485473663 .39530944824 63.3953094482463 .3953094482463 .3953094482463 .7000885009864 .0048828125 64.6144485473665 .5288009643666 .7479400634868 .2718734741270 .10057830811 
71.9292907714874 .062782287676 .5010681152378 .9393463134881 .37763214111 84.1206970214886 .8637619018692 .349891662694 .1785964965895 .3977432251 96.3121032714896 .9216690063597 .2264633178797 .5312423706197 .53124237061 97.5312423706194 .4833908081194 .1785964965893 .8738174438593 .56903076172 92.9594726562592 .349891662691 .4355392456190 .5211791992289 .60682678223 88.6924667358487 .4733276367286 .5589828491285 .6446228027384 .73026275635 83.8159103393682 .9015579223682 .2919769287181 .6824111938581 .07285308838 80.7680587768680 .4632720947380 .1584930419979 .8537063598679 .85370635986 79.5489196777379 .5489196777379 .5489196777379 .2441329956179 .24413299561 78.9393463134878 .6345596313578 .3297805786178 .0249862670977 .41542053223 76.8058471679776 .1962814331175 .5867080688574 .6723632812574 .0627822876 73.4532165527372 .5388565063571 .9292907714871 .3197174072370 .71015167236 70.1005783081169 .4910125732469 .1862335205168 .8814392089868 .88143920898 68.5766525268668 .5766525268668 .5766525268668 .5766525268668 .88143920898 68.8814392089869 .1862335205169 .4910125732469 .4910125732469 .79579162598 70.1005783081170 .4053573608471 .014930725172 .2340774536144 .80340957642 32.0024414062517 .372749328615 .181346893311 -3.04785108566 -7.92441320419 $-10.3626899719-10.6674804688-9.75312423706-8.22919845581-6.095703125$ -3.96220707893 -2.43828105927-.914355397224-9999 1.21914100647 2.133496046066 3.3526360988624 .876562118536 .4004869461067 .9244132041938 .838768959045 9.4483394622810 .0579099655210 .3626899719210 .3626899719210 .66748046875 10.6674804687510 .6674804687510 .6674804687510 .9722604751610 .97226047516 11.2770500183111 .5818300247211 .8866195678712 .191410064712 .80097007751 13.4105501174914 .0201196670514 .934470176715 .8488302230816 .76317977905 17.9823207855219 .5062503814720 .7253894805922 .2493095397924 .07802963257 25.6019496917727 .430660247829 .5641593933131 .6976509094233 .83115005493 35.6598587036137 .7933502197339 .622070312541 .1459884643642 .36513137817 43.5842704772944 .4986305236845 .1082000732445 .717769622846 .02254867554 46.6321296691946 .9369087219247 .5464782714847 .8512611389248 .46083068848 49.0704002380449 .6799812316950 .5943298339851 .2038993835452 .11825942993 53.0326118469253 .6421813964854 .5565414428755 .4708900451756 .38525009155 60.0426712036161 .2618103027362 .1761703491262 .7857398986863 .39530944824 64.004882812564 .3096618652364 .6144485473664 .4324188232461 .87137985229 61.8713798522961 .8713798522961 .8713798522961 .8713798522961 .87137985229 61.8713798522961 .8713798522962 .1761703491262 .1761703491262 .17617034912 62.1761703491262 .48094940186 -9999 -9999 -9999 -9999 -9999 -9999 -9999 -9999 -9999 -9999 -9999 -9999 -9999 -9999 -9999 -9999 -9999 -9999 -9999 -9999 -9999-9999 -9999 -9999 -

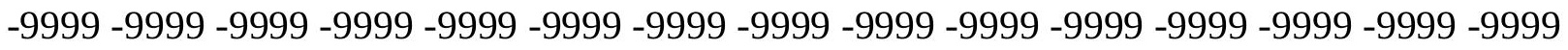
-9999 -9999 -9999 -9999 -9999 -9999 -9999 -9999 -9999 -9999 -9999 -9999 -9999 -9999 -9999 -9999 -9999 -9999 -9999 -9999 -9999 -9999-9999 -9999 -9999 -9999 -

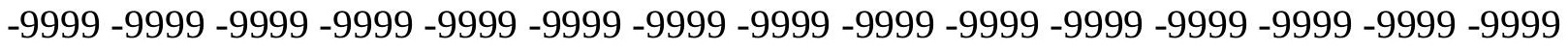

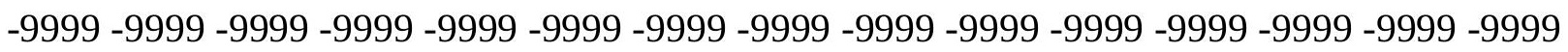
-9999 -9999 -9999 -9999 -9999 -9999 -9999 -9999 -9999 -9999 -9999 -9999 -9999 -9999 -9999 -9999 -9999 -9999 -9999 -9999 -9999 -9999 -9999 -9999-9999 -9999 -9999 -9999 -9999 -9999 -9999 -9999 -9999 -9999 -9999 -9999 -9999 -9999 -9999 -9999 -9999 -9999 -9999 -9999 -9999 -9999 -9999 -9999 -9999 -9999 -9999 -9999 -9999 -9999 -9999 -9999 -9999 -9999 -9999 -9999 
-9999 -9999 -9999 -9999 -9999 -9999 -9999 -9999 -9999 -9999 -9999 -9999 -9999 -9999 -9999 -9999 -9999 68.27187347412 69.49101257324 70.4053573608471.0149307251 71.3197174072371 .6244964599671 .6244964599671 .3197174072371 .31971740723 71.3197174072371 .6244964599671 .9292907714872 .5388565063573 .45321655273 74.3675689697375 .5867080688575 .8914871215874 .9771423339873 .45321655273 72.2340774536171 .014930725170 .1005783081169 .7957916259869 .49101257324 69.1862335205168 .8814392089868 .2718734741267 .6623001098666 .74794006348 66.1383666992265 .8335876464865 .5288009643665 .5288009643665 .52880096436 66.1383666992266 .7479400634867 .9670867919969 .1862335205170 .71015167236 72.5388565063574 .3675689697376 .1962814331178 .3297805786180 .46327209473 83.2063369751 88.6924667358491.1307525634893.2642517089894.48339080811 95.397743225196 .0073165893696 .3121032714896 .9216690063596 .92166900635 97.22646331787 97.2264633178793.8738174438593.8738174438593.56903076172 93.2642517089892 .6546783447391 .7403335571390 .8259735107489 .91161346436 88.9972534179788 .0829010009886 .8637619018685 .9494018554785 .03504943848 84.1206970214883 .206336975182 .5967712402381 .9871978759881 .37763214111 80.7680587768680 .4632720947380 .1584930419979 .8537063598679 .85370635986 79.5489196777379 .5489196777379 .2441329956178 .9393463134878 .63455963135 78.6345596313578 .0249862670977 .7202072143677 .4154205322376 .80584716797 76.1962814331175 .5867080688574 .6723632812574 .062782287673 .14842987061 72.2340774536171 .3197174072370 .7101516723669 .7957916259869 .18623352051 68.5766525268667 .9670867919967 .6623001098667 .3575134277367 .05272674561 66.7479400634866 .7479400634866 .4431610107466 .4431610107466 .44316101074 66.7479400634866 .7479400634866 .7479400634866 .7479400634866 .74794006348 66.7479400634866 .7479400634867 .3575134277368 .5766525268647 .54647827148 $31.0880794525118 .896680831918 .229198455811 .3047851026058-4.57177686691$ $-7.61962795258-9.14355373383-8.83876895905-7.92441320419-6.40048694611$ -4.87656211853 -3.35263609886 -2.13349604607 -.914355397224 -9999.9143553972244 1.8287110328673 .3526360988625 .1813468933116 .7052731513987 .619627952576 8.2291984558118 .5339832305918 .8387689590459 .1435537338269 .143553733826 9.448339462289 .7531242370619 .75312423706110 .0579099655210 .36268997192 10.3626899719210 .6674804687510 .9722604751611 .2770500183111 .88661956787 12.4961900711113 .1057596206713 .715330123914 .6296901702915 .84883022308 17.0679702758818 .28710937519 .811029434221 .0301704406722 .85887908936 24.3828105926526 .2115192413328 .0402297973630 .1737308502232 .00244140625 33.8311500549335 .6598587036137 .4885711669939 .0125007629440 .53641891479 41.7555618286142 .66992187543 .5842704772944 .4986305236845 .10820007324 45.717769622846 .0225486755446 .6321296691947 .2416992187547 .85126113892 48.765621185349 .3751907348649 .9847602844250 .8991203308151 .81346893311 52.7278289794953 .6421813964854 .5565414428755 .1661109924356 .08045959473 60.6522407531761 .5666007995662 .7857398986863 .3953094482464 .0048828125 64.3096618652364 .6144485473664 .9192428588964 .9192428588961 .87137985229 62.1761703491262 .1761703491261 .8713798522961 .8713798522961 .87137985229 61.8713798522961 .8713798522961 .8713798522962 .1761703491262 .17617034912 62.1761703491262 .17617034912 -9999 -9999 -9999 -9999 -9999 -9999 -9999 -9999 -9999 -9999 -9999 -9999 -9999 -9999 -9999 -9999 -9999 -9999 -9999 -9999 -9999 -9999 -9999 -9999 
-9999 -9999 -9999 -9999 -9999 -9999 -9999 -9999 -9999 -9999 -9999 -9999 -9999 -9999 -9999 -9999 -9999 -9999 -9999 -9999 -9999 -9999 -9999 -9999 -9999 -9999 -9999 -9999 -9999 -9999 -9999 -9999 -9999 -9999 -9999 -9999 -9999 -9999 -9999 -9999 -9999

-9999 -9999 -9999 -9999 -9999 -9999 -9999 -9999 -9999 -9999 -9999 -9999 -9999 -9999 -9999 -9999 -9999 -9999 -9999 -9999 -9999 -9999 -9999 -9999 -9999 -9999 -9999-9999 -9999 -9999 -9999 -9999 -9999 -9999 -9999 -9999 -9999 -9999 -9999 -9999 -9999 -9999 -9999 -9999 -9999

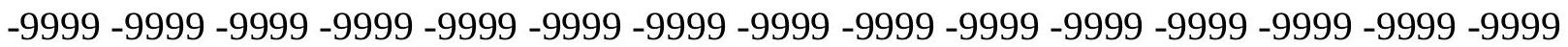
-9999 -9999 -9999 -9999 -9999 -9999 -9999 -9999 -9999 -9999 -9999 -9999 -9999 -9999 -9999 -999 -9999 -9999 -9999 -9999 -9999 -9999 -9999 -9999 -9999 -9999 -9999 -9999 -9999 -9999 -9999 -9999 -9999 -9999 -9999 -9999 -9999 -9999 -9999 -9999 -9999 -9999 -9999 -9999 -9999 -9999 -9999 -9999-9999 74.36756896973 74.97714233398 75.58670806885 75.58670806885 75.5867080688574 .9771423339874 .3675689697373 .7580032348673 .45321655273 73.7580032348674 .062782287674 .6723632812575 .2819290161176 .19628143311 76.8058471679776 .8058471679776 .1962814331174 .9771423339873 .45321655273 72.5388565063572 .2340774536172 .2340774536172 .5388565063572 .53885650635 72.5388565063572 .5388565063571 .9292907714871 .014930725170 .10057830811 69.1862335205168 .5766525268668 .2718734741267 .9670867919968 .27187347412 68.5766525268669 .4910125732470 .4053573608471 .9292907714873 .45321655273 74.9771423339876 .8058471679778 .6345596313580 .4632720947382 .59677124023 85.03504943848 90.2164001464892.0450973510793.2642517089894.17859649658 95.0929565429795 .7025299072396 .3121032714896 .6168823242296 .92166900635 96.9216690063596 .9216690063593 .8738174438593 .5690307617293 .26425170898 92.9594726562592 .0450973510791 .4355392456190 .5211791992289 .60682678223 88.38768768311 87.47332763672 86.2541885376 85.33984375 84.42548370361 83.5111236572382 .5967712402381 .9871978759881 .6824111938581 .07285308838 80.7680587768680 .4632720947380 .1584930419979 .8537063598679 .54891967773 79.2441329956178 .9393463134878 .9393463134878 .6345596313578 .32978057861 77.7202072143677 .4154205322376 .8058471679776 .1962814331175 .58670806885 74.6723632812574 .062782287673 .1484298706172 .2340774536171 .31971740723 70.4053573608469 .4910125732468 .5766525268667 .9670867919967 .05272674561 66.4431610107466 .1383666992265 .5288009643665 .2240066528364 .91924285889 64.6144485473664 .3096618652364 .004882812564 .004882812564 .0048828125 64.004882812563 .7000885009863 .7000885009863 .3953094482462 .78573989868 62.4809494018662 .1761703491263 .3953094482440 .8412094116230 .17373085022 20.1158199310310 .972260475163 .657422065735 -1.21914100647 -4.87656211853 $-6.7052731514-7.3148431778-7.01005792618-6.40048694611-5.18134689331$ -3.96220707893 -3.04785108566 -2.13349604607 -1.21914100647 -.304785102606 .30478510260581 .5239260196693 .6574220657355 .7909169197086 .400486946106 6.7052731513987 .0100579261787 .3148431777957 .6196279525768 .229198455811 8.2291984558118 .5339832305918 .8387689590459 .1435537338269 .44833946228 9.75312423706110 .0579099655210 .3626899719210 .6674804687511 .27705001831 11.5818300247212 .191410064712 .8009700775113 .715330123914 .9344701767 15.8488302230817 .3727493286118 .5918903350820 .1158199310321 .63973999023 23.4684505462625 .2971591949526 .8210906982428 .6497993469230 .47850990295 32.0024414062533 .8311500549335 .6598587036137 .1837806701738 .70771026611 40.2316398620641 .1459884643642 .3651313781743 .2794914245643 .88906097412 
44.4986305236845 .4129791259846 .0225486755446 .6321296691947 .54647827148 48.1560516357449 .0704002380449 .6799812316950 .5943298339851 .50868988037 52.4230384826753 .3373985290554 .2517509460455 .1661109924359 .43310165405 60.9570198059162 .1761703491263 .0905189514264 .004882812564 .30966186523 64.9192428588964 .9192428588965 .2240066528365 .2240066528362 .17617034912 62.1761703491262 .1761703491262 .1761703491262 .1761703491261 .87137985229 61.8713798522961 .8713798522961 .8713798522961 .8713798522961 .87137985229 61.8713798522961 .87137985229 -9999 -9999 -9999 -9999 -9999 -9999 -9999 -9999 -9999

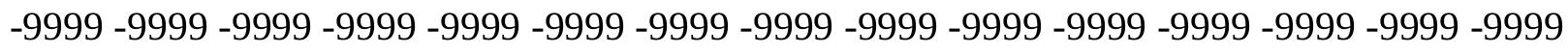
-9999 -9999 -9999 -9999 -9999 -9999 -9999 -9999 -9999 -9999 -9999 -9999 -9999 -9999 -9999 -

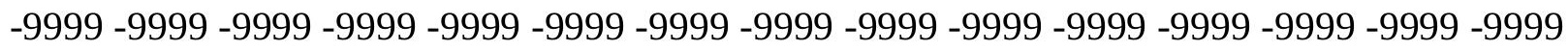
-9999 -9999 -9999 -9999 -9999 -9999 -9999 -9999 -9999 -9999 -9999 -

-9999 -9999 -9999 -9999 -9999 -9999 -9999 -9999 -9999 -9999 -9999 -9999 -9999 -9999 -9999 -9999 -9999 -9999 -9999 -9999 -9999 -9999 -9999 -9999 -9999 -9999 -9999 -9999 -9999 -9999 -9999 -9999 -9999 -9999 -9999 -9999 -9999 -9999 -9999 -9999 -9999 -9999 -9999 -9999 -9999

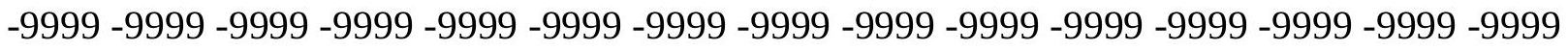
-9999 -9999 -9999 -9999 -9999 -9999 -9999 -9999 -9999 -9999 -9999 -9999 -9999 -9999 -9999 -9999 -9999 -9999 -9999 -9999 -9999 -9999 -9999 -9999 -9999 -9999 -9999 -9999 -9999 -9999 -

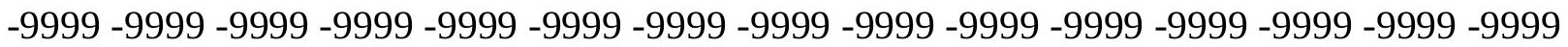
-9999 -9999-9999 -9999 79.85370635986 80.15849304199 80.15849304199 79.85370635986 78.9393463134877 .7202072143676 .5010681152375 .8914871215876 .19628143311 76.8058471679777 .7202072143678 .0249862670978 .9393463134879 .85370635986 80.1584930419979 .2441329956178 .0249862670976 .5010681152375 .89148712158 75.8914871215876 .1962814331176 .8058471679777 .110626220777 .41542053223 77.7202072143677 .4154205322376 .5010681152375 .2819290161173 .75800323486 72.5388565063571 .6244964599671 .3197174072371 .014930725171 .31971740723 71.9292907714872 .5388565063573 .4532165527374 .6723632812576 .19628143311 77.7202072143679 .2441329956180 .7680587768682 .5967712402384 .42548370361 89.302040100190.8259735107492.3498916626 93.2642517089894.17859649658 95.0929565429795 .7025299072396 .3121032714896 .6168823242296 .92166900635 96.9216690063593 .8738174438593 .8738174438593 .8738174438593 .26425170898 92.6546783447392 .0450973510791 .1307525634890 .2164001464888 .99725341797 87.7781066894586 .8637619018685 .6446228027384 .7302627563583 .81591033936 82.9015579223682 .2919769287181 .6824111938581 .3776321411180 .76805877686 80.4632720947380 .1584930419979 .8537063598679 .5489196777379 .24413299561 78.9393463134878 .6345596313578 .3297805786178 .0249862670977 .41542053223 77.110626220776 .5010681152375 .8914871215874 .9771423339874 .36756896973 73.4532165527372 .2340774536171 .3197174072370 .4053573608469 .18623352051 68.2718734741267 .3575134277366 .4431610107465 .5288009643664 .91924285889 64.3096618652364 .004882812563 .3953094482462 .7857398986862 .48094940186 61.8713798522961 .5666007995661 .2618103027360 .9570198059160 .65224075317 60.3474502563560 .3474502563559 .4331016540558 .5187492370657 .29959869385 55.7756805419953 .6421813964839 .3172798156729 .5641593933121 .03017044067 $13.410550117497 .0100579261781 .828711032867-1.82871103287-4.26699209213$ $-5.48613214493-5.79091691971-5.48613214493-4.87656211853-4.26699209213$ $-3.35263609886-2.74306607246-2.13349604607-1.52392601967-.914355397224-9999$ 
1.5239260196693 .3526360988624 .2669920921334 .876562118535 .486132144928 6.0957031256 .4004869461067 .0100579261787 .3148431777957 .924413204193 8.2291984558118 .8387689590459 .1435537338269 .448339462289 .753124237061 10.0579099655210 .3626899719210 .6674804687510 .9722604751611 .58183002472 12.191410064713 .1057596206714 .0201196670515 .2392597198516 .45840072632 17.9823207855219 .2014598846421 .0301704406722 .5541000366224 .07802963257 25.906740188627 .430660247828 .9545898437530 .4785099029532 .30722045898 34.1359291076735 .6598587036137 .1837806701738 .7077102661139 .92684936523 41.1459884643642 .0603485107442 .9747009277343 .5842704772944 .49863052368 45.4129791259846 .0225486755446 .9369087219247 .8512611389248 .46083068848 49.3751907348650 .2895507812551 .2038993835452 .4230384826753 .33739852905 54.2517509460455 .1661109924360 .0426712036161 .2618103027362 .48094940186 63.7000885009864 .3096618652364 .9192428588965 .2240066528365 .52880096436 65.5288009643665 .5288009643662 .4809494018662 .4809494018662 .17617034912 62.1761703491262 .1761703491261 .8713798522961 .8713798522961 .87137985229 $61.8713798522961 .8713798522961 .8713798522961 .8713798522961 .87137985229-9999$ -9999 -9999 -9999 -9999 -9999 -9999 -9999 -9999 -9999 -9999 -9999 -9999 -9999 -9999 -9999 -9999 -9999 -9999 -9999 -9999 -9999 -9999 -9999 -9999 -9999 -9999 -9999 -9999 -9999 - 9999 -9999 -9999 -9999 -9999 -9999 -9999 -9999 -9999 -9999 -9999 -9999 -9999 -9999 -9999 -9999 -

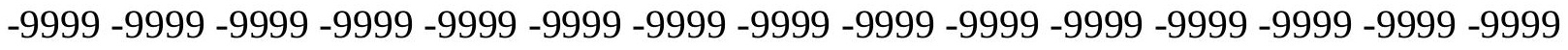
-9999 -9999 -9999 -9999

-9999 -9999 -9999 -9999 -9999 -9999 -9999 -9999 -9999 -9999 -9999 -9999 -9999 -9999 -9999 -9999 -9999 -9999 -9999 -9999 -9999 -9999 -9999 -9999 -9999 -9999 -9999 -9999 -9999 -9999 -

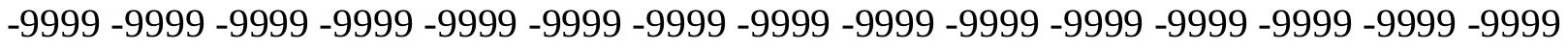

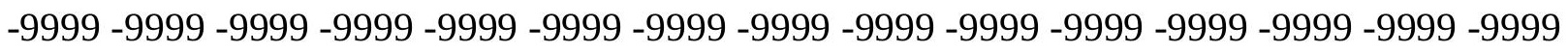
-9999 -9999 -9999 -9999 -9999 -9999 -9999 -9999 -9999 -9999 -9999 -9999 -9999 -9999 -9999 -9999 -9999 -9999 -9999 -9999 -9999 -9999 -9999 -9999 -9999 -9999 -9999 -9999 -9999 -9999 -

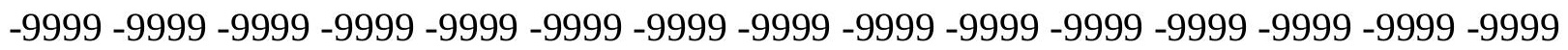
-9999 -9999-9999 -9999 -9999 84.73026275635 85.03504943848 84.73026275635 83.5111236572381 .3776321411179 .5489196777378 .6345596313579 .24413299561 81.0728530883882 .5967712402383 .206336975183 .8159103393685 .94940185547 87.1685485839885 .9494018554783 .8159103393682 .5967712402381 .98719787598 81.98719787598 82.90155792236 83.51112365723 83.206336975183.51112365723 83.81591033936 83.81591033936 82.90155792236 81.37763214111 79.24413299561 77.7202072143676 .5010681152375 .5867080688574 .9771423339874 .97714233398 74.9771423339875 .2819290161175 .8914871215876 .8058471679777 .72020721436 78.9393463134880 .1584930419981 .3776321411182 .9015579223684 .42548370361 88.6924667358490 .2164001464891 .4355392456192 .349891662693 .56903076172 94.4833908081195 .397743225196 .3121032714896 .9216690063597 .22646331787 97.5312423706197 .5312423706194 .4833908081194 .4833908081193 .87381744385 93.5690307617292 .6546783447391 .7403335571390 .8259735107489 .60682678223 88.38768768311 87.16854858398 85.9494018554785.03504943848 84.12069702148 83.5111236572382 .5967712402382 .2919769287181 .6824111938581 .07285308838 80.7680587768680 .4632720947380 .1584930419979 .8537063598679 .54891967773 78.9393463134878 .6345596313578 .3297805786177 .7202072143677 .41542053223 76.8058471679776 .1962814331175 .5867080688574 .6723632812573 .75800323486 
72.8436431884871 .9292907714870 .7101516723669 .4910125732468 .27187347412 67.0527267456166 .1383666992264 .9192428588964 .3096618652363 .39530944824 62.7857398986862 .1761703491261 .5666007995660 .6522407531760 .04267120361 59.4331016540558 .8235282897958 .2139587402357 .6043891906757 .29959869385 56.6900291442956 .0804595947355 .1661109924353 .6421813964852 .11825942993 49.6799812316945 .4129791259838 .0981407165529 .8689403533922 .55410003662 $15.544039726269 .7531242370614 .571776866913 .6095703244209-1.82871103287$ $-3.35263609886-3.96220707893-4.26699209213-3.96220707893-3.65742206573$ $-3.35263609886-2.74306607246-2.43828105927-2.13349604607-1.52392601967$ -.914355397224 -9999 1.21914100647 2.438281059265 3.047851085663 3.962207078934 4.5717768669135 .1813468933115 .7909169197086 .7052731513987 .314843177795 7.9244132041938 .5339832305918 .8387689590459 .1435537338269 .753124237061 9.75312423706110 .0579099655210 .3626899719210 .6674804687510 .97226047516 11.5818300247212 .4961900711113 .4105501174914 .6296901702915 .84883022308 17.3727493286118 .5918903350820 .1158199310321 .6397399902323 .46845054626 24.9923801422126 .5163097381628 .0402297973629 .5641593933131 .08807945251 32.9167900085434 .4407196044935 .9646492004437 .4885711669938 .70771026611 39.9268493652340 .8412094116242 .0603485107442 .9747009277343 .88906097412 44.4986305236845 .4129791259846 .3273391723647 .2416992187548 .15605163574 49.0704002380449 .9847602844251 .2038993835452 .1182594299353 .03261184692 53.9469718933158 .2139587402360 .0426712036161 .5666007995662 .78573989868 64.004882812564 .6144485473665 .2240066528365 .5288009643665 .52880096436 65.8335876464865 .8335876464862 .4809494018662 .4809494018662 .17617034912 62.1761703491261 .8713798522961 .8713798522961 .5666007995661 .56660079956 61.5666007995661 .5666007995661 .5666007995661 .5666007995661 .56660079956 61.56660079956 -9999 -9999 -9999 -9999 -9999 -9999 -9999 -9999 -9999 -9999 -9999 -9999 -9999 -9999 -9999 -9999 -9999 -9999 -9999 -9999 -9999 -9999 -9999 -9999 -9999 -9999 -9999 -

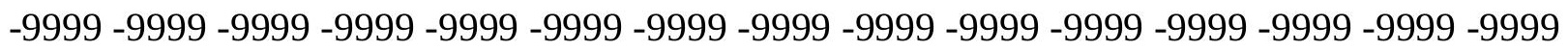
-9999 -9999 -9999 -9999 -9999 -9999 -9999 -9999 -9999 -9999 -9999 -9999 -9999 -9999 -9999 -9999 -9999 -9999 -9999-9999 -9999 -9999

-9999 -9999 -9999 -9999 -9999 -9999 -9999 -9999 -9999 -9999 -9999 -9999 -9999 -9999 -9999 -9999 -9999 -9999 -9999 -9999 -9999 -9999 -9999 -9999 -9999 -9999 -9999 -9999 -9999 -9999 -

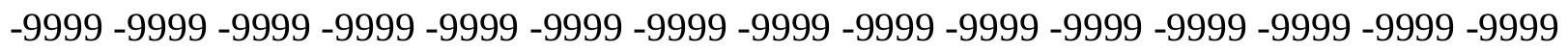
-9999 -9999 -9999 -9999 -9999 -9999 -9999 -9999 -9999 -9999 -9999 -9999 -9999 -9999 -9999

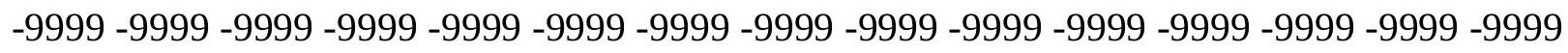

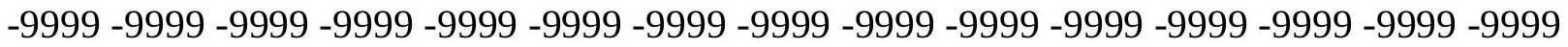

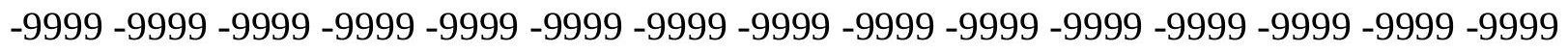
-9999 -9999 -9999 -9999-9999 88.38768768311 89.60682678223 90.52117919922 88.9972534179785 .9494018554782 .9015579223681 .6824111938583 .81591033936 87.47332763672 90.52117919922 91.7403335571391.1307525634896.31210327148 99.3599472045998 .1408081054792 .6546783447393 .8738174438593 .26425170898 90.8259735107496 .6168823242292 .349891662690 .5211791992289 .91161346436 90.5211791992291 .4355392456190 .5211791992288 .3876876831185 .94940185547 84.1206970214882 .5967712402381 .0728530883880 .4632720947379 .85370635986 78.9393463134878 .6345596313578 .9393463134879 .5489196777380 .15849304199 81.0728530883881 .6824111938582 .5967712402383 .5111236572384 .42548370361 
88.6924667358489 .6068267822390 .8259735107491 .7403335571393 .26425170898 94.4833908081195 .397743225196 .3121032714897 .2264633178797 .83602905273 98.1408081054798 .1408081054795 .397743225195 .397743225195 .09295654297 94.4833908081193 .5690307617292 .6546783447391 .7403335571390 .21640014648 88.9972534179787 .7781066894586 .5589828491285 .3398437584 .73026275635 83.8159103393683 .206336975182 .5967712402381 .9871978759881 .68241119385 81.0728530883880 .7680587768680 .4632720947379 .8537063598679 .54891967773 79.2441329956178 .6345596313578 .3297805786177 .7202072143677 .41542053223 76.8058471679776 .1962814331175 .2819290161174 .3675689697373 .45321655273 72.5388565063571 .3197174072370 .1005783081168 .8814392089867 .35751342773 66.1383666992264 .9192428588963 .7000885009862 .7857398986861 .87137985229 60.9570198059160 .3474502563559 .4331016540558 .5187492370657 .60438919067 56.6900291442955 .7756805419955 .1661109924354 .2517509460453 .33739852905 52.4230384826751 .5086898803750 .2895507812548 .765621185346 .93690872192 44.4986305236840 .5364189147935 .9646492004429 .8689403533923 .46845054626 17.3727493286111 .886619567877 .3148431777953 .352636098862 .3047851026058 $-1.21914100647-2.13349604607-2.74306607246-3.04785108566-2.74306607246$ $-2.74306607246-2.74306607246-2.43828105927-2.43828105927-2.13349604607$ -1.52392601967 -.914355397224-9999.6095703244209 1.523926019669 2.133496046066 3.0478510856634 .2669920921335 .1813468933116 .0957031257 .010057926178 7.6196279525768 .2291984558118 .8387689590459 .448339462289 .753124237061 10.0579099655210 .0579099655210 .3626899719210 .6674804687510 .97226047516 11.2770500183112 .191410064713 .1057596206714 .3248996734615 .54403972626 16.7631797790518 .28710937519 .811029434221 .334960937522 .85887908936 24.0780296325725 .6019496917727 .1258792877228 .6497993469230 .47850990295 32.0024414062533 .5263595581135 .0502891540536 .2694282531737 .79335021973 39.0125007629439 .9268493652341 .1459884643642 .0603485107442 .97470092773 43.8890609741244 .8034095764245 .717769622846 .9369087219247 .85126113892 48.765621185349 .6799812316950 .8991203308151 .8134689331152 .72782897949 53.9469718933158 .2139587402360 .0426712036161 .5666007995663 .09051895142 64.004882812564 .6144485473665 .2240066528365 .5288009643665 .83358764648 65.8335876464865 .8335876464862 .4809494018662 .4809494018662 .17617034912 62.1761703491261 .8713798522961 .5666007995661 .5666007995661 .26181030273 61.2618103027361 .2618103027361 .2618103027361 .2618103027361 .26181030273 61.26181030273 -9999 -9999 -9999 -9999 -9999 -9999 -9999 -9999 -9999 -9999 -9999 -9999 -9999 -9999 -9999 -9999 -9999 -9999 -9999 -9999 -9999 -9999 -9999 -9999 -9999 -9999 - 9999 -

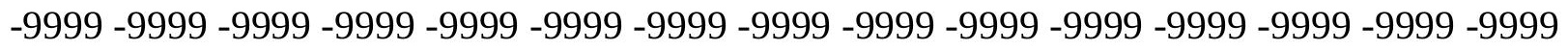

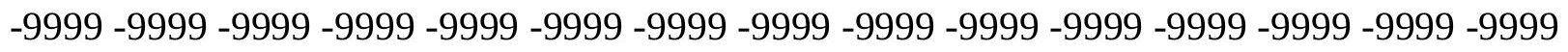
-9999 -9999 -9999 -9999 -9999 -9999 -9999

-9999 -9999 -9999 -9999 -9999 -9999 -9999 -9999 -9999 -9999 -9999 -9999 -9999 -9999 -9999

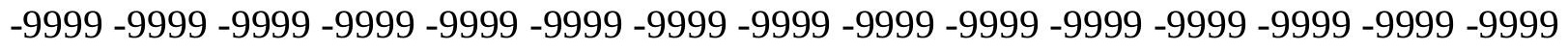

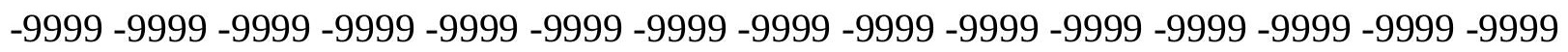

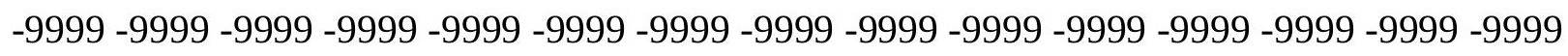
-9999 -9999 -9999 -9999 -9999 -9999 -9999 -9999 -9999 -9999 -9999 -9999 -9999 -9999 -9999 -

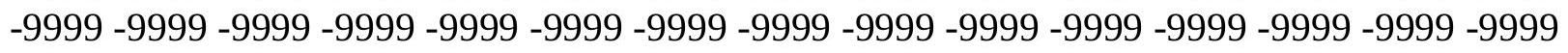

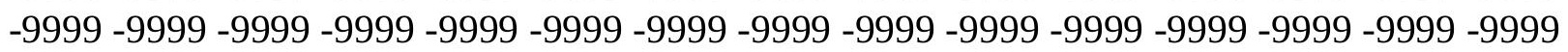


-9999 -9999 -9999 -9999 -9999 -9999 93.5690307617296.3121032714894.48339080811 91.7403335571388 .6924667358485 .9494018554791 .1307525634896 .92166900635 102.1029968262105 .4557037354107 .5891036987110 .9418029785114 .5991973877 115.5136032104112 .7705001831109 .7226028442107 .8938980103109 .4179000854 114.1927032471103 .626899719297 .2264633178796 .0073165893697 .22646331787 98.445587158298 .445587158297 .2264633178793 .5690307617293 .26425170898 91.4355392456188 .3876876831187 .7781066894586 .254188537684 .42548370361 82.9015579223682 .9015579223683 .206336975183 .5111236572383 .51112365723 83.5111236572383 .8159103393684 .4254837036185 .3398437585 .94940185547 89.6068267822390 .5211791992291 .4355392456192 .9594726562594 .48339080811 95.7025299072396 .9216690063597 .8360290527398 .7503814697399 .05516815186 99.3599472045996 .6168823242296 .6168823242296 .0073165893695 .70252990723 94.7881774902393 .8738174438592 .6546783447391 .1307525634889 .60682678223 88.3876876831187 .1685485839885 .9494018554785 .0350494384884 .42548370361 83.8159103393683 .206336975182 .5967712402381 .9871978759881 .68241119385 81.0728530883880 .7680587768680 .1584930419979 .8537063598679 .24413299561 78.9393463134878 .3297805786178 .0249862670977 .4154205322376 .80584716797 76.1962814331175 .2819290161174 .3675689697373 .4532165527372 .23407745361 71.014930725169 .7957916259868 .2718734741266 .7479400634865 .22400665283 63.7000885009862 .4809494018661 .2618103027360 .3474502563559 .43310165405 58.5187492370657 .2995986938556 .3852500915555 .1661109924353 .94697189331 53.0326118469251 .8134689331150 .5943298339849 .6799812316948 .46083068848 47.2416992187545 .717769622843 .8890609741242 .0603485107439 .6220703125 36.8790016174333 .5263595581129 .2593708038324 .0780296325718 .89668083191 13.71533012399 .448339462285 .7909169197083 .047851085663 .9143553972244 -9999 -.914355397224 -1.52392601967 -1.82871103287 -1.82871103287 -2.13349604607 $-2.13349604607-2.13349604607-2.13349604607-2.13349604607-1.82871103287$ -1.21914100647 -.609570324421 -9999 .9143553972244 2.133496046066 3.352636098862 4.5717768669135 .7909169197086 .7052731513987 .9244132041938 .533983230591 9.448339462289 .75312423706110 .3626899719210 .3626899719210 .66748046875 10.6674804687510 .6674804687510 .9722604751611 .2770500183112 .1914100647 13.1057596206714 .3248996734615 .5440397262616 .7631797790517 .98232078552 19.5062503814720 .7253894805922 .2493095397923 .7732391357425 .29715919495 26.8210906982428 .0402297973629 .5641593933131 .0880794525132 .61201095581 34.1359291076735 .3550796508836 .8790016174338 .0981407165539 .01250076294 40.2316398620641 .4507789611842 .3651313781743 .2794914245644 .19384002686 45.4129791259846 .3273391723647 .2416992187548 .4608306884849 .37519073486 50.5943298339851 .5086898803752 .7278289794953 .6421813964854 .86132049561 59.7378807067961 .5666007995662 .7857398986864 .004882812564 .61444854736 65.1771545410265 .5288009643665 .7816162109465 .8335876464865 .83358764648 62.4809494018662 .4809494018662 .1761703491261 .8713798522961 .56660079956 61.5666007995661 .2618103027361 .2618103027360 .9570198059160 .95701980591 60.9570198059160 .9570198059160 .9570198059160 .95701980591 -9999 -9999 -9999 -9999 -9999 -9999 -9999 -9999 -9999 -9999 -9999 -9999 -9999 -9999 -9999 -9999 -9999 -9999 -9999 -9999 -9999 -9999 -9999 -9999 -9999 -9999 -9999 -9999 -9999 -9999 -9999 -9999 -9999 -9999 -9999 -9999 -9999 -9999 -9999 -9999 -9999 -9999 -9999 -9999 -9999 -9999 -9999 -9999 -9999 
-9999 -9999 -9999 -9999 -9999 -9999 -9999 -9999 -9999 -9999 -9999 -9999 -9999 -9999 -9999 -9999 -9999 -9999 -9999 -9999 -9999 -9999 -9999 -9999 -9999 -9999 -9999 -9999 -9999 -9999

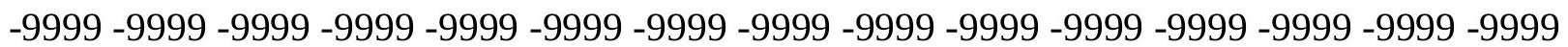
-9999 -9999 -9999 -9999 -9999 -9999 -9999 -9999 -9999 -9999 -9999 -9999 -9999 -9999 -9999

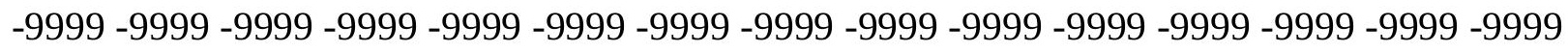
-9999 -9999 -9999 -9999 -9999 -9999 -9999 -9999 -9999 -9999 -9999 -9999 -9999 -9999 -9999 -9999 -9999 -9999 -9999 -9999 -9999 -9999 -9999 -9999 -9999 -9999 -9999 -9999 -9999 -9999 -9999 -9999 -9999 -9999 -9999 -9999 -9999 -9999 -9999 -9999 -9999 -9999 -9999 -9999 -9999 -9999 -9999 -9999 -9999 -9999 -9999 -9999 98.1408081054798.75038146973 98.4455871582 97.8360290527398 .75038146973102 .712600708108 .1986999512115 .2088012695 121.3044967651122 .2188034058123 .7427978516127 .4001998901131 .0576019287 128.3144989014122 .5235977173120 .9997024536115 .5201339722114 .2944030762 109.1130981445112 .4656982422112 .4976272583111 .6355667114110 .0273971558 108.8082962036107 .5891036987106 .0652008057104 .5412979126102 .4077987671 99.6647262573297.2264633178794.4833908081191.13075256348 88.08290100098 88.08290100098 88.38768768311 87.77810668945 86.86376190186 86.2541885376 85.9494018554786 .5589828491286 .8637619018686 .8637619018687 .16854858398 90.8259735107491 .7403335571392 .9594726562594 .1785964965896 .00731658936 97.5312423706199 .0551681518699 .96952056885100 .579101562597 .83602905273 98.1408081054798.1408081054797.5312423706196.9216690063596.00731658936 95.0929565429793.5690307617292.0450973510790.52117919922 88.99725341797 87.7781066894586 .8637619018685 .9494018554785 .0350494384884 .42548370361 83.8159103393683 .206336975182 .5967712402381 .9871978759881 .68241119385 81.0728530883880 .7680587768680 .1584930419979 .8537063598679 .24413299561 78.6345596313578 .0249862670977 .7202072143676 .8058471679776 .19628143311 75.2819290161174 .3675689697373 .4532165527372 .2340774536171 .0149307251 69.4910125732467 .9670867919966 .1383666992264 .6144485473662 .78573989868 61.2618103027360 .0426712036158 .8235282897957 .909179687556 .69002914429 55.4708900451754 .2517509460452 .7278289794951 .5086898803749 .98476028442 48.765621185347 .2416992187545 .717769622844 .4986305236842 .669921875 41.1459884643639 .3172798156737 .1837806701735 .0502891540533 .22158050537 31.0880794525128 .6497993469224 .0780296325719 .5062503814715 .23925971985 11.277050018317 .9244132041935 .1813468933113 .0478510856631 .523926019669 $.6095703244209-9999-.304785102606-.914355397224-1.21914100647-1.52392601967$ -1.82871103287 -2.13349604607 -2.13349604607 -2.13349604607 -2.13349604607 -1.52392601967-.914355397224-9999 1.523926019669 3.0478510856634 .571776866913 5.7909169197087 .3148431777958 .2291984558119 .4483394622810 .05790996552 10.6674804687510 .9722604751611 .2770500183111 .2770500183111 .27705001831 11.2770500183111 .2770500183111 .8866195678712 .4961900711113 .41055011749 14.3248996734615 .5440397262616 .7631797790517 .9823207855219 .20145988464 20.7253894805921 .9445304870623 .4684505462624 .6875991821326 .21151924133 27.7354507446329 .2593708038330 .7833003997832 .0024414062533 .52635955811 34.7455101013235 .9646492004437 .1837806701738 .4029312133839 .6220703125 40.5364189147941 .7555618286142 .66992187543 .8890609741244 .80340957642 45.717769622846 .9369087219247 .8512611389249 .0704002380450 .28955078125 51.2038993835452 .4230384826753 .6421813964854 .8613204956158 .82352828979 
60.9570198059162 .1761703491263 .3405838012764 .1487426757864 .74671173096 65.1962127685565 .4923934936565 .6351013183665 .656944274962 .48094940186 62.1761703491262 .1761703491261 .8713798522961 .5666007995661 .26181030273 60.9570198059160 .6522407531760 .6522407531760 .6522407531760 .34745025635 60.3474502563560 .6522407531760 .65224075317 -9999 -9999 -9999 -9999 -9999 -9999 -9999 -9999 -9999 -9999 -9999 -9999 -9999 -9999 -9999 -9999 -9999 -9999 -9999 -9999 -9999 -9999 -9999 -9999 -9999 -9999 -9999 -9999 -9999 -9999 -9999 -9999 -9999 -9999 -9999 -9999 -9999

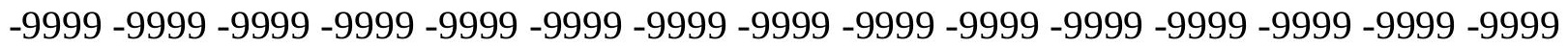
-9999 -9999 -9999 -9999 -9999 -9999 -9999 -9999 -9999 -9999 -9999 -9999 -9999 -9999 -9999 -9999 -9999 -9999 -9999 -9999 -9999 -9999 -9999 -9999 -9999 -9999 -9999 -9999 -9999 -9999 -9999 -9999 -9999 -9999 -9999 -9999 -9999 -9999 -9999 -9999 -9999 -9999 -999 -9999 -9999 -9999 -9999 -9999 -9999 -9999 -9999 -9999 -9999 -9999 -9999 -9999 -9999 -9999 -999 -9999 -9999 -9999 -9999 -9999 -9999 -9999 -9999 -9999 -9999 -9999 -9999 -9999 -9999 -9999 -9999 -9999 -9999 -9999 -9999 -9999 -9999 -9999 -9999 -9999 -9999 -9999 -9999 -9999 -9999 -9999 -9999 -9999 -9999 -9999 -9999 -9999 -9999 -9999 -9999 -9999 -9999 -9999 -9999 -9999

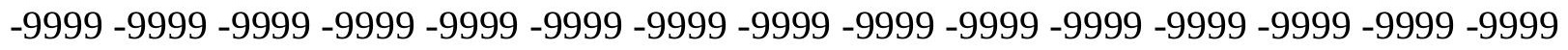
-9999 -9999 -9999 -9999 -9999 -9999 -9999 -9999 102.1029968262108 .1986999512 108.1986999512111 .551399231116 .1231002808119 .7806015015128 .0097961426 131.9720001221132 .2767028809133 .8007049561134 .7149963379135 .6293945312 137.1533050537141 .4203033447143 .2489929199142 .9441986084115 .5381393433 114.8488006592114 .1223144531113 .3578491211112 .5529022217111 .7030487061 110.8010940552109 .8395690918108 .8110809326107 .7102737427106 .532409668 105.2754364014103 .9393157959102 .52896881199 .0551681518696 .31210327148 95.397743225195 .0929565429793 .8738174438591 .1307525634888 .99725341797 88.9972534179789 .6068267822389 .6068267822389 .302040100188 .69246673584 88.6924667358492.6546783447393.56903076172 95.0929565429797.22646331787 99.05516815186100 .5791015625101 .4934005737102 .407798767199 .66472625732 99.9695205688599 .6647262573299 .3599472045998 .7503814697397 .83602905273 96.6168823242295 .0929565429793 .5690307617291 .7403335571390 .21640014648 88.6924667358487 .7781066894586 .8637619018685 .9494018554785 .33984375 84.7302627563584 .1206970214883 .5111236572382 .9015579223682 .29197692871 81.6824111938581 .0728530883880 .7680587768680 .1584930419979 .54891967773 79.2441329956178 .6345596313578 .0249862670977 .110626220776 .50106811523 75.5867080688574 .6723632812573 .7580032348672 .5388565063571 .0149307251 69.4910125732467 .9670867919965 .8335876464864 .004882812562 .17617034912 60.3474502563559 .1283111572357 .6043891906756 .3852500915554 .86132049561 53.6421813964852 .1182594299350 .5943298339849 .0704002380447 .24169921875 45.717769622843 .8890609741242 .3651313781740 .5364189147938 .70771026611 36.8790016174335 .0502891540532 .9167900085430 .7833003997829 .86894035339 28.3450202941926 .5163097381623 .1636695861819 .5062503814715 .84883022308 12.496190071119 .448339462287 .0100579261785 .1813468933113 .657422065735 2.4382810592651 .21914100647 .6095703244209 -9999-9999-.609570324421 -.914355397224 -1.52392601967 -1.82871103287 -2.13349604607 -2.13349604607 -1.82871103287 -1.21914100647 -9999 1.523926019669 3.352636098862 4.87656211853 6.7052731513988 .2291984558119 .4483394622810 .3626899719211 .27705001831 11.8866195678712 .191410064712 .4961900711112 .4961900711112 .49619007111 
12.191410064712 .4961900711112 .8009700775113 .4105501174914 .02011966705 14.934470176716 .1536102294917 .0679702758818 .28710937519 .50625038147 20.7253894805921 .9445304870623 .1636695861824 .6875991821325 .9067401886 27.430660247828 .6497993469230 .1737308502231 .3928699493432 .91679000854 34.1359291076735 .3550796508836 .5742111206137 .4885711669938 .70771026611 39.9268493652340 .8412094116242 .0603485107443 .2794914245644 .19384002686 45.4129791259846 .3273391723647 .5464782714848 .765621185349 .67998123169 50.8991203308152 .1182594299353 .3373985290554 .5565414428755 .77568054199 56.9948196411161 .2618103027362 .2110862731963 .1918525695864 .05771636963 64.6920623779365 .096397399965 .3137283325265 .3765945434662 .48094940186 62.1761703491261 .8713798522961 .5666007995661 .2618103027360 .95701980591 60.6522407531760 .3474502563560 .3474502563560 .0426712036160 .04267120361 60.0426712036160 .0426712036160 .0426712036160 .34745025635 -9999 -9999 -9999-9999 -9999 -9999 -9999 -9999 -9999 -9999 -9999 -9999 -9999 -9999 -9999 -9999 -9999 -9999 -9999 -9999 -9999 -9999 -9999 -9999 -9999 -9999 -9999 -9999 -9999 -9999 -9999 -9999 -9999 -9999

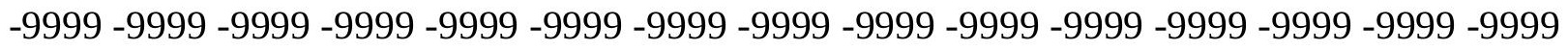
-9999 -9999 -9999 -9999 -9999 -9999 -9999 -9999 -9999 -9999 -9999 -9999 -9999 -9999 -9999 -9999 -9999 -9999 -9999 -9999 -9999 -9999 -9999 -9999 -9999 -9999 -9999 -9999 -9999 -9999 -9999 -9999 -9999 -9999 -9999 -9999 -9999 -9999 -9999 -9999 -9999 -9999 -9999 -9999 -

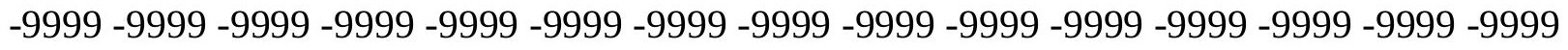

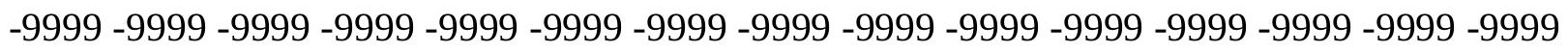
-9999 -9999 -9999 -9999 -9999 -9999 -9999 -9999 -9999 -9999 -9999 -9999 -9999 -9999 -9999 -9999 -9999 -9999 -9999 -9999 -9999 -9999 -9999 -9999 -9999 -9999 -9999 -9999 -9999 -9999 -

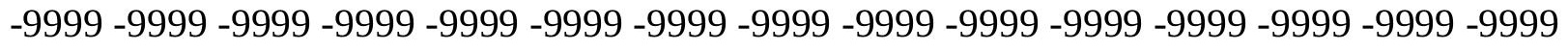
-9999 -9999 -9999 -9999 -9999 -9999 -9999 -9999 104.5412979126110 .0273971558 116.4279022217120 .3900985718133 .1911010742144 .7729034424147 .8208007812 150.2590942383160 .3170013428168 .8509979248158 .9536132812154 .6454467773 155.2121887207158 .4347381592161 .6487426758165 .0374603271116 .3248291016 115.6846008301115 .0114212036114 .304901123113 .5634460449112 .7837371826 111.9593811035111 .0827331543110 .1455154419109 .1412353516108 .0639572144 106.9102401733105 .6783981323104 .3715591431102 .9973831177101 .5709152222 100.114311218398 .6630020141697 .2413635253995 .9008636474692 .3498916626 93.5690307617292 .8417663574292 .2332077026491 .8190155029391 .13075256348 91.1307525634891 .7403335571395 .397743225197 .2264633178799 .35994720459 101.1886978149102 .712600708103 .9317016602101 .4934005737101 .7982025146 102.1029968262101 .7982025146101 .4934005737100 .579101562599 .66472625732 98.445587158296.9216690063595.397743225193.2642517089891.43553924561 89.9116134643688 .6924667358488 .0829010009887 .1685485839886 .55898284912 85.9494018554785 .0350494384884 .1206970214883 .5111236572382 .90155792236 82.2919769287181 .6824111938581 .0728530883880 .7680587768680 .15849304199 79.5489196777378 .9393463134878 .3297805786177 .7202072143676 .80584716797 75.8914871215874 .9771423339874 .062782287672 .8436431884871 .62449645996 69.7957916259867 .9670867919965 .8335876464864 .004882812561 .87137985229 60.0426712036158 .2139587402356 .6900291442955 .1661109924353 .64218139648 51.8134689331150 .2895507812548 .4608306884846 .6321296691944 .80340957642 42.9747009277341 .1459884643639 .0125007629437 .1837806701735 .35507965088 
33.5263595581131 .6976509094229 .8689403533928 .3450202941927 .12587928772 25.906740188624 .0780296325721 .9445304870619 .2014598846416 .15361022949 13.4105501174910 .972260475168 .8387689590456 .7052731513985 .181346893311 3.9622070789342 .7430660724642 .1334960460661 .21914100647 .9143553972244 .3047851026058 -9999 -.304785102606 -.914355397224 -1.21914100647 -1.52392601967 -1.52392601967 -.914355397224 .3047851026058 2.133496046066 4.266992092133 6.0957031257 .9244132041939 .4483394622810 .9722604751611 .88661956787 12.8009700775113 .4105501174913 .715330123914 .0201196670514 .02011966705 14.0201196670513 .715330123913 .715330123914 .0201196670514 .62969017029 14.934470176715 .8488302230816 .7631797790517 .6775398254418 .59189033508 19.811029434220 .7253894805921 .9445304870623 .1636695861824 .38281059265 25.6019496917727 .1258792877228 .3450202941929 .8689403533931 .08807945251 32.3072204589833 .5263595581134 .4407196044935 .6598587036136 .87900161743 38.0981407165539 .3172798156740 .2316398620641 .4507789611842 .669921875 43.5842704772944 .8034095764245 .717769622846 .9369087219248 .15605163574 49.3751907348650.59432983398 51.8134689331153 .3373985290554 .55654144287 55.7756805419956 .9948196411157 .909179687558 .8235282897962 .16623306274 63.3091049194364 .1105957031264 .6337814331164 .9271240234465 .03343200684 62.1761703491261 .8713798522961 .5666007995661 .2618103027360 .95701980591 60.3474502563560 .0426712036160 .0426712036159 .7378807067959 .73788070679 $59.7378807067959 .7378807067959 .7378807067959 .7378807067960 .04267120361-9999$ -9999 -9999 -9999 -9999 -9999 -9999 -9999 -9999 -9999 -9999 -9999 -9999 -9999 -9999 -9999 -9999 -9999 -9999 -9999 -9999 -9999 -9999 -9999 -9999 -9999 -9999 -9999 -9999 -9999 -9999 -

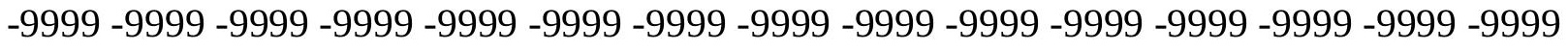
-9999 -9999 -9999 -9999 -9999 -9999 -9999 -9999 -9999 -9999 -9999 -9999 -9999 - -9999 - -999 -9999-9999

-9999 -9999 -9999 -9999 -9999 -9999 -9999 -9999 -9999 -9999 -9999 -9999 -9999 -9999 -9999 -

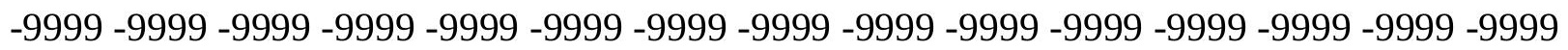
-9999 -9999 -9999 -9999 -9999 -9999 -9999 -9999 -9999 -9999 -9999 -9999 -9999 -9999 -9999 -9999 -9999 -9999 -9999 -9999 -9999 -9999 -9999 -9999 -9999 -9999 -9999 -9999 -9999 -9999 -9999 -9999 -9999 -9999 -9999 -9999 -9999 -9999 -9999 -9999 -9999 -9999-9999 -9999 -9999 -9999 -9999 -9999 -9999 -9999 -9999 -9999 -9999 -9999 -9999 -9999 -9999 -9999 -9999 -9999 -

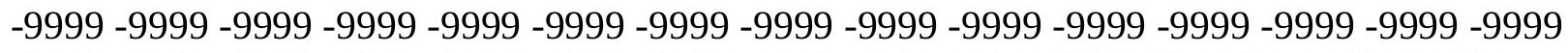
-9999 -9999 -9999 -9999 -9999 -9999 -9999 -9999 -9999 126.7906036377135 .3246002197 146.2969055176160 .0122070312169 .7653045654167 .0233459473165 .1016998291 167.1714324951170 .1116943359170 .7827911377170 .3045043945169 .9460754395 169.845413208169 .7419281006169 .5706939697169 .3196258545116 .5888214111 115.9724349976115 .3281326294114 .6553115845113 .9518432617113 .212387085 112.4293899536111 .5939483643110 .6983947754109 .7355041504108 .7001190186 107.5885238647106 .4014892578105 .1441497803103 .8287200928102 .4738235474 101.10575866799 .7572708129998 .4653930664197 .2679061889696 .19940185547 95.2737579345794 .4945907592893 .8584442138793 .3925552368293 .2318649292 93.7259445190495 .397743225199 .96952056885102 .1029968262104 .2365036011 105.7603988647103 .6268997192104 .2365036011104 .2365036011104 .2365036011 103.9317016602103 .3221969604102 .712600708102 .1029968262100 .8839035034 99.35994720459 97.5312423706195.397743225193.5690307617291.43553924561 
90.5211791992289 .6068267822388 .6924667358488 .0829010009887 .16854858398 86.254188537685 .3398437584 .4254837036183 .8159103393682 .90155792236 82.5967712402381 .9871978759881 .3776321411180 .7680587768680 .15849304199 79.5489196777378 .9393463134878 .0249862670977 .4154205322376 .50106811523 75.5867080688574 .3675689697373 .4532165527371 .9292907714870 .10057830811 68.2718734741266 .1383666992264 .004882812561 .8713798522959 .73788070679 57.909179687556 .0804595947354 .2517509460452 .4230384826750 .59432983398 48.4608306884846 .6321296691944 .4986305236842 .66992187540 .53641891479 38.4029312133836 .2694282531734 .1359291076732 .3072204589830 .47850990295 28.6497993469227 .1258792877225 .906740188624 .9923801422123 .77323913574 22.2493095397920 .7253894805918 .5918903350816 .1536102294914 .02011966705 11.8866195678710 .057909965528 .2291984558116 .7052731513985 .486132144928 4.2669920921333 .3526360988622 .7430660724642 .1334960460661 .523926019669 1.21914100647 .6095703244209 .3047851026058 -9999 -9999-9999 -9999 2.133496046066 4.2669920921336 .4004869461068 .2291984558119 .75312423706111 .27705001831 12.8009700775114 .0201196670514 .6296901702915 .2392597198515 .54403972626 15.8488302230815 .8488302230815 .5440397262615 .5440397262615 .54403972626 15.5440397262615 .8488302230816 .1536102294916 .7631797790517 .67753982544 18.28710937519 .2014598846420 .1158199310321 .0301704406722 .24930953979 23.1636695861824 .3828105926525 .6019496917726 .8210906982428 .04022979736 29.2593708038330 .4785099029531 .6976509094232 .9167900085433 .83115005493 35.0502891540536 .2694282531737 .1837806701738 .4029312133839 .6220703125 40.8412094116242 .0603485107442 .9747009277344 .1938400268645 .10820007324 46.3273391723647 .5464782714849 .0704002380450 .2895507812551 .50868988037 53.0326118469254 .2517509460455 .7756805419956 .9948196411157 .9091796875 59.1283111572360 .0426712036160 .6522407531763 .5564537048364 .15838623047 64.5028305053764 .6402969360461 .8713798522961 .5666007995661 .26181030273 60.9570198059160 .3474502563560 .0426712036159 .7378807067959 .43310165405 59.1283111572359 .1283111572359 .1283111572359 .1283111572359 .12831115723 59.4331016540559 .43310165405 -9999 -9999 -9999 -9999 -9999 -9999 -9999 -9999 -9999 -9999 -9999 -9999 -9999 -9999 -9999 -9999 -9999 -9999 -9999 -9999 -9999 -9999 -9999 -9999 -9999 -9999 -9999 -9999 -9999 -9999 -9999 -9999 -9999 -9999 -9999 -9999 -9999 -9999 -9999 -

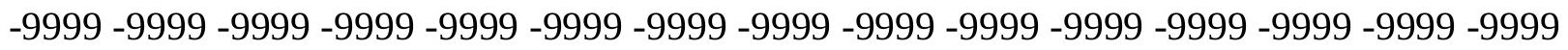
-9999 -9999 -9999 -9999 -9999 -9999 -9999 -9999 -9999

-9999 -9999 -9999 -9999 -9999 -9999 -9999 -9999 -9999 -9999 -9999 -9999 -9999 -9999 -9999

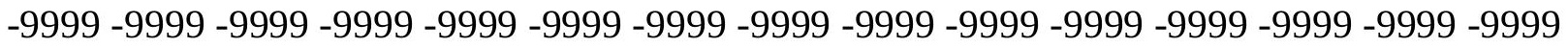

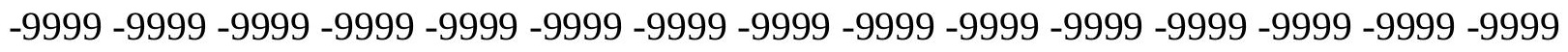

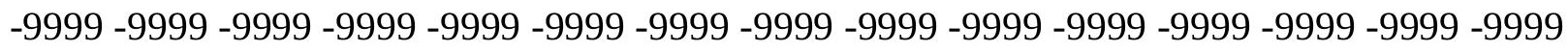

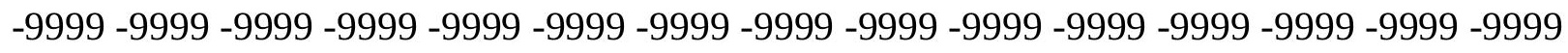
-9999 -9999 -9999 -9999 -9999 -9999 -9999 -9999 -9999 -9999 -9999 -9999 -9999 -9999 -9999 -

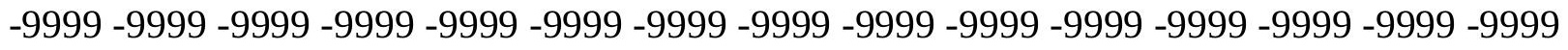
-9999 -9999 -9999-9999 -9999-9999-9999-9999-9999-9999 152.0877990723 164.5839996338175 .8609924316173 .4018554688170 .6392364502169 .2314605713 172.1637878418174 .8650054932176 .8508453369177 .140335083176 .3354187012 175.4211425781175 .1039123535175 .6741333008176 .8777770996177 .9630584717 116.9936141968116 .414390564115 .8136672974115 .1905822754114 .5411605835 
113.8585662842113 .1335906982112 .3573455811111 .5209884644110 .6172332764 109.639831543108 .5867080688107 .4599990845106 .2687835693105 .0280303955 103.7598419189102 .491973877101 .256149292100 .085075378499 .00595092773 98.0385131835997 .1950531005996 .5129623413196 .059852600195 .99673461914 96.6734848022598 .18567657471100 .2742996216102 .712600708104 .8460998535 106.3700027466 106.979598999106.979598999 106.6747970581 106.3700027466 105.7603988647105 .4557037354105 .1509017944104 .5412979126103 .3221969604 101.7982025146100 .274299621698 .1408081054796 .0073165893694 .17859649658 92.9594726562591 .7403335571390 .8259735107489 .6068267822388 .38768768311 87.4733276367286 .254188537685 .3398437584 .7302627563583 .81591033936 83.206336975182 .5967712402381 .9871978759881 .6824111938580 .76805877686 80.1584930419979 .5489196777378 .6345596313578 .0249862670977 .1106262207 75.8914871215874 .9771423339873 .7580032348672 .2340774536170 .40535736084 68.5766525268666 .4431610107464 .004882812561 .8713798522959 .73788070679 57.6043891906755 .4708900451753 .6421813964851 .5086898803749 .37519073486 47.2416992187545 .1082000732442 .9747009277340 .5364189147938 .40293121338 36.2694282531734 .1359291076731 .6976509094229 .5641593933128 .04022979736 26.5163097381625 .2971591949524 .0780296325723 .1636695861821 .94453048706 20.7253894805919 .5062503814717 .9823207855216 .1536102294914 .32489967346 12.8009700775110 .972260475169 .448339462287 .9244132041936 .705273151398 5.4861321449284 .5717768669133 .9622070789343 .3526360988623 .047851085663 2.7430660724642 .7430660724642 .4382810592652 .7430660724643 .047851085663 3.6574220657354 .2669920921335 .7909169197087 .3148431777959 .143553733826 10.6674804687512 .191410064713 .715330123915 .2392597198516 .15361022949 17.0679702758817 .6775398254417 .9823207855217 .9823207855217 .98232078552 17.6775398254417 .3727493286117 .3727493286117 .3727493286117 .37274932861 17.6775398254417 .9823207855218 .5918903350819 .2014598846419 .8110294342 20.7253894805921 .6397399902322 .5541000366223 .4684505462624 .38281059265 25.6019496917726 .5163097381627 .7354507446328 .9545898437530 .17373085022 31.0880794525132 .3072204589833 .2215805053734 .4407196044935 .65985870361 36.5742111206137 .7933502197339 .0125007629440 .2316398620641 .45077896118 42.3651313781743 .5842704772944 .4986305236845 .717769622846 .93690872192 48.4608306884849 .6799812316951 .2038993835452 .7278289794954 .25175094604 55.4708900451756 .9948196411158 .2139587402359 .1283111572360 .04267120361 60.6522407531761 .2618103027361 .5666007995664 .0617446899461 .87137985229 61.8713798522961 .2618103027360 .9570198059160 .3474502563560 .04267120361 59.4331016540559 .1283111572358 .8235282897958 .5187492370658 .51874923706 $58.5187492370658 .5187492370658 .8235282897958 .8235282897959 .12831115723-9999$ -9999 -9999 -9999 -9999 -9999 -9999 -9999 -9999 -9999 -9999 -9999 -9999 -9999 -9999 -9999

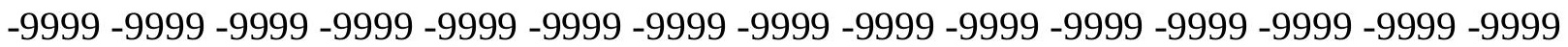

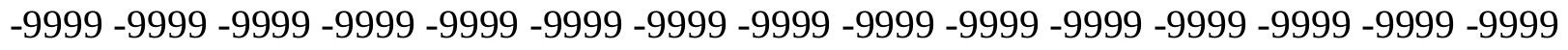
-9999 -9999 -9999 -9999 -9999 -9999 -9999 -9999 -9999 -9999 -9999 -9999 -9999 -9999 -9999 -9999-9999

-9999 -9999 -9999 -9999 -9999 -9999 -9999 -9999 -9999 -9999 -9999 -9999 -9999 -9999 - -9999 -

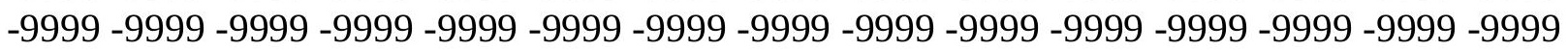

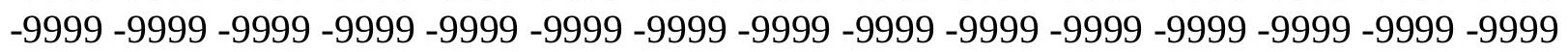


-9999 -9999 -9999 -9999 -9999 -9999 -9999 -9999 -9999 -9999 -9999 -9999 -9999 -9999 -9999 -9999 -9999 -9999 -9999 -9999 -9999 -9999 -9999 -9999 -9999 -9999 -9999 -9999 -9999 -9999 -9999 -9999 -9999 -9999 -9999 -9999 -9999 -9999 -9999 -9999 -9999 -9999 -9999 -9999 -9999 -9999 -9999 -9999 -9999 -9999 -9999 -9999 -9999 -9999 -9999 -9999 -9999 -9999 -9999 -9999 -9999 -9999 -9999 -9999 -9999 -9999 -9999 -9999 -9999 -9999 -9999 158.1835021973 163.3648071289166 .4127044678163 .974395752162 .4505004883167 .9365997314 174.337097168174 .9467010498174 .0323028564174 .9467010498175 .8609924316 176.7754058838175 .8115081787178 .37449646179 .4176940918118 .0629501343 117.5501785278117 .0233230591116 .4828033447115 .9262924194115 .3482971191 114.7400665283114 .091506958113 .3917388916112 .6307830811111 .7993545532 110.892036438109 .9075546265108 .8516921997107 .7359390259106 .5788879395 105.4047851562104 .2425231934103 .1225357056102 .0767288208101 .1270675659 100.314231872699 .6942672729599 .3619537353599 .47002410889100 .1894989014 101.4934005737103 .7480010986106 .6747970581109 .1130981445113 .075302124 110.3321990967109 .7226028442112 .1608963013111 .24659729107 .5891036987 107.5891036987107 .5891036987106 .979598999106 .0652008057104 .8460998535 103.0174026489101 .188697814999 .0551681518697 .2264633178795 .70252990723 94.1785964965892 .9594726562591 .4355392456189 .9116134643688 .69246673584 87.4733276367286 .5589828491285 .6446228027385 .0350494384884 .12069702148 83.5111236572382 .9015579223682 .2919769287181 .6824111938581 .07285308838 80.4632720947379 .5489196777378 .6345596313577 .7202072143676 .80584716797 75.5867080688574 .3675689697372 .8436431884871 .014930725168 .88143920898 66.7479400634864 .3096618652361 .8713798522959 .7378807067957 .60438919067 55.1661109924353 .0326118469250 .8991203308148 .765621185346 .32733917236 43.8890609741241 .4507789611839 .3172798156736 .8790016174334 .44071960449 32.3072204589830 .1737308502228 .0402297973626 .5163097381624 .99238014221 23.7732391357422 .8588790893621 .6397399902320 .7253894805919 .50625038147 18.28710937517 .0679702758815 .8488302230814 .6296901702913 .10575962067 11.5818300247210 .362689971928 .8387689590457 .6196279525766 .400486946106 5.4861321449284 .876562118534 .5717768669134 .5717768669134 .571776866913 4.5717768669135 .1813468933115 .7909169197086 .7052731513987 .924413204193 9.14355373382610 .0579099655211 .2770500183112 .191410064713 .7153301239 14.934470176716 .4584007263217 .6775398254418 .5918903350819 .50625038147 20.1158199310320 .1158199310320 .1158199310320 .1158199310319 .8110294342 19.5062503814719 .2014598846418 .8966808319118 .8966808319118 .89668083191 19.2014598846419 .5062503814720 .1158199310320 .7253894805921 .3349609375 22.2493095397922 .8588790893623 .7732391357424 .6875991821325 .60194969177 26.5163097381627 .430660247828 .6497993469229 .5641593933130 .47850990295 31.6976509094232 .6120109558133 .8311500549334 .7455101013235 .96464920044 37.1837806701738 .4029312133839 .3172798156740 .5364189147941 .75556182861 42.66992187543 .8890609741245 .1082000732446 .3273391723647 .85126113892 49.3751907348650 .8991203308152 .4230384826753 .9469718933155 .47089004517 56.9948196411158 .2139587402359 .4331016540560 .3474502563560 .95701980591 61.2618103027361 .5666007995661 .8713798522961 .8713798522961 .56660079956 61.2618103027360 .6522407531760 .0426712036159 .4331016540559 .12831115723 58.5187492370658 .2139587402357 .909179687557 .909179687557 .9091796875 
$58.2139587402358 .2139587402358 .5187492370658 .8235282897959 .12831115723-9999$ -9999 -9999 -9999 -9999 -9999 -9999 -9999 -9999 -9999 -9999 -9999 -9999 -9999 -9999 -9999 -9999 -9999 -9999 -9999 -9999 -9999 -9999 -9999 -9999 -9999 -9999 -9999 -9999 -9999 -9999 -9999 -9999 -9999 -9999 -9999 -9999 -9999 -9999 -9999 -9999 -9999 -9999 -9999 -9999 -9999

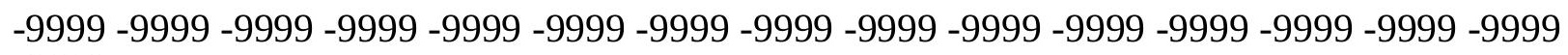
$-9999$

-9999 -9999 -9999 -9999 -9999 -9999 -9999 -9999 -9999 -9999 -9999 -9999 -9999 -9999 -9999 -9999 -9999 -9999 -9999 -9999 -9999 -9999 -9999 -9999 -9999 -9999 -9999 -9999 -9999 -9999

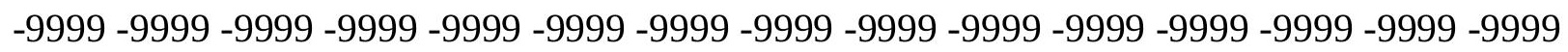

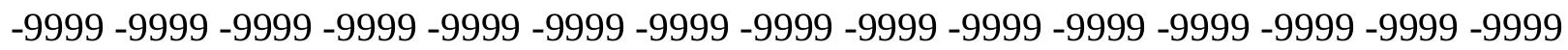

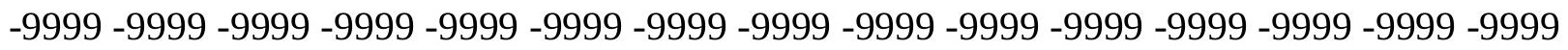

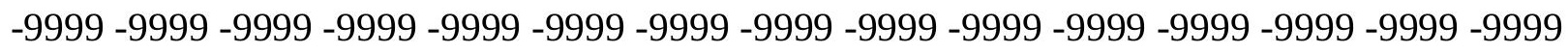

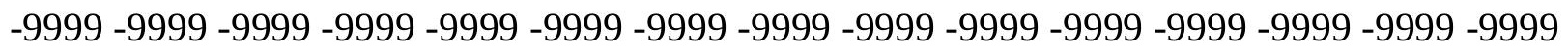
-9999 -9999 -9999 -9999 -9999 -9999 -9999 -9999 -9999 -9999 -9999 141.1154937744 140.5059967041140 .5059967041141 .1154937744142 .6394042969143 .8585968018 145.6873016357148 .4304046631151 .4781951904154 .8307952881158 .1835021973 158.7929992676160 .3170013428165 .4983062744171 .2891998291175 .5561981201 118.7203826904118 .2673568726117 .8096618652117 .3466949463116 .8746795654 116.3860855103 115.8703079224 115.3141555786114.7043151855114.0278701782 113.275604248112 .4424133301111 .5305709839110 .5484237671109 .5120315552 108.4436645508107 .3716964722106 .3283233643105 .3482208252104 .4683074951 103.7386169434103 .2302398682103 .036781311103 .284286499103 .3221969604 104.5412979126107 .5891036987110 .35496521113 .075302124113 .9896011353 113.6848983765112 .4656982422113 .9896011353113 .075302124112 .4656982422 109.7226028442109 .7226028442109 .7226028442108 .8082962036107 .5891036987 106.0652008057103 .9317016602102 .1029968262100 .274299621698 .4455871582 96.6168823242295 .0929565429793 .2642517089891 .7403335571390 .21640014648 88.6924667358487 .4733276367286 .8637619018685 .9494018554785 .33984375 84.7302627563584 .1206970214883 .5111236572382 .9015579223681 .98719787598 81.3776321411180 .4632720947379 .5489196777378 .6345596313577 .41542053223 76.1962814331174 .9771423339873 .4532165527371 .6244964599669 .49101257324 67.0527267456164 .9192428588962 .4809494018660 .0426712036157 .60438919067 55.4708900451753 .0326118469250 .5943298339848 .1560516357445 .7177696228 43.2794914245640 .5364189147938 .0981407165535 .6598587036133 .22158050537 31.0880794525128 .9545898437527 .1258792877225 .2971591949524 .07802963257 22.8588790893621 .6397399902320 .7253894805919 .5062503814718 .59189033508 17.3727493286116 .4584007263215 .2392597198514 .3248996734613 .10575962067 11.8866195678710 .667480468759 .448339462288 .2291984558117 .010057926178 6.4004869461065 .7909169197085 .7909169197085 .7909169197086 .095703125 6.7052731513987 .3148431777958 .5339832305919 .75312423706111 .88661956787 14.0201196670514 .0201196670514 .6296901702915 .5440397262616 .76317977905 17.9823207855219 .2014598846420 .4206008911121 .334960937522 .24930953979 22.5541000366222 .8588790893622 .5541000366222 .2493095397921 .94453048706 21.6397399902321 .0301704406720 .7253894805920 .4206008911120 .42060089111 20.7253894805920 .7253894805921 .0301704406721 .6397399902322 .24930953979 22.8588790893623 .4684505462624 .0780296325724 .9923801422125 .60194969177 
26.5163097381627 .430660247828 .3450202941929 .2593708038330 .17373085022 31.0880794525132 .3072204589833 .2215805053734 .4407196044935 .35507965088 36.5742111206137 .4885711669938 .7077102661139 .9268493652340 .84120941162 42.0603485107443 .2794914245644 .4986305236845 .717769622847 .24169921875 48.765621185350 .2895507812552 .1182594299353 .6421813964855 .47089004517 56.9948196411158 .2139587402359 .4331016540560 .3474502563560 .95701980591 61.5666007995661 .5666007995661 .5666007995661 .5666007995661 .26181030273 60.9570198059160 .3474502563559 .7378807067959 .1283111572358 .51874923706 57.909179687557 .6043891906757 .2995986938557 .2995986938557 .60438919067 57.6043891906757 .909179687558 .2139587402358 .5187492370658 .82352828979 -9999

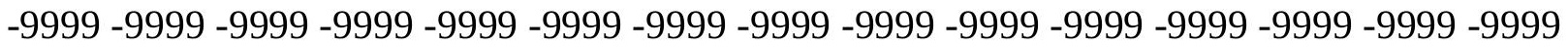

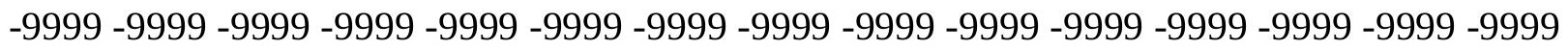
-9999 -

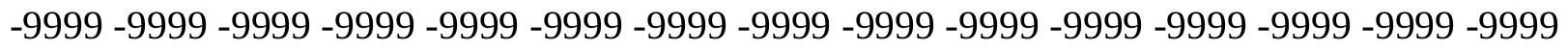
$-9999$

-9999 -9999 -9999 -9999 -9999 -9999 -9999 -9999 -9999 -9999 -9999 -9999 -9999 -9999 -9999 -

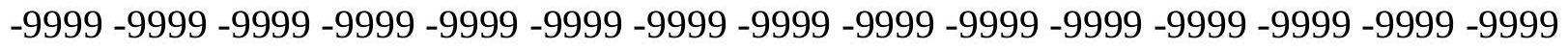

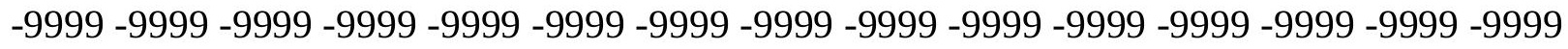

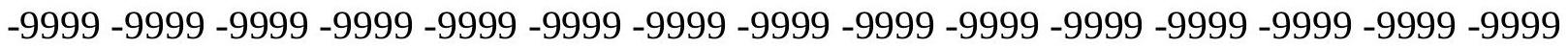

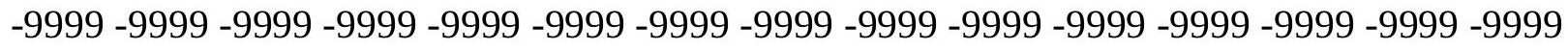

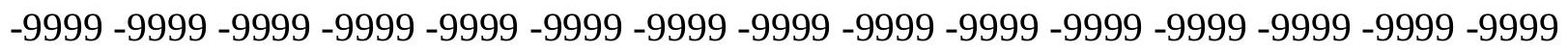

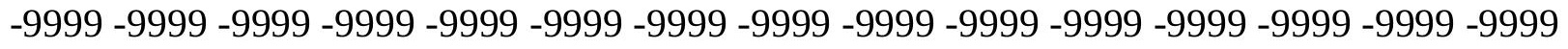
-9999 -9999 -9999 -9999 -9999 -9999 -9999 -9999 -9999 -9999 -9999 -9999 122.8283996582 122.2188034058 123.1332015991 124.3523025513 124.6570968628 124.6570968628 124.9618988037127 .7050018311133 .4958953857139 .2868041992142 .3347015381 145.6873016357150 .8686065674156 .6596069336160 .6217956543119 .9094314575 119.5278625488119 .1507949829118 .7795410156118 .4122085571118 .0429611206 117.6613845825117 .2525177002116 .799118042116 .2838363647115 .6930007935 115.0172729492114 .2551498413113 .4121627808112 .5028839111111 .5493087769 110.5808868408109 .6324462891108 .7429656982107 .9577178955107 .3330612183 106.9421005249106 .8709793091 107.20262146 108.0352859497 109.3905487061 111.2175292969113 .2310791016114 .9388122559115 .4626998901115 .2172927856 114.2944030762112 .1608963013114 .2944030762114 .2944030762111 .8561019897 112.4656982422112 .1608963013111 .551399231110 .3321990967108 .5035018921 106.6747970581104 .8460998535103 .0174026489101 .188697814999 .35994720459 97.5312423706195 .397743225193 .5690307617291 .7403335571389 .91161346436 88.6924667358488.08290100098 87.16854858398 86.55898284912 85.94940185547 85.3398437584 .7302627563583 .8159103393683 .206336975182 .29197692871 81.3776321411180 .4632720947379 .5489196777378 .3297805786177 .1106262207 75.8914871215874 .062782287672 .2340774536170 .1005783081167 .96708679199 65.5288009643663 .0905189514260 .3474502563558 .2139587402355 .77568054199 53.3373985290550 .5943298339848 .1560516357445 .4129791259842 .669921875 40.2316398620637 .4885711669934 .7455101013232 .3072204589830 .17373085022 28.0402297973626 .2115192413324 .6875991821323 .1636695861821 .94453048706 20.7253894805919 .811029434218 .5918903350817 .6775398254416 .45840072632 15.5440397262614 .6296901702913 .715330123912 .8009700775111 .88661956787 
10.667480468759 .448339462288 .2291984558117 .3148431777956 .705273151398 6.4004869461066 .4004869461066 .7052731513987 .3148431777958 .229198455811 9.4483394622810 .6674804687512 .191410064714 .3248996734615 .84883022308 16.7631797790517 .3727493286118 .28710937519 .5062503814720 .72538948059 22.2493095397923 .4684505462624 .3828105926524 .9923801422125 .29715919495 25.6019496917725 .2971591949524 .6875991821324 .0780296325723 .46845054626 22.8588790893622 .5541000366222 .2493095397921 .9445304870621 .94453048706 21.9445304870622 .2493095397922 .5541000366222 .8588790893623 .46845054626 23.7732391357424 .3828105926525 .2971591949525 .906740188626 .51630973816 27.430660247828 .0402297973628 .9545898437529 .8689403533930 .78330039978 31.6976509094232 .6120109558133 .8311500549334 .7455101013235 .96464920044 36.8790016174338 .0981407165539 .0125007629440 .2316398620641 .45077896118 42.66992187543 .8890609741245 .1082000732446 .6321296691948 .15605163574 49.6799812316951 .5086898803753 .3373985290555 .1661109924356 .99481964111 58.5187492370659 .7047119140660 .6522407531761 .2618103027361 .56660079956 61.5666007995661 .5666007995661 .5666007995660 .9570198059160 .65224075317 60.0426712036159 .1283111572358 .5187492370657 .909179687557 .29959869385 56.9948196411156 .6900291442956 .6900291442956 .9948196411157 .29959869385 57.6043891906757 .909179687558 .2139587402358 .51874923706 -9999 -9999 -9999 -9999 -9999 -9999 -9999 -9999 -9999 -9999 -9999 -9999 -9999 -9999 -9999 -9999 -9999 -999 -9999-

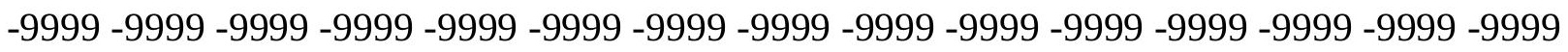

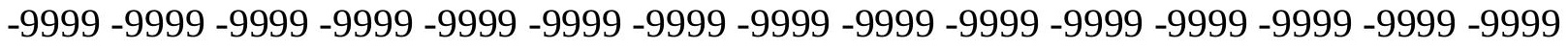

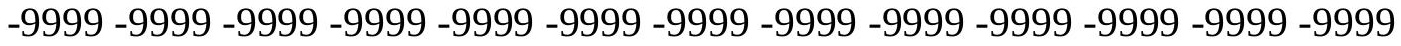

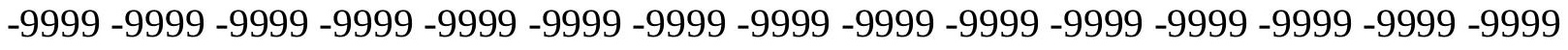

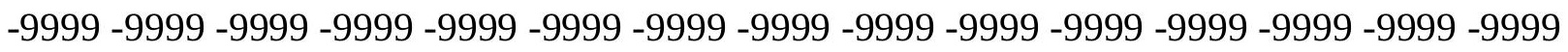

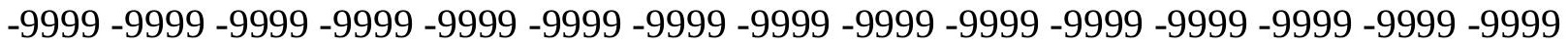

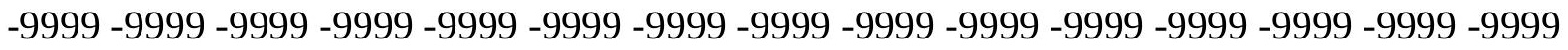

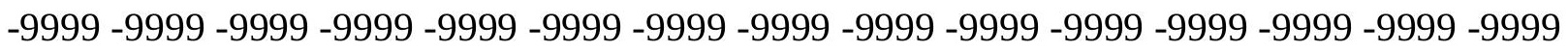

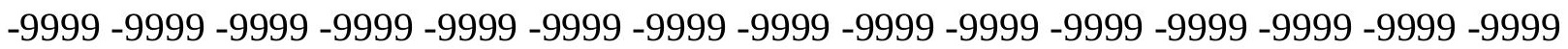

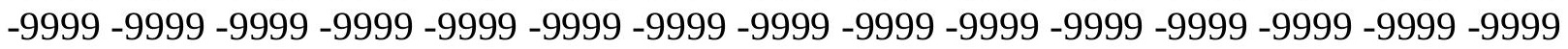
-9999 -9999 -9999 -9999 -9999 -9999 -9999 -9999 -9999 -9999 -9999 -9999-9999 106.3700027466106.979598999 107.5891036987 107.8938980103107.5891036987 106.0652008057 106.6747970581 113.3800964355 120.9997024536126.7906036377 131.6672058105136 .5437011719140 .5059967041143 .5538024902145 .0776977539 120.7852554321120 .4832611084120 .1984405518119 .9313049316119 .6780548096 119.4290161133119 .167930603118 .8735275269118 .5230407715118 .0971755981 117.5815353394116 .9707107544116 .2679214478115 .4874801636114 .6526031494 113.7948379517112 .9498443604112 .1632385254111 .4831848145110 .965927124 110.677116394110 .681098938111 .0319595337111 .773765564112 .8832244873 114.243270874115 .5915222168116 .551109314116 .7651290894116 .1517791748 114.8691864014112 .4656982422111 .8561019897112 .7705001831113 .9896011353 114.5991973877114 .5991973877113 .6848983765112 .4656982422110 .9418029785 109.1130981445107 .2844009399105 .4557037354103 .6268997192101 .4934005737 99.6647262573297 .5312423706195 .397743225193 .2642517089891 .43553924561 90.2164001464889 .6068267822388 .6924667358488 .0829010009887 .16854858398 86.5589828491285 .9494018554785 .0350494384884 .4254837036183 .51112365723 
82.5967712402381 .6824111938580 .7680587768679 .5489196777378 .32978057861 76.8058471679775 .2819290161173 .4532165527371 .3197174072368 .88143920898 66.4431610107464 .004882812561 .5666007995658 .8235282897956 .38525009155 53.9469718933151 .2038993835448 .4608306884845 .717769622842 .97470092773 39.9268493652337 .1837806701734 .4407196044932 .0024414062529 .56415939331 27.7354507446325 .906740188624 .3828105926522 .8588790893621 .63973999023 20.4206008911119 .2014598846417 .9823207855216 .4584007263215 .23925971985 14.3248996734613 .4105501174912 .4961900711111 .8866195678711 .27705001831 10.057909965528 .8387689590457 .6196279525767 .0100579261786 .705273151398 6.7052731513987 .0100579261787 .6196279525768 .5339832305919 .44833946228 10.6674804687512 .191410064713 .715330123915 .5440397262617 .06797027588 18.28710937519 .5062503814720 .7253894805921 .9445304870623 .46845054626 24.9923801422126 .2115192413327 .430660247828 .0402297973628 .34502029419 28.3450202941928 .0402297973627 .1258792877226 .2115192413325 .60194969177 24.6875991821324 .0780296325723 .7732391357423 .4684505462623 .16366958618 23.1636695861823 .1636695861823 .4684505462623 .7732391357424 .07802963257 24.3828105926524 .9923801422125 .6019496917726 .2115192413326 .82109069824 27.430660247828 .0402297973628 .9545898437529 .5641593933130 .47850990295 31.3928699493432 .3072204589833 .2215805053734 .4407196044935 .35507965088 36.5742111206137 .4885711669938 .4029312133839 .622070312540 .53641891479 41.7555618286142 .9747009277344 .1938400268645 .717769622847 .24169921875 49.0704002380451 .2038993835453 .0326118469255 .1661109924356 .99481964111 58.5187492370659 .7378807067960 .6522407531761 .2618103027361 .26181030273 61.2618103027361 .5666007995661 .2618103027360 .9570198059160 .34745025635 59.7378807067958 .8235282897957 .909179687557 .2995986938556 .69002914429 56.3852500915556 .3852500915556 .3852500915556 .6900291442956 .99481964111 57.29959869385 57.6043891906757.9091796875 58.21395874023 -9999 -9999 -9999 -9999 -9999 -9999 -9999 -9999 -9999 -9999 -9999 -9999 -9999 -9999 -9999 -9999 -9999 -9999 -9999 -9999 -9999 -9999 -9999 -9999 -9999 -9999 -9999 -9999 -9999 -9999 -9999 -9999 -9999 -9999

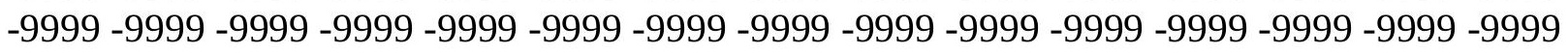
-9999 -9999 -9999 -9999 -9999 -9999 -9999 -9999 -9999 -9999 -9999 -9999 -9999 -

-9999 -9999 -9999 -9999 -9999 -9999 -9999 -9999 -9999 -9999 -9999 -9999 -9999 -9999 -9999 -

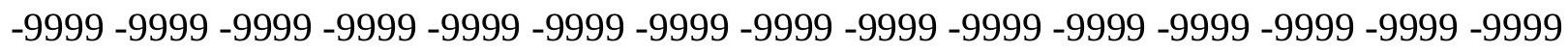
-9999 -9999 -9999 -9999 -9999 -9999 -9999 -9999 -9999 -9999 -9999 -9999 -9999 -9999 -9999 -9999 -9999 -9999 -9999 -9999 -9999 -9999 -9999 -9999 -9999 -9999 -9999 -9999 -9999 -9999 -

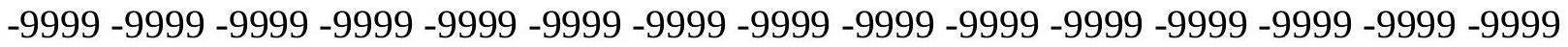

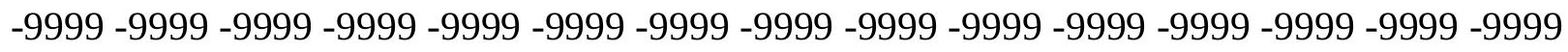

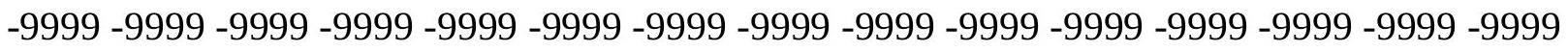
-9999 -9999 -9999 -9999 -9999 -9999 -9999 -9999 -9999 -9999 -9999 -9999 -9999 -9999 92.3498916626 93.8738174438594.4833908081194.4833908081193.87381744385 94.7881774902399 .96952056885106 .979598999112 .7705001831117 .9517974854 122.2188034058125 .2667007446127 .0953979492127 .4001998901125 .5715026855 121.7838668823121 .5758132935121 .3997268677121 .2549133301121 .1331329346 121.0161056519120 .8867645264120 .7116470337120 .458732605120 .1037826538 119.6366271973119 .0609283447118 .3974990845117 .6775741577116 .9365386963 116.2089309692115 .5322570801114 .9532928467114 .5238647461114 .2978744507 
114.323135376114 .6338882446115 .2292251587116 .0453720093116 .9672393799 117.7699737549118 .2066345215118 .0699539185117 .2791137695115 .9402313232 114.5526657104112 .7705001831114 .0796127319115 .2901229858116 .3334884644 117.0374984741115 .5136032104113 .9896011353112 .1608963013110 .6370010376 109.1130981445107 .2844009399105 .4557037354103 .6268997192101 .7982025146 99.6647262573297 .5312423706195 .397743225193 .5690307617292 .3498916626 91.1307525634890 .5211791992289 .6068267822388 .6924667358488 .08290100098 87.1685485839886 .5589828491285 .6446228027384 .7302627563583 .81591033936 82.9015579223681 .9871978759880 .7680587768679 .5489196777378 .32978057861 76.5010681152374 .6723632812572 .8436431884870 .4053573608467 .96708679199 65.5288009643662 .7857398986860 .3474502563557 .6043891906754 .86132049561 52.1182594299349 .0704002380446 .3273391723643 .2794914245640 .53641891479 37.4885711669934 .7455101013232 .0024414062529 .5641593933127 .4306602478 25.6019496917724 .0780296325722 .5541000366221 .334960937520 .11581993103 18.5918903350817 .0679702758815 .5440397262614 .0201196670512 .80097007751 11.5818300247210 .6674804687510 .0579099655210 .057909965528 .533983230591 7.3148431777956 .7052731513986 .0957031255 .7909169197086 .0957031257 .010057926178 7.9244132041939 .14355373382610 .3626899719211 .5818300247213 .10575962067 14.6296901702916 .1536102294917 .6775398254419 .2014598846420 .72538948059 22.2493095397924 .0780296325725 .906740188627 .7354507446329 .25937080383 30.4785099029531 .0880794525131 .0880794525131 .0880794525130 .47850990295 29.5641593933128 .3450202941927 .1258792877226 .2115192413325 .60194969177 24.9923801422124 .6875991821324 .3828105926524 .3828105926524 .38281059265 24.3828105926524 .6875991821324 .9923801422125 .2971591949525 .60194969177 25.906740188626 .5163097381627 .1258792877227 .430660247828 .04022979736 28.6497993469229 .5641593933130 .1737308502231 .0880794525132 .00244140625 32.9167900085433 .8311500549335 .0502891540535 .9646492004436 .87900161743 38.0981407165539 .0125007629439 .9268493652341 .1459884643642 .36513137817 43.5842704772945 .1082000732446 .6321296691948 .4608306884850 .59432983398 52.7278289794954 .8613204956156 .9948196411158 .8235282897959 .98098754883 60.748191833561 .223770141661 .2618103027361 .5666007995661 .55672454834 61.2618103027360 .6522407531760 .0426712036159 .1283111572358 .51874923706 57.6043891906756 .6900291442956 .0804595947355 .7756805419955 .77568054199 56.0804595947356 .3852500915556 .6900291442956 .9948196411157 .29959869385 57.909179687558 .2139587402358 .51874923706 -9999 -9999 -9999 -9999 -9999 -9999 -9999 -9999 -9999 -9999 -9999 -9999 -9999 -9999 -9999 -9999 -9999 -9999 -9999 -9999 -9999 -9999

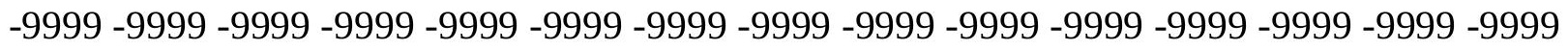

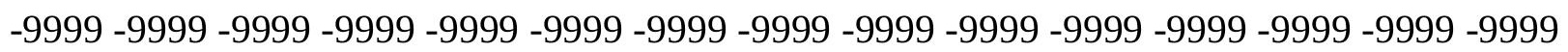
-9999 -9999 -9999 -9999 -9999 -9999 -9999 -9999 -9999 -9999 -9999 -9999 -9999 -9999 -9999 -9999 -9999 -9999 -9999 -9999 -9999 -9999 -9999 -9999

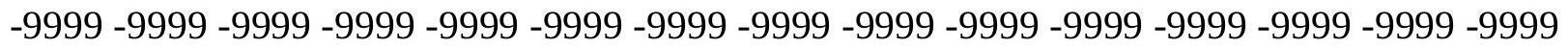
-9999 -9999 -9999 -9999 -9999 -9999 -9999 -9999 -9999 -9999 -9999 -9999 -9999 -9999 -9999 -9999 -9999 -9999 -9999 -9999 -9999 -9999 -9999 -9999 -9999 -9999 -9999 -9999 -9999 -9999 -9999 -9999 -9999 -9999 -9999 -9999 -9999 -9999 -9999 -9999 -9999 -9999 -9999 -9999 -9999 -9999 -9999 -9999 -9999 -9999 -9999 -9999 -9999 -9999 -9999 -9999 -9999 -9999 -9999 -9999 -

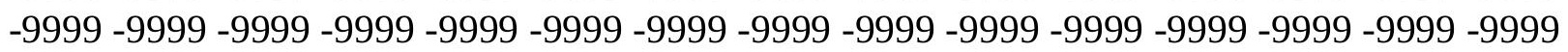


-9999 -9999 -9999 -9999 -9999 -9999 -9999 -9999 -9999 -9999 -9999 -9999 -9999 -9999 81.3776321411183 .5111236572384 .4254837036185 .3398437586 .2541885376 88.0829010009891 .4355392456195 .70252990723100 .8839035034105 .7603988647 112.4656982422118 .2565994263120 .9997024536122 .8283996582123 .43800354 123.0316390991122 .8283996582122 .7857818604122 .7351608276122 .7277679443 122.7592697144122 .8006210327122 .810874939122 .736038208122 .5383987427 122.203918457121 .7370681763121 .1793899536120 .5720672607119 .9506912231 119.3409347534118 .7733078003118 .2842330933117 .9181289673117 .7209091187 117.7409591675117 .9889144897118 .4299163818118 .9856491089119 .5371246338 119.9194335938119 .9746017456119 .5900192261118 .7488937378117 .6117782593 116.5243606567115 .9251861572116 .051902771116 .748664856117 .4526748657 117.5596618652116 .6912307739115 .3581237793113 .9896011353112 .1608963013 110.0273971558108 .8082962036107 .2844009399105 .4557037354103 .6268997192 101.493400573799 .6647262573297 .5312423706195 .7025299072394 .17859649658 92.9594726562592 .0450973510791 .1307525634890 .5211791992289 .60682678223 88.6924667358488.08290100098 87.16854858398 86.2541885376 85.33984375 84.4254837036183 .5111236572382 .2919769287181 .0728530883879 .85370635986 78.3297805786176 .5010681152374 .3675689697372 .2340774536169 .79579162598 67.3575134277364 .6144485473661 .8713798522959 .1283111572356 .38525009155 53.3373985290550 .2895507812547 .2416992187544 .1938400268641 .14598846436 38.0981407165535 .3550796508832 .3072204589829 .8689403533927 .73545074463 25.906740188624 .0780296325722 .8588790893621 .334960937520 .11581993103 18.5918903350816 .7631797790514 .934470176712 .8009700775110 .97226047516 9.448339462287 .9244132041937 .3148431777956 .7052731513986 .095703125 5.1813468933114 .876562118534 .5717768669134 .876562118535 .486132144928 6.4004869461067 .9244132041939 .4483394622810 .9722604751612 .1914100647 13.715330123914 .934470176716 .4584007263217 .9823207855219 .50625038147 21.334960937523 .4684505462625 .6019496917728 .0402297973630 .47850990295 32.6120109558133 .8311500549334 .7455101013234 .4407196044933 .83115005493 32.9167900085431 .6976509094230 .1737308502228 .6497993469227 .73545074463 27.1258792877226 .5163097381625 .906740188625 .6019496917725 .60194969177 25.2971591949525 .2971591949525 .6019496917725 .6019496917725 .9067401886 26.2115192413326 .5163097381626 .8210906982427 .1258792877227 .73545074463 28.3450202941928 .9545898437529 .5641593933130 .1737308502231 .08807945251 32.0024414062532 .6120109558133 .8311500549334 .7455101013235 .65985870361 36.5742111206137 .4885711669938 .4029312133839 .3172798156740 .53641891479 41.7555618286142 .66992187544 .1938400268645 .717769622847 .54647827148 49.6799812316952 .1182594299354 .5565414428756 .9948196411158 .82352828979 60.0244865417560 .6643943786660 .9616088867261 .0408363342361 .00393295288 60.8851432800360 .7174453735460 .3474502563559 .7378807067958 .82352828979 58.2139587402357 .2995986938556 .3852500915555 .7756805419955 .47089004517 55.4708900451755 .7756805419956 .0804595947356 .3852500915556 .99481964111 57.2995986938557 .6043891906758 .2139587402358 .51874923706 -9999-9999 -9999 -9999 -9999 -9999 -9999 -9999 -9999 -9999 -9999 -9999 -9999-9999 -9999 -9999 -9999 -9999 -9999

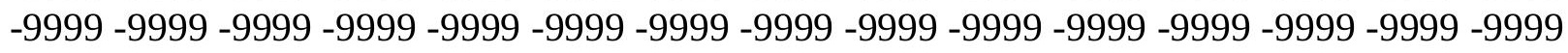

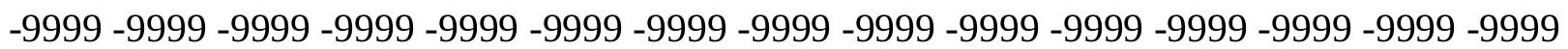


-9999 -9999 -9999 -9999 -9999 -9999 -9999 -9999 -9999 -9999 -9999 -9999

-9999 -9999 -9999 -9999 -9999 -9999 -9999 -9999 -9999 -9999 -9999 -9999 -9999 -9999 -9999

-9999 -9999 -9999 -9999 -9999 -9999 -9999 -9999 -9999 -9999 -9999 -9999 -9999 -9999 -9999

-9999 -9999 -9999 -9999 -9999 -9999 -9999 -9999 -9999 -9999 -9999 -9999 -9999 -9999 -9999

-9999 -9999 -9999 -9999 -9999 -9999 -9999 -9999 -9999 -9999 -9999 -9999 -9999 -9999 -9999

-9999 -9999 -9999 -9999 -9999 -9999 -9999 -9999 -9999 -9999 -9999 -9999 -9999 -9999 -9999 -

-9999 -9999 -9999 -9999 -9999 -9999 -9999 -9999 -9999 -9999 -9999 -9999 -9999 -9999 -9999

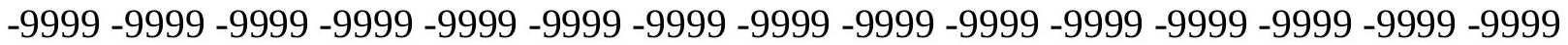

-9999 -9999 -9999 -9999 -9999 -9999 -9999 -9999 -9999 -9999 -9999 -9999 -9999 -9999 -9999

81.6824111938582 .5967712402383 .206336975183 .8159103393684 .73026275635

86.254188537689 .302040100196 .92166900635104 .8460998535111 .8561019897

117.0374984741120 .6949005127122 .5235977173123 .43800354123 .7427978516

123.7427978516123 .7427978516124 .0475006104124 .1738128662124 .3438720703

124.568649292124 .7740707397124 .8800888062124 .833732605124 .6086883545

124.2345962524123 .7565307617123 .249458313122 .7462692261122 .2648544312

121.8078231812121 .3990707397121 .0740737915120 .8847427368120 .8795776367

121.0664215088121 .3855056763121 .7411880493122 .0112991333122 .0774841309

121.8507614136121 .2977294922120 .4614334106119 .4868087769118 .596786499

118.0330963135117 .8771057129118 .0177993774118 .1460800171117 .8761291504

117.1517333984116 .0336303711114 .7665405273113 .4809265137112 .4656982422

110.3321990967108 .1986999512106 .979598999105 .1509017944103 .3221969604

101.188697814999.3599472045997.8360290527396.3121032714895.09295654297

93.8738174438592 .9594726562592 .0450973510791 .1307525634890 .21640014648 89.6068267822388 .6924667358487 .7781066894586 .8637619018685 .94940185547 85.0350494384883 .8159103393682 .9015579223681 .6824111938580 .15849304199 78.3297805786176 .5010681152374 .3675689697371 .9292907714869 .49101257324 66.7479400634864 .004882812560 .9570198059157 .909179687554 .86132049561 51.8134689331148 .765621185345 .717769622842 .66992187539 .6220703125 36.5742111206133 .5263595581130 .7833003997828 .3450202941926 .21151924133 24.3828105926523 .1636695861821 .6397399902320 .4206008911118 .59189033508 16.4584007263214 .0201196670511 .277050018318 .8387689590456 .705273151398 4.876562118533 .6574220657353 .0478510856632 .7430660724642 .438281059265 2.4382810592652 .4382810592653 .0478510856634 .2669920921335 .790916919708 7.9244132041939 .75312423706111 .2770500183112 .8009700775114 .02011966705 14.934470176716 .1536102294917 .6775398254419 .5062503814721 .63973999023 24.0780296325726 .5163097381629 .5641593933132 .3072204589835 .35507965088 37.1837806701737 .7933502197337 .1837806701735 .9646492004434 .74551010132 33.2215805053731 .3928699493429 .8689403533928 .9545898437528 .34502029419 27.7354507446327 .1258792877226 .8210906982426 .5163097381626 .51630973816 26.2115192413326 .2115192413326 .5163097381626 .5163097381626 .82109069824 26.8210906982427 .1258792877227 .7354507446328 .0402297973628 .34502029419 28.9545898437529 .5641593933130 .1737308502231 .0880794525131 .69765090942 32.6120109558133 .5263595581134 .4407196044935 .3550796508836 .26942825317 37.1837806701738 .0981407165539 .0125007629439 .9268493652340 .84120941162 42.0603485107443 .2794914245644 .8034095764246 .6321296691949 .07040023804 51.5086898803754 .2517509460456 .6900291442958 .8235282897959 .92539596558 
60.4207153320360 .5640563964860 .4964408874560 .3301658630460 .11415481567 59.8839149475159 .6469841003459 .4163360595758 .5187492370657 .9091796875 56.9948196411156 .0804595947355 .1661109924355 .4708900451755 .47089004517 55.7756805419956 .0804595947356 .6900291442956 .9948196411157 .29959869385 57.6043891906758 .2139587402358 .51874923706 -9999 -9999 -9999 -9999 -9999 -9999 -9999 -9999 -9999 -9999 -9999 -9999 -9999 -9999 -9999 -9999 -9999 -9999 -9999 -9999 -9999 -9999

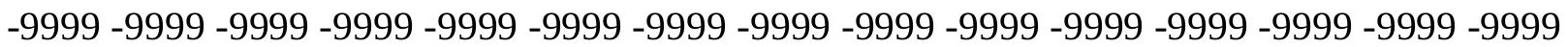

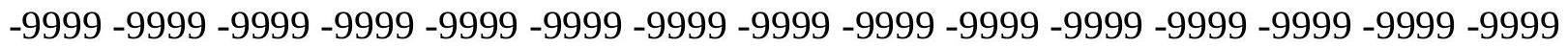
-9999 -9999 -9999 -9999 -9999 -9999 -9999 -9999 -9999

-9999 -9999 -9999 -9999 -9999 -9999 -9999 -9999 -9999 -9999 -9999 -9999 -9999 -9999 -9999 -9999 -9999 -9999 -9999 -9999 -9999 -9999 -9999 -9999 -9999 -9999 -9999 -9999 -9999 -9999 -999 -9999 -9999 -9999 -9999 -9999 -9999 -9999 -9999 -9999 -9999 -9999 -9999 -9999 -9999 -9999 -999 -9999 -9999 -9999 -9999 -9999 -9999 -9999 -9999 -9999 -9999 -9999 -9999 -9999 -9999 -9999 -9999 -9999 -9999 -9999 -9999 -9999 -9999 -9999 -9999 -9999 -9999 -9999 -9999 -9999 -9999 -9999 -9999 -9999 -9999 -9999 -9999 -9999 -9999 -9999 -9999 -9999 -9999 -9999 -9999 -9999

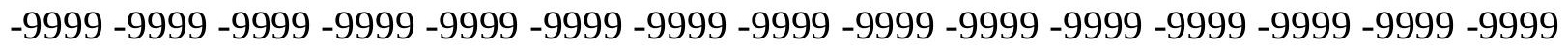
-9999 -9999 -9999 -9999 -9999 -9999 -9999 -9999 -9999 -9999 -9999 -9999 -9999 -9999 -9999 -9999 84.12069702148 84.42548370361 84.7302627563585.64462280273 87.16854858398 91.1307525634897 .53124237061104 .5412979126110 .9418029785115 .818397522 119.4757995605121 .9140014648123 .1332015991123 .7427978516124 .3523025513 124.6570968628124 .9618988037125 .4240264893125 .7189712524126 .1092376709 126.5234909058126 .8131332397126 .9024505615126 .7490234375126 .4276123047 126.0148773193125 .6067199707125 .2230987549124 .8787612915124 .542678833 124.2147979736123 .9110107422123 .6903915405123 .6557235718123 .8128662109 124.0834655762124 .3266067505124 .4049377441124 .2272644043123 .7698364258 123.0749053955122 .2205734253121 .3188018799120 .4908981323119 .8317871094 119.3582229614118 .9864578247118 .5581512451117 .9232406616117 .0596389771 116.0129318237114 .8914413452113 .8205718994112 .6598968506111 .1444396973 109.754699707108 .8082962036106 .3700027466104 .5412979126102 .712600708 100.883903503499 .3599472045997 .8360290527396 .6168823242295 .70252990723 94.4833908081193 .5690307617292 .9594726562592 .0450973510791 .13075256348 90.2164001464889 .302040100188 .3876876831187 .4733276367286 .55898284912 85.64462280273 84.73026275635 83.51112365723 82.29197692871 80.76805877686 78.9393463134876 .8058471679774 .6723632812571 .9292907714869 .18623352051 66.1383666992263 .0905189514260 .0426712036156 .9948196411153 .64218139648 50.8991203308147 .8512611389244 .4986305236841 .4507789611838 .09814071655 35.0502891540532 .0024414062529 .2593708038326 .8210906982424 .99238014221 23.4684505462622 .2493095397920 .7253894805918 .8966808319116 .45840072632 13.105759620679 .7531242370616 .7052731513983 .6574220657351 .21914100647 -9999 -.609570324421 -.609570324421 -.304785102606 -9999.3047851026058 1.21914100647 2.7430660724645 .1813468933117 .61962795257610 .0579099655211 .88661956787 13.1057596206714 .0201196670514 .934470176715 .8488302230817 .37274932861 19.2014598846421 .334960937523 .7732391357426 .8210906982429 .86894035339 33.2215805053736 .5742111206139 .622070312539 .622070312538 .70771026611 37.4885711669935 .9646492004434 .4407196044932 .6120109558130 .78330039978 30.1737308502229 .2593708038328 .6497993469228 .3450202941927 .73545074463 
27.4306602478 27.4306602478 27.12587928772 27.12587928772 27.12587928772 27.1258792877227 .430660247827 .430660247827 .7354507446328 .04022979736 28.3450202941928 .6497993469229 .2593708038329 .8689403533930 .47850990295 31.0880794525131 .6976509094232 .6120109558133 .5263595581134 .44071960449 35.0502891540535 .9646492004436 .8790016174337 .7933502197338 .40293121338 39.3172798156740 .2316398620641 .4507789611842 .3651313781743 .88906097412 45.717769622847 .8512611389250 .8991203308153 .6421813964856 .38525009155 58.5187492370659 .5367355346759 .9458465576259 .980331420959 .79413223267 59.5231018066459 .227401733458 .9515075683658 .7090301513758 .49754333496 58.3336181640657 .6043891906756 .9948196411156 .0804595947355 .77568054199 55.7756805419955 .7756805419956 .0804595947356 .3852500915556 .69002914429 57.2995986938557 .6043891906757 .909179687558 .2139587402358 .51874923706 -9999 -9999 -9999 -9999 -9999 -9999 -9999 -9999 -9999 -9999 -9999 -9999 -9999 -9999 -9999 -9999 -9999 -9999 -9999 -9999 -9999 -9999 -9999 -9999 -9999 -9999 -9999 -9999 -9999 -9999 -9999 -9999 -9999 -9999 -9999 -9999 -9999 -9999 -9999 -9999 -9999 -9999 -9999 -9999 -9999 -9999

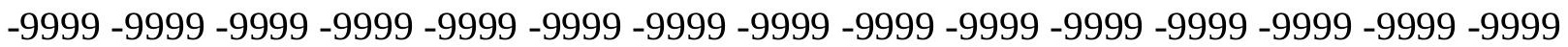

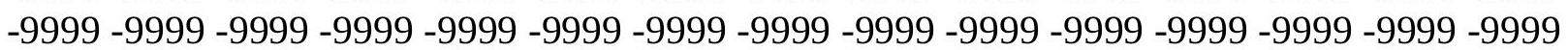
-9999 -9999 -9999 -9999 -9999 -9999 -9999 -9999 -9999 -9999 -9999 -9999 -9999 -9999 -9999 -999 -9999 -9999 -9999 -9999 -9999 -9999 -9999 -9999 -9999 -9999 -9999 -9999 -9999 -9999 -9999 -9999 -9999 -9999 -9999 -9999 -9999 -9999 -9999 -9999 -9999 -9999 -9999 -9999 -9999 -9999 -9999 -9999 -9999 -9999 -9999 -9999 -9999 -9999 -9999 -9999 -9999 -9999 -9999 -9999 -9999 -9999 -9999 -9999 -9999 -9999 -9999 -9999 -9999 -9999 -9999 -9999 -9999 -9999 -9999 -9999 -9999 -9999 -9999 -9999 -9999 -9999 -9999 -9999 -9999 -9999 -9999 -9999 -9999 -9999 -9999 -9999 -9999 -9999 -9999 -9999 -9999 -9999 -9999 -9999 -9999 -9999 -9999 -9999 -9999 -9999 -9999 -9999 87.77810668945 87.7781066894588.3876876831189.91161346436 94.1785964965899 .35994720459104 .8460998535110 .3321990967114 .9039993286 118.2565994263120 .6949005127122 .5235977173123 .43800354124 .3523025513 124.9618988037125 .5715026855126 .4448776245126 .7949829102127 .3184890747 127.9231796265128 .4264984131128 .5729675293128 .4673156738128 .1647644043 127.7959060669127 .4684524536127 .2223358154127 .0449295044126 .8549423218 126.6250152588126 .3224487305126 .0487365723125 .9621963501126 .1416244507 126.4740600586126 .7237243652126 .6983718872126 .3085021973125 .6244430542 124.7746353149123 .869392395122 .9805374146122 .1361999512121 .3273010254 120.5189819336119 .6566009521118 .6911239624117 .6138839722116 .4637756348 115.3124923706114 .2280654907113 .2295684814112 .2077407837111 .153137207 110.0866088867108 .8299865723107 .1597213745105 .3968429565103 .6268997192 102.1029968262100 .883903503499 .3599472045998 .1408081054797 .22646331787 96.3121032714895 .397743225194 .4833908081193 .5690307617292 .95947265625 92.0450973510790 .8259735107489 .9116134643689 .302040100188 .38768768311 87.4733276367286 .5589828491285 .6446228027384 .7302627563583 .2063369751 81.6824111938579 .5489196777377 .4154205322374 .6723632812571 .92929077148 68.8814392089865 .8335876464862 .4809494018659 .1283111572356 .08045959473 53.3373985290550 .2895507812547 .2416992187543 .8890609741240 .53641891479 36.8790016174333 .5263595581130 .4785099029527 .7354507446325 .60194969177 23.7732391357422 .8588790893621 .6397399902319 .5062503814716 .45840072632 $12.19141006478 .2291984558114 .266992092133 .6095703244209-2.13349604607$ 
-3.96220707893 -4.57177686691 -4.57177686691 -3.96220707893 -2.74306607246 -1.21914100647 -9999 1.21914100647 4.87656211853 8.229198455811 10.66748046875 12.4961900711113 .715330123914 .3248996734614 .6296901702915 .23925971985 16.7631797790518 .28710937520 .4206008911122 .8588790893625 .9067401886 28.9545898437532 .6120109558135 .9646492004438 .4029312133839 .31727981567 39.0125007629438 .0981407165536 .8790016174335 .0502891540533 .52635955811 32.3072204589831 .0880794525130 .4785099029529 .8689403533929 .25937080383 28.9545898437528 .6497993469228 .3450202941928 .0402297973628 .04022979736 27.7354507446327 .7354507446328 .0402297973628 .0402297973628 .34502029419 28.3450202941928 .6497993469228 .9545898437529 .5641593933129 .86894035339 30.4785099029531 .0880794525132 .0024414062532 .6120109558133 .52635955811 34.4407196044935 .0502891540535 .9646492004436 .5742111206137 .48857116699 38.0981407165539 .0125007629439 .9268493652340 .8412094116241 .75556182861 42.9747009277344 .4986305236846 .6321296691949 .3751907348652 .42303848267 55.4708900451757 .6043891906758 .8397789001559 .2451972961459 .19244766235 58.9252433776958 .5756225585958 .2327156066957 .9353904724157 .71098327637 57.5441665649457 .4395332336457 .3951911926356 .9948196411156 .38525009155 56.0804595947356 .0804595947356 .3852500915556 .3852500915556 .69002914429 56.9948196411157 .2995986938557 .6043891906757 .909179687558 .21395874023 58.5187492370658 .69990539551 -9999 -9999 -9999 -9999 -9999 -9999 -9999 -9999 -9999 -9999 -9999 -9999 -9999 -9999 -9999 -9999 -9999 -9999 -9999 -9999 -9999 -9999 -9999 -9999 -9999 -9999 -9999 -9999 -9999 -9999 -9999 -9999 -9999 -9999 -9999 -9999 -9999 -9999 -9999 -9999 -9999 -9999 -9999 -9999 -9999 -9999 -9999 -9999 -9999 -9999 -9999 -9999 -9999 -9999 -9999 -9999 -9999 -9999-9999 -9999

-9999 -9999 -9999 -9999 -9999 -9999 -9999 -9999 -9999 -9999 -9999 -9999 -9999 -9999 -9999 -9999 -9999 -9999 -9999 -9999 -9999 -9999 -9999 -9999 -9999 -9999 -9999 -9999 -9999 -9999 -9999 -9999 -9999 -9999 -9999 -9999 -9999 -9999 -9999 -9999 -9999 -9999 -9999 -9999 -9999 -9999 -9999 -9999 -9999 -9999 -9999 -9999 -9999 -9999 -9999 -9999 -9999 -9999 -9999 -9999 -9999 -9999 -9999 -9999 -9999 -9999 -9999 -9999 -9999 -9999 -9999 -9999 -9999 -9999 -9999 -9999 -9999 -9999 -9999 -9999 -9999 -9999 -9999 -9999 -9999 -9999 -9999 -9999 -9999 -9999 -9999 -9999 -9999 -9999 -9999 -9999 -9999 -9999 -9999 -9999 -9999 -9999 -9999 -9999 -9999 -9999 -9999 -9999 -9999 -9999 -9999 -9999 -9999 -9999 -9999 -9999 -9999 -9999 -9999 -9999 -9999 -9999 92.65467834473 92.349891662692.6546783447393.87381744385 97.22646331787101 .4934005737105 .7603988647110 .3321990967113 .9896011353 117.342300415119 .7806015015121 .6092987061122 .8283996582124 .0475006104 124.9618988037125 .8762969971126 .7906036377127 .4001998901128 .0570220947 128.7507324219129 .533706665129 .533706665129 .533706665129 .2288970947 128.9241027832128 .6192932129128 .6192932129128 .5650482178128 .5850982666 128.4804077148128 .167678833127 .7513122559127 .5960998535126 .4858016968 128.4660644531128 .8883666992128 .8346862793128 .208190918127 .274230957 126.2532348633125 .3005523682124 .4321212769123 .5718383789122 .61378479 121.468132019120 .1024398804118 .5575942993116 .9430389404115 .3922729492 114.0237503052112 .8952102661111 .9764862061111 .1751251221110 .4084320068 109.5696792603108 .5022583008107 .2564926147105 .8428039551104 .4378967285 103.1238632202101 .7982025146100 .579101562599 .6647262573298 .75038146973 97.8360290527396 .9216690063596 .3121032714895 .397743225194 .48339080811 
93.5690307617292 .6546783447391 .7403335571390 .8259735107490 .21640014648 89.6068267822388 .6924667358488 .0829010009887 .1685485839885 .94940185547 84.4254837036182 .5967712402380 .1584930419977 .7202072143674 .67236328125 71.6244964599668 .5766525268665 .2240066528361 .8713798522959 .12831115723 56.3852500915553 .3373985290550 .2895507812546 .9369087219243 .27949142456 39.622070312535 .6598587036131 .6976509094228 .6497993469225 .9067401886 24.3828105926523 .1636695861821 .9445304870620 .4206008911116 .15361022949 $11.277050018316 .0957031251 .523926019669-2.43828105927-5.79091691971$ -7.92441320419-8.83876895905 -8.53398323059 -7.3148431778 -5.79091691971 $-3.35263609886-.6095703244211 .219141006475 .1813468933118 .838768959045$ 11.8866195678713 .4105501174914 .0201196670514 .3248996734614 .62969017029 15.2392597198516 .1536102294917 .3727493286119 .2014598846421 .3349609375 24.3828105926527 .430660247830 .7833003997834 .1359291076736 .57421112061 38.0981407165538 .4029312133837 .7933502197336 .8790016174335 .65985870361 34.4407196044933 .2215805053732 .0024414062531 .3928699493430 .78330039978 30.1737308502229 .8689403533929 .2593708038328 .9545898437528 .95458984375 28.6497993469228 .6497993469228 .6497993469228 .6497993469228 .64979934692 28.6497993469228 .9545898437529 .2593708038329 .5641593933129 .86894035339 30.1737308502230 .7833003997831 .3928699493432 .0024414062532 .91679000854 33.5263595581134 .4407196044935 .0502891540535 .9646492004436 .57421112061 37.4885711669938 .0981407165538 .7077102661139 .3172798156740 .23163986206 40.8412094116241 .7555618286143 .2794914245645 .1082000732447 .85126113892 50.8991203308154 .2517509460456 .8555145263758 .0277786254958 .33684921265 58.2097778320357 .88476562557 .5071487426857 .1511955261256 .86751937866 56.666854858456 .5517921447856 .5208892822356 .5682754516656 .67878723145 56.6900291442956 .6900291442956 .6900291442956 .6900291442956 .99481964111 57.2995986938557 .6043891906757 .6043891906757 .909179687558 .21395874023 58.44630050659 58.51874923706 58.66580963135 -9999 -9999 -9999 -9999 -9999 -9999 -9999 -9999 -9999 -9999 -9999 -9999 -9999 -9999 -9999 -9999 -9999 -9999 -9999 -9999 -9999 -9999 -9999 -9999 -9999 -9999 -9999 -9999 -9999 -9999 -9999 -9999 -9999 -9999 -9999 -9999 -9999

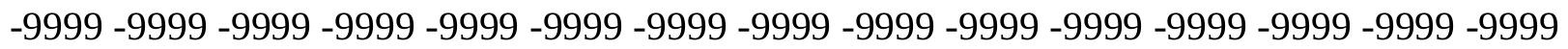
-9999 -9999 -9999 -9999 -9999 -9999-9999-9999

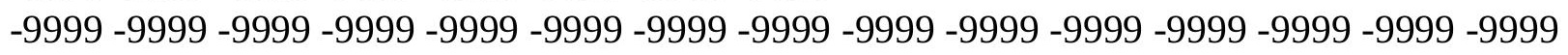

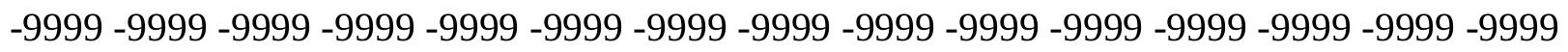
-9999 -9999 -9999 -9999 -9999 -9999 -9999 -9999 -9999 -9999 -9999 -9999 -9999 -9999 -9999 -

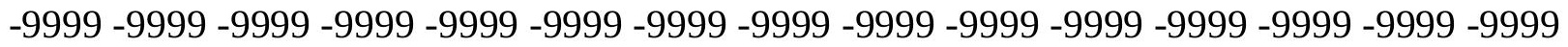

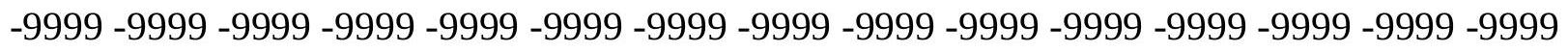

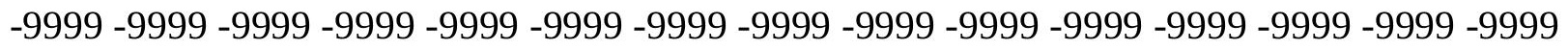
-9999 -9999 -9999 -9999 -9999 -9999 -9999 -9999 -9999 -9999 -9999 -9999 -9999 -9999 -9999 -9999 -9999 -9999 -9999 -9999 -9999 -9999 -9999 -9999 -9999 -9999 -9999 -9999 -9999 -9999 -9999 -9999-9999 97.5312423706197.22646331787 97.5312423706199.96952056885 103.6268997192106 .979598999110 .3321990967113 .3800964355116 .4279022217 118.5614013672120 .6949005127122 .2188034058123 .43800354124 .6570968628 125.5715026855126 .4858016968127 .4001998901128 .3144989014128 .9241027832 129.2288970947129 .533706665129 .533706665129 .533706665129 .2288970947 128.9241027832 129.2288970947 129.2288970947129.533706665129.533706665 
129.2288970947 128.6192932129 128.0097961426 128.3144989014129.8885955811 130.7918395996130 .6582641602129 .7418212891128 .5457305908127 .3798751831 126.4499740601125 .6945114136124 .8929901123123 .8348846436122 .3567123413 120.4422531128118 .2196884155115 .9446258545113 .8765563965112 .2143478394 111.0214385986110 .2252197266109 .6765518188109 .2057952881108 .6586151123 107.9344863892107 .0293045044105 .9861297607104 .8924331665103 .8229904175 102.7777938843101 .7877960205100 .579101562599 .9420471191499 .05516815186 98.445587158297 .8360290527397 .2264633178796 .3121032714895 .3977432251 94.4833908081193 .5690307617292 .9594726562592 .349891662691 .74033355713 91.1307525634890 .2164001464889 .6068267822388 .6924667358487 .47332763672 85.3398437583 .206336975180 .4632720947377 .7202072143674 .67236328125 71.6244964599668 .5766525268665 .5288009643662 .4809494018659 .73788070679 56.9948196411153 .9469718933150 .5943298339846 .9369087219242 .669921875 38.0981407165533 .8311500549329 .8689403533926 .5163097381624 .99238014221 23.7732391357422 .2493095397919 .5062503814715 .2392597198510 .05790996552 $4.266992092133-1.21914100647-6.095703125-10.0579099655-12.4961900711$ $-13.4105501175-12.8009700775-10.9722604752-8.53398323059-5.79091691971$ $-2.43828105927 .60957032442095 .79091691970810 .36268999719212 .80097007751$ 13.715330123914 .3248996734614 .3248996734614 .6296901702914 .9344701767 15.5440397262616 .4584007263217 .6775398254419 .811029434222 .55410003662 25.6019496917728 .9545898437532 .0024414062534 .7455101013236 .26942825317 36.8790016174336 .8790016174336 .5742111206135 .6598587036134 .74551010132 33.5263595581132 .9167900085432 .0024414062531 .3928699493430 .78330039978 30.4785099029530 .1737308502229 .8689403533929 .5641593933129 .25937080383 29.2593708038329 .2593708038329 .2593708038329 .2593708038329 .25937080383 29.2593708038329 .5641593933129 .8689403533930 .1737308502230 .78330039978 31.0880794525131 .6976509094232 .3072204589833 .2215805053733 .83115005493 34.7455101013235 .3550796508835 .9646492004436 .5742111206137 .48857116699 38.0981407165538 .7077102661139 .0125007629439 .622070312540 .23163986206 40.8412094116241 .7555618286142 .9747009277345 .4129791259849 .37519073486 54.5565414428756 .2550392150957 .0426788330157 .2374763488857 .05920028687 56.7133407592856 .3345260620156 .0022163391155 .7454757690455 .58434295654 55.529708862355 .5854492187555 .7471542358455 .9955673217856 .29467010498 56.6027259826756 .8856582641657 .1331291198757 .3586158752457 .58498382568 57.8171195983958 .0416793823258 .2139587402358 .3971672058158 .50392150879 58.5187492370658 .67870330811 -9999 -9999 -9999 -9999 -9999 -9999 -9999 -9999 -9999

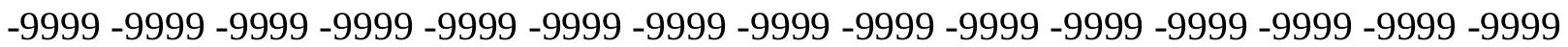

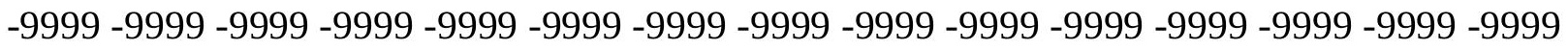

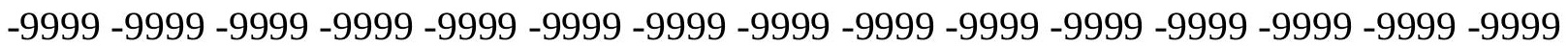
-9999 -9999 -9999 -9999 -9999 -9999

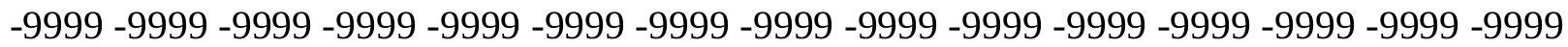
-9999 -

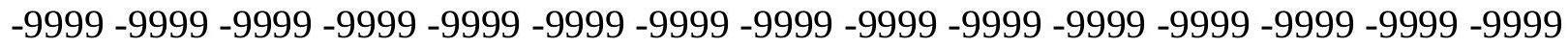
-9999 -

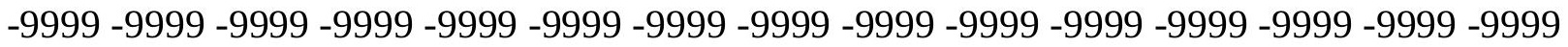

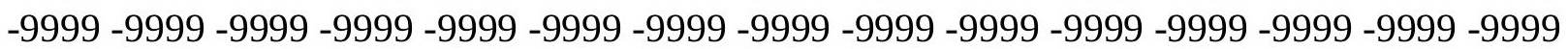


-9999 -9999 -9999 -9999 -9999 -9999 -9999 -9999 -9999 -9999 -9999 -9999 -9999 -9999 -9999 -9999 -9999 -9999 -9999 -9999 -9999 -9999 -9999 -9999 -9999 -9999 -9999 -9999 -9999 -9999 -9999 -9999 -9999 -9999 102.4077987671 102.1029968262103 .0174026489105 .7603988647 108.1986999512110 .6370010376113 .075302124115 .5136032104117 .647102356 119.4757995605121 .3044967651122 .8283996582124 .0475006104125 .2667007446 126.4858016968127 .4001998901128 .0097961426128 .6192932129129 .2288970947 129.533706665129 .533706665129 .2288970947129 .2288970947129 .2288970947 129.2288970947129 .2288970947129 .2288970947129 .2288970947128 .9241027832 128.6192932129128 .3144989014128 .9241027832130 .4479980469132 .2767028809 131.7633056641130 .6701202393129 .2369384766126 .1809997559125 .8762969971 126.8354263306126 .2354660034125 .1568069458123 .3588562012120 .816078186 117.7758255005114 .6645507812111 .951385498109 .9534912109108 .7329559326 108.139793396107 .9170150757107 .8054504395107 .6144104004107 .244758606 106.6727676392105 .9595336914105 .1561355591104 .3160400391103 .4667053223 102.6216964722101 .7982254028101 .0186157227100 .334884643699 .81044006348 99.3599472045998 .7503814697398 .1408081054797 .2264633178796 .31210327148 95.7025299072394 .7881774902394 .1785964965893 .8738174438593 .26425170898 92.6546783447392 .0450973510791 .4355392456190 .2164001464888 .38768768311 85.9494018554783 .5111236572380 .7680587768678 .0249862670974 .97714233398 71.9292907714869 .1862335205166 .4431610107463 .7000885009860 .95701980591 57.909179687554 .8613204956150 .5943298339846 .0225486755441 .45077896118 36.5742111206132 .0024414062527 .7354507446326 .5163097381624 .99238014221 22.5541000366219 .2014598846414 .629690170298 .8387689590452 .438281059265 -3.65742206573 -9.75312423706 -14.3248996735 -17.3727493286 -17.9823207855 -17.0679702759 -14.6296901703 -11.5818300247 -7.92441320419-3.96220707893 .30478510260585 .79091691970811 .5818300247212 .8009700775113 .7153301239 14.0201196670514 .0201196670514 .3248996734614 .6296901702914 .9344701767 15.5440397262616 .4584007263217 .9823207855220 .7253894805924 .07802963257 27.1258792877230 .1737308502232 .6120109558134 .4407196044935 .35507965088 35.9646492004435 .6598587036135 .3550796508834 .7455101013233 .83115005493 33.2215805053732 .6120109558132 .0024414062531 .6976509094231 .08807945251 30.7833003997830 .4785099029530 .1737308502229 .8689403533929 .86894035339 29.8689403533929 .5641593933129 .5641593933129 .8689403533929 .86894035339 30.1737308502230 .4785099029530 .7833003997831 .0880794525131 .69765090942 32.3072204589832 .9167900085433 .5263595581134 .1359291076735 .05028915405 35.6598587036136 .2694282531736 .8790016174337 .4885711669938 .09814071655 38.7077102661139 .0125007629439 .3172798156739 .3172798156739 .6220703125 40.5364189147941 .4507789611844 .1938400268649 .6799812316953 .26212692261 55.1812477111855 .9028434753455 .9911727905355 .7806777954155 .44892883301 55.1138763427754 .8197402954154 .6032562255954 .4903907775954 .50309371948 54.6585655212454 .9626884460455 .3978157043555 .9103202819856 .42361068726 56.8681945800857 .2122421264657 .4728088378957 .7024765014657 .944896698 58.218330383358 .4667472839458 .5187492370658 .5187492370658 .66683197021 58.72037887573 -9999 -9999 -9999 -9999 -9999 -9999 -9999 -9999 -9999 -9999 -9999 -9999 -9999 -9999 -9999 -9999 -9999 -9999 -9999 -9999 -9999 -9999 -9999 -9999 -9999 -9999 -9999 -9999 -9999 -9999 -9999 -9999 -9999 -9999 -9999 -9999 -9999 -9999 -9999 -9999 -9999 -9999 
-9999 -9999 -9999 -9999 -9999 -9999 -9999 -9999 -9999 -9999 -9999 -9999 -9999 -9999 -9999 -9999-9999-9999

-9999 -9999 -9999 -9999 -9999 -9999 -9999 -9999 -9999 -9999 -9999 -9999 -9999 -9999 -9999 -9999 -9999 -9999 -9999 -9999 -9999 -9999 -9999 -9999 -9999 -9999 -9999 -9999 -9999 -9999 -9999 -9999 -9999 -9999 -9999 -9999 -9999 -9999 -9999 -9999 -9999 -9999 -9999 - -9999 - -9999 -9999 -9999 -9999 -9999 -9999 -9999 -9999 -9999 -9999 -9999 -9999 -9999 -9999 -9999 -9999

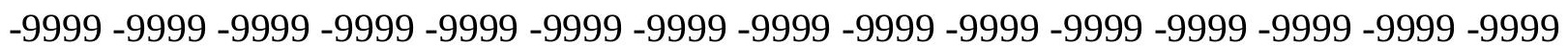
-9999 -9999 -9999 -9999 -9999 -9999 -9999 -9999 -9999 -9999 -9999 -9999 -9999 -9999 -9999 -9999 -9999 -9999 -9999 -9999 -9999 -9999 -9999 -9999 -9999 -9999 -9999 -9999 -9999 -9999 -9999 -9999 -9999 -9999 -9999 -9999 -9999 -9999 -9999 -9999 -9999 -9999 -9999 -9999 -9999 -9999 -9999 -9999-9999-9999 106.6747970581 106.3700027466 107.2844009399 108.8082962036110 .6370010376112 .7705001831114 .5991973877116 .7326965332 118.5614013672120 .3900985718121 .9140014648123 .43800354124 .9618988037 126.1809997559127 .0953979492128 .0097961426128 .6192932129128 .9241027832 129.2288970947129 .2288970947129 .2288970947128 .9241027832128 .9241027832 128.9241027832128 .6192932129128 .6192932129128 .6192932129128 .3144989014 128.3144989014128 .3144989014128 .9241027832130 .1432037354131 .0576019287 131.6672058105131 .0576019287129 .2288970947127 .7050018311127 .0953979492 127.4001998901127 .696975708126 .695098877124 .6129379272121 .3567504883 117.3011550903 113.1370010376109.6652297974 107.3435516357 106.2015380859 105.9454727173106 .1480331421106 .4511184692106 .6352310181106 .6006622314 106.3329467773105 .8856658936105 .3227996826104 .6830825806103 .9937438965 103.2872390747102 .5935897827101 .9491271973101 .4006347656100 .9479522705 100.5479660034100 .118415832599 .6647262573299 .0551681518698 .14080810547 97.5312423706196 .9216690063596 .3121032714895 .7025299072395 .3977432251 94.7881774902394 .4833908081193 .5690307617292 .6546783447390 .82597351074 88.6924667358486 .254188537683 .8159103393681 .3776321411178 .63455963135 75.5867080688572 .8436431884870 .1005783081167 .3575134277364 .91924285889 62.1761703491259 .1283111572354 .5565414428749 .9847602844245 .10820007324 40.2316398620635 .6598587036132 .0024414062529 .5641593933127 .12587928772 24.0780296325720 .1158199310314 .629690170298 .5339832305911 .523926019669 -5.48613214493 -12.4961900711 -18.287109375 -21.9445304871 -22.5541000366 -21.0301704407 -17.9823207855 -14.3248996735 -10.0579099655 -5.48613214493 -.609570324421 4.2669920921338.83876895904511.27705001831 12.49619007111 12.8009700775113 .1057596206713 .4105501174913 .715330123914 .32489967346 14.934470176715 .8488302230817 .3727493286119 .811029434222 .55410003662 25.6019496917728 .3450202941930 .7833003997832 .6120109558133 .83115005493 34.7455101013234 .7455101013234 .7455101013234 .4407196044933 .83115005493 33.2215805053732 .9167900085432 .6120109558132 .0024414062531 .69765090942 31.3928699493431 .0880794525130 .7833003997830 .4785099029530 .47850990295 30.1737308502230 .1737308502230 .1737308502230 .1737308502230 .47850990295 30.4785099029530 .7833003997831 .0880794525131 .6976509094232 .00244140625 32.6120109558133 .2215805053733 .8311500549334 .7455101013235 .35507965088 35.9646492004436 .5742111206137 .1837806701737 .7933502197338 .40293121338 38.7077102661139 .0125007629439 .0125007629439 .0125007629439 .01250076294 39.622070312540 .8412094116244 .4986305236849 .3751907348652 .36223602295 
53.9702186584554 .5568161010754 .6234245300354 .4458160400454 .18715667725 53.9154891967853 .6775817871153 .5101013183653 .4472846984953 .52917098999 53.7958106994654 .2749900817954 .9625854492255 .7945442199756 .62195587158 57.3082427978557 .7657279968358 .0080795288158 .1323547363358 .24319458008 58.4781570434658 .8235282897958 .7617835998558 .7437705993758 .75741577148 58.77954864502 -9999 -9999 -9999 -9999 -9999 -9999 -9999 -9999 -9999 -9999 -9999 -9999 -9999 -9999 -9999 -9999 -9999 -9999 -9999 -9999 -9999 -9999 -9999 -9999 -9999 -9999 -9999

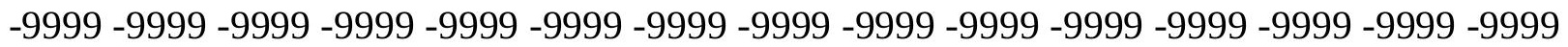

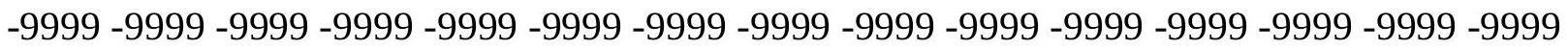
-9999-9999-9999

-9999 -9999 -9999 -9999 -9999 -9999 -9999 -9999 -9999 -9999 -9999 -9999 -9999 -9999 -9999 -9999 -9999 -9999 -9999 -9999 -9999 -9999 -9999 -9999 -9999 -9999 -9999 -9999 -9999 -9999 -9999 -9999 -9999 -9999 -9999 -9999 -9999 -9999 -9999 -9999 -9999 -9999 -9999 -9999 -9999 -9999 -9999 -9999 -9999 -9999 -9999 -9999 -9999 -9999 -9999 -9999 -9999 -9999 -9999 -9999 -9999 -9999 -9999 -9999 -9999 -9999 -9999 -9999 -9999 -9999 -9999 -9999 -9999 -9999 -9999

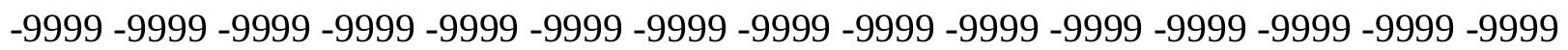

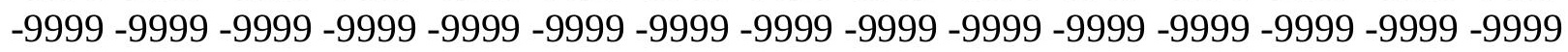

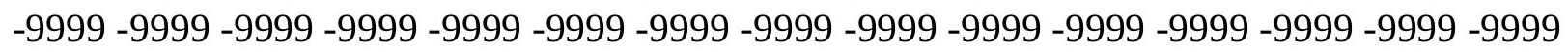
-9999 -9999 -9999 -9999 -9999-9999 110.6370010376 110.3321990967 109.7226028442 110.6370010376112 .4656982422113 .9896011353115 .818397522117 .647102356 119.4757995605121 .3044967651122 .8283996582124 .3523025513125 .8762969971 126.7906036377127 .7050018311128 .0097961426128 .6192932129128 .6192932129 128.6192932129128 .6192932129128 .6192932129128 .3144989014128 .3144989014 128.0097961426128 .0097961426128 .0097961426127 .7050018311128 .0097961426 128.0097961426128 .6192932129129 .2288970947129 .8385009766130 .1432037354 130.1432037354129 .533706665128 .9241027832128 .6192932129129 .2288970947 129.3055114746128 .401473999126 .096282959122 .1602096558116 .8445663452 111.4248504639107 .126739502104 .5856246948103 .7221298218103 .9774017334 104.6747436523105 .3912506104105 .907409668106 .1465835571106 .1073455811 105.8623657227105 .4708099365104 .9808654785104 .417388916103 .8236083984 103.239074707102 .6991348267102 .2323760986101 .8424682617101 .5017471313 101.1717758179100 .7845077515100 .274299621699 .6647262573299 .05516815186 98.445587158298 .1408081054797 .8360290527397 .5312423706196 .92166900635 96.6168823242296 .0073165893694 .7881774902393 .2642517089891 .43553924561 88.9972534179786 .8637619018684 .4254837036181 .9871978759879 .24413299561 76.5010681152373 .7580032348671 .3197174072368 .5766525268665 .52880096436 62.1761703491258 .2139587402353 .6421813964849 .0704002380444 .49863052368 40.2316398620636 .5742111206133 .5263595581130 .7833003997826 .82109069824 $21.9445304870616 .153610229499 .448339462281 .828711032867-5.79091691971$ -14.0201196671 -21.3349609375 -25.9067401886 -26.2115192413 -23.7732391357 -20.4206008911 -16.1536102295 -11.8866195679 -7.3148431778 -2.43828105927 1.5239260196695 .4861321449288 .53398323059110 .3626899719211 .27705001831 11.8866195678712 .4961900711113 .1057596206713 .715330123914 .32489967346 15.2392597198516 .7631797790518 .8966808319121 .6397399902324 .38281059265 26.8210906982429 .2593708038331 .0880794525132 .3072204589833 .52635955811 33.8311500549334 .1359291076733 .8311500549333 .5263595581133 .22158050537 
33.2215805053732 .6120109558132 .3072204589832 .0024414062531 .69765090942 31.3928699493431 .3928699493431 .0880794525130 .7833003997830 .78330039978 30.7833003997830 .7833003997830 .7833003997830 .7833003997831 .08807945251 31.3928699493431 .6976509094232 .0024414062532 .6120109558133 .22158050537 33.8311500549334 .4407196044935 .0502891540535 .6598587036136 .26942825317 36.8790016174337 .7933502197338 .0981407165538 .7077102661139 .01250076294 39.3172798156739 .0125007629438 .7077102661138 .7077102661139 .01250076294 40.5364189147944 .8034095764249 .0704002380451 .8274803161652 .83856201172 53.1897392272953 .2575836181653 .1825561523453 .0409851074252 .85900115967 52.6908721923852 .5784416198752 .5646057128952 .7105865478553 .0958442688 53.7809982299854 .7934761047456 .0804595947356 .9948196411157 .9091796875 58.5187492370658 .8235282897959 .1283111572358 .8235282897958 .82352828979 58.8235282897958 .8235282897958 .8235282897958 .8235282897958 .82352828979 58.82352828979 -9999 -9999 -9999 -9999 -9999 -9999 -9999 -9999 -9999 -9999 -9999 -9999 -9999 -9999 -9999 -9999 -9999 -9999 -9999 -9999 -9999 -9999 -9999 -9999 -9999 -9999 -9999

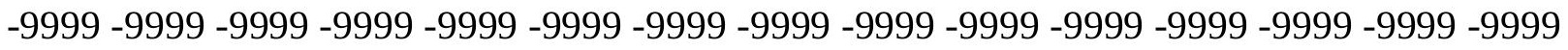
-9999 -9999 -9999 -9999 -9999 -9999 -9999 -9999 -9999 -9999 -9999 -9999 -9999 -9999 -9999 -9999 -9999

-9999 -9999 -9999 -9999 -9999 -9999 -9999 -9999 -9999 -9999 -9999 -9999 -9999 -9999 -9999

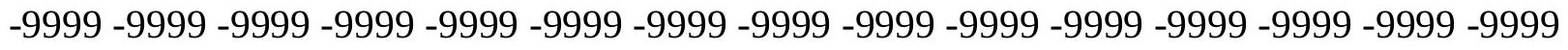
-9999 -9999 -9999 -9999 -9999 -9999 -9999 -9999 -9999 -9999 -9999 -9999 -9999 -9999 -9999 -9999 -9999 -9999 -9999 -9999 -9999 -9999 -9999 -9999 -9999 -9999 -9999 -9999 -9999 -9999 -9999 -9999 -9999 -9999 -9999 -9999 -9999 -9999 -9999 -9999 -9999 -9999-9999-9999-9999 -999 -9999 -9999 -9999 -9999 -9999 -9999 -9999 -9999 -9999 -9999 -9999 -9999 -9999 -9999 -9999 -9999 -9999 -9999 -9999 -9999 -9999 -9999 -9999 -9999 -9999 -9999 -9999 -9999 -9999 -9999 -9999 -9999 -9999 -9999 -9999 -9999 -9999 -9999 -9999 -9999 -9999 -9999 -9999 -9999 -9999 -9999 -9999 -9999 -9999 -9999 -9999 -9999 116.4279022217 114.5991973877113 .075302124 112.4656982422113 .6848983765115 .2088012695117 .0374984741118 .8662033081 120.6949005127122 .5235977173124 .0475006104125 .5715026855126 .4858016968 127.4001998901127 .7050018311128 .0097961426128 .3144989014128 .3144989014 128.0097961426128 .0097961426127 .7050018311127 .7050018311127 .4001998901 127.4001998901127 .4001998901127 .0953979492127 .4001998901127 .4001998901 127.7050018311128 .3144989014128 .9241027832129 .2288970947129 .533706665 129.8385009766129 .8385009766130 .1432037354130 .7528076172130 .7528076172 129.8385009766127 .4001998901123 .1332015991116 .3458175659108 .5035018921 100.579101562599 .35994720459100 .5791015625102 .7040634155103 .8365249634 104.8570022583105 .581817627105 .9829864502106 .082611084105 .9519882202 105.6631011963105 .2574996948104 .7741622925104 .2580108643103 .7470932007 103.2736587524 102.8586273193102.5099334717 102.2108535767 101.9304885864 101.619178772101 .2419662476100 .8167495728100 .274299621699 .96952056885 99.6647262573299 .6647262573299 .3599472045999 .0551681518698 .75038146973 98.1408081054796 .9216690063595 .7025299072393 .8738174438591 .74033355713 89.60682678223 87.47332763672 85.33984375 82.59677124023 80.15849304199 77.4154205322374 .6723632812571 .9292907714868 .8814392089865 .52880096436 61.8713798522957 .6043891906753 .3373985290549 .0704002380444 .80340957642 41.1459884643637 .7933502197334 .1359291076729 .8689403533924 .68759918213 
18.8966808319111 .886619567874 .266992092133 -3.96220707893 -12.8009700775 $-21.3349609375-28.3450202942-27.4306602478-24.6875991821-21.3349609375$ -17.0679702759 -13.1057596207-8.83876895905 -4.57177686691 -.304785102606 3.0478510856635 .7909169197087 .9244132041939 .4483394622810 .36268997192 11.2770500183111 .8866195678712 .8009700775113 .715330123914 .62969017029 16.1536102294918 .28710937520 .4206008911122 .8588790893625 .29715919495 27.430660247829 .5641593933131 .0880794525132 .3072204589832 .91679000854 33.5263595581133 .5263595581133 .5263595581133 .2215805053733 .22158050537 32.9167900085432 .6120109558132 .3072204589832 .0024414062532 .00244140625 31.6976509094231 .3928699493431 .3928699493431 .0880794525131 .08807945251 31.0880794525131 .0880794525131 .3928699493431 .3928699493431 .69765090942 32.0024414062532 .6120109558132 .9167900085433 .5263595581134 .13592910767 35.0502891540535 .6598587036136 .2694282531736 .8790016174337 .48857116699 38.0981407165538 .7077102661139 .3172798156739 .622070312539 .6220703125 39.3172798156739 .0125007629438 .7077102661139 .0125007629440 .84120941162 44.8034095764250 .8991203308151 .6031913757351 .7293701171951 .90568161011 52.0937080383352 .1920051574752 .1874237060552 .1031379699752 .01371383667 51.9677810668952 .0091018676852 .2079391479552 .7078056335453 .62277603149 54.8613204956155 .4708900451758 .5187492370660 .9570198059161 .87137985229 61.8713798522960 .9570198059160 .0426712036159 .4331016540558 .82352828979 $58.8235282897958 .8235282897958 .8235282897958 .8235282897958 .82352828979-9999$ -9999 -9999 -9999 -9999 -9999 -9999 -9999 -9999 -9999 -9999 -9999 -9999 -9999 -9999 -9999 -9999 -9999 -9999 -9999 -9999 -9999 -9999 -9999 -9999 -9999 -9999 -9999 -9999 -9999 -9999 -9999 -9999 -9999 -9999 -9999 -9999 -9999 -9999 -9999 -9999 -9999 -9999 -9999 -9999 -9999 -9999 -9999 -9999 -9999 -9999 -9999 -9999 -9999 -9999 -9999 -9999 -9999 -9999

-9999 -9999 -9999 -9999 -9999 -9999 -9999 -9999 -9999 -9999 -9999 -9999 -9999 -9999 -9999 -9999 -9999 -9999 -9999 -9999 -9999 -9999 -9999 -9999 -9999 -9999 -9999 -9999 -9999 -9999

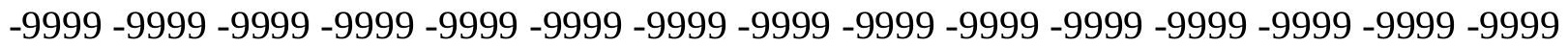
-9999 -9999 -9999 -9999 -9999 -9999 -9999 -9999 -9999 -9999 -9999 -9999 -9999 -9999 -9999 -9999 -9999 -9999 -9999 -9999 -9999 -9999 -9999 -9999 -9999 -9999 -9999 -9999 -9999 -9999 -9999 -9999 -9999 -9999 -9999 -9999 -9999 -9999 -9999 -9999 -9999 -9999 -9999 -9999 -9999 -9999 -9999 -9999 -9999 -9999 -9999 -9999 -9999 -9999 -9999 -9999 -9999 -9999 -9999 -9999

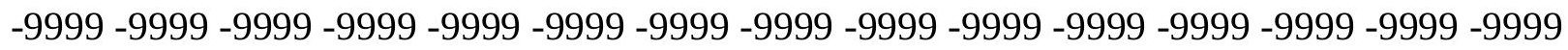
-9999 -9999 -9999 -9999 -9999 -9999 -9999 -9999 -9999 121.6092987061120 .0852966309 118.5614013672117 .342300415116 .7326965332118 .2565994263120 .3900985718 122.2188034058123 .7427978516125 .2667007446126 .1809997559127 .0953979492 127.4001998901127 .7050018311127 .7050018311127 .7050018311127 .4001998901 127.4001998901127 .0953979492126 .7906036377126 .7906036377126 .4858016968 126.4858016968126 .4858016968126 .4858016968126 .7906036377127 .0953979492 127.4001998901128 .0097961426128 .6192932129129 .2288970947129 .8385009766 130.7528076172131 .3623962402131 .6672058105131 .6672058105130 .1432037354 127.4001998901122 .5235977173116 .1231002808109 .1130981445103 .3221969604 100.8839035034100 .5791015625101 .7982025146103 .8896560669104 .9744796753 105.7339706421106 .1744918823106 .2987976074106 .2018661499105 .9381790161 105.5571365356105 .1006317139104 .6177825928104 .1407165527103 .6977310181 103.3077011108102 .9780960083102 .7028656006102 .4605331421102 .2241744995 
101.9770812988101 .7263031006101 .1886978149101 .1886978149101 .1886978149 101.1886978149101 .1886978149100 .8839035034100 .5791015625100 .2742996216 99.3599472045998.1408081054796.3121032714894.4833908081192.65467834473 90.5211791992288 .3876876831185 .9494018554783 .5111236572380 .76805877686 78.0249862670975 .2819290161172 .2340774536168 .8814392089865 .22400665283 61.2618103027357 .2995986938553 .3373985290549 .6799812316946 .02254867554 42.0603485107438 .4029312133833 .8311500549328 .9545898437522 .85887908936 16.153610229498 .533983230591 -9999 -8.83876895905 -17.0679702759 -22.8588790894 -24.3828105927 -23.1636695862 -20.4206008911 -17.0679702759-13.4105501175 $-9.75312423706-6.095703125-2.43828105927 .60957032442093 .352636098862$ 5.4861321449287 .3148431777958 .5339832305919 .75312423706110 .97226047516 11.5818300247212 .8009700775114 .0201196670515 .5440397262617 .37274932861 19.5062503814721 .6397399902323 .7732391357425 .906740188628 .04022979736 29.5641593933131 .0880794525132 .0024414062532 .6120109558132 .91679000854 33.2215805053733 .2215805053732 .9167900085432 .9167900085432 .61201095581 32.6120109558132 .3072204589832 .0024414062532 .0024414062531 .69765090942 31.6976509094231 .3928699493431 .3928699493431 .3928699493431 .39286994934 31.6976509094232 .0024414062532 .3072204589832 .6120109558132 .91679000854 33.5263595581134 .1359291076734 .7455101013235 .3550796508836 .26942825317 36.8790016174337 .4885711669938 .0981407165538 .7077102661139 .31727981567 39.622070312539 .9268493652340 .2316398620639 .9268493652339 .92684936523 39.622070312539 .622070312541 .1459884643650 .8991203308153 .03261184692 50.2895507812550 .675357818651 .047428131151 .4054908752451 .69565963745 51.8287391662651 .8372077941951 .8271293640151 .8728446960452 .00654602051 52.2577285766652 .8118247985853 .3373985290554 .8613204956158 .21395874023 61.8713798522965 .2240066528367 .0527267456166 .4431610107464 .61444854736 62.7857398986861 .2618103027359 .7378807067958 .5187492370658 .51874923706 58.5187492370658 .5187492370658 .51874923706 -9999 -9999 -9999 -9999 -9999 -9999-9999 -9999 -9999 -9999 -9999 -9999 -9999 -9999 -9999 -9999 -9999 -9999 -9999 -9999 -9999 -9999 -

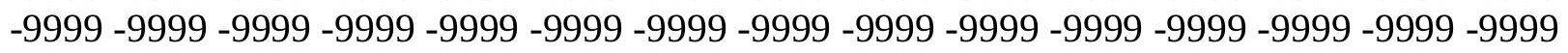

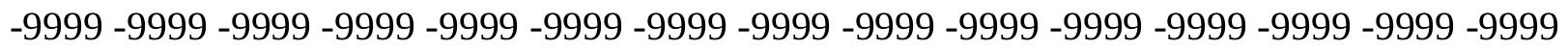
-9999 -9999 -9999 -9999-9999 -9999 -9999

-9999 -9999 -9999 -9999 -9999 -9999 -9999 -9999 -9999-9999 -9999 -9999 -9999 -9999 -9999 -

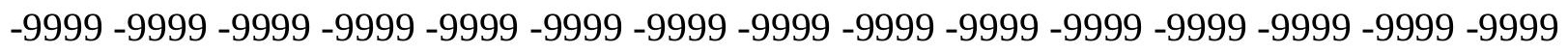
-9999 -9999 -9999 -9999 -9999 -9999 -9999 -9999 -9999 -9999 -9999 -9999 -9999 -9999 -9999

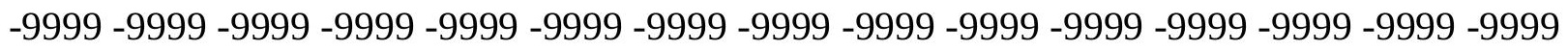

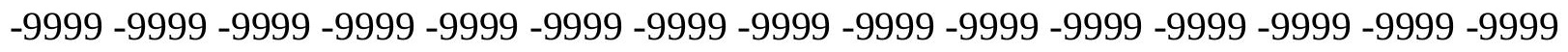

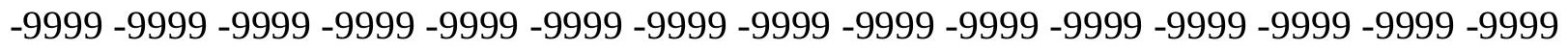

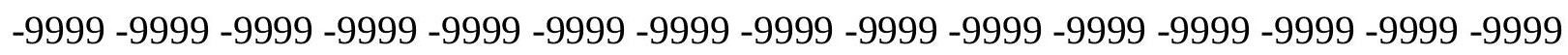
-9999 -9999 -9999 -9999 -9999 -9999 -9999 -9999 -9999 -9999 -9999 -9999 -9999 -9999 -9999 -9999-9999-9999 -9999-9999 -9999 -9999-9999 -9999-9999 -9999 127.0953979492 125.5715026855124 .0475006104122 .8283996582121 .9140014648122 .2188034058 123.7427978516125 .2667007446126 .1809997559126 .7906036377127 .0953979492 127.0953979492127 .0953979492127 .0953979492126 .7906036377126 .4858016968 126.1809997559126 .1809997559125 .8762969971125 .8762969971125 .8762969971 125.8762969971125 .8762969971125 .8762969971126 .1809997559126 .4858016968 
127.0953979492128 .0097961426128 .9241027832130 .1432037354131 .3623962402 132.2767028809132 .5814971924132 .2767028809130 .7528076172127 .4001998901 122.8283996582117 .0374984741111 .24659729106 .3700027466103 .6268997192 103.0174026489103 .6268997192104 .8460998535105 .6718521118106 .3290481567 106.6747970581106 .7636642456106 .6279144287106 .3243942261105 .9026947021 105.4245529175104 .9286727905104 .4476318359104 .0028305054103 .6125030518 103.2847213745103 .0195770264102 .8081665039102 .6395568848102 .5086364746 102.4077987671102 .1029968262102 .1029968262102 .1029968262102 .4077987671 102.712600708102 .712600708102 .712600708102 .1029968262101 .4934005737 100.274299621698 .75038146973100 .274299621695 .397743225193 .56903076172 91.4355392456188 .9972534179786 .5589828491283 .8159103393681 .07285308838 78.0249862670974 .9771423339871 .9292907714868 .5766525268664 .91924285889 61.2618103027357 .6043891906753 .9469718933150 .5943298339846 .63212966919 42.9747009277338 .4029312133833 .8311500549328 .3450202941922 .24930953979 $15.239259719857 .010057926178-1.52392601967$-10.0579099655 -15.8488302231 -18.5918903351 -18.8966808319-17.6775398254 -15.5440397263 -13.1057596207 $-10.0579099655-7.01005792618-3.96220707893-1.219141006471 .21914100647$ 3.3526360988625 .1813468933116 .7052731513988 .2291984558119 .44833946228 10.3626899719211 .5818300247212 .8009700775114 .3248996734616 .15361022949 18.28710937520 .4206008911122 .5541000366224 .6875991821326 .51630973816 28.3450202941929 .8689403533931 .0880794525132 .0024414062532 .61201095581 32.6120109558132 .9167900085432 .9167900085432 .9167900085432 .61201095581 32.6120109558132 .3072204589832 .3072204589832 .0024414062532 .00244140625 32.0024414062531 .6976509094231 .6976509094231 .6976509094232 .00244140625 32.0024414062532 .3072204589832 .6120109558132 .9167900085433 .52635955811 34.1359291076734 .7455101013235 .3550796508835 .9646492004436 .57421112061 37.4885711669938 .0981407165538 .7077102661139 .3172798156739 .92684936523 40.2316398620640 .5364189147940 .8412094116240 .8412094116240 .84120941162 41.1459884643642 .0603485107444 .8034095764248 .765621185349 .37519073486 51.8134689331150 .2895507812550 .7960510253951 .4974784851151 .81346893311 51.5086898803751 .5086898803751 .8134689331152 .1182594299352 .42303848267 52.7278289794953 .6421813964855 .1661109924357 .6043891906760 .95701980591 64.9192428588968 .8814392089872 .2340774536170 .1005783081167 .35751342773 64.6144485473662 .4809494018660 .6522407531759 .4331016540558 .51874923706 58.5187492370658 .5187492370658 .51874923706 -9999 -9999 -9999 -9999 -9999 -9999 -9999 -9999 -9999 -9999 -9999 -9999 -9999 -9999 -9999 -9999 -9999 -9999 -9999 -9999 -9999 -9999

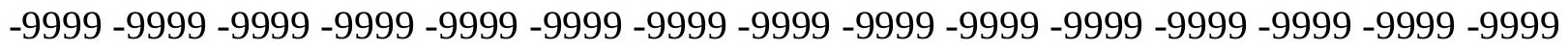

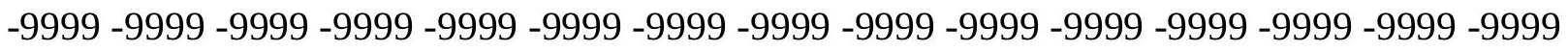
-9999 -9999 -9999 -9999-9999-9999 -9999

-9999 -9999 -9999 -9999 -9999 -9999 -9999 -9999 -9999 -9999 -9999 -9999 -9999 -9999 -9999

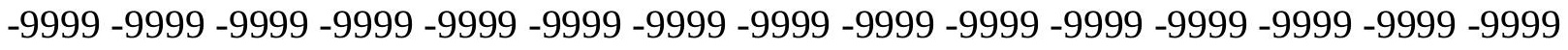

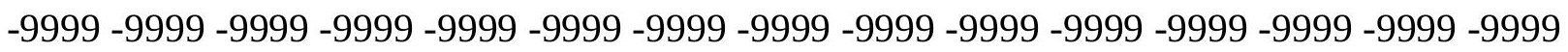
-9999 -9999 -9999 -9999 -9999 -9999 -9999 -9999 -9999 -9999 -9999 -9999 -9999 -9999 -9999 -9999 -9999 -9999 -9999 -9999 -9999 -9999 -9999 -9999 -9999 -9999 -9999 -9999 -9999 -9999 -

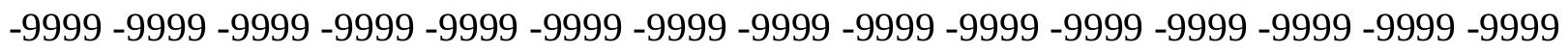

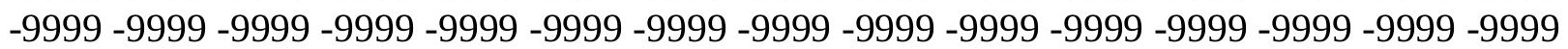


-9999 -9999 -9999 -9999 -9999 -9999 -9999 -9999 -9999 -9999 -9999 -9999 -9999 -9999 -9999 -9999 -9999 -9999 -9999 -9999 -9999 -9999 -9999 -9999 -9999 -9999 -9999 -9999 132.5814971924131 .0576019287129 .8385009766128 .9241027832128 .9241027832 128.3144989014126 .4858016968126 .4858016968126 .7906036377126 .7906036377 126.4858016968126 .4858016968126 .1809997559125 .8762969971125 .5715026855 125.2667007446125 .2667007446125 .2667007446125 .2667007446125 .2667007446 125.2667007446125 .2667007446125 .2667007446125 .5715026855126 .1809997559 127.0953979492128 .3144989014130 .1432037354131 .6672058105132 .5814971924 133.1911010742133 .1911010742131 .3623962402128 .0097961426123 .7427978516 118.5614013672113 .3800964355109 .4179000854106 .6747970581105 .7603988647 105.4557037354106 .0652008057106 .6747970581107 .2844009399107 .4276809692 107.2844009399 107.2114562988 106.6747970581 106.0652008057 105.7567977905 105.1509017944104 .5412979126104 .221282959103 .8119125366103 .4709320068 103.2038497925103 .0122528076102 .8967590332102 .8611526489102 .9128875732 103.0174026489103 .0174026489103 .0174026489103 .6268997192103 .9317016602 104.2365036011104 .2365036011104 .2365036011103 .3221969604105 .7603988647 104.8460998535103 .3221969604101 .493400573799 .0551681518693 .87381744385 91.7403335571389 .302040100186 .5589828491283 .5111236572380 .76805877686 77.7202072143674 .6723632812571 .6244964599668 .2718734741264 .91924285889 61.8713798522958 .5187492370655 .1661109924351 .5086898803747 .85126113892 43.5842704772939 .3172798156734 .7455101013229 .5641593933123 .46845054626 $16.153610229497 .314843177795-1.52392601967-7.3148431778-11.2770500183$ -13.4105501175 -13.7153301239 -13.4105501175 -11.8866195679-10.0579099655 $-7.92441320419-5.48613214493-2.74306607246-.3047851026061 .523926019669$ 3.3526360988625 .1813468933116 .4004869461067 .9244132041939 .143553733826 10.3626899719211 .8866195678713 .4105501174915 .2392597198517 .06797027588 19.2014598846421 .0301704406723 .1636695861824 .9923801422126 .82109069824 28.6497993469230 .1737308502231 .3928699493431 .6976509094232 .00244140625 32.3072204589832 .6120109558132 .6120109558132 .6120109558132 .61201095581 32.3072204589832 .3072204589832 .3072204589832 .0024414062532 .00244140625 32.0024414062532 .0024414062532 .0024414062532 .0024414062532 .30722045898 32.6120109558132 .9167900085433 .2215805053733 .8311500549334 .44071960449 35.0502891540535 .6598587036136 .5742111206137 .1837806701738 .09814071655 38.7077102661139 .3172798156739 .9268493652340 .2316398620640 .84120941162 41.1459884643641 .4507789611841 .7555618286142 .0603485107442 .669921875 44.1938400268646 .3273391723648 .1560516357449 .6799812316949 .98476028442 50.8991203308151 .8134689331152 .7278289794953 .0326118469253 .33739852905 53.6421813964853 .6421813964853 .9469718933154 .5565414428755 .16611099243 56.0804595947357 .6043891906760 .0426712036163 .0905189514266 .74794006348 69.7957916259871 .6244964599670 .7101516723668 .2718734741265 .83358764648 63.7000885009861 .5666007995660 .0426712036159 .1283111572358 .21395874023 58.2139587402358 .2139587402358 .21395874023 -9999 -9999 -9999 -9999 -9999 -9999 -9999 -9999 -9999 -9999 -9999 -9999 -9999 -9999 -9999 -9999 -9999 -9999 -9999-9999 -9999 -9999 -9999 -9999 -9999 -9999 -9999 -9999 -9999 -9999 -9999 -9999 -9999 -9999 -9999 -9999 -9999 -

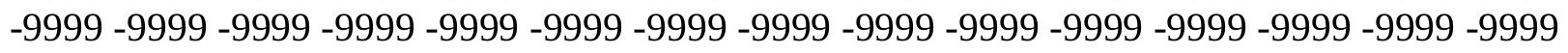
-9999 -9999 -9999 -9999-9999-9999 
-9999 -9999 -9999 -9999 -9999 -9999 -9999 -9999 -9999 -9999 -9999 -9999 -9999 -9999 -9999 -9999 -9999 -9999 -9999 -9999 -9999 -9999 -9999 -9999 -9999 -9999 -9999 -9999 -9999 -9999

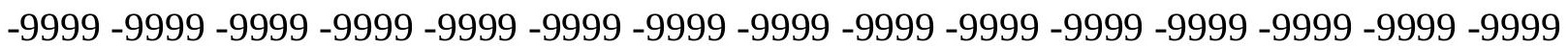
-9999 -9999 -9999 -9999 -9999 -9999 -9999 -9999 -9999 -9999 -9999 -9999 -9999 -9999 -9999 -9999 -9999 -9999 -9999 -9999 -9999 -9999 -9999 -9999 -9999 -9999 -9999 -9999 -9999 -9999 -9999 -9999 -9999 -9999 -9999 -9999 -9999 -9999 -9999 -9999 -9999 -9999 -9999 -9999 -9999 -9999 -9999 -9999 -9999 -9999 -9999 -9999 -9999 -9999 -9999 -9999 -9999 -9999 -9999 -9999

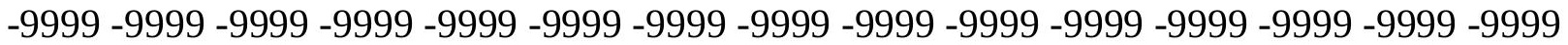
-9999 -9999 -9999 -9999 -9999-9999 -9999 -9999 -9999 -9999 -9999 -9999 -9999 -9999 -9999 -9999 -9999 135.9342041016135.6293945312 134.1054992676132.2767028809 130.1432037354128 .0097961426126 .1809997559125 .8762969971125 .5715026855 125.2667007446124 .9618988037124 .6570968628124 .6570968628124 .6570968628 124.6570968628124 .6570968628124 .6570968628124 .6570968628124 .6570968628 124.9618988037125 .2667007446126 .1809997559127 .7050018311129 .8385009766 132.233215332133 .4411468506134 .4102020264134 .1054992676131 .9720001221 128.6192932129124 .3523025513119 .7806015015115 .5136032104111 .8561019897 109.4179000854108 .1986999512107 .5891036987107 .8938980103107 .8938980103 108.1986999512108 .1986999512108 .1986999512107 .8938980103107 .2844009399 106.6747970581105 .7603988647105 .1509017944104 .9008712769103 .9317016602 103.6268997192103 .3221969604103 .2999267578103 .1123123169103 .028175354 103.0584945679103 .212928772103 .3221969604103 .6268997192103 .9317016602 104.5412979126105 .1509017944105 .7603988647105 .7603988647105 .7603988647 108.5035018921107 .8938980103106 .979598999105 .7603988647103 .9317016602 101.493400573796 .3121032714893 .8738174438591 .4355392456188 .69246673584 85.9494018554783 .206336975180 .4632720947377 .4154205322374 .67236328125 71.6244964599668 .5766525268665 .5288009643662 .4809494018659 .43310165405 56.0804595947352 .7278289794949 .0704002380445 .4129791259841 .14598846436 36.8790016174332 .0024414062526 .5163097381617 .372749328618 .533983230591 $1.828711032867-3.04785108566-6.7052731514-8.83876895905-10.0579099655$ $-10.0579099655-9.44833946228-8.22919845581-6.40048694611-4.26699209213$ -2.13349604607 -9999 1.828711032867 3.657422065735 5.1813468933116.400486946106 7.6196279525769 .14355373382610 .6674804687512 .191410064714 .02011966705 15.8488302230817 .9823207855219 .811029434221 .9445304870623 .77323913574 25.6019496917727 .1258792877228 .6497993469229 .8689403533930 .78330039978 31.3928699493431 .6976509094232 .0024414062532 .0024414062532 .30722045898 32.3072204589832 .3072204589832 .3072204589832 .3072204589832 .30722045898 32.3072204589832 .0024414062532 .3072204589832 .3072204589832 .30722045898 32.6120109558132 .9167900085433 .2215805053733 .5263595581134 .13592910767 34.7455101013235 .3550796508836 .2694282531736 .8790016174337 .79335021973 38.4029312133839 .3172798156739 .9268493652340 .2316398620640 .84120941162 41.1459884643641 .7555618286142 .0603485107442 .3651313781742 .97470092773 43.8890609741245 .4129791259847 .2416992187549 .0704002380450 .59432983398 51.8134689331153 .0326118469253 .9469718933154 .8613204956155 .47089004517 55.7756805419956 .0804595947356 .3852500915556 .6900291442956 .99481964111 57.6043891906758 .8235282897960 .0426712036162 .1761703491264 .61444854736 67.0527267456169 .4910125732470 .4053573608469 .7957916259868 .27187347412 
66.1383666992264 .004882812562 .1761703491260 .6522407531759 .73788070679 58.8235282897957 .909179687557 .909179687557 .9091796875 -9999 -9999 -9999 -9999 -9999 -9999 -9999 -9999 -9999 -9999 -9999 -9999 -9999 -9999 -9999 -9999 -9999 -9999 -9999 -9999 -9999 -9999 -9999 -9999 -9999 -9999 -9999 -9999 -9999 -9999 -9999 -9999 -9999 -9999 -9999 -9999 -9999 -9999 -9999 -9999 -9999 -9999 -9999 -9999 -9999 -9999 -9999 -9999 - -9999 -9999 -9999 -9999 -9999 -9999 -9999 -9999 -9999 -9999

-9999 -9999 -9999 -9999 -9999 -9999 -9999 -9999 -9999 -9999 -9999 -9999 -9999 -9999 -9999

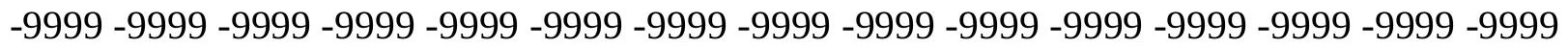

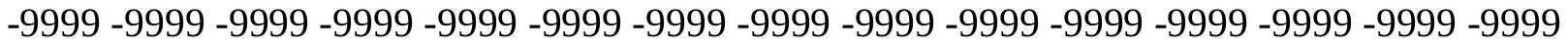
-9999 -9999 -9999 -9999 -9999 -9999 -9999 -9999 -9999 -9999 -9999 -9999 -9999 -9999 -9999

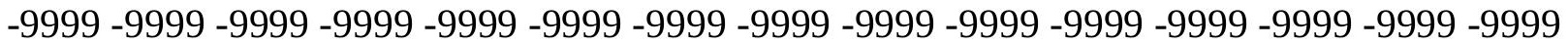
-9999 -9999 -9999 -9999 -9999 -9999 -9999 -9999 -9999 -9999 -9999 -9999 -9999 -9999 -9999 -9999 -9999 -9999 -9999 -9999 -9999 -9999 -9999 -9999 -9999 -9999 -9999 -9999 -9999 -9999 -9999 -9999 -9999 -9999 -9999 -9999 -9999 -9999 -9999 -9999 -9999 -9999 -9999 -9999 - 9999 -9999 -9999 -9999 -9999 -9999 -9999 -9999 -9999 -9999 -9999 -9999 -9999 -9999 -9999 -9999 -9999 -9999 -9999 -9999-9999-9999 138.3724975586 136.2389984131 134.1054992676 131.6672058105129 .533706665127 .4001998901126 .1809997559125 .5715026855 124.9618988037124 .9618988037124 .6570968628125 .5715026855123 .43800354 124.3523025513124 .9618988037124 .6570968628124 .3523025513125 .5715026855 128.3144989014131 .7047424316132 .9206542969133 .9708709717134 .4801635742 133.888458252131 .9645385742128 .9241027832124 .9618988037120 .6949005127 117.0374984741113 .9896011353111 .551399231110 .3321990967109 .7226028442 109.4179000854109 .4179000854109 .4179000854109 .1130981445108 .8082962036 108.5035018921107 .8938980103107 .2844009399106 .3700027466105 .4557037354 104.8460998535103 .9317016602103 .3221969604103 .0174026489103 .0174026489 103.0174026489103 .0174026489103 .0174026489103 .3221969604103 .6268997192 103.9317016602104 .5412979126105 .1509017944105 .7603988647106 .6747970581 107.2844009399 107.2844009399 110.0273971558109.7226028442 108.8082962036 107.2844009399105 .455703735499 .9695205688598 .1408081054795 .70252990723 93.2642517089890 .8259735107488 .0829010009885 .3398437582 .59677124023 80.1584930419977 .4154205322374 .6723632812571 .9292907714869 .18623352051 66.4431610107463 .7000885009860 .6522407531757 .6043891906754 .55654144287 51.2038993835447 .5464782714843 .8890609741239 .3172798156733 .52635955811 26.2115192413318 .5918903350811 .581830024725 .486132144928 .6095703244209 -3.35263609886 -5.79091691971 -7.3148431778 -7.92441320419 -7.92441320419 -7.01005792618 -5.48613214493 -3.35263609886 -1.21914100647.6095703244209 2.4382810592653 .6574220657355 .1813468933116 .4004869461067 .924413204193 9.4483394622811 .2770500183113 .1057596206714 .934470176716 .76317977905 18.5918903350820 .7253894805922 .5541000366224 .3828105926525 .9067401886 27.430660247828 .6497993469229 .5641593933130 .4785099029530 .78330039978 31.3928699493431 .6976509094232 .0024414062532 .0024414062532 .00244140625 32.0024414062532 .3072204589832 .3072204589832 .3072204589832 .30722045898 32.3072204589832 .3072204589832 .6120109558132 .6120109558132 .91679000854 33.5263595581133 .8311500549334 .4407196044935 .0502891540535 .65985870361 36.5742111206137 .4885711669938 .0981407165539 .0125007629439 .6220703125 40.2316398620640 .8412094116241 .4507789611841 .7555618286142 .06034851074 
42.3651313781742 .66992187543 .2794914245644 .4986305236846 .02254867554 47.8512611389249 .6799812316951 .8134689331153 .6421813964855 .47089004517 56.6900291442957 .6043891906758 .5187492370658 .8235282897959 .12831115723 59.4331016540559 .4331016540559 .7378807067960 .3474502563560 .95701980591 62.1761703491263 .3953094482465 .2240066528367 .0527267456168 .27187347412 68.8814392089868 .5766525268667 .3575134277365 .8335876464864 .0048828125 62.4809494018661 .2618103027360 .0426712036159 .1283111572358 .21395874023 57.6043891906757 .60438919067 -9999 -9999 -9999 -9999 -9999 -9999 -9999 -9999 -9999 -9999 -9999 -9999 -9999 -9999 -9999 -9999 -9999 -9999 -9999 -9999 -9999 -9999 -9999 -9999 -9999 -9999 -9999 -9999 -9999 -9999 -9999 -9999 -9999 -9999 -9999 -9999 -9999 -9999 -9999 -

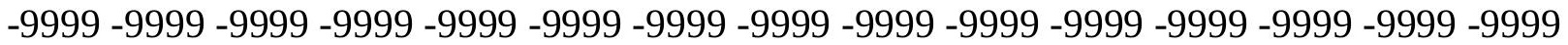
-9999 -9999-9999-9999

-9999 -9999 -9999 -9999 -9999 -9999 -9999 -9999 -9999 -9999 -9999 -9999 -9999 -9999 -9999 -9999 -9999 -9999 -9999 -9999 -9999 -9999 -9999 -9999 -9999 -9999 -9999 -9999 -9999 -9999 -9999 -9999 -9999 -9999 -9999 -9999 -9999 -9999 -9999 -9999 -9999 -9999 -9999 -9999 -9999

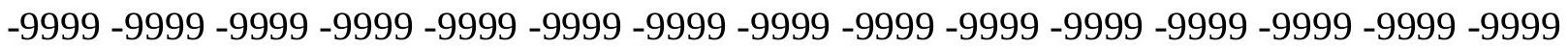

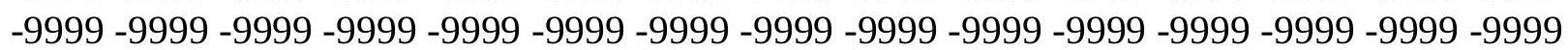
-9999 -9999 -9999 -9999 -9999 -9999 -9999 -9999 -9999 -9999 -9999 -9999 -9999 -9999 -9999 -999 -9999 -9999 -9999 -9999 -9999 -9999 -9999 -9999 -9999 -9999 -9999 -9999 -9999 -9999 -9999 -9999 -9999 -9999 -9999 -9999 -9999 -9999 -9999 -9999 -9999 -9999 -9999 -9999 -9999 -9999 -

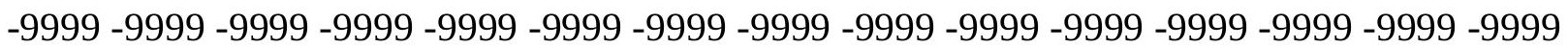
-9999 -9999 -9999 -9999 -9999 -9999 -9999 -9999 -9999 -9999 -9999 -9999 -9999 -9999 -9999 125.7838287354125 .5442657471125 .3220062256124 .7499008179124 .7974853516 125.0951080322125 .2122802734124 .6570968628125 .8762969971129 .2288970947 133.4958953857138 .3307800293134 .1267547607134 .2374420166133 .4530334473 131.6306915283128 .8357696533125 .2667007446121 .3044967651117 .9517974854 115.5136032104113 .6848983765112 .4656982422111 .8561019897111 .24659729 110.9418029785110 .6370010376110 .3321990967110 .0273971558109 .4179000854 108.5035018921107 .8938980103106 .979598999106 .0652008057105 .1509017944 104.5412979126103 .9317016602103 .3221969604102 .712600708102 .4077987671 102.712600708102 .712600708103 .0174026489103 .6268997192104 .2365036011 104.8460998535105 .4557037354106 .3700027466106 .979598999107 .8938980103 108.1986999512108 .1986999512110 .6161956787109 .7226028442105 .1509017944 103.3221969604101 .493400573799 .6647262573297 .2264633178795 .09295654297 92.349891662689 .9116134643687 .4733276367284 .7302627563582 .29197692871 79.8537063598677 .4154205322374 .9771423339872 .5388565063570 .10057830811 67.6623001098664 .9192428588962 .1761703491259 .4331016540556 .69002914429 53.6421813964849 .9847602844245 .717769622840 .5364189147934 .13592910767 27.430660247821 .0301704406714 .629690170298 .8387689590453 .657422065735 -.304785102606 -3.65742206573 -6.095703125 -7.3148431778 -7.3148431778 -6.40048694611 -4.57177686691 -2.13349604607-9999 1.21914100647 2.743066072464 3.962207078934 5.4861321449287 .0100579261788 .53398323059110 .3626899719212 .1914100647 13.715330123915 .5440397262617 .6775398254419 .5062503814721 .03017044067 22.8588790893624 .3828105926525 .906740188627 .430660247828 .34502029419 29.2593708038329 .8689403533930 .4785099029531 .0880794525131 .39286994934 31.6976509094231 .6976509094232 .0024414062532 .0024414062532 .00244140625 
32.0024414062532 .3072204589832 .3072204589832 .3072204589832 .61201095581 32.9167900085433 .2215805053733 .5263595581134 .1359291076734 .74551010132 35.3550796508835 .9646492004436 .8790016174337 .7933502197338 .40293121338 39.3172798156740 .2316398620640 .8412094116241 .4507789611841 .75556182861 42.0603485107442 .0603485107442 .3651313781742 .66992187543 .27949142456 44.1938400268645 .717769622847 .8512611389250 .5943298339853 .03261184692 55.7756805419957 .909179687559 .7378807067960 .9570198059161 .87137985229 62.1761703491262 .4809494018662 .4809494018662 .4809494018662 .48094940186 62.7857398986863 .0905189514263 .7000885009864 .6144485473665 .52880096436 66.4431610107467 .3575134277367 .6623001098667 .0527267456166 .13836669922 64.9192428588963 .7000885009862 .4809494018661 .2618103027360 .34745025635 $59.4331016540558 .2139587402357 .2995986938556 .9948196411156 .99481964111-9999$ -9999 -9999 -9999 -9999 -9999 -9999 -9999 -9999 -9999 -9999 -9999 -9999 -9999 -9999 -9999

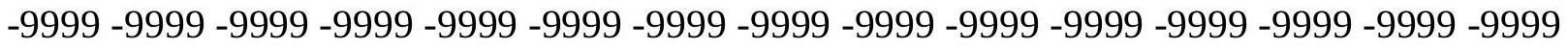
-9999 -9999 -9999 -9999 -9999 -9999 -9999 -9999 -9999 -9999 -9999 -9999 -9999 -9999 -9999 -9999 -9999 -9999 -9999-9999 -9999 -9999 -9999 -9999-9999-9999 -

-9999 -9999 -9999 -9999 -9999 -9999 -9999 -9999 -9999 -9999 -9999 -9999 -9999 -9999 -9999 -9999 -9999 -9999 -9999 -9999 -9999 -9999 -9999 -9999 -9999 -9999 -9999 -9999 -9999 - 9999 -9999 -9999 -9999 -9999 -9999 -9999 -9999 -9999 -9999 -9999 -9999 -9999 -9999 -9999 -9999 -

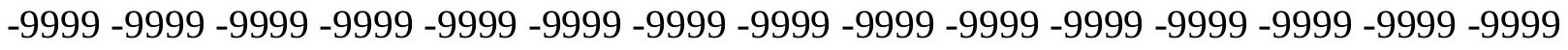

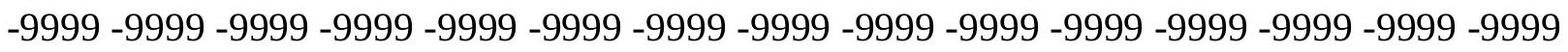
-9999 -9999 -9999 -9999 -9999 -9999 -9999 -9999 -9999 -9999 -9999 -9999 -9999 -9999 -9999 -9999 -9999 -9999 -9999 -9999 -9999 -9999 -9999 -9999 -9999 -9999 -9999 -9999 -9999 -9999 -

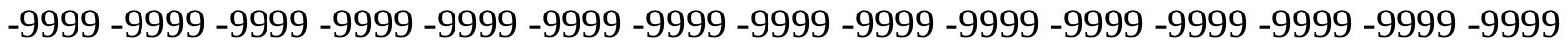

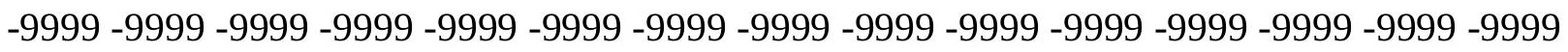
-9999 -9999 -9999 -9999 -9999 -9999 -9999 -9999 -9999 -9999 -9999 -9999 -9999 -9999 -9999 -9999 -9999 -9999 -9999-9999 126.1294021606126.1809997559 126.7906036377 125.2667007446129 .533706665133 .4958953857137 .1533050537142 .3856658936 143.9710083008143 .0978240967138 .8314819336128 .7646331787125 .7342224121 121.9140014648118 .8662033081116 .4279022217115 .2088012695114 .2944030762 113.6848983765113 .3800964355112 .7705001831112 .4656982422111 .8561019897 110.9418029785110 .3321990967109 .4179000854108 .5035018921107 .5891036987 106.6747970581106 .0652008057105 .1509017944104 .5412979126103 .6268997192 103.0174026489102 .712600708102 .4077987671102 .4077987671102 .712600708 103.3221969604103 .9317016602104 .5412979126105 .4557037354106 .3700027466 107.2844009399 108.1986999512108.8082962036109.1130981445108.5035018921 107.5891036987106 .0652008057104 .5412979126102 .712600708100 .8839035034 98.7503814697396 .3121032714893 .8738174438591 .4355392456188 .99725341797 86.8637619018684 .4254837036182 .2919769287180 .1584930419977 .72020721436 75.5867080688573 .4532165527371 .3197174072368 .8814392089866 .74794006348 64.3096618652361 .5666007995658 .8235282897955 .7756805419951 .50868988037 46.6321296691941 .1459884643635 .3550796508829 .5641593933123 .46845054626 17.0679702758810 .972260475165 .181346893311 .3047851026058 -3.65742206573 $-6.095703125-7.01005792618-6.40048694611-4.87656211853-3.04785108566$ $-.914355397224 .30478510260581 .8287110328673 .3526360988624 .87656211853$ 6.4004869461067 .9244132041939 .4483394622811 .2770500183113 .10575962067 
14.6296901702916 .4584007263218 .28710937520 .1158199310321 .63973999023 23.1636695861824 .6875991821325 .906740188627 .1258792877228 .04022979736 28.9545898437529 .8689403533930 .4785099029530 .7833003997831 .08807945251 31.3928699493431 .6976509094231 .6976509094232 .0024414062532 .00244140625 32.0024414062532 .3072204589832 .3072204589832 .6120109558132 .91679000854 33.2215805053733 .5263595581134 .1359291076734 .7455101013235 .35507965088 35.9646492004436 .8790016174337 .7933502197338 .7077102661139 .6220703125 40.5364189147941 .4507789611842 .0603485107442 .0603485107442 .06034851074 42.0603485107442 .0603485107442 .0603485107442 .66992187543 .58427047729 45.1082000732447 .5464782714850 .5943298339854 .2517509460457 .60438919067 60.6522407531762 .7857398986864 .004882812565 .2240066528365 .52880096436 65.8335876464865 .8335876464865 .5288009643665 .2240066528364 .91924285889 64.9192428588964 .9192428588965 .2240066528365 .5288009643666 .13836669922 66.4431610107466 .4431610107465 .8335876464865 .2240066528364 .30966186523 63.3953094482462 .1761703491261 .2618103027360 .3474502563559 .43310165405 58.5187492370657 .2995986938556 .6900291442956 .69002914429 -9999 -9999 -9999 -9999 -9999 -9999 -9999 -9999 -9999 -9999 -9999 -9999 -9999 -9999 -9999 -9999 -9999 -9999 -9999 -9999 -9999 -9999 -9999 -9999 -9999 -9999 -9999 -9999 -9999 -9999 -9999 -9999 -9999 -9999 -999 -9999 -9999 -9999 -9999 -9999 -9999 -9999 -9999 -9999 -9999 -9999 -9999 -9999 -9999 -9999 -9999 -9999 -9999 -9999-9999-9999-9999-9999

-9999 -9999 -9999 -9999 -9999 -9999 -9999 -9999 -9999 -9999 -9999 -9999 -9999 -9999 -9999

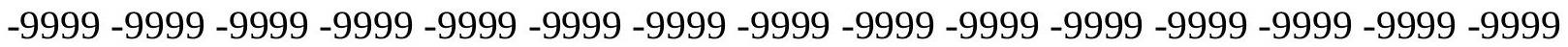
-9999 -9999 -9999 -9999 -9999 -9999 -9999 -9999 -9999 -9999 -9999 -9999 -9999 -9999 -9999 -9999 -9999 -9999 -9999 -9999 -9999 -9999 -9999 -9999 -9999 -9999 -9999 -9999 -9999 -9999 -9999 -9999 -9999 -9999 -9999 -9999 -9999 -9999 -9999 -9999 -9999 -9999 -9999 -9999 -9999 -9999 -9999 -9999 -9999 -9999 -9999 -9999 -9999 -9999 -9999 -9999 -9999 -9999 -9999 -9999 -9999 -9999 -9999 -9999 -9999 -9999 -9999 -9999 -9999 -9999 -9999 -9999 -9999 -9999 -9999

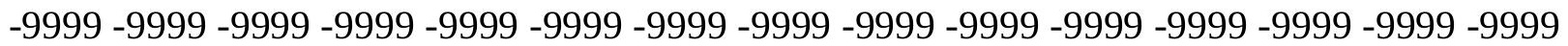
-9999 -9999 -9999 -9999 -9999 -9999 -9999 -9999 -9999 -9999 -9999 -9999 -9999 -9999 -9999 -9999 -9999 -9999 -9999 -9999 -9999 -9999 -9999 -9999 -9999 -9999 -9999 -9999 -9999 -9999 -9999 -9999-9999 -9999 -9999 -9999-9999 -9999 -9999 133.8813323975126 .7906036377 129.8385009766139 .8963928223142 .9281768799141 .681137085136 .8484954834 131.9720001221127 .7050018311123 .5174102783120 .0504684448117 .80884552 116.7326965332116 .1231002808115 .5616073608115 .0746765137114 .5991973877 113.9896011353113 .075302124112 .1608963013111 .24659729110 .3321990967 109.4179000854108 .5035018921107 .5891036987106 .6747970581105 .7603988647 105.1509017944104 .5412979126103 .9317016602103 .3221969604102 .712600708 102.4077987671102 .4077987671102 .712600708103 .3221969604103 .9317016602 104.8460998535106 .0652008057106 .979598999108 .1986999512109 .1130981445 109.4179000854108 .8082962036107 .8938980103106 .6747970581105 .1509017944 103.6268997192101 .798202514699 .6647262573297 .5312423706195 .3977432251 92.9594726562590 .8259735107488 .6924667358486 .5589828491284 .42548370361 82.2919769287180 .4632720947378 .3297805786176 .5010681152374 .36756896973 72.5388565063570 .4053573608468 .2718734741266 .1383666992263 .70008850098 60.6522407531756 .6900291442952 .1182594299347 .2416992187542 .36513137817 37.1837806701732 .0024414062524 .9923801422118 .5918903350811 .88661956787 
5.486132144928 -9999 -4.57177686691 -6.095703125 -5.79091691971 -4.57177686691 -3.04785108566 -1.21914100647-9999 1.5239260196693.047851085663 4.571776866913 6.0957031257 .6196279525769 .14355373382610 .6674804687512 .49619007111 14.0201196670515 .5440397262617 .3727493286118 .8966808319120 .42060089111 21.9445304870623 .4684505462624 .6875991821325 .906740188626 .82109069824 28.0402297973628 .6497993469229 .5641593933129 .8689403533930 .47850990295 30.7833003997831 .0880794525131 .3928699493431 .6976509094232 .00244140625 32.0024414062532 .3072204589832 .3072204589832 .6120109558132 .91679000854 33.2215805053733 .5263595581134 .1359291076734 .7455101013235 .35507965088 35.9646492004436 .8790016174337 .7933502197338 .7077102661139 .92684936523 40.8412094116241 .7555618286142 .3651313781742 .3651313781742 .06034851074 41.7555618286141 .4507789611841 .4507789611841 .7555618286142 .36513137817 43.8890609741246 .3273391723650 .2895507812554 .8613204956159 .43310165405 63.0905189514265 .5288009643667 .3575134277368 .2718734741268 .88143920898 69.1862335205168 .8814392089868 .2718734741267 .6623001098666 .74794006348 66.1383666992265 .8335876464865 .5288009643665 .5288009643665 .52880096436 65.5288009643665 .2240066528364 .9192428588964 .3096618652363 .70008850098 62.7857398986861 .8713798522961 .2618103027360 .3474502563559 .43310165405 58.5187492370657 .2995986938556 .3852500915556 .0804595947356 .38525009155 -9999 -9999 -9999 -9999 -9999 -9999 -9999 -9999 -9999 -9999 -9999 -9999 -9999 -9999 -9999 -9999

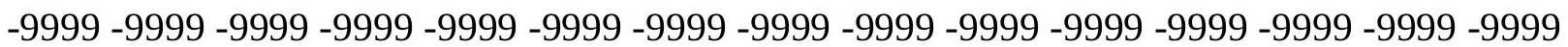
-9999 -9999 -9999 -9999 -9999 -9999 -9999 -9999 -9999 -9999 -9999 -9999 -9999 -9999 -9999 -9999 -9999 -9999 -9999 -9999 -9999 -9999 -9999 -9999 -9999

-9999 -9999 -9999 -9999 -9999 -9999 -9999 -9999 -9999 -9999 -9999 -9999 -9999 -9999 -9999 -9999 -9999 -9999 -9999 -9999 -9999 -9999 -9999 -9999 -9999 -9999 -9999 -9999 -9999 -9999 -9999 -9999 -9999 -9999 -9999 -9999 -9999 -9999 -9999 -9999 -9999 -9999 -9999 -9999 -9999 -9999 -9999 -9999 -9999 -9999 -9999 -9999 -9999 -9999 -9999 -9999 -9999 -9999 -9999 -9999

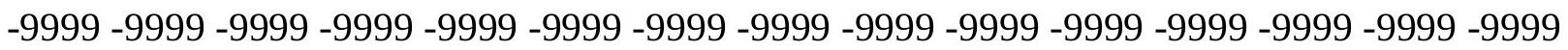

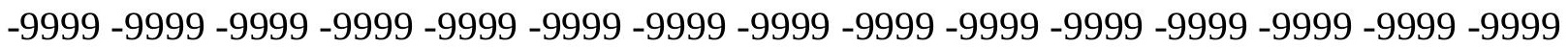

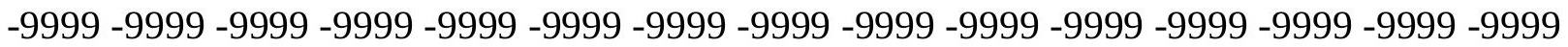
-9999 -9999 -9999 -9999 -9999 -9999 -9999 -9999 -9999 -9999 -9999 -9999 -9999 -9999 -9999 -9999 -9999 -9999 -9999 -9999 -9999 -9999 -9999 -9999 -9999 -9999 -9999 -9999 -9999 -9999

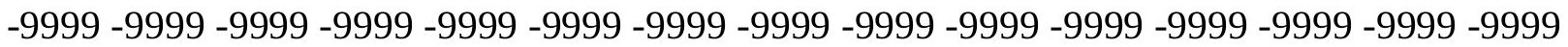
-9999 -9999 -9999 -9999 -9999 -9999 -9999 -9999 -9999 -9999 -9999 -9999 -9999 -9999 132.8863067627131 .6672058105129 .8385009766127 .7050018311125 .1484527588 121.8709640503119 .6104888916118 .2593154907117 .4897537231117 .1555786133 116.6392822266116 .0033493042115 .2308425903114 .3168563843113 .3800964355 112.4656982422111 .24659729110 .3321990967109 .4179000854108 .5035018921 107.5891036987106 .6747970581106 .0652008057105 .4557037354104 .5412979126 103.9317016602103 .3221969604103 .0019760132102 .4077987671102 .4077987671 102.4077987671103 .0174026489103 .9317016602105 .1509017944106 .3700027466 107.5891036987108 .5533828735108 .8459472656108 .605178833107 .8501739502 106.6747970581105 .4557037354103 .9317016602102 .4077987671100 .5791015625 98.445587158296 .3121032714894 .1785964965892 .349891662690 .21640014648 88.0829010009886 .254188537684 .4254837036182 .5967712402380 .76805877686 79.2441329956177 .4154205322375 .5867080688573 .7580032348671 .92929077148 
69.7957916259867 .3575134277364 .6144485473660 .9570198059156 .99481964111 52.4230384826747 .8512611389243 .2794914245638 .0981407165532 .00244140625 $25.6019496917718 .8966808319111 .886619567874 .87656211853-1.82871103287$ $-3.04785108566-3.35263609886-3.04785108566-2.13349604607-.609570324421$ .30478510260581 .8287110328673 .3526360988624 .5717768669136 .095703125 7.6196279525769 .14355373382610 .6674804687511 .8866195678713 .41055011749 14.934470176716 .4584007263217 .9823207855219 .5062503814720 .72538948059 22.2493095397923 .4684505462624 .6875991821325 .906740188626 .82109069824 27.7354507446328 .3450202941929 .2593708038329 .8689403533930 .47850990295 30.7833003997831 .0880794525131 .3928699493431 .6976509094232 .00244140625 32.0024414062532 .3072204589832 .6120109558132 .9167900085433 .22158050537 33.5263595581134.13592910767 34.74551010132 35.3550796508835.96464920044 36.8790016174337 .7933502197338 .7077102661139 .622070312540 .53641891479 41.7555618286142 .3651313781742 .0603485107441 .7555618286141 .14598846436 40.8412094116240 .5364189147940 .5364189147941 .1459884643642 .36513137817 44.4986305236848 .765621185354 .5565414428761 .2618103027365 .22400665283 68.2718734741270 .1005783081171 .6244964599672 .2340774536172 .23407745361 71.6244964599670 .7101516723669 .4910125732468 .2718734741267 .05272674561 66.4431610107465 .5288009643665 .2240066528364 .6144485473664 .61444854736 64.3096618652364 .004882812563 .3953094482463 .0905189514262 .48094940186 61.5666007995660 .9570198059160 .0426712036159 .1283111572358 .21395874023 57.2995986938556 .3852500915555 .7756805419955 .77568054199 -9999 -9999 -9999-9999 -9999 -9999 -9999 -9999 -9999 -9999 -9999 -9999 -9999 -9999 -9999 -9999 -9999 -9999 -9999 -9999 -9999 -9999 -9999 -9999 -9999 -9999 -9999 -9999 -9999 -9999 -9999 -9999 -9999 -9999 -

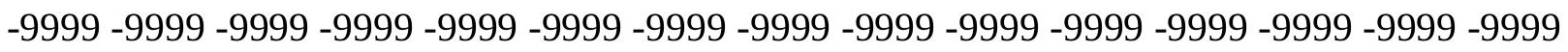
-9999 -9999 -9999 -9999-9999-9999-9999 -9999 -9999 -9999 -9999 -9999 -9999 -9999 -9999 -9999 -9999 -9999 -9999 -9999 -9999 -9999

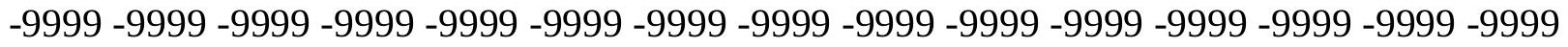
-9999 -9999 -9999 -9999 -9999 -9999 -9999 -9999 -9999 -9999 -9999 -9999 -9999 -9999 -9999 -9999 -9999 -9999 -9999 -9999 -9999 -9999 -9999 -9999 -9999 -9999 -9999 -9999 -9999 -9999 -9999 -9999 -9999 -9999 -9999 -9999 -9999 -9999 -9999 -9999 -9999 -9999 -9999 -9999 -9999

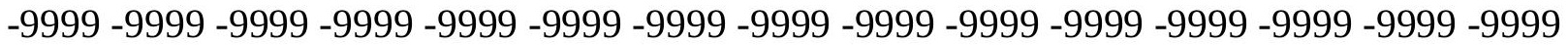

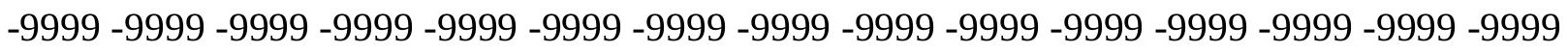
-9999 -9999 -9999 -9999 -9999 -9999 -9999 -9999 -9999 -9999 -9999 -9999 -9999 -9999 -9999 -9999 -9999 -9999 -9999 -9999 -9999 -9999 -9999 -9999 -9999 -9999 -9999 -9999 -9999 -9999 -

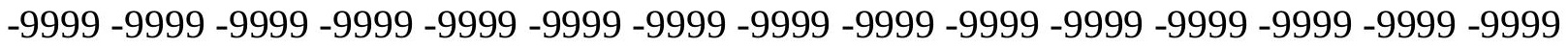

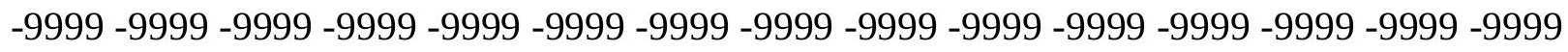
-9999 -9999 -9999 -9999 123.6516418457 121.4395294189119 .9531707764119 .0619125366 118.5706634521118 .2235183716117 .2521743774116 .3889694214115 .4477310181 114.4512405396113 .3800964355112 .1608963013111 .24659729110 .3321990967 109.4179000854108.5035018921 107.8938980103107.2844009399 106.3700027466 105.7603988647105 .1509017944104 .2365036011103 .6268997192103 .0174026489 102.712600708102 .4077987671102 .4077987671102 .712600708103 .6268997192 104.8460998535106 .3700027466107 .3860855103107 .7607955933107 .7355194092 107.2844009399106.5611495972 105.4557037354104.2365036011 102.712600708 101.188697814999 .3599472045997 .5312423706195 .397743225193 .56903076172 
91.4355392456189 .6068267822388 .0829010009886 .254188537684 .73026275635 83.206336975181 .3776321411179 .8537063598678 .3297805786176 .50106811523 74.6723632812572 .8436431884870 .4053573608467 .6623001098664 .30966186523 60.6522407531756 .6900291442952 .4230384826748 .1560516357443 .58427047729 38.0981407165532 .6120109558126 .5163097381619 .811029434212 .1914100647 5.7909169197082 .133496046066 .3047851026058 -9999 -9999.9143553972244 1.8287110328673 .0478510856634 .2669920921335 .4861321449286 .705273151398 7.9244132041939 .4483394622810 .6674804687511 .8866195678713 .10575962067 14.6296901702915 .8488302230817 .0679702758818 .5918903350819 .8110294342 21.0301704406722 .2493095397923 .4684505462624 .6875991821325 .60194969177 26.5163097381627 .430660247828 .3450202941928 .9545898437529 .86894035339 30.4785099029530 .7833003997831 .0880794525131 .3928699493431 .69765090942 32.0024414062532 .3072204589832 .6120109558132 .9167900085433 .22158050537 33.5263595581133 .8311500549334 .4407196044935 .0502891540535 .65985870361 36.5742111206137 .1837806701738 .0981407165539 .0125007629440 .23163986206 40.8412094116241 .4507789611841 .4507789611840 .8412094116240 .53641891479 39.9268493652339 .622070312539 .622070312539 .9268493652340 .84120941162 42.66992187546 .3273391723653 .3373985290560 .6522407531766 .44316101074 70.4053573608472 .8436431884874 .3675689697374 .6723632812574 .67236328125 73.7580032348672 .5388565063570 .7101516723669 .1862335205167 .66230010986 66.4431610107465 .2240066528364 .6144485473664 .004882812563 .70008850098 63.3953094482463 .0905189514262 .7857398986862 .4809494018661 .87137985229 61.2618103027360 .6522407531759 .7378807067959 .1283111572358 .21395874023 57.2995986938556 .3852500915555 .4708900451755 .4708900451755 .47089004517 -9999 -9999 -9999 -9999 -9999 -9999 -9999 -9999 -9999 -9999 -9999 -9999 -9999 -9999 -9999 -9999 -9999 -9999 -9999 -9999 -9999 -9999 -9999 -9999 -9999 -9999 -9999 -9999 -9999 -9999 -9999 -

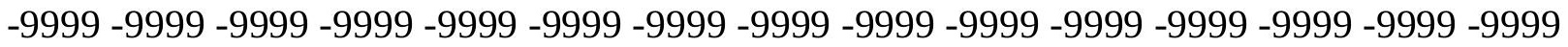
-9999 -9999 -9999 -9999 -9999 -9999 -9999 -9999 -9999

-9999 -9999 -9999 -9999 -9999 -9999 -9999 -9999 -9999 -9999 -9999 -9999 -9999 -9999 -9999 -9999 -9999 -9999 -9999 -9999 -9999 -9999 -9999 -9999 -9999 -9999 -9999 -9999 -9999 -9999 -9999 -9999 -9999 -9999 -9999 -9999 -9999 -9999 -9999 -9999 -9999 -9999 -9999 -9999 -9999

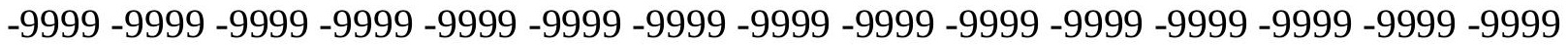

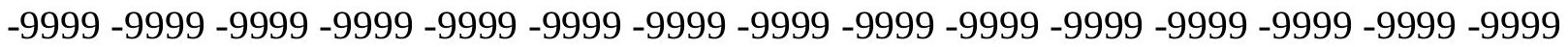
-9999 -9999 -9999 -9999 -9999 -9999 -9999 -9999 -9999 -9999 -9999 -9999 -9999 -9999 -9999 -9999 -9999 -9999 -9999 -9999 -9999 -9999 -9999 -9999 -9999 -9999 -9999 -9999 -9999 -9999 -9999 -9999 -9999 -9999 -9999 -9999 -9999 -9999 -9999 -9999 -9999 -9999 -9999 -9999 -9999

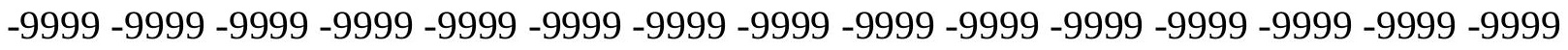

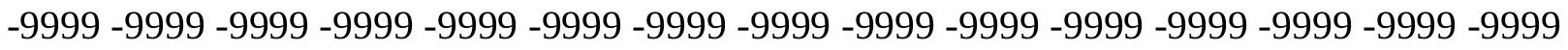
-9999 -9999 -9999 -9999 -9999 -9999 -9999 -9999 -9999 -9999 -9999 -9999 -9999 -9999 -9999 -9999 -9999 -9999 -9999 -9999 -9999 -9999 -9999 123.1332015991119 .330039978 118.72996521117 .9367828369116 .4812011719115 .4420394897114 .2944030762 113.075302124112 .1608963013110 .9418029785110 .3321990967109 .4179000854 109.1130981445108 .5035018921107 .8938980103106 .979598999106 .3700027466 105.4557037354104 .8460998535103 .9317016602103 .3221969604102 .712600708 102.712600708102 .712600708103 .0174026489103 .3221969604104 .2365036011 105.7603988647106 .6222915649106 .7859344482106 .637802124106 .0652008057 
105.4557037354104 .2365036011103 .0174026489101 .493400573799 .96952056885 98.1408081054796 .3121032714894 .4833908081192 .6546783447391 .13075256348 89.302040100187 .7781066894586 .5589828491285 .0350494384883 .51112365723 81.9871978759880 .7680587768678 .9393463134877 .4154205322375 .28192901611 72.8436431884870 .1005783081167 .0527267456163 .3953094482459 .73788070679 56.0804595947352 .4230384826748 .4608306884843 .5842704772938 .40293121338 33.2215805053728 .0402297973620 .1158199310313 .410550117498 .838768959045 6.0957031254 .2669920921333 .6574220657353 .9622070789344 .266992092133 5.1813468933116 .0957031257 .0100579261787 .9244132041938 .838768959045 10.0579099655210 .9722604751612 .191410064713 .1057596206714 .32489967346 15.5440397262616 .7631797790517 .6775398254418 .8966808319120 .11581993103 21.334960937522 .5541000366223 .4684505462624 .6875991821325 .60194969177 26.5163097381627 .430660247828 .3450202941929 .2593708038329 .86894035339 30.4785099029530 .7833003997831 .3928699493431 .6976509094231 .69765090942 32.0024414062532 .3072204589832 .6120109558132 .9167900085433 .22158050537 33.8311500549334 .1359291076734 .7455101013235 .3550796508836 .26942825317 36.8790016174337 .7933502197338 .4029312133839 .3172798156739 .92684936523 40.2316398620640 .2316398620639 .9268493652339 .622070312539 .31727981567 39.0125007629439 .0125007629439 .3172798156739 .9268493652341 .45077896118 43.8890609741253 .0326118469261 .2618103027367 .9670867919972 .53885650635 75.2819290161176 .5010681152376 .5010681152376 .1962814331175 .58670806885 73.4532165527371 .3197174072369 .1862335205167 .6623001098666 .13836669922 64.9192428588963 .7000885009863 .0905189514262 .7857398986862 .48094940186 62.1761703491262 .1761703491261 .8713798522961 .2618103027360 .95701980591 60.3474502563559 .4331016540558 .8235282897957 .909179687557 .29959869385 56.3852500915555 .4708900451754 .8613204956155 .16611099243 -9999 -9999 -9999 -9999 -9999 -9999 -9999 -9999 -9999 -9999 -9999 -9999 -9999 -9999 -9999 -9999 -9999 -9999 -9999

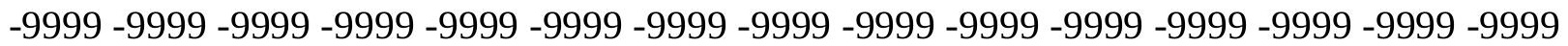
-9999 -9999 -9999 -9999 -9999 -9999 -9999 -9999 -9999 -9999 -9999 -9999 -9999 -9999 -9999 -9999 -9999 -9999-9999-9999-9999

-9999 -9999 -9999 -9999 -9999 -9999 -9999 -9999 -9999 -9999 -9999 -9999 -9999 -9999 -9999

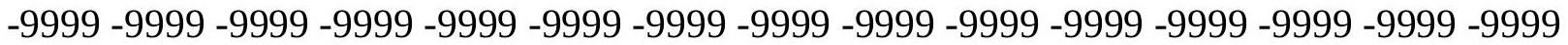

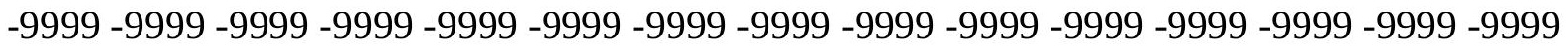
-9999 -9999 -9999 -9999 -9999 -9999 -9999 -9999 -9999 -9999 -9999 -9999 -9999 -9999 -9999 -9999 -9999 -9999 -9999 -9999 -9999 -9999 -9999 -9999 -9999 -9999 -9999 -9999 -9999 -9999 -9999 -9999 -9999 -9999 -9999 -9999 -9999 -9999 -9999 -9999 -9999 -9999 -9999 -9999 -9999

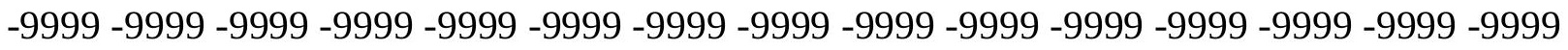

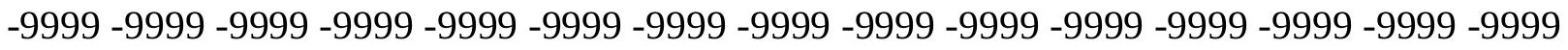
-9999 -9999 -9999 -9999 -9999 -9999 -9999 -9999 -9999 -9999 -9999 -9999 -9999 -9999 -9999 -9999 -9999 -9999 -9999 -9999 -9999 -9999 -9999 -9999 -9999 -9999 -9999 -9999 -9999 -9999 -

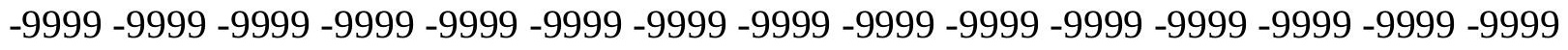
-9999 -9999-9999 -9999 -9999 -9999-9999-9999-9999 124.0475006104 121.9140014648 118.7629547119117 .7490768433116 .5548248291115 .2088012695113 .9896011353 112.7705001831111 .8561019897111 .24659729110 .6370010376110 .1923675537 109.6748199463109 .1130981445108 .5035018921107 .5891036987106 .6747970581 105.7603988647104 .8460998535104 .2365036011103 .3221969604103 .0174026489 
102.712600708102 .712600708103 .0174026489103 .6268997192104 .2365036011 105.1509017944105 .7603988647105 .8371505737105 .604598999105 .1509017944 104.2365036011103 .0174026489101 .7982025146100 .274299621698 .75038146973 97.2264633178795 .397743225193 .8738174438592 .0450973510790 .52117919922 89.302040100188.08290100098 86.55898284912 85.33984375 84.12069702148 82.5967712402381 .0728530883879 .5489196777377 .4154205322375 .28192901611 72.5388565063569 .1862335205165 .8335876464862 .1761703491258 .82352828979 56.0804595947352 .7278289794948 .4608306884843 .5842704772938 .70771026611 33.2215805053726 .8210906982420 .7253894805915 .5440397262612 .1914100647 9.7531242370618 .5339832305917 .9244132041937 .6196279525767 .924413204193 8.5339832305918 .8387689590459 .75312423706110 .3626899719210 .97226047516 11.8866195678712 .8009700775113 .4105501174914 .3248996734615 .23925971985 16.1536102294917 .3727493286118 .28710937519 .5062503814720 .42060089111 21.6397399902322 .5541000366223 .7732391357424 .6875991821325 .60194969177 26.5163097381627 .430660247828 .3450202941929 .2593708038330 .17373085022 30.4785099029531 .0880794525131 .3928699493431 .6976509094232 .00244140625 32.3072204589832 .6120109558132 .9167900085433 .2215805053733 .52635955811 34.1359291076734 .4407196044935 .0502891540535 .6598587036136 .26942825317 36.8790016174337 .7933502197338 .4029312133838 .7077102661139 .01250076294 39.0125007629439 .0125007629439 .0125007629438 .7077102661138 .70771026611 38.7077102661139 .3172798156740 .5364189147942 .66992187547 .24169921875 54.8613204956163 .3953094482470 .4053573608474 .9771423339877 .1106262207 77.7202072143677 .4154205322376 .5010681152374 .9771423339873 .14842987061 70.7101516723668 .8814392089867 .0527267456165 .5288009643664 .0048828125 63.0905189514262 .1761703491261 .8713798522961 .5666007995661 .56660079956 61.5666007995661 .2618103027360 .9570198059160 .3474502563560 .04267120361 59.4331016540558 .5187492370657 .909179687556 .9948196411156 .38525009155 55.4708900451754 .5565414428754 .5565414428754 .86132049561 -9999 -9999 -9999 -9999 -9999 -9999 -9999 -9999 -9999 -9999 -9999 -9999 -9999 -9999 -9999 -9999 -9999 -9999 -9999 -9999 -9999 -9999 -9999 -9999 -9999 -9999 -9999 -9999 -9999 -9999 -9999 -9999 -9999 -9999

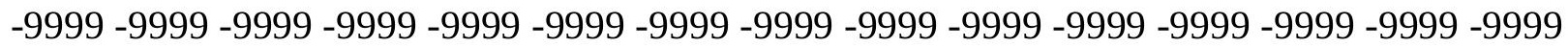
-9999 -9999 -9999 -9999 -9999

-9999 -9999 -9999 -9999 -9999 -9999 -9999 -9999 -9999 -9999 -9999 -9999 -9999 -9999 -9999 -9999 -9999 -9999 -9999 -9999 -9999 -9999 -9999 -9999 -9999 -9999 -9999 -9999 -9999 -9999 -9999 -9999 -9999 -9999 -9999 -9999 -9999 -9999 -9999 -9999 -9999 -9999 -9999 -9999 -9999 -

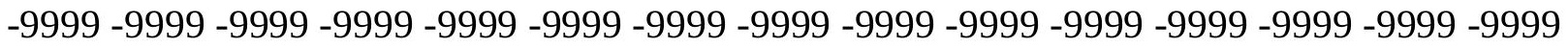

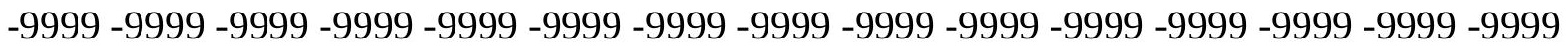

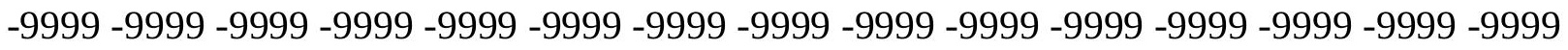

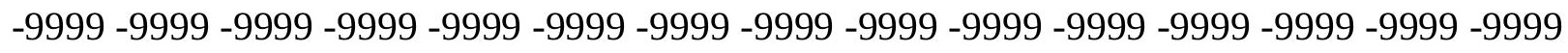
-9999 -9999 -9999 -9999 -9999 -9999 -9999 -9999 -9999 -9999 -9999 -9999 -9999 -9999 -9999 -

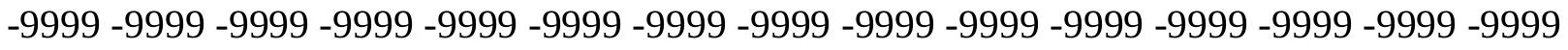

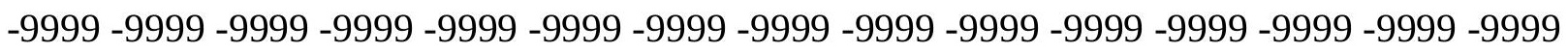
-9999 -9999 -9999 -9999 -9999 -9999 -9999 -9999 -9999 -9999 -9999 -9999 -9999 -9999 -9999 -9999 -9999 -9999 -9999 -9999 -9999 -9999 -9999 -9999 -9999 124.0475006104 122.2188034058120 .0852966309117 .3209533691116 .0870132446114 .5991973877 113.3800964355112 .4656982422111 .8561019897111 .551399231111 .2899093628 
110.7541122437110 .1831207275109 .5536956787108 .8333282471108 .1986999512 107.2844009399106 .0652008057104 .8460998535103 .9317016602103 .3221969604 102.712600708102 .712600708102 .712600708103 .0174026489103 .6268997192 104.2365036011104 .8260574341105 .005859375104 .8460998535104 .5412979126 103.9317016602103 .0174026489101 .7982025146100 .579101562599 .35994720459 97.8360290527396 .3121032714894 .7881774902393 .2642517089891 .74033355713 90.5211791992289 .302040100188 .0829010009886 .8637619018685 .64462280273 84.4254837036182 .9015579223681 .0728530883879 .2441329956177 .1106262207 74.3675689697371 .3197174072367 .9670867919964 .3096618652360 .65224075317 60.0426712036156 .3852500915552 .1182594299347 .8512611389242 .97470092773 37.7933502197332 .3072204589826 .8210906982421 .9445304870618 .287109375 15.5440397262613 .4105501174912 .191410064711 .5818300247211 .27705001831 11.2770500183111 .5818300247211 .8866195678712 .191410064712 .49619007111 13.1057596206713 .4105501174914 .0201196670514 .6296901702915 .54403972626 16.1536102294917 .0679702758817 .6775398254418 .8966808319119 .8110294342 20.7253894805921 .6397399902322 .8588790893623 .7732391357424 .68759918213 25.906740188626 .8210906982427 .7354507446328 .6497993469229 .56415939331 30.1737308502230 .7833003997831 .0880794525131 .3928699493432 .00244140625 32.3072204589832 .3072204589832 .6120109558132 .9167900085433 .52635955811 33.8311500549334 .1359291076734 .7455101013235 .0502891540535 .65985870361 36.2694282531736 .8790016174337 .1837806701737 .7933502197338 .09814071655 38.0981407165538 .0981407165538 .0981407165538 .4029312133838 .40293121338 39.0125007629439 .9268493652341 .7555618286145 .1082000732450 .59432983398 57.909179687566 .1383666992273 .1484298706176 .8058471679778 .02498626709 78.0249862670977 .110626220775 .5867080688573 .7580032348671 .62449645996 69.4910125732467 .6623001098665 .8335876464864 .6144485473663 .39530944824 62.4809494018661 .5666007995661 .2618103027360 .9570198059160 .95701980591 60.9570198059160 .6522407531760 .3474502563560 .0426712036159 .73788070679 59.1283111572358 .5187492370657 .909179687556 .9948196411156 .08045959473 55.4708900451754 .5565414428754 .2517509460454 .55654144287 -9999 -9999 -9999 -9999 -9999 -9999 -9999 -9999 -9999 -9999 -9999 -9999 -9999 -9999 -9999 -9999 -9999 -9999 -9999 -9999 -9999 -9999 -9999 -9999 -9999 -9999 -9999 -9999 -9999 -9999 -9999 -9999 -9999-999 -999 -

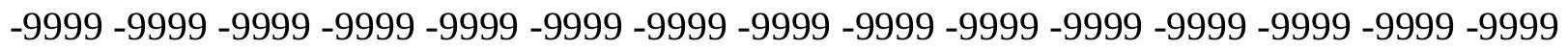
-9999 -9999-9999-9999-9999

-9999 -9999 -9999 -9999 -9999 -9999 -9999 -9999 -9999 -9999 -9999 -9999 -9999 -9999 -9999

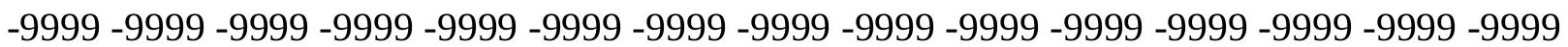

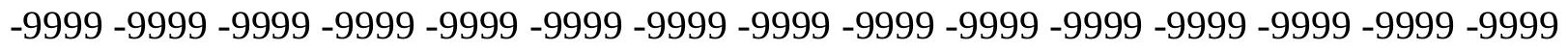

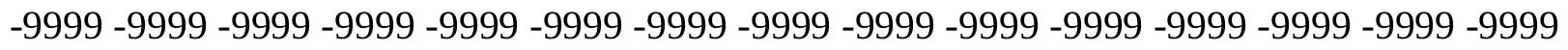

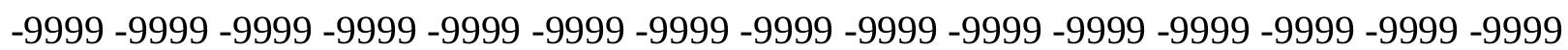
-9999 -9999 -9999 -9999 -9999 -9999 -9999 -9999 -9999 -9999 -9999 -9999 -9999 -9999 -9999 -

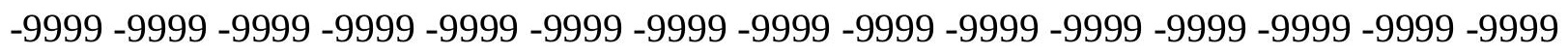

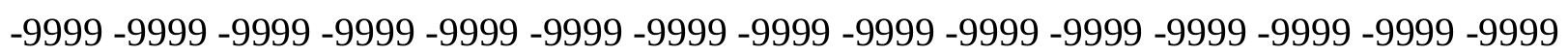
-9999 -9999 -9999 -9999 -9999 -9999 -9999 -9999 -9999 -9999 -9999 -9999 -9999 -9999 -9999 -9999 -9999 -9999 -9999 -9999 -9999 -9999 -9999 -9999 -9999 -9999 -9999 -9999 -9999 -9999 -9999 -9999 -9999 -9999 -9999 -9999 -9999 -9999 -9999 -9999 -9999 -9999 -9999 -9999 -9999 -9999 -9999 -9999 -9999 -9999 -9999 -9999 -9999 -9999 -9999 -9999 -9999 121.9140014648 
119.7806015015117 .647102356115 .8636398315114 .2944030762113 .3800964355 112.7705001831112 .7705001831113 .075302124111 .6981735229111 .0896224976 110.4387130737109 .751953125108 .9859313965108 .0241241455106 .890335083 105.7603988647104 .5412979126103 .6268997192103 .0174026489102 .4077987671 102.4077987671102 .712600708103 .0174026489103 .3221969604103 .9317016602 104.2365036011104 .2365036011103 .9317016602103 .6268997192103 .0174026489 102.1029968262100 .883903503499 .6647262573298 .445587158297 .22646331787 95.7025299072394 .1785964965892 .9594726562591 .7403335571390 .82597351074 89.60682678223 88.38768768311 87.16854858398 85.64462280273 84.42548370361 82.5967712402380 .7680587768678 .6345596313576 .1962814331173 .45321655273 70.4053573608467 .0527267456164 .3096618652362 .1761703491259 .12831115723 55.4708900451751 .2038993835446 .6321296691942 .0603485107436 .87900161743 32.3072204589827 .7354507446324 .0780296325721 .0301704406718 .89668083191 17.0679702758815 .8488302230815 .2392597198514 .6296901702914 .32489967346 14.3248996734614 .3248996734614 .3248996734614 .6296901702914 .9344701767 14.934470176715 .2392597198515 .8488302230816 .1536102294916 .76317977905 17.6775398254418 .28710937519 .2014598846420 .1158199310321 .03017044067 22.2493095397923 .1636695861824 .0780296325724 .9923801422126 .21151924133 27.1258792877228 .0402297973628 .9545898437529 .8689403533930 .47850990295 31.0880794525131 .3928699493431 .6976509094232 .0024414062532 .30722045898 32.6120109558132 .9167900085433 .2215805053733 .5263595581133 .83115005493 34.4407196044934 .7455101013235 .0502891540535 .6598587036135 .96464920044 36.2694282531736 .8790016174336 .8790016174337 .1837806701737 .48857116699 37.7933502197338 .0981407165538 .7077102661139 .622070312540 .84120941162 43.2794914245647 .2416992187552 .7278289794959 .7378807067967 .96708679199 75.8914871215877 .4154205322377 .4154205322376 .8058471679775 .28192901611 73.4532165527371 .3197174072369 .4910125732467 .3575134277365 .83358764648 64.6144485473663 .3953094482462 .4809494018661 .8713798522961 .26181030273 60.9570198059160 .6522407531760 .6522407531760 .6522407531760 .34745025635 60.0426712036159 .7378807067959 .4331016540558 .8235282897958 .21395874023 57.6043891906756 .9948196411156 .0804595947355 .4708900451754 .55654144287 53.9469718933154 .25175094604 -9999 -9999 -9999 -9999 -9999 -9999 -9999 -9999 -9999 -9999 -9999 -9999 -9999 -9999 -9999 -9999 -9999 -9999-9999-9999 -9999-9999-9999- -9999 -9999 -9999 -9999 -9999 -9999 -9999 -9999 -9999 -9999 -9999 -9999 -9999 -9999 -9999 -9999 -9999 -9999 -9999 -9999 -9999 -9999 -9999 -9999 -9999 -9999 -9999 -9999 -9999 -9999 -9999 -9999 -9999 -9999 -9999 -9999 -9999 -9999 -9999 -9999 -9999 -9999 -9999 -9999 -9999 -9999

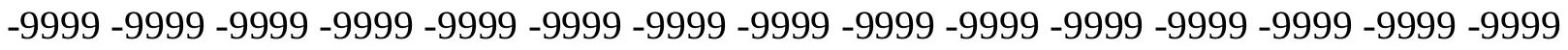

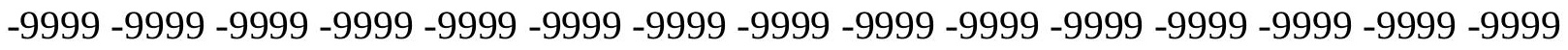
-9999 -9999 -9999 -9999 -9999 -9999 -9999 -9999 -9999 -9999 -9999 -9999 -9999 -9999 -9999 -9999 -9999 -9999 -9999 -9999 -9999 -9999 -9999 -9999 -9999 -9999 -9999 -9999 -9999 -9999 -

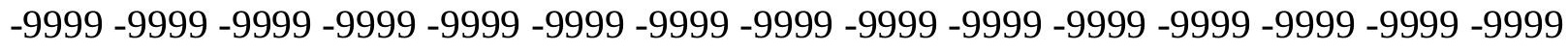

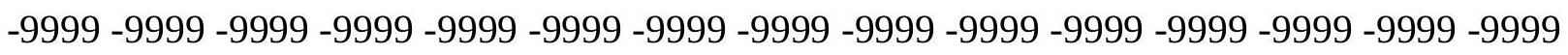
-9999 -9999 -9999 -9999 -9999 -9999 -9999 -9999 -9999 -9999 -9999 -9999 -9999 -9999 -9999 -9999 -9999 -9999 -9999 -9999 -9999 -9999 -9999 -9999 -9999 -9999 -9999 -9999 -9999 -9999 -9999 -9999 -9999 -9999 -9999 -9999 -9999 -9999 -9999 -9999 -9999 -9999 -9999 -9999 -9999 -9999 -9999 -9999 -9999 -9999 -9999 -9999 -9999 -9999 -9999 -9999 -9999 -9999 -9999 -9999 
-9999 -9999 -9999 -9999 -9999 -9999 -9999 -9999 -9999 -9999 -9999 -9999 -9999 122.2188034058119 .7806015015117 .9517974854115 .818397522114 .2944030762 113.9896011353114 .2944030762114 .7281799316114 .8655471802114 .9039993286 113.9896011353110 .3695602417109 .5018997192108 .4992294312107 .3720474243 106.1736755371104 .9777450562103 .9317016602103 .0174026489102 .4077987671 102.1029968262102 .1029968262102 .4077987671102 .712600708103 .0174026489 103.3221969604103 .6268997192103 .6268997192103 .3221969604102 .712600708 102.1029968262101 .1886978149100 .274299621699 .0551681518697 .83602905273 96.6168823242295 .397743225194 .1785964965892 .9594726562592 .04509735107 90.8259735107489 .6068267822388 .3876876831187 .1685485839885 .64462280273 84.1206970214882 .2919769287180 .1584930419978 .0249862670975 .28192901611 72.5388565063569 .7957916259867 .0527267456164 .6144485473661 .56660079956 58.2139587402354 .5565414428750 .2895507812546 .0225486755441 .45077896118 37.1837806701733 .2215805053729 .5641593933126 .5163097381624 .07802963257 21.9445304870620 .4206008911119 .2014598846418 .28710937517 .67753982544 17.3727493286117 .0679702758816 .7631797790516 .4584007263216 .45840072632 16.4584007263216 .4584007263216 .4584007263216 .7631797790517 .06797027588 17.6775398254418 .28710937518 .8966808319119 .811029434220 .72538948059 21.6397399902322 .5541000366223 .4684505462624 .6875991821325 .60194969177 26.5163097381627 .7354507446328 .6497993469229 .5641593933130 .47850990295 31.0880794525131 .3928699493431 .6976509094232 .0024414062532 .30722045898 32.6120109558132 .9167900085433 .2215805053733 .5263595581133 .83115005493 34.1359291076734 .4407196044934 .7455101013235 .0502891540535 .35507965088 35.6598587036135 .9646492004436 .2694282531736 .5742111206136 .87900161743 37.4885711669938 .0981407165538 .7077102661139 .9268493652341 .75556182861 44.4986305236848 .4608306884853 .3373985290559 .7378807067966 .44316101074 71.9292907714874 .6723632812574 .9771423339874 .3675689697372 .53885650635 70.7101516723668 .5766525268666 .4431610107464 .9192428588963 .70008850098 63.0905189514262 .1761703491261 .5666007995661 .2618103027360 .95701980591 60.6522407531760 .3474502563560 .3474502563560 .3474502563560 .34745025635 60.0426712036159 .7378807067959 .4331016540558 .8235282897958 .21395874023 57.6043891906756 .9948196411156 .0804595947355 .4708900451754 .55654144287 53.94697189331 53.94697189331 54.25175094604 -9999 -9999 -9999 -9999 -9999 -9999 -9999 -9999 -9999 -9999 -9999 -9999 -9999 -9999 -9999 -9999 -9999 -9999 -9999 -9999 -9999 -9999 -9999 -9999 -9999 -9999 -9999 -9999 -9999 -9999 -9999 -9999 -9999 -9999 -9999 -9999 -9999

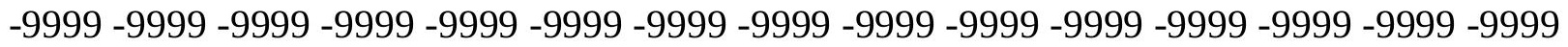
$-9999$

-9999 -9999 -9999 -9999 -9999 -9999 -9999 -9999 -9999-9999 -9999 -9999 -9999 -9999 -9999 -9999 -9999 -9999 -9999 -9999 -9999 -9999 -9999 -9999 -9999 -9999 -9999 -9999 -9999 -9999 -9999 -9999 -9999 -9999 -9999 -9999 -9999 -9999 -9999 -9999 -9999 -9999 -9999 -9999 -9999 -

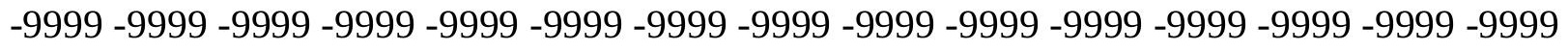

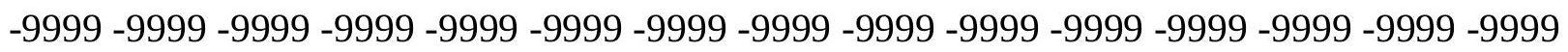
-9999 -9999 -9999 -9999 -9999 -9999 -9999 -9999 -9999 -9999 -9999 -9999 -9999 -9999 -9999 -9999 -9999 -9999 -9999 -9999 -9999 -9999 -9999 -9999 -9999 -9999 -9999 -9999 -9999 -9999 -

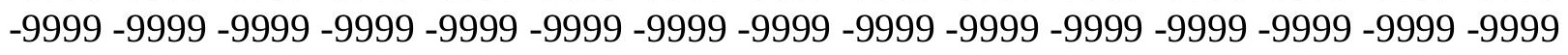

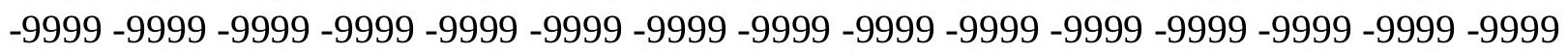


-9999 -9999 -9999 -9999 -9999 -9999 -9999 -9999 -9999 -9999 -9999 -9999 -9999 -9999 -9999 -9999 -9999 -9999 -9999 -9999 -9999 -9999 -9999 -9999 -9999 -9999 -9999 -9999 -9999 -9999 -9999 -9999 -9999 -9999 -9999 -9999 -9999 -9999 -9999 -9999 -9999 -9999 -9999 -9999 -9999 121.3044967651118 .5614013672117 .0374984741116 .4279022217116 .1231002808 116.2281265259116 .3051223755116 .1813964844115 .6634216309114 .9039993286 113.3800964355111 .551399231107 .6840057373106 .4513168335105 .2201690674 104.0543441772102 .9988250732102 .1029968262101 .4934005737101 .4934005737 101.4934005737101 .7982025146102 .4077987671102 .712600708103 .0174026489 103.0174026489103 .0174026489102 .4077987671102 .1029968262101 .4934005737 100.579101562599 .6647262573298 .445587158297 .5312423706196 .31210327148 95.397743225194 .1785964965892 .9594726562591 .7403335571390 .52117919922 89.302040100188 .0829010009886 .8637619018685 .3398437583 .51112365723 81.6824111938579 .5489196777377 .110626220774 .6723632812572 .23407745361 69.4910125732466 .7479400634864 .004882812560 .9570198059157 .29959869385 53.6421813964849 .6799812316945 .717769622842 .0603485107438 .09814071655 34.7455101013231 .6976509094229 .2593708038326 .8210906982424 .99238014221 23.4684505462622 .5541000366221 .6397399902320 .7253894805920 .11581993103 19.5062503814718 .8966808319118 .28710937517 .9823207855217 .67753982544 17.3727493286117 .3727493286117 .6775398254417 .9823207855218 .287109375 19.2014598846419 .811029434220 .7253894805921 .334960937522 .24930953979 23.1636695861824 .0780296325725 .2971591949526 .2115192413327 .12587928772 28.3450202941929 .2593708038330 .4785099029531 .0880794525131 .39286994934 31.6976509094232 .3072204589832 .6120109558132 .6120109558132 .91679000854 33.2215805053733 .5263595581133 .5263595581133 .8311500549334 .13592910767 34.1359291076734 .4407196044934 .7455101013235 .0502891540535 .35507965088 35.6598587036135 .9646492004436 .5742111206137 .1837806701738 .09814071655 39.0125007629440 .5364189147942 .3651313781745 .1082000732448 .7656211853 53.0326118469257 .909179687563 .0905189514267 .3575134277370 .10057830811 71.014930725170 .7101516723669 .1862335205167 .3575134277365 .22400665283 63.3953094482462 .1761703491261 .5666007995661 .2618103027361 .26181030273 60.9570198059160 .6522407531760 .6522407531760 .3474502563560 .34745025635 60.3474502563560 .3474502563560 .0426712036160 .0426712036159 .73788070679 59.1283111572358 .8235282897958 .2139587402357 .6043891906756 .99481964111 56.0804595947355 .4708900451754 .5565414428753 .9469718933153 .64218139648 53.94697189331 -9999 -9999 -9999 -9999 -9999 -9999 -9999 -9999 -9999 -9999 -9999 -9999 -9999 -9999 -9999 -9999 -9999 -9999 -9999 -9999 -9999 -9999 -9999 -9999 -9999 -9999 -9999

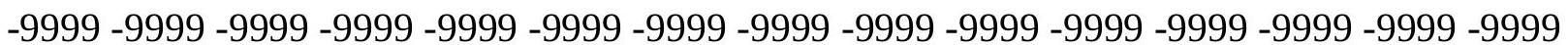
-9999 -9999 -9999 -9999 -9999 -9999 -9999 -9999 -9999 -9999 -9999 -9999 -9999 -9999 -9999 -9999 -9999 -9999 -9999 -9999 -9999 -9999 -9999 -9999 -9999 -9999 -9999 -9999 -9999 -9999 -9999 -9999 -9999 -9999 -9999 -9999 -9999 -9999 -9999 - -9999 -9999 -9999 -9999 -9999 -9999 -9999 -9999 -9999 -9999 -9999 -9999 -9999 -9999 -9999 -9999 -9999

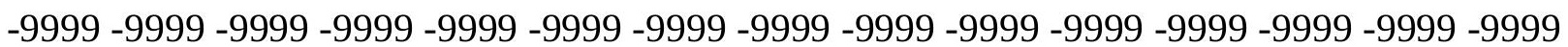
-9999 -9999 -9999 -9999 -9999 -9999 -9999 -9999 -9999 -9999 -9999 -9999 -9999 -9999 -9999 -9999 -9999 -9999 -9999 -9999 -9999 -9999 -9999 -9999 -9999 -9999 -9999 -9999 -9999 -9999 -9999 -9999 -9999 -9999 -9999 -9999 -9999 -9999 -9999 -9999 -9999 -9999 -9999 -9999 -9999

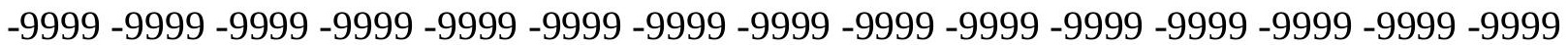


-9999 -9999 -9999 -9999 -9999 -9999 -9999 -9999 -9999 -9999 -9999 -9999 -9999 -9999 -9999 -9999 -9999 -9999 -9999 -9999 -9999 -9999 -9999 -9999 -9999 -9999 -9999 -9999 -9999 -9999

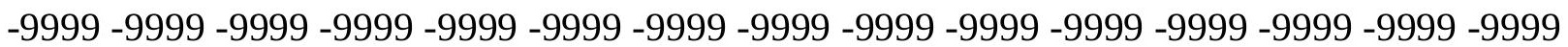
-9999 -9999 -9999 -9999 -9999 -9999 -9999 -9999 -9999 -9999 -9999 -9999 -9999 -9999 -9999 -9999 -9999 122.2188034058 120.6949005127 119.4757995605 119.7806015015 119.4757995605117 .1812591553116 .7075805664115 .8207855225114 .4714355469 112.7705001831110 .6370010376108 .5035018921105 .4245834351104 .1923522949 102.712600708101 .7982025146100 .8839035034100 .8839035034100 .8839035034 101.1886978149101 .7982025146102 .1029968262102 .4077987671102 .712600708 102.712600708102 .4077987671102 .1029968262101 .4934005737100 .8839035034 100.274299621699 .3599472045998 .445587158297 .2264633178796 .31210327148 95.0929565429794 .1785964965892 .9594726562591 .7403335571390 .52117919922 89.302040100187 .7781066894586 .254188537684 .7302627563582 .90155792236 81.0728530883878 .9393463134876 .5010681152374 .062782287671 .62449645996 69.1862335205166 .4431610107463 .3953094482460 .3474502563556 .99481964111 53.3373985290549 .9847602844246 .3273391723642 .9747009277339 .92684936523 36.8790016174334 .1359291076731 .6976509094229 .5641593933128 .04022979736 26.8210906982425 .6019496917724 .3828105926523 .4684505462622 .55410003662 21.6397399902320 .7253894805920 .1158199310319 .5062503814718 .89668083191 18.5918903350818 .5918903350818 .5918903350818 .8966808319119 .50625038147 20.1158199310320 .7253894805921 .6397399902322 .2493095397923 .16366958618 24.0780296325724 .9923801422125 .906740188626 .8210906982428 .04022979736 29.2593708038330 .4785099029531 .0880794525131 .3928699493432 .00244140625 32.3072204589832 .6120109558132 .9167900085433 .2215805053733 .52635955811 33.5263595581133 .5263595581133 .8311500549333 .8311500549334 .13592910767 34.1359291076734 .4407196044934 .4407196044935 .0502891540535 .35507965088 35.9646492004436 .5742111206137 .1837806701738 .0981407165539 .31727981567 40.8412094116242 .9747009277345 .4129791259848 .4608306884852 .11825942993 55.7756805419959 .1283111572363 .0905189514265 .5288009643666 .74794006348 66.7479400634865 .5288009643664 .004882812561 .8713798522960 .04267120361 59.7378807067960 .0426712036160 .0426712036160 .0426712036160 .34745025635 60.3474502563560 .3474502563560 .3474502563560 .3474502563560 .34745025635 60.3474502563560 .0426712036160 .0426712036159 .7378807067959 .43310165405 58.8235282897958 .2139587402357 .6043891906756 .9948196411156 .38525009155 55.4708900451754 .8613204956153 .9469718933153 .3373985290553 .64218139648 -9999 -9999 -9999 -9999 -9999 -9999 -9999 -9999 -9999 -9999 -9999 -9999 -9999 -9999 -9999 -9999 -9999 -9999 -9999 -9999 -9999 -9999 -9999 -9999 -9999 -9999 -9999 -9999 -9999 -9999 -9999

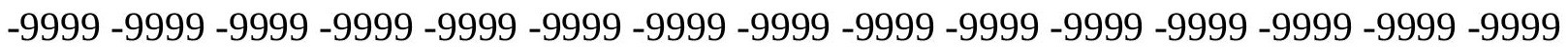
-9999 -9999 -9999 -9999 -9999 -9999 -9999

-9999 -9999 -9999 -9999 -9999 -9999 -9999 -9999 -9999 -9999 -9999 -9999 -9999 -9999 -9999 -9999 -9999 -9999 -9999 -9999 -9999 -9999 -9999 -9999 -9999 -9999 -9999 -9999 -9999 -9999

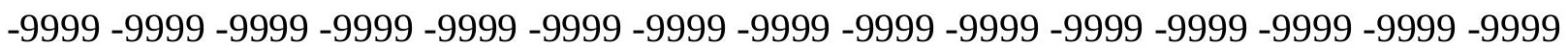
-9999 -9999 -9999 -9999 -9999 -9999 -9999 -9999 -9999 -9999 -9999 -9999 -9999 -9999 -9999 -9999 -9999 -9999 -9999 -9999 -9999 -9999 -9999 -9999 -9999 -9999 -9999 -9999 -9999 -9999 -9999 -9999 -9999 -9999 -9999 -9999 -9999 -9999 -9999 -9999 -9999 -9999 -9999 -9999 -9999

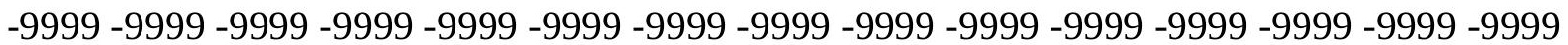


-9999 -9999 -9999 -9999 -9999 -9999 -9999 -9999 -9999 -9999 -9999 -9999 -9999 -9999 -9999 -9999 -9999 -9999 -9999 -9999 -9999 -9999 -9999 -9999 -9999 -9999 -9999 -9999 -9999 -9999

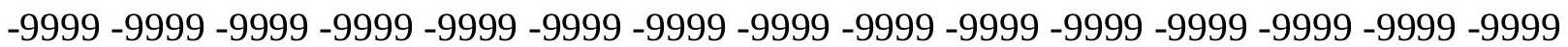
-9999 -9999 -9999 -9999 -9999 -9999 -9999 -9999 -9999 -9999 -9999 -9999 -9999 -9999 -9999 -9999 -9999 -9999 -9999 -9999 -9999 -9999 -9999 -9999 -9999 -9999 -9999 -9999 -9999 -9999 -9999 -9999-9999 126.4858016968 125.2667007446124.3523025513122.8283996582 120.6949005127119 .4757995605116 .3221054077114 .9978942871113 .3069992065 111.3646621704109 .4179000854106 .979598999104 .5412979126102 .712600708 101.1886978149100 .274299621699 .96952056885100 .2742996216100 .5791015625 101.1886978149101 .7982025146102 .1029968262102 .4077987671102 .4077987671 102.4077987671102 .4077987671101 .7982025146101 .4934005737100 .8839035034 99.9695205688599 .0551681518698 .1408081054797 .2264633178796 .00731658936 95.0929565429793 .8738174438592 .6546783447391 .4355392456190 .21640014648 88.6924667358487 .4733276367285 .9494018554784 .1206970214882 .29197692871 80.4632720947378 .3297805786176 .1962814331173 .7580032348671 .31971740723 68.8814392089866 .1383666992263 .0905189514260 .3474502563556 .99481964111 53.9469718933150 .5943298339847 .5464782714844 .8034095764242 .06034851074 39.3172798156736 .8790016174334 .7455101013232 .9167900085431 .39286994934 29.8689403533928 .6497993469227 .1258792877225 .906740188624 .68759918213 23.7732391357422 .5541000366221 .6397399902320 .7253894805920 .11581993103 19.811029434219 .811029434219 .811029434220 .4206008911120 .72538948059 21.334960937521 .9445304870622 .8588790893623 .4684505462624 .07802963257 24.9923801422125 .906740188626 .8210906982428 .0402297973628 .95458984375 30.1737308502231 .0880794525131 .6976509094232 .3072204589832 .61201095581 32.9167900085433 .2215805053733 .5263595581133 .8311500549333 .83115005493 33.8311500549333 .8311500549333 .8311500549333 .8311500549334 .13592910767 34.1359291076734 .4407196044934 .7455101013235 .0502891540535 .65985870361 36.5742111206137 .1837806701738 .4029312133839 .622070312541 .14598846436 43.2794914245645 .4129791259848 .1560516357450 .8991203308153 .94697189331 56.6900291442959 .4331016540561 .5666007995662 .4809494018662 .78573989868 62.1761703491260 .9570198059159 .7378807067958 .5187492370658 .21395874023 58.5187492370658 .8235282897959 .4331016540559 .7378807067960 .04267120361 60.3474502563560 .3474502563560 .6522407531760 .6522407531760 .34745025635 60.3474502563560 .0426712036159 .7378807067959 .4331016540558 .82352828979 58.5187492370657 .909179687556 .9948196411156 .3852500915555 .47089004517 54.8613204956153 .9469718933153 .3373985290553 .33739852905 -9999 -9999 -9999 -9999 -9999 -9999 -9999 -9999 -9999 -9999 -9999 -9999 -9999 -9999 -9999 -9999 -9999 -9999 -9999 -9999 -9999 -9999 -9999 -9999 -9999 -9999 -9999 -9999 -9999 -9999 -9999 -9999 -9999 -9999 -9999 -9999 -9999 -9999 -9999 -9999 -9999 -9999 -9999 -9999 -9999 -9999 -9999 -9999 -9999 -9999 -9999-9999-9999 -9999 -9999 -9999 -9999 -9999 -9999 -9999 -9999 -9999 -9999 -9999 -9999 -9999 -9999 -9999 -9999 -9999 -9999 -9999 -9999 -9999 -9999 -9999 -9999 -9999 -9999 -9999-9999-9999-9999 -9999 -9999 -9999 -9999 -9999 -9999 -9999 -9999 -9999 -9999 -9999 -9999 -9999 -9999 -9999 -9999 -9999 -9999 -9999 -9999 -9999 -9999 -9999 -9999 -9999 -9999 -9999 -9999 -9999 -9999 -9999 -9999 -9999 -9999 -9999 -9999 -9999 -9999 -9999 -9999 -9999 -9999 -9999 -9999 -9999

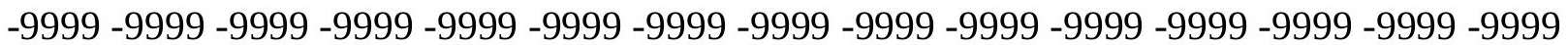


-9999 -9999 -9999 -9999 -9999 -9999 -9999 -9999 -9999 -9999 -9999 -9999 -9999 -9999 -9999 -9999 -9999 -9999 -9999 -9999 -9999 -9999 -9999 -9999 -9999 -9999 -9999 -9999 -9999 -9999

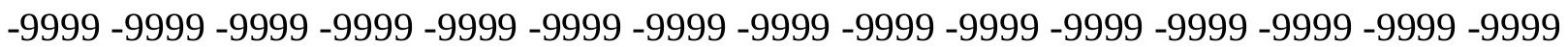
-9999 -9999 -9999 -9999 -9999 -9999 -9999 -9999 -9999 -9999 -9999 -9999 -9999 -9999 -9999 -9999 -9999 -9999 -9999 -9999 -9999 -9999 -9999 -9999 -9999 -9999 -9999 -9999 -9999 -9999 -9999 -9999 -9999 -9999 -9999 -9999 -9999 -9999 -9999 -9999 -9999 -9999 -9999 -9999 -9999 -9999 -9999 -9999 -9999 -9999 128.9241027832127 .0953979492124 .9618988037 122.2188034058119 .4757995605115 .1322860718113 .4619064331111 .540473938 109.4116668701107 .0998077393104 .8460998535102 .4077987671100 .5791015625 99.6647262573299 .3599472045999 .66472625732100 .2742996216100 .8839035034 101.4934005737101 .7982025146102 .4077987671102 .4077987671102 .712600708 102.4077987671102 .4077987671101 .7982025146101 .4934005737100 .5791015625 99.9695205688599 .0551681518698 .1408081054796 .9216690063596 .00731658936 94.7881774902393 .5690307617292 .349891662691 .1307525634889 .91161346436 88.38768768311 86.86376190186 85.33984375 83.51112365723 81.68241119385 79.8537063598677 .7202072143675 .5867080688573 .4532165527371 .0149307251 68.5766525268666 .1383666992263 .3953094482460 .6522407531757 .60438919067 54.8613204956152 .1182594299349 .3751907348646 .9369087219244 .19384002686 42.0603485107439 .9268493652337 .7933502197335 .9646492004434 .44071960449 32.9167900085431 .3928699493429 .8689403533928 .3450202941927 .12587928772 25.6019496917724 .0780296325722 .8588790893621 .9445304870621 .3349609375 21.334960937521 .334960937521 .6397399902321 .9445304870622 .55410003662 22.8588790893623 .4684505462624 .0780296325724 .6875991821325 .29715919495 25.906740188626 .8210906982428 .0402297973628 .9545898437530 .17373085022 31.0880794525132 .0024414062532 .6120109558133 .2215805053733 .52635955811 33.8311500549334 .1359291076734 .4407196044934 .4407196044934 .44071960449 34.4407196044934 .1359291076734 .1359291076734 .1359291076734 .13592910767 34.1359291076734 .7455101013235 .0502891540535 .6598587036136 .57421112061 37.4885711669938 .7077102661139 .9268493652341 .4507789611843 .27949142456 45.4129791259847 .5464782714849 .9847602844252 .4230384826754 .55654144287 56.6900291442958 .2139587402359 .1283111572359 .1283111572359 .12831115723 58.5187492370657 .909179687557 .6043891906757 .2995986938557 .60438919067 58.2139587402358 .8235282897959 .4331016540559 .7378807067960 .34745025635 60.6522407531760 .6522407531760 .6522407531760 .6522407531760 .65224075317 60.3474502563560 .0426712036159 .4331016540559 .1283111572358 .51874923706 57.909179687557 .2995986938556 .3852500915555 .7756805419954 .86132049561 53.9469718933153 .3373985290553 .33739852905 -9999 -9999 -9999 -9999 -9999 -9999 -9999 -9999 -9999 -9999 -9999 -9999 -9999 -9999 -9999 -9999 -9999 -9999 -9999 -9999 -9999 -9999 -9999 -9999 -9999 -9999 -9999 -9999 -9999 -9999 -9999 -9999 -9999 -9999 -9999 -9999 -9999 -9999 -9999 -9999 -9999 -9999 -9999 -9999 -9999 -9999 -9999 -9999 -9999 -9999 -9999 -9999 $-9999$

-9999 -9999 -9999 -9999 -9999 -9999 -9999 -9999 -9999 -9999 -9999 -9999 -9999 -9999 -9999 -9999 -9999 -9999 -9999 -9999 -9999 -9999 -9999 -9999 -9999 -9999 -9999 -9999 -9999 -9999 -9999 -9999 -9999 -9999 -9999 -9999 -9999 -9999 -9999 -9999 -9999 -9999 -9999 -9999 -9999 -9999 -9999 -9999 -9999 -9999 -9999 -9999 -9999 -9999 -9999 -9999 -9999 -9999 -9999 -9999

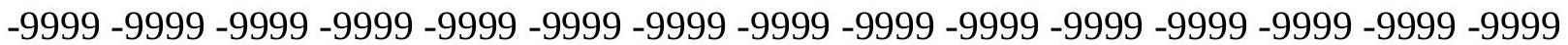


-9999 -9999 -9999 -9999 -9999 -9999 -9999 -9999 -9999 -9999 -9999 -9999 -9999 -9999 -9999 -9999 -9999 -9999 -9999 -9999 -9999 -9999 -9999 -9999 -9999 -9999 -9999 -9999 -9999 -9999 -9999 -9999 -9999 -9999 -9999 -9999 -9999 -9999 -9999 -9999 -9999 -9999 -9999 -9999 -9999 -9999 -9999 -9999 -9999 -9999 -9999 -9999 -9999 -9999 -9999 -9999 -9999 -9999 -9999 -9999 -9999 -9999 -9999 -9999 -9999 -9999 -9999 -9999 -9999 -9999 -9999 -9999 -9999 -9999 -9999 -9999 -9999 -9999 -9999 -9999 -9999 -9999 -9999 -9999 -9999 -9999 -9999 -9999 -9999 -9999 -9999 -9999 -9999 -9999 -9999 -9999 -9999 -9999 -9999 -9999 -9999 -9999 -9999 -9999 -9999 -9999 -9999 -9999 -9999 -9999 -9999 -9999 128.9241027832126 .4858016968123 .7427978516 120.6949005127117 .647102356111 .3430175781109 .1688842773106 .8607711792 104.4671096802102 .053466796999 .9695205688599 .0551681518699 .05516815186 99.66472625732100 .2742996216100 .8839035034101 .4934005737101 .7982025146 102.4077987671102 .712600708102 .712600708102 .712600708102 .712600708 102.4077987671102 .1029968262101 .4934005737100 .579101562599 .96952056885 99.0551681518697 .8360290527396 .9216690063595 .7025299072394 .48339080811 93.2642517089892 .0450973510790 .8259735107489 .302040100188 .08290100098 86.5589828491284 .7302627563583 .206336975181 .3776321411179 .54891967773 77.4154205322375 .2819290161173 .1484298706171 .014930725168 .57665252686 66.1383666992263 .7000885009861 .2618103027358 .8235282897956 .38525009155 53.9469718933151 .5086898803749 .0704002380446 .9369087219244 .80340957642 42.66992187540 .8412094116239 .0125007629437 .4885711669935 .65985870361 34.1359291076732 .3072204589830 .7833003997828 .9545898437527 .12587928772 25.6019496917724 .3828105926523 .7732391357423 .4684505462623 .46845054626 23.4684505462623 .7732391357424 .0780296325724 .3828105926524 .68759918213 24.9923801422125 .6019496917725 .906740188626 .5163097381627 .4306602478 28.3450202941929 .2593708038330 .4785099029531 .3928699493432 .61201095581 33.2215805053733 .8311500549334 .4407196044934 .7455101013235 .05028915405 35.0502891540535 .0502891540535 .0502891540535 .0502891540534 .74551010132 34.4407196044934 .4407196044934 .4407196044934 .4407196044934 .74551010132 35.3550796508835 .9646492004436 .8790016174337 .7933502197339 .01250076294 40.2316398620641 .7555618286143 .5842704772945 .4129791259847 .24169921875 49.3751907348651 .2038993835453 .0326118469254 .5565414428755 .77568054199 56.6900291442956 .9948196411156 .9948196411156 .9948196411156 .69002914429 56.6900291442956 .6900291442957 .2995986938557 .909179687558 .51874923706 59.1283111572359 .7378807067960 .3474502563560 .6522407531760 .95701980591 60.9570198059160 .9570198059160 .6522407531760 .6522407531760 .34745025635 59.7378807067959 .4331016540558 .8235282897958 .2139587402357 .29959869385 56.6900291442955 .7756805419954 .8613204956154 .2517509460453 .33739852905 53.0326118469253 .33739852905 -9999 -9999 -9999 -9999 -9999 -9999 -9999 -9999 -9999 -9999 -9999 -9999 -9999 -9999 -9999 -9999 -9999 -9999 -9999 -9999 -9999 -9999 -9999 -9999

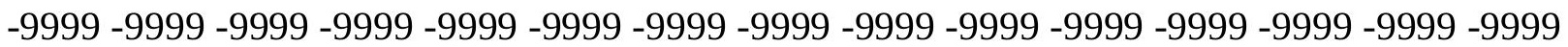
-9999 -9999 -9999 -9999 -9999 -9999 -9999 -9999 -9999 -9999 -9999 -9999 -9999

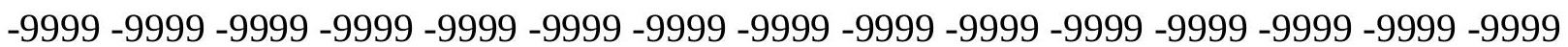
-9999 -9999 -9999 -9999 -9999 -9999 -9999 -9999 -9999 -9999 -9999 -9999 -9999 -9999 -9999 -9999 -9999 -9999 -9999 -9999 -9999 -9999 -9999 -9999 -9999 -9999 -9999 -9999 -9999 -9999 -999 -9999 -9999 -9999 -9999 -9999 -9999 -9999 -9999 -9999 -9999 -9999 -9999 -9999 -9999 -9999

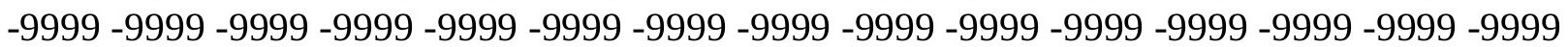


-9999 -9999 -9999 -9999 -9999 -9999 -9999 -9999 -9999 -9999 -9999 -9999 -9999 -9999 -9999 -9999 -9999 -9999 -9999 -9999 -9999 -9999 -9999 -9999 -9999 -9999 -9999 -9999 -9999 -9999 -9999 -9999 -9999 -9999 -9999 -9999 -9999 -9999 -9999 -9999 -9999 -9999 -9999 -9999 -9999 -9999 -9999 -9999 -9999 -9999 -9999 -9999 -9999 -9999 -9999 -9999 -9999 -9999 -9999 -9999 -9999 -9999 -9999 -9999 -9999 -9999 -9999 -9999 -9999 -9999 -9999 -9999 -9999 -9999 -9999 -9999 -9999 -9999 -9999 -9999 -9999 -9999 -9999 -9999 -9999 -9999 -9999 -9999 -9999 -9999 -9999 -9999 -9999 -9999 -9999 -9999 -9999 -9999 -9999 -9999 -9999 -9999 -9999 -9999 -9999 -9999 -9999 -9999 -9999 -9999 -9999 -9999 -9999 -9999 128.0097961426125 .2667007446 122.5235977173119 .7806015015116 .4279022217106 .5595245361104 .2193603516 101.9976654053100 .161628723199 .0551681518699 .3599472045999 .66472625732 100.5791015625101 .1886978149101 .4934005737102 .1029968262102 .712600708 103.0174026489103 .3221969604103 .3221969604103 .3221969604103 .0174026489 102.712600708102 .1029968262101 .4934005737100 .579101562599 .66472625732 98.7503814697397 .8360290527396 .6168823242295 .397743225194 .17859649658 92.9594726562591 .7403335571390 .5211791992288 .9972534179787 .47332763672 85.9494018554784 .4254837036182 .5967712402381 .0728530883879 .24413299561 77.110626220775 .2819290161173 .1484298706171 .014930725168 .88143920898 66.7479400634864 .6144485473662 .4809494018660 .3474502563558 .21395874023 56.0804595947353 .9469718933151 .8134689331149 .6799812316947 .54647827148 45.717769622843 .8890609741242 .0603485107440 .5364189147938 .70771026611 36.8790016174335 .0502891540532 .9167900085430 .7833003997828 .95458984375 27.430660247826 .5163097381626 .2115192413326 .2115192413325 .9067401886 25.906740188626 .2115192413326 .2115192413326 .5163097381626 .82109069824 26.8210906982427 .430660247827 .7354507446328 .3450202941928 .95458984375 29.8689403533931 .0880794525132 .3072204589833 .5263595581134 .44071960449 35.0502891540535 .6598587036135 .9646492004435 .9646492004436 .26942825317 36.2694282531735 .9646492004435 .6598587036135 .6598587036135 .35507965088 35.0502891540535 .0502891540535 .0502891540535 .0502891540535 .65985870361 36.5742111206137 .4885711669938 .4029312133839 .622070312540 .84120941162 42.0603485107443 .5842704772945 .4129791259846 .9369087219248 .7656211853 50.2895507812551 .8134689331153 .0326118469253 .9469718933154 .86132049561 55.1661109924355 .4708900451755 .4708900451755 .7756805419956 .08045959473 56.3852500915556 .9948196411157 .6043891906758 .2139587402359 .12831115723 60.0426712036160 .6522407531760 .9570198059161 .2618103027361 .26181030273 61.2618103027360 .9570198059160 .9570198059160 .6522407531760 .04267120361 59.7378807067959 .1283111572358 .2139587402357 .6043891906756 .69002914429 56.0804595947355 .1661109924354 .2517509460453 .3373985290553 .03261184692 53.33739852905 -9999 -9999 -9999 -9999 -9999 -9999 -9999 -9999 -9999 -9999 -9999 -9999 -9999 -9999 -9999 -9999 -9999 -9999 -9999 -9999 -9999 -9999 -9999 -9999 -9999 -9999 -9999 -9999 -9999 -9999 -9999 -9999 -9999 -9999 -9999 -9999 -9999 -9999 -9999 -9999 -9999 -9999 -9999 -9999 -9999 -9999 -9999 -9999 -9999 -9999 -9999 -9999

-9999 -9999 -9999 -9999 -9999 -9999 -9999 -9999 -9999 -9999 -9999 -9999 -9999 -9999 -9999 -9999 -9999 -9999 -9999 -9999 -9999 -9999 -9999 -9999 -9999 -9999 -9999 -9999 -9999 -9999 -9999 -9999 -9999 -9999 -9999 -9999 -9999 -9999 -9999 -9999 -9999 -9999 -9999 -9999 -9999 -9999 -9999 -9999 -9999 -9999 -9999 -9999 -9999 -9999 -9999 -9999 -9999 -9999 -9999 -9999

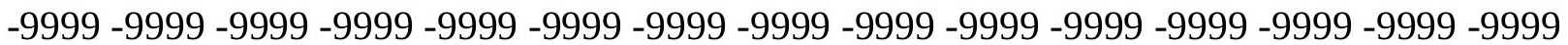


-9999 -9999 -9999 -9999 -9999 -9999 -9999 -9999 -9999 -9999 -9999 -9999 -9999 -9999 -9999 -9999 -9999 -9999 -9999 -9999 -9999 -9999 -9999 -9999 -9999 -9999 -9999 -9999 -9999 -9999 -9999 -9999 -9999 -9999 -9999 -9999 -9999 -9999 -9999 -9999 -9999 -9999 -9999 -9999 -9999 -9999 -9999 -9999 -9999 -9999 -9999 -9999 -9999 -9999 -9999 -9999 -9999 -9999 -9999 -9999 -9999 -9999 -9999 -9999 -9999 -9999 -9999 -9999 -9999 -9999 -9999 -9999 -9999 -9999 -9999 -9999 -9999 -9999 -9999 -9999 -9999 -9999 -9999 -9999 -9999 -9999 -9999 -9999 -9999 -9999 -9999 -9999 -9999 -9999 -9999 -9999 -9999 -9999 -9999 -9999 -9999 -9999 -9999 -9999 -9999 -9999 -9999 -9999 -9999 -9999 -9999 -9999 -9999 -9999 -9999 -9999 127.4001998901 124.9618988037122 .2188034058119 .1709976196104 .278213501102 .3255767822 100.808280944899 .99506378174100 .0169754028100 .5791015625101 .1886978149 101.4934005737102 .1029968262102 .4077987671103 .0174026489103 .3221969604 103.6268997192103 .9317016602103 .9317016602103 .6268997192103 .3221969604 102.712600708102 .1029968262101 .4934005737100 .579101562599 .66472625732 98.7503814697397 .5312423706196 .3121032714895 .397743225194 .17859649658 92.6546783447391 .4355392456189 .9116134643688 .3876876831187 .16854858398 85.6446228027383 .8159103393682 .2919769287180 .7680587768678 .93934631348 77.110626220775 .2819290161173 .4532165527371 .6244964599669 .49101257324 67.6623001098665 .8335876464864 .004882812562 .1761703491260 .34745025635 58.5187492370656 .3852500915554 .2517509460452 .1182594299350 .28955078125 48.4608306884846 .6321296691945 .1082000732443 .2794914245641 .45077896118 39.622070312537 .4885711669935 .0502891540532 .9167900085431 .08807945251 30.1737308502229 .8689403533929 .5641593933129 .2593708038328 .95458984375 28.9545898437528 .9545898437528 .9545898437528 .9545898437528 .95458984375 29.2593708038329 .5641593933129 .8689403533930 .4785099029531 .08807945251 32.3072204589833 .8311500549334 .7455101013235 .6598587036136 .57421112061 36.8790016174337 .1837806701737 .4885711669937 .4885711669937 .48857116699 37.1837806701736 .8790016174336 .5742111206136 .2694282531735 .96464920044 35.9646492004435 .6598587036135 .6598587036136 .2694282531737 .18378067017 38.0981407165539 .0125007629439 .9268493652341 .1459884643642 .36513137817 43.8890609741245 .1082000732446 .6321296691948 .1560516357449 .67998123169 50.8991203308151 .8134689331152 .7278289794953 .3373985290553 .94697189331 54.2517509460454 .5565414428755 .1661109924355 .4708900451756 .08045959473 56.6900291442957 .2995986938558 .2139587402359 .1283111572360 .04267120361 60.9570198059161 .2618103027361 .2618103027361 .5666007995661 .56660079956 61.2618103027361 .2618103027360 .9570198059160 .3474502563560 .04267120361 59.4331016540558 .5187492370657 .909179687556 .9948196411156 .38525009155 55.4708900451754 .5565414428753 .6421813964853 .0326118469253 .03261184692 -9999 -9999 -9999 -9999 -9999 -9999 -9999 -9999 -9999 -9999 -9999 -9999 -9999 -9999 -9999 -9999 -9999 -9999 -9999 -9999 -9999 -9999 -9999 -9999 -9999 -9999 -9999 -9999 -9999 -9999 -9999 -9999 -9999 -9999 -9999 -9999 -9999 -9999 -9999 -9999 -9999 -9999 -9999 -9999 -9999 -9999 -9999 -9999 -9999 -9999-9999 -9999

-9999 -9999 -9999 -9999 -9999 -9999 -9999 -9999 -9999 -9999 -9999 -9999 -9999 -9999 -9999 -9999 -9999 -9999 -9999 -9999 -9999 -9999 -9999 -9999 -9999 -9999 -9999 -9999 -9999 -9999 -9999 -9999 -9999 -9999 -9999 -9999 -9999 -9999 -9999 -9999 -9999 -9999 -9999 -9999 -9999 -9999 -9999 -9999 -9999 -9999 -9999 -9999 -9999 -9999 -9999 -9999 -9999 -9999 -9999 -9999

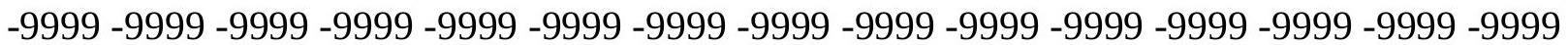


-9999 -9999 -9999 -9999 -9999 -9999 -9999 -9999 -9999 -9999 -9999 -9999 -9999 -9999 -9999 -9999 -9999 -9999 -9999 -9999 -9999 -9999 -9999 -9999 -9999 -9999 -9999 -9999 -9999 -9999

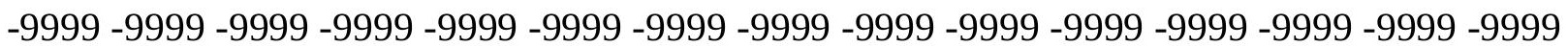
-9999 -9999 -9999 -9999 -9999 -9999 -9999 -9999 -9999 -9999 -9999 -9999 -9999 -9999 -9999 -9999 -9999 -9999 -9999 -9999 -9999 -9999 -9999 -9999 -9999 -9999 -9999 -9999 -9999 -9999 -9999 -9999 -9999 -9999 -9999 -9999 -9999 -9999 -9999 -9999 -9999 -9999 -9999 -9999 -9999

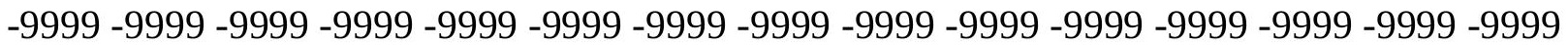
-9999 -9999 -9999 -9999 -9999 -9999 -9999 -9999 -9999 -9999 -9999 -9999 -9999 127.7050018311124 .9618988037120 .9997024536117 .0374984741101 .717628479 101.0543899536100 .9599914551101 .2972183228101 .70652771102 .1029968262 102.712600708103 .0174026489103 .6268997192104 .2365036011104 .4314651489 104.5132293701104 .4564361572104 .2365036011103 .9317016602103 .6268997192 103.0174026489102 .1029968262101 .4934005737100 .579101562599 .35994720459 98.445587158297 .2264633178796 .3121032714895 .0929565429793 .56903076172 92.349891662690 .8259735107489 .6068267822388 .0829010009886 .55898284912 85.3398437583 .8159103393682 .2919769287180 .7680587768678 .93934631348 77.4154205322375 .5867080688574 .062782287672 .2340774536170 .40535736084 68.8814392089867 .3575134277365 .8335876464864 .3096618652362 .78573989868 60.6522407531758 .5187492370656 .6900291442954 .5565414428753 .03261184692 51.5086898803749 .9847602844248 .1560516357446 .3273391723644 .49863052368 42.3651313781739 .9268493652337 .7933502197336 .2694282531735 .05028915405 34.4407196044933 .8311500549333 .2215805053732 .9167900085432 .61201095581 32.3072204589832 .0024414062531 .6976509094231 .3928699493431 .69765090942 32.0024414062532 .3072204589832 .9167900085433 .5263595581134 .44071960449 35.6598587036136 .5742111206137 .4885711669938 .0981407165538 .70771026611 39.0125007629439 .0125007629439 .0125007629439 .0125007629438 .70771026611 38.4029312133838 .0981407165537 .7933502197337 .4885711669937 .18378067017 36.8790016174337 .1837806701737 .4885711669938 .0981407165539 .01250076294 39.622070312540 .5364189147941 .7555618286142 .66992187543 .88906097412 45.4129791259846 .6321296691947 .8512611389249 .0704002380449 .98476028442 51.2038993835451 .8134689331152 .4230384826753 .0326118469253 .64218139648 53.9469718933154 .5565414428755 .1661109924355 .7756805419956 .38525009155 57.2995986938558 .2139587402359 .1283111572360 .0426712036160 .65224075317 61.2618103027361 .5666007995661 .8713798522961 .8713798522961 .87137985229 61.5666007995661 .2618103027360 .9570198059160 .3474502563559 .73788070679 59.1283111572358 .2139587402357 .2995986938556 .3852500915555 .47089004517 54.5565414428753 .6421813964852 .7278289794953 .03261184692 -9999-9999 -9999-9999 -9999 -9999 -9999 -9999 -9999 -9999 -9999 -9999 -9999 -9999 -9999 -9999 -9999 -9999 -9999 -9999 -9999 -9999 -9999 -9999 -9999 -9999 -9999 -9999 -9999 -9999 -9999 -9999 -9999 -9999 -9999 -9999 -9999 -9999 -9999 -9999 -9999 -9999 -9999 -9999 -9999 -9999 -9999 -9999 -9999 $-9999-9999-9999$

-9999 -9999 -9999 -9999 -9999 -9999 -9999 -9999 -9999 -9999 -9999 -9999 -9999 -9999 -9999 -9999 -9999 -9999 -9999 -9999 -9999 -9999 -9999 -9999 -9999 -9999 -9999 -9999 -9999 -9999 -9999 -9999 -9999 -9999 -9999 -9999 -9999 -9999 -9999 -9999 -9999 -9999 -9999 -9999 -9999 -9999 -9999 -9999 -9999 -9999 -9999 -9999 -9999 -9999 -9999 -9999 -9999 -9999 -9999 -9999

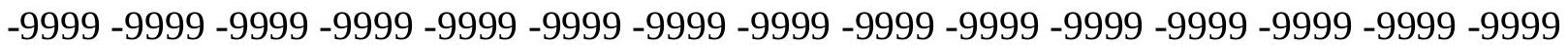


-9999 -9999 -9999 -9999 -9999 -9999 -9999 -9999 -9999 -9999 -9999 -9999 -9999 -9999 -9999 -9999 -9999 -9999 -9999 -9999 -9999 -9999 -9999 -9999 -9999 -9999 -9999 -9999 -9999 -9999 -9999 -9999 -9999 -9999 -9999 -9999 -9999 -9999 -9999 -9999 -9999 -9999 -9999 -9999 -9999 -9999 -9999 -9999 -9999 -9999 -9999 -9999 -9999 -9999 -9999 -9999 -9999 -9999 -9999 -9999 -9999 -9999 -9999 -9999 -9999 -9999 -9999 -9999 -9999 -9999 -9999 -9999 -9999 -9999 -9999 -9999 -9999 -9999 -9999 -9999 -9999 -9999 -9999 -9999 -9999 -9999 -9999 -9999 -9999 -9999 -9999 -9999 -9999 -9999 -9999 -9999 -9999 -9999 -9999 -9999 -9999 -9999 -9999 -9999 -9999 -9999 -9999 -9999 -9999 -9999 -9999 -9999 -9999 -9999 -9999 -9999 -9999 -9999 -9999 -9999 126.1809997559122 .5235977173118 .8662033081114 .5991973877101 .9737243652 102.1347198486102 .4554977417102 .712600708103 .3221969604103 .9317016602 104.5412979126104 .8460998535105 .0581207275105 .1046295166105 .0458450317 104.8883590698104 .6308746338104 .2365036011103 .6268997192103 .0174026489 102.1029968262101 .1886978149100 .274299621699 .3599472045998 .14080810547 97.2264633178796 .0073165893694 .4833908081193 .2642517089891 .74033355713 90.5211791992288 .9972534179787 .7781066894586 .5589828491285 .03504943848 83.5111236572382 .2919769287180 .7680587768679 .2441329956177 .72020721436 76.1962814331174 .6723632812573 .1484298706171 .6244964599670 .10057830811 68.8814392089867 .6623001098666 .1383666992264 .3096618652362 .48094940186 60.6522407531758 .8235282897957 .2995986938555 .7756805419954 .55654144287 53.0326118469251 .5086898803749 .6799812316947 .5464782714845 .41297912598 43.2794914245641 .7555618286140 .2316398620639 .622070312538 .70771026611 38.0981407165537 .4885711669936 .8790016174336 .2694282531735 .65985870361 35.0502891540534 .7455101013234 .7455101013234 .7455101013235 .05028915405 35.6598587036136 .2694282531737 .1837806701738 .0981407165539 .01250076294 39.622070312540 .2316398620640 .5364189147940 .8412094116240 .84120941162 40.8412094116240 .8412094116240 .5364189147939 .9268493652339 .6220703125 39.3172798156739 .0125007629438 .7077102661138 .4029312133838 .40293121338 38.7077102661139 .3172798156739 .9268493652340 .5364189147941 .45077896118 42.3651313781743 .2794914245644 .1938400268645 .4129791259846 .63212966919 47.5464782714848 .765621185349 .6799812316950 .5943298339851 .20389938354 51.8134689331152 .4230384826753 .0326118469253 .6421813964854 .25175094604 54.8613204956155 .4708900451756 .3852500915557 .2995986938557 .9091796875 58.8235282897959 .7378807067960 .6522407531761 .2618103027361 .87137985229 61.8713798522962 .1761703491262 .1761703491261 .8713798522961 .87137985229 61.2618103027360 .9570198059160 .3474502563559 .4331016540558 .82352828979 57.909179687556 .9948196411155 .7756805419954 .8613204956153 .94697189331 53.0326118469253 .03261184692 -9999 -9999 -9999 -9999 -9999 -9999 -9999 -9999 -9999 -9999 -9999 -9999 -9999 -9999 -9999 -9999 -9999 -9999 -9999 -9999 -9999 -9999 -9999 -9999 -9999 -9999 -9999 -9999 -9999 -9999 -9999 -9999 -9999 -9999 -9999 -9999 -9999 -9999 -9999 -9999 -9999 -9999 -9999 -9999 -9999 -9999 -9999 -9999 -9999 -9999 -9999 -9999 -9999 -9999 -9999 -9999 -9999 -9999 -9999 -9999 -9999 -9999 -9999 -9999 -9999 -9999 -9999 -9999 -9999 -9999 -9999 -9999 -9999 -9999 -9999 -9999 -9999 -9999 -9999-9999-9999-9999 -9999 -9999 -9999 -9999 -9999 -9999 -9999 -9999 -9999 -9999 -9999 -9999 -9999 -9999 -9999 -9999 -9999 -9999 -9999 -9999 -9999 -9999 -9999 -9999 -9999 -9999 -9999 -9999 -9999 -9999 -9999 -9999 -9999 -9999 -9999 -9999 -9999 -9999 -9999 -9999 -9999 -9999 -9999 -9999 -9999

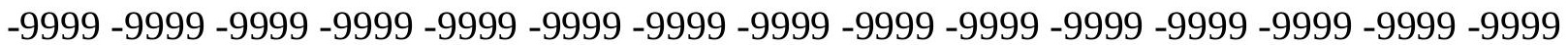


-9999 -9999 -9999 -9999 -9999 -9999 -9999 -9999 -9999 -9999 -9999 -9999 -9999 -9999 -9999 -9999 -9999 -9999 -9999 -9999 -9999 -9999 -9999 -9999 -9999 -9999 -9999 -9999 -9999 -9999 -9999 -9999 -9999 -9999 -9999 -9999 -9999 -9999 -9999 -9999 -9999 -9999 -9999 -9999 -9999 -9999 -9999 -9999 -9999 -9999 -9999 -9999 -9999 -9999 -9999 -9999 -9999 -9999 -9999 -9999 -9999 -9999 -9999 -9999 -9999 -9999 -9999 -9999 -9999 -9999 -9999 -9999 -9999 -9999 -9999 -9999 -9999 -9999 -9999 -9999 -9999 -9999 -9999 -9999 -9999 -9999 -9999 -9999 -9999 -9999 -9999 -9999 -9999 -9999 -9999 -9999 -9999 -9999 -9999 -9999 -9999 -9999 -9999 -9999 -9999 -9999 127.7050018311 124.3523025513 120.3900985718 115.5136032104103.1020202637 103.365272522103 .6268997192104 .2365036011104 .8460998535105 .4557037354 105.7603988647106 .0652008057106 .0652008057105 .6578903198105 .5142669678 105.2815704346104 .9578933716104 .5412979126103 .6268997192102 .712600708 101.7982025146100 .883903503499 .9695205688599 .0551681518697 .83602905273 96.9216690063595 .7025299072394 .1785964965892 .9594726562591 .43553924561 90.2164001464888 .9972534179787 .7781066894586 .254188537685 .03504943848 83.51112365723 82.29197692871 80.7680587768679.54891967773 78.02498626709 76.8058471679775 .5867080688574 .062782287672 .8436431884871 .62449645996 70.4053573608468 .8814392089867 .3575134277365 .8335876464864 .30966186523 62.7857398986861 .2618103027360 .0426712036158 .8235282897957 .60438919067 56.3852500915554 .5565414428752 .4230384826750 .5943298339848 .7656211853 47.2416992187546 .0225486755445 .1082000732444 .1938400268643 .58427047729 42.66992187541 .7555618286140 .8412094116239 .9268493652339 .01250076294 38.7077102661138 .4029312133838 .4029312133838 .4029312133838 .70771026611 39.3172798156739 .9268493652340 .8412094116241 .4507789611842 .06034851074 42.66992187542 .9747009277342 .9747009277343 .2794914245642 .97470092773 42.66992187542 .3651313781741 .7555618286141 .4507789611840 .84120941162 40.5364189147940 .2316398620639 .9268493652339 .9268493652340 .23163986206 40.5364189147940 .8412094116241 .4507789611842 .0603485107442 .97470092773 43.8890609741244 .4986305236845 .717769622846 .6321296691947 .54647827148 48.4608306884849 .3751907348649 .9847602844250 .8991203308151 .50868988037 52.1182594299352 .7278289794953 .3373985290553 .9469718933154 .86132049561 55.4708900451756 .3852500915557 .2995986938557 .909179687559 .12831115723 59.7378807067960 .6522407531761 .5666007995661 .8713798522962 .48094940186 62.4809494018662 .4809494018662 .4809494018662 .1761703491261 .87137985229 61.2618103027360 .6522407531760 .0426712036159 .1283111572358 .21395874023 57.2995986938556 .3852500915555 .1661109924354 .2517509460453 .03261184692 53.33739852905 -9999 -9999 -9999 -9999 -9999 -9999 -9999 -9999 -9999 -9999 -9999 -9999

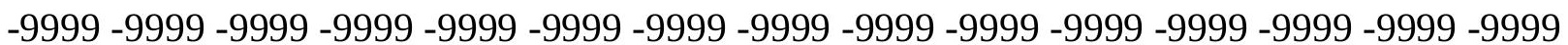

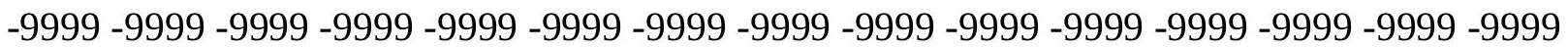
-9999 -9999 -9999 -9999 -9999 -9999 -9999 -9999 -9999 -9999 -9999 -9999 -9999 -9999 -9999 -9999 -9999 -9999 -9999 -9999 -9999 -9999 -9999 -9999 -9999 -9999 -9999 -9999 -9999 -9999 -9999 -9999 -9999 -9999 -9999 -9999 -9999 -9999 -9999 -9999

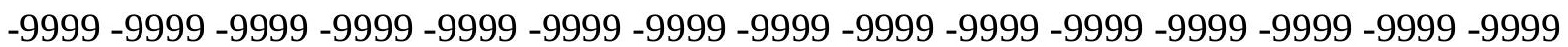
-9999 -9999 -9999 -9999 -9999 -9999 -9999 -9999 -9999 -9999 -9999 -9999 -9999 -9999 -9999 -9999 -9999 -9999 -9999 -9999 -9999 -9999 -9999 -9999 -9999 -9999 -9999 -9999 -9999 -9999 -9999 -9999 -9999 -9999 -9999 -9999 -9999 -9999 -9999 -9999 -9999 -9999 -9999 -9999 -9999

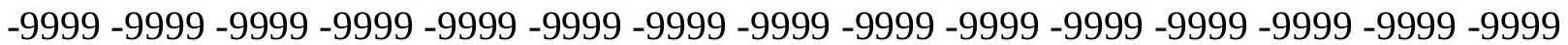


-9999 -9999 -9999 -9999 -9999 -9999 -9999 -9999 -9999 -9999 -9999 -9999 -9999 -9999 -9999 -9999 -9999 -9999 -9999 -9999 -9999 -9999 -9999 -9999 -9999 -9999 -9999 -9999 -9999 -9999 -9999 -9999 -9999 -9999 -9999 -9999 -9999 -9999 -9999 -9999 -9999 -9999 -9999 -9999 -9999 -9999 -9999 -9999 -9999 -9999 -9999 -9999 -9999 -9999 -9999 -9999 -9999 -9999 -9999 -9999 -9999 -9999 -9999 -9999 -9999 -9999 -9999 -9999 -9999 -9999 -9999 -9999 -9999 -9999 -9999 -9999 -9999 -9999 -9999 -9999 -9999 -9999 -9999 -9999 -9999 -9999 -9999 -9999 -9999 -9999 -9999 -9999-9999 124.9618988037120.0852966309 114.9039993286110 .0273971558 104.7670822144105 .1509017944105 .8588638306106 .3700027466106 .979598999 106.979598999107 .2844009399106 .979598999106 .6747970581105 .8877487183 105.5647735596105 .0799636841104 .2365036011103 .6268997192102 .712600708 101.7982025146100 .579101562599 .6647262573298 .7503814697397 .53124237061 96.6168823242295 .397743225193 .8738174438592 .6546783447391 .43553924561 90.2164001464888 .9972534179787 .4733276367286 .254188537685 .03504943848 83.5111236572382 .2919769287181 .0728530883879 .8537063598678 .63455963135 77.4154205322376 .5010681152375 .2819290161174 .062782287672 .84364318848 71.6244964599670 .4053573608468 .8814392089867 .3575134277366 .13836669922 64.9192428588963 .7000885009862 .7857398986861 .8713798522960 .95701980591 59.1283111572357 .2995986938555 .4708900451753 .9469718933152 .42303848267 51.2038993835450 .5943298339849 .6799812316949 .0704002380448 .15605163574 46.9369087219245 .717769622844 .4986305236843 .2794914245642 .669921875 42.0603485107442 .0603485107442 .0603485107442 .3651313781742 .669921875 43.2794914245643 .8890609741244 .1938400268644 .8034095764245 .10820007324 45.4129791259845 .4129791259845 .4129791259845 .1082000732444 .80340957642 44.4986305236843 .8890609741243 .2794914245642 .66992187542 .36513137817 42.0603485107441 .7555618286141 .4507789611841 .4507789611841 .75556182861 42.0603485107442 .3651313781742 .9747009277343 .5842704772944 .19384002686 45.1082000732445 .717769622846 .6321296691947 .5464782714848 .15605163574 49.0704002380449 .9847602844250 .5943298339851 .2038993835451 .81346893311 52.4230384826753 .3373985290553 .9469718933154 .5565414428755 .47089004517 56.3852500915557 .2995986938558 .2139587402359 .1283111572360 .04267120361 60.9570198059161 .5666007995662 .1761703491262 .7857398986863 .09051895142 63.0905189514263 .0905189514262 .7857398986862 .4809494018661 .87137985229 61.2618103027360 .6522407531759 .7378807067958 .8235282897957 .60438919067 56.6900291442955 .4708900451754 .5565414428753 .3373985290553 .33739852905 -9999 -9999 -9999 -9999 -9999 -9999 -9999 -9999 -9999 -9999 -9999 -9999 -9999 -9999 -9999 -9999 -9999 -9999 -9999 -9999 -9999 -9999 -9999 -9999 -9999 -9999 -9999 -9999 -9999 -9999 -9999

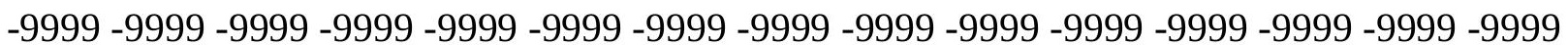
-9999 -9999 -9999-9999-9999-9999

-9999 -9999 -9999 -9999 -9999 -9999 -9999 -9999 -9999 -9999 -9999 -9999 -9999 -9999 -9999 -9999 -9999 -9999 -9999 -9999 -9999 -9999 -9999 -9999 -9999 -9999 -9999 -9999 -9999 -9999 -9999 -9999 -9999 -9999 -9999 -9999 -9999 -9999 -9999 -9999 -9999 -9999 -9999 -9999 -9999

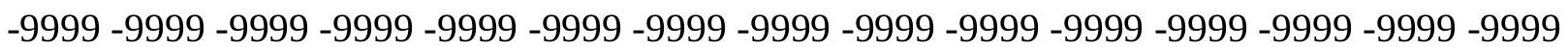
-9999 -9999 -9999 -9999 -9999 -9999 -9999 -9999 -9999 -9999 -9999 -9999 -9999 -9999 -9999 -9999 -9999 -9999 -9999 -9999 -9999 -9999 -9999 -9999 -9999 -9999 -9999 -9999 -9999 -9999 -9999 -9999 -9999 -9999 -9999 -9999 -9999 -9999 -9999 -9999 -9999 -9999 -9999 -9999 -9999

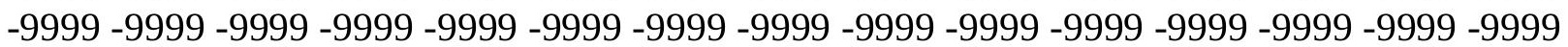


-9999 -9999 -9999 -9999 -9999 -9999 -9999 -9999 -9999 -9999 -9999 -9999 -9999 -9999 -9999 -9999 -9999 -9999 -9999 -9999 -9999 -9999 -9999 -9999 -9999 -9999 -9999 -9999 -9999 -9999

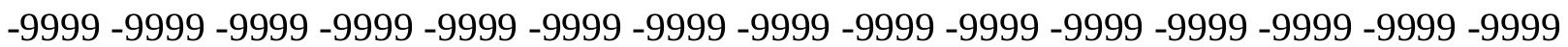
-9999 -9999 -9999 -9999 -9999 -9999 -9999 -9999 -9999 -9999 -9999 -9999 -9999 -9999 -9999 -9999 -9999 -9999 -9999 -9999 -9999 -9999 -9999 -9999 -9999 -9999 -9999 -9999 -9999 -9999 -9999 -9999 -9999 -9999 -9999 119.4757995605114 .5991973877110 .3321990967 107.8938980103106 .8595809937107 .4207000732107 .8938980103108 .1986999512 108.1986999512107 .8938980103107 .5891036987107 .2844009399106 .3700027466 105.6060028076104 .8460998535103 .9317016602103 .255317688102 .1029968262 101.1886978149100 .274299621699 .3599472045998 .445587158297 .22646331787 96.3121032714895 .397743225194 .1785964965892 .9594726562591 .74033355713 90.2164001464888 .6924667358487 .4733276367286 .254188537685 .03504943848 83.8159103393682 .5967712402381 .6824111938580 .4632720947379 .54891967773 78.3297805786177 .4154205322376 .1962814331175 .2819290161174 .0627822876 72.8436431884871 .6244964599670 .4053573608469 .1862335205168 .27187347412 67.0527267456166 .4431610107465 .5288009643664 .6144485473663 .09051895142 61.5666007995660 .0426712036158 .5187492370657 .6043891906756 .38525009155 55.7756805419955 .1661109924354 .5565414428753 .6421813964852 .11825942993 50.5943298339849 .0704002380447 .8512611389246 .6321296691946 .02254867554 45.717769622845 .717769622845 .717769622846 .0225486755446 .32733917236 46.9369087219247 .2416992187547 .8512611389248 .1560516357448 .15605163574 48.1560516357447 .8512611389247 .5464782714847 .2416992187546 .63212966919 46.0225486755445 .4129791259844 .8034095764244 .1938400268643 .58427047729 43.2794914245642 .9747009277342 .9747009277342 .9747009277342 .97470092773 43.2794914245643 .8890609741244 .1938400268644 .8034095764245 .41297912598 46.0225486755446 .9369087219247 .5464782714848 .1560516357449 .07040023804 49.6799812316950 .2895507812551 .2038993835451 .8134689331152 .42303848267 53.0326118469253 .9469718933154 .5565414428755 .4708900451756 .38525009155 57.2995986938558 .2139587402359 .1283111572360 .0426712036160 .95701980591 61.8713798522962 .7857398986863 .3953094482463 .7000885009863 .70008850098 63.7000885009863 .3953094482463 .0905189514262 .7857398986861 .87137985229 61.2618103027360 .3474502563559 .4331016540558 .2139587402356 .99481964111 55.7756805419954 .5565414428753 .3373985290553 .33739852905 -9999 -9999 -9999 -9999 -9999 -9999 -9999 -9999 -9999 -9999 -9999 -9999 -9999 -9999 -9999 -9999 -9999 -9999 -9999 -9999 -9999 -9999 -9999 -9999 -9999 -9999 -9999 -9999 -9999 -9999 -9999 -9999 -9999 -9999 -9999 -9999 -9999 -9999 -9999 -9999 -9999 -9999 -9999 -9999 -9999 -9999 -9999 -9999 -9999 $-9999-9999-9999$

-9999 -9999 -9999 -9999 -9999 -9999 -9999 -9999 -9999 -9999 -9999 -9999 -9999 -9999 -9999 -9999 -9999 -9999 -9999 -9999 -9999 -9999 -9999 -9999 -9999 -9999 -9999 -9999 -9999 -9999 -9999 -9999 -9999 -9999 -9999 -9999 -9999 -9999 -9999 -9999 -9999 -9999 -9999 - -9999 -9999 -9999 -9999 -9999 -9999 -9999 -9999 -9999 -9999 -9999 -9999 -9999 -9999 -9999 -9999 -9999

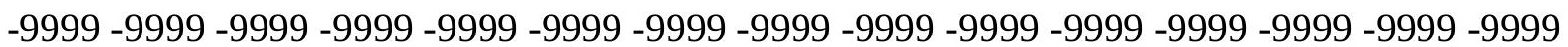
-9999 -9999 -9999 -9999 -9999 -9999 -9999 -9999 -9999 -9999 -9999 -9999 -9999 -9999 -9999 -9999 -9999 -9999 -9999 -9999 -9999 -9999 -9999 -9999 -9999 -9999 -9999 -9999 -9999 -9999 -9999 -9999 -9999 -9999 -9999 -9999 -9999 -9999 -9999 -9999 -9999 -9999 -9999 -9999 -9999

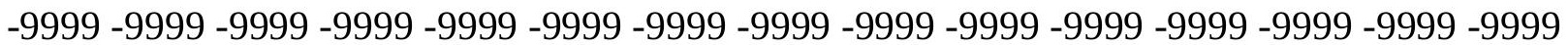


-9999 -9999 -9999 -9999 -9999 -9999 -9999 -9999 -9999 -9999 -9999 -9999 -9999 -9999 -9999 -9999 -9999 -9999 -9999 -9999 -9999 -9999 -9999 -9999 -9999 -9999 -9999 -9999 -9999 -9999

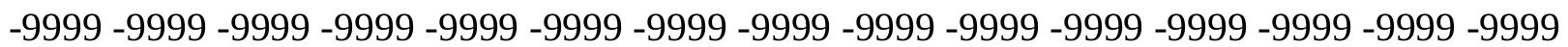
-9999 -9999 -9999 -9999 -9999 -9999 -9999 -9999 -9999 -9999 -9999 -9999 -9999 -9999 -9999 -9999 -9999 -9999 -9999 -9999 -9999-9999 115.5136032104112 .7705001831110 .9418029785 108.3087615967 108.7482376099 109.0589675903109.1130981445108.8082962036 108.5035018921107 .8938980103107 .2844009399106 .3700027466105 .4557037354 104.5412979126103 .6268997192102 .712600708101 .7982025146100 .8839035034 99.9695205688599 .0551681518698 .1408081054797 .2264633178796 .31210327148 95.397743225194 .4833908081192 .9594726562591 .1307525634889 .60682678223 88.38768768311 87.16854858398 85.9494018554785.03504943848 84.12069702148 82.9015579223681 .9871978759881 .0728530883880 .1584930419979 .24413299561 78.3297805786177 .4154205322376 .1962814331175 .2819290161174 .0627822876 73.1484298706171 .9292907714871 .014930725170 .1005783081169 .49101257324 68.5766525268667 .6623001098666 .4431610107465 .2240066528364 .0048828125 62.7857398986861 .8713798522961 .2618103027360 .3474502563559 .73788070679 59.4331016540558 .8235282897956 .9948196411154 .8613204956153 .33739852905 51.8134689331150 .5943298339849 .9847602844249 .3751907348649 .07040023804 49.0704002380449 .3751907348649 .6799812316949 .9847602844250 .28955078125 50.5943298339850 .8991203308150 .8991203308150 .8991203308150 .59432983398 49.9847602844249 .3751907348648 .765621185348 .1560516357447 .24169921875 46.6321296691946 .0225486755445 .4129791259844 .8034095764244 .49863052368 44.1938400268644 .1938400268644 .1938400268644 .1938400268644 .49863052368 44.8034095764245 .4129791259846 .0225486755446 .3273391723646 .93690872192 47.5464782714848 .4608306884849 .0704002380449 .6799812316950 .28955078125 50.8991203308151 .8134689331152 .4230384826753 .0326118469253 .94697189331 54.5565414428755 .4708900451756 .3852500915557 .2995986938558 .21395874023 59.1283111572360 .3474502563561 .2618103027362 .1761703491263 .09051895142 64.004882812564 .3096618652364 .6144485473664 .6144485473664 .30966186523 64.004882812563 .3953094482462 .7857398986861 .8713798522960 .95701980591 59.7378807067958 .8235282897957 .6043891906756 .3852500915554 .86132049561 53.6421813964853 .64218139648 -9999 -9999 -9999 -9999 -9999 -9999 -9999 -9999 -9999 -9999 -9999 -9999 -9999 -9999 -9999 -9999 -9999 -9999 -9999 -9999 -9999 -9999 -9999 -9999 -9999 -9999 -9999 -9999 -9999 -9999 -9999 -9999 -9999 -9999 -9999 -9999 -9999 -9999 -9999 -9999 -9999 -9999 -9999 -9999 -9999 -9999 -9999 -9999 -9999 -9999 -9999 -9999 -9999 -9999 -9999 -9999 -9999 -9999 -9999 -9999 -9999 -9999 -9999 -9999 -9999 -9999 -9999 -9999 -9999 -9999 -9999 -9999 -9999 -9999 -9999 -9999 -9999 -9999 -9999 -9999 -9999 -9999

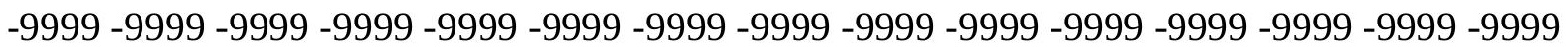
-9999 -9999 -9999 -9999 -9999 -9999 -9999 -9999 -9999 -9999 -9999 -9999 -9999 -9999 -9999 -9999 -9999 -9999 -9999 -9999 -9999 -9999 -9999 -9999 -9999 -9999 -9999 -9999 -9999 -9999 -

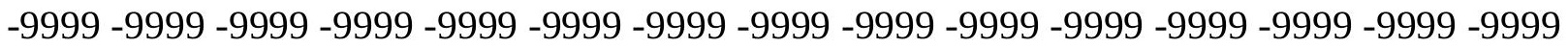

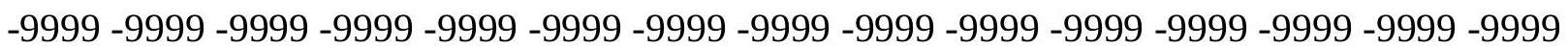
-9999 -9999 -9999 -9999 -9999 -9999 -9999 -9999 -9999 -9999 -9999 -9999 -9999 -9999 -9999 -9999 -9999 -9999 -9999 -9999 -9999 -9999 -9999 -9999 -9999 -9999 -9999 -9999 -9999 -9999 -9999 -9999 -9999 -9999 -9999 -9999 -9999 -9999 -9999 -9999 -9999 -9999 -9999 -9999 -9999

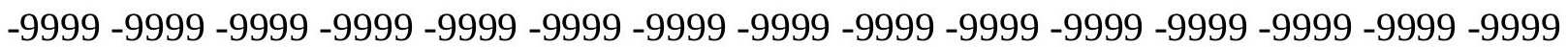


-9999 -9999 -9999 -9999 -9999 -9999 -9999 -9999 -9999 -9999 -9999 -9999 -9999 -9999 -9999 -9999 -9999 -9999 -9999 -9999 -9999 -9999 -9999 -9999 -9999 -9999 -9999 -9999 -9999 -9999 -9999 -9999 -9999 -9999 -9999 -9999 -9999 -9999 -9999 115.5136032104113 .075302124 109.492805481109 .760017395109 .8566513062109 .7226028442109 .1130981445 108.5035018921107 .5891036987106 .979598999106 .0652008057105 .1509017944 104.2365036011103 .3221969604102 .4077987671101 .4933929443100 .5791015625 99.6647262573298 .7503814697398 .1408081054797 .2264633178796 .31210327148 95.7025299072393 .8738174438592 .0450973510790 .5211791992288 .99725341797 88.0829010009887 .1685485839886 .254188537685 .3398437584 .42548370361 83.5111236572382 .5967712402381 .6824111938581 .0728530883880 .15849304199 79.2441329956178 .3297805786177 .4154205322376 .5010681152375 .58670806885 74.6723632812573 .7580032348672 .8436431884872 .2340774536171 .31971740723 70.4053573608469 .4910125732468 .5766525268667 .6623001098666 .74794006348 65.8335876464865 .2240066528364 .6144485473664 .004882812563 .39530944824 62.1761703491260 .6522407531758 .8235282897957 .2995986938555 .77568054199 54.5565414428753 .6421813964853 .0326118469252 .7278289794952 .42303848267 52.4230384826752 .7278289794953 .0326118469253 .3373985290553 .64218139648 53.6421813964853 .6421813964853 .6421813964853 .0326118469252 .42303848267 51.8134689331150 .8991203308150 .2895507812549 .3751907348648 .46083068848 47.8512611389246 .9369087219246 .3273391723646 .0225486755445 .7177696228 45.4129791259845 .4129791259845 .4129791259845 .4129791259845 .7177696228 46.0225486755446 .3273391723646 .6321296691947 .2416992187547 .85126113892 48.4608306884849 .0704002380449 .6799812316950 .2895507812550 .89912033081 51.5086898803752 .4230384826753 .0326118469253 .9469718933154 .86132049561 55.4708900451756 .3852500915557 .6043891906758 .5187492370659 .43310165405 60.3474502563561 .5666007995662 .7857398986863 .7000885009864 .61444854736 64.9192428588965 .2240066528365 .2240066528365 .2240066528364 .61444854736 64.3096618652363 .3953094482462 .4809494018661 .5666007995660 .34745025635 59.1283111572357 .909179687556 .6900291442955 .1661109924353 .94697189331 53.64218139648 -9999 -9999 -9999 -9999 -9999 -9999 -9999 -9999 -9999 -9999 -9999 -9999 -9999 -9999 -9999 -9999 -9999 -9999 -9999 -9999 -9999 -9999 -9999 -9999 -9999 -9999 -9999 -9999 -9999 -9999 -9999 -9999 -9999 -9999 -9999 -9999 -9999 -9999 -9999 -9999 -9999 -9999 -9999 -9999 -9999 -9999 -9999 -9999 -9999 -9999 -9999 -9999

-9999 -9999 -9999 -9999 -9999 -9999 -9999 -9999 -9999 -9999 -9999 -9999 -9999 -9999 -9999 -9999 -9999 -9999 -9999 -9999 -9999 -9999 -9999 -9999 -9999 -9999 -9999 -9999 -9999 -9999 -9999 -9999 -9999 -9999 -9999 -9999 -9999 -9999 -9999 -9999 -9999 -9999 -9999 -9999 -9999 -9999 -9999 -9999 -9999 -9999 -9999 -9999 -9999 -9999 -9999 -9999 -9999 -9999 -9999 -9999

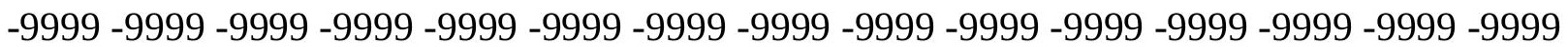
-9999 -9999 -9999 -9999 -9999 -9999 -9999 -9999 -9999 -9999 -9999 -9999 -9999 -9999 -9999 -9999 -9999 -9999 -9999 -9999 -9999 -9999 -9999 -9999 -9999 -9999 -9999 -9999 - -9999 -9999 -9999 -9999 -9999 -9999 -9999 -9999 -9999 -9999 -9999 -9999 -9999 -9999 -9999 -9999 -9999

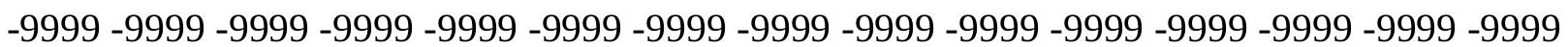
-9999 -9999 -9999 -9999 -9999 -9999 -9999 -9999 -9999 -9999 -9999 -9999 -9999 -9999 -9999 -9999 -9999 -9999 -9999 -9999 -9999 -9999 -9999 -9999 -9999 -9999 -9999 -9999 -9999 -9999 -9999 -9999 -9999 -9999 -9999 -9999 -9999 -9999 -9999 -9999 -9999 -9999 -9999 -9999 -9999

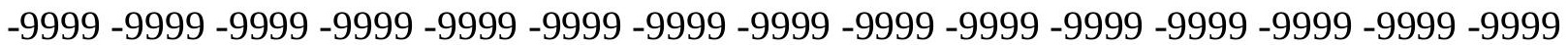


-9999 -9999 -9999 -9999 -9999 -9999 -9999 -9999 -9999 -9999 117.342300415 114.5991973877110 .3496170044110 .4199295044110 .3205871582110 .0273971558 109.1130981445108 .1986999512107 .2844009399106 .3700027466105 .4557037354 104.5412979126103 .6268997192102 .712600708101 .7982025146100 .8839035034 100.250946044999 .3599472045998 .445587158297 .8360290527396 .92166900635 95.7025299072394 .1785964965892 .349891662690 .8259735107489 .60682678223 88.9972534179788 .0829010009887 .1685485839886 .5589828491285 .64462280273 84.7302627563584 .1206970214883 .206336975182 .5967712402381 .68241119385 80.7680587768680 .1584930419979 .2441329956178 .3297805786177 .72020721436 76.8058471679775 .8914871215875 .2819290161174 .6723632812573 .75800323486 73.1484298706172 .2340774536171 .3197174072370 .7101516723670 .10057830811 69.1862335205168 .5766525268667 .9670867919967 .3575134277366 .74794006348 65.5288009643664 .004882812562 .4809494018660 .6522407531759 .12831115723 57.909179687556 .9948196411156 .3852500915555 .7756805419955 .77568054199 55.7756805419955 .7756805419956 .0804595947356 .3852500915556 .69002914429 56.6900291442956 .3852500915556 .0804595947355 .4708900451754 .86132049561 54.2517509460453 .3373985290552 .4230384826751 .2038993835450 .28955078125 49.3751907348648 .765621185348 .1560516357447 .5464782714846 .93690872192 46.6321296691946 .3273391723646 .3273391723646 .3273391723646 .32733917236 46.3273391723646 .6321296691946 .9369087219247 .5464782714847 .85126113892 48.4608306884849 .0704002380449 .6799812316950 .2895507812550 .89912033081 51.5086898803752 .4230384826753 .0326118469253 .9469718933154 .86132049561 55.7756805419956 .6900291442957 .6043891906758 .5187492370659 .73788070679 60.6522407531761 .8713798522963 .0905189514264 .3096618652365 .22400665283 65.8335876464866 .1383666992266 .1383666992265 .8335876464865 .52880096436 64.9192428588964 .3096618652363 .3953094482462 .1761703491260 .95701980591 59.7378807067958 .5187492370656 .9948196411155 .4708900451754 .25175094604 53.94697189331 -9999 -9999 -9999 -9999 -9999 -9999 -9999 -9999 -9999 -9999 -9999 -9999 -9999 -9999 -9999 -9999 -9999 -9999 -9999 -9999 -9999 -9999 -9999 -9999 -9999 -9999 -9999 -999 -

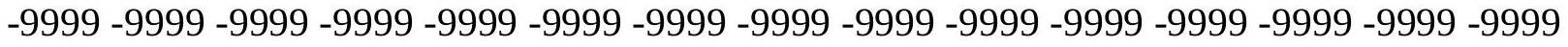
-9999 -9999 -9999 -9999 -9999 -9999 -9999 -9999 -9999 -9999

-9999 -9999 -9999 -9999 -9999 -9999 -9999 -9999 -9999 -9999 -9999 -9999 -9999 -9999 -9999

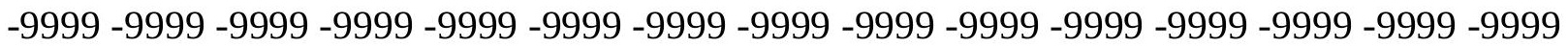
-9999 -9999 -9999 -9999 -9999 -9999 -9999 -9999 -9999 -9999 -9999 -9999 -9999 -9999 -9999 -9999 -9999 -9999 -9999 -9999 -9999 -9999 -9999 -9999 -9999 -9999 -9999 -9999 -9999 -9999 -9999 -9999 -9999 -9999 -9999 -9999 -9999 -9999 -9999 -9999 -9999 -9999 -9999 -9999 -9999

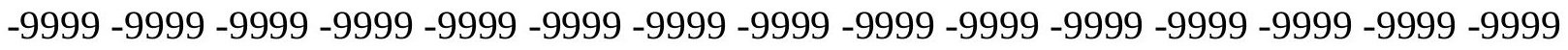

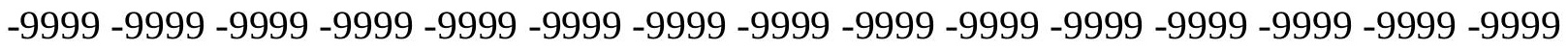
-9999 -9999 -9999 -9999 -9999 -9999 -9999 -9999 -9999 -9999 -9999 -9999 -9999 -9999 -9999 -9999 -9999 -9999 -9999 -9999 -9999 -9999 -9999 -9999 -9999 -9999 -9999 -9999 -9999 -9999 -

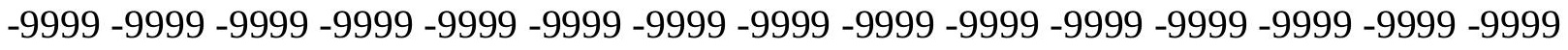

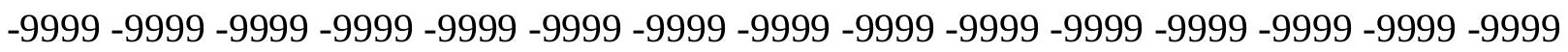
-9999 -9999 -9999 -9999 -9999 -9999 -9999 -9999 -9999 -9999 -9999 -9999 -9999 -9999 -9999 -9999 -9999 -9999 -9999 -9999 -9999 -9999 -9999 -9999 -9999 -9999 -9999 -9999 -9999 -9999 -9999 -9999 -9999 -9999 -9999 -9999 -9999 -9999 -9999 -9999 -9999 118.5614013672 115.818397522110 .8388442993110 .6724700928110 .2344436646109 .4179000854 
108.5035018921107 .5891036987106 .6747970581105 .7603988647104 .8460998535 103.9317016602103 .0174026489102 .1029968262101 .4934005737100 .5791015625 99.6647262573299 .0551681518698 .1408081054797 .2264633178796 .00731658936 94.4833908081192 .6546783447391 .1307525634890 .2164001464889 .60682678223 88.9972534179788 .0829010009887 .4733276367286 .8637619018685 .94940185547 85.3398437584 .7302627563583 .8159103393683 .206336975182 .59677124023 81.6824111938581 .0728530883880 .1584930419979 .5489196777378 .93934631348 78.0249862670977 .4154205322376 .8058471679776 .1962814331175 .28192901611 74.6723632812574 .062782287673 .4532165527372 .8436431884872 .23407745361 71.6244964599671 .014930725170 .4053573608469 .4910125732468 .27187347412 66.7479400634865 .2240066528363 .7000885009862 .4809494018661 .26181030273 60.3474502563559 .4331016540559 .1283111572358 .8235282897958 .51874923706 58.8235282897958 .8235282897959 .1283111572359 .4331016540559 .12831115723 59.1283111572358 .5187492370657 .909179687557 .2995986938556 .38525009155 55.4708900451754 .2517509460453 .3373985290552 .1182594299351 .20389938354 50.2895507812549 .3751907348648 .765621185348 .1560516357447 .85126113892 47.24169921875 47.24169921875 46.9369087219246.9369087219246.93690872192 47.2416992187547 .2416992187547 .5464782714848 .1560516357448 .46083068848 49.0704002380449 .6799812316950 .2895507812550 .8991203308151 .50868988037 52.4230384826753 .0326118469253 .9469718933154 .8613204956155 .77568054199 56.9948196411157 .909179687558 .8235282897960 .0426712036161 .26181030273 62.4809494018663 .7000885009864 .9192428588965 .8335876464866 .44316101074 66.7479400634867 .0527267456167 .0527267456166 .4431610107465 .83358764648 65.2240066528364 .3096618652363 .0905189514261 .5666007995660 .34745025635 58.8235282897957 .2995986938556 .0804595947354 .5565414428753 .94697189331 -9999 -9999 -9999 -9999 -9999 -9999 -9999 -9999 -9999 -9999 -9999 -9999 -9999 -9999 -9999 -9999 -9999 -9999 -9999 -9999 -9999 -9999 -9999 -9999 -9999 -9999 -9999 -9999 -9999 -9999 -9999

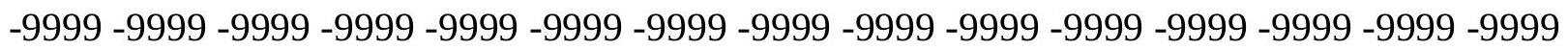
-9999 -9999 -9999 -9999-9999-9999

-9999 -9999 -9999 -9999 -9999 -9999 -9999 -9999 -9999 -9999 -9999 -9999 -9999 -9999 -9999 -9999 -9999 -9999 -9999 -9999 -9999 -9999 -9999 -9999-9999 -9999 -9999 -9999 -9999 -9999 -9999 -9999 -9999 -9999 -9999 -9999 -9999 -9999 -9999 -9999 -9999 -9999 -9999 -9999 -9999 -

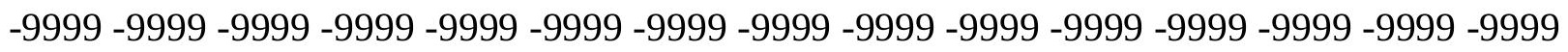
-9999 -9999 -9999 -9999 -9999 -9999 -9999 -9999 -9999 -9999 -9999 -9999 -9999 -9999 -9999 -9999 -9999 -9999 -9999 -9999 -9999 -9999 -9999 -9999 -9999 -9999 -9999 -9999 -9999 -9999

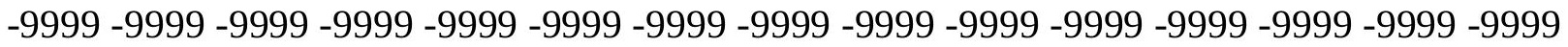

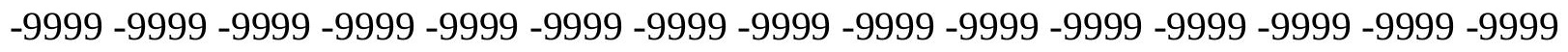

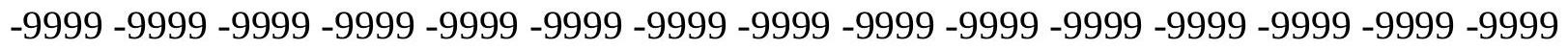
-9999 -9999 -9999 -9999 -9999 -9999 -9999 -9999 -9999 -9999 -9999 -9999 -9999 -9999 -9999 -

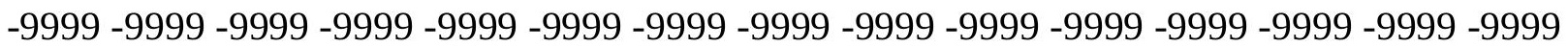

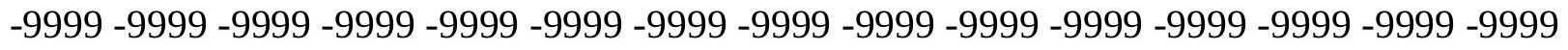

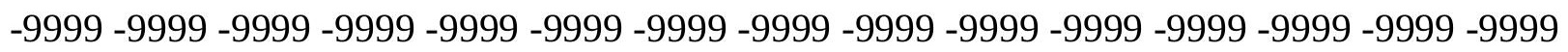
-9999 -9999 -9999 -9999 -9999 -9999 -9999 -9999 -9999 -9999-9999 -9999 119.4757995605 116.1231002808110 .8729858398110 .3752746582109 .6550140381108 .8031845093 107.8938980103106 .6747970581105 .7603988647104 .8460998535103 .9317016602 103.3221969604102 .4077987671101 .7982025146100 .883903503499 .96952056885 
99.3599472045998 .392723083597 .2264633178796 .0073165893694 .78817749023 93.2642517089892 .0450973510791 .1307525634890 .5211791992289 .91161346436 89.3020401001 88.38768768311 87.77810668945 87.16854858398 86.55898284912 85.9494018554785 .3398437584 .4254837036183 .8159103393683 .2063369751

82.5967712402381 .9871978759881 .3776321411180 .4632720947379 .85370635986 79.2441329956178 .6345596313578 .0249862670977 .4154205322376 .80584716797 76.1962814331175 .8914871215875 .2819290161174 .6723632812574 .0627822876 73.4532165527372 .5388565063571 .6244964599670 .7101516723669 .18623352051 67.9670867919966 .4431610107465 .2240066528364 .004882812566 .44316101074 67.3575134277366 .4431610107465 .2240066528364 .3096618652361 .26181030273 61.5666007995661 .5666007995661 .8713798522961 .5666007995661 .26181030273 60.6522407531760 .3474502563559 .4331016540558 .5187492370657 .29959869385 56.0804595947354 .8613204956153 .9469718933152 .7278289794951 .81346893311 50.8991203308149 .9847602844249 .3751907348648 .765621185348 .46083068848 47.8512611389247 .5464782714847 .5464782714847 .5464782714847 .54647827148 47.5464782714847 .8512611389248 .1560516357448 .4608306884849 .07040023804 49.6799812316950 .2895507812550 .8991203308151 .5086898803752 .42303848267 53.3373985290553 .9469718933155 .1661109924356 .0804595947356 .99481964111 58.2139587402359 .4331016540560 .6522407531761 .8713798522963 .09051895142 64.6144485473665 .8335876464866 .7479400634867 .3575134277367 .96708679199 67.9670867919967 .9670867919967 .6623001098667 .0527267456166 .13836669922 64.9192428588963 .7000885009862 .4809494018660 .9570198059159 .12831115723 57.6043891906756 .0804595947354 .8613204956154 .25175094604 -9999 -9999 -9999 -9999 -9999 -9999 -9999 -9999 -9999 -9999 -9999 -9999 -9999 -9999 -9999 -9999 -9999 -9999 -9999 -9999 -9999 -9999 -9999 -9999 -9999 -9999 -9999 -9999 -9999 -9999 -9999 -9999 -9999 -9999

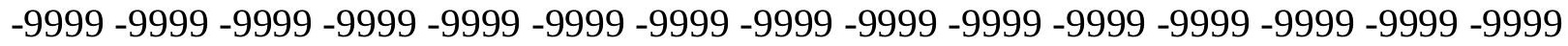
-9999 -9999 -9999

-9999 -9999 -9999 -9999 -9999 -9999 -9999 -9999 -9999 -9999 -9999 -9999 -9999 -9999 -9999 -9999 -9999 -9999 -9999 -9999 -9999 -9999 -9999 -9999 -9999 -9999 -9999 -9999 -9999 -9999 -9999 -9999 -9999 -9999 -9999 -9999 -9999 -9999 -9999 -9999 -9999 -9999 -9999 -9999 -9999 -9999 -9999 -9999 -9999 -9999 -9999 -9999 -9999 -9999 -9999 -9999 -9999 -9999 -9999 -9999

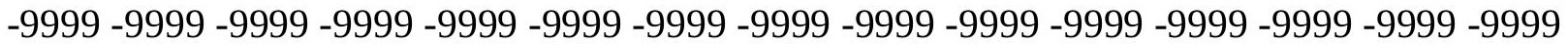

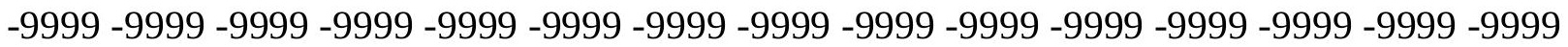
-9999 -9999 -9999 -9999 -9999 -9999 -9999 -9999 -9999 -9999 -9999 -9999 -9999 -9999 -9999 -9999 -9999 -9999 -9999 -9999 -9999 -9999 -9999 -9999 -9999 -9999 -9999 -9999 -9999 -9999 -9999 -9999 -9999 -9999 -9999 -9999 -9999 -9999 -9999 -9999 -9999 -9999 -9999 -9999 -9999

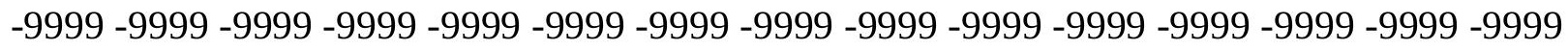

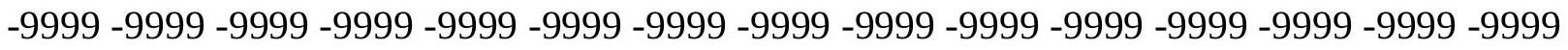
-9999 -9999 -9999 -9999 -9999 -9999 -9999 -9999 -9999 -9999 -9999 -9999 -9999 -9999 -9999 -9999 -9999 -9999 -9999 -9999 -9999 -9999 -9999 -9999 -9999 -9999 -9999 -9999 -9999 -9999 -9999 -9999 -9999 -9999 -9999 -9999 -9999 -9999 -9999 -9999 -9999 -9999 -9999 120.0852966309116 .7326965332110 .5126342773109 .7226028442108 .8082962036 107.8938980103106 .979598999106 .0652008057105 .1509017944104 .2365036011 103.3221969604102 .712600708101 .7982025146101 .1886978149100 .2742996216 99.6647262573298 .445587158297 .5110549926896 .3121032714895 .09295654297 93.8738174438592 .9594726562592 .0450973510791 .4355392456190 .82597351074 
90.2164001464889 .302040100188 .6924667358488 .0829010009887 .47332763672 86.8637619018686 .254188537685 .6446228027385 .3398437584 .73026275635 84.1206970214883 .5111236572382 .9015579223682 .2919769287181 .68241119385 81.0728530883880 .4632720947379 .8537063598679 .2441329956178 .93934631348 78.3297805786177 .7202072143677 .4154205322376 .8058471679776 .19628143311 75.5867080688574 .6723632812573 .7580032348672 .8436431884871 .62449645996 70.1005783081168 .8814392089871 .3197174072371 .9292907714872 .53885650635 73.1484298706172 .5388565063571 .6244964599671 .014930725170 .10057830811 69.4910125732468 .2718734741263 .7000885009863 .7000885009863 .09051895142 62.7857398986862 .1761703491261 .5666007995660 .3474502563559 .12831115723 57.909179687556 .6900291442955 .4708900451754 .2517509460453 .33739852905 52.1182594299351 .2038993835450 .5943298339849 .6799812316949 .37519073486 48.765621185348 .4608306884848 .1560516357447 .8512611389247 .85126113892 47.8512611389247 .8512611389248 .1560516357448 .4608306884849 .07040023804 49.3751907348649 .9847602844250 .8991203308151 .5086898803752 .42303848267 53.3373985290554 .2517509460455 .1661109924356 .3852500915557 .29959869385 58.5187492370659 .7378807067961 .2618103027362 .4809494018664 .0048828125 65.5288009643666 .7479400634867 .6623001098668 .2718734741268 .88143920898 69.1862335205168 .8814392089868 .5766525268667 .9670867919967 .05272674561 65.8335876464864 .6144485473663 .0905189514261 .2618103027359 .73788070679 57.909179687556 .3852500915554 .8613204956154 .55654144287 -9999 -9999 -9999 -9999 -9999 -9999 -9999 -9999 -9999 -9999 -9999 -9999 -9999 -9999 -9999 -9999 -9999 -9999 -9999 -9999 -9999 -9999 -9999 -9999 -9999 -9999 -9999 -9999 -9999 -9999 -9999 -9999 -9999 -9999 -

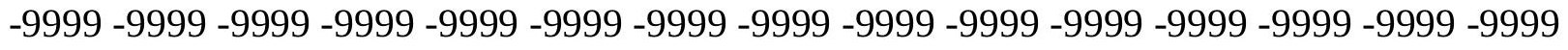
-9999 -9999-9999

-9999 -9999 -9999 -9999 -9999 -9999 -9999 -9999 -9999 -9999 -9999 -9999 -9999 -9999 -9999 -9999 -9999 -9999 -9999 -9999 -9999 -9999 -9999 -9999 -9999 -9999 -9999 -9999 -9999 -9999 -

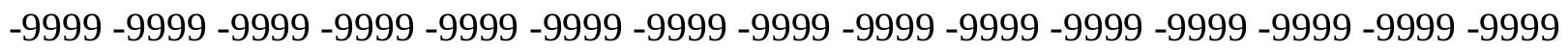
-9999 -9999 -9999 -9999 -9999 -9999 -9999 -9999 -9999 -9999 -9999 -9999 -9999 -9999 -9999 -9999 -9999 -9999 -9999 -9999 -9999 -9999 -9999 -9999 -9999 -9999 -9999 -9999 -9999 -9999 -9999 -9999 -9999 -9999 -9999 -9999 -9999 -9999 -9999 -9999 -9999 -9999-9999 -9999 -9999 -9999 -9999 -9999 -9999 -9999 -9999 -9999 -9999 -9999 -9999 -9999 -9999 -9999 -9999 -9999 -

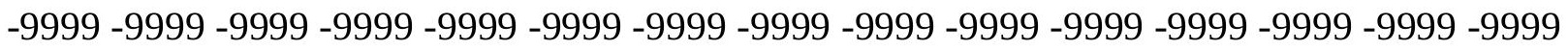
-9999 -9999 -9999 -9999 -9999 -9999 -9999 -9999 -9999 -9999 -9999 -9999 -9999 -9999 -9999 -9999 -9999 -9999 -9999 -9999 -9999 -9999 -9999 -9999 -9999 -9999 -9999 -9999 -9999 -9999 -

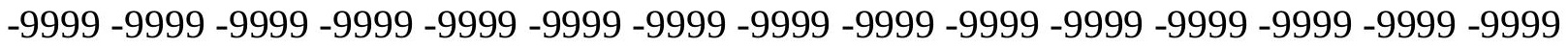

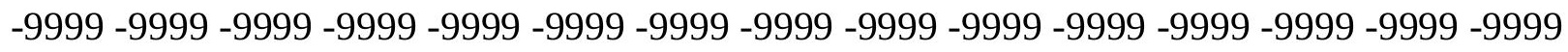

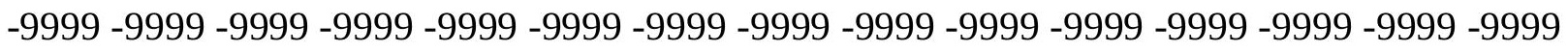
-9999 -9999 -9999 -9999 -9999 -9999 -9999 -9999 -9999 -9999 -9999 -9999 -9999 -9999 120.6949005127117 .0374984741113 .3800964355109 .0868148804107 .8938980103 106.979598999106 .0652008057105 .1509017944104 .2365036011103 .6268997192 102.712600708102 .1029968262101 .4934005737100 .579101562599 .96952056885 99.0551681518697 .8360290527396 .7954254150495 .7025299072394 .78817749023 93.8738174438592 .9594726562592 .349891662691 .4355392456190 .82597351074 90.2164001464889 .6068267822388 .9972534179788 .6924667358488 .08290100098 87.47332763672 86.86376190186 86.2541885376 85.9494018554785.33984375 
84.7302627563584 .1206970214883 .5111236572383 .206336975182 .59677124023 81.9871978759881 .3776321411181 .0728530883880 .4632720947380 .15849304199 79.5489196777378 .9393463134878 .3297805786178 .0249862670977 .1106262207 76.5010681152378 .6345596313577 .7202072143677 .110626220776 .50106811523 76.1962814331176 .1962814331176 .8058471679777 .110626220777 .41542053223 77.4154205322376 .8058471679776 .1962814331175 .5867080688574 .67236328125 73.4532165527371 .6244964599670 .1005783081168 .5766525268664 .30966186523 63.7000885009862 .7857398986861 .8713798522960 .6522407531759 .43310165405 58.2139587402356 .9948196411155 .7756805419954 .5565414428753 .33739852905 52.4230384826751 .5086898803750 .8991203308149 .9847602844249 .37519073486 49.0704002380448 .4608306884848 .1560516357448 .1560516357448 .15605163574 48.1560516357448 .1560516357448 .4608306884849 .0704002380449 .37519073486 49.9847602844250 .5943298339851 .5086898803752 .4230384826753 .33739852905 54.2517509460455 .4708900451756 .6900291442957 .6043891906759 .12831115723 60.3474502563561 .8713798522963 .3953094482464 .9192428588966 .44316101074 67.6623001098668 .5766525268669 .4910125732470 .1005783081170 .10057830811 70.1005783081169 .7957916259868 .8814392089867 .9670867919966 .74794006348 65.2240066528363 .7000885009861 .8713798522960 .0426712036158 .21395874023 56.3852500915554 .8613204956154 .55654144287 -9999 -9999 -9999 -9999 -9999 -9999 -9999 -9999 -9999 -9999 -9999 -9999 -9999 -9999 -9999 -9999 -9999 -9999 -9999 -9999 -9999 -9999 -9999 -9999 -9999 -9999 -9999 -9999 -9999 -9999 -9999 -9999 -9999 -9999 -9999 -9999 -9999 -9999 -9999 -9999 -9999 -9999 -9999 -9999 -9999 -9999 -9999 -9999 -9999 -9999 -9999 -9999 -9999 -9999 -9999 -9999 -9999 -9999 -9999 -9999 -9999 -9999 -9999 -9999 -9999 -9999 -9999 -9999 -9999 -9999 -9999 -9999 -9999 -9999 -9999 -9999 -9999 -9999 -9999 -9999 -9999 -9999 -9999 -9999 -9999 -9999 -9999 -9999 -9999 -9999 -9999 -9999 -9999 -9999 -9999 -9999 -9999 -9999 -9999 -9999 -9999 -9999 -9999 -9999 -9999 -9999 -9999 -9999 -9999 -9999 -9999 -9999 -9999 -9999 -9999 -9999 -9999 -9999 -9999 -9999 -9999 -9999 -9999 -9999 -9999 -9999 -9999

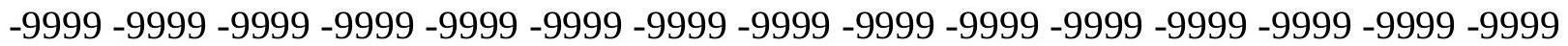

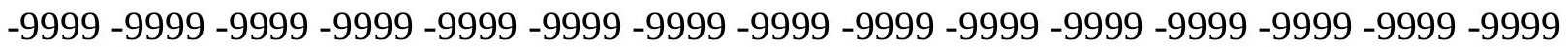
-9999 -9999 -9999 -9999 -9999 -9999 -9999 -9999 -9999 -9999 -9999 -9999 -9999 -9999 -9999 -9999 -9999 -9999 -9999 -9999 -9999 -9999 -9999 -9999 -9999 -9999 -9999 -9999 -9999 -9999 -

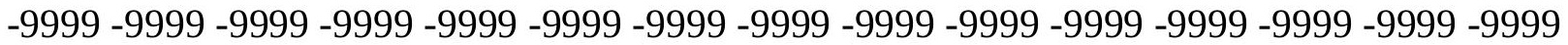

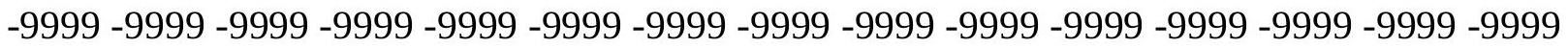
-9999 -9999 -9999 -9999 -9999 -9999 -9999 -9999 -9999 -9999 -9999 -9999 -9999 -9999 -9999 -9999 -9999 -9999 -9999 -9999 -9999 -9999 -9999 -9999 -9999 -9999 -9999 -9999 -9999 -9999 -9999 -9999 -9999 -9999 -9999 -9999 -9999 -9999 -9999 -9999 -9999 -9999 -9999 -9999 -9999 -9999 117.342300415 113.3800964355 108.2671051025106.979598999 106.0652008057 105.1509017944104 .2365036011103 .6268997192103 .0174026489102 .4077987671 101.7982025146100 .8839035034100 .274299621699 .3599472045998 .4455871582 97.2264633178796 .3121032714895 .397743225194 .4833908081193 .87381744385 92.9594726562592 .349891662691 .7403335571391 .1307525634890 .52117919922 89.91161346436 89.60682678223 88.9972534179788.3876876831188.08290100098 87.4733276367286 .8637619018686 .5589828491285 .9494018554785 .33984375 84.7302627563584 .4254837036183 .8159103393683 .5111236572382 .90155792236 82.2919769287181 .9871978759881 .3776321411181 .0728530883880 .46327209473 79.8537063598679 .2441329956178 .6345596313581 .6824111938581 .37763214111 
80.7680587768680 .4632720947380 .1584930419980 .1584930419980 .15849304199 80.4632720947380 .7680587768681 .0728530883881 .0728530883880 .76805877686 80.1584930419979 .5489196777378 .6345596313577 .4154205322375 .89148712158 73.7580032348671 .3197174072365 .5288009643667 .9670867919964 .0048828125 63.0905189514261 .8713798522960 .6522407531759 .4331016540558 .21395874023 56.9948196411155 .7756805419954 .5565414428753 .6421813964852 .72782897949 51.8134689331150 .8991203308150 .2895507812549 .6799812316949 .07040023804 48.765621185348 .4608306884848 .1560516357448 .1560516357448 .15605163574 48.4608306884848 .765621185349 .3751907348649 .9847602844250 .59432983398 51.5086898803752 .4230384826753 .3373985290554 .5565414428755 .77568054199 56.6900291442958 .2139587402359 .4331016540560 .9570198059162 .48094940186 64.3096618652365 .8335876464867 .3575134277368 .8814392089869 .79579162598 70.7101516723671 .014930725171 .3197174072371 .3197174072370 .71015167236 70.1005783081168 .8814392089867 .6623001098665 .8335876464864 .0048828125 62.1761703491260 .3474502563558 .2139587402356 .3852500915554 .86132049561 54.86132049561 -9999 -9999 -9999 -9999 -9999 -9999 -9999 -9999 -9999 -9999 -9999 -9999 -9999 -9999 -9999 -9999 -9999 -9999 -9999 -9999 -9999 -9999 -9999 -9999 -9999 -9999 -9999 -9999 -9999 -9999 -9999 -9999 -9999 -9999 -9999 -9999 -9999 -9999 -9999 -9999 -9999 - -9999 -9999 -9999 -9999 -9999 -9999 -9999 -9999 -9999 -9999 -9999

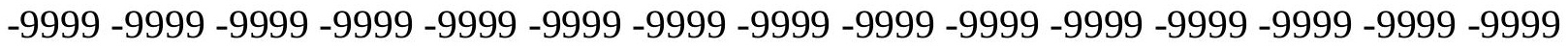

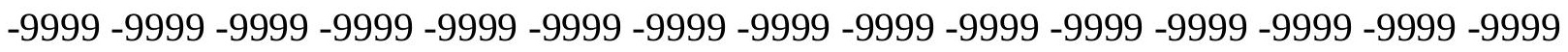
-9999 -9999 -9999 -9999 -9999 -9999 -9999 -9999 -9999 -9999 -9999 -9999 -9999 -9999 -9999 -9999 -9999 -9999 -9999 -9999 -9999 -9999 -9999 -9999 -9999 -9999 -9999 -9999 -9999 -9999 -

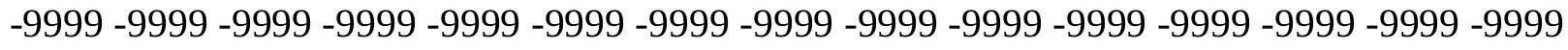

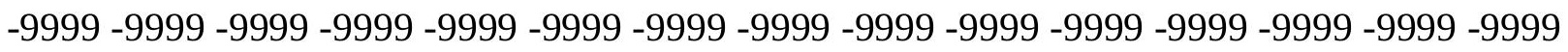
-9999 -9999 -9999 -9999 -9999 -9999 -9999 -9999 -9999 -9999 -9999 -9999 -9999 -9999 -9999 -9999 -9999 -9999 -9999 -9999 -9999 -9999 -9999 -9999 -9999 -9999 -9999 -9999 -9999 -9999

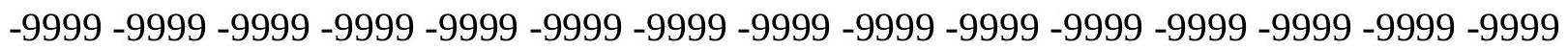
-9999 -9999 -9999 -9999 -9999 -9999 -9999 -9999 -9999 -9999 -9999 -9999 -9999 -9999 -9999 -9999 -9999 -9999 -9999 -9999 -9999 -9999 -9999 -9999 -9999 -9999 -9999 -9999 -9999 -9999 -9999 -9999 -9999 -9999 -9999 -9999 -9999 -9999 -9999-9999 -9999 -9999 -9999 -9999 -9999 -9999 -9999 -9999 -9999 -9999 -9999 -9999 -9999 -9999 -9999 -9999 -9999 -9999 -9999 -9999 -

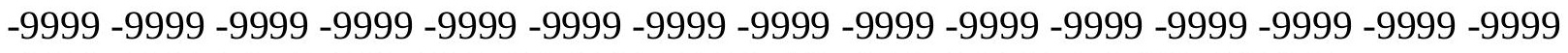
-9999 -9999 117.9517974854113.9896011353 107.4772415161 106.0652008057 105.1509017944104 .2365036011103 .6268997192103 .3221969604102 .712600708 102.1029968262101 .4934005737100 .579101562599 .6647262573298 .75038146973 97.83602905273 96.9216690063596.0073165893695.2459182739394.48339080811 93.87381744385 93.2642517089892.6546783447392.0450973510791.43553924561 90.8259735107490 .2164001464889 .9116134643689 .302040100188 .99725341797 88.3876876831187 .7781066894587 .4733276367286 .8637619018686 .55898284912 85.9494018554785 .6446228027385 .0350494384884 .4254837036184 .12069702148 83.8159103393683 .206336975182 .9015579223682 .2919769287181 .68241119385 81.0728530883880 .4632720947383 .206336975183 .5111236572383 .51112365723 83.206336975183.2063369751 83.2063369751 83.206336975183.2063369751 83.5111236572383 .8159103393683 .8159103393683 .8159103393683 .81591033936 83.206336975182 .5967712402381 .6824111938580 .4632720947378 .93934631348 
76.8058471679774 .062782287671 .9292907714870 .1005783081165 .22400665283 64.3096618652363 .0905189514261 .8713798522960 .6522407531759 .43310165405 58.2139587402356 .9948196411155 .7756805419954 .5565414428753 .64218139648 52.7278289794951 .8134689331150 .8991203308149 .9847602844249 .37519073486 49.0704002380448 .4608306884848 .1560516357448 .1560516357448 .15605163574 48.4608306884848 .765621185349 .3751907348649 .9847602844250 .59432983398 51.5086898803752 .4230384826753 .6421813964854 .5565414428755 .77568054199 57.2995986938558 .5187492370660 .0426712036161 .5666007995663 .39530944824 65.2240066528367 .0527267456168 .5766525268669 .7957916259871 .0149307251 71.6244964599672 .2340774536172 .5388565063572 .2340774536171 .92929077148 71.014930725170 .1005783081168 .5766525268666 .7479400634864 .61444854736 62.4809494018660 .3474502563558 .2139587402356 .3852500915555 .16611099243 55.16611099243 -9999 -9999 -9999 -9999 -9999 -9999 -9999 -9999 -9999 -9999 -9999 -9999 -9999 -9999 -9999 -9999 -9999 -9999 -9999 -9999 -9999 -9999 -9999 -9999 -9999 -9999 -9999 -9999 -9999 -9999 -9999 -9999 -9999 -9999 -9999 -9999 -9999 -9999 -9999 -9999 -9999 -9999 -9999 -9999 -9999 -9999 -9999 -9999 -9999 -9999 -9999 -9999

-9999 -9999 -9999 -9999 -9999 -9999 -9999 -9999 -9999 -9999 -9999 -9999 -9999 -9999 -9999 -9999 -9999 -9999 -9999 -9999 -9999 -9999 -9999 -9999 -9999 -9999 -9999 -9999 -9999 -9999 -9999 -9999 -9999 -9999 -9999 -9999 -9999 -9999 -9999 -9999 -9999 -9999 -9999 -9999 -9999 -9999 -9999 -9999 -9999 -9999 -9999 -9999 -9999 -9999 -9999 -9999 -9999 -9999 -9999 -9999

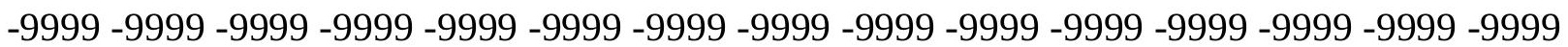
-9999 -9999 -9999 -9999 -9999 -9999 -9999 -9999 -9999 -9999 -9999 -9999 -9999 -9999 -9999 -9999 -9999 -9999 -9999 -9999 -9999 -9999 -9999 -9999 -9999 -9999 -9999 -9999 -9999 -9999 -9999 -9999 -9999 -9999 -9999 -9999 -9999 -9999 -9999 -9999 -9999 -9999 -9999 -9999 -9999

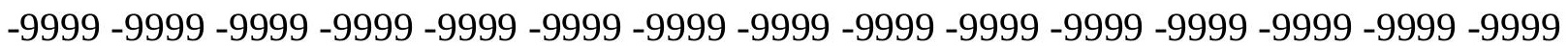
-9999 -9999 -9999 -9999 -9999 -9999 -9999 -9999 -9999 -9999 -9999 -9999 -9999 -9999 -9999 -9999 -9999 -9999 -9999 -9999 -9999 -9999 -9999 -9999 -9999 -9999 -9999 -9999 -9999 -9999 -9999 -9999 -9999 -9999 -9999 -9999 -9999 -9999 -9999 -9999 -9999 -9999 -9999 -9999 -9999

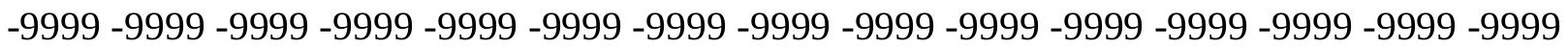

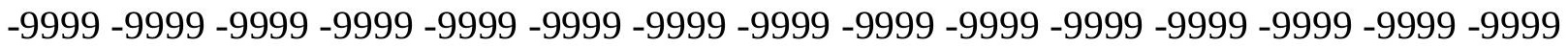
-9999 -9999 -9999 -9999 114.5991973877 106.8106079102 105.8516464233104.5412979126 103.9317016602103 .6268997192103 .0174026489102 .4077987671101 .7982025146 100.883903503499 .9695205688599 .0551681518698 .445587158297 .53124237061 96.6168823242295 .9840087890695 .0929565429794 .4833908081193 .87381744385 93.2642517089892 .6546783447392 .0450973510791 .7403335571391 .13075256348 90.5211791992290 .2164001464889 .6068267822389 .302040100188 .69246673584 88.3876876831187 .7781066894587 .4733276367286 .8637619018686 .55898284912 85.9494018554785 .6446228027385 .3398437584 .7302627563584 .42548370361 83.8159103393683 .5111236572382 .9015579223682 .2919769287181 .68241119385 84.4254837036184 .7302627563585 .0350494384885 .3398437585 .3398437585 .33984375 85.3398437585 .6446228027385 .9494018554785 .9494018554786 .2541885376 86.254188537685 .9494018554785 .6446228027385 .0350494384884 .12069702148 82.9015579223681 .0728530883878 .9393463134876 .8058471679774 .36756896973 72.2340774536169 .7957916259865 .2240066528364 .004882812563 .09051895142 61.8713798522960 .3474502563559 .1283111572357 .909179687556 .69002914429 55.7756805419954 .5565414428753 .3373985290552 .4230384826751 .50868988037 
50.5943298339849 .9847602844249 .3751907348648 .765621185348 .46083068848 48.1560516357448 .1560516357448 .1560516357448 .765621185349 .07040023804 49.6799812316950 .5943298339851 .5086898803752 .4230384826753 .64218139648 54.8613204956156 .0804595947357 .6043891906759 .1283111572360 .65224075317 62.4809494018664 .3096618652366 .1383666992267 .9670867919969 .49101257324 71.014930725171 .9292907714872 .8436431884873 .1484298706173 .45321655273 73.4532165527373 .1484298706172 .2340774536171 .014930725169 .49101257324 67.3575134277365 .2240066528362 .7857398986860 .6522407531758 .51874923706 56.3852500915555 .4708900451755 .16611099243 -9999 -9999 -9999 -9999 -9999 -9999 -9999 -9999 -9999 -9999 -9999 -9999 -9999 -9999 -9999 -9999 -9999 -9999 -9999 -9999 -9999 -9999 -9999 -9999 -9999 -9999 -9999 -9999 -9999 -9999 -9999 -9999 -9999 -9999 -9999 -9999 -9999 -9999 -9999 -9999 -9999 -9999 -9999 -9999 -9999 -9999 -9999 -9999 -9999 -9999 -9999 -9999 -9999 -9999 -9999 -9999 -9999 -9999 -9999 -9999 -9999 -9999 -9999 -9999 -9999 -9999 -9999 -9999 -9999 -9999 -9999 -9999 -9999 -9999 -9999 -9999 -9999 -9999 -9999 -9999 -9999 - 9999 -9999 -9999 -9999 -9999 -9999 -9999 -9999 -9999 -9999 -9999 -9999 -9999 -9999 -9999 -9999

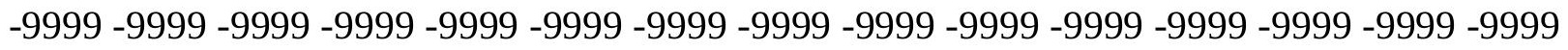
-9999 -9999 -9999 -9999 -9999 -9999 -9999 -9999 -9999 -9999 -9999 -9999 -9999 -9999 -9999 -9999 -9999 -9999 -9999 -9999 -9999 -9999 -9999 -9999 -9999 -9999 -9999 -9999 -9999 -9999 -9999 -9999 -9999 -9999 -9999 -9999 -9999 -9999 -9999 -9999 -9999 -9999 -9999 -9999 -9999 -

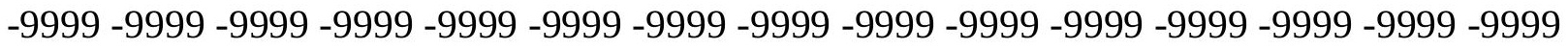

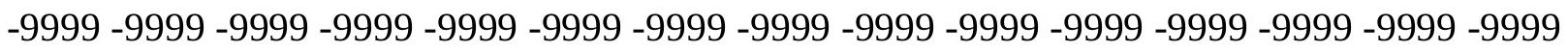
-9999 -9999 -9999 -9999 -9999 -9999 -9999 -9999 -9999 -9999 -9999 -9999 -9999 -9999 -9999 -9999 -9999 -9999 -9999 -9999 -9999 -9999 -9999 -9999 -9999 -9999 -9999 -9999 -9999 -9999 -

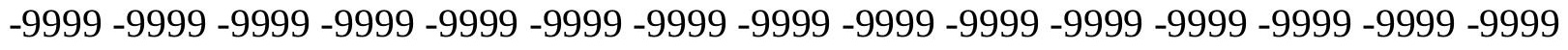
-9999 -9999 -9999 -9999 -9999 -9999 -9999 -9999 -9999 -9999 -9999 -9999 -9999 -9999 -9999 -9999 -9999 -9999 -9999 -9999 -9999 -9999 -9999 -9999 -9999 -9999 -9999 -9999 -9999 -9999 -9999 -9999 -9999 -9999-9999 115.5136032104106 .3537139893105 .529335022 104.8130340576103 .9317016602103 .5928726196103 .0174026489102 .4077987671 101.4934005737100 .579101562599 .6647262573298 .7503814697397 .83602905273 97.2264633178796.3121032714895.7025299072395.0929565429794.48339080811 93.8738174438593 .2642517089892 .9594726562592 .349891662692 .04509735107 91.4355392456190 .8259735107490 .5211791992289 .9116134643689 .60682678223 88.9972534179788 .6924667358488 .3876876831187 .7781066894587 .47332763672 86.8637619018686 .5589828491286 .254188537685 .6446228027385 .33984375 84.7302627563584 .4254837036183 .8159103393683 .206336975182 .59677124023 85.3398437585 .9494018554786 .254188537686 .5589828491286 .86376190186 86.86376190186 87.16854858398 87.47332763672 87.47332763672 87.77810668945 87.7781066894587 .7781066894587 .7781066894587 .4733276367286 .86376190186 85.9494018554784 .7302627563582 .9015579223681 .0728530883878 .63455963135 76.5010681152374 .062782287671 .6244964599666 .1383666992265 .22400665283 64.004882812562 .7857398986861 .5666007995660 .3474502563559 .12831115723 57.909179687556 .6900291442955 .4708900451754 .2517509460453 .33739852905 52.1182594299351 .2038993835450 .2895507812549 .6799812316948 .7656211853 48.4608306884848 .1560516357448 .1560516357448 .1560516357448 .46083068848 49.0704002380449 .6799812316950 .5943298339851 .5086898803752 .42303848267 53.6421813964855 .1661109924356 .3852500915557 .909179687559 .43310165405 
61.2618103027363 .0905189514265 .2240066528367 .0527267456169 .18623352051 70.7101516723671 .9292907714872 .8436431884873 .7580032348674 .0627822876 74.3675689697374 .3675689697374 .062782287673 .4532165527371 .92929077148 70.4053573608467 .9670867919965 .5288009643663 .0905189514260 .65224075317 58.2139587402356 .0804595947355 .4708900451755 .47089004517 -9999 -9999 -9999 -9999 -9999 -9999 -9999 -9999 -9999 -9999 -9999 -9999 -9999 -9999 -9999 -9999 -9999 -9999 -9999 -9999 -9999 -9999 -9999 -9999 -9999 -9999 -9999 -9999 -9999 -9999 -9999 -9999 -9999 -9999

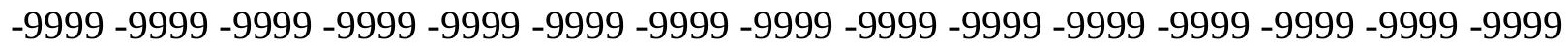
-9999-9999-9999

-9999 -9999 -9999 -9999 -9999 -9999 -9999 -9999 -9999 -9999 -9999 -9999 -9999 -9999 -9999

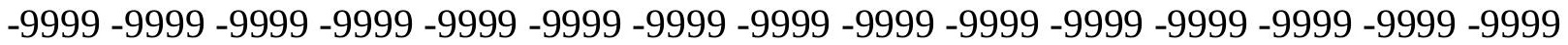
-9999 -9999 -9999 -9999 -9999 -9999 -9999 -9999 -9999 -9999 -9999 -9999 -9999 -9999 -9999 -9999 -9999 -9999 -9999 -9999 -9999 -9999 -9999 -9999 -9999 -9999 -9999 -9999 -9999 -9999 -9999 -9999 -9999 -9999 -9999 -9999 -9999 -9999 -9999 -9999 -9999 -9999 -9999 -9999 -9999 -9999 -9999 -9999 -9999 -9999 -9999 -9999 -9999 -9999 -9999 -9999 -9999 -9999 -9999 -9999

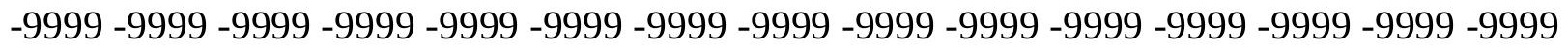
-9999 -9999 -9999 -9999 -9999 -9999 -9999 -9999 -9999 -9999 -9999 -9999 -9999 -9999 -9999 -

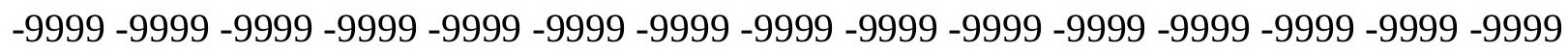

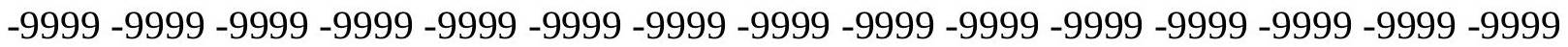

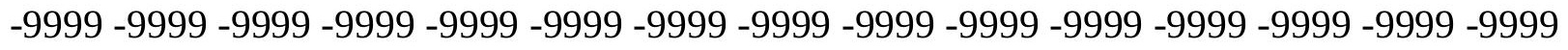

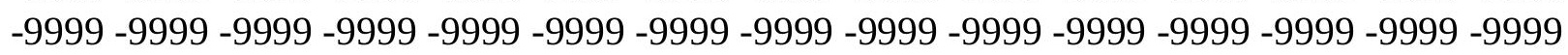

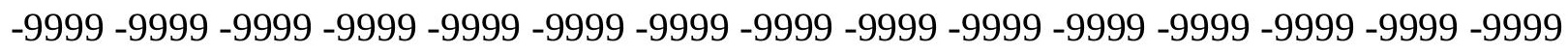
-9999 -9999 -9999 -9999 -9999 -9999 -9999 -9999 -9999 -9999 -9999 -9999 -9999 -9999 -9999 -9999 -9999-9999 -9999-9999-9999-9999 106.1258163452 105.4249954224 104.793762207 104.2202072144103 .6268997192102 .712600708101 .7982025146100 .8839035034 99.9695205688599.0551681518698.445587158297.5312423706196.92166900635 96.3121032714895 .7025299072395 .0929565429794 .4833908081194 .17859649658 93.5690307617292 .9594726562592 .6546783447392 .0450973510791 .74033355713 91.1307525634890 .8259735107490 .2164001464889 .9116134643689 .3020401001 88.9972534179788 .6924667358488 .0829010009887 .7781066894587 .47332763672 86.8637619018686 .5589828491285 .9494018554785 .6446228027385 .03504943848 84.7302627563584 .1206970214883 .5111236572382 .9015579223686 .55898284912 87.16854858398 87.47332763672 87.77810668945 88.08290100098 88.38768768311 88.6924667358488 .6924667358488 .9972534179788 .9972534179788 .99725341797 88.9972534179788 .6924667358488 .0829010009887 .1685485839885 .94940185547 84.1206970214882 .2919769287180 .1584930419978 .0249862670975 .58670806885 73.1484298706170 .4053573608466 .1383666992264 .9192428588963 .70008850098 62.4809494018661 .2618103027360 .0426712036158 .8235282897957 .60438919067 56.3852500915555 .1661109924353 .9469718933152 .7278289794951 .81346893311 50.5943298339849 .6799812316949 .0704002380448 .4608306884848 .15605163574 47.8512611389248 .1560516357448 .4608306884848 .765621185349 .67998123169 50.5943298339851 .5086898803752 .7278289794953 .9469718933155 .16611099243 56.6900291442958 .2139587402359 .7378807067961 .5666007995663 .70008850098 65.8335876464867 .9670867919969 .7957916259871 .3197174072372 .53885650635 73.4532165527374 .3675689697374 .9771423339875 .2819290161175 .28192901611 74.9771423339874 .3675689697373 .1484298706171 .014930725168 .57665252686 
65.8335876464863 .0905189514260 .6522407531758 .2139587402356 .08045959473 55.7756805419955 .77568054199 -9999 -9999 -9999 -9999 -9999 -9999 -9999 -9999 -9999 -9999 -9999 -9999 -9999 -9999 -9999 -9999 -9999 -9999 -9999 -9999 -9999 -9999 -9999 -9999 -9999 -9999 -9999 -9999 -9999 -9999 -9999 -9999 -9999 -9999 -9999 -9999 -9999 -9999 -9999 -9999 -9999 -9999 -9999 -9999 -9999 -9999 -9999 -9999 -9999 -9999 -9999 -9999 -9999 -9999 -9999 -9999 -9999 -9999 -9999 -9999 -9999 -9999 -9999 -9999 -9999 -9999 -9999

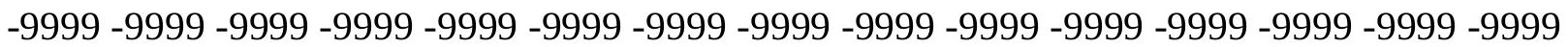

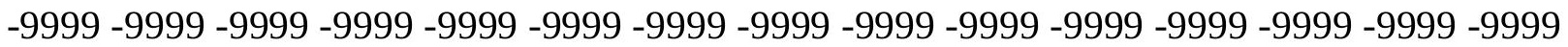
-9999 -9999 -9999 -9999 -9999 -9999 -9999 -9999 -9999 -9999 -9999 -9999 -9999 -9999 -9999 -9999 -9999 -9999 -9999 -9999 -9999 -9999 -9999 -9999 -9999 -9999 -9999 -9999 -9999 -9999 -9999 -9999 -9999 -9999 -9999 -9999 -9999 -9999 -9999 -9999 -9999 -9999 -9999 -9999 -9999 -9999 -9999 -9999 -9999 -9999 -9999 -9999 -9999 -9999 -9999 -9999 -9999 -9999 -9999 -9999 -9999 -9999 -9999 -9999 -9999 -9999 -9999 -9999 -9999 -9999 -9999 -9999 -9999 -9999 -9999 -9999 -9999 -9999 -9999 -9999 -9999 -9999 -9999 -9999 -9999 -9999 -9999 -9999 -9999 -9999 -9999 -9999 -9999 -9999 -9999 -9999 -9999 -9999 -9999 -9999 -9999 -9999 -9999 -9999 -9999

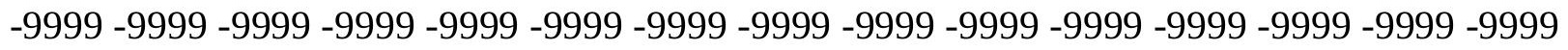
-9999 -9999 -9999 -9999 -9999 -9999 -9999 -9999 -9999 -9999 -9999 -9999 -9999 -9999 -9999 -9999 -9999 -9999 -9999 -9999 -9999 -9999 -9999 -9999 -9999 -9999 -9999 -9999 -9999 -9999 -999 -9999 -9999 -9999 -9999 -9999 -9999 -9999 -9999 -9999 -9999 -9999 -9999 -9999 -9999 -9999 -9999 -9999 -9999 -9999 -9999 -9999 -9999 -9999 106.0169219971 105.3757476807 104.7528839111104 .0944824219103 .3221969604102 .1029968262100 .8839035034 99.9695205688599 .3599472045998 .7503814697398 .1408081054797 .53124237061 96.9216690063596 .3121032714895 .7025299072395 .0929565429794 .76629638672 94.1785964965893 .5690307617293 .2642517089892 .6546783447392 .3498916626 91.7403335571391 .4355392456190 .8259735107490 .5211791992290 .21640014648 89.6068267822389 .302040100188 .9972534179788 .3876876831188 .08290100098 87.7781066894587 .1685485839886 .8637619018686 .254188537685 .94940185547 85.33984375 84.73026275635 84.42548370361 83.81591033936 86.86376190186 87.4733276367288 .0829010009888 .3876876831188 .9972534179789 .3020401001 89.6068267822389 .6068267822389 .9116134643689 .9116134643689 .91161346436 89.60682678223 89.3020401001 88.69246673584 87.77810668945 86.55898284912 85.0350494384883 .206336975181 .3776321411179 .2441329956176 .80584716797 74.3675689697371 .6244964599666 .7479400634865 .8335876464864 .61444854736 63.3953094482462 .1761703491260 .9570198059159 .7378807067958 .51874923706 57.2995986938556 .0804595947354 .5565414428753 .3373985290552 .42303848267 51.2038993835449 .9847602844249 .3751907348648 .4608306884848 .15605163574 47.8512611389247 .8512611389248 .1560516357448 .765621185349 .37519073486 50.2895507812551 .5086898803752 .7278289794953 .9469718933155 .47089004517 56.9948196411158 .5187492370660 .3474502563562 .1761703491264 .0048828125 66.1383666992268 .2718734741270 .1005783081171 .6244964599672 .84364318848 73.7580032348674 .6723632812575 .2819290161175 .5867080688575 .58670806885 75.2819290161174 .6723632812573 .7580032348671 .3197174072368 .57665252686 65.8335876464863 .0905189514260 .3474502563557 .909179687556 .08045959473 55.77568054199 -9999 -9999 -9999 -9999 -9999 -9999 -9999 -9999 -9999 -9999 -9999 -9999 -9999 -9999 -9999 -9999 -9999 -9999 -9999 -9999 -9999 -9999 -9999 -9999 -9999 -9999 -9999

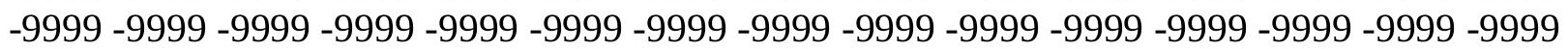


-9999 -9999 -9999 -9999 -9999 -9999 -9999 -9999 -9999 -9999 -9999

-9999 -9999 -9999 -9999 -9999 -9999 -9999 -9999 -9999 -9999 -9999 -9999 -9999 -9999 -9999

-9999 -9999 -9999 -9999 -9999 -9999 -9999 -9999 -9999 -9999 -9999 -9999 -9999 -9999 -9999

-9999 -9999 -9999 -9999 -9999 -9999 -9999 -9999 -9999 -9999 -9999 -9999 -9999 -9999 -9999

-9999 -9999 -9999 -9999 -9999 -9999 -9999 -9999 -9999 -9999 -9999 -9999 -9999 -9999 -9999 -

-9999 -9999 -9999 -9999 -9999 -9999 -9999 -9999 -9999 -9999 -9999 -9999 -9999 -9999 -9999 -

-9999 -9999 -9999 -9999 -9999 -9999 -9999 -9999 -9999 -9999 -9999 -9999 -9999 -9999 -9999 -

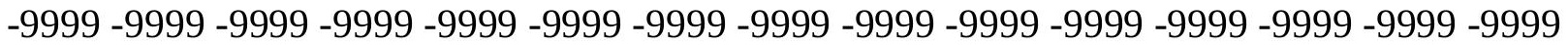

-9999 -9999 -9999 -9999 -9999 -9999 -9999 -9999 -9999 -9999 -9999 -9999 -9999 -9999 -9999

-9999 -9999 -9999 -9999 -9999 -9999 -9999 -9999 -9999 -9999 -9999 -9999 -9999 -9999 -9999 -

-9999 -9999 -9999 -9999 -9999 -9999 -9999 -9999 -9999 -9999 -9999 -9999 -9999 -9999 -9999 -

-9999 -9999 -9999 -9999 -9999 -9999 -9999 -9999 -9999 -9999 -9999 -9999 -9999 -9999 -9999

-9999 -9999 -9999 -9999 -9999 -9999 -9999 -9999 -9999 -9999 -9999 -9999 -9999 -9999 -9999 -

-9999 -9999 -9999 -9999 -9999 -9999 -9999 -9999 -9999 -9999 -9999 -9999 -9999 -9999 -9999 -

-9999 -9999 -9999 -9999 -9999 -9999 -9999 -9999 -9999 -9999 -9999 -9999 -9999 -9999 -9999

-9999 -9999 -9999 -9999-9999-9999 -9999 -9999 -9999 105.898399353105 .2278137207

104.5030136108103 .6198501587102 .4077987671100 .8839035034100 .2742996216 99.6647262573299 .0551681518698 .445587158297 .8360290527397 .22646331787 96.9216690063596 .3121032714895 .7025299072395 .0929565429794 .72018432617 94.1785964965893 .8738174438593 .2642517089892 .9594726562592 .3498916626 92.0450973510791 .4355392456191 .1307525634890 .8259735107490 .21640014648 89.9116134643689 .6068267822388 .9972534179788 .6924667358488 .38768768311 87.7781066894587 .4733276367287 .1685485839886 .5589828491285 .94940185547 85.6446228027385 .0350494384884 .4254837036187 .1685485839887 .77810668945 88.3876876831188 .9972534179789 .302040100189 .6068267822389 .91161346436 90.2164001464890 .2164001464890 .2164001464890 .2164001464899 .91161346436 89.60682678223 88.9972534179788.08290100098 86.86376190186 85.64462280273 83.8159103393681 .9871978759879 .8537063598677 .7202072143675 .28192901611 72.8436431884867 .6623001098666 .7479400634865 .5288009643664 .30966186523 63.0905189514261 .8713798522960 .6522407531759 .4331016540558 .21395874023 56.6900291442955 .4708900451754 .2517509460453 .0326118469251 .50868988037 50.5943298339849 .3751907348648 .765621185348 .1560516357447 .54647827148 47.5464782714847 .8512611389248 .4608306884849 .3751907348650 .59432983398 51.5086898803753 .0326118469254 .2517509460455 .7756805419957 .29959869385 58.8235282897960 .6522407531762 .4809494018664 .3096618652366 .44316101074 68.2718734741270 .1005783081171 .6244964599672 .8436431884873 .75800323486 74.6723632812575 .2819290161175 .5867080688575 .5867080688575 .28192901611 74.3675689697373 .1484298706171 .014930725168 .2718734741265 .52880096436 $62.7857398986860 .0426712036157 .6043891906756 .0804595947356 .08045959473-9999$ -9999 -9999 -9999 -9999 -9999 -9999 -9999 -9999 -9999 -9999 -9999 -9999 -9999 -9999 -9999 -9999 -9999 -9999 -9999 -9999 -9999 -9999 -9999 -9999 -9999 -9999 -9999 -9999 -9999 -9999

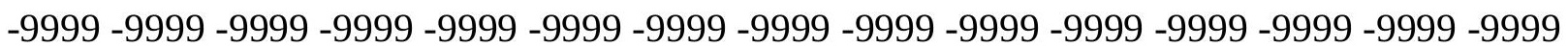
-9999 -9999 -9999 -9999 -9999 -9999 -9999 -9999 -9999 -9999 -9999 -9999 -9999 -9999 -9999 -9999 -9999 -9999 -9999 -9999 -9999 -9999 -9999 -9999 -9999 -9999 -9999 -9999 -9999 -9999 -9999 -9999 -9999 -9999 -9999 -9999 -9999

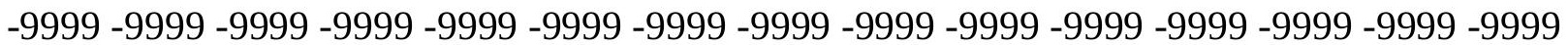


-9999 -9999 -9999 -9999 -9999 -9999 -9999 -9999 -9999 -9999 -9999 -9999 -9999 -9999 -9999 -9999 -9999 -9999 -9999 -9999 -9999 -9999 -9999 -9999 -9999 -9999 -9999 -9999 -9999 -9999 -9999 -9999 -9999 -9999 -9999 -9999 -9999 -9999 -9999 -9999 -9999 -9999 -9999 -9999 -9999 -9999 -9999 -9999 -9999 -9999 -9999 -9999 -9999 -9999 -9999 -9999 -9999 -9999 -9999 -9999 -9999 -9999 -9999 -9999 -9999 -9999 -9999 -9999 -9999 -9999 -9999 -9999 -9999 -9999 -9999 -9999 -9999 -9999 -9999 -9999 -9999 -9999 -9999 -9999 -9999 -9999 -9999 -9999 -9999 -9999 -9999 -9999 -9999 -9999 -9999 -9999 -9999 -9999 -9999 -9999 -9999 -9999 -9999 -9999 -9999

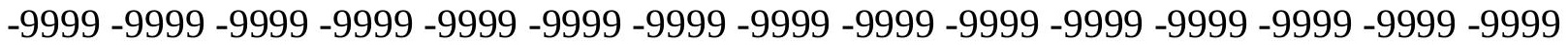
-9999 -9999 -9999 -9999 -9999 -9999 -9999 -9999 -9999 -9999 -9999 -9999 -9999 -9999 -9999 -9999 -9999 -9999 -9999 -9999 -9999 -9999 -9999 -9999 -9999 -9999 -9999 -9999 -9999 -9999 -

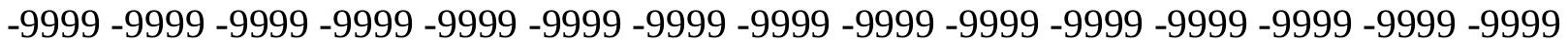
-9999 -9999 -9999 -9999 -9999 -9999 -9999 -9999 -9999 -9999 114.5991973877 104.9011230469104 .0236053467103 .0620422363102 .1029968262100 .2742996216 99.9695205688599 .3599472045998 .7503814697398 .445587158297 .83602905273 97.2264633178796 .9216690063596 .3121032714895 .7025299072395 .27830505371 94.7103576660294 .1785964965893 .8738174438593 .2642517089892 .95947265625 92.6546783447392 .0450973510791 .7403335571391 .1307525634890 .82597351074 90.5211791992290 .2164001464889 .6068267822389 .302040100188 .99725341797 88.3876876831188 .0829010009887 .4733276367287 .1685485839886 .55898284912 86.254188537685 .6446228027385 .0350494384884 .4254837036187 .77810668945 88.3876876831188 .9972534179789 .302040100189 .6068267822389 .91161346436 90.2164001464890 .5211791992290 .5211791992290 .2164001464890 .21640014648 89.6068267822388 .9972534179788 .0829010009887 .1685485839885 .94940185547 84.4254837036182 .5967712402380 .4632720947378 .3297805786176 .19628143311 73.7580032348668 .5766525268667 .3575134277366 .4431610107465 .22400665283 64.004882812562 .7857398986861 .5666007995660 .3474502563558 .82352828979 57.6043891906756 .3852500915554 .8613204956153 .6421813964852 .11825942993 50.8991203308149 .6799812316948 .765621185348 .1560516357447 .54647827148 47.5464782714847 .8512611389248 .4608306884849 .3751907348650 .59432983398 51.8134689331153 .0326118469254 .5565414428756 .0804595947357 .60438919067 59.4331016540560 .9570198059162 .7857398986864 .6144485473666 .44316101074 68.2718734741269 .7957916259871 .3197174072372 .5388565063573 .75800323486 74.3675689697374 .9771423339875 .2819290161175 .2819290161174 .67236328125 73.7580032348672 .2340774536170 .1005783081167 .6623001098664 .91924285889 $62.4809494018659 .7378807067957 .2995986938556 .3852500915556 .08045959473-9999$ -9999 -9999 -9999 -9999 -9999 -9999 -9999 -9999 -9999 -9999 -9999 -9999 -9999 -9999 -9999

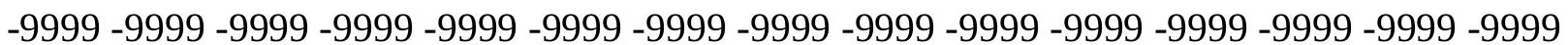

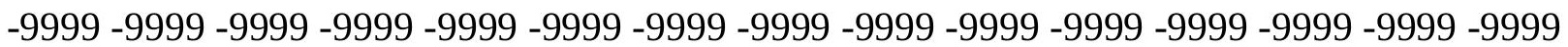
-9999 -9999 -9999 -9999 -9999 -9999 -9999

-9999 -9999 -9999 -9999 -9999 -9999 -9999 -9999 -9999 -9999 -9999 -9999 -9999 -9999 -9999 -9999 -9999 -9999 -9999 -9999 -9999 -9999 -9999 -9999 -9999 -9999 -9999 -9999 -9999 -9999

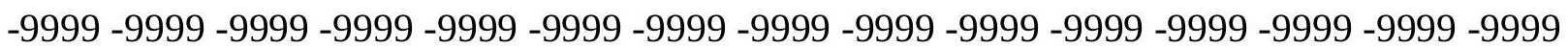
-9999 -9999 -9999 -9999 -9999 -9999 -9999 -9999 -9999 -9999 -9999 -9999 -9999 -9999 -9999 -9999 -9999 -9999 -9999 -9999 -9999 -9999 -9999 -9999 -9999 -9999 -9999 -9999 -9999 -9999 -9999 -9999 -9999 -9999 -9999 -9999 -9999 -9999 -9999 -9999 -9999 -9999 -9999 -9999 -9999

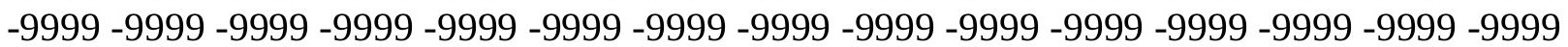


-9999 -9999 -9999 -9999 -9999 -9999 -9999 -9999 -9999 -9999 -9999 -9999 -9999 -9999 -9999 -9999 -9999 -9999 -9999 -9999 -9999 -9999 -9999 -9999 -9999 -9999 -9999 -9999 -9999 -9999 -9999 -9999 -9999 -9999 -9999 -9999 -9999 -9999 -9999 -9999 -9999 -9999 -9999 -9999 -9999 -9999 -9999 -9999 -9999 -9999 -9999 -9999 -9999 -9999 -9999 -9999 -9999 -9999 -9999 -9999 -9999 -9999 -9999 -9999 -9999 -9999 -9999 -9999 -9999 -9999 -9999 -9999 -9999 -9999 -9999 -9999 -9999 -9999 -9999 -9999 -9999 -9999 -9999 -9999 -9999 -9999 -9999 -9999 -9999 -9999 -9999 -9999 -9999 -9999 -9999 -9999 -9999 -9999 -9999 -9999 -9999 -9999 -9999 -9999 -9999 -999 -9999 -9999 -9999 -9999 -9999 -9999 -9999 -9999 -9999 -9999 -9999 114.5991973877 104.5481033325103 .6851043701102 .763923645101 .7982025146100 .5791015625 99.6647262573299 .0551681518698 .7503814697398 .1408081054797 .83602905273 97.2264633178796 .9216690063596 .3121032714895 .7025299072395 .2247467041 94.6598129272594 .1785964965893 .8738174438593 .5690307617292 .95947265625 92.6546783447392 .0450973510791 .7403335571391 .4355392456191 .13075256348 90.5211791992290 .2164001464889 .9116134643689 .302040100188 .99725341797 88.6924667358488 .0829010009887 .7781066894587 .1685485839886 .55898284912 86.254188537685 .6446228027385 .0350494384887 .4733276367288 .08290100098 88.6924667358489 .302040100189 .6068267822389 .9116134643690 .21640014648 90.2164001464890 .2164001464890 .2164001464889 .9116134643689 .60682678223 88.9972534179788 .0829010009887 .1685485839885 .9494018554784 .42548370361 82.9015579223681 .0728530883878 .9393463134876 .8058471679774 .67236328125 72.5388565063568 .2718734741267 .0527267456166 .1383666992264 .91924285889 63.7000885009862 .4809494018661 .2618103027359 .7378807067958 .51874923706 57.2995986938555 .7756805419954 .5565414428753 .0326118469251 .50868988037 50.2895507812549 .0704002380448 .1560516357447 .5464782714847 .24169921875 47.5464782714848 .4608306884849 .3751907348650 .5943298339852 .11825942993 53.3373985290554 .8613204956156 .3852500915557 .909179687559 .73788070679 61.2618103027363 .0905189514264 .6144485473666 .4431610107467 .96708679199 69.4910125732471 .014930725172 .2340774536173 .1484298706173 .75800323486 74.3675689697374 .6723632812574 .3675689697373 .7580032348672 .84364318848 71.3197174072369 .1862335205167 .0527267456164 .3096618652361 .87137985229 59.4331016540556 .9948196411156 .3852500915556 .38525009155 -9999 -9999 -9999 -9999 -9999 -9999 -9999 -9999 -9999 -9999 -9999 -9999 -9999 -9999 -9999 -9999 -9999 -9999 -9999 -9999 -9999 -9999 -9999 -9999 -9999 -9999 -9999 -9999 -9999 -9999 -9999 -9999 -9999 -9999 -

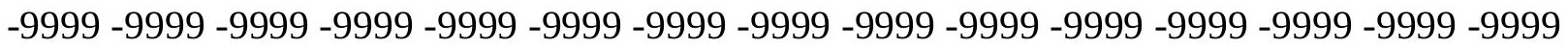
-9999 -9999-9999-9999

-9999 -9999 -9999 -9999 -9999 -9999 -9999 -9999 -9999 -9999 -9999 -9999 -9999 -9999 -9999 -9999 -9999 -9999 -9999 -9999 -9999 -9999 -9999 -9999 -9999 -9999 -9999 -9999 -9999 -9999

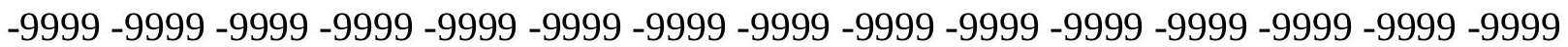
-9999 -9999 -9999 -9999 -9999 -9999 -9999 -9999 -9999 -9999 -9999 -9999 -9999 -9999 -9999 -9999 -9999 -9999 -9999 -9999 -9999 -9999 -9999 -9999 -9999 -9999 -9999 -9999 -9999 -9999 -9999 -9999 -9999 -9999 -9999 -9999 -9999 -9999 -9999 -9999 -9999 -9999 -9999 -9999 -9999

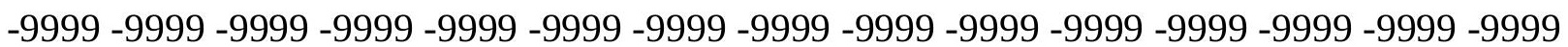
-9999 -9999 -9999 -9999 -9999 -9999 -9999 -9999 -9999 -9999 -9999 -9999 -9999 -9999 -9999 -9999 -9999 -9999 -9999 -9999 -9999 -9999 -9999 -9999 -9999 -9999 -9999 -9999 -9999 -9999 -9999 -9999 -9999 -9999 -9999 -9999 -9999 -9999 -9999 -9999 -9999 -9999 -9999 -9999 -9999

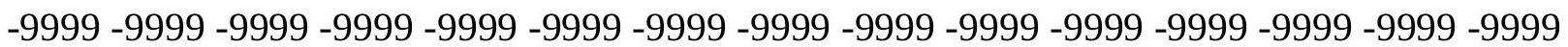


-9999 -9999 -9999 -9999 -9999 -9999 -9999 -9999 -9999 -9999 -9999 -9999 -9999 -9999 -9999 -9999 -9999 -9999 -9999 -9999 -9999 -9999 -9999 -9999 -9999 -9999 -9999 -9999 -9999 -9999

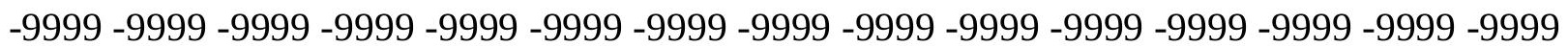
-9999 -9999 -9999 -9999 -9999 -9999 -9999 -9999 -9999 -9999 -9999 -9999 113.6848983765 104.3068695068103 .4750289917102 .6164169312101 .493400573799 .96952056885 99.6647262573299 .0551681518698 .7503814697398 .1408081054797 .83602905273 97.2264633178796 .6168823242296 .3121032714895 .7025299072395 .09295654297 94.6464996337994 .1785964965893 .8738174438593 .5690307617292 .95947265625 92.6546783447392 .349891662691 .7403335571391 .4355392456191 .13075256348 90.8259735107490 .2164001464889 .9116134643689 .6068267822388 .99725341797 88.6924667358488 .0829010009887 .7781066894587 .1685485839886 .55898284912 86.254188537685 .6446228027385 .0350494384887 .7781066894588 .38768768311 88.9972534179789 .302040100189 .6068267822389 .9116134643689 .91161346436 89.9116134643689 .9116134643689 .6068267822389 .302040100188 .69246673584 87.7781066894586 .8637619018685 .6446228027384 .4254837036182 .90155792236 81.0728530883879 .2441329956177 .4154205322375 .2819290161173 .45321655273 68.8814392089867 .9670867919966 .7479400634865 .5288009643664 .61444854736 63.3953094482462 .1761703491260 .6522407531759 .4331016540558 .21395874023 56.6900291442955 .4708900451753 .9469718933152 .4230384826750 .89912033081 49.6799812316948 .4608306884847 .5464782714847 .2416992187547 .85126113892 48.765621185349 .6799812316950 .8991203308152 .4230384826753 .94697189331 55.1661109924356 .6900291442958 .5187492370660 .0426712036161 .56660079956 63.0905189514264 .9192428588966 .4431610107467 .9670867919969 .18623352051 70.7101516723671 .6244964599672 .5388565063573 .1484298706173 .75800323486 73.7580032348673 .4532165527372 .8436431884871 .6244964599670 .10057830811 68.2718734741266 .1383666992263 .7000885009861 .2618103027358 .82352828979 56.6900291442956 .6900291442956 .38525009155 -9999 -9999 -9999 -9999 -9999 -9999 -9999 -9999 -9999 -9999 -9999 -9999 -9999 -9999 -9999 -9999 -9999 -9999 -9999 -9999 -9999 -9999 -9999 -9999 -9999 -9999 -9999 -9999 -9999 -9999 -9999 -9999 -9999 -9999 -9999 -9999 -9999

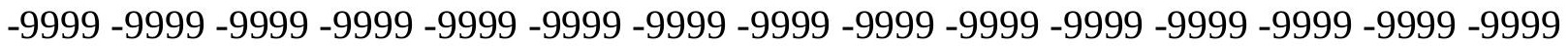
$-9999$

-9999 -9999 -9999 -9999 -9999 -9999 -9999 -9999 -9999 -9999 -9999 -9999 -9999 -9999 -9999 -9999 -9999 -9999 -9999 -9999 -9999 -9999 -9999 -9999 -9999 -9999 -9999 -9999 -9999 -9999 -9999 -9999 -9999 -9999 -9999 -9999 -9999 -9999 -9999 -9999 -9999 -9999 -9999 -9999 -9999 -9999 -9999 -9999 -9999 -9999 -9999 -9999 -9999 -9999 -9999 -9999 -9999 -9999 -9999 -9999 -9999 -9999 -9999 -9999 -9999 -9999 -9999 -9999 -9999 -9999 -9999 -9999 -9999 -9999 -9999

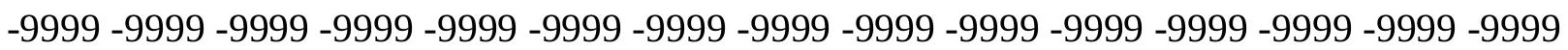

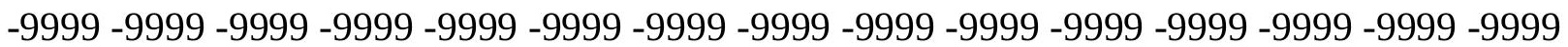
-9999 -9999 -9999 -9999 -9999 -9999 -9999 -9999 -9999 -9999 -9999 -9999 -9999 -9999 -9999 -9999 -9999 -9999 -9999 -9999 -9999 -9999 -9999 -9999 -9999 -9999 -9999 -9999 -9999 -9999 -9999 -9999 -9999 -9999 -9999 -9999 -9999 -9999 -9999 -9999 -9999 -9999 -9999 -9999 -9999

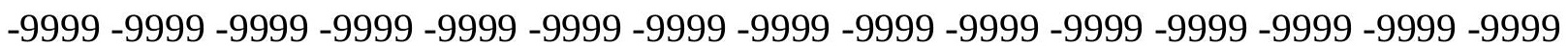
-9999 -9999 -9999 -9999 -9999 -9999 -9999 -9999 -9999 -9999 -9999 -9999 -9999 -9999 -9999 -9999 -9999 -9999 -9999 -9999 -9999 -9999 -9999 -9999 -9999 -9999 -9999 -9999 -9999 -9999 -9999 -9999 -9999 -9999 -9999 -9999 -9999 -9999 -9999 -9999 -9999 -9999 -9999 -9999 -9999 -9999 -9999 -9999 -9999 -9999 -9999 -9999 -9999 -9999 -9999 -9999 -9999 -9999 -9999 
104.1431884766103 .3528900146102 .5518569946101 .798202514699 .96952056885 99.6647262573299 .3599472045998 .7503814697398 .1408081054797 .83602905273 97.2264633178796 .6168823242296 .0073165893695 .7025299072395 .09295654297 94.6951065063594 .1785964965893 .8738174438593 .5690307617292 .95947265625 92.6546783447392 .349891662692 .0450973510791 .4355392456191 .13075256348 90.8259735107490 .2164001464889 .9116134643689 .6068267822388 .99725341797 88.6924667358488 .0829010009887 .7781066894587 .1685485839886 .55898284912 85.9494018554785 .6446228027385 .0350494384888 .0829010009888 .38768768311 88.9972534179789 .302040100189 .302040100189 .6068267822389 .60682678223 89.302040100189 .302040100188 .6924667358488 .0829010009887 .47332763672 86.5589828491285 .6446228027384 .1206970214882 .9015579223681 .37763214111 79.5489196777377 .7202072143675 .8914871215874 .062782287669 .79579162598 68.5766525268667 .6623001098666 .4431610107465 .2240066528364 .30966186523 63.0905189514261 .8713798522960 .6522407531759 .1283111572357 .9091796875 56.3852500915555 .1661109924353 .6421813964852 .1182594299350 .59432983398 49.3751907348648.15605163574 47.5464782714848.15605163574 49.07040023804 50.2895507812551 .5086898803753 .0326118469254 .2517509460455 .77568054199 57.2995986938558 .8235282897960 .3474502563561 .8713798522963 .39530944824 64.9192428588966 .1383666992267 .6623001098668 .8814392089870 .10057830811 71.014930725171 .9292907714872 .5388565063572 .8436431884872 .84364318848 72.5388565063571 .6244964599670 .7101516723669 .1862335205167 .35751342773 65.2240066528363 .0905189514260 .6522407531758 .5187492370656 .69002914429 56.6900291442956 .69002914429 -9999 -9999 -9999 -9999 -9999 -9999 -9999 -9999 -9999 -9999 -9999 -9999 -9999 -9999 -9999 -9999 -9999 -9999 -9999 -9999 -9999 -9999 -9999 -9999

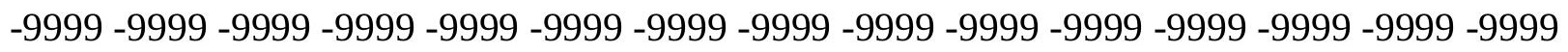
-9999 -9999 -9999 -9999 -9999 -9999 -9999 -9999 -9999 -9999 -9999 -9999 -9999 -9999 -9999 -9999 -9999 -9999 -9999 -9999 -9999 -9999 -9999 -9999 -9999 -9999 -9999 -9999 - -9999 -

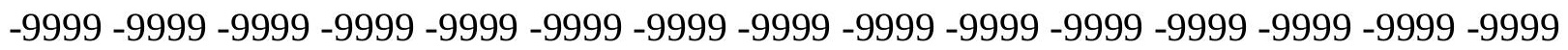
-9999 -9999 -9999 -9999 -9999 -9999 -9999 -9999 -9999 -9999 -9999 -9999 -9999 -9999 -9999 -9999 -9999 -9999 -9999 -9999 -9999 -9999 -9999 -9999 -9999 -9999 -9999 -9999 -9999 -9999 -9999 -9999 -9999 -9999 -9999 -9999 -9999 -9999 -9999 -9999 -9999 -9999-9999 -9999 -9999 -9999 -9999 -9999 -9999 -9999 -9999 -9999 -9999 -9999 -9999 -9999 -9999 -9999 -9999 -9999 -

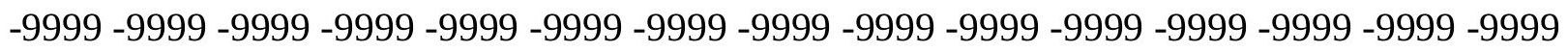
-9999 -9999 -9999 -9999 -9999 -9999 -9999 -9999 -9999 -9999 -9999 -9999 -9999 -9999 -9999 -9999 -9999 -9999 -9999 -9999 -9999 -9999 -9999 -9999 -9999 -9999 -9999 -9999 -9999 -9999 -

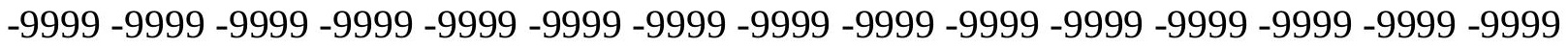

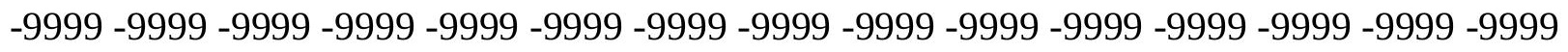

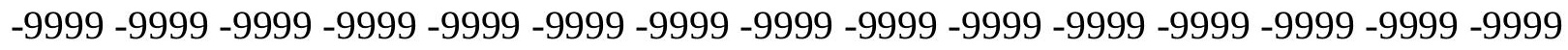
-9999 -9999 -9999 -9999 -9999 -9999 -9999 -9999 -9999 -9999 -9999 -9999 -9999 -9999 -9999 -9999 -9999 -9999 -9999 -9999 -9999 -9999 -9999 -9999 -9999 -9999 -9999 -9999 -9999 -9999 -

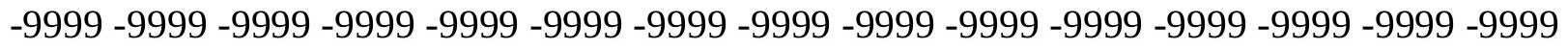
104.0799560547 103.3815002441 102.6484451294101.7982025146100.2742996216 99.6647262573299 .3599472045998 .7503814697398 .1408081054797 .53124237061 96.9216690063596 .6168823242296 .0073165893695 .397743225195 .09295654297 94.4833908081194 .1785964965893 .8738174438593 .5690307617292 .95947265625 92.6546783447392 .349891662692 .0450973510791 .4355392456191 .13075256348 
90.8259735107490 .2164001464889 .9116134643689 .302040100188 .99725341797 88.3876876831188 .0829010009887 .4733276367287 .1685485839886 .55898284912 85.9494018554785 .6446228027385 .0350494384887 .7781066894588 .38768768311 88.6924667358488 .6924667358488 .9972534179788 .9972534179788 .99725341797 88.6924667358488 .3876876831187 .7781066894587 .1685485839886 .2541885376 85.3398437584 .1206970214882 .9015579223681 .3776321411179 .85370635986 78.0249862670976 .5010681152374 .6723632812570 .4053573608469 .49101257324 68.2718734741267 .3575134277366 .1383666992265 .2240066528364 .0048828125 62.7857398986861 .5666007995660 .3474502563559 .1283111572357 .60438919067 56.3852500915554 .8613204956153 .3373985290551 .8134689331150 .59432983398 49.6799812316949 .0704002380449 .3751907348649 .9847602844251 .20389938354 52.1182594299353 .6421813964854 .8613204956156 .0804595947357 .60438919067 59.1283111572360 .6522407531761 .8713798522963 .3953094482464 .61444854736 66.1383666992267 .3575134277368 .5766525268669 .4910125732470 .40535736084 71.014930725171 .6244964599671 .6244964599671 .6244964599671 .31971740723 70.7101516723669 .4910125732467 .9670867919966 .4431610107464 .30966186523 $62.4809494018660 .3474502563558 .2139587402356 .9948196411156 .69002914429-9999$ -9999 -9999 -9999 -9999 -9999 -9999 -9999 -9999 -9999 -9999 -9999 -9999 -9999 -9999 -9999 -9999 -9999 -9999 -9999 -9999 -9999 -9999 -9999 -9999 -9999 -9999 -9999 -9999 -9999 -9999 -

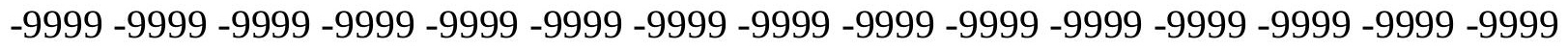
-9999 -9999-9999-9999-9999 -9999-9999-9999

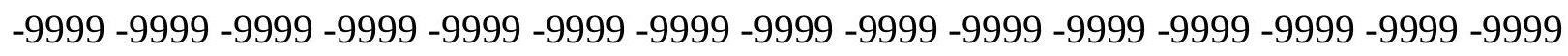
-9999 -9999 -9999 -9999 -9999 -9999 -9999 -9999 -9999 -9999 -9999 -9999 -9999 -9999 -9999 -

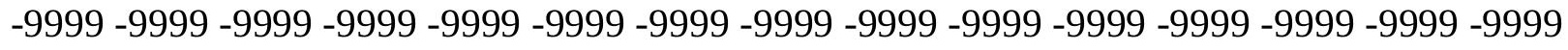

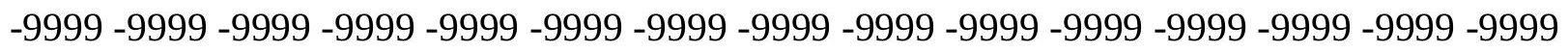
-9999 -9999 -9999 -9999 -9999 -9999 -9999 -9999 -9999 -9999 -9999 -9999 -9999 -9999 -9999 -9999 -9999 -9999 -9999 -9999 -9999 -9999 -9999 -9999 -9999 -9999 -9999 -9999 -9999 - -9999 -

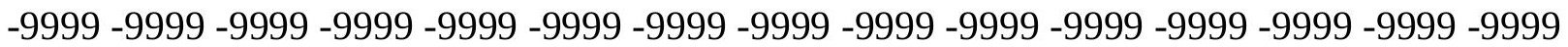
-9999 -9999 -9999 -9999 -9999 -9999 -9999 -9999 -9999 -9999 -9999 -9999 -9999 -9999 -9999

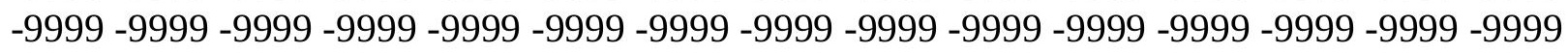
-9999 -9999 -9999 -9999 -9999 -9999 -9999 -9999 -9999 -9999 -9999 -9999 -9999 -9999 -9999 -9999 -9999 -9999 -9999 -9999 -9999 -9999 -9999 -9999 -9999 -9999 -9999 -9999 -9999 -9999 -

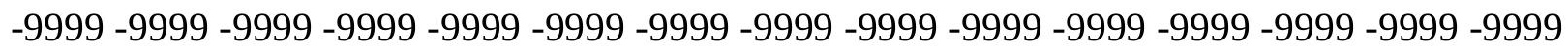

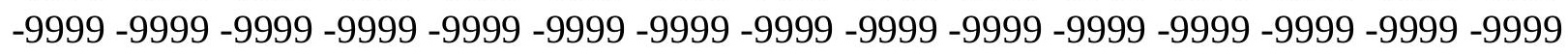
-9999 -9999 -9999 -9999 -9999 -9999 -9999 -9999 -9999 -9999 -9999 -9999 -9999 -9999 -9999 -9999 -9999 -9999 -9999 -9999 -9999 -9999 -9999 -9999 -9999 -9999 -9999 -9999 -9999 -9999 -9999 104.0304641724 103.2872695923 102.4683151245101.4934005737 100.2742996216 99.9695205688599 .3599472045998 .7503814697398 .1408081054797 .53124237061 96.9216690063596 .3121032714895 .7025299072395 .397743225194 .78817749023 94.4833908081194 .1785964965893 .8738174438593 .5690307617292 .95947265625 92.6546783447392 .349891662692 .0450973510791 .4355392456191 .13075256348 90.8259735107490 .2164001464889 .9116134643689 .302040100188 .99725341797 88.38768768311 88.08290100098 87.47332763672 86.86376190186 86.55898284912 85.9494018554785 .3398437585 .0350494384887 .7781066894588 .08290100098 88.0829010009888 .3876876831188 .3876876831188 .3876876831188 .08290100098 87.7781066894587 .1685485839886 .5589828491285 .9494018554785 .03504943848 
83.81591033936 82.59677124023 81.3776321411179.85370635986 78.32978057861 76.8058471679772 .2340774536171 .3197174072370 .1005783081169 .18623352051 68.2718734741267 .0527267456165 .8335876464864 .9192428588963 .70008850098 62.4809494018661 .5666007995660 .3474502563559 .1283111572357 .60438919067 56.3852500915554 .8613204956153 .3373985290552 .1182594299351 .20389938354 50.5943298339850 .8991203308151 .2038993835452 .1182594299353 .03261184692 54.2517509460455 .4708900451756 .6900291442958 .2139587402359 .43310165405 60.9570198059162 .1761703491263 .3953094482464 .6144485473665 .83358764648 67.0527267456167 .9670867919968 .8814392089869 .7957916259870 .40535736084 70.7101516723670 .7101516723670 .7101516723670 .1005783081169 .49101257324 68.5766525268667 .0527267456165 .5288009643663 .7000885009861 .87137985229 60.0426712036158 .2139587402356 .9948196411156 .99481964111 -9999 -9999 -9999 -9999 -9999 -9999 -9999 -9999 -9999 -9999 -9999 -9999 -9999 -9999 -9999 -9999 -9999 -9999 -9999 -9999 -9999 -9999 -9999 -9999 -9999 -9999 -9999 -9999 -9999 -9999 -9999 -9999 -9999 -9999 -9999 -9999 -9999 -9999 -9999 -9999 -9999 -9999 -9999 -9999 -9999 -9999 -9999 -9999 -9999 -9999 -9999 -9999 -9999 -9999

-9999 -9999 -9999 -9999 -9999 -9999 -9999 -9999 -9999 -9999 -9999 -9999 -9999 -9999 -9999 -9999 -9999 -9999 -9999 -9999 -9999 -9999 -9999 -9999 -9999 -9999 -9999 -9999 -9999 -9999 -9999 -9999 -9999 -9999 -9999 -9999 -9999 -9999 -9999 -9999 -9999 -9999 -9999 -9999 -9999 -9999 -9999 -9999 -9999 -9999 -9999 -9999 -9999 -9999 -9999 -9999 -9999 -9999 -9999 -9999 -9999 -9999 -9999 -9999 -9999 -9999 -9999 -9999 -9999 -9999 -9999 -9999 -9999 -9999 -9999 -9999 -9999 -9999 -9999 -9999 -9999 -9999 -9999 -9999 -9999 -9999 -9999 -9999 -9999 -9999 -9999 -9999 -9999 -9999 -9999 -9999 -9999 -9999 -9999 -9999 -9999 -9999 -9999 -9999 -9999 -9999 -9999 -9999 -9999 -9999 -9999 -9999 -9999 -9999 -9999 -9999 -9999 -9999 -9999 -9999 -9999 -9999 -9999 -9999 -9999 -9999 -9999 -9999 -9999 -9999 -9999 -9999 -9999 -9999 -9999 -9999 -9999 -9999 -9999 -9999 -9999 -9999 -9999 -9999 -9999 -9999 -9999 -9999 -9999 -9999 -9999 -9999 -9999 -9999 -9999 -9999 -9999 -9999 -9999 -9999 -9999 -9999 -9999 -9999 -9999 -9999 -9999 -9999 -9999 -9999 -9999 -9999 -9999 -9999 -9999 -9999 -9999 -9999 -9999 -9999

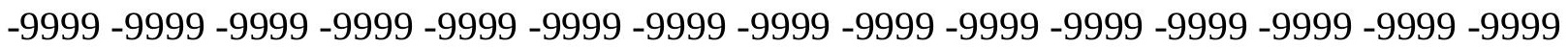

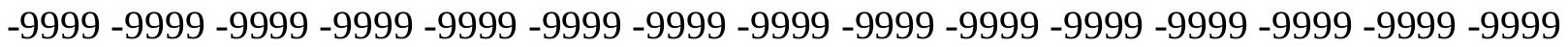
-9999 -9999 -9999 -9999 -9999 -9999 -9999 -9999 -9999 -9999 -9999 -9999 -9999 -9999 -9999 -9999 -9999 103.7937927246102.9407272339102.0031509399100.8839035034 100.274299621699 .6647262573299 .0551681518698 .445587158297 .53124237061 96.9216690063596 .6168823242296 .0073165893695 .7025299072395 .09295654297 94.7881774902394 .4833908081194 .1785964965893 .8738174438593 .56903076172 92.9594726562592 .6546783447392 .349891662691 .7403335571391 .43553924561 91.1307525634890 .5211791992290 .2164001464889 .6068267822389 .3020401001 88.69246673584 88.38768768311 87.77810668945 87.47332763672 86.86376190186 86.2541885376 85.9494018554785.33984375 85.03504943848 84.42548370361 87.4733276367287 .7781066894587 .7781066894587 .7781066894587 .47332763672 87.1685485839886 .5589828491285 .9494018554785 .3398437584 .42548370361 83.5111236572382 .5967712402381 .3776321411179 .8537063598678 .63455963135 77.110626220772 .8436431884871 .9292907714871 .014930725170 .10057830811 68.8814392089867 .9670867919966 .7479400634865 .8335876464864 .61444854736 63.7000885009862 .4809494018661 .5666007995660 .3474502563559 .12831115723 57.909179687556 .6900291442955 .1661109924353 .9469718933153 .03261184692 
52.4230384826752 .4230384826752 .7278289794953 .3373985290553 .94697189331 55.1661109924356 .0804595947357 .2995986938558 .5187492370659 .73788070679 60.9570198059162 .1761703491263 .3953094482464 .6144485473665 .52880096436 66.7479400634867 .6623001098668 .5766525268669 .1862335205169 .49101257324 69.7957916259869 .7957916259869 .7957916259869 .1862335205168 .57665252686 67.3575134277366 .1383666992264 .9192428588963 .0905189514261 .56660079956 59.7378807067957 .909179687557 .2995986938556 .99481964111 -9999 -9999 -9999 -9999 -9999 -9999 -9999 -9999 -9999 -9999 -9999 -9999 -9999 -9999 -9999 -9999 -9999 -9999 -9999

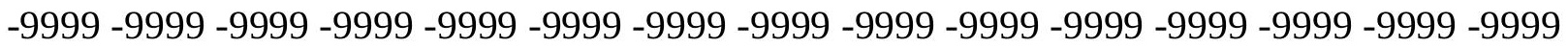

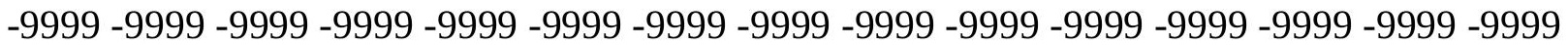
-9999 -9999 -9999 -9999-9999

-9999 -9999 -9999 -9999 -9999 -9999 -9999 -9999 -9999 -9999 -9999 -9999 -9999 -9999 -9999 -9999 -9999 -9999 -9999 -9999 -9999 -9999 -9999 -9999 -9999 -9999 -9999 -9999 -9999 -9999 -9999 -9999 -9999 -9999 -9999 -9999 -9999 -9999 -9999 -9999 -9999 -9999 -9999 -9999 - 9999 -9999 -9999 -9999 -9999 -9999 -9999 -9999 -9999 -9999 -9999 -9999 -9999 -9999 -9999 -9999

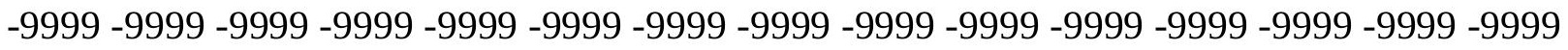
-9999 -9999 -9999 -9999 -9999 -9999 -9999 -9999 -9999 -9999 -9999 -9999 -9999 -9999 -9999 -9999 -9999 -9999 -9999 -9999 -9999 -9999 -9999 -9999 -9999 -9999 -9999 -9999 -9999 -9999 -999 -9999 -9999 -9999 -9999 -9999 -9999 -9999 -9999 -9999 -9999 -9999 -9999 -9999 -9999 -9999 -9999 -9999 -9999 -9999 -9999 -9999 -9999 -9999 -9999 -9999 -9999 -9999 -9999 -9999 -9999 -9999 -9999 -9999 -9999 -9999 -9999 -9999 -9999 -9999 -9999 -9999 -9999 -9999 -9999 -9999 -999 -9999 -9999 -9999 -9999 -9999 -9999 -9999 -9999 -9999 -9999 -9999 -9999 -9999 -9999 -9999 -9999 -9999 -9999 -9999 -9999 -9999 -9999 -9999 -9999 -9999 -9999 -9999 -9999 -9999 -9999 -9999 -9999 -9999 -9999 -9999 -9999 -9999 -9999 -9999 -9999 -9999 -9999 -9999 -9999 -9999 -9999 -9999 -9999 -9999 -9999 -9999 -9999 -9999 -9999 -9999 -9999 -9999 -9999 -9999 -9999 -9999 -9999 -9999 -9999 -9999 -9999 -9999 -9999 -9999 -9999 -9999 -9999 -9999 -9999 -9999 -9999 -9999 -9999 110.0273971558102.4420776367 101.5320358276100 .6771316528 99.9695205688599 .3599472045998 .445587158297 .8360290527397 .22646331787 96.6168823242296 .3121032714895 .7025299072395 .397743225195 .09295654297 94.7881774902394 .4833908081194 .1785964965893 .8738174438593 .26425170898 92.9594726562592 .6546783447392 .349891662691 .7403335571391 .43553924561 91.1307525634890 .5211791992290 .2164001464889 .6068267822388 .99725341797 88.6924667358488.08290100098 87.77810668945 87.16854858398 86.86376190186 86.254188537685 .9494018554785 .3398437584 .7302627563584 .42548370361 87.1685485839887 .1685485839886 .8637619018686 .8637619018686 .55898284912 86.254188537685 .6446228027385 .0350494384884 .1206970214883 .2063369751 82.2919769287181 .0728530883879 .8537063598678 .6345596313574 .36756896973 73.4532165527372 .5388565063571 .6244964599670 .7101516723669 .79579162598 68.8814392089867 .6623001098666 .7479400634865 .8335876464864 .61444854736 63.7000885009862 .7857398986861 .8713798522960 .9570198059159 .73788070679 58.2139587402356 .9948196411155 .7756805419954 .8613204956154 .25175094604 53.9469718933153 .9469718933154 .5565414428755 .1661109924355 .77568054199 56.6900291442957 .909179687558 .8235282897960 .0426712036161 .26181030273 62.4809494018663 .3953094482464 .6144485473665 .5288009643666 .44316101074 67.3575134277367 .9670867919968 .5766525268668 .8814392089869 .18623352051 69.1862335205168 .8814392089868 .2718734741267 .6623001098666 .74794006348 
65.5288009643664 .3096618652362 .7857398986860 .9570198059159 .43310165405 57.909179687557 .2995986938557 .29959869385 -9999 -9999 -9999 -9999 -9999 -9999 -9999 -9999 -9999 -9999 -9999 -9999 -9999 -9999 -9999 -9999 -9999 -9999 -9999 -9999 -9999 -9999 -9999 -9999 -9999 -9999 -9999 -9999 -9999 -9999 -9999 -9999 -9999 -9999 -9999 -9999 -9999

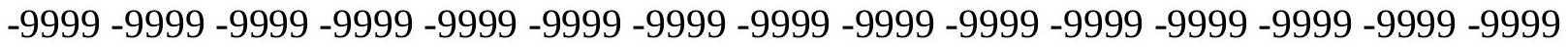
$-9999-9999$

-9999 -9999 -9999 -9999 -9999 -9999 -9999 -9999 -9999 -9999 -9999 -9999 -9999 -9999 -9999 -9999 -9999 -9999 -9999 -9999 -9999 -9999 -9999 -9999 -9999 -9999 -9999 -9999 -9999 -9999 -999 -9999 -9999 -9999 -9999 -9999 -9999 -9999 -9999 -9999 -9999 -9999 -9999 -9999 -9999 -9999 -9999 -9999 -9999 -9999 -9999 -9999 -9999 -9999 -9999 -9999 -9999 -9999 -9999 -9999 -9999 -

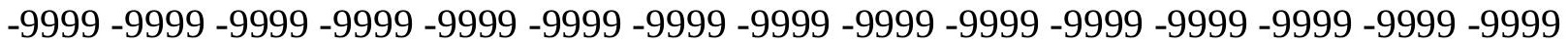
-9999 -9999 -9999 -9999 -9999 -9999 -9999 -9999 -9999 -9999 -9999 -9999 -9999 -9999 -9999 -9999 -9999 -9999 -9999 -9999 -9999 -9999 -9999 -9999 -9999 -9999 -9999 -9999 -9999 -9999 -9999 -9999 -9999 -9999 -9999 -9999 -9999 -9999 -9999 -9999 -9999 -9999 -9999 -9999 -9999 -9999 -9999 -9999 -9999 -9999 -9999 -9999 -9999 -9999 -9999 -9999 -9999 -9999 -9999 -9999

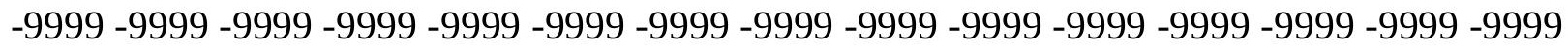
-9999 -9999 -9999 -9999 -9999 -9999 -9999 -9999 -9999 -9999 -9999 -9999 -9999 -9999 -9999 -

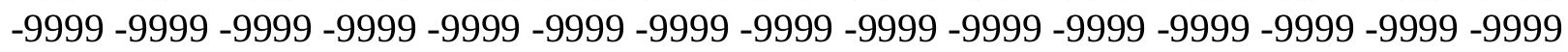

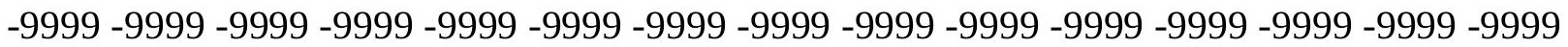

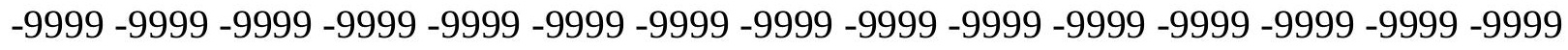

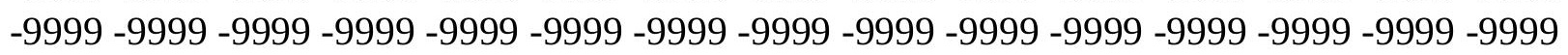
-9999 -9999-9999-9999 108.1986999512 101.9684295654101 .0720062256100 .2142562866 99.3599472045998 .7503814697397 .8360290527397 .2264633178796 .92166900635 96.3121032714896 .0073165893695 .7025299072395 .397743225195 .09295654297 94.7881774902394 .4833908081194 .1785964965893 .8738174438593 .26425170898 92.9594726562592 .6546783447392 .0450973510791 .7403335571391 .43553924561 90.8259735107490 .5211791992289 .9116134643689 .302040100188 .99725341797 88.38768768311 88.08290100098 87.47332763672 87.16854858398 86.55898284912 86.2541885376 85.64462280273 85.33984375 84.7302627563584.12069702148 83.8159103393686 .5589828491286 .254188537685 .9494018554785 .64462280273 85.0350494384884 .4254837036183 .8159103393682 .9015579223681 .98719787598 81.0728530883879 .8537063598675 .8914871215874 .9771423339874 .0627822876 73.4532165527372 .5388565063571 .6244964599670 .7101516723669 .49101257324 68.5766525268667 .6623001098666 .7479400634865 .8335876464864 .91924285889 64.004882812563 .0905189514262 .1761703491261 .2618103027359 .73788070679 58.5187492370657 .2995986938556 .3852500915555 .7756805419955 .47089004517 55.4708900451755 .7756805419956 .0804595947356 .6900291442957 .60438919067 58.5187492370659 .4331016540560 .3474502563561 .5666007995662 .48094940186 63.3953094482464 .6144485473665 .5288009643666 .1383666992267 .05272674561 67.6623001098667 .9670867919968 .2718734741268 .5766525268668 .27187347412 68.2718734741267 .6623001098667 .0527267456166 .1383666992264 .91924285889 63.7000885009862 .1761703491260 .9570198059159 .4331016540557 .9091796875 57.60438919067 57.29959869385 -9999 -9999 -9999 -9999 -9999-9999 -9999 -9999 -9999 -9999 -9999 -9999 -9999 -9999 -9999 -9999 -9999 -9999 -9999 -9999 -9999 -9999 -9999 -9999

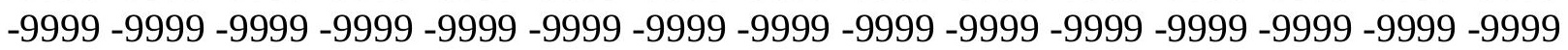

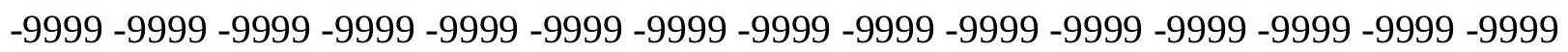


-9999 -9999 -9999 -9999 -9999 -9999 -9999 -9999 -9999 -9999 -9999 -9999 -9999 -9999 -9999 -9999 -9999 -9999 -9999 -9999 -9999 -9999 -9999 -9999 -9999 -9999 -9999 -9999 -9999 -9999 -9999 -9999 -9999 -9999 -9999 -9999 -9999 -9999 -9999 -9999 -9999 -9999 -9999 -9999 -9999 -9999 -9999 -9999 -9999 -9999 -9999 -9999 -9999 -9999 -9999 -9999 -9999 -9999 -9999 -9999 -9999 -9999 -9999 -9999 -9999 -9999 -9999 -9999 -9999 -9999 -9999 -9999 -9999 -9999 -9999 -9999 -9999 -9999 -9999 -9999 -9999 -9999 -9999 -9999 -9999 -9999 -9999 -9999 -9999 -9999 -9999 -9999 -9999 -9999 -9999 -9999 -9999 -9999 -9999 -9999 -9999 -9999 -9999 -9999 -9999

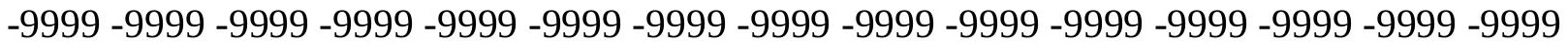
-9999 -9999 -9999 -9999 -9999 -9999 -9999 -9999 -9999 -9999 -9999 -9999 -9999 -9999 -9999 -9999 -9999 -9999 -9999 -9999 -9999 -9999 -9999 -9999 -9999 -9999 -9999 -9999 -9999 -9999 -9999 -9999 -9999 -9999 -9999 -9999 -9999 -9999 -9999 -9999 -9999 -9999 -9999 -9999 -9999 -9999 -9999 -9999 -9999 -9999 -9999 -9999 -9999 -9999 -9999 -9999 -9999 -9999 -9999 -9999

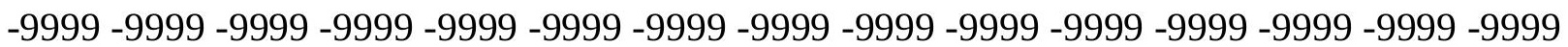
-9999 -9999 -9999 -9999 -9999 -9999 -9999 -9999 -9999 -9999 -9999 -9999 -9999 -9999 -9999 -9999 -9999 -9999 -9999 -9999 -9999 -9999 -9999 -9999 -9999 -9999 -9999 -9999 -9999 -9999 -9999 -9999 -9999 -9999 -9999 106.6747970581 101.4907989502100 .5593566895 99.3599472045998.7503814697398.1408081054797.5312423706196.92166900635 96.6168823242296 .0073165893695 .7025299072395 .397743225195 .3977432251 95.0929565429794 .7881774902394 .4833908081194 .1785964965893 .56903076172 93.2642517089892 .9594726562592 .349891662692 .0450973510791 .66282653809 91.1256332397590 .5211791992290 .2164001464889 .6068267822389 .3020401001 88.6924667358488 .3876876831188 .0829010009887 .4733276367287 .16854858398 86.5589828491285 .9494018554785 .6446228027385 .0350494384884 .73026275635 84.1206970214883 .5111236572383 .206336975182 .5967712402385 .03504943848 84.7302627563584 .1206970214883 .5111236572382 .5967712402378 .63455963135 78.0249862670977 .4154205322376 .5010681152375 .5867080688574 .97714233398 74.062782287673 .1484298706172 .2340774536171 .3197174072370 .40535736084 69.4910125732468 .5766525268667 .6623001098666 .7479400634865 .83358764648 64.9192428588964 .3096618652363 .3953094482462 .4809494018661 .26181030273 60.0426712036158 .8235282897957 .909179687557 .2995986938556 .99481964111 56.6900291442956 .9948196411157 .2995986938557 .909179687558 .51874923706 59.1283111572360 .0426712036160 .6522407531761 .8713798522962 .78573989868 63.7000885009864 .6144485473665 .2240066528366 .1383666992266 .74794006348 67.3575134277367 .6623001098667 .9670867919967 .9670867919967 .96708679199 67.6623001098667 .0527267456166 .4431610107465 .5288009643664 .61444854736 63.3953094482462 .1761703491260 .6522407531759 .4331016540557 .9091796875 57.6043891906757 .60438919067 -9999 -9999 -9999 -9999 -9999 -9999 -9999 -9999 -9999 -9999 -9999 -9999 -9999 -9999 -9999 -9999 -9999 -9999 -9999 -9999 -9999 -9999 -9999 -9999 -9999 -9999 -9999 -9999 -9999 -9999 -9999 -9999 -9999 -9999 -9999 -9999 -9999 -9999 -9999 -9999 -9999 -9999 -9999 -9999 -9999 -9999 -9999 -9999 -9999 -9999 -9999 -9999 -9999 -9999 -9999 -9999 -9999 -9999 -9999 -9999 -9999 -9999 -9999 -9999 -9999 -9999 -9999 -9999 -9999

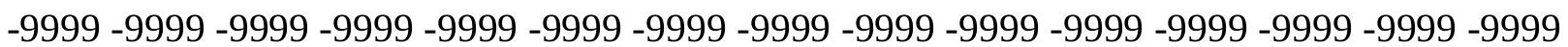
-9999 -9999 -9999 -9999 -9999 -9999 -9999 -9999 -9999 -9999 -9999 -9999 -9999 -9999 -9999 -9999 -9999 -9999 -9999 -9999 -9999 -9999 -9999 -9999 -9999 -9999 -9999 -9999 -9999 -9999 -9999 -9999 -9999 -9999 -9999 -9999 -9999 -9999 -9999 -9999 -9999 -9999 -9999 -9999 -9999

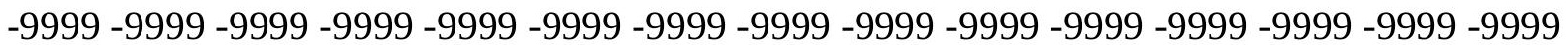


-9999 -9999 -9999 -9999 -9999 -9999 -9999 -9999 -9999 -9999 -9999 -9999 -9999 -9999 -9999 -9999 -9999 -9999 -9999 -9999 -9999 -9999 -9999 -9999 -9999 -9999 -9999 -9999 -9999 -9999 -9999 -9999 -9999 -9999 -9999 -9999 -9999 -9999 -9999 -9999 -9999 -9999 -9999 -9999 -9999 -9999 -9999 -9999 -9999 -9999 -9999 -9999 -9999 -9999 -9999 -9999 -9999 -9999 -9999 -9999 -9999 -9999 -9999 -9999 -9999 -9999 -9999 -9999 -9999 -9999 -9999 -9999 -9999 -9999 -9999 -9999 -9999 -9999 -9999 -9999 -9999 -9999 -9999 -9999 -9999 -9999 -9999 -9999 -9999 -9999 -9999 -9999 -9999 -9999 -9999 -9999 -9999 -9999 -9999 -9999 -9999 -9999 -9999 -9999 -9999

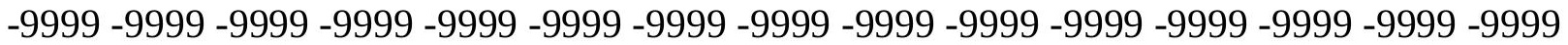
-9999 -9999 -9999 -9999 -9999 -9999 -9999 -9999 -9999 -9999 -9999 -9999 -9999 -9999 -9999 -9999 -9999 -9999-9999 -9999 -9999 105.7603988647102 .71260070899 .66472625732 98.7503814697398 .1408081054797 .5312423706196 .9216690063596 .61688232422 96.3121032714896 .0073165893695 .7025299072395 .7025299072395 .3977432251 95.0929565429794 .7881774902394 .4833908081194 .1785964965893 .56903076172 93.2642517089892 .6546783447392 .349891662691 .7403335571391 .43553924561 90.8259735107490 .4874267578189 .9116134643689 .6068267822388 .99725341797 88.6924667358488 .3876876831187 .7781066894587 .4733276367286 .86376190186 86.5589828491285 .9494018554785 .6446228027385 .0350494384884 .42548370361 84.1206970214883 .5111236572382 .9015579223682 .5967712402381 .98719787598 81.3776321411180 .7680587768679 .8537063598679 .2441329956178 .63455963135 77.7202072143677 .110626220776 .1962814331175 .5867080688574 .67236328125 73.7580032348672 .8436431884872 .2340774536171 .3197174072370 .40535736084 69.4910125732468 .5766525268667 .6623001098666 .7479400634866 .13836669922 65.2240066528364 .3096618652363 .3953094482462 .1761703491261 .26181030273 60.3474502563559 .4331016540558 .8235282897958 .5187492370658 .21395874023 58.2139587402358 .5187492370658 .8235282897959 .4331016540559 .73788070679 60.3474502563561 .2618103027362 .1761703491263 .0905189514264 .0048828125 64.6144485473665 .5288009643666 .1383666992266 .7479400634867 .05272674561 67.3575134277367 .6623001098667 .6623001098667 .3575134277367 .05272674561 66.4431610107465 .8335876464865 .2240066528364 .004882812563 .09051895142 61.8713798522960 .6522407531759 .4331016540558 .2139587402357 .9091796875 -9999 -9999 -9999 -9999 -9999 -9999 -9999 -9999 -9999 -9999 -9999 -9999 -9999 -9999 -9999 -9999 -9999 -9999 -9999 -9999 -9999 -9999 -9999 -9999 -9999 -9999 -9999 -9999 -9999 -9999 -9999 -9999 -9999 -9999 -9999 -9999 -9999 -9999 -9999 -9999 -9999 -9999 -9999 -9999 -9999 -9999 -9999 -9999 -9999 -9999-9999-9999-9999-9999-9999 -9999 -9999 -9999 -9999 -9999 -9999 -9999 -9999 -9999 -9999 -9999 -9999 -9999 -9999 -9999 -9999 -9999 -9999 -9999 -9999 -9999 -9999 -9999 -9999 -9999 -9999 -9999 -9999 -9999 -9999 -9999 -9999 -9999 -9999 -9999 -9999 -9999 -9999 -9999 -9999 -9999 -9999 -9999 -9999 -9999

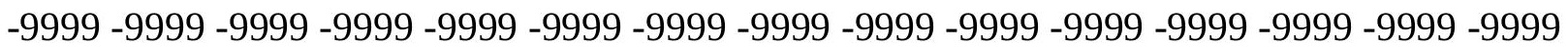
-9999 -9999 -9999 -9999 -9999 -9999 -9999 -9999 -9999 -9999 -9999 -9999 -9999 -9999 -9999 -9999 -9999 -9999 -9999 -9999 -9999 -9999 -9999 -9999 -9999 -9999 -9999 -9999 -9999 -9999 -9999 -9999 -9999 -9999 -9999 -9999 -9999 -9999 -9999 -9999 -9999 -9999 -9999 -9999 -9999

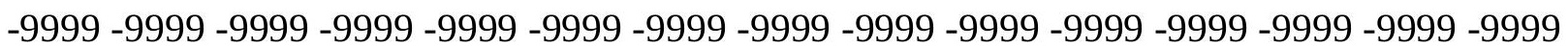
-9999 -9999 -9999 -9999 -9999 -9999 -9999 -9999 -9999 -9999 -9999 -9999 -9999 -9999 -9999 -9999 -9999 -9999 -9999 -9999 -9999 -9999 -9999 -9999 -9999 -9999 -9999 -9999 -9999 -9999 -9999 -9999 -9999 -9999 -9999 -9999 -9999 -9999 -9999 -9999 -9999 -9999 -9999 -9999 -9999

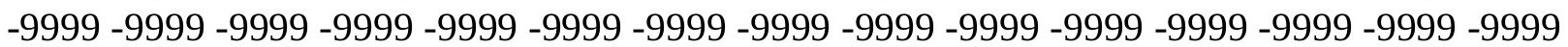


-9999 -9999 -9999 -9999 -9999 -9999 -9999 -9999 -9999 -9999 -9999 -9999 -9999 -9999 -9999 -9999 -9999 -9999 -9999 -9999 -9999 -9999 -9999 -9999 -9999 -9999 -9999 -9999 -9999 -9999 -9999 -9999 -9999 -9999 -9999 -9999 -9999 -9999 -9999 -9999 -9999 -9999 -9999 -9999 -9999 -9999 -9999 -9999 -9999 -9999 -9999 -9999 105.1509017944 102.1029968262 99.35994720459 98.1408081054797 .5312423706197 .2264633178796 .9216690063596 .61688232422 96.3121032714896 .0073165893696 .0073165893695 .7025299072395 .3977432251 95.0929565429794 .7881774902394 .4833908081193 .8738174438593 .56903076172 92.9594726562592 .349891662692 .0450973510791 .7403335571391 .13075256348 90.8259735107490 .2164001464889 .8991928100689 .3944015502988 .91623687744 88.38768768311 88.08290100098 87.77810668945 87.16854858398 86.86376190186 86.254188537685 .9494018554785 .3398437585 .0350494384884 .42548370361 83.8159103393683 .5111236572382 .9015579223682 .2919769287181 .68241119385 81.0728530883880 .4632720947379 .8537063598679 .2441329956178 .32978057861 77.7202072143676 .8058471679776 .1962814331175 .2819290161174 .36756896973 73.7580032348672 .8436431884871 .9292907714871 .3197174072370 .40535736084 69.4910125732468 .5766525268667 .9670867919967 .0527267456166 .13836669922 65.2240066528364 .3096618652363 .3953094482462 .4809494018661 .56660079956 60.6522407531760 .0426712036159 .7378807067959 .4331016540559 .43310165405 59.7378807067960 .0426712036160 .3474502563560 .6522407531761 .26181030273 61.8713798522962 .7857398986863 .3953094482464 .3096618652364 .91924285889 65.5288009643666 .1383666992266 .4431610107467 .0527267456167 .05272674561 67.3575134277367 .3575134277367 .0527267456166 .7479400634866 .13836669922 65.5288009643664 .9192428588964 .004882812562 .7857398986861 .87137985229 60.6522407531759 .4331016540558 .5187492370658 .21395874023 -9999 -9999 -9999 -9999 -9999 -9999 -9999 -9999 -9999 -9999 -9999 -9999 -9999 -9999 -9999 -9999 -9999 -9999 -9999 -9999 -9999 -9999 -9999 -9999 -9999 -9999 -9999 -9999 -9999 -9999 -9999 -9999 -9999 -9999

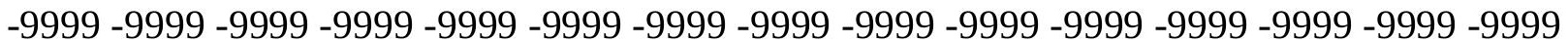
-9999-9999-9999-9999-9999-9999

-9999 -9999 -9999 -9999 -9999 -9999 -9999 -9999 -9999 -9999 -9999 -9999 -9999 -9999 -9999 -9999 -9999 -9999 -9999 -9999 -9999 -9999 -9999 -9999 -9999 -9999 -9999 -9999 -9999 -9999 -9999 -9999 -9999 -9999 -9999 -9999 -9999 -9999 -9999 -9999 -9999 -9999 -9999 -9999 -9999 -9999 -9999 -9999 -9999 -9999 -9999 -9999 -9999 -9999 -9999 -9999 -9999 -9999 -9999 -9999 -9999 -9999 -9999 -9999 -9999 -9999 -9999 -9999 -9999 -9999 -9999 -9999 -9999 -9999 -9999 -9999 -9999 -9999 -9999 -9999 -9999 -9999 -9999 -9999 -9999 -9999 -9999 -9999 -9999 -9999 -9999 -9999 -9999 -9999 -9999 -9999 -9999 -9999 -9999 -9999 -9999 -9999 -9999 -9999 -9999 -9999 -9999 -9999 -9999 -9999 -9999 -9999 -9999 -9999 -9999 -9999 -9999 -9999 -9999 -9999 -9999 -9999 -9999 -9999 -9999 -9999 -9999 -9999 -9999 -9999 -9999 -9999 -9999 -9999 -9999

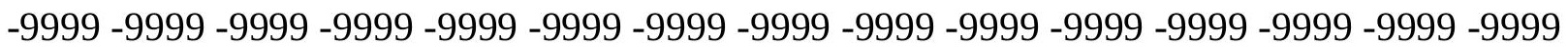
-9999 -9999 -9999 -9999 -9999 -9999 -9999 -9999 -9999 -9999 -9999 -9999 -9999 -9999 -9999 -9999 -9999 -9999 -9999 -9999 -9999 -9999 -9999 -9999 -9999 -9999 -9999 -9999 - -9999 -9999 -9999 -9999 -9999 -9999 -9999 -9999 -9999 -9999 -9999 -9999 -9999 -9999 -9999 -9999 -9999

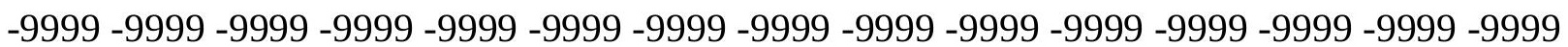
-9999 -9999 -9999 -9999 -9999 -9999 -9999 -9999 -9999 -9999 -9999 -9999 -9999 -9999 -9999 -9999 -9999 -9999 -9999 -9999 -9999 -9999 -9999 104.8460998535102 .1029968262 99.3599472045997.5312423706197.2264633178796.9216690063596.92166900635 96.6168823242296 .3121032714896 .3121032714896 .0073165893696 .00731658936 
95.7025299072395 .397743225195 .0929565429794 .4833908081193 .56903076172 93.2642517089892 .6546783447392 .349891662692 .0450973510791 .72940826416 91.1307525634890 .7460021972790 .2164001464889 .7369918823289 .23183441162 88.6924667358488 .3876876831187 .7781066894587 .4733276367287 .16854858398 86.5589828491286 .254188537685 .6446228027385 .3398437584 .73026275635 84.4254837036183 .8159103393683 .206336975182 .9015579223682 .29197692871 81.6824111938581 .0728530883880 .1584930419979 .5489196777378 .93934631348 78.3297805786177 .4154205322376 .8058471679775 .8914871215875 .28192901611 74.3675689697373 .4532165527372 .8436431884871 .9292907714871 .31971740723 70.4053573608469 .4910125732468 .8814392089867 .9670867919967 .05272674561 66.1383666992265 .2240066528364 .6144485473663 .7000885009862 .78573989868 62.1761703491261 .5666007995661 .2618103027360 .9570198059160 .95701980591 60.9570198059160 .9570198059161 .2618103027361 .8713798522962 .17617034912 62.7857398986863 .3953094482464 .004882812564 .6144485473665 .22400665283 65.8335876464866 .1383666992266 .7479400634867 .0527267456167 .05272674561 67.0527267456167 .0527267456167 .0527267456166 .4431610107466 .13836669922 65.5288009643664 .6144485473663 .7000885009862 .7857398986861 .87137985229 60.6522407531759 .7378807067958 .8235282897958 .51874923706 -9999 -9999 -9999 -9999 -9999 -9999 -9999 -9999 -9999 -9999 -9999 -9999 -9999 -9999 -9999 -9999 -9999 -9999 -9999 -9999 -9999 -9999 -9999 -9999 -9999 -9999 -9999 -9999 -9999 -9999 -9999 -9999 -9999 -9999 -

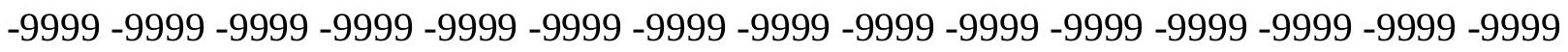
-9999 -9999 -9999-9999-9999-9999

-9999 -9999 -9999 -9999 -9999 -9999 -9999 -9999 -9999 -9999 -9999 -9999 -9999 -9999 -9999 -9999 -9999 -9999 -9999 -9999 -9999 -9999 -9999 -9999 -9999 -9999 -9999 -9999 -9999 -9999 -

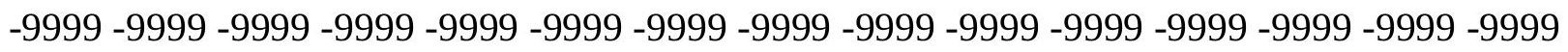
-9999 -9999 -9999 -9999 -9999 -9999 -9999 -9999 -9999 -9999 -9999 -9999 -9999 -9999 -9999 -9999 -9999 -9999 -9999 -9999 -9999 -9999 -9999 -9999 -9999 -9999 -9999 -9999 -9999 -9999

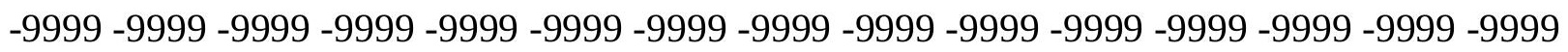
-9999 -9999 -9999 -9999 -9999 -9999 -9999 -9999 -9999 -9999 -9999 -9999 -9999 -9999 -9999 -9999 -9999 -9999 -9999 -9999 -9999 -9999 -9999 -9999 -9999 -9999 -9999 -9999 -9999 -9999 -9999 -9999 -9999 -9999 -9999 -9999 -9999 -9999 -9999 -9999 -9999 -9999 -9999 -9999 -9999

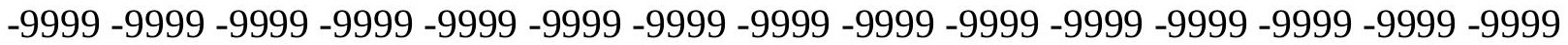

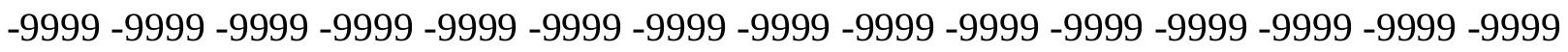
-9999 -9999 -9999 -9999 -9999 -9999 -9999 -9999 -9999 -9999 -9999 -9999 -9999 -9999 -9999 -9999 -9999 -9999 -9999 -9999 -9999 -9999 -9999 -9999 -9999 -9999 -9999 -9999 -9999 -9999 -9999 -9999 -9999 -9999 -9999 -9999 -9999 -9999 -9999 -9999 -9999 -9999 -9999 -9999 -9999

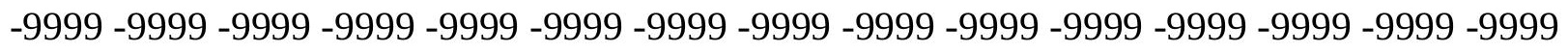
-9999 -9999 -9999 -9999-9999-9999 -9999 -9999-9999 104.5412979126102.1029968262 100.274299621698 .445587158297 .5312423706197 .2264633178796 .92166900635 96.9216690063596 .6168823242296 .6168823242296 .6168823242296 .31210327148 96.0073165893695 .397743225194 .7881774902394 .1785964965893 .56903076172 92.9594726562592 .6546783447392 .6133193969792 .1036682128991 .60029602051 91.0956802368290 .5924148559690 .0931472778389 .6063766479588 .99725341797 88.6924667358488 .0829010009887 .7781066894587 .4577865600686 .86376190186 86.5589828491286 .254188537685 .6446228027385 .3398437584 .73026275635 84.1206970214883 .8159103393683 .206336975182 .5967712402381 .98719787598 
81.3776321411180 .7680587768680 .1584930419979 .5489196777378 .63455963135 78.0249862670977 .4154205322376 .5010681152375 .8914871215874 .97714233398 74.3675689697373 .4532165527372 .8436431884871 .9292907714871 .31971740723 70.4053573608469 .7957916259868 .8814392089867 .9670867919967 .35751342773 66.4431610107465 .5288009643664 .9192428588964 .004882812563 .39530944824 62.7857398986862 .4809494018662 .1761703491262 .1761703491262 .17617034912 62.1761703491262 .4809494018662 .7857398986863 .0905189514263 .70008850098 64.004882812564 .6144485473665 .2240066528365 .8335876464866 .13836669922 66.4431610107466 .7479400634867 .0527267456167 .0527267456167 .05272674561 67.0527267456166 .7479400634866 .4431610107466 .1383666992265 .52880096436 64.6144485473663 .7000885009862 .7857398986861 .8713798522960 .95701980591 59.7378807067959 .1283111572359 .12831115723 -9999 -9999 -9999 -9999 -9999 -9999 -9999 -9999 -9999 -9999 -9999 -9999 -9999 -9999 -9999 -9999 -9999 -9999 -9999 -9999 -9999 -9999 -9999 -9999 -9999 -9999 -9999 -9999 -9999 -9999 -9999 -9999 -9999 -9999 -9999 -9999 - 9999 -9999 -9999 -9999 -9999 -9999 -9999 -9999 -9999 -9999 -9999 -9999 -9999 -9999 -999 - -9999 -9999 -9999 -9999

-9999 -9999 -9999 -9999 -9999 -9999 -9999 -9999 -9999 -9999 -9999 -9999 -9999 -9999 -9999 -9999 -9999 -9999 -9999 -9999 -9999 -9999 -9999 -9999 -9999 -9999 -9999 -9999 -9999 -9999 -9999 -9999 -9999 -9999 -9999 -9999 -9999 -9999 -9999 -9999 -9999 -9999 -9999 -9999 -9999 -

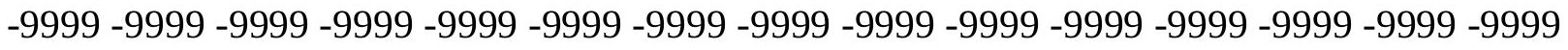
-9999 -9999 -9999 -9999 -9999 -9999 -9999 -9999 -9999 -9999 -9999 -9999 -9999 -9999 -9999 -9999 -9999 -9999 -9999 -9999 -9999 -9999 -9999 -9999 -9999 -9999 -9999 -9999 -9999 -9999 -9999 -9999 -9999 -9999 -9999 -9999 -9999 -9999 -9999 -9999 -9999 -9999 -9999 -9999 -9999 -9999 -9999 -9999 -9999 -9999 -9999 -9999 -9999 -9999 -9999 -9999 -9999 -9999 -9999 -9999 -9999 -9999 -9999 -9999 -9999 -9999 -9999 -9999 -9999 -9999 -9999 -9999 -9999 -9999 -9999 -9999 -9999 -9999 -9999 -9999 -9999 -9999 -9999 -9999 -9999 -9999 -9999 -9999 -9999 -9999 -9999 -9999 -9999 -9999 -9999 -9999 -9999 -9999 -9999 -9999 -9999 -9999 -9999 -9999 -9999 -

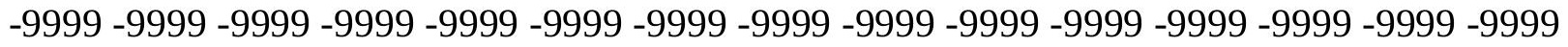
-9999 -9999 -9999 -9999 -9999 -9999 -9999 -9999 -9999 -9999 -9999 -9999 -9999 -9999 -9999 -9999 -9999 -9999 -9999 -9999 -9999 -9999 -9999 -9999 -9999 -9999 -9999 -9999 -9999 -999 -9999 -9999 -9999 -9999 -9999 -9999 -9999 -9999 -9999 -9999 -9999 -9999 -9999 -9999 -9999 -9999 -9999 -9999 -9999 -9999 -9999 -9999 -9999 -9999 -9999 -9999 103.3221969604 101.798202514699 .2002716064598 .6194458007898 .1408081054797 .83602905273 97.2264633178796 .9216690063596 .9216690063596 .9216690063596 .92166900635 96.2052688598695 .397743225194 .4833908081193 .8738174438593 .56903076172 93.5148010253992 .9926986694392 .4753799438591 .9626235961991 .45391845703 90.951736450290 .4588088989389 .9116134643689 .302040100188 .99725341797 88.38768768311 88.08290100098 87.47332763672 87.16854858398 86.86376190186 86.5589828491285 .9494018554785 .6446228027385 .0350494384884 .73026275635 84.1206970214883 .5111236572382 .9015579223682 .5967712402381 .98719787598 81.3776321411180 .4632720947379 .8537063598679 .2441329956178 .63455963135 78.0249862670977 .110626220776 .5010681152375 .8914871215874 .97714233398 74.3675689697373 .4532165527372 .8436431884871 .9292907714871 .31971740723 70.4053573608469 .7957916259868 .8814392089868 .2718734741267 .35751342773 66.7479400634866 .1383666992265 .2240066528364 .6144485473664 .30966186523 64.004882812563 .7000885009863 .3953094482463 .3953094482463 .39530944824 
63.7000885009864 .004882812564 .3096618652364 .6144485473664 .91924285889 65.5288009643665 .8335876464866 .1383666992266 .7479400634867 .05272674561 67.0527267456167 .3575134277367 .3575134277367 .3575134277367 .05272674561 66.7479400634866 .4431610107466 .1383666992265 .5288009643664 .61444854736 64.004882812563 .0905189514262 .1761703491261 .2618103027360 .04267120361 59.73788070679 -9999 -9999 -9999 -9999 -9999 -9999 -9999 -9999 -9999 -9999 -9999 -9999 -9999 -9999 -9999 -9999 -9999 -9999 -9999 -9999 -9999 -9999 -9999 -9999 -9999 -9999 -9999 -9999 -9999 -9999 -9999 -9999 -9999 -9999 -9999 -9999 -9999 -9999 -9999 -9999 -9999 -9999 -9999 -9999 -9999 -9999 -9999 -9999 -9999 -9999 -9999 -9999 -9999 -9999 -9999 -9999 -9999 -9999 -9999 -9999 -9999 -9999 -9999 -9999 -9999 -9999 -9999 -9999 -9999 -9999 -9999

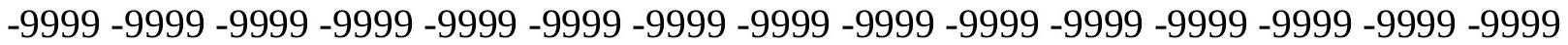
-9999 -9999 -9999 -9999 -9999 -9999 -9999 -9999 -9999 -9999 -9999 -9999 -9999 -9999 -9999 -9999 -9999 -9999 -9999 -9999 -9999 -9999 -9999 -9999 -9999 -9999 -9999 -9999 -9999 -9999 -9999 -9999 -9999 -9999 -9999 -9999 -9999 -9999 -9999 -9999 -9999 -9999 -9999 -9999 - 9999 -9999 -9999 -9999 -9999 -9999 -9999 -9999 -9999 -9999 -9999 -9999 -9999 -9999 -9999 -9999

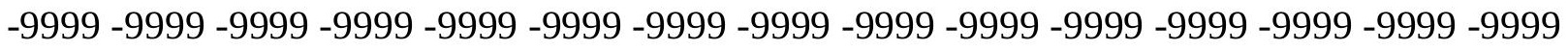

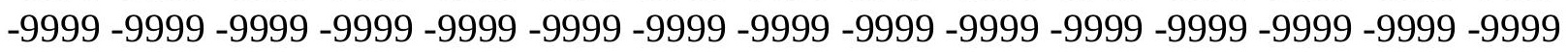
-9999 -9999 -9999 -9999 -9999 -9999 -9999 -9999 -9999 -9999 -9999 -9999 -9999 -9999 -9999 -999 -9999 -9999 -9999 -9999 -9999 -9999 -9999 -9999 -9999 -9999 -9999 -9999 -9999 -9999 -9999 -9999 -9999 -9999 -9999 -9999 -9999 -9999 -9999 -9999 -9999 -9999 -9999 -9999 -9999 -9999 -9999 -9999 -9999 -9999 -9999 -9999 -9999 -9999 -9999 -9999 -9999 -9999 -9999 -9999 -9999 -9999 -9999 -9999 -9999 -9999 -9999 -9999 -9999 -9999 -9999 -9999 -9999 -9999 -9999 -9999 -9999 -9999 -9999 -9999 -9999 -9999 -9999 -9999 -9999 -9999 -9999 -9999 -9999 -9999 -9999 -9999 -9999 -9999 -9999 -9999 -9999 -9999 -9999 -9999 -9999 -9999 -9999 -9999 -9999 -9999 -9999 -9999 -9999-9999-9999 -9999-9999-9999 -9999-9999-9999-9999 105.4557037354 104.2365036011100 .295204162699 .9818725585999 .798271179299 .90213012695 100.5791015625100 .5791015625100 .274299621699 .9695205688599 .35994720459 96.0915069580195 .5359573364394 .1785964965893 .8738174438593 .90785980225 93.377090454192.852256774992.3334960937591.821853637791.31962585449 90.8295593261790 .355056762789 .6068267822389 .302040100188 .69246673584 88.38768768311 87.77810668945 87.47332763672 87.16854858398 86.86376190186 86.3842544555785 .9494018554785 .6446228027385 .0350494384884 .42548370361 84.1206970214883 .5111236572382 .9015579223682 .2919769287181 .68241119385 81.0728530883880 .4632720947379 .8537063598679 .2441329956178 .32978057861 77.7202072143677 .110626220776 .5010681152375 .5867080688574 .97714233398 74.3675689697373 .4532165527372 .8436431884872 .2340774536171 .31971740723 70.7101516723669 .7957916259869 .1862335205168 .5766525268667 .66230010986 67.0527267456166 .4431610107465 .8335876464865 .5288009643665 .22400665283 64.9192428588964 .6144485473664 .6144485473664 .6144485473664 .91924285889 64.9192428588965 .2240066528365 .5288009643665 .8335876464866 .13836669922 66.4431610107466 .7479400634867 .0527267456167 .3575134277367 .66230010986 67.6623001098667 .6623001098667 .6623001098667 .3575134277367 .05272674561 66.7479400634866 .1383666992265 .5288009643664 .9192428588964 .0048828125 63.3953094482462 .4809494018661 .5666007995660 .6522407531760 .34745025635 -9999 -9999 -9999 -9999 -9999 -9999 -9999 -9999 -9999 -9999 -9999 -9999 -9999 -9999 -9999 -9999 -9999 -9999 -9999 -9999 -9999 -9999 -9999 -9999 -9999 -9999 -9999 -9999 -9999 -9999 -9999 
-9999 -9999 -9999 -9999 -9999 -9999 -9999 -9999 -9999 -9999 -9999 -9999 -9999 -9999 -9999 -9999 -9999 -9999 -9999 -9999 -9999 -9999 -9999 -9999 -9999

-9999 -9999 -9999 -9999 -9999 -9999 -9999 -9999 -9999 -9999 -9999 -9999 -9999 -9999 -9999 -9999 -9999 -9999 -9999 -9999 -9999 -9999 -9999 -9999 -9999 -9999 -9999 -9999 -9999 -9999 -9999 -9999 -9999 -9999 -9999 -9999 -9999 -9999 -9999-9999 -9999 -9999 -9999 -9999 -9999 -9999 -9999 -9999 -9999 -9999 -9999 -9999 -9999 -9999 -9999 -9999 -9999 -9999 -9999 -9999 -9999 -9999 -9999 -9999 -9999 -9999 -9999 -9999 -9999 -9999 -9999 -9999 -9999 -9999 -9999

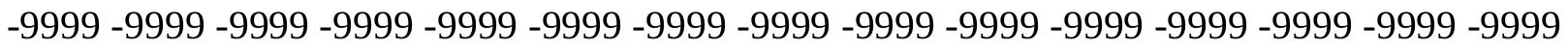

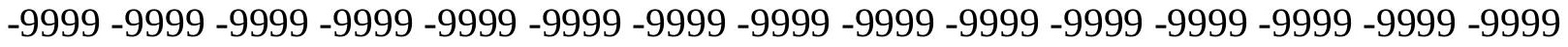
-9999 -9999 -9999 -9999 -9999 -9999 -9999 -9999 -9999 -9999 -9999 -9999 -9999 -9999 -9999

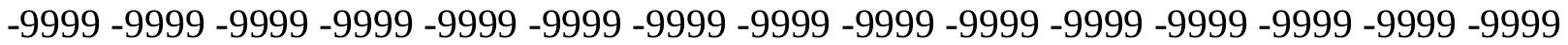
-9999 -9999 -9999 -9999 -9999 -9999 -9999 -9999 -9999 -9999 -9999 -9999 -9999 -9999 -9999 -9999 -9999 -9999 -9999 -9999 -9999 -9999 -9999 -9999 -9999 -9999 -9999 -9999 -9999 -9999 -9999 -9999 -9999 -9999 -9999 -9999 -9999 -9999 -9999 -9999 -9999 -9999 -9999 -9999 - 9999 -9999 -9999 -9999 -9999 -9999 -9999 -9999 -9999 -9999 -9999 -9999 -9999 -9999 -9999 -9999

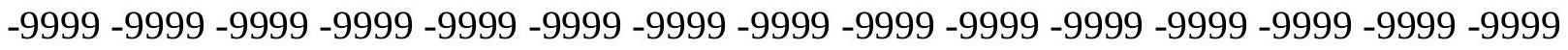
-9999 -9999 -9999 -9999 -9999 -9999 -9999 -9999 -9999 -9999 -9999 -9999 -9999 -9999 -9999 -9999 -9999 -9999 -9999 -9999 -9999 -9999 -9999 -9999 -9999 -9999 -9999 -9999 108.5035018921102 .4348526001102 .3624801636102 .5579681396103 .0911941528 103.8257064819104 .424156189104 .9886550903105 .7603988647105 .4557037354 96.5282058715895.9619903564595.4030914306694.8511962890694.30611419678 93.767997741793 .2370758056692 .7138900756892 .1996231079191 .69624328613 91.2058868408290 .7300109863389 .9116134643689 .302040100188 .99725341797 88.69246673584 88.38768768311 87.77810668945 87.47332763672 87.16854858398 86.7765655517686 .254188537685 .8913955688585 .3398437585 .03504943848 84.4254837036183 .8159103393683 .206336975182 .9015579223682 .29197692871 81.6824111938581 .0728530883880 .4632720947379 .5489196777378 .93934631348 78.3297805786177 .7202072143677 .110626220776 .1962814331175 .58670806885 74.9771423339874 .3675689697373 .4532165527372 .8436431884872 .23407745361 71.6244964599670 .7101516723670 .1005783081169 .4910125732468 .88143920898 68.2718734741267 .6623001098667 .0527267456166 .7479400634866 .44316101074 66.1383666992265 .8335876464865 .8335876464865 .8335876464865 .83358764648 66.1383666992266 .1383666992266 .4431610107466 .7479400634867 .05272674561 67.3575134277367 .6623001098667 .6623001098667 .9670867919967 .96708679199 67.9670867919967 .9670867919967 .6623001098667 .6623001098667 .35751342773 66.7479400634866 .4431610107465 .8335876464865 .2240066528364 .30966186523 $63.7000885009862 .7857398986861 .8713798522961 .2618103027361 .26181030273-9999$ -9999 -9999 -9999 -9999 -9999 -9999 -9999 -9999 -9999 -9999 -9999 -9999 -9999 -9999 -9999 -

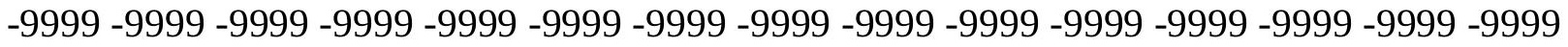
-9999 -9999 -9999 -9999 -9999 -9999 -9999 -9999 -9999 -9999 -9999 -9999 -9999 -9999 - -999 -9999 -9999 -9999-9999-9999-9999-9999 -9999 -9999-9999

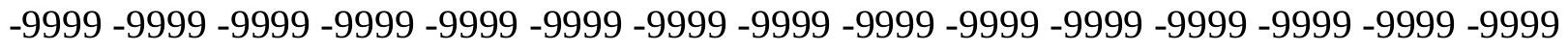
-9999 -9999 -9999 -9999 -9999 -9999 -9999 -9999 -9999 -9999 -9999 -9999 -9999 -9999 -9999 -9999 -9999 -9999 -9999 -9999 -9999 -9999 -9999 -9999-9999 -9999 -9999 -9999 -9999 -9999 -9999 -9999 -9999 -9999 -9999 -9999 -9999 -9999 -9999 -9999 -9999 -9999 -9999 -9999 -9999 -

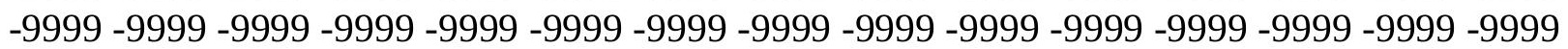


-9999 -9999 -9999 -9999 -9999 -9999 -9999 -9999 -9999 -9999 -9999 -9999 -9999 -9999 -9999 -9999 -9999 -9999 -9999 -9999 -9999 -9999 -9999 -9999 -9999 -9999 -9999 -9999 -9999 -9999 -9999 -9999 -9999 -9999 -9999 -9999 -9999 -9999 -9999 -9999 -9999 -9999 -9999 -9999 -9999 -9999 -9999 -9999 -9999 -9999 -9999 -9999 -9999 -9999 -9999 -9999 -9999 -9999 -9999 -9999 -9999 -9999 -9999 -9999 -9999 -9999 -9999 -9999 -9999 -9999 -9999 -9999 -9999 -9999 -9999 -9999 -9999 -9999 -9999 -9999 -9999 -9999 -9999 -9999 -9999 -9999 -9999 -9999 -9999 -9999 -9999 -9999 -9999 -9999 -9999 -9999 -9999 -9999 -9999 -9999 -9999 -9999 -9999 -9999 -9999

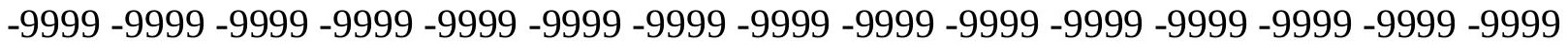

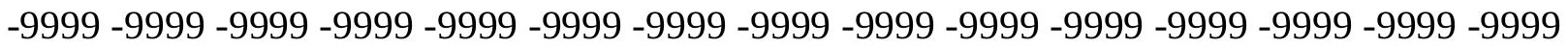
-9999 -9999 -9999 -9999 -9999 -9999 -9999 -9999 -9999 -9999 -9999 -9999 -9999 -9999 -9999 -9999 -9999 -9999 -9999 -9999 -9999 -9999 -9999 -9999 -9999 -9999 -9999 -9999 112.7705001831112 .1608963013105 .1004638672105 .5879135132106 .3781051636 107.362159729108 .4675140381109 .6235733032110 .6610412598111 .2239151001 96.9647674560596 .3892593383895 .8215866088995 .2616958618294 .70953369141 94.1653289794993 .629470825293 .1027145385792 .5860214233492 .08087921143 91.58872222991 .11049652190 .2164001464889 .9116134643689 .3020401001 88.9972534179788 .6924667358488 .3876876831187 .7781066894587 .47332763672 87.1428756713986 .6895675659286 .2277832031285 .7809448242285 .33984375 84.7302627563584 .4254837036183 .8159103393683 .206336975182 .59677124023 81.9871978759881 .3776321411180 .7680587768680 .1584930419979 .54891967773 78.9393463134878 .3297805786177 .7202072143677 .110626220776 .19628143311 75.5867080688574 .9771423339874 .3675689697373 .7580032348672 .84364318848 72.2340774536171 .6244964599671 .014930725170 .4053573608469 .79579162598 69.1862335205168 .8814392089868 .2718734741267 .9670867919967 .66230010986 67.3575134277367 .0527267456167 .0527267456167 .0527267456167 .05272674561 67.0527267456167 .3575134277367 .3575134277367 .6623001098667 .96708679199 67.9670867919968 .2718734741268 .2718734741268 .5766525268668 .57665252686 68.5766525268668 .2718734741268 .2718734741267 .9670867919967 .66230010986 67.0527267456166 .7479400634866 .1383666992265 .5288009643664 .61444854736 64.004882812563 .0905189514262 .4809494018662 .17617034912 -9999 -9999 -9999 -9999 -9999 -9999 -9999 -9999 -9999 -9999 -9999 -9999 -9999 -9999 -9999 -9999 -9999 -9999 -9999 -9999 -9999 -9999 -9999 -9999 -9999 -9999 -9999 -9999 -9999 -9999 -9999 -9999 -9999 -9999 -9999 -9999 -9999 -9999 -9999 -9999 -9999 -9999 -9999 -9999 -9999 -9999 -9999 -9999 -9999 -9999 -9999-9999-9999-9999-9999-9999-9999 -9999 -9999 -9999 -9999 -9999 -9999 -9999 -9999 -9999 -9999 -9999 -9999 -9999 -9999 -9999 -9999 -9999 -9999 -9999 -9999 -9999 -9999 -9999 -9999 -9999 -9999 -9999 -9999 -9999 -9999 -9999 -9999 -9999 -9999 -9999 -9999 -9999 -9999 -9999 -9999 -9999 -9999 -9999 -9999 -9999

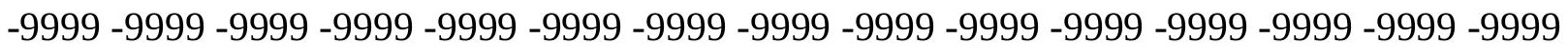
-9999 -9999 -9999 -9999 -9999 -9999 -9999 -9999 -9999 -9999 -9999 -9999 -9999 -9999 -9999 -9999 -9999 -9999 -9999 -9999 -9999 -9999 -9999 -9999 -9999 -9999 -9999 -9999 -9999 -9999 -9999 -9999 -9999 -9999 -9999 -9999 -9999 -9999 -9999 -9999 -9999 -9999 -9999 -9999 -9999

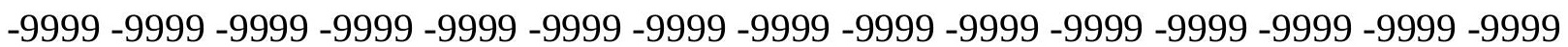
-9999 -9999 -9999 -9999 -9999 -9999 -9999 -9999 -9999 -9999 -9999 -9999 -9999 -9999 -9999 -9999 -9999 -9999 -9999 -9999 -9999 -9999 -9999 -9999 -9999 -9999 -9999 -9999 -9999 -9999 -9999 -9999 -9999 -9999 -9999 -9999 -9999 -9999 -9999 -9999 -9999 -9999 -9999 -9999 -9999

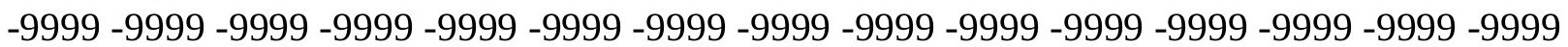


-9999 -9999 -9999 -9999 -9999 -9999 -9999 -9999 -9999 -9999 -9999 -9999 -9999 -9999 -9999 -9999 -9999 -9999 -9999 -9999 -9999 -9999 -9999 -9999 -9999 -9999 -9999 -9999 -9999 -9999

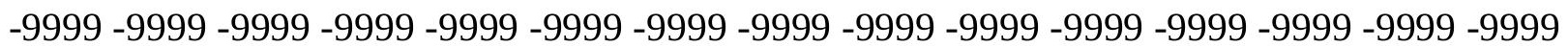
-9999 -9999 -9999 -9999 -9999 -9999 -9999 -9999 -9999 -9999 -9999 -9999 -9999 -9999 117.0374984741116 .7326965332108 .7170715332109 .713104248110 .9473953247 112.3596878052113 .8482666016115 .222076416116 .2837905884116 .7497634888 96.8179550170996 .2426986694395 .675918579195 .1177139282294 .56840515137 94.0284194946393 .4984970092892 .9794158935592 .4721832275491 .9776763916 91.4355392456190 .8259735107490 .2164001464889 .6068267822389 .3020401001 88.9972534179788 .6924667358488 .3876876831187 .960517883387 .47332763672 87.056076049886 .5589828491286 .1556701660285 .6446228027385 .20566558838 84.7302627563584 .1206970214883 .5111236572383 .206336975182 .59677124023 81.9871978759881 .3776321411180 .7680587768680 .1584930419979 .54891967773 78.9393463134878 .3297805786177 .7202072143677 .110626220776 .19628143311 75.5867080688574 .9771423339874 .3675689697373 .7580032348673 .14842987061 72.5388565063571 .9292907714871 .3197174072370 .7101516723670 .10057830811 69.7957916259869 .4910125732468 .8814392089868 .5766525268668 .57665252686 68.2718734741268 .2718734741268 .2718734741268 .2718734741268 .27187347412 68.2718734741268 .5766525268668 .5766525268668 .8814392089868 .88143920898 68.8814392089869 .1862335205169 .1862335205168 .8814392089868 .88143920898 68.8814392089868 .5766525268668 .2718734741267 .9670867919967 .35751342773 67.0527267456166 .4431610107465 .8335876464864 .9192428588964 .0048828125 63.3953094482463 .3953094482463 .09051895142 -9999 -9999 -9999 -9999 -9999 -9999 -9999 -9999 -9999 -9999 -9999 -9999 -9999 -9999 -9999 -9999 -9999 -9999 -9999 -9999 -9999 -9999 -9999 -9999 -9999 -9999 -9999 -9999 -9999 -9999 -9999 -9999 -9999 -9999 -9999 -9999 -9999 -9999 -9999 -9999 -9999 -9999 -9999 -9999 -9999 -9999 -9999 -9999 -9999 -9999 -9999 -9999 -9999 -9999 -9999 -9999 -9999

-9999 -9999 -9999 -9999 -9999 -9999 -9999 -9999 -9999 -9999 -9999 -9999 -9999 -9999 -9999 -9999 -9999 -9999 -9999 -9999 -9999 -9999 -9999 -9999 -9999 -9999 -9999 -9999 -9999 -9999 -9999 -9999 -9999 -9999 -9999 -9999 -9999 -9999 -9999 -9999 -9999 -9999 -9999 -9999 -9999 -9999 -9999 -9999 -9999 -9999 -9999 -9999 -9999 -9999 -9999 -9999 -9999 -9999 -9999 -9999 -9999 -9999 -9999 -9999 -9999 -9999 -9999 -9999 -9999 -9999 -9999 -9999 -9999 -9999 -9999 -9999 -9999 -9999 -9999 -9999 -9999 -9999 -9999 -9999 -9999 -9999 -9999 -9999 -9999 -9999 -9999 -9999 -9999 -9999 -9999 -9999 -9999 -9999 -9999 -9999 -9999 -9999 -9999 -9999 -9999

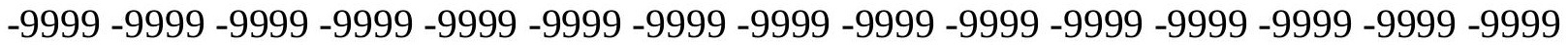
-9999 -9999 -9999 -9999 -9999 -9999 -9999 -9999 -9999 -9999 -9999 -9999 -9999 -9999 -9999

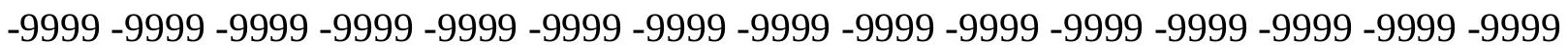

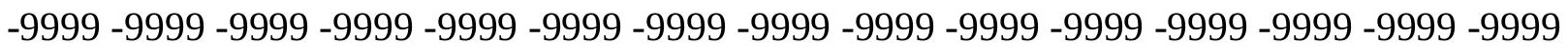
-9999 -9999 -9999 -9999 -9999 -9999 -9999 -9999 -9999 -9999 -9999 -9999 -9999 -9999 -9999 -9999 -9999 -9999 -9999 -9999 -9999 -9999 -9999 -9999 -9999 -9999 -9999 -9999 - -9999 -9999 -9999 -9999 -9999 -9999 -9999 -9999 -9999 -9999 -9999 -9999 -9999 -9999 -9999 -9999 -9999

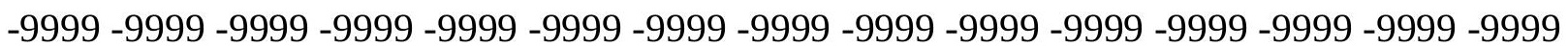
-9999 -9999 -9999 -9999 -9999 -9999 -9999 -9999 -9999 -9999 -9999 -9999 -9999 -9999 -9999 -999 121.3044967651111 .8461608887112 .9974594116114 .3981018066115 .9845352173 117.6505661011119 .2406463623120 .5771102905121 .441383361897 .24794006348 96.6661071777396 .093338012795 .529861450294 .9760818481494 .43241119385 
93.89947509766 93.3778457641692.8682098388792.3710632324291.88684844971 91.1307525634890 .5211791992290 .2164001464889 .6068267822389 .3020401001 88.9972534179788 .6924667358488 .3239593505987 .8775863647587 .42742156982 86.9767227172986 .5242919921986 .0584030151485 .5871658325285 .03504943848 84.5326080322384 .008377075283 .5111236572382 .9015579223682 .29197692871 81.6824111938581 .0728530883880 .7680587768680 .1584930419979 .54891967773 78.9393463134878 .3297805786177 .7202072143677 .110626220776 .50106811523 75.8914871215875 .2819290161174 .6723632812574 .062782287673 .45321655273 72.8436431884872 .2340774536171 .6244964599671 .3197174072370 .71015167236 70.4053573608470 .1005783081169 .7957916259869 .4910125732469 .49101257324 69.1862335205169 .1862335205169 .1862335205169 .1862335205169 .18623352051 69.4910125732469 .4910125732469 .4910125732469 .7957916259869 .79579162598 69.7957916259869 .7957916259869 .4910125732469 .4910125732469 .18623352051 68.8814392089868 .5766525268668 .2718734741267 .9670867919967 .35751342773 66.7479400634866 .1383666992265 .2240066528364 .6144485473664 .61444854736 64.3096618652364 .30966186523 -9999 -9999 -9999 -9999 -9999 -9999 -9999 -9999 -9999

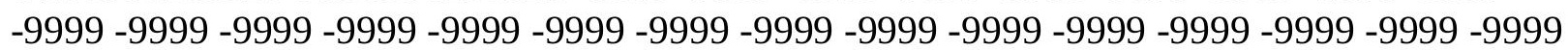
-9999 -9999 -9999 -9999 -9999 -9999 -9999 -9999 -9999 -9999 -9999 -9999 -9999 -9999 -9999 -9999 -9999 -9999 -9999 -9999 -9999 -9999 -9999 -9999 -9999 -9999 -9999 -9999 -9999 -9999 $-9999-9999-9999$

-9999 -9999 -9999 -9999 -9999 -9999 -9999 -9999 -9999 -9999 -9999 -9999 -9999 -9999 -9999 -9999 -9999 -9999 -9999 -9999 -9999 -9999 -9999 -9999 -9999 -9999 -9999 -9999 -9999 -9999 -9999 -9999 -9999 -9999 -9999 -9999 -9999 -9999 -9999 -9999 -9999 -9999 -9999 -9999 -9999 -9999 -9999 -9999 -9999 -9999 -9999 -9999 -9999 -9999 -9999 -9999 -9999 -9999 -9999 -9999

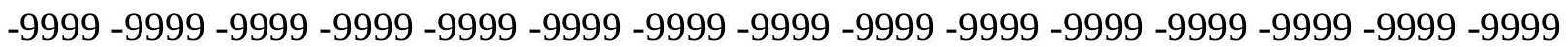
-9999 -9999 -9999 -9999 -9999 -9999 -9999 -9999 -9999 -9999 -9999 -9999 -9999 -9999 -9999 -9999 -9999 -9999 -9999 -9999 -9999 -9999 -9999 -9999 -9999 -9999 -9999 -9999 -9999 -9999 -9999 -9999 -9999 -9999 -9999 -9999 -9999 -9999 -9999 -9999 -9999 -9999 -9999 -9999 -9999

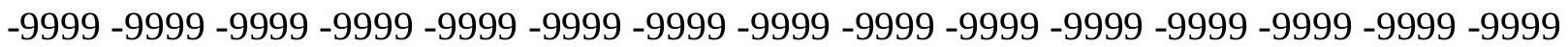

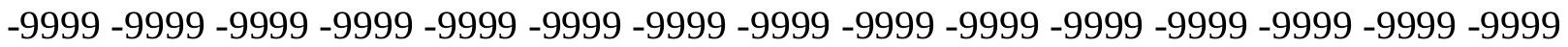
-9999 -9999 -9999 -9999 -9999 -9999 -9999 -9999 -9999 -9999 -9999 -9999 -9999 -9999 -9999 -

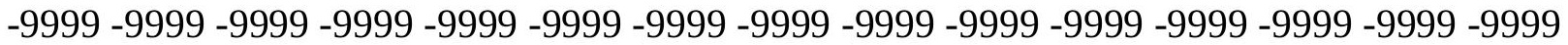
-9999 -9999 -9999 -9999 -9999 -9999 -9999 -9999 -9999 -9999 -9999 -9999 -9999 -9999 -9999 -9999 -9999 -9999 -9999 -9999 -9999 -9999 -9999 -9999 -9999 -9999 -9999 -9999 -9999 -9999 -

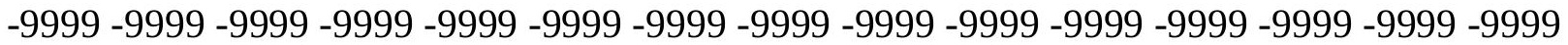
-9999 -9999 -9999 -9999 -9999 -9999 -9999 -9999 -9999 -9999 -9999 -9999 -9999 -9999 -9999 126.1809997559126 .7906036377116 .1419372559117 .6258239746119 .2831192017 121.0149765015122 .6874542236124 .1345214844125 .1800613403125 .6713409424 97.0912704467896 .5132369995195 .9450531005995 .3871688842894 .83995819092 94.3039321899493 .7794876098693 .2670745849692 .7669296264692 .27925872803 91.8038330078190 .8259735107490 .5211791992290 .2164001464889 .91161346436 89.5649185180789 .1268844604588 .6865158081188 .2429428100687 .79593658447 87.3460006713986 .8637619018686 .4276504516685 .9494018554785 .45533752441 84.9501876831184 .4254837036183 .8159103393683 .3979339599682 .90155792236 82.2919769287181 .6824111938581 .0728530883880 .4632720947379 .85370635986 79.5489196777378 .9393463134878 .3297805786177 .7202072143677 .1106262207 
76.5010681152375 .8914871215875 .2819290161174 .6723632812574 .0627822876 73.4532165527373 .1484298706172 .5388565063572 .2340774536171 .62449645996 71.3197174072371 .014930725170 .7101516723670 .4053573608470 .40535736084 70.1005783081170 .1005783081170 .1005783081170 .1005783081170 .10057830811 70.4053573608470 .4053573608470 .4053573608470 .4053573608470 .40535736084 70.4053573608470 .4053573608470 .1005783081169 .7957916259869 .79579162598 69.49101257324 69.1862335205168.57665252686 68.2718734741267.66230010986 67.0527267456166 .4431610107466 .1383666992265 .5852127075265 .31005096436 65.0868453979564 .8391036987364 .40084838867 -9999 -9999 -9999 -9999 -9999 -9999 -9999 -9999 -9999 -9999 -9999 -9999 -9999 -9999 -9999 -9999 -9999 -9999 -9999 -9999 -9999 -9999 -9999 -9999 -9999 -9999 -9999 -9999 -9999 -9999 -9999 -9999 -9999 -9999 -9999 -9999 -9999 -999 -

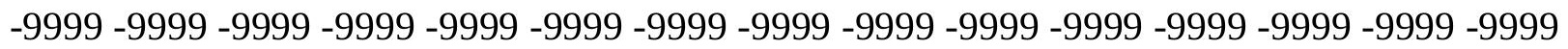
-9999 -9999-9999-9999

-9999 -9999 -9999 -9999 -9999 -9999 -9999 -9999 -9999 -9999 -9999 -9999 -9999 -9999 -9999 -9999 -9999 -9999 -9999 -9999 -9999 -9999 -9999 -9999 -9999 -9999 -9999 -9999 -9999 -9999 -

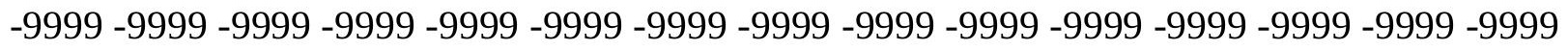
-9999 -9999 -9999 -9999 -9999 -9999 -9999 -9999 -9999 -9999 -9999 -9999 -9999 -9999 -9999 -9999 -9999 -9999 -9999 -9999 -9999 -9999 -9999 -9999 -9999 -9999 -9999 -9999 -9999 -9999 -9999 -9999 -9999 -9999 -9999 -9999 -9999 -9999 -9999 -9999 -9999 -9999 -9999 -9999 -9999

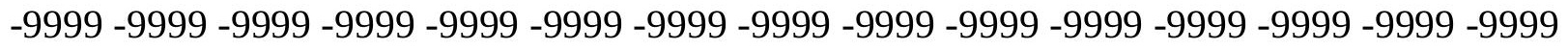

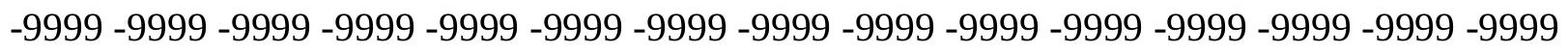

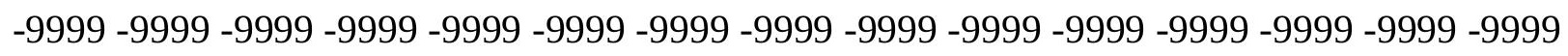
-9999 -9999 -9999 -9999 -9999 -9999 -9999 -9999 -9999 -9999 -9999 -9999 -9999 -9999 -9999 -

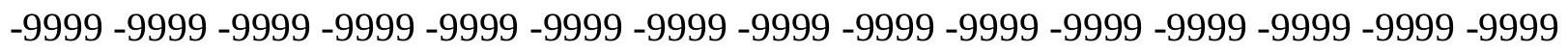

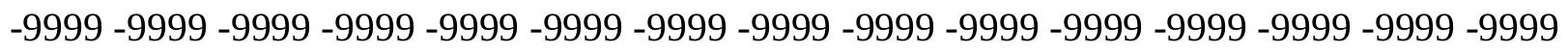
-9999 -9999 -9999 -9999 -9999 -9999 -9999 -9999 -9999 -9999 -9999 -9999 -9999 -9999 -9999 -9999 -9999 -9999 -9999 -9999 -9999 -9999 -9999 -9999 -9999 -9999 -9999 -9999 -9999 - -9999 -

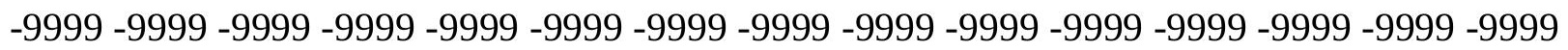
-9999 -9999 -9999 -9999 -9999 -9999 -9999 -9999 -9999 -9999 -9999 -9999 -9999 -9999 -9999 -9999 131.6672058105 119.0825042725120.5811538696122.2287979126123.9352340698 125.5790405273127 .0115280151128 .0665893555128 .554214477597 .51750183105 96.9347686767696 .3622665405395 .8004760742295 .2497100830194 .71040344238 94.1828002929793 .6671981811593 .163650512792 .6721725463992 .19241333008 91.72377777191 .1307525634890 .81445312590 .3696441650489 .91161346436 89.48770904541 89.0466384887788.60363006592 88.15756988525 87.70732116699 87.25134277344 86.78871154785 86.2541885376 85.83679199219 85.33984375 84.7302627563584 .3746719360483 .8159103393683 .206336975182 .59677124023 82.2919769287181 .6824111938581 .0728530883880 .4632720947379 .85370635986 79.2441329956178 .9393463134878 .3297805786177 .7202072143677 .1106262207 76.5010681152375 .8914871215875 .2819290161174 .9771423339874 .36756896973 73.7580032348673 .4532165527373 .1484298706172 .5388565063572 .23407745361 71.9292907714871 .6244964599671 .6244964599671 .3197174072371 .31971740723 71.014930725171 .014930725171 .014930725171 .014930725171 .014930725171 .0149307251 71.014930725171 .3197174072371 .014930725171 .014930725171 .0149307251 70.7101516723670 .4053573608470 .1005783081169 .7957916259869 .49101257324 69.1862335205168 .5766525268667 .9670867919967 .6623001098667 .16733551025 
66.7504272460966 .3405838012765 .9727783203165 .6717529296965 .32479858398 64.92226409912 -9999 -9999 -9999 -9999 -9999 -9999 -9999 -9999 -9999 -9999 -9999 -9999 -9999 -9999 -9999 -9999 -9999 -9999 -9999 -9999 -9999 -9999 -9999 -9999 -9999 -9999 -9999 -9999 -9999 -9999 -9999 -9999 -9999 -9999 -9999 -9999 -9999 -9999 -9999 -9999 -9999 -9999 -9999 -9999 -9999 -9999 -9999 -9999 -9999 -9999 -9999 -9999 -9999 -9999 -9999 -9999 -9999 -9999 -9999 -9999 -9999 -9999 -9999 -9999 -9999 -9999 -9999 -9999 -9999 -9999 -9999

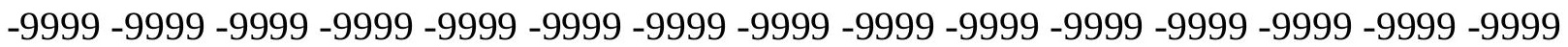
-9999 -9999 -9999 -9999 -9999 -9999 -9999 -9999 -9999 -9999 -9999 -9999 -9999 -9999 -9999 -9999 -9999 -9999 -9999 -9999 -9999 -9999 -9999 -9999 -9999 -9999 -9999 -9999 -9999 -9999 -9999 -9999 -9999 -9999 -9999 -9999 -9999 -9999 -9999 -9999 -9999 -9999 -9999 -9999 -9999 -9999 -9999 -9999 -9999 -9999 -9999 -9999 -9999 -9999 -9999 -9999 -9999 -9999 -9999 -9999 -

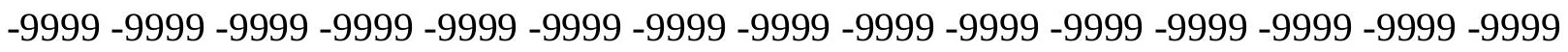
-9999 -9999 -9999 -9999 -9999 -9999 -9999 -9999 -9999 -9999 -9999 -9999 -9999 -9999 -9999 -9999 -9999 -9999 -9999 -9999 -9999 -9999 -9999 -9999 -9999 -9999 -9999 -9999 -9999 -9999 -9999 -9999 -9999 -9999 -9999 -9999 -9999 -9999 -9999 -9999 -9999 -9999 -9999 -9999 -9999

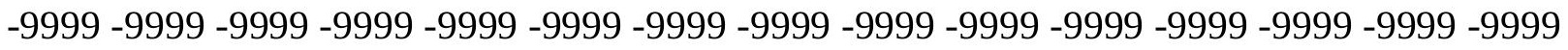
-9999 -9999 -9999 -9999 -9999 -9999 -9999 -9999 -9999 -9999 -9999 -9999 -9999 -9999 -9999 -9999 -9999 -9999 -9999 -9999 -9999 -9999 -9999 -9999 -9999 -9999 -9999 -9999 -9999 -9999 -

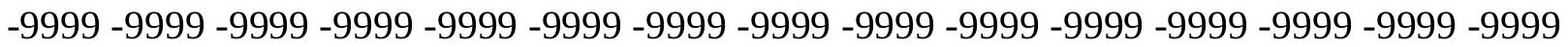

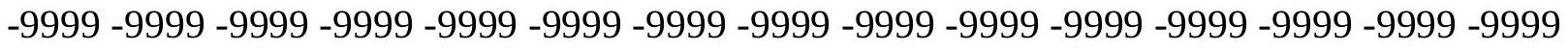

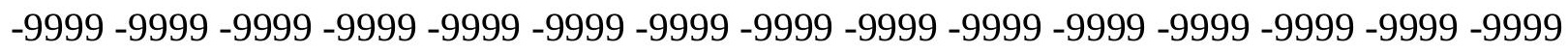
-9999 135.6293945312 138.3724975586123.2350158691 124.8117294312126.4234008789 127.9606323242129 .2878723145130 .2493743896130 .6736297607130 .3879241943 97.3571014404396.7805633544996.2149581909295.660568237395.1177444458 94.586639404394 .0674438476693 .5600814819393 .0644378662192 .58006286621 92.1063461303791 .6421279907291 .1859359741290 .7358779907290 .28996276855 89.8462524414189 .4030303955188 .9587631225688 .5119247436588 .06101989746 87.6050415039187 .1436462402386 .6771545410286 .2078247070385 .64462280273 85.2664871215884 .7302627563584 .1206970214883 .8159103393683 .2063369751 82.5967712402381 .9871978759881 .6824111938581 .0728530883880 .46327209473 79.8537063598679 .2441329956178 .9393463134878 .3297805786177 .72020721436 77.110626220776 .8058471679776 .1962814331175 .5867080688575 .28192901611 74.6723632812574 .3675689697373 .7580032348673 .4532165527373 .14842987061 72.8436431884872 .5388565063572 .2340774536172 .2340774536171 .92929077148 71.9292907714871 .9292907714871 .9292907714871 .9292907714871 .92929077148 71.9292907714871 .9292907714871 .9292907714871 .9292907714871 .62449645996 71.6244964599671 .3197174072371 .014930725170 .4053573608470 .10057830811 69.7957916259869 .4910125732469 .1862335205168 .8023605346768 .3674697876 67.9062423706167 .4393615722767 .0073089599666 .5959014892666 .21684265137 65.8330154418965 .43286895752 -9999 -9999 -9999 -9999 -9999 -9999 -9999 -9999 -9999

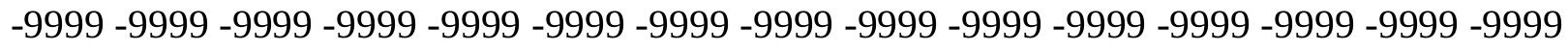

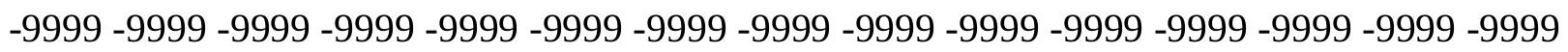

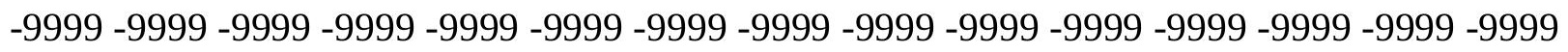
$-9999-9999$

-9999 -9999 -9999 -9999 -9999 -9999 -9999 -9999 -9999 -9999 -9999 -9999 -9999 -9999 -9999

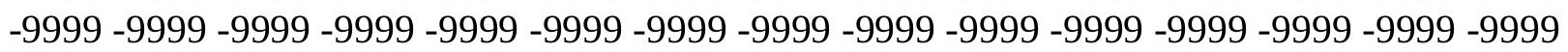


-9999 -9999 -9999 -9999 -9999 -9999 -9999 -9999 -9999 -9999 -9999 -9999 -9999 -9999 -9999 -9999 -9999 -9999 -9999 -9999 -9999 -9999 -9999 -9999 -9999 -9999 -9999 -9999 -9999 -9999 -9999 -9999 -9999 -9999 -9999 -9999 -9999 -9999 -9999 -9999 -9999 -9999 -9999 -9999 -9999 -9999 -9999 -9999 -9999 -9999 -9999 -9999 -9999 -9999 -9999 -9999 -9999 -9999 -9999 -9999 -9999 -9999 -9999 -9999 -9999 -9999 -9999 -9999 -9999 -9999 -9999 -9999 -9999 -9999 -9999 -9999 -9999 -9999 -9999 -9999 -9999 -9999 -9999 -9999 -9999 -9999 -9999 -9999 -9999 -9999 -9999 -9999 -9999 -9999 -9999 -9999 -9999 -9999 -9999 -9999 -9999 -9999 -9999 -9999 -9999

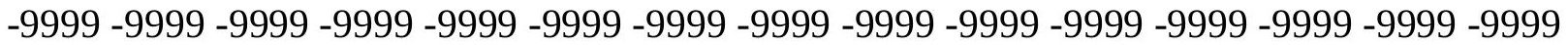
-9999 -9999 -9999 -9999 -9999 -9999 -9999 -9999 -9999 -9999 -9999 -9999 -9999 -9999 -9999 -9999 -9999 -9999 -9999 -9999 -9999 -9999 -9999 -9999 -9999 -9999 -9999 -9999 -9999 -9999 -

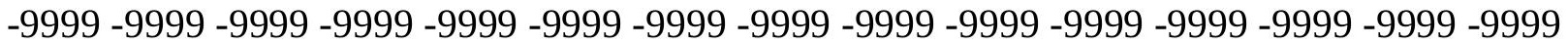
-9999 -9999 -9999 -9999 -9999 -9999 -9999 -9999 -9999 -9999 -9999 -9999 -9999 -9999 -9999

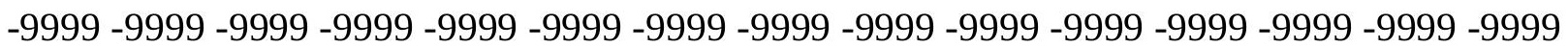
-9999 -9999 -9999 -9999 -9999 -9999 -9999 -9999 -9999 -9999 -9999 -9999 -9999 -9999 -9999 -9999 -9999 142.3347015381 125.5747451782 127.0381622314 128.5077056885 129.8908233643131 .061920166131 .8944091797132 .2315216064131 .9450531006 97.7794876098697 .1991195678796 .6297607421996 .0716629028395 .52512359619 94.9902191162194 .467079162693 .9555282592893 .4553909301892 .96614837646 92.4871826171992 .017433166591 .5556488037191 .1002349853590 .64953613281 90.2018127441489 .7554016113389 .3086776733488 .8600540161188 .40814971924 87.9522552490287 .4733276367287 .0305099487386 .5589828491286 .10498046875 85.6424026489385 .0350494384884 .7098693847784 .1206970214883 .51112365723 83.206336975182 .5967712402381 .9871978759881 .6025619506881 .02364349365 80.4632720947379 .8537063598679 .5489196777378 .9393463134878 .32978057861 77.7202072143677 .4154205322376 .8058471679776 .1962814331175 .89148712158 75.5867080688574 .9771423339874 .6723632812574 .3675689697374 .0627822876 73.7580032348673 .4532165527373 .1484298706172 .8436431884872 .84364318848 72.8436431884872 .5388565063572 .5388565063572 .5388565063572 .53885650635 72.5388565063572 .5388565063572 .5388565063572 .5388565063572 .53885650635 72.2340774536171 .9292907714871 .6244964599671 .014930725170 .40535736084 70.4053573608470 .7101516723670 .3467941284269 .8083343505969 .23990631104 68.6926269531268 .163642883367 .6735153198267 .2128143310566 .78009033203 66.3653106689565 .95726776123 -9999 -9999 -9999 -9999 -9999 -9999 -9999 -9999 -9999 -9999 -9999 -9999 -9999 -9999 -9999 -9999 -9999 -9999 -9999 -9999 -9999 -9999 -9999 -9999

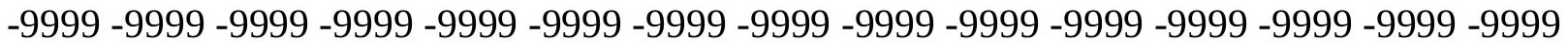
-9999 -9999 -9999 -9999 -9999 -9999 -9999 -9999 -9999 -9999 -9999 -9999 -9999 -9999 -9999 -9999-9999

-9999 -9999 -9999 -9999 -9999 -9999 -9999 -9999 -9999 -9999 -9999 -9999 -9999 -9999 -9999 -9999 -9999 -9999 -9999 -9999 -9999 -9999 -9999 -9999 -9999 -9999 -9999 -9999 -9999 -9999 -9999 -9999 -9999 -9999 -9999 -9999 -9999 -9999 -9999 -9999 -9999 -9999 -9999 -9999 -9999 -9999 -9999 -9999 -9999 -9999 -9999 -9999 -9999 -9999 -9999 -9999 -9999 -9999 -9999 -9999 -999 -9999 -9999 -9999 -9999 -9999 -9999 -9999 -9999 -9999 -9999 -9999 -9999 -9999 -9999 -9999 -9999 -9999 -9999 -9999 -9999 -9999 -9999 -9999 -9999 -9999 -9999 -9999 -9999 -9999 -9999 -9999 -9999 -9999 -9999 -9999 -9999 -9999 -9999 -9999 -9999 -9999 -9999 -9999 -9999 -9999 -9999 -9999 -9999 -9999 -9999 -9999 -9999 -9999 -9999 -9999 -9999 -9999 -9999 -9999 -9999

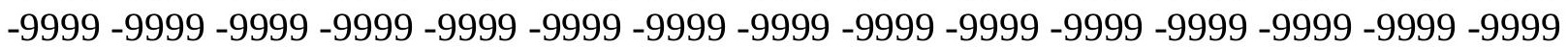


-9999 -9999 -9999 -9999 -9999 -9999 -9999 -9999 -9999 -9999 -9999 -9999 -9999 -9999 -9999 -9999 -9999 -9999 -9999 -9999 -9999 -9999 -9999 -9999 -9999 -9999 -9999 -9999 -9999 -9999 -9999 -9999 -9999 -9999 -9999 -9999 -9999 -9999 -9999 -9999 -9999 -9999 -9999 -9999 -9999 -9999 -9999 -9999 -9999 -9999 -9999 -9999 -9999 -9999 -9999 -9999 -9999 -9999 -9999 -9999 -9999 -9999 -9999 -9999 -9999 -9999 -9999 -9999 -9999 -9999 -9999 -9999 -9999 -9999 -9999 -9999 -9999 -9999 -9999 -9999 -9999 -9999 -9999 -9999 -9999 -9999 -9999 -9999 -9999 -9999 -9999 -9999 -9999 -9999 -9999 -9999 -9999 -9999 -9999 -9999 -9999 -9999 -9999 -9999 -9999 -9999 -9999 144.7729034424 148.0216674805 128.9370117188130 .2440185547 131.4429626465132 .4368438721133 .1129150391133 .3486328125133 .0393676758 132.108322143697 .6172180175897 .0441665649496 .4823074340895 .93189239502 95.3929672241294 .8655929565494 .3495712280393 .8446655273493 .35034179688 92.8659820556692 .39062591 .9231796264691 .4622650146591 .00645446777 90.5541915893690 .1039047241289 .654022216889 .2030410766688 .74977111816 88.2937011718887 .8353424072387 .3759155273486 .8637619018686 .45797729492 85.9494018554785 .5406188964885 .0350494384884 .4254837036184 .12069702148 83.5111236572383 .1479721069382 .5967712402381 .9871978759881 .53694915771 81.002647399980 .4632720947379 .8537063598679 .5489196777378 .93934631348 78.3297805786178 .0249862670977 .4154205322377 .110626220776 .50106811523 76.1962814331175 .8914871215875 .2819290161174 .9771423339874 .67236328125 74.3675689697374 .062782287674 .062782287673 .7580032348673 .45321655273 73.4532165527373 .4532165527373 .4532165527373 .4532165527373 .45321655273 73.4532165527373 .4532165527373 .4532165527373 .4532165527373 .14842987061 72.8436431884872 .8436431884872 .2340774536171 .9292907714871 .92929077148 72.2340774536172 .2340774536171 .5932006835970 .869552612370 .16300964355 69.5052261352568 .8995742797968 .3425369262767 .829521179267 .35432434082 66.9107818603566 .49282836914 -9999 -9999 -9999 -9999 -9999 -9999 -9999 -9999 -9999 -9999 -9999 -9999 -9999 -9999 -9999 -9999 -9999 -9999 -9999 -9999 -9999 -9999 -9999 -9999 -9999 -9999 -9999 -9999 -9999 -9999 -9999 -9999 -9999 -9999 -9999 -9999 -9999 -9999 -9999 -9999 -9999 -9999 -9999 -9999 -9999 -9999 -9999 -9999 -9999 -9999 -9999 -9999 -9999 -9999 $-9999-9999$

-9999 -9999 -9999 -9999 -9999 -9999 -9999 -9999 -9999 -9999 -9999 -9999 -9999 -9999 -9999 -9999 -9999 -9999 -9999 -9999 -9999 -9999 -9999 -9999 -9999 -9999 -9999 -9999 -9999 -9999 -9999 -9999 -9999 -9999 -9999 -9999 -9999 -9999 -9999 -9999 -9999 -9999 -9999 -9999 -9999 -9999 -9999 -9999 -9999 -9999 -9999 -9999 -9999 -9999 -9999 -9999 -9999 -9999 -9999 -9999 -9999 -9999 -9999 -9999 -9999 -9999 -9999 -9999 -9999 -9999 -9999 -9999 -9999 -9999 -9999 -9999 -9999 -9999 -9999 -9999 -9999 -9999 -9999 -9999 -9999 -9999 -9999 -9999 -9999 -9999

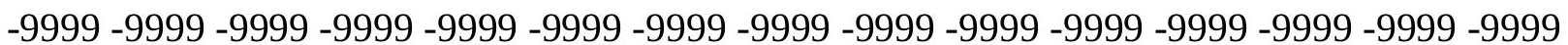

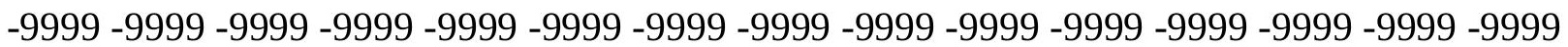
-9999 -9999 -9999 -9999 -9999 -9999 -9999 -9999 -9999 -9999 -9999 -9999 -9999 -9999 -9999 -9999 -9999 -9999 -9999 -9999 -9999 -9999 -9999 -9999 -9999 -9999 -9999 -9999 -9999 -9999 -9999 -9999 -9999 -9999 -9999 -9999 -9999 -9999 -9999 -9999 -9999 -9999 -9999 -9999 -9999

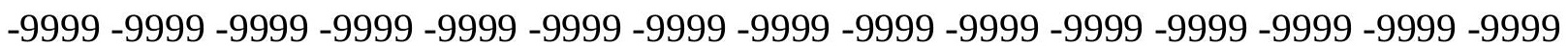
-9999 -9999 -9999 -9999 -9999 -9999 -9999 -9999 -9999 -9999 -9999 -9999 -9999 -9999 -9999 -9999 -9999 -9999 -9999 -9999 -9999 -9999 -9999 -9999 -9999 -9999 -9999 -9999 -9999 -9999 -9999 -9999 -9999 -9999 -9999 -9999 -9999 -9999 -9999 -9999 -9999 -9999 -9999 -9999 -9999

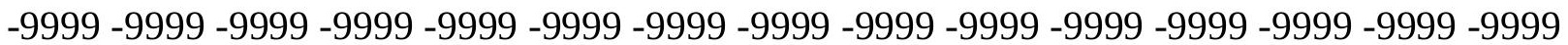


-9999 -9999 -9999 149.4331665039130.5065460205131.6352081299132.6516876221 133.4667358398133 .9838409424134 .1063537598133 .74269104132 .8441619873 98.0342330932697 .4575500488396 .8919143676896 .3375320434695 .79442596436 95.2626419067494 .7419357299894 .2320632934693 .7324981689593 .24264526367 92.7616119384892 .2884292602591 .8218841552791 .3607254028390 .90355682373 90.4489517211989 .9954605102589 .5417327880989 .0867309570388 .63005065918 88.172149658287 .7140274047987 .1685485839886 .7998580932686 .2541885376 85.8875045776485 .3398437584 .9697113037184 .4254837036184 .0299987793 83.5111236572382 .9015579223682 .5275115966881 .9871978759881 .37763214111 81.0419845581180 .4632720947380 .0635986328179 .5217056274478 .93934631348 78.5287857055778 .0249862670977 .7202072143677 .110626220776 .80584716797 76.5010681152376 .1962814331175 .8914871215875 .2819290161174 .97714233398 74.9771423339874 .6723632812574 .3675689697374 .3675689697374 .0627822876 74.062782287674 .062782287674 .062782287674 .062782287674 .062782287674 .0627822876 74.062782287674 .062782287673 .7580032348673 .7580032348673 .45321655273 73.1484298706172 .8436431884873 .4532165527373 .7580032348673 .36241149902 72.6602401733471 .8308639526471 .0120468139670 .2718429565469 .59756469727 68.9824447631868 .422286987367 .910720825267 .4412765502967 .0082244873 -9999 -9999 -9999 -9999 -9999 -9999 -9999 -9999 -9999 -9999 -9999 -9999 -9999 -9999 -9999 -9999 -9999

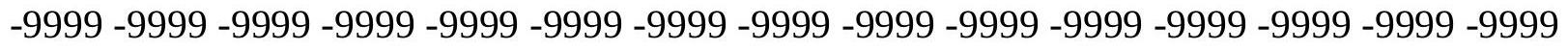

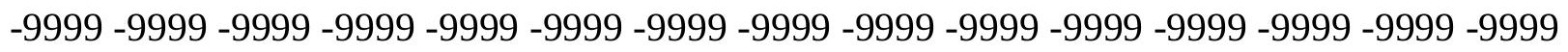
-9999 -9999 -9999 -9999 -9999 -9999 -9999 -9999 -9999 -9999 -9999 -9999 -9999 -9999 -9999 -9999 -9999 -9999 -9999 -9999 -9999 -9999 -9999 - -9999 -9999 -9999 -9999 -9999 -9999 -9999 -9999 -9999 -9999 -9999 -9999 -9999 -9999 -9999 -9999 -9999 -9999 -9999 -9999 -9999 -9999 -9999 -9999 -9999 -9999 -9999 -9999 -9999 -9999 -9999 -9999 -9999 -9999 -9999 -9999 -9999 -9999 -9999 -9999 -9999 -9999 -9999 -9999 -9999 -9999 -9999 -9999 -9999 -9999 -9999 -9999 -9999 -9999 -9999 -9999 -9999 -9999 -9999 -9999 -9999

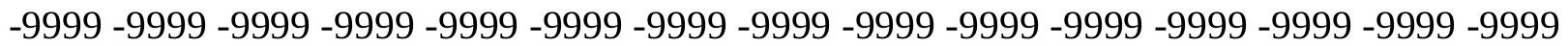
-9999 -9999 -9999 -9999 -9999 -9999 -9999 -9999 -9999 -9999 -9999 -9999 -9999 -9999 -9999 -9999 -9999 -9999 -9999 -9999 -9999 -9999 -9999 -9999 -9999 -9999 -9999 -9999 -9999 -9999 -9999 -9999 -9999 -9999 -9999 -9999 -9999 -9999 -9999 -9999 -9999 -9999 -9999 -9999 -9999

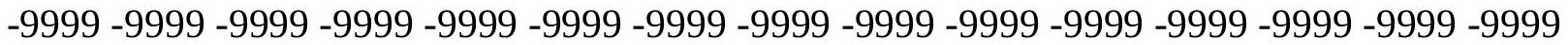

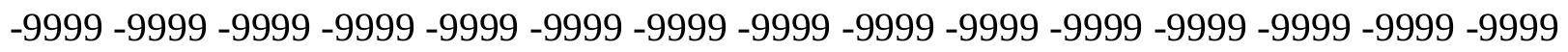
-9999 -9999 -9999 -9999 -9999 -9999 -9999 -9999 -9999 -9999 -9999 -9999 -9999 -9999 -9999 -9999 -9999 -9999 -9999 -9999 -9999 -9999 -9999 -9999 -9999 -9999 -9999 -9999 -9999 -9999

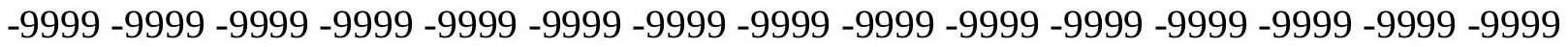

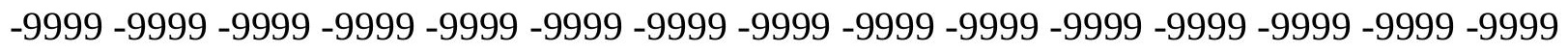

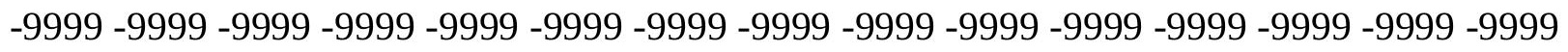
-9999 -9999 -9999 149.9542999268 152.4530792236132.7308654785133.5518951416 134.1806030273134 .5355529785134 .5370483398134 .1109771729133 .2206268311 131.841262817497 .8693542480597 .299942016696 .7415542602596 .194190979 95.6578750610495 .1323623657294 .6174087524494 .1125106811593 .61710357666 93.1303558349692 .6513977050892 .1791534423891 .7125015258891 .25019836426 90.7909851074290 .333572387789 .8767776489389 .4196929931688 .96192932129 88.503761291588 .0459289550887 .4733276367287 .1333389282286 .55898284912 86.2237625122185 .6446228027385 .3129730224684 .7302627563584 .38813781738 
83.8159103393683 .4316787719782 .9015579223682 .4594955444381 .98374938965 81.5178756713981 .0477676391680 .4632720947380 .0748748779379 .54891967773 79.1351470947378 .6345596313578 .3297805786178 .0249862670977 .41542053223 77.110626220776 .8058471679776 .5010681152376 .1962814331175 .89148712158 75.5867080688575 .2819290161174 .9771423339874 .6723632812574 .67236328125 74.6723632812574 .3675689697374 .3675689697374 .3675689697374 .67236328125 74.6723632812574 .6723632812574 .6723632812574 .6723632812574 .36756896973 74.062782287674 .062782287674 .3675689697374 .9771423339874 .78442382812 74.2383117675873 .468338012772 .5940017700271 .7311782836970 .93872070312 70.2169799804769 .5582962036168 .9608993530368 .419082641667 .92650604248 67.47719573975 -9999 -9999 -9999 -9999 -9999 -9999 -9999 -9999 -9999 -9999 -9999 -9999

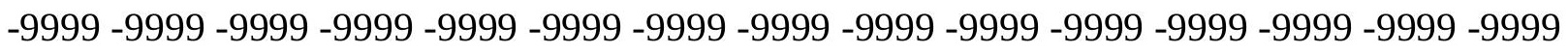
-9999 -9999 -9999 -9999 -9999 -9999 -9999 -9999 -9999 -9999 -9999 -9999 -9999 -9999 -9999 -9999 -9999 -9999 -9999 -9999 -9999 -9999 -9999 -9999 -9999 -9999 -9999 -9999 -9999 -9999 -9999 -9999 -9999 -9999 -9999 -9999 -9999 -9999 -9999 -9999 -9999 -9999 -9999 -9999

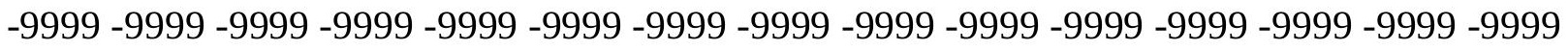
-9999 -9999 -9999 -9999 -9999 -9999 -9999 -9999 -9999 -9999 -9999 -9999 -9999 -9999 -9999 -9999 -9999 -9999 -9999 -9999 -9999 -9999 -9999 -9999 -9999 -9999 -9999 -9999 -9999 -9999 -9999 -9999 -9999 -9999 -9999 -9999 -9999 -9999 -9999 -9999 -9999 -9999 -9999 -9999 -9999 -

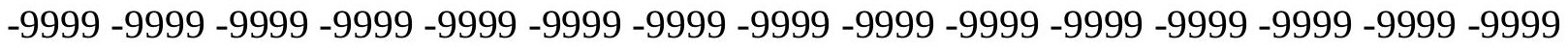

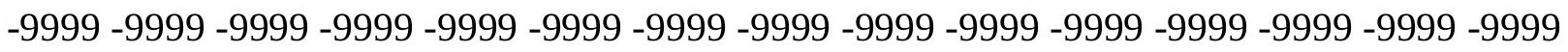
-9999 -9999 -9999 -9999 -9999 -9999 -9999 -9999 -9999 -9999 -9999 -9999 -9999 -9999 -9999 -9999 -9999 -9999 -9999 -9999 -9999 -9999 -9999 -9999 -9999 -9999 -9999 -9999 -9999 -9999 -

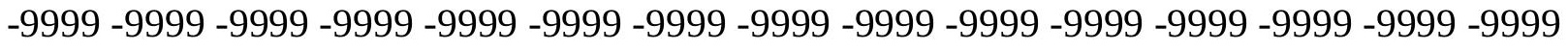

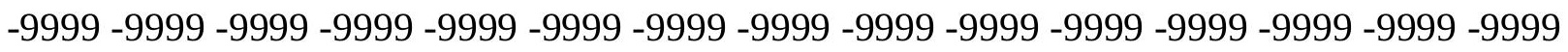
-9999 -9999 -9999 -9999 -9999 -9999 -9999 -9999 -9999 -9999 -9999 -9999 -9999 -9999 -9999 -9999 -9999 -9999 -9999 -9999 -9999 -9999 -9999 -9999 -9999 -9999 -9999 -9999 -9999 -9999 -

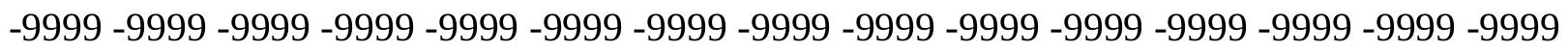
-9999 -9999 -9999 -9999 -9999 -9999 -9999 -9999 -9999 -9999 -9999 -9999 -9999 -9999 -9999 -9999 -9999 -9999 -9999 -9999 -9999 -9999 -9999 -9999 -9999 -9999 -9999 -9999 -9999 -9999 -9999 -9999 -9999 -9999 151.9477996826 153.5269775391 134.2019348145134.6406860352 134.8301849365134 .704284668134 .2028961182133 .304473877131 .9797210693 98.27911376953 97.7059478759897.143554687596.5919113159296.05101776123 95.520645141695 .000564575294 .4902954101693 .9893188476693 .49687194824 93.0121612548892 .5342102050892 .0620193481491 .5944824218891 .13050842285 90.6689758300890 .2088623046989 .6068267822389 .2900848388788 .69246673584 88.37294769287 87.77810668945 87.46059417725 87.006278991786.55271148682 86.09958648682 85.64462280273 85.19146728516 84.7302627563584.27084350586 83.8047561645583 .3377838134882 .8733901977582 .4140167236381 .95795440674 81.502365112381 .0444869995180 .5910110473680 .1510543823279 .73239898682 79.2441329956178 .9393463134878 .5717620849678 .0249862670977 .72020721436 77.4154205322377 .110626220776 .8058471679776 .5010681152376 .19628143311 75.8914871215875 .5867080688575 .2819290161174 .9771423339874 .97714233398 74.9771423339874 .9771423339874 .9771423339874 .9771423339875 .28192901611 75.2819290161175 .2819290161175 .2819290161174 .9771423339874 .67236328125 74.9771423339875 .8914871215875 .8852310180775 .514228820874 .85195159912 
74.0326690673873 .1442031860472 .278877258371 .4737091064570 .72764587402 70.0427474975669 .4217910766668 .8602905273468 .3525543212967 .89233398438 -9999 -9999 -9999 -9999 -9999 -9999 -9999 -9999 -9999 -9999 -9999 -9999 -9999 -9999 -9999 -9999 -9999 -9999 -9999 -9999 -9999 -9999 -9999 -9999 -9999 -9999 -9999 -9999 -9999 -9999 -9999 -9999 -9999 -9999 -9999 -9999 -9999 -9999 -9999 -9999 -9999 -9999 -9999 -9999 -9999 - -9999 -9999 -9999 -9999 -9999 -9999 -9999 -9999 -9999 -9999 -9999

-9999 -9999 -9999 -9999 -9999 -9999 -9999 -9999 -9999 -9999 -9999 -9999 -9999 -9999 -9999 -9999 -9999 -9999 -9999 -9999 -9999 -9999 -9999 -9999 -9999 -9999 -9999 -9999 -9999 -9999 -9999 -9999 -9999 -9999 -9999 -9999 -9999 -9999 -9999 -9999 -9999 -9999 -9999 -9999 -9999 -9999 -9999 -9999 -9999 -9999 -9999 -9999 -9999 -9999 -9999 -9999 -9999 -9999 -9999 -9999 -

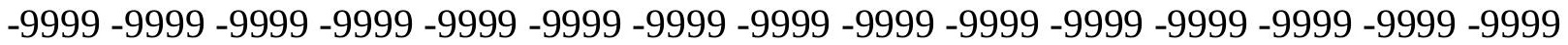
-9999 -9999 -9999 -9999 -9999 -9999 -9999 -9999 -9999 -9999 -9999 -9999 -9999 -9999 -9999 -9999 -9999 -9999 -9999 -9999 -9999 -9999 -9999 -9999 -9999 -9999 -9999 -9999 -9999 -9999 -9999 -9999 -9999 -9999 -9999 -9999 -9999 -9999 -9999 -9999 -9999 -9999 -9999 -9999 -9999 -9999 -9999 -9999 -9999 -9999 -9999 -9999 -9999 -9999 -9999 -9999 -9999 -9999 -9999 -9999

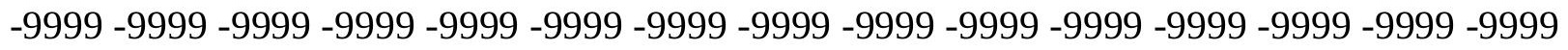
-9999 -9999 -9999 -9999 -9999 -9999 -9999 -9999 -9999 -9999 -9999 -9999 -9999 -9999 -9999 -9999 -9999 -9999 -9999 -9999 -9999 -9999 -9999 -9999 -9999 -9999 -9999 -9999 -9999 -9999 -

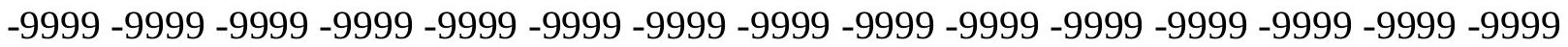

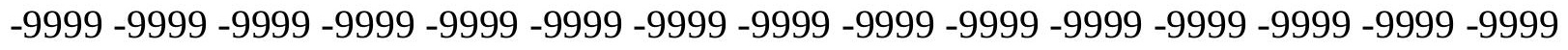

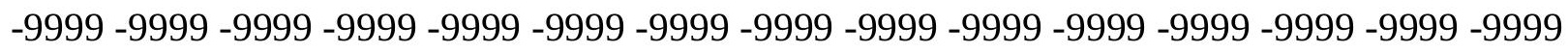

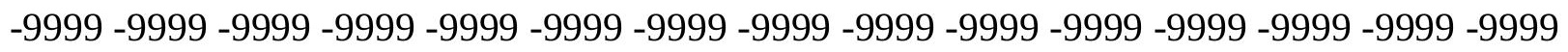
-9999 -9999 -9999-9999 150.8686065674 151.9437866211 134.6524810791 134.899810791 134.9218292236134 .6643218994134 .0792388916133 .1473388672131 .8485717773 130.159469604598 .109512329197 .5431365966896 .9872207641696 .44176483154 95.9065399169995 .3813400268694 .8657150268694 .3592147827193 .86112213135 93.3707199096792.8871154785292.4094314575291.93666839691.43553924561 90.8259735107490 .5211791992289 .9116134643689 .6068267822388 .99725341797 88.6924667358488 .0829010009887 .7781066894587 .3291625976686 .86376190186 86.4246292114385 .9494018554785 .5224304199285 .070587158284 .6176071167 84.16425323486 83.71222686768 83.26306152344 82.8170318603582.37347412109 81.9327468872181 .4969406127981 .0705718994180 .6584396362380 .15849304199 79.8537063598679 .5053863525479 .1013412475678 .6345596313578 .3189239502 77.9871749877977 .6998672485477 .4154205322376 .8058471679776 .50106811523 76.1962814331175 .8914871215875 .8914871215875 .5867080688575 .28192901611 75.2819290161175 .2819290161175 .2819290161175 .5867080688575 .58670806885 75.8914871215875 .8914871215876 .1962814331176 .1962814331175 .89148712158 76.5010681152376 .7287292480576 .5142669677775 .9791412353575 .23522186279 74.3854446411173 .5152359008872 .6689605712971 .8708648681671 .1199798584 70.4285964965869 .799530029369 .230194091868 .7160034179768 .25119018555 -9999-9999 -9999 -9999-9999 -9999 -9999 -9999 -9999 -9999 -9999-9999 -9999 -9999 -9999 -9999 -9999 -

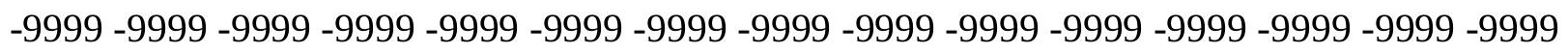

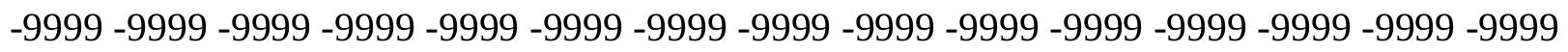
-9999 -9999 -9999 -9999 -9999 -9999 -9999 -9999 -9999

-9999 -9999 -9999 -9999 -9999 -9999 -9999 -9999 -9999 -9999 -9999 -9999 -9999 -9999 -9999

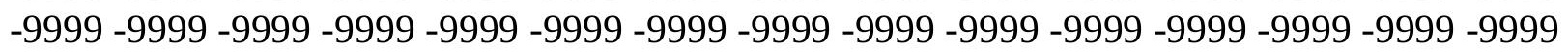


-9999 -9999 -9999 -9999 -9999 -9999 -9999 -9999 -9999 -9999 -9999 -9999 -9999 -9999 -9999 -9999 -9999 -9999 -9999 -9999 -9999 -9999 -9999 -9999 -9999 -9999 -9999 -9999 -9999 -9999 -9999 -9999 -9999 -9999 -9999 -9999 -9999 -9999 -9999 -9999 -9999 -9999 -9999 -9999 -9999 -9999 -9999 -9999 -9999 -9999 -9999 -9999 -9999 -9999 -9999 -9999 -9999 -9999 -9999 -9999 -9999 -9999 -9999 -9999 -9999 -9999 -9999 -9999 -9999 -9999 -9999 -9999 -9999 -9999 -9999 -9999 -9999 -9999 -9999 -9999 -9999 -9999 -9999 -9999 -9999 -9999 -9999 -9999 -9999 -9999 -9999 -9999 -9999 -9999 -9999 -9999 -9999 -9999 -9999 -9999 -9999 -9999 -9999 -9999 -9999

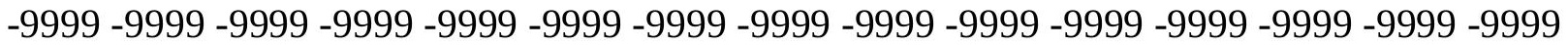
-9999 -9999 -9999 -9999 -9999 -9999 -9999 -9999 -9999 -9999 -9999 -9999 -9999 -9999 -9999 -9999 -9999 -9999 -9999 -9999 -9999 -9999 -9999 -9999 -9999 -9999 -9999 -9999 -9999 -9999 -

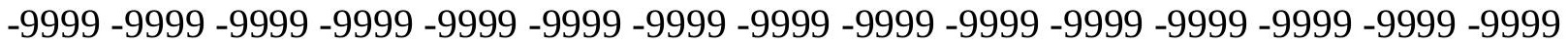
-9999 -9999 -9999 -9999 -9999 -9999 -9999 -9999 -9999 -9999 -9999 -9999 -9999 -9999 -9999

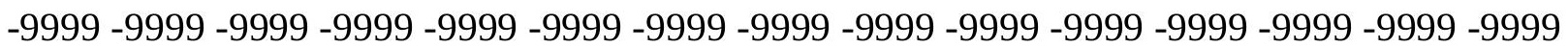
-9999 -9999 -9999 -9999 -9999 -9999 -9999 -9999 -9999 -9999 -9999 -9999 -9999 -9999 -9999 -9999 -9999 -9999 -9999 -9999 149.6495056152 150.7082366943135 .0025482178 134.8548431396134 .4606628418133 .7787628174132 .8013153076131 .4996032715 129.859497070398 .5102691650497 .9399490356497 .3797988891696 .82981872559 96.2897949218895 .7595291137795 .2386245727594 .7266616821394 .22300720215 93.7270126342893 .237861633392 .7547683715892 .2768478393691 .74033355713 91.1307525634890 .5211791992290 .2164001464889 .9116134643689 .3020401001 88.9972534179788 .3876876831188 .0829010009887 .6480331420987 .16854858398 86.7456436157286 .2966461181685 .8489837646585 .4025268554784 .95725250244 84.5136642456184 .0727081298883 .6351013183683 .2007904052782 .76988220215 82.3438110351681 .9254608154381 .5176239013781 .1224288940480 .74025726318 80.364822387779 .9875335693479 .5489196777379 .2180099487378 .84925079346 78.5106887817478 .0249862670977 .7202072143677 .3738174438577 .1106262207 76.8058471679776 .5010681152376 .1962814331175 .8914871215875 .58670806885 75.5867080688575 .5867080688575 .5867080688575 .8914871215876 .19628143311 76.5010681152376 .8058471679777 .110626220777 .110626220777 .1106262207 77.7202072143677 .3986129760776 .889091491776 .2055435180775 .41108703613 74.566680908273 .7202148437572 .9143753051872 .1375274658271 .40438079834 70.724746704170 .1024932861369 .5364761352569 .0237731933668 .55979156494 68.13966369629 -9999 -9999 -9999 -9999 -9999 -9999 -9999 -9999 -9999 -9999 -9999 -9999 -9999 -9999 -9999 -9999 -9999 -9999 -9999 -9999 -9999 -9999 -9999 -9999 -9999 -9999 -9999

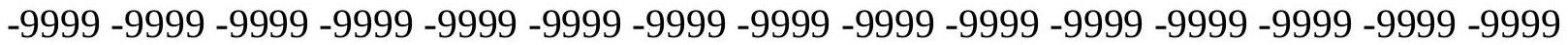
-9999 -9999 -9999 -9999 -9999 -9999 -9999 -9999 -9999 -9999 -9999 -9999 -9999 -9999 -9999 -9999 -9999 -9999 -9999 -9999 -9999 -9999 -9999 -9999 -9999 -9999 -9999 -9999

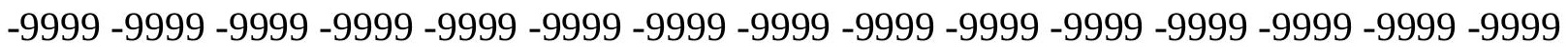
-9999 -9999 -9999 -9999 -9999 -9999 -9999 -9999 -9999 -9999 -9999 -9999 -9999 -9999 -9999 -9999 -9999 -9999 -9999 -9999 -9999 -9999 -9999 -9999 -9999 -9999 -9999 -9999 -9999 -9999 -9999 -9999 -9999 -9999 -9999 -9999 -9999 -9999 -9999 -9999 -9999 -9999 -9999 -9999 -9999

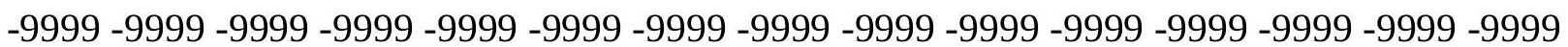
-9999 -9999 -9999 -9999 -9999 -9999 -9999 -9999 -9999 -9999 -9999 -9999 -9999 -9999 -9999 -9999 -9999 -9999 -9999 -9999 -9999 -9999 -9999 -9999 -9999 -9999 -9999 -9999 -9999 -9999 -9999 -9999 -9999 -9999 -9999 -9999 -9999 -9999 -9999 -9999 -9999 -9999 -9999 -9999 -9999

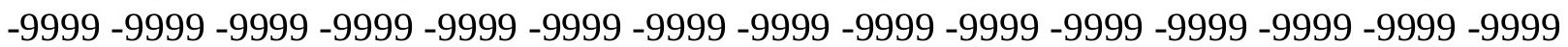


-9999 -9999 -9999 -9999 -9999 -9999 -9999 -9999 -9999 -9999 -9999 -9999 -9999 -9999 -9999 -9999 -9999 -9999 -9999 -9999 -9999 -9999 -9999 -9999 -9999 -9999 -9999 -9999 -9999 -9999 -9999 -9999 -9999 -9999 -9999 -9999 -9999 -9999 -9999 -9999 -9999 -9999 -9999 -9999 -9999 -9999 -9999 -9999 -9999 -9999 -9999 -9999 -9999 -9999 -9999 -9999 -9999 -9999 -9999 -9999 -9999 -9999 -9999 -9999 -9999 -9999 -9999 -9999 -9999 -9999 -9999 -9999 -9999 -9999 -9999 -9999 -9999 -9999 -9999 -9999 -9999 -9999 -9999 -9999 -9999 -9999 -9999 -9999 -9999 -9999 -9999 -9999 -9999 -9999 -9999-9999 148.4304046631 134.9901580811 134.66796875 134.1308135986133 .3456420898132 .3018035889130 .9831542969129 .368560791 98.9078445434698 .3336105346797 .7692794799897 .2148437596 .67009735107 96.1348648071395 .6087722778395 .0914688110494 .5823745727594 .08090209961 93.5863189697393 .0979232788192 .6149215698292 .1365966796991 .43553924561 90.8259735107490 .5211791992289 .9116134643689 .6068267822389 .3020401001 88.6924667358488 .3876876831187 .963310241787 .4733276367287 .06303405762 86.6162948608486 .1719055175885 .7300796508885 .2910079956184 .85499572754 84.4225311279383 .9940567016683 .5697708129983 .1501922607482 .73676300049 82.3316650390681 .9364318847781 .5514602661181 .1751327514680 .80388641357 80.4331588745180 .0614700317479 .6918334960979 .3308105468878 .93934631348 78.6266021728578 .2462844848677 .8527526855577 .4154205322377 .1106262207 76.8058471679776 .5010681152376 .1962814331175 .8914871215875 .89148712158 75.8914871215875 .8914871215876 .1962814331176 .5010681152377 .1106262207 77.4154205322377 .7202072143678 .0249862670978 .0249862670978 .07780456543 77.7000122070377 .0323486328176 .2478027343875 .4271545410274 .60214233398 73.8045349121173 .0389556884872 .3022613525471 .6032791137770 .95010375977 70.3467483520569 .7932357788169 .28823089668 .82895660468 .41184234619 -9999 -9999 -9999 -9999 -9999 -9999 -9999 -9999 -9999 -9999 -9999 -9999 -9999 -9999 -9999 -9999 -9999 -9999 -9999 -9999 -9999 -9999 -9999 -9999 -9999 -9999 -9999 -9999 -9999 -9999 -9999 -9999 -9999 -9999 -9999 -9999 -9999 -9999 -9999 -9999 -9999 -9999 -9999 -9999 -9999 -9999 -9999 -9999 -9999 -9999 -9999 -9999 -9999-9999 -9999

-9999 -9999 -9999 -9999 -9999 -9999 -9999 -9999 -9999 -9999 -9999 -9999 -9999 -9999 -9999 -9999 -9999 -9999 -9999 -9999 -9999 -9999 -9999 -9999 -9999 -9999 -9999 -9999 -9999 -9999 -9999 -9999 -9999 -9999 -9999 -9999 -9999 -9999 -9999 -9999 -9999 -9999 -9999 -9999 -9999 -9999 -9999 -9999 -9999 -9999 -9999 -9999 -9999 -9999 -9999 -9999 -9999 -9999 -9999 -9999 -9999 -9999 -9999 -9999 -9999 -9999 -9999 -9999 -9999 -9999 -9999 -9999 -9999 -9999 -9999 -9999 -9999 -9999 -9999 -9999 -9999 -9999 -9999 -9999 -9999 -9999 -9999 -9999 -9999 -9999 -9999 -9999 -9999 -9999 -9999 -9999 -9999 -9999 -9999 -9999 -9999 -9999 -9999 -9999 -9999 -9999 -9999 -9999 -9999 -9999 -9999 -9999 -9999 -9999 -9999 -9999 -9999 -9999 -9999 -9999 -

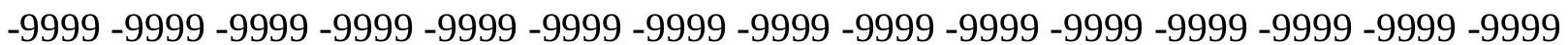

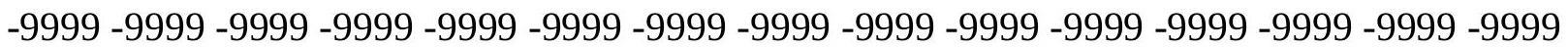
-9999 -9999 -9999 -9999 -9999 -9999 -9999 -9999 -9999 -9999 -9999 -9999 -9999 -9999 -9999 -9999 -9999 -9999 -9999 -9999 -9999 -9999 -9999 -9999 -9999 -9999 -9999 -9999 -9999 -9999 -9999 -9999 -9999 -9999 -9999 -9999 -9999 -9999 -9999 -9999 -9999 -9999 -9999 -9999 -9999

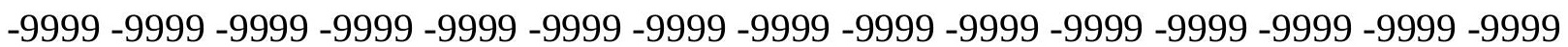
-9999 -9999 -9999 -9999 -9999 -9999 -9999 -9999 -9999 -9999 -9999 -9999 -9999 -9999 -9999 -9999 -9999 -9999 -9999 -9999 -9999 -9999 -9999 -9999 -9999 -9999 -9999 -9999 -9999 -9999 -9999 -9999 -9999 -9999 -9999 -9999 147.5160064697 147.8208007812 134.3967590332 133.7086334229132 .8083953857131 .6855773926130 .328125128 .7352905273 
126.853088378998 .7238082885798 .1553573608497 .596542358497 .04716491699 96.5070724487395 .9759292602595 .453407287694 .9390029907294 .43218994141 93.9323120117293 .4387283325292 .9507293701292 .4676971435591 .43553924561 91.1307525634890 .5211791992290 .2164001464889 .9116134643689 .3020401001 88.99725341797 88.6924667358488.27504730225 87.77810668945 87.37675476074 86.9322128295986 .4909133911186 .0531234741285 .6190948486385 .18909454346 84.763389587484 .3423767089883 .9264678955183 .5163726806683 .1131439209 82.718048095782 .3316802978581 .9536209106481 .5822906494181 .21555328369 80.8514099121180 .4891967773480 .1292572021579 .7732162475679 .4200592041 79.062919616778 .6908340454178 .3116378784277 .9652023315477 .72020721436 77.110626220776 .8058471679776 .5010681152376 .1962814331176 .19628143311 75.8914871215876 .1962814331176 .5010681152376 .8058471679777 .72020721436 78.3297805786178 .6345596313578 .9393463134878 .9393463134878 .4266204834 77.7525024414176 .9565048217876 .1306457519575 .3245697021574 .54545593262 73.8007888793973 .0859451293972 .4008712768671 .7471618652371 .12994384766 70.5530471801870 .017715454169 .524276733469 .0718307495168 .65863800049 -9999 -9999 -9999 -9999 -9999 -9999 -9999 -9999 -9999 -9999 -9999 -9999 -9999 -9999 -9999 -9999 -9999 -9999 -9999 -9999 -9999 -9999 -9999 -9999 -9999 -9999 -9999 -9999 -9999 -9999 -9999 -9999 -9999 -9999 -9999 -9999 -9999 -9999 -9999 -9999 -9999 -9999 -9999 -9999 -9999 -9999 -9999 -9999 -9999 -9999 -9999-9999-9999-9999-9999

-9999 -9999 -9999 -9999 -9999 -9999 -9999 -9999 -9999 -9999 -9999 -9999 -9999 -9999 -9999 -9999 -9999 -9999 -9999 -9999 -9999 -9999 -9999 -9999 -9999 -9999 -9999 -9999 -9999 -9999 -9999 -9999 -9999 -9999 -9999 -9999 -9999 -9999 -9999 -9999 -9999 -9999 -9999 -9999 -9999 -9999 -9999 -9999 -9999 -9999 -9999 -9999 -9999 -9999 -9999 -9999 -9999 -9999 -9999 -9999 -

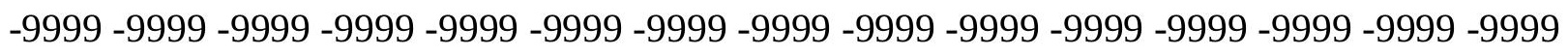
-9999 -9999 -9999 -9999 -9999 -9999 -9999 -9999 -9999 -9999 -9999 -9999 -9999 -9999 -9999 -9999 -9999 -9999 -9999 -9999 -9999 -9999 -9999 -9999 -9999 -9999 -9999 -9999 -9999 -9999

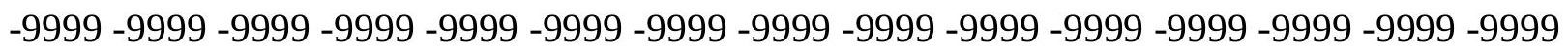
-9999 -9999 -9999 -9999 -9999 -9999 -9999 -9999 -9999 -9999 -9999 -9999 -9999 -9999 -9999 -9999 -9999 -9999 -9999 -9999 -9999 -9999 -9999 -9999 -9999 -9999 -9999 -9999 -9999 -9999 -9999 -9999 -9999 -9999 -9999 -9999 -9999 -9999 -9999-9999 -9999 -9999 -9999 -9999 -9999 -9999 -9999 -9999 -9999 -9999 -9999 -9999 -9999 -9999 -9999 -9999 -9999 -9999 -9999 -9999 -

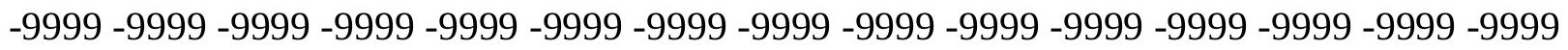
-9999 -9999 -9999 -9999 -9999 -9999 -9999 -9999 -9999 -9999 -9999 -9999 -9999 -9999 -9999 -9999 -9999 -9999 -9999 -9999 -9999 -9999 -9999 -9999 -9999 -9999 -9999 -9999 -9999 -9999 -9999 -9999 -9999 -9999 -9999-9999 -9999 -9999 -9999 -9999 -9999 -9999 -9999 -9999 - 9999 -9999 -9999-9999 -9999-9999-9999-9999 146.2969055176 134.0737762451 133.2278900146 132.2020111084130 .988571167129 .5848999023127 .9907226562126 .1637802124 99.1101837158298 .5376815795997 .9745712280397 .4206695556696 .8758392334 96.3397674560595 .8121795654395 .2926101684694 .7806091308694 .27556610107 93.776924133393.284034729 92.7963562011792.3133239746191.13075256348 90.8259735107490 .5211791992289 .9116134643689 .6068267822389 .3020401001 88.9972534179788 .5830612182688 .0829010009887 .6864700317487 .24388885498 86.8053207397586 .3710021972785 .9411544799885 .5160293579185 .09585571289 84.6810379028384 .2720947265683 .869697570883 .4744491577183 .08685302734 82.7069244384882 .3341522216881 .967361450281 .6053085327181 .2469329834 
80.8917312622180 .5394058227580 .1895828247179 .8410110473679 .49083709717 79.1374053955178 .778732299878 .3297805786178 .0249862670977 .72020721436 77.110626220776 .8058471679776 .5010681152376 .1962814331176 .19628143311 76.1962814331176 .8058471679777 .4154205322378 .3297805786179 .24413299561 79.8537063598679 .8537063598679 .5489196777378 .6262817382877 .6390838623 76.7080230712975 .8731002807675 .1189193725674 .4173202514673 .74806976318 73.0993728637772 .4719696044971 .8685455322371 .2910614013770 .74305725098 70.22739410469 .7463531494169 .3009643554768 .8913269043 -9999 -9999 -9999 -9999 -9999 -9999 -9999 -9999 -9999 -9999 -9999 -9999 -9999 -9999 -9999 -9999 -9999 -9999 -9999

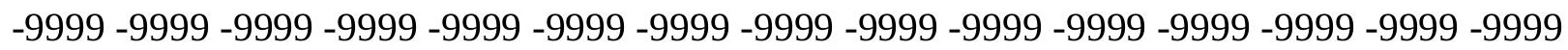

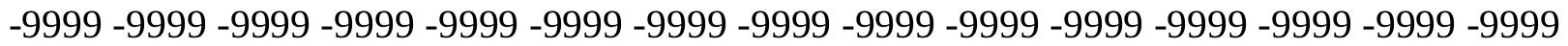
-9999 -9999 -9999-9999-9999-9999

-9999 -9999 -9999 -9999 -9999 -9999 -9999 -9999 -9999 -9999 -9999 -9999 -9999 -9999 -9999 -9999 -9999 -9999 -9999 -9999 -9999 -9999 -9999 -9999 -9999 -9999 -9999 -9999 -9999 -9999 -9999 -9999 -9999 -9999 -9999 -9999 -9999 -9999 -9999 -9999 -9999 -9999 -9999 -9999 -9999

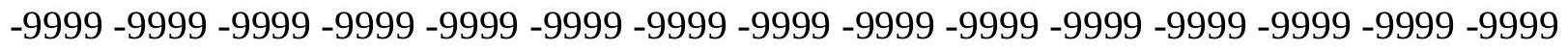
-9999 -9999 -9999 -9999 -9999 -9999 -9999 -9999 -9999 -9999 -9999 -9999 -9999 -9999 -9999 -9999 -9999 -9999 -9999 -9999 -9999 -9999 -9999 -9999 -9999 -9999 -9999 -9999 -9999 -9999 -

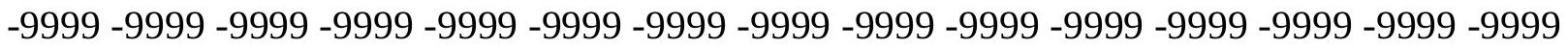

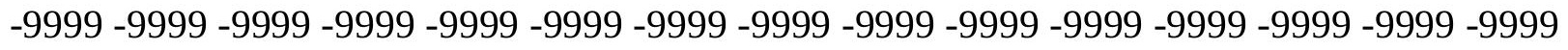

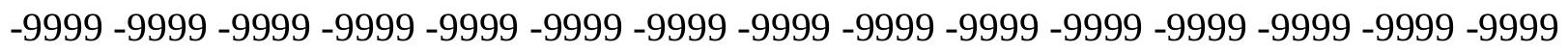
-9999 -9999 -9999 -9999 -9999 -9999 -9999 -9999 -9999 -9999 -9999 -9999 -9999 -9999 -9999 -9999 -9999 -9999 -9999 -9999 -9999 -9999 -9999 -9999 -9999 -9999 -9999 -9999 -9999 -9999 -

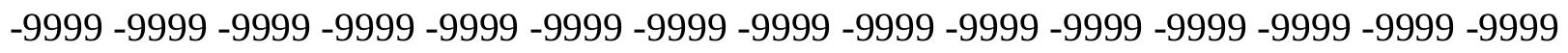

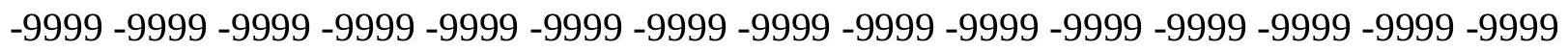
-9999 -9999 -9999 -9999 -9999 -9999 -9999 -9999 -9999 -9999 -9999 -9999 -9999 -9999 -9999

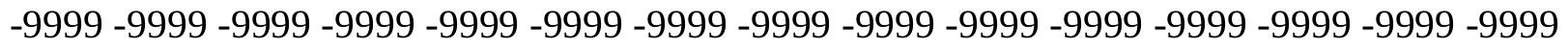

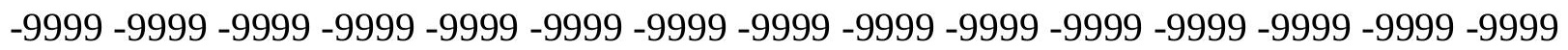
-9999 -9999-9999-9999-9999-9999-9999 144.7729034424 144.1634063721 132.7220153809 131.5589599609130 .2431335449128 .7790374756127 .1706771851125 .3830490112 123.367355346798.9159393310598.3486175537197.7902984619197.24085235596 96.7000045776496 .1675033569395 .6429290771595 .1258850097794 .61582183838 94.1122436523493 .6145782470793 .1223220825292 .6349868774491 .74033355713 90.8259735107490 .5211791992290 .2164001464889 .9116134643689 .60682678223 89.302040100188 .6924667358488 .3876876831187 .9917602539187 .55081939697 87.1145477294986 .6831588745186 .2568206787185 .8357620239385 .42022705078 85.0106353759884 .6074600219784 .2112350463983 .8221511840883 .44013977051 83.0649261474682 .6963348388782 .3339614868281 .9771499633881 .62517547607 81.2775955200280 .9340438842880 .5938491821380 .2557678222779 .91795349121 79.5774383544979 .2282943725678 .8600540161178 .4488677978578 .02498626709 77.7202072143677 .110626220776 .8058471679776 .5010681152376 .19628143311 76.1962814331176 .8058471679778 .0249862670979 .2441329956180 .46327209473 81.0728530883880 .7680587768679 .8537063598678 .7173309326277 .41291046143 76.3624954223675 .5510330200274 .8856735229574 .2792053222773 .70059967041 73.1241073608472 .5544586181671 .9999160766671 .4599151611370 .93808746338 70.4392547607469 .9680633544969 .5276565551869 .11986541748 -9999 -9999-9999 -9999 
-9999 -9999 -9999 -9999 -9999 -9999 -9999 -9999 -9999 -9999 -9999 -9999 -9999 -9999 -9999 -9999 -9999 -9999 -9999 -9999 -9999 -9999 -9999 -9999 -9999 -9999 -9999 -9999 -9999 -9999 -9999 -9999 -9999 -9999 -9999 -9999 -9999 -9999 -9999 -9999 -9999 -9999 -9999 -9999 -9999 -9999 -9999 -9999 -9999 -9999-9999

-9999 -9999 -9999 -9999 -9999 -9999 -9999 -9999 -9999 -9999 -9999 -9999 -9999 -9999 -9999 -9999 -9999 -9999 -9999 -9999 -9999 -9999 -9999 -9999 -9999 -9999 -9999 -9999 -9999 -9999 -9999 -9999 -9999 -9999 -9999 -9999 -9999 -9999 -9999 -9999 -9999 -9999 -9999 -9999 -9999 -9999 -9999 -9999 -9999 -9999 -9999 -9999 -9999 -9999 -9999 -9999 -9999 -9999 -9999 -9999 -9999 -9999 -9999 -9999 -9999 -9999 -9999 -9999 -9999 -9999 -9999 -9999 -9999 -9999 -9999 -9999 -9999 -9999 -9999 -9999 -9999 -9999 -9999 -9999 -9999 -9999 -9999 -9999 -9999 -9999 -

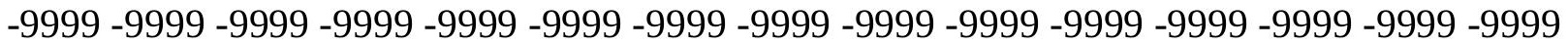
-9999 -9999 -9999 -9999 -9999 -9999 -9999 -9999 -9999 -9999 -9999 -9999 -9999 -9999 -9999 -9999 -9999 -9999 -9999 -9999 -9999 -9999 -9999 -9999 -9999 -9999 -9999 -9999 -9999 -9999 -9999 -9999 -9999 -9999 -9999 -9999 -9999 -9999 -9999 -9999 -9999 -9999 -9999 -9999 -9999 -9999 -9999 -9999 -9999 -9999 -9999 -9999 -9999 -9999 -9999 -9999 -9999 -9999 -9999 -9999

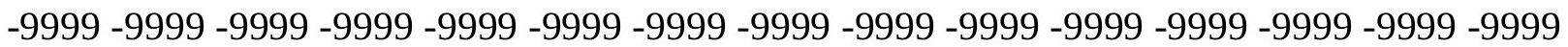

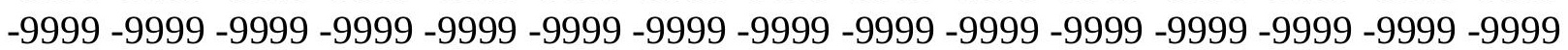
-9999 -9999 -9999 -9999 -9999 -9999 -9999 -9999 -9999 -9999 -9999 -9999 -9999 -9999 -9999 -9999 -9999 -9999 -9999 -9999 -9999 -9999 -9999 -9999 -9999 -9999 -9999 -9999 -9999 -9999 -9999 -9999 -9999 -9999 -9999 -9999 -9999 -9999 -9999 -9999 -9999 -9999 -9999 -9999 -9999 -9999 -9999 -9999 -9999 -9999 -9999 -9999 -9999 142.6394042969132 .227355957 130.9155273438129 .4840087891127 .9499130249126 .3085708618124 .5527267456 122.606727600199 .2897720336998 .7183456420998 .1557235717897 .60179901123 97.0563125610496 .5190505981495 .9896316528395 .4677047729594 .95277404785 94.4443969726693 .9420547485493 .4453048706192 .9537124633892 .3498916626 91.1307525634890 .8259735107490 .5211791992290 .2164001464889 .91161346436 89.3020401001 88.99725341797 88.69246673584 88.29219055176 87.85251617432 87.4180984497186 .989120483486 .565711975186 .1481246948285 .73658752441 85.331474304284 .9330902099684 .5417022705184 .157226562583 .77939605713 83.4079132080183 .0431289672982 .6856155395582 .3354873657281 .99217224121 81.6552581787181 .3243484497180 .9985885620180 .6761093139680 .35415649414 80.0282592773479 .6908035278379 .3291625976678 .9361495971778 .49747467041 78.0249862670977 .7202072143677 .110626220776 .5010681152376 .19628143311 76.5010681152377 .110626220778 .6345596313580 .4632720947381 .98719787598 82.9015579223682 .5967712402381 .0728530883878 .8748703002977 .11328125 76.0139389038175 .2786331176874 .7107543945374 .2059326171973 .70901489258 73.2036437988372 .6861267089872 .1728744506871 .6620483398471 .15846252441 70.6693878173870 .2021636962969 .7621688842869 .3529510498 -9999 -9999 -9999 -9999 -9999 -9999 -9999 -9999 -9999 -9999 -9999 -9999 -9999 -9999 -9999 -9999 -9999 -9999 -9999 -9999 -9999 -9999 -9999 -9999 -9999 -9999 -9999 -9999 -9999 -9999 -9999 -9999 -9999 -9999 -

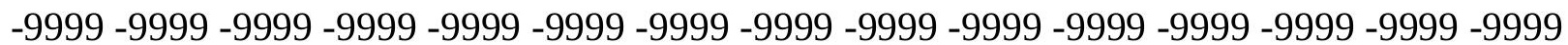
$-9999-9999-9999-9999-9999-9999$ -9999 -9999 -9999 -9999 -9999 -9999 -9999 -9999 -9999 -9999 -9999 -9999 -9999 -9999 -9999 -9999 -9999 -9999 -9999 -9999 -9999 -9999 -9999 -9999 -9999 -9999 -9999 -9999 -9999 -9999 -9999 -9999 -9999 -9999 -9999 -9999 -9999 -9999 -9999 -9999 -9999 -9999 -9999 -9999 -9999

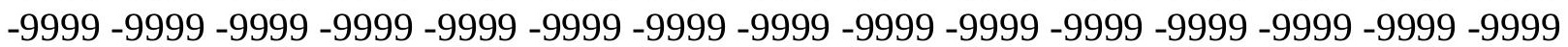


-9999 -9999 -9999 -9999 -9999 -9999 -9999 -9999 -9999 -9999 -9999 -9999 -9999 -9999 -9999 -9999 -9999 -9999 -9999 -9999 -9999 -9999 -9999 -9999 -9999 -9999 -9999 -9999 -9999 -9999 -9999 -9999 -9999 -9999 -9999 -9999 -9999 -9999 -9999 -9999 -9999 -9999 -9999 -9999 -9999 -9999 -9999 -9999 -9999 -9999 -9999 -9999 -9999 -9999 -9999 -9999 -9999 -9999 -9999 -9999 -9999 -9999 -9999 -9999 -9999 -9999 -9999 -9999 -9999 -9999 -9999 -9999 -9999 -9999 -9999 -9999 -9999 -9999 -9999 -9999 -9999 -9999 -9999 -9999 -9999 -9999 -9999 -9999 -9999 -9999 -9999 -9999 -9999 -9999 -9999 -9999 -9999 -9999 -9999 -9999 -9999 -9999 -9999 -9999 -9999

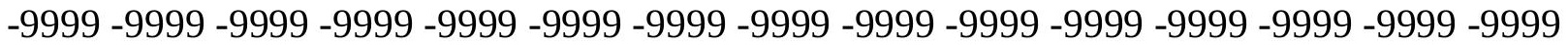
-9999 -9999 -9999 -9999 -9999 -9999 -9999 -9999 -9999 -9999 -9999 -9999 -9999 -9999 -9999 -9999 -9999 -9999 -9999 -9999 -9999 -9999 -9999 -9999 -9999 -9999 -9999 -9999 -9999 -9999 -9999 -9999 -9999 -9999 -9999 -9999 -9999 -9999 -9999 -9999 -9999 -9999 -9999 -9999 -9999 -9999 -9999 -9999 -9999 -9999 -9999 -9999 -9999 -9999 -9999 -9999 -9999 -9999 -9999 -9999 -9999 -9999 -9999 -9999 -9999 -9999 -9999 -9999 141.7250976562140 .2012023926 130.3135681152128 .752822876127 .1325302124125 .462097168123 .7213973999 121.8446350098119 .780601501599 .0834960937598 .5166854858497 .95839691162 97.4084091186596 .8665390014696 .3324356079195 .8057861328195 .28614044189 94.7731018066494 .2662048339893 .765060424893 .2692794799892 .7786026001 91.7403335571390 .8259735107490 .5211791992290 .2164001464889 .91161346436 89.6068267822389 .302040100188 .9972534179788 .5875167846788 .14872741699 87.7157287597787 .2886886596786 .8677368164186 .4531326293986 .04509735107 85.6438903808685 .2495498657284 .8619613647584 .4808349609484 .10622406006 83.7384490966883 .3784408569383 .0275039672982 .6864852905382 .35506439209 82.0327377319381 .7189788818481 .4125442504981 .1106109619180 .80912017822 80.5026321411180 .1839141845779 .8409347534279 .464569091878 .93934631348 78.6345596313578 .0249862670977 .7202072143677 .110626220776 .50106811523 76.5010681152377 .110626220779 .2441329956181 .6824111938584 .12069702148 85.6446228027385 .0350494384882 .5967712402378 .9393463134876 .98403930664 75.889930725175 .2013931274474 .6972045898474 .2631759643673 .8366317749 73.3812255859472 .9012603759872 .4157638549871 .9199523925871 .42160797119 70.9313964843870 .4594650268670 .013389587469 .59812927246 -9999 -9999 -9999 -9999 -9999 -9999 -9999 -9999 -9999 -9999 -9999 -9999 -9999 -9999 -9999 -9999 -9999 -9999 -9999

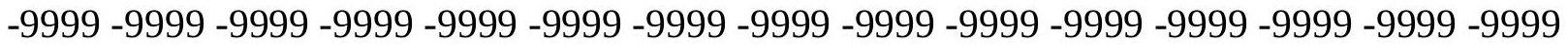
-9999 -9999 -9999 -9999 -9999 -9999 -9999 -9999 -9999 -9999 -9999 -9999 -9999 -9999 -9999 -9999 -9999 -9999 -9999-9999-9999

-9999 -9999 -9999 -9999 -9999 -9999 -9999 -9999 -9999 -9999 -9999 -9999 -9999 -9999 -9999 -9999 -9999 -9999 -9999 -9999 -9999 -9999 -9999 -9999 -9999 -9999 -9999 -9999 -9999 -9999 -9999 -9999 -9999 -9999 -9999 -9999 -9999 -9999 -9999 -9999 -9999 -9999 -9999 -9999 -9999

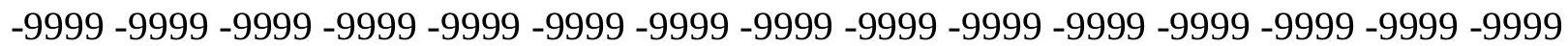
-9999 -9999 -9999 -9999 -9999 -9999 -9999 -9999 -9999 -9999 -9999 -9999 -9999 -9999 -9999 -9999 -9999 -9999 -9999 -9999 -9999 -9999 -9999 -9999 -9999 -9999 -9999 -9999 -9999 -9999 -9999 -9999 -9999 -9999 -9999 -9999 -9999 -9999 -9999 -9999 -9999 -9999 -9999 -9999 -9999 -999 -9999 -9999 -9999 -9999 -9999 -9999 -9999 -9999 -9999 -9999 -9999 -9999 -9999 -9999 -9999 -9999 -9999 -9999 -9999 -9999 -9999 -9999 -9999 -9999 -9999 -9999 -9999 -9999 -9999 -9999 -9999 -9999 -9999 -9999 -9999 -9999 -9999 -9999 -9999 -9999 -9999 -9999 -9999 -9999 -9999 -9999 -9999 -9999 -9999 -9999 -9999 -9999 -9999 -9999 -9999 -9999 -9999 -9999 -9999 -9999

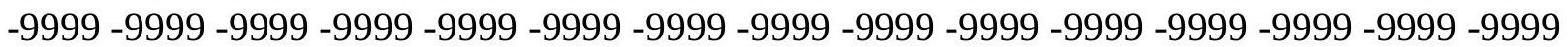


-9999 -9999 -9999 -9999 -9999 -9999 -9999 -9999 -9999 -9999 -9999 -9999 -9999 -9999 -9999 -9999 -9999 -9999 -9999 -9999 -9999 -9999 -9999 -9999 -9999 -9999 -9999 -9999 -9999 -9999 -9999 -9999 -9999 -9999 -9999 -9999 -9999 -9999 -9999 -9999 -9999 -9999 -9999 -9999 -9999 -9999 -9999 -9999 -9999 -9999 -9999 -9999 -9999 -9999 -9999 -9999 -9999 -9999 -9999 -9999 -9999 -9999 -9999 -9999 -9999 -9999 -9999-9999 -9999 139.8006134033129 .806854248 128.0999908447126 .3680496216124 .6503677368122 .954574585121 .1595458984 119.170997619699 .4437408447398 .8728485107498 .3103332519597 .75598907471 97.2096557617296 .6710128784296 .13979339695 .6155853271595 .09803771973 94.5867233276494 .0812988281293 .5814056396593 .0868377685592 .59742736816 91.4355392456190 .8259735107490 .5211791992290 .2164001464889 .91161346436 89.6068267822389 .302040100188 .8776702880988 .4393920898488 .00742340088 87.5819168090887 .1630096435586 .7509689331186 .3460083007885 .94822692871 85.5573272705185 .1728210449284 .7943725585984 .4226455688584 .05921173096 83.7059783935583 .3645248413183 .0359191894582 .7199935913182 .41618347168 82.1237106323281 .8409118652381 .5641174316481 .2882537841881 .00727081299 80.7136230468880 .3984985351680 .0508880615279 .5489196777379 .18665313721 78.6345596313578 .3297805786177 .7202072143677 .4154205322377 .1106262207 77.4154205322380 .1584930419983 .206336975186 .254188537688 .69246673584 88.6924667358485 .0350494384879 .5489196777377 .4693298339876 .20615386963 75.4248352050874 .915176391674 .5144424438574 .1205444335973 .69539642334 73.2350921630972 .7528457641672 .2518463134871 .7411422729571 .23559570312 70.7482452392670 .2883071899469 .86165618896 -9999 -9999 -9999 -9999 -9999 -9999 -9999 -9999 -9999 -9999 -9999 -9999 -9999 -9999 -9999 -9999 -9999 -9999 -9999 -9999 -9999 -9999 -9999 -9999 -9999 -9999 -9999 -9999 -9999 -9999 -9999 -9999 -9999 -9999 -9999 -9999 -9999

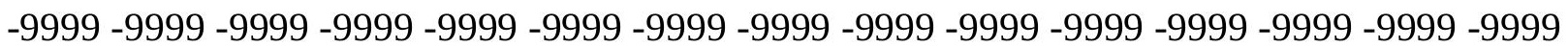
-9999-9999-9999

-9999 -9999 -9999 -9999 -9999 -9999 -9999 -9999 -9999 -9999 -9999 -9999 -9999 -9999 -9999 -9999 -9999 -9999 -9999 -9999 -9999 -9999 -9999 -9999 -9999 -9999 -9999 -9999 -9999 -9999 -9999 -9999 -9999 -9999 -9999 -9999 -9999 -9999 -9999 -9999 -9999 -9999 -9999 -9999 -9999 -9999 -9999 -9999 -9999 -9999 -9999 -9999 -9999 -9999 -9999 -9999 -9999 -9999 -9999 -9999 -9999 -9999 -9999 -9999 -9999 -9999 -9999 -9999 -9999 -9999 -9999 -9999 -9999 -9999 -9999 -

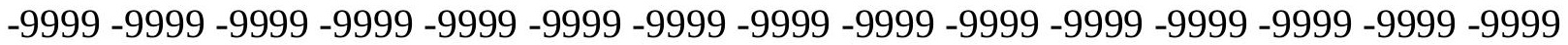
-9999 -9999 -9999 -9999 -9999 -9999 -9999 -9999 -9999 -9999 -9999 -9999 -9999 -9999 -9999 -9999 -9999 -9999 -9999 -9999 -9999 -9999 -9999 -9999 -9999 -9999 -9999 -9999 -9999 -9999 -

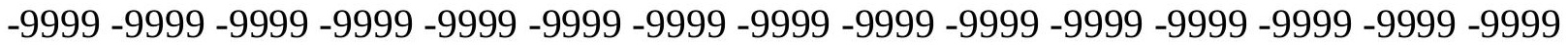
-9999 -9999 -9999 -9999 -9999 -9999 -9999 -9999 -9999 -9999 -9999 -9999 -9999 -9999 -9999 -9999 -9999 -9999 -9999 -9999 -9999 -9999 -9999 -9999 -9999 -9999 -9999 -9999 -9999 -9999

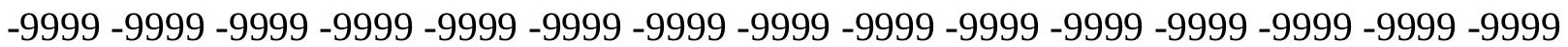
-9999 -9999 -9999 -9999 -9999 -9999 -9999 -9999 -9999 -9999 -9999 -9999 -9999 -9999 -9999 -9999 -9999 -9999 -9999 -9999 -9999 -9999 -9999 -9999 -9999 -9999 -9999 -9999 -9999 -9999 -9999 -9999 -9999 -9999 -9999 -9999 -9999 -9999 -9999 -9999 -9999 -9999 -9999 -9999 -9999 -9999 -9999 -9999 -9999 -9999 -9999 -9999 -9999 -9999 -9999 -9999 -9999 -9999 -9999 -9999 -9999 -9999 -9999 -9999 -9999 -9999-9999 -9999 -9999 139.6420593262136 .9432373047 127.5913772583125 .7090072632123 .894203186122 .2302398682120 .6949005127 118.8662033081117 .037498474199 .2239456176898 .6573181152398 .09874725342 97.5480880737397 .0050582885796 .4694137573295 .9407958984495 .41889190674 
94.9032974243294 .3937072753993 .8898086547993 .3914260864392 .89841461182 92.349891662691 .1307525634890 .8259735107490 .5211791992290 .21640014648 89.9116134643689 .6068267822389 .1628875732488 .7248077392688 .29355621338 87.869277954187 .4520874023487 .0422821044986 .6400146484486 .24519348145 85.8572158813585 .4754333496185 .0996932983484 .7314605712984 .3736114502 84.0292282104583 .7001190185583 .3871231079183 .089988708582 .80809020996 82.5403900146582 .2848510742282 .0372772216881 .7919616699281 .54246520996 81.2813110351680 .9992828369180 .6849060058680 .1584930419979 .85370635986 79.5489196777379 .2441329956178 .6345596313578 .3297805786178 .63455963135 79.2441329956181 .3776321411184 .4254837036187 .4733276367290 .52117919922 92.6546783447387 .4733276367281 .9871978759878 .3297805786176 .86643981934 75.9298095703175 .3853607177774 .9869689941474 .6092987060574 .1809387207 73.7079467773473 .1972579956172 .6655273437572 .1217575073271 .58538818359 71.0715408325270 .5901794433670 .14712524414 -9999 -9999 -9999 -9999 -9999 -9999 -9999 -9999 -9999 -9999 -9999 -9999 -9999 -9999 -9999 -9999 -9999 -9999 -9999 -9999 -9999 -9999

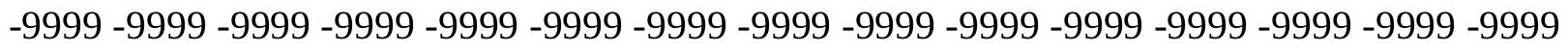
-9999 -9999 -9999 -9999 -9999 -9999 -9999 -9999 -9999 -9999 -9999 -9999 -9999 -9999 -9999 -9999 -9999-9999

-9999 -9999 -9999 -9999 -9999 -9999 -9999 -9999 -9999 -9999 -9999 -9999 -9999 -9999 -9999

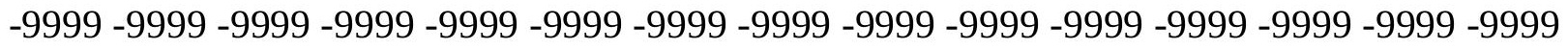

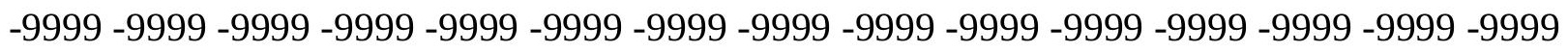
-9999 -9999 -9999 -9999 -9999 -9999 -9999 -9999 -9999 -9999 -9999 -9999 -9999 -9999 -9999 -9999 -9999 -9999 -9999 -9999 -9999 -9999 -9999 -9999 -9999 -9999 -9999 -9999 -9999 -9999 -

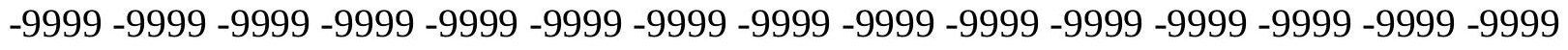

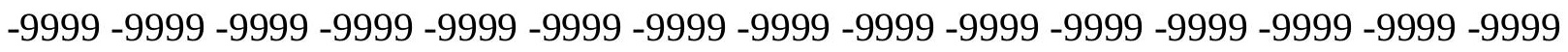
-9999 -9999 -9999 -9999 -9999 -9999 -9999 -9999 -9999 -9999 -9999 -9999 -9999 -9999 -9999 -9999 -9999 -9999 -9999 -9999 -9999 -9999 -9999 -9999 -9999 -9999 -9999 -9999 -9999 - 9999 - -999 -

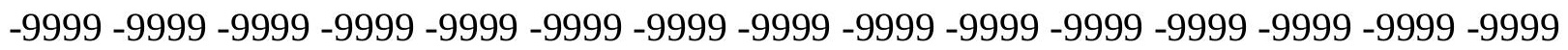
-9999 -9999 -9999 -9999 -9999 -9999 -9999 -9999 -9999 -9999 -9999 -9999 -9999 -9999 -9999 -9999 -9999 -9999 -9999 -9999 -9999 -9999 -9999 -9999 -9999 -9999 -9999 -9999 -9999 -9999 -9999 -9999 -9999 -9999 -9999 -9999 -9999 -9999 -9999-9999 -9999 -9999 -9999 -9999 -9999 -9999 -9999 -9999 -9999 -9999 -9999 -9999 -9999 -9999 -9999 -9999 -9999 -9999 -9999 -9999 -

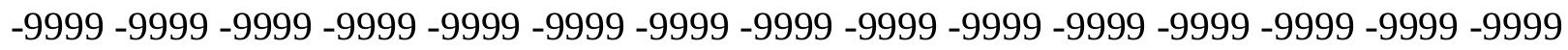
-9999 -9999 -9999 -9999 -9999 -9999 -9999 -9999 -9999 -9999 -9999 -9999 -9999 -9999 -9999 -9999 -9999 -9999 -9999 -9999 -9999 -9999 -9999 -9999-9999 137.0167999268 133.3080444336125 .2518997192123 .259223938121 .5000991821120 .0852966309 118.5614013672117 .34230041599 .5696258544998 .9989929199298 .43631744385 97.88146972656 97.3341979980596.7942810058696.2613983154395.73526763916 95.2155303955194 .7019195556694 .1941299438593 .6920318603593 .19550323486 92.7046127319391 .7403335571390 .8259735107490 .5211791992290 .52117919922 90.2164001464889 .8888702392689 .302040100188 .9972534179788 .57460784912 88.1513290405387 .7356414794987 .3278121948286 .9279174804786 .53565216064 86.1501998901485 .7710189819385 .3985290527385 .0350875854584 .68458557129 84.3509750366284 .0363006591883 .741210937583 .4653320312583 .20801544189 82.9678878784282 .7425842285282 .5276565551882 .3170700073282 .10391998291 81.8805999755981 .6385803222781 .3692550659281 .071846008380 .7592010498 
80.4632720947380 .1584930419979 .8537063598679 .8537063598680 .15849304199 81.37763214111 82.90155792236 85.33984375 87.77810668945 89.60682678223 89.9116134643687 .1685485839882 .9015579223679 .5489196777377 .63732910156 76.6141738891676 .0615158081175 .6982345581175 .3209686279374 .85864257812 74.3228988647573 .7492294311573 .1572570800872 .5591430664171 .9774017334 71.4276885986370 .9189910888770 .45590209961 -9999 -9999 -9999 -9999 -9999 -9999 -9999 -9999 -9999 -9999 -9999 -9999 -9999 -9999 -9999 -9999 -9999 -9999 -9999 -9999 -9999 -9999

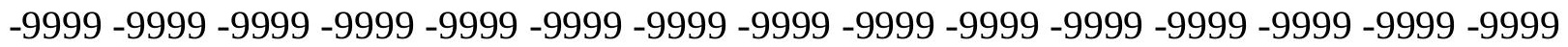

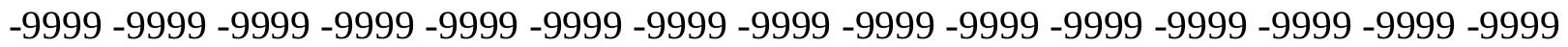
-9999-9999-9999

-9999 -9999 -9999 -9999 -9999 -9999 -9999 -9999 -9999 -9999 -9999 -9999 -9999 -9999 -9999 -9999 -9999 -9999 -9999 -9999 -9999 -9999 -9999 -9999 -9999 -9999 -9999 -9999 -9999 -9999 -9999 -9999 -9999 -9999 -9999 -9999 -9999 -9999 -9999 -9999 -9999 -9999 -9999 -9999 -9999 -9999 -9999 -9999 -9999 -9999 -9999 -9999 -9999 -9999 -9999 -9999 -9999 -9999 -9999 -9999 -9999 -9999 -9999 -9999 -9999 -9999 -9999 -9999 -9999 -9999 -9999 -9999 -9999 -9999 -9999

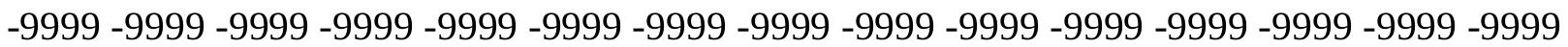

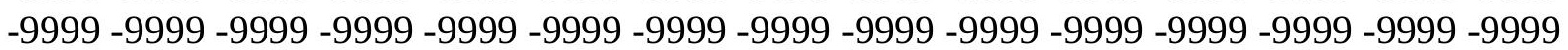
-9999 -9999 -9999 -9999 -9999 -9999 -9999 -9999 -9999 -9999 -9999 -9999 -9999 -9999 -9999 -999 -9999 -9999 -9999 -9999 -9999 -9999 -9999 -9999 -9999 -9999 -9999 -9999 -9999 -9999 -9999 -9999 -9999 -9999 -9999 -9999 -9999 -9999 -9999 -9999 -9999 -9999 -9999 -9999 -9999 -9999 -9999 -9999 -9999 -9999 -9999 -9999 -9999 -9999 -9999 -9999 -9999 -9999 -9999 -9999 -9999 -9999 -9999 -9999 -9999 -9999 -9999 -9999 -9999 -9999 -9999 -9999 -9999 -9999 -9999 -9999 -9999 -9999 -9999 -9999 -9999 -9999 -9999 -9999 -9999 -9999 -9999 -9999 -9999 -9999 -9999 -9999 -9999 -9999 -9999 -9999 -9999 -9999 -9999 -9999 -9999 -9999 -9999 -9999 -9999 -9999 -9999 -9999 -9999 -9999 -9999 -9999 -9999 -9999 -9999 -9999 -9999 -9999 -9999 -9999 -9999 -9999 -9999 -9999 -9999 -9999 -9999 -9999 -9999 -9999 -9999 -9999 -9999 -9999 -9999 -9999 -9999 -9999 -9999 -9999 -9999 -9999 -9999 -9999 -9999 -9999 -9999 133.9211578369 125.1804351807122 .9439468384120 .9193649292119 .4757995605118 .5614013672 117.9517974854117 .34230041599 .3350677490298 .7683868408298 .20947265625 97.6580810546997 .1140289306696 .5770187377996 .0468063354595 .52307128906 95.0055618286194 .4940261840893 .9883270263793 .4883880615292 .99429321289 92.5061721801891 .7403335571390 .8259735107490 .5211791992290 .21640014648 89.9116134643689 .6068267822389 .2814941406288 .8511047363388 .42868804932 88.0143508911187 .6083297729587 .2105712890686 .820587158286 .43743896484 86.0609741210985 .6925048828185 .3352737426884 .9937744140684 .67240905762 84.3734130859484 .0974807739383 .8442764282283 .6131896972783 .40259552002 83.20973968506 83.0299224853582.85688018799 82.68329620361 82.50144195557 82.29197692871 81.98719787598 81.68241119385 81.3776321411181.37763214111 81.0728530883881 .0728530883881 .3776321411181 .9871978759882 .90155792236 84.4254837036185 .9494018554787 .1685485839887 .1685485839887 .47332763672 85.6446228027382 .5967712402379 .8537063598678 .1745071411177 .28103637695 76.9199752807676 .67104339676 .2707061767675 .7148590087975 .06744384766 74.3853378295973 .7055282592873 .0363693237372 .3999252319371 .809425354 71.2709960937570 .7867507934670 .35499572754 -9999 -9999 -9999 -9999 -9999 -9999 -9999 -9999 -9999 -9999 -9999 -9999 -9999 -9999 -9999 -9999 -9999 -9999 -9999 -9999 -9999 -9999

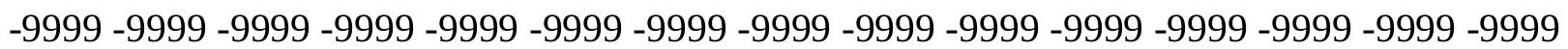


-9999 -9999 -9999 -9999 -9999 -9999 -9999 -9999 -9999 -9999 -9999 -9999 -9999 -9999 -9999 $-9999-9999$

-9999 -9999 -9999 -9999 -9999 -9999 -9999 -9999 -9999 -9999 -9999 -9999 -9999 -9999 -9999 -9999 -9999 -9999 -9999 -9999 -9999 -9999 -9999 -9999 -9999 -9999 -9999 -9999 -9999 -9999 -9999 -9999 -9999 -9999 -9999 -9999 -9999 -9999 -9999 -9999 -9999 -9999-9999 -9999 -9999 -

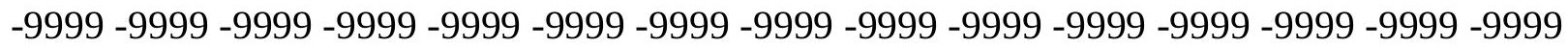
-9999 -9999 -9999 -9999 -9999 -9999 -9999 -9999 -9999 -9999 -9999 -9999 -9999 -9999 -9999 -9999 -9999 -9999 -9999 -9999 -9999 -9999 -9999 -9999 -9999 -9999 -9999 -9999 -9999 -9999 -9999 -9999 -9999 -9999 -9999 -9999 -9999 -9999 -9999 -9999 -9999 -9999 -9999 -9999 -9999 -9999 -9999 -9999 -9999 -9999 -9999 -9999 -9999 -9999 -9999 -9999 -9999 -9999 -9999 -9999 -9999 -9999 -9999 -9999 -9999 -9999 -9999 -9999 -9999 -9999 -9999 -9999 -9999 -9999 -9999 -9999 -9999 -9999 -9999 -9999 -9999 -9999 -9999 -9999 -9999 -9999 -9999 -9999 -9999 -9999 -9999 -9999 -9999 -9999 -9999 -9999 -9999 -9999 -9999 -9999 -9999 -9999 -9999 -9999 -9999 -9999 -9999 -9999 -9999 -9999 -9999 -9999 -9999 -9999 -9999 -9999 -9999 -9999 -9999 -9999 -9999 -9999 -9999 -9999 -9999 -9999 -9999 -9999 -9999 -9999 -9999 -9999 -9999 -9999 -9999

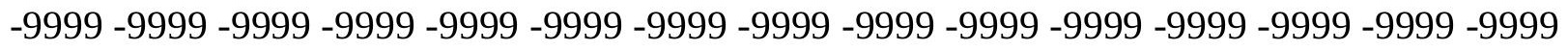

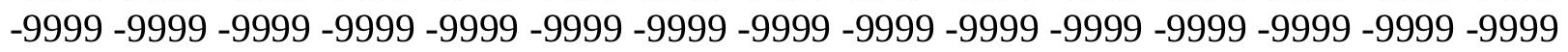

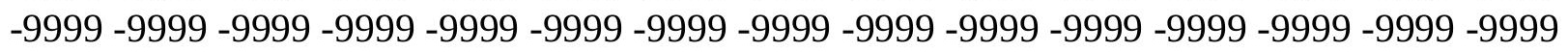
-9999 -9999 -9999 -9999-9999 -9999 -9999 -9999 -9999 -9999 -9999 136.0050506592 130.3829956055123 .3645706177120 .9997024536119 .1709976196119 .4757995605 119.4757995605119 .170997619699 .6651687622199 .09458160498 .53170013428 97.97630310059 97.42823791504 96.88722991943 96.3530807495195.82548522949 95.3042297363394 .7890777587994 .2799301147593 .7767181396593 .27954101562 92.7885742187592 .3041458129991 .4355392456190 .8259735107490 .52117919922 90.2164001464889 .9116134643689 .5535049438589 .1234207153388 .70180511475 88.28874206543 87.88443756104 87.4887008667 87.10084533691 86.71995544434 86.3464355468885 .9826889038185 .6328735351685 .3016815185584 .99348449707 84.7107162475684 .4543991088984 .2244033813584 .0202560424883 .84015655518 83.6810302734483 .5377807617283 .4037857055783 .206336975182 .90155792236 82.9015579223682 .5967712402382 .2919769287182 .2919769287182 .29197692871 82.2919769287182 .2919769287182 .9015579223683 .5111236572384 .42548370361 85.6446228027386 .5589828491287 .1685485839886 .8637619018685 .94940185547 84.1206970214881 .3776321411179 .2441329956178 .3297805786177 .80563354492 78.0626754760777 .9794082641677 .4517593383876 .6978683471775 .87255859375 75.0595092773474 .2754364013773 .5282592773472 .8367309570372 .20652770996 71.6405410766671 .1371459960970 .69233703613 -9999 -9999 -9999 -9999 -9999 -9999 -9999

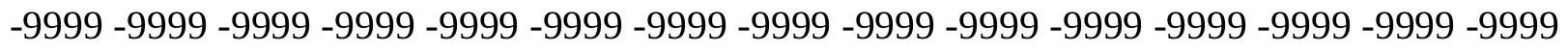

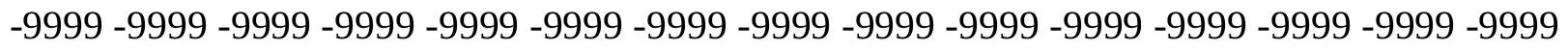

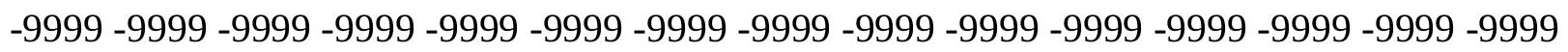
$-9999-9999$

-9999 -9999 -9999 -9999 -9999-9999 -9999 -9999 -9999 -9999 -9999 -9999 -9999 -9999 -9999 -

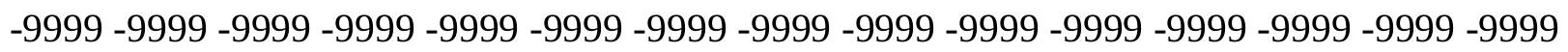

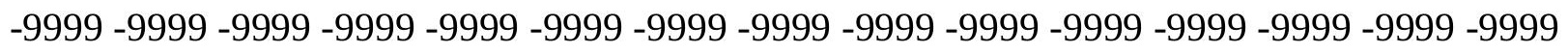
-9999 -9999 -9999 -9999 -9999 -9999 -9999 -9999 -9999 -9999 -9999 -9999 -9999 -9999 -9999 -

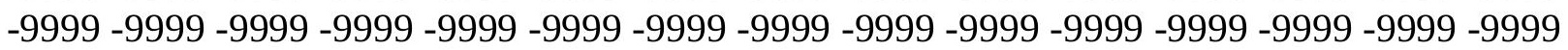

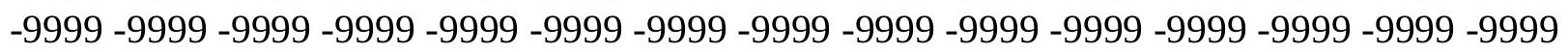


-9999 -9999 -9999 -9999 -9999 -9999 -9999 -9999 -9999 -9999 -9999 -9999 -9999 -9999 -9999 -9999 -9999 -9999 -9999 -9999 -9999 -9999 -9999 -9999 -9999 -9999 -9999 -9999 -9999 -9999 -9999 -9999 -9999 -9999 -9999 -9999 -9999 -9999 -9999 -9999 -9999 -9999 -9999 -9999 -9999 -9999 -9999 -9999 -9999 -9999 -9999 -9999 -9999 -9999 -9999 -9999 -9999 -9999 -9999 -9999 -9999 -9999 -9999 -9999 -9999 -9999 -9999 -9999 -9999 -9999 -9999 -9999 -9999 -9999 -9999 -9999 -9999 -9999 -9999 -9999 -9999 -9999 -9999 -9999 -9999 -9999 -9999 -9999 -9999 -9999 -9999 -9999 -9999 -9999 -9999 -9999 -9999 -9999 -9999 -9999 -9999 -9999 -9999 -9999 -9999

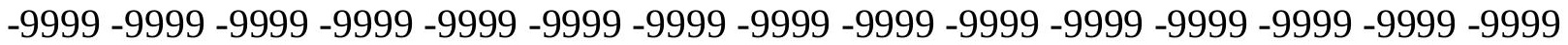

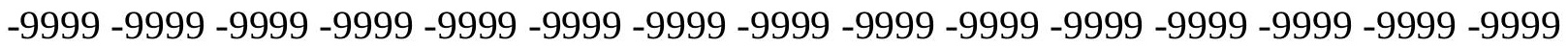
-9999 -9999 -9999 -9999 -9999 -9999 -9999 -9999 -9999 -9999 -9999 -9999 -9999 -9999 -9999 -999 -9999 -9999 -9999 -9999 -9999 -9999 -9999 -9999 -9999 -9999 -9999 -9999 133.9458618164 124.8641662598121 .3044967651120 .9997024536121 .6092987061121 .9140014648 121.6092987061120 .694900512799 .4146118164198 .8478393554798 .28853607178 97.7365722656297 .1916961669996 .653739929296 .1224212646595 .59756469727 95.0789489746194 .5665054321394 .0601730346793 .5600891113393 .06643676758 92.5795669555792 .0998306274491 .4355392456190 .8259735107490 .52117919922 89.9116134643689 .6068267822389 .302040100188 .9710617065488 .55927276611 88.1566543579187 .7629165649487 .3771972656286 .9986190795986 .62824249268 86.2696380615285 .9278945922985 .6077575683685 .3132705688585 .04689788818 84.8101501464884 .6032638549884 .4259567260784 .2763519287184 .15113067627 84.0447692871183 .9499969482483 .8159103393683 .5111236572383 .2063369751 83.206336975183.2063369751 83.2063369751 82.9015579223683.2063369751 83.206336975183 .8159103393684 .7302627563585 .9494018554786 .86376190186 87.7781066894587 .7781066894587 .1685485839885 .6446228027383 .51112365723 80.7680587768678 .0249862670977 .110626220778 .6345596313579 .54891967773 79.6444168090878 .7115402221777 .6304931640676 .6036224365275 .66750335693 74.8067703247174 .0073852539173 .2689056396572 .6084289550872 .02154541016 71.5039291381871 .0495223999 -9999 -9999 -9999 -9999 -9999 -9999 -9999 -9999 -9999 -9999 -9999 -9999 -9999 -9999 -9999 -9999 -9999 -9999 -9999 -9999 -9999 -9999 -9999 -9999 -9999 -9999 -9999 -9999 -9999 -9999 -9999 -9999 -9999 -9999 -9999 -9999 -9999 -9999 -9999 -9999 -9999 -9999 -9999 -9999 -9999 -9999 -9999 -9999 -9999 -9999 -9999 -9999 -9999 -9999 -

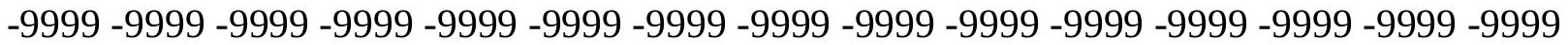
-9999 -9999 -9999 -9999 -9999 -9999 -9999 -9999 -9999 -9999 -9999 -9999 -9999 -9999 -9999 -9999 -9999 -9999 -9999 -9999 -9999 -9999 -9999 -9999 -9999 -9999 -9999 -9999 -9999 -9999 -

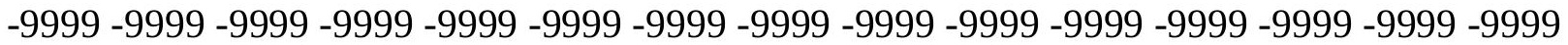
-9999 -9999 -9999 -9999 -9999 -9999 -9999 -9999 -9999 -9999 -9999 -9999 -9999 -9999 -9999 -9999 -9999 -9999 -9999 -9999 -9999 -9999 -9999 -9999 -9999 -9999 -9999 -9999 -9999 -9999

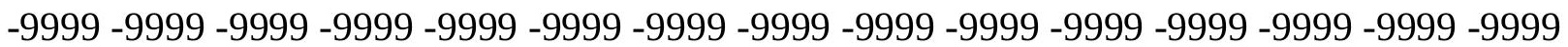
-9999 -9999 -9999 -9999 -9999 -9999 -9999 -9999 -9999 -9999 -9999 -9999 -9999 -9999 -9999 -9999 -9999 -9999 -9999 -9999 -9999 -9999 -9999 -9999 -9999 -9999 -9999 -9999 -9999 -9999 -

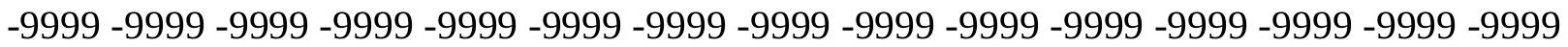
-9999 -9999 -9999 -9999 -9999 -9999 -9999 -9999 -9999 -9999 -9999 -9999 -9999 -9999 -9999 -9999 -9999 -9999 -9999 -9999 -9999 -9999 -9999 -9999 -9999 -9999 -9999 -9999 -9999 -9999 -9999 -9999 -9999 -9999 -9999 -9999 -9999 -9999 -9999 -9999 -9999 -9999 -9999 -9999 -9999 -9999 -9999 -9999 -9999 -9999 -9999 -9999 -9999 -9999 -9999 -9999 -9999 -9999 -9999 -9999

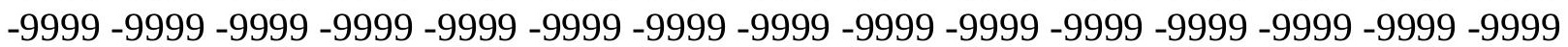


-9999 -9999 -9999 -9999 -9999 -9999 -9999 -9999 -9999 -9999 -9999 -9999 -9999 -9999 -9999 -9999 -9999 -9999 -9999 -9999 -9999 -9999 -9999 -9999 -9999 -9999 -9999 140.0982513428 133.1590423584125 .9509429932124 .9618988037125 .2667007446125 .2667007446 124.9618988037123 .742797851699 .7281646728599 .1575851440498 .59446716309 98.0387039184697 .4900741577196 .9484252929796 .4135208129995 .88520812988 95.3632888793994 .8477172851694 .338447570893 .8356323242293 .33947753906 92.8503646850692 .3686599731491 .8948516845791 .1307525634890 .52117919922 90.2164001464889 .9116134643689 .302040100189 .2367019653388 .82622528076 88.4253463745188 .0336532592887 .6501617431687 .2740631103586 .90702819824 86.5537414550886 .2202072143685 .9112548828185 .6305694580185 .38050842285 85.16294097984 .9785385131884 .8272628784284 .7072448730584 .61499786377 84.5445632934684 .4254837036184 .4254837036184 .1206970214883 .81591033936 83.8159103393683 .8159103393683 .8159103393683 .5111236572383 .51112365723 83.81591033936 84.12069702148 85.33984375 86.86376190186 88.38768768311 88.99725341797 88.99725341797 87.77810668945 85.9494018554783.81591033936 81.0728530883878 .3297805786175 .5867080688581 .6824111938582 .29197692871 80.4632720947379 .6561813354578 .265342712477 .1128234863376 .12734222412 75.247627258374 .437573 .6874389648473 .0061264038172 .408767700271 .88428497314 71.42543029785 -9999 -9999 -9999 -9999 -9999 -9999 -9999 -9999 -9999 -9999 -9999 -9999 -9999 -9999 -9999 -9999 -9999 -9999 -9999 -9999 -9999 -9999 -9999 -9999 -9999 -9999 -9999

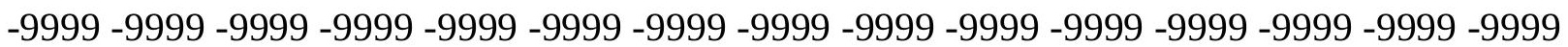
-9999 -9999 -9999 -9999 -9999 -9999 -9999 -9999 -9999 -9999 -9999 -9999 -9999 -9999 -9999 -9999 -9999 -9999 -9999 -9999 -9999 -9999 -9999 -9999 -9999 -9999 -9999 -9999 -9999 -9999 -9999 -9999 -9999 -9999 -9999 -9999 -9999 -9999 -9999 -9999 -9999 -9999

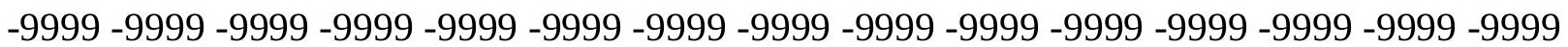
-9999 -9999 -9999 -9999 -9999 -9999 -9999 -9999 -9999 -9999 -9999 -9999 -9999 -9999 -9999 -9999 -9999 -9999 -9999 -9999 -9999 -9999 -9999 -9999 -9999 -9999 -9999 -9999 -9999 -9999 -9999 -9999 -9999 -9999 -9999 -9999 -9999 -9999 -9999 -9999 -9999 -9999 -9999 -9999 -9999 -9999 -9999 -9999 -9999 -9999 -9999 -9999 -9999 -9999 -9999 -9999 -9999 -9999 -9999 -9999 -9999 -9999 -9999 -9999 -9999 -9999 -9999 -9999 -9999 -9999 -9999 -9999 -9999 -9999 -9999 -9999 -9999 -9999 -9999 -9999 -9999 -9999 -9999 -9999 -9999 -9999 -9999 -9999 -9999 -9999 -

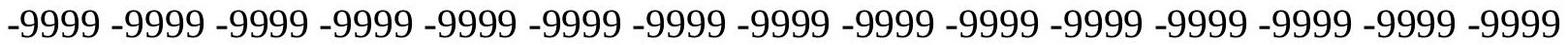
-9999 -9999 -9999 -9999 -9999 -9999 -9999 -9999 -9999 -9999 -9999 -9999 -9999 -9999 -9999 -9999 -9999 -9999 -9999 -9999 -9999 -9999 -9999 -9999 -9999 -9999 -9999 -9999 -9999 -9999 -

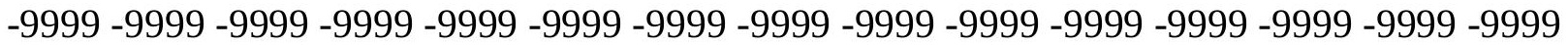
-9999 -9999 -9999 -9999 -9999 -9999 -9999 -9999 -9999 -9999 -9999 -9999 -9999 -9999 -9999 -9999 -9999 -9999 -9999 -9999 -9999 -9999 -9999 -9999 -9999 -9999 -9999 -9999 -9999 -9999

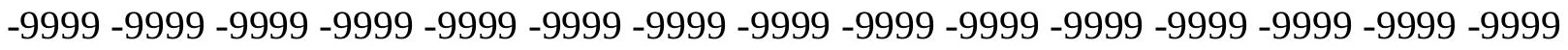
-9999 -9999 -9999 -9999 -9999 -9999 -9999 -9999 -9999 -9999 -9999 -9999 -9999 141.2872009277129 .769317627129 .5897827148129 .8385009766129 .533706665 128.3144989014126 .7906036377100 .03511810399 .460792541598 .89393615723 98.3344650268697 .7821807861397 .2369613647596 .6986083984496 .16698455811 95.6419143676895 .1233749389694 .6113510131894 .1060104370193 .6075592041 93.1164093017692 .632957458592 .1577072143691 .6910858154390 .82597351074 90.2164001464889 .9116134643689 .6068267822389 .302040100188 .99725341797 88.6908035278388 .3012771606487 .9201889038187 .5468063354587 .18334960938 
86.8354492187586 .5099945068486 .2119293212985 .9446563720785 .7103729248 85.5111694335985 .348068237385 .2212829589885 .1290130615285 .06768798828 85.0309295654385 .00976562584 .7302627563584 .7302627563584 .42548370361 84.4254837036184 .4254837036184 .3635940551884 .06557464683 .81591033936 83.51112365723 83.81591033936 85.03504943848 87.47332763672 89.60682678223 90.5211791992289 .9116134643688 .6924667358486 .5589828491284 .42548370361 82.5967712402381 .3776321411182 .9015579223688 .9972534179784 .42548370361 79.8537063598679 .8537063598678 .4447326660277 .3224945068476 .40046691895 75.5770187377974 .8042526245174 .0729751586973 .3943786621172 .79837799072 72.2763290405371 .8191986084 -9999 -9999 -9999 -9999 -9999 -9999 -9999 -9999 -9999 -9999 -9999 -9999 -9999 -9999 -9999 -9999 -9999 -9999 -9999 -9999 -9999 -9999 -9999 -9999 -9999 -9999 -9999 -9999 -9999 -9999 -9999 -9999 -9999 -9999 -9999 -9999 -9999 -9999 -9999

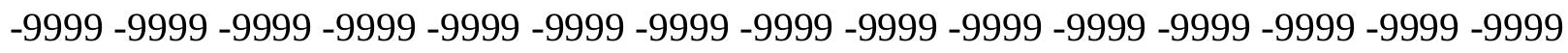
-9999 -9999 -9999 -9999 -9999 -9999 -9999 -9999 -9999 -9999 -9999 -9999 -9999 -9999 -9999 -9999 -9999 -9999 -9999 -9999 -9999 -9999 -9999 -9999 -9999 -9999 -9999 -9999 -9999 -9999

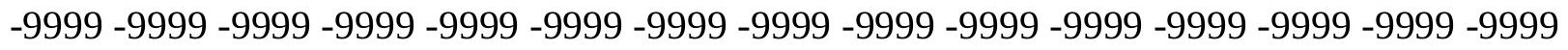
-9999 -9999 -9999 -9999 -9999 -9999 -9999 -9999 -9999 -9999 -9999 -9999 -9999 -9999 -9999 -

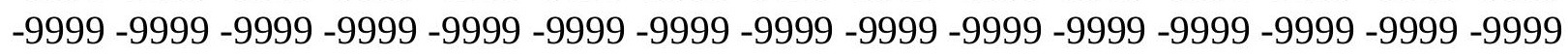

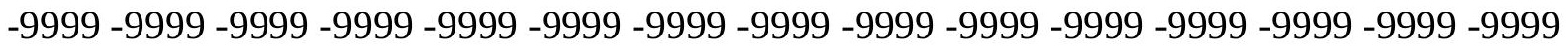

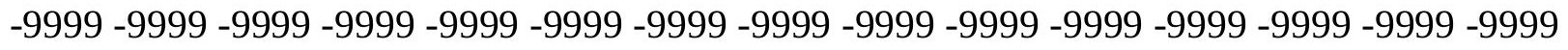

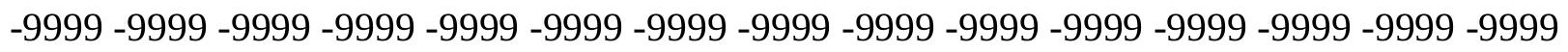

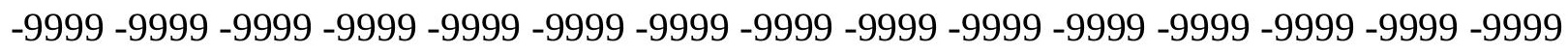
-9999 -9999 -9999 -9999 -9999 -9999 -9999 -9999 -9999 -9999 -9999 -9999 -9999 -9999 -9999 -

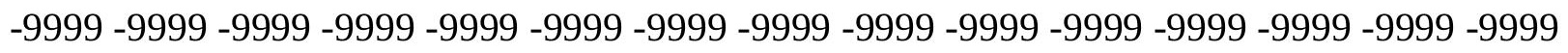

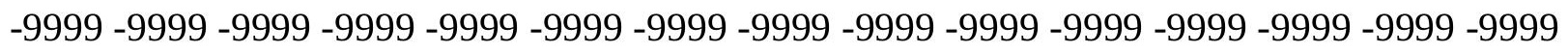
-9999 -9999 -9999 -9999 -9999 -9999 -9999 -9999 -9999 -9999 -9999 -9999 -9999 -9999 -9999 -9999 -9999 -9999 -9999 -9999 -9999 -9999 -9999 -9999 -9999 -9999 -9999 -9999 -9999 - -9999 -

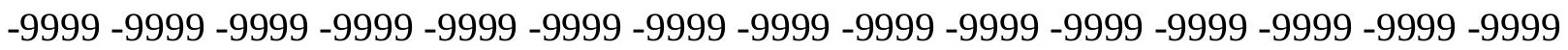

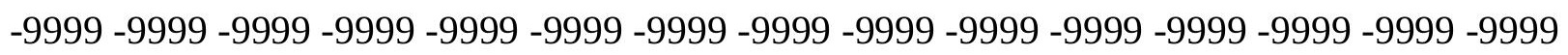
-9999 -9999 -9999 -9999 -9999 -9999 -9999 -9999 -9999 -9999 -9999 -9999 -9999 150.1703948975142 .0299072266133 .4501953125133 .6450653076133 .4958953857 131.9720001221129 .8385009766127 .095397949299 .7573165893699 .18679046631 98.6236877441498 .0678558349697 .5191879272596 .9775085449296 .44271087646 95.9146499633895.3933181762794.8787231445394.3710556030393.8705291748 93.3775711059692 .8925857543992 .4161148071391 .9486007690491 .49052429199 90.8259735107489 .9116134643689 .6068267822389 .302040100188 .99725341797 88.95314025879 88.56596374512 88.18752288818 87.81718444824 87.4575958252 87.1151809692486 .7975311279386 .5097808837986 .2551269531286 .03559112549 85.8533859252985 .7097625732485 .6051712036185 .5379028320385 .5043182373 85.4977188110485 .3398437585 .3398437585 .0350494384885 .0350494384885 .03504943848 85.0350494384884 .7302627563584 .1206970214883 .5111236572382 .59677124023 82.2919769287183 .206336975186 .5589828491290 .2164001464891 .43553924561 90.8259735107488 .9972534179787 .1685485839885 .6446228027384 .42548370361 84.1206970214885 .6446228027386 .254188537683 .8159103393679 .54891967773 78.9393463134878 .1353988647577 .251251220776 .5078506469775 .8049621582 75.109786987374 .4273376464873 .7781524658273 .1905822753972 .67947387695 
72.23084259033 -9999 -9999 -9999 -9999 -9999 -9999 -9999 -9999 -9999 -9999 -9999 -9999 -9999 -9999 -9999 -9999 -9999 -9999 -9999 -9999 -9999 -9999 -9999 -9999 -9999 -9999 -9999

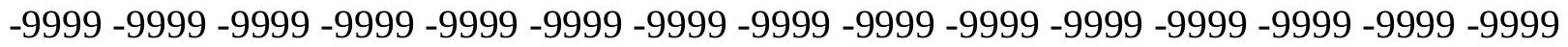
-9999 -9999 -9999 -9999 -9999 -9999 -9999 -9999 -9999 -9999 -9999 -9999

-9999 -9999 -9999 -9999 -9999 -9999 -9999 -9999 -9999 -9999 -9999 -9999 -9999 -9999 -9999 -9999 -9999 -9999 -9999 -9999 -9999 -9999 -9999 -9999 -9999 -9999 -9999 -9999 -9999 -9999 -

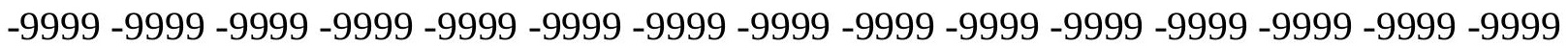

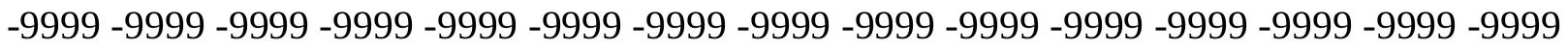
-9999 -9999 -9999 -9999 -9999 -9999 -9999 -9999 -9999 -9999 -9999 -9999 -9999 -9999 -9999 -9999 -9999 -9999 -9999 -9999 -9999 -9999 -9999 -9999 -9999 -9999 -9999 -9999 -9999 -9999 -9999 -9999 -9999 -9999 -9999 -9999 -9999 -9999 -9999 -9999 -9999 -9999 -9999 -9999 -9999 -9999 -9999 -9999 -9999 -9999 -9999 -9999 -9999 -9999 -9999 -9999 -9999 -9999 -9999 -9999 -9999 -9999 -9999 -9999 -9999 -9999 -9999 -9999 -9999 -9999 -9999 -9999 -9999 -9999 -9999 -9999 -9999 -9999 -9999 -9999 -9999 -9999 -9999 -9999 -9999 -9999 -9999 -9999 -9999 -9999 -9999 -9999 -9999 -9999 -9999 -9999 -9999 -9999 -9999 -9999 -9999 -9999 -9999 -9999 -9999

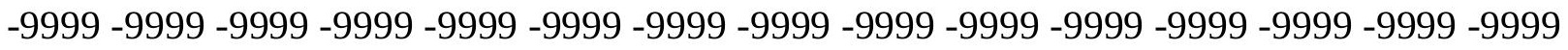
-9999 -9999 -9999 -9999 -9999 -9999 -9999 -9999 -9999 -9999 -9999 -9999 -9999 -9999 -9999 -9999 -9999 -9999 -9999 -9999 -9999 -9999 -9999 -9999 -9999 -9999 -9999 -9999 -9999 -9999 -9999 -9999 -9999 -9999 -9999 -9999 -9999 -9999 -9999 -9999 -9999 -9999 -9999 -9999 -9999 -9999 -9999 -9999 -9999 -9999 -9999 -9999 -9999 -9999 -9999 -9999 -9999 -9999 -9999 -9999 -9999 -9999 -9999 -9999 -9999 -9999 -9999 -9999 -9999 -9999 -9999 -9999 -9999 -9999 149.6495056152136 .5238647461136 .619354248136 .3177185059135 .0198059082 132.2767028809129 .2288970947100 .047142028899 .4729995727598 .90635681152 98.3470611572397 .7950515747197 .2501678466896 .712333679296 .18143463135 95.6574935913195 .1405181884894 .630714416594 .1283264160293 .63378143311 93.1474914550892 .6700210571392 .2018203735491 .7434005737391 .2950592041 90.5211791992289 .6068267822389 .302040100189 .302040100188 .99725341797 88.8277740478588 .452285766688 .0853652954187 .7299957275487 .39317321777 87.0830230712986 .804824829186 .5616531372186 .3553848266686 .18826293945 86.06169128418 85.97631072998 85.93046569824 85.92050933838 85.93944549561 85.9494018554785 .6446228027385 .6446228027385 .6446228027385 .64462280273 85.3398437585 .0350494384884 .3732299804783 .206336975181 .68241119385 79.8537063598679 .2441329956182 .2919769287190 .8259735107490 .52117919922 89.91161346436 88.99725341797 87.47332763672 86.2541885376 85.33984375 85.0350494384885 .0350494384883 .8159103393681 .6824111938578 .63455963135 78.2972717285277 .5907058715877 .0581130981476 .5352859497175 .97415161133 75.3730163574274 .7538528442474 .148582458573 .5866241455173 .09481811523 72.66115570068 -9999 -9999 -9999 -9999 -9999 -9999 -9999 -9999 -9999 -9999 -9999 -9999 -9999 -9999 -9999 -9999 -9999 -9999 -9999 -9999 -9999 -9999 -9999 -9999 -9999 -9999 -9999 -9999 -9999 -9999 -9999 -9999 -9999 -9999 -9999 -9999 -9999 -9999 -9999 -9999 -9999 -9999 -9999 -9999 -9999 -9999 -9999 -9999 -9999 -9999 -9999 -9999 -9999 -9999

-9999 -9999 -9999 -9999 -9999 -9999 -9999 -9999 -9999 -9999 -9999 -9999 -9999 -9999 -9999 -9999 -9999 -9999 -9999 -9999 -9999 -9999 -9999 -9999 -9999 -9999 -9999 -9999 -9999 -9999 -9999 -9999 -9999 -9999 -9999 -9999 -9999 -9999 -9999 -9999 -9999 -9999 -9999 -9999 -9999 -9999 -9999 -9999 -9999 -9999 -9999 -9999 -9999 -9999 -9999 -9999 -9999 -9999 -9999 -9999

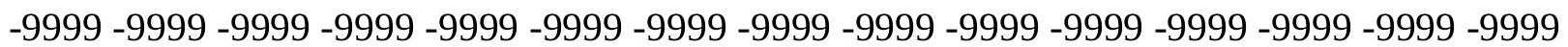


-9999 -9999 -9999 -9999 -9999 -9999 -9999 -9999 -9999 -9999 -9999 -9999 -9999 -9999 -9999 -9999 -9999 -9999 -9999 -9999 -9999 -9999 -9999 -9999 -9999 -9999 -9999 -9999 -9999 -9999 -9999 -9999 -9999 -9999 -9999 -9999 -9999 -9999 -9999 -9999 -9999 -9999 -9999 -9999 -9999 -9999 -9999 -9999 -9999 -9999 -9999 -9999 -9999 -9999 -9999 -9999 -9999 -9999 -9999 -9999 -9999 -9999 -9999 -9999 -9999 -9999 -9999 -9999 -9999 -9999 -9999 -9999 -9999 -9999 -9999 -9999 -9999 -9999 -9999 -9999 -9999 -9999 -9999 -9999 -9999 -9999 -9999 -9999 -9999 -9999 -9999 -9999 -9999 -9999 -9999 -9999 -9999 -9999 -9999 -9999 -9999 -9999 -9999 -9999 -9999

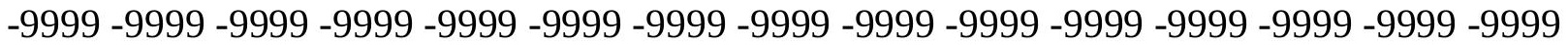
-9999 -9999 -9999 -9999 -9999 -9999 -9999 -9999 -9999 -9999 -9999 -9999 -9999 -9999 -9999 -9999 -9999 -9999 -9999 -9999 -9999 -9999 -9999 -9999 -9999 -9999 -9999 -9999 -9999 -9999 -

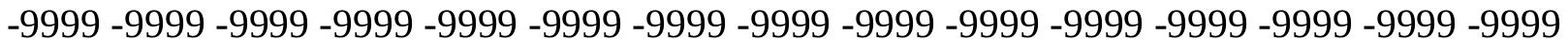
-9999 -9999 -9999 -9999 -9999 -9999 -9999 -9999 -9999 -9999 -9999 -9999 -9999 -9999 161.8408966064149 .3446960449138 .5723266602138 .1560668945137 .1533050537 133.8007049561130 .4479980469127 .400199890199 .7525253295999 .18240356445 98.61974334717 98.0644912719797.5165252685596.9757919311596.44220733643 95.9158096313595 .3966369628994 .884902954194 .38085937593 .88494110107 93.3975677490292 .9193115234492 .4506301879991 .9920654296991 .54392242432 91.1065597534290 .2164001464889 .6068267822389 .302040100189 .3020401001 89.0866165161188 .7143936157288 .3513031005988 .0005416870187 .66943359375 87.3664169311587 .0968627929786 .8637619018686 .6688766479586 .51446533203 86.4019927978586 .3322067260786 .3035049438586 .3122100830186 .2541885376 86.254188537685 .9494018554785 .9494018554785 .9494018554785 .94940185547 85.9494018554785 .5800476074284 .6650772094783 .206336975181 .07285308838 78.6345596313575 .8914871215873 .1484298706182 .5967712402387 .16854858398 88.3876876831188 .0829010009887 .4733276367286 .254188537685 .64462280273 84.7302627563583 .8159103393681 .9871978759880 .1584930419977 .72020721436 77.4653472900477 .2517929077176 .9581909179776 .5890579223676 .13915252686 75.6220779418975 .0688400268674 .512832641673 .9872741699273 .52500915527

73.11200714111 -9999 -9999 -9999 -9999 -9999 -9999 -9999 -9999 -9999 -9999 -9999 -9999 -9999 -9999 -9999 -9999 -9999 -9999 -9999 -9999 -9999 -9999 -9999 -9999 -9999 -9999 -9999 -9999 -9999 -9999 -9999 -9999 -9999 -9999 -9999 -9999 -9999 -9999 -9999 -9999 -9999 -9999 -9999 -9999 -9999 -9999 -9999 -9999 -9999 -9999 -9999 -9999 -9999 -9999

-9999 -9999 -9999 -9999 -9999 -9999 -9999 -9999 -9999 -9999 -9999 -9999 -9999 -9999 -9999 -9999 -9999 -9999 -9999 -9999 -9999 -9999 -9999 -9999 -9999 -9999 -9999 -9999 -9999 -9999 -

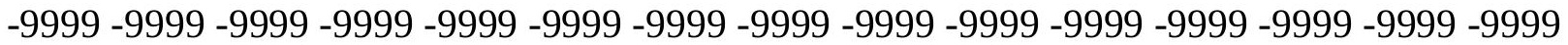
-9999 -9999 -9999 -9999 -9999 -9999 -9999 -9999 -9999 -9999 -9999 -9999 -9999 -9999 -9999 -9999 -9999 -9999 -9999 -9999 -9999 -9999 -9999 -9999 -9999 -9999 -9999 -9999 -9999 -9999

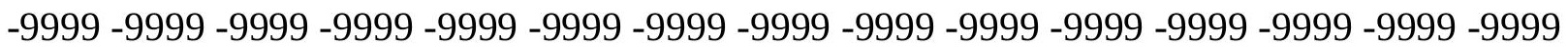
-9999 -9999 -9999 -9999 -9999 -9999 -9999 -9999 -9999 -9999 -9999 -9999 -9999 -9999 -9999 -9999 -9999 -9999 -9999 -9999 -9999 -9999 -9999 -9999 -9999 -9999 -9999 -9999 -9999 -9999 -9999 -9999 -9999 -9999 -9999 -9999 -9999 -9999 -9999 -9999 -9999 -9999 -9999 -9999 -9999 -9999 -9999 -9999 -9999 -9999 -9999 -9999 -9999 -9999 -9999 -9999 -9999 -9999 -9999 -9999 -9999 -9999 -9999 -9999 -9999 -9999 -9999 -9999 -9999 -9999 -9999 -9999 -9999 -9999 -9999 -9999 -9999 -9999 -9999 -9999 -9999 -9999 -9999 -9999 -9999 -9999 -9999 -9999 -9999 -9999 -9999 -9999 -9999 -9999 -9999 -9999 -9999 -9999 -9999 -9999 -9999 -9999 -9999 -9999 -9999

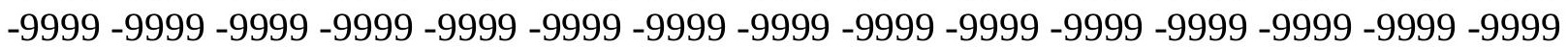


-9999 -9999 -9999 -9999 -9999 -9999 -9999 -9999 -9999 -9999 -9999 -9999 -9999 -9999 -9999 -9999 -9999 -9999 -9999 -9999 -9999 -9999 -9999 -9999 -9999 -9999 -9999 -9999 -9999 -9999 -9999 -9999 -9999 -9999 -9999 -9999 -9999 -9999 -9999 -9999 -9999 -9999 -9999 -9999 -9999 157.5738983154139 .5585021973138 .7087860107137 .0872344971134 .4102020264 131.0576019287128 .0097961426100 .02542877299 .4518966674898 .88594818115 98.327560424897 .7766265869197 .233123779396 .6969985961996 .16830444336 95.6471099853595 .1336288452194 .6281204223694 .1310272216893 .64277648926 93.1639328002992 .6949691772592 .2364273071391 .788650512791 .35202026367 90.8259735107489 .9116134643689 .6068267822389 .6068267822389 .3020401001 88.9736251831188 .6147689819388 .2689971923887 .9436950683687 .64739227295 87.385459899987 .1608352661186 .9752044677786 .8308105468886 .72912597656 86.6709213256886 .6546020507886 .6765136718886 .7294616699286 .55898284912 86.5589828491286 .5589828491286 .5589828491286 .5589828491286 .2541885376 85.9494018554785 .0350494384883 .8159103393681 .3776321411178 .63455963135 76.1962814331176 .1962814331179 .8537063598684 .1206970214886 .55898284912 87.1685485839886 .8637619018685 .9494018554785 .3398437584 .12069702148 82.9015579223681 .6824111938579 .8537063598678 .3297805786177 .68129730225 77.3493652343877 .0684585571376 .7408218383876 .3426742553775 .88166809082 75.3830490112374 .8803939819374 .4021530151473 .9735641479573 .58554077148 -9999 -9999 -9999 -9999 -9999 -9999 -9999 -9999 -9999 -9999 -9999 -9999 -9999 -9999 -9999 -9999

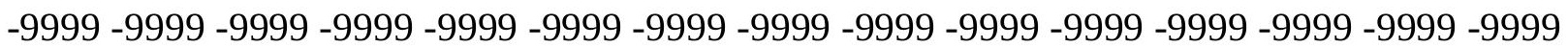

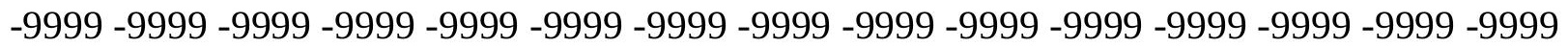
-9999 -9999 -9999 -9999 -9999 -9999 -9999 -9999

-9999 -9999 -9999 -9999 -9999 -9999 -9999 -9999 -9999 -9999 -9999 -9999 -9999 -9999 -9999

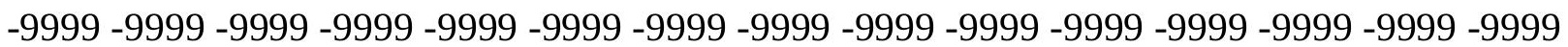
-9999 -9999 -9999 -9999 -9999 -9999 -9999 -9999 -9999 -9999 -9999 -9999 -9999 -9999 -9999 -9999 -9999 -9999 -9999 -9999 -9999 -9999 -9999 -9999 -9999 -9999 -9999 -9999 -9999 -9999 -9999 -9999 -9999 -9999 -9999 -9999 -9999 -9999 -9999 -9999 -9999 -9999 -9999 -9999 -9999 -9999 -9999 -9999 -9999 -9999 -9999 -9999 -9999 -9999 -9999 -9999 -9999 -9999 -9999 -9999 -9999 -9999 -9999 -9999 -9999 -9999 -9999 -9999 -9999 -9999 -9999 -9999 -9999 -9999 -9999 -9999 -9999 -9999 -9999 -9999 -9999 -9999 -9999 -9999 -9999 -9999 -9999 -9999 -9999 -9999 -9999 -9999 -9999 -9999 -9999 -9999 -9999 -9999 -9999 -9999 -9999 -9999 -9999 -9999 -9999 -9999 -9999 -9999 -9999 -9999 -9999 -9999 -9999 -9999 -9999 -9999 -9999 -9999 -9999 -9999 -9999 -9999 -9999 -9999 -9999 -9999 -9999 -9999 -9999 -9999 -9999 -9999 -9999 -9999 -9999 -

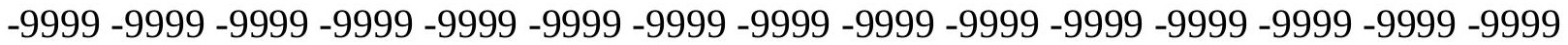
-9999 -9999 -9999 -9999 -9999 -9999 -9999 -9999 -9999 -9999 -9999 -9999 -9999 -9999 -9999 -9999 -9999 -9999 -9999 -9999 -9999 -9999 -9999 -9999 -9999 -9999 -9999 -9999 -9999 -9999

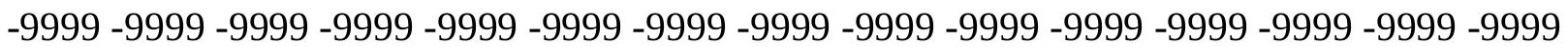
-9999 -9999 -9999 -9999 -9999 -9999 -9999 -9999 -9999 -9999 -9999 -9999 -9999 -9999 -9999 -9999 -9999 -9999 -9999 -9999 -9999 -9999 -9999 -9999 -9999 -9999 -9999 -9999 -9999 -9999 -999 -9999 144.7729034424138.4409637451 136.523651123134.1054992676131.0576019287 128.3144989014125 .571502685599 .7148513793999 .1456832885798 .58425140381 98.0304565429797 .4843139648496 .9457778930796 .4149398803795 .8918762207 95.3768234252994 .8700332641694 .3719635009893 .8830261230593 .40377807617 92.934707641692 .4763488769592 .0290832519591 .5933151245191 .16926574707 90.7572784423889 .9116134643689 .6068267822389 .5944137573289 .22960662842 
88.87535095215 88.53489685059 88.2154464721787.9253540039187.66992950439 87.4520568847787 .2733917236387 .1361312866287 .0416946411186 .99080657959 86.981857299887 .0112075805787 .0717620849686 .8637619018686 .86376190186 86.8637619018686 .8637619018686 .8637619018686 .8637619018686 .55898284912 85.6446228027384 .4254837036182 .5967712402380 .7680587768678 .93934631348 79.2441329956181 .0728530883883 .5111236572385 .3398437586 .2541885376 86.254188537685 .6446228027384 .7302627563583 .8159103393682 .59677124023 81.37763214111 80.46327209473 79.54891967773 78.47370910645 77.8159866333 77.3764114379976 .9948043823276 .5984268188576 .1685638427775 .71501159668 75.2595901489374 .8336486816474 .4446258544974 .084396362373 .74921417236 -9999 -9999 -9999 -9999 -9999 -9999 -9999 -9999 -9999 -9999 -9999 -9999 -9999 -9999 -9999 -9999

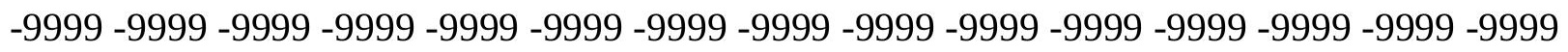

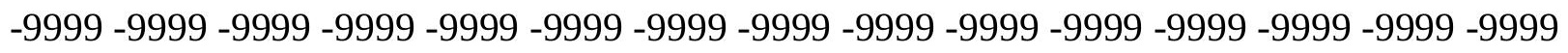
-9999 -9999 -9999 -9999-9999-9999 -9999

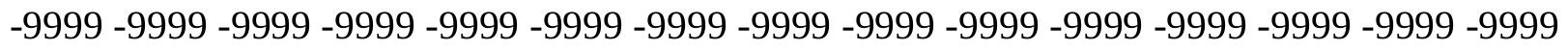

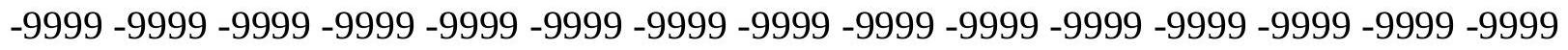

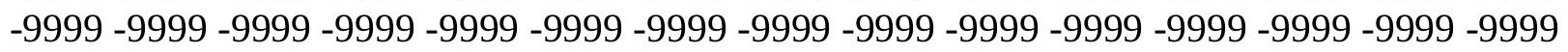

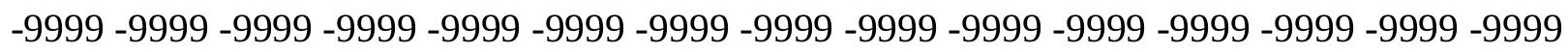

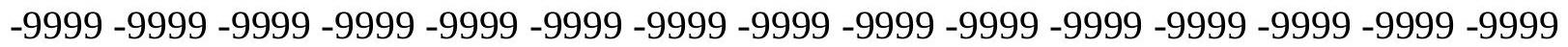

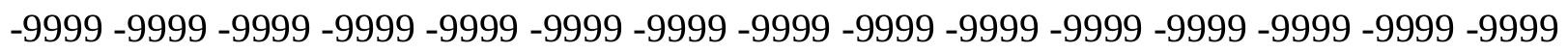

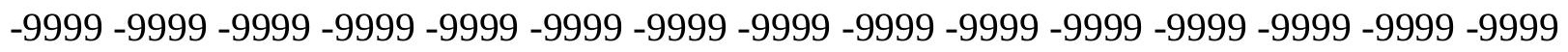

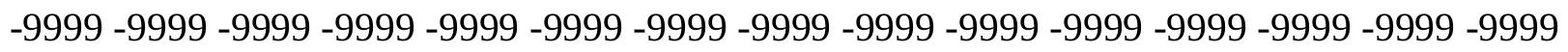

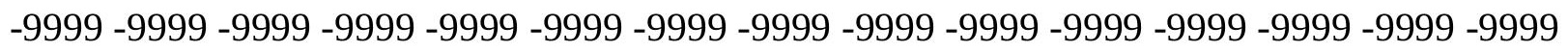

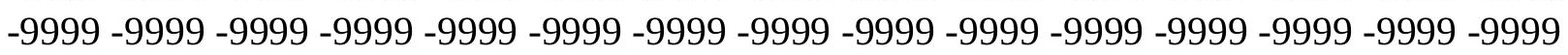

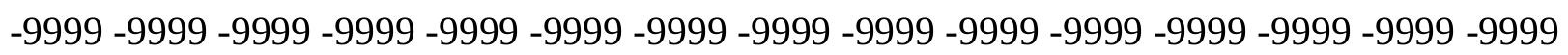

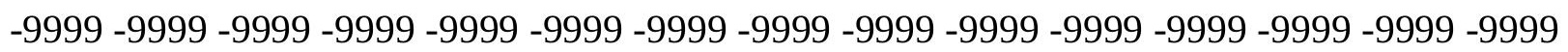
-9999 -9999 -9999 -9999 -9999 -9999 -9999 -9999 -9999 -9999 -9999 -9999 -9999 - -9999 - -9999 -

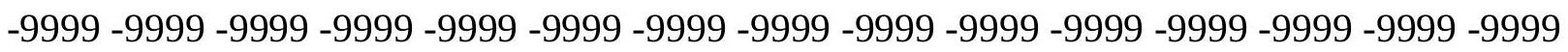

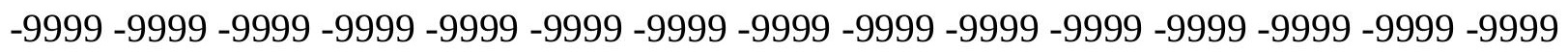

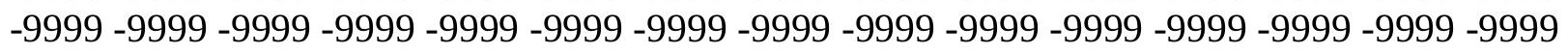
-9999 -9999 -9999 -9999 -9999 -9999 -9999 -9999 -9999 -9999 -9999 -9999 -9999 -9999 -9999 -9999 145.3825073242 137.8521270752 135.3246002197133.1911010742 130.7528076172 128.3144989014125 .876296997199 .9713363647599 .3990325927798 .83463287354 98.2780761718897 .7294006347797 .1885833740296 .6557388305796 .13095855713 95.6144866943495.10659027194.607704162694.1182403564593.63876342773 93.1697387695392 .7117156982492 .2650833129991 .8302764892691 .40756225586 90.9973144531290 .5211791992290 .214981079189 .84262847989 .4818649292 89.13250732422 88.79762268066 88.48397827148 88.19953918457 87.94944000244 87.73657989502 87.56257629395 87.42956542969 87.33885192871 87.29105377197 87.28451538086 87.31561279297 87.37743377686 87.16854858398 87.16854858398 87.16854858398 87.16854858398 87.16854858398 87.16854858398 86.86376190186 86.4725646972785 .6446228027384 .4254837036182 .9015579223681 .98719787598 81.9871978759882 .9015579223684 .1206970214885 .3398437585 .94940185547 85.6446228027385 .3398437584 .4254837036183 .5111236572382 .59677124023 81.3776321411180 .7680587768680 .1584930419979 .0725555419978 .29740142822 77.7486877441477 .3060531616276 .8973922729576 .4892501831176 .07692718506 
75.6633834838975 .2877578735474 .9417724609474 .6105117797974 .29326629639 -9999 -9999 -9999 -9999 -9999 -9999 -9999 -9999 -9999 -9999 -9999 -9999 -9999 -9999 -9999 -9999 -9999 -9999 -9999 -9999 -9999 -9999 -9999 -9999 -9999 -9999 -9999 -9999 -9999 -9999 - 9999 -9999 -9999 -9999 -9999 -9999 -9999 -9999 -9999 -9999 -9999 -9999 -9999 -9999 -9999 -9999 -9999 -9999 -9999 -9999-9999-9999-9999

-9999 -9999 -9999 -9999 -9999 -9999 -9999 -9999 -9999 -9999 -9999 -9999 -9999 -9999 -9999

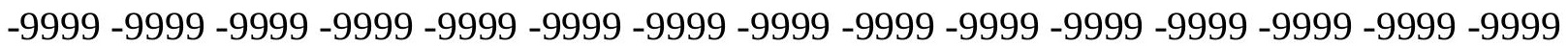
-9999 -9999 -9999 -9999 -9999 -9999 -9999 -9999 -9999 -9999 -9999 -9999 -9999 -9999 -9999 -9999 -9999 -9999 -9999 -9999 -9999 -9999 -9999 -9999 -9999 -9999 -9999 -9999 -9999 -9999 -9999 -9999 -9999 -9999 -9999 -9999 -9999 -9999 -9999 -9999 -9999 -9999 -9999 -9999 -9999 -9999 -9999 -9999 -9999 -9999 -9999 -9999 -9999 -9999 -9999 -9999 -9999 -9999 -9999 -9999 -999 -9999 -9999 -9999 -9999 -9999 -9999 -9999 -9999 -9999 -9999 -9999 -9999 -9999 -9999 -9999 -9999 -9999 -9999 -9999 -9999 -9999 -9999 -9999 -9999 -9999 -9999 -9999 -9999 -9999 -9999 -9999 -9999 -9999 -9999 -9999 -9999 -9999 -9999 -9999 -9999 -9999 -9999 -9999 -9999 -9999 -9999 -9999 -9999 -9999 -9999 -9999 -9999 -9999 -9999 -9999 -9999 -9999 -9999 -9999 -9999

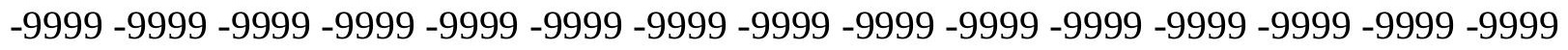
-9999 -9999 -9999 -9999 -9999 -9999 -9999 -9999 -9999 -9999 -9999 -9999 -9999 -9999 -9999 -9999 -9999 -9999 -9999 -9999 -9999 -9999 -9999 -9999 -9999 -9999 -9999 -9999 -9999 -9999 -

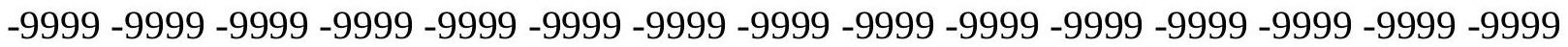

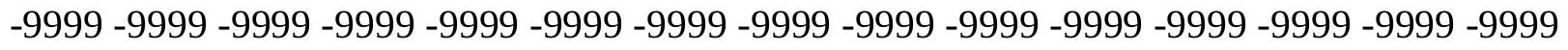

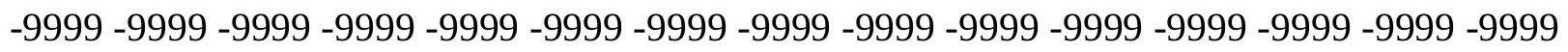

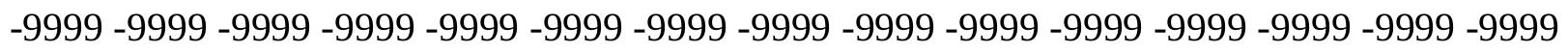
-9999 -9999 135.9342041016133.8007049561 132.2767028809130.1432037354 128.0097961426125 .8762969971123 .742797851699 .6459884643699 .07870483398 98.5194778442497 .9683685302797 .4253845214896 .8906707763796 .36430358887 95.8465576171995 .3376922607494 .8381423950294 .3483047485493 .86873626709 93.3998947143692 .9423294067492 .4964370727592 .0626754760791 .64134979248 91.2328796386790 .8375015258890 .4554595947389 .9116134643689 .72984313965 89.3855590820389 .056365966888 .7483825683688 .4689559936588 .22301483154 88.0134277343887 .8418502807687 .7103118896587 .6199569702187 .57124328613 87.56240844727 87.58985900879 87.64692687988 87.47332763672 87.47332763672 87.4733276367287 .4733276367287 .4733276367287 .4733276367287 .47332763672 87.1010513305786 .5589828491285 .9494018554785 .0350494384884 .42548370361 84.4254837036184 .7302627563585 .0350494384885 .6446228027385 .64462280273 85.3398437584 .7302627563584 .1206970214883 .206336975182 .29197692871 81.3776321411180 .7680587768679 .8537063598679 .2222061157278 .61051177979 78.0621109008877 .6140213012777 .2225570678776 .8486862182676 .48082733154 $76.1157836914175 .7837905883875 .4681549072375 .165458679274 .86487579346-9999$ -9999 -9999 -9999 -9999 -9999 -9999 -9999 -9999 -9999 -9999 -9999 -9999 -9999 -9999 -9999 -9999 -9999 -9999 -9999 -9999 -9999 -9999 -9999 -9999 -9999 -9999 -9999 -9999 -9999 - -999 -

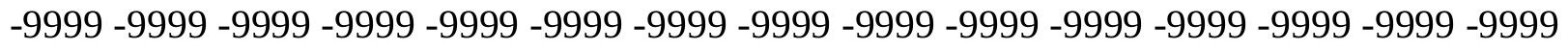
-9999 -9999 -9999-9999-9999-9999-9999

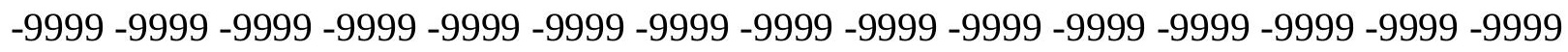
-9999 -9999 -9999 -9999 -9999 -9999 -9999 -9999 -9999-9999 -9999 -9999 -9999 -9999 -9999 -

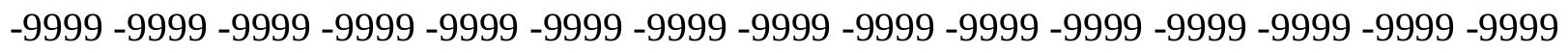

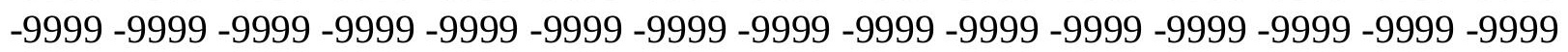


-9999 -9999 -9999 -9999 -9999 -9999 -9999 -9999 -9999 -9999 -9999 -9999 -9999 -9999 -9999 -9999 -9999 -9999 -9999 -9999 -9999 -9999 -9999 -9999 -9999 -9999 -9999 -9999 -9999 -9999 -9999 -9999 -9999 -9999 -9999 -9999 -9999 -9999 -9999 -9999 -9999 -9999 -9999 -9999 -9999 -9999 -9999 -9999 -9999 -9999 -9999 -9999 -9999 -9999 -9999 -9999 -9999 -9999 -9999 -9999 -9999 -9999 -9999 -9999 -9999 -9999 -9999 -9999 -9999 -9999 -9999 -9999 -9999 -9999 -9999 -9999 -9999 -9999 -9999 -9999 -9999 -9999 -9999 -9999 -9999 -9999 -9999 -9999 -9999 -9999 -9999 -9999 -9999 -9999 -9999 -9999 -9999 -9999 -9999 -9999 -9999 -9999 -9999 -9999 -9999

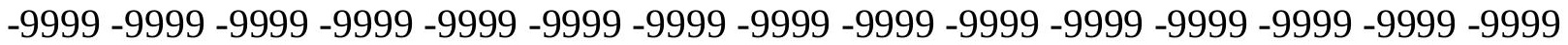
-9999 -9999 -9999 -9999 -9999 -9999 -9999 -9999 -9999 -9999 -9999 -9999 -9999 -9999 -9999 -9999 -9999 -9999 -9999 -9999 -9999 -9999 -9999 -9999 -9999 -9999 -9999 -9999 -9999 -9999 -

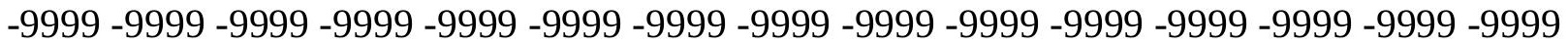
-9999 -9999 -9999 -9999 -9999 -9999 -9999 -9999 -9999 -9999 -9999 -9999 -9999 -9999 -9999 -9999 -9999 -9999 -9999 -9999 -9999 -9999 -9999 -9999 -9999 -9999 -9999 -9999 -9999 -9999 -9999 -9999 135.6293945312133.1911010742 131.6672058105129.8385009766 128.0097961426126 .1809997559124 .047500610499 .8866500854599 .3165512085 98.7547302246198 .2012939453197 .6562597 .1197586059696 .591934204196 .07303619385 95.5633239746195 .0632324218894 .5731430053794 .0935974121193 .62504577637 93.1680374145592 .7229614257892 .290313720791 .8704071044991 .46370697021 91.0705032348690 .691123962490 .2164001464889 .9116134643689 .63379669189 89.31025695801 89.0076599121188.73257446289 88.48963165283 88.28173828125 88.1105575561587 .9779968261787 .8850097656287 .8318252563587 .81657409668 87.8356857299887 .8827209472787 .7781066894587 .7781066894587 .77810668945 87.7781066894587 .7781066894587 .7781066894587 .7781066894587 .47332763672 87.1685485839886 .8637619018686 .5589828491286 .254188537685 .94940185547 85.9494018554785 .9494018554785 .9494018554785 .6446228027385 .33984375 84.4254837036183 .8159103393682 .9015579223681 .9871978759881 .07285308838 80.4632720947379 .5489196777379 .2441329956178 .7353973388778 .23822784424 77.8659591674877 .5628204345777 .268554687576 .9577178955176 .6460647583 76.3342132568476 .0372009277375 .7490463256875 .46269226074 -9999 -9999 -9999 -9999 -9999 -9999 -9999 -9999 -9999 -9999 -9999 -9999 -9999 -9999 -9999 -9999 -9999 -9999 -9999 -9999 -9999 -9999 -9999 -9999 -9999 -9999 -9999 -9999 -9999 -9999 -9999 -9999 -9999 -9999 -

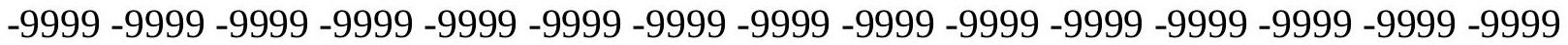
-9999 -9999-9999-9999

-9999 -9999 -9999 -9999 -9999 -9999 -9999 -9999 -9999 -9999 -9999 -9999 -9999 -9999 -9999 -9999 -9999 -9999 -9999 -9999 -9999 -9999 -9999 -9999 -9999 -9999 -9999 -9999 -9999 -9999 -9999 -9999 -9999 -9999 -9999 -9999 -9999 -9999 -9999 -9999 -9999 -9999 -9999 -9999 -9999 -9999 -9999 -9999 -9999 -9999 -9999 -9999 -9999 -9999 -9999 -9999 -9999 -9999 -9999 -9999

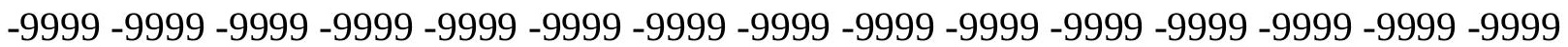
-9999 -9999 -9999 -9999 -9999 -9999 -9999 -9999 -9999 -9999 -9999 -9999 -9999 -9999 -9999 -9999 -9999 -9999 -9999 -9999 -9999 -9999 -9999 -9999 -9999 -9999 -9999 -9999 -9999 -9999 -9999 -9999 -9999 -9999 -9999 -9999 -9999 -9999 -9999 -9999 -9999 -9999 -9999 -9999 -9999

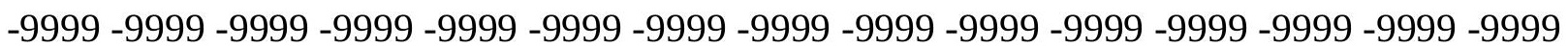
-9999 -9999 -9999 -9999 -9999 -9999 -9999 -9999 -9999 -9999 -9999 -9999 -9999 -9999 -9999 -9999 -9999 -9999 -9999 -9999 -9999 -9999 -9999 -9999 -9999 -9999 -9999 -9999 -9999 -9999 -9999 -9999 -9999 -9999 -9999 -9999 -9999 -9999 -9999 -9999 -9999 -9999 -9999 -9999 -9999

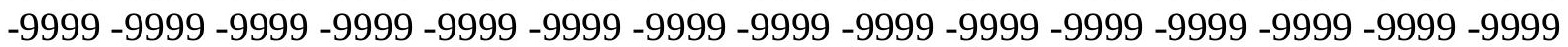


-9999 -9999 -9999 -9999 -9999 -9999 -9999 -9999 -9999 -9999 -9999 -9999 -9999 -9999 -9999 -9999 -9999 -9999 -9999 -9999 -9999 -9999 -9999 -9999 -9999 -9999 -9999 -9999 -9999 -9999 -9999 -9999 -9999 -9999 -9999 -9999 -9999 -9999 -9999 -9999 -9999 -9999 -9999 -9999 -9999 -9999 -9999 -9999 -9999 -9999 -9999 -9999 -9999 -9999 -9999 -9999 -9999 -9999 -9999 -9999 -9999 -9999-9999 133.8007049561 131.9720001221 130.1432037354128.3144989014 126.4858016968124 .3523025513122 .523597717399 .5481796264698 .98384857178 98.428153991797 .881141662697 .3429794311596 .8137893676896 .29384613037 95.7833938598695 .2828674316494 .7926254272594 .313201904393 .84502410889 93.3886413574292 .9444351196392 .5129165649492 .0944366455191 .68948364258 91.2983856201290 .9215698242290 .5211791992290 .210655212489 .87643432617 89.5583419799889 .2607040405388 .9892349243288 .7482376098688 .54062652588 88.3680877685588 .2323532104588 .1341629028388 .073524475188 .04844665527 88.0553970336988 .0829010009888 .0829010009888 .0829010009888 .08290100098 87.7781066894587 .7781066894587 .7781066894587 .7781066894587 .77810668945 87.7781066894587 .4733276367287 .4733276367287 .1685485839886 .86376190186 86.5589828491286 .5589828491286 .254188537685 .6446228027385 .03504943848 84.4254837036183 .5111236572382 .5967712402381 .6824111938580 .76805877686 79.8537063598679 .5489196777379 .2441329956178 .6620788574278 .28748321533 78.1009216308677 .9503784179777 .7539825439577 .5170669555777 .24046325684 76.9463119506876 .6479644775476 .3619613647576 .0841293335 -9999 -9999 -9999 -9999 -9999 -9999 -9999 -9999 -9999 -9999 -9999 -9999 -9999 -9999 -9999 -9999 -9999 -9999 -9999 -9999 -9999 -9999 -9999 -9999 -9999 -9999 -9999 -9999 -9999 -9999 -9999 -9999 -9999 -9999 -9999 -9999 -9999 -9999 -9999 -9999 -9999 -9999 -9999 -9999 -9999 -9999 -9999 -9999 -9999 $-9999-9999-9999-9999$

-9999 -9999 -9999 -9999 -9999 -9999 -9999 -9999 -9999 -9999 -9999 -9999 -9999 -9999 -9999 -9999 -9999 -9999 -9999 -9999 -9999 -9999 -9999 -9999 -9999 -9999 -9999 -9999 -9999 -9999 -9999 -9999 -9999 -9999 -9999 -9999 -9999 -9999 -9999 -9999 -9999 -9999 -9999 -9999 -9999 -9999 -9999 -9999 -9999 -9999 -9999 -9999 -9999 -9999 -9999 -9999 -9999 -9999 -9999 -9999 -9999 -9999 -9999 -9999 -9999 -9999 -9999 -9999 -9999 -9999 -9999 -9999 -9999 -9999 -9999 -9999 -9999 -9999 -9999 -9999 -9999 -9999 -9999 -9999 -9999 -9999 -9999 -9999 -9999 -9999 -9999 -9999 -9999 -9999 -9999 -9999 -9999 -9999 -9999 -9999 -9999 -9999 -9999 -9999 -9999 -9999 -9999 -9999 -9999 -9999 -9999 -9999 -9999 -9999 -9999 -9999 -9999 -9999 -9999 -9999 -9999 -9999 -9999 -9999 -9999 -9999 -9999 -9999 -9999 -9999 -9999 -9999 -9999 -9999 -9999 -9999 -9999 -9999 -9999 -9999 -9999 -9999 -9999 -9999 -9999 -9999 -9999 -9999 -9999 -9999 -

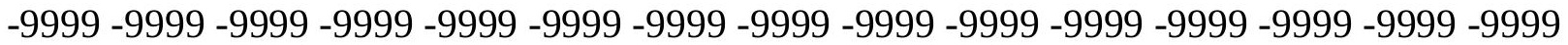
-9999 -9999 -9999 -9999 -9999 -9999 -9999 -9999 -9999 -9999 -9999 -9999 -9999 -9999 -9999 -9999 -9999 -9999 -9999 -9999 -9999 -9999 -9999 -9999 -9999 -9999 -9999 -9999 -9999 -9999

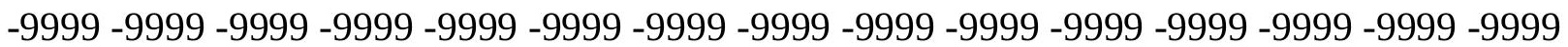
-9999 -9999 -9999 -9999 -9999 -9999 -9999 -9999 -9999 -9999 -9999 -9999 -9999 -9999 -9999 -9999 -9999 -9999 -9999 -9999 -9999 -9999 -9999 -9999 -9999 -9999 -9999 -9999 -9999 -9999 -9999 -9999 -9999 -9999 -9999 -9999 -9999 -9999 -9999 -9999 -9999 -9999 -9999 -9999 -9999 -9999 -9999-9999 134.7149963379 132.5814971924130 .7528076172128 .9241027832 127.0953979492124 .9618988037123 .133201599199 .7736740112399 .20687866211 98.648994445898 .1000900268697 .5603485107497 .0298843383896 .50897979736 95.9978790283295 .4969940185595 .0066757202194 .5274429321394 .05970001221 93.6039810180793 .1606750488392 .7302932739392 .313201904391 .90992736816 
91.5208358764691 .1464309692490 .7868881225690 .4423065185590 .11274719238 89.79970550537 89.50653076172 89.237998962488.9980545043988.7896194458 88.6143112182688 .4736862182688 .3682937622188 .2979278564588 .26050567627 88.2526016235488 .2685165405388 .3005752563588 .3388519287188 .08290100098 88.0829010009888 .0829010009888 .0829010009888 .0829010009888 .08290100098 88.0829010009887 .7781066894587 .7781066894587 .4733276367287 .16854858398 87.1685485839886 .5589828491286 .254188537685 .6446228027385 .03504943848 84.1206970214883 .5111236572382 .5967712402381 .6824111938580 .46327209473 79.5489196777379 .2441329956178 .9393463134878 .3297805786178 .30978393555 78.3580398559678 .3989028930778 .3237228393678 .1453170776477 .89459228516 77.6064758300877 .303848266677 .0024566650476 .71949768066 -9999 -9999 -9999 -9999 -9999 -9999 -9999 -9999 -9999 -9999 -9999 -9999 -9999 -9999 -9999 -9999 -9999 -9999 -9999 -9999 -9999 -9999 -9999 -9999 -9999 -9999 -9999 -9999 -9999 -9999 -9999 -9999 -9999 -9999 -

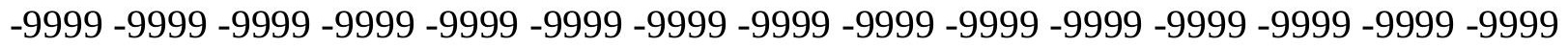
-9999 -9999-9999-9999

-9999 -9999 -9999 -9999 -9999 -9999 -9999 -9999 -9999-9999 -9999 -9999 -9999 -9999 -9999 -9999 -9999 -9999 -9999 -9999 -9999 -9999 -9999 -9999 -9999 -9999 -9999 -9999 -9999 -9999 -9999 -9999 -9999 -9999 -9999 -9999 -9999 -9999 -9999 -9999 -9999 -9999 -9999 -9999 -9999 -

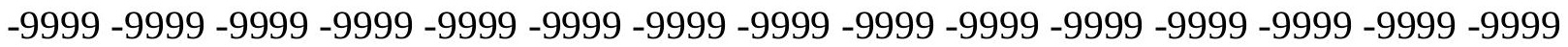

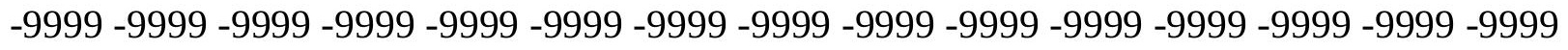

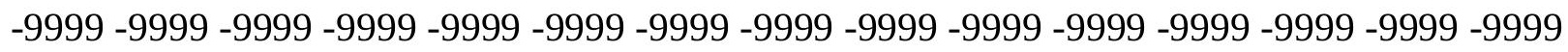
-9999 -9999 -9999 -9999 -9999 -9999 -9999 -9999 -9999 -9999 -9999 -9999 -9999 -9999 -9999 -9999 -9999 -9999 -9999 -9999 -9999 -9999 -9999 -9999 -9999 -9999 -9999 -9999 -9999 -9999 -

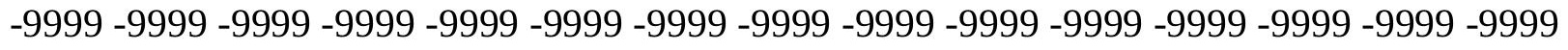

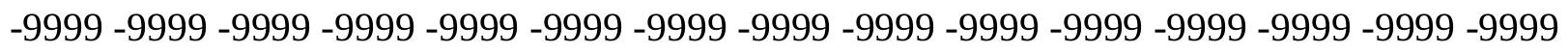
-9999 -9999 -9999 -9999 -9999 -9999 -9999 -9999 -9999 -9999 -9999 -9999 -9999 -9999 -9999 -9999 -9999 -9999 -9999 -9999 -9999 -9999 -9999 -9999 -9999 -9999 -9999 -9999 -9999 - -9999 -

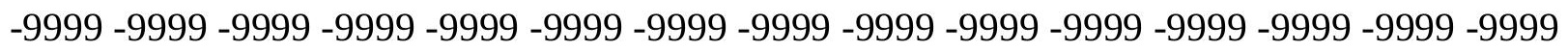
-9999 -9999 -9999 -9999 -9999 -9999 -9999 -9999 -9999 -9999 -9999 -9999 -9999 -9999 -9999 -9999 -9999 -9999 -9999 -9999 -9999 -9999 -9999 -9999 -9999 -9999 -9999 -9999 -9999 -9999 -9999 -9999 -9999 -9999 -9999 -9999 -9999 -9999 -9999 -9999 -9999 -9999-9999 -9999 -9999 -9999 -9999 -9999 -9999 -9999 -9999 -9999 -9999 -9999 -9999 -9999 -9999 -9999 -9999 -9999 -9999 -9999-9999-9999 133.4909667969 131.4851379395129.533706665 127.7050018311 125.8762969971123 .7427978516121 .914001464899 .4238204956198 .86380767822 98.3130722045997 .7718124389697 .2401428222796 .7183609008896 .20668029785 95.7055053710995.2151794433694.7361755371194.2688980102593.81386566162 93.3714599609492 .9421844482492 .5264282226692 .1247329711991 .73750305176 91.3653182983491 .0084915161190 .6673202514690 .3419570922990 .0334777832 89.7442703247189 .4781417846789 .2386322021589 .0286102294988 .84957885742 88.702850341888 .5888290405388 .5072326660288 .4559402465888 .43164825439 88.42914581299 88.38768768311 88.38768768311 88.38768768311 88.38768768311 88.3876876831188 .0829010009888 .0829010009888 .0829010009888 .08290100098 88.0829010009887 .7781066894587 .7781066894587 .4733276367287 .16854858398 86.8637619018686 .254188537685 .6446228027385 .0350494384884 .12069702148 83.5111236572382 .5967712402381 .6824111938580 .4632720947379 .85370635986 79.2441329956178 .6345596313578 .0249862670978 .3297805786178 .64455413818 
78.880714416578 .9313125610478 .8152770996178 .5906982421978 .30391693115 77.9884643554777 .6745376586977 .374168396 -9999 -9999 -9999 -9999 -9999 -9999 -9999 -9999 -9999 -9999 -9999 -9999 -9999 -9999 -9999 -9999 -9999 -9999 -9999 -9999 -9999 -9999 -

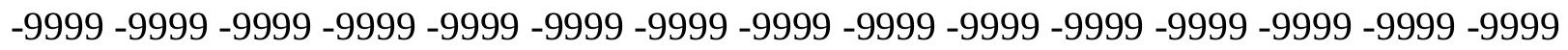

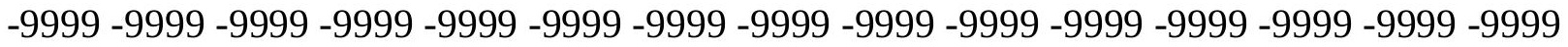
$-9999$

-9999 -9999 -9999 -9999 -9999 -9999 -9999 -9999 -9999 -9999 -9999 -9999 -9999 -9999 -9999

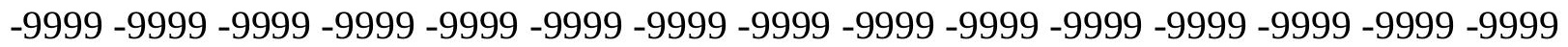
-9999 -9999 -9999 -9999 -9999 -9999 -9999 -9999 -9999 -9999 -9999 -9999 -9999 -9999 -9999 -9999 -9999 -9999 -9999 -9999 -9999 -9999 -9999 -9999 -9999 -9999 -9999 -9999 -9999 -9999 -9999 -9999 -9999 -9999 -9999 -9999 -9999 -9999 -9999 -9999 -9999 -9999 -9999 -9999 -9999 -999 -9999 -9999 -9999 -9999 -9999 -9999 -9999 -9999 -9999 -9999 -9999 -9999 -9999 -9999 -9999 -9999 -9999 -9999 -9999 -9999 -9999 -9999 -9999 -9999 -9999 -9999 -9999 -9999 -9999 -9999 -9999 -9999 -9999 -9999 -9999 -9999 -9999 -9999 -9999 -9999 -9999 -9999 -9999 -9999 -9999 -9999 -9999 -9999 -9999 -9999 -9999 -9999 -9999 -9999 -9999 -9999 -9999 -9999 -9999 -9999

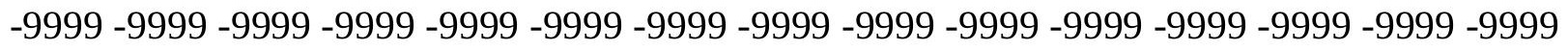
-9999 -9999 -9999 -9999 -9999 -9999 -9999 -9999 -9999 -9999 -9999 -9999 -9999 -9999 -9999 -

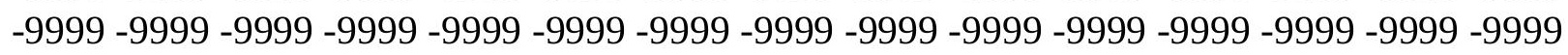
-9999 -9999 -9999 -9999 -9999 -9999 -9999 -9999 -9999 -9999 -9999 -9999 -9999 -9999 -9999

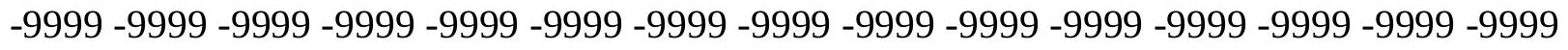

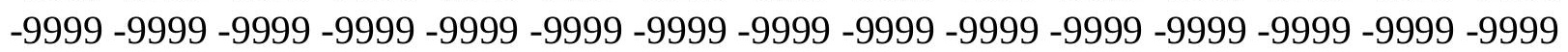

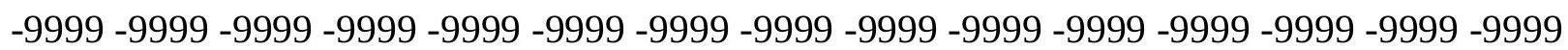
-9999 -9999 -9999 -9999 -9999 -9999 -9999 -9999 -9999 -9999 -9999 -9999 -9999 -9999 -9999 -9999 -9999 -9999 -9999 134.4102020264132.3315124512130.4479980469128.6192932129 126.4858016968124 .6570968628122 .828399658299 .6347427368299 .07263946533 98.5201187133897 .97739410497 .4445877075296 .9219741821396 .40977478027 95.9083709716895 .4180755615294 .9393386840894 .4725418090894 .01819610596 93.5766601562593 .1484527587992 .7339401245192 .3336944580191 .94815063477 91.5779266357491 .2234649658290 .8852310180790 .2164001464890 .21640014648 89.91161346436 89.60682678223 89.47019958496 89.25827789307 89.07511901855 88.9217605590888 .7984466552788 .7049636840888 .6393508911188 .59837341309 88.5771408081188 .5694122314588 .566963195888 .5600891113388 .38768768311 88.38768768311 88.38768768311 88.28003692627 88.08290100098 88.08290100098 88.0829010009887 .7781066894587 .7781066894587 .4733276367287 .16854858398 86.5589828491286 .254188537685 .6446228027385 .0350494384884 .12069702148 83.5111236572382 .5967712402381 .6824111938580 .7680587768680 .15849304199 79.2441329956178 .6345596313578 .0249862670977 .7202072143678 .93934631348 79.3079071044979 .4960784912179 .4712448120179 .2887191772579 .00964355469 78.6943740844778 .3585586547978 .04064178467 -9999 -9999 -9999 -9999 -9999 -9999 -9999 -9999 -9999 -9999 -9999 -9999 -9999 -9999 -9999 -9999 -9999 -9999 -9999 -9999 -9999 -9999

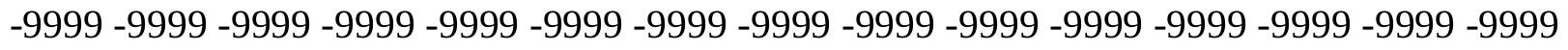
-9999 -9999 -9999 -9999 -9999 -9999 -9999 -9999 -9999 -9999 -9999 -9999 -9999 -9999 -9999 $-9999$

-9999 -9999 -9999 -9999 -9999 -9999 -9999 -9999 -9999 -9999 -9999 -9999 -9999 -9999 -9999 -9999 -9999 -9999 -9999 -9999 -9999 -9999 -9999 -9999 -9999 -9999 -9999 -9999 -9999 -9999 -

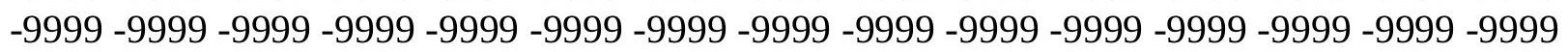


-9999 -9999 -9999 -9999 -9999 -9999 -9999 -9999 -9999 -9999 -9999 -9999 -9999 -9999 -9999 -9999 -9999 -9999 -9999 -9999 -9999 -9999 -9999 -9999 -9999 -9999 -9999 -9999 -9999 -9999 -9999 -9999 -9999 -9999 -9999 -9999 -9999 -9999 -9999 -9999 -9999 -9999 -9999 -9999 -9999 -9999 -9999 -9999 -9999 -9999 -9999 -9999 -9999 -9999 -9999 -9999 -9999 -9999 -9999 -9999 -9999 -9999 -9999 -9999 -9999 -9999 -9999 -9999 -9999 -9999 -9999 -9999 -9999 -9999 -9999 -9999 -9999 -9999 -9999 -9999 -9999 -9999 -9999 -9999 -9999 -9999 -9999 -9999 -9999 -9999 -9999 -9999 -9999 -9999 -9999 -9999 -9999 -9999 -9999 -9999 -9999 -9999 -9999 -9999 -9999

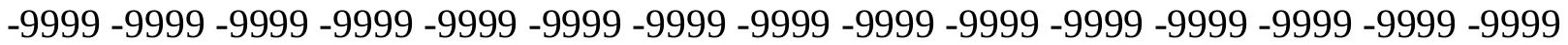
-9999 -9999 -9999 -9999 -9999 -9999 -9999 -9999 -9999 -9999 -9999 -9999 -9999 -9999 -9999 -9999 -9999 -9999 -9999 -9999 -9999 -9999 -9999 -9999 -9999 -9999 -9999 -9999 -9999 -9999 -

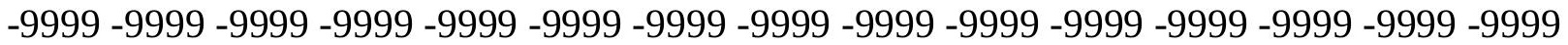
-9999 -9999 -9999 -9999 -9999 -9999 -9999 -9999 -9999 -9999 -9999 -9999 -9999 -9999 -9999

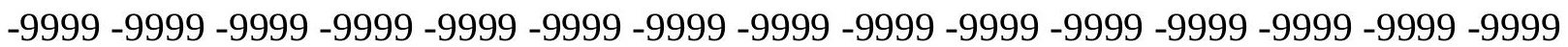
-9999 -9999 -9999 -9999 -9999 -9999 -9999 -9999 -9999 -9999 -9999 -9999 -9999 -9999 -9999 -9999 -9999 -9999 -9999-9999 133.2666168213 131.3623962402 129.533706665 127.4001998901125 .5715026855123 .742797851699 .8396453857499 .27546691895 98.7211914062598 .1770477294997 .643142700297 .1197509765696 .60707092285 96.1054763793995 .6152420043995 .1367950439594 .670486450294 .21681213379 93.7761154174893 .3488845825292 .9355087280392 .5365600585992 .1524887085 91.7839508056691 .4314422607490 .8259735107489 .9116134643689 .91161346436 89.9116134643689 .6068267822389 .6068267822389 .302040100189 .29231262207 89.1325836181689 .0002899169988 .8952713012788 .8158874511788 .75910949707 88.720138549888 .6931457519588 .6708679199288 .6451568603588 .60847473145 88.5545043945388 .3876876831188 .3876876831188 .3876876831188 .08290100098 88.0829010009887 .7781066894587 .7781066894587 .4733276367287 .16854858398 86.5589828491286 .254188537685 .6446228027385 .0350494384884 .42548370361 83.5111236572382 .9015579223681 .9871978759881 .0728530883880 .46327209473 79.8537063598678 .9393463134878 .3297805786177 .7202072143678 .32978057861 79.5489196777379 .9482116699280 .0365219116279 .9351654052779 .69822692871 79.3878784179779 .0495605468878 .70854949951 -9999 -9999 -9999 -9999 -9999 -9999 -9999 -9999 -9999 -9999 -9999 -9999 -9999 -9999 -9999 -9999 -9999 -9999 -9999 -9999 -9999 -9999 -9999 -9999 -9999 -9999 -9999 -9999 -9999 -9999 -9999 -9999 -9999 -9999 -9999 -9999 -9999 -9999 -9999 -9999 -9999 -9999 -9999 -9999 -9999 -9999 -9999 -9999 -9999 -9999 -9999 -9999 $-9999$

-9999 -9999 -9999 -9999 -9999 -9999 -9999 -9999 -9999 -9999 -9999 -9999 -9999 -9999 -9999 -9999 -9999 -9999 -9999 -9999 -9999 -9999 -9999 -9999 -9999 -9999 -9999 -9999 -9999 -9999 -9999 -9999 -9999 -9999 -9999 -9999 -9999 -9999 -9999 -9999 -9999 -9999 -9999 -9999 -9999

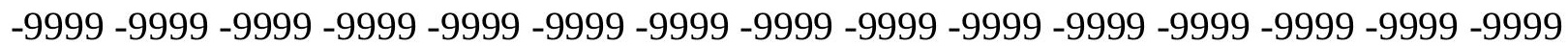
-9999 -9999 -9999 -9999 -9999 -9999 -9999 -9999 -9999 -9999 -9999 -9999 -9999 -9999 -9999 -9999 -9999 -9999 -9999 -9999 -9999 -9999 -9999 -9999 -9999 -9999 -9999 -9999 -9999 -9999 -9999 -9999 -9999 -9999 -9999 -9999 -9999 -9999 -9999 -9999 -9999 -9999 -9999 -9999 -9999 -9999 -9999 -9999 -9999 -9999 -9999 -9999 -9999 -9999 -9999 -9999 -9999 -9999 -9999 -9999 -9999 -9999 -9999 -9999 -9999 -9999 -9999 -9999 -9999 -9999 -9999 -9999 -9999 -9999 -9999 -9999 -9999 -9999 -9999 -9999 -9999 -9999 -9999 -9999 -9999 -9999 -9999 -9999 -9999 -9999 -9999 -9999 -9999 -9999 -9999 -9999 -9999 -9999 -9999 -9999 -9999 -9999 -9999 -9999 -9999

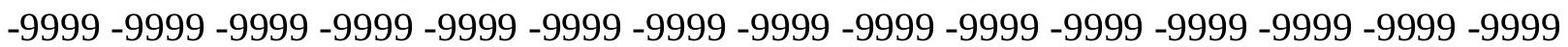


-9999 -9999 -9999 -9999 -9999 -9999 -9999 -9999 -9999 -9999 -9999 -9999 -9999 -9999 -9999 -9999 -9999 -9999 -9999 -9999 -9999 -9999 -9999 -9999 -9999 -9999 -9999 -9999 -9999 -9999

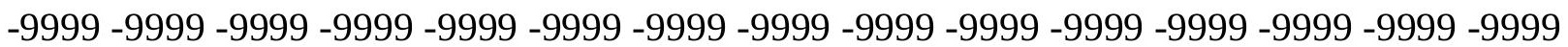
-9999 -9999 -9999 -9999 -9999 -9999 -9999 -9999 -9999 -9999 -9999 -9999 -9999 -9999 -9999 -9999 -9999 -9999 -9999 -9999 -9999 -9999 -9999 -9999 -9999 -9999 -9999 -9999 -9999 -9999 -9999 -9999 -9999 -9999 -9999 134.4102020264132.3628234863130.4479980469 128.6192932129126 .4858016968124 .6570968628122 .828399658299 .47233581543 98.9163208007898 .3707656860497 .8357849121197 .3116378784296 .79851531982 96.2967605590895 .8066101074295 .3284683227594 .8626480102594 .40961456299 93.9696884155393 .5433578491293 .1309890747192 .7331619262792 .35033416748 91.9831695556691 .6322250366290 .5211791992289 .9116134643689 .91161346436 89.6068267822389 .6068267822389 .6068267822389 .302040100189 .3020401001 89.3020401001 89.19728851318 89.0822525024488.9907150268688.91999053955 88.8654556274488 .8214950561588 .7815628051888 .7389221191488 .68984985352 88.6365432739388 .5833969116288 .5219879150488 .3876876831188 .38768768311 88.0829010009888 .0829010009887 .7781066894587 .4733276367287 .16854858398 86.5589828491286 .254188537685 .6446228027385 .0350494384884 .42548370361 83.8159103393682 .9015579223682 .2919769287181 .3776321411180 .76805877686 80.1584930419979 .5489196777378 .9393463134878 .3297805786178 .32978057861 79.2441329956180 .1584930419980 .4597778320380 .4846191406280 .30780029297 80.0400543212979 .715255737379 .36693572998 -9999 -9999 -9999 -9999 -9999 -9999 -9999 -9999 -9999 -9999 -9999 -9999 -9999 -9999 -9999 -9999 -9999 -9999 -9999 -9999 -9999 -9999 -9999 -9999 -9999 -9999 -9999 -9999 -9999 -9999 -9999 -9999 -9999 -9999 -9999 -9999 -9999 -9999 -9999 -9999 -9999 -9999 -9999 -9999 -9999 -9999 -9999 -9999 -9999 -9999 -9999 -9999 $-9999$

-9999 -9999 -9999 -9999 -9999 -9999 -9999 -9999 -9999 -9999 -9999 -9999 -9999 -9999 -9999 -9999 -9999 -9999 -9999 -9999 -9999 -9999 -9999 -9999 -9999 -9999 -9999 -9999 -9999 -9999 -9999 -9999 -9999 -9999 -9999 -9999 -9999 -9999 -9999 -9999 -9999 -9999 -9999 -9999 -9999 -9999 -9999 -9999 -9999 -9999 -9999 -9999 -9999 -9999 -9999 -9999 -9999 -9999 -9999 -9999 -9999 -9999 -9999 -9999 -9999 -9999 -9999 -9999 -9999 -9999 -9999 -9999 -9999 -9999 -9999 -9999 -9999 -9999 -9999 -9999 -9999 -9999 -9999 -9999 -9999 -9999 -9999 -9999 -9999 -9999 -9999 -9999 -9999 -9999 -9999 -9999 -9999 -9999 -9999 -9999 -9999 -9999 -9999 -9999 -9999 -9999 -9999 -9999 -9999 -9999 -9999 -9999 -9999 -9999 -9999 -9999 -9999 -9999 -9999 -9999 -9999 -9999 -9999 -9999 -9999 -9999 -9999 -9999 -9999 -9999 -9999 -9999 -9999 -9999 -9999

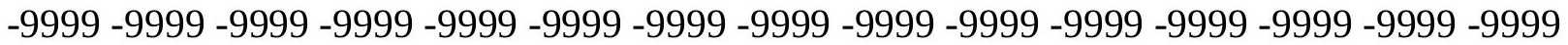
-9999 -9999 -9999 -9999 -9999 -9999 -9999 -9999 -9999 -9999 -9999 -9999 -9999 -9999 -9999 -9999 -9999 -9999 -9999 -9999 -9999 -9999 -9999 -9999 -9999 -9999 -9999 -9999 -9999 -9999

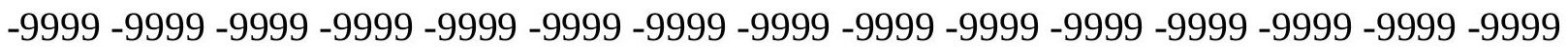
-9999 -9999 -9999 -9999 -9999 -9999 -9999 -9999 -9999 -9999 -9999 -9999 -9999 -9999 -9999 -9999 -9999 -9999 -9999 -9999 -9999 -9999 -9999 -9999 -9999 -9999 -9999 -9999 -9999 -9999 -9999 -9999 -9999 -9999 -9999 -9999 -9999 -9999 -9999 -9999 -9999 -9999 -9999 -9999 -9999 -9999 -9999 -9999 -9999 -9999 -9999 -9999 -9999 -9999 -9999 -9999 -9999 -9999 -9999 -9999 -9999 -9999 -9999 -9999 -9999 -9999 133.3523712158 131.3623962402 129.533706665 127.7050018311125 .5715026855123 .742797851699 .6632080078199 .10543823242 98.5584640502998 .0224151611397 .4975280761796 .9839706420996 .48206329346 95.9920120239395 .5141754150495 .0488357543994 .5964126586994 .15720367432 
93.7316741943493 .320175170992 .9232788085992 .541435241792 .17533111572 91.4355392456189 .9116134643689 .6068267822389 .6068267822389 .60682678223 89.302040100189.302040100189.302040100189.302040100189.302040100189.3020401001 89.2680130004989 .1668930053788 .9972534179788 .9972534179788 .96016693115 88.9064712524488 .8513107299888 .7918395996188 .7342681884888 .67620849609 88.6450119018688 .6924667358488 .3876876831188 .3876876831188 .08290100098 87.7781066894587 .4733276367287 .1685485839886 .8637619018686 .2541885376 85.94940185547 85.33984375 84.73026275635 84.12069702148 83.2063369751 82.5967712402381 .9871978759881 .0728530883880 .4632720947379 .85370635986 79.2441329956178 .9393463134878 .3297805786179 .2441329956179 .85370635986 80.7680587768680 .8818588256880 .8125076293980 .6334533691480 .34610748291 80.0018615722779 .63083648682 -9999 -9999-9999 -9999 -9999 -9999 -9999 -9999 -9999 -9999 -9999 -9999 -9999 -9999 -9999 -9999 -9999 -9999 -9999 -9999 -9999 -9999 -9999 -9999 -9999 -9999 -9999 -9999 -9999 -9999 -9999 -9999 -9999 -9999 -9999 -9999 -9999 -9999 -9999 -9999 -9999 -9999 -9999 -9999 -9999 -9999 -9999 -9999 -9999 -9999 -9999 -9999 -

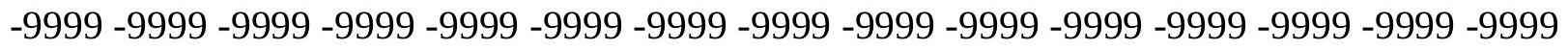
-9999 -9999 -9999 -9999 -9999 -9999 -9999 -9999 -9999 -9999 -9999 -9999 -9999 -9999 -9999 -9999 -9999 -9999 -9999 -9999 -9999 -9999 -9999 -9999 -9999 -9999 -9999 -9999 -9999 -9999 -

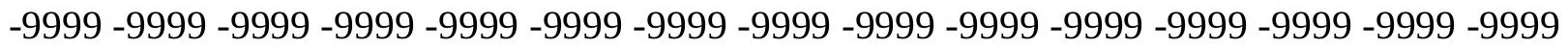

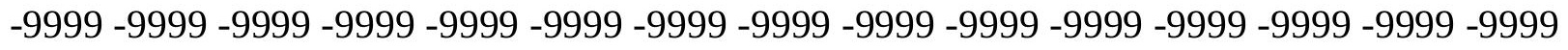

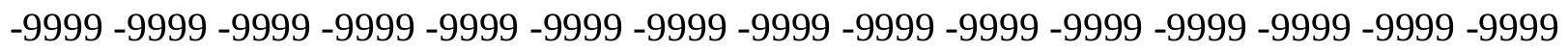
-9999 -9999 -9999 -9999 -9999 -9999 -9999 -9999 -9999 -9999 -9999 -9999 -9999 -9999 -9999 -9999 -9999 -9999 -9999 -9999 -9999 -9999 -9999 -9999 -9999 -9999 -9999 -9999 -9999 -9999 -

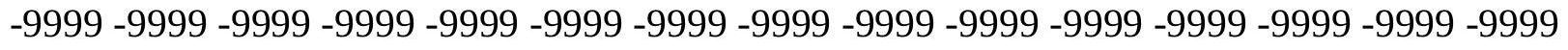

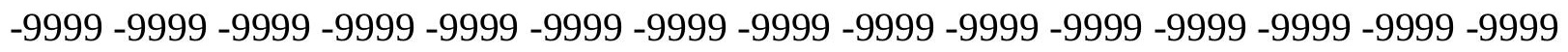
-9999 -9999 -9999 -9999 -9999 -9999 -9999 -9999 -9999 -9999 -9999 -9999 -9999 -9999 -9999 -9999 -9999 -9999 -9999 -9999 -9999 -9999 -9999 -9999 -9999 -9999 -9999 -9999 -9999 - -9999 -

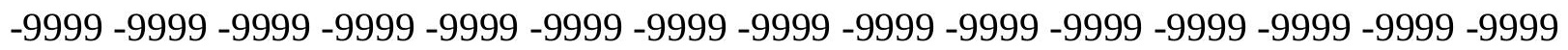
-9999 -9999 -9999 -9999 -9999 -9999 -9999 -9999 -9999 -9999 -9999 -9999 -9999 -9999 -9999 -9999 -9999 -9999 -9999 -9999 -9999 -9999 -9999 -9999 -9999 -9999 -9999 -9999 -9999 -9999 -9999 -9999 -9999 -9999 -9999 -9999 -9999 -9999 -9999 -9999 -9999 -9999-9999 -9999 -9999 -9999 -9999 -9999 -9999 -9999 -9999 -9999 -9999 -9999 -9999 -9999 -9999 -9999 -9999 -9999 -9999 -9999-9999-9999-9999-9999-9999 132.476776123 130.4479980469 128.6192932129 126.7906036377124 .9618988037122 .828399658299 .2885589599698 .74015045166 98.2030029296997 .6773605346797 .163360595796 .6613006591896 .17134094238 95.6938095092895 .228927612394 .7770767211994 .3385238647593 .91369628906 93.5029220581193.10676574707 92.7256546020591.74033355713 89.91161346436 89.302040100189.302040100189.302040100189.302040100189.302040100189.3020401001 89.3020401001 89.302040100189.302040100189.302040100189.302040100189.3020401001 89.25296020508 89.17635345459 89.10912322998 88.99725341797 88.98413085938 88.9245071411188 .8709869384888 .8095855712988 .6924667358488 .69246673584 88.69246673584 88.38768768311 88.08290100098 88.08290100098 87.77810668945 87.47332763672 86.8637619018686.55898284912 85.9494018554785.33984375 85.0350494384884 .4254837036183 .5111236572382 .9015579223682 .29197692871 81.6824111938581 .0728530883880 .4632720947379 .8537063598679 .24413299561 78.9393463134879 .2441329956179 .8537063598680 .7680587768681 .07285308838 
81.26573944092 81.1734848022580.92825317383 80.5954132080180.21949005127 -9999 -9999 -9999 -9999 -9999 -9999 -9999 -9999 -9999 -9999 -9999 -9999 -9999 -9999 -9999 -9999

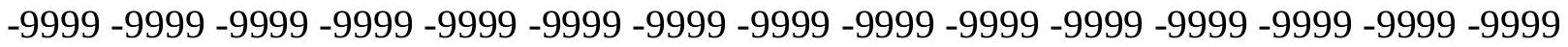
-9999 -9999 -9999 -9999 -9999 -9999 -9999 -9999 -9999 -9999 -9999 -9999 -9999 -9999 -9999 -9999 -9999 -9999-9999-9999-9999

-9999 -9999 -9999 -9999 -9999 -9999 -9999 -9999 -9999 -9999 -9999 -9999 -9999 -9999 -9999

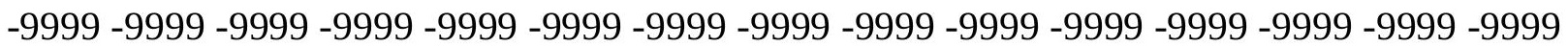

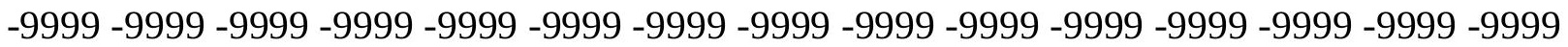

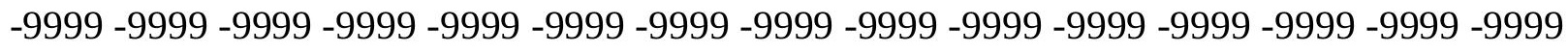
-9999 -9999 -9999 -9999 -9999 -9999 -9999 -9999 -9999 -9999 -9999 -9999 -9999 -9999 -9999

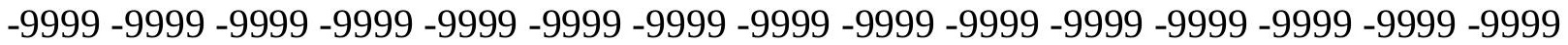
-9999 -9999 -9999 -9999 -9999 -9999 -9999 -9999 -9999 -9999 -9999 -9999 -9999 -9999 -9999 -9999 -9999 -9999 -9999 -9999 -9999 -9999 -9999 -9999 -9999 -9999 -9999 -9999 -9999 -9999 -9999 -9999 -9999 -9999 -9999 -9999 -9999 -9999 -9999 -9999 -9999 -9999 -9999 -9999 - 9999 -9999 -9999 -9999 -9999 -9999 -9999 -9999 -9999 -9999 -9999 -9999 -9999 -9999 -9999 -9999

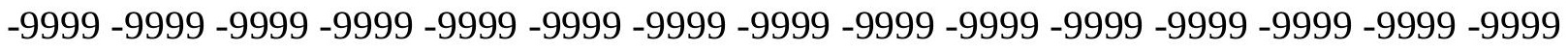
-9999 -9999 -9999 -9999 -9999 -9999 -9999 -9999 -9999 -9999 -9999 -9999 -9999 -9999 -9999 -9999 -9999 -9999 -9999 -9999 -9999 -9999 -9999 -9999 -9999 -9999 -9999 -9999 -9999 -9999 -9999 -9999 -9999 -9999 -9999 -9999 -9999 -9999 -9999 -9999 -9999 -9999 -9999 -9999 -9999 -

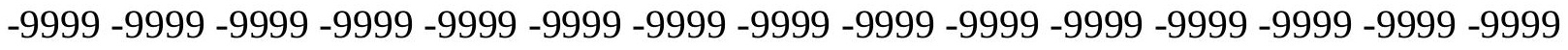

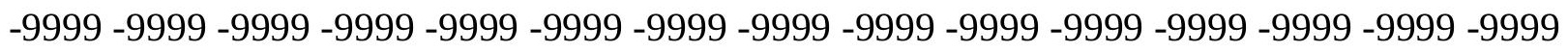
-9999 -9999 -9999 -9999 -9999 -9999 -9999 -9999 -9999 -9999 -9999 -9999 -9999 -9999 -9999 -9999 -9999 -9999 -9999-9999-9999-9999 133.4958953857131 .6221466064129 .6721343994 127.7050018311125 .8762969971124 .047500610499 .4656295776498 .91572570801 98.3774414062597 .851005554297 .3365325927796 .8342971801896 .34440612793 95.8671569824295 .4027099609494 .9514007568494 .5134429931694 .08922576904 93.6790466308693 .2834243774492 .9027938842890 .5211791992288 .38768768311 88.38768768311 88.69246673584 88.69246673584 88.99725341797 88.99725341797 88.99725341797 88.9972534179788.99725341797 89.302040100189.3020401001 89.3020401001 89.302040100189.302040100189.302040100189.26284790039 89.1958160400489 .1327133178789 .0730819702188 .9972534179788 .9933013916 88.99725341797 88.69246673584 88.69246673584 88.38768768311 88.38768768311 88.0829010009887 .7781066894587 .4733276367287 .1685485839886 .55898284912 86.2541885376 85.64462280273 85.03504943848 84.7302627563584.12069702148 83.5111236572382 .9015579223682 .2919769287181 .6824111938581 .07285308838 80.4632720947379 .8537063598679 .5489196777379 .5489196777380 .15849304199 80.7680587768681 .3776321411181 .6824111938581 .6156845092881 .43950653076 81.1422805786180 .76995849609 -9999 -9999 -9999 -9999 -9999 -9999 -9999 -9999 -9999 -9999 -9999 -9999 -9999 -9999 -9999 -9999 -9999 -9999 -9999 -9999 -9999 -9999 -9999 -9999 -9999 -9999 -9999 -9999 -9999 -9999 -9999 -9999 -9999 -9999 -9999 -9999 -9999 -9999 -9999 -

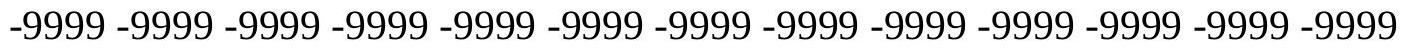

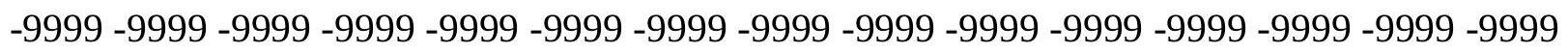
-9999 -9999 -9999 -9999 -9999 -9999 -9999 -9999 -9999 -9999 -9999 -9999 -9999 -9999 -9999 -9999 -9999 -9999 -9999 -9999 -9999 -9999 -9999 -9999-9999 -9999 -9999 -9999 -9999 -9999 -9999 -9999 -9999 -9999 -9999 -9999 -9999 -9999 -9999 -9999 -9999 -9999 -9999 -9999 -9999 -

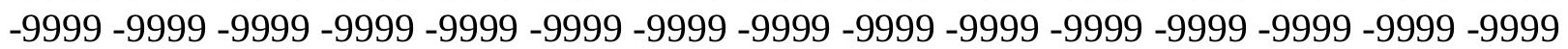


-9999 -9999 -9999 -9999 -9999 -9999 -9999 -9999 -9999 -9999 -9999 -9999 -9999 -9999 -9999 -9999 -9999 -9999 -9999 -9999 -9999 -9999 -9999 -9999 -9999 -9999 -9999 -9999 -9999 -9999 -9999 -9999 -9999 -9999 -9999 -9999 -9999 -9999 -9999 -9999 -9999 -9999 -9999 -9999 -9999 -9999 -9999 -9999 -9999 -9999 -9999 -9999 -9999 -9999 -9999 -9999 -9999 -9999 -9999 -9999 -9999 -9999 -9999 -9999 -9999 -9999 -9999 -9999 -9999 -9999 -9999 -9999 -9999 -9999 -9999 -9999 -9999 -9999 -9999 -9999 -9999 -9999 -9999 -9999 -9999 -9999 -9999 -9999 -9999 -9999 -9999 -9999 -9999 -9999 -9999 -9999 -9999 -9999 -9999 -9999 -9999 -9999 -9999 -9999 -9999

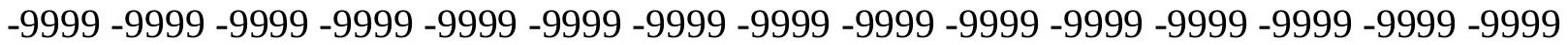
-9999 -9999 -9999 -9999 -9999 -9999 -9999 -9999 -9999 -9999 -9999 -9999 -9999 -9999 -9999 -9999 -9999 -9999 -9999 -9999 -9999 -9999 -9999 -9999 -9999 -9999 -9999 -9999 -9999 -9999 -9999 -9999 -9999 -9999 -9999 -9999 -9999 -9999 -9999 -9999 -9999 -9999 -9999 -9999 -9999 -9999 -9999 -9999 -9999 -9999 -9999 -9999 -9999 -9999 -9999 -9999 -9999 -9999 -9999 -9999 -9999 -9999 -9999 -9999 -9999 -9999 -9999 -9999 132.7553863525130 .7528076172 128.9241027832127 .0953979492125 .2667007446123 .133201599199 .08519744873 98.5457077026498 .018417358497 .5034255981497 .0009613037196 .51110839844 96.0341033935595 .5700607299895 .1192474365294 .6818237304794 .25812530518 93.8484039306693 .4531555175892 .349891662689 .302040100187 .47332763672 87.7781066894588 .0829010009888 .3876876831188 .6924667358488 .69246673584 88.9972534179788 .9972534179788 .9972534179788 .9972534179789 .3020401001 89.302040100189 .302040100189 .302040100189 .302040100189 .302040100189 .3020401001 89.28067016602 89.22704315186 89.18872070312 88.9972534179788.99725341797 88.9972534179788 .6924667358488 .6924667358488 .3876876831188 .08290100098 87.7781066894587 .4733276367287 .1685485839886 .8637619018686 .55898284912 85.9494018554785 .3398437585 .0350494384884 .4254837036183 .81591033936 83.206336975182 .5967712402382 .2919769287181 .6824111938581 .07285308838 80.4632720947380 .1584930419979 .8537063598680 .4632720947381 .07285308838 81.3776321411181 .6824111938581 .9871978759881 .8980026245181 .63340759277 81.27420806885 -9999 -9999 -9999 -9999 -9999 -9999 -9999 -9999 -9999 -9999 -9999 -9999 -9999 -9999 -9999 -9999 -9999 -9999 -9999 -9999 -9999 -9999 -9999 -9999 -9999 -9999 -9999 -9999 -9999 -9999 -9999 -9999 -9999 -9999 -9999 -9999 -9999 -9999 -9999 -9999 -9999 -9999 -9999 -9999 -9999 -9999 -9999 -9999 -9999 -9999 -9999 -9999

-9999 -9999 -9999 -9999 -9999 -9999 -9999 -9999 -9999 -9999 -9999 -9999 -9999 -9999 -9999 -9999 -9999 -9999 -9999 -9999 -9999 -9999 -9999 -9999 -9999 -9999 -9999 -9999 -9999 -9999 -9999 -9999 -9999 -9999 -9999 -9999 -9999 -9999 -9999 -9999 -9999 -9999 -9999 -9999 -9999

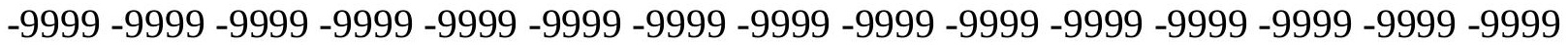
-9999 -9999 -9999 -9999 -9999 -9999 -9999 -9999 -9999 -9999 -9999 -9999 -9999 -9999 -9999 -9999 -9999 -9999 -9999 -9999 -9999 -9999 -9999 -9999 -9999 -9999 -9999 -9999 -9999 -9999

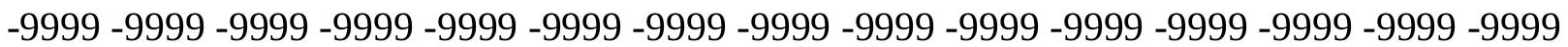
-9999 -9999 -9999 -9999 -9999 -9999 -9999 -9999 -9999 -9999 -9999 -9999 -9999 -9999 -9999 -9999 -9999 -9999 -9999 -9999 -9999 -9999 -9999 -9999 -9999 -9999 -9999 -9999 -9999 -9999 -9999 -9999 -9999 -9999 -9999 -9999 -9999 -9999 -9999 -9999 -9999 -9999 -9999 -9999 -9999

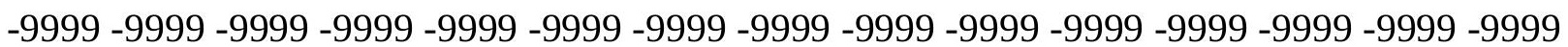
-9999 -9999 -9999 -9999 -9999 -9999 -9999 -9999 -9999 -9999 -9999 -9999 -9999 -9999 -9999 -9999 -9999 -9999 -9999 -9999 -9999 -9999 -9999 -9999 -9999 -9999 -9999 -9999 -9999 -9999 -9999 -9999 -9999 -9999 -9999 -9999 -9999 -9999 -9999 -9999 -9999 -9999 -9999 -9999 -9999

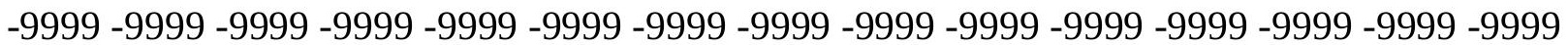


-9999 -9999 -9999 -9999 -9999 -9999 -9999 -9999 -9999 -9999 -9999 -9999 -9999 -9999 -9999 -9999 -9999 -9999 -9999 -9999 -9999 -9999 -9999 -9999 -9999 -9999 -9999 -9999 -9999 -9999 -9999 -9999 -9999 -9999 -9999 -9999 -9999 -9999 133.8007049561131 .9720001221 130.1432037354128 .3144989014126 .4858016968124 .352302551399 .24849700928 98.7077102661198.1794891357497.6639022827197.1611557006896.67128753662 96.19448089695 .7307891845795 .2804260253994 .843475341894 .42021942139 94.0108489990293 .615798950292 .0450973510788 .6924667358487 .47332763672 87.7781066894587 .7781066894588 .0829010009888 .3876876831188 .69246673584 88.6924667358488 .6924667358488 .9972534179788 .9972534179788 .99725341797 89.3020401001 89.302040100189.302040100189.3020401001 89.302040100189.3020401001 89.302040100189.3020401001 89.302040100189.302040100189.3020401001 88.9972534179788 .9972534179788 .6924667358488 .6924667358488 .38768768311 88.0829010009887 .7781066894587 .4733276367287 .1685485839886 .55898284912 86.254188537685 .9494018554785 .3398437584 .7302627563584 .42548370361 83.8159103393683 .206336975182 .9015579223682 .2919769287181 .68241119385 81.3776321411180 .7680587768680 .4632720947380 .7680587768681 .37763214111 81.6824111938581 .9871978759882 .2919769287182 .2764434814582 .07012176514 81.73175811768 -9999 -9999 -9999 -9999 -9999 -9999 -9999 -9999 -9999 -9999 -9999 -9999 -9999 -9999 -9999 -9999 -9999 -9999 -9999 -9999 -9999 -9999 -9999 -9999 -9999 -9999 -9999

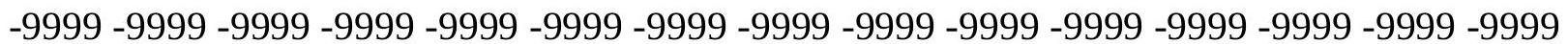
-9999 -9999 -9999 -9999 -9999 -9999 -9999 -9999 -9999 -9999

-9999 -9999 -9999 -9999 -9999 -9999 -9999 -9999 -9999 -9999 -9999 -9999 -9999 -9999 -9999 -9999 -9999 -9999 -9999 -9999 -9999 -9999 -9999 -9999 -9999 -9999 -9999 -9999 -9999 -9999 -9999 -9999 -9999 -9999 -9999 -9999 -9999 -9999 -9999 -9999 -9999 -9999 -9999 -9999 -9999

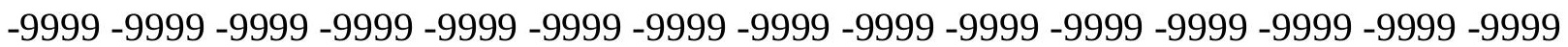
-9999 -9999 -9999 -9999 -9999 -9999 -9999 -9999 -9999 -9999 -9999 -9999 -9999 -9999 -9999 -9999 -9999 -9999 -9999 -9999 -9999 -9999 -9999 -9999 -9999 -9999 -9999 -9999 -9999 -9999 -9999 -9999 -9999 -9999 -9999 -9999 -9999 -9999 -9999 -9999 -9999 -9999 -9999 -9999 -9999 -9999 -9999 -9999 -9999 -9999 -9999 -9999 -9999 -9999 -9999 -9999 -9999 -9999 -9999 -9999 -9999 -9999 -9999 -9999 -9999 -9999 -9999 -9999 -9999 -9999 -9999 -9999 -9999 -9999 -9999 -9999 -9999 -9999 -9999 -9999 -9999 -9999 -9999 -9999 -9999 -9999 -9999 -9999 -9999 -9999 -

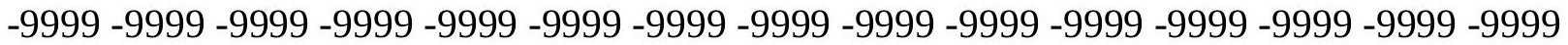
-9999 -9999 -9999 -9999 -9999 -9999 -9999 -9999 -9999 -9999 -9999 -9999 -9999 -9999 -9999 -9999 -9999 -9999 -9999 -9999 -9999 -9999 -9999 -9999 -9999 -9999 -9999 -9999 -9999 -9999 -9999 -9999 -9999 -9999 -9999 -9999 -9999 -9999 -9999 -9999 -9999 -9999 -9999 -9999 -9999 -9999 -9999 -9999 -9999 -9999 -9999 -9999 -9999 -9999 -9999 -9999 -9999 -9999 -9999 -9999 -9999 -9999 -9999 -9999 -9999 -9999 -9999 -9999 -9999 -9999 -9999 -9999 -9999 -9999 -9999

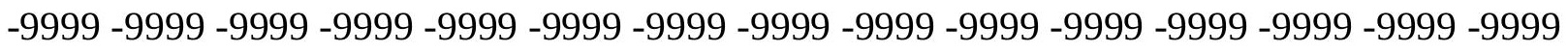
-9999 -9999 -9999 -9999 -9999 -9999 -9999 -9999 -9999 133.1911010742131 .3623962402 129.533706665127 .7050018311125 .8762969971123 .742797851698 .86346435547 98.3342208862397 .8179626464897 .314865112396 .824920654396 .34825897217 95.8848800659295 .4349136352594 .9983825683694 .5754928588994 .16636657715 93.7713699340891 .1307525634888 .0829010009887 .4733276367287 .47332763672 87.7781066894588 .0829010009888 .0829010009888 .3876876831188 .69246673584 88.69246673584 88.9972534179788.99725341797 88.99725341797 89.3020401001 89.3020401001 89.302040100189.302040100189.302040100189.59700012207 
89.53220367432 89.302040100189.302040100189.302040100189.3020401001 89.3020401001 88.99725341797 88.99725341797 88.69246673584 88.38768768311 88.0829010009888 .0829010009887 .7781066894587 .1685485839886 .86376190186 86.5589828491286 .254188537685 .6446228027385 .3398437584 .73026275635 84.4254837036183 .8159103393683 .5111236572382 .9015579223682 .59677124023 81.9871978759881 .6824111938581 .3776321411181 .0728530883881 .68241119385 81.9871978759882 .2919769287182 .5967712402382 .5967712402382 .46226501465 82.14935302734 -9999 -9999 -9999 -9999 -9999 -9999 -9999 -9999 -9999 -9999 -9999 -9999 -9999 -9999 -9999 -9999 -9999 -9999 -9999 -9999 -9999 -9999 -9999 -9999 -9999 -9999 -9999 -9999 -9999 -9999 -9999 -9999 -9999 -9999 -9999 -9999 -9999 -9999 -9999 -9999 -9999 -9999 -9999 -9999 -9999 -9999 -9999 -9999 -9999 -9999 -9999 -9999

-9999 -9999 -9999 -9999 -9999 -9999 -9999 -9999 -9999 -9999 -9999 -9999 -9999 -9999 -9999

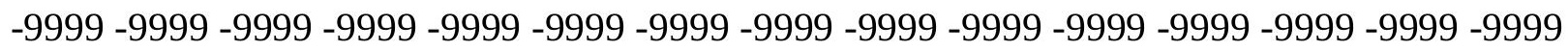
-9999 -9999 -9999 -9999 -9999 -9999 -9999 -9999 -9999 -9999 -9999 -9999 -9999 -9999 -9999 -9999 -9999 -9999 -9999 -9999 -9999 -9999 -9999 -9999 -9999 -9999 -9999 -9999 -9999 -9999

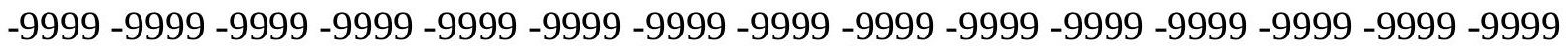

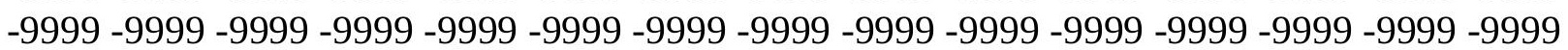
-9999 -9999 -9999 -9999 -9999 -9999 -9999 -9999 -9999 -9999 -9999 -9999 -9999 -9999 -9999 -999 -9999 -9999 -9999 -9999 -9999 -9999 -9999 -9999 -9999 -9999 -9999 -9999 -9999 -9999 -9999 -9999 -9999 -9999 -9999 -9999 -9999 -9999 -9999 -9999 -9999 -9999 -9999 -9999 -9999 -9999

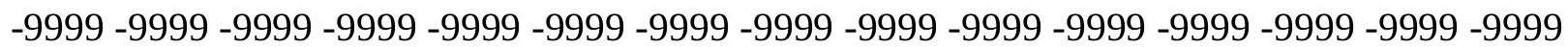

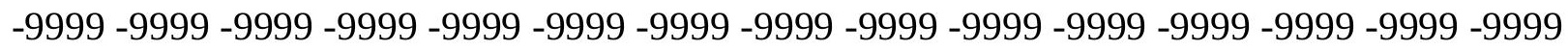
-9999 -9999 -9999 -9999 -9999 -9999 -9999 -9999 -9999 -9999 -9999 -9999 -9999 -9999 -9999 -9999 -9999 -9999 -9999 -9999 -9999 -9999 -9999 -9999 -9999 -9999 -9999 -9999 -9999 -9999

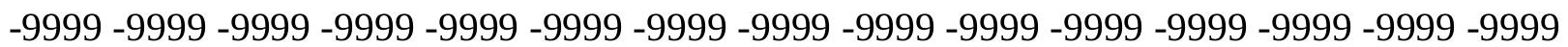
-9999 -9999 -9999 -9999 -9999 -9999 -9999 -9999 -9999 -9999 -9999 -9999 -9999 -9999 -9999 -9999 -9999 -9999 -9999 -9999 -9999 -9999 -9999 -9999 -9999 -9999 -9999 -9999 -9999 -9999 -9999 -9999 -9999 -9999 -9999 -9999 -9999 -9999 -9999 -9999 -9999 -9999 -9999 -9999 -9999 -9999 -9999 -9999 -9999 -9999 -9999 -9999 -9999 -9999 134.4102020264 132.5814971924 131.0074310303129 .2288970947127 .0953979492125 .266700744699 .0129699707 98.4825897216897 .9655685424897 .4620437622196 .971954345796 .49538421631 96.0322570800895 .5826492309695 .1464920043994 .723907470794 .31494140625 93.5690307617290 .5211791992287 .7781066894587 .4733276367287 .47332763672 87.7781066894587 .7781066894588 .0829010009888 .3876876831188 .38768768311 88.6924667358488 .6924667358488 .9972534179788 .9972534179789 .3020401001 89.302040100189 .302040100189 .6068267822389 .6068267822389 .60682678223 89.6068267822389 .5633697509889 .470001220789 .302040100189 .3020401001 89.302040100189 .302040100188 .9972534179788 .6924667358488 .69246673584 88.38768768311 88.08290100098 87.77810668945 87.47332763672 87.16854858398 86.8637619018686 .5589828491285 .9494018554785 .6446228027385 .33984375 84.7302627563584 .4254837036184 .1206970214883 .5111236572383 .2063369751 82.9015579223682 .5967712402382 .2919769287181 .9871978759881 .98719787598 82.2919769287182 .5967712402382 .5967712402382 .9015579223682 .85929107666 82.52791595459 -9999 -9999 -9999 -9999 -9999 -9999 -9999 -9999 -9999 -9999 -9999 -9999 -9999 -9999 -9999 -9999 -9999 -9999 -9999 -9999 -9999 -9999 -9999 -9999 -9999 -9999 -9999

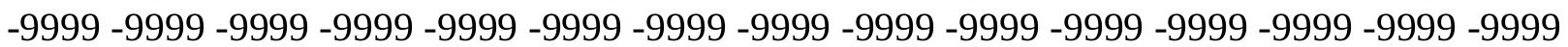


-9999 -9999 -9999 -9999 -9999 -9999 -9999 -9999 -9999 -9999

-9999 -9999 -9999 -9999 -9999 -9999 -9999 -9999 -9999 -9999 -9999 -9999 -9999 -9999 -9999

-9999 -9999 -9999 -9999 -9999 -9999 -9999 -9999 -9999 -9999 -9999 -9999 -9999 -9999 -9999

-9999 -9999 -9999 -9999 -9999 -9999 -9999 -9999 -9999 -9999 -9999 -9999 -9999 -9999 -9999

-9999 -9999 -9999 -9999 -9999 -9999 -9999 -9999 -9999 -9999 -9999 -9999 -9999 -9999 -9999 -

-9999 -9999 -9999 -9999 -9999 -9999 -9999 -9999 -9999 -9999 -9999 -9999 -9999 -9999 -9999 -

-9999 -9999 -9999 -9999 -9999 -9999 -9999 -9999 -9999 -9999 -9999 -9999 -9999 -9999 -9999 -

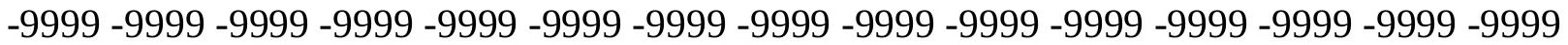

-9999 -9999 -9999 -9999 -9999 -9999 -9999 -9999 -9999 -9999 -9999 -9999 -9999 -9999 -9999

-9999 -9999 -9999 -9999 -9999 -9999 -9999 -9999 -9999 -9999 -9999 -9999 -9999 -9999 -9999 -

-9999 -9999 -9999 -9999 -9999 -9999 -9999 -9999 -9999 -9999 -9999 -9999 -9999 -9999 -9999 -

-9999 -9999 -9999 -9999 -9999 -9999 -9999 -9999 -9999 -9999 -9999 -9999 -9999 -9999 -9999

-9999 -9999 -9999 -9999 -9999 -9999 -9999 -9999 -9999 -9999 -9999 -9999 -9999 -9999 -9999 -

-9999 -9999 -9999 -9999 -9999 -9999 -9999 -9999 -9999 -9999 -9999 -9999 -9999 -9999 -9999 -

-9999 -9999 -9999 -9999 -9999 -9999 -9999 -9999 -9999 -9999 -9999 -9999 -9999 -9999 -9999

-9999 -9999 -9999 -9999 -9999 -9999 -9999 -9999 -9999 -9999 -9999 -9999 -9999 -9999 -9999

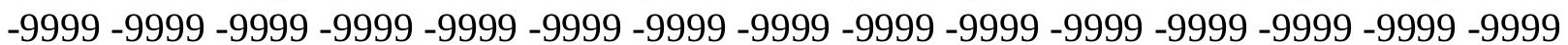

-9999 -9999 -9999 -9999 -9999 -9999 -9999 -9999 -9999 -9999 -9999 -9999 -9999 -9999 -9999 -

-9999 -9999 -9999 -9999 -9999 -9999 -9999 -9999 -9999 -9999 134.1054992676

132.2767028809130 .4479980469128 .6192932129126 .7906036377124 .6570968628

98.6246566772598 .1067657470797 .6027297973697 .112442016696 .63591766357

96.1730117797995 .7237243652395 .2879104614394 .8656005859494 .4567489624

93.2642517089890 .2164001464887 .4733276367287 .4733276367287 .47332763672

87.4733276367287 .7781066894588 .0829010009888 .0829010009888 .38768768311

88.6924667358488 .6924667358488 .9972534179788 .9972534179789 .3020401001

89.302040100189 .302040100189 .6068267822389 .6068267822389 .60682678223

89.6068267822389 .6068267822389 .6068267822389 .6068267822389 .60682678223

89.302040100189.3020401001 88.99725341797 88.9972534179788.69246673584

88.6924667358488 .3876876831188 .0829010009887 .7781066894587 .47332763672

87.1685485839886 .8637619018686 .5589828491285 .9494018554785 .64462280273

85.3398437585 .0350494384884 .7302627563584 .1206970214883 .81591033936

83.5111236572383 .206336975183 .206336975182 .9015579223682 .59677124023

82.5967712402382 .9015579223682 .9015579223683 .206336975183 .2063369751

82.80899047852 -9999 -9999 -9999 -9999 -9999 -9999 -9999 -9999 -9999 -9999 -9999 -9999

-9999 -9999 -9999 -9999 -9999 -9999 -9999 -9999 -9999 -9999 -9999 -9999 -9999 -9999 -9999

-9999 -9999 -9999 -9999 -9999 -9999 -9999 -9999 -9999 -9999 -9999 -9999 -9999 -9999 -9999

-9999 -9999 -9999 -9999 -9999 -9999 -9999 -9999 -9999 -9999

-9999 -9999 -9999 -9999 -9999 -9999 -9999 -9999 -9999 -9999 -9999 -9999 -9999 -9999 -9999

-9999 -9999 -9999 -9999 -9999 -9999 -9999 -9999 -9999 -9999 -9999 -9999 -9999 -9999 -9999 -

-9999 -9999 -9999 -9999 -9999 -9999 -9999 -9999 -9999 -9999 -9999 -9999 -9999 -9999 -9999 -

-9999 -9999 -9999 -9999 -9999 -9999 -9999 -9999 -9999 -9999 -9999 -9999 -9999 -9999 -9999

-9999 -9999 -9999 -9999 -9999 -9999 -9999 -9999 -9999 -9999 -9999 -9999-9999-9999-9999 -

-9999 -9999 -9999 -9999 -9999 -9999 -9999 -9999 -9999 -9999 -9999 -9999 -9999 -9999 -9999 -

-9999 -9999 -9999 -9999 -9999 -9999 -9999 -9999 -9999 -9999 -9999 -9999 -9999 -9999 -9999 -

-9999 -9999 -9999 -9999 -9999 -9999 -9999 -9999 -9999 -9999 -9999 -9999 -9999 -9999 -9999

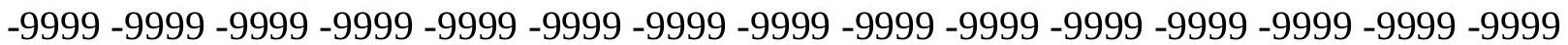


-9999 -9999 -9999 -9999 -9999 -9999 -9999 -9999 -9999 -9999 -9999 -9999 -9999 -9999 -9999 -9999 -9999 -9999 -9999 -9999 -9999 -9999 -9999 -9999 -9999 -9999 -9999 -9999 -9999 -9999 -9999 -9999 -9999 -9999 -9999 -9999 -9999 -9999 -9999 -9999 -9999 -9999 -9999 -9999 -9999 -9999 -9999 -9999 -9999 -9999 -9999 -9999 -9999 -9999 -9999 -9999 -9999 -9999 -9999 -9999 -9999 -9999 -9999 -9999 -9999 -9999 -9999 -9999 -9999 -9999 -9999 -9999 -9999 -9999 -9999 -9999 -9999 -9999 -9999 -9999 -9999 -9999 -9999 -9999 -9999 -9999 -9999 -9999 -9999 -9999 -9999 -9999 -9999 -9999 -9999 -9999 -9999 -9999 -9999 -9999 -9999 -9999 -9999 -9999 -9999 -9999 -9999 -9999 -9999 -9999 -9999 -9999 -9999 -9999 -9999 -9999 -9999 -9999 -9999 -9999 -9999 -9999 -9999 -9999 -9999 -9999 -9999 -9999 -9999 -9999 135.6293945312 133.8007049561132 .2767028809130 .4479980469128 .6192932129126 .4858016968 98.7604522705198 .2415695190497 .7369308471797 .246376037696 .76985168457 96.3071517944395 .8581924438595 .4227294921995 .0007095336994 .59198760986 93.2642517089889 .9116134643687 .1685485839887 .1685485839887 .47332763672 87.4733276367287 .7781066894587 .7781066894588 .0829010009888 .38768768311 88.3876876831188 .6924667358488 .9972534179788 .9972534179789 .3020401001 89.302040100189 .6068267822389 .6068267822389 .6068267822389 .60682678223 89.6068267822389 .6068267822389 .6068267822389 .6068267822389 .60682678223 89.6068267822389 .302040100189 .302040100188 .9972534179788 .99725341797 88.6924667358488 .6924667358488 .3876876831188 .0829010009887 .77810668945 87.4733276367287 .1685485839886 .8637619018686 .5589828491286 .2541885376 85.9494018554785 .6446228027385 .3398437585 .0350494384884 .73026275635 84.4254837036184 .1206970214883 .8159103393683 .5111236572383 .51112365723 83.206336975183.206336975183.206336975183.206336975183.2063369751 82.98717498779 -9999 -9999 -9999 -9999 -9999 -9999 -9999 -9999 -9999 -9999 -9999 -9999 -9999 -9999 -9999 -9999 -9999 -9999 -9999 -9999 -9999 -9999 -9999 -9999 -9999 -9999 -9999 -9999 -9999 -9999 -9999 -9999 -9999 -9999 -9999 -9999 -9999 -9999 -9999 -9999 -9999 -9999 -9999 -9999 -9999 -9999 -9999 -9999 -9999 -9999 -9999 -9999

-9999 -9999 -9999 -9999 -9999 -9999 -9999 -9999 -9999 -9999 -9999 -9999 -9999 -9999 -9999 -9999 -9999 -9999 -9999 -9999 -9999 -9999 -9999 -9999 -9999 -9999 -9999 -9999 -9999 -9999 -9999 -9999 -9999 -9999 -9999 -9999 -9999 -9999 -9999 -9999 -9999 -9999 -9999 -9999 -9999 -9999 -9999 -9999 -9999 -9999 -9999 -9999 -9999 -9999 -9999 -9999 -9999 -9999 -9999 -9999 -

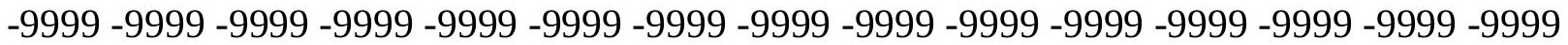
-9999 -9999 -9999 -9999 -9999 -9999 -9999 -9999 -9999 -9999 -9999 -9999 -9999 -9999 -9999 -9999 -9999 -9999 -9999 -9999 -9999 -9999 -9999 -9999 -9999 -9999 -9999 -9999 -9999 -9999 -

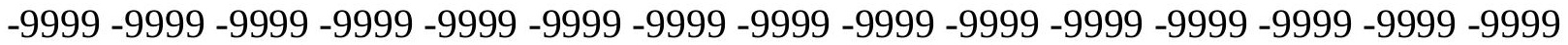
-9999 -9999 -9999 -9999 -9999 -9999 -9999 -9999 -9999 -9999 -9999 -9999 -9999 -9999 -9999 -9999 -9999 -9999 -9999 -9999 -9999 -9999 -9999 -9999 -9999 -9999 -9999 -9999 -9999 -9999

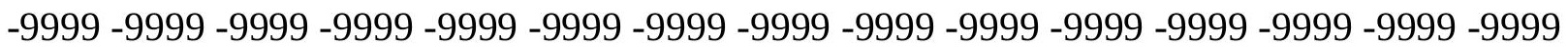
-9999 -9999 -9999 -9999 -9999 -9999 -9999 -9999 -9999 -9999 -9999 -9999 -9999 -9999 -9999 -9999 -9999 -9999 -9999 -9999 -9999 -9999 -9999 -9999 -9999 -9999 -9999 -9999 -9999 -9999 -9999 -9999 -9999 -9999 -9999 -9999 -9999 -9999 -9999 -9999 -9999 -9999 -9999 -9999 -9999 -9999 -9999 -9999 -9999 -9999 -9999 -9999 -9999 -9999 -9999 -9999 -9999 -9999 -9999 -9999 -9999 -9999 -9999 -9999 -9999 -9999 -9999 -9999 -9999 -9999 -9999 -9999 -9999 -9999 -9999 -9999 -9999 -9999 -9999 -9999 -9999 -9999 -9999 -9999 -9999 -9999 -9999 -9999 -9999 -9999 -9999 -9999 -9999 -9999 -9999 -9999 -9999 -9999 -9999 -9999 -9999 135.6293945312 134.1054992676132 .2767028809130 .4479980469128 .3144989014126 .1809997559 
98.3700942993297 .8647384643697 .3738479614396 .8973083496196 .43482971191 95.9862365722795 .551193237395 .1295394897594 .7210388183693 .26425170898 89.9116134643687 .1685485839887 .4733276367287 .4733276367287 .47332763672 87.7781066894587 .7781066894588 .0829010009888 .0829010009888 .38768768311 88.6924667358488 .9972534179788 .9972534179789 .302040100189 .3020401001 89.6068267822389 .6068267822389 .6068267822389 .9036331176889 .88270568848 89.9116134643689 .9116134643689 .9116134643689 .6068267822389 .60682678223 89.6068267822389 .302040100189 .302040100188 .9972534179788 .99725341797 88.6924667358488 .6924667358488 .3876876831188 .0829010009887 .77810668945 87.4733276367287 .1685485839886 .8637619018686 .5589828491286 .2541885376 85.9494018554785 .6446228027385 .6446228027385 .3398437585 .03504943848 84.7302627563584 .4254837036184 .4254837036184 .1206970214883 .81591033936 83.5111236572383 .5111236572383 .5111236572383 .5111236572383 .13872528076 82.65825653076 -9999 -9999 -9999 -9999 -9999 -9999 -9999 -9999 -9999 -9999 -9999 -9999 -9999 -9999 -9999 -9999 -9999 -9999 -9999 -9999 -9999 -9999 -9999 -9999 -9999 -9999 -9999

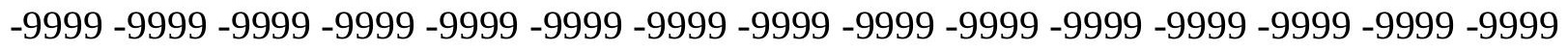
-9999 -9999 -9999 -9999 -9999 -9999-9999 -9999 -9999 -9999 -9999 -9999 -9999 -9999 -9999 -9999 -9999 -9999 -9999 -9999 -9999 -9999 -9999 -9999 -9999 -9999 -9999 -9999 -9999 -9999 -9999 -9999 -9999 -9999 -9999 -9999 -9999 -9999 -9999 -

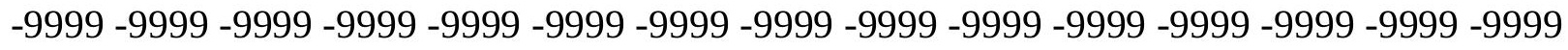
-9999 -9999 -9999 -9999 -9999 -9999 -9999 -9999 -9999 -9999 -9999 -9999 -9999 -9999 -9999 -9999 -9999 -9999 -9999 -9999 -9999 -9999 -9999 -9999 -9999 -9999 -9999 -9999 -9999 -9999 -9999 -9999 -9999 -9999 -9999 -9999 -9999 -9999 -9999 -9999 -9999 -9999-9999-9999-9999 -999 -9999 -9999 -9999 -9999 -9999 -9999 -9999 -9999 -9999 -9999 -9999 -9999 -9999 -9999 -9999 -9999 -9999 -9999 -9999 -9999 -9999 -9999 -9999 -9999 -9999 -9999 -9999 -9999 -9999 -9999 -9999 -9999 -9999 -9999 -9999 -9999 -9999 -9999 -9999 -9999 -9999 -9999 -9999 -9999 -9999 -9999 -9999 -9999 -9999 -9999 -9999 -9999 -9999 -9999 -9999 -9999 -9999 -9999 -9999 -9999

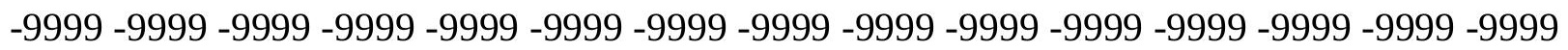
-9999 -9999 -9999 -9999 -9999 -9999 -9999 -9999 -9999 -9999 -9999 -9999 -9999 -9999 -9999 -9999 -9999 -9999 -9999 -9999 -9999 -9999 -9999 -9999 -9999 -9999 -9999 -9999 -9999 -9999 -9999 -9999 -9999 -9999 -9999 -9999 -9999 -9999 -9999 -9999 -9999 -9999 -9999 -9999 -9999

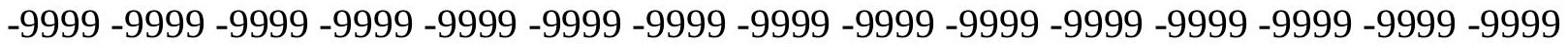

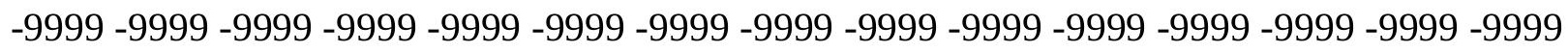
-9999 -9999 -9999 -9999 -9999 -9999 -9999 -9999 -9999 -9999 -9999 -9999 -9999 -9999 -9999 -9999 -9999 -9999 -9999 -9999 -9999 -9999 -9999 -9999 -9999 -9999 -9999 135.9342041016 134.4102020264132 .5814971924130 .4479980469128 .314498901498 .49238586426 97.9861755371197 .4948654174897 .0182876586996 .5560607910296 .10791778564 95.6734237670995 .2523193359494 .8442230224693 .2642517089899 .91161346436 87.7781066894587 .4733276367287 .4733276367287 .4733276367287 .47332763672 87.7781066894588 .0829010009888 .0829010009888 .3876876831188 .69246673584 88.9972534179788 .9972534179789 .302040100189 .6068267822389 .60682678223 89.6068267822389 .9116134643689 .9116134643689 .8961791992289 .91161346436 89.9116134643689 .9116134643689 .9116134643689 .9116134643689 .60682678223 89.60682678223 89.60682678223 89.302040100189.3020401001 88.99725341797 88.6924667358488 .6924667358488 .3876876831188 .0829010009887 .77810668945 87.47332763672 87.47332763672 87.16854858398 86.86376190186 86.55898284912 
86.2541885376 85.9494018554785.9494018554785.6446228027385.33984375 85.0350494384885 .0350494384884 .7302627563584 .4254837036183 .81591033936 $83.8159103393683 .8159103393683 .5111236572383 .2593307495182 .79187774658-9999$ -9999 -9999 -9999 -9999 -9999 -9999 -9999 -9999 -9999 -9999 -9999 -9999 -9999 -9999 -9999 -9999 -9999 -9999 -9999 -9999 -9999 -9999 -9999 -9999 -9999 -9999 -9999-9999 -9999 -9999 -

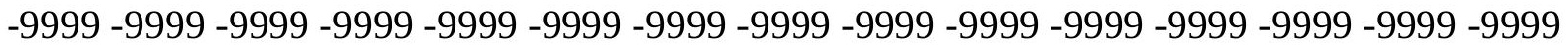
-9999 -9999-9999-9999-9999

-9999 -9999 -9999 -9999 -9999 -9999 -9999 -9999 -9999 -9999 -9999 -9999 -9999 -9999 -9999 -9999 -9999 -9999 -9999 -9999 -9999 -9999 -9999 -9999 -9999 -9999 -9999 -9999 -9999 -9999 -9999 -9999 -9999 -9999 -9999 -9999 -9999 -9999 -9999 -9999 -9999 -9999 -9999 -9999 -9999

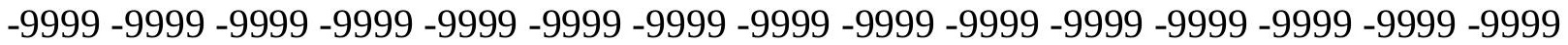
-9999 -9999 -9999 -9999 -9999 -9999 -9999 -9999 -9999 -9999 -9999 -9999 -9999 -9999 -9999 -9999 -9999 -9999 -9999 -9999 -9999 -9999 -9999 -9999 -9999 -9999 -9999 -9999 -9999 -9999 -9999 -9999 -9999 -9999 -9999 -9999 -9999 -9999 -9999 -9999 -9999 -9999 -9999 -9999 - 9999 -9999 -9999 -9999 -9999 -9999 -9999 -9999 -9999 -9999 -9999 -9999 -9999 -9999 -9999 -9999

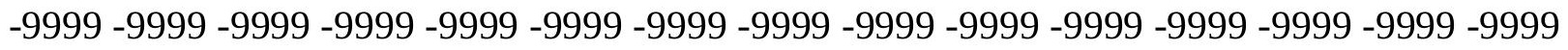
-9999 -9999 -9999 -9999 -9999 -9999 -9999 -9999 -9999 -9999 -9999 -9999 -9999 -9999 -9999 -9999 -9999 -9999 -9999 -9999 -9999 -9999 -9999 -9999 -9999 -9999 -9999 -9999 -9999 -9999 -9999 -9999 -9999 -9999 -9999 -9999 -9999 -9999 -9999 -9999 -9999 -9999 -9999 -9999 -9999 -9999 -9999 -9999 -9999 -9999 -9999 -9999 -9999 -9999 -9999 -9999 -9999 -9999 -9999 -9999 -9999 -9999 -9999 -9999 -9999 -9999 -9999 -9999 -9999 -9999 -9999 -9999 -9999 -9999 -9999 -9999 -9999 -9999 -9999 -9999 -9999 -9999 -9999 -9999 -9999 -9999 -9999 -9999 -9999 -9999 -9999 -9999 -9999 -9999 -9999 -9999 -9999 -9999 -9999 -9999 -9999 -9999 -9999 -9999 -9999 -9999 -9999 -9999 -9999 -9999 -9999 -9999 -9999 -9999 -9999 -9999 -9999 -9999 -9999 -9999 -9999 -9999-9999-9999 -9999-9999 -9999 -9999-9999-9999 -9999-9999 138.0677032471 136.5437011719134 .9125213623132 .8863067627130 .4479980469127 .7050018311 98.101287841897 .6094436645597 .1327819824296 .6708450317496 .22328186035 95.7895431518695 .3692398071394 .9618682861393 .5690307617289 .91161346436 88.0829010009887 .7781066894587 .4733276367287 .4733276367287 .47332763672 87.7781066894587 .7781066894588 .0829010009888 .3876876831188 .69246673584 88.9972534179789 .302040100189 .302040100189 .6068267822389 .60682678223 89.9116134643689 .9116134643689 .9116134643689 .9116134643689 .91161346436 89.9116134643689 .9116134643689 .9116134643689 .9116134643689 .91161346436 89.6068267822389 .6068267822389 .6068267822389 .302040100189 .3020401001 88.9972534179788 .6924667358488 .6924667358488 .3876876831188 .08290100098 88.0829010009887 .7781066894587 .4733276367287 .1685485839887 .16854858398 86.8637619018686 .5589828491286 .254188537686 .254188537685 .94940185547 85.6446228027385 .3398437585 .0350494384884 .7302627563584 .42548370361 84.1206970214883 .8159103393683 .8159103393683 .417266845782 .8928604126 -9999 -9999 -9999 -9999 -9999 -9999 -9999 -9999 -9999 -9999 -9999 -9999 -9999 -9999 -9999 -9999 -9999

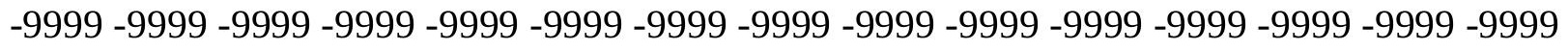

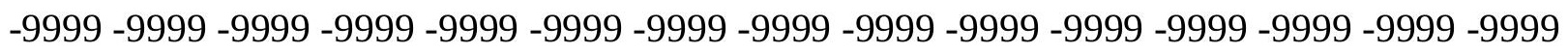
-9999 -9999-9999-9999 -9999 -9999 -9999 -9999 -9999 -9999 -9999 -9999 -9999 -9999 -9999 -9999 -9999 -9999 -9999 -9999 -9999 -9999 -9999 -9999 -9999 -9999 -9999 -9999 -9999 -9999 -9999 -9999 -9999 -9999 -9999 -9999 -9999 -9999 -9999 -9999 -9999 -9999 -9999 -9999 -9999 -9999 -9999 -9999 -9999 
-9999 -9999 -9999 -9999 -9999 -9999 -9999 -9999 -9999 -9999 -9999 -9999 -9999 -9999 -9999 -9999 -9999 -9999 -9999 -9999 -9999 -9999 -9999 -9999 -9999 -9999 -9999 -9999 -9999 -9999 -9999 -9999 -9999 -9999 -9999 -9999 -9999 -9999 -9999 -9999 -9999 -9999 -9999 -9999 -9999 -9999 -9999 -9999 -9999 -9999 -9999 -9999 -9999 -9999 -9999 -9999 -9999 -9999 -9999 -9999 -9999 -9999 -9999 -9999 -9999 -9999 -9999 -9999 -9999 -9999 -9999 -9999 -9999 -9999 -9999 -9999 -9999 -9999 -9999 -9999 -9999 -9999 -9999 -9999 -9999 -9999 -9999 -9999 -9999 -9999 -9999 -9999 -9999 -9999 -9999 -9999 -9999 -9999 -9999 -9999 -9999 -9999 -9999 -9999 -9999

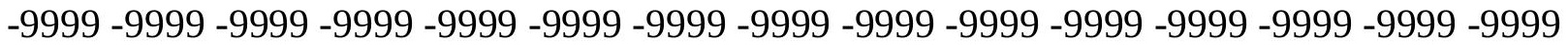
-9999 -9999 -9999 -9999 -9999 -9999 -9999 -9999 -9999 -9999 -9999 -9999 -9999 -9999 -9999 -9999 -9999 -9999 -9999 -9999 -9999 -9999 -9999 -9999 -9999 -9999 -9999 -9999 -9999 -9999 -9999 -9999 -9999 -9999 -9999 -9999 -9999 -9999 -9999 -9999 -9999 -9999 -9999 -9999 -9999 -9999 -9999 -9999 -9999 -9999 -9999 -9999 -9999 -9999 -9999 -9999 -9999 -9999 -9999 -9999

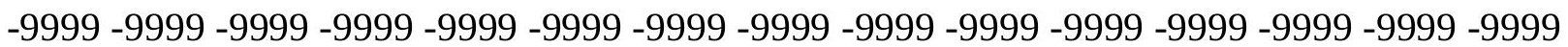
-9999 -9999 -9999 -9999 -9999 -9999 -9999 -9999 -9999 -9999 -9999 -9999 -9999 -9999 -9999 -9999 -9999 -9999 -9999 -9999 -9999 -9999 -9999 -9999 -9999 -9999 -9999 -9999 138.9819946289137 .2131500244135 .358001709133 .1911010742130 .1432037354 98.2099533081197 .7174148559697 .2406082153396 .7789993286196 .33216094971 95.8994293212995 .4802856445395 .074081420993 .5690307617289 .91161346436 88.0829010009887 .7781066894587 .4733276367287 .4733276367287 .47332763672 87.47332763672 87.77810668945 88.08290100098 88.38768768311 88.69246673584 88.9972534179789 .302040100189 .6068267822389 .6068267822389 .91161346436 89.9116134643689 .9116134643690 .2164001464890 .2164001464890 .21640014648 90.2164001464890 .2164001464890 .2164001464889 .9116134643689 .91161346436 89.9116134643689 .9116134643689 .6068267822389 .6068267822389 .3020401001 89.3020401001 88.9972534179788.99725341797 88.6924667358488.38768768311 88.3876876831188 .0829010009887 .7781066894587 .7781066894587 .47332763672 87.1685485839887 .1685485839886 .8637619018686 .5589828491286 .2541885376 86.254188537685 .9494018554785 .6446228027385 .3398437584 .73026275635 84.4254837036184 .1206970214883 .8159103393683 .5111236572382 .96562194824 -9999 -9999 -9999 -9999 -9999 -9999 -9999 -9999 -9999 -9999 -9999 -9999 -9999 -9999 -9999 -9999 -9999 -9999 -9999 -9999 -9999 -9999 -9999 -9999 -9999 -9999 -9999 -9999 -9999 -9999 -9999 -

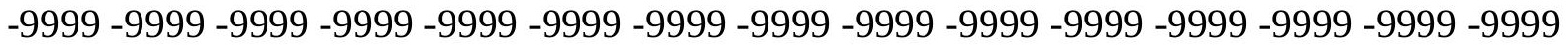
$-9999-9999-9999-9999-9999$

-9999 -9999 -9999 -9999 -9999 -9999 -9999 -9999 -9999 -9999 -9999 -9999 -9999 -9999 -9999

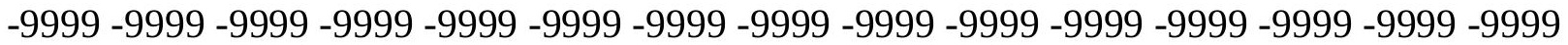
-9999 -9999 -9999 -9999 -9999 -9999 -9999 -9999 -9999 -9999 -9999 -9999 -9999 -9999 -9999 -9999 -9999 -9999 -9999 -9999 -9999 -9999 -9999 -9999 -9999 -9999 -9999 -9999 -9999 -9999

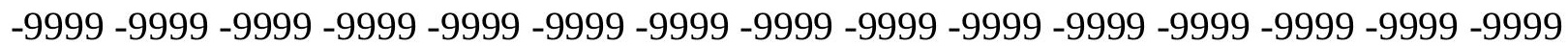
-9999 -9999 -9999 -9999 -9999 -9999 -9999 -9999 -9999 -9999 -9999 -9999 -9999 -9999 -9999 -9999 -9999 -9999 -9999 -9999 -9999 -9999 -9999 -9999 -9999 -9999 -9999 -9999 -9999 -9999 -9999 -9999 -9999 -9999 -9999 -9999 -9999 -9999 -9999 -9999 -9999 -9999 -9999 -9999 -9999 -999 -9999 -9999 -9999 -9999 -9999 -9999 -9999 -9999 -9999 -9999 -9999 -9999 -9999 -9999 -9999 -9999 -9999 -9999 -9999 -9999 -9999 -9999 -9999 -9999 -9999 -9999 -9999 -9999 -9999 -9999 -9999 -9999 -9999 -9999 -9999 -9999 -9999 -9999 -9999 -9999 -9999 -9999 -9999 -9999 -9999 -9999 -9999 -9999 -9999 -9999 -9999 -9999 -9999 -9999 -9999 -9999 -9999 -9999 -9999 -9999

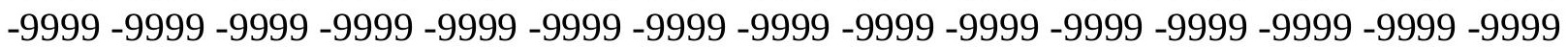


-9999 -9999 -9999 -9999 -9999 -9999 -9999 -9999 -9999 -9999 -9999 -9999 -9999 -9999 -9999 -9999 -9999 -9999 -9999 -9999 -9999 -9999 -9999 -9999 -9999 -9999 -9999 -9999 -9999 -9999 -9999 -9999 -9999 -9999 -9999 -9999 -9999 -9999 -9999 -9999 -9999 -9999 -9999 -9999 -9999 -9999 -9999 -9999 -9999 -9999 -9999 -9999 -9999 -9999 -9999 -9999 -9999 -9999 -9999 -9999 -9999 -9999 -9999 -9999 -9999 -9999 -9999 -9999 -9999 -9999 -9999 -9999 -9999 143.2489929199140 .2012023926137 .5875549316135 .4801940918132 .8863067627 98.3120117187597 .8185653686597 .3414993286196 .8802413940496 .43428039551 96.0028533935595 .5853042602595 .1808395385793 .8738174438589 .91161346436 87.47332763672 87.16854858398 87.16854858398 87.16854858398 87.16854858398 87.4733276367287 .7781066894588 .0829010009888 .3876876831188 .69246673584 88.9972534179789 .302040100189 .6068267822389 .6068267822389 .91161346436 89.9116134643690 .2016601562590 .2164001464890 .2164001464890 .21640014648 90.2164001464890 .2164001464890 .2164001464890 .2164001464890 .21640014648 89.9116134643689 .9116134643689 .9116134643689 .6068267822389 .60682678223 89.60682678223 89.3020401001 89.3020401001 88.9972534179788.69246673584 88.6924667358488 .3876876831188 .3876876831188 .0829010009887 .77810668945 87.7781066894587 .4733276367287 .1685485839886 .8637619018686 .86376190186 86.5589828491286 .254188537685 .9494018554785 .6446228027385 .03504943848 $84.7302627563584 .1206970214883 .8159103393683 .5111236572382 .97386932373-9999$ -9999 -9999 -9999 -9999 -9999 -9999 -9999 -9999 -9999 -9999 -9999 -9999 -9999 -9999 -9999

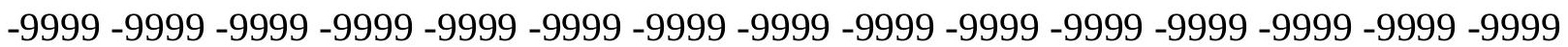

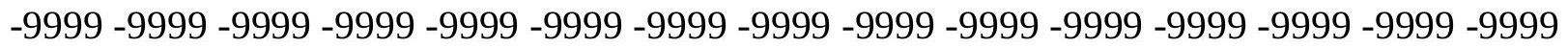
$-9999-9999-9999-9999-9999$

-9999 -9999 -9999 -9999 -9999 -9999 -9999 -9999 -9999 -9999 -9999 -9999 -9999 -9999 -9999

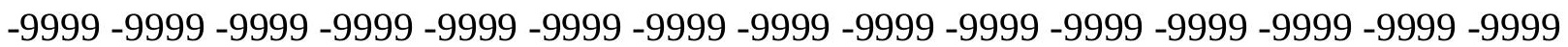
-9999 -9999 -9999 -9999 -9999 -9999 -9999 -9999 -9999 -9999 -9999 -9999 -9999 -9999 -9999 -9999 -9999 -9999 -9999 -9999 -9999 -9999 -9999 -9999 -9999 -9999 -9999 -9999 -9999 -9999 -9999 -9999 -9999 -9999 -9999 -9999 -9999 -9999 -9999 -9999 -9999 -9999 -9999 -9999 -9999

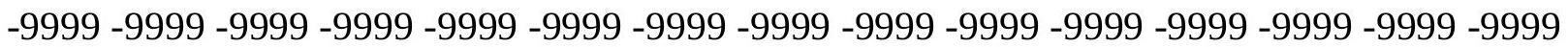
-9999 -9999 -9999 -9999 -9999 -9999 -9999 -9999 -9999 -9999 -9999 -9999 -9999 -9999 -9999 -9999 -9999 -9999 -9999 -9999 -9999 -9999 -9999 -9999 -9999 -9999 -9999 -9999 -9999 -9999

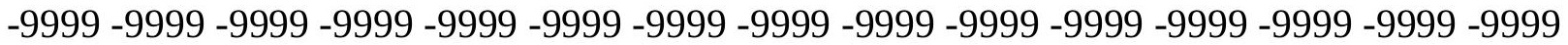

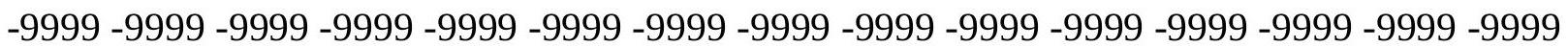
-9999 -9999 -9999 -9999 -9999 -9999 -9999 -9999 -9999 -9999 -9999 -9999 -9999 -9999 -9999

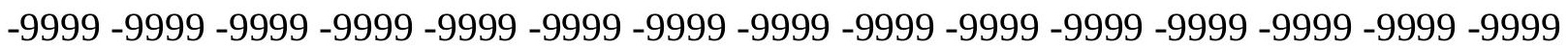
-9999 -9999 -9999 -9999 -9999 -9999 -9999 -9999 -9999 -9999 -9999 -9999 -9999 -9999 -9999 -9999 -9999 -9999 -9999 -9999 -9999 -9999 -9999 -9999 -9999 -9999 -9999 -9999 -9999 -9999

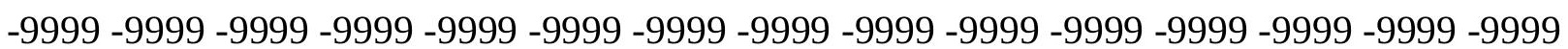
-9999 -9999 -9999 -9999 -9999 -9999 -9999 -9999 -9999 -9999 -9999 -9999 -9999 -9999 -9999 -9999 -9999 -9999 -9999 -9999 -9999 -9999 -9999 -9999 -9999 -9999 -9999 -9999 -9999 -9999 -9999 -9999 -9999 -9999 -9999 -9999 -9999 -9999 -9999 -9999 -9999 -9999 -9999 -9999 143.2489929199141 .4203033447137 .4672088623135 .0220336914131 .9720001221 97.9124450683697 .4349441528396 .9740066528396 .5290679931696 .09928131104 95.6838531494195 .2818298339894 .1785964965889 .9116134643686 .86376190186 86.5589828491286 .5589828491286 .8637619018686 .8637619018687 .47332763672 87.7781066894588 .0829010009888 .3876876831188 .9972534179789 .3020401001 
89.6068267822389 .6068267822389 .9116134643689 .9116134643690 .21640014648 90.2164001464890 .2164001464890 .2164001464890 .5211791992290 .52117919922 90.5211791992290 .2164001464890 .2164001464890 .2164001464890 .21640014648 90.2164001464889 .9116134643689 .9116134643689 .9116134643689 .60682678223 89.6068267822389 .302040100189 .302040100188 .9972534179788 .99725341797 88.6924667358488 .6924667358488 .3876876831188 .3876876831188 .08290100098 87.7781066894587 .4733276367287 .4733276367287 .1685485839886 .86376190186 86.5589828491286 .254188537685 .9494018554785 .3398437585 .03504943848

84.4254837036183 .8159103393683 .5111236572382 .93183898926 -9999 -9999 -9999 -9999 -9999 -9999 -9999 -9999 -9999 -9999 -9999 -9999 -9999 -9999 -9999 -9999 -9999 -9999 -9999 -9999 -9999 -9999 -9999 -9999 -9999 -9999 -9999 -9999 -9999 -9999 -9999 -9999 -9999 -9999 -

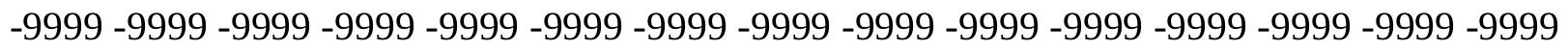
-9999 -9999

-9999 -9999 -9999 -9999 -9999 -9999 -9999 -9999 -9999 -9999 -9999 -9999 -9999 -9999 -9999 -9999 -9999 -9999 -9999 -9999 -9999 -9999 -9999 -9999 -9999 -9999 -9999 -9999 -9999 -9999

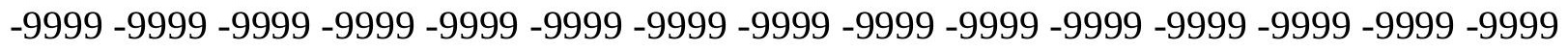
-9999 -9999 -9999 -9999 -9999 -9999 -9999 -9999 -9999 -9999 -9999 -9999 -9999 -9999 -9999 -9999 -9999 -9999 -9999 -9999 -9999 -9999 -9999 -9999 -9999 -9999 -9999 -9999 -9999 -9999 -9999 -9999 -9999 -9999 -9999 -9999 -9999 -9999 -9999 -9999 -9999 -9999 -9999 -9999 -9999 -999 -

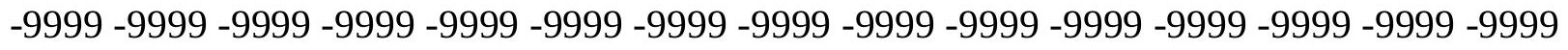
-9999 -9999 -9999 -9999 -9999 -9999 -9999 -9999 -9999 -9999 -9999 -9999 -9999 -9999 -9999

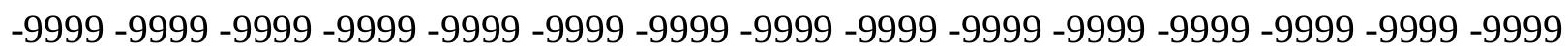
-9999 -9999 -9999 -9999 -9999 -9999 -9999 -9999 -9999 -9999 -9999 -9999 -9999 -9999 -9999 -9999 -9999 -9999 -9999 -9999 -9999 -9999 -9999 -9999 -9999 -9999 -9999 -9999 -9999 -9999 -

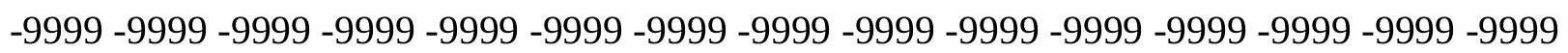
-9999 -9999 -9999 -9999 -9999 -9999 -9999 -9999 -9999 -9999 -9999 -9999 -9999 -9999 -9999 -9999 -9999 -9999 -9999 -9999 -9999 -9999 -9999 -9999 -9999 -9999 -9999 -9999 -9999 - -9999 -

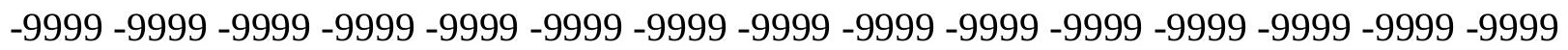
-9999 -9999 -9999 -9999 -9999 -9999 -9999 -9999 -9999 -9999 -9999 -9999 -9999 -9999 -9999 -9999 -9999 -9999 -9999 -9999 -9999 -9999 -9999 -9999 -9999 -9999 -9999 -9999 -9999 -9999 -9999 -9999 -9999 -9999 -9999 -9999 -9999 -9999 -9999 -9999 -9999 -9999 -9999 -9999 146.2969055176144 .4682006836141 .7250976562136 .6594543457133 .8267974854 97.9984512329197 .5202789306697 .0595932006896 .6158218383896 .18801879883 95.7752990722795 .376541137794 .4833908081190 .2164001464886 .55898284912 85.9494018554786 .254188537686 .5589828491286 .8637619018687 .16854858398 87.7781066894588 .3876876831188 .6924667358488 .9972534179789 .3020401001 89.60682678223 89.91161346436 90.21640014648 90.21640014648 90.21640014648 90.5211791992290 .5211791992290 .5211791992290 .5211791992290 .52117919922 90.5211791992290 .5211791992290 .5211791992290 .5211791992290 .21640014648 90.2164001464890 .2164001464890 .2164001464889 .9116134643689 .91161346436 89.9116134643689 .6068267822389 .6068267822389 .302040100189 .3020401001 88.99725341797 88.99725341797 88.69246673584 88.69246673584 88.38768768311 88.0829010009887 .7781066894587 .4733276367287 .1685485839886 .86376190186 86.5589828491286 .254188537685 .9494018554785 .6446228027385 .03504943848 84.42548370361 83.81591033936 83.51112365723 82.81576538086 -9999 -9999 -9999 -9999 -9999 -9999 -9999 -9999 -9999 -9999 -9999 -9999 -9999 -9999 -9999 -9999 -9999 -9999 -9999 
-9999 -9999 -9999 -9999 -9999 -9999 -9999 -9999 -9999 -9999 -9999 -9999 -9999 -9999 -9999 -9999 -9999 -9999 -9999 -9999 -9999 -9999 -9999 -9999 -9999 -9999 -9999 -9999 -9999 -9999 $-9999-9999$

-9999 -9999 -9999 -9999 -9999 -9999 -9999 -9999 -9999 -9999 -9999 -9999 -9999 -9999 -9999 -9999 -9999 -9999 -9999 -9999 -9999 -9999 -9999 -9999 -9999 -9999 -9999-9999 -9999 -9999 -9999 -9999 -9999 -9999 -9999 -9999 -9999 -9999 -9999 -9999 -9999 -9999 -9999 -9999 -9999 -9999 -9999 -9999 -9999 -9999 -9999 -9999 -9999 -9999 -9999 -9999 -9999 -9999 -9999 -9999

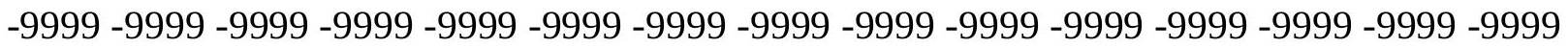

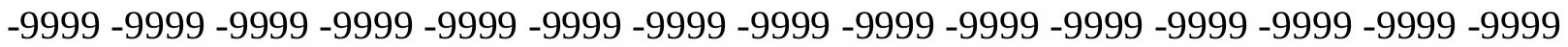
-9999 -9999 -9999 -9999 -9999 -9999 -9999 -9999 -9999 -9999 -9999 -9999 -9999 -9999 -9999 -

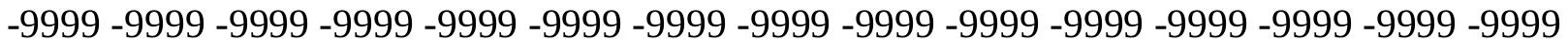
-9999 -9999 -9999 -9999 -9999 -9999 -9999 -9999 -9999 -9999 -9999 -9999 -9999 -9999 -9999 -9999 -9999 -9999 -9999 -9999 -9999 -9999 -9999 -9999 -9999 -9999 -9999 -9999 -9999 -9999 -9999 -9999 -9999 -9999 -9999 -9999 -9999 -9999 -9999 -9999 -9999 -9999 -9999 -9999 -9999 -9999 -9999 -9999 -9999 -9999 -9999 -9999 -9999 -9999 -9999 -9999 -9999 -9999 -9999 -9999

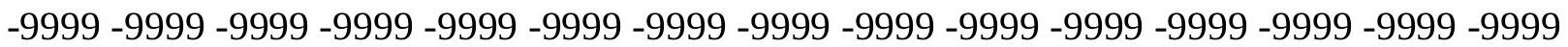

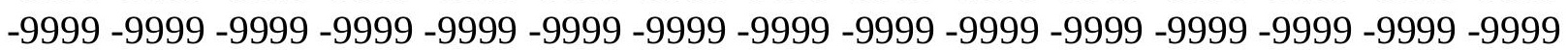
-9999 -9999 -9999 -9999 -9999 -9999 -9999 -9999 -9999 -9999 -9999 -9999 -9999 -9999 -9999 -9999 -9999 -9999 -9999 -9999 -9999 -9999 -9999 -9999 -9999 -9999 -9999 -9999 -9999 -9999 -9999 -9999 -9999 -9999 -9999 -9999 -9999 -9999 -9999 -9999 -9999 -9999 -9999 -9999 -9999 -9999 -9999 -9999 -9999 -9999 -9999 -9999 -9999 -9999 -9999 -9999 -9999 -9999 -9999 -9999 147.5160064697 144.7729034424 141.4203033447134.9624328613131.4984741211 97.5965728759897 .1360397338996 .6935501098696 .2681045532295 .85874176025 95.4642028808695 .0832519531290 .2164001464886 .8637619018685 .64462280273 85.9494018554786 .254188537686 .8637619018687 .4733276367287 .77810668945 88.3876876831188.9972534179789.3020401001 89.60682678223 89.91161346436 90.2164001464890 .2164001464890 .5211791992290 .5211791992290 .52117919922 90.5211791992290 .5211791992290 .5211791992290 .5211791992290 .52117919922 90.5211791992290 .5211791992290 .5211791992290 .5211791992290 .52117919922 90.2164001464890 .2164001464890 .2164001464890 .2164001464889 .91161346436 89.9116134643689 .6068267822389 .6068267822389 .302040100189 .3020401001 88.9972534179788 .9972534179788 .6924667358488 .6924667358488 .38768768311 88.0829010009887 .7781066894587 .4733276367287 .1685485839886 .86376190186 86.5589828491285 .9494018554785 .6446228027385 .0350494384884 .42548370361 83.8159103393683 .206336975182 .61499023438 -9999 -9999 -9999 -9999 -9999 -9999 -9999 -9999 -9999 -9999 -9999 -9999 -9999 -9999 -9999 -9999 -9999 -9999 -9999 -9999 -9999 -9999 -9999 -9999 -9999 -9999 -9999 -9999 -9999 -9999 -9999 -9999 -9999 -9999 -9999 -9999 -9999

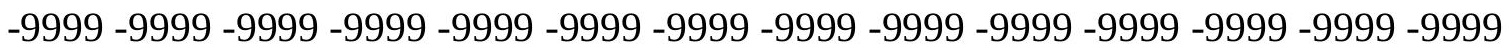
-9999 -9999 -9999 -9999 -9999 -9999 -9999 -9999 -9999 -9999 -9999 -9999 -9999 -9999 -9999 -9999 -9999 -9999 -9999 -9999 -9999 -9999 -9999 -9999 -9999 -9999 -9999 -9999 -9999 -9999 -9999 -9999 -9999 -9999 -9999 -9999 -9999 -9999 -9999 -9999 -9999 -9999 -9999 -9999 -9999

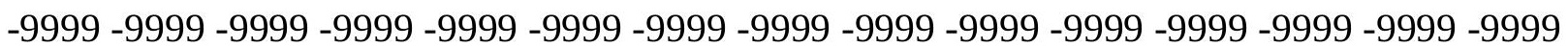
-9999 -9999 -9999 -9999 -9999 -9999 -9999 -9999 -9999 -9999 -9999 -9999 -9999 -9999 -9999 -9999 -9999 -9999 -9999 -9999 -9999 -9999 -9999 -9999 -9999 -9999 -9999 -9999 -9999 -9999 -9999 -9999 -9999 -9999 -9999 -9999 -9999 -9999 -9999 -9999 -9999 -9999 -9999 -9999 -9999

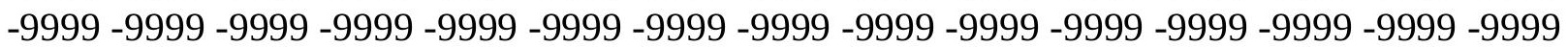


-9999 -9999 -9999 -9999 -9999 -9999 -9999 -9999 -9999 -9999 -9999 -9999 -9999 -9999 -9999 -9999 -9999 -9999 -9999 -9999 -9999 -9999 -9999 -9999 -9999 -9999 -9999 -9999 -9999 -9999 -9999 -9999 -9999 -9999 -9999 -9999 -9999 -9999 -9999 -9999 -9999 -9999 -9999 -9999 -9999 -9999 -9999 -9999 -9999 -9999 -9999 -9999 -9999 -9999 -9999 -9999 -9999 -9999 -9999 -9999 -9999 -9999 -9999 -9999 -9999 -9999 -9999 -9999 -9999 -9999 -9999 -9999 -9999 -9999 -9999 -9999 -9999 -9999 -9999 -9999 -9999 -9999 -9999 -9999 -9999 -9999 -9999 -9999 -9999 -9999 -9999 -9999 -9999 -9999 -9999 -9999 -9999 -9999 -9999 -9999 -9999 -9999 -9999 -9999 -9999

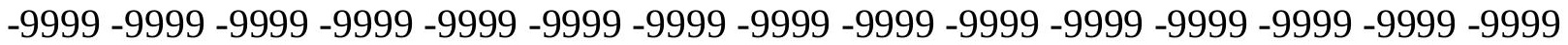

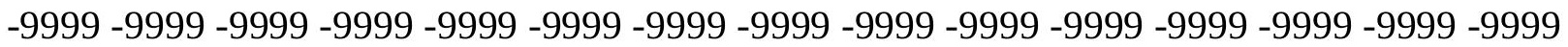
-9999 -9999 -9999 -9999 -9999 -9999 -9999 -9999 -9999 -9999 -9999 -9999 -9999 -9999 -9999 152.0877990723147 .5160064697143 .8585968018139 .5915985107132 .1536254883 97.66294097997 .2024459838996 .7613525390696 .3386230468895 .93328094482 95.5440139770595 .1693496704190 .8259735107487 .4733276367285 .33984375 85.9494018554786 .254188537686 .8637619018687 .4733276367288 .08290100098 88.6924667358488 .9972534179789 .6068267822389 .9116134643690 .21640014648 90.2164001464890 .5211791992290 .5211791992290 .8259735107490 .82597351074 90.8259735107490 .8259735107490 .8259735107490 .8259735107490 .82597351074 90.8259735107490 .8259735107490 .5211791992290 .5211791992290 .52117919922 90.5211791992290 .5211791992290 .2164001464890 .2164001464890 .21640014648 89.9116134643689 .9116134643689 .9116134643689 .6068267822389 .60682678223 89.3020401001 88.9972534179788.99725341797 88.69246673584 88.38768768311 88.0829010009887 .7781066894587 .4733276367287 .1685485839886 .86376190186 86.5589828491285 .9494018554785 .6446228027385 .0350494384884 .42548370361 83.8159103393683 .206336975182 .4054107666 -9999 -9999 -9999 -9999 -9999 -9999 -9999 -9999 -9999 -9999 -9999 -9999 -9999 -9999 -9999 -9999 -9999 -9999 -9999 -9999 -9999 -9999 -9999 -9999 -9999 -9999 -9999 -9999 -9999 -9999 -9999 -9999 -9999 -9999 -9999 -9999 -9999 -9999 -9999 -9999 -9999 -9999 -9999 -9999 -9999 -9999 -9999 -9999 -9999 -9999 -9999 -9999 -9999 -9999 -9999 -9999 -9999 -9999 -9999 -9999 -9999 -9999 -9999 -9999 -9999 -9999 -9999 -9999 -9999 -9999 -9999 -9999 -9999 -9999 -9999 -9999 -9999 -9999 -9999 -9999 -9999 -9999 -9999 -9999 -9999 -9999 -9999 -9999 -9999 -9999 -9999 -9999 -9999 -9999 -9999 -9999 -9999 -9999 -9999 -9999 -9999 -9999 -9999 -9999 -9999 -9999 -9999 -9999 -9999 -9999 -9999 -

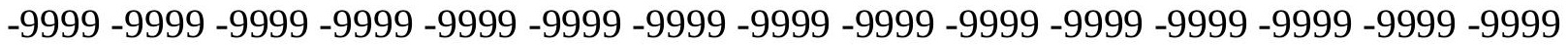
-9999 -9999 -9999 -9999 -9999 -9999 -9999 -9999 -9999 -9999 -9999 -9999 -9999 -9999 -9999 -9999 -9999 -9999 -9999 -9999 -9999 -9999 -9999 -9999 -9999 -9999 -9999 -9999 -9999 -9999 -

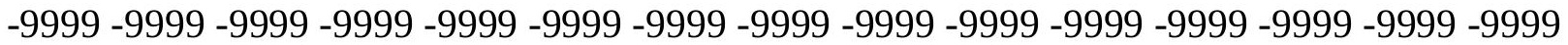
-9999 -9999 -9999 -9999 -9999 -9999 -9999 -9999 -9999 -9999 -9999 -9999 -9999 -9999 -9999 -9999 -9999 -9999 -9999 -9999 -9999 -9999 -9999 -9999 -9999 -9999 -9999 -9999 -9999 -9999

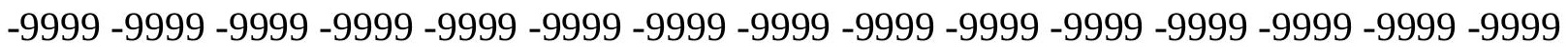
-9999 -9999 -9999 -9999 -9999 -9999 -9999 -9999 -9999 -9999 -9999 -9999 -9999 -9999 -9999 -9999 -9999 -9999 -9999 -9999 -9999 -9999 -9999 -9999 -9999 -9999 -9999 -9999 -9999 -9999 -9999 -9999 -9999 -9999 -9999 -9999 -9999 -9999 -9999 -9999 -9999 -9999 -9999 -9999 -9999 -9999 -9999 -9999 -9999 -9999 -9999 -9999 -9999 -9999 -9999 -9999 -9999 -9999 -9999 -9999 -9999 -9999 -9999 -9999 -9999 -9999 -9999 -9999 -9999 -9999 -9999 -9999 -9999 -9999 -9999 -9999 -9999 -9999 -9999 -9999 -9999 -9999 -9999 -9999 -9999 -9999 -9999 -9999 -9999 -9999 -9999 -9999 -9999 -9999 -9999 -9999 -9999 -9999 -9999 -9999 -9999 -9999 -9999 -9999 -9999 -9999 149.6495056152 145.9920959473141.7250976562137.1533050537128.7194976807 
97.2580184936596.8184051513796.3986968994195.9980010986395.61503601074 95.248184204192 .9594726562588 .9972534179785 .9494018554785 .94940185547 86.5589828491287 .1685485839887 .7781066894588 .3876876831188 .99725341797 89.6068267822389 .9116134643690 .2164001464890 .5211791992290 .52117919922 90.8259735107490 .8259735107490 .8259735107490 .8259735107490 .82597351074 90.8259735107490 .8259735107490 .8259735107490 .8259735107490 .82597351074 90.8259735107490 .8259735107490 .8259735107490 .5211791992290 .52117919922 90.5211791992290 .5211791992290 .5211791992290 .2164001464890 .21640014648 90.2164001464889 .9116134643689 .9116134643689 .6068267822389 .60682678223 89.302040100188 .9972534179788 .6924667358488 .3876876831188 .08290100098 87.7781066894587 .4733276367287 .1685485839886 .8637619018686 .2541885376 85.9494018554785 .3398437585 .0350494384884 .4254837036183 .51112365723 82.9015579223682 .12750244141 -9999 -9999 -9999 -9999 -9999 -9999 -9999 -9999 -9999 -9999 -9999 -9999 -9999 -9999 -9999 -9999 -9999 -9999 -9999 -9999 -9999 -9999 -9999 -9999 -9999 -9999 -9999 -9999 -9999 -9999 -9999 -9999 -9999 -9999 -9999 -9999 -9999 -9999 -9999 -

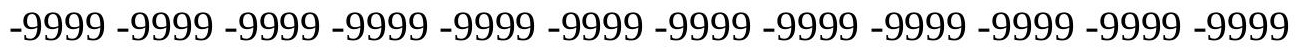

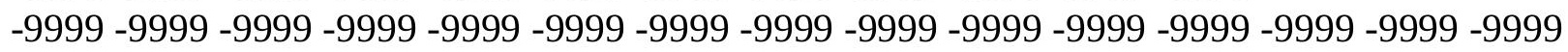
-9999 -9999 -9999 -9999 -9999 -9999 -9999 -9999 -9999 -9999 -9999 -9999 -9999 -9999 -9999 -999 -9999 -9999 -9999 -9999 -9999 -9999 -9999 -9999 -9999 -9999 -9999 -9999 -9999 -9999 -9999 -9999 -9999 -9999 -9999 -9999 -9999 -9999 -9999 -9999 -9999 -9999 -9999 -9999 -9999 -9999 -9999 -9999 -9999 -9999 -9999 -9999 -9999 -9999 -9999 -9999 -9999 -9999 -9999 -9999 -9999 -9999 -9999 -9999 -9999 -9999 -9999 -9999 -9999 -9999 -9999 -9999 -9999 -9999 -9999 -9999 -9999 -9999 -9999 -9999 -9999 -9999 -9999 -9999 -9999 -9999 -9999 -9999-9999-9999-9999 -999 -9999 -9999 -9999 -9999 -9999 -9999 -9999 -9999 -9999 -9999 -9999 -9999 -9999 -9999 -9999 -9999 -9999 -9999 -9999 -9999 -9999 -9999 -9999 -9999 -9999 -9999 -9999 -9999 -9999 -9999 -9999 -9999 -9999 -9999 -9999 -9999 -9999 -9999 -9999 -9999 -9999 -9999 -9999 -9999 -9999 -9999 -9999 -9999 -9999 -9999 -9999 -9999 -9999 -9999 -9999 -9999 -9999 -9999 -9999 -9999

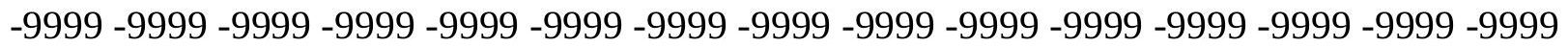
-9999 -9999 -9999 -9999 -9999 -9999 -9999 -9999 -9999 -9999 -9999 -9999 -9999 -9999 -9999 -9999 -9999 -9999 -9999 -9999 -9999 -9999 -9999 -9999 -9999 -9999 -9999 -9999 -9999 -9999 -9999 -9999 -9999 -9999 -9999 -9999 -9999 -9999 -9999 -9999 -9999 -9999 -9999 -9999 -9999

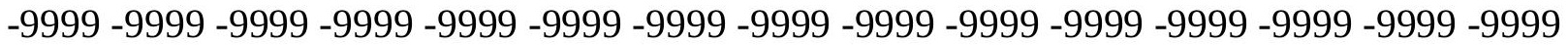

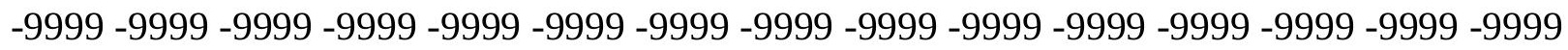

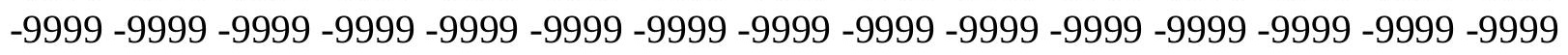
-9999 -9999 147.5160064697 143.2489929199 138.6772003174133.4958953857 97.3019866943496 .8636779785296 .4470443725696 .0513687133895 .67552947998 95.3178329467894 .97544097991 .1307525634887 .7781066894586 .55898284912 87.16854858398 87.77810668945 88.38768768311 88.99725341797 89.3020401001 89.9116134643690 .2164001464890 .5211791992290 .8259735107490 .82597351074 91.1307525634891 .1307525634891 .1307525634891 .1307525634891 .13075256348 91.1307525634891 .1307525634891 .1307525634890 .8259735107490 .82597351074 90.8259735107490 .8259735107490 .8259735107490 .8259735107490 .82597351074 90.8259735107490 .5211791992290 .5211791992290 .5211791992290 .52117919922 90.2164001464890 .2164001464889 .9116134643689 .9116134643689 .60682678223 89.3020401001 88.9972534179788.6924667358488.3876876831188.08290100098 87.77810668945 87.47332763672 87.16854858398 86.55898284912 86.2541885376 
85.6446228027385 .3398437584 .7302627563584 .1206970214883 .2063369751

82.5967712402381 .76407623291 -9999 -9999 -9999 -9999 -9999 -9999 -9999 -9999 -9999

-9999 -9999 -9999 -9999 -9999 -9999 -9999 -9999 -9999 -9999 -9999 -9999 -9999 -9999 -9999

-9999 -9999 -9999 -9999 -9999 -9999 -9999 -9999 -9999 -9999 -9999 -9999 -9999 -9999 -9999

-9999 -9999 -9999 -9999 -9999 -9999 -9999 -9999 -9999 -9999 -9999 -9999 -

-9999 -9999 -9999 -9999 -9999 -9999 -9999 -9999 -9999 -9999 -9999 -9999 -9999 -9999 -9999

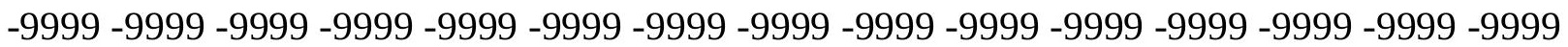

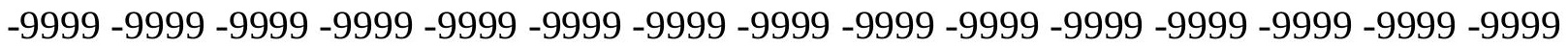

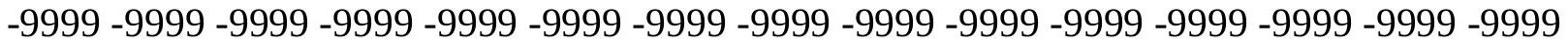

-9999 -9999 -9999 -9999 -9999 -9999 -9999 -9999 -9999 -9999 -9999 -9999 -9999 -9999 -9999

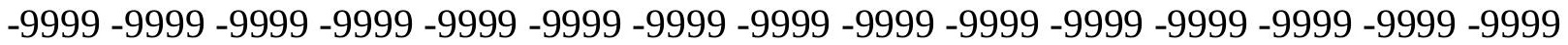

-9999 -9999 -9999 -9999 -9999 -9999 -9999 -9999 -9999 -9999 -9999 -9999 -9999 -9999 -9999 -

-9999 -9999 -9999 -9999 -9999 -9999 -9999 -9999 -9999 -9999 -9999 -9999 -9999 -9999 -9999 -

-9999 -9999 -9999 -9999 -9999 -9999 -9999 -9999 -9999 -9999 -9999 -9999 -9999 -9999 -9999

-9999 -9999 -9999 -9999 -9999 -9999 -9999 -9999 -9999 -9999 -9999 -9999 -9999 -9999 -9999 -

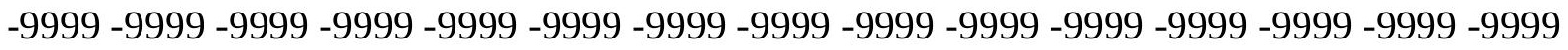

-9999 -9999 -9999 -9999 -9999 -9999 -9999 -9999 -9999 -9999 -9999 -9999 -9999 -9999 -9999 -

-9999 -9999 -9999 -9999 -9999 -9999 -9999 -9999 -9999 -9999 -9999 -9999 -9999 -9999 -9999 -

-9999 -9999 -9999 -9999 -9999 -9999 -9999 -9999 -9999 -9999 -9999 -9999 -9999 -9999 -9999 -

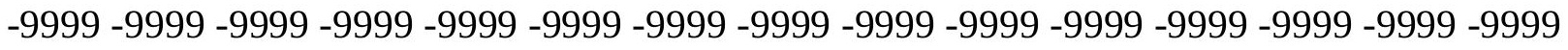

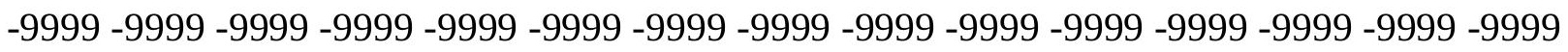

-9999 -9999 -9999 -9999 -9999 -9999 -9999 -9999 -9999 -9999 -9999 -9999 -9999 -9999 -9999 -

-9999 -9999 -9999 -9999 -9999 -9999 -9999 -9999 -9999 -9999 -9999 -9999 -9999 -9999 -9999 -

-9999 -9999 148.987701416145 .0776977539140 .2012023926135 .0198059082

129.838500976696 .8937988281296 .4795150756896 .0886001586995 .72018432617

95.3726501464895 .0427474975693 .2642517089889 .6068267822386 .86376190186

87.4733276367288 .0829010009888 .6924667358489 .302040100189 .91161346436

90.2164001464890 .8259735107490 .8259735107491 .1307525634891 .13075256348

91.4355392456191 .4355392456191 .4355392456191 .4355392456191 .43553924561

91.1307525634891 .1307525634891 .1307525634891 .1307525634891 .13075256348

91.1307525634890 .8259735107490 .8259735107490 .8259735107490 .82597351074 90.8259735107490 .8259735107490 .8259735107490 .5211791992290 .52117919922 90.5211791992290 .2164001464890 .2164001464889 .9116134643689 .60682678223 89.302040100189.302040100188.9972534179788.3876876831188.08290100098 87.7781066894587 .4733276367286 .8637619018686 .5589828491285 .94940185547 85.6446228027385 .0350494384884 .4254837036183 .8159103393682 .90155792236 81.9871978759881 .37763214111 -9999 -9999 -9999 -9999 -9999 -9999 -9999 -9999 -9999

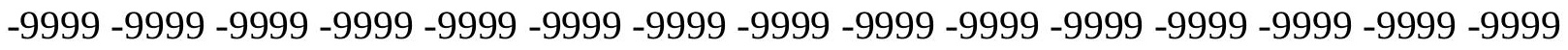

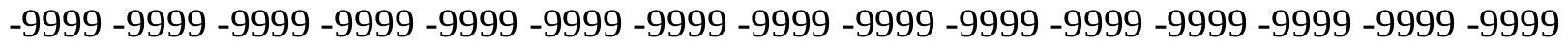
-9999 -9999 -9999 -9999 -9999 -9999 -9999 -9999 -9999 -9999 -9999 -9999 -

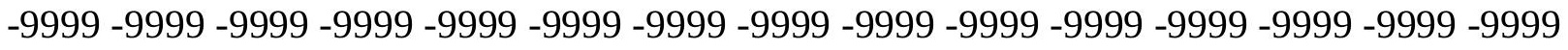

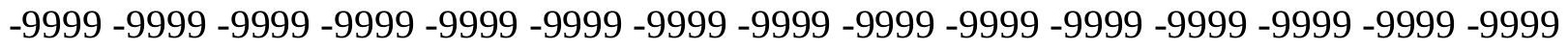
-9999 -9999 -9999 -9999 -9999 -9999 -9999 -9999 -9999 -9999 -9999 -9999 -9999 -9999 -9999 -9999 -9999 -9999 -9999 -9999 -9999 -9999 -9999 -9999-9999 -9999 -9999 -9999 -9999 -9999 -9999 -9999 -9999 -9999 -9999 -9999 -9999 -9999 -9999 -9999 -9999 -9999 -9999 -9999 -9999 -

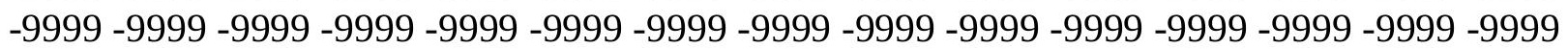


-9999 -9999 -9999 -9999 -9999 -9999 -9999 -9999 -9999 -9999 -9999 -9999 -9999 -9999 -9999 -9999 -9999 -9999 -9999 -9999 -9999 -9999 -9999 -9999 -9999 -9999 -9999 -9999 -9999 -9999 -9999 -9999 -9999 -9999 -9999 -9999 -9999 -9999 -9999 -9999 -9999 -9999 -9999 -9999 -9999 -9999 -9999 -9999 -9999 -9999 -9999 -9999 -9999 -9999 -9999 -9999 -9999 -9999 -9999 -9999 -9999 -9999 -9999 -9999 -9999 -9999 -9999 -9999 -9999 -9999 -9999 -9999 -9999 -9999 -9999 -9999 -9999 -9999 -9999 -9999 -9999 -9999 -9999 -9999 -9999 -9999 -9999 -9999 -9999 -9999 -9999 -9999 -9999 -9999 -9999 -9999 -9999 -9999 -9999 -9999 -9999 -9999 -9999 -9999 -9999

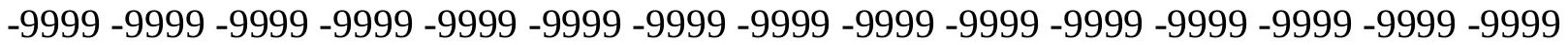
-9999 -9999 -9999 -9999 -9999 -9999 -9999 -9999 -9999 -9999 -9999 -9999 -9999 -9999 -9999 -9999 -9999 -9999 -9999 -9999 -9999 -9999 -9999 -9999 -9999 -9999 -9999 -9999 -9999 -9999 -9999 -9999 -9999 -9999 -9999 -9999 -9999 -9999 -9999 -9999 -9999 -9999 -9999 -9999 -9999 -9999 -9999 -9999 -9999 -9999 -9999 -9999 -9999 -9999 -9999 -9999 -9999 -9999 -9999 -9999 -9999 -9999-9999 146.6015930176141.4203033447 136.2389984131 131.0576019287 96.902061462496 .4880523681696 .10044097995 .7388153076295 .40179443359 95.0859985351694 .7871170043991 .7403335571388 .0829010009888 .08290100098 88.6924667358489 .302040100189 .9116134643690 .5211791992290 .82597351074 91.1307525634891 .4355392456191 .4355392456191 .7403335571391 .74033355713 91.7403335571391 .7403335571391 .4355392456191 .4355392456191 .43553924561 91.1307525634891 .1307525634891 .1307525634891 .1307525634891 .13075256348 91.1307525634891 .1307525634891 .1307525634890 .8259735107490 .82597351074 90.8259735107490 .8259735107490 .8259735107490 .5211791992290 .52117919922 90.5211791992290 .2164001464889 .9116134643689 .6068267822389 .60682678223 89.302040100188.6924667358488.3876876831188.08290100098 87.77810668945 87.1685485839886 .8637619018686 .254188537685 .6446228027385 .33984375 84.7302627563584 .1206970214883 .206336975182 .5967712402381 .68241119385 81.07285308838 -9999 -9999 -9999 -9999 -9999 -9999 -9999 -9999 -9999 -9999 -9999 -9999 -9999 -9999 -9999 -9999 -9999 -9999 -9999 -9999 -9999 -9999 -9999 -9999 -9999 -9999 -9999 -9999 -9999 -9999 -9999 -9999 -9999 -9999 -9999 -9999 -9999 -9999 -9999 -9999 -9999 -9999 -9999 -9999 -9999 -9999 -9999 -9999 -9999 -9999 -9999

-9999 -9999 -9999 -9999 -9999 -9999 -9999 -9999 -9999 -9999 -9999 -9999 -9999 -9999 -9999 -9999 -9999 -9999 -9999 -9999 -9999 -9999 -9999 -9999 -9999 -9999 -9999 -9999 -9999 -9999 -

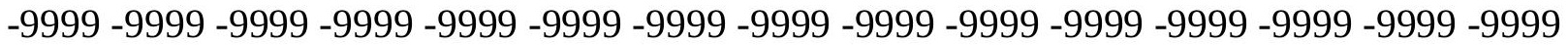
-9999 -9999 -9999 -9999 -9999 -9999 -9999 -9999 -9999 -9999 -9999 -9999 -9999 -9999 -9999 -9999 -9999 -9999 -9999 -9999 -9999 -9999 -9999 -9999 -9999 -9999 -9999 -9999 -9999 -9999 -

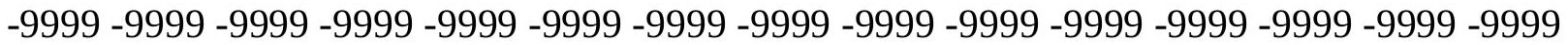
-9999 -9999 -9999 -9999 -9999 -9999 -9999 -9999 -9999 -9999 -9999 -9999 -9999 -9999 -9999 -9999 -9999 -9999 -9999 -9999 -9999 -9999 -9999 -9999 -9999 -9999 -9999 -9999 -9999 -9999

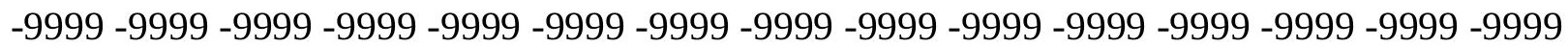
-9999 -9999 -9999 -9999 -9999 -9999 -9999 -9999 -9999 -9999 -9999 -9999 -9999 -9999 -9999 -9999 -9999 -9999 -9999 -9999 -9999 -9999 -9999 -9999 -9999 -9999 -9999 -9999 -9999 -9999 -9999 -9999 -9999 -9999 -9999 -9999 -9999 -9999 -9999 -9999 -9999 -9999 -9999 -9999 -9999 -999 -9999 -9999 -9999 -9999 -9999 -9999 -9999 -9999 -9999 -9999 -9999 -9999 -9999 -9999 -9999 -9999 -9999 -9999 -9999 -9999 -9999 -9999 -9999 -9999 -9999 -9999 -9999 -9999 -9999 -9999 -9999 -9999 -9999 -9999 -9999 -9999 -9999 -9999 -9999 -9999 -9999 -9999 -9999 -9999 -9999 -9999 -9999 -9999 -9999 -9999 -9999 -9999 -9999 -9999 -9999 -9999 -9999 -9999 -9999 -9999

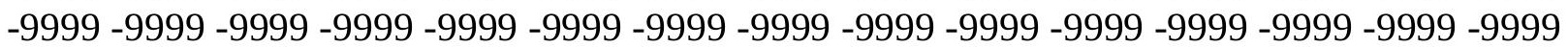


-9999 -9999 -9999 -9999 -9999 -9999 -9999 -9999 -9999 -9999 -9999 -9999 -9999 -9999 -9999 -9999 -9999-9999 147.3026580811 142.9441986084137.4580993652 131.9720001221 127.095397949296.4633255004996.0762405395595.7197189331195.39290618896 95.0926055908294 .8142089843893 .5690307617289 .9116134643688 .69246673584 89.3020401001 89.9116134643690.5211791992291.1307525634891.43553924561 91.7403335571391 .7403335571392 .0450973510792 .0450973510792 .04509735107 92.0450973510791 .7403335571391 .7403335571391 .4355392456191 .43553924561 91.4355392456191 .4355392456191 .1307525634891 .1307525634891 .13075256348 91.1307525634891 .1307525634891 .1307525634891 .1307525634891 .13075256348 91.1307525634890 .8259735107490 .8259735107490 .8259735107490 .52117919922 90.5211791992290 .2164001464890 .2164001464889 .9116134643689 .60682678223 88.99725341797 88.69246673584 88.38768768311 87.77810668945 87.47332763672 86.8637619018686 .5589828491285 .9494018554785 .3398437584 .73026275635 84.1206970214883 .5111236572382 .9015579223681 .9871978759881 .07285308838 80.46327209473 -9999 -9999 -9999 -9999 -9999 -9999 -9999 -9999 -9999 -9999 -9999 -9999

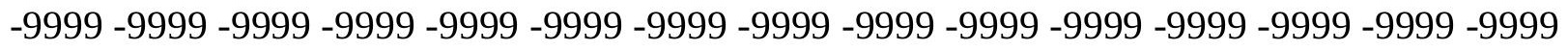
-9999 -9999 -9999 -9999 -9999 -9999 -9999 -9999 -9999 -9999 -9999 -9999 -9999 -9999 -9999 -9999 -9999 -9999 -9999 -9999 -9999 -9999 -9999 -9999 -9999 -9999 -9999 -9999 -9999 -9999 -9999 -9999 -9999 -9999 -9999 -9999 -9999 -9999 -9999

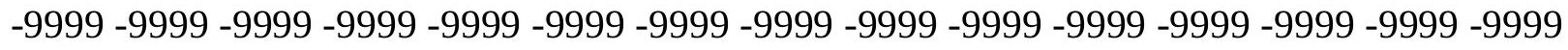

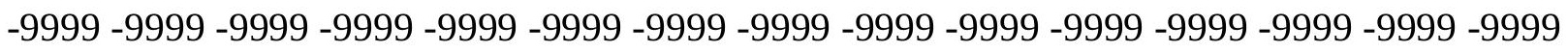
-9999 -9999 -9999 -9999 -9999 -9999 -9999 -9999 -9999 -9999 -9999 -9999 -9999 -9999 -9999 -9999 -9999 -9999 -9999 -9999 -9999 -9999 -9999 -9999 -9999 -9999 -9999 -9999 -9999 -9999 -

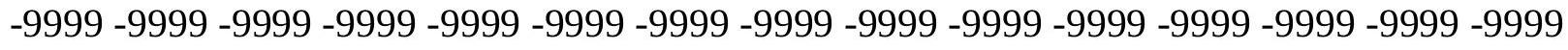

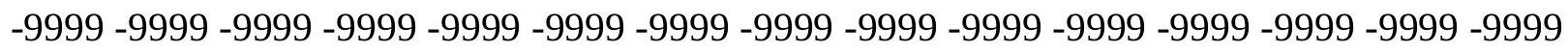
-9999 -9999 -9999 -9999 -9999 -9999 -9999 -9999 -9999 -9999 -9999 -9999 -9999 -9999 -9999 -9999 -9999 -9999 -9999 -9999 -9999 -9999 -9999 -9999 -9999 -9999 -9999 -9999 -9999 -9999 -

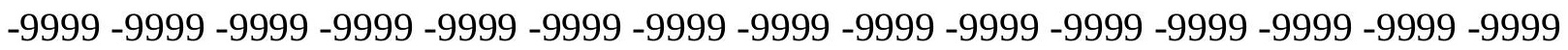
-9999 -9999 -9999 -9999 -9999 -9999 -9999 -9999 -9999 -9999 -9999 -9999 -9999 -9999 -9999 -9999 -9999 -9999 -9999 -9999 -9999 -9999 -9999 -9999 -9999 -9999 -9999 -9999 -9999 -9999 -9999 -9999 -9999 -9999 -9999 -9999 -9999 -9999 -9999-9999 -9999 -9999 -9999 -9999 -9999 -9999 -9999 -9999 -9999 -9999 -9999 -9999 -9999 -9999 -9999 -9999 -9999 -9999 -9999 -9999 -

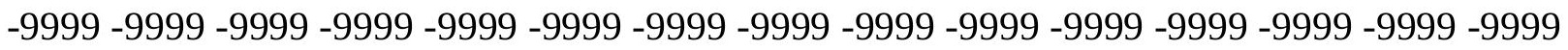
-9999 -9999 -9999 -9999 -9999 -9999 -9999 -9999 -9999 -9999 -9999 -9999 -9999 -9999 -9999 -9999 -9999 -9999 -9999 -9999 -9999 -9999 -9999 -9999 -9999 -9999 -9999 -9999 -9999 -9999 -9999 -9999 -9999 -9999 -9999 -9999 -9999 -9999 -9999 -9999 -9999 -9999 -9999 -9999 -9999 -9999 -9999 -9999 -9999 143.8585968018 138.6772003174133 .1911010742128 .0097961426 96.3983612060596 .007812595 .6538162231495 .3363952636795 .05289459229 94.7985839843894 .5664825439591 .4355392456189 .302040100189 .91161346436 90.5211791992291 .1307525634891 .4355392456192 .0450973510792 .04509735107 92.3498916626 92.349891662692.3498916626 92.349891662692.04509735107 92.0450973510791 .7403335571391 .7403335571391 .4355392456191 .43553924561 91.4355392456191 .1307525634891 .1307525634891 .1307525634891 .13075256348 91.1307525634891 .1307525634891 .1307525634891 .1307525634891 .13075256348 91.1307525634891 .1307525634890 .8259735107490 .8259735107490 .52117919922 90.5211791992290 .2164001464889 .9116134643689 .6068267822388 .99725341797 
88.6924667358488 .0829010009887 .7781066894587 .1685485839886 .55898284912 86.254188537685 .6446228027385 .0350494384884 .4254837036183 .81591033936 $83.206336975182 .2919769287181 .6824111938580 .7680587768679 .85370635986-9999$ -9999 -9999 -9999 -9999 -9999 -9999 -9999 -9999 -9999 -9999 -9999 -9999 -9999 -9999 -9999 -9999 -9999 -9999 -9999 -9999 -9999 -9999 -9999 -9999 -9999 -9999 -9999-9999 -9999 -9999 -

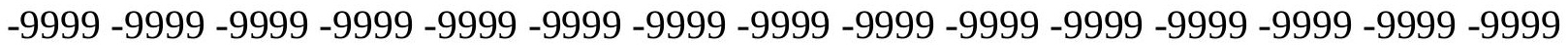
-9999 -9999 -9999-9999-9999

-9999 -9999 -9999 -9999 -9999 -9999 -9999 -9999 -9999 -9999 -9999 -9999 -9999 -9999 -9999

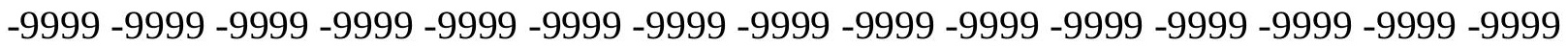
-9999 -9999 -9999 -9999 -9999 -9999 -9999 -9999 -9999 -9999 -9999 -9999 -9999 -9999 -9999 -

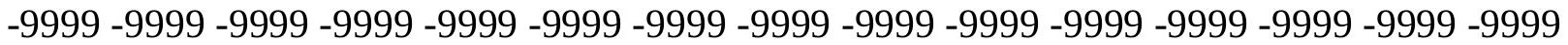
-9999 -9999 -9999 -9999 -9999 -9999 -9999 -9999 -9999 -9999 -9999 -9999 -9999 -9999 -9999 -9999 -9999 -9999 -9999 -9999 -9999 -9999 -9999 -9999 -9999 -9999 -9999 -9999 -9999 -9999 -9999 -9999 -9999 -9999 -9999 -9999 -9999 -9999 -9999 -9999 -9999 -9999 -9999 -9999 - 9999 -9999 -9999 -9999 -9999 -9999 -9999 -9999 -9999 -9999 -9999 -9999 -9999 -9999 -9999 -9999

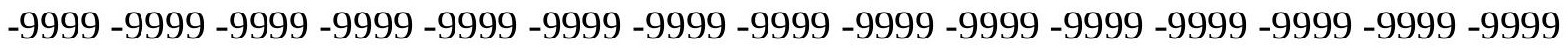
-9999 -9999 -9999 -9999 -9999 -9999 -9999 -9999 -9999 -9999 -9999 -9999 -9999 -9999 -9999 -9999 -9999 -9999 -9999 -9999 -9999 -9999 -9999 -9999 -9999 -9999 -9999 -9999 -9999 -9999 -9999 -9999 -9999 -9999 -9999 -9999 -9999 -9999 -9999 -9999 -9999 -9999 -9999 -9999 -9999 -

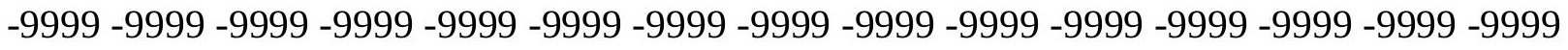

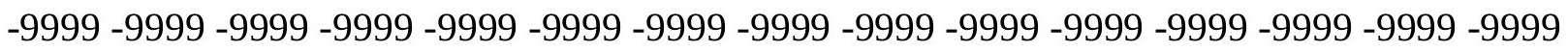
-9999 -9999 -9999 -9999 -9999 -9999 -9999 -9999 -9999 -9999 -9999 -9999 -9999 -9999 -9999 -9999 -9999 -9999 -9999 -9999 -9999 -9999 -9999 -9999 -9999 -9999 -9999 -9999 -9999 -9999 -

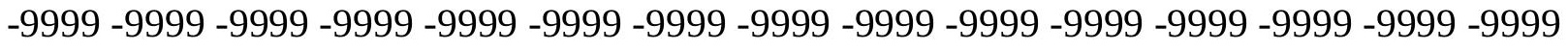

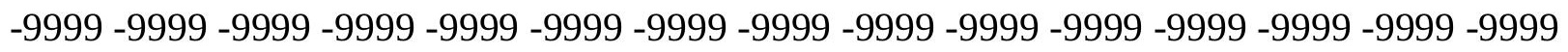
-9999 -9999 -9999 -9999 144.1634063721 139.8963928223134 .7149963379129 .2288970947 124.352302551395 .8880386352595 .5327606201295 .2231140136794 .95738983154 94.7310714721794 .5357513427793 .2642517089890 .2164001464890 .52117919922 91.1307525634891 .7403335571392 .349891662692 .349891662692 .65467834473 92.6546783447392 .6546783447392 .6546783447392 .6546783447392 .3498916626 92.0450973510792 .0450973510791 .7403335571391 .7403335571391 .43553924561 91.4355392456191 .4355392456191 .1307525634891 .1307525634891 .13075256348 91.1307525634891 .1307525634891 .1307525634891 .1307525634891 .13075256348 91.1307525634891 .1307525634891 .1307525634890 .8259735107490 .82597351074 90.5211791992290 .2164001464889 .9116134643689 .6068267822388 .99725341797 88.38768768311 88.08290100098 87.47332763672 86.86376190186 86.2541885376 85.9494018554785.33984375 84.73026275635 84.12069702148 83.2063369751

82.5967712402381 .6824111938581 .0728530883880 .1584930419979 .24413299561 -9999 -9999 -9999 -9999 -9999 -9999 -9999 -9999 -9999 -9999 -9999 -9999 -9999 -9999 -9999 -9999 -9999 -9999 -9999 -9999 -9999 -9999 -9999 -9999 -9999 -9999 -9999 -9999 -9999 -9999 -9999 -

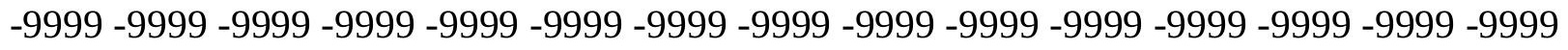
-9999 -9999-9999-9999-9999

-9999 -9999 -9999 -9999 -9999-9999 -9999 -9999 -9999 -9999 -9999 -9999 -9999 -9999 -9999 -9999 -9999 -9999 -9999 -9999 -9999 -9999 -9999 -9999-9999 -9999 -9999 -9999 -9999 -9999 -9999 -9999 -9999 -9999 -9999 -9999 -9999 -9999 -9999 -9999 -9999 -9999 -9999 -9999 -9999 -

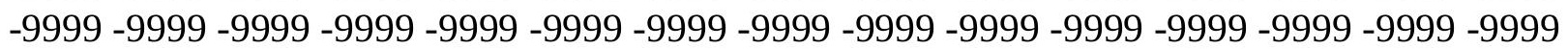


-9999 -9999 -9999 -9999 -9999 -9999 -9999 -9999 -9999 -9999 -9999 -9999 -9999 -9999 -9999 -9999 -9999 -9999 -9999 -9999 -9999 -9999 -9999 -9999 -9999 -9999 -9999 -9999 -9999 -9999 -9999 -9999 -9999 -9999 -9999 -9999 -9999 -9999 -9999 -9999 -9999 -9999 -9999 -9999 -9999 -9999 -9999 -9999 -9999 -9999 -9999 -9999 -9999 -9999 -9999 -9999 -9999 -9999 -9999 -9999 -9999 -9999 -9999 -9999 -9999 -9999 -9999 -9999 -9999 -9999 -9999 -9999 -9999 -9999 -9999 -9999 -9999 -9999 -9999 -9999 -9999 -9999 -9999 -9999 -9999 -9999 -9999 -9999 -9999 -9999 -9999 -9999 -9999 -9999 -9999 -9999 -9999 -9999 -9999 -9999 -9999 -9999 -9999 -9999 -9999

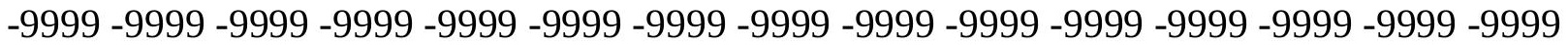
-9999 -9999 -9999 -9999 -9999 -9999 -9999 -9999 -9999 -9999 -9999 -9999 -9999 -9999 -9999 -9999 -9999 -9999 -9999 -9999 -9999 -9999 -9999 -9999 -9999 -9999 -9999 -9999 -9999 -9999 -

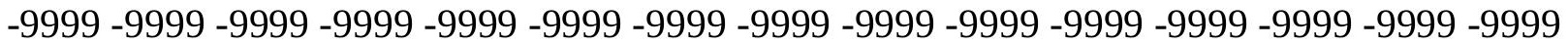
-9999 -9999 -9999 -9999 -9999 -9999 -9999 -9999 -9999 -9999 -9999 -9999 -9999 -9999 -9999

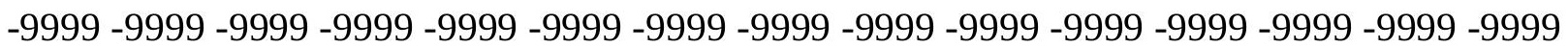
-9999 -9999 -9999 -9999 -9999 -9999 -9999 -9999 -9999 -9999 -9999 -9999 -9999 -9999 -9999 -9999 -9999 -9999 -9999 -9999 140.5059967041135 .9342041016131 .0576019287 125.571502685595 .710372924895 .3483123779395 .0431747436594 .79515075684 94.6003952026494 .4492187593 .5588912963990 .8259735107491 .13075256348 91.7403335571392 .349891662692 .9594726562592 .9594726562593 .26425170898 93.2642517089892 .9594726562592 .9594726562592 .6546783447392 .65467834473 92.349891662692 .0450973510791 .7403335571391 .7403335571391 .43553924561 91.4355392456191 .4355392456191 .1307525634891 .1307525634891 .43553924561 91.4355392456191 .4355392456191 .4355392456191 .4355392456191 .43553924561 91.4355392456191 .4355392456191 .1307525634891 .1307525634890 .82597351074 90.5211791992290 .2164001464889 .9116134643689 .302040100188 .99725341797 88.3876876831187 .7781066894587 .1685485839886 .5589828491285 .94940185547 85.3398437584 .7302627563584 .1206970214883 .5111236572382 .90155792236 81.9871978759881 .3776321411180 .4632720947379 .5489196777378 .63455963135 -9999 -9999 -9999 -9999 -9999 -9999 -9999 -9999 -9999 -9999 -9999 -9999 -9999 -9999 -9999 -9999 -9999 -9999 -9999 -9999 -9999 -9999 -9999 -9999 -9999 -9999 -9999 -9999 -9999 -9999 -9999

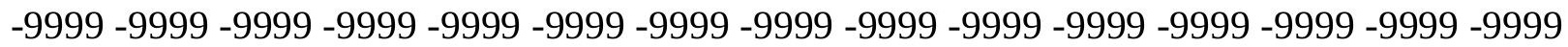
-9999 -9999 -9999-9999-9999

-9999 -9999 -9999 -9999 -9999 -9999 -9999 -9999 -9999 -9999 -9999 -9999 -9999 -9999 -9999 -9999 -9999 -9999 -9999 -9999 -9999 -9999 -9999 -9999 -9999 -9999 -9999 -9999 -9999 -9999 -9999 -9999 -9999 -9999 -9999 -9999 -9999 -9999 -9999 -9999 -9999 -9999 -9999 -9999 -9999 -

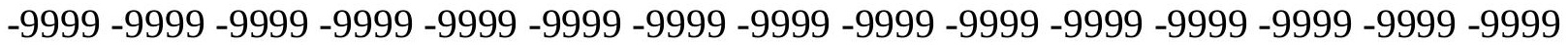
-9999 -9999 -9999 -9999 -9999 -9999 -9999 -9999 -9999 -9999 -9999 -9999 -9999 -9999 -9999 -9999 -9999 -9999 -9999 -9999 -9999 -9999 -9999 -9999 -9999 -9999 -9999 -9999 -9999 -9999

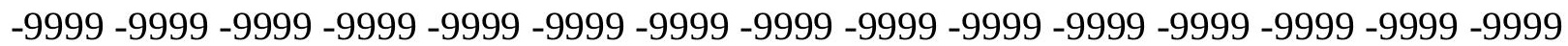
-9999 -9999 -9999 -9999 -9999 -9999 -9999 -9999 -9999 -9999 -9999 -9999 -9999 -9999 -9999 -9999 -9999 -9999 -9999 -9999 -9999 -9999 -9999 -9999 -9999 -9999 -9999 -9999 -9999 -9999 -9999 -9999 -9999 -9999 -9999 -9999 -9999 -9999 -9999 -9999 -9999 -9999 -9999 -9999 -9999 -999 -9999 -9999 -9999 -9999 -9999 -9999 -9999 -9999 -9999 -9999 -9999 -9999 -9999 -9999 -9999 -9999 -9999 -9999 -9999 -9999 -9999 -9999 -9999 -9999 -9999 -9999 -9999 -9999 -9999 -9999 -9999 -9999 -9999 -9999 -9999 -9999 -9999 -9999 -9999 -9999 -9999 -9999 -9999 -9999 -9999 -9999 -9999 -9999 -9999 -9999 -9999 -9999 -9999 -9999 -9999 -9999 -9999 -9999 -9999 -9999

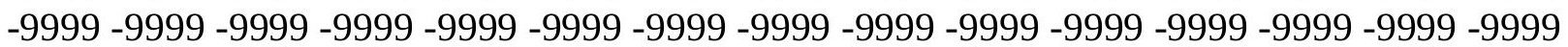


-9999 -9999 -9999 -9999 -9999 -9999 -9999 -9999 -9999 -9999 -9999 -9999 -9999 -9999 -9999 -9999 -9999 -9999 -9999 -9999 -9999 -9999 -9999 -9999 -9999 -9999 -9999 -9999 -9999 -9999 -9999 -9999 -9999 -9999 -9999 -9999 -9999 -9999 -9999 -9999 -9999 -9999 -9999 -9999 -9999 -9999 -9999 -9999 -9999-9999 140.8106994629136 .8484954834132 .5814971924 127.705001831195 .467910766695 .0910339355594 .7845840454194 .55179595947 94.3908386230594 .2911224365294 .2347564697392 .5508270263792 .04509735107 92.6546783447393 .2642517089893 .2642517089893 .5690307617293 .56903076172 93.5690307617293 .2642517089893 .2642517089892 .9594726562592 .65467834473 92.349891662692 .0450973510791 .7403335571391 .7403335571391 .43553924561 91.4355392456191 .4355392456191 .4355392456191 .4355392456191 .43553924561 91.4355392456191 .4355392456191 .4355392456191 .4355392456191 .43553924561 91.4355392456191 .4355392456191 .4355392456191 .1307525634890 .82597351074 90.8259735107490 .2164001464889 .9116134643689 .302040100188 .99725341797 88.3876876831187 .7781066894586 .8637619018686 .254188537685 .64462280273 85.0350494384884 .4254837036183 .8159103393682 .9015579223682 .29197692871 81.3776321411180 .7680587768679 .8537063598678 .9393463134878 .02498626709 -9999 -9999 -9999 -9999 -9999 -9999 -9999 -9999 -9999 -9999 -9999 -9999 -9999 -9999-9999-9999 -9999 -9999 -9999 -9999 -9999 -9999 -9999 -9999 -9999 -9999 -9999 -9999 -9999 -9999 -9999 -9999 -9999 -9999 -9999 -9999 -9999 -9999 -9999 -9999 -9999 -9999 -9999 -9999 -9999 -9999 $-9999-9999-9999-9999-9999$

-9999 -9999 -9999 -9999 -9999 -9999 -9999 -9999 -9999 -9999 -9999 -9999 -9999 -9999 -9999 -9999 -9999 -9999 -9999 -9999 -9999 -9999 -9999 -9999 -9999 -9999 -9999 -9999 -9999 -9999 -9999 -9999 -9999 -9999 -9999 -9999 -9999 -9999 -9999 -9999 -9999 -9999 -9999 -9999 -9999 -9999 -9999 -9999 -9999 -9999 -9999 -9999 -9999 -9999 -9999 -9999 -9999 -9999 -9999 -9999

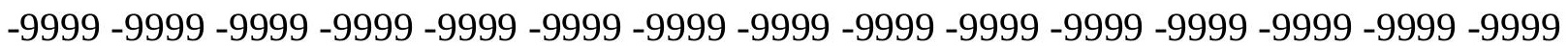
-9999 -9999 -9999 -9999 -9999 -9999 -9999 -9999 -9999 -9999 -9999 -9999 -9999 -9999 -9999 -9999 -9999 -9999 -9999 -9999 -9999 -9999 -9999 -9999 -9999 -9999 -9999 -9999 -9999 -9999 -9999 -9999 -9999 -9999 -9999 -9999 -9999 -9999 -9999 -9999 -9999 -9999 -9999 -9999 -9999 -9999 -9999 -9999 -9999 -9999 -9999 -9999 -9999 -9999 -9999 -9999 -9999 -9999 -9999 -9999 -9999 -9999 -9999 -9999 -9999 -9999 -9999 -9999 -9999 -9999 -9999 -9999 -9999 -9999 -9999 -9999 -9999 -9999 -9999 -9999 -9999 -9999 -9999 -9999 -9999 -9999 -9999 -9999 -9999 -9999 -9999 -9999 -9999 -9999 -9999 -9999 -9999 -9999 -9999 -9999 -9999 -9999 -9999 -9999 -9999 -9999 -9999 -9999 -9999 -9999 -9999 -9999 -9999 -9999 -9999 -9999 -9999 -9999 -9999 -9999 -9999 -9999 -9999 -9999 -9999 -9999 -9999 -9999 -9999 -9999 -9999 -9999 -9999 -9999 -9999 -

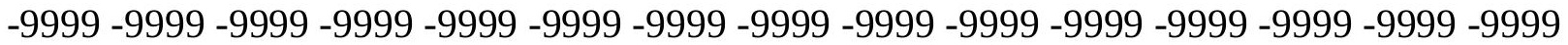
-9999 -9999 -9999 -9999 -9999 -9999 -9999 -9999 -9999 -9999 -9999 -9999 -9999 -9999 -9999 -9999 -9999 -9999 -9999 -9999 -9999 -9999 -9999 -9999 -9999 -9999 -9999 -9999 -9999 -9999 -9999 -9999 -9999 -9999 -9999 -9999 -9999 -9999 -9999 -9999 -9999 -9999 -9999 -9999 -9999 -9999 -9999 -9999-9999-9999-9999 137.4580993652 133.4958953857 129.533706665 124.961898803794 .7528686523494 .4354476928794 .2116088867294 .08332061768 94.0410308837994 .0634918212993 .9932861328192 .9594726562593 .56903076172 93.8738174438593.8738174438593.8738174438593.87381744385 93.87381744385 93.5690307617293 .2642517089892 .9594726562592 .6546783447392 .3498916626 92.0450973510791 .7403335571391 .7403335571391 .4355392456191 .43553924561 91.4355392456191 .4355392456191 .4355392456191 .4355392456191 .43553924561 91.4355392456191 .7403335571391 .7403335571391 .7403335571391 .74033355713 
91.7403335571391 .4355392456191 .4355392456191 .1307525634890 .82597351074 90.5211791992289 .9116134643689 .302040100188 .6924667358488 .08290100098 87.4733276367286 .8637619018685 .9494018554785 .3398437584 .73026275635 83.8159103393683 .206336975182 .5967712402381 .6824111938580 .76805877686 79.8537063598678 .9393463134878 .0249862670977 .41542053223 -9999 -9999 -9999-9999 -9999 -9999 -9999 -9999 -9999 -9999 -9999 -9999 -9999 -9999 -9999 -9999 -9999 -9999 -9999 -9999 -9999 -9999 -9999 -9999 -9999 -9999 -9999 -9999 -9999 -9999 -9999 -9999 -9999 -9999 -999 -

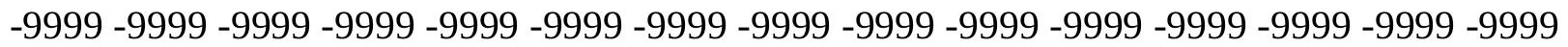
$-9999-9999$

-9999 -9999 -9999 -9999 -9999 -9999 -9999 -9999 -9999 -9999 -9999 -9999 -9999 -9999 -9999 -9999 -9999 -9999 -9999 -9999 -9999 -9999 -9999 -9999 -9999 -9999 -9999 -9999 -9999 -9999 -999 -9999 -9999 -9999 -9999 -9999 -9999 -9999 -9999 -9999 -9999 -9999 -9999 -9999 -9999 -9999 -9999 -9999 -9999 -9999 -9999 -9999 -9999 -9999 -9999 -9999 -9999 -9999 -9999 -9999 -9999

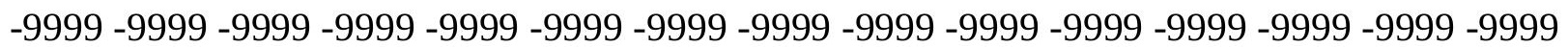
-9999 -9999 -9999 -9999 -9999 -9999 -9999 -9999 -9999 -9999 -9999 -9999 -9999 -9999 -9999 -9999 -9999 -9999 -9999 -9999 -9999 -9999 -9999 -9999 -9999 -9999 -9999 -9999 - -9999 - -9999 -

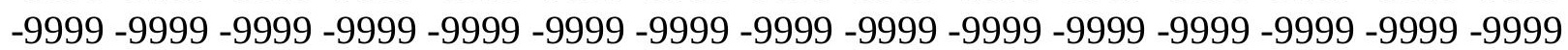

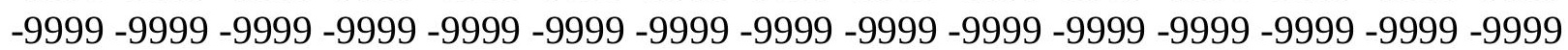
-9999 -9999 -9999 -9999 -9999 -9999 -9999 -9999 -9999 -9999 -9999 -9999 -9999 -9999 -9999 -9999 -9999 -9999 -9999 -9999 -9999 -9999 -9999 -9999 -9999 -9999 -9999 -9999 -9999 -9999 -9999 -9999 -9999 -9999 -9999 -9999 -9999 -9999 -9999 -9999 -9999 -9999 -9999 -9999 -9999

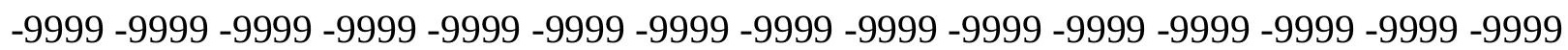
-9999 -9999 -9999 -9999 -9999 -9999 -9999 -9999 -9999 -9999 -9999 -9999 -9999 -9999 -9999

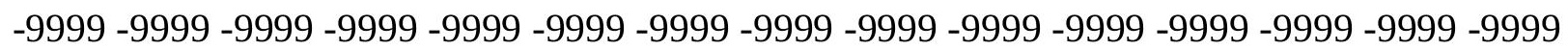

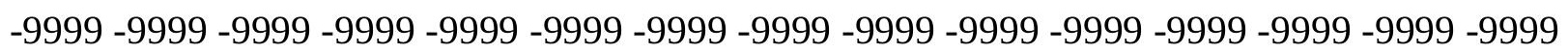
-9999 -9999 -9999 -9999 -9999 -9999 -9999 -9999 -9999 -9999 -9999 -9999 -9999 -9999 -9999 -9999 -9999 -9999 -9999 -9999 -9999 -9999 -9999 -9999 -9999 -9999 -9999 -9999 -9999 -9999 -9999 -9999 -9999 -9999 -9999 -9999 137.7628936768 134.4102020264130.7528076172 127.095397949294 .3275527954193 .9845352172993 .7574920654393 .65535736084 93.6724472045993.7867660522593.9570922851693.8738174438594.17859649658 94.1785964965894 .2775039672994 .1785964965894 .1785964965893 .87381744385 93.5690307617293 .2642517089892 .9594726562592 .6546783447392 .3498916626 92.0450973510791 .7403335571391 .7403335571391 .4355392456191 .43553924561 91.4355392456191 .4355392456191 .4355392456191 .4355392456191 .74033355713 91.7403335571391 .7403335571391 .7403335571391 .7403335571391 .74033355713 91.7403335571391 .7403335571391 .4355392456191 .1307525634890 .82597351074 90.5211791992289 .9116134643689 .302040100188 .6924667358488 .08290100098 87.1685485839886 .5589828491285 .6446228027385 .0350494384884 .12069702148 83.5111236572382 .5967712402381 .9871978759881 .0728530883880 .15849304199 79.2441329956178 .3297805786177 .4154205322376 .44769287109 -9999 -9999 -9999 -9999 -9999 -9999 -9999 -9999 -9999 -9999 -9999 -9999 -9999 -9999 -9999 -9999 -9999 -9999 -9999 -9999 -9999 -9999 -9999 -9999 -9999 -9999 -9999 -9999 -9999 -9999 -9999 -9999 -9999 -9999 -

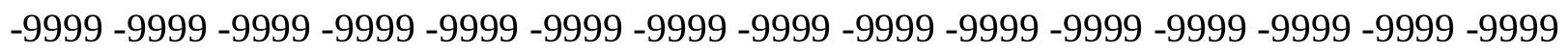
$-9999-9999$

-9999 -9999 -9999 -9999 -9999 -9999 -9999 -9999 -9999 -9999 -9999 -9999 -9999 -9999 -9999

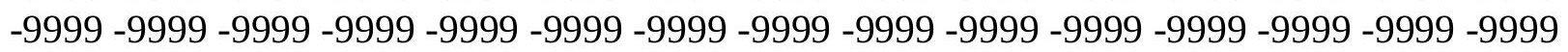


-9999 -9999 -9999 -9999 -9999 -9999 -9999 -9999 -9999 -9999 -9999 -9999 -9999 -9999 -9999 -9999 -9999 -9999 -9999 -9999 -9999 -9999 -9999 -9999 -9999 -9999 -9999 -9999 -9999 -9999 -9999 -9999 -9999 -9999 -9999 -9999 -9999 -9999 -9999 -9999 -9999 -9999 -9999 -9999 -9999 -9999 -9999 -9999 -9999 -9999 -9999 -9999 -9999 -9999 -9999 -9999 -9999 -9999 -9999 -9999 -9999 -9999 -9999 -9999 -9999 -9999 -9999 -9999 -9999 -9999 -9999 -9999 -9999 -9999 -9999 -9999 -9999 -9999 -9999 -9999 -9999 -9999 -9999 -9999 -9999 -9999 -9999 -9999 -9999 -9999 -9999 -9999 -9999 -9999 -9999 -9999 -9999 -9999 -9999 -9999 -9999 -9999 -9999 -9999 -9999

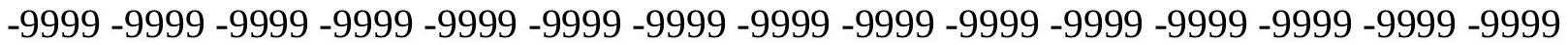
-9999 -9999 -9999 -9999 -9999 -9999 -9999 -9999 -9999 -9999 -9999 -9999 -9999 -9999 -9999 -9999 -9999 -9999 -9999 -9999 -9999 -9999 -9999 -9999 -9999 -9999 -9999 -9999 -9999 -9999 -

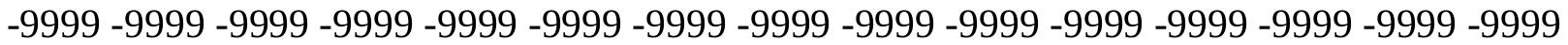
-9999 -9999 -9999 -9999 -9999 -9999 -9999 -9999 -9999 -9999 -9999 -9999 -9999 -9999 -9999

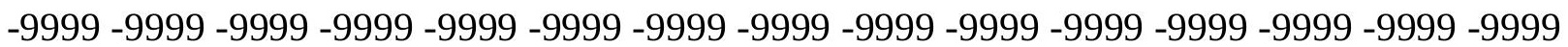
-9999 -9999 -9999 -9999 -9999 -9999 -9999 -9999 -9999 -9999 -9999 -9999 -9999 -9999 -9999 -9999 -9999 -9999 -9999 -9999 -9999 -9999 -9999 -9999 -9999 -9999 -9999 -9999 -9999 -9999 -9999 -9999 -9999 -9999 -9999 -9999 -9999 -9999 -9999 -9999 -9999 -9999 -9999 -9999 -9999 -9999 -9999 -9999 -9999 -9999 -9999 -9999 134.4102020264131 .3623962402128 .0097961426 124.352302551393.426200866793.1763305664193.08506774902 93.15586853027 93.3701477050893 .6783294677794 .012138366794 .2850952148494 .43500518799 94.4833908081194 .4833908081194 .1785964965893 .8738174438593 .56903076172 93.2642517089892 .9594726562592 .6546783447392 .349891662692 .04509735107 91.7403335571391 .7403335571391 .4355392456191 .4355392456191 .43553924561 91.4355392456191 .4355392456191 .7403335571391 .7403335571391 .74033355713 91.7403335571392 .0450973510792 .0450973510792 .0450973510791 .74033355713 91.7403335571391 .4355392456191 .4355392456190 .8259735107490 .52117919922 89.9116134643689 .302040100188 .6924667358487 .7781066894587 .16854858398 86.254188537685 .6446228027384 .7302627563583 .8159103393683 .2063369751 82.2919769287181 .3776321411180 .4632720947379 .5489196777378 .63455963135 77.7202072143676 .5010681152375 .54405975342 -9999 -9999 -9999 -9999 -9999 -9999 -9999 -9999 -9999 -9999 -9999 -9999 -9999 -9999 -9999 -9999 -9999 -9999 -9999 -9999 -9999 -9999 -9999 -9999 -9999 -9999 -9999 -9999 -9999 -9999 -9999 -9999 -9999 -9999 -9999 -9999 -9999 -9999 -9999 -9999 -9999 -9999 -9999 -9999 -9999 -9999 -9999 -9999 -9999 -9999 -9999 -9999 -9999 -9999 -9999 -9999 -9999 -9999 -9999 -9999 -9999 -9999 -9999 -9999 -9999 -9999 -9999 -9999 -9999 -9999 -9999 -9999 -9999 -9999 -9999 -9999 -9999 -9999 -9999 -9999 -9999 -

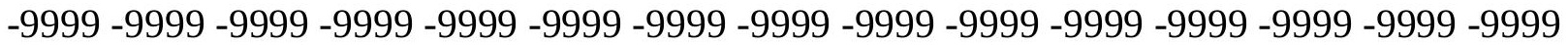
-9999 -9999 -9999 -9999 -9999 -9999 -9999 -9999 -9999 -9999 -9999 -9999 -9999 -9999 -9999 -9999 -9999 -9999 -9999 -9999 -9999 -9999 -9999 -9999 -9999 -9999 -9999 -9999 -9999 -9999

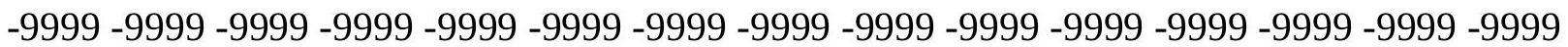
-9999 -9999 -9999 -9999 -9999 -9999 -9999 -9999 -9999 -9999 -9999 -9999 -9999 -9999 -9999 -9999 -9999 -9999 -9999 -9999 -9999 -9999 -9999 -9999 -9999 -9999 -9999 -9999 -9999 -9999 -9999 -9999 -9999 -9999 -9999 -9999 -9999 -9999 -9999 -9999 -9999 -9999 -9999 -9999 -9999 -999 -9999 -9999 -9999 -9999 -9999 -9999 -9999 -9999 -9999 -9999 -9999 -9999 -9999 -9999 -9999 -9999 -9999 -9999 -9999 -9999 -9999 -9999 -9999 -9999 -9999 -9999 -9999 -9999 -9999 -9999 -9999 -9999 -9999 -9999 -9999 -9999 -9999 -9999 -9999 -9999 -9999 -9999 -9999 -9999 -9999 -9999 -9999 -9999 -9999 -9999 -9999 -9999 -9999 -9999 -9999 -9999 -9999 -9999 -9999 -9999

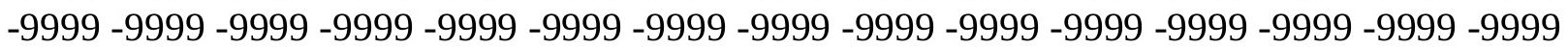


-9999 -9999 -9999 -9999 -9999 -9999 -9999 -9999 -9999 -9999 -9999 -9999 -9999 -9999 -9999 -9999 -9999 -9999 -9999 -9999 -9999 -9999 -9999 -9999 -9999 -9999 -9999 -9999 -9999 -9999 -9999 -9999 -9999 -9999 -9999 -9999 -9999 -9999 -9999 -9999 -9999 -9999 -9999 -9999 -9999 -9999 -9999 -9999 -9999 -9999 -9999 -9999 -9999 -9999 -9999 -9999 -9999 -9999 -9999 -9999 -9999 -9999 -9999 -9999 -9999 -9999 -9999 -9999 130.7528076172127 .4001998901 123.4380035492 .7625122070392 .4619598388792 .3542709350692 .45927429199 92.7677917480593 .2328491210993 .7640151977594 .2306900024494 .49235534668 94.4833908081194 .4833908081194 .1785964965893 .8738174438593 .56903076172 93.2642517089892 .9594726562592 .6546783447392 .349891662692 .04509735107 91.7403335571391 .4355392456191 .4355392456191 .4355392456191 .43553924561 91.4355392456191 .4355392456191 .7403335571391 .7403335571392 .04509735107 92.0450973510792 .0450973510792 .0450973510792 .0450973510792 .04509735107 91.7403335571391 .7403335571391 .4355392456191 .1307525634890 .52117919922 89.91161346436 89.3020401001 88.6924667358487.7781066894586.86376190186 86.254188537685 .3398437584 .4254837036183 .5111236572382 .59677124023 81.6824111938580 .7680587768679 .8537063598678 .9393463134878 .02498626709 76.8058471679775 .8914871215874 .71748352051 -9999 -9999 -9999 -9999 -9999 -9999 -9999 -9999 -9999 -9999 -9999 -9999 -9999 -9999 -9999 -9999 -9999 -9999 -9999 -9999 -9999 -9999 -9999 -9999 -9999 -9999 -9999 -9999 -9999 -9999 -9999 -9999 -9999 -9999 -9999 -9999 -9999 -9999 -9999 -9999 -9999 -9999 -9999 -9999 -9999 -9999 -9999 -9999 -9999 -9999 -9999 -

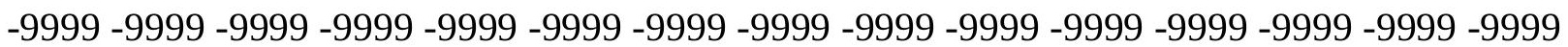
-9999 -9999 -9999 -9999 -9999 -9999 -9999 -9999 -9999 -9999 -9999 -9999 -9999 -9999 -9999 -9999 -9999 -9999 -9999 -9999 -9999 -9999 -9999 -9999 -9999 -9999 -9999 -9999 -9999 -9999 -9999 -9999 -9999 -9999 -9999 -9999 -9999 -9999 -9999 -9999 -9999 -9999 -9999 -9999 -9999

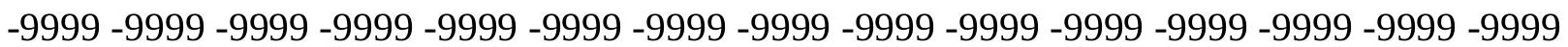
-9999 -9999 -9999 -9999 -9999 -9999 -9999 -9999 -9999 -9999 -9999 -9999 -9999 -9999 -9999 -9999 -9999 -9999 -9999 -9999 -9999 -9999 -9999 -9999 -9999 -9999 -9999 -9999 -9999 -9999 -9999 -9999 -9999 -9999 -9999 -9999 -9999 -9999 -9999 -9999 -9999 -9999 -9999 -9999 -9999 -9999 -9999 -9999 -9999 -9999 -9999 -9999 -9999 -9999 -9999 -9999 -9999 -9999 -9999 -9999 -9999 -9999 -9999 -9999 -9999 -9999 -9999 -9999 -9999 -9999 -9999 -9999 -9999 -9999 -9999 -9999 -9999 -9999 -9999 -9999 -9999 -9999 -9999 -9999 -9999 -9999 -9999 -9999 -9999 -9999 -

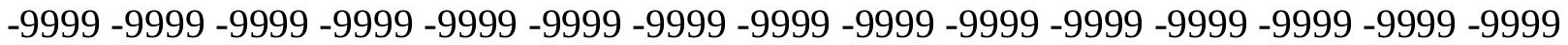
-9999 -9999 -9999 -9999 -9999 -9999 -9999 -9999 -9999 -9999 -9999 -9999 -9999 -9999 -9999 -9999 -9999 -9999 -9999 -9999 -9999 -9999 -9999 -9999 -9999 -9999 -9999 -9999 -9999 -9999 -

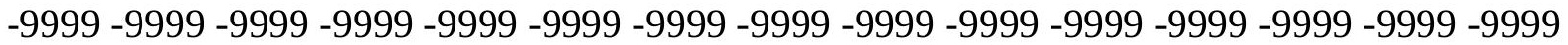
-9999 -9999 -9999 -9999 -9999 -9999 -9999 -9999 -9999 -9999 -9999 -9999 -9999 -9999 -9999 -9999 -9999 -9999 -9999 -9999 -9999 -9999 -9999 -9999 -9999 -9999 -9999 -9999 -9999 -9999 -9999 -9999 -9999 -9999 -9999 -9999 -9999 -9999 -9999 -9999 -9999 -9999 -9999 -9999 -9999 -9999 -9999 -9999 -9999 -9999 -9999 -9999 -9999 129.8385009766125 .8762969971 121.6092987061116 .427902221791 .6229476928791 .4589538574291 .55792236328 91.9345321655392 .5517272949293 .3087539672994 .0258178710994 .48339080811 94.4833908081194 .1785964965893 .8738174438593 .5690307617293 .26425170898 92.9594726562592 .6546783447392 .349891662692 .0450973510791 .74033355713 91.7403335571391 .4355392456191 .4355392456191 .4355392456191 .43553924561 91.4355392456191 .7403335571391 .7403335571392 .0450973510792 .04509735107 92.0450973510792 .349891662692 .349891662692 .0450973510792 .04509735107 
92.0450973510791 .7403335571391 .4355392456191 .1307525634890 .52117919922 89.91161346436 89.302040100188.3876876831187.77810668945 86.86376190186 85.9494018554785 .0350494384884 .1206970214883 .206336975182 .29197692871 81.3776321411180 .1584930419979 .2441329956178 .3297805786177 .1106262207 76.1962814331174 .9771423339873 .8264465332 -9999 -9999 -9999 -9999 -9999 -9999 -9999 -9999 -9999 -9999 -9999 -9999 -9999 -9999 -9999 -9999 -9999 -9999 -9999 -9999 -9999 -9999 -9999 -9999 -9999 -9999 -9999 -9999 -9999 -9999 -9999 -9999 -9999 -9999 -9999 -9999 -999 -9999 -9999 -9999 -9999 -9999 -9999 -9999 -9999 -9999 -9999 -9999 -9999 -9999 -9999 -9999 -9999 -9999 -9999 -9999 -9999 -9999 -9999 -9999 -9999 -9999 -9999 -9999 -9999 -9999 -9999 -9999 -9999 -9999 -9999 -9999 -9999 -9999 -9999 -9999 -9999 -9999 -9999 -9999 -9999 -

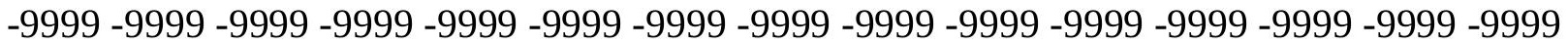
-9999 -9999 -9999 -9999 -9999 -9999 -9999 -9999 -9999 -9999 -9999 -9999 -9999 -9999 -9999 -9999 -9999 -9999 -9999 -9999 -9999 -9999 -9999 -9999 -9999 -9999 -9999 -9999 -9999 -9999 -9999 -9999 -9999 -9999 -9999 -9999 -9999 -9999 -9999 -9999 -9999 -9999 -9999 -9999 - 9999 -9999 -9999 -9999 -9999 -9999 -9999 -9999 -9999 -9999 -9999 -9999 -9999 -9999 -9999 -9999

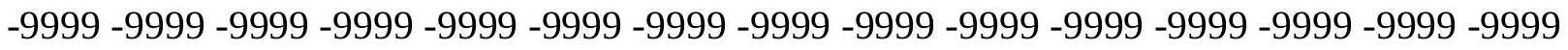

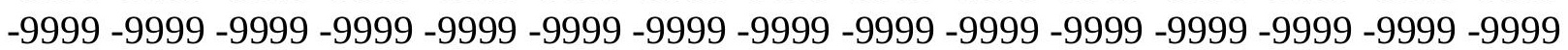
-9999 -9999 -9999 -9999 -9999 -9999 -9999 -9999 -9999 -9999 -9999 -9999 -9999 -9999 -9999 -999 -9999 -9999 -9999 -9999 -9999 -9999 -9999 -9999 -9999 -9999 -9999 -9999 -9999 -9999 -9999 -9999 -9999 -9999 -9999 -9999 -9999 -9999 -9999 -9999 -9999 -9999 -9999 -9999 -9999 -9999 -9999 -9999 -9999 -9999 -9999 -9999 -9999 -9999 -9999 -9999 -9999 -9999 -9999 -9999 -9999 -999 -9999 -9999 -9999 -9999 -9999 -9999 -9999 -9999 -9999 -9999 -9999 -9999 -9999 -9999 -9999 -9999 -9999 -9999 -9999 -9999 -9999 -9999 -9999 -9999 -9999 -9999 -9999 -9999 -9999 -9999 -9999 -9999 -9999 -9999 -9999 -9999 -9999 -9999 -9999 -9999 -9999 -9999 -9999 -9999 -9999 -9999 -9999 -9999 -9999 -9999 -9999 -9999 -9999 -9999 -9999 -9999 -9999 -9999 -9999 -9999 -9999 -9999 -9999 -9999 -9999 -9999 -9999 -9999 -9999 -9999 -9999 -9999 -9999 -9999 -9999 -9999 -9999 -9999 -9999 -9999 -9999 -9999 -9999 -9999 124.0475006104 119.4757995605 114.294403076290 .6909179687590 .4160079956190 .446014404390 .82800292969 91.5632781982492 .5527191162193 .5690307617294 .1785964965894 .17859649658 93.8738174438593 .5690307617293 .2642517089893 .2642517089892 .95947265625 92.6546783447392 .349891662692 .0450973510791 .7403335571391 .43553924561 91.4355392456191 .4355392456191 .4355392456191 .4355392456191 .74033355713 91.7403335571392 .0450973510792 .0450973510792 .0450973510792 .3498916626 92.349891662692 .349891662692 .349891662692 .349891662692 .04509735107 91.7403335571391 .4355392456191 .1307525634890 .5211791992289 .91161346436 88.9972534179788 .3876876831187 .4733276367286 .5589828491285 .64462280273 84.7302627563583 .8159103393682 .9015579223681 .6824111938580 .76805877686 79.5489196777378 .6345596313577 .4154205322376 .5010681152375 .28192901611 74.3675689697372 .86014556885 -9999 -9999 -9999 -9999 -9999 -9999 -9999 -9999 -9999 -9999 -9999 -9999 -9999 -9999 -9999 -9999 -9999 -9999 -9999 -9999 -9999 -9999 -9999 -9999

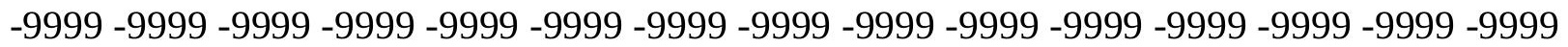
-9999 -9999 -9999 -9999 -9999 -9999 -9999 -9999 -9999 -9999 -9999 -9999 -9999 -9999 -9999 -9999 -9999 -9999 -9999 -9999 -9999 -9999 -9999 -9999 -9999 -9999 -9999 -9999 -9999 -9999 -9999 -9999 -9999 -9999 -9999 -9999 -9999 -9999 -9999 -9999 -9999 -9999 -9999 -9999 -9999 -9999 -9999 -9999 -9999 -9999 -9999 -9999 -9999 -9999 -9999 -9999 -9999 -

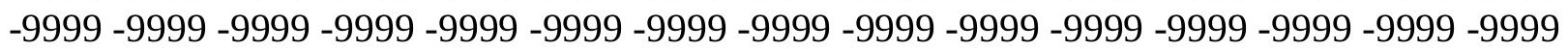


-9999 -9999 -9999 -9999 -9999 -9999 -9999 -9999 -9999 -9999 -9999 -9999 -9999 -9999 -9999 -9999 -9999 -9999 -9999 -9999 -9999 -9999 -9999 -9999 -9999 -9999 -9999 -9999 -9999 -9999 -9999 -9999 -9999 -9999 -9999 -9999 -9999 -9999 -9999 -9999 -9999 -9999 -9999 -9999 -9999 -9999 -9999 -9999 -9999 -9999 -9999 -9999 -9999 -9999 -9999 -9999 -9999 -9999 -9999 -9999 -9999 -9999 -9999 -9999 -9999 -9999 -9999 -9999 -9999 -9999 -9999 -9999 -9999 -9999 -9999 -9999 -9999 -9999 -9999 -9999 -9999 -9999 -9999 -9999 -9999 -9999 -9999 -9999 -9999 -9999 -9999 -9999 -9999 -9999 -9999 -9999 -9999 -9999 -9999 -9999 -9999 -9999 -9999 -9999 -9999

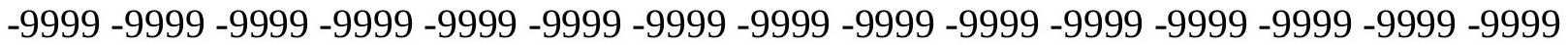
-9999 -9999 -9999 -9999 -9999 -9999 -9999 -9999 -9999 -9999 -9999 -9999 -9999 -9999 -9999 -9999 -9999 -9999 -9999 -9999 -9999 -9999 -9999 -9999 -9999 -9999 -9999 -9999 -9999 -9999 -

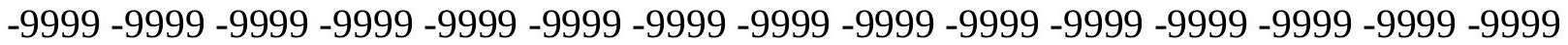
-9999 -9999 -9999 -9999 -9999 -9999 -9999 -9999 -9999 -9999 -9999 -9999 -9999 -9999 -9999

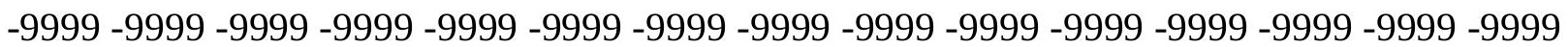
-9999 -9999 -9999 -9999 -9999 -9999 -9999 -9999 -9999 -9999 -9999 -9999 -9999 -9999 -9999 -9999 -9999 -9999 -9999 -9999 -9999 -9999 -9999 -9999 121.9140014648117 .342300415 112.1608963013106 .370002746689 .2881851196389 .1694412231489 .46208953857 90.2291336059691 .4320373535292 .6546783447393 .5690307617293 .56903076172 93.5690307617293 .2642517089892 .9594726562592 .6546783447392 .65467834473 92.349891662692 .0450973510791 .7403335571391 .7403335571391 .43553924561 91.4355392456191 .1307525634891 .4355392456191 .4355392456191 .74033355713 92.0450973510792 .0450973510792 .349891662692 .349891662692 .3498916626 92.349891662692 .349891662692 .349891662692 .349891662692 .04509735107 91.7403335571391 .4355392456191 .1307525634890 .5211791992289 .91161346436 88.9972534179788 .3876876831187 .4733276367286 .5589828491285 .33984375 84.4254837036183 .5111236572382 .2919769287181 .3776321411180 .15849304199 78.9393463134878 .0249862670976 .8058471679775 .5867080688574 .36756896973 73.4532165527371 .79763031006 -9999 -9999 -9999 -9999 -9999 -9999 -9999 -9999 -9999 -9999 -9999 -9999 -9999 -9999 -9999 -9999 -9999 -9999 -9999 -9999 -9999 -9999 -9999 -9999

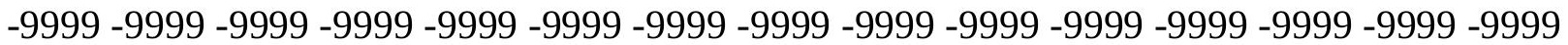
-9999 -9999 -9999 -9999 -9999 -9999 -9999 -9999 -9999 -9999 -9999 -9999 -9999 -9999 -9999 -9999 -9999 -9999 -9999 -9999 -9999 -9999 -9999 -9999 -9999 -9999 -9999

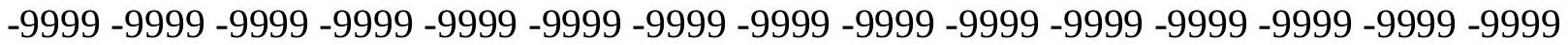
-9999 -9999 -9999 -9999 -9999 -9999 -9999 -9999 -9999 -9999 -9999 -9999 -9999 -9999 -9999 -9999 -9999 -9999 -9999 -9999 -9999 -9999 -9999 -9999 -9999 -9999 -9999 -9999 -9999 -9999 -

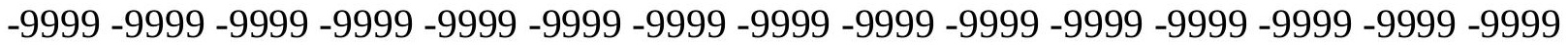
-9999 -9999 -9999 -9999 -9999 -9999 -9999 -9999 -9999 -9999 -9999 -9999 -9999 -9999 -9999 -9999 -9999 -9999 -9999 -9999 -9999 -9999 -9999 -9999 -9999 -9999 -9999 -9999 -9999 -9999

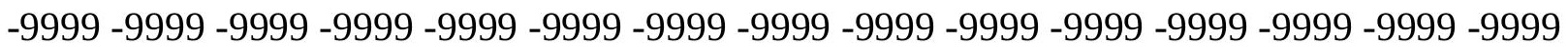
-9999 -9999 -9999 -9999 -9999 -9999 -9999 -9999 -9999 -9999 -9999 -9999 -9999 -9999 -9999 -9999 -9999 -9999 -9999 -9999 -9999 -9999 -9999 -9999 -9999 -9999 -9999 -9999 -9999 -9999 -9999 -9999 -9999 -9999 -9999 -9999 -9999 -9999 -9999 -9999 -9999 -9999 -9999 -9999 -9999

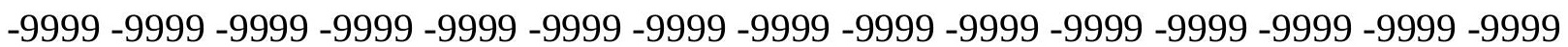
-9999 -9999 -9999 -9999 -9999 -9999 -9999 -9999 -9999 -9999 -9999 -9999 -9999 -9999 -9999 -9999 -9999 -9999 -9999 -9999 -9999 -9999 -9999 -9999 -9999 -9999 -9999 -9999 -9999 -9999 -9999 -9999 -9999 -9999 -9999 -9999 -9999 -9999 -9999 -9999 -9999 -9999 -9999 -9999 -9999

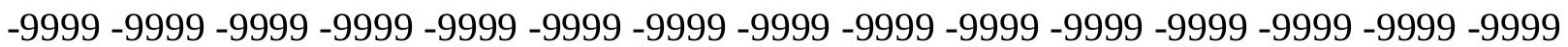


-9999 -9999 -9999 -9999 -9999 -9999 -9999 -9999 -9999 -9999 -9999 -9999 -9999 -9999 -9999 -9999 -9999 -9999 -9999 -9999 -9999 -9999 -9999 -9999 -9999 -9999 -9999 -9999 -9999 -9999 -9999 -9999 -9999 -9999 -9999 -9999 -9999 -9999 -9999 -9999 114.9039993286 109.7226028442103 .931701660288 .1862945556687 .8630676269587 .9510345459 87.1685485839889 .9116134643691 .7403335571392 .6546783447393 .26425170898 93.2642517089892 .9594726562592 .6546783447392 .349891662692 .3498916626 92.0450973510791 .7403335571391 .7403335571391 .4355392456191 .43553924561 91.4355392456191 .4355392456191 .4355392456191 .7403335571391 .74033355713 92.0450973510792 .349891662692 .349891662692 .349891662692 .65467834473 92.6546783447392 .6546783447392 .6546783447392 .349891662692 .3498916626 92.0450973510791 .4355392456191 .1307525634890 .5211791992289 .91161346436 88.9972534179788.08290100098 87.16854858398 86.2541885376 85.33984375 84.1206970214882 .9015579223681 .9871978759880 .7680587768679 .54891967773 78.3297805786177 .110626220775 .8914871215874 .9771423339873 .75800323486 72.52590179443 -9999 -9999 -9999 -9999 -9999 -9999 -9999 -9999 -9999 -9999 -9999 -9999 -9999 -9999 -9999 -9999 -9999 -9999 -9999 -9999 -9999 -9999 -9999 -9999 -9999 -9999 -9999

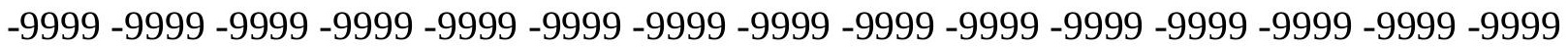
-9999 -9999 -9999 -9999 -9999 -9999 -9999 -9999 -9999 -9999 -9999 -9999 -9999 -9999 -9999 -9999 -9999 -9999 -9999 -9999 -9999 -9999 -9999 -9999 -9999 -9999 -9999 -9999 -9999 -9999 -9999 -9999 -9999 -9999 -9999 -9999 -9999 -9999 -9999 -9999

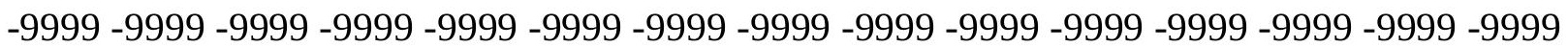
-9999 -9999 -9999 -9999 -9999 -9999 -9999 -9999 -9999 -9999 -9999 -9999 -9999 -9999 -9999 -9999 -9999 -9999 -9999 -9999 -9999 -9999 -9999 -9999 -9999 -9999 -9999 -9999 -9999 -9999 -9999 -9999 -9999 -9999 -9999 -9999 -9999 -9999 -9999 -9999 -9999 -9999 -9999 -9999 -9999

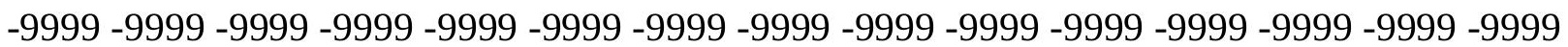

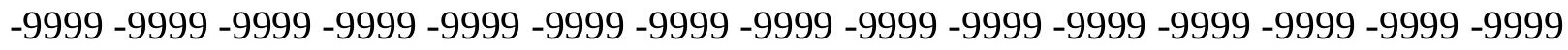
-9999 -9999 -9999 -9999 -9999 -9999 -9999 -9999 -9999 -9999 -9999 -9999 -9999 -9999 -9999 -9999 -9999 -9999 -9999 -9999 -9999 -9999 -9999 -9999 -9999 -9999 -9999 -9999 -9999 -9999

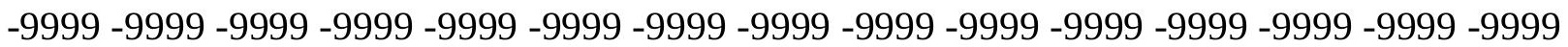
-9999 -9999 -9999 -9999 -9999 -9999 -9999 -9999 -9999 -9999 -9999 -9999 -9999 -9999 -9999 -9999 -9999 -9999 -9999 -9999 -9999 -9999 -9999 -9999 -9999 -9999 -9999 -9999 -9999 -9999 -

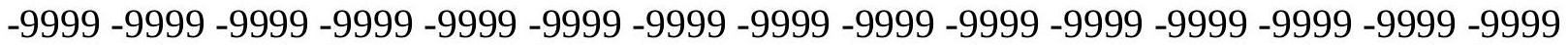
-9999 -9999 -9999 -9999 -9999 -9999 -9999 -9999 -9999 -9999 -9999 -9999 -9999 -9999 -9999 -9999 -9999 -9999 -9999 -9999 -9999 -9999 -9999 -9999 -9999 -9999 -9999 -9999 -9999 -9999 -

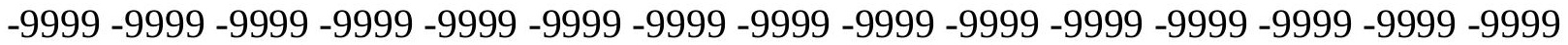
-9999 -9999 -9999 -9999 -9999 -9999 -9999 -9999 -9999 -9999 -9999 -9999 -9999 -9999 -9999 -9999 -9999 -9999 -9999 -9999 -9999 -9999 -9999 -9999-9999 112.7705001831

107.5891036987101 .798202514695 .7025299072386 .7143859863383 .51112365723 83.8159103393688 .0829010009890 .8259735107492 .0450973510792 .65467834473 92.6546783447392 .349891662692 .349891662692 .0450973510791 .74033355713 91.7403335571391 .4355392456191 .4355392456191 .4355392456191 .43553924561 91.4355392456191 .7403335571391 .7403335571392 .0450973510792 .04509735107 92.349891662692 .349891662692 .6546783447392 .6546783447392 .65467834473 92.6546783447392 .6546783447392 .6546783447392 .6546783447392 .3498916626 92.0450973510791 .7403335571391 .1307525634890 .5211791992289 .91161346436 88.9972534179788 .0829010009887 .1685485839885 .9494018554785 .03504943848 
83.8159103393682 .5967712402381 .3776321411180 .1584930419978 .93934631348 77.7202072143676 .5010681152375 .2819290161174 .062782287672 .84364318848 71.46379089355 -9999 -9999 -9999 -9999 -9999 -9999 -9999 -9999 -9999 -9999 -9999 -9999 -9999 -9999 -9999 -9999 -9999 -9999 -9999 -9999 -9999 -9999 -9999 -9999 -9999 -9999 -9999 -9999 -9999 -9999 -9999 -9999 -9999 -9999 -9999 -9999 -9999 -9999 -9999 -9999 -9999 - -9999 -9999 -9999 -9999 -9999 -9999 -9999 -9999 -9999 -9999 -9999

-9999 -9999 -9999 -9999 -9999 -9999 -9999 -9999 -9999 -9999 -9999 -9999 -9999 -9999 -9999

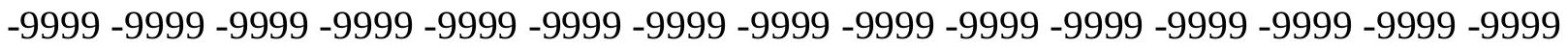

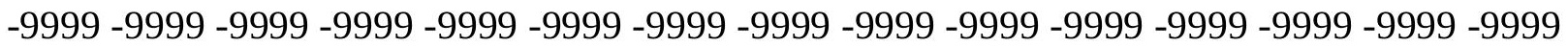
-9999 -9999 -9999 -9999 -9999 -9999 -9999 -9999 -9999 -9999 -9999 -9999 -9999 -9999 -9999

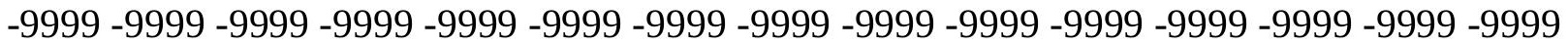
-9999 -9999 -9999 -9999 -9999 -9999 -9999 -9999 -9999 -9999 -9999 -9999 -9999 -9999 -9999 -9999 -9999 -9999 -9999 -9999 -9999 -9999 -9999 -9999 -9999 -9999 -9999 -9999 -9999 -9999 -9999 -9999 -9999 -9999 -9999 -9999 -9999 -9999 -9999 -9999 -9999 -9999 -9999 -9999 - 9999 -9999 -9999 -9999 -9999 -9999 -9999 -9999 -9999 -9999 -9999 -9999 -9999 -9999 -9999 -9999

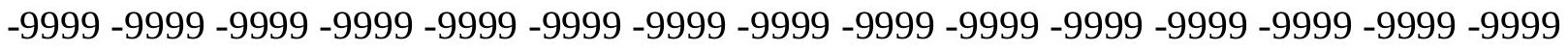
-9999 -9999 -9999 -9999 -9999 -9999 -9999 -9999 -9999 -9999 -9999 -9999 -9999 -9999 -9999 -9999 -9999 -9999 -9999 -9999 -9999 -9999 -9999 -9999 -9999 -9999 -9999 -9999 -9999 -9999 -999 -9999 -9999 -9999 -9999 -9999 -9999 -9999 -9999 -9999 -9999 -9999 -9999 -9999 -9999 -9999 -9999 -9999 -9999 -9999 -9999 -9999 -9999 -9999 -9999 -9999 -9999 -9999 -9999 -9999 -9999 -9999 -9999 -9999 -9999 -9999 -9999 -9999 -9999 -9999 -9999 -9999 -9999 -9999 -9999 -9999 -9999 -9999 -9999 -9999 -9999 -9999 -9999 -9999 -9999 -9999 -9999 -9999 -9999 -9999 -9999 -9999 -9999 -9999 -9999 -9999 -9999 -9999 -9999 -9999 -9999 -9999 -9999 -9999 -9999 -9999 -9999 -9999 -9999 -9999 -9999 -9999 -9999 -9999 -9999 -9999 -9999 -9999 -9999 -9999 -9999 -9999 -9999 -9999 -9999 -9999 -9999 -9999 -9999 -9999 -9999 -9999 105.7603988647 99.9695205688594 .1785964965885 .9238967895581 .6824111938582 .59677124023 86.5589828491290 .2164001464891 .4355392456192 .0450973510792 .04509735107 92.0450973510792 .0450973510791 .7403335571391 .7403335571391 .43553924561 91.4355392456191 .4355392456191 .4355392456191 .4355392456191 .74033355713 91.7403335571392 .0450973510792 .0450973510792 .349891662692 .3498916626 92.6546783447392 .6546783447392 .9594726562592 .9594726562592 .95947265625 92.9594726562592 .9594726562592 .6546783447392 .349891662692 .04509735107 91.7403335571391 .1307525634890 .5211791992289 .9116134643688 .99725341797 88.0829010009886 .8637619018685 .9494018554784 .7302627563583 .51112365723 82.29197692871 81.07285308838 79.54891967773 78.32978057861 77.1106262207 75.8914871215874 .3675689697373 .1484298706171 .9292907714870 .29719543457 -9999 -9999 -9999 -9999 -9999 -9999 -9999 -9999 -9999 -9999 -9999 -9999 -9999 -9999 -9999 -9999

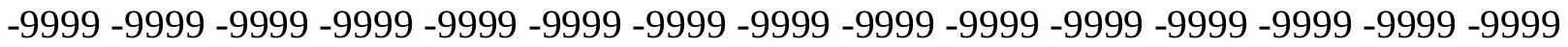

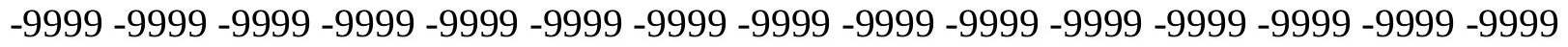
-9999 -9999 -9999-9999-9999-9999

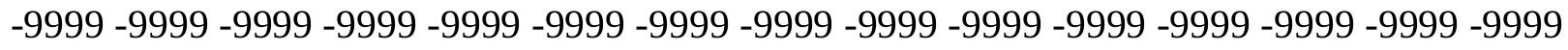

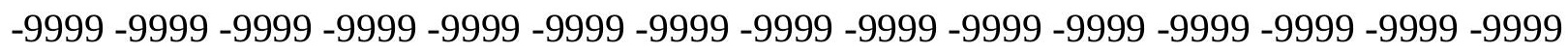
-9999 -9999 -9999 -9999 -9999 -9999 -9999 -9999 -9999 -9999 -9999 -9999 -9999 -9999 -9999 -9999 -9999 -9999 -9999 -9999 -9999 -9999 -9999 -9999-9999 -9999 -9999 -9999 -9999 -9999 -9999 -9999 -9999 -9999 -9999 -9999 -9999 -9999 -9999 -9999 -9999 -9999 -9999 -9999 -9999 -

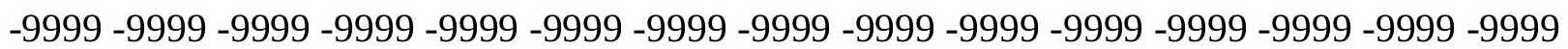


-9999 -9999 -9999 -9999 -9999 -9999 -9999 -9999 -9999 -9999 -9999 -9999 -9999 -9999 -9999 -9999 -9999 -9999 -9999 -9999 -9999 -9999 -9999 -9999 -9999 -9999 -9999 -9999 -9999 -9999 -9999 -9999 -9999 -9999 -9999 -9999 -9999 -9999 -9999 -9999 -9999 -9999 -9999 -9999 -9999 -9999 -9999 -9999 -9999 -9999 -9999 -9999 -9999 -9999 -9999 -9999 -9999 -9999 -9999 -9999 -9999 -9999 -9999 -9999 -9999 -9999 -9999 -9999 -9999 -9999 -9999 -9999 -9999 -9999 -9999 -9999 -9999 -9999 -9999 -9999 -9999 -9999 -9999 -9999 -9999 -9999 -9999 -9999 -9999 -9999 -9999 -9999 -9999 -9999 -9999 -9999 -9999 -9999 -9999 -9999 -9999 -9999 -9999 -9999 -9999

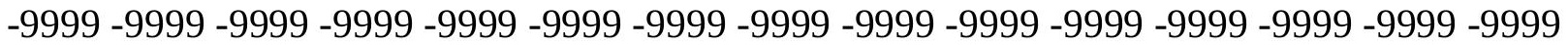
-9999 -9999 -9999 -9999 -9999 -9999 -9999 -9999 -9999 -9999 -9999 -9999 -9999 -9999 -9999 -9999 -9999 -9999 -9999 -9999 -9999 -9999 -9999 -9999 -9999 -9999 -9999 -9999 -9999 -9999 -9999 -9999 -9999 -9999 -9999 -9999 -9999 -9999 -9999 -9999 -9999 -9999 -9999 -9999 -9999 -9999 -9999 -9999 -9999 -9999 -9999 -9999 -9999 -9999 -9999 -9999 -9999 -9999 -9999 -9999 -9999 -9999 -9999 -9999 -9999 -9999 -9999 -9999 -9999 -9999 -9999 104.5412979126 98.7503814697392 .9594726562587 .1685485839881 .0728530883882 .29197692871 85.6446228027388 .6924667358490 .2164001464891 .1307525634891 .43553924561 91.7403335571391 .7403335571391 .4355392456191 .4355392456191 .43553924561 91.4355392456191 .4355392456191 .7403335571391 .7403335571392 .04509735107 92.0450973510792 .349891662692 .349891662692 .6546783447392 .65467834473 92.9594726562592 .9594726562592 .9594726562593 .2642517089893 .26425170898 92.9594726562592 .9594726562592 .9594726562592 .6546783447392 .3498916626 92.0450973510791 .4355392456190 .8259735107489 .9116134643688 .99725341797 88.0829010009886 .8637619018685 .6446228027384 .4254837036183 .2063369751 81.9871978759880 .4632720947379 .2441329956177 .7202072143676 .50106811523 $74.9771423339873 .7580032348672 .2340774536170 .9433288574269 .16086578369-9999$ -9999 -9999 -9999 -9999 -9999 -9999 -9999 -9999 -9999 -9999 -9999 -9999 -9999 -9999 -9999 -9999 -9999 -9999 -9999 -9999 -9999 -9999 -9999 -9999 -9999 -9999 -9999 -9999 -9999 -9999

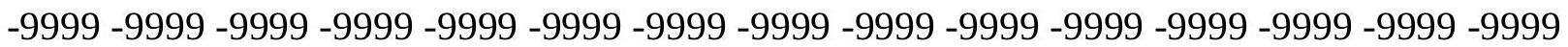
-9999-9999-9999-9999-9999-9999

-9999 -9999 -9999 -9999 -9999 -9999 -9999 -9999 -9999 -9999 -9999 -9999 -9999 -9999 -9999

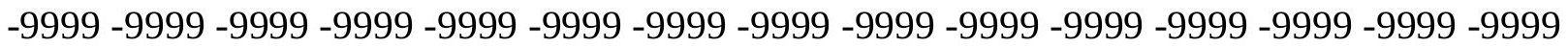
-9999 -9999 -9999 -9999 -9999 -9999 -9999 -9999 -9999 -9999 -9999 -9999 -9999 -9999 -9999 -

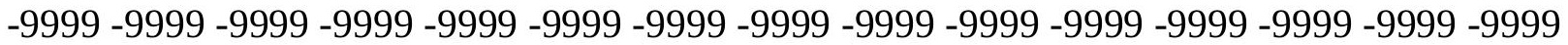
-9999 -9999 -9999 -9999 -9999 -9999 -9999 -9999 -9999 -9999 -9999 -9999 -9999 -9999 -9999 -9999 -9999 -9999 -9999 -9999 -9999 -9999 -9999 -9999 -9999 -9999 -9999 -9999 -9999 -9999 -

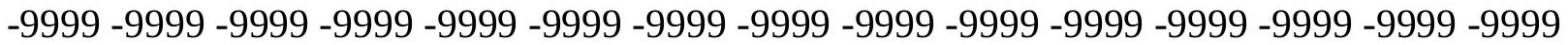
-9999 -9999 -9999 -9999 -9999 -9999 -9999 -9999 -9999 -9999 -9999 -9999 -9999 -9999 -9999 -9999 -9999 -9999 -9999 -9999 -9999 -9999 -9999 -9999 -9999 -9999 -9999 -9999 -9999 -9999

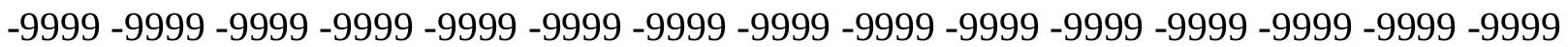
-9999 -9999 -9999 -9999 -9999 -9999 -9999 -9999 -9999 -9999 -9999 -9999 -9999 -9999 -9999 -9999 -9999 -9999 -9999 -9999 -9999 -9999 -9999 -9999 -9999 -9999 -9999 -9999 -9999 -9999 -

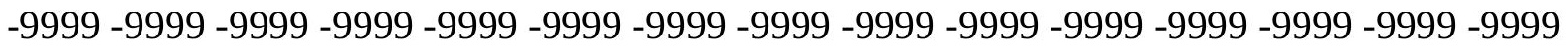
-9999 -9999 -9999 -9999 -9999 -9999 -9999 -9999 -9999 -9999 -9999 -9999 -9999 -9999 -9999 -9999 -9999 -9999 -9999 -9999 -9999 -9999 -9999 -9999 -9999 -9999 -9999 -9999 -9999 -9999 -9999 -9999 -9999 -9999 -9999 -9999 -9999 -9999 -9999 -9999 -9999 -9999 -9999 -9999 -9999 -9999 -9999 -9999 -9999 -9999 -9999 -9999 -9999 -9999 -9999 -9999 -9999 -9999 -9999 -9999

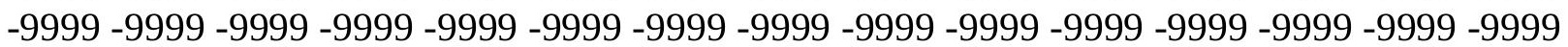


-9999 -9999 -9999 -9999 -9999 -9999 -9999 -9999 -9999 -9999 -9999 -9999 98.14080810547 92.6546783447387 .1685485839881 .6824111938582 .2919769287185 .03504943848 87.47332763672 89.302040100190.5211791992291.1307525634891.43553924561 91.4355392456191 .4355392456191 .4355392456191 .4355392456191 .43553924561 91.7403335571391 .7403335571392 .0450973510792 .349891662692 .3498916626 92.6546783447392 .6546783447392 .9594726562592 .9594726562593 .26425170898 93.2642517089893 .2642517089893 .2642517089893 .2642517089893 .26425170898 93.2642517089892 .9594726562592 .9594726562592 .6546783447392 .04509735107 91.4355392456190 .8259735107489 .9116134643688 .9972534179787 .77810668945 86.8637619018685 .3398437584 .1206970214882 .9015579223681 .37763214111 79.8537063598678 .6345596313577 .110626220775 .5867080688574 .36756896973 72.8436431884871 .3197174072369 .9064407348668 .09610748291 -9999 -9999 -9999 -9999 -9999 -9999 -9999 -9999 -9999 -9999 -9999 -9999 -9999 -9999 -9999 -9999 -9999 -9999 -9999 -9999 -9999 -9999 -9999 -9999 -9999 -9999 -9999 -9999 -9999 -9999 -9999 -9999 -9999 - 9999 -9999 -9999 -9999 -9999 -9999 -9999 -9999 -9999 -9999 -9999 -9999 -9999 -9999 -9999 -9999 -9999-9999-9999

-9999 -9999 -9999 -9999 -9999 -9999 -9999 -9999 -9999 -9999 -9999 -9999 -9999 -9999 -9999 -9999 -9999 -9999 -9999 -9999 -9999 -9999 -9999 -9999 -9999 -9999 -9999 -9999 -9999 -9999 -9999 -9999 -9999 -9999 -9999 -9999 -9999 -9999 -9999 -9999 -9999 -9999 -9999 -9999 -9999 -

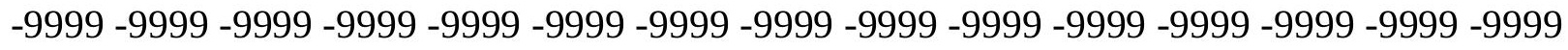

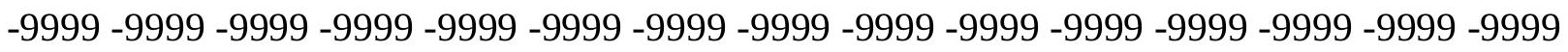
-9999 -9999 -9999 -9999 -9999 -9999 -9999 -9999 -9999 -9999 -9999 -9999 -9999 -9999 -9999 -9999 -9999 -9999 -9999 -9999 -9999 -9999 -9999 -9999 -9999 -9999 -9999 -9999 -9999 -9999 -

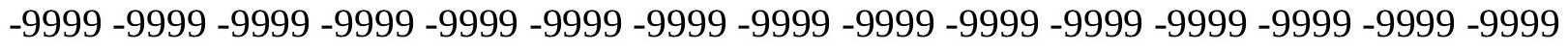

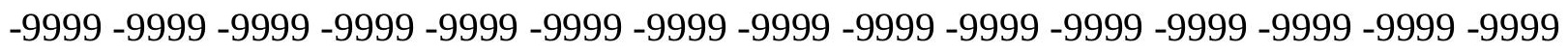
-9999 -9999 -9999 -9999 -9999 -9999 -9999 -9999 -9999 -9999 -9999 -9999 -9999 -9999 -9999 -9999 -9999 -9999 -9999 -9999 -9999 -9999 -9999 -9999 -9999 -9999 -9999 -9999 -9999 -9999

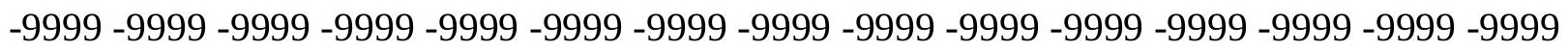
-9999 -9999 -9999 -9999 -9999 -9999 -9999 -9999 -9999 -9999 -9999 -9999 -9999 -9999 -9999 -9999 -9999 -9999 -9999 -9999 -9999 -9999 -9999 -9999 -9999 -9999 -9999 -9999 -9999 -9999 -9999 -9999 -9999 -9999 -9999 -9999 -9999 -9999 -9999-9999 -9999 -9999 -9999 -9999 -9999 -9999 -9999 -9999 -9999 -9999 -9999 -9999 -9999 -9999 -9999 -9999 -9999 -9999 -9999 -9999 -

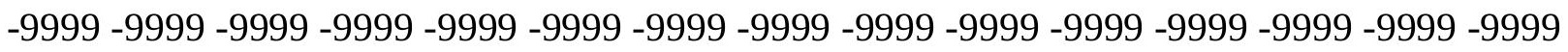
-9999 -9999 -9999 -9999 -9999 -9999 -9999 -9999 -9999 -9999 -9999 -9999 -9999 -9999 -9999 -999 -9999 -9999 -9999 -9999 -9999 -9999 -9999 -9999 -9999 -9999 -9999 -9999 -9999 92.9594726562587 .7781066894582 .9015579223682 .2919769287185 .03504943848 87.16854858398 88.9972534179790.2164001464890.8259735107491.13075256348 91.4355392456191 .4355392456191 .7403335571391 .7403335571391 .74033355713 92.0450973510792 .349891662692 .349891662692 .6546783447392 .65467834473 92.9594726562592 .9594726562593 .2642517089893 .2642517089893 .26425170898 93.5690307617293 .5690307617293 .5690307617293 .5690307617293 .56903076172 93.2642517089893.2642517089892.95947265625 92.6546783447392.3498916626 91.7403335571390 .8259735107489 .9116134643688 .9972534179787 .77810668945 86.5589828491285 .3398437583 .8159103393682 .5967712402381 .07285308838 79.5489196777378 .0249862670976 .5010681152374 .9771423339873 .45321655273 71.9292907714870 .7101516723668 .82802581787 -9999 -9999 -9999 -9999 -9999 -9999 -9999 
-9999 -9999 -9999 -9999 -9999 -9999 -9999 -9999 -9999 -9999 -9999 -9999 -9999 -9999 -9999 -9999 -9999 -9999 -9999 -9999 -9999 -9999 -9999 -9999 -9999 -9999 -9999 -9999 -9999 -9999 -

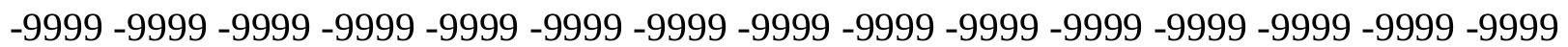
$-9999$

-9999 -9999 -9999 -9999 -9999 -9999 -9999 -9999 -9999 -9999 -9999 -9999 -9999 -9999 -9999 -9999 -9999 -9999 -9999 -9999 -9999 -9999 -9999 -9999 -9999 -9999 -9999 -9999 -9999 -9999 -9999 -9999 -9999 -9999 -9999 -9999 -9999 -9999 -9999 -9999 -9999 -9999 -9999 -9999 -9999 -999 -

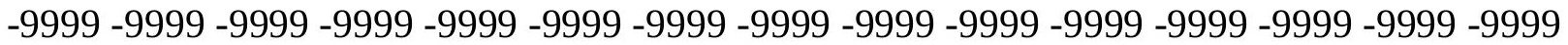

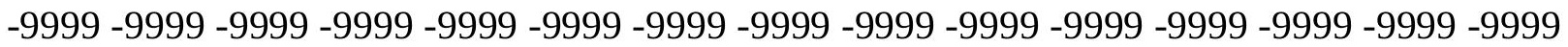
-9999 -9999 -9999 -9999 -9999 -9999 -9999 -9999 -9999 -9999 -9999 -9999 -9999 -9999 -9999 -

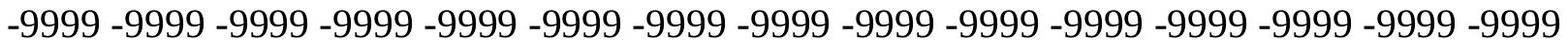
-9999 -9999 -9999 -9999 -9999 -9999 -9999 -9999 -9999 -9999 -9999 -9999 -9999-9999-9999 -9999 -9999 -9999 -9999 -9999 -9999 -9999 -9999 -9999 -9999 -9999 -9999 -9999 -9999 -9999 -9999 -9999 -9999 -9999 -9999 -9999 -9999 -9999 -9999 -9999 -9999 -9999 -9999 -9999 -9999 -9999 -9999 -9999 -9999 -9999 -9999 -9999 -9999 -9999 -9999 -9999 -9999 -9999 -9999 -9999

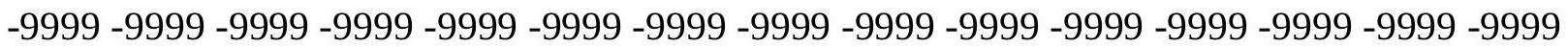

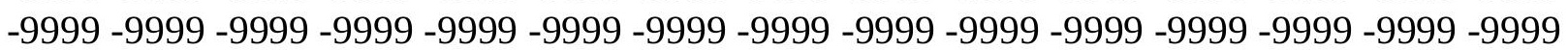
-9999 -9999 -9999 -9999 -9999 -9999 -9999 -9999 -9999 -9999 -9999 -9999 -9999 -9999 -9999 -999 -9999 -9999 -9999 -9999 -9999 -9999 -9999 -9999 -9999 -9999 -9999 -9999 -9999 -9999 -9999 -9999 -9999 -9999 -9999 -9999 -9999 -9999 -9999 -9999 -9999 -9999 -9999 -9999 -9999 -9999

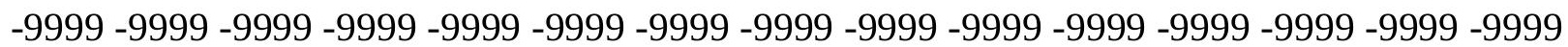

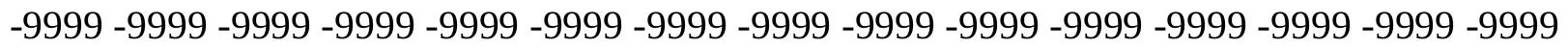
-9999 -9999 -9999 -9999 -9999 -9999 -9999 -9999 -9999 -9999 -9999 -9999 -9999 93.8738174438589 .6068267822385 .3398437583 .8159103393685 .94940185547 87.7781066894589 .302040100190 .2164001464890 .8259735107491 .13075256348 91.4355392456191 .7403335571392 .0450973510792 .349891662692 .3498916626 92.6546783447392 .6546783447392 .9594726562592 .9594726562593 .26425170898 93.2642517089893 .5690307617293 .5690307617293 .5690307617293 .56903076172 93.8738174438593 .8738174438593 .8738174438593 .5690307617293 .56903076172 93.5690307617293 .2642517089893 .2642517089892 .9594726562592 .3498916626 91.7403335571391 .1307525634890 .2164001464888 .9972534179787 .77810668945 86.5589828491285 .0350494384883 .5111236572381 .9871978759880 .46327209473 78.9393463134877 .4154205322375 .8914871215874 .062782287672 .53885650635 71.014930725169 .7259902954167 .8876953125 -9999 -9999 -9999 -9999 -9999 -9999 -9999 -9999 -9999 -9999 -9999 -9999 -9999 -9999 -9999 -9999 -9999 -9999 -9999 -9999 -9999 -9999 -9999 -9999 -9999 -9999 -9999 -9999 -9999 -9999 -9999 -9999 -9999 -9999 -9999 -9999 -9999 -9999 -9999 -9999 -9999 -9999 -9999 -9999 -9999 -9999 -9999 -9999 -9999 -9999 -9999 -9999 $-9999$

-9999 -9999 -9999 -9999 -9999 -9999 -9999 -9999 -9999 -9999 -9999 -9999 -9999 -9999 -9999 -9999 -9999 -9999 -9999 -9999 -9999 -9999 -9999 -9999 -9999 -9999 -9999 -9999 -9999 -9999 -9999 -9999 -9999 -9999 -9999 -9999 -9999 -9999 -9999 -9999 -9999 -9999 -9999 -9999 -9999 -999 -

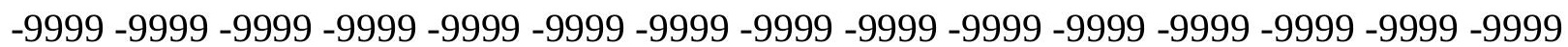
-9999 -9999 -9999 -9999 -9999 -9999 -9999 -9999 -9999 -9999 -9999 -9999 -9999 -9999 -9999 -9999 -9999 -9999 -9999 -9999 -9999 -9999 -9999 -9999 -9999 -9999 -9999 -9999 -9999 -9999

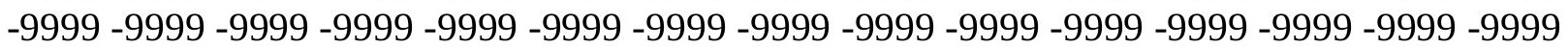

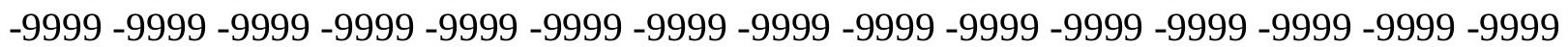


-9999 -9999 -9999 -9999 -9999 -9999 -9999 -9999 -9999 -9999 -9999 -9999 -9999 -9999 -9999 -9999 -9999 -9999 -9999 -9999 -9999 -9999 -9999 -9999 -9999 -9999 -9999 -9999 -9999 -9999 -9999 -9999 -9999 -9999 -9999 -9999 -9999 -9999 -9999 -9999 -9999 -9999 -9999 -9999 -9999 -9999 -9999 -9999 -9999 -9999 -9999 -9999 -9999 -9999 -9999 -9999 -9999 -9999 -9999 -9999 -9999 -9999 -9999 -9999 -9999 -9999 -9999 -9999 -9999 -9999 -9999 -9999 -9999 -9999 -9999 -9999 -9999 -9999 -9999 -9999 -9999 -9999 -9999 -9999 -9999 -9999 -9999 -9999 -9999 -9999 -9999 -9999 -9999 -9999 -9999 -9999 -9999 -9999 -9999 -9999 -9999 -9999 -9999 -9999 -9999

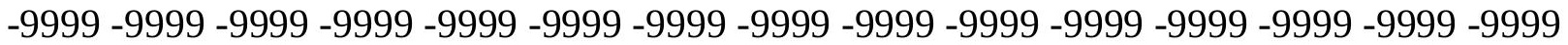
-9999 -9999 -9999 -9999 -9999 -9999 -9999 -9999 -9999 -9999 -9999 -9999 -9999 -9999 -9999 -9999 -9999 -9999 -9999 -9999 -9999 -9999 -9999 -9999 -9999 -9999 -9999 -9999 -9999 -9999 -9999 -9999 -9999 -9999 -9999 -9999 -9999 -9999 -9999 -9999 -9999 -9999 -9999 -9999 91.7403335571388 .0829010009886 .254188537687 .7781066894588 .99725341797 90.2164001464891 .1307525634891 .4355392456191 .7403335571392 .04509735107 92.6546783447392 .6546783447392 .9594726562592 .9594726562593 .26425170898 93.2642517089893 .5690307617293 .5690307617293 .5690307617293 .87381744385 93.8738174438593 .8738174438593 .8738174438593 .8738174438593 .87381744385 93.8738174438593 .8738174438593 .8738174438593 .8738174438593 .56903076172 93.5690307617293 .2642517089892 .9594726562592 .349891662692 .04509735107 91.1307525634890 .2164001464888 .9972534179787 .7781066894586 .2541885376 84.7302627563583 .206336975181 .6824111938580 .1584930419978 .32978057861 76.8058471679774 .9771423339873 .4532165527371 .9292907714870 .40535736084 68.7952880859467 .07371520996 -9999 -9999 -9999 -9999 -9999 -9999 -9999 -9999 -9999 -9999 -9999 -9999 -9999 -9999 -9999 -9999 -9999 -9999 -9999 -9999 -9999 -9999 -9999 -9999 -9999 -9999 -9999 -9999 -9999 -9999 -9999 -9999 -9999 -9999 -9999 -9999 -9999 -9999 -9999 -9999 -9999 -9999 -9999 -9999 -9999 -9999 -9999 -9999 -9999 -9999 -9999 -9999 -9999 -9999 -9999 -9999 -9999 -9999 -9999 -9999 -9999 -9999 -9999 -9999 -9999 -9999 -9999 -9999 -9999 -9999 -9999 -9999 -9999 -9999 -9999 -9999 -9999 -9999 -9999 -9999 -9999 -9999 -9999 -9999 -9999 -9999 -9999 -9999 -9999 -9999 -9999 -9999 -9999 -9999 -9999 -9999 -9999 -9999 -9999 -9999 -9999 -9999 -9999 -9999 -9999 -9999 -9999 -9999 -9999 -9999 -9999 -9999 -9999 -9999 -9999 -9999 -9999 -9999 -9999 -9999 -9999 -9999 -9999 -9999 -9999 -9999 -9999 -9999 -9999 -9999 -9999 -9999 -9999 -9999 -9999 -9999 -9999 -9999 -9999 -9999 -9999 -9999 -9999 -

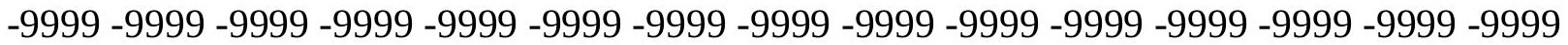
-9999 -9999 -9999 -9999 -9999 -9999 -9999 -9999 -9999 -9999 -9999 -9999 -9999 -9999 -9999 -9999 -9999 -9999 -9999 -9999 -9999 -9999 -9999 -9999 -9999 -9999 -9999 -9999 -9999 -9999 -

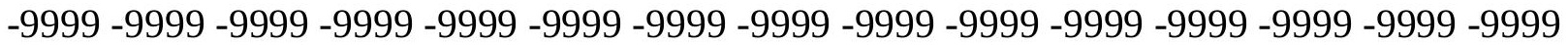
-9999 -9999 -9999 -9999 -9999 -9999 -9999 -9999 -9999 -9999 -9999 -9999 -9999 -9999 -9999 -9999 -9999 -9999 -9999 -9999 -9999 -9999 -9999 -9999 -9999 -9999 -9999 -9999 -9999 -9999

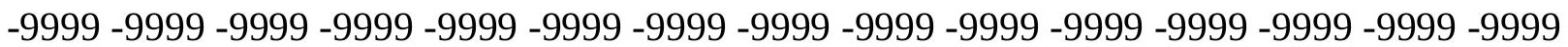
-9999 -9999 -9999 -9999 -9999 -9999 -9999 -9999 -9999 -9999 -9999 -9999 -9999 -9999 -9999 -9999 -9999 -9999 -9999 -9999 -9999 -9999 -9999 -9999 -9999 -9999 -9999 -9999 -9999 -9999 -9999 -9999 -9999 -9999 -9999 -9999 -9999 -9999 -9999 -9999 -9999 -9999 -9999 -9999 -9999 -999 -9999 -9999 -9999 -9999 -9999 -9999 -9999 -9999 -9999 -9999 -9999 -9999 -9999 -9999 -9999 -9999 -9999 -9999 -9999 -9999 -9999 -9999 -9999 -9999 -9999 -9999 -9999 -9999 -9999 -9999 -9999 -9999 -9999 -9999 -9999 -9999 -9999 -9999 -9999 -9999 -9999 -9999 -9999 -9999 93.8738174438591 .1307525634889 .302040100190 .2164001464890 .89322662354 91.7403335571392 .349891662692 .6546783447392 .9594726562593 .26425170898 
96.6168823242296 .9216690063593 .8738174438593 .8738174438593 .87381744385 94.1785964965894 .1785964965894 .1785964965894 .1785964965894 .17859649658 94.1785964965894 .1785964965894 .1785964965894 .1785964965894 .17859649658 94.1785964965894 .1785964965894 .1785964965893 .8738174438593 .87381744385 93.5690307617293 .2642517089892 .9594726562592 .349891662691 .74033355713 91.1307525634889 .9116134643688 .9972534179787 .4733276367286 .2541885376 84.7302627563582 .9015579223681 .3776321411179 .5489196777378 .02498626709 76.1962814331174 .3675689697372 .5388565063571 .014930725169 .49101257324 68.0572814941466 .4541015625 -9999 -9999 -9999 -9999 -9999 -9999 -9999 -9999 -9999 -9999 -9999 -9999 -9999 -9999 -9999 -9999 -9999 -9999 -9999 -9999 -9999 -9999 -9999 -9999

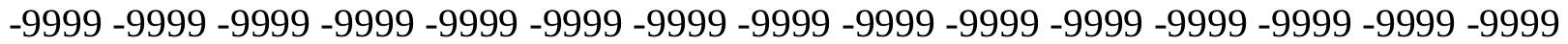
-9999 -9999 -9999 -9999 -9999 -9999 -9999 -9999 -9999 -9999 -9999 -9999 -9999 -9999 -9999 -9999 -9999 -9999 -9999 -9999 -9999 -9999 -9999 -9999 -9999 -9999 -9999 -9999 -9999 -9999 -9999 -9999 -9999 -9999 -9999 -9999 -9999 -9999 -9999 -9999 -9999 -9999 -9999 -9999 -9999 -9999 -9999 -9999 -9999 -9999 -9999 -9999 -9999 -9999 -9999 -9999 -9999 -9999 -9999

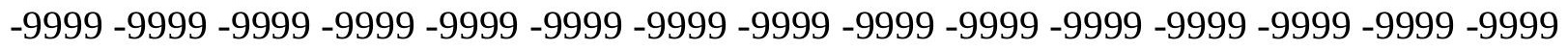

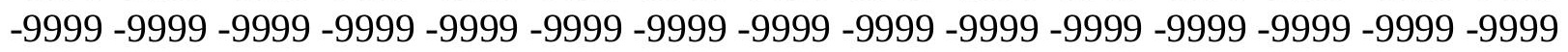

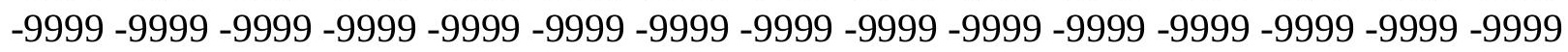
-9999 -9999 -9999 -9999 -9999 -9999 -9999 -9999 -9999 -9999 -9999 -9999 -9999 -9999 -9999 -999 -

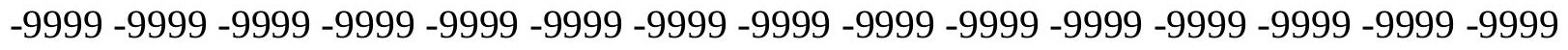

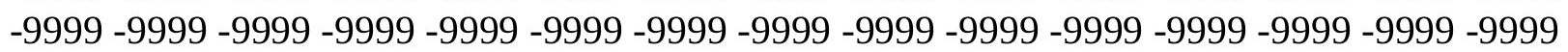

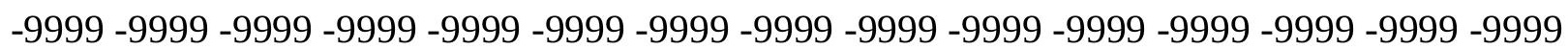
-9999 -9999 -9999 -9999 -9999 -9999 -9999 -9999 -9999 -9999 -9999 -9999 -9999 -9999 -9999 -

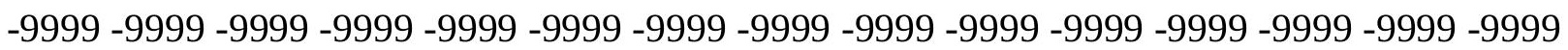

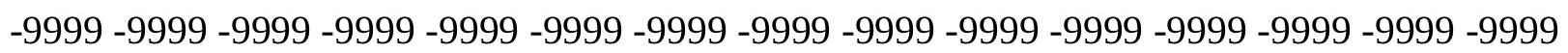
-9999 -9999 -9999 -9999 -9999 -9999 -9999 -9999 -9999 -9999 -9999 -9999 -9999 -9999 -9999 -9999 -9999 -9999 -9999 -9999 -9999 -9999 -9999 -9999 -9999 -9999 -9999 -9999 -9999 - -9999 -

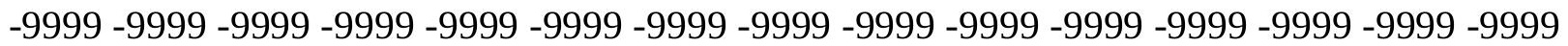

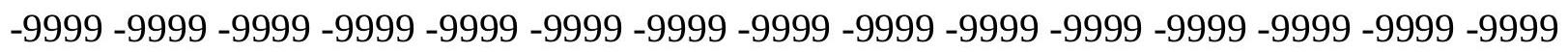

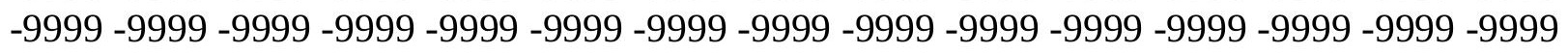

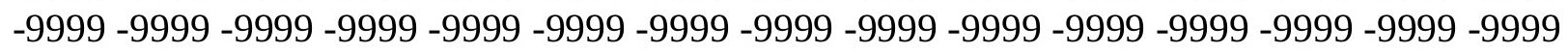
94.1785964965892 .349891662692 .26757812592 .8619537353593 .56903076172 93.8738174438594 .1785964965897 .8360290527398 .445587158298 .75038146973 98.7503814697398 .445587158298 .1408081054794 .7881774902394 .78817749023 94.7881774902394 .7881774902394 .7881774902394 .7881774902394 .78817749023 94.7881774902394 .7881774902394 .4833908081194 .4833908081194 .48339080811 94.4833908081194 .1785964965894 .1785964965893 .8738174438593 .56903076172 93.2642517089892 .9594726562592 .349891662691 .7403335571390 .82597351074 89.9116134643688 .6924667358487 .4733276367285 .9494018554784 .42548370361 82.9015579223681 .0728530883879 .2441329956177 .4154205322375 .58670806885 73.7580032348671 .9292907714870 .1005783081168 .8814392089867 .33261108398 65.70893096924 -9999 -9999 -9999 -9999 -9999 -9999 -9999 -9999 -9999 -9999 -9999 -9999 -9999 -9999 -9999 -9999 -9999 -9999 -9999 -9999 -9999 -9999 -9999 -9999 -9999 -9999 -9999 - -999 -9999 -9999 -9999 -9999 -9999 -9999 -9999 -9999 -9999 -9999 -9999 -9999 -9999 -9999 -9999 -9999 -9999 -9999 -9999 -9999 -9999 -9999 -9999 -9999 -9999 -9999 -

-9999 -9999 -9999 -9999 -9999 -9999 -9999 -9999 -9999 -9999 -9999 -9999 -9999 -9999 -9999 
-9999 -9999 -9999 -9999 -9999 -9999 -9999 -9999 -9999 -9999 -9999 -9999 -9999 -9999 -9999 -9999 -9999 -9999 -9999 -9999 -9999 -9999 -9999 -9999 -9999 -9999 -9999 -9999 -9999 -9999 -9999 -9999 -9999 -9999 -9999 -9999 -9999 -9999 -9999 -9999 -9999 -9999 -9999 -9999 -9999 -9999 -9999 -9999 -9999 -9999 -9999 -9999 -9999 -9999 -9999 -9999 -9999 -9999 -9999 -9999 -9999 -9999 -9999 -9999 -9999 -9999 -9999 -9999 -9999 -9999 -9999 -9999 -9999 -9999 -9999 -9999 -9999 -9999 -9999 -9999 -9999 -9999 -9999 -9999 -9999 -9999 -9999 -9999 -9999 -9999 -9999 -9999 -9999 -9999 -9999 -9999 -9999 -9999 -9999 -9999 -9999 -9999 -9999 -9999 -9999

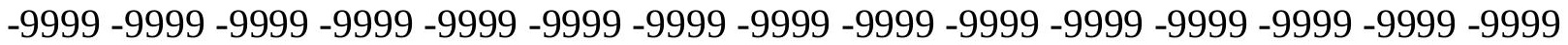
-9999 -9999 -9999 -9999 -9999 -9999 -9999 -9999 -9999 -9999 -9999 -9999 -9999 -9999 -9999 -9999 -9999 -9999 -9999 -9999 -9999 -9999 -9999 -9999 -9999 -9999 -9999 -9999 -9999 -9999 -

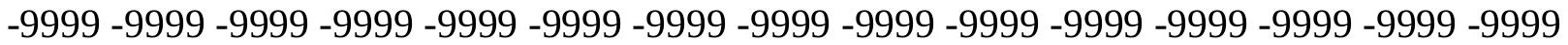
-9999 -9999 -9999 -9999 -9999 -9999 -9999 -9999 -9999 -9999 -9999 -9999 -9999 -9999 -9999

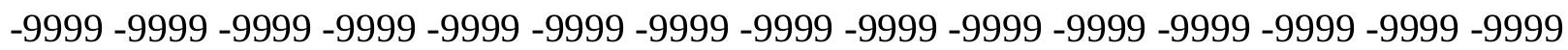
-9999 -9999 -9999 -9999 -9999 -9999 -9999 -9999 -9999 -9999 -9999 -9999 -9999 -9999 -9999 -9999 -9999 -9999 -9999 -9999 -9999 -9999 -9999 -9999 -9999 -9999 -9999 -9999 -9999 -9999 -9999 -9999 -9999 -9999 -9999 -9999 -9999 -9999 -9999 -9999 -9999 -9999 -9999 -9999 -9999 -9999 -9999 -9999 -9999 -9999 -9999 -9999 -9999 -9999 -9999 -9999 -9999 -9999 -9999 -9999 -9999 -9999 -9999 -9999 -9999 -9999 -9999 -9999 -9999 -9999 -9999 -9999 -9999 -9999 -9999 96.6168823242295 .397743225195 .0929565429794 .8224716186595 .42241668701 95.7025299072395 .7025299072399 .66472625732100 .2742996216100 .5791015625 100.274299621699 .9695205688599 .6647262573299 .0551681518695 .70252990723 95.397743225195 .397743225195 .397743225195 .397743225195 .09295654297 95.0929565429795 .0929565429795 .0929565429794 .7881774902394 .78817749023 94.4833908081194 .4833908081194 .1785964965893 .8738174438593 .56903076172 93.2642517089892 .9594726562592 .349891662691 .7403335571390 .82597351074 89.9116134643688 .6924667358487 .4733276367285 .9494018554784 .42548370361 82.5967712402380 .7680587768678 .9393463134876 .8058471679774 .97714233398 72.8436431884871 .014930725169 .4910125732468 .2718734741266 .59931182861 64.90242004395 -9999 -9999 -9999 -9999 -9999 -9999 -9999 -9999 -9999 -9999 -9999 -9999 -9999 -9999 -9999 -9999 -9999 -9999 -9999 -9999 -9999 -9999 -9999 -9999 -9999 -9999 -9999 -9999 -9999 -9999 -9999 -9999 -9999 -9999 -9999 -9999 -9999 -9999 -9999 -9999 -9999 -9999 -9999 -9999 -9999 -9999 -9999 -9999 -9999 -9999 -9999 -9999 -9999

-9999 -9999 -9999 -9999 -9999 -9999 -9999 -9999 -9999 -9999 -9999 -9999 -9999 -9999 -9999 -9999 -9999 -9999 -9999 -9999 -9999 -9999 -9999 -9999 -9999 -9999 -9999 -9999 -9999 -9999 -

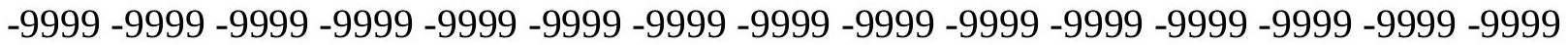
-9999 -9999 -9999 -9999 -9999 -9999 -9999 -9999 -9999 -9999 -9999 -9999 -9999 -9999 -9999 -9999 -9999 -9999 -9999 -9999 -9999 -9999 -9999 -9999 -9999 -9999 -9999 -9999 -9999 -9999

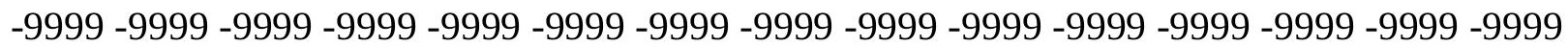
-9999 -9999 -9999 -9999 -9999 -9999 -9999 -9999 -9999 -9999 -9999 -9999 -9999 -9999 -9999 -9999 -9999 -9999 -9999 -9999 -9999 -9999 -9999 -9999 -9999 -9999 -9999 -9999 -9999 -9999 -9999 -9999 -9999 -9999 -9999 -9999 -9999 -9999 -9999 -9999 -9999 -9999 -9999 -9999 -9999 -999 -9999 -9999 -9999 -9999 -9999 -9999 -9999 -9999 -9999 -9999 -9999 -9999 -9999 -9999 -9999 -9999 -9999 -9999 -9999 -9999 -9999 -9999 -9999 -9999 -9999 -9999 -9999 -9999 -9999 -9999 -9999 -9999 -9999 -9999 -9999 -9999 -9999 -9999 -9999 -9999 -9999 -9999 -9999 -9999 -9999 -9999 -9999 -9999 -9999 -9999 -9999 -9999 -9999 -9999 -9999 -9999 -9999 -9999 -9999 -9999

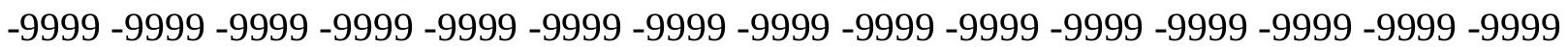


-9999 -9999 -9999 -9999 -9999 -9999 -9999 -9999 -9999 -9999 -9999 -9999 -9999 -9999 -9999 -9999 -9999 -9999 -9999 -9999 -9999 -9999 -9999 -9999 -9999 -9999 -9999 -9999 -9999 -9999 -9999 -9999 -9999 -9999 -9999 -9999 -9999 -9999 -9999 -9999 -9999 -9999 -9999 -9999 -9999 -9999 -9999 -9999 -9999 -9999 -9999 -9999 -9999 -9999 -9999 -9999 -9999 -9999 -9999 -9999 -9999 -9999 -9999 -9999 -9999 -9999 -9999 -9999 -9999 -9999 -9999 -9999 -9999 -9999 -9999 -9999 97.83602905273 97.22646331787 96.75704956055 97.485069274997.53124237061 100.5791015625101 .1886978149101 .7982025146101 .7982025146101 .7982025146 101.4934005737100 .8839035034100 .274299621699 .6647262573296 .31210327148 96.0073165893696 .0073165893696 .0073165893695 .7025299072395 .70252990723 95.397743225195 .397743225195 .0929565429795 .0929565429794 .78817749023 94.4833908081194 .1785964965894 .1785964965893 .8738174438593 .26425170898 92.9594726562592 .349891662691 .7403335571390 .8259735107489 .91161346436 88.6924667358487 .4733276367285 .9494018554784 .4254837036182 .59677124023 80.7680587768678 .6345596313576 .5010681152374 .3675689697372 .53885650635 70.4053573608468 .8814392089867 .3575134277365 .8089523315464 .10894012451 -9999 -9999 -9999 -9999 -9999 -9999 -9999 -9999 -9999 -9999 -9999 -9999 -9999 -9999 -9999 -9999

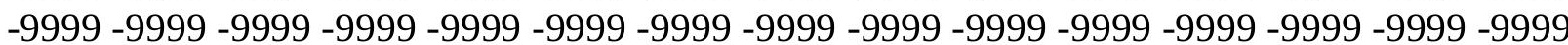

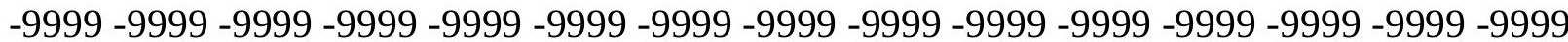
-9999 -9999 -9999 -9999 -9999 -9999 -9999

-9999 -9999 -9999 -9999 -9999 -9999 -9999 -9999 -9999 -9999 -9999 -9999 -9999 -9999 -9999

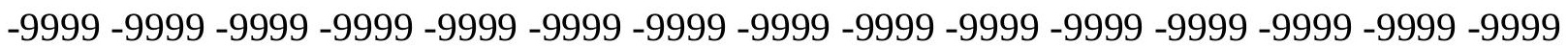
-9999 -9999 -9999 -9999 -9999 -9999 -9999 -9999 -9999 -9999 -9999 -9999 -9999 -9999 -9999 -9999 -9999 -9999 -9999 -9999 -9999 -9999 -9999 -9999 -9999 -9999 -9999 -9999 -9999 -9999 -9999 -9999 -9999 -9999 -9999 -9999 -9999 -9999 -9999 -9999 -9999 -9999 -9999 -9999 -9999 -9999 -9999 -9999 -9999 -9999 -9999 -9999 -9999 -9999 -9999 -9999 -9999 -9999 -9999 -9999 -9999 -9999 -9999 -9999 -9999 -9999 -9999 -9999 -9999 -9999 -9999 -9999 -9999 -9999 -9999 -9999 -9999 -9999 -9999 -9999 -9999 -9999 -9999 -9999 -9999 -9999 -9999 -9999 -9999 -9999 -9999 -9999 -9999 -9999 -9999 -9999 -9999 -9999 -9999 -9999 -9999 -9999 -9999 -9999 -9999 -9999 -9999 -9999 -9999 -9999 -9999 -9999 -9999 -9999 -9999 -9999 -9999 -9999 -9999 -9999 -9999 -9999 -9999 -9999 -9999 -9999 -9999 -9999 -9999 -9999 -9999 -9999 -9999 -9999 -9999 -9999 -9999 -9999 -9999 -9999 -9999 -9999 -9999 -9999 -9999 -9999 -9999 -9999 -9999 -9999 -9999 -9999 -9999 -9999 -9999 -9999 -9999 -9999 -9999 -9999 -9999 -9999 -9999 -9999 -9999 -9999 -9999 -9999 -9999 -9999 -9999 -9999 -9999 -9999 -9999 -9999 -9999 -9999 -9999 -9999 -9999 -9999 -9999 -9999 -9999 -9999 -9999 -9999 -9999 -9999 -9999 -9999 -9999 -9999 -9999 -9999 -9999 -9999 -9999 -9999 -9999 -9999 -9999 -9999 -9999 -9999 -9999 -9999 -9999 -9999 -9999 -9999 -9999 -9999 -9999 -9999 -9999 -9999 -9999 -9999 -9999 -9999 -9999 -9999 -9999

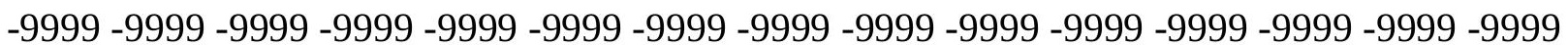
-9999 -9999 -9999 -9999 -9999 -9999 -9999 -9999 -9999 -9999 -9999 -9999 -9999 -9999 -9999 -9999 100.274299621699.6647262573299.6647262573299.5740356445399.35994720459 102.1217269897102 .712600708103 .0174026489103 .0174026489103 .0174026489 102.4077987671101 .7982025146101 .1886978149100 .579101562597 .22646331787 96.9216690063596 .6168823242296 .3121032714896 .3121032714896 .00731658936 95.7025299072395 .7025299072395 .397743225195 .0929565429795 .09295654297 94.7881774902394 .4833908081194 .1785964965893 .8738174438593 .26425170898 92.9594726562592 .349891662691 .7403335571390 .8259735107489 .91161346436 88.6924667358487 .4733276367285 .9494018554784 .4254837036182 .59677124023 
80.4632720947378 .3297805786176 .1962814331174 .062782287671 .92929077148 70.1005783081168 .2718734741266 .7479400634865 .0726623535263 .32760620117 -9999 -9999 -9999 -9999 -9999 -9999 -9999 -9999 -9999 -9999 -9999 -9999 -9999 -9999 -9999 -9999

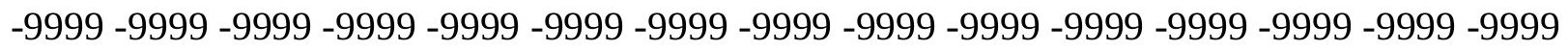
-9999 -9999 -9999 -9999 -9999 -9999 -9999 -9999 -9999-9999 -9999 -9999 -9999 -9999 - -9999 -9999 -9999 -9999 -9999 -9999-9999-9999

-9999 -9999 -9999 -9999 -9999 -9999 -9999 -9999 -9999 -9999 -9999 -9999 -9999 -9999 -9999

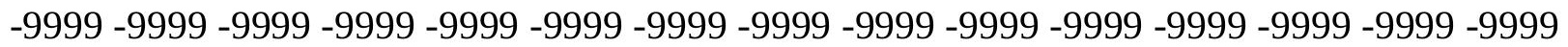

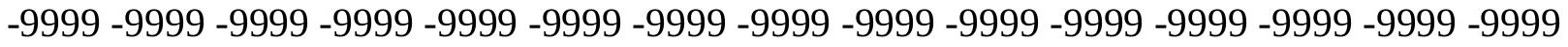
-9999 -9999 -9999 -9999 -9999 -9999 -9999 -9999 -9999 -9999 -9999 -9999 -9999 -9999 -9999

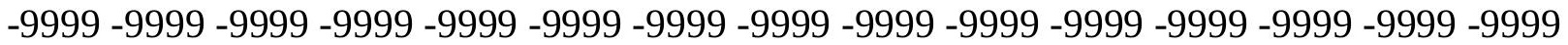
-9999 -9999 -9999 -9999 -9999 -9999 -9999 -9999 -9999 -9999 -9999 -9999 -9999 -9999 -9999 -9999 -9999 -9999 -9999 -9999 -9999 -9999 -9999 -9999 -9999 -9999 -9999 -9999 -9999 -9999 -9999 -9999 -9999 -9999 -9999 -9999 -9999 -9999 -9999 -9999 -9999 -9999 -9999 -9999 - 9999 -9999 -9999 -9999 -9999 -9999 -9999 -9999 -9999 -9999 -9999 -9999 -9999 -9999 -9999 -9999

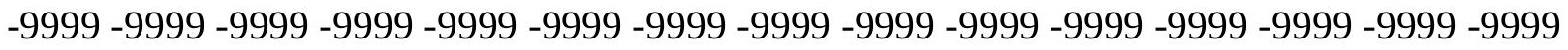
-9999 -9999 -9999 -9999 -9999 -9999 -9999 -9999 -9999 -9999 -9999 -9999 -9999 -9999 -9999 -9999 -9999 -9999 -9999 -9999 -9999 -9999 -9999 -9999 -9999 -9999 -9999 -9999 -9999 -9999 -9999 -9999 -9999 -9999 -9999 -9999 -9999 -9999 -9999 -9999 -9999 -9999 -9999 -9999 -9999 -9999 -9999 -9999 -9999 -9999 -9999 -9999 -9999 -9999 -9999 -9999 -9999 -9999 -9999 -9999 -9999 -9999 -9999 -9999 -9999 -9999 -9999 -9999 -9999 -9999 -9999 -9999 -9999 -9999 -9999 -9999 -9999 -9999 -9999 -9999 -9999 -9999 -9999 -9999 -9999 -9999 -9999 -9999 -9999 -9999 -9999 -9999 -9999 -9999 -9999 -9999 -9999 -9999 -9999 -9999 -9999 -9999 -9999 -9999 -9999 -9999 -9999 -9999 -9999 -9999 -9999 -9999 -9999 -9999 -9999 -9999 -9999 -9999 -9999 -9999 -9999 -9999 -9999 -9999 -9999 -9999 -9999 -9999 -9999 -9999 -9999 -9999 -9999 -9999 -9999 -9999 102.4077987671 101.7982025146101.4934005737101.4934005737101.1886978149 103.2085952759103 .8882980347104 .2365036011103 .9317016602103 .6268997192 103.3221969604102 .712600708102 .1029968262101 .493400573797 .83602905273 97.5312423706197 .2264633178796 .9216690063596 .6168823242296 .61688232422 96.3121032714896 .0073165893695 .7025299072395 .397743225195 .09295654297 94.7881774902394 .4833908081194 .1785964965893 .8738174438593 .26425170898 92.9594726562592 .349891662691 .7403335571390 .8259735107489 .91161346436 88.6924667358487 .4733276367286 .254188537684 .4254837036182 .59677124023 80.4632720947378 .3297805786176 .1962814331173 .7580032348671 .62449645996 69.4910125732467 .6623001098666 .1383666992264 .3828201293962 .58180618286 -9999 -9999 -9999 -9999 -9999 -9999 -9999 -9999 -9999 -9999 -9999 -9999 -9999 -9999 -9999 -9999

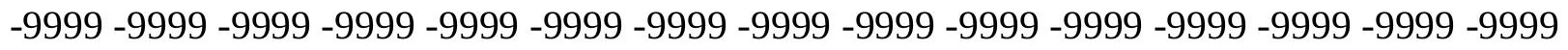

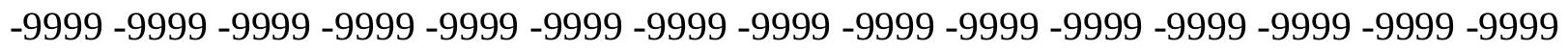
-9999 -9999 -9999 -9999-9999 -9999-9999

-9999 -9999 -9999 -9999 -9999 -9999 -9999 -9999 -9999 -9999 -9999 -9999 -9999 -9999 -9999

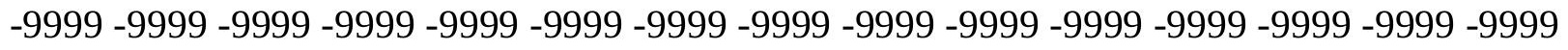

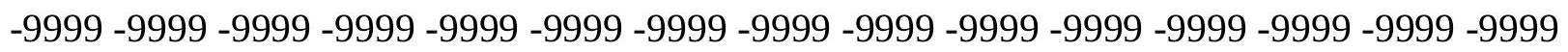
-9999 -9999 -9999 -9999 -9999 -9999 -9999 -9999 -9999 -9999 -9999 -9999 -9999 -9999 -9999 -9999 -9999 -9999 -9999 -9999 -9999 -9999 -9999 -9999-9999 -9999 -9999 -9999 -9999 -9999 -9999 -9999 -9999 -9999 -9999 -9999 -9999 -9999 -9999 -9999 -9999 -9999 -9999 -9999 -9999 -

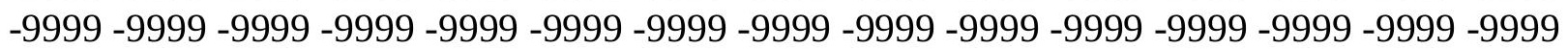


-9999 -9999 -9999 -9999 -9999 -9999 -9999 -9999 -9999 -9999 -9999 -9999 -9999 -9999 -9999 -9999 -9999 -9999 -9999 -9999 -9999 -9999 -9999 -9999 -9999 -9999 -9999 -9999 -9999 -9999 -9999 -9999 -9999 -9999 -9999 -9999 -9999 -9999 -9999 -9999 -9999 -9999 -9999 -9999 -9999 -9999 -9999 -9999 -9999 -9999 -9999 -9999 -9999 -9999 -9999 -9999 -9999 -9999 -9999 -9999 -9999 -9999 -9999 -9999 -9999 -9999 -9999 -9999 -9999 -9999 -9999 -9999 -9999 -9999 -9999 -9999 -9999 -9999 -9999 -9999 -9999 -9999 -9999 -9999 -9999 -9999 -9999 -9999 -9999 -9999 -9999 -9999 -9999 -9999 -9999 -9999 -9999 -9999 -9999 -9999 -9999 -9999 -9999 -9999 -9999

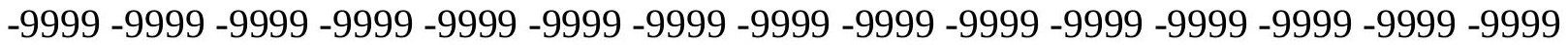
-9999 -9999 -9999 -9999 -9999 -9999 -9999 -9999 -9999 -9999 -9999 -9999 -9999 -9999 -9999 -9999 -9999 -9999 -9999 -9999 -9999 -9999 -9999 -9999 -9999 -9999 -9999 -9999 -9999 -9999 -9999 -9999 -9999 -9999 -9999 -9999 -9999 -9999 -9999 -9999 -9999 -9999 -9999 -9999 -9999 -9999 -9999 -9999 -9999 -9999 -9999 -9999 -9999 -9999 -9999 -9999 -9999 -9999 -9999 -9999 -9999-9999 103.6268997192103.0174026489103.0174026489102.712600708 102.4077987671104 .6971664429104 .9537734985104 .8460998535104 .5412979126 103.9317016602103 .3221969604102 .71260070899 .0551681518698 .75038146973 98.1408081054797.8360290527397.5312423706197.2264633178796.92166900635 96.6168823242296 .3121032714896 .0073165893695 .7025299072395 .3977432251 95.0929565429794 .7881774902394 .4833908081193 .8738174438593 .56903076172 92.9594726562592 .349891662691 .7403335571390 .8259735107489 .91161346436 88.9972534179787 .7781066894586 .5589828491284 .7302627563582 .90155792236 80.7680587768678 .3297805786175 .8914871215873 .4532165527371 .0149307251 $68.8814392089867 .3575134277365 .5288009643663 .7000885009861 .85591125488-9999$ -9999 -9999 -9999 -9999 -9999 -9999 -9999 -9999 -9999 -9999 -9999 -9999 -9999 -9999 -9999 -9999 -9999 -9999 -9999 -9999 -9999 -9999 -9999 -9999 -9999 -9999 -9999 -9999 -9999 -9999

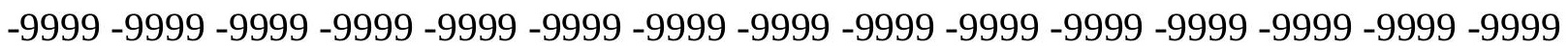
-9999 -9999 -9999 -9999 -9999 -9999 -9999 -9999 -9999 -9999 -9999 -9999 -9999 -9999 -9999 -9999 -9999 -9999 -9999 -9999 -9999 -9999 -9999 -9999 -9999 -9999 -9999 -9999 -9999 -9999 -9999 -9999 -9999 -9999 -9999 -9999 -9999 -9999 -9999 -9999 -9999 -9999 -9999 -9999 -9999 -9999 -9999 -9999 -9999 -9999 -9999 -9999

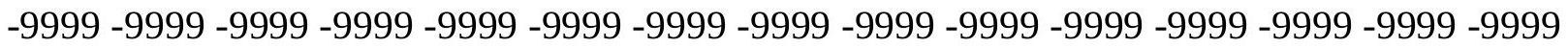
-9999 -9999 -9999 -9999 -9999 -9999 -9999 -9999 -9999 -9999 -9999 -9999 -9999 -9999 -9999 -

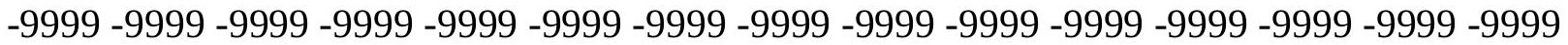
-9999 -9999 -9999 -9999 -9999 -9999 -9999 -9999 -9999 -9999 -9999 -9999 -9999 -9999 -9999 -9999 -9999 -9999 -9999 -9999 -9999 -9999 -9999 -9999 -9999 -9999 -9999 -9999 -9999 -9999 -

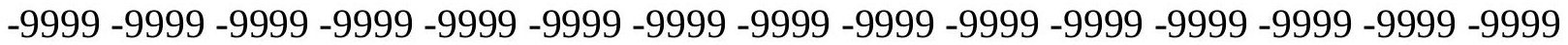
-9999 -9999 -9999 -9999 -9999 -9999 -9999 -9999 -9999 -9999 -9999 -9999 -9999 -9999 -9999 -9999 -9999 -9999 -9999 -9999 -9999 -9999 -9999 -9999 -9999 -9999 -9999 -9999 -9999 -9999

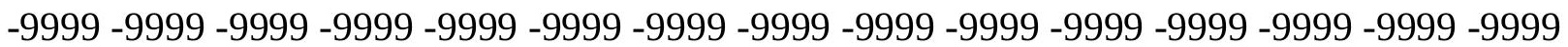
-9999 -9999 -9999 -9999 -9999 -9999 -9999 -9999 -9999 -9999 -9999 -9999 -9999 -9999 -9999 -9999 -9999 -9999 -9999 -9999 -9999 -9999 -9999 -9999 -9999 -9999 -9999 -9999 -9999 -9999 -

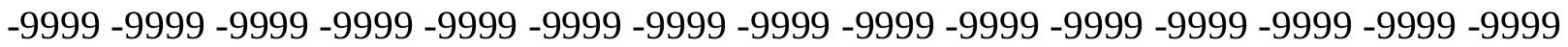
-9999 -9999 -9999 -9999 -9999 -9999 -9999 -9999 -9999 -9999 -9999 -9999 -9999 -9999 -9999 -9999 -9999 -9999 -9999 -9999 -9999 -9999 -9999 -9999 -9999 -9999 -9999 -9999 -9999 -9999 -9999 -9999 -9999 -9999 -9999 -9999 -9999 -9999 -9999 -9999 -9999 -9999 -9999 -9999 -9999 -9999 -9999 -9999 -9999 -9999 -9999 -9999 -9999 -9999 -9999 -9999 -9999 -9999 -9999 -9999 -9999 -9999 105.1509017944 104.5412979126104.2365036011 103.9317016602 
103.6268997192105 .3193969727105 .5693817139105 .6317443848105 .4557037354 104.8460998535103 .9317016602100 .274299621699 .9695205688599 .35994720459 99.0551681518698.445587158298.1408081054797.8360290527397.53124237061 96.9216690063596 .6168823242296 .3121032714896 .0073165893695 .70252990723 95.397743225195 .0929565429794 .4833908081194 .1785964965893 .56903076172 93.2642517089892 .6546783447391 .7403335571391 .1307525634890 .21640014648 89.302040100188.3876876831186.8637619018685.33984375 83.2063369751 81.0728530883878 .6345596313575 .8914871215873 .1484298706170 .71015167236 $68.5766525268666 .7479400634864 .9192428588963 .0905189514261 .12924575806-9999$ -9999 -9999 -9999 -9999 -9999 -9999 -9999 -9999 -9999 -9999 -9999 -9999 -9999 -9999 -9999 -9999 -9999 -9999 -9999 -9999 -9999 -9999 -9999 -9999 -9999 -9999 -9999 -9999 -9999 -9999 -

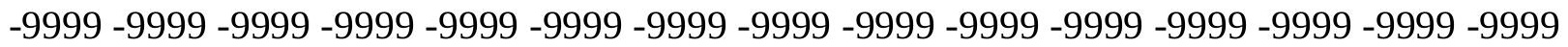
-9999 -9999 -9999 -9999 -9999 -9999 -9999

-9999 -9999 -9999 -9999 -9999 -9999 -9999 -9999 -9999 -9999 -9999 -9999 -9999 -9999 -999 -9999 -9999 -9999 -9999 -9999 -9999 -9999 -9999 -9999 -9999 -9999 -9999 -9999 -9999 -9999

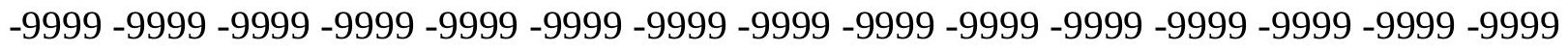
-9999 -9999 -9999 -9999 -9999 -9999 -9999 -9999 -9999 -9999 -9999 -9999 -9999 -9999 -9999 -9999 -9999 -9999 -9999 -9999 -9999 -9999 -9999 -9999 -9999 -9999 -9999 -9999 -9999 -9999 -999 -9999 -9999 -9999 -9999 -9999 -9999 -9999 -9999 -9999 -9999 -9999 -9999 -9999 -9999 -9999 -

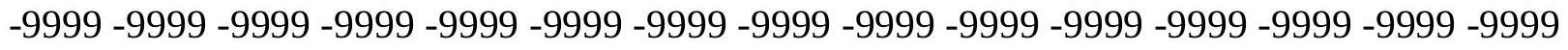
-9999 -9999 -9999 -9999 -9999 -9999 -9999 -9999 -9999 -9999 -9999 -9999 -9999 -9999 -9999 -9999 -9999 -9999 -9999 -9999 -9999 -9999 -9999 -9999 -9999 -9999 -9999 -9999 -9999 -9999 -9999 -9999 -9999 -9999 -9999 -9999 -9999 -9999 -9999 -9999 -9999 -9999 -9999 -9999 -9999 -9999 -9999 -9999 -9999 -9999 -9999 -9999 -9999 -9999 -9999 -9999 -9999 -9999 -9999 -9999 -9999 -9999 -9999 -9999 -9999 -9999 -9999 -9999 -9999 -9999 -9999 -9999 -9999 -9999 -9999 -9999 -9999 -9999 -9999 -9999 -9999 -9999 -9999 -9999 -9999 -9999 -9999 -9999 -9999 -9999 -9999 -9999 -9999 -9999 -9999 -9999 -9999 -9999 -9999 -9999 -9999 -9999 -9999 -9999 -9999 -

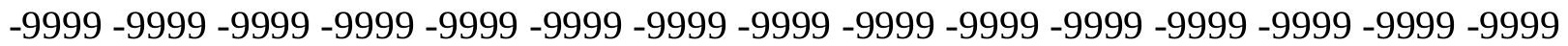
-9999 -9999 -9999 -9999 -9999 -9999 -9999 -9999 -9999 -9999 -9999 -9999 -9999 -9999 -9999 -9999 -9999 -9999 -9999 -9999 -9999 -9999 -9999 -9999 -9999 -9999 -9999 -9999 -9999 -999 -9999 -9999 -9999 -9999 -9999 -9999 -9999 -9999 -9999 -9999 -9999 -9999 -9999 -9999 -9999 -9999 -9999 -9999 -9999 -9999 -9999 -9999 -9999 -9999 -9999 -9999 -9999 -9999 -9999 -9999 -9999-9999-9999 105.7603988647 105.4557037354 105.1509017944 104.8460998535 105.800163269106 .0078353882106 .0674667358105 .9749298096105 .4557037354 101.7982025146101 .1886978149100 .5791015625100 .274299621699 .66472625732 99.0551681518698 .7503814697398 .445587158297 .8360290527397 .53124237061 97.2264633178796 .6168823242296 .3121032714896 .0073165893695 .70252990723 95.0929565429794 .7881774902394 .1785964965893 .8738174438593 .26425170898 92.6546783447392 .0450973510791 .4355392456190 .5211791992289 .60682678223 88.6924667358487 .4733276367285 .9494018554783 .8159103393681 .37763214111 78.9393463134875 .8914871215873 .1484298706170 .4053573608468 .27187347412 66.1383666992264 .3096618652362 .1761703491260 .34745025635 -9999 -9999 -9999 -9999 -9999 -9999 -9999 -9999 -9999 -9999 -9999 -9999 -9999 -9999 -9999 -9999 -9999 -9999 -9999 -9999 -9999 -9999 -9999 -9999 -9999 -9999 -9999 -9999-9999 -9999 -9999 -9999 -9999 -9999 -

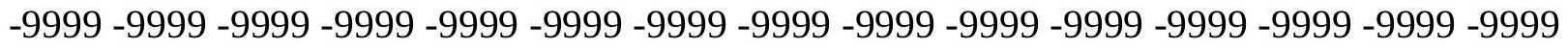
$-9999-9999-9999-9999$ 
-9999 -9999 -9999 -9999 -9999 -9999 -9999 -9999 -9999 -9999 -9999 -9999 -9999 -9999 -9999 -9999 -9999 -9999 -9999 -9999 -9999 -9999 -9999 -9999 -9999 -9999 -9999 -9999 -9999 -9999 -9999 -9999 -9999 -9999 -9999 -9999 -9999 -9999 -9999 -9999 -9999 -9999 -9999 -9999 -9999 -9999 -9999 -9999 -9999 -9999 -9999 -9999 -9999 -9999 -9999 -9999 -9999 -9999 -9999 -9999 -9999 -9999 -9999 -9999 -9999 -9999 -9999 -9999 -9999 -9999 -9999 -9999 -9999 -9999 -9999 -9999 -9999 -9999 -9999 -9999 -9999 -9999 -9999 -9999 -9999 -9999 -9999 -9999 -9999 -9999 -9999 -9999 -9999 -9999 -9999 -9999 -9999 -9999 -9999 -9999 -9999 -9999 -9999 -9999 -9999

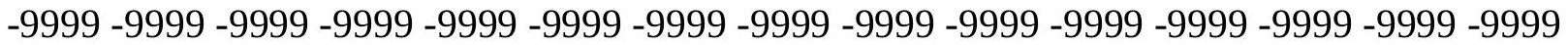
-9999 -9999 -9999 -9999 -9999 -9999 -9999 -9999 -9999 -9999 -9999 -9999 -9999 -9999 -9999 -9999 -9999 -9999 -9999 -9999 -9999 -9999 -9999 -9999 -9999 -9999 -9999 -9999 -9999 -9999 -

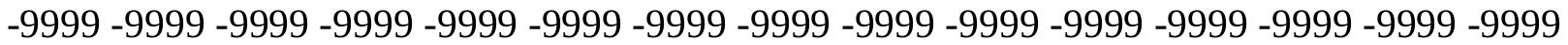
-9999 -9999 -9999 -9999 -9999 -9999 -9999 -9999 -9999 -9999 -9999 -9999 -9999 -9999 -9999

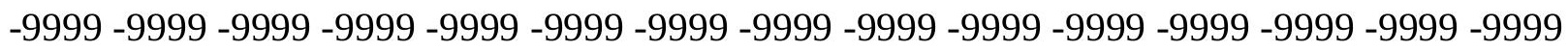
-9999 -9999 -9999 -9999 -9999 -9999 -9999 -9999 -9999 -9999 -9999 -9999 -9999 -9999 -9999 -9999 -9999 -9999 -9999 -9999 -9999 -9999 -9999 -9999 -9999 -9999 -9999 -9999 -9999 -9999 -9999 -9999 -9999 -9999 -9999 -9999 -9999 -9999 -9999 -9999 -9999 -9999 -9999 -9999 -9999 -9999 -9999 -9999 -9999 -9999 -9999 -9999 -9999 -9999 -9999 -9999 -9999 -9999 -9999 -9999 -9999 -9999 -9999 -9999 -9999 -9999 -9999 -9999 -9999 -9999 -9999 -9999 -9999 -9999 -9999 -9999 -9999 -9999 -9999 -9999 -9999 -9999 -9999 -9999 -9999 -9999 -9999 -9999 -9999 -9999 -9999 -9999-9999 106.979598999 106.6747970581 106.0652008057 105.7603988647 105.4557037354106 .2666473389106 .1760025024105 .7244949341104 .5411682129 102.712600708102 .1029968262101 .4934005737100 .8839035034100 .2742996216 99.9695205688599 .3599472045998 .7503814697398 .445587158297 .83602905273 97.5312423706196 .9216690063596 .6168823242296 .3121032714895 .70252990723 95.397743225195 .0929565429794 .4833908081194 .1785964965893 .56903076172 92.9594726562592 .349891662691 .7403335571390 .8259735107490 .21640014648 89.302040100188.08290100098 86.55898284912 84.4254837036181.98719787598 79.2441329956176 .1962814331173 .1484298706170 .1005783081167 .66230010986 65.5288009643663 .3953094482461 .5666007995659 .43310165405 -9999 -9999 -9999 -9999 -9999 -9999 -9999 -9999 -9999 -9999 -9999 -9999 -9999 -9999 -9999 -9999 -9999 -9999 -9999 -9999 -9999 -9999 -9999 -9999 -9999 -9999 -9999 -9999 -9999 -9999 -9999 -9999 -9999 -9999 -

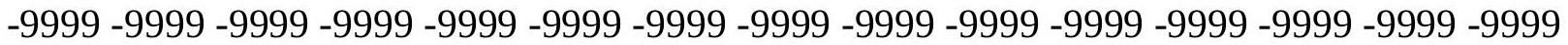
-9999 -9999-9999-9999

-9999 -9999 -9999 -9999 -9999 -9999 -9999 -9999 -9999 -9999 -9999 -9999 -9999 -9999 -9999 -9999 -9999 -9999 -9999 -9999 -9999 -9999 -9999 -9999 -9999 -9999 -9999 -9999 -9999 -9999 -9999 -9999 -9999 -9999 -9999 -9999 -9999 -9999 -9999 -9999 -9999 -9999 -9999 -9999 -9999 -9999 -9999 -9999 -9999 -9999 -9999 -9999 -9999 -9999 -9999 -9999 -9999 -9999 -9999 -9999

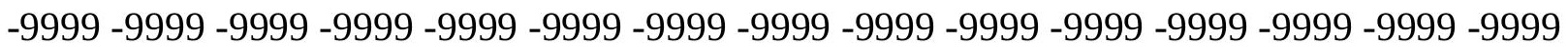
-9999 -9999 -9999 -9999 -9999 -9999 -9999 -9999 -9999 -9999 -9999 -9999 -9999 -9999 -9999 -9999 -9999 -9999 -9999 -9999 -9999 -9999 -9999 -9999 -9999 -9999 -9999 -9999 -9999 -9999 -9999 -9999 -9999 -9999 -9999 -9999 -9999 -9999 -9999 -9999 -9999 -9999 -9999 -9999 -9999 -9999 -9999 -9999 -9999 -9999 -9999 -9999 -9999 -9999 -9999 -9999 -9999 -9999 -9999 -9999 -9999 -9999 -9999 -9999 -9999 -9999 -9999 -9999 -9999 -9999 -9999 -9999 -9999 -9999 -9999 -9999 -9999 -9999 -9999 -9999 -9999 -9999 -9999 -9999 -9999 -9999 -9999 -9999 -9999 -9999 -9999 -9999 -9999 -9999 -9999 -9999 -9999 -9999 -9999 -9999 -9999 -9999 -9999 -9999 -9999

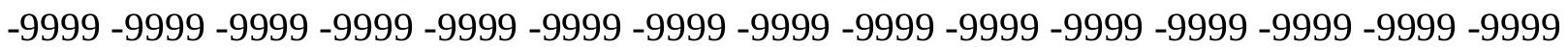


-9999 -9999 -9999 -9999 -9999 -9999 -9999 -9999 -9999 -9999 -9999 -9999 -9999 -9999 -9999 -9999 -9999 -9999 -9999 -9999 -9999 -9999 -9999 -9999 -9999 -9999 -9999 -9999 -9999 -9999 -9999 -9999 -9999 -9999 -9999 -9999 -9999 -9999 -9999 -9999 -9999 -9999 -9999 -9999 -9999 -9999 -9999 -9999 -9999 -9999 -9999 -9999 -9999 -9999 -9999 -9999 -9999 -9999 -9999 -9999 -9999 -9999 -9999 -9999 -9999 -9999 -9999 -9999 -9999 -9999 -9999 -9999 -9999 -9999 -9999 -9999 -9999 -9999 -9999 -9999 -9999 -9999 -9999 -9999 -9999 -9999 -9999 -9999 -9999 -9999 -9999 -9999 -9999 -9999 107.5891036987 107.2844009399 106.6747970581 106.3700027466 105.7603988647106 .1411972046105 .5304794312104 .2365036011103 .3221969604 102.712600708102 .1029968262101 .4934005737100 .8839035034100 .2742996216 99.9695205688599 .3599472045998 .7503814697398 .1408081054797 .83602905273 97.2264633178796 .9216690063596 .3121032714896 .0073165893695 .70252990723 95.397743225194 .7881774902394 .4833908081193 .8738174438593 .56903076172 92.9594726562592 .0450973510791 .4355392456190 .8259735107489 .91161346436 88.9972534179787 .4733276367285 .3398437582 .5967712402379 .54891967773 76.1962814331173 .1484298706169 .7957916259867 .3575134277365 .22400665283 63.0905189514260 .9570198059158 .82352828979 -9999 -9999 -9999 -9999 -9999 -9999 -9999

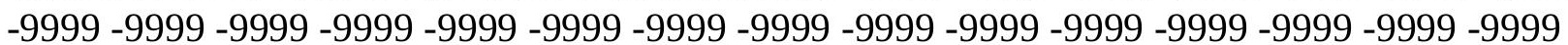
-9999 -9999 -9999 -9999 -9999 -9999 -9999 -9999 -9999 -9999 -9999 -9999 -9999 -9999 -9999 -

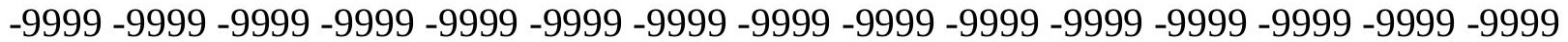
$-9999$

-9999 -9999 -9999 -9999 -9999 -9999 -9999 -9999 -9999 -9999 -9999 -9999 -9999 -9999 -9999 -9999 -9999 -9999 -9999 -9999 -9999 -9999 -9999 -9999 -9999 -9999 -9999 -9999 -9999 -9999 -9999 -9999 -9999 -9999 -9999 -9999 -9999 -9999 -9999 -9999 -9999 -9999 -9999 -9999 -9999 -9999 -9999 -9999 -9999 -9999 -9999 -9999 -9999 -9999 -9999 -9999 -9999 -9999 -9999 -9999

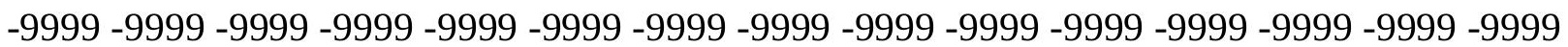
-9999 -9999 -9999 -9999 -9999 -9999 -9999 -9999 -9999 -9999 -9999 -9999 -9999 -9999 -9999 -9999 -9999 -9999 -9999 -9999 -9999 -9999 -9999 -9999 -9999 -9999 -9999 -9999 -9999 -9999 -9999 -9999 -9999 -9999 -9999 -9999 -9999 -9999 -9999 -9999 -9999 -9999 -9999 -9999 -9999 -9999 -9999 -9999 -9999 -9999 -9999 -9999 -9999 -9999 -9999 -9999 -9999 -9999 -9999 -9999 -9999 -9999 -9999 -9999 -9999 -9999 -9999 -9999 -9999 -9999 -9999 -9999 -9999 -9999 -9999 -9999 -9999 -9999 -9999 -9999 -9999 -9999 -9999 -9999 -9999 -9999 -9999 -9999 -9999 -9999 -9999 -9999 -9999 -9999 -9999 -9999 -9999 -9999 -9999 -9999 -9999 -9999 -9999 -9999 -9999 -9999 -9999 -9999 -9999 -9999 -9999 -9999 -9999 -9999 -9999 -9999 -9999 -9999 -9999 -9999 -9999 -9999 -9999 -9999 -9999 -9999 -9999 -9999 -9999 -9999 -9999 -9999 -9999 -9999 -9999

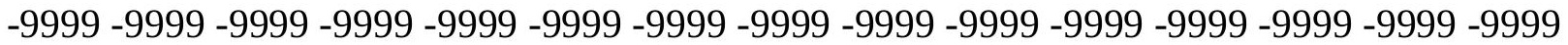
-9999 -9999 -9999 -9999 -9999 -9999 -9999 -9999 -9999 -9999 -9999 -9999 -9999 -9999 -9999 -9999 -9999 -9999 -9999 -9999 -9999 -9999 -9999 -9999 -9999 -9999 -9999 -9999 -9999 -9999

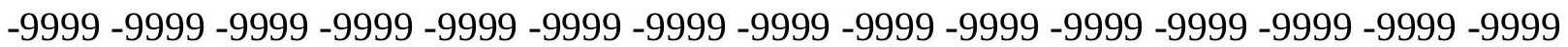
-9999 -9999 -9999 -9999 -9999 -9999 -9999 -9999 -9999 -9999 -9999 -9999 -9999 -9999 -9999 -9999 -9999 -9999 -9999 -9999 108.1986999512 107.5891036987 107.2844009399 106.6747970581106 .0652008057105 .4557037354104 .8394088745104 .1220703125 103.6268997192103 .0174026489102 .4077987671101 .7982025146100 .8839035034 100.274299621699 .6647262573299 .0551681518698 .7503814697398 .14080810547 97.5312423706197 .2264633178796 .6168823242296 .3121032714896 .00731658936 95.397743225195 .0929565429794 .7881774902394 .4833908081193 .87381744385 93.2642517089892 .6546783447392 .0450973510791 .4355392456190 .52117919922 
89.6068267822388 .0829010009885 .9494018554783 .206336975180 .15849304199 76.5010681152373 .1484298706170 .1005783081167 .3575134277364 .91924285889 62.4809494018660 .04267120361 -9999 -9999 -9999 -9999 -9999 -9999 -9999 -9999 -9999 -9999 -9999 -9999 -9999 -9999 -9999 -9999 -9999 -9999 -9999 -9999 -9999 -9999 -9999 -9999 -9999 -9999 -9999 -9999 -9999 -9999 -9999 -9999 -9999 -9999 -9999 -9999-9999 -9999 -9999 -9999 -9999 -9999 -9999 -9999 -9999 -9999 -9999 -9999 -9999 -9999 -9999 -9999 -9999 -9999 -9999 -9999 -9999 -9999 -9999 -9999 -9999 -9999 -9999 -9999 -9999 -9999 -9999 -9999 -9999 -

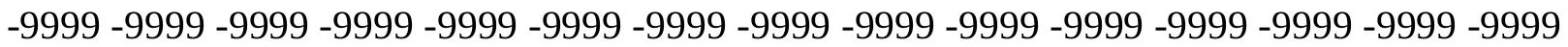
-9999 -9999 -9999 -9999 -9999 -9999 -9999 -9999 -9999 -9999 -9999 -9999 -9999 -9999 -9999 -9999 -9999 -9999 -9999 -9999 -9999 -9999 -9999 -9999 -9999 -9999 -9999 -9999 -9999 -9999 -

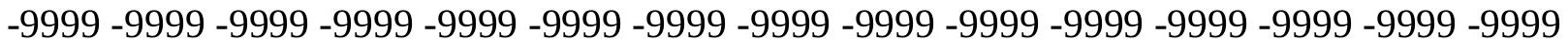
-9999 -9999 -9999 -9999 -9999 -9999 -9999 -9999 -9999 -9999 -9999 -9999 -9999 -9999 -9999 -9999 -9999 -9999 -9999 -9999 -9999 -9999 -9999 -9999 -9999 -9999 -9999 -9999 -9999 -9999 -9999 -9999 -9999 -9999 -9999 -9999 -9999 -9999 -9999 -9999 -9999 -9999 -9999 -9999 -9999 -9999 -9999 -9999 -9999 -9999 -9999 -9999 -9999 -9999 -9999 -9999 -9999 -9999 -9999 -9999 -9999 -9999 -9999 -9999 -9999 -9999 -9999 -9999 -9999 -9999 -9999 -9999 -9999 -9999 -9999 -9999 -9999 -9999 -9999 -9999 -9999 -9999 -9999 -9999 -9999 -9999 -9999 -9999 -9999 -9999 -9999 -9999 -9999 -9999 -9999 -9999 -9999 -9999 -9999 -9999 -9999 -9999 -9999 -9999 -9999 -9999 -9999 -9999 -9999 -9999 -9999 -9999 -9999 -9999 -9999 -9999 -9999 -9999 -9999 -9999 -9999 -9999 -9999 -9999 -9999 -9999 -9999 -9999 -9999 -9999 -9999 -9999 -9999 -9999 -9999 -9999 -9999 -9999 -9999 -9999 -9999 -9999 -9999 -9999 -9999 -9999 -9999 -9999 -9999 -9999 -9999 -9999 -9999 -9999 -9999 -9999 -9999 -9999 -9999 -9999 -9999 -9999 -9999 -9999 -9999 -9999 -9999 -9999 -9999 -9999 -9999 -9999 -9999 -9999 -9999 -9999 -9999 -9999 -9999 -9999 -9999 -9999 -9999 -9999 -9999 -9999 -9999 -9999 -9999 -9999 -9999 -9999 -9999 -9999 -9999 -9999 -9999 -9999 -9999 -9999 -9999 -9999 -9999 -9999 -9999 -9999 -9999 -9999 -9999 -9999 -9999 -9999 -9999 -9999-9999 109.1130981445108.5035018921 107.8938980103 107.5891036987106 .979598999105 .9755172729105 .3863830566104 .8133468628 104.2365036011103 .6268997192103 .0174026489102 .4077987671101 .4934005737 100.8839035034100 .274299621699 .6647262573299 .0551681518698 .4455871582 97.8360290527397 .2264633178796 .9216690063596 .6168823242296 .00731658936 95.7025299072395 .397743225195 .0929565429794 .7881774902394 .48339080811 93.8738174438593 .2642517089892 .6546783447392 .0450973510791 .13075256348 89.91161346436 88.6924667358486.86376190186 83.81591033936 80.46327209473 76.8058471679773 .4532165527370 .4053573608467 .3575134277364 .30966186523 61.8713798522959 .43310165405 -9999 -9999 -9999 -9999 -9999 -9999 -9999 -9999 -9999 -9999 -9999 -9999 -9999 -9999 -9999 -9999 -9999 -9999 -9999 -9999 -9999 -9999 -9999 -9999

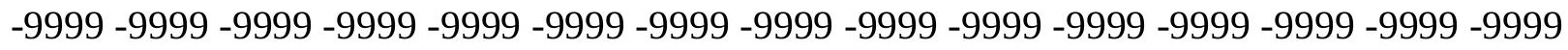

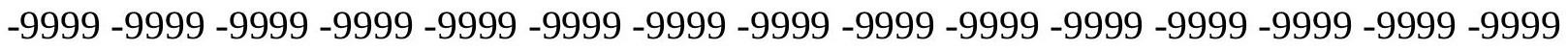
-9999 -9999 -9999 -9999 -9999 -9999 -9999 -9999 -9999 -9999 -9999 -9999 -9999 -9999 -9999 -9999 -9999 -9999 -9999 -9999 -9999 -9999 -9999 -9999 -9999 -9999 -9999 -9999 -9999 -9999 -9999 -9999 -9999 -9999 -9999 -9999 -9999 -9999 -9999 -9999 -9999 -9999 -9999 -9999 -9999 -999 -9999 -9999 -9999 -9999 -9999 -9999 -9999 -9999 -9999 -9999 -9999 -9999 -9999 -9999 -9999 -9999 -9999 -9999 -9999 -9999 -9999 -9999 -9999 -9999 -9999 -9999 -9999 -9999 -9999 -9999 -9999 -9999 -9999 -9999 -9999 -9999 -9999 -9999 -9999 -9999 -9999 -9999 -9999 -9999 -9999 -9999 -9999 -9999 -9999 -9999 -9999 -9999 -9999 -9999 -9999 -9999 -9999 -9999 -9999 -9999

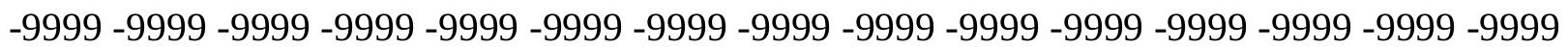


-9999 -9999 -9999 -9999 -9999 -9999 -9999 -9999 -9999 -9999 -9999 -9999 -9999 -9999 -9999 -9999 -9999 -9999 -9999 -9999 -9999 -9999 -9999 -9999 -9999 -9999 -9999 -9999 -9999 -9999 -9999 -9999 -9999 -9999 -9999 -9999 -9999 -9999 -9999 -9999 -9999 -9999 -9999 -9999 -9999 -9999 -9999 -9999 -9999 -9999 -9999 -9999 -9999 -9999 -9999 -9999 -9999 -9999 -9999 -9999 -9999 -9999 -9999 -9999 -9999 -9999 -9999 -9999 -9999 -9999 -9999 -9999 -9999 -9999 -9999 -9999 -9999 -9999 -9999 -9999 -9999 -9999 -9999 -9999 -9999 -9999 -9999 -9999 -9999 -9999 -9999 -9999 -9999 -9999 -9999 -9999 -9999 -9999 -9999 -9999 -9999 -9999 -9999 -9999 -9999

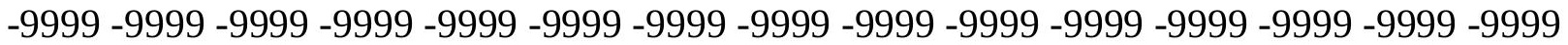
-9999 -9999 -9999 -9999 -9999 -9999 -9999 -9999 -9999 -9999 -9999 -9999 -9999 -9999 -9999 -9999 -9999 -9999 -9999 -9999 -9999 -9999 -9999 -9999 -9999 -9999 -9999 -9999 -9999 -9999 -9999 -9999 -9999 -9999 -9999 -9999 -9999 -9999 -9999 -9999 -9999 -9999 -9999 -9999 -9999 -9999 -9999 -9999 -9999 -9999 -9999 109.4179000854 108.8082962036108.1986999512 107.5891036987106 .979598999105 .9700927734105 .4667510986104 .9135131836 104.2365036011103 .6268997192103 .0174026489102 .1029968262101 .4934005737 100.579101562599 .9695205688599 .3599472045998 .7503814697398 .14080810547 97.5312423706196 .9216690063596 .6168823242296 .3121032714896 .00731658936 95.7025299072395 .397743225195 .0929565429794 .7881774902394 .48339080811 93.8738174438593 .2642517089892 .349891662691 .4355392456190 .21640014648 88.6924667358486 .5589828491283 .8159103393680 .4632720947377 .1106262207 73.7580032348670 .4053573608467 .3575134277364 .3096618652361 .56660079956 58.82352828979 -9999 -9999 -9999 -9999 -9999 -9999 -9999 -9999 -9999 -9999 -9999 -9999 -9999 -9999 -9999 -9999 -9999 -9999 -9999 -9999 -9999 -9999 -9999 -9999 -9999 -9999 -9999 -9999 -9999 -9999 -9999 -9999 -9999 -9999 -9999 -9999 -9999 -9999 -9999 -9999 -9999 -9999 -9999 -9999 -9999 -9999 -9999 -9999 -9999 -9999 -9999 -9999 -9999 -9999

-9999 -9999 -9999 -9999 -9999 -9999 -9999 -9999 -9999 -9999 -9999 -9999 -9999 -9999 -9999 -9999 -9999 -9999 -9999 -9999 -9999 -9999 -9999 -9999 -9999 -9999 -9999 -9999 -9999 -9999 -9999 -9999 -9999 -9999 -9999 -9999 -9999 -9999 -9999 -9999 -9999 -9999 -9999 -9999 -9999 -9999 -9999 -9999 -9999 -9999 -9999 -9999 -9999 -9999 -9999 -9999 -9999 -9999 -9999 -9999 -9999 -9999 -9999 -9999 -9999 -9999 -9999 -9999 -9999 -9999 -9999 -9999 -9999 -9999 -9999

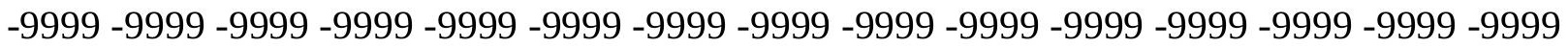
-9999 -9999 -9999 -9999 -9999 -9999 -9999 -9999 -9999 -9999 -9999 -9999 -9999 -9999 -9999 -

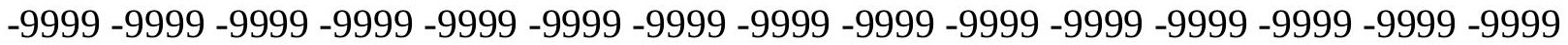
-9999 -9999 -9999 -9999 -9999 -9999 -9999 -9999 -9999 -9999 -9999 -9999 -9999 -9999 -9999 -9999 -9999 -9999 -9999 -9999 -9999 -9999 -9999 -9999 -9999 -9999 -9999 -9999 -9999 -9999 -

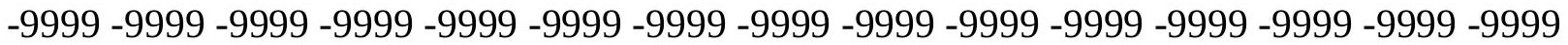
-9999 -9999 -9999 -9999 -9999 -9999 -9999 -9999 -9999 -9999 -9999 -9999 -9999 -9999 -9999 -9999 -9999 -9999 -9999 -9999 -9999 -9999 -9999 -9999 -9999 -9999 -9999 -9999 -9999 -9999

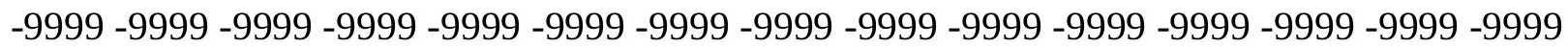
-9999 -9999 -9999 -9999 -9999 -9999 -9999 -9999 -9999 -9999 -9999 -9999 -9999 -9999 -9999 -9999 -9999 -9999 -9999 -9999 -9999 -9999 -9999 -9999 -9999 -9999 -9999 -9999 -9999 -9999 -9999 -9999 -9999 -9999 -9999 -9999 -9999 -9999 -9999 -9999 -9999 -9999 -9999 -9999 -9999 -999 -9999 -9999 -9999 -9999 -9999 -9999 -9999 -9999 -9999 -9999 -9999 -9999 -9999 -9999 -9999 -9999 -9999 -9999 -9999 -9999 -9999 -9999 -9999 -9999 -9999 -9999 -9999 -9999 -9999 -9999 -9999 -9999 -9999 -9999 -9999 -9999 -9999 109.4179000854 109.1130981445108 .5035018921 107.8938980103106 .979598999106 .1083908081105 .630355835105 .1509017944 104.2365036011103 .6268997192102 .712600708101 .7982025146101 .1886978149 
100.274299621699.6647262573299.0551681518698.445587158297.83602905273 97.2264633178796.9216690063596.3121032714896.3121032714896.00731658936 95.7025299072395 .397743225195 .397743225194 .7881774902394 .48339080811 93.8738174438592 .9594726562591 .7403335571390 .5211791992288 .69246673584 86.254188537683 .8159103393680 .4632720947377 .110626220773 .75800323486 70.4053573608467 .0527267456164 .004882812564 .3096618652358 .51874923706 -9999 -9999 -9999 -9999 -9999 -9999 -9999 -9999 -9999 -9999 -9999 -9999 -9999 -9999 -9999 -9999

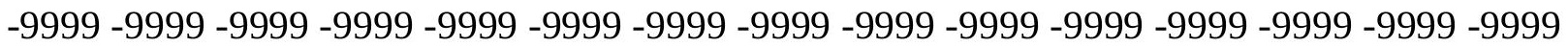

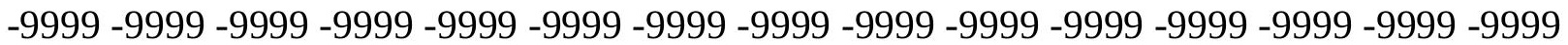
-9999 -9999 -9999 -9999 -9999 -9999-9999 -9999

-9999 -9999 -9999 -9999 -9999 -9999 -9999 -9999 -9999 -9999 -9999 -9999 -9999 -9999 -9999 -9999 -9999 -9999 -9999 -9999 -9999 -9999 -9999 -9999 -9999 -9999 -9999 -9999 -9999 -9999 -9999 -9999 -9999 -9999 -9999 -9999 -9999 -9999 -9999 -9999 -9999 -9999 -9999 -9999 -9999 -9999 -9999 -9999 -9999 -9999 -9999 -9999 -9999 -9999 -9999 -9999 -9999 -9999 -9999 -9999 -9999 -9999 -9999 -9999 -9999 -9999 -9999 -9999 -9999 -9999 -9999 -9999 -9999 -9999 -9999 -9999 -9999 -9999 -9999 -9999 -9999 -9999 -9999 -9999 -9999 -9999 -9999 -9999 -9999 -9999

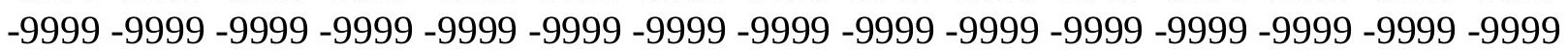
-9999 -9999 -9999 -9999 -9999 -9999 -9999 -9999 -9999 -9999 -9999 -9999 -9999 -9999 -9999 -999 -9999 -9999 -9999 -9999 -9999 -9999 -9999 -9999 -9999 -9999 -9999 -9999 -9999 -9999 -9999 -9999 -9999 -9999 -9999 -9999 -9999 -9999 -9999 -9999 -9999 -9999 -9999 -9999 -9999 -9999 -9999 -9999 -9999 -9999 -9999 -9999 -9999 -9999 -9999 -9999 -9999 -9999 -9999 -9999 -9999 -9999 -9999 -9999 -9999 -9999 -9999 -9999 -9999 -9999 -9999 -9999 -9999 -9999 -9999 -9999 -9999 -9999 -9999 -9999 -9999 -9999 -9999 -9999 -9999 -9999 -9999 -9999 -9999 -9999 -9999 -9999 -9999 -9999 -9999 -9999 -9999 -9999 -9999 -9999 -9999 -9999 -9999 -9999 -9999 -9999 -9999 -9999 -9999 -9999 -9999 -9999 -9999 -9999 -9999 -9999 -9999 -9999 -9999 -9999 -9999 -9999 -9999 -9999 -9999 -9999 -9999 -9999 -9999 -9999 -9999 -9999 -9999 -9999 -9999 -9999 -9999 -9999 -9999 -9999 -9999 -9999 -9999 -9999 -9999 -9999 -9999 -9999 -9999 -9999 -9999 -

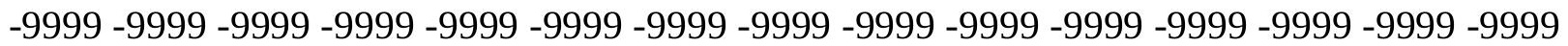
-9999 -9999 -9999 -9999 -9999 -9999 -9999 -9999 -9999 -9999 -9999 -9999 -9999 -9999 -9999 -999 -9999 -9999 -9999 -9999 -9999 -9999 -9999 -9999 109.7226028442109 .1130981445 108.5035018921107 .8938980103106 .979598999106 .2265930176105 .6095504761 104.8460998535104 .2365036011103 .3221969604102 .4077987671101 .4934005737 100.883903503499 .9695205688599 .0551681518698 .445587158297 .83602905273 97.2264633178796 .9216690063596 .6168823242296 .3121032714896 .31210327148 96.0073165893696 .0073165893695 .7025299072395 .397743225194 .78817749023 94.1785964965893 .2642517089892 .0450973510790 .5211791992288 .38768768311 86.254188537683 .5111236572380 .4632720947377 .4154205322374 .0627822876 70.4053573608467 .0527267456164 .004882812564 .004882812557 .9091796875 -9999-9999 -9999 -9999 -9999 -9999 -9999 -9999 -9999 -9999 -9999 -9999 -9999 -9999 -9999 -9999 -9999 -9999 -9999 -9999 -9999 -9999 -9999 -9999 -9999 -9999 -9999 -9999 -9999 -9999 -9999 -9999 -

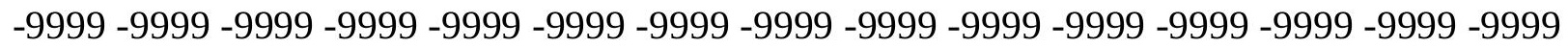
-9999 -9999 -9999 -9999 -9999 -9999-9999

-9999 -9999 -9999 -9999 -9999 -9999 -9999 -9999 -9999 -9999 -9999 -9999 -9999 -9999 -9999 -9999 -9999 -9999 -9999 -9999 -9999 -9999 -9999 -9999 -9999 -9999 -9999 -9999 -9999 -9999 -9999 -9999 -9999 -9999 -9999 -9999 -9999 -9999 -9999 -9999 -9999 -9999 -9999 -9999 -9999

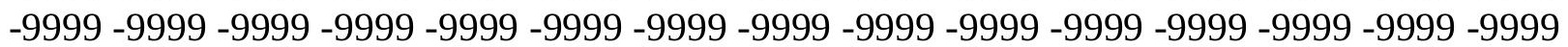


-9999 -9999 -9999 -9999 -9999 -9999 -9999 -9999 -9999 -9999 -9999 -9999 -9999 -9999 -9999 -9999 -9999 -9999 -9999 -9999 -9999 -9999 -9999 -9999 -9999 -9999 -9999 -9999 -9999 -9999 -9999 -9999 -9999 -9999 -9999 -9999 -9999 -9999 -9999 -9999 -9999 -9999 -9999 -9999 - 9999 -9999 -9999 -9999 -9999 -9999 -9999 -9999 -9999 -9999 -9999 -9999 -9999 -9999 -9999 -9999 -9999 -9999 -9999 -9999 -9999 -9999 -9999 -9999 -9999-9999 -9999 -9999 -9999 -9999 -9999 -9999 -9999 -9999 -9999 -9999 -9999 -9999 -9999 -9999 -9999 -9999 -9999 -9999 -9999 -9999 -9999 -9999 -9999 -9999 -9999 -9999 -9999 -9999 -9999 -9999 -9999 -9999 -9999 -9999 -9999 -999 -

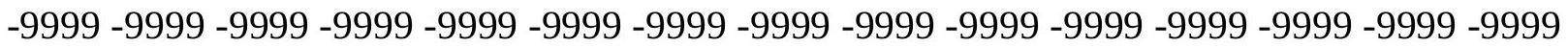
-9999 -9999 -9999 -9999 -9999 -9999 -9999 -9999 -9999 -9999 -9999 -9999 -9999 -9999 -9999 -9999 -9999 -9999 -9999 -9999 -9999 -9999 -9999 -9999 -9999 -9999 -9999 -9999 -9999 -9999

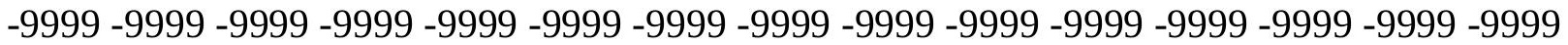
-9999 -9999 -9999 -9999 -9999 -9999 -9999 -9999 -9999 -9999 -9999 -9999 -9999 -9999 -9999 -9999 -9999 -9999 -9999 -9999 -9999 -9999 -9999 -9999 -9999 -9999 -9999 -9999 -9999 -9999 -

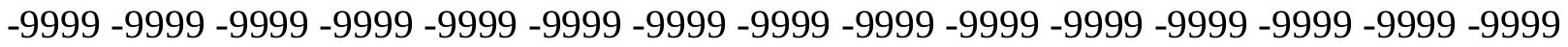
-9999 -9999 -9999 -9999 -9999 -9999 -9999 -9999 -9999 -9999 -9999 -9999 -9999 -9999 -9999 -9999 -9999 -9999 -9999 -9999 -9999 -9999 -9999 -9999 -9999 109.1130981445 108.5035018921107 .8938980103106 .7393722534106 .0884933472105 .3557128906 104.5412979126103 .9317016602103 .0174026489102 .1029968262101 .1886978149 100.274299621699.3599472045998.75038146973 98.1408081054797.53124237061 96.9216690063596 .6168823242296 .6168823242296 .3121032714896 .31210327148 96.3121032714896 .3121032714896 .0073165893695 .397743225194 .78817749023 93.5690307617292 .0450973510790 .5211791992288 .3876876831186 .2541885376 83.5111236572380 .7680587768677 .4154205322374 .062782287670 .71015167236 67.3575134277367 .0527267456164 .004882812557 .9091796875 -9999 -9999 -9999 -9999 -9999 -9999 -9999 -9999 -9999 -9999 -9999 -9999 -9999 -9999 -9999 -9999 -9999 -9999 -9999 -9999 -9999 -9999 -9999 -9999 -9999 -9999 -9999 -9999 -9999 -9999 -9999 -9999 -9999 -9999 -9999 -9999 -9999 -9999 -9999 -9999 -9999 -9999 -9999 -9999 -9999 -9999 -9999 -9999 -9999 -9999 -9999-9999-9999-9999

-9999 -9999 -9999 -9999 -9999 -9999 -9999 -9999 -9999 -9999 -9999 -9999 -9999 -9999 -9999 -9999 -9999 -9999 -9999 -9999 -9999 -9999 -9999 -9999 -9999 -9999 -9999 -9999 -9999 -9999 -9999 -9999 -9999 -9999 -9999 -9999 -9999 -9999 -9999 -9999 -9999 -9999 -9999 -9999 -9999

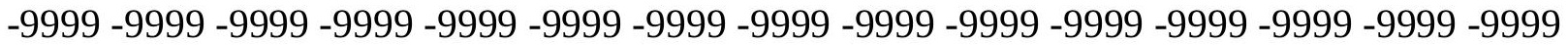

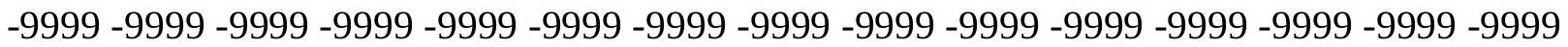
-9999 -9999 -9999 -9999 -9999 -9999 -9999 -9999 -9999 -9999 -9999 -9999 -9999 -9999 -9999 -9999 -9999 -9999 -9999 -9999 -9999 -9999 -9999 -9999 -9999 -9999 -9999 -9999 -9999 -9999 -9999 -9999 -9999 -9999 -9999 -9999 -9999 -9999 -9999 -9999 -9999 -9999 -9999 -9999 -9999

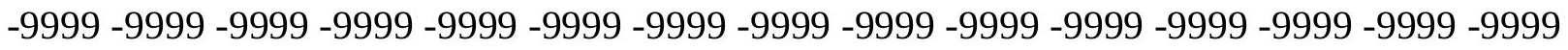

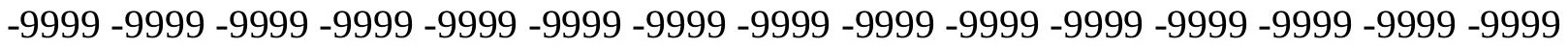

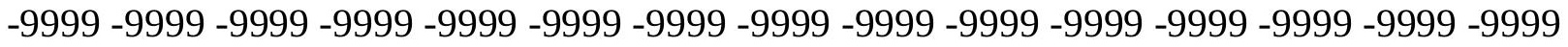
-9999 -9999 -9999 -9999 -9999 -9999 -9999 -9999 -9999 -9999 -9999 -9999 -9999 -9999 -9999 -

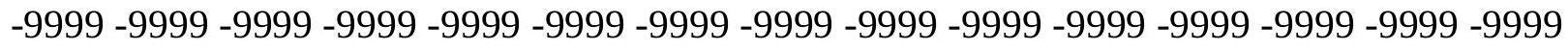

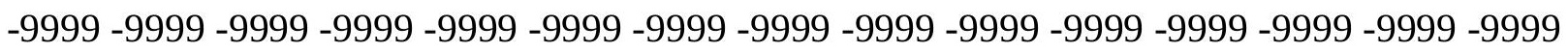
-9999 -9999 -9999 -9999 -9999 -9999 -9999 -9999 -9999 -9999 -9999 -9999 -9999 -9999 -9999 -9999 -9999 -9999 -9999 -9999 -9999 -9999 -9999 -9999-9999 -9999 -9999 -9999 -9999 -9999 -9999 -9999 -9999 -9999 -9999 -9999 -9999 -9999 -9999 -9999 -9999 -9999 -9999 -9999 -9999 -9999 -9999 -9999 -9999 -9999 -9999 -9999 -9999 -9999 -9999 -9999 -9999 -9999 -9999 -9999 
-9999 -9999 -9999 -9999 -9999 -9999 -9999 -9999 -9999 -9999 -9999 -9999 -9999 -9999 -9999 -9999 -9999 -9999 -9999 -9999 -9999 -9999 -9999 -9999 -9999 -9999 -9999 108.5035018921 107.8938980103106 .5584259033105 .8240737915105 .0402450562104 .2365036011 103.3221969604102 .4077987671101 .4934005737100 .579101562599 .66472625732 98.75038146973 98.1408081054797.53124237061 97.2264633178796.92166900635 96.6168823242296 .6168823242296 .6168823242296 .6168823242296 .61688232422 96.6168823242296 .0073165893695 .397743225193 .8738174438592 .3498916626 90.5211791992288 .3876876831186 .254188537683 .8159103393681 .07285308838 77.7202072143674 .3675689697371 .014930725167 .6623001098667 .05272674561 64.004882812557 .60438919067 -9999 -9999 -9999 -9999 -9999 -9999 -9999 -9999 -9999 -9999 -9999 -9999 -9999 -9999 -9999 -9999 -9999 -9999 -9999 -9999 -9999 -9999 -9999 -9999 -9999 -9999 -9999 -9999 -9999 -9999 -9999 -9999 -9999 -9999 -9999 -9999 -9999 -9999 -9999 -9999 -9999 -9999 -9999 -9999 -9999 -9999 -9999 -9999 -9999 -9999 -9999 -9999 -9999 -9999 -9999 -9999 -9999 -9999 -9999 -9999 -9999 -9999 -9999 -9999 -9999 -9999 -9999 -9999 -9999 -9999 -9999 -9999 -9999 -9999 -9999 -9999 -9999 -9999 -9999 -9999 -9999 -9999 -9999 -9999 -9999 -9999 -9999 -9999 -9999 -9999 -9999 -9999 -9999 -9999 -9999 -9999 -9999 -9999 -9999 -9999 -9999 -9999 -9999 -9999 -9999 -9999 -9999 -9999 -9999 -9999 -9999 -9999 -9999 -9999 -9999 -9999 -9999 -9999 -9999 -9999 -9999 -9999 -9999 -9999 -9999 -9999 -9999 -9999 -9999 -9999 -9999 -9999 -9999 -9999 -9999 -9999 -9999 -9999 -9999 -9999 -9999 -9999 -9999 -9999 -9999 -9999 -9999 -9999 -9999 -9999 -9999 -9999 -9999 -9999 -9999 -9999 -9999 -9999 -9999

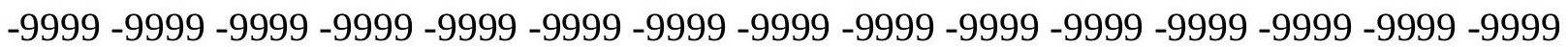
-9999 -9999 -9999 -9999 -9999 -9999 -9999 -9999 -9999 -9999 -9999 -9999 -9999 -9999 -9999 -9999 -9999 -9999 -9999 -9999 -9999 -9999 -9999 -9999 -9999 -9999 -9999 -9999 -9999 -9999 -9999 -9999 -9999 -9999 -9999 -9999 -9999 -9999 -9999 -9999 -9999 -9999 -9999 -9999 -9999

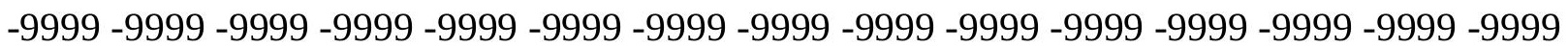
-9999 -9999 -9999 -9999 -9999 -9999 -9999 -9999 -9999 -9999 -9999 -9999 -9999 -9999 -9999 -9999 -9999 -9999 -9999 -9999 -9999 -9999 -9999 -9999 -9999 -9999 -9999 -9999 -9999 -9999 -9999 -9999 -9999 -9999 -9999 -9999 -9999 -9999 -9999 -9999 -9999 -9999 -9999 -9999 -9999 -9999 -9999 -9999 -9999 -9999 -9999 -9999 -9999 -9999 -9999 -9999 -9999 -9999 -9999 -9999 -9999 -9999 -9999 -9999 -9999 -9999 -9999 -9999 -9999 -9999 -9999 -9999 -9999 -9999 -9999 -9999 -9999 -9999 -9999 -9999 -9999 -9999 -9999 -9999 -9999 -9999 -9999 -9999 -9999 -9999 -

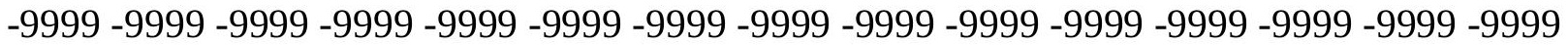
-9999 -9999 -9999 -9999 -9999 -9999 -9999 -9999 -9999 -9999 -9999 -9999 -9999 -9999 107.5891036987106 .2876739502105 .4927368164104 .6191482544103 .6874923706 102.712600708101 .7982025146100 .579101562599 .9695205688599 .05516815186 98.445587158297 .8360290527397 .2264633178799 .9695205688596 .92166900635 96.9216690063596 .9216690063596 .9216690063597 .2264633178797 .22646331787 96.9216690063596 .0073165893694 .7881774902392 .6546783447390 .82597351074 88.6924667358486 .5589828491284 .1206970214881 .3776321411178 .32978057861 74.9771423339871 .6244964599667 .9670867919967 .3575134277364 .0048828125 57.9091796875 -9999 -9999 -9999 -9999 -9999 -9999 -9999 -9999 -9999 -9999 -9999 -9999 -9999 -9999 -9999 -9999 -9999 -9999 -9999 -9999 -9999 -9999 -9999 -9999 -9999-9999 -9999 -9999 -9999 -9999 -9999 -9999 -9999 -9999 -9999 -9999 -9999 -9999 -9999 -9999 -9999 -9999 -9999 -9999 -9999 -9999 -9999 -9999 -9999 -9999 -9999 -9999 -9999 -9999 -9999 -9999 -9999 -9999 -9999 -9999 -9999 -9999 -9999 -9999 -9999 -9999 -9999 -9999 -9999

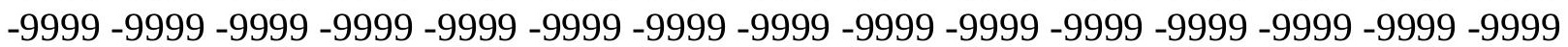


-9999 -9999 -9999 -9999 -9999 -9999 -9999 -9999 -9999 -9999 -9999 -9999 -9999 -9999 -9999 -9999 -9999 -9999 -9999 -9999 -9999 -9999 -9999 -9999 -9999 -9999 -9999 -9999 -9999 -9999 -

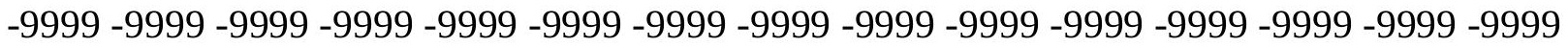
-9999 -9999 -9999 -9999 -9999 -9999 -9999 -9999 -9999 -9999 -9999 -9999 -9999 -9999 -9999 -9999 -9999 -9999 -9999 -9999 -9999 -9999 -9999 -9999-9999 -9999 -9999 -9999 -9999 -9999 -9999 -9999 -9999 -9999 -9999 -9999 -9999 -9999 -9999 -9999 -9999 -9999 -9999 -9999 -9999 -9999 -9999 -9999 -9999 -9999 -9999 -9999 -9999 -9999 -9999 -9999 -9999 -9999 -9999 -9999

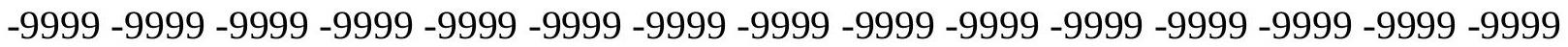

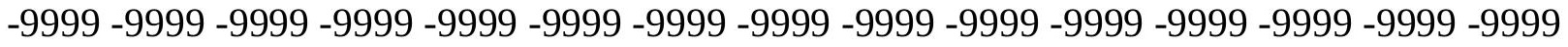
-9999 -9999 -9999 -9999 -9999 -9999 -9999 -9999 -9999 -9999 -9999 -9999 -9999 -9999 -9999 -9999 -9999 -9999 -9999 -9999 -9999 -9999 -9999 -9999 -9999 -9999 -9999 -9999 -9999 -9999 -9999 -9999 -9999 -9999 -9999 -9999 -9999 -9999 -9999 -9999 -9999 -9999 -9999 -9999 -9999 -9999 -9999 -9999 -9999 -9999 -9999 -9999 -9999 -9999 -9999 -9999 -9999 -9999 -9999 -9999 -

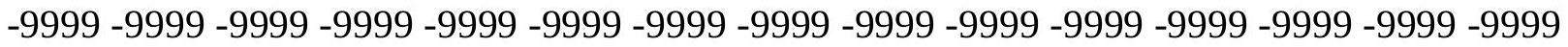
-9999 -9999 -9999 -9999 -9999 -9999 -9999 -9999 -9999 -9999 -9999 -9999 -9999 -9999 -9999

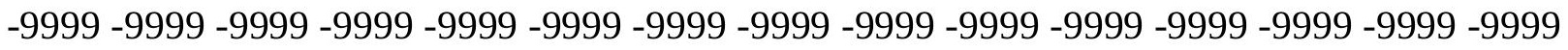
-9999 -9999 -9999 -9999 -9999 -9999 -9999 -9999 -9999 -9999 -9999 -9999 -9999 -9999 -9999 -9999 -9999 -9999 -9999 -9999 -9999 -9999 -9999 -9999 -9999 -9999 -9999 -9999 -9999 -9999 -9999 106.6747970581 105.0774612427 104.142829895103.1713943481 102.1704101562 101.1401367188100 .159469604599 .35994720459101 .7982025146101 .1886978149 100.5791015625100 .2742996216100 .2742996216100 .2742996216100 .2742996216 97.5312423706197 .8360290527397 .8360290527397 .8360290527396 .92166900635 95.397743225196 .6168823242294 .4833908081192 .349891662686 .86376190186 84.4254837036181 .6824111938578 .9393463134875 .5867080688572 .23407745361 68.5766525268666 .9850311279361 .5666007995658 .21395874023 -9999 -9999 -9999 -9999 -9999 -9999 -9999 -9999 -9999 -9999 -9999 -9999 -9999 -9999 -9999 -9999 -9999 -9999 -9999 -9999 -9999 -9999 -9999 -9999 -9999 -9999 -9999 -9999 -9999 -9999 -9999 -9999 -9999 -9999 -

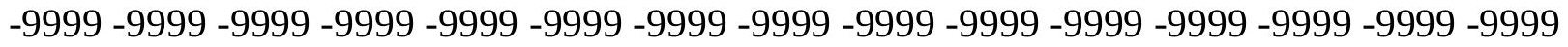
-9999 -9999 -9999 -9999-9999

-9999 -9999 -9999 -9999 -9999 -9999 -9999 -9999 -9999 -9999 -9999 -9999 -9999 -9999 -9999

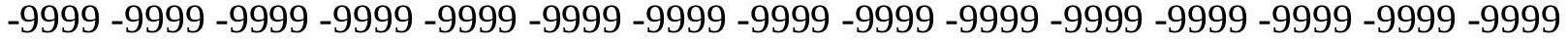
-9999 -9999 -9999 -9999 -9999 -9999 -9999 -9999 -9999 -9999 -9999 -9999 -9999 -9999 -9999 -

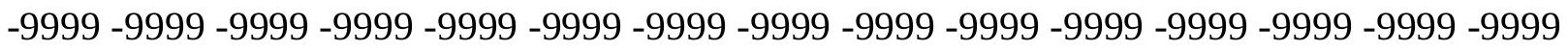

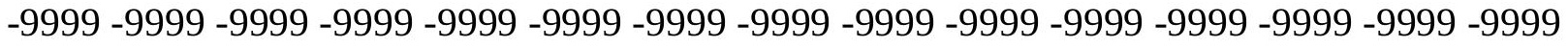
-9999 -9999 -9999 -9999 -9999 -9999 -9999 -9999 -9999 -9999 -9999 -9999 -9999 -9999 -9999 -

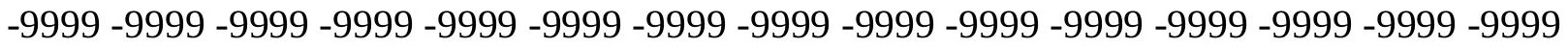

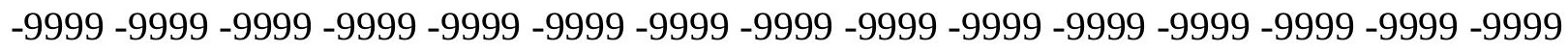

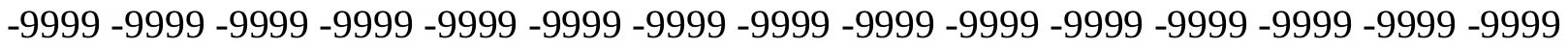

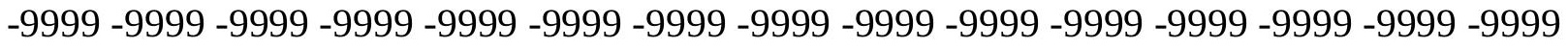
-9999 -9999 -9999 -9999 -9999 -9999 -9999 -9999 -9999 -9999 -9999 -9999 -9999 -9999 -9999 -

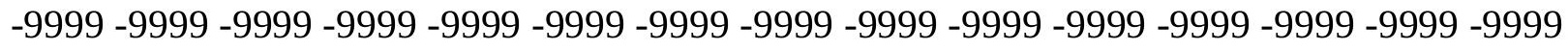

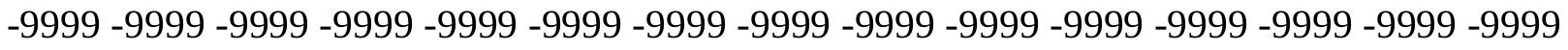
-9999 -9999 -9999 -9999 -9999 -9999 -9999 -9999 -9999 -9999 -9999 -9999 -9999 -9999 -9999 -9999 -9999 -9999 -9999 -9999 -9999 -9999 -9999 -9999 -9999 -9999 -9999 -9999 -9999 -9999 -9999 -9999 -9999 -9999 -9999 -9999 -9999 -9999 -9999 -9999 -9999 -9999 -9999 -9999 -9999 -

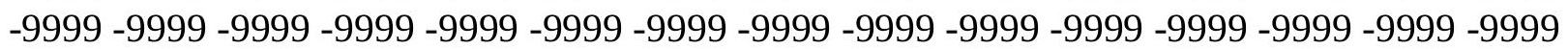


-9999 -9999 -9999 -9999 -9999 -9999 -9999 -9999 -9999 -9999 -9999 -9999 -9999 -9999 -9999 -9999 -9999 -9999 -9999 -9999 -9999 -9999 -9999 -9999 -9999 -9999 -9999 -9999 -9999 -9999 -9999 -9999 -9999 -9999 -9999 -9999 -9999 -9999 -9999 -9999 -9999 -9999 -9999 -9999 -9999 -9999 -9999 -9999 -9999-9999 102.8252029419 101.9489974976100.5791015625 99.6647262573299 .0551681518698 .445587158297 .8360290527397 .53124237061 97.2264633178797 .2264633178797 .5312423706197 .8360290527399 .05780792236 98.7503814697398 .7503814697397 .8360290527396 .3121032714896 .47281646729 95.2609786987392 .5207672119188 .6585388183685 .0350494384882 .24694061279 79.2847900390676 .1515426635772 .8436431884870 .0439147949265 .52880096436 61.87137985229 -9999 -9999 -9999 -9999 -9999 -9999 -9999 -9999 -9999 -9999 -9999 -9999 -9999 -9999 -9999 -9999 -9999 -9999 -9999 -9999 -9999 -9999 -9999 -9999 -9999 -9999 -9999 -9999 -9999 -9999 -9999 -9999 -9999 -9999 -9999 -9999 -9999 -9999 -9999 -9999 -9999 -9999 -9999 -9999 -9999 -9999 -9999 -9999 -9999 -9999 -9999 -9999 -9999 -9999 -9999 -9999 -9999 -9999 -9999 -9999 -9999 -9999 -9999 -9999 -9999 -9999 -9999 -9999 -9999 -9999 -9999 -9999 -9999 -9999 -9999 -9999 -9999 -9999 -9999 -9999 -9999 -9999 -9999 -9999 -9999 -9999 -9999 -9999 -9999 -9999 -9999 -9999 -9999 -9999 -9999 -9999 -9999 -9999 -9999 -9999 -9999 -9999 -9999 -9999 -9999 -9999 -9999 -9999 -9999 -9999 -9999 -9999 -9999 -9999 -9999 -9999 -9999 -9999 -9999 -9999 -9999 -9999 -9999 -9999 -9999 -9999 -9999 -9999 -9999 -9999 -9999 -9999 -9999 -9999 -9999 -9999 -9999 -9999 -9999 -9999 -9999 -9999 -9999 -9999 -9999 -9999 -9999 -9999 -9999 -9999 -9999 -9999 -9999 -9999 -9999 -9999 -9999 -9999 -9999 -9999

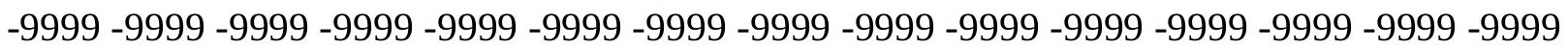
-9999 -9999 -9999 -9999 -9999 -9999 -9999 -9999 -9999 -9999 -9999 -9999 -9999 -9999 -9999 -9999 -9999 -9999 -9999 -9999 -9999 -9999 -9999 -9999 -9999 -9999 -9999 -9999 -9999 -9999 -9999 -9999 -9999 -9999 -9999 -9999 -9999 -9999 -9999 -9999 -9999 -9999 -9999 -9999 -9999

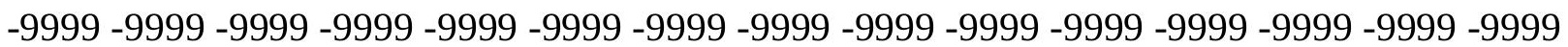
-9999 -9999 -9999 -9999 -9999 -9999 -9999 -9999 -9999 -9999 -9999 -9999 -9999 -9999 -9999 -9999 -9999 -9999 -9999 -9999 -9999 -9999 -9999 -9999 -9999 -9999 -9999 -9999 -9999 -9999 -9999 -9999 -9999 -9999 -9999 -9999 -9999 -9999 -9999 -9999 -9999 -9999 -9999 -9999 -9999 -9999 -9999 -9999 -9999 -9999 -9999 -9999 -9999 -9999 -9999 -9999 -9999 -9999 -9999 -9999 -9999 -9999 -9999 -9999 -9999 -9999 -9999 -9999 -9999 -9999 -9999 -9999 -9999 -9999 -9999 -9999 -9999 -9999 -9999 -9999 -9999 -9999 -9999 -9999 -9999 -9999 -9999 -9999 -9999 -9999 -

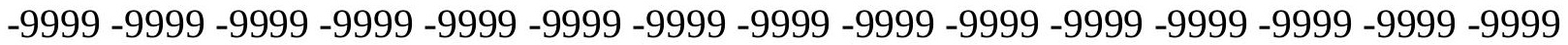
-9999 -9999 -9999 -9999 -9999 -9999 -9999 -9999 -9999 -9999 -9999 -9999 -9999 -9999 -9999 -9999 -9999 -9999 -9999 -9999-9999 -9999 -9999 -9999-9999 98.4455871582 98.1408081054797 .5312423706197 .2264633178797 .2264633178797 .53124237061 97.8360290527398 .7503814697399 .3599472045999 .242607116798 .33358001709 96.9216690063594 .7881774902392 .349891662690 .2164001464887 .77810668945 85.3398437582 .8060073852579 .7275161743277 .110626220773 .75800323486 70.1005783081166 .44316101074 -9999 -9999 -9999 -9999 -9999 -9999 -9999 -9999 -9999 -9999 -9999 -9999 -9999 -9999 -9999 -9999 -9999 -9999 -9999 -9999 -9999 -9999 -9999 -9999

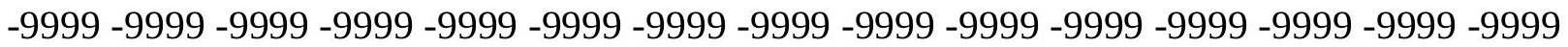

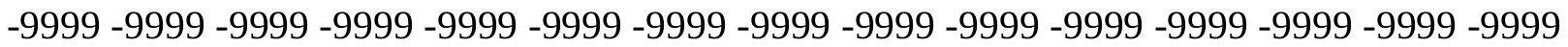
$-9999-9999$

-9999 -9999 -9999 -9999 -9999 -9999 -9999 -9999 -9999 -9999 -9999 -9999 -9999 -9999 -9999 -9999 -9999 -9999 -9999 -9999 -9999 -9999 -9999 -9999 -9999 -9999 -9999 -9999 -9999 -9999

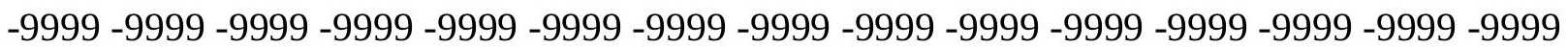


-9999 -9999 -9999 -9999 -9999 -9999 -9999 -9999 -9999 -9999 -9999 -9999 -9999 -9999 -9999 -9999 -9999 -9999 -9999 -9999 -9999 -9999 -9999 -9999 -9999 -9999 -9999 -9999 -9999 -9999 -9999 -9999 -9999 -9999 -9999 -9999 -9999 -9999 -9999 -9999 -9999 -9999 -9999 -9999 - 9999 -9999 -9999 -9999 -9999 -9999 -9999 -9999 -9999 -9999 -9999 -9999 -9999 -9999 -9999 -9999 -9999 -9999 -9999 -9999 -9999 -9999 -9999 -9999 -9999-9999 -9999 -9999 -9999 -9999 -9999 -9999 -9999 -9999 -9999 -9999 -9999 -9999 -9999 -9999 -9999 -9999 -9999 -9999 -9999 -9999 -9999 -9999 -9999 -9999 -9999 -9999 -9999 -9999 -9999 -9999 -9999 -9999 -9999 -9999 -9999

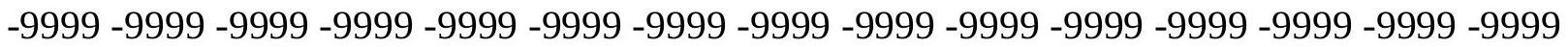

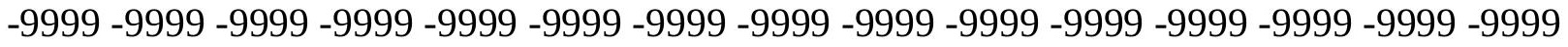
-9999 -9999 -9999 -9999 -9999 -9999 -9999 -9999 -9999 -9999 -9999 -9999 -9999 -9999 -9999 -9999 -9999 -9999 -9999 -9999 -9999 -9999 -9999 -9999 -9999 -9999 -9999 -9999 -9999 -9999 -9999 -9999 -9999 -9999 -9999 -9999 -9999 -9999 -9999 -9999 -9999 -9999 -9999 -9999 -9999 -9999 -9999 -9999 -9999 -9999 -9999 -9999 -9999 -9999 -9999 -9999 -9999 -9999 -9999 -9999 -

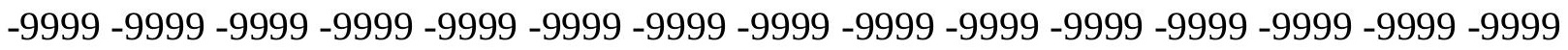
-9999 -9999 -9999 -9999 -9999 -9999 -9999 -9999 -9999 -9999 -9999 -9999 -9999 -9999 -9999 -

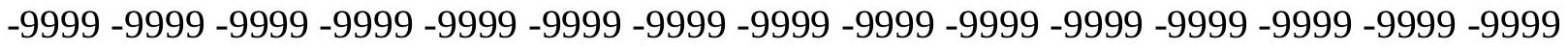
-9999 -9999 -9999 -9999 -9999 -9999 -9999 -9999 -9999 -9999 -9999 -9999 -9999 -9999 -9999 -9999 -9999 -9999 -9999 -9999 -9999 -9999 -9999 -9999 -9999 -9999 -9999 -9999 -9999 -9999 -9999 -9999 -9999 -9999 -9999 -9999 -9999 -9999 -9999 -9999 -9999 -9999 -9999 -9999 -9999 -

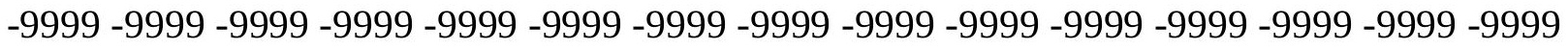
-9999 -9999 -9999 -9999 -9999 -9999 -9999 -9999 -9999 -9999 -9999 -9999 -9999 -9999 -9999 -999 -9999 -9999 -9999 -9999 -9999 -9999 -9999 -9999 -9999 -9999 -9999 -9999 -9999 -9999 - 9999 -9999 -9999 -9999 -9999 -9999 -9999 -9999 -9999 -9999 -9999 -9999 -9999 -9999 -9999 -

-9999 -9999 -9999 -9999 -9999 -9999 -9999 -9999 -9999 -9999 -9999 -9999 -9999 -9999 -9999 -

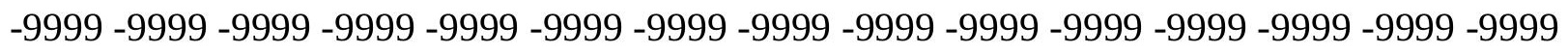
-9999 -9999 -9999 -9999 -9999 -9999 -9999 -9999 -9999 -9999 -9999 -9999 -9999 -9999 -9999 -9999 -9999 -9999 -9999 -9999 -9999 -9999 -9999 -9999 -9999 -9999 -9999 -9999 -9999 -9999 -

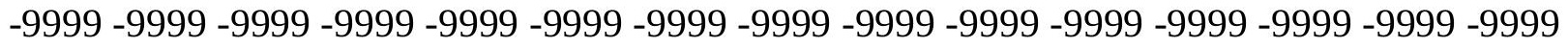
-9999 -9999 -9999 -9999 -9999 -9999 -9999 -9999 -9999 -9999 -9999 -9999 -9999 -9999 -9999 -9999 -9999 -9999 -9999 -9999 -9999 -9999 -9999 -9999 -9999 -9999 -9999 -9999 -9999 -999 -

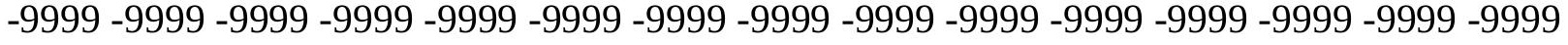
-9999 -9999 -9999 -9999 -9999 -9999 -9999 -9999 -9999 -9999 -9999 -9999 -9999 -9999 -9999 -

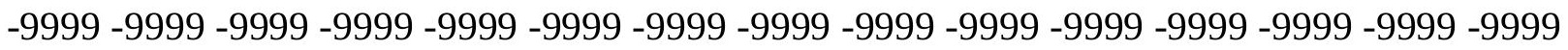

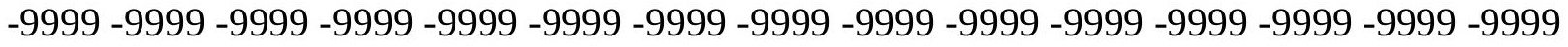

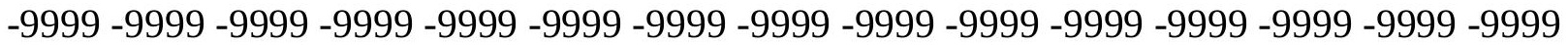

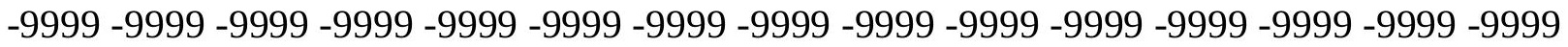

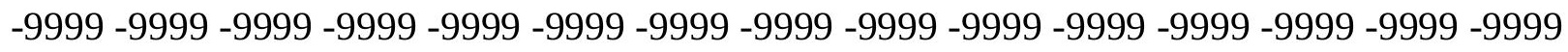

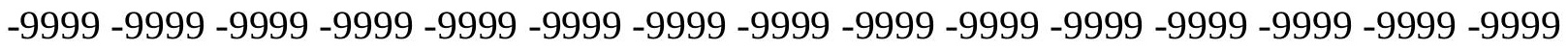

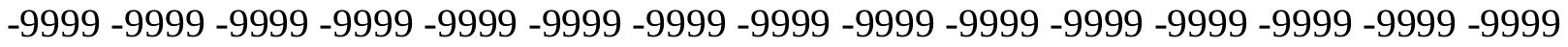
-9999 -9999 -9999 -9999 -9999 -9999 -9999 -9999 -9999 -9999 -9999 -9999 -9999 -9999 -9999 -

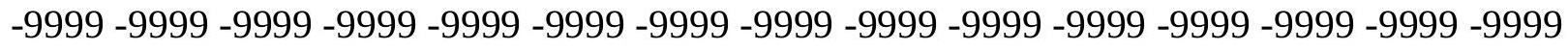

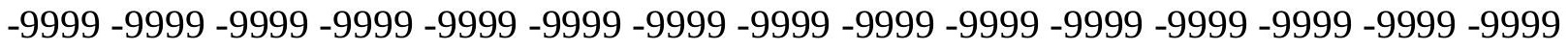
-9999 -9999 -9999 -9999 -9999 -9999 -9999 -9999 -9999 -9999 -9999 -9999 -9999 -9999 -9999 -9999 -9999 -9999 -9999 -9999 -9999 -9999 -9999 -9999-9999 -9999 -9999 -9999 -9999 -9999 -9999 -9999 -9999 -9999 -9999 -9999 -9999 -9999 -9999 -9999 -9999 -9999 -9999 -9999 -9999 -

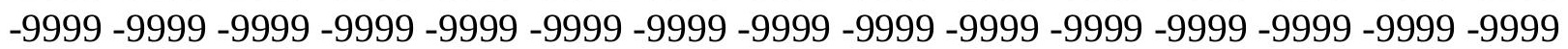


-9999 -9999 -9999 -9999 -9999 -9999 -9999 -9999 -9999 -9999 -9999 -9999 -9999 -9999 -9999 -9999 -9999 -9999 -9999 -9999 -9999 -9999 -9999 -9999 -9999 -9999 -9999 -9999 -9999 -9999 -9999 -9999 -9999 -9999 -9999 -9999 -9999 -9999 -9999 -9999 -9999 -9999 -9999 -9999 -9999 -9999 -9999 -9999 -9999 -9999 -9999 -9999 -9999 -9999 -9999 -9999 -9999 -9999 -9999 -9999 -9999 -9999 -9999 -9999 -9999 -9999 -9999 -9999-9999 -9999 -9999 -9999 -9999 -9999 -9999 -9999 -9999 -9999 -9999 -9999 -9999 -9999 -9999 -9999 -9999 -9999 -9999 -9999 -9999 -9999 -9999 -9999 -9999 -9999 -9999 -9999 -9999 -9999 -9999 -9999 -9999 -9999 -9999 -9999

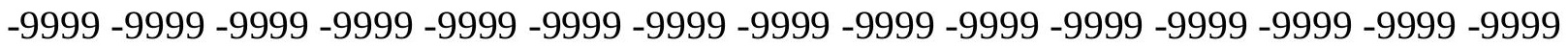

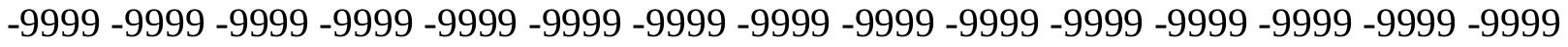
-9999 -9999 -9999 -9999 -9999 -9999 -9999 -9999 -9999 -9999 -9999 -9999 -9999 -9999 -9999 -9999 -9999 -9999 -9999 -9999 -9999 -9999 -9999 -9999 -9999 -9999 -9999 -9999 -9999 -9999 -9999 -9999 -9999 -9999 -9999 -9999 -9999 -9999 -9999 -9999 -9999 -9999 -9999 -9999 -9999 -9999 -9999 -9999 -9999 -9999 -9999 -9999 -9999 -9999 -9999 -9999 -9999 -9999 -9999 -9999 -

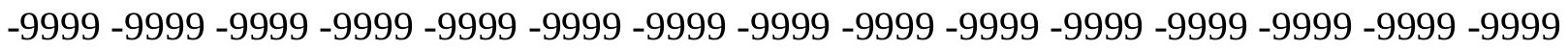
-9999 -9999 -9999 -9999 -9999 -9999 -9999 -9999 -9999 -9999 -9999 -9999 -9999 -9999 -9999 -

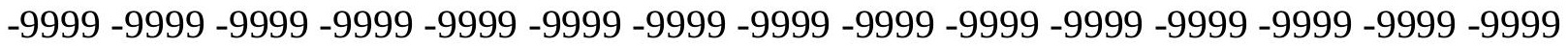
-9999 -9999 -9999 -9999 -9999 -9999 -9999 -9999 -9999 -9999 -9999 -9999 -9999 -9999 -9999 -9999 -9999 -9999 -9999 -9999 -9999 -9999 -9999 -9999 -9999 -9999 -9999 -9999 -9999 -9999 -9999 -9999 -9999 -9999 -9999 -9999 -9999 -9999 -9999 -9999 -9999 -9999 -9999 -9999 -9999 -

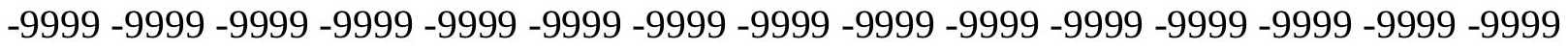

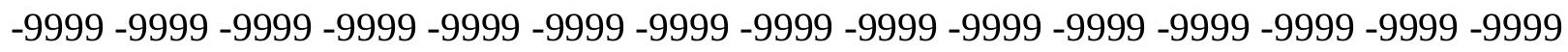
-9999 -9999 -9999 -9999 -9999 -9999 -9999 -9999 -9999 -9999 -9999 -9999 -9999 -9999 -9999 -9999 -9999 -9999 -9999 -9999 -9999 -9999 -9999 -9999 -9999 -9999 -9999 -9999 -9999 -9999 -9999 -9999 -9999 -9999 -9999 -9999 -9999 -9999 -9999 -9999 -9999 -9999 -9999 -9999 -9999 -

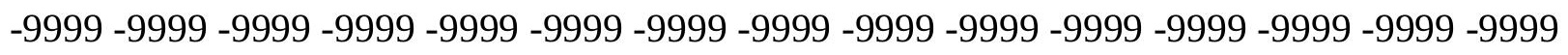
-9999 -9999 -9999 -9999 -9999 -9999 -9999 -9999 -9999 -9999 -9999 -9999 -9999 -9999 -9999 -9999 -9999 -9999 -9999 -9999 -9999 -9999 -9999 -9999 -9999 -9999 -9999 -9999 -9999 -9999 -

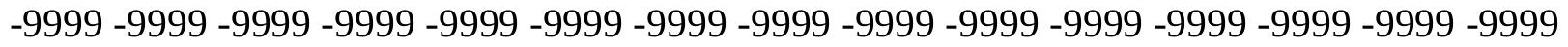
-9999 -9999 -9999 -9999 -9999 -9999 -9999 -9999 -9999 -9999 -9999 -9999 -9999 -9999 -9999 -9999 -9999 -9999 -9999 -9999 -9999 -9999 -9999 -9999 -9999 -9999 -9999 -9999 - -999 -

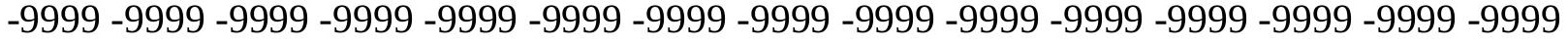
-9999 -9999 -9999 -9999 -9999 -9999 -9999 -9999 -9999 -9999 -9999 -9999 -9999 -9999 -9999 -

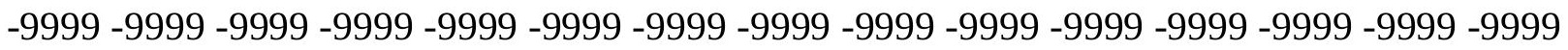

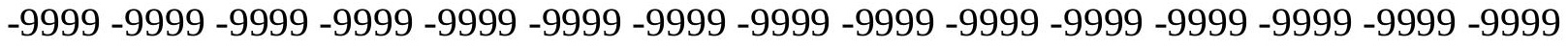

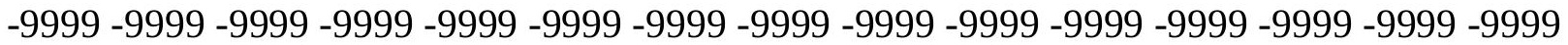

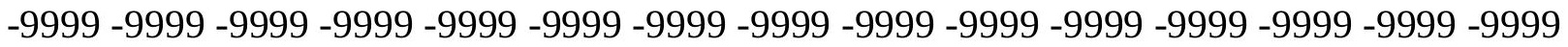

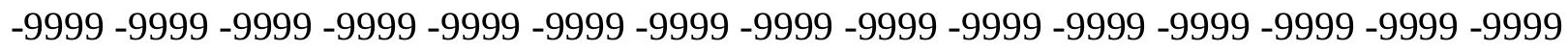

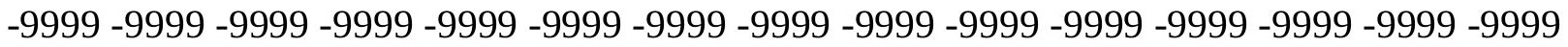

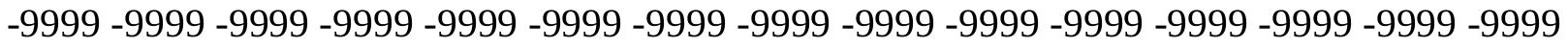
-9999 -9999 -9999 -9999 -9999 -9999 -9999 -9999 -9999 -9999 -9999 -9999 -9999 -9999 -9999 -

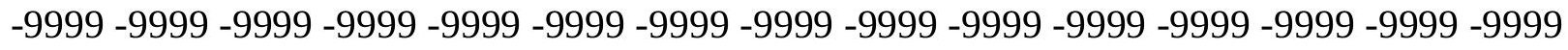

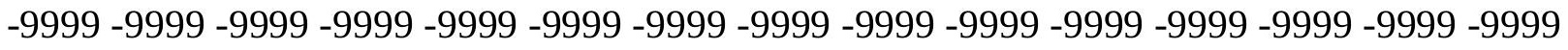
-9999 -9999 -9999 -9999 -9999 -9999 -9999 -9999 -9999 -9999 -9999 -9999 -9999 -9999 -9999 -9999 -9999 -9999 -9999 -9999 -9999 -9999 -9999 -9999-9999 -9999 -9999 -9999 -9999 -9999 -9999 -9999 -9999 -9999 -9999 -9999 -9999 -9999 -9999 -9999 -9999 -9999 -9999 -9999 -9999 -

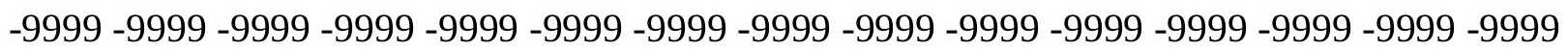


-9999 -9999 -9999 -9999 -9999 -9999 -9999 -9999 -9999 -9999 -9999 -9999 -9999 -9999 -9999 -9999 -9999 -9999 -9999 -9999 -9999 -9999 -9999 -9999 -9999 -9999 -9999 -9999 -9999 -9999 -

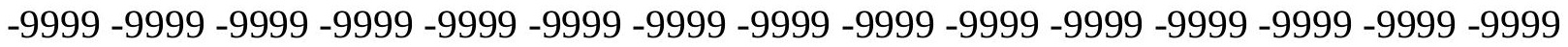
-9999 -9999 -9999 -9999 -9999 -9999 -9999 -9999 -9999 -9999 -9999 -9999 -9999 -9999 -9999 -9999 -9999 -9999 -9999 -9999 -9999 -9999 -9999 -9999-9999 -9999 -9999 -9999 -9999 -9999 -9999 -9999 -9999 -9999 -9999 -9999 -9999 -9999 -9999 -9999 -9999 -9999 -9999 -9999 -9999 -9999 -9999 -9999 -9999 -9999 -9999 -9999 -9999 -9999 -9999 -9999 -9999 -9999 -9999 -9999

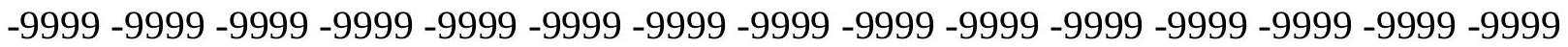
-9999 -9999 -9999 -9999 -9999 -9999 -9999 -9999 -9999 -9999 -9999 -9999 -9999 -9999 -9999 -9999 -9999 -9999 -9999 -9999 -9999 -9999 -9999 -9999 -9999 -9999 -9999 -9999 -9999

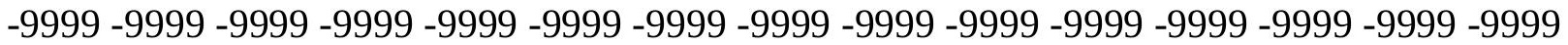
-9999 -9999 -9999 -9999 -9999 -9999 -9999 -9999 -9999 -9999 -9999 -9999 -9999 -9999 -9999 -9999 -9999 -9999 -9999 -9999 -9999 -9999 -9999 -9999 -9999 -9999 -9999 -9999 -9999 -9999 -9999 -9999 -9999 -9999 -9999 -9999 -9999 -9999 -9999 -9999 -9999 -9999 -9999 -9999 - 9999 -9999 -9999 -9999 -9999 -9999 -9999 -9999 -9999 -9999 -9999 -9999 -9999 -9999 -9999 -9999

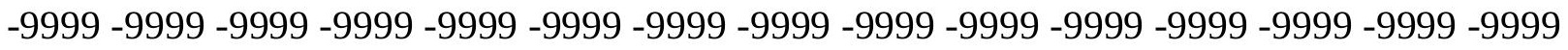
-9999 -9999 -9999 -9999 -9999 -9999 -9999 -9999 -9999 -9999 -9999 -9999 -9999 -9999 -9999 -9999 -9999 -9999 -9999 -9999 -9999 -9999 -9999 -9999 -9999 -9999 -9999 -9999 -9999 -9999 -9999 -9999 -9999 -9999 -9999 -9999 -9999 -9999 -9999 -9999 -9999 -9999 -9999 -9999 -9999 -

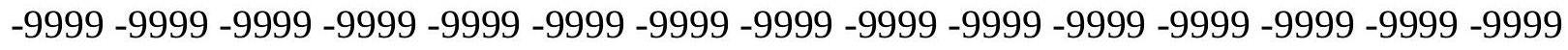

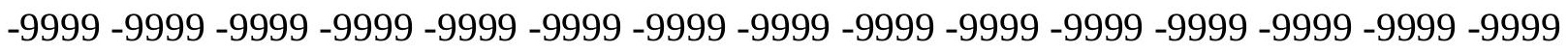
-9999 -9999 -9999 -9999 -9999 -9999 -9999 -9999 -9999 -9999 -9999 -9999 -9999 -9999 -9999 -9999 -9999 -9999 -9999 -9999 -9999 -9999 -9999 -9999 -9999 -9999 -9999 -9999 -9999 -9999 -9999 -9999 -9999 -9999 -9999 -9999 -9999 -9999 -9999 -9999 -9999 -9999 -9999 -9999 -9999 -

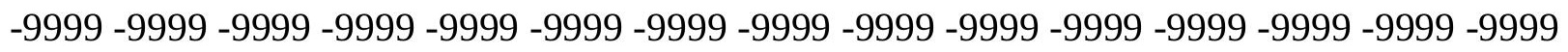
-9999 -9999 -9999 -9999 -9999 -9999 -9999 -9999 -9999 -9999 -9999 -9999 -9999 -9999 -9999 -9999 -9999 -9999 -9999 -9999 -9999 -9999 -9999 -9999 -9999 -9999 -9999 -9999 -9999 -9999 -

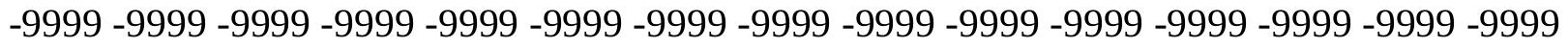
-9999 -9999 -9999 -9999 -9999 -9999 -9999 -9999 -9999 -9999 -9999 -9999 -9999 -9999 -9999 -9999 -9999 -9999 -9999 -9999 -9999 -9999 -9999 -9999 -9999 -9999 -9999 -9999 -9999 -999 -9999 -9999 -9999 -9999 -9999 -9999 -9999 -9999 -9999 -9999 -9999 -9999 -9999 -9999 -9999 -9999 -9999 -9999 -9999 -9999 -9999 -9999 -9999 -9999 -9999 -9999 -9999 -9999 -9999 -9999 -

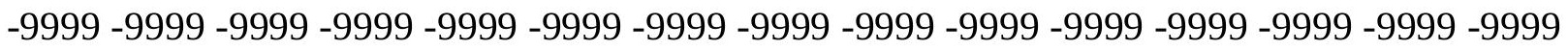

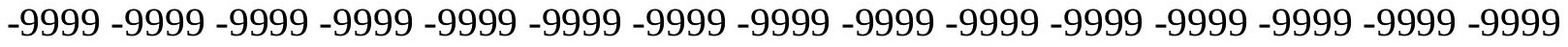
-9999 -9999 -9999 -9999 -9999 -9999 -9999 -9999 -9999 -9999 -9999 -9999 -9999 -9999 -

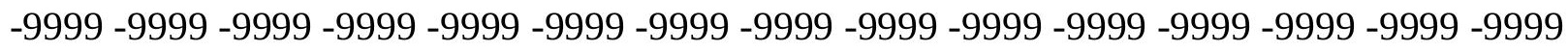

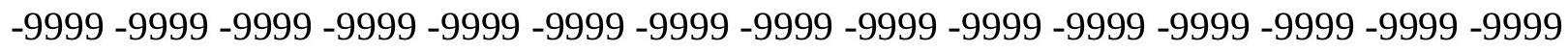

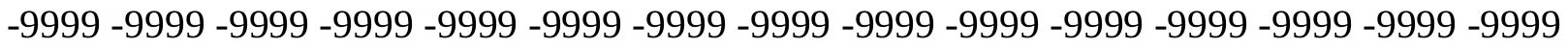
-9999 -9999 -9999 -9999 -9999 -9999 -9999 -9999 -9999 -9999 -9999 -9999 -9999 - 9999 - -999 -9999 -9999 -9999 -9999 -9999 -9999 -9999 -9999 -9999 -9999 -9999 -9999 -9999 -9999 -9999 -

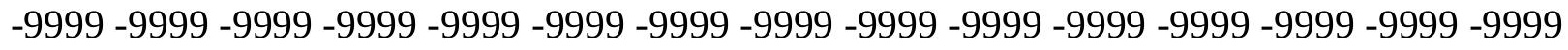

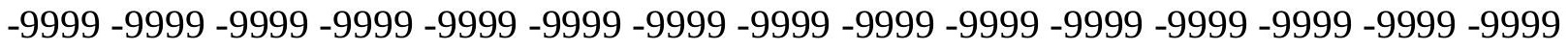
-9999 -9999 -9999 -9999 -9999 -9999 -9999 -9999 -9999 -9999 -9999 -9999 -9999 -9999 -9999 -9999 -9999 -9999 -9999 -9999 -9999 -9999 -9999 -9999-9999 -9999 -9999 -9999 -9999 -9999 -9999 -9999 -9999 -9999 -9999 -9999 -9999 -9999 -9999 -9999 -9999 -9999 -9999 -9999 -9999 -

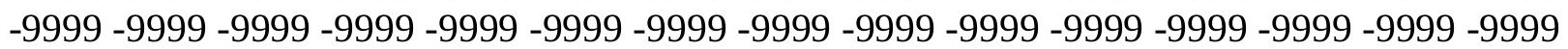


-9999 -9999 -9999 -9999 -9999 -9999 -9999 -9999 -9999 -9999 -9999 -9999 -9999 -9999 -9999 -9999 -9999 -9999 -9999 -9999 -9999 -9999 -9999 -9999 -9999 -9999 -9999 -9999 -9999 -9999 -

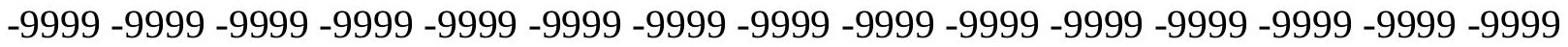
-9999 -9999 -9999 -9999 -9999 -9999 -9999 -9999 -9999 -9999 -9999 -9999 -9999 -9999 -9999 -9999 -9999 -9999 -9999 -9999 -9999 -9999 -9999 -9999-9999 -9999 -9999 -9999 -9999 -9999 -9999 -9999 -9999 -9999 -9999 -9999 -9999 -9999 -9999 -9999 -9999 -9999 -9999 -9999 -9999 -9999 -9999 -9999 -9999 -9999 -9999 -9999 -9999 -9999 -9999 -9999 -9999 -9999 -9999 -9999

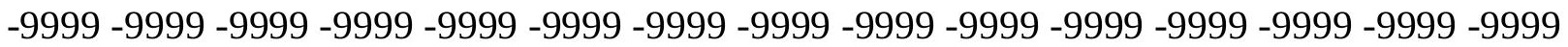

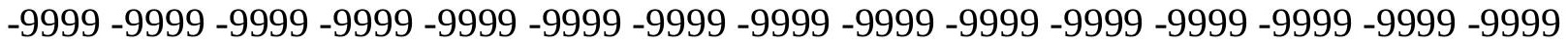
-9999 -9999 -9999 -9999 -9999 -9999 -9999 -9999 -9999 -9999 -9999 -9999 -9999 -9999 -9999 -9999 -9999 -9999 -9999 -9999 -9999 -9999 -9999 -9999 -9999 -9999 -9999 -9999 -9999 -9999 -9999 -9999 -9999 -9999 -9999 -9999 -9999 -9999 -9999 -9999 -9999 -9999 -9999 -9999 -9999 -9999 -9999 -9999 -9999 -9999 -9999 -9999 -9999 -9999 -9999 -9999 -9999 -9999 -9999 -9999 -9999 -9999 -9999 -9999 -9999 -9999 -9999 -9999 -9999 -9999 -9999 -9999 -9999 -9999 -9999 -9999 -9999 -9999 -9999 -9999 -9999 -9999 -9999 -9999 -9999 -9999 -9999 -9999 -9999 -9999 -9999 -9999 -9999 -9999 -9999 -9999 -9999 -9999 -9999 -9999 -9999 -9999 - 9999 - -999 -

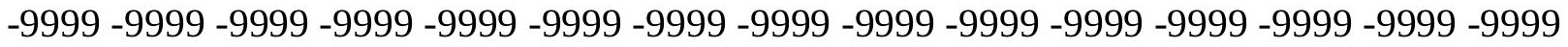
-9999 -9999 -9999 -9999 -9999 -9999 -9999 -9999 -9999 -9999 -9999 -9999 -9999 -9999 -9999 -9999 -9999 -9999 -9999 -9999 -9999 -9999 -9999 -9999 -9999 -9999 -9999 -9999 -9999 -9999 -

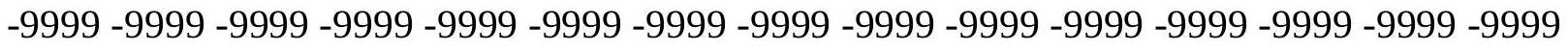
-9999 -9999 -9999 -9999 -9999 -9999 -9999 -9999 -9999 -9999 -9999 -9999 -9999 -9999 -9999

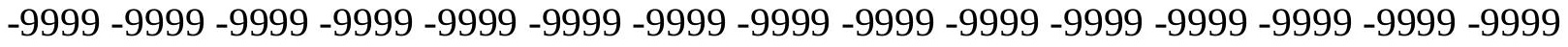
-9999 -9999 -9999 -9999 -9999 -9999 -9999 -9999 -9999 -9999 -9999 -9999 -9999 -9999 -9999 -9999 -9999 -9999 -9999 -9999 -9999 -9999 -9999 -9999 -9999 -9999 -9999 -9999 -9999 -9999 -

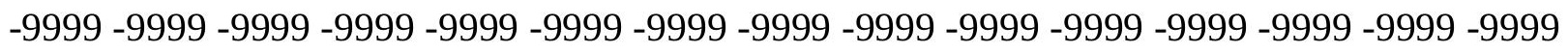
-9999 -9999 -9999 -9999 -9999 -9999 -9999 -9999 -9999 -9999 -9999 -9999 -9999 -9999 -9999 -9999 -9999 -9999 -9999 -9999 -9999 -9999 -9999 -9999 -9999 -9999 -9999 -9999 -9999 -9999 -

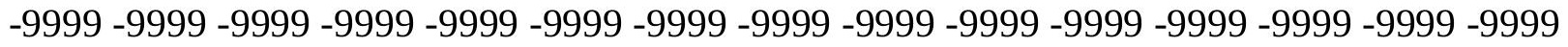
-9999 -9999 -9999 -9999 -9999 -9999 -9999 -9999 -9999 -9999 -9999 -9999 -9999 -9999 -9999 -9999 -9999 -9999 -9999 -9999 -9999 -9999 -9999 -9999 -9999 -9999 -9999 -9999 -9999 -999 -

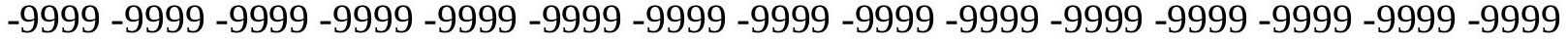
-9999 -9999 -9999 -9999 -9999 -9999 -9999 -9999 -9999 -9999 -9999 -9999 -9999 -9999 -9999 -

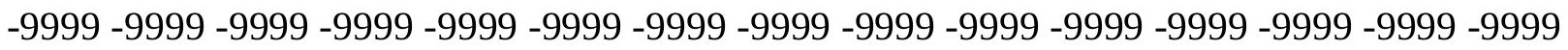

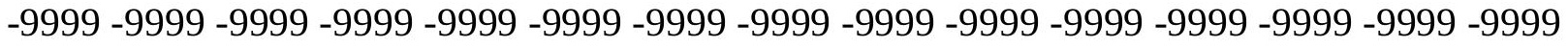

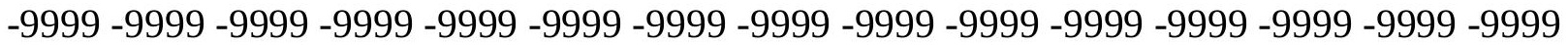
-9999 -9999 -9999 -9999 -9999 -9999 -9999 -9999 -9999 -9999 -9999 -9999 -9999 -9999 -9999 -

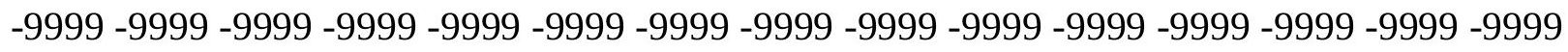

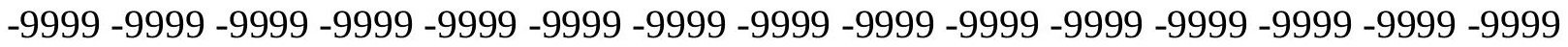
-9999 -9999 -9999 -9999 -9999 -9999 -9999 -9999 -9999 -9999 -9999 -9999 -9999 - 9999 - -999 -9999 -9999 -9999 -9999 -9999 -9999 -9999 -9999 -9999 -9999 -9999 -9999 -9999 -9999 -9999 -

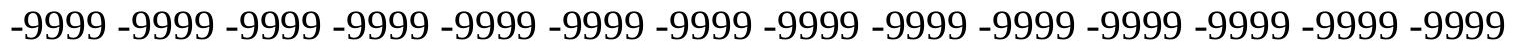

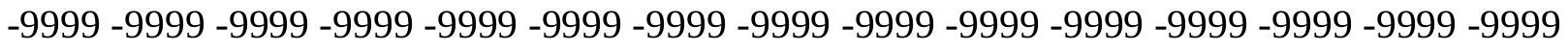
-9999 -9999 -9999 -9999 -9999 -9999 -9999 -9999 -9999 -9999 -9999 -9999 -9999 -9999 -9999 -9999 -9999 -9999 -9999 -9999 -9999 -9999 -9999 -9999-9999 -9999 -9999 -9999 -9999 -9999 -9999 -9999 -9999 -9999 -9999 -9999 -9999 -9999 -9999 -9999 -9999 -9999 -9999 -9999 -9999 -

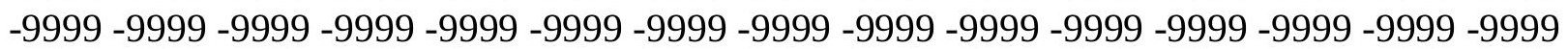


-9999 -9999 -9999 -9999 -9999 -9999 -9999 -9999 -9999 -9999 -9999 -9999 -9999 -9999 -9999 -9999 -9999 -9999 -9999 -9999 -9999 -9999 -9999 -9999 -9999 -9999 -9999 -9999 -9999 -9999 -9999 -9999 -9999 -9999 -9999 -9999 -9999 -9999 -9999 -9999 -9999 -9999 -9999 -9999 - 9999 -9999 -9999 -9999 -9999 -9999 -9999 -9999 -9999 -9999 -9999 -9999 -9999 -9999 -9999 -9999 -9999 -9999 -9999 -9999 -9999 -9999 -9999 -9999 -9999-9999 -9999 -9999 -9999 -9999 -9999 -9999 -9999 -9999 -9999 -9999 -9999 -9999 -9999 -9999 -9999 -9999 -9999 -9999 -9999 -9999 -9999 -9999 -9999 -9999 -9999 -9999 -9999 -9999 -9999 -9999 -9999 -9999 -9999 -9999 -9999

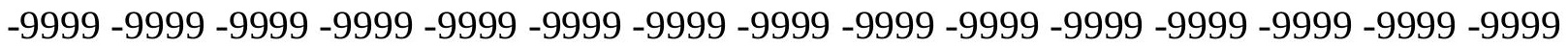
-9999 -9999 -9999 -9999 -9999 -9999 -9999 -9999 -9999 -9999 -9999 -9999 -9999 -9999 -9999 -9999 -9999 -9999 -9999 -9999 -9999 -9999 -9999 -9999 -9999 -9999 -9999 -9999 -9999 -9999

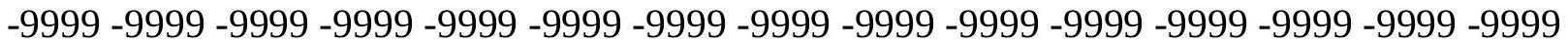
-9999 -9999 -9999 -9999 -9999 -9999 -9999 -9999 -9999 -9999 -9999 -9999 -9999 -9999 -9999 -9999 -9999 -9999 -9999 -9999 -9999 -9999 -9999 -9999 -9999 -9999 -9999 -9999 -9999 -9999 -

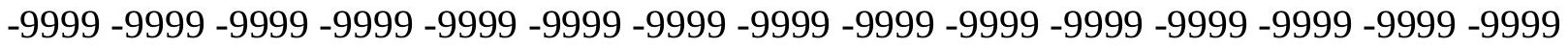
-9999 -9999 -9999 -9999 -9999 -9999 -9999 -9999 -9999 -9999 -9999 -9999 -9999 -9999 -9999

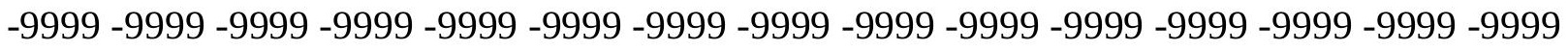
-9999 -9999 -9999 -9999 -9999 -9999 -9999 -9999 -9999 -9999 -9999 -9999 -9999 -9999 -9999 -9999 -9999 -9999 -9999 -9999 -9999 -9999 -9999 -9999 -9999 -9999 -9999 -9999 -9999 - 9999 -9999 -9999 -9999 -9999 -9999 -9999 -9999 -9999 -9999 -9999 -9999 -9999 -9999 -9999 -9999 -9999 -9999 -9999 -9999 -9999 -9999 -9999 -9999 -9999 -9999 -9999 -9999 -9999 -9999 -9999 -9999 -9999 -9999 -9999 -9999 -9999 -9999 -9999 -9999 -9999 -9999 -9999 -9999 -9999 -9999 -9999 -9999 -9999 -9999 -9999 -9999 -9999 -9999 -9999 -9999 -9999 -9999 -9999 -9999 -9999 -9999 -9999 -9999 -9999 -9999 -9999 -9999 -9999 -9999 -9999 -9999 -9999 -9999 -9999 -9999 -9999 -9999 -9999 -9999 -9999 -9999 -9999 -9999 -9999 -9999 -9999 -9999 -9999 -9999 -9999 -9999 -9999 -9999 -9999 -9999 -9999 -9999 -9999 -9999 -9999 -9999 -9999 -9999 -9999 -9999 -9999 -9999 -9999 -9999 -9999 -9999 -9999 -9999 -9999 -9999 -9999 -9999 -9999 -9999 -9999 -9999 -9999 -9999 -9999 -9999 -9999 -9999 -9999 -9999 -9999 -9999 -9999 -9999 -9999 -9999 -9999 -9999 -9999 -9999 -9999 -9999 -9999 -9999 -9999 -9999 -9999 -9999 -9999 -9999 -9999 -9999 -9999 -9999 -9999 -9999 -9999 -9999 -9999 -9999 -9999 -9999 -9999 -9999 -9999 -9999 -9999 -9999 -9999 -9999 -9999 -9999 -9999 -9999 -9999 -9999 -9999 -9999 -9999 -999 -9999 -9999 -9999 -9999 -9999 -9999 -9999 -9999 -9999 -9999 -9999 -9999 -9999 -9999 -9999 -9999 -9999 -9999 -9999 -9999 -9999 -9999 -9999 -9999 -9999 -9999 -9999 -9999 -9999 -9999 -

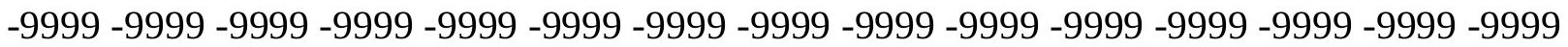

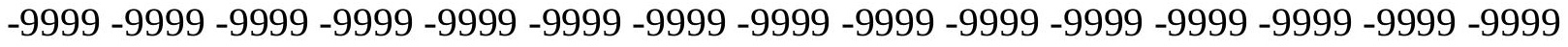

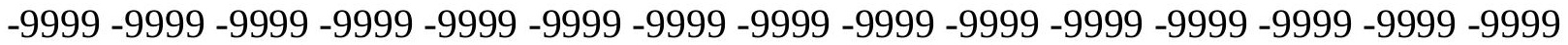
-9999 -9999 -9999 -9999 -9999 -9999 -9999 -9999 -9999 -9999 -9999 -9999 -9999 -9999 -9999

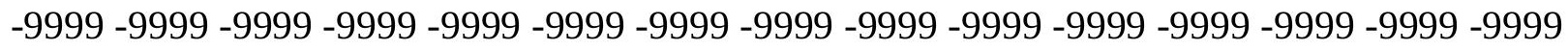

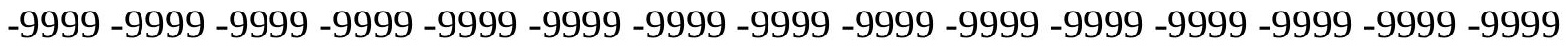

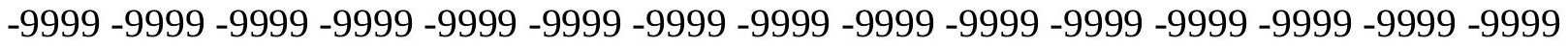
-9999 -9999 -9999 -9999 -9999 -9999 -9999 -9999 -9999 -9999 -9999 -9999 -9999 -9999 -9999 -

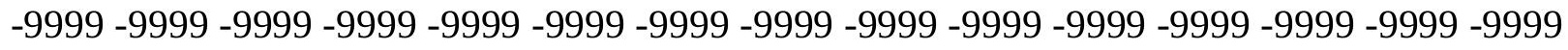

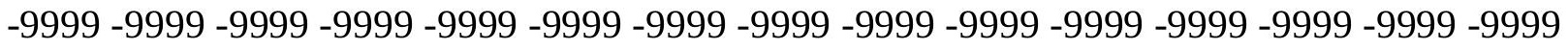
-9999 -9999 -9999 -9999 -9999 -9999 -9999 -9999 -9999 -9999 -9999 -9999 -9999 -9999 -9999 -9999 -9999 -9999 -9999 -9999 -9999 -9999 -9999 -9999-9999 -9999 -9999 -9999 -9999 -9999 -9999 -9999 -9999 -9999 -9999 -9999 -9999 -9999 -9999 -9999 -9999 -9999 -9999 -9999 -9999 -

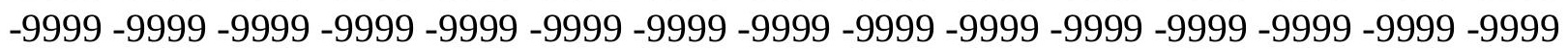


-9999 -9999 -9999 -9999 -9999 -9999 -9999 -9999 -9999 -9999 -9999 -9999 -9999 -9999 -9999 -9999 -9999 -9999 -9999 -9999 -9999 -9999 -9999 -9999 -9999 -9999 -9999 -9999 -9999 -9999 -9999 -9999 -9999 -9999 -9999 -9999 -9999 -9999 -9999 -9999 -9999 -9999 -9999 -9999 -9999 -9999 -9999 -9999 -9999 -9999 -9999 -9999 -9999 -9999 -9999 -9999 -9999 -9999 -9999 -9999 -9999 -9999 -9999 -9999 -9999 -9999 -9999 -9999 -9999 -9999 -9999 -9999 -9999 -9999 -9999 -9999 -9999 -9999 -9999 -9999 -9999 -9999 -9999 -9999 -9999 -9999 -9999 -9999 -9999 -9999 -9999 -9999 -9999 -9999 -9999 -9999 -9999 -9999 -9999 -9999 -9999 -9999 -9999 -9999 -

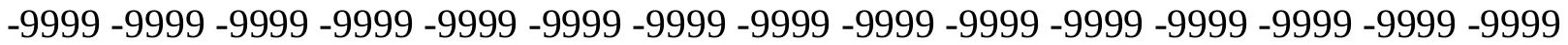
-9999 -9999 -9999 -9999 -9999 -9999 -9999 -9999 -9999 -9999 -9999 -9999 -9999 -9999 -9999 -9999 -9999 -9999 -9999 -9999 -9999 -9999 -9999 -9999 -9999 -9999 -9999 -9999 -9999 -9999 -

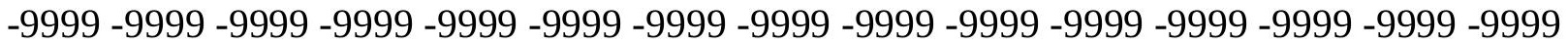
-9999 -9999 -9999 -9999 -9999 -9999 -9999 -9999 -9999 -9999 -9999 -9999 -9999 -9999 -9999 -9999 -9999 -9999 -9999 -9999 -9999 -9999 -9999 -9999 -9999 -9999 -9999 -9999 -9999 -9999 -9999 -9999 -9999 -9999 -9999 -9999 -9999 -9999 -9999 -9999 -9999 -9999 -9999 -9999 -9999 -9999 -9999 -9999 -9999 -9999 -9999 -9999 -9999 -9999 -9999 -9999 -9999 -9999 -9999 -9999 -9999 -9999 -9999 -9999 -9999 -9999 -9999 -9999 -9999 -9999 -9999 -9999 -9999 -9999 -9999 -9999 -9999 -9999 -9999 -9999 -9999 -9999 -9999 -9999 -9999 -9999 -9999 -9999 -9999 -9999 -9999 -9999 -9999 -9999 -9999 -9999 -9999 -9999 -9999 -9999 -9999 -9999 -9999 -9999 -9999 -9999 -9999 -9999 -9999 -9999 -9999 -9999 -9999 -9999 -9999 -9999 -9999 -9999 -9999 -9999 -9999 -9999 -9999 -9999 -9999 -9999 -9999 -9999 -9999 -9999 -9999 -9999 -9999 -9999 -9999

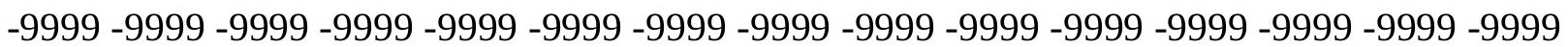
-9999 -9999 -9999 -9999 -9999 -9999 -9999 -9999 -9999 -9999 -9999 -9999 -9999 -9999 -9999 -9999 -9999 -9999 -9999 -9999 -9999 -9999 -9999 -9999 -9999 -9999 -9999 -9999 -9999 -9999 -9999 -9999 -9999 -9999 -9999 -9999 -9999 -9999 -9999 -9999 -9999 -9999 -9999 -9999 -9999

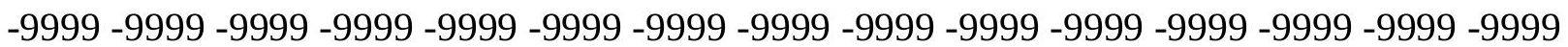
-9999 -9999 -9999 -9999 -9999 -9999 -9999 -9999 -9999 -9999 -9999 -9999 -9999 -9999 -9999 -9999 -9999 -9999 -9999 -9999 -9999 -9999 -9999 -9999 -9999 -9999 -9999 -9999 -9999 -9999 -9999 -9999 -9999 -9999 -9999 -9999 -9999 -9999 -9999 -9999 -9999 -9999 -9999 -9999

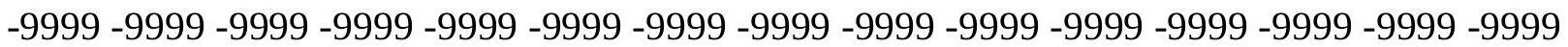
-9999 -9999 -9999 -9999 -9999 -9999 -9999 -9999 -9999 -9999 -9999 -9999 -9999 -9999 -9999 -9999 -9999 -9999 -9999 -9999 -9999 -9999 -9999 -9999 -9999 -9999 -9999 -9999 -9999 -9999 -

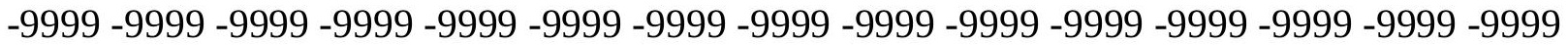
-9999 -9999 -9999 -9999 -9999 -9999 -9999 -9999 -9999 -9999 -9999 -9999 -9999 -9999 -9999 -9999 -9999 -9999 -9999 -9999 -9999 -9999 -9999 -9999 -9999 -9999 -9999 -9999 -9999 -9999 -9999 -9999 -9999 -9999 -9999 -9999 -9999 -9999 -9999 -9999 -9999 -9999 -9999 -9999 -9999 -9999 -9999 -9999 -9999 -9999 -9999 -9999 -9999 -9999 -9999 -9999 -9999 -9999 -9999 -9999 -9999 -9999 -9999 -9999 -9999 -9999 -9999 -9999 -9999 -9999 -9999 -9999 -9999 -9999 -9999

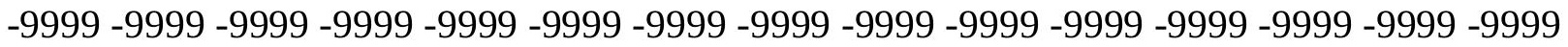
-9999 -9999 -9999 -9999 -9999 -9999 -9999 -9999 -9999 -9999 -9999 -9999 -9999 -9999 -9999 -9999 -9999 -9999 -9999 -9999 -9999 -9999 -9999 -9999 -9999 -9999 -9999 -9999 -9999 -9999 -

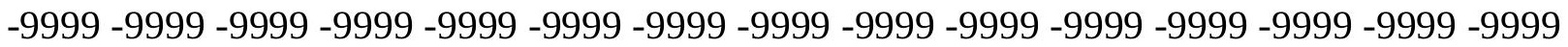
-9999 -9999 -9999 -9999 -9999 -9999 -9999 -9999 -9999 -9999 -9999 -9999 -9999 -9999 -9999 -9999 -9999 -9999 -9999 -9999 -9999 -9999 -9999 -9999 -9999 -9999 -9999 -9999 -9999 -9999 -9999 -9999 -9999 -9999 -9999 -9999 -9999 -9999 -9999 -9999 -9999 -9999 -9999 -9999 -9999 -9999 -9999 -9999 -9999 -9999 -9999 -9999 -9999 -9999 -9999 -9999 -9999 -9999 -9999 -9999

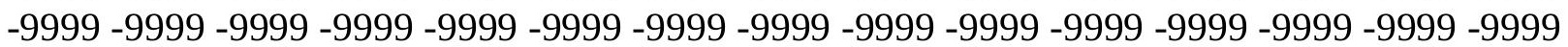


-9999 -9999 -9999 -9999 -9999 -9999 -9999 -9999 -9999 -9999 -9999 -9999 -9999 -9999 -9999 -9999 -9999 -9999 -9999 -9999 -9999 -9999 -9999 -9999 -9999 -9999 -9999 -9999 -9999 -9999 -

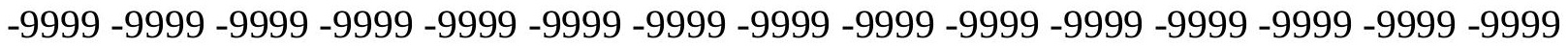
-9999 -9999 -9999 -9999 -9999 -9999 -9999 -9999 -9999 -9999 -9999 -9999 -9999 -9999 -9999 -9999 -9999 -9999 -9999 -9999 -9999 -9999 -9999 -9999-9999 -9999 -9999 -9999 -9999 -9999 -9999 -9999 -9999 -9999 -9999 -9999 -9999 -9999 -9999 -9999 -9999 -9999 -9999 -9999 -9999 -9999 -9999 -9999 -9999 -9999 -9999 -9999 -9999 -9999 -9999 -9999 -9999 -9999 -9999 -

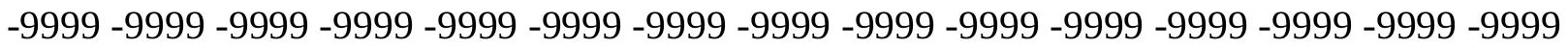

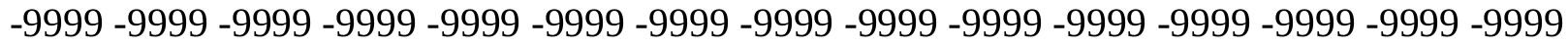
-9999 -9999 -9999 -9999 -9999 -9999 -9999 -9999 -9999 -9999 -9999 -9999 -9999 -9999 -9999 -9999 -9999 -9999 -9999 -9999 -9999 -9999 -9999 -9999 -9999 -9999 -9999 -9999 -9999 -9999 -9999 -9999 -9999 -9999 -9999 -9999 -9999 -9999 -9999 -9999 -9999 -9999 -9999 -9999 -9999 -9999 -9999 -9999 -9999 -9999 -9999 -9999 -9999 -9999 -9999 -9999 -9999 -9999 -9999 -9999 -9999 -9999 -9999 -9999 -9999 -9999 -9999 -9999 -9999 -9999 -9999 -9999 -9999 -9999 -9999 -9999 -9999 -9999 -9999 -9999 -9999 -9999 -9999 -9999 -9999 -9999 -9999 -9999 -9999 -9999 -

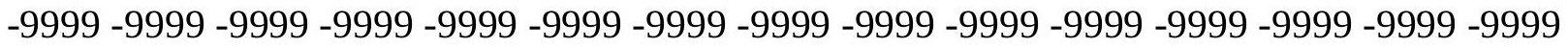
-9999 -9999 -9999 -9999 -9999 -9999 -9999 -9999 -9999 -9999 -9999 -9999 -9999 -9999 -9999 -9999 -9999 -9999 -9999 -9999 -9999 -9999 -9999 -9999 -9999 -9999 -9999 -9999 -9999 -9999 -9999 -9999 -9999 -9999 -9999 -9999 -9999 -9999 -9999 -9999 -9999 -9999 -9999 -9999 -9999 -

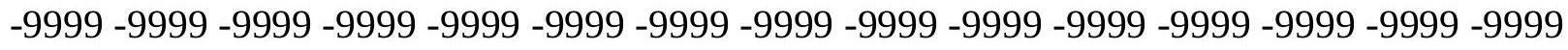

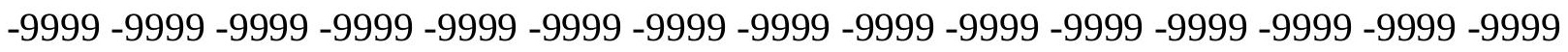

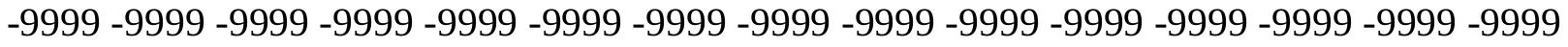
-9999 -9999 -9999 -9999 -9999 -9999 -9999 -9999 -9999 -9999 -9999 -9999 -9999 -9999 -9999 -9999 -9999 -9999 -9999 -9999 -9999 -9999 -9999 -9999 -9999 -9999 -9999 -9999 -9999 -9999 -

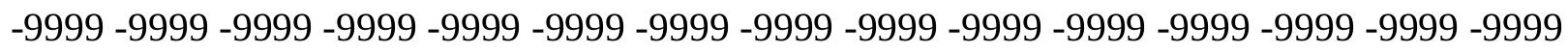
-9999 -9999 -9999 -9999 -9999 -9999 -9999 -9999 -9999 -9999 -9999 -9999 -9999 -9999 -9999 -9999 -9999 -9999 -9999 -9999 -9999 -9999 -9999 -9999 -9999 -9999 -9999 -9999 -9999 -9999 -

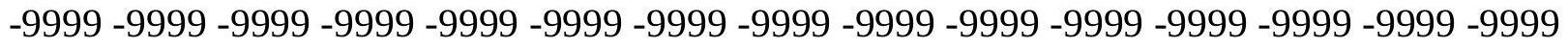
-9999 -9999 -9999 -9999 -9999 -9999 -9999 -9999 -9999 -9999 -9999 -9999 -9999 -9999 -9999 -9999 -9999 -9999 -9999 -9999 -9999 -9999 -9999 -9999 -9999 -9999 -9999 -9999 -9999 -999 -9999 -9999 -9999 -9999 -9999 -9999 -9999 -9999 -9999 -9999 -9999 -9999 -9999 -9999 -9999 -

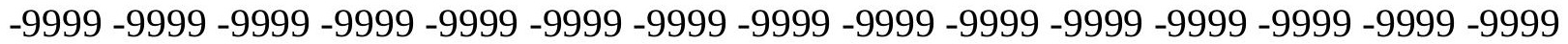

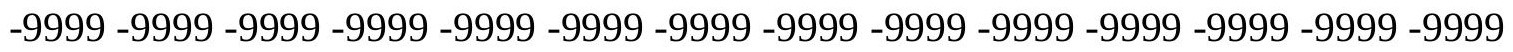

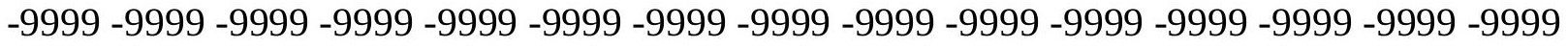

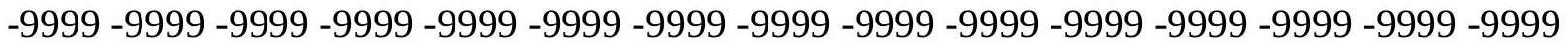

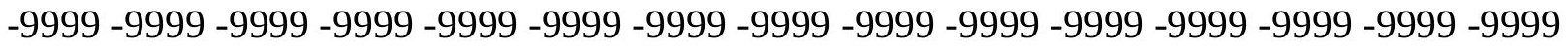

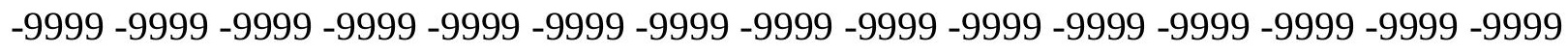

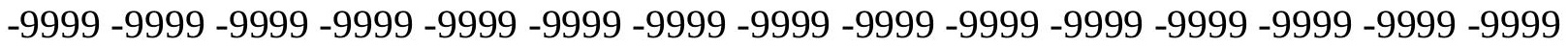

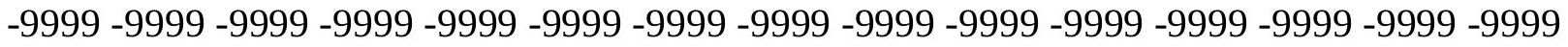
-9999 -9999 -9999 -9999 -9999 -9999 -9999 -9999 -9999 -9999 -9999 -9999 -9999 -9999 -9999 -

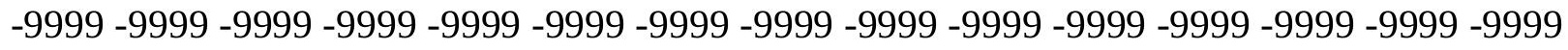

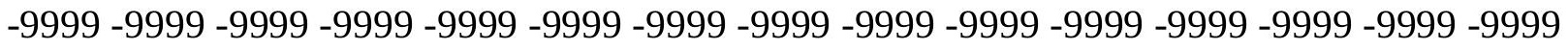
-9999 -9999 -9999 -9999 -9999 -9999 -9999 -9999 -9999 -9999 -9999 -9999 -9999 -9999 -9999 -9999 -9999 -9999 -9999 -9999 -9999 -9999 -9999 -9999-9999 -9999 -9999 -9999 -9999 -9999 -9999 -9999 -9999 -9999 -9999 -9999 -9999 -9999 -9999 -9999 -9999 -9999 -9999 -9999 -9999 -

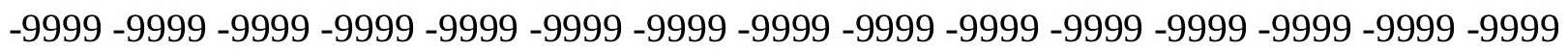


-9999 -9999 -9999 -9999 -9999 -9999 -9999 -9999 -9999 -9999 -9999 -9999 -9999 -9999 -9999 -9999 -9999 -9999 -9999 -9999 -9999 -9999 -9999 -9999 -9999 -9999 -9999 -9999 -9999 -9999 -

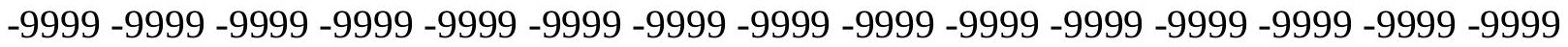
-9999 -9999 -9999 -9999 -9999 -9999 -9999 -9999 -9999 -9999 -9999 -9999 -9999 -9999 -9999 -9999 -9999 -9999 -9999 -9999 -9999 -9999 -9999 -9999-9999 -9999 -9999 -9999 -9999 -9999 -9999 -9999 -9999 -9999 -9999 -9999 -9999 -9999 -9999 -9999 -9999 -9999 -9999 -9999 -9999 -9999 -9999 -9999 -9999 -9999 -9999 -9999 -9999 -9999 -9999 -9999 -9999 -9999 -9999 -9999

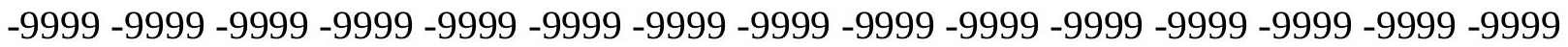

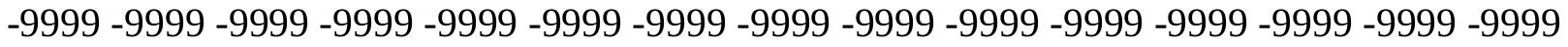
-9999 -9999 -9999 -9999 -9999 -9999 -9999 -9999 -9999 -9999 -9999 -9999 -9999 -9999 -9999 -9999 -9999 -9999 -9999 -9999 -9999 -9999 -9999 -9999 -9999 -9999 -9999 -9999 -9999 -9999 -9999 -9999 -9999 -9999 -9999 -9999 -9999 -9999 -9999 -9999 -9999 -9999 -9999 -9999 -9999 -9999 -9999 -9999 -9999 -9999 -9999 -9999 -9999 -9999 -9999 -9999 -9999 -9999 -9999 -9999 -9999 -9999 -9999 -9999 -9999 -9999 -9999 -9999 -9999 -9999 -9999 -9999 -9999 -9999 -9999 -9999 -9999 -9999 -9999 -9999 -9999 -9999 -9999 -9999 -9999 -9999 -9999 -9999 -9999 -

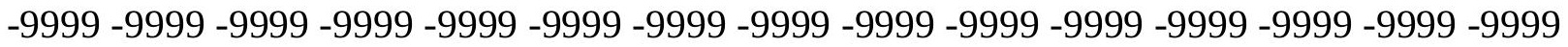
-9999 -9999 -9999 -9999 -9999 -9999 -9999 -9999 -9999 -9999 -9999 -9999 -9999 -9999 -9999 -9999 -9999 -9999 -9999 -9999 -9999 -9999 -9999 -9999 -9999 -9999 -9999 -9999 -9999 -9999 -9999 -9999 -9999 -9999 -9999 -9999 -9999 -9999 -9999 -9999 -9999 -9999 -9999 -9999 -9999 -

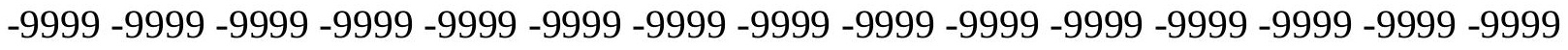
-9999 -9999 -9999 -9999 -9999 -9999 -9999 -9999 -9999 -9999 -9999 -9999 -9999 -9999 -9999

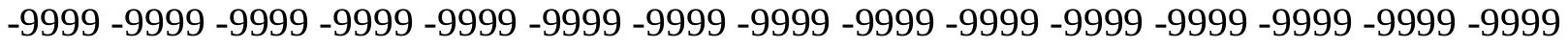
-9999 -9999 -9999 -9999 -9999 -9999 -9999 -9999 -9999 -9999 -9999 -9999 -9999 -9999 -9999 -9999 -9999 -9999 -9999 -9999 -9999 -9999 -9999 -9999 -9999 -9999 -9999 -9999 -9999 -9999 -

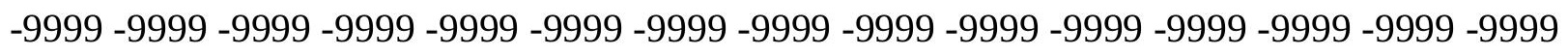
-9999 -9999 -9999 -9999 -9999 -9999 -9999 -9999 -9999 -9999 -9999 -9999 -9999 -9999 -9999 -9999 -9999 -9999 -9999 -9999 -9999 -9999 -9999 -9999 -9999 -9999 -9999 -9999 -9999 -9999 -

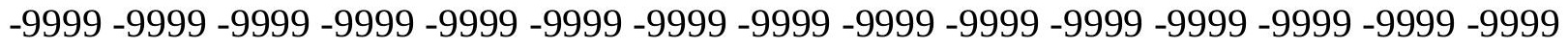
-9999 -9999 -9999 -9999 -9999 -9999 -9999 -9999 -9999 -9999 -9999 -9999 -9999 -9999 -9999 -9999 -9999 -9999 -9999 -9999 -9999 -9999 -9999 -9999 -9999 -9999 -9999 -9999 -9999 -999 -9999 -9999 -9999 -9999 -9999 -9999 -9999 -9999 -9999 -9999 -9999 -9999 -9999 -9999 -9999 -9999 -9999 -9999 -9999 -9999 -9999 -9999 -9999 -9999 -9999 -9999 -9999 -9999 -9999 -9999 -

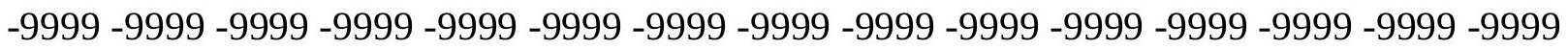

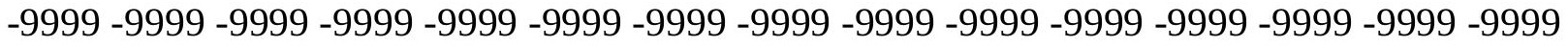

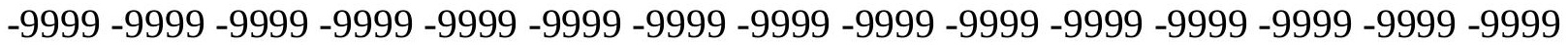
-9999 -9999 -9999 -9999 -9999 -9999 -9999 -9999 -9999 -9999 -9999 -9999 -9999 -9999 -9999 -

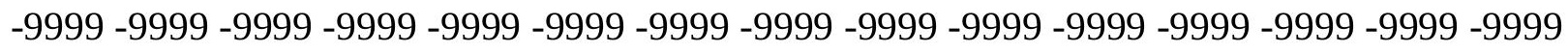

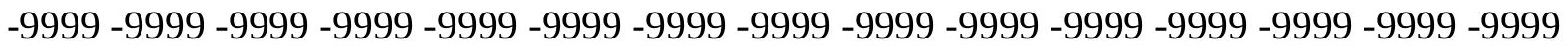
-9999 -9999 -9999 -9999 -9999 -9999 -9999 -9999 -9999 -9999 -9999 -9999 -9999 -9999 - -999 -9999 -9999 -9999 -9999 -9999 -9999 -9999 -9999 -9999 -9999 -9999 -9999 -9999 -9999 -9999 -

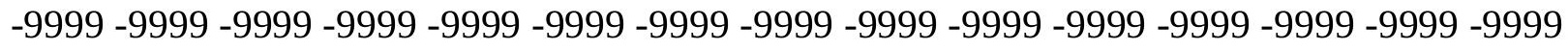

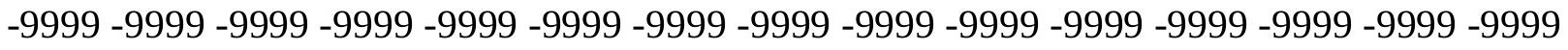
-9999 -9999 -9999 -9999 -9999 -9999 -9999 -9999 -9999 -9999 -9999 -9999 -9999 -9999 -9999 -9999 -9999 -9999 -9999 -9999 -9999 -9999 -9999 -9999-9999 -9999 -9999 -9999 -9999 -9999 -9999 -9999 -9999 -9999 -9999 -9999 -9999 -9999 -9999 -9999 -9999 -9999 -9999 -9999 -9999 -

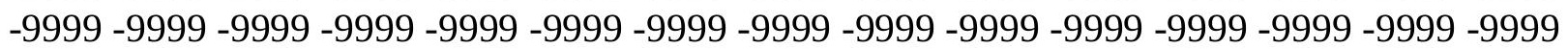


-9999 -9999 -9999 -9999 -9999 -9999 -9999 -9999 -9999 -9999 -9999 -9999 -9999 -9999 -9999 -9999 -9999 -9999 -9999 -9999 -9999 -9999 -9999 -9999 -9999 -9999 -9999 -9999 -9999 -9999 -

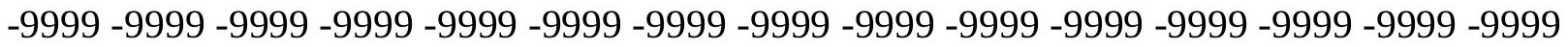
-9999 -9999 -9999 -9999 -9999 -9999 -9999 -9999 -9999 -9999 -9999 -9999 -9999 -9999 -9999 -9999 -9999 -9999 -9999 -9999 -9999 -9999 -9999 -9999-9999 -9999 -9999 -9999 -9999 -9999 -9999 -9999 -9999 -9999 -9999 -9999 -9999 -9999 -9999 -9999 -9999 -9999 -9999 -9999 -9999 -9999 -9999 -9999 -9999 -9999 -9999 -9999 -9999 -9999 -9999 -9999 -9999 -9999 -9999 -9999

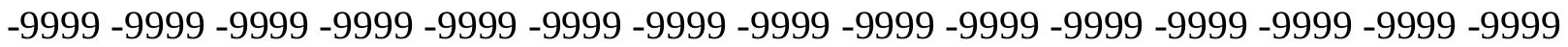

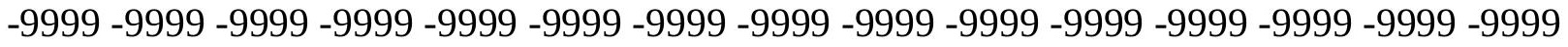
-9999 -9999 -9999 -9999 -9999 -9999 -9999 -9999 -9999 -9999 -9999 -9999 -9999 -9999 -9999 -9999 -9999 -9999 -9999 -9999 -9999 -9999 -9999 -9999 -9999 -9999 -9999 -9999 -9999 -9999 -9999 -9999 -9999 -9999 -9999 -9999 -9999 -9999 -9999 -9999 -9999 -9999 -9999 -9999 -9999 -9999 -9999 -9999 -9999 -9999 -9999 -9999 -9999 -9999 -9999 -9999 -9999 -9999 -9999 -9999 -

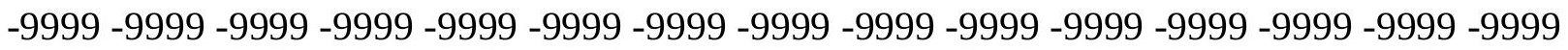
-9999 -9999 -9999 -9999 -9999 -9999 -9999 -9999 -9999 -9999 -9999 -9999 -9999 -9999 -9999 -

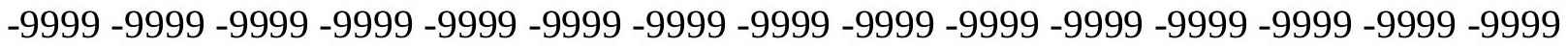
-9999 -9999 -9999 -9999 -9999 -9999 -9999 -9999 -9999 -9999 -9999 -9999 -9999 -9999 -9999 -9999 -9999 -9999 -9999 -9999 -9999 -9999 -9999 -9999 -9999 -9999 -9999 -9999 -9999 -9999 -9999 -9999 -9999 -9999 -9999 -9999 -9999 -9999 -9999 -9999 -9999 -9999 -9999 -9999 - -999 -

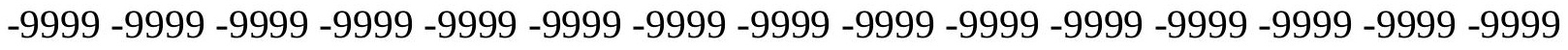

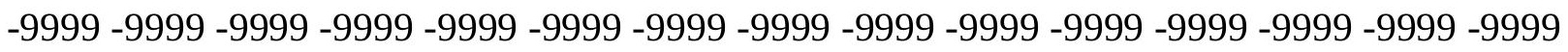
-9999 -9999 -9999 -9999 -9999 -9999 -9999 -9999 -9999 -9999 -9999 -9999 -9999 -9999 -9999 -9999 -9999 -9999 -9999 -9999 -9999 -9999 -9999 -9999 -9999 -9999 -9999 -9999 -9999 -9999 -9999 -9999 -9999 -9999 -9999 -9999 -9999 -9999 -9999 -9999 -9999 -9999 -9999 -9999 -9999 -

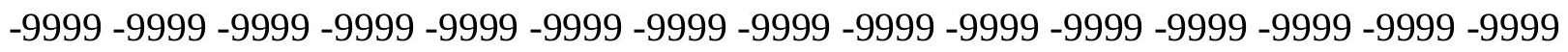
-9999 -9999 -9999 -9999 -9999 -9999 -9999 -9999 -9999 -9999 -9999 -9999 -9999 -9999 -9999 -9999 -9999 -9999 -9999 -9999 -9999 -9999 -9999 -9999 -9999 -9999 -9999 -9999 -9999 -9999 -

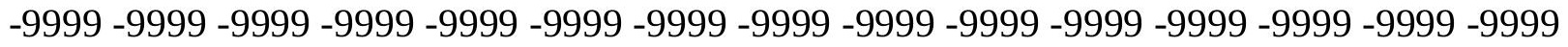
-9999 -9999 -9999 -9999 -9999 -9999 -9999 -9999 -9999 -9999 -9999 -9999 -9999 -9999 -9999 -9999 -9999 -9999 -9999 -9999 -9999 -9999 -9999 -9999 -9999 -9999 -9999 -9999 -9999 -999 -

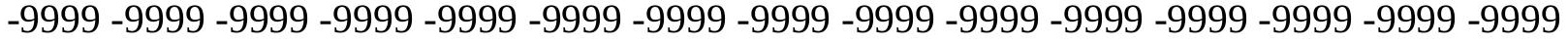
-9999 -9999 -9999 -9999 -9999 -9999 -9999 -9999 -9999 -9999 -9999 -9999 -9999 -9999 -9999 -

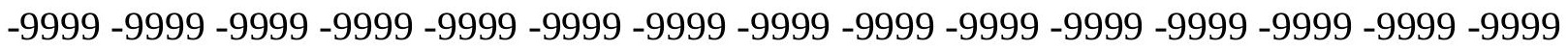

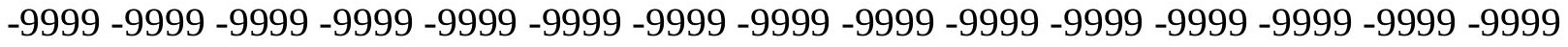

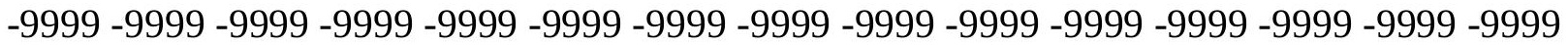

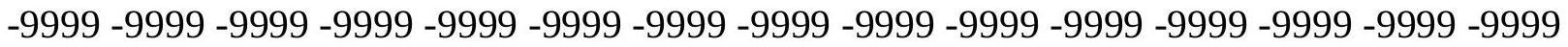

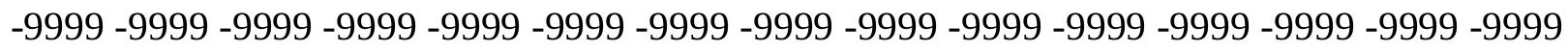

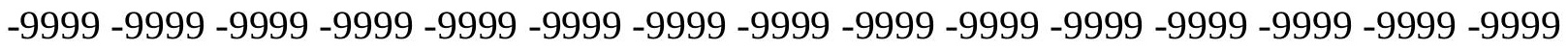

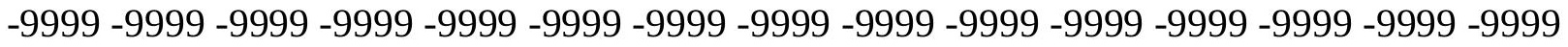
-9999 -9999 -9999 -9999 -9999 -9999 -9999 -9999 -9999 -9999 -9999 -9999 -9999 -9999 -9999 -

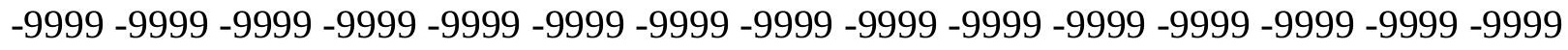

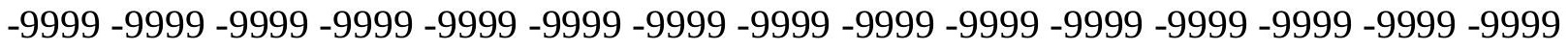
-9999 -9999 -9999 -9999 -9999 -9999 -9999 -9999 -9999 -9999 -9999 -9999 -9999 -9999 -9999 -9999 -9999 -9999 -9999 -9999 -9999 -9999 -9999 -9999 -9999 -9999 -9999 -9999 -9999 -9999 -9999 -9999 -9999 -9999 -9999 -9999 -9999 -9999 -9999 -9999 -9999 -9999 -9999 -9999 -

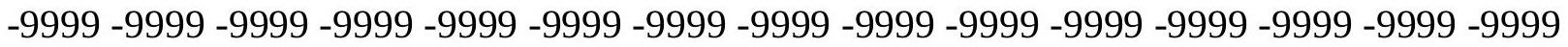


-9999 -9999 -9999 -9999 -9999 -9999 -9999 -9999 -9999 -9999 -9999 -9999 -9999 -9999 -9999 -9999 -9999 -9999 -9999 -9999 -9999 -9999 -9999 -9999 -9999 -9999 -9999 -9999 -9999 -9999 -

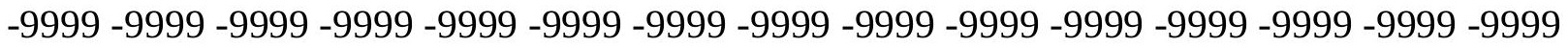
-9999 -9999 -9999 -9999 -9999 -9999 -9999 -9999 -9999 -9999 -9999 -9999 -9999 -9999 -9999 -9999 -9999 -9999 -9999 -9999 -9999 -9999 -9999 -9999-9999 -9999 -9999 -9999 -9999 -9999 -9999 -9999 -9999 -9999 -9999 -9999 -9999 -9999 -9999 -9999 -9999 -9999 -9999 -9999 -9999 -9999 -9999 -9999 -9999 -9999 -9999 -9999 -9999 -9999 -9999 -9999 -9999 -9999 -9999 -9999

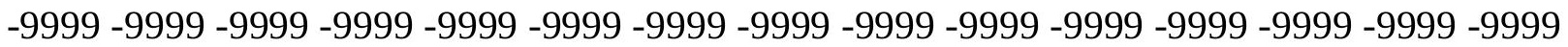

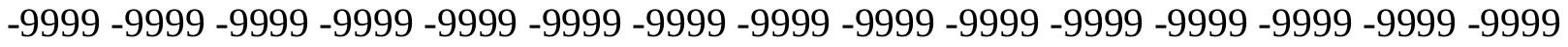
-9999 -9999 -9999 -9999 -9999 -9999 -9999 -9999 -9999 -9999 -9999 -9999 -9999 -9999 -9999 -9999 -9999 -9999 -9999 -9999 -9999 -9999 -9999 -9999 -9999 -9999 -9999 -9999 -9999 -9999 -9999 -9999 -9999 -9999 -9999 -9999 -9999 -9999 -9999 -9999 -9999 -9999 -9999 -9999 -9999 -9999 -9999 -9999 -9999 -9999 -9999 -9999 -9999 -9999 -9999 -9999 -9999 -9999 -9999 -9999 -

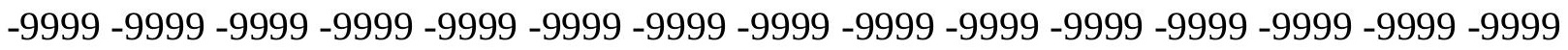
-9999 -9999 -9999 -9999 -9999 -9999 -9999 -9999 -9999 -9999 -9999 -9999 -9999 -9999 -9999 -

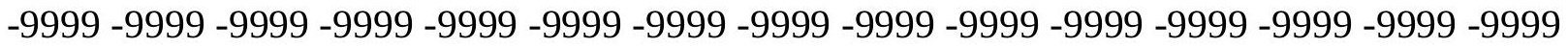
-9999 -9999 -9999 -9999 -9999 -9999 -9999 -9999 -9999 -9999 -9999 -9999 -9999 -9999 -9999 -9999 -9999 -9999 -9999 -9999 -9999 -9999 -9999 -9999 -9999 -9999 -9999 -9999 -9999 - 9999 -9999 -9999 -9999 -9999 -9999 -9999 -9999 -9999 -9999 -9999 -9999 -9999 -9999 -9999 -9999 -

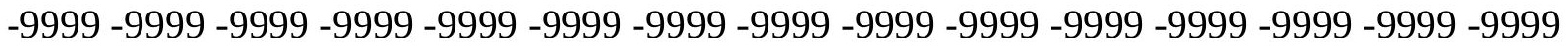

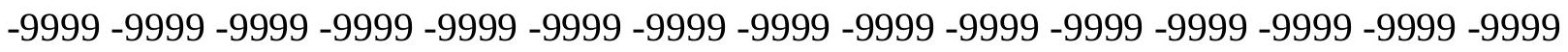
-9999 -9999 -9999 -9999 -9999 -9999 -9999 -9999 -9999 -9999 -9999 -9999 -9999 -9999 - 9999 -9999 -9999 -9999 -9999 -9999 -9999 -9999 -9999 -9999 -9999 -9999 -9999 -9999 -9999 -9999 -9999 -9999 -9999 -9999 -9999 -9999 -9999 -9999 -9999 -9999 -9999 -9999 -9999 -9999 -9999 -9999 -9999 -9999 -9999 -9999 -9999 -9999 -9999 -9999 -9999 -9999 -9999 -9999 -9999 -9999 -9999 -9999 -9999 -9999 -9999 -9999 -9999 -9999 -9999 -9999 -9999 -9999 -9999 -9999 -9999 -9999 -9999 -9999 -9999 -9999 -9999 -9999 -9999 -9999 -9999 -9999 -9999 -9999 -9999 -

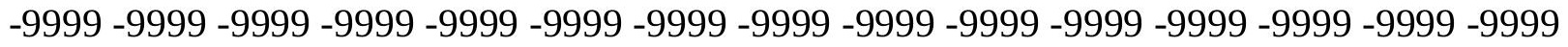
-9999 -9999 -9999 -9999 -9999 -9999 -9999 -9999 -9999 -9999 -9999 -9999 -9999 -9999 -9999 -9999 -9999 -9999 -9999 -9999 -9999 -9999 -9999 -9999 -9999 -9999 -9999 -9999 -9999 -999 -9999 -9999 -9999 -9999 -9999 -9999 -9999 -9999 -9999 -9999 -9999 -9999 -9999 -9999 -9999 -9999 -9999 -9999 -9999 -9999 -9999 -9999 -9999 -9999 -9999 -9999 -9999 -9999 -9999 -9999 -

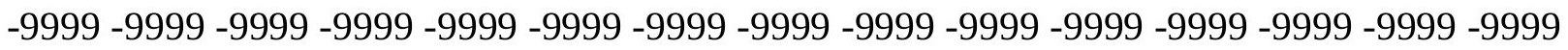

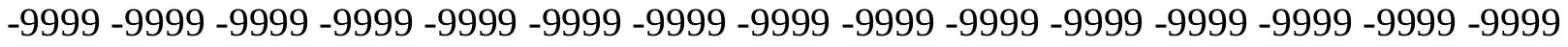

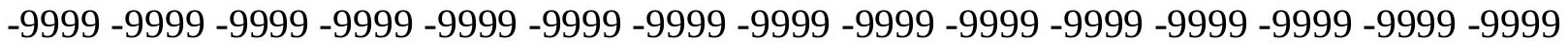

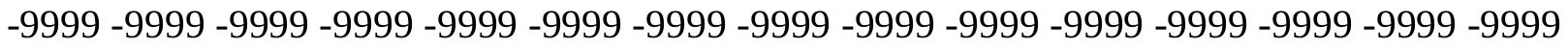

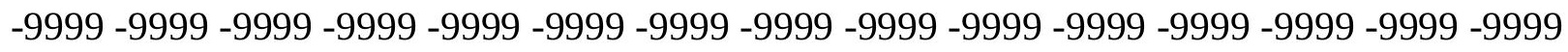

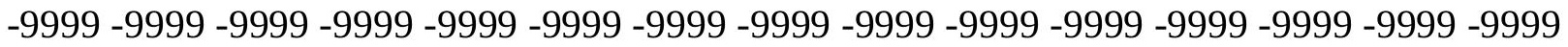

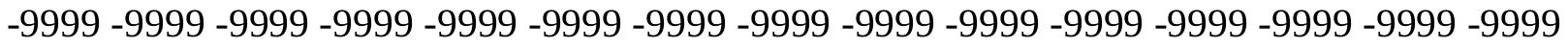
-9999 -9999 -9999 -9999 -9999 -9999 -9999 -9999 -9999 -9999 -9999 -9999 -9999 -9999 -9999 -

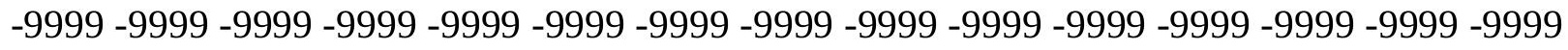

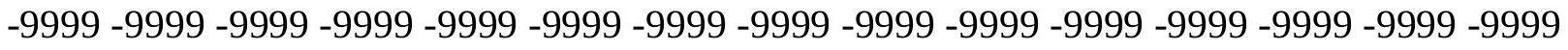
-9999 -9999 -9999 -9999 -9999 -9999 -9999 -9999 -9999 -9999 -9999 -9999 -9999 -9999 -9999 -9999 -9999 -9999 -9999 -9999 -9999 -9999 -9999 -9999-9999 -9999 -9999 -9999 -9999 -9999 -9999 -9999 -9999 -9999 -9999 -9999 -9999 -9999 -9999 -9999 -9999 -9999 -9999 -9999 -9999 -

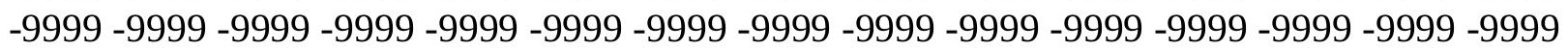


-9999 -9999 -9999 -9999 -9999 -9999 -9999 -9999 -9999 -9999 -9999 -9999 -9999 -9999 -9999 -9999 -9999 -9999 -9999 -9999 -9999 -9999 -9999 -9999 -9999 -9999 -9999 -9999 -9999 -9999 -9999 -9999 -9999 -9999 -9999 -9999 -9999 -9999 -9999 -9999 -9999 -9999 -9999 -9999 - 9999 -9999 -9999 -9999 -9999 -9999 -9999 -9999 -9999 -9999 -9999 -9999 -9999 -9999 -9999 -9999 -9999 -9999 -9999 -9999 -9999 -9999 -9999 -9999 -9999 -9999 -9999 -9999 -9999 -9999 -9999 -9999 -9999 -9999 -9999 -9999 -9999 -9999 -9999 -9999 -9999 -9999 -9999 -9999 -9999 -9999 -9999 -9999 -9999 -9999 -9999 -9999 -9999 -9999 -9999 -9999 -9999 -9999 -9999 -9999

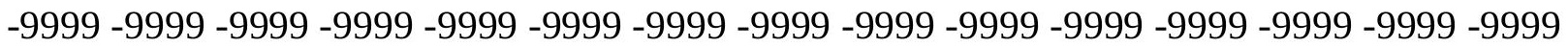

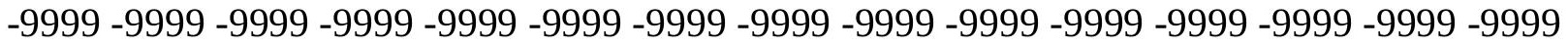
-9999 -9999 -9999 -9999 -9999 -9999 -9999 -9999 -9999 -9999 -9999 -9999 -9999 -9999 -9999 -9999 -9999 -9999 -9999 -9999 -9999 -9999 -9999 -9999 -9999 -9999 -9999 -9999 -9999 -9999 -9999 -9999 -9999 -9999 -9999 -9999 -9999 -9999 -9999 -9999 -9999 -9999 -9999 -9999 -9999 -9999 -9999 -9999 -9999 -9999 -9999 -9999 -9999 -9999 -9999 -9999 -9999 -9999 -9999 -9999 -9999 -9999 -9999 -9999 -9999 -9999 -9999 -9999 -9999 -9999 -9999 -9999 -9999 -9999 -9999 -9999 -9999 -9999 -9999 -9999 -9999 -9999 -9999 -9999 -9999 -9999 -9999 -9999 -9999 -9999 -

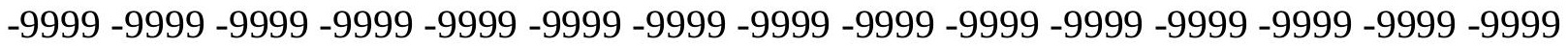
-9999 -9999 -9999 -9999 -9999 -9999 -9999 -9999 -9999 -9999 -9999 -9999 -9999 -9999 -9999 -9999 -9999 -9999 -9999 -9999 -9999 -9999 -9999 -9999 -9999 -9999 -9999 -9999 -9999 - 9999 -9999 -9999 -9999 -9999 -9999 -9999 -9999 -9999 -9999 -9999 -9999 -9999 -9999 -9999 -9999 -

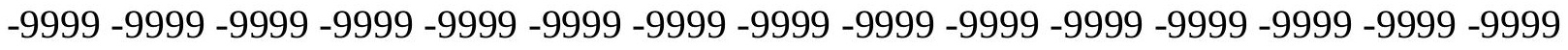

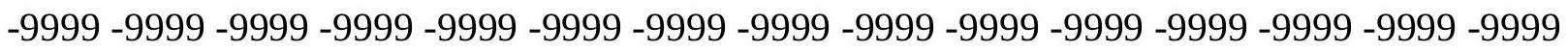

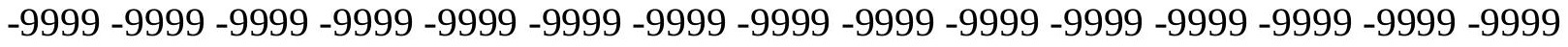
-9999 -9999 -9999 -9999 -9999 -9999 -9999 -9999 -9999 -9999 -9999 -9999 -9999 -9999 -9999 -9999 -9999 -9999 -9999 -9999 -9999 -9999 -9999 -9999 -9999 -9999 -9999 -9999 -9999 -9999 -

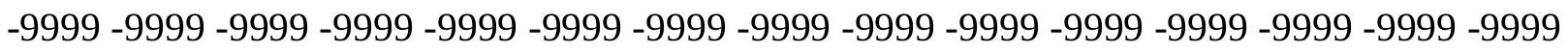
-9999 -9999 -9999 -9999 -9999 -9999 -9999 -9999 -9999 -9999 -9999 -9999 -9999 -9999 -9999 -9999 -9999 -9999 -9999 -9999 -9999 -9999 -9999 -9999 -9999 -9999 -9999 -9999 -9999 -9999 -

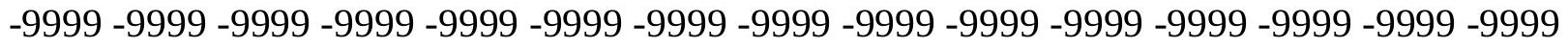
-9999 -9999 -9999 -9999 -9999 -9999 -9999 -9999 -9999 -9999 -9999 -9999 -9999 -9999 -9999 -9999 -9999 -9999 -9999 -9999 -9999 -9999 -9999 -9999 -9999 -9999 -9999 -9999 -9999 -999 -9999 -9999 -9999 -9999 -9999 -9999 -9999 -9999 -9999 -9999 -9999 -9999 -9999 -9999 -9999 -9999 -9999 -9999 -9999 -9999 -9999 -9999 -9999 -9999 -9999 -9999 -9999 -9999 -9999 -

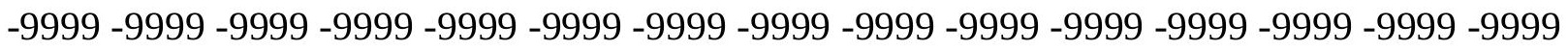

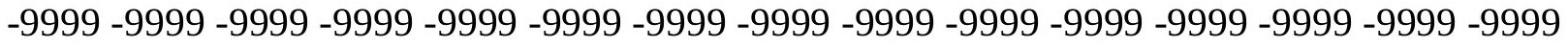

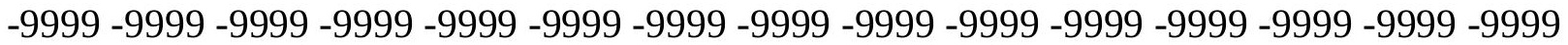

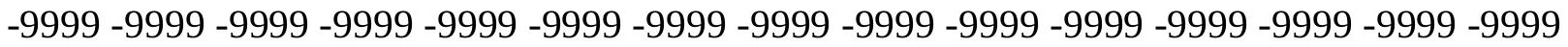

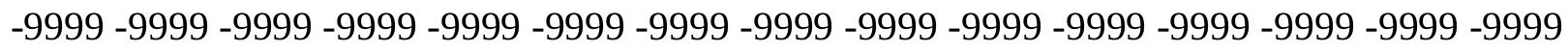

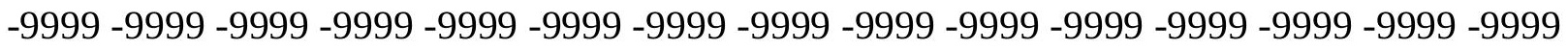

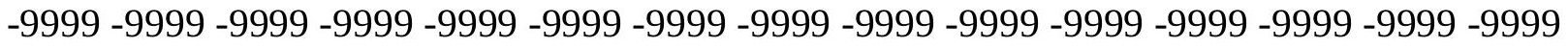
-9999 -9999 -9999 -9999 -9999 -9999 -9999 -9999 -9999 -9999 -9999 -9999 -9999 -9999 -9999 -

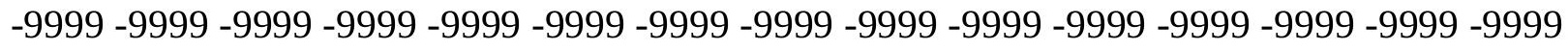

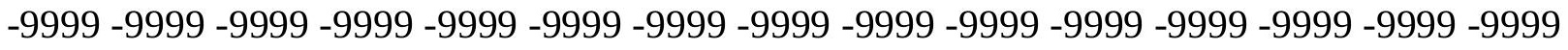
-9999 -9999 -9999 -9999 -9999 -9999 -9999 -9999 -9999 -9999 -9999 -9999 -9999 -9999 -9999 -9999 -9999 -9999 -9999 -9999 -9999 -9999 -9999 -9999-9999 -9999 -9999 -9999 -9999 -9999 -9999 -9999 -9999 -9999 -9999 -9999 -9999 -9999 -9999 -9999 -9999 -9999 -9999 -9999 -9999 -

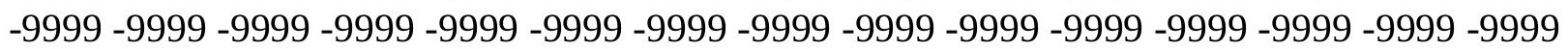




$$
\begin{aligned}
& \text {-9999 -9999 -9999 -9999 -9999 -9999 -9999 -9999 -9999 -9999 -9999 -9999 -9999 -9999 -9999 } \\
& \text {-9999 -9999 -9999 -9999 -9999 -9999 -9999 -9999 -9999 -9999 -9999 -9999 -9999 -9999 -9999 - } \\
& \text {-9999 -9999 -9999 -9999 -9999 -9999 -9999 -9999 -9999 -9999 -9999 -9999 -9999 -9999 - 9999 - } \\
& \text {-9999 -9999 -9999 -9999 -9999 -9999 -9999 -9999 -9999 -9999 -9999 -9999 -9999 -9999 -9999 } \\
& \text {-9999 -9999 -9999 -9999 -9999 -9999 -9999 -9999 -9999 -9999 -9999 -9999 -9999 -9999 -9999 - } \\
& \text {-9999 -9999 -9999 -9999 -9999 -9999 -9999 -9999 -9999 -9999 -9999 -9999 -9999 -9999 -9999 } \\
& \text {-9999 -9999 -9999 -9999 -9999 -9999 -9999 -9999 -9999 -9999 -9999 -9999 -9999 -9999 -9999 }
\end{aligned}
$$

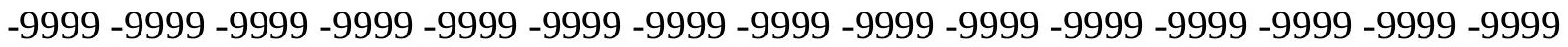

$$
\begin{aligned}
& \text {-9999 -9999 -9999 -9999 -9999 -9999 -9999 -9999 -9999 -9999 -9999 -9999 -9999 -9999 -9999 - } \\
& \text {-9999 -9999 -9999 -9999 -9999 -9999 -9999 -9999 -9999 -9999 -9999 -9999 -9999 -9999 -9999 - } \\
& \text {-9999 -9999 -9999 -9999 -9999 -9999 -9999 -9999 -9999 -9999 -9999 -9999 -9999 -9999 -999 -999 -999 -999 -999 }
\end{aligned}
$$


u8top_elev 


$\begin{array}{ll}\text { ncols } & 389 \\ \text { nrows } & 437 \\ \text { xllcorner } & 545925 \\ \text { yllcorner } & 100925 \\ \text { cellsize } & 150\end{array}$

NODATA_value -9999

-9999 -9999 -9999 -9999 -9999 -9999 -9999 -9999 -9999 -9999 -9999 -9999 -9999 -9999 -9999 -9999 -9999 -9999 -9999 -9999 -9999 -9999 -9999 -9999 -9999 -9999 -9999 -9999 -9999 -9999 -999 -9999 -9999 -9999 -9999 -9999 -9999 -9999 -9999 -9999 -9999 -9999 -9999 -9999 -9999 -9999 -9999 -9999 -9999 -9999 -9999 -9999 -9999 -9999 -9999 -9999 -9999 -9999 -9999 -9999 -9999

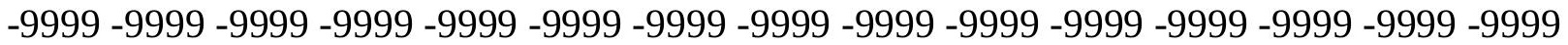
-9999 -9999 -9999 -9999 -9999 -9999 -9999 -9999 -9999 -9999 -9999 -9999 -9999 -9999 -9999 -9999 -9999 -9999 -9999 -9999 -9999 -9999 -9999 -9999 -9999 -9999 -9999 -9999 -9999 -9999 -9999 -9999 -9999 -9999 -9999 -9999 -9999 -9999 -9999 -9999 -9999 -9999 -9999 -9999 - 9999 -9999 -9999 -9999 -9999 -9999 -9999 -9999 -9999 -9999 -9999 -9999 -9999 -9999 -9999 -9999

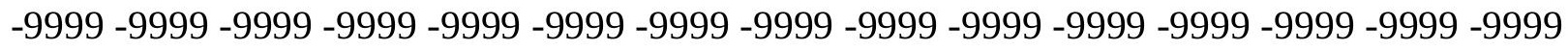
-9999 -9999 -9999 -9999 -9999 -9999 -9999 -9999 -9999 -9999 -9999 -9999 -9999 -9999 -9999 -9999 -9999 -9999 -9999 -9999 -9999 -9999 -9999 -9999 -9999 -9999 -9999 -9999 -9999 -9999 -999 -9999 -9999 -9999 -9999 -9999 -9999 -9999 -9999 -9999 -9999 -9999 -9999 -9999 -9999 -9999 -9999 -9999 -9999 -9999 -9999 -9999 -9999 -9999 -9999 -9999 -9999 -9999 -9999 -9999 -9999 -9999 -9999 -9999 -9999 -9999 -9999 -9999 -9999 -9999 -9999 -9999 -9999 -9999 -9999 -9999 -9999 -9999 -9999 -9999 -9999 -9999 -9999 -9999 -9999 -9999 -9999 -9999 -9999 -9999 -9999 -9999 -9999 -9999 -9999 -9999 -9999 -9999 -9999 -9999 -9999 -9999 -9999 -9999 -9999 -9999 -9999 -9999 -9999 -9999 -9999 -9999 -9999 -9999 -9999 -9999 -9999 -9999 -9999 -9999 -9999 -9999 -9999 -9999 -9999 -9999 -9999 -9999 -9999 -9999 -9999 -9999 -9999 -9999 -9999 -9999 -9999 -9999 -9999 -9999 -9999 -9999 -9999 -9999 -9999 -9999 -9999 -9999 -9999 -9999 -9999 -9999 -9999 -9999 -9999 -9999 -9999 -9999 -9999 -9999 -9999 -9999 -9999 -9999 -9999 -9999 -9999 -9999 -9999 -9999 -9999 -9999 -9999 -9999 -9999 -9999 -9999 -9999 -9999 -9999 -9999 -9999 -9999 -9999 -9999 -9999 -9999 -9999 -9999 -9999 -9999 -9999 -9999 -9999 -9999 -9999 -9999 -9999 -9999 -9999 -9999 -9999 -9999 -9999 -9999 -9999 -9999 -9999 -9999 -9999 -999 -9999 -9999 -9999 -9999 -9999 -9999 -9999 -9999 -9999 -9999 -9999 -9999 -9999 -9999 -9999 -9999 -9999 -9999 -9999 -9999 -9999 -9999 -9999 -9999 -9999 -9999 -9999 -9999 -9999 -

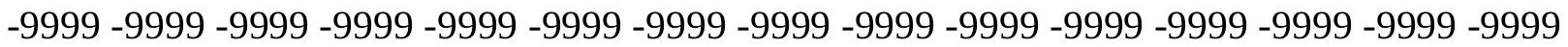
-9999 -9999 -9999 -9999 -9999 -9999 -9999 -9999 -9999 -9999 -9999 -9999 -9999 -9999 -9999 -9999 -9999 -9999 -9999 -9999 -9999 -9999 -9999 -9999 -9999 -9999 -9999 -9999 -9999 -9999 -

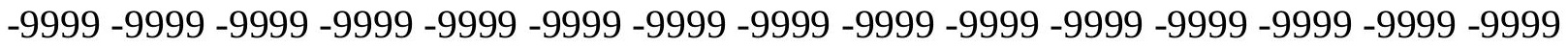

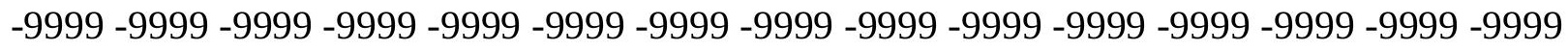
-9999 -9999 -9999 -9999 -9999 -9999 -9999 -9999 -9999 -9999 -9999 -9999 -9999 - 9999 - -9999 -9999 -9999 -9999 -9999 -9999 -9999 -9999 -9999 -9999 -9999 -9999 -9999 -9999 - 9999 - -999 -9999 -9999 -9999 -9999 -9999 -9999 -9999 -9999 -9999 -9999 -9999 -9999 -9999 -9999 -9999 -

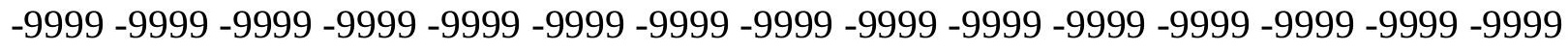

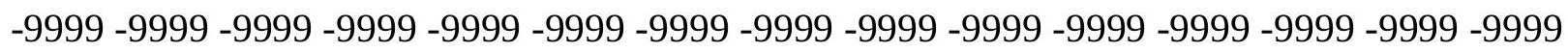
-9999 -9999 -9999 -9999 -9999 -9999 -9999 -9999 -9999 -9999 -9999 -9999 -9999 -9999 -9999 -9999 -9999 -9999 -9999 -9999 -9999 -9999 -9999 -9999-9999 -9999 -9999 -9999 -9999 -9999 -9999 -9999 -9999 -9999 -9999 -9999 -9999 -9999 -9999 -9999 -9999 -9999 -9999 -9999 -9999 -

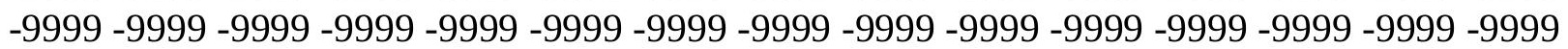


-9999 -9999 -9999 -9999 -9999 -9999 -9999 -9999 -9999 -9999 -9999 -9999 -9999 -9999 -9999 -9999 -9999 -9999 -9999 -9999 -9999 -9999 -9999 -9999 -9999 -9999 -9999 -9999 -9999 -9999 -

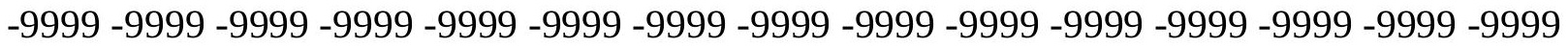
-9999 -9999 -9999 -9999 -9999 -9999 -9999 -9999 -9999 -9999 -9999 -9999 -9999 -9999 -9999 -9999 -9999 -9999 -9999 -9999 -9999 -9999 -9999 -9999-9999 -9999 -9999 -9999 -9999 -9999 -9999 -9999 -9999 -9999 -9999 -9999 -9999 -9999 -9999 -9999 -9999 -9999 -9999 -9999 -9999 -9999 -9999 -9999 -9999 -9999 -9999 -9999 -9999 -9999 -9999 -9999 -9999 -9999 -9999 -9999

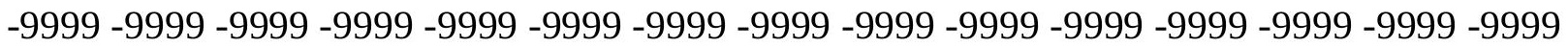

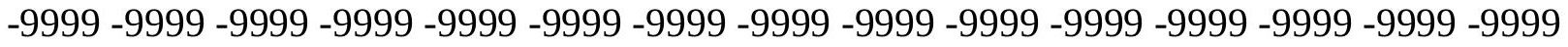
-9999 -9999 -9999 -9999 -9999 -9999 -9999 -9999 -9999 -9999 -9999 -9999 -9999 -9999 -9999 -9999 -9999 -9999 -9999 -9999 -9999 -9999 -9999 -9999 -9999 -9999 -9999 -9999 -9999 -9999 -9999 -9999 -9999 -9999 -9999 -9999 -9999 -9999 -9999 -9999 -9999 -9999 -9999 -9999 -9999 -9999 -9999 -9999 -9999 -9999 -9999 -9999 -9999 -9999 -9999 -9999 -9999 -9999 -9999 -9999 -9999 -9999 -9999 -9999 -9999 -9999 -9999 -9999 -9999 -9999 -9999 -9999 -9999 - 9999 -9999 -9999 -9999 -9999 -9999 -9999 -9999 -9999 -9999 -9999 -9999 -9999 -9999 -9999 -9999

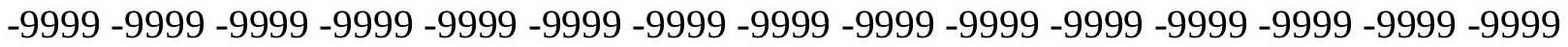
-9999 -9999 -9999 -9999 -9999 -9999 -9999 -9999 -9999 -9999 -9999 -9999 -9999 -9999 -9999 -9999 -9999 -9999 -9999 -9999 -9999 -9999 -9999 -9999 -9999 -9999 -9999 -9999 -9999 -9999 -9999 -9999 -9999 -9999 -9999 -9999 -9999 -9999 -9999 -9999 -9999 -9999 -9999 -9999 -9999 -

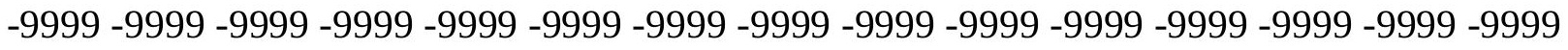

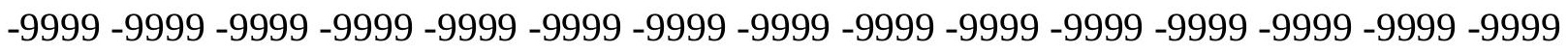
-9999 -9999 -9999 -9999 -9999 -9999 -9999 -9999 -9999 -9999 -9999 -9999 -9999 -9999 -9999 -9999 -9999 -9999 -9999 -9999 -9999 -9999 -9999 -9999 -9999 -9999 -9999 -9999 -9999 -9999 -9999 -9999 -9999 -9999 -9999 -9999 -9999 -9999 -9999 -9999 -9999 -9999 -9999 -9999 -9999 -

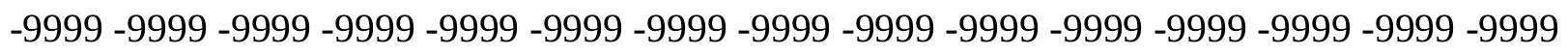
-9999 -9999 -9999 -9999 -9999 -9999 -9999 -9999 -9999 -9999 -9999 -9999 -9999 -9999 -9999 -9999 -9999 -9999 -9999 -9999 -9999 -9999 -9999 -9999 -9999 -9999 -9999 -9999 -9999 -9999 -

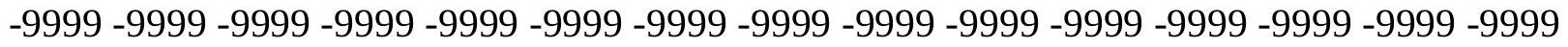
-9999 -9999 -9999 -9999 -9999 -9999 -9999 -9999 -9999 -9999 -9999 -9999 -9999 -9999 -9999 -9999 -9999 -9999 -9999 -9999 -9999 -9999 -9999 -9999 -9999 -9999 -9999 -9999 -9999 -999 -9999 -9999 -9999 -9999 -9999 -9999 -9999 -9999 -9999 -9999 -9999 -9999 -9999 -9999 -9999 -9999 -9999 -9999 -9999 -9999 -9999 -9999 -9999 -9999 -9999 -9999 -9999 -9999 -9999 -9999 -

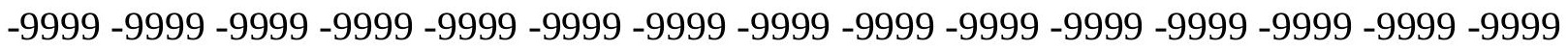

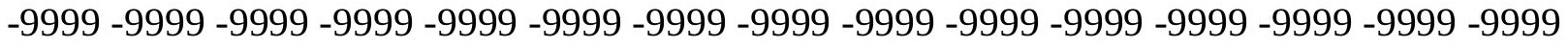

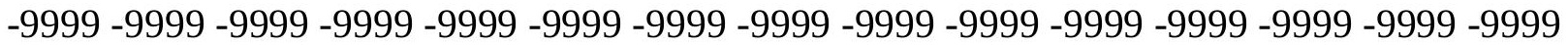

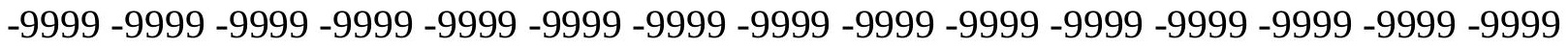

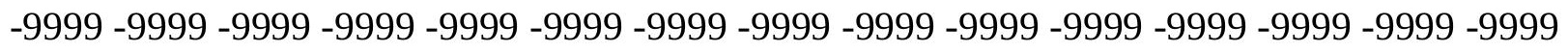

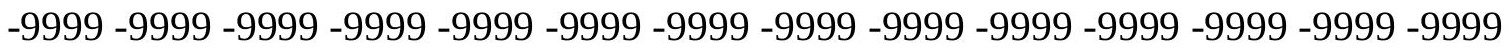
-9999 -9999 -9999 -9999 -9999 -9999 -9999 -9999 -9999 -9999 -9999 -9999 -9999 -9999 -9999 -9999 -9999 -9999 -9999 -9999 -9999 -9999 -9999 -9999 -9999 -9999 -9999 -9999 -9999 -9999 -

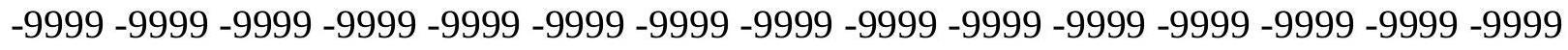

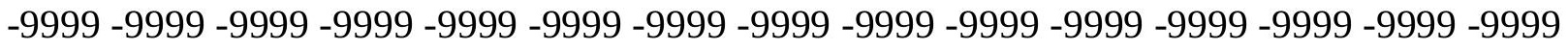
-9999 -9999 -9999 -9999 -9999 -9999 -9999 -9999 -9999 -9999 -9999 -9999 -9999 -9999 -9999 -9999 -9999 -9999 -9999 -9999 -9999 -9999 -9999 -9999-9999 -9999 -9999 -9999 -9999 -9999 -9999 -9999 -9999 -9999 -9999 -9999 -9999 -9999 -9999 -9999 -9999 -9999 -9999 -9999 -9999 -

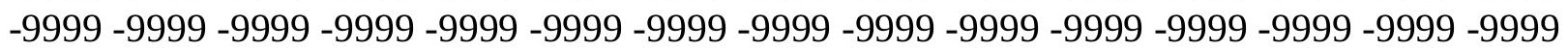


-9999 -9999 -9999 -9999 -9999 -9999 -9999 -9999 -9999 -9999 -9999 -9999 -9999 -9999 -9999 -9999 -9999 -9999 -9999 -9999 -9999 -9999 -9999 -9999 -9999 -9999 -9999 -9999 -9999 -9999 -9999 -9999 -9999 -9999 -9999 -9999 -9999 -9999 -9999 -9999 -9999 -9999 -9999 -9999 - 9999 -9999 -9999 -9999 -9999 -9999 -9999 -9999 -9999 -9999 -9999 -9999 -9999 -9999 -9999 -9999 -9999 -9999 -9999 -9999 -9999 -9999 -9999 -9999 -9999 -9999 -9999 -9999 -9999 -9999 -9999 -9999 -9999 -9999 -9999 -9999 -9999 -9999 -9999 -9999 -9999 -9999 -9999 -9999 -9999 -9999 -9999 -9999 -9999 -9999 -9999 -9999 -9999 -9999 -9999 -9999 -9999 -9999 -9999 -9999 -9999

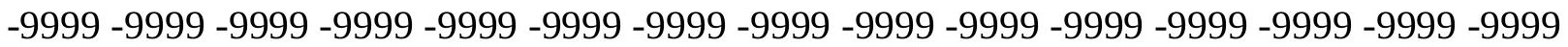
-9999 -9999 -9999 -9999 -9999 -9999 -9999 -9999 -9999 -9999 -9999 -9999 -9999 -9999 -9999 -9999 -9999 -9999 -9999 -9999 -9999 -9999 -9999 -9999 -9999 -9999 -9999 -9999 -9999 -9999

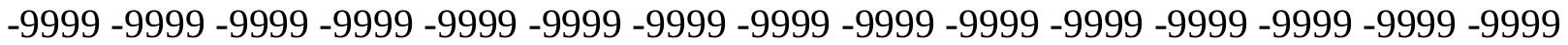
-9999 -9999 -9999 -9999 -9999 -9999 -9999 -9999 -9999 -9999 -9999 -9999 -9999 -9999 -9999 -9999 -9999 -9999 -9999 -9999 -9999 -9999 -9999 -9999 -9999 -9999 -9999 -9999 -9999 -9999 -

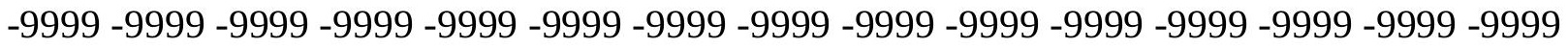
-9999 -9999 -9999 -9999 -9999 -9999 -9999 -9999 -9999 -9999 -9999 -9999 -9999 -9999 -9999

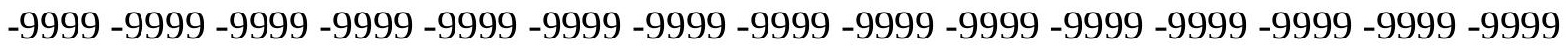
-9999 -9999 -9999 -9999 -9999 -9999 -9999 -9999 -9999 -9999 -9999 -9999 -9999 -9999 -9999 -9999 -9999 -9999 -9999 -9999 -9999 -9999 -9999 -9999 -9999 -9999 -9999 -9999 -9999 - -999 -9999 -9999 -9999 -9999 -9999 -9999 -9999 -9999 -9999 -9999 -9999 -9999 -9999 -9999 -9999 -9999 -9999 -9999 -9999 -9999 -9999 -9999 -9999 -9999 -9999 -9999 -9999 -9999 -9999 -9999 -9999 -9999 -9999 -9999 -9999 -9999 -9999 -9999 -9999 -9999 -9999 -9999 -9999 -9999 -9999 -999 -9999 -9999 -9999 -9999 -9999 -9999 -9999 -9999 -9999 -9999 -9999 -9999 -9999 -9999 -9999 -9999 -9999 -9999 -9999 -9999 -9999 -9999 -9999 -9999 -9999 -9999 -9999 -9999 -9999 -9999 -9999 -9999 -9999 -9999 -9999 -9999 -9999 -9999 -9999 -9999 -9999 -9999 -9999 -9999 -9999 -9999 -9999 -9999 -9999 -9999 -9999 -9999 -9999 -9999 -9999 -9999 -9999 -9999 -9999 -9999 -9999 -9999 -9999 -9999 -9999 -9999 -9999 -9999 -9999 -9999 -9999 -9999 -9999 -9999 -9999 -9999 -9999 -9999 -9999 -9999 -9999 -9999 -9999 -9999 -9999 -9999 -9999 -9999 -9999 -9999 -9999 -9999 -9999 -9999 -9999 -9999 -9999 -9999 -9999 -9999 -9999 -9999 -9999 -9999 -9999 -9999 -9999 -9999 -9999 -9999 -9999 -9999 -9999 -9999 -9999 -9999 -9999 -9999 -9999 -9999 -9999 -9999 -9999 -9999 -9999 -9999 -9999 -9999 -9999 -9999 -9999 -9999 -9999 -9999 -999 -9999 -9999 -9999 -9999 -9999 -9999 -9999 -9999 -9999 -9999 -9999 -9999 -9999 -9999 -9999 -9999 -9999 -9999 -9999 -9999 -9999 -9999 -9999 -9999 -9999 -9999 -9999 -9999 -9999 -9999 -

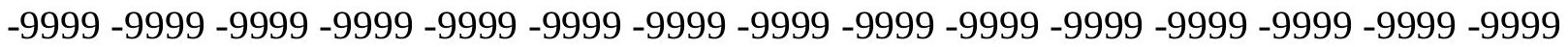

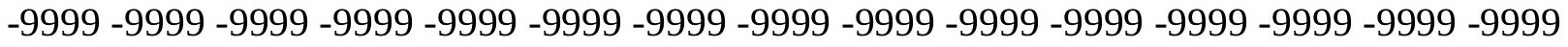

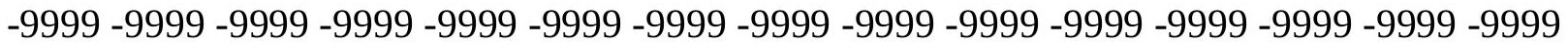
-9999 -9999 -9999 -9999 -9999 -9999 -9999 -9999 -9999 -9999 -9999 -9999 -9999 -9999 -9999

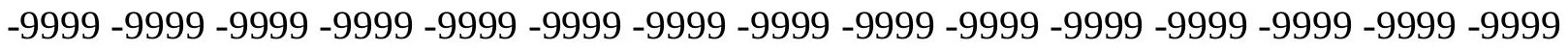

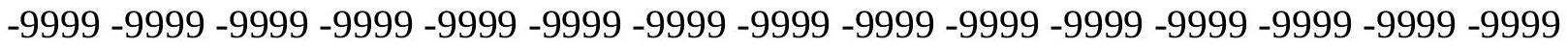

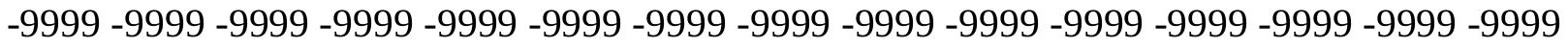
-9999 -9999 -9999 -9999 -9999 -9999 -9999 -9999 -9999 -9999 -9999 -9999 -9999 -9999 -9999 -

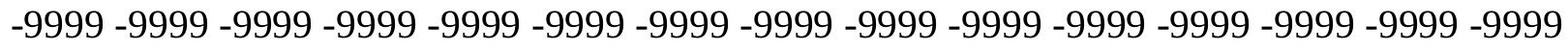

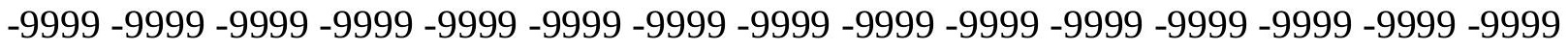
-9999 -9999 -9999 -9999 -9999 -9999 -9999 -9999 -9999 -9999 -9999 -9999 -9999 -9999 -9999 -9999 -9999 -9999 -9999 -9999 -9999 -9999 -9999 -9999 -9999 -9999 -9999 -9999 - -9999 -9999 -9999 -9999 -9999 -9999 -9999 -9999 -9999 -9999 -9999 -9999 -9999 -9999 -9999 -9999 -

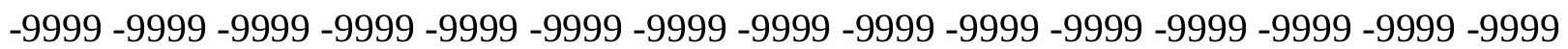


-9999 -9999 -9999 -9999 -9999 -9999 -9999 -9999 -9999 -9999 -9999 -9999 -9999 -9999 -9999 -9999 -9999 -9999 -9999 -9999 -9999 -9999 -9999 -9999 -9999 -9999 -9999 -9999 -9999 -9999 -9999 -9999 -9999 -9999 -9999 -9999 -9999 -9999 -9999 -9999 -9999 -9999 -9999 -9999 - 9999 -9999 -9999 -9999 -9999 -9999 -9999 -9999 -9999 -9999 -9999 -9999 -9999 -9999 -9999 -9999 -9999 -9999 -9999 -9999 -9999 -9999 -9999 -9999 -9999-9999 -9999 -9999 -9999 -9999 -9999 -9999 -9999 -9999 -9999 -9999 -9999 -9999 -9999 -9999 -9999 -9999 -9999 -9999 -9999 -9999 -9999 -9999 -9999 -9999 -9999 -9999 -9999 -9999 -9999 -9999 -9999 -9999 -9999 -9999 -9999

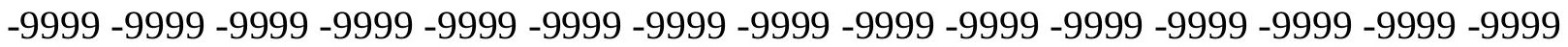

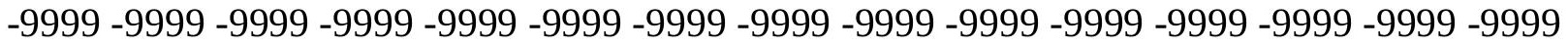
-9999 -9999 -9999 -9999 -9999 -9999 -9999 -9999 -9999 -9999 -9999 -9999 -9999 -9999 -9999

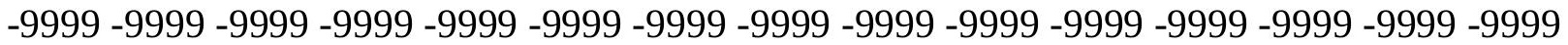
-9999 -9999 -9999 -9999 -9999 -9999 -9999 -9999 -9999 -9999 -9999 -9999 -9999 -9999 -9999 -9999 -9999 -9999 -9999 -9999 -9999 -9999 -9999 -9999 -9999 -9999 -9999 -9999 -9999 -9999 -

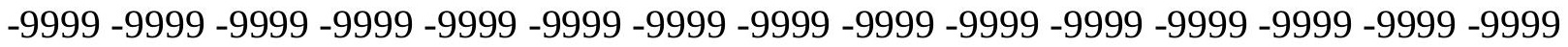
-9999 -9999 -9999 -9999 -9999 -9999 -9999 -9999 -9999 -9999 -9999 -9999 -9999 -9999 -9999

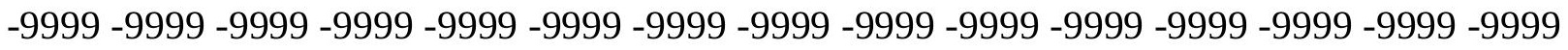
-9999 -9999 -9999 -9999 -9999 -9999 -9999 -9999 -9999 -9999 -9999 -9999 -9999 -9999 -9999 -9999 -9999 -9999 -9999 -9999 -9999 -9999 -9999 -9999 -9999 -9999 -9999 -9999 -9999 -9999 -9999 -9999 -9999 -9999 -9999 -9999 -9999 -9999 -9999 -9999 -9999 -9999 -9999 -9999 -9999 -9999 -9999 -9999 -9999 -9999 -9999 -9999 -9999 -9999 -9999 -9999 -9999 -9999 -9999 -9999 -9999 -9999 -9999 -9999 -9999 -9999 -9999 -9999 -9999 -9999 -9999 -9999 -9999 -9999 -9999 -999 -9999 -9999 -9999 -9999 -9999 -9999 -9999 -9999 -9999 -9999 -9999 -9999 -9999 -9999 -9999 -9999 -9999 -9999 -9999 -9999 -9999 -9999 -9999 -9999 -9999 -9999 -9999 -9999 -9999 -9999 -9999 -9999 -9999 -9999 -9999 -9999 -9999 -9999 -9999 -9999 -9999 -9999 -9999 -9999 -9999 -9999 -9999 -9999 -9999 -9999 -9999 -9999 -9999 -9999 -9999 -9999 -9999 -9999 -9999 -9999 -9999 -9999 -9999 -9999 -9999 -9999 -9999 -9999 -9999 -9999 -9999 -9999 -9999 -9999 -9999 -9999 -9999 -9999 -9999 -9999 -9999 -9999 -9999 -9999 -9999 -9999 -9999 -9999 -9999 -9999 -9999 -9999 -9999 -9999 -9999 -9999 -9999 -9999 -9999 -9999 -9999 -9999 -9999 -9999 -9999 -9999 -9999 -9999 -9999 -9999 -9999 -9999 -9999 -9999 -9999 -9999 -9999 -9999 -9999 -9999 -9999 -9999 -9999 -9999 -9999 -9999 -9999 -9999 -9999 -9999 -9999 -9999 -9999 -999 -9999 -9999 -9999 -9999 -9999 -9999 -9999 -9999 -9999 -9999 -9999 -9999 -9999 -9999 -9999 -9999 -9999 -9999 -9999 -9999 -9999 -9999 -9999 -9999 -9999 -9999 -9999 -9999 -9999 -9999 -

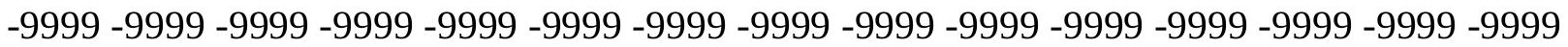

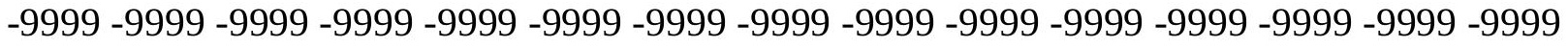

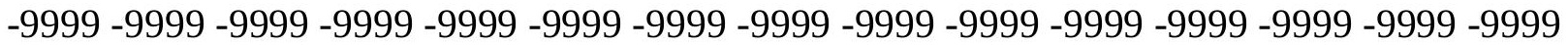
-9999 -9999 -9999 -9999 -9999 -9999 -9999 -9999 -9999 -9999 -9999 -9999 -9999 -9999 -9999

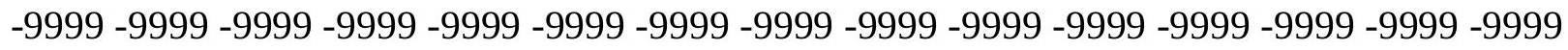

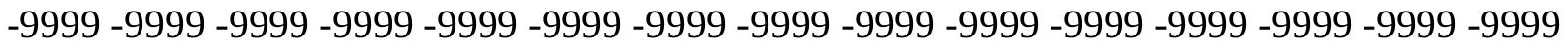
-9999 -9999 -9999 -9999 -9999 -9999 -9999 -9999 -9999 -9999 -9999 -9999 -9999 -9999 -9999 -9999 -9999 -9999 -9999 -9999 -9999 -9999 -9999 -9999 -9999 -9999 -9999 -9999 -9999 -9999 -

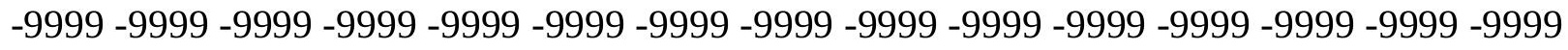

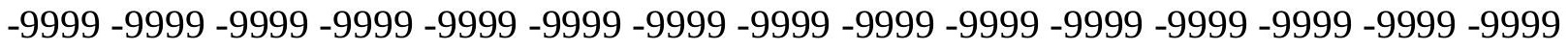
-9999 -9999 -9999 -9999 -9999 -9999 -9999 -9999 -9999 -9999 -9999 -9999 -9999 -9999 -9999 -9999 -9999 -9999 -9999 -9999 -9999 -9999 -9999 -9999-9999 -9999 -9999 -9999 -9999 -9999 -9999 -9999 -9999 -9999 -9999 -9999 -9999 -9999 -9999 -9999 -9999 -9999 -9999 -9999 -9999 -

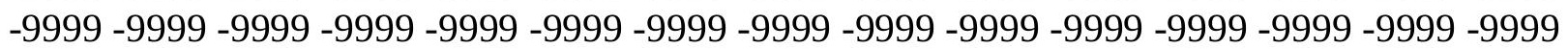


-9999 -9999 -9999 -9999 -9999 -9999 -9999 -9999 -9999 -9999 -9999 -9999 -9999 -9999 -9999 -9999 -9999 -9999 -9999 -9999 -9999 -9999 -9999 -9999 -9999 -9999 -9999 -9999 -9999 -9999 -9999 -9999 -9999 -9999 -9999 -9999 -9999 -9999 -9999 -9999 -9999 -9999 -9999 -9999 - 9999 -9999 -9999 -9999 -9999 -9999 -9999 -9999 -9999 -9999 -9999 -9999 -9999 -9999 -9999

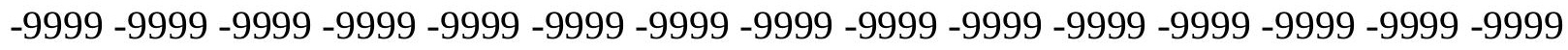
-9999 -9999 -9999 -9999 -9999 -9999 -9999 -9999 -9999 -9999 -9999 -9999 -9999 -9999 -9999 -9999 -9999 -9999 -9999 -9999 -9999 -9999 -9999 -9999 -9999 -9999 -9999 -9999 -9999 -9999

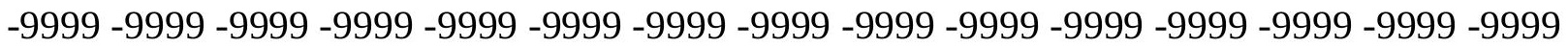

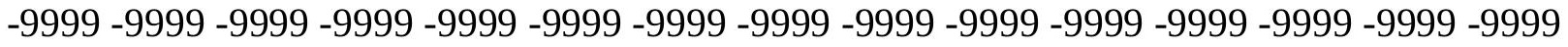
-9999 -9999 -9999 -9999 -9999 -9999 -9999 -9999 -9999 -9999 -9999 -9999 -9999 -9999 -9999 -9999 -9999 -9999 -9999 -9999 -9999 -9999 -9999 -9999 -9999 -9999 -9999 -9999 -9999 -9999 -9999 -9999 -9999 -9999 -9999 -9999 -9999 -9999 -9999 -9999 -9999 -9999 -9999 -9999 -9999 -9999 -9999 -9999 -9999 -9999 -9999 -9999 -9999 -9999 -9999 -9999 -9999 -9999 -9999 -9999 -

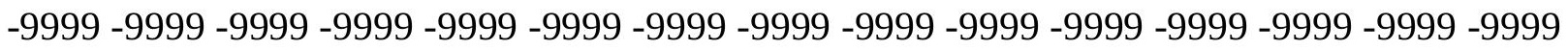
-9999 -9999 -9999 -9999 -9999 -9999 -9999 -9999 -9999 -9999 -9999 -9999 -9999 -9999 -9999 -

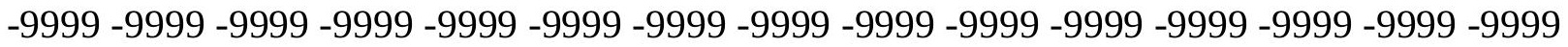
-9999 -9999 -9999 -9999 -9999 -9999 -9999 -9999 -9999 -9999 -9999 -9999 -9999 -9999 -9999 -9999 -9999 -9999 -9999 -9999 -9999 -9999 -9999 -9999 -9999 -9999 -9999 -9999 -9999 -9999 -9999 -9999 -9999 -9999 -9999 -9999 -9999 -9999 -9999 -9999 -9999 -9999 -9999 -9999 -9999 -

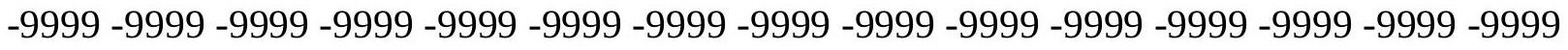
-9999 -9999 -9999 -9999 -9999 -9999 -9999 -9999 -9999 -9999 -9999 -9999 -9999 -9999 -9999

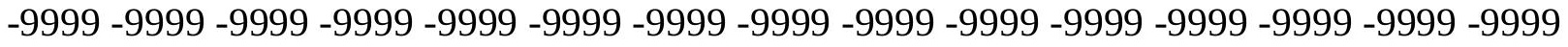
-9999 -9999 -9999 -9999 -9999 -9999 -9999 -9999 -9999 -9999 -9999 -9999 -9999 -9999 -9999 -9999 -9999 -9999 -9999 -9999 -9999 -9999 -9999 -9999 -9999 -9999 -9999 -9999 -9999 -9999 -9999 -9999 -9999 -9999 -9999 -9999 -9999 -9999 -9999 -9999 -9999 -9999 -9999 -9999 -9999 -9999 -9999 -9999 -9999 -9999 -9999 -9999 -9999 -9999 -9999 -9999 -9999 -9999 -9999 -9999 -9999 -9999 -9999 -9999 -9999 -9999 -9999 -9999 -9999 -9999 -9999 -9999 -9999 -9999 -9999 -9999 -9999 -9999 -9999 -9999 -9999 -9999 -9999 -9999 -9999 -9999 -9999 -9999 -9999 -9999 -9999 -9999 -9999 -9999 -9999 -9999 -9999 -9999 -9999 -9999 -9999 -9999 -9999 -9999 -9999 -9999 -9999 -9999 -9999 -9999 -9999 -9999 -9999 -9999 -9999 -9999 -9999 -9999 -9999 -9999 -9999 -9999 -9999 -9999 -9999 -9999 -9999 -9999 -9999 -9999 -9999 -9999 -9999 -9999 -9999 -9999 -9999 -9999 -9999 -9999 -9999 -9999 -9999 -9999 -9999 -9999 -9999 -9999 -9999 -

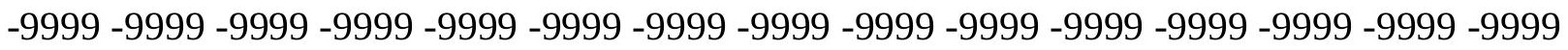

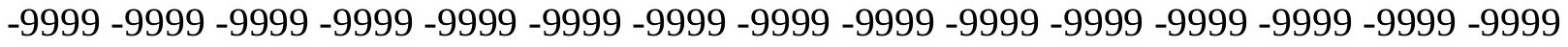
-9999 -9999 -9999 -9999 -9999 -9999 -9999 -9999 -9999 -9999 -9999 -9999 -9999 -9999 -9999 -

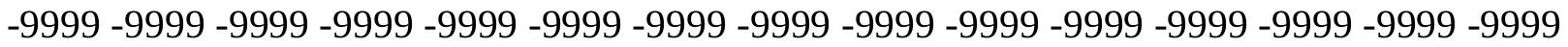

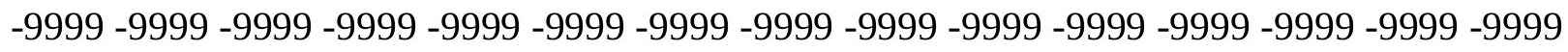

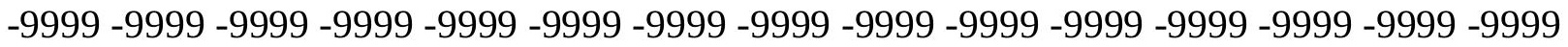

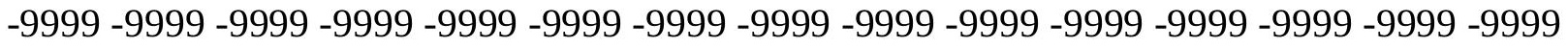
-9999 -9999 -9999 -9999 -9999 -9999 -9999 -9999 -9999 -9999 -9999 -9999 -9999 -9999 -9999 -

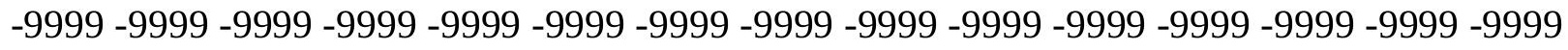

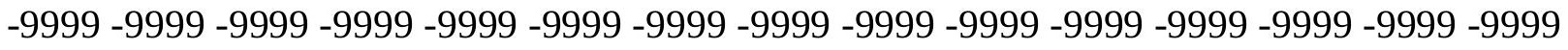
-9999 -9999 -9999 -9999 -9999 -9999 -9999 -9999 -9999 -9999 -9999 -9999 -9999 -9999 -9999 -9999 -9999 -9999 -9999 -9999 -9999 -9999 -9999 -9999-9999 -9999 -9999 -9999 -9999 -9999 -9999 -9999 -9999 -9999 -9999 -9999 -9999 -9999 -9999 -9999 -9999 -9999 -9999 -9999 -9999 -

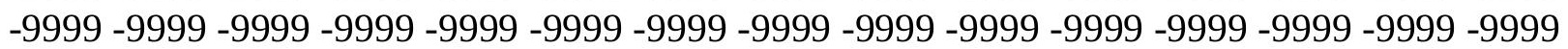


-9999 -9999 -9999 -9999 -9999 -9999 -9999 -9999 -9999 -9999 -9999 -9999 -9999 -9999 -9999 -9999 -9999 -9999 -9999 -9999 -9999 -9999 -9999 -9999 -9999 -9999 -9999 -9999 -9999 -9999 -9999 -9999 -9999 -9999 -9999 -9999 -9999 -9999 -9999 -9999 -9999 -9999 -9999 -9999 - 9999 -9999 -9999 -9999 -9999 -9999 -9999 -9999 -9999 -9999 -9999 -9999 -9999 -9999 -9999 -9999 -9999 -9999 -9999 -9999 -9999 -9999 -9999 -9999 -9999 -9999 -9999 -9999 -9999 -9999 -9999 -9999 -9999 -9999 -9999 -9999 -9999 -9999 -9999 -9999 -9999 -9999 -9999 -9999 -9999 -9999 -9999 -9999 -9999 -9999 -9999 -9999 -9999 -9999 -9999 -9999 -9999 -9999 -9999 -9999 -9999

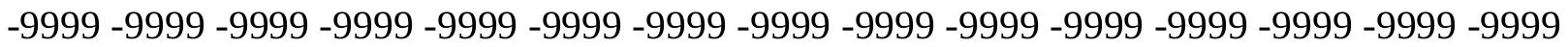

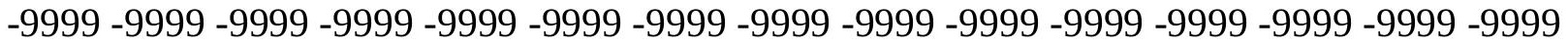
-9999 -9999 -9999 -9999 -9999 -9999 -9999 -9999 -9999 -9999 -9999 -9999 -9999 -9999 -9999 -9999 -9999 -9999 -9999 -9999 -9999 -9999 -9999 -9999 -9999 -9999 -9999 -9999 -9999 -9999 -9999 -9999 -9999 -9999 -9999 -9999 -9999 -9999 -9999 -9999 -9999 -9999 -9999 -9999 -9999 -9999 -9999 -9999 -9999 -9999 -9999 -9999 -9999 -9999 -9999 -9999 -9999 -9999 -9999 -9999 -9999 -9999 -9999 -9999 -9999 -9999 -9999 -9999 -9999 -9999 -9999 -9999 -9999 -9999 -9999 -9999 -9999 -9999 -9999 -9999 -9999 -9999 -9999 -9999 -9999 -9999 -9999 -9999 -9999 -

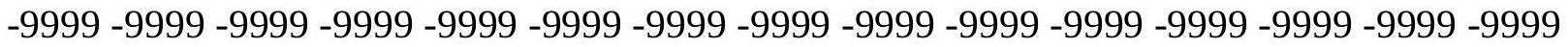
-9999 -9999 -9999 -9999 -9999 -9999 -9999 -9999 -9999 -9999 -9999 -9999 -9999 -9999 -9999 -9999 -9999 -9999 -9999 -9999 -9999 -9999 -9999 -9999 -9999 -9999 -9999 -9999 -9999 -9999 -9999 -9999 -9999 -9999 -9999 -9999 -9999 -9999 -9999 -9999 -9999 -9999 -9999 -9999 -9999 -9999 -9999 -9999 -9999 -9999 -9999 -9999 -9999 -9999 -9999 -9999 -9999 -9999 -9999 -9999 -9999 -9999 -9999 -9999 -9999 -9999 -9999 -9999 -9999 -9999 -9999 -9999 -9999 -9999 -9999 -999 -9999 -9999 -9999 -9999 -9999 -9999 -9999 -9999 -9999 -9999 -9999 -9999 -9999 -9999 -9999 -9999 -9999 -9999 -9999 -9999 -9999 -9999 -9999 -9999 -9999 -9999 -9999 -9999 -9999 -9999 -9999 -9999 -9999 -9999 -9999 -9999 -9999 -9999 -9999 -9999 -9999 -9999 -9999 -9999 -9999 -9999 -9999 -9999 -9999 -9999 -9999 -9999 -9999 -9999 -9999 -9999 -9999 -9999 -9999 -9999 -9999 -9999 -9999 -9999 -9999 -9999 -9999 -9999 -9999 -9999 -9999 -9999 -9999 -9999 -9999 -9999 -9999 -9999 -9999 -9999 -9999 -9999 -9999 -9999 -9999 -9999 -9999 -9999 -9999 -9999 -9999 -9999 -9999 -9999 -9999 -9999 -9999 -9999 -9999 -9999 -9999 -9999 -9999 -9999 -9999 -9999 -9999 -9999 -9999 -9999 -9999 -9999 -9999 -9999 -9999 -9999 -9999 -9999 -9999 -9999 -9999 -9999 -9999 -9999 -9999 -9999 -9999 -9999 -9999 -9999 -9999 -9999 -9999 -9999 -999 -9999 -9999 -9999 -9999 -9999 -9999 -9999 -9999 -9999 -9999 -9999 -9999 -9999 -9999 -9999 -9999 -9999 -9999 -9999 -9999 -9999 -9999 -9999 -9999 -9999 -9999 -9999 -9999 -9999 -9999 -

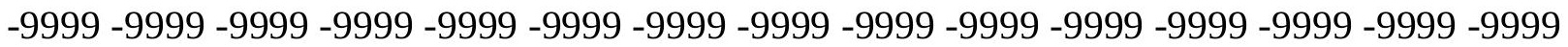

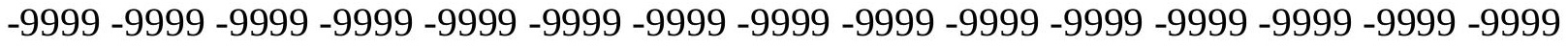

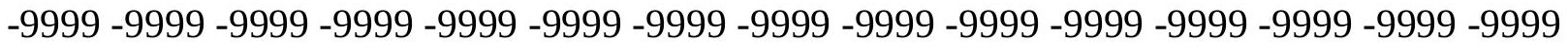
-9999 -9999 -9999 -9999 -9999 -9999 -9999 -9999 -9999 -9999 -9999 -9999 -9999 -9999 -9999 -9999 -9999 -9999 -9999 -9999 -9999 -9999 -9999 -9999 -9999 -9999 -9999 -9999 -9999 -

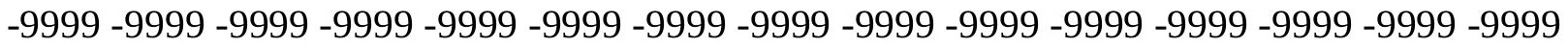
-9999 -9999 -9999 -9999 -9999 -9999 -9999 -9999 -9999 -9999 -9999 -9999 -9999 -9999 -9999 -9999 -9999 -9999 -9999 -9999 -9999 -9999 -9999 -9999 -9999 -9999 -9999 -9999 -9999 -9999 -

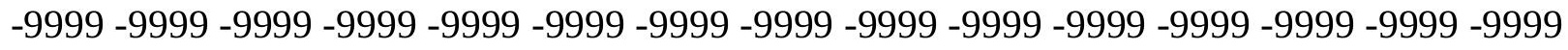

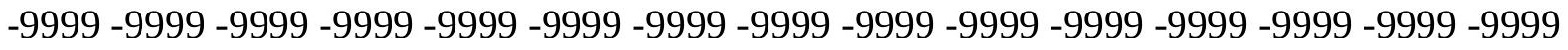
-9999 -9999 -9999 -9999 -9999 -9999 -9999 -9999 -9999 -9999 -9999 -9999 -9999 -9999 -9999 -9999 -9999 -9999 -9999 -9999 -9999 -9999 -9999 -9999-9999 -9999 -9999 -9999 -9999 -9999 -9999 -9999 -9999 -9999 -9999 -9999 -9999 -9999 -9999 -9999 -9999 -9999 -9999 -9999 -9999 -

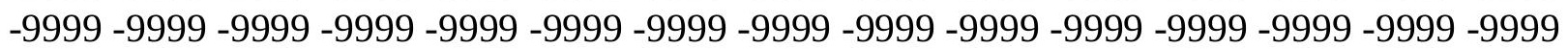


-9999 -9999 -9999 -9999 -9999 -9999 -9999 -9999 -9999 -9999 -9999 -9999 -9999 -9999 -9999 -9999 -9999 -9999 -9999 -9999 -9999 -9999 -9999 -9999 -9999 -9999 -9999 -9999 -9999 -9999 -

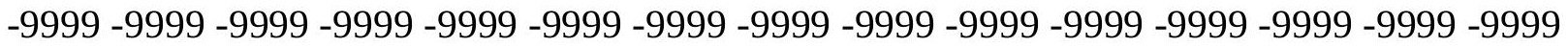
-9999 -9999 -9999 -9999 -9999 -9999 -9999 -9999 -9999 -9999 -9999 -9999 -9999 -9999 -9999 -9999 -9999 -9999 -9999 -9999 -9999 -9999 -9999 -9999-9999 -9999 -9999 -9999 -9999 -9999 -9999 -9999 -9999 -9999 -9999 -9999 -9999 -9999 -9999 -9999 -9999 -9999 -9999 -9999 -9999 -9999 -9999 -9999 -9999 -9999 -9999 -9999 -9999 -9999 -9999 -9999 -9999 -9999 -9999 -9999

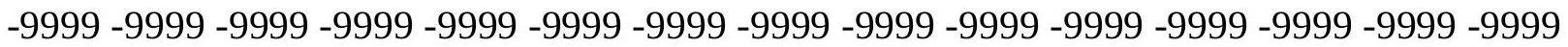

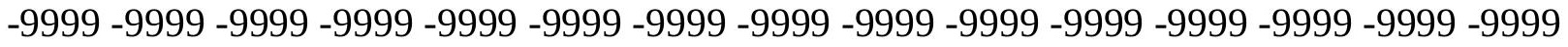
-9999 -9999 -9999 -9999 -9999 -9999 -9999 -9999 -9999 -9999 -9999 -9999 -9999 -9999 -9999 -9999 -9999 -9999 -9999 -9999 -9999 -9999 -9999 -9999 -9999 -9999 -9999 -9999 -9999 -9999 -9999 -9999 -9999 -9999 -9999 -9999 -9999 -9999 -9999 -9999 -9999 -9999 -9999 -9999 -9999 -9999 -9999 -9999 -9999 -9999 -9999 -9999 -9999 -9999 -9999 -9999 -9999 -9999 -9999 -9999 -9999 -9999 -9999 -9999 -9999 -9999 -9999 -9999 -9999 -9999 -9999 -9999 -9999 -9999 -9999 -9999 -9999 -9999 -9999 -9999 -9999 -9999 -9999 -9999 -9999 -9999 -9999 -9999 -9999 -9999 -

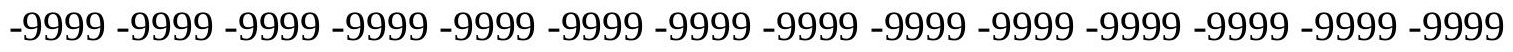
-9999 -9999 -9999 -9999 -9999 -9999 -9999 -9999 -9999 -9999 -9999 -9999 -9999 -9999 -9999 -9999 -9999 -9999 -9999 -9999 -9999 -9999 -9999 -9999 -9999 -9999 -9999 -9999 -9999 -9999 -9999 -9999 -9999 -9999 -9999 -9999 -9999 -9999 -9999 -9999 -9999 -9999 -9999 -9999 -9999 -

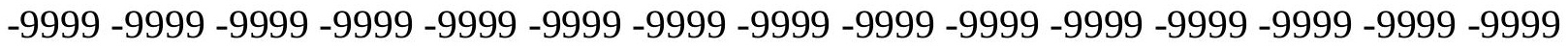

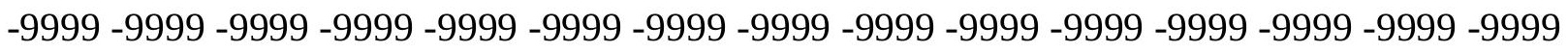
-9999 -9999 -9999 -9999 -9999 -9999 -9999 -9999 -9999 -9999 -9999 -9999 -9999 -9999 - 9999 -9999 -9999 -9999 -9999 -9999 -9999 -9999 -9999 -9999 -9999 -9999 -9999 -9999 -9999 -9999 -9999 -9999 -9999 -9999 -9999 -9999 -9999 -9999 -9999 -9999 -9999 -9999 -9999 -9999 -9999 -

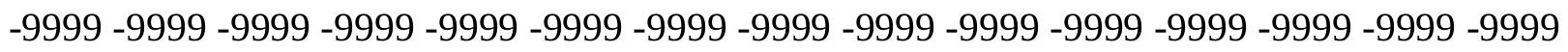
-9999 -9999 -9999 -9999 -9999 -9999 -9999 -9999 -9999 -9999 -9999 -9999 -9999 -9999 -9999 -9999 -9999 -9999 -9999 -9999 -9999 -9999 -9999 -9999 -9999 -9999 -9999 -9999 -9999 -9999 -

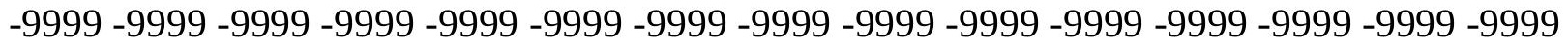
-9999 -9999 -9999 -9999 -9999 -9999 -9999 -9999 -9999 -9999 -9999 -9999 -9999 -9999 -9999 -9999 -9999 -9999 -9999 -9999 -9999 -9999 -9999 -9999 -9999 -9999 -9999 -9999 -9999 -999 -

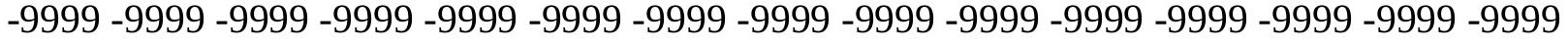
-9999 -9999 -9999 -9999 -9999 -9999 -9999 -9999 -9999 -9999 -9999 -9999 -9999 -9999 -9999 -

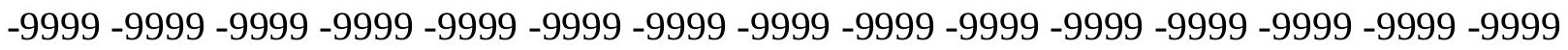

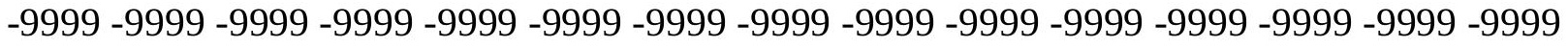

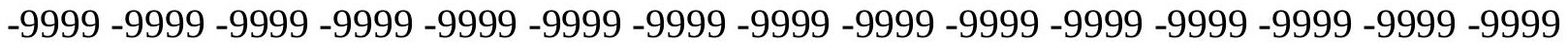
-9999 -9999 -9999 -9999 -9999 -9999 -9999 -9999 -9999 -9999 -9999 -9999 -9999 -9999 -9999 -

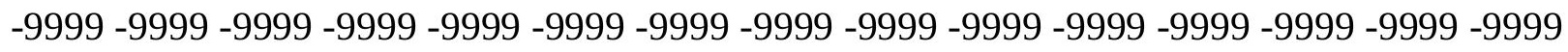

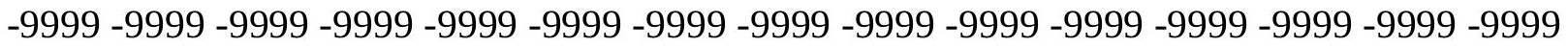
-9999 -9999 -9999 -9999 -9999 -9999 -9999 -9999 -9999 -9999 -9999 -9999 -9999 - 9999 - -999 -9999 -9999 -9999 -9999 -9999 -9999 -9999 -9999 -9999 -9999 -9999 -9999 -9999 -9999 -9999 -

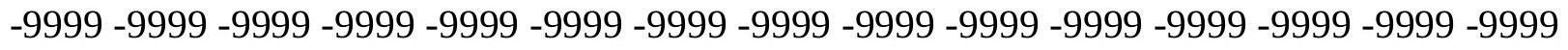

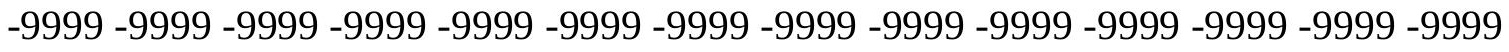
-9999 -9999 -9999 -9999 -9999 -9999 -9999 -9999 -9999 -9999 -9999 -9999 -9999 -9999 -9999 -9999 -9999 -9999 -9999 -9999 -9999 -9999 -9999 -9999-9999 -9999 -9999 -9999 -9999 -9999 -9999 -9999 -9999 -9999 -9999 -9999 -9999 -9999 -9999 -9999 -9999 -9999 -9999 -9999 -9999 -

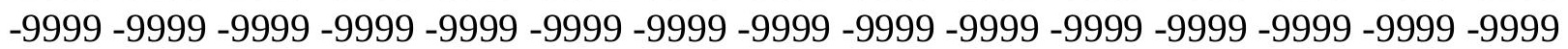


-9999 -9999 -9999 -9999 -9999 -9999 -9999 -9999 -9999 -9999 -9999 -9999 -9999 -9999 -9999 -9999 -9999 -9999 -9999 -9999 -9999 -9999 -9999 -9999 -9999 -9999 -9999 -9999 -9999 -9999 -

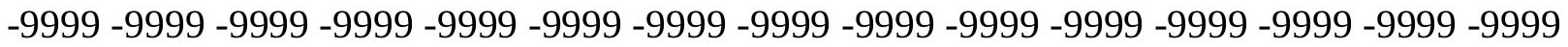
-9999 -9999 -9999 -9999 -9999 -9999 -9999 -9999 -9999 -9999 -9999 -9999 -9999 -9999 -9999 -9999 -9999 -9999 -9999 -9999 -9999 -9999 -9999 -9999-9999 -9999 -9999 -9999 -9999 -9999 -9999 -9999 -9999 -9999 -9999 -9999 -9999 -9999 -9999 -9999 -9999 -9999 -9999 -9999 -9999 -9999 -9999 -9999 -9999 -9999 -9999 -9999 -9999 -9999 -9999 -9999 -9999 -9999 -9999 -9999

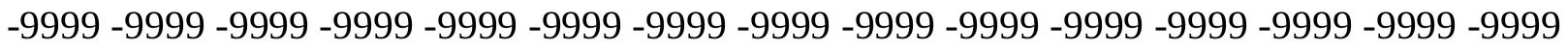

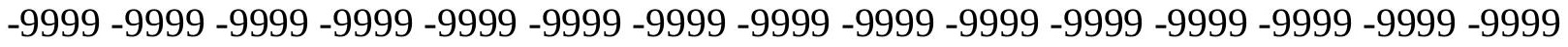
-9999 -9999 -9999 -9999 -9999 -9999 -9999 -9999 -9999 -9999 -9999 -9999 -9999 -9999 -9999 -9999 -9999 -9999 -9999 -9999 -9999 -9999 -9999 -9999 -9999 -9999 -9999 -9999 -9999 -9999 -9999 -9999 -9999 -9999 -9999 -9999 -9999 -9999 -9999 -9999 -9999 -9999 -9999 -9999 -9999 -9999 -9999 -9999 -9999 -9999 -9999 -9999 -9999 -9999 -9999 -9999 -9999 -9999 -9999 -9999 -

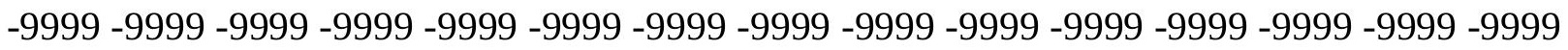
-9999 -9999 -9999 -9999 -9999 -9999 -9999 -9999 -9999 -9999 -9999 -9999 -9999 -9999 -9999 -

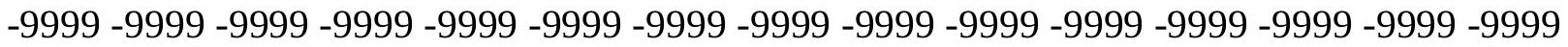
-9999 -9999 -9999 -9999 -9999 -9999 -9999 -9999 -9999 -9999 -9999 -9999 -9999 -9999 -9999 -9999 -9999 -9999 -9999 -9999 -9999 -9999 -9999 -9999 -9999 -9999 -9999 -9999 -9999 -9999 -9999 -9999 -9999 -9999 -9999 -9999 -9999 -9999 -9999 -9999 -9999 -9999 -9999 -9999 -9999 -

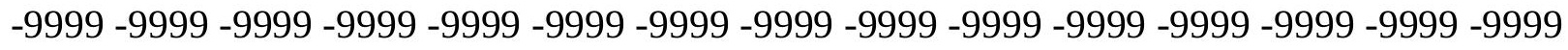

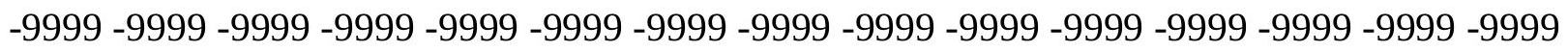
-9999 -9999 -9999 -9999 -9999 -9999 -9999 -9999 -9999 -9999 -9999 -9999 -9999 -9999 -9999 -9999 -9999 -9999 -9999 -9999 -9999 -9999 -9999 -9999 -9999 -9999 -9999 -9999 -9999 -9999 -9999 -9999 -9999 -9999 -9999 -9999 -9999 -9999 -9999 -9999 -9999 -9999 -9999 -9999 -

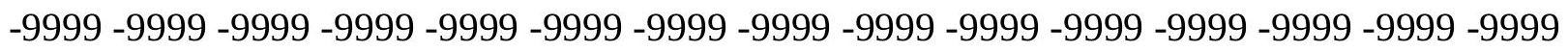
-9999 -9999 -9999 -9999 -9999 -9999 -9999 -9999 -9999 -9999 -9999 -9999 -9999 -9999 -9999 -9999 -9999 -9999 -9999 -9999 -9999 -9999 -9999 -9999 -9999 -9999 -9999 -9999 -9999 -9999 -

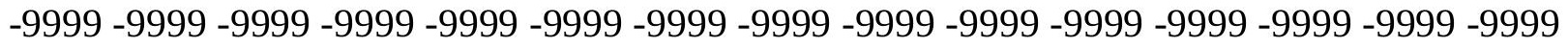
-9999 -9999 -9999 -9999 -9999 -9999 -9999 -9999 -9999 -9999 -9999 -9999 -9999 -9999 -9999 -9999 -9999 -9999 -9999 -9999 -9999 -9999 -9999 -9999 -9999 -9999 -9999 -9999 -9999 -999 -

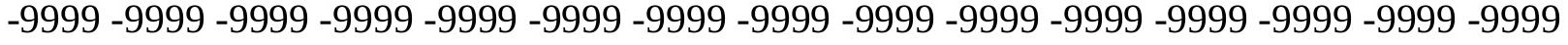
-9999 -9999 -9999 -9999 -9999 -9999 -9999 -9999 -9999 -9999 -9999 -9999 -9999 -9999 -9999 -

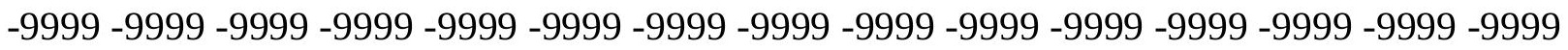

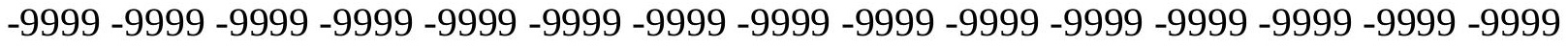

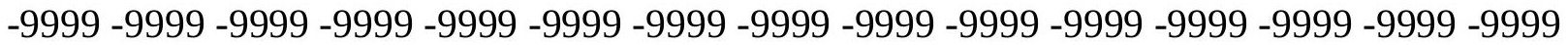

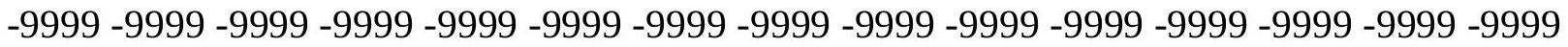

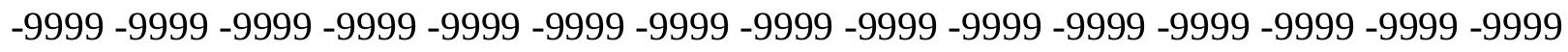

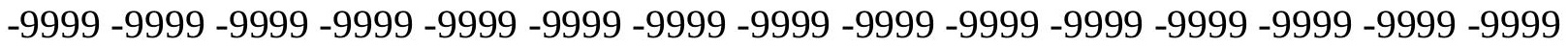

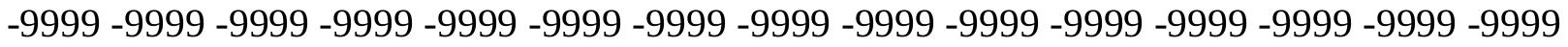
-9999 -9999 -9999 -9999 -9999 -9999 -9999 -9999 -9999 -9999 -9999 -9999 -9999 -9999 -9999 -

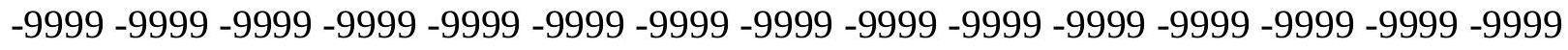

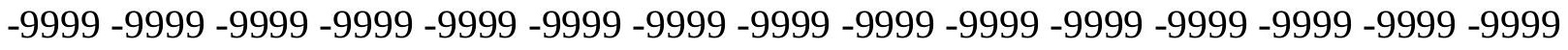
-9999 -9999 -9999 -9999 -9999 -9999 -9999 -9999 -9999 -9999 -9999 -9999 -9999 -9999 -9999 -9999 -9999 -9999 -9999 -9999 -9999 -9999 -9999 -9999-9999 -9999 -9999 -9999 -9999 -9999 -9999 -9999 -9999 -9999 -9999 -9999 -9999 -9999 -9999 -9999 -9999 -9999 -9999 -9999 -9999 -

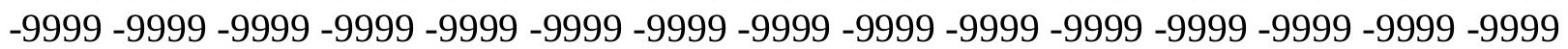


-9999 -9999 -9999 -9999 -9999 -9999 -9999 -9999 -9999 -9999 -9999 -9999 -9999 -9999 -9999 -9999 -9999 -9999 -9999 -9999 -9999 -9999 -9999 -9999 -9999 -9999 -9999 -9999 -9999 -

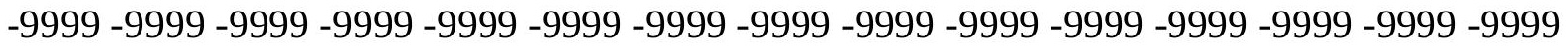
-9999 -9999 -9999 -9999 -9999 -9999 -9999 -9999 -9999 -9999 -9999 -9999 -9999 -9999 -9999 -9999 -9999 -9999 -9999 -9999 -9999 -9999 -9999 -9999 -9999 -9999 -9999 -9999 -9999 -9999 -9999 -9999 -9999 -9999 -9999 -9999 -9999 -9999 -9999 -9999 -9999 -9999 -9999 -9999 -9999 -9999 -9999 -9999 -9999 -9999 -9999 -9999 -9999 -9999 -9999 -9999 -9999 -9999 -9999 -9999

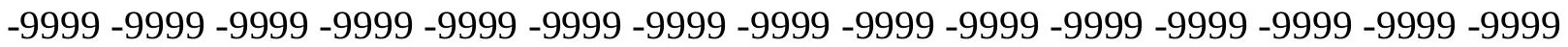

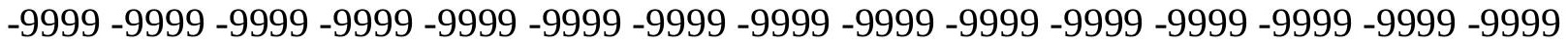
-9999 -9999 -9999 -9999 -9999 -9999 -9999 -9999 -9999 -9999 -9999 -9999 -9999 -9999 -9999 -9999 -9999 -9999 -9999 -9999 -9999 -9999 -9999 -9999 -9999 -9999 -9999 -9999 -9999 -9999 -9999 -9999 -9999 -9999 -9999 -9999 -9999 -9999 -9999 -9999 -9999 -9999 -9999 -9999 -9999 -9999 -9999 -9999 -9999 -9999 -9999 -9999 -9999 -9999 -9999 -9999 -9999 -9999 -9999 -9999 -9999 -9999 -9999 -9999 -9999 -9999 -9999 -9999 -9999 -9999 -9999 -9999 -9999 -9999 -9999 -9999 -9999 -9999 -9999 -9999 -9999 -9999 -9999 -9999 -9999 -9999 -9999 -9999 -9999 -9999 -

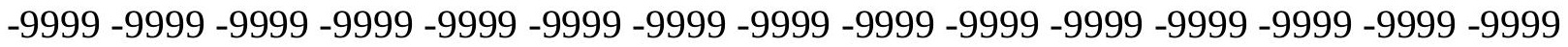
-9999 -9999 -9999 -9999 -9999 -9999 -9999 -9999 -9999 -9999 -9999 -9999 -9999 -9999 -9999 -9999 -9999 -9999 -9999 -9999 -9999 -9999 -9999 -9999 -9999 -9999 -9999 -9999 -9999 - 9999 -9999 -9999 -9999 -9999 -9999 -9999 -9999 -9999 -9999 -9999 -9999 -9999 -9999 -9999 -9999 -

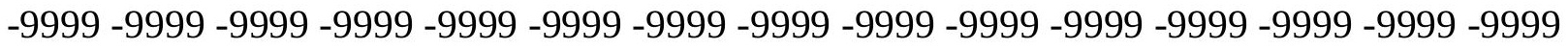

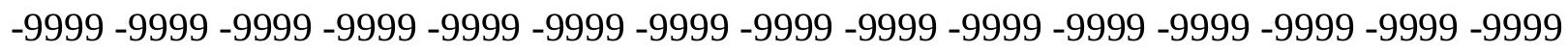

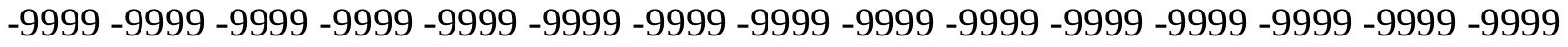
-9999 -9999 -9999 -9999 -9999 -9999 -9999 -9999 -9999 -9999 -9999 -9999 -9999 -9999 -9999 -9999 -9999 -9999 -9999 -9999 -9999 -9999 -9999 -9999 -9999 -9999 -9999 -9999 -9999 -9999 -

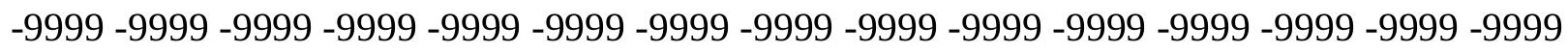
-9999 -9999 -9999 -9999 -9999 -9999 -9999 -9999 -9999 -9999 -9999 -9999 -9999 -9999 -9999 -9999 -9999 -9999 -9999 -9999 -9999 -9999 -9999 -9999 -9999 -9999 -9999 -9999 -9999 -9999 -9999 -9999 -9999 -9999 -9999 -9999 -9999 -9999 -9999 -9999 -9999 -9999 -9999 -9999 -9999 -9999 -9999 -9999 -9999 -9999 -9999 -9999 -9999 -9999 -9999 -9999 -9999 -9999 -9999 -9999 -9999 -9999 -9999 -9999 -9999 -9999 -9999 -9999 -9999 -9999 -9999 -9999 -9999 -999 -

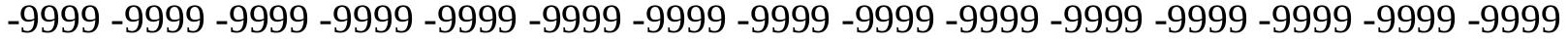
-9999 -9999 -9999 -9999 -9999 -9999 -9999 -9999 -9999 -9999 -9999 -9999 -9999 -9999 -9999 -

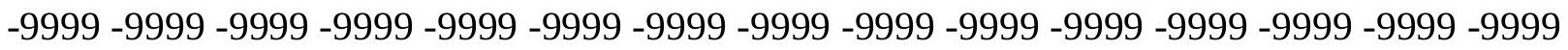

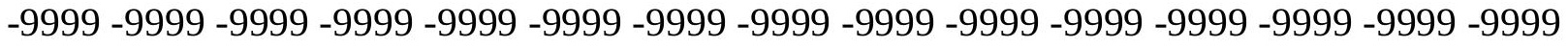

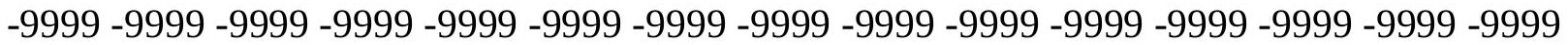

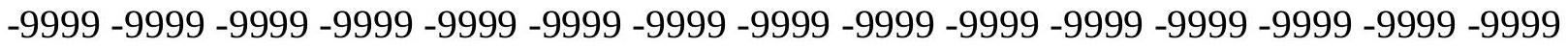

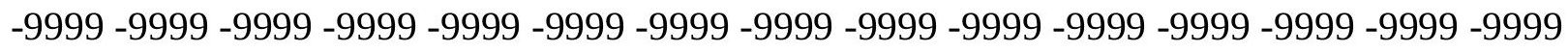

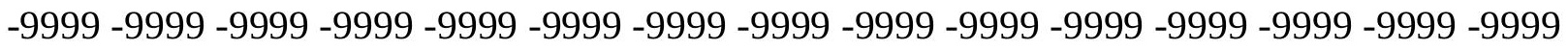

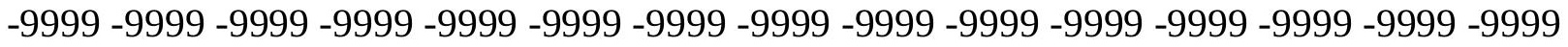
-9999 -9999 -9999 -9999 -9999 -9999 -9999 -9999 -9999 -9999 -9999 -9999 -9999 -9999 -9999 -

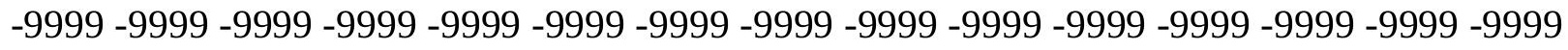

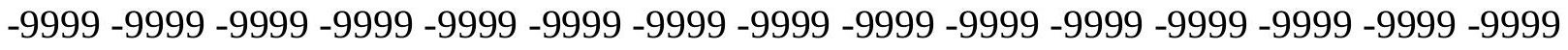
-9999 -9999 -9999 -9999 -9999 -9999 -9999 -9999 -9999 -9999 -9999 -9999 -9999 -9999 -9999 -9999 -9999 -9999 -9999 -9999 -9999 -9999 -9999 -9999-9999 -9999 -9999 -9999 -9999 -9999 -9999 -9999 -9999 -9999 -9999 -9999 -9999 -9999 -9999 -9999 -9999 -9999 -9999 -9999 -9999 -

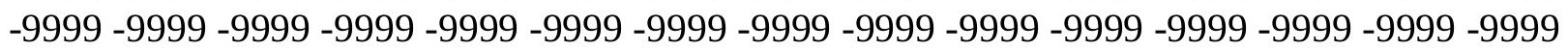


-9999 -9999 -9999 -9999 -9999 -9999 -9999 -9999 -9999 -9999 -9999 -9999 -9999 -9999 -9999 -9999 -9999 -9999 -9999 -9999 -9999 -9999 -9999 -9999 -9999 -9999 -9999 -9999 -9999 -9999 -

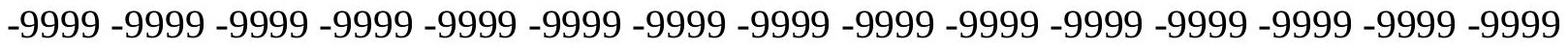
-9999 -9999 -9999 -9999 -9999 -9999 -9999 -9999 -9999 -9999 -9999 -9999 -9999 -9999 -9999 -9999 -9999 -9999 -9999 -9999 -9999 -9999 -9999 -9999-9999 -9999 -9999 -9999 -9999 -9999 -9999 -9999 -9999 -9999 -9999 -9999 -9999 -9999 -9999 -9999 -9999 -9999 -9999 -9999 -9999 -

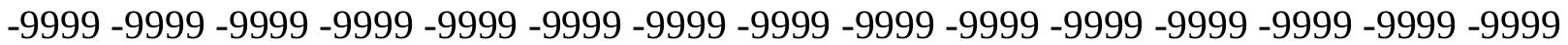
-9999 -9999 -9999 -9999 -9999 -9999 -9999 -9999 -9999 -9999 -9999 -9999 -9999 -9999 -9999 -9999 -9999 -9999 -9999 -9999 -9999 -9999 -9999 -9999 -9999 -9999 -9999 -9999 -9999 -9999 -9999 -9999 -9999 -9999 -9999 -9999 -9999 -9999 -9999 -9999 -9999 -9999 -9999 -9999 -9999 -9999 -9999 -9999 -9999 -9999 -9999 -9999 -9999 -9999 -9999 -9999 -9999 -9999 -9999 -9999 -9999 -9999 -9999 -9999 -9999 -9999 -9999 -9999 -9999 -9999 -9999 -9999 -9999 -9999 -9999 -9999 -9999 -9999 -9999 -9999 -9999 -9999 -9999 -9999 -9999 -9999 -9999 -9999 -9999 -9999 -9999 -9999 -9999 -9999 -9999 -9999 -9999 -9999 -9999 -9999 -9999 -9999 -9999 -9999 -9999 -9999 -9999 -9999 -9999 -9999 -9999 -9999 -9999 -9999 -9999 -9999 -9999 -9999 -9999 -

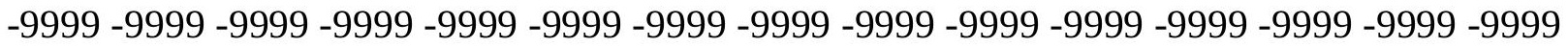
-9999 -9999 -9999 -9999 -9999 -9999 -9999 -9999 -9999 -9999 -9999 -9999 -9999 -9999 -9999 -9999 -9999 -9999 -9999 -9999 -9999 -9999 -9999 -9999 -9999 -9999 -9999 -9999 -9999 -9999 -9999 -9999 -9999 -9999 -9999 -9999 -9999 -9999 -9999 -9999 -9999 -9999 -9999 -9999 -9999 -

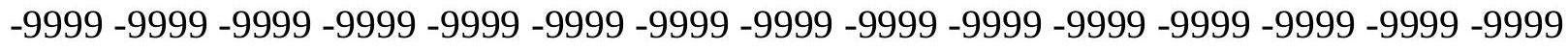

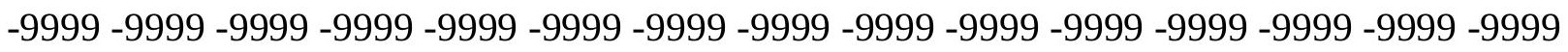
-9999 -9999 -9999 -9999 -9999 -9999 -9999 -9999 -9999 -9999 -9999 -9999 -9999 -9999 - 9999 -9999 -9999 -9999 -9999 -9999 -9999 -9999 -9999 -9999 -9999 -9999 -9999 -9999 -9999 -9999 -9999 -9999 -9999 -9999 -9999 -9999 -9999 -9999 -9999 -9999 -9999 -9999 -9999 -9999 -9999 -

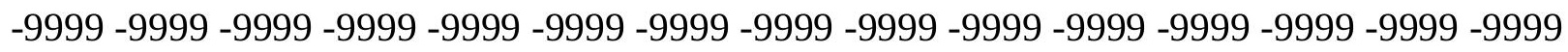
-9999 -9999 -9999 -9999 -9999 -9999 -9999 -9999 -9999 -9999 -9999 -9999 -9999 -9999 -9999 -9999 -9999 -9999 -9999 -9999 -9999 -9999 -9999 -9999 -9999 -9999 -9999 -9999 -9999 -9999 -

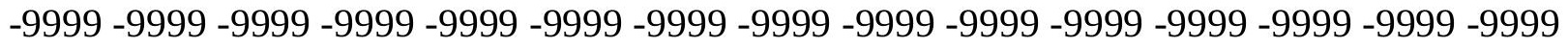
-9999 -9999 -9999 -9999 -9999 -9999 -9999 -9999 -9999 -9999 -9999 -9999 -9999 -9999 -9999 -9999 -9999 -9999 -9999 -9999 -9999 -9999 -9999 -9999 -9999 -9999 -9999 -9999 -9999 -999 -9999 -9999 -9999 -9999 -9999 -9999 -9999 -9999 -9999 -9999 -9999 -9999 -9999 -9999 -9999 -9999 -9999 -9999 -9999 -9999 -9999 -9999 -9999 -9999 -9999 -9999 -9999 -9999 -9999 -9999 -

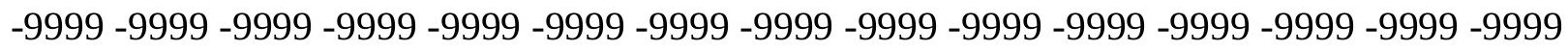

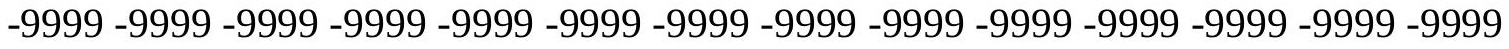
-9999 -9999 -9999 -9999 -9999 -9999 -9999 -9999 -9999 -9999 -9999 -9999 -9999 -9999 -9999

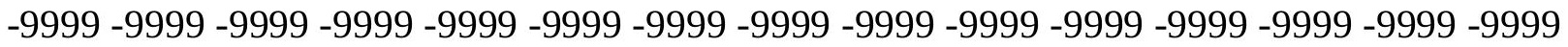

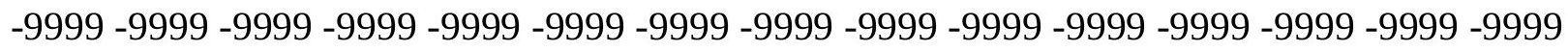

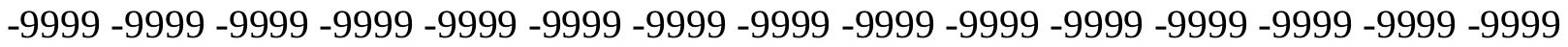

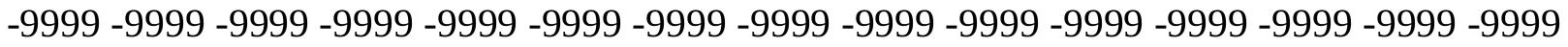
-9999 -9999 -9999 -9999 -9999 -9999 -9999 -9999 -9999 -9999 -9999 -9999 -9999 -9999 -9999 -

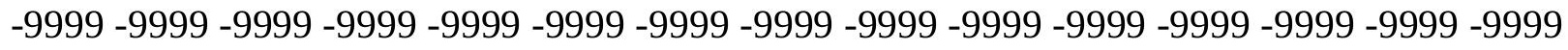

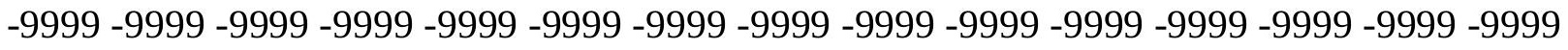
-9999 -9999 -9999 -9999 -9999 -9999 -9999 -9999 -9999 -9999 -9999 -9999 -9999 -9999 -9999 -9999 -9999 -9999 -9999 -9999 -9999 -9999 -9999 -9999-9999 -9999 -9999 -9999 -9999 -9999 -9999 -9999 -9999 -9999 -9999 -9999 -9999 -9999 -9999 -9999 -9999 -9999 -9999 -9999 -9999 -

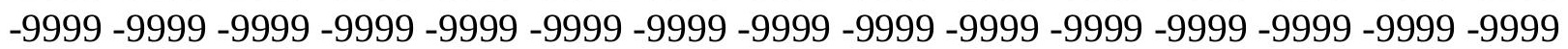


-9999 -9999 -9999 -9999 -9999 -9999 -9999 -9999 -9999 -9999 -9999 -9999 -9999 -9999 -9999 -9999 -9999 -9999 -9999 -9999 -9999 -9999 -9999 -9999 -9999 -9999 -9999 -9999 -9999 -9999 -

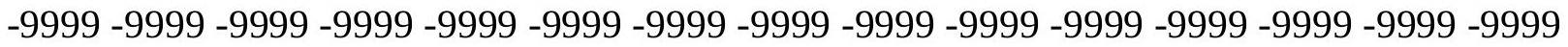
-9999 -9999 -9999 -9999 -9999 -9999 -9999 -9999 -9999 -9999 -9999 -9999 -9999 -9999 -9999 -9999 -9999 -9999 -9999 -9999 -9999 -9999 -9999 -9999-9999 -9999 -9999 -9999 -9999 -9999 -9999 -9999 -9999 -9999 -9999 -9999 -9999 -9999 -9999 -9999 -9999 -9999 -9999 -9999 -9999 -9999 -9999 -9999 -9999 -9999 -9999 -9999 -9999 -9999 -9999 -9999 -9999 -9999 -9999 -9999

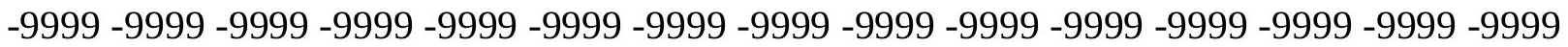

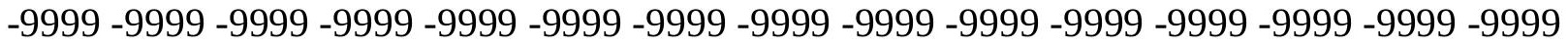
-9999 -9999 -9999 -9999 -9999 -9999 -9999 -9999 -9999 -9999 -9999 -9999 -9999 -9999 -9999 -9999 -9999 -9999 -9999 -9999 -9999 -9999 -9999 -9999 -9999 -9999 -9999 -9999 -9999 -9999 -9999 -9999 -9999 -9999 -9999 -9999 -9999 -9999 -9999 -9999 -9999 -9999 -9999 -9999 -9999 -9999 -9999 -9999 -9999 -9999 -9999 -9999 -9999 -9999 -9999 -9999 -9999 -9999 -9999 -9999 -9999 -9999 -9999 -9999 -9999 -9999 -9999 -9999 -9999 -9999 -9999 -9999 -9999 -9999 -9999 -9999 -9999 -9999 -9999 -9999 -9999 -9999 -9999 -9999 -9999 -9999 -9999 -9999 -9999

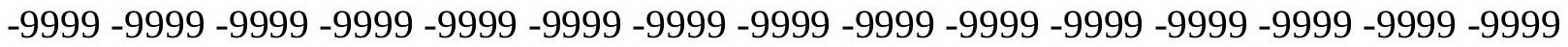
-9999 -9999 -9999 -9999 -9999 -9999 -9999 -9999 -9999 -9999 -9999 -9999 -9999 -9999 -9999 -9999 -9999 -9999 -9999 -9999 -9999 -9999 -9999 -9999 -9999 -9999 -9999 -9999 -9999 -9999 -9999 -9999 -9999 -9999 -9999 -9999 -9999 -9999 -9999 -9999 -9999 -9999 -9999 -9999 -9999 -

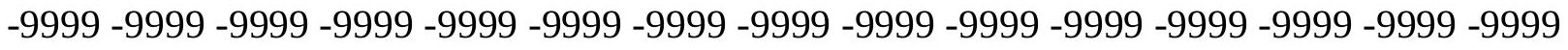

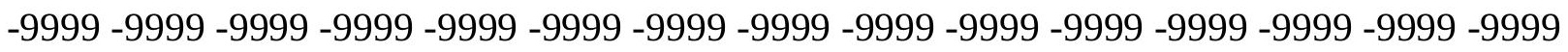
-9999 -9999 -9999 -9999 -9999 -9999 -9999 -9999 -9999 -9999 -9999 -9999 -9999 -9999 -9999 -9999 -9999 -9999 -9999 -9999 -9999 -9999 -9999 -9999 -9999 -9999 -9999 -9999 -9999 -9999 -9999 -9999 -9999 -9999 -9999 -9999 -9999 -9999 -9999 -9999 -9999 -9999 -9999 -9999 -9999 -

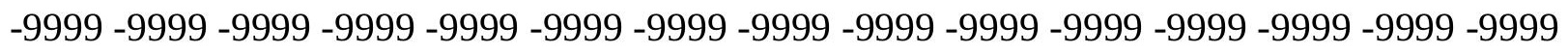
-9999 -9999 -9999 -9999 -9999 -9999 -9999 -9999 -9999 -9999 -9999 -9999 -9999 -9999 -9999 -9999 -9999 -9999 -9999 -9999 -9999 -9999 -9999 -9999 -9999 -9999 -9999 -9999 -9999 -9999 -

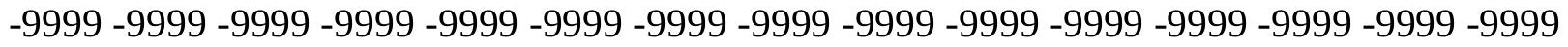
-9999 -9999 -9999 -9999 -9999 -9999 -9999 -9999 -9999 -9999 -9999 -9999 -9999 -9999 -9999 -9999 -9999 -9999 -9999 -9999 -9999 -9999 -9999 -9999 -9999 -9999 -9999 -9999 -9999 -999 -9999 -9999 -9999 -9999 -9999 -9999 -9999 -9999 -9999 -9999 -9999 -9999 -9999 -9999 -9999 -9999 -9999 -9999 -9999 -9999 -9999 -9999 -9999 -9999 -9999 -9999 -9999 -9999 -9999 -9999 -

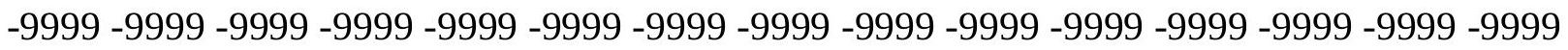

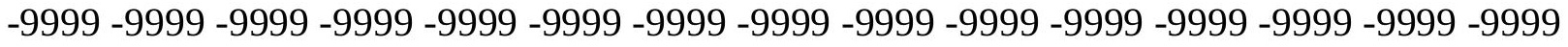

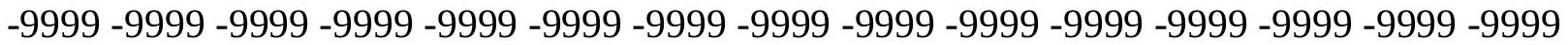

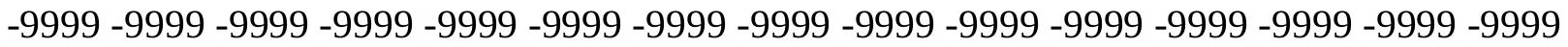

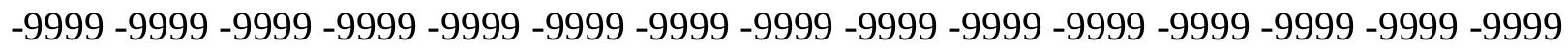

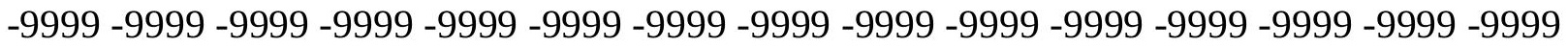
-9999 -9999 -9999 -9999 -9999 -9999 -9999 -9999 -9999 -9999 -9999 -9999 -9999 - 9999 - -999 -9999 -9999 -9999 -9999 -9999 -9999 -9999 -9999 -9999 -9999 -9999 -9999 -9999 -9999 - -999 -

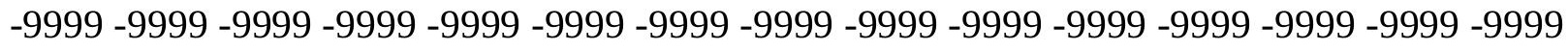

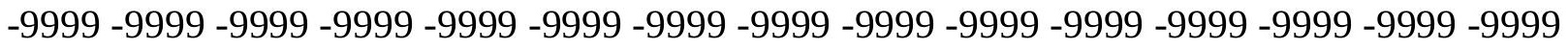
-9999 -9999 -9999 -9999 -9999 -9999 -9999 -9999 -9999 -9999 -9999 -9999 -9999 -9999 -9999 -9999 -9999 -9999 -9999 -9999 -9999 -9999 -9999 -9999-9999 -9999 -9999 -9999 -9999 -9999 -9999 -9999 -9999 -9999 -9999 -9999 -9999 -9999 -9999 -9999 -9999 -9999 -9999 -9999 -9999 -

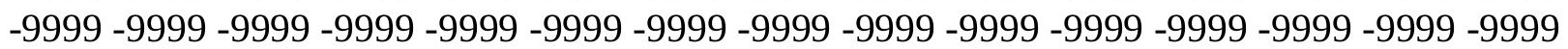


-9999 -9999 -9999 -9999 -9999 -9999 -9999 -9999 -9999 -9999 -9999 -9999 -9999 -9999 -9999 -9999 -9999 -9999 -9999 -9999 -9999 -9999 -9999 -9999 -9999 -9999 -9999 -9999 -9999 -9999 -9999 -9999 -9999 -9999 -9999 -9999 -9999 -9999 -9999 -9999 -9999 -9999 -9999 -9999 -9999 -9999 -9999 -9999 -9999 -9999 -9999 -9999 -9999 -9999 -9999 -9999 -9999 -9999 -9999 -9999 -9999 -9999 -9999 -9999 -9999 -9999 -9999 -9999 -9999 -9999 -9999 -9999 -9999 -9999 -9999 -9999 -9999 -9999 -9999 -9999 -9999 -9999 -9999 -9999 -9999 -9999 -9999 -9999 -9999 -9999 -9999 -9999 -9999 -9999 -9999 -9999 -9999 -9999 -9999 -9999 -9999 -9999 -9999 -9999 -9999 -

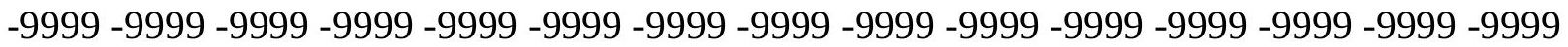
-9999 -9999 -9999 -9999 -9999 -9999 -9999 -9999 -9999 -9999 -9999 -9999 -9999 -9999 -9999 -9999 -9999 -9999 -9999 -9999 -9999 -9999 -9999 -9999 -9999 -9999 -9999 -9999 -9999 -9999 -

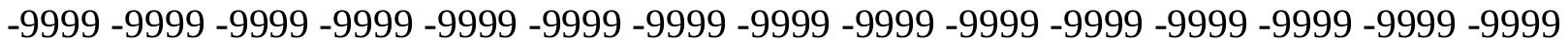
-9999 -9999 -9999 -9999 -9999 -9999 -9999 -9999 -9999 -9999 -9999 -9999 -9999 -9999 -9999 -9999 -9999 -9999 -9999 -9999 -9999 -9999 -9999 -9999 -9999 -9999 -9999 -9999 -9999 -9999 -9999 -9999 -9999 -9999 -9999 -9999 -9999 -9999 -9999 -9999 -9999 -9999 -9999 -9999 -9999 -9999 -9999 -9999 -9999 -9999 -9999 -9999 -9999 -9999 -9999 -9999 -9999 -9999 -9999 -9999

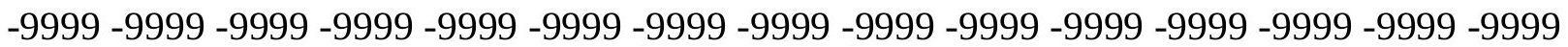
-9999 -9999 -9999 -9999 -9999 -9999 -9999 -9999 -9999 -9999 -9999 -9999 -9999 -9999 -9999 -9999 -9999 -9999 -9999 -9999 -9999 -9999 -9999 -9999 -9999 -9999 -9999 -9999 -9999 -9999 -9999 -9999 -9999 -9999 -9999 -9999 -9999 -9999 -9999 -9999 -9999 -9999 -9999 -9999 -9999 -9999 -9999 -9999 -9999 -9999 -9999 -9999 -9999 -9999 -9999 -9999 -9999 -9999 -9999 -9999 -9999 -9999 -9999 -9999 -9999 -9999 -9999 -9999 -9999 -9999 -9999 -9999 -9999 -9999 -9999 -9999 -9999 -9999 -9999 -9999 -9999 -9999 -9999 -9999 -9999 -9999 -9999 -9999 -9999 -9999 -9999 -9999 -9999 -9999 -9999 -9999 -9999 -9999 -9999 -9999 -9999 -9999 -9999 -9999 -9999 -9999 -9999 -9999 -9999 -9999 -9999 -9999 -9999 -9999 -9999 -9999 -9999 -9999 -9999 -9999 -9999 -9999 -9999 -9999 -9999 -9999 -9999 -9999 -9999 -9999 -9999 -9999 -9999 -9999 -9999 -9999 -9999 -9999 -9999 -9999 -9999 -9999 -9999 -9999 -9999 -9999 -9999 -9999 -9999 -9999 -9999 -9999 -9999 -9999 -9999 -9999 -9999 -9999 -9999 -9999 -9999 -9999 -9999 -9999 -9999 -9999 -9999 -9999 -9999 -9999 -9999 -9999 -9999 -9999 -9999 -9999 -9999 -9999 -9999

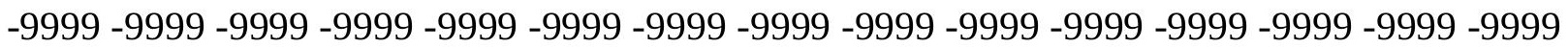
-9999 -9999 -9999 -9999 -9999 -9999 -9999 -9999 -9999 -9999 -9999 -9999 -9999 -9999 -9999 -9999 -9999 -9999 -9999 -9999 -9999 -9999 -9999 -9999 -9999 -9999 -9999 -9999 -9999 -9999 -

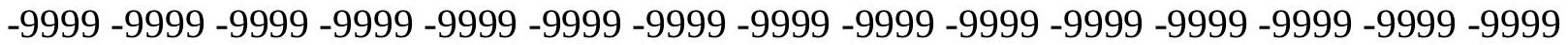
-9999 -9999 -9999 -9999 -9999 -9999 -9999 -9999 -9999 -9999 -9999 -9999 -9999 -9999 -9999 -9999 -9999 -9999 -9999 -9999 -9999 -9999 -9999 -9999 -9999 -9999 -9999 -9999 -9999 -9999 -9999 -9999 -9999 -9999 -9999 -9999 -9999 -9999 -9999 -9999 -9999 -9999 -9999 -9999 -9999 -9999 -9999 -9999 -9999 -9999 -9999 -9999 -9999 -9999 -9999 -9999 -9999 -9999 -9999 -9999 -9999 -9999 -9999 -9999 -9999 -9999 -9999 -9999 -9999 -9999 -9999 -9999 -9999 -9999 -9999

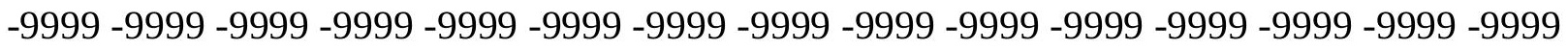
-9999 -9999 -9999 -9999 -9999 -9999 -9999 -9999 -9999 -9999 -9999 -9999 -9999 -9999 -9999 -9999 -9999 -9999 -9999 -9999 -9999 -9999 -9999 -9999 -9999 -9999 -9999 -9999 -9999 -9999 -9999 -9999 -9999 -9999 -9999 -9999 -9999 -9999 -9999 -9999 -9999 -9999 -9999 -9999 -9999 -999 -9999 -9999 -9999 -9999 -9999 -9999 -9999 -9999 -9999 -9999 -9999 -9999 -9999 -9999 -9999 -9999 -9999 -9999 -9999 -9999 -9999 -9999 -9999 -9999 -9999 -9999 -9999 -9999 -9999 -9999 -9999 -9999 -9999 -9999 -9999 -9999 -9999 -9999 -9999 -9999 -9999 -9999 -9999 -9999 -9999 -9999 -9999 -9999 -9999 -9999 -9999 -9999 -9999 -9999 -9999 -9999 -9999 -9999 -9999 -9999 -9999 -9999 -9999 -9999 -9999 -9999 -9999 -9999 -9999 -9999 -9999 -9999 -9999 -9999 
-9999 -9999 -9999 -9999 -9999 -9999 -9999 -9999 -9999 -9999 -9999 -9999 -9999 -9999 -9999 -9999 -9999 -9999 -9999 -9999 -9999 -9999 -9999 -9999 -9999 -9999 -9999 -9999 -9999 -9999 -

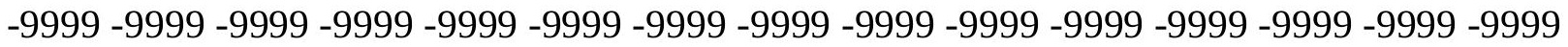
-9999 -9999 -9999 -9999 -9999 -9999 -9999 -9999 -9999 -9999 -9999 -9999 -9999 -9999 -9999 -9999 -9999 -9999 -9999 -9999 -9999 -9999 -9999 -9999-9999 -9999 -9999 -9999 -9999 -9999 -9999 -9999 -9999 -9999 -9999 -9999 -9999 -9999 -9999 -9999 -9999 -9999 -9999 -9999 -9999 -9999 -9999 -9999 -9999 -9999 -9999 -9999 -9999 -9999 -9999 -9999 -9999 -9999 -9999 -9999

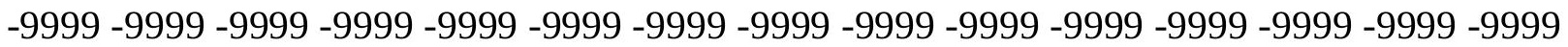

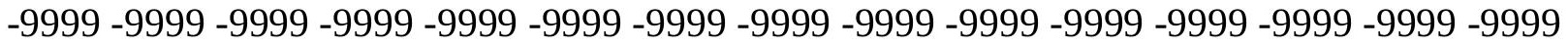
-9999 -9999 -9999 -9999 -9999 -9999 -9999 -9999 -9999 -9999 -9999 -9999 -9999 -9999 -9999 -9999 -9999 -9999 -9999 -9999 -9999 -9999 -9999 -9999 -9999 -9999 -9999 -9999 -9999 -9999 -9999 -9999 -9999 -9999 -9999 -9999 -9999 -9999 -9999 -9999 -9999 -9999 -9999 -9999 -9999 -9999 -9999 -9999 -9999 -9999 -9999 -9999 -9999 -9999 -9999 -9999 -9999 -9999 -9999 -9999 -

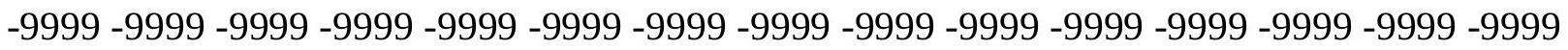
-9999 -9999 -9999 -9999 -9999 -9999 -9999 -9999 -9999 -9999 -9999 -9999 -9999 -9999 -9999 -

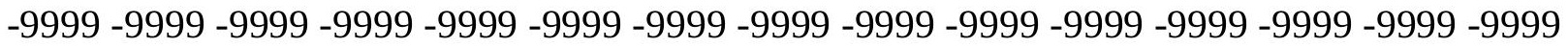
-9999 -9999 -9999 -9999 -9999 -9999 -9999 -9999 -9999 -9999 -9999 -9999 -9999 -9999 -9999 -9999 -9999 -9999 -9999 -9999 -9999 -9999 -9999 -9999 -9999 -9999 -9999 -9999 -9999 -9999 -9999 -9999 -9999 -9999 -9999 -9999 -9999 -9999 -9999 -9999 -9999 -9999 -9999 -9999 -9999 -

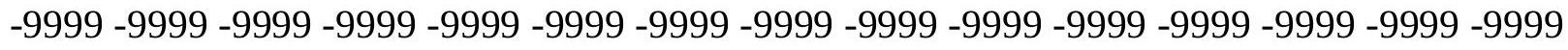

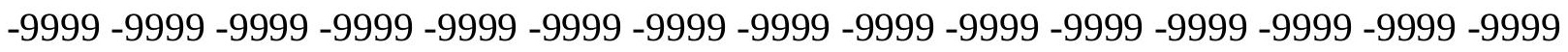

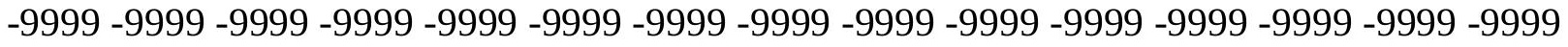
-9999 -9999 -9999 -9999 -9999 -9999 -9999 -9999 -9999 -9999 -9999 -9999 -9999 -9999 -9999 -9999 -9999 -9999 -9999 -9999 -9999 -9999 -9999 -9999 -9999 -9999 -9999 -9999 -9999 -9999 -

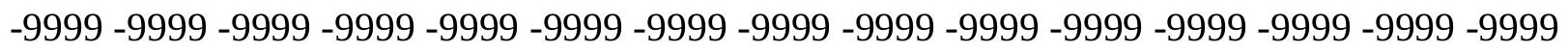
-9999 -9999 -9999 -9999 -9999 -9999 -9999 -9999 -9999 -9999 -9999 -9999 -9999 -9999 -9999 -9999 -9999 -9999 -9999 -9999 -9999 -9999 -9999 -9999 -9999 -9999 -9999 -9999 -9999 -

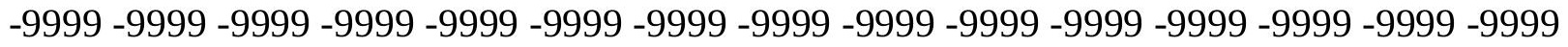
-9999 -9999 -9999 -9999 -9999 -9999 -9999 -9999 -9999 -9999 -9999 -9999 -9999 -9999 -9999 -9999 -9999 -9999 -9999 -9999 -9999 -9999 -9999 -9999 -9999 -9999 -9999 -9999 -9999 -999 -

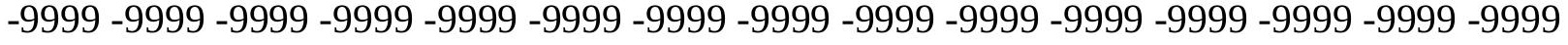
-9999 -9999 -9999 -9999 -9999 -9999 -9999 -9999 -9999 -9999 -9999 -9999 -9999 -9999 -9999 -

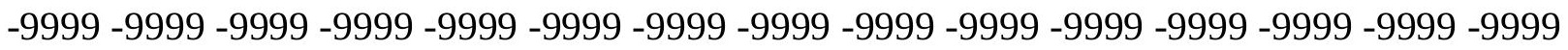

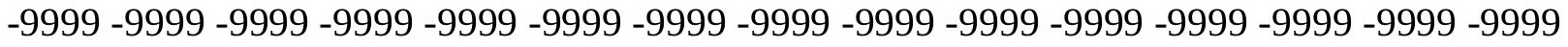

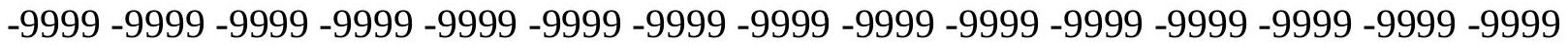
-9999 -9999 -9999 -9999 -9999 -9999 -9999 -9999 -9999 -9999 -9999 -9999 -9999 -9999 -9999

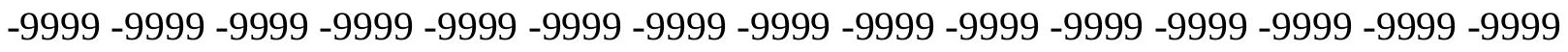

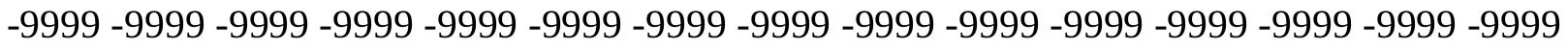
-9999 -9999 -9999 -9999 -9999 -9999 -9999 -9999 -9999 -9999 -9999 -9999 -9999 - 9999 - -999 -9999 -9999 -9999 -9999 -9999 -9999 -9999 -9999 -9999 -9999 -9999 -9999 -9999 -9999 -9999 -

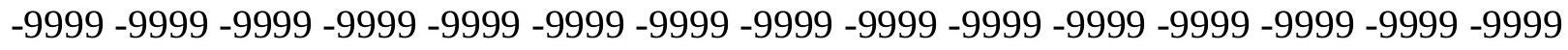

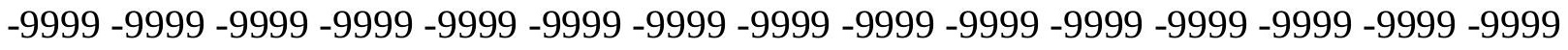
-9999 -9999 -9999 -9999 -9999 -9999 -9999 -9999 -9999 -9999 -9999 -9999 -9999 -9999 -9999 -9999 -9999 -9999 -9999 -9999 -9999 -9999 -9999 -9999-9999 -9999 -9999 -9999 -9999 -9999 -9999 -9999 -9999 -9999 -9999 -9999 -9999 -9999 -9999 -9999 -9999 -9999 -9999 -9999 -9999 -

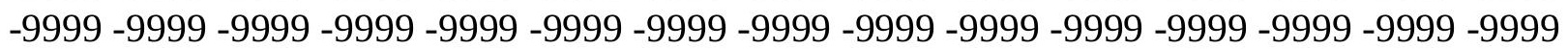


-9999 -9999 -9999 -9999 -9999 -9999 -9999 -9999 -9999 -9999 -9999 -9999 -9999 -9999 -9999 -9999 -9999 -9999 -9999 -9999 -9999 -9999 -9999 -9999 -9999 -9999 -9999 -9999 -9999 -9999 -9999 -9999 -9999 -9999 -9999 -9999 -9999 -9999 -9999 -9999 -9999 -9999 -9999 -9999 - 9999 -9999 -9999 -9999 -9999 -9999 -9999 -9999 -9999 -9999 -9999 -9999 -9999 -9999 -9999 -9999 -9999 -9999 -9999 -9999 -9999 -9999 -9999 -9999 -9999 -9999 -9999 -9999 -9999 -9999 - -9999 -9999 -9999 -9999 -9999 -9999 -9999 -9999 -9999 -9999 -9999 -9999 -9999 -9999 -9999 -9999 -9999 -9999 -9999 -9999 -9999 -9999 -9999 -9999 -9999 -9999 -9999 -9999 -9999 -9999

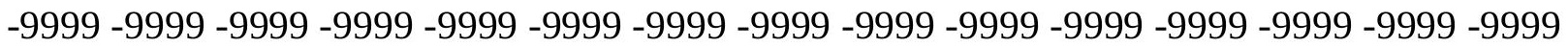

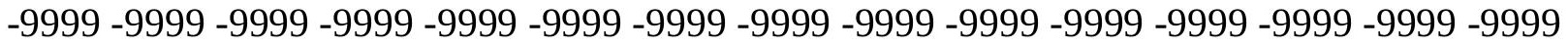
-9999 -9999 -9999 -9999 -9999 -9999 -9999 -9999 -9999 -9999 -9999 -9999 -9999 -9999 -9999

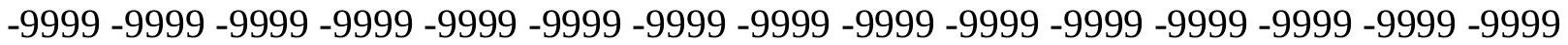
-9999 -9999 -9999 -9999 -9999 -9999 -9999 -9999 -9999 -9999 -9999 -9999 -9999 -9999 -9999 -9999 -9999 -9999 -9999 -9999 -9999 -9999 -9999 -9999 -9999 -9999 -9999 -9999 -9999 -9999 -9999 -9999 -9999 -9999 -9999 -9999 -9999 -9999 -9999 -9999 -9999 -9999 -9999 -9999 - -9999 -9999 -9999 -9999 -9999 -9999 -9999 -9999 -9999 -9999 -9999 -9999 -9999 -9999 -9999 -9999

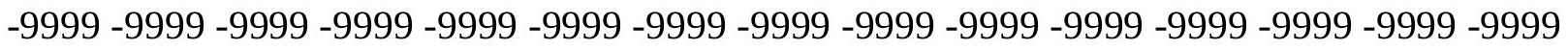
-9999 -9999 -9999 -9999 -9999 -9999 -9999 -9999 -9999 -9999 -9999 -9999 -9999 -9999 -9999 -9999 -9999 -9999 -9999 -9999 -9999 -9999 -9999 -9999 -9999 -9999 -9999 -9999 -9999 -9999 -9999 -9999 -9999 -9999 -9999 -9999 -9999 -9999 -9999 -9999 -9999 -9999 -9999 -9999 -9999 -

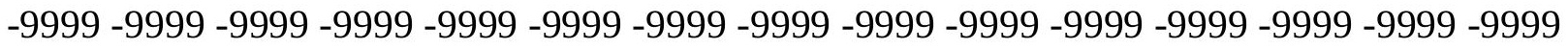
-9999 -9999 -9999 -9999 -9999 -9999 -9999 -9999 -9999 -9999 -9999 -9999 -9999 -9999 -9999 -999 -9999 -9999 -9999 -9999 -9999 -9999 -9999 -9999 -9999 -9999 -9999 -9999 -9999 -9999 -9999 -9999 -9999 -9999 -9999 -9999 -9999 -9999 -9999 -9999 -9999 -9999 -9999 -9999 -9999 -9999 -9999 -9999 -9999 -9999 -9999 -9999 -9999 -9999 -9999 -9999 -9999 -9999 -9999 -9999 -9999 -9999 -9999 -9999 -9999 -9999 -9999 -9999 -9999 -9999 -9999 -9999 -9999 -9999 -9999 -9999 -9999 -9999 -9999 -9999 -9999 -9999 -9999 -9999 -9999 -9999 -9999 -9999 -9999 -9999 -9999 -9999 -9999 -9999 -9999 -9999 -9999 -9999 -9999 -9999 -9999 -9999 -9999 -9999 -9999 -9999 -9999 -9999 -9999 -9999 -9999 -9999 -9999 -9999 -9999 -9999 -9999 -9999 -9999 -9999 -9999 -9999 -9999 -9999 -9999 -9999 -9999 -9999 -9999 -9999 -9999 -9999 -9999 -9999 -9999 -9999 -9999 -9999 -9999 -9999 -9999 -9999 -9999 -9999 -9999 -9999 -9999 -9999 -9999 -9999 -999 -9999 -9999 -9999 -9999 -9999 -9999 -9999 -9999 -9999 -9999 -9999 -9999 -9999 -9999 -9999 -9999 -9999 -9999 -9999 -9999 -9999 -9999 -9999 -9999 -9999 -9999 -9999 -9999 -9999 -

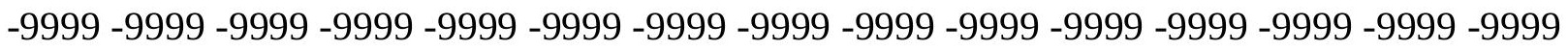

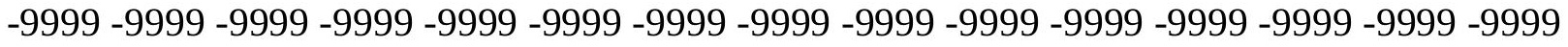

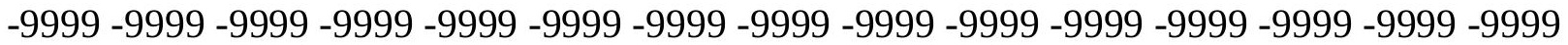
-9999 -9999 -9999 -9999 -9999 -9999 -9999 -9999 -9999 -9999 -9999 -9999 -9999 -9999 -9999 -

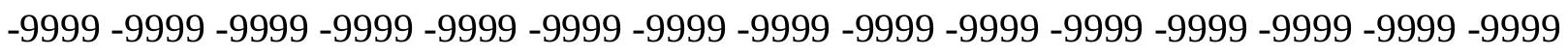

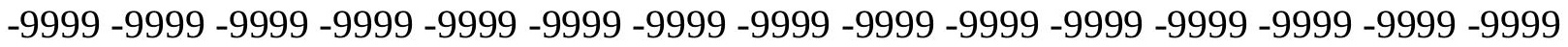

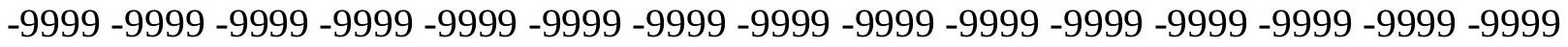
-9999 -9999 -9999 -9999 -9999 -9999 -9999 -9999 -9999 -9999 -9999 -9999 -9999 -9999 -9999 -

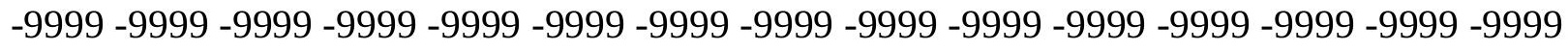

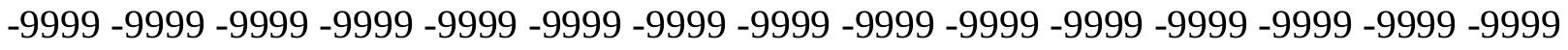
-9999 -9999 -9999 -9999 -9999 -9999 -9999 -9999 -9999 -9999 -9999 -9999 -9999 -9999 -9999 -9999 -9999 -9999 -9999 -9999 -9999 -9999 -9999 -9999-9999 -9999 -9999 -9999 -9999 -9999 -9999 -9999 -9999 -9999 -9999 -9999 -9999 -9999 -9999 -9999 -9999 -9999 -9999 -9999 -9999 -

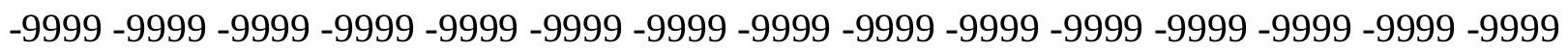


-9999 -9999 -9999 -9999 -9999 -9999 -9999 -9999 -9999 -9999 -9999 -9999 -9999 -9999 -9999 -9999 -9999 -9999 -9999 -9999 -9999 -9999 -9999 -9999 -9999 -9999 -9999 -9999 -9999 -9999 -

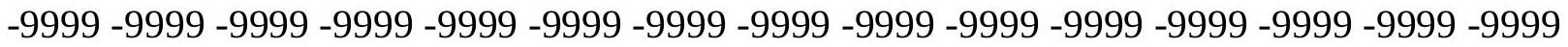
-9999 -9999 -9999 -9999 -9999 -9999 -9999 -9999 -9999 -9999 -9999 -9999 -9999 -9999 -9999 -9999 -9999 -9999 -9999 -9999 -9999 -9999 -9999 -9999-9999 -9999 -9999 -9999 -9999 -9999 -9999 -9999 -9999 -9999 -9999 -9999 -9999 -9999 -9999 -9999 -9999 -9999 -9999 -9999 -9999 -9999 -9999 -9999 -9999 -9999 -9999 -9999 -9999 -9999 -9999 -9999 -9999 -9999 -9999 -9999

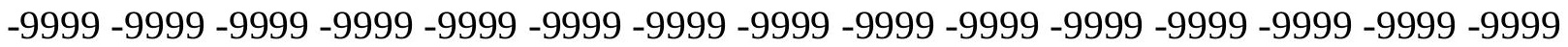

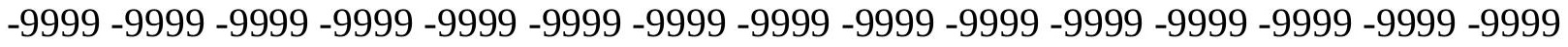
-9999 -9999 -9999 -9999 -9999 -9999 -9999 -9999 -9999 -9999 -9999 -9999 -9999 -9999 -9999 -9999 -9999 -9999 -9999 -9999 -9999 -9999 -9999 -9999 -9999 -9999 -9999 -9999 -9999 -9999 -9999 -9999 -9999 -9999 -9999 -9999 -9999 -9999 -9999 -9999 -9999 -9999 -9999 -9999 -9999 -9999 -9999 -9999 -9999 -9999 -9999 -9999 -9999 -9999 -9999 -9999 -9999 -9999 -9999 -9999 -9999 -9999 -9999 -9999 -9999 -9999 -9999 -9999 -9999 -9999 -9999 -9999 -9999 - 9999 -9999 -9999 -9999 -9999 -9999 -9999 -9999 -9999 -9999 -9999 -9999 -9999 -9999 -9999 -9999

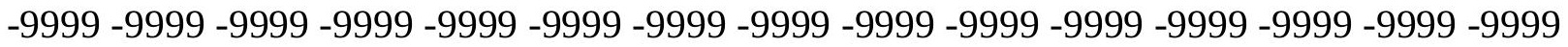
-9999 -9999 -9999 -9999 -9999 -9999 -9999 -9999 -9999 -9999 -9999 -9999 -9999 -9999 -9999 -9999 -9999 -9999 -9999 -9999 -9999 -9999 -9999 -9999 -9999 -9999 -9999 -9999 -9999 -9999 -9999 -9999 -9999 -9999 -9999 -9999 -9999 -9999 -9999 -9999 -9999 -9999 -9999 -9999 -9999 -

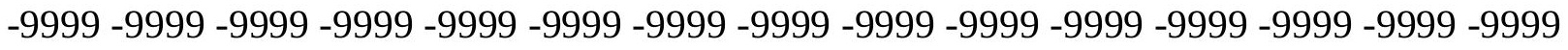

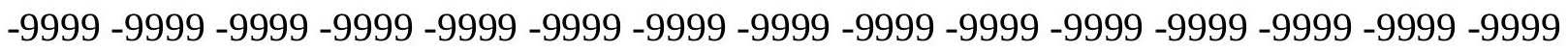
-9999 -9999 -9999 -9999 -9999 -9999 -9999 -9999 -9999 -9999 -9999 -9999 -9999 -9999 -9999 -9999 -9999 -9999 -9999 -9999 -9999 -9999 -9999 -9999 -9999 -9999 -9999 -9999 -9999 -9999 -9999 -9999 -9999 -9999 -9999 -9999 -9999 -9999 -9999 -9999 -9999 -9999 -9999 -9999 -9999 -

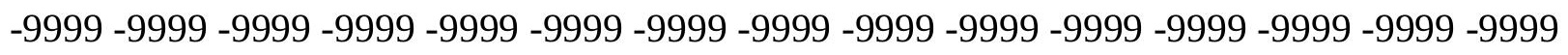
-9999 -9999 -9999 -9999 -9999 -9999 -9999 -9999 -9999 -9999 -9999 -9999 -9999 -9999 -9999 -9999 -9999 -9999 -9999 -9999 -9999 -9999 -9999 -9999 -9999 -9999 -9999 -9999 -9999 -9999 -

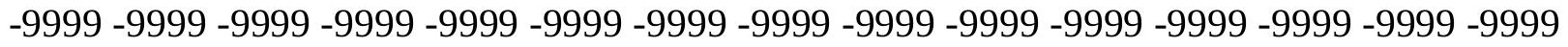
-9999 -9999 -9999 -9999 -9999 -9999 -9999 -9999 -9999 -9999 -9999 -9999 -9999 -9999 -9999 -9999 -9999 -9999 -9999 -9999 -9999 -9999 -9999 -9999 -9999 -9999 -9999 -9999 -9999 -999 -9999 -9999 -9999 -9999 -9999 -9999 -9999 -9999 -9999 -9999 -9999 -9999 -9999 -9999 -9999 -9999 -9999 -9999 -9999 -9999 -9999 -9999 -9999 -9999 -9999 -9999 -9999 -9999 -9999 -9999 -

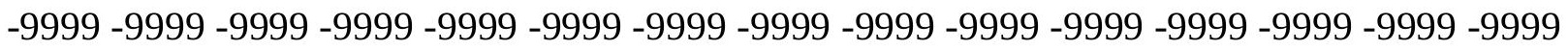

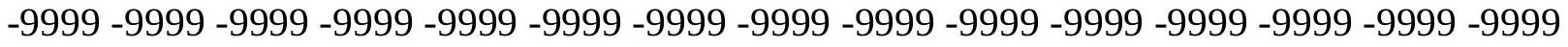

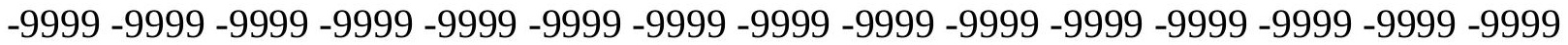

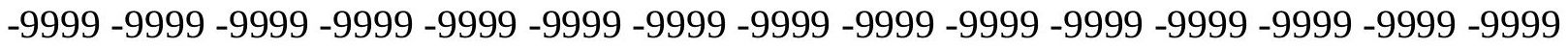

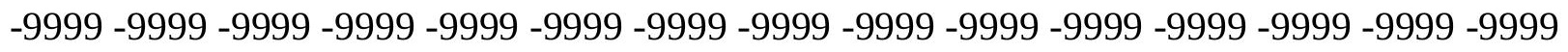

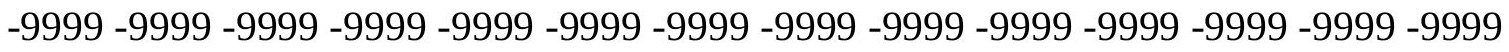
-9999 -9999 -9999 -9999 -9999 -9999 -9999 -9999 -9999 -9999 -9999 -9999 -9999 -9999 -9999 -9999 -9999 -9999 -9999 -9999 -9999 -9999 -9999 -9999 -9999 -9999 -9999 -9999 -9999 -9999 -

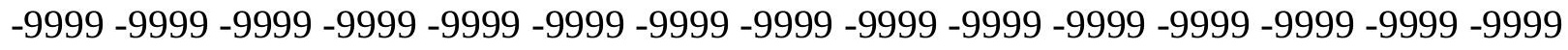

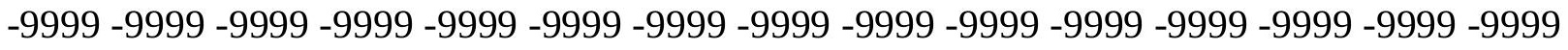
-9999 -9999 -9999 -9999 -9999 -9999 -9999 -9999 -9999 -9999 -9999 -9999 -9999 -9999 -9999 -9999 -9999 -9999 -9999 -9999 -9999 -9999 -9999 -9999-9999 -9999 -9999 -9999 -9999 -9999 -9999 -9999 -9999 -9999 -9999 -9999 -9999 -9999 -9999 -9999 -9999 -9999 -9999 -9999 -9999 -

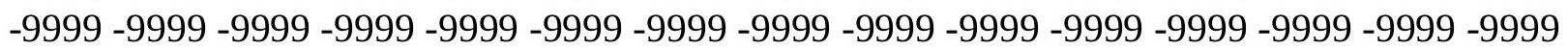


-9999 -9999 -9999 -9999 -9999 -9999 -9999 -9999 -9999 -9999 -9999 -9999 -9999 -9999 -9999 -9999 -9999 -9999 -9999 -9999 -9999 -9999 -9999 -9999 -9999 -9999 -9999 -9999 -9999 -9999 -9999 -9999 -9999 -9999 -9999 -9999 -9999 -9999 -9999 -9999 -9999 -9999 -9999 -9999 - 9999 -9999 -9999 -9999 -9999 -9999 -9999 -9999 -9999 -9999 -9999 -9999 -9999 -9999 -9999 -9999 -9999 -9999 -9999 -9999 -9999 -9999 -9999 -9999 -9999 -9999 -9999 -9999 -9999 -9999 -9999 -9999 -9999 -9999 -9999 -9999 -9999 -9999 -9999 -9999 -9999 -9999 -9999 -9999 -9999 -9999 -9999 -9999 -9999 -9999 -9999 -9999 -9999 -9999 -9999 -9999 -9999 -9999 -9999 -9999 -9999

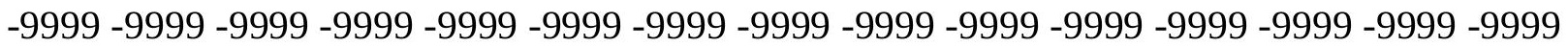
-9999 -9999 -9999 -9999 -9999 -9999 -9999 -9999 -9999 -9999 -9999 -9999 -9999 -9999 -9999 -9999 -9999 -9999 -9999 -9999 -9999 -9999 -9999 -9999 -9999 -9999 -9999 -9999 -9999 -9999

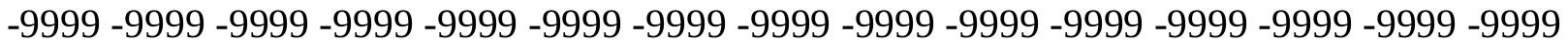
-9999 -9999 -9999 -9999 -9999 -9999 -9999 -9999 -9999 -9999 -9999 -9999 -9999 -9999 -9999 -9999 -9999 -9999 -9999 -9999 -9999 -9999 -9999 -9999 -9999 -9999 -9999 -9999 -9999 -9999 -

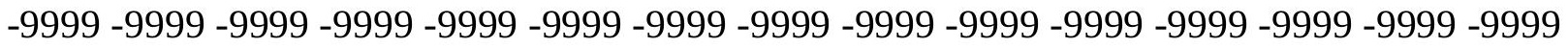
-9999 -9999 -9999 -9999 -9999 -9999 -9999 -9999 -9999 -9999 -9999 -9999 -9999 -9999 -9999

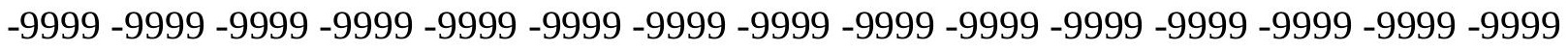
-9999 -9999 -9999 -9999 -9999 -9999 -9999 -9999 -9999 -9999 -9999 -9999 -9999 -9999 -9999 -9999 -9999 -9999 -9999 -9999 -9999 -9999 -9999 -9999 -9999 -9999 -9999 -9999 -9999 - -999 -9999 -9999 -9999 -9999 -9999 -9999 -9999 -9999 -9999 -9999 -9999 -9999 -9999 -9999 -9999 -9999 -9999 -9999 -9999 -9999 -9999 -9999 -9999 -9999 -9999 -9999 -9999 -9999 -9999 -9999 -9999 -9999 -9999 -9999 -9999 -9999 -9999 -9999 -9999 -9999 -9999 -9999 -9999 -9999 -9999 -999 -9999 -9999 -9999 -9999 -9999 -9999 -9999 -9999 -9999 -9999 -9999 -9999 -9999 -9999 -9999 -9999 -9999 -9999 -9999 -9999 -9999 -9999 -9999 -9999 -9999 -9999 -9999 -9999 -9999 -9999 -9999 -9999 -9999 -9999 -9999 -9999 -9999 -9999 -9999 -9999 -9999 -9999 -9999 -9999 -9999 -9999 -9999 -9999 -9999 -9999 -9999 -9999 -9999 -9999 -9999 -9999 -9999 -9999 -9999 -9999 -9999 -9999 -9999 -9999 -9999 -9999 -9999 -9999 -9999 -9999 -9999 -9999 -9999 -9999 -9999 -9999 -9999 -9999 -9999 -9999 -9999 -9999 -9999 -9999 -9999 -9999 -9999 -9999 -9999 -9999 -9999 -9999 -9999 -9999 -9999 -9999 -9999 -9999 -9999 -9999 -9999 -9999 -9999 -9999 -9999 -9999 -9999 -9999 -9999 -9999 -9999 -9999 -9999 -9999 -9999 -9999 -9999 -9999 -9999 -9999 -9999 -9999 -9999 -9999 -9999 -9999 -9999 -9999 -9999 -9999 -9999 -9999 -9999 -9999 -999 -9999 -9999 -9999 -9999 -9999 -9999 -9999 -9999 -9999 -9999 -9999 -9999 -9999 -9999 -9999 -9999 -9999 -9999 -9999 -9999 -9999 -9999 -9999 -9999 -9999 -9999 -9999 -9999 -9999 -9999 -

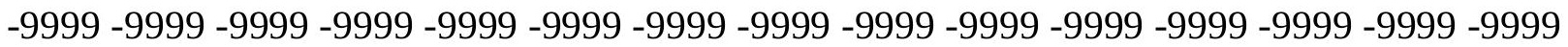

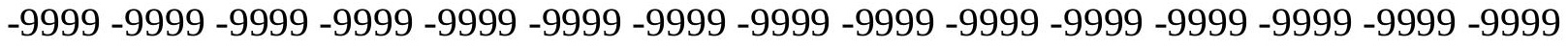

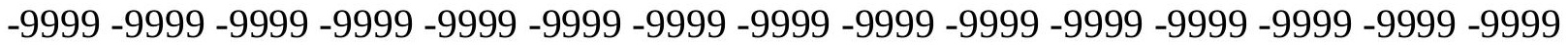
-9999 -9999 -9999 -9999 -9999 -9999 -9999 -9999 -9999 -9999 -9999 -9999 -9999 -9999 -9999

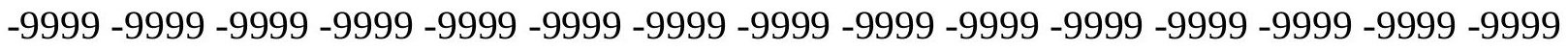

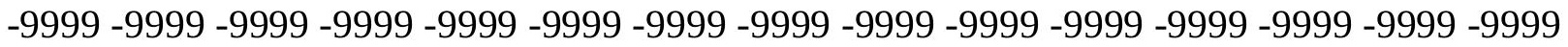

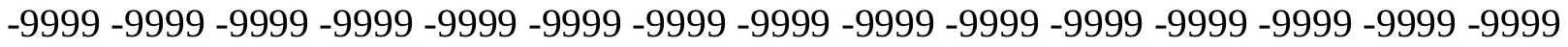
-9999 -9999 -9999 -9999 -9999 -9999 -9999 -9999 -9999 -9999 -9999 -9999 -9999 -9999 -9999 -

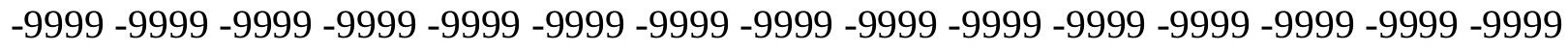

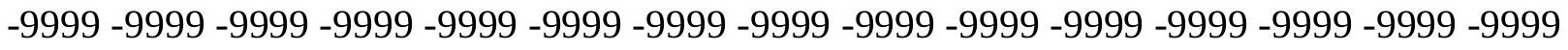
-9999 -9999 -9999 -9999 -9999 -9999 -9999 -9999 -9999 -9999 -9999 -9999 -9999 -9999 -9999 -9999 -9999 -9999 -9999 -9999 -9999 -9999 -9999 -9999 -9999 -9999 -9999 -9999 - -9999 -9999 -9999 -9999 -9999 -9999 -9999 -9999 -9999 -9999 -9999 -9999 -9999 -9999 -9999 -9999 -

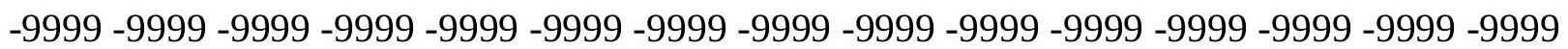


-9999 -9999 -9999 -9999 -9999 -9999 -9999 -9999 -9999 -9999 -9999 -9999 -9999 -9999 -9999 -9999 -9999 -9999 -9999 -9999 -9999 -9999 -9999 -9999 -9999 -9999 -9999 -9999 -9999 -9999 -9999 -9999 -9999 -9999 -9999 -9999 -9999 -9999 -9999 -9999 -9999 -9999 -9999 -9999 - 9999 -9999 -9999 -9999 -9999 -9999 -9999 -9999 -9999 -9999 -9999 -9999 -9999 -9999 -9999 -9999 -9999 -9999 -9999 -9999 -9999 -9999 -9999 -9999 -9999-9999 -9999 -9999 -9999 -9999 -9999 -9999 -9999 -9999 -9999 -9999 -9999 -9999 -9999 -9999 -9999 -9999 -9999 -9999 -9999 -9999 -9999 -9999 -9999 -9999 -9999 -9999 -9999 -9999 -9999 -9999 -9999 -9999 -9999 -9999 -9999

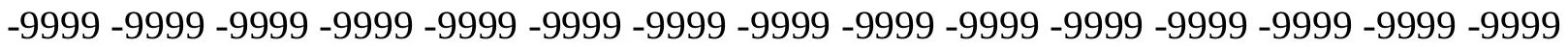

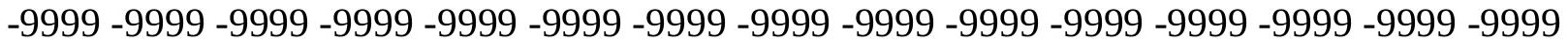
-9999 -9999 -9999 -9999 -9999 -9999 -9999 -9999 -9999 -9999 -9999 -9999 -9999 -9999 -9999

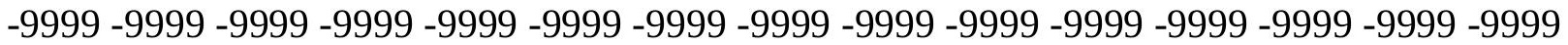
-9999 -9999 -9999 -9999 -9999 -9999 -9999 -9999 -9999 -9999 -9999 -9999 -9999 -9999 -9999 -9999 -9999 -9999 -9999 -9999 -9999 -9999 -9999 -9999 -9999 -9999 -9999 -9999 -9999 -9999 -

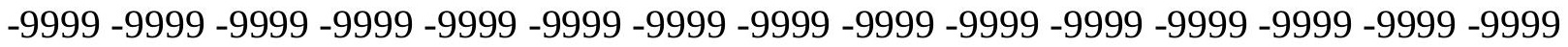
-9999 -9999 -9999 -9999 -9999 -9999 -9999 -9999 -9999 -9999 -9999 -9999 -9999 -9999 -9999

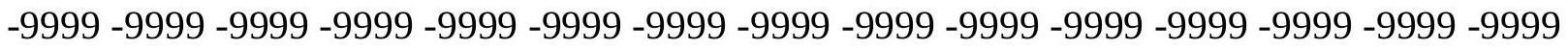
-9999 -9999 -9999 -9999 -9999 -9999 -9999 -9999 -9999 -9999 -9999 -9999 -9999 -9999 -9999 -9999 -9999 -9999 -9999 -9999 -9999 -9999 -9999 -9999 -9999 -9999 -9999 -9999 -9999 -9999 -9999 -9999 -9999 -9999 -9999 -9999 -9999 -9999 -9999 -9999 -9999 -9999 -9999 -9999 -9999 -9999 -9999 -9999 -9999 -9999 -9999 -9999 -9999 -9999 -9999 -9999 -9999 -9999 -9999 -9999 -9999 -9999 -9999 -9999 -9999 -9999 -9999 -9999 -9999 -9999 -9999 -9999 -9999 -9999 -9999 -999 -9999 -9999 -9999 -9999 -9999 -9999 -9999 -9999 -9999 -9999 -9999 -9999 -9999 -9999 -9999 -9999 -9999 -9999 -9999 -9999 -9999 -9999 -9999 -9999 -9999 -9999 -9999 -9999 -9999 -9999 -9999 -9999 -9999 -9999 -9999 -9999 -9999 -9999 -9999 -9999 -9999 -9999 -9999 -9999 -9999 -9999 -9999 -9999 -9999 -9999 -9999 -9999 -9999 -9999 -9999 -9999 -9999 -9999 -9999 -9999 -9999 -9999 -9999 -9999 -9999 -9999 -9999 -9999 -9999 -9999 -9999 -9999 -9999 -9999 -9999 -9999 -9999 -9999 -9999 -9999 -9999 -9999 -9999 -9999 -9999 -9999 -9999 -9999 -9999 -9999 -9999 -9999 -9999 -9999 -9999 -9999 -9999 -9999 -9999 -9999 -9999 -9999 -9999 -9999 -9999 -9999 -9999 -9999 -9999 -9999 -9999 -9999 -9999 -9999 -9999 -9999 -9999 -9999 -9999 -9999 -9999 -9999 -9999 -9999 -9999 -9999 -9999 -9999 -9999 -9999 -9999 -9999 -9999 -999 -9999 -9999 -9999 -9999 -9999 -9999 -9999 -9999 -9999 -9999 -9999 -9999 -9999 -9999 -9999 -9999 -9999 -9999 -9999 -9999 -9999 -9999 -9999 -9999 -9999 -9999 -9999 -9999 -9999 -9999 -

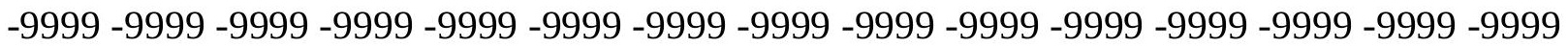

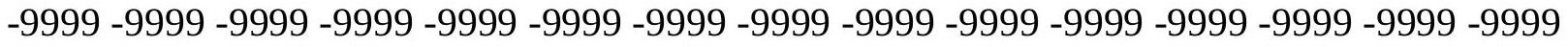

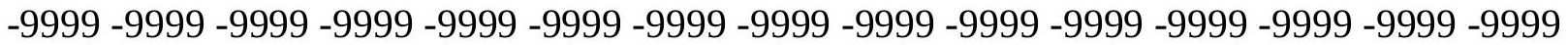
-9999 -9999 -9999 -9999 -9999 -9999 -9999 -9999 -9999 -9999 -9999 -9999 -9999 -9999 -9999

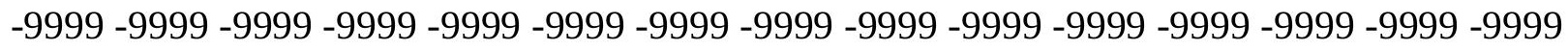

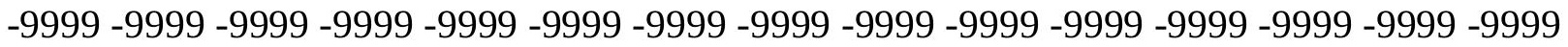
-9999 -9999 -9999 -9999 -9999 -9999 -9999 -9999 -9999 -9999 -9999 -9999 -9999 -9999 -9999 -9999 -9999 -9999 -9999 -9999 -9999 -9999 -9999 -9999 -9999 -9999 -9999 -9999 -9999 -9999 -

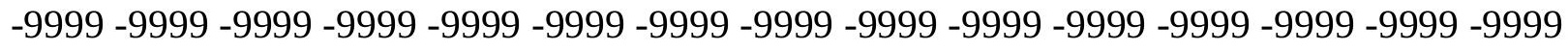

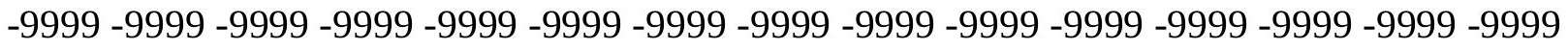
-9999 -9999 -9999 -9999 -9999 -9999 -9999 -9999 -9999 -9999 -9999 -9999 -9999 -9999 -9999 -9999 -9999 -9999 -9999 -9999 -9999 -9999 -9999 -9999-9999 -9999 -9999 -9999 -9999 -9999 -9999 -9999 -9999 -9999 -9999 -9999 -9999 -9999 -9999 -9999 -9999 -9999 -9999 -9999 -9999 -

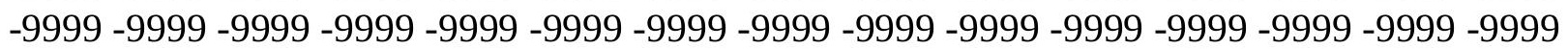


-9999 -9999 -9999 -9999 -9999 -9999 -9999 -9999 -9999 -9999 -9999 -9999 -9999 -9999 -9999 -9999 -9999 -9999 -9999 -9999 -9999 -9999 -9999 -9999 -9999 -9999 -9999 -9999 -9999 -9999 -9999 -9999 -9999 -9999 -9999 -9999 -9999 -9999 -9999 -9999 -9999 -9999 -9999 -9999 - 9999 -9999 -9999 -9999 -9999 -9999 -9999 -9999 -9999 -9999 -9999 -9999 -9999 -9999 -9999

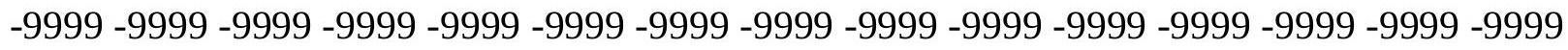
-9999 -9999 -9999 -9999 -9999 -9999 -9999 -9999 -9999 -9999 -9999 -9999 -9999 -9999 -9999 -9999 -9999 -9999 -9999 -9999 -9999 -9999 -9999 -9999 -9999 -9999 -9999 -9999 -9999 -9999

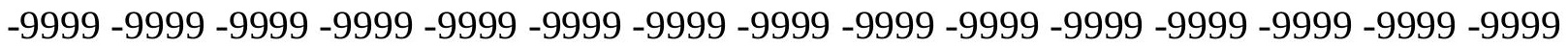

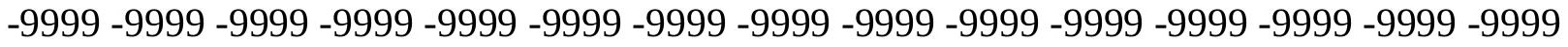
-9999 -9999 -9999 -9999 -9999 -9999 -9999 -9999 -9999 -9999 -9999 -9999 -9999 -9999 -9999 -9999 -9999 -9999 -9999 -9999 -9999 -9999 -9999 -9999 -9999 -9999 -9999 -9999 -9999 -9999 -9999 -9999 -9999 -9999 -9999 -9999 -9999 -9999 -9999 -9999 -9999 -9999 -9999 -9999 -9999 -9999 -9999 -9999 -9999 -9999 -9999 -9999 -9999 -9999 -9999 -9999 -9999 -9999 -9999 -9999 -

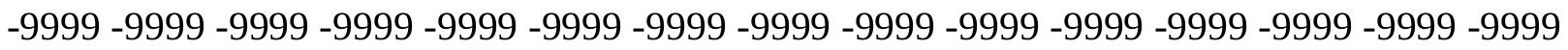
-9999 -9999 -9999 -9999 -9999 -9999 -9999 -9999 -9999 -9999 -9999 -9999 -9999 -9999 -9999 -

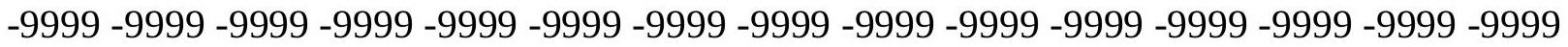
-9999 -9999 -9999 -9999 -9999 -9999 -9999 -9999 -9999 -9999 -9999 -9999 -9999 -9999 -9999 -9999 -9999 -9999 -9999 -9999 -9999 -9999 -9999 -9999 -9999 -9999 -9999 -9999 -9999 -9999 -9999 -9999 -9999 -9999 -9999 -9999 -9999 -9999 -9999 -9999 -9999 -9999 -9999 -9999 -9999 -

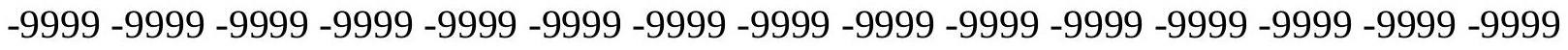
-9999 -9999 -9999 -9999 -9999 -9999 -9999 -9999 -9999 -9999 -9999 -9999 -9999 -9999 -9999

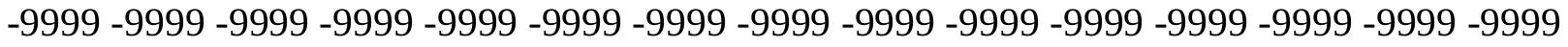
-9999 -9999 -9999 -9999 -9999 -9999 -9999 -9999 -9999 -9999 -9999 -9999 -9999 -9999 -9999 -9999 -9999 -9999 -9999 -9999 -9999 -9999 -9999 -9999 -9999 -9999 -9999 -9999 -9999 -9999 -9999 -9999 -9999 -9999 -9999 -9999 -9999 -9999 -9999 -9999 -9999 -9999 -9999 -9999 -9999 -9999 -9999 -9999 -9999 -9999 -9999 -9999 -9999 -9999 -9999 -9999 -9999 -9999 -9999 -9999 -9999 -9999 -9999 -9999 -9999 -9999 -9999 -9999 -9999 -9999 -9999 -9999 -9999 -9999 -9999 -9999 -9999 -9999 -9999 -9999 -9999 -9999 -9999 -9999 -9999 -9999 -9999 -9999 -9999 -9999 -9999 -9999 -9999 -9999 -9999 -9999 -9999 -9999 -9999 -9999 -9999 -9999 -9999 -9999 -9999 -9999 -9999 -9999 -9999 -9999 -9999 -9999 -9999 -9999 -9999 -9999 -9999 -9999 -9999 -9999 -9999 -9999 -9999 -9999 -9999 -9999 -9999 -9999 -9999 -9999 -9999 -9999 -9999 -9999 -9999 -9999 -9999 -9999 -9999 -9999 -9999 -9999 -9999 -9999 -9999 -9999 -9999 -9999 -9999 -

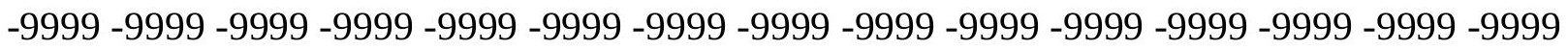

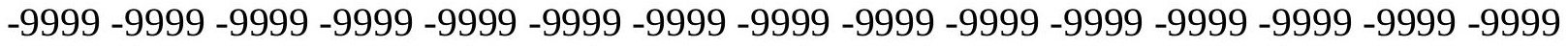
-9999 -9999 -9999 -9999 -9999 -9999 -9999 -9999 -9999 -9999 -9999 -9999 -9999 -9999 -9999 -

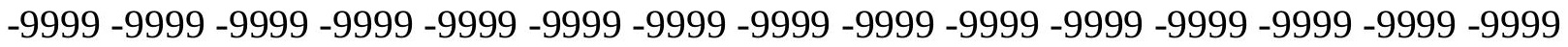

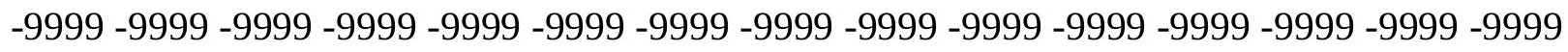

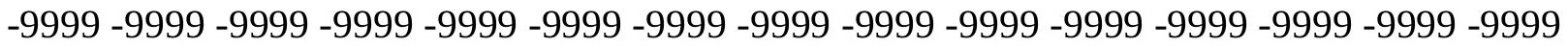

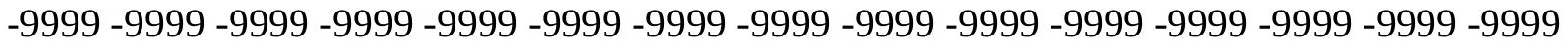
-9999 -9999 -9999 -9999 -9999 -9999 -9999 -9999 -9999 -9999 -9999 -9999 -9999 -9999 -9999 -

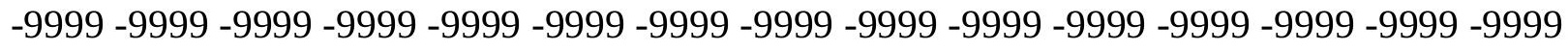

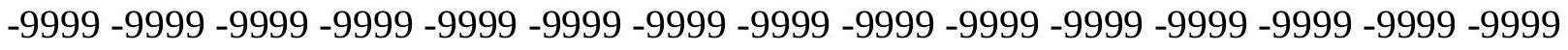
-9999 -9999 -9999 -9999 -9999 -9999 -9999 -9999 -9999 -9999 -9999 -9999 -9999 -9999 -9999 -9999 -9999 -9999 -9999 -9999 -9999 -9999 -9999 -9999-9999 -9999 -9999 -9999 -9999 -9999 -9999 -9999 -9999 -9999 -9999 -9999 -9999 -9999 -9999 -9999 -9999 -9999 -9999 -9999 -9999 -

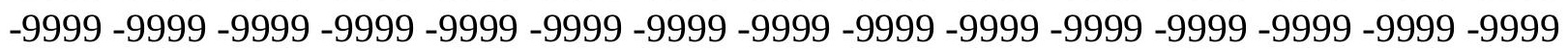


-9999 -9999 -9999 -9999 -9999 -9999 -9999 -9999 -9999 -9999 -9999 -9999 -9999 -9999 -9999 -9999 -9999 -9999 -9999 -9999 -9999 -9999 -9999 -9999 -9999 -9999 -9999 -9999 -9999 -9999 -9999 -9999 -9999 -9999 -9999 -9999 -9999 -9999 -9999 -9999 -9999 -9999 -9999 -9999 - 9999 -9999 -9999 -9999 -9999 -9999 -9999 -9999 -9999 -9999 -9999 -9999 -9999 -9999 -9999 -9999 -9999 -9999 -9999 -9999 -9999 -9999 -9999 -9999 -9999 -9999 -9999 -9999 -9999 -9999 -9999 -9999 -9999 -9999 -9999 -9999 -9999 -9999 -9999 -9999 -9999 -9999 -9999 -9999 -9999 -9999 -9999 -9999 -9999 -9999 -9999 -9999 -9999 -9999 -9999 -9999 -9999 -9999 -9999 -9999 -9999

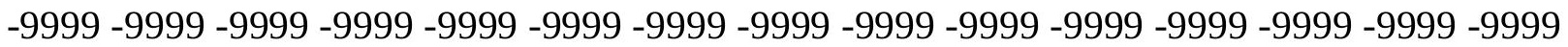

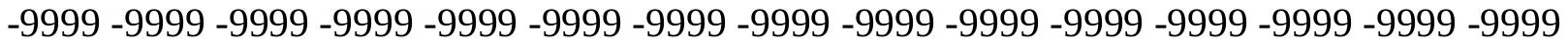
-9999 -9999 -9999 -9999 -9999 -9999 -9999 -9999 -9999 -9999 -9999 -9999 -9999 -9999 -9999 -9999 -9999 -9999 -9999 -9999 -9999 -9999 -9999 -9999 -9999 -9999 -9999 -9999 -9999 -9999 -9999 -9999 -9999 -9999 -9999 -9999 -9999 -9999 -9999 -9999 -9999 -9999 -9999 -9999 -9999 -9999 -9999 -9999 -9999 -9999 -9999 -9999 -9999 -9999 -9999 -9999 -9999 -9999 -9999 -9999 -9999 -9999 -9999 -9999 -9999 -9999 -9999 -9999 -9999 -9999 -9999 -9999 -9999 -9999 -9999 -9999 -9999 -9999 -9999 -9999 -9999 -9999 -9999 -9999 -9999 -9999 -9999 -9999 -9999 -

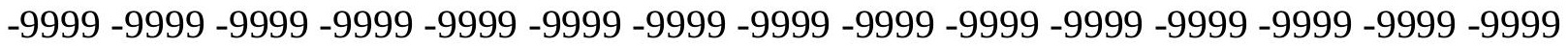
-9999 -9999 -9999 -9999 -9999 -9999 -9999 -9999 -9999 -9999 -9999 -9999 -9999 -9999 -9999 -9999 -9999 -9999 -9999 -9999 -9999 -9999 -9999 -9999 -9999 -9999 -9999 -9999 -9999 -9999 -9999 -9999 -9999 -9999 -9999 -9999 -9999 -9999 -9999 -9999 -9999 -9999 -9999 -9999 -9999 -9999 -9999 -9999 -9999 -9999 -9999 -9999 -9999 -9999 -9999 -9999 -9999 -9999 -9999 -9999 -9999 -9999 -9999 -9999 -9999 -9999 -9999 -9999 -9999 -9999 -9999 -9999 -9999 -9999 -9999 -999 -9999 -9999 -9999 -9999 -9999 -9999 -9999 -9999 -9999 -9999 -9999 -9999 -9999 -9999 -9999 -9999 -9999 -9999 -9999 -9999 -9999 -9999 -9999 -9999 -9999 -9999 -9999 -9999 -9999 -9999 -9999 -9999 -9999 -9999 -9999 -9999 -9999 -9999 -9999 -9999 -9999 -9999 -9999 -9999 -9999 -9999 -9999 -9999 -9999 -9999 -9999 -9999 -9999 -9999 -9999 -9999 -9999 -9999 -9999 -9999 -9999 -9999 -9999 -9999 -9999 -9999 -9999 -9999 -9999 -9999 -9999 -9999 -9999 -9999 -9999 -9999 -9999 -9999 -9999 -9999 -9999 -9999 -9999 -9999 -9999 -9999 -9999 -9999 -9999 -9999 -9999 -9999 -9999 -9999 -9999 -9999 -9999 -9999 -9999 -9999 -9999 -9999 -9999 -9999 -9999 -9999 -9999 -9999 -9999 -9999 -9999 -9999 -9999 -9999 -9999 -9999 -9999 -9999 -9999 -9999 -9999 -9999 -9999 -9999 -9999 -9999 -9999 -9999 -9999 -9999 -9999 -9999 -9999 -9999 -999 -9999 -9999 -9999 -9999 -9999 -9999 -9999 -9999 -9999 -9999 -9999 -9999 -9999 -9999 -9999 -9999 -9999 -9999 -9999 -9999 -9999 -9999 -9999 -9999 -9999 -9999 -9999 -9999 -9999 -9999 -

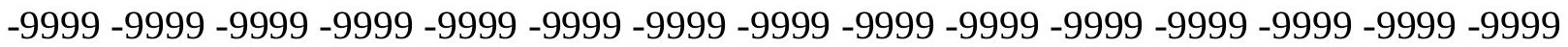

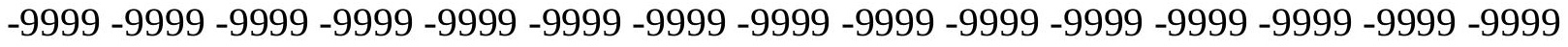

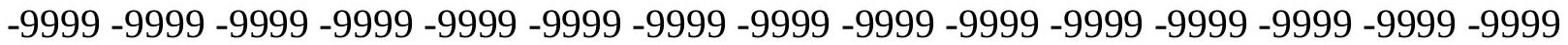
-9999 -9999 -9999 -9999 -9999 -9999 -9999 -9999 -9999 -9999 -9999 -9999 -9999 -9999 -9999 -9999 -9999 -9999 -9999 -9999 -9999 -9999 -9999 -9999 -9999 -9999 -9999 -9999 -9999 -

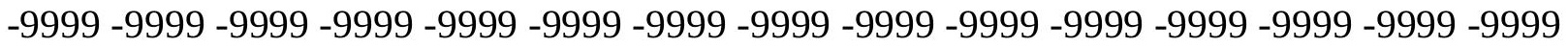
-9999 -9999 -9999 -9999 -9999 -9999 -9999 -9999 -9999 -9999 -9999 -9999 -9999 -9999 -9999 -9999 -9999 -9999 -9999 -9999 -9999 -9999 -9999 -9999 -9999 -9999 -9999 -9999 -9999 -9999 -

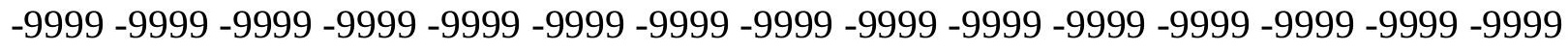

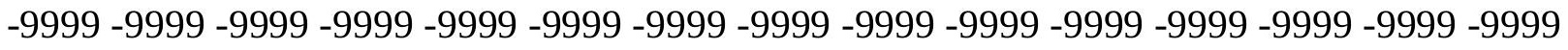
-9999 -9999 -9999 -9999 -9999 -9999 -9999 -9999 -9999 -9999 -9999 -9999 -9999 -9999 -9999 -9999 -9999 -9999 -9999 -9999 -9999 -9999 -9999 -9999-9999 -9999 -9999 -9999 -9999 -9999 -9999 -9999 -9999 -9999 -9999 -9999 -9999 -9999 -9999 -9999 -9999 -9999 -9999 -9999 -9999 -

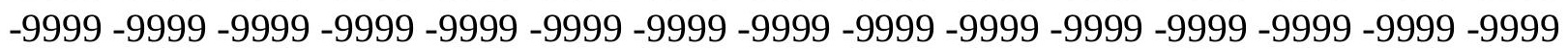


-9999 -9999 -9999 -9999 -9999 -9999 -9999 -9999 -9999 -9999 -9999 -9999 -9999 -9999 -9999 -9999 -9999 -9999 -9999 -9999 -9999 -9999 -9999 -9999 -9999 -9999 -9999 -9999 -9999 -9999 -

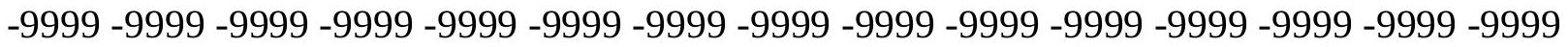
-9999 -9999 -9999 -9999 -9999 -9999 -9999 -9999 -9999 -9999 -9999 -9999 -9999 -9999 -9999 -9999 -9999 -9999 -9999 -9999 -9999 -9999 -9999 -9999-9999 -9999 -9999 -9999 -9999 -9999 -9999 -9999 -9999 -9999 -9999 -9999 -9999 -9999 -9999 -9999 -9999 -9999 -9999 -9999 -9999 -9999 -9999 -9999 -9999 -9999 -9999 -9999 -9999 -9999 -9999 -9999 -9999 -9999 -9999 -9999

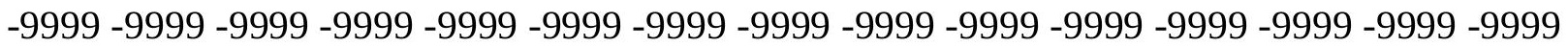

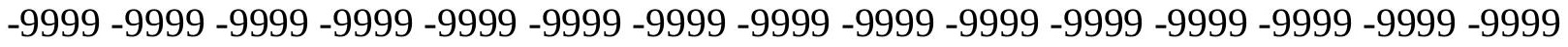
-9999 -9999 -9999 -9999 -9999 -9999 -9999 -9999 -9999 -9999 -9999 -9999 -9999 -9999 -9999 -9999 -9999 -9999 -9999 -9999 -9999 -9999 -9999 -9999 -9999 -9999 -9999 -9999 -9999 -9999 -9999 -9999 -9999 -9999 -9999 -9999 -9999 -9999 -9999 -9999 -9999 -9999 -9999 -9999 -9999 -9999 -9999 -9999 -9999 -9999 -9999 -9999 -9999 -9999 -9999 -9999 -9999 -9999 -9999 -9999 -9999 -9999 -9999 -9999 -9999 -9999 -9999 -9999 -9999 -9999 -9999 -9999 -9999 -9999 -9999 -9999 -9999 -9999 -9999 -9999 -9999 -9999 -9999 -9999 -9999 -9999 -9999 -9999 -9999 -9999 -

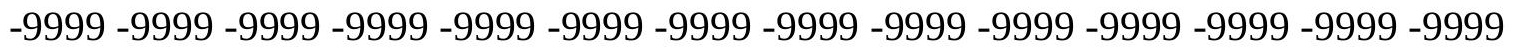
-9999 -9999 -9999 -9999 -9999 -9999 -9999 -9999 -9999 -9999 -9999 -9999 -9999 -9999 -9999 -9999 -9999 -9999 -9999 -9999 -9999 -9999 -9999 -9999 -9999 -9999 -9999 -9999 -9999 -9999 -9999 -9999 -9999 -9999 -9999 -9999 -9999 -9999 -9999 -9999 -9999 -9999 -9999 -9999 -9999 -

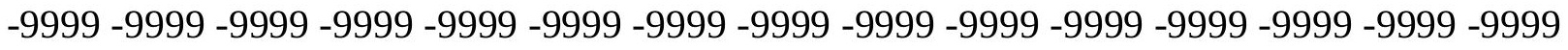

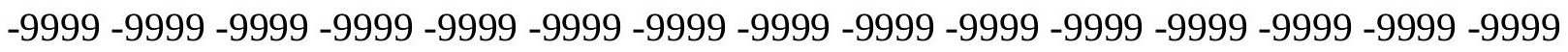
-9999 -9999 -9999 -9999 -9999 -9999 -9999 -9999 -9999 -9999 -9999 -9999 -9999 -9999 - 9999 -9999 -9999 -9999 -9999 -9999 -9999 -9999 -9999 -9999 -9999 -9999 -9999 -9999 -9999 -9999 -9999 -9999 -9999 -9999 -9999 -9999 -9999 -9999 -9999 -9999 -9999 -9999 -9999 -9999 -9999 -

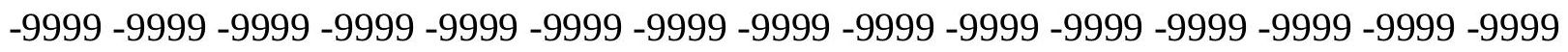
-9999 -9999 -9999 -9999 -9999 -9999 -9999 -9999 -9999 -9999 -9999 -9999 -9999 -9999 -9999 -9999 -9999 -9999 -9999 -9999 -9999 -9999 -9999 -9999 -9999 -9999 -9999 -9999 -9999 -9999 -

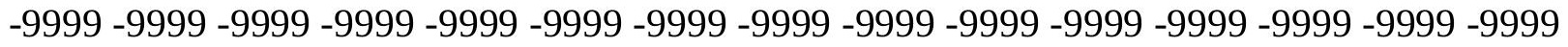
-9999 -9999 -9999 -9999 -9999 -9999 -9999 -9999 -9999 -9999 -9999 -9999 -9999 -9999 -9999 -9999 -9999 -9999 -9999 -9999 -9999 -9999 -9999 -9999 -9999 -9999 -9999 -9999 -9999 -999 -

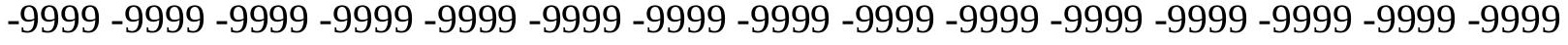
-9999 -9999 -9999 -9999 -9999 -9999 -9999 -9999 -9999 -9999 -9999 -9999 -9999 -9999 -9999 -

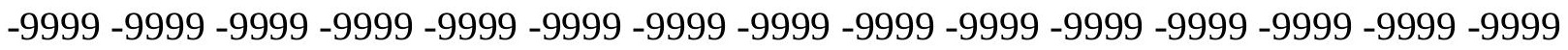

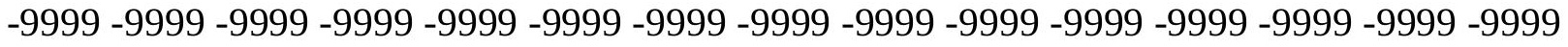

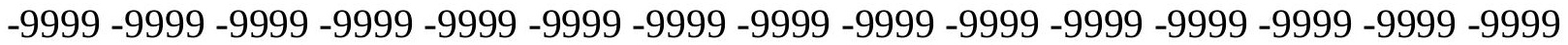
-9999 -9999 -9999 -9999 -9999 -9999 -9999 -9999 -9999 -9999 -9999 -9999 -9999 -9999 -9999 -

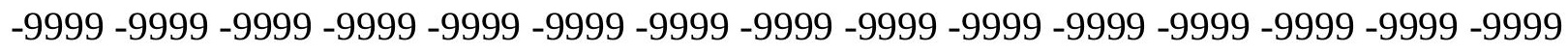

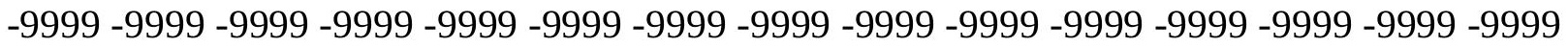
-9999 -9999 -9999 -9999 -9999 -9999 -9999 -9999 -9999 -9999 -9999 -9999 -9999 - 9999 - -999 -9999 -9999 -9999 -9999 -9999 -9999 -9999 -9999 -9999 -9999 -9999 -9999 -9999 -9999 -9999 -

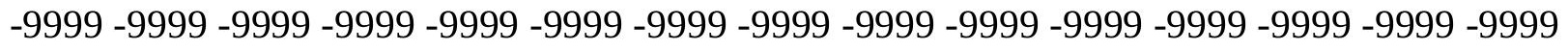

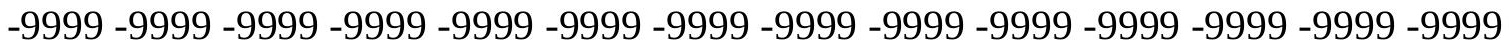
-9999 -9999 -9999 -9999 -9999 -9999 -9999 -9999 -9999 -9999 -9999 -9999 -9999 -9999 -9999 -9999 -9999 -9999 -9999 -9999 -9999 -9999 -9999 -9999-9999 -9999 -9999 -9999 -9999 -9999 -9999 -9999 -9999 -9999 -9999 -9999 -9999 -9999 -9999 -9999 -9999 -9999 -9999 -9999 -9999 -

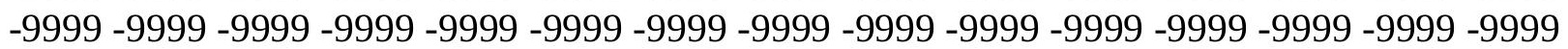


-9999 -9999 -9999 -9999 -9999 -9999 -9999 -9999 -9999 -9999 -9999 -9999 -9999 -9999 -9999 -9999 -9999 -9999 -9999 -9999 -9999 -9999 -9999 -9999 -9999 -9999 -9999 -9999 -9999 -9999 -

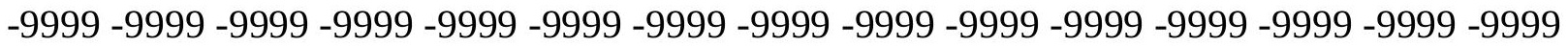
-9999 -9999 -9999 -9999 -9999 -9999 -9999 -9999 -9999 -9999 -9999 -9999 -9999 -9999 -9999 -9999 -9999 -9999 -9999 -9999 -9999 -9999 -9999 -9999-9999 -9999 -9999 -9999 -9999 -9999 -9999 -9999 -9999 -9999 -9999 -9999 -9999 -9999 -9999 -9999 -9999 -9999 -9999 -9999 -9999 -9999 -9999 -9999 -9999 -9999 -9999 -9999 -9999 -9999 -9999 -9999 -9999 -9999 -9999 -9999

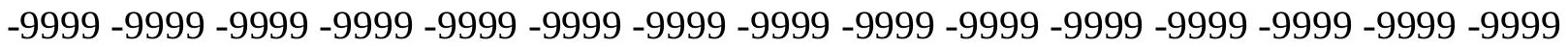

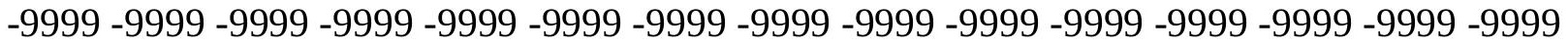
-9999 -9999 -9999 -9999 -9999 -9999 -9999 -9999 -9999 -9999 -9999 -9999 -9999 -9999 -9999 -9999 -9999 -9999 -9999 -9999 -9999 -9999 -9999 -9999 -9999 -9999 -9999 -9999 -9999 -9999 -9999 -9999 -9999 -9999 -9999 -9999 -9999 -9999 -9999 -9999 -9999 -9999 -9999 -9999 -9999 -9999 -9999 -9999 -9999 -9999 -9999 -9999 -9999 -9999 -9999 -9999 -9999 -9999 -9999 -9999 -

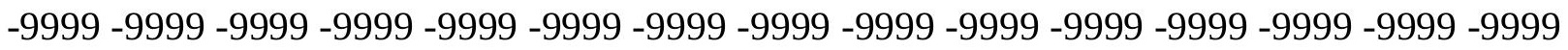
-9999 -9999 -9999 -9999 -9999 -9999 -9999 -9999 -9999 -9999 -9999 -9999 -9999 -9999 -9999 -

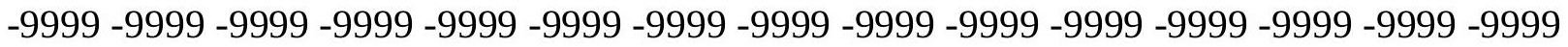
-9999 -9999 -9999 -9999 -9999 -9999 -9999 -9999 -9999 -9999 -9999 -9999 -9999 -9999 -9999 -9999 -9999 -9999 -9999 -9999 -9999 -9999 -9999 -9999 -9999 -9999 -9999 -9999 -9999 -9999 -9999 -9999 -9999 -9999 -9999 -9999 -9999 -9999 -9999 -9999 -9999 -9999 -9999 -9999 -9999 -

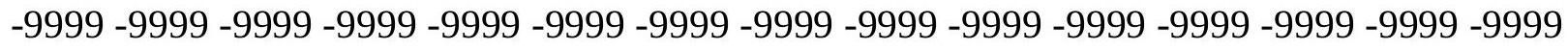

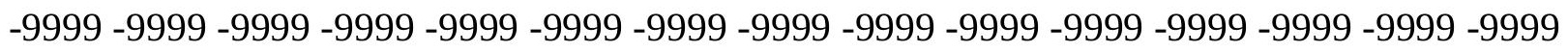
-9999 -9999 -9999 -9999 -9999 -9999 -9999 -9999 -9999 -9999 -9999 -9999 -9999 -9999 -9999 -9999 -9999 -9999 -9999 -9999 -9999 -9999 -9999 -9999 -9999 -9999 -9999 -9999 -9999 -9999 -9999 -9999 -9999 -9999 -9999 -9999 -9999 -9999 -9999 -9999 -9999 -9999 -9999 -9999 -

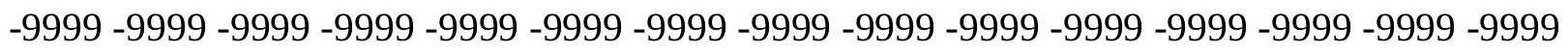
-9999 -9999 -9999 -9999 -9999 -9999 -9999 -9999 -9999 -9999 -9999 -9999 -9999 -9999 -9999 -9999 -9999 -9999 -9999 -9999 -9999 -9999 -9999 -9999 -9999 -9999 -9999 -9999 -9999 -9999 -

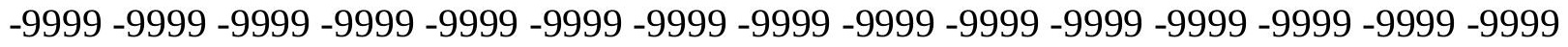
-9999 -9999 -9999 -9999 -9999 -9999 -9999 -9999 -9999 -9999 -9999 -9999 -9999 -9999 -9999 -9999 -9999 -9999 -9999 -9999 -9999 -9999 -9999 -9999 -9999 -9999 -9999 -9999 -9999 -999 -

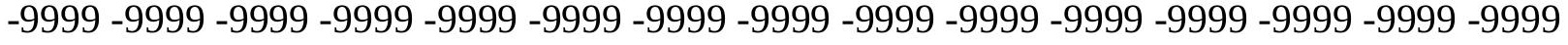
-9999 -9999 -9999 -9999 -9999 -9999 -9999 -9999 -9999 -9999 -9999 -9999 -9999 -9999 -9999 -

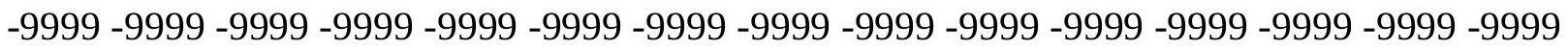

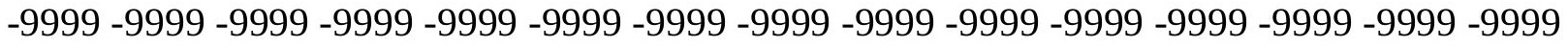

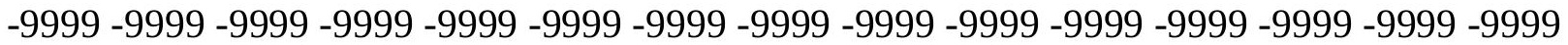

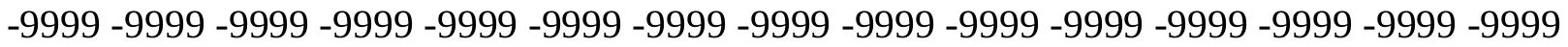

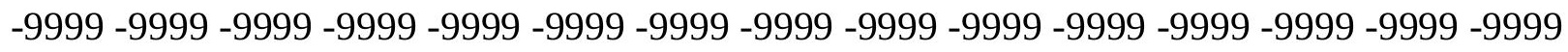

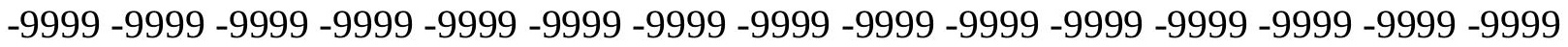

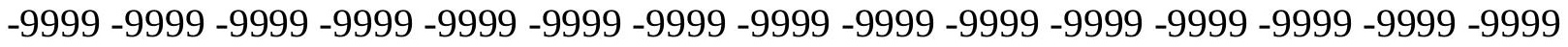
-9999 -9999 -9999 -9999 -9999 -9999 -9999 -9999 -9999 -9999 -9999 -9999 -9999 -9999 -9999 -

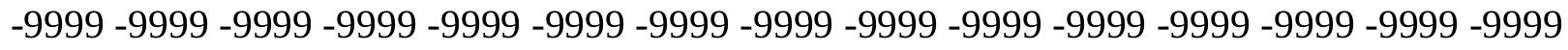

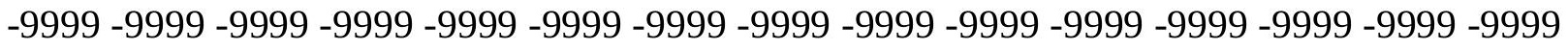
-9999 -9999 -9999 -9999 -9999 -9999 -9999 -9999 -9999 -9999 -9999 -9999 -9999 -9999 -9999 -9999 -9999 -9999 -9999 -9999 -9999 -9999 -9999 -9999-9999 -9999 -9999 -9999 -9999 -9999 -9999 -9999 -9999 -9999 -9999 -9999 -9999 -9999 -9999 -9999 -9999 -9999 -9999 -9999 -9999 -

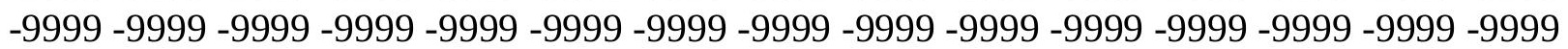


-9999 -9999 -9999 -9999 -9999 -9999 -9999 -9999 -9999 -9999 -9999 -9999 -9999 -9999 -9999 -9999 -9999 -9999 -9999 -9999 -9999 -9999 -9999 -9999 -9999 -9999 -9999 -9999 -9999 -

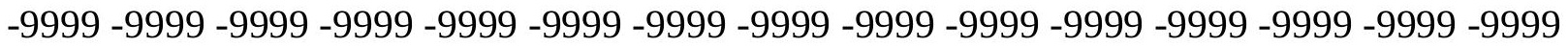
-9999 -9999 -9999 -9999 -9999 -9999 -9999 -9999 -9999 -9999 -9999 -9999 -9999 -9999 -9999 -9999 -9999 -9999 -9999 -9999 -9999 -9999 -9999 -9999 -9999 -9999 -9999 -9999 -9999 -9999 -9999 -9999 -9999 -9999 -9999 -9999 -9999 -9999 -9999 -9999 -9999 -9999 -9999 -9999 -9999 -9999 -9999 -9999 -9999 -9999 -9999 -9999 -9999 -9999 -9999 -9999 -9999 -9999 -9999 -9999

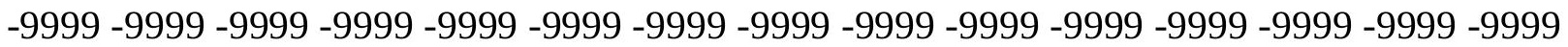

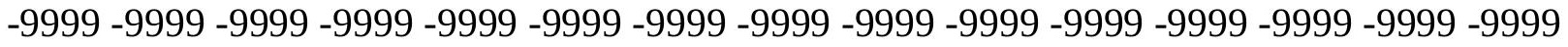
-9999 -9999 -9999 -9999 -9999 -9999 -9999 -9999 -9999 -9999 -9999 -9999 -9999 -9999 -9999 -9999 -9999 -9999 -9999 -9999 -9999 -9999 -9999 -9999 -9999 -9999 -9999 -9999 -9999 -9999 -9999 -9999 -9999 -9999 -9999 -9999 -9999 -9999 -9999 -9999 -9999 -9999 -9999 -9999 -9999 -9999 -9999 -9999 -9999 -9999 -9999 -9999 -9999 -9999 -9999 -9999 -9999 -9999 -9999 -9999 -9999 -9999 -9999 -9999 -9999 -9999 -9999 -9999 -9999 -9999 -9999 -9999 -9999 -9999 -9999 -9999 -9999 -9999 -9999 -9999 -9999 -9999 -9999 -9999 -9999 -9999 -9999 -9999 -9999 -9999 -

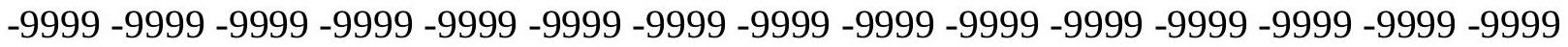
-9999 -9999 -9999 -9999 -9999 -9999 -9999 -9999 -9999 -9999 -9999 -9999 -9999 -9999 -9999 -9999 -9999 -9999 -9999 -9999 -9999 -9999 -9999 -9999 -9999 -9999 -9999 -9999 -9999 - 9999 -9999 -9999 -9999 -9999 -9999 -9999 -9999 -9999 -9999 -9999 -9999 -9999 -9999 -9999 -9999 -

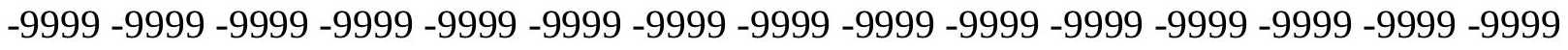

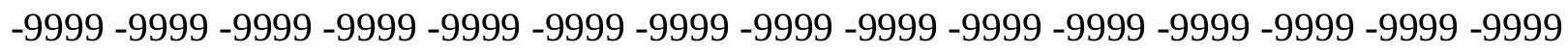

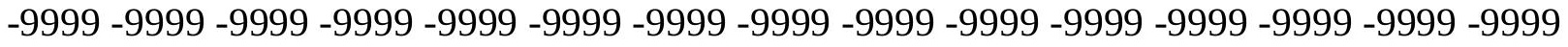
-9999 -9999 -9999 -9999 -9999 -9999 -9999 -9999 -9999 -9999 -9999 -9999 -9999 -9999 -9999 -9999 -9999 -9999 -9999 -9999 -9999 -9999 -9999 -9999 -9999 -9999 -9999 -9999 -9999 -9999 -

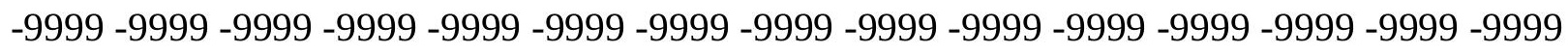
-9999 -9999 -9999 -9999 -9999 -9999 -9999 -9999 -9999 -9999 -9999 -9999 -9999 -9999 -9999 -9999 -9999 -9999 -9999 -9999 -9999 -9999 -9999 -9999 -9999 -9999 -9999 -9999 -9999 -9999 -9999 -9999 -9999 -9999 -9999 -9999 -9999 -9999 -9999 -9999 -9999 -9999 -9999 -9999 -9999 -9999 -9999 -9999 -9999 -9999 -9999 -9999 -9999 -9999 -9999 -9999 -9999 -9999 -9999 -9999 -9999 -9999 -9999 -9999 -9999 -9999 -9999 -9999 -9999 -9999 -9999 -9999 -9999 -999 -

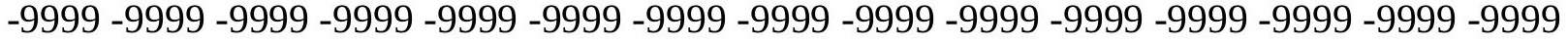
-9999 -9999 -9999 -9999 -9999 -9999 -9999 -9999 -9999 -9999 -9999 -9999 -9999 -9999 -9999 -

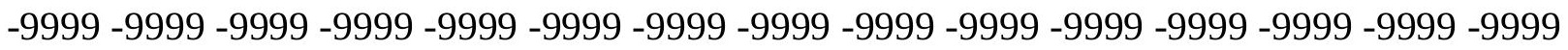

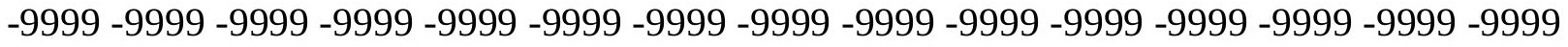

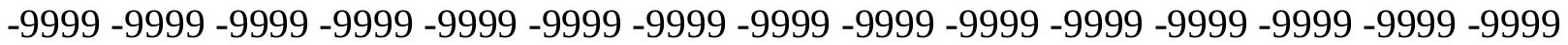

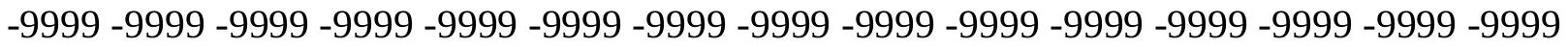

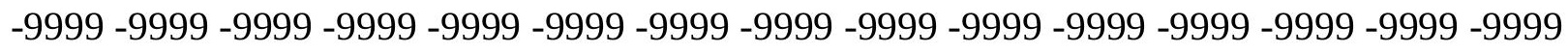

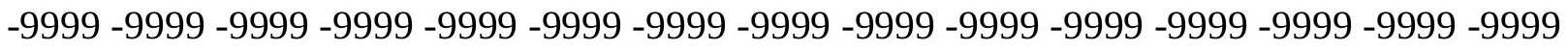

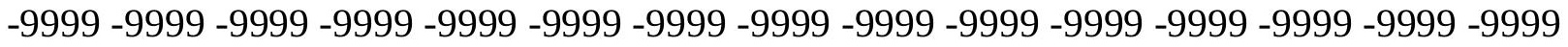
-9999 -9999 -9999 -9999 -9999 -9999 -9999 -9999 -9999 -9999 -9999 -9999 -9999 -9999 -9999 -

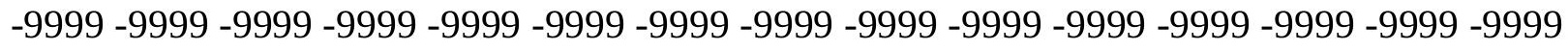

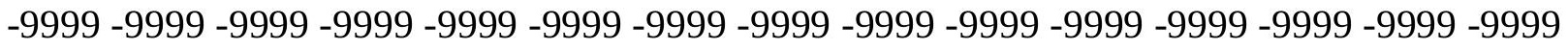
-9999 -9999 -9999 -9999 -9999 -9999 -9999 -9999 -9999 -9999 -9999 -9999 -9999 -9999 -9999 -9999 -9999 -9999 -9999 -9999 -9999 -9999 -9999 -9999-9999 -9999 -9999 -9999 -9999 -9999 -9999 -9999 -9999 -9999 -9999 -9999 -9999 -9999 -9999 -9999 -9999 -9999 -9999 -9999 -9999 -

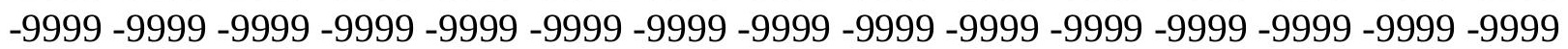


-9999 -9999 -9999 -9999 -9999 -9999 -9999 -9999 -9999 -9999 -9999 -9999 -9999 -9999 -9999 -9999 -9999 -9999 -9999 -9999 -9999 -9999 -9999 -9999 -9999 -9999 -9999 -9999 -9999 -9999 -

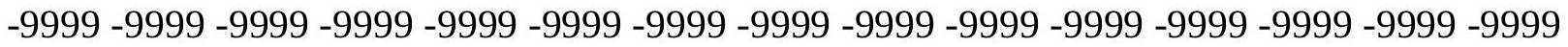
-9999 -9999 -9999 -9999 -9999 -9999 -9999 -9999 -9999 -9999 -9999 -9999 -9999 -9999 -9999 -9999 -9999 -9999 -9999 -9999 -9999 -9999 -9999 -9999-9999 -9999 -9999 -9999 -9999 -9999 -9999 -9999 -9999 -9999 -9999 -9999 -9999 -9999 -9999 -9999 -9999 -9999 -9999 -9999 -9999 -

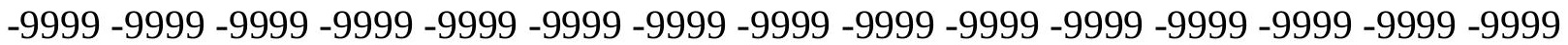
-9999 -9999 -9999 -9999 -9999 -9999 -9999 -9999 -9999 -9999 -9999 -9999 -9999 -9999 -9999 -9999 -9999 -9999 -9999 -9999 -9999 -9999 -9999 -9999 -9999 -9999 -9999 -9999 -9999 -9999 -9999 -9999 -9999 -9999 -9999 -9999 -9999 -9999 -9999 -9999 -9999 -9999 -9999 -9999 -9999 -9999 -9999 -9999 -9999 -9999 -9999 -9999 -9999 -9999 -9999 -9999 -9999 -9999 -9999 -9999 -9999 -9999 -9999 -9999 -9999 -9999 -9999 -9999 -9999 -9999 -9999 -9999 -9999 -9999 -9999 -9999 -9999 -9999 -9999 -9999 -9999 -9999 -9999 -9999 -9999 -9999 -9999 -9999 -9999 -9999 -9999 -9999 -9999 -9999 -9999 -9999 -9999 -9999 -9999 -9999 -9999 -9999 -9999 -9999 -9999 -9999 -9999 -9999 -9999 -9999 -9999 -9999 -9999 -9999 -9999 -9999 -9999 -9999 -9999 -

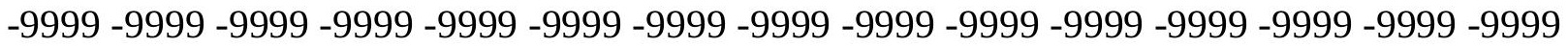
-9999 -9999 -9999 -9999 -9999 -9999 -9999 -9999 -9999 -9999 -9999 -9999 -9999 -9999 -9999 -9999 -9999 -9999 -9999 -9999 -9999 -9999 -9999 -9999 -9999 -9999 -9999 -9999 -9999 -9999 -9999 -9999 -9999 -9999 -9999 -9999 -9999 -9999 -9999 -9999 -9999 -9999 -9999 -9999 -9999 -

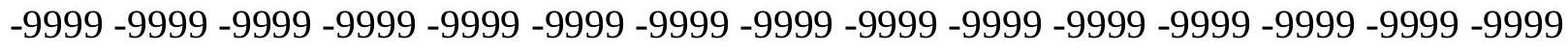

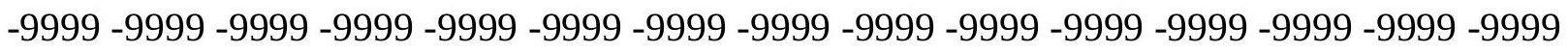
-9999 -9999 -9999 -9999 -9999 -9999 -9999 -9999 -9999 -9999 -9999 -9999 -9999 -9999 - 9999 -9999 -9999 -9999 -9999 -9999 -9999 -9999 -9999 -9999 -9999 -9999 -9999 -9999 -9999 -9999 -9999 -9999 -9999 -9999 -9999 -9999 -9999 -9999 -9999 -9999 -9999 -9999 -9999 -9999 -9999 -

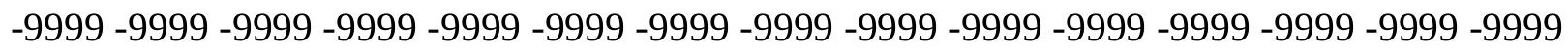
-9999 -9999 -9999 -9999 -9999 -9999 -9999 -9999 -9999 -9999 -9999 -9999 -9999 -9999 -9999 -9999 -9999 -9999 -9999 -9999 -9999 -9999 -9999 -9999 -9999 -9999 -9999 -9999 -9999 -9999 -

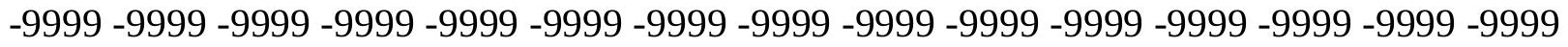
-9999 -9999 -9999 -9999 -9999 -9999 -9999 -9999 -9999 -9999 -9999 -9999 -9999 -9999 -9999 -9999 -9999 -9999 -9999 -9999 -9999 -9999 -9999 -9999 -9999 -9999 -9999 -9999 -9999 -999 -9999 -9999 -9999 -9999 -9999 -9999 -9999 -9999 -9999 -9999 -9999 -9999 -9999 -9999 -9999 -9999 -9999 -9999 -9999 -9999 -9999 -9999 -9999 -9999 -9999 -9999 -9999 -9999 -9999 -9999 -

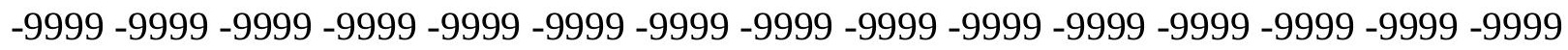

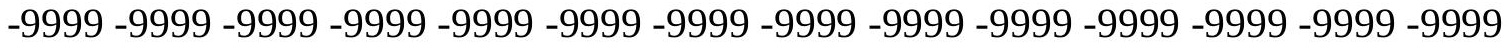
-9999 -9999 -9999 -9999 -9999 -9999 -9999 -9999 -9999 -9999 -9999 -9999 -9999 -9999 -9999

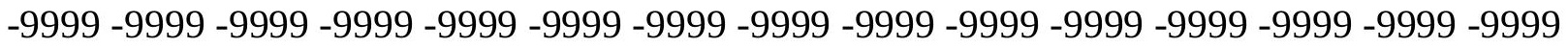

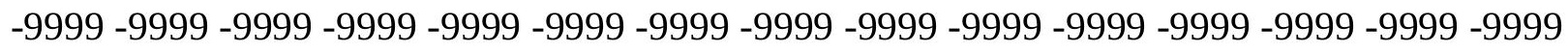

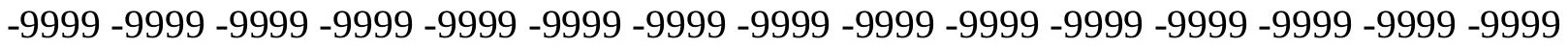

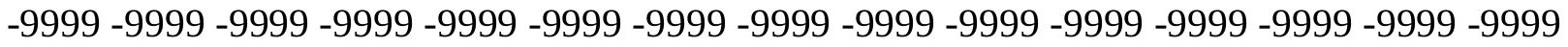
-9999 -9999 -9999 -9999 -9999 -9999 -9999 -9999 -9999 -9999 -9999 -9999 -9999 -9999 -9999 -

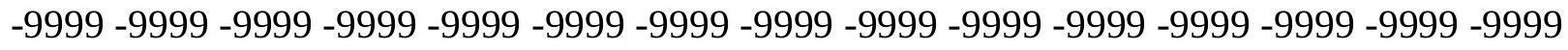

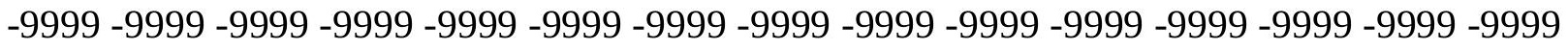
-9999 -9999 -9999 -9999 -9999 -9999 -9999 -9999 -9999 -9999 -9999 -9999 -9999 -9999 -9999 -9999 -9999 -9999 -9999 -9999 -9999 -9999 -9999 -9999-9999 -9999 -9999 -9999 -9999 -9999 -9999 -9999 -9999 -9999 -9999 -9999 -9999 -9999 -9999 -9999 -9999 -9999 -9999 -9999 -9999 -

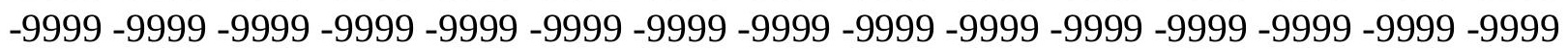


-9999 -9999 -9999 -9999 -9999 -9999 -9999 -9999 -9999 -9999 -9999 -9999 -9999 -9999 -9999 -9999 -9999 -9999 -9999 -9999 -9999 -9999 -9999 -9999 -9999 -9999 -9999 -9999 -9999 -9999 -

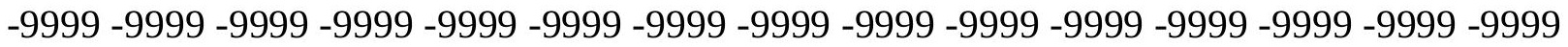
-9999 -9999 -9999 -9999 -9999 -9999 -9999 -9999 -9999 -9999 -9999 -9999 -9999 -9999 -9999 -9999 -9999 -9999 -9999 -9999 -9999 -9999 -9999 -9999-9999 -9999 -9999 -9999 -9999 -9999 -9999 -9999 -9999 -9999 -9999 -9999 -9999 -9999 -9999 -9999 -9999 -9999 -9999 -9999 -9999 -9999 -9999 -9999 -9999 -9999 -9999 -9999 -9999 -9999 -9999 -9999 -9999 -9999 -9999 -9999

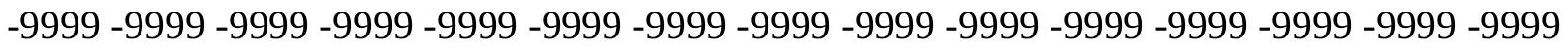

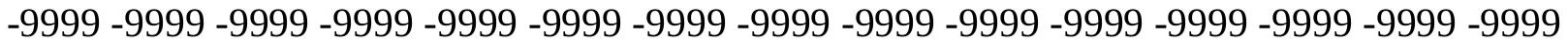
-9999 -9999 -9999 -9999 -9999 -9999 -9999 -9999 -9999 -9999 -9999 -9999 -9999 -9999 -9999 -9999 -9999 -9999 -9999 -9999 -9999 -9999 -9999 -9999 -9999 -9999 -9999 -9999 -9999 -9999 -9999 -9999 -9999 -9999 -9999 -9999 -9999 -9999 -9999 -9999 -9999 -9999 -9999 -9999 -9999 -9999 -9999 -9999 -9999 -9999 -9999 -9999 -9999 -9999 -9999 -9999 -9999 -9999 -9999 -9999 -9999 -9999 -9999 -9999 -9999 -9999 -9999 -9999 -9999 -9999 -9999 -9999 -9999 -9999 -9999 -9999 -9999 -9999 -9999 -9999 -9999 -9999 -9999 -9999 -9999 -9999 -9999 -9999 -9999

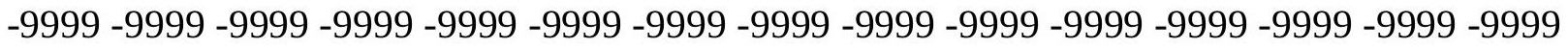
-9999 -9999 -9999 -9999 -9999 -9999 -9999 -9999 -9999 -9999 -9999 -9999 -9999 -9999 -9999 -9999 -9999 -9999 -9999 -9999 -9999 -9999 -9999 -9999 -9999 -9999 -9999 -9999 -9999 -9999 -9999 -9999 -9999 -9999 -9999 -9999 -9999 -9999 -9999 -9999 -9999 -9999 -9999 -9999 -9999 -

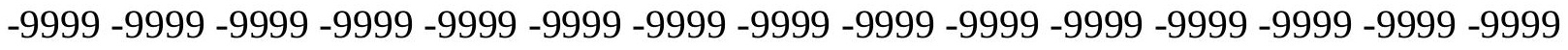

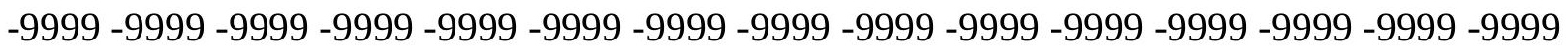
-9999 -9999 -9999 -9999 -9999 -9999 -9999 -9999 -9999 -9999 -9999 -9999 -9999 -9999 -9999 -9999 -9999 -9999 -9999 -9999 -9999 -9999 -9999 -9999 -9999 -9999 -9999 -9999 -9999 -9999 -9999 -9999 -9999 -9999 -9999 -9999 -9999 -9999 -9999 -9999 -9999 -9999 -9999 -9999 -9999 -

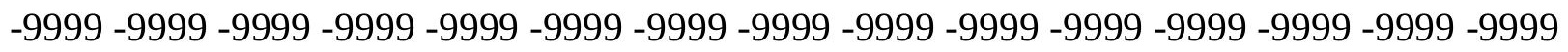
-9999 -9999 -9999 -9999 -9999 -9999 -9999 -9999 -9999 -9999 -9999 -9999 -9999 -9999 -9999 -9999 -9999 -9999 -9999 -9999 -9999 -9999 -9999 -9999 -9999 -9999 -9999 -9999 -9999 -9999 -

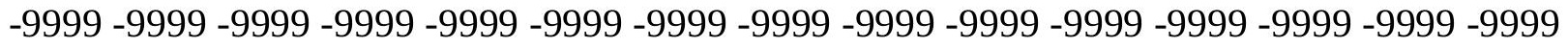
-9999 -9999 -9999 -9999 -9999 -9999 -9999 -9999 -9999 -9999 -9999 -9999 -9999 -9999 -9999 -9999 -9999 -9999 -9999 -9999 -9999 -9999 -9999 -9999 -9999 -9999 -9999 -9999 -9999 -999 -9999 -9999 -9999 -9999 -9999 -9999 -9999 -9999 -9999 -9999 -9999 -9999 -9999 -9999 -9999 -9999 -9999 -9999 -9999 -9999 -9999 -9999 -9999 -9999 -9999 -9999 -9999 -9999 -9999 -9999 -

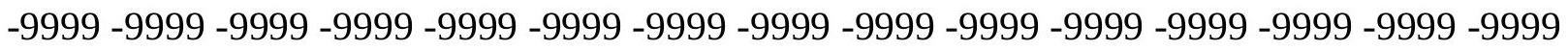

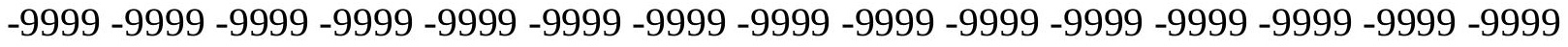

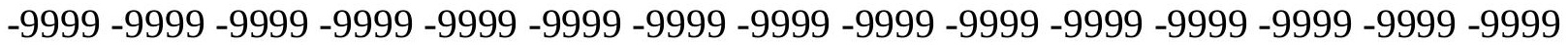

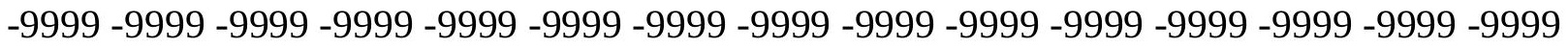

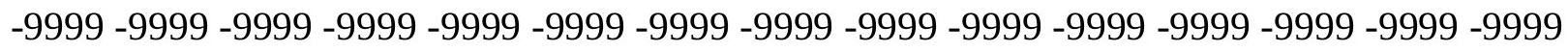

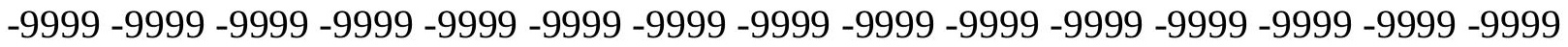
-9999 -9999 -9999 -9999 -9999 -9999 -9999 -9999 -9999 -9999 -9999 -9999 -9999 - 9999 - -999 -9999 -9999 -9999 -9999 -9999 -9999 -9999 -9999 -9999 -9999 -9999 -9999 -9999 -9999 - -999 -

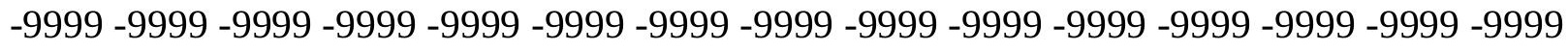

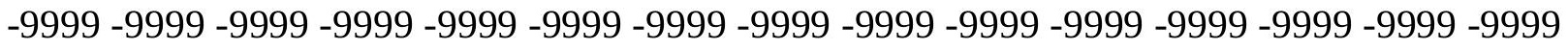
-9999 -9999 -9999 -9999 -9999 -9999 -9999 -9999 -9999 -9999 -9999 -9999 -9999 -9999 -9999 -9999 -9999 -9999 -9999 -9999 -9999 -9999 -9999 -9999-9999 -9999 -9999 -9999 -9999 -9999 -9999 -9999 -9999 -9999 -9999 -9999 -9999 -9999 -9999 -9999 -9999 -9999 -9999 -9999 -9999 -

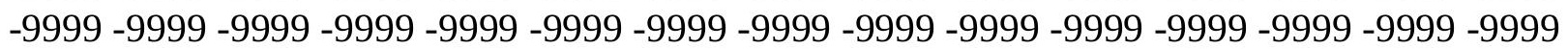


-9999 -9999 -9999 -9999 -9999 -9999 -9999 -9999 -9999 -9999 -9999 -9999 -9999 -9999 -9999 -9999 -9999 -9999 -9999 -9999 -9999 -9999 -9999 -9999 -9999 -9999 -9999 -9999 -9999 -9999 -9999 -9999 -9999 -9999 -9999 -9999 -9999 -9999 -9999 -9999 -9999 -9999 -9999 -9999 -9999 -9999 -9999 -9999 -9999 -9999 -9999 -9999 -9999 -9999 -9999 -9999 -9999 -9999 -9999 -9999 -9999 -9999 -9999 -9999 -9999 -9999 -9999 -9999 -9999 -9999 -9999 -9999 -9999 -9999 -9999 -9999 -9999 -9999 -9999 -9999 -9999 -9999 -9999 -9999 -9999 -9999 -9999 -9999 -9999 -9999 -9999 -9999 -9999 -9999 -9999 -9999 -9999 -9999 -9999 -9999 -9999 -9999 -9999 -9999 -9999 -

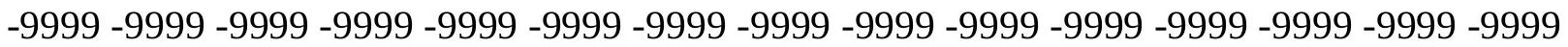
-9999 -9999 -9999 -9999 -9999 -9999 -9999 -9999 -9999 -9999 -9999 -9999 -9999 -9999 -9999 -9999 -9999 -9999 -9999 -9999 -9999 -9999 -9999 -9999 -9999 -9999 -9999 -9999 -9999 -9999 -

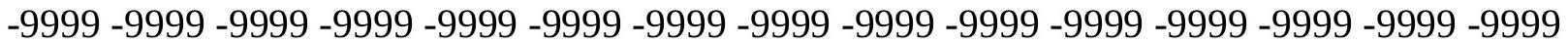
-9999 -9999 -9999 -9999 -9999 -9999 -9999 -9999 -9999 -9999 -9999 -9999 -9999 -9999 -9999 -9999 -9999 -9999 -9999 -9999 -9999 -9999 -9999 -9999 -9999 -9999 -9999 -9999 -9999 -9999 -9999 -9999 -9999 -9999 -9999 -9999 -9999 -9999 -9999 -9999 -9999 -9999 -9999 -9999 -9999 -9999 -9999 -9999 -9999 -9999 -9999 -9999 -9999 -9999 -9999 -9999 -9999 -9999 -9999 -9999

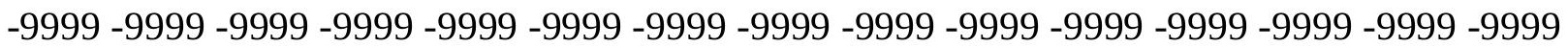
-9999 -9999 -9999 -9999 -9999 -9999 -9999 -9999 -9999 -9999 -9999 -9999 -9999 -9999 -9999 -9999 -9999 -9999 -9999 -9999 -9999 -9999 -9999 -9999 -9999 -9999 -9999 -9999 -9999 -9999 -9999 -9999 -9999 -9999 -9999 -9999 -9999 -9999 -9999 -9999 -9999 -9999 -9999 -9999 -9999 -9999 -9999 -9999 -9999 -9999 -9999 -9999 -9999 -9999 -9999 -9999 -9999 -9999 -9999 -9999 -9999 -9999 -9999 -9999 -9999 -9999 -9999 -9999 -9999 -9999 -9999 -9999 -9999 -9999 -9999 -9999 -9999 -9999 -9999 -9999 -9999 -9999 -9999 -9999 -9999 -9999 -9999 -9999 -9999 -9999 -9999 -9999 -9999 -9999 -9999 -9999 -9999 -9999 -9999 -9999 -9999 -9999 -9999 -9999 -9999 -9999 -9999 -9999 -9999 -9999 -9999 -9999 -9999 -9999 -9999 -9999 -9999 -9999 -9999 -9999 -9999 -9999 -9999 -9999 -9999 -9999 -9999 -9999 -9999 -9999 -9999 -9999 -9999 -9999 -9999 -9999 -9999 -9999 -9999 -9999 -9999 -9999 -9999 -9999 -9999 -9999 -9999 -9999 -9999 -9999 -9999 -9999 -9999 -9999 -9999 -9999 -9999 -9999 -9999 -9999 -9999 -9999 -9999 -9999 -9999 -9999 -9999 -9999 -9999 -9999 -9999 -9999 -9999 -9999 -9999 -9999 -9999 -9999 -9999

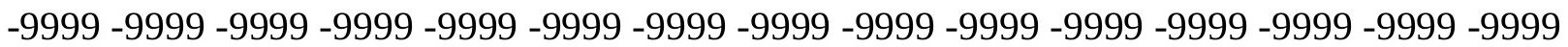
-9999 -9999 -9999 -9999 -9999 -9999 -9999 -9999 -9999 -9999 -9999 -9999 -9999 -9999 -9999 -9999 -9999 -9999 -9999 -9999 -9999 -9999 -9999 -9999 -9999 -9999 -9999 -9999 -9999 -9999 -

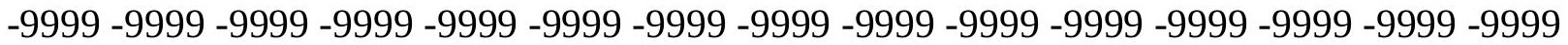
-9999 -9999 -9999 -9999 -9999 -9999 -9999 -9999 -9999 -9999 -9999 -9999 -9999 -9999 -9999 -9999 -9999 -9999 -9999 -9999 -9999 -9999 -9999 -9999 -9999 -9999 -9999 -9999 -9999 -9999 -9999 -9999 -9999 -9999 -9999 -9999 -9999 -9999 -9999 -9999 -9999 -9999 -9999 -9999 -9999 -9999 -9999 -9999 -9999 -9999 -9999 -9999 -9999 -9999 -9999 -9999 -9999 -9999 -9999 -9999 -9999 -9999 -9999 -9999 -9999 -9999 -9999 -9999 -9999 -9999 -9999 -9999 -9999 -9999 -9999

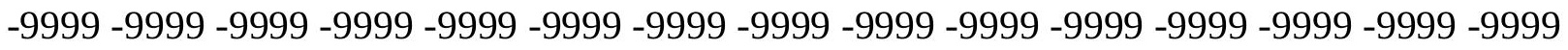
-9999 -9999 -9999 -9999 -9999 -9999 -9999 -9999 -9999 -9999 -9999 -9999 -9999 -9999 -9999 -9999 -9999 -9999 -9999 -9999 -9999 -9999 -9999 -9999 -9999 -9999 -9999 -9999 -9999 -9999 -9999 -9999 -9999 -9999 -9999 -9999 -9999 -9999 -9999 -9999 -9999 -9999 -9999 -9999 -9999 -999 -9999 -9999 -9999 -9999 -9999 -9999 -9999 -9999 -9999 -9999 -9999 -9999 -9999 -9999 -9999 -9999 -9999 -9999 -9999 -9999 -9999 -9999 -9999 -9999 -9999 -9999 -9999 -9999 -9999 -9999 -9999 -9999 -9999 -9999 -9999 -9999 -9999 -9999 -9999 -9999 -9999 -9999 -9999 -9999 -9999 -9999 -9999 -9999 -9999 -9999 -9999 -9999 -9999 -9999 -9999 -9999 -9999 -9999 -9999 -9999 -9999 -9999 -9999 -9999 -9999 -9999 -9999 -9999 -9999 -9999 -9999 -9999 -9999 -9999 
-9999 -9999 -9999 -9999 -9999 -9999 -9999 -9999 -9999 -9999 -9999 -9999 -9999 -9999 -9999 -9999 -9999 -9999 -9999 -9999 -9999 -9999 -9999 -9999 -9999 -9999 -9999 -9999 -9999 -9999 -

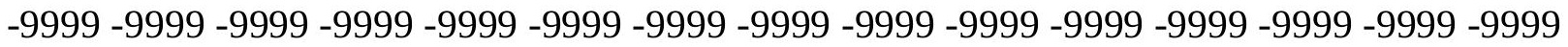
-9999 -9999 -9999 -9999 -9999 -9999 -9999 -9999 -9999 -9999 -9999 -9999 -9999 -9999 -9999 -9999 -9999 -9999 -9999 -9999 -9999 -9999 -9999 -9999-9999 -9999 -9999 -9999 -9999 -9999 -9999 -9999 -9999 -9999 -9999 -9999 -9999 -9999 -9999 -9999 -9999 -9999 -9999 -9999 -9999 -9999 -9999 -9999 -9999 -9999 -9999 -9999 -9999 -9999 -9999 -9999 -9999 -9999 -9999 -9999

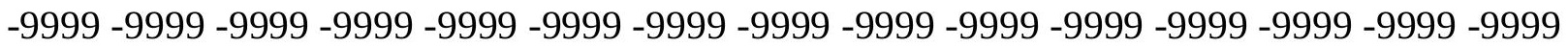

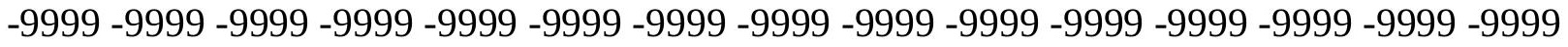
-9999 -9999 -9999 -9999 -9999 -9999 -9999 -9999 -9999 -9999 -9999 -9999 -9999 -9999 -9999 -9999 -9999 -9999 -9999 -9999 -9999 -9999 -9999 -9999 -9999 -9999 -9999 -9999 -9999 -9999 -9999 -9999 -9999 -9999 -9999 -9999 -9999 -9999 -9999 -9999 -9999 -9999 -9999 -9999 -9999 -9999 -9999 -9999 -9999 -9999 -9999 -9999 -9999 -9999 -9999 -9999 -9999 -9999 -9999 -9999 -

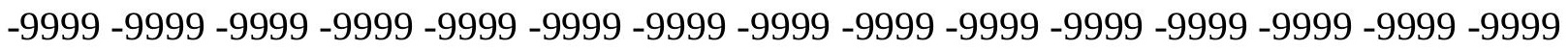
-9999 -9999 -9999 -9999 -9999 -9999 -9999 -9999 -9999 -9999 -9999 -9999 -9999 -9999 -9999 -

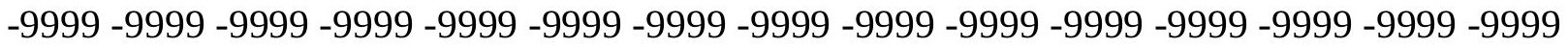
-9999 -9999 -9999 -9999 -9999 -9999 -9999 -9999 -9999 -9999 -9999 -9999 -9999 -9999 -9999 -9999 -9999 -9999 -9999 -9999 -9999 -9999 -9999 -9999 -9999 -9999 -9999 -9999 -9999 -9999 -9999 -9999 -9999 -9999 -9999 -9999 -9999 -9999 -9999 -9999 -9999 -9999 -9999 -9999 -9999 -

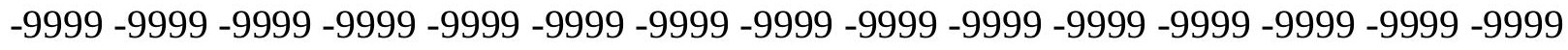

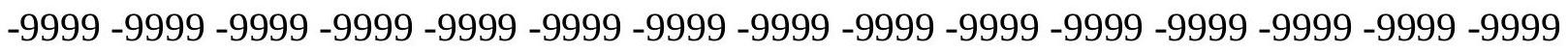

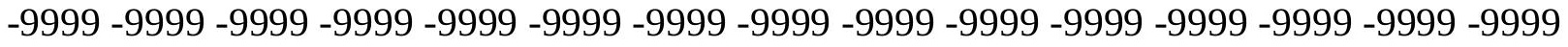
-9999 -9999 -9999 -9999 -9999 -9999 -9999 -9999 -9999 -9999 -9999 -9999 -9999 -9999 -9999 -9999 -9999 -9999 -9999 -9999 -9999 -9999 -9999 -9999 -9999 -9999 -9999 -9999 -9999 -9999 -

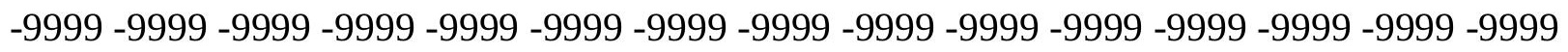
-9999 -9999 -9999 -9999 -9999 -9999 -9999 -9999 -9999 -9999 -9999 -9999 -9999 -9999 -9999 -9999 -9999 -9999 -9999 -9999 -9999 -9999 -9999 -9999 -9999 -9999 -9999 -9999 -9999 -

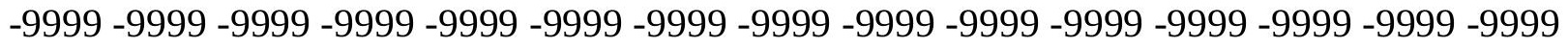
-9999 -9999 -9999 -9999 -9999 -9999 -9999 -9999 -9999 -9999 -9999 -9999 -9999 -9999 -9999 -9999 -9999 -9999 -9999 -9999 -9999 -9999 -9999 -9999 -9999 -9999 -9999 -9999 -9999 -999 -

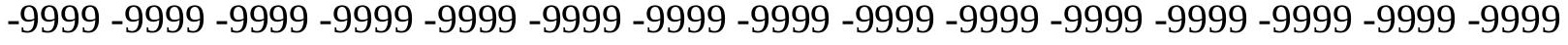
-9999 -9999 -9999 -9999 -9999 -9999 -9999 -9999 -9999 -9999 -9999 -9999 -9999 -9999 -9999 -

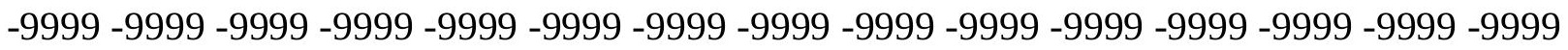

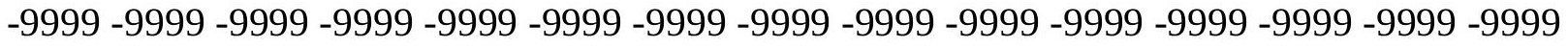

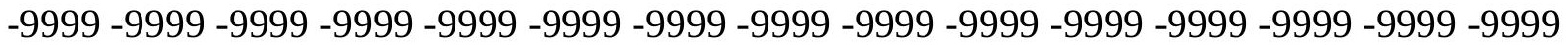
-9999 -9999 -9999 -9999 -9999 -9999 -9999 -9999 -9999 -9999 -9999 -9999 -9999 -9999 -9999

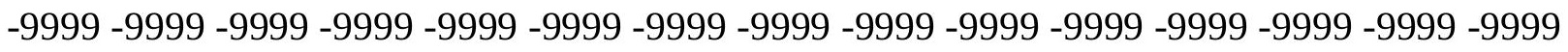

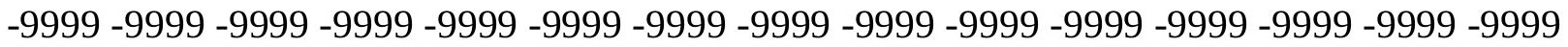
-9999 -9999 -9999 -9999 -9999 -9999 -9999 -9999 -9999 -9999 -9999 -9999 -9999 - 9999 - -999 -9999 -9999 -9999 -9999 -9999 -9999 -9999 -9999 -9999 -9999 -9999 -9999 -9999 -9999 -9999 -

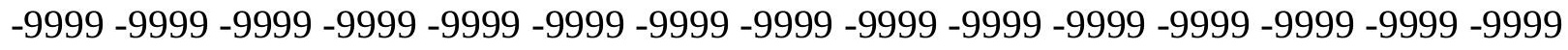

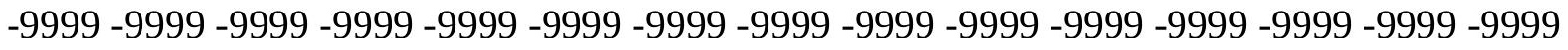
-9999 -9999 -9999 -9999 -9999 -9999 -9999 -9999 -9999 -9999 -9999 -9999 -9999 -9999 -9999 -9999 -9999 -9999 -9999 -9999 -9999 -9999 -9999 -9999-9999 -9999 -9999 -9999 -9999 -9999 -9999 -9999 -9999 -9999 -9999 -9999 -9999 -9999 -9999 -9999 -9999 -9999 -9999 -9999 -9999 -

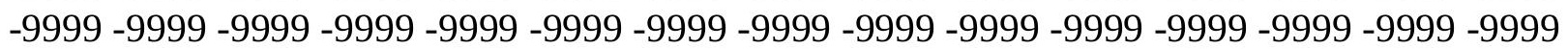


-9999 -9999 -9999 -9999 -9999 -9999 -9999 -9999 -9999 -9999 -9999 -9999 -9999 -9999 -9999 -9999 -9999 -9999 -9999 -9999 -9999 -9999 -9999 -9999 -9999 -9999 -9999 -9999 -9999 -9999 -9999 -9999 -9999 -9999 -9999 -9999 -9999 -9999 -9999 -9999 -9999 -9999 -9999 -9999 - 9999 -9999 -9999 -9999 -9999 -9999 -9999 -9999 -9999 -9999 -9999 -9999 -9999 -9999 -9999 -9999 -9999 -9999 -9999 -9999 -9999 -9999 -9999 -9999 -9999 -9999 -9999 -9999 -9999 -9999 - -9999 -9999 -9999 -9999 -9999 -9999 -9999 -9999 -9999 -9999 -9999 -9999 -9999 -9999 -9999 -9999 -9999 -9999 -9999 -9999 -9999 -9999 -9999 -9999 -9999 -9999 -9999 -9999 -9999 -9999

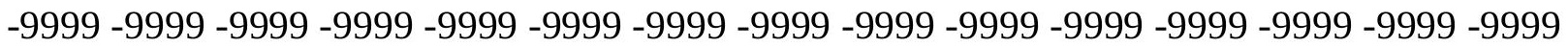

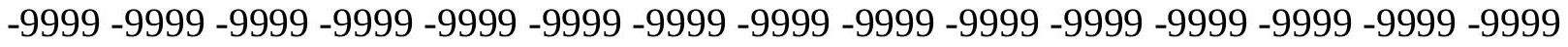
-9999 -9999 -9999 -9999 -9999 -9999 -9999 -9999 -9999 -9999 -9999 -9999 -9999 -9999 -9999

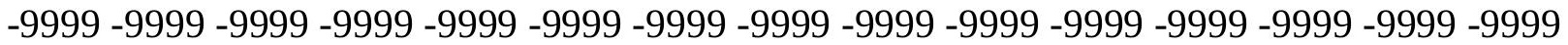
-9999 -9999 -9999 -9999 -9999 -9999 -9999 -9999 -9999 -9999 -9999 -9999 -9999 -9999 -9999 -9999 -9999 -9999 -9999 -9999 -9999 -9999 -9999 -9999 -9999 -9999 -9999 -9999 -9999 -9999 -9999 -9999 -9999 -9999 -9999 -9999 -9999 -9999 -9999 -9999 -9999 -9999 -9999 -9999 - -9999 -9999 -9999 -9999 -9999 -9999 -9999 -9999 -9999 -9999 -9999 -9999 -9999 -9999 -9999 -9999

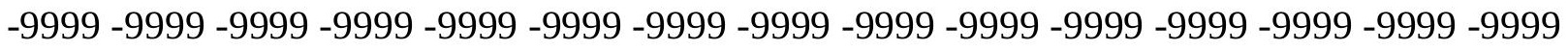
-9999 -9999 -9999 -9999 -9999 -9999 -9999 -9999 -9999 -9999 -9999 -9999 -9999 -9999 -9999 -9999 -9999 -9999 -9999 -9999 -9999 -9999 -9999 -9999 -9999 -9999 -9999 -9999 -9999 -9999 -9999 -9999 -9999 -9999 -9999 -9999 -9999 -9999 -9999 -9999 -9999 -9999 -9999 -9999 -9999 -

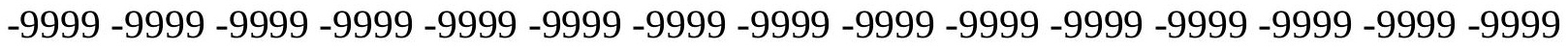
-9999 -9999 -9999 -9999 -9999 -9999 -9999 -9999 -9999 -9999 -9999 -9999 -9999 -9999 -9999 -999 -9999 -9999 -9999 -9999 -9999 -9999 -9999 -9999 -9999 -9999 -9999 -9999 -9999 -9999 -9999 -9999 -9999 -9999 -9999 -9999 -9999 -9999 -9999 -9999 -9999 -9999 -9999 -9999 -9999 -9999 -9999 -9999 -9999 -9999 -9999 -9999 -9999 -9999 -9999 -9999 -9999 -9999 -9999 -9999 -9999 -9999 -9999 -9999 -9999 -9999 -9999 -9999 -9999 -9999 -9999 -9999 -9999 -9999 -9999 -9999 -9999 -9999 -9999 -9999 -9999 -9999 -9999 -9999 -9999 -9999 -9999 -9999 -9999 -9999 -9999 -9999 -9999 -9999 -9999 -9999 -9999 -9999 -9999 -9999 -9999 -9999 -9999 -9999 -9999 -9999 -9999 -9999 -9999 -9999 -9999 -9999 -9999 -9999 -9999 -9999 -9999 -9999 -9999 -9999 -9999 -9999 -9999 -9999 -9999 -9999 -9999 -9999 -9999 -9999 -9999 -9999 -9999 -9999 -9999 -9999 -9999 -9999 -9999 -9999 -9999 -9999 -9999 -9999 -9999 -9999 -9999 -9999 -9999 -9999 -999 -9999 -9999 -9999 -9999 -9999 -9999 -9999 -9999 -9999 -9999 -9999 -9999 -9999 -9999 -9999 -9999 -9999 -9999 -9999 -9999 -9999 -9999 -9999 -9999 -9999 -9999 -9999 -9999 -9999 -

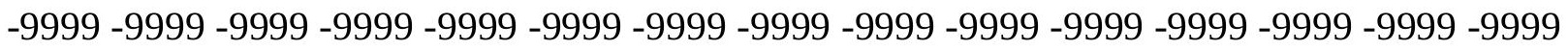

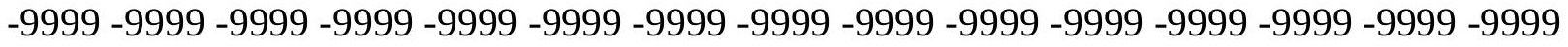

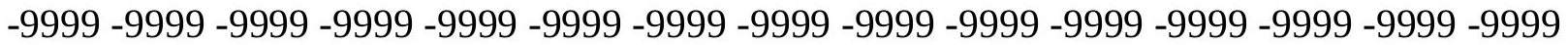
-9999 -9999 -9999 -9999 -9999 -9999 -9999 -9999 -9999 -9999 -9999 -9999 -9999 -9999 -9999 -

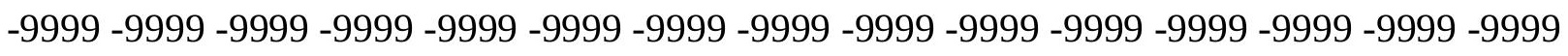

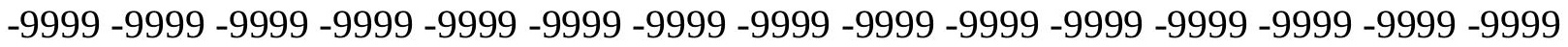

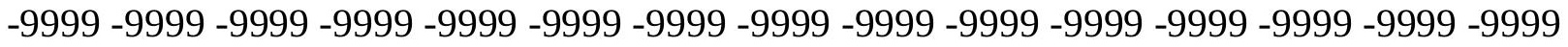
-9999 -9999 -9999 -9999 -9999 -9999 -9999 -9999 -9999 -9999 -9999 -9999 -9999 -9999 -9999 -

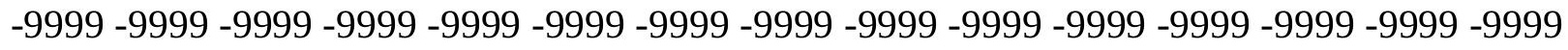

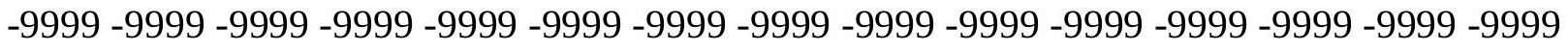
-9999 -9999 -9999 -9999 -9999 -9999 -9999 -9999 -9999 -9999 -9999 -9999 -9999 -9999 -9999 -9999 -9999 -9999 -9999 -9999 -9999 -9999 -9999 -9999-9999 -9999 -9999 -9999 -9999 -9999 -9999 -9999 -9999 -9999 -9999 -9999 -9999 -9999 -9999 -9999 -9999 -9999 -9999 -9999 -9999 -

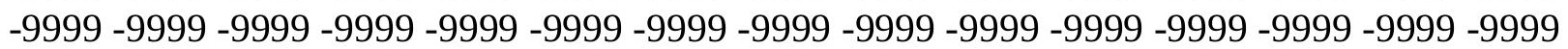


-9999 -9999 -9999 -9999 -9999 -9999 -9999 -9999 -9999 -9999 -9999 -9999 -9999 -9999 -9999 -9999 -9999 -9999 -9999 -9999 -9999 -9999 -9999 -9999 -9999 -9999 -9999 -9999 -9999 -9999 -

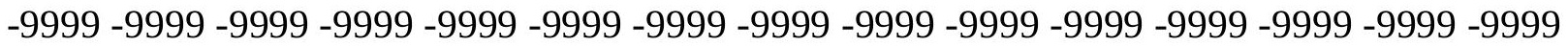
-9999 -9999 -9999 -9999 -9999 -9999 -9999 -9999 -9999 -9999 -9999 -9999 -9999 -9999 -9999 -9999 -9999 -9999 -9999 -9999 -9999 -9999 -9999 -9999-9999 -9999 -9999 -9999 -9999 -9999 -9999 -9999 -9999 -9999 -9999 -9999 -9999 -9999 -9999 -9999 -9999 -9999 -9999 -9999 -9999 -9999 -9999 -9999 -9999 -9999 -9999 -9999 -9999 -9999 -9999 -9999 -9999 -9999 -9999 -9999

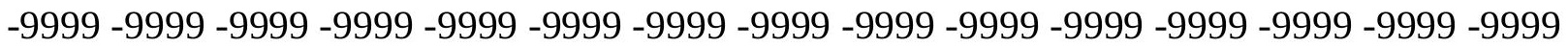

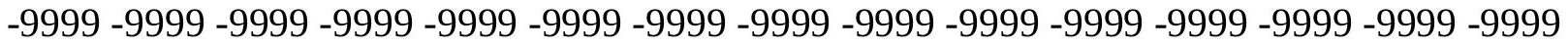
-9999 -9999 -9999 -9999 -9999 -9999 -9999 -9999 -9999 -9999 -9999 -9999 -9999 -9999 -9999 -9999 -9999 -9999 -9999 -9999 -9999 -9999 -9999 -9999 -9999 -9999 -9999 -9999 -9999 -9999 -9999 -9999 -9999 -9999 -9999 -9999 -9999 -9999 -9999 -9999 -9999 -9999 -9999 -9999 -9999 -9999 -9999 -9999 -9999 -9999 -9999 -9999 -9999 -9999 -9999 -9999 -9999 -9999 -9999 -9999 -9999 -9999 -9999 -9999 -9999 -9999 -9999 -9999 -9999 -9999 -9999 -9999 -9999 - 9999 -9999 -9999 -9999 -9999 -9999 -9999 -9999 -9999 -9999 -9999 -9999 -9999 -9999 -9999 -9999

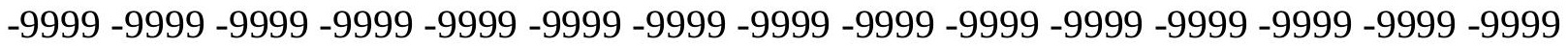
-9999 -9999 -9999 -9999 -9999 -9999 -9999 -9999 -9999 -9999 -9999 -9999 -9999 -9999 -9999 -9999 -9999 -9999 -9999 -9999 -9999 -9999 -9999 -9999 -9999 -9999 -9999 -9999 -9999 -9999 -9999 -9999 -9999 -9999 -9999 -9999 -9999 -9999 -9999 -9999 -9999 -9999 -9999 -9999 -9999 -

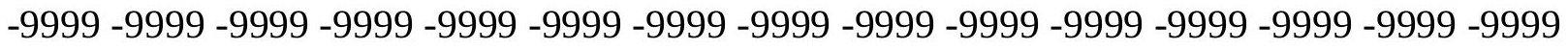

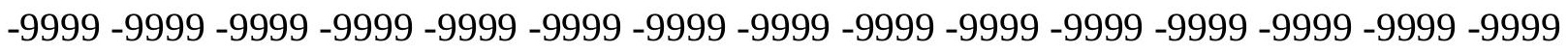
-9999 -9999 -9999 -9999 -9999 -9999 -9999 -9999 -9999 -9999 -9999 -9999 -9999 -9999 -9999 -9999 -9999 -9999 -9999 -9999 -9999 -9999 -9999 -9999 -9999 -9999 -9999 -9999 -9999 -9999 -9999 -9999 -9999 -9999 -9999 -9999 -9999 -9999 -9999 -9999 -9999 -9999 -9999 -9999 -9999 -

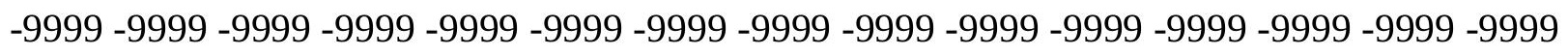
-9999 -9999 -9999 -9999 -9999 -9999 -9999 -9999 -9999 -9999 -9999 -9999 -9999 -9999 -9999 -9999 -9999 -9999 -9999 -9999 -9999 -9999 -9999 -9999 -9999 -9999 -9999 -9999 -9999 -9999 -

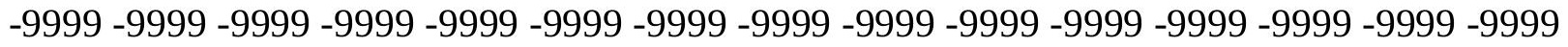
-9999 -9999 -9999 -9999 -9999 -9999 -9999 -9999 -9999 -9999 -9999 -9999 -9999 -9999 -9999 -9999 -9999 -9999 -9999 -9999 -9999 -9999 -9999 -9999 -9999 -9999 -9999 -9999 -9999 -999 -9999 -9999 -9999 -9999 -9999 -9999 -9999 -9999 -9999 -9999 -9999 -9999 -9999 -9999 -9999 -9999 -9999 -9999 -9999 -9999 -9999 -9999 -9999 -9999 -9999 -9999 -9999 -9999 -9999 -9999 -

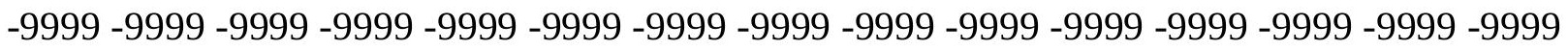

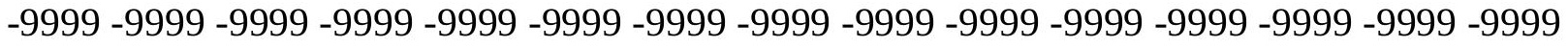

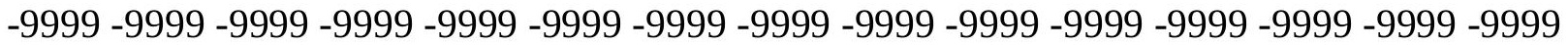

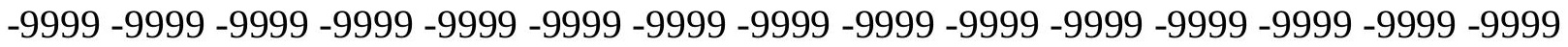

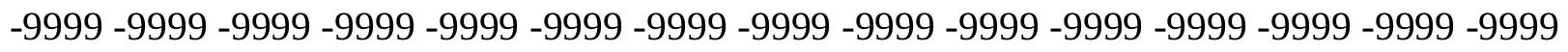

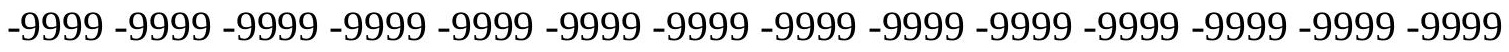
-9999 -9999 -9999 -9999 -9999 -9999 -9999 -9999 -9999 -9999 -9999 -9999 -9999 -9999 -9999 -9999 -9999 -9999 -9999 -9999 -9999 -9999 -9999 -9999 -9999 -9999 -9999 -9999 -9999 -9999 -

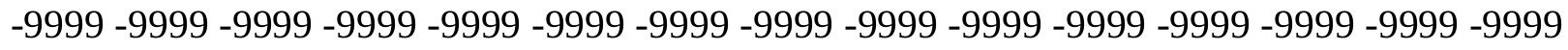

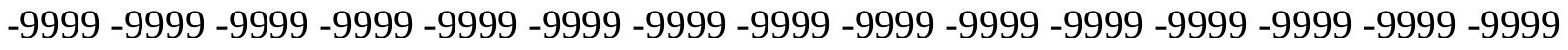
-9999 -9999 -9999 -9999 -9999 -9999 -9999 -9999 -9999 -9999 -9999 -9999 -9999 -9999 -9999 -9999 -9999 -9999 -9999 -9999 -9999 -9999 -9999 -9999-9999 -9999 -9999 -9999 -9999 -9999 -9999 -9999 -9999 -9999 -9999 -9999 -9999 -9999 -9999 -9999 -9999 -9999 -9999 -9999 -9999 -

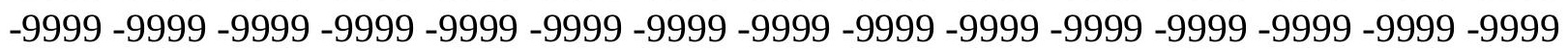


-9999 -9999 -9999 -9999 -9999 -9999 -9999 -9999 -9999 -9999 -9999 -9999 -9999 -9999 -9999 -9999 -9999 -9999 -9999 -9999 -9999 -9999 -9999 -9999 -9999 -9999 -9999 -9999 -9999 -9999 -9999 -9999 -9999 -9999 -9999 -9999 -9999 -9999 -9999 -9999 -9999 -9999 -9999 -9999 - 9999 -9999 -9999 -9999 -9999 -9999 -9999 -9999 -9999 -9999 -9999 -9999 -9999 -9999 -9999 -9999 -9999 -9999 -9999 -9999 -9999 -9999 -9999 -9999 -9999 -9999 -9999 -9999 -9999 -9999 -9999 -9999 -9999 -9999 -9999 -9999 -9999 -9999 -9999 -9999 -9999 -9999 -9999 -9999 -9999 -9999 -9999 -9999 -9999 -9999 -9999 -9999 -9999 -9999 -9999 -9999 -9999 -9999 -9999 -9999 -9999

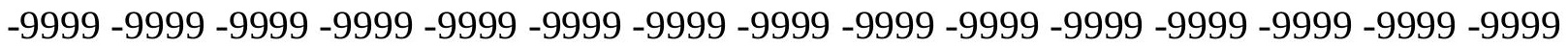
-9999 -9999 -9999 -9999 -9999 -9999 -9999 -9999 -9999 -9999 -9999 -9999 -9999 -9999 -9999 -9999 -9999 -9999 -9999 -9999 -9999 -9999 -9999 -9999 -9999 -9999 -9999 -9999 -9999 -9999

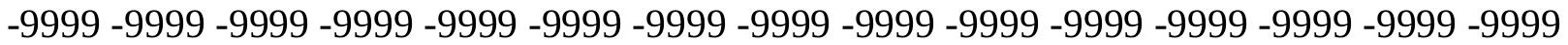
-9999 -9999 -9999 -9999 -9999 -9999 -9999 -9999 -9999 -9999 -9999 -9999 -9999 -9999 -9999 -9999 -9999 -9999 -9999 -9999 -9999 -9999 -9999 -9999 -9999 -9999 -9999 -9999 -9999 -9999 -

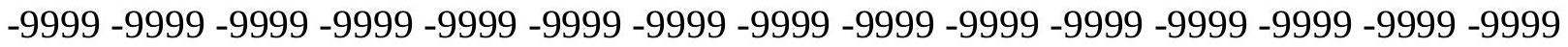
-9999 -9999 -9999 -9999 -9999 -9999 -9999 -9999 -9999 -9999 -9999 -9999 -9999 -9999 -9999

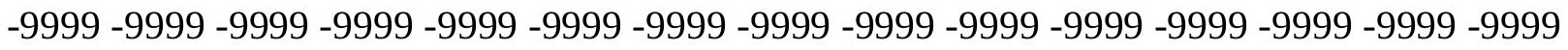
-9999 -9999 -9999 -9999 -9999 -9999 -9999 -9999 -9999 -9999 -9999 -9999 -9999 -9999 -9999 -9999 -9999 -9999 -9999 -9999 -9999 -9999 -9999 -9999 -9999 -9999 -9999 -9999 -9999 - -999 -9999 -9999 -9999 -9999 -9999 -9999 -9999 -9999 -9999 -9999 -9999 -9999 -9999 -9999 -9999 -9999 -9999 -9999 -9999 -9999 -9999 -9999 -9999 -9999 -9999 -9999 -9999 -9999 -9999 -9999 -9999 -9999 -9999 -9999 -9999 -9999 -9999 -9999 -9999 -9999 -9999 -9999 -9999 -9999 -9999 -999 -9999 -9999 -9999 -9999 -9999 -9999 -9999 -9999 -9999 -9999 -9999 -9999 -9999 -9999 -9999 -9999 -9999 -9999 -9999 -9999 -9999 -9999 -9999 -9999 -9999 -9999 -9999 -9999 -9999 -9999 -9999 -9999 -9999 -9999 -9999 -9999 -9999 -9999 -9999 -9999 -9999 -9999 -9999 -9999 -9999 -9999 -9999 -9999 -9999 -9999 -9999 -9999 -9999 -9999 -9999 -9999 -9999 -9999 -9999 -9999 -9999 -9999 -9999 -9999 -9999 -9999 -9999 -9999 -9999 -9999 -9999 -9999 -9999 -9999 -9999 -9999 -9999 -9999 -9999 -9999 -9999 -9999 -9999 -9999 -9999 -9999 -9999 -9999 -9999 -9999 -9999 -9999 -9999 -9999 -9999 -9999 -9999 -9999 -9999 -9999 -9999 -9999 -9999 -9999 -9999 -9999 -9999 -9999 -9999 -9999 -9999 -9999 -9999 -9999 -9999 -9999 -9999 -9999 -9999 -9999 -9999 -9999 -9999 -9999 -9999 -9999 -9999 -9999 -9999 -9999 -9999 -9999 -9999 -9999 -999 -9999 -9999 -9999 -9999 -9999 -9999 -9999 -9999 -9999 -9999 -9999 -9999 -9999 -9999 -9999 -9999 -9999 -9999 -9999 -9999 -9999 -9999 -9999 -9999 -9999 -9999 -9999 -9999 -9999 -9999 -

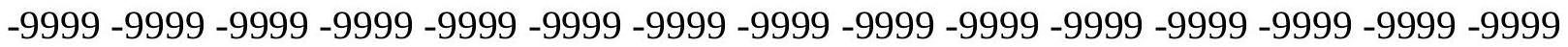

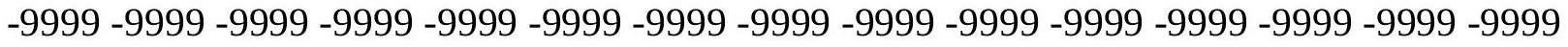

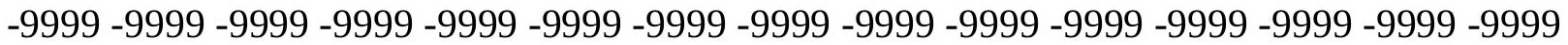
-9999 -9999 -9999 -9999 -9999 -9999 -9999 -9999 -9999 -9999 -9999 -9999 -9999 -9999 -9999

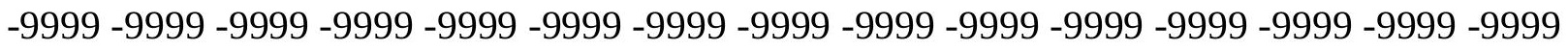

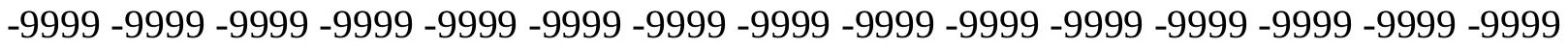

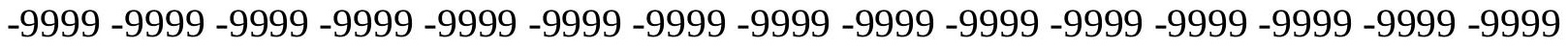
-9999 -9999 -9999 -9999 -9999 -9999 -9999 -9999 -9999 -9999 -9999 -9999 -9999 -9999 -9999 -

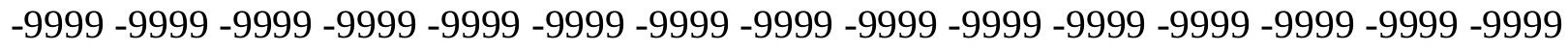

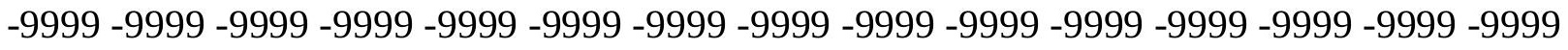
-9999 -9999 -9999 -9999 -9999 -9999 -9999 -9999 -9999 -9999 -9999 -9999 -9999 -9999 -9999 -9999 -9999 -9999 -9999 -9999 -9999 -9999 -9999 -9999 -9999 -9999 -9999 -9999 - -9999 -9999 -9999 -9999 -9999 -9999 -9999 -9999 -9999 -9999 -9999 -9999 -9999 -9999 -9999 -9999 -

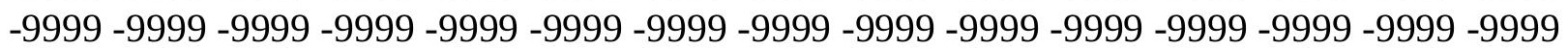


-9999 -9999 -9999 -9999 -9999 -9999 -9999 -9999 -9999 -9999 -9999 -9999 -9999 -9999 -9999 -9999 -9999 -9999 -9999 -9999 -9999 -9999 -9999 -9999 -9999 -9999 -9999 -9999 -9999 -9999 -9999 -9999 -9999 -9999 -9999 -9999 -9999 -9999 -9999 -9999 -9999 -9999 -9999 -9999 - 9999 -9999 -9999 -9999 -9999 -9999 -9999 -9999 -9999 -9999 -9999 -9999 -9999 -9999 -9999 -9999 -9999 -9999 -9999 -9999 -9999 -9999 -9999 -9999 -9999-9999 -9999 -9999 -9999 -9999 -9999 -9999 -9999 -9999 -9999 -9999 -9999 -9999 -9999 -9999 -9999 -9999 -9999 -9999 -9999 -9999 -9999 -9999 -9999 -9999 -9999 -9999 -9999 -9999 -9999 -9999 -9999 -9999 -9999 -9999 -9999

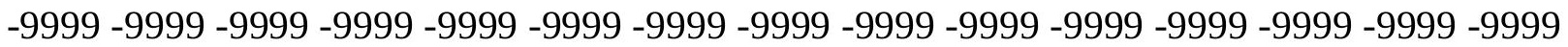

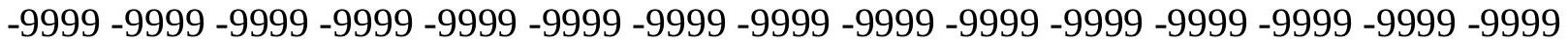
-9999 -9999 -9999 -9999 -9999 -9999 -9999 -9999 -9999 -9999 -9999 -9999 -9999 -9999 -9999

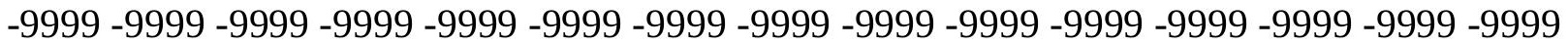
-9999 -9999 -9999 -9999 -9999 -9999 -9999 -9999 -9999 -9999 -9999 -9999 -9999 -9999 -9999 -9999 -9999 -9999 -9999 -9999 -9999 -9999 -9999 -9999 -9999 -9999 -9999 -9999 -9999 -9999 -

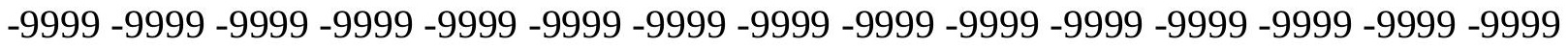
-9999 -9999 -9999 -9999 -9999 -9999 -9999 -9999 -9999 -9999 -9999 -9999 -9999 -9999 -9999

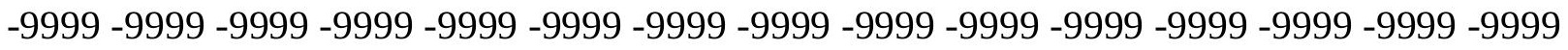
-9999 -9999 -9999 -9999 -9999 -9999 -9999 -9999 -9999 -9999 -9999 -9999 -9999 -9999 -9999 -9999 -9999 -9999 -9999 -9999 -9999 -9999 -9999 -9999 -9999 -9999 -9999 -9999 -9999 -9999 -9999 -9999 -9999 -9999 -9999 -9999 -9999 -9999 -9999 -9999 -9999 -9999 -9999 -9999 -9999 -9999 -9999 -9999 -9999 -9999 -9999 -9999 -9999 -9999 -9999 -9999 -9999 -9999 -9999 -9999 -9999 -9999 -9999 -9999 -9999 -9999 -9999 -9999 -9999 -9999 -9999 -9999 -9999 -9999 -9999 -999 -9999 -9999 -9999 -9999 -9999 -9999 -9999 -9999 -9999 -9999 -9999 -9999 -9999 -9999 -9999 -9999 -9999 -9999 -9999 -9999 -9999 -9999 -9999 -9999 -9999 -9999 -9999 -9999 -9999 -9999 -9999 -9999 -9999 -9999 -9999 -9999 -9999 -9999 -9999 -9999 -9999 -9999 -9999 -9999 -9999 -9999 -9999 -9999 -9999 -9999 -9999 -9999 -9999 -9999 -9999 -9999 -9999 -9999 -9999 -9999 -9999 -9999 -9999 -9999 -9999 -9999 -9999 -9999 -9999 -9999 -9999 -9999 -9999 -9999 -9999 -9999 -9999 -9999 -9999 -9999 -9999 -9999 -9999 -9999 -9999 -9999 -9999 -9999 -9999 -9999 -9999 -9999 -9999 -9999 -9999 -9999 -9999 -9999 -9999 -9999 -9999 -9999 -9999 -9999 -9999 -9999 -9999 -9999 -9999 -9999 -9999 -9999 -9999 -9999 -9999 -9999 -9999 -9999 -9999 -9999 -9999 -9999 -9999 -9999 -9999 -9999 -9999 -9999 -9999 -9999 -9999 -9999 -9999 -999 -9999 -9999 -9999 -9999 -9999 -9999 -9999 -9999 -9999 -9999 -9999 -9999 -9999 -9999 -9999 -9999 -9999 -9999 -9999 -9999 -9999 -9999 -9999 -9999 -9999 -9999 -9999 -9999 -9999 -9999 -

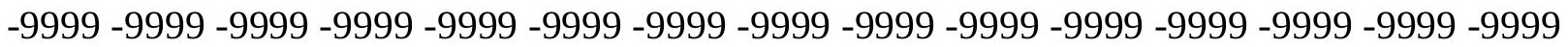

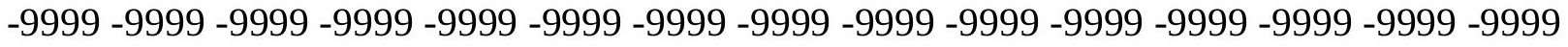

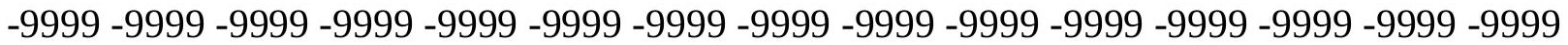
-9999 -9999 -9999 -9999 -9999 -9999 -9999 -9999 -9999 -9999 -9999 -9999 -9999 -9999 -9999

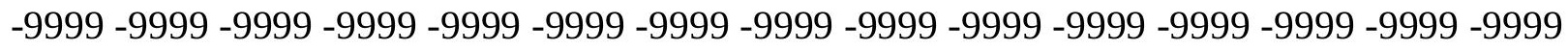

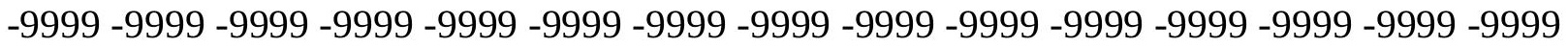
-9999 -9999 -9999 -9999 -9999 -9999 -9999 -9999 -9999 -9999 -9999 -9999 -9999 -9999 -9999 -9999 -9999 -9999 -9999 -9999 -9999 -9999 -9999 -9999 -9999 -9999 -9999 -9999 -9999 -9999 -

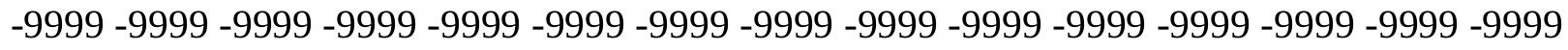

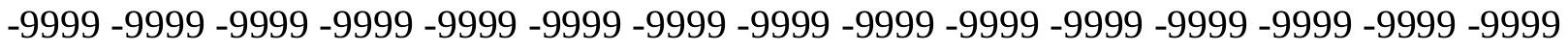
-9999 -9999 -9999 -9999 -9999 -9999 -9999 -9999 -9999 -9999 -9999 -9999 -9999 -9999 -9999 -9999 -9999 -9999 -9999 -9999 -9999 -9999 -9999 -9999-9999 -9999 -9999 -9999 -9999 -9999 -9999 -9999 -9999 -9999 -9999 -9999 -9999 -9999 -9999 -9999 -9999 -9999 -9999 -9999 -9999 -

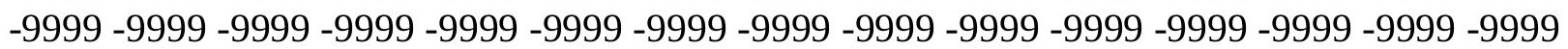


-9999 -9999 -9999 -9999 -9999 -9999 -9999 -9999 -9999 -9999 -9999 -9999 -9999 -9999 -9999 -9999 -9999 -9999 -9999 -9999 -9999 -9999 -9999 -9999 -9999 -9999 -9999 -9999 -9999 -9999 -9999 -9999 -9999 -9999 -9999 -9999 -9999 -9999 -9999 -9999 -9999 -9999 -9999 -9999 - 9999 -9999 -9999 -9999 -9999 -9999 -9999 -9999 -9999 -9999 -9999 -9999 -9999 -9999 -9999

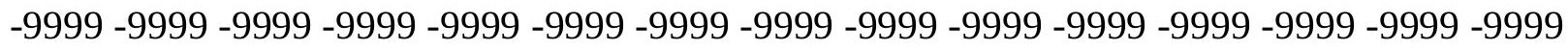
-9999 -9999 -9999 -9999 -9999 -9999 -9999 -9999 -9999 -9999 -9999 -9999 -9999 -9999 -9999 -9999 -9999 -9999 -9999 -9999 -9999 -9999 -9999 -9999 -9999 -9999 -9999 -9999 -9999 -9999

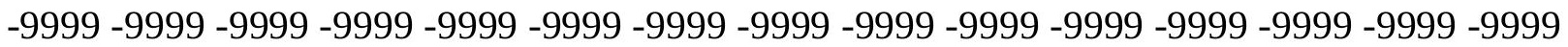

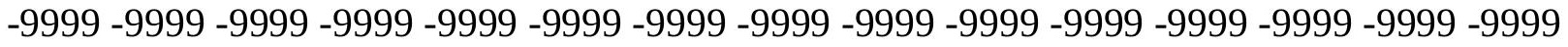
-9999 -9999 -9999 -9999 -9999 -9999 -9999 -9999 -9999 -9999 -9999 -9999 -9999 -9999 -9999 -9999 -9999 -9999 -9999 -9999 -9999 -9999 -9999 -9999 -9999 -9999 -9999 -9999 -9999 -9999 -9999 -9999 -9999 -9999 -9999 -9999 -9999 -9999 -9999 -9999 -9999 -9999 -9999 -9999 -9999 -9999 -9999 -9999 -9999 -9999 -9999 -9999 -9999 -9999 -9999 -9999 -9999 -9999 -9999 -9999 -

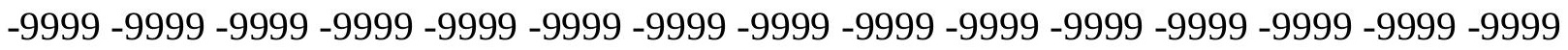
-9999 -9999 -9999 -9999 -9999 -9999 -9999 -9999 -9999 -9999 -9999 -9999 -9999 -9999 -9999 -

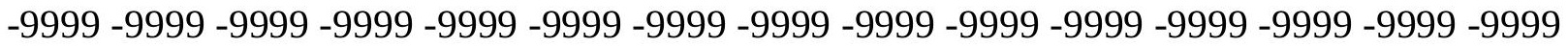
-9999 -9999 -9999 -9999 -9999 -9999 -9999 -9999 -9999 -9999 -9999 -9999 -9999 -9999 -9999 -9999 -9999 -9999 -9999 -9999 -9999 -9999 -9999 -9999 -9999 -9999 -9999 -9999 -9999 -9999 -9999 -9999 -9999 -9999 -9999 -9999 -9999 -9999 -9999 -9999 -9999 -9999 -9999 -9999 -9999 -

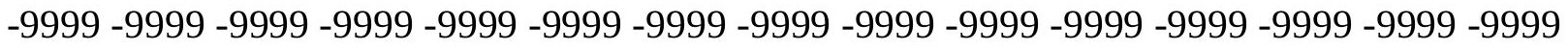
-9999 -9999 -9999 -9999 -9999 -9999 -9999 -9999 -9999 -9999 -9999 -9999 -9999 -9999 -9999

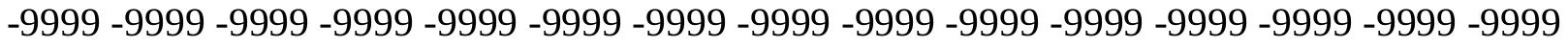
-9999 -9999 -9999 -9999 -9999 -9999 -9999 -9999 -9999 -9999 -9999 -9999 -9999 -9999 -9999 -9999 -9999 -9999 -9999 -9999 -9999 -9999 -9999 -9999 -9999 -9999 -9999 -9999 -9999 -9999 -9999 -9999 -9999 -9999 -9999 -9999 -9999 -9999 -9999 -9999 -9999 -9999 -9999 -9999 -9999 -9999 -9999 -9999 -9999 -9999 -9999 -9999 -9999 -9999 -9999 -9999 -9999 -9999 -9999 -9999 -9999 -9999 -9999 -9999 -9999 -9999 -9999 -9999 -9999 -9999 -9999 -9999 -9999 -9999 -9999 -9999 -9999 -9999 -9999 -9999 -9999 -9999 -9999 -9999 -9999 -9999 -9999 -9999 -9999 -9999 -9999 -9999 -9999 -9999 -9999 -9999 -9999 -9999 -9999 -9999 -9999 -9999 -9999 -9999 -9999 -9999 -9999 -9999 -9999 -9999 -9999 -9999 -9999 -9999 -9999 -9999 -9999 -9999 -9999 -9999 -9999 -9999 -9999 -9999 -9999 -9999 -9999 -9999 -9999 -9999 -9999 -9999 -9999 -9999 -9999 -9999 -9999 -9999 -9999 -9999 -9999 -9999 -9999 -9999 -9999 -9999 -9999 -9999 -9999 -

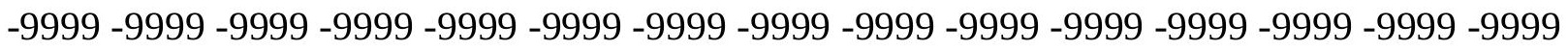

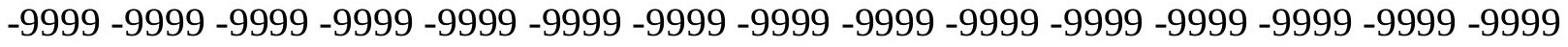
-9999 -9999 -9999 -9999 -9999 -9999 -9999 -9999 -9999 -9999 -9999 -9999 -9999 -9999 -9999 -

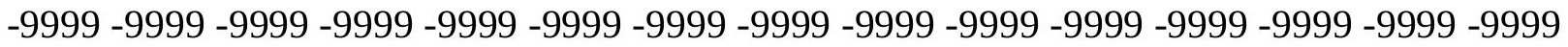

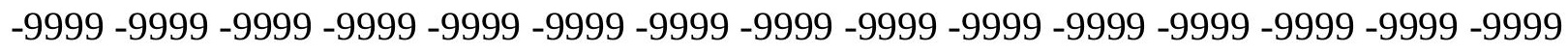

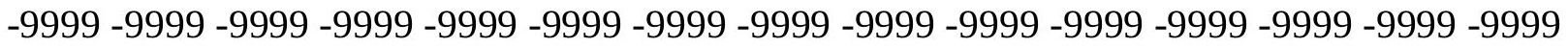

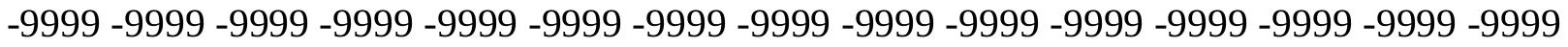
-9999 -9999 -9999 -9999 -9999 -9999 -9999 -9999 -9999 -9999 -9999 -9999 -9999 -9999 -9999 -

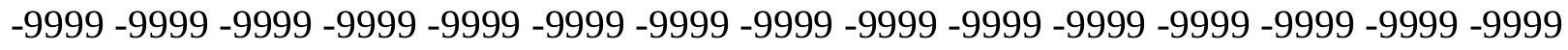

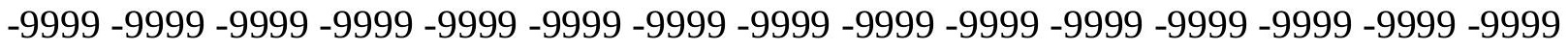
-9999 -9999 -9999 -9999 -9999 -9999 -9999 -9999 -9999 -9999 -9999 -9999 -9999 -9999 -9999 -9999 -9999 -9999 -9999 -9999 -9999 -9999 -9999 -9999-9999 -9999 -9999 -9999 -9999 -9999 -9999 -9999 -9999 -9999 -9999 -9999 -9999 -9999 -9999 -9999 -9999 -9999 -9999 -9999 -9999 -

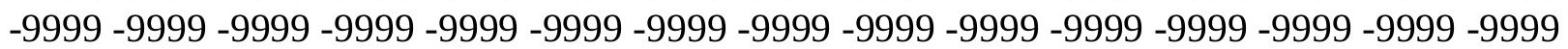


-9999 -9999 -9999 -9999 -9999 -9999 -9999 -9999 -9999 -9999 -9999 -9999 -9999 -9999 -9999 -9999 -9999 -9999 -9999 -9999 -9999 -9999 -9999 -9999 -9999 -9999 -9999 -9999 -9999 -9999 -9999 -9999 -9999 -9999 -9999 -9999 -9999 -9999 -9999 -9999 -9999 -9999 -9999 -9999 - 9999 -9999 -9999 -9999 -9999 -9999 -9999 -9999 -9999 -9999 -9999 -9999 -9999 -9999 -9999 -9999 -9999 -9999 -9999 -9999 -9999 -9999 -9999 -9999 -9999 -9999 -9999 -9999 -9999 -9999 -9999 -9999 -9999 -9999 -9999 -9999 -9999 -9999 -9999 -9999 -9999 -9999 -9999 -9999 -9999 -9999 -9999 -9999 -9999 -9999 -9999 -9999 -9999 -9999 -9999 -9999 -9999 -9999 -9999 -9999 -9999

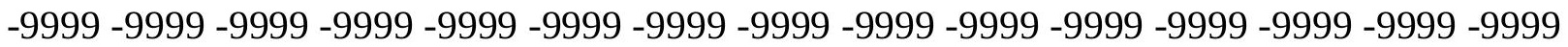

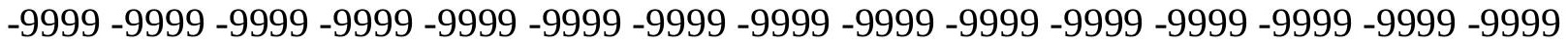
-9999 -9999 -9999 -9999 -9999 -9999 -9999 -9999 -9999 -9999 -9999 -9999 -9999 -9999 -9999 -9999 -9999 -9999 -9999 -9999 -9999 -9999 -9999 -9999 -9999 -9999 -9999 -9999 -9999 -9999 -9999 -9999 -9999 -9999 -9999 -9999 -9999 -9999 -9999 -9999 -9999 -9999 -9999 -9999 -9999 -9999 -9999 -9999 -9999 -9999 -9999 -9999 -9999 -9999 -9999 -9999 -9999 -9999 -9999 -9999 -9999 -9999 -9999 -9999 -9999 -9999 -9999 -9999 -9999 -9999 -9999 -9999 -9999 -9999 -9999 -9999 -9999 -9999 -9999 -9999 -9999 -9999 -9999 -9999 -9999 -9999 -9999 -9999 -9999 -

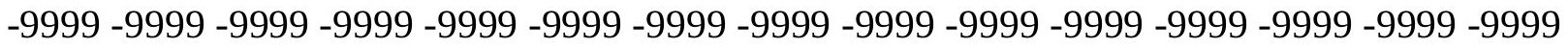
-9999 -9999 -9999 -9999 -9999 -9999 -9999 -9999 -9999 -9999 -9999 -9999 -9999 -9999 -9999 -9999 -9999 -9999 -9999 -9999 -9999 -9999 -9999 -9999 -9999 -9999 -9999 -9999 -9999 -9999 -9999 -9999 -9999 -9999 -9999 -9999 -9999 -9999 -9999 -9999 -9999 -9999 -9999 -9999 -9999 -9999 -9999 -9999 -9999 -9999 -9999 -9999 -9999 -9999 -9999 -9999 -9999 -9999 -9999 -9999 -9999 -9999 -9999 -9999 -9999 -9999 -9999 -9999 -9999 -9999 -9999 -9999 -9999 -9999 -9999 -999 -9999 -9999 -9999 -9999 -9999 -9999 -9999 -9999 -9999 -9999 -9999 -9999 -9999 -9999 -9999 -9999 -9999 -9999 -9999 -9999 -9999 -9999 -9999 -9999 -9999 -9999 -9999 -9999 -9999 -9999 -9999 -9999 -9999 -9999 -9999 -9999 -9999 -9999 -9999 -9999 -9999 -9999 -9999 -9999 -9999 -9999 -9999 -9999 -9999 -9999 -9999 -9999 -9999 -9999 -9999 -9999 -9999 -9999 -9999 -9999 -9999 -9999 -9999 -9999 -9999 -9999 -9999 -9999 -9999 -9999 -9999 -9999 -9999 -9999 -9999 -9999 -9999 -9999 -9999 -9999 -9999 -9999 -9999 -9999 -9999 -9999 -9999 -9999 -9999 -9999 -9999 -9999 -9999 -9999 -9999 -9999 -9999 -9999 -9999 -9999 -9999 -9999 -9999 -9999 -9999 -9999 -9999 -9999 -9999 -9999 -9999 -9999 -9999 -9999 -9999 -9999 -9999 -9999 -9999 -9999 -9999 -9999 -9999 -9999 -9999 -9999 -9999 -9999 -9999 -9999 -9999 -9999 -9999 -9999 -999 -9999 -9999 -9999 -9999 -9999 -9999 -9999 -9999 -9999 -9999 -9999 -9999 -9999 -9999 -9999 -9999 -9999 -9999 -9999 -9999 -9999 -9999 -9999 -9999 -9999 -9999 -9999 -9999 -9999 -9999 -

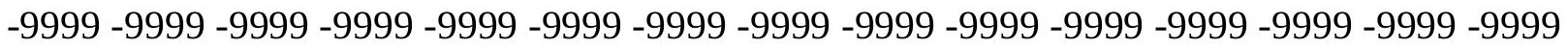

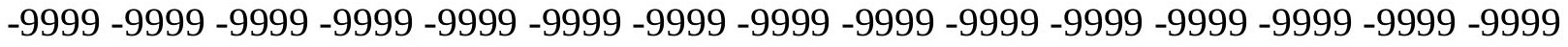

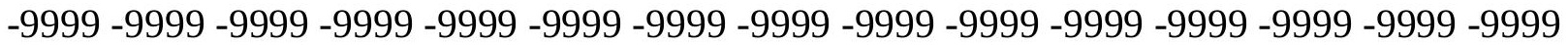
-9999 -9999 -9999 -9999 -9999 -9999 -9999 -9999 -9999 -9999 -9999 -9999 -9999 -9999 -9999 -9999 -9999 -9999 -9999 -9999 -9999 -9999 -9999 -9999 -9999 -9999 -9999 -9999 -9999 -

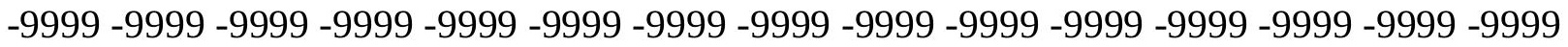
-9999 -9999 -9999 -9999 -9999 -9999 -9999 -9999 -9999 -9999 -9999 -9999 -9999 -9999 -9999 -9999 -9999 -9999 -9999 -9999 -9999 -9999 -9999 -9999 -9999 -9999 -9999 -9999 -9999 -9999 -

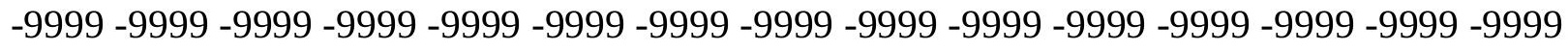

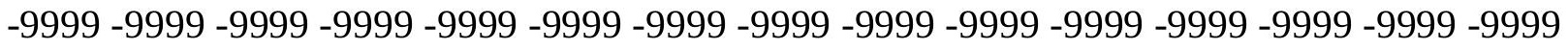
-9999 -9999 -9999 -9999 -9999 -9999 -9999 -9999 -9999 -9999 -9999 -9999 -9999 -9999 -9999 -9999 -9999 -9999 -9999 -9999 -9999 -9999 -9999 -9999-9999 -9999 -9999 -9999 -9999 -9999 -9999 -9999 -9999 -9999 -9999 -9999 -9999 -9999 -9999 -9999 -9999 -9999 -9999 -9999 -9999 -

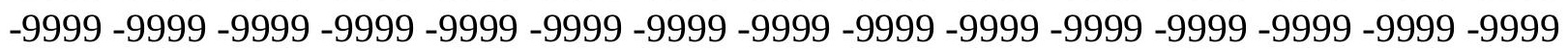


-9999 -9999 -9999 -9999 -9999 -9999 -9999 -9999 -9999 -9999 -9999 -9999 -9999 -9999 -9999 -9999 -9999 -9999 -9999 -9999 -9999 -9999 -9999 -9999 -9999 -9999 -9999 -9999 -9999 -9999 -

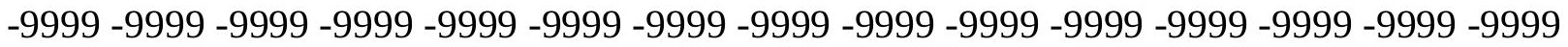
-9999 -9999 -9999 -9999 -9999 -9999 -9999 -9999 -9999 -9999 -9999 -9999 -9999 -9999 -9999 -9999 -9999 -9999 -9999 -9999 -9999 -9999 -9999 -9999-9999 -9999 -9999 -9999 -9999 -9999 -9999 -9999 -9999 -9999 -9999 -9999 -9999 -9999 -9999 -9999 -9999 -9999 -9999 -9999 -9999 -9999 -9999 -9999 -9999 -9999 -9999 -9999 -9999 -9999 -9999 -9999 -9999 -9999 -9999 -9999

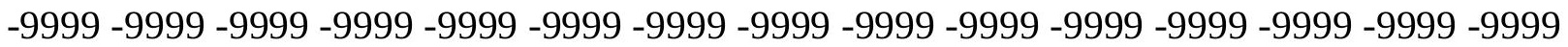

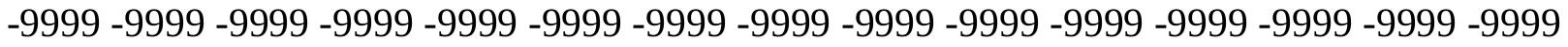
-9999 -9999 -9999 -9999 -9999 -9999 -9999 -9999 -9999 -9999 -9999 -9999 -9999 -9999 -9999 -9999 -9999 -9999 -9999 -9999 -9999 -9999 -9999 -9999 -9999 -9999 -9999 -9999 -9999 -9999 -9999 -9999 -9999 -9999 -9999 -9999 -9999 -9999 -9999 -9999 -9999 -9999 -9999 -9999 -9999 -9999 -9999 -9999 -9999 -9999 -9999 -9999 -9999 -9999 -9999 -9999 -9999 -9999 -9999 -9999 -9999 -9999 -9999 -9999 -9999 -9999 -9999 -9999 -9999 -9999 -9999 -9999 -9999 -9999 -9999 -9999 -9999 -9999 -9999 -9999 -9999 -9999 -9999 -9999 -9999 -9999 -9999 -9999 -9999 -9999 -

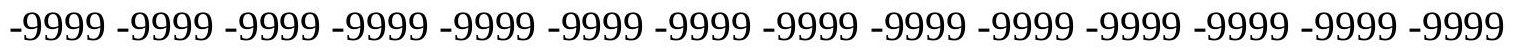
-9999 -9999 -9999 -9999 -9999 -9999 -9999 -9999 -9999 -9999 -9999 -9999 -9999 -9999 -9999 -9999 -9999 -9999 -9999 -9999 -9999 -9999 -9999 -9999 -9999 -9999 -9999 -9999 -9999 -9999 -9999 -9999 -9999 -9999 -9999 -9999 -9999 -9999 -9999 -9999 -9999 -9999 -9999 -9999 -9999 -

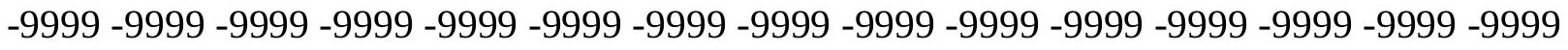

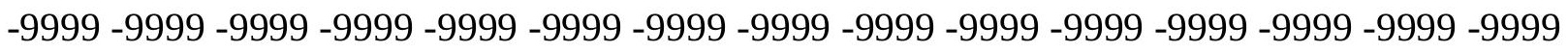
-9999 -9999 -9999 -9999 -9999 -9999 -9999 -9999 -9999 -9999 -9999 -9999 -9999 -9999 - 9999 -9999 -9999 -9999 -9999 -9999 -9999 -9999 -9999 -9999 -9999 -9999 -9999 -9999 -9999 -9999 -9999 -9999 -9999 -9999 -9999 -9999 -9999 -9999 -9999 -9999 -9999 -9999 -9999 -9999 -9999 -

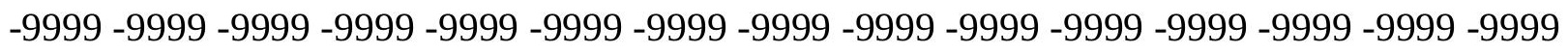
-9999 -9999 -9999 -9999 -9999 -9999 -9999 -9999 -9999 -9999 -9999 -9999 -9999 -9999 -9999 -9999 -9999 -9999 -9999 -9999 -9999 -9999 -9999 -9999 -9999 -9999 -9999 -9999 -9999 -9999 -

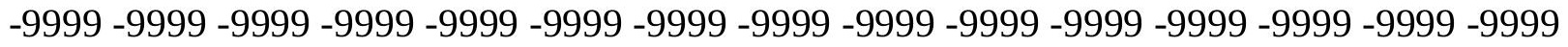
-9999 -9999 -9999 -9999 -9999 -9999 -9999 -9999 -9999 -9999 -9999 -9999 -9999 -9999 -9999 -9999 -9999 -9999 -9999 -9999 -9999 -9999 -9999 -9999 -9999 -9999 -9999 -9999 -9999 -999 -

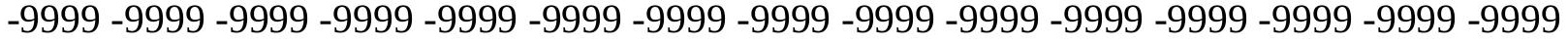
-9999 -9999 -9999 -9999 -9999 -9999 -9999 -9999 -9999 -9999 -9999 -9999 -9999 -9999 -9999 -

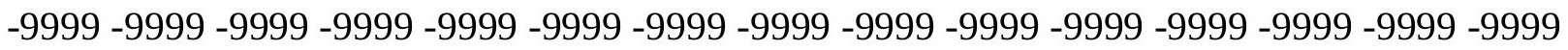

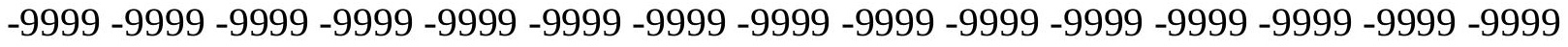

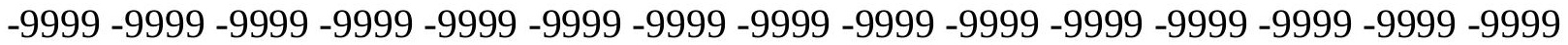
-9999 -9999 -9999 -9999 -9999 -9999 -9999 -9999 -9999 -9999 -9999 -9999 -9999 -9999 -9999 -

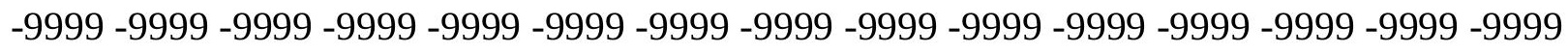

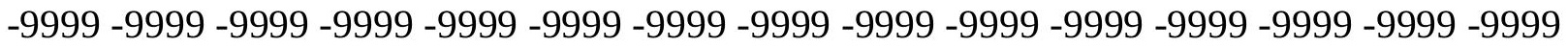
-9999 -9999 -9999 -9999 -9999 -9999 -9999 -9999 -9999 -9999 -9999 -9999 -9999 - 9999 - -999 -9999 -9999 -9999 -9999 -9999 -9999 -9999 -9999 -9999 -9999 -9999 -9999 -9999 -9999 -9999 -

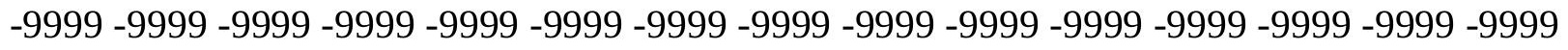

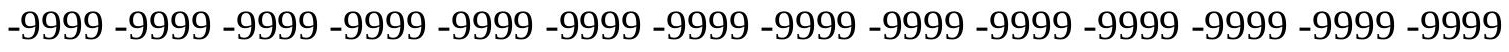
-9999 -9999 -9999 -9999 -9999 -9999 -9999 -9999 -9999 -9999 -9999 -9999 -9999 -9999 -9999 -9999 -9999 -9999 -9999 -9999 -9999 -9999 -9999 -9999-9999 -9999 -9999 -9999 -9999 -9999 -9999 -9999 -9999 -9999 -9999 -9999 -9999 -9999 -9999 -9999 -9999 -9999 -9999 -9999 -9999 -

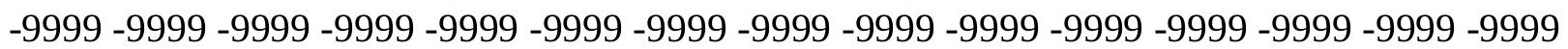


-9999 -9999 -9999 -9999 -9999 -9999 -9999 -9999 -9999 -9999 -9999 -9999 -9999 -9999 -9999 -9999 -9999 -9999 -9999 -9999 -9999 -9999 -9999 -9999 -9999 -9999 -9999 -9999 -9999 -9999 -

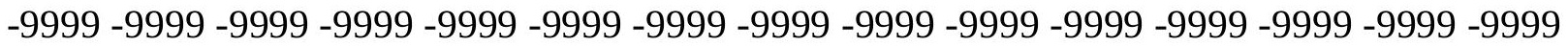
-9999 -9999 -9999 -9999 -9999 -9999 -9999 -9999 -9999 -9999 -9999 -9999 -9999 -9999 -9999 -9999 -9999 -9999 -9999 -9999 -9999 -9999 -9999 -9999-9999 -9999 -9999 -9999 -9999 -9999 -9999 -9999 -9999 -9999 -9999 -9999 -9999 -9999 -9999 -9999 -9999 -9999 -9999 -9999 -9999 -9999 -9999 -9999 -9999 -9999 -9999 -9999 -9999 -9999 -9999 -9999 -9999 -9999 -9999 -9999

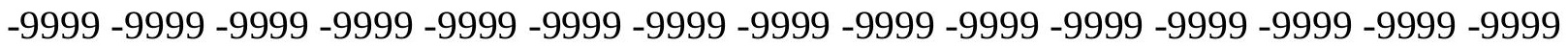

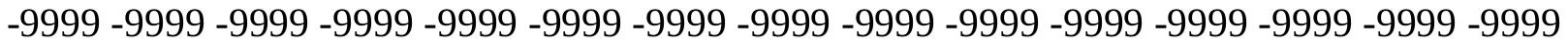
-9999 -9999 -9999 -9999 -9999 -9999 -9999 -9999 -9999 -9999 -9999 -9999 -9999 -9999 -9999 -9999 -9999 -9999 -9999 -9999 -9999 -9999 -9999 -9999 -9999 -9999 -9999 -9999 -9999 -9999 -9999 -9999 -9999 -9999 -9999 -9999 -9999 -9999 -9999 -9999 -9999 -9999 -9999 -9999 -9999 -9999 -9999 -9999 -9999 -9999 -9999 -9999 -9999 -9999 -9999 -9999 -9999 -9999 -9999 -9999 -

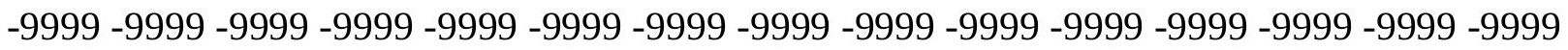
-9999 -9999 -9999 -9999 -9999 -9999 -9999 -9999 -9999 -9999 -9999 -9999 -9999 -9999 -9999 -

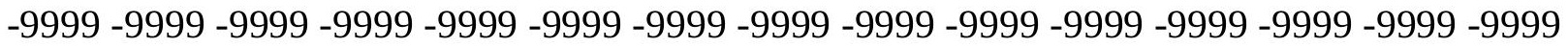
-9999 -9999 -9999 -9999 -9999 -9999 -9999 -9999 -9999 -9999 -9999 -9999 -9999 -9999 -9999 -9999 -9999 -9999 -9999 -9999 -9999 -9999 -9999 -9999 -9999 -9999 -9999 -9999 -9999 -9999 -9999 -9999 -9999 -9999 -9999 -9999 -9999 -9999 -9999 -9999 -9999 -9999 -9999 -9999 -9999 -

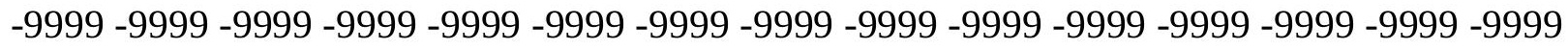

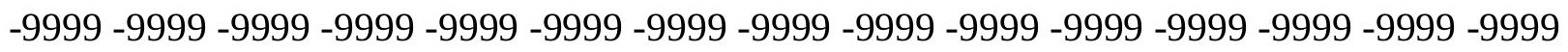
-9999 -9999 -9999 -9999 -9999 -9999 -9999 -9999 -9999 -9999 -9999 -9999 -9999 -9999 -9999 -9999 -9999 -9999 -9999 -9999 -9999 -9999 -9999 -9999 -9999 -9999 -9999 -9999 -9999 -9999 -9999 -9999 -9999 -9999 -9999 -9999 -9999 -9999 -9999 -9999 -9999 -9999 -9999 -9999 -

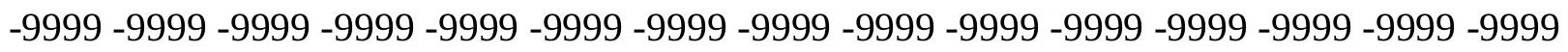
-9999 -9999 -9999 -9999 -9999 -9999 -9999 -9999 -9999 -9999 -9999 -9999 -9999 -9999 -9999 -9999 -9999 -9999 -9999 -9999 -9999 -9999 -9999 -9999 -9999 -9999 -9999 -9999 -9999 -9999 -

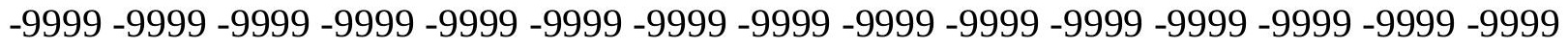
-9999 -9999 -9999 -9999 -9999 -9999 -9999 -9999 -9999 -9999 -9999 -9999 -9999 -9999 -9999 -9999 -9999 -9999 -9999 -9999 -9999 -9999 -9999 -9999 -9999 -9999 -9999 -9999 -9999 -999 -

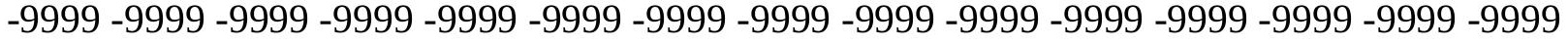
-9999 -9999 -9999 -9999 -9999 -9999 -9999 -9999 -9999 -9999 -9999 -9999 -9999 -9999 -9999 -

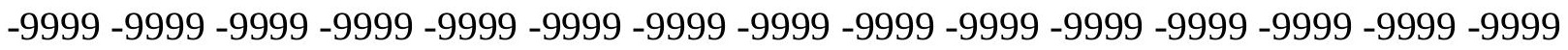

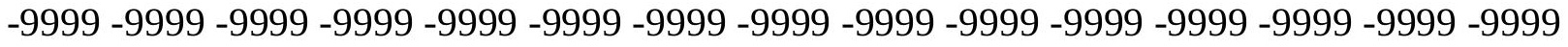

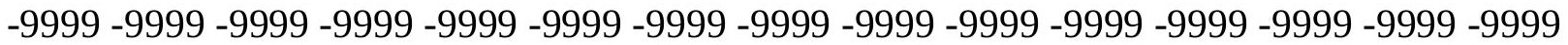

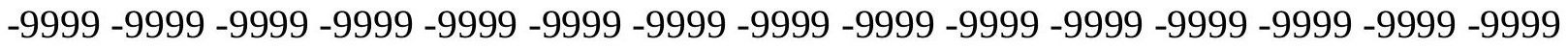

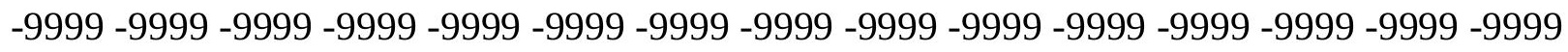

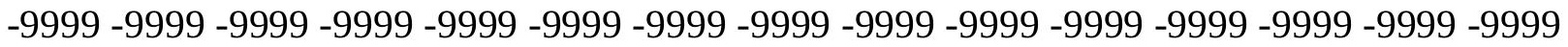

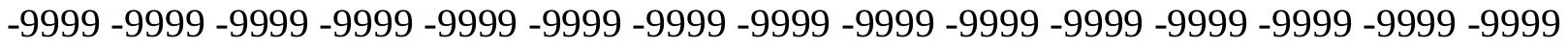
-9999 -9999 -9999 -9999 -9999 -9999 -9999 -9999 -9999 -9999 -9999 -9999 -9999 -9999 -9999 -

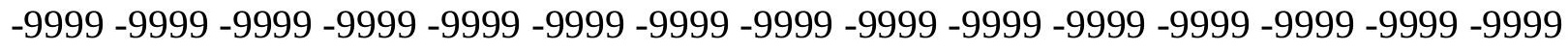

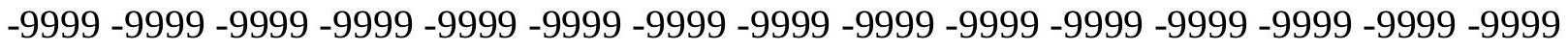
-9999 -9999 -9999 -9999 -9999 -9999 -9999 -9999 -9999 -9999 -9999 -9999 -9999 -9999 -9999 -9999 -9999 -9999 -9999 -9999 -9999 -9999 -9999 -9999-9999 -9999 -9999 -9999 -9999 -9999 -9999 -9999 -9999 -9999 -9999 -9999 -9999 -9999 -9999 -9999 -9999 -9999 -9999 -9999 -9999 -

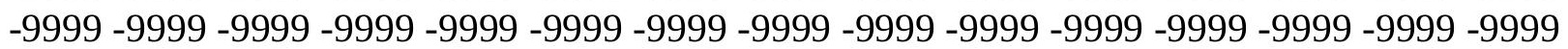


-9999 -9999 -9999 -9999 -9999 -9999 -9999 -9999 -9999 -9999 -9999 -9999 -9999 -9999 -9999 -9999 -9999 -9999 -9999 -9999 -9999 -9999 -9999 -9999 -9999 -9999 -9999 -9999 -9999 -

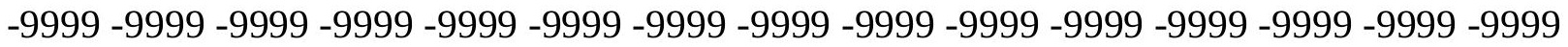
-9999 -9999 -9999 -9999 -9999 -9999 -9999 -9999 -9999 -9999 -9999 -9999 -9999 -9999 -9999 -9999 -9999 -9999 -9999 -9999 -9999 -9999 -9999 -9999 -9999 -9999 -9999 -9999 -9999 -9999 -9999 -9999 -9999 -9999 -9999 -9999 -9999 -9999 -9999 -9999 -9999 -9999 -9999 -9999 -9999 -9999 -9999 -9999 -9999 -9999 -9999 -9999 -9999 -9999 -9999 -9999 -9999 -9999 -9999 -9999

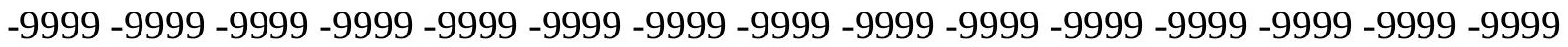

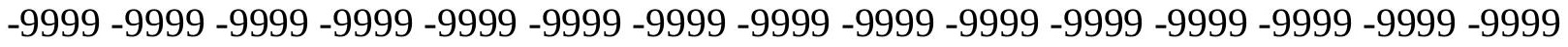
-9999 -9999 -9999 -9999 -9999 -9999 -9999 -9999 -9999 -9999 -9999 -9999 -9999 -9999 -9999 -9999 -9999 -9999 -9999 -9999 -9999 -9999 -9999 -9999 -9999 -9999 -9999 -9999 -9999 -9999 -9999 -9999 -9999 -9999 -9999 -9999 -9999 -9999 -9999 -9999 -9999 -9999 -9999 -9999 -9999 -9999 -9999 -9999 -9999 -9999 -9999 -9999 -9999 -9999 -9999 -9999 -9999 -9999 -9999 -9999 -9999 -9999 -9999 -9999 -9999 -9999 -9999 -9999 -9999 -9999 -9999 -9999 -9999 -9999 -9999 -9999 -9999 -9999 -9999 -9999 -9999 -9999 -9999 -9999 -9999 -9999 -9999 -9999 -9999 -9999 -

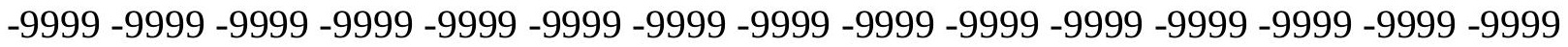
-9999 -9999 -9999 -9999 -9999 -9999 -9999 -9999 -9999 -9999 -9999 -9999 -9999 -9999 -9999 -9999 -9999 -9999 -9999 -9999 -9999 -9999 -9999 -9999 -9999 -9999 -9999 -9999 -9999 - 9999 -9999 -9999 -9999 -9999 -9999 -9999 -9999 -9999 -9999 -9999 -9999 -9999 -9999 -9999 -9999 -

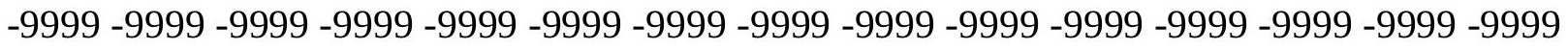

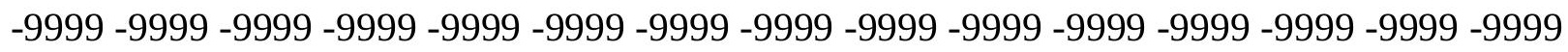

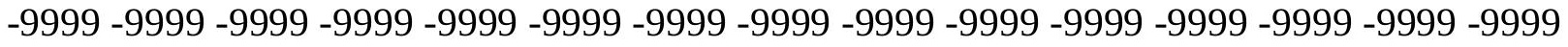
-9999 -9999 -9999 -9999 -9999 -9999 -9999 -9999 -9999 -9999 -9999 -9999 -9999 -9999 -9999 -9999 -9999 -9999 -9999 -9999 -9999 -9999 -9999 -9999 -9999 -9999 -9999 -9999 -9999 -9999 -

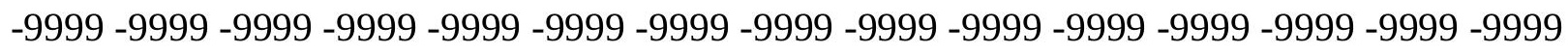
-9999 -9999 -9999 -9999 -9999 -9999 -9999 -9999 -9999 -9999 -9999 -9999 -9999 -9999 -9999 -9999 -9999 -9999 -9999 -9999 -9999 -9999 -9999 -9999 -9999 -9999 -9999 -9999 -9999 -9999 -9999 -9999 -9999 -9999 -9999 -9999 -9999 -9999 -9999 -9999 -9999 -9999 -9999 -9999 -9999 -9999 -9999 -9999 -9999 -9999 -9999 -9999 -9999 -9999 -9999 -9999 -9999 -9999 -9999 -9999 -9999 -9999 -9999 -9999 -9999 -9999 -9999 -9999 -9999 -9999 -9999 -9999 -9999 -999 -

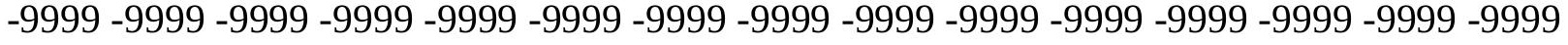
-9999 -9999 -9999 -9999 -9999 -9999 -9999 -9999 -9999 -9999 -9999 -9999 -9999 -9999 -9999 -

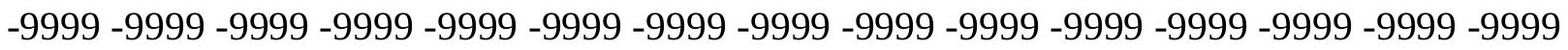

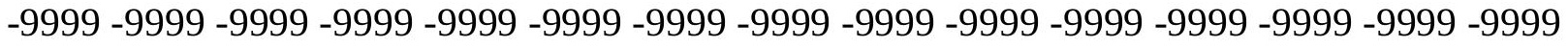

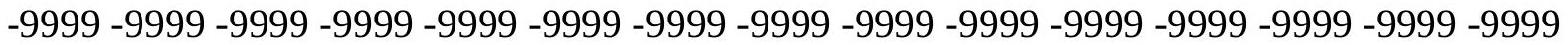

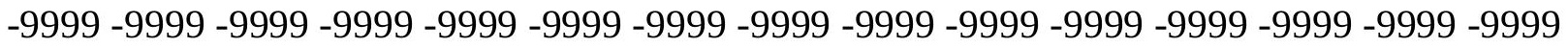

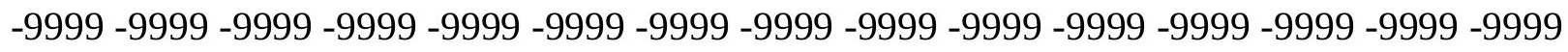

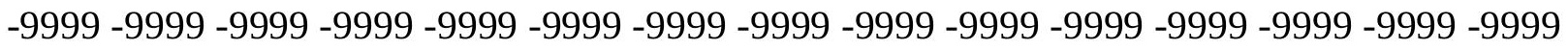

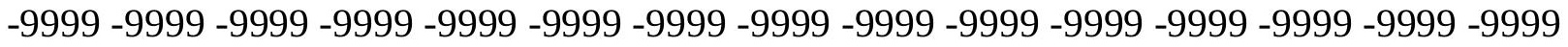
-9999 -9999 -9999 -9999 -9999 -9999 -9999 -9999 -9999 -9999 -9999 -9999 -9999 -9999 -9999 -

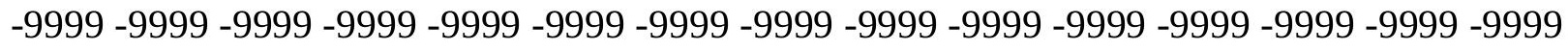

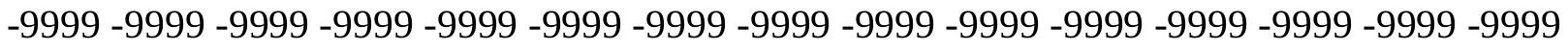
-9999 -9999 -9999 -9999 -9999 -9999 -9999 -9999 -9999 -9999 -9999 -9999 -9999 -9999 -9999 -9999 -9999 -9999 -9999 -9999 -9999 -9999 -9999 -9999-9999 -9999 -9999 -9999 -9999 -9999 -9999 -9999 -9999 -9999 -9999 -9999 -9999 -9999 -9999 -9999 -9999 -9999 -9999 -9999 -9999 -

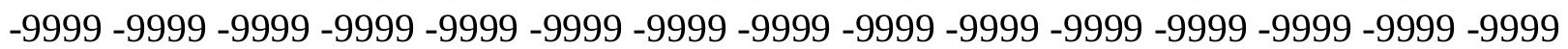


-9999 -9999 -9999 -9999 -9999 -9999 -9999 -9999 -9999 -9999 -9999 -9999 -9999 -9999 -9999 -9999 -9999 -9999 -9999 -9999 -9999 -9999 -9999 -9999 -9999 -9999 -9999 -9999 -9999 -9999 -

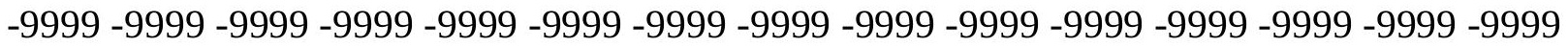
-9999 -9999 -9999 -9999 -9999 -9999 -9999 -9999 -9999 -9999 -9999 -9999 -9999 -9999 -9999 -9999 -9999 -9999 -9999 -9999 -9999 -9999 -9999 -9999-9999 -9999 -9999 -9999 -9999 -9999 -9999 -9999 -9999 -9999 -9999 -9999 -9999 -9999 -9999 -9999 -9999 -9999 -9999 -9999 -9999 -

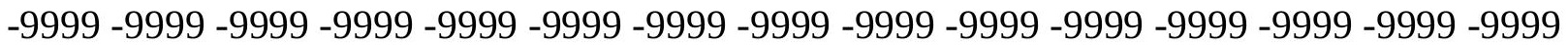
-9999 -9999 -9999 -9999 -9999 -9999 -9999 -9999 -9999 -9999 -9999 -9999 -9999 -9999 -9999 -9999 -9999 -9999 -9999 -9999 -9999 -9999 -9999 -9999 -9999 -9999 -9999 -9999 -9999 -9999 -9999 -9999 -9999 -9999 -9999 -9999 -9999 -9999 -9999 -9999 -9999 -9999 -9999 -9999 -9999 -9999 -9999 -9999 -9999 -9999 -9999 -9999 -9999 -9999 -9999 -9999 -9999 -9999 -9999 -9999 -9999 -9999 -9999 -9999 -9999 -9999 -9999 -9999 -9999 -9999 -9999 -9999 -9999 -9999 -9999 -9999 -9999 -9999 -9999 -9999 -9999 -9999 -9999 -9999 -9999 -9999 -9999 -9999 -9999 -9999 -9999 -9999 -9999 -9999 -9999 -9999 -9999 -9999 -9999 -9999 -9999 -9999 -9999 -9999 -9999 -9999 -9999 -9999 -9999 -9999 -9999 -9999 -9999 -9999 -9999 -9999 -9999 -9999 -9999 -

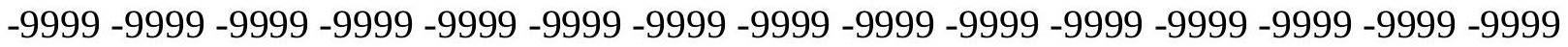
-9999 -9999 -9999 -9999 -9999 -9999 -9999 -9999 -9999 -9999 -9999 -9999 -9999 -9999 -9999 -9999 -9999 -9999 -9999 -9999 -9999 -9999 -9999 -9999 -9999 -9999 -9999 -9999 -9999 -9999 -9999 -9999 -9999 -9999 -9999 -9999 -9999 -9999 -9999 -9999 -9999 -9999 -9999 -9999 -9999 -

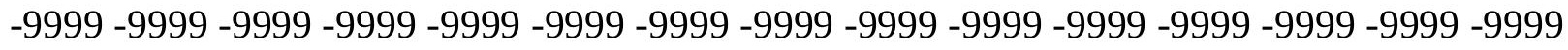

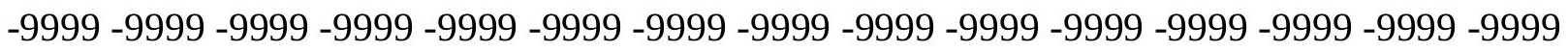
-9999 -9999 -9999 -9999 -9999 -9999 -9999 -9999 -9999 -9999 -9999 -9999 -9999 -9999 - 9999 -9999 -9999 -9999 -9999 -9999 -9999 -9999 -9999 -9999 -9999 -9999 -9999 -9999 -9999 -9999 -9999 -9999 -9999 -9999 -9999 -9999 -9999 -9999 -9999 -9999 -9999 -9999 -9999 -9999 -9999 -

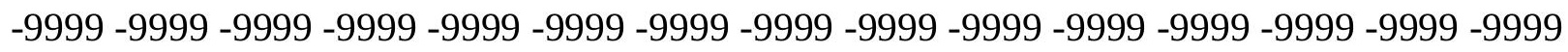
-9999 -9999 -9999 -9999 -9999 -9999 -9999 -9999 -9999 -9999 -9999 -9999 -9999 -9999 -9999 -9999 -9999 -9999 -9999 -9999 -9999 -9999 -9999 -9999 -9999 -9999 -9999 -9999 -9999 -9999 -

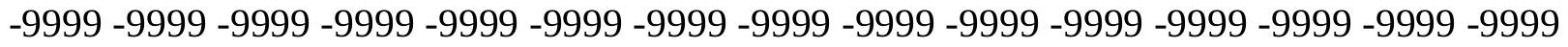
-9999 -9999 -9999 -9999 -9999 -9999 -9999 -9999 -9999 -9999 -9999 -9999 -9999 -9999 -9999 -9999 -9999 -9999 -9999 -9999 -9999 -9999 -9999 -9999 -9999 -9999 -9999 -9999 -9999 -999 -9999 -9999 -9999 -9999 -9999 -9999 -9999 -9999 -9999 -9999 -9999 -9999 -9999 -9999 -9999 -9999 -9999 -9999 -9999 -9999 -9999 -9999 -9999 -9999 -9999 -9999 -9999 -9999 -9999 -9999 -

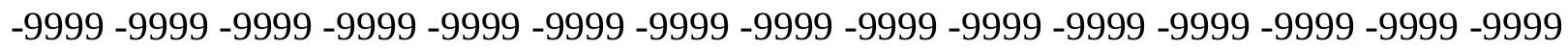

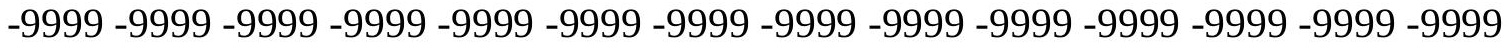
-9999 -9999 -9999 -9999 -9999 -9999 -9999 -9999 -9999 -9999 -9999 -9999 -9999 -9999 -9999

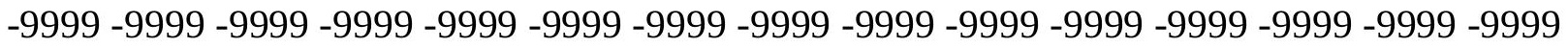

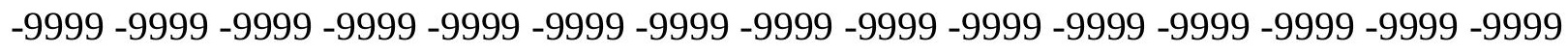

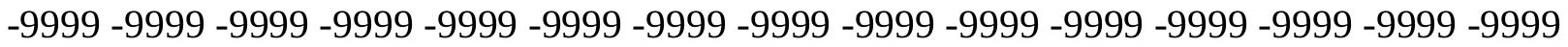

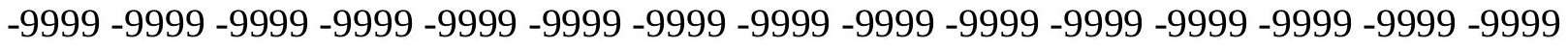
-9999 -9999 -9999 -9999 -9999 -9999 -9999 -9999 -9999 -9999 -9999 -9999 -9999 -9999 -9999 -

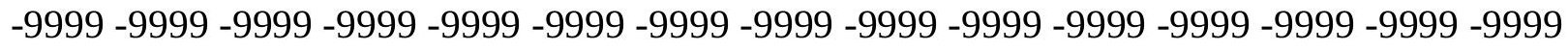

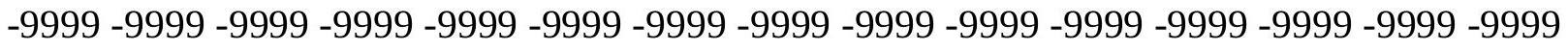
-9999 -9999 -9999 -9999 -9999 -9999 -9999 -9999 -9999 -9999 -9999 -9999 -9999 -9999 -9999 -9999 -9999 -9999 -9999 -9999 -9999 -9999 -9999 -9999-9999 -9999 -9999 -9999 -9999 -9999 -9999 -9999 -9999 -9999 -9999 -9999 -9999 -9999 -9999 -9999 -9999 -9999 -9999 -9999 -9999 -

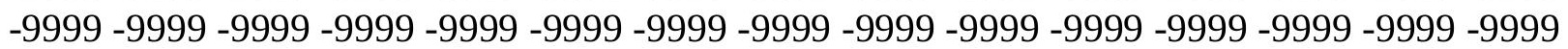


-9999 -9999 -9999 -9999 -9999 -9999 -9999 -9999 -9999 -9999 -9999 -9999 -9999 -9999 -9999 -9999 -9999 -9999 -9999 -9999 -9999 -9999 -9999 -9999 -9999 -9999 -9999 -9999 -9999 -9999 -

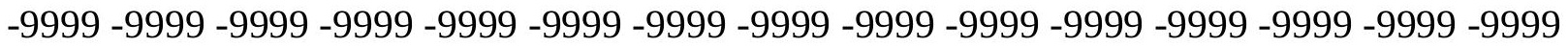
-9999 -9999 -9999 -9999 -9999 -9999 -9999 -9999 -9999 -9999 -9999 -9999 -9999 -9999 -9999 -9999 -9999 -9999 -9999 -9999 -9999 -9999 -9999 -9999-9999 -9999 -9999 -9999 -9999 -9999 -9999 -9999 -9999 -9999 -9999 -9999 -9999 -9999 -9999 -9999 -9999 -9999 -9999 -9999 -9999 -9999 -9999 -9999 -9999 -9999 -9999 -9999 -9999 -9999 -9999 -9999 -9999 -9999 -9999 -9999

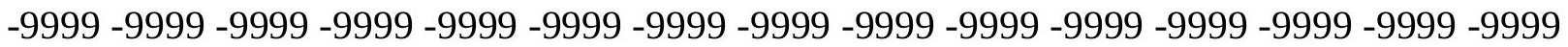

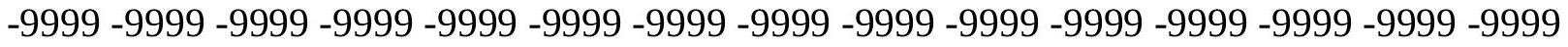
-9999 -9999 -9999 -9999 -9999 -9999 -9999 -9999 -9999 -9999 -9999 -9999 -9999 -9999 -9999 -9999 -9999 -9999 -9999 -9999 -9999 -9999 -9999 -9999 -9999 -9999 -9999 -9999 -9999 -9999 -9999 -9999 -9999 -9999 -9999 -9999 -9999 -9999 -9999 -9999 -9999 -9999 -9999 -9999 -9999 -9999 -9999 -9999 -9999 -9999 -9999 -9999 -9999 -9999 -9999 -9999 -9999 -9999 -9999 -9999 -9999 -9999 -9999 -9999 -9999 -9999 -9999 -9999 -9999 -9999 -9999 -9999 -9999 -9999 -9999 -9999 -9999 -9999 -9999 -9999 -9999 -9999 -9999 -9999 -9999 -9999 -9999 -9999 -9999

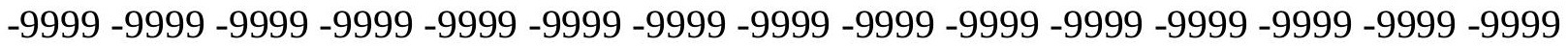
-9999 -9999 -9999 -9999 -9999 -9999 -9999 -9999 -9999 -9999 -9999 -9999 -9999 -9999 -9999 -9999 -9999 -9999 -9999 -9999 -9999 -9999 -9999 -9999 -9999 -9999 -9999 -9999 -9999 -9999 -9999 -9999 -9999 -9999 -9999 -9999 -9999 -9999 -9999 -9999 -9999 -9999 -9999 -9999 -9999 -

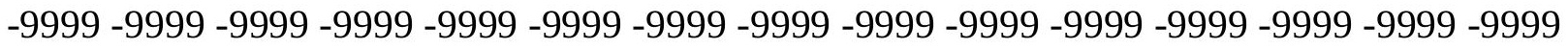

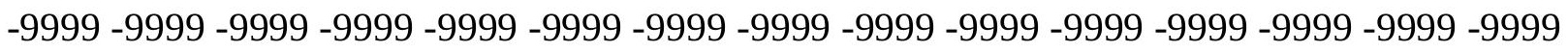
-9999 -9999 -9999 -9999 -9999 -9999 -9999 -9999 -9999 -9999 -9999 -9999 -9999 -9999 -9999 -9999 -9999 -9999 -9999 -9999 -9999 -9999 -9999 -9999 -9999 -9999 -9999 -9999 -9999 -9999 -9999 -9999 -9999 -9999 -9999 -9999 -9999 -9999 -9999 -9999 -9999 -9999 -9999 -9999 -9999 -

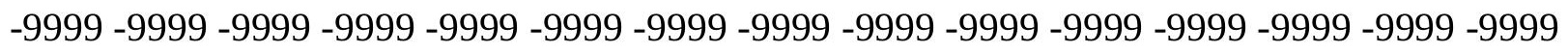
-9999 -9999 -9999 -9999 -9999 -9999 -9999 -9999 -9999 -9999 -9999 -9999 -9999 -9999 -9999 -9999 -9999 -9999 -9999 -9999 -9999 -9999 -9999 -9999 -9999 -9999 -9999 -9999 -9999 -9999 -

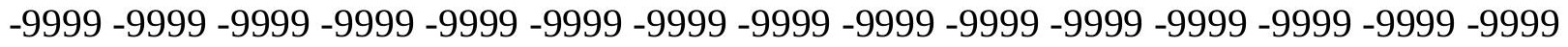
-9999 -9999 -9999 -9999 -9999 -9999 -9999 -9999 -9999 -9999 -9999 -9999 -9999 -9999 -9999 -9999 -9999 -9999 -9999 -9999 -9999 -9999 -9999 -9999 -9999 -9999 -9999 -9999 -9999 -999 -9999 -9999 -9999 -9999 -9999 -9999 -9999 -9999 -9999 -9999 -9999 -9999 -9999 -9999 -9999 -9999 -9999 -9999 -9999 -9999 -9999 -9999 -9999 -9999 -9999 -9999 -9999 -9999 -9999 -9999 -

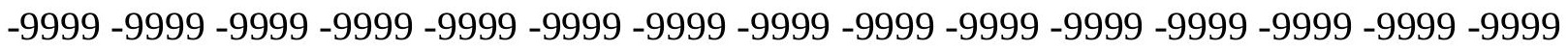

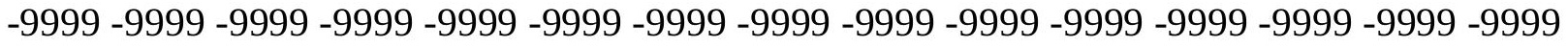

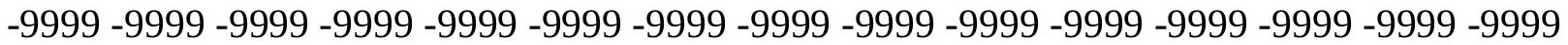

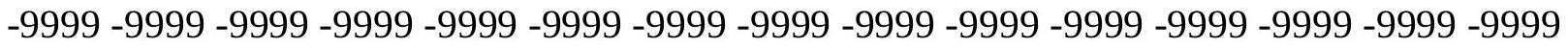

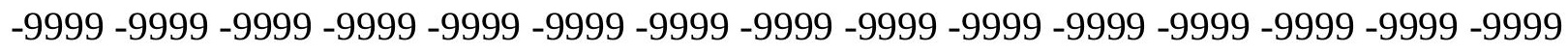

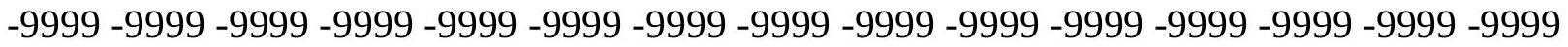
-9999 -9999 -9999 -9999 -9999 -9999 -9999 -9999 -9999 -9999 -9999 -9999 -9999 - 9999 - -999 -9999 -9999 -9999 -9999 -9999 -9999 -9999 -9999 -9999 -9999 -9999 -9999 -9999 -9999 - -999 -

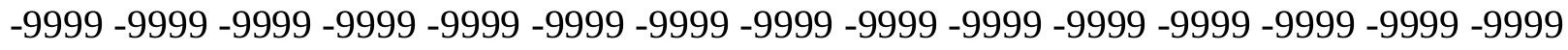

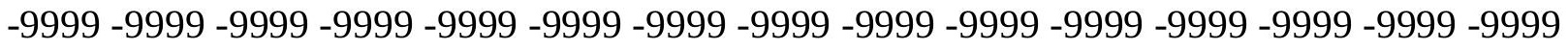
-9999 -9999 -9999 -9999 -9999 -9999 -9999 -9999 -9999 -9999 -9999 -9999 -9999 -9999 -9999 -9999 -9999 -9999 -9999 -9999 -9999 -9999 -9999 -9999-9999 -9999 -9999 -9999 -9999 -9999 -9999 -9999 -9999 -9999 -9999 -9999 -9999 -9999 -9999 -9999 -9999 -9999 -9999 -9999 -9999 -

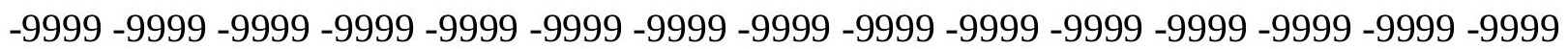


-9999 -9999 -9999 -9999 -9999 -9999 -9999 -9999 -9999 -9999 -9999 -9999 -9999 -9999 -9999 -9999 -9999 -9999 -9999 -9999 -9999 -9999 -9999 -9999 -9999 -9999 -9999 -9999 -9999 -9999 -9999 -9999 -9999 -9999 -9999 -9999 -9999 -9999 -9999 -9999 -9999 -9999 -9999 -9999 -9999 -9999 -9999 -9999 -9999 -9999 -9999 -9999 -9999 -9999 -9999 -9999 -9999 -9999 -9999 -9999 -9999 -9999 -9999 -9999 -9999 -9999 -9999 -9999 -9999 -9999 -9999 -9999 -9999 -9999 -9999 -9999 -9999 -9999 -9999 -9999 -9999 -9999 -9999 -9999 -9999 -9999 -9999 -9999 -9999 -9999 -9999 -9999 -9999 -9999 -9999 -9999 -9999 -9999 -9999 -9999 -9999 -9999 -9999 -9999 -9999 -

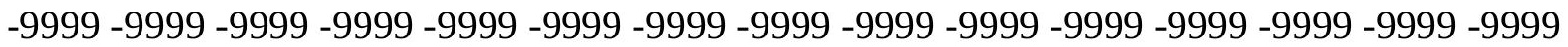
-9999 -9999 -9999 -9999 -9999 -9999 -9999 -9999 -9999 -9999 -9999 -9999 -9999 -9999 -9999 -9999 -9999 -9999 -9999 -9999 -9999 -9999 -9999 -9999 -9999 -9999 -9999 -9999 -9999 -9999 -

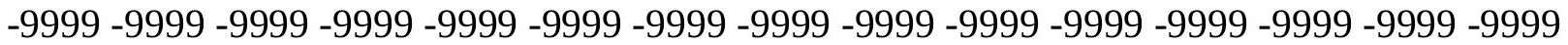
-9999 -9999 -9999 -9999 -9999 -9999 -9999 -9999 -9999 -9999 -9999 -9999 -9999 -9999 -9999 -9999 -9999 -9999 -9999 -9999 -9999 -9999 -9999 -9999 -9999 -9999 -9999 -9999 -9999 -9999 -9999 -9999 -9999 -9999 -9999 -9999 -9999 -9999 -9999 -9999 -9999 -9999 -9999 -9999 -9999 -9999 -9999 -9999 -9999 -9999 -9999 -9999 -9999 -9999 -9999 -9999 -9999 -9999 -9999 -9999

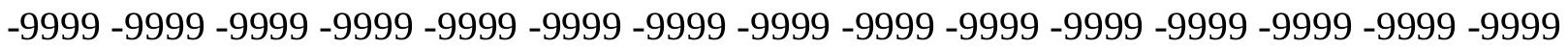
-9999 -9999 -9999 -9999 -9999 -9999 -9999 -9999 -9999 -9999 -9999 -9999 -9999 -9999 -9999 -9999 -9999 -9999 -9999 -9999 -9999 -9999 -9999 -9999 -9999 -9999 -9999 -9999 -9999 -9999 -9999 -9999 -9999 -9999 -9999 -9999 -9999 -9999 -9999 -9999 -9999 -9999 -9999 -9999 -9999 -9999 -9999 -9999 -9999 -9999 -9999 -9999 -9999 -9999 -9999 -9999 -9999 -9999 -9999 -9999 -9999 -9999 -9999 -9999 -9999 -9999 -9999 -9999 -9999 -9999 -9999 -9999 -9999 -9999 -9999 -9999 -9999 -9999 -9999 -9999 -9999 -9999 -9999 -9999 -9999 -9999 -9999 -9999 -9999 -9999 -9999 -9999 -9999 -9999 -9999 -9999 -9999 -9999 -9999 -9999 -9999 -9999 -9999 -9999 -9999 -9999 -9999 -9999 -9999 -9999 -9999 -9999 -9999 -9999 -9999 -9999 -9999 -9999 -9999 -9999 -9999 -9999 -9999 -9999 -9999 -9999 -9999 -9999 -9999 -9999 -9999 -9999 -9999 -9999 -9999 -9999 -9999 -9999 -9999 -9999 -9999 -9999 -9999 -9999 -9999 -9999 -9999 -9999 -9999 -9999 -9999 -9999 -9999 -9999 -9999 -9999 -9999 -9999 -9999 -9999 -9999 -9999 -9999 -9999 -9999 -9999 -9999 -9999 -9999 -9999 -9999 -9999 -9999 -9999 -9999 -9999 -9999 -9999 -9999

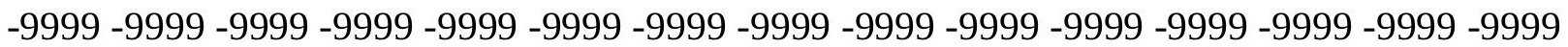
-9999 -9999 -9999 -9999 -9999 -9999 -9999 -9999 -9999 -9999 -9999 -9999 -9999 -9999 -9999 -9999 -9999 -9999 -9999 -9999 -9999 -9999 -9999 -9999 -9999 -9999 -9999 -9999 -9999 -9999 -

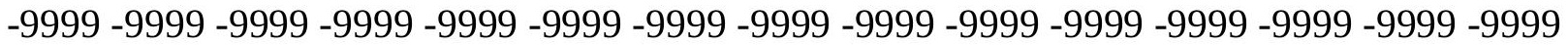
-9999 -9999 -9999 -9999 -9999 -9999 -9999 -9999 -9999 -9999 -9999 -9999 -9999 -9999 -9999 -9999 -9999 -9999 -9999 -9999 -9999 -9999 -9999 -9999 -9999 -9999 -9999 -9999 -9999 -9999 -9999 -9999 -9999 -9999 -9999 -9999 -9999 -9999 -9999 -9999 -9999 -9999 -9999 -9999 -9999 -9999 -9999 -9999 -9999 -9999 -9999 -9999 -9999 -9999 -9999 -9999 -9999 -9999 -9999 -9999 -9999 -9999 -9999 -9999 -9999 -9999 -9999 -9999 -9999 -9999 -9999 -9999 -9999 -9999 -9999

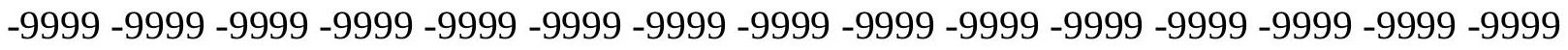
-9999 -9999 -9999 -9999 -9999 -9999 -9999 -9999 -9999 -9999 -9999 -9999 -9999 -9999 -9999 -9999 -9999 -9999 -9999 -9999 -9999 -9999 -9999 -9999 -9999 -9999 -9999 -9999 -9999 -9999 -9999 -9999 -9999 -9999 -9999 -9999 -9999 -9999 -9999 -9999 -9999 -9999 -9999 -9999 -9999 -999 -9999 -9999 -9999 -9999 -9999 -9999 -9999 -9999 -9999 -9999 -9999 -9999 -9999 -9999 -9999 -9999 -9999 -9999 -9999 -9999 -9999 -9999 -9999 -9999 -9999 -9999 -9999 -9999 -9999 -9999 -9999 -9999 -9999 -9999 -9999 -9999 -9999 -9999 -9999 -9999 -9999 -9999 -9999 -9999 -9999 -9999 -9999 -9999 -9999 -9999 -9999 -9999 -9999 -9999 -9999 -9999 -9999 -9999 -9999 -9999 -9999 -9999 -9999 -9999 -9999 -9999 -9999 -9999 -9999 -9999 -9999 -9999 -9999 -9999 
-9999 -9999 -9999 -9999 -9999 -9999 -9999 -9999 -9999 -9999 -9999 -9999 -9999 -9999 -9999 -9999 -9999 -9999 -9999 -9999 -9999 -9999 -9999 -9999 -9999 -9999 -9999 -9999 -9999 -9999 -

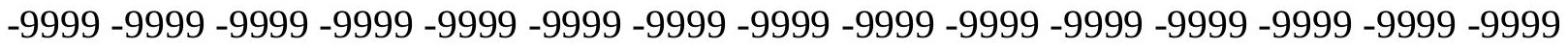
-9999 -9999 -9999 -9999 -9999 -9999 -9999 -9999 -9999 -9999 -9999 -9999 -9999 -9999 -9999 -9999 -9999 -9999 -9999 -9999 -9999 -9999 -9999 -9999-9999 -9999 -9999 -9999 -9999 -9999 -9999 -9999 -9999 -9999 -9999 -9999 -9999 -9999 -9999 -9999 -9999 -9999 -9999 -9999 -9999 -9999 -9999 -9999 -9999 -9999 -9999 -9999 -9999 -9999 -9999 -9999 -9999 -9999 -9999 -9999

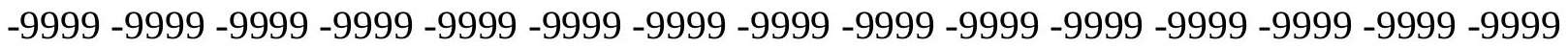

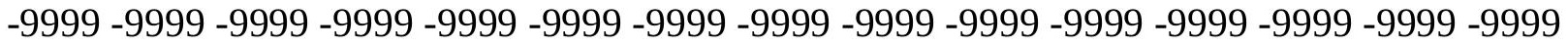
-9999 -9999 -9999 -9999 -9999 -9999 -9999 -9999 -9999 -9999 -9999 -9999 -9999 -9999 -9999 -9999 -9999 -9999 -9999 -9999 -9999 -9999 -9999 -9999 -9999 -9999 -9999 -9999 -9999 -9999 -9999 -9999 -9999 -9999 -9999 -9999 -9999 -9999 -9999 -9999 -9999 -9999 -9999 -9999 -9999 -9999 -9999 -9999 -9999 -9999 -9999 -9999 -9999 -9999 -9999 -9999 -9999 -9999 -9999 -9999 -

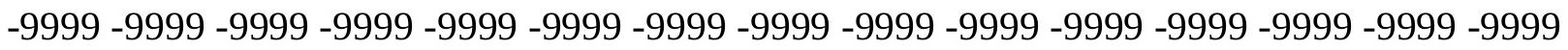
-9999 -9999 -9999 -9999 -9999 -9999 -9999 -9999 -9999 -9999 -9999 -9999 -9999 -9999 -9999 -

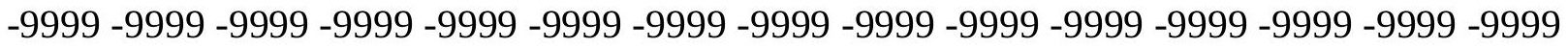
-9999 -9999 -9999 -9999 -9999 -9999 -9999 -9999 -9999 -9999 -9999 -9999 -9999 -9999 -9999 -9999 -9999 -9999 -9999 -9999 -9999 -9999 -9999 -9999 -9999 -9999 -9999 -9999 -9999 -9999 -9999 -9999 -9999 -9999 -9999 -9999 -9999 -9999 -9999 -9999 -9999 -9999 -9999 -9999 -9999 -

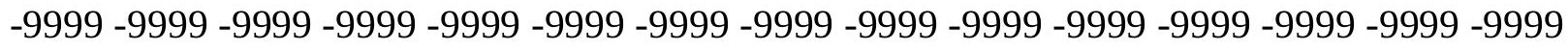

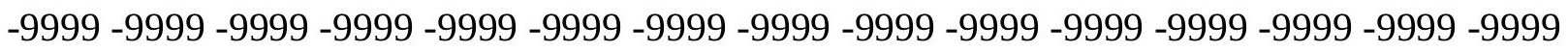

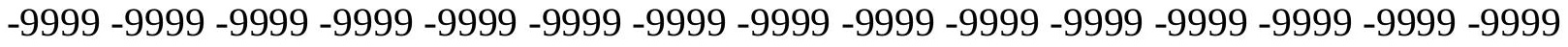
-9999 -9999 -9999 -9999 -9999 -9999 -9999 -9999 -9999 -9999 -9999 -9999 -9999 -9999 -9999 -9999 -9999 -9999 -9999 -9999 -9999 -9999 -9999 -9999 -9999 -9999 -9999 -9999 -9999 -9999 -

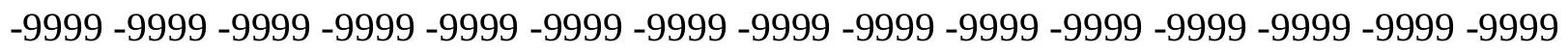
-9999 -9999 -9999 -9999 -9999 -9999 -9999 -9999 -9999 -9999 -9999 -9999 -9999 -9999 -9999 -9999 -9999 -9999 -9999 -9999 -9999 -9999 -9999 -9999 -9999 -9999 -9999 -9999 -9999 -

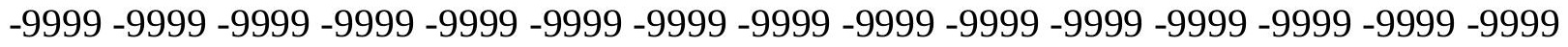
-9999 -9999 -9999 -9999 -9999 -9999 -9999 -9999 -9999 -9999 -9999 -9999 -9999 -9999 -9999 -9999 -9999 -9999 -9999 -9999 -9999 -9999 -9999 -9999 -9999 -9999 -9999 -9999 -9999 -999 -

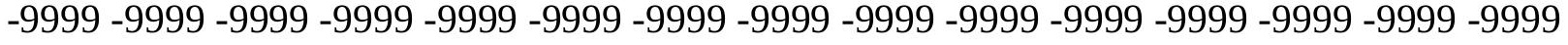
-9999 -9999 -9999 -9999 -9999 -9999 -9999 -9999 -9999 -9999 -9999 -9999 -9999 -9999 -9999 -

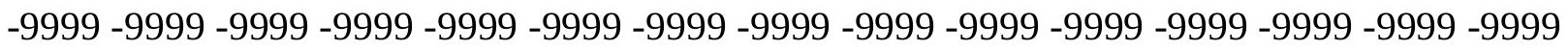

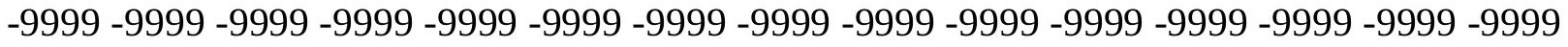

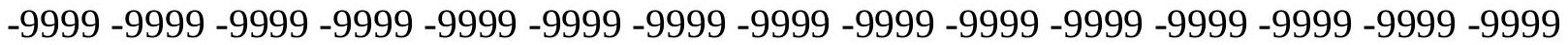
-9999 -9999 -9999 -9999 -9999 -9999 -9999 -9999 -9999 -9999 -9999 -9999 -9999 -9999 -9999

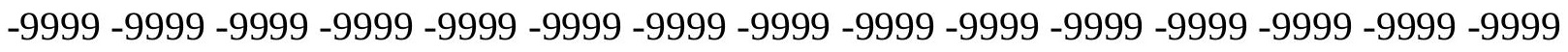

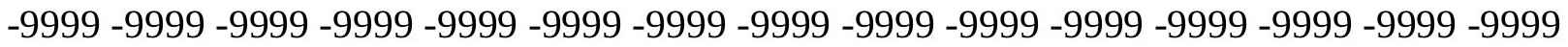
-9999 -9999 -9999 -9999 -9999 -9999 -9999 -9999 -9999 -9999 -9999 -9999 -9999 - 9999 - -999 -9999 -9999 -9999 -9999 -9999 -9999 -9999 -9999 -9999 -9999 -9999 -9999 -9999 -9999 -9999 -

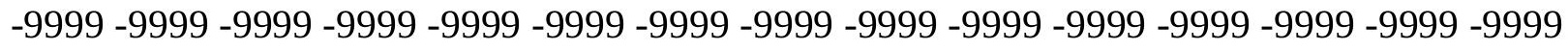

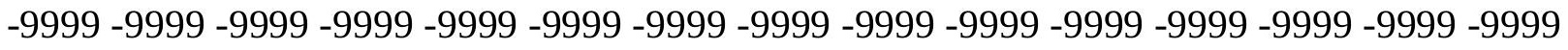
-9999 -9999 -9999 -9999 -9999 -9999 -9999 -9999 -9999 -9999 -9999 -9999 -9999 -9999 -9999 -9999 -9999 -9999 -9999 -9999 -9999 -9999 -9999 -9999-9999 -9999 -9999 -9999 -9999 -9999 -9999 -9999 -9999 -9999 -9999 -9999 -9999 -9999 -9999 -9999 -9999 -9999 -9999 -9999 -9999 -

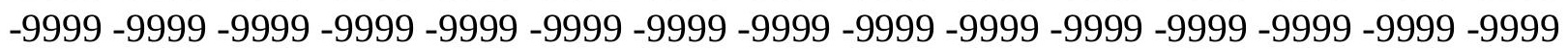


-9999 -9999 -9999 -9999 -9999 -9999 -9999 -9999 -9999 -9999 -9999 -9999 -9999 -9999 -9999 -9999 -9999 -9999 -9999 -9999 -9999 -9999 -9999 -9999 -9999 -9999 -9999 -9999 -9999 -9999 -9999 -9999 -9999 -9999 -9999 -9999 -9999 -9999 -9999 -9999 -9999 -9999 -9999 -9999 -9999 -9999 -9999 -9999 -9999 -9999 -9999 -9999 -9999 -9999 -9999 -9999 -9999 -9999 -9999 -9999 -9999 -9999 -9999 -9999 -9999 -9999 -9999 -9999 -9999 -9999 -9999 -9999 -9999 -9999 -9999 -9999 -9999 -9999 -9999 -9999 -9999 -9999 -9999 -9999 -9999 -9999 -9999 -9999 -9999 -9999 -9999 -9999 -9999 -9999 -9999 -9999 -9999 -9999 -9999 -9999 -9999 -9999 -9999 -9999

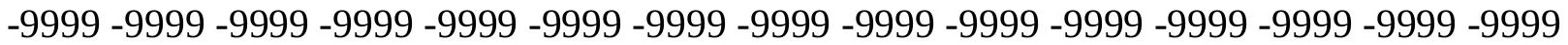
-9999 -9999 -9999 -9999 -9999 -9999 -9999 -9999 -9999 -9999 -9999 -9999 -9999 -9999 -9999 -9999 -9999 -9999 -9999 -9999 -9999 -9999 -9999 -9999 -9999 -9999 -9999 -9999 -9999 -9999 -

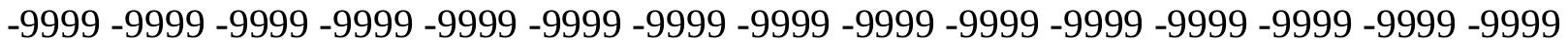
-9999 -9999 -9999 -9999 -9999 -9999 -9999 -9999 -9999 -9999 -9999 -9999 -9999 -9999 -9999

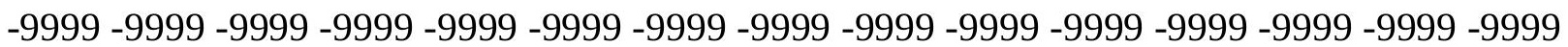
-9999 -9999 -9999 -9999 -9999 -9999 -9999 -9999 -9999 -9999 -9999 -9999 -9999 -9999 -9999 -9999 -9999 -9999 -9999 -9999 -9999 -9999 -9999 -9999 -9999 -9999 -9999 -9999 -9999 -9999 -9999 -9999 -9999 -9999 -9999 -9999 -9999 -9999 -9999 -9999 -9999 -9999 -9999 -9999 -9999 -

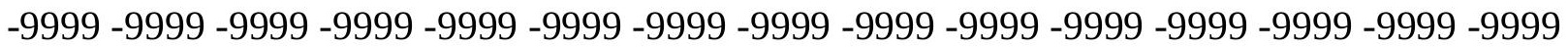
-9999 -9999 -9999 -9999 -9999 75.28192901611 74.97714233398 74.97714233398 74.9771423339874 .9771423339875 .2819290161175 .5867080688576 .19628143311 76.5010681152376 .1962814331175 .5867080688574 .9771423339874 .67236328125 74.3675689697374 .062782287674 .062782287674 .3675689697374 .36756896973 74.6723632812575 .2819290161175 .2819290161175 .5867080688575 .58670806885 75.5867080688575 .2819290161175 .2819290161175 .2819290161175 .28192901611 75.2819290161175 .5867080688575 .8914871215876 .1962814331176 .50106811523 76.5010681152376 .1962814331176 .1962814331176 .1962814331176 .19628143311 76.50106811523 -9999 -9999 -9999 -9999 -9999 -9999 -9999 -9999 -9999 -9999 -9999 -9999 -9999 -9999 -9999 -9999 -9999 -9999 -9999 -9999 -9999 -9999 -9999 -9999 -9999 -9999 -9999 -9999 -9999 -9999 -9999 -9999 -9999 -9999 -9999 -9999 -9999 -9999 -9999 -9999 -9999 -9999 -9999 -9999 -9999 -9999 -9999 -9999 -9999 -9999 -9999 -9999 -9999 -9999 -9999 -9999 -9999 -9999 -9999 -9999 -9999 -9999 -9999 -9999 -9999 -9999 -9999 -9999 -9999 -9999 -9999 -9999 -9999 -9999 -9999 -9999 -9999 -9999 -9999 -9999 -9999 -9999 -9999 -9999 -9999 -9999 -9999 -

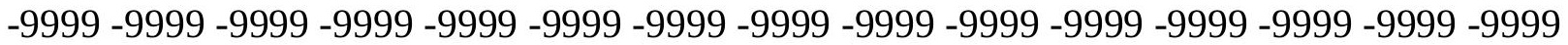
-9999 -9999 -9999 -9999 -9999 -9999 -9999 -9999 -9999 -9999 -9999 -9999 -9999 -9999 -9999 -9999 -9999 -9999 -9999 -9999 -9999 -9999 -9999 -9999 -9999 -9999 -9999 -9999 -9999 -9999 -

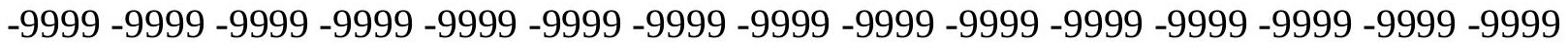
-9999 -9999 -9999 -9999 -9999 -9999 -9999 -9999 -9999 -9999 -9999 -9999 -9999 -9999 -9999 -9999 -9999 -9999 -9999 -9999 -9999 -9999 -9999 -9999 -9999 -9999 -9999 -9999 -9999 -9999 -9999-9999-9999 -9999 -9999 -9999 -9999 -9999 -9999 -9999 -9999 -9999 -9999 -9999 -9999 -9999 -9999 -9999 -9999 -9999 -9999 -9999 -9999 -9999 -9999 -9999 -9999 -9999 -9999 -9999 -9999 -9999 -9999 -9999 -9999 -9999 -9999 -9999 -9999 -9999 -9999 -9999 -9999 -9999 -9999 -9999 -9999 -9999 -9999 -9999 -9999 -9999 -9999 -9999 -9999 -9999 -9999 -9999 -9999 -9999 -9999 -9999 -9999 -9999 -9999 -9999 -9999 -9999 -9999 -9999 -9999 -9999 -9999 -9999 -9999 -9999 -9999 -9999 -9999 -9999 -9999 -9999 -9999 -9999 -9999 -9999 -9999 -9999 -9999 -9999 -9999 -9999 -9999 -9999 -9999 -9999 -9999 -9999 -9999 -9999 -9999 -9999 -9999 -9999 -9999 -9999 -9999 -9999

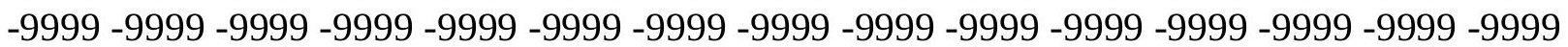


-9999 -9999 -9999 -9999 -9999 -9999 -9999 -9999 -9999 -9999 -9999 -9999 -9999 -9999 -9999 -9999 -9999 -9999 -9999 -9999 -9999 -9999 -9999 -9999 -9999 -9999 -9999 -9999 -9999 -9999 -9999 -9999 -9999 -9999 -9999 -9999 -9999 -9999 -9999 76.50106811523 76.80584716797 76.1962814331175 .2819290161174 .6723632812574 .062782287673 .75800323486 73.1484298706172 .8436431884872 .5388565063572 .2340774536172 .23407745361 71.9292907714871 .9292907714871 .9292907714872 .2340774536172 .23407745361 72.8436431884873 .4532165527374 .062782287673 .4532165527372 .84364318848 72.5388565063572 .2340774536171 .9292907714871 .6244964599671 .92929077148 71.9292907714872 .2340774536172 .5388565063572 .8436431884873 .14842987061 73.4532165527374 .062782287674 .3675689697374 .062782287674 .0627822876 74.062782287674 .062782287674 .062782287674 .062782287674 .36756896973 74.6723632812574 .6723632812574 .062782287673 .1484298706172 .84364318848 72.8436431884872 .8436431884873 .1484298706173 .4532165527373 .75800323486 74.3675689697375 .2819290161176 .19628143311 -9999 -9999 -9999 -9999 -9999 -9999 -9999 -9999 -9999 -9999 -9999 -9999 -9999 -9999 -9999 -9999 -9999 -9999 -9999 -9999 -9999 -9999 -9999 -9999 -9999 -9999 -9999 -9999 -9999 -9999 -9999 -9999 -9999 -9999 -9999 -9999 -9999

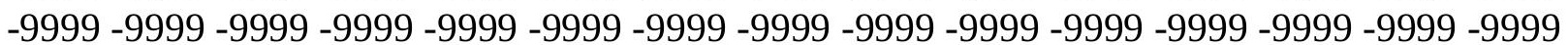
-9999 -9999 -9999 -9999 -9999 -9999 -9999 -9999 -9999 -9999 -9999 -9999 -9999 -9999 -9999 -9999 -9999 -9999 -9999 -9999 -9999 -9999 -9999 -9999 -9999 -9999 -9999 -9999 -9999 -9999 -9999 -9999 -9999 -9999 -9999 -9999 -9999 -9999 -9999 -9999 -9999 -9999 -9999 -9999 -9999

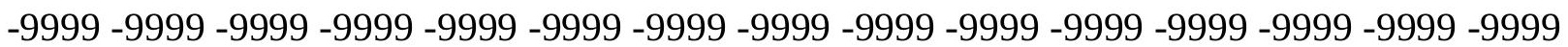
-9999 -9999 -9999 -9999 -9999 -9999 -9999 -9999 -9999 -9999 -9999 -9999 -9999 -9999 -9999 -9999 -9999 -9999 -9999 -9999 -9999 -9999 -9999 -9999 -9999 -9999 -9999 -9999 -9999 -9999 -9999 -9999 -9999 -9999 -9999 -9999 -9999 -9999 -9999 -9999 -9999 -9999 -9999 -9999 -9999

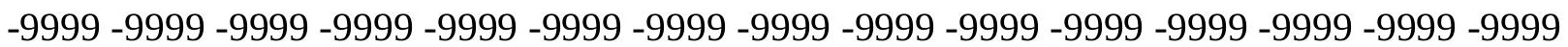
-9999-9999-9999

-9999 -9999 -9999 -9999 -9999 -9999 -9999 -9999 -9999 -9999 -9999 -9999 -9999 -9999 -9999 -9999 -9999 -9999 -9999 -9999 -9999 -9999 -9999 -9999 -9999 -9999 -9999 -9999 -9999 -9999 -9999 -9999 -9999 -9999 -9999 -9999 -9999 -9999 -9999 -9999 -9999 -9999 -9999 -9999 -9999 -9999 -9999 -9999 -9999 -9999 -9999 -9999 -9999 -9999 -9999 -9999 -9999 -9999 -9999 -9999 -9999 -9999 -9999 -9999 -9999 -9999 -9999 -9999 -9999 -9999 -9999 -9999 -9999 -9999 -9999 -9999 -9999 -9999 -9999 -9999 -9999 -9999 -9999 -9999 -9999 -9999 -9999 -9999 -9999 -9999 -9999 -9999 -9999 -9999 -9999 -9999 -9999 -9999 -9999 -9999 -9999 -9999 -9999 -9999 -9999 -9999 -9999 -9999 -9999 -9999 -9999 -9999 -9999 -9999 -9999 -9999 -9999 -9999 -9999 -9999

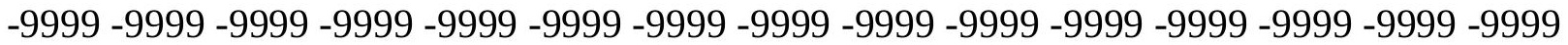
-9999 -9999 -9999 -9999 -9999 -9999 -9999 -9999 -9999 -9999 -9999 -9999 -9999 -9999 -9999 -9999 73.14842987061 72.84364318848 72.53885650635 72.23407745361 72.23407745361 72.2340774536172 .5388565063572 .8436431884873 .4532165527373 .45321655273 73.1484298706172 .5388565063571 .9292907714871 .3197174072370 .71015167236 70.4053573608470 .4053573608470 .4053573608470 .4053573608470 .40535736084 70.4053573608470 .4053573608470 .7101516723671 .014930725171 .31971740723 71.9292907714872 .5388565063572 .8436431884872 .8436431884872 .23407745361 71.9292907714871 .6244964599671 .3197174072371 .3197174072371 .31971740723 71.3197174072371 .6244964599671 .9292907714872 .2340774536172 .53885650635 72.8436431884873 .1484298706173 .1484298706173 .1484298706173 .14842987061 73.1484298706173 .1484298706173 .1484298706173 .1484298706173 .45321655273 
73.4532165527373 .4532165527372 .8436431884871 .9292907714871 .0149307251 70.4053573608469 .7957916259869 .4910125732469 .7957916259870 .40535736084 71.014930725171 .9292907714872 .8436431884874 .062782287675 .28192901611 76.1962814331176 .50106811523 -9999 -9999 -9999 -9999 -9999 -9999 -9999 -9999 -9999 -9999 -9999 -9999 -9999 -9999 -9999 -9999 -9999 -9999 -9999 -9999 -9999-9999 -9999 -9999 -9999 -9999 -9999 -9999 -9999 -9999 -9999 -9999 -9999 -9999 -9999 -9999 -9999 -9999 -9999 -9999 -9999 -9999 -9999 -9999 -9999 -9999 -9999 -9999 -9999 -9999 -9999 -9999 -9999 -9999

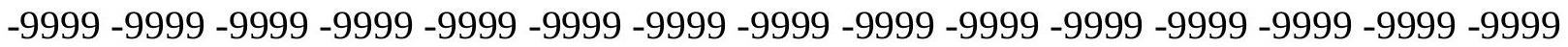
-9999 -9999 -9999 -9999 -9999 -9999 -9999 -9999 -9999 -9999 -9999 -9999 -9999 -9999 -9999 -9999 -9999 -9999 -9999 -9999 -9999 -9999 -9999 -9999 -9999 -9999 -9999 -9999 -9999 -9999 -

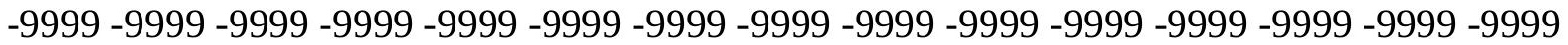
-9999 -9999 -9999 -9999 -9999 -9999 -9999 -9999 -9999 -9999 -9999 -9999 -9999 -9999 -9999 -9999 -9999 -9999 -9999 -9999 -9999 -9999 -9999 -9999 -9999 -9999 -9999 -9999 -9999 -9999 -9999 -9999 -9999 -9999 -9999 -9999 -9999 -9999 -9999 -9999 -9999 -9999 -9999 -9999 -9999 -9999 -9999 -9999 -9999 -9999 -9999 -9999 -9999 -9999 -9999 -9999 -9999

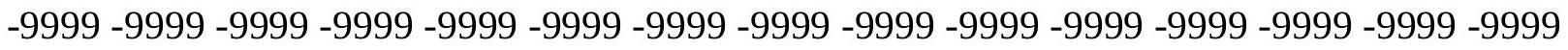

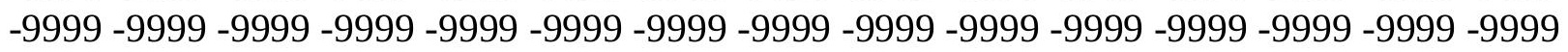

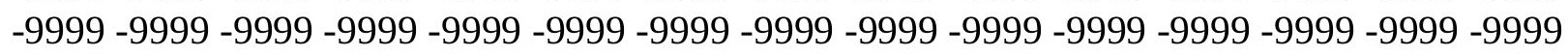

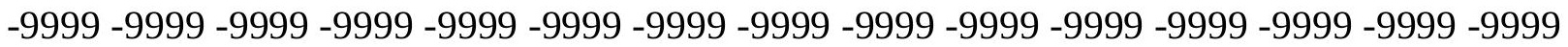

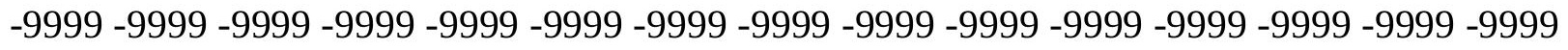

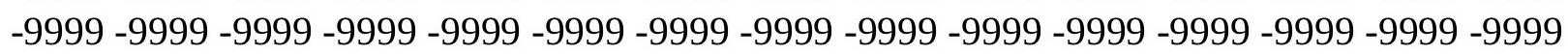

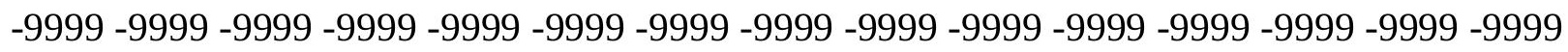
-9999 -9999 -9999 -9999 -9999 -9999 -9999 -9999 -9999 -9999 -9999 -9999 -9999 -9999 -9999 -9999 -9999 -9999 -9999 -9999 -9999 -9999 -9999 -9999 -9999 -9999 -9999 -9999 -9999 -9999 -9999 -9999 -9999 -9999 -9999 -9999 -9999 -9999 -9999 -9999 73.75800323486 74.062782287673 .1484298706172 .2340774536171 .6244964599671 .0149307251 70.4053573608470 .1005783081169 .7957916259869 .4910125732469 .49101257324 69.4910125732471 .3197174072370 .1005783081170 .7101516723671 .0149307251 71.014930725171 .014930725170 .7101516723670 .4053573608470 .10057830811 69.7957916259869 .7957916259869 .7957916259869 .7957916259869 .79579162598 69.7957916259870 .1005783081170 .1005783081170 .4053573608471 .0149307251 71.3197174072371 .9292907714871 .9292907714871 .9292907714871 .62449645996 71.3197174072371 .014930725171 .014930725170 .7101516723670 .71015167236 71.014930725171 .014930725171 .3197174072371 .6244964599671 .62449645996 71.9292907714872 .2340774536172 .2340774536172 .5388565063572 .23407745361 72.2340774536172 .2340774536172 .2340774536172 .2340774536172 .23407745361 72.2340774536171 .9292907714871 .6244964599671 .014930725170 .10057830811 69.4910125732468 .5766525268667 .6623001098667 .0527267456167 .05272674561 67.6623001098668 .5766525268669 .4910125732470 .7101516723671 .92929077148 73.1484298706173 .4532165527373 .4532165527373 .7580032348674 .0627822876 74.6723632812575 .58670806885 -9999 -9999 -9999 -9999 -9999 -9999 -9999 -9999 -9999 -9999 -9999 -9999 -9999 -9999 -9999 -9999 -9999 -9999 -9999 -9999 -9999 -9999 -9999 -9999 -

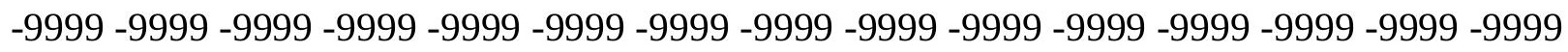
-9999 -9999 -9999 -9999 -9999 -9999 -9999 -9999 -9999 -9999 -9999 -9999 -9999 -9999 -9999 -9999 -9999 -9999 -9999 -9999 -9999 -9999 -9999 -9999 -9999 -9999 -9999 -9999 -9999 -9999 -

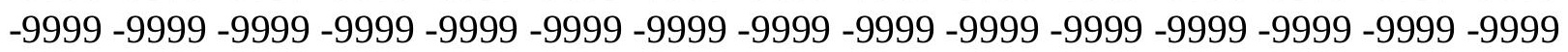


-9999 -9999 -9999 -9999 -9999 -9999 -9999 -9999 -9999 -9999 -9999 -9999 -9999 -9999 -9999 -9999 -9999 -9999 -9999 -9999 -9999 -9999 -9999 -9999 -9999 -9999 -9999 -9999 -9999 -9999

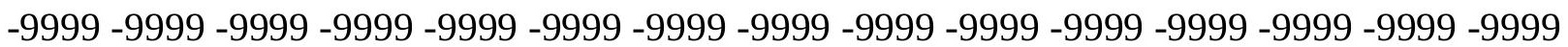
-9999 -9999 -9999 -9999 -9999 -9999 -9999 -9999 -9999 -9999 -9999 -9999 -9999 -9999 -9999 -9999 -9999 -9999 -9999 -9999 -9999 -9999 -9999 -9999-9999 -9999 -9999 -9999 -9999 - -9999 -9999 -9999 -9999 -9999 -9999 -9999 -9999

-9999 -9999 -9999 -9999 -9999 -9999 -9999 -9999 -9999 -9999 -9999 -9999 -9999 -9999 -9999

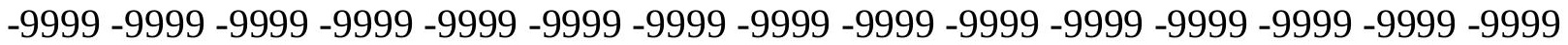
-9999 -9999 -9999 -9999 -9999 -9999 -9999 -9999 -9999 -9999 -9999 -9999 -9999 -9999 -9999 -9999 -9999 -9999 -9999 -9999 -9999 -9999 -9999 -9999 -9999 -9999 -9999 -9999 -9999 -9999 -9999 -9999 -9999 -9999 -9999 -9999 -9999 -9999 -9999 -9999 -9999 -9999 -9999 -9999 -9999 -9999 -9999 -9999 -9999 -9999 -9999 -9999 -9999 -9999 -9999 -9999 -9999 -9999 -9999 -9999

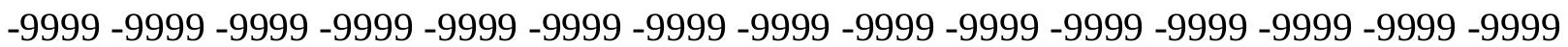
-9999 -9999 -9999 -9999 -9999 -9999 -9999 -9999 -9999 -9999 -9999 -9999 -9999 -9999 -9999 -9999 -9999 -9999 -9999 -9999 -9999 -9999 -9999 -9999 -9999 -9999 -9999 -9999 -9999 -9999 -9999 -9999 -9999 -9999 -9999 -9999 -9999 70.1005783081170.1005783081170.40535736084 70.7101516723670 .7101516723670 .4053573608469 .4910125732468 .88143920898 68.2718734741268 .2718734741267 .9670867919967 .9670867919968 .27187347412 68.2718734741268 .5766525268669 .1862335205169 .4910125732470 .10057830811 70.4053573608470 .4053573608470 .1005783081170 .1005783081169 .79579162598 69.4910125732469 .4910125732469 .1862335205169 .1862335205169 .18623352051 69.4910125732469 .4910125732469 .4910125732469 .7957916259870 .10057830811 70.4053573608470 .7101516723671 .014930725171 .014930725171 .0149307251 71.014930725170 .7101516723670 .7101516723670 .4053573608470 .40535736084 70.4053573608470 .4053573608470 .4053573608470 .7101516723671 .0149307251 71.014930725171 .3197174072371 .3197174072371 .6244964599671 .62449645996 71.6244964599671 .3197174072371 .3197174072371 .3197174072371 .31971740723 71.3197174072371 .014930725170 .7101516723670 .4053573608469 .79579162598 69.1862335205168 .2718734741267 .6623001098666 .7479400634866 .13836669922 65.5288009643665 .2240066528365 .2240066528366 .1383666992267 .35751342773 68.5766525268669 .4910125732469 .7957916259869 .7957916259870 .10057830811 70.4053573608471 .014930725171 .9292907714873 .1484298706174 .36756896973

76.1962814331177 .72020721436 -9999 -9999 -9999 -9999 -9999 -9999 -9999 -9999 -9999 -9999 -9999 -9999 -9999 -9999 -9999 -9999 -9999 -9999 -9999 -9999 -9999 -9999 -9999 -9999 -9999 -9999 -9999 -9999 -9999 -9999 -9999 -9999 -9999 -9999 -9999 -9999 -9999 -9999 -9999 -9999 -9999 -9999 -9999 -9999 -9999 -9999 -9999 -9999 -9999 -9999 -9999 -9999 -9999 -9999

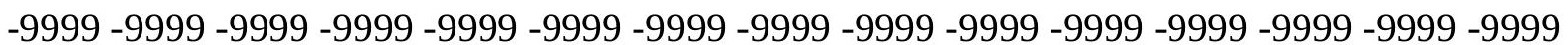

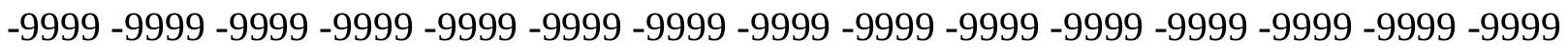
-9999 -9999 -9999 -9999 -9999 -9999 -9999 -9999 -9999 -9999 -9999 -9999 -9999 -9999 -9999 -9999 -9999 -9999 -9999 -9999 -9999 -9999 -9999 -9999 -9999 -9999 -9999 -9999 - -9999 -9999 -9999 -9999 -9999 -9999 -9999 -9999 -9999 -9999 -9999 -9999 -9999 -9999 -9999 -9999 -9999

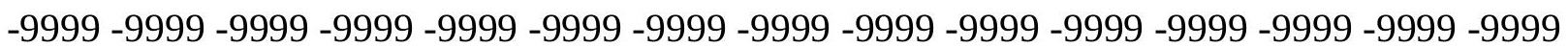

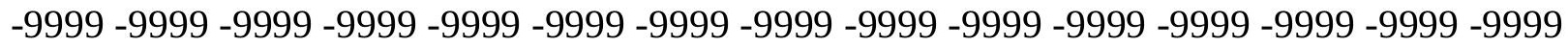
$-9999-9999-9999$

-9999 -9999 -9999 -9999 -9999 -9999 -9999 -9999 -9999 -9999 -9999 -9999 -9999 -9999 -9999

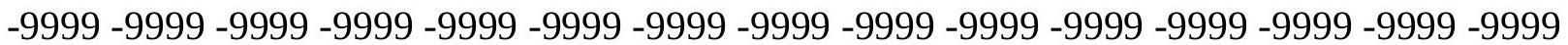


-9999 -9999 -9999 -9999 -9999 -9999 -9999 -9999 -9999 -9999 -9999 -9999 -9999 -9999 -9999 -9999 -9999 -9999 -9999 -9999 -9999 -9999 -9999 -9999 -9999 -9999 -9999 -9999 -9999 -9999 -9999 -9999 -9999 -9999 -9999 -9999 -9999 -9999 -9999 -9999 -9999 -9999 -9999 -9999 -9999 -9999 -9999 -9999 -9999 -9999 -9999 -9999 -9999 -9999 -9999 -9999 -9999 -9999 -9999 -9999 -9999 -9999 -9999 -9999 -9999 -9999 -9999 -9999 -9999 -9999 -9999 -9999 -9999 -9999 -9999 -9999 -9999 -9999 -9999 -9999 -9999 -9999 -9999 -9999 -9999 -9999 -9999 -9999 -9999 -9999 -9999 -9999 -9999 -9999 -9999 -9999 -9999 -9999 -9999 -9999 -9999 -9999 -9999 -9999 -9999 -9999 -9999 -9999 -9999 -9999 68.27187347412 67.9670867919967.66230010986 67.3575134277367 .6623001098667 .9670867919968 .2718734741268 .27187347412 67.9670867919967 .9670867919967 .6623001098667 .6623001098667 .35751342773 67.6623001098667 .6623001098667 .9670867919968 .2718734741268 .57665252686 68.8814392089869 .1862335205169 .4910125732469 .4910125732469 .49101257324 69.4910125732469 .1862335205169 .1862335205168 .8814392089868 .88143920898 68.8814392089868 .8814392089868 .8814392089869 .1862335205169 .18623352051 69.4910125732469 .4910125732469 .7957916259870 .1005783081170 .40535736084 70.4053573608470 .4053573608470 .4053573608470 .4053573608470 .10057830811 70.1005783081170 .1005783081169 .7957916259870 .1005783081170 .10057830811 70.1005783081170 .4053573608470 .4053573608470 .4053573608470 .71015167236 70.7101516723670 .7101516723670 .7101516723670 .4053573608470 .40535736084 70.4053573608470 .4053573608470 .1005783081170 .1005783081169 .79579162598 69.1862335205168 .5766525268667 .9670867919967 .3575134277366 .74794006348 66.1383666992265 .5288009643664 .9192428588964 .9192428588965 .22400665283 65.5288009643666 .4431610107467 .0527267456167 .6623001098668 .27187347412 68.2718734741268 .2718734741268 .2718734741268 .5766525268668 .88143920898 69.4910125732471 .014930725172 .5388565063574 .3675689697376 .19628143311 78.0249862670979 .8537063598681 .6824111938583 .81591033936 -9999 -9999 -9999 -9999 -9999 -9999 -9999 -9999 -9999 -9999 -9999 -9999 -9999 -9999 -9999 -9999 -9999 -9999 -9999 -9999 -9999 -9999 -9999 -9999 -9999 -9999 -9999 -9999 -9999 -9999 -9999 -9999 -9999 -9999 -9999 -9999 -9999 -9999 -9999 -9999 -9999 -9999 -9999 -9999 -9999 -9999 -9999 -9999 -9999 -9999 -9999 -9999 -9999 -9999 -9999 -9999 -9999 -9999 -9999 -9999 -9999 -9999 -9999 -9999 -9999 -9999 -9999 -9999 -9999 -9999 -9999 -9999 -9999 -9999 -9999 -9999 -9999 -9999 -9999 -9999 -9999 -9999 -9999 -9999 -9999 -9999 -9999 -9999 -9999 -9999 -9999 -9999 -9999 -9999 -9999 -9999 -9999 -9999 -9999 -9999 -9999 -9999 -9999 -9999 -9999 -9999 -9999 -9999 -9999 -9999 -9999 -9999 -9999 -9999 -9999 -9999 -9999 -9999 -9999 -9999 -9999 -9999 -9999 -9999 -9999 -9999 -9999 -9999 -9999 -9999 -9999 -9999 -9999 -9999 -9999 -9999 -9999 -9999 -9999 -9999 -9999 -9999 -9999 -9999 -9999 -9999 -9999 -9999 -9999 -9999 -9999 -9999 -9999 -9999 $-9999-9999-9999$

-9999 -9999 -9999 -9999 -9999 -9999 -9999 -9999 -9999 -9999 -9999 -9999 -9999 -9999 -9999 -9999 -9999 -9999 -9999 -9999 -9999 -9999 -9999 -9999 -9999 -9999 -9999 -9999 -9999 -9999 -9999 -9999 -9999 -9999 -9999 -9999 -9999 -9999 -9999 -9999 -9999 -9999 -9999 -9999 -9999 -9999 -9999 -9999 -9999 -9999 -9999 -9999 -9999 -9999 -9999 -9999 -9999 -9999 -9999 -9999

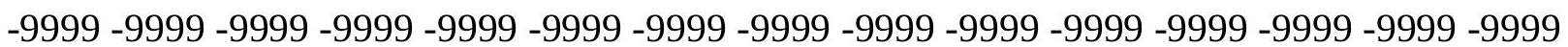
-9999 -9999 -9999 -9999 -9999 -9999 -9999 -9999 -9999 -9999 -9999 -9999 -9999 -9999 -9999 -9999 -9999 -9999 -9999 -9999 -9999 -9999 -9999 -9999 -9999 -9999 -9999 -9999 -9999 -9999 -9999 -9999 -9999 -9999 -9999 -9999 -9999 -9999 -9999 -9999 -9999 -9999 -9999 -9999 -9999

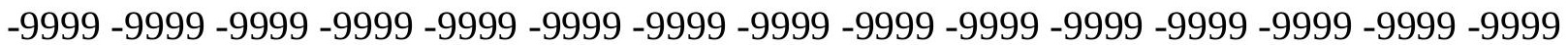


-9999 -9999 -9999 67.35751342773 66.44316101074 65.83358764648 65.22400665283 64.9192428588965 .8335876464866 .4431610107467 .0527267456167 .05272674561 67.3575134277367 .3575134277367 .0527267456167 .0527267456167 .05272674561 67.0527267456167 .0527267456167 .0527267456167 .3575134277367 .66230010986 67.9670867919968 .2718734741268 .5766525268668 .5766525268668 .88143920898 68.8814392089868 .8814392089868 .5766525268668 .5766525268668 .57665252686 68.5766525268668 .5766525268668 .5766525268668 .5766525268668 .57665252686 68.8814392089868 .8814392089869 .1862335205169 .4910125732469 .49101257324 69.7957916259869 .7957916259869 .7957916259869 .7957916259869 .79579162598 69.7957916259869 .4910125732469 .4910125732469 .4910125732469 .49101257324 69.4910125732469 .4910125732469 .7957916259869 .7957916259869 .79579162598 69.7957916259869 .7957916259869 .7957916259869 .7957916259869 .79579162598 69.4910125732469 .4910125732469 .4910125732469 .1862335205168 .88143920898 68.5766525268668 .2718734741267 .6623001098667 .0527267456166 .44316101074 66.1383666992265 .5288009643664 .9192428588964 .6144485473664 .61444854736 64.9192428588965 .2240066528365 .8335876464866 .4431610107467 .05272674561 67.3575134277367 .3575134277367 .3575134277367 .6623001098667 .96708679199 68.2718734741268 .8814392089869 .7957916259871 .014930725172 .23407745361 73.4532165527374 .3675689697376 .5010681152378 .3297805786180 .46327209473 82.2919769287184 .42548370361 -9999 -9999 -9999 -9999 -9999 -9999 -9999 -9999 -9999 -9999 -9999 -9999 -9999 -9999 -9999 -9999 -9999 -9999 -9999 -9999 -9999 -9999 -9999 -9999 -9999 -9999 -9999 -9999 -9999 -9999 -9999 -9999 -9999 -9999 -9999 -9999 -9999 -9999 -9999 -9999 -9999 -9999 -9999 -9999 -9999 -9999 -9999 -9999 -9999 -9999 -9999 -9999 -9999 -9999 -9999 -9999 -9999 -9999 -9999 -9999 -9999 -9999 -9999 -9999 -9999 -9999 -9999 -9999 -9999

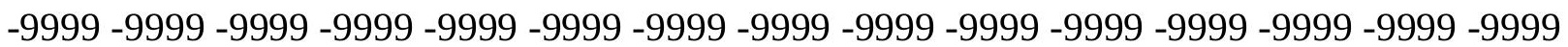
-9999 -9999 -9999 -9999 -9999 -9999 -9999 -9999 -9999 -9999 -9999 -9999 -9999 -9999 -9999 -9999 -9999 -9999 -9999 -9999 -9999 -9999 -9999 -9999 -9999 -9999 -9999 -9999 -9999 -9999 -9999 -9999 -9999 -9999 -9999 -9999 -9999 -9999 -9999 -9999 -9999 -9999 -9999 -9999 -9999 -9999 -9999 -9999 -9999 -9999 -9999 -9999 -9999 -9999 -9999 -9999 -9999 -9999 -9999 -9999 -9999 -9999 -9999 -9999-9999 -9999 -9999 -9999 -9999-9999 -9999 -9999 -9999 -9999 -9999 -9999 -9999 -9999 -9999 -9999 -9999 -9999 -9999 -9999 -9999 -9999 -9999 -9999 -9999 -9999 -9999 -9999 -9999 -9999 -9999 -9999 -9999 -9999 -9999 -9999 -9999 -9999 -9999 -9999 -9999 -9999 -9999 -9999 -9999 -9999 -9999 -9999 -9999 -9999 -9999 -9999 -9999 -9999 -9999 -9999 -9999 -9999 -9999 -9999 -9999 -9999 -9999 -9999 -9999 -9999 -9999 -9999 -9999 -9999 -9999 -9999 -9999 -9999 -9999 -9999 -9999 -9999 -9999 -9999 -9999 -9999 -9999 -9999 -9999 -9999 -9999 -9999 -9999 -9999 -9999 -9999 -9999 -9999 -9999 -9999 -9999 -9999 -9999 -9999 -9999 -9999 -9999 -9999 -9999 -9999 -9999 -9999 -9999 -9999 -9999 -9999

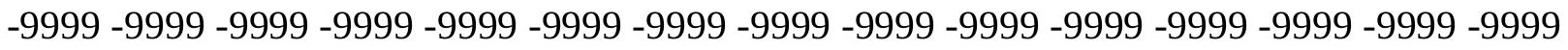
-9999 -9999 -9999 -9999 -9999 -9999 -9999 -9999 -9999 -9999 -9999 -9999 -9999 -9999 -9999 -999965.52880096436 64.9192428588964.3096618652363.7000885009863.09051895142 63.0905189514263 .7000885009864 .6144485473665 .2240066528365 .83358764648 66.1383666992266 .1383666992266 .4431610107466 .4431610107466 .44316101074 66.4431610107466 .4431610107466 .4431610107466 .4431610107466 .74794006348 67.0527267456167 .3575134277367 .6623001098667 .9670867919967 .96708679199 68.2718734741268 .2718734741268 .2718734741268 .2718734741268 .27187347412 67.9670867919967 .9670867919967 .9670867919967 .9670867919968 .27187347412 
68.2718734741268 .2718734741268 .5766525268668 .5766525268668 .88143920898 69.1862335205169 .1862335205169 .1862335205169 .1862335205169 .18623352051 69.1862335205169 .1862335205169 .1862335205169 .1862335205168 .88143920898 68.8814392089868 .8814392089869 .1862335205169 .1862335205169 .18623352051 69.18623352051 69.18623352051 69.1862335205168.88143920898 68.88143920898 68.8814392089868 .5766525268668 .5766525268668 .2718734741268 .27187347412 67.9670867919967 .6623001098667 .3575134277366 .7479400634866 .44316101074 65.8335876464865 .2240066528364 .9192428588964 .6144485473664 .30966186523 64.3096618652364 .6144485473664 .9192428588965 .2240066528365 .83358764648 66.1383666992266 .4431610107466 .4431610107466 .7479400634867 .05272674561 67.0527267456167 .6623001098668 .2718734741269 .1862335205170 .10057830811 71.3197174072372 .5388565063573 .7580032348674 .9771423339876 .19628143311 77.4154205322379 .2441329956181 .0728530883883 .2063369751 -9999 -9999 -9999 -9999 -9999 -9999 -9999 -9999 -9999 -9999 -9999 -9999 -9999 -9999 -9999 -9999 -9999 -9999 -9999 -9999 -9999 -9999 -9999 -9999 -9999 -9999 -9999 -9999 -9999 -9999 -9999 -9999 -9999 -9999 -

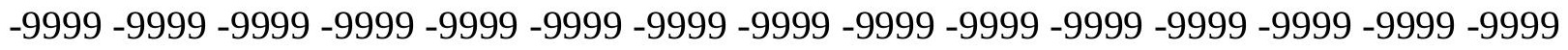
-9999 -9999 -9999 -9999 -9999 -9999 -9999 -9999 -9999 -9999 -9999 -9999 -9999 -9999 -9999 -9999 -9999 -9999 -9999 -9999 -9999 -9999 -9999 -9999 -9999 -9999 -9999 -9999 -9999 -9999 -

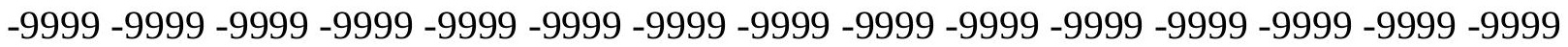

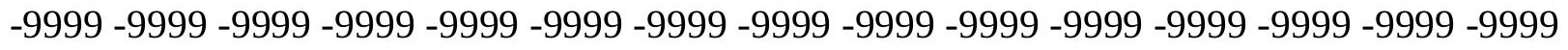

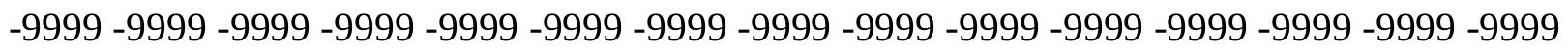
-9999 -9999 -9999 -9999 -9999 -9999 -9999 -9999 -9999 -9999 -9999 -9999 -9999 -9999 -9999 -9999 -9999 -9999 -9999 -9999 -9999 -9999 -9999 -9999 -9999 -9999 -9999 -9999 -9999 -9999 -

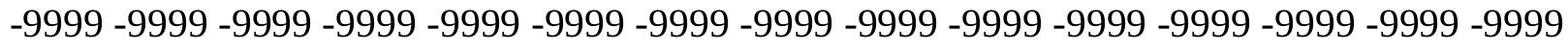

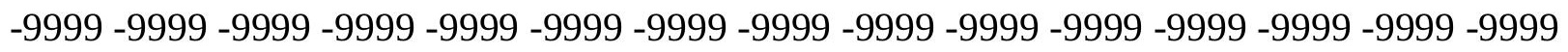
-9999 -9999 -9999 -9999 -9999 -9999 -9999 -9999 -9999 -9999 -9999 -9999 -9999 -9999 -9999 -

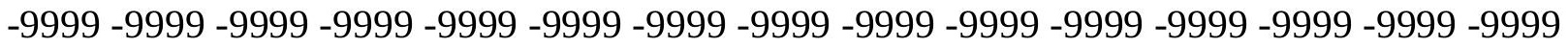

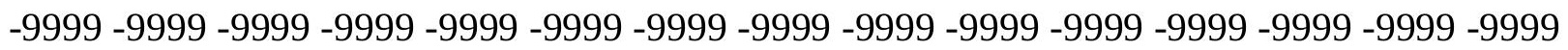
-9999 -9999 -9999 -9999 -9999 -9999 -9999 -9999 -9999 -9999 -9999 -9999 -9999 -9999 -9999 -9999 -9999 -9999 -9999 -9999 -9999 -9999 -9999 -9999 -9999 -9999 -9999 -9999 -9999 -9999 -9999 -9999 -9999 -9999 -9999 -9999 -9999 -9999 -9999-9999 -9999 -9999 -9999 -9999 - -9999 -9999 -9999 -9999 -9999 -9999 -9999 -9999 -9999 -9999 -9999 -9999 -9999 -9999 -9999 62.4809494018662 .4809494018662 .1761703491261 .5666007995661 .26181030273 60.9570198059161 .5666007995662 .1761703491262 .7857398986863 .39530944824 64.004882812564 .6144485473664 .9192428588965 .2240066528365 .22400665283 65.5288009643665 .5288009643665 .5288009643665 .8335876464865 .83358764648 66.1383666992266 .1383666992266 .4431610107466 .7479400634867 .05272674561 67.0527267456167 .3575134277367 .6623001098667 .6623001098667 .66230010986 67.6623001098667 .6623001098667 .6623001098667 .6623001098667 .66230010986 67.6623001098667 .9670867919967 .9670867919967 .9670867919968 .27187347412 68.2718734741268 .5766525268668 .5766525268668 .5766525268668 .57665252686 68.8814392089868 .8814392089868 .8814392089868 .5766525268668 .57665252686 68.5766525268668 .5766525268668 .5766525268668 .5766525268668 .57665252686 68.5766525268668 .5766525268668 .5766525268668 .2718734741268 .27187347412 68.2718734741268 .2718734741267 .9670867919967 .9670867919967 .66230010986 67.6623001098667 .3575134277367 .0527267456166 .7479400634866 .44316101074 
65.8335876464865 .5288009643665 .2240066528364 .6144485473664 .30966186523 64.3096618652364 .004882812564 .004882812564 .3096618652364 .30966186523 64.9192428588965 .2240066528365 .5288009643665 .5288009643665 .83358764648 66.1383666992266 .1383666992266 .7479400634867 .0527267456167 .66230010986 68.5766525268669 .4910125732470 .4053573608471 .6244964599672 .84364318848 74.062782287675 .2819290161176 .5010681152377 .7202072143678 .63455963135 80.1584930419981 .9871978759883 .81591033936 -9999 -9999 -9999 -9999 -9999 -9999 -9999 -9999 -9999 -9999 -9999 -9999 -9999 -9999 -9999 -9999 -9999 -9999 -9999 -9999 -9999 -9999 -9999 -9999 -9999 -9999 -9999 -9999 -9999 -9999 -9999 -9999 -9999 -9999 -9999 -9999 -9999 -9999 -9999 -9999 -9999 -9999 -9999 -9999 -9999 -9999 -9999 -9999 -9999 -9999 -9999 -9999 -

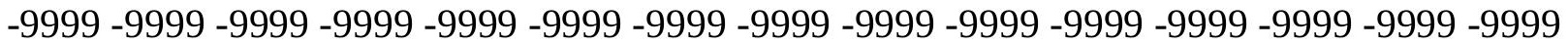
-9999 -9999 -9999 -9999 -9999 -9999 -9999 -9999 -9999 -9999 -9999 -9999 -9999 -9999 -9999 -9999 -9999 -9999 -9999 -9999 -9999 -9999 -9999 -9999 -9999 -9999 -9999 -9999 -9999 -9999 -9999 -9999 -9999 -9999 -9999 -9999 -9999 -9999 -9999 -9999 -9999 -9999 -9999 -9999 -9999 -9999 -9999 -9999 -9999 -9999 -9999 -9999 -9999 -9999 -9999 -9999 -9999 -9999 -9999 -9999 -9999 -9999 -9999 -9999 -9999 -9999 -9999 -9999 -9999 -9999 -9999 -9999 -9999 -9999 -999 -9999 -9999 -9999 -9999 -9999 -9999 -9999 -9999 -9999 -9999 -9999 -9999 -9999 -9999 -9999 -9999 -9999 -9999 -9999 -9999 -9999 -9999 -9999 -9999 -9999 -9999 -9999 -9999 -9999 -9999 -9999 -9999 -9999 -9999 -9999 -9999 -9999 -9999 -9999 -9999 -9999 -9999 -9999 -9999 -9999 -9999 -9999 -9999 -9999 -9999 -9999 -9999 -9999 -9999 -9999

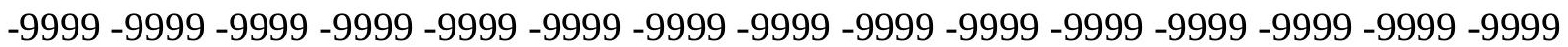
-9999 -9999 -9999 -9999 -9999 -9999 -9999 -9999 -9999 -9999 -9999 -9999 -9999 -9999 -9999 -9999 -9999 -9999 -9999 -9999 -9999 -9999 -9999 -9999 -9999 -9999 -9999 -9999 -9999 -9999 -9999 -9999 -9999 -9999 -9999 -9999 -9999 -9999 -9999 -9999 -9999 -9999 -9999 -9999 -9999 -9999 -9999 -9999 -9999 -9999 -9999 -9999 -9999 -9999 -9999 -9999 -9999 -9999 -9999 -9999 -9999 -9999 -9999 -9999 -9999 -9999 -9999 -9999 -9999 -9999 -9999 -9999 60.34745025635 59.7378807067959 .4331016540559 .1283111572358 .8235282897958 .51874923706 58.8235282897959 .7378807067960 .3474502563560 .9570198059161 .56660079956 62.1761703491262 .7857398986863 .3953094482463 .7000885009864 .0048828125 64.3096618652364 .6144485473664 .6144485473664 .9192428588964 .91924285889 65.2240066528365 .5288009643665 .5288009643665 .8335876464866 .13836669922 66.4431610107466 .4431610107466 .7479400634867 .0527267456167 .05272674561 67.0527267456167 .0527267456167 .3575134277367 .3575134277367 .35751342773 67.3575134277367 .3575134277367 .3575134277367 .6623001098667 .66230010986 67.6623001098667 .9670867919967 .9670867919968 .2718734741268 .27187347412 68.2718734741268 .2718734741268 .2718734741268 .2718734741268 .27187347412 68.2718734741267 .9670867919967 .9670867919967 .9670867919967 .96708679199 67.9670867919967 .9670867919967 .9670867919967 .6623001098667 .66230010986 67.6623001098667 .3575134277367 .3575134277367 .3575134277367 .05272674561 66.7479400634866 .7479400634866 .4431610107466 .1383666992265 .83358764648 65.5288009643665 .2240066528364 .9192428588964 .6144485473664 .30966186523 64.004882812563 .7000885009863 .7000885009863 .7000885009863 .70008850098 64.004882812564 .3096618652364 .6144485473664 .6144485473664 .91924285889 65.2240066528365 .5288009643665 .5288009643666 .1383666992266 .44316101074 67.0527267456167 .6623001098668 .5766525268669 .7957916259870 .71015167236 71.9292907714873 .1484298706174 .3675689697375 .2819290161176 .50106811523 
77.4154205322378 .0249862670978 .9393463134880 .7680587768682 .90155792236 -9999 -9999 -9999 -9999 -9999 -9999 -9999 -9999 -9999 -9999 -9999 -9999 -9999 -9999 -9999 -9999

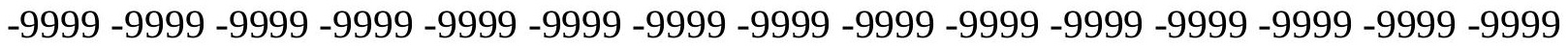
-9999 -9999 -9999 -9999 -9999 -9999 -9999 -9999 -9999 -9999 -9999 -9999 -9999 -9999 -9999 -9999 -9999 -9999 -9999 -9999 -9999 -9999 -9999 -9999-9999 -9999 -9999 -9999 -9999 -9999 -9999 -9999 -9999 -9999 -9999 -9999 -9999 -9999 -9999 -9999 -9999 -9999 -9999 -9999 -9999

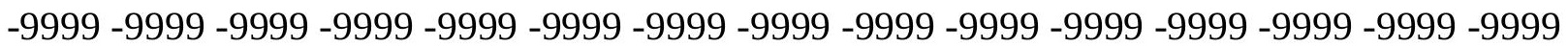

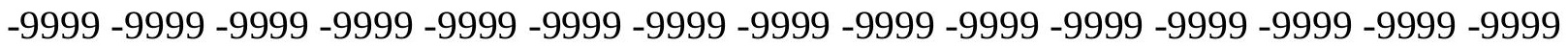

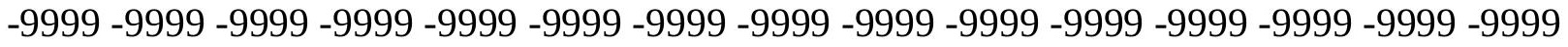
-9999 -9999 -9999 -9999 -9999 -9999 -9999 -9999 -9999 -9999 -9999 -9999 -9999 -9999 -9999

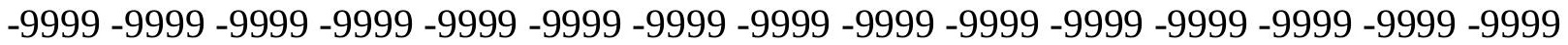
-9999 -9999 -9999 -9999 -9999 -9999 -9999 -9999 -9999 -9999 -9999 -9999 -9999 -9999 -9999 -9999 -9999 -9999 -9999 -9999 -9999 -9999 -9999 -9999 -9999 -9999 -9999 -9999 -9999 -9999 -9999 -9999 -9999 -9999 -9999 -9999 -9999 -9999 -9999 -9999 -9999 -9999 -9999 -9999 - 9999 -9999 -9999 -9999 -9999 -9999 -9999 -9999 -9999 -9999 -9999 -9999 -9999 -9999 -9999 -9999

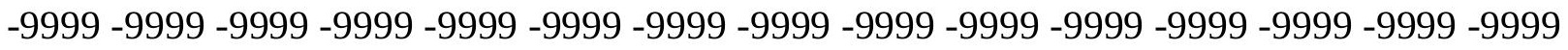
-9999 -9999 -9999 -9999 -9999 -9999 -9999 -9999 -9999 -9999 -9999 -9999 -9999 -9999 -9999 -9999 -9999 -9999 -9999 -9999 -9999 -9999 -9999 -9999 -9999 -9999 -9999 -9999 -9999 -9999 -9999 -9999 -9999 -9999 -9999 -9999 -9999 -9999 -9999 -9999 -9999 -9999 -9999 -9999 -9999 -9999 -9999 -9999-9999 -9999 -9999 -9999 -9999 -9999-9999 59.12831115723

58.5187492370657 .909179687557 .2995986938556 .9948196411156 .38525009155 56.0804595947356 .9948196411157 .6043891906758 .5187492370659 .12831115723 59.7378807067960 .3474502563560 .9570198059161 .5666007995662 .17617034912 62.7857398986863 .0905189514263 .3953094482463 .7000885009864 .0048828125 64.004882812564 .3096618652364 .6144485473664 .9192428588964 .91924285889 65.2240066528365 .5288009643665 .8335876464865 .8335876464866 .13836669922 66.4431610107466 .4431610107466 .7479400634866 .7479400634866 .74794006348 66.7479400634867 .0527267456167 .0527267456167 .0527267456167 .05272674561 67.3575134277367 .3575134277367 .3575134277367 .6623001098667 .66230010986 67.6623001098667 .6623001098667 .9670867919967 .9670867919967 .96708679199 67.6623001098667 .6623001098667 .6623001098667 .6623001098667 .66230010986 67.6623001098667 .3575134277367 .3575134277367 .3575134277367 .35751342773 67.0527267456167 .0527267456166 .7479400634866 .7479400634866 .74794006348 66.4431610107466 .1383666992266 .1383666992265 .8335876464865 .52880096436 65.2240066528365 .2240066528364 .9192428588964 .6144485473664 .30966186523 64.004882812563 .7000885009863 .3953094482463 .3953094482463 .39530944824 63.3953094482463 .3953094482463 .3953094482463 .7000885009864 .0048828125 64.004882812564 .3096618652364 .6144485473664 .6144485473664 .91924285889 65.5288009643665 .8335876464866 .4431610107467 .0527267456167 .96708679199 68.8814392089869 .7957916259871 .014930725171 .9292907714873 .14842987061 74.062782287674 .9771423339875 .8914871215876 .5010681152376 .80584716797 77.7202072143679 .5489196777381 .68241119385 -9999 -9999 -9999 -9999 -9999 -9999 -9999 -9999 -9999 -9999 -9999 -9999 -9999 -9999 -9999 -9999 -9999 -9999 -9999 -9999 -9999 -9999 -9999 -9999 -9999 -9999 -9999 -9999 -9999 -9999 -9999-9999 -9999 -9999 -9999 -9999 -9999 -9999 -9999 -9999 -9999 -9999 -9999 -9999 -9999 -9999 -9999 -9999 -9999 -9999 -9999 -9999 -

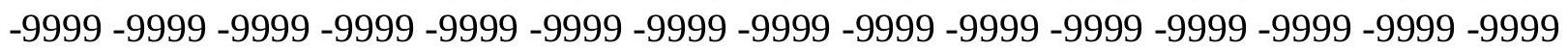


-9999 -9999 -9999 -9999 -9999 -9999 -9999 -9999 -9999 -9999 -9999 -9999 -9999 -9999 -9999 -9999 -9999 -9999 -9999 -9999 -9999 -9999 -9999 -9999 -9999 -9999 -9999 -9999 -9999 -9999 -9999 -9999 -9999 -9999 -9999 -9999 -9999 -9999 -9999 -9999 -9999 -9999 -9999 -9999 -9999 -9999 -9999 -9999 -9999 -9999 -9999 -9999 -9999 -9999 -9999 -9999 -9999 -9999 -9999 -9999

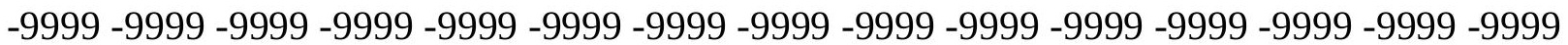
-9999 -9999 -9999 -9999 -9999 -9999-9999 -9999

-9999 -9999 -9999 -9999 -9999 -9999 -9999 -9999 -9999 -9999 -9999 -9999 -9999 -9999 -9999

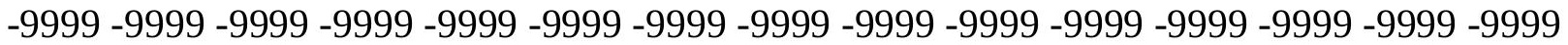

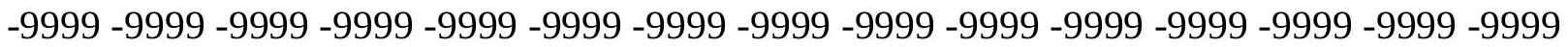
-9999 -9999 -9999 -9999 -9999 -9999 -9999 -9999 -9999 -9999 -9999 -9999 -9999 -9999 -9999 -9999 -9999 -9999 -9999 -9999 -9999 -9999 -9999 -9999 -9999 -9999 -9999 -9999 -9999 -9999 -9999 -9999 -9999 -9999 -9999 -9999 -9999 -9999 -9999 -9999 -9999 -9999 -9999 -9999 -9999

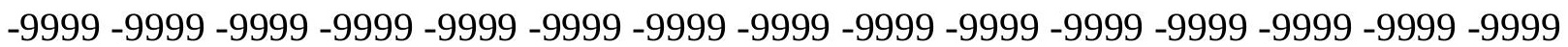
-9999 -9999 -9999 -9999 -9999 -9999 -9999 -9999 -9999 -9999 -9999 -9999 -9999 -9999 -9999 -9999 -9999 -9999 -9999 -9999 -9999 -9999 -9999 -9999 57.29959869385 56.99481964111 56.3852500915555 .7756805419955 .1661109924354 .5565414428754 .55654144287 55.1661109924355 .7756805419956 .3852500915557 .2995986938557 .9091796875 58.5187492370659 .4331016540560 .0426712036160 .6522407531761 .26181030273 61.5666007995662 .1761703491262 .4809494018662 .7857398986863 .09051895142 63.3953094482463 .7000885009863 .7000885009864 .004882812564 .30966186523 64.6144485473664 .9192428588965 .2240066528365 .5288009643665 .52880096436 65.8335876464866 .1383666992266 .1383666992266 .4431610107466 .44316101074 66.4431610107466 .7479400634866 .7479400634866 .7479400634866 .74794006348 67.0527267456167 .0527267456167 .0527267456167 .3575134277367 .35751342773 67.3575134277367 .3575134277367 .3575134277367 .3575134277367 .35751342773 67.3575134277367 .3575134277367 .3575134277367 .0527267456167 .05272674561 67.0527267456167 .0527267456166 .7479400634866 .7479400634866 .74794006348 66.4431610107466 .4431610107466 .1383666992266 .1383666992265 .83358764648 65.8335876464865 .5288009643665 .2240066528364 .9192428588964 .91924285889 64.6144485473664 .3096618652364 .004882812563 .7000885009863 .70008850098 63.3953094482463 .0905189514263 .0905189514263 .0905189514262 .78573989868 62.7857398986863 .0905189514263 .0905189514263 .0905189514263 .39530944824 63.7000885009863 .7000885009864 .004882812564 .004882812564 .30966186523 64.6144485473665 .2240066528365 .8335876464866 .4431610107467 .05272674561 67.9670867919968 .8814392089869 .7957916259871 .014930725171 .92929077148 72.8436431884873 .7580032348674 .6723632812575 .2819290161175 .89148712158 $76.1962814331176 .8058471679778 .3297805786180 .1584930419981 .98719787598-9999$ -9999 -9999 -9999 -9999 -9999 -9999 -9999 -9999 -9999 -9999 -9999 -9999 -9999 -9999 -9999 -9999 -9999 -9999 -9999 -9999 -9999 -9999 -9999 -9999 -9999 -9999 -9999 -9999 -9999 -9999 -9999 -9999 -9999 -9999 -9999 -9999 -9999 -9999 -9999 -9999 -9999 -9999 -9999 -9999 -9999 -9999 -9999 -9999 -9999 -9999 -9999 -9999 -9999 -9999 -9999 -9999 -9999 -9999 -9999 -9999 -9999 -9999 -9999 -9999 -9999 -9999 -9999 -9999 -9999 -9999 -9999 -9999 -9999 -9999 -9999 -9999 -9999 -9999 -9999 -9999 -9999 -9999 -9999 -9999 -9999 -9999 -9999 -9999 -9999 -9999 -9999 -9999 -9999 -9999 -9999 -9999 -9999 -9999 -9999 -9999 -9999 -9999 -9999 -9999 -9999 -9999 -9999 -9999 -9999 -9999 -9999 -9999 -9999 -9999 -9999 -9999 -9999 -9999 -9999 -9999

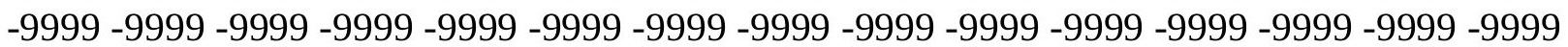


-9999 -9999 -9999 -9999 -9999 -9999 -9999 -9999 -9999 -9999 -9999 -9999

-9999 -9999 -9999 -9999 -9999 -9999 -9999 -9999 -9999 -9999 -9999 -9999 -9999 -9999 -9999

-9999 -9999 -9999 -9999 -9999 -9999 -9999 -9999 -9999 -9999 -9999 -9999 -9999 -9999 -9999

-9999 -9999 -9999 -9999 -9999 -9999 -9999 -9999 -9999 -9999 -9999 -9999 -9999 -9999 -9999

-9999 -9999 -9999 -9999 -9999 -9999 -9999 -9999 -9999 -9999 -9999 -9999 -9999 -9999 -9999 -

-9999 -9999 -9999 -9999 -9999 -9999 -9999 -9999 -9999 -9999 -9999 -9999 -9999 -9999 -9999 -

-9999 -9999 -9999 -9999 -9999 -9999 -9999 -9999 -9999 -9999 -9999 -9999 -9999 -9999 -9999 -

-9999 -9999 -9999 -9999 -9999 -9999 -9999 -9999 -9999 -9999 -9999 -9999 -9999 -9999 -9999

-9999 -9999 -9999 -9999 -9999 -9999 -9999 -9999 -9999 -9999 -9999 -9999 -9999 -9999 -9999 -

-9999 -9999 -9999 -9999 -9999 -9999-9999 56.08045959473 55.7756805419955.16611099243

54.5565414428754 .2517509460453 .6421813964853 .3373985290553 .33739852905

53.6421813964854 .2517509460454 .8613204956155 .4708900451756 .08045959473

56.6900291442957 .6043891906758 .2139587402358 .8235282897959 .43310165405 60.0426712036160 .6522407531760 .9570198059161 .5666007995661 .87137985229 62.1761703491262 .4809494018662 .7857398986863 .0905189514263 .39530944824 63.7000885009864 .004882812564 .3096618652364 .6144485473664 .91924285889 65.2240066528365 .2240066528365 .5288009643665 .8335876464865 .83358764648 66.1383666992266 .1383666992266 .1383666992266 .4431610107466 .44316101074 66.4431610107466 .7479400634866 .7479400634866 .7479400634867 .05272674561 67.0527267456167 .0527267456167 .0527267456167 .0527267456167 .05272674561 67.0527267456167 .0527267456167 .0527267456166 .7479400634866 .74794006348 66.7479400634866 .4431610107466 .4431610107466 .1383666992266 .13836669922 66.1383666992265 .8335876464865 .8335876464865 .5288009643665 .22400665283 65.2240066528364 .9192428588964 .6144485473664 .6144485473664 .30966186523 64.004882812564 .004882812563 .7000885009863 .3953094482463 .09051895142 63.0905189514262 .7857398986862 .7857398986862 .4809494018662 .48094940186 62.4809494018662 .4809494018662 .4809494018662 .7857398986862 .78573989868 62.7857398986863 .0905189514263 .0905189514263 .3953094482463 .39530944824 63.7000885009864 .004882812564 .6144485473664 .9192428588965 .52880096436 66.4431610107467 .0527267456167 .9670867919968 .8814392089869 .79579162598 70.7101516723671 .6244964599672 .5388565063573 .1484298706174 .0627822876 74.3675689697374 .9771423339875 .5867080688575 .8914871215877 .1106262207 78.6345596313580 .15849304199 -9999 -9999 -9999 -9999 -9999 -9999 -9999 -9999 -9999 -9999 -9999 -9999 -9999 -9999 -9999 -9999 -9999 -9999 -9999 -9999 -9999 -9999 -9999 -9999 -9999 -9999 -9999 -9999 -9999 -9999 -9999 -9999 -9999 -9999 -9999 -9999 -9999 -9999 -9999 -9999 -9999 -9999 -9999 -9999 -9999 -9999 -9999 -9999 -9999 -9999 -9999 -9999 -9999 -9999 -

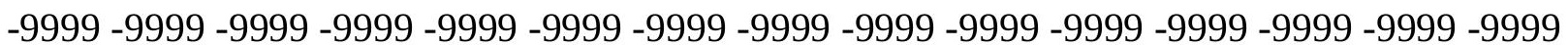
-9999 -9999 -9999 -9999 -9999 -9999 -9999 -9999 -9999 -9999 -9999 -9999 -9999 -9999 -9999 -9999 -9999 -9999 -9999 -9999 -9999 -9999 -9999 -9999 -9999 -9999 -9999 -9999 -9999 -9999 -9999 -9999 -9999 -9999 -9999 -9999 -9999 -9999 -9999 -9999 -9999 -9999 -9999 -9999 -9999 -9999 -9999 -9999 -9999 -9999 -9999 -9999 -9999 -9999 -9999 -9999 -9999 -9999 -9999 -9999

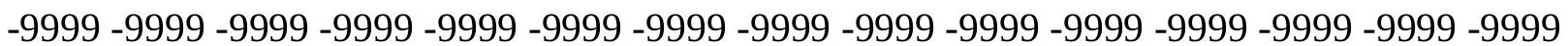
-9999 -9999-9999

-9999 -9999 -9999 -9999 -9999 -9999 -9999 -9999 -9999 -9999 -9999 -9999 -9999 -9999 -9999 -9999 -9999 -9999 -9999 -9999 -9999 -9999 -9999 -9999 -9999 -9999 -9999 -9999 -9999 -9999

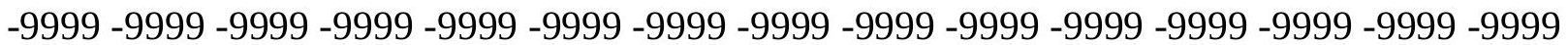


-9999 -9999 -9999 -9999 -9999 -9999 -9999 -9999 -9999 -9999 -9999 -9999 -9999 -9999 -9999 -9999 -9999 -9999 -9999 -9999 -9999 -9999 -9999 -9999 -9999 -9999 -9999 -9999 -9999 -9999 -9999 -9999 -9999 -9999 -9999 -9999 -9999 -9999 -9999 -9999 -9999 -9999 -9999 -9999 -9999 -9999 -9999 -9999 -9999 -9999 -9999 -9999 -9999 -9999 -9999 -9999 -9999 -9999 -9999 -9999 -9999 -9999 -9999 -9999 -9999 -9999 -9999 -9999 -9999 -9999 -9999 -9999 -9999 -9999 -9999 -9999 -9999 -9999 -9999 -9999 54.5565414428754 .2517509460453 .94697189331 53.3373985290553 .0326118469252 .7278289794952 .7278289794952 .72782897949 52.4230384826752 .7278289794952 .7278289794953 .3373985290553 .64218139648 54.5565414428755 .1661109924355 .7756805419956 .3852500915556 .99481964111 57.6043891906758 .5187492370658 .8235282897959 .4331016540560 .04267120361 60.3474502563560 .9570198059161 .2618103027361 .5666007995662 .17617034912 62.4809494018662 .7857398986863 .0905189514263 .3953094482463 .70008850098 64.004882812564 .3096618652364 .6144485473664 .9192428588964 .91924285889 65.2240066528365 .5288009643665 .5288009643665 .8335876464865 .83358764648 66.1383666992266 .1383666992266 .4431610107466 .4431610107466 .44316101074 66.4431610107466 .7479400634866 .7479400634866 .7479400634866 .74794006348 66.7479400634866 .7479400634866 .7479400634866 .4431610107466 .44316101074 66.4431610107466 .1383666992266 .1383666992266 .1383666992265 .83358764648 65.8335876464865 .5288009643665 .5288009643665 .2240066528364 .91924285889 64.9192428588964 .6144485473664 .3096618652364 .3096618652364 .0048828125 63.7000885009863 .7000885009863 .3953094482463 .0905189514262 .78573989868 62.7857398986862 .4809494018662 .4809494018662 .1761703491262 .17617034912 62.1761703491262 .1761703491262 .1761703491262 .1761703491262 .17617034912 62.1761703491262 .1761703491262 .4809494018662 .4809494018662 .48094940186 62.7857398986862 .7857398986863 .0905189514263 .3953094482463 .70008850098 64.3096618652364 .9192428588965 .5288009643666 .1383666992267 .05272674561 67.9670867919968 .8814392089869 .4910125732470 .4053573608471 .31971740723 71.9292907714872 .5388565063573 .1484298706173 .7580032348674 .0627822876 74.6723632812574 .9771423339875 .5867080688577 .110626220778 .32978057861 79.85370635986 -9999 -9999 -9999 -9999 -9999 -9999 -9999 -9999 -9999 -9999 -9999 -9999 -9999 -9999 -9999 -9999 -9999 -9999 -9999 -9999 -9999 -9999 -9999 -9999 -9999 -9999 -9999 -9999 -9999 -9999 -9999 -9999 -9999 -9999 -9999 -9999 -9999 -9999 -9999 -9999 -9999 -9999 -9999 -9999 -9999 -9999 -9999 -9999 -9999 -9999 -9999 -9999 -9999 -9999 -9999 -9999 -9999 -9999 -9999 -9999 -9999 -9999 -9999 -9999 -9999 -9999 -9999 -9999 -9999 -9999 -9999 -9999

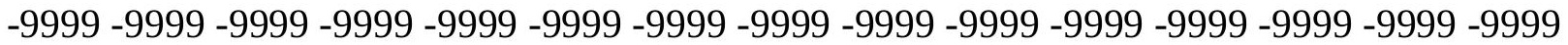
-9999 -9999 -9999 -9999 -9999 -9999 -9999 -9999 -9999 -9999 -9999 -9999 -9999 -9999 -9999 -9999 -9999 -9999 -9999 -9999 -9999 -9999 -9999 -9999 -9999 -9999 -9999 -9999 -9999 -9999

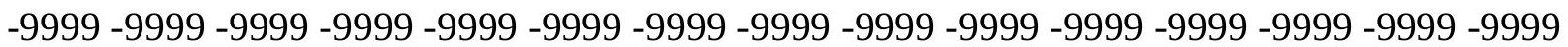
-9999 -9999 -9999 -9999 -9999 -9999 -9999 -9999 -9999 -9999 -9999 -9999 -9999 -9999 -9999 -9999 -9999 -9999 -9999 -9999 -9999 -9999 -9999 -9999 -9999 -9999 -9999 -9999 -9999 -9999 -9999 -9999 -9999 -9999 -9999 -9999 -9999 -9999 -9999 -9999 -9999 -9999 -9999

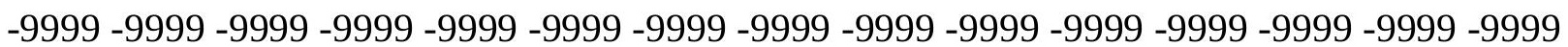
-9999 -9999 -9999 -9999 -9999 -9999 -9999 -9999 -9999 -9999 -9999 -9999 -9999 -9999 -9999 -9999 -9999 -9999 -9999 -9999 -9999 -9999 -9999 -9999 -9999 -9999 -9999 -9999 -9999 -9999 -9999 -9999 -9999 -9999 -9999 -9999 -9999 -9999 -9999 -9999 -9999 -9999 -9999 -9999 -9999

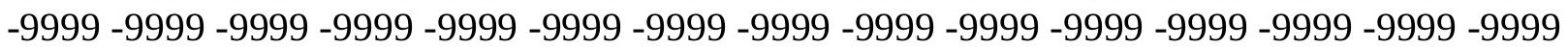


-9999 -9999 -9999 -9999 -9999 -9999 -9999 -9999 -9999 -9999 -9999 -9999 -9999 -9999 -9999 -9999 -9999-9999 53.0326118469252.7278289794952.4230384826751.81346893311 51.5086898803751 .8134689331151 .8134689331151 .8134689331151 .81346893311 51.8134689331151 .8134689331151 .8134689331152 .1182594299352 .42303848267 53.0326118469253 .3373985290553 .9469718933154 .8613204956155 .47089004517 56.0804595947356 .6900291442957 .2995986938557 .909179687558 .51874923706 59.1283111572359 .4331016540560 .0426712036160 .3474502563560 .95701980591 61.2618103027361 .5666007995661 .8713798522962 .4809494018662 .78573989868 63.0905189514263 .3953094482463 .7000885009864 .004882812564 .30966186523 64.6144485473664 .9192428588964 .9192428588965 .2240066528365 .52880096436 65.5288009643665 .8335876464865 .8335876464866 .1383666992266 .13836669922 66.1383666992266 .1383666992266 .4431610107466 .4431610107466 .44316101074 66.4431610107466 .4431610107466 .4431610107466 .1383666992266 .13836669922 66.1383666992265 .8335876464865 .8335876464865 .8335876464865 .52880096436 65.5288009643665 .2240066528364 .9192428588964 .9192428588964 .61444854736 64.3096618652364 .3096618652364 .004882812563 .7000885009863 .39530944824 63.3953094482463 .0905189514262 .7857398986862 .7857398986862 .48094940186 62.1761703491262 .1761703491261 .8713798522961 .8713798522961 .56660079956 61.5666007995661 .5666007995661 .5666007995661 .5666007995661 .56660079956 61.5666007995661 .5666007995661 .8713798522961 .8713798522961 .87137985229 61.8713798522962 .1761703491262 .1761703491262 .4809494018662 .78573989868 63.0905189514263 .3953094482464 .004882812564 .6144485473665 .22400665283 66.1383666992266 .7479400634867 .6623001098668 .5766525268669 .18623352051 70.1005783081170 .7101516723671 .3197174072371 .9292907714872 .53885650635 72.8436431884873 .1484298706173 .7580032348673 .7580032348674 .0627822876 75.5867080688576 .8058471679778 .02498626709 -9999 -9999 -9999 -9999 -9999 -9999 -9999 -9999 -9999 -9999 -9999 -9999 -9999 -9999 -9999 -9999-9999 -9999 -9999 -9999 -9999 -9999 - -999 -

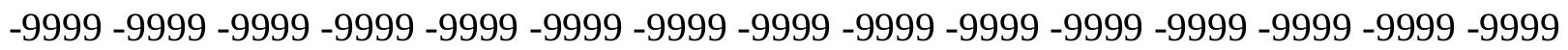
-9999 -9999 -9999 -9999 -9999 -9999 -9999 -9999 -9999 -9999 -9999 -9999 -9999 -9999 -9999 -9999 -9999 -9999 -9999 -9999 -9999 -9999 -9999 -9999 -9999 -9999 -9999 -9999 -9999 -9999 -9999 -9999 -9999 -9999 -9999 -9999 -9999 -9999 -9999 -9999 -9999 -9999-9999 -9999 -9999 -9999 -9999 -9999 -9999 -9999 -9999 -9999 -9999 -9999 -9999 -9999 -9999 -9999 -9999 -9999 -

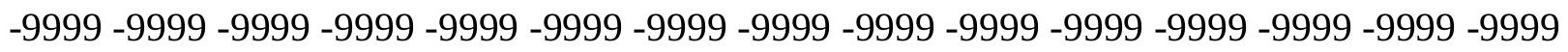
-9999 -9999 -9999 -9999 -9999 -9999 -9999 -9999 -9999 -9999 -9999 -9999 -9999 -9999 -9999

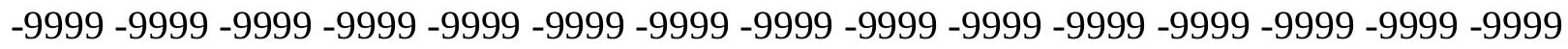
$-9999-9999$

-9999 -9999 -9999 -9999 -9999 -9999 -9999 -9999 -9999 -9999 -9999 -9999 -9999 -9999 -9999 -

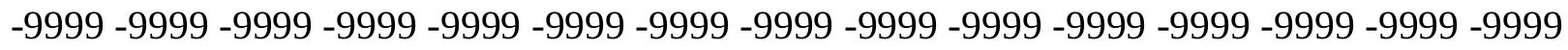
-9999 -9999 -9999 -9999 -9999 -9999 -9999 -9999 -9999 -9999 -9999 -9999 -9999 -9999 -9999 -9999 -9999 -9999 -9999 -9999 -9999 -9999 -9999 -9999 -9999 -9999 -9999 -9999 -9999 - -999 -

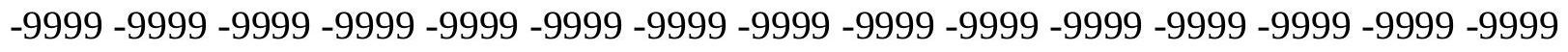

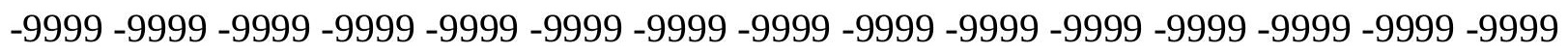
-9999 -9999 -9999 -9999 -9999 -9999 -9999 -9999 -9999 -9999 -9999 -9999 -9999 -9999 -9999 -9999 -9999 -9999 -9999 -9999 -9999 -9999 -9999 -9999 -9999 -9999 -9999 -9999 -9999 -9999 -9999 51.5086898803751.20389938354 50.59432983398 50.28955078125 50.28955078125 50.2895507812550 .5943298339850 .5943298339850 .5943298339850 .89912033081 
50.8991203308150 .8991203308150 .8991203308150 .8991203308151 .20389938354 51.5086898803752 .1182594299352 .4230384826753 .0326118469253 .64218139648 54.2517509460454 .8613204956155 .7756805419956 .3852500915556 .99481964111 57.2995986938557 .909179687558 .5187492370659 .1283111572359 .43310165405 60.0426712036160 .3474502563560 .9570198059161 .2618103027361 .56660079956 62.1761703491262 .4809494018662 .7857398986863 .0905189514263 .39530944824 63.7000885009864 .004882812564 .3096618652364 .6144485473664 .91924285889 65.2240066528365 .2240066528365 .5288009643665 .5288009643665 .83358764648 65.8335876464865 .8335876464865 .8335876464866 .1383666992266 .13836669922 66.1383666992266 .1383666992266 .1383666992265 .8335876464865 .83358764648 65.8335876464865 .5288009643665 .5288009643665 .5288009643665 .22400665283 64.9192428588964 .9192428588964 .6144485473664 .6144485473664 .30966186523 64.004882812563 .7000885009863 .7000885009863 .3953094482463 .09051895142 62.7857398986862 .4809494018662 .4809494018662 .1761703491261 .87137985229 61.8713798522961 .5666007995661 .2618103027361 .2618103027361 .26181030273 60.9570198059160 .9570198059160 .9570198059160 .9570198059160 .95701980591 60.9570198059161 .2618103027361 .2618103027361 .2618103027361 .26181030273 61.2618103027361 .2618103027361 .5666007995661 .5666007995661 .56660079956 61.8713798522962 .1761703491262 .7857398986863 .0905189514263 .70008850098 64.3096618652364 .9192428588965 .8335876464866 .4431610107467 .35751342773 67.9670867919968 .5766525268669 .4910125732470 .1005783081170 .71015167236 71.014930725171 .6244964599671 .9292907714872 .2340774536172 .53885650635 $72.8436431884873 .1484298706173 .7580032348675 .2819290161177 .41542053223-9999$

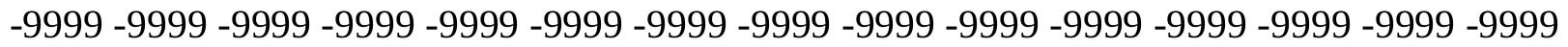

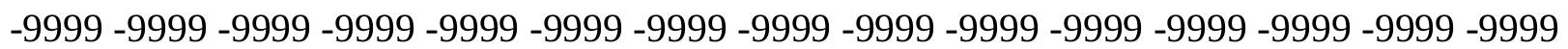

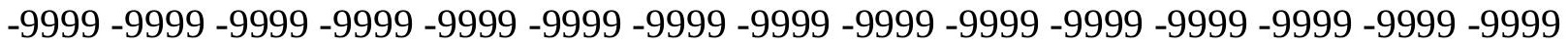

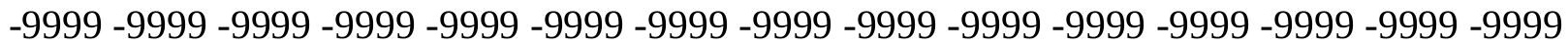

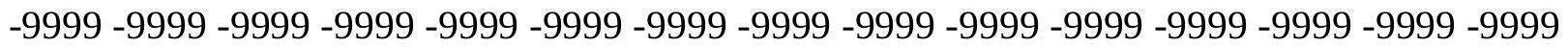

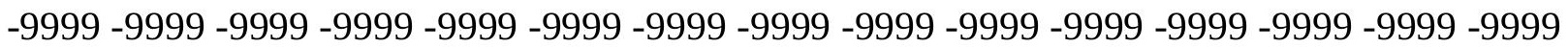

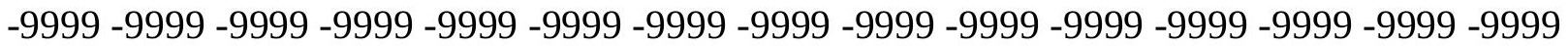

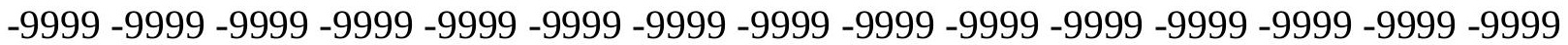

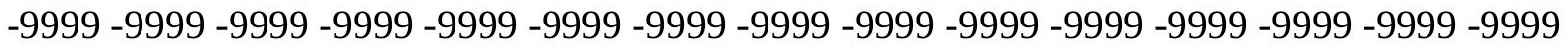
-9999 -9999 -9999 -9999 -9999 -9999 -9999

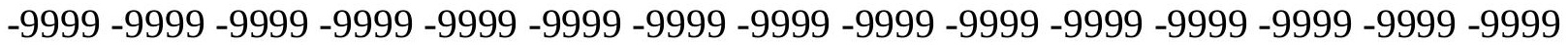

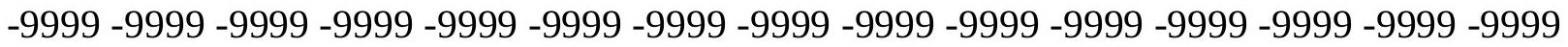

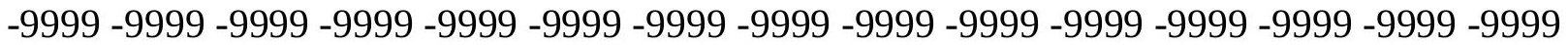

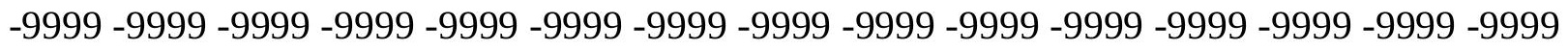

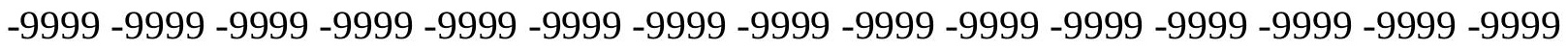

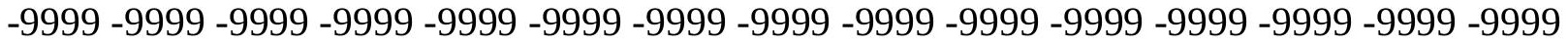

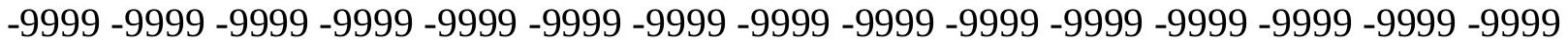
-9999 -9999 -9999 -9999 -9999 -9999 -9999 -9999 -9999 -9999 -9999 -9999 -9999 -9999 50.2895507812549 .6799812316949 .0704002380448 .765621185348 .7656211853 49.0704002380449 .0704002380449 .3751907348649 .3751907348649 .67998123169 49.6799812316949 .6799812316949 .6799812316949 .9847602844249 .98476028442 49.9847602844250 .2895507812550 .5943298339851 .2038993835451 .50868988037 52.1182594299352 .7278289794953 .3373985290553 .9469718933154 .55654144287 
55.1661109924355 .7756805419956 .3852500915556 .9948196411157 .60438919067 58.2139587402358 .5187492370659 .1283111572359 .7378807067960 .04267120361 60.6522407531760 .9570198059161 .5666007995661 .8713798522962 .17617034912 62.7857398986863 .0905189514263 .3953094482463 .7000885009864 .0048828125 64.3096618652364 .6144485473664 .6144485473664 .9192428588965 .22400665283 65.2240066528365 .5288009643665 .5288009643665 .5288009643665 .83358764648 65.8335876464865 .8335876464865 .8335876464865 .8335876464865 .52880096436 65.5288009643665 .5288009643665 .5288009643665 .2240066528365 .22400665283 64.9192428588964 .9192428588964 .6144485473664 .3096618652364 .0048828125 64.004882812563 .7000885009863 .3953094482463 .0905189514263 .09051895142 62.7857398986862 .4809494018662 .1761703491261 .8713798522961 .56660079956 61.5666007995661 .2618103027360 .9570198059160 .9570198059160 .65224075317 60.6522407531760 .3474502563560 .3474502563560 .3474502563560 .34745025635 60.3474502563560 .3474502563560 .6522407531760 .6522407531760 .65224075317 60.6522407531760 .6522407531760 .6522407531760 .6522407531760 .65224075317 60.9570198059160 .9570198059161 .2618103027361 .5666007995661 .87137985229 62.1761703491262 .7857398986863 .3953094482464 .004882812564 .61444854736 65.5288009643666 .1383666992266 .7479400634867 .3575134277368 .27187347412 68.8814392089869 .4910125732469 .7957916259870 .4053573608470 .71015167236 71.014930725171 .3197174072371 .6244964599671 .9292907714872 .53885650635

73.1484298706175 .5867080688578 .02498626709 -9999 -9999 -9999 -9999 -9999 -9999 -9999 -9999 -9999 -9999 -9999 -9999 -9999 -9999 -9999 -9999 -9999 -9999 -9999 -9999 -9999 -9999 -9999 -9999 -9999 -9999 -9999 -9999 -9999 -9999 -9999 -9999 -9999 -9999 -9999 -9999 -9999 -9999 -9999 -9999 -9999 -9999 -9999 -9999 -9999 -9999 -9999 -9999 -9999 -9999 -9999 -9999 -9999 -9999 -9999 -9999 -9999 -9999 -9999 -9999 -9999 -9999 -9999 -9999 -9999 -9999 -9999 -9999 -9999 -9999 -9999 -9999 -9999 -9999 -9999 -9999 -9999 -9999 -9999 -9999 -9999 -9999 -9999 -9999 -9999 -9999 -9999 -9999 -9999 -9999 -9999 -9999 -9999 -9999 -9999 -9999 -9999

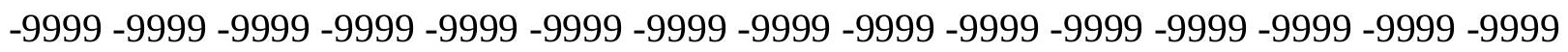
-9999 -9999 -9999 -9999 -9999 -9999 -9999 -9999 -9999 -9999 -9999 -9999 -9999 -9999 -9999 -9999 -9999 -9999 -9999 -9999 -9999 -9999 -9999 -9999 -9999 -9999 -9999 -9999 -9999 -9999 -9999 -9999 -9999 -9999 -9999 -9999 -9999 -9999 -9999 -9999 -9999 -9999 -9999 -9999 -9999

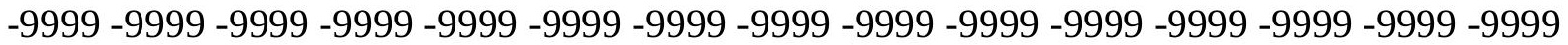

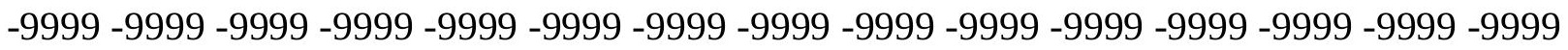
-9999 -9999 -9999 -9999 -9999 -9999 -9999 -9999 -9999 -9999 -9999 -9999 -9999 -9999 -9999 -9999 -9999 -9999 -9999 -9999 -9999 -9999 -9999 -9999 -9999 -9999 -9999 -9999 -9999 -9999 -9999 -9999 -9999 -9999 -9999 -9999 -9999 -9999 -9999 -9999 -9999 -9999 -9999 -9999 -9999

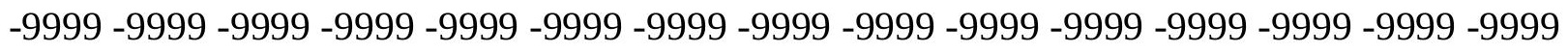
-9999 -9999-9999-9999 -9999-9999 -9999 -9999-9999-9999 -9999-9999 49.37519073486 48.765621185348 .1560516357447 .5464782714847 .2416992187547 .54647827148 47.8512611389247 .8512611389248 .1560516357448 .1560516357448 .46083068848 48.4608306884848 .4608306884848 .765621185348 .765621185348 .7656211853 49.0704002380449 .0704002380449 .3751907348649 .6799812316950 .28955078125 50.5943298339851 .2038993835451 .8134689331152 .4230384826753 .03261184692 53.6421813964854 .2517509460454 .8613204956155 .4708900451756 .08045959473 56.6900291442957 .2995986938557 .6043891906758 .2139587402358 .82352828979 59.4331016540559 .7378807067960 .3474502563560 .6522407531761 .26181030273 
61.5666007995662 .1761703491262 .4809494018662 .7857398986863 .09051895142 63.7000885009864 .004882812564 .004882812564 .3096618652364 .61444854736 64.9192428588964 .9192428588965 .2240066528365 .2240066528365 .22400665283 65.5288009643665 .5288009643665 .5288009643665 .5288009643665 .52880096436 65.2240066528365 .2240066528365 .2240066528364 .9192428588964 .91924285889 64.6144485473664 .6144485473664 .3096618652364 .004882812564 .0048828125 63.7000885009863 .3953094482463 .0905189514262 .7857398986862 .48094940186 62.1761703491262 .1761703491261 .8713798522961 .5666007995661 .26181030273 60.9570198059160 .6522407531760 .3474502563560 .3474502563560 .04267120361 60.0426712036159 .7378807067959 .7378807067959 .7378807067959 .43310165405 59.4331016540559 .7378807067959 .7378807067960 .0426712036160 .04267120361 60.0426712036160 .0426712036160 .0426712036160 .0426712036160 .04267120361 60.0426712036160 .0426712036160 .0426712036160 .3474502563560 .65224075317 60.9570198059161 .2618103027361 .8713798522962 .4809494018663 .09051895142 63.7000885009864 .3096618652364 .9192428588965 .5288009643666 .13836669922 67.0527267456167 .6623001098667 .9670867919968 .5766525268669 .18623352051 69.4910125732470 .1005783081170 .4053573608470 .7101516723671 .31971740723 71.9292907714872 .5388565063573 .7580032348675 .8914871215878 .32978057861 80.46327209473 -9999 -9999 -9999 -9999 -9999 -9999 -9999 -9999 -9999 -9999 -9999 -9999

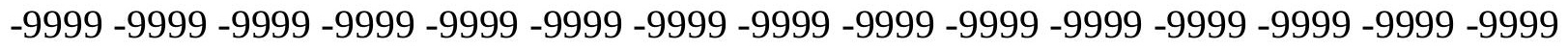
-9999 -9999 -9999 -9999 -9999 -9999 -9999 -9999 -9999 -9999 -9999 -9999 -9999 -9999 -9999

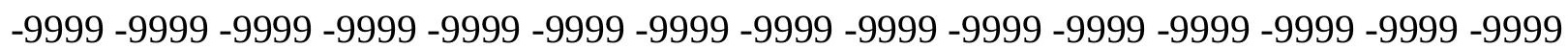
-9999 -9999 -9999 -9999 -9999 -9999 -9999 -9999 -9999 -9999 -9999 -9999 -9999 -9999 -9999 -

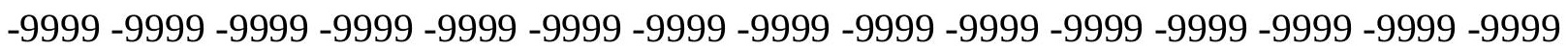

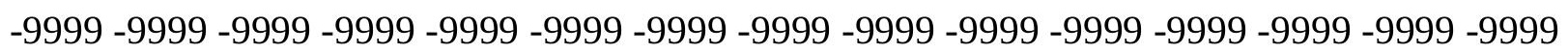
-9999 -9999 -9999 -9999 -9999 -9999 -9999 -9999 -9999 -9999 -9999 -9999 -9999 -9999 -9999 -9999 -9999 -9999 -9999 -9999 -9999 -9999 -9999 -9999 -9999 -9999 -9999 -9999 -9999 -9999 -9999 -9999 -9999 -9999 -9999 -9999 -9999-9999 -9999

-9999 -9999 -9999 -9999 -9999 -9999 -9999 -9999 -9999 -9999 -9999 -9999 -9999 -9999 -9999 -

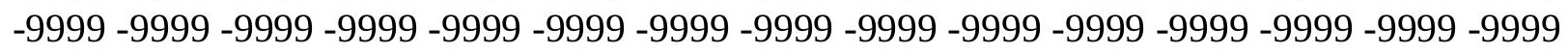
-9999 -9999 -9999 -9999 -9999 -9999 -9999 -9999 -9999 -9999 -9999 -9999 -9999 -9999 -9999 -9999 -9999 -9999 -9999 -9999 -9999 -9999 -9999 -9999 -9999 -9999 -9999 -9999 -9999 -9999 -

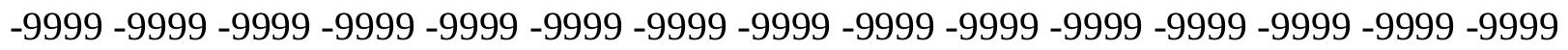
-9999 -9999 -9999 -9999 -9999 -9999 -9999 -9999 -9999 -9999 -9999 -9999 -9999 -9999 -9999

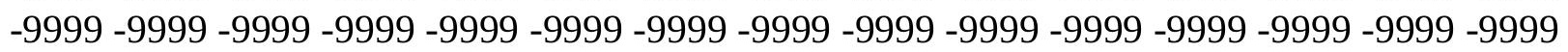
-9999 -9999 -9999 -9999 -9999 -9999 -9999 -9999 -9999 -9999 48.46083068848 47.8512611389247 .2416992187546 .6321296691946 .6321296691946 .32733917236 46.3273391723646 .6321296691946 .6321296691946 .9369087219246 .93690872192 47.24169921875 47.24169921875 47.24169921875 47.5464782714847.54647827148 47.8512611389247 .8512611389248 .1560516357448 .1560516357448 .46083068848 48.765621185349 .3751907348649 .6799812316950 .2895507812550 .89912033081 51.5086898803751 .8134689331152 .4230384826753 .3373985290553 .94697189331 54.5565414428755 .1661109924355 .7756805419956 .3852500915556 .99481964111 57.2995986938557 .909179687558 .5187492370659 .1283111572359 .73788070679 60.0426712036160 .6522407531760 .9570198059161 .5666007995661 .87137985229 62.4809494018662 .7857398986863 .0905189514263 .3953094482463 .70008850098 
64.004882812564 .3096618652364 .6144485473664 .6144485473664 .91924285889 64.9192428588965 .2240066528365 .2240066528365 .2240066528365 .22400665283 65.2240066528365 .2240066528364 .9192428588964 .9192428588964 .91924285889 64.6144485473664 .6144485473664 .3096618652364 .004882812563 .70008850098 63.7000885009863 .3953094482463 .0905189514262 .7857398986862 .48094940186 62.1761703491261 .8713798522961 .5666007995661 .2618103027361 .26181030273 60.9570198059160 .6522407531760 .3474502563560 .0426712036159 .73788070679 59.4331016540559 .4331016540559 .1283111572359 .1283111572358 .82352828979 58.8235282897958 .8235282897958 .8235282897958 .8235282897959 .12831115723 59.1283111572359 .4331016540559 .4331016540559 .4331016540559 .43310165405 59.1283111572359 .1283111572359 .1283111572359 .1283111572359 .12831115723 59.4331016540559 .7378807067960 .0426712036160 .3474502563560 .65224075317 61.2618103027361 .8713798522962 .4809494018663 .0905189514263 .70008850098 64.3096618652365 .2240066528365 .8335876464866 .4431610107467 .05272674561 67.3575134277367 .9670867919968 .5766525268668 .8814392089869 .49101257324 69.7957916259870 .4053573608471 .014930725171 .9292907714873 .14842987061 74.062782287676 .1962814331178 .3297805786180 .15849304199 -9999 -9999 -9999-9999 -9999 -9999 -9999 -9999 -9999 -9999 -9999 -9999 -9999 -9999 -9999 -9999 -9999 -9999 -9999 -9999 -9999 -9999 -9999 -9999 -9999 -9999 -9999 -9999 -9999 -9999 -9999 -9999 -9999 -9999 -

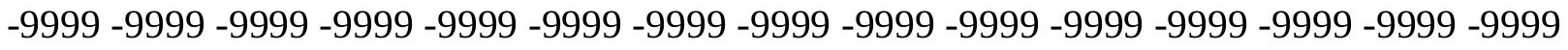

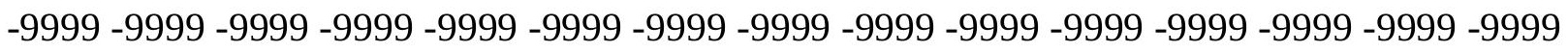
-9999 -9999 -9999 -9999 -9999 -9999 -9999 -9999 -9999 -9999 -9999 -9999 -9999 -9999 -9999 -9999 -9999 -9999 -9999 -9999 -9999 -9999 -9999 -9999 -9999 -9999 -9999 -9999 -9999 -9999 -

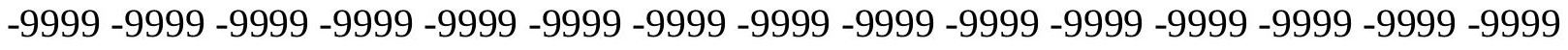

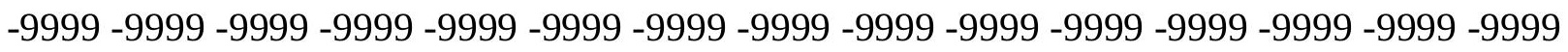
-9999 -9999 -9999 -9999 -9999 -9999 -9999 -9999 -9999 -9999 -9999 -9999 -9999 -9999 -9999 -

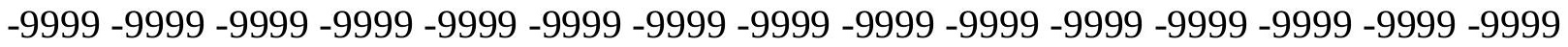

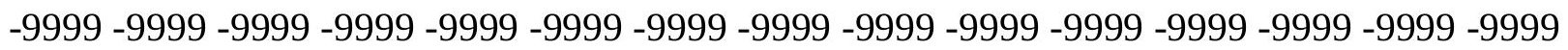
-9999 -9999 -9999 -9999 -9999 -9999 -9999 -9999 -9999 -9999 -9999 -9999 -9999 -9999 -9999 -9999 -9999 -9999 -9999 -9999 -9999 -9999 -9999 -9999 -9999 -9999 -9999 -9999 -9999 -9999 -9999 -9999 -9999 -9999 -9999 -9999 -9999 -9999 -9999-9999 -9999 -9999 -9999 -9999 -9999 -9999 -9999 -9999 -9999 -9999 -9999 -9999 -9999 -9999 -9999 -9999 -9999 -9999 -9999 -9999 -

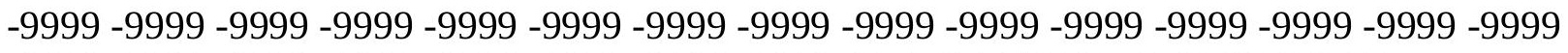
-9999 -9999 -9999 -9999 -9999 -9999 -9999 -9999 47.85126113892 46.93690872192 46.0225486755445 .4129791259845 .4129791259845 .717769622845 .41297912598 45.4129791259845 .4129791259845 .4129791259845 .717769622845 .7177696228 45.717769622846 .0225486755446 .0225486755446 .3273391723646 .32733917236 46.6321296691946 .6321296691946 .9369087219246 .9369087219247 .24169921875 47.5464782714847 .8512611389248 .4608306884848 .765621185349 .37519073486 49.6799812316950 .2895507812550 .8991203308151 .5086898803752 .11825942993 52.7278289794953 .3373985290553 .9469718933154 .5565414428755 .47089004517 56.0804595947356 .6900291442957 .2995986938557 .6043891906758 .21395874023 58.8235282897959 .4331016540560 .0426712036160 .3474502563560 .95701980591 61.5666007995661 .8713798522962 .1761703491262 .7857398986863 .09051895142 63.3953094482463 .7000885009864 .004882812564 .3096618652364 .30966186523 64.6144485473664 .6144485473664 .9192428588964 .9192428588964 .91924285889 
64.9192428588964 .9192428588964 .9192428588964 .6144485473664 .61444854736 64.3096618652364 .3096618652364 .004882812563 .7000885009863 .70008850098 63.3953094482463 .0905189514262 .7857398986862 .4809494018662 .17617034912 61.8713798522961 .5666007995661 .2618103027360 .9570198059160 .65224075317 60.3474502563560 .0426712036159 .7378807067959 .4331016540559 .43310165405 59.1283111572358 .8235282897958 .5187492370658 .5187492370658 .21395874023 57.909179687557 .909179687557 .909179687557 .909179687557 .9091796875 58.2139587402358 .5187492370658 .8235282897958 .8235282897958 .82352828979 58.5187492370658 .2139587402358 .2139587402358 .2139587402358 .21395874023 58.2139587402358 .2139587402358 .5187492370658 .8235282897959 .43310165405 59.7378807067960 .3474502563560 .9570198059161 .5666007995662 .17617034912 62.7857398986863 .3953094482464 .004882812564 .6144485473665 .22400665283 65.8335876464866 .4431610107466 .7479400634867 .3575134277367 .96708679199 68.5766525268669 .1862335205169 .7957916259870 .4053573608471 .31971740723 72.2340774536173 .4532165527374 .3675689697375 .8914871215877 .72020721436 79.85370635986 -9999 -9999 -9999 -9999 -9999 -9999 -9999 -9999 -9999 -9999 -9999 -9999 -9999 -9999 -9999 -9999 -9999 -9999 -9999 -9999 -9999 -9999 -9999 -9999 -9999 -9999 -9999 -9999 -9999 -9999 -9999 -9999 -9999 -9999 -9999 -9999 -9999 -9999 -9999 -9999 -9999 - 9999 -9999 -9999 -9999 -9999 -9999 -9999 -9999 -9999 -9999 -9999 -9999 -9999 -9999 -9999 -9999 -

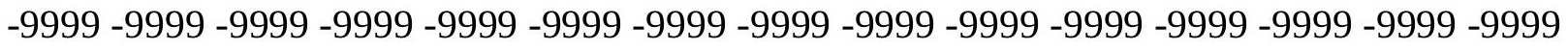

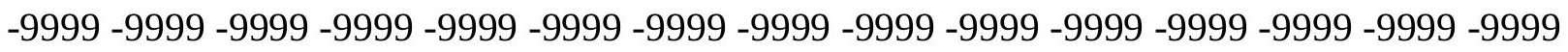
-9999 -9999 -9999 -9999 -9999 -9999 -9999 -9999 -9999 -9999 -9999 -9999 -9999 -9999 -9999 -9999 -9999 -9999 -9999 -9999 -9999 -9999 -9999 -9999 -9999 -9999 -9999 -9999 -9999 -9999 -

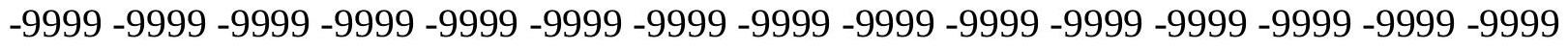
-9999-9999-9999-9999-9999-9999

-9999 -9999 -9999 -9999 -9999 -9999 -9999 -9999 -9999 -9999 -9999 -9999 -9999 -9999 -9999 -9999 -9999 -9999 -9999 -9999 -9999 -9999 -9999 -9999 -9999 -9999 -9999 -9999 -9999 -9999 -

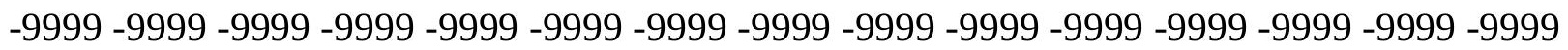
-9999 -9999 -9999 -9999 -9999 -9999 -9999 -9999 -9999 -9999 -9999 -9999 -9999 -9999 -9999 -9999 -9999 -9999 -9999 -9999 -9999 -9999 -9999 -9999 -9999 -9999 -9999 -9999 -9999 -999 -9999 -9999 -9999 -9999 -9999 -9999 -9999 -9999 -9999-9999 -9999 -9999 -9999 -9999 -9999 -9999 -9999 -9999 -9999 -9999 -9999 -9999 -9999 -9999 -9999 -9999 -9999 -9999 -9999 -9999 -9999 -9999 -9999 -9999 -9999-9999 47.24169921875 46.32733917236 45.41297912598 44.1938400268644 .1938400268644 .1938400268644 .4986305236844 .49863052368 44.4986305236844 .4986305236844 .4986305236844 .4986305236844 .49863052368 44.4986305236844 .8034095764244 .8034095764245 .1082000732445 .10820007324 45.4129791259845 .4129791259845 .717769622845 .717769622846 .02254867554 46.3273391723646 .6321296691946 .9369087219247 .2416992187547 .85126113892 48.1560516357448 .765621185349 .3751907348649 .9847602844250 .59432983398 51.2038993835451 .8134689331152 .4230384826753 .0326118469253 .64218139648 54.2517509460455 .1661109924355 .7756805419956 .3852500915556 .99481964111 57.6043891906758 .2139587402358 .8235282897959 .4331016540559 .73788070679 60.3474502563560 .9570198059161 .2618103027361 .8713798522962 .17617034912 62.4809494018663 .0905189514263 .3953094482463 .7000885009864 .0048828125 64.004882812564 .3096618652364 .3096618652364 .6144485473664 .61444854736 64.6144485473664 .6144485473664 .6144485473664 .3096618652364 .30966186523 
64.3096618652364 .004882812564 .004882812563 .7000885009863 .39530944824 63.0905189514262 .7857398986862 .4809494018662 .4809494018662 .17617034912 61.8713798522961 .2618103027360 .9570198059160 .6522407531760 .34745025635 60.0426712036159 .7378807067959 .4331016540559 .1283111572358 .82352828979 58.5187492370658 .2139587402357 .909179687557 .909179687557 .60438919067 57.2995986938557 .2995986938556 .9948196411156 .9948196411156 .99481964111 56.9948196411157 .2995986938557 .6043891906757 .909179687557 .9091796875 57.909179687557 .6043891906757 .2995986938556 .9948196411156 .99481964111 56.9948196411156 .9948196411157 .2995986938557 .6043891906757 .9091796875 58.2139587402358 .8235282897959 .1283111572359 .7378807067960 .34745025635 60.9570198059161 .5666007995662 .1761703491262 .7857398986863 .39530944824 64.004882812564 .6144485473665 .2240066528365 .8335876464866 .44316101074 67.0527267456167 .6623001098668 .2718734741268 .8814392089869 .79579162598 70.7101516723671 .6244964599672 .5388565063573 .4532165527374 .36756896973 75.5867080688577 .4154205322378 .93934631348 -9999 -9999 -9999 -9999 -9999 -9999 -9999 -9999 -9999 -9999 -9999 -9999 -9999 -9999 -9999 -9999 -9999 -9999 -9999 -9999 -9999 -9999 -9999 -9999 -9999 -9999 -9999 -9999 -9999 -9999 -9999 -9999 -9999 -9999 -9999 -9999 -9999 -9999 -9999 -9999 -9999 -9999 -9999 -9999 -9999 -9999 -9999 -9999 -9999 -9999 -9999 -9999 -9999 -9999 -9999 -9999 -9999 -9999 -9999 -9999 -9999 -9999 -9999 -9999 -9999 -9999 -9999 -9999 -9999 -9999 -9999 -9999 -9999 -9999 -9999 -9999 -9999 -9999 -9999 -9999 -9999 -9999

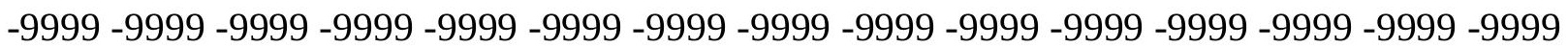
-9999 -9999 -9999 -9999 -9999 -9999 -9999 -9999 -9999 -9999 -9999 -9999 -9999 -9999 -9999 -9999 -9999 -9999 -9999 -9999 -9999 -9999 -9999 -9999 -9999 -9999 -9999 -9999 -9999 -9999 -9999 -9999 -9999 -9999 -9999 -9999 -9999 -9999 -9999 -9999

-9999 -9999 -9999 -9999 -9999 -9999 -9999 -9999 -9999 -9999 -9999 -9999 -9999 -9999 -9999 -9999 -9999 -9999 -9999 -9999 -9999 -9999 -9999 -9999 -9999 -9999 -9999 -9999 -9999 -9999 -9999 -9999 -9999 -9999 -9999 -9999 -9999 -9999 -9999 -9999 -9999 -9999 -9999 -9999 -9999 -9999 -9999 -9999 -9999 -9999 -9999 -9999 -9999 -9999 -9999 -9999 -9999 -9999 -9999 -9999 -9999 -9999 -9999 -9999 -9999 -9999 -9999 -9999 -9999 -9999 -9999 -9999 -9999 -9999 -9999

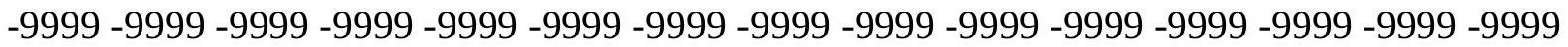
-9999 -9999 -9999 -9999 -9999 -9999 -9999 -9999 -9999 -9999 -9999 -9999 -9999 -9999 -9999 -9999 -9999 -9999 -9999 -9999 45.4129791259844.80340957642 43.88906097412 43.2794914245643 .2794914245643 .2794914245643 .2794914245643 .27949142456 43.2794914245643 .2794914245643 .2794914245643 .2794914245643 .27949142456 43.2794914245643 .5842704772943 .5842704772943 .5842704772943 .88906097412 43.8890609741244 .1938400268644 .1938400268644 .4986305236844 .80340957642 45.1082000732445 .1082000732445 .717769622846 .0225486755446 .32733917236 46.9369087219247 .2416992187547 .8512611389248 .4608306884849 .07040023804 49.6799812316950 .2895507812550 .8991203308151 .5086898803752 .11825942993 52.7278289794953 .3373985290554 .2517509460454 .8613204956155 .47089004517 56.0804595947356 .6900291442957 .2995986938557 .909179687558 .51874923706 59.1283111572359 .7378807067960 .3474502563560 .9570198059161 .26181030273 61.8713798522962 .1761703491262 .4809494018662 .7857398986863 .09051895142 63.3953094482463 .7000885009864 .004882812564 .004882812564 .30966186523 64.3096618652364 .3096618652364 .3096618652364 .3096618652364 .0048828125 64.004882812563 .7000885009863 .7000885009863 .3953094482463 .09051895142 
63.0905189514262 .7857398986862 .4809494018662 .1761703491261 .87137985229 61.5666007995661 .2618103027360 .9570198059160 .3474502563560 .04267120361 59.7378807067959 .4331016540559 .1283111572358 .8235282897958 .51874923706 58.2139587402357 .909179687557 .6043891906757 .2995986938556 .99481964111 56.6900291442956 .3852500915556 .3852500915556 .0804595947356 .08045959473 55.7756805419955 .7756805419956 .0804595947356 .3852500915556 .69002914429 56.9948196411156 .3852500915556 .0804595947355 .7756805419955 .77568054199 55.7756805419955 .7756805419956 .0804595947356 .0804595947356 .38525009155 56.6900291442957 .2995986938557 .6043891906758 .2139587402358 .82352828979 59.1283111572359 .7378807067960 .3474502563560 .9570198059161 .56660079956 62.1761703491263 .0905189514263 .7000885009864 .3096618652364 .91924285889 65.5288009643666 .1383666992266 .7479400634867 .3575134277368 .27187347412 69.1862335205169 .7957916259870 .7101516723671 .6244964599672 .53885650635 73.4532165527374 .062782287674 .9771423339876 .8058471679778 .32978057861 -9999 -9999 -9999 -9999 -9999 -9999 -9999 -9999 -9999 -9999 -9999 -9999 -9999 -9999 -9999 -9999

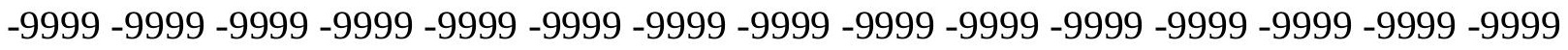
-9999 -9999 -9999 -9999 -9999 -9999 -9999 -9999 -9999 -9999 -9999 -9999 -9999 -9999 -9999 -9999 -9999 -9999 -9999 -9999 -9999 -9999 -9999 -9999 -9999 -9999 -9999 -9999 -9999 -9999 -9999 -9999 -9999 -9999 -9999 -9999 -9999 -9999 -9999 -9999 -9999 -9999 -9999 -9999 -9999 -9999 -9999 -9999 -9999 -9999 -9999 -9999 -9999 -9999 -9999 -9999 -9999 -9999 -9999 -9999 -9999 -9999 -9999 -9999 -9999 -9999 -9999 -9999 -9999 -9999 -9999 -9999 -9999 -9999 -9999 -9999 -9999 -9999 -9999 -9999 -9999 -9999 -9999 -9999 -9999 -9999 -9999 -9999 -9999 -9999 -9999 -9999 -9999 -9999 -9999 -9999 -9999 -9999 -9999 -9999 -9999 -9999 -9999 -9999 -9999 -9999 -9999 -9999 -9999 -9999 -9999 -9999 -9999 -9999 -9999 -9999 -9999 -9999 -9999 -9999 -9999 -9999 -9999 -9999 -9999 -9999 -9999 -9999 -9999 -9999 -9999 -9999 -9999 -9999 -9999 -9999 -9999 -9999 -9999 -9999 -9999 -9999 -9999 -9999 -9999 -9999 -9999 -9999 -9999 -9999 -9999 -9999 -9999 -9999 -9999 -9999 -9999 -9999 -9999 -9999 -9999 -9999 -9999 -9999 -9999 -

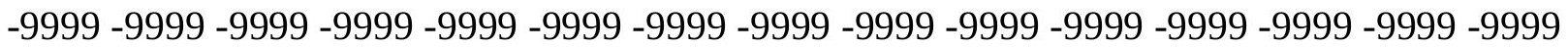

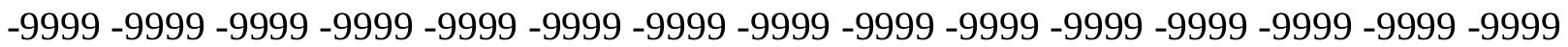
-9999 -9999 -9999 -9999 -9999 -9999 -9999 -9999 -9999 -9999 -9999 -9999 -9999 -9999 -9999 -9999 -9999 -9999 43.8890609741243.2794914245642.3651313781741.75556182861 41.7555618286141 .7555618286142 .0603485107442 .0603485107442 .06034851074 42.0603485107442 .0603485107442 .0603485107442 .0603485107442 .06034851074 42.0603485107442 .0603485107442 .3651313781742 .3651313781742 .36513137817 42.66992187542 .66992187542 .9747009277343 .2794914245643 .27949142456 43.5842704772943 .8890609741244 .1938400268644 .4986305236844 .80340957642 45.4129791259845 .717769622846 .3273391723646 .6321296691947 .24169921875 47.8512611389248 .4608306884849 .0704002380449 .6799812316950 .59432983398 51.2038993835451 .8134689331152 .4230384826753 .0326118469253 .94697189331 54.5565414428755 .1661109924355 .7756805419956 .6900291442957 .29959869385 57.909179687558 .5187492370659 .1283111572359 .7378807067960 .34745025635 60.6522407531761 .2618103027361 .5666007995662 .1761703491262 .48094940186 62.7857398986863 .0905189514263 .3953094482463 .7000885009863 .70008850098 63.7000885009864 .004882812564 .004882812564 .004882812563 .70008850098 63.7000885009863 .7000885009863 .3953094482463 .0905189514263 .09051895142 62.7857398986862 .4809494018662 .1761703491261 .8713798522961 .56660079956 
61.2618103027360 .9570198059160 .6522407531760 .3474502563560 .04267120361 59.4331016540559 .1283111572358 .8235282897958 .5187492370658 .21395874023 57.909179687557 .2995986938556 .9948196411156 .6900291442956 .38525009155 56.0804595947355 .7756805419955 .4708900451755 .4708900451755 .16611099243 54.8613204956154 .8613204956154 .8613204956154 .8613204956154 .86132049561 54.8613204956154 .8613204956154 .5565414428754 .2517509460454 .25175094604 54.2517509460454 .2517509460454 .5565414428754 .8613204956155 .16611099243 55.4708900451755 .7756805419956 .0804595947356 .6900291442956 .99481964111 57.6043891906758 .2139587402358 .8235282897959 .4331016540560 .04267120361 60.6522407531761 .2618103027361 .8713798522962 .4809494018663 .09051895142 63.7000885009864 .6144485473665 .2240066528365 .8335876464866 .74794006348 67.3575134277368 .2718734741269 .1862335205169 .7957916259870 .71015167236 71.6244964599672 .5388565063573 .1484298706173 .7580032348674 .36756896973 75.8914871215877 .72020721436 -9999 -9999 -9999 -9999 -9999 -9999 -9999 -9999 -9999 -9999 -9999 -9999 -9999 -9999 -9999 -9999 -9999 -9999 -9999 -9999 -9999 -9999 -9999 -9999

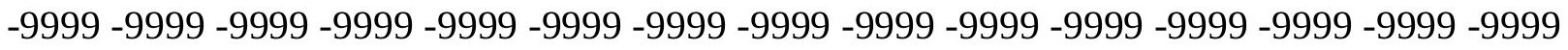
-9999 -9999 -9999 -9999 -9999 -9999 -9999 -9999 -9999 -9999 -9999 -9999 -9999 -9999 -9999 -9999 -9999 -9999 -9999 -9999 -9999 -9999 -9999 -9999 -9999 -9999 -9999 -9999 -9999 -9999 -9999 -9999 -9999 -9999 -9999 -9999 -9999 -9999 -9999 -9999 -9999 -9999 -9999 -9999 -9999 -

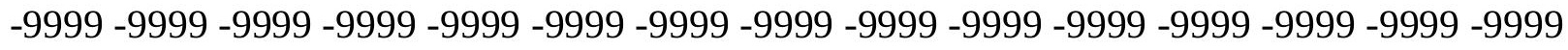
-9999 -9999 -9999 -9999 -9999 -9999 -9999 -9999 -9999 -9999 -9999 -9999 -9999 -9999 -9999 -9999 -9999 -9999 -9999 -9999 -9999 -9999 -9999 -9999 -9999 -9999 -9999 -9999 -9999 -9999 -9999 -9999-9999-9999-9999-9999

-9999 -9999 -9999 -9999 -9999 -9999 -9999 -9999 -9999 -9999 -9999 -9999 -9999 -9999 -9999

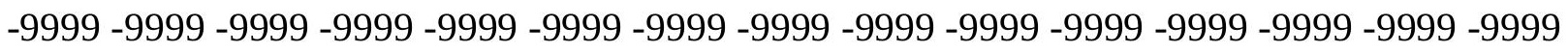
-9999 -9999 -9999 -9999 -9999 -9999 -9999 -9999 -9999 -9999 -9999 -9999 -9999 -9999 -9999 -9999 -9999 -9999 -9999 -9999 -9999 -9999 -9999 -9999 -9999 -9999 -9999 -9999 -9999 -9999 -

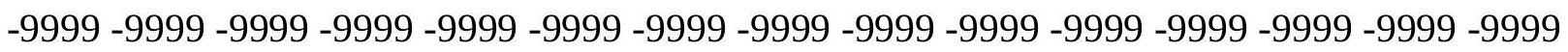
-9999 -9999 -9999 -9999 -9999 -9999 -9999 -9999 -9999 -9999 -9999 -9999 -9999 -9999 -9999 -9999 -9999 -9999 -9999 -9999 -9999 -9999 -9999 -9999 -9999 -9999 -9999 -9999 -9999 -9999 -9999 -9999 42.06034851074 41.1459884643639 .9268493652339 .31727981567 39.622070312540 .2316398620640 .5364189147940 .5364189147940 .53641891479 40.8412094116240 .8412094116240 .8412094116240 .8412094116240 .84120941162 40.8412094116240 .8412094116240 .8412094116241 .1459884643641 .14598846436 41.4507789611841 .4507789611841 .7555618286141 .7555618286142 .06034851074 42.3651313781742 .66992187542 .66992187542 .9747009277343 .58427047729 43.8890609741244 .1938400268644 .8034095764245 .1082000732445 .7177696228 46.3273391723646 .9369087219247 .5464782714848 .1560516357448 .7656211853 49.3751907348649 .9847602844250 .8991203308151 .5086898803752 .11825942993 53.0326118469253 .6421813964854 .2517509460455 .1661109924355 .77568054199 56.3852500915556 .9948196411157 .909179687558 .5187492370659 .12831115723 59.7378807067960 .0426712036160 .6522407531761 .2618103027361 .56660079956 62.1761703491262 .4809494018662 .7857398986863 .0905189514263 .09051895142 63.3953094482463 .3953094482463 .3953094482463 .7000885009863 .39530944824 63.3953094482463 .3953094482463 .0905189514263 .0905189514262 .78573989868 62.4809494018662 .1761703491261 .8713798522961 .5666007995661 .26181030273 
60.9570198059160 .6522407531760 .3474502563560 .0426712036159 .73788070679 59.4331016540558 .8235282897958 .5187492370658 .2139587402357 .9091796875 57.2995986938556 .9948196411156 .6900291442956 .3852500915556 .08045959473 55.7756805419955 .4708900451755 .1661109924354 .8613204956154 .55654144287 54.2517509460453 .9469718933153 .6421813964853 .3373985290553 .33739852905 53.0326118469252 .7278289794952 .4230384826752 .1182594299352 .11825942993 52.4230384826752 .7278289794953 .0326118469253 .3373985290553 .64218139648 53.9469718933154 .2517509460454 .5565414428755 .1661109924355 .47089004517 56.0804595947356 .6900291442956 .9948196411157 .6043891906758 .21395874023 58.8235282897959 .4331016540560 .0426712036160 .6522407531761 .56660079956 62.1761703491262 .7857398986863 .3953094482464 .3096618652364 .91924285889 65.8335876464866 .4431610107467 .3575134277368 .2718734741269 .18623352051 69.7957916259870 .7101516723671 .3197174072372 .2340774536172 .84364318848 73.4532165527374 .062782287675 .5867080688577 .72020721436 -9999 -9999 -9999 -9999 -9999 -9999 -9999 -9999 -9999 -9999 -9999 -9999 -9999 -9999 -9999 -9999 -9999 -9999 -9999

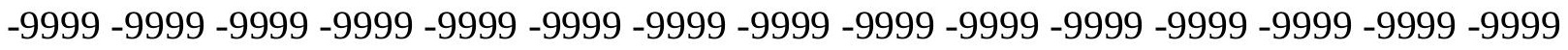
-9999 -9999 -9999 -9999 -9999 -9999 -9999 -9999 -9999 -9999 -9999 -9999 -9999 -9999 -9999 -

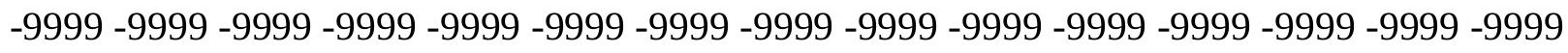
-9999 -9999 -9999 -9999 -9999 -9999 -9999 -9999 -9999 -9999 -9999 -9999 -9999 -9999 -9999 -

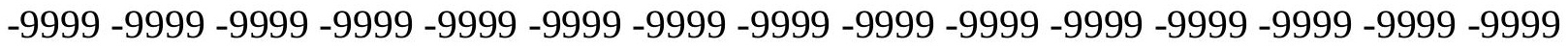

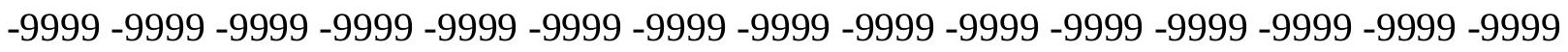
-9999 -9999 -9999 -9999 -9999 -9999 -9999 -9999 -9999 -9999 -9999 -9999 -9999 -9999 -9999 -9999 -9999 -9999 -9999 -9999-9999-9999 -9999 -9999-9999

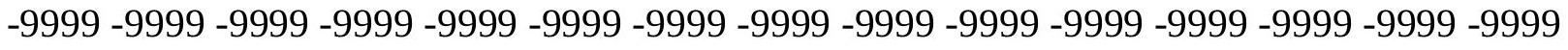

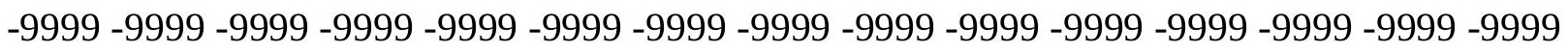
-9999 -9999 -9999 -9999 -9999 -9999 -9999 -9999 -9999 -9999 -9999 -9999 -9999 -9999 -9999 -

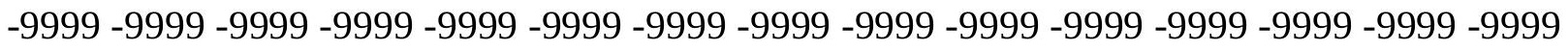

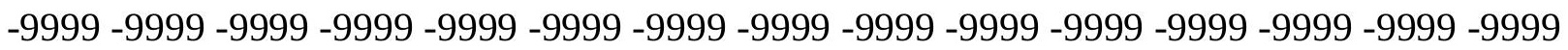
-9999 -9999 -9999 -9999 -9999 -9999 -9999 -9999 -9999 -9999 -9999 -9999 -9999 -9999 -9999 -9999 -9999 -9999 -9999 -9999 -9999 -9999 -9999 -9999 -9999 -9999 -9999 -9999 -9999 -9999 -9999 40.53641891479 39.3172798156737.79335021973 37.4885711669937 .79335021973 38.0981407165538 .7077102661139 .0125007629439 .0125007629439 .31727981567 39.31727981567 39.31727981567 39.6220703125 39.6220703125 39.6220703125 39.622070312539 .622070312539 .622070312539 .9268493652339 .92684936523 40.2316398620640 .2316398620640 .5364189147940 .5364189147940 .84120941162 41.1459884643641 .4507789611841 .7555618286142 .0603485107442 .36513137817 42.66992187543 .2794914245643 .5842704772944 .1938400268644 .80340957642 45.1082000732445 .717769622846 .3273391723646 .9369087219247 .85126113892 48.4608306884849 .0704002380449 .6799812316950 .5943298339851 .20389938354 52.1182594299352 .7278289794953 .3373985290554 .2517509460454 .86132049561 55.7756805419956 .3852500915556 .9948196411157 .6043891906758 .21395874023 59.1283111572359 .4331016540560 .0426712036160 .6522407531761 .26181030273 61.5666007995661 .8713798522962 .1761703491262 .4809494018662 .78573989868 63.0905189514263 .0905189514263 .0905189514263 .0905189514263 .09051895142 63.0905189514263 .0905189514262 .7857398986862 .4809494018662 .48094940186 62.1761703491261 .8713798522961 .5666007995661 .2618103027360 .95701980591 
60.6522407531760 .0426712036159 .7378807067959 .4331016540559 .12831115723 58.5187492370658 .2139587402357 .909179687557 .6043891906756 .99481964111 56.6900291442956 .3852500915556 .0804595947355 .7756805419955 .16611099243 54.8613204956154 .5565414428754 .2517509460453 .9469718933153 .64218139648 53.0326118469252 .7278289794952 .4230384826752 .1182594299351 .81346893311 51.5086898803751 .2038993835450 .5943298339849 .6799812316950 .28955078125 50.8991203308151 .2038993835451 .8134689331152 .1182594299352 .42303848267 52.7278289794953 .0326118469253 .6421813964853 .9469718933154 .55654144287 54.8613204956155 .4708900451756 .0804595947356 .6900291442957 .29959869385 57.909179687558 .5187492370659 .1283111572359 .7378807067960 .34745025635 61.2618103027361 .8713798522962 .4809494018663 .3953094482464 .0048828125 64.9192428588965 .5288009643666 .4431610107467 .3575134277368 .27187347412 68.8814392089869 .7957916259870 .4053573608471 .3197174072371 .92929077148 72.5388565063573 .1484298706174 .062782287675 .8914871215877 .72020721436 -9999 -9999 -9999 -9999 -9999 -9999 -9999 -9999 -9999 -9999 -9999 -9999 -9999 -9999 -9999 -9999 -9999 -9999 -9999 -9999 -9999 -9999 -9999 -9999 -9999 -9999 -9999 -9999 -9999 -9999 -9999 -9999 -9999 -9999 -9999 -9999 -9999 -9999 -9999 -9999 -9999 -9999 -9999 -9999 -9999 -9999 -9999 -9999 -9999 -9999 -9999 -9999 -9999 -9999 -9999 -9999 -9999 -9999 -9999 -9999 -9999 -9999 -9999 -9999 -9999 -9999 -9999 -9999 -9999 -9999 -9999 -9999 -9999 -9999 -9999 -9999 -9999 -9999 -9999 -9999 -9999 -9999 -9999 -9999 -9999 -9999 -9999 -9999 -9999 -9999 -9999

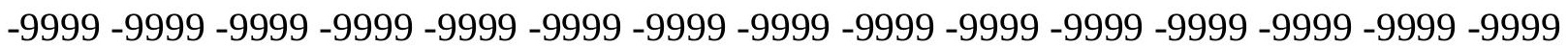
-9999 -9999 -9999 -9999 -9999 -9999 -9999 -9999 -9999 -9999 -9999 -9999 -9999 -9999 -9999 -9999 -9999 -9999 -9999 -9999 -9999 -9999 -9999 -9999 -9999 -9999 -9999 -

-9999 -9999 -9999 -9999 -9999 -9999 -9999 -9999 -9999 -9999 -9999 -9999 -9999 -9999 -9999 -9999 -9999 -9999 -9999 -9999 -9999 -9999 -9999 -9999 -9999 -9999 -9999 -9999 -9999 -9999 -9999 -9999 -9999 -9999 -9999 -9999 -9999 -9999 -9999 -9999 -9999 -9999 -9999 -9999 -9999 -9999 -9999 -9999 -9999 -9999 -9999 -9999 -9999 -9999 -9999 -9999 -9999 -9999 -9999 -9999 -9999 -9999 -9999 -9999 -9999 -9999 -9999 -9999 -9999 -9999 -9999 -9999 -9999 -9999 -9999

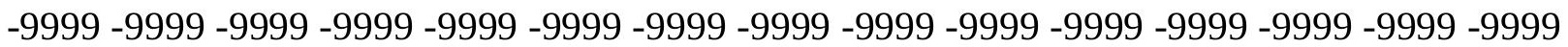
-9999 -9999 -9999 -9999 -9999 -9999 -9999 -9999 -9999 -9999 -9999 -9999 -9999 -9999 40.5364189147939 .0125007629437 .4885711669936 .2694282531735 .96464920044 35.9646492004436 .2694282531736 .5742111206137 .1837806701737 .48857116699 37.4885711669937 .7933502197337 .7933502197338 .0981407165538 .09814071655 38.0981407165538 .4029312133838 .4029312133838 .4029312133838 .40293121338 38.7077102661138 .7077102661139 .0125007629439 .0125007629439 .31727981567 39.622070312539 .622070312539 .9268493652340 .2316398620640 .53641891479 40.8412094116241 .1459884643641 .7555618286142 .0603485107442 .669921875 42.9747009277343 .5842704772944 .1938400268644 .8034095764245 .41297912598 46.0225486755446 .6321296691947 .2416992187548 .1560516357448 .7656211853 49.3751907348650 .2895507812550 .8991203308151 .8134689331152 .42303848267 53.3373985290553 .9469718933154 .8613204956155 .4708900451756 .38525009155 56.9948196411157 .6043891906758 .2139587402358 .8235282897959 .43310165405 60.0426712036160 .6522407531760 .9570198059161 .5666007995661 .87137985229 62.1761703491262 .4809494018662 .4809494018662 .7857398986862 .78573989868 62.7857398986862 .7857398986862 .7857398986862 .4809494018662 .17617034912 62.1761703491261 .8713798522961 .5666007995661 .2618103027360 .95701980591 
60.6522407531760 .3474502563560 .0426712036159 .4331016540559 .12831115723 58.8235282897958 .5187492370657 .909179687557 .6043891906757 .29959869385 56.9948196411156 .3852500915556 .0804595947355 .7756805419955 .16611099243 54.8613204956154 .5565414428754 .2517509460453 .6421813964853 .33739852905 53.0326118469252 .7278289794952 .1182594299351 .8134689331151 .50868988037 51.2038993835450 .8991203308150 .2895507812549 .6799812316949 .07040023804 48.765621185349 .0704002380449 .3751907348649 .9847602844250 .59432983398 50.8991203308151 .2038993835451 .8134689331152 .1182594299352 .42303848267 53.0326118469253 .3373985290553 .9469718933154 .5565414428754 .86132049561 55.4708900451756 .0804595947356 .6900291442957 .2995986938557 .9091796875 58.8235282897959 .4331016540560 .0426712036160 .9570198059161 .56660079956 62.4809494018663 .0905189514264 .004882812564 .6144485473665 .52880096436 66.44316101074 67.35751342773 67.9670867919968.88143920898 69.49101257324 70.4053573608471 .014930725171 .6244964599672 .5388565063573 .14842987061 74.062782287675 .8914871215877 .72020721436 -9999 -9999 -9999 -9999 -9999 -9999 -9999

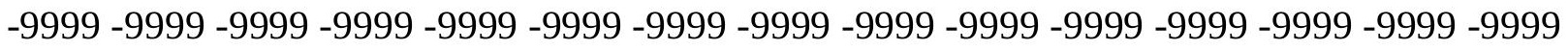
-9999 -9999 -9999 -9999 -9999 -9999 -9999 -9999 -9999 -9999 -9999 -9999 -9999 -9999 -9999 -9999 -9999 -9999 -9999 -9999 -9999 -9999 -9999 -9999 -9999 -9999 -9999 -9999 -9999 -9999 -

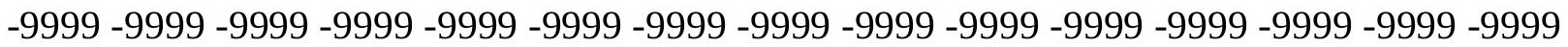

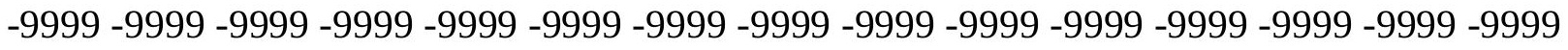

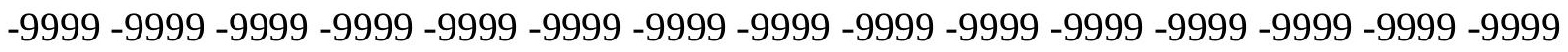
-9999 -9999 -9999 -9999 -9999 -9999 -9999 -9999 -9999 -9999 -9999 -9999 -9999 -9999 -9999 -

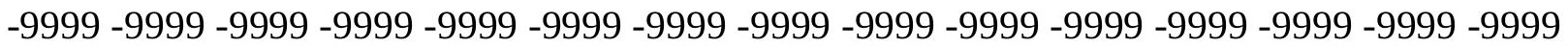
-9999 -9999-9999-9999-9999

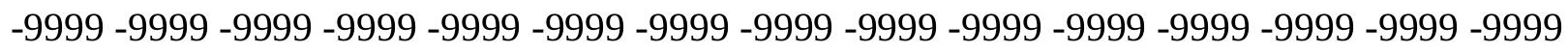
-9999 -9999 -9999 -9999 -9999 -9999 -9999 -9999 -9999 -9999 -9999 -9999 -9999 -9999 -9999

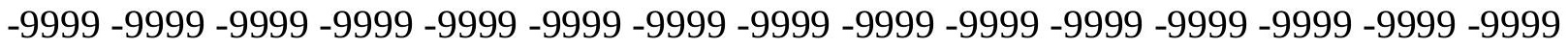

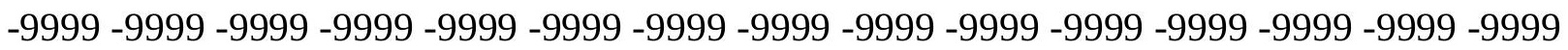
-9999 -9999 -9999 -9999 -9999 -9999 -9999 -9999 -9999 -9999 -9999 -9999 -9999 -9999 -9999 -9999 -9999 -9999 -9999 -9999 -9999 -9999 -9999 -9999 -9999 -9999 -9999 -9999 -9999 -9999 -9999 -9999 -9999 -9999 -9999 -9999 -9999 -9999 -9999 -9999 -9999 -9999 -9999 39.0125007629437 .7933502197336 .2694282531735 .0502891540534 .74551010132 34.4407196044934 .7455101013235 .0502891540535 .3550796508835 .65985870361 35.9646492004436 .2694282531736 .2694282531736 .5742111206136 .57421112061 36.8790016174336 .8790016174336 .8790016174337 .1837806701737 .18378067017 37.1837806701737 .4885711669937 .4885711669937 .7933502197337 .79335021973 38.0981407165538 .4029312133838 .7077102661138 .7077102661139 .01250076294 39.3172798156739 .9268493652340 .2316398620640 .5364189147941 .14598846436 41.4507789611842 .0603485107442 .3651313781742 .9747009277343 .58427047729 44.1938400268644 .8034095764245 .717769622846 .3273391723646 .93690872192 47.8512611389248 .4608306884849 .0704002380449 .9847602844250 .89912033081 51.5086898803752 .4230384826753 .0326118469253 .9469718933154 .55654144287 55.4708900451756 .0804595947356 .9948196411157 .6043891906758 .21395874023 58.8235282897959 .4331016540560 .0426712036160 .6522407531760 .95701980591 61.2618103027361 .5666007995661 .8713798522962 .1761703491262 .17617034912 62.1761703491262 .1761703491262 .1761703491262 .1761703491261 .87137985229 
61.8713798522961 .5666007995661 .2618103027360 .9570198059160 .65224075317 60.3474502563560 .0426712036159 .7378807067959 .4331016540558 .82352828979 58.5187492370658 .2139587402357 .909179687557 .2995986938556 .99481964111 56.6900291442956 .0804595947355 .7756805419955 .4708900451754 .86132049561 54.5565414428754 .2517509460453 .6421813964853 .3373985290553 .03261184692 52.4230384826752 .1182594299351 .8134689331151 .2038993835450 .89912033081 50.5943298339850 .2895507812549 .6799812316949 .3751907348648 .7656211853 48.4608306884848 .1560516357448 .1560516357448 .4608306884849 .07040023804 49.3751907348649 .6799812316950 .2895507812550 .5943298339850 .89912033081 51.5086898803751 .8134689331152 .4230384826752 .7278289794953 .33739852905 53.9469718933154 .5565414428755 .1661109924355 .7756805419956 .38525009155 56.9948196411157 .6043891906758 .5187492370659 .1283111572359 .73788070679 60.6522407531761 .2618103027362 .1761703491263 .0905189514263 .70008850098 64.6144485473665 .5288009643666 .4431610107467 .0527267456167 .96708679199 68.5766525268669 .4910125732470 .1005783081171 .014930725171 .62449645996 $72.5388565063573 .1484298706174 .3675689697376 .1962814331177 .72020721436-9999$ -9999 -9999 -9999 -9999 -9999 -9999 -9999 -9999 -9999 -9999 -9999 -9999 -9999 -9999 -9999 -9999 -9999 -9999 -9999 -9999 -9999 -9999 -9999 -9999 -9999 -9999 -9999 -9999 -9999 -9999 -9999 -9999 -9999 -9999 -9999 -9999 -9999 -9999 -9999 -9999 -9999 -9999 -9999 -9999 -9999 -9999 -9999 -9999 -9999 -9999 -9999 -9999 -9999 -9999 -9999 -9999 -9999 -9999 -9999 -9999 -9999 -9999 -9999 -9999 -9999 -9999 -9999 -9999 -9999 -9999 -9999 -9999 -9999 -9999 -9999 -9999 -9999 -9999 -9999 -9999 -9999 -9999 -9999 -9999 -9999 -9999 -9999 -9999 -9999 -9999 -9999 -9999 -9999 -9999 -9999 -9999 -9999 -9999 -9999 -9999 -9999 -9999 -9999 -9999 -9999 -9999 -9999 -9999 -9999 -9999 -9999 -9999 -9999 -9999 -9999 -9999 -9999 -9999 -9999 -999 -999 -9999 -9999 -9999 -9999 -9999 -9999 -9999 -9999 -9999 -9999

-9999 -9999 -9999 -9999 -9999 -9999 -9999 -9999 -9999 -9999 -9999 -9999 -9999 -9999 -9999 -9999 -9999 -9999 -9999 -9999 -9999 -9999 -9999 -9999 -9999 -9999 -9999 -9999 -9999 -9999 -

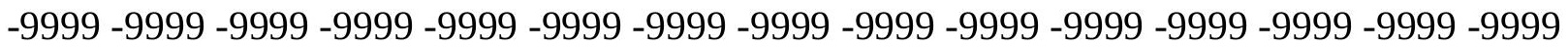

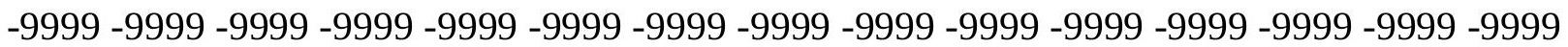
-9999 -9999 -9999 -9999 -9999 -9999 -9999 -9999 -9999 -9999 -9999 -9999 -9999 -9999 -999 -9999 -9999 -9999 -9999 -9999 -9999 -9999 -9999 -9999 -9999 -9999 -9999 -9999 -9999 -9999 -9999 -9999 -9999 -9999 -9999 -9999 -9999 -9999 -9999 -9999 -9999 38.40293121338 37.4885711669936 .2694282531735 .0502891540534 .1359291076733 .52635955811 33.2215805053733 .2215805053733 .2215805053733 .5263595581133 .83115005493 34.1359291076734 .4407196044934 .7455101013235 .0502891540535 .05028915405 35.3550796508835 .3550796508835 .6598587036135 .6598587036135 .65985870361 35.9646492004435 .9646492004436 .2694282531736 .2694282531736 .57421112061 36.5742111206136 .8790016174337 .1837806701737 .4885711669937 .79335021973 38.0981407165538 .4029312133838 .7077102661139 .0125007629439 .6220703125 39.9268493652340 .2316398620640 .8412094116241 .4507789611842 .06034851074 42.66992187543 .2794914245643 .8890609741244 .4986305236845 .10820007324 46.0225486755446 .6321296691947 .2416992187548 .1560516357449 .07040023804 49.6799812316950 .5943298339851 .2038993835452 .1182594299353 .03261184692 53.6421813964854 .5565414428755 .4708900451756 .0804595947356 .99481964111 57.6043891906758 .2139587402358 .8235282897959 .4331016540560 .04267120361 60.3474502563560 .9570198059161 .2618103027361 .5666007995661 .56660079956 
61.8713798522961 .8713798522961 .8713798522961 .8713798522961 .56660079956 61.5666007995661 .2618103027360 .9570198059160 .6522407531760 .34745025635 60.0426712036159 .7378807067959 .4331016540559 .1283111572358 .82352828979 58.2139587402357 .909179687557 .6043891906756 .9948196411156 .69002914429 56.3852500915555 .7756805419955 .4708900451755 .1661109924354 .55654144287 54.2517509460453 .9469718933153 .3373985290553 .0326118469252 .72782897949 52.1182594299351 .8134689331151 .2038993835450 .8991203308150 .59432983398 49.9847602844249 .6799812316949 .3751907348648 .765621185348 .46083068848 47.8512611389247 .5464782714847 .5464782714847 .5464782714847 .85126113892 48.1560516357448 .4608306884848 .765621185349 .0704002380449 .67998123169 49.9847602844250 .2895507812550 .8991203308151 .2038993835451 .81346893311 52.4230384826752 .7278289794953 .3373985290553 .9469718933154 .55654144287 55.1661109924356 .0804595947356 .6900291442957 .2995986938558 .21395874023 58.8235282897959 .7378807067960 .3474502563561 .2618103027362 .17617034912 62.7857398986863 .7000885009864 .6144485473665 .5288009643666 .13836669922 67.0527267456167 .9670867919968 .5766525268669 .4910125732470 .10057830811 71.014930725171 .6244964599672 .5388565063573 .1484298706174 .67236328125 76.1962814331178 .02498626709 -9999 -9999 -9999 -9999 -9999 -9999 -9999 -9999 -9999 -9999 -9999 -9999 -9999 -9999 -9999 -9999 -9999 -9999 -9999 -9999 -9999 -9999 -9999 -9999

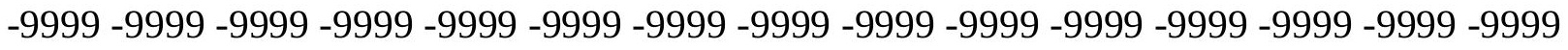

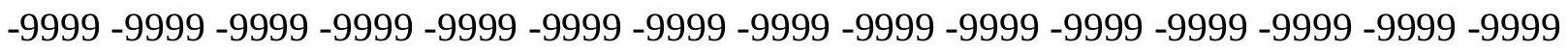
-9999 -9999 -9999 -9999 -9999 -9999 -9999 -9999 -9999 -9999 -9999 -9999 -9999 -9999 -9999 -9999 -9999 -9999 -9999 -9999 -9999 -9999 -9999 -9999 -9999 -9999 -9999 -9999 -9999 -9999 -

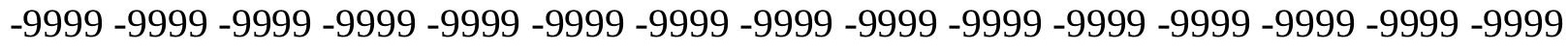

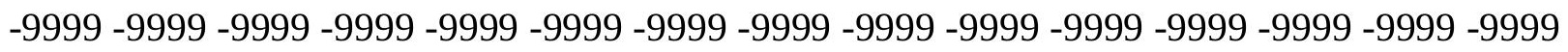

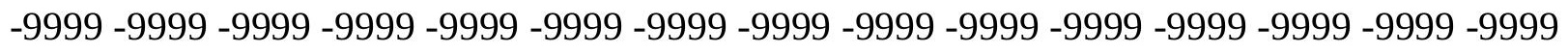
$-9999$

-9999 -9999 -9999 -9999 -9999 -9999 -9999 -9999 -9999 -9999 -9999 -9999 -9999 -9999 -9999 -9999 -9999 -9999 -9999 -9999 -9999 -9999 -9999 -9999 -9999 -9999 -9999 -9999 -9999 -9999 -9999 -9999 -9999 -9999 -9999 -9999 -9999 -9999 -9999 -9999 -9999 -9999 -9999 -9999 -9999 -9999 -9999 -9999 -9999 -9999 -9999 -9999 -9999 -9999 -9999 -9999 -9999 -9999 -9999 -9999 -9999 -9999 -9999 -9999 -9999 -9999 -9999 -9999 -9999 -9999 -9999 -9999 -9999 -9999 -9999 -

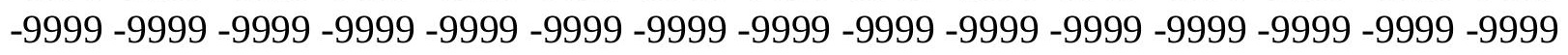
-9999 -9999 -9999 -9999-9999 -9999 -9999 -9999-9999 -9999 36.87900161743 35.3550796508834 .1359291076733 .8311500549333 .2215805053732 .30722045898 31.6976509094231 .3928699493431 .6976509094231 .6976509094232 .00244140625 32.3072204589832 .6120109558132 .9167900085433 .2215805053733 .52635955811 33.83115005493 33.83115005493 34.13592910767 34.13592910767 34.44071960449 34.4407196044934 .7455101013234 .7455101013235 .0502891540535 .05028915405 35.3550796508835 .3550796508835 .6598587036135 .9646492004436 .26942825317 36.5742111206136 .8790016174337 .1837806701737 .4885711669938 .09814071655 38.4029312133838 .7077102661139 .3172798156739 .622070312540 .23163986206 40.8412094116241 .4507789611842 .0603485107442 .66992187543 .27949142456 43.8890609741244 .8034095764245 .4129791259846 .3273391723646 .93690872192 47.8512611389248 .765621185349 .3751907348650 .2895507812551 .20389938354 51.8134689331152 .7278289794953 .6421813964854 .5565414428755 .16611099243 
56.0804595947356 .6900291442957 .6043891906758 .2139587402358 .82352828979 59.4331016540560 .0426712036160 .3474502563560 .6522407531760 .95701980591 61.2618103027361 .2618103027361 .2618103027361 .2618103027361 .26181030273 60.9570198059160 .9570198059160 .6522407531760 .3474502563560 .04267120361 59.7378807067959 .4331016540559 .1283111572358 .8235282897958 .51874923706 57.909179687557 .6043891906757 .2995986938556 .6900291442956 .38525009155 56.0804595947355 .4708900451755 .1661109924354 .8613204956154 .55654144287 53.9469718933153 .6421813964853 .0326118469252 .7278289794952 .42303848267 51.8134689331151 .5086898803750 .8991203308150 .5943298339850 .28955078125 49.6799812316949 .3751907348648 .765621185348 .4608306884848 .15605163574 47.5464782714847 .2416992187546 .9369087219246 .9369087219246 .93690872192 46.9369087219247 .2416992187547 .5464782714847 .8512611389248 .15605163574 48.4608306884848 .765621185349 .3751907348649 .6799812316950 .28955078125 50.5943298339851 .2038993835451 .8134689331152 .4230384826753 .03261184692 53.6421813964854 .2517509460454 .8613204956155 .7756805419956 .38525009155 57.2995986938557 .909179687558 .8235282897959 .4331016540560 .34745025635 61.2618103027361 .8713798522962 .7857398986863 .7000885009864 .61444854736 65.5288009643666 .1383666992267 .0527267456167 .9670867919968 .57665252686 69.4910125732470 .1005783081171 .014930725171 .6244964599672 .53885650635 73.1484298706174 .6723632812576 .50106811523 -9999 -9999 -9999 -9999 -9999 -9999 -9999 -9999 -9999 -9999 -9999 -9999 -9999 -9999 -9999 -9999 -9999 -9999 -9999 -9999 -9999 -9999 -9999 -9999 -9999 -9999 -9999 -9999 -9999 -9999 -9999 -9999 -9999 -9999 -9999 -9999 -9999 -

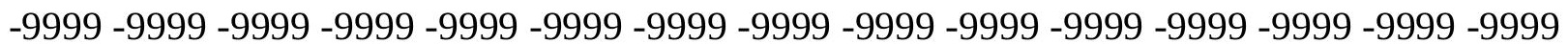
-9999 -9999 -9999 -9999 -9999 -9999 -9999 -9999 -9999 -9999 -9999 -9999 -9999 -9999 -9999 -9999 -9999 -9999 -9999 -9999 -9999 -9999 -9999 -9999 -9999 -9999 -9999 -9999 -9999 -9999 -9999 -9999 -9999 -9999 -9999 -9999 -9999 -9999 -9999 -9999 -9999 -9999 -9999 -9999 -9999 -9999 -9999 -9999 -9999 -9999 -9999 -9999 -9999 -9999 -9999 -9999 -9999 -9999 -9999 -9999

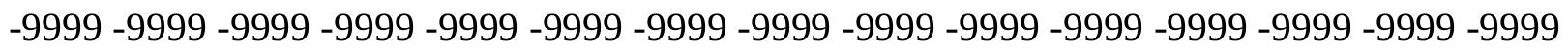
-9999 -9999-9999

-9999 -9999 -9999 -9999 -9999 -9999 -9999 -9999 -9999 -9999 -9999 -9999 -9999 -9999 -9999 -9999 -9999 -9999 -9999 -9999 -9999 -9999 -9999 -9999 -9999 -9999 -9999 -9999 -9999 -9999

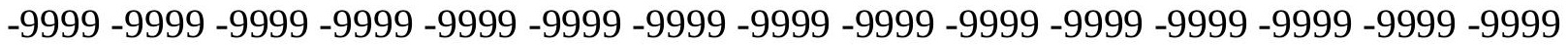

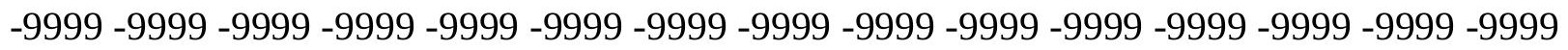
-9999 -9999 -9999 -9999 -9999 -9999 -9999 -9999 -9999 -9999 -9999 -9999 -9999 -9999 -9999

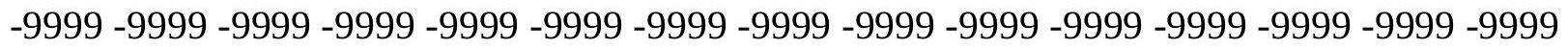
-9999 -9999 -9999 -9999 -9999 -9999 -9999 -9999 -9999 35.3550796508833 .83115005493 32.3072204589832 .0024414062532 .0024414062531 .3928699493430 .78330039978 29.8689403533930 .1737308502230 .1737308502230 .4785099029530 .78330039978 31.0880794525131 .3928699493431 .6976509094232 .0024414062532 .30722045898 32.3072204589832 .6120109558132 .6120109558132 .9167900085432 .91679000854 33.2215805053733 .2215805053733 .5263595581133 .5263595581133 .83115005493 34.1359291076734 .4407196044934 .4407196044934 .7455101013235 .05028915405 35.3550796508835 .6598587036135 .9646492004436 .5742111206136 .87900161743 37.1837806701737 .7933502197338 .0981407165538 .7077102661139 .01250076294 39.622070312540 .2316398620640 .8412094116241 .4507789611842 .06034851074 42.9747009277343 .5842704772944 .1938400268645 .1082000732446 .02254867554 
46.6321296691947 .5464782714848 .4608306884849 .0704002380449 .98476028442 50.8991203308151 .8134689331152 .7278289794953 .6421813964854 .25175094604 55.1661109924356 .0804595947356 .6900291442957 .6043891906758 .21395874023 58.8235282897959 .4331016540559 .7378807067960 .0426712036160 .34745025635 60.6522407531760 .6522407531760 .6522407531760 .6522407531760 .65224075317 60.3474502563560 .3474502563560 .0426712036159 .7378807067959 .43310165405 59.1283111572358 .8235282897958 .5187492370657 .909179687557 .60438919067 57.2995986938556 .9948196411156 .3852500915556 .0804595947355 .77568054199 55.1661109924354 .8613204956154 .5565414428754 .2517509460453 .64218139648 53.3373985290553 .0326118469252 .4230384826752 .1182594299351 .50868988037 51.2038993835450 .8991203308150 .2895507812549 .9847602844249 .37519073486 49.0704002380448 .4608306884848 .1560516357447 .8512611389247 .24169921875 46.9369087219246 .6321296691946 .3273391723646 .3273391723646 .32733917236 46.3273391723646 .3273391723646 .6321296691946 .9369087219247 .24169921875 47.5464782714847 .8512611389248 .1560516357448 .765621185349 .07040023804 49.6799812316950 .2895507812550 .8991203308151 .2038993835451 .81346893311 52.7278289794953 .3373985290553 .9469718933154 .8613204956155 .47089004517 56.0804595947356 .9948196411157 .909179687558 .5187492370659 .43310165405 60.3474502563561 .2618103027361 .8713798522962 .7857398986863 .70008850098 64.6144485473665 .2240066528366 .1383666992267 .0527267456167 .96708679199 68.5766525268669 .4910125732470 .1005783081171 .014930725171 .92929077148 72.5388565063573 .4532165527374 .9771423339876 .50106811523 -9999 -9999 -9999 -9999 -9999 -9999 -9999 -9999 -9999 -9999 -9999 -9999 -9999 -9999 -9999 -9999 -9999 -9999 -9999

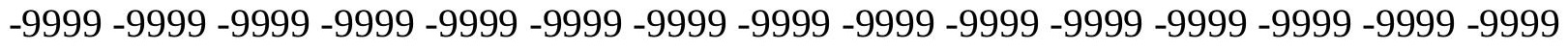

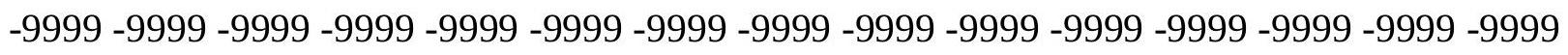
-9999 -9999 -9999 -9999 -9999 -9999 -9999 -9999 -9999 -9999 -9999 -9999 -9999 -9999 -9999 -9999 -9999 -9999 -9999 -9999 -9999 -9999 -9999 -9999 -9999 -9999 -9999 -9999 -9999 -9999 -

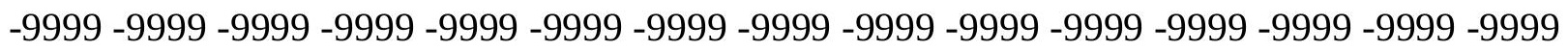
-9999 -9999 -9999 -9999 -9999 -9999 -9999 -9999 -9999 -9999 -9999 -9999 -9999 -9999 -9999 -9999 -9999 -9999 -9999 -9999 -9999 -9999 -9999 -9999 -9999 -9999 -9999 -9999 -9999 -9999 -9999 -9999-9999-9999-9999

-9999 -9999 -9999 -9999 -9999 -9999 -9999 -9999 -9999 -9999 -9999 -9999 -9999 -9999 -9999

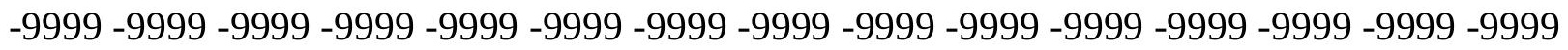
-9999 -9999 -9999 -9999 -9999 -9999 -9999 -9999 -9999 -9999 -9999 -9999 -9999 -9999 -9999 -9999 -9999 -9999 -9999 -9999 -9999 -9999 -9999 -9999 -9999 -9999 -9999 -9999 -9999 -9999 -9999 -9999 -9999 -9999 -9999 -9999 -9999 -9999 -9999 -9999 -9999 -9999 -9999 -9999 - -9999 -

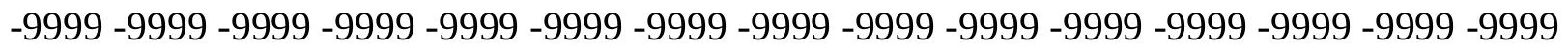
-9999 -9999 -9999 -9999 -9999 -9999 -9999 -9999 34.1359291076732 .61201095581 31.3928699493430 .7833003997830 .4785099029530 .4785099029529 .86894035339 29.2593708038328 .9545898437528 .9545898437528 .9545898437529 .25937080383 29.5641593933129 .8689403533930 .1737308502230 .4785099029530 .78330039978 30.7833003997831 .0880794525131 .3928699493431 .3928699493431 .69765090942 31.6976509094232 .0024414062532 .0024414062532 .3072204589832 .61201095581 32.6120109558132 .9167900085433 .2215805053733 .2215805053733 .52635955811 33.8311500549334 .1359291076734 .4407196044935 .0502891540535 .35507965088 35.6598587036136 .2694282531736 .5742111206136 .8790016174337 .48857116699 
38.0981407165538 .4029312133839 .0125007629439 .622070312540 .23163986206 40.8412094116241 .7555618286142 .3651313781743 .2794914245643 .88906097412 44.8034095764245 .4129791259846 .3273391723647 .2416992187548 .15605163574 49.0704002380449 .6799812316950 .5943298339851 .5086898803752 .42303848267 53.3373985290554 .2517509460455 .1661109924356 .0804595947356 .99481964111 57.6043891906758 .2139587402358 .8235282897959 .1283111572359 .73788070679 59.7378807067960 .0426712036160 .0426712036160 .0426712036160 .04267120361 60.0426712036159 .7378807067959 .4331016540559 .4331016540559 .12831115723 58.8235282897958 .2139587402357 .909179687557 .6043891906757 .29959869385 56.9948196411156 .3852500915556 .0804595947355 .7756805419955 .47089004517 54.8613204956154 .5565414428754 .2517509460453 .9469718933153 .33739852905 53.0326118469252 .7278289794952 .1182594299351 .8134689331151 .50868988037 50.8991203308150 .5943298339849 .9847602844249 .6799812316949 .07040023804 48.765621185348 .1560516357447 .8512611389247 .5464782714846 .93690872192 46.6321296691946 .3273391723646 .0225486755445 .717769622845 .7177696228 45.4129791259845 .4129791259845 .717769622845 .717769622846 .02254867554 46.3273391723646 .6321296691946 .9369087219247 .2416992187547 .85126113892 48.1560516357448 .765621185349 .0704002380449 .6799812316950 .28955078125 50.8991203308151 .5086898803752 .4230384826753 .0326118469253 .64218139648 54.5565414428755 .1661109924356 .0804595947356 .9948196411157 .60438919067 58.5187492370659 .4331016540560 .3474502563560 .9570198059161 .87137985229 62.7857398986863 .7000885009864 .6144485473665 .5288009643666 .13836669922 67.0527267456167 .9670867919968 .5766525268669 .4910125732470 .40535736084 71.014930725171 .9292907714872 .5388565063573 .4532165527375 .28192901611 76.80584716797 -9999 -9999 -9999 -9999 -9999 -9999 -9999 -9999 -9999 -9999 -9999 -9999 -9999 -9999 -9999 -9999 -9999 -9999 -9999 -9999 -9999 -9999 -9999 -9999 -9999 -9999 -9999 -9999 -9999 -9999 -9999 -9999 -9999 -9999 -9999 -9999 -9999 -9999 -9999 -9999 -9999 -9999

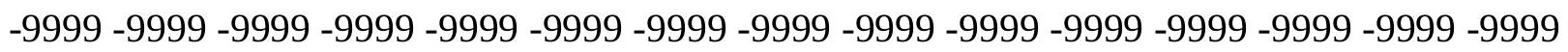
-9999 -9999 -9999 -9999 -9999 -9999 -9999 -9999 -9999 -9999 -9999 -9999 -9999 -9999 -9999 -9999 -9999 -9999 -9999 -9999 -9999 -9999 -9999 -9999 -9999 -9999 -9999 -9999 -9999 -9999 -9999 -9999 -9999 -9999 -9999 -9999 -9999 -9999 -9999 -9999 -9999 -9999 -9999 -9999 -9999 -9999 -9999 -9999 -9999 -9999 -9999 -9999 -9999 -9999 -9999 -9999 -9999 -9999 -9999 -9999 -

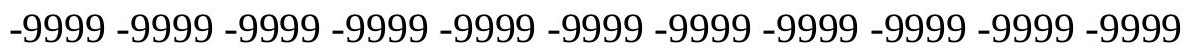

-9999 -9999 -9999 -9999 -9999 -9999 -9999 -9999 -9999 -9999 -9999 -9999 -9999 -9999 -9999 -9999 -9999 -9999 -9999 -9999 -9999 -9999 -9999 -9999 -9999 -9999 -9999 -9999 -9999 -9999 -

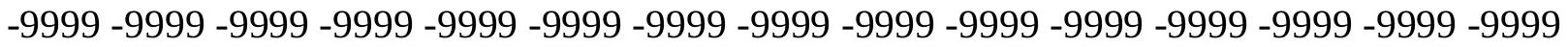

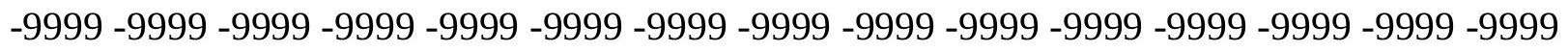

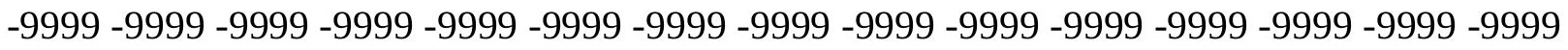
-9999 -9999 -9999 -9999 -9999 -9999 -9999 -9999 -9999 -9999 -9999 -9999 -9999 -9999 -9999 -9999-9999 -9999 -9999-9999-9999-9999 32.9167900085431 .3928699493430 .17373085022 29.8689403533929 .8689403533929 .2593708038328 .9545898437528 .64979934692 28.3450202941928 .0402297973627 .7354507446328 .0402297973628 .04022979736 28.3450202941928 .6497993469228 .9545898437529 .2593708038329 .25937080383 29.5641593933129 .8689403533930 .1737308502230 .1737308502230 .47850990295 30.4785099029530 .7833003997830 .7833003997831 .0880794525131 .39286994934 31.3928699493431 .6976509094232 .0024414062532 .3072204589832 .61201095581 
32.9167900085433 .2215805053733 .5263595581133 .8311500549334 .13592910767 34.4407196044935 .0502891540535 .3550796508835 .9646492004436 .26942825317 36.8790016174337 .4885711669937 .7933502197338 .4029312133839 .01250076294 39.622070312540 .5364189147941 .1459884643641 .7555618286142 .669921875 43.5842704772944 .1938400268645 .1082000732446 .0225486755446 .93690872192 47.8512611389248 .765621185349 .6799812316950 .5943298339851 .50868988037 52.4230384826753 .3373985290554 .2517509460455 .1661109924356 .08045959473 56.9948196411157 .6043891906758 .2139587402358 .5187492370659 .12831115723 59.4331016540559 .4331016540559 .4331016540559 .4331016540559 .43310165405 59.1283111572359 .1283111572358 .8235282897958 .5187492370658 .21395874023 57.909179687557 .6043891906757 .2995986938556 .6900291442956 .38525009155 56.0804595947355 .7756805419955 .1661109924354 .8613204956154 .55654144287 54.2517509460453 .9469718933153 .3373985290553 .0326118469252 .72782897949 52.4230384826751 .8134689331151 .5086898803751 .2038993835450 .59432983398 50.2895507812549 .9847602844249 .3751907348649 .0704002380448 .46083068848 48.1560516357447 .5464782714847 .2416992187546 .6321296691946 .32733917236 46.0225486755445 .717769622845 .4129791259845 .1082000732444 .80340957642 44.8034095764244 .8034095764244 .8034095764245 .1082000732445 .10820007324 45.4129791259845 .717769622846 .0225486755446 .3273391723646 .63212966919 47.2416992187547 .5464782714848 .1560516357448 .765621185349 .37519073486 49.9847602844250 .5943298339851 .2038993835452 .1182594299352 .72782897949 53.6421813964854 .2517509460455 .1661109924356 .0804595947356 .69002914429 57.6043891906758 .5187492370659 .4331016540560 .3474502563560 .95701980591 61.8713798522962 .7857398986863 .7000885009864 .6144485473665 .52880096436 66.1383666992267 .0527267456167 .9670867919968 .5766525268669 .49101257324 70.4053573608471 .014930725171 .6244964599672 .2340774536173 .75800323486 75.28192901611 -9999 -9999 -9999 -9999 -9999 -9999 -9999 -9999 -9999 -9999 -9999 -9999 -9999 -9999 -9999 -9999 -9999 -9999 -9999 -9999 -9999 -9999 -9999 -9999 -9999 -9999 -9999 -9999 -9999 -9999 -9999 -9999 -9999 -9999 -9999 -9999 -9999 -9999 -9999 -9999 -9999 -9999 -9999 -9999 -9999 -9999 -9999 -9999 -9999 -9999 -9999 -9999 -9999 -9999 -9999 -9999 -9999 -9999 -9999 -9999 -9999 -9999 -9999 -9999 -9999 -9999 -9999 -9999 -9999 -9999 -9999 -9999

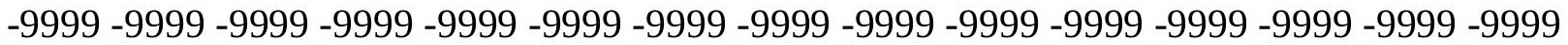

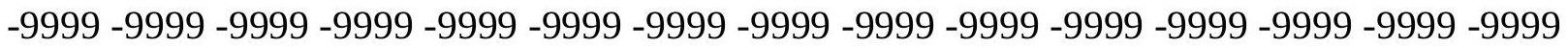
-9999 -9999 -9999 -9999 -9999 -9999 -9999 -9999 -9999 -9999 -9999 -9999 -9999 -9999 -9999 -9999 -9999 -9999 -9999 -9999 -9999 -9999 -9999 -9999 -9999 -9999

-9999 -9999 -9999 -9999 -9999 -9999 -9999 -9999 -9999 -9999 -9999 -9999 -9999 -9999 -9999

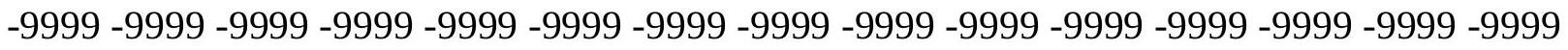

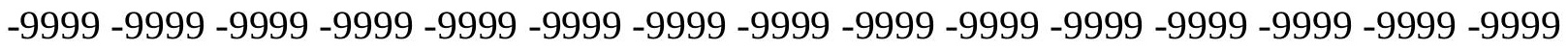
-9999 -9999 -9999 -9999 -9999 -9999 -9999 -9999 -9999 -9999 -9999 -9999 -9999 -9999 -9999 -9999 -9999 -9999 -9999 -9999 -9999 -9999 -9999 -9999 -9999 -9999 -9999 -9999 -9999 -9999 -

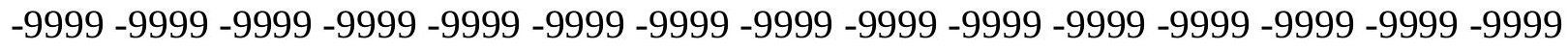
-9999 -9999 -9999 -9999-9999-9999 31.6976509094230 .4785099029529 .25937080383 28.6497993469228 .6497993469228 .6497993469228 .3450202941928 .04022979736 27.430660247827 .430660247827 .1258792877227 .1258792877227 .12587928772 27.1258792877227 .430660247827 .430660247827 .7354507446328 .04022979736 28.3450202941928 .3450202941928 .6497993469228 .9545898437528 .95458984375 
29.2593708038329 .2593708038329 .5641593933129 .8689403533929 .86894035339 30.1737308502230 .1737308502230 .4785099029530 .7833003997831 .08807945251 31.3928699493431 .6976509094232 .0024414062532 .3072204589832 .61201095581 33.2215805053733 .5263595581133 .8311500549334 .4407196044934 .74551010132 35.0502891540535 .6598587036136 .2694282531736 .5742111206137 .18378067017 37.7933502197338 .4029312133839 .3172798156739 .9268493652340 .53641891479 41.4507789611842 .0603485107442 .9747009277343 .8890609741244 .80340957642 45.717769622846 .6321296691947 .5464782714848 .4608306884849 .37519073486 50.2895507812551 .5086898803752 .4230384826753 .3373985290554 .55654144287 55.1661109924356 .0804595947356 .9948196411157 .6043891906757 .9091796875 58.5187492370658 .5187492370658 .8235282897958 .8235282897958 .82352828979 58.5187492370658 .5187492370658 .2139587402357 .909179687557 .60438919067 57.2995986938556 .9948196411156 .6900291442956 .0804595947355 .77568054199 55.4708900451755 .1661109924354 .8613204956154 .5565414428753 .94697189331 53.6421813964853 .3373985290553 .0326118469252 .7278289794952 .42303848267 52.1182594299351 .5086898803751 .2038993835450 .8991203308150 .59432983398 49.9847602844249 .6799812316949 .3751907348648 .765621185348 .46083068848 47.8512611389247 .5464782714846 .9369087219246 .6321296691946 .02254867554 45.717769622845 .4129791259845 .1082000732444 .8034095764244 .49863052368 44.1938400268644 .1938400268644 .1938400268644 .1938400268644 .19384002686 44.1938400268644 .4986305236844 .8034095764245 .1082000732445 .41297912598 45.717769622846 .3273391723646 .6321296691947 .2416992187547 .85126113892 48.4608306884849 .0704002380449 .6799812316950 .2895507812551 .20389938354 51.8134689331152 .7278289794953 .3373985290554 .2517509460455 .16611099243 55.7756805419956 .6900291442957 .6043891906758 .5187492370659 .43310165405 60.3474502563561 .2618103027361 .8713798522962 .7857398986863 .70008850098 64.6144485473665 .5288009643666 .4431610107467 .0527267456167 .96708679199 68.8814392089869 .4910125732470 .1005783081171 .014930725171 .62449645996 72.2340774536174 .062782287675 .58670806885 -9999 -9999 -9999 -9999 -9999 -9999 -9999 -9999 -9999 -9999 -9999 -9999 -9999 -9999 -9999 -9999 -9999 -9999 -9999 -9999 -9999 -9999 -9999 -9999 -9999 -9999 -9999 -9999 -9999 -9999 -9999 -9999 -9999 -9999 -9999 -9999 -9999

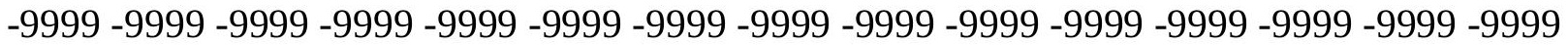

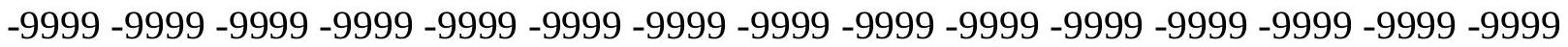
-9999 -9999 -9999 -9999 -9999 -9999 -9999 -9999 -9999 -9999 -9999 -9999 -9999 -9999 -9999 -9999 -9999 -9999 -9999 -9999 -9999 -9999 -9999 -9999 -9999 -9999 -9999 -9999 -9999 -9999 -9999 -9999 -9999 -9999 -9999 -9999 -9999 -9999 -9999 -9999 -9999 -9999 -9999 -9999 -9999

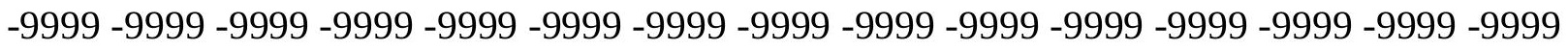

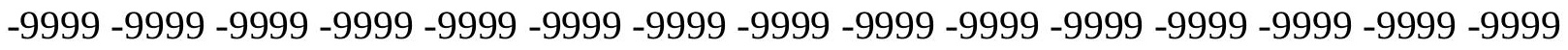
-9999 -9999 -9999 -9999 -9999 -9999 -9999 -9999 -9999 -9999 -9999 -9999 -9999 - 9999 - -999 -9999 -9999 -9999 -9999 -9999 -9999 -9999 -9999 -9999 -9999 -9999 -9999 -9999 -9999 -9999 -

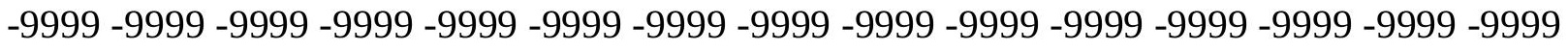

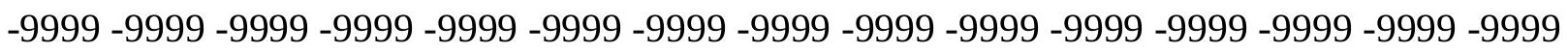
-9999 -9999 -9999 -9999 -9999 -9999 -9999 -9999 -9999 -9999 -9999 -9999 -9999 -9999 -9999 -9999 -9999 -9999 -9999 -9999-9999 29.56415939331 28.34502029419 27.73545074463 27.7354507446327 .7354507446327 .430660247827 .1258792877226 .82109069824 26.5163097381626 .5163097381626 .2115192413326 .2115192413326 .21151924133 
26.2115192413326 .2115192413326 .5163097381626 .8210906982426 .82109069824 27.1258792877227 .430660247827 .430660247827 .7354507446327 .73545074463 28.0402297973628 .3450202941928 .3450202941928 .6497993469228 .64979934692 28.9545898437529 .2593708038329 .5641593933129 .5641593933129 .86894035339 30.1737308502230 .4785099029530 .7833003997831 .3928699493431 .69765090942 32.0024414062532 .3072204589832 .9167900085433 .2215805053733 .52635955811 34.1359291076734 .4407196044935 .0502891540535 .6598587036135 .96464920044 36.5742111206137 .1837806701737 .7933502197338 .7077102661139 .31727981567 39.9268493652340 .8412094116241 .4507789611842 .3651313781743 .27949142456 44.1938400268645 .1082000732446 .0225486755447 .2416992187548 .15605163574 49.3751907348650 .2895507812551 .5086898803752 .4230384826753 .33739852905 54.5565414428755 .4708900451756 .0804595947356 .6900291442957 .29959869385 57.6043891906757 .909179687557 .909179687557 .909179687557 .9091796875 57.6043891906757 .6043891906757 .2995986938556 .9948196411156 .69002914429 56.0804595947355 .7756805419955 .4708900451755 .1661109924354 .86132049561 54.5565414428754 .2517509460453 .9469718933153 .6421813964853 .33739852905 52.7278289794952 .4230384826752 .1182594299351 .8134689331151 .50868988037 51.2038993835450 .8991203308150 .5943298339850 .2895507812549 .67998123169 49.3751907348649 .0704002380448 .765621185348 .1560516357447 .85126113892 47.2416992187546 .9369087219246 .3273391723646 .0225486755445 .7177696228 45.1082000732444 .8034095764244 .4986305236844 .1938400268643 .88906097412 43.5842704772943 .5842704772943 .2794914245643 .2794914245643 .27949142456 43.5842704772943 .5842704772943 .8890609741244 .1938400268644 .49863052368 44.8034095764245 .1082000732445 .717769622846 .3273391723646 .63212966919 47.24169921875 48.15605163574 48.765621185349.3751907348650.28955078125 50.8991203308151 .8134689331152 .4230384826753 .3373985290554 .25175094604 55.1661109924355 .7756805419956 .6900291442957 .6043891906758 .51874923706 59.4331016540560 .3474502563561 .2618103027362 .1761703491263 .09051895142 64.004882812564 .6144485473665 .5288009643666 .4431610107467 .35751342773 67.9670867919968 .8814392089869 .4910125732470 .1005783081171 .0149307251 71.6244964599672 .5388565063574 .3675689697375 .89148712158 -9999 -9999 -9999 -9999 -9999 -9999 -9999 -9999 -9999 -9999 -9999 -9999 -9999 -9999 -9999 -9999 -9999 -9999 -9999

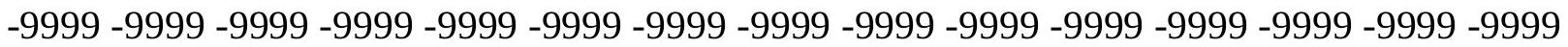

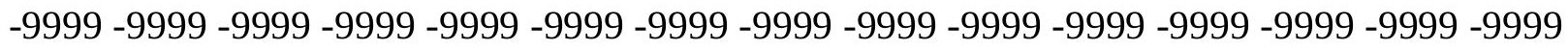
-9999 -9999 -9999 -9999 -9999 -9999 -9999 -9999 -9999 -9999 -9999 -9999 -9999 -9999 -9999 -

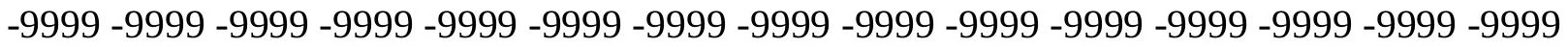

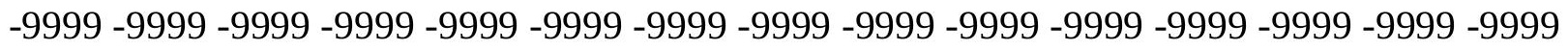

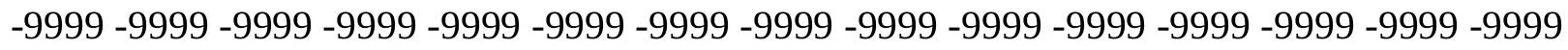
-9999 -9999 -9999 -9999 -9999 -9999 -9999 -9999 -9999 -9999 -9999 -9999 -9999 -9999 -9999 $-9999-9999$

-9999 -9999 -9999 -9999 -9999-9999 -9999 -9999 -9999 -9999 -9999 -9999 -9999 -9999 -9999 -

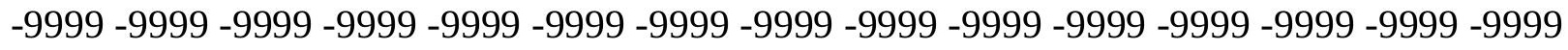
-9999 -9999 -9999 -9999 -9999 -9999 -9999 -9999 -9999 -9999 -9999 -9999 -9999 -9999 -9999 -9999 -9999 -9999 -9999 -9999 -9999 -9999 -9999 -9999 -9999 -9999 -9999 -9999 -9999 -9999 -9999 -9999 -9999 -9999 -9999 -9999 -9999 -9999 -9999 -9999 -9999 -9999 -9999 -9999 -9999 -

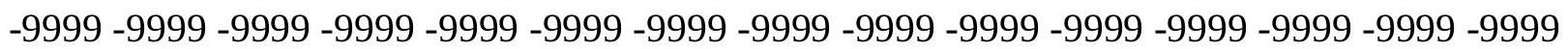


-9999 -9999 -9999 -9999-9999 28.95458984375 27.7354507446326.82109069824 26.8210906982426 .8210906982426 .5163097381626 .5163097381626 .21151924133 25.906740188625 .6019496917725 .6019496917725 .2971591949525 .29715919495 25.2971591949525 .2971591949525 .2971591949525 .6019496917725 .60194969177 25.906740188626 .2115192413326 .2115192413326 .5163097381626 .51630973816 26.8210906982426 .8210906982427 .1258792877227 .430660247827 .4306602478 27.7354507446328 .0402297973628 .0402297973628 .3450202941928 .64979934692 28.9545898437529 .2593708038329 .5641593933129 .8689403533930 .17373085022 30.4785099029530 .7833003997831 .3928699493431 .6976509094232 .00244140625 32.6120109558132 .9167900085433 .2215805053733 .8311500549334 .13592910767 34.7455101013235 .3550796508835 .9646492004436 .5742111206137 .18378067017 37.7933502197338 .7077102661139 .3172798156740 .2316398620641 .14598846436 41.7555618286142 .66992187543 .8890609741244 .8034095764245 .7177696228 46.9369087219247 .8512611389249 .0704002380450 .2895507812551 .50868988037 52.4230384826753 .6421813964854 .5565414428755 .1661109924356 .08045959473 56.3852500915556 .9948196411156 .9948196411157 .2995986938556 .99481964111 56.9948196411156 .6900291442956 .3852500915556 .0804595947355 .77568054199 55.4708900451755 .1661109924354 .8613204956154 .5565414428754 .25175094604 53.6421813964853 .3373985290553 .0326118469252 .7278289794952 .42303848267 52.1182594299351 .8134689331151 .8134689331151 .5086898803751 .20389938354 50.8991203308150 .5943298339850 .2895507812549 .9847602844249 .37519073486 49.0704002380448 .765621185348 .4608306884848 .1560516357447 .54647827148 47.2416992187546 .6321296691946 .3273391723646 .0225486755445 .41297912598 45.1082000732444 .4986305236844 .1938400268643 .8890609741243 .58427047729 43.2794914245642 .9747009277342 .66992187542 .66992187542 .66992187542 .669921875 42.66992187542 .66992187542 .9747009277343 .2794914245643 .58427047729 43.8890609741244 .1938400268644 .8034095764245 .4129791259845 .7177696228 46.3273391723647 .2416992187547 .8512611389248 .4608306884849 .37519073486 49.9847602844250 .8991203308151 .5086898803752 .4230384826753 .33739852905 54.2517509460455 .1661109924355 .7756805419956 .6900291442957 .60438919067 58.5187492370659 .4331016540560 .3474502563561 .2618103027362 .17617034912 63.0905189514264 .004882812564 .9192428588965 .5288009643666 .44316101074 67.35751342773 67.9670867919968.88143920898 69.49101257324 70.10057830811 71.014930725171 .6244964599672 .8436431884874 .36756896973 -9999 -9999 -9999-9999 -9999 -9999 -9999 -9999 -9999 -9999 -9999 -9999 -9999 -9999 -9999 -9999 -9999 -9999 -9999 -9999 -9999 -9999 -9999 -9999 -9999 -9999 -9999 -9999 -9999 -9999 -9999 -9999 -9999 -9999

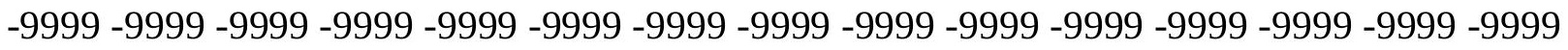

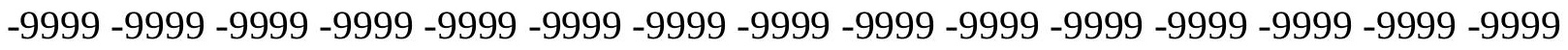
-9999 -9999 -9999 -9999 -9999 -9999 -9999 -9999 -9999 -9999 -9999 -9999 -9999 -9999 -9999 -9999 -9999 -9999 -9999 -9999 -9999 -9999 -9999 -9999 -9999 -9999 -9999 -9999 -9999 -9999 -

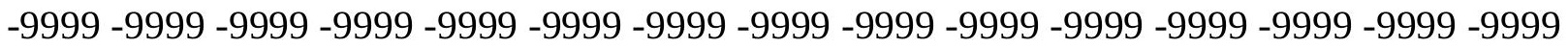

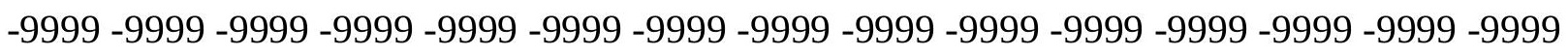
-9999-9999

-9999 -9999 -9999 -9999 -9999 -9999 -9999 -9999 -9999 -9999 -9999 -9999 -9999 -9999 -9999 -9999 -9999 -9999 -9999 -9999 -9999 -9999 -9999 -9999 -9999 -9999 -9999 -9999 -9999 -9999 -9999 -9999 -9999 -9999 -9999 -9999 -9999 -9999 -9999 -9999 -9999 -9999 -9999 -9999 -9999 
-9999 -9999 -9999 -9999 -9999 -9999 -9999 -9999 -9999 -9999 -9999 -9999 -9999 -9999 -9999 -9999 -9999 -9999 -9999 -9999 -9999 -9999 -9999 -9999 -9999 -9999 -9999 -9999 -9999 -9999 -9999 -9999 -9999 -9999 -9999 -9999 -9999 -9999 -9999 -9999 -9999 -9999 -9999 -9999 -9999 -9999 -9999 -9999 -9999 28.64979934692 27.430660247826.5163097381625.9067401886 25.906740188625 .906740188625 .6019496917725 .6019496917725 .29715919495 24.9923801422124 .9923801422124 .6875991821324 .3828105926524 .38281059265 24.3828105926524 .3828105926524 .3828105926524 .6875991821324 .68759918213 24.9923801422124 .9923801422125 .2971591949525 .2971591949525 .60194969177 25.6019496917725 .906740188626 .2115192413326 .2115192413326 .51630973816 26.5163097381626 .8210906982427 .1258792877227 .430660247827 .73545074463 27.7354507446328 .0402297973628 .3450202941928 .9545898437529 .25937080383 29.5641593933129 .8689403533930 .1737308502230 .4785099029531 .08807945251 31.3928699493431 .6976509094232 .0024414062532 .6120109558132 .91679000854 33.5263595581134 .1359291076734 .7455101013235 .3550796508835 .96464920044 36.5742111206137 .1837806701738 .0981407165538 .7077102661139 .6220703125 40.5364189147941 .4507789611842 .3651313781743 .2794914245644 .19384002686 45.4129791259846 .6321296691947 .8512611389249 .0704002380450 .28955078125 51.2038993835452 .4230384826753 .3373985290554 .2517509460455 .16611099243 55.7756805419956 .0804595947356 .3852500915556 .3852500915556 .08045959473 55.7756805419955 .4708900451755 .1661109924354 .8613204956154 .55654144287 54.2517509460453 .9469718933153 .6421813964853 .3373985290553 .03261184692 52.7278289794952 .4230384826752 .1182594299351 .8134689331151 .50868988037 51.2038993835450 .8991203308150 .8991203308150 .5943298339850 .28955078125 49.9847602844249 .6799812316949 .3751907348649 .0704002380448 .7656211853 48.4608306884848 .1560516357447 .8512611389247 .5464782714846 .93690872192 46.6321296691946 .3273391723645 .717769622845 .4129791259844 .80340957642 44.4986305236844 .1938400268643 .5842704772943 .2794914245642 .97470092773 42.66992187542 .3651313781742 .0603485107442 .0603485107441 .75556182861 41.7555618286141 .7555618286142 .0603485107442 .0603485107442 .36513137817 42.66992187542 .9747009277343 .2794914245643 .8890609741244 .19384002686 44.8034095764245 .4129791259846 .3273391723646 .9369087219247 .54647827148 48.4608306884849 .0704002380449 .9847602844250 .8991203308151 .50868988037 52.4230384826753 .3373985290554 .2517509460455 .1661109924356 .08045959473 56.9948196411157 .909179687558 .8235282897959 .7378807067960 .65224075317 61.5666007995662 .1761703491263 .0905189514264 .004882812564 .91924285889 65.8335876464866 .4431610107467 .3575134277367 .9670867919968 .88143920898 69.4910125732470 .1005783081171 .014930725171 .6244964599672 .84364318848 74.36756896973 -9999 -9999 -9999 -9999 -9999 -9999 -9999 -9999 -9999 -9999 -9999 -9999 -9999 -9999 -9999 -9999 -9999 -9999 -9999 -9999 -9999 -9999 -9999 -9999 -9999 -9999 -9999 -9999 -9999 -9999 -9999 -9999 -9999 -9999 -9999 -9999 -9999 -9999 -9999 -9999 - -9999 -9999 -9999 -9999 -9999 -9999 -9999 -9999 -9999 -9999 -9999 -9999 -9999 -9999 -9999 -9999 -9999

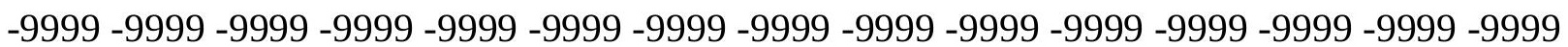
-9999 -9999 -9999 -9999 -9999 -9999 -9999 -9999 -9999 -9999 -9999 -9999 -9999 -9999 -9999 -9999 -9999 -9999 -9999 -9999 -9999 -9999 -9999 -9999 -9999 -9999 -9999 -9999 -9999 -9999 -9999 -9999 -9999 -9999 -9999 -9999 -9999 -9999 -9999 -9999 -9999 -9999 -9999 -9999 -9999 -9999 -9999 -9999 -9999 -9999 -9999 -9999 -9999 
-9999 -9999 -9999 -9999 -9999 -9999 -9999 -9999 -9999 -9999 -9999 -9999 -9999 -9999 -9999 -9999 -9999 -9999 -9999 -9999 -9999 -9999 -9999 -9999 -9999 -9999 -9999 -9999 -9999 -9999

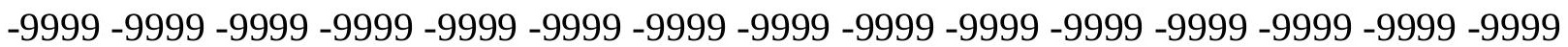
-9999 -9999 -9999 -9999 -9999 -9999 -9999 -9999 -9999 -9999 -9999 -9999 -9999 -9999 -9999 -9999 -9999 -9999 -9999 -9999 -9999 -9999 -9999 -9999 -9999 -9999 -9999 -9999 -9999 -9999 -9999 -9999 -9999 -9999 -9999 -9999 -9999 -9999 -9999 -9999 -9999 -9999 -9999 -9999 -9999 -9999 -9999 -9999 28.3450202941927.12587928772 26.2115192413325 .60194969177 25.2971591949525 .2971591949524 .9923801422124 .9923801422124 .68759918213 24.3828105926524 .0780296325724 .0780296325723 .7732391357423 .77323913574 23.4684505462623 .4684505462623 .4684505462623 .4684505462623 .77323913574 23.7732391357424 .0780296325724 .0780296325724 .3828105926524 .38281059265 24.6875991821324 .6875991821324 .9923801422124 .9923801422125 .29715919495 25.2971591949525 .6019496917725 .906740188626 .2115192413326 .21151924133 26.5163097381626 .8210906982427 .1258792877227 .430660247827 .73545074463 28.0402297973628 .3450202941928 .6497993469229 .2593708038329 .56415939331 29.8689403533930 .1737308502230 .4785099029531 .0880794525131 .39286994934 31.6976509094232 .3072204589832 .9167900085433 .2215805053733 .83115005493 34.4407196044935 .0502891540535 .6598587036136 .5742111206137 .18378067017 38.0981407165538 .7077102661139 .622070312540 .8412094116241 .75556182861 42.66992187543 .8890609741245 .1082000732446 .3273391723647 .54647827148 48.765621185349 .9847602844251 .2038993835452 .4230384826753 .33739852905 54.2517509460454 .5565414428755 .1661109924355 .1661109924355 .16611099243 54.8613204956154 .5565414428754 .2517509460453 .9469718933153 .33739852905 53.0326118469252 .7278289794952 .4230384826752 .1182594299351 .81346893311 51.5086898803751 .5086898803751 .2038993835450 .8991203308150 .59432983398 50.5943298339850 .2895507812549 .9847602844249 .6799812316949 .67998123169 49.3751907348649 .0704002380449 .0704002380448 .765621185348 .46083068848 48.1560516357447 .8512611389247 .5464782714847 .2416992187546 .93690872192 46.6321296691946 .0225486755445 .717769622845 .4129791259844 .80340957642 44.4986305236843 .8890609741243 .5842704772942 .9747009277342 .669921875 42.3651313781742 .0603485107441 .7555618286141 .4507789611841 .14598846436 41.1459884643641 .1459884643641 .1459884643641 .1459884643641 .14598846436 41.4507789611841 .7555618286142 .0603485107442 .3651313781742 .97470092773 43.2794914245643 .8890609741244 .4986305236845 .4129791259846 .02254867554 46.6321296691947 .5464782714848 .1560516357449 .0704002380449 .98476028442 50.8991203308151 .5086898803752 .4230384826753 .3373985290554 .25175094604 55.1661109924356 .0804595947356 .9948196411157 .909179687558 .82352828979 59.7378807067960 .6522407531761 .5666007995662 .4809494018663 .39530944824 64.3096618652364 .9192428588965 .8335876464866 .4431610107467 .35751342773 67.9670867919968 .8814392089869 .4910125732470 .1005783081170 .71015167236 71.6244964599673 .1484298706174 .67236328125 -9999 -9999 -9999 -9999 -9999 -9999 -9999 -9999 -9999 -9999 -9999 -9999 -9999 -9999 -9999 -9999 -9999 -9999 -9999 -9999 -9999 -9999 -9999 -9999 -9999 -9999 -9999 -9999 -9999 -9999 -9999 -9999 -9999 -9999 -9999 -9999 -9999 -9999 -9999 -9999 -9999 -9999 -9999 -9999 -9999 -9999 -9999 -9999 -9999 -9999 -9999 -9999 -9999 -9999 -9999 -9999 -9999 -9999 -9999 -9999 -9999 -9999 -9999 -9999 -9999 -9999 -9999

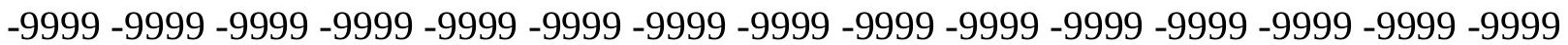


-9999 -9999 -9999 -9999 -9999 -9999 -9999 -9999 -9999 -9999 -9999 -9999 -9999 -9999 -9999 -9999 -9999 -9999 -9999 -9999 -9999 -9999 -9999 -9999 -9999 -9999 -9999 -9999 -9999 -9999 -9999 -9999 -9999 -9999 -9999 -9999 -9999 -9999 -9999 -9999 -9999 -9999

-9999 -9999 -9999 -9999 -9999 -9999 -9999 -9999 -9999 -9999 -9999 -9999 -9999 -9999 -9999 -9999 -9999 -9999 -9999 -9999 -9999 -9999 -9999 -9999 -9999 -9999 -9999 -9999 -9999 -9999 -9999 -9999 -9999 -9999 -9999 -9999 -9999 -9999 -9999 -9999 -9999 -9999 -9999 -9999 -9999 -9999 -9999 -9999 -9999 -9999 -9999 -9999 -9999 -9999 -9999 -9999 -9999 -9999 -9999 -9999

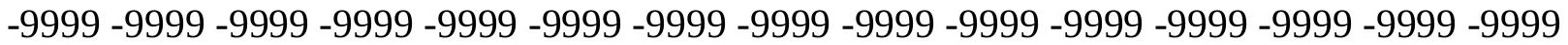
-9999 -9999 -9999 -9999 -9999 -9999 -9999 -9999 -9999 -9999 -9999 -9999 -9999 -9999 -9999 -9999 -9999 -9999 27.12587928772 25.906740188625.2971591949524.99238014221 24.6875991821324 .3828105926524 .3828105926524 .0780296325723 .77323913574 23.4684505462623 .4684505462623 .1636695861823 .1636695861822 .85887908936 22.8588790893622 .8588790893622 .8588790893622 .8588790893622 .85887908936 22.8588790893623 .1636695861823 .1636695861823 .1636695861823 .46845054626 23.4684505462623 .7732391357424 .0780296325724 .0780296325724 .38281059265 24.3828105926524 .6875991821324 .9923801422125 .2971591949525 .29715919495 25.6019496917725 .906740188626 .2115192413326 .5163097381626 .82109069824 27.1258792877227 .430660247827 .7354507446328 .0402297973628 .34502029419 28.6497993469228 .9545898437529 .5641593933129 .8689403533930 .17373085022 30.4785099029531 .0880794525131 .3928699493432 .0024414062532 .61201095581 32.9167900085433 .5263595581134 .1359291076735 .0502891540535 .65985870361 36.2694282531737 .1837806701738 .0981407165539 .0125007629439 .92684936523 41.1459884643642 .0603485107443 .2794914245644 .4986305236845 .7177696228 47.2416992187548 .4608306884849 .6799812316950 .8991203308152 .11825942993 53.0326118469253 .6421813964853 .9469718933153 .9469718933153 .94697189331 53.6421813964853 .0326118469252 .7278289794952 .1182594299351 .81346893311 51.5086898803751 .2038993835450 .8991203308150 .5943298339850 .59432983398 50.2895507812549 .9847602844249 .9847602844249 .6799812316949 .67998123169 49.3751907348649 .0704002380449 .0704002380448 .765621185348 .7656211853 48.4608306884848 .4608306884848 .1560516357447 .8512611389247 .85126113892 47.5464782714847 .2416992187546 .9369087219246 .6321296691946 .32733917236 46.0225486755445 .717769622845 .1082000732444 .8034095764244 .49863052368 43.8890609741243 .5842704772942 .9747009277342 .66992187542 .06034851074 41.7555618286141 .4507789611841 .1459884643640 .8412094116240 .53641891479 40.2316398620640 .2316398620640 .2316398620640 .2316398620640 .23163986206 40.5364189147940 .8412094116241 .1459884643641 .4507789611842 .06034851074 42.66992187543 .2794914245643 .8890609741244 .4986305236845 .10820007324 46.0225486755446 .6321296691947 .5464782714848 .1560516357449 .07040023804 49.9847602844250 .8991203308151 .8134689331152 .7278289794953 .64218139648 54.5565414428755 .4708900451756 .3852500915557 .2995986938558 .21395874023 59.1283111572360 .0426712036160 .9570198059161 .5666007995662 .48094940186 63.3953094482464 .3096618652365 .2240066528365 .8335876464866 .74794006348 67.3575134277367 .9670867919968 .8814392089869 .4910125732470 .10057830811 70.7101516723671 .6244964599673 .45321655273 -9999 -9999 -9999 -9999 -9999 -9999 -9999 -9999 -9999 -9999 -9999 -9999 -9999 -9999 -9999 -9999 -9999 -9999 -9999 -9999 -9999 -9999

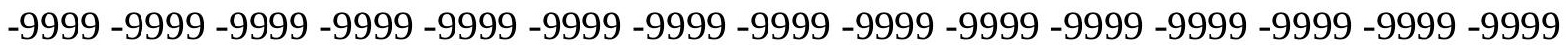


-9999 -9999 -9999 -9999 -9999 -9999 -9999 -9999 -9999 -9999 -9999 -9999 -9999 -9999 -9999 -9999 -9999 -9999 -9999 -9999 -9999 -9999 -9999 -9999 -9999 -9999 -9999 -9999 -9999 -9999 -9999 -9999 -9999 -9999 -9999 -9999 -9999 -9999 -9999 -9999 -9999 -9999 -9999 -9999 -9999 -9999 -9999 -9999 -9999 -9999 -9999 -9999 -9999 -9999 -9999 -9999 -9999 -9999 -9999 -9999 -9999 -9999 -9999 -9999 -9999 -9999 -9999 -9999 -9999 -9999 -9999 -9999 -9999 -9999 -9999 -9999 -9999 -9999 -9999 -9999 -9999 -9999 -9999 -9999 -9999 -9999 -9999

-9999 -9999 -9999 -9999 -9999 -9999 -9999 -9999 -9999 -9999 -9999 -9999 -9999 -9999 -9999

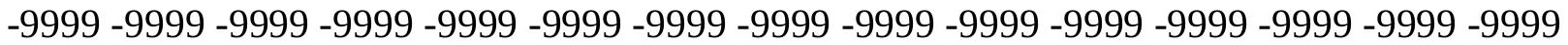

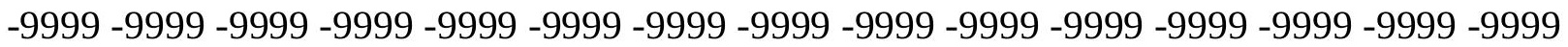
-9999 -9999 -9999 -9999 -9999 -9999 -9999 -9999 -9999 -9999 -9999 -9999 -9999 -9999 -9999 -

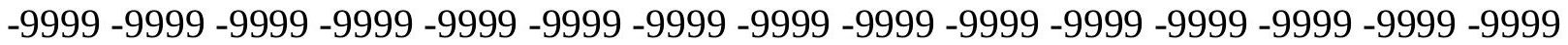
-9999 -9999 -9999 -9999 -9999 -9999 -9999 -9999 -9999 -9999 -9999 -9999 -9999 -9999 -9999 -9999 -9999-9999 25.906740188624.9923801422124.6875991821324.38281059265 24.0780296325723 .7732391357423 .4684505462623 .1636695861823 .16366958618 22.8588790893622 .5541000366222 .2493095397922 .2493095397921 .94453048706 21.9445304870621 .9445304870621 .9445304870621 .9445304870621 .94453048706 21.9445304870622 .2493095397922 .2493095397922 .5541000366222 .55410003662 22.5541000366222 .8588790893622 .8588790893623 .1636695861823 .46845054626 23.4684505462623 .7732391357424 .0780296325724 .0780296325724 .38281059265 24.6875991821324 .9923801422125 .2971591949525 .6019496917725 .9067401886 26.2115192413326 .5163097381626 .8210906982427 .1258792877227 .4306602478 27.7354507446328 .0402297973628 .3450202941928 .6497993469228 .95458984375 29.2593708038329 .8689403533930 .1737308502230 .4785099029531 .08807945251 31.6976509094232 .0024414062532 .6120109558133 .2215805053733 .83115005493 34.7455101013235 .3550796508836 .2694282531737 .1837806701738 .09814071655 39.0125007629440 .2316398620641 .4507789611842 .66992187543 .88906097412 45.4129791259846 .6321296691948 .1560516357449 .3751907348650 .59432983398 51.5086898803752 .1182594299352 .7278289794952 .7278289794952 .42303848267 52.1182594299351 .5086898803750 .8991203308150 .5943298339849 .98476028442 49.6799812316949 .3751907348649 .3751907348649 .0704002380449 .07040023804 48.765621185348 .765621185348 .765621185348 .4608306884848 .46083068848 48.1560516357448 .1560516357447 .8512611389247 .8512611389247 .54647827148 47.5464782714847 .5464782714847 .2416992187547 .2416992187546 .93690872192 46.9369087219246 .6321296691946 .3273391723646 .0225486755445 .7177696228 45.4129791259845 .1082000732444 .8034095764244 .4986305236843 .88906097412 43.5842704772942 .9747009277342 .66992187542 .0603485107441 .75556182861 41.1459884643640 .8412094116240 .5364189147940 .2316398620639 .92684936523 39.622070312539 .622070312539 .3172798156739 .3172798156739 .6220703125 39.622070312539 .9268493652340 .2316398620640 .5364189147941 .14598846436 41.7555618286142 .3651313781742 .9747009277343 .5842704772944 .19384002686 45.1082000732445 .717769622846 .6321296691947 .5464782714848 .46083068848 49.0704002380449 .9847602844250 .8991203308151 .8134689331152 .72782897949 53.6421813964854 .5565414428755 .4708900451756 .3852500915557 .29959869385 58.2139587402359 .1283111572360 .0426712036160 .9570198059161 .87137985229 62.7857398986863 .7000885009864 .3096618652365 .2240066528365 .83358764648 66.7479400634867 .3575134277367 .9670867919968 .8814392089869 .18623352051 
69.7957916259870 .4053573608471 .9292907714873 .75800323486 -9999 -9999 -9999 -9999 -9999 -9999 -9999 -9999 -9999 -9999 -9999 -9999 -9999 -9999 -9999 -9999 -9999 -9999 -9999

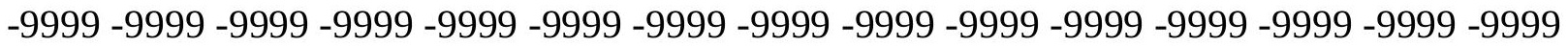
-9999 -9999 -9999 -9999 -9999 -9999 -9999 -9999 -9999 -9999 -9999 -9999 -9999 -9999 -9999 -9999 -9999 -9999 -9999 -9999 -9999 -9999 -9999 -9999 -9999 -9999 -9999-9999 -9999 -9999 -9999 -9999 -9999 -9999 -9999 -9999 -9999 -9999 -9999 -9999 -9999 -9999 -9999 -9999 -9999 -9999 -9999 -9999 -9999 -9999 -9999 -9999 -9999 -9999 -9999 -9999 -9999 -9999 -9999 -9999

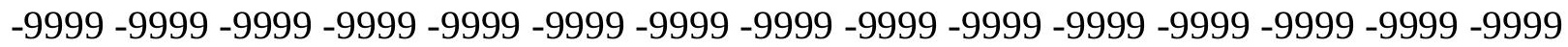
-9999 -9999 -9999 -9999 -9999 -9999 -9999 -9999 -9999 -9999 -9999 -9999 -9999 -9999 -9999 -9999 -9999 -9999 -9999 -9999 -9999 -9999 -9999 -9999 -9999 -9999 -9999 -9999 -9999 -9999 -9999 -9999 -9999 -9999 -9999 -9999 -9999 -9999 -9999 -9999 -9999 -9999 -9999 -9999 -9999 -9999 -9999 -9999 -9999 -9999 -9999 -9999 -9999 -9999 -9999 -9999 -9999 -9999 -9999 -9999 -9999 -9999 -9999 -9999 -9999 -9999 -9999 -9999 -9999 -9999 -9999 -9999 -9999 -9999 -9999 -9999 -9999 -9999 -9999 -9999 -9999 -9999 -9999 -9999 -9999 -9999 -9999 -9999 - 9999 -9999 -9999 -9999 -9999 -9999 -9999 -9999 -9999 -9999 -9999 -9999 -9999 -9999 -9999 -9999 -9999 -9999 25.906740188624.9923801422124.38281059265 24.07802963257 23.7732391357423 .4684505462623 .1636695861822 .8588790893622 .55410003662 22.2493095397921 .9445304870621 .6397399902321 .6397399902321 .3349609375 21.334960937521 .0301704406721 .0301704406721 .0301704406721 .03017044067 21.0301704406721 .334960937521 .334960937521 .334960937521 .63973999023 21.6397399902321 .9445304870621 .9445304870622 .2493095397922 .24930953979 22.5541000366222 .5541000366222 .8588790893623 .1636695861823 .46845054626 23.4684505462623 .7732391357424 .0780296325724 .3828105926524 .68759918213 24.9923801422125 .2971591949525 .2971591949525 .6019496917725 .9067401886 26.2115192413326 .5163097381626 .8210906982427 .1258792877227 .4306602478 27.7354507446328 .0402297973628 .6497993469228 .9545898437529 .25937080383 29.5641593933130 .1737308502230 .4785099029531 .0880794525131 .69765090942 32.3072204589832 .9167900085433 .5263595581134 .4407196044935 .35507965088 36.2694282531737 .1837806701738 .0981407165539 .3172798156740 .53641891479 41.7555618286142 .9747009277344 .4986305236846 .0225486755447 .54647827148 48.765621185349 .9847602844250 .5943298339851 .2038993835451 .20389938354 50.8991203308150 .2895507812549 .6799812316949 .0704002380448 .46083068848 48.1560516357447 .8512611389247 .8512611389247 .5464782714847 .54647827148 47.5464782714847 .5464782714847 .2416992187547 .2416992187547 .24169921875 46.9369087219246 .9369087219246 .9369087219246 .9369087219246 .63212966919 46.6321296691946 .6321296691946 .6321296691946 .6321296691946 .32733917236 46.3273391723646 .0225486755446 .0225486755445 .717769622845 .7177696228 45.4129791259845 .1082000732444 .8034095764244 .4986305236843 .88906097412 43.5842704772942 .9747009277342 .66992187542 .0603485107441 .75556182861 41.1459884643640 .8412094116240 .2316398620639 .9268493652339 .6220703125 39.3172798156739 .0125007629438 .7077102661138 .7077102661138 .70771026611 38.7077102661138 .7077102661139 .0125007629439 .3172798156739 .92684936523 40.2316398620640 .8412094116241 .4507789611842 .0603485107442 .669921875 43.5842704772944 .1938400268645 .1082000732446 .0225486755446 .63212966919 47.5464782714848 .4608306884849 .3751907348650 .2895507812551 .20389938354 52.1182594299353 .0326118469253 .9469718933154 .8613204956155 .77568054199 
56.6900291442957 .6043891906758 .5187492370659 .4331016540560 .34745025635 61.2618103027361 .8713798522962 .7857398986863 .7000885009864 .61444854736 65.2240066528366 .1383666992266 .7479400634867 .3575134277367 .96708679199 68.5766525268669 .1862335205169 .7957916259870 .7101516723672 .53885650635 74.0627822876 -9999 -9999 -9999 -9999 -9999 -9999 -9999 -9999 -9999 -9999 -9999 -9999 -9999 -9999 -9999 -9999 -9999 -9999 -9999 -9999 -9999 -9999 -9999 -9999 -9999 -9999 -9999 -9999 -9999 -9999 -9999 -9999 -9999 -9999 -9999 -9999 -9999 -9999 -9999 -9999 -9999 -9999

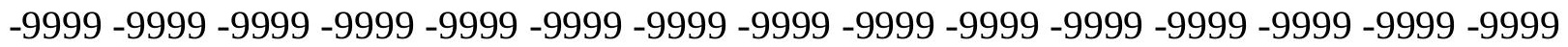
-9999 -9999 -9999 -9999 -9999 -9999 -9999 -9999 -9999 -9999 -9999 -9999 -9999 -9999 -9999 -

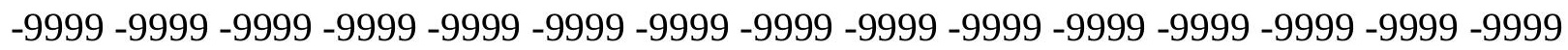
-9999 -9999 -9999 -9999 -9999 -9999 -9999 -9999 -9999 -9999 -9999 -9999 -9999 -9999 -9999 -999 -

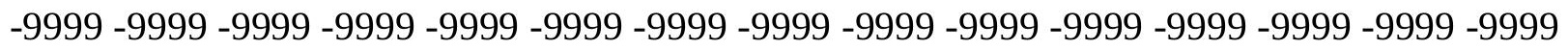
-9999 -9999 -9999-9999-9999

-9999 -9999 -9999 -9999 -9999 -9999 -9999 -9999 -9999 -9999 -9999 -9999 -9999 -9999 -9999 -9999 -9999 -9999 -9999 -9999 -9999 -9999 -9999 -9999 -9999 -9999 -9999 -9999 -9999 -9999

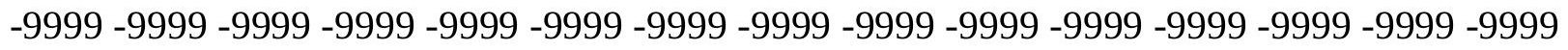

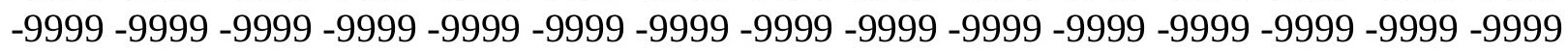

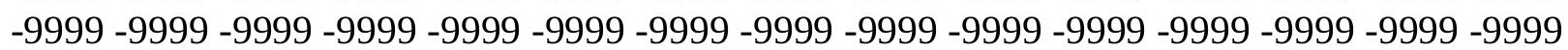

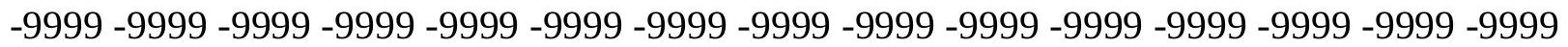
-9999 -9999 24.9923801422124.07802963257 23.7732391357423 .46845054626 23.1636695861822 .5541000366222 .2493095397921 .9445304870621 .63973999023 21.334960937521 .0301704406721 .0301704406720 .7253894805920 .42060089111 20.4206008911120 .4206008911120 .4206008911120 .1158199310320 .11581993103 20.4206008911120 .4206008911120 .4206008911120 .4206008911120 .72538948059 20.7253894805921 .0301704406721 .0301704406721 .334960937521 .3349609375 21.6397399902321 .9445304870621 .9445304870622 .2493095397922 .55410003662 22.8588790893622 .8588790893623 .1636695861823 .4684505462623 .77323913574 24.0780296325724 .3828105926524 .3828105926524 .6875991821324 .99238014221 25.2971591949525 .6019496917725 .906740188626 .2115192413326 .21151924133 26.5163097381626 .8210906982427 .1258792877227 .430660247828 .04022979736 28.3450202941928 .6497993469228 .9545898437529 .5641593933129 .86894035339 30.4785099029531 .0880794525131 .6976509094232 .3072204589833 .22158050537 33.8311500549334 .7455101013235 .9646492004436 .8790016174337 .79335021973 39.0125007629440 .5364189147942 .0603485107443 .5842704772945 .41297912598 46.9369087219248 .1560516357448 .765621185349 .3751907348649 .37519073486 49.0704002380448 .4608306884847 .5464782714846 .9369087219246 .32733917236 46.0225486755446 .0225486755446 .0225486755446 .0225486755446 .02254867554 46.0225486755446 .0225486755446 .0225486755446 .0225486755445 .7177696228 45.717769622845 .717769622845 .717769622845 .717769622845 .717769622845 .7177696228 45.717769622845 .717769622845 .717769622845 .717769622845 .41297912598 45.4129791259845 .4129791259845 .1082000732445 .1082000732444 .80340957642 44.4986305236844 .1938400268643 .8890609741243 .5842704772943 .27949142456 42.66992187542 .3651313781741 .7555618286141 .4507789611840 .84120941162 40.2316398620639 .9268493652339 .3172798156739 .0125007629438 .70771026611 38.4029312133838 .0981407165537 .7933502197337 .7933502197337 .79335021973 38.0981407165538 .0981407165538 .4029312133839 .0125007629439 .31727981567 
39.9268493652340 .5364189147941 .4507789611842 .0603485107442 .669921875 43.5842704772944 .4986305236845 .1082000732446 .0225486755446 .93690872192 47.8512611389248 .765621185349 .3751907348650 .2895507812551 .20389938354 52.1182594299353 .3373985290554 .2517509460455 .1661109924356 .08045959473 56.9948196411157 .909179687558 .8235282897959 .7378807067960 .34745025635 61.2618103027362 .1761703491263 .0905189514263 .7000885009864 .61444854736 65.2240066528366 .1383666992266 .7479400634867 .3575134277367 .96708679199 68.5766525268669 .1862335205169 .7957916259871 .3197174072373 .14842987061 -9999 -9999 -9999 -9999 -9999 -9999 -9999 -9999 -9999 -9999 -9999 -9999 -9999 -9999 -9999 -9999 -9999 -9999 -9999 -9999 -9999 -9999 -9999 -9999 -9999 -9999 -9999 -9999 -9999 -9999 -9999

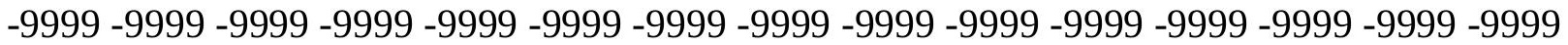
-9999 -9999 -9999 -9999 -9999 -9999 -9999 -9999 -9999 -9999 -9999 -9999 -9999 -9999 -9999 -9999 -9999 -9999 -9999 -9999 -9999 -9999 -9999 -9999 -9999 -9999 -9999 -9999 -9999 -9999 -9999 -9999 -9999 -9999 -9999 -9999 -9999 -9999 -9999 -9999 -9999 -9999 -9999 -9999 -9999 -9999 -9999 -9999 -9999 -9999 -9999 -9999 -9999 -9999 -9999 -9999 -9999 -9999 -9999 -9999

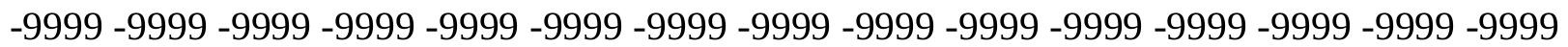
$-9999$

-9999 -9999 -9999 -9999 -9999 -9999 -9999 -9999 -9999 -9999 -9999 -9999 -9999 -9999 -9999 -9999 -9999 -9999 -9999 -9999 -9999 -9999 -9999 -9999 -9999 -9999 -9999 -9999 -9999 -9999 -9999 -9999 -9999 -9999 -9999 -9999 -9999 -9999 -9999 -9999 -9999 -9999 -9999 -9999 -9999 -

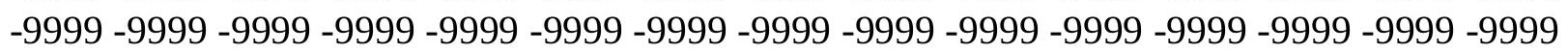

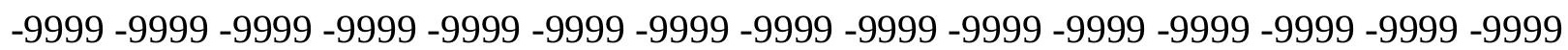
-9999 -9999 -9999 -9999 -9999 -9999 -9999 -9999 -9999 -9999 -9999 -9999 -9999 -9999 -9999 -9999 -9999 24.0780296325723.1636695861822.8588790893622.55410003662 22.2493095397921 .9445304870621 .6397399902321 .334960937521 .03017044067 20.7253894805920 .4206008911120 .1158199310319 .811029434219 .8110294342 19.5062503814719 .5062503814719 .5062503814719 .5062503814719 .50625038147 19.5062503814719 .5062503814719 .5062503814719 .811029434219 .8110294342 20.1158199310320 .1158199310320 .4206008911120 .4206008911120 .72538948059 20.7253894805921 .0301704406721 .334960937521 .334960937521 .63973999023 21.9445304870622 .2493095397922 .5541000366222 .5541000366222 .85887908936 23.1636695861823 .4684505462623 .4684505462623 .7732391357424 .07802963257 24.3828105926524 .3828105926524 .6875991821324 .9923801422125 .29715919495 25.6019496917725 .6019496917725 .906740188626 .2115192413326 .51630973816 26.8210906982427 .1258792877227 .430660247827 .7354507446328 .34502029419 28.6497993469229 .2593708038329 .5641593933130 .1737308502231 .08807945251 31.6976509094232 .6120109558133 .2215805053734 .1359291076735 .05028915405 36.2694282531737 .4885711669939 .0125007629440 .5364189147942 .36513137817 44.1938400268645 .717769622846 .6321296691947 .2416992187547 .24169921875 46.9369087219246 .0225486755445 .4129791259844 .4986305236844 .19384002686 43.8890609741243 .8890609741243 .8890609741244 .1938400268644 .19384002686 44.4986305236844 .4986305236844 .4986305236844 .4986305236844 .49863052368 44.4986305236844 .4986305236844 .4986305236844 .4986305236844 .49863052368 44.4986305236844 .8034095764244 .8034095764244 .8034095764244 .80340957642 44.8034095764244 .8034095764244 .8034095764244 .4986305236844 .49863052368 44.1938400268644 .1938400268643 .8890609741243 .5842704772943 .27949142456 
42.9747009277342 .3651313781742 .0603485107441 .4507789611840 .84120941162 40.5364189147939 .9268493652339 .3172798156739 .0125007629438 .40293121338 38.0981407165537 .7933502197337 .4885711669937 .1837806701737 .18378067017 37.1837806701737 .1837806701737 .4885711669937 .7933502197338 .09814071655 38.7077102661139 .3172798156739 .9268493652340 .5364189147941 .45077896118 42.0603485107442 .9747009277343 .5842704772944 .4986305236845 .41297912598 46.3273391723646 .9369087219247 .8512611389248 .765621185349 .67998123169 50.5943298339851 .5086898803752 .4230384826753 .3373985290554 .25175094604 55.1661109924356 .0804595947356 .9948196411157 .909179687558 .82352828979 59.7378807067960 .6522407531761 .5666007995662 .4809494018663 .09051895142 64.004882812564 .6144485473665 .5288009643666 .1383666992266 .74794006348 67.3575134277368 .2718734741268 .8814392089869 .4910125732470 .10057830811 71.9292907714873 .75800323486 -9999 -9999 -9999 -9999 -9999 -9999 -9999 -9999 -9999 -9999 -9999 -9999 -9999 -9999 -9999 -9999 -9999 -9999 -9999 -9999 -9999 -9999 -9999 -9999 -9999 -9999 -9999 -9999 -9999 -9999 -9999 -9999 -9999 -9999 -9999 -9999 -9999 -9999 -9999

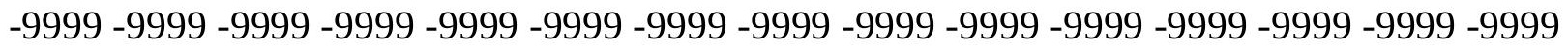
-9999 -9999 -9999 -9999 -9999 -9999 -9999 -9999 -9999 -9999 -9999 -9999 -9999 -9999 -9999 -9999 -9999 -9999 -9999 -9999 -9999 -9999 -9999 -9999 -9999 -9999 -9999 -9999 -9999 -9999 -9999 -9999 -9999 -9999 -9999 -9999 -9999 -9999 -9999 -9999 -9999 -9999 -9999 -9999 -9999

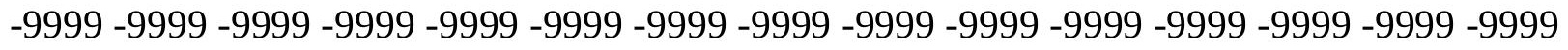
-9999-9999-9999-9999-9999-9999-9999

-9999 -9999 -9999 -9999 -9999 -9999 -9999 -9999 -9999 -9999 -9999 -9999 -9999 -9999 -9999 -9999 -9999 -9999 -9999 -9999 -9999 -9999 -9999 -9999 -9999 -9999 -9999 -9999 -9999 -9999 -

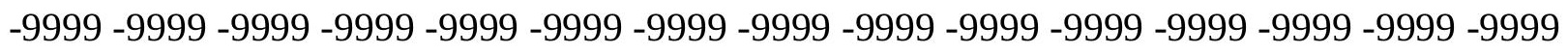

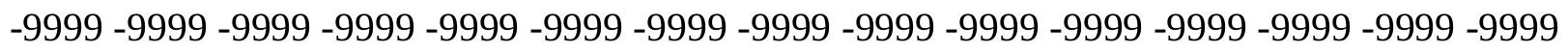
-9999 -9999 -9999 -9999 -9999 -9999 -9999 -9999 -9999 -9999 -9999 -9999 -9999 -9999 -9999 -9999 -9999 -9999 -9999 -9999-9999 -9999 -9999 -9999 -9999 -9999 -9999 -9999 -9999 - 9999 -9999 -9999 23.4684505462622.55410003662 22.24930953979 21.94453048706 21.6397399902321 .0301704406720 .7253894805920 .4206008911120 .11581993103 19.811029434219 .5062503814719 .2014598846419 .2014598846418 .89668083191 18.8966808319118 .5918903350818 .5918903350818 .5918903350818 .59189033508 18.5918903350818 .8966808319118 .8966808319118 .8966808319119 .20145988464 19.2014598846419 .5062503814719 .5062503814719 .811029434219 .8110294342 20.1158199310320 .4206008911120 .4206008911120 .7253894805921 .03017044067 21.334960937521 .334960937521 .6397399902321 .9445304870621 .94453048706 22.2493095397922 .5541000366222 .8588790893622 .8588790893623 .16366958618 23.4684505462623 .4684505462623 .7732391357424 .0780296325724 .07802963257 24.3828105926524 .6875991821324 .6875991821324 .9923801422125 .29715919495 25.2971591949525 .6019496917725 .906740188626 .2115192413326 .51630973816 26.8210906982427 .1258792877227 .7354507446328 .0402297973628 .64979934692 29.2593708038329 .8689403533930 .4785099029531 .0880794525131 .69765090942 32.6120109558133 .5263595581135 .0502891540536 .8790016174339 .01250076294 40.8412094116242 .66992187543 .5842704772944 .1938400268644 .19384002686 44.1938400268643 .2794914245642 .3651313781742 .0603485107441 .75556182861 41.7555618286142 .0603485107442 .0603485107442 .3651313781742 .669921875 42.9747009277342 .9747009277342 .9747009277342 .9747009277342 .97470092773 
42.9747009277343 .2794914245643 .2794914245643 .2794914245643 .27949142456 43.5842704772943 .5842704772943 .8890609741243 .8890609741243 .88906097412 43.8890609741244 .1938400268644 .1938400268644 .1938400268643 .88906097412 43.8890609741243 .5842704772943 .5842704772943 .2794914245642 .97470092773 42.3651313781742 .0603485107441 .7555618286141 .1459884643640 .53641891479 39.9268493652339 .622070312539 .0125007629438 .4029312133837 .79335021973 37.4885711669937 .1837806701736 .5742111206136 .5742111206136 .26942825317 36.2694282531736 .2694282531736 .5742111206136 .8790016174337 .48857116699 37.7933502197338 .4029312133839 .3172798156739 .9268493652340 .53641891479 41.4507789611842 .3651313781742 .9747009277343 .8890609741244 .80340957642 45.717769622846 .3273391723647 .2416992187548 .1560516357449 .07040023804 49.9847602844250 .8991203308151 .8134689331152 .7278289794953 .64218139648 54.5565414428755 .4708900451756 .3852500915557 .2995986938558 .21395874023 59.1283111572360 .0426712036160 .9570198059161 .8713798522962 .48094940186 63.3953094482464 .004882812564 .9192428588965 .5288009643666 .13836669922 67.0527267456167 .6623001098668 .2718734741268 .8814392089869 .79579162598 71.014930725172 .5388565063574 .36756896973 -9999 -9999 -9999 -9999 -9999 -9999 -9999 -9999 -9999 -9999 -9999 -9999 -9999 -9999 -9999 -9999 -9999 -9999 -9999 -9999 -9999 -9999 -9999 -9999 -9999 -9999 -9999 -9999 -9999 -9999 -9999 -9999 -9999 -9999 -9999 -9999 -9999 -

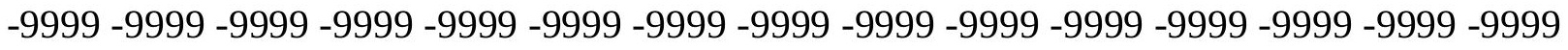

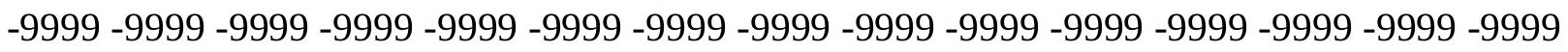
-9999 -9999 -9999 -9999 -9999 -9999 -9999 -9999 -9999 -9999 -9999 -9999 -9999 -9999 -9999 -9999 -9999 -9999 -9999 -9999 -9999 -9999 -9999 -9999 -9999 -9999 -9999 -9999 -9999 -9999 -

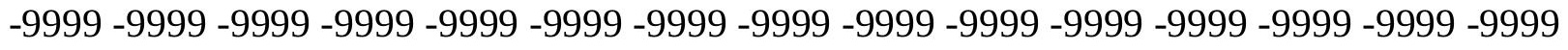
-9999 -9999 -9999 -9999-9999 -9999-9999-9999

-9999 -9999 -9999 -9999 -9999 -9999 -9999 -9999 -9999 -9999 -9999 -9999 -9999 -9999 -9999 -9999 -9999 -9999 -9999 -9999 -9999 -9999 -9999 -9999 -9999 -9999 -9999 -9999 -9999 -9999 -

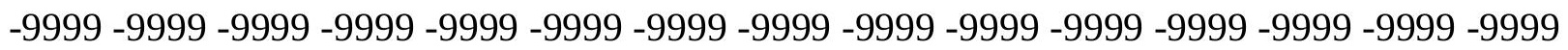
-9999 -9999 -9999 -9999 -9999 -9999 -9999 -9999 -9999 -9999 -9999 -9999 -9999 -9999 -9999 -9999 -9999 -9999 -9999 -9999 -9999 -9999 -9999 -9999 -9999 -9999 -9999 -9999 -9999 -9999 -9999 -9999 -9999 -9999 -9999 -9999 -9999 -9999 -9999 -9999 -9999 -9999 -9999 -9999 -9999 -9999 -9999 22.55410003662 21.6397399902321.3349609375 21.03017044067 20.7253894805920 .4206008911119 .811029434219 .5062503814719 .20145988464 18.8966808319118 .5918903350818 .28710937518 .28710937517 .98232078552 17.9823207855217 .9823207855217 .9823207855217 .9823207855217 .98232078552 17.98232078552 17.98232078552 17.98232078552 18.287109375 18.287109375 18.5918903350818 .5918903350818 .8966808319118 .8966808319119 .20145988464 19.5062503814719 .5062503814719 .811029434220 .1158199310320 .11581993103 20.4206008911120 .7253894805921 .0301704406721 .0301704406721 .3349609375 21.6397399902321 .6397399902321 .9445304870621 .9445304870622 .24930953979 22.5541000366222 .5541000366222 .8588790893622 .8588790893623 .16366958618 23.1636695861823 .4684505462623 .4684505462623 .7732391357423 .77323913574 24.0780296325724 .0780296325724 .3828105926524 .3828105926524 .68759918213 24.9923801422125 .2971591949525 .2971591949525 .906740188626 .21151924133 26.5163097381627 .1258792877227 .430660247827 .7354507446328 .04022979736 28.6497993469229 .2593708038330 .1737308502232 .0024414062534 .13592910767 
36.8790016174339 .0125007629439 .9268493652339 .9268493652339 .92684936523 40.2316398620639 .3172798156738 .7077102661139 .0125007629439 .31727981567 39.622070312540 .2316398620640 .5364189147940 .8412094116241 .14598846436 41.1459884643641 .4507789611841 .4507789611841 .4507789611841 .75556182861 41.7555618286141 .7555618286142 .0603485107442 .0603485107442 .36513137817 42.3651313781742 .66992187542 .66992187542 .9747009277342 .97470092773 43.2794914245643 .2794914245643 .5842704772943 .5842704772943 .58427047729 43.2794914245643 .2794914245642 .9747009277342 .9747009277342 .669921875 42.3651313781741 .7555618286141 .4507789611840 .8412094116240 .23163986206 39.622070312539 .0125007629438 .7077102661138 .0981407165537 .48857116699 36.8790016174336 .5742111206135 .9646492004435 .6598587036135 .65985870361 35.6598587036135 .6598587036135 .9646492004436 .2694282531736 .57421112061 37.1837806701737 .7933502197338 .7077102661139 .3172798156739 .92684936523 40.8412094116241 .7555618286142 .3651313781743 .2794914245644 .19384002686 45.1082000732446 .0225486755446 .6321296691947 .5464782714848 .46083068848 49.3751907348650 .2895507812551 .2038993835452 .1182594299353 .03261184692 53.9469718933154 .8613204956155 .7756805419956 .6900291442957 .60438919067 58.5187492370659 .4331016540560 .3474502563561 .2618103027361 .87137985229 62.7857398986863 .3953094482464 .3096618652364 .9192428588965 .83358764648 66.4431610107467 .0527267456167 .9670867919968 .5766525268669 .18623352051 70.1005783081171 .6244964599673 .45321655273 -9999 -9999 -9999 -9999 -9999 -9999 -9999

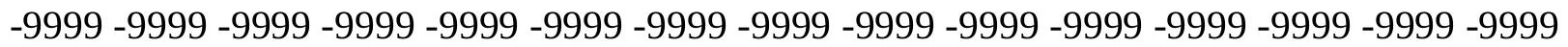
-9999 -9999 -9999 -9999 -9999 -9999 -9999 -9999 -9999 -9999 -9999 -9999 -9999 -9999 -9999 -9999 -9999 -9999 -9999 -9999 -9999 -9999 -9999 -9999 -9999 -9999 -9999 -9999 -9999 -9999 -9999 -9999 -9999 -9999 -9999 -9999 -9999 -9999 -9999 -9999 -9999 -9999 -9999 -9999 -9999 -9999 -9999 -9999 -9999 -9999 -9999 -9999 -9999 -9999 -9999 -9999 -9999 -9999 -9999 -9999 -9999 -9999 -9999 -9999 -9999 -9999 -9999 -9999 -9999 -9999 -9999 -9999 -9999 -9999 -9999 -

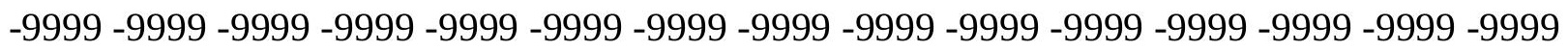
-9999 -9999 -9999 -9999 -9999 -9999 -9999 -9999

-9999 -9999 -9999 -9999 -9999 -9999 -9999 -9999 -9999 -9999 -9999 -9999 -9999 -9999 -9999 -9999 -9999 -9999 -9999 -9999 -9999 -9999 -9999 -9999 -9999 -9999 -9999 -9999 -9999 -9999

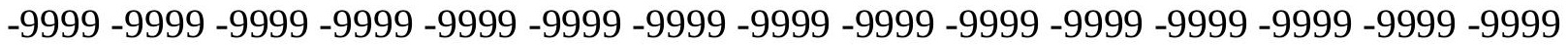

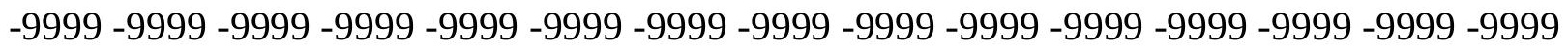
-9999 -9999 -9999 -9999 -9999 -9999 -9999 -9999 -9999 -9999 -9999 -9999 -9999 -9999 -9999 -9999 -9999 -9999 -9999 -9999 -9999 -9999 -9999 -9999 -9999 -9999 -9999 -9999 -9999 -9999 -9999 -9999 21.9445304870621 .0301704406720 .7253894805920 .11581993103 19.811029434219 .5062503814719 .2014598846418 .5918903350818 .287109375 17.9823207855217 .6775398254417 .6775398254417 .3727493286117 .37274932861 17.0679702758817 .0679702758817 .0679702758817 .0679702758817 .06797027588 17.0679702758817 .3727493286117 .3727493286117 .3727493286117 .67753982544 17.67753982544 17.98232078552 18.28710937518.28710937518.59189033508 18.8966808319118 .8966808319119 .2014598846419 .5062503814719 .50625038147 19.811029434220 .1158199310320 .1158199310320 .4206008911120 .72538948059 20.7253894805921 .0301704406721 .0301704406721 .334960937521 .3349609375 21.6397399902321 .6397399902321 .9445304870621 .9445304870621 .94453048706 22.2493095397922 .2493095397922 .2493095397922 .5541000366222 .55410003662 
22.5541000366222 .5541000366222 .8588790893622 .8588790893622 .85887908936 22.8588790893623 .1636695861823 .1636695861823 .4684505462623 .46845054626 23.7732391357424 .0780296325724 .0780296325724 .0780296325724 .07802963257 24.0780296325724 .0780296325724 .6875991821325 .6019496917728 .04022979736 31.3928699493434 .1359291076734 .7455101013234 .1359291076733 .52635955811 33.2215805053733 .5263595581134 .4407196044935 .9646492004437 .18378067017 37.7933502197338 .4029312133838 .7077102661139 .0125007629439 .31727981567 39.622070312539 .9268493652339 .9268493652339 .9268493652340 .23163986206 40.2316398620640 .5364189147940 .5364189147940 .8412094116241 .14598846436 41.1459884643641 .4507789611841 .7555618286142 .0603485107442 .36513137817 42.3651313781742 .66992187542 .66992187542 .9747009277342 .97470092773 42.9747009277342 .9747009277342 .66992187542 .66992187542 .36513137817 42.0603485107441 .4507789611841 .1459884643640 .5364189147939 .92684936523 39.3172798156738 .7077102661138 .0981407165537 .7933502197337 .18378067017 36.5742111206135 .9646492004435 .6598587036135 .0502891540534 .74551010132 34.7455101013234 .7455101013235 .0502891540535 .3550796508835 .96464920044 36.5742111206137 .1837806701738 .0981407165538 .7077102661139 .6220703125 40.2316398620641 .1459884643642 .0603485107442 .66992187543 .58427047729 44.4986305236845 .4129791259846 .3273391723647 .2416992187548 .15605163574 48.765621185349 .6799812316950 .8991203308151 .8134689331152 .72782897949 53.6421813964854 .5565414428755 .4708900451756 .3852500915557 .29959869385 57.909179687558 .8235282897959 .7378807067960 .6522407531761 .56660079956 62.1761703491263 .0905189514263 .7000885009864 .6144485473665 .22400665283 66.1383666992266 .7479400634867 .3575134277368 .2718734741268 .88143920898 69.7957916259870 .7101516723672 .2340774536174 .0627822876 -9999 -9999 -9999 -9999

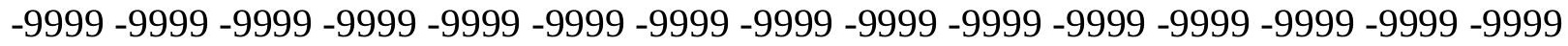

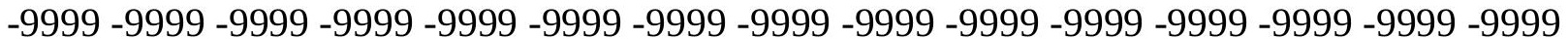

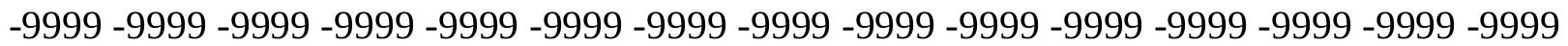

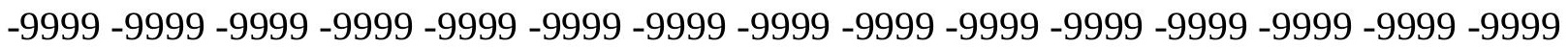

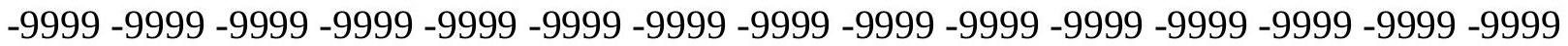

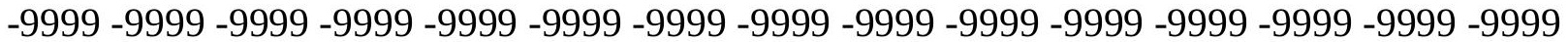

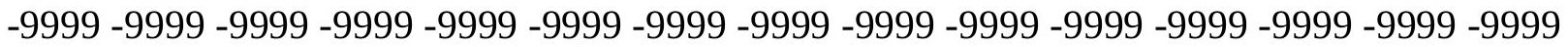
-9999 -9999 -9999 -9999 -9999 -9999 -9999 -9999 -9999 -9999

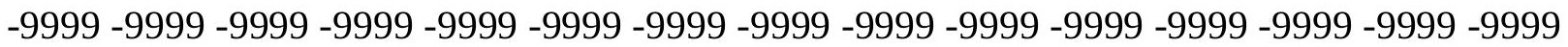

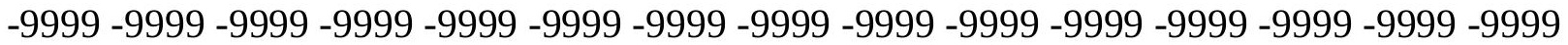

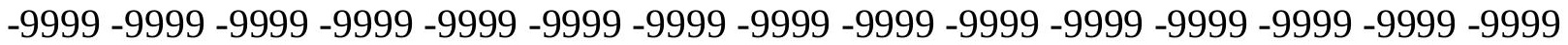

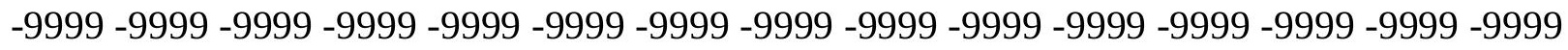

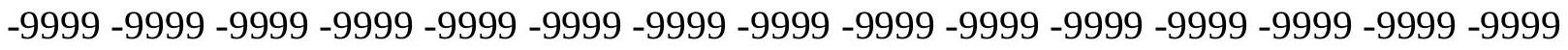

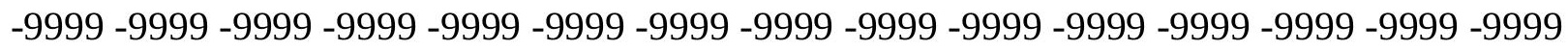
-9999-9999 21.03017044067 20.11581993103 19.8110294342 19.50625038147 18.8966808319118 .5918903350818 .28710937517 .6775398254417 .37274932861 17.0679702758817 .0679702758816 .7631797790516 .4584007263216 .45840072632 16.45840072632 16.45840072632 16.45840072632 16.45840072632 16.45840072632 16.4584007263216 .4584007263216 .7631797790516 .7631797790517 .06797027588 17.0679702758817 .3727493286117 .6775398254417 .6775398254417 .98232078552 18.28710937518 .28710937518 .5918903350818 .8966808319118 .89668083191 
19.20145988464 19.5062503814719.5062503814719.811029434219.8110294342 20.1158199310320 .1158199310320 .4206008911120 .4206008911120 .72538948059 20.7253894805920 .7253894805921 .0301704406721 .0301704406721 .03017044067 21.0301704406721 .0301704406721 .334960937521 .334960937521 .3349609375 21.334960937521 .0301704406721 .0301704406721 .0301704406721 .03017044067 21.0301704406721 .0301704406721 .0301704406721 .0301704406721 .03017044067 21.0301704406721 .0301704406720 .7253894805920 .4206008911120 .11581993103 19.5062503814718 .8966808319118 .28710937518 .28710937519 .50625038147 23.1636695861828 .6497993469227 .7354507446326 .8210906982425 .9067401886 25.2971591949526 .5163097381630 .4785099029533 .5263595581135 .05028915405 35.9646492004436 .5742111206137 .1837806701737 .4885711669937 .79335021973 38.0981407165538 .0981407165538 .4029312133838 .4029312133838 .70771026611 38.7077102661139 .0125007629439 .3172798156739 .622070312539 .92684936523 39.9268493652340 .5364189147940 .8412094116241 .1459884643641 .45077896118 41.7555618286141 .7555618286142 .0603485107442 .3651313781742 .36513137817 42.3651313781742 .66992187542 .3651313781742 .3651313781742 .06034851074 41.7555618286141 .4507789611840 .8412094116240 .5364189147939 .92684936523 39.3172798156738 .7077102661138 .0981407165537 .4885711669936 .87900161743 36.2694282531735 .6598587036135 .0502891540534 .7455101013234 .13592910767 34.1359291076734 .1359291076734 .4407196044935 .0502891540535 .35507965088 35.9646492004436 .8790016174337 .4885711669938 .4029312133839 .01250076294 39.9268493652340 .5364189147941 .4507789611842 .3651313781743 .27949142456 43.8890609741244 .8034095764245 .717769622846 .6321296691947 .54647827148 48.4608306884849 .3751907348650 .2895507812551 .2038993835452 .11825942993 53.0326118469253 .9469718933154 .8613204956155 .7756805419956 .69002914429 57.6043891906758 .5187492370659 .1283111572360 .0426712036160 .95701980591 61.5666007995662 .4809494018663 .3953094482464 .004882812564 .91924285889 65.5288009643666 .1383666992267 .0527267456167 .6623001098668 .57665252686 $69.1862335205170 .1005783081171 .3197174072372 .8436431884874 .36756896973-9999$ -9999 -9999 -9999 -9999 -9999 -9999 -9999 -9999 -9999 -9999 -9999 -9999 -9999 -9999 -9999 -9999 -9999 -9999 -9999 -9999 -9999 -9999 -9999 -9999 -9999 -9999 -9999 -9999 -9999 -9999 -9999 -9999 -9999 -9999 -9999 -9999 -9999 -9999 -9999 -9999 -9999 -9999 -9999 -9999 -9999 -9999 -9999 -9999 -9999 -9999 -9999 -9999 -9999 -9999 -9999 -9999 -9999 -9999 -9999 -9999 -9999 -9999 -9999 -9999 -9999 -9999 -9999 -9999 -9999 -9999 -9999 -9999 -9999 -9999 -9999 -

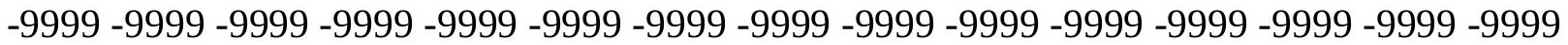
-9999 -9999 -9999 -9999 -9999 -9999 -9999 -9999 -9999 -9999 -9999 -9999 -9999 -9999 -9999 -9999 -9999 -9999 -9999 -9999 -9999 -9999 -9999 -9999 -9999 -9999 -9999

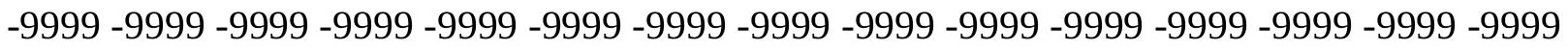
-9999 -9999 -9999 -9999 -9999 -9999 -9999 -9999 -9999 -9999 -9999 -9999 -9999 -9999 -9999 -9999 -9999 -9999 -9999 -9999 -9999 -9999 -9999 -9999 -9999 -9999 -9999 -9999 -9999 -9999 -9999 -9999 -9999 -9999 -9999 -9999 -9999 -9999 -9999 -9999 -9999 -9999 -9999 -9999 -9999 -9999 -9999 -9999 -9999 -9999 -9999 -9999 -9999 -9999 -9999 -9999 -9999 -9999 -9999 -9999 -9999 -9999 -9999 -9999 -9999 -9999 -9999 -9999 -9999 -9999 -9999 -9999 -9999 -9999 -9999 -9999 -9999 20.1158199310319.5062503814718.89668083191 18.59189033508 18.287109375 17.6775398254417 .3727493286117 .0679702758816 .7631797790516 .45840072632 16.1536102294915 .8488302230815 .8488302230815 .5440397262615 .54403972626 
15.5440397262615 .5440397262615 .5440397262615 .8488302230815 .84883022308 15.8488302230816 .1536102294916 .1536102294916 .4584007263216 .45840072632 16.7631797790517 .0679702758817 .3727493286117 .3727493286117 .67753982544 17.9823207855217 .9823207855218 .28710937518 .5918903350818 .59189033508 18.8966808319119 .2014598846419 .2014598846419 .5062503814719 .50625038147 19.5062503814719 .811029434219 .811029434219 .811029434219 .8110294342 20.1158199310320 .1158199310320 .1158199310320 .1158199310320 .11581993103 20.1158199310320 .1158199310320 .1158199310319 .811029434219 .8110294342 19.811029434219 .5062503814719 .5062503814719 .2014598846419 .20145988464 18.8966808319118 .8966808319118 .5918903350818 .5918903350818 .287109375 17.9823207855217 .6775398254417 .0679702758816 .1536102294915 .23925971985 13.715330123912 .191410064710 .6674804687510 .0579099655211 .27705001831 15.5440397262618 .28710937519 .2014598846418 .8966808319118 .28710937518 .287109375 28.3450202941931 .0880794525132 .9167900085434 .1359291076734 .74551010132 35.3550796508835 .9646492004436 .2694282531736 .5742111206136 .57421112061 36.8790016174336 .8790016174337 .1837806701737 .1837806701737 .48857116699 37.7933502197338 .0981407165538 .4029312133838 .7077102661139 .31727981567 39.622070312539 .9268493652340 .5364189147940 .8412094116241 .14598846436 41.4507789611841 .7555618286142 .0603485107442 .0603485107442 .06034851074 42.0603485107442 .0603485107441 .7555618286141 .7555618286141 .14598846436 40.8412094116240 .2316398620639 .622070312539 .0125007629438 .40293121338 37.7933502197337 .1837806701736 .5742111206135 .9646492004435 .35507965088 34.7455101013234 .1359291076733 .8311500549333 .5263595581133 .52635955811 34.1359291076734 .4407196044935 .0502891540535 .6598587036136 .26942825317 37.1837806701737 .7933502197338 .7077102661139 .3172798156740 .23163986206 41.1459884643641 .7555618286142 .66992187543 .5842704772944 .49863052368 45.4129791259846 .0225486755446 .9369087219247 .8512611389248 .7656211853 49.6799812316950 .5943298339851 .5086898803752 .4230384826753 .33739852905 54.2517509460455 .1661109924356 .0804595947356 .9948196411157 .9091796875 58.8235282897959 .4331016540560 .3474502563561 .2618103027362 .17617034912 62.7857398986863 .7000885009864 .3096618652365 .2240066528365 .83358764648 66.7479400634867 .3575134277368 .2718734741268 .8814392089869 .49101257324 70.4053573608471 .6244964599673 .14842987061 -9999 -9999 -9999 -9999 -9999 -9999 -9999 -9999 -9999 -9999 -9999 -9999 -9999 -9999 -9999 -9999 -9999 -9999 -9999 -9999 -9999 -9999 -9999 -9999 -9999 -9999 -9999 -9999 -9999 -9999 -9999 -9999 -9999 -9999 -9999 -9999 -9999 -

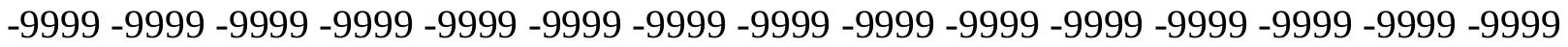

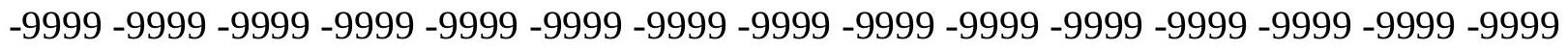

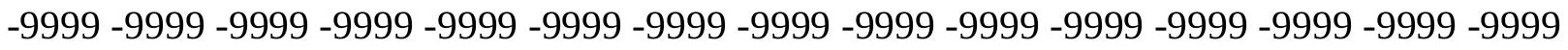
-9999 -9999 -9999 -9999 -9999 -9999 -9999 -9999 -9999 -9999 -9999 -9999 -9999 - 9999 - -999 -

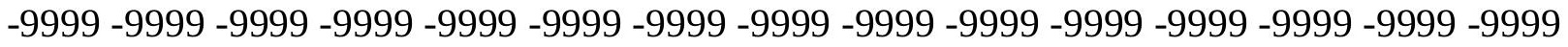
-9999 -9999 -9999-9999-9999-9999

-9999 -9999-9999 -9999 -9999 -9999 -9999 -9999 -9999-9999 -9999 -9999 -9999 -9999 -999 -9999 -9999 -9999 -9999 -9999 -9999 -9999 -9999 -9999 -9999 -9999 -9999 -9999 -9999 -9999 -9999 -9999 -9999 -9999 -9999 -9999 -9999 -9999 -9999 -9999 -9999 -9999 -9999 -9999 -9999 -9999 -9999 -9999 -9999 -9999 -9999 -9999 -9999 -9999 -9999 -9999 -9999 -9999 -9999 -9999 -

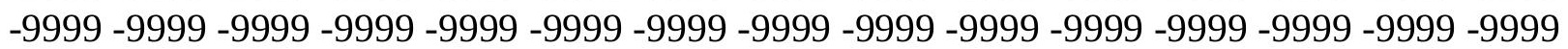


-9999 -9999 -9999 -9999 -9999 -9999 -9999 -9999 -9999 -9999 -9999 -9999 -9999 -9999 -9999 -9999 -9999 19.5062503814718.59189033508 18.287109375 17.67753982544 17.37274932861 16.7631797790516 .4584007263216 .1536102294915 .8488302230815 .54403972626 15.2392597198515 .2392597198514 .934470176714 .934470176714 .9344701767 14.934470176714 .934470176714 .934470176714 .934470176715 .23925971985 15.2392597198515 .5440397262615 .5440397262615 .8488302230816 .15361022949 16.4584007263216 .4584007263216 .7631797790517 .0679702758817 .06797027588 17.3727493286117 .6775398254417 .9823207855217 .9823207855218 .287109375 18.28710937518 .5918903350818 .5918903350818 .8966808319118 .89668083191 18.8966808319119 .2014598846419 .2014598846419 .2014598846419 .20145988464 19.2014598846419 .2014598846419 .2014598846419 .2014598846419 .20145988464 18.8966808319118 .8966808319118 .8966808319118 .5918903350818 .59189033508 18.28710937517 .9823207855217 .6775398254417 .6775398254417 .37274932861 17.0679702758816 .7631797790516 .4584007263216 .1536102294915 .84883022308 15.2392597198514 .6296901702914 .0201196670512 .8009700775111 .58183002472 9.448339462287 .3148431777954 .876562118531 .828711032867 -.609570324421 5.18134689331110 .0579099655212 .8009700775114 .0201196670515 .23925971985 18.28710937523 .7732391357428 .0402297973630 .4785099029532 .00244140625 33.2215805053733 .8311500549334 .1359291076734 .4407196044934 .74551010132 35.0502891540535 .0502891540535 .3550796508835 .6598587036135 .65985870361 35.9646492004436 .2694282531736 .8790016174337 .1837806701737 .48857116699 38.0981407165538 .4029312133839 .0125007629439 .3172798156739 .92684936523 40.2316398620640 .8412094116241 .1459884643641 .4507789611841 .75556182861 41.7555618286141 .7555618286141 .7555618286141 .7555618286141 .45077896118 41.1459884643640 .8412094116240 .2316398620639 .622070312539 .01250076294 38.4029312133837 .7933502197336 .8790016174336 .2694282531735 .65985870361 35.0502891540534 .4407196044934 .1359291076733 .5263595581133 .22158050537 33.5263595581133 .8311500549334 .1359291076734 .7455101013235 .35507965088 35.9646492004436 .8790016174337 .4885711669938 .4029312133839 .01250076294 39.9268493652340 .8412094116241 .4507789611842 .3651313781743 .27949142456 43.8890609741244 .8034095764245 .717769622846 .6321296691947 .54647827148 48.4608306884849 .3751907348650 .2895507812551 .2038993835452 .11825942993 53.0326118469253 .9469718933154 .8613204956155 .7756805419956 .38525009155 57.2995986938558 .2139587402359 .1283111572360 .0426712036160 .65224075317 61.5666007995662 .4809494018663 .0905189514264 .004882812564 .61444854736 65.5288009643666 .1383666992267 .0527267456167 .6623001098668 .57665252686 69.1862335205169 .7957916259870 .7101516723672 .2340774536173 .75800323486 -9999 -9999 -9999 -9999 -9999 -9999 -9999 -9999 -9999 -9999 -9999 -9999 -9999 -9999 -9999 -9999 -9999 -9999 -9999 -9999 -9999 -9999 -9999 -9999 -9999 -9999 -9999 -9999 -9999 -9999 -9999 -9999 -9999 -9999 -9999 -9999 -9999 -9999 -9999 -9999 -9999 -9999 -9999 -9999 -9999 -9999 -

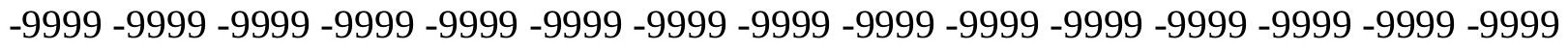

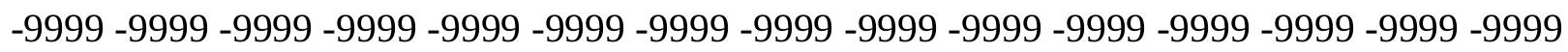

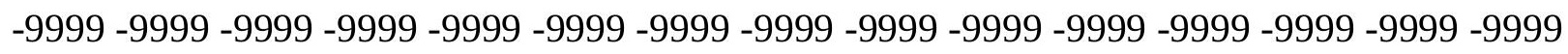
-9999 -9999 -9999 -9999 -9999 -9999 -9999 -9999 -9999 -9999 -9999 -9999 -9999 -9999 -9999 -9999 -9999 -9999 -9999 -9999 -9999 -9999 -9999 -9999 -9999 -9999

-9999 -9999 -9999 -9999 -9999 -9999 -9999 -9999 -9999 -9999 -9999 -9999 -9999 -9999 -9999 
-9999 -9999 -9999 -9999 -9999 -9999 -9999 -9999 -9999 -9999 -9999 -9999 -9999 -9999 -9999 -9999 -9999 -9999 -9999 -9999 -9999 -9999 -9999 -9999 -9999 -9999 -9999 -9999 -9999 -9999

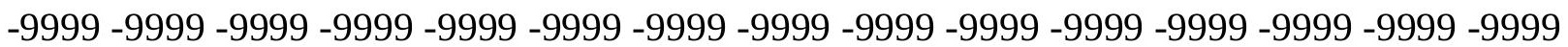
-9999 -9999 -9999 -9999 -9999 -9999 -9999 -9999 -9999 -9999 -9999 -9999 -9999 -9999 -9999 -9999 -9999 -9999 -9999 -9999 -9999 -9999 -9999 -9999 -9999 -9999 -9999 -9999 -9999 -9999 -9999 -9999 18.59189033508 17.67753982544 17.37274932861 16.76317977905 16.4584007263215 .8488302230815 .5440397262615 .2392597198514 .9344701767 14.6296901702914 .6296901702914 .3248996734614 .3248996734614 .32489967346 14.0201196670514 .3248996734614 .3248996734614 .3248996734614 .32489967346 14.6296901702914 .934470176714 .934470176715 .2392597198515 .54403972626 15.5440397262615 .8488302230816 .1536102294916 .4584007263216 .45840072632 16.7631797790517 .0679702758817 .3727493286117 .3727493286117 .67753982544 17.6775398254417 .9823207855217 .9823207855218 .28710937518 .28710937518 .287109375 18.5918903350818 .5918903350818 .5918903350818 .5918903350818 .59189033508 18.5918903350818 .5918903350818 .28710937518 .28710937518 .28710937517 .98232078552 17.9823207855217 .6775398254417 .3727493286117 .0679702758816 .76317977905 16.4584007263216 .1536102294915 .8488302230815 .5440397262615 .23925971985 14.934470176714 .3248996734614 .0201196670513 .4105501174912 .80097007751 12.191410064711 .2770500183110 .057909965528 .5339832305916 .705273151398 $4.2669920921331 .523926019669-.914355397224-1.523926019671 .21914100647$ 5.1813468933118 .83876895904511 .2770500183114 .0201196670517 .37274932861 21.334960937525 .2971591949528 .0402297973629 .8689403533931 .08807945251 32.0024414062532 .6120109558132 .9167900085433 .2215805053733 .22158050537 33.5263595581133 .8311500549333 .8311500549334 .1359291076734 .44071960449 35.0502891540535 .3550796508835 .6598587036136 .2694282531736 .87900161743 37.1837806701737 .7933502197338 .4029312133839 .0125007629439 .31727981567 39.9268493652340 .5364189147940 .8412094116241 .1459884643641 .45077896118 41.4507789611841 .7555618286141 .4507789611841 .4507789611841 .14598846436 40.5364189147940 .2316398620639 .622070312539 .0125007629438 .09814071655 37.4885711669936 .8790016174336 .2694282531735 .6598587036135 .05028915405 34.4407196044933 .8311500549333 .5263595581133 .5263595581133 .52635955811 33.5263595581134 .1359291076734 .4407196044935 .0502891540535 .96464920044 36.5742111206137 .4885711669938 .0981407165539 .0125007629439 .6220703125 40.5364189147941 .1459884643642 .0603485107442 .9747009277343 .58427047729 44.4986305236845 .4129791259846 .3273391723647 .2416992187548 .15605163574 48.765621185349 .6799812316950 .5943298339851 .5086898803752 .42303848267 53.3373985290554 .2517509460455 .1661109924356 .0804595947356 .99481964111 57.909179687558 .8235282897959 .4331016540560 .3474502563561 .26181030273 61.8713798522962 .7857398986863 .3953094482464 .3096618652364 .91924285889 65.8335876464866 .4431610107467 .3575134277367 .9670867919968 .57665252686 69.4910125732470 .1005783081171 .014930725172 .53885650635 -9999 -9999 -9999 -9999 -9999 -9999 -9999 -9999 -9999 -9999 -9999 -9999 -9999 -9999 -9999 -9999 -9999 -9999-9999 -9999 -9999 -9999 -9999 -9999 -9999 -9999 -9999 -9999 -9999 -9999 -9999 -9999 -9999 -9999 -9999 -9999 -9999 -9999 -9999 -9999 -9999 -9999 -9999 -9999 -9999 -9999 -9999 -9999 -9999 -999 -

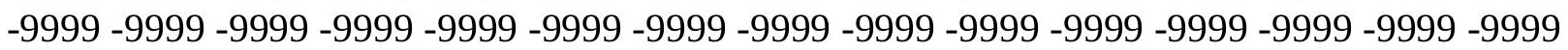

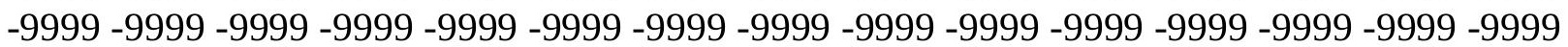


-9999 -9999 -9999 -9999 -9999 -9999 -9999 -9999 -9999 -9999 -9999 -9999 -9999 -9999 -9999 -9999 -9999 -9999 -9999 -9999 -9999 -9999 -9999 -9999 -9999 -9999 -9999 -9999 -9999 -9999 -9999-9999 -9999 -9999-9999-9999-9999 -9999

-9999 -9999 -9999 -9999 -9999 -9999 -9999 -9999 -9999 -9999 -9999 -9999 -9999 -9999 -9999 -9999 -9999 -9999 -9999 -9999 -9999 -9999 -9999 -9999 -9999 -9999 -9999-9999 -9999 -9999 -9999 -9999 -9999 -9999 -9999 -9999 -9999 -9999 -9999 -9999 -9999 -9999 -9999 -9999 -9999

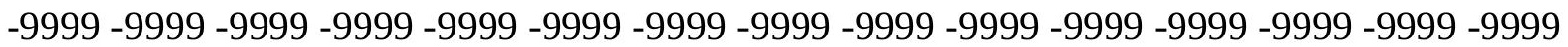
-9999 -9999 -9999 -9999 -9999 -9999 -9999 -9999 -9999 -9999 -9999 -9999 -9999 -9999 -9999 -999 -9999 -9999 -9999 -9999 -9999 -9999 -9999 -9999 -9999 -9999 -9999 -9999 -9999 -9999 -9999 -9999-9999 17.6775398254417.0679702758816.4584007263215.84883022308 15.5440397262615 .2392597198514 .6296901702914 .3248996734614 .02011966705 14.0201196670513 .715330123913 .715330123913 .4105501174913 .41055011749 13.4105501174913 .715330123913 .715330123913 .715330123914 .02011966705 14.0201196670514 .3248996734614 .6296901702914 .934470176714 .9344701767 15.2392597198515 .5440397262615 .8488302230816 .1536102294916 .15361022949 16.4584007263216 .7631797790517 .0679702758817 .0679702758817 .37274932861 17.3727493286117 .6775398254417 .6775398254417 .6775398254417 .98232078552 17.9823207855217 .9823207855217 .9823207855217 .9823207855217 .98232078552 17.9823207855217 .6775398254417 .6775398254417 .6775398254417 .37274932861 17.37274932861 17.0679702758816.76317977905 16.45840072632 16.15361022949 15.8488302230815 .5440397262615 .2392597198514 .6296901702914 .32489967346 14.0201196670513 .4105501174913 .1057596206712 .4961900711111 .88661956787 11.2770500183110 .6674804687510 .057909965529 .1435537338267 .924413204193 6.7052731513984 .876562118533 .047851085663 .9143553972244 -.304785102606 -9999 1.219141006474 .2669920921337 .61962795257610 .3626899719213 .41055011749 16.7631797790520 .1158199310323 .4684505462626 .2115192413328 .04022979736 29.2593708038330 .1737308502230 .7833003997831 .0880794525131 .39286994934 31.3928699493431 .6976509094232 .0024414062532 .3072204589832 .61201095581 32.9167900085433 .5263595581133 .8311500549334 .4407196044935 .05028915405 35.3550796508835 .9646492004436 .5742111206137 .1837806701737 .79335021973 38.4029312133839 .0125007629439 .622070312540 .2316398620640 .84120941162 41.1459884643641 .4507789611841 .4507789611841 .4507789611841 .14598846436 40.8412094116240 .5364189147939 .9268493652339 .3172798156738 .70771026611 38.0981407165537 .4885711669936 .8790016174336 .2694282531735 .65985870361 35.0502891540534 .4407196044934 .1359291076733 .8311500549333 .52635955811 33.5263595581133 .8311500549334 .1359291076734 .4407196044935 .05028915405 35.6598587036136 .5742111206137 .1837806701737 .7933502197338 .70771026611 39.3172798156740 .2316398620640 .8412094116241 .7555618286142 .669921875 43.2794914245644 .1938400268645 .1082000732446 .0225486755446 .93690872192 47.5464782714848 .4608306884849 .3751907348650 .2895507812551 .20389938354 52.1182594299353 .0326118469253 .9469718933154 .8613204956155 .77568054199 56.6900291442957 .2995986938558 .2139587402359 .1283111572360 .04267120361 60.6522407531761 .5666007995662 .4809494018663 .0905189514264 .0048828125 64.6144485473665 .5288009643666 .1383666992266 .7479400634867 .66230010986 68.2718734741268 .8814392089869 .4910125732470 .1005783081171 .31971740723 72.84364318848 -9999 -9999 -9999 -9999 -9999 -9999 -9999 -9999 -9999 -9999 -9999 -9999 
-9999 -9999 -9999 -9999 -9999 -9999 -9999 -9999 -9999 -9999 -9999 -9999 -9999 -9999 -9999 -9999 -9999 -9999 -9999 -9999 -9999 -9999 -9999 -9999 -9999 -9999 -9999 -9999 -9999 -9999

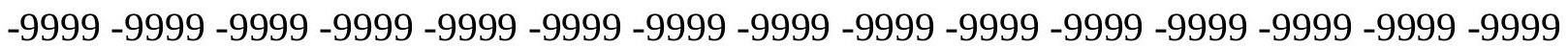
-9999 -9999 -9999 -9999 -9999 -9999 -9999 -9999 -9999 -9999 -9999 -9999 -9999 -9999 -9999 -9999 -9999 -9999 -9999 -9999 -9999 -9999 -9999 -9999 -9999 -9999 -9999 -9999 -9999 -9999 -9999 -9999 -9999 -9999 -9999 -9999 -9999 -9999 -9999 -9999 -9999 -9999 -9999 -9999 -9999 -999 -9999 -9999 -9999 -9999 -9999 -9999 -9999 -9999 -9999 -9999 -9999 -9999 -9999 -9999 -9999 -9999 -9999 -9999 -9999 -9999 -9999 -9999 -9999 -9999 -9999 -9999 -9999 -9999 -9999

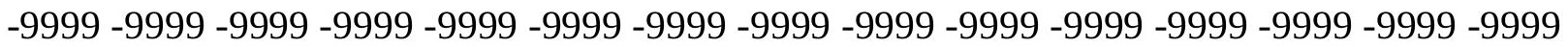
-9999 -9999 -9999 -9999 -9999 -9999 -9999 -9999 -9999 -9999 -9999 -9999 -9999 -9999 -9999 -9999 -9999 -9999 -9999 -9999 -9999 -9999 -9999 -9999 -9999 -9999 -9999 -9999 -9999 -9999 -9999 -9999 -9999 -9999 -9999 -9999 -9999 -9999 -9999 -9999 -9999 -9999 -9999 -9999 -9999

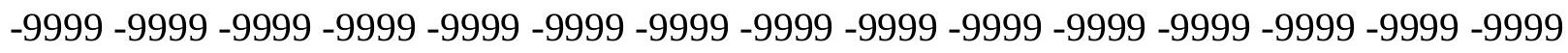
-9999 -9999 16.7631797790516 .1536102294915 .5440397262615 .23925971985 14.6296901702914 .3248996734614 .0201196670513 .715330123913 .41055011749 13.1057596206713 .1057596206712 .8009700775112 .8009700775112 .80097007751 12.8009700775113 .1057596206713 .1057596206713 .4105501174913 .41055011749 13.715330123914 .0201196670514 .3248996734614 .3248996734614 .62969017029 14.934470176715 .2392597198515 .5440397262615 .8488302230816 .15361022949 16.1536102294916 .4584007263216 .7631797790516 .7631797790517 .06797027588 17.0679702758817 .3727493286117 .3727493286117 .3727493286117 .67753982544 17.6775398254417 .6775398254417 .6775398254417 .3727493286117 .37274932861 17.3727493286117 .0679702758817 .0679702758816 .7631797790516 .76317977905 16.4584007263216 .1536102294915 .8488302230815 .5440397262615 .23925971985 14.934470176714 .3248996734614 .0201196670513 .4105501174912 .80097007751 12.4961900711111 .8866195678711 .2770500183110 .6674804687510 .05790996552 9.448339462288 .8387689590458 .2291984558117 .6196279525766 .705273151398 5.4861321449284 .5717768669133 .3526360988622 .1334960460661 .828711032867 2.1334960460663 .6574220657355 .4861321449288 .22919845581110 .66748046875 13.4105501174916 .4584007263219 .2014598846421 .9445304870624 .38281059265 26.2115192413327 .430660247828 .3450202941928 .6497993469229 .25937080383 29.5641593933129 .8689403533929 .8689403533930 .1737308502230 .78330039978 31.0880794525131 .3928699493431 .6976509094232 .3072204589832 .91679000854 33.5263595581134 .1359291076734 .7455101013235 .3550796508836 .26942825317 36.8790016174337 .4885711669938 .0981407165539 .0125007629439 .6220703125 40.2316398620640 .5364189147941 .1459884643641 .1459884643641 .14598846436 41.1459884643640 .8412094116240 .5364189147939 .9268493652339 .31727981567 38.7077102661138 .0981407165537 .4885711669936 .8790016174336 .26942825317 35.6598587036135 .0502891540534 .4407196044934 .1359291076733 .83115005493 33.8311500549333 .8311500549333 .8311500549334 .1359291076734 .74551010132 35.3550796508835 .6598587036136 .5742111206137 .1837806701737 .79335021973 38.4029312133839 .3172798156739 .9268493652340 .8412094116241 .45077896118 42.3651313781743 .2794914245643 .8890609741244 .8034095764245 .7177696228 46.3273391723647 .2416992187548 .1560516357449 .0704002380449 .98476028442 50.8991203308151 .8134689331152 .7278289794953 .6421813964854 .55654144287 55.1661109924356 .0804595947356 .9948196411157 .909179687558 .82352828979 
59.4331016540560 .3474502563561 .2618103027361 .8713798522962 .78573989868 63.7000885009864 .3096618652364 .9192428588965 .8335876464866 .44316101074 67.0527267456167 .9670867919968 .5766525268669 .1862335205169 .79579162598 70.4053573608471 .9292907714873 .14842987061 -9999 -9999 -9999 -9999 -9999 -9999 -9999 -9999 -9999 -9999 -9999 -9999 -9999 -9999 -9999 -9999 -9999 -9999 -9999 -9999 -9999 -9999 -9999 -9999 -9999 -9999 -9999 -9999 -9999 -9999 -9999 -9999 -9999 -9999 -9999 -9999 -9999

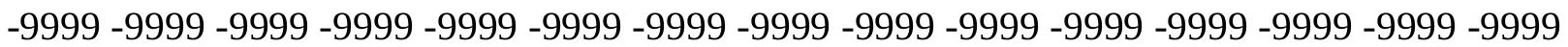

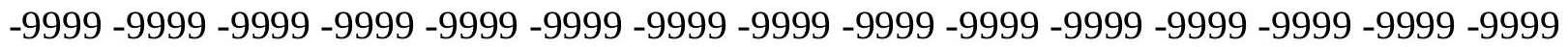
-9999 -9999 -9999 -9999 -9999 -9999 -9999 -9999 -9999 -9999 -9999 -9999 -9999 -9999 -9999 -9999 -9999 -9999 -9999 -9999 -9999 -9999 -9999 -9999 -9999 -9999 -9999 -9999 -9999 -9999 -

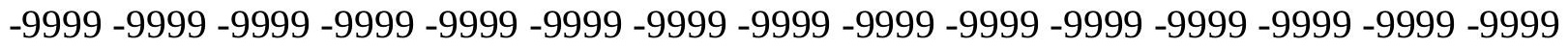
$-9999-9999-9999$

-9999 -9999 -9999 -9999 -9999 -9999 -9999 -9999 -9999 -9999 -9999 -9999 -9999 -9999 -9999 -9999 -9999 -9999 -9999 -9999 -9999 -9999 -9999 -9999 -9999 -9999 -9999 -9999 -9999 -9999 -9999 -9999 -9999 -9999 -9999 -9999 -9999 -9999 -9999 -9999 -9999 -9999 -9999 -9999 -9999 -

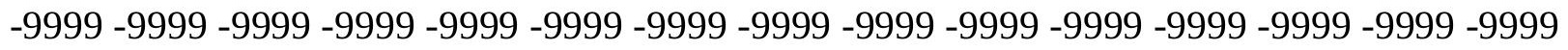

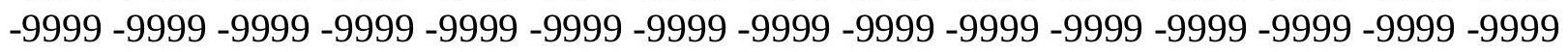
-9999 -9999 -9999 -9999 -9999 -9999 -9999 -9999 -9999 -9999 -9999 -9999 -9999 -9999 -9999 -9999-9999 16.15361022949 15.2392597198514.62969017029 14.32489967346 13.715330123913 .4105501174913 .1057596206712 .8009700775112 .49619007111 12.4961900711112 .191410064712 .191410064712 .191410064712 .1914100647 12.4961900711112 .4961900711112 .8009700775112 .8009700775113 .10575962067 13.4105501174913 .715330123914 .0201196670514 .3248996734614 .32489967346 14.6296901702914 .934470176715 .2392597198515 .5440397262615 .84883022308 16.1536102294916 .4584007263216 .4584007263216 .7631797790516 .76317977905 17.0679702758817 .0679702758817 .0679702758817 .3727493286117 .37274932861 17.3727493286117 .0679702758817 .0679702758817 .0679702758817 .06797027588 16.7631797790516 .7631797790516 .4584007263216 .1536102294915 .84883022308 15.5440397262615 .2392597198514 .934470176714 .6296901702914 .02011966705 13.715330123913 .1057596206712 .8009700775112 .191410064711 .58183002472 10.9722604751610 .362689971929 .7531242370619 .1435537338268 .533983230591 7.9244132041937 .3148431777957 .0100579261786 .4004869461065 .790916919708 5.1813468933114 .5717768669134 .2669920921334 .2669920921334 .87656211853 5.4861321449286 .4004869461067 .9244132041939 .4483394622811 .58183002472 13.715330123916 .1536102294918 .5918903350820 .7253894805922 .85887908936 24.3828105926525 .2971591949526 .2115192413326 .8210906982427 .12587928772 27.7354507446328 .0402297973628 .3450202941928 .6497993469228 .95458984375 29.2593708038329 .8689403533930 .1737308502230 .7833003997831 .39286994934 32.0024414062532 .6120109558133 .5263595581134 .1359291076734 .74551010132 35.6598587036136 .5742111206137 .1837806701738 .0981407165538 .70771026611 39.622070312540 .2316398620640 .5364189147941 .1459884643641 .14598846436 41.1459884643640 .8412094116240 .2316398620639 .9268493652339 .31727981567 38.7077102661138 .0981407165537 .4885711669936 .8790016174336 .26942825317 35.6598587036135 .0502891540534 .7455101013234 .4407196044934 .13592910767 34.1359291076734 .1359291076734 .1359291076734 .4407196044934 .74551010132 35.3550796508835 .9646492004436 .5742111206137 .1837806701737 .79335021973 
38.4029312133839 .3172798156739 .9268493652340 .5364189147941 .45077896118 42.0603485107442 .9747009277343 .5842704772944 .4986305236845 .41297912598 46.3273391723646 .9369087219247 .8512611389248 .765621185349 .67998123169 50.5943298339851 .5086898803752 .4230384826753 .0326118469253 .94697189331 54.8613204956155 .7756805419956 .6900291442957 .6043891906758 .51874923706 59.1283111572360 .0426712036160 .9570198059161 .5666007995662 .48094940186 63.0905189514264 .004882812564 .6144485473665 .5288009643666 .13836669922 66.7479400634867 .3575134277367 .9670867919968 .5766525268669 .18623352051 69.7957916259870 .7101516723672 .23407745361 -9999 -9999 -9999 -9999 -9999 -9999 -9999 -9999 -9999 -9999 -9999 -9999 -9999 -9999 -9999 -9999 -9999 -9999 -9999 -9999 -9999 -9999 -9999 -9999 -9999 -9999 -9999 -9999 -9999 -9999 -9999 -9999 -9999 -9999 -9999 -9999 -9999 -9999 -9999 -9999 -9999 -9999 -9999 -9999 -9999 -9999 -9999 -9999 -9999 -9999 -9999 -9999 -9999 -9999 -9999 -9999 -9999 -9999 -9999 -9999 -9999 -9999 -9999 -9999 -9999 -9999 -9999 -9999 -9999 -9999 -9999 -9999 -9999 -9999 -9999 -9999 -9999 -9999 -9999 -9999 -9999 - 9999 -9999 -9999 -9999 -9999 -9999 -9999 -9999 -9999 -9999 -9999 -9999 -9999 -9999 -9999 -9999

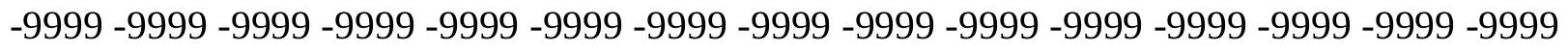
-9999 -9999-9999

-9999 -9999 -9999 -9999 -9999 -9999 -9999 -9999 -9999 -9999 -9999 -9999 -9999 -9999 -9999 -9999 -9999 -9999 -9999 -9999 -9999 -9999 -9999 -9999 -9999 -9999 -9999 -9999 -9999 -9999 -

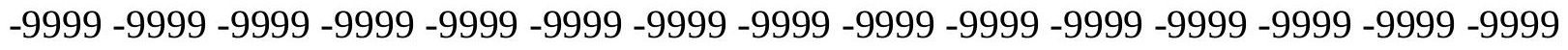

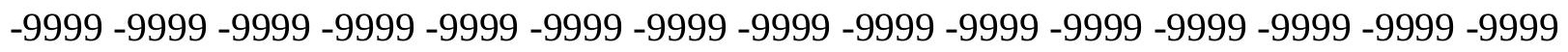
-9999 -9999 -9999 -9999 -9999 -9999 -9999 -9999 -9999 -9999 -9999 -9999 -9999 -9999 -9999 -9999 -9999 -9999 -9999 -9999 -9999 -9999 -9999 -9999 -9999 -9999 -9999 -9999 -9999 -9999 -9999 -9999 15.23925971985 14.3248996734613.715330123913.41055011749 12.8009700775112 .4961900711112 .191410064712 .191410064711 .88661956787 11.5818300247211 .5818300247211 .5818300247211 .5818300247211 .88661956787 11.8866195678712 .191410064712 .191410064712 .4961900711112 .80097007751 13.1057596206713 .4105501174913 .715330123914 .0201196670514 .32489967346 14.6296901702914 .934470176715 .2392597198515 .5440397262615 .84883022308 16.1536102294916 .1536102294916 .4584007263216 .4584007263216 .76317977905 16.7631797790517 .0679702758817 .0679702758817 .0679702758817 .06797027588 17.0679702758816 .7631797790516 .7631797790516 .7631797790516 .45840072632 16.4584007263216 .1536102294915 .8488302230815 .5440397262615 .23925971985 14.934470176714 .6296901702914 .0201196670513 .715330123913 .10575962067 12.8009700775112 .191410064711 .5818300247210 .9722604751610 .36268997192 9.7531242370619 .1435537338268 .5339832305917 .9244132041937 .314843177795 6.7052731513986 .4004869461065 .7909169197085 .4861321449285 .181346893311 5.1813468933115 .1813468933115 .7909169197086 .4004869461067 .619627952576 8.8387689590459 .4483394622810 .0579099655210 .9722604751612 .49619007111 14.0201196670515 .8488302230817 .6775398254419 .5062503814721 .03017044067 22.5541000366223 .4684505462624 .3828105926524 .9923801422125 .29715919495 25.6019496917726 .2115192413326 .5163097381626 .8210906982427 .4306602478 27.7354507446328 .3450202941928 .6497993469229 .2593708038329 .86894035339 30.4785099029531 .3928699493432 .0024414062532 .9167900085433 .52635955811 34.4407196044935 .3550796508836 .2694282531737 .1837806701738 .09814071655 38.7077102661139 .622070312540 .2316398620640 .8412094116240 .84120941162 
40.8412094116240 .5364189147940 .2316398620639 .622070312539 .01250076294 38.4029312133838 .0981407165537 .4885711669936 .8790016174336 .26942825317 35.6598587036135 .3550796508835 .0502891540534 .7455101013234 .44071960449 34.4407196044934 .4407196044934 .4407196044934 .7455101013235 .05028915405 35.6598587036135 .9646492004436 .5742111206137 .1837806701737 .79335021973 38.4029312133839 .0125007629439 .9268493652340 .5364189147941 .14598846436 42.0603485107442 .66992187543 .5842704772944 .1938400268645 .10820007324 46.0225486755446 .6321296691947 .5464782714848 .4608306884849 .37519073486 50.2895507812551 .2038993835452 .1182594299352 .7278289794953 .64218139648 54.5565414428755 .4708900451756 .3852500915557 .2995986938557 .9091796875 58.8235282897959 .7378807067960 .6522407531761 .2618103027362 .17617034912 62.7857398986863 .7000885009864 .3096618652365 .2240066528365 .83358764648 66.4431610107467 .0527267456167 .6623001098668 .2718734741268 .88143920898 69.4910125732470 .1005783081171 .3197174072372 .84364318848 -9999 -9999 -9999 -9999 -9999 -9999 -9999 -9999 -9999 -9999 -9999 -9999 -9999 -9999 -9999 -9999 -9999 -9999 -9999

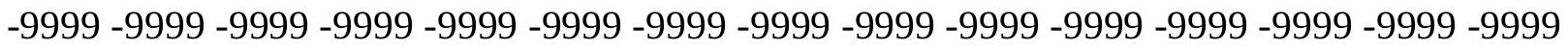
-9999 -9999 -9999 -9999 -9999 -9999 -9999 -9999 -9999 -9999 -9999 -9999 -9999 -9999 -9999 -9999 -9999 -9999 -9999 -9999 -9999 -9999 -9999 -9999 -9999 -9999 -9999 -9999 -9999 - 9999 -9999 -9999 -9999 -9999 -9999 -9999 -9999 -9999 -9999 -9999 -9999 -9999 -9999 -9999 -9999 -

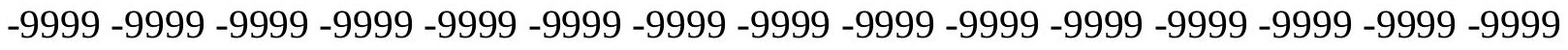

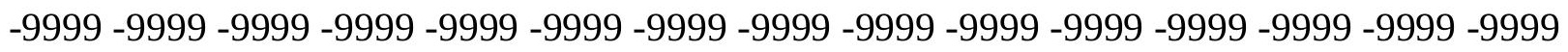
-9999 -9999-9999-9999-9999

-9999 -9999 -9999 -9999 -9999 -9999 -9999 -9999 -9999 -9999 -9999 -9999 -9999 -9999 -9999

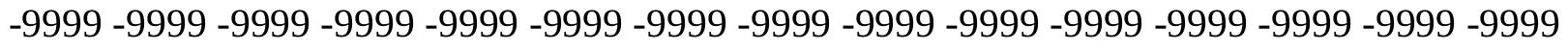

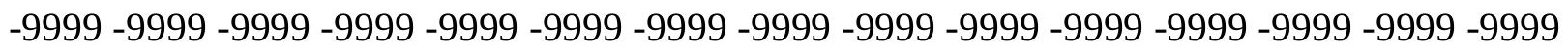
-9999 -9999 -9999 -9999 -9999 -9999 -9999 -9999 -9999 -9999 -9999 -9999 -9999 -9999 -9999 -9999 -9999 -9999 -9999 -9999 -9999 -9999 -9999 -9999 -9999 -9999 -9999 -9999 -9999 -9999 -

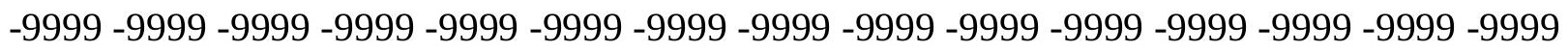
-9999 -9999 14.3248996734613.41055011749 13.10575962067 12.49619007111 12.191410064711 .8866195678711 .5818300247211 .2770500183111 .27705001831 10.9722604751610 .9722604751610 .9722604751611 .2770500183111 .27705001831 11.5818300247211 .5818300247211 .8866195678712 .191410064712 .49619007111 12.8009700775113 .1057596206713 .4105501174914 .0201196670514 .32489967346 14.6296901702914 .934470176715 .2392597198515 .5440397262615 .84883022308 16.1536102294916 .1536102294916 .4584007263216 .4584007263216 .76317977905 16.7631797790516 .7631797790516 .7631797790516 .7631797790516 .76317977905 16.7631797790516 .7631797790516 .4584007263216 .4584007263216 .15361022949 15.8488302230815 .5440397262615 .2392597198514 .934470176714 .62969017029 14.3248996734613 .715330123913 .4105501174912 .8009700775112 .49619007111 11.8866195678711 .2770500183110 .667480468759 .7531242370619 .143553733826 8.5339832305917 .9244132041937 .3148431777956 .7052731513986 .095703125 5.7909169197085 .4861321449285 .1813468933114 .876562118534 .87656211853 5.1813468933115 .7909169197086 .705273151398 8.2291984558119.753124237061 11.8866195678711 .5818300247211 .5818300247212 .191410064712 .80097007751 14.0201196670515 .2392597198516 .7631797790518 .28710937519 .50625038147 20.7253894805921 .6397399902322 .2493095397922 .8588790893623 .46845054626 
23.7732391357424 .3828105926524 .6875991821325 .2971591949525 .60194969177 26.2115192413326 .5163097381627 .1258792877227 .7354507446328 .34502029419 29.2593708038329 .8689403533930 .4785099029531 .3928699493432 .30722045898 32.9167900085433 .8311500549335 .0502891540535 .9646492004436 .87900161743 37.7933502197339 .0125007629439 .622070312540 .2316398620640 .84120941162 40.8412094116240 .5364189147939 .9268493652339 .3172798156739 .01250076294 38.4029312133837 .7933502197337 .1837806701736 .8790016174336 .26942825317 35.9646492004435 .3550796508835 .0502891540534 .7455101013234 .74551010132 34.7455101013234 .7455101013234 .7455101013235 .0502891540535 .35507965088 35.6598587036136 .2694282531736 .8790016174337 .1837806701737 .79335021973 38.4029312133839 .0125007629439 .622070312540 .5364189147941 .14598846436 41.7555618286142 .66992187543 .2794914245644 .1938400268644 .80340957642 45.717769622846 .6321296691947 .2416992187548 .1560516357449 .07040023804 49.9847602844250 .8991203308151 .8134689331152 .4230384826753 .33739852905 54.2517509460455 .1661109924356 .0804595947356 .9948196411157 .60438919067 58.5187492370659 .4331016540560 .3474502563560 .9570198059161 .87137985229 62.4809494018663 .3953094482464 .004882812564 .9192428588965 .52880096436 66.1383666992266 .7479400634867 .3575134277367 .9670867919968 .57665252686 69.1862335205169 .4910125732470 .4053573608471 .6244964599673 .14842987061 -9999 -9999 -9999 -9999 -9999 -9999 -9999 -9999 -9999 -9999 -9999 -9999 -9999 -9999 -9999 -9999

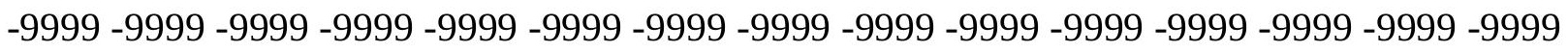
-9999 -9999 -9999 -9999 -9999 -9999 -9999 -9999 -9999 -9999 -9999 -9999 -9999 -9999 -9999 -9999 -9999 -9999 -9999 -9999 -9999 -9999 -9999 -9999 -9999 -9999 -9999 -9999 -9999 -9999 -

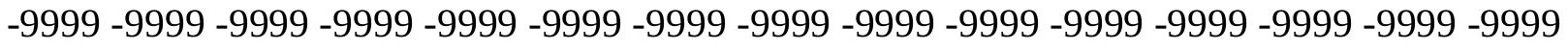

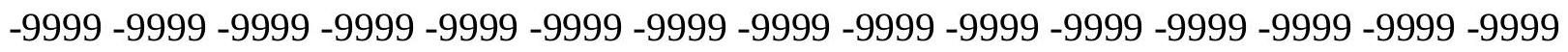

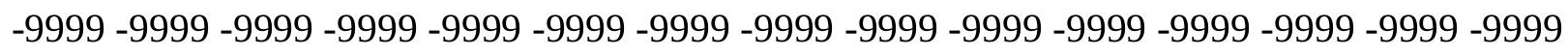
-9999 -9999 -9999 -9999-9999-9999-9999

-9999 -9999 -9999 -9999 -9999 -9999 -9999 -9999 -9999 -9999 -9999 -9999 -9999 -9999 -9999 -9999 -9999 -9999 -9999 -9999 -9999 -9999 -9999 -9999 -9999 -9999 -9999 -9999 -9999 -9999 -9999 -9999 -9999 -9999 -9999 -9999 -9999 -9999 -9999 -9999 -9999 -9999 -9999 -9999 -9999 -9999 -9999 -9999 -9999 -9999 -9999 -9999 -9999 -9999-9999 -9999 -9999 -9999 -9999 -9999 -9999 -9999 -9999 -9999 -9999 -9999 -9999 -9999 -9999 -9999 -9999 -9999 -9999 -9999 -9999 -

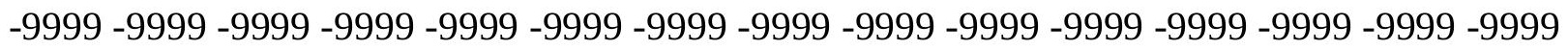
-9999 -9999 13.715330123912.80097007751 12.191410064711 .8866195678711 .27705001831 10.9722604751610 .9722604751610 .6674804687510 .6674804687510 .66748046875 10.6674804687510 .6674804687510 .6674804687510 .9722604751611 .27705001831 11.2770500183111 .5818300247211 .8866195678712 .4961900711112 .80097007751 13.1057596206713 .4105501174914 .0201196670514 .3248996734614 .62969017029 14.934470176715 .2392597198515 .5440397262615 .8488302230816 .15361022949 16.4584007263216 .4584007263216 .7631797790516 .7631797790516 .76317977905 16.7631797790516 .7631797790516 .7631797790516 .7631797790516 .76317977905 16.4584007263216 .4584007263216 .1536102294915 .8488302230815 .54403972626 15.2392597198514 .934470176714 .6296901702914 .0201196670513 .7153301239 13.1057596206712 .8009700775112 .191410064711 .5818300247210 .97226047516 10.362689971929 .7531242370618 .8387689590458 .2291984558117 .619627952576 7.0100579261786 .4004869461065 .7909169197085 .1813468933114 .87656211853 
4.5717768669134 .5717768669134 .5717768669134 .5717768669135 .181346893311 6.0957031257 .3148431777958 .83876895904510 .3626899719211 .88661956787 12.191410064712 .191410064712 .4961900711113 .1057596206713 .7153301239 14.6296901702915 .8488302230816 .7631797790517 .9823207855218 .89668083191 19.811029434220 .4206008911121 .0301704406721 .6397399902321 .94453048706 22.5541000366223 .1636695861823 .4684505462624 .0780296325724 .38281059265 24.9923801422125 .6019496917726 .2115192413326 .8210906982427 .73545074463 28.3450202941928 .9545898437529 .8689403533930 .7833003997831 .69765090942 32.6120109558133 .5263595581134 .7455101013235 .6598587036136 .87900161743 37.7933502197339 .0125007629439 .9268493652340 .2316398620640 .23163986206 39.9268493652339 .622070312539 .0125007629438 .7077102661138 .09814071655 37.7933502197337 .1837806701736 .8790016174336 .2694282531735 .96464920044 35.6598587036135 .3550796508835 .0502891540535 .0502891540535 .05028915405 35.0502891540535 .0502891540535 .3550796508835 .6598587036135 .96464920044 36.5742111206136 .8790016174337 .4885711669937 .7933502197338 .40293121338 39.0125007629439 .622070312540 .2316398620641 .1459884643641 .75556182861 42.3651313781743 .2794914245643 .8890609741244 .8034095764245 .41297912598 46.3273391723647 .2416992187547 .8512611389248 .765621185349 .67998123169 50.5943298339851 .5086898803752 .1182594299353 .0326118469253 .94697189331 54.8613204956155 .7756805419956 .6900291442957 .2995986938558 .21395874023 59.1283111572360 .0426712036160 .6522407531761 .5666007995662 .17617034912 63.0905189514263 .7000885009864 .6144485473665 .2240066528365 .83358764648 66.4431610107467 .0527267456167 .6623001098668 .2718734741268 .88143920898 69.1862335205169 .7957916259870 .7101516723672 .23407745361 -9999 -9999 -9999 -9999 -9999 -9999 -9999 -9999 -9999 -9999 -9999 -9999 -9999 -9999 -9999 -9999 -9999 -9999 -9999 -9999 -9999 -9999 -9999 -9999 -9999 -9999 -9999 -9999 -9999 -9999 -9999 -9999 -9999 -9999 -9999 -9999 -9999 -9999 -9999 -9999 -9999 -9999 -9999 -9999 -9999 -9999 -9999 -9999 -9999 -9999 -9999 -9999 -9999 -9999 -9999 -9999 -9999 -9999 -9999 -9999 -9999 -9999 -9999 -9999 -9999 -9999 -9999 -9999 -9999 -9999 -9999 -9999 -9999 -9999 -9999 -9999 -9999 -9999 -9999

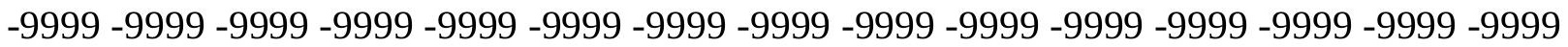
-9999 -9999 -9999 -9999 -9999 -9999 -9999 -9999 -9999 -9999 -9999 -9999 -9999 -9999 -9999 -9999-9999-9999-9999

-9999 -9999 -9999 -9999 -9999 -9999 -9999 -9999 -9999 -9999 -9999 -9999 -9999 -9999 -9999 -9999 -9999 -9999 -9999 -9999 -9999 -9999 -9999 -9999 -9999 -9999 -9999 -9999 -9999 -9999 -

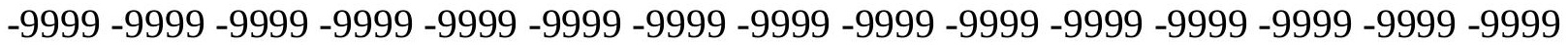
-9999 -9999 -9999 -9999 -9999 -9999 -9999 -9999 -9999 -9999 -9999 -9999 -9999 -9999 -9999 -9999 -9999 -9999 -9999 -9999 -9999 -9999 -9999 -9999 -9999 -9999 -9999 -9999 -9999 -9999 -9999 -9999 -9999 -9999 -9999 -9999 -9999 -9999 -9999 -9999 -9999 -9999 -9999 -9999 -9999 -9999 -9999 13.1057596206711 .8866195678711 .5818300247210 .97226047516 10.6674804687510 .3626899719210 .3626899719210 .0579099655210 .05790996552 10.0579099655210 .0579099655210 .3626899719210 .3626899719210 .66748046875 10.9722604751611 .2770500183111 .5818300247211 .8866195678712 .49619007111 12.8009700775113 .1057596206713 .715330123914 .0201196670514 .32489967346 14.6296901702915 .2392597198515 .5440397262615 .8488302230816 .15361022949 16.1536102294916 .4584007263216 .7631797790516 .7631797790516 .76317977905 16.7631797790517 .0679702758816 .7631797790516 .7631797790516 .76317977905 
16.4584007263216 .4584007263216 .1536102294915 .8488302230815 .54403972626 15.2392597198514 .934470176714 .6296901702914 .0201196670513 .7153301239 13.1057596206712 .4961900711112 .191410064711 .5818300247210 .97226047516 10.057909965529 .448339462288 .8387689590458 .2291984558117 .314843177795 6.7052731513986 .0957031255 .4861321449284 .876562118534 .571776866913 4.2669920921333 .9622070789343 .9622070789343 .9622070789344 .571776866913 5.1813468933116 .0957031257 .3148431777958 .83876895904510 .05790996552 11.2770500183111 .8866195678712 .191410064712 .191410064712 .80097007751 13.1057596206714 .0201196670514 .6296901702915 .5440397262616 .45840072632 17.37274932861 17.98232078552 18.59189033508 19.2014598846419.8110294342 20.4206008911120 .7253894805921 .334960937521 .9445304870622 .24930953979 22.8588790893623 .4684505462624 .0780296325724 .6875991821325 .29715919495 26.2115192413326 .8210906982427 .430660247828 .3450202941929 .25937080383 30.1737308502231 .0880794525132 .0024414062533 .2215805053734 .13592910767 35.3550796508836 .5742111206137 .7933502197338 .7077102661139 .6220703125 39.622070312539 .3172798156739 .0125007629438 .7077102661138 .09814071655 37.7933502197337 .4885711669936 .8790016174336 .5742111206136 .26942825317 35.9646492004435 .6598587036135 .6598587036135 .3550796508835 .35507965088 35.3550796508835 .3550796508835 .3550796508835 .6598587036135 .96464920044 36.2694282531736 .5742111206137 .1837806701737 .4885711669938 .09814071655 38.7077102661139 .0125007629439 .622070312540 .2316398620641 .14598846436 41.7555618286142 .3651313781742 .9747009277343 .8890609741244 .49863052368 45.4129791259846 .0225486755446 .9369087219247 .8512611389248 .46083068848 49.3751907348650 .2895507812551 .2038993835452 .1182594299352 .72782897949 53.6421813964854 .5565414428755 .4708900451756 .3852500915557 .29959869385 57.909179687558 .8235282897959 .7378807067960 .3474502563561 .26181030273 61.8713798522962 .7857398986863 .3953094482464 .3096618652364 .91924285889 65.5288009643666 .1383666992266 .7479400634867 .3575134277367 .96708679199 68.5766525268668 .8814392089869 .4910125732470 .1005783081171 .31971740723 72.84364318848 -9999 -9999 -9999 -9999 -9999 -9999 -9999 -9999 -9999 -9999 -9999 -9999 -9999 -9999 -9999 -9999 -9999 -9999 -9999 -9999 -9999 -9999 -9999 -9999 -9999 -9999 -9999

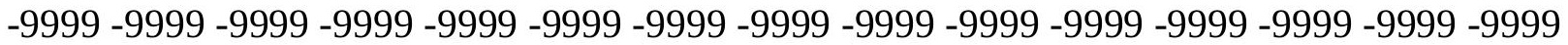
-9999 -9999 -9999 -9999 -9999 -9999 -9999 -9999 -9999 -9999 -9999 -9999 -9999 -9999 -9999 -9999 -9999 -9999 -9999 -9999 -9999 -9999 -9999 -9999 -9999 -9999 -9999 -9999 -9999 -9999 -9999 -9999 -9999 -9999 -9999 -9999 -9999 -9999 -9999 -9999 -9999 -9999 -9999 -9999 -9999 -9999 -9999 -9999 -9999 -9999 -9999 -9999 -9999 -9999 -9999 -9999 -9999 -9999 -9999 -9999 -9999 -9999 -9999 -9999 -9999 -9999 -9999 -9999 -9999 -9999

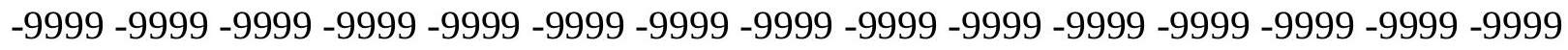
-9999 -9999 -9999 -9999 -9999 -9999 -9999 -9999 -9999 -9999 -9999 -9999 -9999 -9999 -9999 -9999 -9999 -9999 -9999 -9999 -9999 -9999 -9999 -9999 -9999 -9999 -9999 -9999 -9999 -9999 -9999 -9999 -9999 -9999 -9999 -9999 -9999 -9999 -9999-9999 -9999 -9999 -9999-999 - -999 -9999 -9999 -9999 -9999 -9999 -9999 -9999 -9999 -9999 -9999 -9999 -9999 -9999 -9999 -9999 -9999 -9999 -9999 -9999 -9999 -9999 -9999 -9999 -9999 -9999 -9999 -9999 -9999 -9999 -9999 -999 -9999 -9999 12.49619007111 11.27705001831 10.9722604751610.36268997192 10.057909965529 .7531242370619 .7531242370619 .448339462289 .44833946228 9.7531242370619 .7531242370619 .75312423706110 .0579099655210 .36268997192 
10.6674804687510 .9722604751611 .5818300247211 .8866195678712 .49619007111 12.8009700775113 .4105501174913 .715330123914 .3248996734614 .62969017029 14.934470176715 .5440397262615 .8488302230816 .1536102294916 .45840072632 16.4584007263216 .7631797790516 .7631797790517 .0679702758817 .06797027588 17.0679702758817 .0679702758817 .0679702758816 .7631797790516 .76317977905 16.4584007263216 .4584007263216 .1536102294915 .8488302230815 .54403972626 14.934470176714 .6296901702914 .3248996734613 .715330123913 .10575962067 12.8009700775112 .191410064711 .5818300247210 .9722604751610 .05790996552 9.448339462288 .8387689590458 .2291984558117 .3148431777956 .705273151398 6.0957031255 .4861321449284 .876562118534 .2669920921333 .962207078934 3.6574220657353 .3526360988623 .6574220657353 .6574220657354 .266992092133 4.876562118535 .7909169197087 .0100579261788 .2291984558119 .44833946228 10.3626899719210 .9722604751611 .2770500183111 .5818300247211 .88661956787 12.4961900711113 .1057596206713 .715330123914 .3248996734614 .9344701767 15.8488302230816 .4584007263217 .0679702758817 .6775398254417 .98232078552 18.5918903350819 .2014598846419 .811029434220 .1158199310320 .72538948059 21.334960937521 .9445304870622 .5541000366223 .1636695861823 .77323913574 24.6875991821325 .2971591949526 .2115192413326 .8210906982427 .73545074463 28.6497993469229 .5641593933130 .4785099029531 .3928699493432 .61201095581 33.8311500549334 .7455101013235 .9646492004437 .1837806701738 .09814071655 38.4029312133838 .4029312133838 .0981407165537 .7933502197337 .48857116699 37.4885711669937 .1837806701736 .8790016174336 .5742111206136 .26942825317 35.9646492004435 .9646492004435 .6598587036135 .6598587036135 .65985870361 35.6598587036135 .6598587036135 .6598587036135 .9646492004436 .26942825317 36.5742111206136 .8790016174337 .1837806701737 .7933502197338 .09814071655 38.7077102661139 .3172798156739 .622070312540 .2316398620640 .84120941162 41.4507789611842 .3651313781742 .9747009277343 .5842704772944 .49863052368 45.1082000732446 .0225486755446 .6321296691947 .5464782714848 .46083068848 49.0704002380449 .9847602844250 .8991203308151 .8134689331152 .72782897949 53.3373985290554 .2517509460455 .1661109924356 .0804595947356 .99481964111 57.6043891906758 .5187492370659 .4331016540560 .3474502563560 .95701980591 61.8713798522962 .4809494018663 .0905189514264 .004882812564 .61444854736 65.2240066528365 .8335876464866 .4431610107467 .0527267456167 .66230010986 68.2718734741268 .5766525268669 .1862335205169 .7957916259870 .40535736084 71.9292907714873 .45321655273 -9999 -9999 -9999 -9999 -9999 -9999 -9999 -9999 -9999 -9999 -9999 -9999 -9999 -9999 -9999 -9999 -9999 -9999 -9999 -9999 -9999 -9999 -9999 -9999

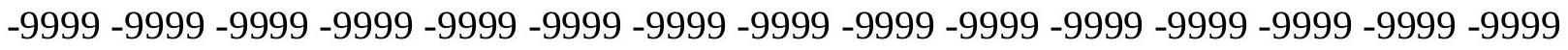

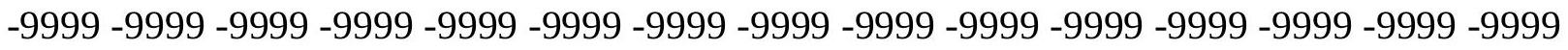
-9999 -9999 -9999 -9999 -9999 -9999 -9999 -9999 -9999 -9999 -9999 -9999 -9999 -9999 -9999 -9999 -9999 -9999 -9999 -9999 -9999 -9999 -9999 -9999 -9999 -9999 -9999 -9999 -9999 -9999 -

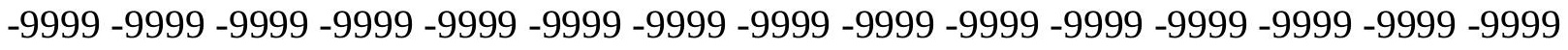
-9999 -9999 -9999 -9999 -9999 -9999 -9999 -9999 -9999 -9999 -9999 -9999 -9999 -9999 -9999 -9999 -9999 -9999 -9999 -9999 -9999 -9999 -9999 -9999 -9999 -9999 -9999 -9999 -9999 -9999 -9999 -9999 -9999 -9999 -9999 -9999-9999 -9999 -9999 -9999 -9999 -9999 -9999 -9999 -9999 -9999 -9999 -9999 -9999 -9999 -9999 -9999 -9999 -9999 -9999 -9999 -9999 -

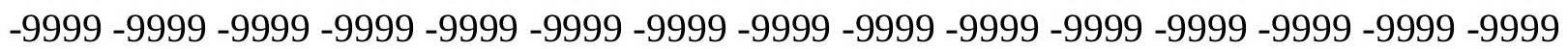


-9999 -9999 -9999 -9999 -9999 -9999 -9999 -9999 -9999 -9999 -9999 -9999 -9999 -9999 -9999 -9999 -9999 -9999 -9999 -9999 -9999 -9999 -9999 -9999 -9999 -9999 -9999 -9999 -9999 -9999 -9999 -9999 12.1914100647 10.9722604751610.3626899719210.05790996552 9.7531242370619 .448339462289 .1435537338269 .1435537338269 .143553733826 9.1435537338269 .448339462289 .75312423706110 .0579099655210 .36268997192 10.6674804687510 .9722604751611 .5818300247212 .191410064712 .49619007111 13.1057596206713 .715330123914 .0201196670514 .6296901702914 .9344701767 15.5440397262615 .8488302230816 .1536102294916 .4584007263216 .76317977905 16.7631797790517 .0679702758817 .0679702758817 .3727493286117 .37274932861 17.3727493286117 .3727493286117 .0679702758817 .0679702758816 .76317977905 16.7631797790516 .4584007263216 .1536102294915 .5440397262615 .23925971985 14.934470176714 .3248996734614 .0201196670513 .4105501174912 .80097007751 12.191410064711 .5818300247210 .9722604751610 .362689971929 .753124237061 8.8387689590458 .2291984558117 .3148431777956 .7052731513986 .095703125 5.4861321449284 .876562118534 .2669920921333 .6574220657353 .352636098862 3.0478510856633 .0478510856633 .0478510856633 .3526360988623 .962207078934 4.5717768669135 .4861321449286 .4004869461067 .3148431777958 .533983230591 9.1435537338269 .75312423706110 .3626899719210 .6674804687510 .97226047516 11.5818300247211 .8866195678712 .4961900711113 .1057596206713 .7153301239 14.3248996734614 .934470176715 .5440397262615 .8488302230816 .45840072632 17.0679702758817 .6775398254417 .9823207855218 .5918903350819 .20145988464 19.811029434220 .4206008911121 .0301704406721 .6397399902322 .24930953979 23.1636695861823 .7732391357424 .6875991821325 .2971591949526 .21151924133 27.1258792877228 .0402297973628 .9545898437529 .8689403533930 .78330039978 31.6976509094232 .9167900085434 .1359291076735 .0502891540535 .96464920044 36.5742111206136 .8790016174337 .1837806701736 .8790016174336 .87900161743 36.8790016174336 .5742111206136 .5742111206136 .2694282531736 .26942825317 35.9646492004435 .9646492004435 .6598587036135 .6598587036135 .65985870361 35.6598587036135 .9646492004435 .9646492004436 .2694282531736 .57421112061 36.8790016174337 .1837806701737 .4885711669937 .7933502197338 .40293121338 38.7077102661139 .3172798156739 .9268493652340 .2316398620640 .84120941162 41.4507789611842 .0603485107442 .9747009277343 .5842704772944 .19384002686 45.1082000732445 .717769622846 .6321296691947 .2416992187548 .15605163574 49.0704002380449 .6799812316950 .5943298339851 .5086898803752 .42303848267 53.3373985290553 .9469718933154 .8613204956155 .7756805419956 .69002914429 57.6043891906758 .2139587402359 .1283111572360 .0426712036160 .65224075317 61.5666007995662 .1761703491263 .0905189514263 .7000885009864 .30966186523 64.9192428588965 .5288009643666 .1383666992266 .7479400634867 .35751342773 67.9670867919968 .5766525268668 .8814392089869 .4910125732470 .10057830811 71.014930725172 .53885650635 -9999 -9999 -9999 -9999 -9999 -9999 -9999 -9999 -9999 -9999 -9999 -9999 -9999 -9999 -9999 -9999 -9999 -9999 -9999 -9999 -9999 -9999 -9999 -9999

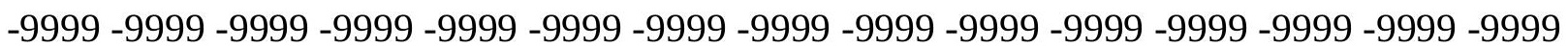
-9999 -9999 -9999 -9999 -9999 -9999 -9999 -9999 -9999 -9999 -9999 -9999 -9999 -9999 -9999 -9999 -9999 -9999 -9999 -9999 -9999 -9999 -9999 -9999 -9999 -9999 -9999 -9999 -9999 -9999 -9999 -9999 -9999 -9999 -9999 -9999 -9999 -9999 -9999 -9999 -9999 -9999 -9999 -9999 -9999

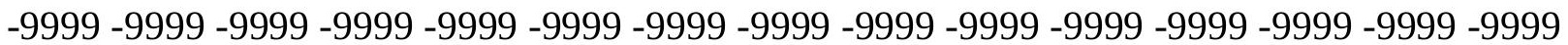


-9999 -9999 -9999 -9999 -9999 -9999 -9999 -9999 -9999 -9999 -9999 -9999

-9999 -9999 -9999 -9999 -9999 -9999 -9999 -9999 -9999 -9999 -9999 -9999 -9999 -9999 -9999

-9999 -9999 -9999 -9999 -9999 -9999 -9999 -9999 -9999 -9999 -9999 -9999 -9999 -9999 -9999

-9999 -9999 -9999 -9999 -9999 -9999 -9999 -9999 -9999 -9999 -9999 -9999 -9999 -9999 -9999

-9999 -9999 -9999 -9999 -9999 -9999 -9999 -9999 -9999 -9999 -9999 -9999 -9999 -9999 -9999

-9999 -9999 -9999 -9999 -9999 -9999 -9999 -9999 -9999 -9999 -9999 -9999 -9999 -9999 -9999 -

-9999 -9999 -9999 -9999 -9999 -9999 -9999 -9999 -9999 -9999 -9999 -9999 -9999 -9999 -9999 -999 -

-9999 -9999 11.8866195678710 .6674804687510 .057909965529 .44833946228

9.1435537338268 .8387689590458 .8387689590458 .8387689590458 .838768959045

8.8387689590459 .1435537338269 .448339462289 .75312423706110 .36268997192

10.6674804687511 .2770500183111 .5818300247212 .191410064712 .80097007751 13.4105501174914 .0201196670514 .6296901702914 .934470176715 .54403972626

15.8488302230816 .1536102294916 .4584007263216 .7631797790517 .06797027588 17.3727493286117 .3727493286117 .6775398254417 .6775398254417 .67753982544 17.6775398254417 .6775398254417 .3727493286117 .3727493286117 .06797027588 16.7631797790516 .4584007263216 .1536102294915 .5440397262615 .23925971985 14.6296901702914 .3248996734613 .715330123913 .1057596206712 .49619007111 11.8866195678711 .2770500183110 .667480468759 .7531242370619 .143553733826 8.5339832305917 .6196279525767 .0100579261786 .0957031255 .486132144928 4.876562118534 .2669920921333 .6574220657353 .3526360988623 .047851085663 2.7430660724642 .7430660724642 .7430660724643 .0478510856633 .352636098862 3.9622070789344 .876562118535 .7909169197086 .7052731513987 .314843177795 8.2291984558118 .8387689590459 .448339462289 .75312423706110 .05790996552 10.3626899719210 .9722604751611 .2770500183111 .8866195678712 .49619007111 12.8009700775113 .4105501174914 .0201196670514 .6296901702914 .9344701767 15.5440397262616 .1536102294916 .4584007263217 .0679702758817 .67753982544 18.28710937518 .8966808319119 .5062503814720 .1158199310320 .72538948059 21.6397399902322 .2493095397923 .1636695861823 .7732391357424 .68759918213 25.2971591949526 .2115192413327 .1258792877228 .0402297973628 .95458984375 29.8689403533930 .7833003997831 .6976509094232 .9167900085434 .13592910767 35.0502891540535 .6598587036135 .9646492004435 .9646492004436 .26942825317 36.2694282531736 .2694282531736 .2694282531736 .2694282531735 .96464920044 35.9646492004435 .9646492004435 .9646492004435 .9646492004435 .96464920044 35.9646492004436 .2694282531736 .2694282531736 .5742111206136 .57421112061 36.8790016174337 .1837806701737 .4885711669938 .0981407165538 .40293121338 38.7077102661139 .3172798156739 .9268493652340 .2316398620640 .84120941162 41.4507789611842 .0603485107442 .66992187543 .5842704772944 .19384002686 44.8034095764245 .717769622846 .3273391723647 .2416992187547 .85126113892 48.765621185349 .6799812316950 .2895507812551 .2038993835452 .11825942993 53.0326118469253 .9469718933154 .8613204956155 .4708900451756 .38525009155 57.2995986938558 .2139587402358 .8235282897959 .7378807067960 .65224075317 61.2618103027362 .1761703491262 .7857398986863 .3953094482464 .30966186523 64.9192428588965 .5288009643666 .1383666992266 .4431610107467 .05272674561 67.6623001098668 .2718734741268 .5766525268669 .1862335205169 .79579162598 70.1005783081171 .6244964599673 .14842987061 -9999 -9999 -9999 -9999 -9999 -9999 -9999 -9999 -9999 -9999 -9999 -9999 -9999 -9999 -9999 -9999 -9999 -9999 -9999 -9999 -9999 -9999 
-9999 -9999 -9999 -9999 -9999 -9999 -9999 -9999 -9999 -9999 -9999 -9999 -9999 -9999 -9999 -9999 -9999 -9999 -9999 -9999 -9999 -9999 -9999 -9999 -9999 -9999 -9999 -9999 -9999 -9999

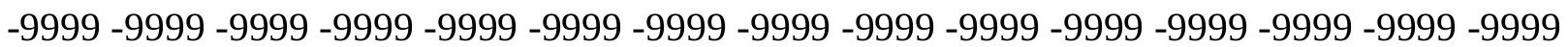
-9999 -9999 -9999 -9999 -9999 -9999 -9999 -9999 -9999 -9999 -9999 -9999 -9999 -9999 -9999 -9999 -9999 -9999 -9999 -9999 -9999 -9999 -9999 -9999 -9999 -9999 -9999 -9999 -9999 -9999 -9999 -9999 -9999 -9999 -9999 -9999 -9999 -9999 -9999 -9999 -9999 -9999 -9999 -9999 -9999 -9999 -9999 -9999 -9999 -9999 -9999 -9999 -9999 -9999 -9999 -9999 -9999 -9999

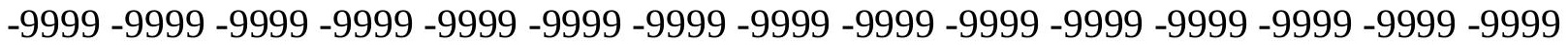

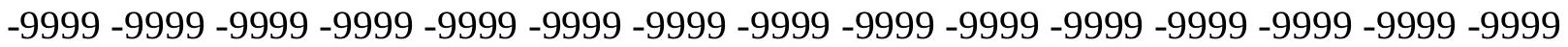
-9999 -9999 -9999 -9999 -9999 -9999 -9999 -9999 -9999 -9999 -9999 -9999 -9999 -9999 -9999 -9999 -9999 -9999 -9999 -9999 -9999 -9999 -9999 -9999 -9999 -9999 -9999 -9999 -9999 -9999 -9999 -9999 -9999 -9999 -9999 -9999 -9999 -9999 -9999 -9999 -9999 -9999 -9999 -9999 -9999 -9999 -9999 11.5818300247210 .362689971929 .7531242370619 .143553733826 8.8387689590458 .8387689590458 .5339832305918 .5339832305918 .533983230591 8.8387689590459 .1435537338269 .448339462289 .75312423706110 .36268997192 10.6674804687511 .2770500183111 .8866195678712 .4961900711113 .10575962067 13.715330123914 .3248996734614 .934470176715 .5440397262616 .15361022949 16.4584007263216 .7631797790517 .0679702758817 .3727493286117 .67753982544 17.9823207855217 .9823207855217 .9823207855217 .9823207855217 .98232078552 17.9823207855217 .9823207855217 .6775398254417 .3727493286117 .37274932861 16.7631797790516 .4584007263216 .1536102294915 .5440397262615 .23925971985 14.6296901702914 .0201196670513 .4105501174912 .8009700775112 .1914100647 11.5818300247210 .9722604751610 .057909965529 .448339462288 .838768959045 7.9244132041937 .3148431777956 .4004869461065 .7909169197085 .181346893311 4.2669920921333 .6574220657353 .3526360988622 .7430660724642 .438281059265 2.4382810592652 .4382810592652 .4382810592652 .7430660724643 .047851085663 3.6574220657354 .2669920921334 .876562118535 .7909169197086 .400486946106 7.0100579261787 .6196279525768 .2291984558118 .8387689590459 .143553733826 9.448339462289 .75312423706110 .3626899719210 .6674804687511 .27705001831 11.5818300247212 .191410064712 .4961900711113 .1057596206713 .41055011749 14.0201196670514 .6296901702915 .2392597198515 .5440397262616 .15361022949 16.7631797790517 .3727493286117 .9823207855218 .5918903350819 .50625038147 20.1158199310320 .7253894805921 .334960937522 .2493095397922 .85887908936 23.7732391357424 .6875991821325 .2971591949526 .2115192413327 .12587928772 28.0402297973628 .6497993469229 .5641593933131 .0880794525132 .30722045898 33.2215805053734 .1359291076734 .7455101013235 .0502891540535 .35507965088 35.6598587036135 .6598587036135 .6598587036135 .9646492004435 .96464920044 35.9646492004435 .9646492004435 .9646492004435 .9646492004435 .96464920044 36.2694282531736 .2694282531736 .5742111206136 .5742111206136 .87900161743 37.1837806701737 .4885711669937 .7933502197338 .0981407165538 .40293121338 39.0125007629439 .3172798156739 .9268493652340 .2316398620640 .84120941162 41.4507789611842 .0603485107442 .66992187543 .2794914245643 .88906097412 44.8034095764245 .4129791259846 .3273391723646 .9369087219247 .85126113892 48.4608306884849 .3751907348650 .2895507812550 .8991203308151 .81346893311 52.7278289794953 .6421813964854 .5565414428755 .4708900451756 .08045959473 56.9948196411157 .909179687558 .8235282897959 .4331016540560 .34745025635 
61.2618103027361 .8713798522962 .4809494018663 .3953094482464 .0048828125 64.6144485473665 .2240066528365 .8335876464866 .4431610107467 .05272674561 67.3575134277367 .9670867919968 .5766525268668 .8814392089869 .49101257324 69.7957916259870 .7101516723672 .2340774536173 .36405944824 -9999 -9999 -9999 -9999 -9999 -9999 -9999 -9999 -9999 -9999 -9999 -9999 -9999 -9999 -9999 -9999 -9999 -9999 -9999 -9999 -9999 -9999 -9999 -9999 -9999 -9999 -9999 -9999 -9999 -9999 -9999 -9999 -9999 -9999 -9999 -9999 -9999 -9999 -9999 -9999 -9999 -9999 -9999 -9999 -9999 -9999 -9999 -9999 -9999

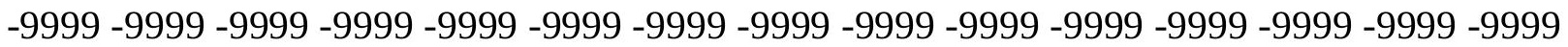
-9999 -9999 -9999 -9999 -9999 -9999 -9999 -9999 -9999 -9999 -9999 -9999 -9999 -9999 -9999 -9999 -9999 -9999 -9999 -9999 -9999 -9999 -9999 -9999 -9999 -9999 -9999 -9999 -9999 -9999 -

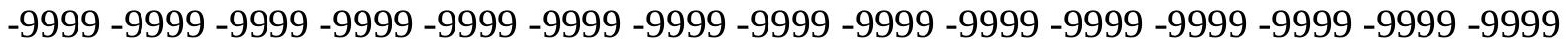
-9999 -9999 -9999 -9999 -9999 -9999 -9999 -9999 -9999 -9999 -9999 -9999 -9999 -9999 -9999 -9999 -9999 -9999 -9999 -9999 -9999 -9999 -9999 -9999 -9999 -9999 -9999 -9999 -9999 -9999 -9999 -9999 -9999 -9999 -9999 -9999 -9999 -9999 -9999 -9999 -9999 -9999 -9999 -9999 -9999 -9999 -9999 -9999 -9999 -9999 -9999 -9999 -9999 -9999 -9999 -9999 -9999 -9999 -9999 -9999

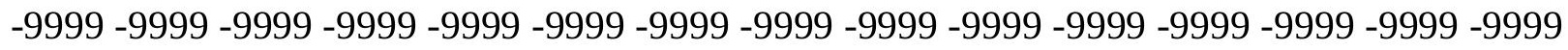

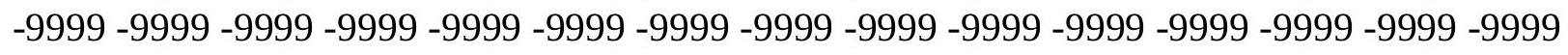
-9999 13.715330123911 .5818300247210 .362689971929 .7531242370619 .143553733826 8.8387689590458 .5339832305918 .5339832305918 .5339832305918 .533983230591 8.8387689590459 .1435537338269 .448339462289 .75312423706110 .36268997192 10.9722604751611 .5818300247212 .191410064713 .1057596206713 .7153301239 14.3248996734614 .934470176715 .5440397262616 .1536102294916 .76317977905 17.0679702758817 .6775398254417 .9823207855218 .28710937518 .287109375 18.5918903350818 .5918903350818 .5918903350818 .5918903350818 .59189033508 18.5918903350818 .28710937517 .9823207855217 .6775398254417 .37274932861 17.0679702758816 .7631797790516 .1536102294915 .8488302230815 .23925971985 14.6296901702914 .0201196670513 .4105501174912 .8009700775111 .88661956787 11.2770500183110 .667480468759 .7531242370619 .1435537338268 .229198455811 7.6196279525766 .7052731513986 .0957031255 .4861321449284 .571776866913 3.9622070789343 .3526360988623 .0478510856632 .4382810592652 .133496046066 2.1334960460662 .1334960460662 .1334960460662 .4382810592652 .743066072464 3.0478510856633 .6574220657354 .2669920921334 .876562118535 .486132144928 6.0957031256 .705273151398 7.314843177795 7.619627952576 8.229198455811 8.5339832305918 .8387689590459 .1435537338269 .4483394622810 .05790996552 10.3626899719210 .9722604751611 .2770500183111 .5818300247212 .1914100647 12.8009700775113 .1057596206713 .715330123914 .3248996734614 .62969017029 15.2392597198515 .8488302230816 .4584007263217 .0679702758817 .98232078552 18.5918903350819 .2014598846419 .811029434220 .7253894805921 .3349609375 22.2493095397922 .8588790893623 .7732391357424 .6875991821325 .29715919495 26.2115192413327 .1258792877228 .0402297973629 .2593708038330 .47850990295 31.6976509094232 .6120109558133 .5263595581134 .1359291076734 .44071960449 34.7455101013235 .0502891540535 .3550796508835 .6598587036135 .65985870361 35.6598587036135 .9646492004435 .9646492004435 .9646492004436 .26942825317 36.2694282531736 .5742111206136 .5742111206136 .8790016174337 .18378067017 37.4885711669937 .4885711669937 .7933502197338 .4029312133838 .70771026611 39.0125007629439 .3172798156739 .9268493652340 .2316398620640 .84120941162 
41.4507789611842 .0603485107442 .66992187543 .2794914245643 .88906097412 44.4986305236845 .4129791259846 .0225486755446 .6321296691947 .54647827148 48.4608306884849 .0704002380449 .9847602844250 .8991203308151 .81346893311 52.4230384826753 .3373985290554 .2517509460455 .1661109924356 .08045959473 56.9948196411157 .6043891906758 .5187492370659 .4331016540560 .04267120361 60.9570198059161 .5666007995662 .4809494018663 .0905189514263 .70008850098 64.3096618652364 .9192428588965 .5288009643666 .1383666992266 .74794006348 67.0527267456167 .6623001098668 .2718734741268 .5766525268669 .18623352051 69.7957916259870 .1005783081171 .014930725172 .53885650635 -9999 -9999 -9999 -9999 -9999 -9999 -9999 -9999 -9999 -9999 -9999 -9999 -9999 -9999 -9999 -9999 -9999 -9999 -9999 -9999 -9999 -9999 -9999 -9999 -9999 -9999 -9999 -9999 -9999 -9999 -9999 -9999 -9999 -9999 -9999 -9999 -9999 -9999 -9999 -9999 -9999 -9999 -9999 -9999 -9999 -9999 -9999 -9999 -9999 -9999 -9999 -9999 -9999 -9999 -9999 -9999 -9999 -9999 -9999 -9999 -9999 -9999 -9999 -9999 -

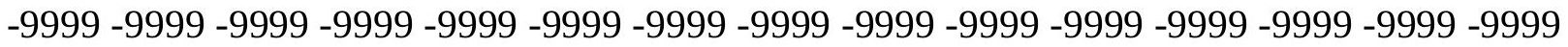
-9999 -9999 -9999 -9999 -9999 -9999 -9999 -9999 -9999 -9999 -9999 -9999 -9999 -9999 -9999 -

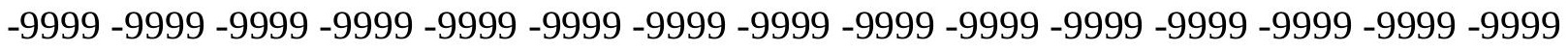
-9999 -9999 -9999 -9999 -9999 -9999 -9999 -9999 -9999 -9999 -9999 -9999 -9999 -9999 -9999 -9999 -9999 -9999 -9999 -9999 -9999 -9999 -9999 -9999 -9999 -9999 -9999 -9999 -9999 -9999 -9999 -9999 -9999 -9999 -9999 -9999 -9999 -9999 -9999 -9999 -9999 -9999 -9999 -9999 -9999 -9999 -9999 -9999 -9999 -9999 -9999 -9999 -9999 -9999 -9999 -9999 -9999 -9999 -9999 -9999 -9999 -9999 -9999 -9999 -9999 -9999 -9999 -9999 -9999 -9999 -9999 -9999 -9999 -9999 -9999 -9999 -9999 -9999 -9999 -9999 -9999 -9999 -9999 -9999 -9999 -9999 -9999 -9999 -9999 -9999 -9999 14.02011966705 11.88661956787 10.362689971929.7531242370619.143553733826 8.8387689590458 .5339832305918 .5339832305918 .5339832305918 .533983230591 8.8387689590459 .1435537338269 .4483394622810 .0579099655210 .66748046875 11.2770500183111 .8866195678712 .8009700775113 .4105501174914 .32489967346 14.934470176715 .8488302230816 .4584007263217 .0679702758817 .67753982544 17.9823207855218 .28710937518 .5918903350818 .8966808319119 .20145988464 19.2014598846419 .2014598846419 .2014598846419 .2014598846419 .20145988464 18.8966808319118 .8966808319118 .5918903350818 .28710937517 .98232078552 17.37274932861 17.06797027588 16.45840072632 15.84883022308 15.23925971985 14.6296901702914 .0201196670513 .4105501174912 .4961900711111 .88661956787 10.9722604751610 .362689971929 .448339462288 .8387689590457 .924413204193 7.3148431777956 .4004869461065 .7909169197084 .876562118534 .266992092133 3.6574220657353 .0478510856632 .7430660724642 .1334960460661 .828711032867 1.8287110328671 .8287110328671 .8287110328671 .8287110328672 .133496046066 2.7430660724643 .0478510856633 .6574220657354 .2669920921334 .87656211853 5.4861321449285 .7909169197086 .4004869461066 .7052731513987 .010057926178 7.6196279525767 .9244132041938 .2291984558118 .5339832305918 .838768959045 9.1435537338269 .75312423706110 .0579099655210 .3626899719210 .97226047516 11.2770500183111 .8866195678712 .191410064712 .8009700775113 .41055011749 14.0201196670514 .6296901702915 .2392597198515 .8488302230816 .45840072632 17.0679702758817 .6775398254418 .28710937519 .2014598846419 .8110294342 20.7253894805921 .334960937522 .2493095397922 .8588790893623 .77323913574 24.6875991821325 .6019496917726 .8210906982428 .0402297973629 .25937080383 30.4785099029531 .3928699493432 .3072204589832 .9167900085433 .52635955811 
34.1359291076734 .4407196044934 .7455101013235 .0502891540535 .35507965088 35.6598587036135 .6598587036135 .9646492004435 .9646492004436 .26942825317 36.5742111206136 .5742111206136 .8790016174336 .8790016174337 .18378067017 37.4885711669937 .7933502197338 .0981407165538 .4029312133838 .70771026611 39.0125007629439 .622070312539 .9268493652340 .2316398620640 .84120941162 41.4507789611842 .0603485107442 .3651313781742 .9747009277343 .88906097412 44.4986305236845 .1082000732445 .717769622846 .6321296691947 .24169921875 48.1560516357449 .0704002380449 .6799812316950 .5943298339851 .50868988037 52.4230384826753 .3373985290553 .9469718933154 .8613204956155 .77568054199 56.6900291442957 .6043891906758 .5187492370659 .1283111572360 .04267120361 60.6522407531761 .5666007995662 .1761703491263 .0905189514263 .70008850098 64.3096618652364 .9192428588965 .5288009643665 .8335876464866 .44316101074 67.0527267456167 .3575134277367 .9670867919968 .2718734741268 .88143920898 69.1862335205169 .7957916259870 .1005783081171 .6244964599672 .84364318848 -9999 -9999 -9999 -9999 -9999 -9999 -9999 -9999 -9999 -9999 -9999 -9999 -9999 -9999 -9999 -9999

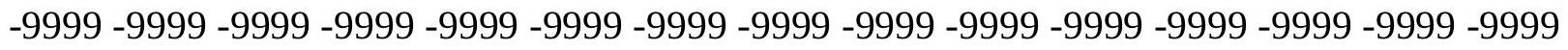
-9999 -9999 -9999 -9999 -9999 -9999 -9999 -9999 -9999 -9999 -9999 -9999 -9999 -9999 -9999 -9999 -9999 -9999 -9999 -9999 -9999 -9999 -9999 -9999 -9999 -9999 -9999 -9999 -9999 -9999 -9999 -9999 -9999 -9999 -9999 -9999 -9999 -9999 -9999 -9999 -9999 -9999 -9999 -9999 -9999 -

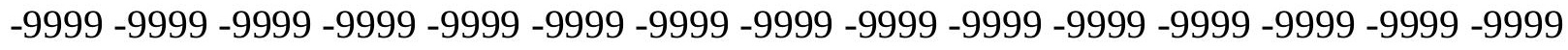

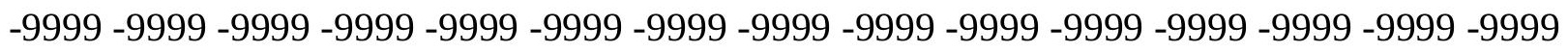
$-9999-9999$

-9999 -9999 -9999 -9999 -9999 -9999 -9999 -9999 -9999 -9999 -9999 -9999 -9999 -9999 -9999

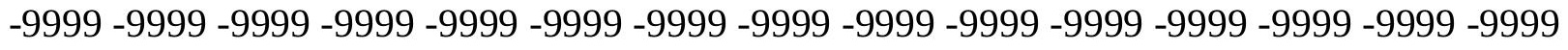

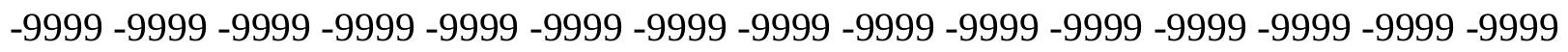
-9999 -9999 -9999 -9999 -9999 -9999 -9999 -9999 -9999 -9999 -9999 -9999 -9999 -9999 -9999 -

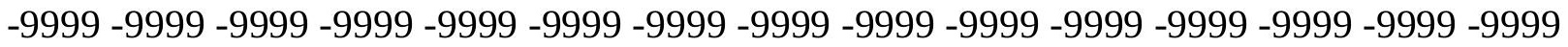

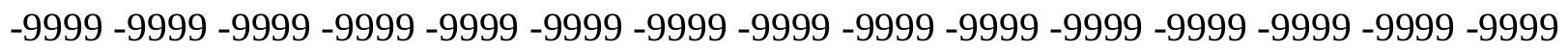
-9999 14.62969017029 12.80097007751 10.66748046875 9.7531242370619.143553733826 8.8387689590458 .5339832305918 .5339832305918 .5339832305918 .838768959045 8.8387689590459 .448339462289 .75312423706110 .3626899719210 .97226047516 11.8866195678712 .4961900711113 .4105501174914 .3248996734614 .9344701767 15.8488302230816 .7631797790517 .3727493286117 .9823207855218 .59189033508 18.8966808319119 .2014598846419 .5062503814719 .811029434220 .11581993103 20.1158199310320 .1158199310320 .1158199310319 .811029434219 .8110294342 19.5062503814719 .2014598846418 .8966808319118 .5918903350818 .287109375 17.6775398254417 .3727493286116 .7631797790516 .1536102294915 .54403972626 14.6296901702914 .0201196670513 .4105501174912 .4961900711111 .58183002472 10.9722604751610 .057909965529 .448339462288 .5339832305917 .619627952576 7.0100579261786 .0957031255 .4861321449284 .876562118533 .962207078934 3.3526360988623 .0478510856632 .4382810592652 .1334960460661 .828711032867 1.5239260196691 .5239260196691 .5239260196691 .8287110328671 .828711032867 2.1334960460662 .7430660724643 .0478510856633 .6574220657354 .266992092133 4.5717768669135 .1813468933115 .4861321449285 .7909169197086 .095703125 6.7052731513987 .0100579261787 .3148431777957 .6196279525767 .924413204193 8.2291984558118 .5339832305918 .8387689590459 .1435537338269 .753124237061 
10.0579099655210 .6674804687510 .9722604751611 .5818300247211 .88661956787 12.4961900711113 .1057596206713 .715330123914 .3248996734614 .9344701767 15.5440397262616 .1536102294916 .7631797790517 .6775398254418 .287109375 18.8966808319119 .811029434220 .4206008911121 .334960937522 .24930953979 23.1636695861824 .0780296325725 .2971591949526 .5163097381627 .73545074463 28.9545898437530 .1737308502231 .0880794525132 .0024414062532 .61201095581 33.2215805053733 .8311500549334 .4407196044934 .7455101013235 .05028915405 35.3550796508835 .6598587036135 .9646492004435 .9646492004436 .26942825317 36.5742111206136 .5742111206136 .8790016174337 .1837806701737 .48857116699 37.4885711669937 .7933502197338 .0981407165538 .4029312133838 .70771026611 39.0125007629439 .622070312539 .9268493652340 .2316398620640 .84120941162 41.4507789611841 .7555618286142 .3651313781742 .9747009277343 .58427047729 44.1938400268644 .8034095764245 .717769622846 .3273391723647 .24169921875 47.8512611389248 .765621185349 .6799812316950 .2895507812551 .20389938354 52.1182594299353 .0326118469253 .9469718933154 .8613204956155 .77568054199 56.3852500915557 .2995986938558 .2139587402359 .1283111572359 .73788070679 60.6522407531761 .2618103027362 .1761703491262 .7857398986863 .39530944824 64.004882812564 .6144485473665 .2240066528365 .8335876464866 .13836669922 66.7479400634867 .3575134277367 .6623001098668 .2718734741268 .57665252686 68.8814392089869 .4910125732469 .7957916259870 .4053573608471 .92929077148 73.01182556152 -9999 -9999 -9999 -9999 -9999 -9999 -9999 -9999 -9999 -9999 -9999 -9999 -9999 -9999 -9999 -9999 -9999 -9999 -9999 -9999 -9999 -9999 -9999 -9999 -9999 -9999 -9999 -9999 -9999 -9999 -9999 -9999 -9999 -9999 -9999 -9999 -9999 -9999 -9999 -9999 -9999 -9999 -9999 -9999 -9999 -9999 -9999 -9999 -9999 -9999 -9999 -9999 -9999 -9999 -9999 -9999 -9999

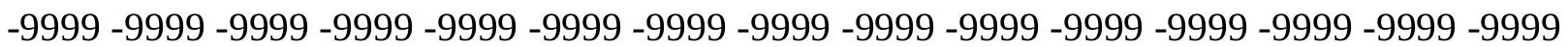
-9999 -9999 -9999 -9999 -9999 -9999 -9999 -9999 -9999 -9999 -9999 -9999 -9999 -9999 -9999 -9999 -9999 -9999 -9999 -9999 -9999 -9999 -9999 -9999 -9999 -9999 -9999 -9999 -9999 -9999 -9999 -9999-9999-9999-9999

-9999 -9999 -9999 -9999 -9999 -9999 -9999 -9999 -9999 -9999 -9999 -9999 -9999 -9999 -9999

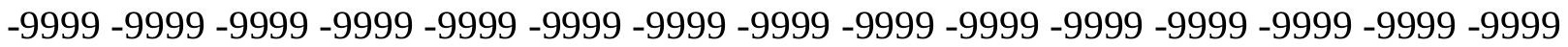
-9999 -9999 -9999 -9999 -9999 -9999 -9999 -9999 -9999 -9999 -9999 -9999 -9999 -9999 -9999 -9999 -9999 -9999 -9999 -9999 -9999 -9999 -9999 -9999 -9999 -9999 -9999 -9999 -9999 -9999 -9999 -9999 -9999 -9999 -9999 -9999 -9999 -9999 -9999 -9999 -9999 -9999 -9999 -9999 -9999 -9999 -9999 -9999 -9999 -9999 -9999 -9999 -9999 -9999 -9999 -9999 -9999 -9999 -9999 -9999 -9999 15.8488302230813 .715330123911 .5818300247210 .057909965529 .44833946228 9.1435537338269 .1435537338268 .8387689590458 .8387689590459 .143553733826 9.448339462289 .75312423706110 .0579099655210 .6674804687511 .58183002472 12.191410064713 .1057596206714 .0201196670514 .934470176715 .84883022308 16.7631797790517 .6775398254418 .28710937518 .8966808319119 .50625038147 20.1158199310320 .4206008911120 .7253894805920 .7253894805921 .03017044067 21.0301704406721 .0301704406720 .7253894805920 .7253894805920 .42060089111 20.1158199310319 .811029434219 .5062503814719 .2014598846418 .59189033508 18.28710937517 .6775398254417 .0679702758816 .4584007263215 .54403972626 14.934470176714 .0201196670513 .1057596206712 .4961900711111 .58183002472 10.6674804687510 .057909965529 .1435537338268 .2291984558117 .619627952576 6.7052731513986 .0957031255 .1813468933114 .5717768669133 .962207078934 
3.3526360988622 .7430660724642 .1334960460661 .8287110328671 .523926019669 1.5239260196691 .219141006471 .219141006471 .5239260196691 .523926019669 1.8287110328672 .1334960460662 .7430660724643 .0478510856633 .657422065735 3.9622070789344 .2669920921334 .876562118535 .1813468933115 .486132144928 5.7909169197086 .0957031256 .4004869461066 .7052731513987 .010057926178 7.3148431777957 .6196279525767 .9244132041938 .2291984558118 .533983230591 8.8387689590459 .448339462289 .75312423706110 .3626899719210 .66748046875 11.2770500183111 .8866195678712 .191410064712 .8009700775113 .41055011749 14.0201196670514 .6296901702915 .2392597198516 .1536102294916 .76317977905 17.3727493286118 .28710937518 .8966808319119 .811029434220 .72538948059 21.6397399902322 .8588790893624 .0780296325725 .2971591949526 .51630973816 27.7354507446328 .6497993469229 .8689403533930 .7833003997831 .69765090942 32.6120109558133 .2215805053733 .8311500549334 .1359291076734 .74551010132 35.0502891540535 .3550796508835 .6598587036135 .9646492004436 .26942825317 36.5742111206136 .8790016174336 .8790016174337 .1837806701737 .48857116699 37.7933502197338 .0981407165538 .0981407165538 .4029312133838 .70771026611 39.0125007629439 .622070312539 .9268493652340 .2316398620640 .84120941162 41.1459884643641 .7555618286142 .3651313781742 .9747009277343 .58427047729 44.1938400268644 .8034095764245 .4129791259846 .0225486755446 .93690872192 47.8512611389248 .4608306884849 .3751907348650 .2895507812550 .89912033081 51.8134689331152 .7278289794953 .6421813964854 .5565414428755 .47089004517 56.3852500915557 .2995986938557 .909179687558 .8235282897959 .73788070679 60.6522407531761 .2618103027361 .8713798522962 .7857398986863 .39530944824 64.004882812564 .6144485473665 .2240066528365 .5288009643666 .13836669922 66.4431610107467 .0527267456167 .3575134277367 .9670867919968 .27187347412 68.5766525268669 .1862335205169 .4910125732469 .7957916259870 .71015167236 72.23407745361 -9999 -9999 -9999 -9999 -9999 -9999 -9999 -9999 -9999 -9999 -9999 -9999 -9999 -9999 -9999 -9999 -9999 -9999 -9999 -9999 -9999 -9999 -9999 -9999 -9999 -9999 -9999

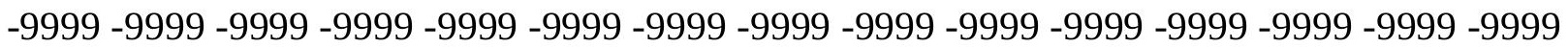

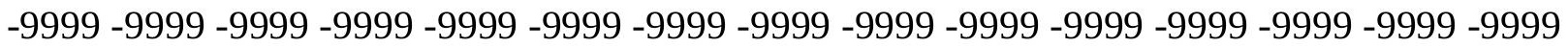
-9999 -9999 -9999 -9999 -9999 -9999 -9999 -9999 -9999 -9999 -9999 -9999 -9999 -9999 -9999 -

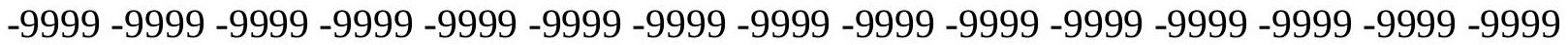
-9999 -9999 -9999 -9999 -9999 -9999 -9999 -9999 -9999 -9999 -9999 -9999 -9999 -9999 -9999 -9999 -9999-9999-9999-9999

-9999 -9999 -9999 -9999 -9999 -9999 -9999 -9999 -9999 -9999 -9999 -9999 -9999 -9999 -9999 -9999 -9999 -9999 -9999 -9999 -9999 -9999 -9999 -9999 -9999 -9999 -9999 -9999 -9999 -9999 -9999 -9999 -9999 -9999 -9999 -9999 -9999 -9999 -9999 -9999 -9999 -9999 -9999 -9999 -9999

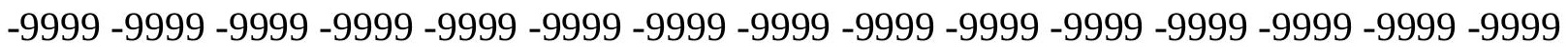
-9999 -9999 -9999 -9999 -9999 -9999 -9999 -9999 -9999 -9999 -9999 -9999 -9999 -9999 -9999 -9999 -9999 -9999 -9999 -9999 -9999 -9999 -9999 -9999 -9999 -9999 -9999 -9999 -9999 -9999 -999 -9999 17.6775398254415.2392597198513.1057596206712.1914100647 10.05790996552 9.7531242370619 .7531242370619 .448339462289 .448339462289 .44833946228 9.75312423706110 .0579099655210 .6674804687511 .2770500183112 .1914100647 13.1057596206714 .0201196670514 .934470176715 .8488302230817 .06797027588 17.9823207855218 .8966808319119 .5062503814720 .1158199310320 .72538948059 21.0301704406721 .334960937521 .6397399902321 .9445304870621 .94453048706 
21.9445304870621 .6397399902321 .6397399902321 .334960937521 .03017044067 20.7253894805920 .4206008911120 .1158199310319 .5062503814719 .20145988464 18.5918903350817 .9823207855217 .3727493286116 .4584007263215 .84883022308 14.934470176714 .0201196670513 .1057596206712 .4961900711111 .58183002472 10.667480468759 .7531242370618 .8387689590458 .2291984558117 .314843177795 6.4004869461065 .7909169197085 .1813468933114 .2669920921333 .657422065735 3.0478510856632 .7430660724642 .1334960460661 .8287110328671 .523926019669 1.219141006471 .219141006471 .219141006471 .219141006471 .523926019669 1.5239260196691 .8287110328672 .1334960460662 .7430660724643 .047851085663 3.3526360988623 .6574220657353 .9622070789344 .2669920921334 .571776866913 4.876562118535 .1813468933115 .4861321449285 .7909169197086 .095703125 6.4004869461066 .4004869461066 .7052731513987 .0100579261787 .314843177795 7.9244132041938 .2291984558118 .5339832305919 .1435537338269 .44833946228 10.0579099655210 .3626899719210 .9722604751611 .5818300247212 .1914100647 12.4961900711113 .1057596206713 .715330123914 .6296901702915 .23925971985 15.8488302230816 .7631797790517 .3727493286118 .28710937519 .20145988464 20.4206008911121 .334960937522 .5541000366223 .7732391357424 .99238014221 26.2115192413327 .430660247828 .6497993469229 .5641593933130 .78330039978 31.6976509094232 .3072204589833 .2215805053733 .8311500549334 .44071960449 34.7455101013235 .3550796508835 .6598587036135 .9646492004436 .26942825317 36.5742111206136 .8790016174336 .8790016174337 .1837806701737 .48857116699 37.7933502197338 .0981407165538 .4029312133838 .4029312133838 .70771026611 39.0125007629439 .622070312539 .9268493652340 .2316398620640 .53641891479 41.1459884643641 .4507789611842 .0603485107442 .66992187543 .27949142456 43.8890609741244 .4986305236845 .1082000732446 .0225486755446 .63212966919 47.5464782714848 .1560516357449 .0704002380449 .9847602844250 .89912033081 51.8134689331152 .7278289794953 .3373985290554 .2517509460455 .16611099243 56.0804595947356 .9948196411157 .909179687558 .8235282897959 .73788070679 60.3474502563561 .2618103027361 .8713798522962 .4809494018663 .09051895142 63.7000885009864 .3096618652364 .9192428588965 .5288009643665 .83358764648 66.4431610107466 .7479400634867 .0527267456167 .6623001098667 .96708679199 68.2718734741268 .5766525268669 .1862335205169 .4910125732469 .79579162598 71.3197174072372 .53885650635 -9999 -9999 -9999 -9999 -9999 -9999 -9999 -9999 -9999 -9999 -9999 -9999 -9999 -9999 -9999 -9999 -9999 -9999 -9999 -9999 -9999 -9999 -9999 -9999

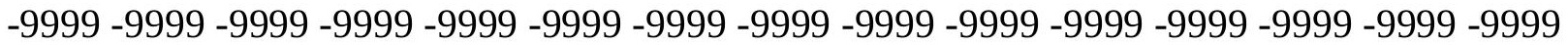
-9999 -9999 -9999 -9999 -9999 -9999 -9999 -9999 -9999 -9999 -9999 -9999 -9999 -9999 -9999 -9999 -9999 -9999 -9999 -9999 -9999 -9999 -9999 -9999 -9999 -9999 -9999 -9999 -9999 -9999

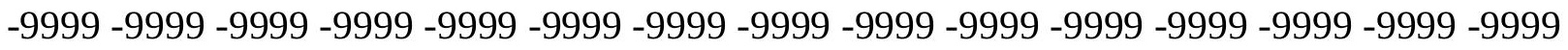
-9999 -9999 -9999 -9999 -9999 -9999 -9999 -9999 -9999 -9999 -9999 -9999 -9999 -9999 -9999 -9999 -9999 -9999 -9999-9999-9999-9999 -9999 -9999 -9999 -9999 -9999 -9999 -9999 -9999 -9999 -9999 -9999 -9999 -9999 -9999 -9999 -9999 -9999 -9999 -9999 -9999 -9999 -9999 -9999 -9999 -9999 -9999 -9999 -9999 -9999 -9999 -9999 -9999 -9999 -9999 -9999 -9999 -9999 -9999 -9999 -9999 -9999 -9999 -9999 -9999 -9999 -9999 -9999 -9999 -9999 -9999 -9999 -9999 -9999 -9999 -9999 -9999 -9999 -9999 -9999 -9999 -9999 -9999 -9999 -9999 -9999 -9999 -9999 -9999 -9999 -9999 -9999 -9999 -9999 -9999 -9999

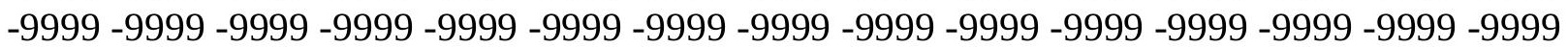


22.2493095397919 .811029434217 .3727493286114 .934470176712 .49619007111 10.9722604751610 .6674804687510 .6674804687510 .3626899719210 .36268997192 10.3626899719210 .3626899719210 .6674804687511 .2770500183111 .88661956787 12.8009700775113 .715330123914 .934470176715 .8488302230817 .06797027588 17.9823207855219 .2014598846420 .1158199310320 .7253894805921 .3349609375 21.9445304870622 .5541000366222 .5541000366222 .8588790893622 .85887908936 22.8588790893622 .8588790893622 .5541000366222 .5541000366222 .24930953979 21.9445304870621 .6397399902321 .0301704406720 .7253894805920 .11581993103 19.5062503814718 .8966808319118 .28710937517 .6775398254416 .76317977905 15.8488302230814 .934470176714 .0201196670513 .1057596206712 .1914100647 11.2770500183110 .362689971929 .7531242370618 .8387689590457 .924413204193 7.0100579261786 .4004869461065 .4861321449284 .876562118534 .266992092133 3.6574220657353 .0478510856632 .4382810592652 .1334960460661 .828711032867 1.5239260196691 .219141006471 .21914100647 .91435539722441 .21914100647 1.219141006471 .5239260196691 .5239260196691 .8287110328672 .133496046066 2.4382810592652 .7430660724643 .3526360988623 .6574220657353 .962207078934 3.9622070789344 .2669920921334 .5717768669134 .876562118534 .87656211853 5.1813468933115 .4861321449285 .4861321449285 .7909169197086 .095703125 6.4004869461066 .7052731513987 .0100579261787 .3148431777957 .924413204193 8.2291984558118 .5339832305919 .1435537338269 .4483394622810 .05790996552 10.6674804687511 .2770500183111 .8866195678712 .4961900711113 .10575962067 13.715330123914 .3248996734615 .2392597198515 .8488302230816 .76317977905 17.6775398254418 .8966808319119 .811029434221 .0301704406722 .24930953979 23.4684505462624 .9923801422126 .2115192413327 .430660247828 .64979934692 29.5641593933130 .7833003997831 .6976509094232 .6120109558133 .22158050537 33.8311500549334 .4407196044935 .0502891540535 .3550796508835 .65985870361 35.9646492004436 .5742111206136 .5742111206136 .8790016174337 .18378067017 37.4885711669937 .7933502197338 .0981407165538 .4029312133838 .40293121338 38.7077102661139 .0125007629439 .3172798156739 .9268493652340 .23163986206 40.5364189147940 .8412094116241 .4507789611842 .0603485107442 .36513137817 42.9747009277343 .5842704772944 .1938400268645 .1082000732445 .7177696228 46.3273391723647 .2416992187548 .1560516357448 .765621185349 .67998123169 50.5943298339851 .5086898803752 .4230384826753 .3373985290554 .25175094604 55.1661109924356 .0804595947356 .9948196411157 .909179687558 .51874923706 59.4331016540560 .3474502563560 .9570198059161 .8713798522962 .48094940186 63.0905189514263 .7000885009864 .3096618652364 .9192428588965 .22400665283 65.8335876464866 .1383666992266 .4431610107467 .0527267456167 .35751342773 67.6623001098667 .9670867919968 .2718734741268 .8814392089869 .18623352051 69.4910125732470 .4053573608471 .6244964599672 .81249237061 -9999 -9999 -9999 -9999 -9999 -9999 -9999 -9999 -9999 -9999 -9999 -9999 -9999 -9999 -9999 -9999 -9999 -9999 -9999

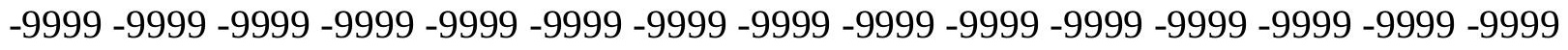

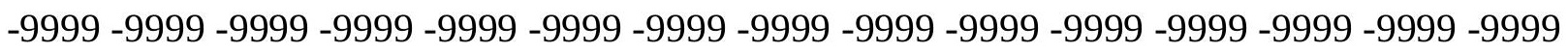
-9999 -9999 -9999 -9999 -9999 -9999 -9999 -9999 -9999 -9999 -9999 -9999 -9999 -9999 -9999 -9999 -9999 -9999 -9999 -9999 -9999 -9999 -9999 -9999 -9999 -9999 -9999 -9999 -9999 -9999 -

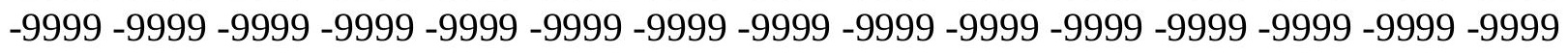
-9999 -9999 -9999 -9999 -9999 -9999 -9999 -9999 -9999 -9999 -9999 
-9999 -9999 -9999 -9999 -9999 -9999 -9999 -9999 -9999 -9999 -9999 -9999 -9999 -9999 -9999 -9999 -9999 -9999 -9999 -9999 -9999 -9999 -9999 -9999 -9999 -9999 -9999 -9999 -9999 -9999 -9999 -9999 -9999 -9999 -9999 -9999 -9999 -9999 -9999 -9999 -9999 -9999 -9999 -9999 -9999 -9999 -9999 -9999 -9999 -9999 -9999 -9999 -9999 -9999 -9999 -9999 -9999 -9999 -9999 -9999 -9999 -9999 -9999 -9999 -9999 -9999 -9999 -9999 -9999 -9999 -9999 -9999-9999 -9999 -9999 -

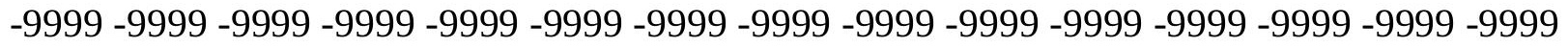
24.6875991821322 .2493095397919 .811029434217 .3727493286114 .9344701767 12.4961900711112 .191410064711 .8866195678711 .5818300247211 .27705001831 10.9722604751611 .2770500183111 .5818300247211 .8866195678712 .80097007751 13.715330123914 .6296901702915 .8488302230817 .0679702758818 .287109375 19.5062503814720 .4206008911121 .334960937522 .2493095397922 .85887908936 23.4684505462623 .7732391357424 .0780296325724 .0780296325724 .07802963257 24.0780296325723 .7732391357423 .4684505462623 .1636695861822 .85887908936 22.5541000366222 .2493095397921 .6397399902321 .334960937520 .72538948059 20.1158199310319 .5062503814718 .8966808319117 .9823207855217 .06797027588 16.1536102294915 .2392597198514 .3248996734613 .1057596206712 .1914100647 11.2770500183110 .362689971929 .448339462288 .5339832305917 .619627952576 7.0100579261786 .0957031255 .4861321449284 .876562118533 .962207078934 3.3526360988623 .0478510856632 .4382810592652 .1334960460661 .523926019669 1.219141006471 .21914100647 .9143553972244 .9143553972244 .9143553972244 .91435539722441 .219141006471 .5239260196691 .5239260196691 .828711032867 2.1334960460662 .4382810592652 .7430660724643 .0478510856633 .352636098862 3.6574220657353 .6574220657353 .9622070789343 .9622070789344 .266992092133 4.5717768669134 .5717768669134 .876562118534 .876562118535 .181346893311 5.4861321449285 .7909169197086 .0957031256 .4004869461066 .705273151398 7.0100579261787 .3148431777957 .9244132041938 .2291984558118 .838768959045 9.1435537338269 .75312423706110 .3626899719210 .9722604751611 .58183002472 12.191410064712 .8009700775113 .715330123914 .3248996734615 .23925971985 16.1536102294917 .3727493286118 .5918903350819 .5062503814721 .03017044067 22.2493095397923 .4684505462624 .6875991821326 .2115192413327 .4306602478 28.6497993469229 .8689403533930 .7833003997831 .6976509094232 .61201095581 33.2215805053734 .1359291076734 .4407196044935 .0502891540535 .65985870361 35.9646492004436 .2694282531736 .5742111206136 .8790016174337 .18378067017 37.4885711669937 .7933502197338 .0981407165538 .0981407165538 .40293121338 38.7077102661139 .0125007629439 .3172798156739 .622070312539 .92684936523 40.5364189147940 .8412094116241 .1459884643641 .7555618286142 .36513137817 42.66992187543 .2794914245644 .1938400268644 .8034095764245 .41297912598 46.3273391723646 .9369087219247 .8512611389248 .4608306884849 .37519073486 50.2895507812551 .2038993835452 .1182594299353 .0326118469253 .94697189331 54.8613204956155 .7756805419956 .6900291442957 .6043891906758 .51874923706 59.4331016540560 .0426712036160 .9570198059161 .5666007995662 .48094940186 63.0905189514263 .7000885009864 .004882812564 .6144485473665 .22400665283 65.5288009643665 .8335876464866 .4431610107466 .7479400634867 .05272674561 67.3575134277367 .6623001098667 .9670867919968 .5766525268668 .88143920898 69.1862335205169 .4910125732470 .7101516723672 .23407745361 -9999 -9999 -9999 -9999 -9999 -9999 -9999 -9999 -9999 -9999 -9999 -9999 -9999 -9999 -9999 -9999 -9999 -9999 -9999 
-9999 -9999 -9999 -9999 -9999 -9999 -9999 -9999 -9999 -9999 -9999 -9999 -9999 -9999 -9999 -9999 -9999 -9999 -9999 -9999 -9999 -9999 -9999 -9999 -9999 -9999 -9999 -9999 -9999 -9999

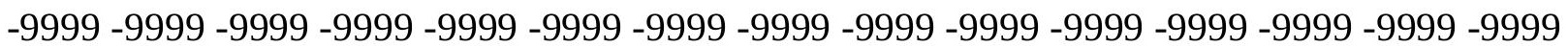
-9999 -9999 -9999 -9999 -9999 -9999 -9999 -9999 -9999 -9999 -9999 -9999 -9999 -9999 -9999

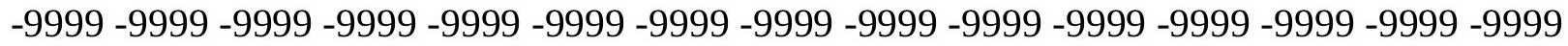
-9999 -9999 -9999 -9999 -9999 -9999 -9999 -9999 -9999 -9999 -9999

-9999 -9999 -9999 -9999 -9999 -9999 -9999 -9999 -9999 -9999 -9999 -9999 -9999 -9999 -9999 -9999 -9999 -9999 -9999 -9999 -9999 -9999 -9999 -9999 -9999 -9999 -9999 -9999 -9999 -9999 -9999 -9999 -9999 -9999 -9999 -9999 -9999 -9999 -9999 -9999 -9999 -9999 -9999 -9999 -9999 -9999 -9999 -9999 -9999 -9999 -9999 -9999 -9999 -9999 -9999 -9999 -9999 -9999 -9999 -9999

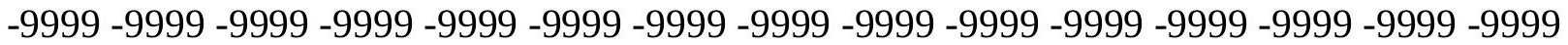
-9999 -9999 -9999 -9999 -9999 -9999 -9999 -9999 -9999 -9999 -9999 -9999 -9999 -9999 -9999 27.430660247824 .9923801422122 .5541000366220 .1158199310317 .67753982544 14.934470176714 .0201196670513 .4105501174912 .8009700775112 .1914100647 11.8866195678711 .8866195678712 .191410064712 .8009700775113 .7153301239 14.6296901702915 .8488302230817 .0679702758818 .5918903350819 .8110294342 21.0301704406722 .2493095397923 .1636695861823 .7732391357424 .38281059265 24.9923801422125 .2971591949525 .2971591949525 .2971591949525 .29715919495 24.9923801422124 .6875991821324 .3828105926524 .0780296325723 .77323913574 23.1636695861822 .8588790893622 .2493095397921 .9445304870621 .3349609375 20.7253894805919 .811029434219 .2014598846418 .28710937517 .37274932861 16.4584007263215 .2392597198514 .3248996734613 .1057596206712 .1914100647 11.2770500183110 .057909965529 .1435537338268 .5339832305917 .619627952576 6.7052731513986 .0957031255 .1813468933114 .5717768669133 .962207078934 3.3526360988622 .7430660724642 .4382810592652 .1334960460661 .523926019669 1.219141006471 .21914100647 .9143553972244 .9143553972244 .9143553972244 .9143553972244 .91435539722441 .219141006471 .5239260196691 .523926019669 1.8287110328672 .1334960460662 .4382810592652 .7430660724642 .743066072464 3.0478510856633 .0478510856633 .3526360988623 .3526360988623 .657422065735 3.6574220657353 .9622070789343 .9622070789344 .2669920921334 .266992092133 4.5717768669134 .5717768669134 .876562118535 .1813468933115 .486132144928 5.7909169197086 .0957031256 .4004869461067 .0100579261787 .314843177795 7.9244132041938 .2291984558118 .8387689590459 .4483394622810 .05790996552 10.6674804687511 .2770500183112 .191410064712 .8009700775113 .7153301239 14.6296901702915 .8488302230817 .0679702758818 .28710937519 .50625038147 20.7253894805921 .9445304870623 .4684505462624 .6875991821326 .21151924133 27.430660247828 .6497993469229 .8689403533931 .0880794525132 .00244140625 32.9167900085433 .5263595581134 .1359291076734 .7455101013235 .35507965088 35.6598587036136 .2694282531736 .5742111206136 .8790016174337 .18378067017 37.4885711669937 .7933502197337 .7933502197338 .0981407165538 .40293121338 38.7077102661139 .0125007629439 .3172798156739 .622070312539 .92684936523 40.2316398620640 .5364189147941 .1459884643641 .4507789611842 .06034851074 42.66992187543 .2794914245643 .8890609741244 .4986305236845 .10820007324 46.0225486755446 .6321296691947 .5464782714848 .4608306884849 .07040023804 49.9847602844250 .8991203308151 .8134689331152 .7278289794953 .64218139648 54.5565414428755 .7756805419956 .6900291442957 .6043891906758 .51874923706 
59.1283111572360 .0426712036160 .9570198059161 .5666007995662 .17617034912 62.7857398986863 .3953094482464 .004882812564 .6144485473664 .91924285889 65.2240066528365 .8335876464866 .1383666992266 .4431610107466 .74794006348 67.0527267456167 .3575134277367 .9670867919968 .2718734741268 .57665252686 $68.8814392089869 .1862335205169 .7957916259871 .3197174072372 .53704071045-9999$ -9999 -9999 -9999 -9999 -9999 -9999 -9999 -9999 -9999 -9999 -9999 -9999 -9999 -9999 -9999 -9999 -9999 -9999 -9999 -9999 -9999 -9999 -9999 -9999 -9999 -9999 -9999 -9999 -9999 -9999

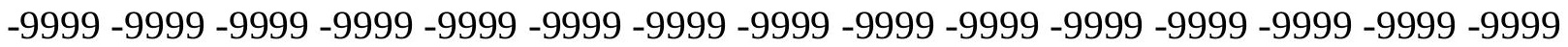
-9999 -9999 -9999 -9999 -9999 -9999 -9999 -9999 -9999 -9999 -9999 -9999 -9999 -9999 -9999 -9999 -9999 -9999 -9999 -9999 -9999 -9999 -9999 -9999 -9999 -9999 -9999 -9999 -9999 -9999 -9999 -9999 -9999 -9999 -9999 -9999 -9999 -9999 -9999 -9999 -9999 -9999 -9999 -9999 -9999 -9999 -9999 -9999 -9999 -9999 -9999 -9999 -9999 -9999 -9999 -9999 -9999 -9999 -

-9999 -9999 -9999 -9999 -9999 -9999 -9999 -9999 -9999 -9999 -9999 -9999 -9999 -9999 -9999 -9999 -9999 -9999 -9999 -9999 -9999 -9999 -9999 -9999 -9999 -9999 -9999 -9999 -9999 -9999 -9999 -9999 -9999 -9999 -9999 -9999 -9999 -9999 -9999 -9999 -9999 -9999 -9999 -9999 -9999

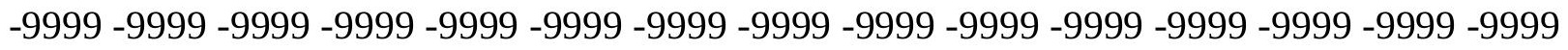
-9999 -9999 -9999 -9999 -9999 -9999 -9999 -9999 -9999 -9999 -9999 -9999 -9999 -9999 -9999 -9999 -9999 -9999 -9999 -9999 -9999 -9999 -9999 -9999 -9999 -9999 -9999 -9999 -9999 -9999 30.4785099029528 .0402297973625 .6019496917723 .1636695861820 .72538948059 18.28710937516 .1536102294915 .2392597198514 .3248996734613 .7153301239 13.1057596206712 .8009700775113 .1057596206713 .715330123914 .62969017029 15.8488302230817 .0679702758818 .5918903350820 .1158199310321 .3349609375 22.8588790893623 .7732391357424 .9923801422125 .6019496917726 .21151924133 26.5163097381626 .8210906982426 .8210906982426 .5163097381626 .51630973816 26.2115192413325 .906740188625 .2971591949524 .9923801422124 .38281059265 23.7732391357423 .4684505462622 .8588790893622 .2493095397921 .63973999023 21.0301704406720 .4206008911119 .5062503814718 .5918903350817 .37274932861 16.4584007263215 .2392597198514 .0201196670513 .1057596206711 .88661956787 10.9722604751610 .057909965529 .1435537338268 .2291984558117 .314843177795 6.7052731513985 .7909169197085 .1813468933114 .5717768669133 .962207078934 3.3526360988622 .7430660724642 .4382810592652 .1334960460661 .523926019669 1.5239260196691 .21914100647 .9143553972244 .9143553972244 .9143553972244 .9143553972244.9143553972244.9143553972244 1.21914100647 1.523926019669 1.5239260196691 .8287110328672 .1334960460662 .1334960460662 .438281059265 2.4382810592652 .7430660724642 .7430660724642 .7430660724643 .047851085663 3.0478510856633 .0478510856633 .0478510856633 .3526360988623 .352636098862 3.6574220657353 .6574220657353 .9622070789343 .9622070789344 .266992092133 4.5717768669134 .876562118535 .1813468933115 .7909169197086 .095703125 6.4004869461067 .0100579261787 .6196279525767 .9244132041938 .533983230591 9.1435537338269 .75312423706110 .6674804687511 .2770500183112 .1914100647 13.1057596206714 .3248996734615 .5440397262616 .7631797790517 .98232078552 19.2014598846420 .4206008911121 .9445304870623 .4684505462624 .68759918213 26.2115192413327 .430660247828 .9545898437530 .1737308502231 .08807945251 32.0024414062532 .9167900085433 .5263595581134 .4407196044935 .05028915405 35.3550796508835 .9646492004436 .2694282531736 .5742111206137 .18378067017 37.1837806701737 .4885711669937 .7933502197338 .0981407165538 .40293121338 
38.4029312133838 .7077102661139 .0125007629439 .3172798156739 .6220703125 39.9268493652340 .2316398620640 .8412094116241 .1459884643641 .75556182861 42.3651313781742 .9747009277343 .5842704772944 .1938400268644 .80340957642 45.717769622846 .3273391723647 .2416992187548 .1560516357448 .7656211853 49.6799812316950 .5943298339851 .5086898803752 .7278289794953 .64218139648 54.5565414428755 .4708900451756 .3852500915557 .2995986938558 .21395874023 59.1283111572360 .0426712036160 .6522407531761 .5666007995662 .17617034912 62.7857398986863 .3953094482463 .7000885009864 .3096618652364 .61444854736 65.2240066528365 .5288009643665 .8335876464866 .1383666992266 .74794006348 67.0527267456167 .3575134277367 .6623001098667 .9670867919968 .27187347412 68.5766525268668 .8814392089869 .4910125732470 .4053573608471 .92929077148 73.06357574463 -9999 -9999 -9999 -9999 -9999 -9999 -9999 -9999 -9999 -9999 -9999 -9999

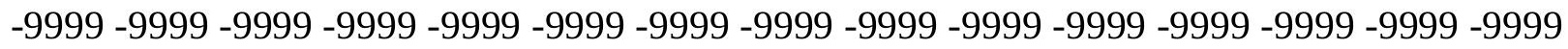

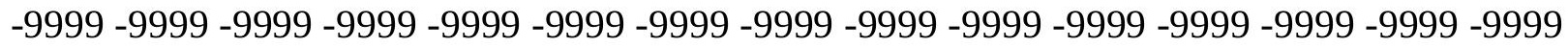

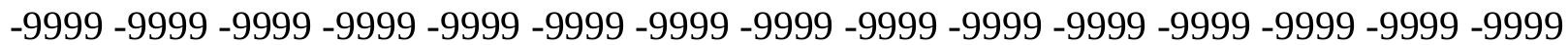

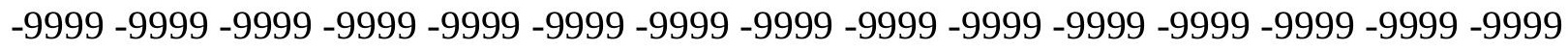

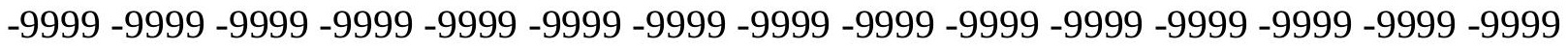

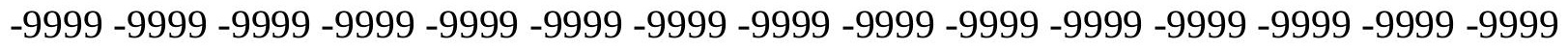
$-9999$

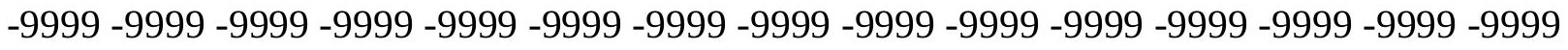

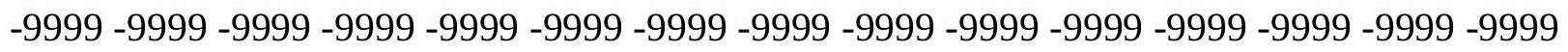

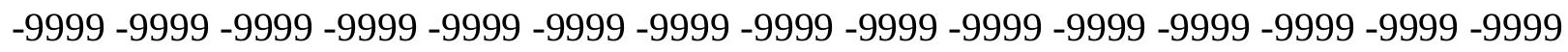

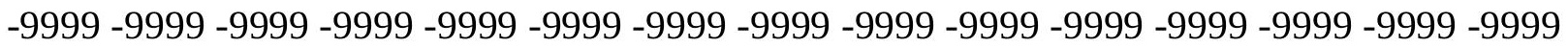

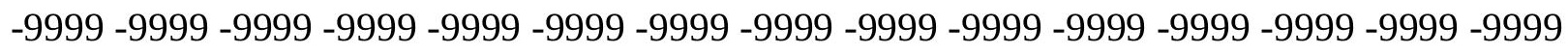

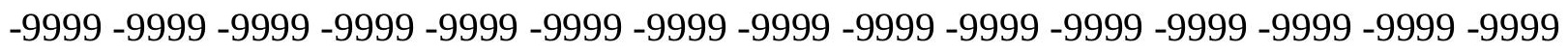
33.8311500549331 .3928699493429 .2593708038326 .8210906982424 .38281059265 21.9445304870619 .2014598846417 .0679702758816 .1536102294914 .9344701767 14.3248996734614 .0201196670514 .0201196670514 .6296901702915 .84883022308 17.0679702758818 .5918903350820 .1158199310321 .9445304870623 .46845054626 24.6875991821325 .906740188626 .8210906982427 .430660247828 .04022979736 28.3450202941928 .3450202941928 .3450202941928 .0402297973627 .73545074463 27.1258792877226 .8210906982426 .2115192413325 .6019496917724 .99238014221 24.3828105926523 .7732391357423 .4684505462622 .8588790893621 .94453048706 21.334960937520 .7253894805919 .811029434218 .8966808319117 .67753982544 16.4584007263215 .2392597198514 .0201196670512 .8009700775111 .88661956787 10.667480468759 .7531242370618 .8387689590457 .9244132041937 .010057926178 6.4004869461065 .7909169197084 .876562118534 .2669920921333 .962207078934 3.3526360988622 .7430660724642 .4382810592652 .1334960460661 .828711032867 1.5239260196691 .21914100647 .9143553972244 .9143553972244 .9143553972244 .9143553972244.9143553972244.9143553972244 .9143553972244 1.21914100647 1.219141006471 .5239260196691 .8287110328671 .8287110328672 .133496046066 2.1334960460662 .1334960460662 .1334960460662 .1334960460662 .438281059265 2.4382810592652 .4382810592652 .4382810592652 .4382810592652 .438281059265 2.7430660724642 .7430660724643 .0478510856633 .0478510856633 .352636098862 3.3526360988623 .6574220657353 .9622070789344 .2669920921334 .87656211853 5.1813468933115 .7909169197086 .0957031256 .7052731513987 .010057926178 
7.6196279525768 .2291984558119 .1435537338269 .75312423706110 .66748046875 11.5818300247212 .8009700775113 .715330123914 .934470176716 .45840072632 17.6775398254419 .2014598846420 .4206008911121 .9445304870623 .46845054626 24.6875991821326 .2115192413327 .7354507446328 .9545898437530 .17373085022 31.3928699493432 .3072204589832 .9167900085433 .8311500549334 .44071960449 35.0502891540535 .6598587036135 .9646492004436 .5742111206136 .87900161743 37.1837806701737 .4885711669937 .7933502197337 .7933502197338 .09814071655 38.4029312133838 .7077102661138 .7077102661139 .0125007629439 .31727981567 39.622070312540 .2316398620640 .5364189147940 .8412094116241 .45077896118 42.0603485107442 .3651313781743 .2794914245643 .8890609741244 .49863052368 45.1082000732446 .0225486755446 .9369087219247 .8512611389248 .46083068848 49.37519073486 50.28955078125 51.5086898803752.4230384826753.33739852905 54.2517509460455 .1661109924356 .0804595947357 .2995986938558 .21395874023 59.1283111572359 .7378807067960 .6522407531761 .2618103027362 .17617034912 62.7857398986863 .0905189514263 .7000885009864 .004882812564 .61444854736 64.9192428588965 .2240066528365 .8335876464866 .1383666992266 .44316101074 66.7479400634867 .0527267456167 .3575134277367 .6623001098667 .96708679199 68.2718734741268 .8814392089869 .1862335205169 .7957916259871 .31971740723 72.53885650635 -9999 -9999 -9999 -9999 -9999 -9999 -9999 -9999 -9999 -9999 -9999 -9999

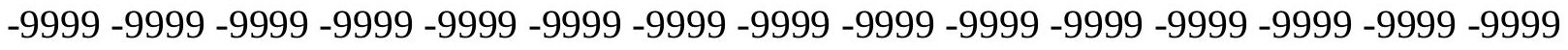
-9999 -9999 -9999 -9999 -9999 -9999 -9999 -9999 -9999 -9999 -9999 -9999 -9999 -9999 -9999 -9999 -9999 -9999 -9999 -9999 -9999 -9999 -9999 -9999 -9999 -9999 -9999 -9999 -9999 -9999 -9999 -9999 -9999 -9999 -9999 -9999 -9999 -9999 -9999 -9999 -9999 -9999-9999-9999-9999 -999 -9999 -9999 -9999 -9999 -9999 -9999 -9999 -9999 -9999 -9999 -9999 -9999 -9999 -9999 -9999 -

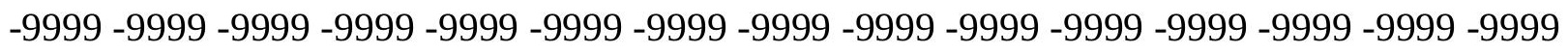
$-9999$

-9999 -9999 -9999 -9999 -9999 -9999 -9999 -9999 -9999 -9999 -9999 -9999 -9999 -9999 -9999 -9999 -9999 -9999 -9999 -9999 -9999 -9999 -9999 -9999 -9999 -9999 -9999 -9999 -9999 -9999 -9999 -9999 -9999 -9999 -9999 -9999 -9999 -9999 -9999 -9999 -9999 -9999 -9999 -9999 -9999 -9999 -9999 -9999 -9999 -9999 -9999 -9999 -9999 -9999 -9999 -9999 -9999 -9999 -9999 -9999 -9999 -9999 -9999 -9999 -9999 -9999 -9999 -9999 -9999 -9999 -9999 -9999 -9999 -9999 -9999 -9999 -9999 -9999 -9999 -9999 -9999 -9999 -9999 -9999 -9999 -9999 -9999 -9999 -9999 40.5364189147937 .4885711669935 .0502891540532 .9167900085430 .78330039978 28.6497993469226 .5163097381623 .7732391357421 .0301704406717 .98232078552 16.4584007263215 .8488302230815 .2392597198515 .5440397262615 .84883022308 17.0679702758818 .5918903350820 .4206008911122 .2493095397924 .07802963257 25.6019496917727 .1258792877228 .3450202941929 .2593708038329 .56415939331 30.1737308502230 .1737308502229 .8689403533929 .5641593933129 .25937080383 28.6497993469228 .3450202941927 .7354507446327 .1258792877226 .21151924133 25.6019496917724 .9923801422124 .3828105926523 .7732391357422 .85887908936 22.2493095397921 .6397399902321 .0301704406720 .1158199310318 .89668083191 17.6775398254416 .1536102294914 .934470176713 .715330123912 .49619007111 11.2770500183110 .362689971929 .448339462288 .5339832305917 .619627952576 6.7052731513986 .0957031255 .4861321449284 .876562118534 .266992092133 3.6574220657353 .3526360988622 .7430660724642 .4382810592652 .133496046066 1.8287110328671 .5239260196691 .219141006471 .21914100647 .9143553972244 
.9143553972244.9143553972244.6095703244209.6095703244209.9143553972244 .9143553972244 .91435539722441 .219141006471 .219141006471 .523926019669 1.5239260196691 .5239260196691 .5239260196691 .5239260196691 .523926019669 1.5239260196691 .5239260196691 .5239260196691 .8287110328671 .828711032867 1.8287110328671 .8287110328671 .8287110328671 .8287110328672 .133496046066 2.1334960460662 .4382810592652 .4382810592652 .7430660724643 .047851085663 3.6574220657353 .9622070789344 .2669920921334 .876562118535 .181346893311 5.7909169197086 .0957031256 .7052731513987 .6196279525768 .229198455811 9.14355373382610 .0579099655211 .2770500183112 .191410064713 .41055011749 14.934470176716 .1536102294917 .6775398254418 .8966808319120 .42060089111 21.9445304870623 .4684505462624 .9923801422126 .5163097381627 .73545074463 28.9545898437530 .1737308502231 .3928699493432 .3072204589833 .22158050537 34.1359291076734 .7455101013235 .3550796508835 .6598587036136 .26942825317 36.5742111206136 .8790016174337 .1837806701737 .4885711669937 .79335021973 37.7933502197338 .0981407165538 .4029312133838 .7077102661138 .70771026611 39.0125007629439 .3172798156739 .9268493652340 .2316398620640 .53641891479 41.1459884643641 .4507789611842 .0603485107442 .66992187543 .27949142456 44.1938400268644 .8034095764245 .717769622846 .6321296691947 .24169921875 48.1560516357449 .0704002380449 .9847602844251 .2038993835452 .11825942993 53.0326118469253 .9469718933155 .1661109924356 .0804595947356 .99481964111 57.909179687558 .8235282897959 .7378807067960 .6522407531761 .26181030273 61.8713798522962 .4809494018663 .0905189514263 .3953094482464 .0048828125 64.3096618652364 .6144485473665 .2240066528365 .5288009643665 .83358764648 66.1383666992266 .4431610107466 .7479400634867 .0527267456167 .35751342773 67.9670867919968 .2718734741268 .5766525268669 .1862335205169 .49101257324 70.4053573608471 .9292907714873 .07357788086 -9999 -9999 -9999 -9999 -9999 -9999 -9999 -9999 -9999 -9999 -9999 -9999 -9999 -9999 -9999 -9999 -9999 -9999 -9999 -9999 -9999 -9999

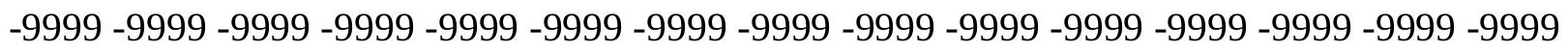
-9999 -9999 -9999 -9999 -9999 -9999 -9999 -9999 -9999 -9999 -9999 -9999 -9999 -9999 -9999 -9999 -9999 -9999 -9999 -9999 -9999 -9999 -9999 -9999 -9999 -9999 -9999 -9999 -9999 -9999 -9999 -9999 -9999 -9999 -9999 -9999 -9999 -9999 -9999 -9999 -9999 -9999 -9999 -9999 -9999

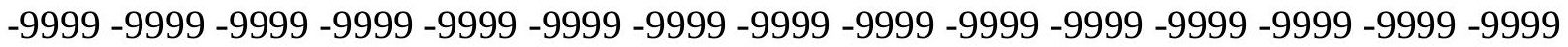
-9999 -9999-9999-9999-9999

-9999 -9999 -9999 -9999 -9999 -9999 -9999 -9999 -9999 -9999 -9999 -9999 -9999 -9999 -9999 -9999 -9999 -9999 -9999 -9999 -9999 -9999 -9999 -9999 -9999 -9999 -9999 -9999 -9999 -9999 -

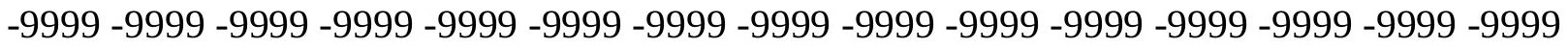

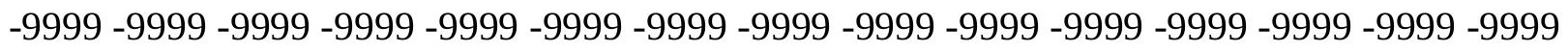

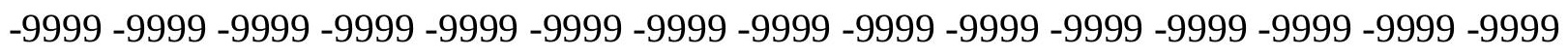
-9999 -9999 -9999 -9999 -9999 -9999 -9999 -9999 -9999 -9999 -9999 -9999 -9999 -9999 44.1938400268641 .4507789611839 .0125007629436 .8790016174335 .05028915405 33.2215805053731 .0880794525128 .9545898437526 .5163097381623 .77323913574 20.7253894805917 .6775398254417 .0679702758817 .0679702758817 .37274932861 18.5918903350820 .4206008911122 .5541000366224 .6875991821326 .51630973816 28.3450202941929 .8689403533930 .7833003997831 .6976509094232 .00244140625 32.0024414062532 .0024414062531 .6976509094231 .0880794525130 .47850990295 29.8689403533929 .2593708038328 .3450202941927 .7354507446326 .82109069824 
26.2115192413325 .2971591949524 .6875991821323 .7732391357423 .16366958618 22.5541000366221 .6397399902321 .0301704406720 .1158199310318 .89668083191 17.37274932861 16.15361022949 14.62969017029 13.41055011749 12.1914100647 10.9722604751610 .057909965528 .8387689590458 .2291984558117 .314843177795 6.4004869461065 .7909169197085 .1813468933114 .5717768669134 .266992092133 3.6574220657353 .3526360988622 .7430660724642 .4382810592652 .133496046066 1.8287110328671 .5239260196691 .219141006471 .21914100647 .9143553972244 6095703244209 .6095703244209.6095703244209.9143553972244.9143553972244.9143553972244 9143553972244.9143553972244.9143553972244.9143553972244.9143553972244 9143553972244.9143553972244.9143553972244.9143553972244.9143553972244 9143553972244.9143553972244.9143553972244.9143553972244.9143553972244 1.219141006471 .219141006471 .5239260196691 .5239260196692 .133496046066 2.4382810592652 .7430660724643 .0478510856633 .6574220657353 .962207078934 4.2669920921334 .876562118535 .4861321449286 .0957031256 .705273151398 7.6196279525768 .5339832305919 .4483394622810 .6674804687511 .88661956787 13.1057596206714 .6296901702915 .8488302230817 .3727493286118 .89668083191 20.4206008911121 .9445304870623 .4684505462624 .9923801422126 .51630973816 28.0402297973629 .2593708038330 .4785099029531 .6976509094232 .61201095581 33.5263595581134 .1359291076734 .7455101013235 .3550796508835 .96464920044 36.2694282531736 .5742111206136 .8790016174337 .1837806701737 .48857116699 37.4885711669937 .7933502197338 .0981407165538 .4029312133838 .40293121338 38.7077102661139 .0125007629439 .3172798156739 .9268493652340 .23163986206 40.5364189147941 .1459884643641 .7555618286142 .3651313781742 .97470092773 43.5842704772944 .4986305236845 .1082000732446 .0225486755446 .93690872192 47.8512611389248 .765621185349 .6799812316950 .8991203308151 .81346893311 52.7278289794953 .9469718933154 .8613204956155 .7756805419956 .69002914429 57.909179687558 .8235282897959 .7378807067960 .3474502563561 .26181030273 61.8713798522962 .4809494018662 .7857398986863 .3953094482463 .70008850098 64.004882812564 .6144485473664 .9192428588965 .2240066528365 .52880096436 65.8335876464866 .1383666992266 .4431610107466 .7479400634867 .35751342773 67.6623001098667 .9670867919968 .2718734741268 .8814392089869 .18623352051 69.7957916259871 .014930725172 .5388565063573 .78978729248 -9999 -9999 -9999 -9999 -9999 -9999 -9999 -9999 -9999 -9999 -9999 -9999 -9999 -9999 -9999 -9999 -9999 -9999 -9999 -9999 -9999 -9999 -9999 -9999 -9999 -9999 -9999 -9999 -9999 -9999 -9999 -9999 -9999 -9999 -

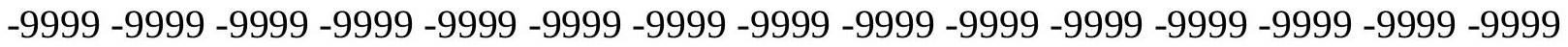

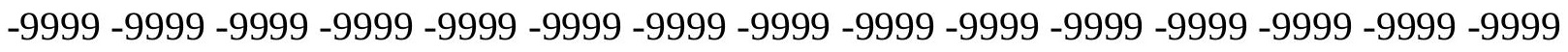

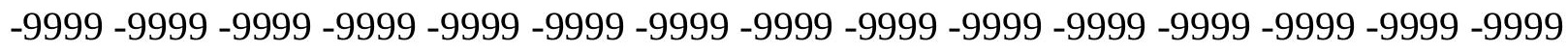

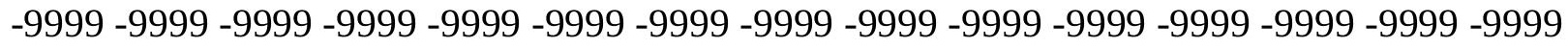
-9999 -9999 -9999 -9999-9999-9999-9999

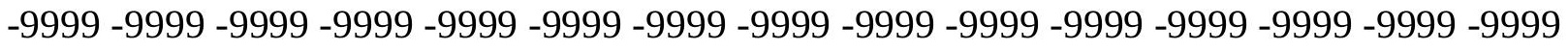

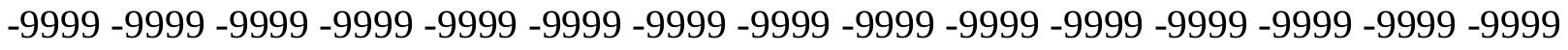
-9999 -9999 -9999 -9999 -9999 -9999 -9999 -9999 -9999 -9999 -9999 -9999 -9999 -9999 -9999 -9999 -9999 -9999 -9999 -9999 -9999 -9999 -9999 -9999-9999 -9999 -9999 -9999 -9999 -9999 -9999 -9999 -9999 -9999 -9999 -9999 -9999 -9999 -9999 -9999 -9999 -9999 -9999 -9999 -9999 -9999 -9999 -9999 -9999 -9999 -9999 -9999 -9999 -9999 -9999 -9999 -9999 -9999 -9999 
47.5464782714845 .1082000732442 .9747009277341 .1459884643639 .31727981567 37.7933502197335 .9646492004434 .4407196044932 .6120109558130 .78330039978 28.3450202941924 .9923801422121 .6397399902318 .8966808319119 .50625038147 20.7253894805922 .8588790893624 .9923801422127 .430660247829 .56415939331 31.3928699493432 .6120109558133 .8311500549334 .4407196044934 .44071960449 34.4407196044933 .8311500549333 .2215805053732 .6120109558131 .69765090942 31.0880794525130 .1737308502229 .2593708038328 .3450202941927 .4306602478 26.5163097381625 .906740188624 .9923801422124 .0780296325723 .16366958618 22.2493095397921 .6397399902320 .7253894805919 .811029434218 .287109375 17.0679702758815 .5440397262614 .0201196670512 .8009700775111 .58183002472 10.362689971929 .448339462288 .5339832305917 .6196279525767 .010057926178 6.0957031255 .4861321449285 .1813468933114 .5717768669133 .962207078934 3.6574220657353 .3526360988622 .7430660724642 .4382810592652 .133496046066 1.8287110328671 .5239260196691 .219141006471 .21914100647 .9143553972244 9143553972244.6095703244209.6095703244209. 3047851026058. 3047851026058 -9999 3047851026058.3047851026058. 3047851026058. 3047851026058. 3047851026058 3047851026058.3047851026058 3047851026058.3047851026058 -9999-9999 -9999 -9999 3047851026058 3047851026058 3047851026058 -9999 -9999 -9999.3047851026058 .3047851026058.3047851026058.6095703244209.9143553972244 1.21914100647 1.5239260196691 .8287110328672 .4382810592652 .7430660724643 .047851085663 3.3526360988623 .9622070789344 .5717768669135 .1813468933116 .095703125 7.0100579261787 .9244132041939 .14355373382610 .3626899719211 .58183002472 13.1057596206714 .3248996734615 .8488302230817 .3727493286118 .89668083191 20.4206008911121 .9445304870623 .4684505462624 .9923801422126 .51630973816 28.0402297973629 .2593708038330 .7833003997831 .6976509094232 .61201095581 33.5263595581134 .4407196044935 .0502891540535 .3550796508835 .96464920044 36.2694282531736 .5742111206136 .8790016174337 .1837806701737 .18378067017 37.4885711669937 .7933502197337 .7933502197338 .0981407165538 .40293121338 38.7077102661139 .0125007629439 .3172798156739 .622070312540 .23163986206 40.8412094116241 .1459884643641 .7555618286142 .66992187543 .27949142456 43.8890609741244 .8034095764245 .717769622846 .6321296691947 .54647827148 48.4608306884849 .3751907348650 .5943298339851 .5086898803752 .42303848267 53.6421813964854 .5565414428755 .4708900451756 .6900291442957 .60438919067 58.5187492370659 .4331016540560 .3474502563560 .9570198059161 .56660079956 62.1761703491262 .4809494018663 .0905189514263 .3953094482464 .0048828125 64.3096618652364 .6144485473664 .9192428588965 .2240066528365 .52880096436 65.8335876464866 .4431610107466 .7479400634867 .0527267456167 .35751342773 67.6623001098668 .2718734741268 .5766525268669 .1862335205169 .79579162598 70.4053573608471 .9292907714873 .39691162109 -9999 -9999 -9999 -9999 -9999 -9999 -9999 -9999 -9999 -9999 -9999 -9999 -9999 -9999 -9999 -9999 -9999 -9999 -9999 -9999 -9999 -9999

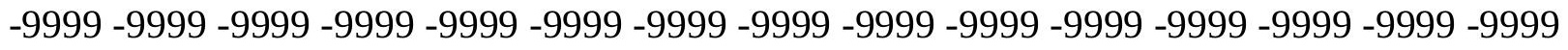

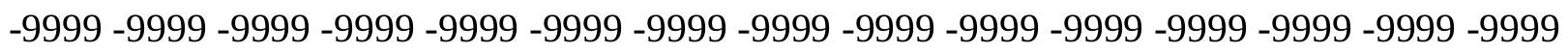

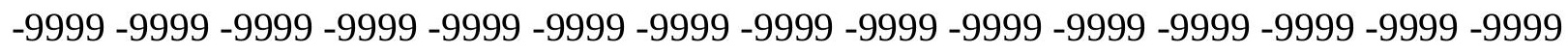
-9999 -9999 -9999 -9999 -9999 -9999 -9999 -9999 -9999 -9999 -9999 -9999 -9999 -9999 -9999 -9999 -9999 -9999 -9999 -9999 -9999 -9999 -9999 -9999 -9999 -9999 -9999 -9999 -9999 -999 -999 -9999 -9999 -9999-9999 
-9999 -9999 -9999 -9999 -9999 -9999 -9999 -9999 -9999 -9999 -9999 -9999 -9999 -9999 -9999 -9999 -9999 -9999 -9999 -9999 -9999 -9999 -9999 -9999 -9999 -9999 -9999 -9999 -9999 -9999

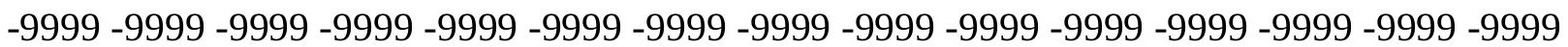
-9999 -9999 -9999 -9999 -9999 -9999 -9999 -9999 -9999 -9999 -9999 -9999 -9999 -9999 -9999 -9999 -9999 -9999 -9999 -9999 -9999 -9999 -9999 -9999 -9999 -9999 -9999 -9999 -9999 -9999 -9999 -9999 -9999 -9999 -9999 -9999 -9999 -9999 -9999 -9999 -9999 -9999 -9999 -9999 50.8991203308148 .765621185346 .9369087219245 .1082000732443 .58427047729 42.3651313781741 .1459884643639 .9268493652339 .3172798156738 .09814071655 36.8790016174334 .4407196044929 .8689403533924 .0780296325722 .24930953979 23.4684505462625 .6019496917728 .3450202941931 .0880794525133 .22158050537 34.7455101013236 .2694282531737 .1837806701737 .4885711669937 .48857116699 36.8790016174335 .9646492004435 .0502891540534 .1359291076732 .91679000854 32.0024414062530 .7833003997829 .8689403533928 .9545898437528 .04022979736 27.1258792877225 .906740188624 .9923801422124 .0780296325723 .16366958618 22.2493095397921 .0301704406720 .1158199310318 .8966808319117 .67753982544 16.1536102294914 .934470176713 .4105501174912 .191410064710 .97226047516 9.7531242370618 .8387689590457 .9244132041937 .0100579261786 .400486946106 5.7909169197085 .1813468933114 .876562118534 .2669920921333 .962207078934 3.6574220657353 .3526360988622 .7430660724642 .4382810592652 .133496046066 1.8287110328671 .5239260196691 .219141006471 .21914100647 .9143553972244 6095703244209.6095703244209.3047851026058 -9999 -9999-.304785102606 -.304785102606 -9999-9999-.304785102606 -.304785102606-.304785102606 -.304785102606 -.609570324421 -.609570324421 -.609570324421 -.609570324421 -.609570324421 -.609570324421 -.304785102606 -.304785102606 -.304785102606 $-.304785102606-.304785102606-.609570324421-.609570324421-.304785102606$ -.304785102606 -.304785102606 -9999 -9999 .3047851026058 .9143553972244 1.219141006471 .5239260196691 .8287110328672 .1334960460662 .438281059265 3.0478510856633 .6574220657354 .5717768669135 .4861321449286 .705273151398 7.6196279525768 .83876895904510 .0579099655211 .5818300247212 .80097007751 14.3248996734615 .8488302230817 .3727493286118 .8966808319120 .42060089111 22.2493095397923 .7732391357425 .2971591949526 .8210906982428 .34502029419 29.5641593933130 .7833003997832 .0024414062532 .9167900085433 .83115005493 34.4407196044935 .0502891540535 .3550796508835 .6598587036136 .26942825317 36.2694282531736 .5742111206136 .8790016174336 .8790016174337 .18378067017 37.4885711669937 .7933502197337 .7933502197338 .0981407165538 .40293121338 39.0125007629439 .3172798156739 .622070312540 .2316398620640 .84120941162 41.4507789611842 .0603485107442 .66992187543 .5842704772944 .49863052368 45.1082000732446 .0225486755446 .9369087219248 .1560516357449 .07040023804 49.9847602844251 .2038993835452 .1182594299353 .3373985290554 .25175094604 55.4708900451756 .3852500915557 .2995986938558 .2139587402359 .12831115723 60.0426712036160 .6522407531761 .2618103027361 .8713798522962 .48094940186 62.7857398986863 .3953094482463 .7000885009864 .004882812564 .30966186523 64.6144485473664 .9192428588965 .5288009643665 .8335876464866 .13836669922 66.4431610107466 .7479400634867 .0527267456167 .6623001098667 .96708679199 68.5766525268668 .8814392089869 .4910125732470 .1005783081171 .31971740723 72.5388565063573 .64826202393 -9999 -9999 -9999 -9999 -9999 -9999 -9999 -9999 -9999 
-9999 -9999 -9999 -9999 -9999 -9999 -9999 -9999 -9999 -9999 -9999 -9999 -9999 -9999 -9999 -9999 -9999 -9999 -9999 -9999 -9999 -9999 -9999 -9999 -9999 -9999 -9999 -9999 -9999 -9999 -9999 -9999 -9999 -9999 -9999 -9999 -9999 -9999 -9999 -9999 -9999 -9999 -9999 -9999 -9999 -9999 -9999 -9999 -9999 -9999 -9999 -9999 -9999 -9999 -9999 -9999 -9999 -9999 -9999 -9999 -9999 -9999 -9999 -9999 -9999 -9999 -9999 -9999 -9999 -9999 -9999 -9999-9999 -9999 -9999 -9999 -9999 -9999 -9999 -9999 -9999 -9999 -9999 -9999 -9999 -9999 -9999 -9999 -9999 -9999 $-9999$

-9999 -9999 -9999 -9999 -9999 -9999 -9999 -9999 -9999 -9999 -9999 -9999 -9999 -9999 -9999

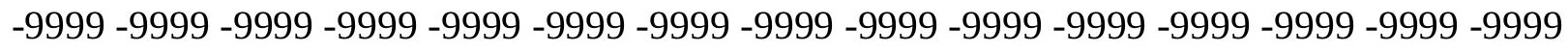
-9999 -9999 -9999 -9999 -9999 -9999 -9999 -9999 -9999 -9999 -9999 -9999 -9999 -9999 -9999 -

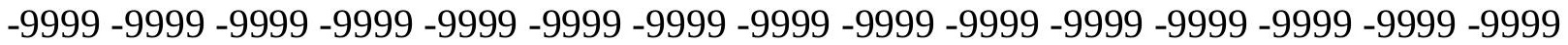
-9999 -9999 -9999 -9999 -9999 -9999 -9999 -9999 -9999 -9999 -9999 -9999 -9999 -9999 -9999 -9999 -9999 -9999 -9999 -9999 -9999 -9999 -9999 -9999 -9999 -9999 -9999 -9999 -9999 53.9469718933152 .4230384826750 .5943298339849 .3751907348648 .15605163574 47.2416992187546 .3273391723646 .0225486755446 .3273391723646 .32733917236 46.0225486755444 .4986305236841 .4507789611837 .1837806701732 .30722045898 28.3450202941929 .5641593933132 .6120109558135 .0502891540537 .18378067017 38.7077102661140 .2316398620641 .1459884643641 .1459884643640 .53641891479 39.622070312538 .0981407165536 .5742111206135 .3550796508833 .83115005493 32.9167900085431 .6976509094230 .4785099029529 .5641593933128 .34502029419 27.430660247826 .2115192413325 .2971591949524 .0780296325722 .85887908936 21.9445304870620 .7253894805919 .5062503814718 .28710937516 .76317977905 15.5440397262614 .0201196670512 .8009700775111 .5818300247210 .36268997192 9.1435537338268 .2291984558117 .3148431777956 .7052731513986 .095703125 5.4861321449285 .1813468933114 .5717768669134 .2669920921333 .962207078934 3.6574220657353 .3526360988623 .0478510856632 .4382810592652 .133496046066 1.8287110328671 .5239260196691 .21914100647 .9143553972244 .6095703244209 6095703244209.3047851026058 -9999-.304785102606-.609570324421 -.914355397224 $-1.21914100647-1.21914100647-1.21914100647-1.52392601967-1.52392601967$ -1.52392601967 -1.82871103287 -1.82871103287 -1.82871103287 -1.82871103287 $-1.52392601967-1.52392601967-1.52392601967-1.21914100647-1.21914100647$ $-1.21914100647-1.21914100647-1.21914100647-1.21914100647-1.21914100647$ $-1.21914100647-1.21914100647-1.21914100647-.914355397224-.609570324421$ -.304785102606 -9999-9999-9999.3047851026058.6095703244209 1.21914100647 1.5239260196692 .4382810592653 .0478510856634 .2669920921335 .181346893311 6.4004869461067 .6196279525768 .83876895904510 .0579099655211 .58183002472 12.8009700775114 .3248996734615 .8488302230817 .3727493286119 .20145988464 20.7253894805922 .2493095397924 .0780296325725 .6019496917727 .12587928772 28.64979934692 29.8689403533931.0880794525132.3072204589833.22158050537 33.8311500549334 .4407196044935 .0502891540535 .3550796508835 .65985870361 35.9646492004435 .9646492004436 .2694282531736 .5742111206136 .57421112061 36.8790016174337 .1837806701737 .4885711669937 .7933502197338 .09814071655 38.4029312133838 .7077102661139 .3172798156739 .622070312540 .23163986206 40.8412094116241 .4507789611842 .3651313781742 .9747009277343 .88906097412 44.8034095764245 .717769622846 .6321296691947 .5464782714848 .7656211853 49.6799812316950 .8991203308151 .8134689331153 .0326118469253 .94697189331 
55.1661109924356 .0804595947356 .9948196411157 .909179687558 .82352828979 59.7378807067960 .3474502563560 .9570198059161 .5666007995662 .17617034912 62.4809494018663 .0905189514263 .3953094482463 .7000885009864 .0048828125 64.6144485473664 .9192428588965 .2240066528365 .5288009643665 .83358764648 66.1383666992266 .4431610107467 .0527267456167 .3575134277367 .96708679199 68.2718734741268 .8814392089869 .1862335205169 .7957916259871 .92929077148 71.9292907714873 .4532165527373 .83263397217 -9999 -9999 -9999 -9999 -9999 -9999 -9999 -9999 -9999 -9999 -9999 -9999 -9999 -9999 -9999 -9999 -9999 -9999 -9999 -9999 -9999 -9999

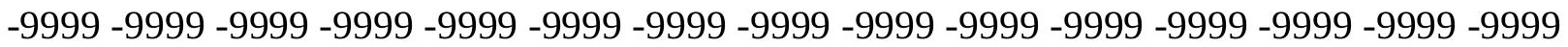
-9999 -9999 -9999 -9999 -9999 -9999 -9999 -9999 -9999 -9999 -9999 -9999 -9999 -9999 -9999 -

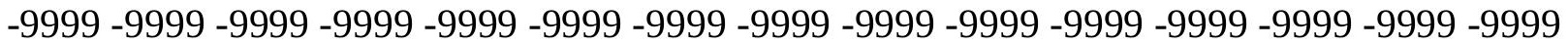
-9999 -9999 -9999 -9999 -9999 -9999 -9999 -9999 -9999 -9999 -9999 -9999 -9999 -9999 -9999 -

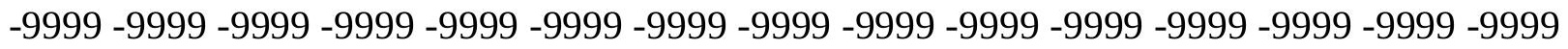
$-9999-9999$

-9999 -9999 -9999 -9999 -9999 -9999 -9999 -9999 -9999 -9999 -9999 -9999 -9999 -9999 -9999

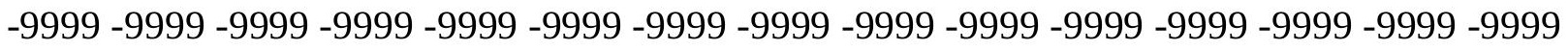

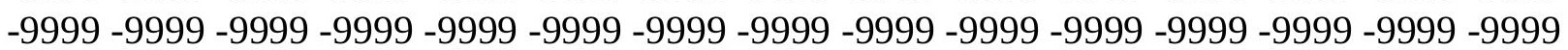
-9999 -9999 -9999 -9999 -9999 -9999 -9999 -9999 -9999 -9999 -9999 -9999 -9999 -9999 -9999 -999 -

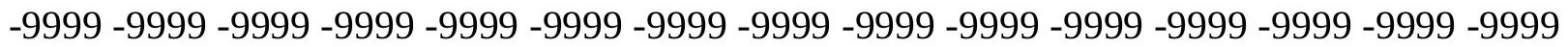
-9999 -9999 -9999 -9999 -9999 -9999 -9999 -9999 -9999 -9999 -9999 -9999 -9999 58.2139587402356 .9948196411155 .7756805419954 .5565414428753 .64218139648 52.7278289794952 .1182594299351 .8134689331152 .1182594299353 .33739852905 54.5565414428755 .4708900451755 .4708900451754 .5565414428752 .42303848267 47.8512611389242 .3651313781738 .4029312133837 .7933502197339 .6220703125 41.4507789611842 .9747009277344 .4986305236845 .4129791259845 .41297912598 44.1938400268642 .3651313781740 .2316398620638 .4029312133836 .57421112061 35.0502891540533 .5263595581132 .3072204589831 .0880794525129 .86894035339 28.9545898437527 .7354507446326 .5163097381625 .2971591949524 .07802963257 22.5541000366221 .334960937520 .1158199310318 .8966808319117 .37274932861 16.1536102294914 .6296901702913 .4105501174911 .8866195678710 .66748046875 9.448339462288 .5339832305917 .6196279525766 .7052731513986 .095703125 5.4861321449285 .1813468933114 .876562118534 .5717768669134 .266992092133 3.9622070789343 .6574220657353 .3526360988623 .0478510856632 .743066072464 2.1334960460661 .8287110328671 .5239260196691 .21914100647 .9143553972244 .6095703244209.3047851026058 -9999-.304785102606-.914355397224 -1.52392601967 $-2.13349604607-2.43828105927-2.74306607246-2.74306607246-3.04785108566$ $-3.04785108566-3.04785108566-3.04785108566-3.04785108566-3.04785108566$ $-3.04785108566-2.74306607246-2.43828105927-2.43828105927-2.13349604607$ $-2.13349604607-2.13349604607-1.82871103287-2.13349604607-2.13349604607$ $-2.13349604607-2.13349604607-2.13349604607-2.13349604607-1.82871103287$ $-1.82871103287-1.52392601967-1.21914100647-.914355397224-.914355397224$ -.609570324421 -.304785102606 -9999.3047851026058 1.21914100647 1.828711032867 2.7430660724643 .9622070789344 .876562118536 .0957031257 .314843177795 8.83876895904510 .0579099655211 .5818300247212 .8009700775114 .32489967346 15.8488302230817 .6775398254419 .2014598846421 .0301704406722 .55410003662 24.3828105926525 .906740188627 .430660247828 .9545898437530 .17373085022 
31.3928699493432 .3072204589833 .2215805053733 .8311500549334 .44071960449 34.7455101013235 .0502891540535 .3550796508835 .6598587036135 .65985870361 35.9646492004436 .2694282531736 .2694282531736 .5742111206136 .87900161743 37.1837806701737 .4885711669937 .7933502197338 .0981407165538 .70771026611 39.0125007629439 .622070312540 .2316398620640 .8412094116241 .75556182861 42.3651313781743 .2794914245644 .1938400268645 .1082000732446 .02254867554 47.2416992187548 .1560516357449 .3751907348650 .2895507812551 .50868988037 52.7278289794953 .6421813964854 .8613204956155 .7756805419956 .69002914429 57.909179687558 .5187492370659 .4331016540560 .0426712036160 .65224075317 61.2618103027361 .8713798522962 .1761703491262 .7857398986863 .09051895142 63.3953094482463 .7000885009864 .3096618652364 .6144485473664 .91924285889 65.2240066528365 .5288009643665 .8335876464866 .4431610107466 .74794006348 67.0527267456167 .6623001098667 .9670867919968 .5766525268669 .18623352051 69.7957916259870 .4053573608471 .014930725172 .5388565063573 .78685760498 -9999

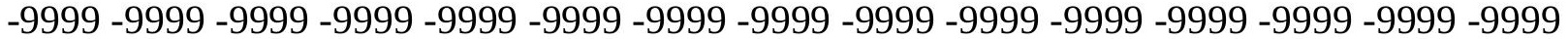

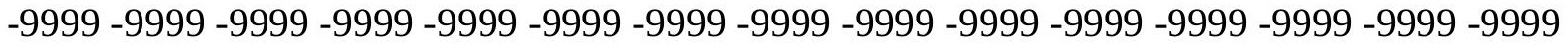

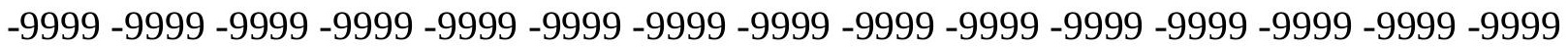

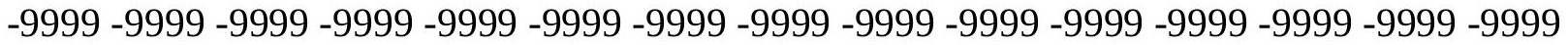

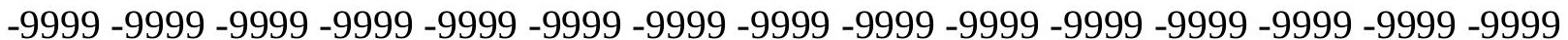

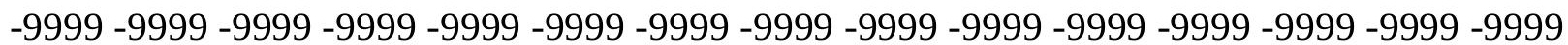
-9999 -9999 -9999 -9999 -9999 -9999 -9999-9999

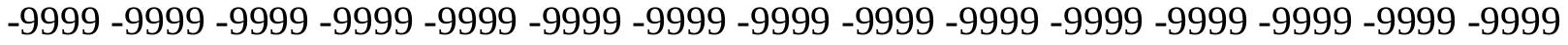
-9999 -

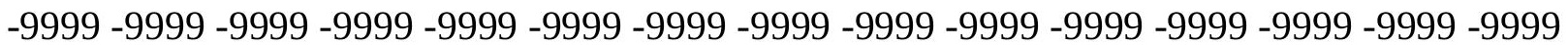

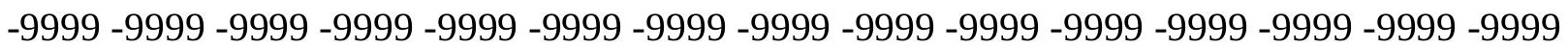

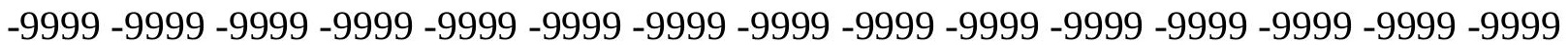
-9999 -9999 -9999 -9999 -9999 -9999 -9999 -9999 -9999 -9999 -9999 -9999 -9999 60.3474502563559 .7378807067959 .1283111572358 .5187492370657 .9091796875 57.6043891906757 .6043891906757 .2995986938558 .2139587402360 .34745025635 62.7857398986865 .5288009643668 .2718734741269 .4910125732469 .49101257324 67.0527267456163 .3953094482460 .3474502563555 .4708900451746 .93690872192 46.0225486755447 .5464782714849 .6799812316950 .8991203308150 .28955078125 47.8512611389245 .1082000732442 .3651313781739 .622070312537 .48857116699 35.6598587036134 .1359291076732 .9167900085431 .6976509094230 .47850990295 29.2593708038328 .0402297973626 .8210906982425 .2971591949523 .77323913574 22.5541000366221 .0301704406719 .5062503814717 .9823207855216 .76317977905 15.2392597198514 .0201196670512 .4961900711111 .2770500183110 .05790996552 8.8387689590457 .6196279525766 .7052731513986 .0957031255 .486132144928 5.1813468933114 .876562118534 .5717768669134 .2669920921334 .266992092133 3.9622070789343 .6574220657353 .3526360988623 .0478510856632 .743066072464 2.4382810592651 .8287110328671 .5239260196691 .21914100647 .6095703244209 .3047851026058 -9999- -.609570324421 -1.21914100647 -1.82871103287 -2.43828105927 $-3.04785108566-3.65742206573-3.96220707893-4.26699209213-4.57177686691$ $-4.57177686691-4.87656211853-4.57177686691-4.57177686691-4.26699209213$ $-4.26699209213-3.96220707893-3.65742206573-3.35263609886-3.04785108566$ $-2.74306607246-2.74306607246-2.74306607246-2.74306607246-2.74306607246$ 
$-2.74306607246-2.74306607246-2.74306607246-2.74306607246-2.74306607246$ $-2.74306607246-2.43828105927-2.43828105927-2.13349604607-1.82871103287$ -1.82871103287 - $1.52392601967-.914355397224-.609570324421-9999.9143553972244$ 1.8287110328672 .7430660724643 .9622070789344 .876562118536 .095703125 7.3148431777958 .83876895904510 .0579099655211 .5818300247213 .10575962067 14.6296901702916 .1536102294917 .9823207855219 .5062503814721 .3349609375 22.8588790893624 .6875991821326 .2115192413327 .7354507446329 .25937080383 30.7833003997831 .6976509094232 .6120109558133 .2215805053733 .83115005493 34.1359291076734 .4407196044934 .7455101013235 .0502891540535 .05028915405 35.3550796508835 .3550796508835 .6598587036135 .9646492004436 .26942825317 36.5742111206136 .8790016174337 .1837806701737 .4885711669937 .79335021973 38.4029312133839 .0125007629439 .622070312540 .2316398620641 .14598846436 41.7555618286142 .66992187543 .5842704772944 .4986305236845 .7177696228 46.6321296691947 .8512611389248 .765621185349 .9847602844251 .20389938354 52.4230384826753 .3373985290554 .5565414428755 .4708900451756 .38525009155 57.6043891906758 .2139587402359 .1283111572359 .7378807067960 .34745025635 60.9570198059161 .5666007995661 .8713798522962 .4809494018662 .78573989868 63.0905189514263 .7000885009864 .004882812564 .3096618652364 .61444854736 64.9192428588965 .2240066528365 .8335876464866 .1383666992266 .44316101074 67.0527267456167 .3575134277367 .9670867919968 .5766525268668 .88143920898 69.4910125732470 .1005783081170 .7101516723671 .6244964599673 .14842987061 73.93996429443 -9999 -9999 -9999 -9999 -9999 -9999 -9999 -9999 -9999 -9999 -9999 -9999 -9999 -9999 -9999 -9999 -9999 -9999 -9999 -9999 -9999 -9999 -9999 -9999 -9999 -9999 -9999 -9999 -9999 -9999 -9999 -9999 -9999 -9999 -9999 -9999 -9999 -9999 -9999 -9999 -9999 -9999

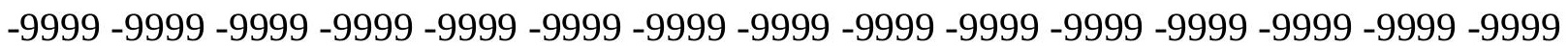
-9999 -9999 -9999 -9999 -9999 -9999 -9999 -9999 -9999 -9999 -9999 -9999 -9999 -9999 -9999 -9999 -9999 -9999 -9999 -9999 -9999 -9999 -9999 -9999 -9999 -9999 -9999 -9999 -9999 -9999 -999 -9999 -9999 -9999 -9999 -9999 -9999 -9999 -9999 -9999 -9999 -9999 -9999 -9999 -9999 -9999 -9999 -9999 -9999 -9999 -9999 -9999 -9999 -9999 -9999 -9999 -9999

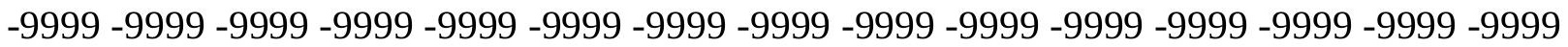
-9999 -9999 -9999 -9999 -9999 -9999 -9999 -9999 -9999 -9999 -9999 -9999 -9999 -9999 -9999 -9999 -9999 -9999 -9999 -9999 -9999 -9999 -9999 -9999 -9999 -9999 -9999 -9999 -9999 -9999 -9999 -9999 -9999 -9999 -9999 -9999 -9999 -9999 -9999 -9999 -9999 -9999 -9999 -9999 -9999 -9999 -9999 -9999 -9999 -9999 -9999 -9999 -9999 -9999 -9999 -9999 -9999 -9999 62.4809494018662 .4809494018662 .4809494018662 .4809494018662 .78573989868 63.0905189514263 .3953094482464 .004882812564 .9192428588966 .74794006348 70.4053573608476 .5010681152382 .2919769287185 .6446228027386 .55898284912 86.5589828491285 .0350494384882 .9015579223678 .6345596313573 .14842987061 64.3096618652351 .8134689331156 .6900291442957 .2995986938555 .16611099243 51.5086898803747 .5464782714843 .8890609741240 .8412094116238 .40293121338 36.2694282531734 .7455101013233 .5263595581132 .3072204589831 .08807945251 29.8689403533928 .6497993469227 .1258792877225 .6019496917723 .77323913574 22.2493095397920 .7253894805918 .8966808319117 .3727493286115 .84883022308 14.6296901702913 .4105501174911 .8866195678710 .667480468759 .44833946228 8.2291984558117 .0100579261786 .0957031255 .4861321449284 .87656211853 4.5717768669134 .5717768669134 .5717768669134 .2669920921334 .266992092133 
4.2669920921333 .9622070789343 .6574220657353 .3526360988623 .047851085663 2.4382810592652 .1334960460661 .523926019669 .9143553972244 .6095703244209 -9999 -.609570324421 -1.21914100647-2.13349604607 -2.74306607246 -3.65742206573 $-4.26699209213-4.87656211853-5.48613214493-5.79091691971-6.095703125$ $-6.40048694611-6.40048694611-6.095703125-6.095703125-5.79091691971-5.48613214493$ $-4.87656211853-4.57177686691-3.96220707893-3.65742206573-3.35263609886$ $-3.35263609886-3.04785108566-3.04785108566-3.35263609886-3.35263609886$ $-3.35263609886-3.65742206573-3.65742206573-3.65742206573-3.65742206573$ $-3.35263609886-3.35263609886-3.04785108566-3.04785108566-2.74306607246$ $-2.43828105927-1.82871103287-1.52392601967-.609570324421-9999.9143553972244$ 1.8287110328672 .7430660724643 .9622070789345 .1813468933116 .400486946106 7.6196279525768 .83876895904510 .3626899719211 .5818300247213 .10575962067 14.934470176716 .4584007263218 .28710937520 .1158199310321 .63973999023 23.4684505462625 .2971591949526 .8210906982428 .3450202941929 .86894035339 30.7833003997831 .6976509094232 .6120109558133 .2215805053733 .52635955811 33.8311500549334 .1359291076734 .1359291076734 .4407196044934 .74551010132 34.7455101013235 .0502891540535 .3550796508835 .3550796508835 .65985870361 35.9646492004436 .2694282531736 .8790016174337 .1837806701737 .79335021973 38.4029312133839 .0125007629439 .622070312540 .5364189147941 .14598846436 42.0603485107442 .9747009277344 .1938400268645 .1082000732446 .32733917236 47.24169921875 48.46083068848 49.6799812316950.8991203308151.81346893311 53.0326118469254 .2517509460455 .1661109924356 .0804595947357 .29959869385 57.909179687558 .8235282897959 .4331016540560 .0426712036160 .65224075317 60.9570198059161 .5666007995662 .1761703491262 .4809494018662 .78573989868 63.3953094482463 .7000885009864 .004882812564 .3096618652364 .61444854736 64.9192428588965 .5288009643665 .8335876464866 .1383666992266 .74794006348 67.0527267456167 .6623001098668 .2718734741268 .8814392089869 .49101257324 70.1005783081170 .7101516723671 .3197174072372 .2340774536173 .45321655273 73.9289855957 -9999 -9999 -9999 -9999 -9999 -9999 -9999 -9999 -9999 -9999 -9999 -9999 -9999 -9999 -9999 -9999 -9999 -9999 -9999 -9999 -9999 -9999 -9999 -9999 -9999 -9999 -9999 -9999 -9999 -9999 -9999 -9999 -9999 -9999 -9999 -9999 -9999 -9999 -9999 -9999 -9999 -9999

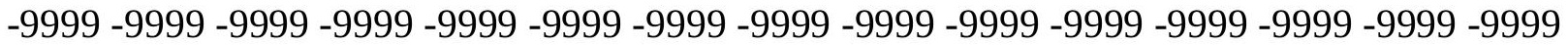

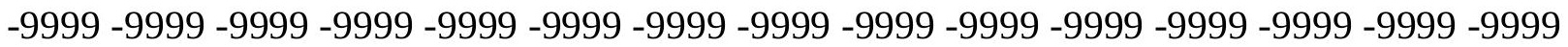
-9999 -9999 -9999 -9999 -9999 -9999 -9999 -9999 -9999 -9999 -9999 -9999 -9999 -9999 -9999 -9999 -9999 -9999 -9999 -9999 -9999 -9999 -9999 -9999-9999

-9999 -9999 -9999 -9999 -9999 -9999 -9999 -9999 -9999 -9999 -9999 -9999 -9999 -9999 -9999

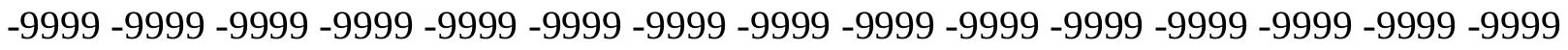

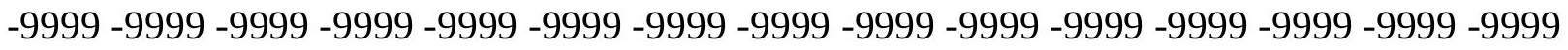
-9999 -9999 -9999 -9999 -9999 -9999 -9999 -9999 -9999 -9999 -9999 -9999 -9999 -9999 -9999 -9999 -9999 -9999 -9999 -9999 -9999 -9999 -9999 -9999 -9999 -9999 -9999 -9999 -9999 -9999 -9999 -9999 -9999 -9999 -9999 -9999 -9999 -9999 -9999-9999 -9999 -9999 64.9192428588965 .5288009643666 .1383666992266 .7479400634867 .66230010986 68.8814392089870 .4053573608471 .3197174072371 .9292907714871 .0149307251 74.36756896973 87.16854858398 92.55363464355 96.369979858498.60824584961 99.4407424926898 .8597106933696 .6887969970792 .4262161254985 .84171295166 76.8352661132869 .5823593139668 .8814392089863 .3953094482459 .12831115723 
53.9469718933149 .0704002380444 .8034095764241 .4507789611839 .01250076294 36.8790016174335 .3550796508834 .1359291076733 .2215805053732 .00244140625 30.7833003997829 .2593708038327 .7354507446325 .906740188624 .07802963257 22.2493095397920 .4206008911118 .5918903350816 .7631797790515 .23925971985 14.0201196670512 .8009700775111 .5818300247210 .362689971929 .143553733826 7.6196279525766 .4004869461065 .4861321449284 .876562118534 .571776866913 4.2669920921334 .2669920921334 .5717768669134 .5717768669134 .571776866913 4.5717768669134 .2669920921333 .9622070789343 .6574220657353 .352636098862 2.7430660724642 .1334960460661 .523926019669 .9143553972244 .3047851026058 -9999 $-.914355397224-1.82871103287-2.74306607246-3.65742206573-4.87656211853$ $-5.48613214493-6.40048694611-7.01005792618-7.3148431778-7.61962795258$ $-7.92441320419-7.92441320419-7.61962795258-7.3148431778-7.01005792618$ $-6.40048694611-5.79091691971-5.18134689331-4.57177686691-4.26699209213$ $-3.96220707893-3.65742206573-3.35263609886-3.65742206573-3.65742206573$ $-3.65742206573-3.96220707893-3.96220707893-4.26699209213-4.26699209213$ $-4.26699209213-4.26699209213-4.26699209213-3.96220707893-3.65742206573$ $-3.65742206573-3.04785108566-2.74306607246-2.13349604607-1.52392601967$ -609570324421 -9999.9143553972244 2.133496046066 3.047851085663 3.962207078934 5.1813468933116 .4004869461067 .6196279525769 .14355373382610 .36268997192 11.8866195678713 .715330123915 .2392597198517 .0679702758818 .89668083191 20.4206008911122 .2493095397924 .0780296325725 .906740188627 .4306602478 28.9545898437530 .1737308502231 .0880794525132 .0024414062532 .61201095581 32.9167900085433 .2215805053733 .2215805053733 .5263595581133 .83115005493 33.8311500549334 .1359291076734 .1359291076734 .4407196044934 .74551010132 35.0502891540535 .3550796508835 .6598587036135 .9646492004436 .57421112061 36.8790016174337 .4885711669938 .0981407165539 .0125007629439 .6220703125 40.5364189147941 .4507789611842 .3651313781743 .5842704772944 .49863052368 45.717769622846 .9369087219247 .8512611389249 .0704002380450 .28955078125 51.5086898803752 .7278289794953 .9469718933154 .8613204956155 .77568054199 56.9948196411157 .6043891906758 .5187492370659 .1283111572359 .73788070679 60.3474502563560 .6522407531761 .2618103027361 .8713798522962 .17617034912 62.4809494018663 .0905189514263 .3953094482463 .7000885009864 .0048828125 64.3096618652364 .9192428588965 .2240066528365 .5288009643665 .83358764648 66.4431610107467 .0527267456167 .3575134277367 .9670867919968 .57665252686 69.1862335205169 .7957916259870 .4053573608471 .014930725171 .31971740723 72.5388565063573 .75800323486 -9999 -9999 -9999 -9999 -9999 -9999 -9999 -9999 -9999

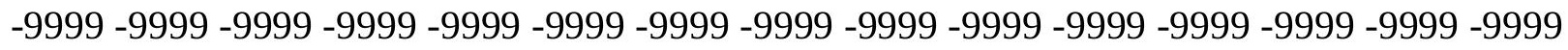

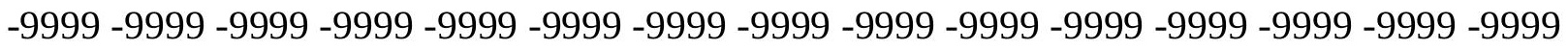

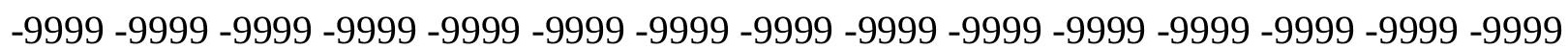
-9999 -9999 -9999 -9999 -9999 -9999 -9999 -9999 -9999 -9999 -9999 -9999 -9999 -9999 -9999 -999 -

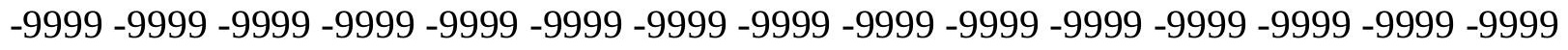
-9999 -9999 -9999 -9999 -9999 -9999 -9999 -9999 -9999 -9999 -9999 -9999 -9999 - -999 - -999 -9999 -9999 -9999 -9999 -9999 -9999 -9999 -9999 -9999 -9999 -9999 -9999 -9999 -9999 -9999 -9999 -9999 -9999 -9999 -9999 -9999 -9999 -9999 -9999 -9999 -9999 -9999 -9999 -9999 -9999 -9999 -9999 -9999 -9999 -9999 -9999 -9999 -9999 -9999 -9999 -9999 -9999 -9999 -9999 -9999 -

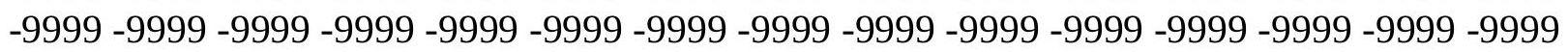


-9999 -9999 -9999 -9999 -9999 -9999 -9999 -9999 -9999 -9999 -9999 -9999 -9999 -9999 -9999 -9999 -9999 -9999 -9999 -9999 -9999 -9999 -9999 -9999 -9999 -9999 -9999 -9999 67.6623001098668 .5766525268669 .4910125732470 .7101516723672 .23407745361 74.9771423339877 .4154205322379 .2441329956181 .0728530883878 .93934631348 81.3776321411192 .2676391601699 .06398010254102 .8746795654105 .3935394287 106.8535614014107 .0501022339104 .7703399658100 .490798950294 .19058990479 86.7728881835980 .4627227783274 .8761978149468 .7768783569360 .65224075317 54.5565414428749 .3751907348645 .1082000732442 .0603485107439 .6220703125 37.7933502197336 .2694282531735 .0502891540534 .1359291076732 .91679000854 31.6976509094230 .1737308502228 .3450202941926 .2115192413324 .38281059265 22.2493095397920 .1158199310317 .9823207855216 .1536102294914 .62969017029 13.4105501174912 .4961900711111 .5818300247210 .362689971929 .143553733826 7.6196279525766 .0957031254 .876562118534 .2669920921334 .266992092133 4.2669920921334 .5717768669134 .5717768669134 .876562118534 .87656211853 4.876562118534 .876562118534 .5717768669134 .2669920921333 .657422065735 3.0478510856632 .4382810592651 .8287110328671 .21914100647 .3047851026058 -.304785102606 - $1.21914100647-2.43828105927-3.65742206573-4.57177686691$ -5.79091691971 -6.7052731514 -7.61962795258 -8.22919845581 -8.83876895905 $-9.14355373383-9.14355373383-9.14355373383-8.83876895905-8.53398323059$ -7.92441320419 -7.3148431778 -6.7052731514 -5.79091691971 -5.18134689331 $-4.57177686691-3.96220707893-3.65742206573-3.65742206573-3.65742206573$ -3.96220707893 -3.96220707893-4.26699209213-4.57177686691 -4.57177686691 $-4.57177686691-4.87656211853-4.87656211853-4.87656211853-4.57177686691$ $-4.57177686691-4.26699209213-3.96220707893-3.35263609886-2.74306607246$ $-2.13349604607-1.21914100647-.304785102606 .30478510260581 .21914100647$ 2.4382810592653 .3526360988624 .2669920921335 .4861321449286 .705273151398 7.9244132041939 .4483394622810 .9722604751612 .4961900711114 .32489967346 15.8488302230817 .6775398254419 .5062503814721 .334960937523 .16366958618 24.9923801422126 .5163097381628 .0402297973629 .5641593933130 .78330039978 31.3928699493432 .0024414062532 .3072204589832 .6120109558132 .61201095581 32.9167900085432 .9167900085433 .2215805053733 .2215805053733 .52635955811 33.8311500549333 .8311500549334 .1359291076734 .4407196044934 .74551010132 35.3550796508835 .6598587036136 .2694282531736 .8790016174337 .48857116699 38.0981407165539 .0125007629439 .9268493652340 .8412094116241 .75556182861 42.66992187543 .8890609741245 .1082000732446 .3273391723647 .54647827148 48.765621185349 .9847602844251 .2038993835452 .4230384826753 .64218139648 54.5565414428755 .7756805419956 .6900291442957 .6043891906758 .21395874023 58.8235282897959 .4331016540560 .0426712036160 .6522407531760 .95701980591 61.5666007995661 .8713798522962 .4809494018662 .7857398986863 .09051895142 63.3953094482463 .7000885009864 .004882812564 .6144485473664 .91924285889 65.2240066528365 .5288009643666 .1383666992266 .7479400634867 .05272674561 67.6623001098668 .2718734741268 .8814392089869 .4910125732470 .10057830811 70.4053573608471 .014930725171 .6244964599672 .8436431884873 .58358764648 -9999 -9999 -9999 -9999 -9999 -9999 -9999 -9999 -9999 -9999 -9999 -9999 -9999 -9999 -9999 -9999 -9999 -9999 -9999 -9999 -9999 -9999 -9999 -9999 -9999 -9999 -9999 -9999 -9999 -9999 -9999 -9999 -9999 -9999 -9999 -9999 -9999 -9999 -9999 -9999 -9999 -9999 -9999 -9999 -9999 -9999 
-9999 -9999 -9999 -9999 -9999 -9999 -9999 -9999 -9999 -9999 -9999 -9999 -9999 -9999 -9999 -9999 -9999 -9999 -9999 -9999 -9999 -9999 -9999 -9999 -9999 -9999 -9999 -9999 -9999 -9999 -9999 -9999 -9999 -9999 -9999 -9999 -9999 -9999 -9999 -9999 -9999 -9999 -9999 -9999 -9999 -9999 -9999-9999-9999-9999

-9999 -9999 -9999 -9999 -9999 -9999 -9999 -9999 -9999 -9999 -9999 -9999 -9999 -9999 -9999 -9999 -9999 -9999 -9999 -9999 -9999 -9999 -9999 -9999 -9999 -9999 -9999 -9999 -9999 -9999 -9999 -9999 -9999 -9999 -9999 -9999 -9999 -9999 -9999 -9999 -9999 -9999 -9999 -9999 -9999

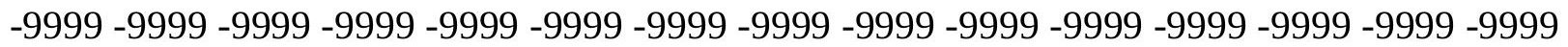
-9999 -9999 -9999 -9999 -9999 -9999 -9999 -9999 -9999 -9999 -9999 -9999 -9999 -9999 -9999 -9999 -9999 -9999-9999 -9999 -9999 -9999 -9999 -9999-9999-9999 -9999 68.88143920898 70.7101516723671 .9292907714873 .4532165527374 .6723632812576 .80584716797 80.15849304199 83.81591033936 86.90336608887 88.30185699463 88.98624420166 92.6025848388798 .16054534912101 .4633102417104 .3147201538106 .5492935181 108.0105056763108 .7211761475108 .8865127563105 .374191284299 .70664215088 93.1806411743286 .553710937579 .6292114257872 .528739929264 .87020874023 54.5565414428749 .3751907348645 .4129791259842 .3651313781740 .23163986206 38.4029312133837 .1837806701736 .2694282531735 .3550796508834 .44071960449 33.2215805053731 .3928699493429 .2593708038326 .8210906982424 .68759918213 22.5541000366220 .1158199310317 .9823207855215 .8488302230814 .02011966705 13.1057596206712 .4961900711111 .8866195678710 .972260475169 .44833946228 7.6196279525765 .7909169197084 .5717768669133 .9622070789343 .962207078934 4.2669920921334 .876562118535 .1813468933115 .4861321449285 .486132144928 5.4861321449285 .4861321449285 .1813468933114 .876562118534 .266992092133 3.6574220657352 .7430660724642 .1334960460661 .21914100647 .3047851026058 -.304785102606 -1.52392601967 -2.74306607246 -3.96220707893 -5.48613214493 $-6.7052731514-7.61962795258-8.53398323059-9.44833946228-9.75312423706$ -10.0579099655 -10.0579099655 -10.0579099655 -9.75312423706 -9.14355373383 $-8.53398323059-7.92441320419-7.01005792618-6.095703125-5.18134689331$ $-4.57177686691-3.96220707893-3.65742206573-3.65742206573-3.96220707893$ $-3.96220707893-4.26699209213-4.57177686691-4.57177686691-4.87656211853$ $-4.87656211853-4.87656211853-5.18134689331-5.18134689331-5.18134689331$ $-4.87656211853-4.87656211853-4.57177686691-3.96220707893-3.35263609886$ -2.74306607246 -1.82871103287-.914355397224-9999 .9143553972244 1.828711032867 2.7430660724643 .6574220657354 .876562118535 .7909169197087 .314843177795 8.53398323059110 .0579099655211 .5818300247213 .4105501174914 .9344701767 16.7631797790518 .5918903350820 .4206008911122 .2493095397924 .07802963257 25.906740188627 .430660247828 .9545898437530 .1737308502230 .78330039978 31.3928699493431 .6976509094232 .0024414062532 .0024414062532 .00244140625 32.3072204589832 .3072204589832 .6120109558132 .6120109558132 .91679000854 33.2215805053733 .2215805053733 .5263595581134 .1359291076734 .44071960449 34.7455101013235 .3550796508835 .9646492004436 .5742111206137 .48857116699 38.0981407165539 .0125007629439 .9268493652341 .1459884643642 .06034851074 43.2794914245644 .4986305236845 .717769622846 .9369087219248 .15605163574 49.3751907348650 .8991203308152 .1182594299353 .0326118469254 .25175094604 55.4708900451756 .3852500915557 .2995986938557 .909179687558 .82352828979 59.4331016540559 .7378807067960 .3474502563560 .6522407531761 .26181030273 
61.5666007995662 .1761703491262 .4809494018662 .7857398986863 .09051895142 63.3953094482463 .7000885009864 .004882812564 .6144485473664 .91924285889 65.2240066528365 .8335876464866 .4431610107466 .7479400634867 .35751342773 67.9670867919968 .5766525268668 .8814392089869 .4910125732470 .10057830811 $70.7101516723671 .3197174072371 .9292907714872 .8436431884873 .46074676514-9999$ -9999 -9999 -9999 -9999 -9999 -9999 -9999 -9999 -9999 -9999 -9999 -9999 -9999 -9999 -9999 -9999 -9999 -9999 -9999 -9999 -9999 -9999 -9999 -9999 -9999 -9999 -9999 -9999 -9999 -9999 -999 -

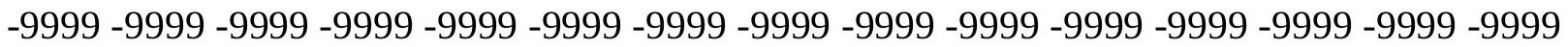

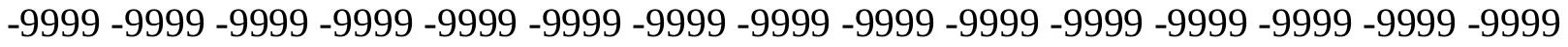
-9999 -9999 -9999 -9999 -9999 -9999 -9999 -9999 -9999 -9999 -9999 -9999 -9999 -9999 -9999

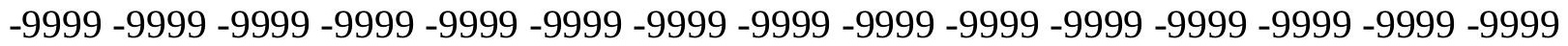
-9999 -9999-9999-9999

-9999 -9999 -9999 -9999 -9999 -9999 -9999 -9999 -9999 -9999 -9999 -9999 -9999 -9999 -9999 -9999 -9999 -9999 -9999 -9999 -9999 -9999 -9999 -9999 -9999 -9999 -9999 -9999 -9999 - 9999 -9999 -9999 -9999 -9999 -9999 -9999 -9999 -9999 -9999 -9999 -9999 -9999 -9999 -9999 -9999

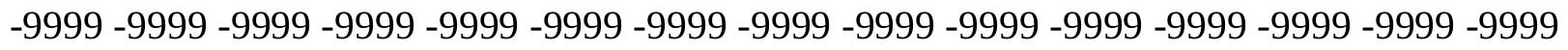
-9999 -9999 -9999 -9999 -9999 -9999 -9999 -9999 -9999 -9999 -9999 -9999 -9999 -9999 -9999 -9999 -9999-9999 -9999 -9999 -9999 -9999 -9999 -9999-9999 -9999 -9999 72.23407745361 74.3675689697375 .8914871215877 .4154205322378 .9393463134881 .07285308838 84.4254837036188 .5048599243290 .4986495971792 .980049133395 .14142608643 97.57564544678100 .1992340088102 .8078079224105 .1513824463107 .0257797241 108.3261871338109 .0376434326109 .2577056885108 .4049530029103 .2427139282 97.1611022949290 .4635696411183 .3047332763775 .7986297607468 .07859039307 60.6173095703149 .0704002380445 .4129791259843 .5842704772941 .75556182861 39.622070312538 .0981407165537 .7933502197337 .1837806701736 .26942825317 35.0502891540532 .9167900085430 .4785099029527 .7354507446325 .29715919495 22.8588790893620 .4206008911117 .9823207855215 .2392597198513 .41055011749 12.8009700775113 .1057596206713 .1057596206712 .191410064710 .36268997192 7.9244132041935 .7909169197084 .2669920921333 .9622070789344 .266992092133 4.876562118535 .4861321449285 .7909169197086 .0957031256 .400486946106 6.4004869461066 .4004869461066 .0957031255 .4861321449284 .87656211853 3.9622070789343 .0478510856632 .4382810592651 .523926019669 .3047851026058 -.304785102606 -1.52392601967 -3.04785108566 -4.26699209213 -5.79091691971 $-7.3148431778-8.53398323059-9.44833946228-10.0579099655-10.3626899719$ $-10.6674804688-10.6674804688-10.3626899719-10.0579099655-9.44833946228$ $-8.83876895905-7.92441320419-7.01005792618-6.095703125-4.87656211853$ $-4.26699209213-3.65742206573-3.35263609886-3.35263609886-3.65742206573$ -3.96220707893 -4.26699209213-4.57177686691 -4.57177686691-4.57177686691 $-4.87656211853-4.87656211853-5.18134689331-5.18134689331-5.48613214493$ $-5.48613214493-5.18134689331-4.87656211853-4.57177686691-3.96220707893$ -3.35263609886-2.13349604607-1.21914100647-9999.6095703244209 1.523926019669 2.1334960460663 .0478510856634 .2669920921335 .1813468933116 .705273151398 7.9244132041939 .4483394622810 .9722604751612 .4961900711114 .32489967346 15.8488302230817 .6775398254419 .5062503814721 .334960937523 .46845054626 25.2971591949527 .1258792877228 .6497993469229 .8689403533930 .47850990295 31.0880794525131 .3928699493431 .3928699493431 .3928699493431 .39286994934 
31.6976509094231 .6976509094231 .6976509094232 .0024414062532 .00244140625 32.3072204589832 .6120109558132 .9167900085433 .2215805053733 .52635955811 34.1359291076734 .4407196044935 .0502891540535 .6598587036136 .57421112061 37.1837806701738 .0981407165539 .3172798156740 .2316398620641 .45077896118 42.66992187543 .8890609741245 .1082000732446 .3273391723647 .85126113892 49.0704002380450 .2895507812551 .5086898803752 .7278289794953 .94697189331 55.1661109924356 .0804595947356 .9948196411157 .909179687558 .51874923706 59.1283111572359 .7378807067960 .3474502563560 .6522407531760 .95701980591 61.5666007995661 .8713798522962 .1761703491262 .4809494018662 .78573989868 63.0905189514263 .3953094482463 .7000885009864 .3096618652364 .61444854736 64.9192428588965 .5288009643665 .8335876464866 .4431610107467 .05272674561 67.6623001098667 .9670867919968 .5766525268669 .1862335205169 .79579162598 70.1005783081170 .7101516723671 .3197174072371 .9292907714873 .14842987061 -9999 -9999 -9999 -9999 -9999 -9999 -9999 -9999 -9999 -9999 -9999 -9999 -9999 -9999 -9999 -9999 -9999 -9999 -9999 -9999 -9999 -9999 -9999 -9999 -9999 -9999 -9999 -9999 -9999 -9999 -9999

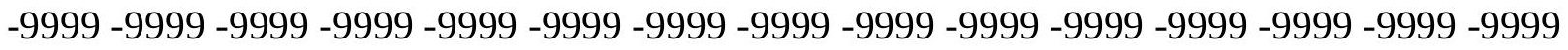
-9999 -9999 -9999 -9999 -9999 -9999 -9999 -9999 -9999 -9999 -9999 -9999 -9999 -9999 -9999 -9999 -9999 -9999 -9999 -9999 -9999 -9999 -9999 -9999 -9999 -9999 -9999 -9999 -9999 -9999 -

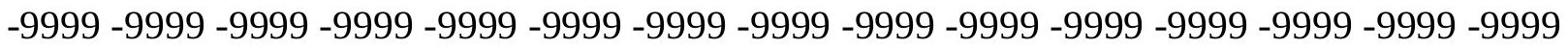
-9999 -9999 -9999-9999

-9999 -9999 -9999 -9999 -9999 -9999 -9999 -9999 -9999 -9999 -9999 -9999 -9999 -9999 -9999 -9999 -9999 -9999 -9999 -9999 -9999 -9999 -9999 -9999 -9999 -9999 -9999 -9999 -9999 -9999 -9999 -9999 -9999 -9999 -9999 -9999 -9999 -9999 -9999 -9999 -9999 -9999 -9999 -9999 -9999 -

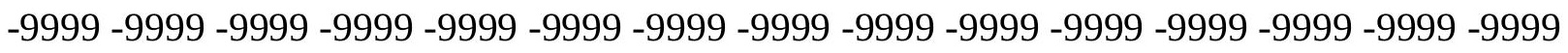

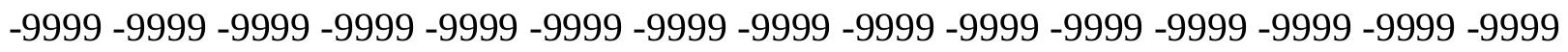
-9999 -9999-9999-9999 -9999 -9999 -9999 -9999 -9999-9999 -9999-9999 76.50106811523 78.6345596313580 .1584930419981 .3776321411182 .9015579223684 .73026275635 87.16854858398 91.7433319091893.483963012795.34674835205 97.34449768066 99.45556640625101 .6145095825103 .694442749105 .5316619873106 .9951019287 108.0145645142108 .5609436035108 .6798934937108 .4114685059105 .5980606079 99.8387603759893 .3368301391686 .2941360473678 .8805007934671 .36750030518 64.1041793823257 .481861114551 .9503173828146 .3273391723644 .43084335327 40.2316398620639 .9268493652339 .6323661804238 .8676872253437 .89025497437 36.549800872834 .7455101013232 .0024414062528 .6497993469225 .9067401886 23.7732391357421 .6397399902318 .28710937514 .934470176712 .80097007751 12.4961900711113 .715330123914 .3248996734613 .715330123911 .58183002472 8.2291984558115 .1813468933113 .9622070789343 .9622070789344 .87656211853 6.0957031256 .7052731513987 .0100579261787 .0100579261787 .010057926178 7.3148431777957 .3148431777957 .0100579261786 .4004869461065 .486132144928 4.5717768669133 .6574220657352 .7430660724641 .828711032867 .9143553972244 -9999 -1.52392601967 -2.74306607246 -4.26699209213 -5.79091691971 -7.3148431778 -8.53398323059-9.75312423706 -10.0579099655 -10.3626899719-10.3626899719 -10.3626899719 -9.75312423706 -9.44833946228 -8.83876895905-8.22919845581 $-7.61962795258-6.7052731514-5.48613214493-4.26699209213-3.35263609886$ $-2.74306607246-2.74306607246-3.04785108566-3.65742206573-3.96220707893$ $-4.26699209213-4.57177686691-4.26699209213-4.26699209213-4.26699209213$ 
$-4.57177686691-4.87656211853-5.18134689331-5.48613214493-5.79091691971$

$-5.79091691971-5.48613214493-5.18134689331-4.57177686691-3.65742206573$ -2.74306607246 -1.52392601967-9999.6095703244209 1.21914100647 2.133496046066 3.0478510856633 .6574220657354 .876562118536 .0957031257 .619627952576 9.14355373382610 .6674804687512 .191410064713 .715330123915 .54403972626 17.0679702758818 .8966808319120 .7253894805922 .8588790893624 .68759918213 26.5163097381628 .3450202941929 .5641593933130 .4785099029530 .78330039978 31.0880794525131 .0880794525131 .0880794525131 .0880794525131 .08807945251 31.0880794525131 .0880794525131 .0880794525131 .3928699493431 .39286994934 31.6976509094232 .0024414062532 .3072204589832 .6120109558133 .22158050537 33.5263595581134 .1359291076734 .7455101013235 .6598587036136 .57421112061 37.4885711669938 .4029312133839 .3172798156740 .5364189147941 .75556182861 42.9747009277344 .4986305236845 .717769622847 .2416992187548 .46083068848 49.9847602844251 .2038993835452 .4230384826753 .6421813964854 .86132049561 56.0804595947356 .9948196411157 .6043891906758 .5187492370659 .12831115723 59.7378807067960 .0426712036160 .6522407531760 .9570198059161 .26181030273 61.5666007995661 .8713798522962 .1761703491262 .4809494018662 .78573989868 63.0905189514263 .3953094482463 .7000885009864 .3096618652364 .61444854736 65.2240066528365 .5288009643666 .1383666992266 .4431610107467 .05272674561 67.6623001098668 .2718734741268 .5766525268669 .1862335205169 .79579162598 $70.1005783081170 .7101516723671 .014930725172 .2340774536173 .0512008667-9999-9999$ -9999 -9999 -9999 -9999 -9999 -9999 -9999 -9999 -9999 -9999 -9999 -9999 -9999 -9999 -9999 -9999 -9999 -9999 -9999 -9999 -9999 -9999 -9999 -9999 -9999 -9999 -9999 -9999 -9999 -9999 -9999 -9999 -9999 -9999 -9999 -9999 -9999 -9999 -9999 -9999 -9999 -9999 -9999 -9999 -9999 -9999 -9999 -9999 -9999 -9999 -9999 -9999 -9999 -9999 -9999 -9999 -9999 -9999 -9999 -9999 -9999 -9999 -9999 -9999 -9999 -9999 -9999 -9999 -9999 -9999 -9999 -9999 -9999 -9999 -9999 -

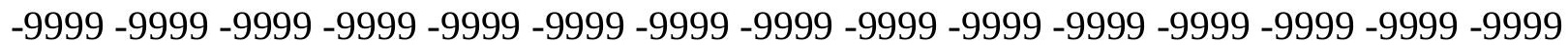
$-9999-9999$

-9999 -9999 -9999 -9999 -9999 -9999 -9999 -9999 -9999 -9999 -9999 -9999 -9999 -9999 -9999 -9999 -9999 -9999 -9999 -9999 -9999 -9999 -9999 -9999 -9999 -9999 -9999 -9999 -9999 -9999 -999 -9999 -9999 -9999 -9999 -9999 -9999 -9999 -9999 -9999 -9999 -9999 -9999 -9999 -9999 -9999

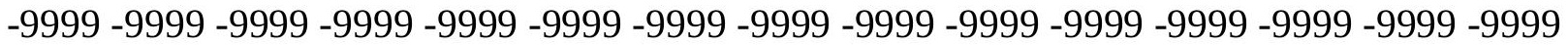
-9999 -9999 -9999 -9999 -9999 -9999 -9999 -9999 -9999 -9999 -9999 -9999 -9999 -9999 -9999 -9999 -9999 -9999 -9999 -9999 -9999 -9999 -9999 -9999 -9999 -9999 -9999 81.07285308838 83.206336975184 .7302627563585 .9494018554787 .1685485839888 .69246673584 90.5211791992294 .014511108495 .6890258789197 .4104537963999 .17767333984 100.9421157837102 .6561737061104 .231842041105 .5732498169106 .5855636597 107.2391433716107 .5117111206107 .436088562107 .0490570068106 .3547973633 101.89058685395 .689598083588 .9339828491281 .8344345092874 .65767669678 67.7107009887761 .3269042968855 .821990966851 .3342971801847 .844581604 45.2456550598143 .3781433105542 .0038375854540 .8602256774939 .66528701782 38.2108116149936 .3742218017634 .1013679504431 .8700046539330 .58482933044 31.379251480135 .0502891540532 .6120109558125 .906740188619 .20145988464 16.4584007263215 .8488302230815 .8488302230814 .6296901702912 .80097007751 7.6196279525764 .2669920921333 .3526360988624 .2669920921336 .400486946106 7.9244132041938 .5339832305918 .2291984558117 .9244132041937 .924413204193 
8.2291984558118 .5339832305918 .5339832305917 .6196279525766 .400486946106 5.1813468933113 .9622070789343 .3526360988622 .7430660724641 .828711032867 $.3047851026058-.609570324421-2.13349604607-3.65742206573-5.18134689331$ $-6.7052731514-8.22919845581-8.83876895905-9.14355373383-9.14355373383$ -9.14355373383 -8.83876895905 -8.22919845581 -7.61962795258 -7.3148431778 $-7.01005792618-6.7052731514-5.79091691971-4.57177686691-3.04785108566$ $-2.13349604607-1.82871103287-1.82871103287-2.43828105927-3.35263609886$ $-3.96220707893-4.26699209213-4.26699209213-3.96220707893-3.35263609886$ $-3.35263609886-3.65742206573-4.26699209213-4.87656211853-5.48613214493$ $-5.79091691971-5.79091691971-5.79091691971-5.48613214493-4.87656211853$ -3.96220707893 -2.74306607246 -1.52392601967-.304785102606 .6095703244209 1.5239260196692 .1334960460662 .7430660724643 .6574220657354 .571776866913 6.0957031257 .6196279525769 .4483394622810 .9722604751612 .49619007111 13.715330123914 .934470176716 .4584007263218 .28710937520 .11581993103 22.2493095397924 .3828105926526 .5163097381628 .0402297973629 .56415939331 30.4785099029530 .7833003997830 .7833003997830 .7833003997830 .47850990295 30.4785099029530 .4785099029530 .4785099029530 .4785099029530 .47850990295 30.4785099029530 .7833003997830 .7833003997831 .0880794525131 .39286994934 31.6976509094232 .3072204589832 .6120109558133 .2215805053733 .83115005493 34.7455101013235 .6598587036136 .5742111206137 .4885711669938 .40293121338 39.622070312540 .8412094116242 .3651313781743 .8890609741245 .10820007324 46.6321296691948 .1560516357449 .3751907348650 .8991203308152 .11825942993 53.3373985290554 .5565414428755 .7756805419956 .6900291442957 .60438919067 58.5187492370659 .1283111572359 .4331016540560 .0426712036160 .34745025635 60.6522407531760 .9570198059161 .2618103027361 .5666007995661 .87137985229 62.1761703491262 .4809494018662 .7857398986863 .0905189514263 .39530944824 63.7000885009864 .3096618652364 .6144485473665 .2240066528365 .83358764648 66.1383666992266 .7479400634867 .3575134277367 .6623001098668 .27187347412 68.5766525268669 .1862335205169 .4910125732470 .1005783081170 .40535736084 71.014930725172 .23407745361 -9999 -9999 -9999 -9999 -9999 -9999 -9999 -9999 -9999 -9999 -9999 -9999 -9999 -9999 -9999 -9999 -9999 -9999 -9999 -9999 -9999 -9999 -9999 -9999 -9999 -9999 -9999 -9999 -9999 -9999 -9999 -9999 -9999 -9999 -9999 -9999 -9999 -9999 -9999

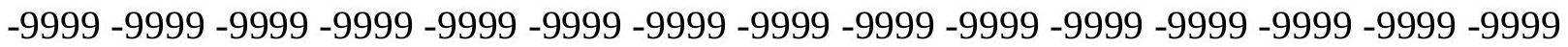
-9999 -9999 -9999 -9999 -9999 -9999 -9999 -9999 -9999 -9999 -9999 -9999 -9999 -9999 -9999 -9999 -9999 -9999 -9999 -9999 -9999 -9999 -9999 -9999 -9999 -9999 -9999 -9999 -9999 -9999 -9999 -9999 -9999 -9999 -9999 -9999 -9999 -9999 -9999-9999

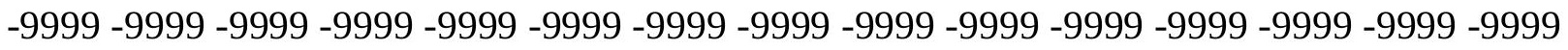

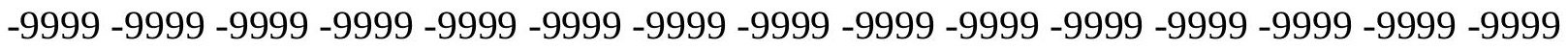

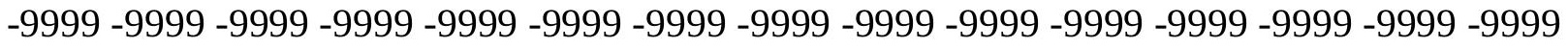
-9999 -9999 -9999 -9999 -9999 -9999 -9999 -9999 -9999 -9999 -9999 -9999 -9999 -9999 -9999 -

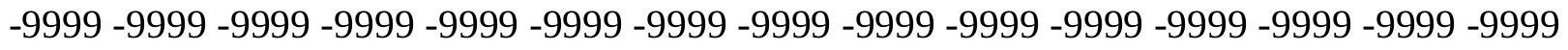
-9999 -9999-9999 -9999 -9999 -9999 -9999 -9999 -9999 -9999 -9999-9999 84.92156219482 86.6447906494188 .2474975585989 .9346618652391 .1307525634892 .65467834473 94.7105865478596 .2164535522597 .7363891601699 .25390625100 .7373886108 102.1513977051103 .4349517822104 .5367584229105 .3897247314105 .937461853 106.165763855106 .0855178833105 .7522888184105 .2365036011104 .5981445312 
103.640686035297.7730331420991.3786239624 84.66796112061 77.88456726074 71.3000183105565 .186248779359 .7901573181255 .2521667480551 .58891296387 48.7244148254446 .5065841674844 .7436714172443 .229904174841 .78776931763 40.2604064941438 .6069946289137 .0031356811535 .9305152893136 .05079269409 37.6596832275439 .2906265258837 .8241539001533 .1608390808128 .06182479858 25.2066173553525 .3476715087929 .0675010681236 .5742111206130 .17373085022 21.9445304870612 .800970077514 .2669920921335 .7909169197088 .533983230591 10.6674804687510 .972260475169 .7531242370618 .8387689590458 .838768959045 9.4483394622810 .0579099655210 .057909965529 .448339462287 .619627952576 5.4861321449283 .9622070789343 .6574220657354 .2669920921334 .266992092133 $2.743066072464 .6095703244209-.914355397224-2.13349604607-3.35263609886$ $-4.57177686691-6.095703125-7.3148431778-6.095703125-5.79091691971-6.095703125$ $-6.095703125-5.18134689331-4.26699209213-4.57177686691-5.18134689331$ -5.18134689331 -4.57177686691 -3.04785108566 -1.52392601967 - 304785102606 -9999 -.609570324421 -1.82871103287 -2.74306607246 -3.65742206573 -4.26699209213 $-4.26699209213-3.04785108566-1.82871103287-1.52392601967-2.13349604607$ $-3.35263609886-4.57177686691-5.18134689331-5.18134689331-5.48613214493$ $-5.48613214493-5.18134689331-4.57177686691-3.96220707893-2.74306607246$ -1.52392601967-9999 1.523926019669 2.438281059265 2.743066072464 3.047851085663 3.6574220657354 .5717768669136 .0957031257 .92441320419310 .05790996552 11.5818300247212 .8009700775114 .0201196670514 .934470176716 .15361022949 17.6775398254419 .5062503814721 .6397399902323 .7732391357426 .21151924133 28.0402297973629 .5641593933130 .4785099029530 .7833003997830 .47850990295 30.1737308502230 .1737308502230 .1737308502230 .1737308502229 .86894035339 29.8689403533929 .8689403533929 .8689403533929 .8689403533930 .17373085022 30.1737308502230 .4785099029531 .0880794525131 .3928699493431 .69765090942 32.3072204589832 .9167900085433 .8311500549334 .7455101013235 .65985870361 36.5742111206137 .4885711669938 .7077102661140 .2316398620641 .45077896118 42.9747009277344 .4986305236846 .0225486755447 .2416992187548 .7656211853 50.2895507812551 .8134689331153 .0326118469254 .2517509460455 .47089004517 56.6900291442957 .6043891906758 .2139587402358 .8235282897959 .43310165405 60.0426712036160 .3474502563560 .6522407531760 .9570198059161 .26181030273 61.2618103027361 .5666007995661 .8713798522961 .8713798522962 .17617034912 62.7857398986863 .0905189514263 .3953094482464 .004882812564 .30966186523 64.9192428588965 .2240066528365 .8335876464866 .1383666992266 .74794006348 67.3575134277367 .6623001098668 .2718734741268 .5766525268668 .88143920898 69.1862335205169 .4910125732470 .1005783081171 .3197174072372 .53885650635 -9999 -9999 -9999 -9999 -9999 -9999 -9999 -9999 -9999 -9999 -9999 -9999 -9999 -9999 -9999 -9999 -9999 -9999 -9999 -9999 -9999 -9999 -9999 -9999 -9999 -9999 -9999 -9999 -9999 -9999 -9999 -9999 -9999 -9999 -9999 -9999 -9999 -9999 -9999 -9999 -9999 -9999 -9999 -9999 -9999 -9999 -

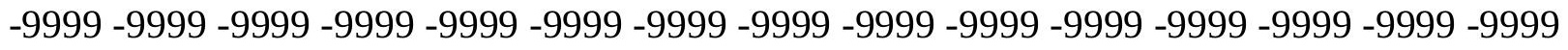

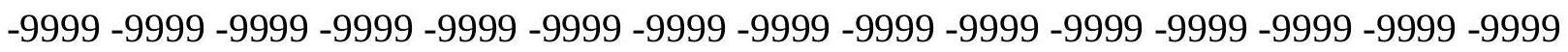

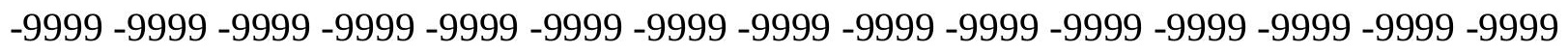
$-9999-9999$

-9999 -9999 -9999 -9999 -9999 -9999 -9999 -9999 -9999 -9999 -9999 -9999 -9999 -9999 -9999

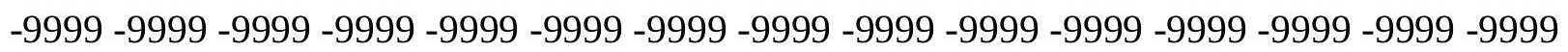


-9999 -9999 -9999 -9999 -9999 -9999 -9999 -9999 -9999 -9999 -9999 -9999 -9999 -9999 -9999 -9999 -9999 -9999 -9999 -9999 -9999 -9999 -9999 -9999 -9999 -9999 -9999 -9999 -9999 -9999 -9999 -9999 -9999 -9999 -9999 -9999 -9999 -9999 -9999 -9999 -9999 -9999 -9999 -9999 -9999 -9999 -9999 -9999 -9999 -9999 -9999 -9999 -9999 -9999 -9999 -9999 85.47352600098 87.1199645996188 .811111450290 .5686264038192 .4232482910294 .41619110107 95.7374572753997 .0607147216898 .3810272216899 .68353271484100 .9433288574 102.1238861084103 .1797103882104 .0607681274104 .7145004272105 .0969696045 105.1772079468104 .9399642944104 .4506759644103 .7980651855103 .1041717529 102.5068054199102 .120384216399 .6840209960993 .6705245971787 .36393737793 80.9881668090874 .7646408081168 .9401168823263 .7099838256859 .19808197021 55.4217567443852 .3357849121149 .8251609802247 .7493629455645 .95144271851 44.3202934265142 .7724685668941 .3454170227140 .2426719665539 .79215621948 40.254467010541 .4130477905342 .0609283447341 .1885452270538 .66299819946 35.9534683227534 .7998771667536 .3846435546940 .4589309692444 .01139831543 42.3763771057138 .2850723266637 .430381774945 .717769622837 .48857116699 28.6497993469221 .6397399902314 .6296901702910 .057909965529 .44833946228 9.75312423706110 .9722604751611 .5818300247211 .5818300247211 .58183002472 9.7531242370615 .7909169197083 .6574220657354 .2669920921336 .705273151398 7.9244132041935 .4861321449282 .438281059265 -9999-.609570324421 -.304785102606 -.914355397224 -1.21914100647 -3.35263609886 -9999.3047851026058 -.914355397224 $-2.43828105927 .6095703244209 .6095703244209-.914355397224-2.74306607246$ -3.04785108566 -2.74306607246-1.21914100647.3047851026058 1.523926019669 $1.828711032867 .6095703244209-.609570324421-2.13349604607-3.04785108566$ $-3.96220707893-4.57177686691-2.13349604607 .6095703244209 .6095703244209$ $-.609570324421-2.13349604607-3.65742206573-3.96220707893-3.96220707893$ -3.96220707893 -3.96220707893 -3.96220707893 -3.35263609886 -2.74306607246 -2.13349604607 -.914355397224 1.219141006473.047851085663 3.962207078934 3.9622070789343 .6574220657353 .9622070789344 .876562118536 .400486946106 8.83876895904511 .2770500183112 .8009700775113 .715330123914 .32489967346 15.2392597198516 .1536102294917 .3727493286118 .8966808319121 .03017044067 23.4684505462625 .906740188628 .3450202941929 .8689403533930 .47850990295 30.7833003997830 .4785099029530 .1737308502229 .8689403533929 .86894035339 29.5641593933129 .5641593933129 .2593708038329 .2593708038329 .25937080383 29.2593708038329 .2593708038329 .5641593933129 .8689403533930 .17373085022 30.4785099029531 .0880794525131 .3928699493432 .0024414062532 .91679000854 33.5263595581134 .4407196044935 .6598587036136 .5742111206137 .79335021973 39.3172798156740 .5364189147942 .0603485107443 .5842704772945 .10820007324 46.6321296691948 .1560516357449 .6799812316951 .2038993835452 .72782897949 54.2517509460455 .4708900451756 .3852500915557 .2995986938558 .21395874023 58.8235282897959 .4331016540559 .7378807067960 .0426712036160 .34745025635 60.6522407531760 .9570198059160 .9570198059161 .2618103027361 .26181030273 61.5666007995661 .8713798522962 .1761703491262 .7857398986863 .09051895142 63.3953094482464 .004882812564 .3096618652364 .9192428588965 .22400665283 65.8335876464866 .1383666992266 .7479400634867 .0527267456167 .66230010986 67.9670867919968 .2718734741268 .5766525268668 .8814392089868 .88143920898 70.1005783081171 .62449645996 -9999 -9999 -9999 -9999 -9999 -9999 -9999 -9999 -9999 
-9999 -9999 -9999 -9999 -9999 -9999 -9999 -9999 -9999 -9999 -9999 -9999 -9999 -9999 -9999 -9999 -9999 -9999 -9999 -9999 -9999 -9999 -9999 -9999 -9999 -9999 -9999 -9999 -9999 -9999 -9999 -9999 -9999 -9999 -9999 -9999 -9999 -9999 -9999 -9999 -9999 -9999 -9999 -9999 -9999 -9999 -9999 -9999 -9999 -9999 -9999 -9999 -9999 -9999 -9999 -9999 -9999 -9999 -9999 -9999

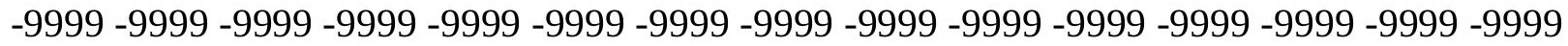
-9999 -9999 -9999 -9999 -9999 -9999 -9999 -9999 -9999

-9999 -9999 -9999 -9999 -9999 -9999 -9999 -9999 -9999 -9999 -9999 -9999 -9999 -9999 -9999 -9999 -9999 -9999 -9999 -9999 -9999 -9999 -9999 -9999 -9999 -9999 -9999 -9999 -9999 -9999 -9999 -9999 -9999 -9999 -9999 -9999 -9999 -9999 -9999 -9999 -9999 -9999 -9999 -9999 -9999 -9999 -9999 -9999 -9999 -9999 -9999 -9999 -9999 -9999 -9999 -9999 -9999 -9999 -9999 -9999 -9999 -9999 -9999 -9999 -9999 -9999 -9999 -9999 -9999 -9999 -9999 -9999 -9999 -9999 -9999 -999 -9999 -9999 -9999 -9999 -9999 -9999 -9999 -9999 -9999 -9999 -9999 87.44232940674 89.1876907348690 .9932403564592 .877517700294 .8667831420996 .99697113037 98.3399200439599 .44327545166100 .5335235596101 .5864334106102 .5687713623 103.4379882812104 .1455841064104 .6403503418104 .872795105104 .8029632568 104.4053421021103 .7010421753102 .7639694214101 .7154693604100 .7293548584 100.032554626599 .86881256104100 .357307434195 .8027801513789 .88719177246 83.8995971679778 .0473098754972 .5318832397567 .4972381591863 .04920959473 59.218894958555 .974330902153 .2530250549350 .9495315551848 .959815979 47.2041549682645 .6557083129944 .3745231628443 .5093078613343 .23174285889 43.5813140869144 .2609214782744 .6612854003944 .352264404343 .41556549072 42.6143074035642 .9461631774944 .9982490539648 .2803649902350 .83704376221 52.0496139526452 .6623649597255 .0040359497157 .2781066894552 .89641952515 44.5227165222236 .4147186279331 .9144592285233 .5263595581125 .29715919495 21.334960937517 .9823207855213 .4105501174912 .4961900711113 .7153301239 13.71533012394 .876562118533 .9622070789344 .2669920921339 .143553733826 13.410550117497 .9244132041934 .2669920921331 .219141006471 .523926019669 2.1334960460663 .3526360988625 .48613214492811 .886619567879 .44833946228 8.5339832305915 .7909169197084 .57177686691310 .362689971926 .705273151398 2.438281059265 .3047851026058 1.21914100647.91435539722443.047851085663 6.0957031257 .9244132041935 .7909169197081 .828711032867 .6095703244209 -1.82871103287 -1.52392601967 -1.52392601967 -6.7052731514 -.914355397224 $4.876562118533 .047851085663 .6095703244209-.609570324421-2.13349604607$ -2.13349604607 -1.82871103287 -.609570324421 -.304785102606 -1.82871103287 $.6095703244209-9999-1.52392601967-99993.6574220657356 .400486946106$ 6.4004869461065 .1813468933114 .876562118534 .876562118535 .181346893311 6.70527315139810 .0579099655213 .4105501174914 .6296901702914 .62969017029 14.934470176715 .5440397262616 .1536102294916 .7631797790517 .98232078552 19.811029434222 .5541000366225 .6019496917728 .3450202941929 .86894035339 30.4785099029530 .1737308502229 .8689403533929 .5641593933129 .56415939331 29.5641593933129 .2593708038329 .2593708038328 .9545898437528 .95458984375 28.6497993469228 .6497993469228 .6497993469228 .9545898437529 .25937080383 29.2593708038329 .8689403533930 .1737308502230 .7833003997831 .39286994934 32.0024414062532 .6120109558133 .5263595581134 .4407196044935 .65985870361 36.8790016174338 .0981407165539 .622070312541 .1459884643642 .669921875 44.1938400268645 .717769622847 .5464782714849 .0704002380450 .89912033081 
52.4230384826753 .9469718933155 .1661109924356 .3852500915557 .29959869385 57.909179687558 .8235282897959 .1283111572359 .7378807067960 .04267120361 60.3474502563560 .3474502563560 .6522407531760 .6522407531760 .95701980591 60.9570198059161 .2618103027361 .5666007995661 .8713798522962 .17617034912 62.7857398986863 .0905189514263 .7000885009864 .004882812564 .61444854736 64.9192428588965 .5288009643665 .8335876464866 .1383666992266 .74794006348 67.0527267456167 .3575134277367 .6623001098667 .6623001098667 .96708679199 68.2718734741269 .1862335205170 .4053573608471 .62449645996 -9999 -9999 -9999 -9999 -9999 -9999 -9999 -9999 -9999 -9999 -9999 -9999 -9999 -9999 -9999 -9999 -9999 -9999 -9999 -9999 -9999 -9999 -9999 -9999 -9999 -9999 -9999 -9999 -9999 -9999 -9999 -9999 -9999 -9999 -

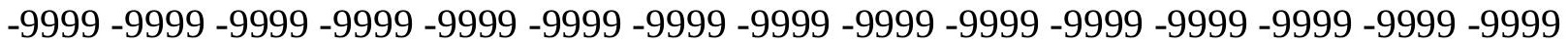
-9999 -9999 -9999 -9999 -9999 -9999 -9999 -9999 -9999 -9999 -9999 -9999 -9999 -9999 -9999

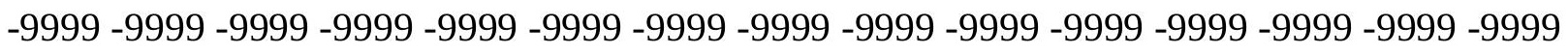
-9999 -9999 -9999 -9999 -9999 -9999 -9999 -9999 -9999 -9999 -9999 -9999 -9999 -9999 -9999 -9999 -9999 -9999 -9999 -9999 -9999 -9999 -9999 -9999 -9999 -9999 -9999 -9999

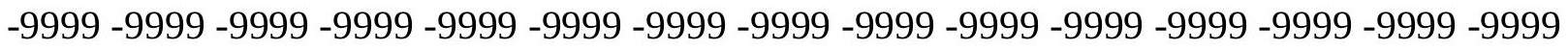
-9999 -9999 -9999 -9999 -9999 -9999 -9999 -9999 -9999 -9999 -9999 -9999 -9999 -9999 -9999 -9999 -9999 -9999 -9999 -9999 -9999 -9999 -9999 -9999 -9999 -9999 -9999 -9999 -9999 -9999 -

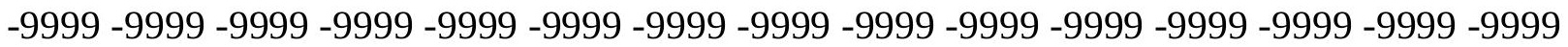
-9999 -9999 -9999 -9999-9999 -9999 -9999-9999 -9999-9999-9999 89.41864776611 91.2525329589893.1555023193495.14347076416 97.23815155029 99.46934509277 101.0052947998101 .8506164551102 .6833190918103 .4714279175104 .174621582 104.7432785034105 .1247406006105 .2625656128105 .1066970825104 .6166381836 103.7679901123102 .6021270752101 .191688537699 .6664505004998 .21837615967 97.135040283296 .823104858497 .6605300903397 .7207107543992 .19631958008 86.60469818115 81.12421417236 75.91272735596 71.08737182617 66.73525238037 62.8974266052259 .571571350156 .7171020507854 .2736740112352 .16596984863 50.3359603881848 .7859840393147 .5662307739346 .7659645080646 .45962142944 46.6167488098147 .0357894897547 .4353027343847 .6329421997147 .73865127563 48.1449012756349 .3332710266151 .4973907470754 .2551383972256 .8784942627 59.1621971130461 .3022880554263 .4332847595263 .6027107238860 .85705184937 55.2199249267649 .5332450866745 .9338951110843 .4096298217838 .90069580078 35.0634155273434 .4536094665539 .0125007629433 .5263595581132 .91679000854 32.3072204589825 .906740188621 .0301704406724 .6875991821329 .25937080383 27.430660247824 .0780296325724 .0780296325724 .6875991821324 .38281059265 25.2971591949529 .8689403533935 .0502891540541 .4507789611844 .80340957642 39.9268493652334 .7455101013236 .5742111206141 .1459884643645 .7177696228 49.0704002380449 .0704002380446 .9369087219243 .8890609741240 .53641891479 38.7077102661135 .9646492004430 .7833003997827 .7354507446332 .91679000854 38.7077102661133 .8311500549327 .7354507446325 .906740188626 .51630973816 32.3072204589835 .6598587036128 .3450202941920 .7253894805923 .77323913574 27.7354507446321 .9445304870616 .7631797790521 .6397399902325 .60194969177 19.2014598846411 .277050018317 .9244132041937 .92441320419312 .1914100647 14.934470176711 .277050018317 .6196279525766 .4004869461067 .314843177795 6.4004869461066 .40048694610611 .5818300247216 .7631797790515 .84883022308 15.2392597198515 .5440397262616 .1536102294916 .4584007263216 .76317977905 
17.0679702758818 .5918903350821 .6397399902325 .6019496917728 .95458984375 30.4785099029530 .4785099029529 .5641593933128 .6497993469228 .34502029419 28.9545898437529 .2593708038329 .2593708038328 .9545898437528 .64979934692 28.6497993469228 .3450202941928 .3450202941928 .3450202941928 .34502029419 28.6497993469228 .6497993469228 .9545898437529 .5641593933129 .86894035339 30.4785099029531 .0880794525131 .6976509094232 .6120109558133 .52635955811 34.7455101013235 .9646492004437 .1837806701738 .4029312133839 .92684936523 41.7555618286143 .2794914245645 .1082000732446 .6321296691948 .46083068848 50.2895507812552 .1182594299353 .6421813964854 .8613204956156 .08045959473 56.9948196411157 .909179687558 .5187492370659 .1283111572359 .43310165405 59.7378807067960 .0426712036160 .3474502563560 .3474502563560 .34745025635 60.6522407531760 .6522407531760 .9570198059161 .2618103027361 .56660079956 61.8713798522962 .4809494018662 .7857398986863 .3953094482463 .70008850098 64.004882812564 .6144485473664 .9192428588965 .2240066528365 .83358764648 66.1383666992266 .4431610107466 .7479400634867 .0527267456167 .05272674561 $67.3575134277367 .6623001098667 .9670867919969 .4910125732470 .71015167236-9999$ -9999 -9999 -9999 -9999 -9999 -9999 -9999 -9999 -9999 -9999 -9999 -9999 -9999 -9999 -9999 -9999 -9999 -9999 -9999 -9999 -9999 -9999 -9999 -9999 -9999 -9999 -9999 -9999 -9999 -9999 -9999 -9999 -9999 -9999 -9999 -9999 -9999 -9999 -9999 -9999 -9999 -9999 -9999 -9999 -9999 -

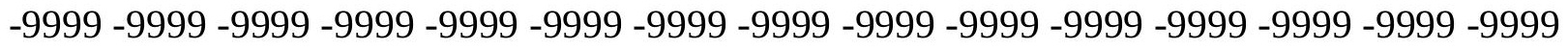

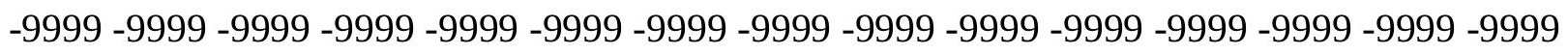
-9999 -9999 -9999 -9999 -9999 -9999 -9999 -9999 -9999 -9999 -9999 -9999 -9999 -9999 -9999 $-9999$

-9999 -9999 -9999 -9999 -9999 -9999 -9999 -9999 -9999 -9999 -9999 -9999 -9999 -9999 -9999

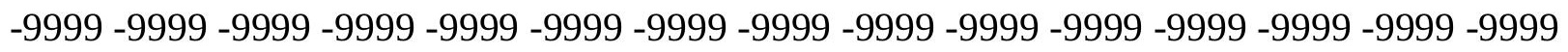
-9999 -9999 -9999 -9999 -9999 -9999 -9999 -9999 -9999 -9999 -9999 -9999 -9999 -9999 -9999 -9999 -9999 -9999 -9999 -9999 -9999 -9999 -9999 -9999 -9999 -9999 -9999 -9999 -9999 - -9999 -

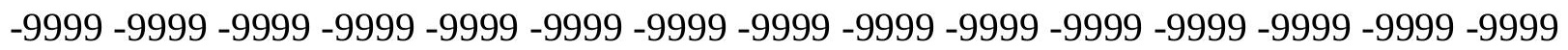
-9999 -9999 -9999 -9999 -9999 -9999 -9999 -9999 -9999-9999 -9999 91.37272644043 93.2833786010795 .2669143676897 .3362503051899 .5085144043101 .8066711426 103.7041244507104 .2664489746104 .8286590576105 .3526535034105 .7902374268 106.0860214233 106.1775054932106.0048370361 105.5116043091 104.6533737183 103.4008331299101 .801002502499 .9194946289197 .8744277954195 .82366943359 93.9862899780392 .811935424893 .2642517089895 .397743225194 .30735778809 89.0985641479583 .9686737060579 .0460205078174 .4351119995170 .21299743652 66.4236145019563 .0797805786160 .1653327941957 .6453132629455 .47641372681 53.6118392944352 .0619277954150 .8601951599150 .0553703308149 .67743301392 49.6947822570850 .0021896362350 .4719238281251 .0356330871651 .75941467285 52.8237495422454 .4142608642656 .555381774959 .0291786193861 .55815505981 63.9535675048866 .1101226806667 .5780410766667 .5164184570365 .61122894287 62.1033058166558 .2241592407254 .9656372070351 .826583862349 .0849609375 47.1274757385347 .3295745849648 .3605804443446 .9650497436545 .08246994019 42.505992889438 .8788337707536 .1781120300337 .0111732482938 .51487731934 37.9757843017637 .0064048767137 .1192626953138 .2323722839439 .63269424438 42.2935409545946 .9235954284752 .7704505920458 .0414428710960 .79127502441 59.4983558654857 .9955253601159 .9452857971264 .7335510253970 .9757232666 
76.1455917358478 .8955917358479 .5135650634880 .2290039062583 .2063369751 78.9393463134871 .9292907714860 .6522407531752 .7278289794955 .77568054199 61.5666007995663 .3953094482463 .7000885009864 .3096618652365 .52880096436 67.0527267456166 .1383666992261 .2618103027356 .9948196411158 .82352828979 60.6522407531756 .6900291442953 .0326118469256 .6900291442958 .82352828979 52.1182594299344 .1938400268640 .8412094116241 .4507789611847 .85126113892 52.1182594299346 .3273391723638 .7077102661135 .0502891540533 .52635955811 32.9167900085432 .9167900085434 .1359291076733 .2215805053726 .51630973816 19.2014598846416 .1536102294917 .0679702758817 .6775398254416 .45840072632 16.1536102294917 .3727493286120 .7253894805925 .906740188630 .17373085022 31.3928699493430 .1737308502227 .7354507446326 .5163097381627 .12587928772 28.3450202941929 .2593708038329 .5641593933129 .2593708038328 .95458984375 28.3450202941928 .0402297973628 .0402297973628 .0402297973628 .04022979736 28.0402297973628 .3450202941928 .3450202941928 .6497993469229 .25937080383 29.5641593933130 .1737308502230 .7833003997831 .6976509094232 .61201095581 33.5263595581134 .7455101013235 .9646492004437 .4885711669939 .01250076294 40.5364189147942 .3651313781744 .1938400268646 .0225486755447 .85126113892 49.6799812316951 .5086898803753 .3373985290554 .8613204956156 .08045959473 56.9948196411157 .909179687558 .5187492370658 .8235282897959 .12831115723 59.4331016540559 .7378807067960 .0426712036160 .0426712036160 .04267120361 60.3474502563560 .3474502563560 .6522407531760 .6522407531761 .26181030273 61.5666007995662 .1761703491262 .4809494018662 .7857398986863 .39530944824 63.7000885009864 .3096618652364 .6144485473664 .9192428588965 .22400665283 65.5288009643665 .8335876464866 .1383666992266 .4431610107466 .44316101074 66.7479400634867 .0527267456167 .0527267456168 .2718734741269 .79579162598 -9999 -9999 -9999 -9999 -9999 -9999 -9999 -9999 -9999 -9999 -9999 -9999 -9999 -9999 -9999 -9999 -9999 -9999 -9999 -9999 -9999 -9999 -9999 -9999 -9999 -9999 -9999 -9999 -9999 -9999 -9999 -9999 -9999 -9999 -9999 -9999 -9999 -9999 -9999 -9999 -9999 -9999 -9999 -9999 -9999 -9999

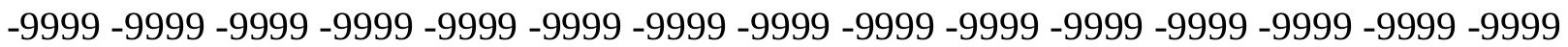

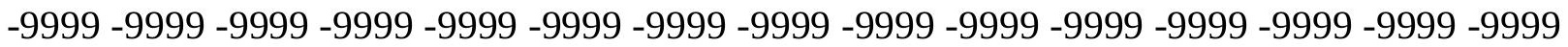
-9999 -9999 -9999 -9999 -9999 -9999 -9999 -9999 -9999 -9999 -9999 -9999 -9999 -9999 -9999 $-9999$

-9999 -9999 -9999 -9999 -9999 -9999 -9999 -9999 -9999 -9999 -9999 -9999 -9999 -9999 -9999 -9999 -9999 -9999 -9999 -9999 -9999 -9999 -9999 -9999 -9999 -9999 -9999 -9999 -9999 -9999 -

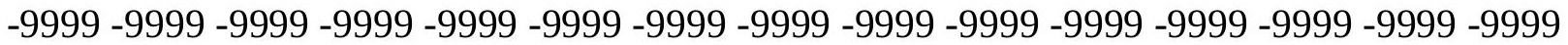
-9999 -9999 -9999 -9999 -9999 -9999 -9999 -9999 -9999 -9999 -9999 -9999 -9999 -9999 -9999 -9999 -9999 -9999 -9999 -9999 -9999 -9999 -9999 -9999 -9999 -9999 -9999 -9999 -9999 -9999 -9999 -9999 -9999 -9999-9999 -9999 -9999 -9999 -9999 -9999 -9999 93.28105926514 95.2562332153397 .3040771484499 .43438720703101 .6595611572103 .9959716797 106.397857666106 .6633987427106 .9553756714107 .2296676636107 .4311523438 107.4940795898107 .3490219116106 .9267425537106 .1630783081105 .0068054199 103.4252624512101 .444137573299 .133514404396 .590820312593 .93943786621 91.3056716918988 .755165100186 .5589828491286 .5589828491292 .04509735107 91.3803787231486 .5781936645581 .9364547729577 .5462799072373 .47771453857 69.7762145996166 .4645462036163 .5435829162661 .0002212524458 .81159973145 56.9418067932155 .4014930725154 .2090339660653 .391044616752 .96181488037 
52.9053153991753 .1744232177753 .7132644653354 .4934768676855 .53636932373 56.8987846374558 .6181488037160 .6518707275462 .8685569763265 .1089630127 67.2083663940468 .9639129638770 .0088729858469 .9911041259868 .74234008789 66.5086288452163 .8057785034261 .0828971862858 .5095176696856 .42930984497 55.1166687011754 .7744560241754 .3668289184653 .5201225280851 .58192062378 49.0694465637246 .5414695739744 .8183479309144 .3884162902844 .59840774536 44.6567077636744 .7073516845745 .3056373596246 .7403869628949 .00949478149 52.3605918884356 .8373489379961 .990512847966 .538085937569 .41094207764 70.7143478393672 .0000305175874 .9802398681680 .1381835937586 .53515625 92.6612472534297 .58316802979101 .3079223633104 .39818573105 .9898681641 103.239295959596.32102966309 87.52787780762 80.46327209473 79.24413299561 82.5967712402388 .2594680786190 .8844528198292 .7723083496194 .14350891113 94.3774566650492 .8353652954190 .0547409057687 .9725799560587 .71723937988 87.5200576782285 .9334793090884 .6208038330184 .9102325439584 .14602661133 80.1302337646575 .063476562572 .2967987060573 .4532165527381 .07285308838 86.8637619018681 .0728530883872 .5388565063567 .3575134277364 .30966186523 64.3096618652365 .2240066528366 .4431610107465 .2240066528357 .60438919067 49.0704002380443 .8890609741239 .9268493652335 .9646492004431 .69765090942 25.906740188621 .0301704406720 .7253894805927 .430660247832 .61201095581 34.1359291076729 .8689403533924 .6875991821323 .7732391357425 .60194969177 28.3450202941930 .4785099029530 .7833003997830 .1737308502229 .56415939331 28.9545898437528 .3450202941928 .0402297973628 .0402297973628 .04022979736 28.0402297973628 .0402297973628 .0402297973628 .3450202941928 .64979934692 28.9545898437529 .5641593933130 .1737308502230 .7833003997831 .69765090942 32.6120109558133 .8311500549335 .0502891540536 .2694282531737 .79335021973 39.622070312541 .1459884643643 .2794914245645 .1082000732447 .24169921875 49.0704002380451 .2038993835453 .0326118469254 .5565414428756 .08045959473 56.9948196411157 .6043891906758 .2139587402358 .5187492370658 .82352828979 59.1283111572359 .4331016540559 .4331016540559 .7378807067959 .73788070679 60.0426712036160 .0426712036160 .3474502563560 .6522407531760 .95701980591 61.2618103027361 .8713798522962 .1761703491262 .4809494018663 .09051895142 63.3953094482463 .7000885009864 .004882812564 .6144485473664 .91924285889 65.2240066528365 .5288009643665 .5288009643665 .8335876464866 .13836669922 66.1383666992266 .4431610107466 .4431610107467 .3575134277368 .57665252686 70.10057830811 -9999 -9999 -9999 -9999 -9999 -9999 -9999 -9999 -9999 -9999 -9999 -9999 -9999 -9999 -9999 -9999 -9999 -9999 -9999 -9999 -9999 -9999 -9999 -9999 -9999 -9999 -9999 -

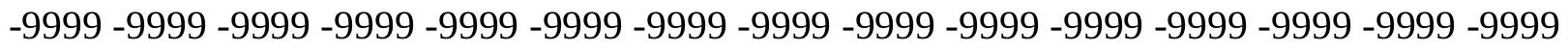

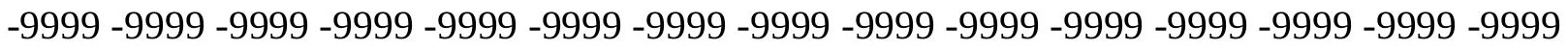
-9999 -9999 -9999 -9999 -9999 -9999 -9999 -9999 -9999 -9999 -9999 -9999 -9999 - 9999 - -999 -

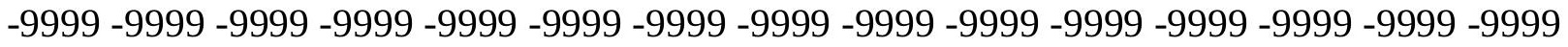
-9999-9999-9999-9999

-9999 -9999-9999 -9999 -9999 -9999 -9999 -9999 -9999-9999 -9999 -9999 -9999 -9999 -9999 -9999 -9999 -9999 -9999 -9999 -9999 -9999 -9999 -9999 -9999 -9999 -9999 -9999 -9999 -9999 -9999 -9999 -9999 -9999 -9999 -9999 -9999 -9999 -9999-9999 -9999 -9999 -9999 -9999 -9999 -9999 -9999 -9999 -9999 -9999 -9999 -9999 -9999 -9999 -9999 -9999 -9999 -9999 -9999 -9999 -

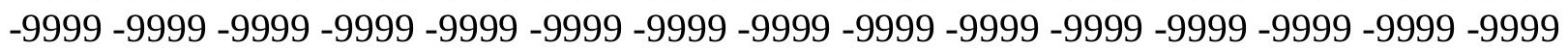


-9999 -9999 -9999 -9999 -9999 -9999 -9999 -9999 -9999 -9999 93.16381835938 95.1249618530397 .1521682739399 .24900054932101 .4220046997103 .6791229248 106.0307388306108 .4864196777109 .0021743774109 .0352325439109 .085395813 109.092918396108 .9779434204108 .6626281738108 .0657653809107 .1132278442 105.744430542103 .9175338745101 .653297424398 .9959106445396 .04437255859 92.9278640747189 .6068267822386 .254188537683 .206336975182 .59677124023 86.254188537691 .7403335571388 .9647598266684 .5938110351680 .42617034912 76.5266723632872 .9408645629969 .6981582641666 .8111190795964 .2804107666 62.1013755798360 .2508735656758 .7325210571357 .5558166503956 .73703765869 56.2858352661156 .1986503601156 .4563674926857 .0330848693857 .90849304199 59.0724372863860 .5152511596762 .2057495117264 .0741577148466 .01734924316 67.9142456054769 .6291198730570 .9867324829171 .7711715698271 .80290222168 71.0114898681669 .5232162475667 .5782928466865 .4275665283263 .33082199097 61.5098838806260 .1464042663659 .1393623352158 .1233062744156 .85001754761 55.028179168752 .8949851989750 .9073295593349 .4912643432648 .7613067627 48.5966148376548 .7792739868249 .2597770690950 .2428932189951 .93299865723 54.4589576721257 .8482589721761 .9777069091866 .4356765747170 .55930328369 73.8746109008876 .6297912597779 .5914993286183 .6291122436589 .13027191162 95.65180969238102 .3853607178108 .6220932007113 .9876861572118 .1076278687 119.8909988403118 .6126327515114 .18699646108 .7057266235104 .793838501 103.9412307739105 .8451004028108 .9699325562111 .9498214722114 .2578430176 115.6659927368115 .8890686035114 .9353561401113 .3973236084112 .1111297607 111.3063583374110 .6259689331109 .7794036865108 .9749984741108 .1231536865 106.5818099976103 .9837265015101 .168746948299 .98712158203100 .2742996216 104.8460998535108 .6473312378105 .8638916016100 .04492187594 .81549835205 91.669639587490 .6851654052790 .86801910490 .5211791992287 .77810668945 82.5967712402376 .1197967529371 .014930725167 .3575134277366 .44316101074 64.9192428588958 .5187492370651 .5086898803747 .8512611389246 .02254867554 45.717769622841 .1459884643629 .5641593933120 .1158199310321 .63973999023 25.2971591949529 .5641593933132 .6120109558133 .8311500549332 .91679000854 31.0880794525129 .5641593933128 .3450202941928 .3450202941928 .04022979736 28.0402297973628 .0402297973627 .7354507446327 .7354507446327 .73545074463 28.0402297973628 .3450202941928 .6497993469229 .2593708038329 .86894035339 30.7833003997831 .6976509094232 .6120109558133 .8311500549335 .35507965088 36.8790016174338 .4029312133840 .2316398620642 .0603485107444 .19384002686 46.3273391723648 .4608306884850 .5943298339852 .4230384826754 .25175094604 55.7756805419956 .6900291442957 .2995986938557 .909179687558 .21395874023 58.5187492370658 .8235282897958 .8235282897959 .1283111572359 .43310165405 59.4331016540559 .7378807067960 .0426712036160 .0426712036160 .34745025635 60.6522407531761 .2618103027361 .5666007995661 .8713798522962 .17617034912 62.7857398986863 .0905189514263 .3953094482463 .7000885009864 .0048828125 64.3096618652364 .6144485473664 .9192428588965 .2240066528365 .22400665283 65.5288009643665 .8335876464865 .8335876464866 .1383666992267 .66230010986 67.6623001098668 .88143920898 -9999 -9999 -9999 -9999 -9999 -9999 -9999 -9999 -9999 -9999 -9999 -9999 -9999 -9999 -9999 -9999 -9999 -9999 -9999 -9999 -9999 -9999 -9999 -9999

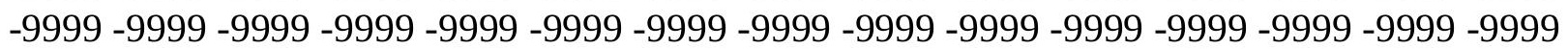


-9999 -9999 -9999 -9999 -9999 -9999 -9999 -9999 -9999 -9999 -9999 -9999 -9999 -9999 -9999 -9999 -9999 -9999 -9999 -9999 -9999 -9999 -9999 -9999 -9999 -9999 -9999 -9999 -9999 -9999 -

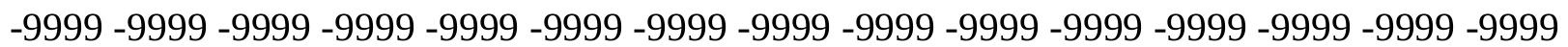
-9999 -9999 -9999 -9999 -9999-9999 -9999

-9999 -9999 -9999 -9999 -9999 -9999 -9999 -9999 -9999 -9999 -9999 -9999 -9999 -9999 -9999 -9999 -9999 -9999 -9999 -9999 -9999 -9999 -9999 -9999 -9999 -9999 -9999 -9999 -9999 -9999 -9999 -9999 -9999 -9999 -9999 -9999 -9999 -9999 -9999 -9999 -9999 -9999 -9999 -9999 -9999

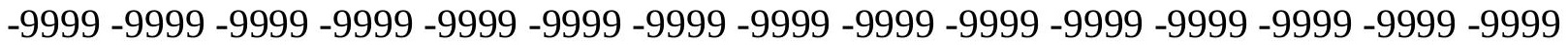

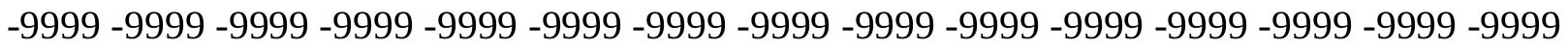
-9999 -9999 -9999 -9999 -9999 -9999 -9999 -9999 -9999 -9999 94.88757324219 96.8915786743298 .95886230469101 .0908432007103 .2910232544105 .5633087158 107.9129333496110 .343788147111 .2303771973111 .0183639526110 .8821258545 110.7474136353110 .5290756226110 .1270141602109 .4542236328108 .4126358032 106.931968689104 .968460083102 .523101806699 .6272811889696 .36328125 92.9077148437588 .3876876831186 .5589828491281 .6824111938579 .85370635986 81.0728530883884 .4254837036188 .6924667358487 .0296325683683 .08317565918 79.3617706298875 .9103317260772 .7622375488369 .9375991821367 .44770812988 65.2957687377963 .481864929261 .9904212951760 .838172912660 .02884674072 59.5730323791559 .4727020263759 .7187652587960 .2941780090361 .1759223938 62.3354110717863 .7323112487865 .3080139160266 .9826507568468 .66250610352 70.2468109130971 .6284332275472 .6862335205173 .2970046997173 .36176300049 72.8460083007871 .7983398437570 .3333740234468 .602951049866 .78514862061 65.0351715087963 .4513282775961 .9831619262760 .5203132629458 .91137695312 57.1167526245155 .2531661987353 .5868034362852 .3464622497651 .62142562866 51.4000701904351 .6272392272952 .2863922119153 .4552078247155 .24736785889 57.7424545288160 .9188766479564 .6334762573268 .5970306396572 .47888946533 76.1082305908279 .6557006835983 .5567092895588 .2816772460994 .05006408691 100.6751327515107 .6839447021114 .518951416116 .4279022217118 .2565994263 120.6949005127123 .43800354122 .7456817627120 .7927398682119 .7578659058 120.0246734619121 .5503768921123 .6818618774125 .7787628174127 .3503494263 128.2060241699128 .4468841553128 .1326599121127 .1856231689126 .2432327271 125.3056793213124 .3730545044122 .5447235107120 .2886886597118 .1594848633 116.3431625366114 .8945999146113 .8122406006113 .0937957764112 .6992492676 112.5119552612112 .3536529541112 .0320968628111 .4306259155110 .5720443726 109.5571975708108 .5023193359107 .4691467285106 .4538269043103 .9034042358 101.865745544498 .6018753051894 .5859146118291 .9437866210990 .39945220947 88.0457992553783 .5735321044978 .7303848266675 .8914871215870 .71015167236 71.3197174072367 .3575134277348 .4608306884829 .5641593933125 .60194969177 26.8210906982432 .0024414062536 .2694282531738 .0981407165536 .26942825317 32.6120109558129 .8689403533928 .6497993469228 .6497993469228 .95458984375 28.6497993469228 .0402297973627 .7354507446327 .430660247827 .4306602478 27.7354507446328 .0402297973628 .3450202941928 .6497993469229 .25937080383 29.8689403533930 .7833003997831 .6976509094232 .9167900085434 .13592910767 35.6598587036137 .1837806701739 .0125007629441 .1459884643643 .27949142456 45.4129791259847 .5464782714849 .6799812316951 .8134689331153 .94697189331 55.4708900451756 .3852500915556 .9948196411157 .2995986938557 .60438919067 
57.909179687558 .2139587402358 .5187492370658 .8235282897958 .82352828979 59.1283111572359 .4331016540559 .7378807067960 .0426712036160 .34745025635 60.6522407531760 .9570198059161 .2618103027361 .5666007995661 .87137985229 62.4809494018662 .7857398986863 .0905189514263 .3953094482463 .70008850098 64.004882812564 .3096618652364 .6144485473664 .6144485473664 .91924285889 65.2240066528365 .2240066528365 .5288009643665 .5288009643665 .52880096436 66.4431610107467 .9670867919969 .49101257324 -9999 -9999 -9999 -9999 -9999 -9999 -9999 -9999 -9999 -9999 -9999 -9999 -9999 -9999 -9999 -9999 -9999 -9999 -9999 -9999 -9999 -9999

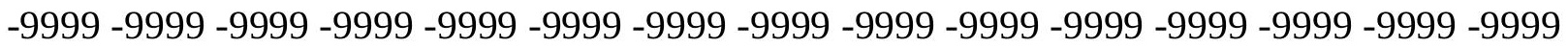
-9999 -9999 -9999 -9999 -9999 -9999 -9999 -9999 -9999 -9999 -9999 -9999 -9999 -9999 -9999 -

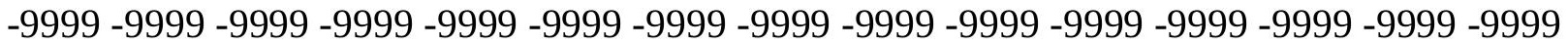
-9999 -9999 -9999 -9999 -9999 -9999 -9999 -9999 -9999 -9999 -9999 -9999 -9999 -9999 -9999 -9999 -9999 -9999 -9999-9999-9999-9999-9999

-9999 -9999 -9999 -9999 -9999 -9999 -9999 -9999 -9999 -9999 -9999 -9999 -9999 -9999 -9999 -9999 -9999 -9999 -9999 -9999 -9999 -9999 -9999 -9999 -9999 -9999 -9999 -9999 -9999 -9999

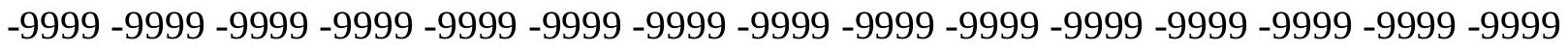
-9999 -9999 -9999 -9999 -9999 -9999 -9999 -9999 -9999 -9999 -9999 -9999 -9999 -9999 -9999 -9999 -9999 -9999 -9999 -9999 -9999 -9999 -9999 -9999 -9999 -9999 -9999 -9999 -9999 -9999 -9999 -9999 -9999 -9999 -9999 -9999 -9999 -9999 -9999 -9999 96.53466033936 98.5712890625100 .6673126221102 .8221588135105 .0365371704107 .3109130859 109.6463241577 112.0422210693 113.2776565552112.8503417969112.5671920776 112.3568344116112 .12109375111 .7481002808111 .1074905396110 .0848846436 108.5972518921106 .5993804932104 .0858230591101 .087867736897 .6801071167 93.2642517089887 .7781066894586 .8637619018685 .0350494384881 .07285308838 79.2441329956181 .9871978759881 .3776321411184 .7302627563585 .52783203125 81.9880523681678 .6830673217875 .6461181640672 .9038009643670 .4711227417 68.3607482910266 .576454162665 .1243515014664 .0011825561563 .19884490967 62.7416954040562 .62695312562 .8464698791563 .3839149475164 .21098327637 65.2882537841866 .5679626464867 .9867019653369 .4631805419970 .91047668457 72.2417831420973 .3730316162174 .2223663330174 .7150115966874 .79317474365 74.431083679273 .6402282714872 .4705276489371 .0063018798869 .35385894775 67.6195297241265 .8749313354564 .1395797729562 .3993148803760 .62613677979 58.8502044677757 .1640739440955 .7154769897554 .6353759765653 .99632263184 53.8145751953154 .0837821960454 .8098411560156 .0296821594257 .79922866821 60.1503105163663 .0518684387266 .3929290771570 .0010986328173 .71476745605 77.4832229614381 .4238357543985 .7913131713990 .8489761352596 .72051239014 103.307975769110 .3009414673114 .2944030762115 .2088012695116 .7326965332 119.7806015015123 .7427978516124 .0501174927122 .8981704712122 .2629318237 122.4596862793123 .4742126465124 .9742889404126 .5318145752127 .8078155518 128.6291503906128 .9874572754128 .6369476318127 .6768264771126 .7214126587 125.770866394124 .8252029419123 .3695907593121 .3460083008119 .3719863892 117.6080474854116 .130531311114 .9687271118114 .1128311157113 .5107498169 113.0661315918112 .6539077759112 .1485137939111 .479095459110 .6390533447 109.6770553589108 .6575241089107 .6375045776106 .6572418213105 .732635498 104.911315918104 .3285903931104 .1516571045104 .5035629272104 .0087432861 103.1424026489102 .2854080299 .5755004882895 .8451309204192 .16264343262 
88.4673843383880 .9938049316467 .9670867919953 .6421813964849 .07040023804 48.765621185348 .765621185347 .2416992187542 .66992187538 .70771026611 33.2215805053729 .5641593933128 .9545898437529 .5641593933130 .17373085022 28.9545898437528 .3450202941927 .7354507446327 .430660247827 .4306602478 27.430660247827 .7354507446327 .7354507446328 .0402297973628 .64979934692 28.9545898437529 .8689403533930 .7833003997831 .6976509094232 .91679000854 34.4407196044936 .2694282531738 .0981407165539 .9268493652342 .06034851074 44.1938400268646 .3273391723648 .765621185350 .8991203308153 .03261184692 54.8613204956155 .7756805419956 .0804595947356 .3852500915556 .99481964111 57.2995986938557 .6043891906757 .909179687558 .2139587402358 .51874923706 58.8235282897959 .1283111572359 .4331016540559 .7378807067960 .04267120361 60.3474502563560 .6522407531760 .9570198059161 .2618103027361 .56660079956 62.1761703491262 .4809494018662 .7857398986863 .0905189514263 .39530944824 63.7000885009864 .004882812564 .004882812564 .3096618652364 .61444854736 64.6144485473664 .9192428588964 .9192428588965 .2240066528365 .22400665283 65.52880096436 67.05272674561 68.27187347412 -9999 -9999 -9999 -9999 -9999 -9999 -9999 -9999 -9999 -9999 -9999 -9999 -9999 -9999 -9999 -9999 -9999 -9999 -9999 -9999 -9999 -9999 -9999 -9999 -9999 -9999 -9999 -9999 -9999 -9999 -9999 -9999 -9999 -9999 -9999 -9999 -9999 -

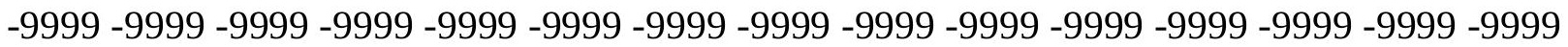

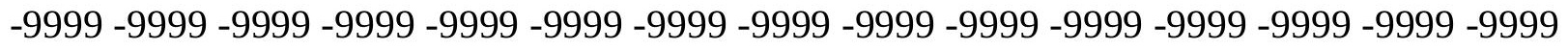

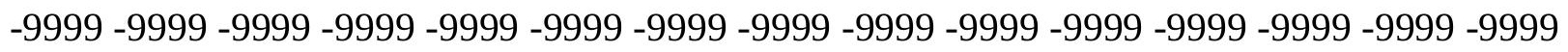
-9999 -9999-9999-9999-9999-9999-9999-9999 -9999 -9999 -9999 -9999 -9999 -9999 -9999 -9999 -9999 -9999 -9999 -9999 -9999 -9999 -9999

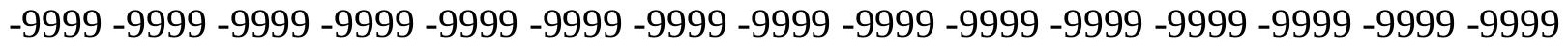

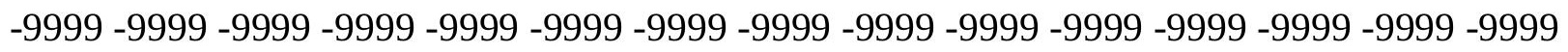
-9999 -9999 -9999 -9999 -9999 -9999 -9999 -9999 -9999 -9999 -9999 -9999 -9999 -9999 -9999 -9999 -9999 -9999 -9999 -9999 -9999 -9999 -9999 -9999 -9999 -9999 -9999 -9999 -9999 -9999 -9999 -9999 -9999-9999 -9999-9999 -9999 -9999 -9999 -9999 98.09967041016 100.1591491699102 .2736434937104 .440788269106 .6588897705108 .9256210327 111.2386856079113 .5942840576115 .1353530884114 .502243042114 .1129150391 113.895614624113 .7387619019113 .5051269531113 .0128097534112 .1153335571 110.7135238647108 .7679901123106 .2865982056103 .31835937599 .94132995605 96.0073165893692 .349891662689 .6068267822386 .8637619018684 .73026275635 83.8159103393684 .4254837036184 .4254837036183 .5111236572382 .59677124023 84.4127655029381 .2598571777378 .3449935913175 .6970291137773 .33473205566 71.2742156982469 .5244522094768 .0917816162166 .9824905395566 .19441986084 65.7304458618265 .5864639282265 .7570190429766 .2261810302766 .9621963501 67.9137191772569 .0363693237370 .2818832397571 .5686798095772 .81491088867 73.9474563598674 .8961334228575 .5993499755976 .0058898925876 .07889556885 75.7968063354575 .1537857055774 .1662368774472 .8764038085971 .34803771973 69.6557464599667 .8673171997166 .0368118286164 .2028579711962 .40413665771 60.6964759826759 .1599006652857 .8858718872156 .9548225402856 .41827392578 56.298271179256 .6031761169457 .3444061279358 .5435981750560 .22645187378 62.401782989565 .0417785644568 .0754394531271 .4086380004974 .96656036377 78.7420654296982 .81723785487 .3415679931692 .4631881713998 .24768829346 104.6225891113111 .3625640869113 .075302124113 .3800964355114 .9039993286 
118.2565994263122.2188034058 124.9072113037124.3282470703 124.0202941895 124.2149200439124 .9180603027125 .9613418579127 .0867385864128 .0653991699 128.751663208129 .0933074951129 .0843505859128 .164352417127 .1966705322 126.2339019775125 .2760391235123 .8493499756122 .0472412109120 .2580108643 118.6016540527117 .1545562744115 .9550552368114 .9966659546114 .2367706299 113.6009140015113 .0023345947112 .3653488159111 .6350250244110 .8018035889 109.881942749 108.9143371582 107.9458999634 107.0305252075106.20728302 105.5217514038105 .0752563477104 .9542617798104 .8986282349103 .9867630005 103.0796661377102 .1784973145101 .2835769653100 .394210815499 .5090637207 98.6278381347793 .8461532592884 .121376037675 .0356674194369 .90200805664 68.8426666259870 .6699295043975 .2819290161166 .1383666992252 .42303848267 35.9646492004428 .6497993469230 .7833003997831 .3928699493430 .47850990295 29.2593708038328 .3450202941928 .0402297973627 .7354507446327 .73545074463 27.7354507446327 .7354507446327 .7354507446327 .7354507446328 .04022979736 28.3450202941928 .9545898437529 .8689403533930 .7833003997832 .00244140625 33.5263595581135 .0502891540536 .8790016174338 .7077102661140 .84120941162 42.66992187545 .1082000732447 .2416992187549 .3751907348651 .50868988037 53.0326118469254 .2517509460454 .8613204956155 .4708900451755 .77568054199 56.3852500915556 .6900291442956 .9948196411157 .6043891906757 .9091796875 58.2139587402358 .5187492370658 .8235282897959 .1283111572359 .73788070679 60.0426712036160 .3474502563560 .6522407531760 .9570198059161 .26181030273 61.8713798522962 .1761703491262 .4809494018662 .7857398986863 .09051895142 63.3953094482463 .7000885009863 .7000885009864 .004882812564 .30966186523 64.3096618652364 .6144485473664 .6144485473664 .9192428588964 .91924285889 65.2240066528365 .8335876464867 .3575134277368 .88143920898 -9999-9999-9999 -9999 -9999 -9999 -9999 -9999 -9999 -9999 -9999 -9999 -9999 -9999 -9999 -9999 -9999 -9999 -9999 -

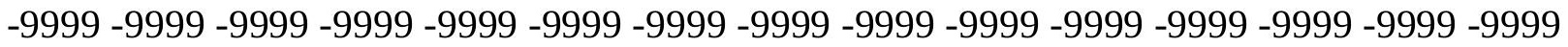

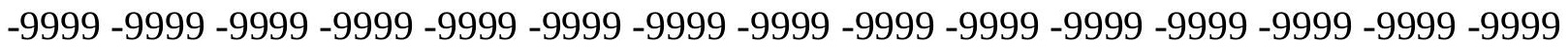

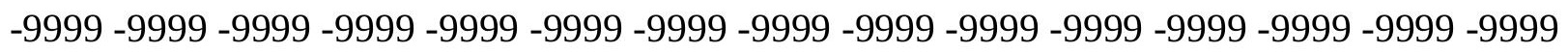

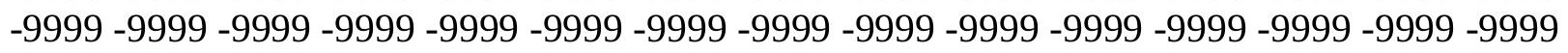
-9999 -9999 -9999 -9999 -9999 -9999 -9999 -9999 -9999 -9999

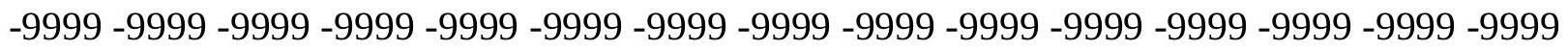

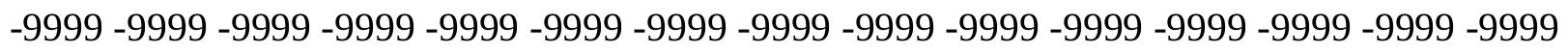

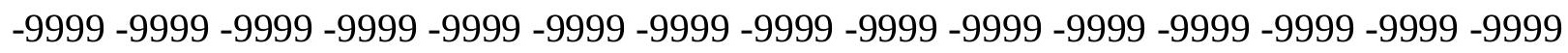
-9999 -9999 -9999 -9999 -9999 -9999 -9999 -9999 -9999 -9999 -9999 -9999 -9999 -9999 -9999

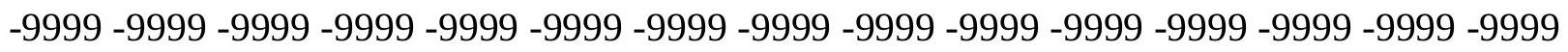
-9999 -9999 -9999 -9999 -9999-9999-9999-9999 -9999-9999 99.57875823975 101.6518936157103 .7755966187105 .9459686279108 .1593933105110 .4113311768 112.6970367432115 .010307312116 .7385482788115 .9118652344115 .4416503906 115.2876815796115 .3109664917115 .3547210693115 .1304321289114 .4514465332 113.195526123111 .353843689108 .9630050659106 .0987930298102 .8908920288 99.5139236450296 .3121032714893 .2642517089890 .8259735107488 .99725341797 88.0829010009887 .4733276367287 .1685485839886 .8637619018686 .2541885376 85.6446228027383 .6432418823280 .8560485839878 .309982299876 .0258102417 74.0217437744172 .3082656860470 .8953094482469 .7883224487368 .98583221436 68.4937133789168 .3011169433668 .3992004394568 .7711715698269 .38516235352 
70.2008438110471 .1729049682672 .2377471923873 .3498306274474 .41133117676 75.3795776367276 .1897583007876 .7803192138777 .1107254028377 .16226959229 76.9168395996176 .3607330322375 .494277954174 .3380508422972 .93321228027 71.336639404369 .6131896972767 .8290328979566 .0477218627964 .33292388916 62.7504043579161 .3689842224160 .2537841796959 .4586029052759 .0200920105 58.9589996337959 .2875175476160 .0172882080161 .1623764038162 .73508453369 64.7362823486367 .1464080810569 .9251327514673 .0247116088976 .41352081299 80.0988922119184 .1354522705188 .6093444824293 .6000671386799 .1335144043 105.1439056396108 .8082962036108 .1986999512108 .1986999512109 .1130981445 111.551399231115 .5136032104121 .3044967651125 .2053375244125 .141456604 125.3595657349125 .873550415126 .6064758301127 .400970459128 .1170043945 128.6378173828128 .9085235596128 .8732910156128 .5137176514127 .6683654785 126.6942367554125 .5497817993124 .0651855469122 .4732513428120 .8693084717 119.342880249117 .9625244141116 .7650909424115 .749786377114 .8861999512 114.1243209839113 .4052658081112 .677734375111 .9060897827111 .0755691528 110.1938323975109 .2852478027108 .3869628906107 .5453186035106 .8165283203 106.2334136963105 .856590271105 .737449646104 .9427337646103 .9946517944 103.0481567383102 .1039123535101 .1618423462100 .220832824799 .27928161621 98.33683013916 97.3956832885796.4606552124 91.47734832764 87.4080581665 86.4258728027387 .4931945800887 .181785583580 .8264312744170 .22113800049 60.0426712036147 .8512611389237 .4885711669932 .9167900085430 .47850990295 29.2593708038328 .9545898437528 .6497993469228 .6497993469228 .64979934692 28.3450202941928 .3450202941928 .0402297973627 .7354507446327 .73545074463 28.0402297973628 .3450202941928 .9545898437529 .8689403533931 .08807945251 32.3072204589833 .8311500549335 .3550796508837 .1837806701739 .31727981567 41.1459884643643 .2794914245645 .4129791259847 .5464782714849 .37519073486 51.2038993835452 .4230384826753 .3373985290554 .2517509460454 .86132049561 55.1661109924355 .7756805419956 .3852500915556 .6900291442957 .29959869385 57.6043891906758 .2139587402358 .5187492370658 .8235282897959 .12831115723 59.4331016540560 .0426712036160 .3474502563560 .6522407531760 .95701980591 61.2618103027361 .8713798522962 .1761703491262 .4809494018662 .78573989868 63.0905189514263 .0905189514263 .3953094482463 .7000885009864 .0048828125 64.004882812564 .3096618652364 .3096618652364 .6144485473664 .61444854736 64.9192428588965 .2240066528366 .1383666992267 .66230010986 -9999 -9999 -9999 -9999 -9999 -9999 -9999 -9999 -9999 -9999 -9999 -9999 -9999 -9999 -9999 -9999 -9999 -9999 -9999 -9999 -9999 -9999 -9999 -9999 -9999 -9999 -9999 -9999 -9999 -9999 -9999 -9999 -9999 -9999

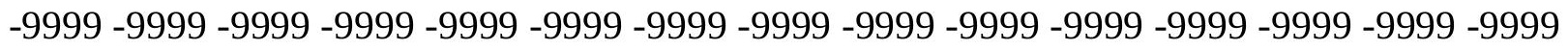

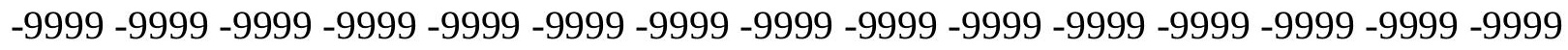

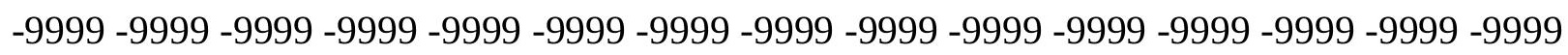
-9999 -9999 -9999 -9999 -9999 -9999 -9999 -9999 -9999 -9999

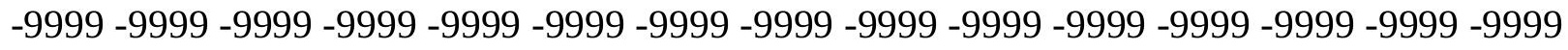

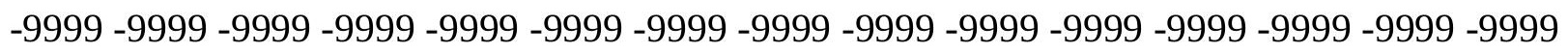
-9999 -9999 -9999 -9999 -9999 -9999 -9999 -9999 -9999 -9999 -9999 -9999 -9999 -9999 -9999 -9999 -9999 -9999 -9999 -9999 -9999 -9999 -9999 -9999 -9999 -9999 -9999 -9999 -9999 -9999 -

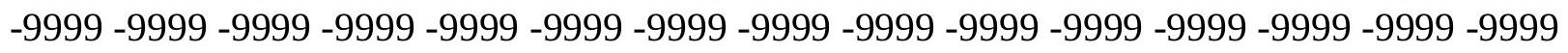
-9999 -9999 -9999 -9999 -9999 -9999 -9999 -9999 -9999 98.94322967529 100.9712295532 
103.0496749878105 .1744384766107 .3404312134109 .5425186157111 .7745819092 114.0300521851116 .3011779785118 .0315933228116 .9980926514116 .4389038086 116.4020385742116 .763168335117 .2174987793117 .4032821655116 .9943466187 115.8908157349114 .1501083374111 .856918335109 .0906143188106 .0713577271 103.017402648999 .6647262573296 .9216690063594 .4833908081192 .65467834473 91.4355392456190 .8259735107490 .5211791992289 .9116134643689 .60682678223 88.6849212646585 .8394927978583 .1818695068480 .741485595778 .53993988037 76.5963211059674 .9222793579173 .5284957885772 .4189224243271 .59729003906 71.0611190795970 .8037490844770 .8140945434671 .0723648071371 .5514831543 72.2141571044973 .0174942016673 .9036254882874 .8313522338975 .73763275146 76.5519943237377 .2493438720777 .7415161132877 .9932556152378 .00946044922 77.7771453857477 .2754821777376 .4999084472775 .4623489379974 .19299316406 72.7382431030371 .156806945869 .5146102905367 .880302429266 .3221282959 64.9051971435563 .68903732362 .7247657775962 .0525245666561 .70076751709 61.6882133483962 .0278511047462 .7307014465363 .8070220947365 .26396942139 67.1011962890669 .30747222971 .8621368408274 .7430648803777 .93885803223 81.459396362385 .3380508422989 .6210250854594 .34487152199 .50846862793 102.712600708102 .4077987671102 .1029968262102 .1029968262102 .712600708 104.2365036011106 .979598999111 .551399231116 .4279022217125 .755859375 125.9994735718126 .4020309448126 .9225845337127 .4815444946127 .9854278564 128.3659362793128 .5425567627128 .4638519287128 .1000061035127 .4525756836 126.5410842896125 .4053497314124 .1005020142122 .6972808838121 .2659835815 119.8761291504118 .5833282471117 .4188537598116 .3883209229115 .4730224609 114.6405944824113 .8525238037113 .0742950439112 .2806777954111 .4602432251 110.6167678833109 .767791748108 .941986084108 .1770477295107 .5188140869 106.998008728106 .6503829956105 .9987869263105 .0184707642104 .0361251831 103.0520935059102 .0664901733101 .0788879395100 .087936401499 .09196472168 98.0905914306697 .0863113403396 .0843124389695 .0914611816494 .1155166626 93.1642837524492 .2460250854591 .3688964843890 .5420532226686 .14939880371 80.2440109252976 .1962814331161 .5666007995645 .4129791259830 .78330039978 29.8689403533930 .1737308502230 .7833003997830 .1737308502230 .17373085022 29.8689403533929 .2593708038328 .3450202941928 .0402297973627 .73545074463 27.7354507446327 .7354507446328 .3450202941928 .9545898437530 .17373085022 31.0880794525132 .6120109558134 .1359291076735 .9646492004437 .79335021973 39.622070312541 .4507789611843 .5842704772945 .4129791259847 .24169921875 49.0704002380450 .5943298339851 .8134689331152 .7278289794953 .33739852905 54.2517509460454 .8613204956155 .4708900451756 .0804595947356 .69002914429 56.9948196411157 .6043891906757 .909179687558 .5187492370658 .82352828979 59.1283111572359 .4331016540560 .0426712036160 .3474502563560 .65224075317 60.9570198059161 .5666007995661 .8713798522962 .1761703491262 .48094940186 62.7857398986862 .7857398986863 .0905189514263 .3953094482463 .70008850098 63.7000885009864 .004882812564 .004882812564 .3096618652364 .30966186523 64.6144485473664 .9192428588965 .2240066528366 .7479400634868 .27187347412 -9999 -9999 -9999 -9999 -9999 -9999 -9999 -9999 -9999 -9999 -9999 -9999 -9999 -9999 -9999 -9999 -9999 -9999 -9999 -9999 -9999 -9999 -9999 -9999 -9999 -9999 -9999 -9999 -9999 -9999 -9999 -

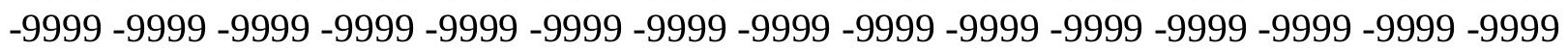


-9999 -9999 -9999 -9999 -9999 -9999 -9999 -9999 -9999 -9999 -9999 -9999 -9999 -9999 -9999 -9999 -9999 -9999 -9999 -9999 -9999 -9999 -9999 -9999 -9999 -9999 -9999 -9999 -9999 -9999 -9999 -9999 -9999 -9999 -9999 -9999 -9999 -9999 -9999 -9999 -9999 -9999

-9999 -9999 -9999 -9999 -9999 -9999 -9999 -9999 -9999 -9999 -9999 -9999 -9999 -9999 -9999 -9999 -9999 -9999 -9999 -9999 -9999 -9999 -9999 -9999 -9999 -9999 -9999-9999 -9999 -9999 -9999 -9999 -9999 -9999 -9999 -9999 -9999 -9999 -9999 -9999 -9999 -9999 -9999 -9999 -9999 -9999 -9999 -9999 -9999 -9999 -9999 -9999 -9999 -9999 -9999 -9999 -9999 -9999 -9999 -9999 -9999 -9999 -9999 -9999 -9999 -9999 -9999 -9999 -9999 -9999 -9999 -9999 -9999 -9999 -9999 -9999 -9999 -9999 -9999-9999 -9999 -9999 -9999 -9999 117.5530700684 102.2769699097 104.353187561106 .4718551636108 .6269989014110 .8124313354113 .0209121704 115.2447280884117 .475112915118 .9636077881117 .6661529541116 .9651412964 116.9991836548117 .950012207118 .9931182861119 .7928771973119 .5812988281 118.5693969727116 .8657684326114 .6305465698111 .9321670532108 .8566741943 105.7603988647102 .71260070899 .9695205688597 .8360290527396 .00731658936 94.7881774902394 .1785964965893 .5690307617292 .9594726562592 .65467834473 90.5503387451287 .8544769287185 .3254241943482 .9917221069380 .8748626709 78.9939880371177 .3611297607475 .9871063232474 .8768615722774 .03116607666 73.4496231079173 .1229324340873 .0408477783273 .1813278198273 .52115631104 74.0234298706174 .6523284912175 .3605880737376 .0990371704176 .82421875 77.4907455444378 .0506515502978 .4496841430778 .6531295776478 .63704681396 78.4034042358477 .9381332397577 .2373428344776 .3108062744175 .1840057373 73.8956985473672 .4956970214871 .0429000854569 .6007995605568 .23320007324 66.998886108465 .9492034912165 .1266937255964 .5644760131864 .28702545166 64.311935424864 .6523132324265 .3186798095766 .3195419311567 .66038513184 69.3419265747171 .3591995239373 .7030563354576 .364540100179 .34075164795 82.63925170898 86.2777252197390.2766571044994.6456985473697.53124237061 97.8360290527397 .8360290527397 .5312423706196 .9216690063596 .92166900635 97.5312423706198 .75038146973101 .1886978149105 .1509017944112 .4656982422 123.7427978516126 .5840301514126 .9706878662127 .3737640381127 .7339782715 127.9851379395128 .0721740723127 .946647644127 .587059021126 .9882583618 126.1717300415125 .166343689124 .0202941895122 .7820281982121 .5089569092 120.2532119751119 .0581130981117 .9499893188116 .9374847412116 .0114364624 115.1525726318114 .3361358643113 .5392150879112 .7446289062111 .9445571899 111.1421966553110 .3507843018109 .5919036865108 .8937225342108 .2870941162 107.8014678955107 .1431884766106 .1386642456105 .1293029785104 .1150741577 103.0958709717102 .0713043213101 .0406188965100 .002334594798 .95490264893 97.8981781005996 .8349838256895 .7709350585994 .7132644653393 .66989135742 92.6484832763791 .6567535400490 .7016448974689 .7892837524488 .93203735352 88.1749343872187 .5158386230577 .7650756835965 .8335876464852 .72782897949 41.4507789611832 .6120109558134 .4407196044933 .8311500549332 .91679000854 32.0024414062530 .4785099029529 .2593708038328 .3450202941927 .73545074463 27.430660247827 .430660247828 .0402297973628 .3450202941929 .25937080383 30.1737308502231 .3928699493432 .9167900085434 .4407196044936 .26942825317 37.7933502197339 .9268493652341 .7555618286143 .5842704772945 .41297912598 46.9369087219248 .4608306884849 .9847602844251 .2038993835452 .11825942993 53.0326118469253 .9469718933154 .5565414428755 .1661109924355 .77568054199 
56.3852500915556 .9948196411157 .2995986938557 .909179687558 .21395874023 58.8235282897959 .1283111572359 .4331016540560 .0426712036160 .34745025635 60.6522407531760 .9570198059161 .5666007995661 .8713798522962 .17617034912 62.4809494018662 .7857398986862 .7857398986863 .0905189514263 .39530944824 63.3953094482463 .7000885009863 .7000885009864 .004882812564 .30966186523 64.3096618652364 .6144485473664 .9192428588965 .5288009643667 .05272674561 -9999 -9999 -9999 -9999 -9999 -9999 -9999 -9999 -9999 -9999 -9999 -9999 -9999 -9999 -9999 -9999 -9999 -9999 -9999 -9999 -9999 -9999 -9999 -9999 -9999 -9999 -9999 -9999 -9999 -9999 -9999 -9999 -9999 -9999 -9999 -9999 -9999 -9999 -9999 -9999 -9999 -9999 -9999 -9999 -9999 -9999 -9999 -9999 -9999 -9999 -9999 -9999 -9999 -9999 -9999 -9999 -9999 -9999 -9999 -9999 -9999 -9999 -9999 -9999 -9999 -9999 -9999 -9999 -9999 -9999 -9999 -9999 -9999 -9999 -9999 -9999 -9999 -9999 -9999-9999 -9999 -9999 -9999 -9999 -9999 -9999-9999-9999 -

-9999 -9999 -9999 -9999 -9999 -9999 -9999 -9999 -9999 -9999 -9999 -9999 -9999 -9999 -9999 -9999 -9999 -9999 -9999 -9999 -9999 -9999 -9999 -9999 -9999 -9999 -9999 -9999 -9999 -9999 -

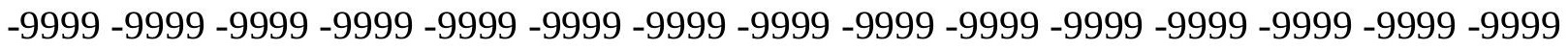

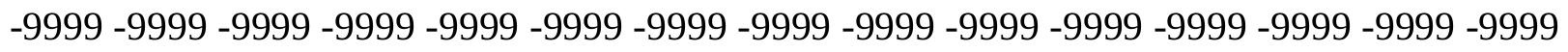

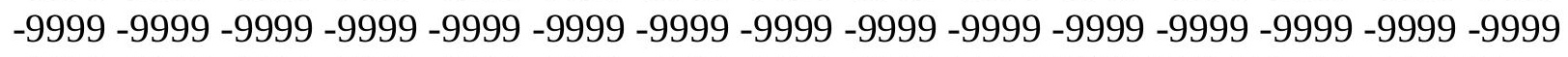
-9999 -9999-9999 -9999 -9999-9999-9999-9999-9999 119.8695831299 120.4304199219 105.565536499107 .6718978882109 .8107376099111 .9751815796114 .1573562622 116.3488388062118 .5403823853119 .481048584117 .841796875116 .8500061035 116.7862319946118 .5272064209120 .8722610474122 .1885528564121 .9644622803 120.9119415283119 .1452178955116 .8231506348114 .2944030762110 .9418029785 107.8938980103105 .1509017944102 .712600708100 .579101562598 .75038146973 97.5312423706196 .9216690063598 .7503814697397 .6792526245194 .91974639893 92.2483062744189 .6966781616287 .2933578491285 .0653533935583 .03353881836 81.2164382934679 .6259994506878 .2727279663177 .1606597900476 .29256439209 75.6642532348675 .2695312575 .0943374633875 .1213607788175 .32512664795 75.6764602661176 .1395492553776 .6759948730577 .2440338134877 .80139923096 78.3065719604578 .7256393432679 .0162200927779 .1521224975679 .10060882568 78.8570785522578 .4173965454177 .7791976928776 .953826904375 .9655456543 74.8467559814573 .6355133056672 .3801269531271 .13755035469 .96363830566 68.9085311889668 .0159835815467 .3226089477566 .8575210571366 .64311218262 66.6963272094767 .0300903320367 .6543655395568 .5767440795969 .80223083496 71.3328857421973 .1678085327175 .3042602539177 .7395706176880 .47360992432 83.5101089477586 .855613708590 .5144348144592 .6546783447393 .26425170898 93.5690307617293 .5690307617293 .2642517089892 .9594726562592 .3498916626 92.349891662692 .349891662693 .2642517089896 .92166900635101 .4934005737 103.3221969604111 .24659729126 .8361358643127 .1353988647127 .383972168 127.5371246338127 .5508880615127 .3920059204127 .0400848389126 .4933624268 125.7638168335124 .8779754639123 .8696212769122 .7797164917121 .6504516602 120.5223999023119 .4289779663118 .3923492432117 .4222793579116 .516204834 115.6637268066114 .8496856689114 .0594940186113 .2819366455112 .5125732422 111.7545089722111 .0181350708110 .3190155029109 .6770782471109 .1131591797 108.3634338379107 .3420257568106 .313583374105 .2779769897104 .2347335815 103.1832885742102 .1228485107101 .052429199299 .9704360961998 .87552642822 97.7680358886796 .6513824462995 .5316467285294 .4165039062593 .31410217285 
92.2322235107491 .1783828735490 .1589889526489 .179412841888 .25308990479 87.39563751221 86.59851837158 85.85660552979 81.13551330566 73.79690551758 70.1005783081155 .1661109924340 .5364189147937 .1837806701736 .26942825317 34.4407196044932 .3072204589830 .4785099029528 .9545898437528 .04022979736 27.7354507446327 .430660247827 .7354507446328 .0402297973628 .34502029419 29.2593708038330 .1737308502231 .3928699493432 .9167900085434 .44071960449 36.2694282531738 .0981407165539 .9268493652341 .7555618286143 .58427047729 45.1082000732446 .9369087219248 .1560516357449 .3751907348650 .59432983398 51.8134689331152 .7278289794953 .6421813964854 .2517509460454 .86132049561 55.7756805419956 .0804595947356 .6900291442957 .2995986938557 .60438919067 58.2139587402358 .8235282897959 .1283111572359 .4331016540560 .04267120361 60.3474502563560 .6522407531761 .2618103027361 .5666007995661 .87137985229 62.1761703491262 .4809494018662 .4809494018662 .7857398986863 .09051895142 63.0905189514263 .3953094482463 .7000885009863 .7000885009864 .0048828125 64.004882812564 .3096618652364 .6144485473664 .9192428588966 .13836669922 67.66230010986 -9999 -9999 -9999 -9999 -9999 -9999 -9999 -9999 -9999 -9999 -9999 -9999 -9999 -9999 -9999 -9999 -9999 -9999 -9999 -9999 -9999 -9999 -9999 -9999 -9999 -9999 -9999 -9999 -9999 -9999 -9999 -9999 -9999 -9999 -9999 -9999 -9999 -9999 -9999 -9999 -9999 -9999 -9999 -9999 -9999 -9999 -9999 -9999 -9999 -9999 -9999 -9999 -9999 -9999 -9999 -9999 -9999 -9999 -9999 -9999 -9999 -9999 -9999 -9999 -9999 -9999 -9999 -9999 -9999 -9999 -9999 -9999 -9999 -9999 -9999 -9999 -9999 -9999 -9999 -9999 -9999 -9999 -9999 -9999 -9999 -9999 -9999

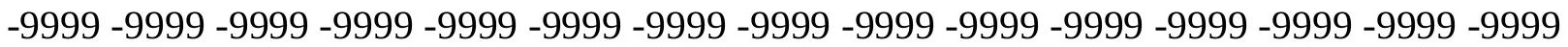
-9999 -9999 -9999 -9999 -9999 -9999 -9999 -9999 -9999 -9999 -9999 -9999 -9999 -9999 -9999 -9999 -9999 -9999 -9999 -9999 -9999 -9999 -9999 -9999 -9999 -9999 -9999 -9999 -9999 -9999 -9999 -9999 -9999 -9999 -9999 -9999 -9999 -9999 -9999 -9999 -9999 -9999 -9999 -9999 -9999 -9999 -9999 -9999 -9999 -9999 -9999 -9999 -9999 -9999 -9999 -9999 -9999 -9999 -9999 -9999 -9999 -9999 -9999 -9999 -9999 -9999 -9999 -9999 -9999 122.0870819092122 .5496902466 106.6896591187108 .7782669067110 .8960952759113 .0359344482115 .1896209717 117.3484573364119 .5030212402119 .4270629883117 .6074676514115 .7750473022 115.818397522117 .342300415124 .0475006104124 .0475006104123 .7427978516 122.5235977173120 .6949005127117 .9517974854115 .2088012695112 .4656982422 109.4179000854106 .979598999104 .5412979126102 .712600708101 .1886978149 99.9695205688599 .05516815186100 .883903503498 .9066467285296 .30797576904 93.7873687744191 .3732910156289 .0914611816486 .9668197631885 .01905059814 83.26580810547 81.71856689453 80.38731384277 79.27581787109 78.38640594482 77.7147293090877 .2544403076276 .992050170976 .9113388061576 .98905944824 77.1991577148477 .5100173950277 .8881301879978 .2971649169978 .70055389404 79.0629882812579 .3488769531279 .5326766967879 .5810394287179 .48246765137 79.2202148437578 .8001708984478 .2117080688577 .4721908569376 .60677337646 75.6440505981474 .6094818115273 .530693054272 .4730606079171 .47789764404 70.5858612060569 .834396362369 .255584716868 .8756408691468 .71521759033 68.7903518676869 .1131591796969 .692939758370 .5364379882871 .64848327637 73.0318984985474 .6882247924876 .6182403564578 .8225936889681 .30125427246 84.0541839599687 .0800476074290 .3734436035290 .2164001464889 .3020401001 89.302040100189 .9116134643690 .2164001464890 .2164001464889 .91161346436 90.2164001464890 .2164001464890 .8259735107492 .0450973510792 .04509735107 
89.9116134643692.95947265625109.7226028442126.7977523804126.9697723389 127.0531387329127 .0171051025126 .8380661011126 .5007095337126 .0034866333 125.3547515869124 .5747375488123 .6895675659122 .7311935425121 .7322006226 120.7238540649119 .7323074341118 .7759246826117 .8648223877117 .0002593994 116.177772522115 .3887786865114 .6245880127113 .8785095215113 .1484832764 112.4376144409111 .7538375854111 .1081466675110 .5138931274109 .6473770142 108.6156845093107 .5753250122106 .5260391235105 .4673919678104 .3985137939 103.318397522 102.2258911133101.119857788199.9987335205198.86144256592 97.708839416596 .5451660156295 .3772048950294 .2130966186593 .06139373779 91.9301834106490 .8273162841889 .7581405639688 .7319641113387 .76127624512 86.839286804285 .944755554285 .0510864257884 .1342391967883 .18672943115 80.9762725830170 .4826354980559 .1283111572346 .9369087219239 .6220703125 36.8790016174334 .1359291076731 .6976509094229 .8689403533928 .64979934692 28.3450202941928 .0402297973627 .7354507446327 .7354507446327 .73545074463 28.3450202941928 .9545898437530 .1737308502231 .3928699493432 .91679000854 34.7455101013236 .2694282531738 .0981407165539 .9268493652341 .75556182861 43.2794914245645 .1082000732446 .6321296691948 .1560516357449 .37519073486 50.5943298339851 .5086898803752 .4230384826753 .3373985290554 .25175094604 54.8613204956155 .4708900451756 .0804595947356 .6900291442956 .99481964111 57.6043891906758 .2139587402358 .5187492370659 .1283111572359 .43310165405 60.0426712036160 .3474502563560 .6522407531761 .2618103027361 .56660079956 61.8713798522962 .1761703491262 .4809494018662 .4809494018662 .78573989868 63.0905189514263 .0905189514263 .3953094482463 .7000885009863 .70008850098 64.004882812564 .004882812564 .3096618652364 .6144485473664 .91924285889 66.4431610107467 .96708679199 -9999 -9999 -9999 -9999 -9999 -9999 -9999 -9999 -9999 -9999 -9999 -9999 -9999 -9999 -9999 -9999 -9999 -9999 -9999 -9999 -9999 -9999 -9999 -9999 -

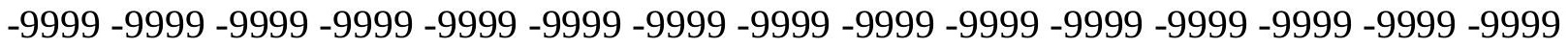

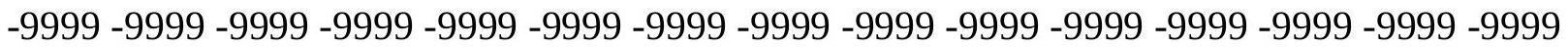
-9999 -9999 -9999 -9999 -9999 -9999 -9999 -9999 -9999 -9999 -9999 -9999 -9999 -9999 -9999

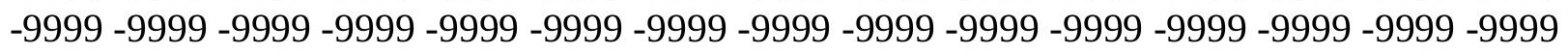
$-9999-9999$

-9999 -9999 -9999 -9999 -9999 -9999 -9999 -9999 -9999 -9999 -9999 -9999 -9999 -9999 -9999

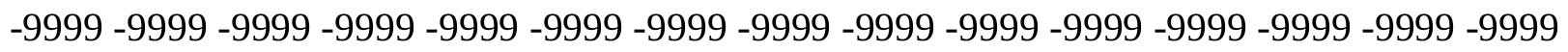

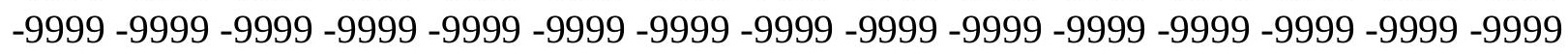
-9999 -9999 -9999 -9999 -9999 -9999 -9999 -9999 -9999 -9999 -9999 -9999 -9999 -9999 -9999 -9999 -9999 -9999 -9999 -9999 -9999 -9999 -9999 -9999 -9999 -9999 -9999 -9999 -9999 -9999 -9999 -9999-9999 -9999 -9999-9999-9999-9999-9999 124.2144012451 124.5729141235 124.9991149902109 .7962417603111 .8889846802114 .0011062622116 .1244430542 118.2503051758120 .3694000244118 .4433135986117 .0374984741113 .075302124 114.2944030762115 .818397522127 .0953979492125 .5715026855124 .3523025513 122.8283996582120 .6949005127118 .2565994263115 .818397522113 .075302124 110.3321990967107 .8938980103105 .7603988647103 .9317016602102 .712600708 101.7982025146100 .8839035034100 .5791015625100 .009094238397 .55864715576 95.1785964965892 .8942718505990 .7285079956188 .703681945886 .83796691895 85.1478347778383 .6441802978582 .3362960815481 .2276458740280 .32010650635 79.6093673706179 .0891952514678 .7469635009878 .5677413940478 .53060150146 
78.6123428344778 .7851715087979 .0198593139679 .2849121093879 .54882049561 79.7808151245179 .9517974853580 .0363616943480 .0124893188579 .86470794678 79.5854797363379 .1698913574278 .6206588745177 .9508514404377 .18031311035 76.3342056274475 .4455337524474 .5324783325273 .6378784179772 .79839324951 72.048133850171 .4197540283270 .9413681030370 .6366424560570 .52383422852 70.6172714233470 .9272689819371 .4627838134872 .229774475173 .23287200928 74.4744491577175 .9575271606477 .6846313476679 .659591674881 .88191223145 84.3484649658287 .0511169433689 .9791030883889 .302040100186 .2541885376 86.254188537687 .1685485839888 .0829010009888 .9972534179789 .60682678223 90.2164001464891 .1307525634891 .1307525634889 .6068267822387 .47332763672 83.5111236572383 .8159103393696 .00731658936110 .3321990967118 .5614013672 121.6092987061113 .6848983765107 .5891036987115 .2088012695125 .5442123413 124.969291687124 .284034729123 .5085449219122 .6676330566121 .7864608765 120.8894348145119 .9971237183119 .1249923706118 .2826538086117 .4736328125 116.6970977783115 .9489517212115 .2246551514114 .520652771113 .836517334 113.1750106812112 .5420913696111 .9451446533110 .9824829102109 .9465332031 108.9006576538107 .8446044922106 .7778701782105 .6997375488104 .6089935303 103.5043029785102 .3841323853101 .247215271100 .092147827198 .91832733154 97.7271881103596 .5237731933695 .3156738281294 .1116790771592 .92087554932 91.7520446777390 .6138305664189 .5141677856488 .4638977050887 .47401428223 86.5261993408285 .5920257568484 .6337356567483 .6126861572382 .50255584717 81.3236465454180 .1720809936572 .8288040161165 .2240066528352 .42303848267 39.0125007629435 .9646492004432 .9167900085430 .7833003997830 .17373085022 29.5641593933128 .9545898437528 .3450202941927 .7354507446327 .4306602478 27.7354507446328 .0402297973628 .9545898437530 .1737308502231 .69765090942 33.2215805053734 .7455101013236 .5742111206138 .0981407165539 .92684936523 41.7555618286143 .2794914245645 .1082000732446 .6321296691947 .85126113892 49.0704002380450 .2895507812551 .5086898803752 .4230384826753 .33739852905 53.9469718933154 .5565414428755 .1661109924355 .7756805419956 .38525009155 56.9948196411157 .6043891906758 .2139587402358 .5187492370659 .12831115723 59.4331016540560 .0426712036160 .3474502563560 .6522407531761 .26181030273 61.5666007995661 .8713798522962 .1761703491262 .1761703491262 .48094940186 62.7857398986863 .0905189514263 .0905189514263 .3953094482463 .39530944824 63.7000885009864 .004882812564 .004882812564 .3096618652364 .30966186523 65.2240066528366 .7479400634868 .27187347412 -9999 -9999 -9999 -9999 -9999 -9999 -9999 -9999 -9999 -9999 -9999 -9999 -9999 -9999 -9999 -9999 -9999 -9999 -9999 -9999 -9999 -9999 -9999 -9999 -9999 -9999 -9999 -9999 -9999 -9999 -9999 -9999 -9999 -9999 -9999 -9999 -9999

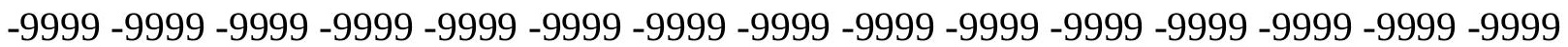
-9999 -9999 -9999 -9999 -9999 -9999 -9999 -9999 -9999 -9999 -9999 -9999 -9999 -9999 -9999 -9999 -9999 -9999 -9999 -9999 -9999 -9999 -9999 -9999 -9999 -9999 -9999 -9999 -9999 -9999 $-9999-9999-9999$

-9999 -9999 -9999 -9999 -9999 -9999 -9999 -9999 -9999 -9999 -9999 -9999 -9999 -9999 -9999 -9999 -9999 -9999 -9999 -9999 -9999 -9999 -9999 -9999 -9999 -9999 -9999 -9999 -9999 -9999 -9999 -9999 -9999 -9999 -9999 -9999 -9999 -9999 -9999 -9999 -9999 -9999 -9999 -9999 -9999 -9999 -9999 -9999 -9999 -9999 -9999 -9999 -9999 -9999 -9999 -9999 -9999 -9999 -9999 -9999

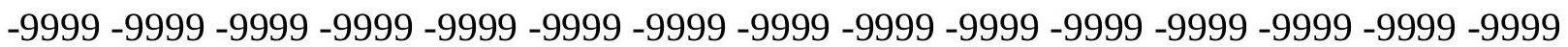


-9999 -9999 -9999 -9999 -9999 -9999 -9999 -9999 126.075668335126 .2538909912 126.5030441284126 .8099365234110 .7303695679112 .7944107056114 .8760528564 116.9673156738119 .0597229004118 .2919387817116 .1231002808111 .8561019897 112.1608963013113 .075302124114 .2944030762128 .4460449219126 .7906036377 124.9618988037122 .8283996582120 .3900985718118 .2565994263115 .5136032104 113.075302124110 .6370010376108 .1986999512106 .3700027466104 .8460998535 103.6268997192102 .712600708102 .4077987671102 .1029968262100 .9964981079 98.6816329956196 .4313278198294 .2681045532292 .2118835449290 .28232574463 88.4957504272586 .8673629760785 .4072952270584 .1241226196383 .02091217041 82.099189758381 .3547592163180 .7817230224680 .3684539794980 .10144042969 79.961914062579 .9293823242279 .9794311523480 .0866851806680 .2239074707 80.3640594482480 .4808349609480 .549522399980 .5486984252980 .45999145508 80.2707443237379 .9726409912179 .5645294189579 .0501098632878 .44037628174 77.7512283325277 .0030517578176 .2240219116275 .4417190551874 .68645477295 73.9775543212973 .3478927612372 .8259429931672 .4357376098672 .19808197021 72.1296463012772 .2401657104572 .5378799438573 .0310363769573 .72782897949 74.6300811767675 .7393798828177 .0585174560578 .5922927856480 .34503173828 82.3228836059684 .517166137786 .911270141689 .4930725097788 .69246673584 85.6446228027385 .3398437586 .254188537688 .0829010009889 .91161346436 91.7403335571392 .9594726562593 .8738174438593 .5690307617292 .04509735107 89.6068267822386 .5589828491286 .5589828491292 .95947265625100 .5791015625 104.8460998535104 .846099853597 .2264633178790 .5211791992293 .26425170898 99.05516815186101 .7982025146105 .7603988647113 .9896011353120 .0852966309 117.9517974854120 .9997024536120 .2448272705119 .4572982788118 .6886062622 117.9432983398117 .2228088379116 .525932312115 .8509216309115 .1963272095 114.5625610352113 .9519271851113 .3686294556112 .357093811111 .321975708 110.2763519287109 .2196121216108 .1513824463107 .0709228516105 .9772338867 104.8687973022103 .7440414429102 .6011734009101 .4387359619100 .2555236816 99.05161285497 .8292160034296 .5940475463995 .3544235229594 .1198425293 92.9001922607491 .7052078247190 .5448684692489 .4294357299888 .37528991699 87.38826751709 86.45199584961 85.5348205566484.5990371704183.61393737793 82.5761947631881 .5437927246180 .7897720336979 .9436187744174 .58090209961 64.7630462646555 .1661109924341 .4507789611834 .7455101013232 .91679000854 32.6120109558132 .0024414062531 .0880794525129 .5641593933128 .34502029419 27.430660247827 .1258792877227 .430660247828 .0402297973628 .95458984375 30.4785099029531 .6976509094233 .2215805053735 .0502891540536 .57421112061 38.4029312133840 .2316398620641 .7555618286143 .5842704772945 .10820007324 46.6321296691947 .8512611389249 .0704002380450 .2895507812551 .20389938354 52.1182594299353 .0326118469253 .6421813964854 .5565414428755 .16611099243 55.7756805419956 .3852500915556 .9948196411157 .6043891906758 .21395874023 58.5187492370659 .1283111572359 .7378807067960 .0426712036160 .34745025635 60.9570198059161 .2618103027361 .5666007995661 .8713798522962 .17617034912 62.1761703491262 .4809494018662 .7857398986863 .0905189514263 .09051895142 63.3953094482463 .3953094482463 .7000885009864 .004882812564 .0048828125 $64.3096618652364 .3096618652365 .5288009643667 .3575134277368 .50366210938-9999$ -9999 -9999 -9999 -9999 -9999 -9999 -9999 -9999 -9999 -9999 -9999 -9999 -9999 -9999 -9999 
-9999 -9999 -9999 -9999 -9999 -9999 -9999 -9999 -9999 -9999 -9999 -9999 -9999 -9999 -9999 -9999 -9999 -9999 -9999 -9999 -9999 -9999 -9999 -9999 -9999 -9999 -9999 -9999 -9999 -9999

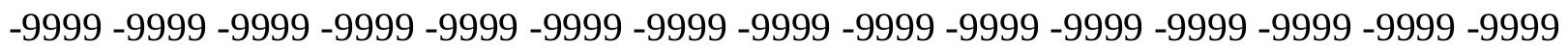
-9999 -9999 -9999 -9999 -9999 -9999 -9999 -9999 -9999 -9999 -9999 -9999 -9999 -9999 -9999 -9999 -9999 -9999 -9999 -9999 -9999 -9999 -9999

-9999 -9999 -9999 -9999 -9999 -9999 -9999 -9999 -9999 -9999 -9999 -9999 -9999 -9999 -9999 -9999 -9999 -9999 -9999 -9999 -9999 -9999 -9999 -9999 -9999 -9999 -9999 -9999 -9999 -9999 -9999 -9999 -9999 -9999 -9999 -9999 -9999 -9999 -9999 -9999 -9999 -9999 -9999 -9999 -9999 -999 -9999 -9999 -9999 -9999 -9999 -9999 -9999 -9999 -9999 -9999 -9999 -9999 -9999 -9999 -9999 -9999 -9999 -9999 -9999 -9999 -9999 -9999 -9999 -9999 -9999 -9999 -9999 -9999 -9999 -9999 -9999 -9999 -9999 -9999 -9999 -9999 -9999 -9999 128.1308898926128 .2043304443 128.3401489258128 .5253143311128 .7458343506113 .6184692383115 .6671218872 117.724609375118 .5614013672114 .9039993286111 .24659729110 .9418029785 111.24659729111 .551399231129 .091293335128 .5796661377127 .0953979492 124.6570968628122 .2188034058119 .7806015015117 .342300415114 .9039993286 112.4656982422110 .0273971558108 .1986999512106 .3700027466104 .8460998535 103.9317016602103 .3221969604103 .0174026489103 .0174026489101 .8792953491 99.6875915527397 .5559158325295 .5043716430793 .5503921508891 .71086883545 90.0000381469788 .4315795898487 .0148162841885 .757530212484 .6623840332 83.7305603027382 .958145141682 .3396835327181 .864677429281 .52095794678 81.29184722981 .1592636108481 .1018905639681 .0977249145581 .1233215332 81.1555786132881 .1720962524481 .1520156860481 .0773696899480 .93296051025 80.708427429280 .3972244262779 .998741149979 .5165634155378 .9602355957 78.3432388305777 .6837768554777 .0036087036176 .3239517211975 .6736907959 75.0708312988374 .5451812744174 .1160354614373 .803848266673 .62450408936 73.5992050170973 .7268676757874 .0163574218874 .4706954956175 .1097869873 75.9231872558676 .915313720778 .0854339599679 .4454345703180 .9846572876 82.7389450073284 .6818695068486 .7968063354589 .0635299682688 .38768768311 85.9494018554785 .6446228027386 .8637619018689 .6068267822392 .95947265625 95.397743225197 .2264633178797 .8360290527397 .5312423706196 .31210327148 94.7881774902394 .4833908081194 .1785964965896 .0073165893697 .53124237061 98.1408081054797 .2264633178793 .2642517089899 .302040100188 .69246673584 88.38768768311 83.51112365723 80.76805877686 87.1685485839893.87381744385 91.4355392456189 .9116134643692 .349891662698 .75038146973106 .6747970581 118.4125366211117 .7536239624117 .1141891479116 .4942398071115 .8936080933 115.3130569458114 .7542037964113 .7599716187112 .729850769111 .689163208 110.6371078491109 .5729675293108 .4962463379107 .4059906006106 .3009338379 105.1792755127104 .039276123102 .8789978027101 .6969223022100 .4919967651 99.2649459838998 .0188446044996 .7601165771595 .4976425170994 .24158477783 93.0027160644591 .7919082641690 .6208724975689 .5035095214888 .45589447021 87.4904632568486 .5906600952185 .729492187584 .8757247924884 .01015472412 83.15559387207 82.43059539795 81.46276092529 80.0891494751 79.05043029785 75.1542053222767 .1019363403358 .5187492370643 .8890609741236 .26942825317 36.2694282531735 .6598587036134 .1359291076731 .3928699493428 .95458984375 27.430660247826 .8210906982426 .8210906982427 .430660247828 .34502029419 29.5641593933130 .7833003997832 .3072204589833 .8311500549335 .35507965088 
36.8790016174338 .7077102661140 .2316398620642 .0603485107443 .58427047729 45.1082000732446 .6321296691947 .8512611389249 .0704002380450 .28955078125 51.2038993835451 .8134689331152 .7278289794953 .6421813964854 .25175094604 54.8613204956155 .7756805419956 .3852500915556 .9948196411157 .60438919067 58.2139587402358 .5187492370659 .1283111572359 .7378807067960 .04267120361 60.3474502563560 .9570198059161 .2618103027361 .5666007995661 .87137985229 62.1761703491262 .4809494018662 .4809494018662 .7857398986863 .09051895142 63.0905189514263 .3953094482463 .3953094482463 .7000885009864 .0048828125 64.004882812564 .3096618652364 .6144485473665 .8335876464867 .66230010986 68.52856445312 -9999 -9999 -9999 -9999 -9999 -9999 -9999 -9999 -9999 -9999 -9999 -9999 -9999 -9999 -9999 -9999 -9999 -9999 -9999 -9999 -9999 -9999 -9999 -9999 -9999 -9999 -9999 -9999 -9999 -9999 -9999 -9999 -9999 -9999 -9999 -9999 -9999 -9999 -9999 -9999 -9999 -9999 -9999 -9999 -9999 -9999 -9999 -9999 -9999 -9999 -9999 -9999 -9999 -9999 -9999 -9999 -9999 -9999 -9999 -9999 -9999 -9999 -9999 -9999 -9999 -9999 -9999 -9999 -9999 -9999 -9999 -9999 -9999 -9999 -9999 -9999 -9999 -9999 -9999 -9999 -9999 -9999 -9999

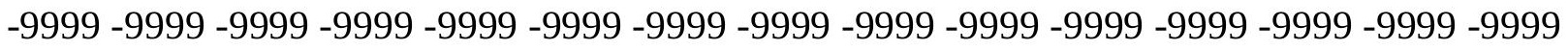
-9999 -9999 -9999 -9999 -9999 -9999 -9999 -9999 -9999 -9999 -9999 -9999 -9999 -9999 -9999 -9999 -9999 -9999 -9999 -9999 -9999 -9999 -9999 -9999 -9999 -9999 -9999 -9999 -9999 -9999 -9999 -9999 -9999 -9999 -9999 -9999 -9999 -9999 -9999 -9999 -9999 -9999 -9999 -9999 -9999 -

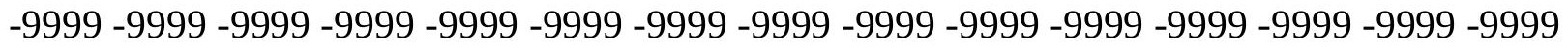
-9999 -9999-9999 -9999-9999 -9999 -9999-9999 130.0952453613130 .0602264404 130.080368042130 .1426086426130 .2334899902129 .8316497803116 .379699707 118.4017028809114 .9039993286110 .6370010376110 .3321990967110 .0273971558 110.0273971558113 .075302124129 .2821350098128 .6860656738126 .7906036377 124.0475006104121 .3044967651118 .8662033081116 .1231002808113 .6848983765 111.24659729109 .1130981445107 .2844009399105 .7603988647104 .5412979126 103.6268997192103 .3221969604103 .0174026489103 .3221969604102 .6658554077 100.585418701298 .5611419677796 .6112518310594 .7512435913192 .99578094482 91.3567962646589 .8461532592888 .4721527099687 .2417221069386 .15703582764 85.2190551757884 .4242324829180 .4632720947383 .2402572631882 .83087921143 82.5248031616282 .3061599731482 .1563415527382 .0563812255981 .98614501953 81.9259872436581 .8569259643681 .761436462481 .6245117187581 .43360900879 81.1802978515680 .8594055175880 .4707717895580 .0177612304779 .50873565674 78.9552688598678 .3728713989377 .7793197631877 .1944427490276 .63903045654 76.1335983276475 .6983642578175 .351280212475 .1091918945374 .98464202881 74.9913635253975 .1368103027375 .4239196777375 .8597183227576 .44867706299 77.1904220581178 .0849533081179 .1352615356480 .3407440185581 .71041107178 83.24890899658 84.9430999755986.80590057373 88.79598999023 88.08290100098 86.8637619018686 .254188537687 .7781066894592 .349891662697 .53124237061 100.8839035034102 .712600708102 .712600708102 .1029968262102 .4077987671 102.4077987671102 .4077987671101 .7982025146101 .4934005737100 .5791015625 99.3599472045998.7503814697396.9216690063594.7881774902394.17859649658 91.1307525634883 .8159103393678 .3297805786179 .8537063598682 .90155792236 81.0728530883877 .7202072143675 .8914871215877 .110626220781 .07285308838 92.3498916626110 .0273971558117 .7073898315117 .145401001116 .6009902954 116.0749740601115 .1812362671114 .1592254639113 .1272888184112 .0842056274 
111.0291061401109 .9611816406108 .8797988892107 .7838439941106 .6718139648 105.5416793823104 .3915786743103 .2195205688102 .0240478516100 .8043365479 99.5616302490298 .2997131347797 .025672912695 .7489013671994 .48013305664 93.2309570312592 .0133209228590 .8401718139689 .7281570434688 .69525909424 87.7559127807686 .9043045043986 .1138610839885 .360626220784 .6314163208 83.9397125244183 .3241043090882 .0707778930780 .813758850179 .79369354248 78.1942520141676 .2625427246169 .9433288574260 .9570198059148 .15605163574 41.4507789611840 .8412094116238 .4029312133834 .4407196044930 .17373085022 28.3450202941927 .430660247826 .8210906982427 .1258792877228 .04022979736 28.9545898437530 .1737308502231 .3928699493432 .9167900085434 .13592910767 35.6598587036137 .1837806701739 .0125007629440 .5364189147942 .06034851074 43.5842704772945 .1082000732446 .6321296691947 .8512611389249 .07040023804 49.9847602844250 .8991203308151 .5086898803752 .4230384826753 .33739852905 54.2517509460454 .8613204956155 .7756805419956 .3852500915556 .99481964111 57.6043891906758 .2139587402358 .8235282897959 .1283111572359 .73788070679 60.0426712036160 .3474502563560 .9570198059161 .2618103027361 .56660079956 61.8713798522962 .1761703491262 .4809494018662 .4809494018662 .78573989868 63.0905189514263 .0905189514263 .3953094482463 .3953094482463 .70008850098 64.004882812564 .004882812564 .3096618652364 .6144485473666 .44316101074 67.57641601562 -9999 -9999 -9999 -9999 -9999 -9999 -9999 -9999 -9999 -9999 -9999 -9999

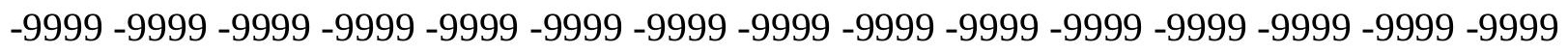
-9999 -9999 -9999 -9999 -9999 -9999 -9999 -9999 -9999 -9999 -9999 -9999 -9999 -9999 -9999 -9999 -9999 -9999 -9999 -9999 -9999 -9999 -9999 -9999 -9999 -9999 -9999 -9999 -9999 -9999 -

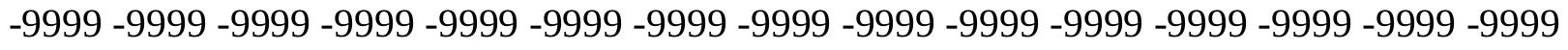

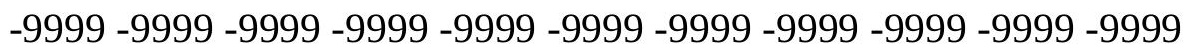

-9999 -9999 -9999 -9999 -9999 -9999 -9999 -9999 -9999 -9999 -9999 -9999 -9999 -9999 -9999

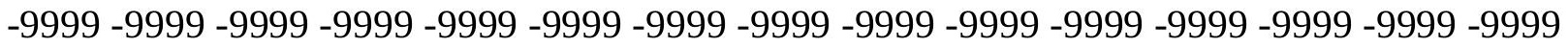

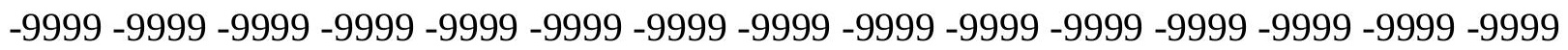
-9999 -9999 -9999 -9999 -9999 -9999 -9999 -9999 -9999 -9999 -9999 -9999 -9999 -9999 -9999

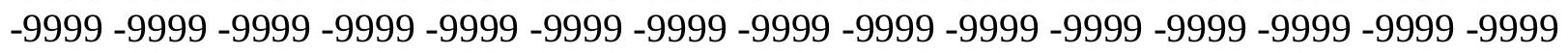
-9999 -9999 -9999 -9999 -9999 -9999 -9999 -9999 131.9599761963131 .8148345947 131.7186584473131 .6580963135130 .4479980469125 .8762969971117 .0201644897 116.1231002808111 .24659729110 .0273971558109 .4179000854108 .8082962036 108.5035018921108 .5035018921129 .4392089844128 .3144989014125 .2667007446 122.5235977173119 .7806015015117 .0374984741114 .2944030762111 .8561019897 109.4179000854 107.5891036987 105.7603988647104.5412979126103.6268997192 103.0174026489102.712600708 102.712600708 103.0174026489103.3646087646 101.384574890199 .4571151733497 .5989227294995 .8241271972794 .14575195312 92.5739212036191 .1184539794989 .7863235473688 .5833663940487 .51118469238 86.5705108642685 .7584075927778 .3297805786179 .5489196777382 .19427490234 83.66372680664 83.37210845947 83.14384460449 82.96263122559 82.81127929688 82.6731567382882 .5322189331182 .3738403320382 .1854858398481 .95685577393 81.6810531616281 .3540496826280 .9759521484480 .5499343872180 .08322143555 79.5858154296979 .0708618164178 .5534896850678 .0503921508877 .57914733887 77.1569900512776 .8009567260776 .5260238647576 .3462371826276 .27241516113 76.3142547607476 .4779357910276 .7689132690477 .1895065307677 .74211883545 
78.4268188476679 .2446212768680 .1948242187581 .2795944213982 .50010681152 83.8597564697385 .3590393066486 .9931259155388 .7439041137788 .99725341797 89.302040100188 .6924667358490 .2164001464896 .31210327148101 .1846160889 103.4702682495105 .7915496826107 .5891036987106 .3700027466107 .2844009399 107.8938980103108 .1986999512107 .5891036987106 .6747970581105 .4557037354 104.5412979126104 .2365036011103 .9317016602104 .2365036011105 .1509017944 101.493400573792 .349891662686 .254188537684 .1206970214883 .2063369751 81.3776321411178 .9393463134875 .8914871215874 .6723632812576 .50106811523 80.7680587768681 .0728530883885 .0350494384898 .4455871582113 .3800964355 116.6116104126115 .6000823975114 .5796203613113 .5489120483112 .5066833496 111.4519729614110 .3839187622109 .3017807007108 .2042922974107 .0897598267 105.9560089111104 .801109314103 .623085022102 .4206314087101 .1931838989 99.94244384766 98.6726989746197.3915100097796.1086883544994.83541870117 93.5839233398492 .3669891357491 .199081420990 .0966644287189 .0799331665 88.16860198975 87.35749053955 86.63081359863 85.9654541015685.34059906006 84.7397766113384 .1350784301883 .1006317138782 .0468902587981 .01634979248 79.4767684936578 .3143692016677 .3957138061573 .8594741821366 .74794006348 54.8613204956146 .6321296691942 .9747009277338 .4029312133833 .52635955811 30.1737308502228 .0402297973627 .1258792877227 .1258792877228 .04022979736 28.9545898437529 .8689403533931 .0880794525132 .0024414062533 .52635955811 34.7455101013236 .2694282531737 .7933502197339 .3172798156740 .84120941162 42.0603485107443 .5842704772945 .1082000732446 .6321296691947 .54647827148 48.4608306884849 .3751907348650 .2895507812551 .2038993835452 .42303848267 53.3373985290553 .9469718933154 .8613204956155 .7756805419956 .38525009155 56.9948196411157 .6043891906758 .2139587402358 .8235282897959 .12831115723 59.7378807067960 .0426712036160 .3474502563560 .9570198059161 .26181030273 61.5666007995661 .8713798522962 .1761703491262 .4809494018662 .78573989868 62.7857398986863 .0905189514263 .3953094482463 .3953094482463 .70008850098 63.7000885009864 .004882812564 .3096618652364 .6144485473664 .91924285889 66.7479400634867 .4481048584 -9999 -9999 -9999 -9999 -9999 -9999 -9999 -9999 -9999 -9999 -9999 -9999 -9999 -9999 -9999 -9999 -9999 -9999 -9999 -9999 -9999 -9999 -9999 -9999

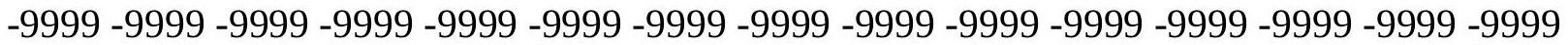
-9999 -9999 -9999 -9999 -9999 -9999 -9999 -9999 -9999-9999 -9999 -9999 -9999-9999-999 - -999 -9999 -9999 -9999 -9999 -9999 -9999 -9999 -9999 -9999 -9999 -9999 -9999 -9999 -9999 -9999 -9999 -9999 -9999 -9999 -9999 -9999 -9999 -9999 -9999 -9999 -9999 -9999 -9999 -9999 -9999 -9999 -9999 -9999 -9999 -9999 -9999 -9999 -9999 -9999 -9999 -9999 -9999 -9999

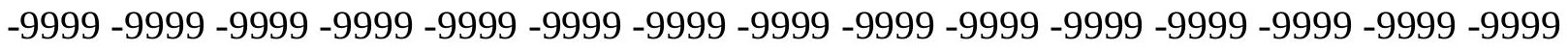

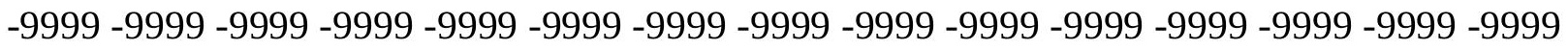
-9999 -9999 -9999 -9999 -9999 -9999 -9999 -9999 -9999 -9999 -9999 -9999 -9999 -9999 -9999 -9999 -9999 -9999 -9999 -9999 -9999 -9999 -9999 -9999 -9999 -9999 -9999 -9999 -9999 -9999 -9999 -9999 -9999 -9999-9999 -9999 -9999 -9999 133.7140960693133 .4586486816 133.2468566895133 .0649871826127 .0953979492123 .1332015991115 .818397522 110.9418029785110 .0273971558108 .8082962036107 .8938980103107 .2844009399 106.979598999106 .6747970581128 .9241027832125 .8762969971123 .1332015991 120.3900985718117 .342300415114 .2944030762111 .551399231109 .1130981445 106.979598999105 .4557037354103 .9317016602102 .712600708102 .1029968262 
101.7982025146101 .4934005737101 .7982025146102 .1029968262103 .0174026489 102.0924072266100 .252098083598 .4762496948296 .7779235839895 .16905975342 93.6585388183692 .2545623779390 .9625549316489 .78710937588 .72903442383 87.7887725830186 .9640502929779 .2441329956175 .2819290161178 .93934631348 82.5967712402384 .3565521240284 .0627059936583 .8136062622183 .59462738037 83.3917770385783 .1915664672982 .9817657470782 .75195312582 .49362945557 82.2011947631881 .8714752197381 .5047988891681 .1040649414180 .67554473877 80.227813720779 .772048950279 .3211212158278 .8891372680778 .49099731445 78.1412429809677 .8542709350677 .6426086425877 .5180206298877 .48937225342 77.5646362304777 .7485961914178 .0455322265678 .456886291578 .98432159424 79.627365112380 .3864974975681 .260604858482 .2498931884883 .35324859619 84.5738830566485 .9093933105587 .3619232177788 .9173431396590 .56913757324 92.3125839233493 .8738174438596 .0641403198298 .05670928955100 .1112976074 102.2230682373104 .3934249878106 .6275482178108 .8082962036108 .1986999512 107.8938980103108 .8082962036109 .1130981445108 .5035018921107 .5891036987 107.2844009399107 .8938980103108 .1986999512108 .8082962036113 .9896011353 121.6092987061117 .647102356104 .2365036011111 .55139923194 .48339080811 92.349891662688 .6924667358483 .206336975178 .3297805786177 .1106262207 76.5010681152374 .3675689697376 .1962814331186 .8637619018699 .05516815186 104.8460998535106 .979598999106 .0652008057113 .9941940308112 .9561157227 111.9053039551110 .8408355713109 .7619018555108 .6671066284107 .5546340942 106.422203064105 .2679138184104 .0898895264102 .8869781494101 .6589279175 100.407783508399 .1381988525497 .8580017089896 .5772247314595 .30728912354 94.0607223510792 .8508148193491 .6923141479590 .6018295288189 .59856414795 88.7021865844787 .9238204956187 .2449111938586 .6431961059686 .09042358398 85.5516433715884 .9771423339884 .2913742065483 .4178543090882 .412109375 81.4864120483481 .006416320881 .2792053222779 .6234359741277 .88516235352 70.7101516723657 .6043891906746 .9369087219242 .0603485107436 .57421112061 31.6976509094228 .6497993469227 .430660247827 .7354507446328 .34502029419 29.2593708038330 .1737308502230 .7833003997831 .6976509094232 .91679000854 34.1359291076735 .3550796508836 .5742111206138 .0981407165539 .31727981567 40.5364189147942 .0603485107443 .5842704772945 .1082000732446 .02254867554 46.9369087219247 .8512611389249 .0704002380449 .9847602844251 .20389938354 52.1182594299353 .0326118469253 .9469718933154 .8613204956155 .77568054199 56.3852500915556 .9948196411157 .6043891906758 .2139587402358 .51874923706 59.1283111572359 .7378807067960 .0426712036160 .6522407531760 .95701980591 61.2618103027361 .5666007995661 .8713798522962 .1761703491262 .48094940186 62.7857398986863 .0905189514263 .0905189514263 .3953094482463 .39530944824 63.7000885009864 .004882812564 .3096618652364 .3096618652364 .61444854736 65.5288009643666 .4826278686567 .29058837891 -9999 -9999 -9999 -9999 -9999 -9999 -9999

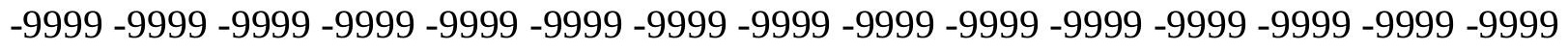

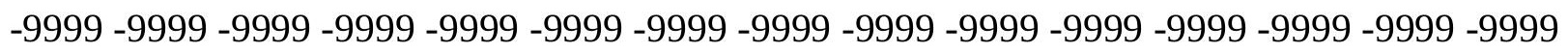
-9999 -9999 -9999 -9999 -9999 -9999 -9999 -9999 -9999 -9999 -9999 -9999 -9999 -9999 -9999 -9999 -9999 -9999 -9999 -9999 -9999 -9999 -9999 -9999 -9999 -9999 -9999 -9999 -9999 -9999 -

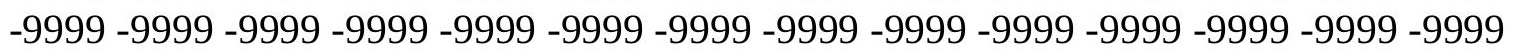
-9999 -9999 -9999 -9999 -9999 -9999 -9999 -9999 -9999 -9999 -9999 -9999 -9999 -9999 -9999 - 
-9999 -9999 -9999 -9999 -9999 -9999 -9999 -9999 -9999 -9999 -9999 -9999 -9999 -9999 -9999 -9999 -9999 -9999 -9999 -9999 -9999 -9999 -9999 -9999 -9999 -9999 -9999 -9999 -9999 -9999 -9999 -9999 -9999 -9999 -9999 -9999 -9999 -9999 -9999 -9999 -9999 -9999 -9999 -9999 -9999 -9999 -9999 -9999 -9999 -9999 -9999 -9999 -9999 -9999 -9999 -9999 -9999 -9999 -9999 -9999 -9999 -9999 -9999 -9999 -9999 -9999 -9999 135.7637329102135 .3480834961134 .983215332 134.6572113037128 .6192932129123 .43800354118 .8662033081111 .551399231 109.7226028442108 .1986999512106 .979598999106 .0652008057105 .1509017944 104.5412979126128 .9241027832125 .2667007446122 .5235977173120 .0852966309 117.342300415114 .2944030762110 .9418029785108 .1986999512106 .0652008057 104.2365036011102 .712600708101 .4934005737100 .8839035034100 .2742996216 99.9695205688599 .96952056885100 .2742996216100 .8839035034101 .7982025146 102.712600708100 .954505920499 .252647399997 .622772216896 .07599639893 94.620391845793 .2630386352592 .0081253051890 .8590469360489 .81597900391 88.8789062587 .1685485839879 .2441329956172 .5388565063575 .58670806885 79.8537063598684 .1206970214884 .9109649658284 .6058273315484 .33118438721 84.0753479003983.82698822021 83.5759124755983.3133773803783.03240203857 82.728378295982 .3989181518682 .0444259643681 .6675720214881 .27370452881 80.8702239990280 .4665756225680 .0737457275479 .7036743164179 .36904907227 79.0821914672978 .8553390502978 .6990585327178 .6232376098678 .63522338867 78.7415390014678 .9459381103579 .251678466879 .659591674880 .17065429688 80.784042358481 .4997024536182 .3162994384883 .2329483032284 .25030517578 85.3651351928786 .5787734985487 .8894577026489 .2938232421990 .78596496582 92.3714294433694 .0362930297995 .7832870483497 .6115875244199 .50986480713 101.479057312103 .5242233276105 .654045105107 .8749847412106 .3700027466 103.6268997192104 .8460998535106 .979598999107 .8938980103108 .8082962036 110.3321990967111 .8561019897112 .1608963013111 .24659729115 .818397522 118.5614013672113 .075302124123 .40990448115 .2088012695109 .1130981445 122.3340835571101 .798202514694 .1785964965886 .254188537681 .98719787598 79.8537063598680 .1584930419983 .206336975190 .2164001464895 .09295654297 85.0350494384876 .1962814331184 .4254837036197 .53124237061108 .8082962036 112.3878479004111 .3306503296110 .2588348389109 .1709060669108 .0649871826 106.9387817383105 .7904663086104 .6183395386103 .4214477539102 .199798584 100.955741882399 .6941604614398 .4229583740297 .1521148681695 .89296722412 94.6579971313593 .4604873657292 .3155364990291 .2376708984490 .24552154541 89.3537521362388 .5934906005987 .9447937011787 .3864898681686 .8890838623 86.41465759277 85.92105865479 85.36908721924 84.75514221191 84.15644836426 83.73110961914 83.68550872803 84.11772155762 83.0236206054781.29527282715 78.8352279663171 .6244964599656 .9948196411144 .8034095764237 .79335021973 32.3072204589828 .6497993469227 .430660247828 .0402297973629 .25937080383 30.1737308502230 .4785099029531 .0880794525131 .6976509094232 .30722045898 33.5263595581134 .4407196044935 .6598587036136 .8790016174337 .79335021973 39.0125007629440 .2316398620641 .7555618286142 .9747009277344 .19384002686 45.1082000732446 .3273391723647 .5464782714848 .765621185349 .98476028442 51.2038993835452 .1182594299353 .3373985290554 .2517509460454 .86132049561 55.7756805419956 .3852500915556 .9948196411157 .6043891906758 .21395874023 58.5187492370659 .1283111572359 .7378807067960 .0426712036160 .65224075317 
60.9570198059161 .2618103027361 .8713798522962 .1761703491262 .17617034912 62.4809494018662 .7857398986863 .0905189514263 .3953094482463 .39530944824 63.7000885009864 .004882812564 .004882812564 .3096618652364 .61444854736 64.9192428588965 .8067626953166 .6855545043967 .52684783936 -9999 -9999 -9999 -9999 -9999 -9999 -9999 -9999 -9999 -9999 -9999 -9999 -9999 -9999 -9999 -9999 -9999 -9999 -9999 -9999 -9999 -9999 -9999 -9999 -9999 -9999 -9999 -9999 -9999 -9999 -9999 -9999 -9999 -9999

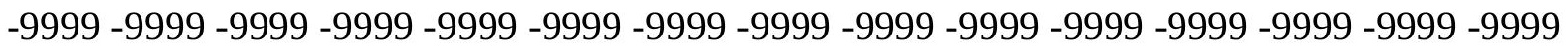
-9999 -9999 -9999 -9999 -9999 -9999 -9999 -9999 -9999 -9999 -9999 -9999 -9999 -9999 -9999 -9999 -9999 -9999 -9999 -9999 -9999 -9999 -9999 -9999 -9999 -9999 -9999 -9999 -9999 -9999 $-9999$

-9999 -9999 -9999 -9999 -9999 -9999 -9999 -9999 -9999 -9999 -9999 -9999 -9999 -9999 -9999 -9999 -9999 -9999 -9999 -9999 -9999 -9999 -9999 -9999 -9999 -9999 -9999 -9999 -9999 -9999 -9999 -9999 -9999 -9999 -9999 -9999 -9999 -9999 -9999 -9999 -9999 -9999 -9999 -9999 -9999 -9999 -9999 -9999 -9999 -9999 -9999 -9999 -9999 -9999 -9999 -9999 -9999 -9999 -9999 -9999 -9999 -9999 -9999 -9999 -9999 -9999 -9999 -9999 -9999 -9999 -9999 -9999 -9999 -9999 -9999 -9999 -9999 -9999 -9999-9999-9999-9999 137.3704223633136.8523101807 136.380279541 127.4001998901118 .2565994263112 .7705001831111 .24659729110 .0273971558 108.1986999512106 .3700027466105 .1509017944103 .9317016602103 .0174026489 102.4077987671123 .43800354120 .6949005127117 .9517974854115 .5136032104 113.3800964355110 .0273971558106 .6747970581104 .2365036011102 .4077987671 100.883903503499 .6647262573299 .0551681518698 .445587158298 .14080810547 97.83602905273 98.1408081054798.445587158299.0551681518699.96952056885 101.1886978149101 .571083068899 .9357681274498 .3671722412196 .87563323975 95.4686431884894 .1525497436592 .9307022094791 .8057174682690 .77742767334 89.8455886840888 .3876876831180 .4632720947372 .2340774536173 .14842987061 77.7202072143681 .9871978759885 .6859970092885 .3352050781285 .01541137695 84.7169036865284 .4301910400484 .1466827392683 .8589477539183 .56120300293 83.24977874756 82.92290496826 82.58110809326 82.22675323486 81.86441040039 81.5003890991281 .1426925659280 .8006820678780 .4844970703180 .20501708984 79.9727096557679 .7980804443479 .6900863647579 .6571807861379 .70545959473 79.8403854370180 .064865112380 .3814392089880 .7904357910281 .29236602783 81.8860931396582 .5712814331183 .3463821411184 .2109832763785 .16366577148 86.20235443115 87.32925415039 88.54133605957 89.83873748779 91.21627044678 92.6767883300894 .2205810546995 .8432617187597 .5423812866299 .31434631348 101.1721878052103 .1154098511105 .1605300903107 .3084411621102 .1029968262 95.0929565429795 .7025299072399 .96952056885104 .5412979126109 .1130981445 112.7705001831115 .2088012695116 .4279022217115 .818397522113 .3800964355 118.2565994263113 .9896011353121 .6092987061123 .1158294678119 .1709976196 122.4734420776122 .1241836548105 .455703735496 .3121032714890 .82597351074 88.38768768311 88.9972534179790.8259735107493.5690307617293.56903076172 86.8637619018681 .3776321411184 .7302627563592 .0450973510799 .66472625732 106.979598999111 .8520431519110 .7911758423109 .7142181396108 .6192779541 107.5041351318106 .3671035767105 .2066726685104 .0221481323102 .8137893677 101.5841903687100 .338356018199 .0840606689597 .8309555053796 .58994293213 95.3729934692494 .1929016113393 .0639572143692 .0009078979591 .01964569092 90.1367492675889 .3684158325288 .7343902587988 .2069015502987 .75682830811 
87.35440063477 86.97491455078 86.6065292358486.26757812586.01659393311 85.940849304286 .0962524414186 .3957214355585 .1448745727583 .50222015381 81.1698303222777 .9352264404369 .7957916259853 .6421813964837 .79335021973 31.3928699493428 .0402297973627 .430660247828 .3450202941930 .17373085022 30.4785099029530 .7833003997831 .0880794525131 .3928699493432 .00244140625 32.9167900085433 .8311500549334 .7455101013235 .6598587036136 .57421112061 37.4885711669938 .4029312133839 .622070312540 .8412094116242 .06034851074 43.2794914245644 .4986305236846 .0225486755447 .2416992187548 .7656211853 49.9847602844251 .2038993835452 .4230384826753 .3373985290554 .25175094604 54.8613204956155 .4708900451756 .3852500915556 .9948196411157 .60438919067 57.909179687558 .5187492370659 .1283111572359 .7378807067960 .04267120361 60.6522407531760 .9570198059161 .5666007995661 .8713798522962 .17617034912 62.4809494018662 .7857398986862 .7857398986863 .0905189514263 .39530944824 63.7000885009863 .7000885009864 .004882812564 .3096618652364 .61444854736 64.9192428588965 .5288009643666 .3610839843867 .2151336669970 .71015167236 -9999 -9999 -9999 -9999 -9999 -9999 -9999 -9999 -9999 -9999 -9999 -9999 -9999 -9999 -9999 -9999 -9999 -9999 -9999 -9999 -9999 -9999 -9999 -9999 -9999 -9999 -9999 -9999 -9999 -9999 -9999 -9999 -9999 -9999 -9999 -9999 -9999 -9999 -9999 -9999 -9999 -9999 -9999 -9999 -9999 -9999 -9999 -9999 -9999 -9999 -9999 -9999 -9999 -9999 -9999 -9999 -9999 -9999 -9999 -9999 -9999 -

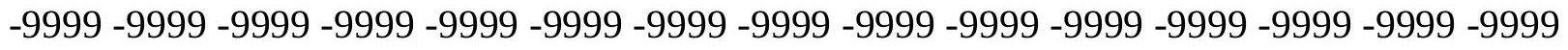
$-9999-9999-9999$

-9999 -9999 -9999 -9999 -9999 -9999 -9999 -9999 -9999 -9999 -9999 -9999 -9999 -9999 -9999 -9999 -9999 -9999 -9999 -9999 -9999 -9999 -9999 -9999 -9999 -9999 -9999 -9999 -9999 -9999 -

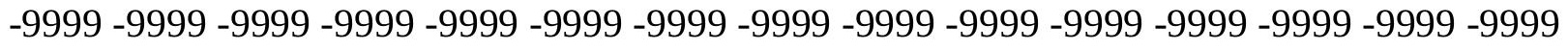

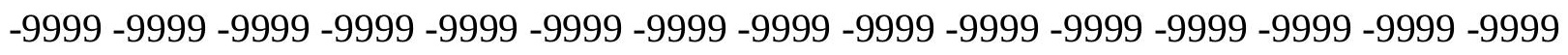
-9999 -9999 -9999 -9999 -9999 -9999 -9999 -9999 -9999 -9999 -9999 -9999 -9999 -9999 -9999 -9999 -9999 -9999 -9999 -9999 -9999 -9999 138.8380737305138 .2209625244128 .0097961426 115.5136032104122 .8283996582113 .3800964355109 .4179000854107 .5891036987 105.7603988647104 .2365036011103 .0174026489101 .7982025146100 .8839035034 99.96952056885117 .647102356115 .2088012695112 .4656982422110 .0273971558 107.2844009399 104.2365036011 101.493400573799.66472625732 98.14080810547 97.2264633178796 .6168823242296 .0073165893695 .7025299072395 .70252990723 95.7025299072396 .0073165893696 .3121032714896 .9216690063597 .83602905273 99.0551681518699 .96952056885100 .534019470299 .0204238891697 .57809448242 96.2140731811594 .9342193603593 .7414779663192 .6379623413191 .62343597412 90.6976013183689 .8583526611388 .9972534179781 .0728530883871 .62449645996 75.5867080688580 .1584930419984 .7302627563585 .9993209838985 .64331817627 85.31092834473 84.99419403076 84.68573760986 84.3789978027384.0691986084 83.7535171508883 .4308853149483 .1018753051882 .7686233520582 .43490600586 82.1061096191481 .7889556884881 .4914550781281 .222236633380 .9906463623 80.8056488037180 .6763229370180 .610351562580 .6150131225680 .69548797607 80.8563995361381 .1000671386781 .4284973144581 .8416976928782 .33985137939 82.9216918945383 .586639404384 .3331375122185 .1606216430786 .06777954102 87.0543746948288 .119422912689 .2629165649490 .4840545654391 .78302764893 93.1564025878994 .6136550903396 .1449356079197 .7596664428799 .45132446289 101.2387084961103 .1136550903105 .0868530273107 .165847778396 .61688232422 
86.2541885376 87.1685485839893.26425170898 101.7982025146110.3321990967 115.5136032104118 .5614013672120 .0852966309120 .3900985718119 .1709976196 117.9517974854117 .647102356119 .1709976196123 .1332015991121 .9140014648 122.6081390381122 .3078842163121 .9977340698121 .6820297241101 .7982025146 99.3599472045999 .6647262573299 .9695205688598 .445587158296 .31210327148 96.3121032714896 .9216690063595 .7025299072396 .0073165893699 .05516815186 103.3221969604106 .3700027466108 .8082962036110 .2946166992109 .2148895264 108.1154251099106 .9947357178105 .8515548706104 .6854324341103 .496925354 102.2888565063101 .066246032799 .8365631103598 .6088714599697 .39328765869 96.2008743286195 .043380737393 .934013366792 .8864593505991 .91623687744 91.0370483398490 .2698516845789 .62416839689 .1180114746188 .70436096191 88.37088775635 88.11183929443 87.92975616455 87.84053039551 87.87049865723 88.0382843017688 .3116226196387 .4179611206186 .238838195884 .72074890137 82.6137237548879 .7264404296975 .9394760131865 .5288009643646 .32733917236 30.4785099029528 .3450202941927 .7354507446328 .3450202941929 .25937080383 30.4785099029531 .0880794525130 .7833003997830 .7833003997831 .39286994934 32.6120109558133 .5263595581134 .1359291076734 .4407196044935 .05028915405 35.6598587036136 .5742111206137 .4885711669938 .7077102661139 .92684936523 41.1459884643642 .66992187544 .1938400268645 .717769622847 .24169921875 48.765621185350 .2895507812551 .5086898803752 .4230384826753 .33739852905 53.9469718933154 .8613204956155 .4708900451756 .0804595947356 .69002914429 57.2995986938557 .909179687558 .5187492370659 .1283111572359 .73788070679 60.3474502563560 .6522407531761 .2618103027361 .5666007995661 .87137985229 62.1761703491262 .4809494018662 .7857398986863 .0905189514263 .39530944824 63.7000885009863 .7000885009864 .004882812564 .3096618652364 .61444854736 65.2240066528365 .5288009643666 .1383666992267 .0930023193467 .84412384033 -9999 -9999 -9999 -9999 -9999 -9999 -9999 -9999 -9999 -9999 -9999 -9999 -9999 -9999 -9999 -9999

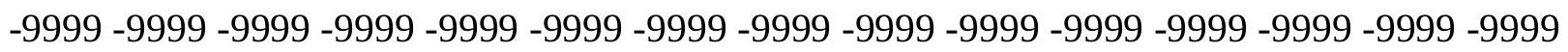
-9999 -9999 -9999 -9999 -9999 -9999 -9999 -9999 -9999 -9999 -9999 -9999 -9999 -9999 -9999 -9999 -9999 -9999 -9999 -9999 -9999 -9999 -9999 -9999 -9999 -9999 -9999 -9999 -9999 -9999

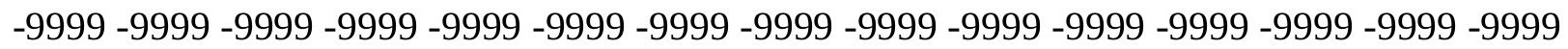
-9999 -9999-9999

-9999 -9999 -9999 -9999 -9999 -9999 -9999 -9999 -9999 -9999 -9999 -9999 -9999 -9999 -9999 -9999 -9999 -9999 -9999 -9999 -9999 -9999 -9999 -9999 -9999 -9999 -9999 -9999 -9999 -9999 -9999 -9999 -9999 -9999 -9999 -9999 -9999 -9999 -9999 -9999 -9999 -9999 -9999 -9999 -9999

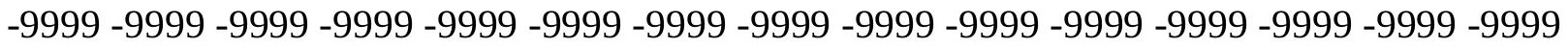

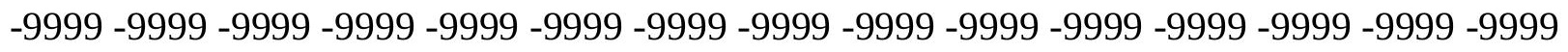
-9999 -9999 -9999-9999-9999 -9999-9999 126.7906036377 111.24659729 102.4077987671 103.9317016602110 .3321990967110 .3321990967107 .5891036987105 .1509017944 103.3221969604101 .7982025146100 .883903503499 .6647262573298 .75038146973 97.83602905273111 .551399231109 .1130981445106 .6747970581103 .9317016602 101.188697814998 .445587158296 .0073165893694 .4833908081193 .87381744385 93.5690307617293 .5690307617293 .2642517089893 .2642517089893 .26425170898 93.2642517089893 .5690307617294 .1785964965894 .7881774902395 .70252990723 96.6168823242297 .5312423706198 .445587158299 .5903778076298 .19203948975 96.866073608495 .6181106567494 .4509277343893 .3664627075292 .36441040039 
91.444473266690 .6045684814589 .8424682617289 .153732299881 .37763214111 75.5867080688578 .0249862670982 .5967712402386 .5966720581186 .21189880371 85.8528747558685 .5129394531285 .185684204184 .8651123046984 .5470199585 84.2294464111383 .9120559692483 .5955810546983 .2818603515682 .97401428223 82.6765365600682 .3950805664182 .1365051269581 .9081497192481 .71809387207 81.5740432739381 .4838943481481 .4543075561581 .4916381835981 .60034942627 81.784461975182 .0458679199282 .3862533569382 .8054122924883 .30339050293 83.8788604736384 .5312118530385 .2588729858486 .0613174438586 .93733215332 87.8868408203188 .9091644287190 .0047607421991 .1734924316492 .4164276123 93.7341232299895 .128494262796 .6011657714898 .1554031372199 .79441833496 101.5232696533103 .3469619751105 .2723007202101 .493400573790 .21640014648 81.6824111938583 .5111236572391 .43553924561103 .0174026489114 .2944030762 119.7806015015121 .9140014648123 .43800354123 .43800354122 .8283996582 121.9140014648121 .9140014648121 .9140014648122 .5235977173122 .8283996582 122.7273483276122 .4698562622122 .2038574219121 .9329681396121 .6605758667 121.3903198242109 .4179000854107 .5891036987104 .5412979126103 .0174026489 103.3221969604104 .2365036011103 .9317016602102 .712600708102 .712600708 103.6268997192105 .1509017944106 .979598999108 .8082962036109 .8492050171 108.7697982788107 .6702270508106 .5494995117105 .4074783325104 .2450332642 103.0652008057101 .8730010986100 .675430297999 .4807662963998 .29804992676 97.1370697021596 .008094787694 .9226913452193 .8930740356492 .93321990967 92.0607223510791 .289337158290 .6463317871190 .1253967285289 .72385406494 89.4428100585989 .2904891967889 .2768707275489 .4081344604589 .67865753174 89.24212646484 88.37538909912 87.50927734375 86.48583984375 85.12287902832 83.2311248779380 .6673355102577 .3192138671973 .2027435302760 .95701980591 44.1938400268632 .3072204589830 .1737308502229 .5641593933128 .95458984375 29.2593708038330 .7833003997829 .5641593933129 .5641593933130 .47850990295 31.6976509094232 .9167900085433 .2215805053733 .2215805053733 .52635955811 33.8311500549334 .4407196044935 .3550796508836 .2694282531737 .48857116699 39.0125007629440 .5364189147942 .3651313781744 .1938400268646 .02254867554 47.5464782714849 .0704002380450 .2895507812551 .5086898803752 .42303848267 53.0326118469253 .9469718933154 .5565414428755 .1661109924356 .08045959473 56.6900291442957 .2995986938557 .909179687558 .5187492370659 .12831115723 59.7378807067960 .3474502563560 .9570198059161 .2618103027361 .56660079956 62.1761703491262 .4809494018662 .7857398986863 .0905189514263 .09051895142 63.3953094482463 .7000885009864 .004882812564 .3096618652364 .91924285889 65.2240066528365 .8335876464866 .4431610107467 .0527267456167 .73860931396 70.71015167236 -9999 -9999 -9999 -9999 -9999 -9999 -9999 -9999 -9999 -9999 -9999 -9999 -9999 -9999 -9999 -9999 -9999 -9999 -9999 -9999 -9999 -9999 -9999 -9999 -9999 -9999 -9999 -9999 -9999 -9999 -9999 -9999 -9999 -9999 -9999 -9999 -9999 -9999 -9999 -9999 -9999 -9999 -

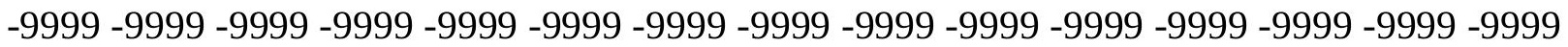

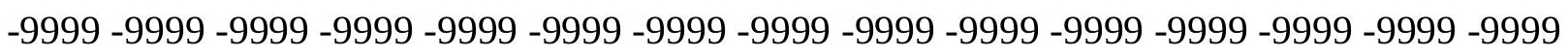
-9999 -9999 -9999-9999-9999-9999 -9999 -9999 -9999 -9999 -9999 -9999 -9999 -9999 -9999 -9999 -9999 -9999 -9999 -9999 -9999 -9999 -9999 -9999 -9999 -9999 -9999 -9999 -9999 -9999 -9999 -9999 -9999 -9999 -9999 -9999 -

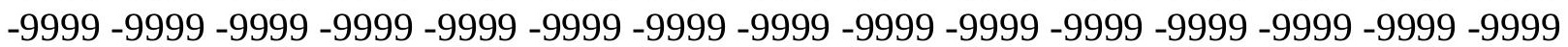


-9999 -9999 -9999 -9999 -9999 -9999 -9999 -9999 -9999 -9999 -9999 -9999 -9999 -9999 -9999

-9999 -9999 -9999 -9999 -9999 -9999 -9999 -9999 -9999 -9999 -9999 -9999 -9999 -9999 -9999

-9999 -9999 -9999 -9999 -9999 -9999 117.9517974854 99.9695205688596.31210327148

97.2264633178799 .96952056885103 .0174026489104 .5412979126103 .9317016602 102.4077987671100 .883903503499 .6647262573298 .7503814697398 .14080810547 96.9216690063596 .00731658936105 .1509017944103 .0174026489100 .5791015625 98.1408081054795 .7025299072392 .9594726562590 .2164001464890 .21640014648 90.2164001464890 .2164001464890 .5211791992290 .5211791992290 .82597351074 90.8259735107490 .8259735107491 .4355392456191 .7403335571392 .3498916626 92.9594726562593 .8738174438594 .7881774902395 .7025299072396 .61688232422 97.5312423706197 .4346389770596 .2149047851695 .0702438354594 .00258636475 93.0116348266692 .0970458984491 .2568511962990 .4889450073289 .78924560547 89.1533737182684 .7302627563579 .2441329956180 .1584930419984 .42548370361 86.7209625244186 .3409118652385 .9828720092885 .6414108276485 .31105804443 84.9879226684684 .6704330444384 .3589248657284 .0544204711983 .75859069824 83.4739227294983 .2041854858482 .9540710449282 .7294616699282 .53660583496 82.3825073242282 .2738189697382 .2174453735482 .2191925048882 .28468322754 82.417831420982 .6222000122182 .8994369506883 .250976562583 .67660522461 84.1762847900484 .7487945556685 .3935241699286 .1090545654386 .89492034912 87.7500762939588 .6745910644589 .6680755615290 .7312774658291 .86457061768 93.0695266723694.3473892211995.700752258397.1319580078198.64488220215 100.2431640625101 .9321289062103 .7166519165103 .322196960494 .48339080811 85.94940185547 81.37763214111 84.4254837036193.56903076172 106.3700027466 118.2565994263122 .8283996582123 .7293395996123 .7741775513123 .7759780884 123.7362213135123 .6576385498123 .5432128906123 .397102356123 .2241210938 123.0300369263119 .4757995605116 .1231002808122 .3717193604122 .1401138306 121.9076309204121 .6777496338121 .4545211792121 .2421951294121 .044921875 110.3321990967109 .7226028442109 .4179000854110 .0273971558110 .0273971558 108.1986999512106 .6747970581106 .979598999108 .1986999512110 .0273971558 110.5187225342109 .4633331299108 .389175415107 .2955780029106 .1827774048 105.0520324707103 .9066009521102 .751449585101 .5930557251100 .4387969971 99.2964782714898 .1743392944397 .0808334350696 .0253753662195 .01808166504 93.9787750244192 .6402740478591 .9360351562591 .76479339691 .21299743652 90.7968826293990 .539482116790 .4672622680790 .5989608764689 .75189971924 88.9576644897588 .279434204187 .6402206420986 .9416046142686 .06256866455 84.8682785034283 .2297134399481 .0487747192478 .2902526855575 .05393218994 71.6817703247161 .5666007995646 .3273391723636 .2694282531733 .22158050537 30.1737308502228 .0402297973626 .5163097381626 .8210906982427 .73545074463 29.2593708038330 .7833003997831 .6976509094232 .0024414062531 .69765090942 31.6976509094232 .0024414062532 .3072204589833 .2215805053734 .13592910767 35.3550796508836 .8790016174338 .7077102661140 .5364189147942 .36513137817 44.4986305236846 .3273391723648 .1560516357449 .3751907348650 .28955078125 51.2038993835452 .1182594299352 .7278289794953 .6421813964854 .25175094604 55.1661109924355 .7756805419956 .6900291442957 .2995986938557 .9091796875 58.8235282897959 .4331016540560 .0426712036160 .6522407531760 .95701980591 61.2618103027361 .8713798522962 .1761703491262 .4809494018662 .78573989868 
63.0905189514263 .3953094482463 .7000885009864 .004882812564 .30966186523 64.9192428588965 .2240066528365 .8335876464866 .4431610107467 .05272674561 67.6811141967868 .3028945922971 .92929077148 -9999 -9999 -9999 -9999 -9999 -9999 -9999 -9999 -9999 -9999 -9999 -9999 -9999 -9999 -9999 -9999 -9999 -9999 -9999 -9999 -9999 -9999 -9999 -9999 -9999 -9999 -9999 -9999 -9999 -9999 -9999 -9999 -9999 -9999-9999 -9999 -9999 -9999 -9999 -9999 -9999 -9999 -9999 -9999 -9999 -9999 -9999 -9999 -9999 -9999 -9999 -9999

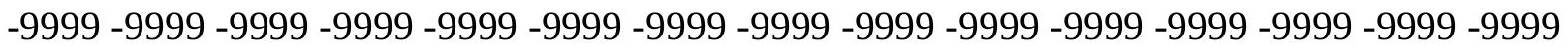
-9999 -9999 -9999 -9999-9999 -9999-9999 -9999 -9999-9999

-9999 -9999 -9999 -9999 -9999 -9999 -9999 -9999 -9999 -9999 -9999 -9999 -9999 -9999 -9999 -9999 -9999 -9999 -9999 -9999 -9999 -9999 -9999 -9999 -9999 -9999 -9999 -9999 -9999 -9999 -

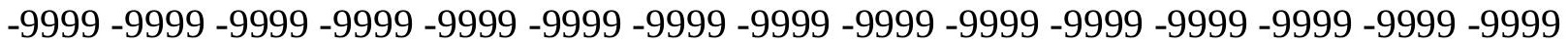
-9999 -9999 -9999 -9999 -9999 -9999 -9999 -9999 -9999 -9999 -9999 -9999 -9999 -9999 -9999 -

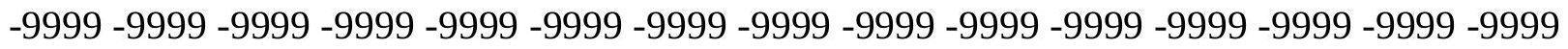
-9999 -9999 -9999 -9999 -9999 125.8762969971 105.4557037354 97.22646331787 94.4833908081194 .7881774902396 .6168823242298 .445587158299 .66472625732 99.9695205688599 .3599472045998 .7503814697398 .1408081054797 .53124237061 96.6168823242296 .00731658936101 .188697814999 .3599472045997 .22646331787 95.0929565429792 .9594726562590 .8259735107488 .6924667358487 .16854858398 86.8637619018686 .8637619018687 .4733276367287 .7781066894588 .08290100098 88.3876876831188 .3876876831188 .6924667358488 .9972534179789 .60682678223 90.2164001464890 .5211791992291 .4355392456192 .349891662692 .95947265625 93.8738174438595 .0929565429796 .0073165893696 .7336349487395 .60893249512 94.5560379028393 .5747680664192 .6648254394591 .8244171142691 .05165863037 90.3428649902389 .69419097989 .1005172729585 .3398437582 .29197692871 81.6824111938585 .3398437586 .7750778198286 .4026565551886 .05015563965 85.7128753662185 .3872528076285 .0716781616284 .7666320800884 .47342681885 84.1937561035283 .9296646118283 .6842803955183 .4615097045983 .26636505127 83.1042022705182 .9810714721782 .9027328491282 .8752593994182 .90372467041 82.993164062583 .147048950283 .3686065673883 .6593093872184 .02051544189 84.4520187377984 .9538497924885 .5249176025486 .164764404386 .87213897705 87.6467208862388 .4876480102589 .3951568603590 .3690414428791 .41031646729 92.5195999145593 .6987915039194 .9494628906296 .2745437622197 .67666625977 99.15990447998100 .7279586792102 .3859786987104 .1385116577103 .3221969604 96.6168823242288 .3876876831184 .1206970214889 .302040100198 .75038146973 109.7226028442119 .1709976196123 .4850921631123 .585647583123 .6446228027 123.6628799438123 .6416015625123 .5834732056123 .4914398193123 .3694839478 123.222366333123 .056060791122 .8760070801120 .9997024536120 .9997024536 121.9140014648122 .0973968506121 .904296875121 .7191772461121 .5467834473 121.392364502120 .783821106114 .9039993286113 .6848983765114 .2944030762 113.6848983765111 .8561019897110 .0273971558109 .7226028442110 .9418029785 112.2311019897111 .2198638916110 .1921005249109 .1471710205108 .0848083496 107.0056991577105 .9115905762104 .8060150146103 .6938781738102 .5811309814 101.4742736816100 .379837036199 .3044586181698 .2545166015694 .90126037598 91.9539947509889 .6755294799888 .13784027187 .3647842407287 .33210754395 87.9113616943488 .967636108489 .8104324340888 .9083023071388 .28207397461 87.7892761230587 .3540267944386 .9265747070386 .4566421508885 .88258361816 
85.1296386718884 .1167449951282 .7716140747181 .0531768798878 .98881530762 76.7149734497174 .5237350463972 .5761184692465 .2240066528353 .94697189331 48.4608306884843 .2794914245636 .2694282531728 .3450202941927 .4306602478 28.0402297973628 .9545898437530 .1737308502230 .4785099029530 .78330039978 30.4785099029530 .1737308502230 .1737308502230 .4785099029531 .08807945251 32.0024414062533 .2215805053734 .7455101013236 .5742111206138 .40293121338 40.8412094116242 .9747009277345 .1082000732446 .9369087219248 .15605163574 49.0704002380449 .9847602844250 .8991203308151 .5086898803752 .42303848267 53.3373985290553 .9469718933154 .8613204956155 .7756805419956 .38525009155 57.2995986938558 .2139587402358 .8235282897959 .4331016540560 .04267120361 60.6522407531760 .9570198059161 .5666007995661 .8713798522962 .17617034912 62.4809494018663 .0905189514263 .3953094482463 .7000885009864 .0048828125 64.3096618652364 .9192428588965 .5288009643665 .8335876464866 .44316101074 67.0527267456167 .6440582275468 .2182922363370 .7101516723672 .84364318848 -9999 -9999 -9999 -9999 -9999 -9999 -9999 -9999 -9999 -9999 -9999 -9999 -9999 -9999 -9999 -9999

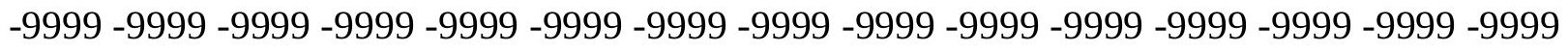
-9999 -9999 -9999 -9999 -9999 -9999 -9999 -9999 -9999 -9999 -9999 -9999 -9999 -9999 -9999 -9999 -9999 -9999 -9999 -9999 -9999 -9999 -9999 -9999 -9999 -9999 -9999 -9999 -9999 -9999 -9999 -9999 -9999 -9999 -9999 -9999 -9999 -9999 -9999 -9999 -9999 -9999 -9999 -9999 -9999 -

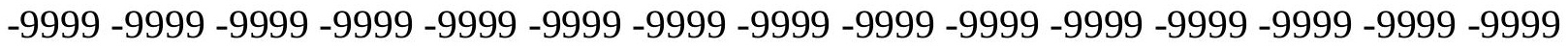

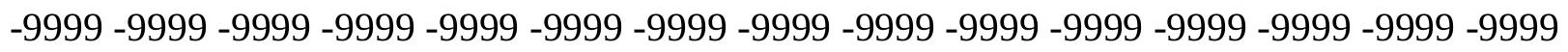
-9999 -9999 -9999 -9999 -9999 -9999 -9999 -9999 -9999 -9999 -9999 -9999 -9999 -9999 -9999 -9999 -9999 -9999 -9999 -9999 -9999 -9999 -9999 -9999 -9999 -9999 -9999 -9999 -9999 -9999 -

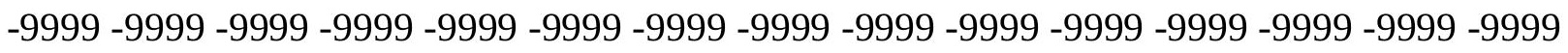
-9999 -9999-9999-9999 138.9819946289 121.3044967651 102.1029968262 93.87381744385 93.5690307617293 .8738174438594 .4833908081195 .397743225196 .31210327148 96.6168823242296 .9216690063596 .9216690063596 .9216690063596 .61688232422 96.0073165893695 .397743225196 .0073165893694 .1785964965892 .04509735107 89.9116134643688 .3876876831186 .8637619018685 .3398437584 .42548370361 84.1206970214884 .4254837036185 .0350494384885 .3398437585 .94940185547 86.254188537686 .5589828491286 .8637619018687 .1685485839887 .47332763672 88.0829010009888 .3876876831188 .9972534179789 .9116134643690 .52117919922 91.1307525634892 .349891662693 .8738174438595 .0929565429796 .00731658936 95.0369567871194 .0641403198293 .1581878662192 .3176116943491 .54077911377 90.824363708590 .1649932861389 .558235168468986 .5589828491284 .12069702148 82.29197692871 85.33984375 86.77458190918 86.4133605957 86.0710067749 85.7444763183685 .432060241785 .1339797973684 .8514633178784 .58631896973 84.3403549194384 .1162261962983 .9171600341883 .7474517822383 .61164093018 83.5149993896583 .4624938964883 .4594802856483 .5104293823283 .61986541748 83.7909011840884 .02651214684 .3280639648484 .6968688964885 .13280487061 85.6360321044986 .2056503295986 .8414001464887 .542266845788 .30809783936 89.1382446289190 .0330734252990 .9925765991292 .0178756713993 .10975646973 94.270233154395 .5010147094796 .8050842285298 .1850814819399 .64498138428 101.1882705688102 .8197174072104 .5433044434106 .0652008057101 .7982025146 94.7881774902391 .1307525634896 .92166900635105 .7603988647113 .075302124 119.1709976196123 .3174057007123 .4276275635123 .4982757568123 .5300598145 
123.523979187123 .4826812744123 .4092941284123 .3078079224123 .1828384399 123.0403213501122 .8858566284122 .7238540649122 .5576629639122 .3904876709 122.2255401611122 .0661849976121 .9164810181121 .7814483643121 .6674041748 121.2530441284120 .3579406738118 .5614013672117 .0374984741116 .4279022217 114.9039993286113 .6848983765113 .075302124113 .8976593018112 .9301757812 111.9482879639110 .9512329102109 .9387969971108 .9111328125107 .8694076538 106.8159332275105 .7546081543104 .6903533936103 .628692627102 .5753326416 101.53573608499 .9390106201295 .5391311645591 .5050506591888 .04376983643 85.3523101806683 .5624084472782 .7034988403382 .7175369262783 .42630767822 84.6403198242285 .8087081909285 .7290573120185 .7360000610485 .70273590088 85.5799789428785 .3457183837984 .9849777221784 .4819107055783 .81910705566 82.9753646850681 .9325714111380 .6958465576279 .3212661743277 .92684936523 76.6888656616275 .7503814697375 .1402664184672 .0531311035267 .96708679199 60.0426712036146 .9369087219234 .1359291076730 .4785099029528 .95458984375 29.5641593933130 .1737308502230 .4785099029530 .1737308502229 .56415939331 28.9545898437528 .6497993469228 .6497993469229 .2593708038330 .17373085022 31.3928699493432 .9167900085434 .7455101013236 .5742111206138 .70771026611 41.1459884643643 .5842704772945 .717769622846 .6321296691947 .54647827148 48.4608306884849 .3751907348650 .2895507812551 .2038993835452 .11825942993 53.0326118469253 .9469718933154 .8613204956155 .7756805419956 .38525009155 57.2995986938558 .2139587402358 .8235282897959 .4331016540560 .04267120361 60.6522407531760 .9570198059161 .5666007995661 .8713798522962 .48094940186 62.7857398986863 .0905189514263 .7000885009864 .004882812564 .30966186523 64.9192428588965 .5288009643665 .8335876464866 .4431610107467 .05272674561 $67.6022109985468 .1287078857468 .6512451171971 .6244964599673 .45321655273-9999$ -9999 -9999 -9999 -9999 -9999 -9999 -9999 -9999 -9999 -9999 -9999 -9999 -9999 -9999 -9999 -9999 -9999 -9999 -9999 -9999 -9999 -9999 -9999 -9999 -9999 -9999 -9999 -9999 -9999 -9999

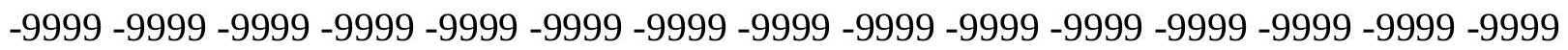
-9999 -9999 -9999 -9999 -9999 -9999 -9999 -9999 -9999 -9999 -9999 -9999 -9999 -9999 -9999 -9999 -9999 -9999 -9999 -9999 -9999 -9999 -9999 -9999 -9999 -9999 -9999 -9999 -9999 -9999 -9999 -9999 -9999 -9999 -9999 -9999 -9999 -9999-9999 -9999 -9999 -9999 -9999 -9999 -9999 -9999 -9999 -9999 -9999 -9999 -9999 -9999 -9999 -9999 -9999 -9999 -9999 -9999 -9999 -

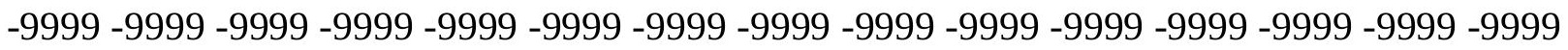
-9999 -9999 -9999 -9999 -9999 -9999 -9999 -9999 -9999 -9999 -9999 -9999 -9999 -9999 -9999 -9999 -9999 -9999 -9999 -9999 -9999 -9999 -9999 -9999 -9999 -9999 -9999 -9999 -9999 -9999 -9999 -9999-9999 144.1634063721 132.8863067627118 .8662033081102 .4077987671 95.397743225194 .1785964965893 .5690307617293 .5690307617293 .87381744385 94.4833908081195 .0929565429795 .7025299072396 .3121032714896 .61688232422 96.6168823242296 .0073165893695 .397743225190 .8259735107489 .3020401001 87.7781066894585 .9494018554784 .7302627563583 .5111236572382 .59677124023 82.2919769287182 .2919769287182 .5967712402382 .9015579223683 .51112365723 84.1206970214884 .4254837036184 .7302627563585 .0350494384885 .33984375 85.6446228027385 .9494018554786 .5589828491286 .8637619018687 .47332763672 88.0829010009888 .9972534179790 .2164001464892 .0450973510792 .65467834473 93.5690307617294 .7881774902394 .4889373779393 .5866165161192 .74600982666 91.9658432006891 .2430801391690 .5747299194389 .9569854736389 .38648986816 
88.8590774536187 .7781066894585 .6446228027382 .9015579223684 .42548370361 86.5589828491286 .3886337280386 .0620346069385 .7532348632885 .46216583252 85.1897201538184 .9376220703184 .7075653076284 .5018463134884 .32317352295 84.175216674884 .0618209838983 .9875488281283 .9567031860483 .97402191162 84.0434646606484 .1691360473684 .3538513183684 .6003494262784 .90991973877 85.2838516235485 .7221374511786 .2251052856486 .7920761108487 .42302703857 88.117187588 .8746337890689 .6948852539190 .5784683227591 .52550506592 92.5371780395593 .6143493652394 .7590255737395 .9728851318497 .25879669189 98.61922454834100 .0578384399101 .5777511597103 .1831970215104 .8775405884 106.6650619507106 .0652008057102 .712600708101 .7982025146107 .2844009399 113.6848983765117 .647102356120 .6949005127123 .1291503906123 .2472839355 123.3268966675123 .3688659668123 .3743972778123 .3462295532123 .2877349854 123.2031707764123 .097114563122 .9752197266122 .8430099487122 .7050170898 122.5645980835122 .424911499122 .2892456055122 .160987854122 .0441360474 121.9438247681121 .8671875121 .7197341919120 .8491897583119 .9759292603 119.09815979118 .2142105103117 .3224182129116 .4213790894115 .5096817017 114.586151123113 .6497268677112 .6997909546111 .7360229492110 .7587127686 109.7685241699108 .7670974731107 .7572631836106 .743347168105 .7304458618 104.723815918103 .7286758423102 .749687194898 .1819915771593 .18556213379 88.46851348877 84.3348999023481.09934234619 78.97691345215 78.01837158203 78.1120910644578 .9692687988380 .3162841796981 .8942413330182 .63591003418 83.2297515869183 .602119445883 .7454757690483 .6535720825283 .34178924561 82.8438720703182 .2145996093881 .4973373413180 .7249832153379 .92892456055 79.1593704223678 .5180358886778 .1056594848678 .0212249755978 .34533691406 79.295478820881 .6809997558681 .3776321411160 .6522407531737 .18378067017 25.2971591949529 .2593708038331 .6976509094232 .3072204589831 .69765090942 30.4785099029528 .9545898437528 .0402297973627 .1258792877227 .12587928772 27.7354507446328 .3450202941929 .5641593933131 .0880794525132 .91679000854 34.7455101013236 .8790016174339 .3172798156741 .4507789611843 .27949142456 44.8034095764245 .717769622846 .6321296691947 .5464782714848 .46083068848 49.6799812316950 .5943298339851 .5086898803752 .7278289794953 .64218139648 54.5565414428755 .7756805419956 .6900291442957 .2995986938558 .21395874023 58.8235282897959 .4331016540560 .0426712036160 .6522407531761 .26181030273 61.5666007995662 .1761703491262 .4809494018663 .0905189514263 .39530944824 63.7000885009864 .3096618652364 .9192428588965 .2240066528365 .83358764648 66.4431610107467 .0527267456167 .5197372436567 .9985809326268 .49203491211 70.4053573608472 .23407745361 -9999 -9999 -9999 -9999 -9999 -9999 -9999 -9999 -9999

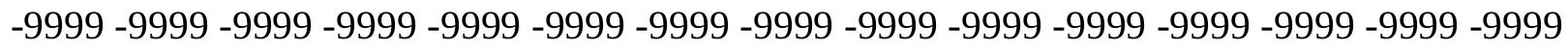
-9999 -9999 -9999 -9999 -9999 -9999 -9999 -9999 -9999 -9999 -9999 -9999 -9999 - 9999 - -999 -9999 -9999 -9999 -9999 -9999 -9999 -9999 -9999 -9999 -9999 -9999 -9999 -9999 -9999 -9999 -

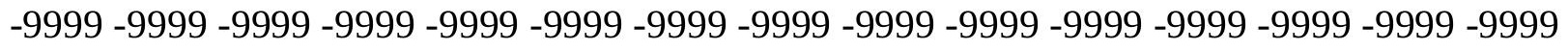
-9999-9999-9999-9999-9999-9999

-9999 -9999 -9999 -9999 -9999-9999 -9999 -9999 -9999 -9999 -9999 -9999 -9999 -9999 -9999 -9999 -9999 -9999 -9999 -9999 -9999 -9999 -9999 -9999-9999 -9999 -9999 -9999 -9999 -9999 -9999 -9999 -9999 -9999 -9999 -9999 -9999 -9999 -9999 -9999 -9999 -9999 -9999 -9999 -9999 -

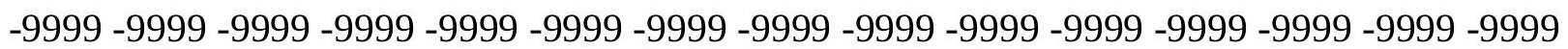


-9999 -9999 -9999 -9999 -9999 -9999 -9999 -9999 -9999 -9999 -9999 -9999 -9999 -9999 -9999 -9999 -9999 148.7351074219142.3347015381 131.6672058105120.6949005127 112.1608963013105 .150901794498 .7503814697395 .0929565429794 .17859649658 94.1785964965893 .8738174438594 .4833908081195 .397743225196 .61688232422 97.2264633178797 .2264633178796 .9216690063587 .4733276367285 .94940185547 84.7302627563583 .5111236572382 .2919769287181 .3776321411180 .76805877686 80.4632720947380 .4632720947380 .4632720947380 .7680587768681 .37763214111 81.9871978759882 .2919769287182 .9015579223683 .206336975183 .51112365723 83.81591033936 84.12069702148 84.12069702148 84.42548370361 84.73026275635 85.3398437585 .6446228027386 .5589828491287 .7781066894588 .99725341797 89.9116134643690.8259735107492.0450973510793.5690307617293.95983123779 93.1196517944392 .3368682861391 .6088867187590 .9330520629990 .3060836792 89.7252502441489 .1870346069388 .6881484985488 .2248535156286 .86376190186 83.8159103393682 .9015579223684 .7302627563586 .254188537686 .04026794434 85.7557373046985 .4925079345785 .2520523071385 .0358886718884 .84609222412 84.6848907470784 .5554122924884 .4608840942484 .4052581787184 .39222717285 84.4260253906284 .5102233886784 .6485671997184 .8436355590885 .0979385376 85.4126434326285 .7890167236386 .2271881103586 .7276306152387 .28993988037 87.9143295288188 .6002883911189 .3480834960990 .1574401855591 .02899932861 91.9629821777392.9606323242294.0227966308695.1514129638796.34801483154 97.6152496337998 .95528411865100 .3713989258101 .8662338257103 .4434204102 105.1056747437106 .8564682007108 .6979522705110 .3321990967112 .1608963013 114.7851409912117 .0020294189119 .3101272583121 .7045669556122 .9175796509 123.0420074463123 .1281585693123 .1771240234123 .1906509399123 .1718521118 123.1244506836123 .0530853271122 .9624862671122 .8580322266122 .7449951172 122.6279830933122 .5105514526122 .3957672119122 .286819458122 .1870498657 122.1005172729122 .0324630737121 .9902877808121 .9825592041121 .3374099731 120.4919586182119 .6430664062118 .7889862061117 .927986145117 .0585403442 116.1791381836115 .288520813114 .385559082113 .4698181152112 .5413894653 111.6011657715110 .6504135132109 .6912384033108 .7268981934107 .7620697021 106.8021621704105 .8524475098104 .9179916382102 .694946289197 .2052154541 91.5615844726686 .010879516680 .9770736694376 .9947738647574 .44081115723 73.4095001220769 .1862335205172 .5388565063576 .1672286987377 .79348754883 79.4975585937580 .7552871704181 .4628067016681 .8458938598681 .87637329102 81.5588531494180 .9980697631880 .3349914550879 .6829071044979 .12461853027 78.703964233478 .4495773315478 .4040069580178 .6029129028379 .11029052734 80.0136566162181 .3741531372182 .7958450317481 .8855819702171 .92929077148 50.8991203308139 .9268493652336 .8790016174336 .8790016174336 .26942825317 34.4407196044932 .0024414062529 .5641593933127 .7354507446326 .51630973816 26.2115192413326 .5163097381627 .430660247828 .3450202941929 .86894035339 31.3928699493433 .2215805053735 .0502891540537 .1837806701739 .31727981567 40.8412094116242 .3651313781743 .5842704772944 .8034095764245 .7177696228 46.9369087219248 .1560516357449 .0704002380450 .2895507812551 .50868988037 52.7278289794953 .6421813964854 .8613204956155 .7756805419956 .69002914429 57.2995986938558 .2139587402358 .8235282897959 .4331016540560 .04267120361 60.6522407531761 .2618103027361 .8713798522962 .1761703491262 .78573989868 
63.0905189514263 .7000885009864 .004882812564 .6144485473665 .22400665283 65.8335876464866 .4431610107466 .7479400634867 .3575134277367 .82223510742 68.3018035888768 .7814178466871 .014930725172 .53885650635 -9999 -9999 -9999 -9999 -9999 -9999 -9999 -9999 -9999 -9999 -9999 -9999 -9999 -9999 -9999 -9999 -9999 -9999 -9999 -9999 -9999 -9999 -9999 -9999 -9999 -9999 -9999 -9999-9999 -9999 -9999 -9999 -9999 -9999 -9999 -9999 -9999 -9999 -9999 -9999 -9999 -9999 -9999 -9999 -9999 -9999 -9999 -9999 -9999

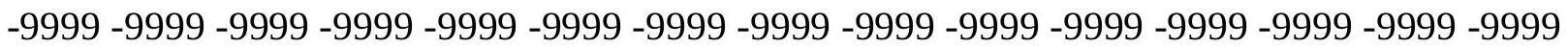
-9999 -9999 -9999 -9999-9999 -9999-9999 -9999 -9999-9999

-9999 -9999 -9999 -9999 -9999 -9999 -9999 -9999 -9999 -9999 -9999 -9999 -9999 -9999 -9999 -9999 -9999 -9999 -9999 -9999 -9999 -9999 -9999 -9999 -9999 -9999 -9999 -9999 -9999 -9999 -9999 -9999 -9999 -9999 -9999 -9999 -9999 -9999 -9999 -9999 -9999 -9999 -9999 -9999 -9999 -9999 -9999 -9999 -9999 -9999 -9999 -9999 -9999 -9999 -9999 -9999 -9999 -9999 -9999 -9999 -9999 -9999 -9999 -9999 -9999 -9999 -9999 -9999 -9999 -9999 -9999 -9999 -9999 -9999 -9999 -9999 152.7181396484151.3635559082146.9064025879 137.4580993652128.6192932129 123.1332015991118 .5614013672113 .6848983765108 .5035018921103 .9317016602 100.274299621696 .9216690063595 .7025299072396 .9216690063598 .14080810547 98.445587158298 .445587158298 .1408081054781 .9871978759881 .07285308838 80.4632720947379 .8537063598679 .2441329956178 .6345596313578 .63455963135 78.6345596313578 .6345596313579 .2441329956179 .5489196777380 .15849304199 80.7680587768681 .0728530883881 .6824111938581 .9871978759881 .98719787598 82.2919769287182 .5967712402382 .5967712402382 .5967712402382 .90155792236 83.206336975183.51112365723 84.12069702148 85.03504943848 85.94940185547 86.8637619018688 .0829010009889 .302040100190 .5211791992291 .74033355713 92.9594726562592 .662384033291 .9303512573291 .2485351562590 .61408996582 90.0247573852589 .4775695800888 .9697799682688 .498184204188 .06034851074 87.4733276367283 .8159103393680 .7680587768681 .6824111938582 .90155792236 85.0350494384885 .7655029296985 .5352478027385 .3311767578185 .15509796143 85.0088119506884 .8949203491284 .8160934448284 .7757110595784 .77696228027 84.8236694335984 .9190979003985 .0667495727585 .2689819335985 .52806091309 85.845008850186 .2210235595786 .6563415527387 .151641845787 .70677185059 88.32216644287 88.99754333496 89.7333450317490.5294647216891.38665771484 92.305252075293 .2865066528394 .3312301635795 .4412460327196 .6178817749 97.8635025024499 .17992401123100 .5699768066102 .0358047485103 .5804367065 105.2059402466106 .9150543213108 .7091827393110 .5901184082112 .5578994751 114.6125717163116 .7520217896118 .9737091064121 .2725830078122 .5235977173 122.8131790161122 .9035949707122 .9565734863122 .9744644165122 .9610595703 122.9206314087122 .858291626122 .7790527344122 .6881408691122 .5905990601 122.4910507202122 .3932266235122 .3001251221122 .2147216797122 .1403045654 122.0810546875122 .0422744751122 .031211853122 .0562210083121 .8196487427 121.0041122437120 .1862945557119 .3643493652118 .5364532471117 .7009429932 116.8561782837116 .0007705688115 .1335067749114 .2539672852113 .3625793457 112.4608383179111 .5506668091110 .6346511841109 .7163696289108 .8007354736 107.8934173584106 .9999923706106 .1258468628103 .085800170997 .26425933838 90.9884796142684 .4584350585978 .1916503906273 .0935745239369 .97109222412 68.9053192138768 .2718734741269 .7957916259872 .3514633178773 .85911560059 75.3095016479576 .8033828735478 .3751068115279 .7174606323279 .91172027588 
79.5434875488378 .8815689086978 .1265182495177 .4878311157277 .09394836426 76.9870071411177 .1540603637777 .5564346313578 .1610107421978 .9372177124 79.8009948730580 .4839248657280 .2181777954177 .4259796142671 .74674987793 60.9570198059153 .6421813964848 .765621185345 .4129791259842 .36513137817 39.0125007629435 .0502891540531 .0880794525128 .0402297973626 .21151924133 25.6019496917726 .2115192413326 .8210906982428 .0402297973628 .95458984375 30.1737308502231 .6976509094233 .5263595581135 .3550796508837 .18378067017 38.7077102661140 .2316398620641 .4507789611842 .66992187543 .88906097412 45.1082000732446 .3273391723647 .5464782714848 .765621185350 .28955078125 51.5086898803752 .7278289794953 .6421813964854 .8613204956155 .77568054199 56.6900291442957 .6043891906758 .2139587402358 .8235282897959 .43310165405 60.0426712036160 .6522407531761 .2618103027361 .8713798522962 .48094940186 62.7857398986863 .3953094482464 .004882812564 .3096618652364 .91924285889 65.5288009643666 .1383666992266 .7479400634867 .0527267456167 .5802154541 68.0945587158268 .5602493286169 .7957916259871 .3197174072372 .20886230469 -9999 -9999 -9999 -9999 -9999 -9999 -9999 -9999 -9999 -9999 -9999 -9999 -9999 -9999 -9999 -9999 -9999 -9999 -9999 -9999 -9999 -9999 -9999 -9999 -9999 -9999 -9999 -9999 -9999 -9999 -9999 -9999 -9999 -9999 -9999 -9999 -9999 -9999 -9999 -9999 -9999 -9999 -9999 -9999 -9999 -9999 -9999 -9999 -9999 -9999 -9999 -9999 -9999 -9999 -9999 -9999 -9999 -9999 -9999 -9999 -9999 -9999 -9999 -9999 -9999 -9999 -9999 -9999 -9999 -9999 -9999 -9999 -9999 -

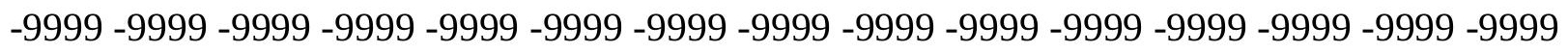
-9999 -9999 -9999 -9999 -9999 -9999 -9999 -9999 -9999 -9999 -9999 -9999 -9999 -9999 -9999 -9999 -9999 -9999 -9999 -9999 -9999 -9999 -9999 -9999 -9999 -9999 -9999 -9999 -9999 -9999 -

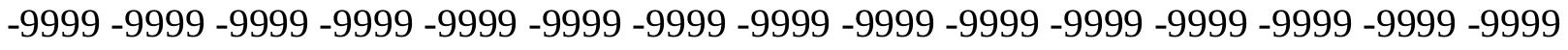

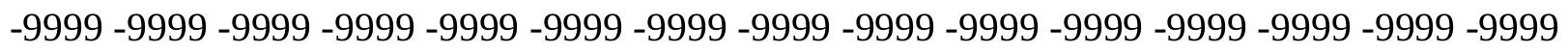
-9999 153.3303070068 151.9518127441 150.6125335693145.3825073242 137.1533050537 132.5814971924128 .9241027832124 .9618988037120 .6949005127116 .1231002808 111.551399231108 .1986999512105 .1509017944101 .4934005737100 .5791015625 100.579101562599 .9695205688599 .3599472045977 .110626220776 .80584716797 76.5010681152376 .5010681152376 .1962814331176 .5010681152376 .50106811523 76.8058471679777 .4154205322378 .0249862670978 .6345596313579 .24413299561 79.5489196777380 .1584930419980 .4632720947380 .7680587768680 .76805877686 81.0728530883881 .0728530883881 .0728530883881 .0728530883881 .07285308838 81.3776321411181 .6824111938581 .9871978759882 .2919769287182 .90155792236 83.8159103393685 .0350494384886 .5589828491287 .7781066894589 .3020401001 90.5211791992291 .4355392456192 .0450973510791 .5290908813590 .88914489746 90.2933654785289 .7392120361389 .2244415283288 .7463378906288 .3028717041 87.8919982910287 .5120773315484 .4254837036178 .9393463134878 .93934631348 81.3776321411184 .1206970214885 .7943878173885 .6008224487385 .43659973145 85.3030624389685 .2022705078185 .1363677978585 .10825347985 .1206741333 85.1771011352585 .2805938720785 .4344406127985 .6408157348685 .90174865723 86.2180633544986 .5908660888787 .0205307006887 .5079345703188 .05317687988 88.6568679809689 .3188629150490 .0397415161190 .8195266723691 .65911865234 92.5589218139693 .520225524994 .54380035495 .6313095092896 .78385162354 98.0034637451299 .29160308838100 .6506500244102 .0822601318103 .5888900757 105.1720123291106 .8337097168108 .574760437110 .3962554932112 .2976608276 
114.278427124116 .3360595703118 .467666626120 .6681594849121 .9140014648 121.9140014648121 .3044967651120 .9997024536119 .7806015015119 .7806015015 122.2188034058122 .6207046509122 .5478897095122 .465675354122 .3789291382 122.2922744751122 .209602356122 .1339035034122 .0679397583122 .0148696899 121.9788513184121 .9650650024121 .9803314209122 .0322570801122 .1290740967 121.5091934204120 .7244873047119 .9367828369119 .1441421509118 .3447341919 117.5367660522116 .7186584473115 .8890609741115 .0475158691114 .1946334839 113.3323745728112 .4632492065111 .5902709961110 .7172241211109 .8490905762 108.9917602539108 .1511764526107 .3335113525104 .541061401498 .60747528076 91.8549346923884 .30356597976 .3973617553769 .4365310668965 .47760772705 64.5527267456165 .8312149047967 .3575134277368 .9969863891670 .19425964355 71.2192687988372 .3162765502973 .553291320874 .9330062866276 .32080841064 77.0685424804776 .3435134887775 .4779129028374 .8497085571374 .61031341553 74.7836074829175 .3041839599676 .0537261962976 .8987045288177 .7074508667 78.2812576293978 .268974304277 .0373001098674 .0299148559669 .65355682373 66.012977600165 .6659088134860 .0426712036154 .8613204956150 .28955078125 45.4129791259839 .9268493652334 .1359291076729 .2593708038326 .51630973816 25.6019496917726 .5163097381627 .430660247828 .0402297973628 .64979934692 29.5641593933130 .7833003997832 .0024414062533 .5263595581135 .05028915405 36.5742111206137 .7933502197339 .3172798156740 .5364189147941 .75556182861 42.9747009277344 .4986305236846 .0225486755447 .5464782714848 .7656211853 50.2895507812551 .5086898803752 .7278289794953 .9469718933154 .86132049561 55.7756805419956 .6900291442957 .6043891906758 .2139587402358 .82352828979 59.7378807067960 .3474502563560 .9570198059161 .2618103027361 .87137985229 62.4809494018663 .0905189514263 .7000885009864 .3096618652364 .61444854736 65.2240066528365 .8335876464866 .4431610107466 .7479400634867 .35751342773 67.8929061889668 .2718734741268 .7007064819370 .1005783081171 .19272613525 71.88653564453 -9999 -9999 -9999 -9999 -9999 -9999 -9999 -9999 -9999 -9999 -9999 -9999 -9999 -9999 -9999 -9999 -9999 -9999 -9999 -9999 -9999 -9999 -9999 -9999 -9999 -9999 -9999 -9999 -9999 -9999 -9999 -9999 -9999 -9999 -9999 -9999 -9999 -9999 -9999 -9999 -9999 -9999 -9999 -9999 -9999 -9999 -9999 -9999 -9999 -9999 -9999 -9999 -9999 -9999 -9999 -9999 -9999 -9999 -9999 -9999 -9999 -9999 -9999 -9999 -9999 -9999 -9999 -9999 -9999 -9999 -9999 -9999 -

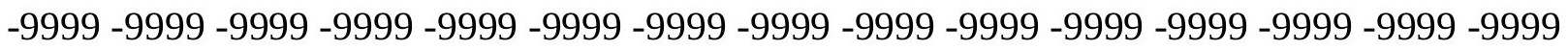
-9999 -9999 -9999 -9999 -9999 -9999 -9999 -9999 -9999 -9999 -9999 -9999 -9999 -9999 -9999 -9999 -9999 -9999 -9999 -9999 -9999 -9999 -9999 -9999 -9999 -9999 -9999 -9999 -9999 -9999 -

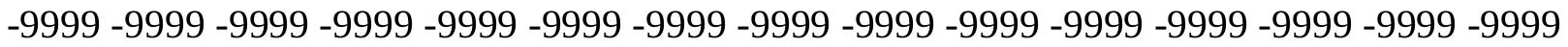

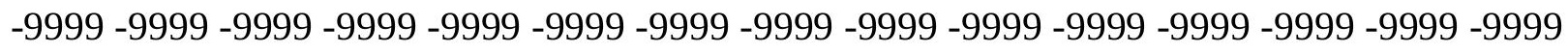
155.2426300049153 .8086395264152 .4108886719151 .0488739014149 .3446960449 141.7250976562137 .1533050537133 .1911010742129 .8385009766126 .4858016968 122.8283996582119 .4757995605117 .647102356115 .2088012695109 .7226028442 103.6268997192102 .4077987671103 .0174026489100 .883903503472 .53885650635 73.1484298706173 .1484298706173 .4532165527373 .7580032348674 .36756896973 74.9771423339875 .5867080688576 .1962814331176 .8058471679777 .72020721436 78.3297805786178 .9393463134879 .2441329956179 .5489196777379 .85370635986 79.8537063598679 .8537063598679 .8537063598679 .5489196777379 .54891967773 79.5489196777379 .5489196777379 .5489196777379 .8537063598680 .15849304199 
80.4632720947381 .0728530883882 .5967712402384 .1206970214885 .64462280273 87.1685485839888 .3876876831189 .6068267822390 .5211791992291 .43553924561 91.1373291015690 .537391662689 .9785461425889 .4589385986388 .9762802124 88.5288467407288 .1147918701287 .7327194213987 .3807296752985 .03504943848 82.2919769287181 .6824111938582 .5967712402383 .8159103393685 .85263061523 85.6986465454185 .5759811401485 .4861297607485 .4307556152385 .41236877441 85.4333724975685 .4968948364385 .6057205200285 .7629241943485 .97051239014 86.230331420986.54305267334 86.9097442627 87.330909729 87.80764770508 88.3402786254988 .9294815063589 .5751571655390 .2779235839891 .03792572021 91.8561935424892 .7332687377993 .6704635620194 .6685028076295 .72888183594 96.8524475097798 .0409011840899 .29534912109100 .617729187102 .0092773438 103.4719161987105 .0066223145106 .6148910522108 .2969894409110 .0534515381 111.8833007812113 .7855377197115 .7574081421117 .7958450317119 .8957901001 122.051574707120 .9997024536117 .9517974854114 .5991973877111 .24659729 110.9418029785116 .7326965332122 .2188034058122 .2678604126122 .1882858276 122.1064987183122 .0270614624121 .9539871216121 .890335083121 .8387756348 121.802154541121 .784324646121 .7899856567121 .8252410889121 .8968963623 122.0127716064122 .0037841797121 .2540817261120 .5025863647119 .747215271 118.9859542847118 .2168045044117 .4379348755116 .6478042603115 .8458480835 115.0327682495114 .2107543945113 .3826599121112 .5517501831111 .7218551636 110.8978805542110 .0857086182109 .2917404175108 .5230712891107 .0708084106 101.363296508894 .5042877197386 .1977615356476 .45815277166 .43021392822 60.3474502563560 .6522407531763 .0905189514264 .6144485473666 .13836669922 66.6830749511767 .2159347534267 .7945861816468 .6546401977569 .81207275391 71.1077651977572 .2077941894572 .757537841872 .2908096313571 .0785369873 69.4122772216869 .0413360595771 .0123443603574 .0746841430775 .08743286133 75.8650131225676 .2027893066475 .8316268920974 .4894485473672 .1838684082 69.5098114013767 .7926330566467 .5283355712968 .1888351440463 .39530944824 58.8235282897953 .0326118469246 .0225486755438 .0981407165530 .78330039978 26.5163097381625 .906740188627 .7354507446328 .3450202941928 .34502029419 28.6497993469229 .2593708038330 .1737308502231 .0880794525132 .30722045898 33.5263595581134 .7455101013235 .9646492004437 .1837806701738 .40293121338 39.622070312541 .1459884643642 .66992187544 .1938400268645 .7177696228 47.5464782714849 .0704002380450 .5943298339851 .8134689331153 .03261184692 53.9469718933154 .8613204956155 .7756805419956 .6900291442957 .60438919067 58.2139587402358 .8235282897959 .7378807067960 .3474502563560 .95701980591 61.5666007995662 .1761703491262 .7857398986863 .3953094482463 .70008850098 64.3096618652364 .9192428588965 .5288009643666 .1383666992266 .44316101074 67.0527267456167 .6623001098667 .9670867919968 .3452072143668 .88143920898 70.4053573608471 .0016403198271 .44934844971 -9999 -9999 -9999 -9999 -9999 -9999 -9999 -9999 -9999-9999 -9999 -9999 -9999 -9999 -9999 -9999-9999 -9999-9999 -9999 -9999 -9999 -

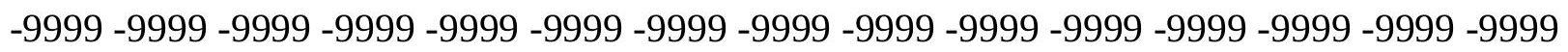
-9999 -9999 -9999 -9999 -9999 -9999 -9999 -9999 -9999 -9999 -9999 -9999 -9999 -9999 -9999

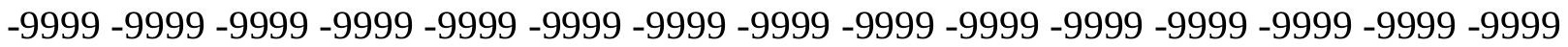
-9999 -9999 -9999-9999

-9999 -9999 -9999 -9999 -9999 -9999 -9999 -9999 -9999 -9999 -9999 -9999 -9999 -9999 -9999 
-9999 -9999 -9999 -9999 -9999 -9999 -9999 -9999 -9999 -9999 -9999 -9999 -9999 -9999 -9999 -9999 -9999 -9999 -9999 -9999 -9999 -9999 -9999 -9999 -9999 -9999 -9999 -9999 -9999 -9999 -9999 -9999 -9999 -9999 -9999 -9999 -9999 -9999 -9999 -9999 -9999 -9999 -9999 -9999 -9999 -9999 -9999 -9999 -9999 -9999 -9999 -9999 -9999 -9999 -9999 -9999 -9999 -9999 -9999 173.4226989746168 .241394043154 .1656341553152 .7525787354151 .3720550537 149.6495056152142 .9441986084137 .4580993652133 .4958953857130 .1432037354 127.7050018311124 .9618988037122 .8283996582122 .5235977173120 .6949005127 113.075302124105 .7603988647102 .712600708102 .4077987671102 .1029968262 68.8814392089869 .7957916259870 .4053573608471 .014930725171 .62449645996 72.5388565063573 .4532165527374 .3675689697375 .2819290161176 .19628143311 76.8058471679777 .7202072143678 .3297805786178 .6345596313578 .93934631348 78.9393463134878 .9393463134878 .9393463134878 .6345596313578 .32978057861 78.3297805786178 .0249862670978 .0249862670978 .0249862670978 .02498626709 78.3297805786178 .6345596313579 .2441329956180 .4632720947381 .98719787598 83.5111236572385 .0350494384886 .5589828491287 .7781066894589 .3020401001 90.5211791992291 .3628234863390 .7609939575290 .1996917724689 .67743682861 89.19223785488 .7426376342888 .3269348144587 .9439086914187 .59199523926 87.2700805664186 .254188537685 .0350494384885 .0350494384885 .33984375 86.0946273803785 .9494628906285 .8360214233485 .755302429285 .70848846436 85.697822570885 .7254943847785 .794227600185 .9063262939586 .06447601318 86.2704772949286 .5261383056686 .8322372436587 .1899108886787 .59983062744 88.0632781982488 .5807113647589 .1527786254989 .7792892456190 .4607925415 91.197547912691 .9907455444392 .8410873413193 .7499313354594 .71796417236 95.7464752197396 .836074829197 .988143920999 .20343780518100 .4835281372 101.8292312622103 .2420349121104 .7224807739106 .2716140747107 .8892822266 109.5755844116111 .3292312622113 .1489028931115 .0317153931116 .9745178223 118.9724349976121 .0200653076120 .3900985718115 .2088012695108 .8082962036 102.712600708100 .5791015625107 .8938980103116 .7326965332117 .9517974854 117.9517974854120 .0852966309121 .6886291504121 .6190643311121 .5616760254 121.5190353394121 .4935531616121 .4884033203121 .5074462891121 .555847168 121.6395263672121 .7659072876121 .9429168701121 .7715072632121 .0580291748 120.3417892456119 .6205825806118 .8921356201118 .1543502808117 .405380249 116.6444778442115 .8722915649115 .0910873413114 .3037261963113 .513343811 112.7236099243111 .9391403198111 .1656723022110 .4097518921109 .6793365479 108.9830551147105 .38343048198 .9385147094790 .5765457153379 .72728729248 66.218467712453 .6421813964857 .6043891906760 .9570198059162 .48094940186 63.0905189514263 .0905189514263 .3953094482463 .2157592773463 .39530944824 64.7718048095766 .0068588256867 .2165527343868 .0232238769567 .78383636475 65.8335876464862 .1761703491260 .9029273986863 .1611442565969 .52707672119 73.0364379882873 .8044815063574 .0367736816473 .626678466872 .57667541504 71.1007080078169 .6935424804768 .949363708569 .0960388183669 .85427856445 70.4447860717867 .3575134277362 .1761703491254 .2517509460444 .19384002686 33.5263595581126 .2115192413326 .2115192413330 .4785099029529 .25937080383 28.6497993469228 .6497993469228 .9545898437529 .8689403533930 .78330039978 31.3928699493432 .3072204589833 .2215805053734 .4407196044935 .35507965088 36.5742111206137 .7933502197339 .3172798156740 .8412094116242 .669921875 
44.1938400268646 .0225486755447 .8512611389249 .3751907348650 .89912033081 51.8134689331153 .0326118469253 .9469718933154 .8613204956155 .77568054199 56.6900291442957 .6043891906758 .2139587402359 .1283111572359 .73788070679 60.3474502563560 .9570198059161 .5666007995662 .1761703491262 .78573989868 63.3953094482464 .004882812564 .6144485473665 .2240066528365 .52880096436 66.1383666992266 .7479400634867 .0527267456167 .515762329167 .9419631958 68.2718734741269 .1862335205170 .0439224243270 .65557098389 -9999 -9999 -9999 -9999 -9999 -9999 -9999 -9999 -9999 -9999 -9999 -9999 -9999 -9999 -9999 -9999 -9999 -9999 -9999

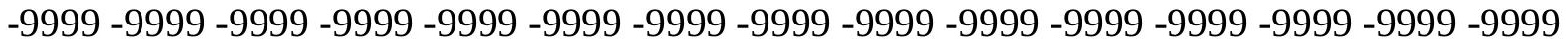
-9999 -9999 -9999 -9999 -9999 -9999 -9999 -9999 -9999 -9999 -9999 -9999 -9999 -9999 -9999

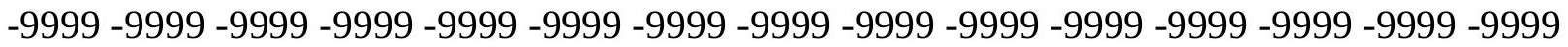
-9999 -9999 -9999 -9999-9999-9999-9999

-9999 -9999 -9999 -9999 -9999 -9999 -9999 -9999 -9999 -9999 -9999 -9999 -9999 -9999 -9999 -9999 -9999 -9999 -9999 -9999 -9999 -9999 -9999 -9999 -9999 -9999 -9999 -9999 -9999 - 9999 -9999 -9999 -9999 -9999 -9999 -9999 -9999 -9999 -9999 -9999 -9999 -9999 -9999 -9999 -9999

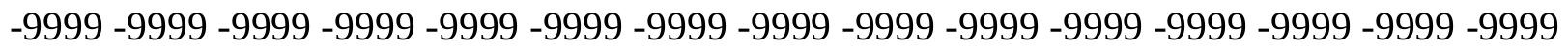
-9999 -9999 -9999 -9999 -9999 -9999 -9999 -9999 -9999 -9999 -9999 -9999 -9999 173.42628479171 .2891998291166 .4127044678154 .4112548828152 .9862823486 151.4781951904145 .0776977539138 .9819946289133 .8007049561129 .8385009766 127.0953979492 124.9618988037 122.2188034058 119.7806015015118 .2565994263 115.5136032104109 .4179000854106 .0652008057104 .2365036011103 .6268997192 103.017402648965 .8335876464867 .0527267456167 .9670867919968 .88143920898 70.1005783081171 .014930725172 .2340774536173 .1484298706174 .36756896973 75.2819290161176 .5010681152377 .4154205322378 .0249862670978 .32978057861 78.3297805786178 .3297805786178 .3297805786178 .0249862670977 .72020721436 77.4154205322377 .110626220776 .8058471679776 .5010681152376 .50106811523 76.5010681152376 .8058471679777 .110626220778 .0249862670978 .93934631348 80.4632720947381 .9871978759883 .5111236572385 .0350494384886 .2541885376 87.7781066894589 .302040100190 .5211791992290 .9667434692490 .40507507324 89.8822097778389 .3964385986388 .9465255737388 .5309295654388 .14859008789 87.79817962646 87.47887420654 87.18977355957 86.93064880371 86.70121765137 86.5018768310586 .3330459594786 .1956329345786 .0900878906286 .01712036133 85.9774780273485 .973075866786 .0059890747186 .0786209106486 .19259643555 86.3499069213986 .552032470786 .8008346557687 .0974731445387 .44345092773 87.8396377563588 .2873764038188 .7871246337989 .3394775390689 .94407653809 90.6013336181691 .3115615844792 .0761108398492 .8958663940493 .77226257324 94.7059402465895 .6980209350696 .7488937377997 .8596038818499 .03062438965 100.2631607056101 .5576934814102 .9153213501104 .3362503052105 .8211364746 107.3695373535 108.9812469482110.6547470093112.3885421753 114.1797027588 116.0251083374117 .9201202393119 .8597106934119 .4757995605114 .2944030762 106.0652008057 95.3977432251 88.3876876831191.4355392456199.35994720459 106.979598999 113.9896011353118.8662033081 121.2674407959 121.1949462891 121.1379547119121 .098739624121 .0790328979121 .0810852051121 .1075820923 121.1624984741121 .250793457121 .3793182373121 .5562210083121 .7919082642 121.5993041992120 .9239501953120 .2445755005119 .558631897118 .8636856079 118.1575469971117 .4391479492116 .7088928223115 .9689025879115 .2217483521 
114.4701004028113 .7170333862112 .9667282104112 .2244567871111 .4966278076 110.7913589478110 .1182174683109 .4874420166104 .628150939996 .78340911865 85.8651123046971 .9292907714853 .0326118469256 .6900291442960 .34745025635 61.5666007995661 .2618103027359 .7378807067959 .1283111572358 .82352828979 58.8235282897960 .0426712036161 .0528526306262 .401092529363 .85734176636 64.4978637695363 .3953094482459 .7378807067954 .2517509460456 .99481964111 65.5288009643668 .4252929687571 .7854843139671 .9765090942471 .65493011475 70.9686279296970 .1827774047969 .6223831176869 .5413665771570 .03475952148 70.8529357910271 .5063476562571 .4692993164170 .3877029418964 .61444854736 53.6421813964840 .2316398620626 .2115192413328 .3450202941929 .86894035339 29.5641593933128 .6497993469228 .6497993469229 .2593708038329 .86894035339 30.4785099029531 .0880794525131 .3928699493432 .3072204589832 .91679000854 33.8311500549335 .0502891540536 .2694282531737 .4885711669939 .01250076294 40.8412094116242 .66992187544 .8034095764246 .6321296691948 .46083068848 49.6799812316950 .8991203308152 .1182594299353 .0326118469253 .94697189331 54.8613204956155 .7756805419956 .6900291442957 .6043891906758 .21395874023 59.1283111572359 .7378807067960 .3474502563561 .2618103027361 .87137985229 62.4809494018663 .0905189514263 .7000885009864 .004882812564 .61444854736 65.2240066528365 .8335876464866 .1383666992266 .7479400634867 .05272674561 67.4912414550867 .9530029296968 .2718734741269 .1862335205169 .98276519775 70.47006988525 -9999 -9999 -9999 -9999 -9999 -9999 -9999 -9999 -9999 -9999 -9999 -9999 -9999 -9999 -9999 -9999 -9999 -9999 -9999 -9999 -9999 -9999 -9999 -9999 -9999 -9999 - -9999 -9999 -9999 -9999 -9999 -9999 -9999 -9999 -9999 -9999 -9999 -9999 -9999 -9999 -9999 -9999 -9999 -9999 -9999 -9999 -9999 -9999 -9999 -9999 -9999 -9999 -9999 -9999 -9999 -9999 -9999 -9999 -9999 -9999 -9999 -9999 -9999 -9999 -9999 -9999 -9999 -9999 -9999 -9999 -9999 -9999 -9999 -9999 -9999 -9999 -9999 -9999 -9999 -9999 -9999 -9999 -9999 -9999 -9999 -9999 -9999 -9999 -9999 -9999 -9999 -9999 -9999 -9999 -9999 -9999 -9999 -9999 -9999 -9999

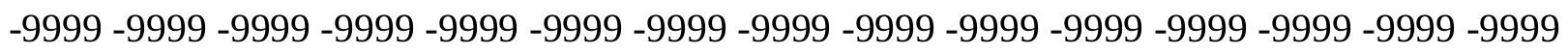
-9999 -9999 -9999 -9999 -9999 -9999 -9999 -9999 -9999 -9999 -9999 -9999 -9999 -9999 -9999 -9999 -9999 -9999 -9999 -9999 -9999 -9999 -9999 -9999 -9999 -9999 -9999 173.4616088867 170.8861236572165 .8031005859161 .2312927246156 .3547973633149 .9542999268 143.2489929199137 .1533050537131 .9720001221127 .4001998901123 .43800354 120.9997024536118 .5614013672115 .5136032104112 .1608963013112 .1608963013 110.0273971558107 .2844009399105 .7603988647105 .1509017944103 .0174026489 61.8713798522963 .3953094482464 .9192428588966 .1383666992267 .35751342773 68.5766525268669 .7957916259871 .014930725172 .2340774536173 .45321655273 74.6723632812575 .8914871215877 .110626220777 .7202072143678 .02498626709 78.0249862670977 .7202072143677 .4154205322377 .110626220776 .50106811523 76.1962814331175 .8914871215875 .5867080688575 .2819290161174 .97714233398 75.2819290161175 .2819290161175 .8914871215876 .5010681152377 .41542053223 78.6345596313580 .1584930419981 .6824111938583 .206336975184 .73026275635 86.254188537687 .7781066894589 .302040100190 .5211791992290 .59696960449 90.0753555297989 .5908126831189 .1423110961988 .7284927368288 .34846496582 88.0010528564587 .6855850219787 .4012451171987 .1477890014686 .92481231689 86.7324981689586 .5709762573286 .4408798217886 .3425292968886 .27654266357 86.24337768555 86.24449920654 86.28169250488 86.3571395874 86.4719543457 
86.6273574829186 .8243255615287 .0646972656287 .3500671386787 .682472229 88.063056945888 .4930648803788 .9727783203189 .5027770996190 .08279418945 90.7131042480591 .3939285278392 .1266632080192 .9123535156293 .75254058838 94.6478652954195 .599327087496 .607139587497 .6720886230598 .79438781738 99.97489929199101 .2137908936102 .5117950439103 .8688430786105 .2853240967 106.7605895996108 .2942123413109 .8845672607111 .5300674438113 .2278137207 114.9747848511116 .7666549683118 .5987854004118 .5614013672113 .6848983765 106.674797058194 .1785964965883 .8159103393682 .2919769287186 .86376190186 99.05516815186112 .1608963013118 .2565994263120 .7539749146120 .6719360352 120.6095809937120 .5685806274120 .5497894287120 .5542297363120 .5831375122 120.6390457153120 .7256546021120 .8489532471121 .0168533325121 .2402648926 121.5317687988121 .4901351929120 .8542251587120 .2124404907119 .5619812012 118.9002838135118 .2258682251117 .5386428833116 .8402481079116 .1327209473 115.4179992676114 .6982345581113 .9767990112111 .551399231107 .5891036987 111.8547668457111 .1864776611110 .5539398193109 .9979095459104 .0672836304 92.6591567993274 .062782287652 .7278289794957 .6043891906760 .65224075317 61.2618103027360 .0426712036158 .2139587402356 .6900291442955 .47089004517 54.8613204956155 .1661109924356 .3852500915557 .6043891906759 .73788070679 61.8713798522961 .2618103027360 .6522407531760 .9570198059164 .0048828125 50.5943298339861 .8713798522966 .6584625244170 .0136184692469 .75028991699 69.3783645629969 .1304168701269 .1600952148469 .589569091870 .3999786377 71.4113998413172 .2964782714872 .7188415527372 .4869613647571 .57739257812 66.4431610107453 .6421813964842 .3651313781736 .5742111206133 .22158050537 30.4785099029528 .3450202941928 .3450202941930 .1737308502230 .17373085022 30.1737308502230 .7833003997830 .7833003997831 .3928699493432 .00244140625 32.6120109558133 .5263595581134 .7455101013235 .9646492004437 .48857116699 39.3172798156741 .1459884643643 .2794914245645 .4129791259847 .24169921875 48.765621185349 .9847602844250 .8991203308151 .8134689331152 .72782897949 53.9469718933154 .8613204956155 .7756805419956 .6900291442957 .60438919067 58.2139587402359 .1283111572359 .7378807067960 .6522407531761 .26181030273 61.8713798522962 .4809494018663 .0905189514263 .7000885009864 .30966186523 64.9192428588965 .2240066528365 .8335876464866 .1383666992266 .74794006348 67.0527267456167 .5416336059667 .9670867919968 .2718734741269 .49101257324 69.81723785470 .16046142578 -9999 -9999 -9999 -9999 -9999 -9999-9999 -9999 -9999 -9999 -9999 -9999 -9999 -9999 -9999 -9999 -9999 -9999 -9999 -9999 -9999 -9999 -9999 -9999 -9999

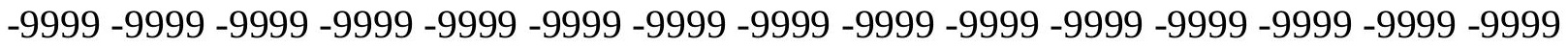

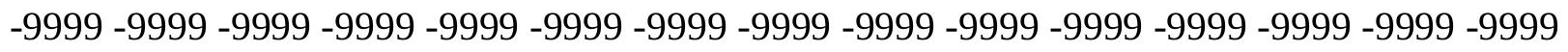

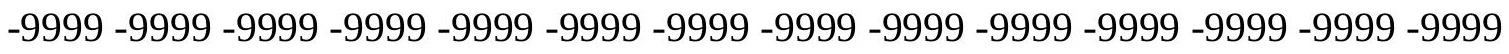

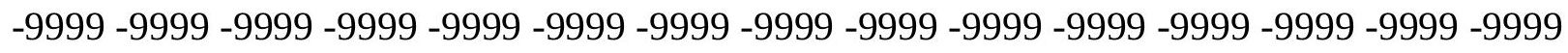
-9999 -9999 -9999 -9999 -9999 -9999 -9999 -9999 -9999 -9999 -9999 -9999 -9999 -9999 -9999 -

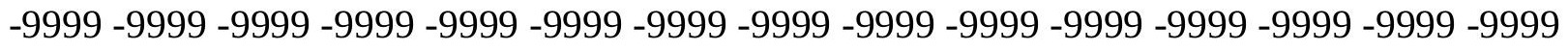

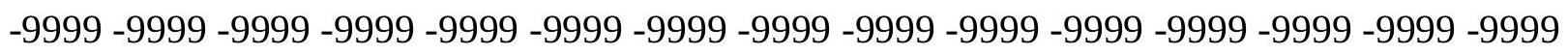
-9999 -9999 -9999 -9999 -9999 -9999 -9999 -9999 -9999 -9999 -9999 173.7274932861 167.0222015381161 .5361022949156 .6596069336151 .7830047607146 .2969055176 138.9819946289131 .9720001221126 .4858016968122 .2188034058117 .9517974854 114.2944030762110 .9418029785110 .0273971558110 .9418029785109 .4179000854 
107.5891036987 104.5412979126101.1886978149100.5791015625104.2365036011 97.8360290527360 .0426712036161 .5666007995663 .0905189514264 .61444854736 65.8335876464867 .3575134277368 .5766525268670 .1005783081171 .31971740723 72.8436431884874 .062782287675 .5867080688576 .8058471679777 .41542053223 77.7202072143677 .4154205322377 .110626220776 .5010681152376 .19628143311 75.5867080688574 .9771423339874 .6723632812574 .3675689697374 .0627822876 73.7580032348673 .7580032348674 .062782287674 .3675689697374 .97714233398 75.8914871215877 .110626220778 .3297805786179 .8537063598681 .37763214111 82.9015579223684 .7302627563586 .254188537687 .7781066894588 .99725341797 90.5211791992290 .2588119506889 .7771377563589 .331619262788 .92107391357 88.5447463989388 .201583862387 .8909988403387 .6122207641687 .36497497559 87.1487731933686 .9636535644586 .8095169067486 .6867752075286 .59554290771 86.5363388061586 .5094528198286 .5159378051886 .5570373535286 .63453674316 86.7493667602586 .9022979736387 .0937881469787 .3254547119187 .59910583496 87.9171524047988 .2810287475688 .6918411254989 .1495819091889 .65476989746 90.2075347900490 .8084182739391 .4574661254992 .1558151245192 .90452575684 93.705223083594 .5586242675895 .4656677246196 .4265060424897 .44184112549 98.5116806030399 .63655853271100 .8162994385102 .0512619019103 .3411407471 104.6861190796106 .08543396107 .5385437012109 .0437774658110 .5995101929 112.2029418945113 .8512039185115 .5402908325117 .2660064697119 .0230484009 115.5136032104110 .9418029785106 .3700027466102 .102996826298 .75038146973 99.05516815186105 .7603988647114 .5991973877119 .7806015015120 .1371612549 120.0388793945119 .9654846191119 .9179382324119 .8959274292119 .8990249634 119.9267272949119 .9797592163120 .0601501465120 .1725387573120 .3240585327 120.5254516602120 .7900924683121 .1346969604121 .44581604120 .8496704102 120.245223999119 .6295013428119 .0005264282118 .3575363159117 .7013244629 117.0330505371116 .3537368774115 .6643600464114 .9671401978113 .075302124 113.5641098022112 .8690872192112 .188079834111 .5297546387110 .9346694946 110.1429901123101 .798202514682 .2919769287131 .3928699493460 .04267120361 62.7857398986861 .5666007995659 .4331016540556 .9948196411154 .86132049561 53.0326118469252 .1182594299351 .8134689331152 .4230384826753 .64218139648 54.8613204956156 .6900291442958 .2139587402360 .6522407531761 .87137985229 60.9570198059155 .1661109924350 .8991203308159 .7378807067966 .13836669922 66.0585250854567 .5837936401467 .8329238891668 .3277359008869 .15843200684 70.2942810058671 .5886917114372 .8217163085973 .7368774414174 .1612701416 73.9806671142673 .1839218139669 .4910125732458 .8235282897949 .07040023804 41.1459884643633 .8311500549328 .9545898437528 .3450202941929 .56415939331 30.1737308502230 .1737308502230 .4785099029530 .1737308502230 .47850990295 31.0880794525131 .6976509094232 .6120109558133 .2215805053734 .44071960449 35.9646492004437 .4885711669939 .622070312541 .7555618286144 .19384002686 46.3273391723647 .5464782714848 .4608306884849 .6799812316950 .59432983398 51.8134689331152 .7278289794953 .6421813964854 .8613204956155 .77568054199 56.6900291442957 .6043891906758 .2139587402359 .1283111572360 .04267120361 60.6522407531761 .2618103027361 .8713798522962 .4809494018663 .09051895142 63.7000885009864 .3096618652364 .9192428588965 .2240066528365 .83358764648 66.1383666992266 .7479400634867 .0527267456167 .5924758911167 .96708679199 
68.2718734741269 .0767974853569 .5789184570372 .53885650635 -9999 -9999 -9999-9999 -9999 -9999 -9999 -9999 -9999 -9999 -9999 -9999 -9999 -9999 -9999 -9999 -9999 -9999 -9999

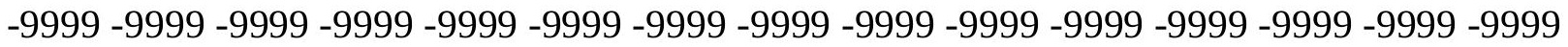
-9999 -9999 -9999 -9999 -9999 -9999 -9999 -9999 -9999 -9999 -9999 -9999 -9999 -9999 -9999

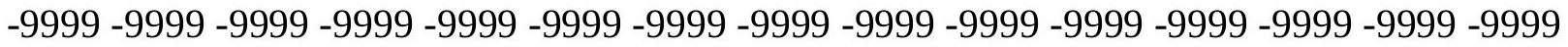
-9999 -9999 -9999-9999

-9999 -9999 -9999 -9999 -9999 -9999 -9999 -9999 -9999 -9999 -9999 -9999 -9999 -9999 -9999 -9999 -9999 -9999 -9999 -9999 -9999 -9999 -9999 -9999 -9999 -9999 -9999 -9999 -9999 -9999 -999 -

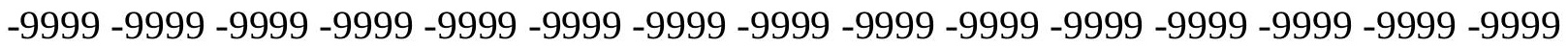
-9999 -9999 -9999 -9999 -9999 -9999 -9999 -9999 -9999 -9999 -9999 -9999 -9999 -9999 -9999 -9999 -9999 -9999 -9999 -9999 -9999 -9999 -9999 -9999 -9999 163.0599975586 158.1835021973153 .0021057129148 .4304046631143 .2489929199138 .0677032471 132.2767028809125 .5715026855119 .1709976196114 .9039993286112 .7705001831 112.1608963013110 .9418029785109 .7226028442108 .5035018921107 .2844009399 105.4557037354102 .102996826298 .1408081054793 .5690307617288 .99725341797 92.9594726562592 .9594726562558 .5187492370660 .3474502563561 .87137985229 63.3953094482464 .6144485473666 .1383666992267 .6623001098669 .18623352051 70.7101516723671 .9292907714873 .4532165527374 .9771423339876 .19628143311 77.110626220777 .110626220776 .8058471679776 .1962814331175 .58670806885 75.2819290161174 .6723632812574 .062782287673 .4532165527373 .14842987061 72.8436431884872 .5388565063572 .5388565063572 .8436431884873 .14842987061 73.7580032348674 .3675689697375 .2819290161176 .5010681152378 .02498626709 79.5489196777381 .0728530883882 .5967712402384 .4254837036185 .94940185547 87.4733276367288 .6924667358489 .9116134643689 .9571609497189 .5160369873 89.11006164551 88.73863220215 88.40076446533 88.09593963623 87.82340240479 87.582862854 87.37377166748 87.19606018066 87.04946136475 86.93419647217 86.8502044677786 .7978363037186 .7772140502986 .789062586 .83406829834 86.9134826660287 .0279998779387 .1783370971787 .3646926879987 .58827972412 87.8507690429788.15460968018 88.50135040283 88.89207458496 89.3265914917 89.8053207397590 .3287582397590 .8980407714891 .5133819580192 .1755065918 92.8851318359493 .643829345794 .4524078369195 .3118515014696 .22235870361 97.1847457885798 .1990890502999 .26564788818100 .3837738037101 .5533981323 102.7739715576104 .0455245972105 .3672637939106 .7385787964108 .1578140259 109.623336792111 .1324691772112 .6824951172114 .2697525024115 .8904724121 117.5399932861117 .647102356115 .818397522119 .4757995605120 .5481033325 119.4757995605116 .1231002808116 .7326965332118 .8662033081119 .5575561523 119.4066543579119 .2855377197119 .195854187119 .1377487183119 .1096038818 119.1092910767119 .1342544556119 .1829681396119 .2552719116119 .3538131714 119.4842300415119 .6564559937119 .8839569092120 .1845397949120 .5778045654 121.0853805542120 .9090042114120 .3407669067119 .7587509155119 .1613464355 118.5482788086117 .9195022583117 .274848938116 .6139373779115 .9374084473 115.2470703125114 .5460739136113 .8385772705113 .1298904419112 .4259796143 111.7526016235111 .1191177368104 .236503601189 .302040100178 .63455963135 60.6522407531762 .1761703491261 .2618103027358 .5187492370655 .77568054199 53.0326118469251 .2038993835449 .9847602844249 .3751907348649 .37519073486 49.6799812316950 .2895507812551 .2038993835453 .0326118469256 .38525009155 
59.1283111572359 .7378807067959 .4331016540556 .9948196411153 .33739852905 52.1182594299357 .6043891906759 .9085502624564 .3988418579167 .22458648682 68.3567657470769 .7981185913171 .4604568481473 .1189804077174 .51367950439 75.457176208575 .8360443115275 .5097427368274 .2376632690471 .71760559082 62.4809494018651 .8134689331141 .4507789611831 .6976509094232 .00244140625 32.0024414062531 .3928699493430 .4785099029529 .5641593933129 .25937080383 29.8689403533930 .4785099029531 .0880794525131 .6976509094232 .30722045898 33.2215805053734 .4407196044935 .9646492004437 .7933502197339 .92684936523 42.3651313781744 .1938400268645 .717769622846 .9369087219248 .15605163574 49.3751907348650 .2895507812551 .5086898803752 .7278289794953 .64218139648 54.8613204956155 .7756805419956 .6900291442957 .6043891906758 .51874923706 59.1283111572360 .0426712036160 .6522407531761 .5666007995662 .17617034912 62.7857398986863 .3953094482464 .004882812564 .3096618652364 .91924285889 65.5288009643665 .8335876464866 .1383666992266 .7479400634867 .05272674561 67.5735855102567 .9670867919968 .5766525268669 .0363311767669 .48751831055 -9999 -9999 -9999 -9999 -9999 -9999 -9999 -9999 -9999 -9999 -9999 -9999 -9999 -9999 -9999 -9999 -9999 -9999 -9999 -9999 -9999 -9999 -9999 -9999 -9999 -9999 -9999 -9999 -9999 -9999 -9999 -9999 -9999 -9999 -9999 -9999 -9999 -9999 -9999 -9999 -9999 -9999 -9999 -9999 -9999 -9999 -

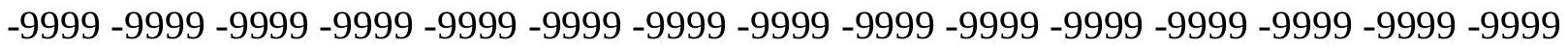
-9999 -9999 -9999-9999-9999-9999-9999

-9999 -9999-9999 -9999 -9999 -9999 -9999 -9999 -9999-9999 -9999 -9999 -9999 -9999 -9999 -9999 -9999 -9999 -9999 -9999 -9999 -9999 -9999 -9999 -9999 -9999 -9999 -9999 -9999 -9999 -9999 -9999 -9999 -9999 -9999 -9999 -9999 -9999 -9999 -9999 -9999 -9999 -9999 -9999 -9999 -

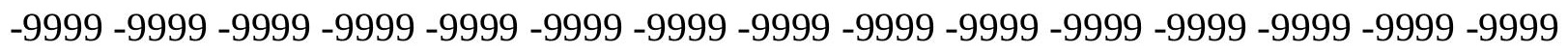
-9999 -9999-9999 -9999-9999 -9999-9999-9999 -9999-9999 140.5059967041 137.1533050537132 .5814971924128 .3144989014123 .43800354117 .647102356 112.1608963013111 .8561019897112 .4656982422112 .1608963013111 .24659729 110.3321990967109 .1130981445107 .8938980103106 .0652008057103 .9317016602 100.883903503496 .9216690063592 .349891662687 .7781066894584 .42548370361 83.8159103393683 .8159103393657 .2995986938559 .1283111572360 .65224075317 62.1761703491263 .7000885009865 .2240066528366 .7479400634868 .27187347412 69.7957916259871 .3197174072372 .5388565063574 .062782287675 .28192901611 75.8914871215875 .8914871215875 .8914871215875 .2819290161174 .67236328125 74.062782287673 .4532165527372 .8436431884872 .2340774536171 .92929077148 71.6244964599671 .3197174072371 .3197174072371 .3197174072371 .62449645996 72.2340774536172 .8436431884873 .7580032348674 .6723632812575 .89148712158 77.4154205322379 .2441329956180 .7680587768682 .5967712402384 .12069702148 85.64462280273 87.16854858398 88.08290100098 88.9972534179789.60682678223 89.29669952393 88.9312210083 88.59957885742 88.30130004883 88.03564453125 87.802314758387 .6006927490287 .4306182861387 .291717529387 .18403625488 87.10735321045 87.06185150146 87.04746246338 87.06462860107 87.11360168457 87.19513702393 87.30961608887 87.45767974854 87.639503479 87.85597991943 88.10832214355 88.39865112305 88.72844696045 89.09879302979 89.50956726074 89.9611816406290 .4543304443490 .9905853271591 .5706558227592 .1951751709 92.8643569946393 .579383850194 .3410797119195 .1505813598696 .00826263428 96.9151229858497 .8715515136798 .8777694702199 .93267059326101 .0356369019 
102.1858520508103 .3832092285104 .6269073486105 .9163131714107 .2497787476 108.6256790161110 .0414276123111 .4944763184112 .9814529419114 .4989929199 116.0430297852117 .6094207764119 .1933135986120 .2720031738120 .0247268677 119.7559127808119 .4806289673119 .2122573853118 .9620819092118 .7394180298 118.5507583618118 .4004364014118 .2897415161118 .2180786133118 .1823959351 118.1786880493118 .2019805908118 .2480392456118 .3138580322118 .399307251 118.5077438354118 .647354126118 .8310546875119 .0770721436119 .4068450928 119.8444366455120 .4118499756121 .0278167725120 .4946975708119 .9447860718 119.3765182495118 .7883987427118 .1788482666117 .5458602905116 .8882369995 116.2056274414115 .4991989136114 .7706451416114 .0227584839113 .2584915161 112.4853439331110 .2711029053102 .102996826289 .9116134643675 .89148712158 60.9570198059161 .8713798522959 .7378807067956 .9948196411154 .25175094604 51.5086898803749 .3751907348648 .1560516357447 .2416992187546 .63212966919 46.6321296691946 .6321296691946 .9369087219247 .2416992187551 .81346893311 55.7756805419958 .5187492370660 .9570198059162 .4809494018655 .77568054199 50.5943298339848 .4608306884850 .8991203308160 .6522407531763 .30344772339 67.2607879638769 .0075225830171 .12573 .2835388183675 .1380081176876 .50077056885 77.2985382080177 .4365768432676 .7012710571374 .89340972972 .09066009521 63.7000885009854 .2517509460446 .0225486755441 .4507789611838 .40293121338 35.0502891540531 .6976509094229 .2593708038328 .3450202941928 .95458984375 30.4785099029530 .4785099029530 .7833003997831 .3928699493432 .00244140625 33.2215805053734 .4407196044935 .9646492004438 .0981407165540 .23163986206 42.3651313781743 .8890609741245 .1082000732446 .3273391723647 .54647827148 48.765621185350 .2895507812551 .5086898803752 .4230384826753 .64218139648 54.8613204956155 .7756805419956 .6900291442957 .6043891906758 .51874923706 59.4331016540560 .3474502563560 .9570198059161 .5666007995662 .17617034912 62.7857398986863 .3953094482464 .004882812564 .6144485473664 .91924285889 65.5288009643665 .8335876464866 .1383666992266 .628623962467 .05272674561 $67.6623001098667 .9670867919968 .5772171020569 .0930786132871 .62449645996-9999$ -9999 -9999 -9999 -9999 -9999 -9999 -9999 -9999 -9999 -9999 -9999 -9999 -9999 -9999 -9999 -9999 -9999 -9999 -9999 -9999 -9999 -9999 -9999 -9999 -9999 -9999 -9999 -9999 -9999 -9999

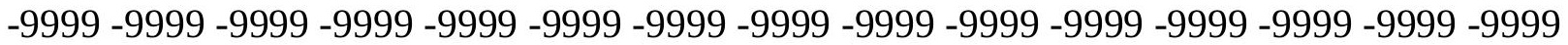

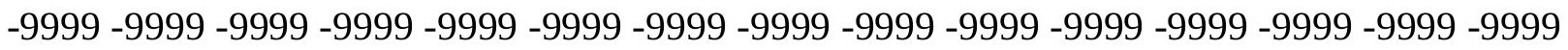
-9999 -9999 -9999-9999-9999-9999

-9999 -9999 -9999 -9999 -9999 -9999 -9999 -9999 -9999 -9999 -9999 -9999 -9999 -9999 -9999 -

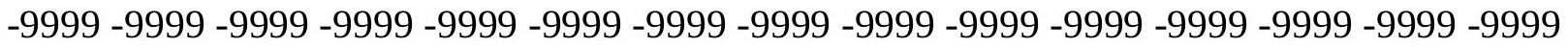

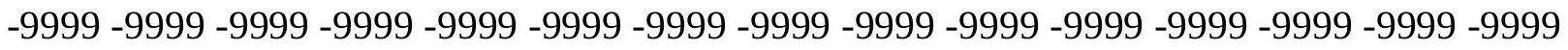

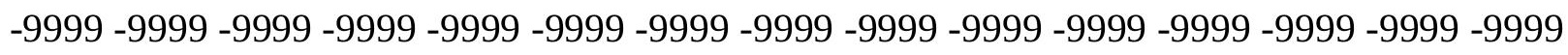
-9999 -9999 -9999 -9999 -9999 -9999 -9999 -9999 -9999 121.3044967651121 .9140014648 119.1709976196115 .2088012695115 .5136032104116 .4279022217114 .2944030762 112.1608963013111 .24659729110 .6370010376110 .3321990967109 .4179000854 108.5035018921107 .2844009399105 .7603988647103 .3221969604100 .5791015625 96.9216690063592 .6546783447388 .0829010009883 .5111236572380 .15849304199 77.7202072143675 .5867080688556 .3852500915558 .2139587402359 .73788070679 61.2618103027362 .7857398986864 .3096618652365 .8335876464867 .35751342773 68.8814392089870 .4053573608471 .6244964599672 .8436431884873 .75800323486 
74.3675689697374 .6723632812574 .6723632812574 .062782287673 .75800323486 73.1484298706172 .5388565063571 .9292907714871 .3197174072370 .71015167236 70.4053573608470 .1005783081170 .1005783081170 .1005783081170 .40535736084 70.7101516723671 .014930725171 .6244964599672 .8436431884874 .0627822876 75.5867080688577 .110626220778 .6345596313580 .4632720947381 .98719787598 83.8159103393685 .0350494384886 .254188537687 .4733276367288 .08290100098 88.69246673584 88.99725341797 88.79889678955 88.50790405273 88.24974822998 88.0241012573287 .8303146362387 .6681518554787 .53710937587 .43711090088 87.36777496338 87.32910919189 87.3208694458 87.34325408936 87.39618682861 87.4800415039187 .5949020385787 .741210937587 .91909027188 .12921142578 88.3723068237388 .649978637788 .963455200289 .3138122558689 .70111083984 90.1258773803790 .5889053344791 .0918655395591 .6357727050892 .22157287598 92.8493576049893 .5197753906294 .2334365844794 .9916839599695 .79524230957 96.6452484130997 .5422210693498 .486610412699 .47724151611100 .5130233765 101.5927886963102 .7162475586103 .8825759888105 .0910720825106 .3400878906 107.6279602051108 .9521484375110 .3102035522111 .6989822388113 .1154937744 114.5561981201116 .0176467896117 .4958953857118 .2565994263114 .9039993286 118.8662033081118 .7264785767118 .3861846924118 .0718078613117 .7938766479 117.5597457886117 .3742752075117 .2387084961117 .151802063117 .1091308594 117.1046066284117 .1305389404117 .1794509888117 .2448043823117 .322807312 117.4135131836117 .5224075317117 .6608200073117 .8468170166118 .1033782959 118.4573974609118 .9337844849119 .5589141846120 .3670654297120 .7012634277 120.1806564331119 .6357040405119 .0631942749118 .4593963623117 .8211746216 117.1457061768116 .4315643311115 .6775817871114 .883682251114 .0502166748 113.1748657227105 .787658691494 .4833908081182 .5967712402368 .57665252686 63.3953094482460 .3474502563557 .909179687555 .1661109924352 .42303848267 49.9847602844247 .8512611389246 .3273391723645 .4129791259844 .80340957642 44.4986305236844 .1938400268644 .4986305236845 .717769622849 .07040023804 53.0326118469256 .3852500915558 .8235282897958 .8235282897955 .16611099243 51.2038993835448 .765621185349 .9847602844254 .8613204956156 .08045959473 61.36606597968 .0015563964870 .7398986816473 .4741134643675 .72748565674 77.3683853149478 .5275573730579 .2094726562579 .2390594482478 .40474700928 76.7449493408274 .7315292358469 .1862335205160 .9570198059153 .64218139648 47.5464782714841 .1459884643634 .7455101013229 .5641593933128 .34502029419 28.9545898437529 .5641593933129 .5641593933129 .5641593933130 .17373085022 31.0880794525131 .6976509094232 .6120109558134 .1359291076736 .26942825317 38.4029312133840 .2316398620642 .0603485107443 .2794914245644 .49863052368 46.0225486755447 .2416992187548 .765621185349 .9847602844251 .20389938354 52.4230384826753 .6421813964854 .8613204956155 .7756805419956 .99481964111 57.909179687558 .8235282897959 .7378807067960 .3474502563561 .26181030273 61.8713798522962 .4809494018663 .0905189514263 .7000885009864 .0048828125 64.6144485473664 .9192428588965 .5288009643665 .8335876464866 .13836669922 66.7040939331167 .0527267456167 .6623001098668 .2718734741268 .77293395996 69.2162933349671 .92929077148 -9999 -9999 -9999 -9999 -9999 -9999 -9999 -9999 -9999 -9999 -9999 -9999 -9999 -9999 -9999 -9999 -9999 -9999 -9999 -9999 -9999 -9999 -9999 -9999

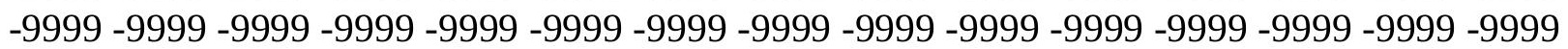


-9999 -9999 -9999 -9999 -9999 -9999 -9999 -9999 -9999 -9999 -9999 -9999 -9999 -9999 -9999 -9999 -9999 -9999 -9999 -9999 -9999 -9999 -9999 -9999 -9999 -9999 -9999

-9999 -9999 -9999 -9999 -9999 -9999 -9999 -9999 -9999 -9999 -9999 -9999 -9999 -9999 -9999 -9999 -9999 -9999 -9999 -9999 -9999 -9999 -9999 -9999 -9999 -9999 -9999 -9999 -9999 -9999 -9999 -9999 -9999 -9999 -9999 -9999 -9999 -9999 -9999 -9999 -9999 -9999 -9999 -9999 -9999 -9999 -9999 -9999 -9999 -9999 -9999 -9999 -9999 -9999 -9999 -9999 -9999 -9999 -9999 -9999 -9999 -9999 -9999 -9999 -9999 -9999 -9999 -9999 123.1332015991119 .1709976196 118.5614013672117 .647102356117 .0374984741116 .7326965332116 .1231002808 114.2944030762112 .4656982422110 .9418029785109 .7226028442108 .8082962036 108.1986999512107 .2844009399105 .7603988647103 .9317016602101 .1886978149 97.8360290527393 .8738174438589 .6068267822385 .0350494384880 .76805877686 76.8058471679773 .1484298706169 .4910125732455 .7756805419957 .29959869385 58.8235282897960 .6522407531762 .1761703491263 .7000885009865 .22400665283 66.7479400634867 .9670867919969 .4910125732470 .7101516723671 .62449645996 72.5388565063573 .1484298706173 .4532165527373 .1484298706173 .14842987061 72.5388565063571 .9292907714871 .3197174072370 .7101516723670 .10057830811 69.4910125732469 .1862335205168 .8814392089868 .5766525268668 .57665252686 68.8814392089868 .8814392089869 .1862335205169 .7957916259870 .71015167236 71.9292907714873 .4532165527374 .9771423339876 .8058471679778 .63455963135 80.1584930419981 .6824111938583 .206336975184 .4254837036185 .64462280273 86.5589828491287 .1685485839887 .4733276367287 .7781066894587 .47332763672 87.1685485839886 .254188537688 .0632553100687 .9092788696387 .78628540039 87.6940841674887 .6321411132887 .6002960205187 .5981369018687 .62564086914 87.682479858487 .7687377929787 .8842468261788 .0292282104588 .20362854004 88.4078750610488 .6423339843888 .9080886840889 .206054687589 .53723907471 89.9019088745190 .3007278442490 .7345046997191 .204795837491 .71262359619 92.2591552734492 .8448104858493 .4701309204194 .1354064941494 .84195709229 95.5909729003996 .3838577270597 .2210388183698 .1029815673899 .02883148193 99.99752807617101 .0076065063102 .0584869385103 .1491928101104 .2788925171 105.4458465576106 .6482696533107 .8835983276109 .1493759155110 .4426193237 111.7605743408113 .1001815796114 .4585800171115 .8327102661117 .2195358276 116.4279022217118 .3089675903117 .8651885986117 .4418029785117 .0529403687 116.7106781006116 .4235916138116 .1975860596116 .0341949463115 .9319152832 115.8849487305115 .8851547241115 .9217376709115 .983543396116 .059715271 116.1418762207116 .2256317139116 .3124313354116 .4109115601116 .5378799438 116.7178344727116 .983039856117 .3583755493117 .8840484619118 .6111907959 119.5668792725120 .7460021973120 .4558868408119 .9241027832119 .3528213501 118.7370605469118 .0715789795117 .3520355225116 .5738754272115 .73387146 114.8295593262110 .6417312622102 .100372314590 .2164001464876 .50106811523 64.004882812561 .2618103027357 .909179687555 .4708900451752 .72782897949 50.2895507812548 .1560516357446 .0225486755444 .8034095764243 .88906097412 42.9747009277342 .66992187542 .9747009277343 .5842704772945 .10820007324 47.5464782714850 .5943298339853 .3373985290555 .1661109924354 .86132049561 52.7278289794949 .9847602844248 .765621185349 .3751907348650 .89912033081 52.4230384826755 .1661109924362 .8607482910270 .5820770263773 .89376831055 76.3121185302777 .9394149780379 .3863449096780 .8040390014681 .82679748535 
81.9300460815480 .9892501831179 .2687377929777 .2691040039173 .75800323486 65.2240066528357 .6043891906749 .6799812316943 .2794914245635 .96464920044 31.3928699493431 .0880794525130 .1737308502228 .9545898437528 .34502029419 28.9545898437530 .4785099029530 .1737308502230 .4785099029532 .61201095581 34.7455101013236 .8790016174338 .4029312133839 .9268493652341 .45077896118 42.66992187544 .1938400268645 .4129791259846 .9369087219248 .46083068848 49.9847602844251 .5086898803752 .7278289794953 .9469718933155 .16611099243 56.0804595947357 .2995986938558 .2139587402359 .1283111572360 .04267120361 60.6522407531761 .5666007995662 .1761703491262 .4809494018663 .09051895142 63.7000885009864 .004882812564 .6144485473664 .9192428588965 .52880096436 65.8335876464866 .3905792236366 .7479400634867 .3575134277367 .96708679199 68.506835937568 .9528579711971 .014930725172 .53885650635 -9999 -9999 -9999 -9999 -9999 -9999 -9999 -9999 -9999 -9999 -9999 -9999 -9999 -9999 -9999 -9999 -9999 -9999 -9999 -9999 -9999 -9999 -9999 -9999 -9999 -9999 -9999 -9999 -9999 -9999 -9999 -9999 -9999 -9999 -9999 -9999 -9999 -9999 -9999 -9999 -9999 -9999 -9999 -9999 -9999 -9999 -9999 -9999 -9999 -9999 -9999 -9999 -9999 -9999 -9999 -9999 -9999 -9999 -9999 -9999 -9999 -9999 -999 - -999 $-9999$

-9999 -9999 -9999 -9999 -9999 -9999 -9999 -9999 -9999 -9999 -9999 -9999 -9999 - -9999 -9999 -9999 -9999 -9999 -9999 -9999 -9999 -9999 -9999 -9999 -9999 -9999 -9999 -9999 -9999 -999 -9999 -9999 -9999 -9999 -9999 -9999 -9999 -9999 -9999 -9999 -9999 -9999 -9999 -9999 -9999 -

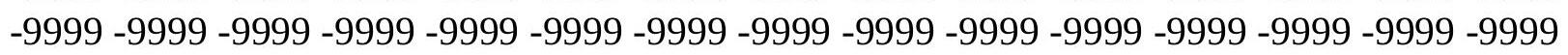
-9999 -9999 -9999 -9999-9999-9999-9999 -9999 134.7149963379 127.7050018311 126.4858016968122 .8283996582121 .9140014648119 .7806015015117 .342300415 115.2088012695113 .6848983765111 .8561019897110 .0273971558108 .5035018921 107.8938980103106 .979598999105 .4557037354103 .017402648999 .96952056885 96.3121032714892 .349891662688 .0829010009883 .5111236572378 .93934631348 74.6723632812570 .1005783081165 .2240066528355 .1661109924356 .69002914429 58.2139587402359 .7378807067961 .5666007995663 .0905189514264 .30966186523 65.8335876464867 .3575134277368 .5766525268669 .4910125732470 .71015167236 71.3197174072371 .9292907714871 .9292907714871 .9292907714871 .62449645996 71.3197174072371 .014930725170 .4053573608469 .4910125732468 .88143920898 68.2718734741267 .9670867919967 .3575134277367 .0527267456166 .74794006348 66.7479400634866 .7479400634867 .0527267456167 .6623001098668 .57665252686 70.1005783081171 .6244964599673 .1484298706174 .9771423339876 .50106811523 78.3297805786179 .8537063598681 .3776321411182 .5967712402383 .81591033936 84.7302627563585 .6446228027386 .254188537686 .5589828491286 .55898284912 86.254188537686 .5589828491287 .4733276367288 .1542892456188 .03955841064 87.9552993774487 .9008331298887 .8758468627987 .8797531127987 .91233062744 87.9730377197388 .0617294311588 .178009033288 .3218765258888 .49308013916 88.6917724609488 .9180221557689 .1724853515689 .4557342529389 .76865386963 90.1116485595790 .4855041503990 .8910293579191 .3295822143691 .80206298828 92.3096389770592 .8530197143693 .4330749511794 .0500640869194 .70512390137 95.3996658325296 .1355209350696 .9133071899497 .7333526611398 .5950088501 99.49756622314100 .4395675659101 .4201126099102 .4379348755103 .49193573 104.5801773071105 .7006378174106 .8506011963108 .0274734497109 .228302002 110.4504623413111 .6912155151112 .9482498169114 .2192382812115 .502166748 
116.7948913574117 .4328460693116 .8883209229116 .371673584115 .8986740112 115.4833984375115 .1363296509114 .8650512695114 .6720504761114 .5559005737 114.5097427368114 .5233154297114 .5826263428114 .6722946167114 .7764968872 114.8812866211114 .9765930176115 .0583496094115 .1307907104115 .2081832886 115.3167648315115 .4819717407115 .7482757568116 .1677093506116 .814491272 117.7241363525118 .8762359619120 .2141647339120 .7564544678120 .2231292725 119.6356506348118 .986618042118 .2689971924117 .4747085571116 .5969161987 113.7638168335108 .8095626831100 .946479797488 .0829010009873 .75800323486 64.9192428588957 .909179687554 .8613204956152 .4230384826749 .98476028442 47.8512611389246 .0225486755444 .4986305236843 .2794914245642 .36513137817 41.7555618286141 .7555618286142 .0603485107442 .9747009277344 .49863052368 46.6321296691949 .0704002380450 .8991203308151 .8134689331151 .50868988037 49.9847602844248 .4608306884847 .2416992187546 .9369087219247 .54647827148 48.4608306884850 .8991203308155 .7756805419965 .2240066528370 .35543060303 75.2102890014677 .7196502685579 .3456726074281 .9427032470784 .2839050293 85.4046936035284 .6568984985482 .5340957641679 .8822097778377 .20350646973 74.7095947265666 .7479400634859 .4331016540552 .4230384826743 .58427047729 39.3172798156736 .2694282531732 .9167900085429 .5641593933127 .12587928772 26.5163097381627 .430660247828 .3450202941929 .8689403533931 .69765090942 33.8311500549335 .3550796508836 .8790016174338 .0981407165539 .31727981567 40.5364189147942 .0603485107443 .5842704772945 .4129791259847 .24169921875 48.765621185350 .2895507812551 .5086898803753 .0326118469254 .25175094604 55.4708900451756 .6900291442957 .6043891906758 .8235282897959 .43310165405 60.3474502563560 .9570198059161 .5666007995662 .1761703491262 .78573989868 63.0905189514263 .7000885009864 .004882812564 .6144485473664 .91924285889 65.5288009643666 .1383666992266 .4431610107467 .0527267456167 .66230010986 68.2718734741268 .7063903808670 .4053573608471 .6244964599672 .84364318848 -9999 -9999 -9999 -9999 -9999 -9999 -9999 -9999 -9999 -9999 -9999 -9999 -9999 -9999 -9999 -9999 -9999 -9999 -9999 -9999 -9999 -9999 -9999 -9999 -9999 -9999 -9999 -9999 -9999 -9999 -9999 -9999 -9999 -9999 -9999 -9999 -9999 -9999 -9999 -9999 -9999 -9999 -9999 -9999 -9999 -9999

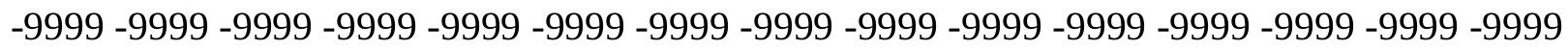
-9999-9999-9999

-9999 -9999 -9999 -9999 -9999 -9999 -9999 -9999 -9999 -9999 -9999 -9999 -9999 -9999 -9999 -9999 -9999 -9999 -9999 -9999 -9999 -9999 -9999 -9999 -9999 -9999 -9999 -9999 -9999 -9999 -9999 -9999 -9999 -9999 -9999 -9999 -9999 -9999 -9999 -9999 -9999 -9999 -9999 -9999 -9999 -9999 -9999 -9999 -9999 -9999 -9999 -9999 -9999 -9999 -9999 -9999 -9999 -9999 -9999 - 9999 -9999 -9999 -9999 -9999-9999 -9999 -9999 -9999 150.2590942383144 .4682006836 138.9819946289134 .4102020264130 .4479980469126 .1809997559120 .6949005127 119.1709976196117 .0374984741114 .5991973877112 .4656982422110 .9418029785 109.7226028442108 .5035018921106 .3700027466103 .322196960499 .96952056885 96.3121032714892 .0450973510787 .7781066894583 .206336975178 .32978057861 73.4532165527368 .5766525268663 .0905189514254 .5565414428756 .08045959473 57.909179687559 .4331016540560 .9570198059162 .4809494018663 .70008850098 65.2240066528366 .4431610107467 .6623001098668 .5766525268669 .49101257324 70.1005783081170 .4053573608470 .7101516723670 .7101516723670 .40535736084 70.1005783081169 .7957916259869 .1862335205168 .5766525268667 .96708679199 
67.3575134277366 .7479400634866 .1383666992265 .5288009643664 .91924285889 64.6144485473664 .6144485473664 .9192428588965 .5288009643666 .74794006348 68.2718734741269 .7957916259871 .3197174072373 .1484298706174 .67236328125 76.5010681152378 .0249862670979 .5489196777380 .7680587768681 .98719787598 83.206336975184 .1206970214885 .0350494384885 .6446228027385 .94940185547 86.254188537686 .5589828491287 .4733276367288 .3876876831188 .29704284668 88.22089385986 88.17403411865 88.15599822998 88.16602325439 88.20369720459 88.26829528809 88.35944366455 88.47655487061 88.61940002441 88.7875289917 88.9808578491289 .1992111206189 .4428939819389 .7121353149490 .00762176514 90.3297882080190 .6795120239391 .0575790405391 .4652175903391 .90321350098 92.3726425170992 .874305725193 .4093322753993 .9783096313594 .58238220215 95.2229461669995 .9021606445396 .6212005615297 .3806533813598 .17990112305 99.0184020996199 .89485931396100 .8081970215101 .7567749023102 .739112854 103.7529144287104 .7957611084105 .8646240234106 .9566116333108 .0686264038 109.1979904175110 .3422012329111 .4992904663112 .6676254272113 .8460769653 115.0337219238116 .2298965454115 .7889862061115 .1692352295114 .6030349731 114.1058807373113 .6929092407113 .3706817627113 .1496582031113 .0198974609 112.9850006104113 .0238800049113 .1220779419113 .2598190308113 .4155807495 113.5691375732113 .7035064697113 .807434082113 .8787002563113 .924697876 113.9741973877114 .0394363403114 .18334198114 .479888916115 .0411224365 115.9179229736117 .0689086914118 .3647842407119 .7213821411120 .968536377 120.404586792119 .3729553223118 .0981445312116 .431427002114 .1884384155 111.1036529541106 .8234481812101 .288528442494 .7881774902377 .1106262207 62.7857398986853 .6421813964851 .5086898803749 .3751907348647 .24169921875 45.4129791259843 .8890609741242 .66992187541 .7555618286140 .84120941162 40.5364189147940 .8412094116241 .4507789611842 .66992187544 .19384002686 46.3273391723648 .1560516357449 .3751907348649 .6799812316949 .07040023804 47.8512611389246 .6321296691945 .4129791259844 .4986305236844 .19384002686 44.1938400268644 .8034095764246 .6321296691949 .9847602844255 .77568054199 66.1383666992267 .7643890380972 .8696746826279 .7494964599685 .44627380371 88.4977874755987 .5628509521584 .4972991943480 .8697280883877 .58476257324 74.9259796142672 .2871017456167 .6623001098661 .2618103027355 .47089004517 49.3751907348643 .8890609741238 .0981407165531 .6976509094226 .51630973816 24.3828105926524 .6875991821326 .5163097381629 .2593708038330 .78330039978 32.6120109558134 .1359291076735 .3550796508836 .2694282531737 .18378067017 38.4029312133839 .622070312541 .4507789611843 .5842704772945 .41297912598 47.2416992187549 .0704002380450 .5943298339852 .1182594299353 .64218139648 54.8613204956156 .0804595947357 .2995986938558 .2139587402359 .12831115723 60.0426712036160 .6522407531761 .2618103027361 .8713798522962 .48094940186 62.7857398986863 .3953094482463 .7000885009864 .3096618652364 .61444854736 65.2240066528365 .5288009643666 .1080093383866 .6136169433667 .35751342773 67.9670867919968 .44448089668 .8399581909270 .7101516723671 .92929077148 -9999 -9999

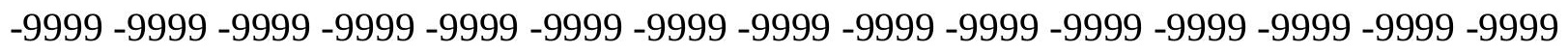
-9999 -9999 -9999 -9999 -9999 -9999 -9999 -9999 -9999 -9999 -9999 -9999 -9999 -9999 -9999 -

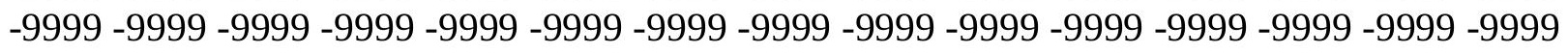

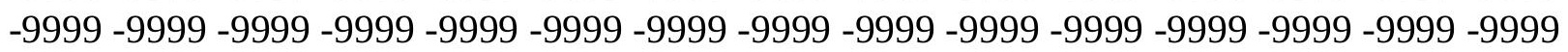


$-9999-9999$

-9999 -9999 -9999 -9999 -9999 -9999 -9999 -9999 -9999 -9999 -9999 -9999 -9999 -9999 -9999 -

-9999 -9999 -9999 -9999 -9999 -9999 -9999 -9999 -9999 -9999 -9999 -9999 -9999 -9999 - 9999 -

-9999 -9999 -9999 -9999 -9999 -9999 -9999 -9999 -9999 -9999 -9999 -9999 -9999 -9999 -9999

-9999 -9999 -9999 -9999 -9999 -9999 -9999 -9999 -9999 -9999 -9999 -9999 -9999 -9999 - -9999 -

-9999 -9999 -9999 -9999 -9999 -9999-9999 -9999 167.0222015381 159.0977935791

152.0877990723147 .5160064697142 .0299072266136 .2389984131130 .7528076172 126.7906036377123 .1332015991119 .7806015015117 .0374984741115 .5136032104 113.9896011353111 .8561019897108 .8082962036105 .1509017944101 .1886978149 97.2264633178793 .2642517089888 .6924667358484 .1206970214878 .93934631348 73.7580032348668 .2718734741262 .1761703491254 .2517509460455 .77568054199 57.2995986938558 .8235282897960 .3474502563561 .8713798522963 .09051895142 64.3096618652365 .5288009643666 .7479400634867 .6623001098668 .27187347412 68.8814392089869 .1862335205169 .4910125732469 .4910125732469 .49101257324 69.1862335205168 .5766525268668 .2718734741267 .6623001098667 .05272674561 66.4431610107465 .8335876464864 .9192428588964 .004882812563 .39530944824 62.7857398986862 .4809494018662 .7857398986863 .7000885009865 .22400665283 66.4431610107468 .2718734741269 .7957916259871 .6244964599673 .14842987061 74.6723632812576 .1962814331177 .7202072143678 .9393463134880 .46327209473 81.6824111938582 .9015579223684 .1206970214885 .0350494384885 .64462280273 86.254188537686 .8637619018687 .4733276367288 .3876876831188 .55860137939 88.4907226562588 .4516143798888 .4406509399488 .4569015502988 .49977111816 88.5683364868288 .6620254516688 .7800292968888 .9219207763789 .08702850342 89.2750854492289 .4856948852589 .718887329189 .9746246337990 .25333404541 90.555381774990 .8816223144591 .2328109741291 .6100997924892 .0142364502 92.44622039795 92.9068450927793.3973541259893.91868591309 94.47227478027 95.0596389770595 .6831359863396 .3445510864397 .0450744628997 .78433990479 98.5617752075299 .37609100342100 .2260894775101 .1098251343102 .0252990723 102.9696807861103 .9399795532104 .9326324463105 .9442596436106 .9714126587 108.0111999512109 .0611038208110 .1194076538111 .1849975586112 .2575683594 113.3373336792114 .4251174927114 .5591964722113 .8276672363113 .1585617065 112.5751342773112 .0876159668111 .7160720825111 .4651260376111 .334236145 111.3147583008 111.3932647705 111.5506820679111 .7617034912111 .9981460571 112.2375717163112 .4501037598112 .6237335205112 .7349624634112 .7911605835 112.7936477661112 .7679367065112 .7708587646112 .9071044922113 .3562011719 114.2053375244115 .397354126116 .6376037598117 .8437042236118 .6134719849 117.6320343018116 .49634552115 .0668563843113 .2088012695110 .810798645 107.8233108521104 .128791809199 .1372909545990 .8259735107478 .93934631348 66.7479400634849 .3751907348647 .8512611389246 .0225486755444 .49863052368 42.9747009277341 .7555618286140 .8412094116239 .9268493652339 .6220703125 39.3172798156739 .622070312540 .5364189147941 .7555618286143 .58427047729 45.717769622847 .5464782714848 .4608306884848 .4608306884847 .24169921875 46.0225486755444 .8034095764243 .5842704772942 .3651313781741 .14598846436 39.9268493652339 .0125007629437 .7933502197335 .6598587036131 .08807945251 45.717769622853 .6421813964863 .3953094482475 .4849472045983 .06175994873 86.8678054809687 .8137435913184 .694061279379 .9799346923876 .32621002197 
73.9548797607472 .0016021728570 .6295928955168 .9787139892665 .52880096436 59.4331016540553 .0326118469246 .0225486755437 .1837806701727 .4306602478 24.6875991821323 .7732391357424 .6875991821326 .8210906982429 .25937080383 31.6976509094232 .9167900085433 .8311500549334 .4407196044935 .05028915405 35.9646492004437 .4885711669939 .3172798156741 .4507789611843 .58427047729 45.717769622847 .8512611389249 .6799812316951 .5086898803753 .03261184692 54.5565414428755 .7756805419956 .9948196411157 .909179687558 .82352828979 59.7378807067960 .3474502563560 .9570198059161 .5666007995661 .87137985229 62.4809494018662 .7857398986863 .3953094482463 .7000885009864 .30966186523 64.6144485473665 .2240066528365 .7654647827166 .266319274967 .05272674561 67.6623001098668 .1807250976668 .6304626464869 .7957916259871 .31971740723 72.53885650635 -9999 -9999 -9999 -9999 -9999 -9999 -9999 -9999 -9999 -9999 -9999 -9999 -9999 -9999 -9999 -9999 -9999 -9999 -9999 -9999 -9999 -9999 -9999 -9999 -9999 -9999 -9999 -9999 -9999 -9999 -9999 -9999 -9999 -9999 -9999 -9999 -9999 -9999 -9999 -9999 -9999 - 9999 -9999 -9999 -9999 -9999 -9999 -9999 -9999 -9999 -9999 -9999 -9999 -9999 -9999 -9999 - -9999 -9999 -9999-9999 -9999-9999-9999

-9999 -9999 -9999 -9999 -9999 -9999 -9999 -9999 -9999 -9999 -9999 -9999 -9999 -9999 -9999 -9999 -9999 -9999 -9999 -9999 -9999 -9999 -9999 -9999 -9999 -9999 -9999 -9999 -9999 -9999 -9999 -9999 -9999 -9999 -9999 -9999 -9999 -9999 -9999 -9999 -9999 -9999 -9999 -9999 -9999 -

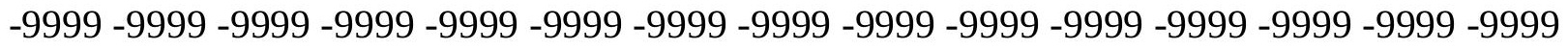
-9999 -9999-9999 -9999 -9999 -9999-9999 -9999 -9999 173.1179962158 165.8031005859 160.0122070312154 .8307952881148 .4304046631142 .3347015381136 .8484954834 132.2767028809 127.7050018311 123.43800354122.5235977173120.9997024536 117.647102356113 .075302124108 .1986999512103 .626899719299 .66472625732 95.397743225191 .1307525634885 .9494018554780 .4632720947374 .97714233398 69.1862335205162 .4809494018653 .9469718933155 .4708900451756 .99481964111 58.5187492370660 .0426712036161 .2618103027362 .4809494018663 .70008850098 64.9192428588965 .8335876464866 .7479400634867 .3575134277367 .96708679199 68.2718734741268 .2718734741268 .2718734741268 .2718734741267 .96708679199 67.6623001098667 .0527267456166 .7479400634866 .1383666992265 .52880096436 64.9192428588964 .004882812563 .0905189514262 .1761703491261 .26181030273 60.6522407531761 .2618103027362 .4809494018664 .004882812565 .52880096436 67.0527267456168 .5766525268670 .1005783081171 .6244964599673 .14842987061 74.6723632812575 .8914871215877 .4154205322378 .9393463134880 .46327209473 81.6824111938583 .206336975184 .1206970214885 .3398437586 .2541885376 86.8637619018687 .7781066894588 .3876876831188 .8239593505988 .7645111084 88.73329925537 88.72954559326 88.75215911865 88.80035400391 88.87303161621 88.9693832397589 .0884017944389 .2294235229589 .3915939331189 .57441711426 89.7773208618290 .0001068115290 .2425460815490 .5048446655390 .78723907471 91.0904388427791 .4151229858491 .7623519897592 .1329193115292 .52778625488 92.9477310180793 .3940811157293 .8681106567494 .3716964721794 .90672302246 95.475868225196 .0813980102596 .7251510620197 .4071807861398 .12699890137 98.8832168579199 .67446136475100 .4984130859101 .3524780273102 .2331237793 103.1365661621104 .0585021973104 .9947814941105 .94140625106 .8949661255 107.8527908325108 .8131637573109 .7753982544110 .7398223877111 .7077789307 112.6814575195113 .1909942627112 .3416061401111 .5659179688110 .885269165 
110.3283615112109 .9100799561109 .640586853109 .5196533203109 .5330657959 109.6725006104109 .9172668457110 .2320327759110 .5849990845110 .9517822266 111.2945175171111 .5812759399111 .7901000977111 .8963012695111 .9002914429 111.7953262329111 .6435928345111 .5874252319111 .8575134277112 .664855957 113.9056930542114 .5477523804114 .7992095947115 .5143890381114 .6211547852 113.4002227783111 .8048248291109 .6987915039106 .9608917236103 .6023635864 99.7024536132895 .0929565429788 .3876876831179 .2441329956169 .79579162598 45.1082000732443 .8890609741242 .66992187541 .4507789611840 .53641891479 39.622070312538 .7077102661138 .0981407165537 .7933502197337 .79335021973 38.4029312133839 .3172798156740 .8412094116242 .66992187544 .80340957642 46.9369087219247 .8512611389246 .9369087219245 .4129791259843 .88906097412 42.9747009277341 .7555618286140 .5364189147938 .7077102661136 .57421112061 34.4407196044932 .0024414062530 .1737308502232 .6120109558136 .87900161743 45.717769622857 .6043891906772 .2340774536179 .4752044677783 .30805206299 84.1479492187582 .6460189819377 .1621780395573 .6416091918972 .211769104 72.0448837280372 .4155883789173 .047714233472 .0408554077168 .88143920898 61.5666007995655 .4708900451747 .8512611389237 .1837806701728 .64979934692 24.6875991821324 .0780296325724 .9923801422126 .8210906982429 .56415939331 31.0880794525132 .0024414062532 .3072204589832 .6120109558133 .52635955811 35.0502891540536 .8790016174339 .3172798156741 .7555618286144 .19384002686 46.6321296691948 .765621185350 .8991203308152 .7278289794954 .25175094604 55.4708900451756 .6900291442957 .6043891906758 .5187492370659 .43310165405 60.0426712036160 .6522407531760 .9570198059161 .5666007995661 .87137985229 62.4809494018662 .7857398986863 .3953094482463 .7000885009864 .30966186523 64.9192428588965 .4891281127965 .9553909301866 .7479400634867 .35751342773 67.9670867919968 .4613342285269 .4910125732470 .4053573608471 .62449645996 72.84364318848 -9999 -9999 -9999 -9999 -9999 -9999 -9999 -9999 -9999 -9999 -9999 -9999

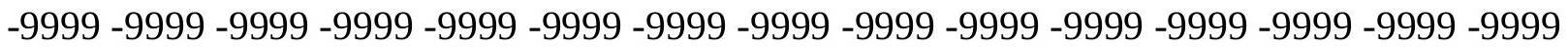

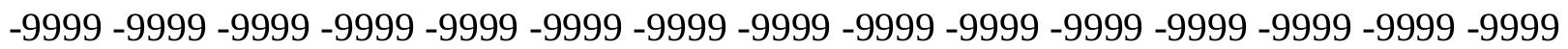

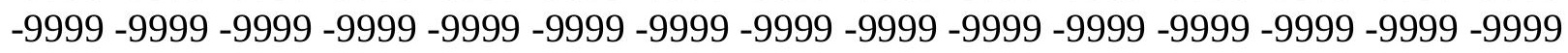
-9999 -9999 -9999 -9999-9999

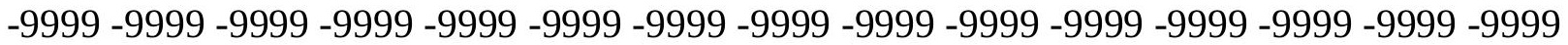

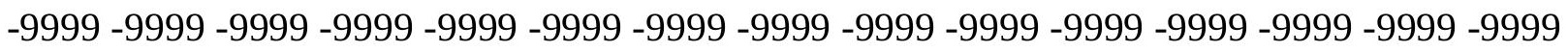

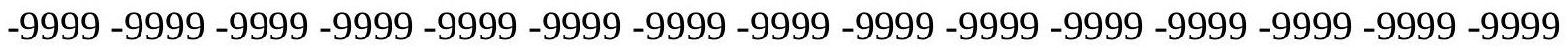

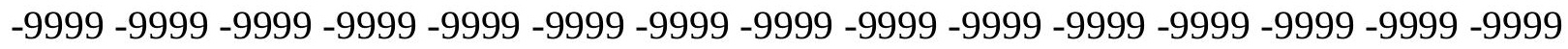
-9999 -9999 -9999 -9999 -9999 -9999 -9999 -9999 -9999 179.8089141846178 .7622833252 173.4226989746165 .8031005859159 .7073974609153 .6116943359148 .1255950928 142.9441986084138 .3724975586134 .4102020264132 .5814971924130 .4479980469 125.8762969971118 .2565994263112 .1608963013107 .2844009399103 .0174026489 98.445587158293 .8738174438588 .6924667358483 .206336975177 .41542053223 71.3197174072352 .4230384826753 .9469718933155 .4708900451756 .99481964111 58.2139587402359 .7378807067960 .9570198059162 .1761703491263 .39530944824 64.3096618652365 .2240066528365 .8335876464866 .4431610107466 .74794006348 67.0527267456167 .3575134277367 .3575134277367 .0527267456167 .05272674561 66.7479400634866 .1383666992265 .8335876464865 .5288009643664 .91924285889 64.3096618652363 .3953094482462 .4809494018661 .5666007995660 .65224075317 
59.7378807067960 .6522407531762 .1761703491263 .3953094482464 .91924285889 66.4431610107467 .6623001098669 .1862335205170 .7101516723671 .92929077148 73.1484298706174 .6723632812575 .8914871215877 .4154205322378 .93934631348 80.7680587768682 .2919769287183 .5111236572384 .7302627563585 .94940185547 86.8637619018687 .4733276367288 .0829010009888 .6924667358488 .99725341797 89.01853942871 89.02213287354 89.05126953125 89.10496520996 89.1819229126 89.2811126709 89.40131378174 89.5416183471789.7009582519589.87860870361 90.073799133390 .2861480712990 .5152511596790 .761154174891 .02395629883 91.3041992187591 .6024398803791 .9196166992292 .2565231323292 .61414337158 92.9932785034293 .3953933715893 .8222122192494 .2761688232494 .75971221924 95.2759704589895 .8276748657296 .4171752929797 .0449829101697 .71081542969 98.4132385253999 .1506423950299 .92024230957100 .71875101 .5417404175 102.3844528198103 .2415466309104 .1078567505104 .978477478105 .8492736816 106.7171173096107 .5801239014108 .4378128052109 .2910842896110 .1422119141 110.9947662354111 .7052230835110 .7344818115109 .8413696289109 .0625610352 108.4315490723 107.9716873169107.695526123 107.6026763916107.6814804077 107.9133300781 108.2714920044 108.7225494385 109.232460022109.7664794922 110.2855148315110 .747543335111 .1125259399111 .3413848877111 .4044647217 111.2892456055111 .0359802246110 .7806167603110 .7835388184111 .3972854614 111.7768936157111 .259147644111 .548538208111 .9846038818111 .4755172729 110.2121582031108 .4705429077106 .108001709102 .939636230598 .89420318604 94.4833908081188 .9972534179784 .4254837036178 .6345596313572 .23407745361 41.1459884643640 .2316398620639 .622070312538 .7077102661137 .79335021973 37.1837806701736 .5742111206136 .2694282531735 .9646492004435 .96464920044 36.5742111206137 .4885711669938 .7077102661140 .5364189147942 .36513137817 44.8034095764246 .6321296691944 .4986305236842 .3651313781741 .14598846436 40.5364189147940 .2316398620638 .4029312133836 .5742111206136 .87900161743 34.7455101013232 .3072204589829 .2593708038331 .0880794525134 .44071960449 41.7555618286150 .8991203308160 .3474502563573 .4532165527377 .32674407959 78.2238006591876 .6768341064573 .0588836669970 .5810089111370 .88455200195 71.4867172241273 .1562576293975 .595565795976 .3262557983475 .77919006348 73.1484298706167 .0527267456162 .4809494018649 .0704002380436 .57421112061 28.9545898437525 .2971591949524 .0780296325724 .9923801422127 .4306602478 29.8689403533930 .1737308502230 .1737308502230 .4785099029531 .39286994934 32.6120109558134 .7455101013237 .1837806701739 .9268493652342 .97470092773 45.717769622848 .4608306884850 .5943298339852 .7278289794954 .25175094604 55.4708900451756 .6900291442957 .6043891906758 .5187492370659 .12831115723 59.7378807067960 .3474502563560 .6522407531761 .2618103027361 .56660079956 62.1761703491262 .4809494018662 .7857398986863 .3953094482464 .0048828125 64.6144485473665 .2240066528365 .6080780029366 .4431610107467 .05272674561 67.9670867919968 .2847518920968 .5952377319370 .1005783081170 .71015167236 71.9292907714873 .14842987061 -9999 -9999 -9999 -9999 -9999 -9999 -9999 -9999 -9999

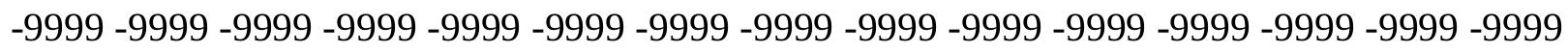

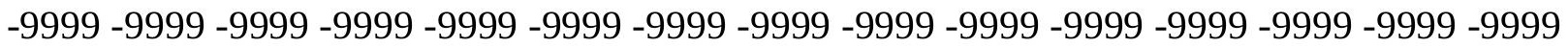

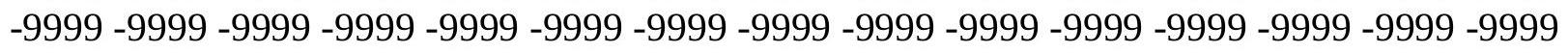
-9999 -9999 -9999 -9999 -9999 -9999 -9999 
-9999 -9999 -9999 -9999 -9999 -9999 -9999 -9999 -9999 -9999 -9999 -9999 -9999 -9999 -9999 -9999 -9999 -9999 -9999 -9999 -9999 -9999 -9999 -9999 -9999 -9999 -9999 -9999 -9999 -9999

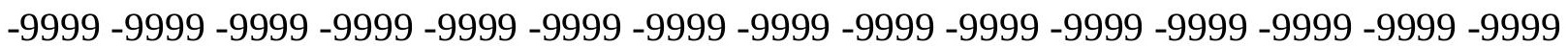
-9999 -9999 -9999 -9999 -9999 -9999 -9999 -9999 -9999 -9999 -9999 -9999 -9999 -9999 -9999 -9999 -9999 -9999 -9999 -9999 -9999 -9999 -9999 -9999 -9999 -9999 179.5116119385 178.4192352295172 .8132019043165 .8031005859159 .0977935791153 .9165039062 149.6495056152145 .6873016357142 .6394042969140 .5059967041137 .4580993652 122.5235977173117 .647102356113 .075302124108 .1986999512103 .0174026489 97.5312423706191 .7403335571386 .254188537680 .1584930419974 .36756896973 52.4230384826753 .9469718933155 .4708900451756 .6900291442958 .21395874023 59.4331016540560 .6522407531761 .8713798522962 .7857398986863 .70008850098 64.6144485473665 .2240066528365 .5288009643665 .8335876464866 .13836669922 66.1383666992266 .1383666992266 .1383666992265 .8335876464865 .83358764648 65.5288009643665 .2240066528364 .9192428588964 .3096618652364 .0048828125 63.3953094482462 .7857398986861 .8713798522961 .2618103027360 .95701980591 61.5666007995662 .4809494018663 .7000885009864 .9192428588966 .13836669922 67.3575134277368 .5766525268669 .7957916259871 .014930725172 .23407745361 73.4532165527374 .6723632812576 .1962814331178 .0249862670979 .54891967773 81.0728530883882 .5967712402384 .1206970214885 .3398437586 .2541885376 86.8637619018687 .4733276367288 .0829010009888 .3876876831189 .3020401001 89.31777191162 89.35357666016 89.41295623779 89.49440765381 89.59665679932 89.7182617187589 .8580474853590 .0147171020590 .1872863769590 .37479400635 90.5766296386790 .7922515869191 .0215301513791 .2644577026491 .52143859863 91.7929077148492 .079658508392 .3824386596792 .7022399902393 .03997802734 93.3973693847793 .7767105102594 .1811370849694 .613845825295 .07852935791 95.5783691406296 .1161499023496 .6927795410297 .3082580566497 .96118164062 98.649696350199 .37049102783100 .119468689100 .8911743164101 .6795883179 102.4780654907103 .2800521851104 .0794296265104 .8709640503105 .6508407593 106.4167022705107 .1681900024107 .9065246582108 .6349029541109 .3580474854 110.0824279785109 .0712509155108 .0519638062107 .1617126465106 .4453353882 105.9358520508105 .6503219604105 .5892333984105 .7385406494106 .0731811523 106.5620193481107 .1720275879107 .8694000244108 .616645813109 .3694839478 110.0754241943110 .6774673462111 .1209487915111 .3605880737111 .3738327026 111.1726303101110 .8313598633110 .6073532104111 .1775512695109 .7063980103 109.5143432617109 .9623336792109 .1502685547108 .3001556396107 .0374679565 105.1862792969102 .626594543599 .3599472045994 .4833908081188 .69246673584 85.33984375 82.29197692871 78.32978057861 74.0627822876 37.18378067017 36.8790016174336 .2694282531735 .9646492004435 .3550796508834 .74551010132 34.4407196044934 .1359291076733 .8311500549333 .8311500549334 .44071960449 35.0502891540536 .2694282531737 .4885711669939 .0125007629440 .23163986206 40.5364189147939 .3172798156738 .0981407165537 .1837806701737 .18378067017 37.1837806701736 .2694282531737 .7933502197336 .8790016174334 .74551010132 32.9167900085431 .3928699493430 .4785099029533 .5263595581138 .40293121338 44.8034095764251 .8134689331159 .4331016540568 .2718734741271 .0149307251 67.6623001098666 .4431610107468 .2718734741267 .6346664428769 .12803649902 71.9250640869175 .3643264770578 .6030654907280 .8049316406281 .73934173584 
81.0728530883872 .5388565063561 .8713798522947 .5464782714836 .87900161743 29.5641593933124 .6875991821323 .4684505462625 .2971591949529 .25937080383 27.7354507446327 .7354507446328 .3450202941929 .2593708038330 .78330039978 32.9167900085435 .3550796508838 .7077102661142 .0603485107445 .41297912598 48.4608306884850 .8991203308153 .0326118469254 .5565414428755 .77568054199 56.6900291442957 .6043891906758 .5187492370659 .1283111572359 .43310165405 60.0426712036160 .3474502563560 .9570198059161 .2618103027361 .56660079956 62.1761703491262 .4809494018663 .0905189514263 .7000885009864 .0048828125 64.6144485473665 .2026748657266 .1383666992266 .7479400634867 .35751342773 67.9859695434668 .4044723510769 .7957916259870 .4053573608471 .31971740723 72.2340774536173 .45321655273 -9999 -9999 -9999 -9999 -9999 -9999 -9999 -9999 -9999 -9999 -9999 -9999 -9999 -9999 -9999 -9999 -9999 -9999 -9999 -9999 -9999 -9999 -9999 -9999 -9999 -9999 -9999 -9999 -9999 -9999 -9999 -9999 -9999 -9999 -9999 -9999 -9999 -9999 -9999 -9999 -9999 -9999 -9999 -9999 -9999 -9999 -9999 -9999 -9999 -9999 -9999 -9999 -9999 -9999 -9999 -9999 -9999-9999-9999-9999

-9999 -9999-9999 -9999 -9999 -9999 -9999 -9999 -9999-9999 -9999 -9999 -9999 -9999 -9999 -9999 -9999 -9999 -9999 -9999 -9999 -9999 -9999 -9999 -9999 -9999 -9999 -9999 -9999 -9999 -9999 -9999 -9999 -9999 -9999 -9999 -9999 -9999 -9999 -9999 -9999 -9999 -9999 -9999 -9999 -9999 -9999 -9999 -9999 -9999 -9999 -9999 -9999 -9999 -9999 -9999 -9999 -9999 -9999 -9999 -9999 -9999 -9999 -9999 -9999 -9999 -9999 -9999 -9999 -9999 -9999 -9999 -9999 178.6062164307178 .5988769531174 .6419067383168 .241394043161 .8408966064 155.7451934814152 .3925933838148 .1255950928142 .0299072266133 .8007049561 127.0953979492121 .3044967651114 .9039993286108 .5035018921101 .7982025146 95.7025299072389 .6068267822383 .206336975177 .110626220752 .72782897949 54.2517509460455 .4708900451756 .9948196411158 .2139587402359 .43310165405 60.6522407531761 .5666007995662 .4809494018663 .3953094482464 .0048828125 64.3096618652364 .9192428588965 .2240066528365 .2240066528365 .22400665283 65.2240066528365 .2240066528365 .2240066528364 .9192428588964 .61444854736 64.6144485473664 .3096618652364 .3096618652364 .004882812563 .70008850098 63.3953094482463 .0905189514262 .7857398986862 .7857398986863 .39530944824 64.004882812564 .6144485473665 .5288009643666 .1383666992267 .05272674561 67.9670867919968 .8814392089870 .1005783081171 .3197174072372 .53885650635 73.7580032348675 .2819290161177 .110626220778 .6345596313580 .15849304199 81.6824111938583 .206336975184 .1206970214885 .0350494384885 .94940185547 86.5589828491287 .1685485839887 .7781066894588 .6924667358489 .60682678223 89.6582336425889 .72348785489 .8096542358489 .9152297973690 .0385055542 90.1780319213990 .3322448730590 .4998931884890 .6797790527390 .87106323242 91.0730209350691 .2853546142691 .5079727172991 .7411422729591 .98522949219 92.2408447265692 .5086288452192 .7896118164193 .0849914550893 .39686584473 93.7281646728594 .0828247070394 .4648895263794 .8787384033295 .32807159424 95.8160781860496 .3440551757896 .9123382568497 .5195999145598 .16376495361 98.8409729003999 .54623413086100 .2729187012101 .0135040283101 .7596817017 102.5031204224103 .2360687256103 .9518203735104 .6455383301105 .314201355 105.957321167106 .5764160156107 .1754150391107 .760093689108 .3383255005 107.4321670532106 .2730407715105 .2499847412104 .424156189103 .8408660889 103.5246429443103 .4774856567103 .6821136475104 .1084747314104 .7235107422 
105.4976806641106 .4034881592107 .4066619873108 .4567565918109 .4860687256 110.4173583984111 .1813354492111 .7291259766112 .0461578369112 .1617889404 112.1580276489112 .1111907959111 .5914535522109 .4179000854107 .2844009399 106.3700027466105 .7603988647105 .1509017944103 .9317016602102 .1029968262 99.35994720459 95.70252990723 91.43553924561 87.16854858398 84.12069702148 81.6824111938578 .9393463134875 .8914871215833 .5263595581133 .52635955811 33.2215805053732 .9167900085432 .6120109558132 .3072204589832 .00244140625 31.6976509094231 .6976509094231 .6976509094232 .0024414062532 .30722045898 33.2215805053733 .8311500549334 .7455101013236 .8790016174336 .57421112061 35.0502891540532 .6120109558132 .9167900085433 .5263595581134 .13592910767 34.1359291076735 .3550796508833 .5263595581132 .9167900085432 .91679000854 32.9167900085433 .2215805053734 .4407196044936 .2694282531740 .53641891479 45.4129791259851 .5086898803756 .3852500915559 .4331016540559 .73788070679 59.7378807067957 .2995986938561 .2618103027364 .0066223144568 .24946594238 73.4897613525478 .8856735229583 .3418197631885 .9861068725685 .57825469971 80.1584930419969 .7957916259860 .0426712036147 .5464782714837 .48857116699 30.7833003997828 .0402297973622 .8588790893622 .5541000366224 .07802963257 26.2115192413327 .430660247828 .3450202941929 .5641593933131 .39286994934 34.1359291076737 .7933502197341 .7555618286145 .4129791259848 .7656211853 51.5086898803753 .6421813964855 .1661109924356 .3852500915557 .29959869385 57.909179687558 .5187492370658 .8235282897959 .4331016540559 .73788070679 60.0426712036160 .6522407531760 .9570198059161 .2618103027361 .56660079956 62.1761703491262 .4809494018663 .0905189514263 .7000885009864 .30966186523 64.8315429687565 .8335876464866 .4431610107467 .0527267456167 .7624130249 68.2095947265669 .1862335205170 .1005783081170 .7101516723671 .62449645996 72.5388565063573 .45321655273 -9999 -9999 -9999 -9999 -9999 -9999 -9999 -9999 -9999 -9999 -9999 -9999 -9999 -9999 -9999 -9999 -9999 -9999 -9999 -9999 -9999 -9999 -9999 -9999

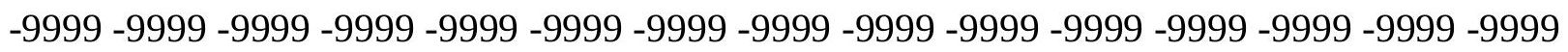

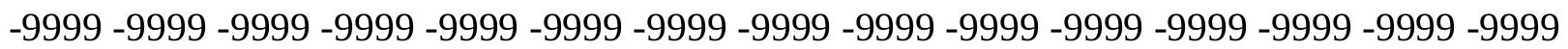
-9999 -9999-9999-9999-9999

-9999 -9999 -9999 -9999 -9999 -9999 -9999 -9999 -9999 -9999 -9999 -9999 -9999 -9999 -9999 -9999 -9999 -9999 -9999 -9999 -9999 -9999 -9999 -9999 -9999 -9999 -9999 -9999 -9999 -9999 -

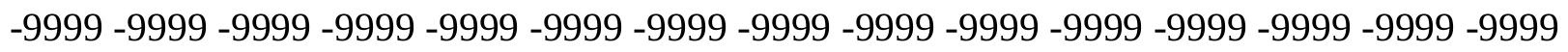

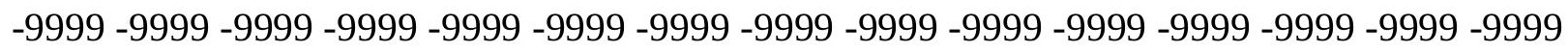

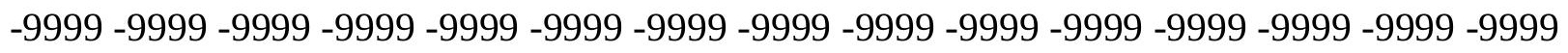
-9999 181.7280578613177.9945068359171.5939941406164.5839996338156.6596069336 149.0399017334144 .7729034424138 .3724975586131 .3623962402123 .7427978516 115.2088012695107 .284400939999 .3599472045992 .0450973510785 .64462280273 79.2441329956153 .0326118469254 .2517509460455 .7756805419956 .99481964111 58.2139587402359 .4331016540560 .6522407531761 .5666007995662 .17617034912 63.0905189514263 .3953094482464 .004882812564 .3096618652364 .30966186523 64.61444854736 64.61444854736 64.3096618652364.3096618652364.30966186523 64.3096618652364 .004882812564 .004882812564 .004882812564 .0048828125 64.004882812564 .004882812564 .3096618652364 .3096618652364 .61444854736 65.2240066528365 .5288009643665 .8335876464866 .1383666992266 .44316101074 66.7479400634867 .0527267456167 .6623001098668 .2718734741269 .18623352051 
70.4053573608471 .6244964599673 .1484298706174 .6723632812576 .50106811523 78.0249862670979 .2441329956180 .7680587768681 .9871978759882 .90155792236 83.81591033936 84.73026275635 85.33984375 86.2541885376 87.16854858398 88.0829010009888 .9972534179789 .9642639160290 .0355911254990 .12673950195 90.2359313964890 .3611984252990 .5007781982490 .6528244018690 .81577301025 90.9881591796991 .1688766479591 .3570251464891 .5521011352591 .75391387939 91.9626235961992 .1785202026492 .4020309448292 .6336746215892 .87452697754 93.1262359619193.3914794921993.6738662719793.9781112670994.30909729004 94.672019958595 .0712280273495 .5104217529395 .9913253784296 .51464080811 97.0791931152397 .68276214698 .3209228515698 .9877700805799 .67532348633 100.3743743896101 .0745697021101 .7652893066102 .436668396103 .080039978 103.6892318726104 .260269165104 .7924728394105 .2875137329105 .7500915527 105.6922073364105 .6065826416105 .6648025513104 .588760376103 .4048233032 102.4331207275101 .7351303101101 .3473129272101 .2748413086101 .4981307983 101.9809265137102 .6903915405103 .6069564819104 .7219085693106 .0151596069 107.4297485352108 .8709335327110 .2264328003111 .4065475464112 .3722686768 113.146522522113 .8075408936114 .5064849854112 .7705001831109 .1130981445 106.0652008057103 .3221969604102 .712600708102 .4077987671101 .7982025146 100.883903503499 .0551681518696 .6168823242293 .5690307617290 .21640014648 86.8637619018684 .4254837036182 .2919769287180 .4632720947378 .32978057861 30.1737308502230 .4785099029530 .4785099029530 .4785099029530 .17373085022 29.8689403533929 .8689403533929 .5641593933129 .2593708038329 .25937080383 29.2593708038329 .2593708038329 .8689403533930 .1737308502230 .17373085022 32.0024414062531 .0880794525127 .7354507446327 .1258792877228 .64979934692 30.1737308502231 .0880794525132 .0024414062531 .6976509094230 .78330039978 29.8689403533931 .3928699493432 .9167900085433 .8311500549334 .44071960449 34.1359291076736 .5742111206139 .9268493652343 .8890609741247 .54647827148 50.8991203308153 .3373985290556 .3852500915561 .2618103027359 .43310165405 58.8235282897963 .972373962470 .6270141601677 .3095474243283 .15855407715 86.7186584472787 .1386947631884 .0664901733477 .7202072143667 .96708679199 59.1283111572350 .5943298339844 .1938400268636 .5742111206128 .64979934692 21.334960937524 .6875991821328 .0402297973628 .9545898437528 .95458984375 29.2593708038330 .7833003997833 .2215805053737 .4885711669942 .06034851074 46.6321296691950 .2895507812553 .0326118469254 .8613204956156 .38525009155 56.9948196411157 .6043891906758 .2139587402358 .5187492370658 .82352828979 59.1283111572359 .4331016540559 .7378807067960 .0426712036160 .65224075317 60.9570198059161 .2618103027361 .8713798522962 .1761703491262 .78573989868 63.3953094482464 .004882812564 .5000610351665 .5288009643666 .13836669922 66.7479400634867 .6623001098667 .9787750244168 .8814392089869 .49101257324 70.4053573608471 .014930725171 .6244964599672 .5388565063573 .75800323486 -9999 -9999 -9999 -9999 -9999 -9999 -9999 -9999 -9999 -9999 -9999 -9999 -9999 -9999 -9999 -9999

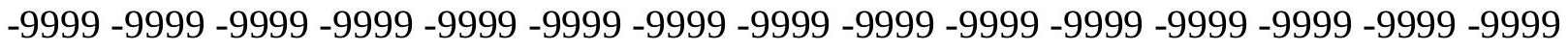
-9999 -9999 -9999 -9999 -9999 -9999 -9999 -9999 -9999 -9999 -9999 -9999 -9999 -9999 -9999 -9999 -9999 -9999 -9999 -9999 -9999 -9999 -9999 -9999 -9999 -9999 -9999 -

-9999 -9999 -9999 -9999 -9999 -9999 -9999 -9999 -9999 -9999 -9999 -9999 -9999 -9999 -9999

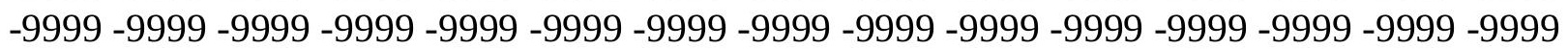


-9999 -9999 -9999 -9999 -9999 -9999 -9999 -9999 -9999 -9999 -9999 -9999 -9999 -9999 -9999 -9999 -9999 -9999 -9999 -9999 -9999 -9999 -9999 -9999 -9999 -9999 -9999 -9999 -9999 -9999 -9999 -9999 -9999 -9999 -9999 -9999 -9999 -9999 -9999 -9999 -9999 -9999 -9999 -9999 -9999 -9999 -9999-9999 186.272567749 180.432800293172.8132019043165.4983062744 156.9642944336150 .5639038086142 .9441986084134 .4102020264124 .6570968628 114.2944030762103 .626899719293 .5690307617287 .4733276367279 .24413299561 53.3373985290554 .8613204956156 .0804595947357 .2995986938558 .51874923706 59.7378807067960 .6522407531761 .5666007995662 .1761703491262 .78573989868 63.3953094482463 .3953094482463 .7000885009863 .7000885009863 .70008850098 63.7000885009863 .7000885009863 .7000885009863 .3953094482463 .39530944824 63.3953094482463 .7000885009863 .7000885009864 .004882812564 .30966186523 64.6144485473665 .2240066528365 .8335876464866 .7479400634867 .35751342773 67.9670867919967 .9670867919967 .6623001098667 .3575134277367 .05272674561 67.0527267456167 .3575134277367 .6623001098668 .5766525268669 .79579162598 71.014930725172 .5388565063574 .3675689697375 .8914871215877 .1106262207 78.3297805786179 .5489196777380 .4632720947381 .3776321411182 .29197692871 83.206336975184 .1206970214885 .0350494384886 .254188537687 .16854858398 88.6924667358489 .9116134643690 .3481369018690 .4445266723690 .55767059326 90.6853027343890 .8253250122190 .9755554199291 .1340942382891 .29917144775 91.4693832397591 .6436157226691 .8211593627992 .0016860961992 .18523406982 92.3720169067492 .5623092651492 .7565231323292 .9558181762793 .16235351562 93.3795242309693 .6116638183693 .8642120361394 .1428756713994 .45376586914 94.802040100195 .1920623779395 .6260833740296 .1052474975696 .6286315918 97.1939697265697 .7963790893698 .4290161132899 .0825042724699 .74570465088 100.4058837891101 .0495910645101 .6641540527102 .2383956909102 .7643890381 103.2370223999103 .6553421021103 .6834793091103 .2773895264102 .9655914307 102.7843856812102 .7647171021102 .927482605101 .7019577026100 .5442352295 99.6836547851699 .1722335815499 .0244750976699 .2150192260799 .69873809814 100.4406814575101 .4394454956102 .728515625104 .3284454346106 .1816940308 108.1348800659110 .0092773438111 .662322998113 .0851745605114 .1952438354 114.9467086792113 .075302124109 .1130981445105 .7603988647102 .712600708 100.579101562599 .6647262573299 .3599472045999 .0551681518698 .14080810547 96.9216690063594 .7881774902392 .349891662689 .302040100186 .86376190186 85.3398437584 .1206970214882 .5967712402381 .0728530883827 .73545074463 28.0402297973627 .7354507446327 .7354507446327 .430660247827 .4306602478 27.1258792877226 .8210906982426 .8210906982426 .5163097381626 .51630973816 26.8210906982427 .1258792877227 .1258792877226 .5163097381625 .9067401886 24.9923801422124 .3828105926524 .3828105926525 .6019496917727 .12587928772 28.6497993469230 .1737308502230 .1737308502229 .2593708038328 .64979934692 28.3450202941931 .6976509094232 .3072204589831 .3928699493432 .00244140625 32.9167900085434 .7455101013237 .1837806701740 .2316398620643 .58427047729 46.9369087219250 .8991203308154 .8613204956157 .2995986938560 .34745025635 58.8235282897966 .4431610107474 .3215026855580 .878768920985 .07792663574 86.740646362382 .8426437377973 .1484298706176 .1962814331171 .0149307251 65.5288009643657 .909179687549 .3751907348640 .2316398620632 .00244140625 33.8311500549333 .2215805053732 .3072204589831 .3928699493430 .47850990295 
30.7833003997833 .5263595581138 .0981407165543 .8890609741248 .7656211853 52.7278289794955 .1661109924356 .6900291442957 .6043891906758 .21395874023 58.2139587402358 .5187492370658 .8235282897958 .8235282897959 .12831115723 59.4331016540559 .7378807067959 .7378807067960 .0426712036160 .65224075317 60.9570198059161 .2618103027361 .8713798522962 .4809494018663 .09051895142 63.6578979492264 .1709518432664 .9192428588965 .8335876464866 .44316101074 67.0527267456167 .6158981323267 .9620056152369 .1862335205169 .79579162598 70.4053573608471 .014930725171 .9292907714872 .8436431884873 .75800323486 -9999 -9999 -9999 -9999 -9999 -9999 -9999 -9999 -9999 -9999 -9999 -9999 -9999 -9999 -9999 -9999 -9999 -9999 -9999 -9999 -9999 -9999 -9999 -9999 -9999 -9999 -9999 -9999 -9999 -9999 -9999

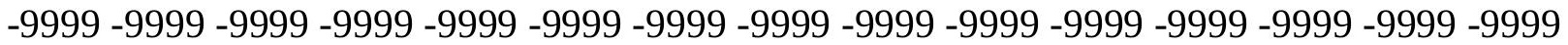
-9999 -9999 -9999 -9999 -9999 -9999 -9999 -9999 -9999 -9999 -9999

-9999 -9999 -9999 -9999 -9999 -9999 -9999 -9999 -9999 -9999 -9999 -9999 -9999 -9999 -9999 -9999 -9999 -9999 -9999 -9999 -9999 -9999 -9999 -9999 -9999 -9999 -9999 -9999 -9999 - 9999 -9999 -9999 -9999 -9999 -9999 -9999 -9999 -9999 -9999 -9999 -9999 -9999 -9999 -9999 -9999

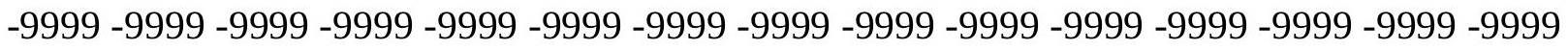
-9999 -9999 -9999 -9999 -9999 -9999 -9999 -9999 -9999 -9999 -9999 -9999 -9999 -9999 -9999 -9999 -9999 -9999-9999 188.4989929199 188.527053833181 .9824371338174 .9467010498 163.3648071289154 .5260925293145 .9920959473135 .0198059082122 .2188034058 108.503501892196 .6168823242286 .5589828491276 .1962814331154 .25175094604 55.4708900451756 .6900291442957 .909179687559 .1283111572360 .04267120361 60.9570198059161 .5666007995662 .4809494018662 .7857398986863 .09051895142 63.3953094482463 .3953094482463 .3953094482463 .0905189514263 .09051895142 63.0905189514262 .7857398986862 .7857398986862 .7857398986862 .78573989868 63.0905189514263 .3953094482463 .7000885009864 .3096618652364 .91924285889 65.8335876464867 .0527267456168 .2718734741269 .4910125732470 .10057830811 69.7957916259869 .1862335205168 .2718734741267 .6623001098667 .05272674561 67.0527267456167 .0527267456167 .9670867919968 .8814392089870 .40535736084 72.2340774536173 .7580032348675 .2819290161176 .5010681152377 .41542053223 78.3297805786179 .2441329956180 .1584930419981 .0728530883881 .98719787598 82.9015579223684 .1206970214885 .3398437586 .5589828491288 .08290100098 89.302040100190 .6598358154390 .7617492675890 .8792190551891 .00964355469 91.1505584716891 .2994232177791 .4539337158291 .6119842529391 .77183532715 91.9321289062592 .0919113159292 .250694274992 .4083862304792 .56509399414 92.7209472656292 .8763351440493 .0325317382893 .19223785493 .35955810547 93.5395736694393 .738418579193 .9626388549894 .2192687988394 .51445007324 94.8534011840895 .2390136718895 .6729812622196 .1548004150496 .68240356445 97.2505722045997.8516311645598.474746704199.1067581176899.73223114014 100.3342819214100 .8966293335101 .4047927856101 .8486404419102 .2216110229 101.9638977051101 .4157028198100 .9085998535100 .4764633179100 .1619644165 100.0160980225100 .0839767456100 .194938659798 .8276672363397 .77570343018 97.1014633178796.8462448120196.9579849243297.3855285644598.07125854492 99.04137420654100 .409538269102 .2963027954104 .6787796021107 .2804412842 108.5470809937109 .9229736328111 .3474960327112 .7891769409112 .7705001831 108.5035018921104 .8460998535101 .798202514699 .6647262573297 .83602905273 96.9216690063596 .6168823242296 .6168823242296 .3121032714895 .09295654297 
93.2642517089891 .7403335571388 .3876876831187 .1685485839886 .86376190186 86.254188537685 .0350494384883 .8159103393625 .6019496917725 .60194969177 25.6019496917725 .2971591949524 .9923801422124 .6875991821324 .38281059265 24.3828105926524 .0780296325724 .0780296325724 .0780296325724 .38281059265 24.3828105926524 .3828105926524 .0780296325723 .4684505462622 .85887908936 22.2493095397922 .5541000366223 .4684505462624 .6875991821326 .21151924133 27.1258792877227 .430660247827 .430660247826 .8210906982426 .51630973816 26.8210906982427 .430660247828 .3450202941928 .9545898437529 .25937080383 30.1737308502231 .3928699493433 .8311500549336 .5742111206139 .6220703125 43.2794914245646 .9369087219250 .8991203308154 .2517509460455 .16611099243 58.2139587402370 .7101516723676 .6443481445381 .387130737384 .4171295166 81.2482299804778 .7780914306681 .3776321411179 .2441329956173 .45321655273 67.0527267456160 .9570198059150 .8991203308143 .2794914245641 .14598846436 39.9268493652338 .0981407165535 .9646492004433 .8311500549332 .61201095581 34.7455101013240 .8412094116247 .8512611389252 .7278289794956 .08045959473 58.2139587402359 .1283111572359 .4331016540559 .4331016540559 .12831115723 58.8235282897958 .8235282897958 .8235282897959 .1283111572359 .12831115723 59.4331016540559 .7378807067959 .7378807067960 .3474502563560 .65224075317 60.9570198059161 .5666007995662 .1761703491262 .7857398986863 .33585739136 63.8516197204664 .6144485473665 .2240066528366 .1383666992266 .74794006348 67.2801818847767 .6674194335968 .8814392089869 .4910125732470 .10057830811 $70.7101516723671 .014930725171 .9292907714872 .8436431884873 .75800323486-9999$ -9999 -9999 -9999 -9999 -9999 -9999 -9999 -9999 -9999 -9999 -9999 -9999 -9999 -9999 -9999 -9999 -9999 -9999 -9999 -9999 -9999 -9999 -9999 -9999 -9999 -9999 -9999 -9999 -9999 -9999 -

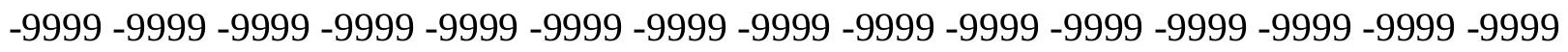
-9999 -9999 -9999 -9999 -9999-9999-9999 -9999 -9999-9999 -9999 -9999 -9999 -9999 -9999 -9999 -9999 -9999 -9999 -9999 -9999 -9999 -9999 -9999 -9999

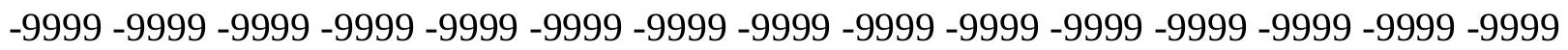
-9999 -9999 -9999 -9999 -9999 -9999 -9999 -9999 -9999 -9999 -9999 -9999 -9999 -9999 -9999 -9999 -9999 -9999 -9999 -9999 -9999 -9999 -9999 -9999 -9999 -9999 -9999 -9999 -9999 -9999 -9999 -9999 -9999 -9999 -9999 -9999 -9999 -9999 -9999 -9999 -9999 -9999 -9999 -9999 -9999 -9999 -9999 -9999 -9999-9999 193.1154327393 192.1475219727 190.2349243164 181.6519012451167 .9365997314158 .4882965088146 .6015930176131 .0576019287 113.380096435599 .0551681518685 .3398437571 .6244964599654 .86132049561 56.3852500915557 .2995986938558 .5187492370659 .7378807067960 .65224075317 61.2618103027362 .1761703491262 .4809494018663 .0905189514263 .09051895142 63.0905189514263 .0905189514262 .7857398986862 .7857398986862 .48094940186 62.1761703491262 .1761703491262 .1761703491262 .1761703491262 .48094940186 62.7857398986863 .0905189514263 .7000885009864 .3096618652365 .22400665283 66.1383666992267 .6623001098668 .8814392089870 .7101516723671 .92929077148 71.014930725170 .1005783081168 .8814392089867 .9670867919967 .05272674561 66.7479400634866 .4431610107467 .0527267456167 .9670867919969 .79579162598 71.6244964599673 .4532165527374 .6723632812575 .5867080688576 .50106811523 77.110626220777 .7202072143678 .6345596313579 .5489196777380 .46327209473 81.6824111938582 .9015579223684 .4254837036185 .9494018554787 .47332763672 88.9972534179790.5211791992291.077003479 91.1991806030391.3328704834 
91.4751968383891 .6232147216891 .7741851806691 .9256057739392 .07536315918 92.2218017578192 .363693237392 .5003738403392 .631561279392 .75726318359 92.8774795532292 .9925842285293 .1040267944393 .2149963378993 .33029937744 93.4557952880993 .5982894897593 .7650833129993 .9641571044994 .20269012451 94.486892700294 .820457458595 .2058410644595 .6432113647596 .1310043335 96.6639785766697 .2337341308697 .8280334472798 .4316329956199 .02627563477 99.5912322998100 .105682373100 .5508575439100 .9134292603100 .692855835 100.087051391699 .4722213745198 .8619079589898 .2842788696397 .79109954834 97.4573974609497 .3699645996197 .5948410034297 .3401336669996 .1233291626 95.3245239257894 .9787597656295 .0183181762795 .3597259521595 .88566589355 96.6569747924897 .9142761230599 .98900604248103 .0018997192104 .3007888794 105.7513885498107 .3610305786109 .0409011841109 .1130981445106 .0652008057 103.0174026489100 .274299621697 .8360290527396 .3121032714895 .09295654297 94.4833908081194 .1785964965894 .1785964965894 .1785964965893 .56903076172 92.0450973510789 .9116134643686 .5589828491288 .3876876831189 .3020401001 88.6924667358487 .4733276367286 .5589828491223 .7732391357423 .46845054626 23.1636695861822 .8588790893622 .5541000366222 .2493095397921 .94453048706 21.6397399902321 .6397399902321 .6397399902321 .6397399902321 .94453048706 21.9445304870621 .9445304870621 .9445304870621 .6397399902321 .03017044067 21.0301704406721 .0301704406721 .6397399902322 .5541000366223 .46845054626 24.3828105926524 .6875991821324 .6875991821324 .6875991821324 .38281059265 24.6875991821324 .9923801422125 .2971591949525 .2971591949525 .60194969177 25.906740188626 .8210906982428 .3450202941930 .1737308502232 .61201095581 35.0502891540538 .0981407165542 .0603485107445 .717769622849 .37519073486 54.5565414428762 .4809494018669 .7957916259876 .0903396606480 .38804626465 80.7167510986381 .2737731933682 .1137695312581 .3776321411179 .24413299561 76.1962814331171 .6244964599662 .4809494018654 .2517509460450 .28955078125 47.8512611389245 .1082000732442 .3651313781739 .9268493652338 .09814071655 37.1837806701747 .5464782714854 .5565414428758 .8235282897960 .65224075317 62.1761703491262 .1761703491261 .2618103027360 .6522407531759 .73788070679 59.4331016540559 .1283111572358 .8235282897958 .8235282897959 .12831115723 59.1283111572359 .4331016540559 .7378807067960 .0426712036160 .34745025635 60.6522407531761 .2618103027361 .8713798522962 .4809494018663 .02773284912 63.5470924377464 .3096618652364 .9192428588965 .8335876464866 .44316101074 66.9955978393667 .4052124023468 .2718734741269 .1862335205169 .79579162598 70.1005783081170 .7101516723671 .3197174072371 .9292907714872 .84364318848 73.75800323486 -9999 -9999 -9999 -9999 -9999 -9999 -9999 -9999 -9999 -9999 -9999 -9999

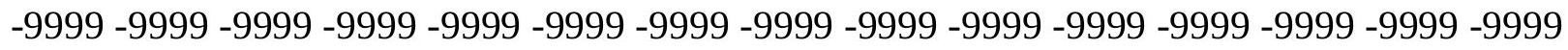
-9999 -9999 -9999 -9999 -9999 -9999 -9999 -9999 -9999 -9999 -9999 -9999 -9999 -9999 -9999 -9999 -9999 -9999 -9999 -9999 -9999 -9999 -9999 -9999 -9999 -9999 -9999 -9999 -

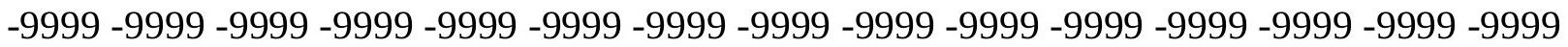
-9999 -9999 -9999 -9999 -9999 -9999 -9999 -9999 -9999 -9999 -9999 -9999 -9999 -9999 -9999 -9999 -9999 -9999 -9999 -9999 -9999 -9999 -9999 -9999 -9999 -9999 -9999 -9999 -9999 -9999 -9999 -9999 -9999 -9999 -9999 -9999 -9999 -9999 -9999 -9999 -9999 -9999 -9999 -9999 -9999 -9999 -9999 -9999 -9999 -9999 -9999 -9999 -9999 -9999 -9999 -9999 -9999 -9999 -9999 -9999 -9999 -9999 -9999 -9999 -9999 -9999 196.9495544434 195.600402832192 .2854309082 
184.1242523193172 .2035980225157 .5738983154140 .2012023926120 .6949005127 101.798202514684 .1206970214867 .0527267456156 .0804595947357 .29959869385 58.5187492370659 .4331016540560 .3474502563561 .2618103027362 .17617034912 62.7857398986863 .0905189514263 .3953094482463 .3953094482463 .39530944824 63.0905189514262 .7857398986862 .1761703491261 .8713798522961 .56660079956 61.5666007995661 .5666007995661 .5666007995661 .8713798522962 .17617034912 62.7857398986863 .3953094482464 .004882812564 .9192428588966 .13836669922 67.6623001098668 .8814392089870 .4053573608471 .3197174072371 .0149307251 70.1005783081168 .8814392089867 .9670867919967 .0527267456166 .13836669922 65.8335876464866 .1383666992267 .0527267456168 .8814392089871 .0149307251 73.1484298706173 .7580032348674 .3675689697374 .9771423339875 .89148712158 76.1962814331177 .110626220778 .0249862670979 .2441329956180 .46327209473 81.9871978759883 .5111236572385 .3398437586 .8637619018688 .69246673584 90.2164001464891 .38867187591 .5159683227591 .6534423828191 .79777526855 91.9455718994192 .093605041592 .2389373779392 .3790130615292 .51183319092 92.6358413696392 .7501678466892 .8542938232492 .9481353759893 .03153991699 93.1048965454193.1697921752993.2298965454193.2906570434693.35871887207 93.4415664672993 .5472030639693 .6843566894593 .8612213134894 .08503723145 94.3605194091894 .691131591895 .0780715942495 .5207366943496 .01425170898 96.5498123168997 .1112213134897 .6958084106498 .2695770263798 .81462097168 99.2904205322399 .6818695068499 .7330780029399 .150245666598 .54093933105 97.8880386352597 .1849670410296 .448242187595 .7346191406295 .14376831055 94.8224716186594 .9296798706195 .5317459106494 .8395004272594 .19186401367 93.8099670410293 .9450836181694 .1935195922994 .450752258394 .80303955078 95.6480026245197 .6482543945399 .79149627686100 .3652877808101 .5092010498 103.3221969604102 .4077987671100 .883903503498 .7503814697396 .92166900635 95.0929565429793 .8738174438592 .9594726562592 .6546783447392 .04509735107 91.7403335571392 .349891662692 .6546783447392 .349891662691 .43553924561 89.9116134643689 .6068267822391 .7403335571391 .4355392456190 .52117919922 89.6068267822388 .9972534179721 .9445304870621 .6397399902321 .03017044067 20.4206008911120 .1158199310319 .5062503814719 .2014598846419 .20145988464 18.8966808319119 .2014598846419 .2014598846419 .5062503814719 .8110294342 20.1158199310320 .1158199310320 .1158199310319 .811029434219 .8110294342 19.811029434220 .1158199310320 .7253894805921 .334960937521 .63973999023 21.9445304870622 .2493095397921 .9445304870621 .9445304870621 .94453048706 21.9445304870621 .9445304870621 .9445304870622 .2493095397922 .24930953979 22.8588790893623 .4684505462624 .6875991821325 .906740188630 .17373085022 28.9545898437533 .5263595581138 .0981407165542 .9747009277348 .7656211853 55.1661109924363 .3953094482469 .4887161254974 .3243179321378 .45796203613 80.8700027465882 .7643508911184 .0459823608484 .6285552978583 .81591033936 83.5111236572373 .7580032348661 .8713798522959 .4331016540555 .47089004517 53.0326118469250 .8991203308148 .4608306884847 .8512611389250 .59432983398 59.7378807067962 .7857398986865 .2240066528366 .7479400634866 .44316101074 65.2240066528363 .3953094482461 .5666007995660 .6522407531759 .73788070679 59.1283111572358 .8235282897958 .8235282897958 .8235282897958 .82352828979 59.1283111572359 .4331016540559 .7378807067960 .0426712036160 .34745025635 
60.9570198059161 .5666007995662 .1761703491262 .725162506163 .39530944824 64.004882812564 .6144485473665 .2240066528366 .1383666992266 .74794006348 67.1344528198267 .3894119262768 .5766525268669 .1862335205169 .79579162598 70.4053573608470 .7101516723671 .3197174072371 .9292907714872 .84364318848 73.45321655273 -9999 -9999 -9999 -9999 -9999 -9999 -9999 -9999 -9999 -9999 -9999 -9999 -9999 -9999 -9999 -9999 -9999 -9999 -9999 -9999 -9999 -9999 -9999 -9999 -9999 -9999 -9999

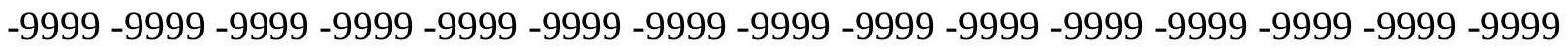
-9999 -9999 -9999 -9999 -9999 -9999 -9999 -9999 -9999 -9999 -9999 -9999

-9999 -9999 -9999 -9999 -9999 -9999 -9999 -9999 -9999 -9999 -9999 -9999 -9999 -9999 -9999 -9999 -9999 -9999 -9999 -9999 -9999 -9999 -9999 -9999 -9999 -9999 -9999 -9999 -9999 -9999 -

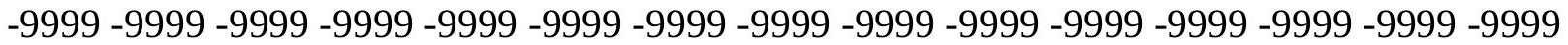
-9999 -9999 -9999 -9999 -9999 -9999 -9999 -9999 -9999 -9999 -9999 -9999 -9999 -9999 -9999 -9999 -9999 -9999 -9999 -9999 -9999 -9999 -9999 -9999 -9999 -9999 -9999 -9999 -9999 -9999 -999 -9999 -9999 -9999 -9999 -9999 -9999 -9999 -9999 198.3590545654195 .2534179688 184.9841918945168 .5462036133147 .8208007812125 .5715026855103 .6268997192 86.8637619018670 .1005783081157 .6043891906758 .8235282897959 .73788070679 60.6522407531761 .2618103027362 .1761703491262 .7857398986863 .39530944824 63.7000885009864 .004882812564 .004882812563 .7000885009863 .09051895142 62.4809494018661 .8713798522961 .5666007995661 .2618103027360 .95701980591 60.9570198059161 .2618103027361 .5666007995661 .8713798522962 .48094940186 63.0905189514263 .7000885009864 .6144485473665 .8335876464867 .05272674561 68.2718734741269 .1862335205170 .1005783081170 .1005783081169 .49101257324 68.8814392089867 .9670867919967 .0527267456166 .1383666992265 .52880096436 65.2240066528366 .4431610107468 .2718734741269 .7957916259871 .31971740723 72.2340774536172 .8436431884873 .4532165527374 .3675689697374 .67236328125 75.2819290161176 .1962814331177 .7202072143679 .2441329956181 .07285308838 83.206336975184 .7302627563586 .5589828491288 .3876876831189 .91161346436 91.6950073242291 .827850341891 .9696655273492 .1166687011792 .26496124268 92.4107971191492 .5507354736392 .6817092895592 .8013229370192 .90765380859 92.9995346069393 .0762023925893 .137420654393 .182891845793 .21301269531 93.2295150756893 .2365188598693 .2400665283293 .2474670410293 .2668838501 93.306922912693 .3768692016693 .4856414794993 .6415023803793 .85031890869 94.1168899536194 .4438400268694 .8320312595 .277626037695 .76874542236 96.3107528686596 .8816833496197 .4488754272597 .9764862060598 .4260559082 98.7587585449298 .391189575297 .8625564575297 .3002395629996 .6575012207 95.8864898681695 .0035018920994 .0544204711993 .1497802734492 .50009155273 92.4057769775493 .1527786254994 .1076660156294 .1785964965893 .56903076172 93.2642517089893.2642517089893.5690307617293.8738174438593.56903076172 94.4833908081194 .4833908081193 .8738174438594 .1785964965893 .26425170898 93.5690307617293 .2642517089892 .0450973510791 .1307525634890 .21640014648 89.9116134643689 .9116134643689 .9116134643690 .2164001464890 .52117919922 91.1307525634891 .4355392456191 .4355392456191 .4355392456190 .82597351074 91.1307525634891 .4355392456191 .4355392456191 .4355392456191 .13075256348 91.1307525634820 .4206008911119 .5062503814718 .8966808319118 .287109375 17.6775398254417 .0679702758816 .7631797790516 .4584007263216 .45840072632 16.4584007263216 .7631797790517 .0679702758817 .6775398254418 .287109375 
18.5918903350818 .8966808319118 .8966808319118 .5918903350818 .59189033508 18.5918903350818 .8966808319119 .2014598846419 .5062503814719 .50625038147 19.5062503814719 .5062503814719 .5062503814719 .2014598846419 .20145988464 19.2014598846419 .2014598846418 .8966808319119 .2014598846419 .20145988464 19.811029434220 .1158199310320 .7253894805921 .9445304870623 .77323913574 27.1258792877231 .3928699493436 .2694282531741 .7555618286147 .85126113892 54.2517509460461 .2618103027365 .6316680908271 .6669998168977 .79263305664 82.6643066406285 .8405838012787 .6068878173887 .5138931274483 .21523284912 72.5388565063572 .8436431884864 .9192428588962 .4809494018661 .56660079956 59.7378807067959 .4331016540558 .5187492370660 .3474502563565 .52880096436 68.8814392089871 .014930725171 .9292907714870 .1005783081167 .66230010986 64.9192428588962 .7857398986860 .9570198059160 .0426712036159 .43310165405 58.8235282897958 .8235282897958 .5187492370658 .8235282897958 .82352828979 59.1283111572359 .4331016540559 .7378807067960 .3474502563560 .65224075317 61.2529907226661 .8627815246662 .4365348815962 .9860420227163 .70008850098 64.3096618652364 .9192428588965 .5288009643666 .4431610107466 .80686187744 67.0566864013768 .2718734741268 .8814392089869 .4910125732469 .79579162598 70.4053573608471 .014930725171 .3197174072371 .9292907714872 .53885650635 73.4532165527374 .0627822876 -9999 -9999 -9999 -9999 -9999 -9999 -9999 -9999 -9999

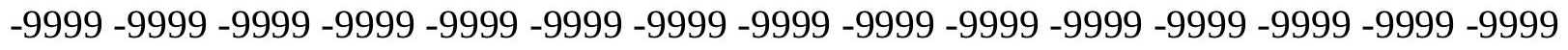

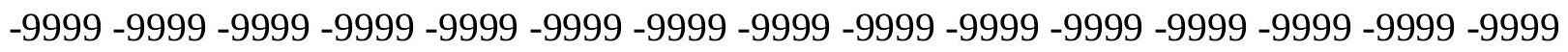
-9999 -9999 -9999 -9999 -9999 -9999 -9999 -9999 -9999 -9999 -9999 -9999 -9999 -9999 -9999 -9999 -9999 -9999 -9999 -9999 -9999 -9999 -9999 -9999 -9999 -9999 -9999 -9999 -

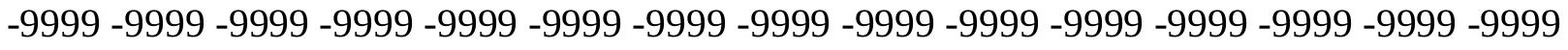

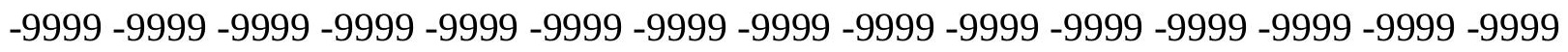
-9999 -9999 -9999 -9999 -9999 -9999 -9999 -9999 -9999 -9999 -9999 -9999 -9999 -9999 -9999 -9999 -9999 -9999 -9999 -9999-9999 -9999 -9999 -9999 -9999 -9999 -9999 -9999 -9999 - 9999 -9999 -9999-9999 -9999 -9999 -9999-9999-9999 -9999 203.2149810791 197.3994445801 179.3965301514154 .8307952881126 .4858016968104 .541297912685 .33984375 72.5388565063559 .7378807067960 .6522407531761 .2618103027361 .87137985229 62.7857398986863 .3953094482464 .004882812564 .6144485473664 .91924285889 64.9192428588964 .9192428588964 .3096618652363 .3953094482462 .48094940186 61.5666007995660 .9570198059160 .6522407531760 .3474502563560 .34745025635 60.6522407531760 .9570198059161 .5666007995662 .1761703491262 .78573989868 63.3953094482464 .3096618652365 .2240066528366 .1383666992267 .05272674561 67.9670867919968 .5766525268668 .8814392089868 .8814392089868 .57665252686 68.2718734741267 .3575134277366 .7479400634866 .1383666992265 .83358764648 66.4431610107467 .6623001098668 .5766525268669 .7957916259870 .40535736084 71.014930725171 .6244964599671 .9292907714872 .5388565063573 .45321655273 74.6723632812576 .5010681152378 .6345596313580 .7680587768682 .90155792236 84.7302627563586 .5589828491288 .0829010009889 .9116134643691 .74033355713 92.1328659057692 .2796325683692 .4300308227592 .579658508392 .72416687012 92.8595657348692.9822311401493.089286804293.1783447265693.24789428711 93.2968597412193.3248214721793.3313064575293.3167190551893.28294372559 93.2345733642693.1781311035293.121513366793.0733413696393.04272460938 93.0392837524493.0723495483493.1508712768693.2819747924893.4719619751 
93.7253189086994 .04492187594 .4287567138794 .8776092529395 .39685058594 95.9596252441496 .5224685668997 .0373458862397 .4567413330197 .65591430664 97.1477890014696 .7324371337996 .2842483520595 .7043304443494 .89562225342 93.9228668212992 .7870712280391 .5757217407290 .5210876464890 .06934356689 90.8878021240291 .4355392456189 .302040100188 .3876876831187 .47332763672 88.0829010009888 .9972534179789 .302040100189 .302040100189 .3020401001 88.9972534179788 .3876876831187 .7781066894587 .4733276367287 .47332763672 87.1685485839886 .8637619018686 .5589828491286 .5589828491286 .55898284912 87.1685485839887 .4733276367288 .0829010009888 .6924667358489 .3020401001 89.9116134643690 .5211791992290 .8259735107490 .8259735107491 .13075256348 91.4355392456191 .7403335571392 .0450973510792 .0450973510719 .50625038147 18.5918903350817 .6775398254416 .7631797790516 .1536102294915 .23925971985 14.6296901702914 .3248996734614 .0201196670514 .0201196670514 .02011966705 14.3248996734614 .934470176715 .5440397262616 .1536102294917 .06797027588 17.6775398254417 .3727493286117 .3727493286117 .0679702758817 .06797027588 17.0679702758817 .0679702758817 .3727493286117 .3727493286117 .06797027588 17.0679702758817 .0679702758816 .7631797790516 .7631797790516 .45840072632 16.4584007263216 .4584007263216 .4584007263216 .4584007263216 .45840072632 16.7631797790517 .0679702758817 .9823207855219 .5062503814721 .94453048706 25.6019496917729 .8689403533935 .0502891540539 .9268493652343 .88906097412 48.1560516357453 .9469718933163 .4931526184172 .3142547607479 .15253448486 84.3838958740287 .9056777954188 .8135147094786 .1799011230582 .01456451416 79.4983596801876 .5010681152371 .014930725167 .6623001098666 .74794006348 66.7479400634867 .6623001098668 .8814392089871 .014930725173 .14842987061 74.3675689697374 .062782287671 .9292907714869 .1862335205166 .13836669922 63.3953094482461 .2618103027360 .0426712036159 .4331016540558 .82352828979 58.5187492370658 .5187492370658 .5187492370658 .8235282897958 .82352828979 59.1283111572359 .7378807067960 .0426712036160 .3474502563560 .95701980591 61.5666007995662 .1761703491262 .7441596984963 .3953094482464 .0048828125 64.6144485473665 .2240066528365 .8335876464866 .3688735961966 .68157196045 67.9670867919968 .2718734741268 .8814392089869 .4910125732470 .10057830811 70.4053573608471 .014930725171 .3197174072371 .6244964599672 .53885650635 73.1484298706173 .75800323486 -9999 -9999-9999 -9999 -9999 -9999 -9999 -9999 -9999 -9999 -9999 -9999 -9999 -9999 -9999 -9999 -9999 -9999 -9999 -9999 -9999 -9999 -9999 -9999 -

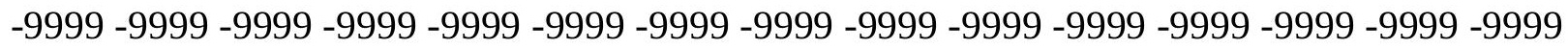
-9999 -9999 -9999 -9999 -9999 -9999 -9999 -9999 -9999 -9999 -9999 -9999 -

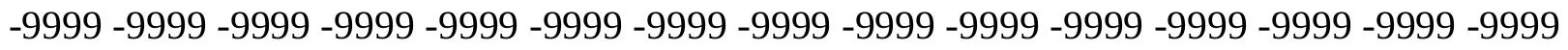

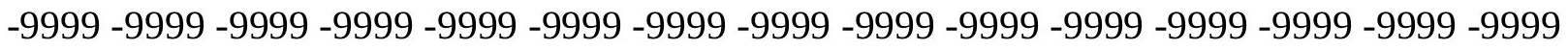
-9999 -9999 -9999 -9999 -9999 -9999 -9999 -9999 -9999 -9999 -9999 -9999 -9999 -9999 -9999 -9999 -9999 -9999 -9999 -9999 -9999 -9999 -9999 -9999 -9999 -9999 -9999 -9999 -9999 -9999 -

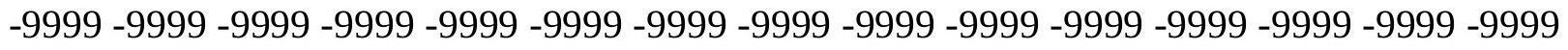
-9999 -9999 -9999 -9999 -9999 -9999 -9999 -9999 -9999 -9999 208.5179595947 191.3831481934168 .5462036133131 .0576019287106 .674797058186 .86376190186 73.1484298706162 .7857398986863 .0905189514263 .3953094482463 .70008850098 64.3096618652364 .9192428588965 .2240066528365 .8335876464866 .13836669922 66.4431610107466 .1383666992265 .5288009643664 .3096618652362 .78573989868 
61.5666007995660 .6522407531760 .0426712036159 .7378807067960 .04267120361 60.3474502563560 .6522407531761 .2618103027361 .8713798522962 .48094940186 63.0905189514263 .7000885009864 .3096618652365 .2240066528365 .83358764648 66.4431610107467 .0527267456167 .6623001098668 .2718734741268 .57665252686 68.5766525268667 .9670867919967 .3575134277367 .0527267456166 .74794006348 66.7479400634867 .3575134277367 .6623001098668 .2718734741268 .88143920898 69.1862335205169 .4910125732469 .7957916259870 .4053573608471 .31971740723 73.1484298706175 .2819290161178 .0249862670980 .4632720947382 .90155792236 85.0350494384886 .8637619018688 .3876876831190 .2164001464892 .04509735107 92.4289321899492 .5813217163192 .7359848022592 .8879318237393 .03218078613 93.1641159057693 .2794647216893 .3748016357493 .4472045898493 .49472808838 93.515907287693 .5100860595793 .4766311645593 .4159469604593 .33009338379 93.2241058349693 .1049652099692 .9809494018692 .8609466552792 .75427246094 92.6706924438592 .6196136474692 .6103134155392 .6507644653392 .74878692627 92.9108352661193 .1424865722793 .4446640014693 .8378524780394 .33548736572 94.8874435424895 .441963195895 .9377212524496 .3125152587996 .336769104 95.8342971801895 .587615966895 .3919982910294 .8166732788194 .02791595459 93.0527801513791 .8867416381890 .5147247314589 .1089019775488 .24680328369 88.6124954223686 .5589828491283 .5111236572380 .1584930419981 .68241119385 83.206336975184 .4254837036185 .3398437585 .6446228027385 .6446228027385 .33984375 84.7302627563584 .1206970214883 .5111236572383 .206336975183 .2063369751 83.206336975183 .206336975183 .5111236572383 .8159103393684 .42548370361 85.33984375 86.2541885376 86.86376190186 87.77810668945 88.69246673584 89.302040100189 .9116134643690 .5211791992291 .1307525634891 .43553924561 92.0450973510792 .349891662692 .9594726562518 .28710937517 .37274932861 16.1536102294914 .934470176714 .0201196670513 .1057596206712 .49619007111 11.8866195678711 .5818300247211 .5818300247211 .5818300247211 .88661956787 12.4961900711113 .4105501174914 .3248996734614 .934470176715 .54403972626 15.8488302230815 .8488302230815 .5440397262615 .5440397262615 .23925971985 15.2392597198515 .2392597198515 .2392597198514 .934470176714 .9344701767 14.6296901702914 .6296901702914 .3248996734614 .3248996734614 .32489967346 14.3248996734614 .3248996734614 .3248996734614 .3248996734614 .32489967346 14.3248996734614 .934470176715 .8488302230817 .6775398254420 .42060089111 23.4684505462627 .7354507446332 .3072204589833 .5263595581136 .87900161743 44.1938400268654 .5565414428765 .5288009643673 .2334747314580 .63743591309 86.5790252685589 .9043350219790 .3775711059689 .2666931152386 .64228820801 83.24664306641 78.64178466797 75.28192901611 73.45321655273 73.75800323486 74.9771423339874 .9771423339874 .9771423339875 .8914871215876 .19628143311 74.9771423339872 .5388565063569 .7957916259866 .4431610107463 .70008850098 61.5666007995660 .0426712036159 .1283111572358 .5187492370658 .51874923706 58.2139587402358 .2139587402358 .5187492370658 .8235282897959 .12831115723 59.4331016540559 .7378807067960 .3404197692960 .6522407531761 .26181030273 61.8713798522962 .4809494018663 .0905189514263 .7000885009864 .30966186523 64.9192428588965 .4738769531265 .939033508366 .2882385253967 .35751342773 67.9670867919968 .5766525268669 .1862335205169 .4910125732470 .10057830811 70.4053573608471 .014930725171 .3197174072371 .6244964599672 .23407745361 
72.8436431884873 .4532165527374 .0627822876 -9999 -9999 -9999 -9999 -9999 -9999 -9999 -9999 -9999 -9999 -9999 -9999 -9999 -9999 -9999 -9999 -9999 -9999 -9999 -9999 -9999 -9999 -9999 -9999 -9999 -9999 -9999 -9999 -9999 -9999 -9999 -9999 -9999 -9999 -9999 - 9999 - -999 -9999 -9999 -9999 -9999 -9999 -9999 -9999 -9999 -9999 -9999 -9999 -9999

-9999 -9999 -9999 -9999 -9999 -9999 -9999 -9999 -9999 -9999 -9999 -9999-9999 -9999 -9999 -9999 -9999 -9999 -9999 -9999 -9999 -9999 -9999 -9999 -9999 -9999 -9999 -9999 -9999 -9999

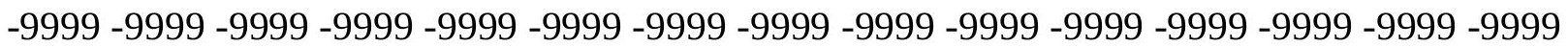
-9999 -9999 -9999 -9999 -9999 -9999 -9999 -9999 -9999 -9999 -9999 -9999 -9999 -9999 -9999 -999 -9999 -9999 -9999 -9999 -9999 -9999 -9999 -9999 -9999 -9999 -9999 -9999 -9999 -9999 -9999 -9999 -9999 -9999 -9999 -9999 -9999-9999 -9999 -9999-9999-9999 202.5383605957 177.5375518799143 .5538024902108 .198699951286 .8637619018665 .83358764648 66.1383666992266 .1383666992265 .8335876464865 .8335876464866 .13836669922 66.4431610107467 .0527267456167 .6623001098667 .9670867919968 .27187347412 67.9670867919967 .0527267456165 .5288009643663 .7000885009861 .56660079956 60.3474502563559 .4331016540559 .4331016540559 .7378807067960 .04267120361 60.3474502563560 .9570198059161 .5666007995662 .1761703491262 .78573989868 63.0905189514263 .7000885009864 .3096618652364 .6144485473665 .22400665283 65.8335876464866 .7479400634867 .9670867919968 .5766525268669 .18623352051 68.8814392089868 .5766525268667 .9670867919967 .6623001098667 .66230010986 67.6623001098667 .6623001098667 .3575134277367 .9670867919968 .27187347412 68.2718734741267 .9670867919968 .2718734741269 .4910125732471 .92929077148 74.9771423339878 .0249862670981 .0728530883883 .8159103393685 .64462280273 87.1685485839888 .6924667358490 .2164001464892 .0450973510792 .71370697021 92.8725585937593 .0326004028393 .188194274993 .3335952758893 .46343994141 93.5727310180793 .6574249267693 .7139358520593 .7398300170993 .73316955566 93.6930770874 93.6187744140693.5107345581193.3711700439593.20550537109 93.021072387792 .8263854980592 .6303405761792 .4422225952192 .27156829834 92.1276245117292 .0194320678791 .9552459716891 .9435577392691 .99271392822 92.1113586425892 .308319091892 .6342391967893 .0804061889693 .6021270752 94.1253509521594 .5837860107494 .8742370605594 .8498687744194 .26879119873 94.2369995117293 .8822097778393 .1143646240292 .2825775146591 .42761993408 90.4895248413189 .3654098510788 .1841964721786 .8637619018684 .73026275635 82.2919769287179 .5489196777377 .7202072143678 .0249862670979 .54891967773 80.7680587768681 .9871978759882 .5967712402383 .206336975182 .90155792236 82.2919769287181 .6824111938581 .0728530883880 .4632720947380 .46327209473 80.4632720947380 .7680587768681 .0728530883881 .6824111938582 .29197692871 83.2063369751 84.12069702148 85.33984375 86.2541885376 87.16854858398 88.0829010009888 .9972534179789 .9116134643690 .5211791992291 .13075256348 92.0450973510792 .6546783447393 .5690307617217 .3727493286115 .84883022308 14.3248996734613 .1057596206712 .191410064710 .9722604751610 .36268997192 9.7531242370619 .448339462289 .1435537338269 .1435537338269 .44833946228 10.0579099655210 .9722604751611 .8866195678713 .1057596206713 .7153301239 14.0201196670514 .0201196670514 .0201196670514 .0201196670513 .7153301239 13.715330123913 .4105501174913 .4105501174913 .1057596206712 .80097007751 12.4961900711112 .4961900711112 .191410064712 .191410064712 .49619007111 12.4961900711112 .8009700775112 .8009700775112 .4961900711112 .49619007111 
12.4961900711112 .8009700775113 .4105501174914 .3248996734615 .84883022308 17.6775398254420 .4206008911122 .5541000366223 .1636695861828 .04022979736 34.7455101013243 .2794914245653 .6421813964864 .6144485473674 .93119812012 83.5137634277389 .4803771972792 .8214187622193 .5315856933691 .67223358154 87.8883743286183 .1918411254978 .6345596313577 .110626220777 .1106262207 78.0249862670978 .3297805786178 .0249862670977 .7202072143676 .50106811523 74.6723632812572 .2340774536169 .1862335205166 .1383666992263 .39530944824 61.2618103027359 .7378807067958 .8235282897958 .5187492370658 .21395874023 58.2139587402358 .2139587402358 .2139587402358 .5187492370658 .82352828979 59.1283111572359 .7198333740260 .0426712036160 .6522407531760 .95701980591 61.5666007995662 .1761703491262 .7857398986863 .3953094482464 .0048828125 64.6144485473665 .1204757690465 .2905654907265 .9098663330166 .20612335205 67.6623001098668 .2718734741268 .8814392089869 .1862335205169 .79579162598 70.1005783081170 .4053573608471 .014930725171 .3197174072371 .62449645996 71.9292907714872 .5388565063573 .1484298706173 .7580032348674 .36756896973 -9999 -9999 -9999 -9999 -9999 -9999 -9999 -9999 -9999 -9999 -9999 -9999 -9999 -9999 -9999 -9999 -9999 -9999 -9999 -9999 -9999 -9999 -9999 -9999 -9999 -9999 -9999 -9999 -9999 -9999 -9999 -

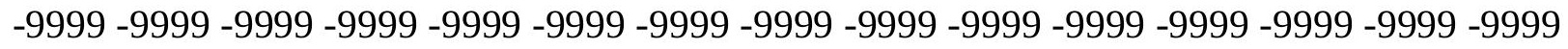
$-9999$

-9999 -9999 -9999 -9999 -9999 -9999 -9999 -9999 -9999 -9999 -9999 -9999 -9999 -9999 -9999

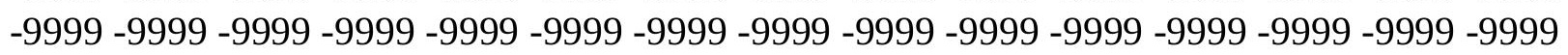

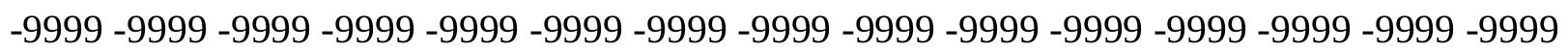
-9999 -9999 -9999 -9999 -9999 -9999 -9999 -9999 -9999 -9999 -9999 -9999 -9999 -9999 -9999 -9999 -9999 -9999 -9999 -9999 -9999 -9999 -9999 -9999 -9999 -9999 -9999 -9999 -9999 -9999 -9999 -9999 -9999 -9999 -9999 -9999 -9999 -9999 -9999 -9999-9999 -9999 190.1990509033 161.5361022949111 .2465972988 .0829010009871 .6244964599670 .71015167236 69.7957916259868 .8814392089868 .2718734741268 .2718734741268 .27187347412 68.8814392089869 .4910125732470 .1005783081170 .7101516723670 .71015167236 69.7957916259867 .6623001098664 .6144485473661 .8713798522959 .73788070679 59.1283111572359 .1283111572359 .4331016540560 .0426712036160 .34745025635 60.9570198059161 .5666007995661 .8713798522962 .4809494018662 .78573989868 63.0905189514263 .3953094482463 .7000885009864 .004882812564 .61444854736 66.1383666992267 .6623001098668 .8814392089869 .7957916259870 .10057830811 69.4910125732469 .1862335205168 .8814392089868 .5766525268668 .27187347412 68.2718734741267 .9670867919967 .9670867919967 .6623001098667 .35751342773 67.0527267456167 .0527267456167 .9670867919971 .014930725174 .97714233398 79.2441329956182 .5967712402385 .0350494384886 .8637619018688 .38768768311 89.60682678223 90.8259735107492.6546783447392.9848556518693.15129089355 93.3182830810593 .4794006347793 .6279373168993 .7575531005993 .86240386963 93.9377441406293 .9792709350693 .9839172363393 .9492568969793 .87426757812 93.75816345215 93.6016159057693.4069671630993.17990112305 92.92789459229 92.6595687866292 .3836364746192 .1091079711991 .8450317382891 .60006713867 91.3825454711991 .20005035491 .0606613159290 .9731979370190 .9493789672991 .015625 91.2118225097791 .564178466892 .0209884643692 .4604415893692 .83152770996 92.9914550781292 .8575363159292 .6546783447392 .0450973510791 .43553924561 90.5211791992289 .6068267822388 .6924667358487 .7781066894586 .2541885376 
85.03504943848 83.2063369751 81.3776321411178.93934631348 77.1106262207 75.8914871215875 .8914871215876 .8058471679778 .3297805786179 .54891967773 80.4632720947381 .0728530883881 .3776321411180 .7680587768679 .85370635986 79.2441329956178 .6345596313578 .3297805786178 .3297805786178 .63455963135 78.9393463134879 .8537063598680 .4632720947381 .3776321411182 .59677124023 83.8159103393684 .7302627563585 .9494018554786 .8637619018688 .08290100098 88.9972534179789 .9116134643690 .8259735107491 .7403335571392 .65467834473 17.9823207855216 .4584007263214 .6296901702913 .1057596206711 .58183002472 10.362689971929 .1435537338268 .2291984558117 .6196279525767 .010057926178 6.7052731513986 .7052731513987 .0100579261787 .6196279525768 .838768959045 9.75312423706110 .9722604751611 .5818300247212 .191410064712 .49619007111 12.4961900711112 .4961900711112 .4961900711112 .191410064711 .88661956787 11.5818300247211 .2770500183110 .9722604751610 .6674804687510 .66748046875 10.3626899719210 .6674804687510 .9722604751611 .2770500183111 .58183002472 11.5818300247211 .2770500183111 .2770500183110 .9722604751611 .27705001831 11.2770500183111 .8866195678712 .4961900711113 .4105501174914 .62969017029 15.8488302230817 .3727493286121 .334960937527 .1258792877234 .74551010132 44.1938400268654 .8613204956167 .0527267456177 .4154205322385 .54605102539 91.6966857910293 .8996582031292 .7820129394589 .1518936157284 .00543212891 78.9393463134878 .6345596313577 .110626220777 .4154205322378 .02498626709 78.3297805786177 .7202072143675 .8914871215873 .4532165527371 .0149307251 67.9670867919965 .2240066528362 .4809494018660 .3474502563559 .43310165405 58.5187492370658 .2139587402357 .909179687557 .909179687557 .9091796875 58.2139587402358 .5187492370658 .8235282897959 .1283111572359 .43310165405 59.7378807067960 .3474502563560 .6522407531761 .2618103027361 .87137985229 62.4809494018663 .0905189514263 .7000885009864 .3096618652364 .7720489502 65.0364608764665 .5589370727565 .8577880859467 .3575134277367 .96708679199 68.2718734741268 .8814392089869 .1862335205169 .7957916259870 .10057830811 70.4053573608470 .7101516723671 .014930725171 .6244964599671 .92929077148 72.2340774536172 .8436431884873 .4532165527374 .0627822876 -9999 -9999 -9999 -9999 -9999 -9999 -9999 -9999 -9999 -9999 -9999 -9999 -9999 -9999 -9999 -9999 -9999 -9999 -9999 -9999 -9999 -9999 -9999 -9999 -9999 -9999 -9999 -9999 -9999 -9999 -9999 -9999 -9999 -9999 -9999 -9999 -9999 -9999 -9999 -9999 -9999 -9999 -9999 -9999 -9999 -9999 -

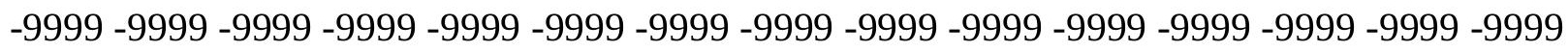
-9999 -9999 -9999 -9999 -9999 -9999 -9999 -9999 -9999 -9999 -9999 -9999 -9999 -9999 -9999 -9999 -9999 -9999 -9999 -9999 -9999 -9999 -9999 -9999 -9999 -9999 -9999 -9999 -9999 - -9999 -

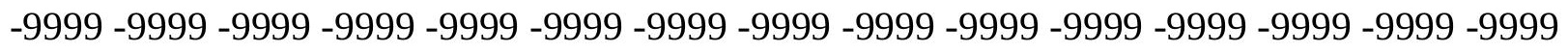

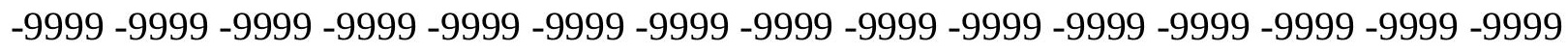
-9999 -9999 -9999 -9999 -9999 -9999 -9999 -9999 -9999 -9999 -9999 -9999 -9999 170.8013458252129 .838500976689 .9116134643678 .0249862670976 .19628143311 74.062782287672 .2340774536171 .014930725170 .4053573608470 .10057830811 70.7101516723671 .3197174072372 .2340774536173 .1484298706173 .75800323486 73.1484298706170 .4053573608466 .4431610107461 .8713798522959 .73788070679 59.1283111572359 .1283111572359 .4331016540560 .0426712036160 .65224075317 60.9570198059161 .5666007995661 .8713798522962 .4809494018662 .78573989868 63.0905189514263 .0905189514263 .3953094482463 .3953094482463 .70008850098 
65.5288009643667 .6623001098669 .1862335205170 .7101516723670 .71015167236 70.4053573608470 .1005783081169 .7957916259869 .7957916259869 .49101257324 69.4910125732469 .1862335205168 .8814392089868 .2718734741267 .66230010986 67.0527267456166 .7479400634867 .0527267456171 .6244964599676 .50106811523 81.0728530883884 .7302627563587 .1685485839888 .3876876831189 .3020401001 90.5211791992291 .7403335571393 .0714721679793 .2397994995193 .41536712646 93.5914840698293 .7606964111393 .9150924682694 .0470886230594 .14968109131 94.2173309326294 .2449569702194 .2288360595794 .1659927368294 .05536651611 93.8963623046993 .6900634765693 .439033508393 .1490325927792 .82747650146 92.4829254150492 .1237564086991 .7585220336991 .3955383300891 .04260253906 90.7068328857490 .3944854736390 .1119613647589 .8667984008889 .6704864502 89.55403137207 89.5611114502 89.7178573608490.0323410034290.34411621094 90.4400634765690 .5211791992289 .9116134643689 .302040100188 .69246673584 88.0829010009887 .4733276367286 .5589828491285 .6446228027384 .42548370361 83.206336975181.98719787598 80.1584930419978.6345596313576.80584716797 75.2819290161174 .6723632812574 .6723632812575 .2819290161176 .19628143311 77.4154205322378 .6345596313579 .5489196777380 .4632720947379 .54891967773 78.3297805786177 .7202072143677 .110626220776 .8058471679776 .80584716797 77.1106262207 77.41542053223 78.02498626709 78.93934631348 80.15849304199 81.0728530883882 .2919769287183 .5111236572384 .7302627563585 .94940185547 87.16854858398 88.08290100098 89.302040100190.2164001464891.43553924561 92.349891662617 .3727493286115 .2392597198513 .4105501174911 .58183002472 10.057909965528 .5339832305917 .3148431777956 .4004869461065 .486132144928 4.876562118534 .2669920921333 .9622070789344 .2669920921335 .486132144928 6.7052731513987 .9244132041938 .8387689590459 .75312423706110 .66748046875 10.9722604751610 .9722604751610 .9722604751610 .9722604751610 .66748046875 10.3626899719210 .057909965529 .7531242370619 .448339462289 .143553733826 8.8387689590458 .8387689590459 .1435537338269 .4483394622810 .05790996552 10.3626899719210 .3626899719210 .3626899719210 .3626899719210 .36268997192 10.3626899719210 .3626899719210 .3626899719210 .3626899719210 .66748046875 10.9722604751611 .8866195678713 .4105501174916 .7631797790521 .63973999023 28.0402297973636 .2694282531745 .717769622855 .4708900451764 .61444854736 76.1962814331185 .3398437588 .0829010009887 .4733276367285 .03504943848 80.7680587768676 .1962814331174 .6723632812574 .6723632812574 .97714233398 75.5867080688575 .5867080688574 .9771423339873 .1484298706171 .31971740723 68.8814392089866 .4431610107464 .004882812561 .5666007995660 .04267120361 58.8235282897958 .2139587402357 .909179687557 .909179687557 .9091796875 57.909179687557 .909179687558 .2139587402358 .5187492370658 .82352828979 59.4331016540559 .7378807067960 .0426712036160 .6522407531761 .26181030273 61.5666007995662 .1761703491262 .7857398986863 .3953094482464 .0048828125 64.4914779663164 .8833236694365 .1569747924865 .5194015502967 .05272674561 67.3575134277367 .9670867919968 .5766525268668 .8814392089869 .18623352051 69.7957916259870 .1005783081170 .4053573608470 .7101516723671 .0149307251 71.3197174072371 .6244964599672 .2340774536172 .5388565063573 .14842987061 73.7580032348674 .36756896973 -9999 -9999 -9999 -9999 -9999 -9999 -9999 -9999 -9999

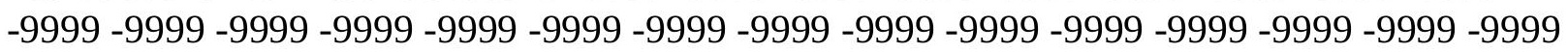


-9999 -9999 -9999 -9999 -9999 -9999 -9999 -9999 -9999 -9999 -9999 -9999 -9999 -9999 -9999 -9999 -9999 -9999 -9999 -9999

-9999 -9999 -9999 -9999 -9999 -9999 -9999 -9999 -9999 -9999 -9999 -9999 -9999 -9999 -9999 -9999 -9999 -9999 -9999 -9999 -9999 -9999 -9999 -9999 -9999 -9999 -9999 -9999 -9999 -9999 -9999 -9999 -9999 -9999 -9999 -9999 -9999 -9999 -9999 -9999 -9999 -9999 -9999 - -9999 - -9999 -

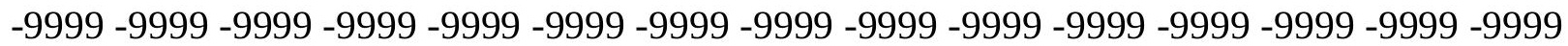

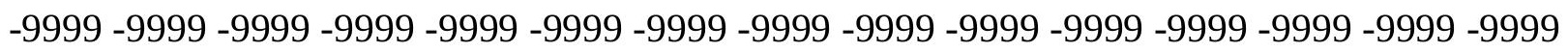
-9999 -9999 -9999 -9999 -9999 -9999 -9999 -9999 -9999 -9999 -9999 -9999 -9999 182.5897674561154 .2212982178100 .883903503485 .9494018554782 .59677124023 78.6345596313575 .5867080688573 .4532165527372 .2340774536171 .92929077148 72.2340774536173 .1484298706174 .062782287675 .2819290161176 .50106811523 76.8058471679774 .6723632812569 .1862335205161 .8713798522960 .34745025635 59.7378807067959 .7378807067960 .0426712036160 .3474502563560 .95701980591 61.2618103027361 .8713798522962 .1761703491262 .4809494018662 .78573989868 63.0905189514263 .0905189514263 .3953094482463 .7000885009864 .30966186523 65.8335876464867 .6623001098669 .4910125732470 .7101516723671 .0149307251 71.014930725170 .7101516723670 .7101516723670 .7101516723670 .71015167236 70.7101516723670 .4053573608470 .1005783081169 .4910125732468 .57665252686 67.9670867919968 .2718734741269 .7957916259873 .4532165527378 .32978057861 83.5111236572387 .1685485839889 .302040100189 .9116134643690 .52117919922 91.4355392456192 .6546783447393 .2970581054793 .4753799438593 .66248321533 93.85074615479 94.0314483642694.1951980590894.3329620361394.43627929688 94.4984512329194 .5135955810594 .4774169921994 .386436462494 .23954772949 94.0365142822393 .7790451049893 .4700775146593 .115509033292 .72257232666 92.2996368408291 .8546066284291 .395370483490 .9292831420990 .46315765381 90.0028228759889 .5530700683689 .1180801391688 .7022781372188 .31269073486 87.9759445190487 .697547912687 .4949264526487 .4853744506887 .77810668945 87.1685485839886 .5589828491286 .254188537685 .6446228027385 .33984375 84.7302627563584 .1206970214883 .5111236572382 .5967712402381 .68241119385 80.4632720947379 .2441329956177 .7202072143676 .5010681152374 .97714233398 74.062782287673 .4532165527373 .4532165527373 .7580032348674 .67236328125 75.5867080688576 .5010681152377 .4154205322378 .0249862670977 .72020721436 76.8058471679776 .1962814331175 .5867080688575 .5867080688575 .58670806885 75.5867080688576 .1962814331176 .8058471679777 .7202072143678 .63455963135 79.8537063598681 .0728530883882 .2919769287183 .5111236572384 .73026275635 85.9494018554787 .1685485839888 .3876876831189 .6068267822390 .82597351074 92.0450973510716 .7631797790514 .6296901702912 .191410064710 .36268997192 8.5339832305916 .7052731513985 .4861321449284 .2669920921333 .352636098862 2.1334960460661 .523926019669 6095703244209 1.5239260196693 .047851085663 4.5717768669136 .0957031257 .3148431777958 .2291984558118 .838768959045 9.448339462289 .7531242370619 .7531242370619 .7531242370619 .44833946228 9.1435537338268 .8387689590458 .5339832305917 .9244132041937 .619627952576 7.3148431777957 .6196279525767 .9244132041938 .5339832305918 .838768959045 9.448339462289 .7531242370619 .75312423706110 .0579099655210 .05790996552 9.7531242370619 .7531242370619 .7531242370619 .448339462289 .143553733826 9.1435537338269 .75312423706110 .9722604751613 .4105501174917 .06797027588 
22.5541000366229 .2593708038336 .5742111206144 .8034095764252 .72782897949 59.4331016540567 .0527267456173 .1484298706172 .5388565063571 .62449645996 70.7101516723670 .1005783081170 .1005783081170 .4053573608470 .71015167236 71.014930725171 .014930725170 .7101516723669 .4910125732467 .96708679199 66.4431610107464 .3096618652362 .1761703491260 .6522407531759 .43310165405 58.5187492370657 .909179687557 .6043891906757 .6043891906757 .60438919067 57.909179687557 .909179687558 .2139587402358 .5187492370658 .82352828979 59.1283111572359 .7378807067960 .0426712036160 .3474502563560 .95701980591 61.5666007995662 .1761703491262 .7857398986863 .3953094482463 .79206848145 64.198944091864 .5728378295964 .9034347534265 .1898040771566 .74794006348 67.0527267456167 .6623001098667 .9670867919968 .5766525268668 .88143920898 69.1862335205169 .7957916259870 .1005783081170 .4053573608470 .71015167236 71.014930725171 .3197174072371 .6244964599671 .9292907714872 .23407745361 72.8436431884873 .4532165527374 .0627822876 -9999 -9999 -9999 -9999 -9999 -9999 -9999 -9999 -9999 -9999 -9999 -9999 -9999 -9999 -9999 -9999 -9999 -9999 -9999 -9999 -9999 -9999

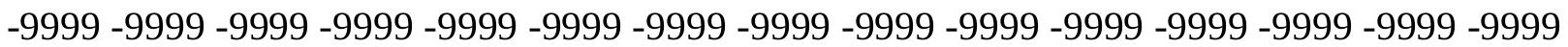
-9999 -9999 -9999-9999-9999-9999

-9999 -9999 -9999 -9999 -9999 -9999 -9999 -9999 -9999 -9999 -9999 -9999 -9999 -9999 -9999 -9999 -9999 -9999 -9999 -9999 -9999 -9999 -9999 -9999 -9999 -9999 -9999 -9999 -9999 -9999 -9999 -9999 -9999 -9999 -9999 -9999 -9999 -9999 -9999 -9999 -9999 -9999 -9999 -9999 -9999 -9999 -9999 -9999 -9999 -9999 -9999 -9999 -9999 -9999 -9999 -9999 -9999 -9999 -9999 -9999 -9999 -9999 -9999 -9999 -9999 -9999 -9999 -9999 -9999 -9999 -9999 -9999 -9999 -9999 -9999 -9999 -9999 -9999 -9999 -9999 -9999 -9999 -9999 -9999 -9999 -9999 -9999 -9999 -9999 174.9762115479135 .629394531296 .3121032714888 .6924667358482 .90155792236 78.3297805786175 .2819290161173 .7580032348673 .1484298706173 .45321655273 74.062782287675 .2819290161176 .8058471679778 .0249862670979 .24413299561 79.5489196777372 .2340774536165 .8335876464862 .4809494018660 .95701980591 60.6522407531760 .6522407531760 .9570198059161 .2618103027361 .87137985229 62.1761703491262 .4809494018662 .7857398986862 .7857398986863 .09051895142 63.3953094482463 .7000885009864 .004882812564 .9192428588966 .13836669922 67.6623001098669 .1862335205170 .4053573608471 .014930725171 .31971740723 71.3197174072371 .3197174072371 .3197174072371 .6244964599671 .92929077148 71.9292907714871 .6244964599670 .7101516723669 .7957916259869 .79579162598 70.4053573608472 .2340774536175 .5867080688580 .1584930419985 .33984375 89.9116134643690 .8259735107490 .8259735107491 .1307525634892 .3498916626 93.3227539062593 .4947357177793 .6858367919993 .8883743286194 .09329986572 94.2901687622194 .4678115844794 .6156005859494 .7234497070394 .78318023682 94.7877731323294 .7325134277394 .6136398315494 .4300918579194 .18199920654 93.8718566894593 .5031814575293 .082168579192 .6160354614392 .11297607422 91.5802841186591 .0248870849690 .4529037475689 .8702011108489 .28165435791 88.6911621093888 .1010360717887 .5113143920986 .9203872680786 .33808898926 85.7517013549885 .1316604614384 .4254837036183 .8159103393683 .2063369751 82.9015579223682 .5967712402382 .2919769287181 .9871978759881 .68241119385 81.3776321411180 .7680587768679 .8537063598678 .9393463134878 .02498626709 76.8058471679775 .8914871215874 .6723632812573 .7580032348672 .84364318848 72.2340774536172 .2340774536172 .5388565063573 .1484298706174 .0627822876 
74.6723632812575 .2819290161175 .5867080688575 .5867080688575 .28192901611 74.6723632812574 .3675689697374 .3675689697374 .3675689697374 .67236328125 74.9771423339875 .8914871215876 .8058471679777 .7202072143678 .93934631348 80.1584930419981 .3776321411182 .5967712402383 .8159103393685 .03504943848 86.254188537687 .4733276367288 .6924667358489 .9116134643618 .89668083191 16.1536102294913 .715330123910 .972260475168 .8387689590457 .010057926178 $5.1813468933113 .6574220657352 .133496046066 .9143553972244-9999-4.26699209213$ -2.43828105927 -.304785102606 1.219141006473.047851085663 4.571776866913 5.7909169197086 .7052731513987 .6196279525768 .2291984558118 .533983230591 8.5339832305918 .5339832305918 .2291984558118 .2291984558117 .619627952576 7.3148431777957 .0100579261786 .7052731513986 .7052731513986 .705273151398 7.0100579261787 .6196279525768 .2291984558118 .5339832305919 .143553733826 9.448339462289 .75312423706110 .0579099655210 .0579099655210 .05790996552 9.7531242370619 .448339462289 .1435537338268 .8387689590458 .838768959045 9.4483394622810 .9722604751613 .715330123917 .3727493286122 .24930953979 28.3450202941935 .0502891540541 .7555618286148 .1560516357453 .33739852905 57.6043891906760 .6522407531761 .5666007995661 .5666007995663 .09051895142 64.004882812564 .9192428588965 .5288009643665 .8335876464866 .13836669922 65.8335876464865 .5288009643664 .6144485473663 .7000885009862 .17617034912 60.6522407531759 .4331016540558 .8235282897958 .2139587402357 .60438919067 57.6043891906757 .6043891906757 .6043891906757 .6043891906757 .9091796875 58.2139587402358 .5187492370658 .8235282897959 .1283111572359 .73788070679 60.0426712036160 .3474502563560 .9570198059161 .5666007995662 .17617034912 62.4809494018663 .0905189514263 .5564231872663 .9359321594264 .28308105469 64.5982589721764 .874298095765 .1076736450266 .7479400634867 .35751342773 67.6623001098667 .9670867919968 .5766525268668 .8814392089869 .18623352051 69.4910125732470 .1005783081170 .4053573608470 .7101516723671 .0149307251 71.3197174072371 .3197174072371 .6244964599671 .9292907714872 .23407745361 72.8436431884873 .45321655273 -9999 -9999 -9999 -9999 -9999 -9999 -9999 -9999 -9999 -9999 -9999 -9999 -9999 -9999 -9999 -9999 -9999 -9999 -9999 -9999 -9999 -9999 -9999 - -9999 -

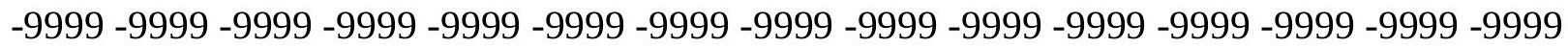
-9999 -9999-9999

-9999 -9999 -9999 -9999 -9999 -9999 -9999 -9999 -9999 -9999 -9999 -9999 -9999 -9999 -9999 -9999 -9999 -9999 -9999 -9999 -9999 -9999 -9999 -9999 -9999 -9999 -9999 -9999 -9999 -9999 -9999 -9999 -9999 -9999 -9999 -9999 -9999 -9999 -9999 -9999 -9999 -9999 -9999 -9999 -9999 -9999 -9999 -9999 -9999 -9999 -9999 -9999 -9999 -9999 -9999 -9999 -9999 -9999 -9999 -9999

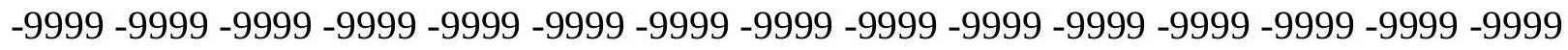

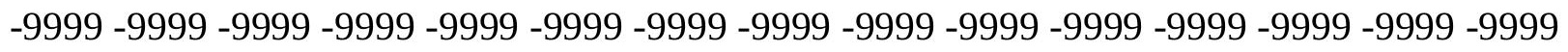
175.8609924316116 .427902221794 .1785964965886 .8637619018680 .76805877686 76.8058471679774 .6723632812573 .7580032348673 .7580032348674 .36756896973 75.2819290161176 .5010681152377 .7202072143678 .6345596313577 .41542053223 73.1484298706168 .2718734741264 .6144485473662 .4809494018661 .56660079956 61.2618103027361 .5666007995661 .8713798522962 .1761703491262 .48094940186 62.7857398986862 .7857398986863 .0905189514263 .3953094482463 .70008850098 64.004882812564 .6144485473665 .5288009643666 .7479400634867 .96708679199 69.1862335205170 .1005783081170 .7101516723671 .014930725171 .31971740723 
71.6244964599671 .9292907714872 .2340774536172 .8436431884873 .45321655273 72.5388565063571 .6244964599671 .014930725171 .014930725171 .92929077148 74.062782287677 .110626220781 .0728530883885 .3398437588 .99725341797 90.5211791992291 .4355392456192 .0450973510792 .9594726562593 .46984863281 93.65346527193 .8619384765694 .0858917236394 .3140640258894 .5336151123 94.7312164306694 .8944091796995 .0114135742295 .0724258422995 .06903839111 94.9959640502994 .8494873046994 .6289291381894 .3348846435593 .97067260742 93.5405654907293 .0513000488392 .5103836059691 .9260864257891 .30498504639 90.6526489257889 .9736251831189 .2729110717888 .5550765991287 .82399749756 87.0815887451286 .3245162963985 .5408935546984 .7159500122183 .83522033691 82.9015579223681 .6824111938580 .7680587768680 .1584930419979 .54891967773 79.5489196777379 .2441329956179 .2441329956178 .9393463134878 .63455963135 78.0249862670977 .4154205322376 .8058471679775 .8914871215874 .97714233398 74.062782287673 .1484298706172 .2340774536171 .6244964599671 .31971740723 71.3197174072371 .6244964599671 .9292907714872 .5388565063573 .14842987061 73.4532165527373 .7580032348673 .7580032348673 .4532165527373 .45321655273 73.1484298706173 .1484298706173 .4532165527373 .7580032348674 .36756896973 74.9771423339875 .8914871215876 .8058471679778 .0249862670979 .24413299561 80.4632720947381 .6824111938582 .9015579223684 .1206970214885 .33984375 86.5589828491288 .0829010009889 .302040100118 .5918903350815 .54403972626 12.496190071119.753124237061 7.314843177795 5.1813468933113.352636098862 1.828711032867 -9999 -1.21914100647 -3.04785108566 -4.57177686691 -4.26699209213 -2.13349604607 -9999 1.523926019669 3.047851085663 4.571776866913 5.486132144928 6.4004869461067 .0100579261787 .3148431777957 .6196279525767 .619627952576 7.3148431777957 .0100579261786 .7052731513986 .4004869461066 .0957031256 .095703125 6.0957031256 .0957031256 .4004869461067 .0100579261787 .6196279525767 .924413204193 8.5339832305919 .1435537338269 .75312423706110 .0579099655210 .36268997192 10.6674804687510 .3626899719210 .057909965529 .7531242370619 .143553733826 8.8387689590458 .8387689590459 .4483394622810 .9722604751613 .7153301239 16.7631797790520 .7253894805926 .8210906982432 .9167900085438 .40293121338 43.8890609741248 .1560516357451 .5086898803753 .3373985290554 .86132049561 56.6900291442958 .2139587402359 .7378807067960 .3474502563560 .65224075317 61.2618103027360 .9570198059161 .5666007995661 .5666007995660 .95701980591 60.3474502563559 .1283111572358 .5187492370657 .909179687557 .60438919067 57.2995986938557 .2995986938557 .2995986938557 .6043891906757 .60438919067 57.909179687558 .2139587402358 .5187492370658 .8235282897959 .43310165405 59.7378807067960 .0426712036160 .6522407531760 .9570198059161 .56660079956 61.8713798522962 .4809494018662 .9044685363863 .3164176940963 .68395996094 64.0157775878964 .3145446777364 .5768585205164 .8004531860466 .44316101074 67.0527267456167 .3575134277367 .6623001098668 .2718734741268 .57665252686 68.8814392089869 .1862335205169 .4910125732469 .7957916259870 .10057830811 70.4053573608470 .7101516723671 .014930725171 .014930725171 .31971740723 71.6244964599671 .9292907714872 .5388565063573 .14842987061 -9999-9999 -9999 -9999 -9999 -9999 -9999 -9999 -9999 -9999 -9999 -9999 -9999 -9999 -9999 -9999 -9999 -9999 -9999

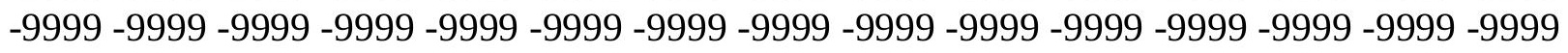
-9999 -9999 -9999 -9999 -9999 -9999 -9999 
-9999 -9999 -9999 -9999 -9999 -9999 -9999 -9999 -9999 -9999 -9999 -9999 -9999 -9999 -9999 -9999 -9999 -9999 -9999 -9999 -9999 -9999 -9999 -9999 -9999 -9999 -9999 -9999 -9999 -9999 -9999 -9999 -9999 -9999 -9999 -9999 -9999 -9999 -9999 -9999 -9999 -9999 -9999 -9999 -9999 -9999 -9999 -9999 -9999 -9999 -9999 -9999 -9999 -9999 -9999 -9999 -9999 -9999 -9999 -9999 -9999 -9999 -9999 -9999 -9999 -9999 -9999 -9999 -9999 -9999 -9999 -9999-9999 -9999 -9999 -9999 -9999 -9999 -9999 -9999 -9999 -9999 -9999 -9999 -9999 -9999 -9999 -9999 -9999 -9999 177.7861022949148 .7351074219100 .579101562590 .2164001464883 .2063369751 78.6345596313575 .5867080688574 .062782287673 .4532165527373 .45321655273 74.062782287674 .9771423339875 .5867080688575 .8914871215874 .36756896973 71.6244964599668 .2718734741265 .2240066528363 .0905189514262 .17617034912 61.8713798522961 .8713798522962 .1761703491262 .4809494018662 .78573989868 63.0905189514263 .0905189514263 .3953094482463 .7000885009864 .0048828125 64.3096618652365 .2240066528365 .8335876464866 .7479400634867 .96708679199 68.8814392089869 .7957916259870 .4053573608470 .7101516723671 .0149307251 71.3197174072371 .6244964599672 .2340774536172 .5388565063572 .84364318848 72.5388565063571 .9292907714871 .6244964599671 .9292907714873 .14842987061 74.9771423339877 .7202072143681 .0728530883884 .4254837036187 .16854858398 89.302040100190.5211791992292.0450973510793.2642517089893.56143951416 93.75976562593 .991485595794 .2446441650494 .5048141479594 .75585174561 94.9815216064595 .1671752929795 .299102783295 .3658599853595 .35758209229 95.2683944702195.0946884155394.8366470336994.4957199096794.07621002197 93.5832595825293 .0243682861392 .4075927734491 .7416152954191 .03247070312 90.2840728759889 .4988555908288 .683456420987 .8397521972786 .97564697266 86.0826721191485 .1679229736384 .2144851684683 .1841964721782 .03741455078 80.7680587768679 .5489196777378 .3297805786177 .7202072143677 .1106262207 76.8058471679776 .8058471679776 .8058471679776 .5010681152376 .19628143311 75.8914871215875 .2819290161174 .6723632812574 .062782287673 .14842987061 72.5388565063571 .9292907714871 .3197174072370 .7101516723670 .40535736084 70.4053573608470 .4053573608470 .7101516723671 .014930725171 .62449645996 71.9292907714872 .2340774536172 .2340774536172 .2340774536172 .23407745361 72.2340774536172 .2340774536172 .5388565063572 .8436431884873 .45321655273 74.062782287674 .9771423339876 .1962814331177 .110626220778 .32978057861 79.5489196777380 .7680587768681 .9871978759883 .206336975184 .42548370361 85.6446228027387 .1685485839888 .3876876831118 .28710937514 .62969017029 $11.277050018318 .2291984558115 .7909169197083 .6574220657351 .523926019669-9999$ $-1.82871103287-3.35263609886-4.87656211853-5.48613214493-4.87656211853$ -3.35263609886 -1.21914100647.3047851026058 2.133496046066 3.352636098862 4.5717768669135 .4861321449286 .0957031256 .4004869461066 .705273151398 6.7052731513986 .4004869461066 .0957031256 .0957031255 .7909169197085 .486132144928 5.4861321449285 .4861321449285 .4861321449285 .7909169197086 .400486946106 7.0100579261787 .6196279525768 .2291984558119 .1435537338269 .753124237061 10.3626899719210 .9722604751611 .2770500183111 .2770500183111 .27705001831 10.6674804687510 .057909965529 .448339462288 .5339832305918 .533983230591 9.14355373382610 .6674804687513 .1057596206716 .4584007263221 .03017044067 25.906740188630 .7833003997835 .9646492004440 .5364189147943 .88906097412 46.6321296691949 .0704002380451 .2038993835453 .0326118469254 .55654144287 
55.7756805419956 .6900291442957 .2995986938557 .6043891906758 .21395874023 58.5187492370658 .5187492370658 .2139587402357 .909179687557 .60438919067 57.2995986938556 .9948196411156 .9948196411156 .9948196411157 .29959869385 57.6043891906757 .6043891906757 .909179687558 .2139587402358 .51874923706 59.1283111572359 .4331016540559 .7378807067960 .0426712036160 .65224075317 60.9570198059161 .5666007995661 .8713798522962 .3387069702162 .75291824341 63.126396179263 .4654731750563 .7749519348164 .0542144775464 .30027770996 64.5116271972766 .1383666992266 .4431610107467 .0527267456167 .35751342773 67.6623001098667 .9670867919968 .5766525268668 .8814392089869 .18623352051 69.4910125732469 .7957916259870 .1005783081170 .1005783081170 .40535736084 70.7101516723670 .7101516723671 .014930725171 .014930725171 .62449645996 72.2340774536172 .84364318848 -9999 -9999 -9999 -9999 -9999 -9999 -9999 -9999 -9999 -9999 -9999 -9999 -9999 -9999 -9999 -9999 -9999 -9999 -9999 -9999 -9999 -9999 -9999 -9999 -9999 -9999 -9999 -9999 -9999 -9999 -9999 -9999 -9999 -9999 -9999 -9999 -9999 -9999 -9999 $-9999$

-9999 -9999 -9999 -9999 -9999 -9999 -9999 -9999 -9999 -9999 -9999 -9999 -9999 -9999 -9999

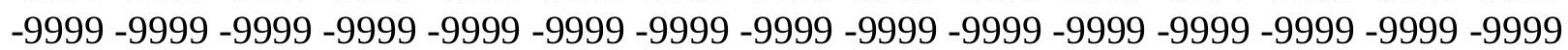
-9999 -9999 -9999 -9999 -9999 -9999 -9999 -9999 -9999 -9999 -9999 -9999 -9999 -9999 -9999 -999 -9999 -9999 -9999 -9999 -9999 -9999 -9999 -9999 -9999 -9999 -9999 -9999 -9999 -9999 -9999 -9999 -9999 -9999 -9999 -9999 -9999 -9999 -9999 -9999 -9999 -9999 -9999 -9999 -9999 -9999 -9999 -9999 -9999 -9999 -9999 -9999 -9999 -9999 -9999 -9999 -9999 -9999 -9999 -9999 -9999 -9999 165.0678710938125.876296997193.56903076172 87.47332763672 81.37763214111 76.5010681152373 .7580032348672 .5388565063571 .9292907714871 .92929077148 72.2340774536172 .5388565063571 .9292907714871 .014930725169 .18623352051 66.7479400634864 .6144485473663 .0905189514262 .1761703491261 .87137985229 61.8713798522962 .4809494018662 .7857398986863 .0905189514263 .09051895142 63.0905189514263 .3953094482463 .7000885009864 .3096618652364 .61444854736 65.5288009643666 .1383666992267 .0527267456167 .9670867919968 .88143920898 69.4910125732469 .7957916259870 .4053573608470 .4053573608470 .71015167236 71.014930725171 .3197174072371 .6244964599671 .6244964599671 .62449645996 71.6244964599671 .6244964599671 .9292907714873 .1484298706174 .97714233398 77.110626220779 .8537063598682 .5967712402385 .0350494384887 .16854858398 88.9972534179791 .1307525634892 .9594726562593 .5870208740293 .80211639404 94.0624084472794 .3529739379994 .6551971435594 .9484710693495 .21257019043 95.429687595 .5837402343895 .6614837646595 .651779174895 .54832458496 95.3479080200295 .0518722534294 .6631164550894 .1873016357493 .63060760498 93.0014877319392 .3086318969791 .5613327026490 .7655258178789 .92388153076 89.03916931152 88.07671356201 87.07275390625 86.10824584961 85.12542724609 84.0507354736382 .9422531127981 .7760162353580 .4632720947378 .93934631348 77.7202072143676 .8058471679775 .8914871215875 .2819290161174 .97714233398 74.9771423339874 .6723632812574 .3675689697374 .062782287673 .75800323486 73.4532165527372 .8436431884872 .2340774536171 .6244964599671 .0149307251 70.7101516723670 .1005783081169 .7957916259869 .4910125732469 .49101257324 69.4910125732469 .7957916259870 .1005783081170 .4053573608470 .40535736084 70.7101516723671 .014930725171 .014930725171 .014930725171 .31971740723 71.3197174072371 .6244964599672 .2340774536172 .8436431884873 .45321655273 
74.3675689697375 .2819290161176 .5010681152377 .4154205322378 .63455963135 79.8537063598681 .0728530883882 .2919769287183 .5111236572384 .73026275635 85.9494018554721 .9445304870617 .6775398254413 .410550117499 .753124237061 $6.4004869461063 .6574220657351 .523926019669-9999-2.13349604607-3.96220707893$ $-5.48613214493-6.40048694611-6.40048694611-5.79091691971-4.26699209213$ $-2.43828105927-.3047851026061 .219141006472 .7430660724643 .962207078934$ 4.876562118535 .4861321449285 .7909169197085 .7909169197085 .790916919708 5.7909169197085 .4861321449285 .1813468933114 .876562118534 .87656211853 4.876562118534 .876562118535 .1813468933115 .4861321449285 .790916919708 6.4004869461067 .3148431777957 .9244132041938 .8387689590459 .753124237061 10.6674804687511 .2770500183112 .191410064712 .191410064712 .1914100647 11.8866195678711 .2770500183110 .057909965528 .8387689590458 .229198455811 8.2291984558119 .14355373382610 .9722604751613 .715330123917 .37274932861 21.334960937525 .6019496917730 .1737308502234 .4407196044938 .09814071655 41.4507789611844 .1938400268646 .6321296691948 .765621185350 .59432983398 52.1182594299353 .0326118469254 .2517509460454 .8613204956155 .77568054199 56.0804595947356 .6900291442956 .6900291442956 .6900291442956 .69002914429 56.6900291442956 .6900291442956 .6900291442956 .9948196411157 .29959869385 57.6043891906757 .909179687558 .2139587402358 .5187492370658 .82352828979 59.1283111572359 .4331016540560 .0426712036160 .3474502563560 .65224075317 60.9570198059161 .5666007995661 .8713798522962 .2775077819862 .63655853271 62.9704971313563 .2796859741263 .5631828308163 .819477081364 .04674530029 64.2437133789164 .4109802246166 .1383666992266 .7479400634867 .05272674561 67.3575134277367 .6623001098667 .9670867919968 .2718734741268 .57665252686 68.8814392089869 .1862335205169 .4910125732469 .7957916259870 .10057830811 70.1005783081170 .4053573608470 .4053573608470 .7101516723670 .71015167236 71.014930725171 .6244964599672 .23407745361 -9999 -9999 -9999 -9999 -9999 -9999 -9999 -9999 -9999 -9999 -9999 -9999 -9999 -9999 -9999 -9999 -9999 -9999 -9999 -9999 -9999 -9999 -9999 -9999 -9999 -9999 -9999 -9999 -9999 -9999 -9999 -9999 -9999 -9999 -9999 -9999 -9999 -9999-9999

-9999 -9999 -9999 -9999 -9999 -9999 -9999 -9999 -9999 -9999 -9999 -9999 -9999 -9999 -9999 -9999 -9999 -9999 -9999 -9999 -9999 -9999 -9999 -9999 -9999 -9999 -9999 -9999 -9999 -9999

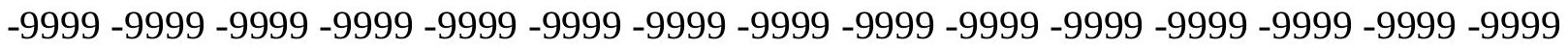
-9999 -9999 -9999 -9999 -9999 -9999 -9999 -9999 -9999 -9999 -9999 -9999 -9999 -9999 -9999 -9999 -9999 -9999 -9999 -9999 -9999 -9999 -9999 -9999 -9999 -9999 -9999 -9999 -9999 -9999 -9999 -9999 -9999 -9999 -9999 -9999 -9999 -9999 -9999 -9999 -9999 -9999 -9999 -9999 -9999 -9999 179.5384979248 155.4403991699110.6370010376 96.00731658936 85.33984375 77.7202072143673 .4532165527371 .3197174072370 .1005783081169 .18623352051 68.8814392089868 .5766525268667 .9670867919967 .0527267456165 .83358764648 64.3096618652363 .0905189514262 .1761703491261 .5666007995661 .26181030273 61.5666007995661 .8713798522962 .4809494018662 .7857398986863 .09051895142 63.0905189514263 .3953094482464 .004882812564 .3096618652364 .91924285889 65.5288009643666 .4431610107467 .0527267456167 .9670867919968 .57665252686 68.8814392089869 .4910125732469 .7957916259869 .7957916259870 .10057830811 70.1005783081170 .4053573608470 .4053573608470 .4053573608470 .40535736084 70.4053573608470 .7101516723671 .3197174072372 .5388565063573 .75800323486 
75.8914871215878 .0249862670980 .1584930419982 .2919769287184 .42548370361 86.5589828491289 .302040100192 .0450973510793 .5372924804793 .76943206787 94.0623931884894 .3979721069394 .7529220581195 .1008148193495 .41578674316 95.6754837036195 .8603668212995 .9551773071395 .9476394653395 .83156585693 95.6047515869195 .2703552246194 .8331909179794 .3007125854593 .68025970459 92.981163024992 .2127761840891 .3849716186590 .5047225952189 .49253082275 88.36599731445 87.2439498901486.13333892822 85.0413360595784.00079345703 82.9648513793981 .7040481567480 .4632720947378 .9393463134877 .41542053223 76.1962814331175 .2819290161174 .3675689697373 .7580032348673 .45321655273 73.1484298706172 .8436431884872 .8436431884872 .5388565063572 .23407745361 71.6244964599671 .3197174072371 .014930725170 .4053573608469 .79579162598 69.4910125732469 .1862335205168 .8814392089868 .5766525268668 .57665252686 68.5766525268668 .8814392089868 .8814392089869 .1862335205169 .49101257324 69.4910125732469 .7957916259870 .1005783081170 .1005783081170 .40535736084 70.7101516723671 .014930725171 .6244964599672 .2340774536172 .84364318848 73.7580032348674 .6723632812575 .5867080688576 .8058471679778 .02498626709 78.9393463134880 .1584930419981 .3776321411182 .5967712402383 .81591033936 85.0350494384821 .334960937516 .4584007263211 .886619567877 .924413204193 $4.2669920921331 .21914100647-.914355397224-3.04785108566-4.87656211853$ $-6.40048694611-7.61962795258-7.92441320419-7.61962795258-6.7052731514$ -5.18134689331 -3.35263609886-1.21914100647.3047851026058 1.828711032867 3.3526360988624 .2669920921334 .876562118535 .1813468933115 .181346893311 5.1813468933114 .876562118534 .5717768669134 .5717768669134 .266992092133 4.2669920921334 .2669920921334 .2669920921334 .5717768669134 .87656211853 5.4861321449286 .0957031256 .7052731513987 .6196279525768 .533983230591 9.4483394622810 .3626899719211 .2770500183111 .8866195678712 .1914100647 12.191410064712 .191410064712 .4961900711110 .362689971928 .838768959045 7.6196279525767 .3148431777957 .9244132041939 .4483394622811 .88661956787 14.934470176718 .28710937522 .2493095397926 .2115192413330 .17373085022 33.8311500549337 .1837806701739 .9268493652342 .66992187545 .10820007324 47.2416992187548 .765621185350 .2895507812551 .5086898803752 .72782897949 53.6421813964854 .2517509460454 .8613204956155 .1661109924355 .47089004517 55.7756805419956 .0804595947356 .3852500915556 .6900291442956 .99481964111 57.2995986938557 .6043891906757 .909179687558 .2139587402358 .51874923706 58.8235282897959 .4295387268159 .7378807067960 .0426712036160 .34745025635 60.6522407531761 .2618103027361 .5666007995661 .8713798522962 .24111557007 62.551475524962 .8476943969763 .1244049072363 .3796920776463 .61135864258 63.8180274963463 .9986457824764 .1532974243265 .8335876464866 .44316101074 66.7479400634867 .0527267456167 .3575134277367 .6623001098667 .96708679199 68.2718734741268 .5766525268668 .8814392089869 .1862335205169 .18623352051 69.4910125732469 .7957916259869 .7957916259870 .1005783081170 .10057830811 70.4053573608470 .4053573608470 .7101516723671 .3197174072371 .92929077148 72.53885650635 -9999 -9999 -9999 -9999 -9999 -9999 -9999 -9999 -9999 -9999 -9999 -9999 -9999 -9999 -9999 -9999 -9999 -9999 -9999 -9999 -9999 -9999 -9999 -9999 -9999 -9999 -9999 -9999 -9999 -9999 -9999 -9999 -9999 -9999 -9999 -9999 -9999

-9999 -9999-9999 -9999 -9999 -9999 -9999 -9999 -9999 -9999 -9999 -9999 -9999 -9999 - 
-9999 -9999 -9999 -9999 -9999 -9999 -9999 -9999 -9999 -9999 -9999 -9999 -9999 -9999 -9999 -9999 -9999 -9999 -9999 -9999 -9999 -9999 -9999 -9999 -9999 -9999 -9999 -9999 -9999 -9999 -9999 -9999 -9999 -9999 -9999 -9999 -9999 -9999 -9999 -9999 -9999 -9999 -9999 -9999 -9999 -9999 -9999 -9999 -9999 -9999 -9999 -9999 -9999 -9999 -9999 -9999 -9999 -9999 -9999 -9999 -9999 -9999 -9999 -9999 -9999 -9999 -9999 -9999 -9999 -9999 -9999 -9999 -9999 -9999 -9999 -9999 -9999 172.2123718262 141.1154937744 106.979598999 90.21640014648 80.1584930419974 .6723632812571 .014930725168 .2718734741266 .44316101074 65.2240066528364 .6144485473663 .7000885009863 .0905189514262 .48094940186 61.5666007995660 .9570198059160 .6522407531760 .3474502563560 .65224075317 60.9570198059161 .2618103027361 .8713798522962 .1761703491262 .78573989868 63.0905189514263 .3953094482464 .004882812564 .6144485473665 .22400665283 65.8335876464866 .4431610107467 .0527267456167 .6623001098668 .27187347412 68.5766525268668 .8814392089868 .8814392089869 .1862335205169 .18623352051 69.1862335205168 .8814392089868 .8814392089868 .8814392089868 .88143920898 69.1862335205169 .4910125732470 .1005783081171 .014930725172 .53885650635 74.062782287675 .5867080688577 .4154205322379 .2441329956181 .07285308838 83.5111236572386 .5589828491289 .9116134643692 .6546783447393 .65032196045 93.9788284301894 .3666763305794 .7852859497195 .201316833595 .58135223389 95.8962936401496 .1218032836996 .2399444580196 .2377395629996 .10995483398 95.8565292358495 .4829330444394 .998329162694 .4115982055793 .7290802002 92.9632186889692 .1193542480591 .2104034423890 .1569213867288 .97737884521 87.7927703857486 .5961074829185 .4089279174884 .2140960693483 .05754089355 81.8910980224680 .4632720947378 .9393463134877 .7202072143676 .19628143311 74.9771423339874 .062782287673 .1484298706172 .5388565063572 .23407745361 71.9292907714871 .6244964599671 .3197174072371 .014930725170 .71015167236 70.4053573608470 .1005783081169 .4910125732469 .1862335205168 .88143920898 68.5766525268668 .2718734741267 .9670867919967 .9670867919967 .96708679199 67.9670867919967 .9670867919968 .2718734741268 .2718734741268 .57665252686 68.8814392089868 .8814392089869 .1862335205169 .4910125732469 .79579162598 70.1005783081170 .4053573608471 .014930725171 .6244964599672 .23407745361 73.1484298706174 .062782287674 .9771423339875 .8914871215877 .1106262207 78.3297805786179 .2441329956180 .4632720947381 .6824111938582 .90155792236 25.6019496917720 .4206008911115 .2392597198510 .362689971925 .790916919708 $1.828711032867-1.21914100647-3.96220707893-6.095703125-7.92441320419$ $-9.14355373383-9.75312423706-9.75312423706-9.44833946228-8.22919845581$ $-6.40048694611-4.57177686691-2.43828105927-99991.219141006472 .743066072464$ 3.6574220657354 .2669920921334 .5717768669134 .5717768669134 .571776866913 4.2669920921333 .9622070789343 .6574220657353 .6574220657353 .657422065735 3.6574220657353 .6574220657353 .9622070789344 .2669920921334 .87656211853 5.4861321449286 .4004869461067 .0100579261787 .9244132041938 .838768959045 9.75312423706110 .6674804687510 .9722604751611 .5818300247211 .58183002472 11.5818300247210 .972260475169 .448339462287 .9244132041937 .010057926178 6.7052731513987 .3148431777958 .53398323059110 .6674804687513 .41055011749 16.4584007263219 .811029434223 .4684505462627 .1258792877230 .78330039978 33.8311500549336 .8790016174339 .622070312542 .0603485107444 .19384002686 46.3273391723647 .8512611389249 .3751907348650 .5943298339851 .81346893311 
52.7278289794953 .6421813964854 .2517509460454 .8613204956155 .16611099243 55.7756805419956 .0804595947356 .3852500915556 .9948196411157 .29959869385 57.6043891906757 .909179687558 .5187492370658 .8235282897959 .12831115723 59.4331016540559 .7378807067960 .0426712036160 .6522407531760 .95701980591 61.2618103027361 .5666007995661 .8713798522962 .2154273986862 .48876953125 62.7518806457562 .9972305297963 .2235832214463 .4296340942463 .61430358887 63.7766838073763 .9165496826264 .989120483466 .1383666992266 .44316101074 66.7479400634867 .0527267456167 .3575134277367 .6623001098667 .96708679199 68.2718734741268 .2718734741268 .5766525268668 .8814392089869 .18623352051 69.1862335205169 .4910125732469 .4910125732469 .7957916259869 .79579162598 70.1005783081170 .1005783081170 .4053573608471 .014930725171 .62449645996 72.23407745361 -9999 -9999 -9999 -9999 -9999 -9999 -9999 -9999 -9999 -9999 -9999 -9999 -9999 -9999 -9999 -9999 -9999 -9999 -9999 -9999 -9999 -9999 -9999 -9999 -9999 -9999 -9999 -9999 -9999 -9999 -9999 -9999 -9999 -9999 -9999 -9999 -9999 -9999 -9999 -9999 -9999 -9999 -9999 -9999 -9999 -9999 -9999 -9999 -9999 -9999 -9999 -9999 -9999 -9999 -9999 -9999 -9999 -9999 -9999 -9999 -9999 -9999 -9999 -9999 -9999 -9999 -9999 -9999 -9999 -9999 -9999 -9999 -9999 -9999 -9999 -9999 -9999 -9999 -9999 -9999 -9999 -9999 -9999 -9999 -9999 -9999 -9999 -9999 -9999 -9999 -9999 -9999 -9999 -9999 -9999 -9999 -9999 -9999 -9999 -9999 -9999 -9999 -9999 -9999 -9999 -9999 -9999 -9999 -9999 -9999 -9999 -9999 -9999 -9999 -9999 -9999 -9999 -9999 -9999 -9999 -9999 -9999 -9999 -9999 -9999 -9999 -9999 -9999 184.7198486328 164.8471374512131.362396240294.17859649658 86.8637619018678 .9393463134871 .6244964599666 .7479400634864 .0048828125 61.8713798522960 .6522407531760 .0426712036159 .4331016540559 .12831115723 58.8235282897958 .8235282897958 .8235282897959 .1283111572359 .43310165405 60.0426712036160 .6522407531761 .2618103027361 .8713798522962 .48094940186 62.7857398986863 .3953094482464 .004882812564 .6144485473665 .22400665283 66.1383666992266 .7479400634867 .3575134277367 .6623001098668 .27187347412 68.2718734741268 .5766525268668 .2718734741268 .2718734741267 .96708679199 67.9670867919967 .6623001098667 .6623001098667 .3575134277367 .35751342773 67.6623001098667 .9670867919968 .5766525268669 .4910125732470 .71015167236 71.9292907714873 .1484298706174 .6723632812575 .8914871215877 .72020721436 80.1584930419983 .5111236572387 .4733276367291 .1307525634893 .430519104 93.7961196899494 .2430725097794 .7369232177795 .2359390258895 .69635009766 96.0816421508896 .3587112426896 .5058898925896 .5111312866296 .37157440186 96.0926055908295 .6845016479595 .1590576171994 .5213775634893 .78359222412 92.9501342773492 .0312576293991 .0140533447389 .8209533691488 .61515045166 87.402198791586 .1684341430784 .9532470703183 .78041839682 .59677124023 80.7680587768679 .2441329956178 .0249862670976 .5010681152375 .28192901611 74.062782287673 .1484298706172 .2340774536171 .6244964599671 .0149307251 70.7101516723670 .4053573608470 .1005783081169 .7957916259869 .49101257324 69.1862335205168 .8814392089868 .5766525268668 .2718734741267 .96708679199 67.6623001098667 .3575134277367 .3575134277367 .3575134277367 .05272674561 67.3575134277367 .3575134277367 .3575134277367 .6623001098667 .66230010986 67.9670867919968 .2718734741268 .5766525268668 .8814392089869 .18623352051 69.4910125732469 .7957916259870 .4053573608471 .014930725171 .92929077148 72.5388565063573 .4532165527374 .3675689697375 .2819290161176 .19628143311 
77.4154205322378 .3297805786179 .5489196777380 .7680587768681 .68241119385 24.3828105926518 .8966808319113 .410550117498 .2291984558113 .352636098862 -.914355397224 -4.57177686691 -7.3148431778 -9.44833946228 -10.9722604752 $-11.8866195679-12.1914100647-11.8866195679-11.2770500183-9.75312423706$ -7.92441320419 -5.79091691971 -3.65742206573 -1.52392601967.3047851026058 1.8287110328673 .0478510856633 .9622070789344 .2669920921333 .962207078934 3.6574220657353 .3526360988623 .3526360988623 .0478510856633 .047851085663 3.0478510856633 .0478510856633 .3526360988623 .3526360988623 .962207078934 4.2669920921334 .876562118535 .4861321449286 .4004869461067 .314843177795 8.2291984558118 .8387689590459 .4483394622810 .0579099655210 .05790996552 10.057909965529 .7531242370618 .8387689590457 .9244132041936 .705273151398 6.0957031256 .0957031256 .7052731513988 .22919845581110 .0579099655212 .49619007111 15.2392597198518 .28710937521 .334960937524 .9923801422128 .34502029419 31.3928699493434 .4407196044937 .1837806701739 .9268493652342 .06034851074 44.1938400268646 .0225486755447 .8512611389249 .0704002380450 .59432983398 51.5086898803752 .4230384826753 .3373985290554 .2517509460454 .86132049561 55.4708900451755 .7756805419956 .3852500915556 .9948196411157 .29959869385 57.909179687558 .2139587402358 .5187492370658 .8235282897959 .31325531006 59.7378807067960 .0426712036160 .3474502563560 .6522407531760 .95701980591 61.2618103027361 .5666007995661 .8713798522962 .2043228149462 .45101165771 62.6821327209562 .8964462280363 .0936737060563 .2733650207563 .43481063843 63.5771827697863 .7001876831164 .9149856567465 .8335876464866 .13836669922 66.4431610107466 .7479400634867 .0527267456167 .0527267456167 .35751342773 67.6623001098667 .9670867919968 .2718734741268 .2718734741268 .57665252686 68.8814392089868 .8814392089869 .1862335205169 .1862335205169 .49101257324 69.4910125732469 .7957916259869 .7957916259870 .1005783081170 .71015167236 71.3197174072371 .92929077148 -9999 -9999 -9999 -9999 -9999 -9999 -9999 -9999 -9999 -9999 -9999 -9999 -9999 -9999 -9999 -9999 -9999 -9999 -9999 -9999 -9999 -9999 -9999 -9999 -9999 -9999 -9999 -9999 -9999 -9999 -9999 -9999 -9999 -9999 -9999

-9999 -9999 -9999 -9999 -9999 -9999 -9999 -9999 -9999 -9999 -9999 -9999 -9999 -9999 -9999 -9999 -9999 -9999 -9999 -9999 -9999 -9999 -9999 -9999 -9999 -9999 -9999 -9999 -9999 -9999

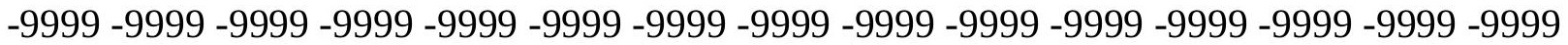

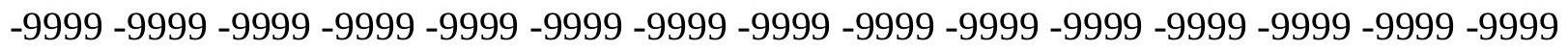

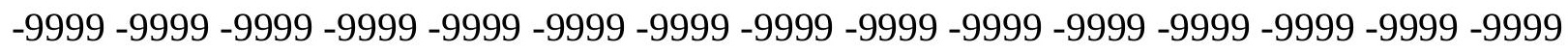
-9999 -9999 -9999 -9999 -9999 -9999 -9999 -9999 -9999 -9999 -9999 -9999 -9999 -9999 -9999 -9999 -9999-9999 185.3418121338166.7174987793122.5235977173101.4934005737 85.33984375 73.4532165527366 .4431610107462 .4809494018659 .43310165405 57.6043891906756 .6900291442956 .3852500915556 .3852500915556 .38525009155 56.9948196411157 .2995986938557 .909179687558 .5187492370659 .43310165405 60.0426712036160 .6522407531761 .5666007995662 .1761703491262 .78573989868 63.3953094482464 .3096618652364 .9192428588965 .5288009643666 .44316101074 67.0527267456167 .6623001098667 .9670867919968 .2718734741268 .27187347412 67.9670867919967 .9670867919967 .3575134277367 .0527267456166 .74794006348 66.4431610107466 .1383666992265 .8335876464865 .8335876464866 .13836669922 66.4431610107467 .0527267456167 .6623001098668 .5766525268669 .79579162598 70.7101516723671 .9292907714873 .1484298706174 .6723632812576 .50106811523 
80.7680587768685 .3398437589 .6068267822392 .9594726562593 .49691772461 94.0090255737394 .5876617431695 .1871566772595 .7504882812596 .22482299805 96.566543579196 .7490463256896 .7606430053796 .6089096069396 .30588531494 95.870956420995 .3135375976694 .6345977783293 .8406600952192 .94215393066 91.9461288452190 .8068923950289 .6127700805788 .407089233487 .21310424805 86.0348968505984 .7302627563583 .206336975181 .3776321411179 .85370635986 78.3297805786177 .110626220775 .5867080688574 .3675689697373 .14842987061 72.2340774536171 .3197174072370 .7101516723670 .1005783081169 .79579162598 69.1862335205168 .8814392089868 .5766525268668 .2718734741267 .96708679199 67.9670867919967 .6623001098667 .3575134277367 .0527267456166 .74794006348 66.7479400634866 .7479400634866 .4431610107466 .4431610107466 .44316101074 66.7479400634866 .7479400634867 .0527267456167 .0527267456167 .35751342773 67.6623001098667 .9670867919968 .2718734741268 .5766525268668 .88143920898 69.4910125732469 .7957916259870 .4053573608471 .3197174072371 .92929077148 72.8436431884873 .4532165527374 .3675689697375 .5867080688576 .50106811523 77.4154205322378 .3297805786179 .5489196777380 .7680587768622 .85887908936 17.0679702758811 .581830024726 .095703125 .6095703244209 -3.96220707893 -7.92441320419 -10.9722604752 -13.1057596207-14.3248996735 -14.9344701767 -14.9344701767 -14.3248996735 -13.1057596207 -11.5818300247 -9.75312423706 -7.3148431778 -5.18134689331 -2.74306607246 -.609570324421 .9143553972244 2.4382810592653 .6574220657353 .6574220657353 .3526360988622 .743066072464 2.7430660724642 .4382810592652 .4382810592652 .4382810592652 .438281059265 2.4382810592652 .7430660724642 .7430660724643 .0478510856633 .657422065735 4.2669920921334 .876562118535 .4861321449286 .4004869461067 .010057926178 7.6196279525768 .2291984558118 .5339832305918 .5339832305917 .924413204193 7.3148431777956 .7052731513985 .7909169197085 .4861321449285 .181346893311 5.4861321449286 .0957031257 .6196279525769 .75312423706111 .58183002472 14.3248996734617 .0679702758820 .1158199310323 .4684505462626 .51630973816 29.8689403533932 .6120109558135 .6598587036138 .0981407165540 .53641891479 42.66992187544 .4986305236846 .3273391723647 .8512611389249 .37519073486 50.5943298339851 .8134689331152 .7278289794953 .6421813964854 .55654144287 55.1661109924355 .7756805419956 .3852500915556 .9948196411157 .60438919067 57.909179687558 .5187492370658 .8235282897959 .1283111572359 .43310165405 60.0312232971260 .3474502563560 .5992851257360 .8935966491761 .20404815674 61.4838676452661 .7456970214861 .9910087585462 .2234077453662 .43893432617 62.6377334594762 .8205108642662 .988006591863 .1404037475663 .27737426758 63.3982009887763 .5025978088463 .590541839664 .8493423461965 .83358764648 65.8335876464866 .1383666992266 .4431610107466 .7479400634867 .05272674561 67.3575134277367 .6623001098667 .6623001098667 .9670867919968 .27187347412 68.2718734741268 .5766525268668 .5766525268668 .8814392089868 .88143920898 69.1862335205169 .1862335205169 .4910125732469 .4910125732469 .79579162598 70.4053573608471 .014930725171 .62449645996 -9999 -9999 -9999 -9999 -9999 -9999 -9999 -9999 -9999 -9999 -9999 -9999 -9999 -9999 -9999 -9999 -9999 -9999 -9999 -9999 -9999 -9999 -9999 -9999 -9999 -9999 -9999 -9999 -9999 -9999 -9999 -9999 -9999 -9999 -

-9999 -9999 -9999 -9999 -9999 -9999 -9999 -9999 -9999 -9999 -9999 -9999 -9999 -9999 -9999

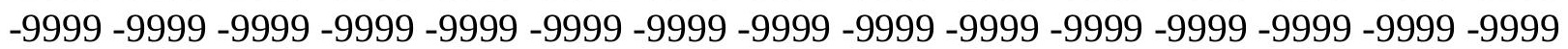


-9999 -9999 -9999 -9999 -9999 -9999 -9999 -9999 -9999 -9999 -9999 -9999 -9999 -9999 -9999 -9999 -9999 -9999 -9999 -9999 -9999 -9999 -9999 -9999 -9999 -9999 -9999 -9999 -9999 -9999 -9999 -9999 -9999 -9999 -9999 -9999 -9999 -9999 -9999 -9999 -9999 -9999 -9999 -9999 -9999 -9999 -9999 -9999 -9999 -9999 -9999 -9999 -9999 -9999 -9999 -9999 -9999 -9999 -9999 -9999 -9999 -9999 -9999 -9999 182.544418335152.6972961426117.64710235691.43553924561 76.5010681152368 .2718734741262 .7857398986858 .5187492370655 .77568054199 54.2517509460453 .9469718933154 .2517509460454 .8613204956155 .47089004517 56.3852500915556 .9948196411157 .909179687558 .8235282897959 .73788070679 60.6522407531761 .2618103027362 .1761703491262 .7857398986863 .70008850098 64.3096618652365 .2240066528366 .1383666992266 .7479400634867 .35751342773 67.9670867919968 .2718734741268 .2718734741268 .2718734741267 .96708679199 67.3575134277366 .7479400634866 .1383666992265 .5288009643665 .22400665283 64.6144485473664 .3096618652364 .3096618652364 .3096618652364 .61444854736 65.2240066528365 .8335876464866 .7479400634867 .6623001098668 .88143920898 70.1005783081171 .3197174072372 .8436431884875 .2819290161178 .93934631348 83.5111236572388 .0829010009892 .0450973510793 .0585098266693 .63969421387 94.3251495361395.0496444702195.7393875122196.3234558105596.74082946777 96.958007812596 .9721603393696 .7954330444396 .475723266696 .0198059082 95.4488983154394 .74330902193 .8903579711992 .9180068969791 .83920288086 90.7168960571389 .4824600219788 .1586761474686 .8637619018685 .64462280273 83.8159103393682 .2919769287180 .7680587768679 .2441329956177 .72020721436 76.1962814331174 .9771423339873 .7580032348672 .5388565063571 .62449645996 70.7101516723670 .1005783081169 .4910125732468 .8814392089868 .57665252686 67.9670867919967 .6623001098667 .3575134277367 .3575134277367 .05272674561 66.7479400634866 .4431610107466 .4431610107466 .1383666992266 .13836669922 65.8335876464865 .8335876464865 .8335876464865 .8335876464866 .13836669922 66.1383666992266 .4431610107466 .4431610107466 .7479400634867 .05272674561 67.3575134277367 .6623001098667 .9670867919968 .2718734741268 .88143920898 69.1862335205169 .7957916259870 .7101516723671 .3197174072371 .92929077148 72.8436431884873 .7580032348674 .3675689697375 .2819290161176 .19628143311 77.4154205322378 .3297805786179 .5489196777321 .334960937514 .9344701767 $9.1435537338263 .352636098862-2.43828105927-7.92441320419-11.8866195679$ -14.9344701767 -16.7631797791 -17.6775398254-17.9823207855 -17.6775398254 -16.7631797791 -15.5440397263 -13.7153301239-11.5818300247-9.14355373383 $-6.7052731514-4.26699209213-2.13349604607-.3047851026061 .523926019669$ 3.0478510856632 .4382810592652 .1334960460661 .8287110328671 .828711032867 1.8287110328671 .8287110328671 .8287110328671 .8287110328671 .828711032867 2.1334960460662 .1334960460662 .4382810592652 .7430660724643 .352636098862 3.9622070789344 .5717768669135 .1813468933115 .7909169197086 .400486946106 6.7052731513987 .0100579261786 .7052731513986 .0957031255 .181346893311 4.2669920921333 .9622070789343 .9622070789343 .9622070789344 .571776866913 5.7909169197087 .0100579261789 .14355373382611 .2770500183113 .7153301239 16.1536102294919 .2014598846422 .2493095397925 .6019496917728 .64979934692 31.3928699493434 .1359291076736 .8790016174339 .3172798156741 .45077896118 43.2794914245645 .1082000732446 .9369087219248 .4608306884849 .98476028442 51.2038993835452 .4230384826753 .3373985290554 .2517509460455 .16611099243 
56.0804595947356 .6900291442957 .2995986938557 .909179687558 .21395874023 58.8235282897959 .1283111572359 .4331016540559 .7378807067960 .04267120361 60.3474502563560 .6522407531760 .9570198059161 .2618103027361 .56660079956 61.8536376953162 .0715484619162 .270931243962 .4521675109962 .61712646484 62.7673377990762 .904159545963 .0281677246163 .1393928527863 .23733901978 63.3217887878463 .3927803039664 .7714462280365 .5288009643665 .52880096436 65.8335876464866 .1383666992266 .4431610107466 .7479400634866 .74794006348 67.0527267456167 .3575134277367 .6623001098667 .6623001098667 .96708679199 67.9670867919968 .2718734741268 .2718734741268 .5766525268668 .57665252686 68.8814392089868 .8814392089869 .1862335205169 .1862335205169 .49101257324 69.7957916259870 .4053573608471 .0149307251 -9999 -9999 -9999 -9999 -9999 -9999 -9999 -9999 -9999 -9999 -9999 -9999 -9999 -9999 -9999 -9999 -9999 -9999 -9999 -9999 -9999 -9999 -9999 -9999 -9999 -9999 -9999 -9999 -9999 -9999 -9999 -9999 -9999

-9999 -9999 -9999 -9999 -9999 -9999 -9999 -9999 -9999 -9999 -9999 -9999 -9999 -9999 -9999 -9999 -9999 -9999 -9999 -9999 -9999 -9999 -9999 -9999 -9999 -9999 -9999 -9999 -9999 -9999

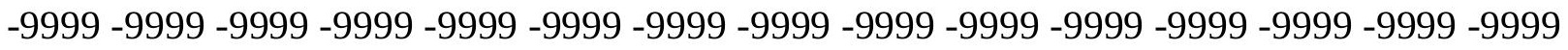
-9999 -9999 -9999 -9999 -9999 -9999 -9999 -9999 -9999 -9999 -9999 -9999 -9999 -9999 -9999 -9999 -9999 -9999 -9999 -9999 -9999 -9999 -9999 -9999 -9999 -9999 -9999 -9999 -9999 -9999 -9999 -9999 -9999 -9999 -9999 -9999 -9999 -9999 -9999 -9999 -9999 -9999 -9999 -9999 -9999 -9999 -9999 -9999 -9999 194.8969573975 171.0406799316 134.1054992676 93.26425170898 84.7302627563574 .9771423339865 .2240066528358 .5187492370654 .55654144287 52.7278289794952 .4230384826753 .0326118469253 .6421813964854 .86132049561 55.7756805419956 .9948196411157 .909179687558 .8235282897959 .73788070679 60.6522407531761 .5666007995662 .1761703491263 .0905189514264 .0048828125 64.9192428588965 .5288009643666 .4431610107467 .3575134277367 .96708679199 68.5766525268668 .8814392089868 .8814392089868 .2718734741267 .96708679199 67.0527267456166 .4431610107465 .5288009643664 .9192428588964 .0048828125 63.7000885009863 .0905189514263 .0905189514263 .0905189514263 .39530944824 63.7000885009864 .3096618652365 .2240066528366 .1383666992267 .05272674561 68.2718734741269 .7957916259871 .6244964599674 .3675689697378 .02498626709 81.9871978759886 .254188537689 .9116134643692 .4643554687593 .12482452393 93.9366836547994 .811103820895 .6500549316496 .36020660496 .8631439209 97.1009140014697 .1045227050896 .896629333596 .5557479858496 .07968902588 95.5139694213994 .826309204193 .9102478027392 .8298492431691 .74033355713 90.5211791992289 .302040100187 .7781066894586 .5589828491285 .03504943848 83.5111236572381 .6824111938580 .1584930419978 .6345596313577 .1106262207 75.8914871215874 .3675689697373 .1484298706172 .2340774536171 .0149307251 70.4053573608469 .4910125732468 .8814392089868 .2718734741267 .66230010986 67.3575134277367 .0527267456166 .7479400634866 .4431610107466 .13836669922 65.8335876464865 .8335876464865 .5288009643665 .5288009643665 .52880096436 65.2240066528365 .2240066528365 .2240066528365 .5288009643665 .52880096436 65.5288009643665 .8335876464865 .8335876464866 .1383666992266 .44316101074 66.7479400634867 .0527267456167 .3575134277367 .6623001098668 .27187347412 68.5766525268669 .1862335205169 .7957916259870 .4053573608471 .31971740723 71.9292907714872 .5388565063573 .4532165527374 .062782287674 .97714233398 75.8914871215876 .8058471679726 .2115192413319 .5062503814712 .1914100647 
5.790916919708 -9999 -7.01005792618 -12.4961900711 -16.4584007263 -18.8966808319 $-20.4206008911-21.0301704407-21.0301704407-20.4206008911-19.2014598846$ $-17.6775398254-15.8488302231-13.4105501175-10.9722604752-8.53398323059$ $-6.095703125-3.65742206573-1.52392601967-9999.6095703244209 .3047851026058$ .6095703244209.9143553972244.9143553972244.9143553972244.9143553972244 .91435539722441 .219141006471 .219141006471 .219141006471 .523926019669 1.8287110328672 .1334960460662 .4382810592652 .7430660724643 .352636098862 3.9622070789344 .5717768669134 .876562118535 .1813468933115 .181346893311 4.876562118534 .2669920921333 .3526360988622 .1334960460662 .438281059265 2.7430660724643 .0478510856633 .9622070789345 .1813468933116 .705273151398 8.53398323059110 .6674804687513 .1057596206715 .8488302230818 .59189033508 21.6397399902324 .6875991821327 .7354507446330 .7833003997833 .52635955811 35.9646492004438 .0981407165540 .5364189147942 .3651313781744 .49863052368 46.3273391723647 .8512611389249 .3751907348650 .8991203308152 .11825942993 53.3373985290554 .2517509460455 .1661109924356 .0804595947356 .99481964111 57.6043891906758 .2139587402358 .5187492370659 .1283111572359 .43310165405 59.7378807067960 .0426712036160 .3474502563560 .6522407531760 .95701980591 61.2618103027361 .5666007995661 .5666007995661 .8713798522962 .17617034912 62.3434219360462 .4809494018662 .6168975830162 .7333030700762 .83843231201 62.9330902099663 .0175666809163 .091655731263 .155269622863 .20848464966 64.6583328247164 .6180114746165 .2240066528365 .5288009643665 .83358764648 66.1383666992266 .1383666992266 .4431610107466 .7479400634867 .05272674561 67.0527267456167 .3575134277367 .3575134277367 .6623001098667 .96708679199 67.9670867919968 .2718734741268 .2718734741268 .5766525268668 .57665252686 68.8814392089868 .8814392089869 .1862335205169 .1862335205169 .49101257324 70.1005783081170 .71015167236 -9999 -9999 -9999 -9999 -9999 -9999 -9999 -9999 -9999

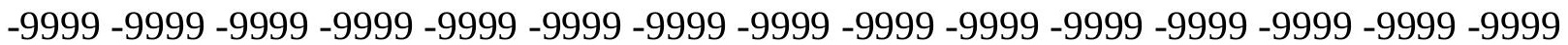
-9999 -9999 -9999 -9999 -9999 -9999 -9999 -9999

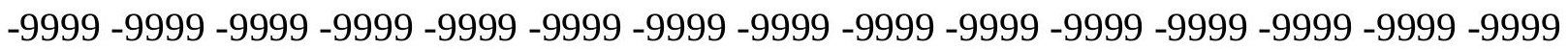

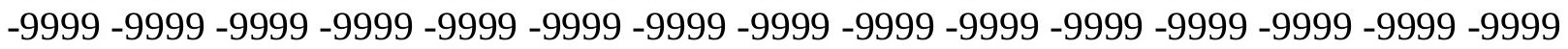

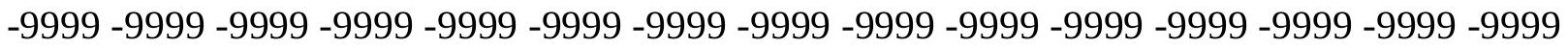

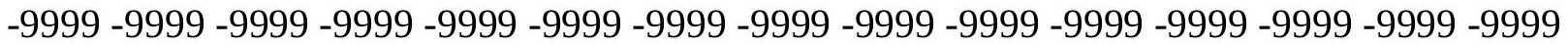

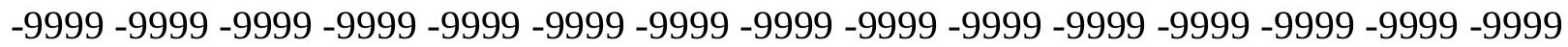

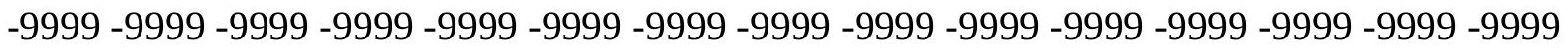
-9999 -9999 -9999 -9999-9999 186.0981903076 164.5839996338 126.1809997559 103.0174026489 83.81591033936 68.57665252686 59.43310165405 54.55654144287 52.4230384826752 .1182594299352 .7278289794953 .6421813964854 .86132049561 56.0804595947357 .2995986938558 .2139587402359 .4331016540560 .34745025635 61.2618103027361 .8713798522962 .7857398986863 .7000885009864 .61444854736 65.5288009643666 .4431610107467 .3575134277368 .2718734741268 .88143920898 69.4910125732469 .4910125732469 .4910125732468 .8814392089867 .96708679199 67.0527267456166 .1383666992265 .2240066528364 .3096618652363 .39530944824 62.7857398986862 .1761703491261 .8713798522961 .8713798522962 .17617034912 62.4809494018663 .0905189514264 .004882812564 .9192428588965 .83358764648 67.3575134277368 .8814392089871 .014930725173 .7580032348676 .80584716797 80.4632720947384 .4254837036187 .7781066894590 .8259735107492 .44163513184 
93.40520477295 94.4513549804795.4520568847796.2827148437596.87554931641 97.1244506835997 .0603713989396 .846405029396 .452285766695 .97692108154 95.397743225194 .7881774902393 .8738174438592 .6546783447391 .43553924561 90.2164001464888 .9972534179787 .7781066894586 .254188537684 .73026275635 83.2063369751 81.3776321411179.8537063598678.32978057861 76.80584716797 75.5867080688574 .062782287672 .8436431884871 .9292907714870 .71015167236 69.7957916259869 .1862335205168 .2718734741267 .6623001098667 .35751342773 66.7479400634866 .4431610107466 .1383666992265 .8335876464865 .52880096436 65.2240066528365 .2240066528364 .9192428588964 .9192428588964 .91924285889 64.6144485473664 .6144485473664 .9192428588964 .9192428588964 .91924285889 64.9192428588965 .2240066528365 .2240066528365 .5288009643665 .83358764648 66.1383666992266 .1383666992266 .7479400634867 .0527267456167 .35751342773 67.9670867919968 .5766525268668 .8814392089869 .4910125732470 .10057830811 70.7101516723671 .6244964599672 .2340774536172 .8436431884873 .45321655273 74.3675689697375 .2819290161126 .5163097381617 .982320785529 .44833946228 $1.21914100647-6.095703125-12.8009700775-17.9823207855-21.0301704407$ $-23.1636695862-24.0780296326-24.3828105927-23.7732391357-22.8588790894$ -21.6397399902 -19.8110294342 -17.6775398254-15.2392597198 -12.8009700775 $-10.3626899719-7.61962795258-5.48613214493-3.35263609886-1.82871103287$ -.914355397224 -.609570324421 -.304785102606 -9999-9999.3047851026058 6095703244209 .6095703244209.9143553972244 1.21914100647 1.5239260196691.828711032867 2.1334960460662 .7430660724643 .3526360988623 .6574220657353 .962207078934 3.6574220657353 .3526360988622 .7430660724642 .1334960460661 .523926019669 1.5239260196691 .8287110328672 .4382810592653 .3526360988624 .87656211853 6.4004869461068 .22919845581110 .3626899719212 .8009700775115 .23925971985 18.28710937521 .0301704406724 .0780296325727 .1258792877230 .17373085022 32.9167900085435 .0502891540537 .4885711669939 .622070312541 .75556182861 43.8890609741245 .717769622847 .5464782714849 .0704002380450 .59432983398 52.1182594299353 .3373985290554 .5565414428755 .4708900451756 .38525009155 57.2995986938557 .909179687558 .5187492370659 .1283111572359 .43310165405 59.7378807067960 .0426712036160 .3474502563560 .6522407531760 .95701980591 61.2618103027361 .2618103027361 .5666007995661 .8713798522961 .87137985229 62.1761703491262 .1761703491262 .4809494018662 .6327629089462 .71413421631 62.7866401672462 .8512496948262 .9084243774462 .9581718444863 .00052261353 63.035575866764 .486610412664 .4919891357464 .9192428588965 .22400665283 65.5288009643665 .5288009643665 .8335876464866 .1383666992266 .44316101074 66.4431610107466 .7479400634866 .7479400634867 .0527267456167 .35751342773 67.3575134277367 .6623001098667 .6623001098667 .9670867919967 .96708679199 68.2718734741268 .2718734741268 .5766525268668 .5766525268668 .88143920898 68.8814392089869 .1862335205169 .7957916259870 .40535736084 -9999 -9999 -9999 -9999 -9999 -9999 -9999 -9999 -9999 -9999 -9999 -9999 -9999 -9999 -9999 -9999 -9999 -9999 -9999 -9999 -9999 -9999 -9999 -9999 -9999 -9999 -9999 -9999 -9999 -9999 -9999 -9999 -9999 -9999 -9999 -9999 -9999 -9999 -9999 -9999 -9999 -9999 -9999 -9999 -9999 -9999

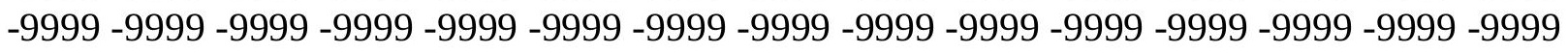

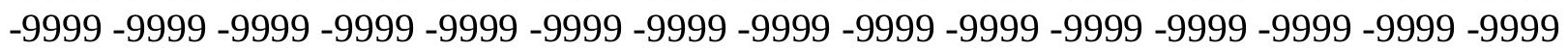


-9999 -9999 -9999 -9999 -9999 -9999 -9999 -9999 -9999 -9999 -9999 -9999 -9999 -9999 -9999 -9999 -9999 -9999 -9999 -9999 -9999 -9999 -9999 -9999 -9999 -9999 -9999 -9999 -9999 -9999 -9999 -9999 -9999 -9999 -9999 -9999 -9999 -9999 -9999 -9999 -9999 -9999 -9999 -9999 -9999 -9999 -9999 -9999-9999-9999 195.4445800781 178.8312530518 151.7830047607 121.914001464890 .8259735107471 .6244964599661 .5666007995656 .08045959473 53.6421813964853 .0326118469253 .6421813964854 .5565414428756 .08045959473 57.2995986938558 .5187492370659 .4331016540560 .3474502563561 .26181030273 62.1761703491263 .0905189514263 .7000885009864 .6144485473665 .52880096436 66.4431610107467 .3575134277368 .2718734741269 .4910125732470 .10057830811 70.7101516723670 .7101516723670 .1005783081169 .4910125732468 .57665252686 67.3575134277366 .1383666992265 .2240066528364 .3096618652363 .09051895142 62.4809494018661 .8713798522961 .2618103027361 .2618103027361 .56660079956 61.8713798522962 .4809494018663 .0905189514264 .004882812565 .22400665283 66.4431610107468 .2718734741270 .4053573608472 .8436431884875 .89148712158 79.2441329956182 .5967712402385 .9494018554788 .9972534179791 .43553924561 92.6990127563593 .9445571899495 .0848464965895 .98520660496 .61688232422 96.9216690063596 .6168823242296 .6168823242296 .0073165893695 .70252990723 95.0929565429794 .1785964965893 .5690307617292 .6546783447391 .43553924561 90.5211791992288 .9972534179787 .4733276367285 .9494018554784 .42548370361 82.9015579223681 .3776321411179 .8537063598678 .0249862670976 .80584716797 75.2819290161174 .062782287672 .5388565063571 .6244964599670 .40535736084 69.4910125732468 .8814392089867 .9670867919967 .3575134277366 .74794006348 66.4431610107465 .8335876464865 .5288009643665 .2240066528364 .91924285889 64.6144485473664 .6144485473664 .3096618652364 .3096618652364 .30966186523 64.3096618652364 .3096618652364 .3096618652364 .3096618652364 .30966186523 64.6144485473664 .6144485473664 .6144485473664 .9192428588965 .22400665283 65.2240066528365 .5288009643665 .8335876464866 .1383666992266 .74794006348 67.0527267456167 .6623001098667 .9670867919968 .5766525268669 .18623352051 69.7957916259870 .1005783081170 .7101516723671 .3197174072371 .92929077148 72.5388565063573 .1484298706127 .430660247817 .067970275886 .400486946106 -3.04785108566 -11.8866195679 -19.5062503815 -23.1636695862 -25.2971591949 -26.5163097382 -27.1258792877 -26.8210906982 -26.2115192413 -25.2971591949 -23.7732391357 -21.9445304871 -19.5062503815 -17.0679702759-14.6296901703 -11.8866195679 -9.44833946228 -7.01005792618 -4.87656211853 -3.35263609886 $-2.43828105927-1.82871103287-1.21914100647-.914355397224-.609570324421$ -.304785102606 -.304785102606 -9999-9999 -9999 -9999-9999 -9999 .3047851026058 3047851026058.6095703244209.9143553972244 1.523926019669 1.828711032867 2.1334960460662 .4382810592652 .4382810592652 .1334960460661 .828711032867 1.21914100647 .9143553972244 .91435539722441 .5239260196692 .133496046066 3.0478510856634 .5717768669136 .0957031258 .22919845581110 .36268997192 12.4961900711115 .2392597198517 .9823207855220 .7253894805923 .77323913574 26.8210906982429 .8689403533932 .3072204589834 .7455101013236 .87900161743 39.0125007629441 .1459884643643 .2794914245645 .4129791259847 .24169921875 49.0704002380450 .5943298339852 .1182594299353 .3373985290554 .55654144287 55.7756805419956 .6900291442957 .6043891906758 .2139587402358 .82352828979 59.4331016540559 .7378807067960 .3474502563560 .6522407531760 .65224075317 
60.9570198059161 .2618103027361 .2618103027361 .5666007995661 .56660079956 61.8713798522961 .8713798522962 .1761703491262 .1761703491262 .48094940186 62.6593933105562 .704795837462 .7441139221262 .7784004211462 .80819702148 62.8336372375562 .8547821044962 .8717193603562 .8847198486364 .30966186523 64.2186431884864 .9192428588965 .2240066528365 .2240066528365 .52880096436 65.8335876464865 .8335876464866 .1383666992266 .1383666992266 .44316101074 66.7479400634866 .7479400634867 .0527267456167 .0527267456167 .35751342773 67.3575134277367 .6623001098667 .6623001098667 .9670867919967 .96708679199 68.2718734741268 .2718734741268 .5766525268668 .8814392089868 .88143920898 69.4910125732470 .1005783081170 .71015167236 -9999 -9999 -9999 -9999 -9999 -9999 -9999

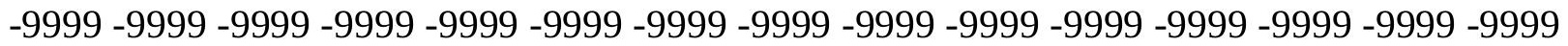
-9999 -9999 -9999 -9999 -9999 -9999-9999

-9999 -9999 -9999 -9999 -9999 -9999 -9999 -9999 -9999 -9999 -9999 -9999 -9999 -9999 -9999 -9999 -9999 -9999 -9999 -9999 -9999 -9999 -9999 -9999 -9999 -9999 -9999 -9999 -9999 -9999 -9999 -9999 -9999 -9999 -9999 -9999 -9999 -9999 -9999 -9999 -9999 -9999 -9999 -9999 -9999 -

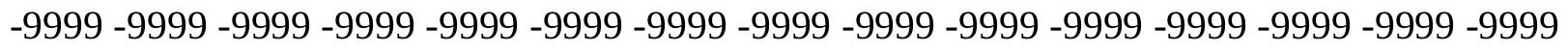
-9999 -9999 -9999 -9999 -9999 -9999 -9999 -9999 -9999 -9999 -9999 -9999 -9999 -9999 -9999 -9999 -9999 -9999 -9999 -9999 -9999 -9999 -9999 -9999 -9999 -9999 -9999 -9999 -9999 -9999 -9999 -9999 -9999 -9999 -9999 -9999 189.8341369629163 .9417419434129 .533706665 90.2164001464876 .8058471679766 .4431610107459 .4331016540556 .08045959473 54.8613204956155 .4708900451756 .6900291442957 .909179687559 .12831115723 60.3474502563561 .2618103027362 .1761703491263 .0905189514263 .70008850098 64.3096618652365 .2240066528365 .8335876464866 .4431610107467 .35751342773 68.2718734741269 .4910125732470 .7101516723671 .6244964599672 .23407745361 71.9292907714871 .3197174072370 .1005783081168 .8814392089867 .66230010986 66.7479400634865 .5288009643664 .6144485473663 .3953094482462 .48094940186 61.8713798522961 .2618103027361 .2618103027361 .2618103027361 .56660079956 62.1761703491262 .7857398986863 .7000885009864 .9192428588966 .13836669922 67.9670867919969 .7957916259872 .2340774536174 .9771423339878 .02498626709 81.0728530883884 .1206970214887 .1685485839889 .6068267822391 .74033355713 93.2642517089894 .4833908081195 .397743225195 .7025299072396 .00731658936 96.0073165893695 .7025299072395 .397743225195 .0929565429794 .48339080811 93.8738174438593 .2642517089892 .6546783447391 .7403335571390 .52117919922 89.3020401001 87.77810668945 86.2541885376 84.42548370361 82.90155792236 81.3776321411179 .5489196777378 .0249862670976 .5010681152374 .97714233398 73.7580032348672 .5388565063571 .3197174072370 .4053573608469 .49101257324 68.5766525268667 .6623001098667 .0527267456166 .4431610107465 .83358764648 65.5288009643664 .9192428588964 .6144485473664 .3096618652364 .30966186523 64.004882812563 .7000885009863 .7000885009863 .7000885009863 .70008850098 63.7000885009863 .7000885009863 .7000885009863 .7000885009864 .0048828125 64.004882812564 .004882812564 .3096618652364 .3096618652364 .61444854736 64.9192428588964 .9192428588965 .2240066528365 .8335876464866 .13836669922 66.4431610107467 .0527267456167 .3575134277367 .6623001098668 .27187347412 68.8814392089869 .1862335205169 .4910125732469 .7957916259870 .10057830811 $70.4053573608430 .1737308502217 .067970275884 .266992092133-6.7052731514$ -15.8488302231 -22.8588790894-26.8210906982 -28.6497993469 -29.2593708038 
-29.2593708038 -28.9545898438 -28.0402297974 -26.8210906982 -25.2971591949 $-23.4684505463-21.3349609375-18.5918903351-16.1536102295-13.4105501175$ $-10.6674804688-8.53398323059-6.40048694611-4.87656211853-3.65742206573$ $-2.74306607246-2.13349604607-1.52392601967-1.21914100647-1.21914100647$ $-.914355397224-.914355397224-.609570324421-.609570324421-.609570324421$ -.609570324421 -.609570324421 -.609570324421 -.304785102606 -.304785102606 -9999 .3047851026058 6095703244209.9143553972244 1.21914100647 1.21914100647 1.21914100647.9143553972244.9143553972244.6095703244209.9143553972244 1.219141006472 .1334960460663 .0478510856634 .5717768669136 .095703125 7.92441320419310 .0579099655212 .4961900711114 .934470176717 .67753982544 20.4206008911123 .4684505462626 .2115192413328 .9545898437531 .69765090942 34.1359291076736 .2694282531738 .7077102661140 .8412094116242 .97470092773 45.1082000732446 .9369087219248 .765621185350 .5943298339852 .11825942993 53.6421813964854 .8613204956156 .0804595947357 .2995986938557 .9091796875 58.8235282897959 .4331016540559 .7378807067960 .3474502563560 .65224075317 60.9570198059160 .9570198059161 .2618103027361 .5666007995661 .56660079956 61.5666007995661 .8713798522961 .8713798522961 .8713798522962 .17617034912 62.1761703491262 .4809494018662 .4809494018662 .7001075744662 .706199646 62.7103919982962 .7132225036662 .7148551940962 .7153053283762 .71457672119 62.712757110664 .004882812563 .9874191284264 .6144485473664 .61444854736 64.9192428588965 .2240066528365 .2240066528365 .5288009643665 .83358764648 65.8335876464866 .1383666992266 .1383666992266 .4431610107466 .74794006348 66.7479400634867 .0527267456167 .0527267456167 .3575134277367 .35751342773 67.6623001098667 .6623001098667 .9670867919967 .9670867919968 .27187347412 68.2718734741268 .5766525268668 .5766525268669 .1862335205169 .79579162598 70.71015167236 -9999 -9999 -9999 -9999 -9999 -9999 -9999 -9999 -9999 -9999 -9999 -9999 -9999 -9999 -9999 -9999 -9999 -9999 -9999 -9999 -9999 -9999 -9999 -9999 -9999 -9999 -9999 $-9999$

-9999 -9999 -9999 -9999 -9999 -9999 -9999 -9999 -9999 -9999 -9999 -9999 -9999 -9999 -9999

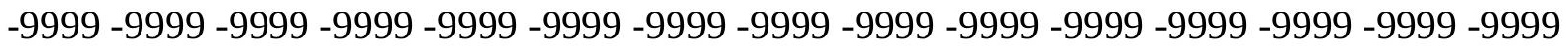
-9999 -9999 -9999 -9999 -9999 -9999 -9999 -9999 -9999 -9999 -9999 -9999 -9999 -9999 -9999

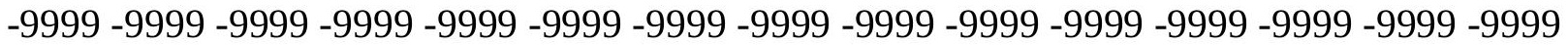
-9999 -9999 -9999 -9999 -9999 -9999 -9999 -9999 -9999-9999 -9999 -9999 -9999-9999-999 - -999 -9999 -9999 -9999 -9999 -9999 -9999 -9999 -9999 -9999 -9999 -9999 -9999 -9999 -9999 -9999 -9999 -9999-9999 -9999 -9999 -9999-9999 174.1410369873 147.2111968994 110.9418029785 89.9116134643674 .3675689697364 .9192428588960 .0426712036158 .21395874023 58.2139587402359 .1283111572360 .6522407531761 .8713798522963 .09051895142 64.004882812564 .6144485473665 .2240066528365 .8335876464866 .44316101074 66.7479400634867 .3575134277367 .9670867919968 .8814392089869 .79579162598 70.7101516723671 .9292907714873 .1484298706173 .7580032348673 .45321655273 72.2340774536170 .7101516723669 .4910125732468 .2718734741267 .35751342773 66.1383666992265 .2240066528364 .3096618652363 .3953094482462 .78573989868 61.8713798522961 .8713798522961 .8713798522962 .1761703491262 .48094940186 63.0905189514264 .004882812564 .9192428588966 .1383666992267 .96708679199 69.7957916259871 .9292907714874 .3675689697377 .110626220779 .85370635986 82.5967712402385 .3398437588 .0829010009890 .5211791992292 .3498916626 
93.5690307617294 .1785964965894 .7881774902395 .0929565429795 .09295654297 95.0929565429795 .0929565429794 .7881774902394 .1785964965893 .87381744385 93.2642517089892 .6546783447391 .7403335571390 .5211791992289 .3020401001 87.7781066894586 .254188537684 .4254837036182 .9015579223681 .37763214111 79.5489196777378 .0249862670976 .5010681152374 .9771423339873 .75800323486 72.5388565063571 .3197174072370 .1005783081169 .1862335205168 .27187347412 67.6623001098666 .7479400634866 .1383666992265 .5288009643665 .22400665283 64.6144485473664 .3096618652364 .004882812563 .7000885009863 .39530944824 63.3953094482463 .0905189514263 .0905189514263 .0905189514263 .09051895142 63.0905189514263 .0905189514263 .3953094482463 .3953094482463 .39530944824 63.3953094482463 .3953094482463 .7000885009863 .7000885009864 .0048828125 64.004882812564 .3096618652364 .6144485473664 .9192428588965 .22400665283 65.5288009643665 .8335876464866 .1383666992266 .7479400634867 .05272674561 67.3575134277367 .3575134277367 .3575134277367 .0527267456167 .05272674561 $35.0502891540518 .591890335083 .047851085663-8.83876895905-18.5918903351$ -25.2971591949-28.9545898438 -30.478509903 -30.7833003998 -30.7833003998 $-30.1737308502-29.2593708038-28.0402297974-26.8210906982-24.6875991821$ $-22.5541000366-19.8110294342-17.3727493286-14.6296901703-12.1914100647$ $-9.75312423706-7.61962795258-6.095703125-4.87656211853-3.65742206573$ -3.04785108566 -2.43828105927 -2.13349604607 -1.82871103287 -1.52392601967 -1.52392601967 - $1.52392601967-1.52392601967-1.52392601967-1.52392601967$ $-1.52392601967-1.52392601967-1.52392601967-1.21914100647-.914355397224$ -.609570324421 -.304785102606 -9999 -9999.3047851026058.6095703244209 .3047851026058.3047851026058.3047851026058 6095703244209 1.21914100647 1.8287110328673 .0478510856634 .2669920921336 .0957031257 .924413204193 10.0579099655212 .4961900711114 .934470176717 .3727493286120 .11581993103 22.8588790893625 .906740188628 .3450202941931 .0880794525133 .52635955811 35.9646492004438 .0981407165540 .5364189147942 .66992187544 .80340957642 46.9369087219248 .765621185350 .5943298339852 .4230384826753 .94697189331 55.4708900451756 .6900291442957 .6043891906758 .5187492370659 .12831115723 59.7378807067960 .3474502563560 .6522407531760 .9570198059161 .26181030273 61.5666007995661 .5666007995661 .5666007995661 .8713798522961 .87137985229 61.8713798522961 .8713798522961 .8713798522962 .1761703491262 .17617034912 62.1761703491262 .4809494018662 .4809494018662 .6683235168562 .64317321777 62.6199073791562 .598636627262 .5792732238862 .5616950988862 .5457611084 63.7000885009863 .7118263244663 .673408508364 .3096618652364 .61444854736 64.6144485473664 .9192428588965 .2240066528365 .2240066528365 .52880096436 65.8335876464865 .8335876464866 .1383666992266 .1383666992266 .44316101074 66.4431610107466 .7479400634866 .7479400634867 .0527267456167 .05272674561 67.3575134277367 .3575134277367 .6623001098667 .9670867919967 .96708679199 68.2718734741268 .2718734741268 .5766525268669 .1862335205169 .79579162598 70.40535736084 -9999 -9999 -9999 -9999 -9999 -9999 -9999 -9999 -9999 -9999 -9999 -9999

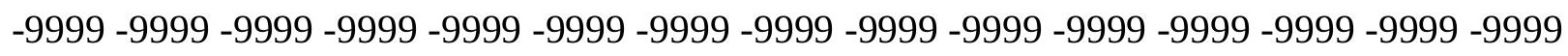
-9999 -9999 -9999 -9999 -9999 -9999 -9999 -9999 -9999 -9999 -9999 -9999 -9999 -9999 -9999 -

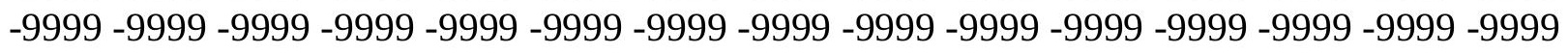

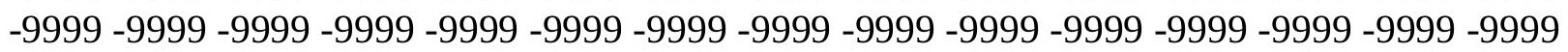


-9999 -9999 -9999 -9999 -9999 -9999 -9999 -9999 -9999 -9999 -9999 -9999 -9999 -9999 -9999 -9999 -9999 -9999 -9999 -9999 -9999 -9999 -9999 -9999 -9999 -9999 -9999 -9999 -9999 -9999 -9999 -9999 -9999 -9999 -9999 -9999 -9999 -9999 -9999 -9999 -9999 -9999 -9999 -9999 -9999 -9999 -9999 -9999 -9999 -9999 -9999 -9999 182.9596099854 158.5885314941133 .1911010742 105.760398864783 .8159103393672 .8436431884866 .1383666992262 .48094940186 61.8713798522962 .7857398986864 .004882812565 .5288009643666 .44316101074 67.3575134277367 .6623001098668 .2718734741268 .2718734741268 .57665252686 68.8814392089869 .1862335205169 .7957916259870 .4053573608471 .0149307251 72.2340774536173 .1484298706174 .6723632812575 .8914871215874 .36756896973 72.8436431884871 .3197174072370 .1005783081169 .1862335205168 .27187347412 67.6623001098666 .7479400634866 .1383666992265 .5288009643664 .61444854736 63.3953094482463 .3953094482463 .3953094482463 .3953094482463 .70008850098 64.004882812564 .6144485473665 .5288009643666 .7479400634868 .27187347412 70.1005783081171 .9292907714874 .062782287676 .5010681152378 .93934631348 81.3776321411184 .1206970214886 .8637619018689 .302040100191 .13075256348 92.349891662693 .2642517089893 .8738174438594 .1785964965894 .48339080811 94.4833908081194 .4833908081194 .1785964965893 .8738174438593 .56903076172 92.9594726562592 .349891662691 .7403335571390 .8259735107489 .60682678223 88.0829010009886 .254188537684 .7302627563583 .206336975181 .37763214111 79.8537063598678 .0249862670976 .5010681152375 .2819290161173 .75800323486 72.5388565063571 .3197174072370 .1005783081169 .1862335205168 .27187347412 67.3575134277366 .7479400634865 .8335876464865 .2240066528364 .91924285889 64.3096618652364 .004882812563 .7000885009863 .3953094482463 .09051895142 62.7857398986862 .7857398986862 .4809494018662 .4809494018662 .48094940186 62.4809494018662 .7857398986862 .7857398986862 .7857398986862 .78573989868 62.7857398986862 .7857398986862 .7857398986862 .7857398986862 .78573989868 63.0905189514263 .0905189514263 .3953094482463 .7000885009864 .0048828125 64.004882812564 .3096618652364 .3096618652364 .6144485473664 .91924285889 64.9192428588964 .9192428588964 .3096618652363 .3953094482462 .78573989868 $41.1459884643620 .115819931033 .352636098862-10.0579099655-20.4206008911$ -27.1258792877 -30.478509903 -31.6976509094 -31.6976509094 -31.0880794525 $-30.478509903-29.8689403534-28.9545898438-27.4306602478-25.6019496918$ $-23.4684505463-20.7253894806-18.287109375-15.5440397263-13.1057596207$ -10.6674804688 -8.83876895905 -7.01005792618 -5.79091691971 -4.57177686691 -3.96220707893 -3.35263609886 -2.74306607246 -2.43828105927 -2.43828105927 $-2.43828105927-2.43828105927-2.43828105927-2.43828105927-2.43828105927$ $-2.43828105927-2.43828105927-2.43828105927-2.13349604607-2.13349604607$ -1.82871103287 -1.52392601967 -.914355397224 -.609570324421 -.304785102606-9999 -9999 -9999-9999.3047851026058.9143553972244 1.828711032867 3.047851085663 4.2669920921336 .0957031257 .92441320419310 .0579099655212 .1914100647 14.6296901702917 .3727493286119 .811029434222 .5541000366225 .29715919495 27.7354507446330 .4785099029532 .9167900085435 .3550796508837 .79335021973 40.2316398620642 .3651313781744 .8034095764246 .9369087219248 .7656211853 50.8991203308152 .7278289794954 .2517509460455 .7756805419956 .99481964111 58.2139587402359 .1283111572359 .7378807067960 .3474502563560 .95701980591 61.2618103027361 .5666007995661 .5666007995661 .8370246887261 .87137985229 
61.8713798522961 .8713798522961 .8713798522961 .8713798522961 .87137985229 61.8713798522962 .1761703491262 .1761703491262 .1761703491262 .17617034912 62.4809494018662 .4809494018662 .4809494018662 .5247535705662 .48187255859 62.4439392089862 .4106483459562 .3816337585462 .356586456363 .44314193726 63.4563064575264 .004882812564 .3096618652364 .3096618652364 .61444854736 64.9192428588964 .9192428588965 .2240066528365 .2240066528365 .52880096436 65.5288009643665 .8335876464866 .1383666992266 .1383666992266 .44316101074 66.4431610107466 .7479400634866 .7479400634867 .0527267456167 .05272674561 67.3575134277367 .3575134277367 .6623001098667 .6623001098667 .96708679199 $68.2718734741268 .2718734741268 .8814392089869 .4910125732470 .10057830811-9999$ -9999 -9999 -9999 -9999 -9999 -9999 -9999 -9999 -9999 -9999 -9999 -9999 -9999 -9999 -9999 -9999 -9999-9999-9999-9999-9999-9999 -9999-9999-9999

-9999 -9999 -9999 -9999 -9999 -9999 -9999 -9999 -9999 -9999 -9999 -9999 -9999 -9999 -9999 -9999 -9999 -9999 -9999 -9999 -9999 -9999 -9999 -9999 -9999 -9999 -9999 -9999 -9999 -9999 -

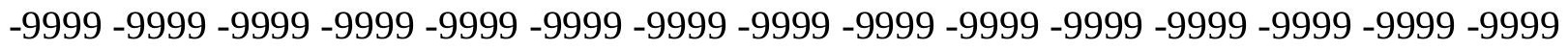

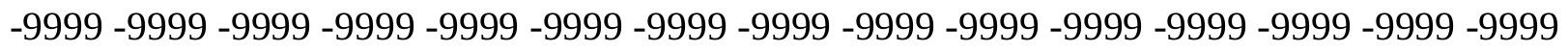

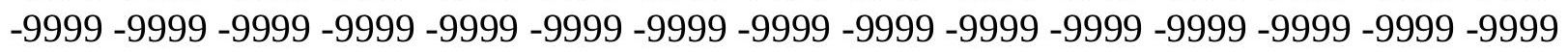

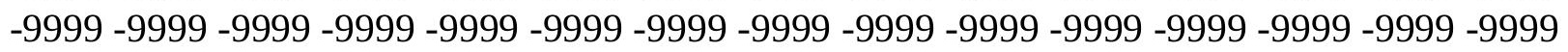
-9999 -9999 -9999 -9999 -9999 -9999 -9999 -9999 168.9925384521145 .7982330322 120.999702453699 .9695205688584 .1206970214873 .4532165527368 .27187347412 66.7479400634867 .3575134277368 .2718734741269 .4910125732470 .40535736084 71.014930725171 .3197174072371 .6244964599671 .6244964599671 .31971740723 71.3197174072371 .3197174072371 .6244964599671 .9292907714872 .53885650635 73.4532165527374 .3675689697375 .5867080688575 .8914871215874 .97714233398 73.4532165527372 .2340774536171 .014930725170 .1005783081169 .79579162598 69.4910125732469 .1862335205168 .8814392089868 .2718734741267 .66230010986 66.7479400634866 .1383666992265 .8335876464865 .5288009643665 .52880096436 65.5288009643666 .1383666992266 .7479400634867 .9670867919969 .18623352051 70.7101516723672 .5388565063574 .3675689697376 .1962814331178 .32978057861 80.4632720947383 .206336975185 .6446228027388 .0829010009890 .21640014648 91.4355392456192 .349891662692 .9594726562593 .2642517089893 .87381744385 93.8738174438594 .1785964965894 .1785964965893 .8738174438593 .56903076172 92.9594726562592 .6546783447391 .7403335571390 .8259735107489 .60682678223 88.0829010009886 .5589828491285 .0350494384883 .206336975181 .68241119385 79.8537063598678 .3297805786176 .8058471679775 .2819290161173 .75800323486 72.5388565063571 .3197174072370 .1005783081169 .1862335205168 .27187347412 67.3575134277366 .4431610107465 .8335876464865 .2240066528364 .61444854736 64.004882812563 .7000885009863 .0905189514262 .7857398986862 .48094940186 62.4809494018662 .1761703491262 .1761703491262 .1761703491262 .17617034912 62.1761703491262 .1761703491262 .1761703491262 .1761703491262 .17617034912 61.8713798522961 .8713798522961 .8713798522961 .5666007995661 .56660079956 61.5666007995661 .8713798522961 .8713798522962 .1761703491262 .17617034912 62.1761703491262 .1761703491262 .1761703491262 .1761703491262 .17617034912 62.1761703491261 .8713798522960 .6522407531759 .1283111572357 .60438919067 $44.4986305236820 .115819931033 .352636098862-9.75312423706-20.7253894806$ $-28.9545898438-30.478509903-32.0024414062-31.6976509094-30.7833003998$ 
-30.1737308502 -29.8689403534 -29.2593708038 -28.0402297974 -26.2115192413 -23.7732391357 -21.3349609375 -18.5918903351 -15.8488302231 -13.4105501175 $-11.2770500183-9.44833946228-7.61962795258-6.40048694611-5.18134689331$ $-4.57177686691-3.96220707893-3.35263609886-3.35263609886-3.04785108566$ -3.04785108566 -3.04785108566 -3.04785108566 -3.04785108566 -3.35263609886 $-3.35263609886-3.35263609886-3.35263609886-3.35263609886-3.04785108566$ $-2.74306607246-2.43828105927-2.13349604607-1.82871103287-1.21914100647$ -.914355397224 -.609570324421 -.304785102606-9999.3047851026058 .9143553972244 1.8287110328673 .0478510856634 .2669920921336 .0957031257 .924413204193 10.0579099655212 .191410064714 .6296901702917 .0679702758819 .8110294342 22.2493095397924 .9923801422127 .430660247829 .8689403533932 .61201095581 35.0502891540537 .4885711669939 .9268493652342 .0603485107444 .49863052368 46.6321296691948 .765621185350 .8991203308152 .7278289794954 .55654144287 56.0804595947357 .6043891906758 .5187492370659 .7378807067960 .34745025635 60.9570198059161 .2618103027361 .5666007995661 .8713798522961 .87137985229 61.8713798522962 .1761703491262 .1761703491261 .8713798522961 .87137985229 61.8713798522961 .8713798522961 .8713798522961 .8713798522962 .17617034912 62.1761703491262 .1761703491262 .1761703491262 .1761703491262 .48094940186 62.4244117736862 .3615722656262 .3066215515162 .259067535462 .21828460693 62.183727264463 .2246665954663 .266178131163 .7000885009864 .0048828125 64.004882812564 .3096618652364 .3096618652364 .6144485473664 .61444854736 64.9192428588965 .2240066528365 .2240066528365 .5288009643665 .52880096436 65.8335876464865 .8335876464866 .1383666992266 .1383666992266 .44316101074 66.4431610107466 .7479400634867 .0527267456167 .0527267456167 .35751342773 67.3575134277367 .6623001098667 .6623001098667 .9670867919967 .96708679199 68.5766525268669 .18623352051 -9999 -9999 -9999 -9999 -9999 -9999 -9999 -9999 -9999 -9999 -9999 -9999 -9999 -9999-9999 -9999 -9999 -9999 -9999 -9999 -9999 -9999 -9999 -9999 $-9999-9999$

-9999 -9999 -9999 -9999 -9999 -9999 -9999 -9999 -9999 -9999 -9999 -9999 -9999 -9999 -9999

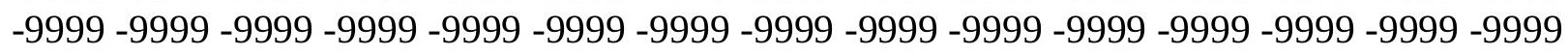
-9999 -9999 -9999 -9999 -9999 -9999 -9999 -9999 -9999 -9999 -9999 -9999 -9999 -9999 -9999 -9999 -9999 -9999 -9999 -9999 -9999 -9999 -9999 -9999 -9999 -9999 -9999 -9999 -9999 -9999 -

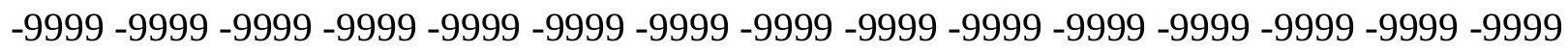

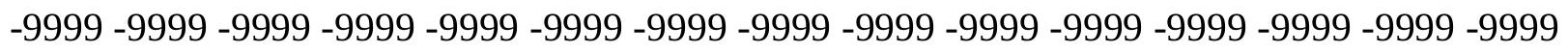
-9999 -9999-9999 -9999 -9999 -9999-9999-9999 -9999 157.5856170654 136.5437011719 113.989601135396 .9216690063581 .3776321411175 .5867080688572 .84364318848 72.5388565063573 .4532165527374 .3675689697374 .9771423339875 .58670806885 75.5867080688575 .5867080688574 .9771423339874 .3675689697373 .75800323486 73.4532165527373 .7580032348674 .062782287674 .6723632812575 .28192901611 76.1962814331176 .8058471679776 .8058471679776 .1962814331174 .97714233398 73.4532165527372 .5388565063572 .2340774536172 .2340774536172 .53885650635 72.5388565063572 .5388565063572 .5388565063571 .9292907714871 .0149307251 70.1005783081169 .1862335205168 .5766525268668 .2718734741267 .96708679199 68.2718734741268 .5766525268669 .4910125732470 .4053573608471 .92929077148 73.4532165527374 .9771423339876 .8058471679778 .6345596313580 .46327209473 82.5967712402385 .0350494384887 .1685485839888 .9972534179790 .21640014648 
91.1307525634892 .0450973510792 .6546783447393 .2642517089893 .56903076172 93.8738174438593 .8738174438593 .8738174438593 .5690307617293 .26425170898 92.6546783447392 .0450973510790 .8259735107489 .9116134643688 .38768768311 86.8637619018685 .3398437583 .5111236572381 .9871978759880 .15849304199 78.6345596313577 .110626220775 .5867080688574 .062782287672 .84364318848 71.6244964599670 .4053573608469 .1862335205168 .2718734741267 .35751342773 66.4431610107465 .8335876464865 .2240066528364 .3096618652364 .0048828125 63.3953094482463 .0905189514262 .4809494018662 .1761703491262 .17617034912 61.8713798522961 .5666007995661 .5666007995661 .5666007995661 .56660079956 61.5666007995661 .5666007995661 .5666007995661 .2618103027361 .26181030273 60.9570198059160 .6522407531760 .3474502563560 .3474502563560 .34745025635 60.3474502563560 .3474502563560 .3474502563560 .3474502563560 .04267120361 60.0426712036159 .7378807067959 .4331016540559 .1283111572358 .82352828979 57.909179687556 .3852500915554 .2517509460451 .8134689331128 .95458984375 $19.506250381474 .87656211853-7.3148431778-18.287109375-27.4306602478$ -32.307220459-32.6120109558 -32.0024414062 -29.8689403534 -30.1737308502 $-30.1737308502-29.5641593933-28.3450202942-26.2115192413-23.7732391357$ $-21.0301704407-18.5918903351-15.8488302231-13.7153301239-11.5818300247$ -9.75312423706 -8.22919845581 -6.7052731514 -5.79091691971 -4.87656211853 $-4.57177686691-3.96220707893-3.96220707893-3.65742206573-3.65742206573$ $-3.65742206573-3.96220707893-3.96220707893-3.96220707893-4.26699209213$ $-4.26699209213-4.26699209213-4.26699209213-3.96220707893-3.96220707893$ -3.65742206573 -3.04785108566 -2.74306607246 -2.13349604607 -1.82871103287 $-1.21914100647-.914355397224-.304785102606-9999.91435539722441 .828711032867$ 3.0478510856634 .2669920921336 .0957031257 .9244132041939 .753124237061 12.191410064714 .3248996734616 .7631797790519 .5062503814721 .94453048706 24.6875991821327 .1258792877229 .5641593933132 .0024414062534 .74551010132 37.1837806701739 .622070312541 .7555618286144 .1938400268646 .63212966919 48.765621185350 .8991203308153 .0326118469254 .8613204956156 .38525009155 57.909179687559 .1283111572360 .0426712036160 .9570198059161 .26181030273 61.8713798522961 .8713798522962 .1761703491262 .1761703491262 .17617034912 62.1761703491262 .1761703491262 .1761703491262 .1761703491261 .87137985229 61.8713798522961 .8713798522961 .8713798522961 .8713798522961 .87137985229 61.8713798522961 .8713798522962 .1761703491262 .1761703491262 .17617034912 62.2348213195862 .1647491455162 .1046791076762 .0537338256862 .01110839844 63.0905189514263 .0804252624562 .9828796386763 .3953094482463 .70008850098 64.004882812564 .004882812564 .3096618652364 .3096618652364 .61444854736 64.6144485473664 .9192428588965 .2240066528365 .2240066528365 .52880096436 65.5288009643665 .8335876464865 .8335876464866 .1383666992266 .13836669922 66.4431610107466 .4431610107466 .7479400634866 .7479400634867 .05272674561 67.3575134277367 .3575134277367 .6623001098667 .6623001098667 .66230010986 68.2718734741268 .88143920898 -9999 -9999 -9999 -9999 -9999 -9999 -9999 -9999 -9999 -9999 -9999 -9999 -9999 -9999 -9999 -9999 -9999 -9999 -9999 -9999 -9999 -9999 -9999 -9999 $-9999$

-9999 -9999 -9999 -9999 -9999 -9999 -9999 -9999 -9999 -9999 -9999 -9999 -9999 -9999 -9999 -9999 -9999 -9999 -9999 -9999 -9999 -9999 -9999 -9999 -9999 -9999 -9999 -9999 -9999 -9999 
-9999 -9999 -9999 -9999 -9999 -9999 -9999 -9999 -9999 -9999 -9999 -9999 -9999 -9999 -9999 -9999 -9999 -9999 -9999 -9999 -9999 -9999 -9999 -9999 -9999 -9999 -9999 -9999 -9999 -9999 -9999 -9999 -9999 -9999 -9999 -9999 -9999 -9999 -9999 -9999 -9999 -9999 -9999 -9999 -9999 -9999 -9999 -9999 -9999 -9999 -9999 -9999 -9999 -9999 -9999 -9999 -9999 -9999 -9999 -9999 -9999 -9999 -9999 -9999 -9999 -9999 -9999 -9999 -9999 168.4366912842 149.4354553223 129.2288970947111 .2465972995 .397743225184 .7302627563580 .15849304199 79.2441329956179 .2441329956179 .5489196777379 .8537063598680 .15849304199 80.1584930419979 .8537063598678 .9393463134877 .7202072143676 .50106811523 75.8914871215876 .1962814331176 .8058471679777 .7202072143678 .02498626709 78.9393463134879 .8537063598680 .1584930419979 .2441329956178 .02498626709 76.5010681152375 .8914871215875 .8914871215876 .1962814331176 .80584716797 77.110626220777 .4154205322377 .7202072143677 .4154205322376 .50106811523 75.2819290161173 .7580032348672 .5388565063571 .6244964599671 .31971740723 71.014930725171 .3197174072371 .9292907714872 .5388565063573 .45321655273 74.6723632812576 .1962814331177 .7202072143679 .2441329956180 .76805877686 82.5967712402384 .4254837036186 .254188537687 .7781066894589 .3020401001 90.2164001464891 .1307525634892 .0450973510792 .6546783447393 .26425170898 93.5690307617293 .8738174438593 .8738174438593 .8738174438593 .56903076172 92.9594726562592 .349891662691 .1307525634890 .2164001464888 .69246673584 87.4733276367285 .6446228027384 .1206970214882 .2919769287180 .46327209473 78.9393463134877 .4154205322375 .8914871215874 .3675689697372 .84364318848 71.6244964599670 .4053573608469 .4910125732468 .5766525268667 .35751342773 66.7479400634865 .8335876464865 .2240066528364 .3096618652363 .70008850098 63.0905189514262 .7857398986862 .1761703491261 .8713798522961 .56660079956 61.5666007995661 .2618103027361 .2618103027360 .9570198059160 .95701980591 60.9570198059160 .9570198059160 .6522407531760 .6522407531760 .04267120361 59.7378807067959 .4331016540559 .1283111572358 .8235282897958 .51874923706 58.5187492370658 .2139587402358 .2139587402357 .909179687557 .60438919067 57.2995986938556 .9948196411156 .3852500915555 .7756805419954 .86132049561 53.6421813964851 .8134689331148 .765621185345 .1082000732430 .47850990295 $22.2493095397910 .05790996552-2.13349604607-13.4105501175-23.4684505463$ $-32.6120109558-32.9167900085-32.6120109558-31.6976509094-30.478509903$ $-30.7833003998-29.8689403534-28.3450202942-25.9067401886-23.1636695862$ $-20.4206008911-17.6775398254-15.2392597198-13.1057596207-11.2770500183$ $-9.75312423706-8.22919845581-7.01005792618-6.095703125-5.48613214493$ $-4.87656211853-4.57177686691-4.26699209213-4.26699209213-4.26699209213$ $-4.26699209213-4.57177686691-4.57177686691-4.87656211853-4.87656211853$ $-5.18134689331-5.18134689331-5.18134689331-4.87656211853-4.87656211853$ $-4.57177686691-3.96220707893-3.65742206573-3.04785108566-2.43828105927$ $-2.13349604607-1.52392601967-.609570324421-9999.60957032442091 .828711032867$ 2.7430660724644 .2669920921335 .7909169197087 .6196279525769 .753124237061 11.8866195678714 .3248996734616 .7631797790519 .2014598846421 .63973999023 24.3828105926526 .8210906982429 .2593708038331 .6976509094234 .13592910767 36.5742111206139 .0125007629441 .4507789611843 .8890609741246 .32733917236 48.4608306884850 .8991203308153 .0326118469255 .1661109924356 .99481964111 58.2139587402359 .4331016540560 .6522407531761 .2618103027361 .87137985229 
62.1761703491262 .4809494018662 .4809494018662 .4809494018662 .48094940186 62.4809494018662 .1761703491262 .1761703491262 .1761703491261 .87137985229 61.8713798522961 .8713798522961 .8713798522961 .8713798522961 .87137985229 61.8713798522961 .8713798522961 .8713798522961 .8713798522961 .87137985229 62.0990180969262 .0160179138261 .9454689025961 .8862113952661 .8371925354 62.7857398986862 .7857398986862 .7478713989363 .0905189514263 .39530944824 63.7000885009863 .7000885009864 .004882812564 .004882812564 .30966186523 64.3096618652364 .6144485473664 .6144485473664 .9192428588964 .91924285889 65.2240066528365 .5288009643665 .5288009643665 .8335876464865 .83358764648 66.1383666992266 .1383666992266 .4431610107466 .4431610107466 .74794006348 66.7479400634867 .0527267456167 .0527267456167 .3575134277367 .35751342773 67.6623001098668 .2718734741268 .88143920898 -9999 -9999 -9999 -9999 -9999 -9999 -9999 -9999 -9999 -9999 -9999 -9999 -9999 -9999 -9999 -9999 -9999 -9999 -9999 -9999 -9999 -9999 $-9999-9999$

-9999 -9999 -9999 -9999 -9999 -9999 -9999 -9999 -9999 -9999 -9999 -9999 -9999 -9999 -9999

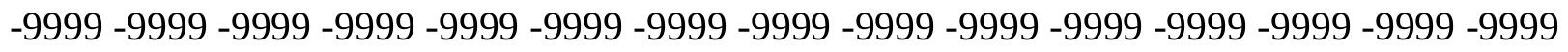
-9999 -9999 -9999 -9999 -9999 -9999 -9999 -9999 -9999 -9999 -9999 -9999 -9999 -9999 -9999 -9999 -9999 -9999 -9999 -9999 -9999 -9999 -9999 -9999 -9999 -9999 -9999 -9999 -9999 -9999 -9999 -9999 -9999 -9999 -9999 -9999 -9999 -9999 -9999 -9999 -9999 -9999 -9999 -9999 -9999 -

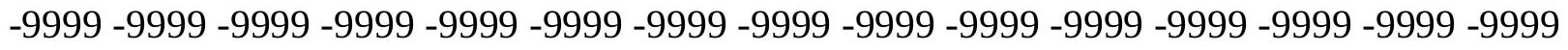
-9999 -9999-9999 -9999-9999 -9999-9999-9999 -9999-9999 161.9644165039 145.9920959473126 .1809997559108 .198699951292 .9594726562588 .69246673584 86.5589828491285 .6446228027385 .0350494384884 .7302627563584 .73026275635 85.0350494384884 .7302627563583 .5111236572381 .3776321411179 .54891967773 78.6345596313579 .2441329956181 .0728530883882 .5967712402383 .2063369751 83.8159103393685 .9494018554787 .1685485839885 .9494018554783 .81591033936 82.5967712402381 .9871978759881 .9871978759882 .9015579223683 .51112365723 83.206336975183 .5111236572383 .8159103393683 .8159103393682 .90155792236 81.3776321411179 .2441329956177 .7202072143676 .5010681152375 .58670806885 74.9771423339874 .9771423339874 .9771423339875 .2819290161175 .89148712158 76.8058471679777 .7202072143678 .9393463134880 .1584930419981 .37763214111 82.9015579223684 .4254837036185 .6446228027387 .1685485839888 .38768768311 89.302040100190.5211791992291.4355392456192.349891662693.26425170898 93.8738174438594 .1785964965894 .4833908081194 .4833908081194 .17859649658 93.5690307617292 .9594726562591 .7403335571390 .5211791992289 .3020401001 88.08290100098 86.2541885376 84.73026275635 82.9015579223681.07285308838 79.2441329956177 .7202072143676 .1962814331174 .6723632812573 .45321655273 71.9292907714870 .7101516723669 .7957916259868 .5766525268667 .66230010986 66.7479400634865 .8335876464865 .2240066528364 .3096618652363 .70008850098 63.0905189514262 .4809494018662 .1761703491261 .5666007995661 .26181030273 61.2618103027360 .9570198059160 .6522407531760 .6522407531760 .65224075317 60.3474502563560 .0426712036160 .0426712036159 .4331016540559 .12831115723 58.5187492370658 .2139587402357 .6043891906757 .2995986938556 .99481964111 56.3852500915556 .0804595947355 .7756805419955 .4708900451754 .86132049561 54.2517509460453 .6421813964853 .0326118469252 .1182594299350 .89912033081 49.3751907348647 .2416992187544 .1938400268639 .622070312533 .52635955811 
$27.1258792877215 .239259719853 .962207078934-6.095703125-15.5440397263$ -23.7732391357 -29.2593708038 -32.307220459 -32.9167900085 -32.307220459 $-31.3928699493-29.8689403534-27.4306602478-24.6875991821-21.6397399902$ $-18.8966808319-16.4584007263-14.3248996735-12.4961900711-10.6674804688$ $-9.14355373383-7.92441320419-7.01005792618-6.095703125-5.48613214493$ $-5.18134689331-4.87656211853-4.57177686691-4.57177686691-4.87656211853$ $-4.87656211853-5.18134689331-5.18134689331-5.48613214493-5.79091691971$ -5.79091691971 -6.095703125-6.095703125 -5.79091691971 -5.48613214493 -5.18134689331 $-4.87656211853-4.26699209213-3.65742206573-3.04785108566-2.43828105927$ $-1.82871103287-.914355397224-.304785102606 .60957032442091 .523926019669$ 2.7430660724644 .2669920921335 .7909169197087 .6196279525769 .44833946228 11.8866195678714 .0201196670516 .4584007263218 .8966808319121 .3349609375 24.0780296325726 .5163097381628 .9545898437531 .3928699493433 .83115005493 36.2694282531738 .4029312133840 .8412094116243 .2794914245645 .7177696228 48.1560516357450 .5943298339853 .0326118469255 .1661109924356 .99481964111 58.5187492370659 .7378807067960 .9570198059161 .5666007995662 .17617034912 62.4809494018662 .4809494018662 .7857398986862 .7857398986862 .48094940186 62.4809494018662 .1761703491262 .1761703491261 .8713798522961 .87137985229 61.5666007995661 .5666007995661 .5666007995661 .5666007995661 .56660079956 61.5666007995661 .5666007995661 .5666007995661 .5666007995661 .56660079956 61.8713798522961 .8582992553761 .7795867919961 .7141265869161 .66060638428 61.6176147460962 .4809494018662 .471813201962 .7857398986863 .09051895142 63.0905189514263 .3953094482463 .7000885009863 .7000885009864 .0048828125 64.004882812564 .3096618652364 .3096618652364 .6144485473664 .61444854736 64.9192428588964 .9192428588965 .2240066528365 .2240066528365 .52880096436 65.5288009643665 .8335876464865 .8335876464866 .1383666992266 .44316101074 66.4431610107466 .7479400634866 .7479400634866 .7479400634867 .05272674561 67.0527267456167 .3575134277367 .9670867919968 .57665252686 -9999 -9999 -9999 -9999 -9999 -9999 -9999 -9999 -9999 -9999 -9999 -9999 -9999 -9999 -9999 -9999 -9999 -9999 -9999 -9999-9999-9999-9999 -9999 -9999 -9999 -9999 -9999 -9999 -9999 -9999 -9999 -9999 -9999 -9999 -9999 -9999 -9999 -9999 -9999 -9999 -9999 -9999 -9999 -9999 -9999 -9999 -9999 -9999 -9999 -9999 -9999 -9999 -9999 -9999 -9999 -9999 -9999 -9999 -9999 -9999 -9999 -9999 -9999 -9999 -9999 -9999 -9999 -9999 -9999 -9999 -9999 -9999 -9999 -9999 -9999 -9999 -9999 -9999 -9999 -9999 -9999 -9999 -9999 -9999 -9999 -9999 -9999 -9999 -9999 -9999 -9999 -9999 -9999 -9999 -9999 -9999 -9999 -9999 -9999 -9999 -9999 -9999 -9999 -9999 -9999 -9999 -9999 -9999 -9999 -9999 -9999 -9999 -9999 -9999 -9999 -9999 -9999 -9999 -9999 -9999 -9999 -9999 -9999 156.9642944336 140.8106994629117 .9517974854106 .065200805798 .1408081054793 .87381744385 92.0450973510790 .2164001464888 .6924667358488 .3876876831189 .60682678223 90.5211791992288 .9972534179785 .9494018554782 .9015579223681 .68241119385 83.8159103393687 .4733276367290 .5211791992291 .7403335571391 .13075256348 96.3121032714899 .3599472045998 .1408081054792 .6546783447393 .87381744385 93.2642517089890 .8259735107496 .6168823242292 .349891662690 .52117919922 89.9116134643690.5211791992291.4355392456190.52117919922 88.38768768311 85.9494018554784 .1206970214882 .5967712402381 .0728530883880 .46327209473 79.8537063598678 .9393463134878 .6345596313578 .9393463134879 .54891967773 
80.1584930419981 .0728530883881 .6824111938582 .5967712402383 .51112365723 84.4254837036185 .6446228027386 .5589828491287 .7781066894588 .69246673584 90.2164001464891 .4355392456192 .349891662693 .2642517089894 .17859649658 94.7881774902395 .0929565429795 .0929565429795 .0929565429794 .48339080811 93.8738174438592 .6546783447391 .7403335571390 .5211791992288 .99725341797 87.1685485839885 .3398437583 .5111236572381 .6824111938579 .85370635986 78.3297805786176 .5010681152374 .9771423339873 .7580032348672 .53885650635 71.3197174072370 .1005783081169 .1862335205167 .9670867919967 .05272674561 66.1383666992265 .2240066528364 .6144485473663 .7000885009863 .09051895142 62.4809494018661 .8713798522961 .5666007995661 .2618103027360 .95701980591 60.6522407531760 .3474502563560 .3474502563560 .0426712036159 .73788070679 59.4331016540559 .1283111572358 .5187492370657 .909179687557 .29959869385 56.6900291442956 .0804595947355 .4708900451754 .8613204956154 .25175094604 53.9469718933153 .3373985290552 .7278289794952 .1182594299351 .20389938354 50.2895507812549 .3751907348648 .1560516357446 .6321296691944 .80340957642 42.66992187539 .9268493652336 .2694282531732 .0024414062525 .9067401886 $17.982320785529 .448339462281 .523926019669-5.18134689331-10.0579099655$ -21.3349609375 -30.1737308502 -30.7833003998 -31.0880794525 -31.6976509094 $-28.3450202942-24.9923801422-22.2493095398-19.5062503815-16.7631797791$ -14.6296901703 -12.8009700775 -10.9722604752 -9.75312423706 -8.53398323059 $-7.3148431778-6.40048694611-5.79091691971-5.48613214493-5.18134689331$ $-4.87656211853-4.87656211853-4.87656211853-5.18134689331-5.18134689331$ $-5.48613214493-5.79091691971-6.095703125-6.40048694611-6.40048694611$ $-6.7052731514-6.7052731514-6.7052731514-6.40048694611-6.095703125-5.48613214493$ $-4.87656211853-4.26699209213-3.65742206573-3.04785108566-2.13349604607$ -1.52392601967-.609570324421.3047851026058 1.21914100647 2.438281059265 3.9622070789345 .4861321449287 .3148431777959 .4483394622811 .58183002472 13.715330123916 .1536102294918 .5918903350821 .0301704406723 .77323913574 26.2115192413328 .6497993469230 .7833003997833 .2215805053735 .65985870361 37.7933502197340 .2316398620642 .66992187545 .1082000732447 .54647827148 49.9847602844252 .7278289794955 .1661109924356 .9948196411158 .51874923706 60.0426712036160 .9570198059161 .5666007995662 .1761703491262 .48094940186 62.7857398986862 .7857398986862 .7857398986862 .4809494018662 .48094940186 62.1761703491262 .1761703491261 .8713798522961 .5666007995661 .56660079956 61.2618103027361 .2618103027361 .2618103027361 .2618103027361 .26181030273 61.2618103027361 .2618103027361 .2618103027361 .2618103027361 .56660079956 61.5666007995661 .605609893861 .5362625122161 .4803085327161 .43606185913 62.1761703491262 .1774406433162 .1291465759362 .7857398986862 .78573989868 63.0905189514263 .0905189514263 .3953094482463 .7000885009863 .70008850098 64.004882812564 .004882812564 .3096618652364 .3096618652364 .61444854736 64.6144485473664 .9192428588964 .9192428588965 .2240066528365 .22400665283 65.5288009643665 .5288009643665 .8335876464865 .8335876464866 .13836669922 66.1383666992266 .4431610107466 .4431610107466 .4431610107466 .74794006348 66.7479400634867 .3575134277367 .9670867919968 .57665252686 -9999 -9999 -9999 -9999 -9999 -9999 -9999 -9999 -9999 -9999 -9999 -9999 -9999 -9999 -9999 -9999 -9999 -9999 -9999 $-9999-9999-9999$ 
-9999 -9999 -9999 -9999 -9999 -9999 -9999 -9999 -9999 -9999 -9999 -9999 -9999 -9999 -9999 -9999 -9999 -9999 -9999 -9999 -9999 -9999 -9999 -9999 -9999 -9999 -9999 -9999 -9999 -9999 -9999 -9999 -9999 -9999 -9999 -9999 -9999 -9999 -9999 -9999 -9999 -9999 -9999 -9999 -9999 -9999 -9999 -9999 -9999 -9999 -9999 -9999 -9999 -9999 -9999 -9999 -9999 -9999 -9999 -9999 -9999 -9999 -9999 -9999 -9999 -9999 -9999 -9999 -9999 -9999 -9999 -9999-9999 -9999 -9999 -9999 -9999 -9999 -9999 -9999 -9999 -9999 -9999 -9999 -9999 -9999 -9999 -9999 -9999 -9999 -9999 -9999 -9999 -9999 -9999 -9999 -9999 -9999 -9999 -9999 -9999 160.7613983154 150.5639038086133 .1911010742114 .5991973877106 .065200805799 .66472625732 96.0073165893693 .2642517089891 .4355392456190 .8259735107493 .56903076172 96.3121032714894 .4833908081191 .7403335571388 .6924667358485 .94940185547 91.1307525634896 .9216690063599 .58092498779100 .0211868286100 .621055603 101.3781661987102 .2845230103103 .322517395104 .468460083105 .6908798218 106.9543304443 108.2205123901 109.4508285522 103.626899719297.22646331787 96.0073165893697 .2264633178798 .445587158298 .445587158297 .22646331787 93.5690307617293 .2642517089891 .4355392456188 .3876876831187 .77810668945 86.2541885376 84.42548370361 82.90155792236 82.9015579223683.2063369751 83.5111236572383 .5111236572383 .5111236572383 .8159103393684 .42548370361 85.33984375 85.94940185547 86.55898284912 87.47332763672 88.38768768311 89.9116134643691.4355392456192.6546783447393.8738174438594.78817749023 95.7025299072396 .0073165893696 .3121032714896 .0073165893695 .70252990723 94.7881774902393 .8738174438592 .9594726562591 .7403335571389 .91161346436 88.0829010009885 .9494018554784 .1206970214882 .2919769287180 .46327209473 78.9393463134877 .110626220775 .5867080688574 .3675689697372 .84364318848 71.6244964599670 .7101516723669 .4910125732468 .5766525268667 .66230010986 66.4431610107465 .5288009643664 .9192428588964 .004882812563 .09051895142 62.4809494018661 .8713798522961 .2618103027360 .9570198059160 .65224075317 60.3474502563560 .3474502563560 .0426712036159 .7378807067959 .43310165405 58.8235282897958 .2139587402357 .6043891906756 .6900291442956 .08045959473 55.1661109924354 .2517509460453 .6421813964852 .7278289794952 .11825942993 51.5086898803750 .5943298339849 .9847602844249 .0704002380448 .15605163574 46.9369087219245 .717769622844 .1938400268642 .3651313781740 .23163986206 38.0981407165535 .3550796508832 .3072204589828 .6497993469224 .38281059265 $18.8966808319113 .105759620677 .6196279525763 .047851085663-.304785102606$ -7.61962795258 -20.115819931 -24.3828105927 -25.9067401886 -25.9067401886 $-24.0780296326-21.3349609375-18.5918903351-16.1536102295-14.0201196671$ $-12.1914100647-10.6674804688-9.44833946228-8.22919845581-7.3148431778$ $-6.7052731514-6.095703125-5.48613214493-5.18134689331-4.87656211853$ $-4.87656211853-4.87656211853-5.18134689331-5.48613214493-5.48613214493$ $-5.79091691971-6.095703125-6.40048694611-6.7052731514-7.01005792618-7.3148431778$ $-7.3148431778-7.3148431778-7.01005792618-6.40048694611-6.095703125-5.48613214493$ $-4.87656211853-4.26699209213-3.35263609886-2.74306607246-1.82871103287$ -914355397224-9999.9143553972244 2.133496046066 3.657422065735 5.181346893311 7.0100579261788 .83876895904510 .9722604751613 .4105501174915 .84883022308 18.28710937520 .7253894805923 .1636695861825 .6019496917728 .04022979736 30.1737308502232 .6120109558134 .7455101013237 .1837806701739 .31727981567 41.7555618286144 .1938400268646 .6321296691949 .3751907348651 .81346893311 
54.5565414428756 .6900291442958 .5187492370659 .7378807067960 .95701980591 61.5666007995662 .1761703491262 .4809494018662 .7857398986862 .78573989868 62.7857398986862 .4809494018662 .4809494018662 .1761703491261 .87137985229 61.5666007995661 .5666007995661 .2618103027361 .2618103027360 .95701980591 60.9570198059160 .9570198059160 .9570198059160 .9570198059160 .95701980591 60.9570198059160 .9570198059161 .2618103027361 .2618103027361 .4224281311 61.3517150878961 .2955513000561 .2520065307661 .8713798522961 .90802001953 61.8986015319862 .4809494018662 .4809494018662 .7857398986862 .78573989868 63.0905189514263 .0905189514263 .3953094482463 .3953094482463 .70008850098 64.004882812564 .004882812564 .3096618652364 .3096618652364 .61444854736 64.6144485473664 .9192428588964 .9192428588965 .2240066528365 .22400665283 65.5288009643665 .5288009643665 .8335876464865 .8335876464865 .83358764648 66.1383666992266 .1383666992266 .4431610107466 .4431610107466 .44316101074 67.0527267456167 .66230010986 -9999 -9999 -9999 -9999 -9999 -9999 -9999 -9999 -9999 -9999 -9999 -9999 -9999 -9999 -9999 -9999 -9999 -9999 -9999 -9999 -9999 -9999 - 9999 - 9999 -

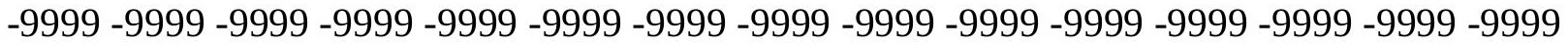

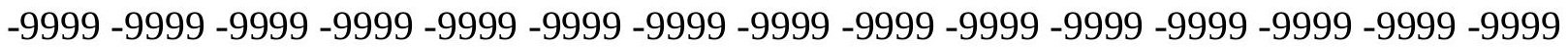

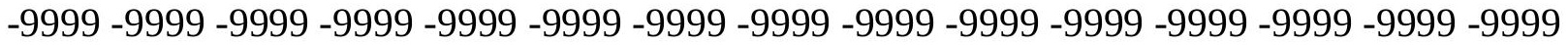

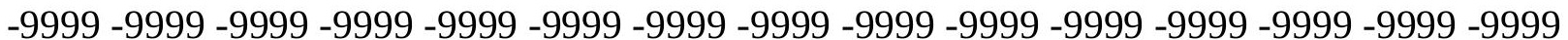

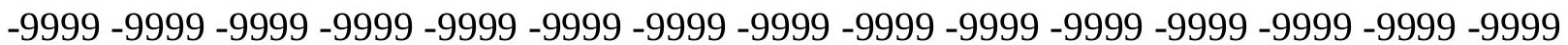
-9999 -9999- 9999-9999-9999 -9999 -9999 -9999 -9999 -9999 -9999 -9999 -9999 -9999 -9999 -9999 156.9642944336 143.5538024902129 .8385009766114 .9039993286103 .017402648999 .05516815186 96.0073165893693 .5690307617293 .5690307617296 .0073165893698 .14080810547 98.7503814697398 .445587158297 .8360290527398 .7503814697398 .83841705322 98.9932708740299 .3105163574299 .80330657959100 .4810180664101 .3434143066 102.3830337524103 .5804672241104 .9079589844106 .3278503418107 .7989654541 109.2702255249110 .7032852173109 .1130981445112 .4656982422112 .4976272583 111.6355667114110 .0273971558108 .8082962036107 .5891036987106 .0652008057 104.5412979126102 .407798767199 .6647262573297 .2264633178794 .48339080811 91.1307525634888 .0829010009888 .0829010009888 .3876876831187 .77810668945 86.8637619018686 .254188537685 .9494018554786 .5589828491286 .86376190186 86.8637619018687 .1685485839887 .7781066894588 .6924667358489 .91161346436 91.1307525634892 .9594726562594 .4833908081196 .0073165893696 .92166900635 97.5312423706197 .8360290527397 .5312423706197 .2264633178796 .31210327148 95.397743225194 .1785964965892 .6546783447390 .8259735107488 .99725341797 87.16854858398 85.03504943848 83.206336975181.37763214111 79.54891967773 78.0249862670976 .5010681152374 .9771423339873 .7580032348672 .53885650635 71.3197174072370 .1005783081169 .1862335205167 .9670867919967 .05272674561 66.1383666992265 .2240066528364 .3096618652363 .3953094482462 .48094940186 61.8713798522961 .2618103027360 .9570198059160 .6522407531760 .34745025635 60.3474502563560 .0426712036159 .4331016540558 .8235282897958 .21395874023 57.2995986938556 .3852500915555 .4708900451754 .5565414428753 .64218139648 52.7278289794951 .5086898803750 .5943298339849 .6799812316948 .7656211853 47.8512611389246 .9369087219246 .0225486755444 .8034095764243 .58427047729 41.7555618286139 .9268493652337 .7933502197335 .6598587036133 .22158050537 
30.7833003997828 .3450202941925 .2971591949521 .9445304870618 .287109375 14.3248996734610 .667480468757 .3148431777952 .438281059265 .6095703244209 -5.79091691971 -16.1536102295 -18.5918903351 -18.5918903351 -17.6775398254 $-15.8488302231-14.0201196671-12.1914100647-10.6674804688-9.44833946228$ $-8.53398323059-7.61962795258-6.7052731514-6.095703125-5.48613214493$ $-5.18134689331-4.87656211853-4.87656211853-4.87656211853-4.87656211853$ $-4.87656211853-5.18134689331-5.48613214493-5.79091691971-6.095703125$ $-6.40048694611-6.7052731514-7.01005792618-7.3148431778-7.61962795258$ $-7.92441320419-7.61962795258-7.3148431778-6.7052731514-6.40048694611$ $-5.79091691971-5.18134689331-4.57177686691-3.96220707893-3.04785108566$ $-2.13349604607-1.21914100647-.304785102606 .30478510260581 .523926019669$ 3.0478510856634 .5717768669136 .4004869461068 .53398323059110 .66748046875 12.8009700775115 .2392597198517 .6775398254420 .4206008911122 .85887908936 25.2971591949527 .430660247829 .8689403533933 .8311500549336 .87900161743 35.9646492004438 .4029312133840 .5364189147942 .9747009277345 .41297912598 48.1560516357450 .8991203308153 .6421813964855 .7756805419957 .9091796875 59.1283111572360 .3474502563561 .2618103027361 .8713798522962 .48094940186 62.4809494018662 .7857398986862 .7857398986862 .4809494018662 .17617034912 62.1761703491261 .8713798522961 .5666007995661 .2618103027360 .95701980591 60.6522407531760 .6522407531760 .6522407531760 .3474502563560 .34745025635 60.6522407531760 .6522407531760 .6522407531760 .6522407531760 .95701980591 60.9570198059161 .2296104431261 .1601638793961 .1061172485461 .065284729 61.5666007995661 .7057266235461 .7010116577162 .1761703491262 .17617034912 62.4809494018662 .4809494018662 .7857398986862 .7857398986863 .09051895142 63.0905189514263 .3953094482463 .3953094482463 .7000885009863 .70008850098 64.004882812564 .004882812564 .3096618652364 .3096618652364 .61444854736 64.6144485473664 .9192428588964 .9192428588965 .2240066528365 .22400665283 65.5288009643665 .5288009643665 .8335876464865 .8335876464865 .83358764648 $66.1383666992266 .1383666992266 .4431610107467 .0527267456167 .66230010986-9999$ -9999 -9999 -9999 -9999 -9999 -9999 -9999 -9999 -9999 -9999 -9999 -9999 -9999 -9999 -9999 -9999 -9999 -9999-9999-9999

-9999 -9999 -9999 -9999 -9999 -9999 -9999 -9999 -9999 -9999 -9999 -9999 -9999 -9999 -9999

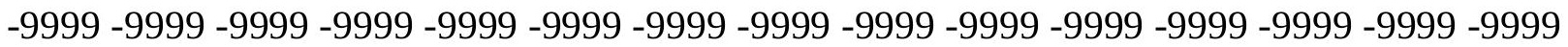
-9999 -9999 -9999 -9999 -9999 -9999 -9999 -9999 -9999 -9999 -9999 -9999 -9999 -9999 -9999 -9999 -9999 -9999 -9999 -9999 -9999 -9999 -9999 -9999 -9999 -9999 -9999 -9999 -9999 -9999 -9999 -9999 -9999 -9999 -9999 -9999 -9999 -9999 -9999 -9999 -9999 -9999 -9999 -9999 -9999 -9999 -9999 -9999 -9999 -9999 -9999 -9999 -9999 -9999 -9999 -9999 -9999 -9999 -9999 -9999 -9999 -9999 -9999 -9999 -9999 -9999 -9999 -9999 -9999 -9999 -9999 -9999 -9999 151.4781951904140 .5059967041128 .3144989014115 .818397522103 .9317016602 99.3599472045994 .48339080811102 .71260070897 .8360290527399 .05516815186 99.2208175659298 .872344970798 .6185684204198 .4774703979598 .47225189209 98.6254501342898 .959960937599 .49324798584100 .2393417358101 .201385498 102.3738937378103 .7358779907105 .2552490234106 .8815078735108 .5700912476 110.2635955811111 .9062576294113 .4477310181114 .1223144531113 .3578491211 112.5529022217111 .7030487061110 .8010940552109 .8395690918108 .8110809326 107.7102737427106 .532409668105 .2754364014103 .9393157959102 .528968811 
99.0551681518696 .3121032714895 .397743225195 .0929565429793 .87381744385 91.1307525634888 .9972534179788 .9972534179789 .6068267822389 .60682678223 89.302040100188 .6924667358488 .6924667358489 .6068267822390 .52117919922 92.0450973510794 .1785964965896 .0073165893697 .5312423706198 .4455871582 99.3599472045999 .3599472045999 .3599472045998 .7503814697398 .14080810547 97.2264633178795 .7025299072394 .1785964965892 .349891662690 .21640014648 88.0829010009886 .254188537684 .1206970214882 .2919769287180 .46327209473 78.9393463134877 .110626220775 .8914871215874 .3675689697373 .14842987061 71.9292907714871 .014930725169 .7957916259868 .8814392089867 .66230010986 66.7479400634865 .5288009643664 .6144485473663 .7000885009862 .78573989868 61.8713798522961 .2618103027360 .9570198059160 .6522407531760 .34745025635 60.3474502563560 .0426712036159 .4331016540558 .5187492370657 .60438919067 56.6900291442955 .4708900451754 .2517509460453 .0326118469251 .81346893311 50.8991203308149 .6799812316948 .4608306884847 .2416992187546 .32733917236 45.1082000732443 .8890609741242 .66992187541 .4507789611839 .92684936523 38.0981407165535 .9646492004433 .2215805053730 .7833003997828 .04022979736 25.906740188623 .7732391357421 .6397399902319 .2014598846416 .45840072632 14.0201196670511 .277050018318 .5339832305914 .5717768669133 .047851085663 $-.609570324421-5.18134689331-7.3148431778-8.83876895905-10.9722604752$ -9.75312423706 -8.83876895905 -7.92441320419 -7.3148431778 -6.7052731514-6.095703125 $-5.79091691971-5.18134689331-4.87656211853-4.57177686691-4.26699209213$ $-4.26699209213-4.26699209213-4.26699209213-4.57177686691-4.87656211853$ $-5.18134689331-5.48613214493-5.79091691971-6.095703125-6.40048694611$ $-6.7052731514-7.01005792618-7.3148431778-7.61962795258-7.61962795258$ $-7.61962795258-7.3148431778-7.01005792618-6.40048694611-6.095703125$ $-5.48613214493-4.87656211853-4.26699209213-3.35263609886-2.74306607246$ -1.82871103287 -.914355397224 -9999 1.21914100647 2.438281059265 4.266992092133 5.7909169197087 .92441320419310 .0579099655212 .4961900711114 .9344701767 17.37274932861 19.8110294342 22.2493095397924.6875991821327.12587928772 29.2593708038331 .0880794525133 .2215805053737 .7933502197336 .87900161743 39.0125007629441 .4507789611843 .5842704772946 .3273391723649 .07040023804 52.1182594299354 .8613204956156 .6900291442958 .2139587402359 .73788070679 60.6522407531761 .5666007995662 .1761703491262 .4809494018662 .48094940186 62.4809494018662 .4809494018662 .1761703491261 .8713798522961 .56660079956 61.2618103027360 .9570198059160 .6522407531760 .3474502563560 .34745025635 60.0426712036160 .0426712036160 .0426712036160 .0426712036160 .04267120361 60.3474502563560 .3474502563560 .6522407531760 .6522407531760 .95701980591 60.9570198059160 .9121665954660 .8760948181260 .8513107299861 .56660079956 61.4944572448761 .8713798522961 .8713798522962 .1761703491262 .17617034912 62.4809494018662 .4809494018662 .7857398986862 .7857398986863 .09051895142 63.0905189514263 .3953094482463 .3953094482463 .7000885009863 .70008850098 64.004882812564 .004882812564 .3096618652364 .3096618652364 .61444854736 64.6144485473664 .9192428588964 .9192428588965 .2240066528365 .22400665283 65.2240066528365 .5288009643665 .5288009643665 .8335876464865 .83358764648 65.8335876464866 .1383666992266 .7479400634867 .35751342773 -9999 -9999 -9999 -9999 -9999 -9999 -9999 -9999 -9999 -9999 -9999 -9999 -9999 -9999 -9999 -9999 -9999 -9999 -9999 
$-9999$

-9999 -9999 -9999 -9999 -9999 -9999 -9999 -9999 -9999 -9999 -9999 -9999 -9999 -9999 -9999

-9999 -9999 -9999 -9999 -9999 -9999 -9999 -9999 -9999 -9999 -9999 -9999 -9999 -9999 - -9999 -

-9999 -9999 -9999 -9999 -9999 -9999 -9999 -9999 -9999 -9999 -9999 -9999 -9999 -9999 -9999

-9999 -9999 -9999 -9999 -9999 -9999 -9999 -9999 -9999-9999 -9999 -9999 -9999 -9999 -9999 -

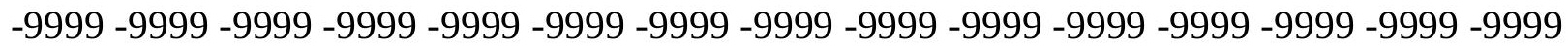

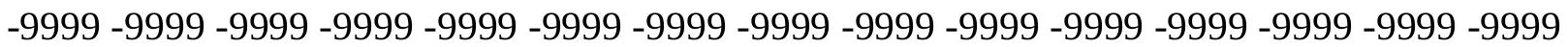

-9999 -9999 -9999 -9999 -9999 -9999 -9999 -9999 -9999 -9999 -9999 -9999 -9999 -9999

146.9064025879 137.4580993652 128.3144989014119.4757995605 111.8561019897

106.3700027466102 .712600708100 .8839035034101 .493400573798 .96215820312

98.5678100585998 .2699584960998 .0892410278398 .0524749755998 .18655395508

98.5196456909299 .0748672485499 .87255859375100 .9214172363102 .2197265625

103.7464599609105 .4604263306107 .3144302368109 .2456512451111 .1819152832

113.0500259399114 .7881469727115 .0114212036114 .304901123113 .5634460449

112.7837371826111 .9593811035111 .0827331543110 .1455154419109 .1412353516 108.0639572144 106.9102401733 105.6783981323104.3715591431 102.9973831177 101.5709152222100 .114311218398 .6630020141697 .2413635253995 .90086364746 92.349891662693 .5690307617292 .8417663574292 .2332077026491 .81901550293 91.1307525634891 .1307525634891 .7403335571392 .349891662694 .17859649658 96.3121032714898 .1408081054799 .66472625732100 .8839035034101 .4934005737 101.4934005737101 .4934005737100 .8839035034100 .274299621699 .05516815186 97.5312423706196 .0073165893693 .8738174438591 .7403335571389 .60682678223 87.4733276367285 .3398437583 .5111236572381 .6824111938579 .85370635986 78.3297805786176 .8058471679775 .5867080688574 .3675689697373 .14842987061 71.9292907714870 .7101516723669 .7957916259868 .5766525268667 .35751342773 66.4431610107465 .2240066528364 .3096618652363 .0905189514262 .17617034912 61.2618103027360 .6522407531760 .3474502563560 .3474502563560 .34745025635 60.0426712036159 .1283111572358 .2139587402356 .9948196411155 .77568054199 54.2517509460453 .0326118469251 .8134689331150 .2895507812548 .7656211853 47.5464782714846 .0225486755444 .8034095764243 .5842704772942 .06034851074 40.8412094116239 .622070312538 .0981407165536 .5742111206134 .44071960449 31.6976509094228 .6497993469225 .906740188623 .1636695861821 .03017044067 19.2014598846417 .3727493286115 .5440397262613 .715330123911 .88661956787 $10.057909965527 .9244132041935 .1813468933112 .133496046066-.609570324421$ -3.35263609886 -4.87656211853 -5.18134689331 -4.87656211853-4.26699209213 $-3.96220707893-3.96220707893-4.26699209213-4.26699209213-3.96220707893$ -3.96220707893 -3.65742206573 -3.35263609886 -3.35263609886 -3.35263609886 $-3.35263609886-3.65742206573-3.96220707893-4.26699209213-4.57177686691$ $-4.87656211853-5.18134689331-5.79091691971-6.095703125-6.40048694611$ $-6.7052731514-7.01005792618-7.3148431778-7.3148431778-7.61962795258-7.3148431778$ $-7.3148431778-7.01005792618-6.40048694611-6.095703125-5.48613214493$ $-5.18134689331-4.57177686691-3.96220707893-3.04785108566-2.43828105927$ $-1.52392601967-.304785102606$.6095703244209 1.8287110328673 .657422065735 5.1813468933117 .3148431777959 .4483394622811 .8866195678714 .02011966705 16.4584007263219 .2014598846421 .6397399902324 .0780296325726 .51630973816 28.3450202941930 .1737308502232 .0024414062533 .8311500549335 .65985870361 
37.4885711669939 .3172798156741 .7555618286144 .1938400268647 .24169921875 49.9847602844252 .7278289794955 .1661109924356 .9948196411158 .82352828979 60.0426712036160 .9570198059161 .5666007995662 .1761703491262 .17617034912 62.4809494018662 .1761703491261 .8713798522961 .5666007995661 .26181030273 60.9570198059160 .3474502563560 .0426712036160 .0426712036159 .73788070679 59.7378807067959 .7378807067959 .7378807067959 .7378807067959 .73788070679 60.0426712036160 .0426712036160 .3474502563560 .3474502563560 .65224075317 60.6522407531760 .7144088745160 .6850929260360 .6667823791561 .26181030273 61.2673950195361 .5666007995661 .8713798522961 .8713798522962 .17617034912 62.1761703491262 .4809494018662 .4809494018662 .4809494018662 .78573989868 62.7857398986863 .0905189514263 .0905189514263 .3953094482463 .39530944824 63.7000885009863 .7000885009864 .004882812564 .004882812564 .30966186523 64.3096618652364 .6144485473664 .6144485473664 .6144485473664 .91924285889 64.9192428588965 .2240066528365 .2240066528365 .2240066528365 .52880096436 $65.5288009643665 .8335876464866 .1383666992266 .7479400634867 .35751342773-9999$ -9999 -9999 -9999 -9999 -9999 -9999 -9999 -9999 -9999 -9999 -9999 -9999 -9999 -9999 -9999 -9999 -9999-9999

-9999 -9999 -9999 -9999 -9999 -9999 -9999 -9999 -9999 -9999 -9999 -9999 -9999 -9999 -9999 -9999 -9999 -9999 -9999 -9999 -9999 -9999 -9999 -9999 -9999 -9999 -9999 -9999 -9999 -9999 -

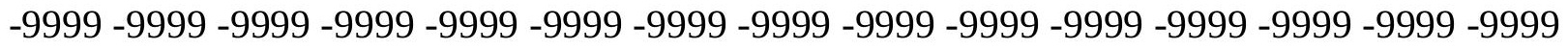

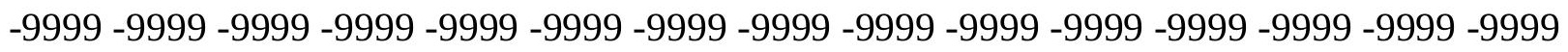
-9999 -9999 -9999 -9999 -9999 -9999 -9999 -9999 -9999 -9999 -9999 -9999 -9999 -9999 -9999 -9999 -9999 -9999 -9999 -9999 -9999 -9999 -9999 -9999 -9999 -9999 -9999 -9999 -9999 - -9999 -9999 -9999 -9999 -9999 -9999 -9999 -9999 -9999 -9999 -9999 -9999 -9999 -9999 -9999 149.9542999268142 .0299072266134 .4102020264128 .0097961426122 .8283996582 120.3900985718119 .1709976196117 .9517974854118 .2565994263120 .9997024536 98.2593688964897 .9048233032297 .6693496704197 .5826797485497 .67594909668 97.9829559326298 .5343551635799 .35712432861100 .4705429077101 .8774108887 103.5616226196105 .48387146107 .5897903442109 .7989120483112 .0124588013 114.1294708252116 .0670013428115 .9724349976115 .3281326294114 .6553115845 113.9518432617113 .212387085112 .4293899536111 .5939483643110 .6983947754 109.7355041504108 .7001190186107 .5885238647106 .4014892578105 .1441497803 103.8287200928102 .4738235474101 .10575866799 .7572708129998 .46539306641 97.2679061889696 .1994018554795 .2737579345794 .4945907592893 .85844421387 93.3925552368293 .231864929293 .7259445190495 .397743225196 .92166900635 99.05516815186101 .1886978149102 .712600708103 .6268997192103 .9317016602 103.9317016602103 .6268997192103 .0174026489102 .4077987671101 .1886978149 99.9695205688598 .1408081054796 .3121032714893 .8738174438591 .74033355713 89.3020401001 86.8637619018684.73026275635 82.9015579223681.07285308838 79.5489196777378 .0249862670976 .8058471679775 .5867080688574 .36756896973 73.1484298706171 .9292907714870 .7101516723669 .7957916259868 .57665252686 67.3575134277366 .1383666992264 .9192428588963 .7000885009862 .78573989868 61.5666007995660 .9570198059160 .3474502563560 .3474502563560 .34745025635 60.0426712036158 .8235282897957 .6043891906756 .0804595947354 .86132049561 53.3373985290551 .8134689331150 .2895507812548 .765621185346 .93690872192 45.4129791259843 .8890609741242 .3651313781740 .8412094116239 .31727981567 
37.7933502197336 .2694282531734 .4407196044932 .9167900085430 .78330039978 27.430660247824 .0780296325720 .7253894805918 .28710937516 .15361022949 14.6296901702913 .1057596206711 .5818300247210 .362689971928 .838768959045 7.6196279525766 .4004869461064 .876562118533 .0478510856631 .21914100647 -9999 -.609570324421 -.609570324421 -.304785102606.3047851026058 -.304785102606 -.914355397224 -1.52392601967 - $1.82871103287-2.13349604607-2.13349604607$ $-2.13349604607-2.13349604607-2.13349604607-2.43828105927-2.74306607246$ $-3.04785108566-3.35263609886-3.65742206573-3.96220707893-4.57177686691$ $-4.87656211853-5.48613214493-5.79091691971-6.095703125-6.40048694611$ $-6.7052731514-7.01005792618-7.01005792618-7.01005792618-7.01005792618$ $-7.01005792618-6.7052731514-6.40048694611-6.095703125-5.79091691971$ $-5.18134689331-4.57177686691-4.26699209213-3.35263609886-2.74306607246$ -1.82871103287 -.914355397224 -9999 1.21914100647 2.743066072464 4.571776866913 6.7052731513988 .83876895904510 .9722604751613 .4105501174915 .84883022308 18.28710937521 .0301704406723 .4684505462625 .906740188627 .73545074463 29.2593708038331 .0880794525132 .6120109558134 .1359291076735 .65985870361 37.4885711669939 .3172798156741 .7555618286144 .8034095764247 .85126113892 50.5943298339853 .3373985290555 .7756805419957 .6043891906759 .12831115723 60.3474502563561 .2618103027361 .8713798522962 .1761703491262 .17617034912 61.8713798522961 .5666007995661 .2618103027360 .9570198059160 .34745025635 60.0426712036159 .7378807067959 .4331016540559 .1283111572359 .12831115723 59.1283111572359 .1283111572359 .1283111572359 .4331016540559 .43310165405 59.7378807067960 .0426712036160 .0426712036160 .3474502563560 .34745025635 60.5139808654860 .4933357238860 .4830474853560 .9570198059161 .05484008789 61.0214424133361 .5666007995661 .5666007995661 .8713798522961 .87137985229 62.1761703491262 .1761703491262 .4809494018662 .4809494018662 .48094940186 62.7857398986862 .7857398986863 .0905189514263 .0905189514263 .39530944824 63.3953094482463 .7000885009863 .7000885009864 .004882812564 .0048828125 64.004882812564 .3096618652364 .3096618652364 .6144485473664 .61444854736 64.9192428588964 .9192428588964 .9192428588965 .2240066528365 .22400665283 65.5288009643665 .5288009643666 .1383666992266 .74794006348 -9999 -9999 -9999 -9999 -9999 -9999 -9999 -9999 -9999 -9999 -9999 -9999 -9999 -9999 -9999 -9999 -9999 -9999 -9999

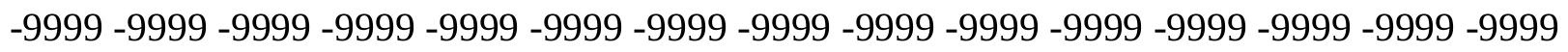

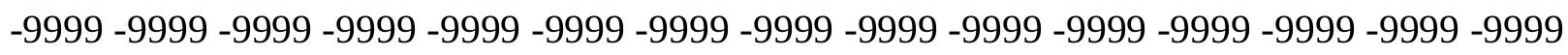
-9999 -9999 -9999 -9999 -9999 -9999 -9999 -9999 -9999 -9999 -9999 -9999 -9999 -9999 -9999

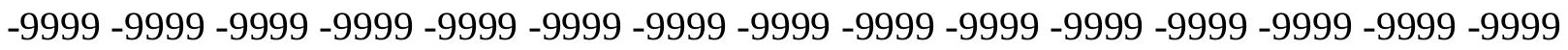

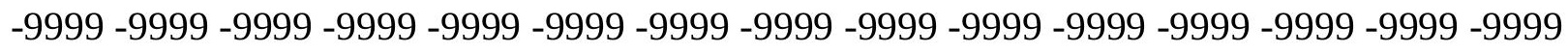

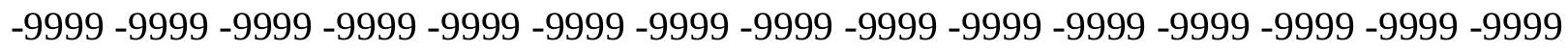

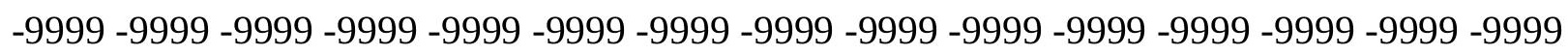
142.9441986084136 .8484954834131 .9720001221128 .9241027832129 .2288970947 130.4479980469129 .533706665130 .1432037354134 .1054992676140 .8106994629 97.53749084473 97.231025695897.0739593505997.1009445190497.35123443604 97.8633956909298 .67494964699 .81647491455101 .3028793335103 .130065918 105.266418457107 .6549530029110 .1913375854112 .7345733643115 .1361236572 117.2764816284116 .9936141968116 .414390564115 .8136672974115 .1905822754 114.5411605835113 .8585662842113 .1335906982112 .3573455811111 .5209884644 
110.6172332764109 .639831543108 .5867080688107 .4599990845106 .2687835693 105.0280303955103 .7598419189102 .491973877101 .256149292100 .0850753784 99.0059509277398 .0385131835997 .1950531005996 .5129623413196 .0598526001 95.9967346191496 .6734848022598 .18567657471100 .2742996216102 .712600708 104.8460998535106 .0652008057106 .979598999106 .979598999106 .6747970581 106.0652008057105 .4557037354104 .5412979126103 .6268997192102 .4077987671 100.883903503498 .7503814697396 .3121032714893 .8738174438591 .43553924561 88.6924667358486 .254188537684 .1206970214882 .5967712402381 .07285308838 79.5489196777378 .3297805786176 .8058471679775 .5867080688574 .36756896973 73.1484298706172 .2340774536171 .014930725169 .7957916259868 .57665252686 67.0527267456165 .8335876464864 .6144485473663 .3953094482462 .17617034912 61.2618103027360 .6522407531760 .0426712036159 .7378807067959 .12831115723 58.2139587402356 .6900291442955 .4708900451753 .6421813964852 .11825942993 50.5943298339848 .765621185346 .9369087219245 .4129791259843 .58427047729 41.7555618286139 .9268493652338 .4029312133836 .5742111206134 .74551010132 32.9167900085431 .0880794525128 .6497993469225 .906740188622 .55410003662 18.8966808319115 .5440397262612 .8009700775110 .972260475169 .753124237061 8.8387689590457 .6196279525766 .4004869461065 .1813468933114 .266992092133 3.9622070789343 .3526360988622 .7430660724642 .1334960460661 .523926019669 1.5239260196691 .5239260196691 .8287110328671 .8287110328671 .523926019669 $.6095703244209-9999-.304785102606-.609570324421-.914355397224-.914355397224$ $-.914355397224-1.21914100647-1.21914100647-1.82871103287-2.13349604607$ $-2.43828105927-3.04785108566-3.35263609886-3.96220707893-4.26699209213$ $-4.87656211853-5.18134689331-5.79091691971-6.095703125-6.40048694611$ $-6.40048694611-6.40048694611-6.40048694611-6.40048694611-6.40048694611$ $-6.40048694611-6.095703125-6.095703125-5.79091691971-5.48613214493-4.87656211853$ $-4.26699209213-3.65742206573-3.04785108566-2.43828105927-1.52392601967$ -.304785102606 6095703244209 2.133496046066 3.9622070789345.790916919708 7.92441320419310 .0579099655212 .4961900711114 .934470176717 .37274932861 19.811029434222 .5541000366224 .9923801422127 .430660247828 .64979934692 29.8689403533931 .3928699493432 .3072204589833 .5263595581135 .05028915405 36.8790016174339 .3172798156742 .0603485107445 .4129791259848 .46083068848 51.5086898803754 .2517509460456 .6900291442958 .5187492370660 .04267120361 60.9570198059161 .5666007995661 .8713798522961 .8713798522961 .87137985229 61.2618103027360 .9570198059160 .3474502563560 .0426712036159 .43310165405 59.1283111572358 .8235282897958 .5187492370658 .5187492370658 .51874923706 58.5187492370658 .8235282897958 .8235282897959 .1283111572359 .43310165405 59.4331016540559 .7378807067960 .0426712036160 .0426712036160 .31265258789 60.3023605346760 .3014373779360 .3071861267160 .8798103332560 .8286781311 61.2618103027361 .2618103027361 .5666007995661 .5666007995661 .87137985229 61.8713798522962 .1761703491262 .1761703491262 .4809494018662 .48094940186 62.4809494018662 .7857398986862 .7857398986863 .0905189514263 .09051895142 63.3953094482463 .3953094482463 .7000885009863 .7000885009863 .70008850098 64.004882812564 .004882812564 .3096618652364 .3096618652364 .61444854736 64.6144485473664 .6144485473664 .9192428588964 .9192428588965 .22400665283 65.2240066528365 .2240066528365 .8335876464866 .44316101074 -9999 -9999 -9999 -9999 
-9999 -9999 -9999 -9999 -9999 -9999 -9999 -9999 -9999 -9999 -9999 -9999 -9999 -9999 -9999 -9999 -9999 -9999 -9999 -9999 -9999 -9999 -9999 -9999 -9999 -9999 -9999 -9999 -9999 -9999 -9999 -9999 -9999 -9999 -9999 -9999 -9999 -9999 -9999 -9999 -9999 -9999 -9999 -9999 -9999 -9999 -9999 -9999 -9999 -9999 -9999 -9999 -9999 -9999 -9999 -9999 -9999 -9999 -9999 -9999 -9999 -9999 -9999 -9999 -9999 -9999 -9999 -9999 -9999 -9999 -9999 -9999 -9999 -9999 -9999 -9999 -9999 -9999 -9999 -9999 -9999 -9999 -9999 -9999 -9999 -9999 -9999 -9999 -9999 -9999 -9999 -9999 -9999 -9999 -9999 -9999 -9999 -9999 -9999 -9999 -9999 -9999 -9999 -9999 -9999 -9999 -9999 -9999 -9999 -9999 -9999 -9999 -9999 -9999 -9999 -9999 -9999 -9999 -9999 -9999 136.2389984131 132.2767028809 130.1432037354130.1432037354131.3623962402 132.2767028809135 .0198059082141 .4203033447148 .4304046631153 .6116943359 96.7943115234496 .5453720092896 .4781875610496 .6368408203197 .06883239746 97.8187332153398 .9458694458100 .4642715454102 .3788833618104 .7187652588 107.4220352173110 .3489456177113 .2955474854116 .0332946777118 .3798217773 118.0629501343117 .5501785278117 .0233230591116 .4828033447115 .9262924194 115.3482971191114 .7400665283114 .091506958113 .3917388916112 .6307830811 111.7993545532110 .892036438109 .9075546265108 .8516921997107 .7359390259 106.5788879395105 .4047851562104 .2425231934103 .1225357056102 .0767288208 101.1270675659100 .314231872699 .6942672729599 .3619537353599 .47002410889 100.1894989014101 .4934005737103 .7480010986106 .6747970581108 .8082962036 110.0273971558110 .3321990967109 .7226028442109 .1130981445108 .1986999512 107.5891036987106 .979598999106 .3700027466105 .1509017944103 .6268997192 101.493400573799 .3599472045996 .6168823242293 .5690307617290 .82597351074 88.0829010009885 .9494018554784 .4254837036182 .9015579223681 .37763214111 79.8537063598678 .6345596313577 .4154205322375 .8914871215874 .97714233398 73.7580032348672 .5388565063571 .3197174072369 .7957916259868 .57665252686 67.0527267456165 .5288009643664 .004882812562 .7857398986861 .56660079956 60.6522407531759 .7378807067959 .1283111572358 .2139587402357 .29959869385 55.7756805419954 .2517509460452 .7278289794950 .8991203308149 .37519073486 47.5464782714845 .717769622843 .5842704772941 .7555618286139 .92684936523 37.7933502197335 .9646492004433 .8311500549332 .0024414062529 .56415939331 27.430660247824 .6875991821321 .6397399902317 .9823207855214 .02011966705 10.362689971927 .3148431777955 .7909169197084 .876562118534 .266992092133 3.6574220657352 .438281059265 .9143553972244 .9143553972244.9143553972244 .91435539722441 .219141006471 .5239260196691 .8287110328672 .133496046066 2.4382810592652 .4382810592652 .4382810592652 .1334960460661 .828711032867 1.21914100647 .6095703244209 -9999 -9999 -9999 -9999 -9999 -.304785102606 $-.914355397224-1.52392601967-1.82871103287-2.13349604607-2.74306607246$ $-3.04785108566-3.65742206573-3.96220707893-4.57177686691-4.87656211853$ $-5.48613214493-5.48613214493-5.79091691971-5.79091691971-5.79091691971$ $-6.095703125-6.095703125-6.095703125-6.095703125-5.79091691971-5.79091691971$ $-5.48613214493-5.18134689331-4.57177686691-3.96220707893-3.65742206573$ $-2.74306607246-1.82871103287-.914355397224-99991.5239260196693 .047851085663$ 5.1813468933117 .3148431777959 .4483394622811 .5818300247214 .02011966705 16.1536102294918 .5918903350821 .0301704406723 .4684505462625 .60194969177 27.1258792877228 .3450202941929 .5641593933130 .4785099029531 .08807945251 32.3072204589834 .1359291076736 .5742111206139 .622070312542 .97470092773 
46.6321296691949 .9847602844253 .3373985290555 .7756805419957 .9091796875 59.7378807067960 .6522407531761 .2618103027361 .8713798522961 .87137985229 61.5666007995661 .2618103027360 .6522407531760 .0426712036159 .43310165405 59.1283111572358 .5187492370658 .2139587402357 .909179687557 .9091796875 57.909179687558 .2139587402358 .2139587402358 .5187492370658 .82352828979 59.1283111572359 .4331016540559 .4331016540559 .7378807067960 .04267120361 60.0426712036160 .1142005920460 .1236801147560 .1384124755960 .65224075317 60.6669502258360 .9570198059161 .2618103027361 .2618103027361 .56660079956 61.5666007995661 .5666007995661 .8713798522961 .8713798522962 .17617034912 62.1761703491262 .1761703491262 .4809494018662 .4809494018662 .78573989868 62.7857398986863 .0905189514263 .0905189514263 .0905189514263 .39530944824 63.3953094482463 .7000885009863 .7000885009864 .004882812564 .0048828125 64.004882812564 .3096618652364 .3096618652364 .6144485473664 .61444854736 64.9192428588964 .9192428588964 .9192428588965 .2240066528365 .83358764648 66.44316101074 -9999 -9999 -9999 -9999 -9999 -9999 -9999 -9999 -9999 -9999 -9999 -9999 -9999 -9999-9999-9999-9999

-9999 -9999 -9999 -9999 -9999 -9999 -9999 -9999 -9999 -9999 -9999 -9999 -9999 -9999 -9999 -9999 -9999 -9999 -9999 -9999 -9999 -9999 -9999 -9999 -9999 -9999 -9999 -9999 -9999 -9999 -

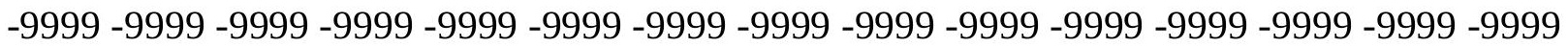

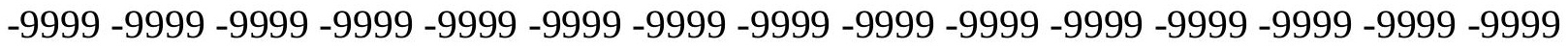

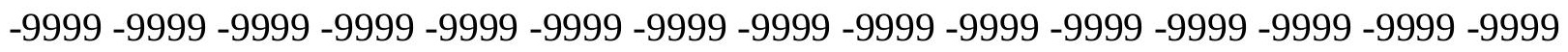
-9999 -9999 -9999 -9999 -9999 -9999 -9999 -9999 -9999 -9999 -9999 -9999 -9999 -9999 -9999 -9999 -9999 -9999 -9999 -9999 -9999 -9999 -9999 -9999 -9999 -9999 -9999 -9999 -9999 -9999 -9999 133.8007049561 130.1432037354128.0097961426126.7906036377127.0953979492 129.533706665133 .8007049561141 .7250976562147 .8208007812145 .3825073242 96.3869781494196.026084899995.8377609252995.8708953857496.18003082275 96.8073043823297 .8138198852599 .25913238525101 .208190918103 .7140731812 106.7465438843110 .1320343018113 .5749969482116 .7185592651119 .2731399536 121.1149520874118 .7203826904118 .2673568726117 .8096618652117 .3466949463 116.8746795654116 .3860855103115 .8703079224115 .3141555786114 .7043151855 114.0278701782113 .275604248112 .4424133301111 .5305709839110 .5484237671 109.5120315552108 .4436645508107 .3716964722106 .3283233643105 .3482208252 104.4683074951103 .7386169434103 .2302398682103 .036781311103 .284286499 103.3221969604104 .5412979126107 .5891036987110 .35496521112 .1898880005 113.2172088623113 .6848983765112 .4656982422110 .9418029785110 .0273971558 109.4179000854109 .4179000854108 .8082962036107 .8938980103106 .6747970581 104.8460998535102 .407798767199 .6647262573296 .6168823242293 .26425170898 90.2164001464888 .3876876831186 .5589828491285 .0350494384883 .51112365723 81.9871978759880 .4632720947379 .2441329956177 .7202072143676 .50106811523 75.5867080688574 .062782287672 .8436431884871 .6244964599670 .10057830811 68.2718734741266 .7479400634865 .2240066528363 .3953094482461 .87137985229 60.6522407531759 .4331016540558 .5187492370657 .2995986938556 .08045959473 54.8613204956153 .3373985290551 .8134689331149 .9847602844248 .15605163574 46.3273391723644 .4986305236842 .3651313781740 .2316398620638 .09814071655 35.9646492004433 .8311500549331 .3928699493429 .2593708038326 .51630973816 24.0780296325721 .0301704406717 .3727493286113 .71533012399 .753124237061 
5.7909169197082 .133496046066 .9143553972244 3047851026058 -9999 -9999 -1.21914100647 -2.13349604607 -2.43828105927 -2.43828105927 -1.82871103287 -.914355397224 -9999.9143553972244 1.523926019669 1.828711032867 2.133496046066 2.1334960460662 .1334960460661 .8287110328671 .5239260196691 .21914100647 6095703244209. 3047851026058 -9999.3047851026058. 6095703244209-9999 -9999 -.609570324421 -.914355397224 -1.21914100647 -1.52392601967 -2.13349604607 $-2.43828105927-2.74306607246-3.35263609886-3.96220707893-4.26699209213$ $-4.57177686691-4.87656211853-4.87656211853-5.18134689331-5.18134689331$ $-5.48613214493-5.79091691971-5.79091691971-5.79091691971-5.79091691971$ $-5.48613214493-5.18134689331-4.87656211853-4.26699209213-3.96220707893$ -3.04785108566 -2.43828105927-1.52392601967-.304785102606 .9143553972244 2.4382810592654 .2669920921336 .4004869461068 .53398323059110 .66748046875 12.8009700775114 .934470176717 .3727493286119 .5062503814721 .63973999023 23.4684505462624 .9923801422126 .2115192413327 .1258792877228 .04022979736 28.6497993469229 .5641593933131 .0880794525133 .8311500549337 .18378067017 41.1459884643645 .1082000732449 .0704002380452 .4230384826755 .47089004517 57.6043891906759 .4331016540560 .6522407531761 .2618103027361 .56660079956 61.5666007995661 .2618103027360 .9570198059160 .3474502563559 .73788070679 59.1283111572358 .5187492370657 .909179687557 .6043891906757 .29959869385 57.2995986938557 .6043891906757 .6043891906757 .909179687558 .21395874023 58.5187492370658 .8235282897959 .1283111572359 .4331016540559 .43310165405 59.7378807067959 .9172401428259 .9313430786159 .9518432617259 .97589492798 60.6522407531760 .5235443115260 .9570198059160 .9570198059160 .95701980591 61.2618103027361 .2618103027361 .5666007995661 .5666007995661 .56660079956 61.8713798522961 .8713798522962 .1761703491262 .1761703491262 .17617034912 62.4809494018662 .4809494018662 .7857398986862 .7857398986862 .78573989868 63.0905189514263 .0905189514263 .3953094482463 .3953094482463 .70008850098 63.7000885009863 .7000885009864 .004882812564 .004882812564 .30966186523 64.3096618652364 .3096618652364 .6144485473664 .6144485473664 .91924285889 65.2240066528365 .83358764648 -9999 -9999 -9999 -9999 -9999 -9999 -9999 -9999 -9999 -9999 -9999 -9999 -9999 -9999 -9999-9999 -9999

-9999 -9999 -9999 -9999 -9999 -9999 -9999 -9999 -9999 -9999 -9999 -9999 -9999 -9999 -9999

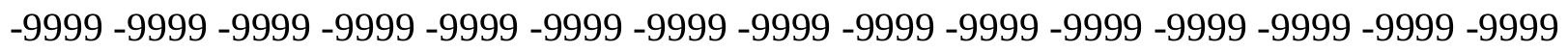
-9999 -9999 -9999 -9999 -9999 -9999 -9999 -9999 -9999 -9999 -9999 -9999 -9999 -9999 -9999 -9999 -9999 -9999 -9999 -9999 -9999 -9999 -9999 -9999 -9999 -9999 -9999 -9999 -9999 -9999

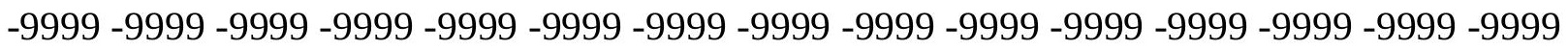

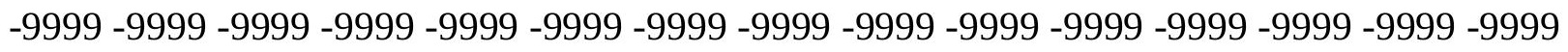

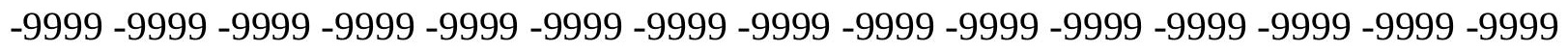
-9999 -9999 126.1809997559 123.43800354121 .6092987061121 .3044967651122 .5235977173 125.5715026855130 .4479980469133 .1911010742130 .1432037354125 .5715026855 95.5572509765695 .2260284423895 .1019134521595 .227813720795 .65020751953 96.4382629394597 .6898345947399 .53098297119102 .0880966187105 .4076156616 109.3084182739 113.3423080444116.9782104492119.7323150635121.4154434204 119.9094314575119 .5278625488119 .1507949829118 .7795410156118 .4122085571 118.0429611206117 .6613845825117 .2525177002116 .799118042116 .2838363647 115.6930007935115 .0172729492114 .2551498413113 .4121627808112 .5028839111 
111.5493087769110 .5808868408109 .6324462891108 .7429656982107 .9577178955 107.3330612183106 .9421005249106 .8709793091107 .20262146108 .0352859497 109.3905487061 111.2175292969 113.2310791016114.9388122559115.4626998901 115.2172927856114 .2944030762112 .1608963013111 .24659729111 .24659729 111.551399231111 .551399231110 .9418029785109 .7226028442107 .8938980103 105.4557037354102 .71260070899 .6647262573296 .6168823242293 .87381744385 91.4355392456189 .302040100187 .4733276367285 .6446228027384 .12069702148 82.5967712402381 .0728530883879 .8537063598678 .6345596313577 .41542053223 76.1962814331174 .9771423339873 .4532165527371 .9292907714870 .10057830811 68.2718734741266 .4431610107464 .3096618652362 .4809494018660 .95701980591 59.4331016540557 .909179687556 .6900291442955 .4708900451753 .94697189331 52.4230384826750 .8991203308149 .0704002380447 .2416992187545 .41297912598 43.5842704772941 .4507789611839 .3172798156736 .8790016174334 .44071960449 32.0024414062529 .2593708038326 .8210906982424 .0780296325721 .03017044067 17.6775398254414 .0201196670510 .057909965526 .0957031252 .133496046066 $-.609570324421-2.74306607246-3.65742206573-3.96220707893-4.57177686691$ $-5.48613214493-6.095703125-6.40048694611-6.095703125-5.48613214493-4.26699209213$ -2.43828105927 -.609570324421 -9999.6095703244209.9143553972244 1.21914100647 1.5239260196691 .5239260196691 .5239260196691 .21914100647 .9143553972244 6095703244209.6095703244209.9143553972244.9143553972244.6095703244209 .3047851026058 -9999-9999-9999-.304785102606-.609570324421 -.914355397224 $-1.21914100647-1.52392601967-2.43828105927-3.04785108566-3.35263609886$ $-3.65742206573-3.65742206573-4.26699209213-4.57177686691-5.18134689331$ $-5.48613214493-5.79091691971-5.79091691971-5.79091691971-5.79091691971$ $-5.48613214493-5.18134689331-4.57177686691-4.26699209213-3.35263609886$ -2.74306607246 -1.82871103287-.914355397224 -9999 1.828711032867 3.657422065735 5.4861321449287 .6196279525769 .75312423706111 .5818300247213 .7153301239 15.8488302230817 .6775398254419 .5062503814721 .334960937522 .85887908936 23.7732391357424 .6875991821325 .6019496917726 .2115192413326 .82109069824 28.3450202941931 .0880794525135 .0502891540539 .622070312544 .49863052368 48.765621185352 .4230384826755 .4708900451757 .909179687559 .43310165405 60.6522407531761 .2618103027361 .5666007995661 .5666007995660 .95701980591 60.6522407531760 .0426712036159 .1283111572358 .5187492370657 .9091796875 57.2995986938556 .9948196411156 .6900291442956 .6900291442956 .99481964111 57.2995986938557 .6043891906757 .909179687558 .2139587402358 .51874923706 58.8235282897959 .1283111572359 .4331016540559 .4331016540559 .72957611084 59.7567634582559 .7883834838959 .8216094970760 .3474502563560 .29658889771 60.6522407531760 .6522407531760 .9570198059160 .9570198059160 .95701980591 61.2618103027361 .2618103027361 .5666007995661 .5666007995661 .56660079956 61.8713798522961 .8713798522961 .8713798522962 .1761703491262 .17617034912 62.4809494018662 .4809494018662 .4809494018662 .7857398986862 .78573989868 63.0905189514263 .0905189514263 .3953094482463 .3953094482463 .39530944824 63.7000885009863 .7000885009864 .004882812564 .004882812564 .0048828125 64.3096618652364 .3096618652364 .6144485473664 .6144485473665 .22400665283 65.83358764648 -9999 -9999 -9999 -9999 -9999 -9999 -9999 -9999 -9999 -9999 -9999 -9999 -9999 -9999 -9999 -9999 
-9999 -9999 -9999 -9999 -9999 -9999 -9999 -9999 -9999 -9999 -9999 -9999 -9999 -9999 -9999 -9999 -9999 -9999 -9999 -9999 -9999 -9999 -9999 -9999 -9999 -9999 -9999 -9999 -9999 -9999 -9999 -9999 -9999 -9999 -9999 -9999 -9999 -9999 -9999 -9999 -9999 -9999 -9999 -9999 -9999 -9999 -9999 -9999 -9999 -9999 -9999 -9999 -9999 -9999 -9999 -9999 -9999 -9999 -9999 -9999 -9999 -9999 -9999 -9999 -9999 -9999 -9999 -9999 -9999 -9999 -9999 -9999-9999 -9999 -9999 -9999 -9999 -9999 -9999 -9999 -9999 -9999 -9999 -9999 -9999 -9999 -9999 -9999 -9999 -9999

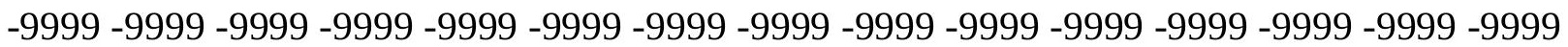
-9999 -9999-9999 118.5614013672 116.4279022217 114.9039993286113 .9896011353 113.9896011353113 .9896011353113 .075302124111 .8561019897109 .7226028442 107.589103698794 .6993026733494 .3875274658294 .2793197631894 .42057800293 94.8845901489395 .7913055419997 .3185119628999 .69178771973103 .1127471924 107.5300750732112 .2284393311116 .4238204956119 .3248214722120 .7256698608 120.7796325684120 .3255462646120 .4824523926120 .1984405518119 .9313049316 119.6780548096119 .4290161133119 .167930603118 .8735275269118 .5230407715 118.0971755981117 .5815353394116 .9707107544116 .2679214478115 .4874801636 114.6526031494113 .7948379517112 .9498443604112 .1632385254111 .4831848145 110.965927124110 .677116394110 .681098938111 .0319595337111 .773765564 112.8832244873114 .243270874115 .5915222168116 .551109314116 .7651290894 116.1517791748114 .8691864014112 .4656982422111 .8561019897112 .7705001831 113.9896011353114 .2944030762113 .9896011353112 .7705001831110 .9418029785 108.8082962036106 .0652008057103 .3221969604100 .274299621697 .53124237061 95.0929565429792 .6546783447390 .5211791992288 .3876876831186 .55898284912 84.7302627563583 .5111236572381 .9871978759881 .0728530883879 .85370635986 78.6345596313577 .110626220775 .5867080688574 .062782287672 .23407745361 70.1005783081167 .9670867919965 .5288009643663 .3953094482461 .26181030273 59.4331016540557 .6043891906756 .0804595947354 .8613204956153 .33739852905 51.8134689331150 .2895507812548 .765621185346 .9369087219244 .80340957642 42.9747009277340 .8412094116238 .4029312133835 .9646492004433 .52635955811 30.7833003997827 .7354507446324 .6875991821321 .6397399902318 .59189033508 $14.934470176711 .277050018317 .3148431777953 .047851085663-.304785102606$ -3.65742206573 -5.79091691971 -7.3148431778 -8.22919845581 -9.14355373383 -9.75312423706 -10.0579099655 -10.3626899719-10.0579099655 -9.14355373383 $-7.92441320419-5.79091691971-3.65742206573-2.13349604607-.914355397224$ -304785102606-9999.6095703244209.9143553972244.9143553972244.9143553972244 6095703244209.6095703244209.6095703244209.9143553972244 1.21914100647 1.21914100647.9143553972244.6095703244209.6095703244209.9143553972244 .9143553972244.9143553972244.6095703244209 1.21914100647.9143553972244 -9999 -1.21914100647 -1.52392601967 -1.82871103287 -2.43828105927 -3.35263609886 -3.96220707893 -4.87656211853 -5.18134689331 -5.79091691971 -5.79091691971 -5.79091691971 -5.79091691971 -5.79091691971 -5.48613214493-4.87656211853 $-4.26699209213-3.65742206573-3.04785108566-2.13349604607$-1.21914100647 -9999 1.5239260196693 .0478510856634 .876562118536 .7052731513988 .533983230591 10.3626899719212 .4961900711114 .3248996734616 .1536102294917 .67753982544 19.2014598846420 .4206008911121 .6397399902322 .5541000366223 .16366958618 24.0780296325724 .9923801422126 .5163097381629 .2593708038333 .83115005493 39.0125007629444 .1938400268649 .0704002380453 .0326118469256 .08045959473 
58.2139587402359 .7378807067960 .9570198059161 .2618103027361 .56660079956 61.2618103027360 .9570198059160 .3474502563559 .7378807067958 .82352828979 57.909179687557 .2995986938556 .6900291442956 .3852500915556 .38525009155 56.3852500915556 .6900291442956 .9948196411157 .2995986938557 .60438919067 57.909179687558 .2139587402358 .5187492370658 .8235282897959 .12831115723 59.4331016540559 .5535316467359 .5936431884859 .6358642578159 .67752456665 59.7162742614760 .0955352783260 .3474502563560 .6522407531760 .65224075317 60.6522407531760 .9570198059160 .9570198059160 .9570198059161 .26181030273 61.2618103027361 .2618103027361 .5666007995661 .5666007995661 .87137985229 61.8713798522961 .8713798522962 .1761703491262 .1761703491262 .48094940186 62.4809494018662 .4809494018662 .7857398986862 .7857398986863 .09051895142 63.0905189514263 .0905189514263 .3953094482463 .3953094482463 .70008850098 63.7000885009863 .7000885009864 .004882812564 .004882812564 .0048828125 64.3096618652364 .6144485473665 .22400665283 -9999 -9999 -9999 -9999 -9999 -9999 -9999 -9999 -9999 -9999 -9999 -9999 -9999 -9999 -9999 -9999

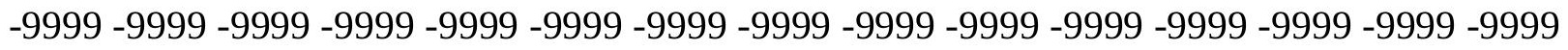
-9999 -9999 -9999 -9999 -9999 -9999 -9999 -9999 -9999 -9999 -9999 -9999 -9999 -9999 -9999 -9999 -9999 -9999 -9999 -9999 -9999 -9999 -9999 -9999 -9999 -9999 -9999 -9999 -9999 -9999 -

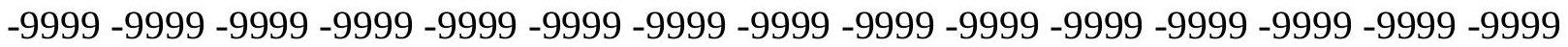

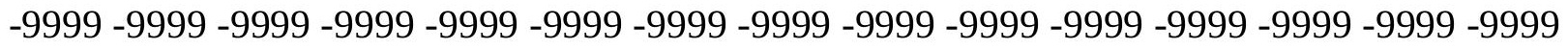

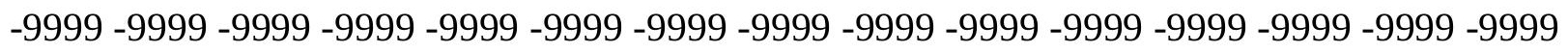

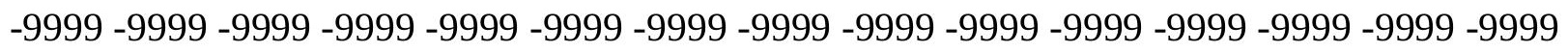
-9999 -9999-9999 114.9039993286111.8561019897 108.8082962036105.4557037354 101.798202514698 .445587158295 .7025299072394 .7881774902394 .48339080811 92.6546783447391 .1307525634892 .349891662693 .4339599609493 .24480438232 93.30117034912 93.7217178344794.7010803222796.5273132324299.59694671631 104.2637176514 109.7851638794 114.3457336426117.2262573242 118.3134307861 117.5206604004115 .5822982788114 .8423233032116 .8271789551119 .9639282227 121.2549133301121 .1331329346121 .0161056519120 .8867645264120 .7116470337 120.458732605120 .1037826538119 .6366271973119 .0609283447118 .3974990845 117.6775741577116 .9365386963116 .2089309692115 .5322570801114 .9532928467 114.5238647461114 .2978744507114 .323135376114 .6338882446115 .2292251587 116.0453720093116 .9672393799117 .7699737549118 .2066345215118 .0699539185 117.2791137695115 .9402313232114 .5526657104112 .7705001831114 .0796127319 115.2901229858116 .3334884644116 .2184143066115 .1971893311113 .6848983765 111.551399231109 .1130981445106 .6747970581103 .9317016602101 .1886978149 98.7503814697396 .0073165893693 .5690307617291 .1307525634888 .99725341797 87.16854858398 85.94940185547 84.42548370361 83.51112365723 82.29197692871 81.0728530883879 .8537063598678 .3297805786176 .5010681152374 .67236328125 72.2340774536170 .1005783081167 .3575134277364 .6144485473662 .17617034912 59.7378807067957 .6043891906756 .0804595947354 .5565414428753 .03261184692 51.5086898803749 .9847602844248 .4608306884846 .6321296691944 .80340957642 42.66992187540 .5364189147938 .0981407165535 .6598587036132 .91679000854 30.1737308502226 .8210906982423 .4684505462620 .1158199310316 .45840072632 $12.800970077518 .8387689590454 .87656211853 .9143553972244-2.74306607246$ $-6.095703125-8.83876895905-10.9722604752-12.1914100647-13.1057596207$ 
-14.0201196671 -14.3248996735 -14.0201196671 -13.7153301239-13.1057596207 $-11.8866195679-9.44833946228-7.01005792618-4.57177686691-3.04785108566$ -1.52392601967 -.609570324421 -9999 -9999 -9999.3047851026058 -9999-9999 .3047851026058.9143553972244 1.21914100647 1.523926019669 1.523926019669 1.5239260196691 .8287110328672 .4382810592652 .7430660724643 .352636098862 3.9622070789344 .5717768669134 .876562118533 .962207078934 .9143553972244 $1.828711032867 .6095703244209-.914355397224-2.43828105927-3.65742206573$ $-4.57177686691-5.18134689331-5.79091691971-6.095703125-6.095703125-6.095703125$ $-6.095703125-5.79091691971-5.18134689331-4.57177686691-3.96220707893$ $-3.35263609886-2.43828105927-1.21914100647-9999.91435539722442 .438281059265$ 4.2669920921335.790916919708 7.619627952576 9.44833946228 11.27705001831 12.8009700775114 .6296901702915 .8488302230817 .3727493286118 .59189033508 19.811029434220 .7253894805921 .334960937522 .2493095397923 .77323913574 25.6019496917728 .6497993469233 .2215805053738 .7077102661144 .49863052368 49.9847602844253 .9469718933156 .9948196411159 .1283111572360 .34745025635 61.2618103027361 .5666007995661 .5567245483461 .2618103027360 .65224075317 60.0426712036159 .1283111572358 .5187492370657 .6043891906756 .69002914429 56.0804595947355 .7756805419955 .7756805419956 .0804595947356 .38525009155 56.6900291442956 .9948196411157 .2995986938557 .909179687558 .21395874023 58.5187492370658 .8235282897959 .1283111572359 .1283111572359 .39311599731 59.4453048706159 .49692535459 .545616149959 .5893363952659 .98136901855 60.3474502563560 .3474502563560 .3474502563560 .6522407531760 .65224075317 60.6522407531760 .9570198059160 .9570198059160 .9570198059161 .26181030273 61.2618103027361 .2618103027361 .5666007995661 .5666007995661 .56660079956 61.8713798522961 .8713798522962 .1761703491262 .1761703491262 .17617034912 62.4809494018662 .4809494018662 .7857398986862 .7857398986862 .78573989868 63.0905189514263 .0905189514263 .3953094482463 .3953094482463 .39530944824 63.7000885009863 .7000885009864 .004882812564 .004882812564 .0048828125 64.6144485473665 .22400665283 -9999 -9999 -9999 -9999 -9999 -9999 -9999 -9999 -9999 -9999 -9999 -9999 -9999 -9999 -9999

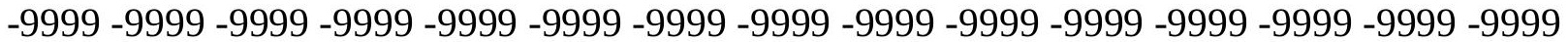

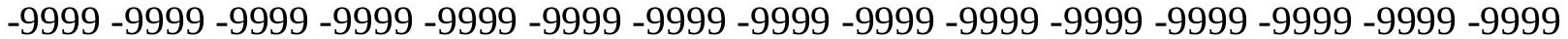

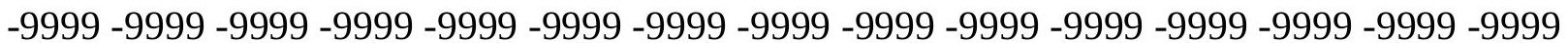

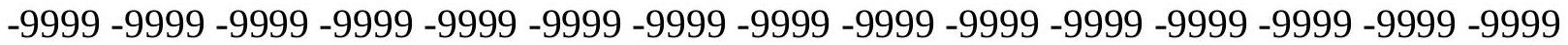

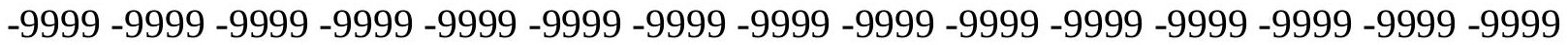

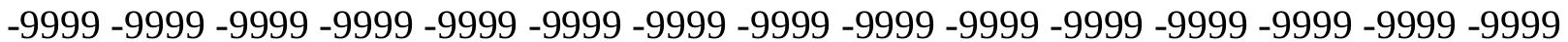

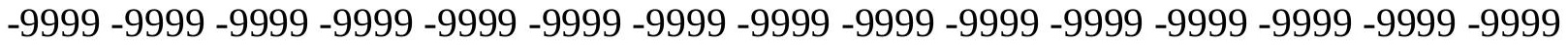
-9999 -9999 -9999 -9999 109.4179000854 104.8460998535 98.4455871582 92.04509735107 86.254188537682 .5967712402382 .2919769287182 .9015579223681 .07285308838 79.5489196777381 .3776321411183 .5111236572384 .4254837036185 .33984375 86.2541885376 88.0829010009891.4355392456195.0146484375 98.80431365967 105.4557037354109 .4179000854111 .8561019897112 .7705001831111 .8561019897 107.8938980103105 .4557037354109 .1130981445113 .9896011353115 .818397522 117.0374984741119 .1709976196122 .2188034058122 .810874939122 .736038208 122.5383987427122 .203918457121 .7370681763121 .1793899536120 .5720672607 119.9506912231119 .3409347534118 .7733078003118 .2842330933117 .9181289673 
117.7209091187117 .7409591675117 .9889144897118 .4299163818118 .9856491089 119.5371246338119 .9194335938119 .9746017456119 .5900192261118 .7488937378 117.6117782593116 .5243606567115 .9251861572116 .051902771116 .748664856 117.4526748657117 .5596618652116 .6912307739115 .3581237793113 .7604522705 111.768157959109 .7226028442107 .2844009399104 .8460998535102 .1029968262 99.6647262573296 .9216690063594 .1785964965891 .7403335571389 .91161346436 88.6924667358487 .1685485839885 .9494018554785 .0350494384883 .81591033936 82.5967712402381 .0728530883879 .2441329956177 .4154205322375 .28192901611 72.5388565063569 .7957916259866 .7479400634863 .3953094482460 .34745025635 58.5187492370656 .6900291442954 .8613204956153 .3373985290551 .81346893311 50.2895507812548 .765621185347 .2416992187545 .4129791259843 .27949142456 40.8412094116238 .4029312133835 .6598587036132 .6120109558129 .86894035339 26.2115192413322 .5541000366218 .8966808319115 .2392597198511 .58183002472 $7.6196279525763 .352636098862-.304785102606-4.57177686691-8.22919845581$ $-11.5818300247-14.0201196671-15.8488302231-17.0679702759-17.6775398254$ $-17.9823207855-17.6775398254-17.3727493286-16.4584007263-14.9344701767$ $-12.4961900711-9.75312423706-7.3148431778-4.87656211853-3.04785108566$ $-1.52392601967-.914355397224-.914355397224-.914355397224-1.21914100647$ $-1.21914100647-914355397224-.304785102606 .3047851026058 .9143553972244$ 1.219141006471 .5239260196691 .8287110328672 .4382810592653 .352636098862 4.5717768669135 .7909169197086 .7052731513987 .6196279525768 .229198455811 9.14355373382611 .277050018315 .7909169197082 .133496046066 -9999 -2.13349604607 $-3.65742206573-4.87656211853-5.48613214493-6.095703125-6.40048694611$ $-6.7052731514-6.40048694611-6.40048694611-6.095703125-5.48613214493$ $-4.87656211853-4.26699209213-3.65742206573-2.74306607246-1.52392601967$ -.304785102606.6095703244209 2.133496046066 3.657422065735 5.181346893311 6.7052731513988 .22919845581110 .0579099655211 .5818300247213 .10575962067 14.3248996734615 .8488302230817 .0679702758817 .9823207855219 .20145988464 20.1158199310321 .334960937522 .8588790893624 .9923801422128 .34502029419 32.9167900085439 .0125007629445 .717769622851 .5086898803755 .47089004517 58.2139587402359 .7378807067960 .9570198059161 .0408363342361 .00393295288 60.8851432800360 .7174453735460 .3474502563559 .7378807067958 .82352828979 58.2139587402357 .2995986938556 .3852500915555 .7756805419955 .47089004517 55.4708900451755 .7756805419956 .0804595947356 .3852500915556 .99481964111 57.2995986938557 .6043891906758 .2139587402358 .5187492370658 .82352828979 58.8235282897959 .1283111572359 .252098083559 .3145523071359 .37355041504 59.4272003173859 .4739265441959 .8966331481959 .6951560974160 .04267120361 60.3474502563560 .3474502563560 .3474502563560 .6522407531760 .65224075317 60.6522407531760 .9570198059160 .9570198059160 .9570198059161 .26181030273 61.2618103027361 .2618103027361 .5666007995661 .5666007995661 .56660079956 61.8713798522961 .8713798522961 .8713798522962 .1761703491262 .17617034912 62.4809494018662 .4809494018662 .7857398986862 .7857398986862 .78573989868 63.0905189514263 .0905189514263 .0905189514263 .3953094482463 .39530944824 63.7000885009863 .7000885009863 .7000885009864 .004882812564 .61444854736 65.22400665283 -9999 -9999 -9999 -9999 -9999 -9999 -9999 -9999 -9999 -9999 -9999 -9999 $-9999-9999$ 
-9999 -9999 -9999 -9999 -9999 -9999 -9999 -9999 -9999 -9999 -9999 -9999 -9999 -9999 -9999 -9999 -9999 -9999 -9999 -9999 -9999 -9999 -9999 -9999 -9999 -9999 -9999 -9999 -9999 -9999 -9999 -9999 -9999 -9999 -9999 -9999 -9999 -9999 -9999 -9999 -9999 -9999 -9999 -9999 -9999 -9999 -9999 -9999 -9999 -9999 -9999 -9999 -9999 -9999 -9999 -9999 -9999 -9999 -9999 -9999 -9999 -9999 -9999 -9999 -9999 -9999 -9999 -9999 -9999 -9999 -9999 -9999-9999 -9999 -9999 -9999 -9999 -9999 -9999 -9999 -9999 -9999 -9999 -9999 -9999 -9999 -9999 -9999 -9999 -9999

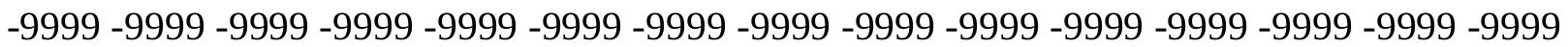
-9999 -9999 -9999-9999-9999 106.0652008057 96.00731658936 87.47332763672 82.2919769287181 .6824111938581 .9871978759881 .9871978759881 .37763214111 81.0728530883881 .0728530883881 .6824111938582 .5967712402383 .2063369751 83.8159103393684 .7302627563586 .254188537689 .302040100192 .3498916626 96.0073165893699 .35994720459101 .1886978149101 .4934005737100 .5791015625 97.8360290527396 .3121032714898 .75038146973102 .4077987671104 .5412979126 106.6747970581108 .8082962036111 .8561019897116 .1231002808120 .3900985718 123.43800354124 .6086883545124 .2345962524123 .7565307617123 .249458313 122.7462692261122 .2648544312121 .8078231812121 .3990707397121 .0740737915 120.8847427368120 .8795776367121 .0664215088121 .3855056763121 .7411880493 122.0112991333122 .0774841309121 .8507614136121 .2977294922120 .4614334106 119.4868087769118 .596786499118 .0330963135117 .8771057129118 .0177993774 118.1460800171117 .8761291504117 .1517333984116 .0336303711114 .7665405273 113.4809265137111 .8042297363109 .9786148071108 .1986999512105 .7603988647 103.0174026489100 .274299621697 .5312423706195 .0929565429792 .95947265625 91.4355392456190 .2164001464888 .9972534179787 .7781066894586 .86376190186 85.6446228027384 .1206970214882 .5967712402380 .7680587768678 .32978057861 75.8914871215872 .8436431884869 .4910125732466 .1383666992262 .78573989868 60.0426712036157 .909179687556 .0804595947354 .2517509460452 .72782897949 51.2038993835449 .6799812316948 .1560516357446 .3273391723644 .19384002686 41.7555618286139 .0125007629435 .9646492004432 .6120109558129 .25937080383 25.6019496917721 .9445304870618 .28710937514 .6296901702910 .66748046875 $6.7052731513982 .438281059265-1.21914100647-5.79091691971-10.0579099655$ -13.7153301239-16.7631797791 -18.8966808319-20.115819931 -21.0301704407 -21.3349609375 -21.0301704407 -20.4206008911 - 19.5062503815 -17.6775398254 $-15.5440397263-12.4961900711-9.75312423706-6.7052731514-4.26699209213$ $-2.74306607246-2.13349604607-2.43828105927-3.04785108566-3.35263609886$ -3.35263609886 -2.74306607246 -2.13349604607-.914355397224.3047851026058 .6095703244209.9143553972244 1.5239260196692.743066072464 3.962207078934 5.4861321449287 .3148431777958 .8387689590459 .75312423706110 .05790996552 $10.6674804687510 .057909965526 .4004869461062 .743066072464-.304785102606$ $-2.43828105927-4.26699209213-5.48613214493-6.095703125-6.7052731514$ $-7.01005792618-7.3148431778-7.01005792618-6.7052731514-6.40048694611$ $-5.79091691971-5.18134689331-4.57177686691-3.65742206573-2.74306607246$ -1.82871103287 -.609570324421 3047851026058 1.523926019669 3.047851085663 4.5717768669135 .7909169197087 .3148431777958 .83876895904510 .36268997192 11.8866195678713 .1057596206714 .3248996734615 .5440397262616 .76317977905 17.9823207855219 .2014598846420 .7253894805922 .5541000366224 .99238014221 28.34502029419 32.6120109558139 .622070312546 .9369087219253 .33739852905 
56.6900291442959 .1283111572360 .3474502563560 .5640563964860 .49644088745 60.3301658630460 .1141548156759 .8839149475159 .6469841003459 .41633605957 58.5187492370657 .909179687556 .9948196411156 .0804595947355 .16611099243 55.4708900451755 .4708900451755 .7756805419956 .0804595947356 .69002914429 56.9948196411157 .2995986938557 .6043891906758 .2139587402358 .51874923706 58.5187492370658 .8235282897959 .059982299859 .1283111572359 .20379257202 59.2671813964859 .3230094909759 .3702812194859 .7304344177259 .54440689087 60.0426712036160 .0426712036160 .0426712036160 .3474502563560 .34745025635 60.3474502563560 .6522407531760 .6522407531760 .6522407531760 .65224075317 60.9570198059160 .9570198059160 .9570198059161 .2618103027361 .26181030273 61.2618103027361 .5666007995661 .5666007995661 .8713798522961 .87137985229 61.8713798522962 .1761703491262 .1761703491262 .4809494018662 .48094940186 62.4809494018662 .7857398986862 .7857398986863 .0905189514263 .09051895142 63.0905189514263 .3953094482463 .3953094482463 .3953094482463 .70008850098 64.004882812564 .61444854736 -9999 -9999 -9999 -9999 -9999 -9999 -9999 -9999 -9999 -9999 -9999-9999-9999-9999

-9999 -9999 -9999 -9999 -9999 -9999 -9999 -9999 -9999 -9999 -9999 -9999 -9999 -9999 -9999 -9999 -9999 -9999 -9999 -9999 -9999 -9999 -9999 -9999 -9999 -9999 -9999 -9999 -9999 -9999 -

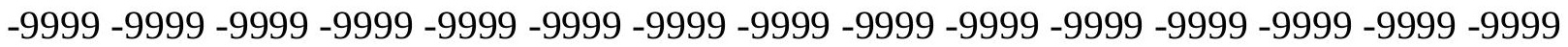

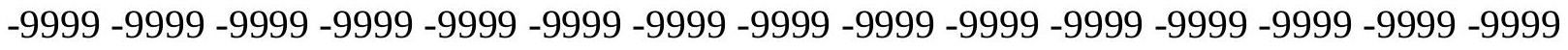

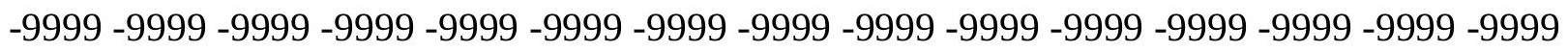
-9999 -9999 -9999 -9999 -9999 -9999 -9999 -9999 -9999 -9999 -9999 -9999 -9999 -9999 -9999 -9999 -9999 -9999 -9999 -9999 -9999 -9999 -9999 -9999 -9999 -9999 -9999 -9999 -9999 -9999 -9999 -9999 -9999 -9999 -9999 -9999 99.35994720459 87.77810668945 86.86376190186 85.94940185547 85.03504943848 84.73026275635 84.12069702148 83.81591033936 83.81591033936 83.81591033936 84.12069702148 84.42548370361 84.73026275635 85.6446228027387 .1685485839889 .6068267822392 .349891662695 .09295654297 96.9216690063597 .5312423706196 .6168823242295 .0929565429793 .56903076172 92.0450973510794 .4833908081194 .4833908081196 .6168823242299 .05516815186 101.4934005737104 .2365036011107 .2844009399110 .3321990967112 .4656982422 114.2944030762114 .5991973877115 .5136032104117 .647102356121 .6092987061 121.5093154907124 .1477661133124 .2147979736123 .9110107422123 .6903915405 123.6557235718123 .8128662109124 .0834655762124 .3266067505124 .4049377441 124.2272644043123 .7698364258123 .0749053955122 .2205734253121 .3188018799 120.4908981323119 .8317871094119 .3582229614118 .9864578247118 .5581512451 117.9232406616117 .0596389771116 .0129318237114 .8914413452113 .8205718994 112.6598968506111 .1444396973109 .754699707108 .1411514282106 .0652008057 103.3221969604100 .579101562598 .1408081054796 .0073165893694 .48339080811 92.9594726562591 .7403335571390 .8259735107489 .6068267822388 .69246673584 87.4733276367285 .9494018554784 .1206970214882 .2919769287179 .54891967773 76.5010681152372 .8436431884869 .1862335205165 .5288009643662 .48094940186 60.0426712036157 .6043891906755 .7756805419953 .9469718933152 .72782897949 51.5086898803749 .9847602844248 .1560516357446 .0225486755443 .58427047729 40.5364189147937 .1837806701733 .2215805053729 .2593708038325 .9067401886 22.2493095397918 .5918903350814 .6296901702910 .667480468756 .400486946106 $2.133496046066-1.82871103287-6.7052731514-11.2770500183-15.5440397263$ 
-18.8966808319 -21.3349609375 -22.8588790894 -23.7732391357 -24.0780296326 $-23.7732391357-23.1636695862-22.2493095398-20.4206008911-18.287109375$ -15.5440397263 -12.1914100647-9.14355373383 -6.095703125 -3.96220707893 $-4.26699209213-4.87656211853-5.79091691971-6.095703125-5.79091691971$ -5.18134689331 -4.57177686691 -3.35263609886 -1.82871103287 -.914355397224-9999 .6095703244209 1.828711032867 3.3526360988625.181346893311 7.314843177795 9.448339462289 .7531242370619 .448339462288 .8387689590457 .010057926178 $3.962207078934 .9143553972244-1.52392601967-3.65742206573-5.18134689331$ $-6.40048694611-7.3148431778-7.61962795258-7.92441320419-7.92441320419$ $-7.61962795258-7.3148431778-7.01005792618-6.40048694611-5.79091691971$ $-4.87656211853-3.96220707893-3.04785108566-2.13349604607-.914355397224-9999$ 1.219141006472 .4382810592653 .6574220657355 .1813468933116 .705273151398 7.9244132041939 .4483394622810 .6674804687512 .191410064713 .41055011749 14.6296901702916 .1536102294917 .3727493286118 .8966808319120 .42060089111 22.5541000366225 .2971591949528 .9545898437534 .1359291076740 .53641891479 47.54647827148 53.33739852905 57.29959869385 59.43310165405 59.94584655762 59.980331420959 .7941322326759 .5231018066459 .227401733458 .95150756836 58.7090301513758 .4975433349658 .3336181640657 .6043891906756 .99481964111 56.0804595947355 .7756805419955 .7756805419955 .7756805419956 .08045959473 56.3852500915556 .6900291442957 .2995986938557 .6043891906757 .9091796875 58.2139587402358 .5187492370658 .5187492370658 .8235282897958 .96102142334 59.0413627624559 .1139564514259 .1778411865259 .2324943542559 .2774887085 59.3124923706159 .36955642759 .7378807067960 .0426712036160 .04267120361 60.0426712036160 .0426712036160 .3474502563560 .3474502563560 .34745025635 60.3474502563560 .6522407531760 .6522407531760 .6522407531760 .95701980591 60.9570198059160 .9570198059161 .2618103027361 .2618103027361 .26181030273 61.5666007995661 .5666007995661 .5666007995661 .8713798522961 .87137985229 62.1761703491262 .1761703491262 .4809494018662 .4809494018662 .48094940186 62.7857398986862 .7857398986862 .7857398986863 .0905189514263 .09051895142 63.3953094482463 .3953094482463 .7000885009864 .004882812564 .61444854736 -9999 -9999 -9999 -9999 -9999 -9999 -9999 -9999 -9999 -9999 -9999 -9999 -9999

-9999 -9999 -9999 -9999 -9999 -9999 -9999 -9999 -9999 -9999 -9999 -9999 -9999 -9999 -9999

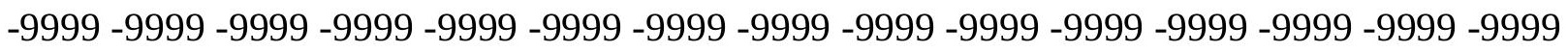
-9999 -9999 -9999 -9999 -9999 -9999 -9999 -9999 -9999 -9999 -9999 -9999 -9999 -9999 -9999 -9999 -9999 -9999 -9999 -9999 -9999 -9999 -9999 -9999 -9999 -9999 -9999 -9999 -9999 -9999

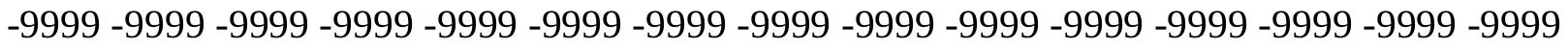

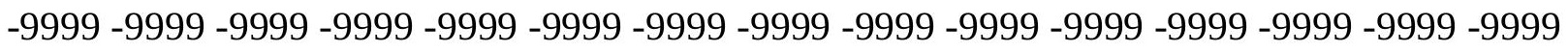

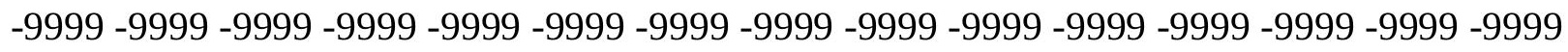
-9999 -9999 -9999 -9999 -9999 -9999 111.551399231102 .102996826296 .61688232422 92.349891662691 .1307525634890 .2164001464889 .302040100188 .69246673584 88.38768768311 88.08290100098 87.77810668945 87.77810668945 87.77810668945 88.38768768311 89.6068267822391.4355392456193.5690307617295.3977432251 96.6168823242296 .9216690063596 .3121032714895 .0929565429793 .56903076172 92.6546783447392 .9594726562593 .5690307617294 .4833908081195 .70252990723 96.9216690063598 .14080810547100 .2742996216102 .1029968262103 .6268997192 104.5412979126104 .8460998535104 .8460998535105 .7603988647106 .979598999 
108.8082962036112 .7705001831120 .0852966309126 .3224487305125 .5889358521 125.6424255371126 .1416244507126 .4740600586126 .7237243652126 .6983718872 126.3085021973125 .6244430542124 .7746353149123 .869392395122 .9805374146 122.1361999512121 .3273010254120 .5189819336119 .6566009521118 .6911239624 117.6138839722116 .4637756348115 .3124923706114 .2280654907113 .2295684814 112.2077407837 111.153137207 110.0866088867 108.8299865723 107.1597213745 105.3968429565103 .6268997192101 .188697814999 .0551681518697 .22646331787 95.7025299072394 .4833908081193 .5690307617292 .6546783447391 .74033355713 90.8259735107489 .302040100187 .7781066894586 .254188537683 .81591033936 80.7680587768677 .110626220772 .8436431884868 .8814392089865 .52880096436 62.4809494018660 .0426712036157 .909179687556 .0804595947354 .86132049561 53.9469718933152 .7278289794950 .8991203308148 .765621185346 .02254867554 42.66992187539 .0125007629435 .0502891540530 .7833003997826 .82109069824 23.1636695861819 .2014598846415 .5440397262611 .277050018317 .314843177795 $2.743066072464-1.52392601967-6.40048694611-11.5818300247-16.4584007263$ $-20.4206008911-23.1636695862-24.6875991821-25.6019496918-26.2115192413$ $-26.2115192413-25.9067401886-24.9923801422-23.4684505463-21.3349609375$ $-18.5918903351-15.5440397263-12.1914100647-8.83876895905-6.095703125$ $-7.3148431778-8.83876895905-9.44833946228-9.44833946228-8.83876895905$ $-7.92441320419-6.7052731514-6.095703125-4.26699209213-2.74306607246$ $-1.82871103287-.609570324421 .60957032442092 .1334960460663 .657422065735$ 5.4861321449286 .7052731513987 .3148431777957 .0100579261786 .095703125 3.657422065735 -9999 -1.52392601967 -3.65742206573 -5.486132144993 -6.7052731514 $-7.92441320419-8.53398323059-8.83876895905-8.83876895905-8.83876895905$ $-8.53398323059-8.22919845581-7.61962795258-7.01005792618-6.095703125$ $-5.18134689331-4.26699209213-3.35263609886-2.43828105927-1.21914100647$-9999 .91435539722442 .1334960460663 .3526360988624 .5717768669135 .790916919708 7.3148431777958 .5339832305919 .75312423706111 .2770500183112 .49619007111 14.0201196670515 .5440397262617 .0679702758818 .5918903350820 .42060089111 22.8588790893625 .906740188629 .8689403533935 .3550796508841 .75556182861 48.1560516357453 .6421813964857 .2995986938558 .8397789001559 .24519729614 59.1924476623558 .9252433776958 .5756225585958 .2327156066957 .93539047241 57.7109832763757 .5441665649457 .4395332336457 .3951911926356 .99481964111 56.3852500915556 .0804595947356 .0804595947356 .3852500915556 .38525009155 56.6900291442956 .9948196411157 .2995986938557 .6043891906757 .9091796875 58.2139587402358 .5187492370658 .6999053955158 .8020858764658 .89379119873 58.9743499755959 .0443801879959 .1041793823259 .1539955139259 .19380569458 59.2235412597759 .2116050720259 .7378807067959 .7378807067959 .73788070679 60.0426712036160 .0426712036160 .0426712036160 .0426712036160 .04267120361 60.3474502563560 .3474502563560 .3474502563560 .3474502563560 .65224075317 60.6522407531760 .6522407531760 .9570198059160 .9570198059160 .95701980591 61.2618103027361 .2618103027361 .5666007995661 .5666007995661 .56660079956 61.8713798522961 .8713798522962 .1761703491262 .1761703491262 .17617034912 62.4809494018662 .4809494018662 .7857398986862 .7857398986862 .78573989868 63.0905189514263 .0905189514263 .3953094482463 .7000885009864 .30966186523 -9999 -9999 -9999 -9999 -9999 -9999 -9999 -9999 -9999 -9999 -9999 -9999 -9999 
-9999 -9999 -9999 -9999 -9999 -9999 -9999 -9999 -9999 -9999 -9999 -9999 -9999 -9999 -9999 -9999 -9999 -9999 -9999 -9999 -9999 -9999 -9999 -9999 -9999 -9999 -9999 -9999 -9999 -9999 -9999 -9999 -9999 -9999 -9999 -9999 -9999 -9999 -9999 -9999 -9999 -9999 -9999 -9999 -9999 -9999 -9999 -9999 -9999 -9999 -9999 -9999 -9999 -9999 -9999 -9999 -9999 -9999 -9999 -9999 -9999 -9999 -9999 -9999 -9999 -9999 -9999 -9999 -9999 -9999 -9999 -9999-9999 -9999 -9999 -9999 -9999 -9999 -9999 -9999 -9999 -9999 -9999 -9999 -9999 -9999 -9999 -9999 -9999 -9999 -9999 -9999 -9999 -9999 -9999 -9999 -9999 -9999 -9999 -9999 -9999 -9999 -9999 -9999 -9999 -9999 -9999-9999-9999-9999-9999-9999 120.0852966309107 .8938980103103 .0174026489 99.0551681518697 .2264633178796 .0073165893695 .0929565429794 .48339080811 93.5690307617292 .9594726562592 .6546783447392 .349891662692 .65467834473 93.2642517089894 .4833908081195 .7025299072396 .9216690063597 .53124237061 97.83602905273 97.2264633178796.3121032714895.0929565429794.48339080811 94.4833908081194 .7881774902395 .397743225196 .3121032714897 .53124237061 98.445587158299 .3599472045999 .96952056885100 .2742996216102 .4077987671 113.684898376596 .6168823242296 .3121032714896 .0073165893693 .87381744385 93.87381744385101 .4934005737110 .0273971558113 .6848983765117 .0374984741 123.7427978516125 .1948318481128 .8883666992128 .8346862793128 .208190918 127.274230957126 .2532348633125 .3005523682124 .4321212769123 .5718383789 122.61378479121 .468132019120 .1024398804118 .5575942993116 .9430389404 115.3922729492114 .0237503052112 .8952102661111 .9764862061111 .1751251221 110.4084320068109 .5696792603108 .5022583008107 .2564926147105 .8428039551 104.4378967285103 .1238632202101 .493400573799 .6647262573298 .14080810547 97.2264633178796 .0073165893695 .397743225194 .4833908081193 .56903076172 92.6546783447391 .4355392456189 .9116134643688 .0829010009885 .33984375 81.0728530883876 .5010681152371 .9292907714868 .5766525268665 .83358764648 63.3953094482461 .2618103027359 .1283111572358 .5187492370657 .60438919067 56.3852500915554 .8613204956152 .4230384826749 .3751907348645 .7177696228 41.7555618286137 .4885711669933 .2215805053728 .9545898437524 .99238014221 21.0301704406717 .0679702758813 .105759620678 .8387689590454 .266992092133 -.304785102606 -5.18134689331 -10.6674804688 -15.8488302231 -21.0301704407 $-23.4684505463-25.2971591949-26.5163097382-27.7354507446-28.0402297974$ $-28.0402297974-27.4306602478-26.2115192413-24.3828105927-21.9445304871$ $-19.2014598846-16.1536102295-13.7153301239-12.4961900711-13.1057596207$ -14.0201196671 -14.0201196671 -13.1057596207-11.5818300247-10.0579099655 -8.53398323059 -7.3148431778 -5.79091691971 -4.57177686691 -3.65742206573 $-2.43828105927-1.21914100647-99991.219141006472 .4382810592653 .047851085663$ $3.3526360988623 .6574220657353 .0478510856631 .523926019669-1.21914100647$ -3.96220707893 -6.095703125 -7.61962795258 -8.83876895905 -9.75312423706 -10.0579099655 -10.3626899719-10.3626899719-10.0579099655 -9.44833946228 $-8.83876895905-8.22919845581-7.3148431778-6.7052731514-5.48613214493$ $-4.57177686691-3.65742206573-2.43828105927-1.52392601967-.304785102606$ .30478510260581 .5239260196692 .7430660724643 .9622070789345 .181346893311 6.7052731513987 .9244132041939 .14355373382610 .6674804687512 .1914100647 13.715330123915 .2392597198517 .0679702758818 .8966808319121 .03017044067 23.4684505462626 .5163097381630 .7833003997836 .2694282531742 .669921875 48.765621185353 .9469718933156 .8555145263758 .0277786254958 .33684921265 
58.2097778320357 .88476562557 .5071487426857 .1511955261256 .86751937866 56.666854858456 .5517921447856 .5208892822356 .5682754516656 .67878723145 56.6900291442956 .6900291442956 .6900291442956 .6900291442956 .99481964111 57.2995986938557 .6043891906757 .6043891906757 .909179687558 .21395874023 58.4463005065958 .5187492370658 .6658096313558 .7676086425858 .85600662231 58.9298171997158 .9915199279859 .0427894592359 .0844268798859 .11643981934 59.1388664245659 .0538711547959 .4331016540559 .7378807067959 .73788070679 59.7378807067959 .7378807067959 .7378807067959 .7378807067960 .04267120361 60.0426712036160 .0426712036160 .0426712036160 .3474502563560 .34745025635 60.3474502563560 .6522407531760 .6522407531760 .6522407531760 .95701980591 60.9570198059160 .9570198059161 .2618103027361 .2618103027361 .56660079956 61.5666007995661 .5666007995661 .8713798522961 .8713798522962 .17617034912 62.1761703491262 .1761703491262 .4809494018662 .4809494018662 .78573989868 62.7857398986862 .7857398986863 .0905189514263 .0905189514263 .70008850098 64.30966186523 -9999 -9999 -9999 -9999 -9999 -9999 -9999 -9999 -9999 -9999 -9999 -9999 -9999 -9999 -9999 -9999 -9999 -9999 -9999 -9999 -9999 -9999 -9999 -9999 -9999 - -9999 - -999 -9999 -9999 -9999 -9999 -9999 -9999 -9999 -9999 -9999 -9999 -9999 -9999 -9999 -9999 -9999 -9999 -9999 -9999 -9999 -9999 -9999 -9999 -9999 -9999 -9999 -9999 -9999 -9999 -9999 -9999 -

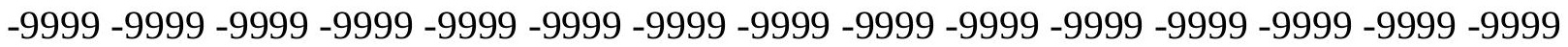

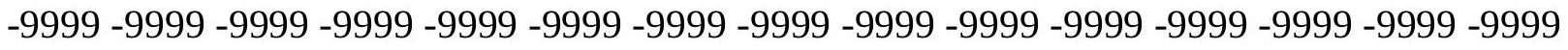

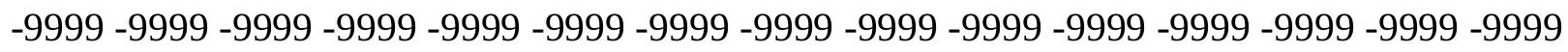

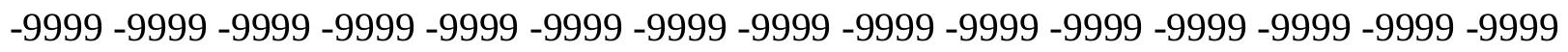
-9999 -9999 -9999 -9999 -9999 -9999 -9999 -9999 121.9140014648 111.8561019897 106.6747970581104 .5412979126103 .3221969604102 .1029968262100 .8839035034 99.9695205688598.7503814697398.1408081054795.8553085327196.19640350342 97.0760192871198.1408081054798.7503814697399.3599472045999.66472625732 99.6647262573299 .0551681518698 .445587158297 .5312423706196 .92166900635 96.92166900635 97.2264633178797.5312423706198.1408081054799.05516815186 99.66472625732100 .2742996216100 .8839035034101 .1886978149101 .1886978149 99.35994720459 96.9216690063596.3121032714893.2642517089891.13075256348 88.9972534179794 .17859649658114 .9039993286101 .7982025146105 .1509017944 110.6370010376117 .342300415124 .9618988037130 .6582641602129 .7418212891 128.1457214355127 .3798751831126 .4499740601125 .6945114136124 .8929901123 123.8348846436122 .3567123413120 .4422531128118 .2196884155115 .9446258545 113.8765563965112 .2143478394111 .0214385986110 .2252197266109 .6765518188 109.2057952881 108.6586151123107.9344863892 107.0293045044 105.9861297607 104.8924331665103 .8229904175102 .7777938843101 .664352417100 .2742996216 99.3599472045998.445587158297.5312423706196.9216690063596.31210327148 95.397743225194 .4833908081193 .2642517089891 .7403335571389 .91161346436 84.7302627563579 .5489196777375 .2819290161171 .9292907714869 .79579162598 67.9670867919966 .1383666992264 .6144485473663 .7000885009862 .78573989868 61.2618103027359 .4331016540556 .6900291442953 .6421813964849 .67998123169 45.4129791259840 .8412094116236 .2694282531731 .6976509094227 .4306602478 23.4684505462619 .5062503814715 .5440397262611 .277050018317 .010057926178 $2.133496046066-2.74306607246-8.22919845581-13.4105501175-18.287109375$ -21.6397399902 -24.3828105927 -26.5163097382 -28.3450202942 -29.5641593933 
-30.1737308502 -29.5641593933 -29.2593708038 -27.7354507446 -25.6019496918 $-23.1636695862-20.7253894806-18.8966808319-18.5918903351-19.2014598846$ $-19.8110294342-18.5918903351-16.4584007263-14.0201196671-11.5818300247$ $-9.44833946228-7.92441320419-6.7052731514-5.79091691971-5.48613214493$ $-4.87656211853-3.65742206573-2.43828105927-1.21914100647-.609570324421$ -.304785102606 -.914355397224 -9999 -9999-.304785102606 -3.657422206573 -6.7052731514 $-8.83876895905-10.6674804688-11.5818300247-11.8866195679-12.1914100647$ $-11.8866195679-11.5818300247-10.9722604752-10.3626899719-9.75312423706$ $-8.83876895905-7.92441320419-7.01005792618-6.095703125-4.87656211853$ $-3.96220707893-2.74306607246-1.82871103287-.609570324421 .3047851026058$ 1.219141006472 .4382810592653 .6574220657354 .876562118536 .095703125 7.3148431777958 .83876895904510 .3626899719211 .8866195678713 .41055011749 15.2392597198517 .0679702758819 .2014598846421 .6397399902324 .38281059265 27.430660247831 .3928699493437 .1837806701743 .2794914245648 .82902526855 53.3689308166556 .2550392150957 .0426788330157 .2374763488857 .05920028687 56.7133407592856 .3345260620156 .0022163391155 .7454757690455 .58434295654 55.529708862355 .5854492187555 .7471542358455 .9955673217856 .29467010498 56.6027259826756 .8856582641657 .1331291198757 .3586158752457 .58498382568 57.8171195983958 .0416793823258 .2139587402358 .3971672058158 .50392150879 58.5187492370658 .6787033081158 .7657012939558 .8235282897958 .90093612671 58.9504890441958 .9911613464459 .022037506159 .0433044433659 .05591201782 58.9535713195859 .4331016540559 .4331016540559 .4331016540559 .43310165405 59.4331016540559 .7378807067959 .7378807067959 .7378807067959 .73788070679 59.7378807067960 .0426712036160 .0426712036160 .0426712036160 .04267120361 60.3474502563560 .3474502563560 .3474502563560 .6522407531760 .65224075317 60.9570198059160 .9570198059160 .9570198059161 .2618103027361 .26181030273 61.5666007995661 .5666007995661 .5666007995661 .8713798522961 .87137985229 62.1761703491262 .1761703491262 .1761703491262 .4809494018662 .48094940186 62.7857398986862 .7857398986863 .0905189514263 .0905189514263 .70008850098 64.17626953125 -9999 -9999 -9999 -9999 -9999 -9999 -9999 -9999 -9999 -9999 -9999

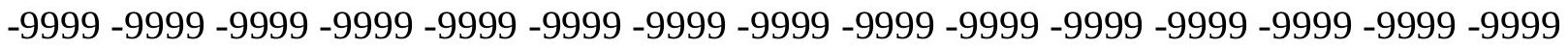

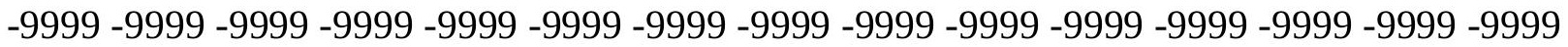

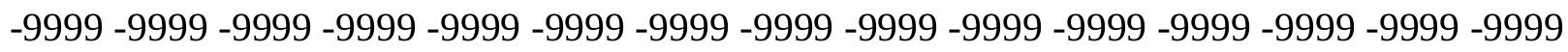

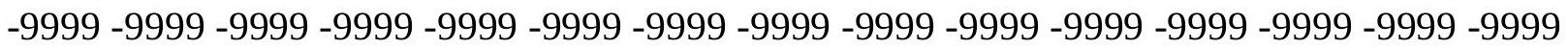

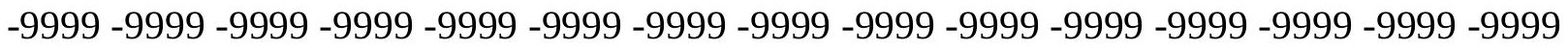

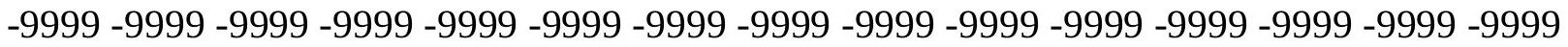

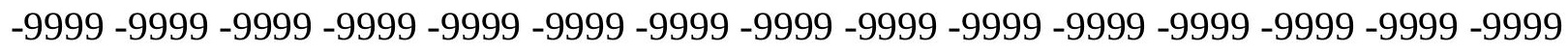
-9999 -9999 -9999 -9999 -9999 -9999 -9999 -9999 -9999 128.0097961426 120.6949005127 113.9896011353110 .0273971558108 .8082962036107 .8938980103106 .3700027466 104.8460998535103 .6268997192102 .71260070899 .78901672363100 .8907928467 102.1029968262102 .4077987671102 .4077987671102 .4077987671102 .1029968262 101.7982025146101 .1886978149100 .5791015625100 .274299621699 .96952056885 100.2742996216100 .5791015625100 .8839035034101 .4934005737101 .7982025146 102.1029968262102 .4077987671102 .4077987671101 .7982025146100 .5791015625 98.7503814697396 .9216690063595 .397743225194 .1785964965895 .09295654297 98.14080810547100 .8839035034102 .712600708103 .9317016602105 .1509017944 
123.43800354111 .24659729114 .9039993286114 .2944030762114 .5991973877 119.7806015015125 .5715026855126 .7412414551126 .2354660034125 .1568069458 123.3588562012120 .816078186117 .7758255005114 .6645507812111 .951385498 109.9534912109108 .7329559326108 .139793396107 .9170150757107 .8054504395 107.6144104004107 .244758606106 .6727676392105 .9595336914105 .1561355591 104.3160400391103 .4667053223102 .6216964722101 .7982254028101 .0186157227 100.274299621699 .6647262573299 .0551681518698 .445587158297 .83602905273 96.9216690063596 .0073165893694 .1785964965891 .7403335571387 .16854858398 82.2919769287178 .0249862670975 .8914871215874 .3675689697373 .14842987061 71.9292907714871 .014930725169 .7957916259868 .5766525268667 .05272674561 64.9192428588961 .8713798522958 .2139587402354 .2517509460449 .67998123169 44.8034095764239 .9268493652335 .0502891540530 .4785099029526 .82109069824 22.8588790893618 .8966808319114 .934470176710 .362689971925 .790916919708 .6095703244209-4.26699209213 -9.75312423706 -14.3248996735 -18.5918903351 -22.2493095398 -25.2971591949 -28.0402297974 -30.478509903 -32.0024414062 -32.9167900085 -32.6120109558 -31.0880794525 -28.9545898438 -26.5163097382 $-24.3828105927-23.4684505463-23.4684505463-24.3828105927-25.2971591949$ -22.2493095398 -18.8966808319-15.5440397263 -12.4961900711-10.0579099655 $-7.92441320419-7.01005792618-6.40048694611-6.7052731514-7.01005792618$ $-5.79091691971-4.87656211853-3.96220707893-3.65742206573-3.65742206573$ $-3.96220707893-3.65742206573-3.65742206573-4.87656211853-7.3148431778$ -10.0579099655 -12.1914100647 -13.7153301239 -14.3248996735 -14.3248996735 $-14.0201196671-13.7153301239-13.1057596207-12.4961900711-11.5818300247$ -10.6674804688 -9.75312423706 -8.53398323059 -7.61962795258-6.40048694611 $-5.18134689331-4.26699209213-3.04785108566-1.82871103287-.914355397224-9999$ 1.219141006472 .1334960460663 .3526360988624 .5717768669135 .790916919708 7.0100579261788 .53398323059110 .0579099655211 .5818300247213 .41055011749 15.5440397262617 .6775398254420 .1158199310322 .5541000366225 .60194969177 28.9545898437533 .2215805053738 .4029312133843 .8030624389648 .79477310181 52.8446311950755 .1812477111855 .9028434753455 .9911727905355 .78067779541 55.4489288330155 .1138763427754 .8197402954154 .6032562255954 .49039077759 54.5030937194854 .6585655212454 .9626884460455 .3978157043555 .91032028198 56.4236106872656 .8681945800857 .2122421264657 .4728088378957 .70247650146 57.94489669858 .218330383358 .4667472839458 .5187492370658 .51874923706 58.6668319702158 .7203788757358 .7818832397558 .8235282897958 .88148117065 58.9195938110458 .9507904052758 .9661445617758 .972518920958 .97172927856 58.8715591430758 .4912414550859 .1283111572359 .4331016540559 .43310165405 59.4331016540559 .4331016540559 .4331016540559 .4331016540559 .73788070679 59.7378807067959 .7378807067959 .7378807067959 .7378807067960 .04267120361 60.0426712036160 .0426712036160 .3474502563560 .3474502563560 .34745025635 60.6522407531760 .6522407531760 .9570198059160 .9570198059160 .95701980591 61.2618103027361 .2618103027361 .5666007995661 .5666007995661 .87137985229 61.8713798522961 .8713798522962 .1761703491262 .1761703491262 .48094940186 62.4809494018662 .4809494018662 .7857398986862 .7857398986863 .39530944824 63.70008850098 -9999 -9999 -9999 -9999 -9999 -9999 -9999 -9999 -9999 -9999 -9999 -9999 -9999 -9999 -9999 -9999 -9999 -9999 -9999 -9999 -9999 -9999 -9999 -9999 -9999 -9999 
-9999 -9999 -9999 -9999 -9999 -9999 -9999 -9999 -9999 -9999 -9999 -9999 -9999 -9999 -9999 -9999 -9999 -9999 -9999 -9999 -9999 -9999 -9999 -9999 -9999 -9999 -9999 -9999 -9999 -9999

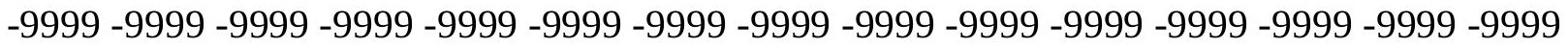
-9999 -9999 -9999 -9999 -9999 -9999 -9999 -9999 -9999 -9999 -9999 -9999 -9999 -9999 -9999 -9999 -9999 -9999 -9999 -9999 -9999 -9999 -9999 -9999 -9999 -9999 -9999-9999 -9999 -9999 -

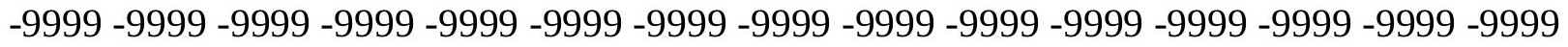
-9999 -9999 -9999 -9999 -9999 -9999 -9999 -9999 -9999 -9999 133.4958953857

126.7906036377121 .9140014648118 .2565994263114 .5991973877112 .4656982422 110.6370010376109 .1130981445107 .8938980103107 .2844009399104 .4266662598 105.5486755371106 .3700027466106 .0652008057105 .7603988647105 .4557037354 104.8460998535104 .5412979126103 .9317016602103 .6268997192103 .6268997192 103.6268997192103 .9317016602104 .2365036011104 .5412979126104 .5412979126 104.8460998535104 .8460998535104 .5412979126103 .6268997192102 .712600708 101.188697814999 .9695205688599 .0551681518699 .05516815186100 .5791015625 102.712600708104 .5412979126105 .7603988647106 .979598999109 .7226028442 114.2944030762110 .3321990967106 .3700027466103 .9317016602104 .5412979126 109.1130981445114 .5991973877118 .8662033081123 .1332015991126 .695098877 124.6129379272121 .3567504883117 .3011550903113 .1370010376109 .6652297974 107.3435516357 106.2015380859 105.9454727173106.1480331421 106.4511184692 106.6352310181106 .6006622314106 .3329467773105 .8856658936105 .3227996826 104.6830825806103 .9937438965103 .2872390747102 .5935897827101 .9491271973 101.4006347656100 .9479522705100 .547966003499 .9695205688599 .66472625732 98.7503814697397 .8360290527396 .0073165893693 .5690307617289 .91161346436 85.3398437581 .0728530883880 .4632720947380 .1584930419979 .24413299561 78.6345596313577 .7202072143676 .8058471679775 .2819290161173 .45321655273 70.7101516723667 .3575134277363 .7000885009859 .1283111572354 .55654144287 49.3751907348644 .1938400268639 .3172798156735 .0502891540531 .08807945251 27.1258792877223 .1636695861818 .8966808319114 .6296901702910 .05790996552 $5.181346893311-9999-4.87656211853-9.75312423706-14.6296901703-18.8966808319$ $-22.8588790894-26.8210906982-30.7833003998-33.8311500549-35.6598587036$ $-35.6598587036-34.1359291077-31.6976509094-28.9545898438-27.1258792877$ -26.5163097382 -26.5163097382 -26.8210906982 -26.2115192413 -23.7732391357 -20.115819931 -16.1536102295 -12.4961900711 -9.75312423706 -7.61962795258 $-6.7052731514-6.40048694611-7.01005792618-7.3148431778-7.3148431778-6.7052731514$ $-6.40048694611-6.40048694611-6.7052731514-7.01005792618-7.3148431778$ $-7.92441320419-9.44833946228-11.5818300247-14.0201196671-16.1536102295$ -17.0679702759 -17.0679702759-16.7631797791 -16.1536102295 -15.2392597198 $-14.6296901703-13.7153301239-12.4961900711-11.5818300247-10.3626899719$ $-9.14355373383-7.92441320419-6.7052731514-5.48613214493-4.26699209213$ -3.04785108566 -2.13349604607-.914355397224 -9999 .9143553972244 1.828711032867 3.0478510856634 .2669920921335 .4861321449286 .7052731513988 .229198455811 9.75312423706111 .5818300247213 .4105501174915 .8488302230818 .287109375 20.7253894805923 .7732391357426 .8210906982430 .4785099029534 .74551010132 39.622070312544 .4333724975648 .9346199035652 .3622360229553 .97021865845 54.5568161010754 .6234245300354 .4458160400454 .1871566772553 .91548919678 53.6775817871153 .5101013183653 .4472846984953 .5291709899953 .79581069946 
54.2749900817954 .9625854492255 .7945442199756 .6219558715857 .30824279785 57.7657279968358 .0080795288158 .1323547363358 .2431945800858 .47815704346 58.8235282897958 .7617835998558 .7437705993758 .7574157714858 .77954864502 58.8063125610458 .8235282897958 .8235282897958 .8235282897958 .82352828979 58.9173126220758 .8968811035258 .8806571960458 .7626533508358 .32829666138 59.1283111572359 .1283111572359 .1283111572359 .1283111572359 .12831115723 59.1283111572359 .4331016540559 .4331016540559 .4331016540559 .43310165405 59.4331016540559 .7378807067959 .7378807067959 .7378807067960 .04267120361 60.0426712036160 .0426712036160 .3474502563560 .3474502563560 .34745025635 60.6522407531760 .6522407531760 .9570198059160 .9570198059161 .26181030273 61.2618103027361 .2618103027361 .5666007995661 .5666007995661 .87137985229 61.8713798522962 .1761703491262 .1761703491262 .1761703491262 .48094940186 62.4809494018662 .7857398986862 .7857398986863 .25806045532 -2.3211877346 -9999 -9999 -9999 -9999 -9999 -9999 -9999-9999 -9999 -9999

-9999 -9999 -9999 -9999 -9999 -9999 -9999 -9999 -9999 -9999 -9999 -9999 -9999 -9999 -9999

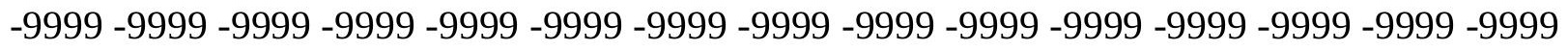
-9999 -9999 -9999 -9999 -9999 -9999 -9999 -9999 -9999 -9999 -9999 -9999 -9999 -9999 -9999 -9999 -9999 -9999 -9999 -9999 -9999 -9999 -9999 -9999 -9999 -9999 -9999 -9999 -9999 -9999 -

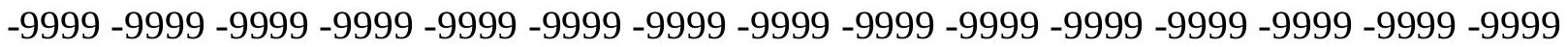

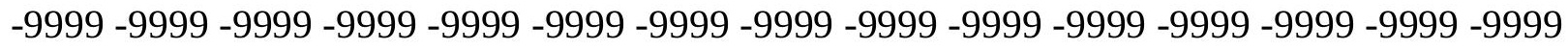

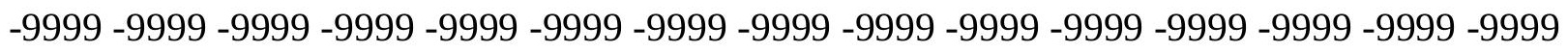
-9999 -9999 -9999 -9999 -9999 -9999 -9999 -9999 -9999-9999 -9999 -9999 133.8007049561 129.8385009766126 .1809997559122 .5235977173119 .1709976196116 .4279022217 114.2944030762112 .1608963013111 .24659729108 .7080001831109 .3835067749 109.5264816284109 .4179000854108 .8082962036108 .5035018921107 .8938980103 107.5891036987107 .5891036987107 .5891036987107 .5891036987107 .8938980103 107.8938980103108 .1986999512107 .8938980103107 .8938980103107 .5891036987 106.979598999106 .3700027466105 .4557037354104 .5412979126103 .6268997192 103.3221969604103 .9317016602105 .7603988647108 .1986999512108 .5035018921 109.4179000854110 .9418029785113 .075302124114 .2944030762112 .1608963013 108.8082962036106 .3700027466106 .0652008057106 .6747970581109 .1130981445 110.0273971558113 .6848983765117 .0374984741118 .8662033081118 .2565994263 116.4279022217108 .3726119995103 .548789978102 .2204818726102 .661781311 103.9774017334104 .6747436523105 .3912506104105 .907409668106 .1465835571 106.1073455811105 .8623657227105 .4708099365104 .9808654785104 .417388916 103.8236083984103 .239074707102 .6991348267102 .2323760986101 .8424682617 101.5017471313101 .1717758179100 .7845077515100 .274299621699 .35994720459 97.8360290527395 .7025299072392 .9594726562589 .9116134643687 .77810668945 87.1685485839886 .5589828491285 .6446228027385 .0350494384884 .12069702148 83.5111236572382 .2919769287179 .8537063598676 .8058471679773 .45321655273 69.1862335205164 .3096618652359 .4331016540553 .9469718933148 .7656211853 43.8890609741239 .3172798156735 .3550796508831 .6976509094227 .73545074463 23.7732391357419 .5062503814714 .934470176710 .362689971925 .486132144928 .3047851026058 -4.57177686691 -9.44833946228 -14.6296901703 -19.5062503815 $-24.6875991821-29.8689403534-35.0502891541-38.4029312134-38.4029312134$ -36.2694282532 -33.2215805054 -30.478509903 -28.9545898438 -28.3450202942 
-28.0402297974 -27.7354507446 -26.2115192413 -23.7732391357 -20.115819931 -16.1536102295 -12.1914100647 -8.83876895905 -6.7052731514 -5.79091691971 $-6.095703125-6.7052731514-7.61962795258-8.22919845581-8.53398323059$ -8.53398323059-8.83876895905 -9.44833946228 -10.0579099655 -10.6674804688 -11.8866195679 -13.4105501175 -15.2392597198 -17.6775398254-19.8110294342 -19.8110294342 -19.5062503815 -18.8966808319-17.9823207855 -17.0679702759 -15.8488302231 -14.9344701767-13.7153301239-12.4961900711-11.2770500183 $-9.75312423706-8.53398323059-7.3148431778-6.095703125-4.57177686691$ -3.35263609886 -2.13349604607 -.914355397224-9999 .9143553972244 1.828711032867 2.7430660724643 .9622070789345 .1813468933116 .4004869461067 .924413204193 9.4483394622811 .5818300247213 .715330123916 .1536102294918 .59189033508 21.6397399902324 .6875991821328 .3450202941932 .0024414062535 .96464920044 40.2316398620644 .8034095764249 .0704002380451 .8274803161652 .83856201172 53.1897392272953 .2575836181653 .1825561523453 .0409851074252 .85900115967 52.6908721923852 .5784416198752 .5646057128952 .7105865478553 .0958442688 53.7809982299854 .7934761047456 .0804595947356 .9948196411157 .9091796875 58.5187492370658 .8235282897959 .1283111572358 .8235282897958 .82352828979 58.8235282897958 .8235282897958 .8235282897958 .8235282897958 .82352828979 58.8235282897958 .8235282897958 .8235282897958 .8235282897958 .82352828979 58.8235282897958 .8052368164158 .7725219726658 .584682464658 .15029907227 58.8235282897958 .8235282897958 .8235282897959 .1283111572359 .12831115723 59.1283111572359 .1283111572359 .1283111572359 .1283111572359 .43310165405 59.4331016540559 .4331016540559 .4331016540559 .7378807067959 .73788070679 59.7378807067960 .0426712036160 .0426712036160 .0426712036160 .34745025635 60.3474502563560 .3474502563560 .6522407531760 .6522407531760 .95701980591 60.9570198059161 .2618103027361 .2618103027361 .5666007995661 .56660079956 61.5666007995661 .8713798522961 .8713798522962 .1761703491262 .17617034912 $62.4809494018662 .4809494018662 .7857398986862 .78573989868-1.5371222496-9999$ -9999 -9999 -9999 -9999 -9999 -9999 -9999 -9999 -9999 -9999 -9999 -9999 -9999 -9999 -9999 -9999 -9999 -9999 -9999 -9999 -9999 -9999 -9999 -9999 -9999 -9999 -9999 -9999 -9999 -9999 -9999 -9999 -9999 -9999 -9999 -9999 -9999 -9999 -9999 -9999 -9999 -9999 -9999 -9999 -9999 -9999 -9999 -9999 -9999 -9999 -9999 -9999 -9999 -9999 -

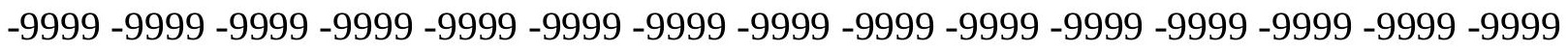
-9999 -9999 -9999 -9999 -9999 -9999 -9999 -9999 -9999 -9999 -9999 -9999 -9999 -9999 -9999 -9999 -9999 -9999 -9999 -9999 -9999 -9999 -9999 -9999 -9999 -9999 -9999 -9999 -9999 -9999 -9999 -9999 -9999 -9999 -9999 -9999 -9999 -9999 -9999 -9999 -9999 -9999 -9999 -9999 -9999

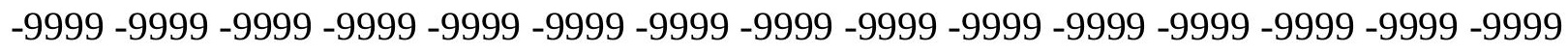
-9999 130.1432037354126.7906036377 124.0475006104121 .9140014648120 .0852966309 118.2565994263112 .2779159546112 .6034545898112 .5995330811112 .3809814453 112.1608963013111 .8561019897111 .551399231111 .551399231111 .551399231 111.8561019897111 .8561019897112 .1608963013112 .1608963013111 .8561019897 111.24659729110 .9418029785110 .3321990967109 .7226028442108 .8082962036 108.1986999512107 .8938980103107 .8938980103108 .5035018921109 .7226028442 110.9418029785111 .8561019897112 .4656982422113 .3800964355114 .5991973877 114.9039993286113 .9896011353112 .1608963013110 .6370010376110 .3321990967 110.6370010376111 .551399231112 .4656982422112 .7705001831111 .8561019897 
108.5035018921106 .979598999104 .236503601199 .3599472045996 .00731658936 97.5312423706199 .04792785645101 .5342254639103 .8365249634104 .8570022583 105.581817627105 .9829864502106 .082611084105 .9519882202105 .6631011963 105.2574996948104 .7741622925104 .2580108643103 .7470932007103 .2736587524 102.8586273193102 .5099334717102 .2108535767101 .9304885864101 .619178772 101.2419662476100 .579101562599 .3599472045997 .8360290527396 .00731658936 94.4833908081193 .8738174438594 .1785964965892 .6546783447391 .74033355713 90.8259735107490 .2164001464889 .6068267822388 .6924667358485 .94940185547 82.9015579223678 .9393463134874 .6723632812569 .4910125732464 .30966186523 58.5187492370653 .3373985290548 .1560516357443 .8890609741239 .92684936523 36.2694282531732 .6120109558128 .6497993469224 .6875991821320 .42060089111 $15.8488302230811 .277050018316 .095703125 .9143553972244-3.96220707893$ $-9.44833946228-15.2392597198-21.3349609375-27.4306602478-34.4407196045$ $-39.6220703125-39.6220703125-37.1837806702-33.8311500549-30.478509903$ -29.8689403534 -29.2593708038 -28.6497993469 -27.7354507446 -25.9067401886 $-23.4684505463-19.8110294342-15.8488302231-11.5818300247-7.92441320419$ $-5.48613214493-5.18134689331-5.79091691971-7.01005792618-8.22919845581$ $-9.14355373383-10.0579099655-10.6674804688-11.2770500183-11.8866195679$ -12.8009700775 -13.7153301239 -15.2392597198 -16.7631797791 -18.5918903351 $-20.4206008911-21.6397399902-21.9445304871-21.3349609375-20.4206008911$ -19.5062503815 -18.287109375 -17.0679702759-15.8488302231 -14.6296901703 $-13.4105501175-11.8866195679-10.3626899719-9.14355373383-7.61962795258$ $-6.40048694611-4.87656211853-3.65742206573-2.13349604607-.914355397224-9999$ .91435539722441 .5239260196692 .4382810592653 .6574220657354 .87656211853 6.0957031257 .6196279525769 .4483394622811 .5818300247213 .7153301239 16.4584007263219 .2014598846422 .2493095397925 .6019496917729 .25937080383 32.9167900085436 .8790016174340 .8412094116244 .8034095764249 .81523895264 51.6031913757351 .7293701171951 .9056816101152 .0937080383352 .19200515747 52.1874237060552 .1031379699752 .0137138366751 .9677810668952 .00910186768 52.2079391479552 .7078056335453 .6227760314954 .8613204956155 .47089004517 56.3852500915557 .6043891906758 .5187492370659 .1283111572359 .12831115723 59.1283111572358 .8235282897958 .8235282897958 .8235282897958 .82352828979 58.8235282897958 .8235282897958 .8235282897958 .8235282897958 .82352828979 58.8235282897958 .8235282897958 .7300109863358 .663360595758 .63647079468 58.3729438781757 .9468383789158 .8235282897958 .8235282897958 .82352828979 58.8235282897958 .8235282897958 .8235282897958 .8235282897958 .82352828979 59.1283111572359 .1283111572359 .1283111572359 .1283111572359 .43310165405 59.4331016540559 .4331016540559 .4331016540559 .7378807067959 .73788070679 60.0426712036160 .0426712036160 .0426712036160 .3474502563560 .34745025635 60.6522407531760 .6522407531760 .9570198059160 .9570198059160 .95701980591 61.2618103027361 .2618103027361 .5666007995661 .5666007995661 .87137985229 61.8713798522962 .1761703491262 .1761703491262 .4809494018662 .48094940186 62.480949401861 .507671236992 -9999 -9999 -9999 -9999 -9999 -9999 -9999 -9999 -9999 $-9999$

-9999 -9999 -9999 -9999 -9999 -9999 -9999 -9999 -9999 -9999 -9999 -9999 -9999 -9999 -9999

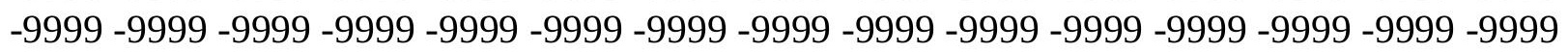


-9999 -9999 -9999 -9999 -9999 -9999 -9999 -9999 -9999 -9999 -9999 -9999 -9999 -9999 -9999 -9999 -9999 -9999 -9999 -9999 -9999 -9999 -9999 -9999 -9999 -9999 -9999 -9999 -9999 -9999

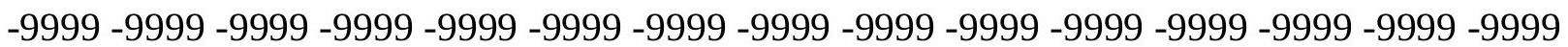
-9999 -9999 -9999 -9999 -9999 -9999 -9999 -9999 -9999 -9999 -9999 -9999 -9999 -9999 -9999 -9999 -9999 -9999 -9999 -9999 -9999 -9999 -9999 -9999 -9999 -9999 -9999 -9999 -9999 -9999 -9999 -9999 -9999 -9999 -9999 -9999 -9999 -9999 -9999 -9999 -9999 -9999 -9999 -9999 -9999 -9999 -9999 -9999 -9999 -9999 129.8385009766127 .7050018311125 .5715026855 123.43800354115 .6786727905115 .7497406006115 .7713394165115 .881187439 116.1231002808115 .5136032104115 .5136032104115 .818397522116 .1231002808 116.4279022217116 .1231002808115 .5136032104114 .9039993286114 .2944030762 113.6848983765113 .075302124112 .4656982422112 .1608963013111 .8561019897 111.8561019897112 .1608963013113 .075302124113 .6848983765114 .2944030762 114.9039993286115 .5136032104116 .1231002808116 .4279022217116 .1231002808 115.5136032104115 .2088012695115 .5136032104115 .818397522116 .7326965332 116.7326965332116 .1231002808114 .2944030762110 .6370010376105 .7603988647 99.9695205688595 .0929565429792 .6546783447393 .5690307617296 .61688232422 99.96952056885103 .3221969604104 .9045639038105 .7339706421106 .1744918823 106.2987976074106 .2018661499105 .9381790161105 .5571365356105 .1006317139 104.6177825928104 .1407165527103 .6977310181103 .3077011108102 .9780960083 102.7028656006102 .4605331421102 .2241744995101 .9770812988101 .7263031006 100.883903503499 .9695205688599 .0551681518698 .445587158298 .14080810547 98.1408081054797 .5312423706196 .6168823242298 .445587158295 .3977432251 94.7881774902393 .2642517089891 .1307525634888 .0829010009884 .42548370361 79.8537063598674 .6723632812568 .8814392089863 .0905189514257 .29959869385 52.4230384826748 .1560516357444 .1938400268640 .8412094116237 .48857116699 34.1359291076730 .1737308502225 .906740188621 .6397399902317 .06797027588 $12.19141006477 .3148431777951 .828711032867-3.65742206573-10.3626899719$ $-17.0679702759-24.3828105927-31.3928699493-36.2694282532-37.7933502197$ $-36.5742111206-34.4407196045-32.0024414062-30.7833003998-29.8689403534$ $-28.9545898438-27.4306602478-25.6019496918-22.8588790894-19.5062503815$ $-15.8488302231-11.8866195679-7.92441320419-4.57177686691-5.18134689331$ $-6.40048694611-7.61962795258-9.14355373383-10.3626899719-11.5818300247$ $-12.4961900711-13.4105501175-14.3248996735-15.2392597198-16.4584007263$ -17.9823207855 -19.2014598846 -20.7253894806 -22.2493095398 -22.8588790894 -23.1636695862 -22.5541000366 -21.6397399902 -20.7253894806 -19.5062503815 -18.287109375 -16.7631797791 -15.5440397263 -14.0201196671-12.4961900711 $-10.9722604752-9.44833946228-8.22919845581-6.7052731514-5.18134689331$ -3.65742206573 -2.43828105927-1.21914100647-9999.6095703244209 1.523926019669 2.4382810592653 .3526360988624 .5717768669135 .7909169197087 .314843177795 9.14355373382611 .2770500183113 .715330123916 .4584007263219 .50625038147 22.8588790893626 .5163097381629 .8689403533933 .5263595581137 .18378067017 40.8412094116248 .4608306884849 .2370414733950 .2895507812550 .6753578186 51.047428131151 .4054908752451 .6956596374551 .8287391662651 .83720779419 51.8271293640151 .8728446960452 .0065460205152 .2577285766652 .81182479858 53.3373985290553 .9469718933154 .5565414428755 .7756805419957 .29959869385 58.8235282897959 .1283111572359 .1283111572359 .1283111572358 .82352828979 
58.8235282897958 .5187492370658 .5187492370658 .5187492370658 .51874923706 58.5187492370658 .5187492370658 .5187492370658 .5187492370658 .51874923706 58.5187492370658 .4569549560558 .4767799377458 .1772117614757 .77972412109 58.5187492370658 .5187492370658 .5187492370658 .5187492370658 .51874923706 58.5187492370658 .8235282897958 .8235282897958 .8235282897958 .82352828979 58.8235282897959 .1283111572359 .1283111572359 .1283111572359 .12831115723 59.4331016540559 .4331016540559 .4331016540559 .7378807067959 .73788070679 60.0426712036160 .0426712036160 .3474502563560 .3474502563560 .34745025635 60.6522407531760 .6522407531760 .9570198059160 .9570198059161 .26181030273 61.2618103027361 .5666007995661 .5666007995661 .8713798522961 .87137985229 61.8713798522962 .1761703491262 .1761703491262 .4533195495612 .06027603149 -9999 -9999 -9999 -9999 -9999 -9999 -9999 -9999 -9999 -9999

-9999 -9999 -9999 -9999 -9999 -9999 -9999 -9999 -9999 -9999 -9999 -9999 -9999 -9999 -9999 -9999 -9999 -9999 -9999 -9999 -9999 -9999 -9999 -9999 -9999 -9999 -9999 -9999 -9999 -9999 -9999 -9999 -9999 -9999 -9999 -9999 -9999 -9999 -9999 -9999 -9999 -9999 -9999 -9999 -9999

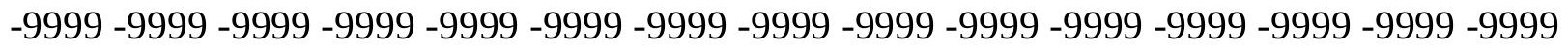
-9999 -9999 -9999 -9999 -9999 -9999 -9999 -9999 -9999 -9999 -9999 -9999 -9999 -9999 -9999 -9999 -9999 -9999 -9999 -9999 -9999 -9999 -9999 -9999 -9999 -9999 -9999 -9999 -9999 -9999 -

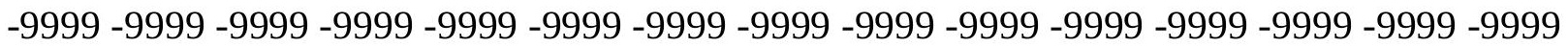

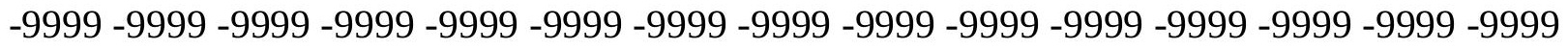
-9999 -9999-9999 -9999 -9999-9999-9999-9999-9999 130.4479980469 128.6192932129 119.2078475952119 .5089187622119 .7437286377119 .8459701538120 .3100738525 121.3044967651120 .9997024536120 .6949005127120 .0852966309119 .1709976196 118.2565994263117.9517974854 117.342300415 116.7326965332116.1231002808 115.818397522115 .5136032104115 .5136032104115 .818397522116 .1231002808 116.4279022217116 .7326965332117 .0374984741117 .342300415117 .9517974854 118.2565994263118 .5614013672118 .8662033081119 .4757995605120 .6949005127 121.6092987061122 .2188034058122 .2188034058120 .6949005127117 .9517974854 113.6848983765108 .1986999512102 .71260070898 .1408081054795 .3977432251 95.397743225196 .9216690063599 .35994720459101 .7982025146103 .9317016602 105.4557037354106 .3700027466106 .7636642456106 .6279144287106 .3243942261 105.9026947021105 .4245529175104 .9286727905104 .4476318359104 .0028305054 103.6125030518103 .2847213745103 .0195770264102 .8081665039102 .6395568848 102.5086364746102 .4077987671102 .1029968262101 .7982025146101 .4934005737 101.1886978149101 .1886978149101 .1886978149100 .8839035034100 .5791015625 99.9695205688599 .3599472045998 .7503814697397 .2264633178795 .3977432251 92.6546783447388 .9972534179784 .4254837036179 .2441329956173 .14842987061 66.7479400634860 .9570198059156 .0804595947351 .8134689331148 .46083068848 45.4129791259842 .3651313781739 .0125007629435 .3550796508831 .39286994934 27.430660247823 .1636695861818 .5918903350813 .71533012398 .229198455811 $2.133496046066-4.57177686691-11.8866195679-19.2014598846-26.2115192413$ -31.3928699493 -34.1359291077 -34.4407196045 -33.5263595581 -32.307220459 -31.0880794525 -29.8689403534 -28.6497993469 -27.1258792877 -25.2971591949 -22.8588790894 -19.8110294342 -16.1536102295 -12.4961900711-9.14355373383 $-7.01005792618-6.7052731514-7.61962795258-8.83876895905-10.3626899719$ $-11.8866195679-13.1057596207-14.3248996735-15.5440397263-16.4584007263$ 
-17.6775398254 -18.8966808319 -20.115819931 -21.3349609375 -22.5541000366 $-23.4684505463-24.0780296326-24.0780296326-23.4684505463-22.8588790894$ -21.6397399902 -20.4206008911 -19.2014598846 -17.6775398254-16.1536102295 $-14.6296901703-13.1057596207-11.5818300247-10.0579099655-8.53398323059$ $-7.01005792618-5.48613214493-3.96220707893-2.74306607246-1.52392601967$ -.304785102606 3047851026058 1.21914100647 2.133496046066 3.047851085663 4.2669920921335 .4861321449287 .0100579261789 .14355373382611 .27705001831 13.715330123916 .7631797790519 .811029434223 .1636695861826 .82109069824 30.4785099029533 .8311500549337 .4885711669940 .8412094116243 .88906097412 46.6321296691948 .765621185350 .2379417419450 .7960510253951 .49747848511 51.8134689331151 .5086898803751 .5086898803751 .5086898803751 .50868988037 51.5086898803751 .8134689331152 .1182594299352 .4230384826753 .03261184692 53.6421813964854 .8613204956156 .3852500915558 .5187492370658 .82352828979 58.5187492370658 .5187492370658 .5187492370658 .5187492370658 .51874923706 58.5187492370658 .5187492370658 .5187492370658 .5187492370658 .51874923706 58.2139587402358 .2139587402358 .2139587402358 .2139587402358 .21395874023 58.2139587402358 .2139587402357 .7499160766658 .2139587402358 .21395874023 58.2139587402358 .5187492370658 .5187492370658 .5187492370658 .51874923706 58.5187492370658 .5187492370658 .5187492370658 .8235282897958 .82352828979 58.8235282897958 .8235282897959 .1283111572359 .1283111572359 .12831115723 59.4331016540559 .4331016540559 .7378807067959 .7378807067959 .73788070679 60.0426712036160 .0426712036160 .3474502563560 .3474502563560 .65224075317 60.6522407531760 .9570198059160 .9570198059161 .2618103027361 .26181030273 61.5666007995661 .5666007995661 .5666007995661 .8713798522961 .87137985229 62.1761703491262 .1761703491240 .73601150513 -9999 -9999 -9999 -9999 -9999 -9999 -9999 -9999 -9999-9999

-9999 -9999 -9999 -9999 -9999 -9999 -9999 -9999 -9999 -9999 -9999 -9999 -9999 -9999 -9999

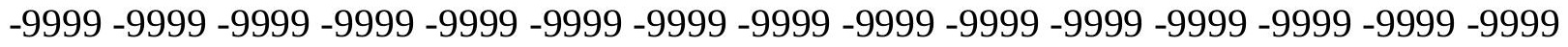
-9999 -9999 -9999 -9999 -9999 -9999 -9999 -9999 -9999 -9999 -9999 -9999 -9999 -9999 -9999 -9999 -9999 -9999 -9999 -9999 -9999 -9999 -9999 -9999 -9999 -9999 -9999 -9999 -9999 -9999 -9999 -9999 -9999 -9999 -9999 -9999 -9999 -9999 -9999 -9999 -9999 -9999 -9999 -9999 -9999

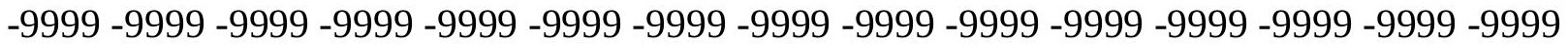

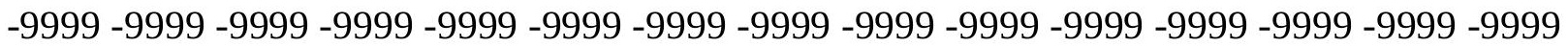
-9999 -9999 -9999 -9999 -9999 -9999 -9999 -9999 -9999 -9999 -9999 -9999 -9999 -9999 -9999 -9999 -9999 -9999 -9999 -9999 -9999 -9999 -9999 -9999 -9999 -9999 -9999 -9999 123.245552063123 .7543029785124 .3709106445124 .9178314209124 .9725799561 124.7131118774124 .4534912109124 .3523025513122 .2188034058121 .3044967651 121.3044967651120 .3900985718119 .7806015015119 .1709976196119 .1709976196 118.8662033081118 .8662033081118 .8662033081118 .8662033081118 .8662033081 119.1709976196119 .4757995605119 .7806015015120 .3900985718120 .9997024536 121.9140014648123 .43800354125 .2667007446127 .0953979492128 .3144989014 128.0097961426126 .1809997559122 .5235977173117 .647102356111 .8561019897 106.3700027466101 .798202514699 .0551681518698 .1408081054798 .4455871582 99.96952056885101 .7982025146103 .3221969604104 .5412979126105 .4557037354 106.0652008057106 .3700027466106 .3700027466106 .0652008057105 .5891265869 105.1073150635104 .5412979126104 .221282959103 .8119125366103 .4709320068 
103.2038497925103 .0122528076102 .8967590332102 .8611526489102 .9128875732 103.0174026489103 .0174026489103 .0174026489103 .0174026489103 .3221969604 103.6268997192103 .6268997192103 .3221969604103 .0174026489102 .712600708 101.7982025146100 .274299621698 .445587158296 .0073165893692 .95947265625 88.6924667358483 .206336975176 .8058471679770 .1005783081164 .0048828125 58.8235282897955 .1661109924352 .4230384826749 .9847602844246 .93690872192 43.5842704772940 .2316398620636 .8790016174333 .2215805053729 .25937080383 24.9923801422120 .1158199310314 .93447017678 .8387689590451 .828711032867 $-5.18134689331-12.8009700775-19.5062503815-25.2971591949-29.2593708038$ -30.7833003998 -31.3928699493 -31.3928699493 -30.1737308502 -29.2593708038 $-28.0402297974-26.8210906982-24.9923801422-22.8588790894-20.115819931$ -17.0679702759 -14.0201196671 -11.2770500183 -9.75312423706 -9.14355373383 -9.75312423706 -10.9722604752 -12.1914100647 -13.7153301239-14.9344701767 -16.1536102295 -17.3727493286 -18.5918903351 -19.8110294342 -21.0301704407 -21.9445304871 -23.1636695862 -23.7732391357 -24.6875991821 -24.9923801422 $-24.6875991821-24.3828105927-23.4684505463-22.2493095398-21.0301704407$ $-19.8110294342-18.287109375-16.7631797791-15.2392597198-13.7153301239$ $-11.8866195679-10.3626899719-8.83876895905-7.3148431778-5.79091691971$ $-4.26699209213-3.04785108566-1.82871103287-.609570324421-9999.9143553972244$ 1.8287110328672 .7430660724643 .6574220657355 .1813468933116 .705273151398 8.53398323059110 .9722604751613 .715330123916 .4584007263219 .8110294342 23.4684505462627 .1258792877230 .7833003997834 .1359291076737 .18378067017 40.2316398620643 .2794914245645 .717769622847 .5464782714848 .7656211853 49.6799812316950 .2895507812550 .2895507812550 .2895507812550 .28955078125 50.2895507812550 .2895507812550 .5943298339850 .5943298339850 .89912033081 51.5086898803751 .8134689331152 .7278289794953 .6421813964854 .55654144287 56.3852500915557 .2995986938557 .6043891906757 .6043891906757 .9091796875 57.909179687558 .2139587402358 .2139587402358 .2139587402358 .21395874023 58.2139587402358 .2139587402358 .2139587402358 .2139587402358 .21395874023 58.2139587402358 .2139587402358 .2139587402358 .2139587402357 .98076248169 58.0946960449258 .2139587402358 .2139587402358 .2139587402358 .21395874023 58.2139587402358 .2139587402358 .2139587402358 .5187492370658 .51874923706 58.5187492370658 .5187492370658 .5187492370658 .8235282897958 .82352828979 58.8235282897959 .1283111572359 .1283111572359 .1283111572359 .43310165405 59.4331016540559 .7378807067959 .7378807067960 .0426712036160 .04267120361 60.3474502563560 .3474502563560 .6522407531760 .6522407531760 .95701980591 60.9570198059160 .9570198059161 .2618103027361 .2618103027361 .56660079956 $61.5666007995661 .8713798522961 .8713798522962 .1761703491262 .36338806152-9999$ -9999 -9999 -9999 -9999 -9999 -9999-9999 -9999 -9999

-9999 -9999 -9999 -9999 -9999 -9999 -9999 -9999 -9999 -9999 -9999 -9999 -9999 -9999 -9999

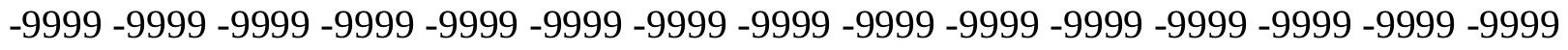

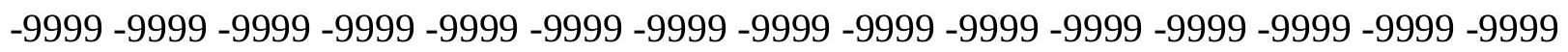

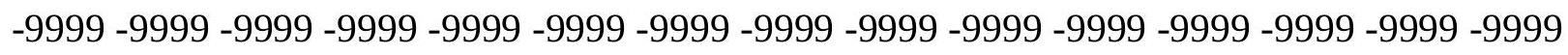
-9999 -9999 -9999 -9999 -9999 -9999 -9999 -9999 -9999 -9999 -9999 -9999 -9999 -9999 -9999 -

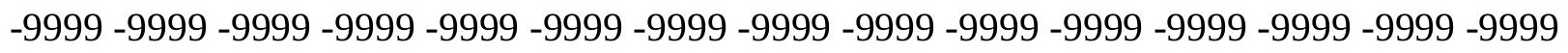

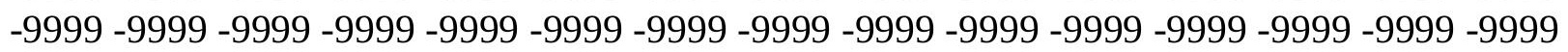


-9999 -9999 -9999 -9999 -9999 -9999 -9999 -9999 -9999 -9999 -9999 -9999 -9999 -9999 -9999 -9999 -9999 -9999 -9999 -9999 -9999 -9999 -9999 -9999 -9999 -9999 -9999 -9999 -9999 -9999 -9999 -9999 128.2670898438 128.1879730225 127.9538879395 127.3515853882 126.1888198853125 .2206726074124 .6692276001124 .0475006104123 .1332015991 124.3523025513122 .5235977173121 .9140014648121 .9140014648121 .9140014648 121.6092987061121 .3044967651121 .3044967651121 .6092987061121 .9140014648 122.5235977173122 .8283996582124 .3523025513126 .4858016968129 .533706665 131.4300079346132 .6717224121132 .9806518555132 .2767028809128 .0097961426 122.5235977173116 .4279022217110 .6370010376106 .0652008057103 .0174026489 101.4934005737101 .1886978149101 .7982025146102 .712600708103 .9317016602 104.8460998535105 .4557037354106 .0652008057106 .0652008057106 .0652008057 105.7603988647105 .1509017944104 .8460998535104 .2365036011103 .9317016602 103.6268997192103 .3221969604103 .2999267578103 .1123123169103 .028175354 103.0584945679103 .212928772103 .3221969604103 .6268997192103 .9317016602 104.4608154297104 .8460998535105 .1509017944105 .4557037354105 .4557037354 105.4557037354104 .8460998535103 .9317016602102 .712600708100 .8839035034 98.445587158295 .7025299072392 .0450973510785 .9494018554779 .24413299561 75.2819290161166 .7479400634860 .9570198059158 .2139587402356 .08045959473 54.2517509460450 .8991203308147 .8512611389244 .8034095764241 .45077896118 38.4029312133834 .7455101013231 .0880794525126 .8210906982421 .63973999023 $16.153610229499 .448339462282 .133496046066-5.18134689331-12.1914100647$ $-18.287109375-22.8588790894-25.6019496918-27.4306602478-28.0402297974$ $-28.0402297974-27.7354507446-27.1258792877-25.9067401886-24.6875991821$ $-22.8588790894-20.7253894806-18.287109375-15.8488302231-13.7153301239$ $-12.4961900711-11.8866195679-12.1914100647-13.1057596207-14.3248996735$ -15.5440397263 -16.7631797791 -17.9823207855 -19.2014598846 -20.4206008911 $-21.6397399902-22.5541000366-23.4684505463-24.3828105927-24.9923801422$ $-25.2971591949-25.6019496918-25.2971591949-24.6875991821-24.0780296326$ $-22.8588790894-21.6397399902-20.115819931-18.8966808319-17.0679702759$ $-15.5440397263-14.0201196671-12.4961900711-10.6674804688-9.14355373383$ -7.61962795258 -6.095703125 -4.57177686691 -3.35263609886 -2.13349604607 -.914355397224 -9999.6095703244209 1.523926019669 2.438281059265 3.352636098862 4.876562118536 .4004869461068 .22919845581110 .6674804687513 .41055011749 16.4584007263219 .811029434223 .4684505462627 .1258792877230 .78330039978 34.1359291076737 .1837806701739 .9268493652342 .3651313781744 .49863052368 46.3273391723647 .5464782714848 .4608306884848 .765621185349 .07040023804 49.0704002380449 .0704002380449 .0704002380449 .3751907348649 .37519073486 49.6799812316949 .9847602844250 .2895507812550 .8991203308151 .50868988037 52.4230384826753 .3373985290554 .5565414428755 .4708900451756 .08045959473 56.6900291442956 .9948196411157 .2995986938557 .6043891906757 .9091796875 57.909179687557 .909179687557 .909179687557 .909179687557 .909179687557 .9091796875 57.909179687557 .909179687557 .909179687557 .909179687557 .909179687557 .9091796875 57.8678207397557 .8314476013257 .909179687557 .909179687557 .9091796875 57.909179687557 .909179687558 .2139587402358 .2139587402358 .21395874023 58.2139587402358 .2139587402358 .5187492370658 .5187492370658 .51874923706 58.8235282897958 .8235282897958 .8235282897959 .1283111572359 .12831115723 
59.4331016540559 .4331016540559 .7378807067959 .7378807067960 .04267120361 60.0426712036160 .0426712036160 .3474502563560 .3474502563560 .65224075317 60.6522407531760 .9570198059160 .9570198059161 .2618103027361 .26181030273 61.5666007995661 .5666007995661 .8713798522961 .8713798522940 .4072303772 -9999 -9999 -9999-9999 -9999 -9999 -9999 -9999 -9999 -9999 -9999 -9999 -9999 -9999 -9999 -9999 -9999 -9999 -9999 -9999 -9999 -9999 -9999 -9999 -9999 -9999 -9999 -9999 -9999 -9999 -9999 -9999 -9999 -9999 -9999 -9999 -9999 -9999 -9999 -9999

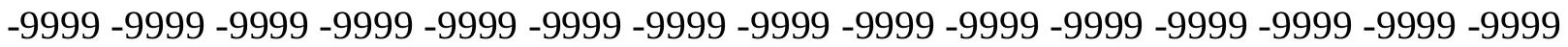

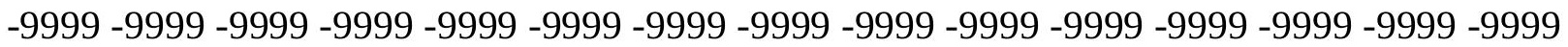
-9999 -9999 -9999 -9999 -9999 -9999 -9999 -9999 -9999 -9999 -9999 -9999 -9999 -9999 -9999 -

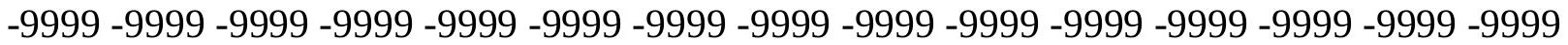
-9999 -9999 -9999 -9999 -9999 -9999 -9999 -9999 -9999 -9999 -9999 -9999 -9999 -9999 -9999 -9999 -9999 -9999 -9999 -9999 -9999 -9999 -9999 -9999 -9999 -9999 -9999 -9999 -9999 -9999 -9999 -9999 -9999 -9999 -9999 -9999 -9999 -9999 -9999 -9999 -9999 -9999 -9999 -9999 -9999 -9999 -9999 -9999 -9999 -9999 -9999 129.442199707 128.652130127 127.9923934937 127.4699401855127 .1120681763126 .9491424561126 .1483306885125 .4044723511 124.9618988037124 .7172851562124 .3742141724124 .0771560669123 .43800354 124.1657714844124 .5502243042124 .6570968628124 .3523025513125 .5715026855 128.3144989014131 .7047424316132 .9206542969133 .9708709717134 .4801635742 133.888458252131 .8904876709127 .4001998901120 .6949005127114 .9039993286 110.3321990967 107.2844009399 105.1509017944 104.2365036011 104.2365036011 104.5412979126105 .1509017944105 .7603988647106 .0652008057106 .0652008057 106.0652008057105 .7603988647105 .4557037354104 .8460998535104 .5412979126 103.9317016602103 .6268997192103 .3221969604103 .0174026489102 .984916687 103.0174026489103.0174026489103.0174026489103.3221969604 103.6268997192 103.9317016602104 .5412979126105 .1509017944105 .7603988647106 .3700027466 106.979598999107 .2844009399106 .979598999106 .6747970581105 .7603988647 104.2365036011102 .407798767199 .6647262573296 .6168823242292 .65467834473 87.1685485839884 .1206970214880 .4632720947375 .5867080688564 .30966186523 61.2618103027358 .8235282897956 .6900291442953 .9469718933151 .20389938354 48.4608306884845 .717769622842 .9747009277339 .9268493652336 .57421112061 32.9167900085428 .6497993469223 .4684505462617 .6775398254410 .36268997192 $2.743066072464-4.26699209213-10.6674804688-15.5440397263-19.5062503815$ -22.2493095398 -23.7732391357 -24.9923801422 -25.2971591949-25.2971591949 -24.9923801422 -24.0780296326 -22.8588790894 -21.3349609375 -19.5062503815 -17.6775398254 -16.1536102295 -15.2392597198 -14.6296901703 -14.9344701767 -15.5440397263 -16.4584007263 -17.6775398254 -18.5918903351 -19.8110294342 $-21.0301704407-22.2493095398-23.1636695862-24.0780296326-24.9923801422$ $-25.6019496918-25.9067401886-26.2115192413-26.2115192413-25.6019496918$ -24.9923801422 -24.3828105927 -23.1636695862 -21.9445304871 -20.4206008911 $-19.2014598846-17.3727493286-15.8488302231-14.3248996735-12.4961900711$ $-10.9722604752-9.44833946228-7.92441320419-6.40048694611-4.87656211853$ -3.35263609886 -2.13349604607 -1.21914100647-9999.3047851026058 1.21914100647 2.1334960460663 .0478510856634 .2669920921335 .7909169197087 .619627952576 10.0579099655212 .8009700775116 .1536102294919 .5062503814723 .46845054626 27.1258792877230 .4785099029533 .8311500549336 .8790016174339 .31727981567 
41.7555618286143 .5842704772945 .1082000732446 .0225486755446 .93690872192 47.2416992187547 .5464782714847 .8512611389247 .8512611389247 .85126113892 47.8512611389248 .1560516357448 .4608306884848 .765621185349 .07040023804 49.6799812316950 .2895507812551 .2038993835452 .1182594299353 .03261184692 53.9469718933154 .5565414428755 .4708900451756 .3852500915556 .69002914429 56.9948196411157 .2995986938557 .2995986938557 .6043891906757 .60438919067 57.6043891906757 .6043891906757 .6043891906757 .6043891906757 .60438919067 57.6043891906757 .6043891906757 .6043891906757 .6043891906757 .60438919067 57.5738525390657 .601699829157 .6043891906757 .6043891906757 .9091796875 57.909179687557 .909179687557 .909179687557 .909179687558 .21395874023 58.2139587402358 .2139587402358 .2139587402358 .5187492370658 .51874923706 58.5187492370658 .8235282897958 .8235282897959 .1283111572359 .12831115723 59.1283111572359 .4331016540559 .4331016540559 .7378807067959 .73788070679 60.0426712036160 .0426712036160 .3474502563560 .3474502563560 .65224075317 60.6522407531760 .9570198059160 .9570198059161 .2618103027361 .26181030273 61.5666007995661 .5666007995661 .8277320861811 .44708824158 -9999 -9999 -9999 -9999 -9999 -9999 -9999 -9999 -9999-9999

-9999 -9999 -9999 -9999 -9999 -9999 -9999 -9999 -9999 -9999 -9999 -9999 -9999 -9999 -9999 -9999 -9999 -9999 -9999 -9999 -9999 -9999 -9999 -9999 -9999 -9999 -9999 -9999 -9999 -9999 -9999 -9999 -9999 -9999 -9999 -9999 -9999 -9999 -9999 -9999 -9999 -9999 -9999 -9999 -9999 -9999 -9999 -9999 -9999 -9999 -9999 -9999 -9999 -9999 -9999 -9999 -9999 -9999 -9999 -9999 -9999 -9999 -9999 -9999 -9999 -9999 -9999 -9999 -9999 -9999 -9999 -9999 -9999 -9999 -9999 -9999 -9999 -9999 -9999 -9999 -9999 -9999 -9999 -9999 -9999 -9999 -9999 -9999 -9999 -9999 -9999 -9999 -9999 -9999 -9999 -9999 -9999 -9999 -9999 -9999 -9999 -9999 -9999 -9999 -9999 -9999 -9999 -9999 -9999 -9999 -9999 -9999 -9999 -9999 -9999 -9999 -9999 -9999 -9999 -9999 -9999 -9999 -9999 -9999 -9999 -9999 -9999 -9999 -9999 -9999 -9999 -9999 -9999 -9999 -9999 -9999 -9999 -9999 -9999 -9999 -9999 -9999 -9999 -9999-9999 132.9054870605 130.2970275879128 .3616638184127 .0803604126126 .2381057739125 .7838287354 125.5442657471125 .3220062256124 .7499008179124 .7974853516125 .0951080322 125.2122802734124 .6570968628125 .8762969971129 .2288970947133 .4958953857 137.2164916992134 .1267547607134 .2374420166133 .4530334473131 .6306915283 128.8357696533124 .3523025513118 .8662033081114 .2944030762111 .24659729 109.1130981445107 .8938980103107 .2844009399106 .979598999106 .979598999 106.979598999106 .979598999106 .6747970581106 .3700027466106 .0652008057 105.4557037354104 .8460998535104 .2365036011103 .6268997192103 .3221969604 103.0174026489102 .712600708102 .4077987671102 .4077987671102 .712600708 102.712600708103 .0174026489103 .6268997192104 .2365036011104 .8460998535 105.4557037354106 .3700027466106 .979598999107 .8938980103108 .1986999512 108.1986999512107 .8938980103106 .6747970581105 .1509017944102 .712600708 99.9695205688596 .6168823242292 .349891662687 .4733276367285 .33984375 82.5967712402378 .3297805786167 .0527267456163 .7000885009860 .95701980591 58.5187492370656 .3852500915553 .9469718933151 .8134689331149 .37519073486 46.9369087219244 .4986305236841 .7555618286138 .4029312133834 .74551010132 30.7833003997825 .906740188618 .5918903350810 .972260475163 .657422065735 $-2.43828105927-8.22919845581-12.8009700775-16.1536102295-18.8966808319$ $-21.0301704407-22.2493095398-23.1636695862-23.7732391357-23.4684505463$ 
-22.8588790894 -21.6397399902 -20.4206008911 -19.2014598846 -17.9823207855 -17.3727493286 -17.0679702759-17.0679702759-17.6775398254-18.5918903351 -19.5062503815 -20.4206008911 -21.6397399902 -22.5541000366 -23.7732391357 -24.3828105927 -25.2971591949-25.9067401886 -26.5163097382 -26.5163097382 -26.5163097382 -26.5163097382 -25.9067401886 -25.2971591949-24.3828105927 $-23.4684505463-21.9445304871-20.7253894806-19.2014598846-17.6775398254$ -16.1536102295 -14.3248996735 -12.8009700775 -10.9722604752 -9.44833946228 $-7.92441320419-6.40048694611-4.87656211853-3.65742206573-2.43828105927$ -1.21914100647 -.304785102606 .3047851026058 1.21914100647 1.828711032867 2.7430660724643 .9622070789345 .1813468933117 .0100579261789 .44833946228 12.191410064715 .5440397262619 .5062503814723 .1636695861827 .12587928772 30.4785099029533 .8311500549336 .5742111206138 .7077102661140 .84120941162 42.3651313781743 .8890609741244 .8034095764245 .4129791259846 .02254867554 46.0225486755446 .3273391723646 .3273391723646 .3273391723646 .63212966919 46.9369087219247 .2416992187547 .5464782714847 .8512611389248 .46083068848 49.0704002380449 .9847602844250 .8991203308151 .8134689331152 .72782897949 53.6421813964854 .5565414428755 .4708900451756 .0804595947356 .69002914429 56.6900291442956 .9948196411156 .9948196411156 .9948196411156 .99481964111 56.9948196411156 .9948196411157 .2995986938557 .2995986938557 .29959869385 57.2995986938557 .2995986938557 .2995986938557 .2995986938557 .29959869385 57.2995986938557 .4388847351157 .6043891906757 .6043891906757 .60438919067 57.6043891906757 .6043891906757 .909179687557 .909179687557 .9091796875 57.909179687558 .2139587402358 .2139587402358 .2139587402358 .51874923706 58.5187492370658 .8235282897958 .8235282897958 .8235282897959 .12831115723 59.1283111572359 .4331016540559 .4331016540559 .7378807067959 .73788070679 60.0426712036160 .0426712036160 .3474502563560 .3474502563560 .65224075317 60.6522407531760 .9570198059160 .9570198059161 .2618103027361 .26181030273 61.5666007995661 .74621582031 6250468492508 -9999 -9999-9999 -9999 -9999 -9999 -9999 -9999 -9999-9999

-9999 -9999 -9999 -9999 -9999 -9999 -9999 -9999 -9999 -9999 -9999 -9999 -9999 -9999 -9999 -9999 -9999 -9999 -9999 -9999 -9999 -9999 -9999 -9999 -9999 -9999 -9999 -9999 -9999 -9999 -9999 -9999 -9999 -9999 -9999 -9999 -9999 -9999 -9999 -9999 -9999 -9999 -9999 -9999 -9999 -

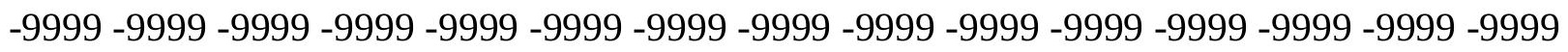
-9999 -9999 -9999 -9999 -9999 -9999 -9999 -9999 -9999 -9999 -9999 -9999 -9999 -9999 -9999 -9999 -9999 -9999 -9999 -9999 -9999 -9999 -9999 -9999 -9999 -9999 -9999 -9999 -9999 -9999 -

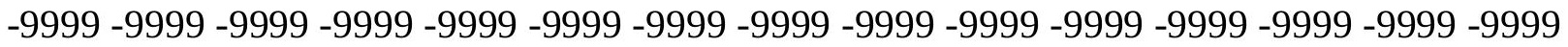

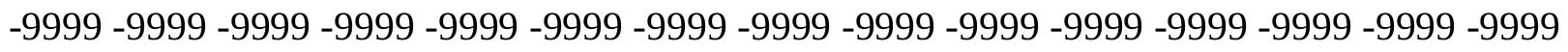

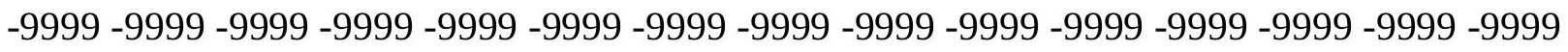
-9999 -9999 -9999 -9999 -9999 -9999 -9999 -9999 -9999 -9999 -9999 -9999 -9999 -9999 -9999 137.4580993652126 .6886825562126 .2448501587126 .0145950317125 .9193496704 126.1294021606126 .1809997559126 .7906036377125 .2667007446129 .533706665 133.4958953857137 .1533050537140 .0225982666139 .8087768555138 .4224395752 135.7822875977128 .7646331787125 .7342224121121 .9140014648117 .9517974854 114.9039993286112 .7705001831111 .551399231110 .6370010376109 .7226028442 109.4179000854108 .8082962036108 .1986999512107 .8938980103106 .979598999 106.3700027466 105.4557037354104.8460998535103.9317016602 103.3221969604 
103.0174026489102 .4077987671102 .4077987671102 .1029968262102 .1029968262 102.4077987671102 .4077987671102 .712600708103 .3221969604103 .9317016602 104.5412979126105 .4557037354106 .3700027466107 .2844009399108 .1986999512 108.8082962036109 .1130981445108 .5035018921107 .2844009399105 .4557037354 102.71260070899 .6647262573296 .0073165893691 .7403335571387 .16854858398 82.2919769287177 .4154205322372 .5388565063568 .5766525268665 .22400665283 62.4809494018660 .0426712036157 .909179687556 .0804595947354 .25175094604 52.4230384826750 .5943298339848 .4608306884846 .3273391723643 .58427047729 40.5364189147936 .5742111206131 .6976509094225 .6019496917718 .59189033508 $11.886619567875 .181346893311-.609570324421-5.48613214493-9.75312423706$ -13.4105501175 -16.7631797791 -19.2014598846 -21.0301704407 -21.9445304871 $-22.5541000366-22.5541000366-22.2493095398-21.3349609375-20.4206008911$ $-19.8110294342-19.2014598846-18.8966808319-19.2014598846-19.8110294342$ $-20.4206008911-21.3349609375-22.2493095398-23.1636695862-24.0780296326$ -24.9923801422 -25.6019496918 -26.2115192413 -26.8210906982 -27.1258792877 -27.1258792877 -27.1258792877 -26.5163097382 -26.2115192413 -25.2971591949 -24.3828105927 -23.1636695862 -21.9445304871 -20.7253894806 -19.2014598846 $-17.6775398254-15.8488302231-14.3248996735-12.8009700775-11.2770500183$ $-9.44833946228-7.92441320419-6.40048694611-4.87656211853-3.65742206573$ $-2.43828105927-1.21914100647-.304785102606 .30478510260581 .21914100647$ 1.8287110328672 .7430660724643 .6574220657354 .5717768669136 .400486946106 8.53398323059111 .5818300247215 .2392597198519 .2014598846423 .16366958618 27.1258792877230 .4785099029533 .5263595581135 .9646492004438 .09814071655 39.9268493652341 .4507789611842 .66992187543 .5842704772944 .19384002686 44.4986305236844 .8034095764244 .8034095764244 .8034095764245 .10820007324 45.1082000732445 .4129791259845 .717769622846 .3273391723646 .63212966919 47.2416992187547 .8512611389248 .765621185349 .3751907348650 .28955078125 51.2038993835452 .4230384826753 .3373985290554 .5565414428755 .47089004517 55.7756805419956 .0804595947356 .3852500915556 .3852500915556 .38525009155 56.6596794128456 .6900291442956 .6900291442956 .6900291442956 .99481964111 56.9948196411156 .9948196411156 .9948196411156 .9948196411156 .99481964111 57.2995986938557 .2995986938557 .2364997863857 .196712493957 .29959869385 57.2995986938557 .6043891906757 .6043891906757 .6043891906757 .60438919067 57.6043891906757 .909179687557 .909179687557 .909179687558 .21395874023 58.2139587402358 .5187492370658 .5187492370658 .5187492370658 .82352828979 58.8235282897959 .1283111572359 .1283111572359 .4331016540559 .43310165405 59.7378807067959 .7378807067960 .0426712036160 .0426712036160 .34745025635 60.3474502563560 .6522407531760 .6522407531760 .9570198059160 .95701980591 61.2618103027361 .5666007995661 .56660079956 -2.84570670128 -9999 -9999 -9999 -9999 -9999 -9999 -9999 -9999-9999 -9999

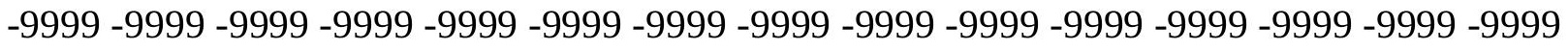

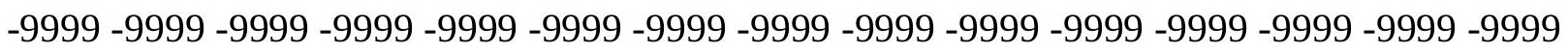
-9999 -9999 -9999 -9999 -9999 -9999 -9999 -9999 -9999 -9999 -9999 -9999 -9999 -9999 -9999 -9999 -9999 -9999 -9999 -9999 -9999 -9999 -9999 -9999 -9999 -9999 -9999 -9999 -9999 -9999 -9999 -9999 -9999 -9999 -9999 -9999 -9999 -9999 -9999 -9999 -9999 -9999 -9999 -9999 -9999 -

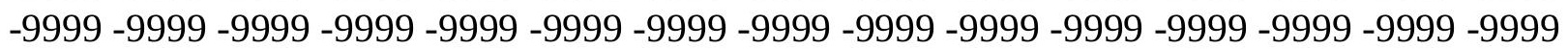


-9999 -9999 -9999 -9999 -9999 -9999 -9999 -9999 -9999 -9999 -9999 -9999 -9999 -9999 -9999 -9999 -9999 -9999 -9999 -9999 -9999 -9999 -9999 -9999 -9999 -9999 -9999 -9999 -9999 -9999

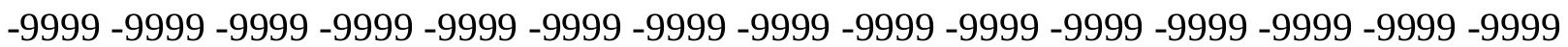
-9999 -9999 -9999 -9999 -9999 -9999 -9999 -9999 -9999 -9999 -9999 -9999 -9999 -9999 -9999 -9999 -9999 -9999 -9999 137.7628936768 135.3246002197132 .8863067627129 .4794158936 128.6192932129133 .8813323975126 .7906036377129 .8385009766139 .8963928223 140.9970550537139 .5840606689136 .8484954834131 .9720001221127 .7050018311 123.5174102783120 .0504684448117 .80884552116 .7326965332115 .2088012695 113.9896011353112 .7705001831111 .8561019897110 .9418029785110 .0273971558 109.1130981445107 .8938980103106 .979598999105 .7603988647104 .8460998535 103.9317016602103 .3221969604102 .712600708102 .1029968262102 .1029968262 101.7982025146101 .7982025146101 .7982025146102 .1029968262102 .4077987671 102.712600708103 .3221969604103 .9317016602104 .8460998535106 .0652008057 106.979598999108 .1986999512109 .1130981445109 .4179000854108 .8082962036 107.2844009399 105.1509017944 102.1029968262 98.445587158294.78817749023 90.5211791992286 .254188537681 .9871978759877 .4154205322373 .14842987061 69.4910125732466 .1383666992263 .3953094482460 .9570198059159 .12831115723 57.2995986938556 .0804595947354 .5565414428753 .3373985290551 .81346893311 49.9847602844247 .8512611389245 .1082000732441 .7555618286137 .48857116699 32.0024414062525 .906740188619 .5062503814713 .105759620677 .010057926178 $1.523926019669-3.35263609886-7.92441320419-12.1914100647-15.5440397263$ $-18.287109375-20.4206008911-21.6397399902-22.2493095398-22.2493095398$ $-21.9445304871-21.3349609375-21.0301704407-20.7253894806-20.4206008911$ $-20.7253894806-21.3349609375-21.9445304871-22.8588790894-23.7732391357$ $-24.3828105927-25.2971591949-25.9067401886-26.5163097382-27.1258792877$ $-27.4306602478-27.4306602478-27.4306602478-27.1258792877-26.8210906982$ $-25.9067401886-25.2971591949-24.0780296326-23.1636695862-21.9445304871$ $-20.4206008911-18.8966808319-17.3727493286-15.8488302231-14.3248996735$ $-12.4961900711-10.9722604752-9.44833946228-7.92441320419-6.40048694611$ $-4.87656211853-3.65742206573-2.13349604607-.914355397224-9999.6095703244209$ 1.219141006471 .8287110328672 .4382810592653 .3526360988624 .266992092133 5.7909169197087 .92441320419310 .9722604751614 .934470176719 .20145988464 23.1636695861827 .1258792877230 .7833003997833 .2215805053735 .65985870361 37.4885711669939 .0125007629440 .5364189147941 .4507789611842 .36513137817 42.9747009277343 .2794914245643 .2794914245643 .2794914245643 .27949142456 43.5842704772943 .5842704772944 .1938400268644 .4986305236845 .10820007324 45.4129791259846 .0225486755446 .6321296691947 .2416992187548 .15605163574 49.0704002380449 .9847602844251 .2038993835452 .1182594299353 .33739852905 54.2517509460454 .8613204956155 .1661109924355 .4708900451755 .77568054199 56.0804595947356 .0804595947356 .0804595947356 .3852500915556 .38525009155 56.3852500915556 .6900291442956 .6900291442956 .6900291442956 .69002914429 56.6900291442956 .9948196411156 .9948196411156 .9855537414656 .9705619812 56.9948196411157 .2995986938557 .2995986938557 .2995986938557 .29959869385 57.6043891906757 .6043891906757 .6043891906757 .6043891906757 .9091796875 57.909179687558 .2139587402358 .2139587402358 .2139587402358 .51874923706 58.5187492370658 .8235282897958 .8235282897959 .1283111572359 .12831115723 
59.4331016540559 .4331016540559 .7378807067959 .7378807067960 .04267120361 60.0426712036160 .3474502563560 .3474502563560 .6522407531760 .65224075317 $60.9570198059161 .2618103027361 .2618103027361 .49089050293-4.10879659653$-9999 -9999 -9999 -9999 -9999 -9999 -9999 -9999 -9999 -9999

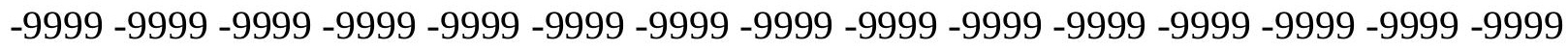
-9999 -9999 -9999 -9999 -9999 -9999 -9999 -9999 -9999 -9999 -9999 -9999 -9999 -9999 -9999 -

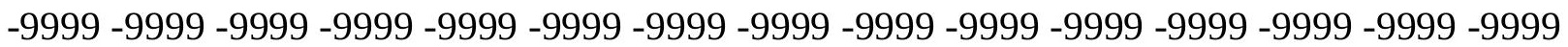

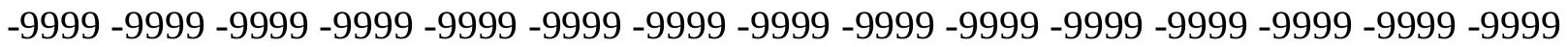

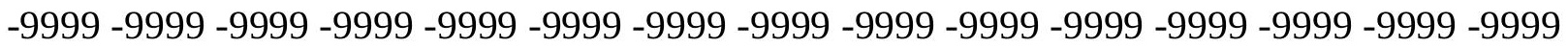
-9999 -9999 -9999 -9999 -9999 -9999 -9999 -9999 -9999 -9999 -9999 -9999 -9999 -9999 -9999 -

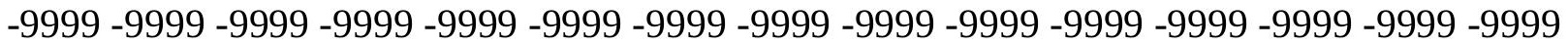
-9999 -9999 -9999 -9999 -9999 -9999 -9999 -9999 -9999 -9999 -9999 -9999 -9999 -9999 -9999 -9999 -9999 -9999 -9999 -9999 -9999 -9999 -9999 -9999 -9999 -9999 -9999 -9999 -9999 -9999 -9999 -9999 -9999 -9999 -9999 -9999 -9999 -9999 -9999 -9999 -9999 -9999 -9999 -9999 -9999 -9999 -9999 -9999 -9999 -9999-9999-9999 138.9819946289136 .8484954834135 .0198059082 133.4958953857131 .6672058105129 .8385009766128 .6192932129132 .8863067627 131.6672058105129 .8385009766127 .7050018311125 .1484527588121 .8709640503 119.6104888916118 .2593154907117 .4897537231117 .1555786133115 .818397522 114.5991973877113 .3800964355111 .8561019897110 .6370010376109 .1130981445 107.5891036987106 .3700027466105 .1509017944103 .9317016602103 .0174026489 102.4077987671102 .1029968262101 .7982025146101 .7982025146101 .4934005737 101.4934005737101 .4934005737101 .7982025146102 .1029968262102 .4077987671 103.0174026489103 .9317016602105 .1509017944106 .3700027466107 .5891036987 108.5533828735108 .8459472656108 .605178833107 .2844009399104 .5412979126 100.883903503497 .2264633178792 .9594726562588 .9972534179785 .03504943848 81.0728530883877 .110626220773 .1484298706169 .7957916259866 .44316101074 63.7000885009861 .2618103027359 .7378807067958 .2139587402357 .29959869385 56.3852500915555 .4708900451754 .2517509460453 .0326118469251 .50868988037 49.3751907348646 .3273391723642 .66992187538 .0981407165532 .91679000854 26.8210906982420 .7253894805914 .93447017678 .8387689590453 .047851085663 $-2.13349604607-7.3148431778-11.8866195679-15.8488302231-18.5918903351$ $-20.4206008911-21.6397399902-21.9445304871-22.2493095398-21.9445304871$ $-21.6397399902-21.6397399902-21.6397399902-21.9445304871-22.5541000366$ $-23.4684505463-24.0780296326-24.9923801422-25.6019496918-26.2115192413$ $-26.8210906982-27.1258792877-27.4306602478-27.7354507446-27.7354507446$ $-27.4306602478-27.1258792877-26.5163097382-25.9067401886-24.9923801422$ $-23.7732391357-22.5541000366-21.3349609375-20.115819931-18.5918903351$ -17.0679702759 -15.5440397263 -14.0201196671 -12.4961900711 -10.6674804688 $-9.14355373383-7.61962795258-6.40048694611-4.87656211853-3.35263609886$ -2.13349604607 -.914355397224-9999.6095703244209 1.523926019669 2.133496046066 2.7430660724643 .6574220657354 .5717768669135 .7909169197087 .314843177795 10.9722604751615 .2392597198519 .2014598846423 .4684505462627 .12587928772 30.4785099029533 .2215805053735 .0502891540536 .5742111206138 .09814071655 39.3172798156740 .5364189147941 .4507789611841 .7555618286142 .06034851074 42.0603485107442 .0603485107442 .0603485107442 .0603485107442 .36513137817 42.66992187543 .2794914245643 .8890609741244 .1938400268644 .49863052368 
45.1082000732445 .717769622846 .6321296691947 .5464782714848 .46083068848 49.6799812316950 .8991203308152 .1182594299353 .0326118469253 .64218139648 54.2517509460454 .5565414428755 .1661109924355 .1661109924355 .47089004517 55.7756805419955 .7756805419956 .0804595947356 .0804595947356 .08045959473 56.3852500915556 .3852500915556 .3852500915556 .6900291442956 .69002914429 56.6900291442956 .6900291442956 .6900291442956 .7739868164156 .99481964111 56.9948196411156 .9948196411157 .2995986938557 .2995986938557 .29959869385 57.6043891906757 .6043891906757 .6043891906757 .909179687557 .9091796875 57.909179687558 .2139587402358 .2139587402358 .5187492370658 .51874923706 58.8235282897958 .8235282897959 .1283111572359 .1283111572359 .43310165405 59.4331016540559 .7378807067959 .7378807067960 .0426712036160 .04267120361 60.3474502563560 .3474502563560 .6522407531760 .9570198059160 .95701980591 61.2618103027361 .26181030273 -4.69056034088 -9999 -9999 -9999 -9999 -9999 -9999 -9999 -9999-9999-9999

-9999 -9999 -9999 -9999 -9999 -9999 -9999 -9999 -9999 -9999 -9999 -9999 -9999 -9999 -9999

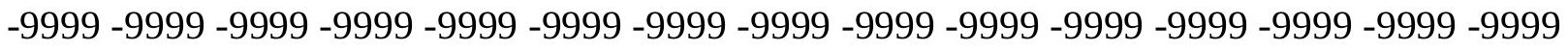
-9999 -9999 -9999 -9999 -9999 -9999 -9999 -9999 -9999 -9999 -9999 -9999 -9999 -9999 -9999 -9999 -9999 -9999 -9999 -9999 -9999 -9999 -9999 -9999 -9999 -9999 -9999 -9999 -9999 -9999 -9999 -9999 -9999 -9999 -9999 -9999 -9999 -9999 -9999 -9999 -9999 -9999 -9999 -9999 -9999 -

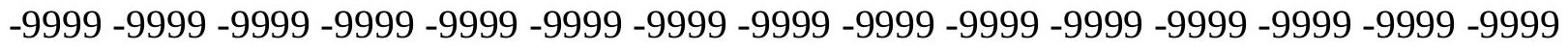

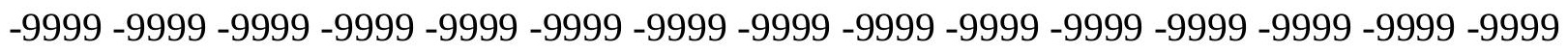
-9999 -9999 -9999 -9999 -9999 -9999 -9999 -9999 -9999 -9999 -9999 -9999 -9999 -9999 -9999 -9999 -9999 -9999 -9999 -9999 -9999 -9999 -9999 -9999 -9999 -9999 -9999 -9999 -9999 -9999 -9999 -9999 -9999 -9999 -9999 -9999 -9999 -9999 -9999 -9999 -9999 -9999 -9999 -9999 -9999 -9999 -9999 -9999 -9999 -9999 -9999-9999 -9999 -9999-9999-9999 139.2868041992 136.8484954834134 .7149963379132 .5814971924130 .7528076172128 .6192932129 127.7050018311126 .7906036377123 .6516418457121 .4395294189119 .9531707764 119.0619125366118 .5706634521118 .2235183716117 .2521743774115 .5136032104 113.9896011353112 .1608963013110 .3321990967108 .8082962036106 .979598999 105.4557037354104 .2365036011103 .3221969604102 .4077987671102 .1029968262 101.7982025146101 .7982025146101 .4934005737101 .4934005737101 .1886978149 101.1886978149101 .1886978149101 .4934005737101 .7982025146102 .712600708 103.6268997192104 .8460998535106 .3700027466107 .3860855103107 .7607955933 107.7355194092106 .3700027466103 .322196960499 .6647262573295 .3977432251 91.1307525634887 .4733276367283 .8159103393680 .1584930419976 .50106811523 72.8436431884869 .4910125732466 .1383666992263 .3953094482461 .26181030273 59.7378807067958 .8235282897958 .2139587402357 .6043891906756 .99481964111 56.3852500915555 .4708900451754 .2517509460452 .7278289794950 .59432983398 47.5464782714843 .8890609741239 .3172798156734 .1359291076728 .34502029419 $22.5541000366216 .4584007263210 .057909965523 .352636098862-2.74306607246$ -8.53398323059 -13.1057596207 -16.4584007263 -18.8966808319-20.7253894806 -21.6397399902 -21.9445304871 -21.9445304871 -21.9445304871 -21.9445304871 $-22.2493095398-22.8588790894-23.4684505463-24.3828105927-24.9923801422$ -25.9067401886 -26.5163097382 -26.8210906982 -27.4306602478 -27.4306602478 $-27.7354507446-27.7354507446-27.4306602478-27.1258792877-26.8210906982$ $-26.2115192413-25.2971591949-24.3828105927-23.1636695862-22.2493095398$ 
-20.7253894806 -19.5062503815 -17.9823207855 -16.4584007263 -14.9344701767 $-13.4105501175-11.8866195679-10.3626899719-8.83876895905-7.3148431778$ $-6.095703125-4.57177686691-3.35263609886-1.82871103287-.609570324421-9999$ .91435539722441 .8287110328672 .4382810592653 .3526360988624 .266992092133 5.1813468933116 .7052731513988 .83876895904511 .8866195678715 .84883022308 19.811029434223 .7732391357427 .430660247830 .4785099029532 .91679000854 34.7455101013235 .9646492004436 .8790016174338 .0981407165539 .31727981567 40.2316398620640 .8412094116240 .8412094116240 .8412094116240 .84120941162 40.5364189147940 .5364189147941 .1459884643641 .7555618286142 .36513137817 42.66992187542 .9747009277343 .2794914245643 .8890609741244 .19384002686 45.1082000732446 .0225486755447 .2416992187548 .4608306884849 .67998123169 50.5943298339851 .8134689331152 .7278289794953 .3373985290553 .94697189331 54.2517509460454 .5565414428754 .8613204956155 .1661109924355 .47089004517 55.4708900451755 .7756805419955 .7756805419956 .0804595947356 .08045959473 56.0804595947356 .3852500915556 .3852500915556 .3852500915556 .38525009155 56.5336570739756 .5951118469256 .6268653869656 .6900291442956 .99481964111 56.9948196411156 .9948196411157 .2995986938557 .2995986938557 .29959869385 57.6043891906757 .6043891906757 .6043891906757 .909179687557 .9091796875 58.2139587402358 .2139587402358 .5187492370658 .5187492370658 .82352828979 58.8235282897959 .1283111572359 .1283111572359 .4331016540559 .43310165405 59.7378807067959 .7378807067960 .0426712036160 .3474502563560 .34745025635 60.6522407531760 .6522407531760 .9570198059160 .9570198059161 .1770362854 -4.98864793777 -9999 -9999 -9999 -9999 -9999 -9999 -9999 -9999 -9999-9999 -9999 -9999 -9999 -9999 -9999 -9999 -9999 -9999 -9999 -9999 -9999 -9999 -9999 -9999 -9999

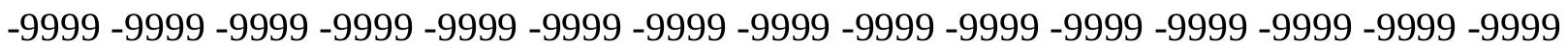
-9999 -9999 -9999 -9999 -9999 -9999 -9999 -9999 -9999 -9999 -9999 -9999 -9999 -9999 -9999 -9999 -9999 -9999 -9999 -9999 -9999 -9999 -9999 -9999 -9999 -9999 -9999 -9999 -9999 -9999 -9999 -9999 -9999 -9999 -9999 -9999 -9999 -9999 -9999 -9999 -9999 -9999 -9999 -9999 -9999

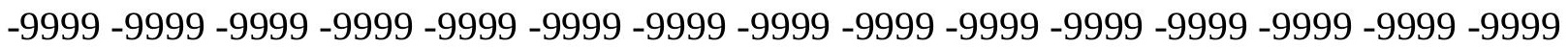

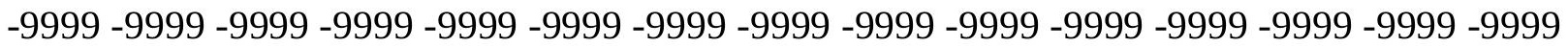
-9999 -9999 -9999 -9999 -9999 -9999 -9999 -9999 -9999 -9999 -9999 -9999 -9999 -9999 -9999 -

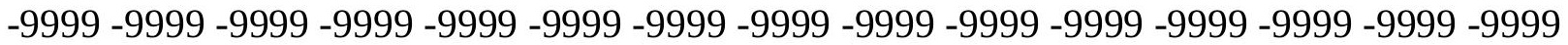
-9999 -9999 -9999 -9999 -9999 -9999 -9999 -9999 -9999 -9999 -9999 -9999 -9999 -9999 -9999 -9999 -9999 -9999 -9999 -9999 -9999 -9999 -9999 -9999 -9999 -9999 -9999 -9999 -9999 139.2868041992136 .8484954834134 .7149963379132 .2767028809130 .1432037354 128.3144989014127 .4001998901126 .1809997559124 .9618988037122 .9779281616 119.330039978118 .72996521117 .9367828369115 .818397522113 .9896011353 111.8561019897110 .0273971558108 .1986999512106 .3700027466104 .5412979126 103.6268997192103 .0174026489102 .712600708102 .4077987671102 .1029968262 101.7982025146101 .4934005737100 .8839035034100 .5791015625100 .2742996216 100.2742996216100 .2742996216100 .8839035034101 .7982025146103 .0174026489 104.2365036011105 .6616439819106 .6222915649106 .7859344482104 .5412979126 101.188697814997 .5312423706193 .5690307617289 .9116134643686 .2541885376 82.5967712402379 .2441329956175 .8914871215872 .2340774536168 .88143920898 65.8335876464863 .0905189514260 .6522407531759 .7378807067959 .12831115723 58.5187492370658 .2139587402358 .2139587402357 .909179687557 .29959869385 
56.6900291442955 .4708900451753 .9469718933151 .8134689331149 .07040023804 45.4129791259841 .1459884643636 .2694282531730 .4785099029524 .07802963257 $16.763179779059 .1435537338261 .523926019669-4.87656211853-10.3626899719$ $-14.3248996735-17.0679702759-19.2014598846-20.7253894806-21.3349609375$ -21.6397399902 -21.6397399902 -21.6397399902 -22.2493095398 -23.1636695862 $-24.0780296326-24.6875991821-25.6019496918-26.2115192413-26.8210906982$ $-27.1258792877-27.4306602478-27.7354507446-27.7354507446-27.4306602478$ $-27.1258792877-26.8210906982-26.2115192413-25.2971591949-24.6875991821$ -23.4684505463 -22.5541000366 -21.3349609375 -20.115819931 -18.5918903351 -17.3727493286 -15.8488302231 -14.3248996735 -12.8009700775 -11.2770500183 -10.0579099655 -8.53398323059-7.01005792618 -5.48613214493 -4.26699209213 $-3.04785108566-1.82871103287-.609570324421 .30478510260581 .21914100647$ 2.1334960460663 .0478510856633 .9622070789345 .1813468933116 .400486946106 7.92441320419310 .3626899719213 .1057596206716 .7631797790520 .42060089111 24.0780296325727 .7354507446330 .4785099029532 .6120109558134 .13592910767 35.0502891540535 .3550796508836 .8790016174337 .7933502197338 .70771026611 39.0125007629439 .622070312539 .9268493652339 .622070312539 .6220703125 39.3172798156740 .2316398620640 .8412094116241 .4507789611841 .75556182861 42.0603485107442 .3651313781742 .3651313781742 .9747009277343 .58427047729 44.8034095764246 .0225486755447 .2416992187548 .4608306884849 .37519073486 50.5943298339851 .5086898803752 .4230384826753 .0326118469253 .64218139648 53.9469718933154 .2517509460454 .5565414428754 .8613204956155 .16611099243 55.1661109924355 .4708900451755 .7756805419955 .7756805419955 .77568054199 56.0804595947356 .0804595947356 .0804595947356 .3852500915556 .38525009155 56.3852500915556 .4573173522956 .6900291442956 .6900291442956 .69002914429 56.9948196411156 .9948196411156 .9948196411157 .2995986938557 .29959869385 57.2995986938557 .6043891906757 .6043891906757 .909179687557 .9091796875 58.2139587402358 .2139587402358 .5187492370658 .5187492370658 .82352828979 58.8235282897959 .1283111572359 .1283111572359 .4331016540559 .43310165405 59.7378807067960 .0426712036160 .0426712036160 .3474502563560 .34745025635 60.6522407531760 .6522407531760 .9570198059160 .95701980591 -5.2219209671 -9999 -9999 -9999 -9999 -9999 -9999 -9999 -9999 -9999 -9999

-9999 -9999 -9999 -9999 -9999 -9999 -9999 -9999 -9999 -9999 -9999 -9999 -9999 -9999 -999 -9999 -9999 -9999 -9999 -9999 -9999 -9999 -9999 -9999 -9999 -9999 -9999 -9999 -9999 -9999 -9999 -9999 -9999 -9999 -9999 -9999 -9999 -9999 -9999 -9999 -9999 -9999 -9999 -9999 -9999 -

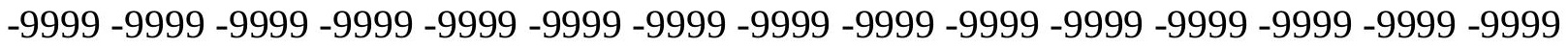

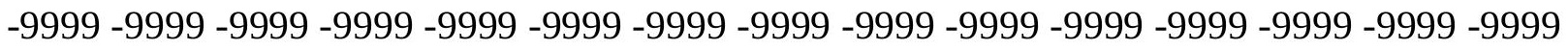

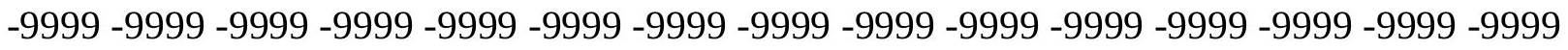
-9999 -9999 -9999 -9999 -9999 -9999 -9999 -9999 -9999 -9999 -9999 -9999 -9999 - 9999 - -999 -9999 -9999 -9999 -9999 -9999 -9999 -9999 -9999 -9999 -9999 -9999 -9999 -9999 -9999 -9999 -

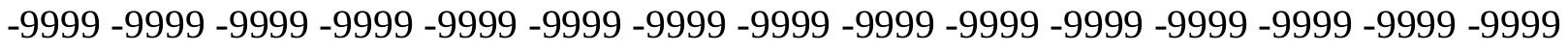

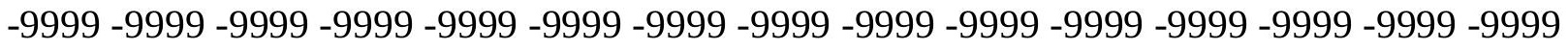
-9999 -9999 -9999 -9999 -9999 -9999 -9999 -9999 -9999 -9999 -9999 -9999 -9999 -9999 -9999 -9999 140.5059967041 138.0677032471 135.9342041016133.8007049561 131.6672058105 129.2288970947 127.0953979492125.5715026855 123.7105331421121 .9066390991 118.7629547119117 .7490768433115 .818397522113 .6848983765111 .551399231 
109.4179000854 107.2844009399 105.4557037354104.2365036011103.6268997192 103.6268997192103 .3221969604103 .0174026489102 .4077987671101 .7982025146 101.1886978149100 .274299621699 .6647262573299 .0551681518698 .75038146973 99.0551681518699 .35994720459100 .2742996216101 .4934005737102 .712600708 103.3221969604103 .0174026489101 .188697814998 .445587158295 .09295654297 91.7403335571388 .3876876831184 .7302627563581 .3776321411178 .32978057861 74.9771423339871 .6244964599668 .5766525268665 .5288009643663 .09051895142 60.9570198059159 .7378807067959 .1283111572358 .8235282897958 .82352828979 58.8235282897958 .8235282897958 .5187492370658 .2139587402357 .60438919067 56.6900291442955 .1661109924353 .3373985290550 .5943298339847 .54647827148 43.5842704772938 .0981407165531 .3928699493423 .4684505462614 .9344701767 $6.400486946106-1.21914100647-7.01005792618-11.2770500183-14.6296901703$ $-17.0679702759-19.2014598846-20.4206008911-21.0301704407-21.0301704407$ $-21.0301704407-21.9445304871-23.1636695862-24.0780296326-24.9923801422$ $-25.6019496918-26.2115192413-26.8210906982-27.1258792877-27.1258792877$ $-27.1258792877-27.1258792877-26.8210906982-26.5163097382-25.9067401886$ $-25.2971591949-24.3828105927-23.7732391357-22.5541000366-21.6397399902$ $-20.4206008911-19.2014598846-17.6775398254-16.4584007263-14.9344701767$ $-13.4105501175-12.1914100647-10.6674804688-9.14355373383-7.92441320419$ $-6.40048694611-5.18134689331-3.65742206573-2.43828105927-1.21914100647$-9999 .60957032442091.828711032867 2.743066072464 3.657422065735 4.87656211853 6.0957031257 .6196279525769 .4483394622811 .8866195678714 .62969017029 17.9823207855221 .334960937524 .6875991821327 .7354507446330 .47850990295 32.3072204589833 .8311500549334 .4407196044934 .7455101013235 .05028915405 35.0502891540535 .6598587036136 .5742111206137 .7933502197338 .40293121338 38.7077102661139 .0125007629439 .3172798156739 .9268493652340 .53641891479 40.8412094116241 .1459884643641 .4507789611841 .4507789611841 .45077896118 41.4507789611842 .3651313781743 .5842704772944 .8034095764246 .02254867554 47.2416992187548 .4608306884849 .6799812316950 .5943298339851 .50868988037 52.1182594299352 .7278289794953 .3373985290553 .6421813964854 .25175094604 54.5565414428754 .5565414428754 .8613204956155 .1661109924355 .16611099243 55.4708900451755 .4708900451755 .7756805419955 .7756805419956 .08045959473 56.0804595947356 .0804595947356 .2452735900956 .3113746643156 .34489822388 56.3852500915556 .6900291442956 .6900291442956 .6900291442956 .99481964111 56.9948196411157 .2995986938557 .2995986938557 .2995986938557 .60438919067 57.6043891906757 .909179687557 .909179687558 .2139587402358 .21395874023 58.5187492370658 .5187492370658 .8235282897958 .8235282897959 .12831115723 59.1283111572359 .4331016540559 .7378807067959 .7378807067960 .04267120361 60.0426712036160 .3474502563560 .3474502563560 .6522407531760 .65224075317 60.8789024353 -5.39519071579 -9999 -9999 -9999 -9999 -9999 -9999 -9999 -9999 -9999 -9999 -9999-

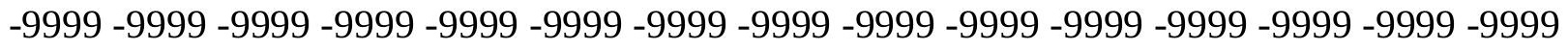

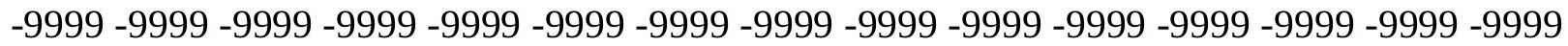

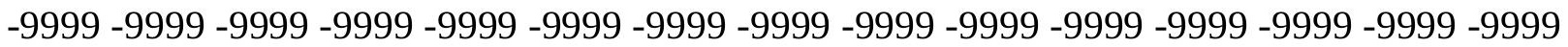

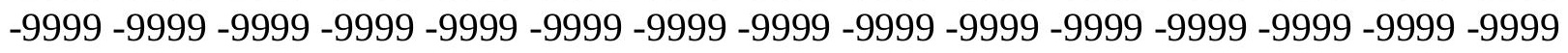

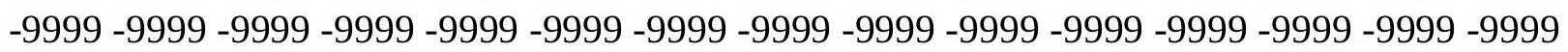


-9999 -9999 -9999 -9999 -9999 -9999 -9999 -9999 -9999 -9999 -9999 -9999 -9999 -9999 -9999 -9999 -9999 -9999 -9999 -9999 -9999 -9999 -9999 -9999 -9999 -9999 -9999 -9999 -9999 -9999 -9999 -9999 -9999 -9999 -9999 -9999 -9999 -9999 -9999 -9999 -9999 -9999 -9999 -9999 -9999 -9999 -9999 -9999 -9999 -9999 -9999 -9999 -9999 -9999 -9999 -9999 -9999 -9999 -9999 -9999 -9999 -9999 -9999 -9999 -9999 -9999 -9999 -9999 -9999 -9999 -9999 -9999 -9999 -9999 -9999 -9999 -9999 -9999 -9999 138.9819946289 136.5437011719134 .1054992676131 .3623962402 128.3144989014125 .8762969971124 .0006561279122 .010925293119 .9252853394 117.3209533691115 .5136032104113 .3800964355111 .24659729109 .1130981445 106.979598999105 .4557037354105 .1509017944105 .1509017944105 .1509017944 104.5412979126103 .6268997192102 .712600708101 .4934005737100 .2742996216 99.0551681518697 .8360290527397 .2264633178796 .9216690063596 .92166900635 97.5312423706198 .445587158299 .0551681518699 .3599472045998 .4455871582 96.9216690063594 .7881774902392 .349891662689 .302040100186 .55898284912 83.5111236572380 .1584930419977 .110626220774 .062782287671 .0149307251 67.9670867919965 .2240066528362 .7857398986860 .9570198059159 .73788070679 59.1283111572359 .1283111572359 .1283111572359 .1283111572359 .43310165405 59.4331016540559 .4331016540559 .4331016540558 .8235282897957 .9091796875 56.6900291442954 .8613204956152 .4230384826749 .6799812316944 .19384002686 37.7933502197330 .1737308502221 .0301704406711 .581830024722 .438281059265 $-2.74306607246-7.01005792618-10.6674804688-14.0201196671-16.7631797791$ -18.5918903351 -19.8110294342 -20.4206008911 -21.0301704407-21.6397399902 $-22.8588790894-23.7732391357-24.6875991821-25.2971591949-25.9067401886$ -26.2115192413 -26.5163097382 -26.5163097382 -26.5163097382 -26.2115192413 $-25.9067401886-25.6019496918-24.9923801422-24.0780296326-23.4684505463$ $-22.5541000366-21.3349609375-20.4206008911-19.2014598846-17.9823207855$ $-16.4584007263-15.2392597198-14.0201196671-12.4961900711-10.9722604752$ $-9.75312423706-8.22919845581-7.01005792618-5.79091691971-4.57177686691$ -3.35263609886 -2.13349604607 -.914355397224 -9999 1.21914100647 2.438281059265 3.3526360988624 .5717768669136 .0957031257 .3148431777959 .143553733826 10.9722604751613 .4105501174916 .1536102294918 .8966808319121 .94453048706 24.9923801422127 .7354507446330 .1737308502232 .0024414062533 .22158050537 33.5263595581132 .9167900085431 .6976509094231 .3928699493427 .73545074463 32.9167900085434 .7455101013236 .5742111206137 .7933502197338 .70771026611 39.3172798156739 .622070312540 .2316398620640 .5364189147940 .84120941162 40.8412094116240 .8412094116240 .8412094116241 .1459884643641 .75556182861 42.66992187543 .8890609741245 .1082000732446 .3273391723647 .54647827148 48.765621185349 .6799812316950 .5943298339851 .5086898803752 .11825942993 52.7278289794953 .3373985290553 .6421813964853 .9469718933154 .25175094604 54.5565414428754 .8613204956154 .8613204956155 .1661109924355 .16611099243 55.4708900451755 .4708900451755 .7756805419955 .7756805419956 .08045959473 56.0804595947356 .0804595947356 .2177276611356 .3852500915556 .38525009155 56.6900291442956 .6900291442956 .6900291442956 .9948196411156 .99481964111 56.9948196411157 .2995986938557 .2995986938557 .6043891906757 .60438919067 57.909179687557 .909179687558 .2139587402358 .2139587402358 .51874923706 58.5187492370658 .8235282897958 .8235282897959 .1283111572359 .43310165405 59.4331016540559 .7378807067959 .7378807067960 .0426712036160 .04267120361 
60.3474502563560 .6522407531760 .6522407531760 .78269958496 -5.594602108 -9999 -9999 -9999 -9999 -9999 -9999 -9999 -9999 -9999 -9999

-9999 -9999 -9999 -9999 -9999 -9999 -9999 -9999 -9999 -9999 -9999 -9999 -9999 -9999 -9999 -9999 -9999 -9999 -9999 -9999 -9999 -9999 -9999 -9999 -9999 -9999 -9999 -9999 -9999 -9999 -9999 -9999 -9999 -9999 -9999 -9999 -9999 -9999 -9999 -9999 -9999 -9999-9999 -9999 -9999 -9999 -9999 -9999 -9999 -9999 -9999 -9999 -9999 -9999 -9999 -9999 -9999 -9999 -9999 -9999

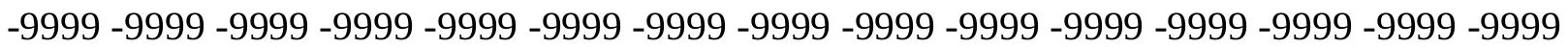
-9999 -9999 -9999 -9999 -9999 -9999 -9999 -9999 -9999 -9999 -9999 -9999 -9999 -9999 -9999 -999 -9999 -9999 -9999 -9999 -9999 -9999 -9999 -9999 -9999 -9999 -9999 -9999 -9999 -9999 -9999 -9999 -9999 -9999 -9999 -9999 -9999 -9999 -9999 -9999 -9999 -9999 -9999 -9999 -9999 -9999 -

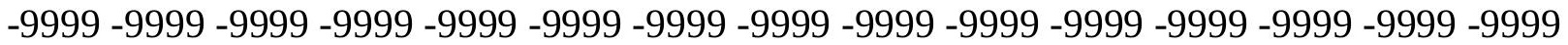
-9999 -9999 -9999 -9999 -9999 -9999 -9999 -9999 -9999 -9999 -9999 -9999 -9999 -9999 -9999

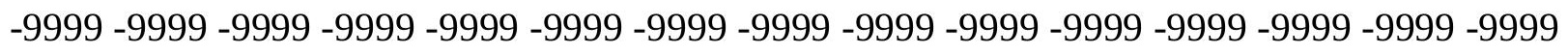
-9999 -9999 -9999 -9999-9999-9999 138.9819946289136 .2389984131133 .1911010742 130.4479980469127 .0953979492124 .0475006104121 .9140014648119 .7777404785 117.6235809326115 .5136032104113 .3800964355111 .24659729109 .7226028442 108.5035018921108 .1986999512107 .8938980103107 .2844009399106 .6747970581 105.4557037354103 .9317016602102 .4077987671100 .579101562598 .75038146973 96.9216690063595 .397743225194 .7881774902394 .4833908081194 .48339080811 95.0929565429795 .397743225195 .397743225194 .4833908081192 .65467834473 91.4355392456189 .6068267822387 .1685485839884 .7302627563581 .98719787598 79.2441329956176 .1962814331173 .4532165527370 .4053573608467 .66230010986 64.9192428588962 .7857398986860 .9570198059159 .7378807067959 .12831115723 58.8235282897959 .1283111572359 .1283111572359 .4331016540559 .73788070679 60.0426712036160 .0426712036160 .0426712036159 .4331016540558 .82352828979 57.2995986938555 .4708900451752 .7278289794948 .1560516357442 .669921875 36.5742111206126 .8210906982417 .677539825449 .448339462283 .352636098862 $-1.21914100647-5.48613214493-9.44833946228-13.4105501175-16.4584007263$ -18.287109375 -19.5062503815 -20.115819931 -21.0301704407-21.9445304871 $-22.8588790894-23.7732391357-24.3828105927-24.9923801422-25.2971591949$ $-25.2971591949-25.2971591949-25.2971591949-24.9923801422-24.6875991821$ $-24.0780296326-23.4684505463-22.8588790894-21.9445304871-21.0301704407$ -20.115819931 -18.8966808319-17.6775398254-16.4584007263 -15.2392597198 $-14.0201196671-12.4961900711-11.2770500183-10.0579099655-8.53398323059$ $-7.3148431778-6.095703125-4.87656211853-3.65742206573-2.43828105927$ $-1.21914100647-.304785102606 .60957032442091 .8287110328673 .047851085663$ 4.2669920921335 .7909169197087 .0100579261788 .53398323059110 .36268997192 12.4961900711114 .6296901702917 .3727493286119 .811029434222 .55410003662 25.2971591949527 .7354507446329 .8689403533931 .6976509094232 .91679000854 32.6120109558131 .0880794525127 .430660247821 .6397399902313 .7153301239 23.7732391357431 .0880794525134 .7455101013236 .8790016174338 .40293121338 39.0125007629439 .9268493652340 .2316398620640 .5364189147940 .53641891479 40.5364189147940 .5364189147940 .5364189147940 .8412094116241 .14598846436 42.0603485107443 .2794914245644 .1938400268645 .4129791259846 .63212966919 47.8512611389249 .0704002380449 .9847602844250 .5943298339851 .50868988037 52.1182594299352 .7278289794953 .0326118469253 .6421813964853 .94697189331 
54.2517509460454 .5565414428754 .5565414428754 .8613204956155 .16611099243 55.1661109924355 .4708900451755 .4708900451755 .4708900451755 .77568054199 55.7756805419956 .0804595947356 .0804595947356 .0804595947356 .38525009155 56.3852500915556 .3852500915556 .6900291442956 .6900291442956 .99481964111 56.9948196411156 .9948196411157 .2995986938557 .2995986938557 .60438919067 57.6043891906757 .909179687557 .909179687558 .2139587402358 .21395874023 58.5187492370658 .8235282897958 .8235282897959 .1283111572359 .12831115723 59.4331016540559 .4331016540559 .7378807067959 .7378807067960 .04267120361 60.3474502563560 .3474502563560 .6522407531760 .65224075317 -5.87391519547 -9999 -9999 -9999 -9999 -9999 -9999 -9999 -9999 -9999 -9999

-9999 -9999 -9999 -9999 -9999 -9999 -9999 -9999 -9999 -9999 -9999 -9999 -9999 -9999 -9999 -9999 -9999 -9999 -9999 -9999 -9999 -9999 -9999 -9999 -9999 -9999 -9999 -9999 -9999 -9999 -9999 -9999 -9999 -9999 -9999 -9999 -9999 -9999 -9999 -9999 -9999 -9999 -9999 -9999 -9999 -9999 -9999 -9999 -9999 -9999 -9999 -9999 -9999 -9999 -9999 -9999 -9999 -9999 -9999 -9999 -9999 -9999 -9999 -9999 -9999 -9999 -9999 -9999 -9999 -9999 -9999 -9999 -9999 -9999 -9999

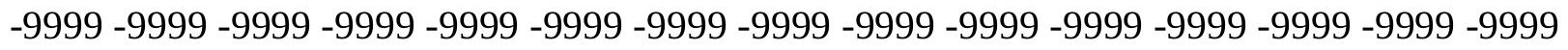

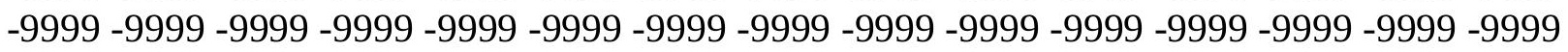

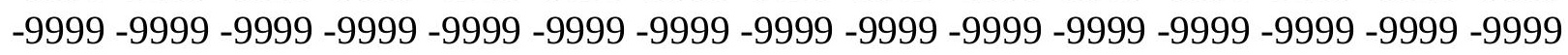

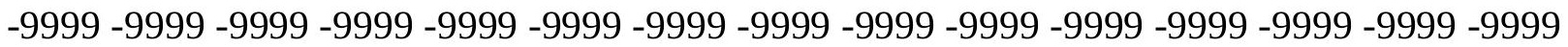

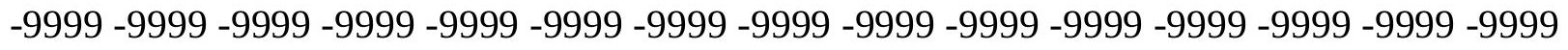

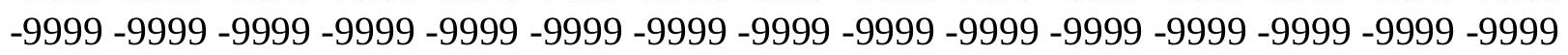
-9999 -9999 -9999 -9999-9999 -9999-9999 -9999 138.3724975586 135.3246002197 131.9720001221128 .9241027832125 .5511398315121 .9556427002119 .7806015015 117.910774231115 .818397522114 .2944030762112 .7705001831112 .1608963013 111.8561019897111 .24659729110 .3321990967109 .1130981445107 .5891036987 105.7603988647103 .6268997192101 .188697814998 .7503814697396 .31210327148 94.1785964965892 .6546783447391 .7403335571391 .7403335571392 .04509735107 92.349891662692 .349891662691 .4355392456190 .2164001464888 .69246673584 87.1685485839885 .3398437583 .206336975180 .7680587768678 .02498626709 75.2819290161172 .5388565063569 .7957916259867 .3575134277364 .91924285889 62.4809494018660 .9570198059159 .7378807067959 .1283111572358 .82352828979 58.8235282897959 .1283111572359 .4331016540559 .7378807067960 .34745025635 60.6522407531760 .6522407531760 .3474502563559 .7378807067958 .82352828979 56.9948196411154 .2517509460450 .5943298339845 .717769622839 .31727981567 31.6976509094223 .7732391357416 .7631797790510 .972260475166 .095703125 $1.523926019669-3.04785108566$-8.53398323059-13.1057596207 -15.8488302231 -17.3727493286 -18.287109375 -19.2014598846 -20.115819931 -21.3349609375 $-22.2493095398-22.8588790894-23.4684505463-23.7732391357-23.7732391357$ $-23.7732391357-23.4684505463-23.1636695862-22.8588790894-22.2493095398$ -21.6397399902 -21.0301704407 -20.115819931 -19.2014598846 -18.287109375 -17.0679702759 -16.1536102295 -14.9344701767 -13.7153301239-12.4961900711 $-11.2770500183-9.75312423706-8.53398323059-7.3148431778-6.095703125$ $-4.87656211853-3.65742206573-2.74306607246-1.52392601967-.609570324421$ .3047851026058 1.523926019669 2.743066072464 3.962207078934 5.181346893311 6.7052731513988 .22919845581110 .0579099655211 .8866195678713 .7153301239 15.8488302230818 .28710937520 .7253894805923 .1636695861825 .60194969177 
27.7354507446329 .5641593933130 .7833003997832 .3072204589831 .39286994934 28.3450202941923 .7732391357418 .5918903350816 .7631797790521 .63973999023 29.2593708038333 .5263595581135 .9646492004437 .7933502197339 .01250076294 39.622070312540 .2316398620640 .2316398620640 .2316398620640 .23163986206 40.2316398620640 .2316398620640 .5364189147941 .1459884643641 .75556182861 42.66992187543 .8890609741245 .1082000732446 .0225486755447 .24169921875 48.4608306884849 .3751907348650 .2895507812550 .8991203308151 .50868988037 52.1182594299352 .7278289794953 .0326118469253 .6421813964853 .94697189331 54.2517509460454 .2517509460454 .5565414428754 .8613204956154 .86132049561 55.1661109924355 .1661109924355 .4708900451755 .4708900451755 .77568054199 55.7756805419955 .7756805419955 .9472122192456 .0804595947356 .08045959473 56.3852500915556 .3852500915556 .6900291442956 .6900291442956 .69002914429 56.9948196411156 .9948196411157 .2995986938557 .2995986938557 .60438919067 57.6043891906757 .909179687557 .909179687558 .2139587402358 .51874923706 58.5187492370658 .8235282897958 .8235282897959 .1283111572359 .12831115723 59.4331016540559 .4331016540559 .7378807067960 .0426712036160 .04267120361 60.3474502563560 .3474502563560 .57911300659 -6.12805891037 -9999 -9999 -9999 -9999 -9999 -9999 -9999 -9999 -9999 -9999

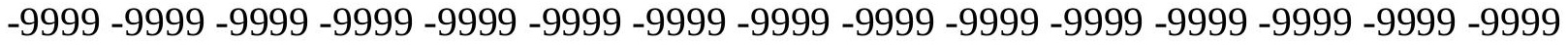

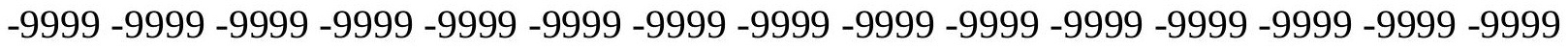

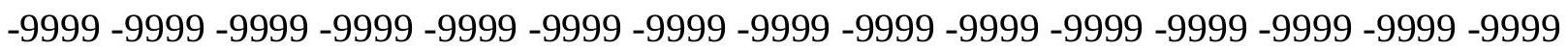

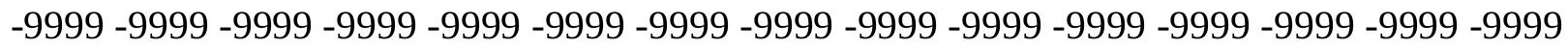
-9999 -

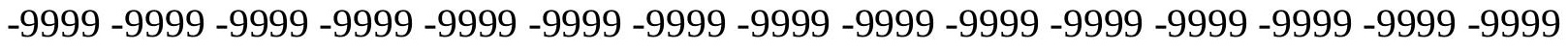

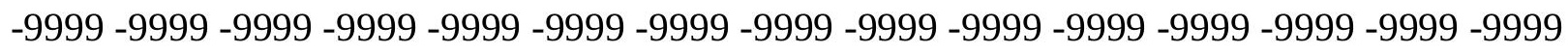

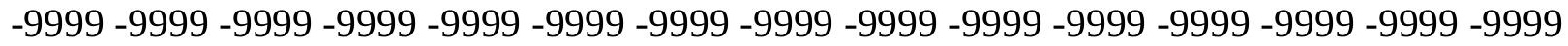

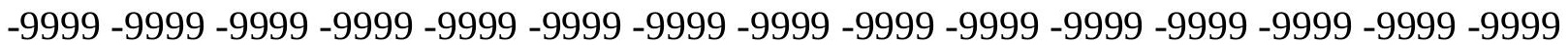

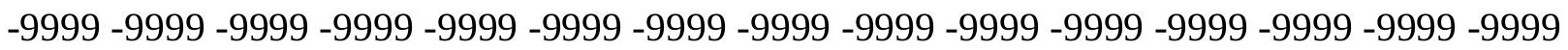

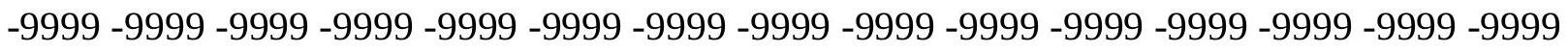
-9999 -9999 -9999 -9999 -9999 -9999 -9999 -9999 -9999 -9999 -9999 132.8498687744 129.3501434326127 .7050018311124 .3523025513120 .5581893921118 .5614013672 117.0374984741116 .3974227905115 .818397522115 .818397522115 .2088012695 113.9896011353112 .1608963013110 .3321990967108 .1986999512105 .4557037354 102.71260070899 .6647262573296 .3121032714893 .5690307617291 .13075256348 89.9116134643689 .6068267822389 .6068267822389 .6068267822389 .60682678223 88.9972534179788.08290100098 86.86376190186 85.33984375 83.81591033936 81.9871978759879 .5489196777377 .4154205322374 .9771423339872 .23407745361 69.4910125732467 .0527267456164 .6144485473662 .4809494018660 .95701980591 59.7378807067958 .8235282897958 .5187492370658 .5187492370658 .51874923706 59.1283111572359 .4331016540560 .0426712036160 .3474502563560 .65224075317 60.6522407531760 .0426712036159 .1283111572357 .6043891906755 .16611099243 51.8134689331147 .5464782714841 .7555618286135 .6598587036129 .25937080383 23.7732391357418 .8966808319115 .2392597198510 .972260475165 .181346893311 $-1.82871103287-8.83876895905-12.4961900711-14.0201196671-14.9344701767$ $-16.1536102295-17.3727493286-18.8966808319-19.8110294342-20.7253894806$ $-21.3349609375-21.3349609375-21.6397399902-21.3349609375-21.3349609375$ 
-21.0301704407 -20.7253894806 -20.115819931 -19.5062503815 -18.8966808319 -17.9823207855 -17.0679702759 -16.1536102295 -15.2392597198 -14.3248996735 $-13.1057596207-11.8866195679-10.6674804688-9.44833946228-8.22919845581$ $-7.01005792618-5.79091691971-4.57177686691-3.65742206573-2.43828105927$ -1.52392601967-.609570324421 -9999 1.21914100647 2.438281059265 3.657422065735 4.876562118536 .4004869461067 .6196279525769 .4483394622811 .27705001831 13.1057596206714 .934470176717 .0679702758819 .2014598846421 .63973999023 23.7732391357425 .6019496917727 .430660247828 .9545898437529 .86894035339 30.1737308502229 .2593708038326 .5163097381622 .8588790893619 .8110294342 19.811029434223 .1636695861828 .3450202941932 .6120109558135 .35507965088 37.4885711669938 .7077102661139 .622070312539 .9268493652340 .23163986206 40.2316398620640 .2316398620640 .2316398620640 .2316398620640 .53641891479 40.8412094116241 .7555618286142 .3651313781743 .5842704772944 .49863052368 45.717769622846 .9369087219247 .8512611389248 .765621185349 .67998123169 50.5943298339851 .2038993835451 .8134689331152 .4230384826752 .72782897949 53.3373985290553 .6421813964853 .9469718933154 .2517509460454 .25175094604 54.5565414428754 .8613204956154 .8613204956155 .1661109924355 .16611099243 55.4708900451755 .4708900451755 .4708900451755 .7756805419955 .77568054199 56.0804595947356 .0804595947356 .0804595947356 .3852500915556 .38525009155 56.6900291442956 .6900291442956 .9948196411156 .9948196411156 .99481964111 57.2995986938557 .2995986938557 .6043891906757 .909179687557 .9091796875 58.2139587402358 .2139587402358 .5187492370658 .5187492370658 .82352828979 58.8235282897959 .1283111572359 .1283111572359 .4331016540559 .73788070679 59.7378807067960 .0426712036160 .0426712036160 .3474502563560 .51486968994 -6.40553379059 -9999 -9999 -9999 -9999 -9999 -9999 -9999 -9999 -9999 -9999 -9999 -9999 -9999 -9999 -9999 -9999 -9999 -9999 -9999 -9999 -9999 -9999 -9999 -9999 -9999 -9999 -9999 -9999 -9999 -9999 -9999 -9999 -9999 -9999 -9999 -9999 -9999 -9999 -9999 -9999 -9999 -9999 -9999 -9999 -9999 -9999 -9999 -9999 -9999 -9999 -9999 -9999 -9999 -9999 -9999 -9999 -9999 -9999 -9999 -9999 -9999 -9999 -9999 -9999 -9999 -9999 -9999 -9999 -9999 -9999

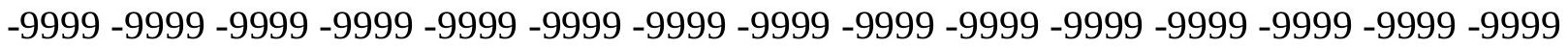
-9999 -9999 -9999 -9999 -9999 -9999 -9999 -9999 -9999 -9999 -9999 -9999 -9999 -9999 -9999 -9999 -9999 -9999 -9999 -9999 -9999 -9999 -9999 -9999 -9999 -9999 -9999 -9999 -9999 -9999 -9999 -9999 -9999 -9999 -9999 -9999 -9999 -9999 -9999 -9999 -9999 -9999 -9999 -9999 -9999 -9999 -9999 -9999 -9999 -9999 -9999 -9999 -9999 -9999 -9999 -9999 -9999 -9999 -9999 -9999 -

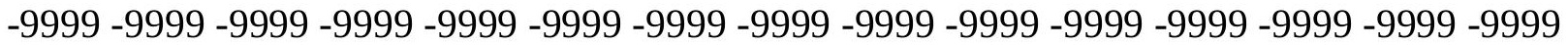
-9999 -9999 -9999 -9999 -9999 -9999 -9999 -9999 -9999 -9999 -9999 -9999 -9999 -9999 -9999 -9999 -9999 -9999 -9999 -9999 -9999 -9999 -9999 -9999 -9999 -9999 -9999 -9999 133.1911010742130 .1432037354127 .4001998901124 .6570968628120 .7568511963 119.9397964478119 .4757995605119 .268699646118 .8662033081117 .1812591553 115.5136032104113 .3800964355110 .6370010376107 .8938980103104 .8460998535 101.188697814997 .5312423706193 .8738174438591 .7403335571390 .52117919922 89.6068267822387 .7781066894587 .7781066894587 .7781066894587 .47332763672 86.5589828491285 .6446228027384 .4254837036182 .9015579223681 .07285308838 79.2441329956176 .8058471679774 .6723632812571 .9292907714869 .49101257324 67.0527267456164 .6144485473662 .4809494018660 .9570198059159 .43310165405 58.5187492370658 .2139587402357 .909179687558 .2139587402358 .51874923706 
58.8235282897959 .4331016540559 .7378807067960 .0426712036160 .04267120361 59.7378807067959 .1283111572357 .6043891906755 .4708900451752 .42303848267 48.765621185344 .1938400268639 .3172798156734 .4407196044930 .47850990295 27.1258792877224 .3828105926521 .6397399902316 .458400726327 .010057926178 -3.65742206573 -6.095703125 -7.92441320419-9.75312423706 -11.8866195679 $-13.7153301239-15.5440397263-16.7631797791-17.6775398254-18.287109375$ -18.287109375 -18.5918903351 -18.5918903351 -18.5918903351 -18.287109375 -17.9823207855 -17.6775398254 -17.0679702759-16.4584007263 -15.8488302231 -14.9344701767 -14.0201196671 -13.1057596207 -12.1914100647 -10.9722604752 -10.0579099655 -8.83876895905 -7.61962795258-6.40048694611 -5.48613214493 $-4.26699209213-3.04785108566-2.13349604607-1.21914100647-.304785102606$ .30478510260581 .219141006472 .1334960460663 .3526360988624 .571776866913 5.7909169197087 .3148431777958 .83876895904510 .6674804687512 .1914100647 14.3248996734616 .1536102294917 .9823207855220 .1158199310322 .24930953979 24.0780296325725 .6019496917727 .1258792877228 .3450202941928 .95458984375 28.6497993469227 .7354507446325 .906740188623 .4684505462621 .94453048706 22.5541000366225 .2971591949529 .2593708038332 .3072204589835 .05028915405 36.8790016174338 .4029312133839 .3172798156739 .622070312539 .92684936523 39.9268493652339 .9268493652339 .9268493652340 .2316398620640 .53641891479 40.8412094116241 .7555618286142 .3651313781743 .2794914245644 .49863052368 45.4129791259846 .6321296691947 .5464782714848 .4608306884849 .37519073486 49.9847602844250 .8991203308151 .5086898803752 .1182594299352 .42303848267 53.0326118469253 .3373985290553 .6421813964853 .9469718933154 .25175094604 54.2517509460454 .5565414428754 .8613204956154 .8613204956155 .16611099243 55.1661109924355 .1661109924355 .4708900451755 .4708900451755 .63272094727 55.7018432617256 .0804595947356 .0804595947356 .0804595947356 .38525009155 56.3852500915556 .6900291442956 .6900291442956 .9948196411156 .99481964111 57.2995986938557 .2995986938557 .6043891906757 .6043891906757 .9091796875 57.909179687558 .2139587402358 .2139587402358 .5187492370658 .51874923706 58.8235282897959 .1283111572359 .1283111572359 .4331016540559 .43310165405 59.7378807067959 .7378807067960 .0426712036160 .3474502563560 .34745025635 -6.76695251465 -9999 -9999 -9999 -9999 -9999 -9999 -9999 -9999 -9999 -9999

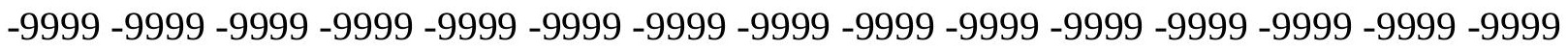
-9999 -9999 -9999 -9999 -9999 -9999 -9999 -9999 -9999 -9999 -9999 -9999 -9999 -9999 -9999 -9999 -9999 -9999 -9999 -9999 -9999 -9999 -9999 -9999 -9999 -9999 -9999 -9999 -9999 -9999 -9999 -9999 -9999 -9999 -9999 -9999 -9999 -9999 -9999 -9999 -9999 -9999 -9999 -9999 -9999

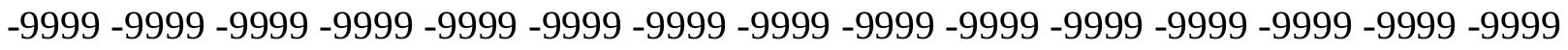

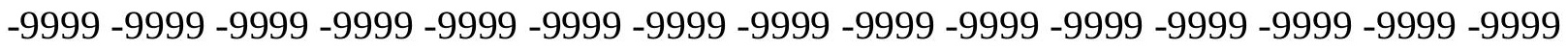
-9999 -9999 -9999 -9999 -9999 -9999 -9999 -9999 -9999 -9999 -9999 -9999 -9999 -9999 -9999 -9999 -9999 -9999 -9999 -9999 -9999 -9999 -9999 -9999 -9999 -9999 -9999 -9999 -9999 -9999 -

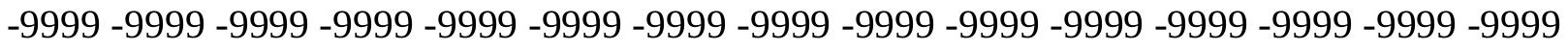

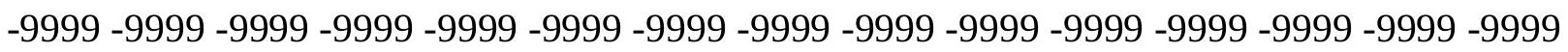
-9999 -9999 -9999 -9999 -9999 -9999 -9999 -9999 -9999 -9999 -9999 -9999 -9999 -9999 -9999 -9999 -9999 -9999 -9999 -9999 -9999 -9999 -9999 -9999 -9999 -9999 -9999 -9999 -9999 -9999 -9999 130.7528076172 128.3144989014 123.1989822388 122.7147521973122 .270942688 121.5615081787120 .2784576416118 .5614013672116 .3221054077113 .6848983765 
110.9418029785107 .5891036987103 .931701660299 .9695205688595 .70252990723 92.0450973510791 .13075256348 89.91161346436 87.47332763672 87.16854858398 87.16854858398 86.86376190186 85.94940185547 85.03504943848 83.81591033936 82.5967712402380 .7680587768678 .9393463134876 .8058471679774 .67236328125 72.2340774536169 .7957916259867 .3575134277364 .9192428588962 .78573989868 60.9570198059159 .4331016540558 .2139587402357 .6043891906757 .29959869385 57.2995986938557 .6043891906758 .2139587402358 .5187492370659 .12831115723 59.4331016540559 .4331016540559 .1283111572358 .5187492370657 .29959869385 55.4708900451753 .0326118469249 .9847602844246 .3273391723642 .669921875 39.3172798156736 .2694282531734 .1359291076732 .9167900085431 .69765090942 29.8689403533918 .591890335088 .8387689590453 .047851085663 -9999 -2.74306607246 $-5.79091691971-8.83876895905-11.2770500183-12.8009700775-13.7153301239$ $-14.3248996735-14.6296901703-14.9344701767-14.9344701767-15.2392597198$ $-14.9344701767-14.9344701767-14.6296901703-14.0201196671-13.7153301239$ $-13.1057596207-12.1914100647-11.5818300247-10.6674804688-9.75312423706$ $-8.83876895905-7.61962795258-6.7052731514-5.48613214493-4.571776866691$ -3.65742206573 -2.43828105927-1.52392601967- -609570324421 -9999.6095703244209 1.219141006472 .1334960460663 .0478510856634 .2669920921335 .486132144928 6.7052731513988 .22919845581110 .0579099655211 .5818300247213 .41055011749 15.2392597198517 .0679702758818 .8966808319120 .7253894805922 .55410003662 24.3828105926525 .906740188626 .8210906982427 .7354507446328 .04022979736 28.0402297973627 .1258792877225 .906740188624 .6875991821324 .07802963257 24.6875991821326 .8210906982429 .5641593933132 .3072204589834 .74551010132 36.5742111206137 .7933502197339 .0125007629439 .3172798156739 .6220703125 39.9268493652339 .9268493652339 .9268493652340 .2316398620640 .53641891479 41.1459884643641 .7555618286142 .3651313781743 .2794914245644 .19384002686 45.4129791259846 .3273391723647 .2416992187548 .1560516357449 .07040023804 49.9847602844250 .5943298339851 .2038993835451 .8134689331152 .11825942993 52.7278289794953 .0326118469253 .3373985290553 .6421813964853 .94697189331 54.2517509460454 .2517509460454 .5565414428754 .8613204956154 .86132049561 55.1661109924355 .1661109924355 .1661109924355 .4708900451755 .47089004517 55.5893173217855 .7756805419955 .7756805419956 .0804595947356 .08045959473 56.3852500915556 .3852500915556 .6900291442956 .6900291442956 .99481964111 56.9948196411157 .2995986938557 .2995986938557 .6043891906757 .60438919067 57.909179687557 .909179687558 .2139587402358 .5187492370658 .51874923706 58.8235282897958 .8235282897959 .1283111572359 .1283111572359 .43310165405 59.4331016540559 .7378807067960 .0426712036160 .0426712036160 .29117965698 -7.13927030563 -9999 -9999 -9999 -9999 -9999 -9999 -9999 -9999 -9999 -9999

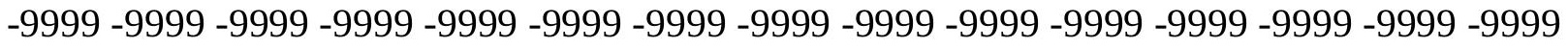

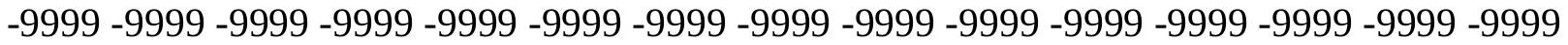

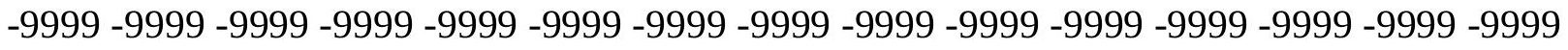

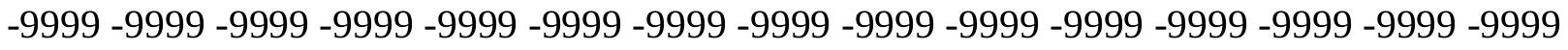

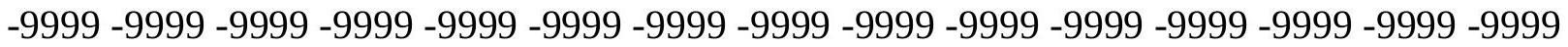

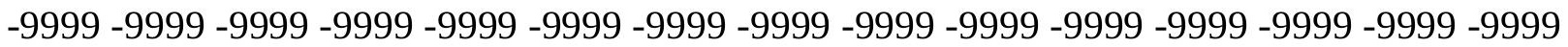

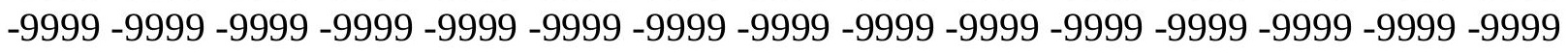

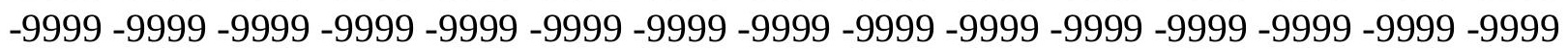


-9999 -9999 -9999 -9999 -9999 -9999 -9999 -9999 -9999 -9999 -9999 -9999 -9999 -9999 -9999 -9999 -9999 -9999 -9999 -9999 -9999 -9999 -9999 -9999 -9999 -9999 -9999 -9999 -9999 -9999 -9999 -9999 -9999 -9999 -9999 -9999 -9999 -9999 -9999 -9999 -9999 -9999 -9999 -9999 -9999 -9999 -9999 -9999 -9999 -9999 -9999 -9999 -9999 -9999 -9999 -9999 -9999 -9999 -9999 -9999 -9999 -9999 -9999 132.2767028809 130.4479980469 124.8982696533124 .034942627 122.818939209121 .1802368164119 .1301422119115 .1322860718113 .4619064331 110.9418029785107 .5891036987103 .626899719299 .3599472045995 .3977432251 91.7403335571389 .302040100188 .0829010009887 .7781066894587 .47332763672 86.8637619018686 .254188537685 .3398437584 .1206970214882 .59677124023 81.0728530883879 .5489196777377 .4154205322375 .2819290161172 .84364318848 70.1005783081167 .6623001098665 .2240066528362 .7857398986860 .95701980591 59.1283111572357 .909179687557 .2995986938556 .9948196411156 .69002914429 56.9948196411157 .2995986938557 .6043891906758 .2139587402358 .51874923706 58.5187492370658 .5187492370657 .909179687556 .9948196411155 .47089004517 53.3373985290551 .2038993835448 .4608306884845 .717769622843 .27949142456 41.4507789611840 .2316398620639 .622070312538 .4029312133835 .35507965088 28.3450202941920 .4206008911114 .020119667059 .448339462285 .181346893311 $1.21914100647-2.74306607246-6.095703125$-7.61962795258 -8.53398323059 $-9.14355373383-9.75312423706-10.3626899719-10.6674804688-11.2770500183$ $-11.2770500183-11.2770500183-10.9722604752-10.6674804688-10.3626899719$ $-9.75312423706-9.14355373383-8.53398323059-7.92441320419-7.01005792618$ $-6.40048694611-5.18134689331-4.26699209213-3.35263609886-2.43828105927$ -1.52392601967 - $.914355397224-9999.60957032442091 .219141006471 .828711032867$ 2.4382810592653 .3526360988624 .2669920921335 .1813468933116 .400486946106 7.9244132041939 .4483394622810 .9722604751612 .8009700775114 .62969017029 16.4584007263217 .9823207855219 .811029434221 .6397399902323 .16366958618 24.3828105926525 .906740188626 .8210906982427 .430660247827 .73545074463 27.7354507446327 .1258792877226 .5163097381625 .906740188625 .9067401886 26.5163097381628 .0402297973630 .1737308502232 .6120109558134 .44071960449 36.2694282531737 .4885711669938 .4029312133839 .0125007629439 .6220703125 39.622070312539 .9268493652339 .9268493652340 .2316398620640 .84120941162 41.1459884643641 .7555618286142 .66992187543 .2794914245644 .19384002686 45.1082000732446 .3273391723647 .2416992187548 .1560516357448 .7656211853 49.6799812316950 .2895507812550 .8991203308151 .5086898803752 .11825942993 52.4230384826752 .7278289794953 .2538833618253 .3373985290553 .64218139648 53.9469718933154 .2517509460454 .2517509460454 .5565414428754 .86132049561 54.8613204956155 .1661109924355 .1661109924355 .1661109924355 .47089004517 55.4708900451755 .7756805419955 .7756805419956 .0804595947356 .08045959473 56.0804595947356 .3852500915556 .3852500915556 .6900291442956 .69002914429 56.9948196411156 .9948196411157 .2995986938557 .2995986938557 .60438919067 57.909179687557 .909179687558 .2139587402358 .2139587402358 .51874923706 58.5187492370658 .8235282897958 .8235282897959 .1283111572359 .43310165405 59.4331016540559 .7378807067959 .7378807067960 .0426712036160 .04267120361 -7.55305433273 -9999 -9999 -9999 -9999 -9999 -9999 -9999 -9999 -9999-9999 -9999 -9999 -9999 -9999 -9999 -9999 -9999 -9999 -9999 -9999 -9999 -9999 -9999 -9999 -9999 -9999 -9999 -9999 -9999 -9999 -9999 -9999 -9999 -9999 -9999 -9999 -9999 -9999 -9999 -9999 
-9999 -9999 -9999 -9999 -9999 -9999 -9999 -9999 -9999 -9999 -9999 -9999 -9999 -9999 -9999 -9999 -9999 -9999 -9999 -9999 -9999 -9999 -9999 -9999 -9999 -9999 -9999 -9999 -9999 -9999

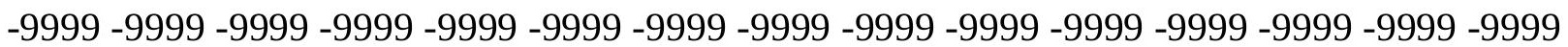
-9999 -9999 -9999 -9999 -9999 -9999 -9999 -9999 -9999 -9999 -9999 -9999 -9999 -9999 -9999 -9999 -9999 -9999 -9999 -9999 -9999 -9999 -9999 -9999 -9999 -9999 -9999 -9999 -9999 -9999 -9999 -9999 -9999 -9999 -9999 -9999 -9999 -9999 -9999 -9999 -9999 -9999 -9999 -9999 -9999 -9999 -9999 -9999 -9999 -9999 -9999 -9999 -9999 -9999 -9999 -9999 -9999 -9999 -9999 -9999

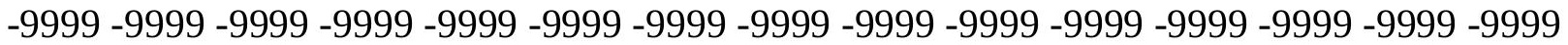

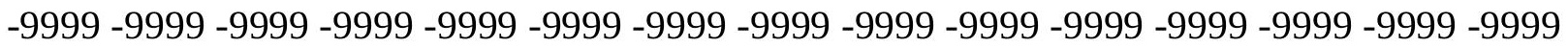
-9999 -9999 -9999 -9999 -9999 -9999 -9999 -9999 -9999 -9999 -9999 -9999 -9999 -9999 -9999 -999 -9999 -9999 -9999 -9999 -9999 133.1911010742131 .3623962402125 .1043930054 123.5417633057121 .6281585693119 .4064788818116 .8695678711111 .3430175781 109.1688842773106 .8607711792104 .236503601199 .9695205688595 .70252990723 91.7403335571390 .5211791992289 .9116134643688 .9972534179788 .08290100098 87.1685485839885 .9494018554784 .7302627563583 .206336975181 .98719787598 80.4632720947378 .3297805786176 .1962814331173 .7580032348671 .0149307251 68.2718734741265 .5288009643663 .0905189514260 .9570198059159 .12831115723 57.6043891906756 .6900291442956 .3852500915556 .0804595947356 .08045959473 56.3852500915556 .6900291442956 .9948196411157 .2995986938557 .60438919067 57.6043891906756 .9948196411156 .3852500915555 .4708900451753 .94697189331 52.1182594299350 .2895507812548 .4608306884846 .9369087219245 .7177696228 45.1082000732444 .4986305236843 .2794914245640 .2316398620635 .65985870361 29.8689403533924 .0780296325719 .2014598846414 .6296901702910 .05790996552 $5.181346893311-9999-.609570324421-1.82871103287-2.74306607246-3.96220707893$ $-5.18134689331-5.79091691971-6.7052731514-7.01005792618-7.01005792618$ $-7.01005792618-7.01005792618-6.7052731514-6.40048694611-6.095703125$ $-5.48613214493-4.87656211853-4.26699209213-3.65742206573-2.74306607246$ -1.82871103287 -.914355397224-.304785102606-9999.6095703244209 1.21914100647 1.8287110328672 .4382810592653 .0478510856633 .6574220657354 .266992092133 5.1813468933116 .0957031257 .3148431777958 .83876895904510 .36268997192 11.8866195678713 .715330123915 .5440397262617 .3727493286119 .20145988464 20.7253894805922 .2493095397923 .4684505462624 .6875991821325 .9067401886 26.8210906982427 .430660247827 .7354507446327 .7354507446327 .4306602478 27.1258792877227 .1258792877227 .1258792877228 .0402297973629 .25937080383 31.0880794525132 .9167900085434 .4407196044935 .9646492004437 .18378067017 38.0981407165538 .7077102661139 .3172798156739 .622070312539 .92684936523 40.2316398620640 .5364189147940 .8412094116241 .4507789611842 .06034851074 42.66992187543 .5842704772944 .4986305236845 .4129791259846 .32733917236 47.2416992187547 .8512611389248 .765621185349 .6799812316950 .28955078125 50.8991203308151 .5086898803751 .8134689331152 .4230384826752 .72782897949 53.0326118469253 .3373985290553 .6421813964853 .9469718933153 .94697189331 54.2517509460454 .5565414428754 .5565414428754 .8613204956154 .86132049561 55.1661109924355 .1661109924355 .1661109924355 .3237571716355 .39468765259 55.7756805419955 .7756805419956 .0804595947356 .0804595947356 .38525009155 56.3852500915556 .6900291442956 .6900291442956 .9948196411156 .99481964111 57.2995986938557 .2995986938557 .6043891906757 .6043891906757 .9091796875 
57.909179687558 .2139587402358 .2139587402358 .5187492370658 .51874923706 58.8235282897959 .1283111572359 .1283111572359 .4331016540559 .43310165405 59.7378807067960 .0426712036160 .04267120361 -7.94606971741 -9999 -9999 -9999 -9999 -9999 -9999 -9999 -9999-9999-9999

-9999 -9999 -9999 -9999 -9999 -9999 -9999 -9999 -9999 -9999 -9999 -9999 -9999 -9999 -9999 -9999 -9999 -9999 -9999 -9999 -9999 -9999 -9999 -9999 -9999 -9999 -9999 -9999 -9999 -9999 -9999 -9999 -9999 -9999 -9999 -9999 -9999 -9999 -9999 -9999 -9999 -9999 -9999 -9999 -9999

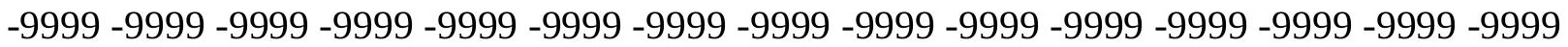

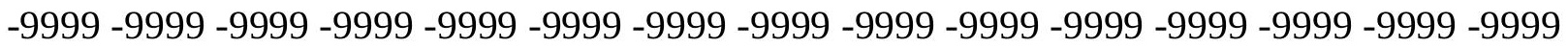
-9999 -9999 -9999 -9999 -9999 -9999 -9999 -9999 -9999 -9999 -9999 -9999 -9999 -9999 -9999

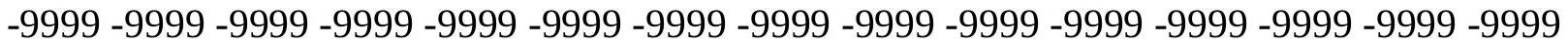
-9999 -9999 -9999 -9999 -9999 -9999 -9999 -9999 -9999 -9999 -9999 -9999 -9999 -9999 -9999 -

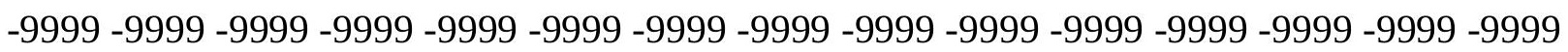
-9999 -9999 -9999 -9999 -9999 -9999 -9999 -9999 -9999 -9999 -9999 -9999 -9999 -9999 -9999 -9999 -9999 -9999 -9999 -9999 -9999 -9999 -9999 -9999 -9999 -9999 -9999 -9999 -9999 -9999

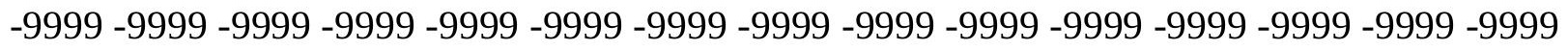
-9999 -9999 -9999 -9999 -9999 -9999 -9999 -9999 130.7528076172123 .9218444824 121.8542022705119 .5263595581116 .9539031982114 .1398620605106 .5595245361 104.2193603516 101.9976654053 100.161628723197.5312423706194.78817749023 93.2642517089891 .7403335571390 .2164001464888 .6924667358487 .16854858398 85.6446228027384 .4254837036183 .206336975181 .6824111938580 .15849304199 77.7202072143675 .2819290161172 .5388565063569 .4910125732466 .44316101074 63.7000885009861 .2618103027359 .1283111572357 .6043891906756 .38525009155 55.7756805419955 .4708900451755 .4708900451755 .4708900451755 .77568054199 56.0804595947356 .3852500915556 .6900291442956 .6900291442956 .38525009155 56.0804595947355 .1661109924354 .2517509460453 .0326118469251 .81346893311 50.5943298339849 .6799812316949 .0704002380448 .765621185348 .15605163574 46.9369087219244 .8034095764241 .4507789611837 .1837806701732 .61201095581 28.0402297973623 .7732391357419 .5062503814715 .2392597198511 .27705001831 8.5339832305916 .4004869461064 .2669920921332 .438281059265 .6095703244209 -.304785102606 -1.52392601967 -1.82871103287 -2.43828105927 -2.43828105927 $-2.74306607246-2.74306607246-2.74306607246-2.43828105927-2.13349604607$ -1.82871103287 -1.21914100647-.914355397224 -9999.3047851026058 1.21914100647 1.5239260196692 .1334960460662 .4382810592652 .7430660724643 .352636098862 3.6574220657354 .2669920921334 .876562118535 .4861321449286 .400486946106 7.3148431777958 .5339832305919 .75312423706111 .2770500183112 .80097007751 14.6296901702916 .4584007263218 .28710937520 .1158199310321 .3349609375 22.8588790893624 .0780296325724 .9923801422126 .2115192413326 .82109069824 27.430660247827 .7354507446328 .0402297973628 .0402297973628 .04022979736 28.0402297973628 .6497993469229 .2593708038330 .4785099029531 .69765090942 33.2215805053734 .7455101013235 .9646492004437 .1837806701737 .79335021973 38.7077102661139 .0125007629439 .622070312539 .9268493652340 .23163986206 40.5364189147941 .1459884643641 .7555618286142 .3651313781742 .97470092773 43.8890609741244 .4986305236845 .4129791259846 .3273391723647 .24169921875 48.1560516357448 .765621185349 .6799812316950 .2895507812550 .89912033081 51.2038993835451 .8134689331152 .1182594299352 .7278289794953 .03261184692 
53.3373985290553 .6421813964853 .6421813964853 .9469718933154 .25175094604 54.2517509460454 .5565414428754 .5565414428754 .8613204956154 .86132049561 55.1661109924355 .1661109924355 .2295188903855 .3023757934655 .47089004517 55.7756805419955 .7756805419956 .0804595947356 .0804595947356 .38525009155 56.3852500915556 .6900291442956 .6900291442956 .9948196411156 .99481964111 57.2995986938557 .2995986938557 .6043891906757 .6043891906757 .9091796875 58.2139587402358 .2139587402358 .5187492370658 .5187492370658 .82352828979 58.8235282897959 .1283111572359 .1283111572359 .4331016540559 .73788070679 59.7378807067959 .9859046936 -8.40184116364 -9999-9999 -9999 -9999-9999 -9999 -9999 -9999-9999-9999

-9999 -9999 -9999 -9999 -9999 -9999 -9999 -9999 -9999 -9999 -9999 -9999 -9999 -9999 -9999 -9999 -9999 -9999 -9999 -9999 -9999 -9999 -9999 -9999 -9999 -9999 -9999 -9999 -9999 -9999 -9999 -9999 -9999 -9999 -9999 -9999 -9999 -9999 -9999 -9999 -9999 -9999 -9999 -9999 -9999 -9999 -9999 -9999 -9999 -9999 -9999 -9999 -9999 -9999 -9999 -9999 -9999 -9999 -9999 -9999 -9999 -9999 -9999 -9999 -9999 -9999 -9999 -9999 -9999 -9999 -9999 -9999 -9999 -9999 -9999

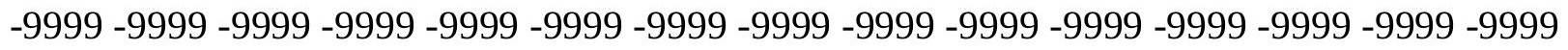
-9999 -9999 -9999 -9999 -9999 -9999 -9999 -9999 -9999 -9999 -9999 -9999 -9999 -9999 -9999 -

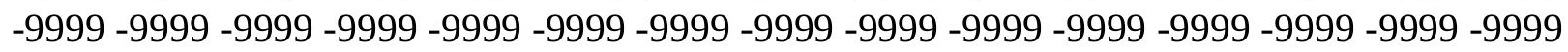

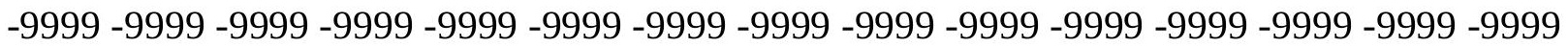

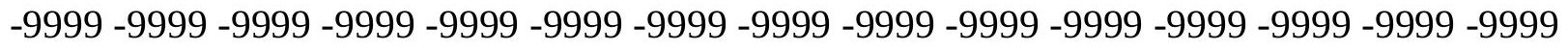

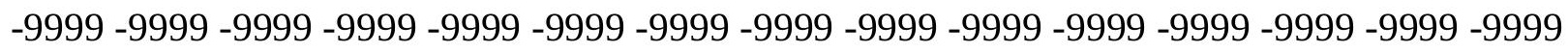

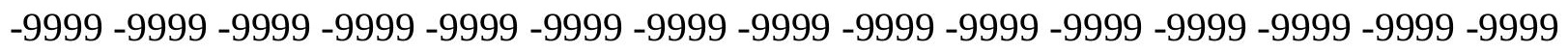
-9999 -9999 -9999 -9999 -9999 -9999 -9999 -9999 -9999 -9999 129.8385009766 121.9862670898119 .6283798218117 .0591659546114 .2754135132104 .278213501 102.3255767822100 .808280944899 .99506378174100 .016975402897 .53124237061 95.0929565429792 .9594726562590 .8259735107488 .9972534179787 .47332763672 86.254188537685 .0350494384883 .8159103393682 .2919769287179 .85370635986 77.4154205322374 .3675689697371 .014930725167 .6623001098664 .61444854736 61.5666007995659 .1283111572357 .2995986938556 .0804595947355 .47089004517 54.8613204956154 .8613204956154 .8613204956154 .8613204956155 .16611099243 55.4708900451755 .7756805419955 .7756805419955 .7756805419955 .47089004517 55.1661109924354 .5565414428753 .9469718933153 .0326118469252 .42303848267 51.8134689331151 .5086898803751 .5086898803751 .2038993835450 .28955078125 48.765621185346 .3273391723643 .2794914245639 .9268493652336 .26942825317 32.6120109558129 .2593708038326 .2115192413323 .1636695861819 .20145988464 15.5440397262612 .19141006479 .448339462287 .3148431777955 .486132144928 4.2669920921333 .3526360988622 .7430660724642 .1334960460661 .523926019669 1.21914100647 .9143553972244 .91435539722441 .219141006471 .21914100647 1.5239260196691 .8287110328672 .4382810592653 .0478510856633 .352636098862 3.9622070789344 .2669920921334 .5717768669134 .5717768669134 .87656211853 5.1813468933115 .4861321449286 .0957031256 .7052731513987 .314843177795 8.2291984558119 .4483394622810 .6674804687512 .191410064714 .02011966705 15.5440397262617 .3727493286119 .2014598846421 .0301704406722 .24930953979 23.4684505462624 .3828105926525 .6019496917726 .5163097381627 .12587928772 27.7354507446328 .0402297973628 .3450202941928 .6497993469228 .95458984375 29.2593708038329 .8689403533930 .4785099029531 .3928699493432 .30722045898 
33.5263595581134 .7455101013235 .9646492004436 .8790016174337 .79335021973 38.4029312133839 .0125007629439 .622070312539 .9268493652340 .53641891479 40.8412094116241 .4507789611842 .0603485107442 .66992187543 .27949142456 44.1938400268644 .8034095764245 .717769622846 .6321296691947 .24169921875 48.1560516357448 .765621185349 .6799812316950 .2895507812550 .89912033081 51.2038993835451 .8134689331152 .1182594299352 .4230384826752 .92534255981 53.0326118469253 .3373985290553 .6421813964853 .9469718933153 .94697189331 54.2517509460454 .5565414428754 .5565414428754 .8613204956154 .86132049561 54.8613204956155 .1661109924355 .1661109924355 .2471046447855 .47089004517 55.7756805419955 .7756805419955 .7756805419956 .0804595947356 .08045959473 56.3852500915556 .3852500915556 .6900291442956 .6900291442956 .99481964111 57.2995986938557 .2995986938557 .6043891906757 .6043891906757 .9091796875 57.909179687558 .2139587402358 .2139587402358 .5187492370658 .51874923706 58.8235282897959 .1283111572359 .1283111572359 .4331016540559 .43310165405 59.7378807067959 .73788070679 -9.00274276733 -9999 -9999 -9999 -9999 -9999 -9999 -9999 -9999 -9999-9999

-9999 -9999 -9999 -9999 -9999 -9999 -9999 -9999 -9999 -9999 -9999 -9999 -9999 -9999 -9999 -9999 -9999 -9999 -9999 -9999 -9999 -9999 -9999 -9999 -9999 -9999 -9999 -9999 -9999 -9999 -999 -9999 -9999 -9999 -9999 -9999 -9999 -9999 -9999 -9999 -9999 -9999 -9999 -9999 -9999 -9999 -

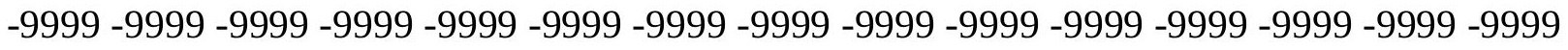
-9999 -9999 -9999 -9999 -9999 -9999 -9999 -9999 -9999 -9999 -9999 -9999 -9999 -9999 -9999 -9999 -9999 -9999 -9999 -9999 -9999 -9999 -9999 -9999 -9999 -9999 -9999 -9999 -9999 -9999 -9999 -9999 -9999 -9999 -9999 -9999 -9999 -9999 -9999 -9999 -9999 -9999 -9999 -9999 -9999 -9999 -9999 -9999 -9999 -9999 -9999 -9999 -9999 -9999 -9999 -9999 -9999 -9999 -9999 -9999 -9999 -9999 -9999 -9999 -9999 -9999 -9999 -9999 -9999 -9999 -9999 -9999 -9999 -9999 -9999 -9999 -9999 -9999 -9999 -9999 -9999 -9999 -9999 -9999 -9999 -9999 -9999 -9999 -9999 -9999 -9999 -9999 -9999 -9999 -9999 -9999 -9999 -9999 -9999 -9999 -9999 -9999 -9999 -9999 -9999 -

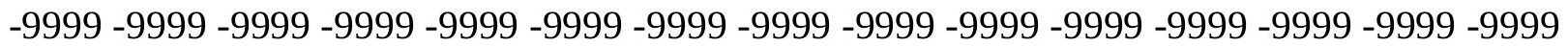
-9999 -9999-9999-9999 -9999-9999 -9999 -9999-9999-9999 -9999-9999 129.8385009766 119.7334213257117 .1948394775114 .4997177124111 .7500228882101 .717628479 101.0543899536100 .9599914551101 .297218322898 .7503814697396 .00731658936 93.2642517089891 .1307525634889 .302040100188 .3876876831187 .47332763672 86.5589828491285 .0350494384882 .5967712402379 .8537063598676 .50106811523 72.8436431884869 .4910125732465 .8335876464862 .4809494018659 .73788070679 57.6043891906756 .3852500915555 .1661109924354 .5565414428754 .25175094604 54.2517509460454 .2517509460454 .5565414428754 .8613204956154 .86132049561 55.1661109924355 .1661109924355 .1661109924354 .8613204956154 .55654144287 54.2517509460453 .9469718933153 .6421813964853 .6421813964853 .64218139648 53.6421813964853 .3373985290553 .0326118469251 .8134689331150 .28955078125 48.1560516357445 .4129791259842 .66992187540 .2316398620637 .79335021973 35.6598587036134 .1359291076728 .9545898437524 .0780296325720 .11581993103 16.7631797790514 .0201196670512 .191410064710 .667480468759 .753124237061 8.5339832305917 .6196279525766 .7052731513985 .7909169197085 .181346893311 4.876562118534 .876562118534 .876562118534 .876562118535 .181346893311 5.4861321449285 .7909169197086 .0957031256 .4004869461066 .705273151398 6.7052731513987 .0100579261787 .0100579261787 .0100579261787 .314843177795 
7.6196279525768 .2291984558118 .8387689590459 .75312423706110 .66748046875 11.8866195678713 .4105501174914 .934470176716 .4584007263218 .287109375 19.811029434221 .6397399902322 .8588790893624 .0780296325724 .99238014221 25.906740188626 .8210906982427 .430660247828 .0402297973628 .34502029419 28.9545898437529 .2593708038329 .5641593933130 .1737308502230 .78330039978 31.3928699493432 .3072204589833 .2215805053734 .1359291076735 .05028915405 36.26942825317 37.18378067017 37.7933502197338 .7077102661139 .31727981567 39.622070312540 .2316398620640 .8412094116241 .1459884643641 .75556182861 42.3651313781742 .9747009277343 .5842704772944 .4986305236845 .10820007324 46.0225486755446 .9369087219247 .5464782714848 .4608306884849 .07040023804 49.6799812316950 .2895507812550 .8991203308151 .5086898803751 .81346893311 52.1182594299352 .4230384826752 .7278289794953 .0326118469253 .33739852905 53.6421813964853 .9469718933153 .9469718933154 .2517509460454 .25175094604 54.5565414428754 .5565414428754 .8613204956154 .8613204956155 .16611099243 55.1661109924355 .1661109924355 .4708900451755 .4708900451755 .77568054199 55.7756805419956 .0804595947356 .0804595947356 .3852500915556 .38525009155 56.6900291442956 .6900291442956 .9948196411156 .9948196411157 .29959869385 57.2995986938557 .6043891906757 .6043891906757 .909179687557 .9091796875 58.2139587402358 .5187492370658 .5187492370658 .8235282897958 .82352828979 59.1283111572359 .1283111572359 .4331016540559 .7378807067959 .73788070679 -9.67698955536 -9999 -9999 -9999 -9999 -9999 -9999 -9999 -9999 -9999 -9999 -9999 -9999 -9999 -9999 -9999 -9999 -9999 -9999 -9999 -9999 -9999 -9999 -9999 -9999 -9999 -9999 -9999 -9999 -9999 -9999 -9999 -9999 -9999 -9999 -9999 -9999 -9999 -9999 -9999 -9999 -

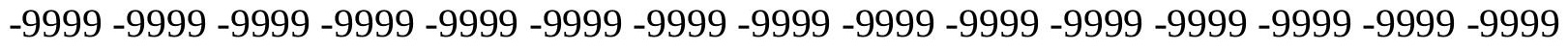

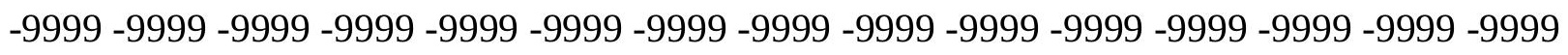
-9999 -9999 -9999 -9999 -9999 -9999 -9999 -9999 -9999 -9999 -9999 -9999 -9999 -9999 -9999 -9999 -9999 -9999 -9999 -9999 -9999 -9999 -9999 -9999 -9999 -9999 -9999 -9999 -9999 -9999 -

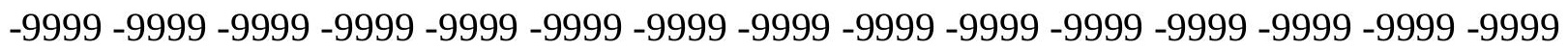
-9999 -9999 -9999 -9999 -9999 -9999 -9999 -9999 -9999 -9999 -9999 -9999 -9999 -9999 -9999 -9999 -9999 -9999 -9999 -9999 -9999 -9999 -9999 -9999 -9999 -9999 -9999 -9999 -9999 -999 -9999 -9999 -9999 -9999 -9999 -9999 -9999 -9999 -9999-9999 -9999 -9999 -9999 -9999 -9999 -9999 -9999 -9999 -9999 -9999 -9999 -9999 -9999 -9999 -9999 -9999 -9999 -9999 -9999 -9999 -

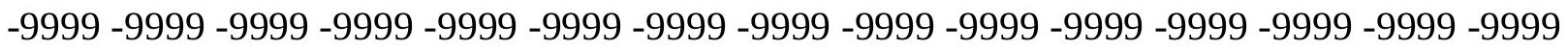
-9999 -9999 -9999 -9999 -9999 -9999 -9999 -9999 -9999 -9999 -9999 -9999 -9999 -9999 -9999 117.4927444458115 .0407104492112 .6017074585110 .1917648315101 .9737243652 102.1347198486102 .455497741799 .3599472045996 .3121032714893 .87381744385 91.43553924561 91.1307525634890.52117919922 89.91161346436 88.38768768311 85.9494018554782 .5967712402379 .2441329956175 .2819290161171 .31971740723 67.6623001098664 .004882812560 .9570198059158 .5187492370656 .69002914429 55.4708900451754 .5565414428753 .9469718933153 .9469718933153 .94697189331 53.9469718933154 .2517509460454 .2517509460454 .5565414428754 .55654144287 54.5565414428754 .5565414428754 .5565414428754 .5565414428754 .55654144287 54.5565414428754 .8613204956154 .8613204956155 .1661109924355 .16611099243 54.8613204956154 .2517509460453 .3373985290551 .8134689331149 .98476028442 47.8512611389246 .0225486755444 .1938400268642 .3651313781739 .92684936523 35.9646492004431 .6976509094227 .430660247824 .0780296325721 .03017044067 
19.2014598846417 .6775398254416 .4584007263215 .2392597198513 .7153301239 12.191410064710 .667480468759 .7531242370619 .1435537338268 .838768959045 8.5339832305918 .5339832305918 .5339832305918 .8387689590459 .143553733826 9.448339462289 .448339462289 .7531242370619 .7531242370619 .44833946228 9.448339462289 .1435537338269 .1435537338269 .448339462289 .753124237061 10.3626899719211 .2770500183112 .191410064713 .4105501174914 .62969017029 16.1536102294917 .6775398254419 .2014598846420 .7253894805922 .24930953979 23.4684505462624 .6875991821325 .6019496917726 .5163097381627 .4306602478 28.0402297973628 .6497993469228 .9545898437529 .2593708038329 .86894035339 30.1737308502231 .0880794525131 .6976509094232 .3072204589832 .91679000854 33.8311500549334 .7455101013235 .6598587036136 .5742111206137 .18378067017 38.0981407165538 .7077102661139 .3172798156739 .9268493652340 .53641891479 41.1459884643641 .7555618286142 .3651313781742 .66992187543 .58427047729 44.1938400268644 .8034095764245 .717769622846 .3273391723647 .24169921875 47.8512611389248 .765621185349 .3751907348649 .9847602844250 .59432983398 50.8991203308151 .5086898803751 .8134689331152 .4230384826752 .72782897949 53.0326118469253 .0326118469253 .3373985290553 .6421813964853 .94697189331 53.9469718933154 .2517509460454 .2517509460454 .5565414428754 .55654144287 54.8613204956154 .8613204956154 .8613204956155 .1661109924355 .16611099243 55.4708900451755 .4708900451755 .7756805419955 .7756805419955 .77568054199 56.0804595947356 .0804595947356 .3852500915556 .3852500915556 .69002914429 56.6900291442956 .9948196411157 .2995986938557 .2995986938557 .60438919067 57.6043891906757 .909179687557 .909179687558 .2139587402358 .21395874023 58.5187492370658 .5187492370658 .8235282897959 .1283111572359 .12831115723 59.4331016540559 .4331016540559 .6849822998 -10.486577034 -9999-9999 -9999 -9999 -9999 -9999 -9999 -9999-9999 -9999

-9999 -9999 -9999 -9999 -9999 -9999 -9999 -9999 -9999 -9999 -9999 -9999 -9999 -9999 -9999

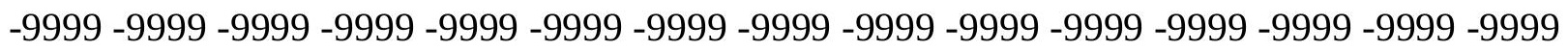
-9999 -9999 -9999 -9999 -9999 -9999 -9999 -9999 -9999 -9999 -9999 -9999 -9999 -9999 -9999 -9999 -9999 -9999 -9999 -9999 -9999 -9999 -9999 -9999 -9999 -9999 -9999 -9999 -9999 -9999 -9999 -9999 -9999 -9999 -9999 -9999 -9999 -9999 -9999-9999 -9999 -9999 -9999 -9999 -9999 -9999 -9999 -9999 -9999 -9999 -9999 -9999 -9999 -9999 -9999 -9999 -9999 -9999 -9999 -9999 -

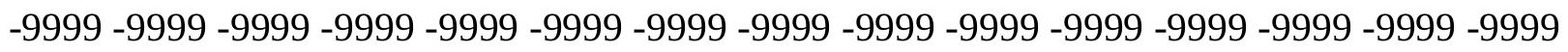
-9999 -9999 -9999 -9999 -9999 -9999 -9999 -9999 -9999 -9999 -9999 -9999 -9999 -9999 -9999 -9999 -9999 -9999 -9999 -9999 -9999 -9999 -9999 -9999 -9999 -9999 -9999 -9999 -9999 -9999 -9999 -9999 -9999 -9999 -9999 -9999 -9999 -9999 -9999 -9999 -9999 -9999 -9999 -9999 - -9999 -

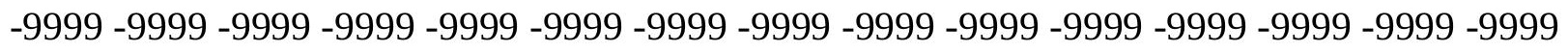

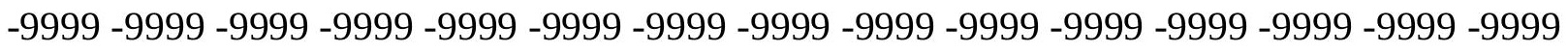
-9999 -9999 -9999 -9999 -9999 -9999 -9999 -9999 -9999 -9999 -9999 -9999 -9999 -9999 -9999 -9999 -9999 115.6748504639113.346572876 110.9411392212103.1020202637103.365272522 102.71260070899 .6647262573297 .5312423706197 .2264633178794 .78817749023 94.1785964965893 .2642517089892 .349891662689 .302040100185 .64462280273 81.9871978759878 .0249862670974 .062782287670 .1005783081166 .13836669922 62.7857398986860 .0426712036157 .6043891906756 .0804595947354 .86132049561 54.2517509460453 .6421813964853 .6421813964853 .9469718933153 .94697189331 53.9469718933154 .2517509460454 .2517509460454 .2517509460454 .55654144287 
54.5565414428754 .8613204956154 .8613204956155 .1661109924355 .47089004517 56.0804595947356 .0804595947356 .3852500915556 .3852500915556 .08045959473 55.4708900451754 .5565414428753 .3373985290551 .8134689331150 .28955078125 48.765621185346 .9369087219244 .4986305236841 .4507789611837 .79335021973 34.4407196044931 .0880794525128 .3450202941926 .2115192413324 .99238014221 24.0780296325722 .8588790893620 .7253894805918 .28710937516 .15361022949 14.6296901702913 .715330123913 .1057596206712 .8009700775112 .49619007111 12.4961900711112 .4961900711112 .8009700775113 .1057596206713 .10575962067 13.1057596206713 .1057596206712 .8009700775112 .191410064711 .88661956787 11.5818300247211 .5818300247211 .8866195678712 .4961900711113 .10575962067 14.0201196670514 .934470176716 .1536102294917 .3727493286118 .89668083191 20.4206008911121 .6397399902323 .1636695861824 .3828105926525 .29715919495 26.2115192413327 .1258792877228 .0402297973628 .6497993469229 .25937080383 29.5641593933129 .8689403533930 .4785099029531 .0880794525131 .69765090942 32.3072204589832 .9167900085433 .5263595581134 .4407196044935 .05028915405 35.9646492004436 .8790016174337 .7933502197338 .4029312133839 .01250076294 39.9268493652340 .5364189147941 .1459884643641 .7555618286142 .06034851074 42.66992187543 .2794914245643 .8890609741244 .8034095764245 .41297912598 46.0225486755446 .9369087219247 .5464782714848 .1560516357449 .07040023804 49.6799812316950 .2895507812550 .5943298339851 .2038993835451 .50868988037 52.1182594299352 .4230384826752 .7278289794953 .0326118469253 .33739852905 53.3373985290553 .6421813964853 .9469718933153 .9469718933154 .25175094604 54.2517509460454 .5565414428754 .5565414428754 .5565414428754 .86132049561 54.8613204956155 .1661109924355 .1661109924355 .1661109924355 .47089004517 55.4708900451755 .7756805419955 .7756805419956 .0804595947356 .08045959473 56.3852500915556 .3852500915556 .6900291442956 .6900291442956 .99481964111 56.9948196411157 .2995986938557 .2995986938557 .6043891906757 .60438919067 57.909179687557 .909179687558 .2139587402358 .5187492370658 .51874923706 58.8235282897958 .8235282897959 .1283111572359 .1283111572359 .43310165405 59.60263442993 -11.5179204941 -9999 -9999 -9999 -9999 -9999 -9999 -9999 -9999 -9999 $-9999$

-9999 -9999 -9999 -9999 -9999 -9999 -9999 -9999 -9999 -9999 -9999 -9999 -9999 -9999 -9999 -9999 -9999 -9999 -9999 -9999 -9999 -9999 -9999 -9999 -9999 -9999 -9999 -9999 -9999 -9999 -9999 -9999 -9999 -9999 -9999 -9999 -9999 -9999 -9999 -9999 -9999 -9999 -9999 -9999 -9999 -

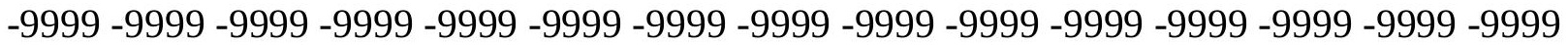
-9999 -9999 -9999 -9999 -9999 -9999 -9999 -9999 -9999 -9999 -9999 -9999 -9999 -9999 -9999 -9999 -9999 -9999 -9999 -9999 -9999 -9999 -9999 -9999 -9999 -9999 -9999 -9999 -9999 -9999

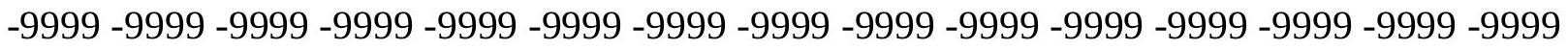
-9999 -9999 -9999 -9999 -9999 -9999 -9999 -9999 -9999 -9999 -9999 -9999 -9999 -9999 -9999 -9999 -9999 -9999 -9999 -9999 -9999 -9999 -9999 -9999 -9999 -9999 -9999 -9999 -9999 -9999 -

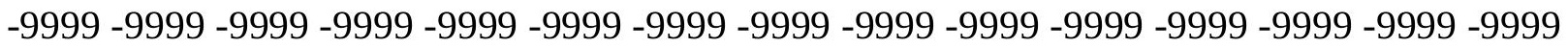
-9999 -9999 -9999 -9999 -9999 -9999 -9999 -9999 -9999 -9999 -9999 -9999 -9999 -9999 -9999 -9999 -9999 -9999 -9999 -9999 -9999 -9999 -9999 -9999 -9999 -9999 -9999 -9999 -9999 -9999 -9999 -9999 -9999 -9999 -9999 -9999 -9999 -9999 -9999 -9999 -9999 -9999 -9999 -9999 -9999 -9999 -9999 -9999 116.1854095459 113.8541412354111 .414390564108 .8182296753 104.7670822144103 .6268997192103 .3221969604102 .1029968262100 .8839035034 
99.6647262573296 .9216690063595 .0929565429792 .349891662688 .69246673584 85.0350494384880 .7680587768676 .8058471679772 .5388565063568 .57665252686 64.9192428588961 .5666007995658 .8235282897956 .6900291442955 .47089004517 54.5565414428753 .9469718933153 .9469718933153 .9469718933153 .94697189331 53.9469718933153 .9469718933153 .9469718933153 .9469718933154 .25175094604 54.5565414428754 .8613204956155 .1661109924355 .4708900451756 .08045959473 56.6900291442956 .9948196411157 .2995986938557 .2995986938557 .29959869385 56.9948196411156 .3852500915555 .4708900451754 .5565414428753 .33739852905 52.1182594299350 .2895507812548 .4608306884846 .0225486755443 .27949142456 40.8412094116238 .0981407165535 .9646492004433 .5263595581133 .52635955811 32.9167900085431 .0880794525128 .6497993469224 .9923801422121 .94453048706 20.1158199310319 .2014598846418 .5918903350817 .9823207855217 .37274932861 17.0679702758816 .7631797790517 .0679702758817 .3727493286117 .67753982544 17.6775398254417 .0679702758816 .4584007263215 .8488302230815 .23925971985 14.6296901702914 .3248996734614 .6296901702914 .934470176715 .23925971985 16.1536102294917 .0679702758817 .9823207855219 .2014598846420 .42060089111 21.6397399902322 .8588790893624 .0780296325725 .2971591949526 .21151924133 27.1258792877228 .0402297973628 .6497993469229 .2593708038329 .86894035339 30.1737308502230 .4785099029531 .0880794525131 .6976509094232 .30722045898 32.9167900085433 .5263595581134 .1359291076735 .0502891540535 .65985870361 36.5742111206137 .1837806701738 .0981407165539 .0125007629439 .6220703125 40.2316398620640 .8412094116241 .7555618286142 .3651313781742 .669921875 43.2794914245643 .8890609741244 .4986305236845 .4129791259846 .02254867554 46.6321296691947 .2416992187548 .1560516357448 .765621185349 .37519073486 49.9847602844250 .5943298339850 .8991203308151 .5086898803751 .81346893311 52.1182594299352 .4230384826752 .7278289794953 .0326118469253 .33739852905 53.3373985290553 .6421813964853 .9469718933153 .9469718933154 .25175094604 54.2517509460454 .5565414428754 .5565414428754 .5565414428754 .86132049561 54.8613204956155 .1661109924355 .1373748779355 .1661109924355 .47089004517 55.4708900451755 .7756805419955 .7756805419956 .0804595947356 .08045959473 56.3852500915556 .3852500915556 .6900291442956 .6900291442956 .99481964111 56.9948196411157 .2995986938557 .2995986938557 .6043891906757 .60438919067 57.909179687557 .909179687558 .2139587402358 .2139587402358 .51874923706 58.5187492370658 .8235282897959 .1283111572359 .1283111572359 .43310165405 59.43310165405 -12.7361850739 -9999 -9999 -9999 -9999 -9999 -9999 -9999 -9999 -9999 $-9999$

-9999 -9999 -9999 -9999 -9999 -9999 -9999 -9999 -9999 -9999 -9999 -9999 -9999 -9999 -9999

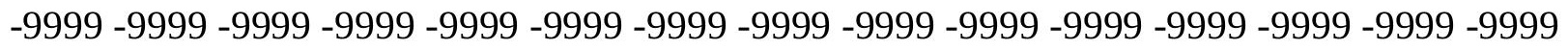
-9999 -9999 -9999 -9999 -9999 -9999 -9999 -9999 -9999 -9999 -9999 -9999 -9999 -9999 -9999 -9999 -9999 -9999 -9999 -9999 -9999 -9999 -9999 -9999 -9999 -9999 -9999 -9999 -9999 -9999 -

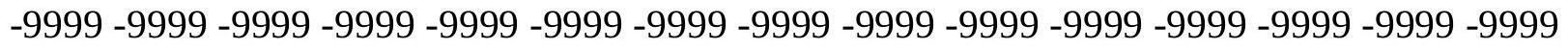

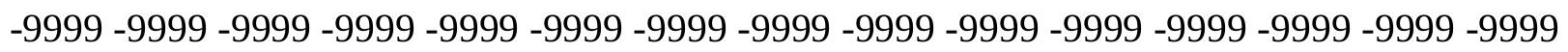

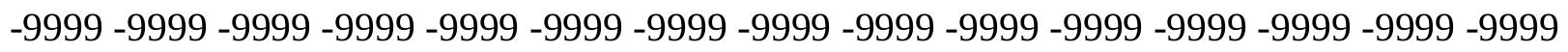
-9999 -9999 -9999 -9999 -9999 -9999 -9999 -9999 -9999 -9999 -9999 -9999 -9999 -9999 -9999 -

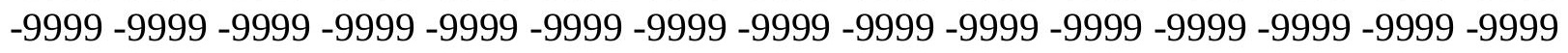

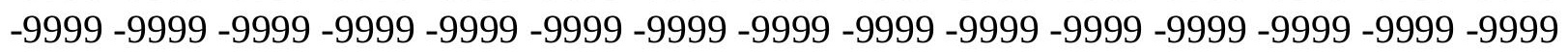


-9999 -9999 -9999 -9999 -9999 -9999 -9999 -9999 -9999 -9999 -9999 -9999 -9999 -9999 -9999 -9999 -9999 -9999 -9999 -9999 -9999 -9999 -9999 -9999 -9999 -9999 -9999 -9999 -9999 -9999 -9999 -9999 -9999 -9999 -9999 -9999 -9999 -9999 -9999 -9999 -9999 -9999 -9999 -9999 -9999 -9999 -9999 -9999 -9999 124.3523025513 114.3390655518112 .05859375109 .9543838501 107.8938980103106 .8595809937106 .3700027466104 .8460998535101 .7982025146 99.9695205688597 .8360290527395 .0929565429791 .7403335571388 .08290100098 84.1206970214879 .8537063598675 .5867080688571 .3197174072367 .35751342773 63.7000885009860 .3474502563557 .909179687556 .3852500915555 .16611099243 54.8613204956154 .5565414428754 .5565414428754 .5565414428754 .25175094604 54.2517509460453 .9469718933153 .9469718933153 .9469718933154 .25175094604 54.8613204956155 .1661109924355 .7756805419956 .3852500915556 .99481964111 57.2995986938557 .909179687557 .909179687557 .909179687557 .9091796875 57.6043891906756 .9948196411156 .3852500915555 .4708900451754 .25175094604 53.0326118469251 .5086898803749 .9847602844248 .4608306884846 .93690872192 45.4129791259844 .1938400268642 .9747009277342 .66992187542 .36513137817 40.5364189147937 .4885711669932 .9167900085428 .0402297973626 .51630973816 25.6019496917724 .6875991821324 .0780296325723 .1636695861822 .55410003662 21.9445304870622 .2493095397922 .8588790893623 .1636695861822 .85887908936 22.2493095397921 .334960937520 .1158199310318 .8966808319118 .287109375 17.6775398254417 .6775398254417 .9823207855218 .28710937518 .89668083191 19.5062503814720 .1158199310321 .334960937522 .2493095397923 .46845054626 24.3828105926525 .2971591949526 .2115192413327 .1258792877228 .04022979736 28.9545898437529 .5641593933130 .1737308502230 .4785099029530 .78330039978 31.3928699493431 .6976509094232 .3072204589832 .9167900085433 .52635955811 34.1359291076734 .7455101013235 .6598587036136 .2694282531737 .18378067017 37.7933502197338 .7077102661139 .622070312540 .2316398620640 .84120941162 41.7555618286142 .3651313781742 .9747009277343 .5842704772944 .19384002686 44.8034095764245 .4129791259846 .0225486755446 .6321296691947 .24169921875 47.8512611389248 .765621185349 .3751907348649 .9847602844250 .28955078125 50.8991203308151 .2038993835451 .8134689331152 .1182594299352 .42303848267 52.7278289794953 .0326118469253 .0326118469253 .3373985290553 .64218139648 53.6421813964853 .9469718933153 .9469718933154 .2517509460454 .25175094604 54.5565414428754 .5565414428754 .5565414428754 .8613204956154 .86132049561 54.8613204956154 .9920616149955 .1661109924355 .4708900451755 .47089004517 55.4708900451755 .7756805419955 .7756805419956 .0804595947356 .08045959473 56.3852500915556 .3852500915556 .6900291442956 .6900291442956 .99481964111 56.9948196411157 .2995986938557 .2995986938557 .6043891906757 .60438919067 57.909179687558 .2139587402358 .2139587402358 .5187492370658 .51874923706 58.8235282897958 .8235282897959 .1283111572359 .1283111572359 .37144088745 -13.8193969727 -9999 -9999 -9999 -9999 -9999 -9999 -9999 -9999 -9999 -9999 -9999 -9999 -9999 -9999 -9999 -9999 -9999 -9999 -9999 -9999 -9999 -9999 -9999 -9999 -9999

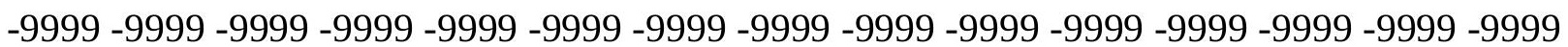
-9999 -9999 -9999 -9999 -9999 -9999 -9999 -9999 -9999 -9999 -9999 -9999 -9999 -9999 -9999 -9999 -9999 -9999 -9999 -9999 -9999 -9999 -9999 -9999 -9999 -9999 -9999 -9999 -9999 -9999

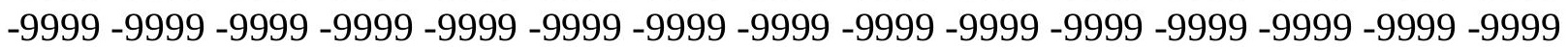

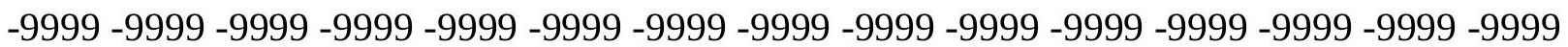


-9999 -9999 -9999 -9999 -9999 -9999 -9999 -9999 -9999 -9999 -9999 -9999 -9999 -9999 -9999 -9999 -9999 -9999 -9999 -9999 -9999 -9999 -9999 -9999 -9999 -9999 -9999 -9999 -9999 -9999 -9999 -9999 -9999 -9999 -9999 -9999 -9999 -9999 -9999 -9999 -9999 -9999 -9999 -9999 -9999 -9999 -9999 -9999 -9999 -9999 -9999 -9999 -9999 -9999 -9999 -9999 -9999 -9999 -9999 -9999 -9999 -9999 -9999 -9999 -9999 -9999 -9999 -9999 -9999 -9999 -9999 -9999 -9999 -9999 -9999 -9999 -9999 -9999 -9999 -9999 -9999 -9999 -9999 -9999 -9999 -9999 -9999 -9999 -9999 -9999 -9999 -9999 -9999 -9999 -9999 -9999 -9999 -9999 -9999 -9999 -9999 -9999 -9999 -9999 -9999 -9999 -9999 -9999 -9999 -9999 -9999 119.7806015015113 .6033248901112 .3087615967 110.9418029785108 .3087615967107 .2844009399105 .4557037354103 .3221969604 100.883903503498 .1408081054794 .7881774902391 .1307525634887 .16854858398 82.9015579223678 .6345596313574 .3675689697370 .4053573608466 .44316101074 62.7857398986859 .7378807067957 .909179687556 .6900291442955 .77568054199 55.4708900451755 .4708900451755 .4708900451754 .8613204956154 .55654144287 54.2517509460453 .9469718933153 .9469718933154 .2517509460454 .86132049561 55.4708900451756 .0804595947356 .6900291442957 .2995986938557 .60438919067 58.2139587402358 .5187492370658 .5187492370658 .5187492370658 .21395874023 57.909179687557 .6043891906756 .9948196411156 .0804595947355 .16611099243 54.2517509460453 .3373985290552 .7278289794952 .4230384826752 .42303848267 52.4230384826752 .1182594299351 .8134689331151 .8134689331150 .59432983398 46.9369087219242 .0603485107437 .4885711669934 .7455101013232 .91679000854 32.0024414062531 .0880794525130 .1737308502228 .9545898437528 .04022979736 28.9545898437529 .5641593933129 .5641593933129 .2593708038328 .34502029419 27.1258792877225 .6019496917723 .7732391357422 .5541000366221 .94453048706 21.6397399902321 .9445304870621 .9445304870621 .9445304870622 .55410003662 22.8588790893623 .7732391357424 .6875991821325 .2971591949526 .21151924133 26.8210906982427 .7354507446328 .3450202941929 .2593708038329 .86894035339 30.4785099029530 .7833003997831 .3928699493431 .6976509094232 .00244140625 32.6120109558132 .9167900085433 .5263595581134 .1359291076734 .74551010132 35.3550796508836 .2694282531736 .8790016174337 .7933502197338 .40293121338 39.3172798156740 .2316398620640 .8412094116241 .7555618286142 .36513137817 43.2794914245643 .8890609741244 .4986305236845 .1082000732445 .7177696228 46.0225486755446 .6321296691947 .2416992187548 .1560516357448 .7656211853 49.3751907348649 .9847602844250 .2895507812550 .8991203308151 .20389938354 51.8134689331152 .1182594299352 .4230384826752 .7278289794953 .03261184692 53.0326118469253 .3373985290553 .6080589294453 .6421813964853 .94697189331 53.9469718933153 .9469718933154 .2517509460454 .2517509460454 .55654144287 54.5565414428754 .5565414428754 .8613204956154 .8613204956154 .86132049561 54.9109115600655 .1661109924355 .4708900451755 .4708900451755 .47089004517 55.7756805419955 .7756805419956 .0804595947356 .0804595947356 .38525009155 56.3852500915556 .6900291442956 .6900291442956 .9948196411156 .99481964111 57.2995986938557 .2995986938557 .6043891906757 .6043891906757 .9091796875 57.909179687558 .2139587402358 .2139587402358 .5187492370658 .82352828979 58.8235282897959 .1283111572359 .1283111572359 .3031578064 -14.2827672958 -9999 -9999 -9999 -9999 -9999 -9999 -9999 -9999 -9999 -9999 -9999 -9999 -9999 -9999 -9999 -9999 -9999 -9999 -9999 -9999 -9999 -9999 -9999 -9999 -9999

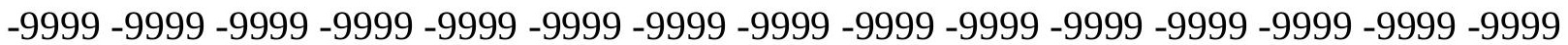


-9999 -9999 -9999 -9999 -9999 -9999 -9999 -9999 -9999 -9999 -9999 -9999 -9999 -9999 -9999 -9999 -9999 -9999 -9999 -9999 -9999 -9999 -9999 -9999 -9999 -9999 -9999 -9999 -9999 -9999 -9999 -9999 -9999 -9999 -9999 -9999 -9999 -9999 -9999 -9999 -9999 -9999 -9999 -9999 -9999 -9999 -9999 -9999 -9999 -9999 -9999 -9999 -9999 -9999 -9999 -9999 -9999 -9999 -9999 -9999 -9999 -9999 -9999 -9999 -9999 -9999 -9999 -9999 -9999 -9999 -9999 -9999 -9999 -9999 -9999 -9999 -9999 -9999 -9999 -9999 -9999 -9999 -9999 -9999 -9999 -9999 -9999 -9999 -9999 -9999 -9999 -9999 -9999 -9999 -9999 -9999 -9999 -9999 -9999 -9999 -9999 -9999 -9999 -9999 -9999

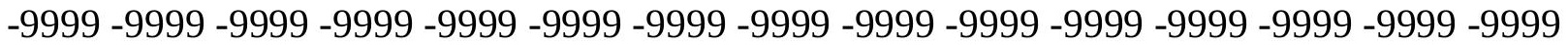
-9999 -9999 -9999 -9999 -9999 -9999 -9999 -9999 -9999 -9999 -9999 -9999 -9999 -9999 -9999 -9999 -9999 -9999 -9999 -9999 -9999 -9999 -9999 -9999 -9999 -9999 -9999 -9999 -9999 -9999 -9999 -9999 -9999 -9999 -9999 -9999 -9999 -9999 -9999 -9999 -9999 -9999 -9999 -9999 -9999 -999 -9999 -9999 -9999 -9999-9999-9999-9999 121.3044967651118 .2565994263114 .0172042847 112.4101638794109 .492805481108 .8082962036106 .3700027466103 .9317016602 100.883903503497 .8360290527394 .1785964965890 .2164001464886 .2541885376 81.9871978759877 .7202072143673 .7580032348669 .4910125732465 .83358764648 62.4809494018660 .0426712036158 .2139587402357 .2995986938556 .69002914429 56.3852500915556 .6900291442955 .7756805419954 .8613204956154 .55654144287 54.2517509460454 .2517509460454 .5565414428755 .1661109924355 .77568054199 56.3852500915556 .9948196411157 .6043891906757 .909179687558 .51874923706 58.8235282897958 .8235282897958 .8235282897958 .8235282897958 .82352828979 58.5187492370658 .2139587402357 .6043891906756 .9948196411156 .69002914429 56.3852500915556 .3852500915556 .9948196411158 .2139587402359 .43310165405 59.4331016540559 .4331016540559 .7378807067960 .3474502563555 .47089004517 50.5943298339846 .3273391723643 .2794914245641 .1459884643639 .6220703125 38.7077102661138 .0981407165537 .4885711669936 .8790016174337 .18378067017 37.1837806701737 .1837806701736 .5742111206135 .6598587036134 .13592910767 31.6976509094229 .5641593933127 .430660247826 .8210906982426 .82109069824 26.5163097381626 .2115192413325 .906740188626 .2115192413326 .51630973816 26.8210906982427 .1258792877227 .7354507446328 .0402297973628 .64979934692 29.2593708038329 .8689403533930 .1737308502230 .7833003997831 .39286994934 31.6976509094232 .0024414062532 .3072204589832 .6120109558133 .22158050537 33.5263595581134 .1359291076734 .7455101013235 .3550796508835 .96464920044 36.8790016174337 .4885711669938 .4029312133839 .3172798156739 .92684936523 40.8412094116241 .7555618286142 .66992187543 .2794914245644 .19384002686 44.8034095764245 .4129791259846 .0225486755446 .6321296691946 .93690872192 47.5464782714848 .1560516357448 .765621185349 .3751907348649 .98476028442 50.5943298339850 .8991203308151 .5086898803751 .8134689331152 .11825942993 52.4230384826752 .7278289794953 .0326118469253 .0326118469253 .33739852905 53.6421813964853 .6421813964853 .9469718933153 .9469718933153 .94697189331 54.2517509460454 .2517509460454 .2517509460454 .5565414428754 .55654144287 54.5565414428754 .8613204956154 .8613204956154 .8613204956154 .88659286499 55.1661109924355 .1661109924355 .4708900451755 .4708900451755 .77568054199 55.7756805419956 .0804595947356 .0804595947356 .3852500915556 .38525009155 56.3852500915556 .6900291442956 .6900291442956 .9948196411157 .29959869385 57.2995986938557 .6043891906757 .6043891906757 .909179687557 .9091796875 58.2139587402358 .2139587402358 .5187492370658 .5187492370658 .82352828979 
58.8235282897959 .1283111572359 .30387496948 -12.9968118668 -9999 -9999 -9999 -9999 -9999 -9999 -9999 -9999 -9999 -9999

-9999 -9999 -9999 -9999 -9999 -9999 -9999 -9999 -9999 -9999 -9999 -9999 -9999 -9999 -9999 -9999 -9999 -9999 -9999 -9999 -9999 -9999 -9999 -9999 -9999 -9999 -9999 -9999 -9999 -9999 -9999 -9999 -9999 -9999 -9999 -9999 -9999 -9999 -9999 -9999 -9999 -9999-9999 -9999 -9999 -9999 -9999 -9999 -9999 -9999 -9999 -9999 -9999 -9999 -9999 -9999 -9999 -9999 -9999 -9999

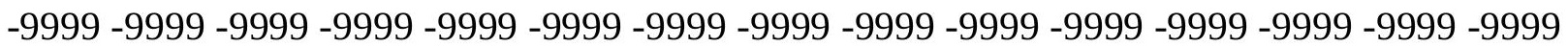
-9999 -9999 -9999 -9999 -9999 -9999 -9999 -9999 -9999 -9999 -9999 -9999 -9999 -9999 -9999 -999 -9999 -9999 -9999 -9999 -9999 -9999 -9999 -9999 -9999 -9999 -9999 -9999 -9999 -9999 -9999 -9999 -9999 -9999 -9999 -9999 -9999 -9999 -9999 -9999 -9999 -9999 -9999 -9999 -9999 -9999 -

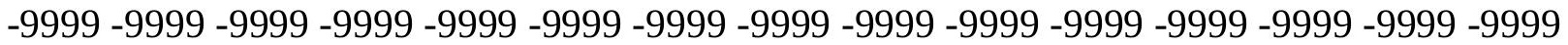

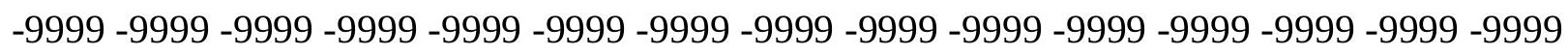
-9999 -9999 -9999 -9999 -9999 -9999 -9999 -9999 -9999 -9999 -9999 -9999 -9999 -9999 -9999 -9999 -9999 -9999 -9999 -9999 -9999 -9999 -9999 -9999 -9999 -9999 -9999 -9999 -9999 -9999 -9999 -9999 -9999 -9999 -9999 -9999 -9999 -9999 -9999 -9999 -9999 -9999 -9999 -9999 -9999 -9999 -9999 -9999 -9999 -9999 -9999 -9999 -9999 123.1332015991120 .0852966309 115.2292327881113 .5304260254110 .3496170044109 .4179000854106 .979598999 103.9317016602 100.5791015625 97.2264633178793.56903076172 89.60682678223 85.6446228027381 .3776321411177 .4154205322373 .1484298706169 .49101257324 65.8335876464863 .0905189514260 .6522407531758 .8235282897957 .9091796875 57.2995986938556 .9948196411156 .3852500915555 .7756805419954 .86132049561 54.5565414428754 .5565414428754 .8613204956155 .4708900451756 .38525009155 56.9948196411157 .6043891906757 .909179687558 .5187492370658 .82352828979 58.8235282897959 .1283111572359 .1283111572359 .1283111572359 .12831115723 59.1283111572358 .8235282897958 .8235282897958 .5187492370658 .51874923706 58.5187492370659 .1283111572360 .6522407531762 .4809494018664 .0048828125 64.6144485473664 .9192428588964 .9192428588964 .6144485473661 .87137985229 57.909179687554 .2517509460451 .2038993835449 .0704002380447 .85126113892 46.9369087219246 .6321296691946 .3273391723646 .3273391723646 .32733917236 46.0225486755445 .4129791259844 .8034095764243 .5842704772941 .75556182861 39.3172798156736 .5742111206133 .5263595581133 .2215805053733 .22158050537 32.6120109558131 .6976509094230 .4785099029530 .4785099029530 .47850990295 30.1737308502230 .1737308502230 .4785099029530 .4785099029530 .78330039978 30.7833003997831 .0880794525131 .3928699493432 .0024414062532 .30722045898 32.6120109558132 .9167900085433 .2215805053733 .5263595581133 .83115005493 34.4407196044934 .7455101013235 .3550796508835 .9646492004436 .87900161743 37.4885711669938 .4029312133839 .0125007629439 .9268493652340 .84120941162 41.7555618286142 .66992187543 .5842704772944 .1938400268645 .10820007324 45.717769622846 .6321296691947 .2416992187547 .5464782714848 .15605163574 48.765621185349 .3751907348649 .9847602844250 .2895507812550 .89912033081 51.2038993835451 .5086898803752 .1182594299352 .4230384826752 .72782897949 52.7278289794953 .0326118469253 .3373985290553 .3373985290553 .64218139648 53.6421813964853 .9345474243253 .9469718933153 .9469718933154 .25175094604 54.2517509460454 .2517509460454 .5565414428754 .5565414428754 .55654144287 54.5565414428754 .8613204956154 .8613204956154 .8613204956154 .88548278809 55.1661109924355 .1661109924355 .4708900451755 .4708900451755 .77568054199 
55.7756805419955 .7756805419956 .0804595947356 .0804595947356 .38525009155 56.3852500915556 .6900291442956 .6900291442956 .9948196411156 .99481964111 57.2995986938557 .2995986938557 .6043891906757 .6043891906757 .9091796875 58.2139587402358 .2139587402358 .5187492370658 .5187492370658 .82352828979 58.8235282897959 .1283111572359 .12831115723 -8.10093975067 -9999 -9999 -9999 -9999 -9999 -9999 -9999 -9999-9999-9999

-9999 -9999 -9999 -9999 -9999 -9999 -9999 -9999 -9999 -9999 -9999 -9999 -9999 -9999 -9999

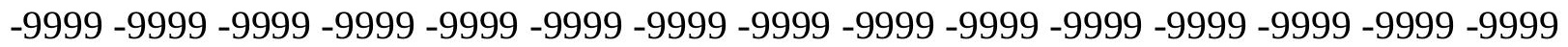
-9999 -9999 -9999 -9999 -9999 -9999 -9999 -9999 -9999 -9999 -9999 -9999 -9999 -9999 -9999 -9999 -9999 -9999 -9999 -9999 -9999 -9999 -9999 -9999 -9999 -9999 -9999 -9999 -9999 -9999

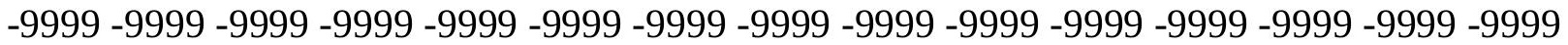
-9999 -9999 -9999 -9999 -9999 -9999 -9999 -9999 -9999 -9999 -9999 -9999 -9999 -9999 -9999 -9999 -9999 -9999 -9999 -9999 -9999 -9999 -9999 -9999 -9999 -9999 -9999 -9999 -9999 -9999 -9999 -9999 -9999 -9999 -9999 -9999 -9999 -9999 -9999 -9999 -9999 -9999 -9999 -9999 -9999 -9999 -9999 -9999 -9999 -9999 -9999 -9999 -9999 -9999 -9999 -9999 -9999 -9999 -9999 -9999

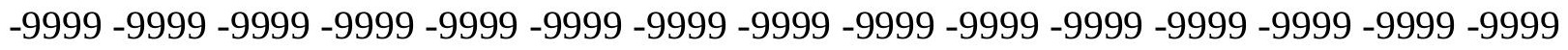

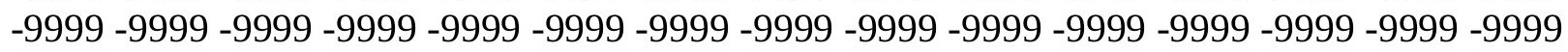
-9999 -9999 -9999 -9999 -9999 -9999 -9999 -9999 -9999 -9999 -9999 -9999 -9999 -9999 -9999 -999 -9999 -9999 -9999 -9999 -9999 -9999 -9999 -9999 -9999 -9999 -9999 -9999 -9999-999 -999 -9999 -9999 -9999 -9999 -9999 -9999 -9999 -9999 -9999 -9999 121.6092987061 116.1930465698114 .3096923828110 .8388442993109 .7226028442106 .6747970581 103.6268997192100 .274299621696 .6168823242292 .9594726562589 .3020401001 85.3398437581 .0728530883877 .110626220773 .1484298706169 .49101257324 66.4431610107463 .3953094482461 .2618103027359 .7378807067958 .82352828979 58.2139587402357 .6043891906756 .6900291442956 .0804595947355 .47089004517 55.4708900451756 .0804595947356 .6900291442957 .2995986938557 .9091796875 58.2139587402358 .5187492370658 .8235282897959 .1283111572359 .12831115723 59.4331016540559 .4331016540559 .4331016540559 .4331016540559 .43310165405 59.4331016540559 .7378807067960 .0426712036160 .3474502563560 .65224075317 61.5666007995663 .3953094482465 .5288009643667 .0527267456168 .27187347412 68.8814392089868 .8814392089868 .2718734741266 .4431610107463 .70008850098 60.9570198059158 .5187492370656 .6900291442955 .4708900451754 .86132049561 55.1661109924355 .4708900451755 .7756805419955 .1661109924354 .55654144287 53.6421813964853 .0326118469252 .1182594299350 .5943298339847 .85126113892 45.1082000732442 .66992187541 .4507789611840 .8412094116239 .6220703125 38.0981407165536 .5742111206135 .6598587036134 .7455101013234 .13592910767 33.5263595581133 .2215805053732 .9167900085432 .9167900085432 .61201095581 32.9167900085432 .9167900085432 .9167900085433 .2215805053733 .52635955811 33.5263595581133 .8311500549334 .1359291076734 .4407196044935 .05028915405 35.3550796508835 .9646492004436 .5742111206137 .4885711669938 .09814071655 39.0125007629439 .9268493652340 .8412094116241 .7555618286142 .669921875 43.5842704772944 .4986305236845 .4129791259846 .0225486755446 .93690872192 47.5464782714848 .4608306884848 .765621185349 .3751907348649 .98476028442 50.2895507812550 .8991203308151 .2038993835451 .8134689331152 .11825942993 52.4230384826752 .7278289794952 .7278289794953 .0326118469253 .33739852905 53.3373985290553 .6421813964853 .6421813964853 .9469718933153 .94697189331 
53.9469718933154.25175094604 54.25175094604 54.25175094604 54.25175094604 54.5565414428754 .5565414428754 .5565414428754 .5565414428754 .86132049561 54.8613204956154 .8613204956154 .8613204956154 .9071350097755 .16611099243 55.1661109924355 .4708900451755 .4708900451755 .7756805419955 .77568054199 55.7756805419956 .0804595947356 .0804595947356 .3852500915556 .38525009155 56.6900291442956 .6900291442956 .9948196411156 .9948196411157 .29959869385 57.2995986938557 .6043891906757 .6043891906757 .909179687557 .9091796875 58.2139587402358 .2139587402358 .5187492370658 .8235282897958 .82352828979 59.1283111572359 .12831115723 -3.19018030167 -9999 -9999 -9999-9999 -9999 -9999 -9999 -9999-9999-9999

-9999 -9999 -9999 -9999 -9999 -9999 -9999 -9999 -9999 -9999 -9999 -9999 -9999 -9999 -9999 -9999 -9999 -9999 -9999 -9999 -9999 -9999 -9999 -9999 -9999 -9999 -9999 -9999 -9999 -9999 -9999 -9999 -9999 -9999 -9999 -9999 -9999 -9999 -9999 -9999 -9999 -9999 -9999 -9999 -9999 -9999 -9999 -9999 -9999 -9999 -9999 -9999 -9999 -9999 -9999 -9999 -9999 -9999 -9999 - 9999 -9999 -9999 -9999 -9999 -9999 -9999 -9999 -9999 -9999 -9999 -9999 -9999 -9999 -9999 -9999

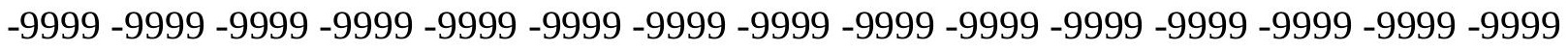
-9999 -9999 -9999 -9999 -9999 -9999 -9999 -9999 -9999 -9999 -9999 -9999 -9999 -9999 -9999 -9999 -9999 -9999 -9999 -9999 -9999 -9999 -9999 -9999 -9999 -9999 -9999 -9999 -9999 -9999 -9999 -9999 -9999 -9999 -9999 -9999 -9999 -9999 -9999 -9999 -9999 -9999 -9999 -9999 -9999 -

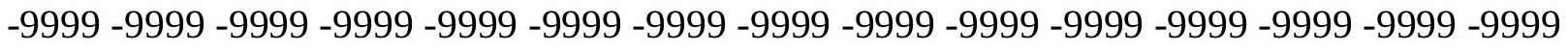

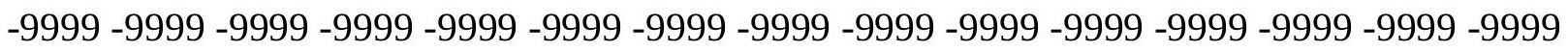
-9999 -9999 -9999 -9999 -9999 -9999 -9999 -9999 -9999 -9999 -9999 -9999 -9999 -9999 -9999 -9999 -9999 -9999 -9999 -9999 -9999 -9999 -9999 -9999 -9999 -9999 -9999 -9999 -9999 -9999 -9999 -9999 -9999 -9999 -9999 -9999 -9999 -9999 -9999 -9999 -9999 122.8283996582 116.8285217285114 .7494735718110 .8729858398109 .7226028442106 .6747970581 103.322196960499 .9695205688596 .3121032714892 .9594726562589 .3020401001 85.0350494384881 .0728530883877 .110626220773 .4532165527370 .10057830811 67.0527267456164 .3096618652361 .8713798522961 .2618103027360 .65224075317 59.7378807067958 .5187492370657 .6043891906756 .9948196411156 .99481964111 57.6043891906758 .2139587402358 .8235282897959 .1283111572359 .43310165405 59.4331016540559 .4331016540559 .4331016540559 .4331016540559 .43310165405 59.7378807067959 .7378807067959 .7378807067959 .7378807067960 .04267120361 60.3474502563560 .9570198059161 .8713798522962 .7857398986864 .0048828125 65.8335876464867 .9670867919969 .7957916259871 .014930725171 .92929077148 72.2340774536171 .6244964599670 .4053573608468 .5766525268666 .44316101074 64.6144485473663 .0905189514262 .4809494018662 .1761703491262 .48094940186 63.3953094482464 .3096618652363 .3953094482462 .1761703491261 .26181030273 60.6522407531760 .0426712036159 .1283111572356 .3852500915553 .64218139648 51.8134689331150 .2895507812548 .765621185347 .2416992187545 .10820007324 42.66992187540 .8412094116239 .3172798156738 .0981407165537 .18378067017 36.2694282531735 .6598587036135 .0502891540534 .7455101013234 .44071960449 34.4407196044934 .4407196044934 .4407196044934 .4407196044934 .44071960449 34.7455101013235 .0502891540535 .3550796508835 .6598587036135 .96464920044 36.5742111206137 .1837806701738 .0981407165538 .7077102661139 .6220703125 40.5364189147941 .4507789611842 .3651313781743 .5842704772944 .49863052368 45.4129791259846 .3273391723647 .2416992187548 .1560516357449 .07040023804 
49.6799812316950 .2895507812550 .5943298339851 .2038993835451 .50868988037 51.8134689331152 .4230384826752 .4230384826752 .7278289794953 .03261184692 53.3373985290553 .3373985290553 .6421813964853 .6421813964853 .94697189331 53.9469718933153 .9469718933153 .9469718933154 .2517509460454 .25175094604 54.2517509460454 .2517509460454 .5565414428754 .5565414428754 .55654144287 54.5565414428754 .5565414428754 .5565414428754 .8613204956154 .86132049561 54.8613204956154 .8613204956154 .9835090637255 .1661109924355 .16611099243 55.4708900451755 .4708900451755 .4708900451755 .7756805419955 .77568054199 56.0804595947356 .0804595947356 .3852500915556 .3852500915556 .69002914429 56.6900291442956 .9948196411156 .9948196411157 .2995986938557 .29959869385 57.6043891906757 .6043891906757 .909179687557 .909179687558 .21395874023 58.2139587402358 .5187492370658 .5187492370658 .8235282897958 .82352828979 59.128311157232 .218629598618 -9999 -9999 -9999 -9999 -9999 -9999 -9999 -9999 -9999 $-9999$

-9999 -9999 -9999 -9999 -9999 -9999 -9999 -9999 -9999 -9999 -9999 -9999 -9999 -9999 -9999

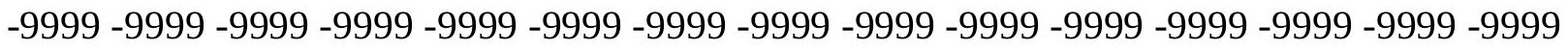
-9999 -9999 -9999 -9999 -9999 -9999 -9999 -9999 -9999 -9999 -9999 -9999 -9999 -9999 -9999 -9999 -9999 -9999 -9999 -9999 -9999 -9999 -9999 -9999 -9999 -9999 -9999 -9999 -9999 -9999 -9999 -9999 -9999 -9999 -9999 -9999 -9999 -9999 -9999 -9999 -9999 -9999 -9999 -9999 -9999 -

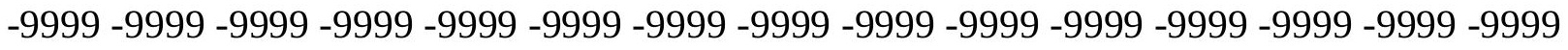

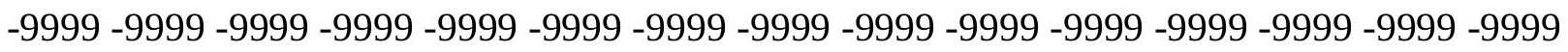
-9999 -9999 -9999 -9999 -9999 -9999 -9999 -9999 -9999 -9999 -9999 -9999 -9999 -9999 -9999 -9999 -9999 -9999 -9999 -9999 -9999 -9999 -9999 -9999 -9999 -9999 -9999 -9999 -9999 -9999 -

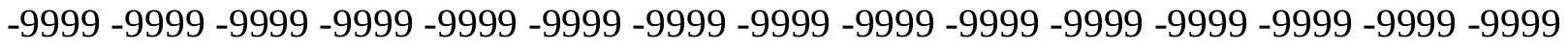

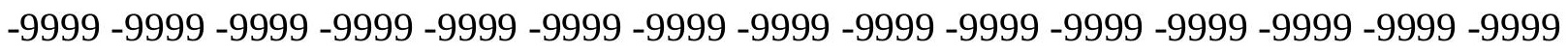
-9999 -9999 -9999 -9999 -9999 -9999 -9999 -9999 -9999 -9999 -9999 -9999 -9999 -9999 -9999 -9999 -9999 -9999 -9999 -9999 -9999 -9999 -9999 -9999 -9999 -9999 -9999 -9999 -9999 - 9999 -9999 -9999 -9999 -9999 -9999 -9999 -9999 -9999 -9999 -9999 -9999 -9999 123.43800354 117.1735076904114 .8946990967110 .5126342773109 .4179000854106 .3700027466 103.017402648999 .6647262573296 .3121032714892 .6546783447388 .99725341797 85.0350494384881 .3776321411177 .7202072143674 .3675689697371 .31971740723 68.2718734741266 .1383666992264 .9192428588964 .004882812562 .78573989868 61.5666007995660 .0426712036159 .1283111572359 .4331016540560 .04267120361 60.3474502563560 .6522407531760 .9570198059160 .6522407531760 .65224075317 60.3474502563560 .0426712036160 .0426712036159 .7378807067960 .04267120361 60.0426712036160 .0426712036160 .0426712036160 .3474502563561 .26181030273 62.1761703491263 .3953094482464 .6144485473666 .1383666992267 .96708679199 70.1005783081171 .9292907714873 .1484298706174 .062782287674 .67236328125 74.3675689697373 .7580032348672 .5388565063571 .014930725169 .79579162598 68.5766525268668 .2718734741268 .2718734741268 .8814392089869 .49101257324 70.1005783081169 .4910125732468 .5766525268667 .9670867919967 .05272674561 66.4431610107465 .2240066528363 .3953094482461 .2618103027359 .43310165405 58.2139587402356 .6900291442954 .2517509460451 .2038993835448 .46083068848 46.0225486755443 .8890609741242 .0603485107440 .5364189147939 .31727981567 38.0981407165537 .1837806701736 .5742111206136 .2694282531735 .96464920044 35.6598587036135 .3550796508835 .3550796508835 .3550796508835 .35507965088 
35.6598587036135 .9646492004436 .2694282531736 .5742111206137 .18378067017 37.7933502197338 .7077102661139 .3172798156740 .2316398620641 .45077896118 42.3651313781743 .2794914245644 .4986305236845 .4129791259846 .63212966919 47.5464782714848 .4608306884849 .3751907348650 .2895507812550 .89912033081 51.5086898803752 .1182594299352 .4230384826752 .7278289794953 .03261184692 53.3373985290553 .3373985290553 .6421813964853 .6421813964853 .94697189331 53.9469718933153 .9469718933154 .2517509460454 .2517509460454 .25175094604 54.2517509460454 .2517509460454 .5565414428754 .5565414428754 .55654144287 54.5565414428754 .5565414428754 .5565414428754 .5565414428754 .55654144287 54.5565414428754 .8613204956154 .8613204956154 .8613204956154 .86132049561 55.1661109924355 .115509033255 .1661109924355 .1661109924355 .47089004517 55.4708900451755 .4708900451755 .7756805419955 .7756805419956 .08045959473 56.0804595947356 .3852500915556 .3852500915556 .6900291442956 .69002914429 56.6900291442956 .9948196411157 .2995986938557 .2995986938557 .60438919067 57.6043891906757 .909179687557 .909179687558 .2139587402358 .21395874023 58.5187492370658 .5187492370658 .8235282897958 .8235282897916 .92799568176 -11.4961252213 -9999 -9999 -9999 -9999 -9999 -9999 -9999 -9999 -9999-9999 -9999 -9999 -9999 -9999 -9999 -9999 -9999 -9999 -9999 -9999 -9999 -9999 -9999 -9999 -9999 -9999 -9999 -9999 -9999 -9999 -9999 -9999 -9999 -9999 -9999 -9999 -9999 -9999 -9999 -9999 -9999 -9999 -9999 -9999 -9999 -9999 -9999 -9999 -9999 -9999 -9999 -9999 -9999 -9999 -9999

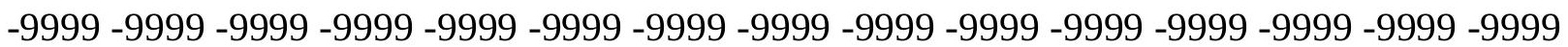
-9999 -9999 -9999 -9999 -9999 -9999 -9999 -9999 -9999 -9999 -9999 -9999 -9999 -9999 -9999 -9999 -9999 -9999 -9999 -9999 -9999 -9999 -9999 -9999 -9999 -9999 -9999 -9999 -9999 -9999 -9999 -9999 -9999 -9999 -9999 -9999 -9999 -9999 -9999 -9999 -9999 -9999 -9999 -9999 -9999

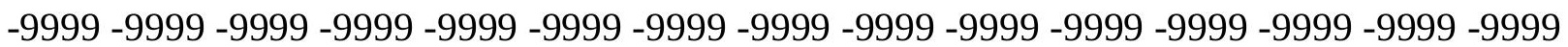
-9999 -9999 -9999 -9999 -9999 -9999 -9999 -9999 -9999 -9999 -9999 -9999 -9999 -9999 -9999 -9999 -9999 -9999 -9999 -9999 -9999 -9999 -9999 -9999 -9999 -9999 -9999 -9999 -9999 -9999 -9999 -9999 -9999 -9999 -9999 -9999 -9999 -9999 -9999 -9999 -9999 -9999 -9999 -9999 -9999 -9999 -9999 -9999 -9999 -9999 -9999 -9999 -9999 -9999 -9999 -9999 -9999 -9999 -9999 -9999

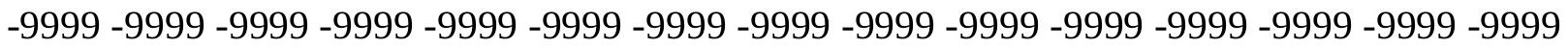
-9999 -9999 -9999 -9999 -9999 -9999 -9999 -9999 -9999 -9999 -9999 -9999 -9999 -9999 117.2675857544 114.8100509644112.0971908569109.0868148804 106.0652008057 102.71260070899 .6647262573296 .3121032714892 .6546783447388 .99725341797 85.64462280273 82.29197692871 78.93934631348 75.89148712158 73.14842987061 71.014930725169 .4910125732468 .2718734741267 .0527267456165 .83358764648 64.3096618652362 .1761703491263 .0905189514263 .3953094482463 .39530944824 63.3953094482463 .0905189514262 .4809494018661 .8713798522961 .56660079956 60.9570198059160 .3474502563560 .3474502563560 .3474502563560 .34745025635 60.3474502563560 .6522407531760 .9570198059161 .8713798522963 .09051895142 64.6144485473666 .1383666992267 .9670867919969 .7957916259871 .92929077148 73.4532165527374 .9771423339876 .1962814331176 .5010681152376 .80584716797 76.5010681152375 .5867080688574 .6723632812574 .062782287673 .45321655273 73.1484298706173 .1484298706173 .7580032348674 .062782287674 .36756896973 74.3675689697373 .7580032348673 .1484298706172 .5388565063571 .62449645996 70.4053573608468 .5766525268667 .0527267456165 .5288009643663 .39530944824 63.3953094482459 .7378807067956 .3852500915553 .0326118469250 .28955078125 
47.5464782714845 .4129791259843 .5842704772942 .0603485107440 .53641891479 39.622070312538 .7077102661137 .7933502197337 .4885711669936 .87900161743 36.5742111206136 .2694282531736 .2694282531736 .2694282531736 .26942825317 36.5742111206136 .8790016174337 .1837806701737 .7933502197338 .40293121338 39.3172798156740 .2316398620641 .1459884643642 .0603485107442 .97470092773 44.1938400268645 .4129791259846 .3273391723647 .5464782714848 .7656211853 49.6799812316950 .5943298339851 .5086898803752 .4230384826753 .03261184692 53.3373985290553 .6421813964853 .9469718933154 .2517509460454 .25175094604 54.2517509460454 .2517509460454 .5565414428754 .5565414428754 .55654144287 54.5565414428754 .5565414428754 .5565414428754 .5565414428754 .55654144287 54.5565414428754 .5565414428754 .5565414428754 .5565414428754 .55654144287 54.5565414428754 .5565414428754 .8613204956154 .8613204956154 .86132049561 54.8613204956154 .8613204956154 .8613204956154 .8613204956155 .16611099243 55.1661109924355 .1661109924355 .1661109924355 .4708900451755 .47089004517 55.4708900451755 .7756805419955 .7756805419956 .0804595947356 .08045959473 56.3852500915556 .3852500915556 .3852500915556 .6900291442956 .69002914429 56.9948196411156 .9948196411157 .2995986938557 .2995986938557 .60438919067 57.6043891906757 .909179687558 .2139587402358 .2139587402358 .51874923706 58.5187492370658 .8235282897958 .823528289796 .425911903381 -18.1928844452 -9999 -9999 -9999 -9999 -9999 -9999 -9999 -9999 -9999 -9999

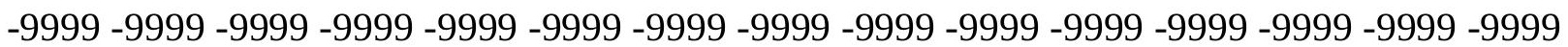
-9999 -9999 -9999 -9999 -9999 -9999 -9999 -9999 -9999 -9999 -9999 -9999 -9999 -9999 -9999 -9999 -9999 -9999 -9999 -9999 -9999 -9999 -9999 -9999 -9999 -9999 -9999 -9999 -9999 -9999 -9999 -9999 -9999 -9999 -9999 -9999 -9999 -9999 -9999 -9999 -9999 -9999 -9999 -9999 -9999 -9999 -9999 -9999 -9999 -9999 -9999 -9999 -9999 -9999 -9999 -9999 -9999 -9999 -9999 -9999 -9999 -9999 -9999 -9999 -9999 -9999 -9999 -9999 -9999 -9999 -9999 -9999 -9999 -9999 -9999 -9999 -9999 -9999 -9999 -9999 -9999 -9999 -9999 -9999 -9999 -9999 -9999 -9999 -9999 -9999 -9999 -9999 -9999 -9999 -9999 -9999 -9999 -9999 -9999 -9999 -9999 -9999 -9999 -9999 -9999 -9999 -9999 -9999 -9999 -9999 -9999 -9999 -9999 -9999 -9999 -9999 -9999 -9999 -9999 -9999 -9999 -9999 -9999 -9999 -9999 -9999 -9999 -9999 -9999 -9999 -9999 -9999 -9999 -9999 -9999 -9999 -9999 -9999 -9999 -9999 -9999 -9999 -9999 -9999 -9999 -9999 -9999 -9999 -9999 -9999 -9999 -9999 -9999 -9999 -9999 -9999 -9999 -9999 -9999 -9999 -9999 -9999 -9999 -9999 -9999 -9999 -9999 -9999 -9999 -9999 -9999 -9999 -9999 -9999 -9999 -9999 -9999 -9999 -9999 -9999 -9999 -9999 -9999 -9999 -9999 -9999 -9999 -9999 -9999 -9999 -9999 -9999 -9999 -9999 -9999 120.9997024536114 .6340713501111 .857383728108 .2671051025105 .7603988647 102.71260070899 .6647262573296 .3121032714892 .9594726562589 .91161346436 86.5589828491283 .5111236572380 .7680587768678 .3297805786176 .19628143311 74.3675689697373 .1484298706172 .2340774536171 .3197174072370 .10057830811 69.1862335205168 .5766525268667 .9670867919967 .3575134277366 .44316101074 65.5288009643664 .6144485473663 .7000885009862 .7857398986862 .17617034912 61.5666007995661 .2618103027360 .9570198059160 .9570198059161 .26181030273 61.2618103027361 .8713798522963 .0905189514264 .3096618652366 .13836669922 67.6623001098669 .4910125732471 .6244964599673 .4532165527374 .97714233398 76.5010681152377 .7202072143678 .3297805786178 .6345596313578 .63455963135 78.3297805786177 .7202072143677 .4154205322377 .110626220777 .1106262207 77.110626220777 .4154205322377 .7202072143678 .0249862670978 .02498626709 
77.7202072143677 .110626220776 .5010681152375 .5867080688574 .36756896973 72.8436431884870 .7101516723668 .2718734741265 .2240066528364 .91924285889 63.0905189514260 .0426712036156 .6900291442953 .6421813964850 .89912033081 48.4608306884846 .3273391723644 .4986305236842 .9747009277341 .75556182861 40.5364189147939 .622070312538 .7077102661138 .0981407165537 .79335021973 37.4885711669937 .1837806701737 .1837806701737 .1837806701737 .18378067017 37.4885711669937 .7933502197338 .4029312133839 .0125007629439 .92684936523 40.5364189147941 .7555618286142 .66992187543 .8890609741244 .80340957642 46.0225486755447 .2416992187548 .4608306884849 .6799812316950 .89912033081 51.8134689331152 .7278289794953 .6421813964854 .2517509460454 .55654144287 54.8613204956155 .1661109924355 .1661109924355 .1661109924355 .16611099243 55.1661109924355 .1661109924355 .1661109924354 .8613204956154 .86132049561 54.8613204956154 .8613204956154 .8613204956154 .8613204956154 .86132049561 54.8613204956154 .8613204956154 .8613204956154 .8613204956154 .86132049561 54.8613204956154 .8613204956154 .8613204956154 .8613204956154 .86132049561 54.8613204956154 .8613204956155 .1661109924355 .1661109924355 .16611099243 55.1661109924355 .4708900451755 .4708900451755 .4708900451755 .47089004517 55.7756805419955 .7756805419956 .0804595947356 .0804595947356 .38525009155 56.3852500915556 .3852500915556 .6900291442956 .6900291442956 .99481964111 56.9948196411157 .2995986938557 .2995986938557 .6043891906757 .60438919067 57.909179687557 .909179687558 .2139587402358 .5187492370658 .51874923706 58.7262306213458 .8235282897919 .43904495239 -14.1051130295 -9999-9999 -9999 -9999 -9999 -9999 -9999 -9999-9999-9999

-9999 -9999 -9999 -9999 -9999 -9999 -9999 -9999 -9999 -9999 -9999 -9999 -9999 -9999 -9999 -9999 -9999 -9999 -9999 -9999 -9999 -9999 -9999 -9999 -9999 -9999 -9999 -9999 -9999 -9999 -9999 -9999 -9999 -9999 -9999 -9999 -9999 -9999 -9999 -9999 -9999 -9999 -9999 -9999 -9999 -9999 -9999 -9999 -9999 -9999 -9999 -9999 -9999 -9999 -9999 -9999 -9999 -9999 -9999 -9999

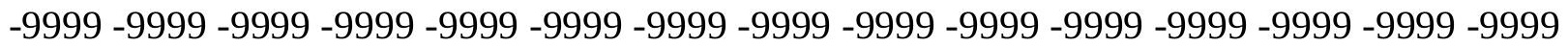

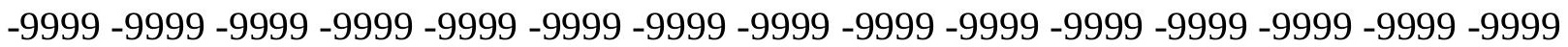
-9999 -9999 -9999 -9999 -9999 -9999 -9999 -9999 -9999 -9999 -9999 -9999 -9999 -9999 -9999 -9999 -9999 -9999 -9999 -9999 -9999 -9999 -9999 -9999 -9999 -9999 -9999 -9999 -9999 -9999 -

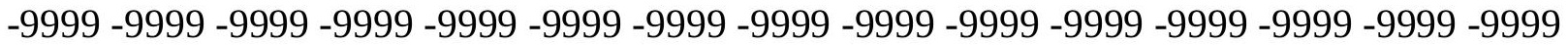

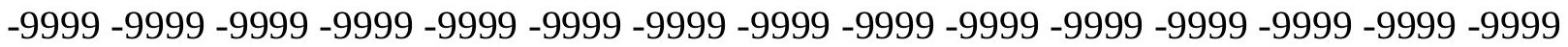
-9999 -9999 -9999 -9999 -9999 -9999 -9999 -9999 -9999 -9999 -9999 -9999 -9999 -9999 -9999 -

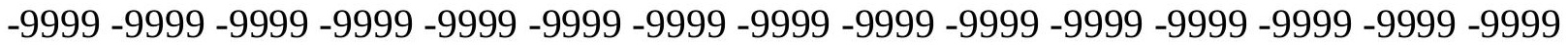
-9999 -9999 -9999 -9999 -9999 -9999 -9999 -9999 -9999 -9999 -9999 -9999 -9999 -9999 -9999

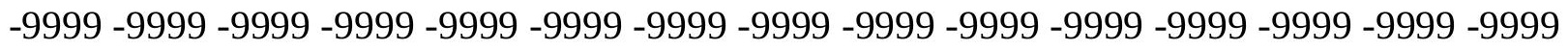
-9999-9999 114.432800293111.6582946777 107.4772415161 105.918548584103.0174026489 99.9695205688596.9216690063594.1785964965891.13075256348 88.38768768311 85.6446228027383 .206336975181 .0728530883879 .5489196777378 .32978057861 77.4154205322377 .110626220776 .8058471679776 .5010681152374 .97714233398 72.8436431884871 .014930725169 .4910125732467 .9670867919966 .44316101074 65.2240066528364 .3096618652363 .3953094482462 .7857398986862 .17617034912 62.1761703491261 .8713798522962 .1761703491262 .4809494018663 .09051895142 64.3096618652365 .5288009643667 .3575134277368 .8814392089870 .71015167236 72.8436431884874 .6723632812576 .1962814331177 .7202072143678 .63455963135 
79.5489196777380 .1584930419980 .4632720947380 .4632720947380 .15849304199 80.1584930419980 .1584930419980 .1584930419980 .1584930419980 .46327209473 80.7680587768680 .7680587768680 .7680587768680 .7680587768680 .15849304199 79.5489196777378 .6345596313577 .4154205322375 .8914871215873 .75800323486 71.014930725168 .8814392089867 .0527267456164 .9192428588962 .48094940186 59.4331016540556 .3852500915553 .6421813964851 .2038993835448 .7656211853 46.9369087219245 .1082000732443 .5842704772942 .3651313781741 .14598846436 40.2316398620639 .622070312539 .0125007629438 .4029312133838 .09814071655 37.7933502197337 .7933502197337 .7933502197338 .0981407165538 .40293121338 39.0125007629439 .622070312540 .2316398620641 .1459884643642 .06034851074 43.2794914245644 .4986305236845 .717769622846 .9369087219248 .15605163574 49.3751907348650 .5943298339851 .8134689331153 .0326118469254 .25175094604 54.8613204956155 .4708900451755 .7756805419956 .0804595947356 .08045959473 56.0804595947356 .0804595947355 .7756805419955 .7756805419955 .77568054199 55.4708900451755 .4708900451755 .4708900451755 .4708900451755 .16611099243 55.1661109924355 .1661109924355 .1661109924355 .1661109924355 .16611099243 55.1661109924354 .8613204956154 .8613204956154 .8613204956154 .86132049561 54.8613204956154 .8613204956154 .8613204956154 .8613204956155 .16611099243 55.1661109924355 .1661109924355 .1602859497155 .1661109924355 .47089004517 55.4708900451755 .4708900451755 .7756805419955 .7756805419955 .77568054199 56.0804595947356 .0804595947356 .3852500915556 .3852500915556 .38525009155 56.6900291442956 .6900291442956 .9948196411156 .9948196411157 .29959869385 57.2995986938557 .6043891906757 .6043891906757 .909179687557 .9091796875 58.2139587402358 .2139587402358 .5187492370658 .7068443298358 .82352828979 27.73011207581 -6.84350538254 -9999 -9999 -9999 -9999 -9999 -9999 -9999 -9999 -9999 $-9999$

-9999 -9999 -9999 -9999 -9999 -9999 -9999 -9999 -9999 -9999 -9999 -9999 -9999 -9999 -9999 -9999 -9999 -9999 -9999 -9999 -9999 -9999 -9999 -9999 -9999 -9999 -9999 -9999 -9999 -9999 -9999 -9999 -9999 -9999 -9999 -9999 -9999 -9999 -9999 -9999 -9999 -9999 -9999 -9999 -9999 -9999 -9999 -9999 -9999 -9999 -9999 -9999 -9999 -9999 -9999 -9999 -9999 -9999 -9999 -999 -9999 -9999 -9999 -9999 -9999 -9999 -9999 -9999 -9999 -9999 -9999 -9999 -9999 -9999 -9999

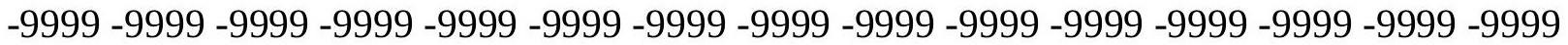

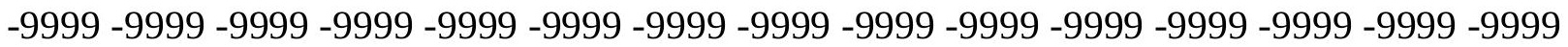

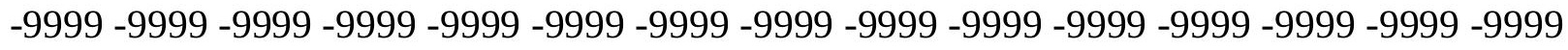
-9999 -9999 -9999 -9999 -9999 -9999 -9999 -9999 -9999 -9999 -9999 -9999 -9999 -9999 -9999 -9999 -9999 -9999 -9999 -9999 -9999 -9999 -9999 -9999 -9999 -9999 -9999 -9999 -9999 -9999

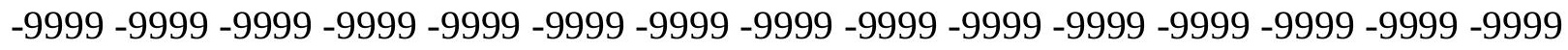

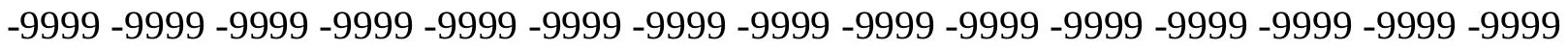
-9999 -9999 -9999 -9999 -9999 -9999 -9999 -9999 -9999 -9999 -9999 -9999 -9999 - 9999 - -999 -9999 -9999 -9999 -9999 -9999 -9999 -9999 -9999 -9999 -9999 -9999 -9999 -9999 -9999 -9999 -9999 -9999-9999 118.5614013672111.7131271362 106.8106079102105.8516464233 103.6268997192100 .883903503498 .1408081054795 .397743225192 .95947265625 90.2164001464887 .7781066894585 .6446228027384 .1206970214882 .90155792236 82.2919769287181 .9871978759882 .5967712402383 .206336975180 .15849304199 77.110626220774 .6723632812572 .2340774536170 .4053573608468 .57665252686 67.0527267456165 .8335876464864 .9192428588964 .004882812563 .39530944824 
63.0905189514263 .0905189514263 .0905189514263 .7000885009864 .30966186523 65.5288009643666 .7479400634868 .2718734741270 .1005783081171 .92929077148 73.7580032348675 .5867080688577 .110626220778 .6345596313579 .85370635986 80.7680587768681 .3776321411181 .6824111938581 .9871978759882 .29197692871 82.29197692871 82.29197692871 82.29197692871 82.59677124023 82.90155792236 82.9015579223683 .206336975183 .206336975182 .9015579223682 .59677124023 81.9871978759881 .0728530883879 .8537063598678 .0249862670975 .89148712158 73.7580032348671 .3197174072369 .1862335205166 .7479400634864 .30966186523 61.5666007995658 .5187492370655 .7756805419953 .3373985290551 .20389938354 49.0704002380447 .2416992187545 .4129791259844 .1938400268642 .97470092773 41.7555618286140 .8412094116239 .9268493652339 .3172798156739 .01250076294 38.4029312133838 .4029312133838 .4029312133838 .4029312133838 .70771026611 39.3172798156739 .9268493652340 .8412094116241 .7555618286142 .669921875 43.8890609741245 .1082000732446 .3273391723647 .5464782714849 .07040023804 50.2895507812551 .5086898803753 .0326118469254 .2517509460455 .47089004517 56.0804595947356 .6900291442956 .9948196411157 .2995986938556 .99481964111 56.9948196411156 .6900291442956 .6900291442956 .3852500915556 .08045959473 56.0804595947356 .0804595947355 .7756805419955 .7756805419955 .77568054199 55.4708900451755 .4708900451755 .4708900451755 .4708900451755 .16611099243 55.1661109924355 .1661109924355 .1661109924355 .1661109924355 .16611099243 55.1661109924355 .1661109924355 .1661109924355 .1661109924355 .16611099243 55.1661109924355 .1661109924355 .1522789001555 .1661109924355 .47089004517 55.4708900451755 .4708900451755 .7756805419955 .7756805419955 .77568054199 56.0804595947356 .0804595947356 .3852500915556 .3852500915556 .38525009155 56.6900291442956 .6900291442956 .9948196411156 .9948196411157 .29959869385 57.2995986938557 .6043891906757 .6043891906757 .909179687557 .9091796875 58.2139587402358 .2139587402358 .5187492370658 .6987876892158 .82352828979 34.0092010498 -1.74741256237 -9999 -9999 -9999 -9999 -9999 -9999 -9999 -9999 -9999 -9999 -9999-

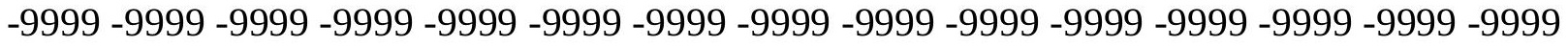

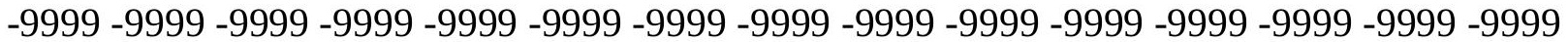
-9999 -

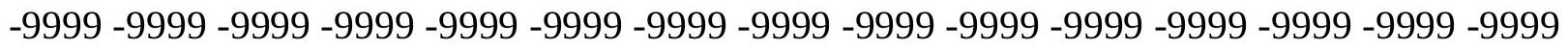

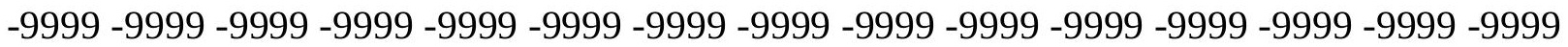

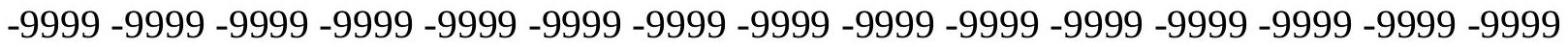
-9999 -9999 -9999 -9999 -9999 -9999 -9999 -9999 -9999 -9999 - -9999 -9999 -999 -9999 -999 -

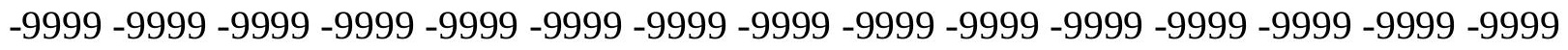

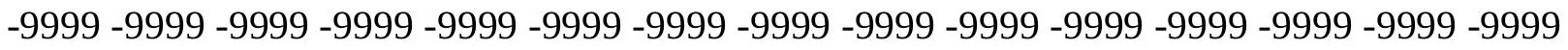

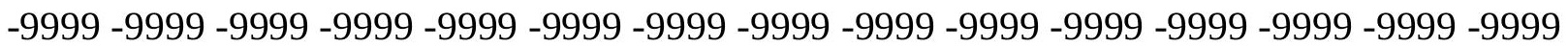

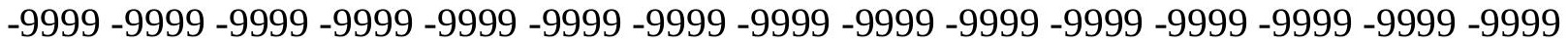

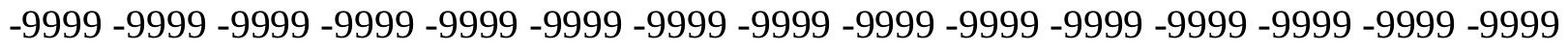

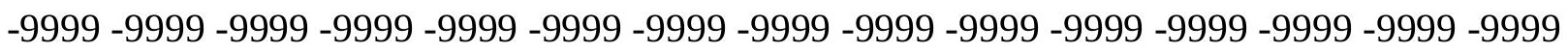
-9999 -9999 -9999-9999 119.4757995605 112.0101242065 106.3537139893105.529335022 104.5621490479102 .102996826299 .6647262573296 .9216690063594 .48339080811 92.0450973510789 .9116134643688 .0829010009886 .8637619018685 .94940185547 85.6446228027385 .6446228027385 .0350494384882 .9015579223680 .15849304199 
77.4154205322374 .9771423339872 .5388565063570 .7101516723668 .88143920898 67.3575134277366 .4431610107465 .5288009643664 .6144485473664 .30966186523 64.3096618652364 .3096618652364 .9192428588965 .5288009643666 .44316101074 67.9670867919969 .4910125732471 .014930725172 .8436431884874 .67236328125 76.1962814331177 .7202072143679 .2441329956180 .4632720947381 .37763214111 82.2919769287182 .9015579223683 .206336975183 .5111236572383 .81591033936 83.8159103393684 .1206970214884 .4254837036184 .4254837036184 .73026275635 84.7302627563584 .7302627563584 .7302627563584 .4254837036183 .81591033936 82.9015579223681 .6824111938579 .8537063598678 .0249862670975 .58670806885 73.4532165527371 .014930725168 .5766525268665 .8335876464863 .09051895142 60.3474502563557 .6043891906755 .1661109924353 .0326118469250 .89912033081 49.0704002380447 .2416992187545 .717769622844 .4986305236843 .27949142456 42.0603485107441 .1459884643640 .2316398620639 .622070312539 .31727981567 39.0125007629439 .0125007629439 .0125007629439 .3172798156739 .6220703125 40.2316398620641 .1459884643642 .0603485107443 .2794914245644 .49863052368 45.717769622846 .9369087219248 .1560516357449 .6799812316950 .89912033081 52.4230384826753 .6421813964855 .1661109924356 .3852500915557 .29959869385 57.909179687557 .909179687557 .909179687557 .909179687557 .60438919067 57.2995986938556 .9948196411156 .9948196411156 .6900291442956 .38525009155 56.3852500915556 .0804595947356 .0804595947356 .0804595947355 .77568054199 55.7756805419955 .7756805419955 .4708900451755 .4708900451755 .47089004517 55.1661109924355 .1661109924355 .1661109924355 .1661109924355 .16611099243 55.1661109924355 .1661109924355 .1661109924355 .1661109924355 .16611099243 55.1661109924355 .1623611450255 .4708900451755 .4708900451755 .47089004517 55.4708900451755 .7756805419955 .7756805419955 .7756805419956 .08045959473 56.0804595947356 .3852500915556 .3852500915556 .3852500915556 .69002914429 56.6900291442956 .9948196411156 .9948196411157 .2995986938557 .29959869385 57.6043891906757 .6043891906757 .909179687557 .909179687558 .21395874023 58.2139587402358 .5187492370658 .5187492370658 .8235282897935 .05598831177 -9999 -9999 -9999 -9999 -9999 -9999 -9999 -9999 -9999 -9999 -9999 -9999 -9999 -9999 -9999 -9999 -9999 -9999 -9999 -9999 -9999 -9999 -9999 -9999 -9999 -9999 -9999 -9999 -9999 -9999 -9999 -9999 -9999 -9999 -9999 -9999 -9999 -9999 -9999 -9999 -9999

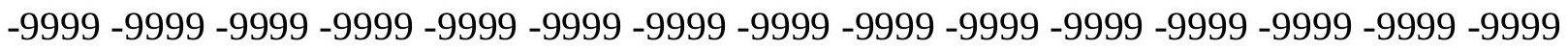
-9999 -9999 -9999 -9999 -9999 -9999 -9999 -9999 -9999 -9999 -9999 -9999 -9999 -9999 -9999

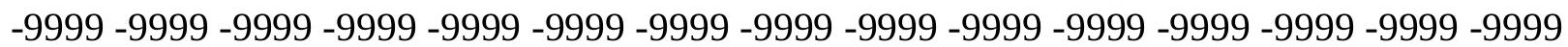
-9999 -9999 -9999 -9999 -9999 -9999 -9999 -9999 -9999 -9999 -9999 -9999 -9999 -9999 -9999

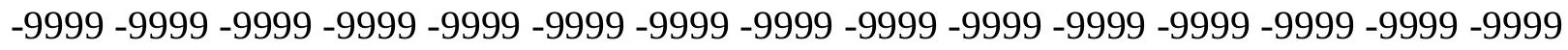

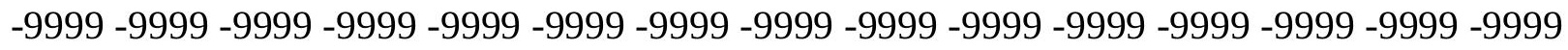
-9999 -9999 -9999 -9999 -9999 -9999 -9999 -9999 -9999 -9999 -9999 -9999 -9999 -9999 -9999

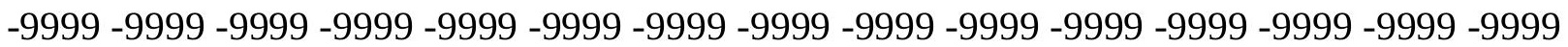

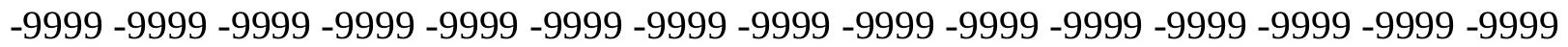
-9999 -9999 -9999 -9999 -9999 -9999 -9999 -9999 -9999 -9999 -9999 -9999 -9999 -9999 -9999 -9999 -9999 -9999 -9999 -9999 -9999 -9999 -9999 -9999 -9999 -9999 -9999 -9999 -9999 -9999 -9999 -9999 -9999 -9999 -9999 -9999 -9999 -9999 -9999 -9999 -9999 -9999 -9999 -9999 -9999 -9999 -9999 -9999 -9999-9999 120.6949005127116 .4279022217106 .1258163452 105.4249954224104 .793762207103 .3221969604100 .883903503498 .4455871582 
95.7025299072393 .5690307617291 .4355392456189 .9116134643688 .69246673584 88.0829010009887 .1685485839886 .254188537684 .4254837036181 .98719787598 79.2441329956176 .8058471679774 .3675689697372 .2340774536170 .71015167236 69.1862335205167 .6623001098666 .7479400634866 .1383666992265 .52880096436 65.5288009643665 .5288009643666 .1383666992266 .7479400634867 .66230010986 68.8814392089870 .4053573608471 .9292907714873 .4532165527375 .28192901611 76.8058471679778 .3297805786179 .5489196777380 .7680587768681 .98719787598 82.9015579223683 .5111236572384 .1206970214884 .4254837036184 .73026275635 85.0350494384885 .3398437585 .6446228027385 .6446228027385 .94940185547 85.9494018554785 .9494018554785 .9494018554785 .6446228027385 .03504943848 84.1206970214882 .9015579223681 .0728530883879 .2441329956177 .1106262207 74.9771423339872 .5388565063570 .1005783081167 .3575134277364 .61444854736 61.8713798522959 .1283111572356 .9948196411154 .8613204956152 .72782897949 50.8991203308149 .0704002380447 .2416992187545 .717769622844 .49863052368 43.2794914245642 .0603485107441 .1459884643640 .5364189147939 .92684936523 39.622070312539 .3172798156739 .3172798156739 .622070312540 .23163986206 40.8412094116241 .4507789611842 .66992187543 .5842704772944 .80340957642 46.0225486755447 .5464782714848 .765621185350 .2895507812551 .50868988037 53.0326118469254 .5565414428755 .7756805419956 .9948196411158 .21395874023 58.5187492370658 .5187492370658 .5187492370658 .2139587402357 .9091796875 57.909179687557 .6043891906757 .2995986938556 .9948196411156 .69002914429 56.6900291442956 .3852500915556 .3852500915556 .0804595947356 .08045959473 56.0804595947355 .7756805419955 .7756805419955 .7756805419955 .47089004517 55.4708900451755 .4708900451755 .4708900451755 .1661109924355 .16611099243 55.1661109924355 .1661109924355 .1661109924355 .1661109924355 .16611099243 55.1661109924355 .2102088928255 .4708900451755 .4708900451755 .47089004517 55.4708900451755 .7756805419955 .7756805419955 .7756805419956 .08045959473 56.0804595947356 .3852500915556 .3852500915556 .6900291442956 .69002914429 56.6900291442956 .9948196411156 .9948196411157 .2995986938557 .29959869385 57.6043891906757 .6043891906757 .909179687557 .909179687558 .21395874023 58.2139587402358 .4967575073258 .6931991577158 .8235282897931 .05200004578 -9999 -9999 -9999 -9999 -9999 -9999 -9999 -9999 -9999 -9999 -9999

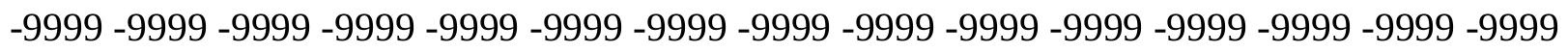
-9999 -9999 -9999 -9999 -9999 -9999 -9999 -9999 -9999 -9999 -9999 -9999 -9999 -9999 -9999 -9999 -9999 -9999 -9999 -9999 -9999 -9999 -9999 -9999 -9999 -9999 -9999 -9999 -9999 -9999

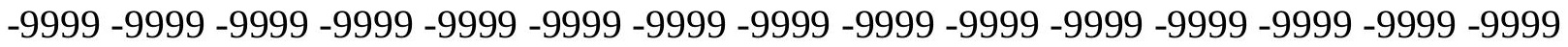

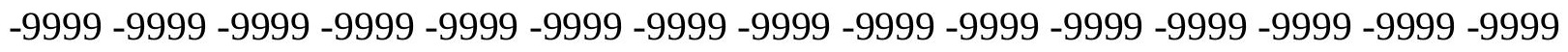

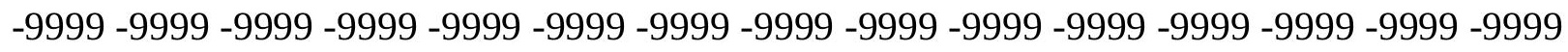
-9999 -9999 -9999 -9999 -9999 -9999 -9999 -9999 -9999 -9999 -9999 -9999 -9999 -9999 -9999 -9999 -9999 -9999 -9999 -9999 -9999 -9999 -9999 -9999 -9999 -9999 -9999 -9999 -9999 - -999 -

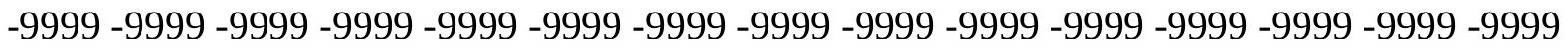

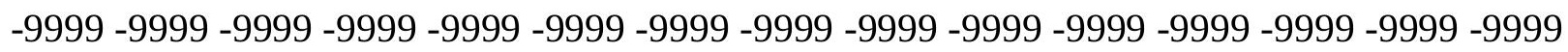
-9999 -9999 -9999 -9999 -9999 -9999 -9999 -9999 -9999 -9999 -9999 -9999 -9999 -9999 -9999 -9999 -9999 -9999 -9999 -9999 -9999 -9999 -9999 -9999 -9999 -9999 -9999 -9999 -9999 -9999 -9999 -9999 -9999 -9999 -9999 -9999 -9999 -9999 -9999 -9999 -9999 -9999 -9999 -9999 -9999 -

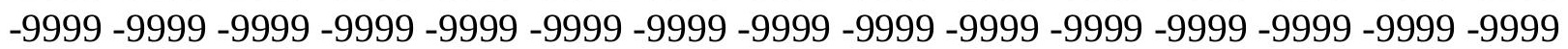


-9999 -9999 -9999 -9999 -9999 -9999 121.6092987061 117.342300415 106.0169219971 105.3757476807104 .7528839111104 .0944824219101 .798202514699 .35994720459 96.6168823242294 .4833908081192 .349891662690 .5211791992289 .3020401001 88.0829010009886 .8637619018685 .3398437583 .206336975180 .76805877686 78.3297805786175 .8914871215874 .062782287672 .2340774536170 .40535736084 69.1862335205168 .2718734741267 .3575134277367 .0527267456166 .74794006348 66.7479400634867 .0527267456167 .9670867919968 .8814392089869 .79579162598 71.3197174072372 .5388565063574 .062782287675 .5867080688577 .1106262207 78.6345596313579 .8537063598681 .0728530883882 .2919769287183 .2063369751 83.8159103393684 .4254837036185 .0350494384885 .3398437585 .94940185547 86.254188537686 .5589828491286 .5589828491286 .8637619018686 .86376190186 86.8637619018686 .5589828491286 .254188537685 .6446228027384 .73026275635 83.5111236572381 .9871978759880 .1584930419978 .3297805786176 .19628143311 73.7580032348671 .3197174072368 .5766525268666 .1383666992263 .39530944824 60.9570198059158 .5187492370656 .3852500915554 .2517509460452 .42303848267 50.5943298339848 .765621185347 .2416992187545 .717769622844 .49863052368 43.2794914245642 .0603485107441 .4507789611840 .5364189147940 .23163986206 39.9268493652339 .622070312539 .9268493652340 .5364189147941 .14598846436 41.7555618286142 .9747009277343 .8890609741245 .1082000732446 .63212966919 47.8512611389249 .3751907348650 .5943298339852 .1182594299353 .33739852905 54.8613204956156 .0804595947357 .2995986938558 .2139587402358 .82352828979 58.8235282897958 .8235282897958 .5187492370658 .2139587402357 .9091796875 57.6043891906757 .6043891906757 .2995986938556 .9948196411156 .99481964111 56.6900291442956 .6900291442956 .3852500915556 .3852500915556 .08045959473 56.0268974304255 .7756805419955 .7756805419955 .7756805419955 .47089004517 55.4708900451755 .4708900451755 .4708900451755 .4708900451755 .47089004517 55.1661109924355 .1661109924355 .1661109924355 .4708900451755 .36615371704 55.2677650451755 .4708900451755 .4708900451755 .4708900451755 .77568054199 55.7756805419955 .7756805419956 .0804595947356 .0804595947356 .08045959473 56.3852500915556 .3852500915556 .6900291442956 .6900291442956 .99481964111 56.9948196411157 .2995986938557 .2995986938557 .2995986938557 .60438919067 57.6043891906757 .909179687558 .2139587402358 .2139587402358 .51874923706 58.5187492370658 .7100677490245 .8600997924822 .37713813782 -9999 -9999 -9999 -9999 -9999 -9999 -9999 -9999 -9999 -9999 -9999

-9999 -9999 -9999 -9999 -9999 -9999 -9999 -9999 -9999 -9999 -9999 -9999 -9999 -9999 -9999 -9999 -9999 -9999 -9999 -9999 -9999 -9999 -9999 -9999 -9999 -9999 -9999 -9999 -9999 - -9999 -

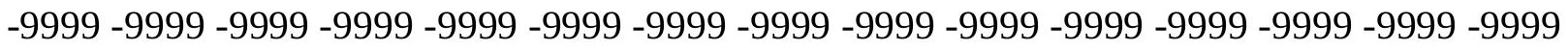

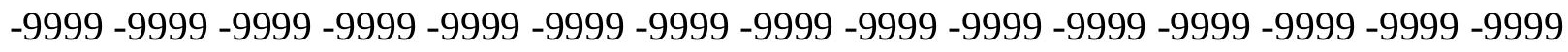
-9999 -9999 -9999 -9999 -9999 -9999 -9999 -9999 -9999 -9999 -9999 -9999 -9999 - 9999 - -999 -9999 -9999 -9999 -9999 -9999 -9999 -9999 -9999 -9999 -9999 -9999 -9999 -9999 -9999 -9999 -

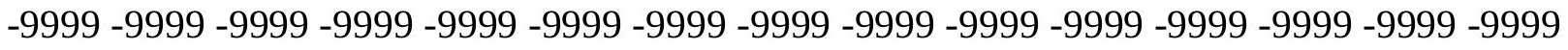

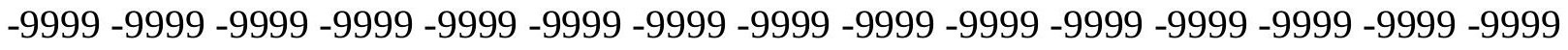
-9999 -9999 -9999 -9999 -9999 -9999 -9999 -9999 -9999 -9999 -9999 -9999 -9999 -9999 -9999 -9999 -9999 -9999 -9999 -9999 -9999 -9999 -9999 -9999-9999 -9999 -9999 -9999 -9999 -9999 -9999 -9999 -9999 -9999 -9999 -9999 -9999 -9999 -9999 -9999 -9999 -9999 -9999 -9999 -9999 -

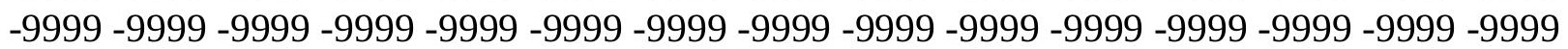


-9999 -9999 -9999 -9999 -9999 -9999 -9999 -9999 -9999 -9999 -9999 -9999 -9999 -9999 -9999 -9999 -9999 -9999 -9999 -9999 -9999 -9999 -9999 -9999 -9999 -9999 -9999 -9999 -9999 -9999 -9999 -9999 -9999 -9999 -9999 -9999 -9999 122.2188034058117 .9517974854105 .898399353 105.2278137207104 .5030136108103 .6198501587102 .215438842899 .66472625732 96.9216690063594 .4833908081192 .0450973510790 .2164001464888 .99725341797 87.4733276367285 .9494018554784 .1206970214881 .9871978759879 .54891967773 77.4154205322375 .2819290161173 .4532165527371 .9292907714870 .71015167236 69.4910125732468 .5766525268668 .2718734741267 .9670867919967 .96708679199 68.2718734741268 .8814392089869 .7957916259870 .7101516723671 .92929077148 73.1484298706174 .6723632812576 .1962814331177 .4154205322378 .93934631348 80.1584930419981 .3776321411182 .2919769287183 .206336975184 .12069702148 84.7302627563585 .3398437585 .9494018554786 .254188537686 .55898284912 86.8637619018687 .1685485839887 .1685485839887 .1685485839887 .16854858398 86.8637619018686 .5589828491285 .9494018554785 .0350494384883 .81591033936 82.5967712402380 .7680587768678 .9393463134876 .8058471679774 .67236328125 72.2340774536169 .7957916259867 .3575134277364 .9192428588962 .48094940186 60.0426712036157 .909179687555 .7756805419953 .9469718933152 .11825942993 50.2895507812548 .765621185347 .2416992187545 .717769622844 .19384002686 43.2794914245642 .0603485107441 .1459884643640 .5364189147940 .23163986206 40.2316398620640 .2316398620640 .8412094116241 .4507789611842 .36513137817 43.2794914245644 .4986305236845 .717769622846 .9369087219248 .15605163574 49.6799812316950 .8991203308152 .4230384826753 .6421813964854 .86132049561 56.0804595947357 .2995986938558 .2139587402358 .5187492370658 .82352828979 58.8235282897958 .5187492370658 .2139587402358 .2139587402357 .9091796875 57.6043891906757 .2995986938557 .2995986938556 .9948196411156 .99481964111 56.6900291442956 .6900291442956 .3852500915556 .3852500915556 .08045959473 56.0804595947356 .0804595947355 .7756805419955 .7756805419955 .77568054199 55.4708900451755 .4708900451755 .4708900451755 .4708900451755 .47089004517 55.4708900451755 .4708900451755 .4708900451755 .4180755615255 .32496261597 55.4708900451755 .4708900451755 .7756805419955 .7756805419955 .77568054199 55.7756805419956 .0804595947356 .0804595947356 .3852500915556 .38525009155 56.3852500915556 .6900291442956 .6900291442956 .9948196411156 .99481964111 57.2995986938557 .2995986938557 .6043891906757 .6043891906757 .9091796875 57.909179687558 .2139587402358 .2139587402358 .5187492370658 .51874923706 58.7421112060542 .2408905029314 .68496322632 -9999 -9999 -9999 -9999 -9999 -9999 -9999 -9999 -9999 -9999-9999 -9999 -9999 -9999 -9999 -9999 -9999 -9999 -9999 -9999 -9999 -9999 -9999 -9999 -9999 -9999

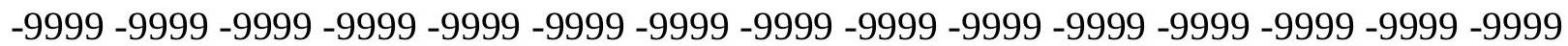
-9999 -9999 -9999 -9999 -9999 -9999 -9999 -9999 -9999 -9999 -9999 -9999 -9999 -9999 -9999 -9999 -9999 -9999 -9999 -9999 -9999 -9999 -9999 -9999 -9999 -9999 -9999 -9999 -9999 -9999 -9999 -9999 -9999 -9999 -9999 -9999 -9999 -9999 -9999 -9999 -9999 -9999 -9999 -9999 -9999

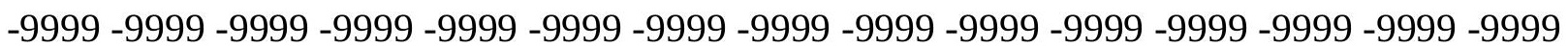
-9999 -9999 -9999 -9999 -9999 -9999 -9999 -9999 -9999 -9999 -9999 -9999 -9999 -9999 -9999 -9999 -9999 -9999 -9999 -9999 -9999 -9999 -9999 -9999 -9999 -9999 -9999 -9999 -9999 -9999 -999 -9999 -9999 -9999 -9999 -9999 -9999 -9999 -9999 -9999 -9999 -9999 -9999 -9999 -9999 -9999

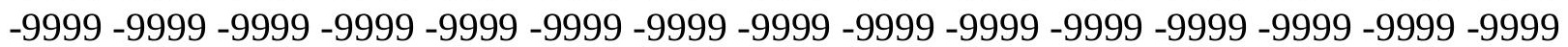


-9999 -9999 -9999 -9999 -9999 -9999 -9999 -9999 -9999 -9999 -9999 -9999 -9999 -9999 -9999 -9999 -9999 -9999 -9999 -9999 -9999 -9999 -9999 -9999 -9999 -9999 -9999 -9999 -9999 -9999 -9999 -9999 -9999 -9999 -9999 -9999 -9999 -9999 -9999 -9999 -9999 -9999 -9999 -9999 -9999 -9999 -9999 -9999 -9999 -9999 -9999 -9999 -9999 -9999 -9999 -9999 -9999 -9999 -9999 -9999 -9999 -9999 -9999 -9999 -9999 -9999 -9999 -9999 122.8283996582118 .5614013672 111.7304077148104 .9011230469104 .0236053467103 .0620422363102 .0970687866 99.3599472045996 .6168823242293 .8738174438591 .1307525634889 .91161346436 88.3876876831186 .8637619018685 .0350494384882 .9015579223680 .76805877686 78.6345596313576 .5010681152374 .6723632812573 .1484298706173 .75800323486 70.7101516723669 .7957916259869 .4910125732469 .1862335205169 .18623352051 69.4910125732469 .7957916259870 .7101516723671 .6244964599672 .53885650635 73.7580032348674 .9771423339876 .5010681152377 .7202072143678 .93934631348 80.1584930419981 .3776321411182 .2919769287183 .206336975184 .12069702148 84.7302627563585 .3398437585 .9494018554786 .254188537686 .55898284912 86.8637619018687 .1685485839887 .4733276367287 .4733276367287 .16854858398 87.1685485839886 .5589828491285 .9494018554785 .0350494384884 .12069702148 82.9015579223681 .3776321411179 .5489196777377 .4154205322375 .28192901611 73.1484298706170 .7101516723668 .5766525268666 .1383666992263 .70008850098 61.5666007995659 .4331016540557 .2995986938555 .4708900451753 .64218139648 51.8134689331149 .9847602844248 .4608306884846 .9369087219245 .41297912598 44.1938400268642 .9747009277342 .0603485107441 .1459884643640 .53641891479 40.5364189147940 .5364189147940 .8412094116241 .7555618286142 .669921875 43.5842704772944 .8034095764246 .0225486755447 .2416992187548 .46083068848 49.9847602844251 .2038993835452 .4230384826753 .6421813964854 .86132049561 56.0804595947356 .9948196411157 .6043891906758 .2139587402358 .51874923706 58.5187492370658 .5187492370658 .2139587402357 .909179687557 .9091796875 57.6043891906757 .6043891906757 .2995986938557 .2995986938556 .99481964111 56.9948196411156 .6900291442956 .6900291442956 .3852500915556 .38525009155 56.0804595947356 .0804595947356 .0804595947355 .7756805419955 .77568054199 55.7756805419955 .4708900451755 .4708900451755 .4708900451755 .47089004517 55.4708900451755 .4708900451755 .4708900451755 .44572830255 .47089004517 55.4708900451755 .7756805419955 .7756805419955 .7756805419955 .77568054199 56.0804595947356 .0804595947356 .0804595947356 .3852500915556 .38525009155 56.3852500915556 .6900291442956 .6900291442956 .9948196411156 .99481964111 57.2995986938557 .2995986938557 .6043891906757 .6043891906757 .9091796875 57.909179687558 .2139587402358 .2139587402358 .5187492370658 .51874923706 58.7543907165540 .11900711068 .949721336365 -9999 -9999 -9999 -9999 -9999 -9999 -9999 -9999 -9999-9999-9999 -9999 -9999 -9999 -9999 -9999 -9999 -9999 -9999 -9999 -9999 -9999 -9999 -9999 -9999 -9999 -9999 -9999 -9999 -9999 -9999 -9999 -9999 -9999 -9999 -9999 -9999 -9999 -9999 -9999 -9999 -9999 -9999 -9999 -9999 -9999 -9999 -9999 -9999 -9999 -9999 -9999 -9999 -9999 -9999 -9999

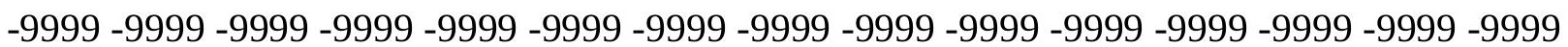
-9999 -9999 -9999 -9999 -9999 -9999 -9999 -9999 -9999 -9999 -9999 -9999 -9999 -9999 -9999 -9999 -9999 -9999 -9999 -9999 -9999 -9999 -9999 -9999 -9999 -9999 -9999 -9999 -9999 -9999 -9999 -9999 -9999 -9999 -9999 -9999 -9999 -9999 -9999 -9999 -9999 -9999 -9999 -9999 -9999

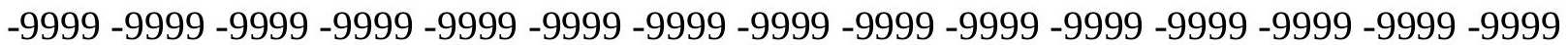


-9999 -9999 -9999 -9999 -9999 -9999 -9999 -9999 -9999 -9999 -9999 -9999 -9999 -9999 -9999 -9999 -9999 -9999 -9999 -9999 -9999 -9999 -9999 -9999 -9999 -9999 -9999 -9999 -9999 -9999 -9999 -9999 -9999 -9999 -9999 -9999 -9999 -9999 -9999 -9999 -9999 -9999 -9999 -9999 -9999 -9999 -9999 -9999 -9999 -9999 -9999 -9999 -9999 -9999 -9999 -9999 -9999 -9999 -9999 -9999 -9999 -9999 -9999 -9999 -9999 -9999 -9999 -9999 -9999 -9999 -9999 -9999 -9999 -9999 -9999 -9999 -9999 -9999 -9999 -9999 -9999 -9999 -9999 -9999 -9999 -9999 -9999 -9999 -9999 -9999 -9999 -9999 -9999 -9999 -9999 -9999 -9999 -9999 -9999 123.1332015991118 .5614013672 111.6903839111104 .5481033325103 .6851043701102 .763923645101 .7338180542 99.0551681518696 .0073165893693 .5690307617291 .7403335571389 .91161346436 88.0829010009886 .254188537684 .1206970214881 .9871978759879 .85370635986 78.0249862670976 .1962814331174 .3675689697373 .1484298706171 .92929077148 71.014930725170 .4053573608470 .1005783081170 .1005783081170 .40535736084 70.7101516723671 .3197174072372 .2340774536173 .1484298706174 .0627822876 75.2819290161176 .5010681152377 .7202072143678 .9393463134880 .15849304199 81.0728530883881 .9871978759882 .9015579223683 .8159103393684 .42548370361 85.0350494384885 .6446228027386 .254188537686 .5589828491286 .86376190186 87.1685485839887 .1685485839887 .1685485839887 .1685485839886 .86376190186 86.5589828491285 .9494018554785 .0350494384884 .1206970214882 .90155792236 81.3776321411179 .8537063598678 .0249862670975 .8914871215873 .75800323486 71.6244964599669 .4910125732467 .3575134277364 .9192428588962 .78573989868 60.9570198059158 .8235282897956 .9948196411154 .8613204956153 .03261184692 51.2038993835449 .6799812316948 .1560516357446 .6321296691945 .10820007324 43.8890609741242 .66992187541 .7555618286141 .1459884643640 .84120941162 40.8412094116241 .1459884643642 .0603485107442 .9747009277343 .88906097412 45.1082000732446 .3273391723647 .5464782714848 .765621185350 .28955078125 51.5086898803752 .7278289794953 .9469718933154 .8613204956155 .77568054199 56.6900291442957 .2995986938557 .909179687557 .909179687558 .21395874023 58.2139587402357 .909179687557 .909179687557 .6043891906757 .60438919067 57.6043891906757 .2995986938557 .2995986938556 .9948196411156 .99481964111 56.9948196411156 .6900291442956 .6900291442956 .3852500915556 .38525009155 56.0804595947356 .0804595947356 .0804595947355 .7756805419955 .77568054199 55.7756805419955 .7756805419955 .4708900451755 .4708900451755 .47089004517 55.4708900451755 .4708900451755 .4708900451755 .4708900451755 .77568054199 55.7756805419955 .7756805419955 .7756805419956 .0804595947356 .08045959473 56.0804595947356 .3852500915556 .3852500915556 .3852500915556 .69002914429 56.6900291442956 .9948196411156 .9948196411156 .9948196411157 .29959869385 57.2995986938557 .6043891906757 .6043891906757 .909179687557 .9091796875 58.2139587402358 .2139587402358 .4922790527358 .5187492370658 .82352828979 37.590744018553 .59477853775 -9999 -9999 -9999 -9999 -9999 -9999 -9999 -9999 -9999 $-9999-9999$ -9999 -9999 -9999 -9999 -9999 -9999 -9999 -9999 -9999 -9999 -9999 -9999 -9999 -9999 -9999 -9999 -9999 -9999 -9999 -9999 -9999 -9999 -9999 -9999 -9999 -9999 -9999-9999-9999-9999 -9999 -9999 -9999 -9999 -9999 -9999 -9999 -9999 -9999 -9999 -9999 -9999 -9999 -9999 -9999 -9999 -9999 -9999 -9999 -9999 -9999 -9999 -9999 -9999 -9999 -9999 -9999 -9999 -9999 -9999 -9999 -9999 -9999 -9999 -9999 -9999 -9999 -9999 -9999 -9999 -9999 -9999 -9999 -9999 -9999

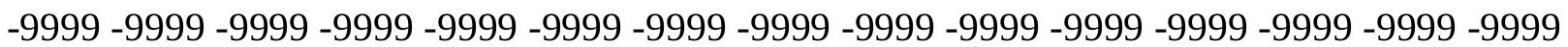


-9999 -9999 -9999 -9999 -9999 -9999 -9999 -9999 -9999 -9999 -9999 -9999 -9999 -9999 -9999 -9999 -9999 -9999 -9999 -9999 -9999 -9999 -9999 -9999 -9999 -9999 -9999 -9999 -9999 -9999 -9999 -9999 -9999 -9999 -9999 -9999 -9999 -9999 -9999 -9999 -9999 -9999 -9999 -9999 -9999 -9999 -9999 -9999 -9999 -9999 -9999 -9999 -9999 -9999 -9999 -9999 -9999 -9999 -9999 -9999 -9999 -9999 -9999 -9999 -9999 -9999 -9999 -9999 -9999 -9999 -9999 -9999 -9999 -9999 -9999 -9999 -9999 -9999 -9999 -9999 -9999 -9999 -9999 -9999 -9999 -9999 -9999 -9999 -9999 -9999 -9999 -9999 -9999 -9999 -9999 -9999 -9999 -9999 -9999 -9999 -9999 -9999 -9999 -9999 -9999

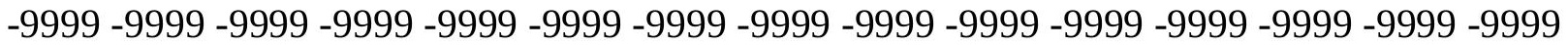
-9999 -9999 -9999 -9999 -9999 -9999 -9999 -9999 -9999 -9999 122.5235977173 117.9517974854111 .3936767578104 .3068695068103 .4750289917102 .6164169312 101.387519836498.7503814697396.3121032714893.8738174438591.74033355713 89.6068267822387 .4733276367285 .3398437583 .206336975181 .07285308838 78.9393463134877 .110626220775 .5867080688574 .3675689697373 .14842987061 72.2340774536171 .6244964599671 .3197174072371 .014930725171 .31971740723 71.6244964599672 .2340774536172 .8436431884873 .7580032348674 .67236328125 75.5867080688576 .8058471679777 .7202072143678 .9393463134879 .85370635986 80.7680587768681 .6824111938582 .5967712402383 .5111236572384 .12069702148 84.7302627563585 .3398437585 .9494018554786 .254188537686 .55898284912 86.8637619018686 .8637619018686 .8637619018686 .8637619018686 .55898284912 86.254188537685 .6446228027384 .7302627563583 .8159103393682 .59677124023 81.3776321411179 .8537063598678 .0249862670976 .1962814331174 .36756896973 72.2340774536170 .4053573608468 .2718734741266 .1383666992264 .0048828125 62.1761703491260 .0426712036158 .2139587402356 .3852500915554 .55654144287 52.7278289794950 .8991203308149 .3751907348647 .5464782714846 .02254867554 44.8034095764243 .5842704772942 .66992187541 .7555618286141 .14598846436 41.1459884643641 .4507789611842 .3651313781743 .2794914245644 .49863052368 45.717769622846 .6321296691947 .8512611389249 .0704002380450 .28955078125 51.5086898803752 .7278289794953 .9469718933154 .8613204956155 .77568054199 56.3852500915556 .9948196411157 .2995986938557 .6043891906757 .9091796875 57.6043891906757 .6043891906757 .6043891906757 .6043891906757 .60438919067 57.6043891906757 .2995986938557 .2995986938557 .2995986938556 .99481964111 56.9948196411156 .9948196411156 .6900291442956 .6900291442956 .38525009155 56.3852500915556 .0804595947356 .0804595947356 .0804595947355 .77568054199 55.7756805419955 .7756805419955 .7756805419955 .7756805419955 .77568054199 55.7756805419955 .6473884582555 .565006256155 .7756805419955 .77568054199 55.7756805419955 .7756805419955 .7756805419956 .0804595947356 .08045959473 56.0804595947356 .3852500915556 .3852500915556 .6900291442956 .69002914429 56.6900291442956 .9948196411156 .9948196411157 .2995986938557 .29959869385 57.6043891906757 .6043891906757 .909179687557 .909179687558 .21395874023 58.2139587402358 .5187492370658 .5187492370658 .5187492370658 .82352828979 33.00570297241 -9999 -9999 -9999 -9999 -9999 -9999 -9999 -9999 -9999 -9999 -9999 -9999 -9999 -9999 -9999 -9999 -9999 -9999 -9999 -9999 -9999 -9999 -9999 -9999 -9999 -9999 -9999 -9999 -9999 -9999 -9999 -9999 -9999 -9999 -9999 -9999 -9999 -9999 -9999 -9999 -9999 -9999 -9999 -9999 -9999 -9999 -9999 -9999 -9999 -9999 -9999 -9999 -9999 -9999 -9999 -9999 -9999 -9999 -9999 -9999 -9999 -9999 -9999 -9999 -9999 -9999 -9999 -9999 -9999 -9999 -9999 -9999

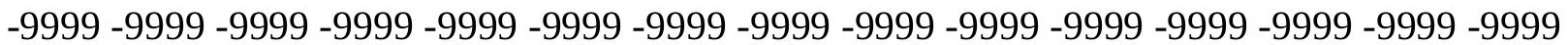


-9999 -9999 -9999 -9999 -9999 -9999 -9999 -9999 -9999 -9999 -9999 -9999 -9999 -9999 -9999 -9999 -9999 -9999 -9999 -9999 -9999 -9999 -9999 -9999 -9999 -9999 -9999 -9999 -9999 -9999 -9999 -9999 -9999 -9999 -9999 -9999 -9999 -9999 -9999 -9999 -9999 -9999 -9999 -9999 -9999 -9999 -9999 -9999 -9999 -9999 -9999 -9999 -9999 -9999 -9999 -9999 -9999 -9999 -9999 -9999 -9999 -9999 -9999 -9999 -9999 -9999 -9999 -9999 -9999 -9999 -9999 -9999 -9999 -9999 -9999 -9999 -9999 -9999 -9999 -9999 -9999 -9999 -9999 -9999 -9999 -9999 -9999 -9999 -9999 -9999 -9999 -9999 -9999 -9999 -9999 -9999 -9999 -9999 -9999 -9999 -9999 -9999 -9999 -9999 -9999

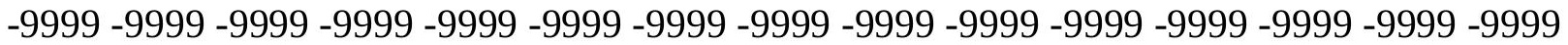
-9999 -9999 -9999 -9999 -9999 -9999 -9999 -9999 -9999 -9999 -9999 -9999 -9999 -9999 -9999 -9999 -9999 -9999 -9999 -9999 -9999 -9999 -9999 -9999 -9999 -9999 121.6092987061 116.7326965332112 .7705001831104 .1431884766103 .3528900146102 .5518569946 101.40180206399 .0551681518696 .3121032714893 .8738174438591 .43553924561 88.9972534179786 .8637619018684 .4254837036182 .2919769287180 .15849304199 78.3297805786176 .8058471679775 .2819290161174 .3675689697373 .45321655273 72.8436431884872 .2340774536172 .2340774536172 .2340774536172 .53885650635 72.8436431884873 .4532165527374 .062782287674 .9771423339875 .89148712158 76.8058471679777 .7202072143678 .6345596313579 .5489196777380 .46327209473 81.37763214111 82.29197692871 83.2063369751 83.81591033936 84.42548370361 85.0350494384885 .3398437585 .9494018554786 .254188537686 .2541885376 86.5589828491286 .5589828491286 .254188537686 .254188537685 .64462280273 85.0350494384884 .4254837036183 .5111236572382 .5967712402381 .07285308838 79.8537063598678 .3297805786176 .5010681152374 .6723632812572 .84364318848 71.014930725168 .8814392089867 .0527267456165 .2240066528363 .09051895142 61.2618103027359 .4331016540557 .6043891906755 .7756805419953 .94697189331 52.1182594299350 .5943298339848 .765621185347 .2416992187545 .7177696228 44.4986305236843 .5842704772942 .66992187542 .0603485107441 .45077896118 42.0603485107442 .9747009277343 .8890609741245 .1082000732446 .02254867554 47.2416992187548 .4608306884849 .6799812316950 .5943298339851 .81346893311 52.7278289794953 .9469718933154 .8613204956155 .4708900451756 .08045959473 56.6900291442956 .9948196411157 .2995986938557 .2995986938557 .29959869385 57.2995986938557 .2995986938557 .2995986938557 .6043891906757 .29959869385 57.2995986938557 .2995986938557 .2995986938557 .2995986938556 .99481964111 56.9948196411156 .6900291442956 .6900291442956 .6900291442956 .38525009155 56.3852500915556 .0804595947356 .0804595947356 .0804595947355 .77568054199 55.7756805419955 .7756805419955 .7756805419955 .7756805419955 .77568054199 55.7397499084555 .7756805419955 .7756805419955 .7756805419955 .77568054199 56.0804595947356 .0804595947356 .0804595947356 .0804595947356 .38525009155 56.3852500915556 .3852500915556 .6900291442956 .6900291442956 .99481964111 56.9948196411156 .9948196411157 .2995986938557 .2995986938557 .60438919067 57.6043891906757 .909179687557 .909179687558 .2139587402358 .21395874023 $58.5187492370658 .5187492370658 .7450485229549 .6085968017625 .0974445343-9999$ -9999 -9999 -9999 -9999 -9999 -9999 -9999 -9999 -9999 -9999 -9999 -9999 -9999 -9999 -9999 -9999 -9999 -9999 -9999 -9999 -9999 -9999 -9999 -9999 -9999 -9999 -9999 -9999 -9999 -9999 -9999 -9999 -9999 -9999 -9999 -9999 -9999 -9999 -9999 -9999 -9999 -9999 -9999 -9999 -9999 -9999 -9999 -9999 -9999 -9999 -9999 -9999 -9999 -9999 -9999 -9999

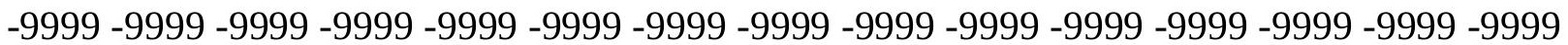


-9999 -9999 -9999 -9999 -9999 -9999 -9999 -9999 -9999 -9999 -9999 -9999 -9999 -9999 -9999 -9999 -9999 -9999 -9999 -9999 -9999 -9999 -9999 -9999 -9999 -9999 -9999 -9999 -9999 -9999 -9999 -9999 -9999 -9999 -9999 -9999 -9999 -9999 -9999 -9999 -9999 -9999 -9999 -9999 -9999 -9999 -9999 -9999 -9999 -9999 -9999 -9999 -9999 -9999 -9999 -9999 -9999 -9999 -9999 -9999 -9999 -9999 -9999 -9999 -9999 -9999 -9999 -9999 -9999 -9999 -9999 -9999 -9999 -9999 -9999 -9999 -9999 -9999 -9999 -9999 -9999 -9999 -9999 -9999 -9999 -9999 -9999 -9999 -9999 -9999 -9999 -9999 -9999 -9999 -9999 -9999 -9999 -9999 -9999 -9999 -9999 -9999 -9999 -9999 -9999

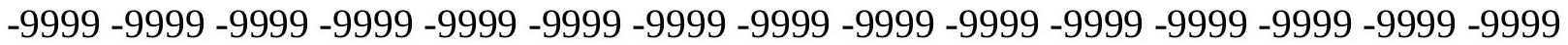
-9999 -9999 -9999 -9999 -9999 -9999 -9999 -9999 -9999 -9999 -9999 -9999 -9999 -9999 -9999 -9999 -9999 -9999 -9999 -9999 -9999 -9999 -9999 -9999 -9999 -9999 -9999 -9999 -9999 -9999 -999 -9999 -9999 -9999 -9999 -9999 -9999 -9999 -9999 -9999 -9999 -9999 -9999 119.7806015015 115.818397522113 .9896011353104 .0799560547103 .3815002441102 .6484451294 101.492462158299 .0551681518696 .0073165893693 .2642517089890 .82597351074 88.0829010009885 .9494018554783 .5111236572381 .3776321411179 .54891967773 78.0249862670976 .5010681152375 .5867080688574 .6723632812573 .75800323486 73.4532165527373 .1484298706173 .1484298706173 .1484298706173 .45321655273 74.062782287674 .6723632812575 .2819290161175 .8914871215876 .80584716797 77.7202072143678 .6345596313579 .2441329956180 .1584930419981 .07285308838 81.6824111938582 .5967712402383 .206336975183 .8159103393684 .42548370361 84.7302627563585 .3398437585 .6446228027385 .6446228027385 .94940185547 85.9494018554785 .9494018554785 .6446228027385 .3398437584 .73026275635 84.1206970214883 .206336975182 .2919769287181 .0728530883879 .85370635986 78.3297805786176 .8058471679774 .9771423339873 .4532165527371 .62449645996 69.7957916259867 .9670867919966 .1383666992264 .3096618652362 .48094940186 60.6522407531758 .8235282897956 .9948196411155 .1661109924353 .33739852905 51.8134689331149 .9847602844248 .4608306884846 .9369087219245 .7177696228 44.4986305236843 .5842704772942 .9747009277342 .9747009277343 .27949142456 43.8890609741244 .8034095764245 .717769622846 .6321296691947 .85126113892 48.765621185349 .9847602844250 .8991203308151 .8134689331153 .03261184692 53.9469718933154 .5565414428755 .4708900451756 .0804595947356 .38525009155 56.6900291442956 .9948196411156 .9948196411157 .2995986938556 .99481964111 57.2995986938557 .2995986938557 .2995986938557 .2995986938557 .29959869385 57.2995986938557 .2995986938557 .2995986938557 .2995986938556 .99481964111 56.9948196411156 .6900291442956 .6900291442956 .6900291442956 .38525009155 56.3852500915556 .0804595947356 .0804595947356 .0804595947356 .08045959473 55.7756805419955 .7756805419955 .7756805419955 .7756805419955 .77568054199 55.7756805419955 .7756805419955 .7756805419956 .0804595947356 .08045959473 56.0804595947356 .0804595947356 .3852500915556 .3852500915556 .38525009155 56.6900291442956 .6900291442956 .9948196411156 .9948196411156 .99481964111 57.2995986938557 .2995986938557 .6043891906757 .6043891906757 .9091796875 57.909179687558 .2139587402358 .2139587402358 .2139587402358 .49067687988 58.5187492370658 .8235282897944 .0957565307616 .90451049805 -9999 -9999 -9999 -9999 -9999 -9999 -9999 -9999 -9999 -9999 -9999 -9999 -9999 -9999 -9999 -9999 -9999 -9999 -9999 -9999 -9999 -9999 -9999 -9999 -9999 -9999 -9999 -9999 -9999 -9999 -9999 -9999 -9999 -9999 -9999 -9999 -9999 -9999 -9999 -9999 -9999 -9999

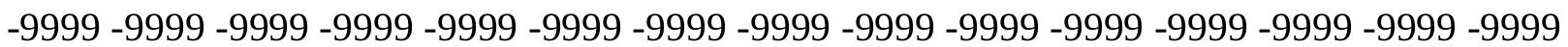


-9999 -9999 -9999 -9999 -9999 -9999 -9999 -9999 -9999 -9999 -9999 -9999 -9999 -9999 -9999 -9999 -9999 -9999 -9999 -9999 -9999 -9999 -9999 -9999 -9999 -9999 -9999 -9999 -9999 -9999 -9999 -9999 -9999 -9999 -9999 -9999 -9999 -9999 -9999 -9999 -9999 -9999 -9999 -9999 -9999 -9999 -9999 -9999 -9999 -9999 -9999 -9999 -9999 -9999 -9999 -9999 -9999 -9999 -9999 -9999 -9999 -9999 -9999 -9999 -9999 -9999 -9999 -9999 -9999 -9999 -9999 -9999 -9999 -9999 -9999 -9999 -9999 -9999 -9999 -9999 -9999 -9999 -9999 -9999 -9999 -9999 -9999 -9999 -9999 -9999 -9999 -9999 -9999 -9999 -9999 -9999 -9999 -9999 -9999 -9999 -9999 -9999 -9999 -9999 -9999 -9999 -9999 -9999 -9999 -9999 -9999 -9999 -9999 -9999 -9999 -9999 -9999 -9999 -9999 -9999 -9999 -9999 -9999 -9999 -9999 -9999 -9999 -9999 -9999 -9999 -9999 -9999 -9999 -9999 -9999 -9999 -9999 -9999 -9999 -9999 -9999 -9999 -9999 -9999 -9999 -9999 -9999 -9999 -9999 -9999 -

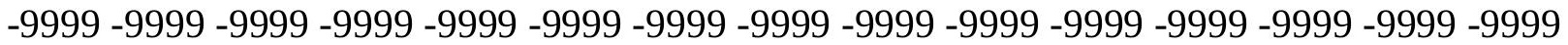
-9999 -9999 -9999 -9999 -9999 -9999 -9999 -9999 -9999 -9999 -9999 -9999 -9999 119.4757995605116 .1231002808113 .075302124104 .0304641724103 .2872695923 102.4683151245101 .271118164198 .445587158295 .397743225192 .65467834473 89.91161346436 87.16854858398 85.03504943848 82.90155792236 81.07285308838 79.2441329956178 .0249862670976 .8058471679775 .8914871215874 .97714233398 74.6723632812574 .062782287674 .062782287674 .062782287674 .36756896973 74.6723632812574 .9771423339875 .5867080688576 .1962814331176 .80584716797 77.4154205322378 .3297805786178 .9393463134879 .8537063598680 .76805877686 81.3776321411181 .9871978759882 .5967712402383 .206336975183 .81591033936 84.1206970214884 .7302627563585 .0350494384885 .0350494384885 .3398437585 .33984375 85.3398437585 .0350494384884 .7302627563584 .1206970214883 .51112365723 82.9015579223681 .9871978759880 .7680587768679 .5489196777378 .32978057861 76.8058471679775 .2819290161173 .7580032348671 .9292907714870 .40535736084 68.5766525268666 .7479400634865 .2240066528363 .3953094482461 .56660079956 60.0426712036158 .2139587402356 .3852500915554 .8613204956153 .03261184692 51.5086898803749 .9847602844248 .4608306884846 .9369087219246 .02254867554 45.1082000732444 .4986305236844 .1938400268644 .4986305236845 .10820007324 45.717769622846 .6321296691947 .5464782714848 .4608306884849 .37519073486 50.2895507812551 .2038993835452 .1182594299353 .0326118469253 .94697189331 54.5565414428755 .1661109924355 .7756805419956 .0804595947356 .38525009155 56.6900291442956 .9948196411156 .9948196411156 .9948196411157 .29959869385 57.2995986938557 .2995986938557 .2995986938557 .2995986938557 .29959869385 57.2995986938557 .2995986938557 .2995986938557 .2995986938556 .99481964111 56.9948196411156 .6900291442956 .6900291442956 .6900291442956 .38525009155 56.3852500915556 .0804595947356 .0804595947356 .0804595947356 .08045959473 56.0804595947356 .0804595947355 .9679756164655 .9126892089856 .08045959473 56.0804595947356 .0804595947356 .0804595947356 .0804595947356 .08045959473 56.3852500915556 .3852500915556 .3852500915556 .6900291442956 .69002914429 56.6900291442956 .9948196411156 .9948196411157 .2995986938557 .29959869385 57.6043891906757 .6043891906757 .6043891906757 .909179687557 .9091796875 58.2139587402358 .2139587402358 .5187492370658 .5187492370658 .71482467651 58.8235282897940 .148242950449 .40896320343 -9999 -9999 -9999 -9999 -9999 -9999 -9999 -9999 -9999 -9999 -9999 -9999 -9999 -9999 -9999 -9999 -9999 -9999 -9999 -9999 -9999 -9999 -9999 -9999 -9999 -9999 -9999

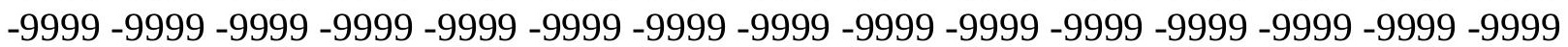


-9999 -9999 -9999 -9999 -9999 -9999 -9999 -9999 -9999 -9999 -9999 -9999 -9999 -9999 -9999 -9999 -9999 -9999 -9999 -9999 -9999 -9999 -9999 -9999 -9999 -9999 -9999 -9999 -9999 -9999 -9999 -9999 -9999 -9999 -9999 -9999 -9999 -9999 -9999 -9999 -9999 -9999 -9999 -9999 -9999 -9999 -9999 -9999 -9999 -9999 -9999 -9999 -9999 -9999 -9999 -9999 -9999 -9999 -9999 -9999 -9999 -9999 -9999 -9999 -9999 -9999 -9999 -9999 -9999 -9999 -9999 -9999 -9999 -9999 -9999 -9999 -9999 -9999 -9999 -9999 -9999 -9999 -9999 -9999 -9999 -9999 -9999 -9999 -9999 -9999 -9999 -9999 -9999 -9999 -9999 -9999 -9999 -9999 -9999 -9999 -9999 -9999 -9999 -9999 -9999

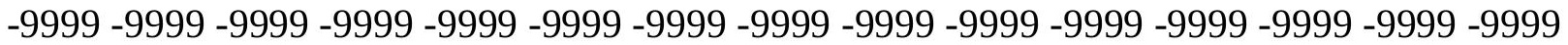
-9999 -9999 -9999 -9999 -9999 -9999 -9999 -9999 -9999 -9999 -9999 -9999 -9999 -9999 -9999 -9999 -9999 -9999 -9999 -9999 -9999 -9999 -9999 -9999 -9999 -9999 -9999 -9999 -9999 -9999 -9999 -9999 -9999 -9999 -9999 -9999 -9999 -9999 -9999 -9999 -9999 -9999 -9999 -9999 -9999 -9999 -9999 -9999 -9999 -9999 -9999 -9999 -9999 -9999 -9999 -9999 -9999 -9999 -9999 -9999 -9999 -9999 -9999 -9999 -9999 -9999 -9999 -9999 -9999 -9999-9999 -9999 -9999 124.6570968628120 .9997024536117 .0374984741113 .9896011353103 .7937927246 102.9407272339102 .0031509399100 .883903503497 .5312423706194 .48339080811 91.4355392456188 .6924667358486 .5589828491284 .4254837036182 .29197692871 80.7680587768679 .2441329956178 .0249862670977 .110626220776 .19628143311 75.8914871215875 .2819290161175 .2819290161174 .9771423339875 .28192901611 75.2819290161175 .5867080688575 .8914871215876 .5010681152377 .1106262207 77.4154205322378 .3297805786178 .9393463134879 .5489196777380 .15849304199 80.7680587768681 .6824111938582 .2919769287182 .5967712402383 .2063369751 83.5111236572384 .1206970214884 .4254837036184 .4254837036184 .73026275635 84.7302627563584 .7302627563584 .4254837036184 .1206970214883 .51112365723 82.9015579223682 .2919769287181 .3776321411180 .4632720947379 .54891967773 78.3297805786176 .8058471679775 .5867080688574 .062782287672 .53885650635 70.7101516723669 .1862335205167 .6623001098665 .8335876464864 .30966186523 62.7857398986860 .9570198059159 .4331016540557 .6043891906756 .08045959473 54.2517509460452 .7278289794951 .2038993835449 .6799812316948 .46083068848 47.5464782714846 .6321296691946 .0225486755445 .717769622846 .02254867554 46.3273391723646 .9369087219247 .5464782714848 .4608306884849 .07040023804 49.9847602844250 .8991203308151 .8134689331152 .4230384826753 .33739852905 53.9469718933154 .5565414428755 .1661109924355 .7756805419956 .08045959473 56.3852500915556 .6900291442956 .6900291442956 .9948196411156 .99481964111 57.2995986938557 .2995986938557 .2995986938557 .2995986938557 .60438919067 57.6043891906757 .6043891906757 .2995986938557 .2995986938557 .29959869385 57.2995986938556 .9948196411156 .9948196411156 .6900291442956 .69002914429 56.6900291442956 .3852500915556 .3852500915556 .3852500915556 .08045959473 56.0804595947356 .0804595947356 .0804595947356 .0804595947356 .08045959473 56.0804595947356 .0804595947356 .0804595947356 .0804595947356 .38525009155 56.3852500915556 .3852500915556 .3852500915556 .6900291442956 .69002914429 56.9948196411156 .9948196411156 .9948196411157 .2995986938557 .29959869385 57.2995986938557 .6043891906757 .6043891906757 .909179687557 .9091796875 58.2139587402358 .2139587402358 .5187492370658 .5187492370658 .51874923706 58.7758941650458 .8235282897934 .748847961431 .194903612137 -9999 -9999 -9999 -9999 -9999 -9999 -9999 -9999 -9999 -9999 -9999 -9999

-9999 -9999 -9999 -9999 -9999 -9999 -9999 -9999 -9999 -9999 -9999 -9999 -9999 -9999 -9999 
-9999 -9999 -9999 -9999 -9999 -9999 -9999 -9999 -9999 -9999 -9999 -9999 -9999 -9999 -9999 -9999 -9999 -9999 -9999 -9999 -9999 -9999 -9999 -9999 -9999 -9999 -9999 -9999 -9999 -9999 -9999 -9999 -9999 -9999 -9999 -9999 -9999 -9999 -9999 -9999 -9999 -9999 -9999 -9999 -9999 -9999 -9999 -9999 -9999 -9999 -9999 -9999 -9999 -9999 -9999 -9999 -9999 -9999 -9999 -9999 -9999 -9999 -9999 -9999 -9999 -9999 -9999 -9999 -9999 -9999 -9999 -9999 -9999 -9999 -9999 -9999 -9999 -9999 -9999 -9999 -9999 -9999 -9999 -9999 -9999 -9999 -9999 -9999 -9999 -9999 -9999 -9999 -9999 -9999 -9999 -9999 -9999 -9999 -9999 -9999 -9999 -9999 -9999 -9999 -9999 -9999 -9999 -9999 -9999 -9999 -9999 -9999 -9999 -9999 -9999 -9999 -9999 -9999 -9999 -9999 -9999 -9999 -9999 -9999 -9999 -9999 -9999 -9999 -9999 -9999 -9999 -9999 -9999 -9999 -9999 -9999 -9999 -9999 -9999 -9999 -9999 -9999 -9999 -9999 -9999 -9999 -9999 -9999 -9999 -9999 -9999 -9999 -9999 -9999 -9999 -9999 -9999 -9999 -9999 -9999 -9999 -9999 -9999 -9999 -9999 -9999 -9999 -9999 -9999 -9999 -9999 -9999 -9999 -9999 -9999 -9999 -9999 -9999 -9999 -9999

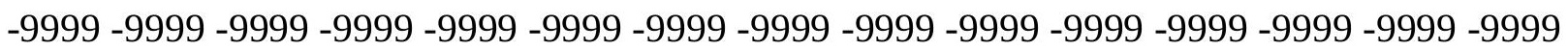
-9999 -9999 -9999 -9999 -9999 -9999 -9999 -9999 -9999 -9999 -9999 -9999 -9999 -9999 126.1809997559121 .6092987061117 .342300415113 .6848983765107 .4470214844 102.4420776367101 .532035827699 .6647262573296 .3121032714893 .26425170898 90.5211791992288 .0829010009885 .9494018554784 .1206970214882 .29197692871 80.7680587768679 .5489196777378 .6345596313577 .7202072143677 .1106262207 76.8058471679776 .5010681152376 .1962814331176 .1962814331176 .19628143311 76.5010681152376 .5010681152376 .8058471679777 .110626220777 .72020721436 78.0249862670978 .6345596313579 .2441329956179 .8537063598680 .46327209473 81.0728530883881 .6824111938582 .2919769287182 .5967712402383 .2063369751 83.5111236572383 .8159103393683 .8159103393684 .1206970214884 .12069702148 83.8159103393683 .8159103393683 .5111236572383 .206336975182 .59677124023 81.9871978759881 .0728530883880 .1584930419979 .2441329956178 .02498626709 76.8058471679775 .5867080688574 .062782287672 .8436431884871 .31971740723 69.7957916259868 .2718734741266 .7479400634865 .2240066528363 .39530944824 61.8713798522960 .3474502563558 .8235282897957 .2995986938555 .77568054199 54.2517509460452 .7278289794951 .2038993835449 .9847602844248 .7656211853 48.1560516357447 .5464782714847 .2416992187547 .2416992187547 .54647827148 48.1560516357448 .4608306884849 .0704002380449 .9847602844250 .59432983398 51.5086898803752 .1182594299352 .7278289794953 .6421813964854 .25175094604 54.8613204956155 .1661109924355 .7756805419956 .0804595947356 .38525009155 56.6900291442956 .6900291442956 .9948196411156 .9948196411157 .29959869385 57.2995986938557 .2995986938557 .6043891906757 .6043891906757 .60438919067 57.6043891906757 .6043891906757 .6043891906757 .2995986938557 .29959869385 57.2995986938556 .9948196411156 .9948196411156 .6900291442956 .69002914429 56.6900291442956 .3852500915556 .3852500915556 .3852500915556 .38525009155 56.3852500915556 .0804595947356 .0804595947356 .0804595947356 .08045959473 56.3852500915556 .3852500915556 .3852500915556 .3852500915556 .38525009155 56.6900291442956 .6900291442956 .6900291442956 .9948196411156 .99481964111 56.9948196411157 .2995986938557 .2995986938557 .6043891906757 .60438919067 57.6043891906757 .909179687557 .909179687558 .2139587402358 .21395874023 58.5187492370658 .5187492370658 .5187492370658 .7244262695358 .82352828979 49.7089691162125 .84077072144 -9999 -9999 -9999 -9999 -9999 -9999 -9999 -9999 -9999 -9999 -9999 -9999 -9999 
-9999 -9999 -9999 -9999 -9999 -9999 -9999 -9999 -9999 -9999 -9999 -9999 -9999 -9999 -9999 -9999 -9999 -9999 -9999 -9999 -9999 -9999 -9999 -9999 -9999 -9999 -9999 -9999 -9999 -9999

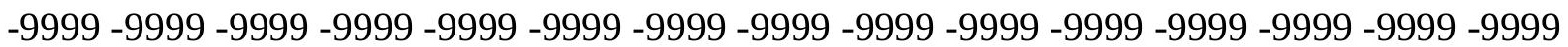
-9999 -9999 -9999 -9999 -9999 -9999 -9999 -9999 -9999 -9999 -9999 -9999 -9999 -9999 -9999 -9999 -9999 -9999 -9999 -9999 -9999 -9999 -9999 -9999 -9999 -9999 -9999 -9999 -9999 -9999 -9999 -9999 -9999 -9999 -9999 -9999 -9999 -9999 -9999 -9999 -9999 -9999 -9999 -9999 -9999 -9999 -9999 -9999 -9999 -9999 -9999 -9999 -9999 -9999 -9999 -9999 -9999 -9999 -9999 -9999

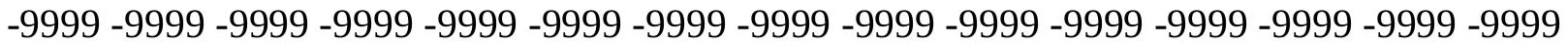
-9999 -9999 -9999 -9999 -9999 -9999 -9999 -9999 -9999 -9999 -9999 -9999 -9999 -9999 -9999 -9999 -9999 -9999 -9999 -9999 -9999 -9999 -9999 -9999 -9999 -9999 -9999 -9999 -9999 -9999 -9999 -9999 -9999 -9999 -9999 -9999 -9999 -9999 -9999 -9999 -9999 -9999 -9999 -9999 -9999 -9999 -9999 -9999 -9999 -9999 -9999 -9999 -9999 -9999 -9999 -9999 -9999 -9999 -9999 -9999

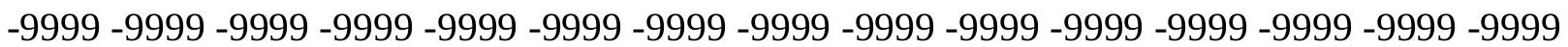
-9999 -9999 -9999 -9999 -9999 -9999 -9999 -9999 -9999 -9999 -9999 -9999 -9999 -9999 -9999 -9999 -9999 -9999 -9999 -9999 -9999 -9999 -9999 -9999 -9999 -9999 -9999 -9999 -9999 -9999 126.4858016968121 .3044967651116 .1231002808111 .8561019897106 .6702957153 101.9684295654101 .072006225698 .445587158295 .397743225192 .3498916626 89.91161346436 87.77810668945 85.64462280273 84.12069702148 82.59677124023 81.3776321411180 .1584930419979 .5489196777378 .6345596313578 .32978057861 78.0249862670977 .7202072143677 .4154205322377 .4154205322377 .41542053223 77.4154205322377 .4154205322377 .7202072143677 .7202072143678 .32978057861 78.6345596313579 .2441329956179 .5489196777380 .1584930419980 .76805877686 81.0728530883881 .6824111938581 .9871978759882 .5967712402382 .90155792236 83.206336975183 .206336975183 .5111236572383 .5111236572383 .51112365723 83.206336975182 .9015579223682 .5967712402381 .9871978759881 .37763214111 80.7680587768679 .8537063598678 .9393463134878 .0249862670976 .80584716797 75.5867080688574 .3675689697373 .1484298706171 .6244964599670 .10057830811 68.8814392089867 .3575134277365 .8335876464864 .3096618652362 .78573989868 61.5666007995660 .0426712036158 .5187492370656 .9948196411155 .47089004517 53.9469718933152 .7278289794951 .5086898803750 .2895507812549 .67998123169 49.0704002380448 .765621185348 .765621185349 .0704002380449 .37519073486 49.6799812316950 .2895507812550 .8991203308151 .5086898803752 .11825942993 52.7278289794953 .3373985290553 .9469718933154 .5565414428754 .86132049561 55.4708900451755 .7756805419956 .0804595947356 .3852500915556 .69002914429 56.6900291442956 .9948196411156 .9948196411157 .2995986938557 .29959869385 57.6043891906757 .6043891906757 .6043891906757 .6043891906757 .60438919067 57.6043891906757 .6043891906757 .6043891906757 .6043891906757 .29959869385 57.2995986938556 .9948196411156 .9948196411156 .9948196411156 .69002914429 56.6900291442956 .6900291442956 .3852500915556 .3852500915556 .38525009155 56.3852500915556 .3488311767656 .3852500915556 .3852500915556 .38525009155 56.3852500915556 .3852500915556 .6900291442956 .6900291442956 .69002914429 56.6900291442956 .9948196411156 .9948196411156 .9948196411157 .29959869385 57.2995986938557 .6043891906757 .6043891906757 .6043891906757 .9091796875 57.909179687558 .2139587402358 .2139587402358 .2139587402358 .51874923706 58.5187492370658 .8235282897958 .8235282897959 .1283111572343 .08750915527 15.56660270691 -9999 -9999 -9999 -9999 -9999 -9999 -9999 -9999 -9999 -9999 -9999 -9999 
$-9999$

-9999 -9999 -9999 -9999 -9999 -9999 -9999 -9999 -9999 -9999 -9999 -9999 -9999 -9999 -9999

-9999 -9999 -9999 -9999 -9999 -9999 -9999 -9999 -9999 -9999 -9999 -9999 -9999 -9999 - 9999 -

-9999 -9999 -9999 -9999 -9999 -9999 -9999 -9999 -9999 -9999 -9999 -9999 -9999 -9999 -9999

-9999 -9999 -9999 -9999 -9999 -9999 -9999 -9999 -9999 -9999 -9999 -9999-9999 -9999 -9999 -

-9999 -9999 -9999 -9999 -9999 -9999 -9999 -9999 -9999 -9999 -9999 -9999 -9999 -9999 -9999

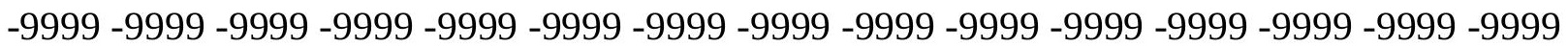

-9999 -9999 -9999 -9999 -9999 -9999 -9999 -9999 -9999 -9999 -9999 -9999 -9999 -9999 -9999 -999 -

-9999 -9999 -9999 -9999 -9999 -9999 -9999 -9999 -9999 -9999 -9999 -9999 -9999 -9999 -9999 -

-9999 -9999 -9999 -9999 -9999 -9999 -9999 -9999 -9999 -9999 -9999 -9999 -9999 -9999 -9999 -

-9999 -9999 -9999 -9999 -9999 -9999 -9999 -9999 -9999 -9999 -9999 -9999 -9999 -9999 -9999 -

-9999 -9999 -9999 -9999 -9999 -9999 -9999 -9999 -9999 -9999 -9999 -9999 -9999 -9999 -9999

-9999 -9999 -9999 -9999 -9999 -9999 -9999 -9999 -9999 -9999 -9999 -9999 -9999 -9999 -9999 -

-9999 -9999 -9999 -9999 -9999 -9999 -9999 -9999 -9999 -9999 -9999 -9999 -9999 -9999 -9999 -

-9999 -9999 -9999 -9999 -9999 -9999 -9999 -9999 -9999 -9999 -9999 -9999 -9999 -9999 -9999

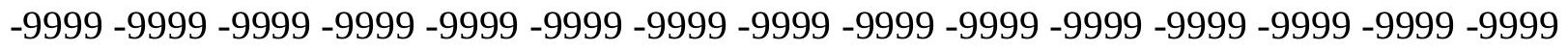

131.6672058105125 .8762969971119 .7806015015113 .6848983765110 .0273971558

105.6494445801101 .4907989502100 .335403442497 .5312423706194 .48339080811

92.0450973510789 .6068267822387 .7781066894585 .9494018554784 .42548370361 83.2063369751 82.29197692871 81.3776321411180.46327209473 80.15849304199

79.5489196777379 .2441329956178 .9393463134878 .6345596313578 .32978057861

78.3297805786178 .0249862670978 .0249862670978 .3297805786178 .32978057861

78.6345596313579 .2441329956179 .5489196777380 .1584930419980 .46327209473 80.7680587768681 .3776321411181 .6824111938581 .9871978759882 .29197692871

82.5967712402382 .5967712402382 .9015579223682 .9015579223682 .90155792236

82.5967712402382 .2919769287181 .9871978759881 .6824111938581 .07285308838

80.4632720947379 .5489196777378 .6345596313577 .7202072143676 .80584716797

75.5867080688574 .3675689697373 .1484298706171 .9292907714870 .71015167236

69.1862335205167 .9670867919966 .4431610107465 .2240066528363 .70008850098

62.4809494018660 .9570198059159 .7378807067958 .2139587402356 .69002914429

55.1661109924353 .9469718933152 .7278289794951 .8134689331151 .20389938354

50.5943298339850 .2895507812550 .2895507812550 .2895507812550 .59432983398

50.8991203308151 .2038993835451 .8134689331152 .1182594299352 .72782897949

53.3373985290553 .9469718933154 .2517509460454 .8613204956155 .16611099243

55.4708900451755 .7756805419956 .0804595947356 .3852500915556 .69002914429

56.6900291442956 .9948196411157 .2995986938557 .2995986938557 .60438919067 57.6043891906757 .909179687557 .909179687557 .909179687557 .9091796875

57.909179687557 .909179687557 .909179687557 .6043891906757 .60438919067

57.2995986938557 .2995986938557 .2995986938556 .9948196411156 .99481964111

56.6900291442956 .6900291442956 .6900291442956 .6900291442956 .5537071228

56.5374259948756 .6900291442956 .6900291442956 .6900291442956 .69002914429

56.6900291442956 .6900291442956 .6900291442956 .9948196411156 .99481964111

56.9948196411156 .9948196411157 .2995986938557 .2995986938557 .29959869385

57.6043891906757 .6043891906757 .909179687557 .909179687557 .9091796875

58.2139587402358 .2139587402358 .5187492370658 .5187492370658 .51874923706

58.8235282897958 .8235282897958 .9993743896559 .1283111572335 .30648040771 
4.087530612946 -9999 -9999 -9999 -9999 -9999 -9999 -9999 -9999 -9999 -9999 -9999 -9999 $-9999$

-9999 -9999 -9999 -9999 -9999 -9999 -9999 -9999 -9999 -9999 -9999 -9999 -9999 -9999 -9999 -9999 -9999 -9999 -9999 -9999 -9999 -9999 -9999 -9999 -9999 -9999 -9999 -9999 -9999 -9999 -9999 -9999 -9999 -9999 -9999 -9999 -9999 -9999 -9999 -9999 -9999 -9999 -9999 -9999 -9999 -999 -9999 -9999 -9999 -9999 -9999 -9999 -9999 -9999 -9999 -9999 -9999 -9999 -9999 -9999 -9999

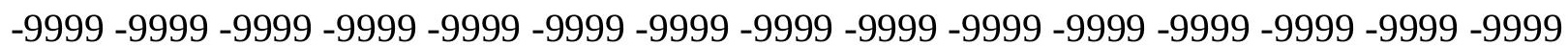
-9999 -9999 -9999 -9999 -9999 -9999 -9999 -9999 -9999 -9999 -9999 -9999 -9999 -9999 -9999 -9999 -9999 -9999 -9999 -9999 -9999 -9999 -9999 -9999 -9999 -9999 -9999 -9999 -9999 -9999

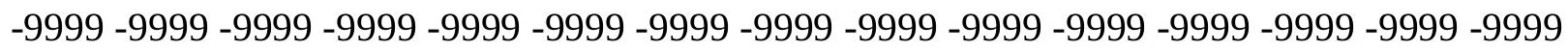
-9999 -9999 -9999 -9999 -9999 -9999 -9999 -9999 -9999 -9999 -9999 -9999 -9999 -9999-999 -9999 -9999 -9999 -9999 -9999 -9999 -9999 -9999 -9999 -9999 -9999 -9999 -9999 -9999 -9999 -9999 -9999 -9999 -9999 -9999 -9999 -9999 -9999 -9999 -9999 -9999 -9999 -9999 -9999 -9999

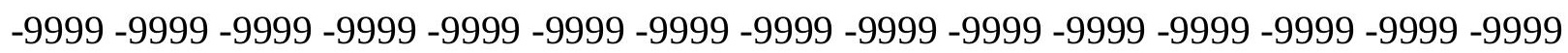
-9999 -9999 -9999 -9999 -9999 -9999 -9999 -9999 -9999 -9999 -9999 -9999 -9999 -9999 -9999

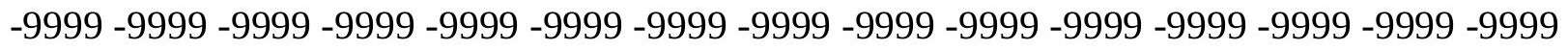

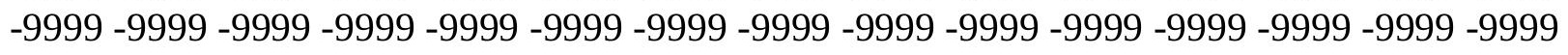
-9999 130.4479980469123.43800354 116.7326965332111.8561019897108.8082962036 104.6675643921102 .127136230599 .5279617309696 .9216690063594 .17859649658 92.0450973510789 .9116134643688 .0829010009886 .5589828491285 .33984375 84.4254837036183 .5111236572382 .5967712402382 .2919769287181 .68241119385 81.3776321411180 .7680587768680 .4632720947379 .8537063598679 .54891967773 79.2441329956178 .9393463134878 .9393463134878 .9393463134879 .24413299561 79.2441329956179 .5489196777380 .1584930419980 .4632720947380 .76805877686 81.0728530883881 .3776321411181 .6824111938581 .9871978759881 .98719787598 82.29197692871 82.29197692871 82.29197692871 82.29197692871 81.98719787598 81.9871978759881 .6824111938581 .0728530883880 .4632720947379 .85370635986 79.2441329956178 .6345596313577 .7202072143676 .5010681152375 .58670806885 74.3675689697373 .4532165527372 .2340774536171 .014930725169 .79579162598 68.2718734741267 .0527267456165 .8335876464864 .6144485473663 .09051895142 61.8713798522960 .6522407531759 .1283111572357 .909179687556 .38525009155 55.4708900451754 .2517509460453 .3373985290552 .7278289794952 .11825942993 51.8134689331151 .8134689331151 .8134689331151 .8134689331152 .11825942993 52.4230384826752 .7278289794953 .0326118469253 .6421813964853 .94697189331 54.5565414428754 .8613204956155 .1661109924355 .4708900451755 .77568054199 56.0804595947356 .3852500915556 .6900291442956 .6900291442956 .99481964111 57.2995986938557 .2995986938557 .6043891906757 .6043891906757 .9091796875 57.909179687558 .2139587402358 .2139587402358 .2139587402358 .21395874023 58.2139587402357 .909179687557 .909179687557 .909179687557 .60438919067 57.6043891906757 .2995986938557 .2995986938557 .2995986938556 .99481964111 56.9948196411156 .9948196411156 .6900291442956 .6900291442956 .69002914429 56.6900291442956 .6900291442956 .6900291442956 .6900291442956 .99481964111 56.9948196411156 .9948196411156 .9948196411156 .9948196411157 .29959869385 57.2995986938557 .2995986938557 .6043891906757 .6043891906757 .60438919067 57.909179687557 .909179687557 .909179687558 .2139587402358 .21395874023 58.5187492370658 .5187492370658 .5187492370658 .8235282897958 .82352828979 
59.0080146789659 .115509033245 .7914581298823 .01812744141 -9999 -9999 -9999 -9999 -9999 -9999 -9999 -9999 -9999 -9999 -9999 -9999 -9999 -9999

-9999 -9999 -9999 -9999 -9999 -9999 -9999 -9999 -9999 -9999 -9999 -9999 -9999 -9999 -9999

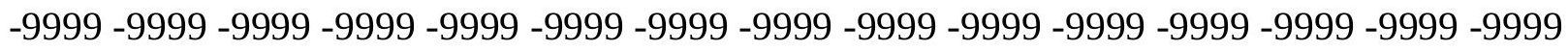
-9999 -9999 -9999 -9999 -9999 -9999 -9999 -9999 -9999-9999 -9999 -9999 -9999 -9999 -9999 -9999 -9999 -9999 -9999 -9999 -9999 -9999 -9999 -9999 -9999 -9999 -9999 -9999 -9999 -9999

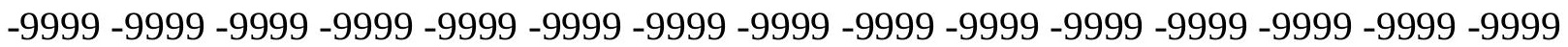

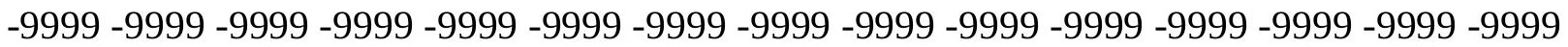

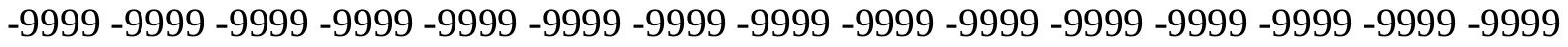
-9999 -9999 -9999 -9999 -9999 -9999 -9999 -9999 -9999 -9999 -9999 -9999 -9999 -9999 -9999

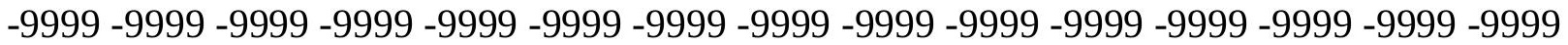
-9999 -9999 -9999 -9999 -9999 -9999 -9999 -9999 -9999 -9999 -9999 -9999 -9999 -9999 -9999 -9999 -9999 -9999 -9999 -9999 -9999 -9999 -9999 -9999 -9999 -9999 -9999 -9999 -9999 -9999 -9999 -9999 -9999 -9999 -9999 -9999 -9999 -9999 -9999 -9999 -9999 -9999 -9999 -9999 - 9999 -9999 -9999 -9999 -9999 -9999 -9999 -9999 -9999 -9999 -9999 -9999 -9999 -9999 -9999 -9999

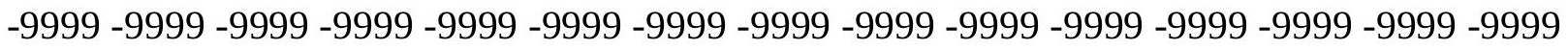
-9999 -9999 -9999 -9999 -9999 -9999 -9999 -9999 -9999 -9999 -9999 -9999 -9999 -9999 -9999 -9999 -9999 128.0097961426120.3900985718 114.2944030762 110.9418029785 108.1986999512103 .8999557495101 .512603759899 .1752395629996 .92166900635 94.4833908081192 .349891662690 .8259735107489 .302040100187 .77810668945 86.86376190186 85.9494018554785.33984375 84.73026275635 84.42548370361 83.8159103393683 .206336975182 .5967712402381 .6824111938581 .07285308838 80.4632720947380 .1584930419979 .8537063598679 .8537063598679 .85370635986 79.8537063598680 .1584930419980 .1584930419980 .4632720947380 .76805877686 81.0728530883881 .0728530883881 .3776321411181 .6824111938581 .68241119385 81.9871978759881 .9871978759881 .9871978759881 .6824111938581 .68241119385 81.3776321411181 .0728530883880 .7680587768680 .1584930419979 .54891967773 78.9393463134878 .3297805786177 .4154205322376 .5010681152375 .58670806885 74.6723632812573 .4532165527372 .2340774536171 .3197174072370 .10057830811 68.8814392089867 .6623001098666 .4431610107465 .2240066528364 .0048828125 62.7857398986861 .5666007995660 .0426712036158 .8235282897957 .60438919067 56.6900291442955 .7756805419954 .8613204956154 .2517509460453 .64218139648 53.3373985290553 .3373985290553 .0326118469253 .3373985290553 .33739852905 53.6421813964853 .9469718933154 .2517509460454 .5565414428754 .86132049561 55.1661109924355 .4708900451755 .7756805419956 .0804595947356 .38525009155 56.3852500915556 .6900291442956 .9948196411156 .9948196411157 .29959869385 57.6043891906757 .6043891906757 .909179687557 .909179687558 .21395874023 58.2139587402358 .5187492370658 .5187492370658 .5187492370658 .51874923706 58.5187492370658 .5187492370658 .2139587402358 .2139587402357 .9091796875 57.909179687557 .6043891906757 .6043891906757 .2995986938557 .29959869385 57.2995986938556 .9948196411156 .9948196411156 .9948196411156 .99481964111 56.9948196411156 .9948196411156 .9948196411156 .9948196411156 .99481964111 57.2995986938557 .2995986938557 .2995986938557 .2995986938557 .29959869385 57.6043891906757 .6043891906757 .6043891906757 .909179687557 .9091796875 57.909179687558 .2139587402358 .2139587402358 .2139587402358 .51874923706 58.5187492370658 .8235282897958 .8235282897958 .8235282897959 .12831115723 
59.1283111572359 .1283111572337 .89773559578 .427178382874 -9999 -9999 -9999 -9999 -9999 -9999 -9999 -9999 -9999 -9999 -9999 -9999 -9999 -9999

-9999 -9999 -9999 -9999 -9999 -9999 -9999 -9999 -9999 -9999 -9999 -9999 -9999 -9999 - -999 -9999 -9999 -9999 -9999 -9999 -9999 -9999 -9999 -9999 -9999 -9999 -9999 -9999 -9999 -9999 -9999 -9999 -9999 -9999 -9999 -9999 -9999 -9999 -9999-9999 -9999 -9999 -9999 -9999 -9999 -9999 -9999 -9999 -9999 -9999 -9999 -9999 -9999 -9999 -9999 -9999 -9999 -9999 -9999 -9999

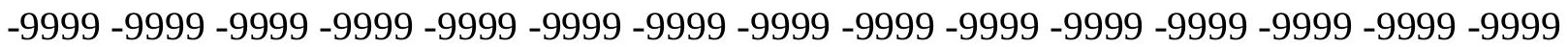

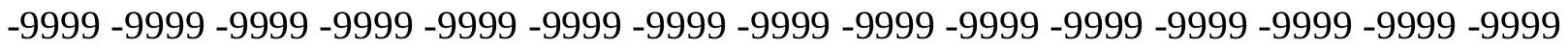

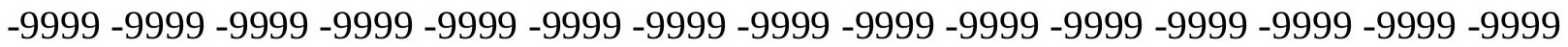
-9999 -9999 -9999 -9999 -9999 -9999 -9999 -9999 -9999 -9999 -9999 -9999 -9999 -9999 -9999 -

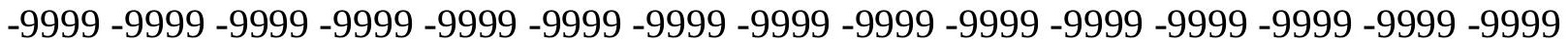
-9999 -9999 -9999 -9999 -9999 -9999 -9999 -9999 -9999 -9999 -9999 -9999 -9999 -9999 -9999 -9999 -9999 -9999 -9999 -9999 -9999 -9999 -9999 -9999 -9999 -9999 -9999 -9999 -9999 -9999 -9999 -9999 -9999 -9999 -9999 -9999 -9999 -9999 -9999 -9999 -9999 -9999 -9999 -9999 - 9999 -9999 -9999 -9999 -9999 -9999 -9999 -9999 -9999 -9999 -9999 -9999 -9999 -9999 -9999 -9999

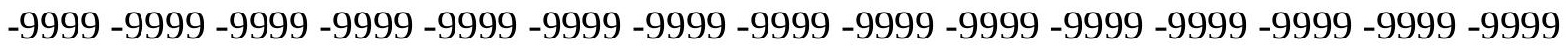
-9999 -9999 -9999 -9999 -9999 -9999 -9999 -9999 -9999 -9999 -9999 -9999 -9999 -9999 -9999 -9999 -9999-9999 125.8762969971 118.5614013672113 .3800964355110 .6370010376 107.5891036987 103.4892578125 101.3523101807 99.26968383789 97.22646331787 95.397743225193 .5690307617292 .0450973510790 .8259735107489 .60682678223 88.69246673584 88.08290100098 87.77810668945 87.47332763672 86.86376190186 86.254188537685 .3398437584 .1206970214883 .206336975182 .29197692871 81.6824111938581 .0728530883881 .0728530883880 .7680587768680 .76805877686 80.7680587768680 .7680587768681 .0728530883881 .0728530883881 .07285308838 81.0728530883881 .3776321411181 .3776321411181 .3776321411181 .68241119385 81.6824111938581 .6824111938581 .3776321411181 .3776321411181 .07285308838 80.7680587768680 .4632720947379 .8537063598679 .2441329956178 .63455963135 78.0249862670977 .110626220776 .5010681152375 .5867080688574 .67236328125 73.4532165527372 .5388565063571 .3197174072370 .4053573608469 .18623352051 67.9670867919967 .0527267456165 .8335876464864 .6144485473663 .39530944824 62.1761703491260 .9570198059159 .7378807067958 .8235282897957 .9091796875 56.9948196411156 .0804595947355 .7756805419955 .1661109924354 .86132049561 54.5565414428754 .5565414428754 .5565414428754 .5565414428754 .86132049561 54.8613204956155 .1661109924355 .4708900451755 .7756805419956 .08045959473 56.0804595947356 .3852500915556 .6900291442956 .9948196411156 .99481964111 56.9948196411157 .2995986938557 .2995986938557 .6043891906757 .9091796875 57.909179687558 .2139587402358 .5187492370658 .5187492370658 .82352828979 58.8235282897958 .8235282897958 .8235282897958 .8235282897958 .82352828979 58.8235282897958 .5187492370658 .5187492370658 .2139587402358 .21395874023 57.909179687557 .909179687557 .6043891906757 .6043891906757 .60438919067 57.2995986938557 .2995986938557 .2995986938557 .2995986938557 .29959869385 57.2995986938557 .2995986938557 .2995986938557 .2995986938557 .29959869385 57.6043891906757 .6043891906757 .6043891906757 .6043891906757 .9091796875 57.909179687557 .909179687557 .909179687558 .2139587402358 .21395874023 58.2139587402358 .5187492370658 .5187492370658 .8235282897958 .82352828979 58.8235282897959 .1283111572359 .1283111572359 .1283111572359 .29259490967 
59.3782653808621 .55931472778 -11.1131868362 -9999 -9999 -9999 -9999 -9999 -9999 -9999 -9999 -9999 -9999 -9999 -9999 -9999-9999

-9999 -9999 -9999 -9999 -9999 -9999 -9999 -9999 -9999 -9999 -9999 -9999 -9999 -9999 -9999 -9999 -9999 -9999 -9999 -9999 -9999 -9999 -9999 -9999 -9999 -9999 -9999 -9999 -9999 -9999 - -999 -9999 -9999 -9999 -9999 -9999 -9999 -9999 -9999 -9999 -9999 -9999 -9999 -9999 - -9999 - -9999 -

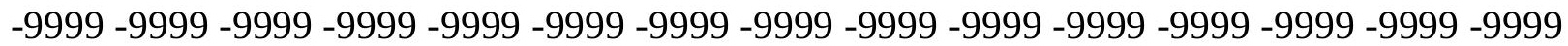

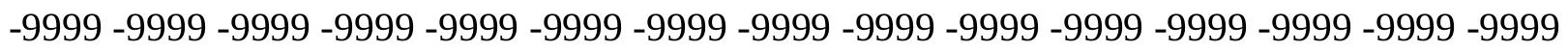
-9999 -9999 -9999 -9999 -9999 -9999 -9999 -9999 -9999 -9999 -9999 -9999 -9999 -9999 -9999

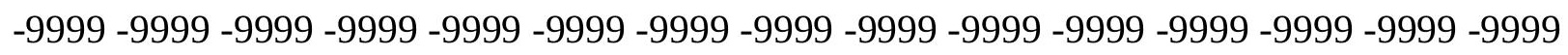

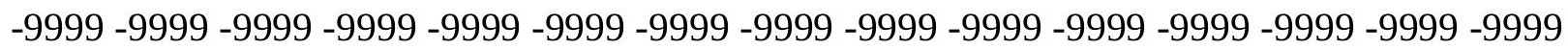

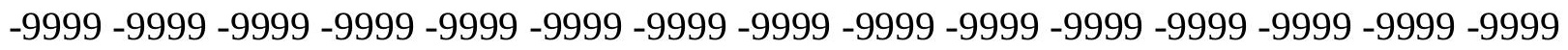

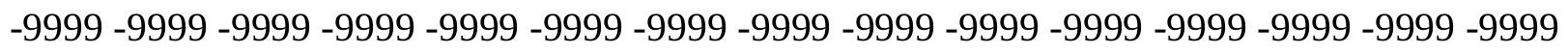

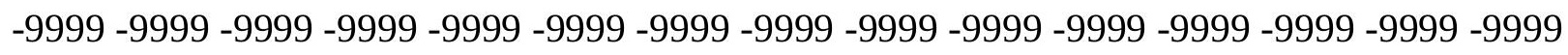
-9999 -9999 -9999 -9999 -9999 -9999 -9999 -9999 -9999 -9999 -9999 -9999 -9999 -9999 -9999 -

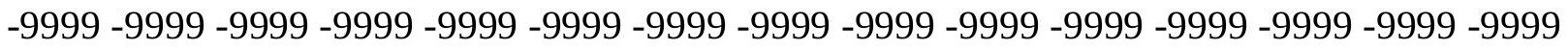

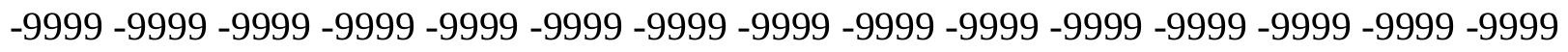

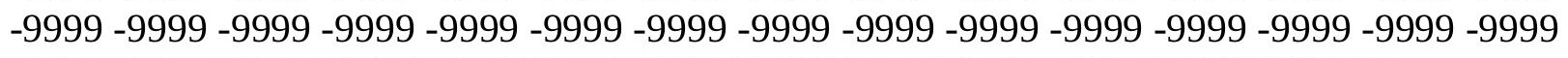
-9999 -9999-9999 131.9720001221 123.7427978516115.818397522 113.075302124 110.0273971558106 .979598999103 .4887771606101 .621757507399 .87007904053 98.2962036132896 .9216690063595 .397743225194 .1785964965892 .95947265625 92.0450973510791 .7403335571391 .4355392456191 .1307525634890 .52117919922 89.6068267822388 .6924667358487 .1685485839885 .6446228027384 .42548370361 83.5111236572383 .206336975182 .5967712402382 .2919769287182 .29197692871 81.9871978759881 .6824111938581 .6824111938581 .3776321411181 .37763214111 81.37763214111 81.37763214111 81.37763214111 81.37763214111 81.37763214111 81.37763214111 81.37763214111 81.07285308838 81.07285308838 80.76805877686 80.4632720947380 .1584930419979 .5489196777378 .9393463134878 .32978057861 77.7202072143677 .110626220776 .1962814331175 .5867080688574 .67236328125 73.7580032348672 .5388565063571 .6244964599670 .7101516723669 .49101257324 68.5766525268667 .3575134277366 .4431610107465 .2240066528364 .0048828125 63.0905189514261 .8713798522960 .9570198059159 .7378807067958 .82352828979 58.2139587402357 .6043891906756 .9948196411156 .6900291442956 .38525009155 56.0804595947356 .0804595947356 .0804595947356 .0804595947356 .08045959473 56.0804595947356 .0804595947356 .3852500915556 .6900291442956 .69002914429 56.9948196411157 .2995986938557 .2995986938557 .6043891906757 .60438919067 57.6043891906757 .909179687557 .909179687558 .2139587402358 .21395874023 58.5187492370658 .8235282897958 .8235282897959 .1283111572359 .12831115723 59.4331016540559 .4331016540559 .4331016540559 .4331016540559 .43310165405 59.1283111572359 .1283111572358 .8235282897958 .8235282897958 .51874923706 58.5187492370658 .2139587402358 .2139587402357 .909179687557 .9091796875 57.6043891906757 .6043891906757 .6043891906757 .6043891906757 .60438919067 57.6043891906757 .6043891906757 .6043891906757 .6043891906757 .60438919067 57.6043891906757 .909179687557 .909179687557 .909179687557 .9091796875 58.2139587402358 .2139587402358 .2139587402358 .5187492370658 .51874923706 58.5187492370658 .8235282897958 .8235282897958 .8235282897959 .12831115723 59.1283111572359 .1283111572359 .4331016540559 .4331016540559 .43310165405 
15.02973079681 -8.28266334534 -33.4809608459 -9999 -9999 -9999 -9999 -9999 -9999 -9999 -9999 -9999 -9999 -9999 -9999 -9999 -9999

-9999 -9999 -9999 -9999 -9999 -9999 -9999 -9999 -9999 -9999 -9999 -9999 -9999 -9999 -9999 -9999 -9999 -9999 -9999 -9999 -9999 -9999 -9999 -9999 -9999 -9999 -9999 -9999 -9999 -9999 -9999 -9999 -9999 -9999 -9999 -9999 -9999 -9999 -9999 -9999 -9999 -9999-9999 -9999 -9999 -9999 -9999 -9999 -9999 -9999 -9999 -9999 -9999 -9999 -9999 -9999 -9999 -9999 -9999 -9999

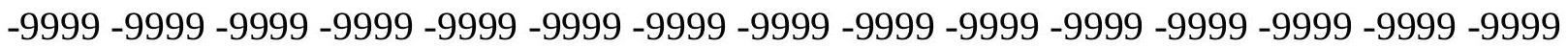
-9999 -9999 -9999 -9999 -9999 -9999 -9999 -9999 -9999 -9999 -9999 -9999 -9999 -9999 -9999 -999 -9999 -9999 -9999 -9999 -9999 -9999 -9999 -9999 -9999 -9999 -9999 -9999 -9999 -9999 -9999 -9999 -9999 -9999 -9999 -9999 -9999 -9999 -9999 -9999 -9999 -9999 -9999 -9999 -9999 -9999 -

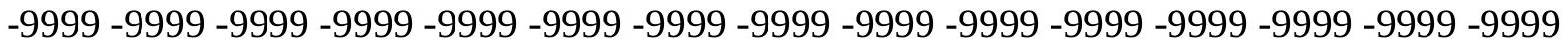
-9999 -9999 -9999 -9999 -9999 -9999 -9999 -9999 -9999 -9999 -9999 -9999 -9999 -9999 -9999 -9999 -9999 -9999 -9999 -9999 -9999 -9999 -9999 -9999 -9999 -9999 -9999 -9999 -9999 -9999 -9999 -9999 -9999 -9999 -9999 -9999 -9999 -9999 -9999 -9999 -9999 -9999 -9999 -9999 -9999 -9999 -9999 -9999 -9999 -9999 -9999 -9999 -9999 -9999 -9999 -9999 -9999 -9999 -9999 -9999

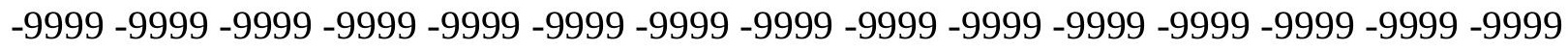

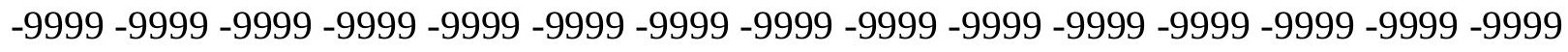
-9999 -9999 -9999 -9999 129.2288970947 121.3044967651 115.5136032104 111.8561019897 109.1130981445106 .979598999104 .8460998535102 .4073181152101 .0379180908 99.2002716064598 .6194458007897 .6289138793996 .9216690063596 .31210327148 95.7025299072395 .7025299072395 .397743225194 .7881774902394 .17859649658 92.9594726562591 .1307525634888 .9972534179787 .4733276367286 .2541885376 85.6446228027385 .0350494384884 .7302627563584 .1206970214883 .51112365723 83.2063369751 82.59677124023 82.29197692871 81.98719787598 81.68241119385 81.6824111938581 .3776321411181 .3776321411181 .3776321411181 .37763214111 81.0728530883881 .0728530883880 .7680587768680 .4632720947380 .15849304199 79.8537063598679 .2441329956178 .9393463134878 .3297805786177 .72020721436 77.110626220776 .1962814331175 .5867080688574 .6723632812573 .75800323486 72.8436431884871 .9292907714871 .014930725169 .7957916259868 .88143920898 67.9670867919966 .7479400634865 .8335876464864 .9192428588963 .70008850098 62.7857398986861 .8713798522960 .9570198059160 .0426712036159 .43310165405 58.8235282897958 .5187492370657 .909179687557 .909179687557 .60438919067 57.6043891906757 .2995986938557 .2995986938557 .2995986938557 .29959869385 57.2995986938557 .2995986938557 .6043891906757 .6043891906757 .9091796875 58.2139587402358 .2139587402358 .5187492370658 .5187492370658 .51874923706 58.5187492370658 .8235282897958 .8235282897958 .8235282897959 .12831115723 59.4331016540559 .4331016540559 .7378807067959 .7378807067960 .04267120361 60.0426712036160 .0426712036160 .0426712036159 .7378807067959 .73788070679 59.7378807067959 .4331016540559 .1283111572360 .6522407531760 .34745025635 60.3474502563560 .0426712036160 .0426712036159 .2716903686558 .21395874023 57.909179687557 .909179687557 .909179687557 .909179687557 .909179687557 .9091796875 57.909179687557 .909179687557 .909179687558 .2139587402358 .21395874023 58.2139587402358 .2139587402358 .2139587402358 .5187492370658 .51874923706 58.5187492370658 .5187492370658 .8235282897958 .8235282897958 .82352828979 59.1283111572359 .1283111572359 .1283111572359 .4331016540559 .43310165405 $59.4331016540559 .7378807067959 .70150756836-4.94721269608$-34.5478935242 -9999 
-9999 -9999 -9999 -9999 -9999 -9999 -9999 -9999 -9999 -9999 -9999 -9999 -9999 -9999

-9999 -9999 -9999 -9999 -9999 -9999 -9999 -9999 -9999 -9999 -9999 -9999 -9999 -9999 -9999

-9999 -9999 -9999 -9999 -9999 -9999 -9999 -9999 -9999 -9999 -9999 -9999 -9999 -9999 -9999

-9999 -9999 -9999 -9999 -9999 -9999 -9999 -9999 -9999 -9999 -9999 -9999 -9999 -9999 -9999

-9999 -9999 -9999 -9999 -9999 -9999 -9999 -9999 -9999 -9999 -9999 -9999 -9999 -9999 -9999

-9999 -9999 -9999 -9999 -9999 -9999 -9999 -9999 -9999 -9999 -9999 -9999 -9999 -9999 -9999 -

-9999 -9999 -9999 -9999 -9999 -9999 -9999 -9999 -9999 -9999 -9999 -9999 -9999 -9999 -9999

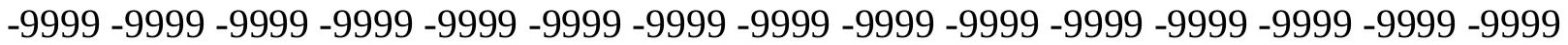

-9999 -9999 -9999 -9999 -9999 -9999 -9999 -9999 -9999 -9999 -9999 -9999 -9999 -9999 -9999

-9999 -9999 -9999 -9999 -9999 -9999 -9999 -9999 -9999 -9999 -9999 -9999 -9999 -9999 -9999 -

-9999 -9999 -9999 -9999 -9999 -9999 -9999 -9999 -9999 -9999 -9999 -9999 -9999 -9999 -9999

-9999 -9999 -9999 -9999 -9999 -9999 -9999 -9999 -9999 -9999 -9999 -9999 -9999 -9999 -9999

-9999 -9999 -9999 -9999 -9999 -9999 -9999 -9999 -9999 -9999 -9999 -9999 -9999 -9999 -9999 -

-9999 -9999 -9999 -9999 -9999 -9999 -9999 -9999 -9999 -9999 -9999 -9999 -9999 -9999 -9999 -

-9999 -9999 -9999 -9999 -9999 -9999 -9999 -9999 -9999 -9999 -9999 -9999 -9999 -9999 -9999

-9999 -9999 -9999 -9999 -9999 -9999 -9999 -9999 -9999 -9999 -9999 -9999 -9999 -9999 -9999

-9999 -9999 -9999 -9999 -9999 126.4858016968 117.647102356112 .4656982422

110.9418029785109 .1130981445107 .8938980103106 .6747970581103 .599281311

102.5341720581100 .295204162699 .9818725585999 .798271179299 .85747528076 99.4902877807699 .2739181518698 .9631500244198 .4505691528397 .70769500732 96.0915069580195 .2090377807693 .8738174438591 .1307525634890 .21640014648 89.3020401001 88.3876876831187.47332763672 86.55898284912 85.64462280273 84.7302627563583 .8159103393683 .206336975182 .5967712402382 .29197692871 81.9871978759881 .6824111938581 .6824111938581 .3776321411181 .37763214111 81.0728530883880 .7680587768680 .7680587768680 .4632720947379 .85370635986 79.5489196777379 .2441329956178 .6345596313578 .0249862670977 .41542053223 76.8058471679776 .1962814331175 .2819290161174 .6723632812573 .75800323486 72.8436431884871 .9292907714871 .014930725170 .1005783081169 .18623352051 68.2718734741267 .3575134277366 .4431610107465 .5288009643664 .61444854736 63.3953094482462 .7857398986861 .8713798522960 .9570198059160 .34745025635 60.0426712036159 .7378807067959 .4331016540559 .1283111572359 .12831115723 58.8235282897958 .8235282897958 .5187492370658 .5187492370658 .51874923706 58.5187492370658 .5187492370658 .5187492370658 .8235282897958 .82352828979 59.1283111572359 .1283111572359 .4331016540559 .4331016540559 .43310165405 59.4331016540559 .7378807067959 .7378807067959 .7378807067959 .73788070679 60.0426712036160 .3474502563560 .3474502563560 .6522407531760 .65224075317 60.6522407531760 .6522407531760 .6522407531760 .6122016906760 .34745025635 60.3474502563560 .0426712036159 .7378807067961 .2618103027360 .95701980591 60.9570198059160 .6522407531760 .3474502563560 .339710235659 .9447593689 60.0426712036158 .5187492370658 .2139587402358 .2139587402358 .21395874023 58.2139587402358 .2139587402358 .2139587402358 .5187492370658 .51874923706 58.5187492370658 .5187492370658 .5187492370658 .5187492370658 .82352828979 58.8235282897958 .8235282897958 .8235282897959 .1283111572359 .12831115723 59.1283111572359 .4331016540559 .4331016540559 .4331016540559 .43310165405 $59.7378807067959 .7378807067959 .7378807067959 .73788070679-17.802854538$ -52.3090744019 -9999 -9999 -9999 -9999 -9999 -9999 -9999 -9999 -9999 -9999 -9999 -9999 
-9999 -9999 -9999

-9999 -9999 -9999 -9999 -9999 -9999 -9999 -9999 -9999 -9999 -9999 -9999 -9999 -9999 -9999

-9999 -9999 -9999 -9999 -9999 -9999 -9999 -9999 -9999 -9999 -9999 -9999 -9999 -9999 - 9999 -

-9999 -9999 -9999 -9999 -9999 -9999 -9999 -9999 -9999 -9999 -9999 -9999 -9999 -9999 -9999

-9999 -9999 -9999 -9999 -9999 -9999 -9999 -9999 -9999 -9999 -9999 -9999-9999 -9999 -9999 -

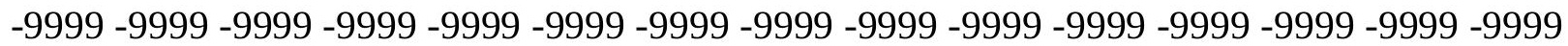

-9999 -9999 -9999 -9999 -9999 -9999 -9999 -9999 -9999 -9999 -9999 -9999 -9999 -9999 -9999 -999 -

-9999 -9999 -9999 -9999 -9999 -9999 -9999 -9999 -9999 -9999 -9999 -9999 -9999 -9999 -9999

-9999 -9999 -9999 -9999 -9999 -9999 -9999 -9999 -9999 -9999 -9999 -9999 -9999 -9999 -9999 -

-9999 -9999 -9999 -9999 -9999 -9999 -9999 -9999 -9999 -9999 -9999 -9999 -9999 -9999 -9999 -

-9999 -9999 -9999 -9999 -9999 -9999 -9999 -9999 -9999 -9999 -9999 -9999 -9999 -9999 -9999

-9999 -9999 -9999 -9999 -9999 -9999 -9999 -9999 -9999 -9999 -9999 -9999 -9999 -9999 -9999

-9999 -9999 -9999 -9999 -9999 -9999 -9999 -9999 -9999 -9999 -9999 -9999 -9999 -9999 -9999 -

-9999 -9999 -9999 -9999 -9999 -9999 -9999 -9999 -9999 -9999 -9999 -9999 -9999 -9999 -9999 -

-9999 -9999 -9999 -9999 -9999 -9999 -9999 -9999 -9999 -9999 -9999 -9999 -9999 -9999 -9999

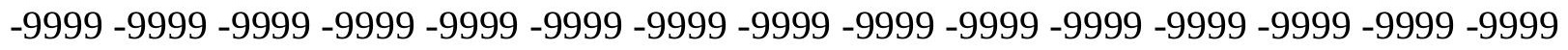

-9999 -9999 -9999 -9999-9999 131.0576019287122 .8283996582114 .5991973877

111.8561019897111 .8561019897111 .24659729110 .0273971558109 .1130981445

105.0954589844102 .4348526001102 .3624801636102 .5579681396102 .9496078491 102.662071228102 .3737258911102 .0122756958101 .4975357056100 .7644958496 96.5282058715895 .9619903564595 .4030914306694 .8511962890694 .30611419678 93.767997741792 .6546783447391 .1307525634889 .6068267822388 .08290100098 86.5589828491285 .6446228027384 .4254837036183 .8159103393683 .2063369751 82.5967712402382 .2919769287181 .9871978759881 .6824111938581 .37763214111 81.0728530883881 .0728530883880 .7680587768680 .1584930419979 .85370635986 79.5489196777378 .9393463134878 .6345596313578 .0249862670977 .41542053223 76.8058471679776 .1962814331175 .2819290161174 .6723632812573 .75800323486 73.1484298706172 .2340774536171 .3197174072370 .4053573608469 .79579162598 68.8814392089867 .9670867919967 .0527267456166 .1383666992265 .22400665283 64.3096618652363 .3953094482462 .7857398986862 .1761703491261 .56660079956 61.2618103027360 .9570198059160 .6522407531760 .6522407531760 .34745025635 60.3474502563560 .0426712036159 .7378807067959 .7378807067959 .43310165405 59.4331016540559 .4331016540559 .7378807067959 .7378807067960 .04267120361 60.0426712036160 .3474502563560 .3474502563560 .6522407531760 .65224075317 60.6522407531760 .6522407531760 .6522407531760 .6522407531760 .95701980591 60.9570198059161 .2618103027361 .2618103027361 .5666007995661 .56660079956 61.5666007995661 .5666007995661 .5666007995661 .2618103027361 .26181030273 60.9570198059160 .6522407531760 .3474502563561 .8713798522961 .56660079956 61.2618103027361 .2618103027360 .9570198059160 .9570198059160 .65224075317 60.6522407531758 .8235282897958 .8235282897958 .8235282897958 .82352828979 58.8235282897958 .8235282897958 .8235282897958 .8235282897958 .82352828979 58.8235282897958 .8235282897958 .8235282897958 .8235282897959 .12831115723 59.1283111572359 .1283111572359 .1283111572359 .4331016540559 .43310165405 59.4331016540559 .4331016540559 .7378807067959 .7378807067959 .73788070679 59.7378807067960 .0426712036159 .9823379516618 .03849411011 -30.6565990448 -63.1836662292 -9999 -9999 -9999 -9999 -9999 -9999 -9999 -9999 -9999 -9999 -9999 -9999 
-9999 -9999 -9999

-9999 -9999 -9999 -9999 -9999 -9999 -9999 -9999 -9999 -9999 -9999 -9999 -9999 -9999 -9999

-9999 -9999 -9999 -9999 -9999 -9999 -9999 -9999 -9999 -9999 -9999 -9999 -9999 -9999 - 9999 -

-9999 -9999 -9999 -9999 -9999 -9999 -9999 -9999 -9999 -9999 -9999 -9999 -9999 -9999 -9999

-9999 -9999 -9999 -9999 -9999 -9999 -9999 -9999 -9999 -9999 -9999 -9999-9999 -9999 -9999 -

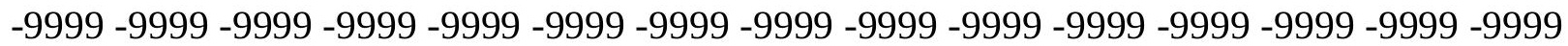

-9999 -9999 -9999 -9999 -9999 -9999 -9999 -9999 -9999 -9999 -9999 -9999 -9999 -9999 -9999 -999 -

-9999 -9999 -9999 -9999 -9999 -9999 -9999 -9999 -9999 -9999 -9999 -9999 -9999 -9999 -9999

-9999 -9999 -9999 -9999 -9999 -9999 -9999 -9999 -9999 -9999 -9999 -9999 -9999 -9999 -9999 -

-9999 -9999 -9999 -9999 -9999 -9999 -9999 -9999 -9999 -9999 -9999 -9999 -9999 -9999 -9999 -

-9999 -9999 -9999 -9999 -9999 -9999 -9999 -9999 -9999 -9999 -9999 -9999 -9999 -9999 -9999

-9999 -9999 -9999 -9999 -9999 -9999 -9999 -9999 -9999 -9999 -9999 -9999 -9999 -9999 -9999

-9999 -9999 -9999 -9999 -9999 -9999 -9999 -9999 -9999 -9999 -9999 -9999 -9999 -9999 -9999 -

-9999 -9999 -9999 -9999 -9999 -9999 -9999 -9999 -9999 -9999 -9999 -9999 -9999 -9999 -9999 -

-9999 -9999 -9999 -9999 -9999 -9999 -9999 -9999 -9999 -9999 -9999 -9999 -9999 -9999 -9999

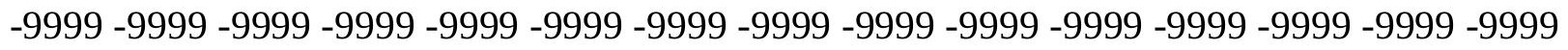

-9999 -9999 -9999 -9999 -9999 -9999 127.7050018311121 .3044967651117 .647102356

115.5136032104114 .5991973877113 .3800964355113 .075302124107 .4363479614

106.8017807007105 .1004638672105 .5879135132105 .5992660522105 .3178100586

105.007232666104 .611328125104 .0908584595103 .411521911696 .96476745605

96.3892593383895 .8215866088995 .2616958618294 .7095336914194 .16532897949

93.6294708252 93.1027145385792.5860214233490.82597351074 88.99725341797

87.1685485839885 .9494018554785 .0350494384884 .1206970214883 .51112365723

82.9015579223682 .5967712402381 .9871978759881 .6824111938581 .37763214111

81.0728530883880 .7680587768680 .1584930419979 .8537063598679 .54891967773

78.9393463134878 .3297805786178 .0249862670977 .4154205322376 .80584716797

76.1962814331175 .5867080688574 .6723632812574 .062782287673 .14842987061

72.5388565063571 .6244964599671 .014930725170 .1005783081169 .18623352051

68.2718734741267 .6623001098666 .7479400634865 .8335876464865 .22400665283

64.3096618652363 .7000885009863 .0905189514262 .4809494018662 .17617034912

61.8713798522961 .8713798522961 .5666007995661 .5666007995661 .26181030273

61.2618103027360 .9570198059160 .6522407531760 .6522407531760 .65224075317

60.6522407531760 .6522407531760 .9570198059160 .9570198059161 .26181030273

61.2618103027361 .5666007995661 .5666007995661 .8713798522961 .87137985229

61.8713798522961 .8713798522961 .8713798522961 .8713798522962 .17617034912

62.1761703491262 .4809494018662 .4809494018662 .4809494018662 .48094940186

62.4809494018662 .1761703491262 .1761703491261 .8713798522961 .56660079956

61.5666007995661 .2618103027360 .9570198059162 .1761703491261 .87137985229

61.6715011596761 .5666007995661 .5005455017161 .238704681460 .95701980591

59.4331016540559 .4331016540559 .4331016540559 .1283111572359 .12831115723

59.1283111572359 .1283111572359 .1283111572359 .1283111572359 .12831115723

59.1283111572359 .4331016540559 .4331016540559 .4331016540559 .43310165405

59.4331016540559 .7378807067959 .7378807067959 .7378807067959 .73788070679

59.7378807067960 .0426712036160 .0426712036160 .0426712036160 .04267120361

60.0426712036160 .16073226929 -7.81425857544 -47.083278656 -9999 -9999 -9999-9999

-9999 -9999 -9999 -9999 -9999 -9999 -9999 -9999 -9999 -9999 -9999 -9999 
-9999 -9999 -9999 -9999 -9999 -9999 -9999 -9999 -9999 -9999 -9999 -9999 -9999 -9999 -9999 -9999 -9999 -9999 -9999 -9999 -9999 -9999 -9999 -9999 -9999 -9999 -9999 -9999 -9999 -9999

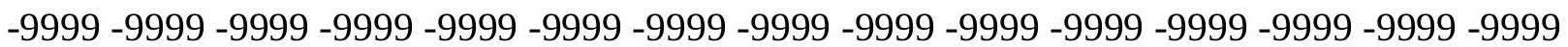
-9999 -9999 -9999 -9999 -9999 -9999 -9999 -9999 -9999 -9999 -9999 -9999 -9999 -9999 -9999 -9999 -9999 -9999 -9999 -9999 -9999 -9999 -9999 -9999 -9999 -9999 -9999 -9999 -9999 -9999 -9999 -9999 -9999 -9999 -9999 -9999 -9999 -9999 -9999 -9999 -9999 -9999 -9999 -9999 -9999 -9999 -9999 -9999 -9999 -9999 -9999 -9999 -9999 -9999 -9999 -9999 -9999 -9999 -9999 -9999

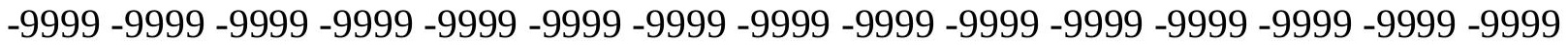
-9999 -9999 -9999 -9999 -9999 -9999 -9999 -9999 -9999 -9999 -9999 -9999 -9999 -9999 -9999 -9999 -9999 -9999 -9999 -9999 -9999 -9999 -9999 -9999 -9999 -9999 -9999 -9999 -9999 -9999 -9999 -9999 -9999 -9999 -9999 -9999 -9999 -9999 -9999 -9999 -9999 -9999 -9999 -9999 -9999 -9999 -9999 -9999 -9999 -9999 -9999 -9999 -9999 -9999 -9999 -9999 -9999 -9999 -9999 -9999

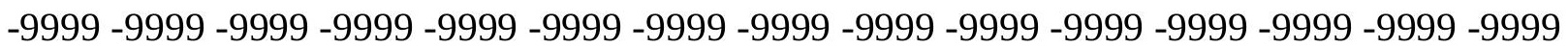
-9999 -9999 -9999 -9999 -9999 -9999 -9999 -9999 -9999 -9999 -9999 -9999 -9999 -9999 -9999 -9999 -9999 -9999 -9999 -9999 -9999 -9999 -9999 -9999 -9999 -9999 -9999 -9999 -9999 -9999 -9999 -9999-9999 -9999 -9999-9999-9999 127.4001998901 124.0475006104 121.3044967651 118.5614013672116 .7326965332117 .0374984741117 .0374984741108 .9732284546 108.5188751221108 .1543045044107 .8466262817107 .5522537231107 .2240447998 106.8169631958106 .3098068237105 .6844940186104 .945312596 .81795501709 96.2426986694395 .675918579195 .1177139282294 .5684051513794 .02841949463 93.4984970092892 .9794158935592 .4721832275491 .4355392456189 .3020401001 87.7781066894586 .254188537685 .3398437584 .4254837036183 .81591033936 83.206336975182 .5967712402382 .2919769287181 .6824111938581 .37763214111 80.7680587768680 .4632720947379 .8537063598679 .5489196777378 .93934631348 78.3297805786178 .0249862670977 .4154205322376 .8058471679776 .19628143311 75.5867080688574 .9771423339874 .062782287673 .4532165527372 .84364318848 71.9292907714871 .3197174072370 .4053573608469 .4910125732468 .88143920898 67.9670867919967 .3575134277366 .4431610107465 .8335876464865 .22400665283 64.6144485473664 .004882812563 .7000885009863 .3953094482463 .09051895142 62.7857398986862 .7857398986862 .4809494018662 .4809494018662 .17617034912 61.8713798522961 .8713798522961 .5666007995661 .5666007995661 .56660079956 61.8713798522961 .8713798522962 .1761703491262 .1761703491262 .48094940186 62.4809494018662 .7857398986862 .7857398986863 .0905189514263 .09051895142 63.0905189514263 .0905189514263 .3953094482463 .3953094482463 .39530944824 63.7000885009863 .7000885009863 .7000885009863 .7000885009863 .39530944824 63.3953094482463 .0905189514262 .7857398986862 .4809494018662 .17617034912 61.8713798522961 .5666007995661 .2618103027362 .1998901367261 .98937606812 62.0593872070361 .8713798522960 .3474502563560 .0426712036160 .04267120361 60.0426712036160 .0426712036159 .7378807067959 .7378807067959 .73788070679 59.7378807067959 .7378807067959 .7378807067959 .7378807067959 .73788070679 59.7378807067959 .7378807067959 .7378807067959 .7378807067960 .04267120361 60.0426712036160 .0426712036160 .0426712036160 .0426712036160 .04267120361 60.3474502563560 .3474502563560 .3474502563560 .3474502563560 .34745025635 60.388671875 -12.1321134567 -52.665145874 -9999 -9999 -9999 -9999 -9999 -9999 -9999 -9999 -9999 -9999 -9999 -9999 -9999 -9999 -9999 -9999 -9999 -9999 -9999 -9999 -9999 -9999 -9999 -9999 -9999 -9999 -9999 -9999 -9999 -9999 -9999 
-9999 -9999 -9999 -9999 -9999 -9999 -9999 -9999 -9999 -9999 -9999 -9999 -9999 -9999 -9999 -9999 -9999 -9999 -9999 -9999 -9999 -9999 -9999 -9999 -9999 -9999 -9999 -9999 -9999 -9999 -9999 -9999 -9999 -9999 -9999 -9999 -9999 -9999 -9999 -9999 -9999 -9999 -9999 -9999 -9999 -9999 -9999 -9999 -9999 -9999 -9999 -9999 -9999 -9999 -9999 -9999 -9999 -9999 -9999 -9999 -9999 -9999 -9999 -9999 -9999 -9999 -9999 -9999 -9999 -9999 -9999 -9999 -9999 -9999 -9999 -9999 -9999 -9999 -9999 -9999 -9999 -9999 -9999 -9999 -9999 -9999 -9999 -9999 -9999 -9999 -9999 -9999 -9999 -9999 -9999 -9999 -9999 -9999 -9999 -9999 -9999 -9999 -9999 -9999 -9999 -9999 -9999 -9999 -9999 -9999 -9999 -9999 -9999 -9999 -9999 -9999 -9999 -9999 -9999 -9999 -9999 -9999 -9999 -9999 -9999 -9999 -9999 -9999 -9999 -9999 -9999 -9999 -9999 -9999 -9999 -9999 -9999 -9999 -9999 -9999 -9999 -9999 -9999 -9999 -9999 -9999 -9999 -9999 -9999 -9999 -9999 -9999 -9999 -9999 -9999 -9999 -9999 -9999 -9999 -9999 -9999 -9999 -9999 -9999 -9999 -9999 -9999 -9999 -9999 -9999 -9999 -9999 -9999 -9999 -9999 -9999 -9999 -9999 -9999 -9999

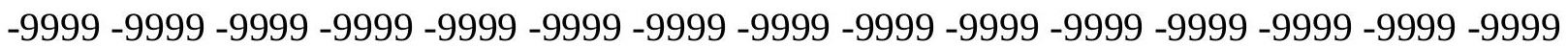
-9999 -9999 -9999 -9999 -9999 -9999 -9999 -9999 -9999 -9999 -9999 -9999 -9999 -9999 -9999 -9999 -9999 -9999 -9999 -9999 -9999 -9999 -9999 -9999 124.6570968628 122.5235977173 121.3044967651121 .6092987061122 .5235977173121 .9140014648110 .4436035156 110.0765075684109 .7538452148109 .4382095337109 .092414856108 .6840362549 108.1966400146107 .6200637817106 .965538024997 .2479400634896 .66610717773 96.093338012795 .529861450294 .9760818481494 .4324111938593 .89947509766 93.3778457641692 .8682098388792 .3710632324291 .4355392456189 .60682678223 88.0829010009886 .8637619018685 .6446228027384 .7302627563584 .12069702148 83.5111236572382 .9015579223682 .2919769287181 .6824111938581 .07285308838 80.7680587768680 .1584930419979 .5489196777378 .9393463134878 .63455963135 78.0249862670977 .4154205322376 .8058471679776 .1962814331175 .58670806885 74.9771423339874 .3675689697373 .7580032348672 .8436431884872 .23407745361 71.6244964599670 .7101516723670 .1005783081169 .1862335205168 .57665252686 67.9670867919967 .0527267456166 .4431610107465 .8335876464865 .22400665283 64.9192428588964 .6144485473664 .004882812564 .004882812563 .70008850098 63.3953094482463 .3953094482463 .0905189514263 .0905189514262 .78573989868 62.7857398986862 .4809494018662 .4809494018662 .7857398986862 .78573989868 62.7857398986863 .0905189514263 .3953094482463 .3953094482463 .70008850098 64.004882812564 .004882812564 .3096618652364 .3096618652364 .61444854736 64.6144485473664 .6144485473664 .6144485473664 .9192428588964 .91924285889 64.9192428588964 .9192428588964 .6144485473664 .6144485473664 .30966186523 64.3096618652363 .7235107421963 .2337226867762 .8051376342862 .45040130615 62.2741127014262 .1761703491261 .8713798522961 .5666007995661 .26181030273 61.2618103027360 .9570198059160 .9570198059160 .6522407531760 .65224075317 60.6522407531760 .3474502563560 .3474502563560 .3474502563560 .34745025635 60.0426712036160 .0426712036160 .0426712036160 .0426712036160 .04267120361 60.0426712036160 .3474502563560 .3474502563560 .3474502563560 .34745025635 60.3474502563560 .3474502563560 .3474502563560 .6522407531760 .65224075317 60.6522407531760 .6522407531760 .6522407531760 .6522407531760 .65224075317 -15.4152851105 -54.7843322754 -9999 -9999 -9999 -9999 -9999 -9999 -9999 -9999 -9999 -9999 -9999 -9999 -9999 -9999 -9999 -9999 -9999 -9999 -9999 -9999 -9999 -9999 -9999 -9999 -9999 -9999 -9999 -9999 -9999 -9999 -9999

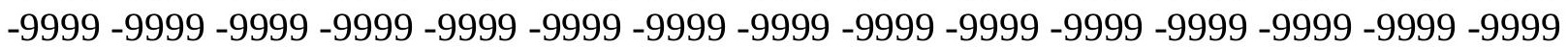


-9999 -9999 -9999 -9999 -9999 -9999 -9999 -9999 -9999 -9999 -9999 -9999 -9999 -9999 -9999 -9999 -9999 -9999 -9999 -9999 -9999 -9999 -9999 -9999 -9999 -9999 -9999 -9999 -9999 -9999 -9999 -9999 -9999 -9999 -9999 -9999 -9999 -9999 -9999 -9999 -9999 -9999 -9999 -9999 -9999 -9999 -9999 -9999 -9999 -9999 -9999 -9999 -9999 -9999 -9999 -9999 -9999 -9999 -9999 -9999 -9999 -9999 -9999 -9999 -9999 -9999 -9999 -9999 -9999 -9999 -9999 -9999 -9999 -9999 -9999 -9999 -9999 -9999 -9999 -9999 -9999 -9999 -9999 -9999 -9999 -9999 -9999 -9999 -9999 -9999 -9999 -9999 -9999 -9999 -9999 -9999 -9999 -9999 -9999 -9999 -9999 -9999 -9999 -9999 -9999

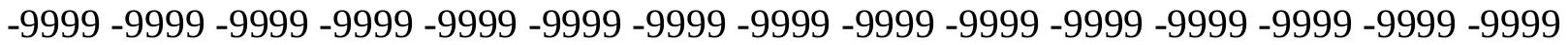
-9999 -9999 -9999 -9999 -9999 -9999 -9999 -9999 -9999 -9999 -9999 -9999 -9999 -9999 -9999 -9999 -9999 -9999 -9999 -9999 -9999 -9999 -9999 -9999 -9999 -9999 -9999 -9999 -9999 -9999 -9999 -9999 -9999 -9999 -9999 -9999 -9999 -9999 -9999 -9999 -9999 -9999 -9999 -9999 -9999 -9999 -9999 -9999 -9999 -9999 -9999 -9999 -9999 -9999 -9999 -9999 -9999 -9999 -9999 -9999

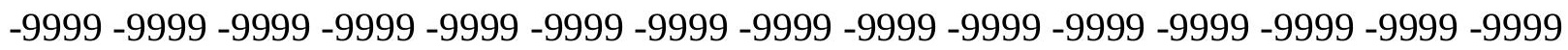
-9999 -9999 -9999 -9999 -9999 -9999 -9999 -9999 -9999 -9999 124.9618988037 124.3523025513124 .9618988037125 .5715026855125 .8762969971112 .1172866821 111.7316436768111 .3822555542111 .0394821167110 .6744155884110 .2630004883 109.7932662964109 .2536315918108 .6538543701107 .990646362397 .09127044678 96.5132369995195 .9450531005995 .3871688842894 .8399581909294 .30393218994 93.7794876098693 .2670745849692 .7669296264692 .2792587280391 .74346160889 90.2164001464888 .6924667358487 .1685485839885 .9494018554785 .03504943848 84.1206970214883 .5111236572382 .9015579223681 .9871978759881 .37763214111 80.7680587768680 .4632720947379 .8537063598679 .2441329956178 .63455963135 78.0249862670977 .4154205322376 .8058471679776 .1962814331175 .58670806885 74.9771423339874 .3675689697373 .7580032348673 .1484298706172 .53885650635 71.9292907714871 .014930725170 .4053573608469 .7957916259869 .18623352051 68.5766525268667 .6623001098667 .0527267456166 .7479400634866 .13836669922 65.5288009643665 .2240066528364 .9192428588964 .6144485473664 .61444854736 64.3096618652364 .004882812564 .004882812563 .7000885009863 .70008850098 63.7000885009863 .3953094482463 .7000885009863 .7000885009863 .70008850098 64.004882812564 .3096618652364 .3096618652364 .6144485473664 .91924285889 65.2240066528365 .2240066528365 .5288009643665 .8335876464865 .83358764648 66.1383666992266 .1383666992266 .1383666992266 .1383666992266 .13836669922 66.1383666992266 .1383666992265 .5852127075265 .3100509643665 .08684539795 64.8391036987364 .4008483886763 .8960151672463 .433868408263 .07847976685 62.8660202026462 .7673950195362 .7643280029362 .4809494018662 .17617034912 61.8713798522961 .8713798522961 .5666007995661 .5666007995661 .26181030273 61.2618103027361 .2618103027360 .9570198059160 .9570198059160 .95701980591 60.6522407531760 .6522407531760 .6522407531760 .6522407531760 .65224075317 60.6522407531760 .6522407531760 .6522407531760 .6522407531760 .65224075317 60.6522407531760 .9570198059160 .9570198059160 .9570198059160 .95701980591 60.9570198059160 .9570198059160 .9570198059160 .9497528076224 .3300151825 -21.9156780243 -9999 -9999 -9999 -9999 -9999 -9999 -9999 -9999 -9999 -9999 -9999 -9999 -9999 -9999-9999-9999-9999 -9999 -9999 -9999 -9999 -9999 -9999 -9999 -9999 -9999 -9999 -9999 -9999 -9999 -9999 -9999 -9999 -9999 -9999 -9999 -9999 -9999 -9999 -9999 -9999 -9999 -9999 -9999 -9999 -9999 -9999

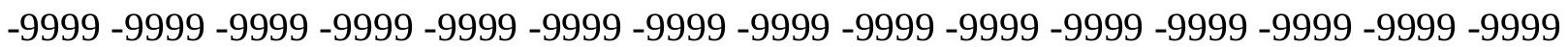


-9999 -9999 -9999 -9999 -9999 -9999 -9999 -9999 -9999 -9999 -9999 -9999 -9999 -9999 -9999 -9999 -9999 -9999 -9999 -9999 -9999 -9999 -9999 -9999 -9999 -9999 -9999 -9999 -9999 -9999

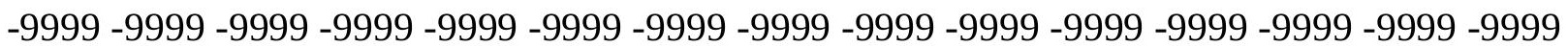
-9999 -9999 -9999 -9999 -9999 -9999 -9999 -9999 -9999 -9999 -9999 -9999 -9999 -9999 -9999 -9999 -9999 -9999 -9999 -9999 -9999 -9999 -9999 -9999 -9999 -9999 -9999 -9999 -9999 -9999 -9999 -9999 -9999 -9999 -9999 -9999 -9999 -9999 -9999 -9999 -9999 -9999 -9999 -9999 -9999 -9999 -9999 -9999 -9999 -9999 -9999 -9999 -9999 -9999 -9999 -9999 -9999 -9999 -9999 -9999

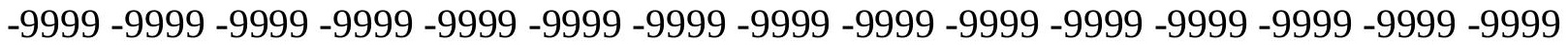
-9999 -9999 -9999 -9999 -9999 -9999 -9999 -9999 -9999 -9999 -9999 -9999 -9999 -9999 -9999 -9999 -9999 -9999 -9999 -9999 -9999 -9999 -9999 -9999 -9999 -9999 -9999 -9999 -9999 -9999 -9999 -9999 -9999 -9999 -9999 -9999 -9999 -9999 -9999 -9999 -9999 -9999 -9999 -9999 -9999 -9999 -9999 -9999 -9999 -9999 -9999 -9999 -9999 -9999 -9999 -9999 -9999 -9999 -9999 -9999 -9999 -9999 -9999 -9999 -9999 -9999 -9999 -9999 -9999 -9999 -9999 126.1809997559 126.7906036377127 .7050018311128 .9241027832130 .1432037354113 .1692810059 112.7871627808112 .4133987427112 .025428772111 .6044311523111 .1377410889 110.6184310913110 .0426635742109 .405281066997 .5175018310596 .93476867676 96.3622665405395 .8004760742295 .2497100830194 .7104034423894 .18280029297 93.6671981811593.163650512792.6721725463992.1924133300891.723777771 90.5211791992288 .6924667358487 .4733276367286 .254188537685 .33984375 84.1206970214883 .5111236572382 .5967712402381 .9871978759881 .37763214111 80.7680587768679 .8537063598679 .5489196777378 .9393463134878 .32978057861 77.7202072143677 .110626220776 .5010681152375 .8914871215875 .28192901611 74.6723632812574 .062782287673 .4532165527372 .8436431884872 .23407745361 71.6244964599671 .014930725170 .1005783081169 .4910125732468 .88143920898 68.2718734741267 .9670867919967 .3575134277366 .7479400634866 .44316101074 66.1383666992265 .8335876464865 .5288009643665 .2240066528364 .91924285889 64.9192428588964 .6144485473664 .6144485473664 .3096618652364 .30966186523 64.3096618652364 .3096618652364 .6144485473664 .6144485473664 .91924285889 65.2240066528365 .5288009643665 .8335876464866 .1383666992266 .44316101074 66.7479400634867 .0527267456167 .0527267456167 .3575134277367 .35751342773 67.6623001098667 .6623001098667 .6623001098667 .5503005981467 .16733551025 66.7504272460966 .3405838012765 .9727783203165 .6717529296965 .32479858398 64.9222640991264 .4717025756864 .0425872802763 .6921615600663 .44676589966 63.2887535095263 .1963958740263 .1266937255963 .035568237362 .90049743652 62.7857398986862 .4809494018662 .4809494018662 .1761703491261 .87137985229 61.8713798522961 .8713798522961 .5666007995661 .5666007995661 .26181030273 61.2618103027361 .2618103027361 .2618103027361 .2618103027361 .26181030273 61.2618103027361 .2618103027361 .2618103027361 .2618103027361 .26181030273 61.2618103027361 .2618103027361 .2618103027361 .2618103027361 .26181030273 61.2618103027361 .2618103027361 .248504638672 .903485298157 -33.8214912415 -9999 -9999 -9999 -9999 -9999 -9999 -9999 -9999 -9999 -9999 -9999 -9999 -9999 -9999 -9999 -9999 $-9999$

-9999 -9999 -9999 -9999 -9999 -9999 -9999 -9999 -9999 -9999 -9999 -9999 -9999 -9999 -9999 -9999 -9999 -9999 -9999 -9999 -9999 -9999 -9999 -9999 -9999 -9999 -9999 -9999 -9999 -9999

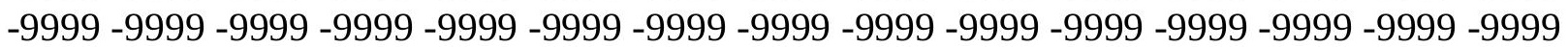

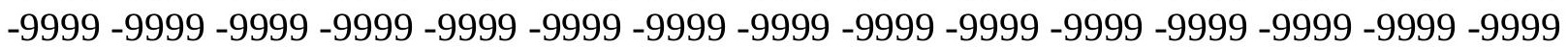


-9999 -9999 -9999 -9999 -9999 -9999 -9999 -9999 -9999 -9999 -9999 -9999 -9999 -9999 -9999 -9999 -9999 -9999 -9999 -9999 -9999 -9999 -9999 -9999 -9999 -9999 -9999 -9999 -9999 -9999

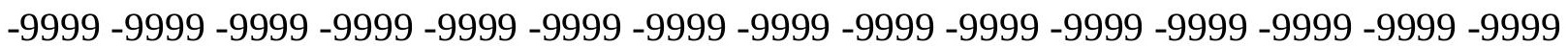
-9999 -9999 -9999 -9999 -9999 -9999 -9999 -9999 -9999 -9999 -9999 -9999 -9999 -9999 -9999 -9999 -9999 -9999 -9999 -9999 -9999 -9999 -9999 -9999 -9999 -9999 -9999 -9999 -9999 -9999 -9999 -9999 -9999 -9999 -9999 -9999 -9999 -9999 -9999 -9999 -9999 -9999 -9999 -9999 -9999 -9999 -9999 -9999 -9999 -9999 -9999 -9999 -9999 -9999 -9999 -9999 -9999 -9999 -9999 -9999

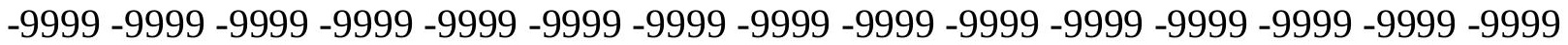
-9999 -9999 -9999 -9999 -9999 -9999 -9999 -9999 -9999 -9999 -9999 -9999 -9999 -9999 -9999 -9999 -9999 -9999 -9999 -9999 -9999 -9999 -9999 -9999 -9999 -9999 -9999 -9999 -9999 -9999 -9999 -9999 -9999 -9999 -9999 -9999 -9999 -9999 -9999 -9999 -9999 -9999 -9999 -9999 -9999 -9999 -9999 -9999 -9999 -9999 -9999 -9999 -9999 -9999 -9999 -9999 127.0953979492 128.0097961426129 .533706665131 .3623962402133 .4958953857114 .4278182983 114.0093460083113 .6007385254113 .1839294434112 .7431945801112 .2665634155 111.744644165111 .1697540283110 .5316696167109 .816207885797 .35710144043 96.7805633544996 .2149581909295 .660568237395 .117744445894 .5866394043 94.0674438476693 .5600814819393 .0644378662192 .5800628662192 .10634613037 91.6421279907290 .5211791992288 .9972534179787 .4733276367286 .2541885376 85.0350494384884 .1206970214883 .206336975182 .2919769287181 .68241119385 81.0728530883880 .1584930419979 .5489196777378 .9393463134878 .32978057861 77.7202072143677 .110626220776 .8058471679776 .1962814331175 .58670806885 74.9771423339874 .3675689697373 .7580032348673 .1484298706172 .53885650635 71.9292907714871 .3197174072370 .7101516723670 .1005783081169 .49101257324 68.8814392089868 .2718734741267 .9670867919967 .3575134277367 .05272674561 66.7479400634866 .4431610107466 .1383666992265 .8335876464865 .52880096436 65.5288009643665 .2240066528365 .2240066528365 .2240066528365 .22400665283 65.2240066528365 .2240066528365 .5288009643665 .5288009643665 .83358764648 66.1383666992266 .4431610107466 .7479400634867 .3575134277367 .66230010986 67.9670867919968 .2718734741268 .5766525268668 .8814392089868 .88143920898 69.1862335205169 .1717605590868 .8023605346768 .367469787667 .90624237061 67.4393615722767 .0073089599666 .5959014892666 .2168426513765 .83301544189 65.4328689575265 .0196304321364 .6269760131864 .2944107055764 .02795410156 63.8270645141663 .6753425598163 .5481109619163 .4149703979563 .25361251831 63.7000885009863 .3953094482463 .0905189514263 .0905189514262 .78573989868 62.7857398986862 .4809494018662 .1761703491262 .1761703491262 .17617034912 61.8713798522961 .8713798522961 .8713798522961 .8713798522961 .87137985229 61.5666007995661 .5666007995661 .5666007995661 .5666007995661 .56660079956 61.5666007995661 .5666007995661 .5666007995661 .5666007995661 .56660079956 61.5666007995661 .5666007995661 .55530929565 -5.29049682617 -39.1062278748 -9999 -9999 -9999 -9999 -9999 -9999 -9999 -9999 -9999 -9999 -9999 -9999 -9999 -9999 -9999 -9999 $-9999$

-9999 -9999 -9999 -9999 -9999 -9999 -9999 -9999 -9999 -9999 -9999 -9999 -9999 -9999 -9999 -9999 -9999 -9999 -9999 -9999 -9999 -9999 -9999 -9999 -9999 -9999 -9999 -9999 -9999 -9999 -9999 -9999 -9999 -9999 -9999 -9999 -9999 -9999 -9999 -9999 -9999 -9999 -9999 -9999 -9999 -999 -9999 -9999 -9999 -9999 -9999 -9999 -9999 -9999 -9999 -9999 -9999 -9999 -9999 -9999 -9999

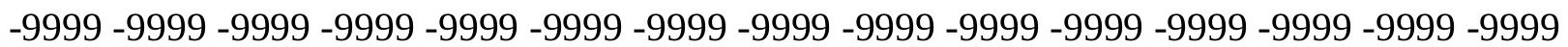


-9999 -9999 -9999 -9999 -9999 -9999 -9999 -9999 -9999 -9999 -9999 -9999 -9999 -9999 -9999 -9999 -9999 -9999 -9999 -9999 -9999 -9999 -9999 -9999 -9999 -9999 -9999 -9999 -9999 -9999 -9999 -9999 -9999 -9999 -9999 -9999 -9999 -9999 -9999 -9999 -9999 -9999 -9999 -9999 -9999 -9999 -9999 -9999 -9999 -9999 -9999 -9999 -9999 -9999 -9999 -9999 -9999 -9999 -9999 -9999 -9999 -9999 -9999 -9999 -9999 -9999 -9999 -9999 -9999 -9999 -9999 -9999 -9999 -9999 -9999 -9999 -9999 -9999 -9999 -9999 -9999 -9999 -9999 -9999 -9999 -9999 -9999 -9999 -9999 -9999 -9999 -9999 -9999 -9999 -9999 -9999 -9999 -9999 -9999 -9999 -9999 -9999 -9999 -9999 -9999

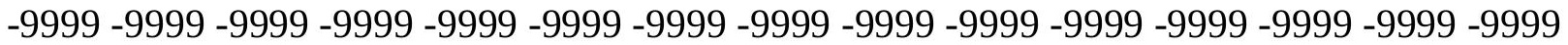
-9999 -9999 -9999 -9999 -9999 -9999 -9999 -9999 -9999 -9999 -9999 -9999 -9999 -9999 -9999 -9999 -9999 -9999 -9999 -9999 -9999 -9999 -9999 -9999 -9999 -9999 -9999 -9999 -9999 -9999 -999 -9999 -9999 -9999 -9999 -9999 -9999 -9999 -9999 -9999 -9999 -9999 -9999 129.2288970947 131.0576019287133 .4958953857135 .9342041016138 .9819946289115 .0826721191 114.6358032227114 .1845779419113 .7152862549113 .2161254883112 .6762924194 112.0853424072111 .4305725098110 .697219848697 .7794876098697 .19911956787 96.6297607421996 .0716629028395 .5251235961994 .9902191162194 .4670791626 93.9555282592893 .4553909301892 .9661483764692 .4871826171992 .0174331665 91.5556488037190 .2164001464888 .6924667358487 .1685485839885 .94940185547 85.0350494384883 .8159103393682 .9015579223682 .2919769287181 .37763214111 80.7680587768679 .8537063598679 .2441329956178 .6345596313578 .02498626709 77.4154205322376 .8058471679776 .1962814331175 .8914871215875 .28192901611 74.6723632812574 .062782287673 .4532165527372 .8436431884872 .23407745361 71.6244964599671 .014930725170 .4053573608470 .1005783081169 .49101257324 68.8814392089868 .5766525268667 .9670867919967 .6623001098667 .35751342773 67.0527267456166 .7479400634866 .4431610107466 .1383666992266 .13836669922 65.8335876464865 .8335876464865 .8335876464865 .8335876464865 .83358764648 65.8335876464866 .1383666992266 .4431610107466 .7479400634867 .05272674561 67.3575134277367 .9670867919968 .2718734741268 .8814392089869 .18623352051 69.7957916259870 .1005783081170 .4053573608470 .4053573608470 .60148620605 70.3467941284269 .8083343505969 .2399063110468 .6926269531268 .1636428833 67.6735153198267 .2128143310566 .7800903320366 .3653106689565 .95726776123 65.5652999877965 .1972427368264 .8708648681664 .5928421020564 .35872650146 64.1627578735463 .9876747131363 .8124275207563 .619274139464 .61444854736 64.3096618652364 .004882812564 .004882812563 .7000885009863 .39530944824 63.3953094482463 .0905189514262 .7857398986862 .7857398986862 .78573989868 62.4809494018662 .4809494018662 .4809494018662 .1761703491262 .17617034912 62.1761703491262 .1761703491262 .1761703491262 .1761703491262 .17617034912 62.1761703491262 .1761703491262 .1761703491262 .1761703491261 .87137985229 61.8713798522929 .69860649109 -10.7409229279 -40.3992462158 -9999 -9999 -9999 -9999 -9999 -9999 -9999 -9999 -9999 -9999 -9999 -9999 -9999 -9999 -9999 -9999 -9999 -9999 -9999 -9999 -9999 -9999 -9999 -9999 -9999 -9999 -9999 -9999 -9999 -9999 -9999 -9999 -9999 -9999 -9999 -9999 -9999 -9999 -9999 -9999 -9999 -9999 -9999 -9999 -9999 -9999 -9999

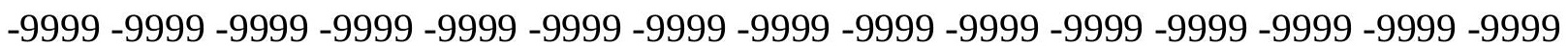
-9999 -9999 -9999 -9999 -9999 -9999 -9999 -9999 -9999 -9999 -9999 -9999 -9999 -9999 -9999 -9999 -9999 -9999 -9999 -9999 -9999 -9999 -9999 -9999 -9999 -9999 -9999 -9999 -9999 -9999 -9999 -9999 -9999 -9999 -9999 -9999 -9999 -9999 -9999 -9999 -9999 -9999 -9999 -9999 -9999

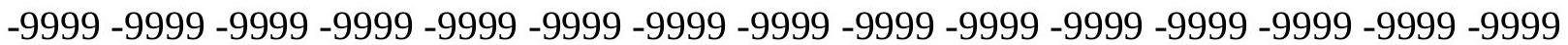


-9999 -9999 -9999 -9999 -9999 -9999 -9999 -9999 -9999 -9999 -9999 -9999 -9999 -9999 -9999 -9999 -9999 -9999 -9999 -9999 -9999 -9999 -9999 -9999 -9999 -9999 -9999 -9999 -9999 -9999 -9999 -9999 -9999 -9999 -9999 -9999 -9999 -9999 -9999 -9999 -9999 -9999 -9999 -9999 -9999 -9999 -9999 -9999 -9999 -9999 -9999 -9999 -9999 -9999 -9999 -9999 -9999 -9999 -9999 -9999 -9999 -9999 -9999 -9999 -9999 -9999 -9999 -9999 -9999 -9999 -9999 -9999 -9999 -9999 -9999 -9999 -9999 -9999 -9999 -9999 -9999 -9999 -9999 -9999 -9999 -9999 -9999 -9999 -9999 -9999 -9999 -9999 -9999 -9999 -9999 -9999 -9999 -9999 -9999 -9999 -9999 -9999 -9999 -9999 -9999

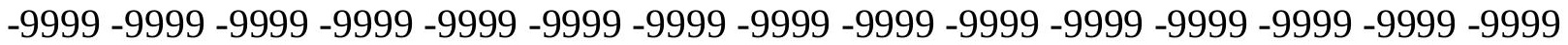
-9999 -9999 -9999 -9999 -9999 -9999 -9999 -9999 -9999 -9999 -9999 -9999 130.4479980469 132.5814971924135 .0198059082137 .7628936768141 .1154937744116 .0346908569 115.5469818115115 .0570526123114 .5525741577114 .0220794678113 .4541244507 112.8372268677112 .158164978111 .4029006958110 .555549621697 .61721801758 97.0441665649496 .4823074340895 .9318923950295 .3929672241294 .86559295654 94.3495712280393 .8446655273493 .3503417968892 .8659820556692 .390625 91.9231796264691 .4622650146589 .9116134643688 .3876876831186 .86376190186 85.6446228027384 .7302627563583 .5111236572382 .5967712402381 .98719787598 81.0728530883880 .4632720947379 .5489196777378 .9393463134878 .32978057861 77.7202072143677 .110626220776 .5010681152375 .8914871215875 .58670806885 74.9771423339874 .3675689697373 .7580032348673 .1484298706172 .53885650635 72.2340774536171 .6244964599671 .014930725170 .4053573608470 .10057830811 69.4910125732469 .1862335205168 .5766525268668 .2718734741267 .96708679199 67.6623001098667 .3575134277367 .0527267456166 .7479400634866 .44316101074 66.4431610107466 .4431610107466 .4431610107466 .4431610107466 .44316101074 66.4431610107466 .7479400634867 .0527267456167 .3575134277367 .96708679199 68.2718734741268 .8814392089869 .4910125732470 .1005783081170 .40535736084 71.014930725171 .6244964599671 .8651351928771 .9924774169972 .02772521973 71.5932006835970 .869552612370 .1630096435569 .5052261352568 .89957427979 68.3425369262767 .829521179267 .3543243408266 .9107818603566 .49282836914 66.1012649536165 .7408828735465 .4120407104565 .1195983886764 .86172485352 64.631561279364 .4180526733464 .2072906494163 .9858436584565 .83358764648 65.5288009643665 .2240066528364 .9192428588964 .6144485473664 .30966186523 64.004882812564 .004882812563 .7000885009863 .3953094482463 .39530944824 63.0905189514263 .0905189514263 .0905189514263 .0905189514262 .78573989868 62.7857398986862 .7857398986862 .7857398986862 .7857398986862 .48094940186 62.4809494018662 .4809494018662 .4809494018662 .4809494018662 .48094940186 62.3271942138712 .95928668976 -18.4625873566 -9999 -9999 -9999 -9999 -9999 -9999 -9999 -9999 -9999 -9999 -9999 -9999 -9999 -9999 -9999 -9999 -9999 -9999

-9999 -9999 -9999 -9999 -9999 -9999 -9999 -9999 -9999 -9999 -9999 -9999 -9999 -9999 -9999 -9999 -9999 -9999 -9999 -9999 -9999 -9999 -9999 -9999 -9999 -9999 -9999 -9999 -9999 -9999 -9999 -9999 -9999 -9999 -9999 -9999 -9999 -9999 -9999 -9999 -9999 -9999 -9999 - -9999 -9999 -9999 -9999 -9999 -9999 -9999 -9999 -9999 -9999 -9999 -9999 -9999 -9999 -9999 -9999 -9999

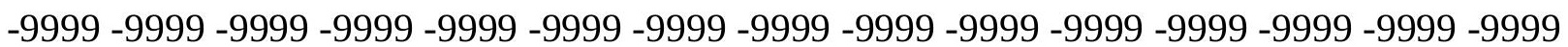
-9999 -9999 -9999 -9999 -9999 -9999 -9999 -9999 -9999 -9999 -9999 -9999 -9999 -9999 -9999 -9999 -9999 -9999 -9999 -9999 -9999 -9999 -9999 -9999 -9999 -9999 -9999 -9999 -9999 -9999 -9999 -9999 -9999 -9999 -9999 -9999 -9999 -9999 -9999 -9999 -9999 -9999 -9999 -9999 -9999

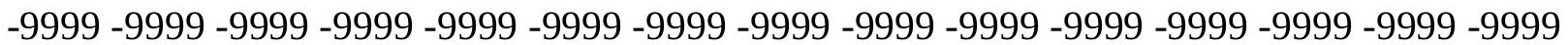


-9999 -9999 -9999 -9999 -9999 -9999 -9999 -9999 -9999 -9999 -9999 -9999 -9999 -9999 -9999 -9999 -9999 -9999 -9999 -9999 -9999 -9999 -9999 -9999 -9999 -9999 -9999 -9999 -9999 -9999 -9999 -9999 -9999 -9999 -9999 -9999 -9999 -9999 -9999 -9999 -9999 -9999 -9999 -9999 -9999 -9999 -9999 -9999 -9999 -9999 -9999 -9999 -9999 -9999 -9999 -9999 -9999 -9999 -9999 -9999 -9999 -9999 -9999 -9999 -9999 -9999 -9999 -9999 -9999 -9999 -9999 -9999 -9999 -9999 -9999 -9999 -9999 -9999 -9999 -9999 -9999 -9999 -9999 -9999 -9999 -9999 -9999 -9999 -9999 -9999 -999 -9999 -9999 -9999 -9999 -9999 -9999 -9999 -9999 -9999 -9999 -9999 -9999 -9999 133.8007049561136 .2389984131139 .2868041992142 .6394042969146 .2969055176 116.3602828979115 .8290634155115 .285369873114 .7182388306114 .1163330078 113.468208313112 .7611846924111 .9826049805111 .11885070898 .03423309326 97.4575500488396 .8919143676896 .3375320434695 .7944259643695 .26264190674 94.7419357299894 .2320632934693 .7324981689593 .2426452636792 .76161193848 92.2884292602591 .8218841552791 .1307525634889 .302040100187 .77810668945 86.5589828491285 .3398437584 .1206970214883 .206336975182 .29197692871 81.3776321411180 .7680587768680 .1584930419979 .2441329956178 .63455963135 78.0249862670977 .4154205322376 .8058471679776 .1962814331175 .89148712158 75.2819290161174 .6723632812574 .062782287673 .4532165527373 .14842987061 72.5388565063571 .9292907714871 .3197174072371 .014930725170 .40535736084 70.1005783081169 .4910125732469 .1862335205168 .8814392089868 .27187347412 67.9670867919967 .6623001098667 .3575134277367 .3575134277367 .05272674561 66.7479400634866 .7479400634866 .7479400634866 .7479400634867 .05272674561 67.0527267456167 .3575134277367 .6623001098668 .2718734741268 .57665252686 69.1862335205169 .7957916259870 .4053573608471 .014930725171 .92929077148 72.5388565063572 .8436431884873 .2206497192473 .3632812573 .36241149902 72.6602401733471 .8308639526471 .0120468139670 .2718429565469 .59756469727 68.9824447631868 .422286987367 .910720825267 .4412765502967 .0082244873 66.608123779366 .2400360107465 .9045639038165 .6006240844765 .32452392578 65.0698165893664 .8282241821364 .5897750854564 .3444900512766 .74794006348 66.4431610107466 .1383666992265 .8335876464865 .5288009643665 .22400665283 64.9192428588964 .6144485473664 .6144485473664 .3096618652364 .0048828125 64.004882812563 .7000885009863 .7000885009863 .7000885009863 .39530944824 63.3953094482463 .3953094482463 .3953094482463 .0905189514263 .09051895142 63.0905189514263 .0905189514262 .7857398986862 .7857398986862 .78573989868 62.7302207946812 .57343196869 -17.6867427826 -9999 -9999 -9999 -9999 -9999 -9999 -9999 -9999 -9999 -9999 -9999 -9999 -9999 -9999 -9999 -9999 -9999 -9999

-9999 -9999 -9999 -9999 -9999 -9999 -9999 -9999 -9999 -9999 -9999 -9999 -9999 -9999 -9999 -9999 -9999 -9999 -9999 -9999 -9999 -9999 -9999 -9999 -9999 -9999 -9999 -9999 -9999 -9999

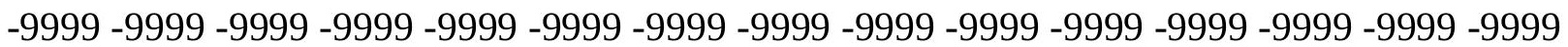
-9999 -9999 -9999 -9999 -9999 -9999 -9999 -9999 -9999 -9999 -9999 -9999 -9999 -9999 -9999 -9999 -9999 -9999 -9999 -9999 -9999 -9999 -9999 -9999 -9999 -9999 -9999 -9999 - -9999 -9999 -9999 -9999 -9999 -9999 -9999 -9999 -9999 -9999 -9999 -9999 -9999 -9999 -9999 -9999 -9999

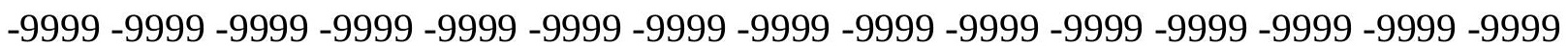
-9999 -9999 -9999 -9999 -9999 -9999 -9999 -9999 -9999 -9999 -9999 -9999 -9999 -9999 -9999 -9999 -9999 -9999 -9999 -9999 -9999 -9999 -9999 -9999 -9999 -9999 -9999 -9999 -9999 -9999 -9999 -9999 -9999 -9999 -9999 -9999 -9999 -9999 -9999 -9999 -9999 -9999 -9999 -9999 -9999

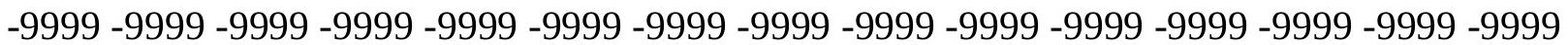


-9999 -9999 -9999 -9999 -9999 -9999 -9999 -9999 -9999 -9999 -9999 -9999 -9999 -9999 -9999 -9999 -9999 -9999 -9999 -9999 -9999 -9999 -9999 -9999 -9999 -9999 -9999 -9999 -9999 -9999 -9999 -9999 -9999 -9999 -9999 -9999 -9999 -9999 -9999 -9999 -9999 -9999 -9999 -9999 -9999 -9999 -9999 -9999 -9999 -9999 -9999 -9999 -9999 -9999 -9999 -9999 -9999 -9999 -9999 -9999 -9999 -9999 -9999 -9999 -9999 -9999 -9999 -9999 -9999 -9999 -9999 -9999 -9999 135.0198059082137 .4580993652140 .2012023926143 .2489929199146 .6015930176 117.0968551636116 .5234680176115 .9387741089115 .3325500488114 .6940612793 114.0125427246113 .2763900757112 .4744949341111 .595413208110 .629737854 97.8693542480597 .299942016696 .7415542602596 .19419097995 .65787506104 95.1323623657294 .6174087524494 .1125106811593 .6171035766693 .13035583496 92.6513977050892 .1791534423891 .7125015258890 .5211791992288 .69246673584 87.4733276367285 .9494018554785 .0350494384883 .8159103393682 .90155792236 81.9871978759881 .0728530883880 .4632720947379 .8537063598678 .93934631348 78.3297805786177 .7202072143677 .110626220776 .8058471679776 .19628143311 75.5867080688574 .9771423339874 .3675689697374 .062782287673 .45321655273 72.8436431884872 .5388565063571 .9292907714871 .3197174072371 .0149307251 70.4053573608470 .1005783081169 .4910125732469 .1862335205168 .88143920898 68.5766525268668 .2718734741267 .9670867919967 .6623001098667 .35751342773 67.3575134277367 .0527267456167 .0527267456167 .3575134277367 .35751342773 67.6623001098667 .9670867919968 .2718734741268 .8814392089869 .18623352051 70.1005783081170 .7101516723671 .3197174072372 .2340774536173 .14842987061 73.7580032348674 .2200546264674 .5152206420974 .6695251464874 .23831176758 73.468338012772 .5940017700271 .7311782836970 .9387207031270 .21697998047 69.5582962036168 .9608993530368 .419082641667 .9265060424867 .47719573975 67.0667114257866 .691543579166 .3490600585966 .0354843139665 .74590301514 65.4738769531265 .2123107910264 .9532775878964 .6890487670967 .96708679199 67.3575134277367 .0527267456166 .7479400634866 .4431610107466 .13836669922 65.8335876464865 .5288009643665 .2240066528365 .2240066528364 .91924285889 64.6144485473664 .6144485473664 .3096618652364 .3096618652364 .0048828125 64.004882812564 .004882812563 .7000885009863 .7000885009863 .70008850098 63.3953094482463 .3953094482463 .3953094482463 .3953094482463 .09051895142 63.0905189514217 .35229873657 -15.291926384 -9999 -9999 -9999 -9999 -9999 -9999 -9999 -9999 -9999 -9999 -9999 -9999 -9999 -9999 -9999 -9999 -9999 -9999 -9999 -9999 -9999 -9999 -9999 -9999 -9999 -9999 -9999 -9999 -9999 -9999 -9999 -9999 -9999

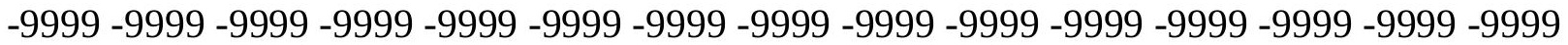
-9999 -9999 -9999 -9999 -9999 -9999 -9999 -9999 -9999 -9999 -9999 -9999 -9999 -9999 -9999

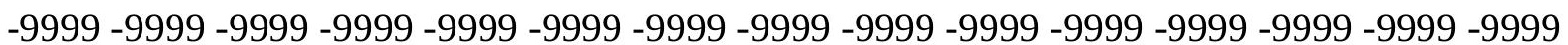

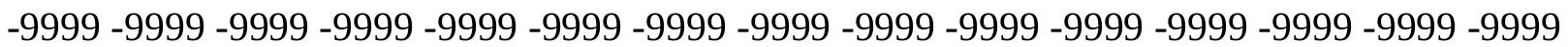
-9999 -9999 -9999 -9999 -9999 -9999 -9999 -9999 -9999 -9999 -9999 -9999 -9999 -9999 -9999 -9999 -9999 -9999 -9999 -9999 -9999 -9999 -9999 -9999 -9999 -9999 -9999 -9999 - -9999 -9999 -9999 -9999 -9999 -9999 -9999 -9999 -9999 -9999 -9999 -9999 -9999 -9999 -9999 -9999 -9999

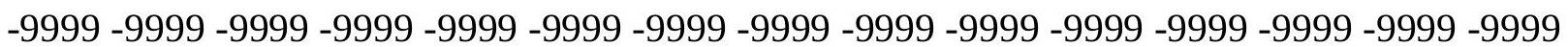
-9999 -9999 -9999 -9999 -9999 -9999 -9999 -9999 -9999 -9999 -9999 -9999 -9999 -9999 -9999 -9999 -9999 -9999 -9999 -9999 -9999 -9999 -9999 -9999 -9999 -9999 -9999 -9999 -9999 -9999 -9999 -9999 -9999 -9999 -9999 -9999 -9999 -9999 -9999 -9999 -9999 -9999 -9999 -9999 -9999

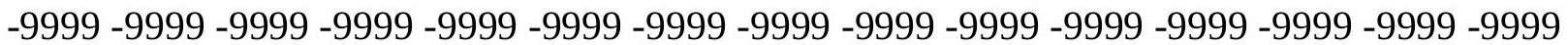


-9999 -9999 -9999 -9999 -9999 -9999 -9999 -9999 -9999 -9999 -9999 -9999 -9999 -9999 -9999 -9999 -9999 -9999 -9999 -9999 -9999 -9999 -9999 -9999 -9999 -9999 -9999 -9999 -9999 -9999 -9999 -9999 -9999 -9999 -9999 -9999 -9999 -9999 -9999 -9999 -9999 -9999 -9999 -9999 138.3724975586140 .8106994629143 .5538024902146 .6015930176149 .6495056152 117.1598510742116 .5342407227115 .888633728115 .213180542114 .4981079102 113.7331008911112 .9085998535112 .0150756836111 .04513549898 .27911376953 97.7059478759897 .143554687596 .5919113159296 .0510177612395 .5206451416 95.000564575294 .4902954101693 .9893188476693 .4968719482493 .01216125488 92.5342102050892 .0620193481491 .4355392456189 .6068267822388 .08290100098 86.8637619018685 .6446228027384 .4254837036183 .5111236572382 .59677124023 81.6824111938580 .7680587768680 .1584930419979 .5489196777378 .93934631348 78.3297805786177 .7202072143677 .110626220776 .5010681152375 .89148712158 75.2819290161174 .9771423339874 .3675689697373 .7580032348673 .45321655273 72.8436431884872 .2340774536171 .9292907714871 .3197174072371 .0149307251 70.4053573608470 .1005783081169 .7957916259869 .4910125732468 .88143920898 68.5766525268668 .2718734741267 .9670867919967 .6623001098667 .66230010986 67.6623001098667 .3575134277367 .6623001098667 .6623001098667 .96708679199 68.2718734741268 .5766525268669 .1862335205169 .7957916259870 .71015167236 71.3197174072372 .2340774536173 .1484298706174 .062782287674 .90847015381 75.4329910278375 .7462158203175 .514228820874 .8519515991274 .03266906738 73.1442031860472 .278877258371 .4737091064570 .7276458740270 .04274749756 69.4217910766668 .8602905273468 .3525543212967 .8923339843867 .4744720459 67.0938262939566 .7459411621166 .4255142211966 .1267547607465 .8430480957 65.5677642822365 .2942047119165 .0161056518668 .8814392089868 .57665252686 67.9670867919967 .6623001098667 .3575134277367 .0527267456166 .74794006348 66.4431610107466 .1383666992265 .8335876464865 .8335876464865 .52880096436 65.2240066528365 .2240066528364 .9192428588964 .9192428588964 .61444854736 64.6144485473664 .3096618652364 .3096618652364 .3096618652364 .0048828125 64.004882812563 .7000885009863 .7000885009863 .6828384399434 .04568862915 8.911955833435 -9999 -9999 -9999 -9999 -9999 -9999 -9999 -9999 -9999 -9999 -9999 -9999 -9999 -9999 -9999 -9999 -9999 -9999 -9999

-9999 -9999 -9999 -9999 -9999 -9999 -9999 -9999 -9999 -9999 -9999 -9999 -9999 -9999 -9999 -9999 -9999 -9999 -9999 -9999 -9999 -9999 -9999 -9999 -9999 -9999 -9999 -9999 -9999 -9999 -9999 -9999 -9999 -9999 -9999 -9999 -9999 -9999 -9999 -9999 -9999 -9999 -9999 -9999 -9999 -

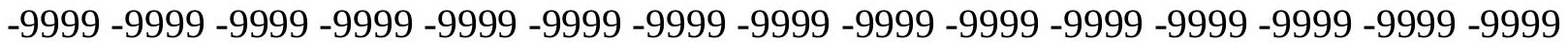
-9999 -9999 -9999 -9999 -9999 -9999 -9999 -9999 -9999 -9999 -9999 -9999 -9999 -9999 -9999 -9999 -9999 -9999 -9999 -9999 -9999 -9999 -9999 -9999 -9999 -9999 -9999 -9999 -9999 -9999

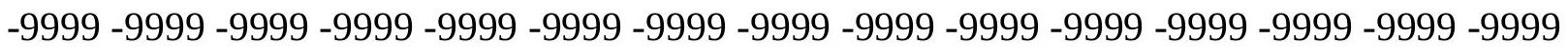
-9999 -9999 -9999 -9999 -9999 -9999 -9999 -9999 -9999 -9999 -9999 -9999 -9999 -9999 -9999 -9999 -9999 -9999 -9999 -9999 -9999 -9999 -9999 -9999 -9999 -9999 -9999 -9999 -9999 -9999 -9999 -9999 -9999 -9999 -9999 -9999 -9999 -9999 -9999 -9999 -9999 -9999 -9999 -9999 -9999

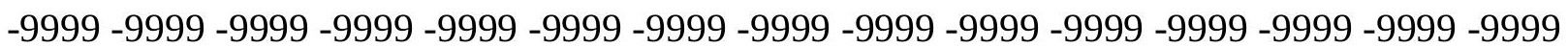
-9999 -9999 -9999 -9999 -9999 -9999 -9999 -9999 -9999 -9999 -9999 -9999 -9999 -9999 -9999 -9999 -9999 -9999 -9999 -9999 -9999 -9999 -9999 -9999 -9999 -9999 -9999 -9999 -9999 -9999 -9999 -9999 -9999 -9999 -9999 -9999 -9999 -9999 -9999 -9999 -9999 -9999 -9999 -9999 -9999

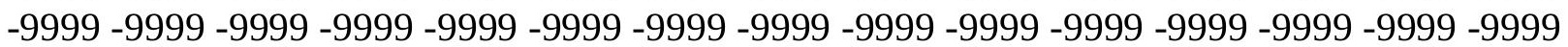


-9999 -9999 -9999 -9999 -9999 -9999 -9999 -9999 -9999 -9999 -9999 -9999 -9999 -9999 138.9819946289141 .1154937744143 .2489929199145 .9920959473148 .4304046631 117.7531661987117 .0881500244116 .4044418335115 .6931991577114 .9457397461 114.1530609131113 .3070297241112 .3997344971111 .4253158569110 .3792572021 98.109512329197 .5431365966896 .9872207641696 .4417648315495 .90653991699 95.3813400268694 .8657150268694 .3592147827193 .8611221313593 .37071990967 92.8871154785292 .4094314575291 .93666839690 .5211791992288 .99725341797 87.4733276367286 .254188537685 .0350494384884 .1206970214883 .2063369751 82.2919769287181 .3776321411180 .7680587768679 .8537063598679 .24413299561 78.6345596313578 .0249862670977 .4154205322376 .8058471679776 .50106811523 75.8914871215875 .2819290161174 .6723632812574 .3675689697373 .75800323486 73.1484298706172 .8436431884872 .2340774536171 .9292907714871 .31971740723 71.014930725170 .4053573608470 .1005783081169 .7957916259869 .49101257324 68.8814392089868 .5766525268668 .2718734741267 .9670867919967 .96708679199 67.6623001098667 .6623001098667 .6623001098667 .9670867919968 .27187347412 68.5766525268668 .8814392089869 .4910125732470 .1005783081171 .0149307251 71.9292907714873 .1484298706174 .062782287675 .2819290161176 .05784606934 76.5918731689576 .5142669677775 .9791412353575 .2352218627974 .38544464111 73.5152359008872 .6689605712971 .8708648681671 .119979858470 .42859649658 69.799530029369 .230194091868 .7160034179768 .2511901855567 .83032226562 67.4473876953167 .0968399047966 .7726974487366 .4687423706166 .17806243896 65.8942031860465 .6112823486370 .4053573608470 .1005783081169 .49101257324 69.1862335205168 .5766525268668 .2718734741267 .9670867919967 .66230010986 67.3575134277367 .0527267456166 .7479400634866 .4431610107466 .44316101074 66.1383666992265 .8335876464865 .5288009643665 .5288009643665 .22400665283 65.2240066528364 .9192428588964 .9192428588964 .6144485473664 .61444854736 64.3096618652364 .3096618652364 .3096618652364 .004882812525 .35797309875 3.059633970261 -9999 -9999 -9999 -9999 -9999 -9999 -9999 -9999 -9999 -9999 -9999 -9999 -9999 -9999 -9999 -9999 -9999 -9999 -9999

-9999 -9999 -9999 -9999 -9999 -9999 -9999 -9999 -9999 -9999 -9999 -9999 -9999 -9999 -9999 -9999 -9999 -9999 -9999 -9999 -9999 -9999 -9999 -9999-9999 -9999 -9999 -9999 -9999 -9999 -9999 -9999 -9999 -9999 -9999 -9999 -9999 -9999 -9999 -9999 -9999 -9999 -9999 -9999 -9999 -

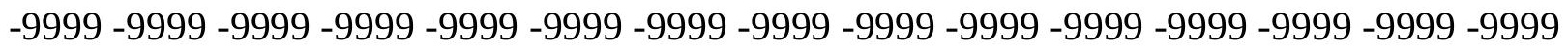
-9999 -9999 -9999 -9999 -9999 -9999 -9999 -9999 -9999 -9999 -9999 -9999 -9999 -9999 -9999 -9999 -9999 -9999 -9999 -9999 -9999 -9999 -9999 -9999 -9999 -9999 -9999 -9999 -9999 -9999

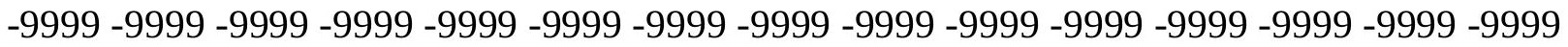

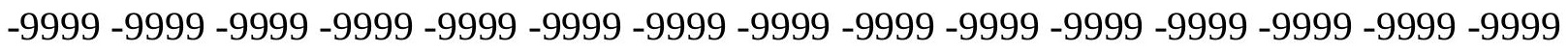

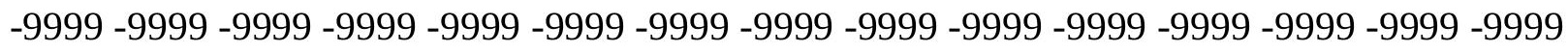
-9999 -9999 -9999 -9999 -9999 -9999 -9999 -9999 -9999 -9999 -9999 -9999 -9999 - 9999 - -999 -9999 -9999 -9999 -9999 -9999 -9999 -9999 -9999 -9999 -9999 -9999 -9999 -9999 -9999 - -999 -

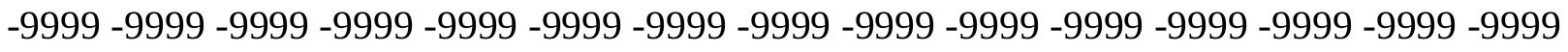

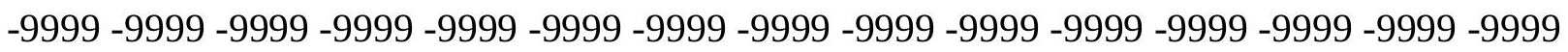
-9999 -9999 -9999 -9999 -9999 -9999 -9999 -9999 -9999 -9999 -9999 -9999 -9999 -9999 -9999 -9999 -9999 -9999 -9999 -9999 -9999 -9999 -9999 -9999-9999 -9999 -9999 -9999 -9999 -9999 -9999 -9999 -9999 -9999 -9999 -9999 -9999 -9999 -9999 -9999 -9999 -9999 -9999 -9999 -9999 141.1154937744 142.9441986084145.0776977539146.9064025879 148.7351074219 
117.612953186116 .8934631348116 .1485824585115 .3707122803114 .5520629883 113.6857681274112 .7652511597111 .7857818604110 .743721008398 .51026916504 97.9399490356497 .3797988891696 .8298187255996 .2897949218895 .75952911377 95.2386245727594 .7266616821394 .2230072021593 .7270126342893 .2378616333 92.7547683715892 .2768478393691 .4355392456189 .9116134643688 .38768768311 86.8637619018685 .6446228027384 .7302627563583 .8159103393682 .90155792236 81.9871978759881 .0728530883880 .4632720947379 .8537063598679 .24413299561 78.6345596313578 .0249862670977 .4154205322376 .8058471679776 .19628143311 75.5867080688575 .2819290161174 .6723632812574 .062782287673 .75800323486 73.1484298706172 .8436431884872 .2340774536171 .9292907714871 .31971740723 71.014930725170 .4053573608470 .1005783081169 .7957916259869 .18623352051 68.8814392089868 .5766525268668 .2718734741268 .2718734741267 .96708679199 67.9670867919967 .9670867919967 .9670867919968 .2718734741268 .57665252686 69.1862335205169 .7957916259870 .4053573608471 .3197174072372 .53885650635 73.7580032348674 .9771423339876 .1962814331177 .1265792846777 .39861297607 76.889091491776 .2055435180775 .4110870361374 .566680908273 .72021484375 72.9143753051872 .1375274658271 .4043807983470 .724746704170 .10249328613 69.5364761352569 .0237731933668 .5597915649468 .1396636962967 .75722503662 67.4065093994167 .0813140869166 .77539062566 .4817352294966 .19380187988 65.9060668945371 .6244964599671 .014930725170 .4053573608470 .10057830811 69.7957916259869 .1862335205168 .8814392089868 .5766525268668 .27187347412 67.9670867919967 .6623001098667 .3575134277367 .0527267456166 .74794006348 66.4431610107466 .4431610107466 .1383666992265 .8335876464865 .83358764648 65.5288009643665 .5288009643665 .2240066528365 .2240066528364 .91924285889 $64.9192428588964 .6144485473664 .5953979492226 .75808143616 .5663199424744-9999$ -9999 -9999 -9999 -9999 -9999 -9999 -9999 -9999 -9999 -9999 -9999 -9999 -9999 -9999 -9999 -9999 -9999 -9999

-9999 -9999-9999 -9999 -9999 -9999 -9999 -9999 -9999 -9999 -9999 -9999 -9999 -9999 -9999 -9999 -9999 -9999 -9999 -9999 -9999 -9999 -9999 -9999 -9999 -9999 -9999 -9999 -9999 -9999 -9999 -9999 -9999 -9999 -9999 -9999 -9999 -9999 -9999 -9999 -9999 -9999 -9999 -9999 -9999 -9999 -9999 -9999 -9999 -9999 -9999 -9999 -9999 -9999 -9999 -9999 -9999-9999 -9999 -9999 -9999 -9999 -9999 -9999 -9999 -9999 -9999 -9999 -9999 -9999 -9999 -9999 -9999 -9999 -9999 -

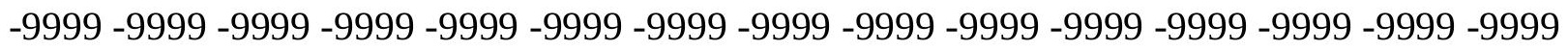
-9999 -9999 -9999 -9999 -9999 -9999 -9999 -9999 -9999 -9999 -9999 -9999 -9999 -9999 -9999 -9999 -9999 -9999 -9999 -9999 -9999 -9999 -9999 -9999 -9999 -9999 -9999 -9999 -9999 -9999 -

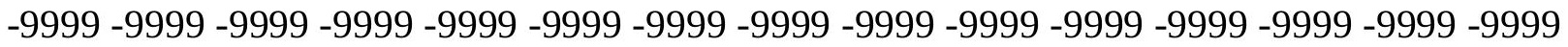

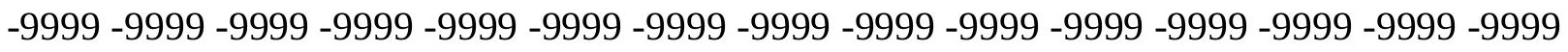

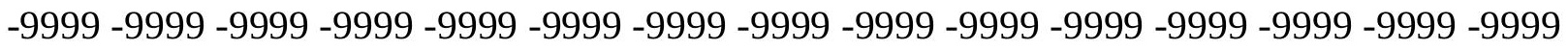
-9999 -9999 -9999 -9999 -9999 -9999 -9999 -9999 -9999 -9999 -9999 -9999 -9999 -9999 -9999 -9999 -9999 -9999 -9999 -9999 -9999 -9999 -9999 -9999 -9999 -9999 -9999 -9999 -9999 -9999 -

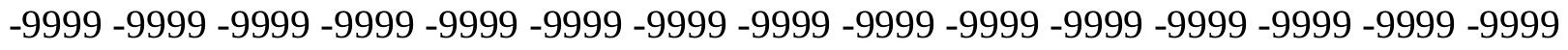

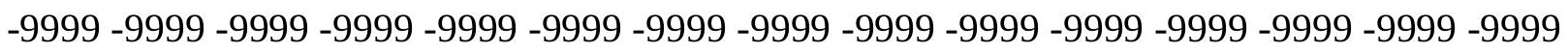
-9999 -9999 -9999 -9999 -9999 -9999 -9999 -9999 -9999 -9999 -9999 -9999 -9999 -9999 -9999 140.8106994629142 .3347015381143 .8585968018145 .6873016357146 .9064025879 147.8208007812117 .3647689819116 .5890426636115 .783241272114 .9406814575 114.055557251113 .1223678589112 .1372451782111 .097099304298 .90784454346 
98.3336105346797.7692794799897.2148437596.6700973510796.13486480713 95.6087722778395 .0914688110494 .5823745727594 .0809020996193 .58631896973 93.0979232788192 .6149215698292 .1210327148490 .5211791992288 .99725341797 87.7781066894586 .5589828491285 .3398437584 .4254837036183 .51112365723 82.5967712402381 .6824111938581 .0728530883880 .1584930419979 .54891967773 78.9393463134878 .3297805786177 .7202072143677 .110626220776 .80584716797 76.1962814331175 .5867080688574 .9771423339874 .6723632812574 .0627822876 73.4532165527373 .1484298706172 .5388565063572 .2340774536171 .62449645996 71.3197174072370 .7101516723670 .4053573608470 .1005783081169 .49101257324 69.1862335205168 .8814392089868 .5766525268668 .2718734741268 .27187347412 67.9670867919967 .9670867919967 .9670867919968 .2718734741268 .57665252686 69.1862335205169 .7957916259870 .4053573608471 .3197174072372 .53885650635 74.062782287675 .5867080688577 .110626220778 .0778045654377 .70001220703 77.0323486328176 .2478027343875 .4271545410274 .6021423339873 .80453491211 73.0389556884872 .3022613525471 .6032791137770 .9501037597770 .34674835205 69.7932357788169 .28823089668 .82895660468 .4118423461968 .03142547607 67.6819686889667 .3574447631867 .0518112182666 .7582168579166 .4700012207 66.1815261840872 .5388565063571 .9292907714871 .6244964599671 .0149307251 70.7101516723670 .1005783081169 .7957916259869 .4910125732469 .18623352051 68.8814392089868 .5766525268668 .2718734741267 .9670867919967 .66230010986 67.3575134277367 .0527267456166 .7479400634866 .7479400634866 .44316101074 66.1383666992265 .8335876464865 .8335876464865 .5288009643665 .52880096436 65.2240066528365 .1669158935539 .9173049926819 .2810382843 -9999 -9999 -9999 -9999 -9999 -9999 -9999 -9999 -9999 -9999 -9999 -9999 -9999 -9999 -9999 -9999 -9999 -9999 -9999 $-9999$

-9999 -9999 -9999 -9999 -9999 -9999 -9999 -9999 -9999 -9999 -9999 -9999 -9999 -9999 -9999 -9999 -9999 -9999 -9999 -9999 -9999 -9999 -9999 -9999 -9999 -9999 -9999 -9999 -9999 -9999 -

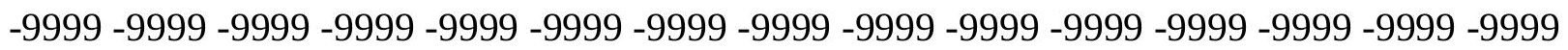
-9999 -9999 -9999 -9999 -9999 -9999 -9999 -9999 -9999 -9999 -9999 -9999 -9999 -9999 -9999 -9999 -9999 -9999 -9999 -9999 -9999 -9999 -9999 -9999 -9999 -9999 -9999 -9999 -9999 -9999 -9999 -9999 -9999 -9999 -9999 -9999 -9999 -9999 -9999 -9999 -9999 -9999-9999 -9999 -9999 -9999 -9999 -9999 -9999 -9999 -9999 -9999 -9999 -9999 -9999 -9999 -9999 -9999 -9999 -9999 -

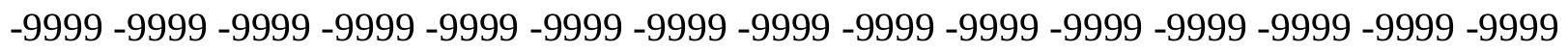
-9999 -9999 -9999 -9999 -9999 -9999 -9999 -9999 -9999 -9999 -9999 -9999 -9999 -9999 -9999 -9999 -9999 -9999 -9999 -9999 -9999 -9999 -9999 -9999 -9999 -9999 -9999 -9999 -9999 -9999 -

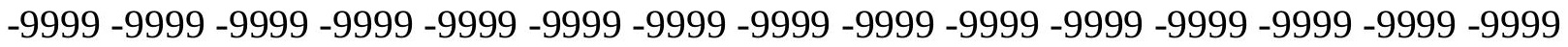

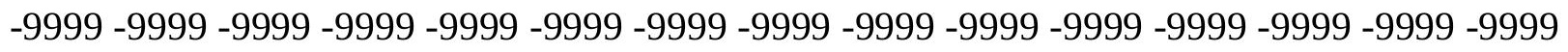

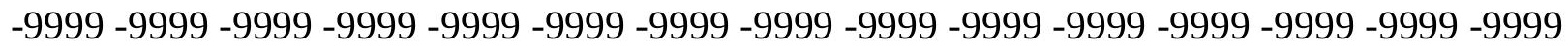
-9999 -9999 -9999 -9999 -9999 -9999 -9999 -9999 -9999 -9999 -9999 -9999 -9999 -9999 -9999 -9999 -9999 -9999 -9999 -9999 -9999 -9999 -9999 -9999 -9999 -9999 -9999 -9999 -9999 - -999 -

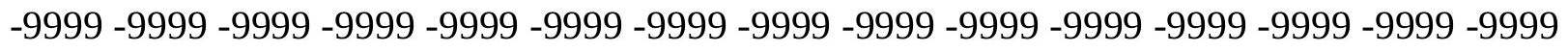
-9999 141.7250976562 142.9441986084144.1634063721 145.6873016357146.6015930176 117.8239135742117 .0204696655116 .189491272115 .3252563477114 .4228668213 113.4776916504112 .4864959717111 .4466323853110 .35720825298 .72380828857 98.1553573608497 .596542358497 .0471649169996 .5070724487395 .97592926025 95.453407287694 .9390029907294 .4321899414193 .9323120117293 .43872833252 
92.9507293701292 .4676971435591 .3563842773489 .9116134643688 .38768768311 87.1685485839885 .9494018554785 .0350494384884 .1206970214883 .2063369751 82.2919769287181 .6824111938580 .7680587768680 .1584930419979 .54891967773 78.9393463134878 .3297805786177 .7202072143677 .110626220776 .50106811523 76.1962814331175 .5867080688574 .9771423339874 .6723632812574 .0627822876 73.4532165527373 .1484298706172 .5388565063571 .9292907714871 .62449645996 71.014930725170 .7101516723670 .1005783081169 .7957916259869 .49101257324 68.8814392089868 .5766525268668 .2718734741268 .2718734741267 .96708679199 67.9670867919967 .9670867919968 .2718734741268 .5766525268668 .88143920898 69.4910125732470 .4053573608471 .3197174072372 .5388565063574 .0627822876 75.8914871215877 .7202072143678 .426620483477 .7525024414176 .95650482178 76.1306457519575 .3245697021574 .5454559326273 .8007888793973 .08594512939 72.4008712768671 .7471618652371 .1299438476670 .5530471801870 .0177154541 69.524276733469 .0718307495168 .6586380004968 .2805938720767 .93278503418 67.6096420288167 .305526733467 .0138397216866 .7279281616266 .44190216064 73.4532165527372 .8436431884872 .5388565063571 .9292907714871 .62449645996 71.3197174072370 .7101516723670 .4053573608470 .1005783081169 .49101257324 69.1862335205168 .8814392089868 .5766525268668 .2718734741267 .96708679199 67.6623001098667 .6623001098667 .3575134277367 .0527267456166 .74794006348 66.4431610107466 .4431610107466 .1383666992265 .8335876464865 .83358764648 65.5288009643634 .288089752216 .246717453 -9999 -9999 -9999 -9999 -9999 -9999 -9999 -9999 -9999 -9999 -9999 -9999 -9999 -9999 -9999 -9999 -9999 -9999 -9999 -9999 -9999 -9999 -9999 -9999 -9999 -9999 -9999 -9999 -9999 -9999 -9999 -9999 -9999 -9999 -9999 -9999 -9999 -9999 -9999 -9999 -9999 -9999 -9999 -9999 -9999 -9999 -9999 -9999 -9999 -9999

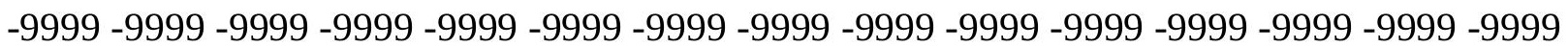
-9999 -9999 -9999 -9999 -9999 -9999 -9999 -9999 -9999 -9999 -9999 -9999 -9999 -9999 -9999 -9999 -9999 -9999 -9999 -9999 -9999 -9999 -9999 -9999 -9999 -9999 -9999 -9999 -9999 -9999 -9999 -9999 -9999 -9999 -9999 -9999 -9999 -9999 -9999 -9999 -9999 -9999 -9999 -9999 -9999 -9999 -9999 -9999 -9999 -9999 -9999 -9999 -9999 -9999 -9999 -9999 -9999 -9999 -9999 -9999 -9999 -9999 -9999 -9999 -9999 -9999 -9999 -9999 -9999 -9999 -9999 -9999 -9999 -9999 -9999 -9999 -9999 -9999 -9999 -9999 -9999 -9999 -9999 -9999 -9999 -9999 -9999 -9999 -9999 -9999 -9999 -9999 -9999 -9999 -9999 -9999 -9999 -9999 -9999 -9999 -9999 -9999 -9999 -9999 -9999 -9999 -9999 -9999 -9999 -9999 -9999 -9999 -9999 -9999 -9999 -9999 -9999 -9999 -9999 -9999 -9999 -9999 -9999 -9999 -9999 -9999 -9999 -9999 -9999 -9999 -9999 -9999 -9999 -9999 -9999 -9999 -9999 -9999 -9999 -9999 -9999 -9999 -9999 -9999 -9999 -9999 -9999 -9999 -9999 -9999 -9999 -9999 -9999 -9999 -9999 -9999 -9999 -9999 -9999 -9999 -9999 -9999 -9999 -9999 -9999 -9999 -9999 -9999 -9999 -9999 -9999 -9999 -9999 -9999 -9999 -9999 -9999 -9999 -9999 -9999 -9999 -9999 -9999 -9999 -9999 -9999 -9999 -9999 -9999 -9999 -9999 -9999 -9999 -9999 -9999 -9999 141.1154937744 142.0299072266 143.2489929199144.1634063721 145.3825073242 145.9920959473117 .4456558228116 .5924072266115 .7088775635114 .7909317017 113.8346405029112 .8372879028111 .7965621948110 .711631774999 .11018371582 98.5376815795997 .9745712280397 .4206695556696 .875839233496 .33976745605 95.8121795654395 .2926101684694 .7806091308694 .2755661010793 .7769241333 93.28403472992 .7963562011792 .1837234497190 .8259735107489 .3020401001 88.0829010009886 .8637619018685 .6446228027384 .7302627563583 .81591033936 82.9015579223682 .2919769287181 .3776321411180 .7680587768680 .15849304199 
79.5489196777378 .9393463134878 .3297805786177 .7202072143677 .1106262207 76.5010681152375 .8914871215875 .5867080688574 .9771423339874 .36756896973 74.062782287673 .4532165527372 .8436431884872 .5388565063571 .92929077148 71.3197174072371 .014930725170 .4053573608470 .1005783081169 .49101257324 69.1862335205168 .8814392089868 .5766525268668 .2718734741267 .96708679199 67.9670867919967 .9670867919967 .9670867919968 .2718734741268 .57665252686 69.1862335205170 .1005783081171 .014930725172 .2340774536174 .0627822876 75.8914871215878 .0249862670978 .6262817382877 .639083862376 .70802307129 75.8731002807675 .1189193725674 .4173202514673 .7480697631873 .09937286377 72.4719696044971 .8685455322371 .2910614013770 .7430572509870 .227394104 69.7463531494169 .3009643554768 .891326904368 .5150985717868 .16856384277 67.8468017578167 .5445938110467 .2556915283266 .9735946655366 .69211578369 74.3675689697374 .062782287673 .4532165527372 .8436431884872 .53885650635 71.9292907714871 .6244964599671 .3197174072370 .7101516723670 .40535736084 70.1005783081169 .7957916259869 .4910125732469 .1862335205168 .88143920898 68.5766525268668 .2718734741267 .9670867919967 .6623001098667 .35751342773 67.0527267456166 .7479400634866 .7479400634866 .4431610107466 .13836669922 66.1072998046941 .2485198974618 .74810409546 -9999 -9999 -9999 -9999 -9999 -9999 -9999 -9999 -9999 -9999 -9999 -9999 -9999 -9999 -9999 -9999 -9999 -9999 -9999 -9999

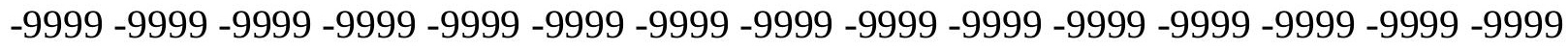
-9999 -9999 -9999 -9999 -9999 -9999 -9999 -9999 -9999 -9999 -9999 -9999 -9999 -9999 -9999 -9999 -9999 -9999 -9999 -9999 -9999 -9999 -9999 -9999 -9999 -9999 -9999 -9999 -9999 -9999 -9999 -9999 -9999 -9999 -9999 -9999 -9999 -9999 -9999 -9999 -9999 -9999-9999-9999-9999 -999 -9999 -9999 -9999 -9999 -9999 -9999 -9999 -9999 -9999 -9999 -9999 -9999 -9999 -9999 -9999 -9999 -9999 -9999 -9999 -9999 -9999 -9999 -9999 -9999 -9999 -9999 -9999 -9999 -9999 -9999 -9999 -9999 -9999 -9999 -9999 -9999 -9999 -9999 -9999 -9999 -9999 -9999 -9999 -9999 -9999 -9999 -9999 -9999 -9999 -9999 -9999 -9999 -9999 -9999 -9999 -9999 -9999 -9999 -9999 -9999

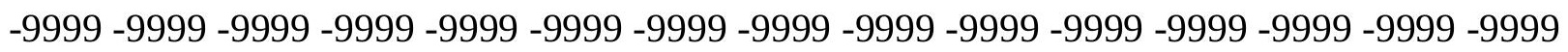
-9999 -9999 -9999 -9999 -9999 -9999 -9999 -9999 -9999 -9999 -9999 -9999 -9999 -9999 -9999 -9999 -9999 -9999 -9999 -9999 -9999 -9999 -9999 -9999 -9999 -9999 -9999 -9999 -9999 -9999 -9999 -9999 -9999 -9999 -9999 -9999 -9999 -9999 -9999 -9999 -9999 -9999 -9999 -9999 -9999

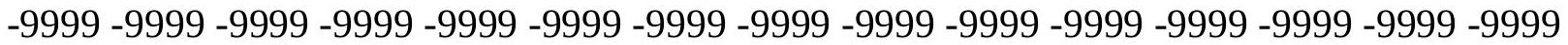

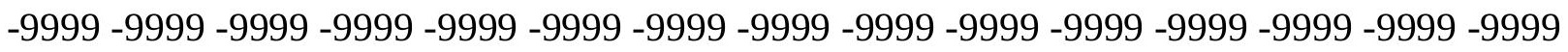
-9999 -9999 -9999 -9999 -9999 -9999 -9999 -9999 -9999 -9999 -9999 -9999 -9999 -9999 -9999 -9999 -9999 -9999 -9999 -9999 -9999 -9999 -9999 -9999 -9999 -9999 -9999 -9999 -9999 -9999 -9999 -9999 141.4203033447 142.3347015381 143.2489929199144.1634063721 144.7729034424117 .8650283813116 .992401123116 .0920181274115 .1603393555 114.1940231323113 .1907653809112 .1486206055111 .0668487549109 .9450073242 98.9159393310598 .3486175537197 .7902984619197 .2408523559696 .70000457764 96.1675033569395 .6429290771595 .1258850097794 .6158218383894 .11224365234 93.61457824707 93.1223220825292.6349868774491.5639419555790.21640014648 88.69246673584 87.47332763672 86.2541885376 85.33984375 84.42548370361 83.5111236572382 .9015579223681 .9871978759881 .3776321411180 .76805877686 80.1584930419979 .2441329956178 .9393463134878 .3297805786177 .72020721436 77.110626220776 .5010681152375 .8914871215875 .2819290161174 .97714233398 74.3675689697373 .7580032348673 .1484298706172 .8436431884872 .23407745361 
71.6244964599671 .3197174072370 .7101516723670 .1005783081169 .79579162598 69.1862335205168 .8814392089868 .5766525268668 .2718734741267 .96708679199 67.9670867919967 .9670867919967 .9670867919967 .9670867919968 .27187347412 68.8814392089869 .4910125732470 .4053573608471 .9292907714873 .45321655273 75.2819290161177 .4154205322378 .7173309326277 .4129104614376 .36249542236 75.5510330200274 .8856735229574 .2792053222773 .7005996704173 .12410736084 72.5544586181671 .9999160766671 .4599151611370 .9380874633870 .43925476074 69.9680633544969 .5276565551869 .1198654174868 .7440261840868 .39776611328 68.0768966674867 .7765350341867 .4907455444367 .2132186889666 .93759155273 75.2819290161174 .9771423339874 .3675689697373 .7580032348673 .45321655273 72.8436431884872 .5388565063571 .9292907714871 .6244964599671 .31971740723 71.014930725170 .4053573608470 .1005783081169 .7957916259869 .49101257324 69.1862335205168 .8814392089868 .5766525268668 .2718734741267 .96708679199 67.6623001098667 .3575134277367 .0527267456167 .0527267456166 .74794006348 66.4431610107443 .8280105590821 .75571060181 -9999 -9999 -9999 -9999 -9999 -9999 -9999 -9999 -9999 -9999 -9999 -9999 -9999 -9999 -9999 -9999 -9999 -9999 -9999 -9999 -9999 -9999 -9999 -9999 -9999 -9999 -9999 -9999 -9999 -9999 -9999 -9999 -9999 -9999 -9999 -9999 -9999 -9999 -9999 -9999 -9999 -9999 -9999 -9999 -9999 -9999 -9999 -9999 -9999 -9999 -

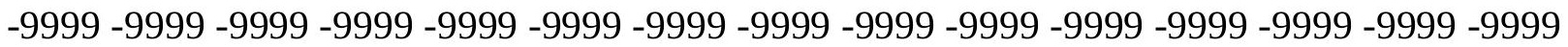

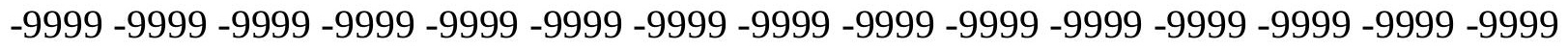

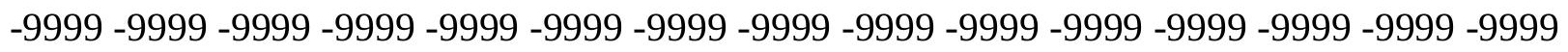

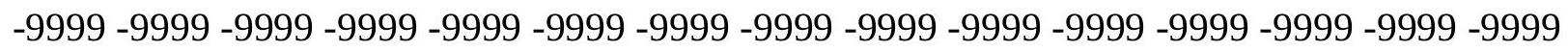
-9999 -9999 -9999 -9999 -9999 -9999 -9999 -9999 -9999 -9999 -9999 -9999 -9999 -9999 -9999 -

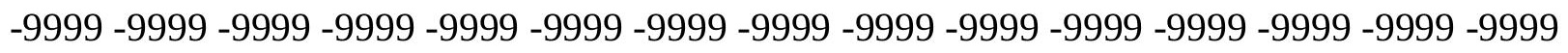

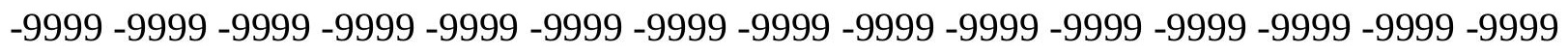
-9999 -9999 -9999 -9999 -9999 -9999 -9999 -9999 -9999 -9999 -9999 -9999 -9999 -9999 -9999

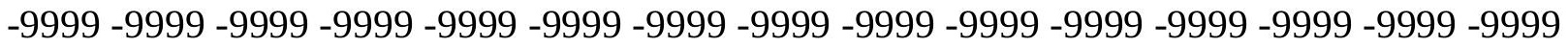

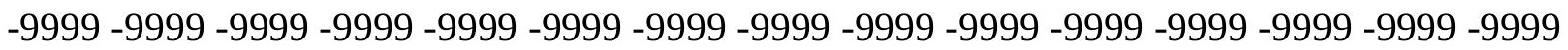
-9999 -9999 -9999 -9999 -9999 -9999 -9999 -9999 -9999 -9999 -9999 -9999 -9999 -9999 -9999

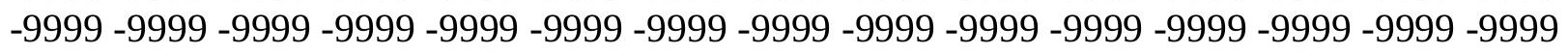
-9999 -9999 -9999 -9999 -9999 -9999 -9999 -9999 -9999 -9999 -9999 -9999 -9999 -9999 -9999 -9999 -9999 -9999 -9999 -9999 -9999 -9999 -9999 -9999 -9999 -9999 -9999 -9999 -9999 -9999 -9999-9999 140.5059967041 141.4203033447142.3347015381 143.2489929199 143.5538024902143 .5538024902117 .388053894116 .473274231115 .5298309326 114.5548095703113 .5462875366112 .5026626587111 .4234313965110 .3082427979 99.2897720336998 .7183456420998 .1557235717897 .6017990112397 .05631256104 96.5190505981495 .9896316528395 .4677047729594 .9527740478594 .44439697266 93.9420547485493 .4453048706192 .9537124633892 .2578201293990 .82597351074 89.60682678223 88.38768768311 87.16854858398 85.9494018554785.03504943848 84.1206970214883 .5111236572382 .5967712402381 .9871978759881 .37763214111 80.7680587768679 .8537063598679 .2441329956178 .6345596313578 .02498626709 77.7202072143677 .110626220776 .5010681152375 .8914871215875 .28192901611 74.6723632812574 .062782287673 .7580032348673 .1484298706172 .53885650635 71.9292907714871 .3197174072371 .014930725170 .4053573608469 .79579162598 69.4910125732468 .8814392089868 .5766525268668 .2718734741267 .96708679199 67.6623001098667 .6623001098667 .6623001098667 .6623001098667 .96708679199 
68.2718734741268 .8814392089869 .7957916259871 .014930725172 .53885650635 74.6723632812576 .8058471679778 .4232482910277 .1132812576 .01393890381 75.2786331176874 .7107543945374 .2059326171973 .7090148925873 .20364379883 72.6861267089872 .1728744506871 .6620483398471 .1584625244170 .66938781738 70.2021636962969 .7621688842869 .352951049868 .9751968383868 .62763214111 68.3067092895568 .0078277587967 .725166320867 .4524993896567 .18329620361 76.1962814331175 .5867080688575 .2819290161174 .6723632812574 .36756896973 73.7580032348673 .4532165527372 .8436431884872 .5388565063571 .92929077148 71.6244964599671 .3197174072371 .014930725170 .4053573608470 .10057830811 69.7957916259869 .4910125732469 .1862335205168 .8814392089868 .57665252686 68.2718734741267 .9670867919967 .6623001098667 .3575134277367 .05272674561 58.0823554992742 .7693939209 -9999 -9999 -9999 -9999 -9999 -9999 -9999 -9999 -9999 -9999 -9999 -9999 -9999 -9999 -9999 -9999 -9999 -9999 -9999 -9999 -9999 -9999 -9999 -9999 -9999 -9999 -9999 -9999 -9999 -9999 -9999 -9999 -9999 -9999 -9999 - -999 -9999 -9999 -9999 -9999 -9999 -9999 -9999 -9999 -9999 -9999 -9999 -9999 -9999 -9999 -9999

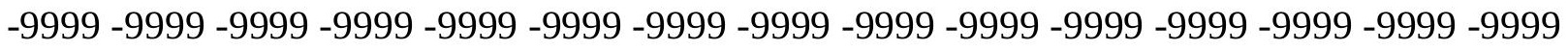
-9999 -9999 -9999 -9999 -9999 -9999 -9999 -9999 -9999 -9999 -9999 -9999 -9999 -9999 -9999 -9999 -9999 -9999 -9999 -9999 -9999 -9999 -9999 -9999 -9999 -9999 -9999 -9999 -9999 -9999 -9999 -9999 -9999 -9999 -9999 -9999 -9999 -9999 -9999 -9999 -9999 -9999 -9999 -9999 -9999 -

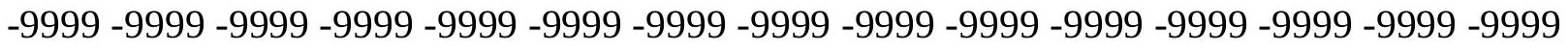

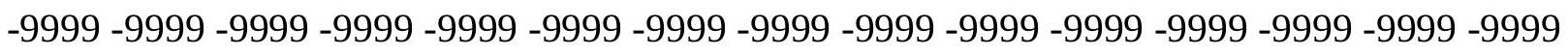

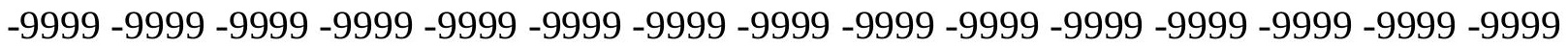
-9999 -9999 -9999 -9999 -9999 -9999 -9999 -9999 -9999 -9999 -9999 -9999 -9999 -9999 -9999 -9999 -9999 -9999 -9999 -9999 -9999 -9999 -9999 -9999 -9999 -9999 -9999 -9999 -9999 -9999 -

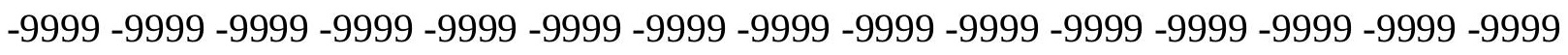
-9999 -9999 -9999 -9999 -9999 -9999 -9999 -9999 -9999 -9999 -9999 -9999 -9999 -9999 -9999 -9999 -9999 -9999 -9999 -9999 -9999 -9999 -9999 -9999 -9999 -9999 -9999 -9999 -9999 -9999 -9999 -9999 -9999 -9999 -9999 -9999 -9999 -9999 -9999 -9999 -9999 -9999 -9999 -9999 -9999 -9999 -9999 -9999 -9999 -9999 -9999 -9999 -9999 -9999 -9999 -9999 -9999 -9999 -9999 -9999 -9999 -9999-9999 140.8106994629 141.7250976562142 .3347015381142 .9441986084 142.6394042969117 .7766571045116 .849937439115 .8967895508114 .9146270752 113.90184021112 .8572006226111 .7805023193110 .6716461182109 .5311813354 99.0834960937598 .5166854858497 .9583969116297 .4084091186596 .86653900146 96.3324356079195 .8057861328195 .2861404418994 .7731018066494 .26620483398 93.765060424893 .2692794799892 .778602600191 .7094726562590 .52117919922 88.9972534179787 .7781066894586 .8637619018685 .9494018554785 .03504943848 84.1206970214883 .5111236572382 .5967712402381 .9871978759881 .37763214111 80.4632720947379 .8537063598679 .2441329956178 .6345596313578 .02498626709 77.4154205322376 .8058471679776 .5010681152375 .8914871215875 .28192901611 74.6723632812574 .062782287673 .4532165527372 .8436431884872 .23407745361 71.6244964599671 .014930725170 .4053573608470 .1005783081169 .49101257324 69.1862335205168 .5766525268668 .2718734741267 .9670867919967 .66230010986 67.3575134277367 .3575134277367 .3575134277367 .6623001098667 .96708679199 68.2718734741269 .1862335205170 .4053573608471 .6244964599673 .45321655273 75.5867080688577 .7202072143676 .9840393066475 .889930725175 .20139312744 74.6972045898474 .2631759643673 .836631774973 .3812255859472 .90126037598 
72.4157638549871 .9199523925871 .4216079711970 .9313964843870 .45946502686 70.013389587469 .5981292724669 .2153701782268 .8644714355568 .54224395752 68.2441482543967 .964286804267 .6963043212967 .4334182739377 .1106262207 76.5010681152375 .8914871215875 .5867080688574 .9771423339874 .67236328125 74.062782287673 .7580032348673 .1484298706172 .8436431884872 .53885650635 71.9292907714871 .6244964599671 .3197174072370 .7101516723670 .40535736084 70.1005783081169 .7957916259869 .4910125732469 .1862335205168 .88143920898 68.5766525268668 .2718734741267 .9272308349667 .6623001098655 .16257858276 40.26205444336 -9999 -9999 -9999 -9999 -9999 -9999 -9999 -9999 -9999 -9999 -9999 -9999 -9999 -9999 -9999 -9999 -9999 -9999 -9999 -9999 -9999

-9999 -9999 -9999 -9999 -9999 -9999 -9999 -9999 -9999 -9999 -9999 -9999 -9999 -9999 -9999 -9999 -9999 -9999 -9999 -9999 -9999 -9999 -9999 -9999 -9999 -9999 -9999 -9999 -9999 -9999 -9999 -9999 -9999 -9999 -9999 -9999 -9999 -9999 -9999 -9999 -9999 -9999 -9999 -9999 -9999 -9999 -9999 -9999 -9999 -9999 -9999 -9999 -9999 -9999 -9999 -9999 -9999 -9999 -9999 - 9999 -9999 -9999 -9999 -9999 -9999 -9999 -9999 -9999 -9999 -9999 -9999 -9999 -9999 -9999 -9999

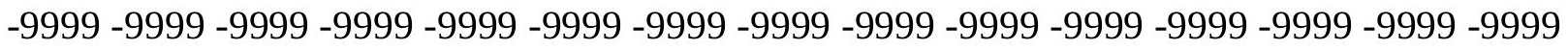
-9999 -9999 -9999 -9999 -9999 -9999 -9999 -9999 -9999 -9999 -9999 -9999 -9999 -9999 -9999 -9999 -9999 -9999 -9999 -9999 -9999 -9999 -9999 -9999 -9999 -9999 -9999 -9999 -9999 -9999 -9999 -9999 -9999 -9999 -9999 -9999 -9999 -9999 -9999 -9999 -9999 -9999 -9999 -9999 -9999 -

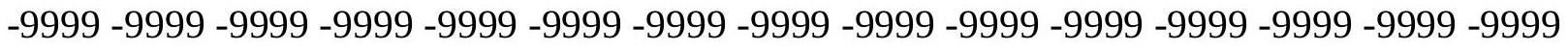

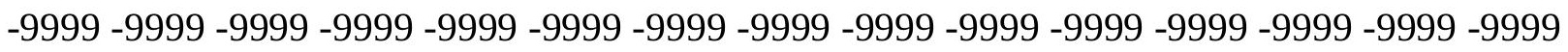
-9999 -9999 -9999 -9999 -9999 -9999 -9999 -9999 -9999 -9999 -9999 -9999 -9999 -9999 -9999 -9999 -9999 -9999 -9999 -9999 -9999 -9999 -9999 -9999 -9999 -9999 -9999 -9999 -9999 -9999 -

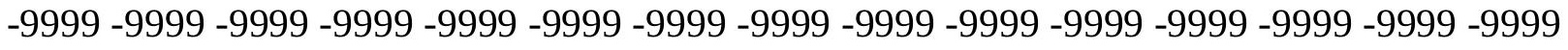

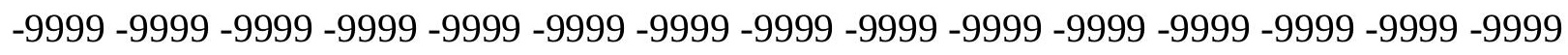

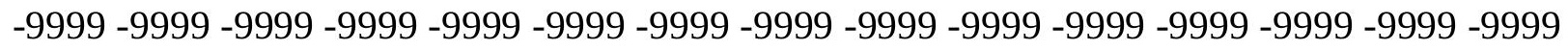
-9999 -9999 -9999 140.5059967041 141.4203033447142 .3347015381142 .6394042969 142.3347015381141 .7250976562117 .218421936116 .2577590942115 .2702941895 114.2546768188113 .2100296021112 .1364746094111 .0341949463109 .9038772583 99.4437408447398 .8728485107498 .3103332519597 .7559890747197 .20965576172 96.6710128784296 .13979339695 .6155853271595 .0980377197394 .58672332764 94.0812988281293 .5814056396593 .0868377685592 .4837493896591 .22247314453 89.9116134643688 .6924667358487 .7781066894586 .5589828491285 .64462280273 85.0350494384884 .1206970214883 .206336975182 .5967712402381 .98719787598 81.3776321411180 .4632720947379 .8537063598679 .2441329956178 .63455963135 78.0249862670977 .4154205322376 .8058471679776 .1962814331175 .58670806885 74.9771423339874 .3675689697373 .7580032348673 .1484298706172 .53885650635 71.9292907714871 .3197174072370 .7101516723670 .1005783081169 .49101257324 69.1862335205168 .5766525268668 .2718734741267 .9670867919967 .66230010986 67.3575134277367 .3575134277367 .0527267456167 .0527267456167 .35751342773 67.9670867919968 .5766525268669 .4910125732470 .7101516723672 .23407745361 74.3675689697376 .8058471679777 .4693298339876 .2061538696375 .42483520508 74.915176391674 .5144424438574 .1205444335973 .6953964233473 .23509216309 72.7528457641672 .2518463134871 .7411422729571 .2355957031270 .74824523926 70.2883071899469 .8616561889669 .4703292846769 .1138153076268 .78880310059 68.4905471801868 .2128295898467 .9489593505967 .6917419433677 .72020721436 
77.110626220776 .8058471679776 .1962814331175 .8914871215875 .28192901611 74.9771423339874 .3675689697374 .062782287673 .4532165527373 .14842987061 72.8436431884872 .2340774536171 .9292907714871 .6244964599671 .0149307251 70.7101516723670 .4053573608470 .1005783081169 .7957916259869 .49101257324 69.1862335205168 .5766525268668 .2718734741267 .9670867919954 .29063796997 38.04709625244 -9999 -9999 -9999 -9999 -9999 -9999 -9999 -9999 -9999 -9999 -9999 -9999 -9999 -9999 -9999 -9999 -9999 -9999 -9999 -9999 -9999

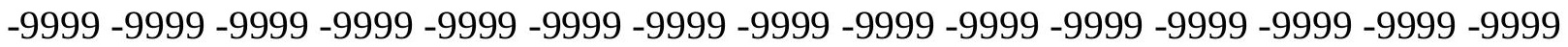

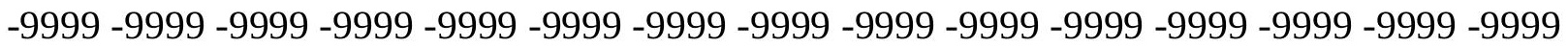
-9999 -9999 -9999 -9999 -9999 -9999 -9999 -9999 -9999 -9999 -9999 -9999 -9999 -9999 -9999 -

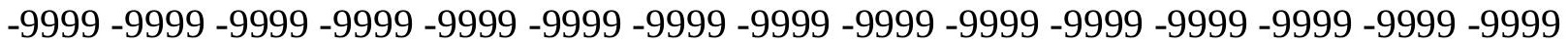
-9999 -9999 -9999 -9999 -9999 -9999 -9999 -9999 -9999 -9999 -9999 -9999 -9999 -9999 -9999 -9999 -9999 -9999 -9999 -9999 -9999 -9999 -9999 -9999 -9999 -9999 -9999 -9999 -9999 -9999 -9999 -9999 -9999 -9999 -9999 -9999 -9999 -9999 -9999 -9999 -9999 -9999 -9999 -9999 -9999 -9999 -9999 -9999 -9999 -9999 -9999 -9999 -9999 -9999 -9999 -9999 -9999 -9999 -9999 -9999

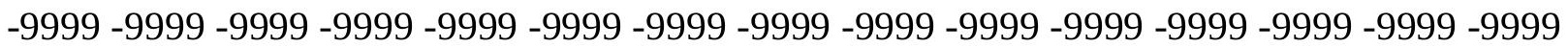

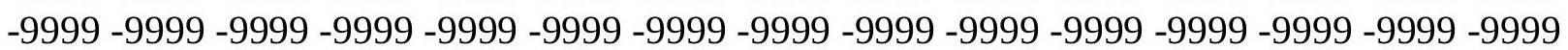
-9999 -9999 -9999 -9999 -9999 -9999 -9999 -9999 -9999 -9999 -9999 -9999 -9999 -9999 -9999 -9999 -9999 -9999 -9999 -9999 -9999 -9999 -9999 -9999 -9999 -9999 -9999 -9999 -9999 -9999 -9999 -9999 -9999 -9999 -9999 -9999 -9999 -9999 -9999 -9999 -9999 -9999 -9999 -9999 -9999 -9999 -9999 -9999 -9999 -9999 -9999 -9999 -9999 -9999 -9999 -9999 -9999 -9999 -9999 -9999 -9999 -9999 -9999 -9999 -9999 -9999 -9999 -9999 -9999 -9999 -9999 -9999 -9999 -9999 -9999 -9999 -9999 -9999 -9999 -9999 -9999 -9999 -9999 -9999 -9999 -9999 -9999 -9999 -9999 -9999 -9999 -9999 -9999 -9999 141.4203033447 142.3347015381142 .6394042969142 .4710693359 141.5322418213117 .5750427246116 .6090240479115 .6182861328114 .6016693115 113.5585632324112 .4893035889111 .3942718506110 .2742538452109 .1298522949 99.2239456176898 .6573181152398 .0987472534297 .5480880737397 .00505828857 96.4694137573295 .9407958984495 .4188919067494 .9032974243294 .39370727539 93.8898086547993 .3914260864392 .8984146118292 .0016632080190 .82597351074 89.6068267822388 .3876876831187 .4733276367286 .5589828491285 .64462280273 84.7302627563584 .1206970214883 .206336975182 .5967712402381 .98719787598 81.0728530883880 .4632720947379 .8537063598679 .2441329956178 .63455963135 78.0249862670977 .4154205322376 .8058471679776 .1962814331175 .28192901611 74.6723632812574 .062782287673 .4532165527372 .8436431884872 .23407745361 71.6244964599671 .014930725170 .4053573608469 .7957916259869 .18623352051 68.5766525268668 .2718734741267 .9670867919967 .6623001098667 .35751342773 67.0527267456167 .0527267456167 .0527267456167 .0527267456167 .66230010986 68.2718734741268 .8814392089869 .7957916259871 .014930725173 .45321655273 75.5867080688578 .0249862670976 .8664398193475 .9298095703175 .38536071777 74.9869689941474 .6092987060574 .180938720773 .7079467773473 .19725799561 72.6655273437572 .1217575073271 .5853881835971 .0715408325270 .59017944336 70.1471252441469 .743995666569 .3797607421969 .0505676269568 .75115203857 68.474754333568 .2141647338978 .9393463134878 .3297805786178 .02498626709 77.4154205322377 .110626220776 .5010681152376 .1962814331175 .58670806885 74.9771423339874 .6723632812574 .3675689697373 .7580032348673 .45321655273 72.8436431884872 .5388565063572 .2340774536171 .6244964599671 .31971740723 
71.014930725170 .7101516723670 .1005783081169 .7957916259869 .49101257324 69.1457672119168 .8312683105561 .9323539733950 .92578125 -9999 -9999 -9999 -9999 -9999 -9999 -9999 -9999 -9999 -9999 -9999 -9999 -9999 -9999 -9999 -9999 -9999 -9999 -9999 -9999-9999-9999

-9999 -9999 -9999 -9999 -9999 -9999 -9999 -9999 -9999 -9999 -9999 -9999 -9999 -9999 -9999 -9999 -9999 -9999 -9999 -9999 -9999 -9999 -9999 -9999 -9999 -9999 -9999 -9999 -9999 -9999 -9999 -9999 -9999 -9999 -9999 -9999 -9999 -9999 -9999 -9999 -9999 -9999 -9999 -9999 -9999

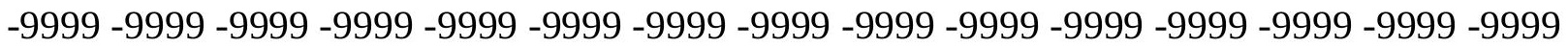

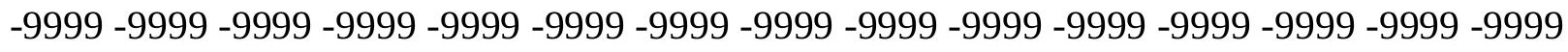
-9999 -9999 -9999 -9999 -9999 -9999 -9999 -9999 -9999 -9999 -9999 -9999 -9999 -9999 -9999 -

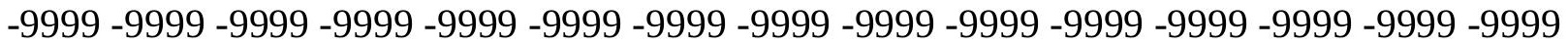
-9999 -9999 -9999 -9999 -9999 -9999 -9999 -9999 -9999 -9999 -9999 -9999 -9999 -9999 -9999 -9999 -9999 -9999 -9999 -9999 -9999 -9999 -9999 -9999 -9999 -9999 -9999 -9999 -9999 -9999 -9999 -9999 -9999 -9999 -9999 -9999 -9999 -9999 -9999 -9999 -9999 -9999 -9999 -9999 -9999 -9999 -9999 -9999 -9999 -9999 -9999 -9999 -9999 -9999 -9999 -9999 -9999 -9999 -9999 -9999

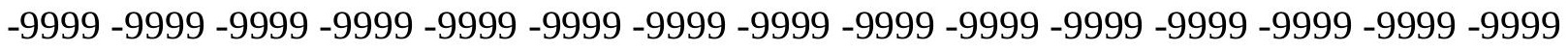
-9999 -9999 -9999 -9999 -9999 -9999 -9999 -9999 -9999 -9999 -9999 -9999 -9999 -9999 -9999 -9999 -9999 -9999 -9999 -9999 -9999 -9999 -9999 -9999 -9999 -9999 -9999 -9999 -9999 -9999 -9999 -9999 -9999 -9999 -9999 -9999 -9999 -9999 -9999 -9999 -9999 -9999 -9999 -9999 -9999 -

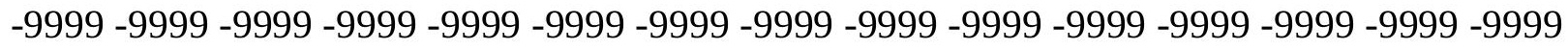
-9999 -9999 -9999-9999 142.0299072266142.9441986084143.3236236572 143.1112518311 142.0443115234140 .0038757324116 .9470291138115 .9549713135114 .9392776489 113.8994827271112 .8359603882111 .7490997314110 .6397399902109 .5086135864 99.5696258544998 .9989929199298 .4363174438597 .8814697265697 .33419799805 96.7942810058696 .2613983154395 .7352676391695 .2155303955194 .70191955566 94.1941299438593 .6920318603593 .1955032348692 .7046127319391 .63858795166 90.5211791992289 .6068267822388 .3876876831187 .4733276367286 .55898284912 85.6446228027384 .7302627563584 .1206970214883 .206336975182 .59677124023 81.9871978759881 .0728530883880 .4632720947379 .8537063598679 .24413299561 78.6345596313578 .0249862670977 .110626220776 .5010681152375 .89148712158 75.2819290161174 .3675689697373 .7580032348673 .1484298706172 .53885650635 71.9292907714871 .014930725170 .4053573608469 .7957916259869 .18623352051 68.8814392089868 .2718734741267 .9670867919967 .6623001098667 .35751342773 67.0527267456166 .7479400634866 .7479400634867 .0527267456167 .35751342773 67.9670867919968 .5766525268669 .4910125732470 .7101516723672 .53885650635 74.6723632812576 .8058471679777 .6373291015676 .6141738891676 .06151580811 75.6982345581175 .3209686279374 .8586425781274 .3228988647573 .74922943115 73.1572570800872 .5591430664171 .977401733471 .4276885986370 .91899108887 70.4559020996170 .0387268066469 .6653366088969 .3309326171969 .02948760986 68.7535400390668 .4952774047979 .5489196777378 .9393463134878 .63455963135 78.0249862670977 .7202072143677 .110626220776 .8058471679776 .19628143311 75.8914871215875 .2819290161174 .9771423339874 .3675689697374 .0627822876 73.4532165527373 .1484298706172 .8436431884872 .2340774536171 .92929077148 71.6244964599671 .014930725170 .7101516723670 .4053573608470 .10057830811 69.6566390991269 .1862335205159 .4239463806247 .72146224976 -9999 -9999 -9999 -9999 -9999 -9999 -9999 -9999 -9999 -9999 -9999 -9999 -9999 -9999 -9999 -9999 -9999 -9999 -9999 
-9999 -9999 -9999

-9999 -9999 -9999 -9999 -9999 -9999 -9999 -9999 -9999 -9999 -9999 -9999 -9999 -9999 -9999

-9999 -9999 -9999 -9999 -9999 -9999 -9999 -9999 -9999 -9999 -9999 -9999 -9999 -9999 - 9999 -

-9999 -9999 -9999 -9999 -9999 -9999 -9999 -9999 -9999 -9999 -9999 -9999 -9999 -9999 -9999

-9999 -9999 -9999 -9999 -9999 -9999 -9999 -9999 -9999 -9999 -9999 -9999-9999 -9999 -9999 -

-9999 -9999 -9999 -9999 -9999 -9999 -9999 -9999 -9999 -9999 -9999 -9999 -9999 -9999 -9999

-9999 -9999 -9999 -9999 -9999 -9999 -9999 -9999 -9999 -9999 -9999 -9999 -9999 -9999 -9999 -999 -

-9999 -9999 -9999 -9999 -9999 -9999 -9999 -9999 -9999 -9999 -9999 -9999 -9999 -9999 -9999

-9999 -9999 -9999 -9999 -9999 -9999 -9999 -9999 -9999 -9999 -9999 -9999 -9999 -9999 -9999 -

-9999 -9999 -9999 -9999 -9999 -9999 -9999 -9999 -9999 -9999 -9999 -9999 -9999 -9999 -9999 -

-9999 -9999 -9999 -9999 -9999 -9999 -9999 -9999 -9999 -9999 -9999 -9999 -9999 -9999 -9999

-9999 -9999 -9999 -9999 -9999 -9999 -9999 -9999 -9999 -9999 -9999 -9999 -9999 -9999 -9999

-9999 -9999 -9999 -9999 -9999 -9999 -9999 -9999 -9999 -9999 -9999 -9999 -9999 -9999 -9999

-9999 -9999 -9999 -9999 -9999 -9999 -9999 -9999 -9999 -9999 -9999 -9999 -9999 -9999 -9999 -

-9999 -9999 -9999 -9999 -9999 -9999 -9999 -9999 -9999 -9999 -9999 -9999 -9999 -9999 -9999

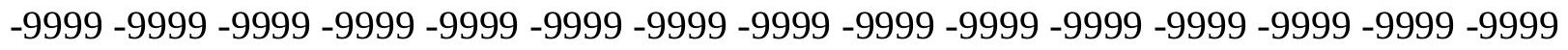

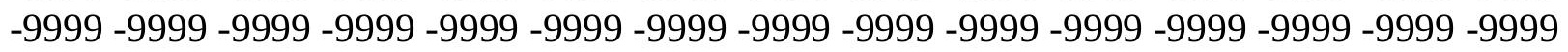

-9999 -9999-9999-9999-9999 143.9361419678144 .6512451172144 .5882110596

143.5689697266141 .4219818115138 .1379547119116 .2776641846115 .2643890381

114.2292938232113 .1726760864112 .094871521110 .9966888428109 .8789749146

108.743293762299 .3350677490298 .7683868408298 .2094726562597 .65808105469

97.1140289306696 .5770187377996 .0468063354595 .5230712890695 .00556182861

94.4940261840893 .9883270263793 .4883880615292 .9942932128992 .47766113281

91.4711990356490 .5211791992289 .302040100188 .3876876831187 .47332763672

86.5589828491285 .6446228027384 .7302627563584 .1206970214883 .2063369751

82.5967712402381 .9871978759881 .0728530883880 .4632720947379 .85370635986

79.2441329956178 .3297805786177 .7202072143677 .110626220776 .19628143311

75.5867080688574 .9771423339874 .062782287673 .4532165527372 .84364318848

71.9292907714871 .3197174072370 .7101516723670 .1005783081169 .49101257324

68.8814392089868 .2718734741267 .9670867919967 .6623001098667 .35751342773

67.0527267456166 .7479400634867 .0527267456167 .0527267456167 .35751342773

67.9670867919968 .5766525268669 .1862335205170 .4053573608471 .62449645996 73.4532165527375 .5867080688577 .7202072143677 .2810363769576 .91997528076

76.67104339676 .2707061767675 .7148590087975 .0674438476674 .38533782959

73.7055282592873 .0363693237372 .3999252319371 .80942535471 .27099609375

70.7867507934670 .3549957275469 .9721145629969 .6321258544969 .328125

69.0518875122168 .7949905395580 .1584930419979 .5489196777379 .24413299561

78.6345596313578 .3297805786177 .7202072143677 .4154205322376 .80584716797

76.5010681152375 .8914871215875 .5867080688574 .9771423339874 .67236328125

74.062782287673 .7580032348673 .4532165527372 .8436431884872 .53885650635

72.2340774536171 .6244964599671 .3197174072371 .014930725170 .40535736084

70.0978622436569 .7836456298858 .6572418212945 .47458648682 -9999 -9999 -9999 -9999 -9999 -9999 -9999 -9999 -9999 -9999 -9999 -9999 -9999 -9999 -9999 -9999 -9999 -9999 -9999 -9999 -9999 -9999

-9999 -9999 -9999 -9999 -9999 -9999 -9999 -9999 -9999 -9999 -9999 -9999 -9999 -9999 -9999

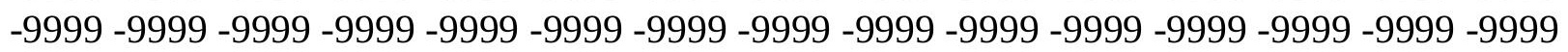


-9999 -9999 -9999 -9999 -9999 -9999 -9999 -9999 -9999 -9999 -9999 -9999 -9999 -9999 -9999 -9999 -9999 -9999 -9999 -9999 -9999 -9999 -9999 -9999 -9999 -9999 -9999 -9999 -9999 -9999 -9999 -9999 -9999 -9999 -9999 -9999 -9999 -9999 -9999 -9999 -9999 -9999 -9999 -9999 -9999 -9999 -9999 -9999 -9999 -9999 -9999 -9999 -9999 -9999 -9999 -9999 -9999 -9999 -9999 -9999 -9999 -9999 -9999 -9999 -9999 -9999 -9999 -9999 -9999 -9999 -9999 -9999 -9999 -9999 -9999 -9999 -9999 -9999 -9999 -9999 -9999 -9999 -9999 -9999 -9999 -9999 -9999 -9999 -9999 -9999 -9999 -9999 -9999 -9999 -9999 -9999 -9999 -9999 -9999 -9999 -9999 -9999 -9999 -9999 -9999

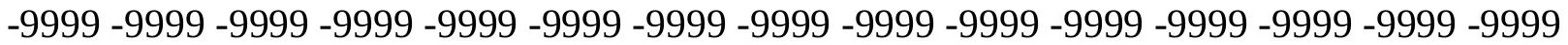
-9999 -9999 -9999 -9999 -9999 -9999 -9999 -9999 -9999 -9999 -9999 -9999 -9999 -9999 -9999 -9999 -9999 -9999 -9999 -9999 -9999 -9999 -9999 -9999 -9999 -9999 -9999 -9999 -9999 -9999 -9999 -9999 -9999 -9999 -9999 -9999 -9999 -9999 -9999 -9999 -9999 -9999 -9999 -9999 -9999 -9999 -9999 -9999 -9999 -9999 -9999 -9999 -9999 -9999 -9999 -9999 -9999 -9999 -9999 -9999

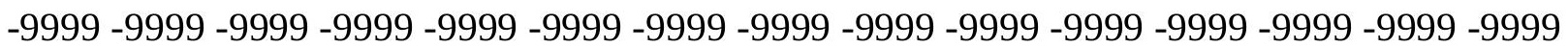
-9999 -9999 -9999 -9999 -9999 -9999 -9999 -9999 -9999 -9999 -9999 -9999 -9999 -9999 -9999 -9999 -9999 -9999 -9999 -9999 145.7224731445146 .7828674316147 .0822143555 146.3176727295144 .2372283936140 .7558288574116 .58543396115 .5755004883 114.5458908081113 .4968414307112 .4286575317111 .3421325684110 .2382278442 109.11863708599.6651687622199.09458160498.5317001342897.97630310059 97.4282379150496 .8872299194396 .3530807495195 .8254852294995 .30422973633 94.7890777587994 .2799301147593 .7767181396593 .2795410156292 .78857421875 92.2808914184691 .2651824951290 .2164001464889 .302040100188 .38768768311 87.1685485839886 .5589828491285 .6446228027384 .7302627563584 .12069702148 83.206336975182 .5967712402381 .6824111938581 .0728530883880 .46327209473 79.8537063598678 .9393463134878 .3297805786177 .4154205322376 .80584716797 76.1962814331175 .2819290161174 .6723632812573 .7580032348673 .14842987061 72.2340774536171 .6244964599671 .014930725170 .1005783081169 .49101257324 68.8814392089868 .5766525268667 .9670867919967 .6623001098667 .35751342773 67.0527267456167 .0527267456167 .0527267456167 .3575134277367 .66230010986 67.9670867919968 .5766525268669 .1862335205170 .1005783081171 .0149307251 72.2340774536173 .7580032348675 .8914871215877 .8056335449278 .06267547607 77.9794082641677 .4517593383876 .6978683471775 .8725585937575 .05950927734 74.2754364013773 .5282592773472 .8367309570372 .2065277099671 .64054107666 71.1371459960970 .6923370361370 .3009567260769 .9558334350669 .64920806885 69.3721542358469 .1156921386780 .4632720947380 .1584930419979 .85370635986 79.2441329956178 .9393463134878 .3297805786178 .0249862670977 .41542053223 77.110626220776 .5010681152376 .1962814331175 .5867080688575 .28192901611 74.6723632812574 .3675689697373 .7580032348673 .4532165527373 .14842987061 72.5388565063572 .2340774536171 .6244964599671 .3197174072370 .95701599121 70.5800018310565 .032791137756 .05531692505 -9999 -9999 -9999 -9999 -9999 -9999 -9999 -9999 -9999 -9999 -9999 -9999 -9999 -9999 -9999 -9999 -9999 -9999 -9999 -9999 -9999 -9999 $-9999$

-9999 -9999 -9999 -9999 -9999 -9999 -9999 -9999 -9999 -9999 -9999 -9999 -9999 -9999 -9999 -9999 -9999 -9999 -9999 -9999 -9999 -9999 -9999 -9999 -9999 -9999 -9999 -9999 -9999 -9999 -9999 -9999 -9999 -9999 -9999 -9999 -9999 -9999 -9999 -9999 -9999 -9999 -9999 -9999 -9999

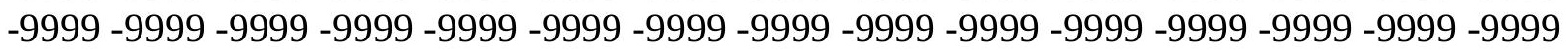

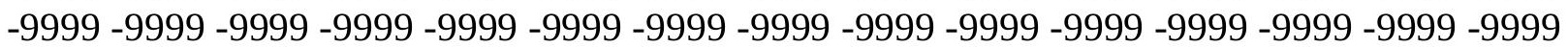


-9999 -9999 -9999 -9999 -9999 -9999 -9999 -9999 -9999 -9999 -9999 -9999 -9999 -9999 -9999 -9999 -9999 -9999 -9999 -9999 -9999 -9999 -9999 -9999 -9999 -9999 -9999 -9999 -9999 -9999 -9999 -9999 -9999 -9999 -9999 -9999 -9999 -9999 -9999 -9999 -9999 -9999 -9999 -9999 -9999 -9999 -9999 -9999 -9999 -9999 -9999 -9999 -9999 -9999 -9999 -9999 -9999 -9999 -9999 -9999 -9999 -9999 -9999 -9999 -9999 -9999 -9999 -9999 -9999 -9999 -9999 -9999 -9999 -9999 -9999 -9999 -9999 -9999 -9999 -9999 -9999 -9999 -9999 -9999 -9999 -9999 -9999 -9999 -9999 -9999 -9999 -9999 -9999 -9999 -9999 -9999 -9999 -9999 -9999 -9999 -9999 -9999 -9999 -9999 -9999

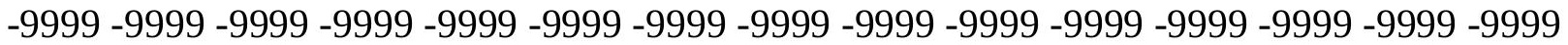
-9999 -9999 -9999 -9999 -9999 -9999 -9999 -9999 -9999 -9999 -9999 -9999 -9999 -9999 -9999 -9999 -9999 -9999 -9999 -9999 -9999 -9999 -9999 -9999 -9999 -9999 -9999 -9999 -9999 -9999 -9999 -9999 -9999 -9999 -9999 -9999 -9999 -9999 -9999 -9999 -9999 -9999 -9999 -9999 -9999 -9999 -9999 -9999 -9999 -9999 -9999 149.751739502150 .6384887695150 .4069976807 148.6686553955145 .2282714844140 .1841278076115 .8738174438114 .8500366211 113.8088150024112 .7504959106111 .6759033203110 .5861129761109 .4828567505 108.368194580199.4146118164198.8478393554798.2885360717897.73657226562 97.1916961669996 .653739929296 .1224212646595 .5975646972795 .07894897461 94.5665054321394 .0601730346793 .5600891113393 .0664367675892 .57956695557 92.050506591891 .1183242797990 .2164001464888 .9972534179788 .08290100098 87.1685485839886 .254188537685 .6446228027384 .7302627563583 .81591033936 83.206336975182 .5967712402381 .6824111938581 .0728530883880 .46327209473 79.5489196777378 .9393463134878 .0249862670977 .4154205322376 .50106811523 75.5867080688574 .9771423339874 .062782287673 .4532165527372 .53885650635 71.9292907714871 .014930725170 .4053573608469 .7957916259869 .18623352051 68.5766525268668 .2718734741267 .6623001098667 .3575134277367 .05272674561 67.0527267456167 .0527267456167 .3575134277367 .6623001098668 .27187347412 68.5766525268669 .1862335205169 .4910125732470 .1005783081171 .0149307251 72.2340774536174 .062782287676 .8058471679779 .5489196777379 .64441680908 78.7115402221777 .6304931640676 .6036224365275 .6675033569374 .80677032471 74.0073852539173 .2689056396572 .6084289550872 .0215454101671 .50392913818 71.049522399970 .6518936157270 .3029022216869 .9940795898469 .71592712402 69.4590606689581 .0728530883880 .4632720947380 .1584930419979 .85370635986 79.2441329956178 .9393463134878 .3297805786178 .0249862670977 .41542053223 77.110626220776 .5010681152376 .1962814331175 .5867080688575 .28192901611 74.9771423339874 .3675689697374 .062782287673 .4532165527373 .14842987061 72.5388565063572 .2340774536171 .9292907714871 .3197174072371 .0149307251 63.1342582702653 .71622467041 -9999 -9999 -9999 -9999 -9999 -9999 -9999 -9999 -9999 -9999 -9999 -9999 -9999 -9999 -9999 -9999 -9999 -9999 -9999 -9999 -9999 -9999 -9999 -9999 -9999 -9999 -9999 -9999 -9999 -9999 -9999 -9999 -9999 -9999 -9999 -9999 -9999 -9999 -9999 -9999 -9999 -9999 -9999 -9999 -9999 -9999 -9999 -9999 -9999 -9999 -9999 -9999 -9999 -9999 -9999 -9999 -9999 -9999 -9999 -9999 -9999 -9999 -9999 -9999 -9999 -9999 - -9999 -9999 -9999 -9999 -9999 -9999 -9999 -9999 -9999 -9999 -9999 -9999 -9999 -9999 -9999 -9999 -9999

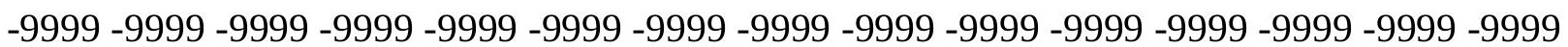
-9999 -9999 -9999 -9999 -9999 -9999 -9999 -9999 -9999 -9999 -9999 -9999 -9999 -9999 -9999 -9999 -9999 -9999 -9999 -9999 -9999 -9999 -9999 -9999 -9999 -9999 -9999 -9999 -9999 -9999 -9999 -9999 -9999 -9999 -9999 -9999 -9999 -9999 -9999 -9999 -9999 -9999 -9999 -9999 -9999

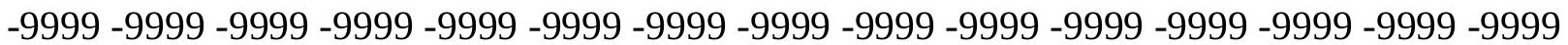


-9999 -9999 -9999 -9999 -9999 -9999 -9999 -9999 -9999 -9999 -9999 -9999 -9999 -9999 -9999 -9999 -9999 -9999 -9999 -9999 -9999 -9999 -9999 -9999 -9999 -9999 -9999 -9999 -9999 -9999 -9999 -9999 -9999 -9999 -9999 -9999 -9999 -9999 -9999 -9999 -9999 -9999 -9999 -9999 -9999 -9999 -9999 -9999 -9999 -9999 -9999 -9999 -9999 -9999 -9999 -9999 -9999 -9999 -9999 -9999 -9999 -9999 -9999 -9999 -9999 -9999 -9999 -9999 -9999 -9999 -9999 -9999 -9999 -9999 -9999 -9999 -9999 -9999 -9999 -9999 -9999 -9999 -9999 -9999 -9999 -9999 -9999 -9999 -9999 -9999 -9999 -9999 -9999 -9999 -9999 -9999 -9999 -9999 -9999 -9999 -9999 -9999 -9999 -9999 -9999 -9999 -9999 -9999 -9999 -9999-9999-9999 155.1089019775155 .7684631348154 .7236633301 151.6508331299146 .6019897461116 .1615447998115 .1436462402114 .1102828979 113.0618438721111 .9992294312110 .9235839844109 .8366241455108 .7403411865 99.7281646728599 .1575851440498 .5944671630998 .0387039184697 .49007415771 96.9484252929796 .4135208129995 .8852081298895 .3632888793994 .84771728516 94.338447570893 .8356323242293 .3394775390692 .8503646850692 .36865997314 91.8881454467890 .9303588867289 .9116134643688 .9972534179788 .08290100098 87.1685485839886 .254188537685 .3398437584 .7302627563583 .81591033936 83.206336975182 .5967712402381 .6824111938581 .0728530883880 .15849304199 79.5489196777378 .6345596313577 .7202072143677 .110626220776 .19628143311 75.2819290161174 .3675689697373 .7580032348672 .8436431884872 .23407745361 71.3197174072370 .7101516723670 .1005783081169 .4910125732468 .88143920898 68.2718734741267 .9670867919967 .3575134277367 .3575134277367 .05272674561 67.3575134277367 .6623001098667 .9670867919968 .2718734741268 .57665252686 68.8814392089869 .1862335205169 .7957916259870 .4053573608471 .0149307251 71.9292907714877 .110626220779 .5489196777380 .4632720947379 .65618133545 78.265342712477 .1128234863376 .1273422241275 .247627258374 .437573 .68743896484 73.0061264038172 .408767700271 .8842849731471 .4254302978571 .02494049072 70.6740875244170 .3639221191470 .0846405029369 .8265991210981 .37763214111 81.0728530883880 .7680587768680 .1584930419979 .8537063598679 .24413299561 78.9393463134878 .6345596313578 .0249862670977 .7202072143677 .1106262207 76.8058471679776 .1962814331175 .8914871215875 .2819290161174 .97714233398 74.3675689697374 .062782287673 .4532165527373 .1484298706172 .53885650635 72.2340774536171 .8895568847771 .3197174072362 .6720809936552 .2928352356 -9999 -9999 -9999 -9999 -9999 -9999 -9999 -9999 -9999 -9999 -9999 -9999 -9999 -9999 -9999 -9999 -9999 -9999 -9999 -9999 -9999 -9999 -9999

-9999 -9999 -9999 -9999 -9999 -9999 -9999 -9999 -9999 -9999 -9999 -9999 -9999 -9999 -9999 -9999 -9999 -9999 -9999 -9999 -9999 -9999 -9999 -9999 -9999 -9999 -9999 -9999 -9999 -9999 -9999 -9999 -9999 -9999 -9999 -9999 -9999 -9999 -9999 -9999 -9999 -9999 -9999 -9999 -9999

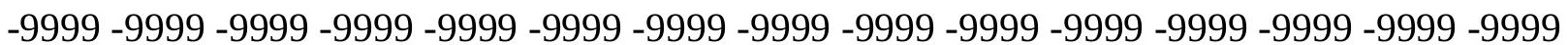

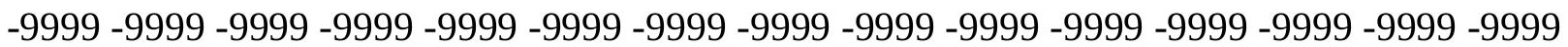
-9999 -9999 -9999 -9999 -9999 -9999 -9999 -9999 -9999 -9999 -9999 -9999 -9999 -9999 -9999 -9999 -9999 -9999 -9999 -9999 -9999 -9999 -9999 -9999 -9999 -9999 -9999 -9999 - -9999 -9999 -9999 -9999 -9999 -9999 -9999 -9999 -9999 -9999 -9999 -9999 -9999 -9999 -9999 -9999 -9999

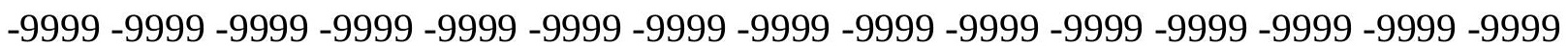
-9999 -9999 -9999 -9999 -9999 -9999 -9999 -9999 -9999 -9999 -9999 -9999 -9999 -9999 -9999 -9999 -9999 -9999 -9999 -9999 -9999 -9999 -9999 -9999 -9999 -9999 -9999 -9999 -9999 -9999 -9999 -9999 -9999 -9999 -9999 -9999 -9999 -9999 -9999 -9999 -9999 -9999 -9999 -9999 -9999

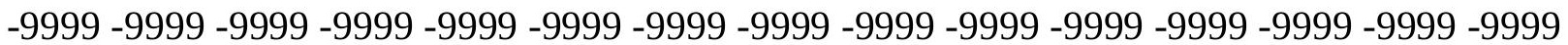


-9999 -9999 -9999 -9999 -9999 -9999 -9999 -9999 -9999 -9999 -9999 -9999 -9999 -9999 -9999 -9999 -9999 -9999 -9999 -9999 -9999 -9999 -9999 -9999 -9999 -9999 -9999 -9999 -9999 -9999 -9999 -9999 -9999 -9999 -9999 -9999 -9999 -9999 -9999 -9999 -9999 -9999 -9999 -9999 -9999 -9999 -9999 -9999 -9999 -9999 -9999 -9999 160.0819396973 162.0764312744162 .0901641846 159.7197723389154 .9324493408148 .4059906006115 .4284591675114 .4028320312 113.3641357422112 .3133239746111 .2515716553110 .1805648804109 .1022186279 100.03511810399 .460792541598 .8939361572398 .3344650268697 .78218078613 97.2369613647596 .6986083984496 .1669845581195 .6419143676895 .12337493896 94.6113510131894 .1060104370193 .607559204193 .1164093017692 .6329574585 92.1577072143691 .6862945556690 .7928924560589 .9116134643688 .69246673584 87.7781066894586 .8637619018686 .254188537685 .3398437584 .73026275635 83.8159103393683 .206336975182 .2919769287181 .6824111938580 .76805877686 80.1584930419979 .2441329956178 .3297805786177 .4154205322376 .50106811523 75.8914871215874 .9771423339874 .062782287673 .1484298706172 .53885650635 71.6244964599671 .014930725170 .1005783081169 .4910125732468 .88143920898 68.5766525268667 .9670867919967 .6623001098667 .3575134277367 .05272674561 67.3575134277367 .6623001098668 .2718734741268 .5766525268668 .88143920898 68.8814392089869 .1862335205169 .4910125732470 .1005783081171 .31971740723 74.062782287678 .9393463134879 .2441329956179 .5489196777379 .85370635986 78.4447326660277 .3224945068476 .4004669189575 .5770187377974 .80425262451 74.0729751586973 .3943786621172 .7983779907272 .2763290405371 .8191986084 71.4199829101671 .0697402954170 .7593994140670 .479072570870 .21913146973 81.6824111938581 .3776321411181 .0728530883880 .7680587768680 .15849304199 79.8537063598679 .2441329956178 .9393463134878 .6345596313578 .02498626709 77.7202072143677 .110626220776 .8058471679776 .1962814331175 .89148712158 75.2819290161174 .9771423339874 .3675689697374 .062782287673 .45321655273 73.1484298706172 .5388565063572 .2340774536167 .8358078002960 .98064804077 51.3484916687 -9999 -9999 -9999 -9999 -9999 -9999 -9999 -9999 -9999 -9999 -9999 -9999 -9999 -9999 -9999 -9999 -9999 -9999 -9999 -9999 -9999 -9999 -9999 -9999 -9999 -9999 -9999 -9999 -9999 -9999 -9999 -9999 -9999 -9999 -9999 -9999 -9999 -9999 -9999 -9999 -9999 -9999 -9999 -9999 -9999 -9999 -9999 -9999 -9999 -9999 -9999 -9999 -9999 -9999 -9999 -9999 -9999 -9999 -9999 -9999 -9999 -9999 -9999 -9999 -9999 -9999 -9999 -9999 -9999 -9999 -9999 -9999 -9999 -9999 -9999 -9999 -9999 -9999 -9999 -9999 -9999 -9999 -9999 -9999 -9999 -9999 -9999 -9999 -9999 -9999 -9999 -9999 -9999 -9999 -9999 -9999 -9999 -9999 -9999 -9999 -9999 -9999 -9999 -9999 -9999 -9999 -9999 -9999 -9999 -9999 -9999 -9999 -9999 -9999 -9999 -9999 -9999 -9999 -9999 -9999 -9999 -9999 -9999 -9999 -9999 -9999 -9999 -9999 -9999 -9999 -9999 -9999 -9999 -9999 -9999 -9999 -9999 -9999 -9999 -9999 -9999 -9999 -9999

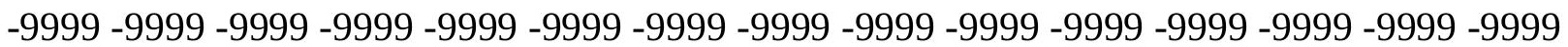
-9999 -9999 -9999 -9999 -9999 -9999 -9999 -9999 -9999 -9999 -9999 -9999 -9999 -9999 -9999 -9999 -9999 -9999 -9999 -9999 -9999 -9999 -9999 -9999 -9999 -9999 -9999 -9999 -9999 -9999 -9999 -9999 -9999 -9999 -9999 -9999 -9999 -9999 -9999 -9999 -9999 -9999 -9999 -9999 -9999

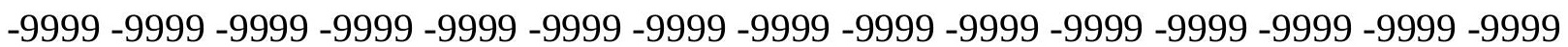
-9999 -9999 -9999 -9999 -9999 -9999 -9999 -9999 -9999 -9999 -9999 -9999 -9999 -9999 -9999 -9999 -9999 -9999 -9999 -9999 -9999 -9999 -9999 -9999 -9999 -9999 -9999 -9999 -9999 -9999 -9999 -9999 -9999 -9999 -9999 -9999 -9999 -9999 -9999 -9999 -9999 -9999 -9999 -9999 -9999 -9999 -9999 -9999 -9999 -9999 -9999 -9999 -9999 168.5462036133170 .1190795898 
168.6111755371164 .356048584157 .9457092285115 .7055053711114 .6874313354 113.6581878662112 .6187896729111 .5704421997110 .5147705078109 .45362854 108.38917541599 .7573165893699 .1867904663198 .6236877441498 .06785583496 97.5191879272596 .9775085449296 .4427108764695 .9146499633895 .39331817627 94.8787231445394 .3710556030393 .870529174893 .3775711059692 .89258575439 92.4161148071391 .9486007690491 .4905242919990 .5878982543989 .60682678223 88.6924667358487 .7781066894586 .8637619018685 .9494018554785 .33984375 84.7302627563583 .8159103393683 .206336975182 .2919769287181 .37763214111 80.7680587768679 .8537063598678 .9393463134878 .0249862670977 .1106262207 76.1962814331175 .2819290161174 .3675689697373 .4532165527372 .53885650635 71.9292907714871 .014930725170 .4053573608469 .7957916259869 .18623352051 68.5766525268667 .9670867919967 .6623001098667 .0527267456166 .74794006348 66.7479400634867 .6623001098668 .5766525268668 .8814392089868 .88143920898 68.5766525268668 .8814392089869 .1862335205169 .7957916259871 .31971740723 73.7580032348676 .5010681152378 .0249862670978 .6345596313578 .93934631348 78.1353988647577 .251251220776 .5078506469775 .804962158275 .1097869873 74.4273376464873 .7781524658273 .1905822753972 .6794738769572 .23084259033 71.8374099731471 .4905014038171 .181228637770 .8999862670970 .63737487793 81.9871978759881 .6824111938581 .3776321411181 .0728530883880 .46327209473 80.1584930419979 .8537063598679 .2441329956178 .9393463134878 .63455963135 78.0249862670977 .7202072143677 .110626220776 .8058471679776 .19628143311 75.8914871215875 .2819290161174 .9771423339874 .3675689697374 .0627822876 73.4532165527373 .1293106079172 .5388565063566 .6651535034259 .65293121338 -9999 -9999 -9999 -9999 -9999 -9999 -9999 -9999 -9999 -9999 -9999 -9999 -9999 -9999 -9999 -9999 -9999 -9999 -9999 -9999 -9999 -9999 -9999 -9999

-9999 -9999 -9999 -9999 -9999 -9999 -9999 -9999 -9999 -9999 -9999 -9999 -9999 -9999 -9999 -9999 -9999 -9999 -9999 -9999 -9999 -9999 -9999 -9999 -9999 -9999 -9999 -9999 -9999 -9999

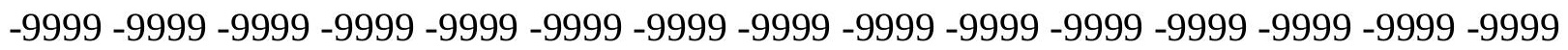
-9999 -9999 -9999 -9999 -9999 -9999 -9999 -9999 -9999 -9999 -9999 -9999 -9999 -9999 -9999 -9999 -9999 -9999 -9999 -9999 -9999 -9999 -9999 -9999 -9999 -9999 -9999 -9999 -9999 -9999 -9999 -9999 -9999 -9999 -9999 -9999 -9999 -9999 -9999 -9999 -9999 -9999 -9999 -9999 -9999 -9999 -9999 -9999 -9999 -9999 -9999 -9999 -9999 -9999 -9999 -9999 -9999 -9999 -9999 -9999 -

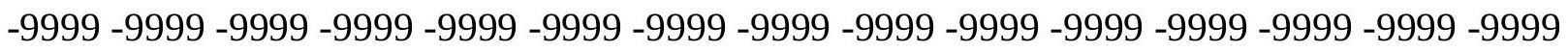
-9999 -9999 -9999 -9999 -9999 -9999 -9999 -9999 -9999 -9999 -9999 -9999 -9999 -9999 -9999 -9999 -9999 -9999 -9999 -9999 -9999 -9999 -9999 -9999 -9999 -9999 -9999 -9999 -9999 -9999 -

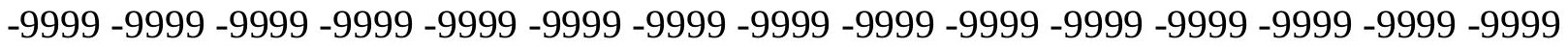

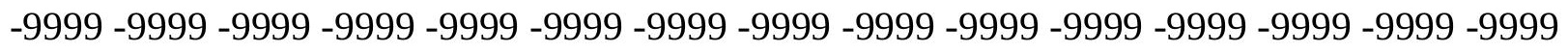

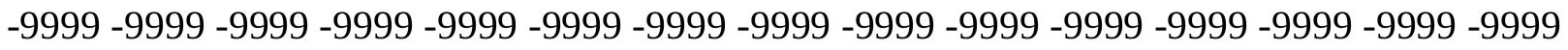
-9999 -9999 -9999 -9999 -9999 -9999 -9999 -9999 -9999 -9999 -9999 -9999 -9999 -9999 -9999 -9999 -9999 -9999 -9999 -9999 -9999 -9999 -9999 -9999 -9999 -9999 -9999 -9999 -9999 -9999 -

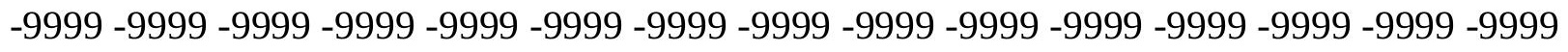
-9999 -9999 -9999 -9999-9999 -9999 -9999 -9999 173.1179962158177 .6896972656 176.9472808838173 .5291900635167 .8516845703160 .0118255615114 .9647064209 113.944519043112 .9159927368111 .8803482056110 .8391647339109 .7942199707 108.7475509644100 .047142028899 .4729995727598 .9063568115298 .34706115723 97.7950515747197 .2501678466896 .712333679296 .1814346313595 .65749359131 
95.1405181884894 .630714416594 .1283264160293 .6337814331193 .14749145508 92.6700210571392 .2018203735491 .7434005737391 .2931594848690 .33577728271 89.3020401001 88.38768768311 87.47332763672 86.86376190186 85.94940185547 85.3398437584 .4254837036183 .8159103393682 .9015579223681 .98719787598 81.3776321411180 .4632720947379 .2441329956178 .3297805786177 .41542053223 76.5010681152375 .5867080688574 .6723632812573 .7580032348672 .84364318848 72.2340774536171 .3197174072370 .7101516723670 .1005783081169 .49101257324 68.8814392089868 .2718734741267 .6623001098667 .0527267456166 .44316101074 66.1383666992266 .7479400634868 .5766525268668 .5766525268668 .27187347412 68.2718734741268 .2718734741268 .5766525268669 .4910125732470 .71015167236 72.2340774536174 .062782287676 .1962814331177 .7202072143678 .29727172852 77.5907058715877 .0581130981476 .5352859497175 .9741516113375 .37301635742 74.7538528442474 .148582458573 .5866241455173 .0948181152372 .66115570068 72.2778472900471 .9367752075271 .6296691894571 .3474731445371 .08134460449 82.2919769287181 .9871978759881 .6824111938581 .3776321411180 .76805877686 80.4632720947380 .1584930419979 .8537063598679 .2441329956178 .93934631348 78.3297805786178 .0249862670977 .4154205322377 .110626220776 .50106811523 76.1962814331175 .5867080688575 .2819290161174 .6723632812574 .36756896973 73.7580032348673 .4532165527372 .8436431884866 .9057159423859 .22159576416 -9999 -9999 -9999 -9999 -9999 -9999 -9999 -9999 -9999 -9999 -9999 -9999 -9999 -9999 -9999 -9999 -9999 -9999-9999-9999-9999 -9999-9999-9999

-9999 -9999 -9999 -9999 -9999 -9999 -9999 -9999 -9999 -9999 -9999 -9999 -9999 -9999 -9999 -9999 -9999 -9999 -9999 -9999 -9999 -9999 -9999 -9999 -9999 -9999 -9999 -9999 -9999 -9999 -

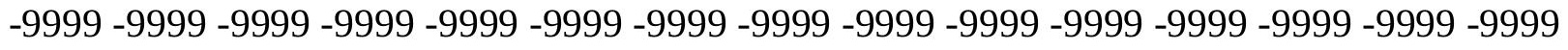

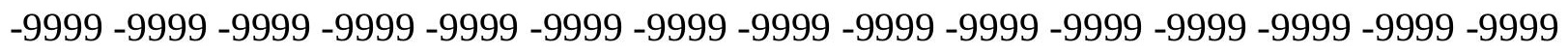
-9999 -9999 -9999 -9999 -9999 -9999 -9999 -9999 -9999 -9999 -9999 -9999 -9999 -9999 -9999 -9999 -9999 -9999 -9999 -9999 -9999 -9999 -9999 -9999 -9999 -9999 -9999 -9999 -9999 - -9999 -

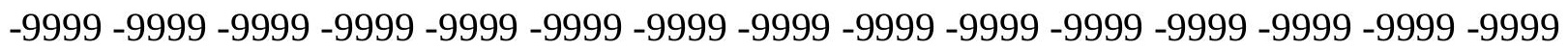
-9999 -9999 -9999 -9999 -9999 -9999 -9999 -9999 -9999 -9999 -9999 -9999 -9999 -9999 -9999 -9999 -9999 -9999 -9999 -9999 -9999 -9999 -9999 -9999 -9999 -9999 -9999 -9999 -9999 -9999 -9999 -9999 -9999 -9999 -9999 -9999 -9999 -9999 -9999 -9999 -9999 -9999-9999 -9999 -9999 -9999 -9999 -9999 -9999 -9999 -9999 -9999 -9999 -9999 -9999 -9999 -9999 -9999 -9999 -9999 -

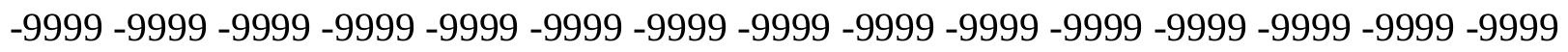
-9999 -9999 -9999 -9999 -9999 -9999 -9999 -9999 -9999 -9999 -9999 -9999 -9999 -9999 -9999 -9999 -9999 -9999 -9999 -9999 -9999 -9999 -9999 -9999 -9999 -9999 -9999 -9999 -9999 -9999 -

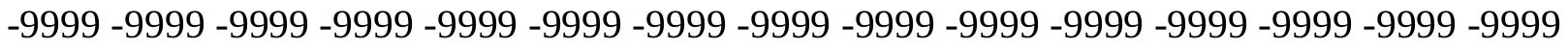

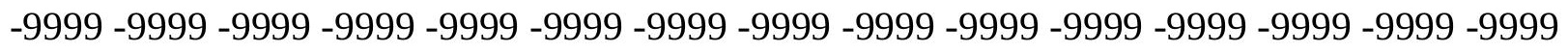
-9999 -9999-9999 -9999-9999-9999-9999-9999-9999 180.1280059814 183.1759033203 180.9551391602176 .8438415527170 .7147521973115 .2350769043114 .2234191895 113.205078125112 .1812667847111 .1535186768110 .1235198975109 .093170166 108.0644836426 99.7525253295999.18240356445 98.6197433471798.06449127197 97.5165252685596 .9757919311596 .4422073364395 .9158096313595 .39663696289 94.884902954194 .38085937593 .8849411010793 .3975677490292 .91931152344 92.4506301879991 .9920654296991 .5439224243291 .045623779390 .12043762207 89.302040100188 .3876876831187 .4733276367286 .8637619018685 .94940185547 85.33984375 84.42548370361 83.51112365723 82.9015579223681.98719787598 
80.7680587768679 .8537063598678 .9393463134878 .0249862670976 .80584716797 75.8914871215874 .9771423339874 .062782287673 .1484298706172 .53885650635 71.6244964599671 .014930725170 .1005783081169 .7957916259869 .18623352051 68.2718734741267 .6623001098666 .7479400634866 .1383666992265 .22400665283 64.6144485473666 .4431610107467 .6623001098667 .9670867919967 .96708679199 67.9670867919968 .2718734741268 .8814392089869 .7957916259871 .0149307251 71.9292907714874 .9771423339877 .4154205322377 .4653472900477 .25179290771 76.9581909179776 .5890579223676 .1391525268675 .6220779418975 .06884002686 74.512832641673 .9872741699273 .5250091552773 .1120071411172 .74250030518 72.409317016672 .1050415039171 .8215789794982 .2275466918982 .59677124023 82.2919769287181 .9871978759881 .6824111938581 .0728530883880 .76805877686 80.4632720947380 .1584930419979 .5489196777379 .2441329956178 .63455963135 78.3297805786178 .0249862670977 .4154205322377 .110626220776 .50106811523 75.8914871215875 .5867080688574 .9771423339874 .6095733642674 .0627822876 73.7580032348671 .5794601440466 .4703903198259 .13745117188 -9999 -9999 -9999 -9999 -9999 -9999 -9999 -9999 -9999 -9999 -9999 -9999 -9999 -9999 -9999 -9999 -9999 -9999 -9999 -9999 -9999-9999-9999-9999

-9999 -9999 -9999 -9999 -9999 -9999 -9999 -9999 -9999 -9999 -9999 -9999 -9999 -9999 -9999 -9999 -9999 -9999 -9999 -9999 -9999 -9999 -9999 -9999 -9999 -9999 -9999 -9999 -9999 -9999 -

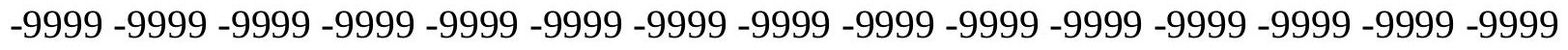

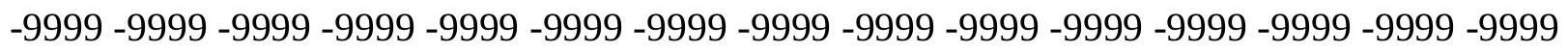

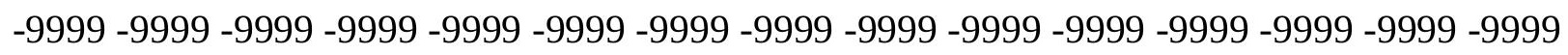
-9999 -9999 -9999 -9999 -9999 -9999 -9999 -9999 -9999 -9999 -9999 -9999 -9999 -9999 -9999 -

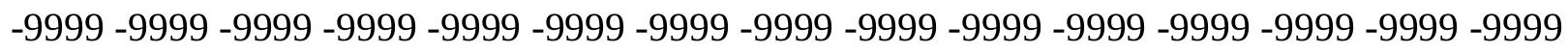

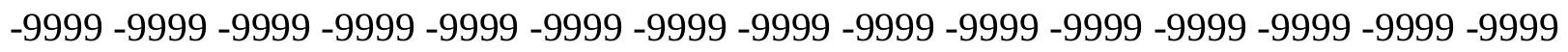
-9999 -9999 -9999 -9999 -9999 -9999 -9999 -9999 -9999 -9999 -9999 -9999 -9999 -9999 -9999 -9999 -9999 -9999 -9999 -9999 -9999 -9999 -9999 -9999 -9999 -9999 -9999 -9999 -9999 - -9999 -

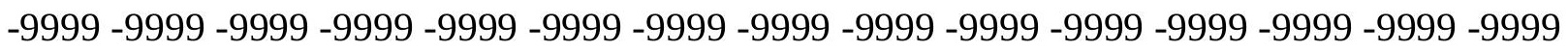

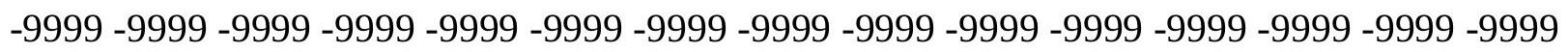

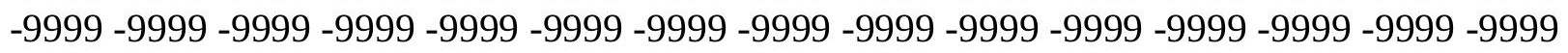
-9999 -9999 -9999 -9999 -9999 -9999 -9999 -9999 -9999 -9999 -9999 -9999 -9999 -9999 -9999

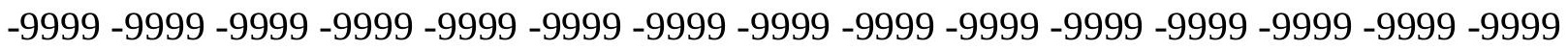

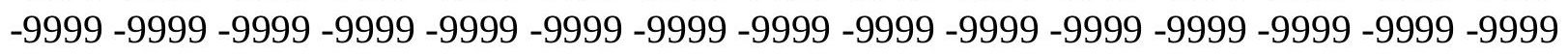
-9999 -9999-9999 -9999-9999-9999-9999-9999-9999 181.3471984863 184.5909729004 185.2991790771183 .5887908936179 .6928405762172 .8132019043114 .4952011108 113.4862594604112 .4733123779111 .4578170776110 .441368103109 .4257125854 108.4127044678100 .02542877299 .4518966674898 .8859481811598 .3275604248 97.7766265869197 .233123779396 .6969985961996 .1683044433695 .64710998535 95.1336288452194 .6281204223694 .1310272216893 .6427764892693 .16393280029 92.6949691772592 .2364273071391 .788650512791 .3520202636790 .82597351074 89.91161346436 88.99725341797 88.38768768311 87.47332763672 86.86376190186 85.9494018554785 .3398437584 .4254837036183 .5111236572382 .59677124023 81.3776321411180 .4632720947379 .2441329956178 .3297805786177 .41542053223 76.5010681152375 .2819290161174 .3675689697373 .4532165527372 .53885650635 71.9292907714871 .014930725170 .4053573608469 .7957916259869 .18623352051 68.5766525268667 .9670867919967 .0527267456166 .1383666992265 .22400665283 
65.2240066528365 .8335876464866 .7479400634867 .0527267456167 .35751342773 67.6623001098667 .9670867919968 .2718734741269 .1862335205170 .40535736084 72.2340774536174 .6723632812577 .7202072143677 .6812973022577 .34936523438 77.0684585571376 .7408218383876 .3426742553775 .8816680908275 .38304901123 74.8803939819374 .4021530151473 .9735641479573 .5855407714873 .23249816895 72.9084167480572 .6070480346772 .3215179443482 .3072967529382 .59677124023 82.2919769287181 .9871978759881 .6824111938581 .3776321411181 .07285308838 80.7680587768680 .4632720947379 .8537063598679 .5489196777379 .24413299561 78.6345596313578 .3297805786177 .7202072143677 .4154205322376 .80584716797 76.5010681152375 .8914871215875 .2819290161174 .9367752075274 .36756896973 74.062782287671 .0790328979565 .9310302734459 .04733276367 -9999 -9999 -9999 -9999 -9999 -9999 -9999 -9999 -9999 -9999 -9999 -9999 -9999 -9999 -9999 -9999 -9999 -9999 -9999 -9999 -9999-9999-9999-9999

-9999 -9999 -9999 -9999 -9999 -9999 -9999 -9999 -9999 -9999 -9999 -9999 -9999 -9999 -9999 -9999 -9999 -9999 -9999 -9999 -9999 -9999 -9999 -9999 -9999 -9999 -9999 -9999 -9999 -9999 -

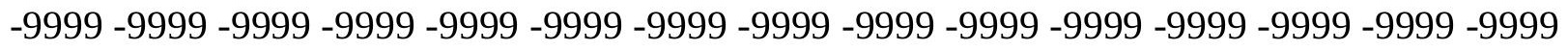
-9999 -9999 -9999 -9999 -9999 -9999 -9999 -9999 -9999 -9999 -9999 -9999 -9999 -9999 -9999 -9999 -9999 -9999 -9999 -9999 -9999 -9999 -9999 -9999 -9999 -9999 -9999 -9999 -9999 -9999 -

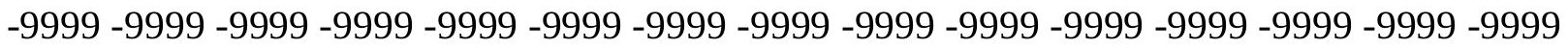

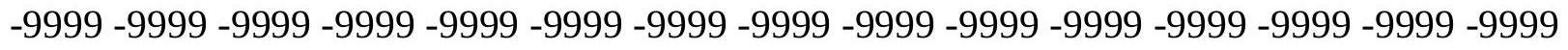

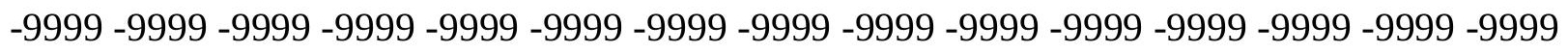

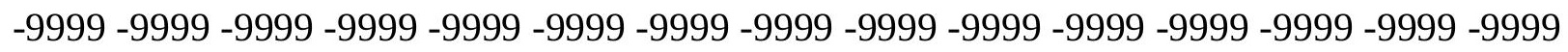
-9999 -9999 -9999 -9999 -9999 -9999 -9999 -9999 -9999 -9999 -9999 -9999 -9999 -9999 -9999 -

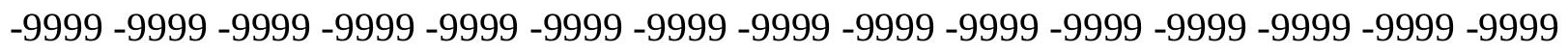

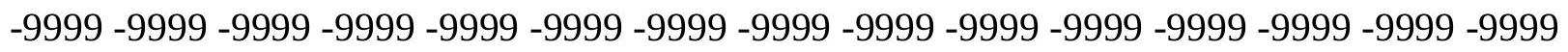
-9999 -9999 -9999 -9999 -9999 -9999 -9999 -9999 -9999 -9999 -9999 -9999 -9999 -9999 -9999 -9999 -9999 -9999 -9999 -9999 -9999 -9999 -9999 -9999 -9999 -9999 -9999 -9999 -9999 - -9999 -

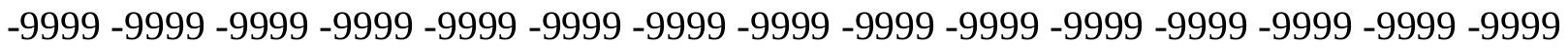

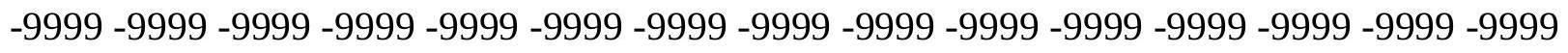
-9999 -9999 -9999 -9999-9999 -9999 -9999 -9999 -9999 -9999 185.0992584229 187.1518707275187 .0618286133184 .2824707031177 .0802001953161 .2312927246 113.7596740723112 .7565231323111 .7520065308110 .7476196289109 .7449493408 108.7456893921107 .751518249599 .7148513793999 .1456832885798 .58425140381 98.0304565429797.4843139648496.94577789307 96.4149398803795.8918762207 95.37682342529 94.8700332641694.3719635009893.88302612305 93.40377807617 92.934707641692 .4763488769592 .0290832519591 .5933151245191 .16926574707 90.6724700927789 .822120666588 .9972534179788 .3876876831187 .47332763672 86.86376190186 85.94940185547 85.03504943848 84.12069702148 83.2063369751 81.9871978759881 .0728530883879 .8537063598678 .6345596313577 .72020721436 76.8058471679775 .5867080688574 .6723632812573 .7580032348672 .84364318848 72.2340774536171 .3197174072370 .7101516723670 .1005783081169 .49101257324 68.8814392089868 .2718734741267 .3575134277366 .7479400634866 .13836669922 65.8335876464866 .1383666992266 .4431610107466 .7479400634867 .05272674561 67.3575134277367 .6623001098667 .9670867919968 .8814392089870 .40535736084 72.5388565063574 .9771423339878 .3297805786178 .4737091064577 .8159866333 77.3764114379976 .9948043823276 .5984268188576 .1685638427775 .71501159668 
75.2595901489374 .8336486816474 .4446258544974 .084396362373 .74921417236 73.4344482421973 .1352539062572 .846260070882 .3828964233482 .90155792236 82.5967712402382 .2919769287181 .9871978759881 .6824111938581 .37763214111 81.0728530883880 .4632720947380 .1584930419979 .8537063598679 .24413299561 78.9393463134878 .6345596313578 .0249862670977 .7202072143677 .1106262207 76.5010681152376 .1962814331175 .5867080688575 .2819290161174 .67236328125 74.3675689697370 .7682418823265 .52053070068 -9999 -9999 -9999 -9999 -9999 -9999 -9999 -9999 -9999 -9999 -9999 -9999 -9999 -9999 -9999 -9999 -9999 -9999 -9999 -9999 -9999 -9999 -9999-9999-9999

-9999 -9999 -9999 -9999 -9999 -9999 -9999 -9999 -9999 -9999 -9999 -9999 -9999 -9999 -9999

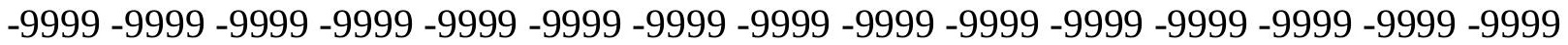
-9999 -9999 -9999 -9999 -9999 -9999 -9999 -9999 -9999 -9999 -9999 -9999 -9999 -9999 -9999 -9999 -9999 -9999 -9999 -9999 -9999 -9999 -9999 -9999 -9999 -9999 -9999 -9999 -9999 -9999 -9999 -9999 -9999 -9999 -9999 -9999 -9999 -9999 -9999 -9999 -9999 -9999 -9999 -9999 -9999 -9999 -9999 -9999 -9999 -9999 -9999 -9999 -9999 -9999 -9999 -9999 -9999 -9999 -9999 -9999

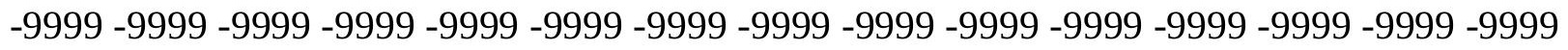
-9999 -9999 -9999 -9999 -9999 -9999 -9999 -9999 -9999 -9999 -9999 -9999 -9999 -9999 -9999 -9999 -9999 -9999 -9999 -9999 -9999 -9999 -9999 -9999 -9999 -9999 -9999 -9999 -9999 -9999 -

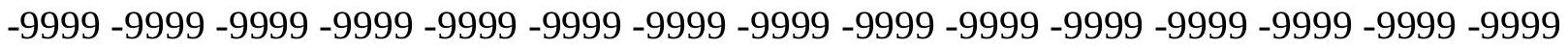

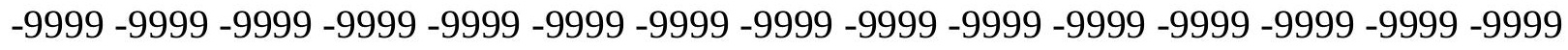

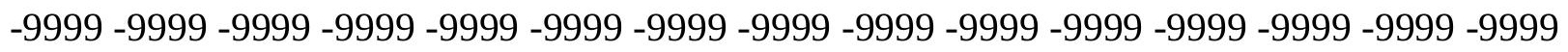

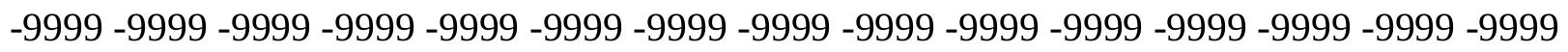
-9999 -9999 -9999 -9999 -9999 -9999 -9999 -9999 -9999 -9999 -9999 -9999 -9999 -9999 -9999 -

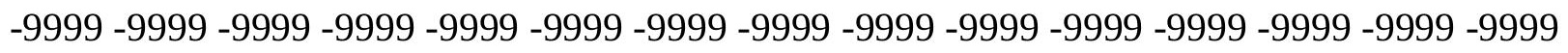

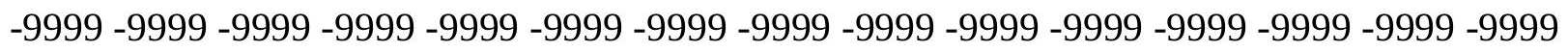
-9999 -9999 -9999 -9999 -9999 -9999 -9999 -9999 -9999 -9999 185.0258026123 187.2369995117 187.3648071289 184.4278259277 176.7754058838161.5361022949 114.0255355835113 .0310668945112 .0362167358111 .0423660278110 .0509643555 109.0635223389 108.0815277199.97133636475 99.3990325927798.83463287354 98.2780761718897 .7294006347797 .1885833740296 .6557388305796 .13095855713 95.6144866943495 .10659027194 .607704162694 .1182403564593 .63876342773 93.1697387695392 .7117156982492 .2650833129991 .8302764892691 .40756225586 90.9973144531290 .5211791992289 .9116134643688 .9972534179788 .38768768311 87.4733276367286 .5589828491285 .6446228027384 .7302627563583 .81591033936 82.5967712402381 .3776321411180 .1584930419979 .2441329956178 .02498626709 77.110626220775 .8914871215874 .9771423339874 .062782287673 .14842987061 72.2340774536171 .6244964599671 .014930725170 .4053573608469 .79579162598 69.1862335205168 .5766525268667 .9670867919967 .3575134277366 .74794006348 66.4431610107466 .4431610107466 .4431610107466 .7479400634866 .74794006348 67.0527267456167 .3575134277367 .9670867919968 .8814392089870 .40535736084 72.2340774536174 .9771423339878 .3297805786179 .0725555419978 .29740142822 77.7486877441477 .3060531616276 .8973922729576 .4892501831176 .07692718506 75.6633834838975 .2877578735474 .9417724609474 .6105117797974 .29326629639 73.9869613647573 .6883697509873 .3938827514682 .4162063598682 .90155792236 82.5967712402382 .2919769287181 .9871978759881 .6824111938581 .37763214111 81.0728530883880 .7680587768680 .4632720947380 .1584930419979 .54891967773 
79.2441329956178 .6345596313578 .3297805786177 .7202072143677 .41542053223 76.8058471679776 .415176391675 .8914871215875 .5867080688574 .97714233398 73.5474548339870 .2144775390665 .19886016846 -9999 -9999 -9999 -9999 -9999 -9999 -9999 -9999 -9999 -9999 -9999 -9999 -9999 -9999 -9999 -9999 -9999 -9999 -9999 -9999 -9999 -9999 -9999 -9999-9999

-9999 -9999 -9999 -9999 -9999 -9999 -9999 -9999 -9999 -9999 -9999 -9999 -9999 -9999 -9999 -9999 -9999 -9999 -9999 -9999 -9999 -9999 -9999 -9999 -9999 -9999 -9999 -9999 -9999 -9999

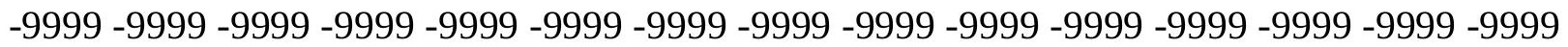
-9999 -9999 -9999 -9999 -9999 -9999 -9999 -9999 -9999 -9999 -9999 -9999 -9999 -9999 -9999 -9999 -9999 -9999 -9999 -9999 -9999 -9999 -9999 -9999 -9999 -9999 -9999 -9999 -9999 -9999 -9999 -9999 -9999 -9999 -9999 -9999 -9999 -9999 -9999 -9999 -9999 -9999 -9999 -9999 -9999 -999 -9999 -9999 -9999 -9999 -9999 -9999 -9999 -9999 -9999 -9999 -9999 -9999 -9999 -9999 -9999 -999 -9999 -9999 -9999 -9999 -9999 -9999 -9999 -9999 -9999 -9999 -9999 -9999 -9999 -9999 -9999 -9999 -9999 -9999 -9999 -9999 -9999 -9999 -9999 -9999 -9999 -9999 -9999 -9999 -9999 -9999 -9999 -9999 -9999 -9999 -9999 -9999 -9999 -9999 -9999 -9999 -9999 -9999 -9999 -9999 -9999

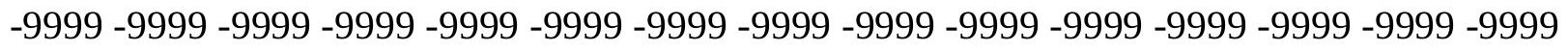
-9999 -9999 -9999 -9999 -9999 -9999 -9999 -9999 -9999 -9999 -9999 -9999 -9999 -9999 -9999 -

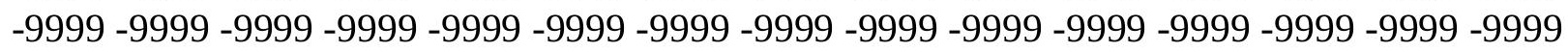
-9999 -9999 -9999 -9999 -9999 -9999 -9999 -9999 -9999 -9999 -9999 -9999 -9999 -9999 -9999

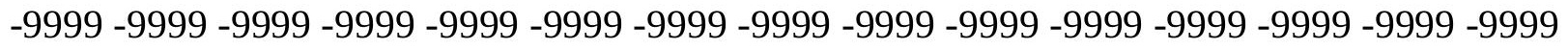

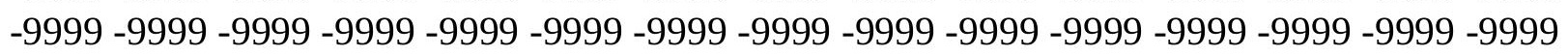
-9999 -9999 -9999 -9999 -9999 -9999-9999 -9999-9999-9999-9999 186.1834106445 185.4728393555181 .5300445557173 .1179962158158 .1835021973143 .5538024902 113.2970504761112 .3105163574111 .325668335110 .3438034058109 .3662719727 108.3944015503 107.429519653399.6459884643699.0787048339898.51947784424 97.9683685302797 .4253845214896 .8906707763796 .3643035888795 .84655761719 95.3376922607494 .8381423950294 .3483047485493 .8687362670993 .39989471436 92.9423294067492 .4964370727592 .0626754760791 .6413497924891 .23287963867 90.8375015258890 .4321060180789 .6068267822388 .9972534179788 .38768768311 87.4733276367286 .5589828491285 .3398437584 .4254837036183 .2063369751 81.9871978759880 .7680587768679 .5489196777378 .3297805786177 .1106262207 76.1962814331175 .2819290161174 .062782287673 .4532165527372 .53885650635 71.6244964599671 .014930725170 .4053573608470 .1005783081169 .49101257324 68.8814392089868 .2718734741267 .9670867919967 .3575134277367 .05272674561 67.0527267456166 .7479400634866 .7479400634866 .7479400634867 .05272674561 67.3575134277367 .9670867919968 .5766525268670 .1005783081171 .92929077148 74.3675689697377 .4154205322379 .2222061157278 .6105117797978 .06211090088 77.6140213012777 .2225570678776 .8486862182676 .4808273315476 .11578369141 75.7837905883875 .4681549072375 .165458679274 .8648757934674 .5651550293 74.2648620605573 .9623489379982 .4163436889682 .9015579223682 .59677124023 82.5967712402382 .2578887939581 .9871978759881 .6824111938581 .37763214111 81.0728530883880 .7680587768680 .1584930419979 .8537063598679 .54891967773 78.9393463134878 .6345596313578 .0249862670977 .7202072143677 .1106262207 76.5010681152376 .1962814331175 .5867080688575 .2819290161173 .16696929932 69.67704772949 64.8989944458 -9999 -9999 -9999 -9999 -9999 -9999 -9999 -9999 -9999 -9999 -9999 -9999 -9999 -9999 -9999 -9999 -9999 -9999 -9999 -9999 -9999 -9999 -9999 -9999 
$-9999$

-9999 -9999 -9999 -9999 -9999 -9999 -9999 -9999 -9999 -9999 -9999 -9999 -9999 -9999 -9999 -9999 -9999 -9999 -9999 -9999 -9999 -9999 -9999 -9999 -9999 -9999 -9999 -9999 -9999 - 9999 -9999 -9999 -9999 -9999 -9999 -9999 -9999 -9999 -9999 -9999 -9999 -9999 -9999 -9999 -9999 -9999 -9999 -9999 -9999 -9999 -9999 -9999 -9999 -9999 -9999 -9999 -9999-9999 -9999 -9999 -

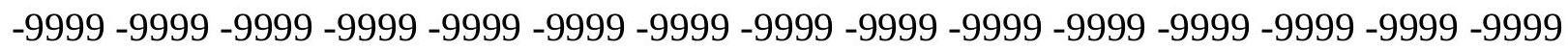

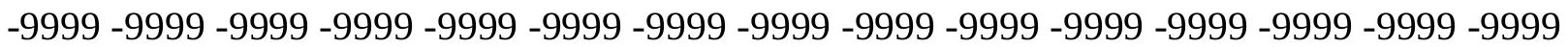
-9999 -9999 -9999 -9999 -9999 -9999 -9999 -9999 -9999 -9999 -9999 -9999 -9999 -9999 -9999 -9999 -9999 -9999 -9999 -9999 -9999 -9999 -9999 -9999 -9999 -9999 -9999 -9999 -9999 -9999 -9999 -9999 -9999 -9999 -9999 -9999 -9999 -9999 -9999 -9999 -9999 -9999 -9999 -9999 -9999 -

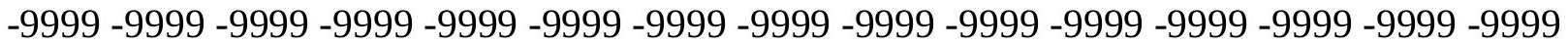

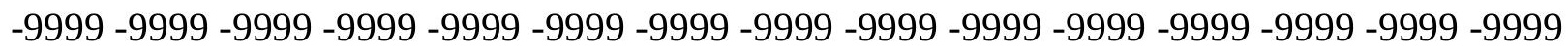

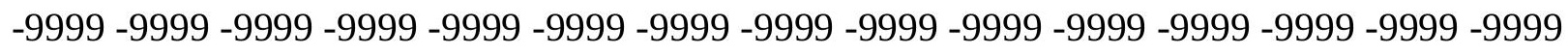
-9999 -9999 -9999 -9999 -9999 -9999 -9999 -9999 -9999 -9999 -9999 -9999 -9999 -9999 -9999 -9999 -9999 -9999 -9999 -9999 -9999 -9999 -9999 -9999 -9999 -9999 -9999 -9999 -9999 -9999

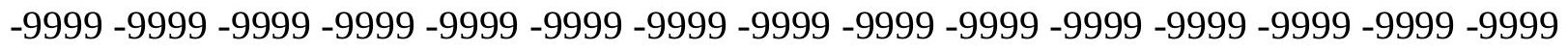

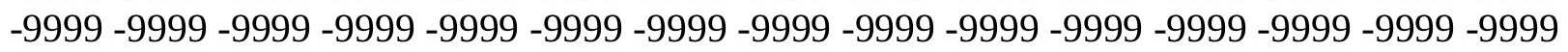
-9999 -9999 -9999 -9999 -9999 -9999 -9999 -9999 -9999 -9999 -9999 184.6661224365 182.5411376953177 .1428070068167 .9365997314154 .2212982178141 .7250976562 113.5547561646112 .5751953125111 .5978240967110 .6238098145109 .6543655396 108.6906433105 107.733818054299.88665008545 99.316551208598.75473022461 98.2012939453197 .6562597 .1197586059696 .591934204196 .0730361938595 .56332397461 95.0632324218894 .5731430053794 .0935974121193 .6250457763793 .16803741455 92.7229614257892 .290313720791 .8704071044991 .4637069702191 .07050323486 90.691123962490 .1969070434689 .6068267822388 .9972534179788 .08290100098 87.16854858398 85.9494018554784.73026275635 83.51112365723 82.29197692871 81.0728530883879 .8537063598678 .6345596313577 .4154205322376 .19628143311 75.2819290161174 .3675689697373 .4532165527372 .5388565063571 .92929077148 71.3197174072370 .7101516723670 .1005783081169 .7957916259869 .18623352051 68.8814392089868 .2718734741267 .9670867919967 .6623001098667 .35751342773 67.0527267456167 .0527267456167 .0527267456167 .0527267456167 .35751342773 67.6623001098668 .5766525268669 .4910125732471 .3197174072373 .45321655273 76.1962814331178 .9393463134878 .7353973388778 .2382278442477 .86595916748 77.5628204345777 .268554687576 .9577178955176 .646064758376 .33421325684 76.0372009277375 .7490463256875 .4626922607475 .1669006347774 .86221313477 74.5490036010782 .3679046630982 .9015579223682 .9015579223682 .59677124023 82.29197692871 81.98719787598 81.68241119385 81.3776321411181.07285308838 80.7680587768680 .4632720947380 .1584930419979 .5489196777379 .20224761963 78.6345596313578 .3297805786177 .7202072143677 .4154205322376 .80584716797 76.1962814331175 .8914871215875 .2819290161172 .8391952514669 .25440216064 64.68524932861 -9999 -9999 -9999 -9999 -9999 -9999 -9999 -9999 -9999 -9999 -9999 -9999 -9999 -9999 -9999 -9999 -9999 -9999 -9999 -9999 -9999 -9999 -9999 -9999 -9999 -

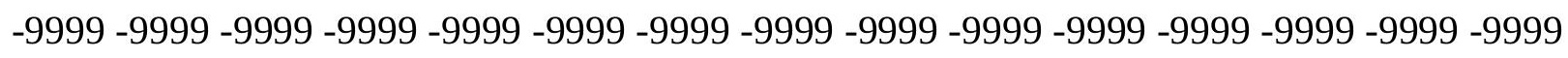
-9999 -9999 -9999 -9999 -9999 -9999 -9999 -9999 -9999 -9999 -9999 -9999 -9999 -9999 -9999 -

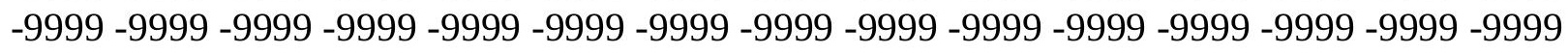

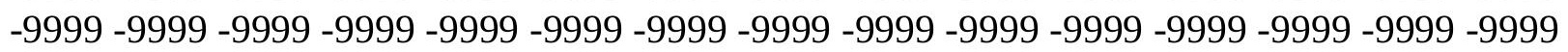


-9999 -9999 -9999 -9999 -9999 -9999 -9999 -9999 -9999 -9999 -9999 -9999 -9999 -9999 -9999 -9999 -9999 -9999 -9999 -9999 -9999 -9999 -9999 -9999 -9999 -9999 -9999 -9999 -9999 -9999 -9999 -9999 -9999 -9999 -9999 -9999 -9999 -9999 -9999 -9999 -9999 -9999 -9999 -9999 -9999 -9999 -9999 -9999 -9999 -9999 -9999 -9999 -9999 -9999 -9999 -9999 -9999 -9999 -9999 -9999 -9999 -9999 -9999 -9999 -9999 -9999 -9999 -9999 -9999 -9999 -9999 -9999 -9999 -9999 -9999 -9999 -9999 -9999 -9999 -9999 -9999 -9999 -9999 -9999 -9999 -9999 -9999 -9999 -9999 -9999 -9999 -9999 -9999 -9999 -9999 -9999 -9999 -9999 -9999 -9999 -9999 -9999 -9999 -9999 -9999

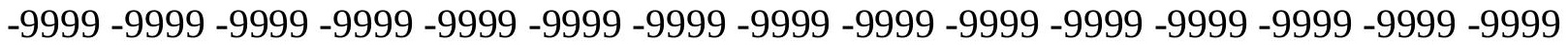

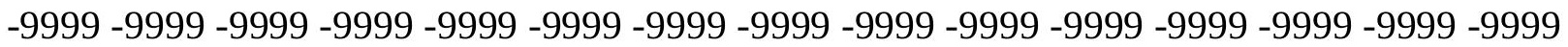
-9999 -9999 -9999 -9999 -9999 -9999 -9999 -9999 -9999 -9999 -9999 -9999 -9999 -9999 -9999 -9999 -9999 -9999 -9999 -9999 -9999 -9999 -9999 -9999 -9999 -9999 -9999 -9999 -9999 -9999 -9999 -9999 -9999 -9999 -9999 -9999 -9999 -9999 -9999 -9999 -9999 -9999 -9999 -9999 -9999 -9999 -9999 -9999 -9999 -9999 -9999 -9999 -9999 -9999 -9999 -9999 -9999 179.6177062988 172.762588501163 .0599975586151 .7830047607142 .6394042969137 .1533050537 112.8304748535111 .8590927124110 .8912963867109 .9281616211108 .9707183838 108.0199737549107 .076782226699 .5481796264698 .9838485717898 .4281539917 97.881141662697 .3429794311596 .8137893676896 .2938461303795 .78339385986 95.2828674316494 .7926254272594 .313201904393 .8450241088993 .38864135742 92.9444351196392 .5129165649492 .0944366455191 .6894836425891 .29838562012 90.9215698242290 .5211791992289 .9116134643689 .6068267822388 .99725341797 87.7781066894586 .5589828491285 .0350494384883 .8159103393682 .59677124023 81.3776321411179 .8537063598678 .6345596313577 .4154205322376 .50106811523 75.2819290161174 .3675689697373 .4532165527372 .8436431884871 .92929077148 71.3197174072370 .7101516723670 .4053573608469 .7957916259869 .49101257324 69.1862335205168 .5766525268668 .2718734741267 .9670867919967 .66230010986 67.6623001098667 .3575134277367 .3575134277367 .3575134277367 .35751342773 67.6623001098668 .2718734741269 .1862335205170 .4053573608471 .92929077148 74.3675689697377 .110626220778 .6620788574278 .2874832153378 .10092163086 77.9503784179777 .7539825439577 .5170669555777 .2404632568476 .94631195068 76.6479644775476 .3619613647576 .084129333575 .7891387939575 .47737121582 75.151084899982 .2996520996182 .9015579223682 .9015579223682 .59677124023 82.2919769287182 .2919769287181 .9871978759881 .6591415405381 .29735565186 80.9788436889680 .4632720947380 .1584930419979 .8537063598679 .24413299561 78.9393463134878 .3297805786178 .0249862670977 .4154205322377 .1106262207 $76.5010681152375 .8914871215874 .773857116772 .4105224609468 .89886474609-9999$ -9999 -9999 -9999 -9999 -9999 -9999 -9999 -9999 -9999 -9999 -9999 -9999 -9999 -9999 -9999 -9999 -9999 -9999 -9999 -9999 -9999 -9999 -9999 -9999-9999

-9999 -9999 -9999 -9999 -9999 -9999 -9999 -9999 -9999 -9999 -9999 -9999 -9999 -9999 -9999 -9999 -9999 -9999 -9999 -9999 -9999 -9999 -9999 -9999 -9999 -9999 -9999 -9999 -9999 -9999 -9999 -9999 -9999 -9999 -9999 -9999 -9999 -9999 -9999 -9999 -9999 -9999 -9999 -9999 -9999 -9999 -9999 -9999 -9999 -9999 -9999 -9999 -9999 -9999 -9999 -9999 -9999 -9999 -9999 -9999

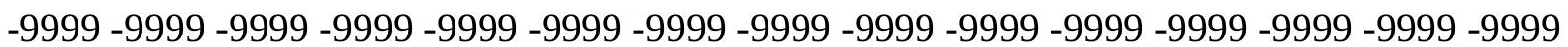
-9999 -9999 -9999 -9999 -9999 -9999 -9999 -9999 -9999 -9999 -9999 -9999 -9999 -9999 -9999 -9999 -9999 -9999 -9999 -9999 -9999 -9999 -9999 -9999 -9999 -9999 -9999 -9999 -9999 -9999 -9999 -9999 -9999 -9999 -9999 -9999 -9999 -9999 -9999 -9999 -9999 -9999 -9999 -9999 -9999

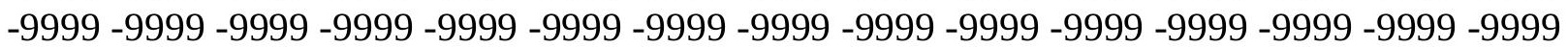


-9999 -9999 -9999 -9999 -9999 -9999 -9999 -9999 -9999 -9999 -9999 -9999 -9999 -9999 -9999 -9999 -9999 -9999 -9999 -9999 -9999 -9999 -9999 -9999 -9999 -9999 -9999 -9999 -9999 -9999 -9999 -9999 -9999 -9999 -9999 -9999 -9999 -9999 -9999 -9999 -9999 -9999 -9999 -9999 -9999 -9999 -9999 -9999 -9999 -9999 -9999 -9999 -9999 -9999 -9999 -9999 -9999 -9999 -9999 -9999 -9999 -9999 -9999 -9999 -9999 -9999 -9999 -9999 -9999 -9999 -9999 -9999 -9999 -9999 -9999 -9999 -9999 -9999 -9999 -9999 -9999 -9999 -9999 -9999 -9999 -9999 -9999 -9999 -9999 -9999 -9999 -9999 -9999 -9999 -9999 -9999 -9999 -9999 -9999 -9999 -9999 -9999 -9999 -9999 -9999 -9999 -9999 -9999 -9999 -9999 -9999 -9999 -9999 -9999 -9999 -9999 -9999 177.4470825195 169.4625244141159 .0977935791150 .8686065674144 .4682006836138 .9819946289 113.0767288208112 .1099014282111 .1467590332110 .1882705688109 .2353515625 108.2888412476107 .349372863899 .7736740112399 .2068786621198 .6489944458 98.1000900268697 .5603485107497 .0298843383896 .5089797973695 .99787902832 95.4969940185595 .0066757202194 .5274429321394 .0597000122193 .60398101807 93.1606750488392 .7302932739392 .313201904391 .9099273681691 .52083587646 91.1464309692490 .7868881225690 .4423065185589 .9116134643689 .60682678223 88.0829010009886 .5589828491285 .3398437583 .8159103393682 .59677124023 81.3776321411179 .8537063598678 .6345596313577 .4154205322376 .50106811523 75.2819290161174 .3675689697373 .4532165527372 .8436431884872 .23407745361 71.6244964599671 .014930725170 .4053573608470 .1005783081169 .79579162598 69.1862335205168 .8814392089868 .5766525268668 .2718734741267 .96708679199 67.9670867919967 .6623001098667 .6623001098667 .6623001098667 .66230010986 67.9670867919968 .2718734741268 .8814392089869 .7957916259870 .71015167236 73.1484298706175 .5867080688577 .7202072143678 .3097839355578 .35803985596 78.3989028930778 .3237228393678 .1453170776477 .8945922851677 .60647583008 77.303848266677 .0024566650476 .7194976806676 .4272079467876 .10604095459 75.7650222778382 .2157287597782 .9015579223682 .9015579223682 .59677124023 82.5967712402382 .2919769287181 .9871978759881 .6824111938581 .37763214111 81.0728530883880 .7680587768680 .1584930419979 .8537063598679 .54891967773 78.9393463134878 .6345596313578 .0249862670977 .7202072143677 .1106262207 76.5010681152376 .1962814331174 .5541000366271 .9954910278368 .56469726562 -9999 -9999 -9999 -9999 -9999 -9999 -9999 -9999 -9999 -9999 -9999 -9999 -9999 -9999 -9999 -9999 -9999 -9999 -9999 -9999 -9999 -9999 -9999 -9999 -9999 -9999 -9999 -9999 -9999 -9999 -9999 -9999 -9999 -9999 -9999 -9999 -9999 -9999 -9999 -9999 -9999 -9999 -9999 -9999 -9999 -9999 -9999 -9999 -9999 -9999 -9999 -9999 -9999 -9999 -9999 -9999

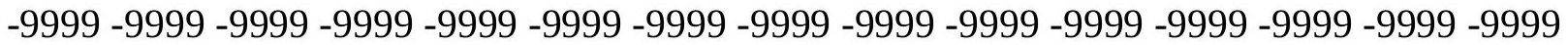
-9999 -9999 -9999 -9999 -9999 -9999 -9999 -9999 -9999 -9999 -9999 -9999 -9999 -9999 -9999

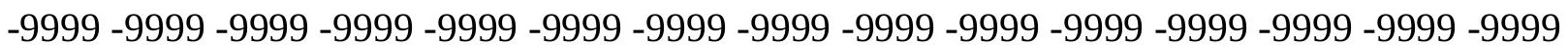

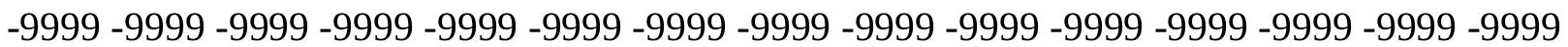
-9999 -9999 -9999 -9999 -9999 -9999 -9999 -9999 -9999 -9999 -9999 -9999 -9999 -9999 -9999 -9999 -9999 -9999 -9999 -9999 -9999 -9999 -9999 -9999 -9999 -9999 -9999 -9999 - -9999 -9999 -9999 -9999 -9999 -9999 -9999 -9999 -9999 -9999 -9999 -9999 -9999 -9999 -9999 -9999 -9999

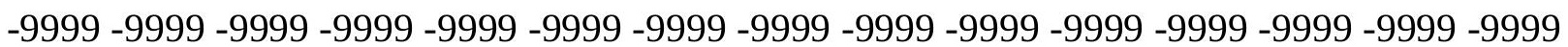
-9999 -9999 -9999 -9999 -9999 -9999 -9999 -9999 -9999 -9999 -9999 -9999 -9999 -9999 -9999 -9999 -9999 -9999 -9999 -9999 -9999 -9999 -9999 -9999 -9999 -9999 -9999 -9999 -9999 -9999 -9999 -9999 -9999 -9999 -9999 -9999 -9999 -9999 -9999 -9999 -9999 -9999 -9999 -9999 -9999

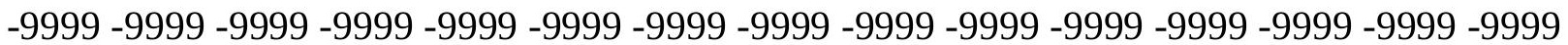


-9999 -9999 -9999 -9999 -9999 -9999 -9999 -9999 -9999 -9999 -9999 -9999 -9999 -9999 -9999 -9999 -9999 -9999 -9999 -9999 -9999 -9999 -9999 -9999 -9999 -9999 -9999 -9999 -9999 -9999 -9999 -9999 -9999 -9999 -9999 -9999 -9999 -9999 -9999 -9999 -9999 -9999 -9999 167.3269958496158 .1835021973151 .1734008789145 .3825073242140 .5059967041 135.9342041016112 .3506164551111 .390625110 .4351959229109 .4851226807 108.5410842896107 .6034011841106 .672302246199 .4238204956198 .86380767822 98.3130722045997 .7718124389697 .2401428222796 .7183609008896 .20668029785 95.7055053710995 .2151794433694 .7361755371194 .2688980102593 .81386566162 93.3714599609492 .9421844482492 .5264282226692 .1247329711991 .73750305176 91.3653182983491 .0084915161190 .6673202514690 .2164001464889 .3020401001 88.0829010009886 .5589828491285 .0350494384883 .8159103393682 .29197692871 81.0728530883879 .8537063598678 .6345596313577 .4154205322376 .19628143311 75.2819290161174 .3675689697373 .4532165527372 .8436431884872 .23407745361 71.6244964599671 .014930725170 .7101516723670 .1005783081169 .79579162598 69.4910125732469 .1862335205168 .8814392089868 .5766525268668 .57665252686 68.2718734741267 .9670867919967 .9670867919967 .9670867919967 .96708679199 68.2718734741268 .5766525268668 .8814392089869 .7957916259870 .71015167236 72.5388565063574 .6723632812576 .8058471679778 .3297805786178 .64455413818 78.880714416578 .9313125610478 .8152770996178 .5906982421978 .30391693115 77.9884643554777 .6745376586977 .37416839677 .075607299876 .74325561523 82.7465286254982 .1306152343882 .9015579223682 .9015579223682 .59677124023 82.5967712402382 .2919769287181 .9871978759881 .6824111938581 .37763214111 81.0728530883880 .7680587768680 .4632720947379 .8537063598679 .54891967773 79.2441329956178 .6345596313578 .3297805786177 .7202072143677 .1106262207 $76.8058471679776 .1962814331174 .3207015991271 .6572113037168 .30420684814-9999$ -9999 -9999 -9999 -9999 -9999 -9999 -9999 -9999 -9999 -9999 -9999 -9999 -9999 -9999 -9999 -9999 -9999 -9999 -9999 -9999 -9999 -9999 -9999 -9999 -9999

-9999 -9999 -9999 -9999 -9999 -9999 -9999 -9999 -9999 -9999 -9999 -9999 -9999 -9999 -9999 -9999 -9999 -9999 -9999 -9999 -9999 -9999 -9999 -9999 -9999 -9999 -9999 -9999 -9999 -9999 -9999 -9999 -9999 -9999 -9999 -9999 -9999 -9999 -9999 -9999 -9999 -9999 -9999 -9999 -9999 -9999 -9999 -9999 -9999 -9999 -9999 -9999 -9999 -9999 -9999 -9999 -9999 -9999 -9999 -9999 -

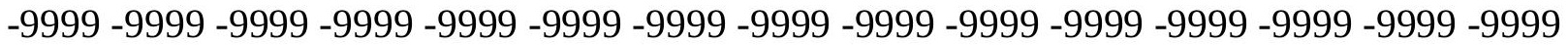
-9999 -9999 -9999 -9999 -9999 -9999 -9999 -9999 -9999 -9999 -9999 -9999 -9999 -9999 -9999 -9999 -9999 -9999 -9999 -9999 -9999 -9999 -9999 -9999 -9999 -9999 -9999 -9999 -9999 -9999 -9999 -9999 -9999 -9999 -9999 -9999 -9999 -9999 -9999 -9999 -9999 -9999 -9999 -9999 -9999 -9999 -9999 -9999 -9999 -9999 -9999 -9999 -9999 -9999 -9999 -9999 -9999 -9999 -9999 -9999 -9999 -9999 -9999 -9999 -9999 -9999 -9999 -9999 -9999 -9999 -9999 -9999 -9999 -9999 -9999

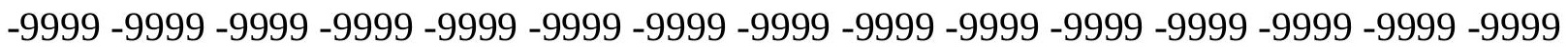
-9999 -9999 -9999 -9999 -9999 -9999 -9999 -9999 -9999 -9999 -9999 -9999 -9999 -9999 -9999 -9999 -9999 -9999 -9999 -9999 -9999 -9999 -9999 -9999 -9999 -9999 -9999 -9999 -9999 -9999 -9999 -9999 -9999 -9999 -9999 -9999 -9999 -9999 -9999 -9999 -9999 -9999 -9999 -9999 -9999

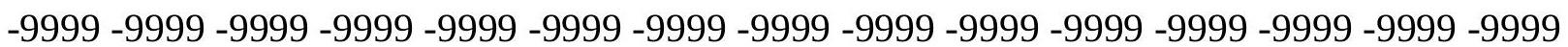

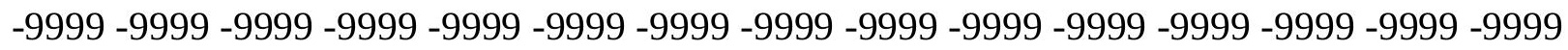
-9999 -9999 -9999 -9999 -9999 -9999 -9999 -9999 -9999 -9999 -9999 -9999 -9999 164.8887023926158 .1835021973151 .7830047607146 .2969055176141 .4203033447 137.4580993652112 .5817642212111 .6235351562110 .6696624756109 .7208404541 
108.7775344849107 .8397293091106 .907234191999 .6347427368299 .07263946533 98.5201187133897 .97739410497 .4445877075296 .9219741821396 .40977478027 95.9083709716895 .4180755615294 .9393386840894 .4725418090894 .01819610596 93.5766601562593 .1484527587992 .7339401245192 .3336944580191 .94815063477 91.5779266357491 .2234649658290 .8441543579189 .9116134643688 .69246673584 87.4733276367285 .9494018554784 .7302627563583 .206336975181 .98719787598 80.7680587768679 .5489196777378 .3297805786177 .110626220776 .19628143311 75.2819290161174 .3675689697373 .4532165527372 .8436431884872 .23407745361 71.6244964599671 .3197174072370 .7101516723670 .4053573608470 .10057830811 69.7957916259869 .4910125732469 .1862335205169 .1862335205168 .88143920898 68.5766525268668 .5766525268668 .5766525268668 .5766525268668 .57665252686 68.8814392089869 .1862335205169 .4910125732470 .1005783081171 .31971740723 72.8436431884874 .3675689697376 .1962814331177 .7202072143678 .92551422119 79.3079071044979 .4960784912179 .4712448120179 .2887191772579 .00964355469 78.6943740844778 .3585586547978 .0406417846777 .7279129028377 .38323974609 82.6368026733482 .0489883422982 .9015579223682 .9015579223682 .59677124023 82.5967712402382 .2919769287181 .9871978759881 .9871978759881 .68241119385 81.0728530883880 .7680587768680 .4632720947380 .1584930419979 .54891967773 79.2441329956178 .6345596313578 .3297805786177 .7202072143677 .1106262207 $76.8058471679775 .8360137939574 .0104141235471 .3729476928768 .1697845459-9999$ -9999 -9999 -9999 -9999 -9999 -9999 -9999 -9999 -9999 -9999 -9999 -9999 -9999 -9999 -9999 -9999 -9999 -9999 -9999 -9999-9999 -9999 -9999 -9999-9999 -9999 -9999 -9999 -9999 -9999 -9999 -9999 -9999 -9999 -9999 -9999 -9999 -9999 -9999 -9999 -9999 -9999 -9999 -9999 -9999 -9999 -9999 -9999 -9999 -9999 -9999 -9999 -9999 -9999 -9999 -9999 -9999 -9999 -9999 -9999 -9999 -9999 -9999 -9999 -9999 -9999 -9999 -9999 -9999 -9999 -9999 -9999 -9999 -9999 -9999 -9999 -9999 -9999 -9999 -9999 -9999 -9999 -9999 -9999 -9999 -9999 -9999 -9999 -9999 -9999 -9999 -9999 -9999 -9999 -9999 -9999 -9999 -9999 -9999 -9999 -9999 -9999 -9999 -9999 -9999 -9999 -9999 -9999 -9999 -9999 -9999 -9999 -9999 -9999 -9999

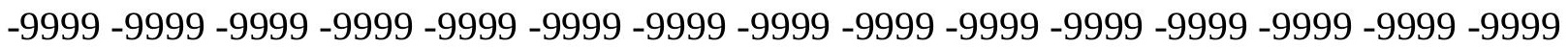
-9999 -9999 -9999 -9999 -9999 -9999 -9999 -9999 -9999 -9999 -9999 -9999 -9999 -9999 -9999 -9999 -9999 -9999 -9999 -9999 -9999 -9999 -9999 -9999 -9999 -9999 -9999 -9999 -9999 -9999 -

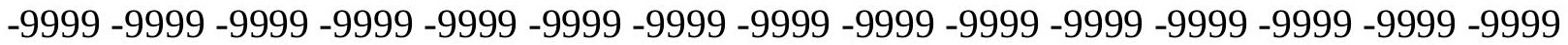
-9999 -9999 -9999 -9999 -9999 -9999 -9999 -9999 -9999 -9999 -9999 -9999 -9999 -9999 -9999 -9999 -9999 -9999 -9999 -9999 -9999 -9999 -9999 -9999 -9999 -9999 -9999 -9999 -9999 -9999 -

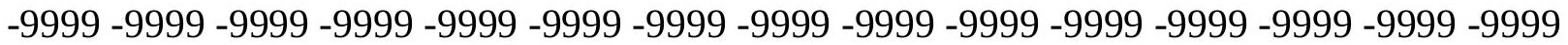
-9999 -9999 -9999 -9999 -9999 -9999 -9999 -9999 -9999 -9999 -9999 -9999 -9999 -9999 -9999 -9999 -9999 -9999 -9999 -9999 -9999 -9999 -9999 -9999 -9999 -9999 -9999 -9999 -9999 -9999

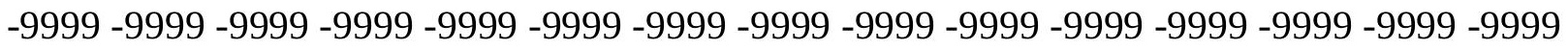
-9999 -9999 -9999 -9999 -9999 -9999 -9999 -9999 -9999 -9999 -9999 -9999 -9999 -9999 157.5738983154152 .3925933838147 .2111968994142 .6394042969138 .6772003174 135.6293945312111 .8459854126110 .8922729492109 .9431533813108 .998840332 108.0590057373107 .123138427799 .8396453857499 .2754669189598 .72119140625 98.1770477294997 .643142700297 .1197509765696 .6070709228596 .10547637939 95.6152420043995 .1367950439594 .670486450294 .2168121337993 .77611541748 93.3488845825292 .9355087280392 .5365600585992 .152488708591 .78395080566 91.4314422607490 .6624069213989 .6068267822388 .0829010009886 .86376190186 
85.3398437584 .1206970214882 .5967712402381 .3776321411180 .15849304199 78.9393463134878 .0249862670976 .8058471679775 .8914871215874 .97714233398 74.062782287673 .4532165527372 .8436431884872 .2340774536171 .62449645996 71.3197174072371 .014930725170 .7101516723670 .4053573608470 .10057830811 69.7957916259869 .4910125732469 .4910125732469 .1862335205169 .18623352051 69.1862335205169 .1862335205169 .1862335205169 .1862335205169 .49101257324 69.7957916259870 .1005783081171 .014930725171 .9292907714873 .14842987061 74.3675689697375 .8914871215877 .4154205322378 .3297805786179 .50273132324 79.9482116699280 .0365219116279 .9351654052779 .6982269287179 .38787841797 79.0495605468878 .7085494995178 .3746566772578 .0191802978582 .57358551025 81.9686279296982 .9015579223682 .9015579223682 .5967712402382 .59677124023 82.2919769287182 .2919769287181 .9871978759881 .6824111938581 .37763214111 80.7680587768680 .4632720947380 .1584930419979 .5489196777379 .24413299561 78.6345596313578 .3297805786177 .7202072143677 .4154205322376 .80584716797 75.623748779373 .7467346191471 .2051391601668 .12883758545 -9999 -9999 -9999 -9999 -9999 -9999 -9999 -9999 -9999 -9999 -9999 -9999 -9999 -9999 -9999 -9999 -9999 -9999 -9999 -9999 -9999 -9999 -9999-9999 -9999 -9999

-9999 -9999 -9999 -9999 -9999 -9999 -9999 -9999 -9999 -9999 -9999 -9999 -9999 -9999 -9999 -9999 -9999 -9999 -9999 -9999 -9999 -9999 -9999 -9999 -9999 -9999 -9999 -9999 -9999 -9999 -

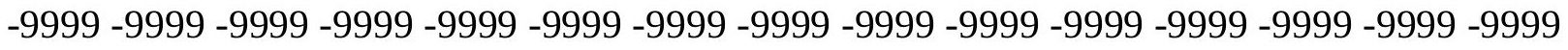

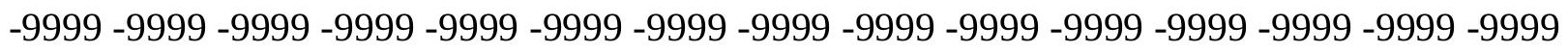
-9999 -9999 -9999 -9999 -9999 -9999 -9999 -9999 -9999 -9999 -9999 -9999 -9999 -9999 -9999 -9999 -9999 -9999 -9999 -9999 -9999 -9999 -9999 -9999 -9999 -9999 -9999 -9999 -9999 -9999 -

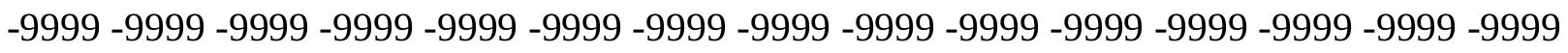

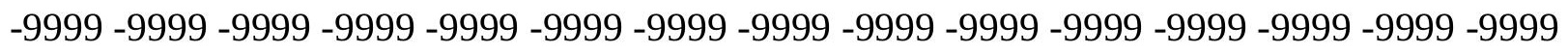
-9999 -9999 -9999 -9999 -9999 -9999 -9999 -9999 -9999 -9999 -9999 -9999 -9999 -9999 -9999

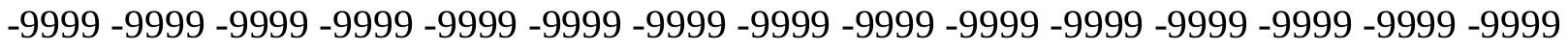

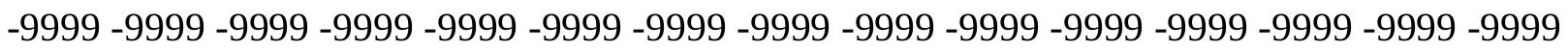
-9999 -9999 -9999 -9999 -9999 -9999 -9999 -9999 -9999 -9999 -9999 -9999 -9999 -9999 -9999 -9999 -9999 -9999 -9999 -9999 -9999 -9999 -9999 -9999 -9999 -9999 -9999 -9999 -9999 -9999 -9999 -9999 -9999 -9999 -9999 -9999 -9999 -9999 -9999 -9999 -9999 -9999 -9999 -9999 -9999 -9999 -9999 -9999 -9999 -9999 -9999 -9999 -9999 -9999 -9999 -9999 -9999 -9999 -9999 -9999 -

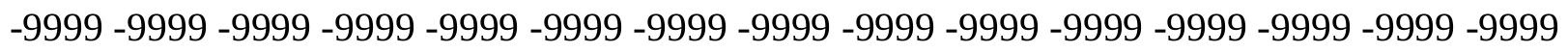
-9999 -9999 -9999 -9999 -9999 -9999 -9999 -9999 -9999 -9999 -9999 -9999 -9999 -9999 157.2691040039152.3925933838147.8208007812143.5538024902 139.8963928223 136.5437011719112 .0585174561111 .1036911011110 .1528091431109 .2058105469 108.2621231079 107.3212432861 106.3833618164 99.4723358154398.91632080078 98.37076568604 97.8357849121197.3116378784296.7985153198296.29676055908 95.8066101074295 .3284683227594 .8626480102594 .4096145629993 .96968841553 93.5433578491293 .1309890747192 .7331619262792 .3503341674891 .90055084229 91.1669998168990 .2451400756888 .9972534179787 .4733276367285 .94940185547 84.4254837036183 .206336975181 .9871978759880 .7680587768679 .54891967773 78.6345596313577 .4154205322376 .5010681152375 .5867080688574 .67236328125 74.062782287673 .1484298706172 .5388565063572 .2340774536171 .62449645996 71.3197174072371 .014930725170 .7101516723670 .4053573608470 .40535736084 70.1005783081170 .1005783081169 .7957916259869 .7957916259869 .79579162598 
69.7957916259869 .7957916259869 .7957916259869 .7957916259870 .10057830811 70.4053573608471 .014930725171 .6244964599672 .5388565063573 .45321655273 74.6723632812575 .8914871215877 .110626220778 .3277282714879 .24413299561 80.0988388061580 .4597778320380 .4846191406280 .3078002929780 .04005432129 79.715255737379 .3669357299879 .0124282836978 .6428070068482 .56231689453 81.9201507568482 .9015579223682 .9015579223682 .5967712402382 .59677124023 82.2919769287182 .2919769287181 .9871978759881 .6824111938581 .37763214111 80.7680587768680 .4632720947380 .1584930419979 .5489196777379 .24413299561 78.6345596313578 .3297805786177 .7202072143677 .4154205322376 .80584716797 75.5182037353573 .5711898803771 .09091949463 -9999 -9999 -9999 -9999 -9999 -9999 -9999

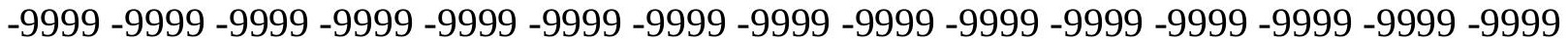
-9999 -9999-9999-9999-9999

-9999 -9999 -9999 -9999 -9999 -9999 -9999 -9999 -9999 -9999 -9999 -9999 -9999 -9999 -9999 -9999 -9999 -9999 -9999 -9999 -9999 -9999 -9999 -9999 -9999 -9999 -9999 -9999 -9999 -9999 -9999 -9999 -9999 -9999 -9999 -9999 -9999 -9999 -9999 -9999 -9999 -9999 -9999 -9999 -9999

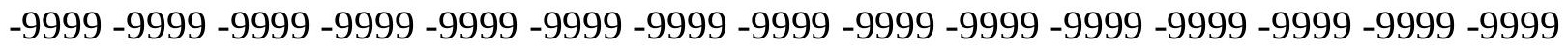
-9999 -9999 -9999 -9999 -9999 -9999 -9999 -9999 -9999 -9999 -9999 -9999 -9999 -9999 -9999 -9999 -9999 -9999 -9999 -9999 -9999 -9999 -9999 -9999 -9999 -9999 -9999 -9999 -9999 -9999 -9999 -9999 -9999 -9999 -9999 -9999 -9999 -9999 -9999 -9999 -9999 -9999 -9999 -9999 -9999 -9999 -9999 -9999 -9999 -9999 -9999 -9999 -9999 -9999 -9999 -9999 -9999 -9999 -9999 -9999 -9999 -9999 -9999 -9999 -9999 -9999 -9999 -9999 -9999 -9999 -9999 -9999 -9999 -9999 -9999 -9999 -9999 -9999 -9999 -9999 -9999 -9999 -9999 -9999 -9999 -9999 -9999 -9999 -9999 -9999 -9999 -9999 -9999 -9999 -9999 -9999 -9999 -9999 -9999 -9999 -9999 -9999 -9999 -9999 -9999 -9999 -9999 -9999 -9999 -9999 -9999 -9999 -9999 -9999 -9999 -9999 -9999 -9999 -9999 -9999 -9999 -9999 -9999 -9999 -9999 -9999 -9999 -9999 -9999 -9999 -9999 -9999 -9999 -9999 -9999 -9999 -9999 -9999 -9999 -9999 -9999 -9999 -9999 -9999 -9999 -9999 -9999 -9999 -9999 -9999 -9999 -9999 -9999 -9999 -9999 -9999 -9999 -9999 -9999 -9999 -9999 -9999 -9999 -9999 -9999

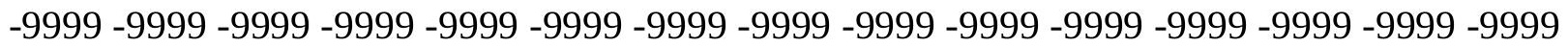
-9999 -9999 -9999 -9999 -9999 -9999 -9999 -9999 -9999 -9999 -9999 -9999 -9999 -9999 -9999 152.6972961426148 .4304046631144 .4682006836141 .1154937744138 .0677032471 135.3246002197111 .3042449951110 .3502655029109 .3990402222108 .4499206543 107.5027770996106 .558586120699 .6632080078199 .1054382324298 .55846405029 98.0224151611397 .4975280761796 .9839706420996 .4820632934695 .99201202393 95.5141754150495 .0488357543994 .5964126586994 .1572036743293 .73167419434 93.320175170992 .9232788085992 .2027740478591 .3510818481490 .51194000244 89.6068267822387 .7781066894586 .254188537684 .7302627563583 .51112365723 82.29197692871 81.07285308838 80.1584930419978.93934631348 78.02498626709 76.8058471679775 .8914871215875 .2819290161174 .3675689697373 .75800323486 73.1484298706172 .5388565063571 .9292907714871 .6244964599671 .31971740723 71.014930725170 .7101516723670 .7101516723670 .4053573608470 .40535736084 70.4053573608470 .4053573608470 .4053573608470 .4053573608470 .40535736084 70.4053573608470 .4053573608470 .7101516723671 .014930725171 .31971740723 71.9292907714872 .5388565063573 .1484298706174 .062782287675 .28192901611 76.1962814331177 .4154205322378 .3297805786179 .1780929565479 .85370635986 80.7056579589880 .8818588256880 .8125076293980 .6334533691480 .34610748291 80.0018615722779 .6308364868279 .2449340820382 .5724258422981 .87770843506 
82.9015579223682 .9015579223682 .5967712402382 .5967712402382 .29197692871 81.9871978759881 .9871978759881 .6824111938581 .3776321411180 .76805877686 80.4632720947380 .1584930419979 .5489196777379 .2441329956178 .63455963135 78.3297805786177 .7202072143677 .110626220776 .8058471679775 .42345428467 73.4608840942471 .01333618164 -9999 -9999 -9999 -9999 -9999 -9999 -9999 -9999 -9999 -9999 -9999 -9999 -9999 -9999 -9999 -9999 -9999 -9999 -9999 -9999 -9999 -9999 -9999 -9999 -9999-9999-9999

-9999 -9999 -9999 -9999 -9999 -9999 -9999 -9999 -9999 -9999 -9999 -9999 -9999 -9999 -9999 -9999 -9999 -9999 -9999 -9999 -9999 -9999 -9999 -9999 -9999 -9999 -9999 -9999 -9999 -9999 -9999 -9999 -9999 -9999 -9999 -9999 -9999 -9999 -9999 -9999 -9999 -9999 -9999 -9999 -9999 -

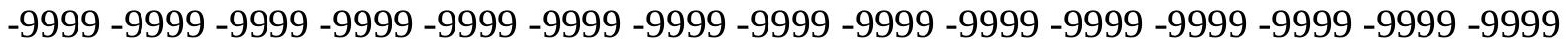
-9999 -9999 -9999 -9999 -9999 -9999 -9999 -9999 -9999 -9999 -9999 -9999 -9999 -9999 -9999 -9999 -9999 -9999 -9999 -9999 -9999 -9999 -9999 -9999 -9999 -9999 -9999 -9999 -9999 -9999 -9999 -9999 -9999 -9999 -9999 -9999 -9999 -9999 -9999 -9999 -9999 -9999 -9999 -9999 -9999 -9999 -9999 -9999 -9999 -9999 -9999 -9999 -9999 -9999 -9999 -9999 -9999 -9999 -9999 -9999

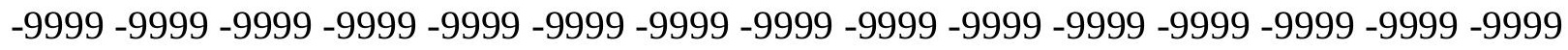
-9999 -9999 -9999 -9999 -9999 -9999 -9999 -9999 -9999 -9999 -9999 -9999 -9999 -9999 -9999 -9999 -9999 -9999 -9999 -9999 -9999 -9999 -9999 -9999 -9999 -9999 -9999 -9999 -9999 -9999 -

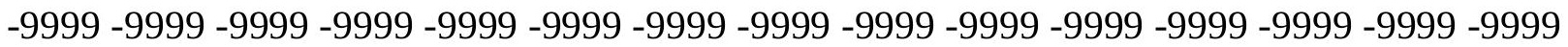

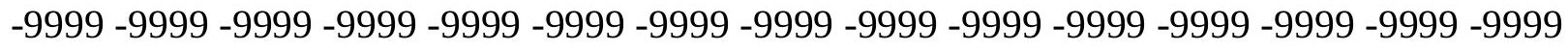

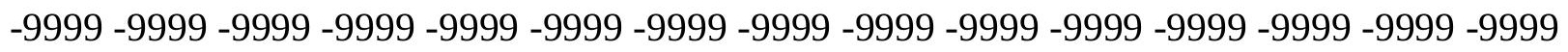

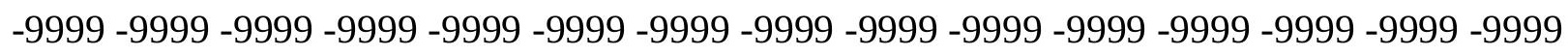
-9999 -9999 -9999 -9999 -9999 -9999 -9999 -9999 -9999 -9999 -9999 -9999 -9999 -9999 -9999 -

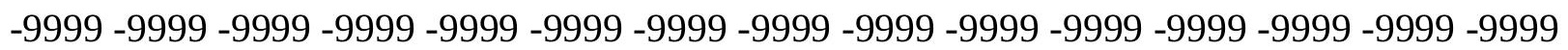
152.6972961426149 .0399017334145 .3825073242142 .0299072266138 .9819946289 136.5437011719134 .4102020264110 .5359420776109 .5792694092108 .6235809326 107.6694259644106 .7188568115105 .775001525999 .2885589599698 .74015045166 98.2030029296997 .6773605346797 .163360595796 .6613006591896 .17134094238 95.6938095092895 .228927612394 .7770767211994 .3385238647593 .91369628906 93.5029220581192 .6736068725691 .6050109863390 .5427169799889 .4002456665 88.0829010009886 .5589828491285 .0350494384883 .5111236572382 .29197692871 81.3776321411180.15849304199 79.24413299561 78.32978057861 77.1106262207 76.1962814331175 .5867080688574 .6723632812574 .062782287673 .45321655273 72.8436431884872 .2340774536171 .9292907714871 .6244964599671 .31971740723 71.014930725171 .014930725171 .014930725170 .7101516723670 .71015167236 70.7101516723670 .7101516723670 .7101516723670 .7101516723671 .0149307251 71.014930725171 .3197174072371 .3197174072371 .6244964599672 .23407745361 72.5388565063573 .4532165527374 .062782287674 .9771423339875 .58670806885 76.8058471679777 .7202072143678 .3297805786179 .2011795043979 .85370635986 80.7115402221781 .0728530883881 .2657394409281 .1734848022580 .92825317383 80.5954132080180 .2194900512779 .8178253173882 .5527801513781 .81833648682 82.9015579223682 .9015579223682 .5967712402382 .5967712402382 .29197692871 81.9871978759881 .9871978759881 .6824111938581 .0728530883880 .76805877686 80.4632720947380 .1584930419979 .5489196777379 .2441329956178 .63455963135 78.0249862670977 .7202072143677 .110626220776 .5010681152375 .26493835449 73.358535766670 .94961547852 -9999 -9999 -9999 -9999 -9999 -9999 -9999 -9999 -9999 
-9999 -9999 -9999 -9999 -9999 -9999 -9999 -9999 -9999 -9999 -9999 -9999 -9999 -9999 -9999 -9999 -9999 -9999

-9999 -9999 -9999 -9999 -9999 -9999 -9999 -9999 -9999 -9999 -9999 -9999 -9999 -9999 -9999 -9999 -9999 -9999 -9999 -9999 -9999 -9999 -9999 -9999 -9999 -9999 -9999 -9999 -9999 -9999 -9999 -9999 -9999 -9999 -9999 -9999 -9999 -9999 -9999 -9999 -9999 -9999-9999 -9999 -9999 -9999 -9999 -9999 -9999 -9999 -9999 -9999 -9999 -9999 -9999 -9999 -9999 -9999 -9999 -9999 -9999 -9999 -9999 -9999 -9999 -9999 -9999 -9999 -9999 -9999 -9999 -9999 -9999 -9999 -9999 -999 -9999 -9999 -9999 -9999 -9999 -9999 -9999 -9999 -9999 -9999 -9999 -9999 -9999 -9999 -9999

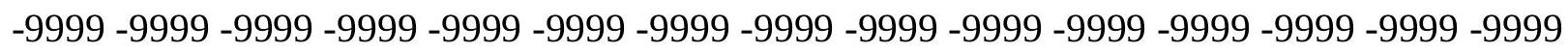
-9999 -9999 -9999 -9999 -9999 -9999 -9999 -9999 -9999 -9999 -9999 -9999 -9999 -9999 -9999 -9999 -9999 -9999 -9999 -9999 -9999 -9999 -9999 -9999 -9999 -9999 -9999 -9999 -9999 -9999 -999 -9999 -9999 -9999 -9999 -9999 -9999 -9999 -9999 -9999 -9999 -9999 -9999 -9999 -9999 -9999 -9999 -9999 -9999 -9999 -9999 -9999 -9999 -9999 -9999 -9999 -9999 -9999 -9999 -9999 -9999 -9999 -9999 -9999 -9999 -9999 -9999 -9999 -9999 -9999 -9999 -9999 -9999 -9999 -9999 -9999 -9999 -9999 -9999 -9999 -9999 -9999 -9999 -9999 -9999 -9999 -9999 -9999 -9999 -9999 -9999

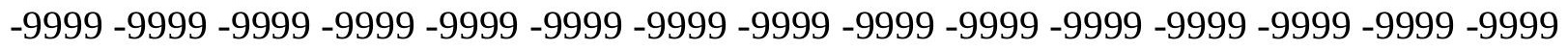
-9999 -9999 -9999 -9999 -9999 -9999 -9999 -9999 -9999 -9999 -9999 -9999 -9999 -9999 -9999 -

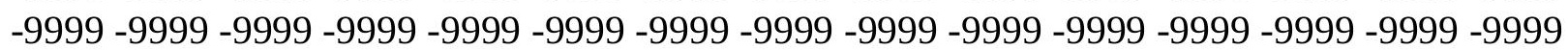
-9999 -9999 -9999 -9999 -9999 -9999 -9999 -9999 -9999 -9999 -9999 -9999 -9999 -9999 -9999 -9999 149.3446960449 146.2969055176 143.2489929199 140.2012023926137.4580993652 135.3246002197110 .7101669312109 .7471618652108 .7843093872107 .8228988647 106.8661499023 105.9178771973 99.4656295776498.9157257080198.37744140625 97.851005554297 .3365325927796 .8342971801896 .3444061279395 .86715698242 95.4027099609494 .9514007568494 .5134429931694 .0892257690493 .44410705566 92.1984558105590 .8899993896589 .5368576049888 .119705200286 .55898284912 85.0350494384883 .5111236572382 .2919769287181 .3776321411180 .15849304199 79.2441329956178 .3297805786177 .4154205322376 .5010681152375 .58670806885 74.9771423339874 .3675689697373 .7580032348673 .1484298706172 .53885650635 72.2340774536171 .9292907714871 .6244964599671 .3197174072371 .31971740723 71.014930725171 .014930725171 .014930725171 .014930725171 .0149307251 71.3197174072371 .3197174072371 .3197174072371 .6244964599671 .62449645996 71.9292907714872 .2340774536172 .5388565063573 .1484298706173 .45321655273 74.062782287674 .9771423339875 .5867080688576 .5010681152377 .1106262207 78.0249862670978 .6345596313579 .4186019897580 .1584930419980 .76805877686 81.3727035522581 .6824111938581 .6156845092881 .4395065307681 .14228057861 80.7699584960980 .3537597656282 .5175933837981 .7282791137782 .90155792236 82.9015579223682 .5967712402382 .5967712402382 .2919769287181 .98719787598 81.6824111938581 .3776321411181 .0728530883880 .7680587768680 .46327209473 79.8537063598679 .5489196777378 .9393463134878 .6345596313578 .02498626709 77.4154205322377 .110626220776 .5010681152375 .1814270019573 .25670623779 70.89101409912 -9999 -9999 -9999 -9999 -9999 -9999 -9999 -9999 -9999 -9999 -9999 -9999 -9999 -9999 -9999 -9999 -9999 -9999 -9999 -9999 -9999 -9999 -9999 -9999 -9999 -9999-9999 - -999 -9999 -9999 -9999 -9999 -9999 -9999 -9999 -9999 -9999 -9999 -9999 -9999 -9999 -9999 -9999 -9999 -9999 -9999 -9999 -9999 -9999 -9999 -9999 -9999 -9999 -9999 -9999 -9999 -9999 -9999 -9999 -9999 -9999 -9999 -9999 -9999 -9999 -9999 -9999 -9999 -9999 -9999 -9999 -9999 -9999 -

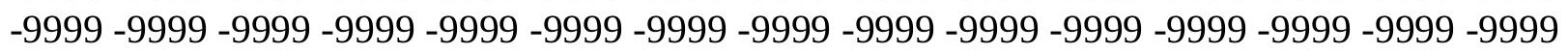


-9999 -9999 -9999 -9999 -9999 -9999 -9999 -9999 -9999 -9999 -9999 -9999 -9999 -9999 -9999 -9999 -9999 -9999 -9999 -9999 -9999 -9999 -9999 -9999 -9999 -9999 -9999 -9999 -9999 -9999 -9999 -9999 -9999 -9999 -9999 -9999 -9999 -9999 -9999 -9999 -9999 -9999 -9999 -9999 -9999 -9999 -9999 -9999 -9999 -9999 -9999 -9999 -9999 -9999 -9999 -9999 -9999 -9999 -9999 -9999 -9999 -9999 -9999 -9999 -9999 -9999 -9999 -9999 -9999 -9999 -9999 -9999 -9999 -9999 -9999 -9999 -9999 -9999 -9999 -9999 -9999 -9999 -9999 -9999 -9999 -9999 -9999 -9999 -9999 -9999 -9999 -9999 -9999 -9999 -9999 -9999 -9999 -9999 -9999 -9999 -9999 -9999 -9999 -9999 -9999

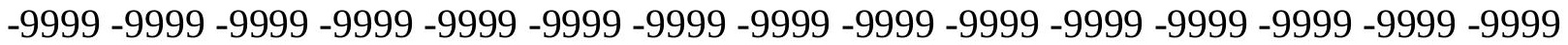
-9999 -9999 -9999 -9999 -9999 -9999 -9999 -9999 -9999 -9999 -9999 -9999 -9999 -9999 -9999 -9999 -9999 -9999 -9999 -9999 -9999 -9999 -9999 -9999 -9999 -9999 -9999 -9999 -9999 -9999 -

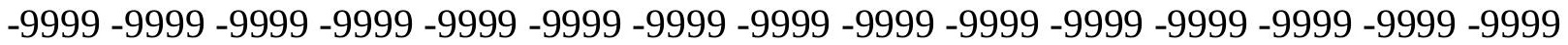
-9999 -9999 -9999 -9999 -9999 -9999 -9999 -9999 -9999 -9999 -9999 -9999 -9999 -9999 -9999 -9999 -9999 -9999 -9999 -9999 -9999 -9999 -9999 -9999 -9999 -9999 -9999 -9999 -9999 -9999 -9999 149.6495056152 146.9064025879 143.8585968018141 .4203033447138 .6772003174 136.5437011719134 .7149963379109 .9038162231108 .9336700439107 .9652633667 107.0026626587106 .0502471924105 .110527038699 .0851974487398 .54570770264 98.018417358497 .5034255981497 .0009613037196 .5111083984496 .03410339355 95.5700607299895 .1192474365294 .6818237304794 .2581253051893 .18516540527 91.7479705810590 .1611480712988 .47070312586 .8637619018684 .73026275635 83.5111236572382 .2919769287181 .3776321411180 .1584930419979 .24413299561 78.3297805786177 .4154205322376 .5010681152375 .8914871215874 .97714233398 74.3675689697373 .7580032348673 .1484298706172 .8436431884872 .23407745361 71.9292907714871 .6244964599671 .6244964599671 .3197174072371 .31971740723 71.3197174072371 .3197174072371 .3197174072371 .3197174072371 .62449645996 71.6244964599671 .9292907714871 .9292907714872 .2340774536172 .53885650635 72.8436431884873 .1484298706173 .4532165527374 .062782287674 .36756896973 74.9771423339875 .5867080688576 .5010681152377 .110626220777 .72020721436 78.6345596313579 .2441329956179 .7630462646580 .4120788574281 .02233886719 81.3776321411181 .6824111938581 .9871978759881 .8980026245181 .63340759277 81.2742080688580 .8473968505982 .4453277587981 .6077728271582 .90155792236 82.9015579223682 .5967712402382 .5967712402382 .2919769287181 .98719787598 81.6824111938581 .3776321411181 .0728530883880 .7680587768680 .15849304199 79.8537063598679 .2441329956178 .9393463134878 .3297805786178 .02498626709 $77.4154205322376 .8058471679776 .5010681152375 .0854187011773 .12410736084-9999$ -9999 -9999 -9999 -9999 -9999 -9999 -9999 -9999 -9999 -9999 -9999 -9999 -9999 -9999 -9999 -9999 -9999 -9999 -9999 -9999 -9999 -9999 -9999 -9999 -9999 -9999 -9999

-9999 -9999 -9999 -9999 -9999 -9999 -9999 -9999 -9999 -9999 -9999 -9999 -9999 -9999 -9999

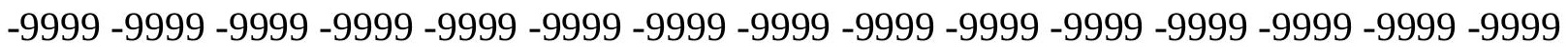
-9999 -9999 -9999 -9999 -9999 -9999 -9999 -9999 -9999 -9999 -9999 -9999 -9999 -9999 -9999 -9999 -9999 -9999 -9999 -9999 -9999 -9999 -9999 -9999 -9999 -9999 -9999 -9999 -9999 -9999 -9999 -9999 -9999 -9999 -9999 -9999 -9999 -9999 -9999 -9999 -9999 -9999 -9999 -9999 -9999

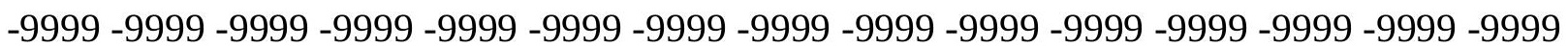
-9999 -9999 -9999 -9999 -9999 -9999 -9999 -9999 -9999 -9999 -9999 -9999 -9999 -9999 -9999 -9999 -9999 -9999 -9999 -9999 -9999 -9999 -9999 -9999 -9999 -9999 -9999 -9999 -9999 -9999 -9999 -9999 -9999 -9999 -9999 -9999 -9999 -9999 -9999 -9999 -9999 -9999 -9999 -9999 -9999

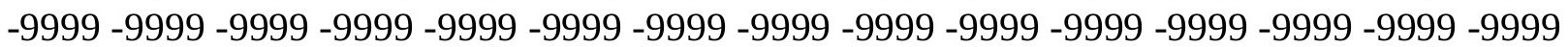


-9999 -9999 -9999 -9999 -9999 -9999 -9999 -9999 -9999 -9999 -9999 -9999 -9999 -9999 -9999 -9999 -9999 -9999 -9999 -9999 -9999 -9999 -9999 -9999 -9999 -9999 -9999 -9999 -9999 -9999 -9999 -9999 -9999 -9999 -9999 -9999 -9999 -9999 -9999 -9999 -9999 -9999 -9999 -9999 -9999 -9999 -9999 -9999 -9999 -9999 -9999 -9999 -9999 -9999 -9999 -9999 -9999 -9999 -9999 -9999 -9999 -9999 -9999 -9999 -9999 -9999 -9999 -9999 -9999 -9999 -9999 -9999 -9999 -9999 -9999 -9999 -9999 -9999 -9999 -9999 -9999 -9999 -9999 -9999 -9999 -9999 -9999 -9999 -9999 -9999 -9999 -9999 -9999 -9999 -9999 -9999 -9999 -9999 -9999 -9999 -9999 -9999 -9999 -9999 -9999 -9999 -9999 147.5160064697 144.7729034424142.3347015381 139.8963928223 137.7628936768135 .6293945312110 .0502624512109 .0729064941108 .0979766846 107.1300048828106 .1735229492105 .230804443499 .2484970092898 .70771026611 98.1794891357497 .6639022827197 .1611557006896 .6712875366296 .194480896 95.7307891845795 .2804260253994 .843475341894 .4034042358493 .00801086426 91.4438171386789 .6598434448287 .5489120483485 .0350494384883 .51112365723 82.2919769287181 .0728530883880 .1584930419979 .2441329956178 .32978057861 77.4154205322376 .5010681152375 .8914871215874 .9771423339874 .36756896973 73.7580032348673 .1484298706172 .8436431884872 .5388565063571 .92929077148 71.6244964599671 .6244964599671 .3197174072371 .3197174072371 .31971740723 71.3197174072371 .3197174072371 .6244964599671 .6244964599671 .92929077148 72.2340774536172 .2340774536172 .5388565063572 .8436431884873 .14842987061 73.4532165527374 .062782287674 .3675689697374 .9771423339875 .28192901611 75.8914871215876 .5010681152377 .110626220777 .7202072143678 .32978057861 78.9393463134879 .5489196777380 .1584930419980 .7680587768681 .31645202637 81.6824111938581 .9871978759882 .2919769287182 .2764434814582 .07012176514 81.7317581176881 .2969589233482 .3896713256881 .4818420410282 .90155792236 82.9015579223682 .5967712402382 .2919769287182 .2919769287181 .98719787598 81.6824111938581 .3776321411181 .0728530883880 .4632720947380 .15849304199 79.8537063598679 .2441329956178 .6345596313578 .3297805786177 .72020721436 $77.4154205322376 .8058471679776 .1962814331174 .830635070872 .90501403809-9999$ -9999 -9999 -9999 -9999 -9999 -9999 -9999 -9999 -9999 -9999 -9999 -9999 -9999 -9999 -9999 -9999 -9999 -9999 -9999 -9999 -9999 -9999 -9999 -9999 -9999 -9999 -9999 -9999 -9999 -9999 -9999 -9999 -9999 -9999 -9999 -9999 -9999 -9999 -9999 -9999 -9999 -9999

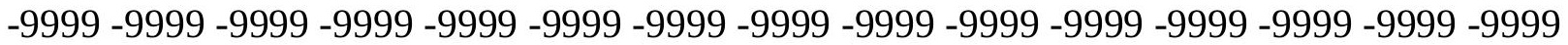
-9999 -9999 -9999 -9999 -9999 -9999 -9999 -9999 -9999 -9999 -9999 -9999 -9999 -9999 -9999 -9999 -9999 -9999 -9999 -9999 -9999 -9999 -9999 -9999 -9999 -9999 -9999 -9999 -9999 -9999 -9999 -9999 -9999 -9999 -9999 -9999 -9999 -9999 -9999 -9999 -9999 -9999 -9999 -9999 -9999 -9999 -9999 -9999 -9999 -9999 -9999 -9999 -9999 -9999 -9999 -9999 -9999 -9999 -9999 -9999 -9999 -9999 -9999 -9999 -9999 -9999 -9999 -9999 -9999 -9999 -9999 -9999 -9999 -9999 -9999

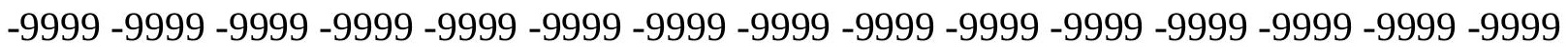
-9999 -9999 -9999 -9999 -9999 -9999 -9999 -9999 -9999 -9999 -9999 -9999 -9999 -9999 -9999 -9999 -9999 -9999 -9999 -9999 -9999 -9999 -9999 -9999 -9999 -9999 -9999 -9999 -9999 -9999 -9999 -9999 -9999 -9999 -9999 -9999 -9999 -9999 -9999 -9999 -9999 -9999 -9999 -9999 -9999

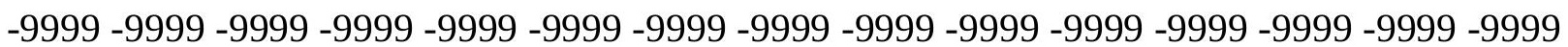
-9999 -9999 -9999 -9999 -9999 -9999 -9999 -9999 -9999 -9999 -9999 -9999 -9999 -9999 -9999 -9999 -9999 -9999 -9999 -9999 -9999 -9999 -9999 -9999 -9999 -9999 -9999 -9999 -9999 -9999 -9999 -9999 -9999 -9999 -9999 -9999 -9999 -9999 -9999 -9999 -9999 -9999 -9999 -9999 -9999

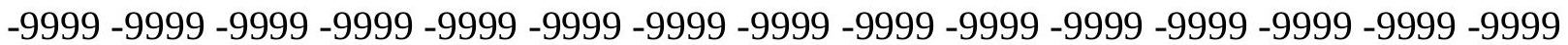


-9999 -9999 -9999 -9999 -9999 -9999 -9999 -9999 -9999 -9999 -9999 -9999 -9999 -9999 -9999 -9999 -9999 147.8208007812 145.3825073242 143.2489929199140.8106994629 138.6772003174136 .8484954834135 .0198059082109 .2030410767108 .2218856812 107.2488632202106 .2883682251105 .342376709104 .410575866798 .86346435547 98.3342208862397 .8179626464897 .314865112396 .824920654396 .34825897217 95.8848800659295 .4349136352594 .9983825683694 .385879516692 .94457244873 91.3168716430789 .4514160156287 .2986373901485 .0350494384882 .90155792236 81.3776321411180 .1584930419979 .2441329956178 .3297805786177 .41542053223 76.5010681152375 .5867080688574 .9771423339874 .3675689697373 .75800323486 73.1484298706172 .8436431884872 .5388565063571 .9292907714871 .62449645996 71.6244964599671 .3197174072371 .3197174072371 .3197174072371 .31971740723 71.3197174072371 .6244964599671 .9292907714871 .9292907714872 .23407745361 72.5388565063572 .8436431884873 .1484298706173 .4532165527374 .0627822876 74.3675689697374 .6723632812575 .2819290161175 .8914871215876 .19628143311 76.8058471679777 .4154205322378 .0249862670978 .6345596313579 .24413299561 79.8537063598680 .1584930419980 .7680587768681 .0728530883881 .67916870117 81.9871978759882 .2919769287182 .5967712402382 .5967712402382 .46226501465 82.1493530273482 .9015579223682 .3848342895581 .3787460327182 .90155792236 82.5967712402382 .5967712402382 .2919769287181 .9871978759881 .98719787598 81.3776321411181 .0728530883880 .7680587768680 .4632720947379 .85370635986 79.5489196777378 .9393463134878 .6345596313578 .0249862670977 .72020721436 77.110626220776 .5010681152375 .8914871215874 .4611968994172 .57859039307 -9999 -9999 -9999 -9999 -9999 -9999 -9999 -9999 -9999 -9999 -9999 -9999 -9999 -9999 -9999 -9999 -9999 -9999 -9999 -9999 -9999 -9999 -9999 -9999 -9999 -9999 -9999 -9999 -

-9999 -9999 -9999 -9999 -9999 -9999 -9999 -9999 -9999 -9999 -9999 -9999 -9999 -9999 -9999 -9999 -9999 -9999 -9999 -9999 -9999 -9999 -9999 -9999 -9999 -9999 -9999 -9999 -9999 -9999 -

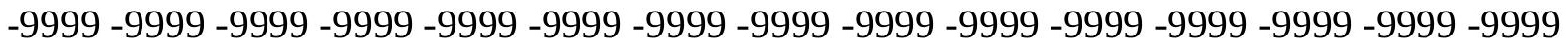

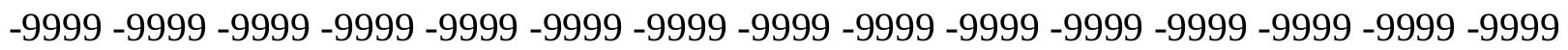
-9999 -9999 -9999 -9999 -9999 -9999 -9999 -9999 -9999 -9999 -9999 -9999 -9999 -9999 -9999 -9999 -9999 -9999 -9999 -9999 -9999 -9999 -9999 -9999 -9999 -9999 -9999 -9999 -9999 -9999 -9999 -9999 -9999 -9999 -9999 -9999 -9999 -9999 -9999 -9999 -9999 -9999-9999 -9999 -9999 -9999 -9999 -9999 -9999 -9999 -9999 -9999 -9999 -9999 -9999 -9999 -9999 -9999 -9999 -9999 -

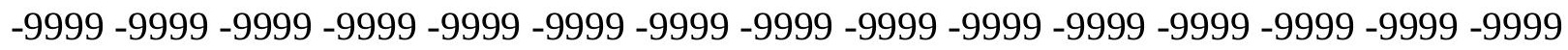
-9999 -9999 -9999 -9999 -9999 -9999 -9999 -9999 -9999 -9999 -9999 -9999 -9999 -9999 -9999 -9999 -9999 -9999 -9999 -9999 -9999 -9999 -9999 -9999 -9999 -9999 -9999 -9999 -9999 -9999 -

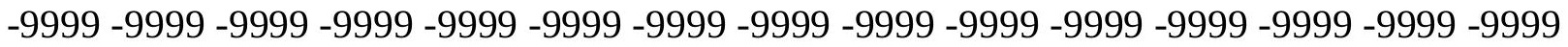

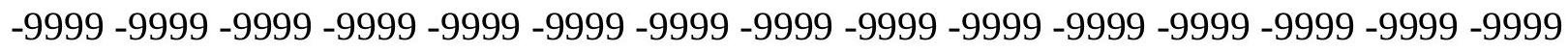

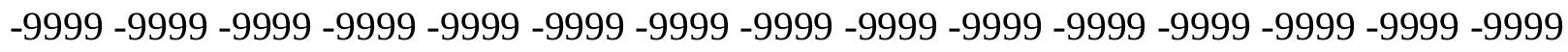
-9999 -9999 -9999 -9999 -9999 -9999 -9999 -9999 -9999 -9999 -9999 -9999 -9999 -9999 -9999 -9999 -9999 -9999 -9999 -9999 -9999 -9999 -9999 -9999 -9999 -9999 -9999 -9999 -9999 -9999 -

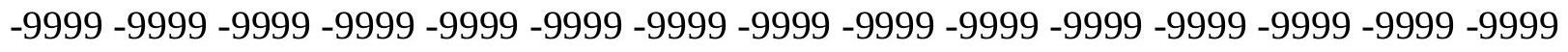
-9999 -9999-9999 145.9920959473144.1634063721 142.0299072266139.8963928223 138.0677032471136 .2389984131109 .3248062134108 .3375015259107 .3594894409 106.3949356079105 .4454650879104 .51059722999 .012969970798 .48258972168 97.9655685424897 .4620437622196 .971954345796 .4953842163196 .03225708008 95.5826492309695 .1464920043994 .4223175048892 .9663543701291 .33390045166 
89.5122375488387 .4733276367285 .0350494384882 .5967712402381 .07285308838 79.5489196777378 .3297805786177 .4154205322376 .5010681152375 .58670806885 74.9771423339874 .3675689697373 .7580032348673 .1484298706172 .84364318848 72.2340774536171 .9292907714871 .6244964599671 .6244964599671 .31971740723 71.3197174072371 .3197174072371 .3197174072371 .3197174072371 .62449645996 71.9292907714871 .9292907714872 .2340774536172 .5388565063572 .84364318848 73.4532165527373 .7580032348674 .062782287674 .6723632812574 .97714233398 75.5867080688576 .1962814331176 .8058471679777 .110626220777 .72020721436 78.3297805786178 .9393463134879 .5489196777379 .8537063598680 .46327209473 80.7680587768681 .3776321411181 .6824111938581 .9871978759882 .29197692871 82.5967712402382 .5967712402382 .9015579223682 .8592910766682 .52791595459 83.2063369751 82.42977142334 81.2748413085982.9015579223682.59677124023 82.5967712402382 .2919769287181 .9871978759881 .6824111938581 .37763214111 81.0728530883880 .7680587768680 .1584930419979 .8537063598679 .24413299561 78.9393463134878 .3297805786178 .0249862670977 .4154205322376 .80584716797 76.1962814331175 .3312683105573 .9823913574272 .18901062012 -9999 -9999 -9999 -9999 -9999 -9999 -9999 -9999 -9999 -9999 -9999 -9999 -9999 -9999 -9999 -9999 -9999 -9999 -9999 -9999 -9999 -9999 -9999 -9999 -9999 -9999 -9999 -9999 -9999 -9999 -9999 -9999 -9999 -9999 -9999 -9999 -9999 -9999 -9999 -9999 -9999 -9999 -9999

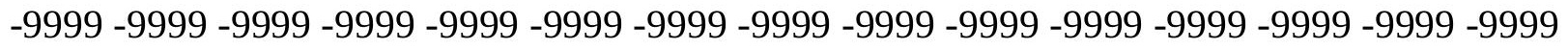

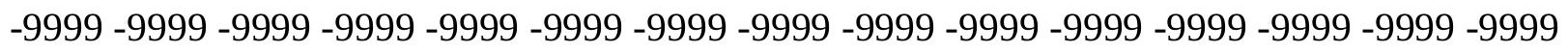

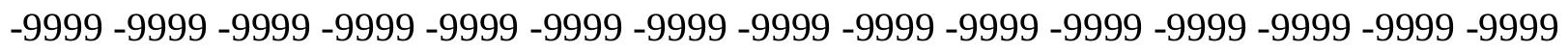
-9999 -9999 -9999 -9999 -9999 -9999 -9999 -9999 -9999 -9999 -9999 -9999 -9999 -9999 -9999 -

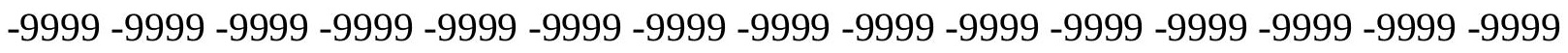

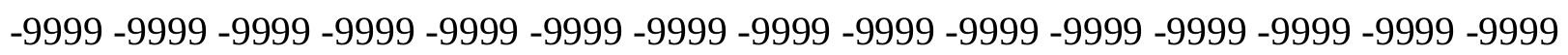
-9999 -9999 -9999 -9999 -9999 -9999 -9999 -9999 -9999 -9999 -9999 -9999 -9999 -9999 -9999 -9999 -9999 -9999 -9999 -9999 -9999 -9999 -9999 -9999 -9999 -9999 -9999 -9999 - -9999 - -9999 -

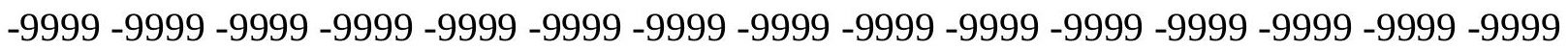

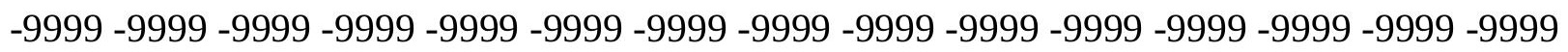

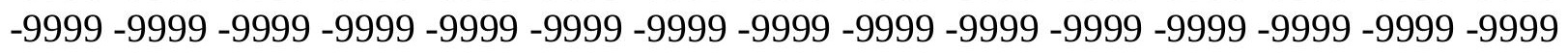
-9999 -9999 -9999 -9999 -9999 -9999 -9999 -9999 -9999 -9999 -9999 -9999 -9999 -9999 -9999

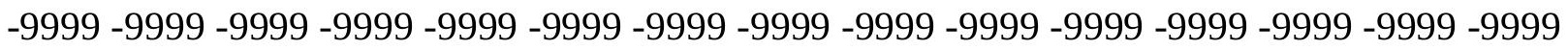

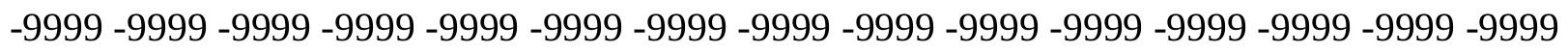

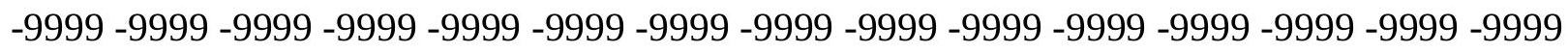

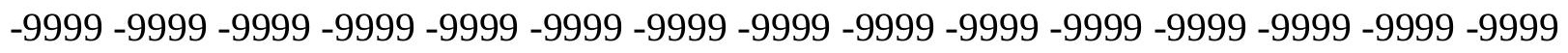
-9999 -9999-9999 146.6015930176144.7729034424142.9441986084142.6394042969 139.2868041992137 .4580993652135 .9342041016108 .4456100464107 .4625320435 106.4937820435105 .5406570435104 .6025390625103 .677314758398 .62465667725 98.1067657470797 .6027297973697 .112442016696 .6359176635796 .17301177979 95.7237243652395 .2879104614394 .4875411987393 .0252609252991 .383934021 89.5476455688587 .4733276367284 .7302627563582 .5967712402380 .76805877686 79.2441329956177 .7202072143676 .8058471679775 .8914871215874 .97714233398 74.3675689697373 .4532165527373 .1484298706172 .5388565063572 .23407745361 71.9292907714871 .6244964599671 .3197174072371 .3197174072371 .31971740723 71.014930725171 .3197174072371 .3197174072371 .6244964599671 .62449645996 71.9292907714872 .2340774536172 .5388565063573 .1484298706173 .45321655273 
73.7580032348674 .3675689697374 .6723632812575 .2819290161175 .89148712158 76.5010681152377 .110626220777 .4154205322378 .0249862670978 .63455963135 79.2441329956179 .8537063598680 .1584930419980 .7680587768681 .07285308838 81.3776321411181 .9871978759882 .2919769287182 .5967712402382 .59677124023 82.9015579223682 .9015579223683 .1202392578183 .1171035766682 .80899047852 83.206336975182 .4219741821382 .9015579223682 .9015579223682 .59677124023 82.2919769287182 .2919769287181 .9871978759881 .6824111938581 .37763214111 80.7680587768680 .4632720947380 .1584930419979 .5489196777379 .24413299561 78.6345596313578 .0249862670977 .7202072143677 .110626220776 .50106811523 75.8914871215874 .8889923095773 .5066986084 -9999 -9999 -9999 -9999 -9999 -9999 -9999 -9999 -9999 -9999 -9999 -9999 -9999 -9999 -9999 -9999 -9999 -9999 -9999 -9999 -9999 -9999 -9999 -9999 -9999 -9999 -9999-9999 -9999

-9999 -9999 -9999 -9999 -9999 -9999 -9999 -9999 -9999 -9999 -9999 -9999 -9999 -9999 -9999 -9999 -9999 -9999 -9999 -9999 -9999 -9999 -9999 -9999 -9999 -9999 -9999 -9999 -9999 -9999 -9999 -9999 -9999 -9999 -9999 -9999 -9999 -9999 -9999 -9999 -9999 -9999 -9999 -9999 -9999

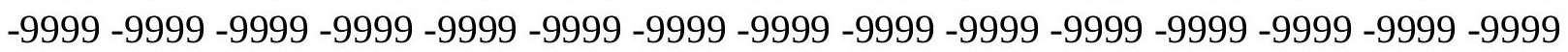

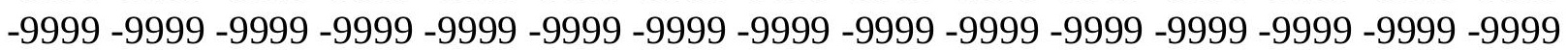
-9999 -9999 -9999 -9999 -9999 -9999 -9999 -9999 -9999 -9999 -9999 -9999 -9999 -9999 -9999 -999 -9999 -9999 -9999 -9999 -9999 -9999 -9999 -9999 -9999 -9999 -9999 -9999 -9999 -9999 -9999 -9999 -9999 -9999 -9999 -9999 -9999 -9999 -9999 -9999 -9999 -9999 -9999 -9999 -9999 -9999 -9999 -9999 -9999 -9999 -9999 -9999 -9999 -9999 -9999 -9999 -9999 -9999 -9999 -9999 -9999 -9999 -9999 -9999 -9999 -9999 -9999 -9999 -9999 -9999 -9999 -9999 -9999 -9999 -9999 -9999 -9999 -9999 -9999 -9999 -9999 -9999 -9999 -9999 -9999 -9999 -9999 -9999 -9999 -9999 -9999 -9999 -9999 -9999 -9999 -9999 -9999 -9999 -9999 -9999 -9999 -9999 -9999 -9999 -9999 -9999 -9999 -9999 -9999 -9999 -9999 -9999 -9999 -9999 -9999 -9999 -9999 -9999 -9999 -9999 -9999 -9999 -9999 -9999 -9999 -9999 -9999 -9999 -9999 -9999 -9999 -9999 -9999 -9999 -9999 -9999 -9999 -9999 -9999 -9999 -9999 -9999 -9999 -9999 -9999 -9999 -9999 -9999 -9999 -9999 -9999

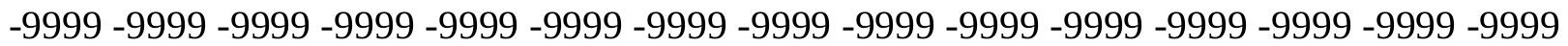
-9999 -9999 -9999 -9999 -9999 -9999 -9999 -9999 -9999 -9999 -9999 -9999 -9999 -9999 -9999 -9999 -9999 -9999 -9999 145.6873016357 143.8585968018142 .3347015381142 .0299072266 140.5059967041137 .1533050537108 .5474624634107 .5590744019106 .5858459473 105.6287765503104 .6870956421103 .758728027398 .7604522705198 .24156951904 97.73693084717 97.2463760376 96.7698516845796.3071517944395.85819244385 95.4227294921994 .5562973022593 .0773773193491 .3879318237389 .44255065918 87.1685485839884 .4254837036182 .2919769287180 .1584930419978 .63455963135 77.4154205322376 .1962814331175 .2819290161174 .3675689697373 .45321655273 72.8436431884872 .5388565063571 .9292907714871 .6244964599671 .31971740723 71.3197174072371 .014930725171 .014930725171 .014930725171 .0149307251 71.014930725171 .3197174072371 .6244964599671 .9292907714872 .23407745361 72.5388565063572 .8436431884873 .4532165527373 .7580032348674 .36756896973 74.9771423339875 .2819290161175 .8914871215876 .5010681152377 .1106262207 77.7202072143678 .3297805786178 .9393463134879 .5489196777380 .15849304199 80.4632720947381 .0728530883881 .3776321411181 .9871978759882 .29197692871 82.5967712402382 .5967712402382 .9015579223683 .1536788940483 .2063369751 83.2063369751 83.2063369751 83.2063369751 82.98717498779 83.2063369751 82.3566284179782.90155792236 82.90155792236 82.59677124023 82.29197692871 
81.9871978759881 .6824111938581 .3776321411181 .0728530883880 .76805877686 80.1584930419979 .8537063598679 .2441329956178 .9393463134878 .32978057861 78.0249862670977 .4154205322376 .8058471679776 .1962814331175 .58670806885 74.5183944702173 .09952545166 -9999 -9999 -9999 -9999 -9999 -9999 -9999 -9999 -9999 -9999 -9999 -9999 -9999 -9999 -9999 -9999 -9999 -9999 -9999 -9999 -9999 -9999 -9999 -9999 -9999 -9999 -9999-9999-9999

-9999 -9999 -9999 -9999 -9999 -9999 -9999 -9999 -9999 -9999 -9999 -9999 -9999 -9999 -9999 -9999 -9999 -9999 -9999 -9999 -9999 -9999 -9999 -9999 -9999 -9999 -9999 -9999 -9999 -9999 -9999 -9999 -9999 -9999 -9999 -9999 -9999 -9999 -9999 -9999 -9999 -9999 -9999 -9999 -9999

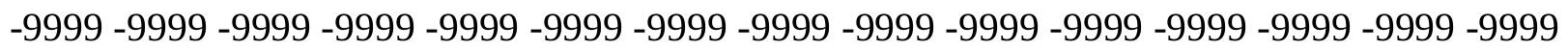
-9999 -9999 -9999 -9999 -9999 -9999 -9999 -9999 -9999 -9999 -9999 -9999 -9999 -9999 -9999 -999 -9999 -9999 -9999 -9999 -9999 -9999 -9999 -9999 -9999 -9999 -9999 -9999 -9999 -9999 -9999 -9999 -9999 -9999 -9999 -9999 -9999 -9999 -9999 -9999 -9999 -9999 -9999 -9999 -9999 -9999 -9999 -9999 -9999 -9999 -9999 -9999 -9999 -9999 -9999 -9999 -9999 -9999 -9999 -9999 -9999 -9999 -9999 -9999 -9999 -9999 -9999 -9999 -9999 -9999 -9999 -9999 -9999 -9999 -9999 -9999

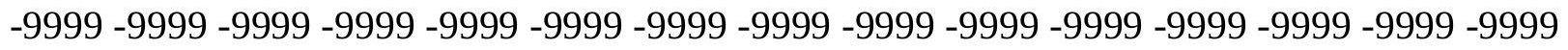

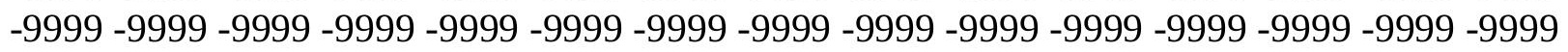

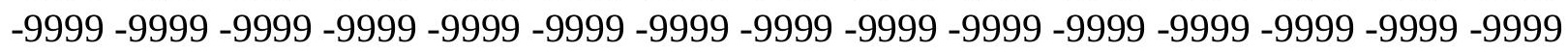

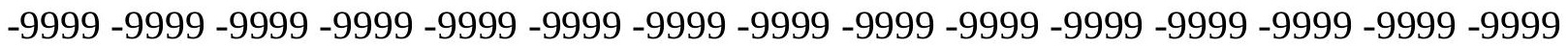

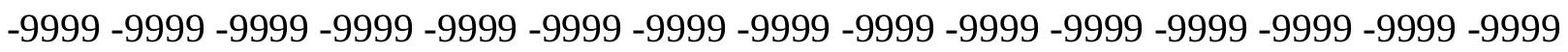

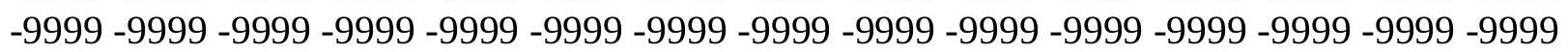

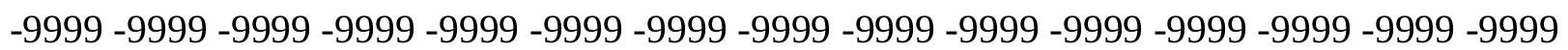
-9999 -9999 -9999 -9999 -9999 -9999 -9999 -9999 -9999 -9999 -9999 -9999 -9999 -9999 -9999 -9999 -9999 -9999 -9999 146.2969055176 144.7729034424143.5538024902 143.5538024902 142.0299072266140 .5059967041138 .6772003174107 .6508636475106 .6725463867 105.7108840942104 .7650299072103 .8329620361102 .911689758398 .37009429932 97.8647384643697 .3738479614396 .8973083496196 .4348297119195 .98623657227 95.551193237394.6125717163193.1111984252991.36455535889 89.30420684814 86.8637619018684 .4254837036181 .9871978759879 .8537063598678 .32978057861 76.8058471679775 .5867080688574 .6723632812573 .7580032348673 .14842987061 72.5388565063571 .9292907714871 .6244964599671 .3197174072371 .0149307251 71.014930725170 .7101516723670 .7101516723670 .7101516723671 .0149307251 71.014930725171 .3197174072371 .6244964599671 .9292907714872 .23407745361 72.8436431884873 .1484298706173 .7580032348674 .3675689697374 .67236328125 75.2819290161175 .8914871215876 .5010681152377 .110626220778 .02498626709 78.6345596313579 .2441329956179 .8537063598680 .4632720947381 .07285308838 81.3776321411181 .9871978759882 .2919769287182 .5967712402382 .90155792236 82.9015579223683 .206336975183 .5111236572383 .5111236572383 .51112365723 83.5111236572383 .5089035034283 .4126815795983 .1387252807682 .65825653076 82.26177215576 82.90155792236 82.90155792236 82.59677124023 82.29197692871 81.9871978759881 .6824111938581 .3776321411180 .7680587768680 .46327209473 80.1584930419979 .5489196777378 .9393463134878 .6345596313578 .02498626709 77.7202072143677 .110626220776 .5010681152375 .8914871215875 .28192901611 74.1798629760772 .71478271484 -9999 -9999 -9999 -9999 -9999 -9999 -9999 -9999 -9999 -9999 -9999 -9999 -9999 -9999 -9999 -9999 -9999 -9999 -9999 -9999 -9999 -9999 -9999 -9999 -9999 -9999 -9999 -9999 -9999 
-9999 -9999 -9999 -9999 -9999 -9999 -9999 -9999 -9999 -9999 -9999 -9999 -9999 -9999 -9999 -9999 -9999 -9999 -9999 -9999 -9999 -9999 -9999 -9999 -9999 -9999 -9999 -9999 -9999 -9999 -9999 -9999 -9999 -9999 -9999 -9999 -9999 -9999 -9999 -9999 -9999 -9999 -9999 -9999 -9999 -9999 -9999 -9999 -9999 -9999 -9999 -9999 -9999 -9999 -9999 -9999 -9999 -9999 -9999 -9999 -9999 -9999 -9999 -9999 -9999 -9999 -9999 -9999 -9999 -9999 -9999 -9999 -9999 -9999 -9999 -9999 -9999 -9999 -9999 -9999 -9999 -9999 -9999 -9999 -9999 -9999 -9999 -9999 -9999 -9999 -9999 -9999 -9999 -9999 -9999 -9999 -9999 -9999 -9999 -9999 -9999 -9999 -9999 -9999 -9999

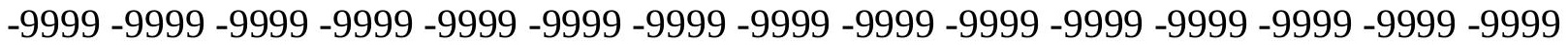
-9999 -9999 -9999 -9999 -9999 -9999 -9999 -9999 -9999 -9999 -9999 -9999 -9999 -9999 -9999 -9999 -9999 -9999 -9999 -9999 -9999 -9999 -9999 -9999 -9999 -9999 -9999 -9999 -9999 -9999 -9999 -9999 -9999 -9999 -9999 -9999 -9999 -9999 -9999 -9999 -9999 -9999 -9999 -9999 -9999 -9999 -9999 -9999 -9999 -9999 -9999 -9999 -9999 -9999 -9999 -9999 -9999 -9999 -9999 -9999

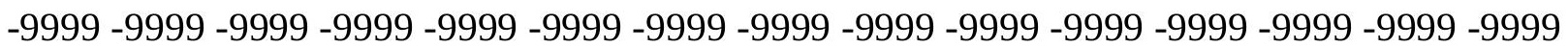
-9999 -9999 -9999 -9999 -9999 -9999 -9999 -9999 -9999 -9999 -9999 -9999 -9999 -9999 -9999 -9999 -9999 -9999 -9999 -9999 -9999 -9999 -9999 -9999 -9999 -9999 -9999 -9999 -9999 -9999

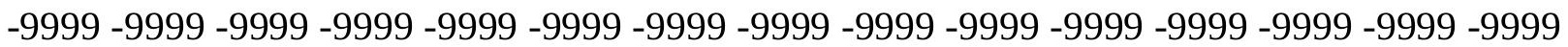
-9999 -9999 -9999 -9999 -9999 -9999 -9999 -9999 -9999 -9999 -9999 -9999 -9999 -9999 -9999 -9999 -9999 -9999 -9999 -9999 145.6873016357 144.4682006836 144.7729034424 143.5538024902142 .3347015381140 .8106994629138 .9819946289106 .7551040649 105.7878723145104 .8369293213103 .9003372192102 .97518920998 .49238586426 97.9861755371197 .4948654174897 .0182876586996 .5560607910296 .10791778564 95.6734237670994 .6470947265693 .1237640380991 .3471527099689 .26835632324 86.8637619018684 .1206970214881 .6824111938579 .5489196777377 .72020721436 76.5010681152374 .9771423339874 .062782287673 .1484298706172 .53885650635 71.9292907714871 .6244964599671 .3197174072371 .014930725170 .71015167236 70.7101516723670 .7101516723670 .7101516723670 .7101516723671 .0149307251 71.014930725171 .3197174072371 .6244964599672 .2340774536172 .53885650635 73.1484298706173 .4532165527374 .062782287674 .6723632812575 .28192901611 75.8914871215876 .5010681152377 .110626220778 .0249862670978 .63455963135 79.2441329956179 .8537063598680 .7680587768681 .3776321411181 .68241119385 82.2919769287182 .5967712402382 .9015579223683 .206336975183 .51112365723 83.5111236572383 .8159103393683 .8159103393683 .8159103393683 .81591033936 83.7817230224683 .6858596801883 .5111236572383 .2593307495182 .79187774658 82.1814193725682 .9015579223682 .5967712402382 .2919769287181 .98719787598 81.6824111938581 .3776321411181 .0728530883880 .4632720947380 .15849304199 79.8537063598679 .2441329956178 .9393463134878 .3297805786177 .72020721436 77.110626220776 .8058471679776 .1962814331175 .5867080688574 .97714233398 73.8298339843872 .32501220703 -9999 -9999 -9999 -9999 -9999 -9999 -9999 -9999 -9999 -9999 -9999 -9999 -9999 -9999 -9999 -9999 -9999 -9999 -9999 -9999 -9999 -9999 -9999 -9999 $-9999-9999-9999-9999-9999$ -9999 -9999 -9999 -9999 -9999 -9999 -9999 -9999 -9999 -9999 -9999 -9999 -9999 -9999 -9999

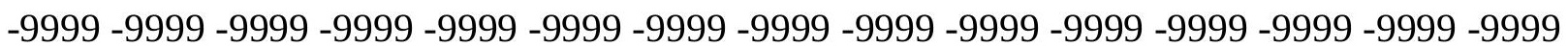
-9999 -9999 -9999 -9999 -9999 -9999 -9999 -9999 -9999 -9999 -9999 -9999 -9999 -9999 -9999 -9999 -9999 -9999 -9999 -9999 -9999 -9999 -9999 -9999 -9999 -9999 -9999 -9999 -9999 -9999 -9999 -9999 -9999 -9999 -9999 -9999 -9999 -9999 -9999 -9999 -9999 -9999 -9999 -9999 -9999

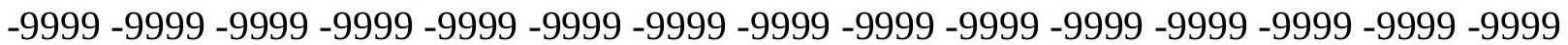


-9999 -9999 -9999 -9999 -9999 -9999 -9999 -9999 -9999 -9999 -9999 -9999 -9999 -9999 -9999 -9999 -9999 -9999 -9999 -9999 -9999 -9999 -9999 -9999 -9999 -9999 -9999 -9999 -9999 -9999 -9999 -9999 -9999 -9999 -9999 -9999 -9999 -9999 -9999 -9999 -9999 -9999 -9999 -9999 -9999 -9999 -9999 -9999 -9999 -9999 -9999 -9999 -9999 -9999 -9999 -9999 -9999 -9999 -9999 -9999 -9999 -9999 -9999 -9999 -9999 -9999 -9999 -9999 -9999 -9999 -9999 -9999 -9999 -9999 -9999 -9999 -9999 -9999 -9999 -9999 -9999 -9999 -9999 -9999 -9999 -9999 -9999 -9999 -9999 -9999 -9999 -9999 -9999 -9999 -9999 -9999 -9999 -9999 -9999 -9999 -9999 -9999 -9999 -9999 -9999

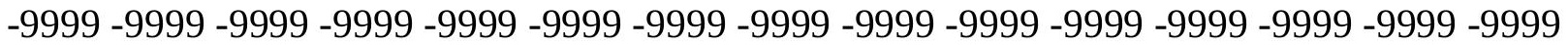

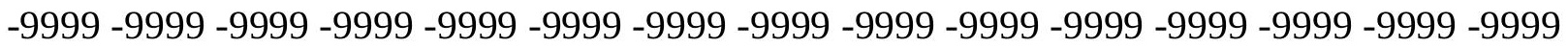
-9999 -9999 -9999 -9999 -9999 -9999 -9999 -9999 -9999 -9999 -9999 -9999 -9999 -9999 -9999 -9999 -9999 -9999 -9999 -9999 -9999 -9999 -9999 -9999 -9999 -9999 -9999 -9999 -9999 -9999 -9999 -9999 -9999 -9999 -9999 146.6015930176145.6873016357 146.2969055176 145.3825073242144 .1634063721142 .9441986084141 .4203033447106 .8339157104 105.8601455688104 .9031295776103 .9611129761103 .0312423706102 .1084976196 98.101287841897 .6094436645597 .1327819824296 .6708450317496 .22328186035 95.7895431518694 .6581344604593 .117889404391 .3217468261789 .23901367188 86.8637619018683 .8159103393681 .3776321411179 .2441329956177 .41542053223 75.8914871215874 .6723632812573 .7580032348672 .8436431884872 .23407745361 71.6244964599671 .3197174072371 .014930725170 .7101516723670 .40535736084 70.4053573608470 .4053573608470 .4053573608470 .7101516723671 .0149307251 71.3197174072371 .6244964599671 .9292907714872 .2340774536172 .84364318848 73.1484298706173 .7580032348674 .3675689697374 .9771423339875 .58670806885 76.5010681152377 .110626220777 .7202072143678 .6345596313579 .24413299561 80.1584930419980 .7680587768681 .3776321411181 .9871978759882 .59677124023 82.9015579223683 .5111236572383 .5111236572383 .8159103393684 .12069702148 84.1206970214884 .1206970214884 .1206970214884 .1206970214884 .12069702148 83.9823455810583 .8159103393683 .6587219238383 .417266845782 .8928604126 82.0458526611382 .9015579223682 .5967712402382 .2919769287181 .98719787598 81.6824111938581 .0728530883880 .7680587768680 .4632720947379 .85370635986 79.5489196777378 .9393463134878 .3297805786178 .0249862670977 .41542053223 76.8058471679776 .1962814331175 .8914871215875 .2819290161174 .67236328125 73.40520477295 -9999 -9999 -9999 -9999 -9999 -9999 -9999 -9999 -9999 -9999 -9999 -9999 -9999 -9999 -9999 -9999 -9999 -9999 -9999 -9999 -9999 -9999 -9999 -9999 -9999 -9999 -9999 -9999 -9999-9999 -9999 -9999 -9999 -9999 -9999 -9999 -9999 -9999 -9999 -9999 -9999 -9999 -9999 -9999 -9999 -9999 -9999 -9999 -9999 -9999 -9999 -9999 -9999 -9999 -9999 -9999 -9999 -9999 -9999 -9999

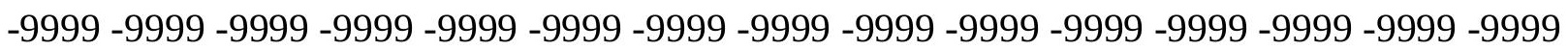

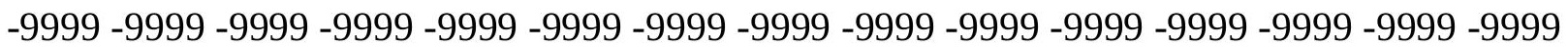
-9999 -9999 -9999 -9999 -9999 -9999 -9999 -9999 -9999 -9999 -9999 -9999 -9999 -9999 -9999 -9999 -9999 -9999 -9999 -9999 -9999 -9999 -9999 -9999 -9999 -9999 -9999 -9999 -9999 -9999 -9999 -9999 -9999 -9999 -9999 -9999 -9999 -9999 -9999 -9999 -9999 -9999 -9999 -9999 -9999

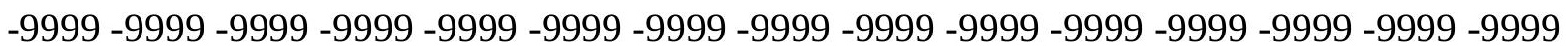
-9999 -9999 -9999 -9999 -9999 -9999 -9999 -9999 -9999 -9999 -9999 -9999 -9999 -9999 -9999 -9999 -9999 -9999 -9999 -9999 -9999 -9999 -9999 -9999 -9999 -9999 -9999 -9999 -9999 -9999 -9999 -9999 -9999 -9999 -9999 -9999 -9999 -9999 -9999 -9999 -9999 -9999 -9999 -9999 -9999

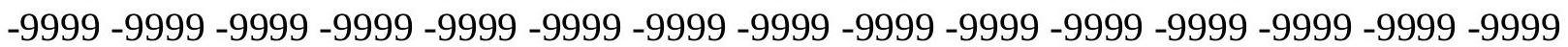


-9999 -9999 -9999 -9999 -9999 -9999 -9999 -9999 -9999 -9999 -9999 -9999 -9999 -9999 -9999 -9999 -9999 -9999 -9999 -9999 -9999 -9999 -9999 -9999 -9999 -9999 -9999 -9999 -9999 -9999

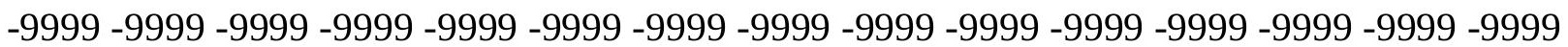
-9999 -9999 -9999 -9999 -9999 -9999 -9999 -9999 -9999 -9999 -9999 -9999 -9999 -9999 -9999 -9999 -9999 -9999 -9999 -9999 -9999 -9999 -9999 -9999 -9999 -9999 -9999 -9999 -9999 -9999 -9999 -9999 -9999 -9999-9999-9999 146.6015930176145 .9920959473146 .9064025879 145.9920959473145 .0776977539143 .8585968018142 .3347015381105 .9275665283 104.9636611938104 .0154418945103 .0801010132102 .152511596798 .20995330811 97.7174148559697 .2406082153396 .7789993286196 .3321609497195 .89942932129 94.6479568481493 .092910766691 .2785186767689 .1310424804786 .55898284912 83.8159103393681 .0728530883878 .9393463134877 .110626220775 .58670806885 74.3675689697373 .4532165527372 .5388565063571 .9292907714871 .31971740723 71.014930725170 .7101516723670 .4053573608470 .4053573608470 .40535736084 70.4053573608470 .4053573608470 .7101516723671 .014930725171 .31971740723 71.6244964599671 .9292907714872 .5388565063573 .1484298706173 .45321655273 74.062782287674 .6723632812575 .2819290161176 .1962814331176 .80584716797 77.4154205322378 .3297805786179 .2441329956179 .8537063598680 .76805877686 81.3776321411182 .2919769287182 .9015579223683 .206336975183 .81591033936 84.1206970214884 .4254837036184 .4254837036184 .4254837036184 .42548370361 84.4254837036184 .4254837036184 .4254837036184 .4254837036184 .12069702148 83.9787368774483 .7549209594783 .4700927734482 .9656219482481 .6664276123 82.9015579223682 .2919769287181 .9871978759881 .6824111938581 .37763214111 81.0728530883880 .4632720947380 .1584930419979 .5489196777379 .24413299561 78.6345596313578 .0249862670977 .7202072143677 .110626220776 .50106811523 75.8914871215875 .2819290161174 .6723632812574 .0000610351672 .86605834961 -9999 -9999 -9999 -9999 -9999 -9999 -9999 -9999 -9999 -9999 -9999 -9999 -9999 -9999 -9999 -9999 -9999 -9999 -9999 -9999 -9999 -9999 -9999 -9999 -9999 -9999 -9999 -9999 -9999 -9999 -9999 -9999 -9999 -9999 -9999 -9999 -9999 -9999 -9999 -9999 -9999 -9999 -9999 -9999 -9999 -9999 -9999 -9999 -9999 -9999 -9999 -9999 -9999 -9999 -9999 -9999 -9999 -9999 -9999 -9999 -9999 -9999 -9999 -9999 -9999 -9999 -9999 -9999 -9999 -9999 -9999 -9999 -9999 -9999 -9999 -9999 -9999 -9999 -9999 -9999 -9999 -9999 -9999 -9999 -9999 -9999 -9999 -9999 -9999 -9999 -9999 -9999 -9999 -9999 -9999 -9999 -9999 -9999 -9999 -9999 -9999 -9999 -9999 -9999 -9999 -9999 -9999 -9999 -9999 -9999 -9999 -9999 -9999 -9999 -9999 -9999 -9999 -9999 -9999 -9999 -9999 -9999 -9999 -9999 -9999 -9999 -9999 -9999 -9999 -9999 -9999 -9999 -9999 -9999 -9999 -9999 -9999 -9999 -9999 -9999 -9999 -9999 -9999 -9999 -9999 -9999 -9999 -9999 -9999 -9999 -9999 -9999 -9999 -9999 -9999 -9999 -9999 -9999 -9999 -9999 -9999 -9999 -9999 -9999 -9999

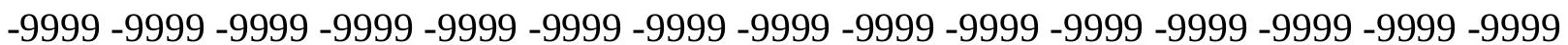

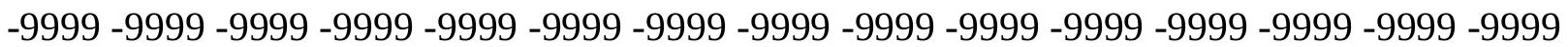
-9999 -9999 -9999 -9999 -9999 -9999 -9999 -9999 -9999 -9999 -9999 -9999 -9999 -9999 -9999 -9999 -9999 -9999 -9999 -9999 -9999 -9999 -9999 -9999 -9999 -9999 -9999 -9999 -9999 -9999 -9999 -9999 -9999 -9999 -9999 -9999 -9999 -9999 -9999 -9999 -9999 -9999 -9999 -9999 -9999

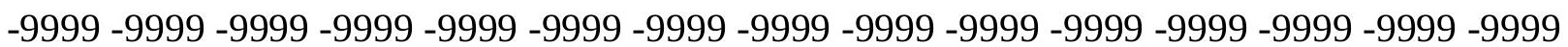
-9999 -9999 -9999 -9999 -9999 -9999 -9999 -9999 -9999 -9999 -9999 -9999 -9999 -9999 -9999 -9999 -9999 -9999 -9999 -9999 -9999 -9999 -9999 -9999 -9999 -9999 -9999 -9999 -9999 -9999 -9999 -9999 -9999 -9999 -9999 -9999 147.8208007812 147.2111968994 146.6015930176 147.5160064697146 .9064025879145 .9920959473145 .0776977539105 .9899291992 
105.0184936523104 .0635299683103 .1222839355102 .189544677798 .31201171875 97.8185653686597 .3414993286196 .8802413940496 .4342803955195 .99439239502 94.6255035400493 .0483703613391 .2143936157289 .0699310302786 .55898284912 83.5111236572381 .0728530883878 .9393463134877 .110626220775 .58670806885 74.3675689697373 .1484298706172 .2340774536171 .6244964599671 .0149307251 70.7101516723670 .4053573608470 .4053573608470 .1005783081170 .10057830811 70.4053573608470 .4053573608470 .7101516723671 .014930725171 .31971740723 71.6244964599672 .2340774536172 .8436431884873 .1484298706173 .75800323486 74.3675689697374 .9771423339875 .8914871215876 .5010681152377 .1106262207 78.0249862670978 .9393463134879 .5489196777380 .4632720947381 .37763214111 81.9871978759882 .9015579223683 .5111236572384 .1206970214884 .42548370361 84.7302627563584 .7302627563585 .0350494384885 .0350494384885 .03504943848 85.0350494384884 .7302627563584 .7302627563584 .4254837036184 .42548370361 84.1206970214883 .8127593994183 .48159027182 .9738693237381 .19876098633 82.5967712402382 .2919769287181 .9871978759881 .3776321411181 .07285308838 80.7680587768680 .1584930419979 .8537063598679 .2441329956178 .63455963135 78.32978057861 77.72020721436 77.1106262207 76.50106811523 76.19628143311 $75.5867080688574 .9771423339874 .3675689697373 .4340591430772 .30267333984-9999$ -9999 -9999 -9999 -9999 -9999 -9999 -9999 -9999 -9999 -9999 -9999 -9999 -9999 -9999 -9999 -9999 -9999 -9999 -9999 -9999 -9999 -9999 -9999 -9999 -9999 -9999 -9999 -9999 -9999 -9999 -9999 -9999 -9999 -9999 -9999 -9999 -9999 -9999 -9999 -9999 -9999 -9999 -9999 -9999 -9999 -9999 -9999 -9999 -9999 -9999 -9999 -9999 -9999 -9999 -9999 -9999 -9999 -9999 -9999 -9999 -9999 -9999 -9999 -9999 -9999 -9999 -9999 -9999 -9999 -9999 -9999 -9999 -9999 -9999 -9999 -9999 -9999 -9999 -9999 -9999 -9999 -9999 -9999 -9999 -9999 -9999 -9999 -9999 -9999 -9999 -9999 -9999 -9999 -9999 -9999 -9999 -9999 -9999 -9999 -9999 -9999 -9999 -9999 -9999 -9999 -9999 -9999 -9999 -9999 -9999 -9999 -9999 -9999 -9999 -9999 -9999 -9999 -9999 -9999 -9999 -9999 -9999 -9999 -9999 -9999 -9999 -9999 -9999 -9999 -9999 -9999 -9999 -9999 -9999 -

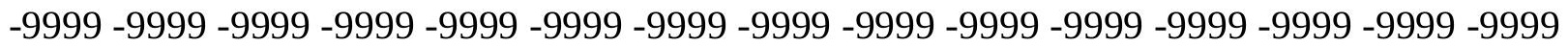
-9999 -9999 -9999 -9999 -9999 -9999 -9999 -9999 -9999 -9999 -9999 -9999 -9999 -9999 -9999 -9999 -9999 -9999 -9999 -9999 -9999 -9999 -9999 -9999 -9999 -9999 -9999 -9999 -9999 -999 -9999 -9999 -9999 -9999 -9999 -9999 -9999 -9999 -9999 -9999 -9999 -9999 -9999 -9999 -9999

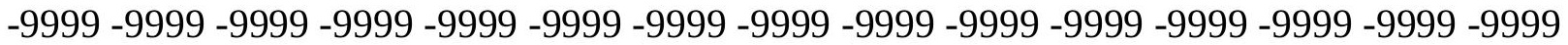
-9999 -9999 -9999 -9999 -9999 -9999 -9999 -9999 -9999-9999 -9999 -9999 -9999-9999-999 - -999 -9999 -9999 -9999 -9999 -9999 -9999 -9999 -9999 -9999 -9999 -9999 -9999 -9999 -9999 -9999 -9999 -9999 -9999 -9999 -9999 -9999 -9999 -9999 -9999 -9999 -9999 -9999 -9999 -9999 -9999 -9999 -9999 -9999 -9999 -9999 -9999 -9999 -9999 -9999 -9999 -9999 -9999 -9999 -9999 -9999

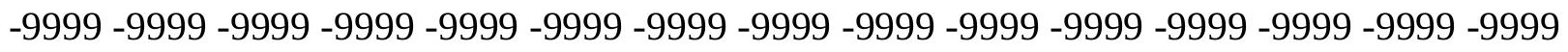
-9999 -9999-9999 -9999 -9999-9999-9999 148.1255950928 148.1255950928 147.8208007812 149.0399017334148 .4304046631147 .5160064697146 .2969055176105 .0674438477 104.10546875103 .1583251953102 .220741272101 .284126281797 .91244506836 97.4349441528396.9740066528396.5290679931695.9924011230594.60907745361 93.0136260986391 .1485519409288 .9938735961986 .5589828491283 .51112365723 81.0728530883878 .9393463134877 .110626220775 .5867080688574 .36756896973 73.1484298706172 .2340774536171 .6244964599671 .014930725170 .71015167236 70.4053573608470 .1005783081170 .1005783081170 .1005783081170 .40535736084 70.4053573608470 .7101516723671 .014930725171 .6244964599671 .92929077148 
72.5388565063572 .8436431884873 .4532165527374 .062782287674 .67236328125 75.5867080688576 .1962814331176 .8058471679777 .7202072143678 .32978057861 79.2441329956180 .1584930419981 .0728530883881 .6824111938582 .59677124023 83.5111236572384 .1206970214884 .7302627563585 .0350494384885 .3398437585 .33984375 85.3398437585 .3398437585 .3398437585 .0350494384885 .0350494384884 .73026275635 84.7302627563584 .4254837036184 .1206970214883 .8159103393683 .4595489502 82.9318389892680 .6819076538182 .5967712402381 .9871978759881 .68241119385 81.0728530883880 .7680587768680 .4632720947379 .8537063598679 .24413299561 78.9393463134878 .3297805786177 .7202072143677 .110626220776 .80584716797 76.1962814331175 .5867080688574 .9771423339874 .3675689697373 .75800323486 72.9316024780371 .79579925537 -9999 -9999 -9999 -9999 -9999 -9999 -9999 -9999 -9999 -9999 -9999 -9999 -9999 -9999 -9999 -9999 -9999 -9999 -9999 -9999 -9999 -9999 -9999 -9999 -9999 -9999 -9999-9999-9999-9999

-9999 -9999 -9999 -9999 -9999 -9999 -9999 -9999 -9999 -9999 -9999 -9999 -9999 -9999 -9999 -9999 -9999 -9999 -9999 -9999 -9999 -9999 -9999 -9999 -9999 -9999 -9999 -9999 -9999 -9999

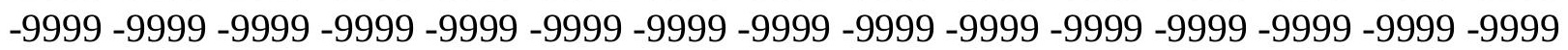

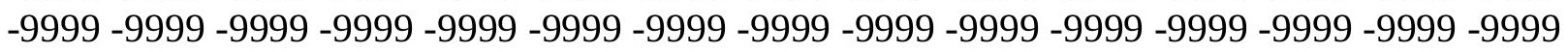
-9999 -9999 -9999 -9999 -9999 -9999 -9999 -9999 -9999 -9999 -9999 -9999 -9999 -9999 -9999 -999 -9999 -9999 -9999 -9999 -9999 -9999 -9999 -9999 -9999 -9999 -9999 -9999 -9999 -9999 -9999 -9999 -9999 -9999 -9999 -9999 -9999 -9999 -9999 -9999 -9999 -9999 -9999 -9999 -9999 -9999 -9999 -9999 -9999 -9999 -9999 -9999 -9999 -9999 -9999 -9999 -9999 -9999 -9999 -9999 -9999 -9999 -9999 -9999 -9999 -9999 -9999 -9999 -9999 -9999 -9999 -9999 -9999 -9999 -9999 -9999 -9999 -9999 -9999 -9999 -9999 -9999 -9999 -9999 -9999 -9999 -9999 -9999-9999-9999-9999 -999 -9999 -9999 -9999 -9999 -9999 -9999 -9999 -9999 -9999 -9999 -9999 -9999 -9999 -9999 -9999 -9999 -9999 -9999 -9999 -9999 -9999 -9999 -9999 -9999 -9999 -9999 -9999 -9999 -9999 -9999 -9999 -9999 -9999 -9999 -9999 -9999 -9999 -9999 -9999 -9999 -9999 -9999 -9999 -9999 -9999 -9999 -9999 -9999 -9999 -9999 -9999 -9999 -9999 -9999 -9999 -9999 -9999 -9999 -9999 -9999

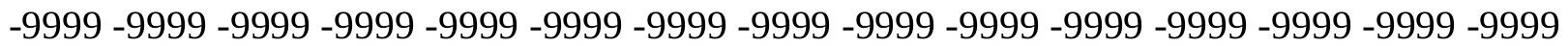
-9999 -9999 -9999 -9999 -9999 -9999 -9999 -9999 -9999 -9999 -9999 -9999 -9999 -9999 -9999 -9999 -9999 -9999 -9999 -9999 -9999 -9999 -9999 -9999 -9999 -9999 -9999 -9999 -9999 -9999 -9999 -9999 -9999 -9999 -9999 -9999-9999 -9999 149.0399017334149 .0399017334 149.0399017334150 .5639038086149 .9542999268149 .3446960449105 .1102523804 104.1413574219 103.1887893677 102.2473983765 101.308563232497.99845123291 97.5202789306697 .0595932006896 .6158218383896 .0131912231494 .62357330322 93.0158920288191 .1350555419988 .9255599975686 .3369445800883 .51112365723 81.0728530883878 .9393463134877 .110626220775 .5867080688574 .36756896973 73.1484298706172 .2340774536171 .6244964599671 .014930725170 .71015167236 70.4053573608470 .4053573608470 .1005783081170 .4053573608470 .40535736084 70.7101516723671 .014930725171 .3197174072371 .6244964599672 .23407745361 72.5388565063573 .1484298706173 .7580032348674 .3675689697374 .97714233398 75.8914871215876 .5010681152377 .110626220778 .0249862670978 .93934631348 79.5489196777380 .4632720947381 .3776321411182 .2919769287182 .90155792236 83.8159103393684 .7302627563585 .3398437585 .3398437585 .6446228027385 .64462280273 85.6446228027385 .6446228027385 .3398437585 .3398437585 .0350494384884 .73026275635 84.7302627563584 .4254837036184 .1206970214883 .8159103393683 .36835479736 82.8157653808680 .2037582397582 .2919769287181 .6824111938581 .37763214111 
80.7680587768680 .4632720947379 .8537063598679 .5489196777378 .93934631348 78.3297805786178 .0249862670977 .4154205322376 .8058471679776 .19628143311 75.5867080688574 .9771423339874 .3675689697374 .062782287673 .45321655273

72.4546737670971 .28298187256 -9999 -9999 -9999 -9999 -9999 -9999 -9999 -9999 -9999 -9999 -9999 -9999 -9999 -9999 -9999 -9999 -9999 -9999 -9999 -9999 -9999 -9999 -9999 -9999 -9999 -9999 -9999-9999-9999-9999

-9999 -9999 -9999 -9999 -9999 -9999 -9999 -9999 -9999 -9999 -9999 -9999 -9999 -9999 -9999

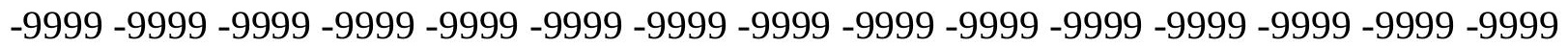
-9999 -9999 -9999 -9999 -9999 -9999 -9999 -9999 -9999 -9999 -9999 -9999 -9999 -9999 -9999 -9999 -9999 -9999 -9999 -9999 -9999 -9999 -9999 -9999 -9999 -9999 -9999 -9999 -9999 -9999 -9999 -9999 -9999 -9999 -9999 -9999 -9999 -9999 -9999 -9999 -9999 -9999 -9999 -9999 -9999 -9999 -9999 -9999 -9999 -9999 -9999 -9999 -9999 -9999 -9999 -9999 -9999 -9999 -9999 -9999 -9999 -9999 -9999 -9999 -9999 -9999 -9999 -9999 -9999 -9999 -9999 -9999 -9999 -9999 -9999 -9999 -9999 -9999 -9999 -9999 -9999 -9999 -9999 -9999 -9999 -9999 -9999 -9999 -9999 -9999 -9999 -9999 -9999 -9999 -9999 -9999 -9999 -9999 -9999 -9999 -9999 -9999 -9999 -9999 -9999

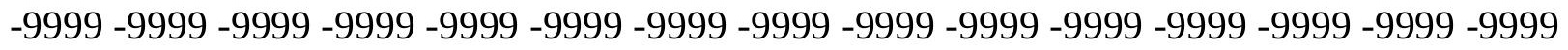
-9999 -9999 -9999 -9999 -9999 -9999 -9999 -9999 -9999 -9999 -9999 -9999 -9999 -9999 -9999 -

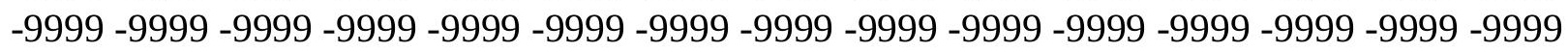

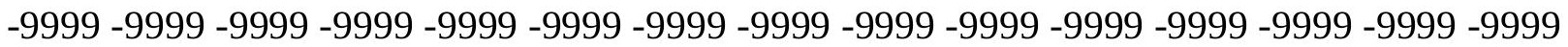

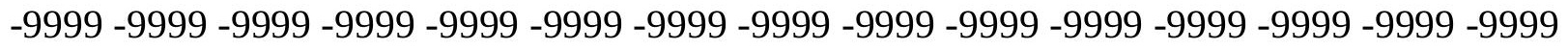

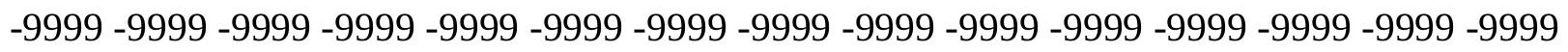

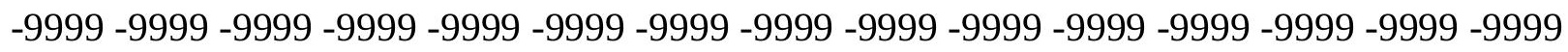
-9999 -9999 -9999 -9999 -9999 -9999 -9999 -9999 -9999 -9999 -9999 -9999 -9999 -9999 -9999 -9999 -9999-9999 -9999 -9999-9999-9999-9999-9999 150.2590942383 150.5639038086 150.5639038086150 .8686065674152 .0877990723150 .8686065674104 .171005249 103.2139205933102 .2703704834101 .3320388794100 .386054992797 .59657287598 97.1360397338996 .6935501098696 .0753784179794 .6964874267693 .10254669189 91.2337799072389 .0469665527386 .5283508300883 .8159103393681 .37763214111 79.2441329956177 .4154205322375 .8914871215874 .6723632812573 .45321655273 72.5388565063571 .9292907714871 .3197174072370 .7101516723670 .40535736084 70.4053573608470 .4053573608470 .4053573608470 .4053573608470 .71015167236 71.014930725171 .3197174072371 .9292907714872 .2340774536172 .84364318848 73.4532165527374 .062782287674 .6723632812575 .2819290161176 .19628143311 76.8058471679777 .7202072143678 .3297805786179 .2441329956180 .15849304199 80.7680587768681 .6824111938582 .5967712402383 .206336975184 .12069702148 84.7302627563585 .3398437585 .6446228027385 .6446228027385 .64462280273 85.6446228027385 .6446228027385 .6446228027385 .3398437585 .03504943848 84.7302627563584 .7302627563584 .4254837036183 .8159103393683 .51112365723 83.206336975182 .6149902343879 .9371185302781 .9871978759881 .37763214111 81.0728530883880 .4632720947380 .1584930419979 .5489196777378 .93934631348 78.6345596313578 .0249862670977 .4154205322376 .8058471679776 .19628143311 75.5867080688575 .2819290161174 .6723632812574 .062782287673 .45321655273 72.8436431884871 .9235839843870 .76435852051 -9999 -9999 -9999 -9999 -9999 -9999 -9999 -9999 -9999 -9999 -9999 -9999 -9999 -9999 -9999 -9999 -9999 -9999 -9999 -9999 -9999 -9999 -9999 -9999 -9999 -9999-9999-9999-9999-9999

-9999 -9999 -9999 -9999 -9999 -9999 -9999 -9999 -9999 -9999 -9999 -9999 -9999 -9999 -9999 
-9999 -9999 -9999 -9999 -9999 -9999 -9999 -9999 -9999 -9999 -9999 -9999 -9999 -9999 -9999 -9999 -9999 -9999 -9999 -9999 -9999 -9999 -9999 -9999 -9999 -9999 -9999 -9999 -9999 -9999 -9999 -9999 -9999 -9999 -9999 -9999 -9999 -9999 -9999 -9999 -9999 -9999 -9999 -9999 -9999 -9999 -9999 -9999 -9999 -9999 -9999 -9999 -9999 -9999 -9999 -9999 -9999 -9999 -9999 -9999 -9999 -9999 -9999 -9999 -9999 -9999 -9999 -9999 -9999 -9999 -9999 -9999 -9999 -9999 -9999 -9999 -9999 -9999 -9999 -9999 -9999 -9999 -9999 -9999 -9999 -9999 -9999 -9999 -9999 -9999 -9999 -9999 -9999 -9999 -9999 -9999 -9999 -9999 -9999 -9999 -9999 -9999 -9999 -9999 -9999

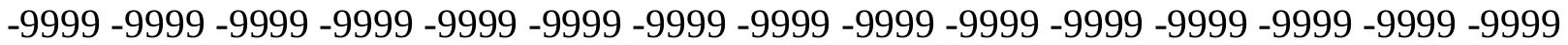
-9999 -9999 -9999 -9999 -9999 -9999 -9999 -9999 -9999 -9999 -9999 -9999 -9999 -9999 -9999 -9999 -9999 -9999 -9999 -9999 -9999 -9999 -9999 -9999 -9999 -9999 -9999 -9999 -9999 -9999 -9999 -9999 -9999 -9999 -9999 -9999 -9999 -9999 -9999 -9999 -9999 -9999 -9999 -9999 -9999 -9999 -9999 -9999 -9999 -9999 -9999 -9999 -9999 -9999 -9999 -9999 -9999 -9999 -9999 -9999

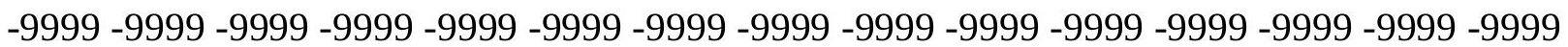
-9999 -9999 -9999 -9999 -9999 -9999 -9999 -9999 -9999 -9999 -9999 -9999 -9999 -9999 -9999 -9999 -9999 -9999 -9999 -9999 -9999 -9999 -9999 -9999 -9999 -9999 -9999 -9999 -9999 -9999 -9999 -9999 -9999 -9999 -9999 -9999 -9999 -9999 -9999 -9999 -9999 -9999 -9999 -9999 -9999 -9999 -9999 -9999 -9999 -9999 -9999 -9999 -9999 -9999 -9999 -9999 151.9459686279 152.7811889648153 .5173339844153 .3579101562104 .1940002441103 .2335205078 102.2898712158101 .3553771973100 .417709350697 .66294097997 .20244598389 96.7613525390696 .1929092407294 .8514938354593 .3069763183691 .51362609863 89.4399185180787 .1259994506884 .7302627563582 .2919769287180 .15849304199 78.0249862670976 .5010681152374 .9771423339873 .7580032348672 .84364318848 72.2340774536171 .6244964599671 .014930725170 .7101516723670 .71015167236 70.4053573608470 .7101516723670 .7101516723671 .014930725171 .31971740723 71.6244964599672 .2340774536172 .5388565063573 .1484298706173 .75800323486 74.3675689697374 .9771423339875 .8914871215876 .5010681152377 .1106262207 78.0249862670978 .6345596313579 .5489196777380 .4632720947381 .07285308838 81.9871978759882 .5967712402383 .5111236572384 .1206970214884 .73026275635 85.3398437585 .6446228027385 .6446228027385 .6446228027385 .64462280273 85.6446228027385 .6446228027385 .3398437585 .0350494384884 .73026275635 84.4254837036184 .1206970214883 .8159103393683 .5111236572382 .90155792236 82.3911514282279 .7912750244181 .6824111938581 .0728530883880 .76805877686 80.1584930419979 .5489196777379 .2441329956178 .6345596313578 .02498626709 77.4154205322376 .8058471679776 .1962814331175 .8914871215875 .28192901611 74.6723632812574 .062782287673 .4532165527372 .8436431884872 .23407745361 71.3365325927770 .20076751709 -9999 -9999 -9999 -9999 -9999 -9999 -9999 -9999 -9999 -9999 -9999 -9999 -9999 -9999 -9999 -9999 -9999 -9999 -9999 -9999 -9999 -9999 -9999 -9999 -9999 -9999 -9999 -9999-9999-9999

-9999 -9999 -9999 -9999 -9999 -9999 -9999 -9999 -9999 -9999 -9999 -9999 -9999 -9999 -9999 -9999 -9999 -9999 -9999 -9999 -9999 -9999 -9999 -9999 -9999 -9999 -9999 -9999 -9999 -9999 -9999 -9999 -9999 -9999 -9999 -9999 -9999 -9999 -9999 -9999 -9999 -9999 -9999 -9999 -9999

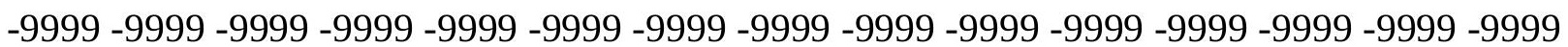
-9999 -9999 -9999 -9999 -9999 -9999 -9999 -9999 -9999 -9999 -9999 -9999 -9999 -9999 -9999 -9999 -9999 -9999 -9999 -9999 -9999 -9999 -9999 -9999 -9999 -9999 -9999 -9999 -9999 -9999 -9999 -9999 -9999 -9999 -9999 -9999 -9999 -9999 -9999 -9999 -9999 -9999 -9999 -9999 -9999

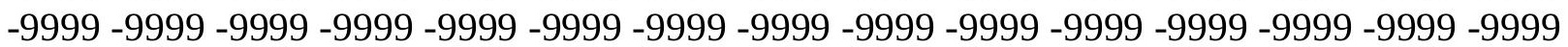


-9999 -9999 -9999 -9999 -9999 -9999 -9999 -9999 -9999 -9999 -9999 -9999 -9999 -9999 -9999 -9999 -9999 -9999 -9999 -9999 -9999 -9999 -9999 -9999 -9999 -9999 -9999 -9999 -9999 -9999 -9999 -9999 -9999 -9999 -9999 -9999 -9999 -9999 -9999 -9999 -9999 -9999 -9999 -9999 -9999 -9999 -9999 -9999 -9999 -9999 -9999 -9999 -9999 -9999 -9999 -9999 -9999 -9999 -9999 -9999 -9999 -9999 -9999 -9999 -9999 -9999 -9999 -9999 -9999 -9999 -9999 -9999 -9999 -9999 -9999 -9999 -9999 -9999 -9999 -9999 -9999 -9999 -9999 -9999 -9999 -9999 -9999 -9999 -9999 -9999 -9999 -9999 -9999 -9999 -9999 -9999 -9999 -9999 -9999 -9999 -9999 -9999 -9999 -9999 -9999 -9999 -9999 -9999 -9999 -9999 -9999 -9999 -9999 -9999 -9999 -9999 -9999 -9999 -9999 -9999 -9999 -9999 -9999 -9999 -9999 -9999 -9999 -9999 -9999 -9999 -9999 -9999 -9999 -9999 -9999 -9999 -9999 -9999 -9999 -9999 -9999 -9999 -9999 -9999 -9999 -9999 -9999 154.0670623779 154.7047424316154 .5773162842153 .0037384033103 .2466659546102 .3050765991 101.3780288696100 .454154968399 .5169219970797 .2580184936596 .81840515137 96.3723831176895 .0994415283293 .6477279663191 .9829101562590 .09071350098 87.9895629882885 .698524475183 .206336975181 .0728530883878 .93934631348 77.110626220775 .5867080688574 .3675689697373 .4532165527372 .53885650635 71.9292907714871 .3197174072371 .014930725171 .014930725170 .71015167236 71.014930725171 .014930725171 .3197174072371 .6244964599671 .92929077148 72.5388565063572 .8436431884873 .4532165527374 .062782287674 .67236328125 75.2819290161176 .1962814331176 .8058471679777 .4154205322378 .32978057861 78.9393463134879 .8537063598680 .4632720947381 .3776321411181 .98719787598 82.9015579223683 .5111236572384 .1206970214884 .7302627563585 .03504943848 85.3398437585 .6446228027385 .6446228027385 .6446228027385 .6446228027385 .33984375 85.3398437585 .0350494384884 .7302627563584 .4254837036183 .81591033936 83.5111236572383 .206336975182 .5967712402382 .0741577148479 .71612548828 81.3776321411180 .7680587768680 .1584930419979 .8537063598679 .24413299561 78.6345596313578 .0249862670977 .4154205322376 .8058471679776 .50106811523 75.8914871215875 .2819290161174 .6723632812574 .062782287673 .45321655273 72.8436431884872 .2340774536171 .6244964599670 .7245559692469 .60083007812 -9999 -9999 -9999 -9999 -9999 -9999 -9999 -9999 -9999 -9999 -9999 -9999 -9999 -9999 -9999 -9999 -9999 -9999 -9999 -9999 -9999 -9999 -9999 -9999 -9999 -9999 -9999 -9999 -9999 -9999 -9999 -9999 -9999 -9999 -9999 -9999 -9999 -9999 -9999 -9999 -9999 -9999 -9999 -9999 -9999

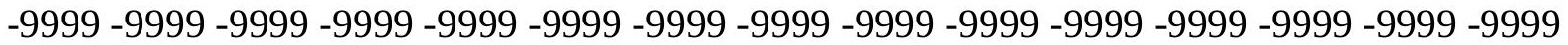
-9999 -9999 -9999 -9999 -9999 -9999 -9999 -9999 -9999 -9999 -9999 -9999 -9999 -9999 -9999 -9999 -9999 -9999 -9999 -9999 -9999 -9999 -9999 -9999 -9999 -9999 -9999 -9999 -9999 -9999 -

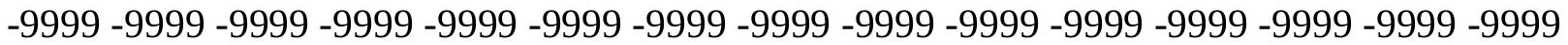
-9999 -9999 -9999 -9999 -9999 -9999 -9999 -9999 -9999 -9999 -9999 -9999 -9999 -9999 -9999 -9999 -9999 -9999 -9999 -9999 -9999 -9999 -9999 -9999 -9999 -9999 -9999 -9999 -9999 -9999

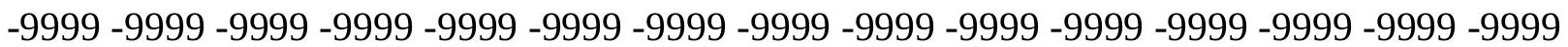
-9999 -9999 -9999 -9999 -9999 -9999 -9999 -9999 -9999 -9999 -9999 -9999 -9999 -9999 -9999 -9999 -9999 -9999 -9999 -9999 -9999 -9999 -9999 -9999 -9999 -9999 -9999 -9999 -9999 -9999 -

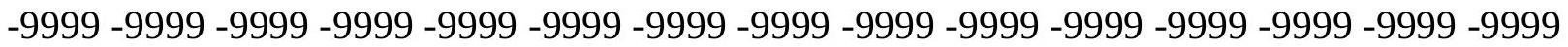
-9999 -9999 -9999 -9999 -9999 -9999 -9999 -9999 -9999 -9999 -9999 -9999 -9999 -9999 -9999 -9999 -9999 -9999 -9999 -9999 -9999 -9999 -9999 -9999 -9999 -9999 -9999 -9999 -9999 -9999 -9999 -9999 -9999 -9999 -9999 -9999 -9999 -9999 -9999 -9999 -9999 -9999 -9999 -9999 -9999 -9999 -9999 -9999 -9999 -9999 -9999 -9999 -9999 -9999 -9999 -9999 -9999 -9999 -9999 -9999

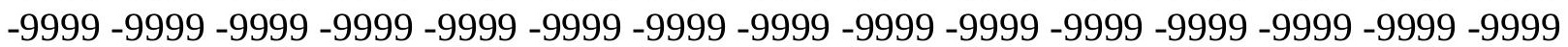


-9999 -9999 -9999 -9999 -9999 -9999 -9999 -9999 -9999 -9999 -9999 -9999 -9999 -9999 -9999 -9999 -9999 -9999 -9999 -9999 -9999 -9999 -9999 -9999 -9999 -9999 -9999 -9999 155.3363037109155 .1106414795153 .6797027588151 .1024780273102 .3139648438 101.3975906372100 .492645263799 .5842742919997 .3019866943496 .86367797852 96.4470443725695 .4315338134894 .1053543090892 .6035690307690 .90693664551 89.01782989502 86.9484481811584.73026275635 82.29197692871 79.85370635986 78.0249862670976 .5010681152374 .9771423339874 .062782287673 .14842987061 72.2340774536171 .9292907714871 .6244964599671 .3197174072371 .31971740723 71.3197174072371 .3197174072371 .6244964599671 .9292907714872 .23407745361 72.8436431884873 .4532165527373 .7580032348674 .3675689697374 .97714233398 75.8914871215876 .5010681152377 .110626220777 .7202072143678 .63455963135 79.2441329956180 .1584930419980 .7680587768681 .6824111938582 .29197692871 82.9015579223683 .5111236572384 .1206970214884 .7302627563585 .03504943848 85.3398437585 .3398437585 .6446228027385 .6446228027385 .3398437585 .33984375 85.0350494384884 .7302627563584 .4254837036184 .1206970214883 .81591033936 83.206336975182 .9015579223682 .2919769287181 .7303924560579 .59954071045 80.7680587768680 .4632720947379 .8537063598679 .2441329956178 .63455963135 78.0249862670977 .4154205322376 .8058471679776 .5010681152375 .89148712158 75.2819290161174 .6723632812574 .062782287673 .4532165527372 .84364318848 $72.2340774536171 .6244964599671 .014930725170 .0553741455168 .95462036133-9999$ -9999 -9999 -9999 -9999 -9999 -9999 -9999 -9999 -9999 -9999 -9999 -9999 -9999 -9999 -9999 -9999 -9999 -9999 -9999 -9999 -9999 -9999 -9999 -9999 -9999 -9999 -9999 -9999 -9999 -9999 -9999 -9999 -9999 -9999 -9999 -9999 -9999 -9999 -9999 -9999 -9999 -9999 -9999 -9999 -9999 -9999 -9999 -9999 -9999 -9999 -9999 -9999 -9999 -9999 -9999 -9999 -9999 -9999 -9999

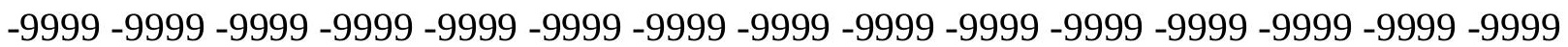
-9999 -9999 -9999 -9999 -9999 -9999 -9999 -9999 -9999 -9999 -9999 -9999 -9999 -9999 -9999 -9999 -9999 -9999 -9999 -9999 -9999 -9999 -9999 -9999 -9999 -9999 -9999 -9999 -9999 -9999 -9999 -9999 -9999 -9999 -9999 -9999 -9999 -9999 -9999 -9999 -9999 -9999 -9999 -9999 -9999

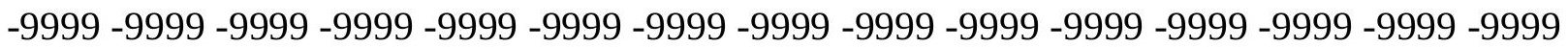

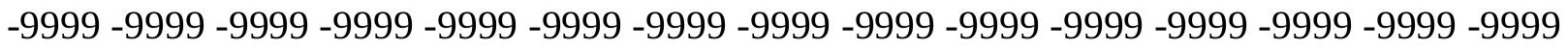
-9999 -9999 -9999 -9999 -9999 -9999 -9999 -9999 -9999 -9999 -9999 -9999 -9999 -9999 -9999 -

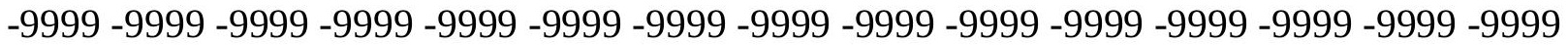
-9999 -9999 -9999 -9999 -9999 -9999 -9999 -9999 -9999 -9999 -9999 -9999 -9999 -9999 -9999 -9999 -9999 -9999 -9999 -9999 -9999 -9999 -9999 -9999 -9999 -9999 -9999 -9999 -9999 -9999 -

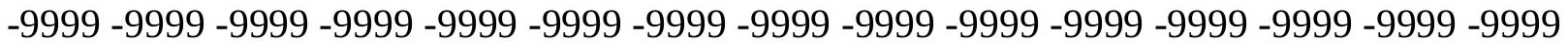
-9999 -9999 -9999 -9999 -9999 -9999 -9999 -9999 -9999 -9999 -9999 -9999 -9999 -9999 -9999 -9999 -9999 -9999 -9999 -9999 -9999 -9999 -9999 -9999 -9999 -9999 -9999 -9999 -9999 -9999

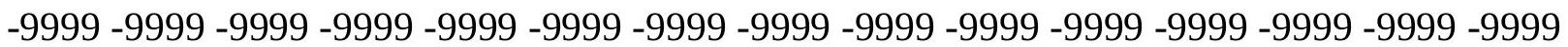
-9999 -9999 -9999 -9999 -9999 -9999 -9999 -9999 -9999 -9999 -9999 -9999 -9999 -9999 -9999 -9999 -9999 -9999 -9999 -9999 -9999 -9999 -9999 -9999 -9999 -9999 -9999 -9999 -9999 155.3735656738154 .2143249512152 .0777130127102 .3133544922101 .4099960327 100.527969360499 .654708862398 .7723693847796 .8937988281296 .47951507568 95.8221511840894 .6419830322393 .3165664672991 .8214492797990 .14421081543 88.29647827148 86.2541885376 83.51112365723 81.07285308838 78.93934631348 77.4154205322375 .8914871215874 .6723632812573 .7580032348672 .84364318848 72.5388565063571 .9292907714871 .6244964599671 .6244964599671 .62449645996 
71.9292907714871 .9292907714872 .2340774536172 .8436431884873 .14842987061 73.7580032348674 .3675689697374 .9771423339875 .5867080688576 .19628143311 76.8058471679777 .4154205322378 .0249862670978 .9393463134879 .54891967773 80.1584930419981 .0728530883881 .6824111938582 .2919769287182 .90155792236 83.5111236572384 .1206970214884 .4254837036184 .7302627563585 .03504943848 85.3398437585 .3398437585 .3398437585 .0350494384885 .0350494384884 .73026275635 84.4254837036184 .1206970214883 .8159103393683 .206336975182 .90155792236 82.2919769287181 .9871978759881 .3459396362379 .3585281372180 .46327209473 79.8537063598679 .2441329956178 .6345596313578 .0249862670977 .41542053223 76.8058471679776 .5010681152375 .8914871215875 .2819290161174 .67236328125 73.7580032348673 .1484298706172 .5388565063571 .9292907714871 .31971740723 70.7101516723670 .1005783081169 .3316268920968 .28580474854 -9999 -9999 -9999 -9999 -9999 -9999 -9999 -9999 -9999 -9999 -9999 -9999 -9999 -9999 -9999 -9999 -9999 -9999 -9999 -9999 -9999 -9999 -9999 -9999 -9999 -9999 -9999 -9999 -9999 -9999 -

-9999 -9999 -9999 -9999 -9999 -9999 -9999 -9999 -9999 -9999 -9999 -9999 -9999 -9999 -9999

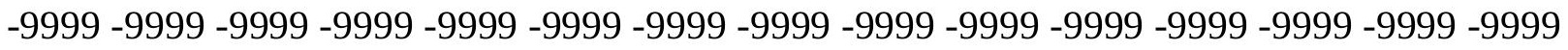
-9999 -9999 -9999 -9999 -9999 -9999 -9999 -9999 -9999 -9999 -9999 -9999 -9999 -9999 -9999 -9999 -9999 -9999 -9999 -9999 -9999 -9999 -9999 -9999 -9999 -9999 -9999 -9999 -9999 -9999 -9999 -9999 -9999 -9999 -9999 -9999 -9999 -9999 -9999 -9999 -9999 -9999 -9999 -9999 -9999 -

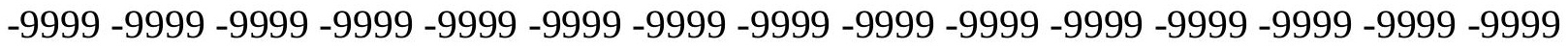

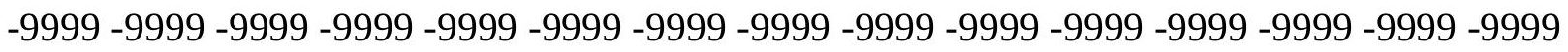
-9999 -9999 -9999 -9999 -9999 -9999 -9999 -9999 -9999 -9999 -9999 -9999 -9999 -9999 -9999 -9999 -9999 -9999 -9999 -9999 -9999 -9999 -9999 -9999 -9999 -9999 -9999 -9999 -9999 -9999 -

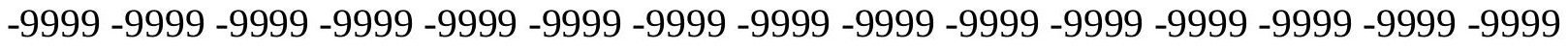

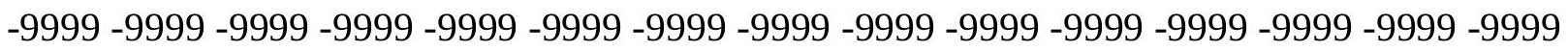
-9999 -9999 -9999 -9999 -9999 -9999 -9999 -9999 -9999 -9999 -9999 -9999 -9999 -9999 -9999 -9999 -9999 -9999 -9999 -9999 -9999 -9999 -9999 -9999 -9999 -9999 -9999 -9999 -9999 -9999 -

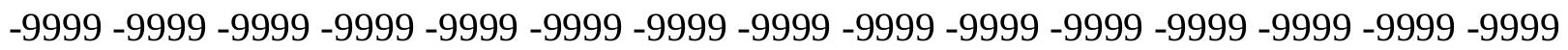
-9999 -9999 -9999 -9999 -9999 -9999 -9999 -9999 -9999 -9999 -9999 -9999 -9999 -9999 -9999 -9999 -9999 -9999 -9999 -9999 -9999 -9999 -9999 -9999 -9999 -9999 -9999 -9999 -9999 -999 -9999 -9999 -9999 -9999 -9999 -9999 -9999 -9999 -9999-9999 -9999 -9999 -9999 -9999 -9999 -9999 -9999 -9999 -9999 -9999 -9999 -9999 -9999 -9999 -9999 -9999 -9999 -9999 -9999 -9999 -999 154.5137939453152 .7277679443150 .0994567871101 .4095153809100 .5523681641 99.7177810668998 .890769958596 .902061462496 .4880523681696 .100440979 95.2087326049894 .0573883056692 .748184204191 .261863708589 .54808807373 87.4886016845785 .0350494384882 .5967712402380 .1584930419978 .32978057861 76.8058471679775 .5867080688574 .3675689697373 .7580032348673 .14842987061 72.5388565063572 .2340774536172 .2340774536172 .2340774536172 .23407745361 72.5388565063572 .8436431884873 .1484298706173 .7580032348674 .0627822876 74.6723632812575 .2819290161175 .8914871215876 .5010681152377 .1106262207 77.7202072143678 .6345596313579 .2441329956179 .8537063598680 .46327209473 81.0728530883881 .6824111938582 .2919769287182 .9015579223683 .51112365723 84.1206970214884 .4254837036184 .7302627563584 .7302627563585 .03504943848 85.0350494384885 .0350494384884 .7302627563584 .7302627563584 .42548370361 84.1206970214883 .8159103393683 .5111236572382 .9015579223682 .59677124023 81.9871978759881 .3776321411180 .8665084838979 .0131454467879 .85370635986 
79.2441329956178 .6345596313578 .0249862670977 .4154205322376 .80584716797 76.1962814331175 .5867080688574 .9771423339874 .3675689697373 .75800323486 73.1484298706172 .5388565063571 .9292907714871 .3197174072370 .71015167236 70.1005783081169 .4910125732468 .6364593505967 .58687591553 -9999 -9999 -9999 -9999 -9999 -9999 -9999 -9999 -9999 -9999 -9999 -9999 -9999 -9999 -9999 -9999 -9999 -9999 -9999 -9999 -9999 -9999 -9999 -9999 -9999 -9999 -9999 -9999 -9999 -9999

-9999 -9999 -9999 -9999 -9999 -9999 -9999 -9999 -9999 -9999 -9999 -9999 -9999 -9999 -9999 -9999 -9999 -9999 -9999 -9999 -9999 -9999 -9999 -9999 -9999 -9999 -9999 -9999 -9999 -9999 -9999 -9999 -9999 -9999 -9999 -9999 -9999 -9999 -9999 -9999 -9999 -9999 -9999 -9999 -9999 -9999 -9999 -9999 -9999 -9999 -9999 -9999 -9999 -9999 -9999 -9999 -9999 -9999 -9999 -9999 -

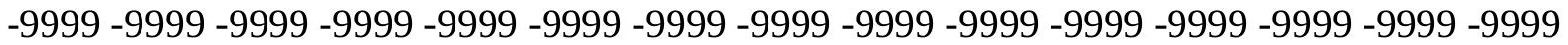
-9999 -9999 -9999 -9999 -9999 -9999 -9999 -9999 -9999 -9999 -9999 -9999 -9999 -9999 -9999 -9999 -9999 -9999 -9999 -9999 -9999 -9999 -9999 -9999 -9999 -9999 -9999 -9999 -9999 -9999 -9999 -9999 -9999 -9999 -9999 -9999 -9999 -9999 -9999 -9999 -9999 -9999 -9999 -9999 -9999 -9999 -9999 -9999 -9999 -9999 -9999 -9999 -9999 -9999 -9999 -9999 -9999 -9999 -9999 -9999

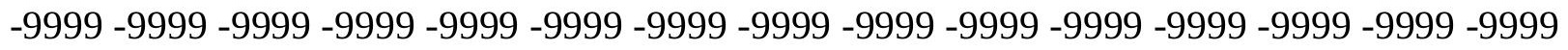
-9999 -9999 -9999 -9999 -9999 -9999 -9999 -9999 -9999 -9999 -9999 -9999 -9999 -9999 -9999 -

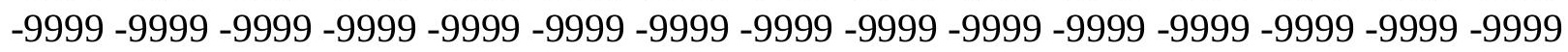

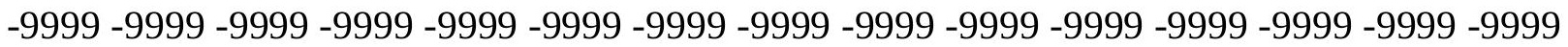

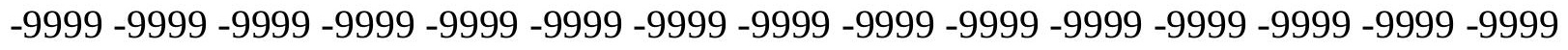

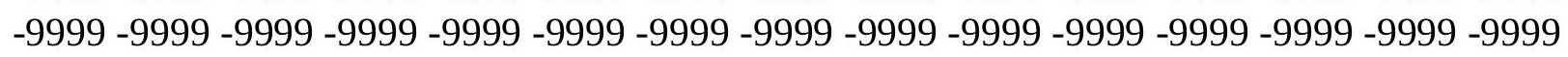

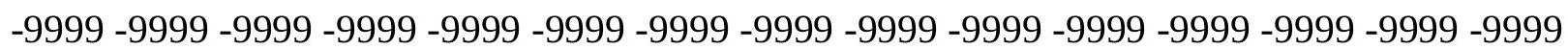
-9999 -9999 -9999 -9999 -9999 -9999 -9999 -9999 -9999 -9999 -9999 -9999 -9999 -9999 -9999 -

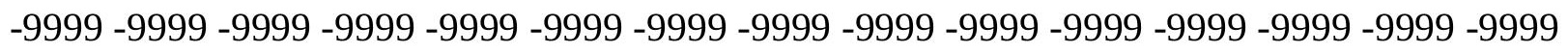
-9999153.0010986328150.6356658936101.3893585205100.556373596299.7606048584 98.990097045998 .2283172607496 .4633255004996 .0762405395595 .71971893311 94.766876220793 .6336059570392 .3196258544990 .7637481689588 .86609649658 86.55898284912 83.8159103393681.37763214111 79.54891967773 77.72020721436 76.5010681152375 .2819290161174 .3675689697373 .7580032348673 .14842987061 72.8436431884872 .8436431884872 .8436431884872 .8436431884873 .14842987061 73.4532165527373 .7580032348674 .062782287674 .6723632812575 .28192901611 75.5867080688576 .1962814331176 .8058471679777 .4154205322378 .32978057861 78.9393463134879 .5489196777380 .1584930419980 .7680587768681 .37763214111 81.9871978759882 .5967712402382 .9015579223683 .5111236572383 .81591033936 84.1206970214884 .4254837036184 .7302627563584 .7302627563584 .73026275635 84.7302627563584 .4254837036184 .4254837036184 .1206970214883 .81591033936 83.5111236572382 .9015579223682 .5967712402381 .9871978759881 .68241119385 81.0728530883880 .380294799878 .6489334106479 .2441329956178 .63455963135 78.0249862670977 .4154205322376 .8058471679776 .1962814331175 .58670806885 74.9771423339874 .3675689697373 .7580032348673 .1484298706172 .53885650635 71.9292907714871 .3197174072370 .7101516723670 .1005783081169 .49101257324 68.8814392089867 .929122924866 .8650970459 -9999 -9999 -9999 -9999 -9999 -9999 -9999 -9999 -9999 -9999 -9999 -9999 -9999 -9999 -9999 -9999 -9999 -9999 -9999-9999 -9999 -9999 -9999 -9999 -9999 -9999-9999-9999-9999-9999

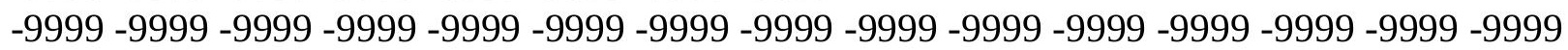

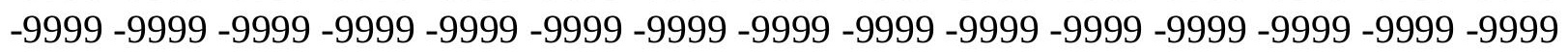


-9999 -9999 -9999 -9999 -9999 -9999 -9999 -9999 -9999 -9999 -9999 -9999 -9999 -9999 -9999 -9999 -9999 -9999 -9999 -9999 -9999 -9999 -9999 -9999 -9999 -9999 -9999 -9999 -9999 -9999 -9999 -9999 -9999 -9999 -9999 -9999 -9999 -9999 -9999 -9999 -9999 -9999 -9999 -9999 -9999 -9999 -9999 -9999 -9999 -9999 -9999 -9999 -9999 -9999 -9999 -9999 -9999 -9999 -9999 -9999 -9999 -9999 -9999 -9999 -9999 -9999 -9999 -9999 -9999 -9999 -9999 -9999 -9999 -9999 -9999 -9999 -9999 -9999 -9999 -9999 -9999 -9999 -9999 -9999 -9999 -9999 -9999 -9999 -9999 -9999 -9999 -9999 -9999 -9999 -9999 -9999 -9999 -9999 -9999 -9999 -9999 -9999 -9999 -9999 -9999

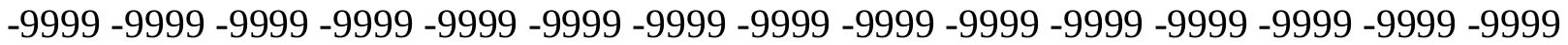
-9999 -9999 -9999 -9999 -9999 -9999 -9999 -9999 -9999 -9999 -9999 -9999 -9999 -9999 -9999 -9999 -9999 -9999 -9999 -9999 -9999 -9999 -9999 -9999 -9999 -9999 -9999 -9999 -9999 -9999 -9999 -9999 -9999 -9999 -9999 -9999 -9999 -9999 -9999 -9999 -9999 -9999 -9999 -9999 -9999 -9999 -9999 -9999 -9999 -9999 -9999 -9999 -9999 -9999 -9999 -9999 -9999 -9999 -9999 -9999

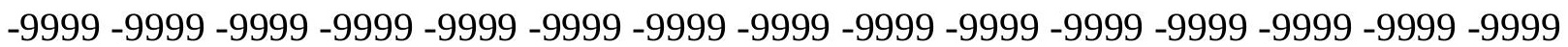
-9999 -9999 -9999 -9999 -9999 -9999 -9999 -9999 -9999 -9999 -9999 -9999 -9999 -9999 -9999 -9999 -9999 -9999 -9999 -9999 -9999 -9999 -9999 -9999 -9999 -9999 -9999 -9999 -9999 -9999 -9999 -9999 -9999 -9999 -9999 -9999 -9999 -9999 -9999 -9999 -9999 -9999 -9999 -9999 -9999 -9999 -9999-9999 147.7261810303100.5297775269 99.76889801025 99.05101013184 98.362724304296 .3983612060596 .007812595 .6538162231495 .33639526367 94.4434585571393 .2999191284291 .9147262573290 .21289062588 .08290100098 85.0350494384882 .5967712402380 .4632720947378 .9393463134877 .41542053223 76.1962814331175 .2819290161174 .3675689697374 .062782287673 .45321655273 73.4532165527373 .4532165527373 .4532165527373 .4532165527373 .75800323486 74.3675689697374 .6723632812574 .9771423339875 .5867080688576 .19628143311 76.8058471679777 .4154205322378 .0249862670978 .6345596313579 .24413299561 79.8537063598680 .4632720947381 .0728530883881 .3776321411181 .98719787598 82.5967712402382 .9015579223683 .5111236572383 .8159103393684 .12069702148 84.1206970214884 .4254837036184 .4254837036184 .4254837036184 .42548370361 84.1206970214883 .8159103393683 .5111236572383 .206336975182 .90155792236 82.5967712402381 .9871978759881 .6824111938581 .0728530883880 .46327209473 79.8285140991278 .2505035400478 .6345596313578 .0249862670977 .41542053223 76.8058471679776 .1962814331175 .5867080688574 .9771423339874 .36756896973 73.7580032348673 .1484298706172 .2340774536171 .6244964599671 .0149307251 70.4053573608469 .7957916259869 .1862335205168 .5766525268667 .96708679199 67.1331939697366 .11524200439 -9999 -9999 -9999 -9999 -9999 -9999 -9999 -9999 -9999 -9999 -9999 -9999 -9999 -9999 -9999 -9999 -9999 -9999 -9999 -9999 -9999 -9999 -9999 -9999 -9999 -9999 -9999 -9999-9999 -9999 -9999 -9999 -9999 -9999 -9999 -9999 -9999 -9999 -9999 -9999 -9999 -9999 -9999 -9999 -9999

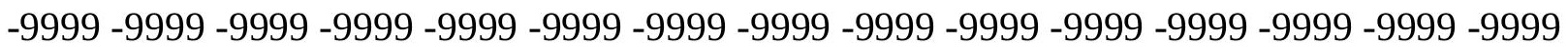
-9999 -9999 -9999 -9999 -9999 -9999 -9999 -9999 -9999 -9999 -9999 -9999 -9999 -9999 -9999 -9999 -9999 -9999 -9999 -9999 -9999 -9999 -9999 -9999 -9999 -9999 -9999 -9999 -9999 -9999 -9999 -9999 -9999 -9999 -9999 -9999 -9999 -9999 -9999 -9999 -9999 -9999 -9999 -9999 -9999

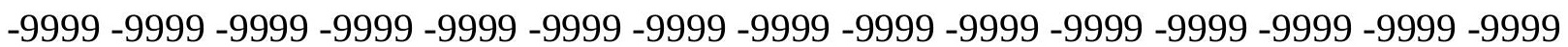
-9999 -9999 -9999 -9999 -9999 -9999 -9999 -9999 -9999 -9999 -9999 -9999 -9999 -9999 -9999 -9999 -9999 -9999 -9999 -9999 -9999 -9999 -9999 -9999 -9999 -9999 -9999 -9999 -9999 -9999 -9999 -9999 -9999 -9999 -9999 -9999 -9999 -9999 -9999 -9999 -9999 -9999 -9999 -9999 -9999

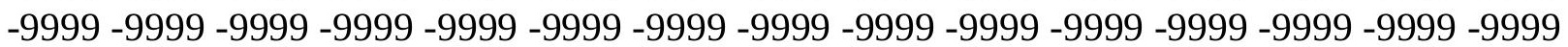


-9999 -9999 -9999 -9999 -9999 -9999 -9999 -9999 -9999 -9999 -9999 -9999 -9999 -9999 -9999 -9999 -9999 -9999 -9999 -9999 -9999 -9999 -9999 -9999 -9999 -9999 -9999 -9999 -9999 -9999 -9999 -9999 -9999 -9999 -9999 -9999 -9999 -9999 -9999 -9999 -9999 -9999 -9999 -9999 -9999 -9999 -9999 -9999 -9999 -9999 -9999 -9999 -9999 -9999 -9999 -9999 -9999 -9999 -9999 -9999 -9999 -9999 -9999 -9999 -9999 -9999 -9999 -9999 -9999 -9999 -9999 -9999 -9999 -9999 -9999 -9999 -9999 -9999 -9999 -9999 -9999 -9999 -9999 -9999 -9999 -9999 -9999 -9999 -9999 -9999 -9999 -9999 -9999 -9999 -9999 -9999 -9999 -9999 -9999 -9999 -9999 -9999 -9999 -9999 -9999 -9999 -9999 -9999 -9999 -9999 -9999 -9999 -9999 -9999 -9999 -9999 -9999 -9999 -9999 -9999 -9999 -9999 -9999 -9999 100.4625930786 99.7284164428799.05410003662 98.42945861816 97.8375854492295 .8880386352595 .5327606201295 .2231140136794 .95738983154 94.1769714355592 .952713012791 .3844985961989 .302040100186 .2541885376 83.8159103393681 .6824111938579 .8537063598678 .3297805786177 .1106262207 76.1962814331175 .2819290161174 .6723632812574 .3675689697374 .0627822876 74.062782287674 .062782287674 .062782287674 .3675689697374 .67236328125 75.2819290161175 .5867080688576 .1962814331176 .8058471679777 .1106262207 77.7202072143678 .3297805786178 .9393463134879 .5489196777380 .15849304199 80.7680587768681 .0728530883881 .6824111938581 .9871978759882 .59677124023 82.9015579223683 .206336975183 .5111236572383 .8159103393684 .12069702148 84.1206970214884 .1206970214884 .1206970214883 .8159103393683 .81591033936 83.5111236572383 .206336975182 .9015579223682 .5967712402381 .98719787598 81.3776321411181 .0728530883880 .4632720947379 .8537063598679 .22123718262 77.7268218994178 .0249862670977 .4154205322376 .8058471679776 .19628143311 75.5867080688574 .9771423339874 .3675689697373 .4532165527372 .84364318848 72.2340774536171 .6244964599671 .014930725170 .4053573608469 .79579162598 $69.1862335205168 .2718734741267 .6623001098667 .0527267456166 .32102966309-9999$ -9999 -9999 -9999 -9999 -9999 -9999 -9999 -9999 -9999 -9999 -9999 -9999 -9999 -9999 -9999 -9999 -9999 -9999 -9999 -9999 -9999 -9999 -9999 -9999 -9999 -9999 -9999 -9999 -9999 -9999 -9999 -9999 -9999 -9999 -9999 -9999 -9999 -9999 -9999 -9999 -9999 -9999 -9999 -9999 -9999 -9999 -9999 -9999 -9999 -9999 -9999 -9999 -9999 -9999 -9999 -9999 -9999 -9999 -9999 -9999 -9999 -9999 -9999 -9999 -9999 -9999 -9999 -9999 -9999 -9999 -9999 -9999 -9999 -9999 -9999 -9999 -9999 -9999 -9999 -9999 -9999 -9999 -9999 -9999 -9999 -9999 -9999 -9999 -9999 -9999 -

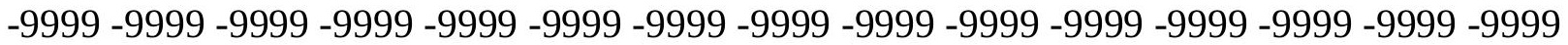
-9999 -9999 -9999 -9999 -9999 -9999 -9999 -9999 -9999 -9999 -9999 -9999 -9999 -9999 -9999 -9999 -9999 -9999 -9999 -9999 -9999 -9999 -9999 -9999 -9999 -9999 -9999 -9999 -9999 -9999 -9999 -9999 -9999 -9999 -9999 -9999 -9999 -9999 -9999 -9999 -9999 -9999 -9999 -9999 -9999 -9999 -9999 -9999 -9999 -9999 -9999 -9999 -9999 -9999 -9999 -9999 -9999 -9999 -9999 -9999 -9999 -9999 -9999 -9999 -9999 -9999 -9999 -9999 -9999 -9999 -9999 -9999 -9999 -9999 -9999

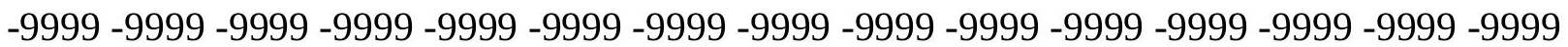
-9999 -9999 -9999 -9999 -9999 -9999 -9999 -9999 -9999 -9999 -9999 -9999 -9999 -9999 -9999 -9999 -9999 -9999 -9999 -9999 -9999 -9999 -9999 -9999 -9999 -9999 -9999 -9999 -9999 -9999 -9999 -9999 -9999 -9999 -9999 -9999 -9999 -9999 -9999 -9999 -9999 -9999 -9999 -9999 -9999

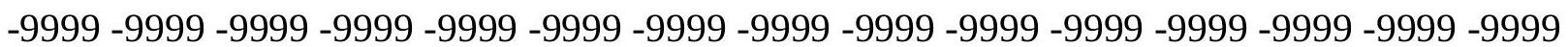
-9999 -9999 -9999 -9999 -9999 -9999 -9999 -9999 -9999 -9999 -9999 -9999 -9999 -9999 -9999 -9999 -9999 -9999 -9999 -9999 -9999 -9999 -9999 -9999 -9999 -9999 -9999 -9999 -9999 -9999 -9999 -9999 -9999 -9999 -9999 -9999 -9999 -9999 -9999 -9999 -9999 -9999 -9999 -9999 -9999 -9999 -9999 -9999 -9999-9999 99.6272048950298.9825210571398.40621185303 
97.8844146728595 .710372924895 .3483123779395 .0431747436594 .79515075684 94.6003952026493 .8562316894592 .3973541259890 .3629379272587 .77810668945 85.0350494384882 .9015579223681 .0728530883879 .5489196777378 .02498626709 77.110626220776 .1962814331175 .5867080688574 .9771423339874 .67236328125 74.6723632812574 .6723632812574 .6723632812574 .9771423339875 .28192901611 75.8914871215876 .1962814331176 .8058471679777 .110626220777 .72020721436 78.3297805786178 .9393463134879 .2441329956179 .8537063598680 .46327209473 80.7680587768681 .3776321411181 .6824111938582 .2919769287182 .59677124023 82.9015579223683 .206336975183 .5111236572383 .5111236572383 .81591033936 83.81591033936 83.81591033936 83.8159103393683.5111236572383.2063369751 83.206336975182 .5967712402382 .2919769287181 .9871978759881 .37763214111 81.0728530883880 .4632720947379 .8537063598679 .2441329956178 .59573364258 77.0686035156277 .4154205322376 .8058471679776 .1962814331175 .58670806885 74.6723632812574 .062782287673 .4532165527372 .8436431884872 .23407745361 71.3197174072370 .7101516723670 .1005783081169 .4910125732468 .88143920898 68.2718734741267 .6623001098667 .0527267456166 .4431610107465 .53480529785 -9999 -9999 -9999 -9999 -9999 -9999 -9999 -9999 -9999 -9999 -9999 -9999 -9999 -9999 -9999 -9999 -9999 -9999 -9999 -9999 -9999 -9999 -9999 -9999 -9999 -9999 -9999 -9999 -9999 -9999 -9999 -

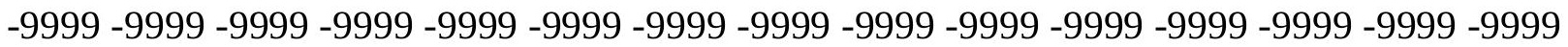

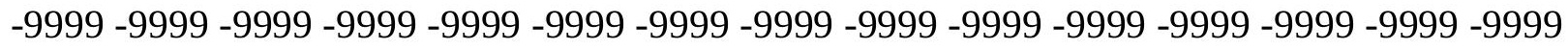

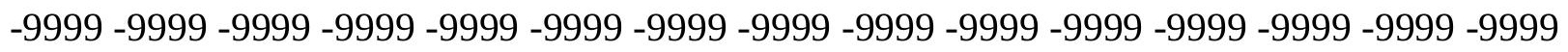

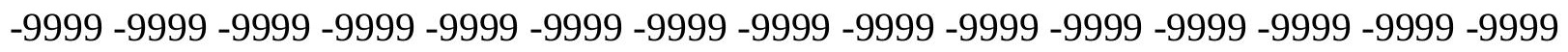
-9999 -9999 -9999 -9999 -9999 -9999 -9999 -9999 -9999 -9999 -9999 -9999 -9999 -9999 -9999 -

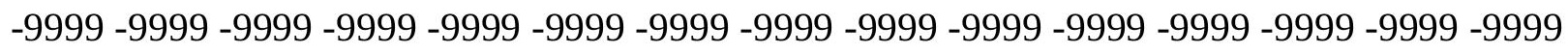

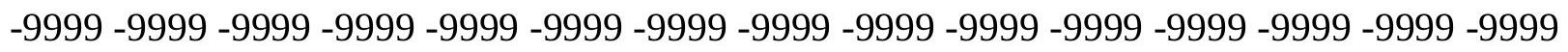
-9999 -9999 -9999 -9999 -9999 -9999 -9999 -9999 -9999 -9999 -9999 -9999 -9999 -9999 -9999 -9999 -9999 -9999 -9999 -9999 -9999 -9999 -9999 -9999 -9999 -9999 -9999 -9999 -9999 - -9999 -

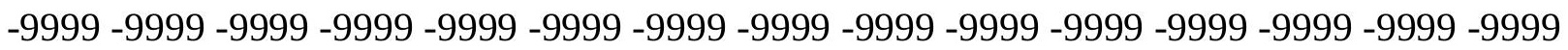

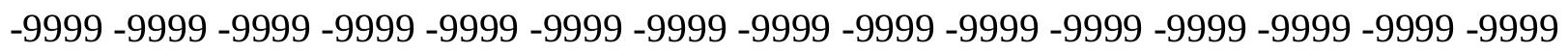

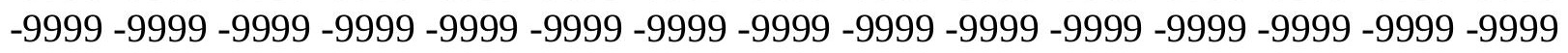
-9999 -9999 -9999 -9999 -9999 -9999 -9999 -9999 -9999 -9999 -9999 -9999 -9999 -9999 -9999

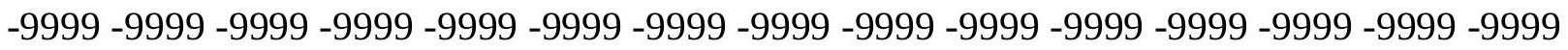

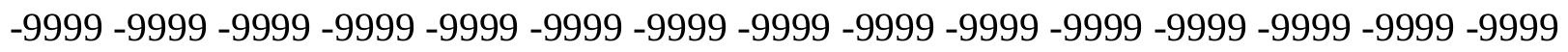

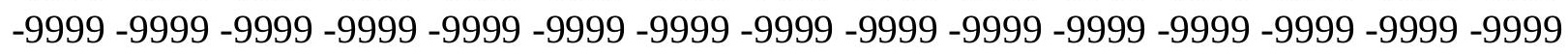

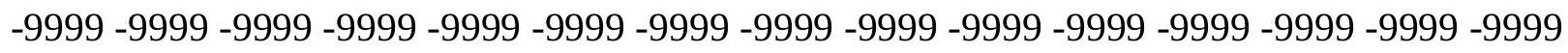

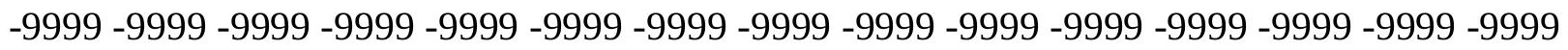
-9999 -9999 -9999 -9999-9999 -9999 98.82246398926 98.27366638184 97.79985046387 95.467910766695 .0910339355594 .7845840454194 .5517959594794 .39083862305 94.2911224365293 .3555908203191 .5743255615289 .302040100186 .55898284912 84.1206970214881 .9871978759880 .4632720947378 .9393463134877 .72020721436 76.8058471679776 .1962814331175 .8914871215875 .5867080688575 .28192901611 75.2819290161175 .5867080688575 .5867080688576 .1962814331176 .50106811523 76.8058471679777 .4154205322377 .7202072143678 .3297805786178 .63455963135 79.2441329956179 .8537063598680 .1584930419980 .7680587768681 .07285308838 81.6824111938581 .9871978759882 .2919769287182 .5967712402382 .90155792236 83.2063369751 83.2063369751 83.51112365723 83.51112365723 83.51112365723 
83.51112365723 83.2063369751 83.206336975182.90155792236 82.59677124023 82.2919769287181 .9871978759881 .3776321411180 .7680587768680 .46327209473 79.8537063598679 .2441329956178 .6345596313577 .9496536254976 .30086517334 76.8058471679775 .8914871215875 .2819290161174 .6723632812574 .0627822876 73.4532165527372 .5388565063571 .9292907714871 .3197174072370 .71015167236 69.7957916259869 .1862335205168 .5766525268667 .9670867919967 .35751342773 66.7479400634866 .1383666992265 .5288009643664 .69190216064 -9999 -9999 -9999 -9999 -9999 -9999 -9999 -9999 -9999 -9999 -9999 -9999 -9999 -9999 -9999 -9999 -9999 -9999 -9999 -9999 -9999 -9999 -9999 -9999 -9999 -9999 -9999 -9999 -9999 -9999 -9999 -9999 -9999 -9999 -9999 -9999 -9999 -9999 -9999 -9999 -9999 -9999 -9999 -9999 -9999 -9999

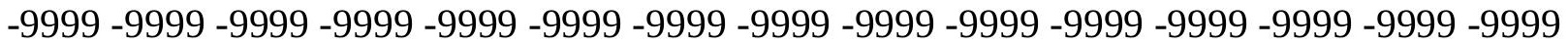
-9999 -9999 -9999 -9999 -9999 -9999 -9999 -9999 -9999 -9999 -9999 -9999 -9999 -9999 -9999 -9999 -9999 -9999 -9999 -9999 -9999 -9999 -9999 -9999 -9999 -9999 -9999 -9999 -9999 -9999 -9999 -9999 -9999 -9999 -9999 -9999 -9999 -9999 -9999 -9999 -9999 -9999 -9999 -9999 - 9999 -9999 -9999 -9999 -9999 -9999 -9999 -9999 -9999 -9999 -9999 -9999 -9999 -9999 -9999 -9999

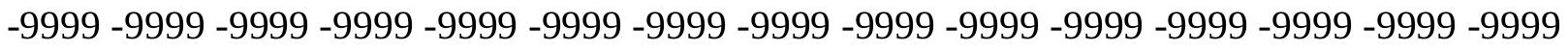
-9999 -9999 -9999 -9999 -9999 -9999 -9999 -9999 -9999 -9999 -9999 -9999 -9999 -9999 -9999 -9999 -9999 -9999 -9999 -9999 -9999 -9999 -9999 -9999 -9999 -9999 -9999 -9999 -9999 -9999 -9999 -9999 -9999 -9999 -9999 -9999 -9999 -9999 -9999 -9999 -9999 -9999 -9999 -9999 -9999 -

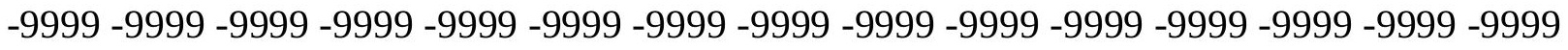

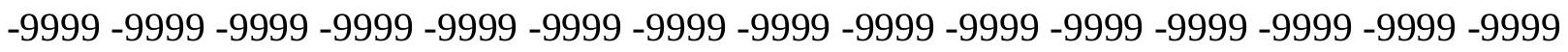
-9999 -9999 -9999 -9999 -9999 -9999 -9999 -9999 -9999 -9999 -9999 -9999 -9999 -9999 -9999 -9999 -9999 -9999 -9999 -9999 -9999 -9999 -9999 -9999 -9999 -9999 -9999 -9999 -9999 -9999 -

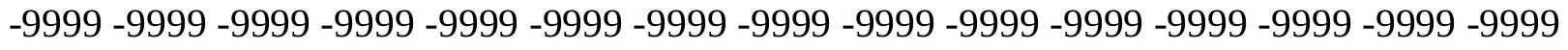

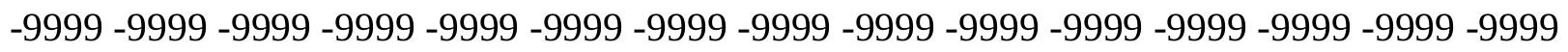
-9999 -9999 -9999 -9999 -9999 -9999 -9999 -9999 -9999 -9999 -9999 -9999 -9999 -9999 -9999 -9999 -9999 -9999 -9999 -9999-9999 -9999 -9999 -9999 -9999 -9999 -9999 -9999 -9999 - 9999 -9999 -9999 -9999 -9999 -9999 -9999 -9999 98.01933288574 97.5650177002 97.192237854 94.7528686523494 .4354476928794 .2116088867294 .0833206176894 .04103088379 94.0634918212992 .7112426757890 .5211791992287 .7781066894585 .03504943848 82.9015579223681 .0728530883879 .8537063598678 .6345596313577 .72020721436 77.110626220776 .5010681152376 .1962814331176 .1962814331176 .19628143311 76.1962814331176 .5010681152376 .8058471679777 .110626220777 .41542053223 78.0249862670978 .3297805786178 .9393463134879 .2441329956179 .85370635986 80.1584930419980 .4632720947381 .0728530883881 .3776321411181 .68241119385 82.2919769287182 .5967712402382 .5967712402382 .9015579223683 .2063369751 83.2063369751 83.2063369751 83.2063369751 83.206336975183.2063369751 82.9015579223682 .9015579223682 .5967712402382 .2919769287181 .68241119385 81.3776321411180 .7680587768680 .4632720947379 .8537063598679 .24413299561 78.6345596313578 .0249862670977 .2489013671975 .4521865844775 .89148712158 75.2819290161174 .6723632812573 .7580032348673 .1484298706172 .53885650635 71.9292907714871 .014930725170 .4053573608469 .7957916259869 .18623352051 68.2718734741267 .6623001098667 .0527267456166 .4431610107465 .83358764648 65.2240066528364 .6144485473663 .78015899658 -9999 -9999 -9999 -9999 -9999 -9999 -9999 -9999 -9999 -9999 -9999 -9999 -9999 -9999 -9999 -9999 -9999 -9999 -9999 -9999 -9999 -9999 -9999 -9999 -9999 -9999 -9999 -9999 -9999 -9999 -9999 
-9999 -9999 -9999 -9999 -9999 -9999 -9999 -9999 -9999 -9999 -9999 -9999 -9999 -9999 -9999 -9999 -9999 -9999 -9999 -9999 -9999 -9999 -9999 -9999 -9999 -9999 -9999 -9999 -9999 -9999 -9999 -9999 -9999 -9999 -9999 -9999 -9999 -9999 -9999 -9999 -9999 -9999 -9999 -9999 -9999 -9999 -9999 -9999 -9999 -9999 -9999 -9999 -9999 -9999 -9999 -9999 -9999 -9999 -9999 -9999 -9999 -9999 -9999 -9999 -9999 -9999 -9999 -9999 -9999 -9999 -9999 -9999 -9999 -9999 -9999 -9999 -9999 -9999 -9999 -9999 -9999 -9999 -9999 -9999 -9999 -9999 -9999 -9999 -9999 -9999 -9999 -9999 -9999 -9999 -9999 -9999 -9999 -9999 -9999 -9999 -9999 -9999 -9999 -9999 -9999

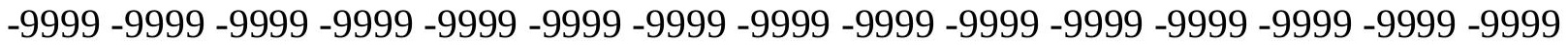
-9999 -9999 -9999 -9999 -9999 -9999 -9999 -9999 -9999 -9999 -9999 -9999 -9999 -9999 -9999 -9999 -9999 -9999 -9999 -9999 -9999 -9999 -9999 -9999 -9999 -9999 -9999 -9999 -9999 -9999 -

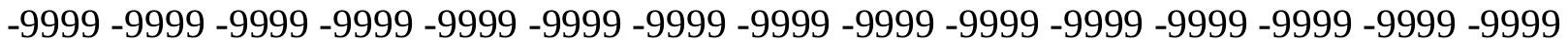
-9999 -9999 -9999 -9999 -9999 -9999 -9999 -9999 -9999 -9999 -9999 -9999 -9999 -9999 -9999

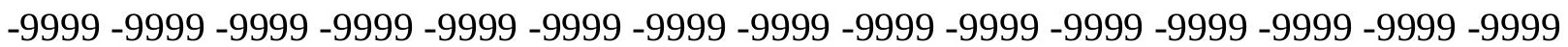
-9999 -9999 -9999 -9999 -9999 -9999 -9999 -9999 -9999 -9999 -9999 -9999 -9999 -9999 -9999 -9999 -9999 -9999 -9999 -9999 -9999 -9999 -9999 -9999 -9999 -9999 -9999 -9999 -9999 -9999 -9999 -9999 -9999 -9999 -9999 -9999 -9999 -9999 -9999 -9999 -9999 -9999 -9999 -9999 -9999 -

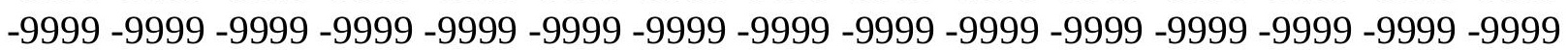
-9999 -9999 -9999 -9999 -9999 -9999 -9999 -9999 -9999 -9999 -9999 -9999 -9999 -9999 -9999 -9999 -9999 -9999 -9999 -9999 -9999 -9999 -9999 97.16728210449 96.79971313477 94.3275527954193 .9845352172993 .7574920654393 .6553573608493 .67244720459 93.7867660522593 .5613632202191 .7403335571388 .3876876831185 .94940185547 83.5111236572381 .6824111938580 .4632720947379 .2441329956178 .32978057861 77.7202072143677 .110626220776 .8058471679776 .8058471679776 .80584716797 76.8058471679777 .110626220777 .4154205322377 .7202072143678 .02498626709 78.6345596313578 .9393463134879 .2441329956179 .8537063598680 .15849304199 80.4632720947381 .0728530883881 .3776321411181 .6824111938581 .98719787598 82.29197692871 82.59677124023 82.9015579223682.9015579223683.2063369751 83.206336975183 .206336975183 .206336975182 .9015579223682 .90155792236 82.5967712402382 .2919769287181 .9871978759881 .6824111938581 .37763214111 80.7680587768680 .1584930419979 .8537063598679 .2441329956178 .63455963135 78.0249862670977 .110626220776 .4476928710974 .5744781494175 .28192901611 74.3675689697373 .7580032348673 .1484298706172 .2340774536171 .62449645996 71.014930725170 .1005783081169 .4910125732468 .8814392089868 .27187347412 67.3575134277366 .7479400634866 .1383666992265 .5288009643664 .91924285889 64.3096618652363 .635608673162 .83081817627 -9999 -9999 -9999 -9999 -9999 -9999 -9999 -9999 -9999 -9999 -9999 -9999 -9999 -9999 -9999 -9999 -9999 -9999 -9999 -9999 -9999 -9999 -9999 -9999 -9999-9999 -9999 -9999-9999 -9999-9999

-9999 -9999 -9999 -9999 -9999 -9999 -9999 -9999 -9999 -9999 -9999 -9999 -9999 -9999 -9999 -9999 -9999 -9999 -9999 -9999 -9999 -9999 -9999 -9999 -9999 -9999 -9999 -9999 -9999 -9999 -9999 -9999 -9999 -9999 -9999 -9999 -9999 -9999 -9999 -9999 -9999 -9999 -9999 -9999 -9999 -9999 -9999 -9999 -9999 -9999 -9999 -9999 -9999 -9999 -9999 -9999 -9999 -9999 -9999 -9999

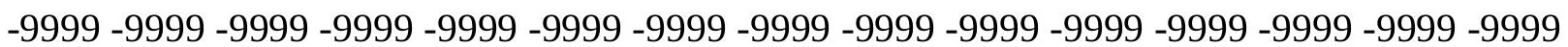
-9999 -9999 -9999 -9999 -9999 -9999 -9999 -9999 -9999 -9999 -9999 -9999 -9999 -9999 -9999 -9999 -9999 -9999 -9999 -9999 -9999 -9999 -9999 -9999 -9999 -9999 -9999 -9999 -9999 -9999 -9999 -9999 -9999 -9999 -9999 -9999 -9999 -9999 -9999 -9999 -9999 -9999 -9999 -9999 -9999

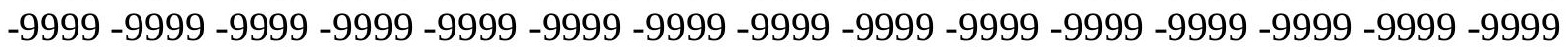


-9999 -9999 -9999 -9999 -9999 -9999 -9999 -9999 -9999 -9999 -9999 -9999 -9999 -9999 -9999 -9999 -9999 -9999 -9999 -9999 -9999 -9999 -9999 -9999 -9999 -9999 -9999 -9999 -9999 -9999 -9999 -9999 -9999 -9999 -9999 -9999 -9999 -9999 -9999 -9999 -9999 -9999 -9999 -9999 -9999 -9999 -9999 -9999 -9999 -9999 -9999 -9999 -9999 -9999 -9999 -9999 -9999 -9999 -9999 -9999 -9999 -9999 -9999 -9999 -9999 -9999 -9999 -9999 -9999 -9999 -9999 -9999 -9999 -9999 -9999 -9999 -9999 -9999 -9999 -9999 -9999 -9999 -9999 -9999 -9999 -9999 -9999 -9999 -9999 -9999 -9999 -9999 -9999 -9999 -9999 -9999 -9999 -9999 -9999 -9999 -9999 -9999 -9999 -9999 -9999

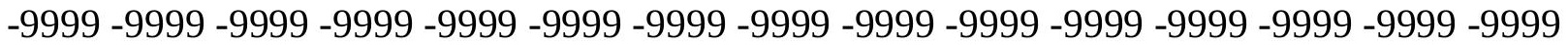
-9999 -9999 -9999 -9999 -9999 -9999 -9999 -9999 -9999 -9999 -9999 -9999 -9999 -9999 -9999 -9999 -9999 -9999 -9999 -9999 -9999 -9999 -9999 -9999 96.19850158691 95.90237426758 93.426200866793.1763305664193.08506774902 93.1558685302793.37014770508 93.6783294677792.04509735107 88.99725341797 86.2541885376 84.12069702148 82.2919769287180 .7680587768679 .5489196777378 .9393463134878 .32978057861 78.0249862670977 .7202072143677 .7202072143677 .7202072143677 .72020721436 78.0249862670978 .3297805786178 .6345596313578 .9393463134879 .24413299561 79.5489196777379 .8537063598680 .4632720947380 .7680587768681 .07285308838 81.3776321411181 .6824111938581 .9871978759882 .2919769287182 .59677124023 82.5967712402382 .9015579223682 .9015579223682 .9015579223682 .90155792236 82.9015579223682 .9015579223682 .9015579223682 .5967712402382 .29197692871 81.9871978759881 .6824111938581 .0728530883880 .7680587768680 .15849304199 79.5489196777379 .2441329956178 .6345596313577 .7202072143677 .1106262207 76.5010681152375 .5440597534273 .6868286132874 .3675689697373 .75800323486 72.8436431884872 .2340774536171 .6244964599670 .7101516723670 .10057830811 69.1862335205168 .5766525268667 .9670867919967 .3575134277366 .44316101074 65.8335876464865 .2240066528364 .6144485473664 .004882812563 .39530944824 62.6853103637761 .87572097778 -9999 -9999 -9999 -9999 -9999 -9999 -9999 -9999 -9999 -9999 -9999 -9999 -9999 -9999 -9999 -9999 -9999 -9999 -9999 -9999 -9999 -9999 -9999 -9999 -9999 -9999 -9999 -9999 -9999 -9999 -9999

-9999 -9999 -9999 -9999 -9999 -9999 -9999 -9999 -9999 -9999 -9999 -9999 -9999 -9999 -9999 -9999 -9999 -9999 -9999 -9999 -9999 -9999 -9999 -9999 -9999 -9999 -9999 -9999 -9999 -9999 -9999 -9999 -9999 -9999 -9999 -9999 -9999 -9999 -9999 -9999 -9999 -9999 -9999 -9999 -9999 -9999 -9999 -9999 -9999 -9999 -9999 -9999 -9999 -9999 -9999 -9999 -9999 -9999 -9999 -9999 -9999 -9999 -9999 -9999 -9999 -9999 -9999 -9999 -9999 -9999 -9999 -9999 -9999 -9999 -9999 -9999 -9999 -9999 -9999 -9999 -9999 -9999 -9999 -9999 -9999 -9999 -9999 -9999 -9999 -9999

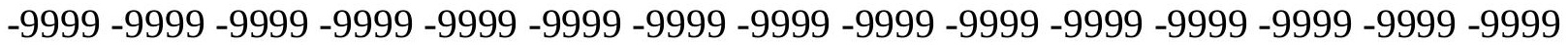
-9999 -9999 -9999 -9999 -9999 -9999 -9999 -9999 -9999 -9999 -9999 -9999 -9999 -9999 -9999 -9999 -9999 -9999 -9999 -9999 -9999 -9999 -9999 -9999 -9999 -9999 -9999 -9999 -9999 -9999

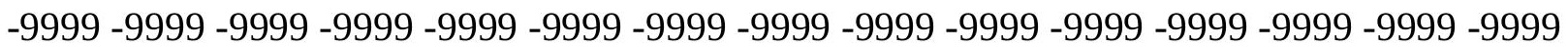
-9999 -9999 -9999 -9999 -9999 -9999 -9999 -9999 -9999 -9999 -9999 -9999 -9999 -9999 -9999 -9999 -9999 -9999 -9999 -9999 -9999 -9999 -9999 -9999 -9999 -9999 -9999 -9999 -9999 -9999 -9999 -9999 -9999 -9999 -9999 -9999 -9999 -9999 -9999 -9999 -9999 -9999 -9999 -9999 -9999

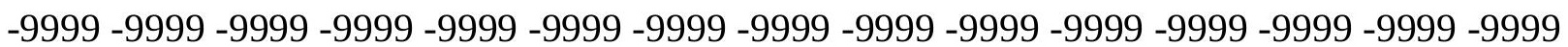
-9999 -9999 -9999 -9999 -9999 -9999 -9999 -9999 -9999 -9999 -9999 -9999 -9999 -9999 -9999 -9999 -9999 -9999 -9999 -9999 -9999 -9999 -9999 -9999 -9999 -9999 -9999 -9999 -9999 -9999 -9999 -9999 -9999 -9999 -9999 -9999 -9999 -9999 -9999 -9999 -9999 -9999 -9999 -9999 -9999

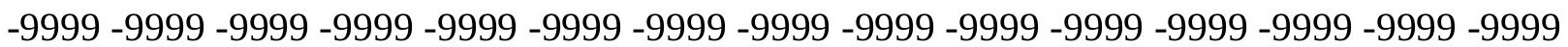


-9999 -9999 -9999 -9999 -9999 -9999 -9999 -9999 -9999-9999 95.0219039917 92.7625122070392 .4619598388792 .3542709350692 .4592742919992 .76779174805 93.2304306030391 .7403335571388 .6924667358486 .254188537684 .42548370361 82.5967712402381 .0728530883880 .1584930419979 .2441329956178 .93934631348 78.6345596313578 .3297805786178 .3297805786178 .3297805786178 .63455963135 78.6345596313578 .9393463134879 .2441329956179 .5489196777379 .85370635986 80.1584930419980 .7680587768681 .0728530883881 .3776321411181 .68241119385 81.9871978759881 .9871978759882 .2919769287182 .5967712402382 .59677124023 82.9015579223682 .9015579223682 .9015579223682 .9015579223682 .90155792236 82.9015579223682 .5967712402382 .5967712402382 .2919769287181 .98719787598 81.6824111938581 .0728530883880 .7680587768680 .1584930419979 .54891967773 79.2441329956178 .6345596313577 .7202072143677 .110626220776 .50106811523 75.7836990356474 .7174835205173 .6005783081173 .4532165527372 .84364318848 72.2340774536171 .3197174072370 .7101516723669 .7957916259869 .18623352051 68.2718734741267 .6623001098667 .0527267456166 .4431610107465 .52880096436 64.9192428588964 .3096618652363 .7000885009863 .0905189514262 .48094940186 61.7503929138260 .92434310913 -9999 -9999 -9999 -9999 -9999 -9999 -9999 -9999 -9999 -9999 -9999 -9999 -9999 -9999 -9999 -9999 -9999 -9999 -9999 -9999 -9999 -9999 -9999 -9999 -9999 -9999 -9999 -9999 -9999 -9999 -9999 -9999 -9999 -9999 -9999 -9999 -9999 -9999 -9999 -9999 -9999 -9999 -9999 -9999 -9999 -9999

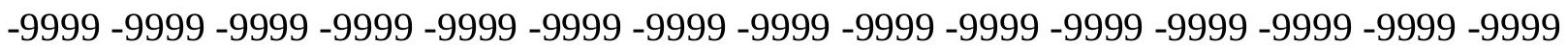
-9999 -9999 -9999 -9999 -9999 -9999 -9999 -9999 -9999 -9999 -9999 -9999 -9999 -9999 -9999 -9999 -9999 -9999 -9999 -9999 -9999 -9999 -9999 -9999 -9999 -9999 -9999 -9999 -9999 -9999 -9999 -9999 -9999 -9999 -9999 -9999 -9999 -9999 -9999 -9999 -9999 -9999 -9999 -9999 -9999

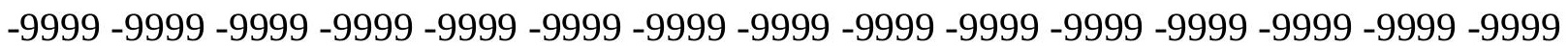
-9999 -9999 -9999 -9999 -9999 -9999 -9999 -9999 -9999 -9999 -9999 -9999 -9999 -9999 -9999 -9999 -9999 -9999 -9999 -9999 -9999 -9999 -9999 -9999 -9999 -9999 -9999 -9999 -9999 -9999 -9999 -9999 -9999 -9999 -9999 -9999 -9999 -9999 -9999 -9999 -9999 -9999 -9999 -9999 -9999 -9999 -9999 -9999 -9999 -9999 -9999 -9999 -9999 -9999 -9999 -9999 -9999 -9999 -9999 -9999 -9999 -9999 -9999 -9999 -9999 -9999 -9999 -9999 -9999 -9999 -9999 -9999 -9999 -9999 -9999 -9999 -9999 -9999 -9999 -9999 -9999 -9999 -9999 -9999 -9999 -9999 -9999 -9999 -9999 -9999 -9999 -9999 -9999 -9999 -9999 -9999 -9999 -9999 -9999 -9999 -9999 -9999 -9999 -9999 -9999 -9999 -9999 -9999 -9999 -9999 -9999 -9999 -9999 -9999 -9999 -9999 -9999 -9999 -9999 -9999 -9999 -9999 -9999 -9999 -9999 -9999 -9999 -9999 -9999 -9999 -9999 -9999 -9999 -9999 -9999 -

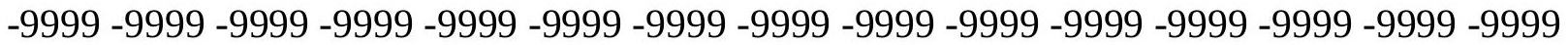
-9999 -9999 -9999 -9999 -9999 -9999 -9999 -9999 -9999 -9999 -9999 -9999 -9999 -9999 -9999 -9999 -9999 -9999 -9999 -9999 -9999 -9999 -9999 -9999 -9999 -9999 -9999 -9999 -9999 -9999 -9999-9999 -9999 -9999-9999 -9999 -9999-9999 -9999 -9999 -9999 93.57837677002 91.6229476928791 .4589538574291 .5579223632891 .9345321655392 .1863861084 90.2164001464888 .3876876831186 .254188537684 .4254837036182 .90155792236 81.3776321411180 .4632720947379 .8537063598679 .2441329956179 .24413299561 79.2441329956179 .2441329956179 .2441329956179 .5489196777379 .54891967773 79.8537063598680 .1584930419980 .4632720947380 .7680587768681 .07285308838 81.3776321411181 .6824111938581 .6824111938581 .9871978759882 .29197692871 82.5967712402382 .5967712402382 .9015579223682 .9015579223682 .90155792236 82.9015579223682 .9015579223682 .9015579223682 .9015579223682 .59677124023 
82.5967712402382 .2919769287181 .9871978759881 .6824111938581 .07285308838 80.7680587768680 .1584930419979 .8537063598679 .2441329956178 .63455963135 77.7202072143677 .110626220776 .5010681152375 .8914871215874 .97714233398 73.826446533272 .7574615478572 .8436431884871 .9292907714871 .31971740723 70.4053573608469 .7957916259868 .8814392089868 .2718734741267 .35751342773 66.7479400634866 .1383666992265 .2240066528364 .6144485473664 .0048828125 63.3953094482462 .7857398986862 .1761703491261 .5666007995660 .81206893921 59.96850585938 -9999 -9999 -9999 -9999 -9999 -9999 -9999 -9999 -9999 -9999 -9999 -9999

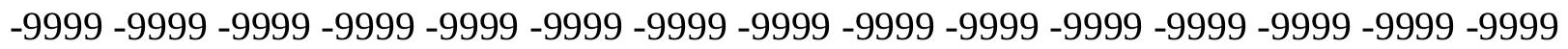
-9999 -9999 -9999-9999

-9999 -9999 -9999 -9999 -9999 -9999 -9999 -9999 -9999 -9999 -9999 -9999 -9999 -9999 -9999 -9999 -9999 -9999 -9999 -9999 -9999 -9999 -9999 -9999 -9999 -9999 -9999 -9999 -9999 -9999

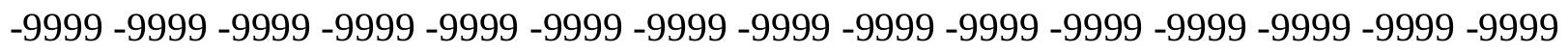
-9999 -9999 -9999 -9999 -9999 -9999 -9999 -9999 -9999 -9999 -9999 -9999 -9999 -9999 -9999 -9999 -9999 -9999 -9999 -9999 -9999 -9999 -9999 -9999 -9999 -9999 -9999 -9999 -9999 -9999

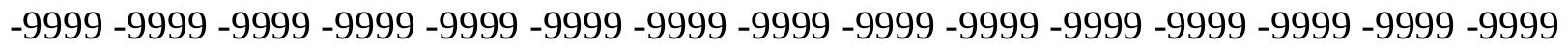
-9999 -9999 -9999 -9999 -9999 -9999 -9999 -9999 -9999 -9999 -9999 -9999 -9999 -9999 -9999 -9999 -9999 -9999 -9999 -9999 -9999 -9999 -9999 -9999 -9999 -9999 -9999 -9999 -9999 -9999 -

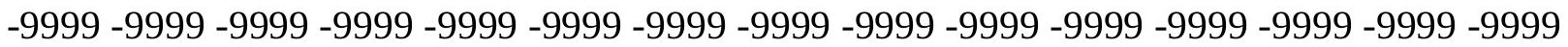

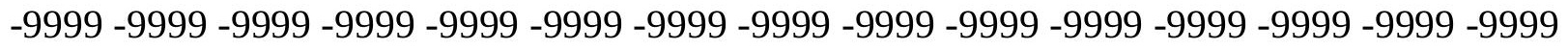

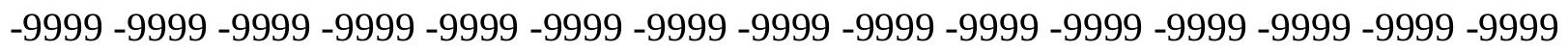
-9999 -9999 -9999 -9999 -9999 -9999 -9999 -9999 -9999 -9999 -9999 -9999 -9999 -9999 -9999 -9999 -9999 -9999 -9999 -9999 -9999 -9999 -9999 -9999 -9999 -9999 -9999 -9999 -9999 -9999 -

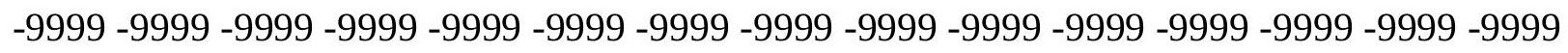

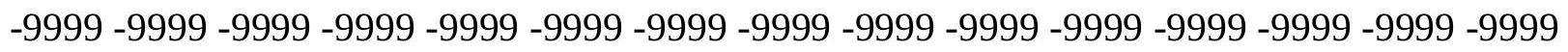
-9999 -9999 -9999 -9999 -9999 -9999 -9999 -9999 -9999 -9999 -9999 -9999 -9999 -9999 -9999 -9999 -9999 -9999 -9999 -9999 -9999 -9999 -9999 -9999 -9999 -9999 -9999 -9999 -9999 - -9999 -

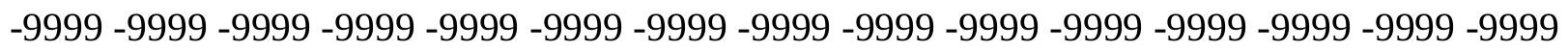
-9999 -9999 -9999 -9999-9999-9999 -9999 -9999 -9999 -9999 -9999 92.1071395874 90.6909179687590 .4160079956190 .446014404390 .8280029296991 .25485992432 89.60682678223 87.77810668945 86.2541885376 84.7302627563583.2063369751 81.9871978759880 .7680587768680 .1584930419979 .8537063598679 .85370635986 79.8537063598679 .8537063598680 .1584930419980 .4632720947380 .46327209473 80.7680587768681 .0728530883881 .3776321411181 .3776321411181 .68241119385 81.9871978759882 .2919769287182 .2919769287182 .5967712402382 .90155792236 82.9015579223682 .9015579223683 .206336975183 .206336975183 .2063369751 83.2063369751 83.2063369751 82.90155792236 82.90155792236 82.59677124023 82.2919769287181 .9871978759881 .6824111938581 .3776321411180 .76805877686 80.4632720947379 .8537063598679 .2441329956178 .6345596313578 .02498626709 77.110626220776 .5010681152375 .8914871215874 .9771423339874 .24890136719 72.8601455688572 .5388565063571 .9292907714871 .014930725170 .40535736084 69.4910125732468 .8814392089867 .9670867919967 .3575134277366 .44316101074 65.8335876464864 .9192428588964 .3096618652363 .7000885009863 .09051895142 62.4809494018661 .8713798522961 .2618103027360 .6522407531759 .82723617554 58.9899597168 -9999 -9999 -9999 -9999 -9999 -9999 -9999 -9999 -9999 -9999 -9999 -9999 -9999 -9999 -9999 -9999 -9999 -9999 -9999 -9999 -9999 -9999 -9999 -9999 -9999 -9999 -9999 
-9999 -9999 -9999 -9999

-9999 -9999 -9999 -9999 -9999 -9999 -9999 -9999 -9999 -9999 -9999 -9999 -9999 -9999 -9999

-9999 -9999 -9999 -9999 -9999 -9999 -9999 -9999 -9999 -9999 -9999 -9999 -9999 -9999 - 9999 -

-9999 -9999 -9999 -9999 -9999 -9999 -9999 -9999 -9999 -9999 -9999 -9999 -9999 -9999 -9999

-9999 -9999 -9999 -9999 -9999 -9999 -9999 -9999 -9999 -9999 -9999 -9999-9999 -9999 -9999 -

-9999 -9999 -9999 -9999 -9999 -9999 -9999 -9999 -9999 -9999 -9999 -9999 -9999 -9999 -9999

-9999 -9999 -9999 -9999 -9999 -9999 -9999 -9999 -9999 -9999 -9999 -9999 -9999 -9999 -9999 -999 -

-9999 -9999 -9999 -9999 -9999 -9999 -9999 -9999 -9999 -9999 -9999 -9999 -9999 -9999 -9999

-9999 -9999 -9999 -9999 -9999 -9999 -9999 -9999 -9999 -9999 -9999 -9999 -9999 -9999 -9999

-9999 -9999 -9999 -9999 -9999 -9999 -9999 -9999 -9999 -9999 -9999 -9999 -9999 -9999 -9999 -

-9999 -9999 -9999 -9999 -9999 -9999 -9999 -9999 -9999 -9999 -9999 -9999 -9999 -9999 -9999

-9999 -9999 -9999 -9999 -9999 -9999 -9999 -9999 -9999 -9999 -9999 -9999 -9999 -9999 -9999

-9999 -9999 -9999 -9999 -9999 -9999 -9999 -9999 -9999 -9999 -9999 -9999 -9999 -9999 -9999

-9999 -9999 -9999 -9999 -9999 -9999 -9999 -9999 -9999 -9999 -9999 -9999 -9999 -9999 -9999 -

-9999 -9999 -9999 -9999 -9999 -9999 -9999 -9999 -9999 -9999 -9999 -9999 -9999 -9999 -9999

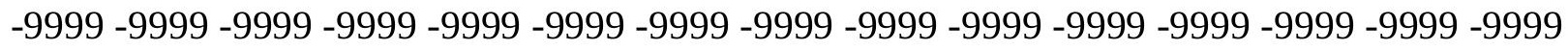

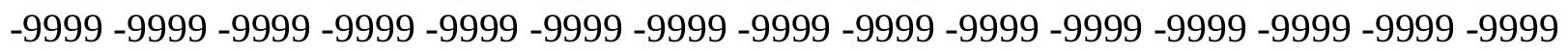

-9999 -9999 -9999 -9999 -9999 -9999 -9999 -9999 -9999 -9999 -9999 -9999 -9999 -9999 -9999 -

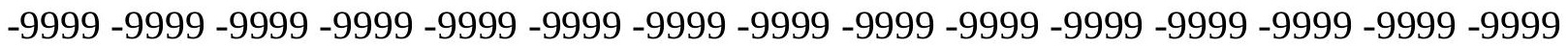

-9999 -9999 -9999 -9999 -9999 -9999 -9999 -9999 -9999 -9999-9999 -9999 89.85469818115

89.28818511963 89.16944122314 89.46208953857 90.21640014648 88.38768768311

87.4733276367286 .5589828491285 .3398437583 .5111236572382 .29197692871

81.0728530883880 .7680587768680 .4632720947380 .4632720947380 .76805877686 80.7680587768681 .0728530883881 .3776321411181 .3776321411181 .68241119385 81.9871978759882 .2919769287182 .2919769287182 .5967712402382 .59677124023 82.9015579223682 .9015579223683 .206336975183 .206336975183 .2063369751 83.5111236572383 .5111236572383 .5111236572383 .206336975183 .2063369751 83.2063369751 82.9015579223682.90155792236 82.59677124023 82.29197692871 81.6824111938581 .3776321411181 .0728530883880 .4632720947379 .85370635986 79.2441329956178 .6345596313578 .0249862670977 .4154205322376 .50106811523 75.8914871215874 .9771423339874 .3675689697373 .4532165527371 .79763031006 71.9292907714871 .014930725170 .1005783081169 .4910125732468 .57665252686 67.6623001098667 .0527267456166 .1383666992265 .5288009643664 .91924285889 64.004882812563 .3953094482462 .7857398986861 .8713798522961 .26181030273 60.6522407531760 .0426712036159 .4331016540558 .7983665466358 .01051330566 -9999 -9999 -9999 -9999 -9999 -9999 -9999 -9999 -9999 -9999 -9999 -9999 -9999 -9999 -9999 -9999

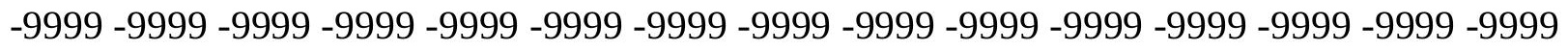

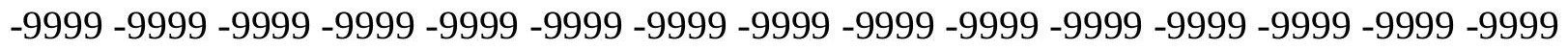
-9999 -9999 -9999 -9999 -9999 -9999 -9999 -9999 -9999 -9999 -9999 -9999 -9999 -9999 -9999 -9999 -9999 -9999 -9999 -9999 -9999 -9999 -9999 -9999 -9999 -9999 -9999 -9999 -9999 -9999 -

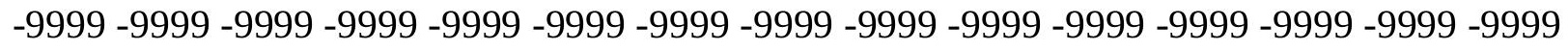

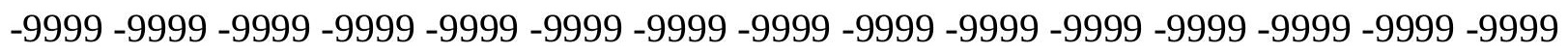

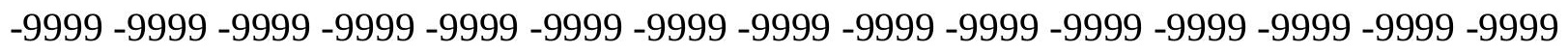
-9999 -9999 -9999 -9999 -9999 -9999 -9999 -9999 -9999 -9999 -9999 -9999 -9999 -9999 -9999 -9999 -9999 -9999 -9999 -9999 -9999 -9999 -9999 -9999 -9999 -9999 -9999 -9999 -9999 -9999 -

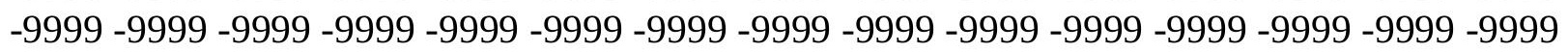


-9999 -9999 -9999 -9999 -9999 -9999 -9999 -9999 -9999 -9999 -9999 -9999 -9999 -9999 -9999 -9999 -9999 -9999 -9999 -9999 -9999 -9999 -9999 -9999 -9999 -9999 -9999 -9999 -9999 -9999 -9999 -9999 -9999 -9999 -9999 -9999 -9999 -9999 -9999 -9999 -9999 -9999 -9999 -9999 -9999 -9999 -9999 -9999 -9999 -9999 -9999 -9999 -9999 -9999 -9999 -9999 -9999 -9999 -9999 -9999 -9999 -9999 -9999 -9999 -9999 -9999 -9999 -9999 -9999 -9999 -9999 -9999 -9999 -9999 -9999 -9999 -9999 -9999 -9999 -9999 -9999 -9999 -9999 -9999 -9999 -9999 -9999 -9999 -9999 -9999 -9999 -9999 -9999 -9999 -9999 -9999 -9999 -9999 -9999 -9999 -9999 -9999 -9999 -9999 -9999

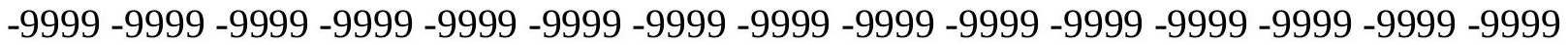

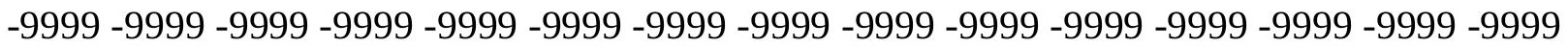
-9999 -9999 -9999 -9999 -9999 -9999 -9999 -9999 -9999 -9999 -9999 -9999 -9999 86.9742965698286 .2020874023485 .7270507812585 .9494018554785 .94940185547 86.8637619018687 .1685485839885 .6446228027383 .8159103393682 .29197692871 81.6824111938581 .0728530883881 .0728530883881 .3776321411181 .68241119385 81.9871978759881 .9871978759882 .2919769287182 .5967712402382 .59677124023 82.9015579223682 .9015579223683 .206336975183 .206336975183 .51112365723 83.5111236572383 .5111236572383 .8159103393683 .8159103393683 .81591033936 83.81591033936 83.81591033936 83.51112365723 83.51112365723 83.51112365723 83.206336975182.90155792236 82.59677124023 82.29197692871 81.98719787598 81.6824111938581 .0728530883880 .7680587768680 .1584930419979 .54891967773 78.9393463134878 .3297805786177 .4154205322376 .8058471679775 .89148712158 75.2819290161174 .3675689697373 .4532165527372 .5259017944370 .6990737915 71.014930725170 .1005783081169 .1862335205168 .5766525268667 .66230010986 66.7479400634866 .1383666992265 .2240066528364 .6144485473663 .70008850098 63.0905189514262 .4809494018661 .5666007995660 .9570198059160 .34745025635 $59.7378807067959 .1283111572358 .5187492370657 .8051834106457 .01962280273-9999$ -9999 -9999 -9999 -9999 -9999 -9999 -9999 -9999 -9999 -9999 -9999 -9999 -9999 -9999 -9999 -9999 -9999 -9999 -9999 -9999 -9999 -9999 -9999 -9999 -9999 -9999 -9999 -9999 -9999 -9999 -9999 -9999 -9999 -9999 -9999 -9999 -9999 -9999 -9999 -9999 -9999 -9999 -9999 -9999 -9999 -9999 -9999 -9999 -9999 -9999 -9999 -9999 -9999 -9999 -9999 -9999 -9999 -9999 -9999 -9999 -9999 -9999 -9999 -9999 -9999 -9999 -9999 -9999 -9999 -9999 -9999 -9999 -9999 -9999 -9999 -9999 -9999 -9999 -9999 -9999 -9999 -9999 -9999 -9999 -9999 -9999 -9999 -9999 -9999 -9999 -

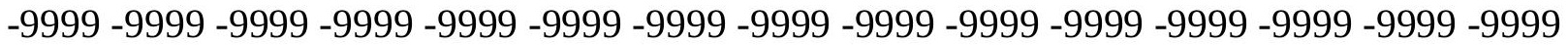
-9999 -9999 -9999 -9999 -9999 -9999 -9999 -9999 -9999 -9999 -9999 -9999 -9999 -9999 -9999 -9999 -9999 -9999 -9999 -9999 -9999 -9999 -9999 -9999 -9999 -9999 -9999 -9999 -9999 -9999

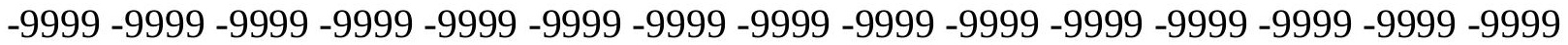
-9999 -9999 -9999 -9999 -9999 -9999 -9999 -9999 -9999 -9999 -9999 -9999 -9999 -9999 -9999 -9999 -9999 -9999 -9999 -9999 -9999 -9999 -9999 -9999 -9999 -9999 -9999 -9999 -9999 -9999

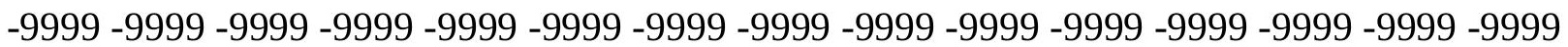
-9999 -9999 -9999 -9999 -9999 -9999 -9999 -9999 -9999 -9999 -9999 -9999 -9999 -9999 -9999 -9999 -9999 -9999 -9999 -9999 -9999 -9999 -9999 -9999 -9999 -9999 -9999 -9999 -9999 -9999 -9999 -9999 -9999 -9999 -9999 -9999 -9999 -9999 -9999 -9999 -9999 -9999 -9999 -9999 -9999

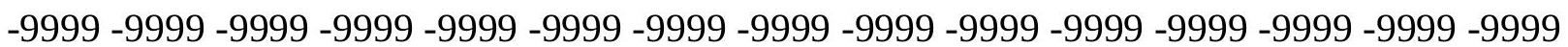
-9999 -9999 -9999 -9999 -9999 -9999 -9999 -9999 -9999 -9999 -9999 -9999 -9999 -9999 -9999 -9999 -9999 -9999 -9999 -9999 -9999 -9999 -9999 -9999 -9999 -9999 -9999 -9999 -9999 -9999 -9999 -9999 -9999 -9999 -9999 -9999 -9999 -9999 -9999 -9999 -9999 -9999 -9999 -9999 -9999 -9999 -9999 -9999 -9999 -9999 -9999 -9999 -9999 -9999 -9999 -9999 -9999 -9999 -9999 
83.1873092651481 .305664062579 .2441329956181 .9871978759886 .86376190186 87.1685485839885 .3398437583 .5111236572382 .2919769287181 .98719787598 81.6824111938581 .9871978759882 .2919769287182 .5967712402382 .90155792236 83.206336975183 .5111236572383 .5111236572383 .8159103393683 .81591033936 84.1206970214884 .1206970214884 .1206970214884 .1206970214884 .12069702148 84.1206970214884 .1206970214884 .1206970214884 .1206970214884 .12069702148 84.1206970214883 .8159103393683 .8159103393683 .5111236572383 .2063369751 82.9015579223682 .5967712402382 .2919769287181 .9871978759881 .37763214111 81.0728530883880 .4632720947379 .8537063598679 .2441329956178 .32978057861 77.7202072143676 .8058471679776 .1962814331175 .2819290161174 .36756896973 73.4532165527372 .8436431884871 .4637908935569 .596817016670 .10057830811 69.18623352051 68.27187347412 67.35751342773 66.74794006348 65.83358764648 64.9192428588964 .3096618652363 .3953094482462 .7857398986861 .87137985229 61.2618103027360 .6522407531760 .0426712036159 .4331016540558 .82352828979 58.2139587402357 .6043891906756 .8101081848156 .02209472656 -9999 -9999 -9999 -9999 -9999 -9999 -9999 -9999 -9999 -9999 -9999 -9999 -9999 -9999 -9999 -9999 -9999 -9999 -9999 -9999 -9999 -9999 -9999 -9999 -9999 -9999 -9999 -9999 -9999 -9999 -9999 -

-9999 -9999 -9999 -9999 -9999 -9999 -9999 -9999 -9999 -9999 -9999 -9999 -9999 -9999 -9999 -9999 -9999 -9999 -9999 -9999 -9999 -9999 -9999 -9999 -9999 -9999 -9999 -9999 -9999 -9999 -

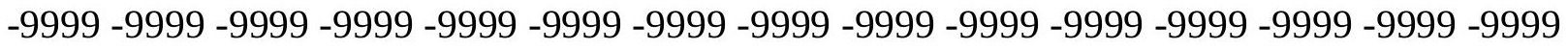

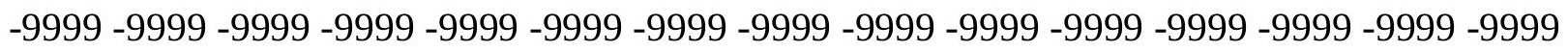
-9999 -9999 -9999 -9999 -9999 -9999 -9999 -9999 -9999 -9999 -9999 -9999 -9999 -9999 -9999 -9999 -9999 -9999 -9999 -9999 -9999 -9999 -9999 -9999 -9999 -9999 -9999 -9999 -9999 -9999 -9999 -9999 -9999 -9999 -9999 -9999 -9999 -9999 -9999 -9999 -9999 -9999 -9999 -9999 -9999 -

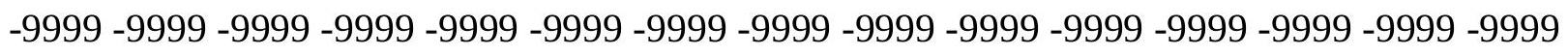
-9999 -9999 -9999 -9999 -9999 -9999 -9999 -9999 -9999 -9999 -9999 -9999 -9999 -9999 -9999 -9999 -9999 -9999 -9999 -9999 -9999 -9999 -9999 -9999 -9999 -9999 -9999 -9999 -9999 -9999 -

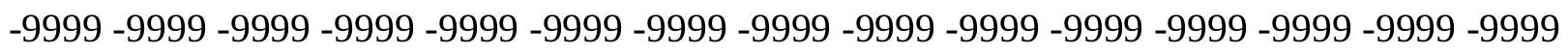
-9999 -9999 -9999 -9999 -9999 -9999 -9999 -9999 -9999 -9999 -9999 -9999 -9999 -9999 -9999 -9999 -9999 -9999 -9999 -9999 -9999 -9999 -9999 -9999 -9999 -9999 -9999 -9999 -9999 -999 -9999 -9999 -9999 -9999 -9999 -9999 -9999 -9999 -9999 -9999 -9999 -9999 -9999 -9999 -9999 -9999 -9999 -9999 -9999 -9999 -9999 -9999 -9999 -9999 -9999 -9999 -9999 -9999 -9999 -9999 -

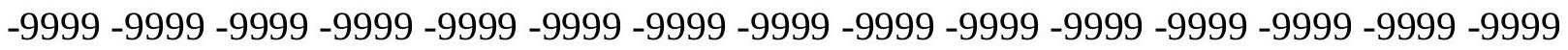

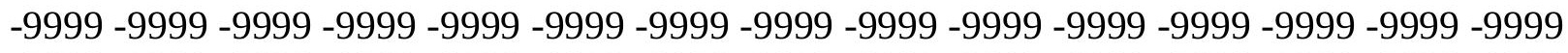
-9999 -9999 -9999 -9999 -9999 -9999 -9999 -9999 -9999 -9999 -9999 -9999 -9999 -9999 -9999 -9999 -9999 -9999 -9999 -9999 -9999 -9999 -9999 -9999 -9999 -9999 -9999 -9999 -9999 81.13938140869 78.63885498047 75.8914871215874.36756896973 88.08290100098 84.7302627563582 .9015579223682 .2919769287182 .2919769287182 .29197692871 82.5967712402382 .9015579223683 .5111236572383 .8159103393684 .12069702148 84.4254837036184 .7302627563584 .7302627563584 .7302627563585 .03504943848 85.0350494384885 .0350494384885 .0350494384885 .0350494384885 .03504943848 84.7302627563584 .7302627563584 .7302627563584 .7302627563584 .42548370361 84.4254837036184 .1206970214883 .8159103393683 .8159103393683 .51112365723 83.206336975182 .5967712402382 .2919769287181 .6824111938581 .37763214111 80.7680587768680 .1584930419979 .5489196777378 .6345596313578 .02498626709 77.110626220776 .5010681152375 .5867080688574 .6723632812573 .75800323486 
72.8436431884871 .9292907714870 .2971954345768 .5000228881869 .18623352051 68.2718734741267 .3575134277366 .4431610107465 .5288009643664 .91924285889 64.004882812563 .0905189514262 .4809494018661 .5666007995660 .95701980591 60.3474502563559 .4331016540558 .8235282897958 .2139587402357 .60438919067 56.9948196411156 .3852500915555 .7690086364755 .02238082886 -9999 -9999 -9999 -9999 -9999 -9999 -9999 -9999 -9999 -9999 -9999 -9999 -9999 -9999 -9999 -9999 -9999 -9999 -9999 -9999 -9999 -9999 -9999 -9999 -9999 -9999 -9999 -9999 -9999 -9999 -9999

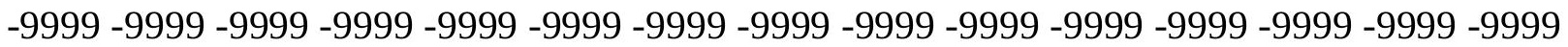
-9999 -9999 -9999 -9999 -9999 -9999 -9999 -9999 -9999 -9999 -9999 -9999 -9999 -9999 -9999 -9999 -9999 -9999 -9999 -9999 -9999 -9999 -9999 -9999 -9999 -9999 -9999 -9999 -9999 -9999 -

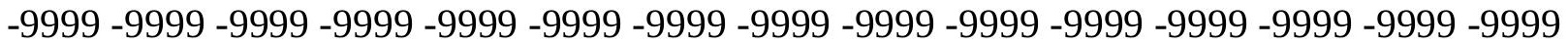
-9999 -9999 -9999 -9999 -9999 -9999 -9999 -9999 -9999 -9999 -9999 -9999 -9999 -9999 -9999 -9999 -9999 -9999 -9999 -9999 -9999 -9999 -9999 -9999 -9999 -9999 -9999 -9999 -9999 -9999 -9999 -9999 -9999 -9999 -9999 -9999 -9999 -9999 -9999 -9999 -9999 -9999 -9999 -9999 -9999 -9999 -9999 -9999 -9999 -9999 -9999 -9999 -9999 -9999 -9999 -9999 -9999 -9999 -9999 -9999 -9999 -9999 -9999 -9999 -9999 -9999 -9999 -9999 -9999 -9999 -9999 -9999 -9999 - -9999 - -9999 -

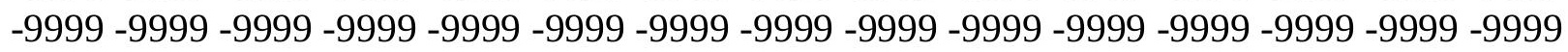

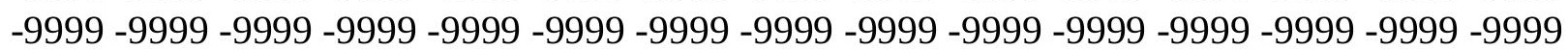
-9999 -9999 -9999 -9999 -9999 -9999 -9999 -9999 -9999 -9999 -9999 -9999 -9999 -9999 -9999 -9999 -9999 -9999 -9999 -9999 -9999 -9999 -9999 -9999 -9999 -9999 -9999 -9999 -9999 -9999

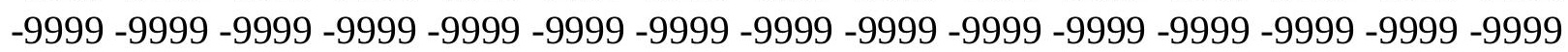

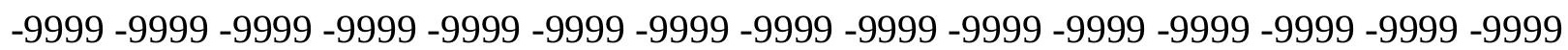
-9999 -9999 -9999 -9999 -9999 -9999 -9999 -9999 -9999 -9999 -9999 -9999-9999-9999-9999 -999 -9999 -9999 -9999 -9999 -9999 -9999 -9999 -9999 -9999 -9999 -9999 -9999 -9999 -9999 -9999 -9999 -9999 -9999 -9999 -9999 -9999 -9999 -9999 -9999 -9999 -9999 -9999 -9999 -9999 -9999 -9999 -9999 -9999 -9999 -9999 -9999 -9999 -9999 -9999 -9999 -9999 -9999 -9999 -9999 -9999 78.1235427856474 .9771423339868 .8814392089871 .014930725177 .41542053223 80.1584930419981 .0728530883881 .9871978759882 .9015579223683 .51112365723 84.1206970214884 .7302627563585 .3398437585 .6446228027385 .64462280273 85.9494018554785 .9494018554785 .9494018554785 .9494018554785 .94940185547 85.9494018554785 .9494018554785 .6446228027385 .6446228027385 .64462280273 85.3398437585 .3398437585 .0350494384885 .0350494384884 .7302627563584 .42548370361 84.1206970214883 .8159103393683 .5111236572383 .206336975182 .59677124023 82.2919769287181 .6824111938581 .0728530883880 .4632720947379 .85370635986 79.2441329956178 .3297805786177 .4154205322376 .8058471679775 .89148712158 74.9771423339874 .062782287673 .1484298706172 .2340774536170 .94332885742 69.1608657836969 .1862335205168 .2718734741267 .3575134277366 .44316101074 65.5288009643664 .6144485473663 .7000885009863 .0905189514262 .17617034912 61.2618103027360 .6522407531760 .0426712036159 .1283111572358 .51874923706 57.909179687557 .2995986938556 .6900291442956 .0804595947355 .47089004517 54.72379684448 -9999 -9999 -9999 -9999 -9999 -9999 -9999 -9999 -9999 -9999 -9999 -9999 -9999 -9999 -9999 -9999 -9999 -9999 -9999 -9999 -9999 -9999 -9999 -9999 -9999 -9999 -9999 -9999 -9999 -9999 -9999-9999

-9999 -9999 -9999 -9999 -9999 -9999 -9999 -9999 -9999 -9999 -9999 -9999 -9999 -9999 -9999 -9999 -9999 -9999 -9999 -9999 -9999 -9999 -9999 -9999 -9999 -9999 -9999 -9999 -9999 -9999 -

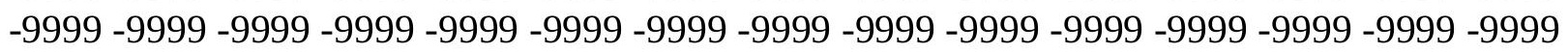


-9999 -9999 -9999 -9999 -9999 -9999 -9999 -9999 -9999 -9999 -9999 -9999 -9999 -9999 -9999 -9999 -9999 -9999 -9999 -9999 -9999 -9999 -9999 -9999 -9999 -9999 -9999 -9999 -9999 -9999 -9999 -9999 -9999 -9999 -9999 -9999 -9999 -9999 -9999 -9999 -9999 -9999 -9999 -9999 -9999 -9999 -9999 -9999 -9999 -9999 -9999 -9999 -9999 -9999 -9999 -9999 -9999 -9999 -9999 -9999 -9999 -9999 -9999 -9999 -9999 -9999 -9999 -9999 -9999 -9999 -9999 -9999 -9999 -9999 -9999 -9999 -9999 -9999 -9999 -9999 -9999 -9999 -9999 -9999 -9999 -9999 -9999 -9999 -9999 -9999 -9999 -9999 -9999 -9999 -9999 -9999 -9999 -9999 -9999 -9999 -9999 -9999 -9999 -9999 -9999

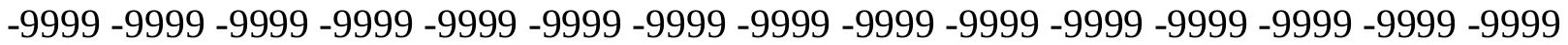
-9999 -9999 -9999 -9999 -9999 -9999 -9999 -9999 -9999 -9999 -9999 -9999 -9999 -9999 -9999 -9999 -9999 -9999 -9999 -9999 -9999 -9999 -9999 -9999 -9999 -9999 -9999 -9999 -9999 -9999 -

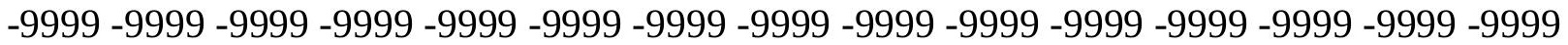
-9999 -9999 -9999 -9999 -9999 -9999 -9999 -9999 -9999 -9999 -9999 -9999 -9999 -9999 -9999

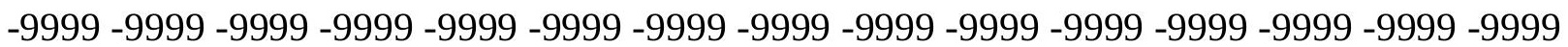
-9999 -9999 -9999 -9999 -9999 -9999 -9999 -9999 -9999 -9999 -9999 -9999 -9999 -9999 -9999 -9999 -9999 -9999 -9999 -9999 -9999 -9999 -9999 -9999 -9999 -9999 -9999 -9999 -9999 -9999 -9999 -9999 -9999 -9999 -9999 -9999 -9999 -9999 -9999 -9999 -9999 -9999 -9999 -9999 -9999 -9999 76.1962814331171.31971740723 68.5766525268673.7580032348677.72020721436 80.4632720947382 .2919769287183 .8159103393684 .7302627563585 .64462280273 86.254188537686 .5589828491286 .8637619018687 .1685485839887 .16854858398 87.1685485839887 .1685485839887 .1685485839886 .8637619018686 .86376190186 86.5589828491286 .5589828491286 .254188537686 .254188537685 .94940185547 85.6446228027385 .6446228027385 .3398437585 .0350494384884 .73026275635 84.4254837036184 .1206970214883 .8159103393683 .206336975182 .90155792236 82.2919769287181 .6824111938581 .0728530883880 .4632720947379 .54891967773 78.9393463134878 .0249862670977 .110626220776 .1962814331175 .28192901611 74.3675689697373 .4532165527372 .2340774536171 .3197174072369 .90644073486 68.0961074829168 .2718734741267 .3575134277366 .4431610107465 .52880096436 64.6144485473663 .7000885009862 .7857398986861 .8713798522960 .95701980591 60.3474502563559 .4331016540558 .8235282897958 .2139587402357 .29959869385 56.6900291442956 .0804595947355 .4708900451754 .8613204956154 .25175094604 53.67851638794 -9999 -9999 -9999 -9999 -9999 -9999 -9999 -9999 -9999 -9999 -9999 -9999 -9999 -9999 -9999 -9999 -9999 -9999 -9999 -9999 -9999 -9999 -9999 -9999 -9999 -9999 -9999 -9999 -9999-9999-9999-9999

-9999 -9999 -9999 -9999 -9999 -9999 -9999 -9999 -9999 -9999 -9999 -9999 -9999 -9999 -9999 -9999 -9999 -9999 -9999 -9999 -9999 -9999 -9999 -9999 -9999 -9999 -9999 -9999 -9999 -9999 -9999 -9999 -9999 -9999 -9999 -9999 -9999 -9999 -9999 -9999 -9999 -9999 -9999 -9999 -9999 -9999 -9999 -9999 -9999 -9999 -9999 -9999 -9999 -9999 -9999 -9999 -9999 -9999 -9999 -9999

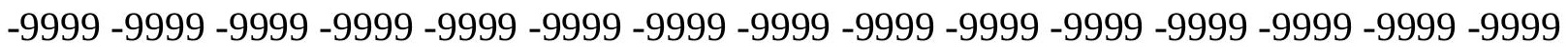
-9999 -9999 -9999 -9999 -9999 -9999 -9999 -9999 -9999 -9999 -9999 -9999 -9999 -9999 -9999 -9999 -9999 -9999 -9999 -9999 -9999 -9999 -9999 -9999 -9999 -9999 -9999 -9999 -9999 -9999 -9999 -9999 -9999 -9999 -9999 -9999 -9999 -9999 -9999 -9999 -9999 -9999 -9999 -9999 -9999

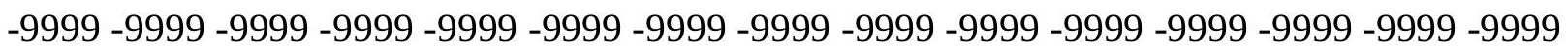
-9999 -9999 -9999 -9999 -9999 -9999 -9999 -9999 -9999 -9999 -9999 -9999 -9999 -9999 -9999 -9999 -9999 -9999 -9999 -9999 -9999 -9999 -9999 -9999 -9999 -9999 -9999 -9999 -9999 -9999 -9999 -9999 -9999 -9999 -9999 -9999 -9999 -9999 -9999 -9999 -9999 -9999 -9999 -9999 -9999

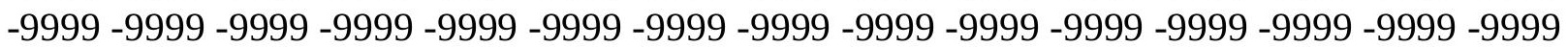


-9999 -9999 -9999 -9999 -9999 -9999 -9999 -9999 -9999 -9999 -9999 -9999 -9999 -9999 -9999 -9999 -9999 -9999 -9999 -9999 -9999 -9999 -9999 -9999 -9999 -9999 -9999 -9999 -9999 -9999 -9999 -9999 -9999 -9999 -9999 -9999 -9999 -9999 -9999 -9999 -9999 -9999 -9999 -9999 -9999 -9999 -9999 -9999 -9999 -9999 -9999 -9999 -9999 -9999 -9999 -9999 -9999 -9999 -9999 -9999 -9999 -9999 -9999 -9999 -9999 -9999 -9999 -9999 -9999 -9999 -9999 -9999 -9999 -9999 -9999 -9999 -9999 -9999 -9999 -9999 -9999 -9999 -9999 -9999 -9999 -9999 -9999 -9999 -9999 -9999 -9999 -999975.58670806885 74.0627822876 74.0627822876 78.02498626709 81.37763214111 83.8159103393685 .3398437586 .5589828491287 .4733276367288 .08290100098 88.3876876831188 .3876876831188 .6924667358488 .3876876831188 .38768768311 88.38768768311 88.08290100098 87.77810668945 87.77810668945 87.47332763672 87.1685485839887 .1685485839886 .8637619018686 .5589828491286 .2541885376 85.9494018554785 .6446228027385 .3398437585 .0350494384884 .73026275635 84.1206970214883 .8159103393683 .206336975182 .9015579223682 .29197692871 81.6824111938581 .0728530883880 .1584930419979 .5489196777378 .63455963135 77.7202072143676 .8058471679775 .8914871215874 .6723632812573 .75800323486 72.8436431884871 .6244964599670 .554122924868 .8280258178767 .11304473877 67.3575134277366 .4431610107465 .5288009643664 .3096618652363 .39530944824 62.4809494018661 .5666007995660 .9570198059160 .0426712036159 .12831115723 58.5187492370657 .6043891906756 .9948196411156 .3852500915555 .77568054199 $55.1661109924354 .5565414428753 .9469718933153 .3373985290552 .65517044067-9999$ -9999 -9999 -9999 -9999 -9999 -9999 -9999 -9999 -9999 -9999 -9999 -9999 -9999 -9999 -9999

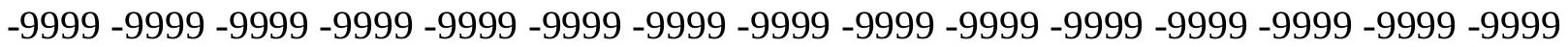
$-9999$

-9999 -9999 -9999 -9999 -9999 -9999 -9999 -9999 -9999 -9999 -9999 -9999 -9999 -9999 -9999 -9999 -9999 -9999 -9999 -9999 -9999 -9999 -9999 -9999 -9999 -9999 -9999 -9999 -9999 -9999 -9999 -9999 -9999 -9999 -9999 -9999 -9999 -9999 -9999 -9999 -9999 -9999 -9999 -9999 -9999 -9999 -9999 -9999 -9999 -9999 -9999 -9999 -9999 -9999 -9999 -9999 -9999 -9999 -9999 -9999 -9999 -9999 -9999 -9999 -9999 -9999 -9999 -9999 -9999 -9999 -9999 -9999 -9999 -9999 -9999 -9999 -9999 -9999 -9999 -9999 -9999 -9999 -9999 -9999 -9999 -9999 -9999 -9999 -9999 -9999 -9999 -9999 -9999 -9999 -9999 -9999 -9999 -9999 -9999 -9999 -9999 -9999 -9999 -9999 -9999 -9999 -9999 -9999 -9999 -9999 -9999 -9999 -9999 -9999 -9999 -9999 -9999 -9999 -9999 -9999 -9999 -9999 -9999 -9999 -9999 -9999 -9999 -9999 -9999 -9999 -9999 -9999 -9999 -9999 -9999 -9999 -9999 -9999 -9999 -9999 -9999 -9999 -9999 -9999 -9999 -9999 -9999 -9999 -9999 -9999 -9999 -9999 -9999 -9999 -9999 -9999 -9999 -9999 -9999 -9999 -9999 -9999 -9999 -9999 -9999 -9999 -9999 -9999 -9999 -9999 -9999 -9999 -9999 -9999 -9999 -9999 -9999 -9999 -9999 -9999 -9999 -9999 -9999 -9999 -9999 -9999 -9999 -9999 -9999 -9999 -9999 -9999 -9999 -9999 -9999

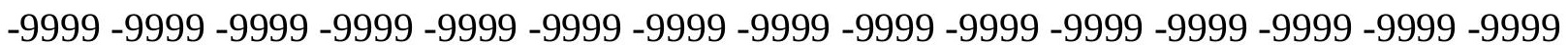
-9999 -9999 -9999 -9999 -9999 -9999 -9999 -9999 -9999 -9999 -9999 -9999 -9999 -9999 -9999 -9999 -9999 -9999 -9999 -9999 -9999 -9999 -9999 -9999 -9999 -9999 -9999 -9999 -9999 -9999 -9999 -9999 -9999 -9999 -9999 -9999 -9999 -9999 -9999 -9999 -9999 -9999 -9999 -9999 -9999 -9999 -9999 -9999 -9999 -9999 -9999 -9999 -9999 -9999 -9999 -9999 -9999 -9999 -9999 -9999 -9999 -9999 -9999 -9999 -9999 -9999 -9999 -9999 -9999 -9999 -9999 -9999 -9999 -9999 -9999 -9999 -9999 -9999 78.63455963135 79.24413299561 81.07285308838 83.81591033936 86.254188537687 .7781066894588 .6924667358489 .6068267822389 .91161346436 90.2164001464890 .2164001464889 .9116134643689 .9116134643689 .60682678223 89.3020401001 89.302040100188.9972534179788.6924667358488.38768768311 
88.0829010009887 .7781066894587 .4733276367287 .1685485839886 .86376190186 86.5589828491285 .9494018554785 .6446228027385 .3398437585 .03504943848 84.4254837036184 .1206970214883 .5111236572382 .9015579223682 .29197692871 81.6824111938580 .7680587768680 .1584930419979 .2441329956178 .32978057861 77.4154205322376 .5010681152375 .2819290161174 .3675689697373 .14842987061 72.2340774536171 .014930725169 .7259902954167 .887695312566 .82501220703 66.4431610107465 .5288009643664 .3096618652363 .3953094482462 .48094940186 61.5666007995660 .6522407531759 .7378807067958 .8235282897958 .21395874023 57.2995986938556 .6900291442955 .7756805419955 .1661109924354 .55654144287 $53.9469718933153 .3373985290552 .7278289794952 .2505493164151 .64050292969-9999$ -9999 -9999 -9999 -9999 -9999 -9999 -9999 -9999 -9999 -9999 -9999 -9999 -9999 -9999 -9999

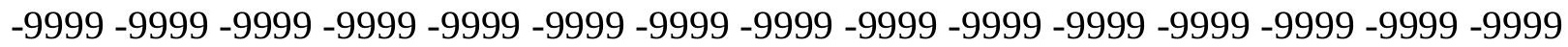
$-9999$

-9999 -9999 -9999 -9999 -9999 -9999 -9999 -9999 -9999 -9999 -9999 -9999 -9999 -9999 -9999 -9999 -9999 -9999 -9999 -9999 -9999 -9999 -9999 -9999 -9999 -9999 -9999 -9999 -9999 -9999

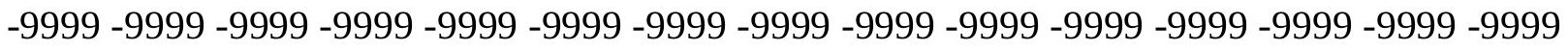

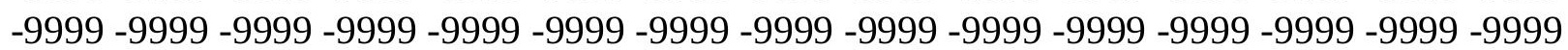
-9999 -9999 -9999 -9999 -9999 -9999 -9999 -9999 -9999 -9999 -9999 -9999 -9999 -9999 -9999 -999 -9999 -9999 -9999 -9999 -9999 -9999 -9999 -9999 -9999 -9999 -9999 -9999 -9999 -9999 -9999 -9999 -9999 -9999 -9999 -9999 -9999 -9999 -9999 -9999 -9999 -9999 -9999 -9999 -9999 -9999 -9999 -9999 -9999 -9999 -9999 -9999 -9999 -9999 -9999 -9999 -9999 -9999 -9999 -9999 -9999 -9999 -9999 -9999 -9999 -9999 -9999 -9999 -9999 -9999 -9999 -9999 -9999 -9999 -9999 -9999 -9999 -9999 -9999 -9999 -9999 -9999 -9999 -9999 -9999 -9999 -9999 -9999 -9999 -9999 -9999 -9999 -9999 -9999 -9999 -9999 -9999 -9999 -9999 -9999 -9999 -9999 -9999 -9999 -9999 -9999 -9999 -9999 -9999 -9999 -9999 -9999 -9999 -9999 -9999 -9999 -9999 -9999 -9999 -9999 -9999 -9999 -9999 -9999 -9999 -9999 -9999 -9999 -9999 -9999 -9999 -9999 -9999 -9999 -9999 -9999 -9999 -9999 -9999 -9999 -9999 -9999 -9999 -9999 -9999 -9999 -9999 -9999 -9999 -9999 -9999 -

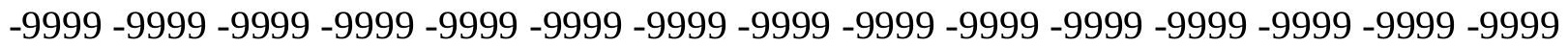
-9999 -9999 -9999 -9999 -9999 -9999 -9999 -9999 -9999 -9999 -9999 -9999 -9999 -9999 -9999

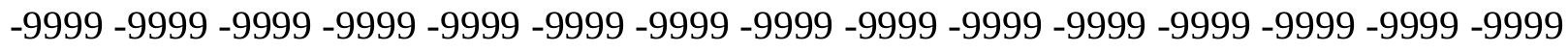
-9999 -9999 -9999 -9999 -9999 -9999 -9999 -9999 -9999 -9999 -9999 -9999 -9999 -9999 -9999 -9999 -9999 -9999 -9999 -9999 -9999 -9999 -9999 -9999 -9999 -9999 -9999 -9999 -9999 -9999 -9999 -9999-9999 83.2063369751 83.81591033936 85.03504943848 87.16854858398 88.9972534179790 .5211791992291 .1307525634891 .7403335571391 .74033355713 91.7403335571391 .7403335571391 .4355392456191 .1307525634890 .82597351074 90.5211791992290 .2164001464889 .9116134643689 .6068267822388 .99725341797 88.69246673584 88.38768768311 88.08290100098 87.77810668945 87.16854858398 86.8637619018686 .5589828491285 .9494018554785 .6446228027385 .03504943848 84.7302627563584 .1206970214883 .5111236572382 .9015579223682 .29197692871 81.6824111938580 .7680587768679 .8537063598678 .9393463134878 .02498626709 77.110626220775 .8914871215874 .9771423339873 .7580032348672 .53885650635 71.3197174072370 .2423171997168 .7952880859467 .0737152099665 .88587188721 65.5288009643664 .6144485473663 .3953094482462 .4809494018661 .26181030273 60.3474502563559 .4331016540558 .5187492370657 .909179687556 .99481964111 56.3852500915555 .4708900451754 .8613204956154 .2517509460453 .64218139648 52.7278289794952 .1182594299351 .8134689331151 .2024917602550 .60396575928 -9999 
-9999 -9999 -9999 -9999 -9999 -9999 -9999 -9999 -9999 -9999 -9999 -9999 -9999 -9999 -9999 -9999 -9999 -9999 -9999 -9999 -9999 -9999 -9999 -9999 -9999 -9999 -9999 -9999 -9999 -9999 $-9999$

-9999 -9999 -9999 -9999 -9999 -9999 -9999 -9999 -9999 -9999 -9999 -9999 -9999 -9999 -9999 -9999 -9999 -9999 -9999 -9999 -9999 -9999 -9999 -9999 -9999 -9999 -9999-9999 -9999 -9999 -9999 -9999 -9999 -9999 -9999 -9999 -9999 -9999 -9999 -9999 -9999 -9999 -9999 -9999 -9999 -9999 -9999 -9999 -9999 -9999 -9999 -9999 -9999 -9999 -9999 -9999 -9999 -9999 -9999 -9999

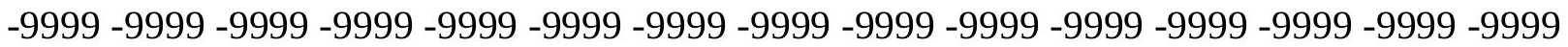
-9999 -9999 -9999 -9999 -9999 -9999 -9999 -9999 -9999 -9999 -9999 -9999 -9999 -9999 -9999 -9999 -9999 -9999 -9999 -9999 -9999 -9999 -9999 -9999 -9999 -9999 -9999 -9999 -9999 -9999 -9999 -9999 -9999 -9999 -9999 -9999 -9999 -9999 -9999 -9999 -9999 -9999 -9999 -9999 -9999 -9999 -9999 -9999 -9999 -9999 -9999 -9999 -9999 -9999 -9999 -9999 -9999 -9999 -9999 -9999 -9999 -9999 -9999 -9999 -9999 -9999 -9999 -9999 -9999 -9999 -9999 -9999 -9999 -9999 -9999 -9999 -9999 -9999 -9999 -9999 -9999 -9999 -9999 -9999 -9999 -9999 -9999 -9999 -9999 -9999 -9999 -9999 -9999 -9999 -9999 -9999 -9999 -9999 -9999 -9999 -9999 -9999 -9999 -9999 -9999

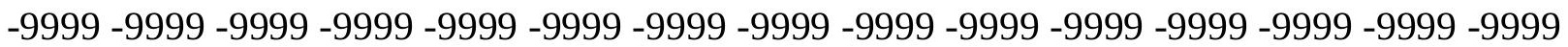

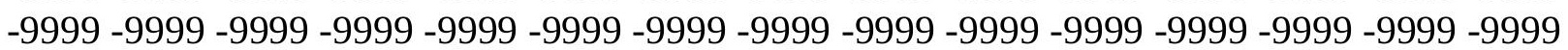
-9999 -9999 -9999 -9999 -9999 -9999 -9999 -9999 -9999 -9999 -9999 -9999 -9999 -9999 -9999 -999 -9999 -9999 -9999 -9999 -9999 -9999 -9999 -9999 -9999 -9999 -9999 -9999 -9999 -9999 -9999 -9999 -9999 -9999 -9999 -9999 -9999 -9999 -9999 -9999 -9999 -9999 -9999 -9999 -9999 -9999 -9999 -9999 -9999 -9999 -9999 -9999 -9999 -9999 -9999 -9999 -9999 -9999 -9999 -9999 -9999 -999 -9999 -9999 -9999 -9999 -9999 -9999 -9999 -9999 -9999 -9999 -9999 -9999 -9999 -9999 -9999 -9999 -9999 -9999 -9999 87.77810668945 88.6924667358490.5211791992292.04509735107 92.9594726562593 .5690307617293 .8738174438593 .5690307617293 .56903076172 93.2642517089892 .9594726562592 .6546783447392 .0450973510791 .74033355713 91.1307525634890 .8259735107490 .2164001464889 .9116134643689 .60682678223 88.9972534179788 .6924667358488 .0829010009887 .7781066894587 .16854858398 86.8637619018686 .254188537685 .9494018554785 .3398437585 .03504943848 84.4254837036183 .8159103393683 .206336975182 .2919769287181 .68241119385 80.7680587768679 .8537063598678 .9393463134878 .0249862670976 .80584716797 75.5867080688574 .6723632812573 .4532165527371 .9292907714870 .71015167236 69.4910125732468 .0572814941466 .454101562564 .9761581420963 .44812393188 63.3953094482462 .4809494018661 .2618103027360 .3474502563559 .43310165405 58.5187492370657 .6043891906756 .6900291442955 .7756805419955 .16611099243 54.5565414428753 .6421813964853 .0326118469252 .4230384826751 .81346893311 51.2038993835450 .5943298339850 .132537841849 .59357070923 -9999 -9999 -9999 -9999 -9999 -9999 -9999 -9999 -9999 -9999 -9999 -9999 -9999 -9999 -9999 -9999 -9999 -9999 -9999 -9999 -9999 -9999 -9999 -9999 -9999 -9999 -9999 -9999 -9999 -9999 -9999 -9999 - -999 -9999 -9999 -9999 -9999 -9999 -9999 -9999 -9999 -9999 -9999 -9999 -9999 -9999 -9999 -9999 -9999 -9999 -9999 -9999 -9999 -9999 -9999 -9999 -9999 -9999 -9999 -9999 -9999 -9999 -9999 -9999 -9999 -9999 -9999 -9999 -9999 -9999 -9999 -9999 -9999 -9999 -9999 -9999 -9999 -9999 -999 -9999 -9999 -9999 -9999 -9999 -9999 -9999 -9999 -9999 -9999 -9999 -9999 -9999 -9999 -9999 -

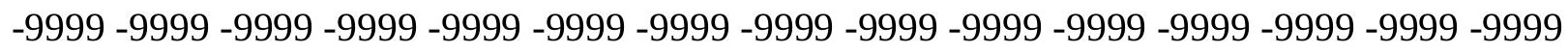
-9999 -9999 -9999 -9999 -9999 -9999 -9999 -9999 -9999 -9999 -9999 -9999 -9999 -9999 -9999 -9999 -9999 -9999 -9999 -9999 -9999 -9999 -9999 -9999 -9999 -9999 -9999 -9999 -9999 -9999 -

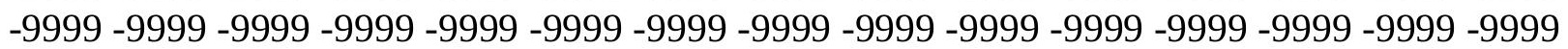


-9999 -9999 -9999 -9999 -9999 -9999 -9999 -9999 -9999 -9999 -9999 -9999 -9999 -9999 -9999 -9999 -9999 -9999 -9999 -9999 -9999 -9999 -9999 -9999 -9999 -9999 -9999 -9999 -9999 -9999 -9999 -9999 -9999 -9999 -9999 -9999 -9999 -9999 -9999 -9999 -9999 -9999 -9999 -9999 -9999 -9999 -9999 -9999 -9999 -9999 -9999 -9999 -9999 -9999 -9999 -9999 -9999 -9999 -9999 -9999 -9999 -9999 -9999 -9999 -9999 -9999 -9999 -9999 -9999 -9999 -9999 -9999 -9999 -9999 -9999 -9999 -9999 -9999 -9999 -9999 -9999 -9999 -9999 -9999 -9999 -9999 -9999 -9999 -9999 -9999 -9999 -9999 -9999 -9999 -9999 -9999 -9999 -9999 -9999 -9999 -9999 -9999 -9999 -9999 -9999

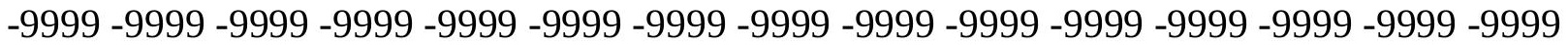
-9999 -9999 -9999 -9999 -9999 -9999 -9999 -9999 -9999 -9999 -9999 -9999 -9999 -9999 -9999 -9999 -9999 -9999 -9999 -9999 -9999 -9999 -9999 -9999 -9999 -9999 -9999 -9999 -9999 -9999 -9999 -9999 -9999 -9999 -9999 -9999 -9999 -9999 -9999 -9999 -9999 -9999 -9999 -9999 -9999 -9999 -9999 -9999 -9999 -9999 92.0450973510793.2642517089893.87381744385 95.397743225195 .7025299072395 .7025299072395 .397743225195 .09295654297 94.7881774902394 .1785964965893 .8738174438593 .2642517089892 .65467834473 92.349891662691 .7403335571391 .1307525634890 .8259735107490 .21640014648 89.6068267822389 .302040100188 .6924667358488 .0829010009887 .77810668945 87.1685485839886 .5589828491286 .254188537685 .6446228027385 .03504943848 84.4254837036183 .8159103393683 .206336975182 .5967712402381 .68241119385 80.7680587768679 .8537063598678 .9393463134877 .7202072143676 .50106811523 75.2819290161174 .062782287672 .8436431884871 .6244964599670 .10057830811 68.8814392089867 .3326110839865 .7089309692464 .0878448486362 .51276016235 62.4809494018661 .2618103027360 .3474502563559 .1283111572358 .21395874023 57.2995986938556 .3852500915555 .4708900451754 .8613204956153 .94697189331 53.3373985290552 .7278289794952 .1182594299351 .5086898803750 .59432983398 49.9847602844249 .6799812316949 .1060638427748 .58726501465 -9999 -9999 -9999 -9999 -9999 -9999 -9999 -9999 -9999 -9999 -9999 -9999 -9999 -9999 -9999 -9999 -9999 -9999 -9999 -9999 -9999 -9999 -9999 -9999 -9999 -9999 -9999 -9999 -9999 -9999 -9999 -9999 -

-9999 -9999 -9999 -9999 -9999 -9999 -9999 -9999 -9999 -9999 -9999 -9999 -9999 -9999 -9999 -9999 -9999 -9999 -9999 -9999 -9999 -9999 -9999 -9999 -9999 -9999 -9999 -9999 -9999 -9999

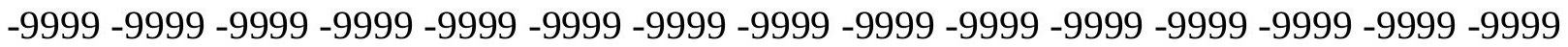
-9999 -9999 -9999 -9999 -9999 -9999 -9999 -9999 -9999 -9999 -9999 -9999 -9999 -9999 -9999 -

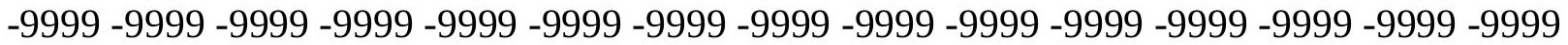
-9999 -9999 -9999 -9999 -9999 -9999 -9999 -9999 -9999 -9999 -9999 -9999 -9999 -9999 -9999 -9999 -9999 -9999 -9999 -9999 -9999 -9999 -9999 -9999 -9999 -9999 -9999 -9999 -9999 -9999 -

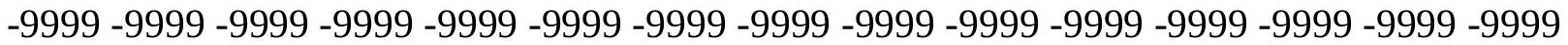
-9999 -9999 -9999 -9999 -9999 -9999 -9999 -9999 -9999 -9999 -9999 -9999 -9999 -9999 -9999 -9999 -9999 -9999 -9999 -9999 -9999 -9999 -9999 -9999 -9999 -9999 -9999 -9999 -9999 -9999

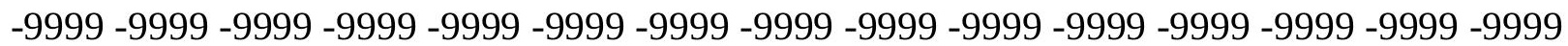
-9999 -9999 -9999 -9999 -9999 -9999 -9999 -9999 -9999 -9999 -9999 -9999 -9999 -9999 -9999 -9999 -9999 -9999 -9999 -9999 -9999 -9999 -9999 -9999 -9999 -9999 -9999 -9999 -9999 -9999 -9999 -9999 -9999 -9999 -9999 -9999 -9999 -9999 -9999 -9999 -9999 -9999 -9999 -9999 -9999 -999 -9999 -9999 -9999 -9999 -9999 -9999 -9999 -9999 -9999 -9999 -9999 -9999 -9999 -9999 -9999 -9999 -9999 -9999 -9999 -9999 -9999 -9999 -9999 -9999 -9999 -9999 -9999 -9999 -9999 -9999 -9999 -9999 -9999 -9999 -9999 -9999 -9999 -9999 -9999 -9999 -9999 -9999 -9999 -9999 -9999 -999 -9999 -9999 -9999 -9999 -9999 -9999 -9999 -9999 -9999 -9999 -9999 -9999 -9999 -9999 -9999

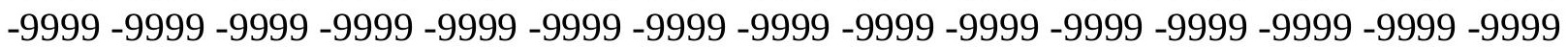


-9999 -9999 -9999 -9999 -9999 -9999 95.7025299072396.61688232422 97.22646331787 97.5312423706197 .2264633178796 .9216690063596 .6168823242296 .00731658936 95.397743225194 .7881774902394 .1785964965893 .5690307617293 .26425170898 92.6546783447392 .0450973510791 .4355392456190 .8259735107490 .21640014648 89.6068267822389 .302040100188 .6924667358488 .0829010009887 .47332763672 86.8637619018686 .5589828491285 .9494018554785 .3398437584 .73026275635 84.1206970214883 .5111236572382 .5967712402381 .9871978759881 .07285308838 79.8537063598678 .9393463134877 .7202072143676 .5010681152374 .97714233398 73.7580032348672 .5388565063571 .014930725169 .4910125732468 .26417541504 66.5993118286164 .9024200439563 .2277107238861 .5993194580161 .56660079956 60.3474502563559 .1283111572358 .2139587402356 .9948196411156 .08045959473 55.1661109924354 .2517509460453 .6421813964853 .0326118469252 .11825942993 51.5086898803750 .8991203308150 .2895507812549 .6799812316949 .07040023804 48.4608306884848 .051479339647 .62911224365 -9999 -9999 -9999 -9999 -9999 -9999 -9999 -9999 -9999 -9999 -9999 -9999 -9999 -9999 -9999 -9999 -9999 -9999 -9999 -9999 -9999 -9999 -9999 -9999 -9999 -9999 -9999 -9999 -9999 -9999 -9999 -9999

-9999 -9999 -9999 -9999 -9999 -9999 -9999 -9999 -9999 -9999 -9999 -9999 -9999 -9999 -9999 -9999 -9999 -9999 -9999 -9999 -9999 -9999 -9999 -9999 -9999 -9999 -9999 -9999 -9999 -9999 -9999 -9999 -9999 -9999 -9999 -9999 -9999 -9999 -9999 -9999 -9999 -9999 -9999 -9999 -9999 -

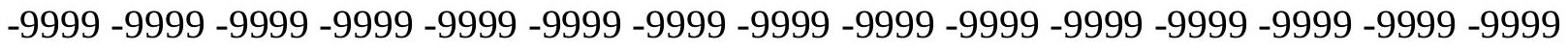

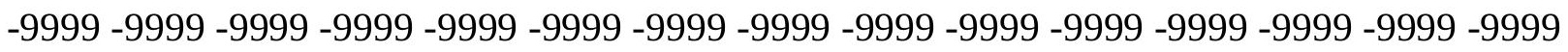
-9999 -9999 -9999 -9999 -9999 -9999 -9999 -9999 -9999 -9999 -9999 -9999 -9999 -9999 -9999 -9999 -9999 -9999 -9999 -9999 -9999 -9999 -9999 -9999 -9999 -9999 -9999 -9999 -9999 -9999 -9999 -9999 -9999 -9999 -9999 -9999 -9999 -9999 -9999 -9999 -9999 -9999 -9999 -9999 -9999 -

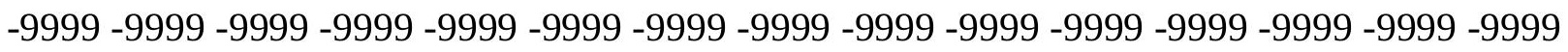
-9999 -9999 -9999 -9999 -9999 -9999 -9999 -9999 -9999 -9999 -9999 -9999 -9999 -9999 -9999 -9999 -9999 -9999 -9999 -9999 -9999 -9999 -9999 -9999 -9999 -9999 -9999 -9999 -9999 -9999 -

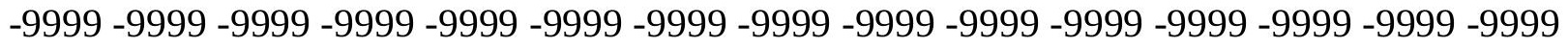
-9999 -9999 -9999 -9999 -9999 -9999 -9999 -9999 -9999 -9999 -9999 -9999 -9999 -9999 -9999 -9999 -9999 -9999 -9999 -9999 -9999 -9999 -9999 -9999 -9999 -9999 -9999 -9999 -9999 -999 -9999 -9999 -9999 -9999 -9999 -9999 -9999 -9999 -9999 -9999 -9999 -9999 -9999 -9999 -9999

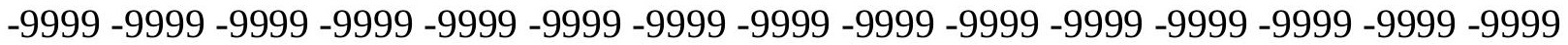

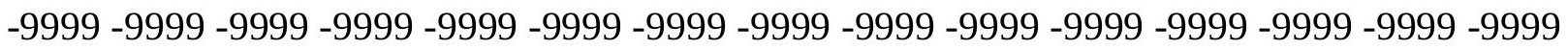

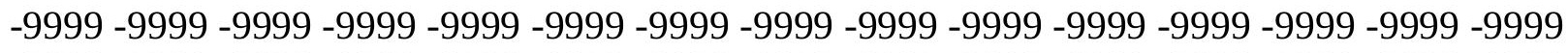
-9999 -9999 -9999 -9999 -9999 -9999 -9999 -9999 -9999 -9999 -9999 -9999 -9999 -9999 -9999 -9999 -9999 -9999 -9999 -9999 -9999-9999 98.1408081054798.75038146973 98.75038146973 98.7503814697398 .445587158297 .8360290527397 .2264633178796 .61688232422 96.0073165893695 .397743225194 .4833908081193 .8738174438593 .26425170898 92.6546783447392 .0450973510791 .4355392456190 .8259735107490 .21640014648 89.60682678223 88.9972534179788.38768768311 87.77810668945 87.47332763672 86.8637619018686 .254188537685 .6446228027385 .0350494384884 .42548370361 83.81591033936 82.90155792236 81.98719787598 81.07285308838 79.85370635986 78.9393463134877 .7202072143676 .1962814331174 .9771423339873 .45321655273 71.9292907714870 .4053573608468 .8814392089867 .3575134277365 .80895233154 64.1089401245162 .3905448913660 .7160873413160 .6522407531759 .43310165405 58.2139587402356 .9948196411156 .0804595947354 .8613204956153 .94697189331 
53.3373985290552 .4230384826751 .8134689331151 .2038993835450 .59432983398 49.9847602844249 .3751907348648 .765621185348 .1560516357447 .54647827148 47.0564422607446 .72483062744 -9999 -9999 -9999 -9999 -9999 -9999 -9999 -9999 -9999 -9999 -9999 -9999 -9999 -9999 -9999 -9999 -9999 -9999 -9999 -9999 -9999 -9999 -9999 -9999 -9999 -9999 -9999 -9999-9999-9999-9999-9999

-9999 -9999 -9999 -9999 -9999 -9999 -9999 -9999 -9999 -9999 -9999 -9999 -9999 -9999 -9999 -9999 -9999 -9999 -9999 -9999 -9999 -9999 -9999 -9999 -9999 -9999 -9999 -9999 -9999 -9999

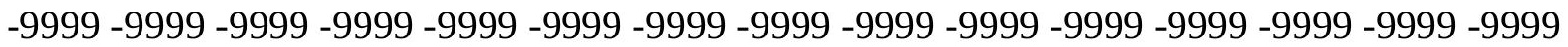
-9999 -9999 -9999 -9999 -9999 -9999 -9999 -9999 -9999 -9999 -9999 -9999 -9999 -9999 -9999 -9999 -9999 -9999 -9999 -9999 -9999 -9999 -9999 -9999 -9999 -9999 -9999 -9999 -9999 -9999

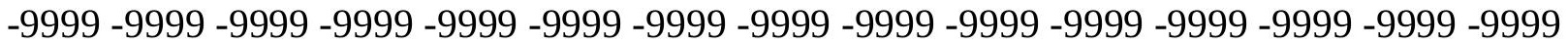
-9999 -9999 -9999 -9999 -9999 -9999 -9999 -9999 -9999 -9999 -9999 -9999 -9999 -9999 -9999 -9999 -9999 -9999 -9999 -9999 -9999 -9999 -9999 -9999 -9999 -9999 -9999 -9999 -9999 -9999 -9999 -9999 -9999 -9999 -9999 -9999 -9999 -9999 -9999 -9999 -9999 -9999 -9999 -9999 - 9999 -9999 -9999 -9999 -9999 -9999 -9999 -9999 -9999 -9999 -9999 -9999 -9999 -9999 -9999 -9999

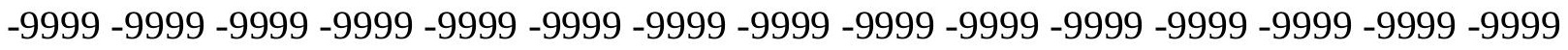
-9999 -9999 -9999 -9999 -9999 -9999 -9999 -9999 -9999 -9999 -9999 -9999 -9999 -9999 -9999 -9999 -9999 -9999 -9999 -9999 -9999 -9999 -9999 -9999 -9999 -9999 -9999 -9999 -9999 -9999 -999 -9999 -9999 -9999 -9999 -9999 -9999 -9999 -9999 -9999 -9999 -9999 -9999 -9999 -9999 -9999 -9999 -9999 -9999 -9999 -9999 -9999 -9999 -9999 -9999 -9999 -9999 -9999 -9999 -9999 -9999 -9999 -9999 -9999 -9999 -9999 -9999 -9999 -9999 -9999 -9999 -9999 -9999 -9999 -9999 -9999 -9999 -9999 -9999 -9999 -9999 -9999 -9999 -9999 -9999 -9999 -9999 -9999 -9999 -9999 -9999 -9999 -9999 -9999 -9999 -9999 -9999 -9999 -9999 -9999 -9999 -9999 -9999 -9999 -9999 -9999 -9999 -9999 -9999 -9999 -9999 -9999 -9999 -9999 -9999 -9999 -9999 -9999 -9999 -9999 -9999 -9999 -9999 -9999 -9999 -9999 -9999 -9999 -9999 99.96952056885 99.96952056885 99.9695205688599.3599472045998.7503814697398.1408081054797.53124237061 96.9216690063596 .0073165893695 .397743225194 .7881774902394 .17859649658 93.2642517089892 .6546783447392 .0450973510791 .4355392456190 .82597351074 90.2164001464889 .302040100188 .6924667358488 .0829010009887 .77810668945 87.1685485839886 .5589828491285 .9494018554785 .3398437584 .73026275635 83.8159103393683 .206336975182 .2919769287181 .0728530883880 .15849304199 78.9393463134877 .4154205322376 .1962814331174 .6723632812573 .14842987061 71.6244964599670 .0699157714868 .2718734741266 .7479400634865 .07266235352 63.3276062011761 .5729331970259 .8546180725159 .4331016540558 .21395874023 56.9948196411155 .7756805419954 .8613204956153 .9469718933153 .03261184692 52.1182594299351 .2038993835450 .5943298339849 .9847602844249 .37519073486 48.765621185348 .1560516357447 .5464782714846 .9369087219246 .32733917236 46.17555236816 -9999 -9999 -9999 -9999 -9999 -9999 -9999 -9999 -9999 -9999 -9999 -9999 -9999 -9999 -9999 -9999 -9999 -9999 -9999 -9999 -9999 -9999 -9999 -9999 -9999 -9999 - 9999 -9999 -9999 -9999-9999-9999-9999

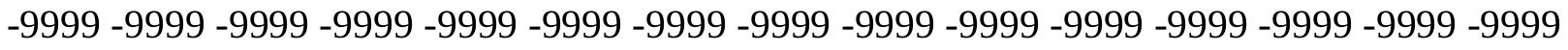

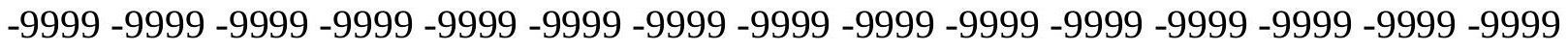
-9999 -9999 -9999 -9999 -9999 -9999 -9999 -9999 -9999 -9999 -9999 -9999 -9999 -9999 -9999 -9999 -9999 -9999 -9999 -9999 -9999 -9999 -9999 -9999-9999 -9999 -9999 -9999 -9999 -9999 -9999 -9999 -9999 -9999 -9999 -9999 -9999 -9999 -9999 -9999 -9999 -9999 -9999 -9999 -9999 -

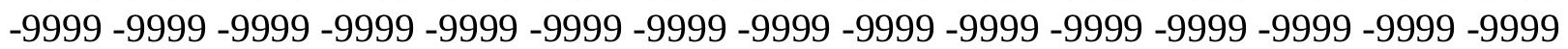


-9999 -9999 -9999 -9999 -9999 -9999 -9999 -9999 -9999 -9999 -9999 -9999 -9999 -9999 -9999 -9999 -9999 -9999 -9999 -9999 -9999 -9999 -9999 -9999 -9999 -9999 -9999 -9999 -9999 -9999 -9999 -9999 -9999 -9999 -9999 -9999 -9999 -9999 -9999 -9999 -9999 -9999 -9999 -9999 -9999 -9999 -9999 -9999 -9999 -9999 -9999 -9999 -9999 -9999 -9999 -9999 -9999 -9999 -9999 -9999 -9999 -9999 -9999 -9999 -9999 -9999 -9999 -9999 -9999 -9999 -9999 -9999 -9999 -9999 -9999 -9999 -9999 -9999 -9999 -9999 -9999 -9999 -9999 -9999 -9999 -9999 -9999 -9999 -9999 -9999 -9999 -9999 -9999 -9999 -9999 -9999 -9999 -9999 -9999 -9999 -9999 -9999 -9999 -9999 -9999

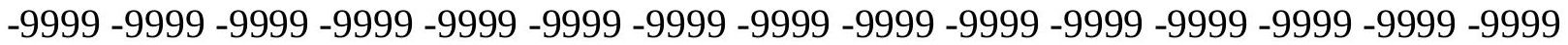
-9999 -9999 -9999 -9999 -9999 -9999 -9999 -9999 -9999 -9999 -9999 -9999 -9999 -9999 -9999 -9999 -9999 -9999 -9999 -9999 -9999 -9999 -9999 -9999 -9999 -9999 -9999 -9999 -9999 -9999 -

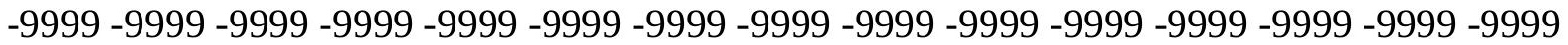
-9999 -9999 -9999 -9999 -9999 -9999 -9999 -9999 -9999 -9999 -9999 -9999 -9999 -9999 -9999 -9999 -9999 -9999 -9999 -9999 -9999 -9999 -9999 -9999 -9999 -9999 -9999 -9999 -9999 -9999 -9999 -9999-9999 -9999 -9999 -9999 -9999 -9999 -9999 100.8839035034 100.5791015625 100.274299621699 .6647262573299 .0551681518698 .445587158297 .53124237061 96.9216690063596 .3121032714895 .397743225194 .7881774902394 .17859649658 93.2642517089892 .6546783447392 .0450973510791 .1307525634890 .52117919922 89.91161346436 89.3020401001 88.6924667358488.08290100098 87.47332763672 86.8637619018686 .254188537685 .6446228027385 .0350494384884 .12069702148 83.5111236572382 .5967712402381 .3776321411180 .1584930419978 .93934631348 77.4154205322376 .1962814331174 .3675689697372 .8436431884871 .31971740723 69.4910125732467 .6623001098666 .1383666992264 .3828201293962 .58180618286 60.7750396728559 .0169105529858 .5187492370657 .2995986938555 .77568054199 54.8613204956153 .6421813964852 .7278289794951 .8134689331150 .89912033081 49.9847602844249 .3751907348648 .765621185348 .1560516357447 .54647827148 47.2416992187546 .6321296691946 .0225486755445 .717769622845 .6145324707 -9999 -9999 -9999 -9999 -9999 -9999 -9999 -9999 -9999 -9999 -9999 -9999 -9999 -9999 -9999 -9999 -9999

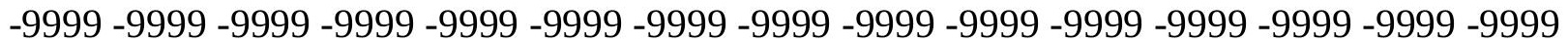
$-9999$

-9999 -9999 -9999 -9999 -9999 -9999 -9999 -9999 -9999 -9999 -9999 -9999 -9999 -9999 -9999 -9999 -9999 -9999 -9999 -9999 -9999 -9999 -9999 -9999 -9999 -9999 -9999 -9999 -9999 -9999 -9999 -9999 -9999 -9999 -9999 -9999 -9999 -9999 -9999 -9999 -9999 -9999 -9999 -9999 -9999 -9999 -9999 -9999 -9999 -9999 -9999 -9999 -9999 -9999 -9999 -9999 -9999 -9999 -9999 -9999 -9999 -9999 -9999 -9999 -9999 -9999 -9999 -9999 -9999 -9999 -9999 -9999 -9999 -9999 -9999

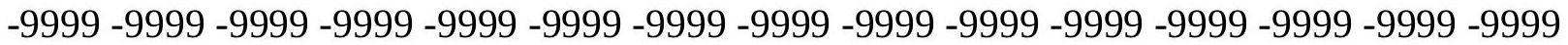
-9999 -9999 -9999 -9999 -9999 -9999 -9999 -9999 -9999 -9999 -9999 -9999 -9999 -9999 -9999 -9999 -9999 -9999 -9999 -9999 -9999 -9999 -9999 -9999 -9999 -9999 -9999 -9999 -9999 -9999

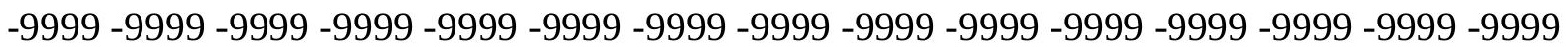
-9999 -9999 -9999 -9999 -9999 -9999 -9999 -9999 -9999 -9999 -9999 -9999 -9999 -9999 -9999 -9999 -9999 -9999 -9999 -9999 -9999 -9999 -9999 -9999 -9999 -9999 -9999 -9999 -9999 -9999 -9999 -9999 -9999 -9999 -9999 -9999 -9999 -9999 -9999 -9999 -9999 -9999 -9999 -9999 -9999

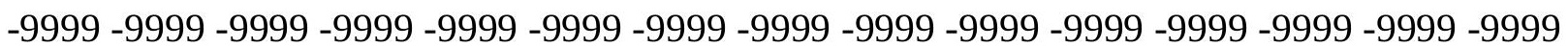
-9999 -9999 -9999 -9999 -9999 -9999 -9999 -9999 -9999 -9999 -9999 -9999 -9999 -9999 -9999 -9999 -9999 -9999 -9999 -9999 -9999 -9999 -9999 -9999 -9999 -9999 -9999 -9999 -9999 -9999 -9999 -9999 -9999 -9999 -9999 -9999 -9999 -9999 -9999 -9999 -9999 -9999 -9999 -9999 -9999

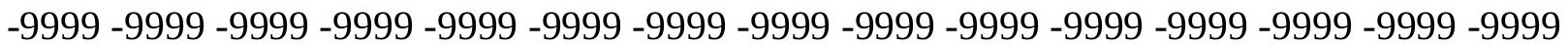


-9999 -9999 -9999 -9999 -9999 -9999 -9999 -9999 -9999 -9999 -9999 -9999 -9999 -9999 -9999 -9999 -9999 -9999 -9999 -9999 -9999 -9999 -9999 -9999 -9999 -9999 -9999 -9999 -9999 -9999 -9999 -9999 -9999 -9999 -9999 -9999 -9999 -9999 -9999 101.7982025146101 .4934005737 100.8839035034100 .274299621699 .6647262573299 .0551681518698 .14080810547 97.5312423706196 .9216690063596 .0073165893695 .397743225194 .78817749023 93.8738174438593 .2642517089892 .349891662691 .7403335571391 .13075256348 90.2164001464889 .6068267822388 .9972534179788 .3876876831187 .77810668945 87.1685485839886 .5589828491285 .9494018554785 .3398437584 .73026275635 83.8159103393682 .9015579223681 .6824111938580 .4632720947378 .93934631348 77.7202072143675 .8914871215874 .3675689697372 .5388565063570 .71015167236 68.8814392089867 .3575134277365 .5288009643663 .7000885009861 .85591125488 59.9996604919458 .1906166076757 .2995986938556 .0804595947354 .86132049561 53.6421813964852 .4230384826751 .5086898803750 .5943298339849 .67998123169 49.0704002380448 .1560516357447 .5464782714846 .9369087219246 .63212966919 46.3273391723646 .0225486755445 .717769622845 .717769622845 .34674072266 -9999-9999 -9999 -9999 -9999 -9999 -9999 -9999 -9999 -9999 -9999 -9999 -9999 -9999 -9999 -9999 -9999

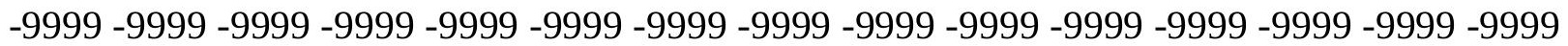
$-9999$

-9999 -9999 -9999 -9999 -9999 -9999 -9999 -9999 -9999 -9999 -9999 -9999 -9999 -9999 -9999 -9999 -9999 -9999 -9999 -9999 -9999 -9999 -9999 -9999 -9999 -9999 -9999 -9999 -9999 -9999

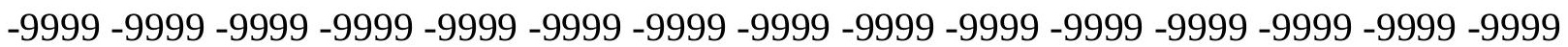
-9999 -9999 -9999 -9999 -9999 -9999 -9999 -9999 -9999 -9999 -9999 -9999 -9999 -9999 -9999 -9999 -9999 -9999 -9999 -9999 -9999 -9999 -9999 -9999 -9999 -9999 -9999 -9999 -9999 -9999 -9999 -9999 -9999 -9999 -9999 -9999 -9999 -9999 -9999 -9999 -9999 -9999 -9999 -9999 -9999

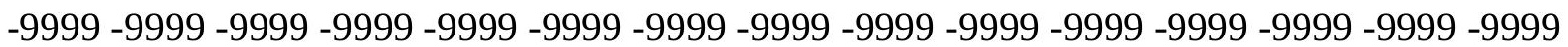
-9999 -9999 -9999 -9999 -9999 -9999 -9999 -9999 -9999 -9999 -9999 -9999 -9999 -9999 -9999 -9999 -9999 -9999 -9999 -9999 -9999 -9999 -9999 -9999 -9999 -9999 -9999 -9999 -9999 -9999 -9999 -9999 -9999 -9999 -9999 -9999 -9999 -9999 -9999 -9999 -9999 -9999 -9999 -9999 -9999 -9999 -9999 -9999 -9999 -9999 -9999 -9999 -9999 -9999 -9999 -9999 -9999 -9999 -9999 -9999 -9999 -9999 -9999 -9999 -9999 -9999 -9999 -9999 -9999 -9999 -9999 -9999 -9999 -9999 -9999 -9999 -9999 -9999 -9999 -9999 -9999 -9999 -9999 -9999 -9999 -9999 -9999 -9999 -9999 -9999 -9999 -9999 -9999 -9999 -9999 -9999 -9999 -9999 -9999 -9999 -9999 -9999 -9999 -9999 -9999 -9999 -9999 -9999 -9999 -9999 -9999 -9999 -9999 -9999 -9999 -9999 -9999 -9999 -9999 -9999 -9999 -9999 -9999 -9999 -9999 -9999 -9999 -9999 -9999 -9999 -9999 -9999 -9999 -9999 -9999 -

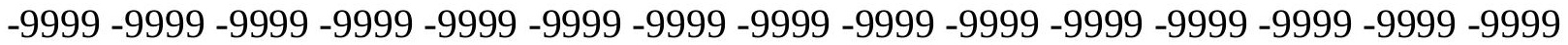
-9999 -9999 -9999 -9999 -9999 -9999 -9999 -9999 -9999 -9999 -9999 -9999 -9999 -9999 -9999 -9999 -9999 -9999 -9999 -9999 -9999 -9999 -9999 -9999 -9999 -9999 -9999 -9999 -9999 -9999 -9999 -9999 -9999 -9999 -9999 -9999 -9999 -9999 -9999 -9999 102.4077987671 101.7982025146100 .8839035034100 .274299621699 .6647262573298 .75038146973 98.1408081054797 .5312423706196 .6168823242296 .0073165893695 .3977432251 94.4833908081193 .8738174438592 .9594726562592 .349891662691 .43553924561 90.8259735107490 .2164001464889 .302040100188 .6924667358488 .08290100098 87.7781066894587 .1685485839886 .5589828491285 .9494018554785 .03504943848 84.1206970214883 .206336975181 .9871978759880 .7680587768679 .24413299561 77.7202072143675 .8914871215874 .3675689697372 .5388565063570 .40535736084 68.5766525268666 .7479400634864 .9192428588963 .0905189514261 .12924575806 
59.2142066955657 .3686141967856 .3852500915554 .8613204956153 .64218139648 52.4230384826751 .5086898803750 .2895507812549 .3751907348648 .46083068848 47.8512611389246 .9369087219246 .6321296691946 .3273391723646 .02254867554 46.0225486755445 .717769622845 .41297912598 -9999 -9999 -9999 -9999 -9999 -9999 -9999 -9999 -9999 -9999 -9999 -9999 -9999 -9999 -9999 -9999 -9999 -9999 -9999 -9999 -9999 -9999 -9999 -9999 -9999 -9999 -9999 -9999 -9999 -9999 -9999 -9999 -9999 -9999 -9999 -

-9999 -9999 -9999 -9999 -9999 -9999 -9999 -9999 -9999 -9999 -9999 -9999 -9999 -9999 -9999 -9999 -9999 -9999 -9999 -9999 -9999 -9999 -9999 -9999 -9999 -9999 -9999 -9999 -9999 -9999 -9999 -9999 -9999 -9999 -9999 -9999 -9999 -9999 -9999 -9999 -9999 -9999 -9999 -9999 -9999 -9999 -9999 -9999 -9999 -9999 -9999 -9999 -9999 -9999 -9999 -9999 -9999 -9999 -9999 -9999 -9999 -9999 -9999 -9999 -9999 -9999 -9999 -9999 -9999 -9999 -9999 -9999 -9999 -9999 -9999 -999 -9999 -9999 -9999 -9999 -9999 -9999 -9999 -9999 -9999 -9999 -9999 -9999 -9999 -9999 -9999 -9999 -9999 -9999 -9999 -9999 -9999 -9999 -9999 -9999 -9999 -9999 -9999 -9999 -9999 -9999 -9999 -9999 -9999 -9999 -9999 -9999 -9999 -9999 -9999 -9999 -9999 -9999 -9999 -9999 -9999 -9999 -9999 -9999 -9999 -9999 -9999 -9999 -9999 -9999 -9999 -9999 -9999 -9999 -9999 -9999

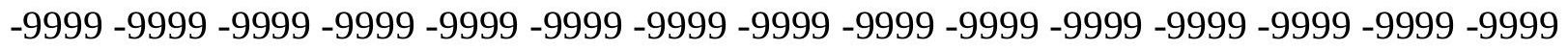
-9999 -9999 -9999 -9999 -9999 -9999 -9999 -9999 -9999 -9999 -9999 -9999 -9999 -9999 -9999 -

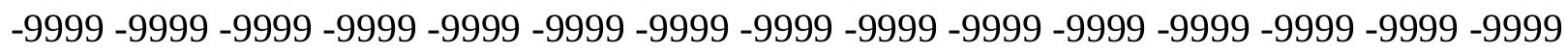

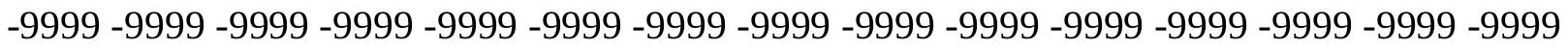

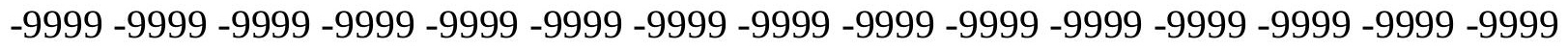

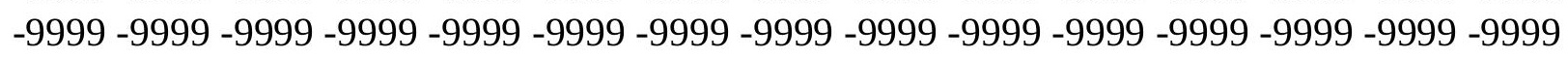

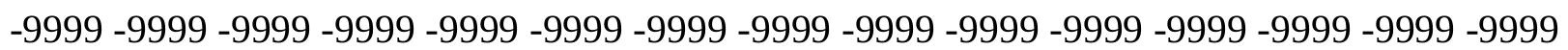
-9999 -9999 -9999 -9999 -9999 -9999 -9999 -9999 -9999 -9999 -9999 -9999 -9999 -9999 -9999 -9999 -9999 -9999 -9999 -9999 -9999 -9999 -9999 -9999 -9999 -9999 -9999 -9999 -9999 -9999 -9999 -9999 -9999 -9999 -9999 -9999 -9999 -9999 -9999 -9999 -9999 -9999 -9999 -9999 -9999 -9999 -9999 -9999 -9999 -9999 -9999 -9999 -9999 -9999 -9999 -9999 102.4077987671 101.7982025146100 .8839035034100 .274299621699 .3599472045998 .75038146973 98.1408081054797 .2264633178796 .6168823242295 .7025299072395 .09295654297 94.1785964965893 .5690307617292 .6546783447392 .0450973510791 .43553924561 90.5211791992289 .9116134643689 .302040100188 .6924667358488 .08290100098 87.7781066894587 .1685485839886 .254188537685 .6446228027384 .73026275635 83.5111236572382 .2919769287181 .0728530883879 .5489196777377 .72020721436 76.1962814331174 .062782287672 .2340774536170 .1005783081168 .20799255371 66.1383666992264 .3096618652362 .1761703491260 .3474502563558 .42078781128 56.5559310913155 .4708900451753 .9469718933152 .7278289794951 .50868988037 50.2895507812549 .0704002380448 .1560516357447 .2416992187546 .63212966919 46.3273391723646 .3273391723646 .0225486755445 .7177696228 -9999 -9999 -9999 -9999 -9999 -9999 -9999 -9999 -9999 -9999 -9999 -9999 -9999 -9999 -9999 -9999 -9999 -9999 -9999

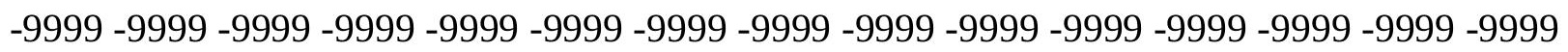
-9999 -9999-9999-9999

-9999 -9999 -9999 -9999 -9999-9999 -9999 -9999 -9999 -9999 -9999 -9999-9999 -9999 -9999 -

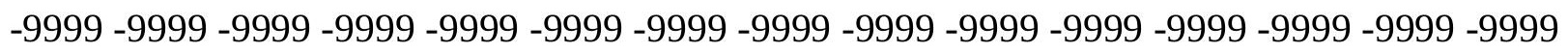

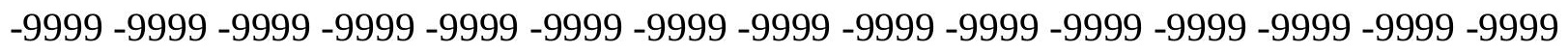
-9999 -9999 -9999 -9999 -9999 -9999 -9999 -9999 -9999 -9999 -9999 -9999 -9999 -9999 -9999 -

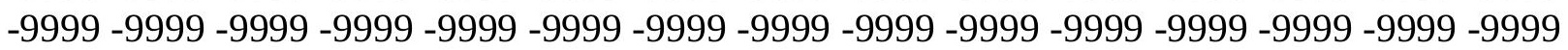

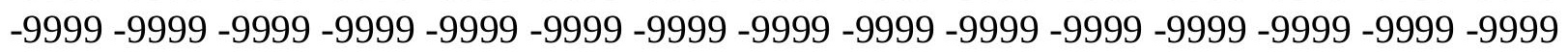


-9999 -9999 -9999 -9999 -9999 -9999 -9999 -9999 -9999 -9999 -9999 -9999 -9999 -9999 -9999 -9999 -9999 -9999 -9999 -9999 -9999 -9999 -9999 -9999 -9999 -9999 -9999 -9999 -9999 -9999 -9999 -9999 -9999 -9999 -9999 -9999 -9999 -9999 -9999 -9999 -9999 -9999 -9999 -9999 -9999 -9999 -9999 -9999 -9999 -9999 -9999 -9999 -9999 -9999 -9999 -9999 -9999 -9999 -9999 -9999 -9999 -9999 -9999 -9999 -9999 -9999 -9999 -9999 -9999 -9999 -9999 -9999 -9999 -9999 -9999 -9999 -9999 -9999 -9999 -9999 -9999 -9999 -9999 -9999 -9999 -9999 -9999 -9999 -9999 -9999 -9999 -9999 -9999 -9999 -9999 -9999 -9999 -9999 -9999 -9999 -9999 -9999 -9999 -9999 -9999

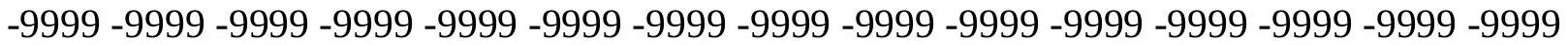
-9999 -9999 -9999 -9999 -9999 -9999 -9999 -9999 -9999 -9999 -9999 -9999 -9999 -9999 -9999 -9999 -9999 -9999 -9999 -9999 -9999 -9999 -9999 -9999 -9999 -9999 -9999 -9999 -9999 -9999 -

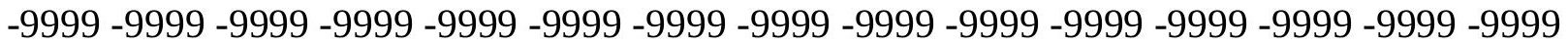
-9999 -9999 -9999 -9999 -9999 -9999 -9999 -9999 -9999 -9999 -9999 -9999 -9999 -9999 -9999

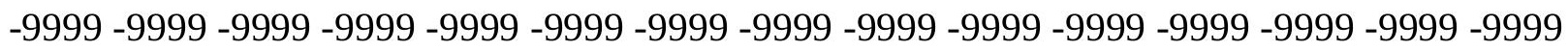
-9999 -9999 -9999 -9999 -9999 -9999 -9999 -9999 -9999 -9999 -9999 103.3221969604 102.4077987671101 .4934005737100 .883903503499 .9695205688599 .35994720459 98.7503814697397 .8360290527397 .2264633178796 .3121032714895 .70252990723 94.7881774902394 .1785964965893 .2642517089892 .6546783447392 .04509735107 91.1307525634890 .5211791992289 .9116134643689 .302040100188 .99725341797 88.38768768311 87.77810668945 86.86376190186 86.2541885376 85.33984375 84.1206970214882 .9015579223681 .3776321411179 .8537063598678 .02498626709 76.1962814331174 .062782287672 .2340774536170 .1005783081167 .66230010986 65.5288009643663 .3953094482461 .5666007995659 .4331016540557 .60438919067 55.7781219482454 .2517509460453 .0326118469251 .5086898803750 .28955078125 49.0704002380448 .1560516357446 .9369087219246 .6321296691946 .32733917236 46.3273391723646 .02254867554 -9999 -9999 -9999 -9999 -9999 -9999 -9999 -9999 -9999 -9999 -9999 -9999 -9999 -9999 -9999 -9999 -9999 -9999 -9999 -9999 -9999 -9999 -9999 -9999 -9999 -9999 -9999 -9999 -9999 -9999 -9999 -9999 -9999 -9999 -9999 -9999 -9999 -9999 -9999 $-9999$

-9999 -9999 -9999 -9999 -9999 -9999 -9999 -9999 -9999 -9999 -9999 -9999 -9999 -9999 -9999

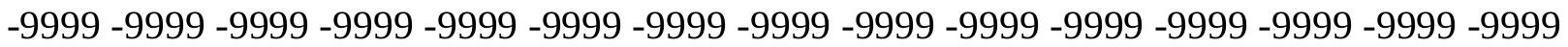
-9999 -9999 -9999 -9999 -9999 -9999 -9999 -9999 -9999 -9999 -9999 -9999 -9999 -9999 -9999 -

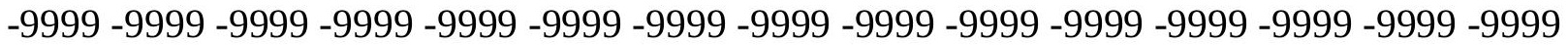

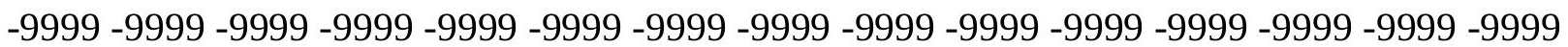
-9999 -9999 -9999 -9999 -9999 -9999 -9999 -9999 -9999 -9999 -9999 -9999 -9999 -9999 -9999 -

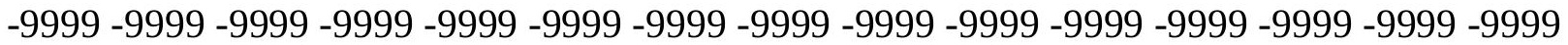
-9999 -9999 -9999 -9999 -9999 -9999 -9999 -9999 -9999 -9999 -9999 -9999 -9999 -9999 -9999 -9999 -9999 -9999 -9999 -9999 -9999 -9999 -9999 -9999 -9999 -9999 -9999 -9999 -9999 -9999

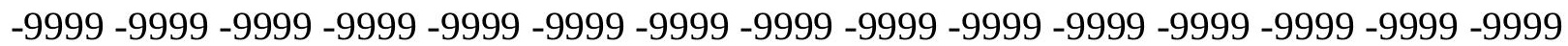
-9999 -9999 -9999 -9999 -9999 -9999 -9999 -9999 -9999 -9999 -9999 -9999 -9999 -9999 -9999 -9999 -9999 -9999 -9999 -9999 -9999 -9999 -9999 -9999 -9999 -9999 -9999 -9999 -9999 -9999 -9999 -9999 -9999 -9999 -9999 -9999 -9999 -9999 -9999 -9999 -9999 -9999 -9999 -9999 -9999 -999 -9999 -9999 -9999 -9999 -9999 -9999 -9999 -9999 -9999 -9999 -9999 -9999 -9999 -9999 -9999 -9999 -9999 -9999 -9999 -9999 -9999 -9999 -9999 -9999 -9999 -9999 -9999 -9999 -9999 -9999 -9999 -9999 -9999 -9999 -9999 -9999 -9999 -9999 -9999 -9999 -9999 -9999 -9999 -9999 -9999 -999 -9999 -9999 -9999 -9999 -9999 -9999 -9999 -9999 -9999 -9999 -9999 -9999 -9999 -9999 -9999

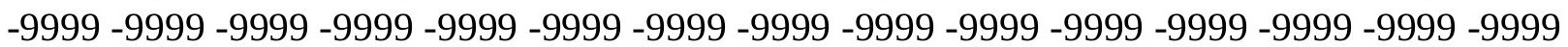


-9999 -9999 -9999 -9999 -9999 -9999 -9999 -9999 -9999 -9999 -9999 -9999 -9999 -9999 -9999 -9999 -9999 -9999 -9999 -9999 -9999 -9999 -9999 -9999 -9999 -9999 -9999 103.3221969604 102.4077987671101 .4934005737100 .579101562599 .9695205688599 .35994720459 98.445587158297 .8360290527396 .9216690063596 .3121032714895 .3977432251 94.7881774902393 .8738174438593 .2642517089892 .6546783447391 .74033355713 91.1307525634890 .5211791992290 .2164001464889 .6068267822388 .99725341797 88.38768768311 87.77810668945 86.86376190186 85.9494018554784.73026275635 83.5111236572381 .9871978759880 .1584930419978 .3297805786176 .50106811523 74.3675689697371 .9292907714869 .7957916259867 .3575134277365 .22400665283 63.0905189514260 .9570198059158 .8235282897956 .9948196411154 .97491836548 53.3373985290551 .8134689331150 .5943298339849 .3751907348648 .15605163574 48.765621185346 .6321296691946 .3273391723646 .3273391723646 .02254867554 -9999 -9999 -9999 -9999 -9999 -9999 -9999 -9999 -9999 -9999 -9999 -9999 -9999 -9999 -9999 -9999 -9999 -9999 -9999 -9999 -9999 -9999 -9999 -9999 -9999 -9999 -9999 -9999 -9999 -9999 -9999 -9999 -9999 -9999 -9999 -9999 -9999 -9999 -9999 -9999 -9999

-9999 -9999 -9999 -9999 -9999 -9999 -9999 -9999 -9999 -9999 -9999 -9999 -9999 -9999 -9999 -9999 -9999 -9999 -9999 -9999 -9999 -9999 -9999 -9999 -9999 -9999 -9999 -9999 -9999 -9999 -9999 -9999 -9999 -9999 -9999 -9999 -9999 -9999 -9999 -9999 -9999 -9999 -9999 -9999 -9999 -9999 -9999 -9999 -9999 -9999 -9999 -9999 -9999 -9999 -9999 -9999 -9999 -9999 -9999 -9999 -9999 -9999 -9999 -9999 -9999 -9999 -9999 -9999 -9999 -9999 -9999 -9999 -9999 -9999 -9999

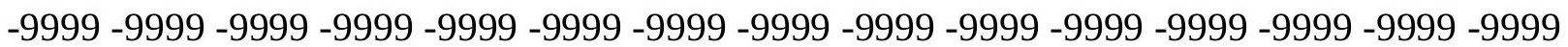
-9999 -9999 -9999 -9999 -9999 -9999 -9999 -9999 -9999 -9999 -9999 -9999 -9999 -9999 -9999 -9999 -9999 -9999 -9999 -9999 -9999 -9999 -9999 -9999 -9999 -9999 -9999 -9999 -9999 -9999 -9999 -9999 -9999 -9999 -9999 -9999 -9999 -9999 -9999 -9999 -9999 -9999 -9999 -9999 -9999

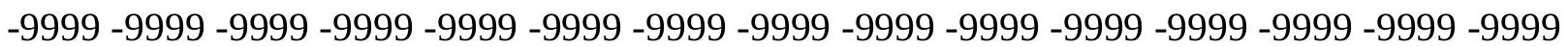
-9999 -9999 -9999 -9999 -9999 -9999 -9999 -9999 -9999 -9999 -9999 -9999 -9999 -9999 -9999 -9999 -9999 -9999 -9999 -9999 -9999 -9999 -9999 -9999 -9999 -9999 -9999 -9999 -9999 -9999 -9999 -9999 -9999 -9999 -9999 -9999 -9999 -9999 -9999 -9999 -9999 -9999 -9999 -9999 -9999 -9999 -9999 -9999 -9999 -9999 -9999 -9999 -9999 -9999 -9999 -9999 -9999 -9999 -9999 -9999 -9999 -9999 -9999 -9999 -9999 -9999 -9999 -9999 -9999 -9999 -9999 -9999 -9999 -9999 -9999 -9999 -9999 -9999 -9999 -9999 -9999 -9999 -9999 -9999 -9999 -9999 -9999 -9999 -9999 -9999 -

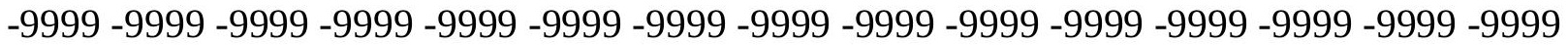
-9999 -9999 -9999 -9999 -9999 -9999 -9999 -9999 -9999 -9999 -9999 -9999 -9999 -9999 -9999 -9999 -9999 -9999 -9999 -9999 -9999 -9999 -9999 -9999 -9999 -9999 -9999 -9999 -9999 -9999 -9999 -9999 -9999 -9999 -9999 -9999 -9999 -9999 -9999 -9999 -9999 -9999 -9999 103.0174026489102 .1029968262101 .1886978149100 .579101562599 .96952056885 99.0551681518698 .445587158297 .5312423706196 .6168823242296 .00731658936 95.0929565429794 .4833908081193 .8738174438593 .2642517089892 .65467834473 92.0450973510791 .4355392456190 .8259735107490 .5211791992289 .91161346436 89.3020401001 88.3876876831187.77810668945 86.55898284912 85.33984375 84.1206970214882 .5967712402380 .7680587768678 .6345596313576 .50106811523 74.3675689697371 .9292907714869 .4910125732467 .0527267456164 .80416107178 62.4809494018660 .0426712036157 .909179687556 .0804595947354 .10143280029 52.4230384826750 .8991203308149 .6799812316948 .1560516357447 .24169921875 46.9369087219246 .6321296691946 .32733917236 -9999 -9999 -9999 -9999 -9999 -9999 -9999 -9999 -9999 -9999 -9999 -9999 -9999 -9999 -9999 -9999 -9999 -9999 -9999 -9999 -9999 -9999 
-9999 -9999 -9999 -9999 -9999 -9999 -9999 -9999 -9999 -9999 -9999 -9999 -9999 -9999 -9999 -9999 -9999 -9999 -9999-9999-9999

-9999 -9999 -9999 -9999 -9999 -9999 -9999 -9999 -9999 -9999 -9999 -9999 -9999 -9999 -9999 -9999 -9999 -9999 -9999 -9999 -9999 -9999 -9999 -9999 -9999 -9999 -9999 -9999 -9999 -9999 -9999 -9999 -9999 -9999 -9999 -9999 -9999 -9999 -9999 -9999 -9999 -9999-9999 -9999 -9999 -9999 -9999 -9999 -9999 -9999 -9999 -9999 -9999 -9999 -9999 -9999 -9999 -9999 -9999 -9999

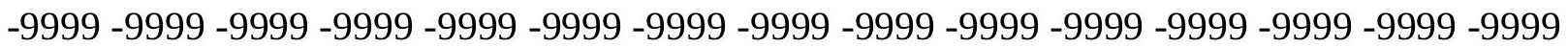

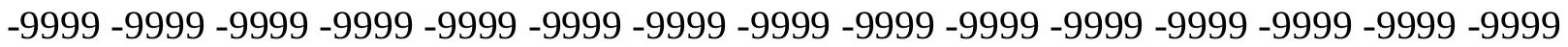

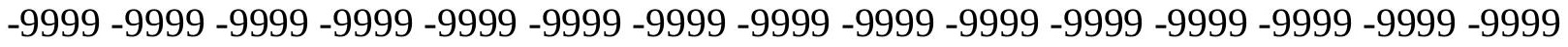
-9999 -9999 -9999 -9999 -9999 -9999 -9999 -9999 -9999 -9999 -9999 -9999 -9999 -9999 -9999

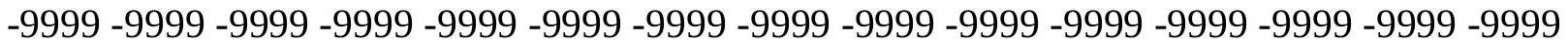
-9999 -9999 -9999 -9999 -9999 -9999 -9999 -9999 -9999 -9999 -9999 -9999 -9999 -9999 -9999 -9999 -9999 -9999 -9999 -9999 -9999 -9999 -9999 -9999 -9999 -9999 -9999 -9999 -9999 -9999 -9999 -9999 -9999 -9999 -9999 -9999 -9999 -9999 -9999 -9999 -9999 -9999 -9999 -9999 - 9999 -9999 -9999 -9999 -9999 -9999 -9999 -9999 -9999 -9999 -9999 -9999 -9999 -9999 -9999 -9999

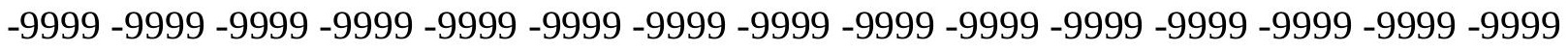
-9999 -9999 -9999 -9999 -9999 -9999 -9999 -9999 -9999 -9999 -9999 -9999 -9999 -9999 -9999 -9999 -9999 -9999 -9999 -9999 -9999 -9999 -9999 -9999 -9999 -9999 -9999 -9999 -9999 -9999 -9999 -9999 -9999 -9999 -9999 -9999 -9999 -9999 -9999 -9999 -9999 -9999 -9999 -9999 -9999 -

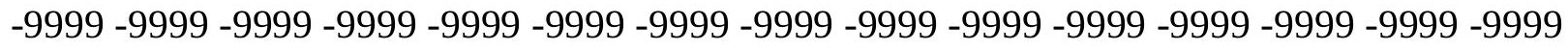

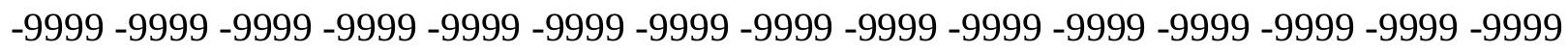
-9999 -9999 -9999 -9999 -9999 -9999 -9999 -9999 -9999 -9999 -9999 -9999 -9999 103.9317016602103 .0174026489102 .1029968262101 .1886978149100 .5791015625 99.6647262573299 .0551681518698 .1408081054797 .2264633178796 .61688232422 95.7025299072395 .0929565429794 .4833908081193 .8738174438593 .26425170898 92.6546783447392 .349891662691 .7403335571391 .1307525634890 .82597351074 90.2164001464889 .302040100188 .3876876831187 .4733276367286 .2541885376 84.7302627563583 .206336975181 .3776321411179 .2441329956176 .80584716797 74.6723632812571 .9292907714869 .4910125732467 .0527267456164 .30966186523 61.8713798522959 .4331016540557 .2995986938555 .1661109924353 .17943191528 51.5086898803749 .9847602844248 .765621185347 .5464782714846 .93690872192 46.6321296691946 .32733917236 -9999 -9999 -9999 -9999 -9999 -9999 -9999 -9999 -9999

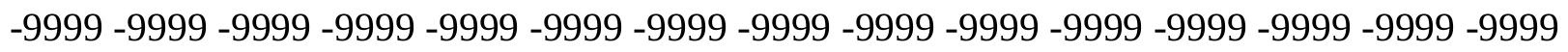

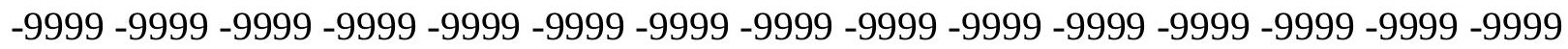
-9999 -9999-9999-9999-9999

-9999 -9999 -9999 -9999 -9999 -9999 -9999 -9999 -9999 -9999 -9999 -9999 -9999 -9999 -9999

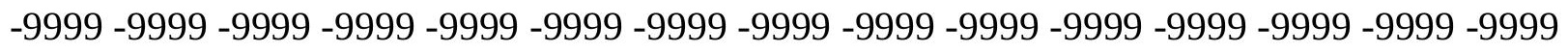

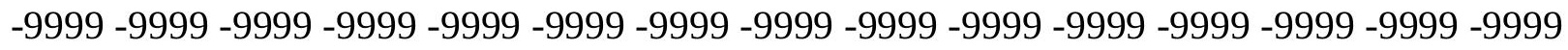
-9999 -9999 -9999 -9999 -9999 -9999 -9999 -9999 -9999 -9999 -9999 -9999 -9999 - 9999 - -999 -9999 -9999 -9999 -9999 -9999 -9999 -9999 -9999 -9999 -9999 -9999 -9999 -9999 -9999 -9999 -

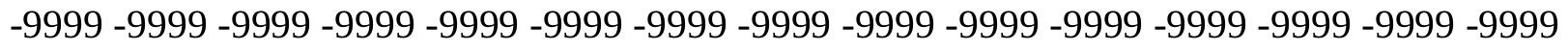

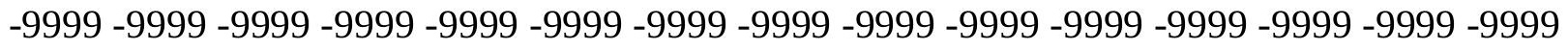
-9999 -9999 -9999 -9999 -9999 -9999 -9999 -9999 -9999 -9999 -9999 -9999 -9999 -9999 -9999 -9999 -9999 -9999 -9999 -9999 -9999 -9999 -9999 -9999-9999 -9999 -9999 -9999 -9999 -9999 -9999 -9999 -9999 -9999 -9999 -9999 -9999 -9999 -9999 -9999 -9999 -9999 -9999 -9999 -9999 -

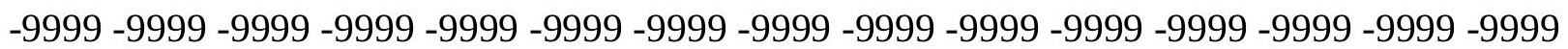


-9999 -9999 -9999 -9999 -9999 -9999 -9999 -9999 -9999 -9999 -9999 -9999 -9999 -9999 -9999 -9999 -9999 -9999 -9999 -9999 -9999 -9999 -9999 -9999 -9999 -9999 -9999 -9999 -9999 -9999 -9999 -9999 -9999 -9999 -9999 -9999 -9999 -9999 -9999 -9999 -9999 -9999 -9999 -9999 -9999 -9999 -9999 -9999 -9999 -9999 -9999 -9999 -9999 -9999 -9999 -9999 -9999 -9999 -9999 -9999 -9999 -9999 -9999 -9999 -9999 -9999 -9999 -9999 -9999 -9999 -9999 -9999 -9999 -9999 -9999 -9999 -9999 -9999 -9999 -9999 -9999 -9999 -9999 -9999 -9999 -9999 -9999 -9999 -9999 -9999 -9999 -9999 -9999 -9999 -9999 -9999 -9999 -9999 -9999 -9999 -9999 -9999 -9999 -9999 -9999

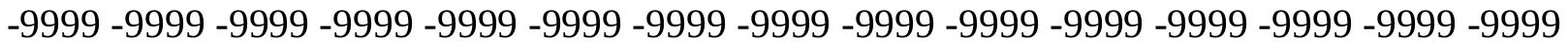
-9999 -9999 -9999 -9999 -9999 -9999 -9999 -9999 -9999 -9999 -9999 -9999 -9999 -9999 103.9317016602103 .0174026489102 .1029968262101 .1886978149100 .2742996216 99.6647262573298 .7503814697397 .8360290527397 .2264633178796 .31210327148 95.7025299072395 .0929565429794 .4833908081193 .8738174438593 .56903076172 92.9594726562592 .6546783447392 .0450973510791 .7403335571391 .13075256348 90.2164001464889 .302040100188 .3876876831187 .1685485839885 .64462280273 83.8159103393681 .9871978759879 .8537063598677 .4154205322374 .97714233398 72.2340774536169 .4910125732466 .7479400634864 .004882812561 .56660079956 58.8235282897956 .6900291442954 .2517509460452 .3293418884350 .59432983398 $49.0704002380447 .8512611389247 .2416992187546 .9369087219246 .63212966919-9999$ -9999 -9999 -9999 -9999 -9999 -9999 -9999 -9999 -9999 -9999 -9999 -9999 -9999 -9999 -9999 -9999 -9999 -9999 -9999 -9999 -9999 -9999 -9999 -9999 -9999 -9999 -9999 -9999 -9999 -9999 -9999 -9999 -9999 -9999 -9999 -9999 -9999 -9999 -9999 -9999 -9999 -9999 -9999 -9999 -9999 -9999 -9999 -9999 -9999 -9999 -9999 -9999 -9999 -9999 -9999 -9999 -9999 -9999 -9999 -9999 -9999 -9999 -9999 -9999 -9999 -9999 -9999 -9999 -9999 -9999 -9999 -9999 -9999 -9999 -9999 -9999 -9999 -9999 -9999 -9999 -9999 -9999 -9999 -9999 -9999 -9999 -9999 -9999 -9999

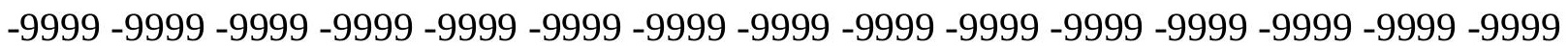
-9999 -9999 -9999 -9999 -9999 -9999 -9999 -9999 -9999 -9999 -9999 -9999 -9999 -9999 -9999 -9999 -9999 -9999 -9999 -9999 -9999 -9999 -9999 -9999 -9999 -9999 -9999 -9999 -9999 -9999 -9999 -9999 -9999 -9999 -9999 -9999 -9999 -9999 -9999 -9999 -9999 -9999 -9999 -9999 -9999 -9999 -9999 -9999 -9999 -9999 -9999 -9999 -9999 -9999 -9999 -9999 -9999 -9999 -9999 -9999 -9999 -9999 -9999 -9999 -9999 -9999 -9999 -9999 -9999 -9999 -9999 -9999 -9999 -9999 -9999 -9999 -9999 -9999 -9999 -9999 -9999 -9999 -9999 -9999 -9999 -9999 -9999 -9999 -9999 -9999 -

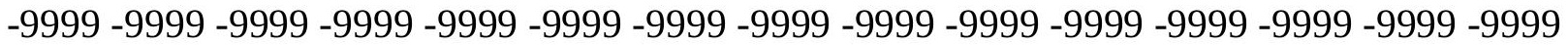
-9999 -9999 -9999 -9999 -9999 -9999 -9999 -9999 -9999 -9999 -9999 -9999 -9999 -9999 -9999 -9999 -9999 -9999 -9999 -9999 -9999 -9999 -9999 -9999 -9999 -9999 -9999 -9999 -9999 -9999 -9999 -9999 -9999 -9999 -9999 -9999 -9999 -9999 -9999 -9999 -9999 -9999 -9999 -9999 -9999 -9999 -9999 -9999 -9999 -9999 -9999 -9999 -9999 -9999 -9999 -9999 -9999 -9999 -9999 -9999 -9999 -9999 -9999 -9999 -9999 -9999 -9999 -9999 -9999 -9999 -9999 -9999 -9999 -9999 -9999

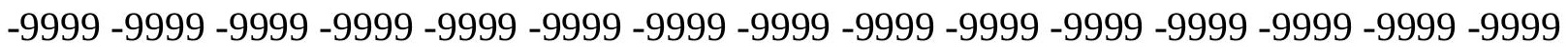
-9999 -9999 -9999 -9999 -9999 -9999 -9999 -9999 -9999 -9999 -9999 -9999 -9999 -9999 -9999 -9999 -9999 -9999 -9999 -9999 -9999 -9999 -9999 -9999 -9999 -9999 -9999 -9999 -9999 -9999 -9999 -9999 -9999 -9999 -9999 -9999 -9999 -9999 -9999 -9999 -9999 -9999 -9999 -9999 -9999 103.6268997192102 .712600708101 .7982025146101 .1886978149100 .2742996216 99.3599472045998.445587158297.8360290527396.9216690063596.31210327148 95.7025299072395 .0929565429794 .7881774902394 .1785964965893 .87381744385 93.5690307617292 .9594726562592 .6546783447392 .0450973510791 .43553924561 90.5211791992289 .302040100188 .0829010009886 .5589828491284 .73026275635 
82.5967712402380 .1584930419977 .7202072143675 .2819290161172 .53885650635 69.4910125732466 .7479400634864 .004882812561 .2618103027358 .51874923706 55.7756805419953 .6421813964851 .5086898803749 .6799812316948 .46083068848 47.8512611389247 .2416992187546 .63212966919 -9999 -9999 -9999 -9999 -9999 -9999 -9999 -9999 -9999 -9999 -9999 -9999 -9999 -9999 -9999 -9999 -9999 -9999 -9999 -9999 -9999 -9999

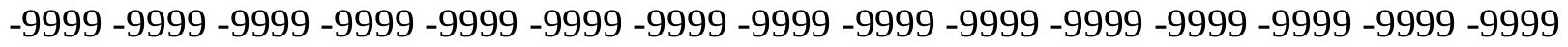
-9999 -9999 -9999 -9999 -9999 -9999 -9999 -9999 -9999

-9999 -9999 -9999 -9999 -9999 -9999 -9999 -9999 -9999 -9999 -9999 -9999 -9999 -9999 -9999 -9999 -9999 -9999 -9999 -9999 -9999 -9999 -9999 -9999 -9999 -9999 -9999 -9999 -9999 -9999 -9999 -9999 -9999 -9999 -9999 -9999 -9999 -9999 -9999 -9999 -9999 -9999 -9999 -9999 -9999 -9999 -9999 -9999 -9999 -9999 -9999 -9999 -9999 -9999 -9999 -9999 -9999 -9999 -9999 -9999 -999 -9999 -9999 -9999 -9999 -9999 -9999 -9999 -9999 -9999 -9999 -9999 -9999 -9999 -9999 -9999

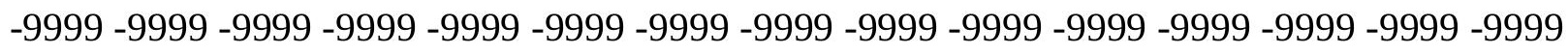
-9999 -9999 -9999 -9999 -9999 -9999 -9999 -9999 -9999 -9999 -9999 -9999 -9999 -9999 -9999 -9999 -9999 -9999 -9999 -9999 -9999 -9999 -9999 -9999 -9999 -9999 -9999 -9999 -9999 -9999

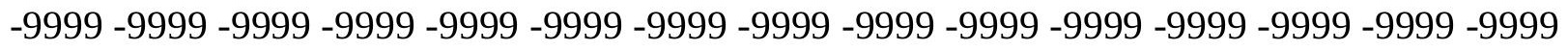
-9999 -9999 -9999 -9999 -9999 -9999 -9999 -9999 -9999 -9999 -9999 -9999 -9999 -9999 -9999 -9999 -9999 -9999 -9999 -9999 -9999 -9999 -9999 -9999 -9999 -9999 -9999 -9999 -9999 -9999 -

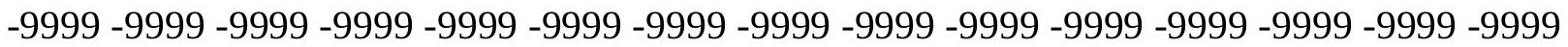

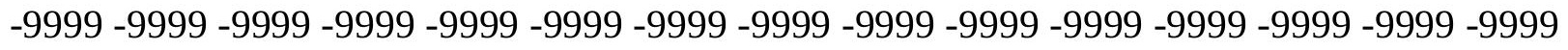

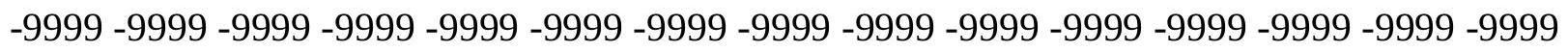

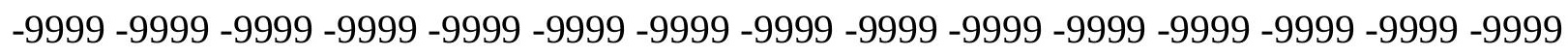
-9999 -9999 -9999 -9999 -9999 -9999 -9999 -9999 -9999 -9999 -9999 -9999 -9999 -9999 -9999 -

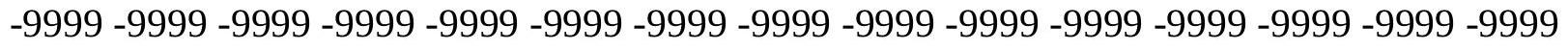

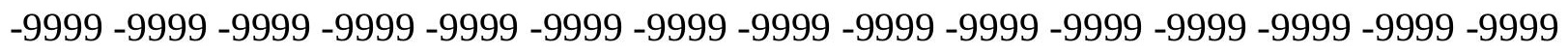
-9999 -9999 -9999 -9999 -9999 -9999 -9999 -9999 -9999 -9999 -9999 -9999 -9999 -9999 -9999 -9999 -9999 -9999 -9999 -9999 -9999 -9999 -9999 -9999 -9999 -9999 -9999 -9999 -9999 -9999 104.5412979126103 .6268997192102 .712600708101 .7982025146100 .8839035034 99.9695205688599 .0551681518698 .445587158297 .5312423706196 .92166900635 96.3121032714895 .7025299072395 .397743225195 .0929565429794 .78817749023 94.4833908081193 .8738174438593 .5690307617292 .9594726562592 .3498916626 91.4355392456190 .5211791992288 .9972534179787 .4733276367285 .64462280273 83.5111236572381 .0728530883878 .3297805786175 .5867080688572 .84364318848 69.7957916259866 .7479400634864 .004882812560 .9570198059157 .9091796875 55.4708900451752 .7278289794950 .5943298339849 .0704002380448 .15605163574 47.5464782714847 .2416992187546 .63212966919 -9999 -9999 -9999 -9999 -9999 -9999 -9999

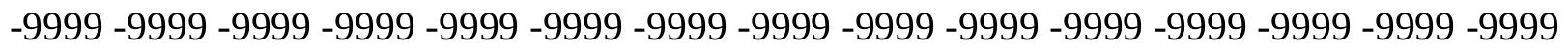

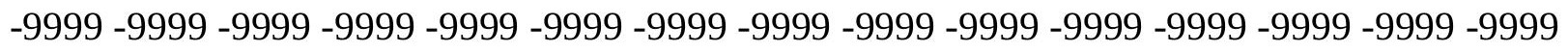
-9999 -9999 -9999 -9999 -9999 -9999 -9999 -9999 -9999

-9999 -9999 -9999 -9999 -9999 -9999 -9999 -9999 -9999 -9999 -9999 -9999 -9999 -9999 -9999

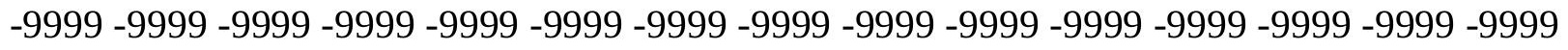

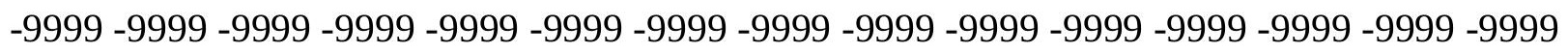

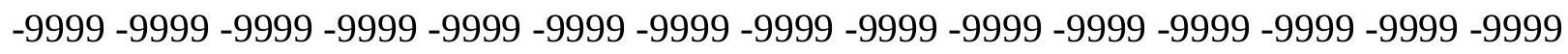
-9999 -9999 -9999 -9999 -9999 -9999 -9999 -9999 -9999 -9999 -9999 -9999 -9999 -9999 -9999 -

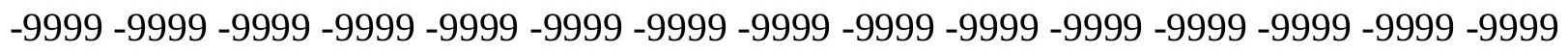

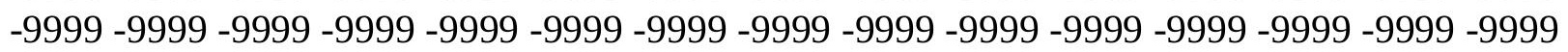


-9999 -9999 -9999 -9999 -9999 -9999 -9999 -9999 -9999 -9999 -9999 -9999 -9999 -9999 -9999 -9999 -9999 -9999 -9999 -9999 -9999 -9999 -9999 -9999 -9999 -9999 -9999 -9999 -9999 -9999 -9999 -9999 -9999 -9999 -9999 -9999 -9999 -9999 -9999 -9999 -9999 -9999 -9999 -9999 -9999 -9999 -9999 -9999 -9999 -9999 -9999 -9999 -9999 -9999 -9999 -9999 -9999 -9999 -9999 -9999 -9999 -9999 -9999 -9999 -9999 -9999 -9999 -9999 -9999 -9999 -9999 -9999 -9999 -9999 -9999 -9999 -9999 -9999 -9999 -9999 -9999 -9999 -9999 -9999 -9999 -9999 -9999 -9999 -9999 -9999 -9999 -9999 -9999 -9999 -9999 -9999 -9999 -9999 -9999 -9999 -9999 -9999 -9999 -9999 -9999

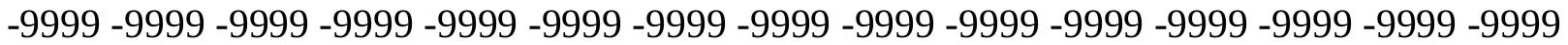
-9999 -9999 -9999 -9999 -9999 -9999 -9999 -9999 -9999 -9999 -9999 -9999 -9999 -9999 -9999 -9999 -9999 -9999 -9999 -9999 -9999 -9999 -9999 -9999 -9999 -9999 -9999 -9999 -9999 -9999 -

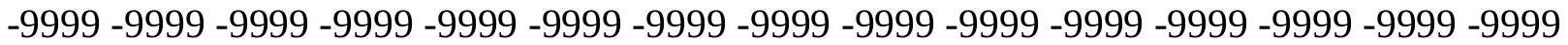
-9999 -9999 -9999 -9999 -9999 -9999 -9999 -9999 -9999 -9999 -9999 -9999 -9999 -9999 -9999 -9999 -9999 -9999 -9999 -9999 -9999 -9999 -9999 -9999 -9999 -9999 -9999 -9999 -9999 -9999 -9999 104.5412979126103.3221969604 102.4077987671 101.4934005737100.5791015625 99.6647262573298 .7503814697398 .1408081054797 .5312423706196 .92166900635 96.3121032714896 .0073165893695 .7025299072395 .397743225195 .09295654297 95.0929565429794 .7881774902394 .1785964965893 .5690307617292 .65467834473 91.7403335571390 .2164001464888 .3876876831186 .5589828491284 .12069702148 81.6824111938578 .9393463134876 .1962814331173 .1484298706170 .10057830811 67.0527267456164 .004882812560 .9570198059157 .909179687554 .86132049561 52.1182594299351 .5086898803749 .0704002380448 .1560516357447 .54647827148 47.24169921875 -9999 -9999 -9999 -9999 -9999 -9999 -9999 -9999 -9999 -9999 -9999 -9999 -9999 -9999 -9999 -9999 -9999 -9999 -9999 -9999 -9999 -9999 -9999 -9999 -9999 -9999 -9999 -9999 -9999 -9999 -9999 -9999 -9999 -9999 -9999 -9999 -9999 -9999 -9999 -9999 -9999 -9999 -9999 -9999-9999-9999-9999

-9999 -9999 -9999 -9999 -9999 -9999 -9999 -9999 -9999 -9999 -9999 -9999 -9999 -9999 -9999 -9999 -9999 -9999 -9999 -9999 -9999 -9999 -9999 -9999 -9999 -9999 -9999 -9999 -9999 -9999 -9999 -9999 -9999 -9999 -9999 -9999 -9999 -9999 -9999 -9999 -9999 -9999 -9999 -9999 -9999 -9999 -9999 -9999 -9999 -9999 -9999 -9999 -9999 -9999 -9999 -9999 -9999 -9999 -9999 -9999

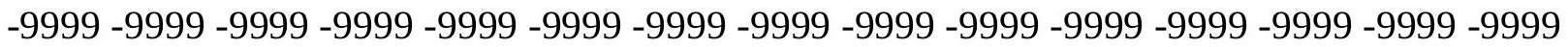
-9999 -9999 -9999 -9999 -9999 -9999 -9999 -9999 -9999 -9999 -9999 -9999 -9999 -9999 -9999 -

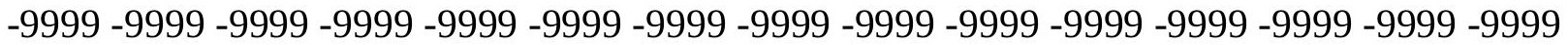
-9999 -9999 -9999 -9999 -9999 -9999 -9999 -9999 -9999 -9999 -9999 -9999 -9999 -9999 -9999 -9999 -9999 -9999 -9999 -9999 -9999 -9999 -9999 -9999 -9999 -9999 -9999 -9999 -9999 -9999 -

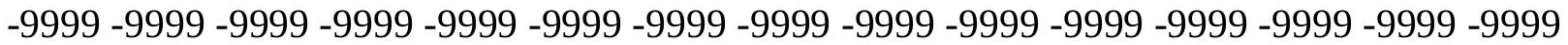
-9999 -9999 -9999 -9999 -9999 -9999 -9999 -9999 -9999 -9999 -9999 -9999 -9999 -9999 -9999 -9999 -9999 -9999 -9999 -9999 -9999 -9999 -9999 -9999 -9999 -9999 -9999 -9999 -9999 -9999

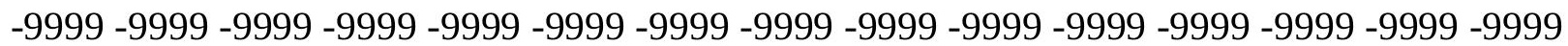
-9999 -9999 -9999 -9999 -9999 -9999 -9999 -9999 -9999 -9999 -9999 -9999 -9999 -9999 -9999 -9999 -9999 -9999 -9999 -9999 -9999 -9999 -9999 -9999 -9999 -9999 -9999 -9999 -9999 -9999 -9999 -9999 -9999 -9999 -9999 -9999 -9999 -9999 -9999 -9999 -9999 -9999 -9999 -9999 -9999 -999 -9999 -9999 -9999 -9999 -9999 -9999 -9999 -9999 -9999 -9999 -9999 -9999 -9999 -9999 -9999 -9999 -9999 -9999 -9999 -9999 -9999 -9999 -9999 -9999 -9999 -9999 -9999 -9999 -9999 -9999 -9999 -9999 -9999 -9999 -9999 -9999 -9999 -9999 -9999 -9999 -9999 -9999 -9999 -9999 -9999 -9999 -9999 -9999 -9999 -9999 -9999 -9999 -9999 -9999 -9999 -9999 -9999 -9999 -9999 -9999 -9999 -9999 104.2365036011 103.0174026489 102.1029968262 101.1886978149 
100.2742996216 99.3599472045998.445587158297.8360290527397.22646331787 96.9216690063596 .6168823242296 .3121032714896 .0073165893696 .00731658936 96.0073165893695 .7025299072395 .397743225194 .7881774902393 .87381744385 92.9594726562591 .4355392456189 .6068267822387 .4733276367285 .03504943848 82.5967712402379 .8537063598676 .8058471679773 .7580032348670 .71015167236 67.3575134277364 .004882812560 .9570198059157 .6043891906754 .86132049561 52.1182594299349 .9847602844249 .0704002380448 .1560516357447 .85126113892 47.24169921875 -9999 -9999 -9999 -9999 -9999 -9999 -9999 -9999 -9999 -9999 -9999 -9999 -9999 -9999 -9999 -9999 -9999 -9999 -9999 -9999 -9999 -9999 -9999 -9999 -9999 -9999 -9999 -

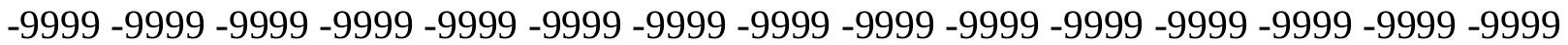
-9999 -9999 -9999 -9999-9999

-9999 -9999 -9999 -9999 -9999 -9999 -9999 -9999 -9999 -9999 -9999 -9999 -9999 -9999 -9999 -9999 -9999 -9999 -9999 -9999 -9999 -9999 -9999 -9999 -9999 -9999 -9999 -9999 -9999 -9999

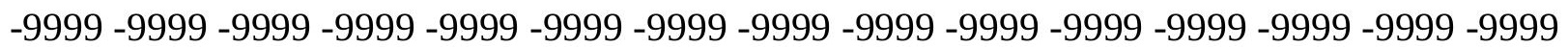
-9999 -9999 -9999 -9999 -9999 -9999 -9999 -9999 -9999 -9999 -9999 -9999 -9999 -9999 -9999 -

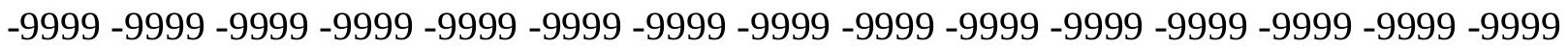

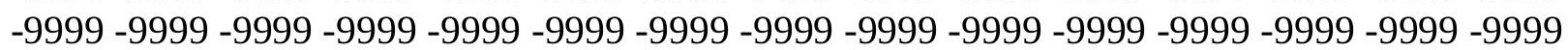
-9999 -9999 -9999 -9999 -9999 -9999 -9999 -9999 -9999 -9999 -9999 -9999 -9999 -9999 -9999 -999 -9999 -9999 -9999 -9999 -9999 -9999 -9999 -9999 -9999 -9999 -9999 -9999 -9999 -9999 -9999 -9999 -9999 -9999 -9999 -9999 -9999 -9999 -9999 -9999 -9999 -9999 -9999 -9999 -9999 -9999 -9999 -9999 -9999 -9999 -9999 -9999 -9999 -9999 -9999 -9999 -9999 -9999 -9999 -9999 -9999 -9999 -9999 -9999 -9999 -9999 -9999 -9999 -9999 -9999 -9999 -9999 -9999 -9999 -9999 -9999 -9999 -9999 -9999 -9999 -9999 -9999 -9999 -9999 -9999 -9999 -9999 -9999 -9999 -9999 -9999 -9999 -9999 -9999 -9999 -9999 -9999 -9999 -9999 -9999 -9999 -9999 -9999 -9999 -9999 -9999 -9999 -9999 -9999 -9999 -9999 -9999 -9999 -9999 -9999 -9999 -9999 -9999 -9999 -9999 -9999 -9999 -9999 -9999 -9999 -9999 -9999 -9999 -9999 -9999 -9999 -9999 -9999 -9999 -9999 -9999 -9999 -9999 -9999 -9999 -9999 -9999 -9999 -9999 -9999 -9999 -9999 -9999 -9999 -9999 -9999

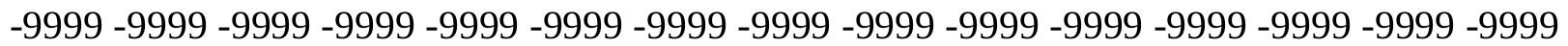
-9999 -9999 -9999 -9999 -9999 -9999 -9999 -9999 -9999 -9999 -9999 -9999 -9999 -9999 -9999 -

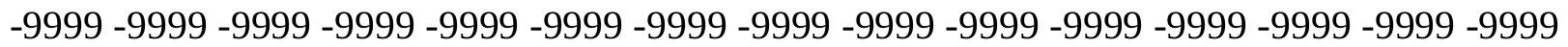
-9999 -9999 -9999 -9999 -9999 -9999 -9999 -9999 -9999 -9999 -9999 -9999 -9999 -9999 -9999 -9999 -9999-9999 103.6484985352 102.5754699707101 .4934005737100 .5791015625 99.6647262573299 .0551681518698 .445587158297 .8360290527397 .22646331787 96.9216690063596 .9216690063596 .6168823242296 .6168823242296 .61688232422 96.6168823242296 .6168823242296 .0073165893695 .397743225194 .17859649658 92.6546783447390 .5211791992288 .3876876831185 .9494018554783 .51112365723 80.4632720947377 .7202072143674 .3675689697371 .3197174072367 .96708679199 64.3096618652360 .9570198059157 .909179687554 .8613204956152 .11825942993 49.9847602844249 .0704002380448 .4608306884847 .85126113892 -9999 -9999 -9999 -9999 -9999 -9999 -9999 -9999 -9999 -9999 -9999 -9999 -9999 -9999 -9999 -9999 -9999 -9999 -9999

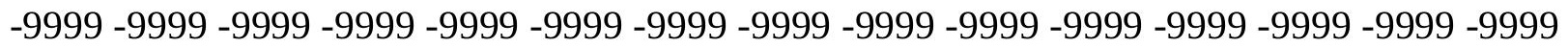
-9999 -9999 -9999 -9999 -9999 -9999 -9999 -9999 -9999 -9999 -9999 -9999 -9999 -9999 -9999 -9999 -9999 -9999 -9999 -9999 -9999 -9999 -9999 -9999 -9999 -9999 -9999 -9999 -9999 -9999 -9999 -9999 -9999 -9999 -9999 -9999 -9999 -9999 -9999 -9999 -9999 -9999 -9999 -9999 -9999 -9999 -9999 -9999 -9999 -9999 -9999 -9999 -9999 -9999 -9999 -9999 -9999 -9999-999 -

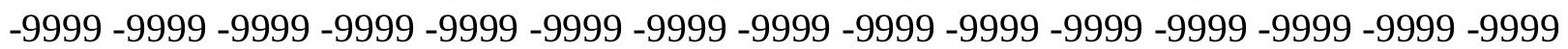


-9999 -9999 -9999 -9999 -9999 -9999 -9999 -9999 -9999 -9999 -9999 -9999 -9999 -9999 -9999 -9999 -9999 -9999 -9999 -9999 -9999 -9999 -9999 -9999 -9999 -9999 -9999 -9999 -9999 -9999 -

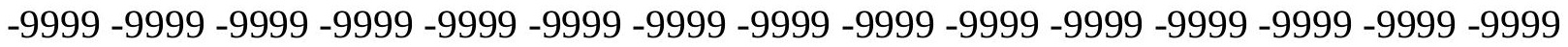
-9999 -9999 -9999 -9999 -9999 -9999 -9999 -9999 -9999 -9999 -9999 -9999 -9999 -9999 -9999 -9999 -9999 -9999 -9999 -9999 -9999 -9999 -9999 -9999-9999 -9999 -9999 -9999 -9999 -9999 -9999 -9999 -9999 -9999 -9999 -9999 -9999 -9999 -9999 -9999 -9999 -9999 -9999 -9999 -9999 -

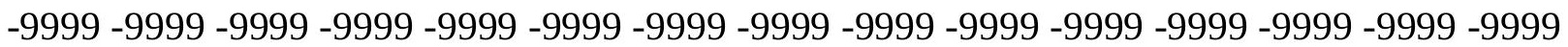

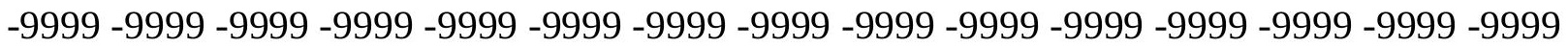

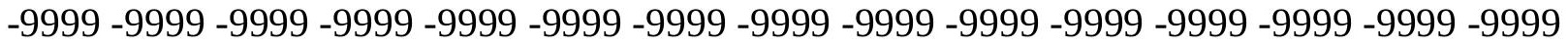
-9999 -9999 -9999 -9999 -9999 -9999 -9999 -9999 -9999 -9999 -9999 -9999 -9999 -9999 -9999

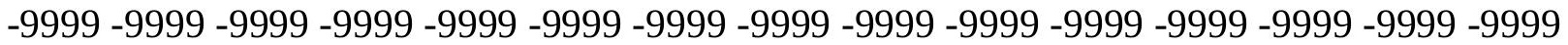
-9999 -9999 -9999 -9999 -9999 -9999 -9999 -9999 -9999 -9999 -9999 -9999 -9999 -9999 -9999 -9999 -9999 -9999 -9999 -9999 -9999 -9999 -9999 -9999 -9999 -9999 -9999 -9999 -9999 -9999 -

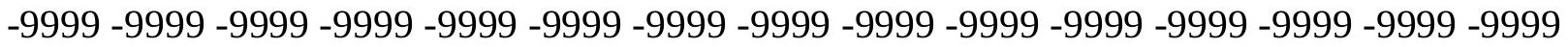
-9999 -9999 -9999 -9999 -9999 -9999 -9999 -9999 -9999 -9999 -9999 -9999 -9999 -9999 -9999

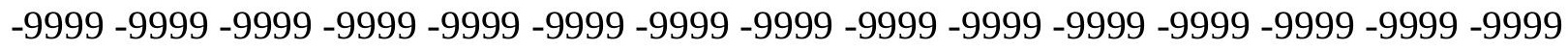
-9999 -9999 -9999 -9999 103.0974502563102.0495986938101.1005783081 100.1594696045 99.3599472045998.75038146973 98.1408081054797.53124237061 97.22646331787 97.22646331787 97.22646331787 97.2264633178797.53124237061 97.53124237061 97.5312423706197.2264633178796.6168823242295.397743225193.56903076172 91.4355392456189 .302040100186 .8637619018684 .1206970214881 .37763214111 78.3297805786175 .2819290161171 .9292907714868 .5766525268664 .91924285889 61.5666007995658 .2139587402355 .1661109924352 .1182594299350 .28955078125 49.3751907348648 .7656211853 -9999 -9999 -9999 -9999 -9999 -9999 -9999 -9999 -9999 -9999 -9999 -9999 -9999 -9999 -9999 -9999 -9999 -9999 -9999 -9999 -9999 -9999 -9999 -9999 -9999 -9999 -9999 -9999 -9999 -9999 -9999 -9999 -9999 -9999 -9999 -9999-9999 -9999 -9999 -9999 -9999 -9999 -9999 -9999 -9999 -9999 -9999 -9999 -9999

-9999 -9999 -9999 -9999 -9999 -9999 -9999 -9999 -9999 -9999 -9999 -9999 -9999 -9999 -9999 -9999 -9999 -9999 -9999 -9999 -9999 -9999 -9999 -9999 -9999 -9999 -9999 -9999 -9999 -9999 -9999 -9999 -9999 -9999 -9999 -9999 -9999 -9999 -9999 -9999 -9999 -9999 -9999 -9999 -999 -9999 -9999 -9999 -9999 -9999 -9999 -9999 -9999 -9999-9999 -9999 -9999 -9999 -9999 -9999 -9999 -9999 -9999 -9999 -9999 -9999 -9999 -9999 -9999 -9999 -9999 -9999 -9999 -9999 -9999 -

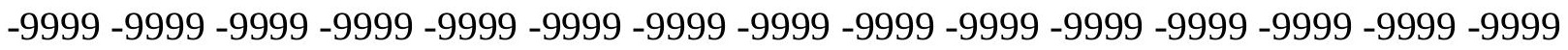

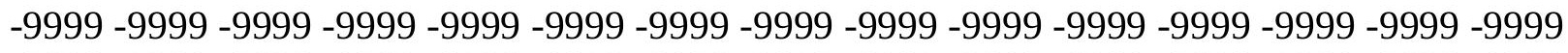
-9999 -9999 -9999 -9999 -9999 -9999 -9999 -9999 -9999 -9999 -9999 -9999 -9999 -9999 -9999 -

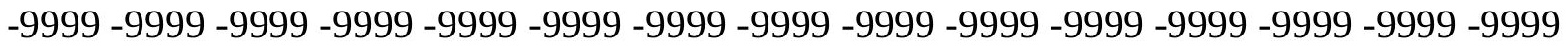

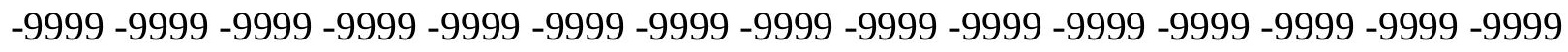

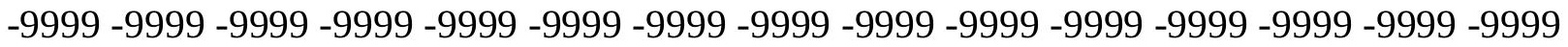
-9999 -9999 -9999 -9999 -9999 -9999 -9999 -9999 -9999 -9999 -9999 -9999 -9999 - 9999 - -999 -9999 -9999 -9999 -9999 -9999 -9999 -9999 -9999 -9999 -9999 -9999 -9999 -9999 -9999 -9999 -

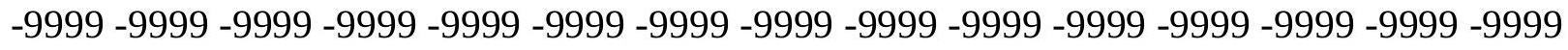

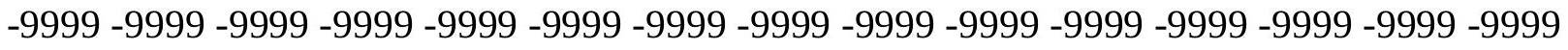
-9999 -9999 -9999 -9999 -9999 -9999 -9999 -9999 -9999 -9999 -9999 -9999 -9999 -9999 -9999 -9999 -9999 -9999 -9999 -9999 -9999 -9999 -9999 -9999-9999 -9999 -9999 -9999 -9999 -9999 -9999 -9999 -9999 -9999 -9999 -9999 -9999 -9999 -9999 -9999 -9999 -9999 -9999 -9999 -9999 -

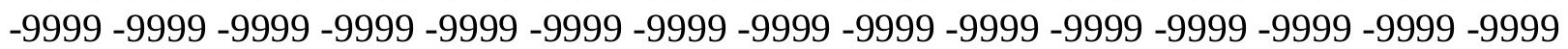


-9999 -9999 -9999 -9999 -9999 -9999 -9999 -9999 -9999 -9999 -9999 -9999 -9999 -9999 -9999 -9999 -9999 -9999 -9999 -9999 102.6961288452 101.7554855347100 .5791015625 99.6647262573299 .0551681518698 .445587158297 .8360290527397 .53124237061 97.2264633178797 .2264633178797 .5312423706197 .8360290527398 .4455871582 98.7503814697398 .445587158297 .5312423706196 .3121032714894 .48339080811 92.349891662689 .9116134643687 .4733276367285 .0350494384882 .24694061279 79.2441329956176 .1515426635772 .8436431884869 .1862335205165 .52880096436 61.8713798522958 .5187492370655 .1661109924352 .4230384826750 .59432983398 49.6799812316949 .07040023804 -9999 -9999 -9999 -9999 -9999 -9999 -9999 -9999 -9999 -9999 -9999 -9999 -9999 -9999 -9999 -9999 -9999 -9999 -9999 -9999 -9999 -9999 -9999 -9999 -9999 -9999 -9999 -9999 -9999 -9999 -9999 -9999 -9999 -9999 -9999 -9999 -9999 -9999 -9999 -9999 -9999 -9999 -9999-9999 -9999-9999 -9999 -9999 -9999

-9999 -9999 -9999 -9999 -9999 -9999 -9999 -9999 -9999 -9999 -9999 -9999 -9999 -9999 -9999 -9999 -9999 -9999 -9999 -9999 -9999 -9999 -9999 -9999 -9999 -9999 -9999 -9999 -9999 -9999 -9999 -9999 -9999 -9999 -9999 -9999 -9999 -9999 -9999 -9999 -9999 -9999 -9999 -9999 -9999

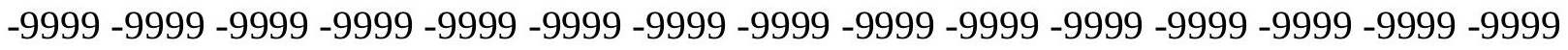

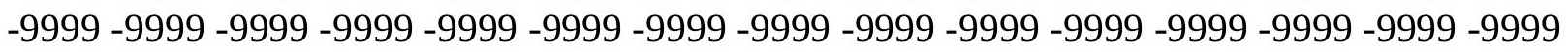
-9999 -9999 -9999 -9999 -9999 -9999 -9999 -9999 -9999 -9999 -9999 -9999 -9999 -9999 -9999 -9999 -9999 -9999 -9999 -9999 -9999 -9999 -9999 -9999 -9999 -9999 -9999 -9999 -9999 -9999 -9999 -9999 -9999 -9999 -9999 -9999 -9999 -9999 -9999 -9999 -9999 -9999 -9999 -9999 -9999 -9999 -9999 -9999 -9999 -9999 -9999 -9999 -9999 -9999 -9999 -9999 -9999 -9999 -9999 -9999 -999 -9999 -9999 -9999 -9999 -9999 -9999 -9999 -9999 -9999 -9999 -9999 -9999 -9999 -9999 -9999 -9999 -9999 -9999 -9999 -9999 -9999 -9999 -9999 -9999 -9999 -9999 -9999 -9999 -9999 -9999 -9999 -9999 -9999 -9999 -9999 -9999 -9999 -9999 -9999 -9999 -9999 -9999 -9999 -9999 -9999 -9999 -9999 -9999 -9999 -9999 -9999 -9999 -9999 -9999 -9999 -9999 -9999 -9999 -9999 -9999 -9999 -9999 -9999 -9999 -9999 -9999 -9999 -9999 -9999 -9999 -9999 -9999 -9999 -9999 -9999 -9999 -9999 -9999 -9999 -9999 -9999 -9999 -9999 -9999 -9999 -9999 -9999 -9999 -9999 -9999 -

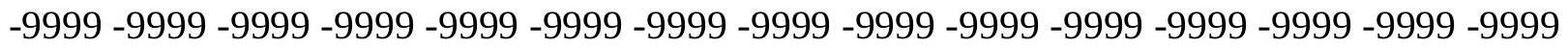
-9999 -9999 -9999 -9999 -9999 -9999 -9999 -9999 -9999 -9999 -9999 -9999 -9999 -9999 -9999 -9999 -9999 -9999 -9999 -9999 -9999 -9999 -9999 -9999 -9999 -9999 -9999 -9999 -9999 -999 -9999 -9999 -9999 -9999 -9999 -9999 -9999 -9999 -9999 -9999 -9999 -9999 -9999 -9999 -9999 -9999 -9999 -9999 -9999 -9999 -9999 -9999 -9999 -9999 -9999 -9999 -9999 -9999 -9999 -9999 -9999 -9999 -9999 -9999 -9999 -9999 102.712600708 101.4934005737 100.2742996216 99.0551681518698 .445587158298 .1408081054797 .5312423706197 .22646331787 97.2264633178797 .5312423706197 .8360290527398 .7503814697399 .22834014893 98.9113388061598 .0586318969796 .7494049072394 .7881774902392 .3498916626 90.2164001464887 .7781066894585 .3398437582 .8060073852579 .72751617432 76.7555236816473 .4406509399470 .0243453979566 .4431610107462 .48094940186 58.8235282897955 .4708900451752 .7278289794951 .2038993835449 .98476028442 -9999 -9999 -9999 -9999 -9999 -9999 -9999 -9999 -9999 -9999 -9999 -9999 -9999 -9999 -9999 -9999 -9999 -9999 -9999 -9999 -9999 -9999 -9999 -9999 -9999 -9999 -9999 -9999 -9999 -9999 -9999 -999 -9999 -9999 -9999 -9999 -9999 -9999 -9999 -9999 -9999 -9999 -9999 -9999 -9999 -9999 -999 -999 -9999 -9999-9999-9999

-9999 -9999 -9999 -9999 -9999 -9999 -9999 -9999 -9999 -9999 -9999 -9999 -9999 -9999 -9999 -9999 -9999 -9999 -9999 -9999 -9999 -9999 -9999 -9999 -9999 -9999 -9999 -9999 -9999 -9999 -

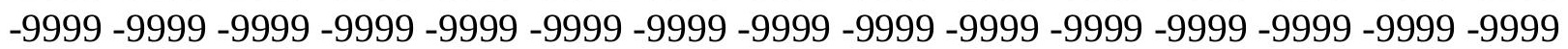


-9999 -9999 -9999 -9999 -9999 -9999 -9999 -9999 -9999 -9999 -9999 -9999 -9999 -9999 -9999 -9999 -9999 -9999 -9999 -9999 -9999 -9999 -9999 -9999 -9999 -9999 -9999 -9999 -9999 -9999 -9999 -9999 -9999 -9999 -9999 -9999 -9999 -9999 -9999 -9999 -9999 -9999 -9999 -9999 -9999 -9999 -9999 -9999 -9999 -9999 -9999 -9999 -9999 -9999 -9999 -9999 -9999 -9999 -9999 -9999 -9999 -9999 -9999 -9999 -9999 -9999 -9999 -9999 -9999 -9999 -9999 -9999 -9999 -9999 -9999 -9999 -9999 -9999 -9999 -9999 -9999 -9999 -9999 -9999 -9999 -9999 -9999 -9999 -9999 -9999 -9999 -9999 -9999 -9999 -9999 -9999 -9999 -9999 -9999 -9999 -9999 -9999 -9999 -9999 -9999 -

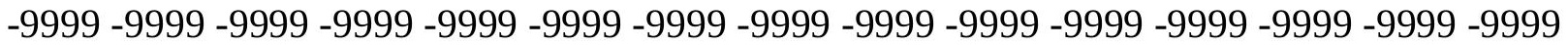
-9999 -9999 -9999 -9999 -9999 -9999 -9999 -9999 -9999 -9999 -9999 -9999 -9999 -9999 -9999 -9999 -9999 -9999 -9999 -9999 -9999 -9999 -9999 -9999 -9999 -9999 -9999 -9999 -9999 -9999 -

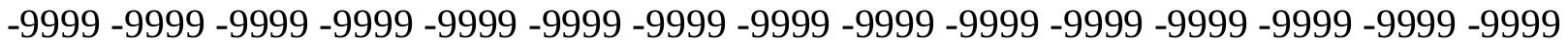
-9999 -9999 -9999 -9999 -9999 -9999 -9999 -9999 -9999 -9999 -9999 -9999 -9999 -9999 -9999

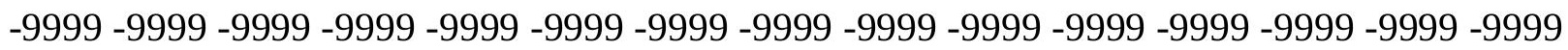
-9999 -9999 -9999 -9999 -9999 -9999 -9999 -9999 -9999 -9999 -9999 -9999 -9999 -9999 -9999 -9999 -9999 -9999 -9999 -9999 -9999 -9999 -9999 -9999 -9999 -9999 -9999 -9999 -9999 -9999

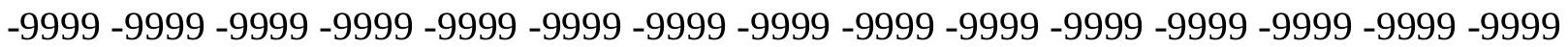
-9999 -9999 -9999 -9999 -9999 -9999 -9999 -9999 -9999 -9999 -9999 -9999 -9999 -9999 -9999 -9999 -9999 -9999 -9999 -9999 -9999-9999 102.4077987671 101.188697814999 .96952056885 98.7503814697398 .1408081054797 .5312423706197 .2264633178796 .92166900635 96.9216690063597 .2264633178798 .1408081054799 .3599472045999 .66472625732 98.7503814697396 .6168823242294 .4833908081192 .0450973510789 .91161346436 87.7781066894585 .3398437583 .206336975180 .7680587768678 .02498626709

74.9771423339871 .3197174072367 .3575134277363 .3953094482459 .43310165405 55.7756805419953 .0326118469251 .81346893311 -9999 -9999 -9999 -9999 -9999 -9999 -9999 -9999 -9999 -9999 -9999 -9999 -9999 -9999 -9999 -9999 -9999 -9999 -9999 -9999 -9999 -9999 -9999 -9999 -9999 -9999 -9999 -9999 -9999 -9999 -9999 -9999 -9999 -9999 -9999 -9999 -9999 -9999 -9999 -9999 -9999 -9999 -9999 -9999 -9999 -9999 -9999 -9999 -9999 -9999 -9999 -9999 -9999 -9999 -9999 -9999 -9999 -9999 -9999 -9999 -9999 -9999 -9999 -9999 -9999 -9999 -9999 -9999 -9999 -9999 -9999 -9999 -9999 -9999 -9999 -9999 -9999 -9999 -9999 -9999 -9999

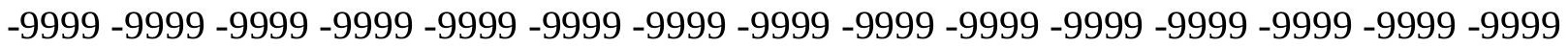
-9999 -9999 -9999 -9999 -9999 -9999 -9999 -9999 -9999 -9999 -9999 -9999 -9999 -9999 -9999 -

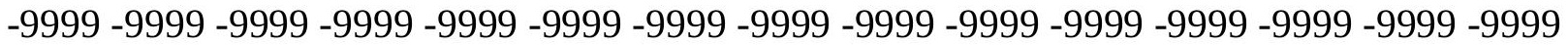
-9999 -9999 -9999 -9999 -9999 -9999 -9999 -9999 -9999 -9999 -9999 -9999 -9999 -9999 -9999 -9999 -9999 -9999 -9999 -9999 -9999 -9999 -9999 -9999 -9999 -9999 -9999 -9999 -9999 -9999 -

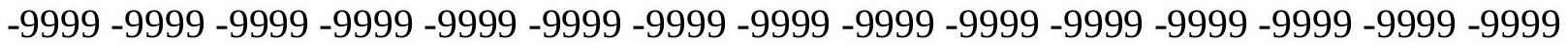
-9999 -9999 -9999 -9999 -9999 -9999 -9999 -9999 -9999 -9999 -9999 -9999 -9999 -9999 -9999 -9999 -9999 -9999 -9999 -9999 -9999 -9999 -9999 -9999 -9999 -9999 -9999 -9999 -9999 -9999

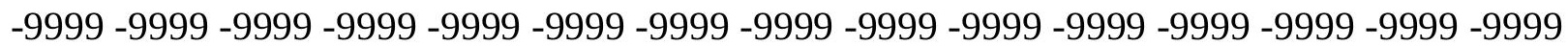
-9999 -9999 -9999 -9999 -9999 -9999 -9999 -9999 -9999 -9999 -9999 -9999 -9999 -9999 -9999 -9999 -9999 -9999 -9999 -9999 -9999 -9999 -9999 -9999 -9999 -9999 -9999 -9999 -9999 -9999 -9999 -9999 -9999 -9999 -9999 -9999 -9999 -9999 -9999 -9999 -9999 -9999 -9999 -9999 -9999 -9999 -9999 -9999 -9999 -9999 -9999 -9999 -9999 -9999 -9999 -9999 -9999 -9999 -9999 -9999 -9999 -9999 -9999 -9999 -9999 -9999 -9999 -9999 -9999 -9999 -9999 -9999 -9999 -9999 -9999 -9999 -9999 -9999 -9999 -9999 -9999 -9999 -9999 -9999 -9999 -9999 -9999 -9999 -9999 -9999 -9999 -9999 -9999 -9999 -9999 -9999 -9999 -9999 -9999 -9999 -9999 -9999 -9999 -9999 -9999

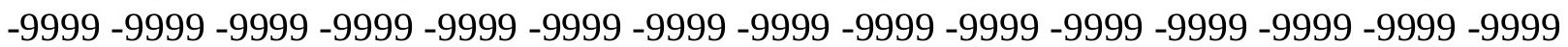


-9999 -9999 -9999 -9999 -9999 -9999 -9999 -9999 -9999 -9999 -9999 -9999 -9999 -9999 -9999 -9999 -9999 -9999 -9999 -9999 -9999 -9999 -9999 102.1029968262100 .8839035034 99.6647262573298 .1408081054797 .5312423706196 .6168823242296 .00731658936 95.7025299072395 .7025299072396 .6168823242298 .1408081054799 .35994720459 97.5312423706195.397743225192.9594726562591.13075256348 88.99725341797 87.1685485839885 .3398437583 .206336975181 .3776321411178 .93934631348 75.8914871215872 .5388565063568 .5766525268664 .6144485473660 .04267120361 57.6043891906753 .9469718933152 .72782897949 -9999 -9999 -9999 -9999 -9999 -9999 -9999

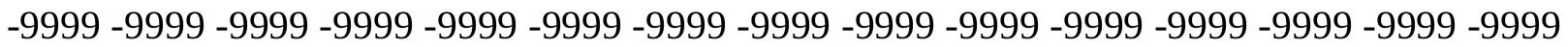
-9999 -9999 -9999 -9999 -9999 -9999 -9999 -9999 -9999 -9999 -9999 -9999 -9999 -9999 -9999 -9999 -9999 -9999 -9999 -9999 -9999 -9999 -9999 -9999 -9999 -9999 -9999 -9999 -9999 -9999 -9999 -9999 -9999 -9999 -9999 -9999 -9999 -9999 -9999 -9999 -9999 -9999 -9999 -9999

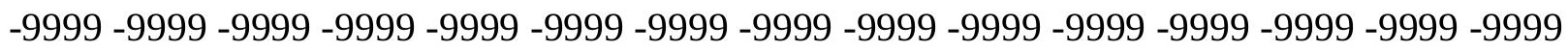
-9999 -9999 -9999 -9999 -9999 -9999 -9999 -9999 -9999 -9999 -9999 -9999 -9999 -9999 -9999 -9999 -9999 -9999 -9999 -9999 -9999 -9999 -9999 -9999 -9999 -9999 -9999 -9999 -9999 -9999

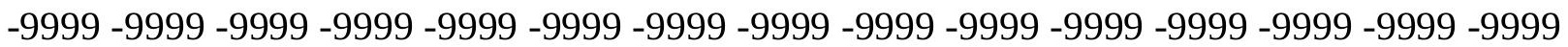
-9999 -9999 -9999 -9999 -9999 -9999 -9999 -9999 -9999 -9999 -9999 -9999 -9999 -9999 -9999 -9999 -9999 -9999 -9999 -9999 -9999 -9999 -9999 -9999 -9999 -9999 -9999 -9999 -9999 -9999 -9999 -9999 -9999 -9999 -9999 -9999 -9999 -9999 -9999 -9999 -9999 -9999 -9999 -9999 -9999 -9999 -9999 -9999 -9999 -9999 -9999 -9999 -9999 -9999 -9999 -9999 -9999 -9999 -9999 -9999

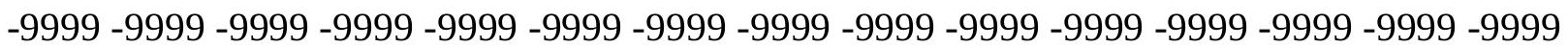
-9999 -9999 -9999 -9999 -9999 -9999 -9999 -9999 -9999 -9999 -9999 -9999 -9999 -9999 -9999 -9999 -9999 -9999 -9999 -9999 -9999 -9999 -9999 -9999 -9999 -9999 -9999 -9999 -9999 -9999 -9999 -9999 -9999 -9999 -9999 -9999 -9999 -9999 -9999 -9999 -9999 -9999 -9999 -9999 -9999

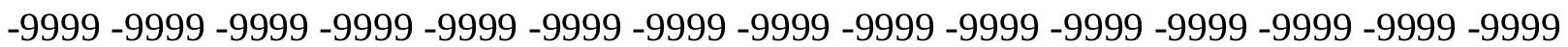
-9999 -9999 -9999 -9999 -9999 -9999 -9999 -9999 -9999 -9999 -9999 -9999 -9999 -9999 -9999 -9999 -9999 -9999 -9999 -9999 -9999 -9999 -9999 -9999 -9999 -9999 -9999 -9999 -9999 -9999 -9999 -9999 -9999 -9999 -9999 -9999 -9999 -9999 -9999 -9999 -9999 -9999 -9999 -9999 -9999 -9999 -9999 -9999 -9999 -9999 -9999 -9999 -9999 -9999 -9999 -9999 -9999 -9999 -9999 -9999 -9999 -9999 -9999 -9999 -9999 -9999 -9999 -9999 -9999 -9999 -9999 -9999 -9999 -9999 -9999 -9999 -9999 -9999 -9999 -9999 -9999 -9999 -9999 -9999 -9999 -9999 -9999 -9999 -9999 -9999 -9999 -9999 -9999 -9999 -9999 -9999 -9999 -9999 -9999 101.7982025146100 .5791015625 99.0551681518697 .5312423706196 .0073165893694 .7881774902393 .87381744385 93.5690307617293 .8738174438594 .7881774902395 .397743225194 .48339080811 92.6546783447390 .8259735107489 .302040100187 .4733276367285 .94940185547 84.7302627563583 .206336975181 .6824111938579 .5489196777377 .1106262207 74.062782287670 .1005783081165 .8335876464861 .5666007995657 .60438919067 54.86132049561 -9999 -9999 -9999 -9999 -9999 -9999 -9999 -9999 -9999 -9999 -9999 -9999 -9999 -9999 -9999 -9999 -9999 -9999 -9999 -9999 -9999 -9999 -9999 -9999 -9999 -9999 -9999 -9999 -9999 -9999 -9999 -9999 -9999 -9999 -9999 -9999 -9999 -9999 -9999 -9999 -9999 -9999 -9999 -9999 -9999 -9999 -9999 -9999 -9999 -9999 -9999 -9999

-9999 -9999 -9999 -9999 -9999 -9999 -9999 -9999 -9999 -9999 -9999 -9999 -9999 -9999 -9999 -9999 -9999 -9999 -9999 -9999 -9999 -9999 -9999 -9999 -9999 -9999 -9999 -9999 -9999 -9999 -9999 -9999 -9999 -9999 -9999 -9999 -9999 -9999 -9999 -9999 -9999 -9999 -9999 -9999 -9999 -9999 -9999 -9999 -9999 -9999 -9999 -9999 -9999 -9999 -9999 -9999 -9999 -9999 -9999 -9999

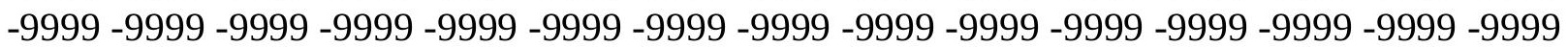


-9999 -9999 -9999 -9999 -9999 -9999 -9999 -9999 -9999 -9999 -9999 -9999 -9999 -9999 -9999 -9999 -9999 -9999 -9999 -9999 -9999 -9999 -9999 -9999 -9999 -9999 -9999 -9999 -9999 -9999 -

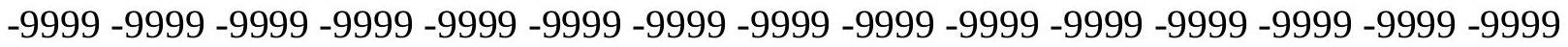
-9999 -9999 -9999 -9999 -9999 -9999 -9999 -9999 -9999 -9999 -9999 -9999 -9999 -9999 -9999 -9999 -9999 -9999 -9999 -9999 -9999 -9999 -9999 -9999-9999 -9999 -9999 -9999 -9999 -9999 -9999 -9999 -9999 -9999 -9999 -9999 -9999 -9999 -9999 -9999 -9999 -9999 -9999 -9999 -9999 -9999 -9999 -9999 -9999 -9999 -9999 -9999 -9999 -9999 -9999 -9999 -9999 -9999 -9999 -9999

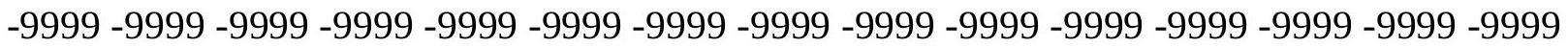

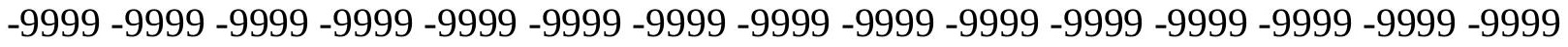
-9999 -9999 -9999 -9999 -9999 -9999 -9999 -9999 -9999 -9999 -9999 -9999 -9999 -9999 -9999 -9999 -9999 -9999 -9999 -9999 -9999 -9999 -9999 -9999 -9999 -9999 -9999 -9999 -9999 -9999 -9999 -9999 -9999 -9999 -9999 -9999 -9999 -9999 -9999 -9999 -9999 -9999 -9999 -9999 -9999 -9999 -9999 -9999 -9999 -9999 -9999 -9999 -9999 -9999 -9999 -9999 -9999 -9999 -9999 -9999 -

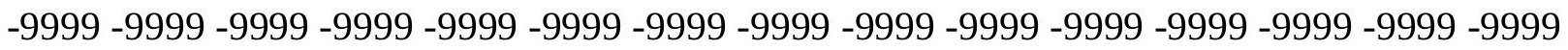
-9999 -9999 -9999 -9999 -9999 -9999 -9999 -9999 -9999 -9999 -9999 -9999 -9999 -9999 -9999 -9999 -9999 -9999 -9999-9999 -9999-9999-9999 -9999-9999 -9999 99.96952056885 98.445587158296 .6168823242294 .7881774902392 .6546783447390 .82597351074 90.5211791992290 .8259735107490 .8259735107490 .5211791992289 .3020401001 88.0829010009886 .8637619018685 .6446228027384 .7302627563583 .81591033936 82.5967712402381 .6824111938580 .1584930419978 .0249862670975 .28192901611 71.6244964599667 .6623001098664 .3096618652360 .34745025635 -9999 -9999 -9999 -9999 -9999 -9999 -9999 -9999 -9999 -9999 -9999 -9999 -9999 -9999 -9999 -9999 -9999 -9999 -9999 -9999 -9999 -9999 -9999 -9999 -9999 -9999 -9999 -9999 -9999 -9999 -9999 -9999 -9999 -9999 -

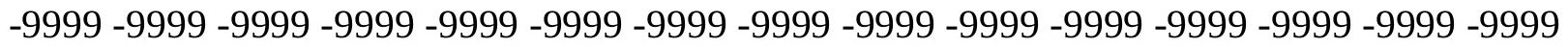
-9999 -9999 -9999-9999

-9999 -9999 -9999 -9999 -9999 -9999 -9999 -9999 -9999 -9999 -9999 -9999 -9999 -9999 -9999 -9999 -9999 -9999 -9999 -9999 -9999 -9999 -9999 -9999 -9999 -9999 -9999 -9999 -9999 -9999 -

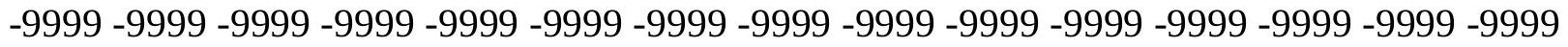
-9999 -9999 -9999 -9999 -9999 -9999 -9999 -9999 -9999 -9999 -9999 -9999 -9999 -9999 -9999 -9999 -9999 -9999 -9999 -9999 -9999 -9999 -9999 -9999 -9999 -9999 -9999 -9999 -9999 -999 -9999 -9999 -9999 -9999 -9999 -9999 -9999 -9999 -9999-9999 -9999 -9999 -9999 -9999 -9999 -9999 -9999 -9999 -9999 -9999 -9999 -9999 -9999 -9999 -9999 -9999 -9999 -9999 -9999 -9999 -

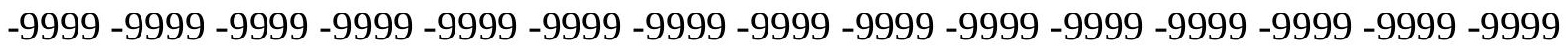

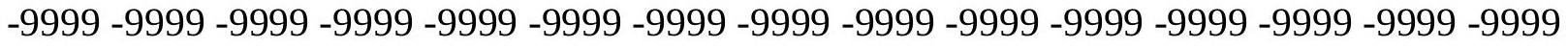
-9999 -9999 -9999 -9999 -9999 -9999 -9999 -9999 -9999 -9999 -9999 -9999 -9999 -9999 -9999 -

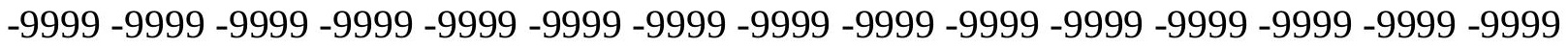

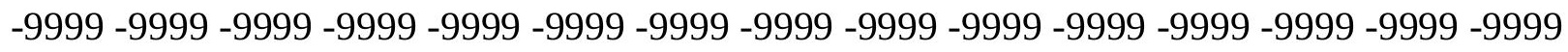

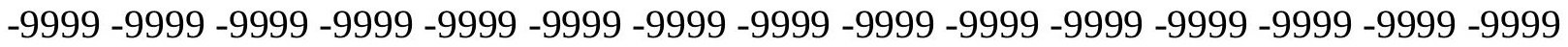

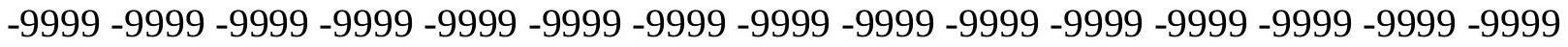
-9999 -9999 -9999 -9999 -9999 -9999 -9999 -9999 -9999 -9999 -9999 -9999 -9999 -9999 -9999 -

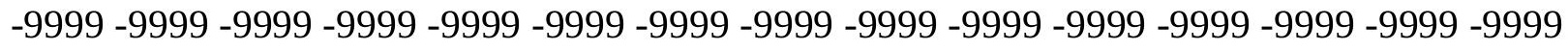

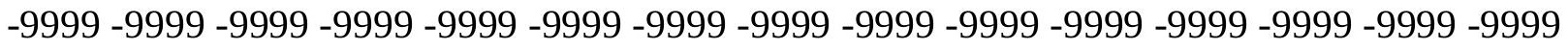
-9999 -9999 -9999 -9999 -9999 -9999 -9999 -9999 -9999 -9999 -9999 -9999 -9999 -9999 -9999 -9999 -9999 -9999 -9999 -9999 -9999 -9999 -9999 -9999-9999 -9999 -9999 -9999 -9999 -9999 -9999 -9999 -9999 -9999 -9999 -9999 -9999 -9999 -9999 -9999 -9999 -9999 -9999 -9999 -9999 -9999 -9999 -9999 -9999 -9999 -9999 -9999 -9999 -9999 -9999 -9999 -9999 -9999 
97.8360290527395 .7025299072393 .5690307617291 .1307525634888 .99725341797 87.1685485839887 .1685485839886 .8637619018685 .9494018554785 .03504943848 84.4254837036183 .8159103393683 .206336975182 .5967712402381 .98719787598 81.3776321411180 .1584930419978 .9393463134877 .110626220774 .97714233398 71.9292907714868 .57665252686 -9999 -9999-9999 -9999 -9999 -9999 -9999 -9999 -9999 -9999 -9999 -9999 -9999 -9999 -9999 -9999 -9999 -9999 -9999 -9999 -9999 -9999 -9999 -9999 -9999 -9999 -9999 -9999 -9999 -9999 -9999 -9999 -9999 -9999 -9999 -9999 -9999 -9999 -9999 -999 -9999 -9999 -9999 -9999 -9999 -9999 -9999 -9999 -9999 -9999 -9999 -9999 -9999 -9999 -9999 -9999 -9999 -9999 -9999 -9999 -9999 -9999 -9999 -9999 -9999 -9999 -9999 -9999 -9999 -9999 -9999 -9999 -9999 -9999 -9999 -9999 -9999 -9999 -9999 -9999 -9999 -9999 -9999 -9999 -9999 -9999 -9999 -9999 -9999 -9999 -9999 -9999 -9999 -9999 -9999 -9999 -9999 -9999 -9999 -9999 -999 -9999 -9999 -9999 -9999 -9999 -9999 -9999 -9999 -9999 -9999 -9999 -9999 -9999 -9999 -9999 -9999 -9999 -9999 -9999 -9999 -9999 -9999 -9999 -9999 -9999 -9999 -9999 -9999 -9999 -9999 -9999 -9999 -9999 -9999 -9999 -9999 -9999 -9999 -9999 -9999 -9999 -9999 -9999 -9999 -9999 -9999 -9999 -9999 -9999 -9999 -9999 -9999 -9999 -9999 -9999 -9999 -9999 -9999 -9999 -9999

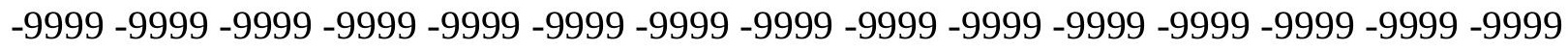
-9999 -9999 -9999 -9999 -9999 -9999 -9999 -9999 -9999 -9999 -9999 -9999 -9999 -9999 -9999 -9999 -9999 -9999 -9999 -9999 -9999 -9999 -9999 -9999 -9999 -9999 -9999 -9999 -9999 -9999 -

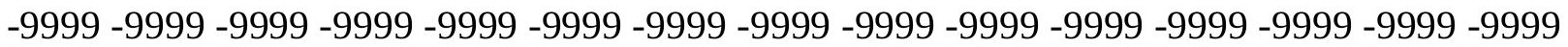

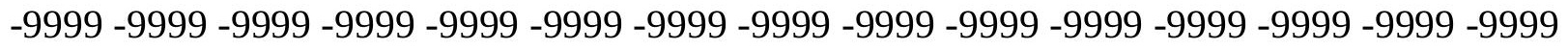

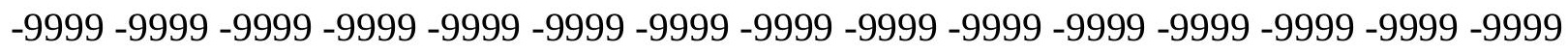

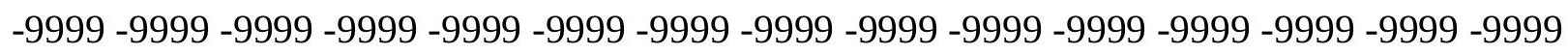
-9999 -9999 -9999 -9999 -9999 -9999 -9999 -9999 -9999 -9999 -9999 -9999 -9999 -9999 -9999 -9999 -9999 -9999 -9999 -9999 -9999 -9999 -9999 -9999 -9999 -9999 -9999 -9999 -9999 -9999 -

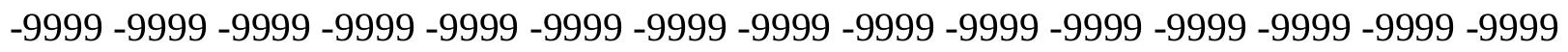
-9999 -9999 -9999 -9999 -9999 -9999 -9999 -9999 -9999 -9999 -9999 -9999 -9999 -9999 -9999

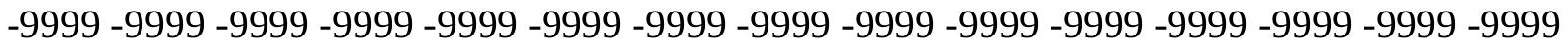

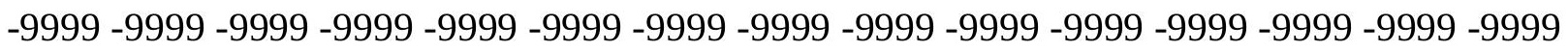

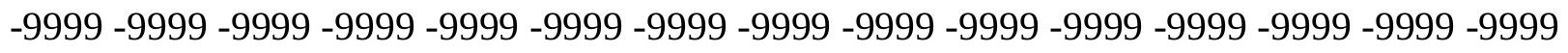
-9999 92.95947265625 90.82597351074 88.9972534179787.16854858398 85.64462280273 84.7302627563583 .8159103393683 .5111236572383 .5111236572383 .51112365723 83.8159103393683 .8159103393683 .8159103393683 .5111236572382 .90155792236 81.6824111938579 .85370635986 -9999 -9999 -9999 -9999 -9999 -9999 -9999 -9999 -9999 -9999 -9999 -9999 -9999 -9999 -9999 -9999 -9999 -9999 -9999 -9999 -9999 -9999 -9999 -9999 -9999 -9999 -9999 -9999 -9999 -9999 -9999 -9999 -9999 -9999 -9999 -9999 -9999 -9999 -9999 -

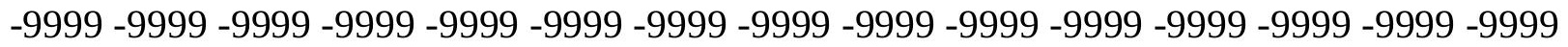
$-9999-9999$

-9999 -9999 -9999 -9999 -9999-9999 -9999 -9999 -9999 -9999 -9999 -9999 -9999 -9999 -9999 -9999 -9999 -9999 -9999 -9999 -9999 -9999 -9999 -9999 -9999 -9999 -9999 -9999 -9999 -9999 -9999 -9999 -9999 -9999 -9999 -9999 -9999 -9999 -9999 -9999 -9999 -9999 -9999 -9999 -9999 -

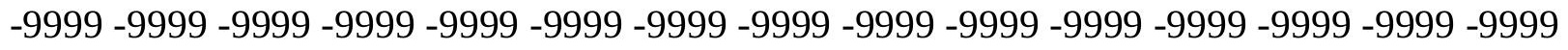

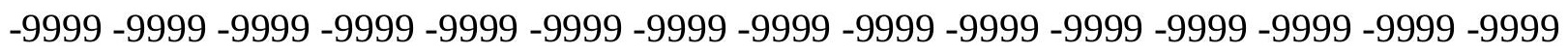

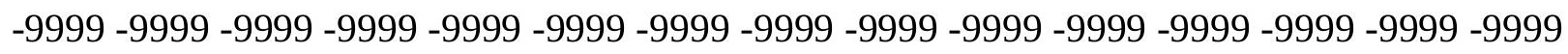
-9999 -9999 -9999 -9999 -9999 -9999 -9999 -9999 -9999 -9999 -9999 -9999 -9999 -9999 -9999 -9999 -9999 -9999 -9999 -9999 -9999 -9999 -9999 -9999 -9999 -9999 -9999 -9999 -9999 -9999 -

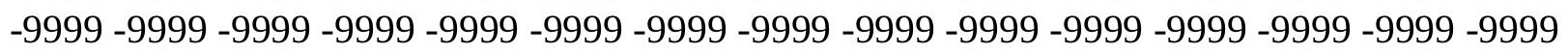


-9999 -9999 -9999 -9999 -9999 -9999 -9999 -9999 -9999 -9999 -9999 -9999 -9999 -9999 -9999 -9999 -9999 -9999 -9999 -9999 -9999 -9999 -9999 -9999 -9999 -9999 -9999 -9999 -9999 -9999 -

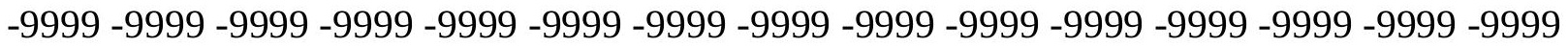
-9999 -9999 -9999 -9999 -9999 -9999 -9999 -9999 -9999 -9999 -9999 -9999 -9999 -9999 -9999 -9999 -9999 -9999 -9999 -9999 -9999 -9999 -9999 -9999-9999 -9999 -9999 -9999 -9999 -9999 -9999 -9999 -9999 -9999 -9999 -9999 -9999 -9999 -9999 -9999 -9999 -9999 -9999 -9999 -9999 -9999 -9999 -9999 -9999 -9999 -9999 -9999 -9999 -9999 -9999 -9999 -9999 -9999 -9999 -9999

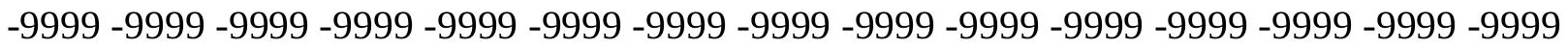

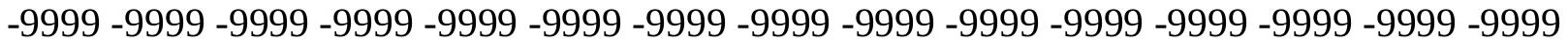
-9999 -9999 -9999 -9999 -9999 -9999 -9999 -9999 -9999 -9999 -9999 -9999 -9999 -9999 -9999 -9999 -9999 -9999 -9999 -9999 -9999 -9999 -9999 -9999 -9999 -9999 -9999 -9999 -9999 -9999 -9999 -9999 -9999 -9999 -9999 -9999 -9999 -9999 -9999 -9999 -9999 -9999 -9999 -9999 -9999 -9999 -9999 -9999 -9999 -9999 -9999 -9999 -9999 -9999 -9999 -9999 -9999 -9999 -9999 -9999 -9999 -9999 -9999 -9999 -9999 -9999 -9999 -9999 -9999 -9999 -9999 -9999 -9999 -9999 -9999 -9999 -9999 -9999 -9999 -9999 -9999 -9999 -9999 -9999 -9999 -9999 -9999 -9999 -9999 -9999 -

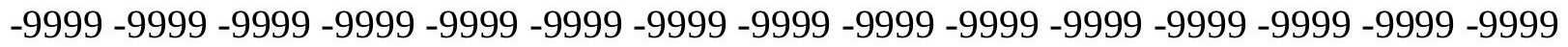
-9999 -9999 -9999 -9999 -9999 -9999 -9999 -9999 -9999 -9999 -9999 -9999 -9999 -9999 -9999 -9999 -9999 -9999 -9999 -9999 -9999 -9999 -9999 -9999 -9999 -9999 -9999 -9999 -9999 -9999 -9999 -9999 -9999 -9999 -9999 -9999 -9999 -9999 -9999 -9999 -9999 -9999 -9999 -9999 -

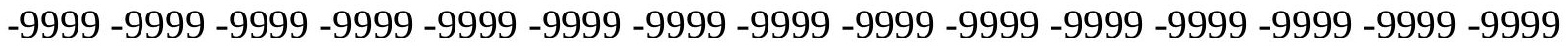
-9999 -9999 -9999 -9999 -9999 -9999 -9999 -9999 -9999 -9999 -9999 -9999 -9999 -9999 -9999 -999 -

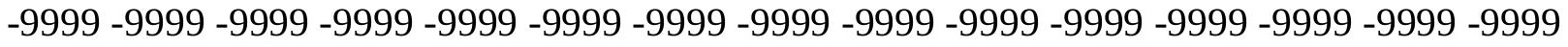
-9999 -9999 -9999 -9999 -9999 -9999 -9999 -9999 -9999 -9999 -9999 -9999 -9999 -9999 -9999 -9999 -9999 -9999 -9999 -9999 -9999 -9999 -9999 -9999 -9999 -9999 -9999 -9999 -9999 -9999 -9999 -9999 -9999 -9999 -9999 -9999 -9999 -9999 -9999 -9999 -9999 -9999 -9999 -9999 -9999 -9999 -9999 -9999 -9999 -9999 -9999 -9999 -9999 -9999 -9999 -9999 -9999 -9999 -9999 -9999 -9999 -9999 -9999 -9999 -9999 -9999 -9999 -9999 -9999 -9999 -9999 -9999 -9999 -9999 -9999 -

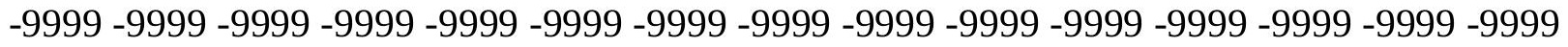
-9999 -9999 -9999 -9999 -9999 -9999 -9999 -9999 -9999 -9999 -9999 -9999 -9999 -9999 -9999 -9999 -9999 -9999 -9999 -9999 -9999 -9999 -9999 -9999 -9999 -9999 -9999 -9999 -9999 -999 -9999 -9999 -9999 -9999 -9999 -9999 -9999 -9999 -9999 -9999 -9999 -9999 -9999 -9999 -9999 -9999 -9999 -9999 -9999 -9999 -9999 -9999 -9999 -9999 -9999 -9999 -9999 -9999 -9999 -9999 -

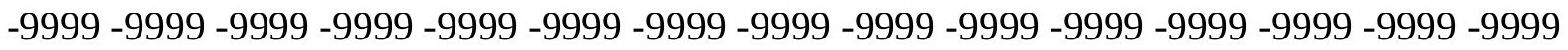

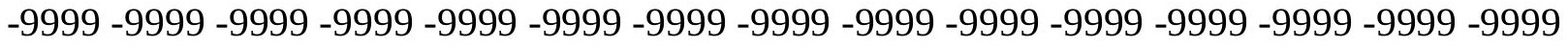

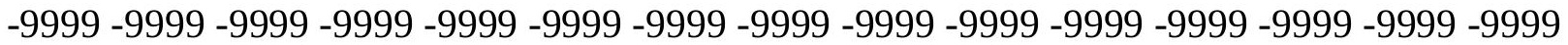
-9999 -9999 -9999 -9999 -9999 -9999 -9999 -9999 -9999 -9999 -9999 -9999 -9999 -9999 -9999

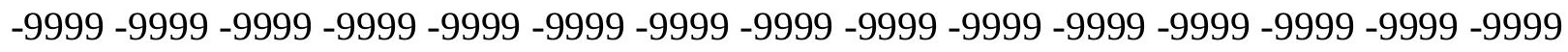

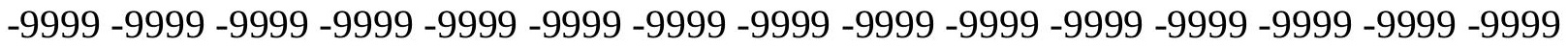
-9999 -9999 -9999 -9999 -9999 -9999 -9999 -9999 -9999 -9999 -9999 -9999 -9999 - 9999 - -999 -9999 -9999 -9999 -9999 -9999 -9999 -9999 -9999 -9999 -9999 -9999 -9999 -9999 -9999 -9999 -

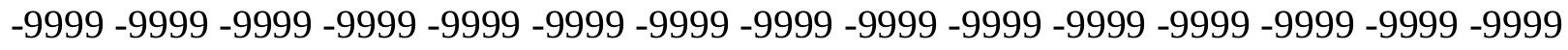

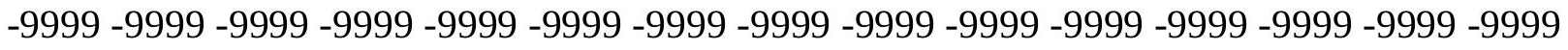
-9999 -9999 -9999 -9999 -9999 -9999 -9999 -9999 -9999 -9999 -9999 -9999 -9999 -9999 -9999 -9999 -9999 -9999 -9999 -9999 -9999 -9999 -9999 -9999 -9999 -9999 -9999 -9999 -9999 -9999 -9999 -9999 -9999 -9999 -9999 -9999 -9999 -9999 -9999 -9999 -9999 -9999 -9999 -9999 -

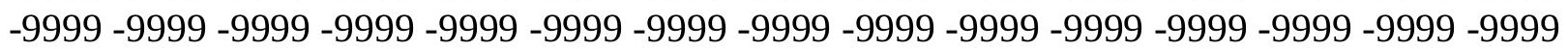


-9999 -9999 -9999 -9999 -9999 -9999 -9999 -9999 -9999 -9999 -9999 -9999 -9999 -9999 -9999 -9999 -9999 -9999 -9999 -9999 -9999 -9999 -9999 -9999 -9999 -9999 -9999 -9999 -9999 -9999 -9999 -9999 -9999 -9999 -9999 -9999 -9999 -9999 -9999 -9999 -9999 -9999 -9999 -9999 - 9999 -9999 -9999 -9999 -9999 -9999 -9999 -9999 -9999 -9999 -9999 -9999 -9999 -9999 -9999 -9999 -9999 -9999 -9999 -9999 -9999 -9999 -9999 -9999 -9999-9999 -9999 -9999 -9999 -9999 -9999 -9999 -9999 -9999 -9999 -9999 -9999 -9999 -9999 -9999 -9999 -9999 -9999 -9999 -9999 -9999 -9999 -9999 -9999 -9999 -9999 -9999 -9999 -9999 -9999 -9999 -9999 -9999 -9999 -9999 -9999

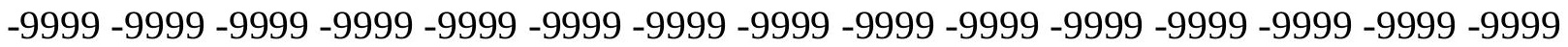

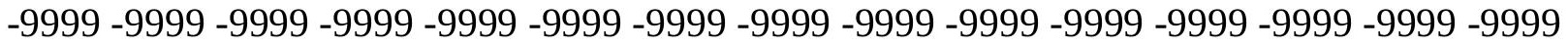
-9999 -9999 -9999 -9999 -9999 -9999 -9999 -9999 -9999 -9999 -9999 -9999 -9999 -9999 -9999 -9999 -9999 -9999 -9999 -9999 -9999 -9999 -9999 -9999 -9999 -9999 -9999 -9999 -9999 -9999 -9999 -9999 -9999 -9999 -9999 -9999 -9999 -9999 -9999 -9999 -9999 -9999 -9999 -9999 -9999 -9999 -9999 -9999 -9999 -9999 -9999 -9999 -9999 -9999 -9999 -9999 -9999 -9999 -9999 -9999 -

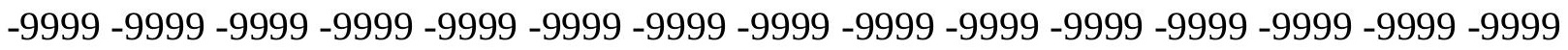
-9999 -9999 -9999 -9999 -9999 -9999 -9999 -9999 -9999 -9999 -9999 -9999 -9999 -9999 -9999 -

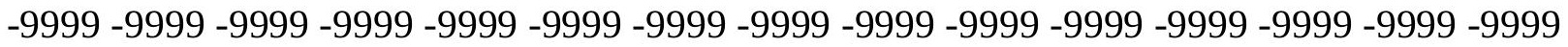
-9999 -9999 -9999 -9999 -9999 -9999 -9999 -9999 -9999 -9999 -9999 -9999 -9999 -9999 -9999 -9999 -9999 -9999 -9999 -9999 -9999 -9999 -9999 -9999 -9999 -9999 -9999 -9999 -9999 -9999 -9999 -9999 -9999 -9999 -9999 -9999 -9999 -9999 -9999 -9999 -9999 -9999 -9999 -9999 -9999 -

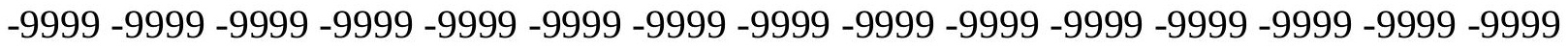
-9999 -9999 -9999 -9999 -9999 -9999 -9999 -9999 -9999 -9999 -9999 -9999 -9999 -9999 -9999 -999 -9999 -9999 -9999 -9999 -9999 -9999 -9999 -9999 -9999 -9999 -9999 -9999 -9999 -9999 - 9999 -9999 -9999 -9999 -9999 -9999 -9999 -9999 -9999 -9999 -9999 -9999 -9999 -9999 -9999 -

-9999 -9999 -9999 -9999 -9999 -9999 -9999 -9999 -9999 -9999 -9999 -9999 -9999 -9999 -9999 -

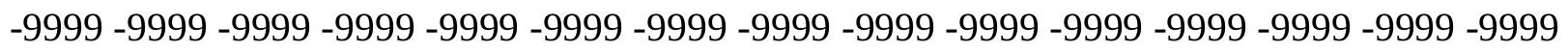
-9999 -9999 -9999 -9999 -9999 -9999 -9999 -9999 -9999 -9999 -9999 -9999 -9999 -9999 -9999 -9999 -9999 -9999 -9999 -9999 -9999 -9999 -9999 -9999 -9999 -9999 -9999 -9999 -9999 -9999 -

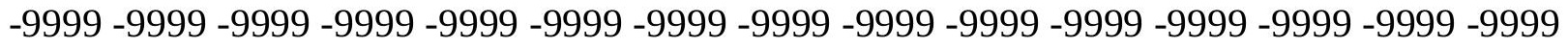
-9999 -9999 -9999 -9999 -9999 -9999 -9999 -9999 -9999 -9999 -9999 -9999 -9999 -9999 -9999 -9999 -9999 -9999 -9999 -9999 -9999 -9999 -9999 -9999 -9999 -9999 -9999 -9999 -9999 -999 -

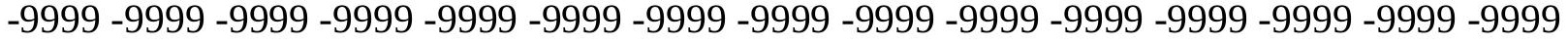
-9999 -9999 -9999 -9999 -9999 -9999 -9999 -9999 -9999 -9999 -9999 -9999 -9999 -9999 -9999 -

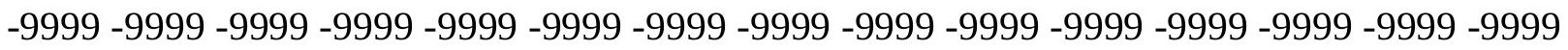

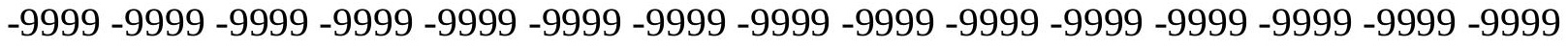

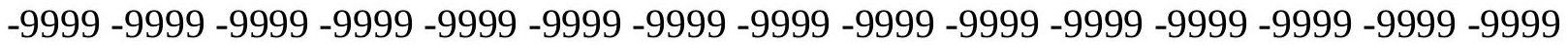

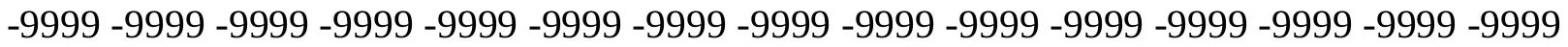

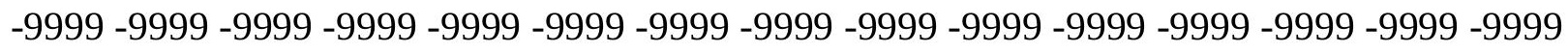

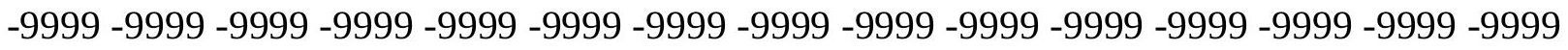

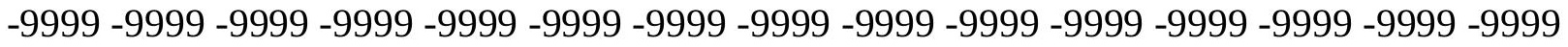
-9999 -9999 -9999 -9999 -9999 -9999 -9999 -9999 -9999 -9999 -9999 -9999 -9999 -9999 -9999 -

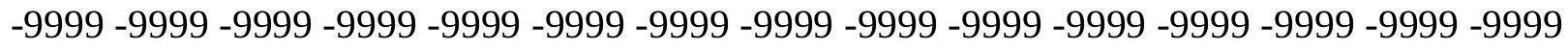

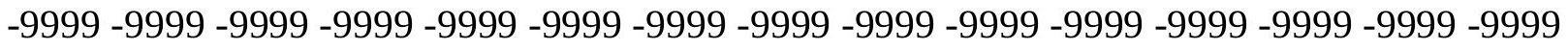
-9999 -9999 -9999 -9999 -9999 -9999 -9999 -9999 -9999 -9999 -9999 -9999 -9999 -9999 -9999 -9999 -9999 -9999 -9999 -9999 -9999 -9999 -9999 -9999-9999 -9999 -9999 -9999 -9999 -9999 -9999 -9999 -9999 -9999 -9999 -9999 -9999 -9999 -9999 -9999 -9999 -9999 -9999 -9999 -9999 -

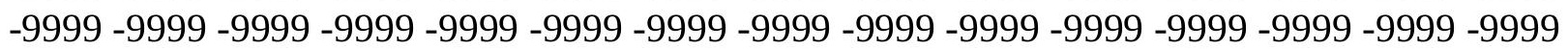


-9999 -9999 -9999 -9999 -9999 -9999 -9999 -9999 -9999 -9999 -9999 -9999 -9999 -9999 -9999 -9999 -9999 -9999 -9999 -9999 -9999 -9999 -9999 -9999 -9999 -9999 -9999 -9999 -9999 -9999 -9999 -9999 -9999 -9999 -9999 -9999 -9999 -9999 -9999 -9999 -9999 -9999 -9999 -9999 -9999 -9999 -9999 -9999 -9999 -9999 -9999 -9999 -9999 -9999 -9999 -9999 -9999 -9999 -9999 -9999 -9999 -9999 -9999 -9999 -9999 -9999 -9999 -9999-9999 -9999 -9999 -9999 -9999 -9999 -9999 -9999 -9999 -9999 -9999 -9999 -9999 -9999 -9999 -9999 -9999 -9999 -9999 -9999 -9999 -9999 -9999 -9999 -9999 -9999 -9999 -9999 -9999 -9999 -9999 -9999 -9999 -9999 -9999 -9999

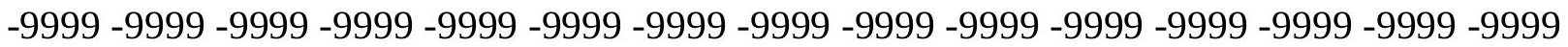

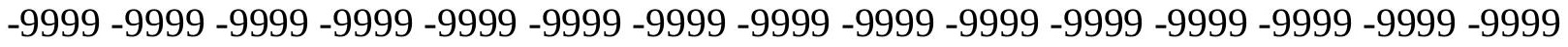
-9999 -9999 -9999 -9999 -9999 -9999 -9999 -9999 -9999 -9999 -9999 -9999 -9999 -9999 -9999 -9999 -9999 -9999 -9999 -9999 -9999 -9999 -9999 -9999 -9999 -9999 -9999 -9999 -9999 -9999 -9999 -9999 -9999 -9999 -9999 -9999 -9999 -9999 -9999 -9999 -9999 -9999 -9999 -9999 -9999 -9999 -9999 -9999 -9999 -9999 -9999 -9999 -9999 -9999 -9999 -9999 -9999 -9999 -9999 -9999 -

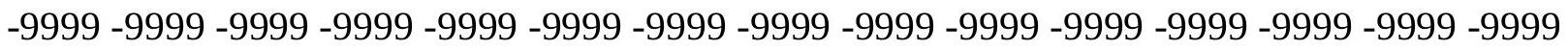
-9999 -9999 -9999 -9999 -9999 -9999 -9999 -9999 -9999 -9999 -9999 -9999 -9999 -9999 -9999 -

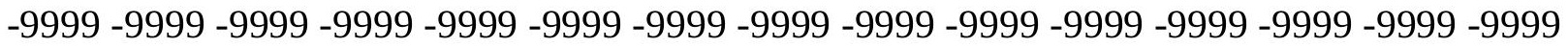
-9999 -9999 -9999 -9999 -9999 -9999 -9999 -9999 -9999 -9999 -9999 -9999 -9999 -9999 -9999 -9999 -9999 -9999 -9999 -9999 -9999 -9999 -9999 -9999 -9999 -9999 -9999 -9999 -9999 -9999 -9999 -9999 -9999 -9999 -9999 -9999 -9999 -9999 -9999 -9999 -9999 -9999 -9999 -9999 -9999 -

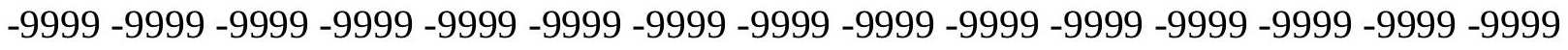

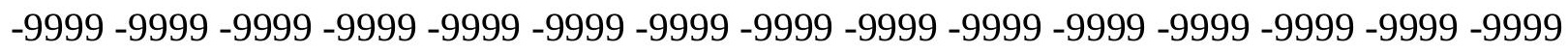
-9999 -9999 -9999 -9999 -9999 -9999 -9999 -9999 -9999 -9999 -9999 -9999 -9999 -9999 -9999 -9999 -9999 -9999 -9999 -9999 -9999 -9999 -9999 -9999 -9999 -9999 -9999 -9999 -9999 -9999 -9999 -9999 -9999 -9999 -9999 -9999 -9999 -9999 -9999 -9999 -9999 -9999 -9999 -9999 -9999 -

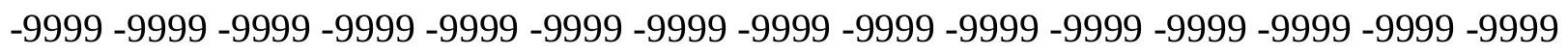
-9999 -9999 -9999 -9999 -9999 -9999 -9999 -9999 -9999 -9999 -9999 -9999 -9999 -9999 -9999 -9999 -9999 -9999 -9999 -9999 -9999 -9999 -9999 -9999 -9999 -9999 -9999 -9999 -9999 -9999 -

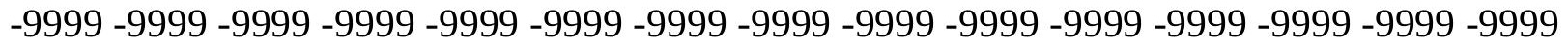
-9999 -9999 -9999 -9999 -9999 -9999 -9999 -9999 -9999 -9999 -9999 -9999 -9999 -9999 -9999 -9999 -9999 -9999 -9999 -9999 -9999 -9999 -9999 -9999 -9999 -9999 -9999 -9999 - -999 -

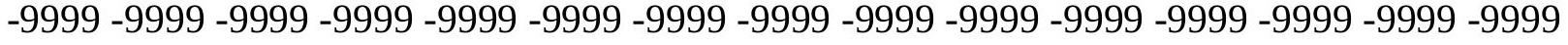
-9999 -9999 -9999 -9999 -9999 -9999 -9999 -9999 -9999 -9999 -9999 -9999 -9999 -9999 -9999 -

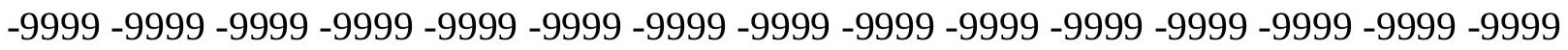

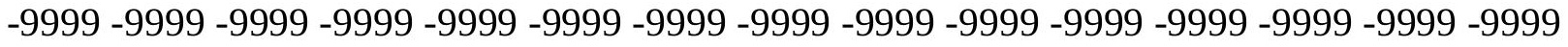

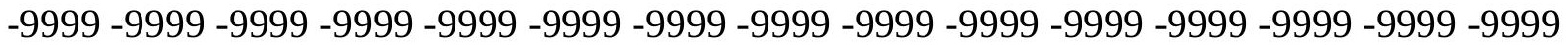

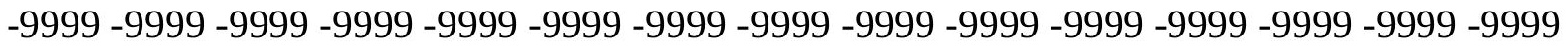

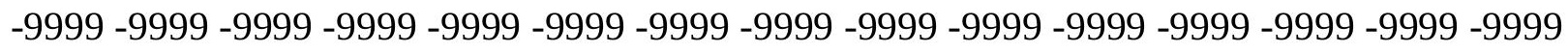

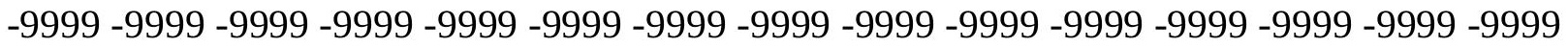

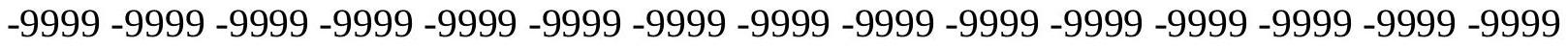
-9999 -9999 -9999 -9999 -9999 -9999 -9999 -9999 -9999 -9999 -9999 -9999 -9999 -9999 -9999 -

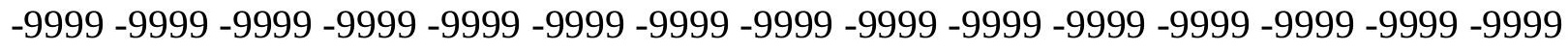

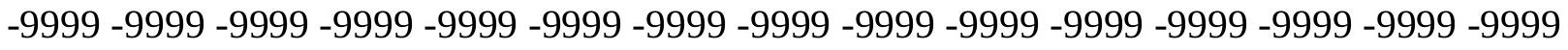
-9999 -9999 -9999 -9999 -9999 -9999 -9999 -9999 -9999 -9999 -9999 -9999 -9999 -9999 -9999 -9999 -9999 -9999 -9999 -9999 -9999 -9999 -9999 -9999-9999 -9999 -9999 -9999 -9999 -9999 -9999 -9999 -9999 -9999 -9999 -9999 -9999 -9999 -9999 -9999 -9999 -9999 -9999 -9999 -9999 -

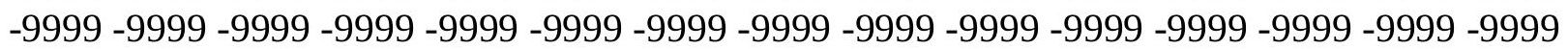


-9999 -9999 -9999 -9999 -9999 -9999 -9999 -9999 -9999 -9999 -9999 -9999 -9999 -9999 -9999 -9999 -9999 -9999 -9999 -9999 -9999 -9999 -9999 -9999 -9999 -9999 -9999 -9999 -9999 -9999 -

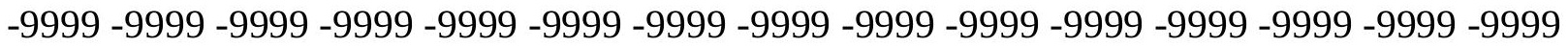
-9999 -9999 -9999 -9999 -9999 -9999 -9999 -9999 -9999 -9999 -9999 -9999 -9999 -9999 -9999 -9999 -9999 -9999 -9999 -9999 -9999 -9999 -9999 -9999-9999 -9999 -9999 -9999 -9999 -9999 -9999 -9999 -9999 -9999 -9999 -9999 -9999 -9999 -9999 -9999 -9999 -9999 -9999 -9999 -9999 -9999 -9999 -9999 -9999 -9999 -9999 -9999 -9999 -9999 -9999 -9999 -9999 -9999 -9999 -9999

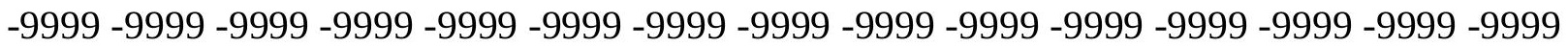
-9999 -9999 -9999 -9999 -9999 -9999 -9999 -9999 -9999 -9999 -9999 -9999 -9999 -9999 -9999 -9999 -9999 -9999 -9999 -9999 -9999 -9999 -9999 -9999 -9999 -9999 -9999 -9999 -9999

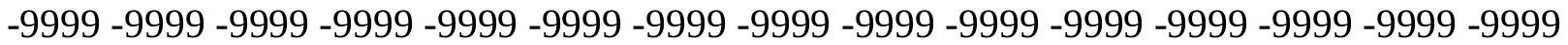
-9999 -9999 -9999 -9999 -9999 -9999 -9999 -9999 -9999 -9999 -9999 -9999 -9999 -9999 -9999 -9999 -9999 -9999 -9999 -9999 -9999 -9999 -9999 -9999 -9999 -9999 -9999 -9999 -9999 -9999 -9999 -9999 -9999 -9999 -9999 -9999 -9999 -9999 -9999 -9999 -9999 -9999 -9999 -9999 - 9999 -9999 -9999 -9999 -9999 -9999 -9999 -9999 -9999 -9999 -9999 -9999 -9999 -9999 -9999 -9999

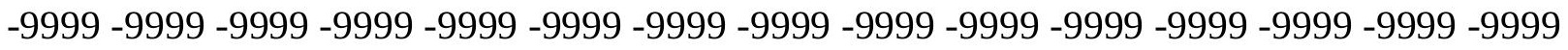
-9999 -9999 -9999 -9999 -9999 -9999 -9999 -9999 -9999 -9999 -9999 -9999 -9999 -9999 -9999 -9999 -9999 -9999 -9999 -9999 -9999 -9999 -9999 -9999 -9999 -9999 -9999 -9999 -9999 -9999 -9999 -9999 -9999 -9999 -9999 -9999 -9999 -9999 -9999 -9999 -9999 -9999 -9999 -9999 -9999 -

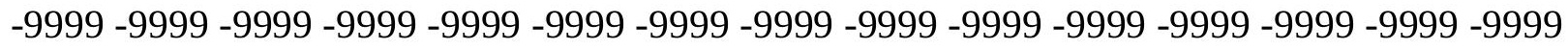

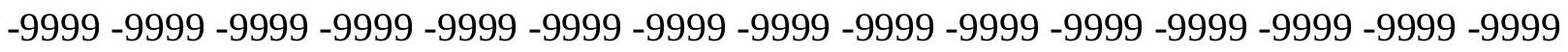
-9999 -9999 -9999 -9999 -9999 -9999 -9999 -9999 -9999 -9999 -9999 -9999 -9999 -9999 -9999 -9999 -9999 -9999 -9999 -9999 -9999 -9999 -9999 -9999 -9999 -9999 -9999 -9999 -9999 -9999 -9999 -9999 -9999 -9999 -9999 -9999 -9999 -9999 -9999 -9999 -9999 -9999 -9999 -9999 -9999 -

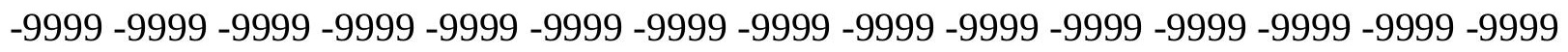
-9999 -9999 -9999 -9999 -9999 -9999 -9999 -9999 -9999 -9999 -9999 -9999 -9999 -9999 -9999 -9999 -9999 -9999 -9999 -9999 -9999 -9999 -9999 -9999 -9999 -9999 -9999 -9999 -9999 -9999 -

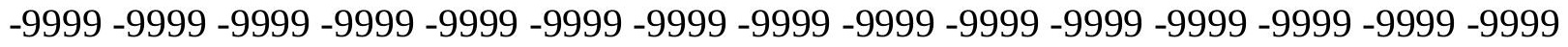
-9999 -9999 -9999 -9999 -9999 -9999 -9999 -9999 -9999 -9999 -9999 -9999 -9999 -9999 -9999 -9999 -9999 -9999 -9999 -9999 -9999 -9999 -9999 -9999 -9999 -9999 -9999 -9999 -9999 -999 -9999 -9999 -9999 -9999 -9999 -9999 -9999 -9999 -9999 -9999 -9999 -9999 -9999 -9999 -9999 -9999 -9999 -9999 -9999 -9999 -9999 -9999 -9999 -9999 -9999 -9999 -9999 -9999 -9999 -9999 -

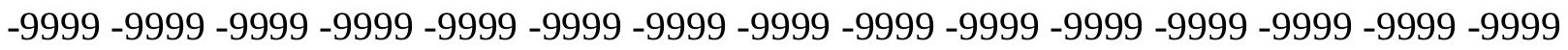

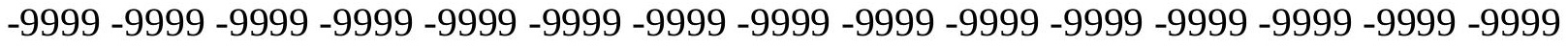
-9999 -9999 -9999 -9999 -9999 -9999 -9999 -9999 -9999 -9999 -9999 -9999 -9999 -9999 -

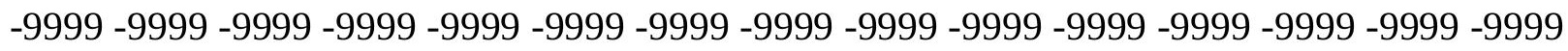

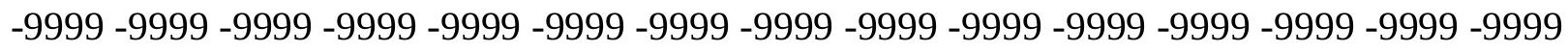

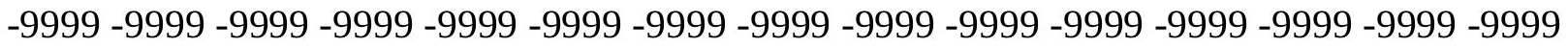
-9999 -9999 -9999 -9999 -9999 -9999 -9999 -9999 -9999 -9999 -9999 -9999 -9999 - 9999 - -999 -9999 -9999 -9999 -9999 -9999 -9999 -9999 -9999 -9999 -9999 -9999 -9999 -9999 -9999 -9999 -

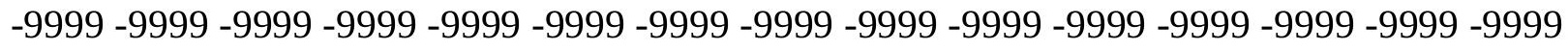

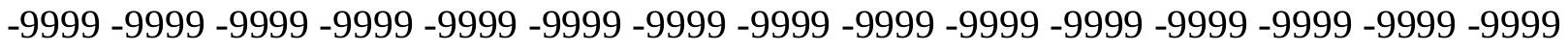
-9999 -9999 -9999 -9999 -9999 -9999 -9999 -9999 -9999 -9999 -9999 -9999 -9999 -9999 -9999 -9999 -9999 -9999 -9999 -9999 -9999 -9999 -9999 -9999-9999 -9999 -9999 -9999 -9999 -9999 -9999 -9999 -9999 -9999 -9999 -9999 -9999 -9999 -9999 -9999 -9999 -9999 -9999 -9999 -9999 -

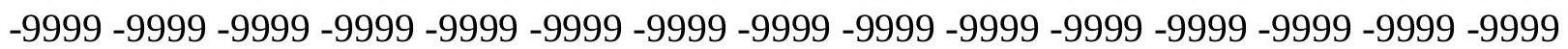


-9999 -9999 -9999 -9999 -9999 -9999 -9999 -9999 -9999 -9999 -9999 -9999 -9999 -9999 -9999 -9999 -9999 -9999 -9999 -9999 -9999 -9999 -9999 -9999 -9999 -9999 -9999 -9999 -9999 -9999 -

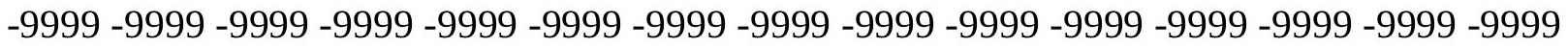
-9999 -9999 -9999 -9999 -9999 -9999 -9999 -9999 -9999 -9999 -9999 -9999 -9999 -9999 -9999 -9999 -9999 -9999 -9999 -9999 -9999 -9999 -9999 -9999-9999 -9999 -9999 -9999 -9999 -9999 -9999 -9999 -9999 -9999 -9999 -9999 -9999 -9999 -9999 -9999 -9999 -9999 -9999 -9999 -9999 -9999 -9999 -9999 -9999 -9999 -9999 -9999 -9999 -9999 -9999 -9999 -9999 -9999 -9999 -9999

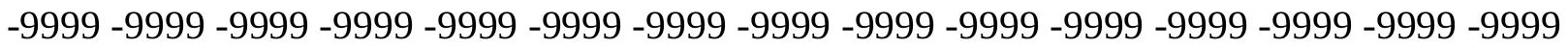

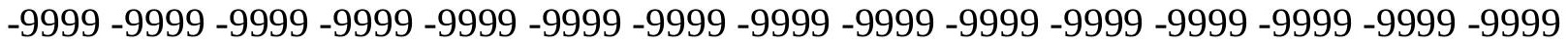
-9999 -9999 -9999 -9999 -9999 -9999 -9999 -9999 -9999 -9999 -9999 -9999 -9999 -9999 -9999 -9999 -9999 -9999 -9999 -9999 -9999 -9999 -9999 -9999 -9999 -9999 -9999 -9999 -9999 -9999 -9999 -9999 -9999 -9999 -9999 -9999 -9999 -9999 -9999 -9999 -9999 -9999 -9999 -9999 -9999 -9999 -9999 -9999 -9999 -9999 -9999 -9999 -9999 -9999 -9999 -9999 -9999 -9999 -9999 -9999 -9999 -9999 -9999 -9999 -9999 -9999 -9999 -9999 -9999 -9999 -9999 -9999 -9999 -9999 -9999 -9999 -9999 -9999 -9999 -9999 -9999 -9999 -9999 -9999 -9999 -9999 -9999 -9999 -9999 -9999 -9999 -9999 -9999 -9999 -9999 -9999 -9999 -9999 -9999 -9999 -9999 -9999 - 9999 - -999 -

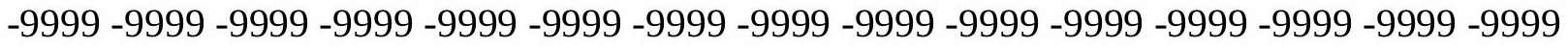
-9999 -9999 -9999 -9999 -9999 -9999 -9999 -9999 -9999 -9999 -9999 -9999 -9999 -9999 -9999 -9999 -9999 -9999 -9999 -9999 -9999 -9999 -9999 -9999 -9999 -9999 -9999 -9999 -9999 -9999 -

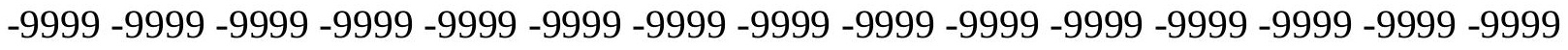
-9999 -9999 -9999 -9999 -9999 -9999 -9999 -9999 -9999 -9999 -9999 -9999 -9999 -9999 -9999

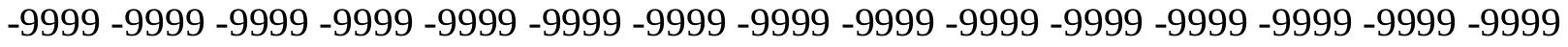
-9999 -9999 -9999 -9999 -9999 -9999 -9999 -9999 -9999 -9999 -9999 -9999 -9999 -9999 -9999 -9999 -9999 -9999 -9999 -9999 -9999 -9999 -9999 -9999 -9999 -9999 -9999 -9999 -9999 -9999 -

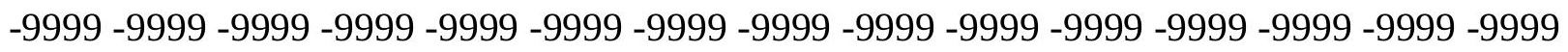
-9999 -9999 -9999 -9999 -9999 -9999 -9999 -9999 -9999 -9999 -9999 -9999 -9999 -9999 -9999 -9999 -9999 -9999 -9999 -9999 -9999 -9999 -9999 -9999 -9999 -9999 -9999 -9999 -9999 -9999 -

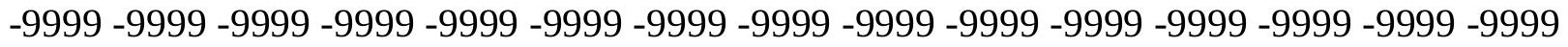
-9999 -9999 -9999 -9999 -9999 -9999 -9999 -9999 -9999 -9999 -9999 -9999 -9999 -9999 -9999 -9999 -9999 -9999 -9999 -9999 -9999 -9999 -9999 -9999 -9999 -9999 -9999 -9999 -9999 -999 -

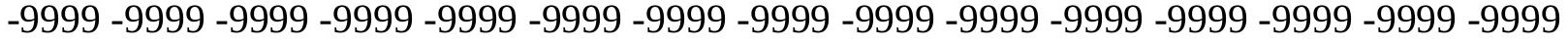
-9999 -9999 -9999 -9999 -9999 -9999 -9999 -9999 -9999 -9999 -9999 -9999 -9999 -9999 -9999 -

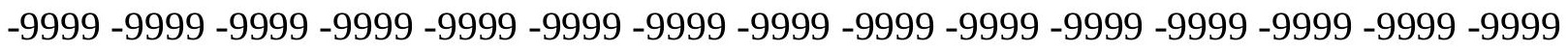

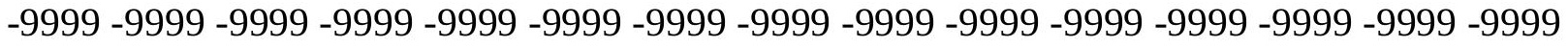

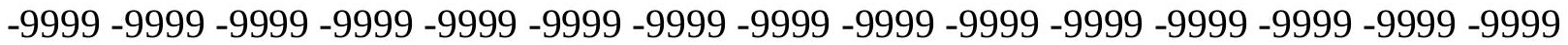
-9999 -9999 -9999 -9999 -9999 -9999 -9999 -9999 -9999 -9999 -9999 -9999 -9999 -9999 -9999 -

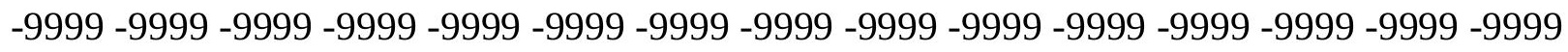

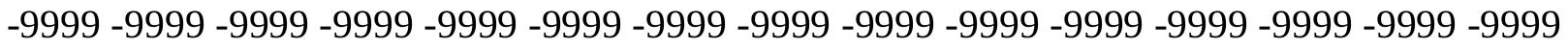
-9999 -9999 -9999 -9999 -9999 -9999 -9999 -9999 -9999 -9999 -9999 -9999 -9999 - 9999 - -999 -9999 -9999 -9999 -9999 -9999 -9999 -9999 -9999 -9999 -9999 -9999 -9999 -9999 -9999 -9999 -

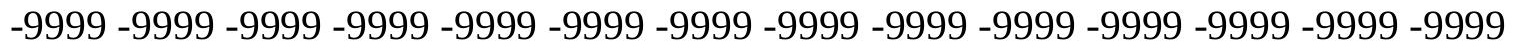

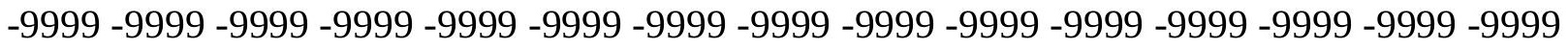
-9999 -9999 -9999 -9999 -9999 -9999 -9999 -9999 -9999 -9999 -9999 -9999 -9999 -9999 -9999 -9999 -9999 -9999 -9999 -9999 -9999 -9999 -9999 -9999-9999 -9999 -9999 -9999 -9999 -9999 -9999 -9999 -9999 -9999 -9999 -9999 -9999 -9999 -9999 -9999 -9999 -9999 -9999 -9999 -9999 -

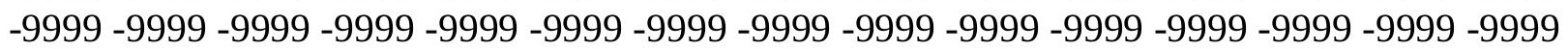


-9999 -9999 -9999 -9999 -9999 -9999 -9999 -9999 -9999 -9999 -9999 -9999 -9999 -9999 -9999 -9999 -9999 -9999 -9999 -9999 -9999 -9999 -9999 -9999 -9999 -9999 -9999 -9999 -9999 -9999 -9999 -9999 -9999 -9999 -9999 -9999 -9999 -9999 -9999 -9999 -9999 -9999 -9999 -9999 - 9999 -9999 -9999 -9999 -9999 -9999 -9999 -9999 -9999 -9999 -9999 -9999 -9999 -9999 -9999 -9999 -9999 -9999 -9999 -9999 -9999 -9999 -9999 -9999 -9999-9999 -9999 -9999 -9999 -9999 -9999 -9999 -9999 -9999 -9999 -9999 -9999 -9999 -9999 -9999 -9999 -9999 -9999 -9999 -9999 -9999 -9999 -9999 -9999 -9999 -9999 -9999 -9999 -9999 -9999 -9999 -9999 -9999 -9999 -9999 -9999

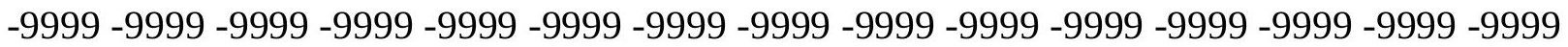
-9999 -9999 -9999 -9999 -9999 -9999 -9999 -9999 -9999 -9999 -9999 -9999 -9999 -9999 -9999 -9999 -9999 -9999 -9999 -9999 -9999 -9999 -9999 -9999 -9999 -9999 -9999 -9999 -9999 -9999

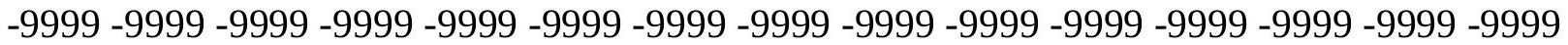
-9999 -9999 -9999 -9999 -9999 -9999 -9999 -9999 -9999 -9999 -9999 -9999 -9999 -9999 -9999 -9999 -9999 -9999 -9999 -9999 -9999 -9999 -9999 -9999 -9999 -9999 -9999 -9999 -9999 -9999 -

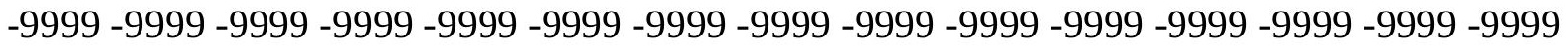
-9999 -9999 -9999 -9999 -9999 -9999 -9999 -9999 -9999 -9999 -9999 -9999 -9999 -9999 -9999

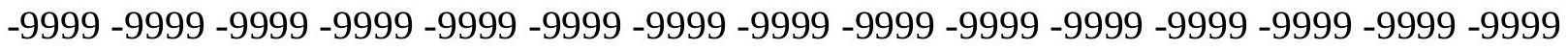
-9999 -9999 -9999 -9999 -9999 -9999 -9999 -9999 -9999 -9999 -9999 -9999 -9999 -9999 -9999 -9999 -9999 -9999 -9999 -9999 -9999 -9999 -9999 -9999 -9999 -9999 -9999 -9999 -9999 - 9999 -9999 -9999 -9999 -9999 -9999 -9999 -9999 -9999 -9999 -9999 -9999 -9999 -9999 -9999 -9999 -9999 -9999 -9999 -9999 -9999 -9999 -9999 -9999 -9999 -9999 -9999 -9999 -9999 -9999 -9999 -9999 -9999 -9999 -9999 -9999 -9999 -9999 -9999 -9999 -9999 -9999 -9999 -9999 -9999 -9999 -9999 -9999 -9999 -9999 -9999 -9999 -9999 -9999 -9999 -9999 -9999 -9999 -9999 -9999 -9999 -9999 -9999 -9999 -9999 -9999 -9999 -9999 -9999 -9999 -9999 -9999 -9999 -9999 -9999 -9999 -9999 -9999 -9999 -9999 -9999 -9999 -9999 -9999 -9999 -9999 -9999 -9999 -9999 -9999 -9999 -9999 -9999 -9999 -9999 -9999 -9999 -9999 -9999 -9999 -9999 -9999 -9999 -9999 -9999 -9999 -9999 -9999 -9999 -9999 -9999 -9999 -9999 -9999 -9999 -9999 -9999 -9999 -9999 -9999 -9999 -9999 -9999 -9999 -9999 -9999 -9999 -9999 -9999 -9999 -9999 -9999 -9999 -9999 -9999 -9999 -9999 -9999 -9999 -9999 -9999 -9999 -9999 -9999 -9999 -9999 -9999 -9999 -9999 -9999 -9999 -9999 -9999 -9999 -9999 -9999 -9999 -9999 -9999 -9999 -9999 -9999 -9999 -9999 -9999 -9999 -9999 -9999 -9999 -9999 -9999 -9999 -9999 -9999 -9999 -9999 -9999 -9999 -9999 -999 -9999 -9999 -9999 -9999 -9999 -9999 -9999 -9999 -9999 -9999 -9999 -9999 -9999 -9999 -9999 -9999 -9999 -9999 -9999 -9999 -9999 -9999 -9999 -9999 -9999 -9999 -9999 -9999 -9999 -9999 -

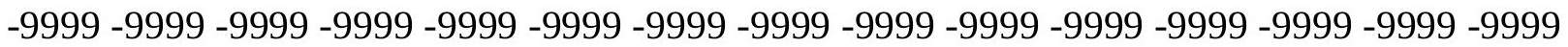

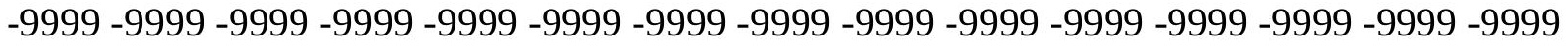

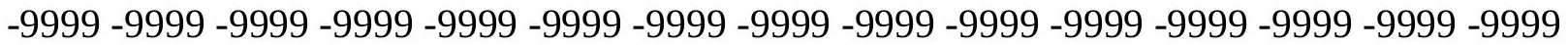
-9999 -9999 -9999 -9999 -9999 -9999 -9999 -9999 -9999 -9999 -9999 -9999 -9999 -9999 -9999

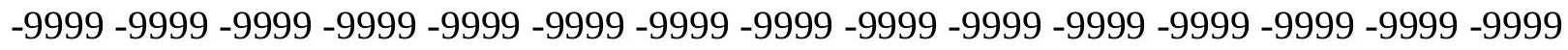

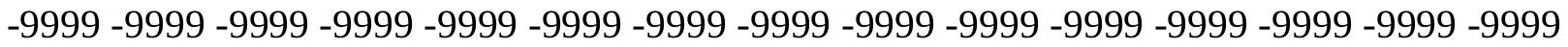

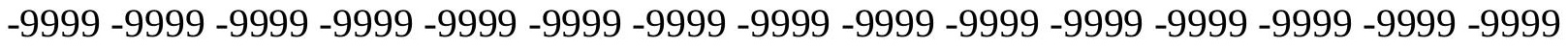
-9999 -9999 -9999 -9999 -9999 -9999 -9999 -9999 -9999 -9999 -9999 -9999 -9999 -9999 -9999 -

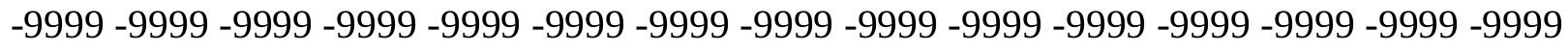

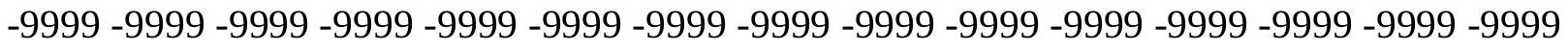
-9999 -9999 -9999 -9999 -9999 -9999 -9999 -9999 -9999 -9999 -9999 -9999 -9999 -9999 -9999 -9999 -9999 -9999 -9999 -9999 -9999 -9999 -9999 -9999-9999 -9999 -9999 -9999 -9999 -9999 -9999 -9999 -9999 -9999 -9999 -9999 -9999 -9999 -9999 -9999 -9999 -9999 -9999 -9999 -9999 -

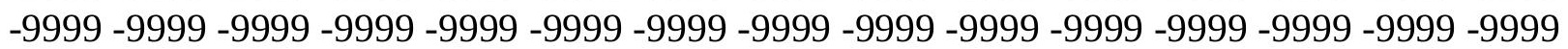


-9999 -9999 -9999 -9999 -9999 -9999 -9999 -9999 -9999 -9999 -9999 -9999 -9999 -9999 -9999 -9999 -9999 -9999 -9999 -9999 -9999 -9999 -9999 -9999 -9999 -9999 -9999 -9999 -9999 -9999 -9999 -9999 -9999 -9999 -9999 -9999 -9999 -9999 -9999 -9999 -9999 -9999 -9999 -9999 -9999 -9999 -9999 -9999 -9999 -9999 -9999 -9999 -9999 -9999 -9999 -9999 -9999 -9999 -9999 -9999 -9999 -9999 -9999 -9999 -9999 -9999 -9999 -9999 -9999 -9999 -9999 -9999 -9999 -9999 -9999 -9999 -9999 -9999 -9999 -9999 -9999 -9999 -9999 -9999 -9999 -9999 -9999 -9999 -9999 -9999 -9999 -9999 -9999 -9999 -9999 -9999 -9999 -9999 -9999 -9999 -9999 -9999 -9999 -9999 -

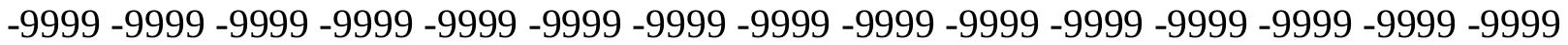
-9999 -9999 -9999 -9999 -9999 -9999 -9999 -9999 -9999 -9999 -9999 -9999 -9999 -9999 -9999 -9999 -9999 -9999 -9999 -9999 -9999 -9999 -9999 -9999 -9999 -9999 -9999 -9999 -9999 -9999 -

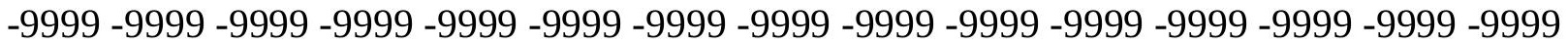
-9999 -9999 -9999 -9999 -9999 -9999 -9999 -9999 -9999 -9999 -9999 -9999 -9999 -9999 -9999 -9999 -9999 -9999 -9999 -9999 -9999 -9999 -9999 -9999 -9999 -9999 -9999 -9999 -9999 -9999 -9999 -9999 -9999 -9999 -9999 -9999 -9999 -9999 -9999 -9999 -9999 -9999 -9999 -9999 -9999 -9999 -9999 -9999 -9999 -9999 -9999 -9999 -9999 -9999 -9999 -9999 -9999 -9999 -9999 -9999 -9999 -9999 -9999 -9999 -9999 -9999 -9999 -9999 -9999 -9999 -9999 -9999 -9999 -9999 -9999 -9999 -9999 -9999 -9999 -9999 -9999 -9999 -9999 -9999 -9999 -9999 -9999 -9999 -9999 -9999 -9999 -9999 -9999 -9999 -9999 -9999 -9999 -9999 -9999 -9999 -9999 -9999 -9999 -9999 -9999 -9999 -9999 -9999 -9999 -9999 -9999 -9999 -9999 -9999 -9999 -9999 -9999 -9999 -9999 -9999 -9999 -9999 -9999 -9999 -9999 -9999 -9999 -9999 -9999 -9999 -9999 -9999 -9999 -9999 -9999

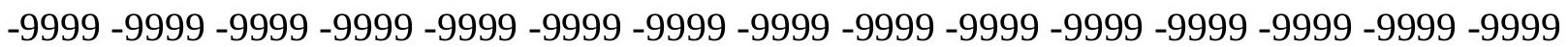
-9999 -9999 -9999 -9999 -9999 -9999 -9999 -9999 -9999 -9999 -9999 -9999 -9999 -9999 -9999 -9999 -9999 -9999 -9999 -9999 -9999 -9999 -9999 -9999 -9999 -9999 -9999 -9999 -9999 -9999 -9999 -9999 -9999 -9999 -9999 -9999 -9999 -9999 -9999 -9999 -9999 -9999 -9999 -9999 -9999

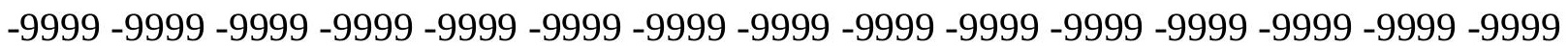
-9999 -9999 -9999 -9999 -9999 -9999 -9999 -9999 -9999 -9999 -9999 -9999 -9999 -9999 -9999 -9999 -9999 -9999 -9999 -9999 -9999 -9999 -9999 -9999 -9999 -9999 -9999 -9999 -9999 -9999 -9999 -9999 -9999 -9999 -9999 -9999 -9999 -9999 -9999 -9999 -9999 -9999 -9999 -9999

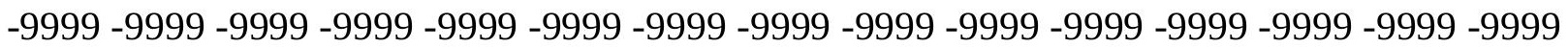
-9999 -9999 -9999 -9999 -9999 -9999 -9999 -9999 -9999 -9999 -9999 -9999 -9999 -9999 -9999 -9999 -9999 -9999 -9999 -9999 -9999 -9999 -9999 -9999 -9999 -9999 -9999 -9999 -9999 -9999 -

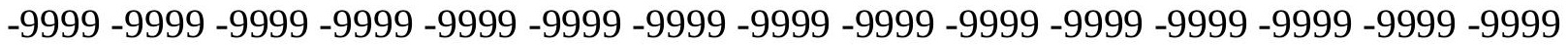
-9999 -9999 -9999 -9999 -9999 -9999 -9999 -9999 -9999 -9999 -9999 -9999 -9999 -9999 -9999 -9999 -9999 -9999 -9999 -9999 -9999 -9999 -9999 -9999 -9999 -9999 -9999 -9999 -9999 -9999 -9999 -9999 -9999 -9999 -9999 -9999 -9999 -9999 -9999 -9999 -9999 -9999 -9999 -9999 -9999 -9999 -9999 -9999 -9999 -9999 -9999 -9999 -9999 -9999 -9999 -9999 -9999 -9999 -9999 -9999 -9999 -9999 -9999 -9999 -9999 -9999 -9999 -9999 -9999 -9999 -9999 -9999 -9999 -9999 -9999

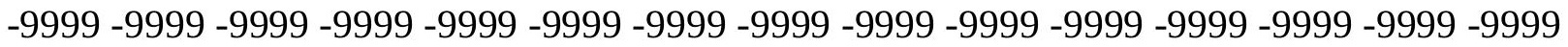
-9999 -9999 -9999 -9999 -9999 -9999 -9999 -9999 -9999 -9999 -9999 -9999 -9999 -9999 -9999 -9999 -9999 -9999 -9999 -9999 -9999 -9999 -9999 -9999 -9999 -9999 -9999 -9999 -9999 -9999 -

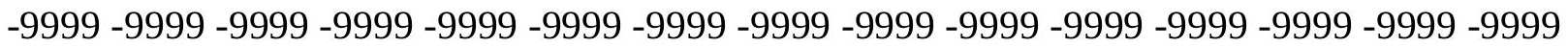
-9999 -9999 -9999 -9999 -9999 -9999 -9999 -9999 -9999 -9999 -9999 -9999 -9999 -9999 -9999 -9999 -9999 -9999 -9999 -9999 -9999 -9999 -9999 -9999 -9999 -9999 -9999 -9999 -9999 -9999 -9999 -9999 -9999 -9999 -9999 -9999 -9999 -9999 -9999 -9999 -9999 -9999 -9999 -9999 -9999 -9999 -9999 -9999 -9999 -9999 -9999 -9999 -9999 -9999 -9999 -9999 -9999 -9999 -9999 -9999

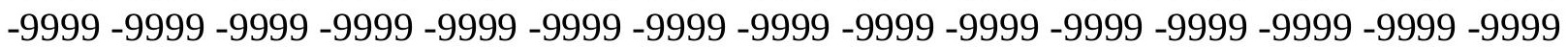


-9999 -9999 -9999 -9999 -9999 -9999 -9999 -9999 -9999 -9999 -9999 -9999 -9999 -9999 -9999 -9999 -9999 -9999 -9999 -9999 -9999 -9999 -9999 -9999 -9999 -9999 -9999 -9999 -9999 -9999 -9999 -9999 -9999 -9999 -9999 -9999 -9999 -9999 -9999 -9999 -9999 -9999 -9999 -9999 -9999 -9999 -9999 -9999 -9999 -9999 -9999 -9999 -9999 -9999 -9999 -9999 -9999 -9999 -9999 -9999 -9999 -9999 -9999 -9999 -9999 -9999 -9999 -9999 -9999 -9999 -9999 -9999-9999 -9999 -9999 -9999 -9999 -9999 -9999 -9999 -9999 -9999 -9999 -9999 -9999 -9999 -9999 -9999 -9999 -9999 -9999 -9999 -9999 -9999 -9999 -9999 -9999 -9999 -9999 -9999 -9999 -9999 -9999 -9999 -9999 -9999 -9999 -9999 -9999 -9999 -9999 -9999 -9999 -9999 -9999 -9999 -9999 -9999 -9999 -9999 -9999 -9999 -9999 -9999 -9999 -9999 -9999 -9999 -9999 -9999 -9999 -9999 -9999 -9999 -9999 -9999 -9999 -9999 -9999 -9999 -9999 -9999 -9999 -9999 -9999 -9999 -9999 -9999 -9999 -9999 -9999 -9999 -9999 -9999 -9999 -9999 -9999 -9999 -9999 -9999 -9999 -9999 -9999 -9999 -9999 -9999 -9999 -9999 -9999 -9999 -9999 -9999 -9999 -9999 -9999 -9999 -9999 -9999 -9999 -9999 -9999 -9999 -9999 -9999 -9999 -9999 -9999 -9999 -9999 -9999 -9999 -9999 -9999 -9999 -9999 -9999 -9999 -9999 -9999 -9999 -9999 -9999 -9999 -9999 -9999 -9999 -9999 -9999 -9999 -9999 -9999 -9999 -9999 -9999 -9999 -9999 -9999 -9999 -9999 -9999 -9999 -9999 -9999 -9999 -

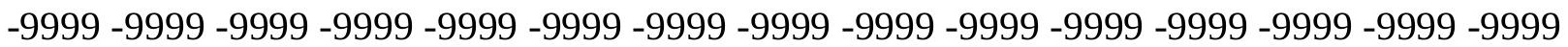
-9999 -9999 -9999 -9999 -9999 -9999 -9999 -9999 -9999 -9999 -9999 -9999 -9999 -9999 -9999 -9999 -9999 -9999 -9999 -9999 -9999 -9999 -9999 -9999 -9999 -9999 -9999 -9999 -9999 -9999 -9999 -9999 -9999 -9999 -9999 -9999 -9999 -9999 -9999 -9999 -9999 -9999 -9999 -9999 -9999 -9999 -9999 -9999 -9999 -9999 -9999 -9999 -9999 -9999 -9999 -9999 -9999 -9999 -9999 -9999 -

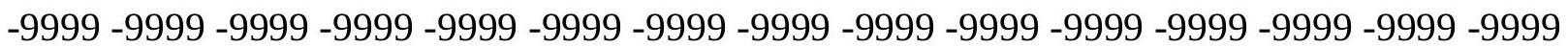
-9999 -9999 -9999 -9999 -9999 -9999 -9999 -9999 -9999 -9999 -9999 -9999 -9999 -9999 -9999 -9999 -9999 -9999 -9999 -9999 -9999 -9999 -9999 -9999 -9999 -9999 -9999 -9999 -9999 -9999 -9999 -9999 -9999 -9999 -9999 -9999 -9999 -9999 -9999 -9999 -9999 -9999 -9999 -9999 -9999 -9999 -9999 -9999 -9999 -9999 -9999 -9999 -9999 -9999 -9999 -9999 -9999 -9999 -9999 -9999 -9999 -9999 -9999 -9999 -9999 -9999 -9999 -9999 -9999 -9999 -9999 -9999 -9999 -9999 -9999 -9999 -9999 -9999 -9999 -9999 -9999 -9999 -9999 -9999 -9999 -9999 -9999 -9999 -9999 -9999 -9999 -9999 -9999 -9999 -9999 -9999 -9999 -9999 -9999 -9999 -9999 -9999 -9999 -9999 -9999

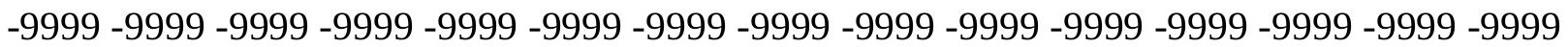
-9999 -9999 -9999 -9999 -9999 -9999 -9999 -9999 -9999 -9999 -9999 -9999 -9999 -9999 -9999 -9999 -9999 -9999 -9999 -9999 -9999 -9999 -9999 -9999 -9999 -9999 -9999 -9999 -9999 -9999 -

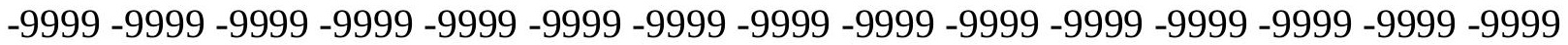
-9999 -9999 -9999 -9999 -9999 -9999 -9999 -9999 -9999 -9999 -9999 -9999 -9999 -9999 - 
u9top_elev 


$\begin{array}{ll}\text { ncols } & 389 \\ \text { nrows } & 437 \\ \text { xllcorner } & 545925 \\ \text { yllcorner } & 100925 \\ \text { cellsize } & 150\end{array}$

NODATA_value -9999

-9999 -9999 -9999 -9999 -9999 -9999 -9999 -9999 -9999 -9999 -9999 -9999 -9999 -9999 -9999 -9999 -9999 -9999 -9999 -9999 -9999 -9999 -9999 -9999 -9999 -9999 -9999 -9999 -9999 -9999 -999 -9999 -9999 -9999 -9999 -9999 -9999 -9999 -9999 -9999 -9999 -9999 -9999 -9999 -9999 -9999 -9999 -9999 -9999 -9999 -9999 -9999 -9999 -9999 -9999 -9999 -9999 -9999 -9999 -9999 -9999

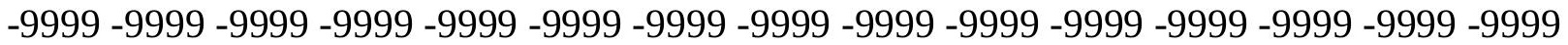
-9999 -9999 -9999 -9999 -9999 -9999 -9999 -9999 -9999 -9999 -9999 -9999 -9999 -9999 -9999 -9999 -9999 -9999 -9999 -9999 -9999 -9999 -9999 -9999 -9999 -9999 -9999 -9999 -9999 -9999 -9999 -9999 -9999 -9999 -9999 -9999 -9999 -9999 -9999 -9999 -9999 -9999 -9999 -9999 - 9999 -9999 -9999 -9999 -9999 -9999 -9999 -9999 -9999 -9999 -9999 -9999 -9999 -9999 -9999 -9999

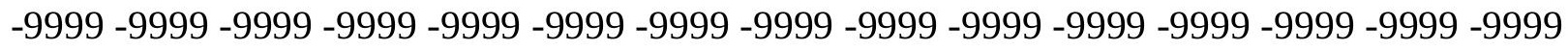
-9999 -9999 -9999 -9999 -9999 -9999 -9999 -9999 -9999 -9999 -9999 -9999 -9999 -9999 -9999 -9999 -9999 -9999 -9999 -9999 -9999 -9999 -9999 -9999 -9999 -9999 -9999 -9999 -9999 -9999 -999 -9999 -9999 -9999 -9999 -9999 -9999 -9999 -9999 -9999 -9999 -9999 -9999 -9999 -9999 -9999 -9999 -9999 -9999 -9999 -9999 -9999 -9999 -9999 -9999 -9999 -9999 -9999 -9999 -9999 -9999 -9999 -9999 -9999 -9999 -9999 -9999 -9999 -9999 -9999 -9999 -9999 -9999 -9999 -9999 -9999 -9999 -9999 -9999 -9999 -9999 -9999 -9999 -9999 -9999 -9999 -9999 -9999 -9999 -9999 -9999 -9999 -9999 -9999 -9999 -9999 -9999 -9999 -9999 -9999 -9999 -9999 -9999 -9999 -9999 -9999 -9999 -9999 -9999 -9999 -9999 -9999 -9999 -9999 -9999 -9999 -9999 -9999 -9999 -9999 -9999 -9999 -9999 -9999 -9999 -9999 -9999 -9999 -9999 -9999 -9999 -9999 -9999 -9999 -9999 -9999 -9999 -9999 -9999 -9999 -9999 -9999 -9999 -9999 -9999 -9999 -9999 -9999 -9999 -9999 -9999 -9999 -9999 -9999 -9999 -9999 -9999 -9999 -9999 -9999 -9999 -9999 -9999 -9999 -9999 -9999 -9999 -9999 -9999 -9999 -9999 -9999 -9999 -9999 -9999 -9999 -9999 -9999 -9999 -9999 -9999 -9999 -9999 -9999 -9999 -9999 -9999 -9999 -9999 -9999 -9999 -9999 -9999 -9999 -9999 -9999 -9999 -9999 -9999 -9999 -9999 -9999 -9999 -9999 -9999 -9999 -9999 -9999 -9999 -9999 -999 -9999 -9999 -9999 -9999 -9999 -9999 -9999 -9999 -9999 -9999 -9999 -9999 -9999 -9999 -9999 -9999 -9999 -9999 -9999 -9999 -9999 -9999 -9999 -9999 -9999 -9999 -9999 -9999 -9999 -

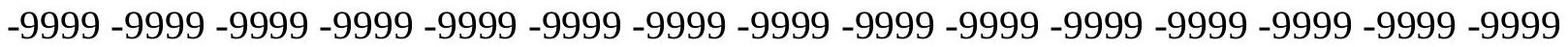
-9999 -9999 -9999 -9999 -9999 -9999 -9999 -9999 -9999 -9999 -9999 -9999 -9999 -9999 -9999 -9999 -9999 -9999 -9999 -9999 -9999 -9999 -9999 -9999 -9999 -9999 -9999 -9999 -9999 -9999 -

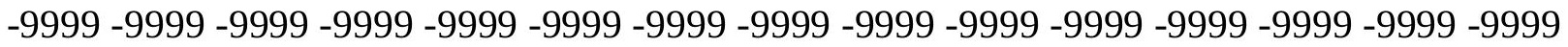

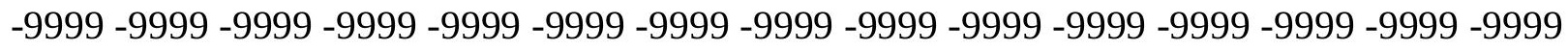
-9999 -9999 -9999 -9999 -9999 -9999 -9999 -9999 -9999 -9999 -9999 -9999 -9999 - 9999 - -9999 -9999 -9999 -9999 -9999 -9999 -9999 -9999 -9999 -9999 -9999 -9999 -9999 -9999 - 9999 - -999 -9999 -9999 -9999 -9999 -9999 -9999 -9999 -9999 -9999 -9999 -9999 -9999 -9999 -9999 -9999 -

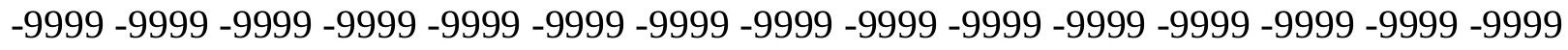

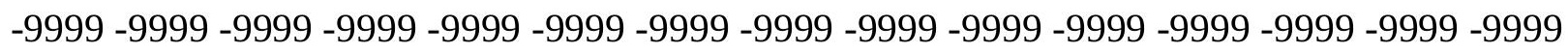
-9999 -9999 -9999 -9999 -9999 -9999 -9999 -9999 -9999 -9999 -9999 -9999 -9999 -9999 -9999 -9999 -9999 -9999 -9999 -9999 -9999 -9999 -9999 -9999-9999 -9999 -9999 -9999 -9999 -9999 -9999 -9999 -9999 -9999 -9999 -9999 -9999 -9999 -9999 -9999 -9999 -9999 -9999 -9999 -9999 -

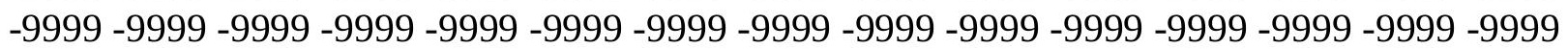


-9999 -9999 -9999 -9999 -9999 -9999 -9999 -9999 -9999 -9999 -9999 -9999 -9999 -9999 -9999 -9999 -9999 -9999 -9999 -9999 -9999 -9999 -9999 -9999 -9999 -9999 -9999 -9999 -9999 -9999 -

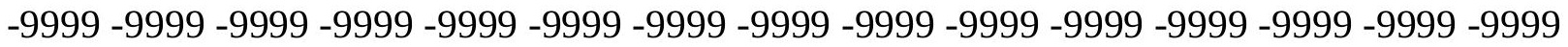
-9999 -9999 -9999 -9999 -9999 -9999 -9999 -9999 -9999 -9999 -9999 -9999 -9999 -9999 -9999 -9999 -9999 -9999 -9999 -9999 -9999 -9999 -9999 -9999-9999 -9999 -9999 -9999 -9999 -9999 -9999 -9999 -9999 -9999 -9999 -9999 -9999 -9999 -9999 -9999 -9999 -9999 -9999 -9999 -9999 -9999 -9999 -9999 -9999 -9999 -9999 -9999 -9999 -9999 -9999 -9999 -9999 -9999 -9999 -9999

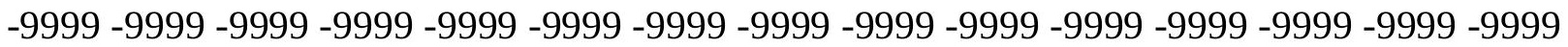

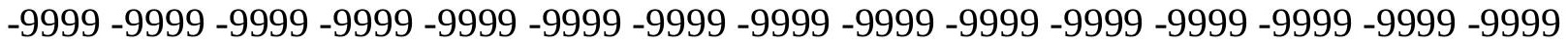
-9999 -9999 -9999 -9999 -9999 -9999 -9999 -9999 -9999 -9999 -9999 -9999 -9999 -9999 -9999 -9999 -9999 -9999 -9999 -9999 -9999 -9999 -9999 -9999 -9999 -9999 -9999 -9999 -9999 -9999 -9999 -9999 -9999 -9999 -9999 -9999 -9999 -9999 -9999 -9999 -9999 -9999 -9999 -9999 -9999 -9999 -9999 -9999 -9999 -9999 -9999 -9999 -9999 -9999 -9999 -9999 -9999 -9999 -9999 -9999 -9999 -9999 -9999 -9999 -9999 -9999 -9999 -9999 -9999 -9999 -9999 -9999 -9999 - 9999 -9999 -9999 -9999 -9999 -9999 -9999 -9999 -9999 -9999 -9999 -9999 -9999 -9999 -9999 -9999

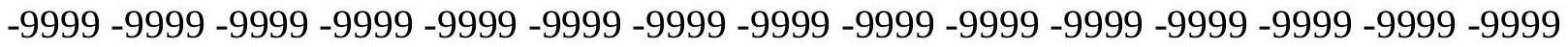
-9999 -9999 -9999 -9999 -9999 -9999 -9999 -9999 -9999 -9999 -9999 -9999 -9999 -9999 -9999 -9999 -9999 -9999 -9999 -9999 -9999 -9999 -9999 -9999 -9999 -9999 -9999 -9999 -9999 -9999 -9999 -9999 -9999 -9999 -9999 -9999 -9999 -9999 -9999 -9999 -9999 -9999 -9999 -9999 -9999 -

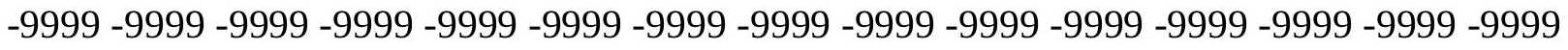

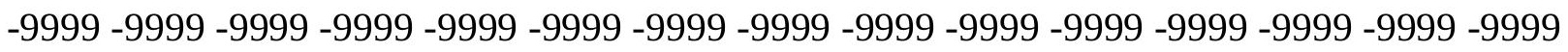
-9999 -9999 -9999 -9999 -9999 -9999 -9999 -9999 -9999 -9999 -9999 -9999 -9999 -9999 -9999 -9999 -9999 -9999 -9999 -9999 -9999 -9999 -9999 -9999 -9999 -9999 -9999 -9999 -9999 -9999 -9999 -9999 -9999 -9999 -9999 -9999 -9999 -9999 -9999 -9999 -9999 -9999 -9999 -9999 -9999 -

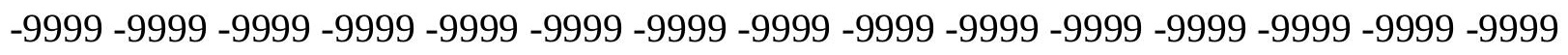
-9999 -9999 -9999 -9999 -9999 -9999 -9999 -9999 -9999 -9999 -9999 -9999 -9999 -9999 -9999 -9999 -9999 -9999 -9999 -9999 -9999 -9999 -9999 -9999 -9999 -9999 -9999 -9999 -9999 -9999 -

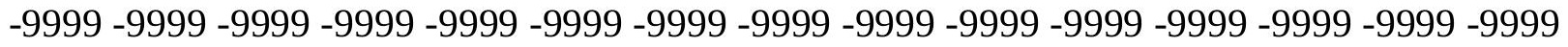
-9999 -9999 -9999 -9999 -9999 -9999 -9999 -9999 -9999 -9999 -9999 -9999 -9999 -9999 -9999 -9999 -9999 -9999 -9999 -9999 -9999 -9999 -9999 -9999 -9999 -9999 -9999 -9999 -9999 -999 -9999 -9999 -9999 -9999 -9999 -9999 -9999 -9999 -9999 -9999 -9999 -9999 -9999 -9999 -9999 -9999 -9999 -9999 -9999 -9999 -9999 -9999 -9999 -9999 -9999 -9999 -9999 -9999 -9999 -9999 -

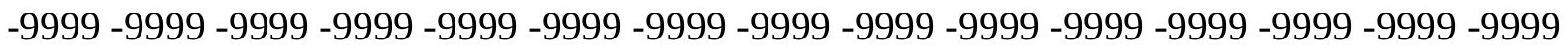

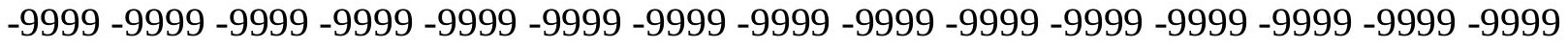

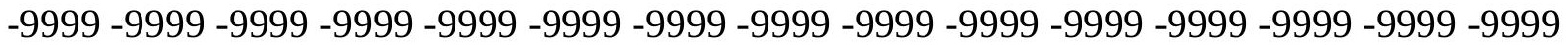

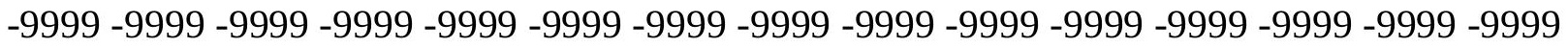

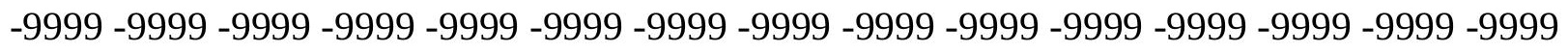

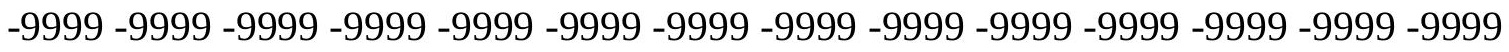
-9999 -9999 -9999 -9999 -9999 -9999 -9999 -9999 -9999 -9999 -9999 -9999 -9999 -9999 -9999 -9999 -9999 -9999 -9999 -9999 -9999 -9999 -9999 -9999 -9999 -9999 -9999 -9999 -9999 -9999 -

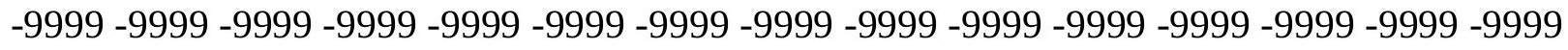

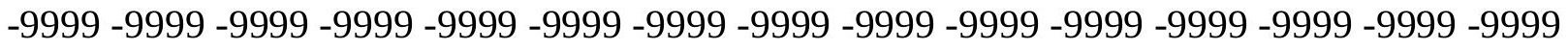
-9999 -9999 -9999 -9999 -9999 -9999 -9999 -9999 -9999 -9999 -9999 -9999 -9999 -9999 -9999 -9999 -9999 -9999 -9999 -9999 -9999 -9999 -9999 -9999-9999 -9999 -9999 -9999 -9999 -9999 -9999 -9999 -9999 -9999 -9999 -9999 -9999 -9999 -9999 -9999 -9999 -9999 -9999 -9999 -9999 -

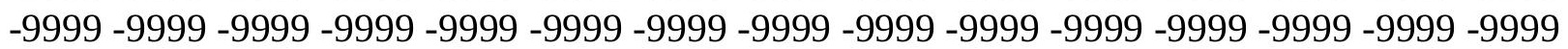


-9999 -9999 -9999 -9999 -9999 -9999 -9999 -9999 -9999 -9999 -9999 -9999 -9999 -9999 -9999 -9999 -9999 -9999 -9999 -9999 -9999 -9999 -9999 -9999 -9999 -9999 -9999 -9999 -9999 -9999 -9999 -9999 -9999 -9999 -9999 -9999 -9999 -9999 -9999 -9999 -9999 -9999 -9999 -9999 - 9999 -9999 -9999 -9999 -9999 -9999 -9999 -9999 -9999 -9999 -9999 -9999 -9999 -9999 -9999 -9999 -9999 -9999 -9999 -9999 -9999 -9999 -9999 -9999 -9999 -9999 -9999 -9999 -9999 -9999 -9999 -9999 -9999 -9999 -9999 -9999 -9999 -9999 -9999 -9999 -9999 -9999 -9999 -9999 -9999 -9999 -9999 -9999 -9999 -9999 -9999 -9999 -9999 -9999 -9999 -9999 -9999 -9999 -9999 -9999 -9999

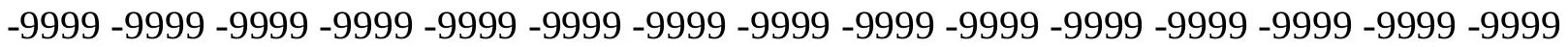
-9999 -9999 -9999 -9999 -9999 -9999 -9999 -9999 -9999 -9999 -9999 -9999 -9999 -9999 -9999 -9999 -9999 -9999 -9999 -9999 -9999 -9999 -9999 -9999 -9999 -9999 -9999 -9999 -9999 -9999

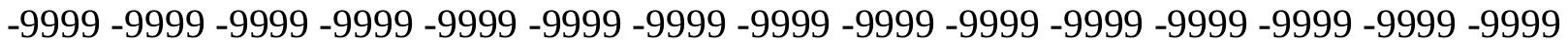
-9999 -9999 -9999 -9999 -9999 -9999 -9999 -9999 -9999 -9999 -9999 -9999 -9999 -9999 -9999 -9999 -9999 -9999 -9999 -9999 -9999 -9999 -9999 -9999 -9999 -9999 -9999 -9999 -9999 -9999 -

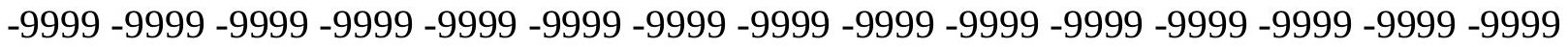
-9999 -9999 -9999 -9999 -9999 -9999 -9999 -9999 -9999 -9999 -9999 -9999 -9999 -9999 -9999

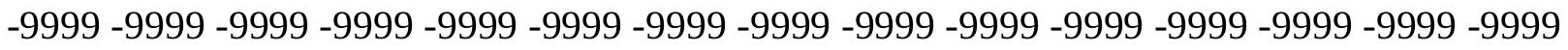
-9999 -9999 -9999 -9999 -9999 -9999 -9999 -9999 -9999 -9999 -9999 -9999 -9999 -9999 -9999 -9999 -9999 -9999 -9999 -9999 -9999 -9999 -9999 -9999 -9999 -9999 -9999 -9999 -9999 - -999 -9999 -9999 -9999 -9999 -9999 -9999 -9999 -9999 -9999 -9999 -9999 -9999 -9999 -9999 -9999 -9999 -9999 -9999 -9999 -9999 -9999 -9999 -9999 -9999 -9999 -9999 -9999 -9999 -9999 -9999 -9999 -9999 -9999 -9999 -9999 -9999 -9999 -9999 -9999 -9999 -9999 -9999 -9999 -9999 -9999 -999 -9999 -9999 -9999 -9999 -9999 -9999 -9999 -9999 -9999 -9999 -9999 -9999 -9999 -9999 -9999 -9999 -9999 -9999 -9999 -9999 -9999 -9999 -9999 -9999 -9999 -9999 -9999 -9999 -9999 -9999 -9999 -9999 -9999 -9999 -9999 -9999 -9999 -9999 -9999 -9999 -9999 -9999 -9999 -9999 -9999 -9999 -9999 -9999 -9999 -9999 -9999 -9999 -9999 -9999 -9999 -9999 -9999 -9999 -9999 -9999 -9999 -9999 -9999 -9999 -9999 -9999 -9999 -9999 -9999 -9999 -9999 -9999 -9999 -9999 -9999 -9999 -9999 -9999 -9999 -9999 -9999 -9999 -9999 -9999 -9999 -9999 -9999 -9999 -9999 -9999 -9999 -9999 -9999 -9999 -9999 -9999 -9999 -9999 -9999 -9999 -9999 -9999 -9999 -9999 -9999 -9999 -9999 -9999 -9999 -9999 -9999 -9999 -9999 -9999 -9999 -9999 -9999 -9999 -9999 -9999 -9999 -9999 -9999 -9999 -9999 -9999 -9999 -9999 -9999 -9999 -9999 -9999 -9999 -9999 -999 -9999 -9999 -9999 -9999 -9999 -9999 -9999 -9999 -9999 -9999 -9999 -9999 -9999 -9999 -9999 -9999 -9999 -9999 -9999 -9999 -9999 -9999 -9999 -9999 -9999 -9999 -9999 -9999 -9999 -9999 -

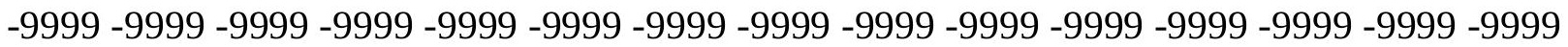

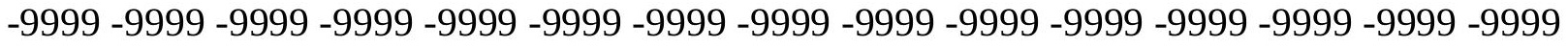

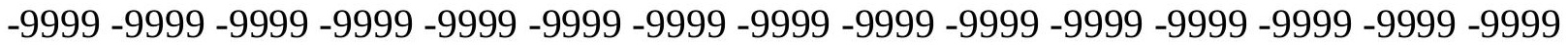
-9999 -9999 -9999 -9999 -9999 -9999 -9999 -9999 -9999 -9999 -9999 -9999 -9999 -9999 -9999

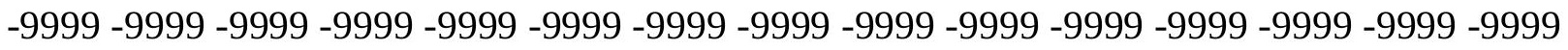

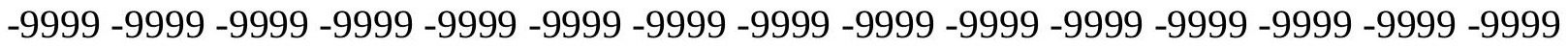

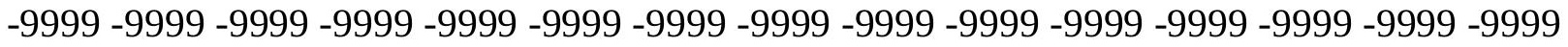
-9999 -9999 -9999 -9999 -9999 -9999 -9999 -9999 -9999 -9999 -9999 -9999 -9999 -9999 -9999 -

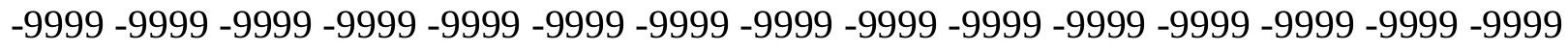

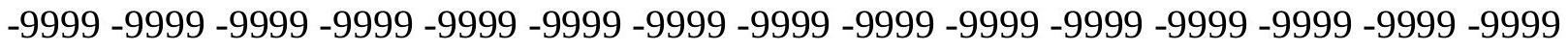
-9999 -9999 -9999 -9999 -9999 -9999 -9999 -9999 -9999 -9999 -9999 -9999 -9999 -9999 -9999 -9999 -9999 -9999 -9999 -9999 -9999 -9999 -9999 -9999 -9999 -9999 -9999 -9999 - -9999 -9999 -9999 -9999 -9999 -9999 -9999 -9999 -9999 -9999 -9999 -9999 -9999 -9999 -9999 -9999 -

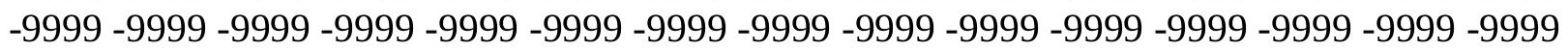


-9999 -9999 -9999 -9999 -9999 -9999 -9999 -9999 -9999 -9999 -9999 -9999 -9999 -9999 -9999 -9999 -9999 -9999 -9999 -9999 -9999 -9999 -9999 -9999 -9999 -9999 -9999 -9999 -9999 -9999 -9999 -9999 -9999 -9999 -9999 -9999 -9999 -9999 -9999 -9999 -9999 -9999 -9999 -9999 - 9999 -9999 -9999 -9999 -9999 -9999 -9999 -9999 -9999 -9999 -9999 -9999 -9999 -9999 -9999 -9999 -9999 -9999 -9999 -9999 -9999 -9999 -9999 -9999 -9999-9999 -9999 -9999 -9999 -9999 -9999 -9999 -9999 -9999 -9999 -9999 -9999 -9999 -9999 -9999 -9999 -9999 -9999 -9999 -9999 -9999 -9999 -9999 -9999 -9999 -9999 -9999 -9999 -9999 -9999 -9999 -9999 -9999 -9999 -9999 -9999

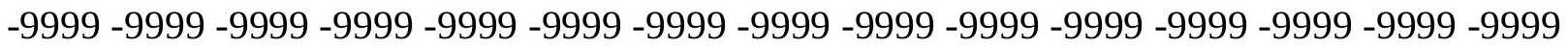

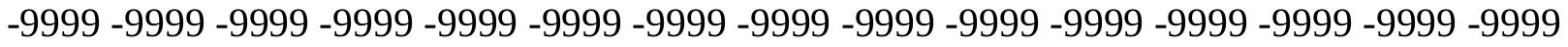
-9999 -9999 -9999 -9999 -9999 -9999 -9999 -9999 -9999 -9999 -9999 -9999 -9999 -9999 -9999

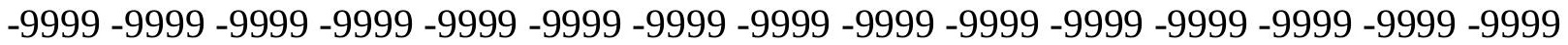
-9999 -9999 -9999 -9999 -9999 -9999 -9999 -9999 -9999 -9999 -9999 -9999 -9999 -9999 -9999 -9999 -9999 -9999 -9999 -9999 -9999 -9999 -9999 -9999 -9999 -9999 -9999 -9999 -9999 -9999 -

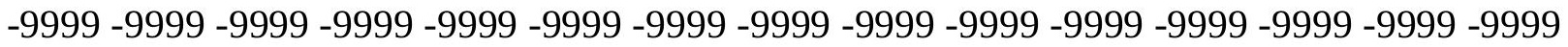
-9999 -9999 -9999 -9999 -9999 -9999 -9999 -9999 -9999 -9999 -9999 -9999 -9999 -9999 -9999

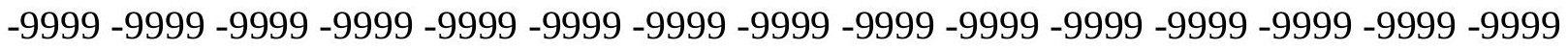
-9999 -9999 -9999 -9999 -9999 -9999 -9999 -9999 -9999 -9999 -9999 -9999 -9999 -9999 -9999 -9999 -9999 -9999 -9999 -9999 -9999 -9999 -9999 -9999 -9999 -9999 -9999 -9999 -9999 -9999 -9999 -9999 -9999 -9999 -9999 -9999 -9999 -9999 -9999 -9999 -9999 -9999 -9999 -9999 -9999 -9999 -9999 -9999 -9999 -9999 -9999 -9999 -9999 -9999 -9999 -9999 -9999 -9999 -9999 -9999 -9999 -9999 -9999 -9999 -9999 -9999 -9999 -9999 -9999 -9999 -9999 -9999 -9999 -9999 -9999 -999 -9999 -9999 -9999 -9999 -9999 -9999 -9999 -9999 -9999 -9999 -9999 -9999 -9999 -9999 -9999 -9999 -9999 -9999 -9999 -9999 -9999 -9999 -9999 -9999 -9999 -9999 -9999 -9999 -9999 -9999 -9999 -9999 -9999 -9999 -9999 -9999 -9999 -9999 -9999 -9999 -9999 -9999 -9999 -9999 -9999 -9999 -9999 -9999 -9999 -9999 -9999 -9999 -9999 -9999 -9999 -9999 -9999 -9999 -9999 -9999 -9999 -9999 -9999 -9999 -9999 -9999 -9999 -9999 -9999 -9999 -9999 -9999 -9999 -9999 -9999 -9999 -9999 -9999 -9999 -9999 -9999 -9999 -9999 -9999 -9999 -9999 -9999 -9999 -9999 -9999 -9999 -9999 -9999 -9999 -9999 -9999 -9999 -9999 -9999 -9999 -9999 -9999 -9999 -9999 -9999 -9999 -9999 -9999 -9999 -9999 -9999 -9999 -9999 -9999 -9999 -9999 -9999 -9999 -9999 -9999 -9999 -9999 -9999 -9999 -9999 -9999 -9999 -9999 -9999 -9999 -9999 -9999 -9999 -999 -9999 -9999 -9999 -9999 -9999 -9999 -9999 -9999 -9999 -9999 -9999 -9999 -9999 -9999 -9999 -9999 -9999 -9999 -9999 -9999 -9999 -9999 -9999 -9999 -9999 -9999 -9999 -9999 -9999 -9999 -

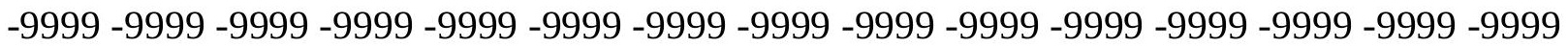

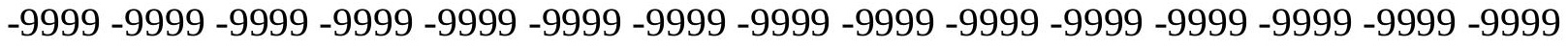

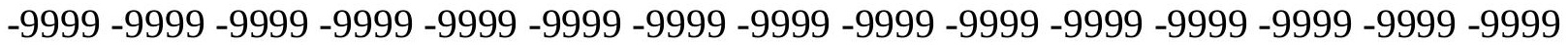
-9999 -9999 -9999 -9999 -9999 -9999 -9999 -9999 -9999 -9999 -9999 -9999 -9999 -9999 -9999

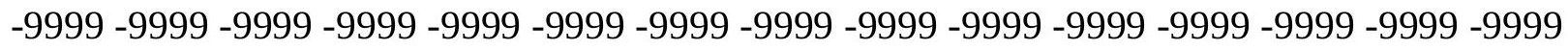

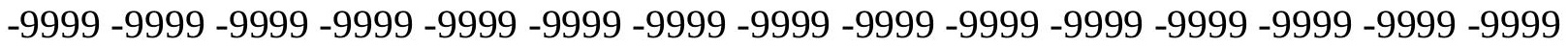
-9999 -9999 -9999 -9999 -9999 -9999 -9999 -9999 -9999 -9999 -9999 -9999 -9999 -9999 -9999 -9999 -9999 -9999 -9999 -9999 -9999 -9999 -9999 -9999 -9999 -9999 -9999 -9999 -9999 -9999 -

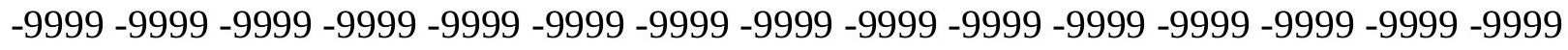

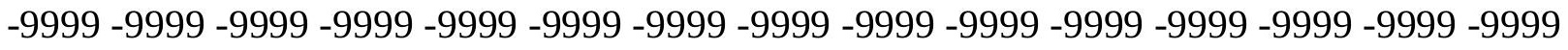
-9999 -9999 -9999 -9999 -9999 -9999 -9999 -9999 -9999 -9999 -9999 -9999 -9999 -9999 -9999 -9999 -9999 -9999 -9999 -9999 -9999 -9999 -9999 -9999-9999 -9999 -9999 -9999 -9999 -9999 -9999 -9999 -9999 -9999 -9999 -9999 -9999 -9999 -9999 -9999 -9999 -9999 -9999 -9999 -9999 -

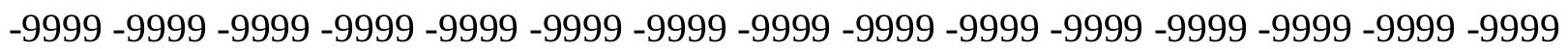


-9999 -9999 -9999 -9999 -9999 -9999 -9999 -9999 -9999 -9999 -9999 -9999 -9999 -9999 -9999 -9999 -9999 -9999 -9999 -9999 -9999 -9999 -9999 -9999 -9999 -9999 -9999 -9999 -9999 -9999 -9999 -9999 -9999 -9999 -9999 -9999 -9999 -9999 -9999 -9999 -9999 -9999 -9999 -9999 - 9999 -9999 -9999 -9999 -9999 -9999 -9999 -9999 -9999 -9999 -9999 -9999 -9999 -9999 -9999

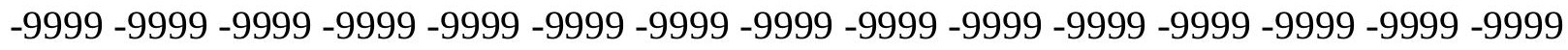
-9999 -9999 -9999 -9999 -9999 -9999 -9999 -9999 -9999 -9999 -9999 -9999 -9999 -9999 -9999 -9999 -9999 -9999 -9999 -9999 -9999 -9999 -9999 -9999 -9999 -9999 -9999 -9999 -9999 -9999

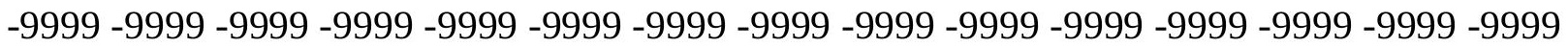

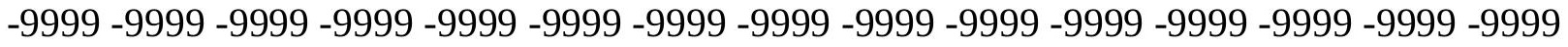
-9999 -9999 -9999 -9999 -9999 -9999 -9999 -9999 -9999 -9999 -9999 -9999 -9999 -9999 -9999 -9999 -9999 -9999 -9999 -9999 -9999 -9999 -9999 -9999 -9999 -9999 -9999 -9999 -9999 -9999 -9999 -9999 -9999 -9999 -9999 -9999 -9999 -9999 -9999 -9999 -9999 -9999 -9999 -9999 -9999 -9999 -9999 -9999 -9999 -9999 -9999 -9999 -9999 -9999 -9999 -9999 -9999 -9999 -9999 -9999 -

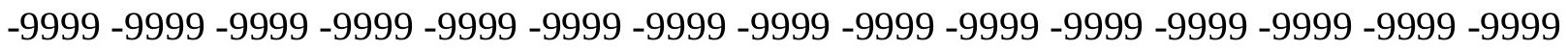
-9999 -9999 -9999 -9999 -9999 -9999 -9999 -9999 -9999 -9999 -9999 -9999 -9999 -9999 -9999 -

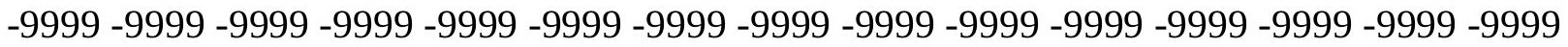
-9999 -9999 -9999 -9999 -9999 -9999 -9999 -9999 -9999 -9999 -9999 -9999 -9999 -9999 -9999 -9999 -9999 -9999 -9999 -9999 -9999 -9999 -9999 -9999 -9999 -9999 -9999 -9999 -9999 -9999 -9999 -9999 -9999 -9999 -9999 -9999 -9999 -9999 -9999 -9999 -9999 -9999 -9999 -9999 -9999 -

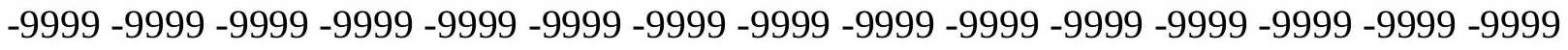
-9999 -9999 -9999 -9999 -9999 -9999 -9999 -9999 -9999 -9999 -9999 -9999 -9999 -9999 -9999

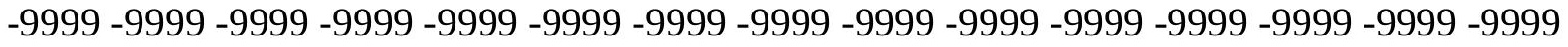
-9999 -9999 -9999 -9999 -9999 -9999 -9999 -9999 -9999 -9999 -9999 -9999 -9999 -9999 -9999 -9999 -9999 -9999 -9999 -9999 -9999 -9999 -9999 -9999 -9999 -9999 -9999 -9999 -9999 -9999 -9999 -9999 -9999 -9999 -9999 -9999 -9999 -9999 -9999 -9999 -9999 -9999 -9999 -9999 -9999 -9999 -9999 -9999 -9999 -9999 -9999 -9999 -9999 -9999 -9999 -9999 -9999 -9999 -9999 -9999 -9999 -9999 -9999 -9999 -9999 -9999 -9999 -9999 -9999 -9999 -9999 -9999 -9999 -9999 -9999 -9999 -9999 -9999 -9999 -9999 -9999 -9999 -9999 -9999 -9999 -9999 -9999 -9999 -9999 -9999 -9999 -9999 -9999 -9999 -9999 -9999 -9999 -9999 -9999 -9999 -9999 -9999 -9999 -9999 -9999 -9999 -9999 -9999 -9999 -9999 -9999 -9999 -9999 -9999 -9999 -9999 -9999 -9999 -9999 -9999 -9999 -9999 -9999 -9999 -9999 -9999 -9999 -9999 -9999 -9999 -9999 -9999 -9999 -9999 -9999 -9999 -9999 -9999 -9999 -9999 -9999 -9999 -9999 -9999 -9999 -9999 -9999 -9999 -9999 -

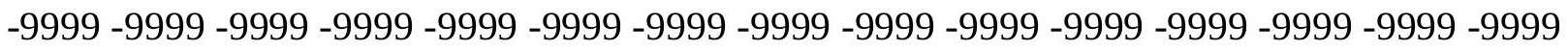

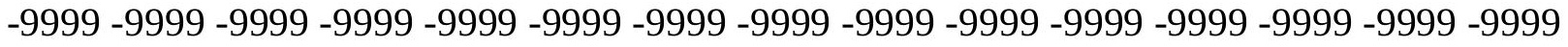
-9999 -9999 -9999 -9999 -9999 -9999 -9999 -9999 -9999 -9999 -9999 -9999 -9999 -9999 -9999 -

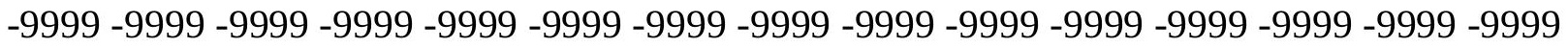

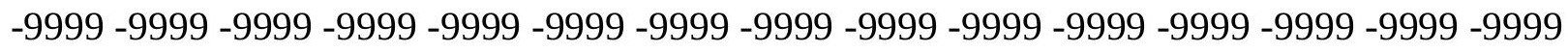

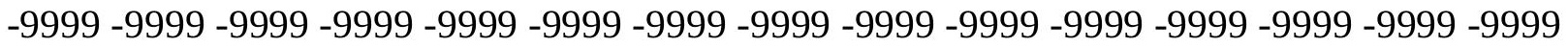

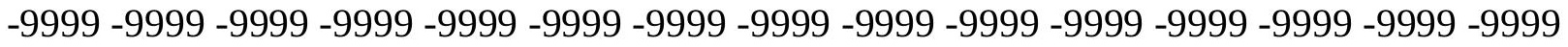
-9999 -9999 -9999 -9999 -9999 -9999 -9999 -9999 -9999 -9999 -9999 -9999 -9999 -9999 -9999 -

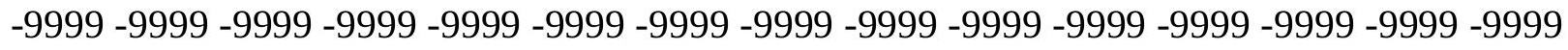

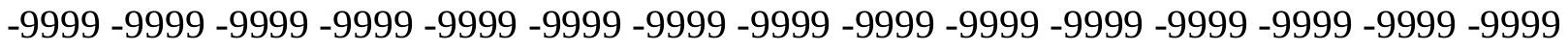
-9999 -9999 -9999 -9999 -9999 -9999 -9999 -9999 -9999 -9999 -9999 -9999 -9999 -9999 -9999 -9999 -9999 -9999 -9999 -9999 -9999 -9999 -9999 -9999-9999 -9999 -9999 -9999 -9999 -9999 -9999 -9999 -9999 -9999 -9999 -9999 -9999 -9999 -9999 -9999 -9999 -9999 -9999 -9999 -9999 -

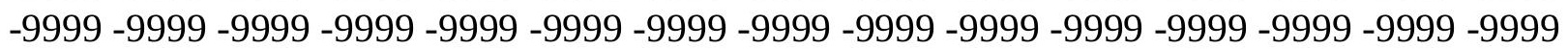


-9999 -9999 -9999 -9999 -9999 -9999 -9999 -9999 -9999 -9999 -9999 -9999 -9999 -9999 -9999 -9999 -9999 -9999 -9999 -9999 -9999 -9999 -9999 -9999 -9999 -9999 -9999 -9999 -9999 -9999 -9999 -9999 -9999 -9999 -9999 -9999 -9999 -9999 -9999 -9999 -9999 -9999 -9999 -9999 - 9999 -9999 -9999 -9999 -9999 -9999 -9999 -9999 -9999 -9999 -9999 -9999 -9999 -9999 -9999 -9999 -9999 -9999 -9999 -9999 -9999 -9999 -9999 -9999 -9999 -9999 -9999 -9999 -9999 -9999 -9999 -9999 -9999 -9999 -9999 -9999 -9999 -9999 -9999 -9999 -9999 -9999 -9999 -9999 -9999 -9999 -9999 -9999 -9999 -9999 -9999 -9999 -9999 -9999 -9999 -9999 -9999 -9999 -9999 -9999 -9999

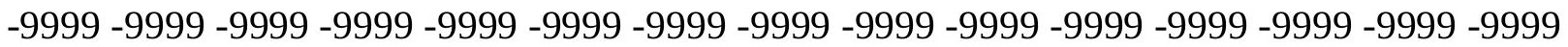

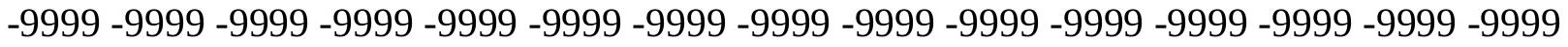
-9999 -9999 -9999 -9999 -9999 -9999 -9999 -9999 -9999 -9999 -9999 -9999 -9999 -9999 -9999 -9999 -9999 -9999 -9999 -9999 -9999 -9999 -9999 -9999 -9999 -9999 -9999 -9999 -9999 -9999 -9999 -9999 -9999 -9999 -9999 -9999 -9999 -9999 -9999 -9999 -9999 -9999 -9999 -9999 -9999 -9999 -9999 -9999 -9999 -9999 -9999 -9999 -9999 -9999 -9999 -9999 -9999 -9999 -9999 -9999 -9999 -9999 -9999 -9999 -9999 -9999 -9999 -9999 -9999 -9999 -9999 -9999 -9999 -9999 -9999 -9999 -9999 -9999 -9999 -9999 -9999 -9999 -9999 -9999 -9999 -9999 -9999 -9999 -9999 -

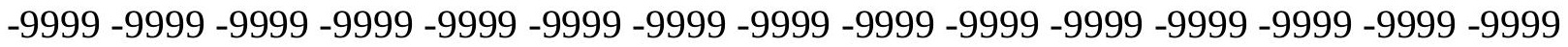
-9999 -9999 -9999 -9999 -9999 -9999 -9999 -9999 -9999 -9999 -9999 -9999 -9999 -9999 -9999 -9999 -9999 -9999 -9999 -9999 -9999 -9999 -9999 -9999 -9999 -9999 -9999 -9999 -9999 -9999 -9999 -9999 -9999 -9999 -9999 -9999 -9999 -9999 -9999 -9999 -9999 -9999 -9999 -9999 -9999 -9999 -9999 -9999 -9999 -9999 -9999 -9999 -9999 -9999 -9999 -9999 -9999 -9999 -9999 -9999 -9999 -9999 -9999 -9999 -9999 -9999 -9999 -9999 -9999 -9999 -9999 -9999 -9999 -9999 -9999 -999 -9999 -9999 -9999 -9999 -9999 -9999 -9999 -9999 -9999 -9999 -9999 -9999 -9999 -9999 -9999 -9999 -9999 -9999 -9999 -9999 -9999 -9999 -9999 -9999 -9999 -9999 -9999 -9999 -9999 -9999 -9999 -9999 -9999 -9999 -9999 -9999 -9999 -9999 -9999 -9999 -9999 -9999 -9999 -9999 -9999 -9999 -9999 -9999 -9999 -9999 -9999 -9999 -9999 -9999 -9999 -9999 -9999 -9999 -9999 -9999 -9999 -9999 -9999 -9999 -9999 -9999 -9999 -9999 -9999 -9999 -9999 -9999 -9999 -9999 -9999 -9999 -9999 -9999 -9999 -9999 -9999 -9999 -9999 -9999 -9999 -9999 -9999 -9999 -9999 -9999 -9999 -9999 -9999 -9999 -9999 -9999 -9999 -9999 -9999 -9999 -9999 -9999 -9999 -9999 -9999 -9999 -9999 -9999 -9999 -9999 -9999 -9999 -9999 -9999 -9999 -9999 -9999 -9999 -9999 -9999 -9999 -9999 -9999 -9999 -9999 -9999 -9999 -9999 -9999 -9999 -9999 -9999 -9999 -9999 -999 -9999 -9999 -9999 -9999 -9999 -9999 -9999 -9999 -9999 -9999 -9999 -9999 -9999 -9999 -9999 -9999 -9999 -9999 -9999 -9999 -9999 -9999 -9999 -9999 -9999 -9999 -9999 -9999 -9999 -9999 -

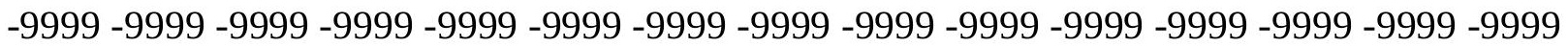

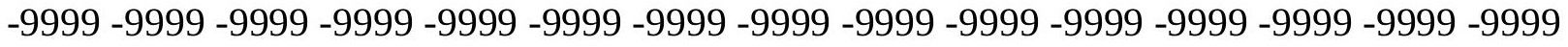

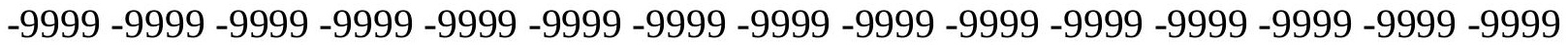
-9999 -9999 -9999 -9999 -9999 -9999 -9999 -9999 -9999 -9999 -9999 -9999 -9999 -9999 -9999 -9999 -9999 -9999 -9999 -9999 -9999 -9999 -9999 -9999 -9999 -9999 -9999 -9999 -9999 -

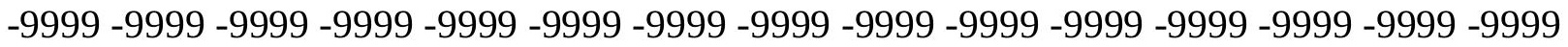
-9999 -9999 -9999 -9999 -9999 -9999 -9999 -9999 -9999 -9999 -9999 -9999 -9999 -9999 -9999 -9999 -9999 -9999 -9999 -9999 -9999 -9999 -9999 -9999 -9999 -9999 -9999 -9999 -9999 -9999 -

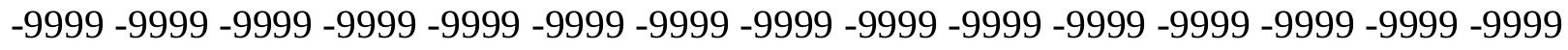

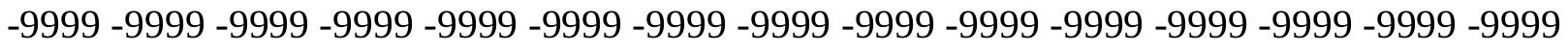
-9999 -9999 -9999 -9999 -9999 -9999 -9999 -9999 -9999 -9999 -9999 -9999 -9999 -9999 -9999 -9999 -9999 -9999 -9999 -9999 -9999 -9999 -9999 -9999-9999 -9999 -9999 -9999 -9999 -9999 -9999 -9999 -9999 -9999 -9999 -9999 -9999 -9999 -9999 -9999 -9999 -9999 -9999 -9999 -9999 -

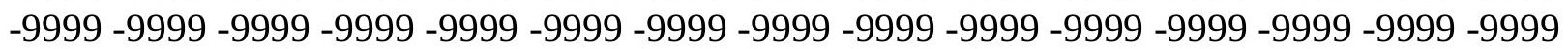


-9999 -9999 -9999 -9999 -9999 -9999 -9999 -9999 -9999 -9999 -9999 -9999 -9999 -9999 -9999 -9999 -9999 -9999 -9999 -9999 -9999 -9999 -9999 -9999 -9999 -9999 -9999 -9999 -9999 -9999 -

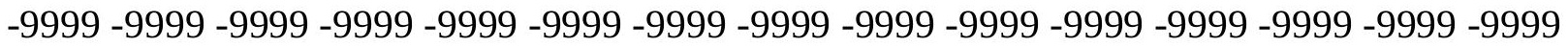
-9999 -9999 -9999 -9999 -9999 -9999 -9999 -9999 -9999 -9999 -9999 -9999 -9999 -9999 -9999 -9999 -9999 -9999 -9999 -9999 -9999 -9999 -9999 -9999-9999 -9999 -9999 -9999 -9999 -9999 -9999 -9999 -9999 -9999 -9999 -9999 -9999 -9999 -9999 -9999 -9999 -9999 -9999 -9999 -9999 -9999 -9999 -9999 -9999 -9999 -9999 -9999 -9999 -9999 -9999 -9999 -9999 -9999 -9999 -9999

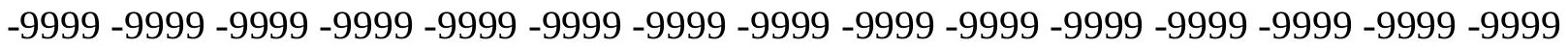

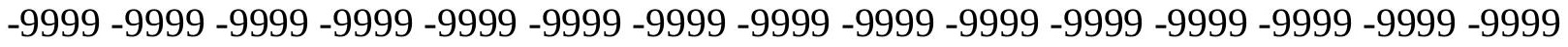
-9999 -9999 -9999 -9999 -9999 -9999 -9999 -9999 -9999 -9999 -9999 -9999 -9999 -9999 -9999 -9999 -9999 -9999 -9999 -9999 -9999 -9999 -9999 -9999 -9999 -9999 -9999 -9999 -9999 -9999 -9999 -9999 -9999 -9999 -9999 -9999 -9999 -9999 -9999 -9999 -9999 -9999 -9999 -9999 -9999 -9999 -9999 -9999 -9999 -9999 -9999 -9999 -9999 -9999 -9999 -9999 -9999 -9999 -9999 -9999 -9999 -9999 -9999 -9999 -9999 -9999 -9999 -9999 -9999 -9999 -9999 -9999 -9999 -9999 -9999 -9999 -9999 -9999 -9999 -9999 -9999 -9999 -9999 -9999 -9999 -9999 -9999 -9999 -9999 -9999 -

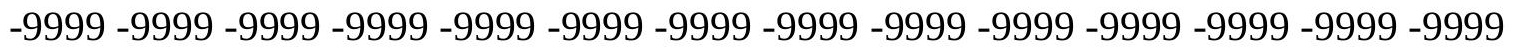
-9999 -9999 -9999 -9999 -9999 -9999 -9999 -9999 -9999 -9999 -9999 -9999 -9999 -9999 -9999 -9999 -9999 -9999 -9999 -9999 -9999 -9999 -9999 -9999 -9999 -9999 -9999 -9999 -9999 -9999 -9999 -9999 -9999 -9999 -9999 -9999 -9999 -9999 -9999 -9999 -9999 -9999 -9999 -9999 -9999 -

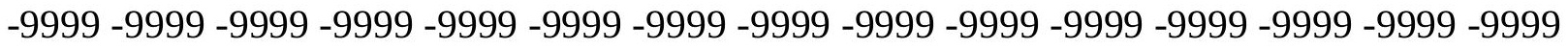

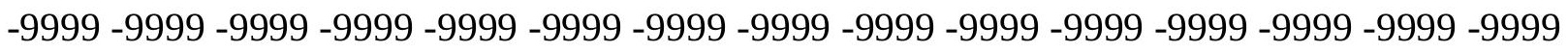
-9999 -9999 -9999 -9999 -9999 -9999 -9999 -9999 -9999 -9999 -9999 -9999 -9999 -9999 - 9999 -9999 -9999 -9999 -9999 -9999 -9999 -9999 -9999 -9999 -9999 -9999 -9999 -9999 -9999 -9999 -9999 -9999 -9999 -9999 -9999 -9999 -9999 -9999 -9999 -9999 -9999 -9999 -9999 -9999 -9999 -

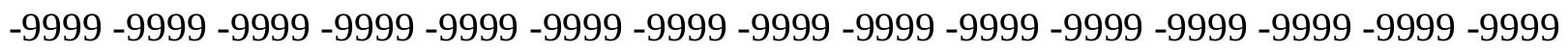
-9999 -9999 -9999 -9999 -9999 -9999 -9999 -9999 -9999 -9999 -9999 -9999 -9999 -9999 -9999 -9999 -9999 -9999 -9999 -9999 -9999 -9999 -9999 -9999 -9999 -9999 -9999 -9999 -9999 -9999 -

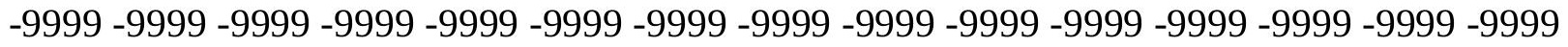
-9999 -9999 -9999 -9999 -9999 -9999 -9999 -9999 -9999 -9999 -9999 -9999 -9999 -9999 -9999 -9999 -9999 -9999 -9999 -9999 -9999 -9999 -9999 -9999 -9999 -9999 -9999 -9999 -9999 -999 -

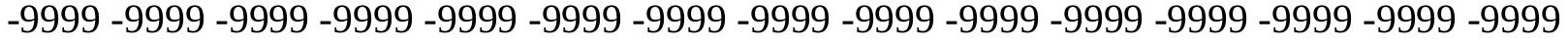
-9999 -9999 -9999 -9999 -9999 -9999 -9999 -9999 -9999 -9999 -9999 -9999 -9999 -9999 -9999 -

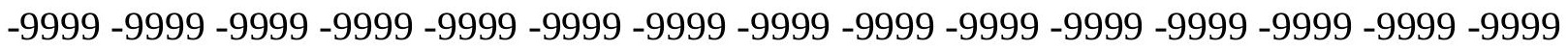

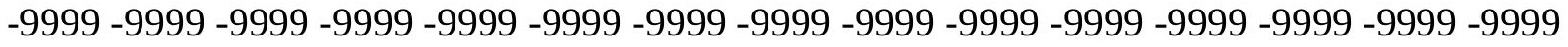

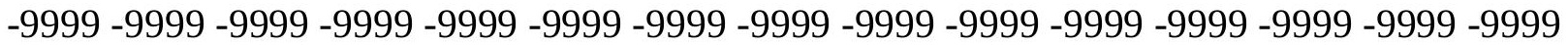
-9999 -9999 -9999 -9999 -9999 -9999 -9999 -9999 -9999 -9999 -9999 -9999 -9999 -9999 -9999 -

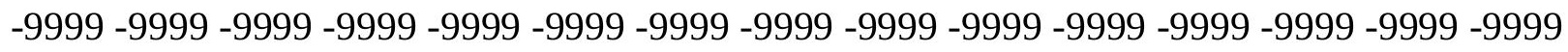

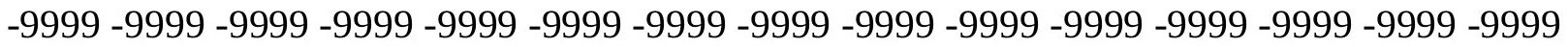
-9999 -9999 -9999 -9999 -9999 -9999 -9999 -9999 -9999 -9999 -9999 -9999 -9999 - 9999 - -999 -9999 -9999 -9999 -9999 -9999 -9999 -9999 -9999 -9999 -9999 -9999 -9999 -9999 -9999 -9999 -

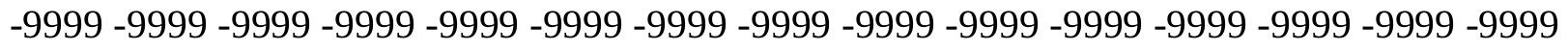

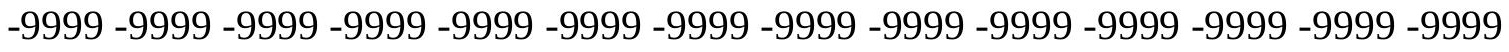
-9999 -9999 -9999 -9999 -9999 -9999 -9999 -9999 -9999 -9999 -9999 -9999 -9999 -9999 -9999 -9999 -9999 -9999 -9999 -9999 -9999 -9999 -9999 -9999-9999 -9999 -9999 -9999 -9999 -9999 -9999 -9999 -9999 -9999 -9999 -9999 -9999 -9999 -9999 -9999 -9999 -9999 -9999 -9999 -9999 -

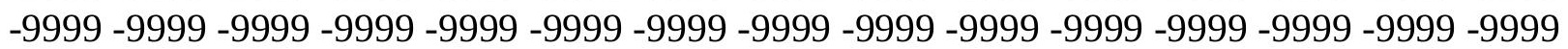


-9999 -9999 -9999 -9999 -9999 -9999 -9999 -9999 -9999 -9999 -9999 -9999 -9999 -9999 -9999 -9999 -9999 -9999 -9999 -9999 -9999 -9999 -9999 -9999 -9999 -9999 -9999 -9999 -9999 -9999 -

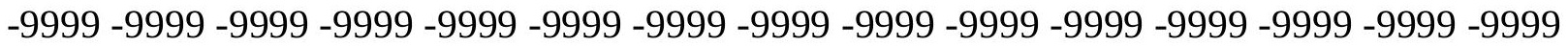
-9999 -9999 -9999 -9999 -9999 -9999 -9999 -9999 -9999 -9999 -9999 -9999 -9999 -9999 -9999 -9999 -9999 -9999 -9999 -9999 -9999 -9999 -9999 -9999-9999 -9999 -9999 -9999 -9999 -9999 -9999 -9999 -9999 -9999 -9999 -9999 -9999 -9999 -9999 -9999 -9999 -9999 -9999 -9999 -9999 -9999 -9999 -9999 -9999 -9999 -9999 -9999 -9999 -9999 -9999 -9999 -9999 -9999 -9999 -9999

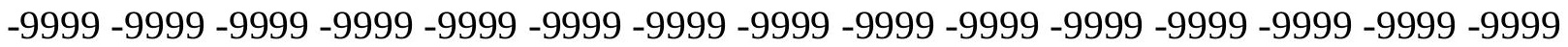

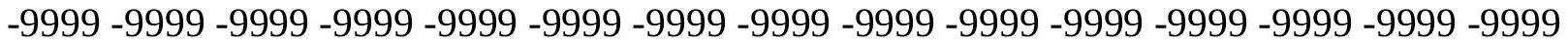
-9999 -9999 -9999 -9999 -9999 -9999 -9999 -9999 -9999 -9999 -9999 -9999 -9999 -9999 -9999 -9999 -9999 -9999 -9999 -9999 -9999 -9999 -9999 -9999 -9999 -9999 -9999 -9999 -9999 -9999 -9999 -9999 -9999 -9999 -9999 -9999 -9999 -9999 -9999 -9999 -9999 -9999 -9999 -9999 -9999 -9999 -9999 -9999 -9999 -9999 -9999 -9999 -9999 -9999 -9999 -9999 -9999 -9999 -9999 -9999 -

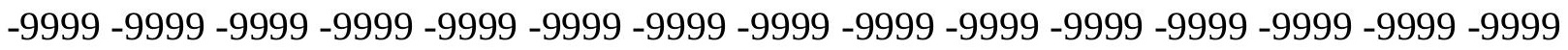
-9999 -9999 -9999 -9999 -9999 -9999 -9999 -9999 -9999 -9999 -9999 -9999 -9999 -9999 -9999 -

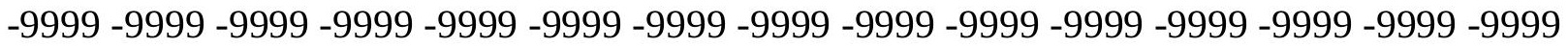
-9999 -9999 -9999 -9999 -9999 -9999 -9999 -9999 -9999 -9999 -9999 -9999 -9999 -9999 -9999 -9999 -9999 -9999 -9999 -9999 -9999 -9999 -9999 -9999 -9999 -9999 -9999 -9999 -9999 -9999 -9999 -9999 -9999 -9999 -9999 -9999 -9999 -9999 -9999 -9999 -9999 -9999 -9999 -9999 -9999 -

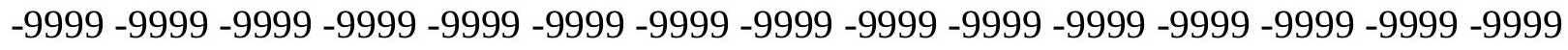

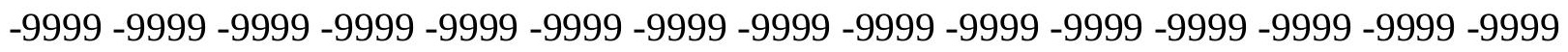
-9999 -9999 -9999 -9999 -9999 -9999 -9999 -9999 -9999 -9999 -9999 -9999 -9999 -9999 -9999 -9999 -9999 -9999 -9999 -9999 -9999 -9999 -9999 -9999 -9999 -9999 -9999 -9999 -9999 -9999 -9999 -9999 -9999 -9999 -9999 -9999 -9999 -9999 -9999 -9999 -9999 -9999 -9999 -9999 -

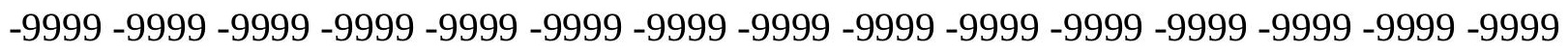
-9999 -9999 -9999 -9999 -9999 -9999 -9999 -9999 -9999 -9999 -9999 -9999 -9999 -9999 -9999 -9999 -9999 -9999 -9999 -9999 -9999 -9999 -9999 -9999 -9999 -9999 -9999 -9999 -9999 -9999 -

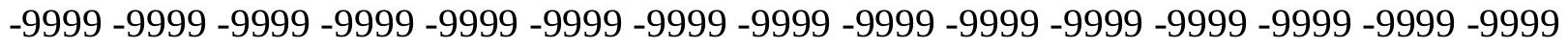
-9999 -9999 -9999 -9999 -9999 -9999 -9999 -9999 -9999 -9999 -9999 -9999 -9999 -9999 -9999 -9999 -9999 -9999 -9999 -9999 -9999 -9999 -9999 -9999 -9999 -9999 -9999 -9999 -9999 -999 -

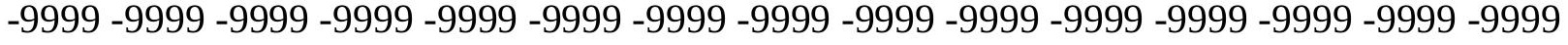
-9999 -9999 -9999 -9999 -9999 -9999 -9999 -9999 -9999 -9999 -9999 -9999 -9999 -9999 -9999 -

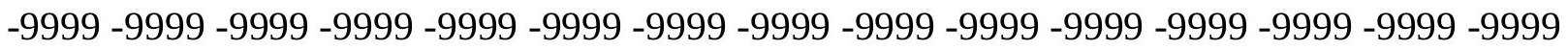

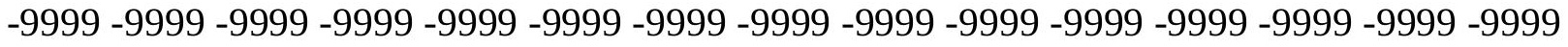

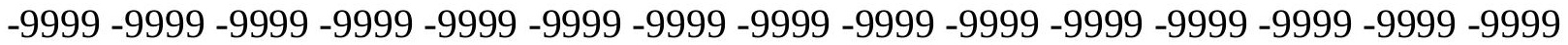

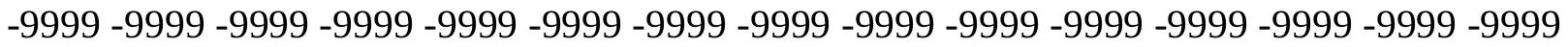

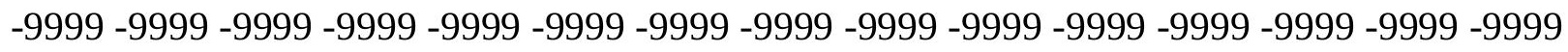

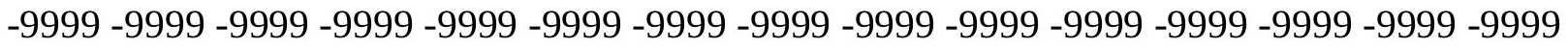

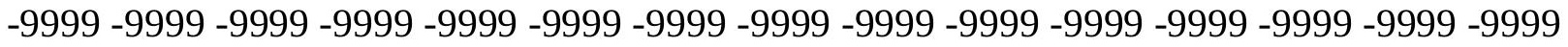
-9999 -9999 -9999 -9999 -9999 -9999 -9999 -9999 -9999 -9999 -9999 -9999 -9999 -9999 -9999 -

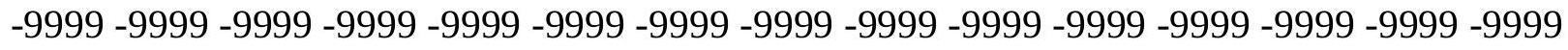

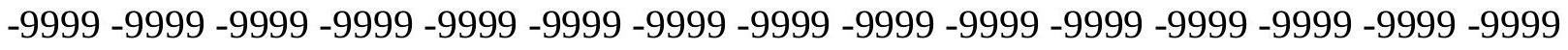
-9999 -9999 -9999 -9999 -9999 -9999 -9999 -9999 -9999 -9999 -9999 -9999 -9999 -9999 -9999 -9999 -9999 -9999 -9999 -9999 -9999 -9999 -9999 -9999-9999 -9999 -9999 -9999 -9999 -9999 -9999 -9999 -9999 -9999 -9999 -9999 -9999 -9999 -9999 -9999 -9999 -9999 -9999 -9999 -9999 -

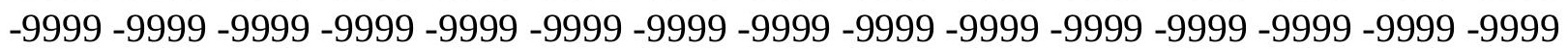


-9999 -9999 -9999 -9999 -9999 -9999 -9999 -9999 -9999 -9999 -9999 -9999 -9999 -9999 -9999 -9999 -9999 -9999 -9999 -9999 -9999 -9999 -9999 -9999 -9999 -9999 -9999 -9999 -9999 -

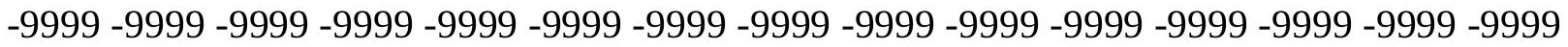
-9999 -9999 -9999 -9999 -9999 -9999 -9999 -9999 -9999 -9999 -9999 -9999 -9999 -9999 -9999 -9999 -9999 -9999 -9999 -9999 -9999 -9999 -9999 -9999 -9999 -9999 -9999 -9999 -9999 -9999 -9999 -9999 -9999 -9999 -9999 -9999 -9999 -9999 -9999 -9999 -9999 -9999 -9999 -9999 -9999 -9999 -9999 -9999 -9999 -9999 -9999 -9999 -9999 -9999 -9999 -9999 -9999 -9999 -9999 -9999

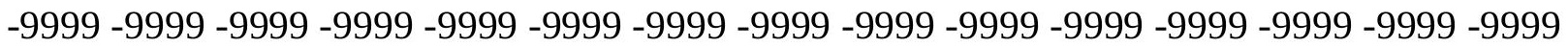

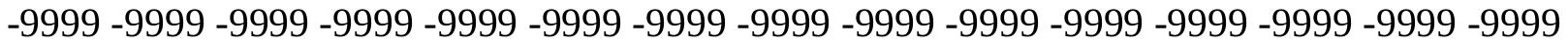
-9999 -9999 -9999 -9999 -9999 -9999 -9999 -9999 -9999 -9999 -9999 -9999 -9999 -9999 -9999 -9999 -9999 -9999 -9999 -9999 -9999 -9999 -9999 -9999 -9999 -9999 -9999 -9999 -9999 -9999 -9999 -9999 -9999 -9999 -9999 -9999 -9999 -9999 -9999 -9999 -9999 -9999 -9999 -9999 -9999 -9999 -9999 -9999 -9999 -9999 -9999 -9999 -9999 -9999 -9999 -9999 -9999 -9999 -9999 -9999 -9999 -9999 -9999 -9999 -9999 -9999 -9999 -9999 -9999 -9999 -9999 -9999 -9999 -9999 -9999 -9999 -9999 -9999 -9999 -9999 -9999 -9999 -9999 -9999 -9999 -9999 -9999 -9999 -9999 -9999 -

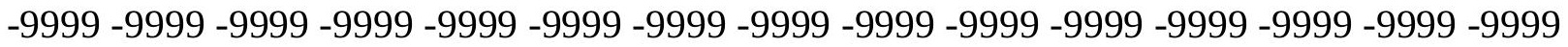
-9999 -9999 -9999 -9999 -9999 -9999 -9999 -9999 -9999 -9999 -9999 -9999 -9999 -9999 -9999 -9999 -9999 -9999 -9999 -9999 -9999 -9999 -9999 -9999 -9999 -9999 -9999 -9999 -9999 - 9999 -9999 -9999 -9999 -9999 -9999 -9999 -9999 -9999 -9999 -9999 -9999 -9999 -9999 -9999 -9999 -

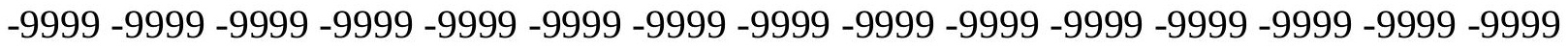

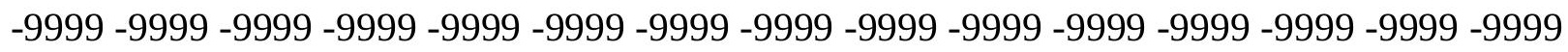

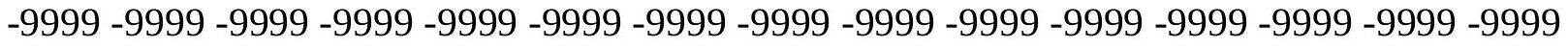
-9999 -9999 -9999 -9999 -9999 -9999 -9999 -9999 -9999 -9999 -9999 -9999 -9999 -9999 -9999 -9999 -9999 -9999 -9999 -9999 -9999 -9999 -9999 -9999 -9999 -9999 -9999 -9999 -9999 -9999 -

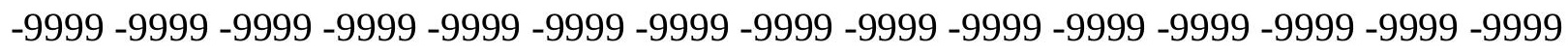
-9999 -9999 -9999 -9999 -9999 -9999 -9999 -9999 -9999 -9999 -9999 -9999 -9999 -9999 -9999 -9999 -9999 -9999 -9999 -9999 -9999 -9999 -9999 -9999 -9999 -9999 -9999 -9999 -9999 -9999 -9999 -9999 -9999 -9999 -9999 -9999 -9999 -9999 -9999 -9999 -9999 -9999 -9999 -9999 -9999 -9999 -9999 -9999 -9999 -9999 -9999 -9999 -9999 -9999 -9999 -9999 -9999 -9999 -9999 -9999 -9999 -9999 -9999 -9999 -9999 -9999 -9999 -9999 -9999 -9999 -9999 -9999 -9999 -999 -

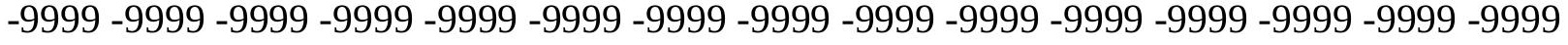
-9999 -9999 -9999 -9999 -9999 -9999 -9999 -9999 -9999 -9999 -9999 -9999 -9999 -9999 -9999 -

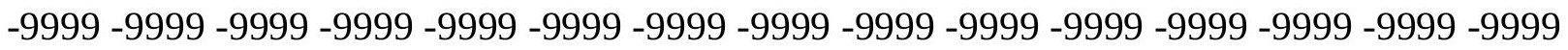

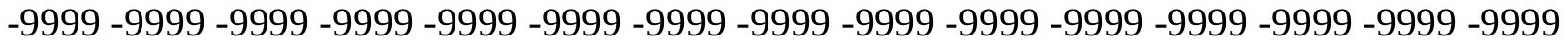

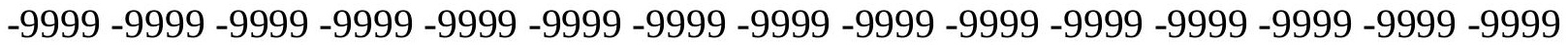

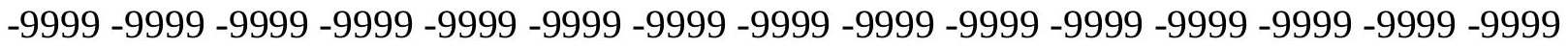

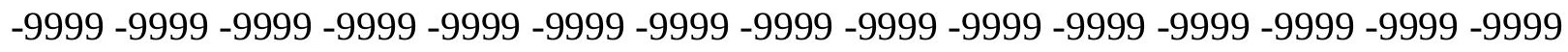

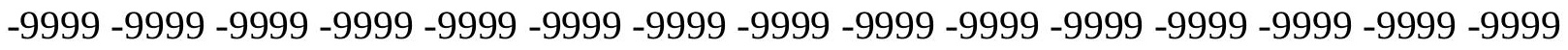

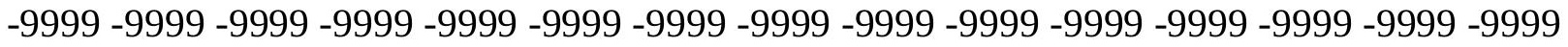
-9999 -9999 -9999 -9999 -9999 -9999 -9999 -9999 -9999 -9999 -9999 -9999 -9999 -9999 -9999 -

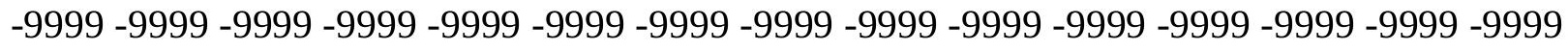

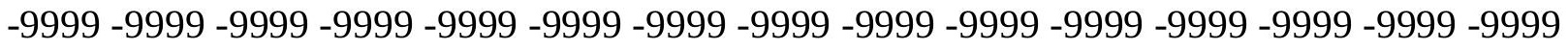
-9999 -9999 -9999 -9999 -9999 -9999 -9999 -9999 -9999 -9999 -9999 -9999 -9999 -9999 -9999 -9999 -9999 -9999 -9999 -9999 -9999 -9999 -9999 -9999-9999 -9999 -9999 -9999 -9999 -9999 -9999 -9999 -9999 -9999 -9999 -9999 -9999 -9999 -9999 -9999 -9999 -9999 -9999 -9999 -9999 -

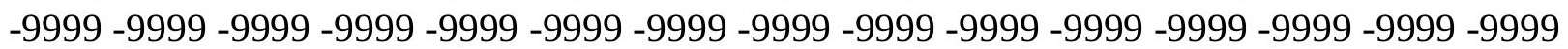


-9999 -9999 -9999 -9999 -9999 -9999 -9999 -9999 -9999 -9999 -9999 -9999 -9999 -9999 -9999 -9999 -9999 -9999 -9999 -9999 -9999 -9999 -9999 -9999 -9999 -9999 -9999 -9999 -9999 -9999 -

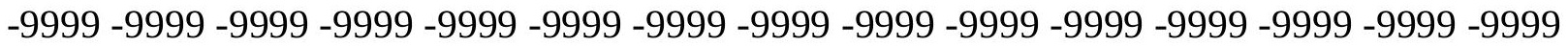
-9999 -9999 -9999 -9999 -9999 -9999 -9999 -9999 -9999 -9999 -9999 -9999 -9999 -9999 -9999 -9999 -9999 -9999 -9999 -9999 -9999 -9999 -9999 -9999-9999 -9999 -9999 -9999 -9999 -9999 -9999 -9999 -9999 -9999 -9999 -9999 -9999 -9999 -9999 -9999 -9999 -9999 -9999 -9999 -9999 -

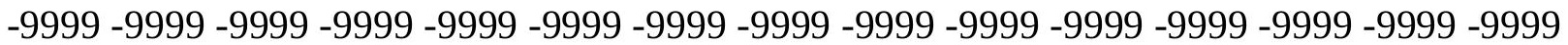
-9999 -9999 -9999 -9999 -9999 -9999 -9999 -9999 -9999 -9999 -9999 -9999 -9999 -9999 -9999 -9999 -9999 -9999 -9999 -9999 -9999 -9999 -9999 -9999 -9999 -9999 -9999 -9999 -9999 -9999 -9999 -9999 -9999 -9999 -9999 -9999 -9999 -9999 -9999 -9999 -9999 -9999 -9999 -9999 -9999 -9999 -9999 -9999 -9999 -9999 -9999 -9999 -9999 -9999 -9999 -9999 -9999 -9999 -9999 -9999 -9999 -9999 -9999 -9999 -9999 -9999 -9999 -9999 -9999 -9999 -9999 -9999 -9999 -9999 -9999 -9999 -9999 -9999 -9999 -9999 -9999 -9999 -9999 -9999 -9999 -9999 -9999 -9999 -9999 -9999 -9999 -9999 -9999 -9999 -9999 -9999 -9999 -9999 -9999 -9999 -9999 -9999 -9999 -9999 -9999 -9999 -9999 -9999 -9999 -9999 -9999 -9999 -9999 -9999 -9999 -9999 -9999 -9999 -9999 -

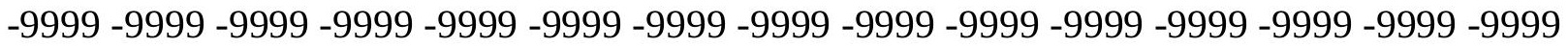
-9999 -9999 -9999 -9999 -9999 -9999 -9999 -9999 -9999 -9999 -9999 -9999 -9999 -9999 -9999 -9999 -9999 -9999 -9999 -9999 -9999 -9999 -9999 -9999 -9999 -9999 -9999 -9999 -9999 -9999 -9999 -9999 -9999 -9999 -9999 -9999 -9999 -9999 -9999 -9999 -9999 -9999 -9999 -9999 -9999 -

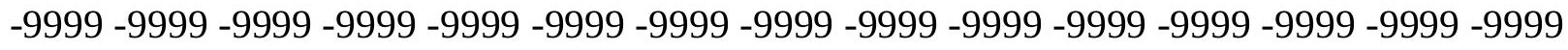

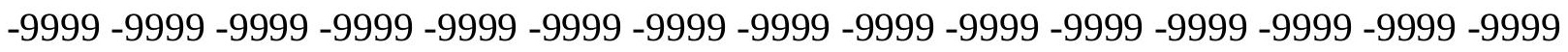
-9999 -9999 -9999 -9999 -9999 -9999 -9999 -9999 -9999 -9999 -9999 -9999 -9999 -9999 - 9999 -9999 -9999 -9999 -9999 -9999 -9999 -9999 -9999 -9999 -9999 -9999 -9999 -9999 -9999 -9999 -9999 -9999 -9999 -9999 -9999 -9999 -9999 -9999 -9999 -9999 -9999 -9999 -9999 -9999 -9999 -

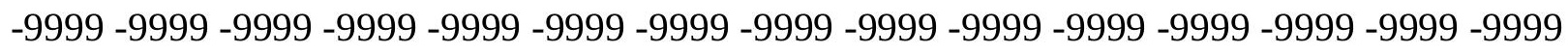
-9999 -9999 -9999 -9999 -9999 -9999 -9999 -9999 -9999 -9999 -9999 -9999 -9999 -9999 -9999 -9999 -9999 -9999 -9999 -9999 -9999 -9999 -9999 -9999 -9999 -9999 -9999 -9999 -9999 -9999 -

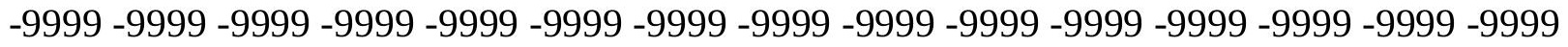
-9999 -9999 -9999 -9999 -9999 -9999 -9999 -9999 -9999 -9999 -9999 -9999 -9999 -9999 -9999 -9999 -9999 -9999 -9999 -9999 -9999 -9999 -9999 -9999 -9999 -9999 -9999 -9999 -9999 -999 -9999 -9999 -9999 -9999 -9999 -9999 -9999 -9999 -9999 -9999 -9999 -9999 -9999 -9999 -9999 -9999 -9999 -9999 -9999 -9999 -9999 -9999 -9999 -9999 -9999 -9999 -9999 -9999 -9999 -9999 -

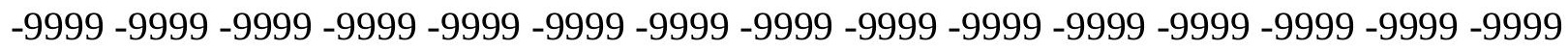

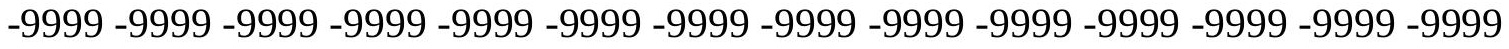
-9999 -9999 -9999 -9999 -9999 -9999 -9999 -9999 -9999 -9999 -9999 -9999 -9999 -9999 -9999

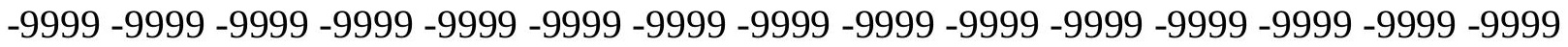

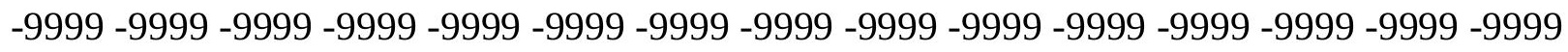

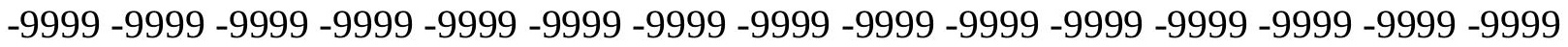

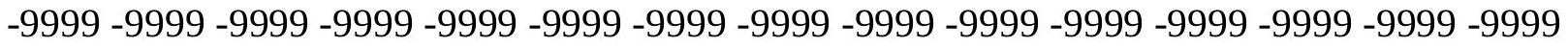
-9999 -9999 -9999 -9999 -9999 -9999 -9999 -9999 -9999 -9999 -9999 -9999 -9999 -9999 -9999 -

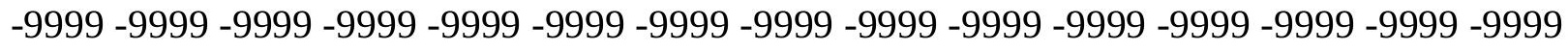

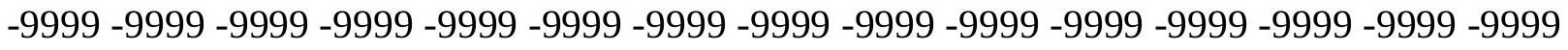
-9999 -9999 -9999 -9999 -9999 -9999 -9999 -9999 -9999 -9999 -9999 -9999 -9999 -9999 -9999 -9999 -9999 -9999 -9999 -9999 -9999 -9999 -9999 -9999-9999 -9999 -9999 -9999 -9999 -9999 -9999 -9999 -9999 -9999 -9999 -9999 -9999 -9999 -9999 -9999 -9999 -9999 -9999 -9999 -9999 -

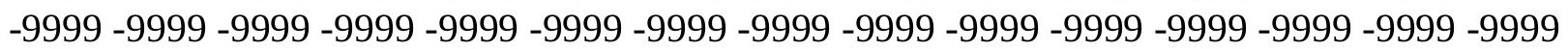


-9999 -9999 -9999 -9999 -9999 -9999 -9999 -9999 -9999 -9999 -9999 -9999 -9999 -9999 -9999 -9999 -9999 -9999 -9999 -9999 -9999 -9999 -9999 -9999 -9999 -9999 -9999 -9999 -9999 -9999 -

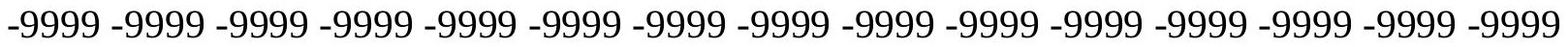
-9999 -9999 -9999 -9999 -9999 -9999 -9999 -9999 -9999 -9999 -9999 -9999 -9999 -9999 -9999 -9999 -9999 -9999 -9999 -9999 -9999 -9999 -9999 -9999-9999 -9999 -9999 -9999 -9999 -9999 -9999 -9999 -9999 -9999 -9999 -9999 -9999 -9999 -9999 -9999 -9999 -9999 -9999 -9999 -9999 -9999 -9999 -9999 -9999 -9999 -9999 -9999 -9999 -9999 -9999 -9999 -9999 -9999 -9999 -9999

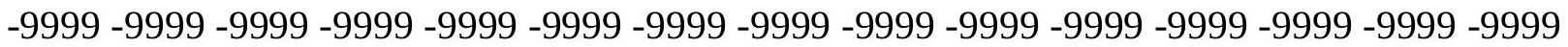

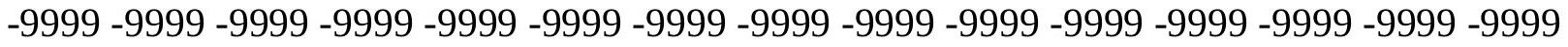
-9999 -9999 -9999 -9999 -9999 -9999 -9999 -9999 -9999 -9999 -9999 -9999 -9999 -9999 -9999 -9999 -9999 -9999 -9999 -9999 -9999 -9999 -9999 -9999 -9999 -9999 -9999 -9999 -9999 -9999 -9999 -9999 -9999 -9999 -9999 -9999 -9999 -9999 -9999 -9999 -9999 -9999 -9999 -9999 -9999 -9999 -9999 -9999 -9999 -9999 -9999 -9999 -9999 -9999 -9999 -9999 -9999 -9999 -9999 -9999 -9999 -9999 -9999 -9999 -9999 -9999 -9999 -9999 -9999 -9999 -9999 -9999 -9999 -9999 -9999 -9999 -9999 -9999 -9999 -9999 -9999 -9999 -9999 -9999 -9999 -9999 -9999 -9999 -9999

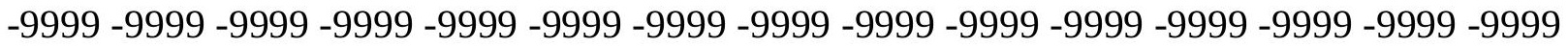
-9999 -9999 -9999 -9999 -9999 -9999 -9999 -9999 -9999 -9999 -9999 -9999 -9999 -9999 -9999 -9999 -9999 -9999 -9999 -9999 -9999 -9999 -9999 -9999 -9999 -9999 -9999 -9999 -9999 -9999 -9999 -9999 -9999 -9999 -9999 -9999 -9999 -9999 -9999 -9999 -9999 -9999 -9999 -9999 -9999 -

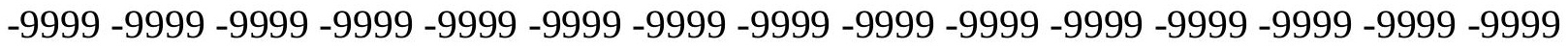

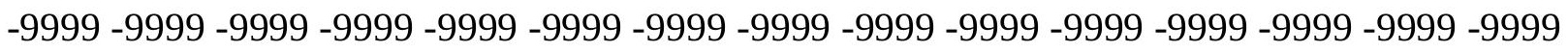
-9999 -9999 -9999 -9999 -9999 -9999 -9999 -9999 -9999 -9999 -9999 -9999 -9999 -9999 -9999 -9999 -9999 -9999 -9999 -9999 -9999 -9999 -9999 -9999 -9999 -9999 -9999 -9999 -9999 -9999 -9999 -9999 -9999 -9999 -9999 -9999 -9999 -9999 -9999 -9999 -9999 -9999 -9999 -9999 -9999 -

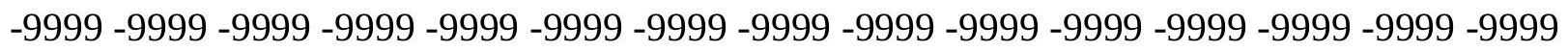
-9999 -9999 -9999 -9999 -9999 -9999 -9999 -9999 -9999 -9999 -9999 -9999 -9999 -9999 -9999 -9999 -9999 -9999 -9999 -9999 -9999 -9999 -9999 -9999 -9999 -9999 -9999 -9999 -9999 -9999 -

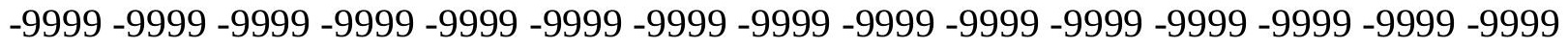
-9999 -9999 -9999 -9999 -9999 -9999 -9999 -9999 -9999 -9999 -9999 -9999 -9999 -9999 -9999 -9999 -9999 -9999 -9999 -9999 -9999 -9999 -9999 -9999 -9999 -9999 -9999 -9999 -9999 -999 -9999 -9999 -9999 -9999 -9999 -9999 -9999 -9999 -9999 -9999 -9999 -9999 -9999 -9999 -9999 -9999 -9999 -9999 -9999 -9999 -9999 -9999 -9999 -9999 -9999 -9999 -9999 -9999 -9999 -9999 -

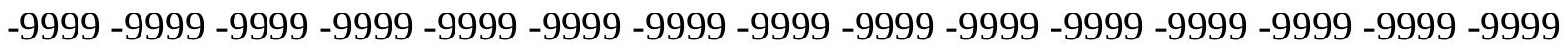

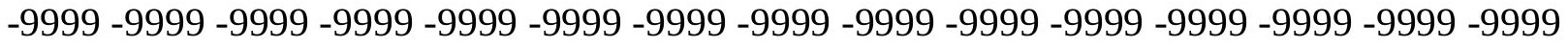

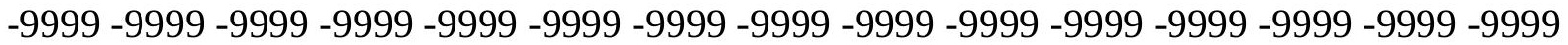

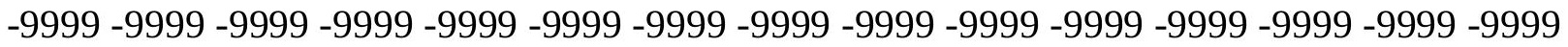

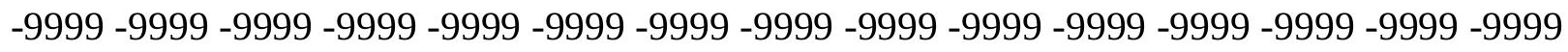

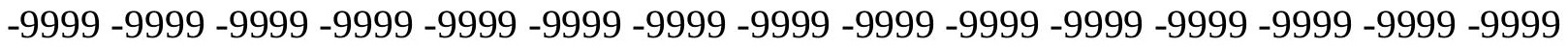
-9999 -9999 -9999 -9999 -9999 -9999 -9999 -9999 -9999 -9999 -9999 -9999 -9999 - 9999 - -999 -9999 -9999 -9999 -9999 -9999 -9999 -9999 -9999 -9999 -9999 -9999 -9999 -9999 -9999 - -999 -

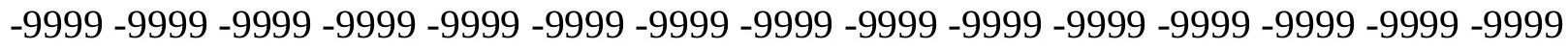

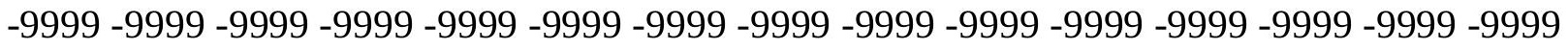
-9999 -9999 -9999 -9999 -9999 -9999 -9999 -9999 -9999 -9999 -9999 -9999 -9999 -9999 -9999 -9999 -9999 -9999 -9999 -9999 -9999 -9999 -9999 -9999-9999 -9999 -9999 -9999 -9999 -9999 -9999 -9999 -9999 -9999 -9999 -9999 -9999 -9999 -9999 -9999 -9999 -9999 -9999 -9999 -9999 -

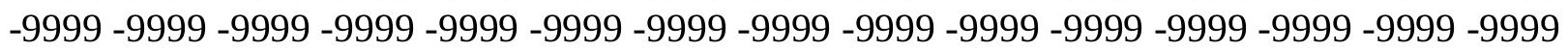


-9999 -9999 -9999 -9999 -9999 -9999 -9999 -9999 -9999 -9999 -9999 -9999 -9999 -9999 -9999 -9999 -9999 -9999 -9999 -9999 -9999 -9999 -9999 -9999 -9999 -9999 -9999 -9999 -9999 -9999 -9999 -9999 -9999 -9999 -9999 -9999 -9999 -9999 -9999 -9999 -9999 -9999 -9999 -9999 -9999 -9999 -9999 -9999 -9999 -9999 -9999 -9999 -9999 -9999 -9999 -9999 -9999 -9999 -9999 -9999 -9999 -9999 -9999 -9999 -9999 -9999 -9999 -9999 -9999 -9999 -9999 -9999 -9999 -9999 -9999 -9999 -9999 -9999 -9999 -9999 -9999 -9999 -9999 -9999 -9999 -9999 -9999 -9999 -9999 -9999 -9999 -9999 -9999 -9999 -9999 -9999 -9999 -9999 -9999 -9999 -9999 -9999 -9999 -9999 -9999 -

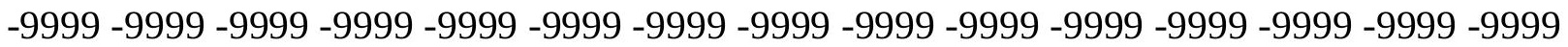
-9999 -9999 -9999 -9999 -9999 -9999 -9999 -9999 -9999 -9999 -9999 -9999 -9999 -9999 -9999 -9999 -9999 -9999 -9999 -9999 -9999 -9999 -9999 -9999 -9999 -9999 -9999 -9999 -9999 -9999 -

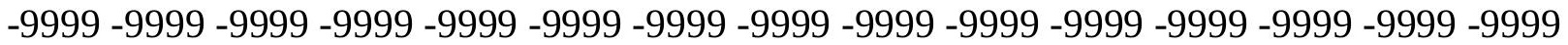
-9999 -9999 -9999 -9999 -9999 -9999 -9999 -9999 -9999 -9999 -9999 -9999 -9999 -9999 -9999 -9999 -9999 -9999 -9999 -9999 -9999 -9999 -9999 -9999 -9999 -9999 -9999 -9999 -9999 -9999 -9999 -9999 -9999 -9999 -9999 -9999 -9999 -9999 -9999 -9999 -9999 -9999 -9999 -9999 -9999 -9999 -9999 -9999 -9999 -9999 -9999 -9999 -9999 -9999 -9999 -9999 -9999 -9999 -9999 -9999

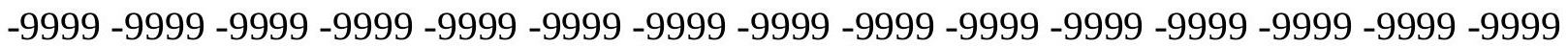
-9999 -9999 -9999 -9999 -9999 -9999 -9999 -9999 -9999 -9999 -9999 -9999 -9999 -9999 -9999 -9999 -9999 -9999 -9999 -9999 -9999 -9999 -9999 -9999 -9999 -9999 -9999 -9999 -9999 -9999 -9999 -9999 -9999 -9999 -9999 -9999 -9999 -9999 -9999 -9999 -9999 -9999 -9999 -9999 -9999 -9999 -9999 -9999 -9999 -9999 -9999 -9999 -9999 -9999 -9999 -9999 -9999 -9999 -9999 -9999 -9999 -9999 -9999 -9999 -9999 -9999 -9999 -9999 -9999 -9999 -9999 -9999 -9999 -9999 -9999 -9999 -9999 -9999 -9999 -9999 -9999 -9999 -9999 -9999 -9999 -9999 -9999 -9999 -9999 -9999 -9999 -9999 -9999 -9999 -9999 -9999 -9999 -9999 -9999 -9999 -9999 -9999 -9999 -9999 -9999 -9999 -9999 -9999 -9999 -9999 -9999 -9999 -9999 -9999 -9999 -9999 -9999 -9999 -9999 -9999 -9999 -9999 -9999 -9999 -9999 -9999 -9999 -9999 -9999 -9999 -9999 -9999 -9999 -9999 -9999 -9999 -9999 -9999 -9999 -9999 -9999 -9999 -9999 -9999 -9999 -9999 -9999 -9999 -9999 -9999 -9999 -9999 -9999 -9999 -9999 -9999 -9999 -9999 -9999 -9999 -9999 -9999 -9999 -9999 -9999 -9999 -9999 -9999 -9999 -9999 -9999 -9999 -9999 -9999 -9999 -9999 -9999 -9999 -9999

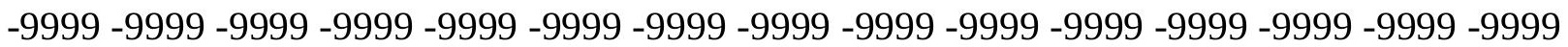
-9999 -9999 -9999 -9999 -9999 -9999 -9999 -9999 -9999 -9999 -9999 -9999 -9999 -9999 -9999 -9999 -9999 -9999 -9999 -9999 -9999 -9999 -9999 -9999 -9999 -9999 -9999 -9999 -9999 -9999 -

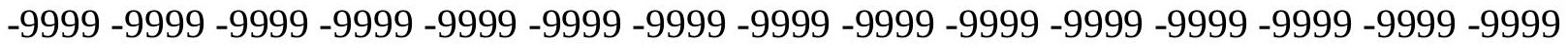
-9999 -9999 -9999 -9999 -9999 -9999 -9999 -9999 -9999 -9999 -9999 -9999 -9999 -9999 -9999 -9999 -9999 -9999 -9999 -9999 -9999 -9999 -9999 -9999 -9999 -9999 -9999 -9999 -9999 -9999 -9999 -9999 -9999 -9999 -9999 -9999 -9999 -9999 -9999 -9999 -9999 -9999 -9999 -9999 -9999 -9999 -9999 -9999 -9999 -9999 -9999 -9999 -9999 -9999 -9999 -9999 -9999 -9999 -9999 -9999 -9999 -9999 -9999 -9999 -9999 -9999 -9999 -9999 -9999 -9999 -9999 -9999 -9999 -9999 -9999

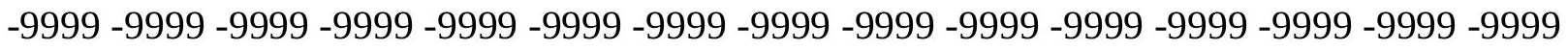
-9999 -9999 -9999 -9999 -9999 -9999 -9999 -9999 -9999 -9999 -9999 -9999 -9999 -9999 -9999 -9999 -9999 -9999 -9999 -9999 -9999 -9999 -9999 -9999 -9999 -9999 -9999 -9999 -9999 -9999 -9999 -9999 -9999 -9999 -9999 -9999 -9999 -9999 -9999 -9999 -9999 -9999 -9999 -9999 -9999 -999 -9999 -9999 -9999 -9999 -9999 -9999 -9999 -9999 -9999 -9999 -9999 -9999 -9999 -9999 -9999 -9999 -9999 -9999 -9999 -9999 -9999 -9999 -9999 -9999 -9999 -9999 -9999 -9999 -9999 -9999 -9999 -9999 -9999 -9999 -9999 -9999 -9999 -9999 -9999 -9999 -9999 -9999 -9999 -9999 -9999 -9999 -9999 -9999 -9999 -9999 -9999 -9999 -9999 -9999 -9999 -9999 -9999 -9999 -9999 -9999 -9999 -9999 -9999 -9999 -9999 -9999 -9999 -9999 -9999 -9999 -9999 -9999 -9999 -9999 
-9999 -9999 -9999 -9999 -9999 -9999 -9999 -9999 -9999 -9999 -9999 -9999 -9999 -9999 -9999 -9999 -9999 -9999 -9999 -9999 -9999 -9999 -9999 -9999 -9999 -9999 -9999 -9999 -9999 -9999 -

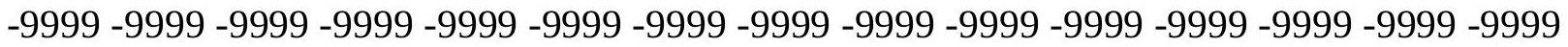
-9999 -9999 -9999 -9999 -9999 -9999 -9999 -9999 -9999 -9999 -9999 -9999 -9999 -9999 -9999 -9999 -9999 -9999 -9999 -9999 -9999 -9999 -9999 -9999-9999 -9999 -9999 -9999 -9999 -9999 -9999 -9999 -9999 -9999 -9999 -9999 -9999 -9999 -9999 -9999 -9999 -9999 -9999 -9999 -9999 -9999 -9999 -9999 -9999 -9999 -9999 -9999 -9999 -9999 -9999 -9999 -9999 -9999 -9999 -9999

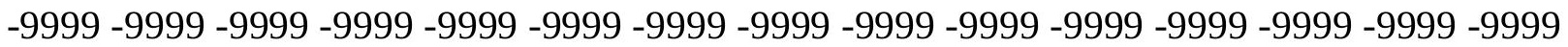

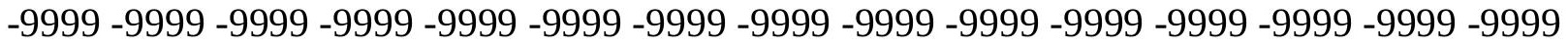
-9999 -9999 -9999 -9999 -9999 -9999 -9999 -9999 -9999 -9999 -9999 -9999 -9999 -9999 -9999 -9999 -9999 -9999 -9999 -9999 -9999 -9999 -9999 -9999 -9999 -9999 -9999 -9999 -9999 -9999 -9999 -9999 -9999 -9999 -9999 -9999 -9999 -9999 -9999 -9999 -9999 -9999 -9999 -9999 -9999 -9999 -9999 -9999 -9999 -9999 -9999 -9999 -9999 -9999 -9999 -9999 -9999 -9999 -9999 -9999 -

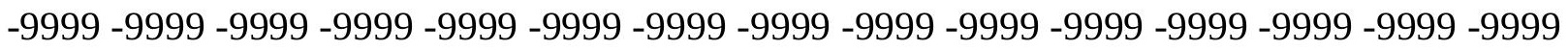
-9999 -9999 -9999 -9999 -9999 -9999 -9999 -9999 -9999 -9999 -9999 -9999 -9999 -9999 -9999 -

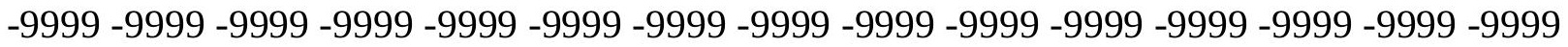
-9999 -9999 -9999 -9999 -9999 -9999 -9999 -9999 -9999 -9999 -9999 -9999 -9999 -9999 -9999 -9999 -9999 -9999 -9999 -9999 -9999 -9999 -9999 -9999 -9999 -9999 -9999 -9999 -9999 -9999 -9999 -9999 -9999 -9999 -9999 -9999 -9999 -9999 -9999 -9999 -9999 -9999 -9999 -9999 -9999 -

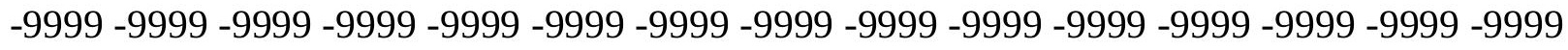

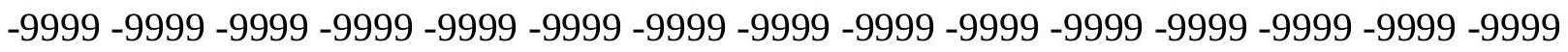

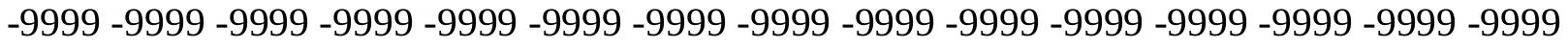
-9999 -9999 -9999 -9999 -9999 -9999 -9999 -9999 -9999 -9999 -9999 -9999 -9999 -9999 -9999 -9999 -9999 -9999 -9999 -9999 -9999 -9999 -9999 -9999 -9999 -9999 -9999 -9999 -9999 -9999 -

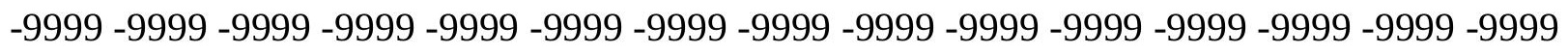
-9999 -9999 -9999 -9999 -9999 -9999 -9999 -9999 -9999 -9999 -9999 -9999 -9999 -9999 -9999 -9999 -9999 -9999 -9999 -9999 -9999 -9999 -9999 -9999 -9999 -9999 -9999 -9999 -9999 -

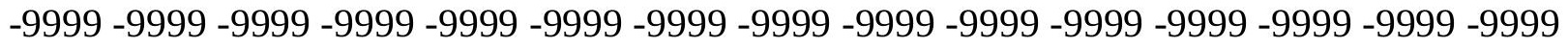
-9999 -9999 -9999 -9999 -9999 -9999 -9999 -9999 -9999 -9999 -9999 -9999 -9999 -9999 -9999 -9999 -9999 -9999 -9999 -9999 -9999 -9999 -9999 -9999 -9999 -9999 -9999 -9999 -9999 -999 -

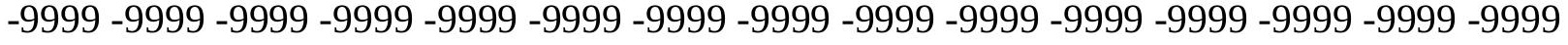
-9999 -9999 -9999 -9999 -9999 -9999 -9999 -9999 -9999 -9999 -9999 -9999 -9999 -9999 -9999 -

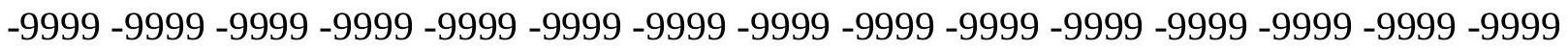

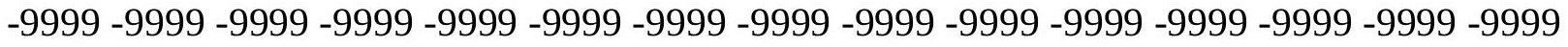

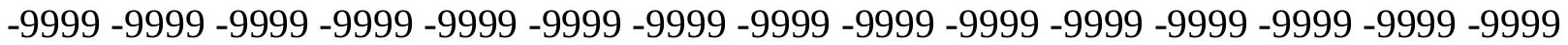
-9999 -9999 -9999 -9999 -9999 -9999 -9999 -9999 -9999 -9999 -9999 -9999 -9999 -9999 -9999

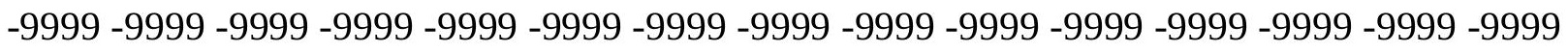

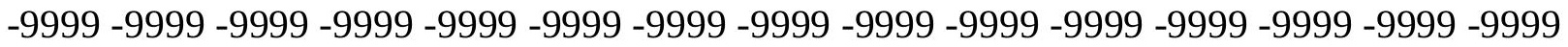
-9999 -9999 -9999 -9999 -9999 -9999 -9999 -9999 -9999 -9999 -9999 -9999 -9999 - 9999 - -999 -9999 -9999 -9999 -9999 -9999 -9999 -9999 -9999 -9999 -9999 -9999 -9999 -9999 -9999 -9999 -

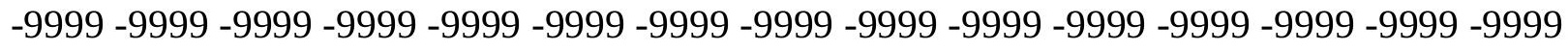

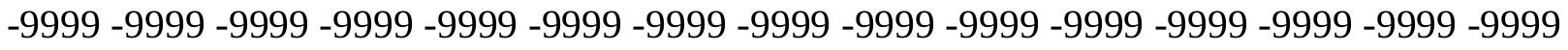
-9999 -9999 -9999 -9999 -9999 -9999 -9999 -9999 -9999 -9999 -9999 -9999 -9999 -9999 -9999 -9999 -9999 -9999 -9999 -9999 -9999 -9999 -9999 -9999-9999 -9999 -9999 -9999 -9999 -9999 -9999 -9999 -9999 -9999 -9999 -9999 -9999 -9999 -9999 -9999 -9999 -9999 -9999 -9999 -9999 -

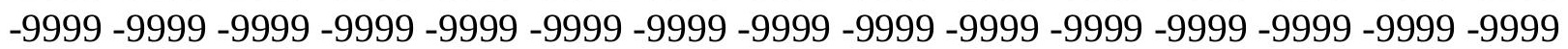


-9999 -9999 -9999 -9999 -9999 -9999 -9999 -9999 -9999 -9999 -9999 -9999 -9999 -9999 -9999 -9999 -9999 -9999 -9999 -9999 -9999 -9999 -9999 -9999 -9999 -9999 -9999 -9999 -9999 -9999 -9999 -9999 -9999 -9999 -9999 -9999 -9999 -9999 -9999 -9999 -9999 -9999 -9999 -9999 - 9999 -9999 -9999 -9999 -9999 -9999 -9999 -9999 -9999 -9999 -9999 -9999 -9999 -9999 -9999 -9999 -9999 -9999 -9999 -9999 -9999 -9999 -9999 -9999 -9999 -9999 -9999 -9999 -9999 -9999 - -9999 -9999 -9999 -9999 -9999 -9999 -9999 -9999 -9999 -9999 -9999 -9999 -9999 -9999 -9999 -9999 -9999 -9999 -9999 -9999 -9999 -9999 -9999 -9999 -9999 -9999 -9999 -9999 -9999 -9999

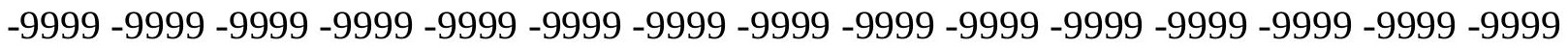

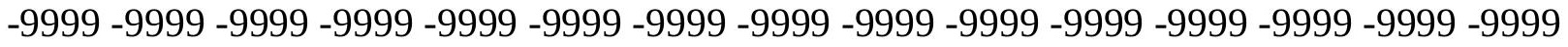
-9999 -9999 -9999 -9999 -9999 -9999 -9999 -9999 -9999 -9999 -9999 -9999 -9999 -9999 -9999

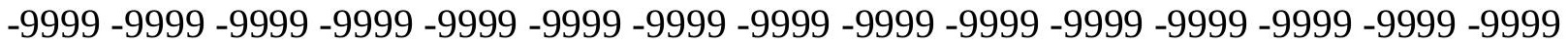
-9999 -9999 -9999 -9999 -9999 -9999 -9999 -9999 -9999 -9999 -9999 -9999 -9999 -9999 -9999 -9999 -9999 -9999 -9999 -9999 -9999 -9999 -9999 -9999 -9999 -9999 -9999 -9999 -9999 -9999 -9999 -9999 -9999 -9999 -9999 -9999 -9999 -9999 -9999 -9999 -9999 -9999 -9999 -9999 - -9999 -9999 -9999 -9999 -9999 -9999 -9999 -9999 -9999 -9999 -9999 -9999 -9999 -9999 -9999 -9999

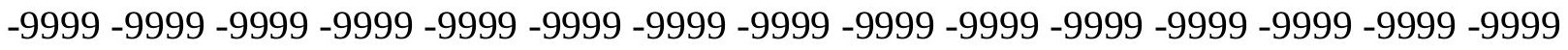
-9999 -9999 -9999 -9999 -9999 -9999 -9999 -9999 -9999 -9999 -9999 -9999 -9999 -9999 -9999 -9999 -9999 -9999 -9999 -9999 -9999 -9999 -9999 -9999 -9999 -9999 -9999 -9999 -9999 -9999 -9999 -9999 -9999 -9999 -9999 -9999 -9999 -9999 -9999 -9999 -9999 -9999 -9999 -9999 -9999 -

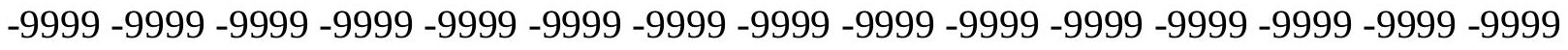
-9999 -9999 -9999 -9999 -9999 -9999 -9999 -9999 -9999 -9999 -9999 -9999 -9999 -9999 -9999 -999 -9999 -9999 -9999 -9999 -9999 -9999 -9999 -9999 -9999 -9999 -9999 -9999 -9999 -9999 -9999 -9999 -9999 -9999 -9999 -9999 -9999 -9999 -9999 -9999 -9999 -9999 -9999 -9999 -9999 -9999 -9999 -9999 -9999 -9999 -9999 -9999 -9999 -9999 -9999 -9999 -9999 -9999 -9999 -9999 -9999 -9999 -9999 -9999 -9999 -9999 -9999 -9999 -9999 -9999 -9999 -9999 -9999 -9999 -9999 -9999 -9999 -9999 -9999 -9999 -9999 -9999 -9999 -9999 -9999 -9999 -9999 -9999 -9999 -9999 -9999 -9999 -9999 -9999 -9999 -9999 -9999 -9999 -9999 -9999 -9999 -9999 -9999 -9999 -9999 -9999 -9999 -9999 -9999 -9999 -9999 -9999 -9999 -9999 -9999 -9999 -9999 -9999 -9999 -9999 -9999 -9999 -9999 -9999 -9999 -9999 -9999 -9999 -9999 -9999 -9999 -9999 -9999 -9999 -9999 -9999 -9999 -9999 -9999 -9999 -9999 -9999 -9999 -9999 -9999 -9999 -9999 -9999 -9999 -9999 -999 -9999 -9999 -9999 -9999 -9999 -9999 -9999 -9999 -9999 -9999 -9999 -9999 -9999 -9999 -9999 -9999 -9999 -9999 -9999 -9999 -9999 -9999 -9999 -9999 -9999 -9999 -9999 -9999 -9999 -

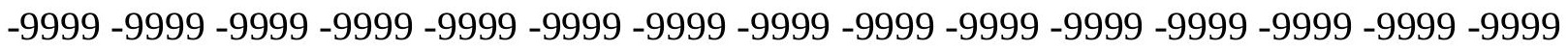

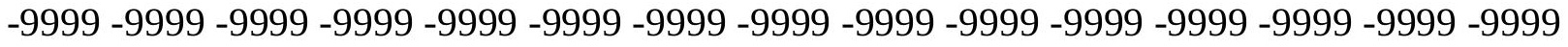

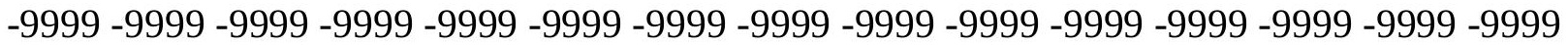
-9999 -9999 -9999 -9999 -9999 -9999 -9999 -9999 -9999 -9999 -9999 -9999 -9999 -9999 -9999 -

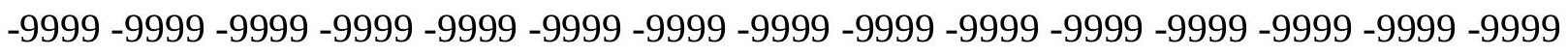

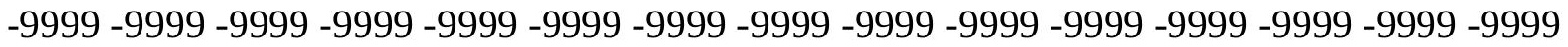

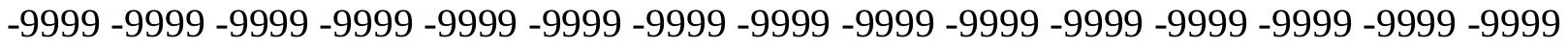
-9999 -9999 -9999 -9999 -9999 -9999 -9999 -9999 -9999 -9999 -9999 -9999 -9999 -9999 -9999 -

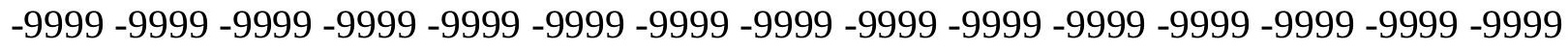

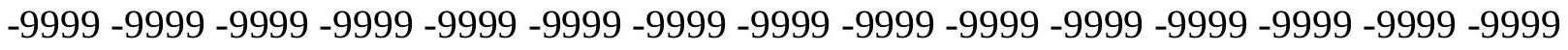
-9999 -9999 -9999 -9999 -9999 -9999 -9999 -9999 -9999 -9999 -9999 -9999 -9999 -9999 -9999 -9999 -9999 -9999 -9999 -9999 -9999 -9999 -9999 -9999-9999 -9999 -9999 -9999 -9999 -9999 -9999 -9999 -9999 -9999 -9999 -9999 -9999 -9999 -9999 -9999 -9999 -9999 -9999 -9999 -9999 -

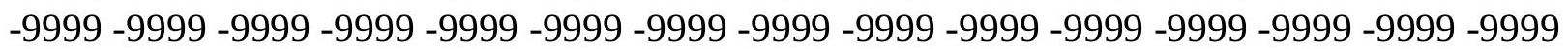


-9999 -9999 -9999 -9999 -9999 -9999 -9999 -9999 -9999 -9999 -9999 -9999 -9999 -9999 -9999 -9999 -9999 -9999 -9999 -9999 -9999 -9999 -9999 -9999 -9999 -9999 -9999 -9999 -9999 -9999 -

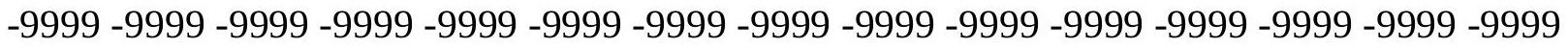
-9999 -9999 -9999 -9999 -9999 -9999 -9999 -9999 -9999 -9999 -9999 -9999 -9999 -9999 -9999 -9999 -9999 -9999 -9999 -9999 -9999 -9999 -9999 -9999-9999 -9999 -9999 -9999 -9999 -9999 -9999 -9999 -9999 -9999 -9999 -9999 -9999 -9999 -9999 -9999 -9999 -9999 -9999 -9999 -9999 -9999 -9999 -9999 -9999 -9999 -9999 -9999 -9999 -9999 -9999 -9999 -9999 -9999 -9999 -9999

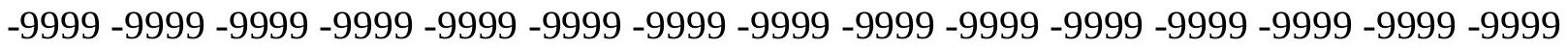

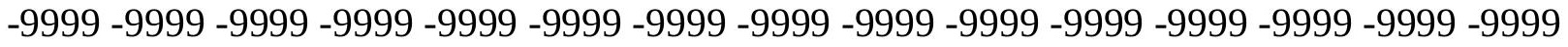
-9999 -9999 -9999 -9999 -9999 -9999 -9999 -9999 -9999 -9999 -9999 -9999 -9999 -9999 -9999 -9999 -9999 -9999 -9999 -9999 -9999 -9999 -9999 -9999 -9999 -9999 -9999 -9999 -9999 -9999 -9999 -9999 -9999 -9999 -9999 -9999 -9999 -9999 -9999 -9999 -9999 -9999 -9999 -9999 -9999 -9999 -9999 -9999 -9999 -9999 -9999 -9999 -9999 -9999 -9999 -9999 -9999 -9999 -9999 -9999 -9999 -9999 -9999 -9999 -9999 -9999 -9999 -9999 -9999 -9999 -9999 -9999 -9999 - 9999 -9999 -9999 -9999 -9999 -9999 -9999 -9999 -9999 -9999 -9999 -9999 -9999 -9999 -9999 -9999

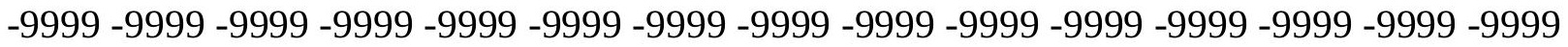
-9999 -9999 -9999 -9999 -9999 -9999 -9999 -9999 -9999 -9999 -9999 -9999 -9999 -9999 -9999 -9999 -9999 -9999 -9999 -9999 -9999 -9999 -9999 -9999 -9999 -9999 -9999 -9999 -9999 -9999 -9999 -9999 -9999 -9999 -9999 -9999 -9999 -9999 -9999 -9999 -9999 -9999 -9999 -9999 -9999 -

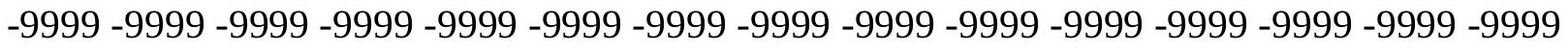

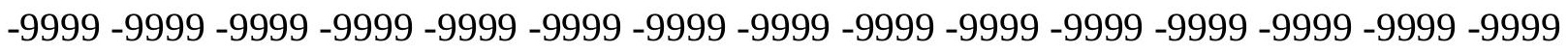
-9999 -9999 -9999 -9999 -9999 -9999 -9999 -9999 -9999 -9999 -9999 -9999 -9999 -9999 -9999 -9999 -9999 -9999 -9999 -9999 -9999 -9999 -9999 -9999 -9999 -9999 -9999 -9999 -9999 -9999 -9999 -9999 -9999 -9999 -9999 -9999 -9999 -9999 -9999 -9999 -9999 -9999 -9999 -9999 -9999 -

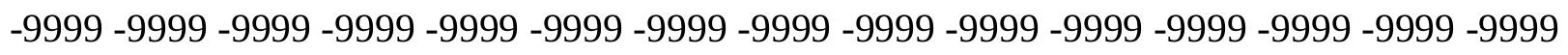
-9999 -9999 -9999 -9999 -9999 -9999 -9999 -9999 -9999 -9999 -9999 -9999 -9999 -9999 -9999 -9999 -9999 -9999 -9999 -9999 -9999 -9999 -9999 -9999 -9999 -9999 -9999 -9999 -9999 -9999 -

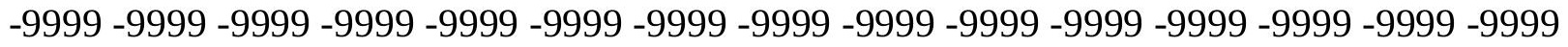
-9999 -9999 -9999 -9999 -9999 -9999 -9999 -9999 -9999 -9999 -9999 -9999 -9999 -9999 -9999 -9999 -9999 -9999 -9999 -9999 -9999 -9999 -9999 -9999 -9999 -9999 -9999 -9999 -9999 -999 -9999 -9999 -9999 -9999 -9999 -9999 -9999 -9999 -9999 -9999 -9999 -9999 -9999 -9999 -9999 -9999 -9999 -9999 -9999 -9999 -9999 -9999 -9999 -9999 -9999 -9999 -9999 -9999 -9999 -9999 -

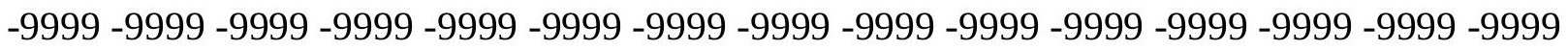

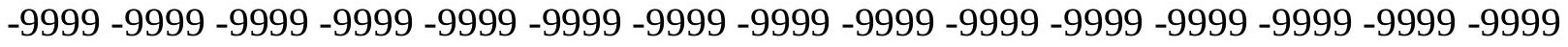

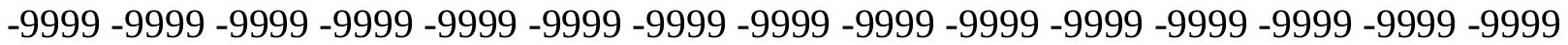

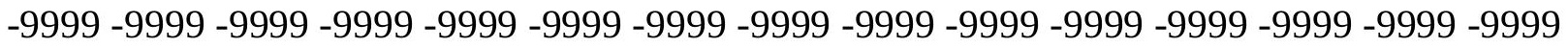

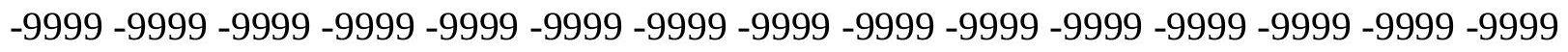

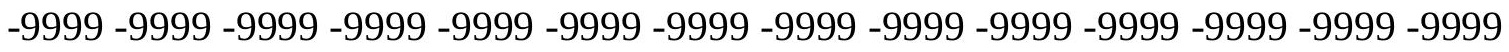
-9999 -9999 -9999 -9999 -9999 -9999 -9999 -9999 -9999 -9999 -9999 -9999 -9999 -9999 -9999 -9999 -9999 -9999 -9999 -9999 -9999 -9999 -9999 -9999 -9999 -9999 -9999 -9999 -9999 -9999 -

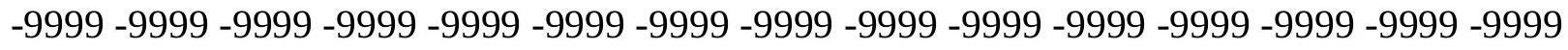

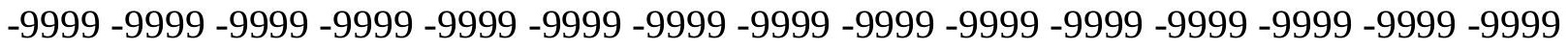
-9999 -9999 -9999 -9999 -9999 -9999 -9999 -9999 -9999 -9999 -9999 -9999 -9999 -9999 -9999 -9999 -9999 -9999 -9999 -9999 -9999 -9999 -9999 -9999-9999 -9999 -9999 -9999 -9999 -9999 -9999 -9999 -9999 -9999 -9999 -9999 -9999 -9999 -9999 -9999 -9999 -9999 -9999 -9999 -9999 -

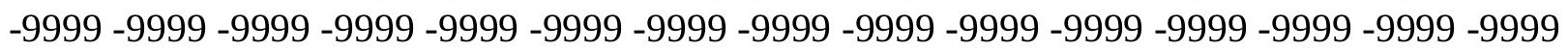


-9999 -9999 -9999 -9999 -9999 -9999 -9999 -9999 -9999 -9999 -9999 -9999 -9999 -9999 -9999 -9999 -9999 -9999 -9999 -9999 -9999 -9999 -9999 -9999 -9999 -9999 -9999 -9999 -9999 -9999 -9999 -9999 -9999 -9999 -9999 -9999 -9999 -9999 -9999 -9999 -9999 -9999 -9999 -9999 - 9999 -9999 -9999 -9999 -9999 -9999 -9999 -9999 -9999 -9999 -9999 -9999 -9999 -9999 -9999 -9999 -9999 -9999 -9999 -9999 -9999 -9999 -9999 -9999 -9999 -9999 -9999 -9999 -9999 -9999 -9999 -9999 -9999 -9999 -9999 -9999 -9999 -9999 -9999 -9999 -9999 -9999 -9999 -9999 -9999 -9999 -9999 -9999 -9999 -9999 -9999 -9999 -9999 -9999 -9999 -9999 -9999 -9999 -9999 -9999 -9999

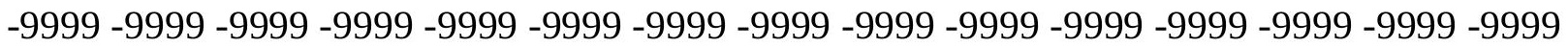
-9999 -9999 -9999 -9999 -9999 -9999 -9999 -9999 -9999 -9999 -9999 -9999 -9999 -9999 -9999 -9999 -9999 -9999 -9999 -9999 -9999 -9999 -9999 -9999 -9999 -9999 -9999 -9999 -9999 -9999

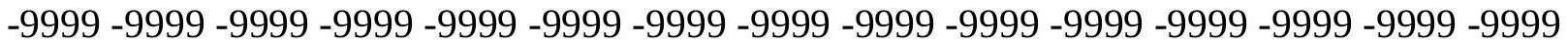
-9999 -9999 -9999 -9999 -9999 -9999 -9999 -9999 -9999 -9999 -9999 -9999 -9999 -9999 -9999 -9999 -9999 -9999 -9999 -9999 -9999 -9999 -9999 -9999 -9999 -9999 -9999 -9999 -9999 -9999 -

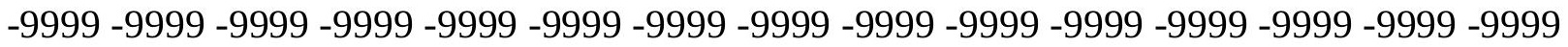
-9999 -9999 -9999 -9999 -9999 -9999 -9999 -9999 -9999 -9999 -9999 -9999 -9999 -9999 -9999

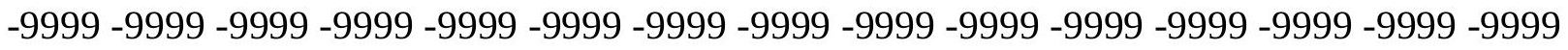
-9999 -9999 -9999 -9999 -9999 -9999 -9999 -9999 -9999 -9999 -9999 -9999 -9999 -9999 -9999 -9999 -9999 -9999 -9999 -9999 -9999 -9999 -9999 -9999 -9999 -9999 -9999 -9999 -9999 - -999 -9999 -9999 -9999 -9999 -9999 -9999 -9999 -9999 -9999 -9999 -9999 -9999 -9999 -9999 -9999 -9999 -9999 -9999 -9999 -9999 -9999 -9999 -9999 -9999 -9999 -9999 -9999 -9999 -9999 -9999 -9999 -9999 -9999 -9999 -9999 -9999 -9999 -9999 -9999 -9999 -9999 -9999 -9999 -9999 -9999 -999 -9999 -9999 -9999 -9999 -9999 -9999 -9999 -9999 -9999 -9999 -9999 -9999 -9999 -9999 -9999 -9999 -9999 -9999 -9999 -9999 -9999 -9999 -9999 -9999 -9999 -9999 -9999 -9999 -9999 -9999 -9999 -9999 -9999 -9999 -9999 -9999 -9999 -9999 -9999 -9999 -9999 -9999 -9999 -9999 -9999 -9999 -9999 -9999 -9999 -9999 -9999 -9999 -9999 -9999 -9999 -9999 -9999 -9999 -9999 -9999 -9999 -9999 -9999 -9999 -9999 -9999 -9999 -9999 -9999 -9999 -9999 -9999 -9999 -9999 -9999 -9999 -9999 -9999 -9999 -9999 -9999 -9999 -9999 -9999 -9999 -9999 -9999 -9999 -9999 -9999 -9999 -9999 -9999 -9999 -9999 -9999 -9999 -9999 -9999 -9999 -9999 -9999 -9999 -9999 -9999 -9999 -9999 -9999 -9999 -9999 -9999 -9999 -9999 -9999 -9999 -9999 -9999 -9999 -9999 -9999 -9999 -9999 -9999 -9999 -9999 -9999 -9999 -9999 -9999 -9999 -9999 -9999 -9999 -9999 -999 -9999 -9999 -9999 -9999 -9999 -9999 -9999 -9999 -9999 -9999 -9999 -9999 -9999 -9999 -9999 -9999 -9999 -9999 -9999 -9999 -9999 -9999 -9999 -9999 -9999 -9999 -9999 -9999 -9999 -9999 -

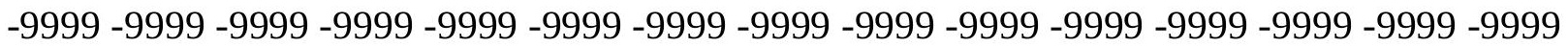

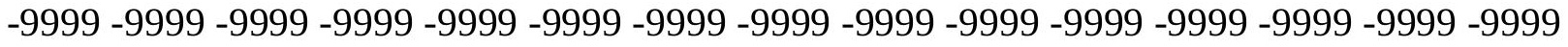

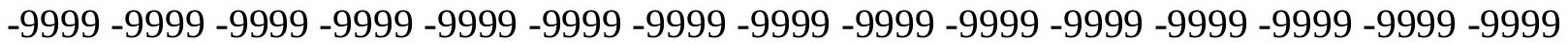
-9999 -9999 -9999 -9999 -9999 -9999 -9999 -9999 -9999 -9999 -9999 -9999 -9999 -9999 -9999

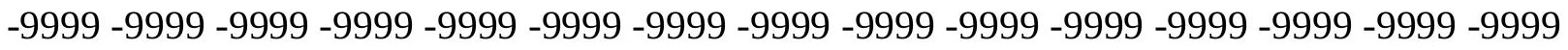

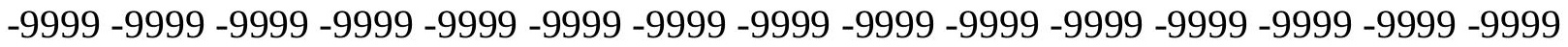

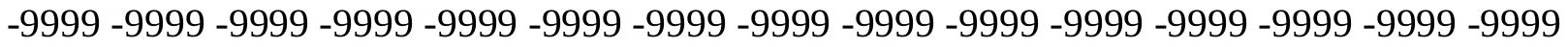
-9999 -9999 -9999 -9999 -9999 -9999 -9999 -9999 -9999 -9999 -9999 -9999 -9999 -9999 -9999 -

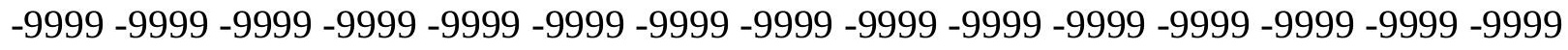

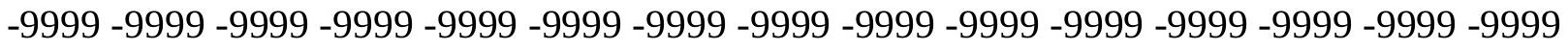
-9999 -9999 -9999 -9999 -9999 -9999 -9999 -9999 -9999 -9999 -9999 -9999 -9999 -9999 -9999 -9999 -9999 -9999 -9999 -9999 -9999 -9999 -9999 -9999 -9999 -9999 -9999 -9999 - -9999 -9999 -9999 -9999 -9999 -9999 -9999 -9999 -9999 -9999 -9999 -9999 -9999 -9999 -9999 -9999 -

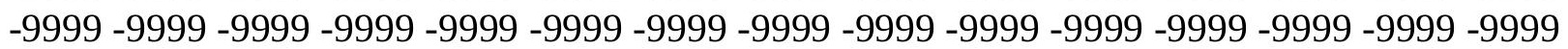


-9999 -9999 -9999 -9999 -9999 -9999 -9999 -9999 -9999 -9999 -9999 -9999 -9999 -9999 -9999 -9999 -9999 -9999 -9999 -9999 -9999 -9999 -9999 -9999 -9999 -9999 -9999 -9999 -9999 -9999 -9999 -9999 -9999 -9999 -9999 -9999 -9999 -9999 -9999 -9999 -9999 -9999 -9999 -9999 - 9999 -9999 -9999 -9999 -9999 -9999 -9999 -9999 -9999 -9999 -9999 -9999 -9999 -9999 -9999 -9999 -9999 -9999 -9999 -9999 -9999 -9999 -9999 -9999 -9999-9999 -9999 -9999 -9999 -9999 -9999 -9999 -9999 -9999 -9999 -9999 -9999 -9999 -9999 -9999 -9999 -9999 -9999 -9999 -9999 -9999 -9999 -9999 -9999 -9999 -9999 -9999 -9999 -9999 -9999 -9999 -9999 -9999 -9999 -9999 -9999

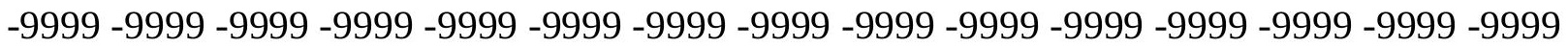

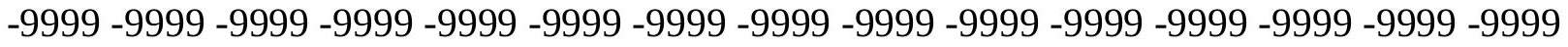
-9999 -9999 -9999 -9999 -9999 -9999 -9999 -9999 -9999 -9999 -9999 -9999 -9999 -9999 -9999

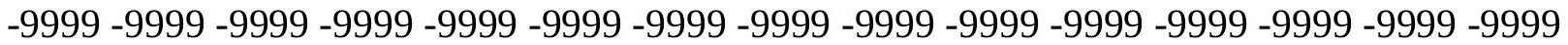
-9999 -9999 -9999 -9999 -9999 -9999 -9999 -9999 -9999 -9999 -9999 -9999 -9999 -9999 -9999 -9999 -9999 -9999 -9999 -9999 -9999 -9999 -9999 -9999 -9999 -9999 -9999 -9999 -9999 -9999 -

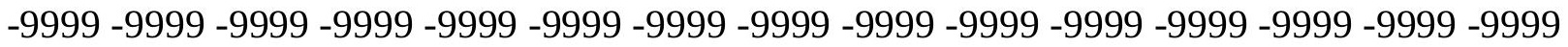
-9999 -9999 -9999 -9999 -9999 -9999 -9999 -9999 -9999 -9999 -9999 -9999 -9999 -9999 -9999

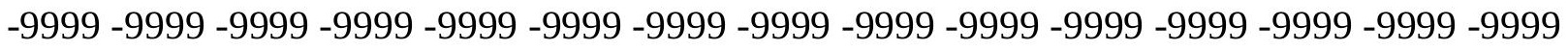
-9999 -9999 -9999 -9999 -9999 -9999 -9999 -9999 -9999 -9999 -9999 -9999 -9999 -9999 -9999 -9999 -9999 -9999 -9999 -9999 -9999 -9999 -9999 -9999 -9999 -9999 -9999 -9999 -9999 -9999 -9999 -9999 -9999 -9999 -9999 -9999 -9999 -9999 -9999 -9999 -9999 -9999 -9999 -9999 -9999 -9999 -9999 -9999 -9999 -9999 -9999 -9999 -9999 -9999 -9999 -9999 -9999 -9999 -9999 -9999 -9999 -9999 -9999 -9999 -9999 -9999 -9999 -9999 -9999 -9999 -9999 -9999 -9999 -9999 -9999 -999 -9999 -9999 -9999 -9999 -9999 -9999 -9999 -9999 -9999 -9999 -9999 -9999 -9999 -9999 -9999 -9999 -9999 -9999 -9999 -9999 -9999 -9999 -9999 -9999 -9999 -9999 -9999 -9999 -9999 -9999 -9999 -9999 -9999 -9999 -9999 -9999 -9999 -9999 -9999 -9999 -9999 -9999 -9999 -9999 -9999 -9999 -9999 -9999 -9999 -9999 -9999 -9999 -9999 -9999 -9999 -9999 -9999 -9999 -9999 -9999 -9999 -9999 -9999 -9999 -9999 -9999 -9999 -9999 -9999 -9999 -9999 -9999 -9999 -9999 -9999 -9999 -9999 -9999 -9999 -9999 -9999 -9999 -9999 -9999 -9999 -9999 -9999 -9999 -9999 -9999 -9999 -9999 -9999 -9999 -9999 -9999 -9999 -9999 -9999 -9999 -9999 -9999 -9999 -9999 -9999 -9999 -9999 -9999 -9999 -9999 -9999 -9999 -9999 -9999 -9999 -9999 -9999 -9999 -9999 -9999 -9999 -9999 -9999 -9999 -9999 -9999 -9999 -9999 -9999 -9999 -9999 -9999 -9999 -999 -9999 -9999 -9999 -9999 -9999 -9999 -9999 -9999 -9999 -9999 -9999 -9999 -9999 -9999 -9999 -9999 -9999 -9999 -9999 -9999 -9999 -9999 -9999 -9999 -9999 -9999 -9999 -9999 -9999 -9999 -

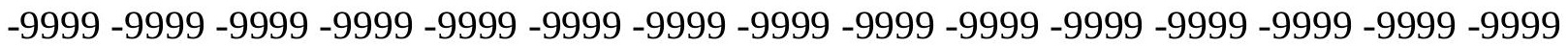

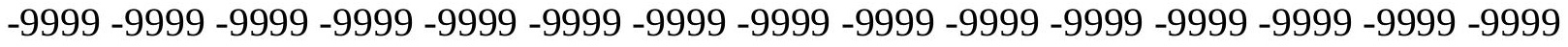

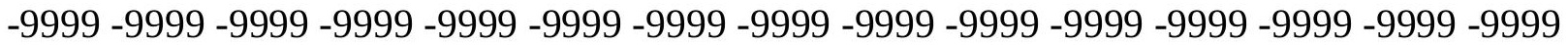
-9999 -9999 -9999 -9999 -9999 -9999 -9999 -9999 -9999 -9999 -9999 -9999 -9999 -9999 -9999

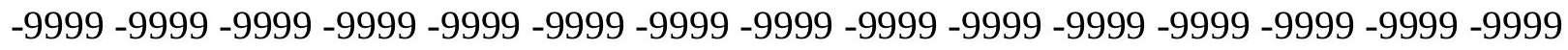

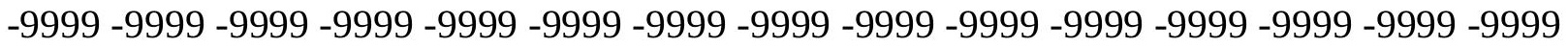
-9999 -9999 -9999 -9999 -9999 -9999 -9999 -9999 -9999 -9999 -9999 -9999 -9999 -9999 -9999 -9999 -9999 -9999 -9999 -9999 -9999 -9999 -9999 -9999 -9999 -9999 -9999 -9999 -9999 -9999 -

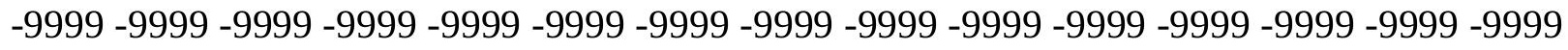

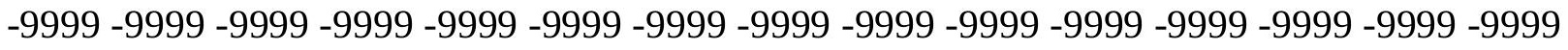
-9999 -9999 -9999 -9999 -9999 -9999 -9999 -9999 -9999 -9999 -9999 -9999 -9999 -9999 -9999 -9999 -9999 -9999 -9999 -9999 -9999 -9999 -9999 -9999-9999 -9999 -9999 -9999 -9999 -9999 -9999 -9999 -9999 -9999 -9999 -9999 -9999 -9999 -9999 -9999 -9999 -9999 -9999 -9999 -9999 -

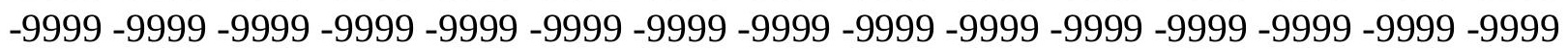


-9999 -9999 -9999 -9999 -9999 -9999 -9999 -9999 -9999 -9999 -9999 -9999 -9999 -9999 -9999 -9999 -9999 -9999 -9999 -9999 -9999 -9999 -9999 -9999 -9999 -9999 -9999 -9999 -9999 -9999 -9999 -9999 -9999 -9999 -9999 -9999 -9999 -9999 -9999 -9999 -9999 -9999 -9999 -9999 - 9999 -9999 -9999 -9999 -9999 -9999 -9999 -9999 -9999 -9999 -9999 -9999 -9999 -9999 -9999

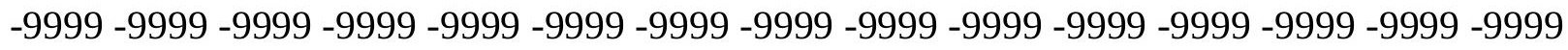
-9999 -9999 -9999 -9999 -9999 -9999 -9999 -9999 -9999 -9999 -9999 -9999 -9999 -9999 -9999 -9999 -9999 -9999 -9999 -9999 -9999 -9999 -9999 -9999 -9999 -9999 -9999 -9999 -9999 -9999

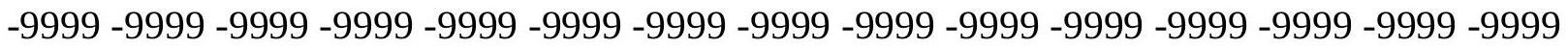

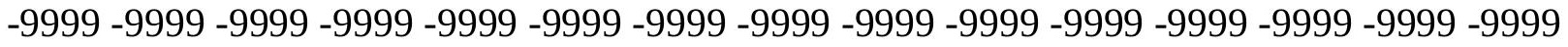
-9999 -9999 -9999 -9999 -9999 -9999 -9999 -9999 -9999 -9999 -9999 -9999 -9999 -9999 -9999 -9999 -9999 -9999 -9999 -9999 -9999 -9999 -9999 -9999 -9999 -9999 -9999 -9999 -9999 -9999 -9999 -9999 -9999 -9999 -9999 -9999 -9999 -9999 -9999 -9999 -9999 -9999 -9999 -9999 -9999 -9999 -9999 -9999 -9999 -9999 -9999 -9999 -9999 -9999 -9999 -9999 -9999 -9999 -9999 -9999 -

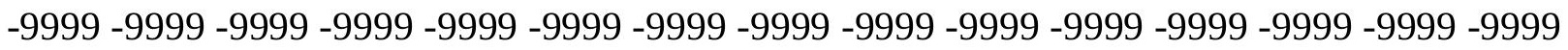
-9999 -9999 -9999 -9999 -9999 -9999 -9999 -9999 -9999 -9999 -9999 -9999 -9999 -9999 -9999 -

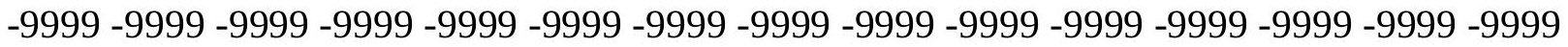
-9999 -9999 -9999 -9999 -9999 -9999 -9999 -9999 -9999 -9999 -9999 -9999 -9999 -9999 -9999 -9999 -9999 -9999 -9999 -9999 -9999 -9999 -9999 -9999 -9999 -9999 -9999 -9999 -9999 -9999 -9999 -9999 -9999 -9999 -9999 -9999 -9999 -9999 -9999 -9999 -9999 -9999 -9999 -9999 -9999 -

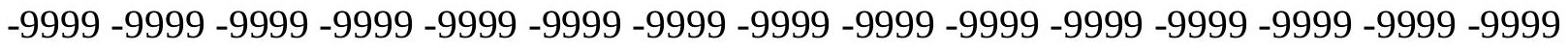
-9999 -9999 -9999 -9999 -9999 -9999 -9999 -9999 -9999 -9999 -9999 -9999 -9999 -9999 -9999

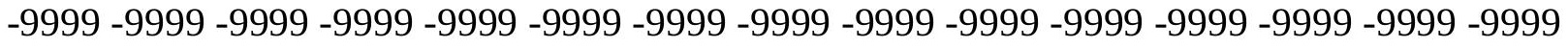
-9999 -9999 -9999 -9999 -9999 -9999 -9999 -9999 -9999 -9999 -9999 -9999 -9999 -9999 -9999 -9999 -9999 -9999 -9999 -9999 -9999 -9999 -9999 -9999 -9999 -9999 -9999 -9999 -9999 -9999 -9999 -9999 -9999 -9999 -9999 -9999 -9999 -9999 -9999 -9999 -9999 -9999 -9999 -9999 -9999 -9999 -9999 -9999 -9999 -9999 -9999 -9999 -9999 -9999 -9999 -9999 -9999 -9999 -9999 -9999 -9999 -9999 -9999 -9999 -9999 -9999 -9999 -9999 -9999 -9999 -9999 -9999 -9999 -9999 -9999 -9999 -9999 -9999 -9999 -9999 -9999 -9999 -9999 -9999 -9999 -9999 -9999 -9999 -9999 -9999 -9999 -9999 -9999 -9999 -9999 -9999 -9999 -9999 -9999 -9999 -9999 -9999 -9999 -9999 -9999 -9999 -9999 -9999 -9999 -9999 -9999 -9999 -9999 -9999 -9999 -9999 -9999 -9999 -9999 -9999 -9999 -9999 -9999 -9999 -9999 -9999 -9999 -9999 -9999 -9999 -9999 -9999 -9999 -9999 -9999 -9999 -9999 -9999 -9999 -9999 -9999 -9999 -9999 -9999 -9999 -9999 -9999 -9999 -9999 -

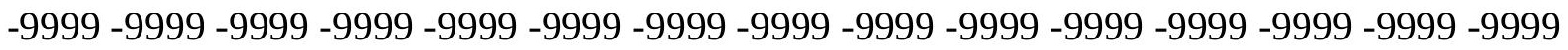

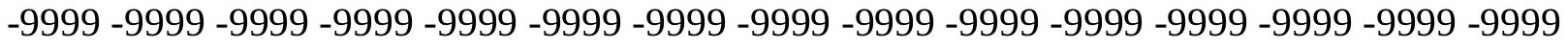
-9999 -9999 -9999 -9999 -9999 -9999 -9999 -9999 -9999 -9999 -9999 -9999 -9999 -9999 -9999 -

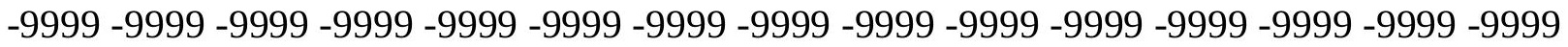

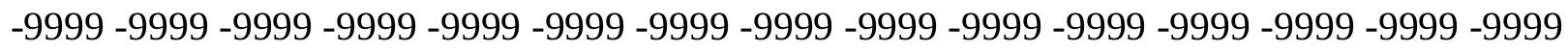

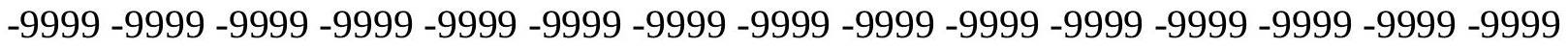

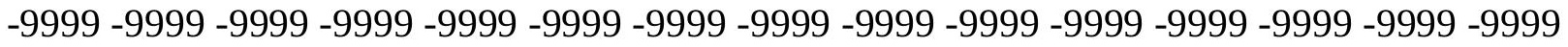
-9999 -9999 -9999 -9999 -9999 -9999 -9999 -9999 -9999 -9999 -9999 -9999 -9999 -9999 -9999 -

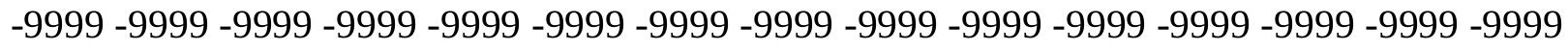

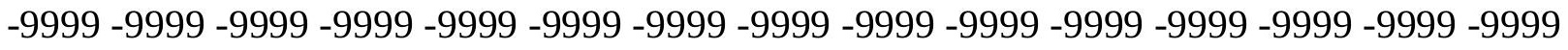
-9999 -9999 -9999 -9999 -9999 -9999 -9999 -9999 -9999 -9999 -9999 -9999 -9999 -9999 -9999 -9999 -9999 -9999 -9999 -9999 -9999 -9999 -9999 -9999-9999 -9999 -9999 -9999 -9999 -9999 -9999 -9999 -9999 -9999 -9999 -9999 -9999 -9999 -9999 -9999 -9999 -9999 -9999 -9999 -9999 -

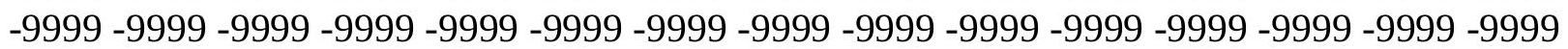


-9999 -9999 -9999 -9999 -9999 -9999 -9999 -9999 -9999 -9999 -9999 -9999 -9999 -9999 -9999 -9999 -9999 -9999 -9999 -9999 -9999 -9999 -9999 -9999 -9999 -9999 -9999 -9999 -9999 -9999 -9999 -9999 -9999 -9999 -9999 -9999 -9999 -9999 -9999 -9999 -9999 -9999 -9999 -9999 - 9999 -9999 -9999 -9999 -9999 -9999 -9999 -9999 -9999 -9999 -9999 -9999 -9999 -9999 -9999 -9999 -9999 -9999 -9999 -9999 -9999 -9999 -9999 -9999 -9999 -9999 -9999 -9999 -9999 -9999 -9999 -9999 -9999 -9999 -9999 -9999 -9999 -9999 -9999 -9999 -9999 -9999 -9999 -9999 -9999 -9999 -9999 -9999 -9999 -9999 -9999 -9999 -9999 -9999 -9999 -9999 -9999 -9999 -9999 -9999 -9999

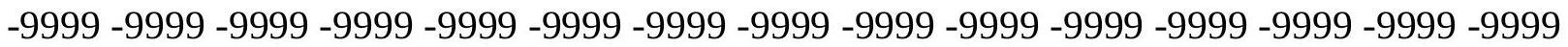

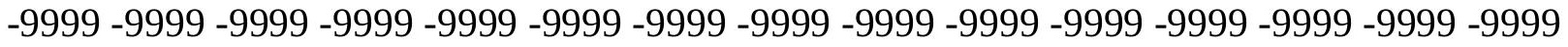
-9999 -9999 -9999 -9999 -9999 -9999 -9999 -9999 -9999 -9999 -9999 -9999 -9999 -9999 -9999 -9999 -9999 -9999 -9999 -9999 -9999 -9999 -9999 -9999 -9999 -9999 -9999 -9999 -9999 -9999 -9999 -9999 -9999 -9999 -9999 -9999 -9999 -9999 -9999 -9999 -9999 -9999 -9999 -9999 -9999 -9999 -9999 -9999 -9999 -9999 -9999 -9999 -9999 -9999 -9999 -9999 -9999 -9999 -9999 -9999 -9999 -9999 -9999 -9999 -9999 -9999 -9999 -9999 -9999 -9999 -9999 -9999 -9999 -9999 -9999 -9999 -9999 -9999 -9999 -9999 -9999 -9999 -9999 -9999 -9999 -9999 -9999 -9999 -9999 -

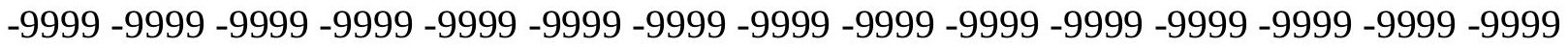
-9999 -9999 -9999 -9999 -9999 -9999 -9999 -9999 -9999 -9999 -9999 -9999 -9999 -9999 -9999 -9999 -9999 -9999 -9999 -9999 -9999 -9999 -9999 -9999 -9999 -9999 -9999 -9999 -9999 -9999 -9999 -9999 -9999 -9999 -9999 -9999 -9999 -9999 -9999 -9999 -9999 -9999 -9999 -9999 -9999 -9999 -9999 -9999 -9999 -9999 -9999 -9999 -9999 -9999 -9999 -9999 -9999 -9999 -9999 -9999 -9999 -9999 -9999 -9999 -9999 -9999 -9999 -9999 -9999 -9999 -9999 -9999 -9999 -9999 -9999 -999 -9999 -9999 -9999 -9999 -9999 -9999 -9999 -9999 -9999 -9999 -9999 -9999 -9999 -9999 -9999 -9999 -9999 -9999 -9999 -9999 -9999 -9999 -9999 -9999 -9999 -9999 -9999 -9999 -9999 -9999 -9999 -9999 -9999 -9999 -9999 -9999 -9999 -9999 -9999 -9999 -9999 -9999 -9999 -9999 -9999 -9999 -9999 -9999 -9999 -9999 -9999 -9999 -9999 -9999 -9999 -9999 -9999 -9999 -9999 -9999 -9999 -9999 -9999 -9999 -9999 -9999 -9999 -9999 -9999 -9999 -9999 -9999 -9999 -9999 -9999 -9999 -9999 -9999 -9999 -9999 -9999 -9999 -9999 -9999 -9999 -9999 -9999 -9999 -9999 -9999 -9999 -9999 -9999 -9999 -9999 -9999 -9999 -9999 -9999 -9999 -9999 -9999 -9999 -9999 -9999 -9999 -9999 -9999 -9999 -9999 -9999 -9999 -9999 -9999 -9999 -9999 -9999 -9999 -9999 -9999 -9999 -9999 -9999 -9999 -9999 -9999 -9999 -9999 -9999 -9999 -9999 -9999 -9999 -9999 -999 -9999 -9999 -9999 -9999 -9999 -9999 -9999 -9999 -9999 -9999 -9999 -9999 -9999 -9999 -9999 -9999 -9999 -9999 -9999 -9999 -9999 -9999 -9999 -9999 -9999 -9999 -9999 -9999 -9999 -9999 -

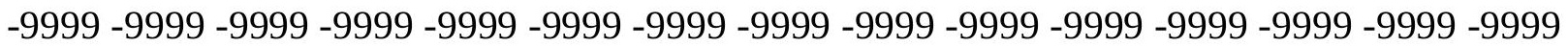

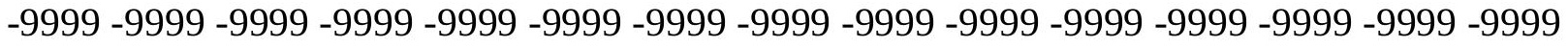

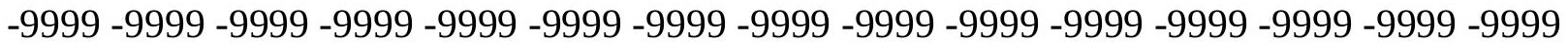
-9999 -9999 -9999 -9999 -9999 -9999 -9999 -9999 -9999 -9999 -9999 -9999 -9999 -9999 -9999 -9999 -9999 -9999 -9999 -9999 -9999 -9999 -9999 -9999 -9999 -9999 -9999 -9999 -9999 -

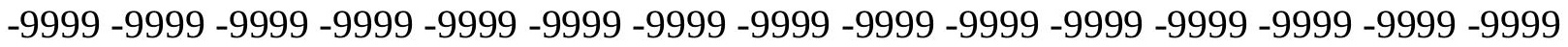
-9999 -9999 -9999 -9999 -9999 -9999 -9999 -9999 -9999 -9999 -9999 -9999 -9999 -9999 -9999 -9999 -9999 -9999 -9999 -9999 -9999 -9999 -9999 -9999 -9999 -9999 -9999 -9999 -9999 -9999 -

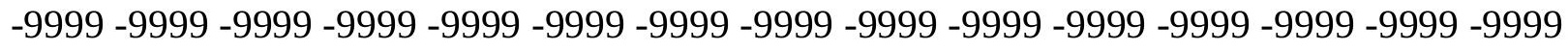

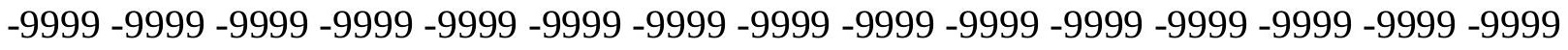
-9999 -9999 -9999 -9999 -9999 -9999 -9999 -9999 -9999 -9999 -9999 -9999 -9999 -9999 -9999 -9999 -9999 -9999 -9999 -9999 -9999 -9999 -9999 -9999-9999 -9999 -9999 -9999 -9999 -9999 -9999 -9999 -9999 -9999 -9999 -9999 -9999 -9999 -9999 -9999 -9999 -9999 -9999 -9999 -9999 -

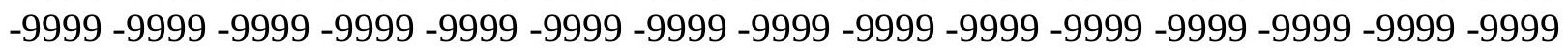


-9999 -9999 -9999 -9999 -9999 -9999 -9999 -9999 -9999 -9999 -9999 -9999 -9999 -9999 -9999 -9999 -9999 -9999 -9999 -9999 -9999 -9999 -9999 -9999 -9999 -9999 -9999 -9999 -9999 -9999 -

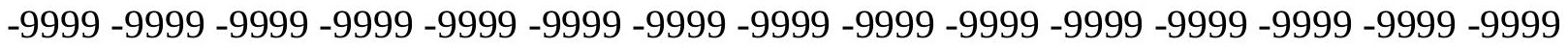
-9999 -9999 -9999 -9999 -9999 -9999 -9999 -9999 -9999 -9999 -9999 -9999 -9999 -9999 -9999 -9999 -9999 -9999 -9999 -9999 -9999 -9999 -9999 -9999-9999 -9999 -9999 -9999 -9999 -9999 -9999 -9999 -9999 -9999 -9999 -9999 -9999 -9999 -9999 -9999 -9999 -9999 -9999 -9999 -9999 -9999 -9999 -9999 -9999 -9999 -9999 -9999 -9999 -9999 -9999 -9999 -9999 -9999 -9999 -9999

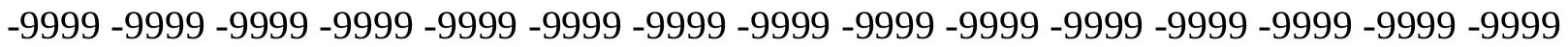

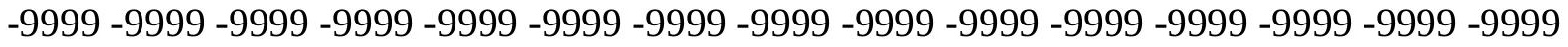
-9999 -9999 -9999 -9999 -9999 -9999 -9999 -9999 -9999 -9999 -9999 -9999 -9999 -9999 -9999 -9999 -9999 -9999 -9999 -9999 -9999 -9999 -9999 -9999 -9999 -9999 -9999 -9999 -9999 -9999 -9999 -9999 -9999 -9999 -9999 -9999 -9999 -9999 -9999 -9999 -9999 -9999 -9999 -9999 -9999 -9999 -9999 -9999 -9999 -9999 -9999 -9999 -9999 -9999 -9999 -9999 -9999 -9999 -9999 -9999 -9999 -9999 -9999 -9999 -9999 -9999 -9999 -9999 -9999 -9999 -9999 -9999 -9999 -9999 -9999 -9999 -9999 -9999 -9999 -9999 -9999 -9999 -9999 -9999 -9999 -9999 -9999 -9999 -9999 -9999 -

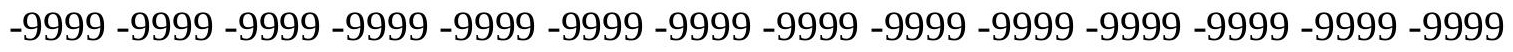
-9999 -9999 -9999 -9999 -9999 -9999 -9999 -9999 -9999 -9999 -9999 -9999 -9999 -9999 -9999 -9999 -9999 -9999 -9999 -9999 -9999 -9999 -9999 -9999 -9999 -9999 -9999 -9999 -9999 -9999 -9999 -9999 -9999 -9999 -9999 -9999 -9999 -9999 -9999 -9999 -9999 -9999 -9999 -9999 -9999 -

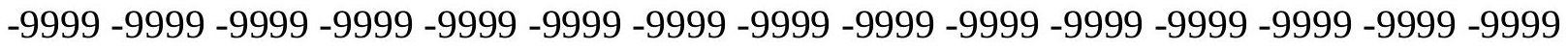

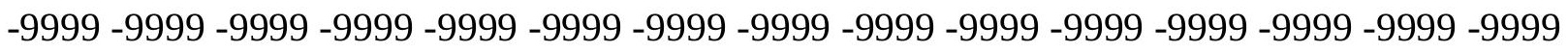
-9999 -9999 -9999 -9999 -9999 -9999 -9999 -9999 -9999 -9999 -9999 -9999 -9999 -9999 - 9999 -9999 -9999 -9999 -9999 -9999 -9999 -9999 -9999 -9999 -9999 -9999 -9999 -9999 -9999 -9999 -9999 -9999 -9999 -9999 -9999 -9999 -9999 -9999 -9999 -9999 -9999 -9999 -9999 -9999 -9999 -

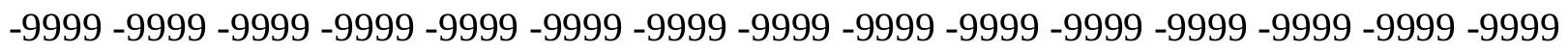
-9999 -9999 -9999 -9999 -9999 -9999 -9999 -9999 -9999 -9999 -9999 -9999 -9999 -9999 -9999 -9999 -9999 -9999 -9999 -9999 -9999 -9999 -9999 -9999 -9999 -9999 -9999 -9999 -9999 -9999 -

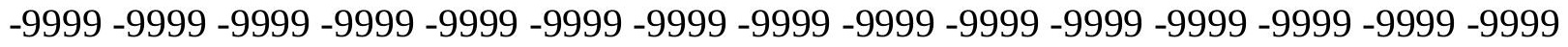
-9999 -9999 -9999 -9999 -9999 -9999 -9999 -9999 -9999 -9999 -9999 -9999 -9999 -9999 -9999 -9999 -9999 -9999 -9999 -9999 -9999 -9999 -9999 -9999 -9999 -9999 -9999 -9999 -9999 -999 -

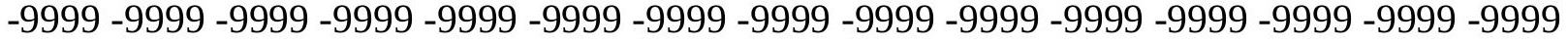
-9999 -9999 -9999 -9999 -9999 -9999 -9999 -9999 -9999 -9999 -9999 -9999 -9999 -9999 -9999 -

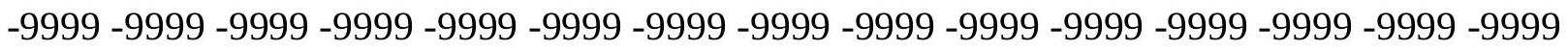

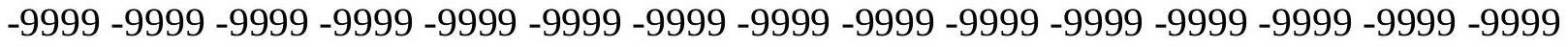

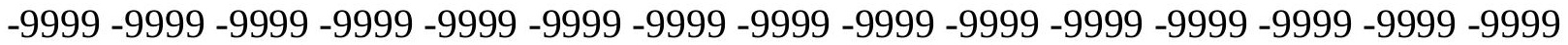
-9999 -9999 -9999 -9999 -9999 -9999 -9999 -9999 -9999 -9999 -9999 -9999 -9999 -9999 -9999 -

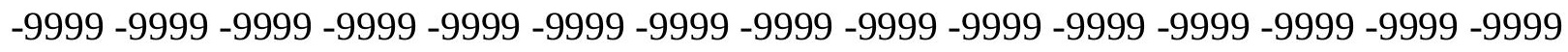

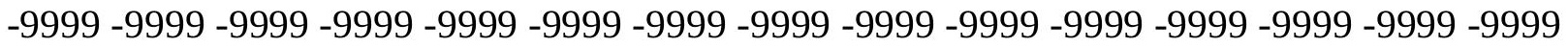
-9999 -9999 -9999 -9999 -9999 -9999 -9999 -9999 -9999 -9999 -9999 -9999 -9999 - 9999 - -999 -9999 -9999 -9999 -9999 -9999 -9999 -9999 -9999 -9999 -9999 -9999 -9999 -9999 -9999 -9999 -

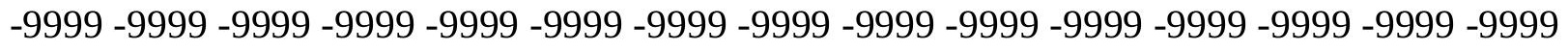

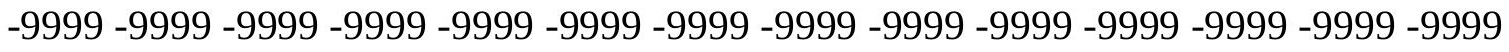
-9999 -9999 -9999 -9999 -9999 -9999 -9999 -9999 -9999 -9999 -9999 -9999 -9999 -9999 -9999 -9999 -9999 -9999 -9999 -9999 -9999 -9999 -9999 -9999-9999 -9999 -9999 -9999 -9999 -9999 -9999 -9999 -9999 -9999 -9999 -9999 -9999 -9999 -9999 -9999 -9999 -9999 -9999 -9999 -9999 -

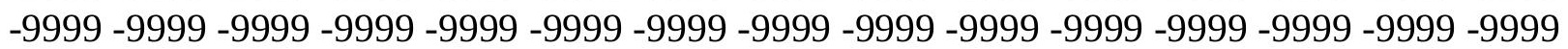


-9999 -9999 -9999 -9999 -9999 -9999 -9999 -9999 -9999 -9999 -9999 -9999 -9999 -9999 -9999 -9999 -9999 -9999 -9999 -9999 -9999 -9999 -9999 -9999 -9999 -9999 -9999 -9999 -9999 -9999 -

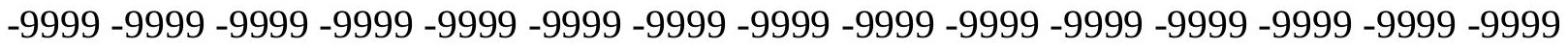
-9999 -9999 -9999 -9999 -9999 -9999 -9999 -9999 -9999 -9999 -9999 -9999 -9999 -9999 -9999 -9999 -9999 -9999 -9999 -9999 -9999 -9999 -9999 -9999-9999 -9999 -9999 -9999 -9999 -9999 -9999 -9999 -9999 -9999 -9999 -9999 -9999 -9999 -9999 -9999 -9999 -9999 -9999 -9999 -9999 -9999 -9999 -9999 -9999 -9999 -9999 -9999 -9999 -9999 -9999 -9999 -9999 -9999 -9999 -9999

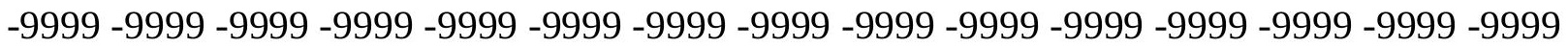

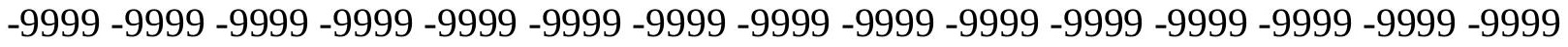
-9999 -9999 -9999 -9999 -9999 -9999 -9999 -9999 -9999 -9999 -9999 -9999 -9999 -9999 -9999 -9999 -9999 -9999 -9999 -9999 -9999 -9999 -9999 -9999 -9999 -9999 -9999 -9999 -9999 -9999 -9999 -9999 -9999 -9999 -9999 -9999 -9999 -9999 -9999 -9999 -9999 -9999 -9999 -9999 -9999 -9999 -9999 -9999 -9999 -9999 -9999 -9999 -9999 -9999 -9999 -9999 -9999 -9999 -9999 -9999 -

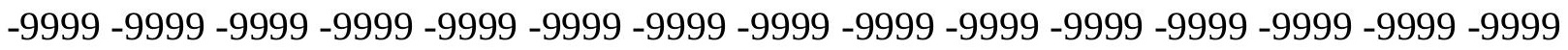
-9999 -9999 -9999 -9999 -9999 -9999 -9999 -9999 -9999 -9999 -9999 -9999 -9999 -9999 -9999 -

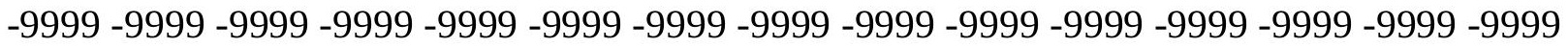
-9999 -9999 -9999 -9999 -9999 -9999 -9999 -9999 -9999 -9999 -9999 -9999 -9999 -9999 -9999 -9999 -9999 -9999 -9999 -9999 -9999 -9999 -9999 -9999 -9999 -9999 -9999 -9999 -9999 -9999 -9999 -9999 -9999 -9999 -9999 -9999 -9999 -9999 -9999 -9999 -9999 -9999 -9999 -9999 -9999 -

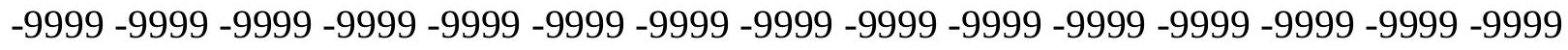

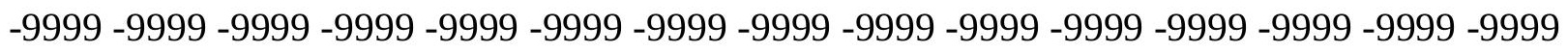
-9999 -9999 -9999 -9999 -9999 -9999 -9999 -9999 -9999 -9999 -9999 -9999 -9999 -9999 -9999 -9999 -9999 -9999 -9999 -9999 -9999 -9999 -9999 -9999 -9999 -9999 -9999 -9999 -9999 -9999 -9999 -9999 -9999 -9999 -9999 -9999 -9999 -9999 -9999 -9999 -9999 -9999 -9999 -9999 -

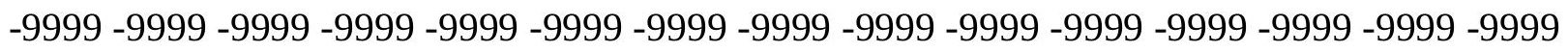
-9999 -9999 -9999 -9999 -9999 -9999 -9999 -9999 -9999 -9999 -9999 -9999 -9999 -9999 -9999 -9999 -9999 -9999 -9999 -9999 -9999 -9999 -9999 -9999 -9999 -9999 -9999 -9999 -9999 -9999 -

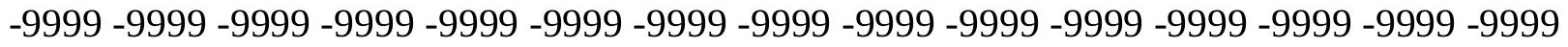
-9999 -9999 -9999 -9999 -9999 -9999 -9999 -9999 -9999 -9999 -9999 -9999 -9999 -9999 -9999 -9999 -9999 -9999 -9999 -9999 -9999 -9999 -9999 -9999 -9999 -9999 -9999 -9999 -9999 -999 -

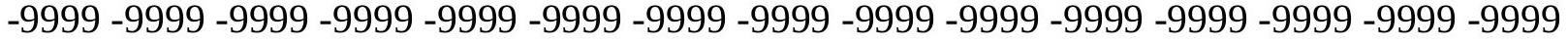
-9999 -9999 -9999 -9999 -9999 -9999 -9999 -9999 -9999 -9999 -9999 -9999 -9999 -9999 -9999 -

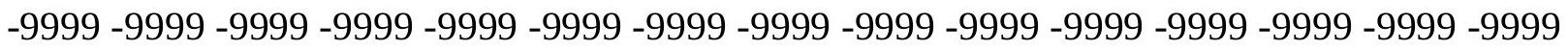

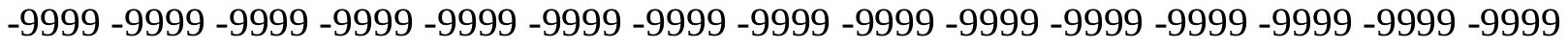

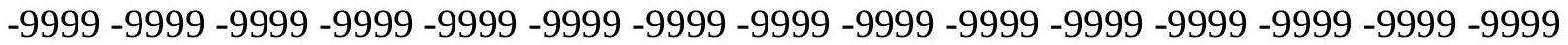

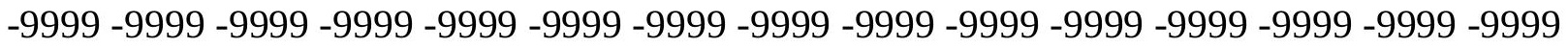

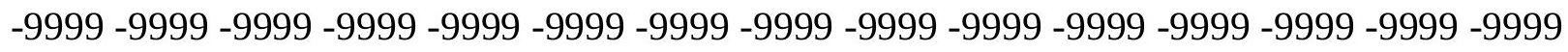

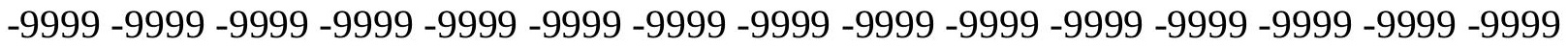

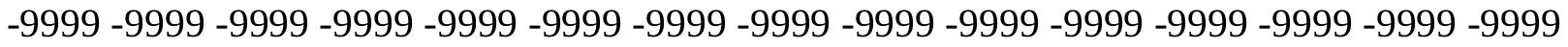
-9999 -9999 -9999 -9999 -9999 -9999 -9999 -9999 -9999 -9999 -9999 -9999 -9999 -9999 -9999 -

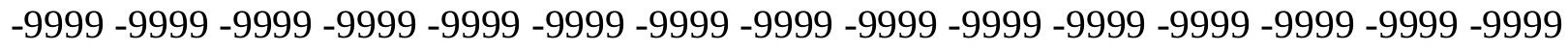

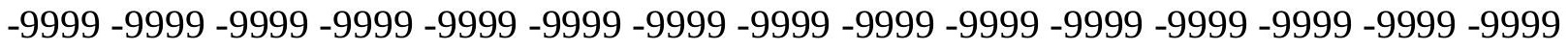
-9999 -9999 -9999 -9999 -9999 -9999 -9999 -9999 -9999 -9999 -9999 -9999 -9999 -9999 -9999 -9999 -9999 -9999 -9999 -9999 -9999 -9999 -9999 -9999-9999 -9999 -9999 -9999 -9999 -9999 -9999 -9999 -9999 -9999 -9999 -9999 -9999 -9999 -9999 -9999 -9999 -9999 -9999 -9999 -9999 -

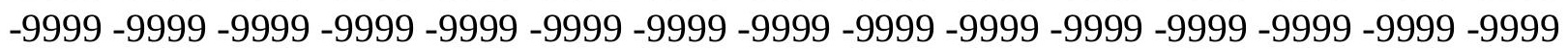


-9999 -9999 -9999 -9999 -9999 -9999 -9999 -9999 -9999 -9999 -9999 -9999 -9999 -9999 -9999 -9999 -9999 -9999 -9999 -9999 -9999 -9999 -9999 -9999 -9999 -9999 -9999 -9999 -9999 -

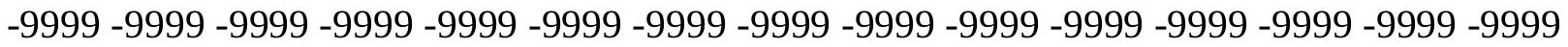
-9999 -9999 -9999 -9999 -9999 -9999 -9999 -9999 -9999 -9999 -9999 -9999 -9999 -9999 -9999 -9999 -9999 -9999 -9999 -9999 -9999 -9999 -9999 -9999 -9999 -9999 -9999 -9999 -9999 -9999 -9999 -9999 -9999 -9999 -9999 -9999 -9999 -9999 -9999 -9999 -9999 -9999 -9999 -9999 -9999 -9999 -9999 -9999 -9999 -9999 -9999 -9999 -9999 -9999 -9999 -9999 -9999 -9999 -9999 -9999

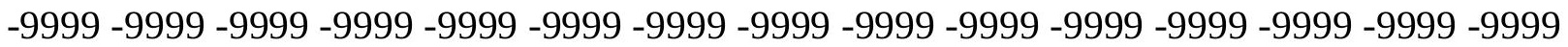

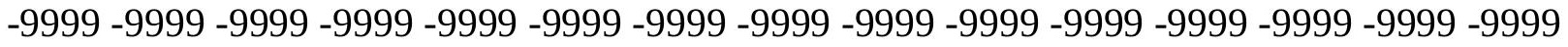
-9999 -9999 -9999 -9999 -9999 -9999 -9999 -9999 -9999 -9999 -9999 -9999 -9999 -9999 -9999 -9999 -9999 -9999 -9999 -9999 -9999 -9999 -9999 -9999 -9999 -9999 -9999 -9999 -9999 -9999 -9999 -9999 -9999 -9999 -9999 -9999 -9999 -9999 -9999 -9999 -9999 -9999 -9999 -9999 -9999 -9999 -9999 -9999 -9999 -9999 -9999 -9999 -9999 -9999 -9999 -9999 -9999 -9999 -9999 -9999 -9999 -9999 -9999 -9999 -9999 -9999 -9999 -9999 -9999 -9999 -9999 -9999 -9999 -9999 -9999 -9999 -9999 -9999 -9999 -9999 -9999 -9999 -9999 -9999 -9999 -9999 -9999 -9999 -9999 -9999 -

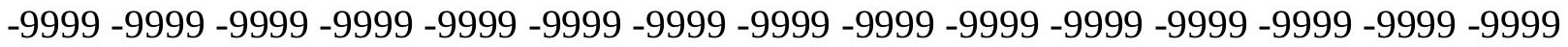
-9999 -9999 -9999 -9999 -9999 -9999 -9999 -9999 -9999 -9999 -9999 -9999 -9999 -9999 -9999 -9999 -9999 -9999 -9999 -9999 -9999 -9999 -9999 -9999 -9999 -9999 -9999 -9999 -9999 - 9999 -9999 -9999 -9999 -9999 -9999 -9999 -9999 -9999 -9999 -9999 -9999 -9999 -9999 -9999 -9999 -

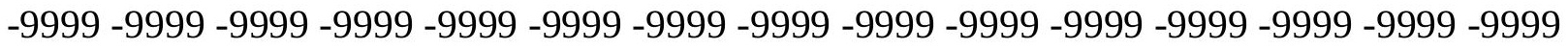

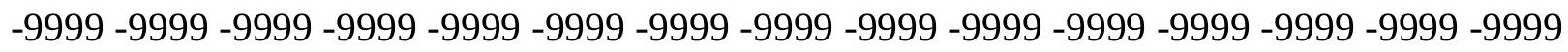

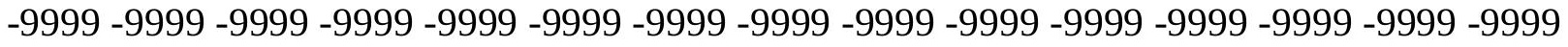
-9999 -9999 -9999 -9999 -9999 -9999 -9999 -9999 -9999 -9999 -9999 -9999 -9999 -9999 -9999 -9999 -9999 -9999 -9999 -9999 -9999 -9999 -9999 -9999 -9999 -9999 -9999 -9999 -9999 -9999 -

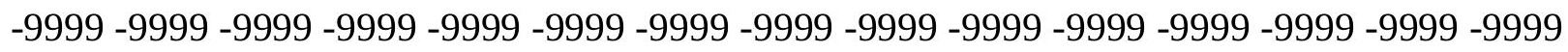
-9999 -9999 -9999 -9999 -9999 -9999 -9999 -9999 -9999 -9999 -9999 -9999 -9999 -9999 -9999 -9999 -9999 -9999 -9999 -9999 -9999 -9999 -9999 -9999 -9999 -9999 -9999 -9999 -9999 -9999 -9999 -9999 -9999 -9999 -9999 -9999 -9999 -9999 -9999 -9999 -9999 -9999 -9999 -9999 -9999 -9999 -9999 -9999 -9999 -9999 -9999 -9999 -9999 -9999 -9999 -9999 -9999 -9999 -9999 -9999 -9999 -9999 -9999 -9999 -9999 -9999 -9999 -9999 -9999 -9999 -9999 -9999 -9999 -999 -

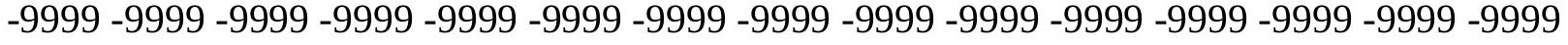
-9999 -9999 -9999 -9999 -9999 -9999 -9999 -9999 -9999 -9999 -9999 -9999 -9999 -9999 -9999 -

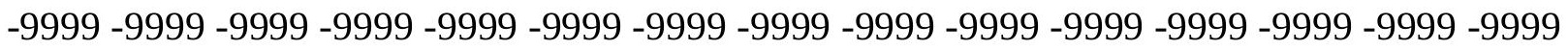

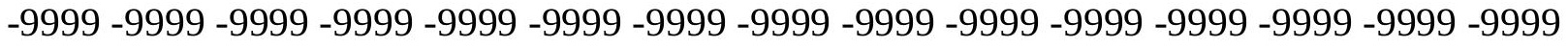

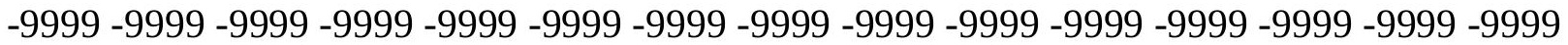

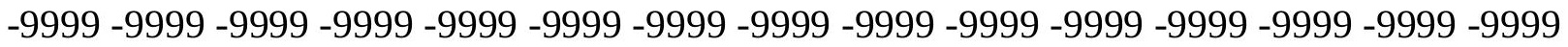

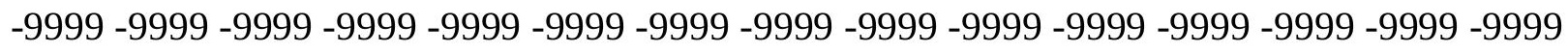

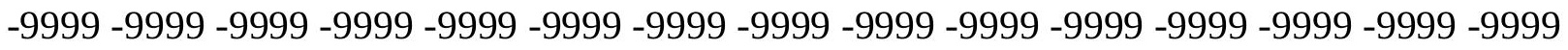

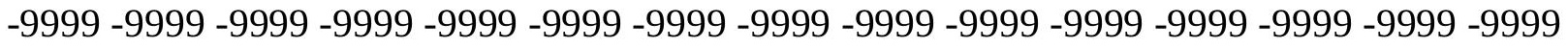
-9999 -9999 -9999 -9999 -9999 -9999 -9999 -9999 -9999 -9999 -9999 -9999 -9999 -9999 -9999 -

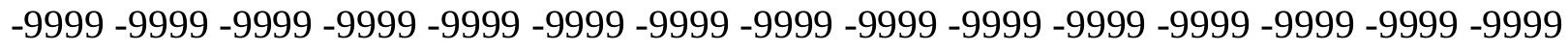

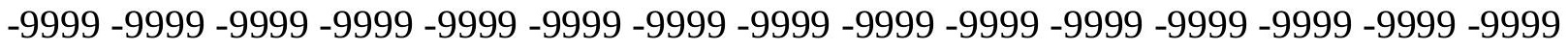
-9999 -9999 -9999 -9999 -9999 -9999 -9999 -9999 -9999 -9999 -9999 -9999 -9999 -9999 -9999 -9999 -9999 -9999 -9999 -9999 -9999 -9999 -9999 -9999-9999 -9999 -9999 -9999 -9999 -9999 -9999 -9999 -9999 -9999 -9999 -9999 -9999 -9999 -9999 -9999 -9999 -9999 -9999 -9999 -9999 -

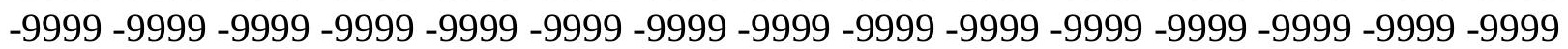


-9999 -9999 -9999 -9999 -9999 -9999 -9999 -9999 -9999 -9999 -9999 -9999 -9999 -9999 -9999 -9999 -9999 -9999 -9999 -9999 -9999 -9999 -9999 -9999 -9999 -9999 -9999 -9999 -9999 -9999 -

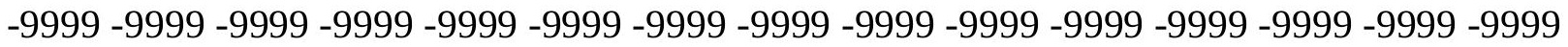
-9999 -9999 -9999 -9999 -9999 -9999 -9999 -9999 -9999 -9999 -9999 -9999 -9999 -9999 -9999 -9999 -9999 -9999 -9999 -9999 -9999 -9999 -9999 -9999-9999 -9999 -9999 -9999 -9999 -9999 -9999 -9999 -9999 -9999 -9999 -9999 -9999 -9999 -9999 -9999 -9999 -9999 -9999 -9999 -9999 -

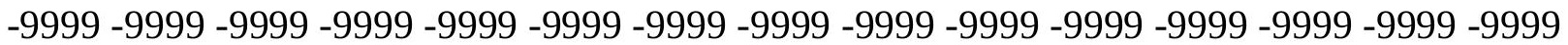
-9999 -9999 -9999 -9999 -9999 -9999 -9999 -9999 -9999 -9999 -9999 -9999 -9999 -9999 -9999 -9999 -9999 -9999 -9999 -9999 -9999 -9999 -9999 -9999 -9999 -9999 -9999 -9999 -9999 -9999 -9999 -9999 -9999 -9999 -9999 -9999 -9999 -9999 -9999 -9999 -9999 -9999 -9999 -9999 -9999 -9999 -9999 -9999 -9999 -9999 -9999 -9999 -9999 -9999 -9999 -9999 -9999 -9999 -9999 -9999 -9999 -9999 -9999 -9999 -9999 -9999 -9999 -9999 -9999 -9999 -9999 -9999 -9999 -9999 -9999 -9999 -9999 -9999 -9999 -9999 -9999 -9999 -9999 -9999 -9999 -9999 -9999 -9999 -9999 -9999 -9999 -9999 -9999 -9999 -9999 -9999 -9999 -9999 -9999 -9999 -9999 -9999 -9999 -9999 -9999 -9999 -9999 -9999 -9999 -9999 -9999 -9999 -9999 -9999 -9999 -9999 -9999 -9999 -9999 -

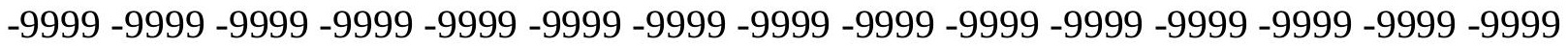
-9999 -9999 -9999 -9999 -9999 -9999 -9999 -9999 -9999 -9999 -9999 -9999 -9999 -9999 -9999 -9999 -9999 -9999 -9999 -9999 -9999 -9999 -9999 -9999 -9999 -9999 -9999 -9999 -9999 -9999 -9999 -9999 -9999 -9999 -9999 -9999 -9999 -9999 -9999 -9999 -9999 -9999 -9999 -9999 -9999 -

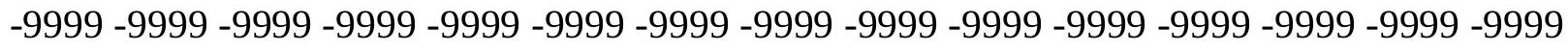

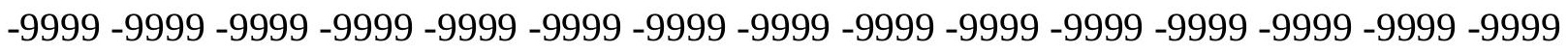
-9999 -9999 -9999 -9999 -9999 -9999 -9999 -9999 -9999 -9999 -9999 -9999 -9999 -9999 - 9999 -9999 -9999 -9999 -9999 -9999 -9999 -9999 -9999 -9999 -9999 -9999 -9999 -9999 -9999 -9999 -9999 -9999 -9999 -9999 -9999 -9999 -9999 -9999 -9999 -9999 -9999 -9999 -9999 -9999 -9999 -

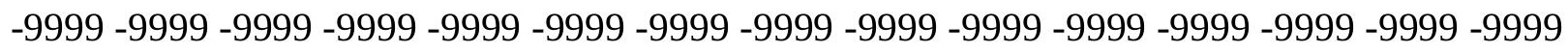
-9999 -9999 -9999 -9999 -9999 -9999 -9999 -9999 -9999 -9999 -9999 -9999 -9999 -9999 -9999 -9999 -9999 -9999 -9999 -9999 -9999 -9999 -9999 -9999 -9999 -9999 -9999 -9999 -9999 -9999 -

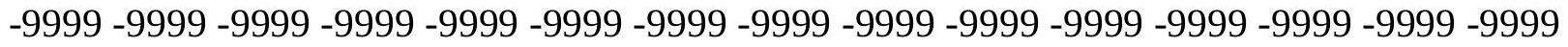
-9999 -9999 -9999 -9999 -9999 -9999 -9999 -9999 -9999 -9999 -9999 -9999 -9999 -9999 -9999 -9999 -9999 -9999 -9999 -9999 -9999 -9999 -9999 -9999 -9999 -9999 -9999 -9999 -9999 -999 -9999 -9999 -9999 -9999 -9999 -9999 -9999 -9999 -9999 -9999 -9999 -9999 -9999 -9999 -9999 -9999 -9999 -9999 -9999 -9999 -9999 -9999 -9999 -9999 -9999 -9999 -9999 -9999 -9999 -9999 -

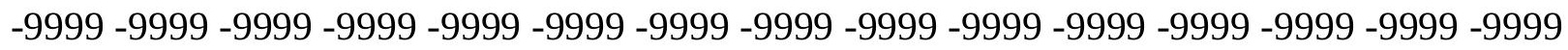

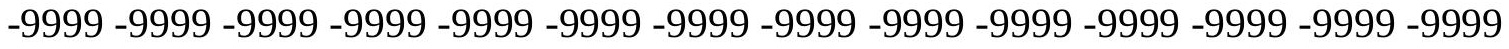
-9999 -9999 -9999 -9999 -9999 -9999 -9999 -9999 -9999 -9999 -9999 -9999 -9999 -9999 -9999

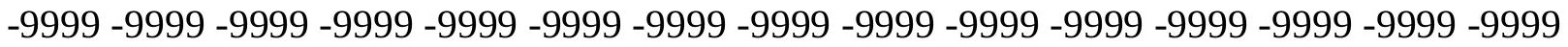

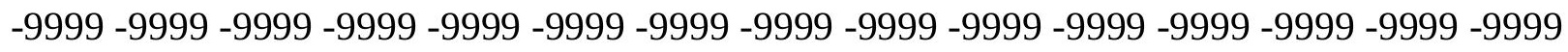

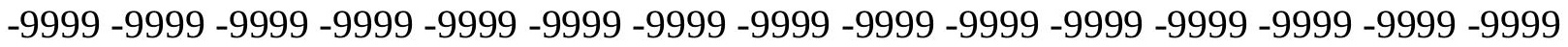

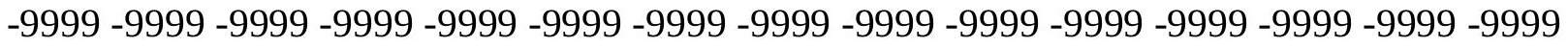
-9999 -9999 -9999 -9999 -9999 -9999 -9999 -9999 -9999 -9999 -9999 -9999 -9999 -9999 -9999 -

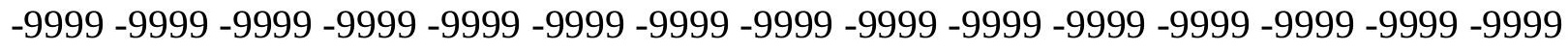

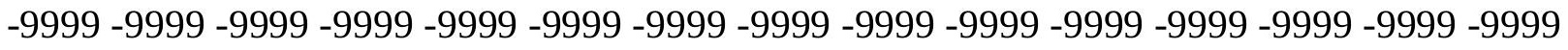
-9999 -9999 -9999 -9999 -9999 -9999 -9999 -9999 -9999 -9999 -9999 -9999 -9999 -9999 -9999 -9999 -9999 -9999 -9999 -9999 -9999 -9999 -9999 -9999-9999 -9999 -9999 -9999 -9999 -9999 -9999 -9999 -9999 -9999 -9999 -9999 -9999 -9999 -9999 -9999 -9999 -9999 -9999 -9999 -9999 -

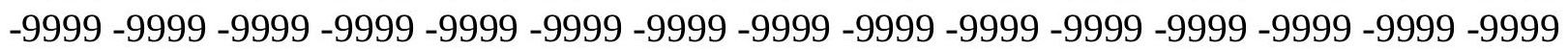


-9999 -9999 -9999 -9999 -9999 -9999 -9999 -9999 -9999 -9999 -9999 -9999 -9999 -9999 -9999 -9999 -9999 -9999 -9999 -9999 -9999 -9999 -9999 -9999 -9999 -9999 -9999 -9999 -9999 -9999 -

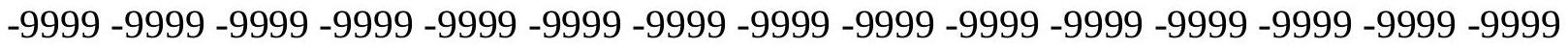
-9999 -9999 -9999 -9999 -9999 -9999 -9999 -9999 -9999 -9999 -9999 -9999 -9999 -9999 -9999 -9999 -9999 -9999 -9999 -9999 -9999 -9999 -9999 -9999-9999 -9999 -9999 -9999 -9999 -9999 -9999 -9999 -9999 -9999 -9999 -9999 -9999 -9999 -9999 -9999 -9999 -9999 -9999 -9999 -9999 -9999 -9999 -9999 -9999 -9999 -9999 -9999 -9999 -9999 -9999 -9999 -9999 -9999 -9999 -9999

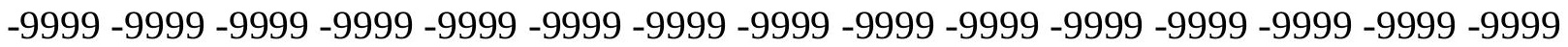

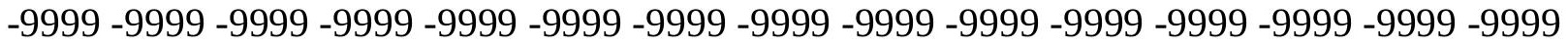
-9999 -9999 -9999 -9999 -9999 -9999 -9999 -9999 -9999 -9999 -9999 -9999 -9999 -9999 -9999 -9999 -9999 -9999 -9999 -9999 -9999 -9999 -9999 -9999 -9999 -9999 -9999 -9999 -9999 -9999 -9999 -9999 -9999 -9999 -9999 -9999 -9999 -9999 -9999 -9999 -9999 -9999 -9999 -9999 -9999 -9999 -9999 -9999 -9999 -9999 -9999 -9999 -9999 -9999 -9999 -9999 -9999 -9999 -9999 -9999 -9999 -9999 -9999 -9999 -9999 -9999 -9999 -9999 -9999 -9999 -9999 -9999 -9999 -9999 -9999 -9999 -9999 -9999 -9999 -9999 -9999 -9999 -9999 -9999 -9999 -9999 -9999 -9999 -9999

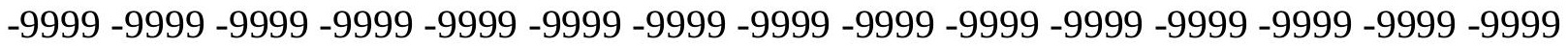
-9999 -9999 -9999 -9999 -9999 -9999 -9999 -9999 -9999 -9999 -9999 -9999 -9999 -9999 -9999 -9999 -9999 -9999 -9999 -9999 -9999 -9999 -9999 -9999 -9999 -9999 -9999 -9999 -9999 -9999 -9999 -9999 -9999 -9999 -9999 -9999 -9999 -9999 -9999 -9999 -9999 -9999 -9999 -9999 -9999 -

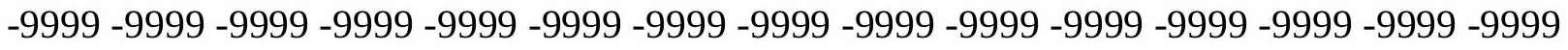

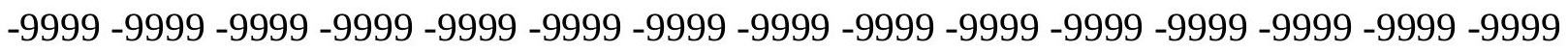
-9999 -9999 -9999 -9999 -9999 -9999 -9999 -9999 -9999 -9999 -9999 -9999 -9999 -9999 -9999 -9999 -9999 -9999 -9999 -9999 -9999 -9999 -9999 -9999 -9999 -9999 -9999 -9999 -9999 -9999 -9999 -9999 -9999 -9999 -9999 -9999 -9999 -9999 -9999 -9999 -9999 -9999 -9999 -9999 -9999 -

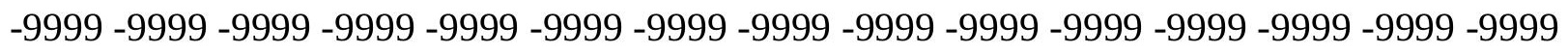
-9999 -9999 -9999 -9999 -9999 -9999 -9999 -9999 -9999 -9999 -9999 -9999 -9999 -9999 -9999 -9999 -9999 -9999 -9999 -9999 -9999 -9999 -9999 -9999 -9999 -9999 -9999 -9999 -9999 -9999 -

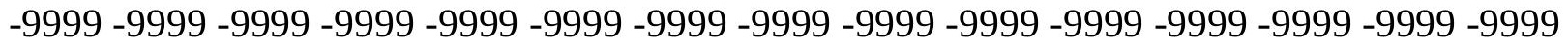
-9999 -9999 -9999 -9999 -9999 -9999 -9999 -9999 -9999 -9999 -9999 -9999 -9999 -9999 -9999 -9999 -9999 -9999 -9999 -9999 -9999 -9999 -9999 -9999 -9999 -9999 -9999 -9999 -9999 -999 -9999 -9999 -9999 -9999 -9999 -9999 -9999 -9999 -9999 -9999 -9999 -9999 -9999 -9999 -9999 -9999 -9999 -9999 -9999 -9999 -9999 -9999 -9999 -9999 -9999 -9999 -9999 -9999 -9999 -9999 -

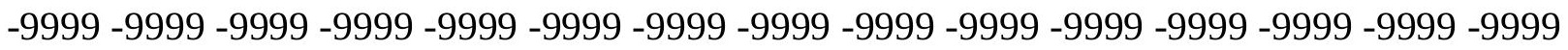

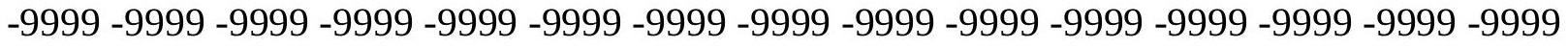

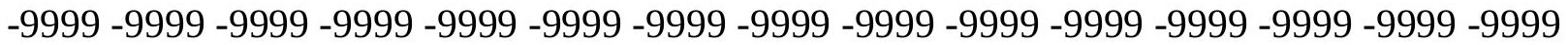

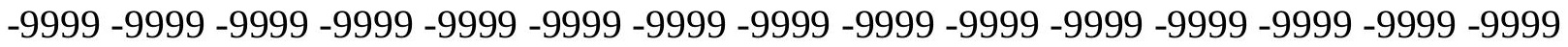

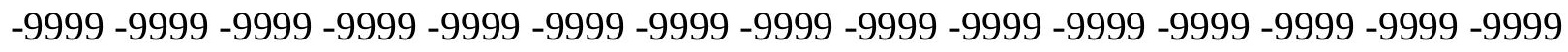

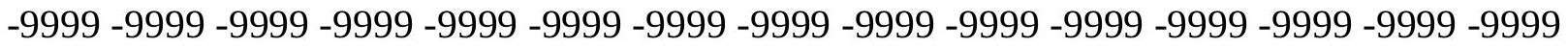
-9999 -9999 -9999 -9999 -9999 -9999 -9999 -9999 -9999 -9999 -9999 -9999 -9999 - 9999 - -999 -9999 -9999 -9999 -9999 -9999 -9999 -9999 -9999 -9999 -9999 -9999 -9999 -9999 -9999 - -999 -

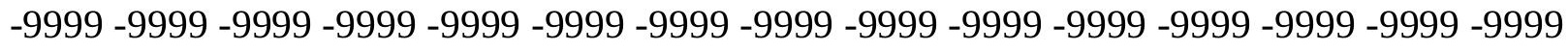

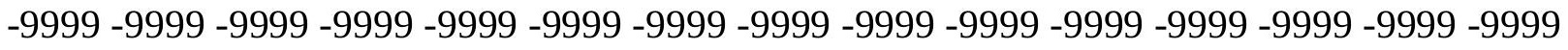
-9999 -9999 -9999 -9999 -9999 -9999 -9999 -9999 -9999 -9999 -9999 -9999 -9999 -9999 -9999 -9999 -9999 -9999 -9999 -9999 -9999 -9999 -9999 -9999-9999 -9999 -9999 -9999 -9999 -9999 -9999 -9999 -9999 -9999 -9999 -9999 -9999 -9999 -9999 -9999 -9999 -9999 -9999 -9999 -9999 -

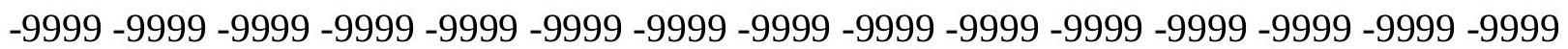


-9999 -9999 -9999 -9999 -9999 -9999 -9999 -9999 -9999 -9999 -9999 -9999 -9999 -9999 -9999 -9999 -9999 -9999 -9999 -9999 -9999 -9999 -9999 -9999 -9999 -9999 -9999 -9999 -9999 -9999 -9999 -9999 -9999 -9999 -9999 -9999 -9999 -9999 -9999 -9999 -9999 -9999 -9999 -9999 -9999 -9999 -9999 -9999 -9999 -9999 -9999 -9999 -9999 -9999 -9999 -9999 -9999 -9999 -9999 -9999 -9999 -9999 -9999 -9999 -9999 -9999 -9999 -9999 -9999 -9999 -9999 -9999 -9999 -9999 -9999 -9999 -9999 -9999 -9999 -9999 -9999 -9999 -9999 -9999 -9999 -9999 -9999 -9999 -9999 -9999 -9999 -9999 -9999 -9999 -9999 -9999 -9999 -9999 -9999 -9999 -9999 -9999 -9999 -9999 -9999 -

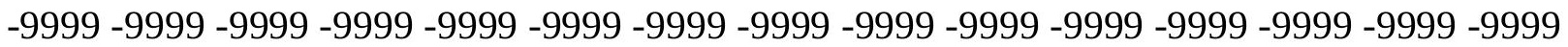
-9999 -9999 -9999 -9999 -9999 -9999 -9999 -9999 -9999 -9999 -9999 -9999 -9999 -9999 -9999 -9999 -9999 -9999 -9999 -9999 -9999 -9999 -9999 -9999 -9999 -9999 -9999 -9999 -9999 -9999 -

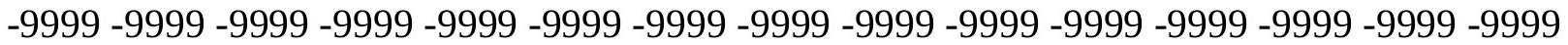
-9999 -9999 -9999 -9999 -9999 -9999 -9999 -9999 -9999 -9999 -9999 -9999 -9999 -9999 -9999 -9999 -9999 -9999 -9999 -9999 -9999 -9999 -9999 -9999 -9999 -9999 -9999 -9999 -9999 -9999 -9999 -9999 -9999 -9999 -9999 -9999 -9999 -9999 -9999 -9999 -9999 -9999 -9999 -9999 -9999 -9999 -9999 -9999 -9999 -9999 -9999 -9999 -9999 -9999 -9999 -9999 -9999 -9999 -9999 -9999

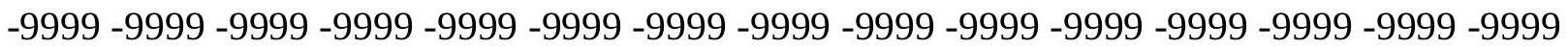
-9999 -9999 -9999 -9999 -9999 -9999 -9999 -9999 -9999 -9999 -9999 -9999 -9999 -9999 -9999 -9999 -9999 -9999 -9999 -9999 -9999 -9999 -9999 -9999 -9999 -9999 -9999 -9999 -9999 -9999 -9999 -9999 -9999 -9999 -9999 -9999 -9999 -9999 -9999 -9999 -9999 -9999 -9999 -9999 -9999 -9999 -9999 -9999 -9999 -9999 -9999 -9999 -9999 -9999 -9999 -9999 -9999 -9999 -9999 -9999 -9999 -9999 -9999 -9999 -9999 -9999 -9999 -9999 -9999 -9999 -9999 -9999 -9999 -9999 -9999 -9999 -9999 -9999 -9999 -9999 -9999 -9999 -9999 -9999 -9999 -9999 -9999 -9999 -9999 -9999 -9999 -9999 -9999 -9999 -9999 -9999 -9999 -9999 -9999 -9999 -9999 -9999 -9999 -9999 -9999 -9999 -9999 -9999 -9999 -9999 -9999 -9999 -9999 -9999 -9999 -9999 -9999 -9999 -9999 -9999 -9999 -9999 -9999 -9999 -9999 -9999 -9999 -9999 -9999 -9999 -9999 -9999 -9999 -9999 -9999 -9999 -9999 -9999 -9999 -9999 -9999 -9999 -9999 -9999 -9999 -9999 -9999 -9999 -9999 -9999 -9999 -9999 -9999 -9999 -9999 -9999 -9999 -9999 -9999 -9999 -9999 -9999 -9999 -9999 -9999 -9999 -9999 -9999 -9999 -9999 -9999 -9999 -9999 -9999 -9999 -9999 -9999 -9999 -9999

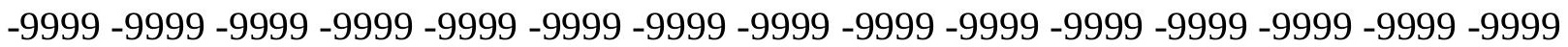
-9999 -9999 -9999 -9999 -9999 -9999 -9999 -9999 -9999 -9999 -9999 -9999 -9999 -9999 -9999 -9999 -9999 -9999 -9999 -9999 -9999 -9999 -9999 -9999 -9999 -9999 -9999 -9999 -9999 -9999 -

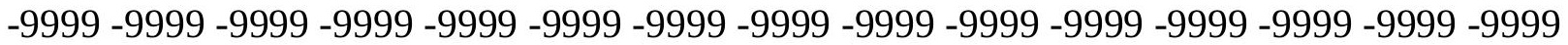
-9999 -9999 -9999 -9999 -9999 -9999 -9999 -9999 -9999 -9999 -9999 -9999 -9999 -9999 -9999 -9999 -9999 -9999 -9999 -9999 -9999 -9999 -9999 -9999 -9999 -9999 -9999 -9999 -9999 -9999 -9999 -9999 -9999 -9999 -9999 -9999 -9999 -9999 -9999 -9999 -9999 -9999 -9999 -9999 -9999 -9999 -9999 -9999 -9999 -9999 -9999 -9999 -9999 -9999 -9999 -9999 -9999 -9999 -9999 -9999 -9999 -9999 -9999 -9999 -9999 -9999 -9999 -9999 -9999 -9999 -9999 -9999 -9999 -9999 -9999

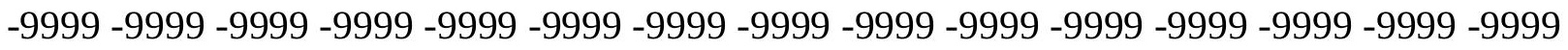
-9999 -9999 -9999 -9999 -9999 -9999 -9999 -9999 -9999 -9999 -9999 -9999 -9999 -9999 -9999 -9999 -9999 -9999 -9999 -9999 -9999 -9999 -9999 -9999 -9999 -9999 -9999 -9999 -9999 -9999 -9999 -9999 -9999 -9999 -9999 -9999 -9999 -9999 -9999 -9999 -9999 -9999 -9999 -9999 -9999 -999 -9999 -9999 -9999 -9999 -9999 -9999 -9999 -9999 -9999 -9999 -9999 -9999 -9999 -9999 -9999 -9999 -9999 -9999 -9999 -9999 -9999 -9999 -9999 -9999 -9999 -9999 -9999 -9999 -9999 -9999 -9999 -9999 -9999 -9999 -9999 -9999 -9999 -9999 -9999 -9999 -9999 -9999 -9999 -9999 -9999 -9999 -9999 -9999 -9999 -9999 -9999 -9999 -9999 -9999 -9999 -9999 -9999 -9999 -9999 -9999 -9999 -9999 -9999 -9999 -9999 -9999 -9999 -9999 -9999 -9999 -9999 -9999 -9999 -9999 
-9999 -9999 -9999 -9999 -9999 -9999 -9999 -9999 -9999 -9999 -9999 -9999 -9999 -9999 -9999 -9999 -9999 -9999 -9999 -9999 -9999 -9999 -9999 -9999 -9999 -9999 -9999 -9999 -9999 -9999 -

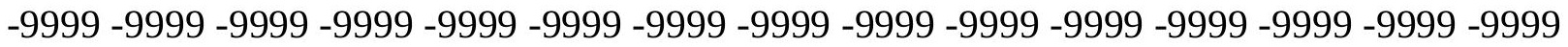
-9999 -9999 -9999 -9999 -9999 -9999 -9999 -9999 -9999 -9999 -9999 -9999 -9999 -9999 -9999 -9999 -9999 -9999 -9999 -9999 -9999 -9999 -9999 -9999-9999 -9999 -9999 -9999 -9999 -9999 -9999 -9999 -9999 -9999 -9999 -9999 -9999 -9999 -9999 -9999 -9999 -9999 -9999 -9999 -9999 -9999 -9999 -9999 -9999 -9999 -9999 -9999 -9999 -9999 -9999 -9999 -9999 -9999 -9999 -9999

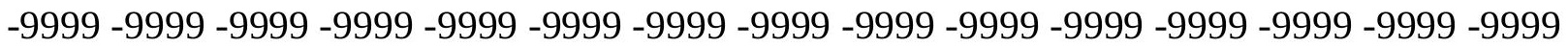

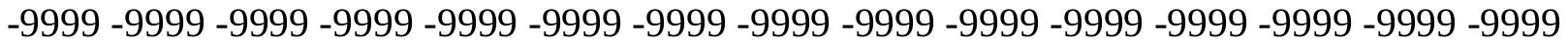
-9999 -9999 -9999 -9999 -9999 -9999 -9999 -9999 -9999 -9999 -9999 -9999 -9999 -9999 -9999 -9999 -9999 -9999 -9999 -9999 -9999 -9999 -9999 -9999 -9999 -9999 -9999 -9999 -9999 -9999 -9999 -9999 -9999 -9999 -9999 -9999 -9999 -9999 -9999 -9999 -9999 -9999 -9999 -9999 -9999 -9999 -9999 -9999 -9999 -9999 -9999 -9999 -9999 -9999 -9999 -9999 -9999 -9999 -9999 -9999 -

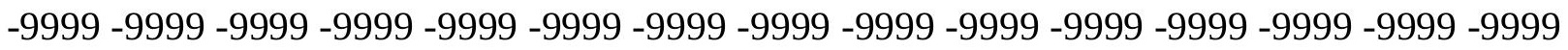
-9999 -9999 -9999 -9999 -9999 -9999 -9999 -9999 -9999 -9999 -9999 -9999 -9999 -9999 -9999 -

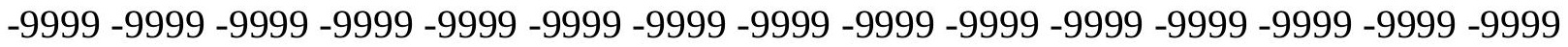
-9999 -9999 -9999 -9999 -9999 -9999 -9999 -9999 -9999 -9999 -9999 -9999 -9999 -9999 -9999 -9999 -9999 -9999 -9999 -9999 -9999 -9999 -9999 -9999 -9999 -9999 -9999 -9999 -9999 -9999 -9999 -9999 -9999 -9999 -9999 -9999 -9999 -9999 -9999 -9999 -9999 -9999 -9999 -9999 -9999 -

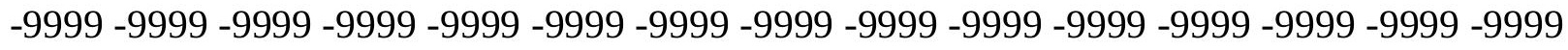

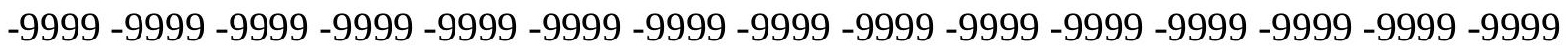

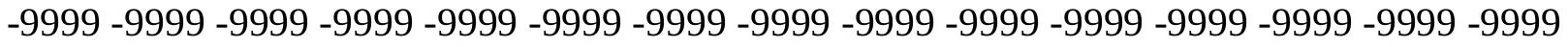
-9999 -9999 -9999 -9999 -9999 -9999 -9999 -9999 -9999 -9999 -9999 -9999 -9999 -9999 -9999 -9999 -9999 -9999 -9999 -9999 -9999 -9999 -9999 -9999 -9999 -9999 -9999 -9999 -9999 -9999 -

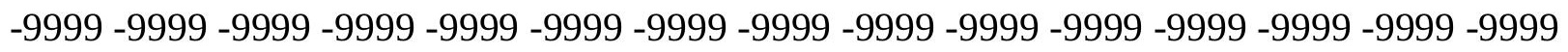
-9999 -9999 -9999 -9999 -9999 -9999 -9999 -9999 -9999 -9999 -9999 -9999 -9999 -9999 -9999 -9999 -9999 -9999 -9999 -9999 -9999 -9999 -9999 -9999 -9999 -9999 -9999 -9999 -9999 -

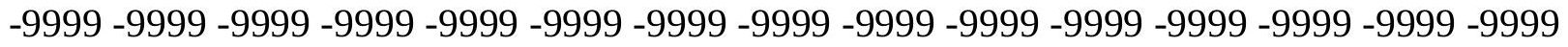
-9999 -9999 -9999 -9999 -9999 -9999 -9999 -9999 -9999 -9999 -9999 -9999 -9999 -9999 -9999 -9999 -9999 -9999 -9999 -9999 -9999 -9999 -9999 -9999 -9999 -9999 -9999 -9999 -9999 -999 -

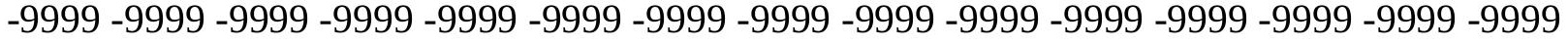
-9999 -9999 -9999 -9999 -9999 -9999 -9999 -9999 -9999 -9999 -9999 -9999 -9999 -9999 -9999 -

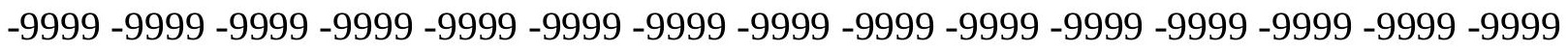

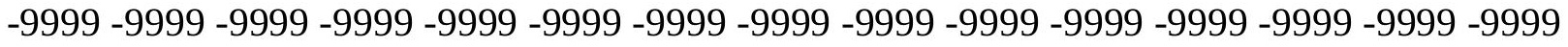

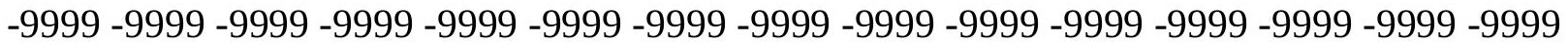
-9999 -9999 -9999 -9999 -9999 -9999 -9999 -9999 -9999 -9999 -9999 -9999 -9999 -9999 -9999

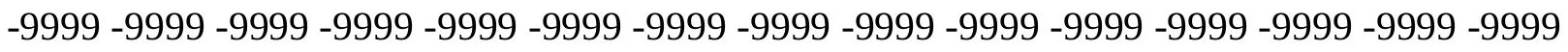

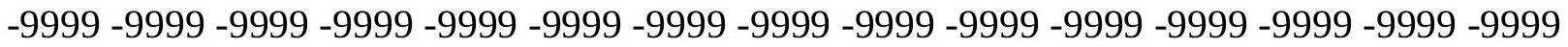
-9999 -9999 -9999 -9999 -9999 -9999 -9999 -9999 -9999 -9999 -9999 -9999 -9999 - 9999 - -999 -9999 -9999 -9999 -9999 -9999 -9999 -9999 -9999 -9999 -9999 -9999 -9999 -9999 -9999 -9999 -

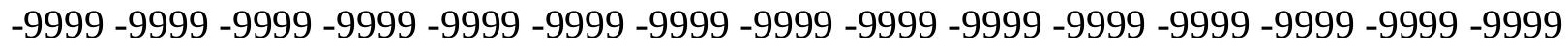

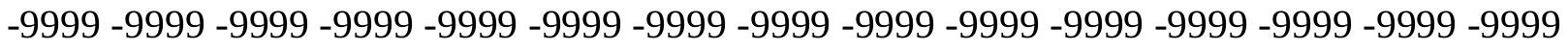
-9999 -9999 -9999 -9999 -9999 -9999 -9999 -9999 -9999 -9999 -9999 -9999 -9999 -9999 -9999 -9999 -9999 -9999 -9999 -9999 -9999 -9999 -9999 -9999-9999 -9999 -9999 -9999 -9999 -9999 -9999 -9999 -9999 -9999 -9999 -9999 -9999 -9999 -9999 -9999 -9999 -9999 -9999 -9999 -9999 -

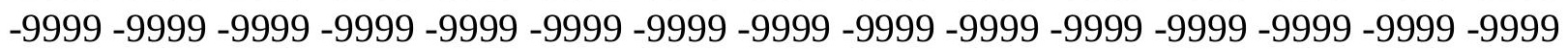


-9999 -9999 -9999 -9999 -9999 -9999 -9999 -9999 -9999 -9999 -9999 -9999 -9999 -9999 -9999 -9999 -9999 -9999 -9999 -9999 -9999 -9999 -9999 -9999 -9999 -9999 -9999 -9999 -9999 -9999 -9999 -9999 -9999 -9999 -9999 -9999 -9999 -9999 -9999 -9999 -9999 -9999 -9999 -9999 - 9999 -9999 -9999 -9999 -9999 -9999 -9999 -9999 -9999 -9999 -9999 -9999 -9999 -9999 -9999 -9999 -9999 -9999 -9999 -9999 -9999 -9999 -9999 -9999 -9999 -9999 -9999 -9999 -9999 -9999 - -9999 -9999 -9999 -9999 -9999 -9999 -9999 -9999 -9999 -9999 -9999 -9999 -9999 -9999 -9999 -9999 -9999 -9999 -9999 -9999 -9999 -9999 -9999 -9999 -9999 -9999 -9999 -9999 -9999 -9999

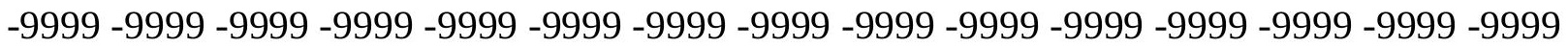

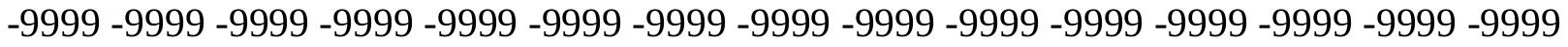
-9999 -9999 -9999 -9999 -9999 -9999 -9999 -9999 -9999 -9999 -9999 -9999 -9999 -9999 -9999

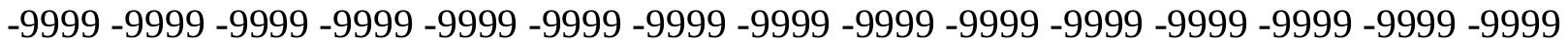
-9999 -9999 -9999 -9999 -9999 -9999 -9999 -9999 -9999 -9999 -9999 -9999 -9999 -9999 -9999 -9999 -9999 -9999 -9999 -9999 -9999 -9999 -9999 -9999 -9999 -9999 -9999 -9999 -9999 -9999 -9999 -9999 -9999 -9999 -9999 -9999 -9999 -9999 -9999 -9999 -9999 -9999 -9999 -9999 - -9999 -9999 -9999 -9999 -9999 -9999 -9999 -9999 -9999 -9999 -9999 -9999 -9999 -9999 -9999 -9999

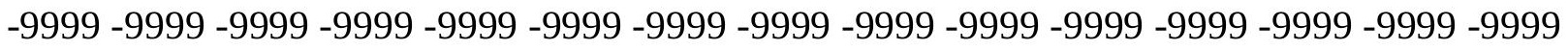
-9999 -9999 -9999 -9999 -9999 -9999 -9999 -9999 -9999 -9999 -9999 -9999 -9999 -9999 -9999 -9999 -9999 -9999 -9999 -9999 -9999 -9999 -9999 -9999 -9999 -9999 -9999 -9999 -9999 -9999 -9999 -9999 -9999 -9999 -9999 -9999 -9999 -9999 -9999 -9999 -9999 -9999 -9999 -9999 -9999 -

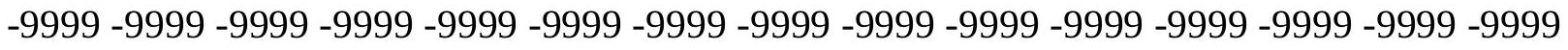
-9999 -9999 -9999 -9999 -9999 -9999 -9999 -9999 -9999 -9999 -9999 -9999 -9999 -9999 -9999 -999 -9999 -9999 -9999 -9999 -9999 -9999 -9999 -9999 -9999 -9999 -9999 -9999 -9999 -9999 -9999 -9999 -9999 -9999 -9999 -9999 -9999 -9999 -9999 -9999 -9999 -9999 -9999 -9999 -9999 -9999 -9999 -9999 -9999 -9999 -9999 -9999 -9999 -9999 -9999 -9999 -9999 -9999 -9999 -9999 -9999 -9999 -9999 -9999 -9999 -9999 -9999 -9999 -9999 -9999 -9999 -9999 -9999 -9999 -9999 -9999 -9999 -9999 -9999 -9999 -9999 -9999 -9999 -9999 -9999 -9999 -9999 -9999 -9999 -9999 -9999 -9999 -9999 -9999 -9999 -9999 -9999 -9999 -9999 -9999 -9999 -9999 -9999 -9999 -9999 -9999 -9999 -9999 -9999 -9999 -9999 -9999 -9999 -9999 -9999 -9999 -9999 -9999 -9999 -9999 -9999 -9999 -9999 -9999 -9999 -9999 -9999 -9999 -9999 -9999 -9999 -9999 -9999 -9999 -9999 -9999 -9999 -9999 -9999 -9999 -9999 -9999 -9999 -9999 -9999 -9999 -9999 -9999 -9999 -9999 -999 -9999 -9999 -9999 -9999 -9999 -9999 -9999 -9999 -9999 -9999 -9999 -9999 -9999 -9999 -9999 -9999 -9999 -9999 -9999 -9999 -9999 -9999 -9999 -9999 -9999 -9999 -9999 -9999 -9999 -

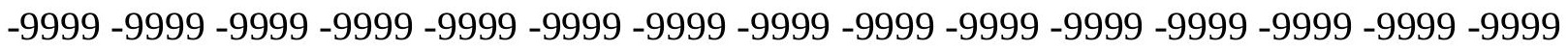

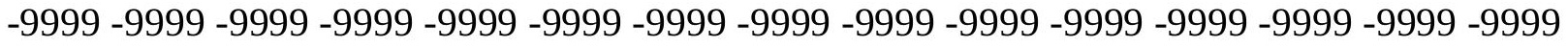

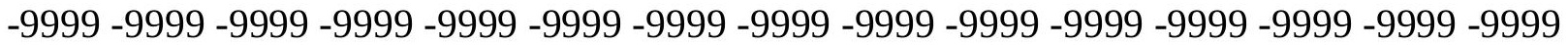
-9999 -9999 -9999 -9999 -9999 -9999 -9999 -9999 -9999 -9999 -9999 -9999 -9999 -9999 -9999 -

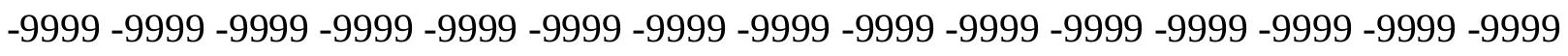

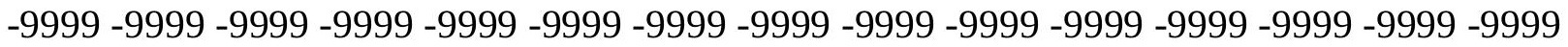

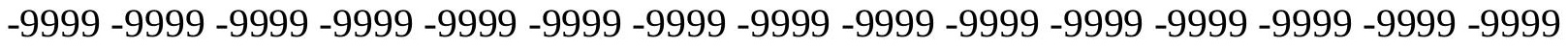
-9999 -9999 -9999 -9999 -9999 -9999 -9999 -9999 -9999 -9999 -9999 -9999 -9999 -9999 -9999 -

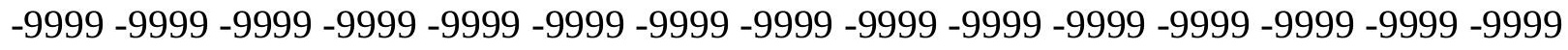

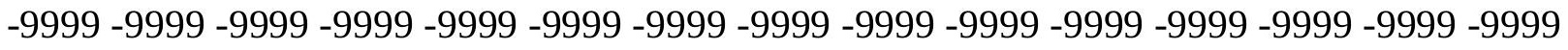
-9999 -9999 -9999 -9999 -9999 -9999 -9999 -9999 -9999 -9999 -9999 -9999 -9999 -9999 -9999 -9999 -9999 -9999 -9999 -9999 -9999 -9999 -9999 -9999-9999 -9999 -9999 -9999 -9999 -9999 -9999 -9999 -9999 -9999 -9999 -9999 -9999 -9999 -9999 -9999 -9999 -9999 -9999 -9999 -9999 -

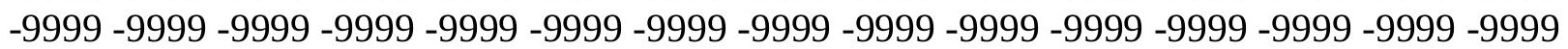


-9999 -9999 -9999 -9999 -9999 -9999 -9999 -9999 -9999 -9999 -9999 -9999 -9999 -9999 -9999 -9999 -9999 -9999 -9999 -9999 -9999 -9999 -9999 -9999 -9999 -9999 -9999 -9999 -9999 -9999 -

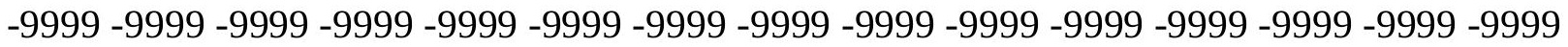
-9999 -9999 -9999 -9999 -9999 -9999 -9999 -9999 -9999 -9999 -9999 -9999 -9999 -9999 -9999 -9999 -9999 -9999 -9999 -9999 -9999 -9999 -9999 -9999-9999 -9999 -9999 -9999 -9999 -9999 -9999 -9999 -9999 -9999 -9999 -9999 -9999 -9999 -9999 -9999 -9999 -9999 -9999 -9999 -9999 -9999 -9999 -9999 -9999 -9999 -9999 -9999 -9999 -9999 -9999 -9999 -9999 -9999 -9999 -9999

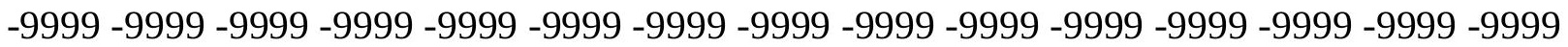

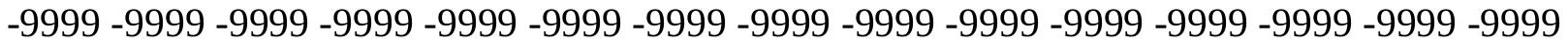
-9999 -9999 -9999 -9999 -9999 -9999 -9999 -9999 -9999 -9999 -9999 -9999 -9999 -9999 -9999 -9999 -9999 -9999 -9999 -9999 -9999 -9999 -9999 -9999 -9999 -9999 -9999 -9999 -9999 -9999 -9999 -9999 -9999 -9999 -9999 -9999 -9999 -9999 -9999 -9999 -9999 -9999 -9999 -9999 -9999 -9999 -9999 -9999 -9999 -9999 -9999 -9999 -9999 -9999 -9999 -9999 -9999 -9999 -9999 -9999 -9999 -9999 -9999 -9999 -9999 -9999 -9999 -9999 -9999 -9999 -9999 -9999 -9999 - 9999 -9999 -9999 -9999 -9999 -9999 -9999 -9999 -9999 -9999 -9999 -9999 -9999 -9999 -9999 -9999

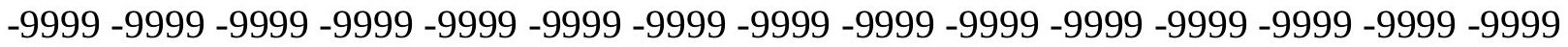
-9999 -9999 -9999 -9999 -9999 -9999 -9999 -9999 -9999 -9999 -9999 -9999 -9999 -9999 -9999 -9999 -9999 -9999 -9999 -9999 -9999 -9999 -9999 -9999 -9999 -9999 -9999 -9999 -9999 -9999 -9999 -9999 -9999 -9999 -9999 -9999 -9999 -9999 -9999 -9999 -9999 -9999 -9999 -9999 -9999 -

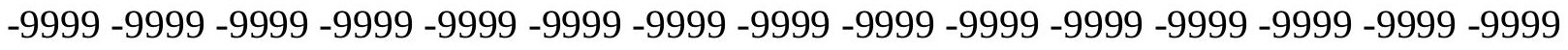

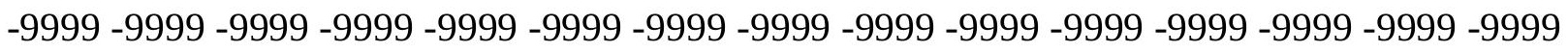
-9999 -9999 -9999 -9999 -9999 -9999 -9999 -9999 -9999 -9999 -9999 -9999 -9999 -9999 -9999 -9999 -9999 -9999 -9999 -9999 -9999 -9999 -9999 -9999 -9999 -9999 -9999 -9999 -9999 -9999 -9999 -9999 -9999 -9999 -9999 -9999 -9999 -9999 -9999 -9999 -9999 -9999 -9999 -9999 -9999 -

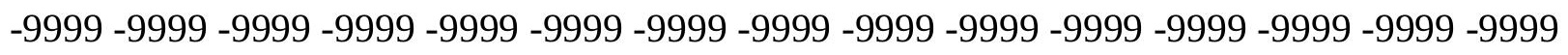
-9999 -9999 -9999 -9999 -9999 -9999 -9999 -9999 -9999 -9999 -9999 -9999 -9999 -9999 -9999 -9999 -9999 -9999 -9999 -9999 -9999 -9999 -9999 -9999 -9999 -9999 -9999 -9999 -9999 -9999 -

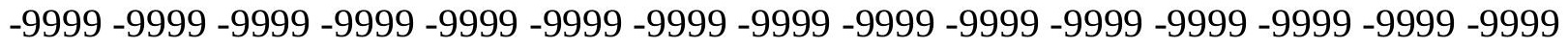
-9999 -9999 -9999 -9999 -9999 -9999 -9999 -9999 -9999 -9999 -9999 -9999 -9999 -9999 -9999 -9999 -9999 -9999 -9999 -9999 -9999 -9999 -9999 -9999 -9999 -9999 -9999 -9999 -9999 -999 -9999 -9999 -9999 -9999 -9999 -9999 -9999 -9999 -9999 -9999 -9999 -9999 -9999 -9999 -9999 -9999 -9999 -9999 -9999 -9999 -9999 -9999 -9999 -9999 -9999 -9999 -9999 -9999 -9999 -9999 -

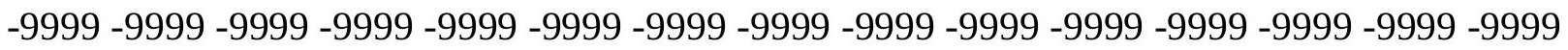

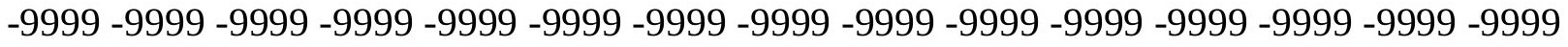

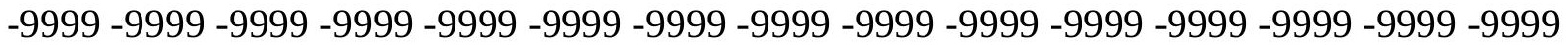

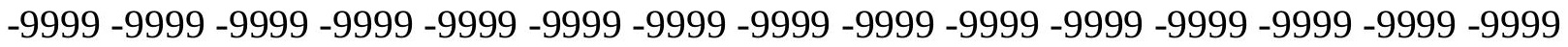

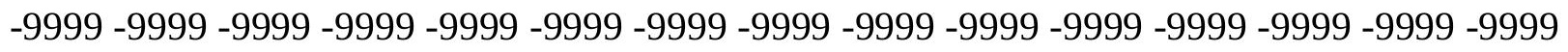

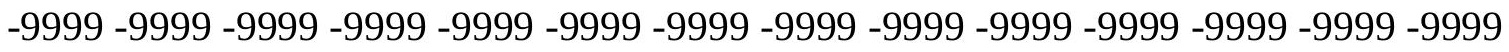
-9999 -9999 -9999 -9999 -9999 -9999 -9999 -9999 -9999 -9999 -9999 -9999 -9999 -9999 -9999 -9999 -9999 -9999 -9999 -9999 -9999 -9999 -9999 -9999 -9999 -9999 -9999 -9999 -9999 -9999 -

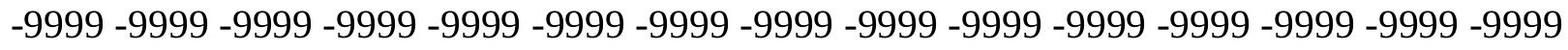

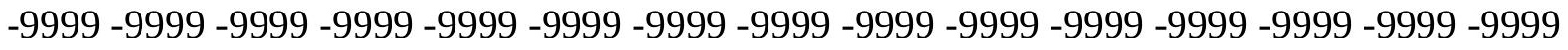
-9999 -9999 -9999 -9999 -9999 -9999 -9999 -9999 -9999 -9999 -9999 -9999 -9999 -9999 -9999 -9999 -9999 -9999 -9999 -9999 -9999 -9999 -9999 -9999-9999 -9999 -9999 -9999 -9999 -9999 -9999 -9999 -9999 -9999 -9999 -9999 -9999 -9999 -9999 -9999 -9999 -9999 -9999 -9999 -9999 -

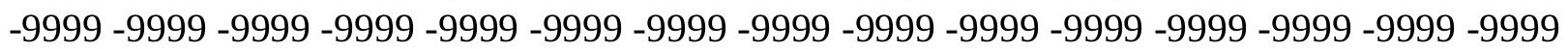


-9999 -9999 -9999 -9999 -9999 -9999 -9999 -9999 -9999 -9999 -9999 -9999 -9999 -9999 -9999 -9999 -9999 -9999 -9999 -9999 -9999 -9999 -9999 -9999 -9999 -9999 -9999 -9999 -9999 -9999 -9999 -9999 -9999 -9999 -9999 -9999 -9999 -9999 -9999 -9999 -9999 -9999 -9999 -9999 - 9999 -9999 -9999 -9999 -9999 -9999 -9999 -9999 -9999 -9999 -9999 -9999 -9999 -9999 -9999 -9999 -9999 -9999 -9999 -9999 -9999 -9999 -9999 -9999 -9999 -9999 -9999 -9999 -9999 -9999 -9999 -9999 -9999 -9999 -9999 -9999 -9999 -9999 -9999 -9999 -9999 -9999 -9999 -9999 -9999 -9999 -9999 -9999 -9999 -9999 -9999 -9999 -9999 -9999 -9999 -9999 -9999 -9999 -9999 -9999 -9999

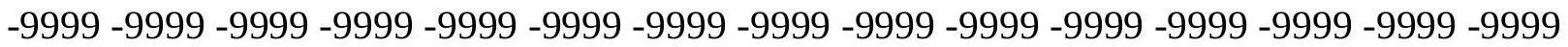
-9999 -9999 -9999 -9999 -9999 -9999 -9999 -9999 -9999 -9999 -9999 -9999 -9999 -9999 -9999 -9999 -9999 -9999 -9999 -9999 -9999 -9999 -9999 -9999 -9999 -9999 -9999 -9999 -9999 -9999

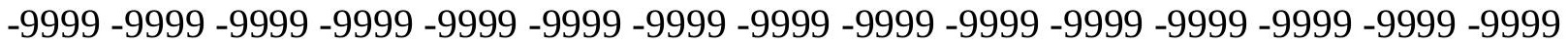
-9999 -9999 -9999 -9999 -9999 -9999 -9999 -9999 -9999 -9999 -9999 -9999 -9999 -9999 -9999 -9999 -9999 -9999 -9999 -9999 -9999 -9999 -9999 -9999 -9999 -9999 -9999 -9999 -9999 -9999 -

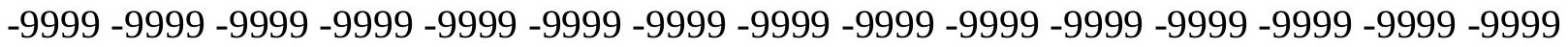
-9999 -9999 -9999 -9999 -9999 -9999 -9999 -9999 -9999 -9999 -9999 -9999 -9999 -9999 -9999

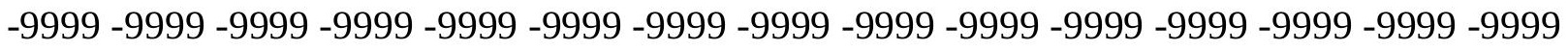
-9999 -9999 -9999 -9999 -9999 -9999 -9999 -9999 -9999 -9999 -9999 -9999 -9999 -9999 -9999 -9999 -9999 -9999 -9999 -9999 -9999 -9999 -9999 -9999 -9999 -9999 -9999 -9999 -9999 - -999 -9999 -9999 -9999 -9999 -9999 -9999 -9999 -9999 -9999 -9999 -9999 -9999 -9999 -9999 -9999 -9999 -9999 -9999 -9999 -9999 -9999 -9999 -9999 -9999 -9999 -9999 -9999 -9999 -9999 -9999 -9999 -9999 -9999 -9999 -9999 -9999 -9999 -9999 -9999 -9999 -9999 -9999 -9999 -9999 -9999 -999 -9999 -9999 -9999 -9999 -9999 -9999 -9999 -9999 -9999 -9999 -9999 -9999 -9999 -9999 -9999 -9999 -9999 -9999 -9999 -9999 -9999 -9999 -9999 -9999 -9999 -9999 -9999 -9999 -9999 -9999 -9999 -9999 -9999 -9999 -9999 -9999 -9999 -9999 -9999 -9999 -9999 -9999 -9999 -9999 -9999 -9999 -9999 -9999 -9999 -9999 -9999 -9999 -9999 -9999 -9999 -9999 -9999 -9999 -9999 -9999 -9999 -9999 -9999 -9999 -9999 -9999 -9999 -9999 -9999 -9999 -9999 -9999 -9999 -9999 -9999 -9999 -9999 -9999 -9999 -9999 -9999 -9999 -9999 -9999 -9999 -9999 -9999 -9999 -9999 -9999 -9999 -9999 -9999 -9999 -9999 -9999 -9999 -9999 -9999 -9999 -9999 -9999 -9999 -9999 -9999 -9999 -9999 -9999 -9999 -9999 -9999 -9999 -9999 -9999 -9999 -9999 -9999 -9999 -9999 -9999 -9999 -9999 -9999 -9999 -9999 -9999 -9999 -9999 -9999 -9999 -9999 -9999 -9999 -9999 -999 -9999 -9999 -9999 -9999 -9999 -9999 -9999 -9999 -9999 -9999 -9999 -9999 -9999 -9999 -9999 -9999 -9999 -9999 -9999 -9999 -9999 -9999 -9999 -9999 -9999 -9999 -9999 -9999 -9999 -9999 -

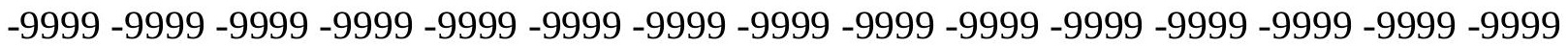

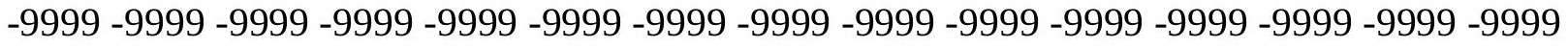

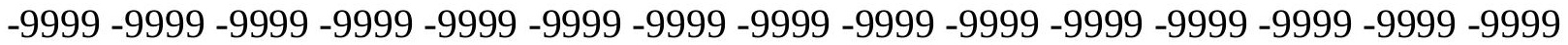
-9999 -9999 -9999 -9999 -9999 -9999 -9999 -9999 -9999 -9999 -9999 -9999 -9999 -9999 -9999

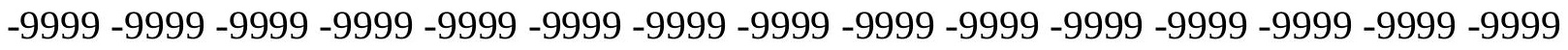

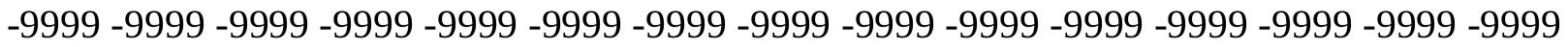

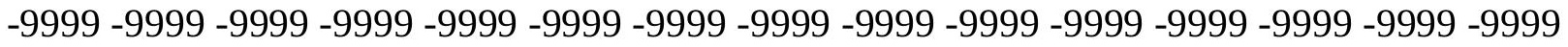
-9999 -9999 -9999 -9999 -9999 -9999 -9999 -9999 -9999 -9999 -9999 -9999 -9999 -9999 -9999 -

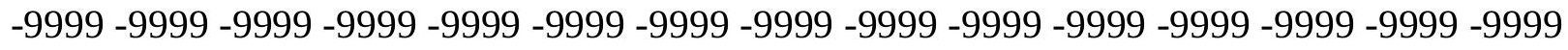

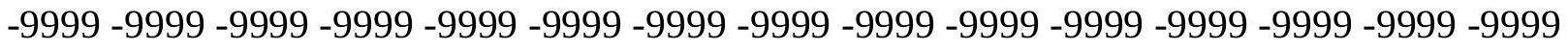
-9999 -9999 -9999 -9999 -9999 -9999 -9999 -9999 -9999 -9999 -9999 -9999 -9999 -9999 -9999 -9999 -9999 -9999 -9999 -9999 -9999 -9999 -9999 -9999 -9999 -9999 -9999 -9999 - -9999 -9999 -9999 -9999 -9999 -9999 -9999 -9999 -9999 -9999 -9999 -9999 -9999 -9999 -9999 -9999 -

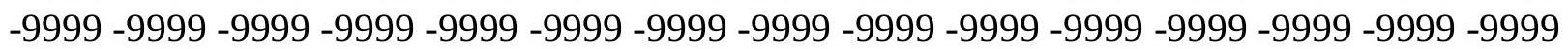


-9999 -9999 -9999 -9999 -9999 -9999 -9999 -9999 -9999 -9999 -9999 -9999 -9999 -9999 -9999 -9999 -9999 -9999 -9999 -9999 -9999 -9999 -9999 -9999 -9999 -9999 -9999 -9999 -9999 -9999 -9999 -9999 -9999 -9999 -9999 -9999 -9999 -9999 -9999 -9999 -9999 -9999 -9999 -9999 - 9999 -9999 -9999 -9999 -9999 -9999 -9999 -9999 -9999 -9999 -9999 -9999 -9999 -9999 -9999 -9999 -9999 -9999 -9999 -9999 -9999 -9999 -9999 -9999 -9999-9999 -9999 -9999 -9999 -9999 -9999 -9999 -9999 -9999 -9999 -9999 -9999 -9999 -9999 -9999 -9999 -9999 -9999 -9999 -9999 -9999 -9999 -9999 -9999 -9999 -9999 -9999 -9999 -9999 -9999 -9999 -9999 -9999 -9999 -9999 -9999

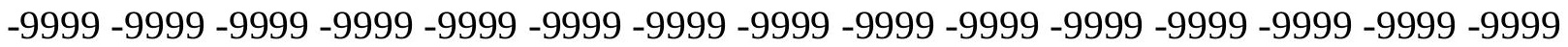

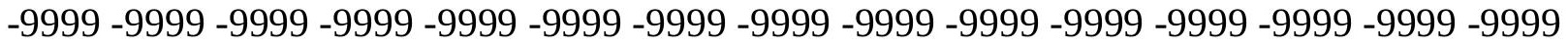
-9999 -9999 -9999 -9999 -9999 -9999 -9999 -9999 -9999 -9999 -9999 -9999 -9999 -9999 -9999

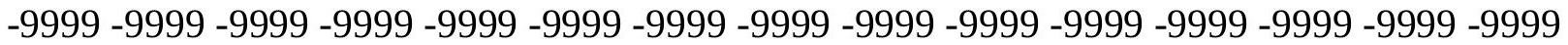
-9999 -9999 -9999 -9999 -9999 -9999 -9999 -9999 -9999 -9999 -9999 -9999 -9999 -9999 -9999 -9999 -9999 -9999 -9999 -9999 -9999 -9999 -9999 -9999 -9999 -9999 -9999 -9999 -9999 -9999 -

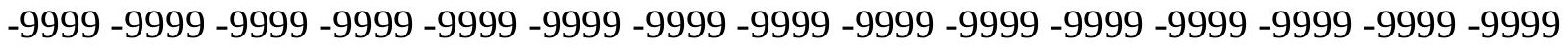
-9999 -9999 -9999 -9999 -9999 -9999 -9999 -9999 -9999 -9999 -9999 -9999 -9999 -9999 -9999

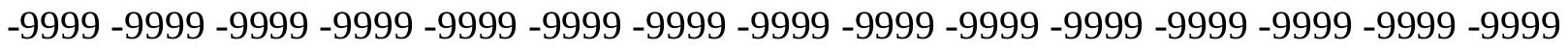
-9999 -9999 -9999 -9999 -9999 -9999 -9999 -9999 -9999 -9999 -9999 -9999 -9999 -9999 -9999 -9999 -9999 -9999 -9999 -9999 -9999 -9999 -9999 -9999 -9999 -9999 -9999 -9999 -9999 -9999 -9999 -9999 -9999 -9999 -9999 -9999 -9999 -9999 -9999 -9999 -9999 -9999 -9999 -9999 -9999 -9999 -9999 -9999 -9999 -9999 -9999 -9999 -9999 -9999 -9999 -9999 -9999 -9999 -9999 -9999 -9999 -9999 -9999 -9999 -9999 -9999 -9999 -9999 -9999 -9999 -9999 -9999 -9999 -9999 -9999 -999 -9999 -9999 -9999 -9999 -9999 -9999 -9999 -9999 -9999 -9999 -9999 -9999 -9999 -9999 -9999 -9999 -9999 -9999 -9999 -9999 -9999 -9999 -9999 -9999 -9999 -9999 -9999 -9999 -9999 -9999 -9999 -9999 -9999 -9999 -9999 -9999 -9999 -9999 -9999 -9999 -9999 -9999 -9999 -9999 -9999 -9999 -9999 -9999 -9999 -9999 -9999 -9999 -9999 -9999 -9999 -9999 -9999 -9999 -9999 -9999 -9999 -9999 -9999 -9999 -9999 -9999 -9999 -9999 -9999 -9999 -9999 -9999 -9999 -9999 -9999 -9999 -9999 -9999 -9999 -9999 -9999 -9999 -9999 -9999 -9999 -9999 -9999 -9999 -9999 -9999 -9999 -9999 -9999 -9999 -9999 -9999 -9999 -9999 -9999 -9999 -9999 -9999 -9999 -9999 -9999 -9999 -9999 -9999 -9999 -9999 -9999 -9999 -9999 -9999 -9999 -9999 -9999 -9999 -9999 -9999 -9999 -9999 -9999 -9999 -9999 -9999 -9999 -9999 -9999 -9999 -9999 -9999 -9999 -999 -9999 -9999 -9999 -9999 -9999 -9999 -9999 -9999 -9999 -9999 -9999 -9999 -9999 -9999 -9999 -9999 -9999 -9999 -9999 -9999 -9999 -9999 -9999 -9999 -9999 -9999 -9999 -9999 -9999 -9999 -

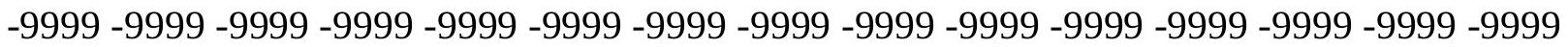

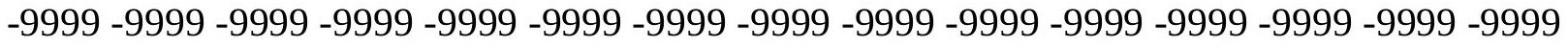

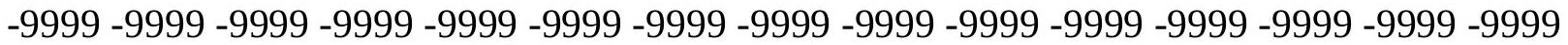
-9999 -9999 -9999 -9999 -9999 -9999 -9999 -9999 -9999 -9999 -9999 -9999 -9999 -9999 -9999

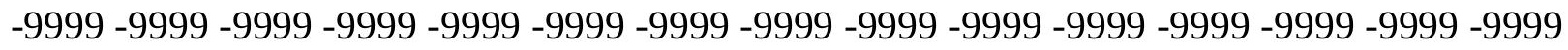

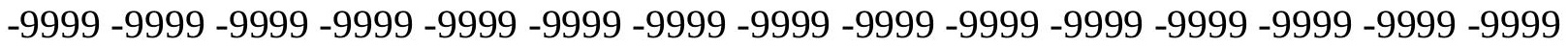
-9999 -9999 -9999 -9999 -9999 -9999 -9999 -9999 -9999 -9999 -9999 -9999 -9999 -9999 -9999 -9999 -9999 -9999 -9999 -9999 -9999 -9999 -9999 -9999 -9999 -9999 -9999 -9999 -9999 -9999 -

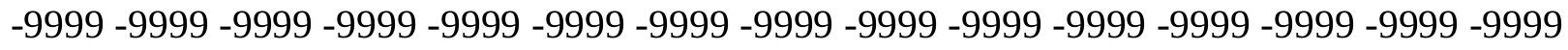

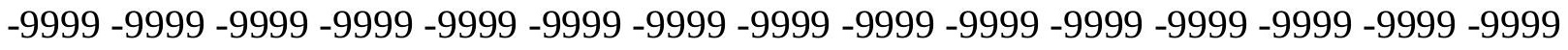
-9999 -9999 -9999 -9999 -9999 -9999 -9999 -9999 -9999 -9999 -9999 -9999 -9999 -9999 -9999 -9999 -9999 -9999 -9999 -9999 -9999 -9999 -9999 -9999-9999 -9999 -9999 -9999 -9999 -9999 -9999 -9999 -9999 -9999 -9999 -9999 -9999 -9999 -9999 -9999 -9999 -9999 -9999 -9999 -9999 -

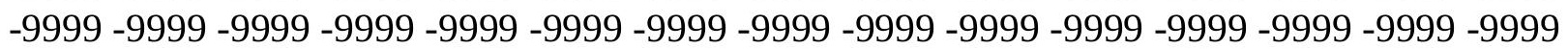


-9999 -9999 -9999 -9999 -9999 -9999 -9999 -9999 -9999 -9999 -9999 -9999 -9999 -9999 -9999 -9999 -9999 -9999 -9999 -9999 -9999 -9999 -9999 -9999 -9999 -9999 -9999 -9999 -9999 -9999 -9999 -9999 -9999 -9999 -9999 -9999 -9999 -9999 -9999 -9999 -9999 -9999 -9999 -9999 - 9999 -9999 -9999 -9999 -9999 -9999 -9999 -9999 -9999 -9999 -9999 -9999 -9999 -9999 -9999

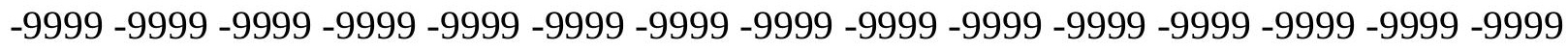
-9999 -9999 -9999 -9999 -9999 -9999 -9999 -9999 -9999 -9999 -9999 -9999 -9999 -9999 -9999 -9999 -9999 -9999 -9999 -9999 -9999 -9999 -9999 -9999 -9999 -9999 -9999 -9999 -9999 -9999

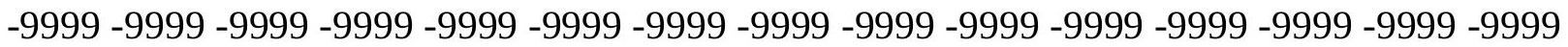

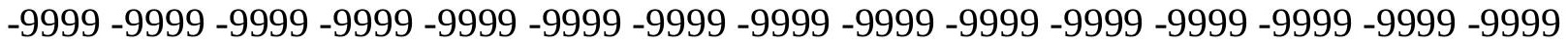
-9999 -9999 -9999 -9999 -9999 -9999 -9999 -9999 -9999 -9999 -9999 -9999 -9999 -9999 -9999 -9999 -9999 -9999 -9999 -9999 -9999 -9999 -9999 -9999 -9999 -9999 -9999 -9999 -9999 -9999 -9999 -9999 -9999 -9999 -9999 -9999 -9999 -9999 -9999 -9999 -9999 -9999 -9999 -9999 -9999 -9999 -9999 -9999 -9999 -9999 -9999 -9999 -9999 -9999 -9999 -9999 -9999 -9999 -9999 -9999 -

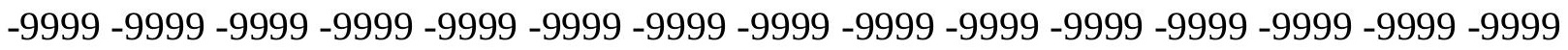
-9999 -9999 -9999 -9999 -9999 -9999 -9999 -9999 -9999 -9999 -9999 -9999 -9999 -9999 -9999 -

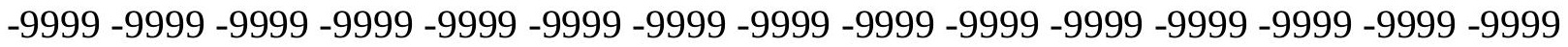
-9999 -9999 -9999 -9999 -9999 -9999 -9999 -9999 -9999 -9999 -9999 -9999 -9999 -9999 -9999 -9999 -9999 -9999 -9999 -9999 -9999 -9999 -9999 -9999 -9999 -9999 -9999 -9999 -9999 -9999 -9999 -9999 -9999 -9999 -9999 -9999 -9999 -9999 -9999 -9999 -9999 -9999 -9999 -9999 -9999 -

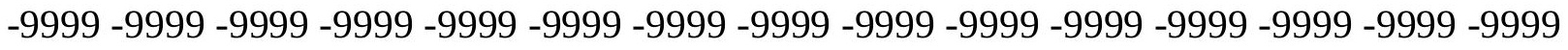
-9999 -9999 -9999 -9999 -9999 -9999 -9999 -9999 -9999 -9999 -9999 -9999 -9999 -9999 -9999

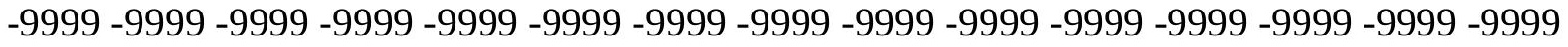
-9999 -9999 -9999 -9999 -9999 -9999 -9999 -9999 -9999 -9999 -9999 -9999 -9999 -9999 -9999 -9999 -9999 -9999 -9999 -9999 -9999 -9999 -9999 -9999 -9999 -9999 -9999 -9999 -9999 -9999 -9999 -9999 -9999 -9999 -9999 -9999 -9999 -9999 -9999 -9999 -9999 -9999 -9999 -9999 -9999 -9999 -9999 -9999 -9999 -9999 -9999 -9999 -9999 -9999 -9999 -9999 -9999 -9999 -9999 -9999 -9999 -9999 -9999 -9999 -9999 -9999 -9999 -9999 -9999 -9999 -9999 -9999 -9999 -9999 -9999 -9999 -9999 -9999 -9999 -9999 -9999 -9999 -9999 -9999 -9999 -9999 -9999 -9999 -9999 -9999 -9999 -9999 -9999 -9999 -9999 -9999 -9999 -9999 -9999 -9999 -9999 -9999 -9999 -9999 -9999 -9999 -9999 -9999 -9999 -9999 -9999 -9999 -9999 -9999 -9999 -9999 -9999 -9999 -9999 -9999 -9999 -9999 -9999 -9999 -9999 -9999 -9999 -9999 -9999 -9999 -9999 -9999 -9999 -9999 -9999 -9999 -9999 -9999 -9999 -9999 -9999 -9999 -9999 -9999 -9999 -9999 -9999 -9999 -9999 -

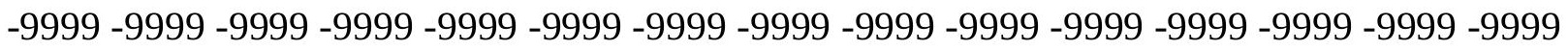

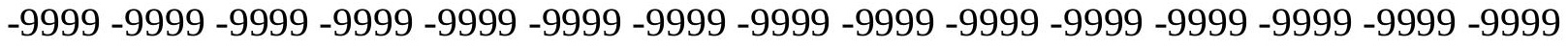
-9999 -9999 -9999 -9999 -9999 -9999 -9999 -9999 -9999 -9999 -9999 -9999 -9999 -9999 -9999 -

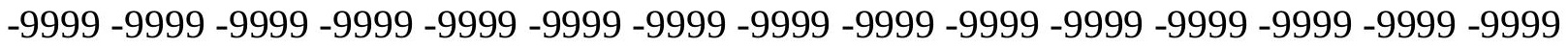

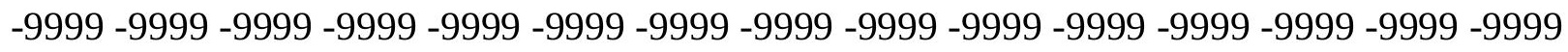

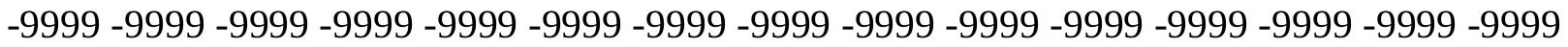

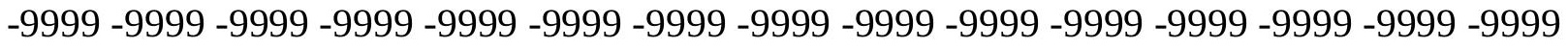
-9999 -9999 -9999 -9999 -9999 -9999 -9999 -9999 -9999 -9999 -9999 -9999 -9999 -9999 -9999 -

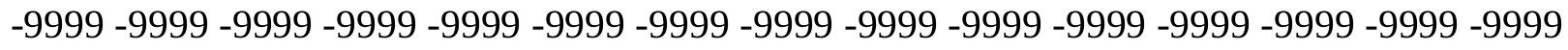

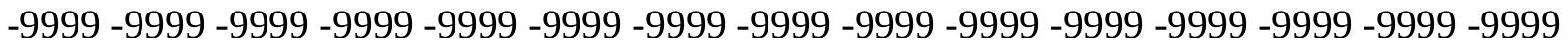
-9999 -9999 -9999 -9999 -9999 -9999 -9999 -9999 -9999 -9999 -9999 -9999 -9999 -9999 -9999 -9999 -9999 -9999 -9999 -9999 -9999 -9999 -9999 -9999-9999 -9999 -9999 -9999 -9999 -9999 -9999 -9999 -9999 -9999 -9999 -9999 -9999 -9999 -9999 -9999 -9999 -9999 -9999 -9999 -9999 -

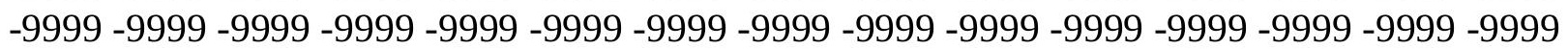


-9999 -9999 -9999 -9999 -9999 -9999 -9999 -9999 -9999 -9999 -9999 -9999 -9999 -9999 -9999 -9999 -9999 -9999 -9999 -9999 -9999 -9999 -9999 -9999 -9999 -9999 -9999 -9999 -9999 -9999 -9999 -9999 -9999 -9999 -9999 -9999 -9999 -9999 -9999 -9999 -9999 -9999 -9999 -9999 - 9999 -9999 -9999 -9999 -9999 -9999 -9999 -9999 -9999 -9999 -9999 -9999 -9999 -9999 -9999 -9999 -9999 -9999 -9999 -9999 -9999 -9999 -9999 -9999 -9999 -9999 -9999 -9999 -9999 -9999 -9999 -9999 -9999 -9999 -9999 -9999 -9999 -9999 -9999 -9999 -9999 -9999 -9999 -9999 -9999 -9999 -9999 -9999 -9999 -9999 -9999 -9999 -9999 -9999 -9999 -9999 -9999 -9999 -9999 -9999 -9999

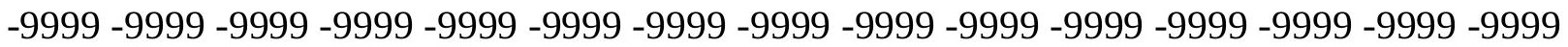

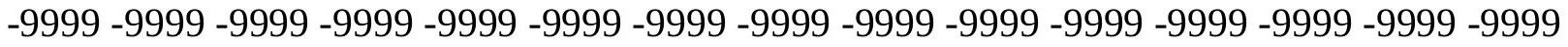
-9999 -9999 -9999 -9999 -9999 -9999 -9999 -9999 -9999 -9999 -9999 -9999 -9999 -9999 -9999 -9999 -9999 -9999 -9999 -9999 -9999 -9999 -9999 -9999 -9999 -9999 -9999 -9999 -9999 -9999 -9999 -9999 -9999 -9999 -9999 -9999 -9999 -9999 -9999 -9999 -9999 -9999 -9999 -9999 -9999 -9999 -9999 -9999 -9999 -9999 -9999 -9999 -9999 -9999 -9999 -9999 -9999 -9999 -9999 -9999 -9999 -9999 -9999 -9999 -9999 -9999 -9999 -9999 -9999 -9999 -9999 -9999 -9999 -9999 -9999 -9999 -9999 -9999 -9999 -9999 -9999 -9999 -9999 -9999 -9999 -9999 -9999 -9999 -9999 -

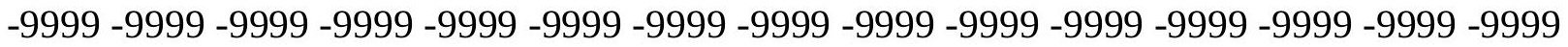
-9999 -9999 -9999 -9999 -9999 -9999 -9999 -9999 -9999 -9999 -9999 -9999 -9999 -9999 -9999 -9999 -9999 -9999 -9999 -9999 -9999 -9999 -9999 -9999 -9999 -9999 -9999 -9999 -9999 -9999 -9999 -9999 -9999 -9999 -9999 -9999 -9999 -9999 -9999 -9999 -9999 -9999 -9999 -9999 -9999 -9999 -9999 -9999 -9999 -9999 -9999 -9999 -9999 -9999 -9999 -9999 -9999 -9999 -9999 -9999 -9999 -9999 -9999 -9999 -9999 -9999 -9999 -9999 -9999 -9999 -9999 -9999 -9999 -9999 -9999 -999 -9999 -9999 -9999 -9999 -9999 -9999 -9999 -9999 -9999 -9999 -9999 -9999 -9999 -9999 -9999 -9999 -9999 -9999 -9999 -9999 -9999 -9999 -9999 -9999 -9999 -9999 -9999 -9999 -9999 -9999 -9999 -9999 -9999 -9999 -9999 -9999 -9999 -9999 -9999 -9999 -9999 -9999 -9999 -9999 -9999 -9999 -9999 -9999 -9999 -9999 -9999 -9999 -9999 -9999 -9999 -9999 -9999 -9999 -9999 -9999 -9999 -9999 -9999 -9999 -9999 -9999 -9999 -9999 -9999 -9999 -9999 -9999 -9999 -9999 -9999 -9999 -9999 -9999 -9999 -9999 -9999 -9999 -9999 -9999 -9999 -9999 -9999 -9999 -9999 -9999 -9999 -9999 -9999 -9999 -9999 -9999 -9999 -9999 -9999 -9999 -9999 -9999 -9999 -9999 -9999 -9999 -9999 -9999 -9999 -9999 -9999 -9999 -9999 -9999 -9999 -9999 -9999 -9999 -9999 -9999 -9999 -9999 -9999 -9999 -9999 -9999 -9999 -9999 -9999 -9999 -9999 -9999 -9999 -9999 -999 -9999 -9999 -9999 -9999 -9999 -9999 -9999 -9999 -9999 -9999 -9999 -9999 -9999 -9999 -9999 -9999 -9999 -9999 -9999 -9999 -9999 -9999 -9999 -9999 -9999 -9999 -9999 -9999 -9999 -9999 -

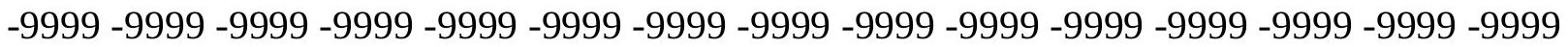

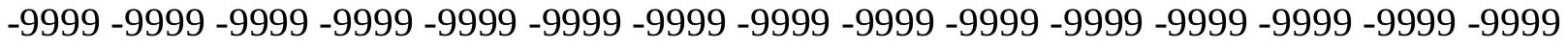

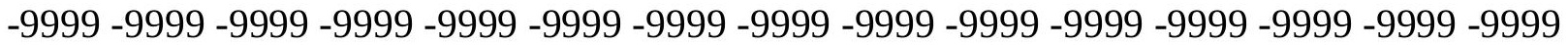
-9999 -9999 -9999 -9999 -9999 -9999 -9999 -9999 -9999 -9999 -9999 -9999 -9999 -9999 -9999 -9999 -9999 -9999 -9999 -9999 -9999 -9999 -9999 -9999 -9999 -9999 -9999 -9999 -9999 -

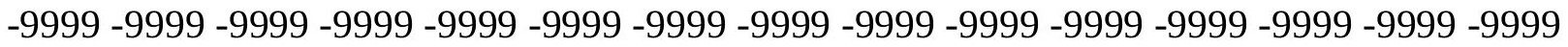
-9999 -9999 -9999 -9999 -9999 -9999 -9999 -9999 -9999 -9999 -9999 -9999 -9999 -9999 -9999 -9999 -9999 -9999 -9999 -9999 -9999 -9999 -9999 -9999 -9999 -9999 -9999 -9999 -9999 -9999 -

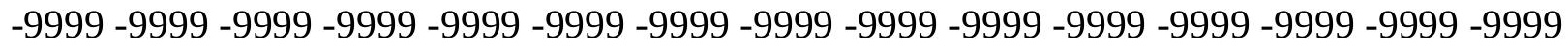

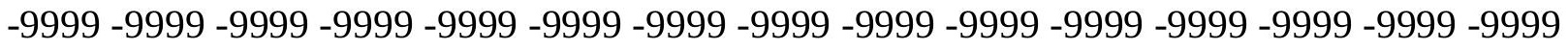
-9999 -9999 -9999 -9999 -9999 -9999 -9999 -9999 -9999 -9999 -9999 -9999 -9999 -9999 -9999 -9999 -9999 -9999 -9999 -9999 -9999 -9999 -9999 -9999-9999 -9999 -9999 -9999 -9999 -9999 -9999 -9999 -9999 -9999 -9999 -9999 -9999 -9999 -9999 -9999 -9999 -9999 -9999 -9999 -9999 -

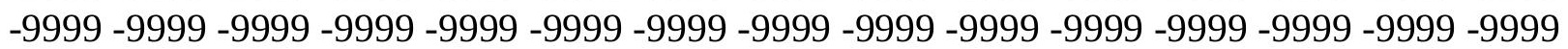


-9999 -9999 -9999 -9999 -9999 -9999 -9999 -9999 -9999 -9999 -9999 -9999 -9999 -9999 -9999 -9999 -9999 -9999 -9999 -9999 -9999 -9999 -9999 -9999 -9999 -9999 -9999 -9999 -9999 -9999 -

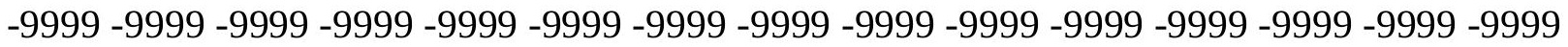
-9999 -9999 -9999 -9999 -9999 -9999 -9999 -9999 -9999 -9999 -9999 -9999 -9999 -9999 -9999 -9999 -9999 -9999 -9999 -9999 -9999 -9999 -9999 -9999-9999 -9999 -9999 -9999 -9999 -9999 -9999 -9999 -9999 -9999 -9999 -9999 -9999 -9999 -9999 -9999 -9999 -9999 -9999 -9999 -9999 -9999 -9999 -9999 -9999 -9999 -9999 -9999 -9999 -9999 -9999 -9999 -9999 -9999 -9999 -9999

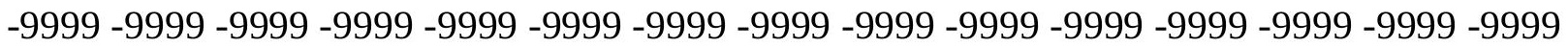

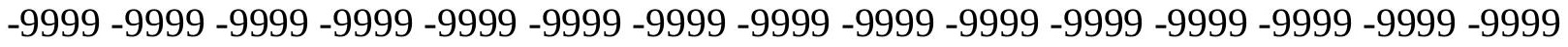
-9999 -9999 -9999 -9999 -9999 -9999 -9999 -9999 -9999 -9999 -9999 -9999 -9999 -9999 -9999 -9999 -9999 -9999 -9999 -9999 -9999 -9999 -9999 -9999 -9999 -9999 -9999 -9999 -9999 -9999 -9999 -9999 -9999 -9999 -9999 -9999 -9999 -9999 -9999 -9999 -9999 -9999 -9999 -9999 -9999 -9999 -9999 -9999 -9999 -9999 -9999 -9999 -9999 -9999 -9999 -9999 -9999 -9999 -9999 -9999 -9999 -9999 -9999 -9999 -9999 -9999 -9999 -9999 -9999 -9999 -9999 -9999 -9999 -9999 -9999 -9999 -9999 -9999 -9999 -9999 -9999 -9999 -9999 -9999 -9999 -9999 -9999 -9999 -9999 -9999 -

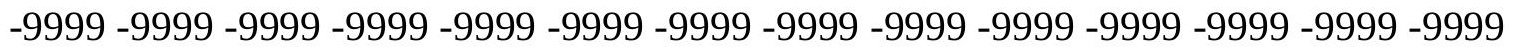
-9999 -9999 -9999 -9999 -9999 -9999 -9999 -9999 -9999 -9999 -9999 -9999 -9999 -9999 -9999 -9999 -9999 -9999 -9999 -9999 -9999 -9999 -9999 -9999 -9999 -9999 -9999 -9999 -9999 -9999 -9999 -9999 -9999 -9999 -9999 -9999 -9999 -9999 -9999 -9999 -9999 -9999 -9999 -9999 -9999 -

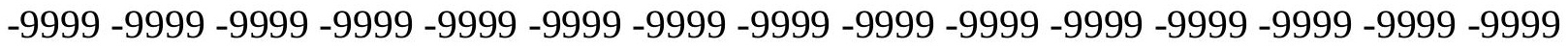

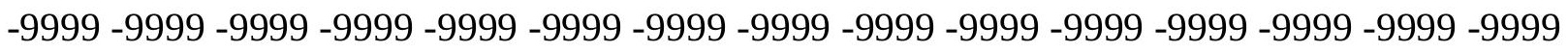
-9999 -9999 -9999 -9999 -9999 -9999 -9999 -9999 -9999 -9999 -9999 -9999 -9999 -9999 - 9999 -9999 -9999 -9999 -9999 -9999 -9999 -9999 -9999 -9999 -9999 -9999 -9999 -9999 -9999 -9999 -9999 -9999 -9999 -9999 -9999 -9999 -9999 -9999 -9999 -9999 -9999 -9999 -9999 -9999 -9999 -

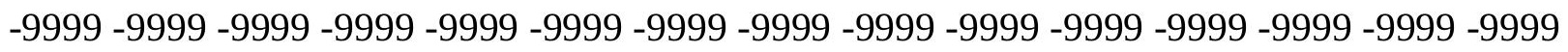
-9999 -9999 -9999 -9999 -9999 -9999 -9999 -9999 -9999 -9999 -9999 -9999 -9999 -9999 -9999 -9999 -9999 -9999 -9999 -9999 -9999 -9999 -9999 -9999 -9999 -9999 -9999 -9999 -9999 -9999 -

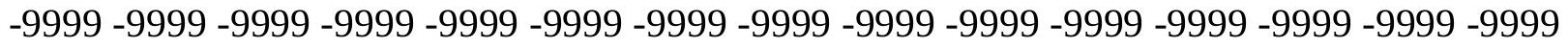
-9999 -9999 -9999 -9999 -9999 -9999 -9999 -9999 -9999 -9999 -9999 -9999 -9999 -9999 -9999 -9999 -9999 -9999 -9999 -9999 -9999 -9999 -9999 -9999 -9999 -9999 -9999 -9999 -9999 -999 -

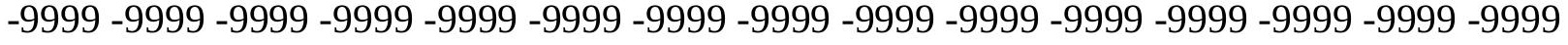
-9999 -9999 -9999 -9999 -9999 -9999 -9999 -9999 -9999 -9999 -9999 -9999 -9999 -9999 -9999 -

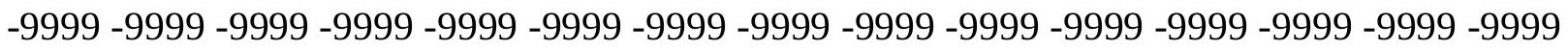

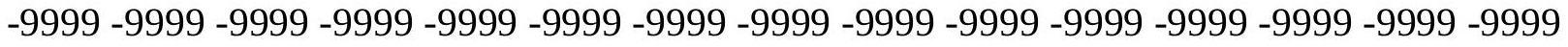

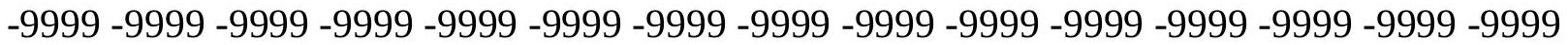
-9999 -9999 -9999 -9999 -9999 -9999 -9999 -9999 -9999 -9999 -9999 -9999 -9999 -9999 -9999 -

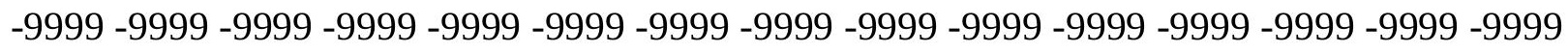

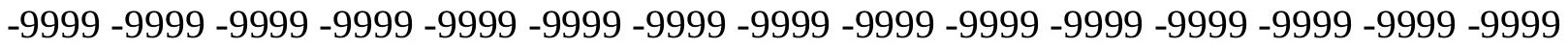
-9999 -9999 -9999 -9999 -9999 -9999 -9999 -9999 -9999 -9999 -9999 -9999 -9999 - 9999 - -999 -9999 -9999 -9999 -9999 -9999 -9999 -9999 -9999 -9999 -9999 -9999 -9999 -9999 -9999 -9999 -

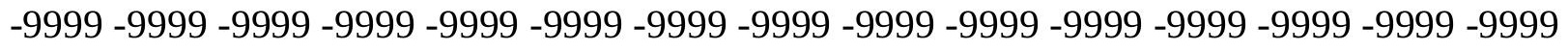

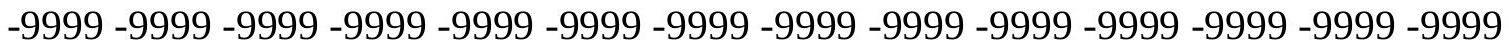
-9999 -9999 -9999 -9999 -9999 -9999 -9999 -9999 -9999 -9999 -9999 -9999 -9999 -9999 -9999 -9999 -9999 -9999 -9999 -9999 -9999 -9999 -9999 -9999-9999 -9999 -9999 -9999 -9999 -9999 -9999 -9999 -9999 -9999 -9999 -9999 -9999 -9999 -9999 -9999 -9999 -9999 -9999 -9999 -9999 -

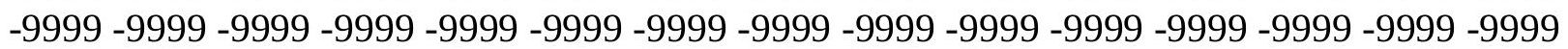


-9999 -9999 -9999 -9999 -9999 -9999 -9999 -9999 -9999 -9999 -9999 -9999 -9999 -9999 -9999 -9999 -9999 -9999 -9999 -9999 -9999 -9999 -9999 -9999 -9999 -9999 -9999 -9999 -9999 -9999 -

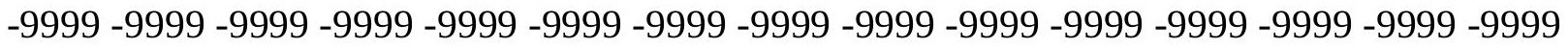
-9999 -9999 -9999 -9999 -9999 -9999 -9999 -9999 -9999 -9999 -9999 -9999 -9999 -9999 -9999 -9999 -9999 -9999 -9999 -9999 -9999 -9999 -9999 -9999-9999 -9999 -9999 -9999 -9999 -9999 -9999 -9999 -9999 -9999 -9999 -9999 -9999 -9999 -9999 -9999 -9999 -9999 -9999 -9999 -9999 -9999 -9999 -9999 -9999 -9999 -9999 -9999 -9999 -9999 -9999 -9999 -9999 -9999 -9999 -9999

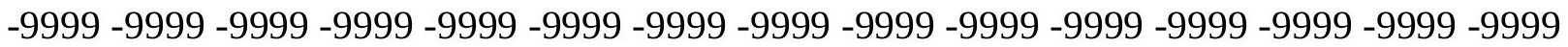

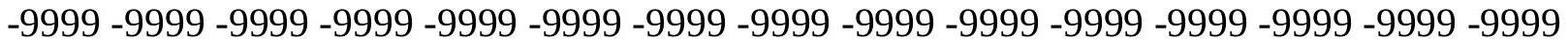
-9999 -9999 -9999 -9999 -9999 -9999 -9999 -9999 -9999 -9999 -9999 -9999 -9999 -9999 -9999 -9999 -9999 -9999 -9999 -9999 -9999 -9999 -9999 -9999 -9999 -9999 -9999 -9999 -9999 -9999 -9999 -9999 -9999 -9999 -9999 -9999 -9999 -9999 -9999 -9999 -9999 -9999 -9999 -9999 -9999 -9999 -9999 -9999 -9999 -9999 -9999 -9999 -9999 -9999 -9999 -9999 -9999 -9999 -9999 -9999 -

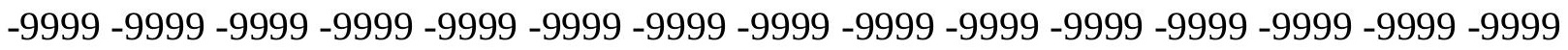
-9999 -9999 -9999 -9999 -9999 -9999 -9999 -9999 -9999 -9999 -9999 -9999 -9999 -9999 -9999 -

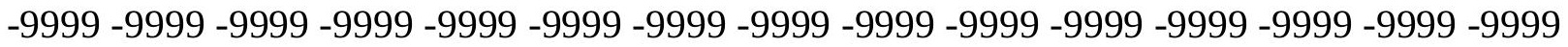
-9999 -9999 -9999 -9999 -9999 -9999 -9999 -9999 -9999 -9999 -9999 -9999 -9999 -9999 -9999 -9999 -9999 -9999 -9999 -9999 -9999 -9999 -9999 -9999 -9999 -9999 -9999 -9999 -9999 -9999 -9999 -9999 -9999 -9999 -9999 -9999 -9999 -9999 -9999 -9999 -9999 -9999 -9999 -9999 -9999 -

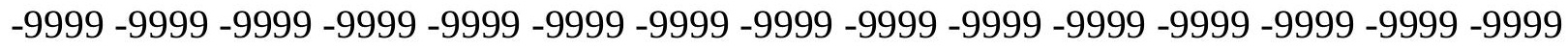

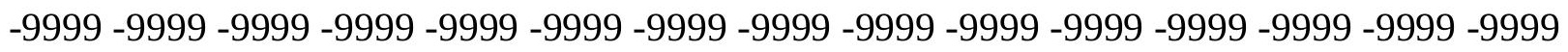
-9999 -9999 -9999 -9999 -9999 -9999 -9999 -9999 -9999 -9999 -9999 -9999 -9999 -9999 -9999 -9999 -9999 -9999 -9999 -9999 -9999 -9999 -9999 -9999 -9999 -9999 -9999 -9999 -9999 -9999 -9999 -9999 -9999 -9999 -9999 -9999 -9999 -9999 -9999 -9999 -9999 -9999 -9999 -9999 -

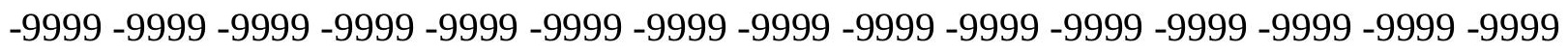
-9999 -9999 -9999 -9999 -9999 -9999 -9999 -9999 -9999 -9999 -9999 -9999 -9999 -9999 -9999 -9999 -9999 -9999 -9999 -9999 -9999 -9999 -9999 -9999 -9999 -9999 -9999 -9999 -9999 -9999 -

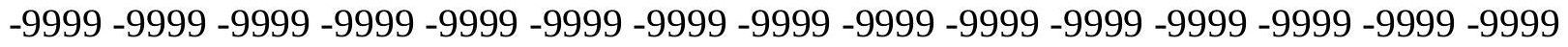
-9999 -9999 -9999 -9999 -9999 -9999 -9999 -9999 -9999 -9999 -9999 -9999 -9999 -9999 -9999 -9999 -9999 -9999 -9999 -9999 -9999 -9999 -9999 -9999 -9999 -9999 -9999 -9999 -9999 -999 -

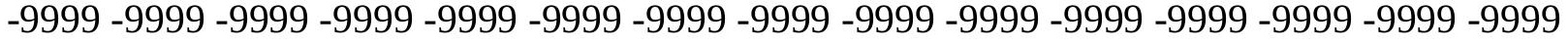
-9999 -9999 -9999 -9999 -9999 -9999 -9999 -9999 -9999 -9999 -9999 -9999 -9999 -9999 -9999 -

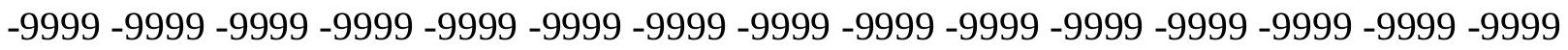

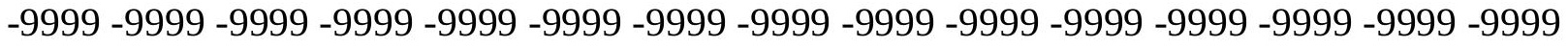

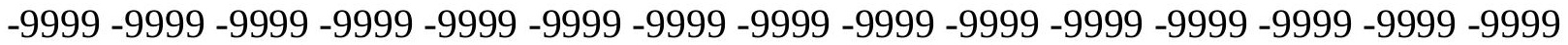

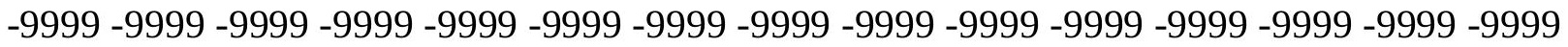

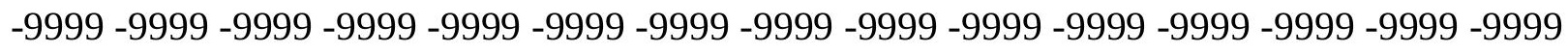

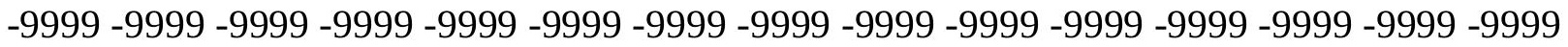

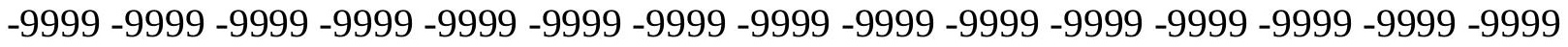
-9999 -9999 -9999 -9999 -9999 -9999 -9999 -9999 -9999 -9999 -9999 -9999 -9999 -9999 -9999 -

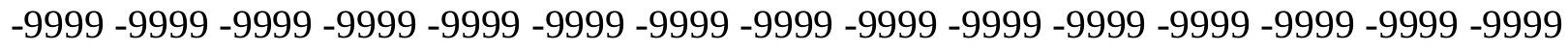

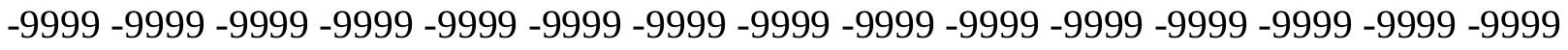
-9999 -9999 -9999 -9999 -9999 -9999 -9999 -9999 -9999 -9999 -9999 -9999 -9999 -9999 -9999 -9999 -9999 -9999 -9999 -9999 -9999 -9999 -9999 -9999-9999 -9999 -9999 -9999 -9999 -9999 -9999 -9999 -9999 -9999 -9999 -9999 -9999 -9999 -9999 -9999 -9999 -9999 -9999 -9999 -9999 -

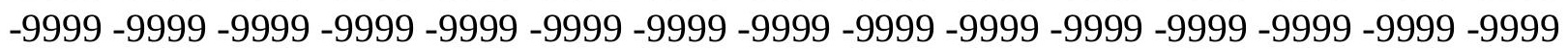


-9999 -9999 -9999 -9999 -9999 -9999 -9999 -9999 -9999 -9999 -9999 -9999 -9999 -9999 -9999 -9999 -9999 -9999 -9999 -9999 -9999 -9999 -9999 -9999 -9999 -9999 -9999 -9999 -9999 -

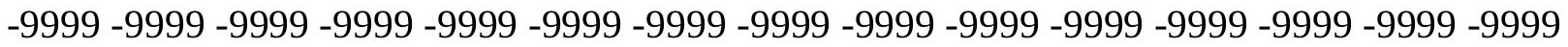
-9999 -9999 -9999 -9999 -9999 -9999 -9999 -9999 -9999 -9999 -9999 -9999 -9999 -9999 -9999 -9999 -9999 -9999 -9999 -9999 -9999 -9999 -9999 -9999 -9999 -9999 -9999 -9999 -9999 -9999 -9999 -9999 -9999 -9999 -9999 -9999 -9999 -9999 -9999 -9999 -9999 -9999 -9999 -9999 -9999 -9999 -9999 -9999 -9999 -9999 -9999 -9999 -9999 -9999 -9999 -9999 -9999 -9999 -9999 -9999

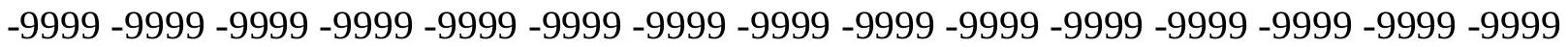

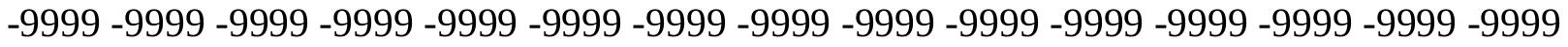
-9999 -9999 -9999 -9999 -9999 -9999 -9999 -9999 -9999 -9999 -9999 -9999 -9999 -9999 -9999 -9999 -9999 -9999 -9999 -9999 -9999 -9999 -9999 -9999 -9999 -9999 -9999 -9999 -9999 -9999 -9999 -9999 -9999 -9999 -9999 -9999 -9999 -9999 -9999 -9999 -9999 -9999 -9999 -9999 -9999 -9999 -9999 -9999 -9999 -9999 -9999 -9999 -9999 -9999 -9999 -9999 -9999 -9999 -9999 -9999 -9999 -9999 -9999 -9999 -9999 -9999 -9999 -9999 -9999 -9999 -9999 -9999 -9999 -9999 -9999 -9999 -9999 -9999 -9999 -9999 -9999 -9999 -9999 -9999 -9999 -9999 -9999 -9999 -9999 -9999 -

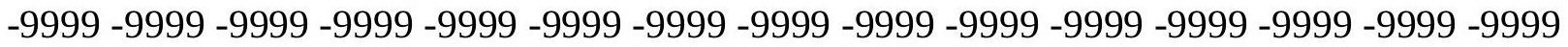
-9999 -9999 -9999 -9999 -9999 -9999 -9999 -9999 -9999 -9999 -9999 -9999 -9999 -9999 -9999 -9999 -9999 -9999 -9999 -9999 -9999 -9999 -9999 -9999 -9999 -9999 -9999 -9999 -9999 - 9999 -9999 -9999 -9999 -9999 -9999 -9999 -9999 -9999 -9999 -9999 -9999 -9999 -9999 -9999 -9999 -

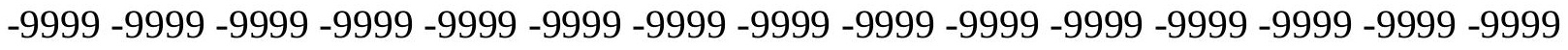

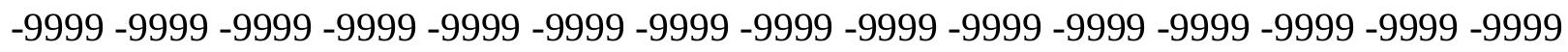

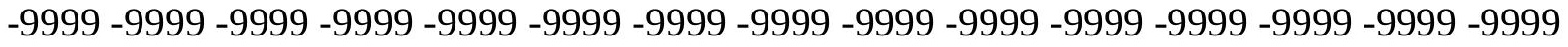
-9999 -9999 -9999 -9999 -9999 -9999 -9999 -9999 -9999 -9999 -9999 -9999 -9999 -9999 -9999 -9999 -9999 -9999 -9999 -9999 -9999 -9999 -9999 -9999 -9999 -9999 -9999 -9999 -9999 -9999 -

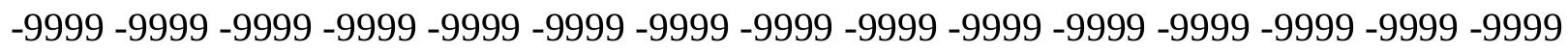
-9999 -9999 -9999 -9999 -9999 -9999 -9999 -9999 -9999 -9999 -9999 -9999 -9999 -9999 -9999 -9999 -9999 -9999 -9999 -9999 -9999 -9999 -9999 -9999 -9999 -9999 -9999 -9999 -9999 -9999 -9999 -9999 -9999 -9999 -9999 -9999 -9999 -9999 -9999 -9999 -9999 -9999 -9999 -9999 -9999 -9999 -9999 -9999 -9999 -9999 -9999 -9999 -9999 -9999 -9999 -9999 -9999 -9999 -9999 -9999 -9999 -9999 -9999 -9999 -9999 -9999 -9999 -9999 -9999 -9999 -9999 -9999 -9999 -999 -

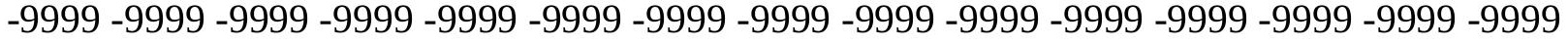
-9999 -9999 -9999 -9999 -9999 -9999 -9999 -9999 -9999 -9999 -9999 -9999 -9999 -9999 -9999 -

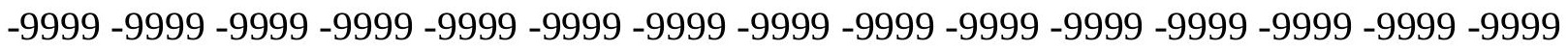

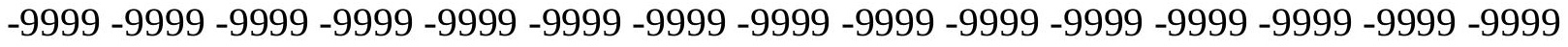

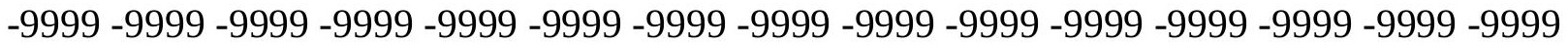

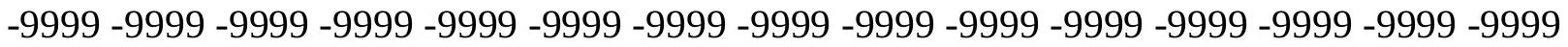

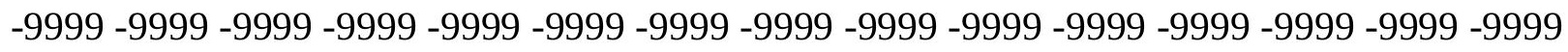

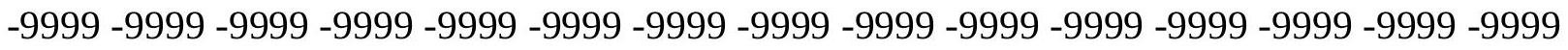

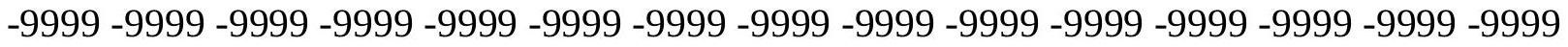
-9999 -9999 -9999 -9999 -9999 -9999 -9999 -9999 -9999 -9999 -9999 -9999 -9999 -9999 -9999 -

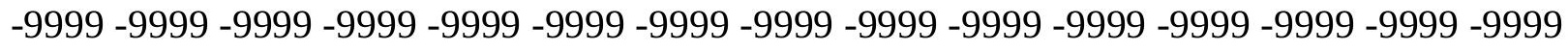

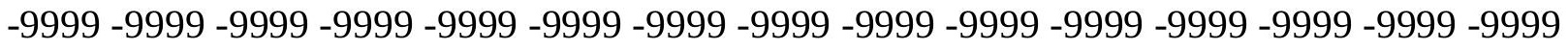
-9999 -9999 -9999 -9999 -9999 -9999 -9999 -9999 -9999 -9999 -9999 -9999 -9999 -9999 -9999 -9999 -9999 -9999 -9999 -9999 -9999 -9999 -9999 -9999-9999 -9999 -9999 -9999 -9999 -9999 -9999 -9999 -9999 -9999 -9999 -9999 -9999 -9999 -9999 -9999 -9999 -9999 -9999 -9999 -9999 -

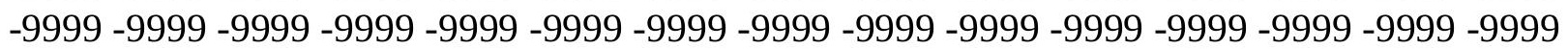


-9999 -9999 -9999 -9999 -9999 -9999 -9999 -9999 -9999 -9999 -9999 -9999 -9999 -9999 -9999 -9999 -9999 -9999 -9999 -9999 -9999 -9999 -9999 -9999 -9999 -9999 -9999 -9999 -9999 -9999 -

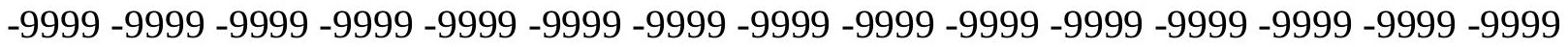
-9999 -9999 -9999 -9999 -9999 -9999 -9999 -9999 -9999 -9999 -9999 -9999 -9999 -9999 -9999 -9999 -9999 -9999 -9999 -9999 -9999 -9999 -9999 -9999-9999 -9999 -9999 -9999 -9999 -9999 -9999 -9999 -9999 -9999 -9999 -9999 -9999 -9999 -9999 -9999 -9999 -9999 -9999 -9999 -9999 -

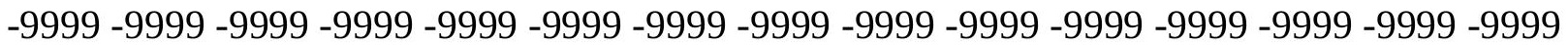
-9999 -9999 -9999 -9999 -9999 -9999 -9999 -9999 -9999 -9999 -9999 -9999 -9999 -9999 -9999 -9999 -9999 -9999 -9999 -9999 -9999 -9999 -9999 -9999 -9999 -9999 -9999 -9999 -9999 -9999 -9999 -9999 -9999 -9999 -9999 -9999 -9999 -9999 -9999 -9999 -9999 -9999 -9999 -9999 -9999 -9999 -9999 -9999 -9999 -9999 -9999 -9999 -9999 -9999 -9999 -9999 -9999 -9999 -9999 -9999 -9999 -9999 -9999 -9999 -9999 -9999 -9999 -9999 -9999 -9999 -9999 -9999 -9999 -9999 -9999 -9999 -9999 -9999 -9999 -9999 -9999 -9999 -9999 -9999 -9999 -9999 -9999 -9999 -9999 -9999 -9999 -9999 -9999 -9999 -9999 -9999 -9999 -9999 -9999 -9999 -9999 -9999 -9999 -9999 -9999 -9999 -9999 -9999 -9999 -9999 -9999 -9999 -9999 -9999 -9999 -9999 -9999 -9999 -9999 -

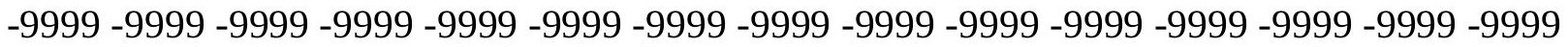
-9999 -9999 -9999 -9999 -9999 -9999 -9999 -9999 -9999 -9999 -9999 -9999 -9999 -9999 -9999 -9999 -9999 -9999 -9999 -9999 -9999 -9999 -9999 -9999 -9999 -9999 -9999 -9999 -9999 -9999 -9999 -9999 -9999 -9999 -9999 -9999 -9999 -9999 -9999 -9999 -9999 -9999 -9999 -9999 -9999 -

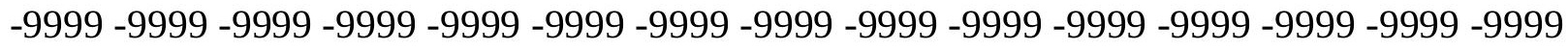

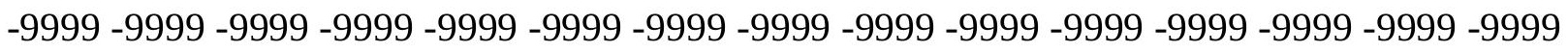
-9999 -9999 -9999 -9999 -9999 -9999 -9999 -9999 -9999 -9999 -9999 -9999 -9999 -9999 - 9999 -9999 -9999 -9999 -9999 -9999 -9999 -9999 -9999 -9999 -9999 -9999 -9999 -9999 -9999 -9999 -9999 -9999 -9999 -9999 -9999 -9999 -9999 -9999 -9999 -9999 -9999 -9999 -9999 -9999 -9999 -

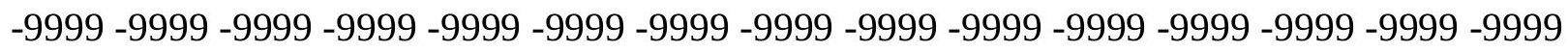
-9999 -9999 -9999 -9999 -9999 -9999 -9999 -9999 -9999 -9999 -9999 -9999 -9999 -9999 -9999 -9999 -9999 -9999 -9999 -9999 -9999 -9999 -9999 -9999 -9999 -9999 -9999 -9999 -9999 -9999 -

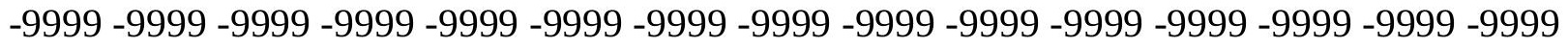
-9999 -9999 -9999 -9999 -9999 -9999 -9999 -9999 -9999 -9999 -9999 -9999 -9999 -9999 -9999 -9999 -9999 -9999 -9999 -9999 -9999 -9999 -9999 -9999 -9999 -9999 -9999 -9999 -9999 -999 -9999 -9999 -9999 -9999 -9999 -9999 -9999 -9999 -9999 -9999 -9999 -9999 -9999 -9999 -9999 -9999 -9999 -9999 -9999 -9999 -9999 -9999 -9999 -9999 -9999 -9999 -9999 -9999 -9999 -9999 -

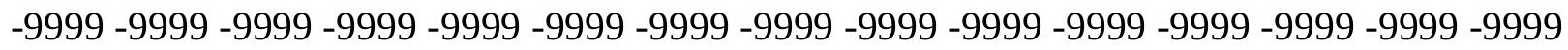

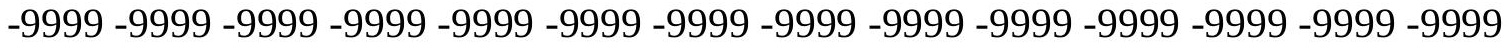
-9999 -9999 -9999 -9999 -9999 -9999 -9999 -9999 -9999 -9999 -9999 -9999 -9999 -9999 -9999

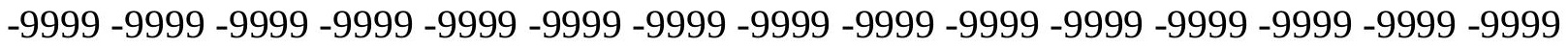

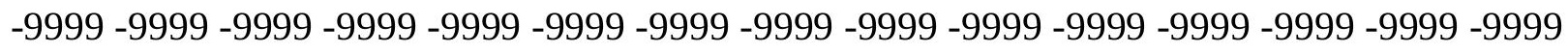

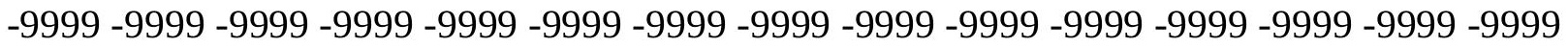

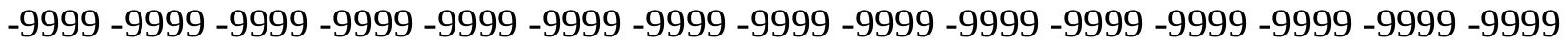
-9999 -9999 -9999 -9999 -9999 -9999 -9999 -9999 -9999 -9999 -9999 -9999 -9999 -9999 -9999 -

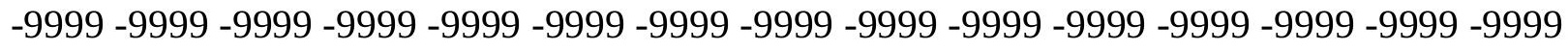

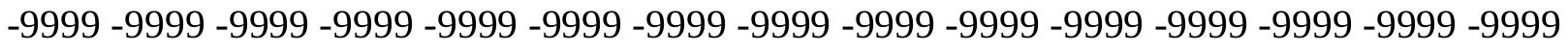
-9999 -9999 -9999 -9999 -9999 -9999 -9999 -9999 -9999 -9999 -9999 -9999 -9999 -9999 -9999 -9999 -9999 -9999 -9999 -9999 -9999 -9999 -9999 -9999-9999 -9999 -9999 -9999 -9999 -9999 -9999 -9999 -9999 -9999 -9999 -9999 -9999 -9999 -9999 -9999 -9999 -9999 -9999 -9999 -9999 -

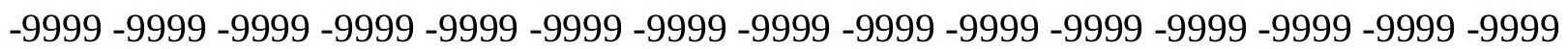


-9999 -9999 -9999 -9999 -9999 -9999 -9999 -9999 -9999 -9999 -9999 -9999 -9999 -9999 -9999 -9999 -9999 -9999 -9999 -9999 -9999 -9999 -9999 -9999 -9999 -9999 -9999 -9999 -9999 -9999 -

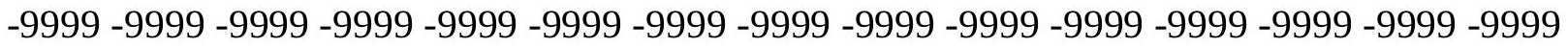
-9999 -9999 -9999 -9999 -9999 -9999 -9999 -9999 -9999 -9999 -9999 -9999 -9999 -9999 -9999 -9999 -9999 -9999 -9999 -9999 -9999 -9999 -9999 -9999-9999 -9999 -9999 -9999 -9999 -9999 -9999 -9999 -9999 -9999 -9999 -9999 -9999 -9999 -9999 -9999 -9999 -9999 -9999 -9999 -9999 -9999 -9999 -9999 -9999 -9999 -9999 -9999 -9999 -9999 -9999 -9999 -9999 -9999 -9999 -9999

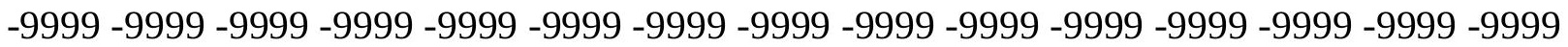

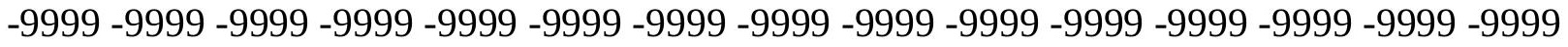
-9999 -9999 -9999 -9999 -9999 -9999 -9999 -9999 -9999 -9999 -9999 -9999 -9999 -9999 -9999 -9999 -9999 -9999 -9999 -9999 -9999 -9999 -9999 -9999 -9999 -9999 -9999 -9999 -9999 -9999 -9999 -9999 -9999 -9999 -9999 -9999 -9999 -9999 -9999 -9999 -9999 -9999 -9999 -9999 -9999 -9999 -9999 -9999 -9999 -9999 -9999 -9999 -9999 -9999 -9999 -9999 -9999 -9999 -9999 -9999 -9999 -9999 -9999 -9999 -9999 -9999 -9999 -9999 -9999 -9999 -9999 -9999 -9999 -9999 -9999 -9999 -9999 -9999 -9999 -9999 -9999 -9999 -9999 -9999 -9999 -9999 -9999 -9999 -9999

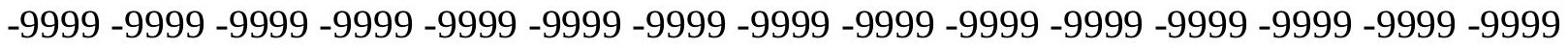
-9999 -9999 -9999 -9999 -9999 -9999 -9999 -9999 -9999 -9999 -9999 -9999 -9999 -9999 -9999 -9999 -9999 -9999 -9999 -9999 -9999 -9999 -9999 -9999 -9999 -9999 -9999 -9999 -9999 -9999 -9999 -9999 -9999 -9999 -9999 -9999 -9999 -9999 -9999 -9999 -9999 -9999 -9999 -9999 -9999 -

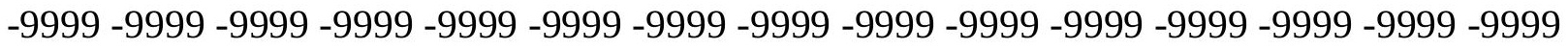

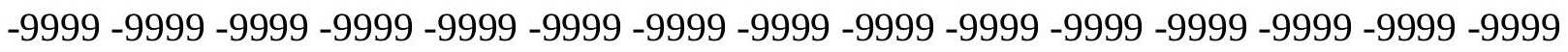
-9999 -9999 -9999 -9999 -9999 -9999 -9999 -9999 -9999 -9999 -9999 -9999 -9999 -9999 -9999 -9999 -9999 -9999 -9999 -9999 -9999 -9999 -9999 -9999 -9999 -9999 -9999 -9999 -9999 -9999 -9999 -9999 -9999 -9999 -9999 -9999 -9999 -9999 -9999 -9999 -9999 -9999 -9999 -9999 -9999 -

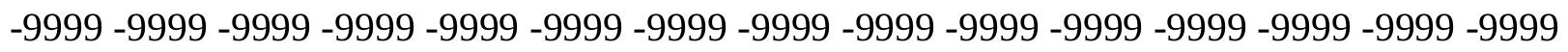
-9999 -9999 -9999 -9999 -9999 -9999 -9999 -9999 -9999 -9999 -9999 -9999 -9999 -9999 -9999 -9999 -9999 -9999 -9999 -9999 -9999 -9999 -9999 -9999 -9999 -9999 -9999 -9999 -9999 -9999 -

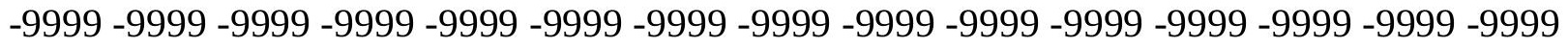
-9999 -9999 -9999 -9999 -9999 -9999 -9999 -9999 -9999 -9999 -9999 -9999 -9999 -9999 -9999 -9999 -9999 -9999 -9999 -9999 -9999 -9999 -9999 -9999 -9999 -9999 -9999 -9999 -9999 -999 -9999 -9999 -9999 -9999 -9999 -9999 -9999 -9999 -9999 -9999 -9999 -9999 -9999 -9999 -9999 -9999 -9999 -9999 -9999 -9999 -9999 -9999 -9999 -9999 -9999 -9999 -9999 -9999 -9999 -9999 -

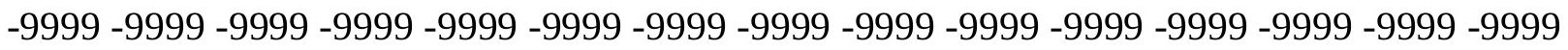

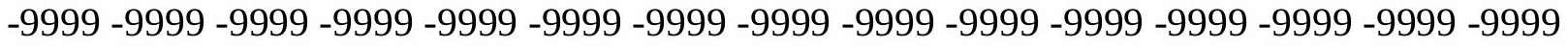

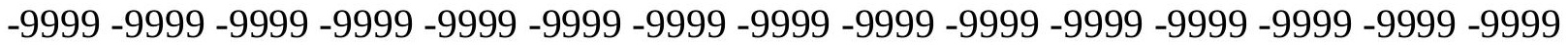

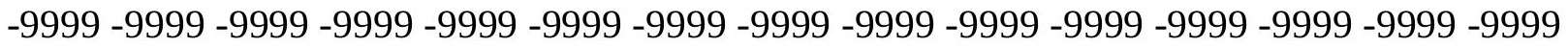

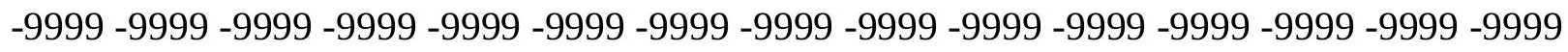

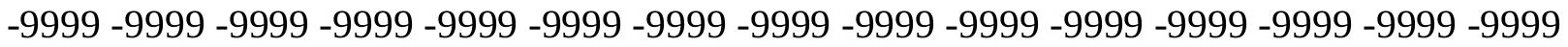
-9999 -9999 -9999 -9999 -9999 -9999 -9999 -9999 -9999 -9999 -9999 -9999 -9999 - 9999 - -999 -9999 -9999 -9999 -9999 -9999 -9999 -9999 -9999 -9999 -9999 -9999 -9999 -9999 -9999 - -999 -

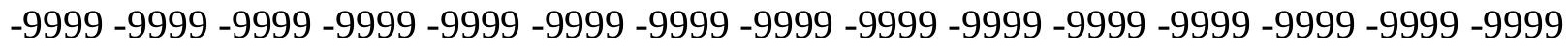

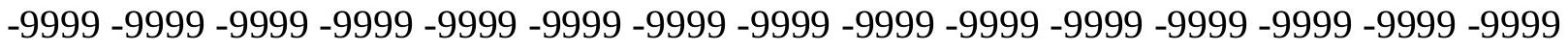
-9999 -9999 -9999 -9999 -9999 -9999 -9999 -9999 -9999 -9999 -9999 -9999 -9999 -9999 -9999 -9999 -9999 -9999 -9999 -9999 -9999 -9999 -9999 -9999-9999 -9999 -9999 -9999 -9999 -9999 -9999 -9999 -9999 -9999 -9999 -9999 -9999 -9999 -9999 -9999 -9999 -9999 -9999 -9999 -9999 -

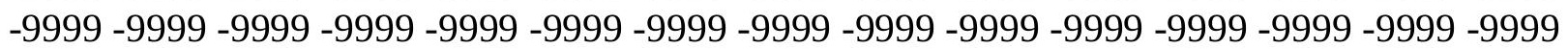


-9999 -9999 -9999 -9999 -9999 -9999 -9999 -9999 -9999 -9999 -9999 -9999 -9999 -9999 -9999 -9999 -9999 -9999 -9999 -9999 -9999 -9999 -9999 -9999 -9999 -9999 -9999 -9999 -9999 -9999 -9999 -9999 -9999 -9999 -9999 -9999 -9999 -9999 -9999 -9999 -9999 -9999 -9999 -9999 -9999 -9999 -9999 -9999 -9999 -9999 -9999 -9999 -9999 -9999 -9999 -9999 -9999 -9999 -9999 -9999 -9999 -9999 -9999 -9999 -9999 -9999 -9999 -9999 -9999 -9999 -9999 -9999 -9999 -9999 -9999 -9999 -9999 -9999 -9999 -9999 -9999 -9999 -9999 -9999 -9999 -9999 -9999 -9999 -9999 -9999 -9999 -9999 -9999 -9999 -9999 -9999 -9999 -9999 -9999 -9999 -9999 -9999 -9999 -9999 -9999 -

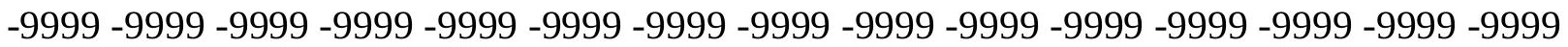
-9999 -9999 -9999 -9999 -9999 -9999 -9999 -9999 -9999 -9999 -9999 -9999 -9999 -9999 -9999 -9999 -9999 -9999 -9999 -9999 -9999 -9999 -9999 -9999 -9999 -9999 -9999 -9999 -9999 -9999 -

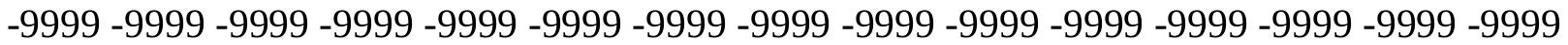
-9999 -9999 -9999 -9999 -9999 -9999 -9999 -9999 -9999 -9999 -9999 -9999 -9999 -9999 -9999 -9999 -9999 -9999 -9999 -9999 -9999 -9999 -9999 -9999 -9999 -9999 -9999 -9999 -9999 -9999 -9999 -9999 -9999 -9999 -9999 -9999 -9999 -9999 -9999 -9999 -9999 -9999 -9999 -9999 -9999 -9999 -9999 -9999 -9999 -9999 -9999 -9999 -9999 -9999 -9999 -9999 -9999 -9999 -9999 -9999

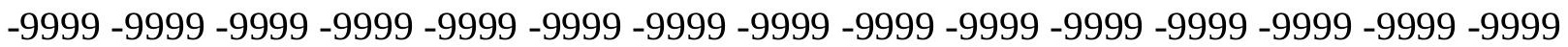
-9999 -9999 -9999 -9999 -9999 -9999 -9999 -9999 -9999 -9999 -9999 -9999 -9999 -9999 -9999 -9999 -9999 -9999 -9999 -9999 -9999 -9999 -9999 -9999 -9999 -9999 -9999 -9999 -9999 -9999 -9999 -9999 -9999 -9999 -9999 -9999 -9999 -9999 -9999 -9999 -9999 -9999 -9999 -9999 -9999 -9999 -9999 -9999 -9999 -9999 -9999 -9999 -9999 -9999 -9999 -9999 -9999 -9999 -9999 -9999 -9999 -9999 -9999 -9999 -9999 -9999 -9999 -9999 -9999 -9999 -9999 -9999 -9999 -9999 -9999 -9999 -9999 -9999 -9999 -9999 -9999 -9999 -9999 -9999 -9999 -9999 -9999 -9999 -9999 -9999 -9999 -9999 -9999 -9999 -9999 -9999 -9999 -9999 -9999 -9999 -9999 -9999 -9999 -9999 -9999 -9999 -9999 -9999 -9999 -9999 -9999 -9999 -9999 -9999 -9999 -9999 -9999 -9999 -9999 -9999 -9999 -9999 -9999 -9999 -9999 -9999 -9999 -9999 -9999 -9999 -9999 -9999 -9999 -9999 -9999 -9999 -9999 -9999 -9999 -9999 -9999 -9999 -9999 -9999 -9999 -9999 -9999 -9999 -9999 -9999 -9999 -9999 -9999 -9999 -9999 -9999 -9999 -9999 -9999 -9999 -9999 -9999 -9999 -9999 -9999 -9999 -9999 -9999 -9999 -9999 -9999 -9999 -9999 -9999 -9999 -9999 -9999 -9999 -9999

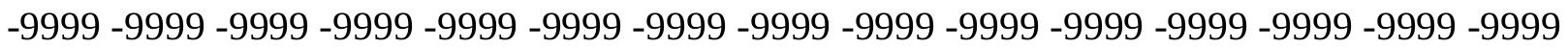
-9999 -9999 -9999 -9999 -9999 -9999 -9999 -9999 -9999 -9999 -9999 -9999 -9999 -9999 -9999 -9999 -9999 -9999 -9999 -9999 -9999 -9999 -9999 -9999 -9999 -9999 -9999 -9999 -9999 -9999 -

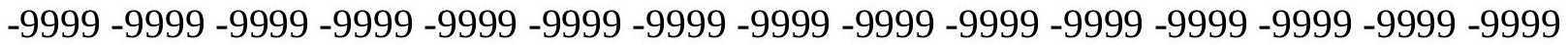
-9999 -9999 -9999 -9999 -9999 -9999 -9999 -9999 -9999 -9999 -9999 -9999 -9999 -9999 -9999 -9999 -9999 -9999 -9999 -9999 -9999 -9999 -9999 -9999 -9999 -9999 -9999 -9999 -9999 -9999 -9999 -9999 -9999 -9999 -9999 -9999 -9999 -9999 -9999 -9999 -9999 -9999 -9999 -9999 -9999 -9999 -9999 -9999 -9999 -9999 -9999 -9999 -9999 -9999 -9999 -9999 -9999 -9999 -9999 -9999 -9999 -9999 -9999 -9999 -9999 -9999 -9999 -9999 -9999 -9999 -9999 -9999 -9999 -9999 -9999

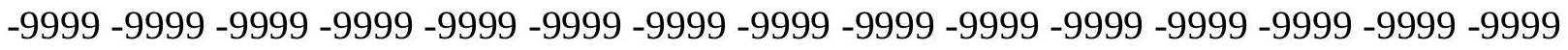
-9999 -9999 -9999 -9999 -9999 -9999 -9999 -9999 -9999 -9999 -9999 -9999 -9999 -9999 -9999 -9999 -9999 -9999 -9999 -9999 -9999 -9999 -9999 -9999 -9999 -9999 -9999 -9999 -9999 -9999 -9999 -9999 -9999 -9999 -9999 -9999 -9999 -9999 -9999 -9999 -9999 -9999 -9999 -9999 -9999 -999 -9999 -9999 -9999 -9999 -9999 -9999 -9999 -9999 -9999 -9999 -9999 -9999 -9999 -9999 -9999 -9999 -9999 -9999 -9999 -9999 -9999 -9999 -9999 -9999 -9999 -9999 -9999 -9999 -9999 -9999 -9999 -9999 -9999 -9999 -9999 -9999 -9999 -9999 -9999 -9999 -9999 -9999 -9999 -9999 -9999 -9999 -9999 -9999 -9999 -9999 -9999 -9999 -9999 -9999 -9999 -9999 -9999 -9999 -9999 -9999 -9999 -9999 -9999 -9999 -9999 -9999 -9999 -9999 -9999 -9999 -9999 -9999 -9999 -9999 
-9999 -9999 -9999 -9999 -9999 -9999 -9999 -9999 -9999 -9999 -9999 -9999 -9999 -9999 -9999 -9999 -9999 -9999 -9999 -9999 -9999 -9999 -9999 -9999 -9999 -9999 -9999 -9999 -9999 -9999 -

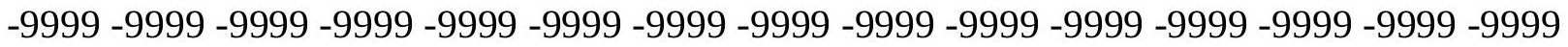
-9999 -9999 -9999 -9999 -9999 -9999 -9999 -9999 -9999 -9999 -9999 -9999 -9999 -9999 -9999 -9999 -9999 -9999 -9999 -9999 -9999 -9999 -9999 -9999-9999 -9999 -9999 -9999 -9999 -9999 -9999 -9999 -9999 -9999 -9999 -9999 -9999 -9999 -9999 -9999 -9999 -9999 -9999 -9999 -9999 -9999 -9999 -9999 -9999 -9999 -9999 -9999 -9999 -9999 -9999 -9999 -9999 -9999 -9999 -9999

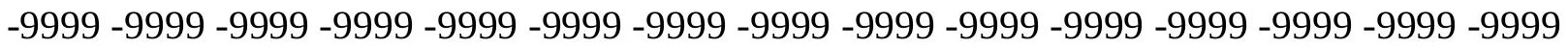

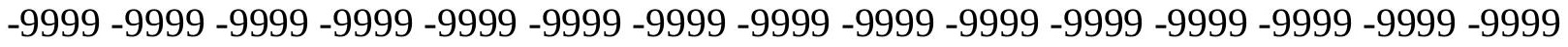
-9999 -9999 -9999 -9999 -9999 -9999 -9999 -9999 -9999 -9999 -9999 -9999 -9999 -9999 -9999 -9999 -9999 -9999 -9999 -9999 -9999 -9999 -9999 -9999 -9999 -9999 -9999 -9999 -9999 -9999 -9999 -9999 -9999 -9999 -9999 -9999 -9999 -9999 -9999 -9999 -9999 -9999 -9999 -9999 -9999 -9999 -9999 -9999 -9999 -9999 -9999 -9999 -9999 -9999 -9999 -9999 -9999 -9999 -9999 -9999 -

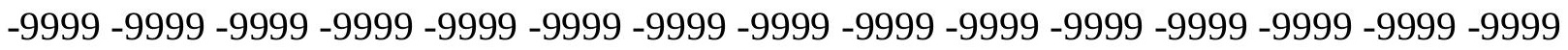
-9999 -9999 -9999 -9999 -9999 -9999 -9999 -9999 -9999 -9999 -9999 -9999 -9999 -9999 -9999 -

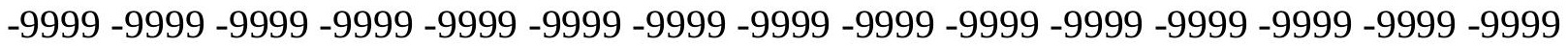
-9999 -9999 -9999 -9999 -9999 -9999 -9999 -9999 -9999 -9999 -9999 -9999 -9999 -9999 -9999 -9999 -9999 -9999 -9999 -9999 -9999 -9999 -9999 -9999 -9999 -9999 -9999 -9999 -9999 -9999 -9999 -9999 -9999 -9999 -9999 -9999 -9999 -9999 -9999 -9999 -9999 -9999 -9999 -9999 -9999 -

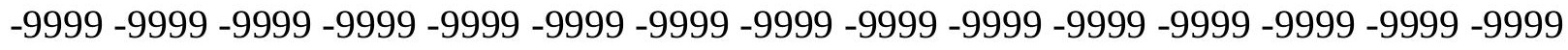

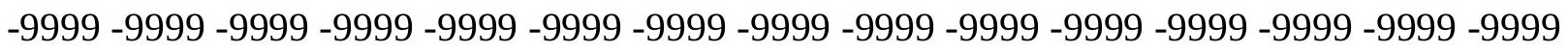

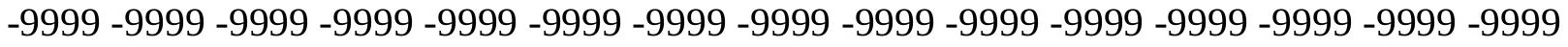
-9999 -9999 -9999 -9999 -9999 -9999 -9999 -9999 -9999 -9999 -9999 -9999 -9999 -9999 -9999 -9999 -9999 -9999 -9999 -9999 -9999 -9999 -9999 -9999 -9999 -9999 -9999 -9999 -9999 -9999 -

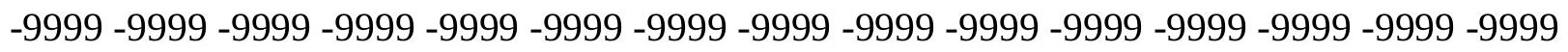
-9999 -9999 -9999 -9999 -9999 -9999 -9999 -9999 -9999 -9999 -9999 -9999 -9999 -9999 -9999 -9999 -9999 -9999 -9999 -9999 -9999 -9999 -9999 -9999 -9999 -9999 -9999 -9999 -9999 -

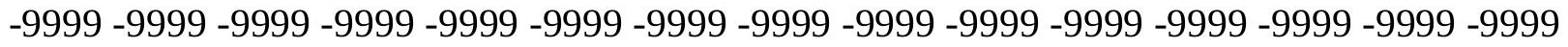
-9999 -9999 -9999 -9999 -9999 -9999 -9999 -9999 -9999 -9999 -9999 -9999 -9999 -9999 -9999 -9999 -9999 -9999 -9999 -9999 -9999 -9999 -9999 -9999 -9999 -9999 -9999 -9999 -9999 -999 -

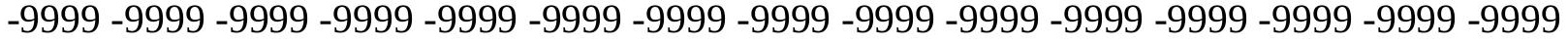
-9999 -9999 -9999 -9999 -9999 -9999 -9999 -9999 -9999 -9999 -9999 -9999 -9999 -9999 -9999 -

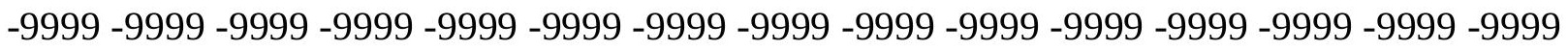

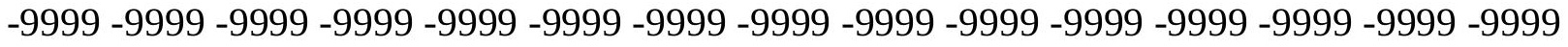

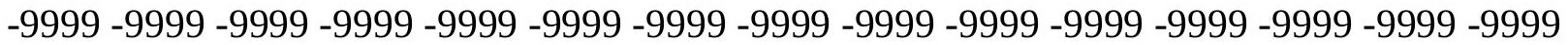
-9999 -9999 -9999 -9999 -9999 -9999 -9999 -9999 -9999 -9999 -9999 -9999 -9999 -9999 -9999

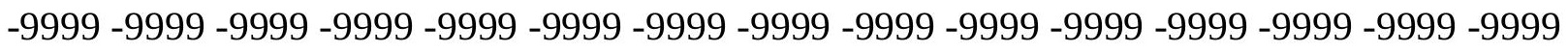

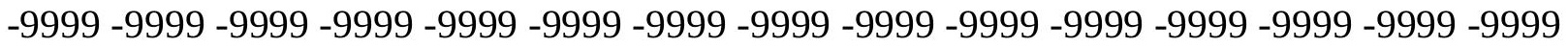
-9999 -9999 -9999 -9999 -9999 -9999 -9999 -9999 -9999 -9999 -9999 -9999 -9999 - 9999 - -999 -9999 -9999 -9999 -9999 -9999 -9999 -9999 -9999 -9999 -9999 -9999 -9999 -9999 -9999 -9999 -

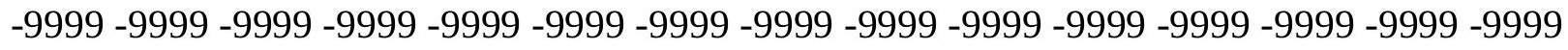

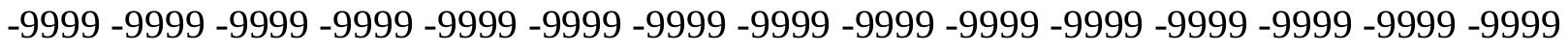
-9999 -9999 -9999 -9999 -9999 -9999 -9999 -9999 -9999 -9999 -9999 -9999 -9999 -9999 -9999 -9999 -9999 -9999 -9999 -9999 -9999 -9999 -9999 -9999-9999 -9999 -9999 -9999 -9999 -9999 -9999 -9999 -9999 -9999 -9999 -9999 -9999 -9999 -9999 -9999 -9999 -9999 -9999 -9999 -9999 -

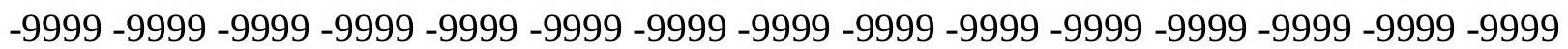


-9999 -9999 -9999 -9999 -9999 -9999 -9999 -9999 -9999 -9999 -9999 -9999 -9999 -9999 -9999 -9999 -9999 -9999 -9999 -9999 -9999 -9999 -9999 -9999 -9999 -9999 -9999 -9999 -9999 -9999 -9999 -9999 -9999 -9999 -9999 -9999 -9999 -9999 -9999 -9999 -9999 -9999 -9999 -9999 - 9999 -9999 -9999 -9999 -9999 -9999 -9999 -9999 -9999 -9999 -9999 -9999 -9999 -9999 -9999 -9999 -9999 -9999 -9999 -9999 -9999 -9999 -9999 -9999 -9999 -9999 -9999 -9999 -9999 -9999 - -9999 -9999 -9999 -9999 -9999 -9999 -9999 -9999 -9999 -9999 -9999 -9999 -9999 -9999 -9999 -9999 -9999 -9999 -9999 -9999 -9999 -9999 -9999 -9999 -9999 -9999 -9999 -9999 -9999 -9999

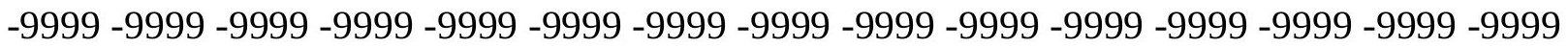

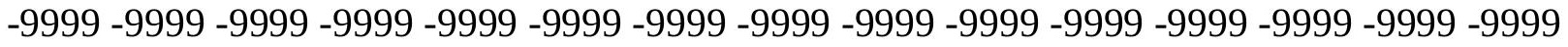
-9999 -9999 -9999 -9999 -9999 -9999 -9999 -9999 -9999 -9999 -9999 -9999 -9999 -9999 -9999

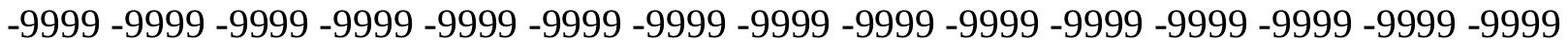
-9999 -9999 -9999 -9999 -9999 -9999 -9999 -9999 -9999 -9999 -9999 -9999 -9999 -9999 -9999 -9999 -9999 -9999 -9999 -9999 -9999 -9999 -9999 -9999 -9999 -9999 -9999 -9999 -9999 -9999 -9999 -9999 -9999 -9999 -9999 -9999 -9999 -9999 -9999 -9999 -9999 -9999 -9999 -9999 - -9999 -9999 -9999 -9999 -9999 -9999 -9999 -9999 -9999 -9999 -9999 -9999 -9999 -9999 -9999 -9999

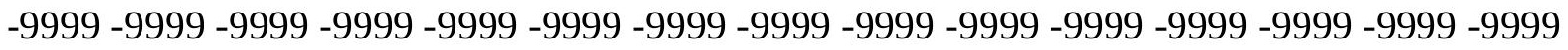
-9999 -9999 -9999 -9999 -9999 -9999 -9999 -9999 -9999 -9999 -9999 -9999 -9999 -9999 -9999 -9999 -9999 -9999 -9999 -9999 -9999 -9999 -9999 -9999 -9999 -9999 -9999 -9999 -9999 -9999 -9999 -9999 -9999 -9999 -9999 -9999 -9999 -9999 -9999 -9999 -9999 -9999 -9999 -9999 -9999 -

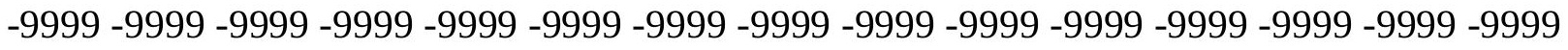
-9999 -9999 -9999 -9999 -9999 -9999 -9999 -9999 -9999 -9999 -9999 -9999 -9999 -9999 -9999 -999 -9999 -9999 -9999 -9999 -9999 -9999 -9999 -9999 -9999 -9999 -9999 -9999 -9999 -9999 -9999 -9999 -9999 -9999 -9999 -9999 -9999 -9999 -9999 -9999 -9999 -9999 -9999 -9999 -9999 -9999 -9999 -9999 -9999 -9999 -9999 -9999 -9999 -9999 -9999 -9999 -9999 -9999 -9999 -9999 -9999 -9999 -9999 -9999 -9999 -9999 -9999 -9999 -9999 -9999 -9999 -9999 -9999 -9999 -9999 -9999 -9999 -9999 -9999 -9999 -9999 -9999 -9999 -9999 -9999 -9999 -9999 -9999 -9999 -9999 -9999 -9999 -9999 -9999 -9999 -9999 -9999 -9999 -9999 -9999 -9999 -9999 -9999 -9999 -9999 -9999 -9999 -9999 -9999 -9999 -9999 -9999 -9999 -9999 -9999 -9999 -9999 -9999 -9999 -9999 -9999 -9999 -9999 -9999 -9999 -9999 -9999 -9999 -9999 -9999 -9999 -9999 -9999 -9999 -9999 -9999 -9999 -9999 -9999 -9999 -9999 -9999 -9999 -9999 -9999 -9999 -9999 -9999 -9999 -9999 -999 -9999 -9999 -9999 -9999 -9999 -9999 -9999 -9999 -9999 -9999 -9999 -9999 -9999 -9999 -9999 -9999 -9999 -9999 -9999 -9999 -9999 -9999 -9999 -9999 -9999 -9999 -9999 -9999 -9999 -

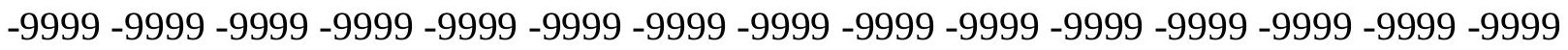

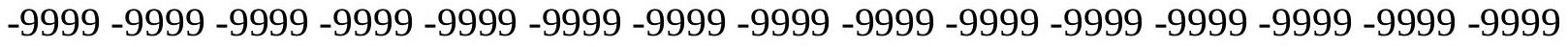

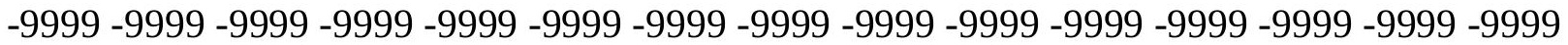
-9999 -9999 -9999 -9999 -9999 -9999 -9999 -9999 -9999 -9999 -9999 -9999 -9999 -9999 -9999 -

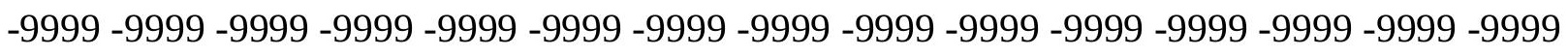

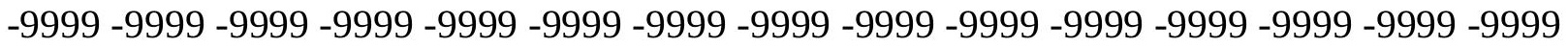

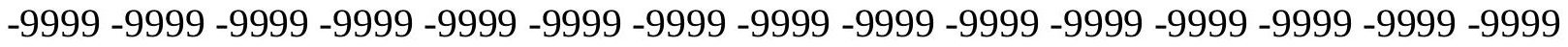
-9999 -9999 -9999 -9999 -9999 -9999 -9999 -9999 -9999 -9999 -9999 -9999 -9999 -9999 -9999 -

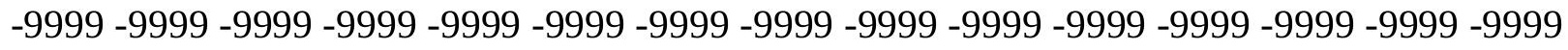

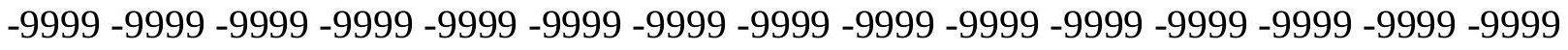
-9999 -9999 -9999 -9999 -9999 -9999 -9999 -9999 -9999 -9999 -9999 -9999 -9999 -9999 -9999 -9999 -9999 -9999 -9999 -9999 -9999 -9999 -9999 -9999-9999 -9999 -9999 -9999 -9999 -9999 -9999 -9999 -9999 -9999 -9999 -9999 -9999 -9999 -9999 -9999 -9999 -9999 -9999 -9999 -9999 -

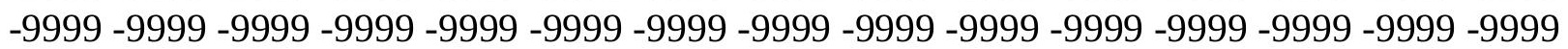


-9999 -9999 -9999 -9999 -9999 -9999 -9999 -9999 -9999 -9999 -9999 -9999 -9999 -9999 -9999 -9999 -9999 -9999 -9999 -9999 -9999 -9999 -9999 -9999 -9999 -9999 -9999 -9999 -9999 -9999 -

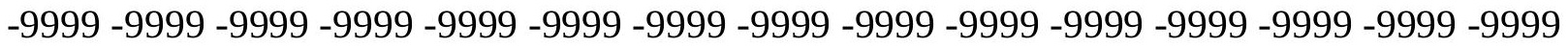
-9999 -9999 -9999 -9999 -9999 -9999 -9999 -9999 -9999 -9999 -9999 -9999 -9999 -9999 -9999 -9999 -9999 -9999 -9999 -9999 -9999 -9999 -9999 -9999-9999 -9999 -9999 -9999 -9999 -9999 -9999 -9999 -9999 -9999 -9999 -9999 -9999 -9999 -9999 -9999 -9999 -9999 -9999 -9999 -9999 -9999 -9999 -9999 -9999 -9999 -9999 -9999 -9999 -9999 -9999 -9999 -9999 -9999 -9999 -9999

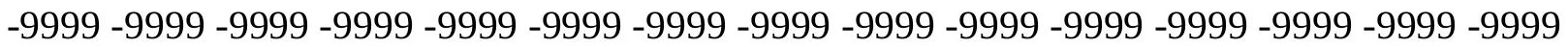

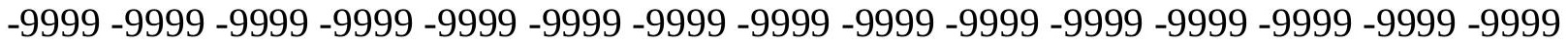
-9999 -9999 -9999 -9999 -9999 -9999 -9999 -9999 -9999 -9999 -9999 -9999 -9999 -9999 -9999 -9999 -9999 -9999 -9999 -9999 -9999 -9999 -9999 -9999 -9999 -9999 -9999 -9999 -9999 -9999 -9999 -9999 -9999 -9999 -9999 -9999 -9999 -9999 -9999 -9999 -9999 -9999 -9999 -9999 -9999 -9999 -9999 -9999 -9999 -9999 -9999 -9999 -9999 -9999 -9999 -9999 -9999 -9999 -9999 -9999 -9999 -9999 -9999 -9999 -9999 -9999 -9999 -9999 -9999 -9999 -9999 -9999 -9999 - 9999 -9999 -9999 -9999 -9999 -9999 -9999 -9999 -9999 -9999 -9999 -9999 -9999 -9999 -9999 -9999

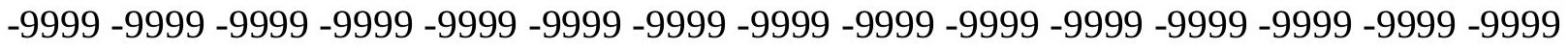
-9999 -9999 -9999 -9999 -9999 -9999 -9999 -9999 -9999 -9999 -9999 -9999 -9999 -9999 -9999 -9999 -9999 -9999 -9999 -9999 -9999 -9999 -9999 -9999 -9999 -9999 -9999 -9999 -9999 -9999 -9999 -9999 -9999 -9999 -9999 -9999 -9999 -9999 -9999 -9999 -9999 -9999 -9999 -9999 -9999 -

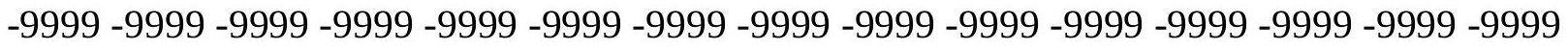

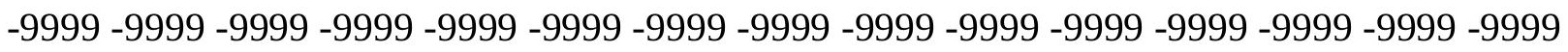
-9999 -9999 -9999 -9999 -9999 -9999 -9999 -9999 -9999 -9999 -9999 -9999 -9999 -9999 -9999 -9999 -9999 -9999 -9999 -9999 -9999 -9999 -9999 -9999 -9999 -9999 -9999 -9999 -9999 -9999 -9999 -9999 -9999 -9999 -9999 -9999 -9999 -9999 -9999 -9999 -9999 -9999 -9999 -9999 -9999 -

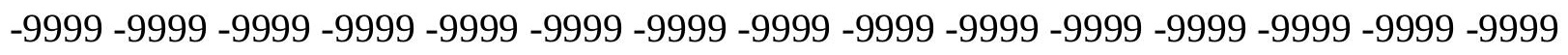
-9999 -9999 -9999 -9999 -9999 -9999 -9999 -9999 -9999 -9999 -9999 -9999 -9999 -9999 -9999 -9999 -9999 -9999 -9999 -9999 -9999 -9999 -9999 -9999 -9999 -9999 -9999 -9999 -9999 -9999 -

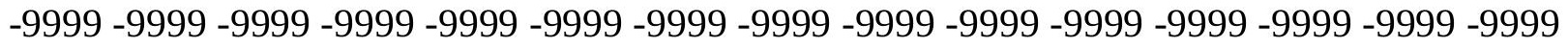
-9999 -9999 -9999 -9999 -9999 -9999 -9999 -9999 -9999 -9999 -9999 -9999 -9999 -9999 -9999 -9999 -9999 -9999 -9999 -9999 -9999 -9999 -9999 -9999 -9999 -9999 -9999 -9999 -9999 -999 -9999 -9999 -9999 -9999 -9999 -9999 -9999 -9999 -9999 -9999 -9999 -9999 -9999 -9999 -9999 -9999 -9999 -9999 -9999 -9999 -9999 -9999 -9999 -9999 -9999 -9999 -9999 -9999 -9999 -9999 -

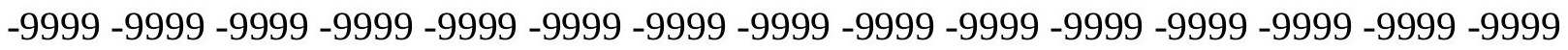

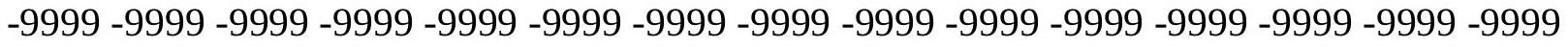

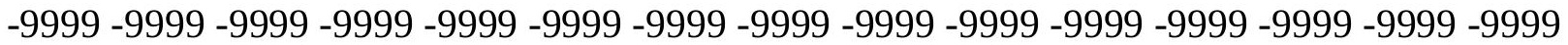

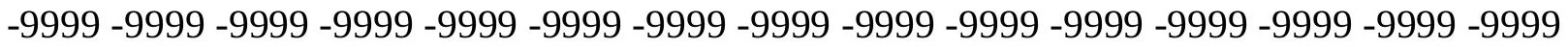

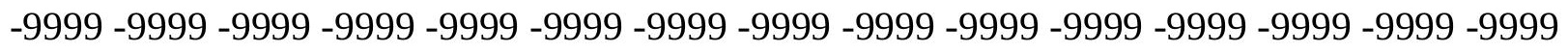

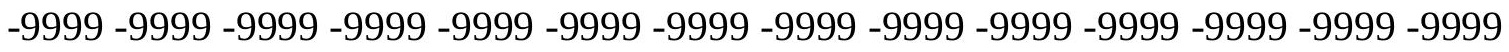
-9999 -9999 -9999 -9999 -9999 -9999 -9999 -9999 -9999 -9999 -9999 -9999 -9999 -9999 -9999 -9999 -9999 -9999 -9999 -9999 -9999 -9999 -9999 -9999 -9999 -9999 -9999 -9999 -9999 -9999 -

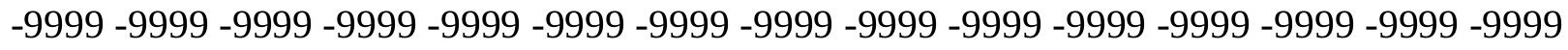

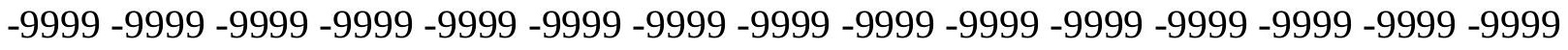
-9999 -9999 -9999 -9999 -9999 -9999 -9999 -9999 -9999 -9999 -9999 -9999 -9999 -9999 -9999 -9999 -9999 -9999 -9999 -9999 -9999 -9999 -9999 -9999-9999 -9999 -9999 -9999 -9999 -9999 -9999 -9999 -9999 -9999 -9999 -9999 -9999 -9999 -9999 -9999 -9999 -9999 -9999 -9999 -9999 -

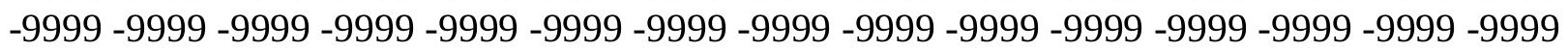


-9999 -9999 -9999 -9999 -9999 -9999 -9999 -9999 -9999 -9999 -9999 -9999 -9999 -9999 -9999 -9999 -9999 -9999 -9999 -9999 -9999 -9999 -9999 -9999 -9999 -9999 -9999 -9999 -9999 -9999 -9999 -9999 -9999 -9999 -9999 -9999 -9999 -9999 -9999 -9999 -9999 -9999 -9999 -9999 - 9999 -9999 -9999 -9999 -9999 -9999 -9999 -9999 -9999 -9999 -9999 -9999 -9999 -9999 -9999 -9999 -9999 -9999 -9999 -9999 -9999 -9999 -9999 -9999 -9999 -9999 -9999 -9999 -9999 -9999 -9999 -9999 -9999 -9999 -9999 -9999 -9999 -9999 -9999 -9999 -9999 -9999 -9999 -9999 -9999 -9999 -9999 -9999 -9999 -9999 -9999 -9999 -9999 -9999 -9999 -9999 -9999 -9999 -9999 -9999 -9999

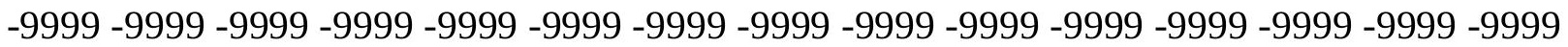
-9999 -9999 -9999 -9999 -9999 -9999 -9999 -9999 -9999 -9999 -9999 -9999 -9999 -9999 -9999 -9999 -9999 -9999 -9999 -9999 -9999 -9999 -9999 -9999 -9999 -9999 -9999 -9999 -9999 -9999

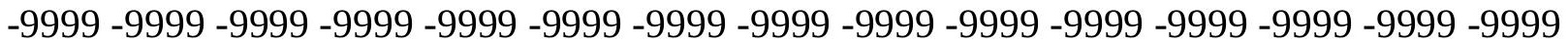
-9999 -9999 -9999 -9999 -9999 -9999 -9999 -9999 -9999 -9999 -9999 -9999 -9999 -9999 -9999 -9999 -9999 -9999 -9999 -9999 -9999 -9999 -9999 -9999 -9999 -9999 -9999 -9999 -9999 -9999 -

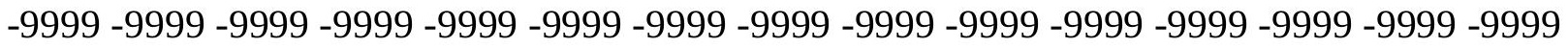
-9999 -9999 -9999 -9999 -9999 -9999 -9999 -9999 -9999 -9999 -9999 -9999 -9999 -9999 -9999

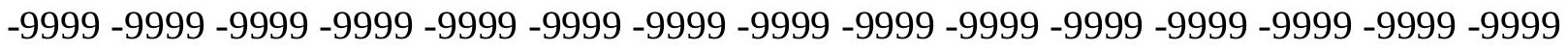
-9999 -9999 -9999 -9999 -9999 -9999 -9999 -9999 -9999 -9999 -9999 -9999 -9999 -9999 -9999 -9999 -9999 -9999 -9999 -9999 -9999 -9999 -9999 -9999 -9999 -9999 -9999 -9999 -9999 - -999 -9999 -9999 -9999 -9999 -9999 -9999 -9999 -9999 -9999 -9999 -9999 -9999 -9999 -9999 -9999 -9999 -9999 -9999 -9999 -9999 -9999 -9999 -9999 -9999 -9999 -9999 -9999 -9999 -9999 -9999 -9999 -9999 -9999 -9999 -9999 -9999 -9999 -9999 -9999 -9999 -9999 -9999 -9999 -9999 -9999 -999 -9999 -9999 -9999 -9999 -9999 -9999 -9999 -9999 -9999 -9999 -9999 -9999 -9999 -9999 -9999 -9999 -9999 -9999 -9999 -9999 -9999 -9999 -9999 -9999 -9999 -9999 -9999 -9999 -9999 -9999 -9999 -9999 -9999 -9999 -9999 -9999 -9999 -9999 -9999 -9999 -9999 -9999 -9999 -9999 -9999 -9999 -9999 -9999 -9999 -9999 -9999 -9999 -9999 -9999 -9999 -9999 -9999 -9999 -9999 -9999 -9999 -9999 -9999 -9999 -9999 -9999 -9999 -9999 -9999 -9999 -9999 -9999 -9999 -9999 -9999 -9999 -9999 -9999 -9999 -9999 -9999 -9999 -9999 -9999 -9999 -9999 -9999 -9999 -9999 -9999 -9999 -9999 -9999 -9999 -9999 -9999 -9999 -9999 -9999 -9999 -9999 -9999 -9999 -9999 -9999 -9999 -9999 -9999 -9999 -9999 -9999 -9999 -9999 -9999 -9999 -9999 -9999 -9999 -9999 -9999 -9999 -9999 -9999 -9999 -9999 -9999 -9999 -9999 -9999 -9999 -9999 -9999 -9999 -9999 -999 -9999 -9999 -9999 -9999 -9999 -9999 -9999 -9999 -9999 -9999 -9999 -9999 -9999 -9999 -9999 -9999 -9999 -9999 -9999 -9999 -9999 -9999 -9999 -9999 -9999 -9999 -9999 -9999 -9999 -9999 -

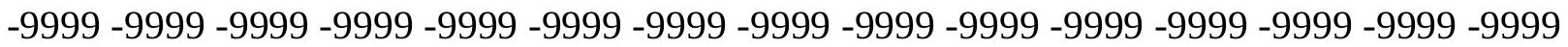

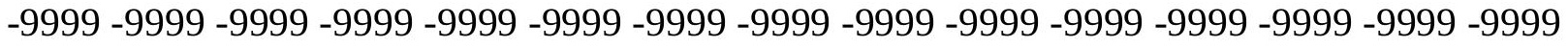

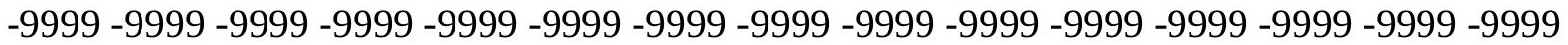
-9999 -9999 -9999 -9999 -9999 -9999 -9999 -9999 -9999 -9999 -9999 -9999 -9999 -9999 -9999

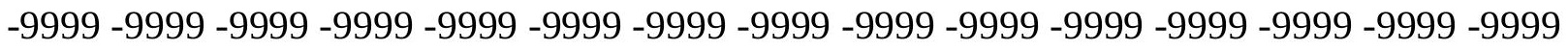

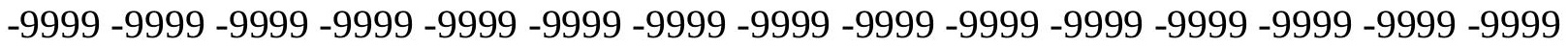

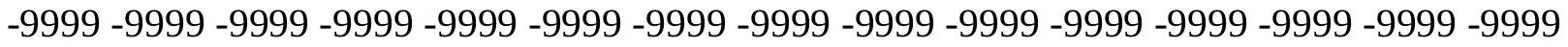
-9999 -9999 -9999 -9999 -9999 -9999 -9999 -9999 -9999 -9999 -9999 -9999 -9999 -9999 -9999 -

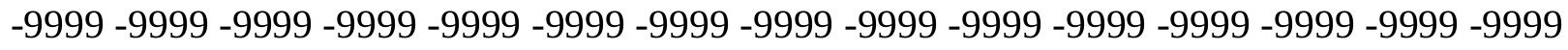

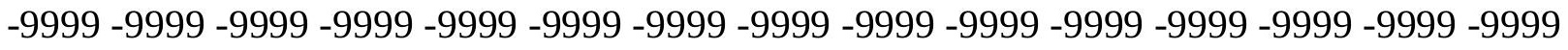
-9999 -9999 -9999 -9999 -9999 -9999 -9999 -9999 -9999 -9999 -9999 -9999 -9999 -9999 -9999 -9999 -9999 -9999 -9999 -9999 -9999 -9999 -9999 -9999 -9999 -9999 -9999 -9999 - -9999 -9999 -9999 -9999 -9999 -9999 -9999 -9999 -9999 -9999 -9999 -9999 -9999 -9999 -9999 -9999 -

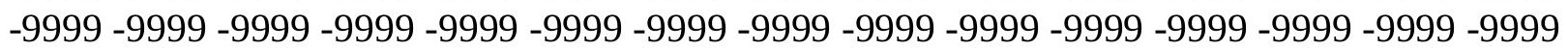


-9999 -9999 -9999 -9999 -9999 -9999 -9999 -9999 -9999 -9999 -9999 -9999 -9999 -9999 -9999 -9999 -9999 -9999 -9999 -9999 -9999 -9999 -9999 -9999 -9999 -9999 -9999 -9999 -9999 -9999 -9999 -9999 -9999 -9999 -9999 -9999 -9999 -9999 -9999 -9999 -9999 -9999 -9999 -9999 - 9999 -9999 -9999 -9999 -9999 -9999 -9999 -9999 -9999 -9999 -9999 -9999 -9999 -9999 -9999 -9999 -9999 -9999 -9999 -9999 -9999 -9999 -9999 -9999 -9999-9999 -9999 -9999 -9999 -9999 -9999 -9999 -9999 -9999 -9999 -9999 -9999 -9999 -9999 -9999 -9999 -9999 -9999 -9999 -9999 -9999 -9999 -9999 -9999 -9999 -9999 -9999 -9999 -9999 -9999 -9999 -9999 -9999 -9999 -9999 -9999

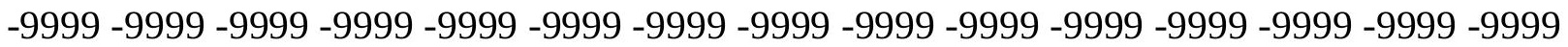

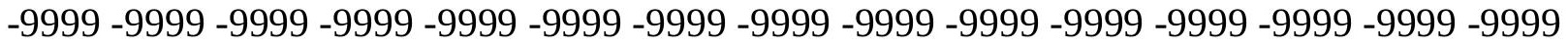
-9999 -9999 -9999 -9999 -9999 -9999 -9999 -9999 -9999 -9999 -9999 -9999 -9999 -9999 -9999

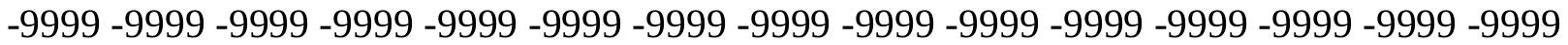
-9999 -9999 -9999 -9999 -9999 -9999 -9999 -9999 -9999 -9999 -9999 -9999 -9999 -9999 -9999 -9999 -9999 -9999 -9999 -9999 -9999 -9999 -9999 -9999 -9999 -9999 -9999 -9999 -9999 -9999 -

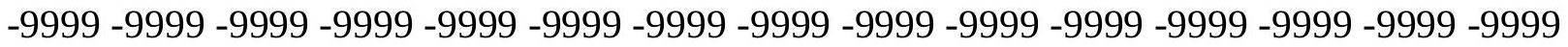
-9999 -9999 -9999 -9999 -9999 -9999 -9999 -9999 -9999 -9999 -9999 -9999 -9999 -9999 -9999

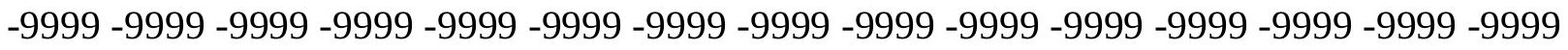
-9999 -9999 -9999 -9999 -9999 -9999 -9999 -9999 -9999 -9999 -9999 -9999 -9999 -9999 -9999 -9999 -9999 -9999 -9999 -9999 -9999 -9999 -9999 -9999 -9999 -9999 -9999 -9999 -9999 -9999 -9999 -9999 -9999 -9999 -9999 -9999 -9999 -9999 -9999 -9999 -9999 -9999 -9999 -9999 -9999 -9999 -9999 -9999 -9999 -9999 -9999 -9999 -9999 -9999 -9999 -9999 -9999 -9999 -9999 -9999 -9999 -9999 -9999 -9999 -9999 -9999 -9999 -9999 -9999 -9999 -9999 -9999 -9999 -9999 -9999 -999 -9999 -9999 -9999 -9999 -9999 -9999 -9999 -9999 -9999 -9999 -9999 -9999 -9999 -9999 -9999 -9999 -9999 -9999 -9999 -9999 -9999 -9999 -9999 -9999 -9999 -9999 -9999 -9999 -9999 -9999 -9999 -9999 -9999 -9999 -9999 -9999 -9999 -9999 -9999 -9999 -9999 -9999 -9999 -9999 -9999 -9999 -9999 -9999 -9999 -9999 -9999 -9999 -9999 -9999 -9999 -9999 -9999 -9999 -9999 -9999 -9999 -9999 -9999 -9999 -9999 -9999 -9999 -9999 -9999 -9999 -9999 -9999 -9999 -9999 -9999 -9999 -9999 -9999 -9999 -9999 -9999 -9999 -9999 -9999 -9999 -9999 -9999 -9999 -9999 -9999 -9999 -9999 -9999 -9999 -9999 -9999 -9999 -9999 -9999 -9999 -9999 -9999 -9999 -9999 -9999 -9999 -9999 -9999 -9999 -9999 -9999 -9999 -9999 -9999 -9999 -9999 -9999 -9999 -9999 -9999 -9999 -9999 -9999 -9999 -9999 -9999 -9999 -9999 -9999 -9999 -9999 -9999 -9999 -999 -9999 -9999 -9999 -9999 -9999 -9999 -9999 -9999 -9999 -9999 -9999 -9999 -9999 -9999 -9999 -9999 -9999 -9999 -9999 -9999 -9999 -9999 -9999 -9999 -9999 -9999 -9999 -9999 -9999 -9999 -

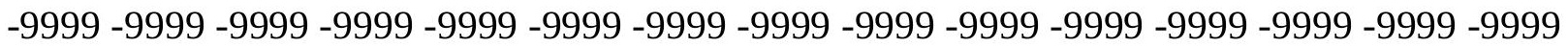

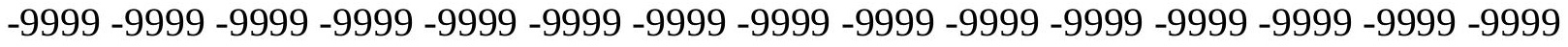

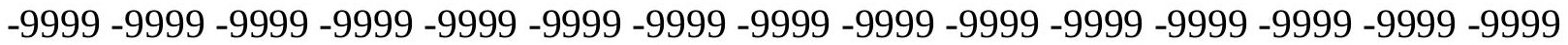
-9999 -9999 -9999 -9999 -9999 -9999 -9999 -9999 -9999 -9999 -9999 -9999 -9999 -9999 -9999

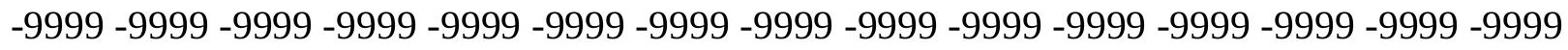

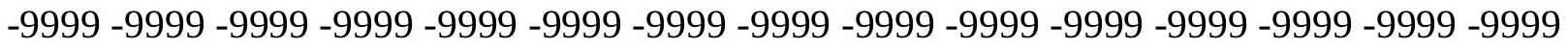
-9999 -9999 -9999 -9999 -9999 -9999 -9999 -9999 -9999 -9999 -9999 -9999 -9999 -9999 -9999 -9999 -9999 -9999 -9999 -9999 -9999 -9999 -9999 -9999 -9999 -9999 -9999 -9999 -9999 -9999 -

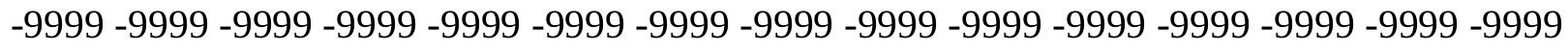

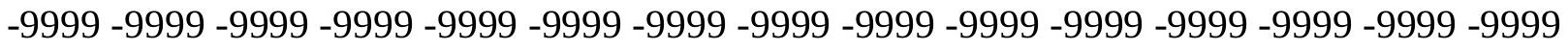
-9999 -9999 -9999 -9999 -9999 -9999 -9999 -9999 -9999 -9999 -9999 -9999 -9999 -9999 -9999 -9999 -9999 -9999 -9999 -9999 -9999 -9999 -9999 -9999-9999 -9999 -9999 -9999 -9999 -9999 -9999 -9999 -9999 -9999 -9999 -9999 -9999 -9999 -9999 -9999 -9999 -9999 -9999 -9999 -9999 -

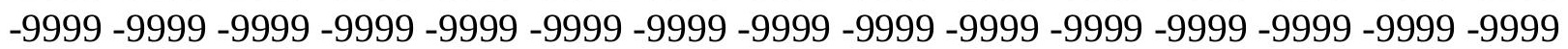


-9999 -9999 -9999 -9999 -9999 -9999 -9999 -9999 -9999 -9999 -9999 -9999 -9999 -9999 -9999 -9999 -9999 -9999 -9999 -9999 -9999 -9999 -9999 -9999 -9999 -9999 -9999 -9999 -9999 -9999 -9999 -9999 -9999 -9999 -9999 -9999 -9999 -9999 -9999 -9999 -9999 -9999 -9999 -9999 - 9999 -9999 -9999 -9999 -9999 -9999 -9999 -9999 -9999 -9999 -9999 -9999 -9999 -9999 -9999

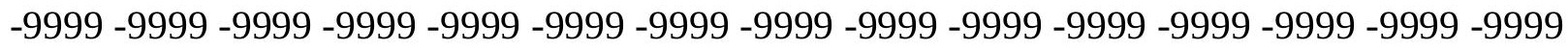
-9999 -9999 -9999 -9999 -9999 -9999 -9999 -9999 -9999 -9999 -9999 -9999 -9999 -9999 -9999 -9999 -9999 -9999 -9999 -9999 -9999 -9999 -9999 -9999 -9999 -9999 -9999 -9999 -9999 -9999

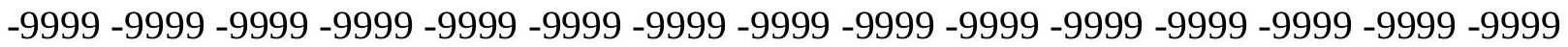

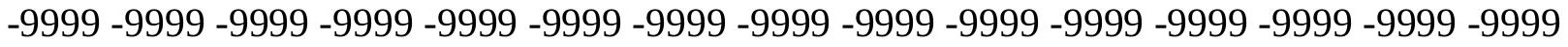
-9999 -9999 -9999 -9999 -9999 -9999 -9999 -9999 -9999 -9999 -9999 -9999 -9999 -9999 -9999 -9999 -9999 -9999 -9999 -9999 -9999 -9999 -9999 -9999 -9999 -9999 -9999 -9999 -9999 -9999 -9999 -9999 -9999 -9999 -9999 -9999 -9999 -9999 -9999 -9999 -9999 -9999 -9999 -9999 -9999 -9999 -9999 -9999 -9999 -9999 -9999 -9999 -9999 -9999 -9999 -9999 -9999 -9999 -9999 -9999 -

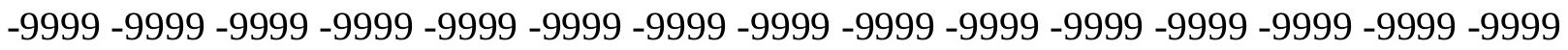
-9999 -9999 -9999 -9999 -9999 -9999 -9999 -9999 -9999 -9999 -9999 -9999 -9999 -9999 -9999 -

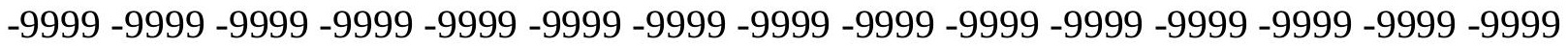
-9999 -9999 -9999 -9999 -9999 -9999 -9999 -9999 -9999 -9999 -9999 -9999 -9999 -9999 -9999 -9999 -9999 -9999 -9999 -9999 -9999 -9999 -9999 -9999 -9999 -9999 -9999 -9999 -9999 -9999 -9999 -9999 -9999 -9999 -9999 -9999 -9999 -9999 -9999 -9999 -9999 -9999 -9999 -9999 -9999 -

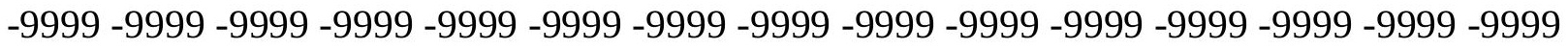
-9999 -9999 -9999 -9999 -9999 -9999 -9999 -9999 -9999 -9999 -9999 -9999 -9999 -9999 -9999

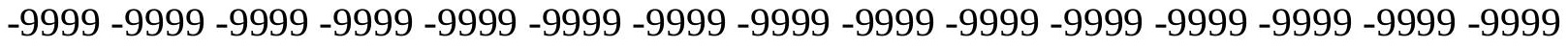
-9999 -9999 -9999 -9999 -9999 -9999 -9999 -9999 -9999 -9999 -9999 -9999 -9999 -9999 -9999 -9999 -9999 -9999 -9999 -9999 -9999 -9999 -9999 -9999 -9999 -9999 -9999 -9999 -9999 -9999 -9999 -9999 -9999 -9999 -9999 -9999 -9999 -9999 -9999 -9999 -9999 -9999 -9999 -9999 -9999 -9999 -9999 -9999 -9999 -9999 -9999 -9999 -9999 -9999 -9999 -9999 -9999 -9999 -9999 -9999 -9999 -9999 -9999 -9999 -9999 -9999 -9999 -9999 -9999 -9999 -9999 -9999 -9999 -9999 -9999 -9999 -9999 -9999 -9999 -9999 -9999 -9999 -9999 -9999 -9999 -9999 -9999 -9999 -9999 -9999 -9999 -9999 -9999 -9999 -9999 -9999 -9999 -9999 -9999 -9999 -9999 -9999 -9999 -9999 -9999 -9999 -9999 -9999 -9999 -9999 -9999 -9999 -9999 -9999 -9999 -9999 -9999 -9999 -9999 -9999 -9999 -9999 -9999 -9999 -9999 -9999 -9999 -9999 -9999 -9999 -9999 -9999 -9999 -9999 -9999 -9999 -9999 -9999 -9999 -9999 -9999 -9999 -9999 -9999 -9999 -9999 -9999 -9999 -9999 -

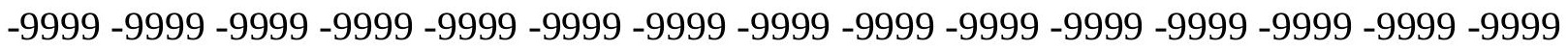

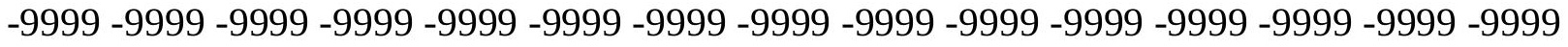
-9999 -9999 -9999 -9999 -9999 -9999 -9999 -9999 -9999 -9999 -9999 -9999 -9999 -9999 -9999 -

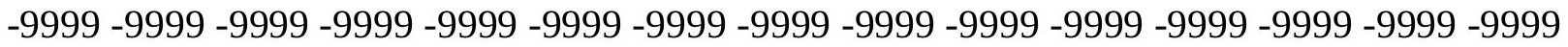

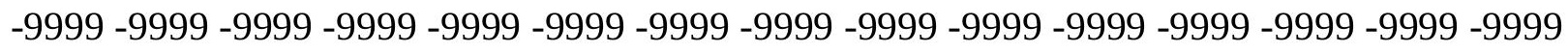

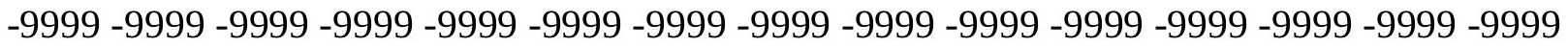

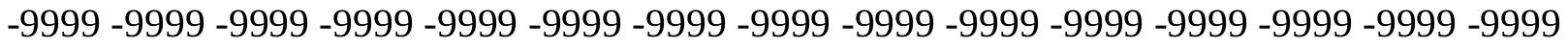
-9999 -9999 -9999 -9999 -9999 -9999 -9999 -9999 -9999 -9999 -9999 -9999 -9999 -9999 -9999 -

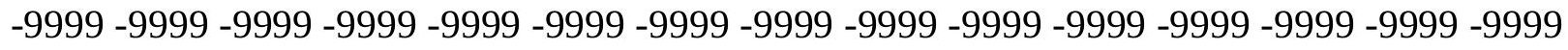

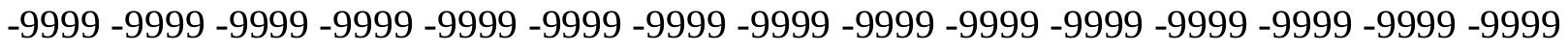
-9999 -9999 -9999 -9999 -9999 -9999 -9999 -9999 -9999 -9999 -9999 -9999 -9999 -9999 -9999 -9999 -9999 -9999 -9999 -9999 -9999 -9999 -9999 -9999-9999 -9999 -9999 -9999 -9999 -9999 -9999 -9999 -9999 -9999 -9999 -9999 -9999 -9999 -9999 -9999 -9999 -9999 -9999 -9999 -9999 -

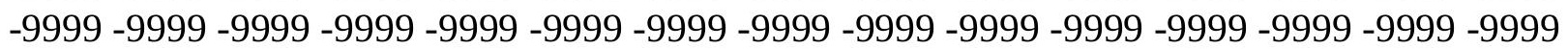


-9999 -9999 -9999 -9999 -9999 -9999 -9999 -9999 -9999 -9999 -9999 -9999 -9999 -9999 -9999 -9999 -9999 -9999 -9999 -9999 -9999 -9999 -9999 -9999 -9999 -9999 -9999 -9999 -9999 -9999 -9999 -9999 -9999 -9999 -9999 -9999 -9999 -9999 -9999 -9999 -9999 -9999 -9999 -9999 - 9999 -9999 -9999 -9999 -9999 -9999 -9999 -9999 -9999 -9999 -9999 -9999 -9999 -9999 -9999 -9999 -9999 -9999 -9999 -9999 -9999 -9999 -9999 -9999 -9999 -9999 -9999 -9999 -9999 -9999 -9999 -9999 -9999 -9999 -9999 -9999 -9999 -9999 -9999 -9999 -9999 -9999 -9999 -9999 -9999 -9999 -9999 -9999 -9999 -9999 -9999 -9999 -9999 -9999 -9999 -9999 -9999 -9999 -9999 -9999 -9999

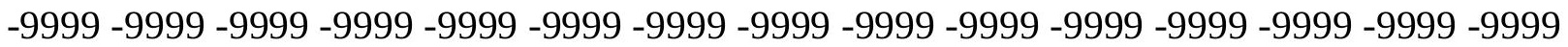

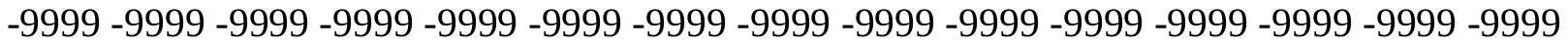
-9999 -9999 -9999 -9999 -9999 -9999 -9999 -9999 -9999 -9999 -9999 -9999 -9999 -9999 -9999 -9999 -9999 -9999 -9999 -9999 -9999 -9999 -9999 -9999 -9999 -9999 -9999 -9999 -9999 -9999 -9999 -9999 -9999 -9999 -9999 -9999 -9999 -9999 -9999 -9999 -9999 -9999 -9999 -9999 -9999 -9999 -9999 -9999 -9999 -9999 -9999 -9999 -9999 -9999 -9999 -9999 -9999 -9999 -9999 -9999 -9999 -9999 -9999 -9999 -9999 -9999 -9999 -9999 -9999 -9999 -9999 -9999 -9999 -9999 -9999 -9999 -9999 -9999 -9999 -9999 -9999 -9999 -9999 -9999 -9999 -9999 -9999 -9999 -9999 -

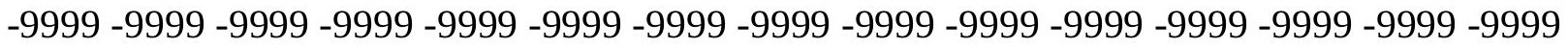
-9999 -9999 -9999 -9999 -9999 -9999 -9999 -9999 -9999 -9999 -9999 -9999 -9999 -9999 -9999 -9999 -9999 -9999 -9999 -9999 -9999 -9999 -9999 -9999 -9999 -9999 -9999 -9999 -9999 -9999 -9999 -9999 -9999 -9999 -9999 -9999 -9999 -9999 -9999 -9999 -9999 -9999 -9999 -9999 -9999 -9999 -9999 -9999 -9999 -9999 -9999 -9999 -9999 -9999 -9999 -9999 -9999 -9999 -9999 -9999 -9999 -9999 -9999 -9999 -9999 -9999 -9999 -9999 -9999 -9999 -9999 -9999 -9999 -9999 -9999 -999 -9999 -9999 -9999 -9999 -9999 -9999 -9999 -9999 -9999 -9999 -9999 -9999 -9999 -9999 -9999 -9999 -9999 -9999 -9999 -9999 -9999 -9999 -9999 -9999 -9999 -9999 -9999 -9999 -9999 -9999 -9999 -9999 -9999 -9999 -9999 -9999 -9999 -9999 -9999 -9999 -9999 -9999 -9999 -9999 -9999 -9999 -9999 -9999 -9999 -9999 -9999 -9999 -9999 -9999 -9999 -9999 -9999 -9999 -9999 -9999 -9999 -9999 -9999 -9999 -9999 -9999 -9999 -9999 -9999 -9999 -9999 -9999 -9999 -9999 -9999 -9999 -9999 -9999 -9999 -9999 -9999 -9999 -9999 -9999 -9999 -9999 -9999 -9999 -9999 -9999 -9999 -9999 -9999 -9999 -9999 -9999 -9999 -9999 -9999 -9999 -9999 -9999 -9999 -9999 -9999 -9999 -9999 -9999 -9999 -9999 -9999 -9999 -9999 -9999 -9999 -9999 -9999 -9999 -9999 -9999 -9999 -9999 -9999 -9999 -9999 -9999 -9999 -9999 -9999 -9999 -9999 -9999 -9999 -9999 -999 -9999 -9999 -9999 -9999 -9999 -9999 -9999 -9999 -9999 -9999 -9999 -9999 -9999 -9999 -9999 -9999 -9999 -9999 -9999 -9999 -9999 -9999 -9999 -9999 -9999 -9999 -9999 -9999 -9999 -9999 -

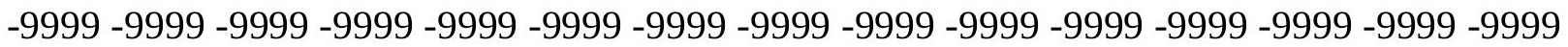

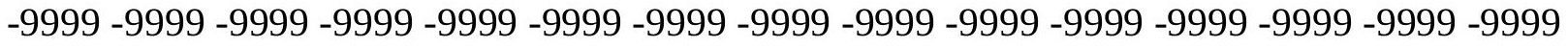

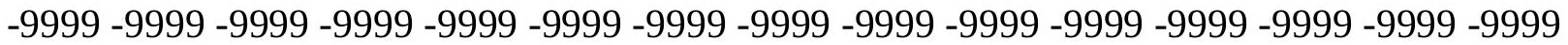
-9999 -9999 -9999 -9999 -9999 -9999 -9999 -9999 -9999 -9999 -9999 -9999 -9999 -9999 -9999 -9999 -9999 -9999 -9999 -9999 -9999 -9999 -9999 -9999 -9999 -9999 -9999 -9999 -9999 -

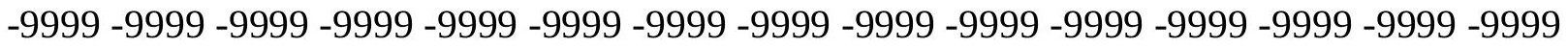
-9999 -9999 -9999 -9999 -9999 -9999 -9999 -9999 -9999 -9999 -9999 -9999 -9999 -9999 -9999 -9999 -9999 -9999 -9999 -9999 -9999 -9999 -9999 -9999 -9999 -9999 -9999 -9999 -9999 -9999 -

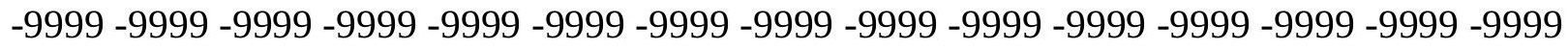

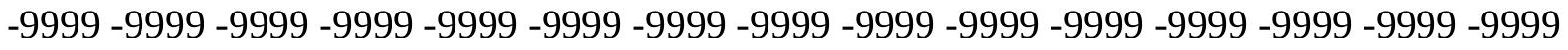
-9999 -9999 -9999 -9999 -9999 -9999 -9999 -9999 -9999 -9999 -9999 -9999 -9999 -9999 -9999 -9999 -9999 -9999 -9999 -9999 -9999 -9999 -9999 -9999-9999 -9999 -9999 -9999 -9999 -9999 -9999 -9999 -9999 -9999 -9999 -9999 -9999 -9999 -9999 -9999 -9999 -9999 -9999 -9999 -9999 -

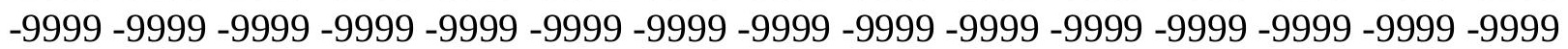


-9999 -9999 -9999 -9999 -9999 -9999 -9999 -9999 -9999 -9999 -9999 -9999 -9999 -9999 -9999 -9999 -9999 -9999 -9999 -9999 -9999 -9999 -9999 -9999 -9999 -9999 -9999 -9999 -9999 -9999 -

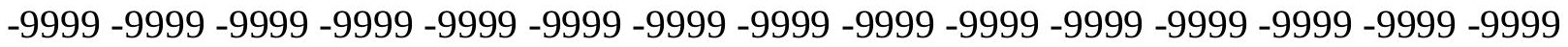
-9999 -9999 -9999 -9999 -9999 -9999 -9999 -9999 -9999 -9999 -9999 -9999 -9999 -9999 -9999 -9999 -9999 -9999 -9999 -9999 -9999 -9999 -9999 -9999-9999 -9999 -9999 -9999 -9999 -9999 -9999 -9999 -9999 -9999 -9999 -9999 -9999 -9999 -9999 -9999 -9999 -9999 -9999 -9999 -9999 -9999 -9999 -9999 -9999 -9999 -9999 -9999 -9999 -9999 -9999 -9999 -9999 -9999 -9999 -9999

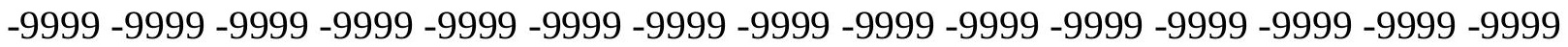

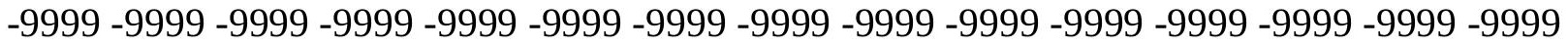
-9999 -9999 -9999 -9999 -9999 -9999 -9999 -9999 -9999 -9999 -9999 -9999 -9999 -9999 -9999 -9999 -9999 -9999 -9999 -9999 -9999 -9999 -9999 -9999 -9999 -9999 -9999 -9999 -9999 -9999 -9999 -9999 -9999 -9999 -9999 -9999 -9999 -9999 -9999 -9999 -9999 -9999 -9999 -9999 -9999 -9999 -9999 -9999 -9999 -9999 -9999 -9999 -9999 -9999 -9999 -9999 -9999 -9999 -9999 -9999 -9999 -9999 -9999 -9999 -9999 -9999 -9999 -9999 -9999 -9999 -9999 -9999 -9999 -9999 -9999 -9999 -9999 -9999 -9999 -9999 -9999 -9999 -9999 -9999 -9999 -9999 -9999 -9999 -9999 -9999 -

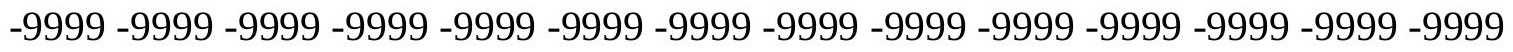
-9999 -9999 -9999 -9999 -9999 -9999 -9999 -9999 -9999 -9999 -9999 -9999 -9999 -9999 -9999 -9999 -9999 -9999 -9999 -9999 -9999 -9999 -9999 -9999 -9999 -9999 -9999 -9999 -9999 -9999 -9999 -9999 -9999 -9999 -9999 -9999 -9999 -9999 -9999 -9999 -9999 -9999 -9999 -9999 -9999 -

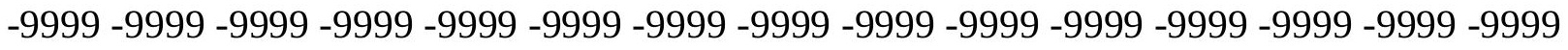

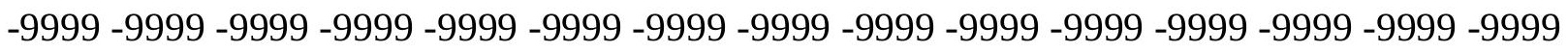
-9999 -9999 -9999 -9999 -9999 -9999 -9999 -9999 -9999 -9999 -9999 -9999 -9999 -9999 - 9999 -9999 -9999 -9999 -9999 -9999 -9999 -9999 -9999 -9999 -9999 -9999 -9999 -9999 -9999 -9999 -9999 -9999 -9999 -9999 -9999 -9999 -9999 -9999 -9999 -9999 -9999 -9999 -9999 -9999 -9999 -

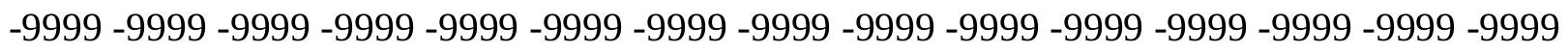
-9999 -9999 -9999 -9999 -9999 -9999 -9999 -9999 -9999 -9999 -9999 -9999 -9999 -9999 -9999 -9999 -9999 -9999 -9999 -9999 -9999 -9999 -9999 -9999 -9999 -9999 -9999 -9999 -9999 -9999 -

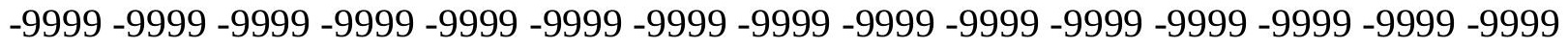
-9999 -9999 -9999 -9999 -9999 -9999 -9999 -9999 -9999 -9999 -9999 -9999 -9999 -9999 -9999 -9999 -9999 -9999 -9999 -9999 -9999 -9999 -9999 -9999 -9999 -9999 -9999 -9999 -9999 -999 -

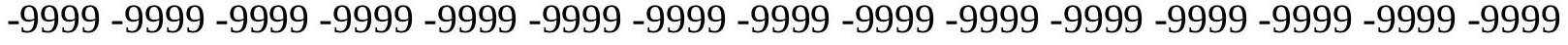
-9999 -9999 -9999 -9999 -9999 -9999 -9999 -9999 -9999 -9999 -9999 -9999 -9999 -9999 -9999 -

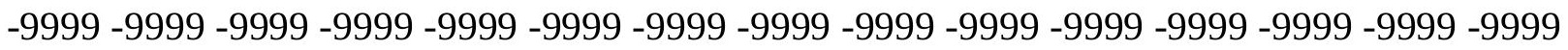

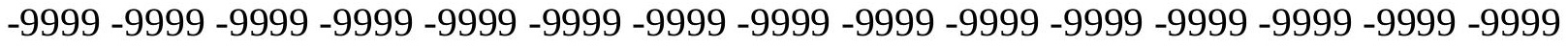

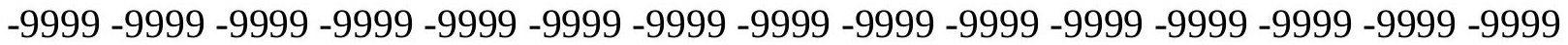
-9999 -9999 -9999 -9999 -9999 -9999 -9999 -9999 -9999 -9999 -9999 -9999 -9999 -9999 -9999 -

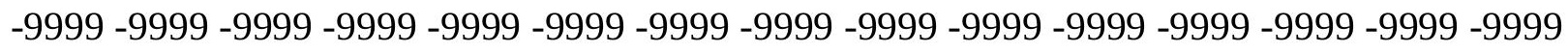

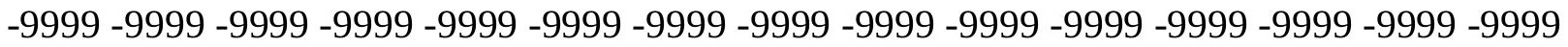
-9999 -9999 -9999 -9999 -9999 -9999 -9999 -9999 -9999 -9999 -9999 -9999 -9999 - 9999 - -999 -9999 -9999 -9999 -9999 -9999 -9999 -9999 -9999 -9999 -9999 -9999 -9999 -9999 -9999 -9999 -

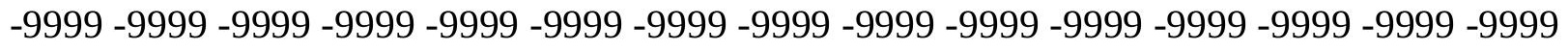

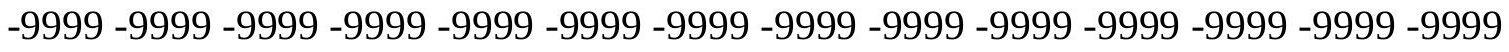
-9999 -9999 -9999 -9999 -9999 -9999 -9999 -9999 -9999 -9999 -9999 -9999 -9999 -9999 -9999 -9999 -9999 -9999 -9999 -9999 -9999 -9999 -9999 -9999-9999 -9999 -9999 -9999 -9999 -9999 -9999 -9999 -9999 -9999 -9999 -9999 -9999 -9999 -9999 -9999 -9999 -9999 -9999 -9999 -9999 -

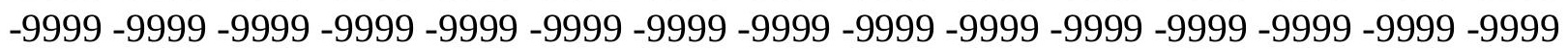


-9999 -9999 -9999 -9999 -9999 -9999 -9999 -9999 -9999 -9999 -9999 -9999 -9999 -9999 -9999 -9999 -9999 -9999 -9999 -9999 -9999 -9999 -9999 -9999 -9999 -9999 -9999 -9999 -9999 -9999 -

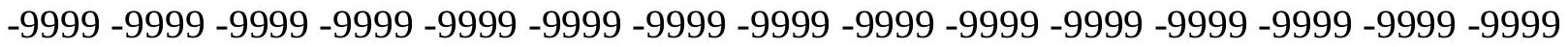
-9999 -9999 -9999 -9999 -9999 -9999 -9999 -9999 -9999 -9999 -9999 -9999 -9999 -9999 -9999 -9999 -9999 -9999 -9999 -9999 -9999 -9999 -9999 -9999-9999 -9999 -9999 -9999 -9999 -9999 -9999 -9999 -9999 -9999 -9999 -9999 -9999 -9999 -9999 -9999 -9999 -9999 -9999 -9999 -9999 -9999 -9999 -9999 -9999 -9999 -9999 -9999 -9999 -9999 -9999 -9999 -9999 -9999 -9999 -9999

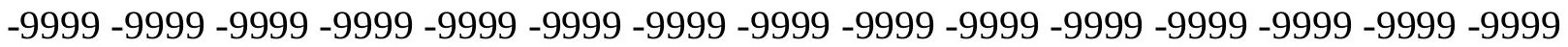

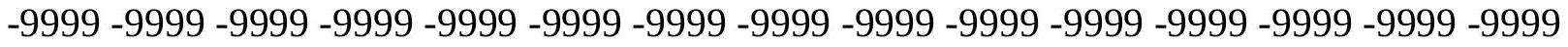
-9999 -9999 -9999 -9999 -9999 -9999 -9999 -9999 -9999 -9999 -9999 -9999 -9999 -9999 -9999 -9999 -9999 -9999 -9999 -9999 -9999 -9999 -9999 -9999 -9999 -9999 -9999 -9999 -9999 -9999 -9999 -9999 -9999 -9999 -9999 -9999 -9999 -9999 -9999 -9999 -9999 -9999 -9999 -9999 -9999 -9999 -9999 -9999 -9999 -9999 -9999 -9999 -9999 -9999 -9999 -9999 -9999 -9999 -9999 -9999 -

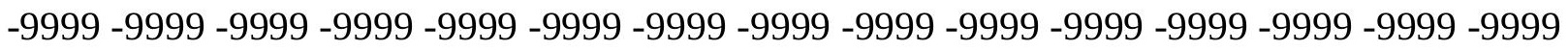
-9999 -9999 -9999 -9999 -9999 -9999 -9999 -9999 -9999 -9999 -9999 -9999 -9999 -9999 -9999 -

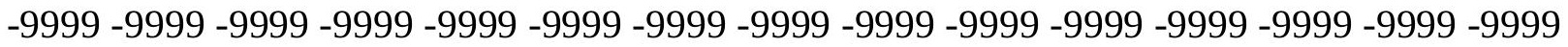
-9999 -9999 -9999 -9999 -9999 -9999 -9999 -9999 -9999 -9999 -9999 -9999 -9999 -9999 -9999 -9999 -9999 -9999 -9999 -9999 -9999 -9999 -9999 -9999 -9999 -9999 -9999 -9999 -9999 -9999 -9999 -9999 -9999 -9999 -9999 -9999 -9999 -9999 -9999 -9999 -9999 -9999 -9999 -9999 -9999 -

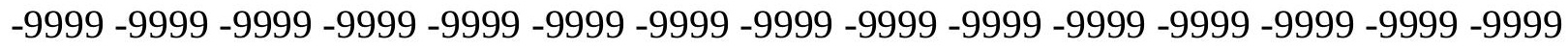

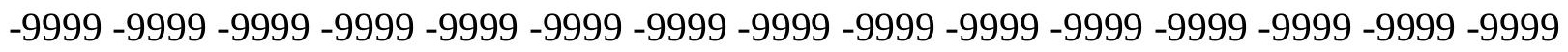
-9999 -9999 -9999 -9999 -9999 -9999 -9999 -9999 -9999 -9999 -9999 -9999 -9999 -9999 -9999 -9999 -9999 -9999 -9999 -9999 -9999 -9999 -9999 -9999 -9999 -9999 -9999 -9999 -9999 -9999 -9999 -9999 -9999 -9999 -9999 -9999 -9999 -9999 -9999 -9999 -9999 -9999 -9999 -9999 -

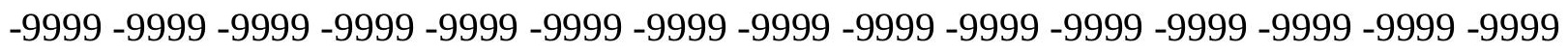
-9999 -9999 -9999 -9999 -9999 -9999 -9999 -9999 -9999 -9999 -9999 -9999 -9999 -9999 -9999 -9999 -9999 -9999 -9999 -9999 -9999 -9999 -9999 -9999 -9999 -9999 -9999 -9999 -9999 -9999 -

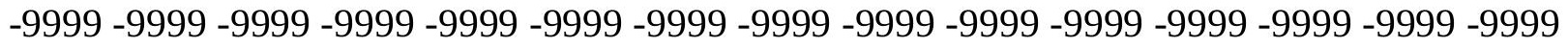
-9999 -9999 -9999 -9999 -9999 -9999 -9999 -9999 -9999 -9999 -9999 -9999 -9999 -9999 -9999 -9999 -9999 -9999 -9999 -9999 -9999 -9999 -9999 -9999 -9999 -9999 -9999 -9999 -9999 -999 -

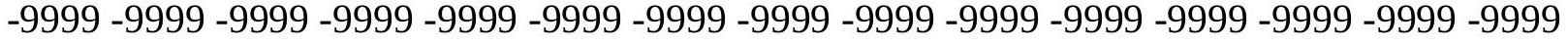
-9999 -9999 -9999 -9999 -9999 -9999 -9999 -9999 -9999 -9999 -9999 -9999 -9999 -9999 -9999 -

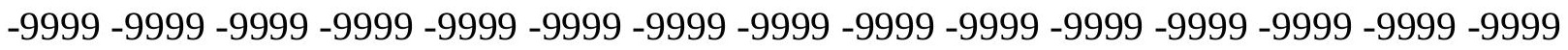

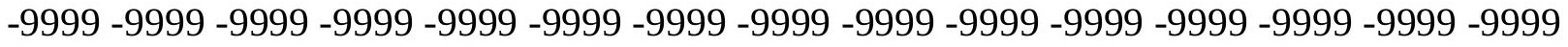

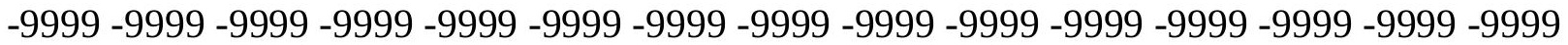

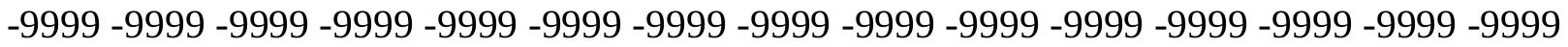

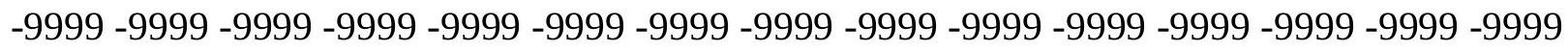

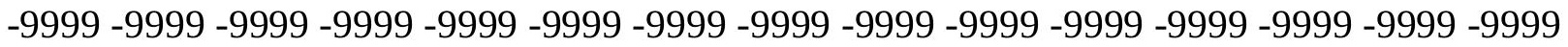

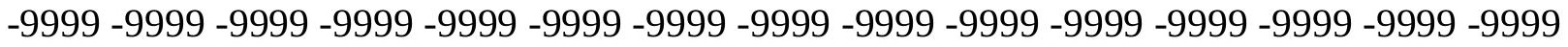
-9999 -9999 -9999 -9999 -9999 -9999 -9999 -9999 -9999 -9999 -9999 -9999 -9999 -9999 -9999 -

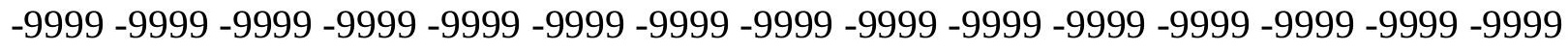

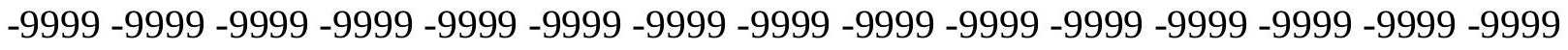
-9999 -9999 -9999 -9999 -9999 -9999 -9999 -9999 -9999 -9999 -9999 -9999 -9999 -9999 -9999 -9999 -9999 -9999 -9999 -9999 -9999 -9999 -9999 -9999-9999 -9999 -9999 -9999 -9999 -9999 -9999 -9999 -9999 -9999 -9999 -9999 -9999 -9999 -9999 -9999 -9999 -9999 -9999 -9999 -9999 -

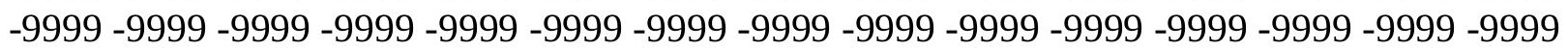


-9999 -9999 -9999 -9999 -9999 -9999 -9999 -9999 -9999 -9999 -9999 -9999 -9999 -9999 -9999 -9999 -9999 -9999 -9999 -9999 -9999 -9999 -9999 -9999 -9999 -9999 -9999 -9999 -9999 -

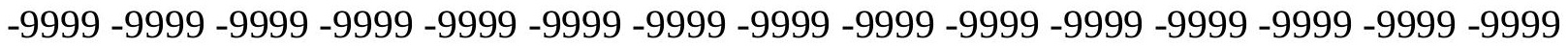
-9999 -9999 -9999 -9999 -9999 -9999 -9999 -9999 -9999 -9999 -9999 -9999 -9999 -9999 -9999 -9999 -9999 -9999 -9999 -9999 -9999 -9999 -9999 -9999 -9999 -9999 -9999 -9999 -9999 -9999 -9999 -9999 -9999 -9999 -9999 -9999 -9999 -9999 -9999 -9999 -9999 -9999 -9999 -9999 -9999 -9999 -9999 -9999 -9999 -9999 -9999 -9999 -9999 -9999 -9999 -9999 -9999 -9999 -9999 -9999

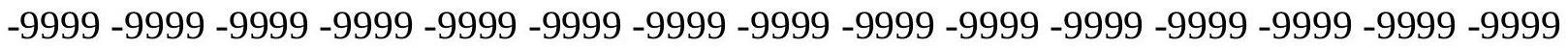

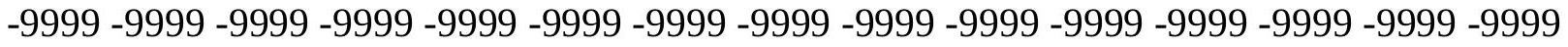
-9999 -9999 -9999 -9999 -9999 -9999 -9999 -9999 -9999 -9999 -9999 -9999 -9999 -9999 -9999 -9999 -9999 -9999 -9999 -9999 -9999 -9999 -9999 -9999 -9999 -9999 -9999 -9999 -9999 -9999 -9999 -9999 -9999 -9999 -9999 -9999 -9999 -9999 -9999 -9999 -9999 -9999 -9999 -9999 -9999 -9999 -9999 -9999 -9999 -9999 -9999 -9999 -9999 -9999 -9999 -9999 -9999 -9999 -9999 -9999 -9999 -9999 -9999 -9999 -9999 -9999 -9999 -9999 -9999 -9999 -9999 -9999 -9999 -9999 -9999 -9999 -9999 -9999 -9999 -9999 -9999 -9999 -9999 -9999 -9999 -9999 -9999 -9999 -9999 -9999 -

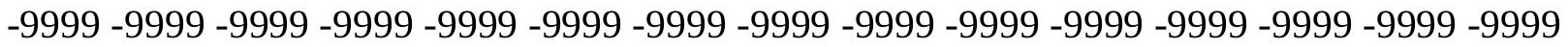
-9999 -9999 -9999 -9999 -9999 -9999 -9999 -9999 -9999 -9999 -9999 -9999 -9999 -9999 -9999 -9999 -9999 -9999 -9999 -9999 -9999 -9999 -9999 -9999 -9999 -9999 -9999 -9999 -9999 - 9999 -9999 -9999 -9999 -9999 -9999 -9999 -9999 -9999 -9999 -9999 -9999 -9999 -9999 -9999 -9999 -

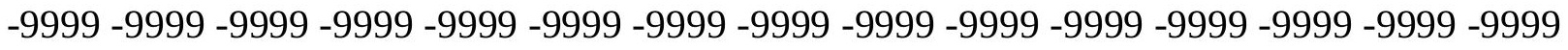

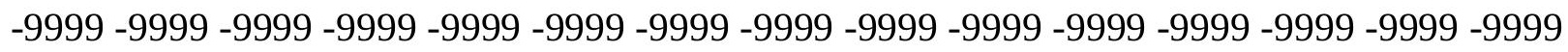

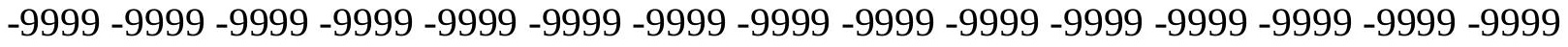
-9999 -9999 -9999 -9999 -9999 -9999 -9999 -9999 -9999 -9999 -9999 -9999 -9999 -9999 -9999 -9999 -9999 -9999 -9999 -9999 -9999 -9999 -9999 -9999 -9999 -9999 -9999 -9999 -9999 -9999 -

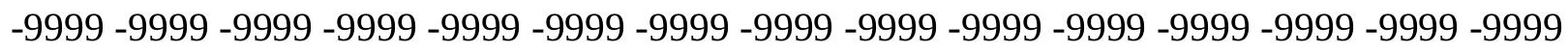
-9999 -9999 -9999 -9999 -9999 -9999 -9999 -9999 -9999 -9999 -9999 -9999 -9999 -9999 -9999 -9999 -9999 -9999 -9999 -9999 -9999 -9999 -9999 -9999 -9999 -9999 -9999 -9999 -9999 -9999 -9999 -9999 -9999 -9999 -9999 -9999 -9999 -9999 -9999 -9999 -9999 -9999 -9999 -9999 -9999 -9999 -9999 -9999 -9999 -9999 -9999 -9999 -9999 -9999 -9999 -9999 -9999 -9999 -9999 -9999 -9999 -9999 -9999 -9999 -9999 -9999 -9999 -9999 -9999 -9999 -9999 -9999 -9999 -999 -

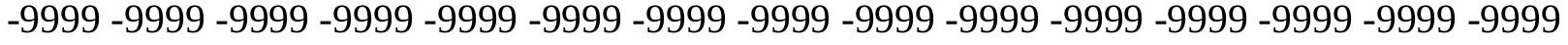
-9999 -9999 -9999 -9999 -9999 -9999 -9999 -9999 -9999 -9999 -9999 -9999 -9999 -9999 -9999 -

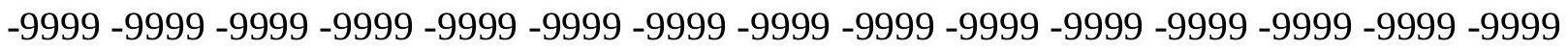

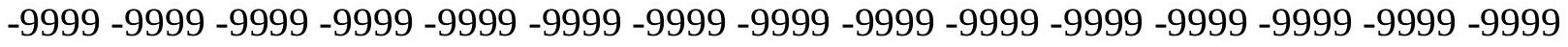

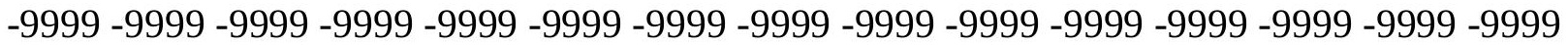

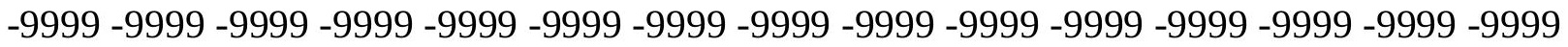

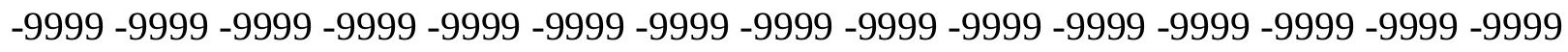

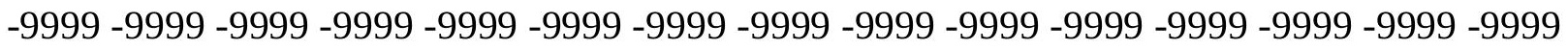

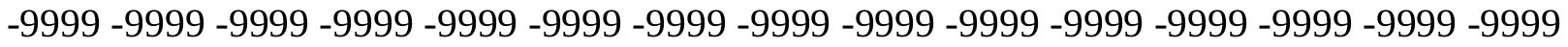
-9999 -9999 -9999 -9999 -9999 -9999 -9999 -9999 -9999 -9999 -9999 -9999 -9999 -9999 -9999 -

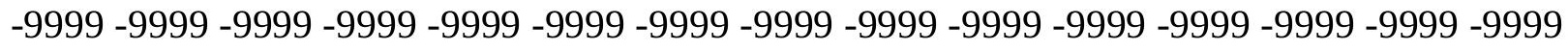

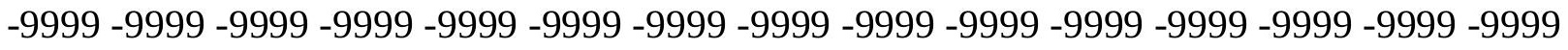
-9999 -9999 -9999 -9999 -9999 -9999 -9999 -9999 -9999 -9999 -9999 -9999 -9999 -9999 -9999 -9999 -9999 -9999 -9999 -9999 -9999 -9999 -9999 -9999-9999 -9999 -9999 -9999 -9999 -9999 -9999 -9999 -9999 -9999 -9999 -9999 -9999 -9999 -9999 -9999 -9999 -9999 -9999 -9999 -9999 -

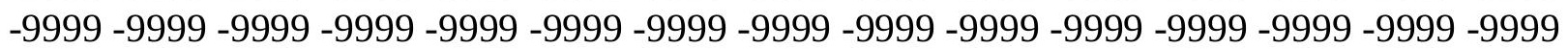


-9999 -9999 -9999 -9999 -9999 -9999 -9999 -9999 -9999 -9999 -9999 -9999 -9999 -9999 -9999 -9999 -9999 -9999 -9999 -9999 -9999 -9999 -9999 -9999 -9999 -9999 -9999 -9999 -9999 -9999 -

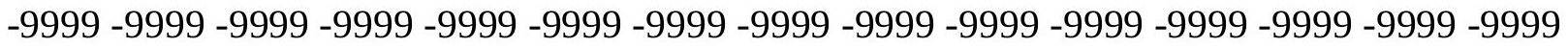
-9999 -9999 -9999 -9999 -9999 -9999 -9999 -9999 -9999 -9999 -9999 -9999 -9999 -9999 -9999 -9999 -9999 -9999 -9999 -9999 -9999 -9999 -9999 -9999-9999 -9999 -9999 -9999 -9999 -9999 -9999 -9999 -9999 -9999 -9999 -9999 -9999 -9999 -9999 -9999 -9999 -9999 -9999 -9999 -9999 -

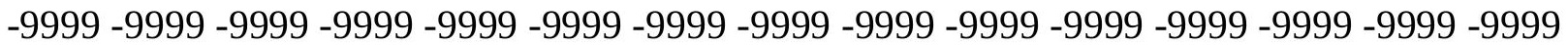
-9999 -9999 -9999 -9999 -9999 -9999 -9999 -9999 -9999 -9999 -9999 -9999 -9999 -9999 -9999 -9999 -9999 -9999 -9999 -9999 -9999 -9999 -9999 -9999 -9999 -9999 -9999 -9999 -9999 -9999 -9999 -9999 -9999 -9999 -9999 -9999 -9999 -9999 -9999 -9999 -9999 -9999 -9999 -9999 -9999 -9999 -9999 -9999 -9999 -9999 -9999 -9999 -9999 -9999 -9999 -9999 -9999 -9999 -9999 -9999 -9999 -9999 -9999 -9999 -9999 -9999 -9999 -9999 -9999 -9999 -9999 -9999 -9999 -9999 -9999 -9999 -9999 -9999 -9999 -9999 -9999 -9999 -9999 -9999 -9999 -9999 -9999 -9999 -9999 -9999 -9999 -9999 -9999 -9999 -9999 -9999 -9999 -9999 -9999 -9999 -9999 -9999 -9999 -9999 -9999 -9999 -9999 -9999 -9999 -9999 -9999 -9999 -9999 -9999 -9999 -9999 -9999 -9999 -9999 -

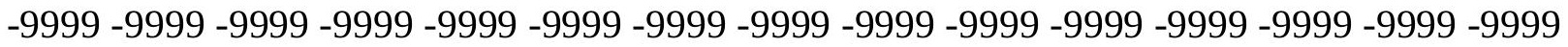
-9999 -9999 -9999 -9999 -9999 -9999 -9999 -9999 -9999 -9999 -9999 -9999 -9999 -9999 -9999 -9999 -9999 -9999 -9999 -9999 -9999 -9999 -9999 -9999 -9999 -9999 -9999 -9999 -9999 -9999 -9999 -9999 -9999 -9999 -9999 -9999 -9999 -9999 -9999 -9999 -9999 -9999 -9999 -9999 -9999 -

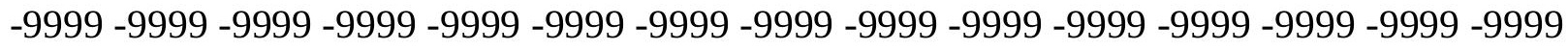

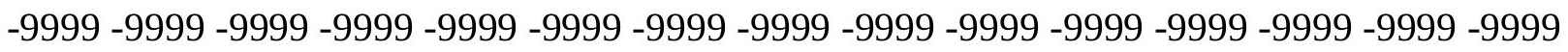
-9999 -9999 -9999 -9999 -9999 -9999 -9999 -9999 -9999 -9999 -9999 -9999 -9999 -9999 - 9999 -9999 -9999 -9999 -9999 -9999 -9999 -9999 -9999 -9999 -9999 -9999 -9999 -9999 -9999 -9999 -9999 -9999 -9999 -9999 -9999 -9999 -9999 -9999 -9999 -9999 -9999 -9999 -9999 -9999 -9999 -

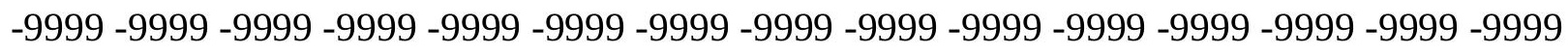
-9999 -9999 -9999 -9999 -9999 -9999 -9999 -9999 -9999 -9999 -9999 -9999 -9999 -9999 -9999 -9999 -9999 -9999 -9999 -9999 -9999 -9999 -9999 -9999 -9999 -9999 -9999 -9999 -9999 -9999 -

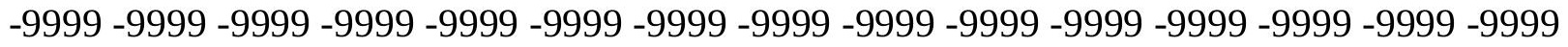
-9999 -9999 -9999 -9999 -9999 -9999 -9999 -9999 -9999 -9999 -9999 -9999 -9999 -9999 -9999 -9999 -9999 -9999 -9999 -9999 -9999 -9999 -9999 -9999 -9999 -9999 -9999 -9999 -9999 -999 -9999 -9999 -9999 -9999 -9999 -9999 -9999 -9999 -9999 -9999 -9999 -9999 -9999 -9999 -9999 -9999 -9999 -9999 -9999 -9999 -9999 -9999 -9999 -9999 -9999 -9999 -9999 -9999 -9999 -9999 -

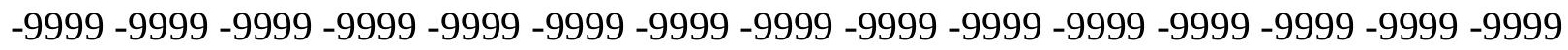

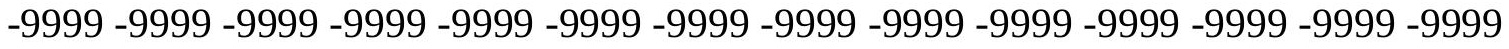
-9999 -9999 -9999 -9999 -9999 -9999 -9999 -9999 -9999 -9999 -9999 -9999 -9999 -9999 -9999

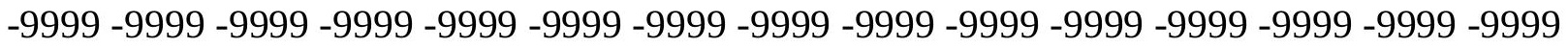

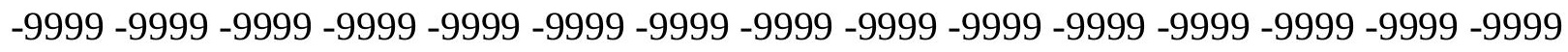

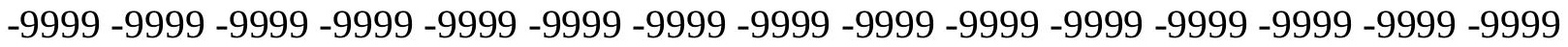

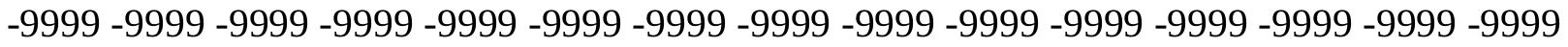
-9999 -9999 -9999 -9999 -9999 -9999 -9999 -9999 -9999 -9999 -9999 -9999 -9999 -9999 -9999 -

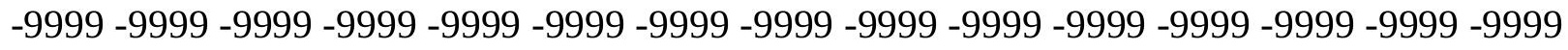

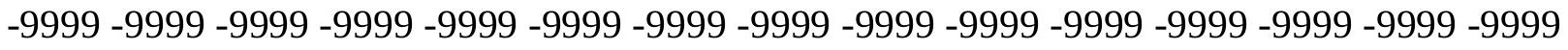
-9999 -9999 -9999 -9999 -9999 -9999 -9999 -9999 -9999 -9999 -9999 -9999 -9999 -9999 -9999 -9999 -9999 -9999 -9999 -9999 -9999 -9999 -9999 -9999-9999 -9999 -9999 -9999 -9999 -9999 -9999 -9999 -9999 -9999 -9999 -9999 -9999 -9999 -9999 -9999 -9999 -9999 -9999 -9999 -9999 -

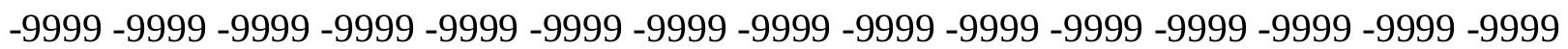


-9999 -9999 -9999 -9999 -9999 -9999 -9999 -9999 -9999 -9999 -9999 -9999 -9999 -9999 -9999 -9999 -9999 -9999 -9999 -9999 -9999 -9999 -9999 -9999 -9999 -9999 -9999 -9999 -9999 -9999 -

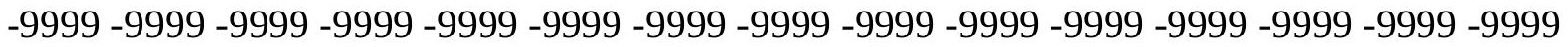
-9999 -9999 -9999 -9999 -9999 -9999 -9999 -9999 -9999 -9999 -9999 -9999 -9999 -9999 -9999 -9999 -9999 -9999 -9999 -9999 -9999 -9999 -9999 -9999-9999 -9999 -9999 -9999 -9999 -9999 -9999 -9999 -9999 -9999 -9999 -9999 -9999 -9999 -9999 -9999 -9999 -9999 -9999 -9999 -9999 -9999 -9999 -9999 -9999 -9999 -9999 -9999 -9999 -9999 -9999 -9999 -9999 -9999 -9999 -9999

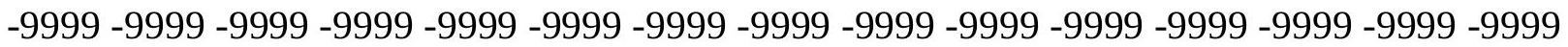

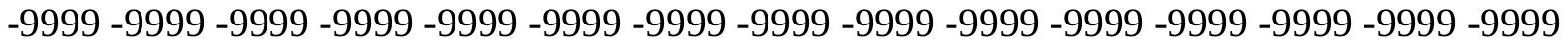
-9999 -9999 -9999 -9999 -9999 -9999 -9999 -9999 -9999 -9999 -9999 -9999 -9999 -9999 -9999 -9999 -9999 -9999 -9999 -9999 -9999 -9999 -9999 -9999 -9999 -9999 -9999 -9999 -9999 -9999 -9999 -9999 -9999 -9999 -9999 -9999 -9999 -9999 -9999 -9999 -9999 -9999 -9999 -9999 -9999 -9999 -9999 -9999 -9999 -9999 -9999 -9999 -9999 -9999 -9999 -9999 -9999 -9999 -9999 -9999 -9999 -9999 -9999 -9999 -9999 -9999 -9999 -9999 -9999 -9999 -9999 -9999 -9999 -9999 -9999 -9999 -9999 -9999 -9999 -9999 -9999 -9999 -9999 -9999 -9999 -9999 -9999 -9999 -9999

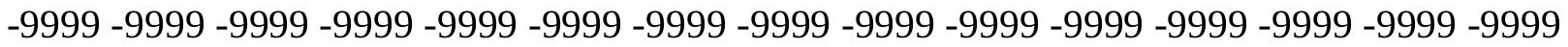
-9999 -9999 -9999 -9999 -9999 -9999 -9999 -9999 -9999 -9999 -9999 -9999 -9999 -9999 -9999 -9999 -9999 -9999 -9999 -9999 -9999 -9999 -9999 -9999 -9999 -9999 -9999 -9999 -9999 -9999 -9999 -9999 -9999 -9999 -9999 -9999 -9999 -9999 -9999 -9999 -9999 -9999 -9999 -9999 -9999 -

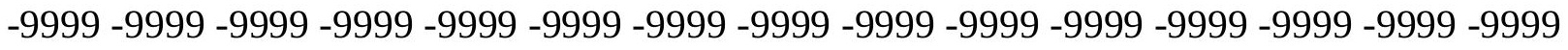

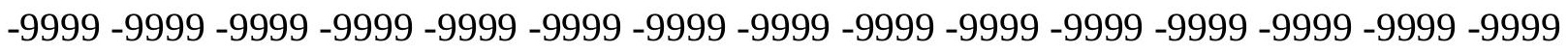
-9999 -9999 -9999 -9999 -9999 -9999 -9999 -9999 -9999 -9999 -9999 -9999 -9999 -9999 -9999 -9999 -9999 -9999 -9999 -9999 -9999 -9999 -9999 -9999 -9999 -9999 -9999 -9999 -9999 -9999 -9999 -9999 -9999 -9999 -9999 -9999 -9999 -9999 -9999 -9999 -9999 -9999 -9999 -9999 -9999 -

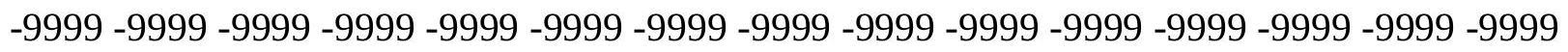
-9999 -9999 -9999 -9999 -9999 -9999 -9999 -9999 -9999 -9999 -9999 -9999 -9999 -9999 -9999 -9999 -9999 -9999 -9999 -9999 -9999 -9999 -9999 -9999 -9999 -9999 -9999 -9999 -9999 -9999 -

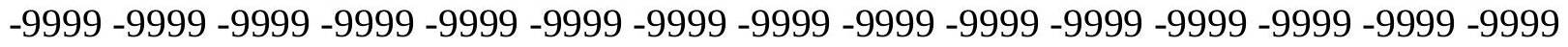
-9999 -9999 -9999 -9999 -9999 -9999 -9999 -9999 -9999 -9999 -9999 -9999 -9999 -9999 -9999 -9999 -9999 -9999 -9999 -9999 -9999 -9999 -9999 -9999 -9999 -9999 -9999 -9999 -9999 -999 -9999 -9999 -9999 -9999 -9999 -9999 -9999 -9999 -9999 -9999 -9999 -9999 -9999 -9999 -9999 -9999 -9999 -9999 -9999 -9999 -9999 -9999 -9999 -9999 -9999 -9999 -9999 -9999 -9999 -9999 -

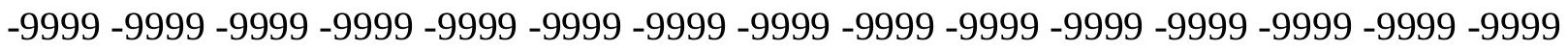

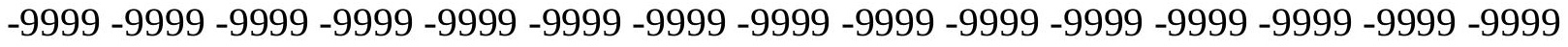

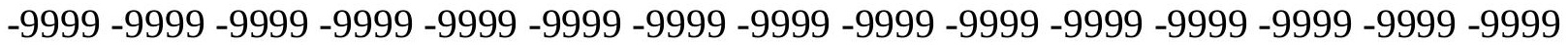

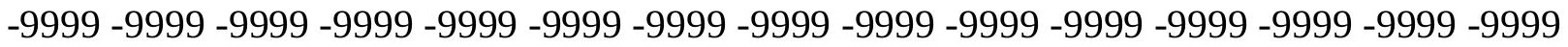

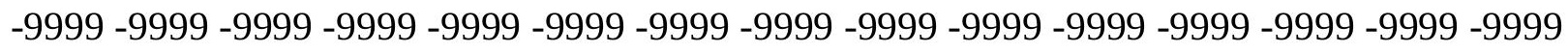

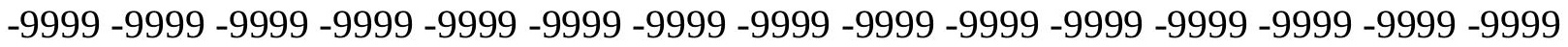
-9999 -9999 -9999 -9999 -9999 -9999 -9999 -9999 -9999 -9999 -9999 -9999 -9999 - 9999 - -999 -9999 -9999 -9999 -9999 -9999 -9999 -9999 -9999 -9999 -9999 -9999 -9999 -9999 -9999 - -999 -

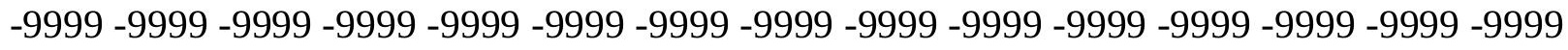

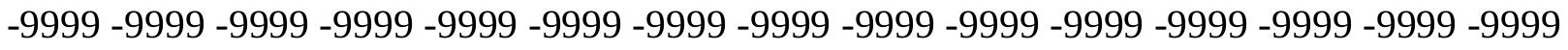
-9999 -9999 -9999 -9999 -9999 -9999 -9999 -9999 -9999 -9999 -9999 -9999 -9999 -9999 -9999 -9999 -9999 -9999 -9999 -9999 -9999 -9999 -9999 -9999-9999 -9999 -9999 -9999 -9999 -9999 -9999 -9999 -9999 -9999 -9999 -9999 -9999 -9999 -9999 -9999 -9999 -9999 -9999 -9999 -9999 -

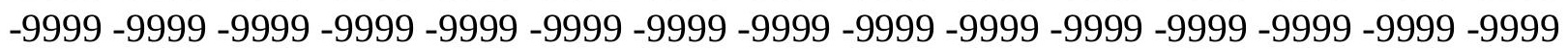


-9999 -9999 -9999 -9999 -9999 -9999 -9999 -9999 -9999 -9999 -9999 -9999 -9999 -9999 -9999 -9999 -9999 -9999 -9999 -9999 -9999 -9999 -9999 -9999 -9999 -9999 -9999 -9999 -9999 -9999 -9999 -9999 -9999 -9999 -9999 -9999 -9999 -9999 -9999 -9999 -9999 -9999 -9999 -9999 -9999 -9999 -9999 -9999 -9999 -9999 -9999 -9999 -9999 -9999 -9999 -9999 -9999 -9999 -9999 -9999 -9999 -9999 -9999 -9999 -9999 -9999 -9999 -9999 -9999 -9999 -9999 -9999 -9999 -9999 -9999 -9999 -9999 -9999 -9999 -9999 -9999 -9999 -9999 -9999 -9999 -9999 -9999 -9999 -9999 -9999 -9999 -9999 -9999 -9999 -9999 -9999 -9999 -9999 -9999 -9999 -9999 -9999 -9999 -9999 -9999 -

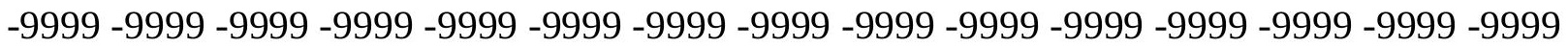
-9999 -9999 -9999 -9999 -9999 -9999 -9999 -9999 -9999 -9999 -9999 -9999 -9999 -9999 -9999 -9999 -9999 -9999 -9999 -9999 -9999 -9999 -9999 -9999 -9999 -9999 -9999 -9999 -9999 -9999 -

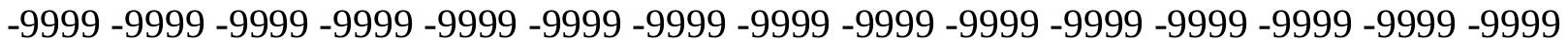
-9999 -9999 -9999 -9999 -9999 -9999 -9999 -9999 -9999 -9999 -9999 -9999 -9999 -9999 -9999 -9999 -9999 -9999 -9999 -9999 -9999 -9999 -9999 -9999 -9999 -9999 -9999 -9999 -9999 -9999 -9999 -9999 -9999 -9999 -9999 -9999 -9999 -9999 -9999 -9999 -9999 -9999 -9999 -9999 -9999 -9999 -9999 -9999 -9999 -9999 -9999 -9999 -9999 -9999 -9999 -9999 -9999 -9999 -9999 -9999

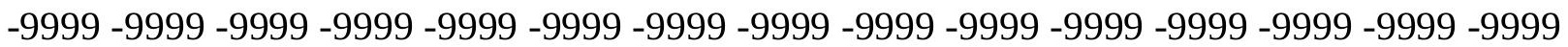
-9999 -9999 -9999 -9999 -9999 -9999 -9999 -9999 -9999 -9999 -9999 -9999 -9999 -9999 -9999 -9999 -9999 -9999 -9999 -9999 -9999 -9999 -9999 -9999 -9999 -9999 -9999 -9999 -9999 -9999 -9999 -9999 -9999 -9999 -9999 -9999 -9999 -9999 -9999 -9999 -9999 -9999 -9999 -9999 -9999 -9999 -9999 -9999 -9999 -9999 -9999 -9999 -9999 -9999 -9999 -9999 -9999 -9999 -9999 -9999 -9999 -9999 -9999 -9999 -9999 -9999 -9999 -9999 -9999 -9999 -9999 -9999 -9999 -9999 -9999 -9999 -9999 -9999 -9999 -9999 -9999 -9999 -9999 -9999 -9999 -9999 -9999 -9999 -9999 -9999 -9999 -9999 -9999 -9999 -9999 -9999 -9999 -9999 -9999 -9999 -9999 -9999 -9999 -9999 -9999 -9999 -9999 -9999 -9999 -9999 -9999 -9999 -9999 -9999 -9999 -9999 -9999 -9999 -9999 -9999 -9999 -9999 -9999 -9999 -9999 -9999 -9999 -9999 -9999 -9999 -9999 -9999 -9999 -9999 -9999 -9999 -9999 -9999 -9999 -9999 -9999 -9999 -9999 -9999 -9999 -9999 -9999 -9999 -9999 -9999 -9999 -9999 -9999 -9999 -9999 -9999 -9999 -9999 -9999 -9999 -9999 -9999 -9999 -9999 -9999 -9999 -9999 -9999 -9999 -9999 -9999 -9999 -9999 -9999 -9999 -9999 -9999 -9999 -9999

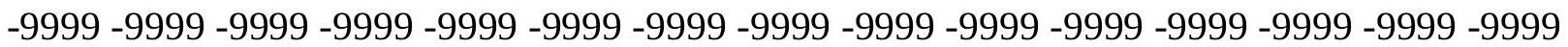
-9999 -9999 -9999 -9999 -9999 -9999 -9999 -9999 -9999 -9999 -9999 -9999 -9999 -9999 -9999 -9999 -9999 -9999 -9999 -9999 -9999 -9999 -9999 -9999 -9999 -9999 -9999 -9999 -9999 -9999 -

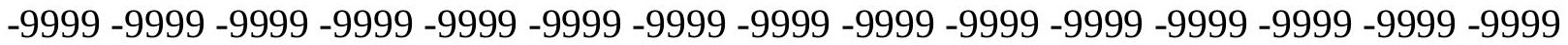
-9999 -9999 -9999 -9999 -9999 -9999 -9999 -9999 -9999 -9999 -9999 -9999 -9999 -9999 -9999 -9999 -9999 -9999 -9999 -9999 -9999 -9999 -9999 -9999 -9999 -9999 -9999 -9999 -9999 -9999 -9999 -9999 -9999 -9999 -9999 -9999 -9999 -9999 -9999 -9999 -9999 -9999 -9999 -9999 -9999 -9999 -9999 -9999 -9999 -9999 -9999 -9999 -9999 -9999 -9999 -9999 -9999 -9999 -9999 -9999 -9999 -9999 -9999 -9999 -9999 -9999 -9999 -9999 -9999 -9999 -9999 -9999 -9999 -9999 -9999

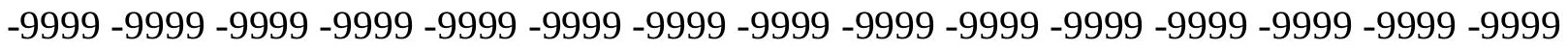
-9999 -9999 -9999 -9999 -9999 -9999 -9999 -9999 -9999 -9999 -9999 -9999 -9999 -9999 -9999 -9999 -9999 -9999 -9999 -9999 -9999 -9999 -9999 -9999 -9999 -9999 -9999 -9999 -9999 -9999 -9999 -9999 -9999 -9999 -9999 -9999 -9999 -9999 -9999 -9999 -9999 -9999 -9999 -9999 -9999 -999 -9999 -9999 -9999 -9999 -9999 -9999 -9999 -9999 -9999 -9999 -9999 -9999 -9999 -9999 -9999 -9999 -9999 -9999 -9999 -9999 -9999 -9999 -9999 -9999 -9999 -9999 -9999 -9999 -9999 -9999 -9999 -9999 -9999 -9999 -9999 -9999 -9999 -9999 -9999 -9999 -9999 -9999 -9999 -9999 -9999 -9999 -9999 -9999 -9999 -9999 -9999 -9999 -9999 -9999 -9999 -9999 -9999 -9999 -9999 -9999 -9999 -9999 -9999 -9999 -9999 -9999 -9999 -9999 -9999 -9999 -9999 -9999 -9999 -9999 
-9999 -9999 -9999 -9999 -9999 -9999 -9999 -9999 -9999 -9999 -9999 -9999 -9999 -9999 -9999 -9999 -9999 -9999 -9999 -9999 -9999 -9999 -9999 -9999 -9999 -9999 -9999 -9999 -9999 -9999 -

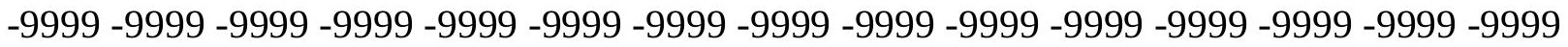
-9999 -9999 -9999 -9999 -9999 -9999 -9999 -9999 -9999 -9999 -9999 -9999 -9999 -9999 -9999 -9999 -9999 -9999 -9999 -9999 -9999 -9999 -9999 -9999-9999 -9999 -9999 -9999 -9999 -9999 -9999 -9999 -9999 -9999 -9999 -9999 -9999 -9999 -9999 -9999 -9999 -9999 -9999 -9999 -9999 -9999 -9999 -9999 -9999 -9999 -9999 -9999 -9999 -9999 -9999 -9999 -9999 -9999 -9999 -9999

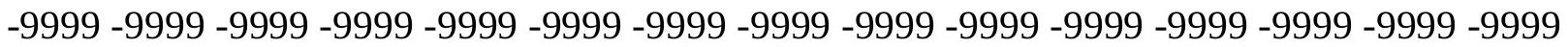

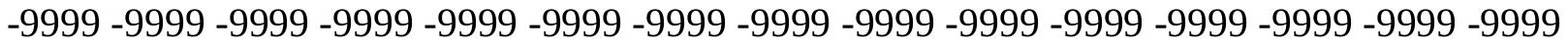
-9999 -9999 -9999 -9999 -9999 -9999 -9999 -9999 -9999 -9999 -9999 -9999 -9999 -9999 -9999 -9999 -9999 -9999 -9999 -9999 -9999 -9999 -9999 -9999 -9999 -9999 -9999 -9999 -9999 -9999 -9999 -9999 -9999 -9999 -9999 -9999 -9999 -9999 -9999 -9999 -9999 -9999 -9999 -9999 -9999 -9999 -9999 -9999 -9999 -9999 -9999 -9999 -9999 -9999 -9999 -9999 -9999 -9999 -9999 -9999 -

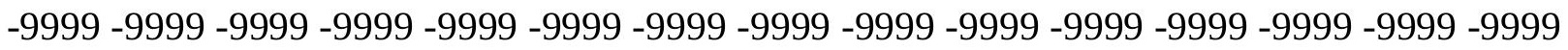
-9999 -9999 -9999 -9999 -9999 -9999 -9999 -9999 -9999 -9999 -9999 -9999 -9999 -9999 -9999 -

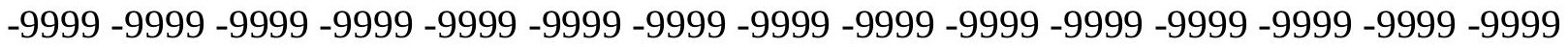
-9999 -9999 -9999 -9999 -9999 -9999 -9999 -9999 -9999 -9999 -9999 -9999 -9999 -9999 -9999 -9999 -9999 -9999 -9999 -9999 -9999 -9999 -9999 -9999 -9999 -9999 -9999 -9999 -9999 -9999 -9999 -9999 -9999 -9999 -9999 -9999 -9999 -9999 -9999 -9999 -9999 -9999 -9999 -9999 -9999 -

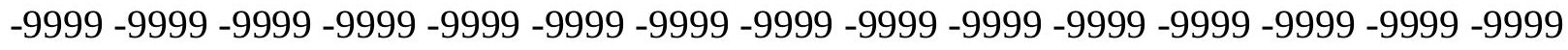

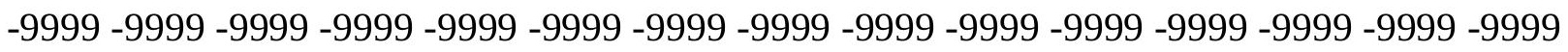

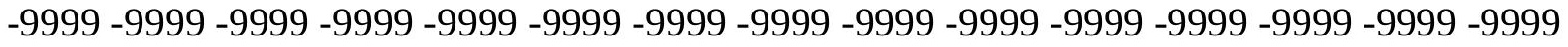
-9999 -9999 -9999 -9999 -9999 -9999 -9999 -9999 -9999 -9999 -9999 -9999 -9999 -9999 -9999 -9999 -9999 -9999 -9999 -9999 -9999 -9999 -9999 -9999 -9999 -9999 -9999 -9999 -9999 -9999 -

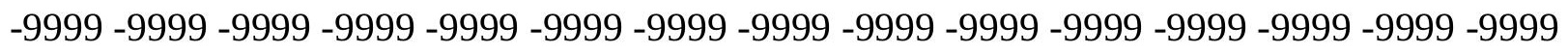
-9999 -9999 -9999 -9999 -9999 -9999 -9999 -9999 -9999 -9999 -9999 -9999 -9999 -9999 -9999 -9999 -9999 -9999 -9999 -9999 -9999 -9999 -9999 -9999 -9999 -9999 -9999 -9999 -9999 -

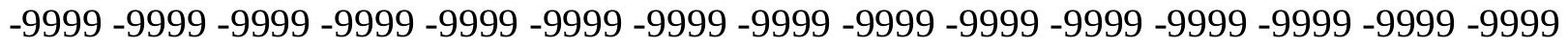
-9999 -9999 -9999 -9999 -9999 -9999 -9999 -9999 -9999 -9999 -9999 -9999 -9999 -9999 -9999 -9999 -9999 -9999 -9999 -9999 -9999 -9999 -9999 -9999 -9999 -9999 -9999 -9999 -9999 -999 -

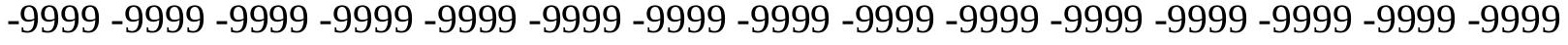
-9999 -9999 -9999 -9999 -9999 -9999 -9999 -9999 -9999 -9999 -9999 -9999 -9999 -9999 -9999 -

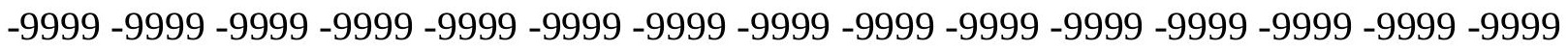

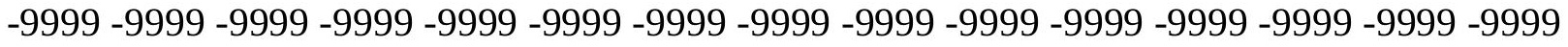

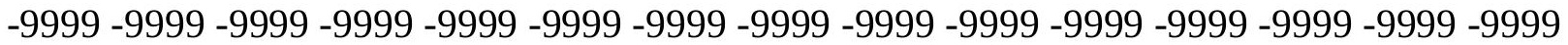
-9999 -9999 -9999 -9999 -9999 -9999 -9999 -9999 -9999 -9999 -9999 -9999 -9999 -9999 -9999

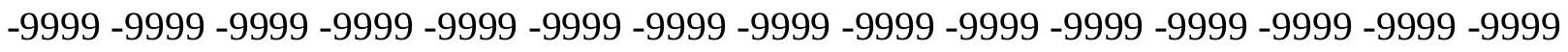

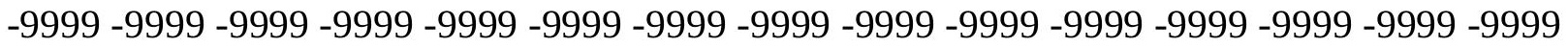
-9999 -9999 -9999 -9999 -9999 -9999 -9999 -9999 -9999 -9999 -9999 -9999 -9999 - 9999 - -999 -9999 -9999 -9999 -9999 -9999 -9999 -9999 -9999 -9999 -9999 -9999 -9999 -9999 -9999 -9999 -

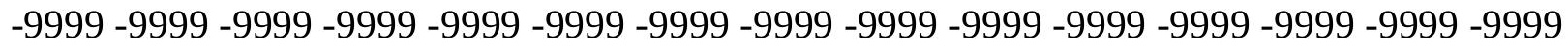

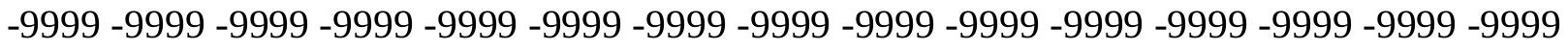
-9999 -9999 -9999 -9999 -9999 -9999 -9999 -9999 -9999 -9999 -9999 -9999 -9999 -9999 -9999 -9999 -9999 -9999 -9999 -9999 -9999 -9999 -9999 -9999-9999 -9999 -9999 -9999 -9999 -9999 -9999 -9999 -9999 -9999 -9999 -9999 -9999 -9999 -9999 -9999 -9999 -9999 -9999 -9999 -9999 -

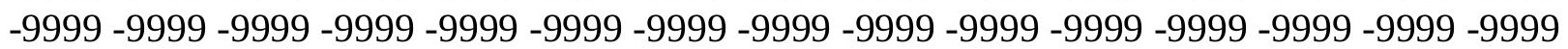


-9999 -9999 -9999 -9999 -9999 -9999 -9999 -9999 -9999 -9999 -9999 -9999 -9999 -9999 -9999 -9999 -9999 -9999 -9999 -9999 -9999 -9999 -9999 -9999 -9999 -9999 -9999 -9999 -9999 -9999 -9999 -9999 -9999 -9999 -9999 -9999 -9999 -9999 -9999 -9999 -9999 -9999 -9999 -9999 - 9999 -9999 -9999 -9999 -9999 -9999 -9999 -9999 -9999 -9999 -9999 -9999 -9999 -9999 -9999 -9999 -9999 -9999 -9999 -9999 -9999 -9999 -9999 -9999 -9999 -9999 -9999 -9999 -9999 -9999 - -9999 -9999 -9999 -9999 -9999 -9999 -9999 -9999 -9999 -9999 -9999 -9999 -9999 -9999 -9999 -9999 -9999 -9999 -9999 -9999 -9999 -9999 -9999 -9999 -9999 -9999 -9999 -9999 -9999 -9999

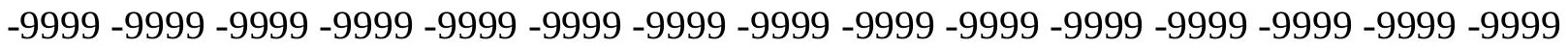

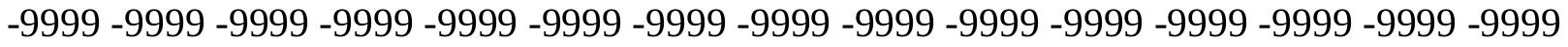
-9999 -9999 -9999 -9999 -9999 -9999 -9999 -9999 -9999 -9999 -9999 -9999 -9999 -9999 -9999

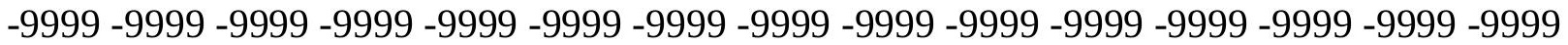
-9999 -9999 -9999 -9999 -9999 -9999 -9999 -9999 -9999 -9999 -9999 -9999 -9999 -9999 -9999 -9999 -9999 -9999 -9999 -9999 -9999 -9999 -9999 -9999 -9999 -9999 -9999 -9999 -9999 -9999 -9999 -9999 -9999 -9999 -9999 -9999 -9999 -9999 -9999 -9999 -9999 -9999 -9999 -9999 - -9999 -9999 -9999 -9999 -9999 -9999 -9999 -9999 -9999 -9999 -9999 -9999 -9999 -9999 -9999 -9999

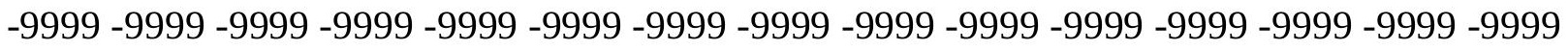
-9999 -9999 -9999 -9999 -9999 -9999 -9999 -9999 -9999 -9999 -9999 -9999 -9999 -9999 -9999 -9999 -9999 -9999 -9999 -9999 -9999 -9999 -9999 -9999 -9999 -9999 -9999 -9999 -9999 -9999 -9999 -9999 -9999 -9999 -9999 -9999 -9999 -9999 -9999 -9999 -9999 -9999 -9999 -9999 -9999 -

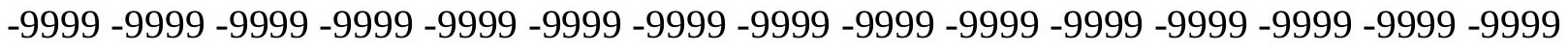
-9999 -9999 -9999 -9999 -9999 -9999 -9999 -9999 -9999 -9999 -9999 -9999 -9999 -9999 -9999 -999 -9999 -9999 -9999 -9999 -9999 -9999 -9999 -9999 -9999 -9999 -9999 -9999 -9999 -9999 -9999 -9999 -9999 -9999 -9999 -9999 -9999 -9999 -9999 -9999 -9999 -9999 -9999 -9999 -9999 -9999 -9999 -9999 -9999 -9999 -9999 -9999 -9999 -9999 -9999 -9999 -9999 -9999 -9999 -9999 -9999 -9999 -9999 -9999 -9999 -9999 -9999 -9999 -9999 -9999 -9999 -9999 -9999 -9999 -9999 -9999 -9999 -9999 -9999 -9999 -9999 -9999 -9999 -9999 -9999 -9999 -9999 -9999 -9999 -9999 -9999 -9999 -9999 -9999 -9999 -9999 -9999 -9999 -9999 -9999 -9999 -9999 -9999 -9999 -9999 -9999 -9999 -9999 -9999 -9999 -9999 -9999 -9999 -9999 -9999 -9999 -9999 -9999 -9999 -9999 -9999 -9999 -9999 -9999 -9999 -9999 -9999 -9999 -9999 -9999 -9999 -9999 -9999 -9999 -9999 -9999 -9999 -9999 -9999 -9999 -9999 -9999 -9999 -9999 -9999 -9999 -9999 -9999 -9999 -9999 -999 -9999 -9999 -9999 -9999 -9999 -9999 -9999 -9999 -9999 -9999 -9999 -9999 -9999 -9999 -9999 -9999 -9999 -9999 -9999 -9999 -9999 -9999 -9999 -9999 -9999 -9999 -9999 -9999 -9999 -

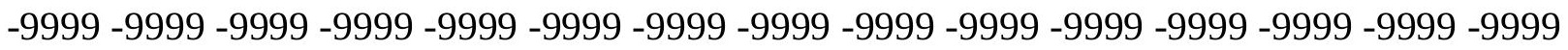

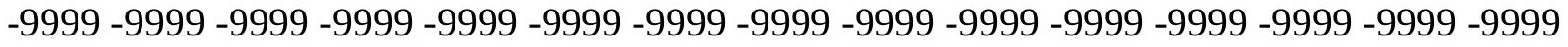

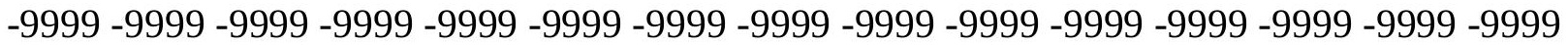
-9999 -9999 -9999 -9999 -9999 -9999 -9999 -9999 -9999 -9999 -9999 -9999 -9999 -9999 -9999 -

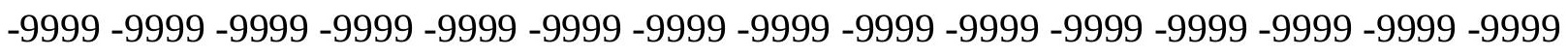

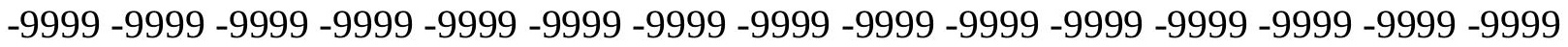

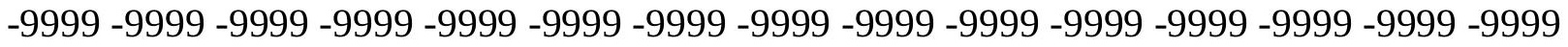
-9999 -9999 -9999 -9999 -9999 -9999 -9999 -9999 -9999 -9999 -9999 -9999 -9999 -9999 -9999 -

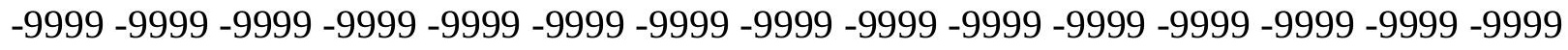

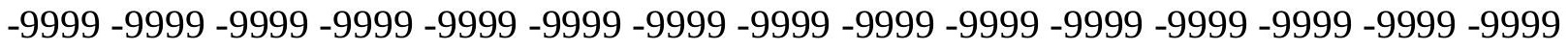
-9999 -9999 -9999 -9999 -9999 -9999 -9999 -9999 -9999 -9999 -9999 -9999 -9999 -9999 -9999 -9999 -9999 -9999 -9999 -9999 -9999 -9999 -9999 -9999-9999 -9999 -9999 -9999 -9999 -9999 -9999 -9999 -9999 -9999 -9999 -9999 -9999 -9999 -9999 -9999 -9999 -9999 -9999 -9999 -9999 -

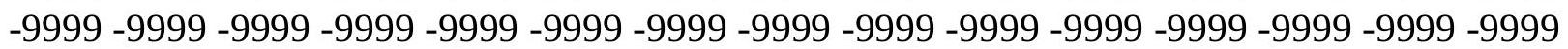


-9999 -9999 -9999 -9999 -9999 -9999 -9999 -9999 -9999 -9999 -9999 -9999 -9999 -9999 -9999 -9999 -9999 -9999 -9999 -9999 -9999 -9999 -9999 -9999 -9999 -9999 -9999 -9999 -9999 -9999 -

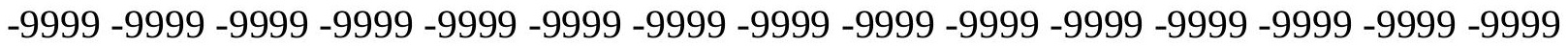
-9999 -9999 -9999 -9999 -9999 -9999 -9999 -9999 -9999 -9999 -9999 -9999 -9999 -9999 -9999 -9999 -9999 -9999 -9999 -9999 -9999 -9999 -9999 -9999-9999 -9999 -9999 -9999 -9999 -9999 -9999 -9999 -9999 -9999 -9999 -9999 -9999 -9999 -9999 -9999 -9999 -9999 -9999 -9999 -9999 -9999 -9999 -9999 -9999 -9999 -9999 -9999 -9999 -9999 -9999 -9999 -9999 -9999 -9999 -9999

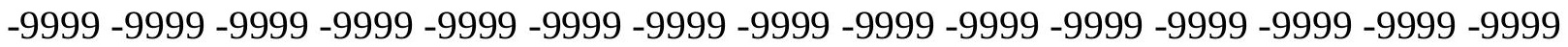

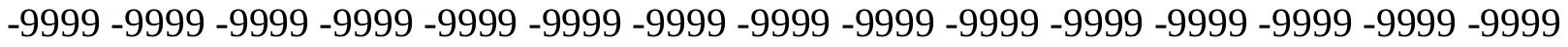
-9999 -9999 -9999 -9999 -9999 -9999 -9999 -9999 -9999 -9999 -9999 -9999 -9999 -9999 -9999 -9999 -9999 -9999 -9999 -9999 -9999 -9999 -9999 -9999 -9999 -9999 -9999 -9999 -9999 -9999 -9999 -9999 -9999 -9999 -9999 -9999 -9999 -9999 -9999 -9999 -9999 -9999 -9999 -9999 -9999 -9999 -9999 -9999 -9999 -9999 -9999 -9999 -9999 -9999 -9999 -9999 -9999 -9999 -9999 -9999 -9999 -9999 -9999 -9999 -9999 -9999 -9999 -9999 -9999 -9999 -9999 -9999 -9999 - 9999 -9999 -9999 -9999 -9999 -9999 -9999 -9999 -9999 -9999 -9999 -9999 -9999 -9999 -9999 -9999

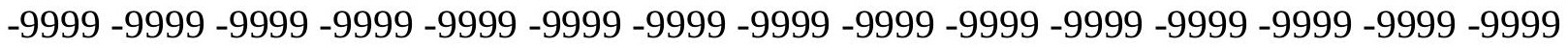
-9999 -9999 -9999 -9999 -9999 -9999 -9999 -9999 -9999 -9999 -9999 -9999 -9999 -9999 -9999 -9999 -9999 -9999 -9999 -9999 -9999 -9999 -9999 -9999 -9999 -9999 -9999 -9999 -9999 -9999 -9999 -9999 -9999 -9999 -9999 -9999 -9999 -9999 -9999 -9999 -9999 -9999 -9999 -9999 -9999 -

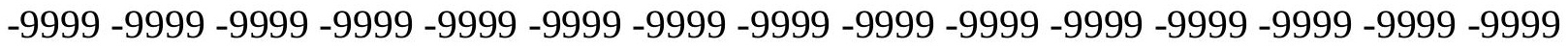

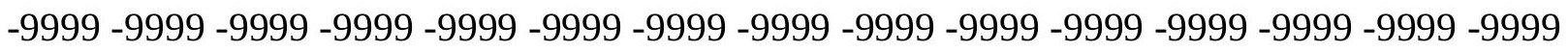
-9999 -9999 -9999 -9999 -9999 -9999 -9999 -9999 -9999 -9999 -9999 -9999 -9999 -9999 -9999 -9999 -9999 -9999 -9999 -9999 -9999 -9999 -9999 -9999 -9999 -9999 -9999 -9999 -9999 -9999 -9999 -9999 -9999 -9999 -9999 -9999 -9999 -9999 -9999 -9999 -9999 -9999 -9999 -9999 -9999 -

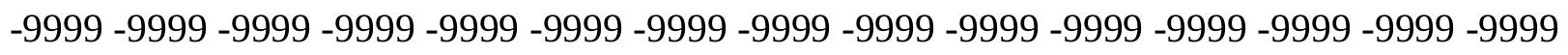
-9999 -9999 -9999 -9999 -9999 -9999 -9999 -9999 -9999 -9999 -9999 -9999 -9999 -9999 -9999 -9999 -9999 -9999 -9999 -9999 -9999 -9999 -9999 -9999 -9999 -9999 -9999 -9999 -9999 -9999 -

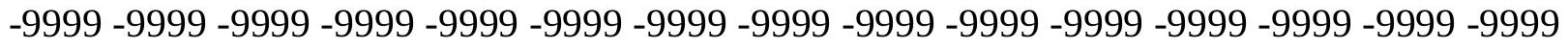
-9999 -9999 -9999 -9999 -9999 -9999 -9999 -9999 -9999 -9999 -9999 -9999 -9999 -9999 -9999 -9999 -9999 -9999 -9999 -9999 -9999 -9999 -9999 -9999 -9999 -9999 -9999 -9999 -9999 -999 -9999 -9999 -9999 -9999 -9999 -9999 -9999 -9999 -9999 -9999 -9999 -9999 -9999 -9999 -9999 -9999 -9999 -9999 -9999 -9999 -9999 -9999 -9999 -9999 -9999 -9999 -9999 -9999 -9999 -9999 -

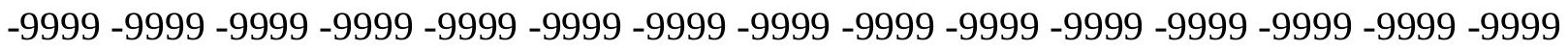

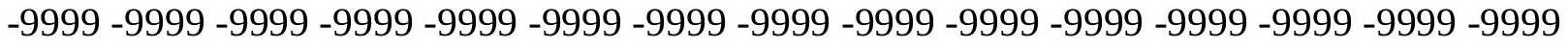

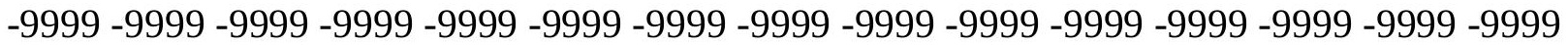

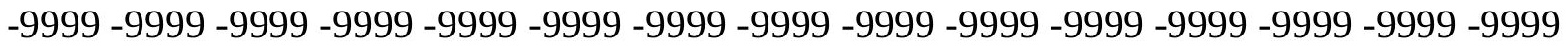

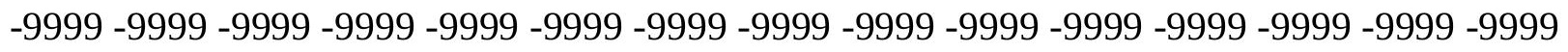

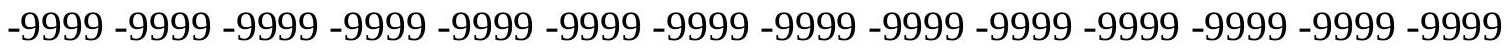
-9999 -9999 -9999 -9999 -9999 -9999 -9999 -9999 -9999 -9999 -9999 -9999 -9999 -9999 -9999 -9999 -9999 -9999 -9999 -9999 -9999 -9999 -9999 -9999 -9999 -9999 -9999 -9999 -9999 -9999 -

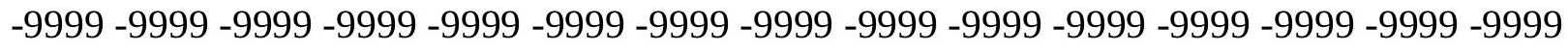

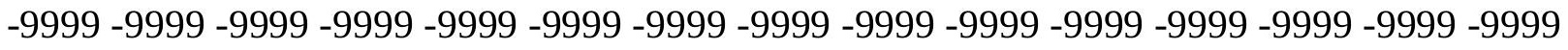
-9999 -9999 -9999 -9999 -9999 -9999 -9999 -9999 -9999 -9999 -9999 -9999 -9999 -9999 -9999 -9999 -9999 -9999 -9999 -9999 -9999 -9999 -9999 -9999-9999 -9999 -9999 -9999 -9999 -9999 -9999 -9999 -9999 -9999 -9999 -9999 -9999 -9999 -9999 -9999 -9999 -9999 -9999 -9999 -9999 -

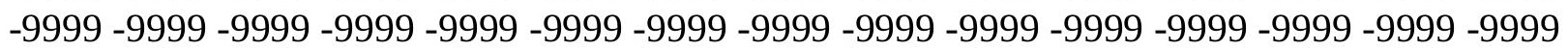


-9999 -9999 -9999 -9999 -9999 -9999 -9999 -9999 -9999 -9999 -9999 -9999 -9999 -9999 -9999 -9999 -9999 -9999 -9999 -9999 -9999 -9999 -9999 -9999 -9999 -9999 -9999 -9999 -9999 -9999 -9999 -9999 -9999 -9999 -9999 -9999 -9999 -9999 -9999 -9999 -9999 -9999 -9999 -9999 - 9999 -9999 -9999 -9999 -9999 -9999 -9999 -9999 -9999 -9999 -9999 -9999 -9999 -9999 -9999 -9999 -9999 -9999 -9999 -9999 -9999 -9999 -9999 -9999 -9999 -9999 -9999 -9999 -9999 -9999 -9999 -9999 -9999 -9999 -9999 -9999 -9999 -9999 -9999 -9999 -9999 -9999 -9999 -9999 -9999 -9999 -9999 -9999 -9999 -9999 -9999 -9999 -9999 -9999 -9999 -9999 -9999 -9999 -9999 -9999 -9999

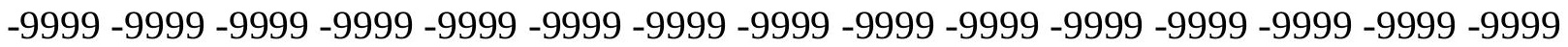
-9999 -9999 -9999 -9999 -9999 -9999 -9999 -9999 -9999 -9999 -9999 -9999 -9999 -9999 -9999 -9999 -9999 -9999 -9999 -9999 -9999 -9999 -9999 -9999 -9999 -9999 -9999 -9999 -9999 -9999

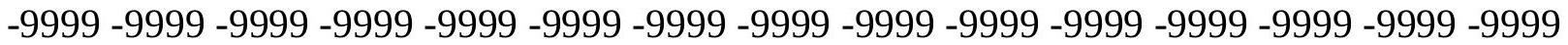
-9999 -9999 -9999 -9999 -9999 -9999 -9999 -9999 -9999 -9999 -9999 -9999 -9999 -9999 -9999 -9999 -9999 -9999 -9999 -9999 -9999 -9999 -9999 -9999 -9999 -9999 -9999 -9999 -9999 -9999 -

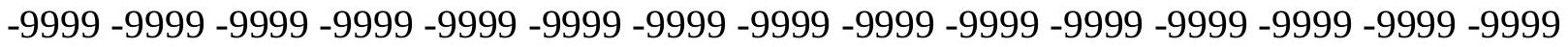
-9999 -9999 -9999 -9999 -9999 -9999 -9999 -9999 -9999 -9999 -9999 -9999 -9999 -9999 -9999

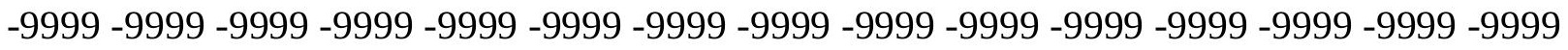
-9999 -9999 -9999 -9999 -9999 -9999 -9999 -9999 -9999 -9999 -9999 -9999 -9999 -9999 -9999 -9999 -9999 -9999 -9999 -9999 -9999 -9999 -9999 -9999 -9999 -9999 -9999 -9999 -9999 - -999 -9999 -9999 -9999 -9999 -9999 -9999 -9999 -9999 -9999 -9999 -9999 -9999 -9999 -9999 -9999 -9999 -9999 -9999 -9999 -9999 -9999 -9999 -9999 -9999 -9999 -9999 -9999 -9999 -9999 -9999 -9999 -9999 -9999 -9999 -9999 -9999 -9999 -9999 -9999 -9999 -9999 -9999 -9999 -9999 -9999 -999 -9999 -9999 -9999 -9999 -9999 -9999 -9999 -9999 -9999 -9999 -9999 -9999 -9999 -9999 -9999 -9999 -9999 -9999 -9999 -9999 -9999 -9999 -9999 -9999 -9999 -9999 -9999 -9999 -9999 -9999 -9999 -9999 -9999 -9999 -9999 -9999 -9999 -9999 -9999 -9999 -9999 -9999 -9999 -9999 -9999 -9999 -9999 -9999 -9999 -9999 -9999 -9999 -9999 -9999 -9999 -9999 -9999 -9999 -9999 -9999 -9999 -9999 -9999 -9999 -9999 -9999 -9999 -9999 -9999 -9999 -9999 -9999 -9999 -9999 -9999 -9999 -9999 -9999 -9999 -9999 -9999 -9999 -9999 -9999 -9999 -9999 -9999 -9999 -9999 -9999 -9999 -9999 -9999 -9999 -9999 -9999 -9999 -9999 -9999 -9999 -9999 -9999 -9999 -9999 -9999 -9999 -9999 -9999 -9999 -9999 -9999 -9999 -9999 -9999 -9999 -9999 -9999 -9999 -9999 -9999 -9999 -9999 -9999 -9999 -9999 -9999 -9999 -9999 -9999 -9999 -9999 -9999 -9999 -9999 -999 -9999 -9999 -9999 -9999 -9999 -9999 -9999 -9999 -9999 -9999 -9999 -9999 -9999 -9999 -9999 -9999 -9999 -9999 -9999 -9999 -9999 -9999 -9999 -9999 -9999 -9999 -9999 -9999 -9999 -9999 -

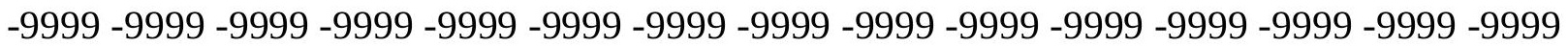

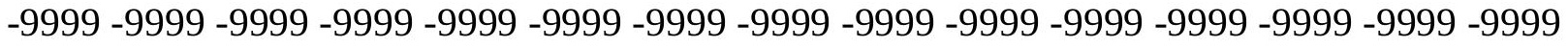

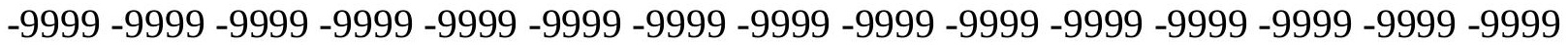
-9999 -9999 -9999 -9999 -9999 -9999 -9999 -9999 -9999 -9999 -9999 -9999 -9999 -9999 -9999

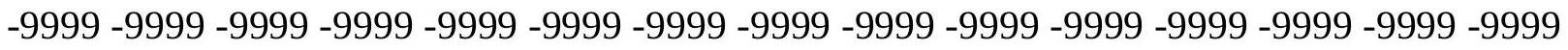

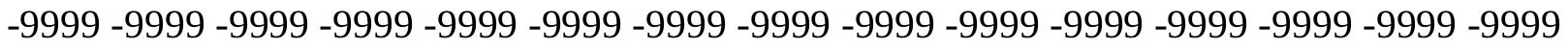

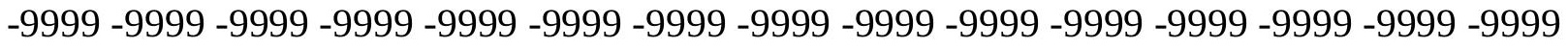
-9999 -9999 -9999 -9999 -9999 -9999 -9999 -9999 -9999 -9999 -9999 -9999 -9999 -9999 -9999 -

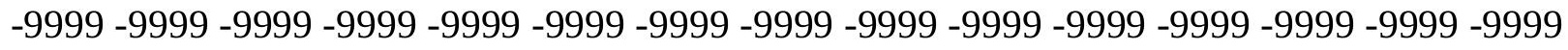

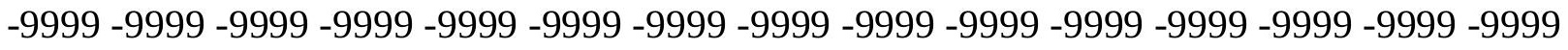
-9999 -9999 -9999 -9999 -9999 -9999 -9999 -9999 -9999 -9999 -9999 -9999 -9999 -9999 -9999 -9999 -9999 -9999 -9999 -9999 -9999 -9999 -9999 -9999 -9999 -9999 -9999 -9999 - -9999 -9999 -9999 -9999 -9999 -9999 -9999 -9999 -9999 -9999 -9999 -9999 -9999 -9999 -9999 -9999 -

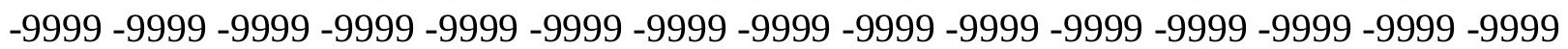


-9999 -9999 -9999 -9999 -9999 -9999 -9999 -9999 -9999 -9999 -9999 -9999 -9999 -9999 -9999 -9999 -9999 -9999 -9999 -9999 -9999 -9999 -9999 -9999 -9999 -9999 -9999 -9999 -9999 -9999 -9999 -9999 -9999 -9999 -9999 -9999 -9999 -9999 -9999 -9999 -9999 -9999 -9999 -9999 -9999 -9999 -9999 -9999 -9999 -9999 -9999 -9999 -9999 -9999 -9999 -9999 -9999 -9999 -9999 -9999 -9999 -9999 -9999 -9999 -9999 -9999 -9999 -9999 -9999 -9999 -9999 -9999 -9999 -9999 -9999 -9999 -9999 -9999 -9999 -9999 -9999 -9999 -9999 -9999 -9999 -9999 -9999 -9999 -9999 -9999 -9999 -9999 -9999 -9999 -9999 -9999 -9999 -9999 -9999 -9999 -9999 -9999 -9999 -9999 -9999

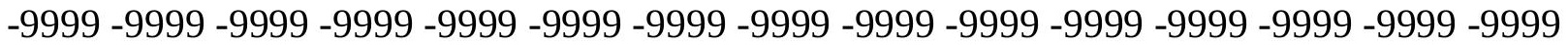
-9999 -9999 -9999 -9999 -9999-9999 -9999 -9999 -9999 -9999 -9999 -9999 -9999 -9999 -9999 7.3148431777957 .3148431777957 .3148431777957 .3148431777957 .010057926178 7.0100579261787 .0100579261787 .3148431777957 .3148431777957 .314843177795 7.6196279525767 .6196279525767 .9244132041938 .2291984558118 .533983230591 8.8387689590459 .1435537338269 .448339462289 .75312423706110 .05790996552 10.36268997192 -9999 -9999 -9999 -9999 -9999 -9999 -9999 -9999 -9999 -9999 -9999 -9999 -9999 -9999 -9999 -9999 -9999 -9999 -9999 -9999 -9999 -9999 -9999 -9999 -9999 -9999 -9999 -9999 -9999 -9999 -9999 -9999 -9999 -9999 -9999 -9999 -9999 -9999 -9999 -9999 -9999 -9999 -9999 -9999 -9999 -9999 -9999 -9999 -9999 -9999 -9999 -9999 -9999 -9999 -9999 -9999 -9999 -9999 -9999 -9999 -9999 -9999 -9999 -9999 -9999 -9999 -9999 -9999 -9999 -9999 -9999 -9999 -9999 -9999 -9999 -9999 -9999 -9999 -9999 -9999 -9999 -9999 -9999 -9999 -9999 -9999 -9999 -9999 -9999 -9999 -9999 -9999 -9999 -9999 -9999 -9999 -9999 -9999 -9999 -9999 -9999 -9999

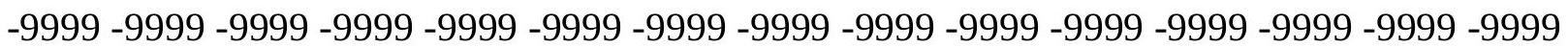
-9999 -9999 -9999 -9999 -9999 -9999 -9999 -9999 -9999 -9999 -9999 -9999 -9999 -9999 -9999 -9999 -9999 -9999 -9999 -9999 -9999 -9999 -9999 -9999 -9999 -9999 -9999 -9999 -9999 -9999 -9999 -9999 -9999 -9999 -9999 -9999 -9999 -9999 -9999 -9999 -9999 -9999 -9999 -9999 -9999

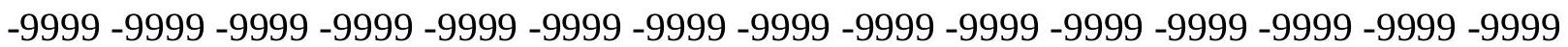
-9999 -9999 -9999 -9999 -9999 -9999 -9999 -9999 -9999 -9999 -9999 -9999 -9999 -9999 -9999 -9999 -9999 -9999 -9999 -9999 -9999 -9999 -9999 -9999 -9999 -9999

-9999 -9999 -9999 -9999 -9999 -9999 -9999 -9999 -9999 -9999 -9999 -9999 -9999 -9999 -9999 -9999 -9999 -9999 -9999 -9999 -9999 -9999 -9999 -9999 -9999 -9999 -9999 -9999 -9999 -9999 -9999 -9999 -9999 -9999 -9999 -9999 -9999 -9999 -9999 -9999 -9999 -9999 -9999 -9999 -9999 -9999 -9999 -9999 -9999 -9999 -9999 -9999 -9999 -9999 -9999 -9999 -9999 -9999 -9999 -9999 -

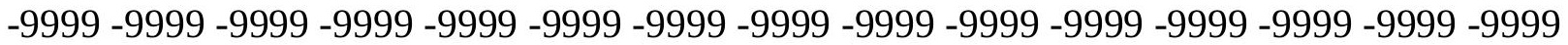
-9999 -9999 -9999 -9999 -9999 -9999 -9999 -9999 -9999 -9999 -9999 -9999 -9999 -9999 -9999 -9999 -9999 -9999 -9999 -9999 -9999 -9999 -9999 -9999 -9999 -9999 -9999 -9999 -9999 -9999 -

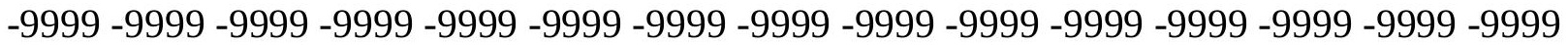
-9999 -9999 -9999 -9999 -9999 -9999 -9999 -9999 -9999 -9999 -9999 -9999 -9999 -9999 -9999 -9999 -9999 -9999 -9999 -9999 -9999 -9999 -9999 -9999 -9999 -9999 -9999 -9999 -9999 -9999 -9999 -9999 -9999 -9999-9999 -9999 -9999 -9999 6.705273151398 6.400486946106 6.0957031255 .7909169197085 .7909169197085 .4861321449285 .486132144928 5.4861321449285 .1813468933115 .1813468933115 .1813468933115 .181346893311 5.1813468933115 .4861321449285 .7909169197085 .7909169197086 .0957031256 .095703125 6.4004869461066 .7052731513987 .0100579261787 .0100579261787 .314843177795 7.6196279525767 .9244132041938 .2291984558118 .5339832305919 .143553733826 9.448339462289 .75312423706110 .3626899719210 .66748046875 -9999 -9999 -9999-9999 -9999 -9999 -9999 -9999 -9999 -9999 -9999 -9999 -9999 -9999 -9999 -9999 -9999 -9999 -9999

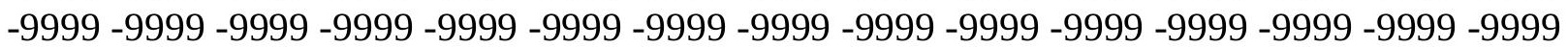


-9999 -9999 -9999 -9999 -9999 -9999 -9999 -9999 -9999 -9999 -9999 -9999 -9999 -9999 -9999 -9999 -9999 -9999 -9999 -9999 -9999 -9999 -9999 -9999 -9999 -9999 -9999 -9999 -9999 -9999 -9999 -9999 -9999 -9999 -9999 -9999 -9999 -9999 -9999 -9999 -9999 -9999 -9999 -9999 -9999 -9999 -9999 -9999 -9999 -9999 -9999 -9999 -9999 -9999 -9999 -9999 -9999 -9999 -9999 -9999 -9999 -9999 -9999 -9999 -9999 -9999 -9999 -9999 -9999 -9999 -9999 -9999 -9999 -9999 -9999 -9999 -9999 -9999 -9999 -9999 -9999 -9999 -9999 -9999 -9999 -9999 -9999 -9999 -9999 -9999 -9999 -9999 -9999 -9999 -9999 -9999 -9999 -9999 -9999 -9999 -9999 -9999 -9999 -9999 -9999

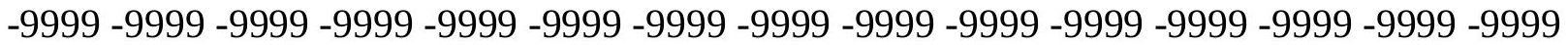
-9999 -9999 -9999 -9999 -9999 -9999 -9999 -9999 -9999 -9999 -9999 -9999 -9999 -9999 -9999 -9999 -9999 -9999 -9999 -9999 -9999 -9999 -9999 -9999 -9999 -9999 -9999 -9999 -9999 -9999 -

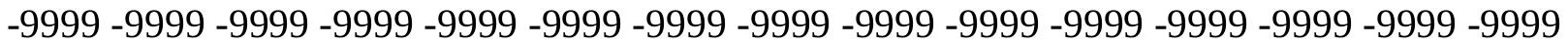
-9999 -9999 -9999 -9999 -9999 -9999 -9999 -9999 -9999 -9999 -9999 -9999 -9999 -9999 -9999

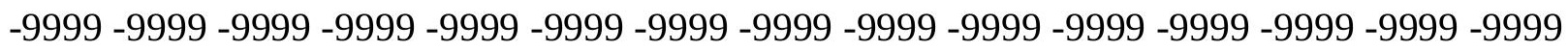
-9999 -9999 -9999 -9999 -9999 -9999 -9999 -9999 -9999 -9999 -9999 -9999 -9999 -9999 -9999 -9999 -9999 -9999 -9999 -9999 -9999 -9999 -9999 -9999 -9999 -9999 -9999 -9999 -9999 -9999

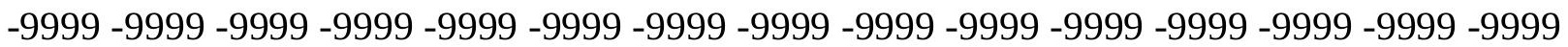
-9999 -9999 -9999 -9999 -9999 -9999 -9999 -9999 -9999 -9999 -9999 -9999 -9999 -9999 -9999 -9999 -9999 -9999 -9999 -9999 -9999 -9999 -9999 -9999 -9999 -9999 -9999 -9999 -9999 -9999 -9999 -9999 -9999 -9999 -9999 -9999 -9999 -9999 -9999 -9999 -9999 -9999 -9999 -9999 -9999 -9999 -9999 -9999 -9999 -9999 -9999 -9999 -9999 -9999 -9999 -9999 -9999 -9999 -9999 -9999 -9999 -9999 -9999 -9999 -9999 -9999 -9999 -9999 -9999 -9999 -9999 -9999 -9999 -9999 -9999 -9999 -99996.400486946106 6.095703125 5.7909169197085.4861321449285.181346893311 4.876562118534 .5717768669134 .2669920921333 .9622070789343 .657422065735 3.6574220657353 .6574220657353 .6574220657353 .6574220657353 .657422065735 3.6574220657353 .9622070789343 .9622070789343 .9622070789344 .266992092133 4.2669920921334 .5717768669134 .876562118534 .876562118535 .181346893311 5.4861321449285 .7909169197085 .7909169197086 .0957031256 .400486946106 6.7052731513987 .0100579261787 .3148431777957 .9244132041938 .229198455811 8.5339832305919 .1435537338269 .4483394622810 .0579099655210 .36268997192 10.9722604751611 .27705001831 -9999 -9999 -9999 -9999 -9999 -9999 -9999 -9999 -9999 -9999 -9999 -9999 -9999 -9999 -9999 -9999 -9999 -9999 -9999 -9999 -9999 -9999 -9999 -9999

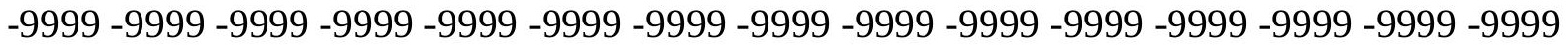
-9999 -9999 -9999 -9999 -9999 -9999 -9999 -9999 -9999 -9999 -9999 -9999 -9999 -9999 -9999 -9999 -9999 -9999 -9999 -9999 -9999 -9999 -9999 -9999 -9999 -9999 -9999 -9999 -9999 -9999 -

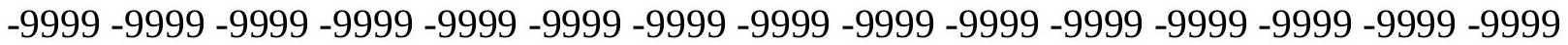
-9999 -9999 -9999 -9999 -9999 -9999 -9999 -9999 -9999 -9999 -9999 -9999 -9999 -9999 -9999 -9999 -9999 -9999 -9999 -9999 -9999 -9999 -9999 -9999 -9999 -9999 -9999 -9999 -9999 -9999

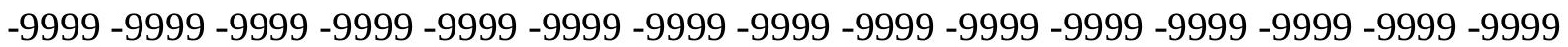
-9999 -9999 -9999 -9999 -9999 -9999 -9999 -9999 -9999 -9999 -9999 -9999 -9999 -9999 -9999 -9999 -9999 -9999 -9999 -9999 -9999 -9999 -9999 -9999 -9999 -9999 -9999 -9999 -9999 -9999 -9999 -9999 -9999 -9999 -9999 -9999 -9999 -9999 -9999 -9999 -9999 -9999 -9999 -9999 -9999 -999 -9999 -9999 -9999 -9999 -9999 -9999 -9999 -9999 -9999 -9999 -9999 -9999 -9999 -9999 -9999 -9999 -9999 -9999-9999-9999-9999

-9999 -9999 -9999 -9999 -9999 -9999 -9999 -9999 -9999 -9999 -9999 -9999 -9999 -9999 -9999 -9999 -9999 -9999 -9999 -9999 -9999 -9999 -9999 -9999 -9999 -9999 -9999 -9999 -9999 -9999

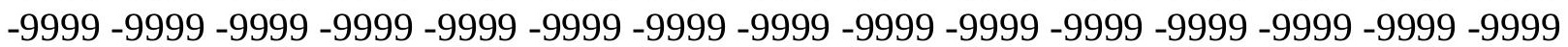


-9999 -9999 -9999 -9999 -9999 -9999 -9999 -9999 -9999 -9999 -9999 -9999 -9999 -9999 -9999 -9999 -9999 -9999 -9999 -9999 -9999 -9999 -9999 -9999 -9999 -9999 -9999 -9999 -9999 -9999 -9999 -9999 -9999 -9999 -9999 -9999 -9999 -9999 -9999 -9999 -9999 -9999 -9999 -9999 -9999 -9999 -9999 -9999 -9999 -9999 -9999 -9999 -9999 -9999 -9999 -9999 -9999 -9999 -9999 -9999 -9999 -9999 -9999 -9999 -9999 -9999 -9999 -9999 -9999 -9999 -9999 -9999 -9999 -9999 -9999 -9999 -9999 -9999 -9999 -9999 -9999 -9999 -9999 -9999 -9999 -9999 -9999 -9999 -9999 -9999 -9999 -9999 -9999 -9999 -9999 -9999 -9999 -9999 -9999 -9999 -9999 -9999 -9999 -9999 4.876562118534 .5717768669134 .2669920921333 .9622070789343 .657422065735 3.35263609886219 .81102943423 .0478510856632 .7430660724642 .743066072464 2.7430660724642 .4382810592652 .4382810592652 .4382810592652 .438281059265 2.4382810592652 .4382810592652 .4382810592652 .4382810592652 .438281059265 2.7430660724642 .7430660724643 .0478510856633 .0478510856633 .352636098862 3.6574220657353 .6574220657353 .9622070789344 .2669920921334 .571776866913 4.5717768669134 .876562118535 .1813468933115 .4861321449285 .790916919708 6.4004869461066 .7052731513987 .0100579261787 .6196279525767 .924413204193 8.5339832305918 .8387689590459 .448339462289 .75312423706110 .36268997192 10.6674804687511 .2770500183111 .58183002472 -9999 -9999-9999 -9999 -9999 -9999-9999 -9999 -9999 -9999 -9999 -9999 -9999 -9999 -9999 -9999 -9999 -9999 -9999 -9999 -9999 -9999 -9999 -9999 -9999 -9999 -9999 -9999 -9999 -9999 -9999 -9999 -9999 -9999 -9999 -9999 -9999 -9999 -9999 -9999 -9999 -9999 -9999 -9999 -9999 -9999 -9999 -9999 -9999 -9999 -9999 -9999

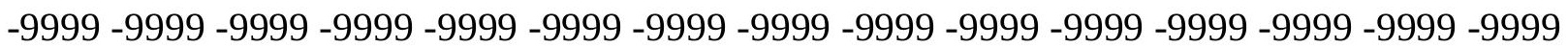
-9999 -9999 -9999 -9999 -9999 -9999 -9999 -9999 -9999 -9999 -9999 -9999 -9999 -9999 -9999 -9999 -9999 -9999 -9999 -9999 -9999 -9999 -9999 -9999 -9999 -9999 -9999 -9999 -9999 -9999 -9999 -9999 -9999 -9999 -9999 -9999 -9999 -9999 -9999 -9999 -9999 -9999 -9999 -9999 -9999

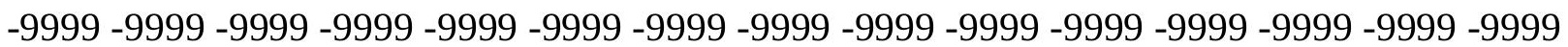
-9999 -9999 -9999 -9999 -9999 -9999 -9999 -9999 -9999 -9999 -9999 -9999 -9999 -9999 -9999 -9999 -9999 -9999 -9999 -9999 -9999 -9999 -9999 -9999 -9999 -9999 -9999 -9999 -9999 -9999 -9999 -9999 -9999 -9999 -9999 -9999 -9999 -9999 -9999 -9999 -9999 -9999 -9999 -9999 -9999

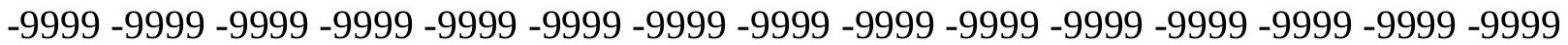
-9999 -9999 -9999 -9999-9999 -9999 -9999 -9999 -9999 -9999 -9999 -9999 -9999 -9999 -9999 -9999 -9999 -9999 -9999 -9999 -9999 -9999 -9999 -9999 -9999 -9999 -9999 -9999 -9999 -9999 -9999 -9999 -9999 -9999 -9999 -9999 -9999 -9999 -9999 -9999 -9999 -9999 -9999 -9999 -9999 -9999 -9999 -9999 -9999 -9999 -9999 -9999 -9999 -9999 -9999 -9999 -9999 -9999 -9999 -9999 -9999 -9999 -9999 -9999 -9999 -9999 -9999 -9999 -9999 -9999 -9999 -9999 -9999 -9999 -9999 -9999 -9999 -9999 -9999 -9999 -9999 -9999 -9999 -9999 -9999 -9999 -9999 -9999 -9999 -9999 -9999 -9999 -9999 -9999 -9999 -9999 -9999 -9999 -9999 -9999 -9999 -9999 -9999 -9999 -9999 -9999 -9999 -9999 -9999 -9999

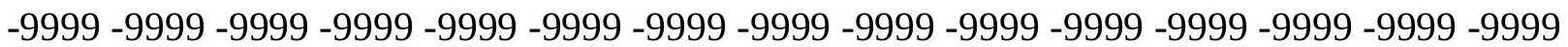
-9999 -9999 -9999 -9999 -9999 -9999 -9999 -9999 -9999 -9999 -9999 -9999 -9999 -9999 -9999 -9999 -9999 -9999 -9999 -9999 -9999 -9999 -9999 -9999 -9999 -9999 3.352636098862 3.0478510856632 .4382810592652 .1334960460662 .1334960460662 .133496046066 2.1334960460661 .8287110328671 .8287110328671 .5239260196691 .523926019669 1.5239260196691 .5239260196691 .5239260196691 .5239260196691 .21914100647 1.219141006471 .219141006471 .219141006471 .219141006471 .219141006471 .21914100647 1.219141006471 .219141006471 .5239260196691 .8287110328671 .828711032867 2.1334960460662 .1334960460662 .4382810592652 .7430660724643 .047851085663 
3.0478510856633 .3526360988623 .6574220657353 .9622070789344 .571776866913 4.876562118535 .1813468933115 .4861321449286 .0957031256 .400486946106 7.0100579261787 .3148431777957 .9244132041938 .2291984558118 .838768959045 9.1435537338269 .75312423706110 .3626899719210 .6674804687511 .27705001831 11.8866195678712 .49619007111 -9999 -9999 -9999 -9999 -9999 -9999 -9999 -9999 -9999 -9999 -9999 -9999 -9999 -9999 -9999 -9999 -9999 -9999 -9999 -9999 -9999 -9999 -9999 -9999 -9999 -9999 -9999 -9999 -9999 -9999 -9999 -9999 -9999 -9999 -9999 -9999 -9999 -9999 -9999

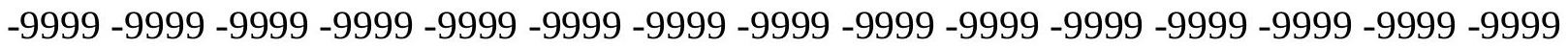
-9999 -9999 -9999 -9999 -9999 -9999 -9999 -9999 -9999 -9999 -9999 -9999 -9999 -9999 -9999 -9999 -9999 -9999 -9999 -9999 -9999 -9999 -9999 -9999 -9999 -9999 -9999 -9999 -9999 -9999 -

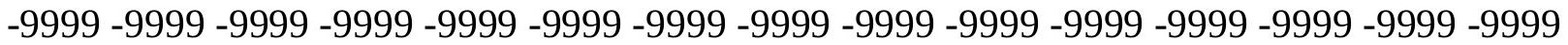
-9999 -9999 -9999 -9999 -9999 -9999 -9999 -9999 -9999 -9999 -9999 -9999 -9999 -9999 -9999 -9999 -9999 -9999 -9999 -9999 -9999 -9999 -9999 -9999 -9999 -9999 -9999 -9999 -9999 -9999 -9999 -9999 -9999 -9999 -9999 -9999 -9999 -9999 -9999 -9999 -9999 -9999 -9999 -9999 -9999 -9999 -9999 -9999 -9999 -9999 -9999 -9999 -9999 -9999 -9999 -9999 -9999 -9999 -9999 -9999

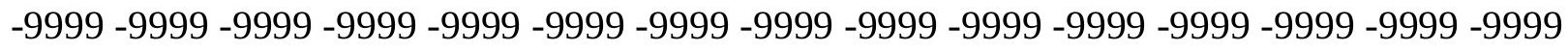
-9999 -9999 -9999 -9999 -9999 -9999 -9999 -9999 -9999 -9999 -9999 -9999 -9999 -9999 -9999 -9999 -9999 -9999 -9999 -9999 -9999 -9999 -9999 -9999 -9999 -9999 -9999 -9999 -9999 -9999 -

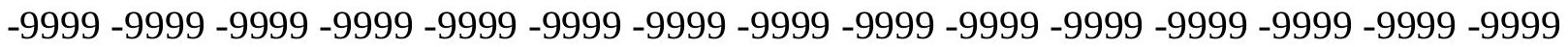

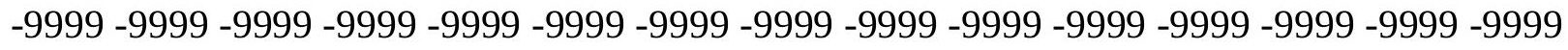

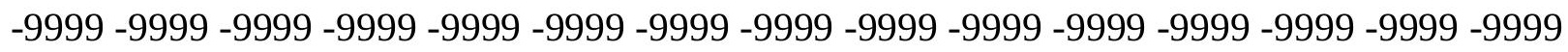
-9999 -9999 -9999 -9999 -9999 -9999 -9999 -9999 -9999 -9999 -9999 -9999 -9999 -9999 -9999 -9999 -9999 -9999 -9999 -9999 -9999 -9999 -9999 -9999 -9999 -9999 -9999 -9999 -9999 -9999 -

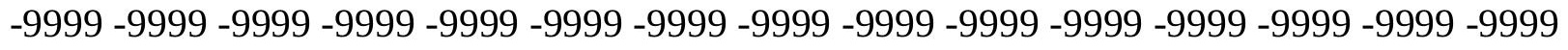
-9999 -9999 -9999 -9999 -9999 -9999 -9999 -9999 -9999 -9999 -9999 -9999 -9999 -9999 -9999 -9999 -9999 -9999 -9999 -9999 -9999 -9999 -9999 -9999 -9999 -9999 -9999 -9999 -9999 -9999 -9999 -9999 -9999 -9999 -9999 -9999 -9999 -9999 -9999 2.133496046066 1.523926019669 1.21914100647.6095703244209.3047851026058 3047851026058.3047851026058 3047851026058.3047851026058 3047851026058 -9999 -9999 -9999 -9999 -9999 -9999 .3047851026058 -9999 -9999 -9999 -9999 -9999 -9999 -9999 -9999.3047851026058 3047851026058.6095703244209.6095703244209.9143553972244.9143553972244 1.219141006471 .5239260196691 .8287110328671 .8287110328672 .133496046066 2.4382810592653 .0478510856633 .3526360988623 .6574220657353 .962207078934 4.5717768669134 .876562118535 .1813468933115 .7909169197086 .400486946106 6.7052731513987 .3148431777957 .9244132041938 .2291984558118 .838768959045 9.448339462289 .75312423706110 .3626899719210 .9722604751611 .58183002472 11.8866195678712 .49619007111 -9999 -9999 -9999 -9999 -9999 -9999 -9999 -9999 -9999

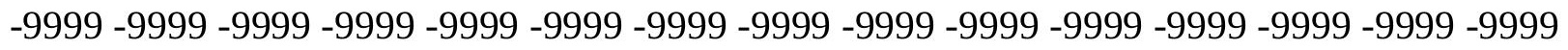
-9999 -9999 -9999 -9999 -9999 -9999 -9999 -9999 -9999 -9999 -9999 -9999 -9999 -9999 -9999 -9999 -9999 -9999 -9999 -9999 -9999 -9999 -9999 -9999 -9999 -9999 -9999 -9999 -9999 -9999 -

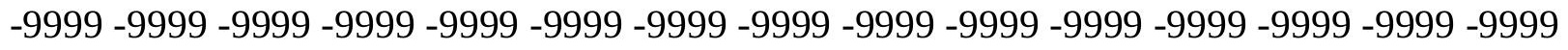

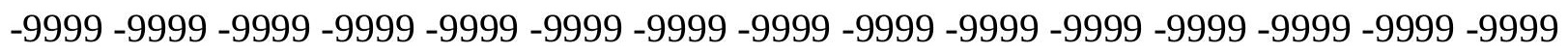

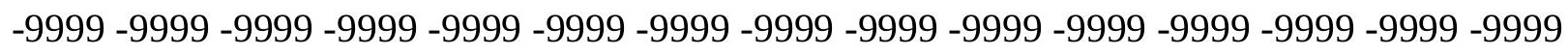
-9999 -9999 -9999 -9999 -9999 -9999 -9999 -9999 -9999 -9999 -9999 -9999 -9999 -9999 -9999 -9999 -9999 -9999 -9999 -9999 -9999 -9999 -9999 -9999 -9999 -9999 -9999 -9999 -9999 -9999 -

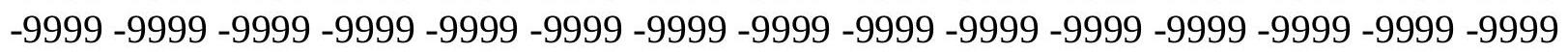


-9999 -9999 -9999 -9999 -9999 -9999 -9999 -9999 -9999 -9999 -9999 -9999 -9999 -9999 -9999 -9999 -9999 -9999 -9999 -9999 -9999 -9999 -9999 -9999 -9999 -9999 -9999 -9999 -9999 -9999 -9999 -9999 -9999 -9999 -9999 -9999 -9999 -9999 -9999 -9999 -9999 -9999 -9999

-9999 -9999 -9999 -9999 -9999 -9999 -9999 -9999 -9999 -9999 -9999 -9999 -9999 -9999 -9999 -9999 -9999 -9999 -9999 -9999 -9999 -9999 -9999 -9999 -9999 -9999 -9999 -9999 -9999 -9999 -9999 -9999 -9999 -9999 -9999 -9999 -9999 -9999 -9999 -9999 -9999 -9999 -9999 -9999 -9999 -9999 -9999 -9999 -9999 -9999 -9999 -9999 -9999 -9999 -9999 -9999 -9999 -9999 -9999 -9999

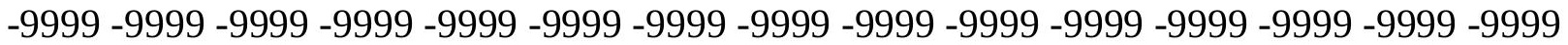
-9999 -9999 -9999 -9999 -9999 -9999 -9999 -9999 -9999 -9999 -9999 -9999 -9999 -9999 -9999 -9999 -9999 -9999 -9999 -9999 -9999 -9999 -9999 -9999 -9999 -9999 -9999 -9999 -9999 -9999 -9999 -9999 -9999 -9999 -9999 -9999 -9999 -9999 -9999 -9999 -9999 -9999 -9999 -9999 -9999 -9999 -9999 -9999 -9999 -9999 -9999 -9999 -9999 -9999 -9999 -9999 -9999 -9999 -9999 -9999 -9999-9999 -9999 -9999-9999-9999.9143553972244.6095703244209. 3047851026058-9999 -.304785102606 -.609570324421 -.609570324421 -.914355397224 -.914355397224 $-.914355397224-.914355397224-.914355397224-.914355397224-1.21914100647$ $-1.21914100647-1.21914100647-1.21914100647-1.21914100647-.914355397224$ $-.914355397224-.914355397224-.914355397224-.914355397224-.914355397224$ -.914355397224 -.914355397224 -.914355397224 -.914355397224 -.609570324421 -.609570324421 -.304785102606 -.304785102606 -9999 -9999 -9999 .3047851026058 .6095703244209.6095703244209.9143553972244 1.5239260196691 .828711032867 2.1334960460662 .4382810592652 .7430660724643 .3526360988623 .657422065735 4.2669920921334 .5717768669135 .1813468933115 .7909169197086 .400486946106 6.7052731513987 .3148431777957 .9244132041938 .5339832305919 .143553733826 9.4483394622810 .0579099655210 .6674804687511 .2770500183111 .58183002472 12.191410064712 .80097007751 -9999 -9999 -9999 -9999 -9999 -9999 -9999 -9999 -9999 -9999 -9999 -9999 -9999 -9999 -9999 -9999 -9999 -9999 -9999 -9999 -9999 -9999 -9999 -9999 -9999 -9999 -9999 -9999 -9999 -9999 -9999 -9999 -9999 -9999 -9999 -9999 -9999 -9999 -9999 -9999 -9999 -9999 -9999 -9999 -9999 -9999 -9999 -9999 -9999 -9999 -9999 -9999 -9999 -9999 -9999 -9999 -9999 -9999 -9999 -9999 -9999 -9999 -9999 -9999 -9999 -9999 -9999 -9999 -9999

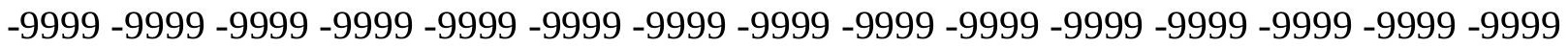
-9999 -9999 -9999 -9999 -9999 -9999 -9999 -9999 -9999 -9999 -9999 -9999 -9999 -9999 -9999 -

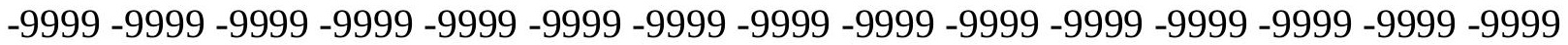
-9999 -9999 -9999 -9999 -9999 -9999 -9999 -9999 -9999 -9999 -9999 -9999 -9999 -9999 -9999 -9999 -9999 -9999 -9999 -9999 -9999 -9999 -9999 -9999 -9999 -9999 -9999 -9999 -9999 -9999 -

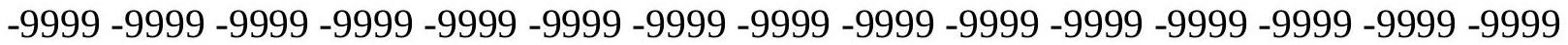
-9999 -9999 -9999 -9999 -9999 -9999 -9999 -9999 -9999 -9999 -9999 -9999 -9999 -9999 -9999 -9999 -9999 -9999 -9999 -9999 -9999 -9999 -9999 -9999 -9999 -9999

-9999 -9999 -9999 -9999 -9999 -9999 -9999 -9999 -9999 -9999 -9999 -9999 -9999 -9999 -9999 -9999 -9999 -9999 -9999 -9999 -9999 -9999 -9999 -9999 -9999 -9999 -9999 -9999 -9999 -9999 -9999 -9999 -9999 -9999 -9999 -9999 -9999 -9999 -9999 -9999 -9999 -9999 -9999 -9999 -9999 -9999 -9999 -9999 -9999 -9999 -9999 -9999 -9999 -9999 -9999 -9999 -9999 -9999 -9999 -9999 -9999 -9999 -9999 -9999 -9999 -9999 -9999 -9999 -9999 -9999 -9999 -9999 -9999 -9999 -9999 -9999 -9999 -9999 -9999 -9999 -9999 -9999 -9999 -9999 -9999 -9999 -9999 -9999 -9999 -9999 -9999 -9999 -9999 -9999 -9999 -9999 -9999 -9999 -9999 -9999 -9999 -9999 -9999 -9999 -9999 -9999 -9999 -9999 -9999 -9999 -9999 -9999 -9999 -9999 -9999 -9999 -9999 -9999 -9999 -9999

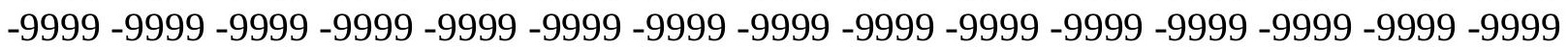


-9999 -9999 -9999 -9999 -9999 -.304785102606 -.914355397224 -1.21914100647 -1.52392601967 -1.82871103287 -1.82871103287 -2.13349604607 -2.13349604607 $-2.13349604607-2.43828105927-2.43828105927-2.43828105927-2.43828105927$ $-2.43828105927-2.74306607246-2.74306607246-2.74306607246-2.74306607246$ $-2.43828105927-2.43828105927-2.43828105927-2.43828105927-2.13349604607$ $-2.13349604607-2.13349604607-2.13349604607-2.13349604607-2.13349604607$ -1.82871103287 -1.82871103287 -1.52392601967 -1.52392601967 -1.21914100647 $-1.21914100647-.914355397224-.914355397224-.609570324421-.304785102606-9999$ -9999.3047851026058.6095703244209.9143553972244 1.21914100647 1.828711032867 2.1334960460662 .4382810592653 .0478510856633 .6574220657353 .962207078934 4.5717768669135 .1813468933115 .7909169197086 .4004869461067 .010057926178 7.6196279525768 .2291984558118 .8387689590459 .1435537338269 .753124237061 10.3626899719210 .9722604751611 .5818300247212 .191410064712 .49619007111 13.10575962067 -9999 -9999 -9999 -9999 -9999 -9999 -9999 -9999 -9999 -9999 -9999 -9999 -9999 -9999 -9999 -9999 -9999 -9999 -9999 -9999 -9999 -9999 -9999 -9999 -9999 -9999 -9999

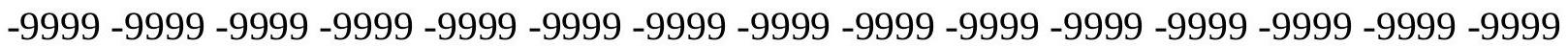
-9999 -9999 -9999 -9999 -9999 -9999 -9999 -9999 -9999 -9999 -9999 -9999 -9999 -9999 -9999 -9999 -9999 -9999 -9999 -9999 -9999 -9999 -9999 -9999 -9999 -9999 -9999 -9999 -9999 -9999 -9999 -9999 -9999 -9999 -9999 -9999 -9999 -9999 -9999 -9999 -9999 -9999 -9999 -9999 -9999 -9999 -9999 -9999 -9999 -9999 -9999 -9999 -9999 -9999 -9999 -9999 -9999 -9999 -9999 -9999

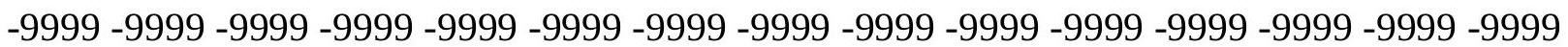
-9999 -9999 -9999 -9999 -9999 -9999 -9999 -9999 -9999 -9999 -9999 -9999 -9999 -9999 -9999 -9999 -9999 -9999 -9999 -9999 -9999 -9999 -9999 -9999 -9999 -9999 -9999 -9999 -9999 -9999 -9999 -9999 -9999 -9999 -9999 -9999 -9999 -9999 -9999 -9999 -9999 -9999 -9999 -9999 -9999

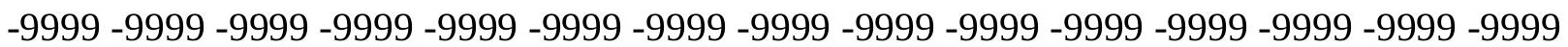
-9999 -9999 -9999 -9999-9999-9999 -9999 -9999 -9999 -9999 -9999 -9999 -9999 -9999 -9999 -9999 -9999 -9999 -9999 -9999 -9999 -9999 -9999 -9999 -9999 -9999 -9999 -9999 -9999 -9999 -9999 -9999 -9999 -9999 -9999 -9999 -9999 -9999 -9999 -9999 -9999 -9999 -9999 -9999 -9999 -9999 -9999 -9999 -9999 -9999 -9999

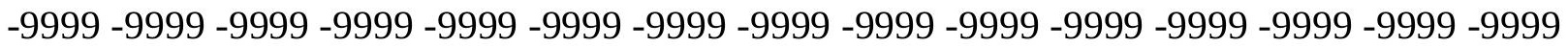
-9999 -9999 -9999 -9999 -9999 -9999 -9999 -9999 -9999 -9999 -9999 -9999 -9999 -9999 -9999 -

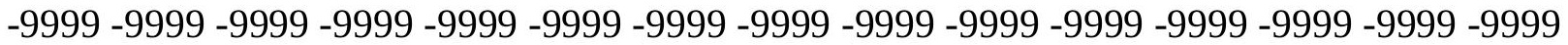
-9999 -9999 -9999 -9999 -9999 -9999 -9999 -9999 -9999 -9999 -9999 -9999 -9999 -9999 -9999 -9999 -9999 -9999 -9999 -9999 -9999 -9999 -9999 -9999 -9999 -9999 -9999 -9999 -9999 -9999 -9999 -9999 -9999 -9999 -9999 -9999 -9999 -9999 -9999 -9999 -9999 -9999 -9999 -9999 -9999 -9999 -9999 -1.21914100647 - $1.52392601967-2.13349604607-2.43828105927$ $-2.74306607246-3.04785108566-3.04785108566-3.35263609886-3.35263609886$ $-3.65742206573-3.65742206573-3.65742206573-3.96220707893-3.96220707893$ -3.96220707893 -3.96220707893 -3.96220707893 -4.26699209213 -4.26699209213 $-4.26699209213-4.26699209213-3.96220707893-3.96220707893-3.96220707893$ $-3.65742206573-3.65742206573-3.65742206573-3.35263609886-3.35263609886$ $-3.35263609886-3.04785108566-3.04785108566-2.74306607246-2.43828105927$ $-2.43828105927-2.43828105927-2.13349604607-2.13349604607-1.82871103287$ $-1.82871103287-1.52392601967-1.21914100647-.914355397224-.609570324421$ -304785102606 -9999. 3047851026058.6095703244209.9143553972244 1.523926019669 1.8287110328672 .4382810592653 .0478510856633 .6574220657354 .266992092133 
4.876562118535 .4861321449286 .0957031256 .7052731513987 .314843177795 7.9244132041938 .5339832305919 .1435537338269 .75312423706110 .05790996552 $10.6674804687511 .2770500183111 .8866195678712 .4961900711113 .10575962067-9999$ -9999 -9999 -9999 -9999 -9999 -9999 -9999 -9999 -9999 -9999 -9999 -9999 -9999 -9999 -9999 -9999 -9999 -9999 -9999 -9999 -9999 -9999 -9999 -9999-9999 -9999 -9999 -9999 -9999 -9999 -9999 -9999 -9999 -9999 -9999 -9999 -9999 -9999 -9999 -9999 -9999 -9999 -9999 -9999 -9999 -9999 -9999 -9999 -9999 -9999 -9999 -9999 -9999 -9999 -9999 -9999 -9999 -9999 -9999 -9999 -

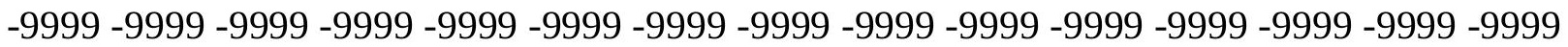

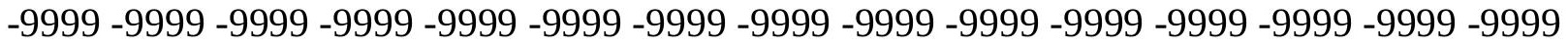
-9999 -9999 -9999 -9999 -9999 -9999 -9999 -9999 -9999 -9999 -9999 -9999 -9999 -9999 -9999

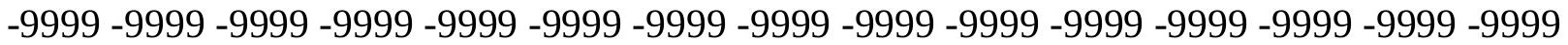
-9999 -9999 -9999 -9999 -9999 -9999 -9999 -9999 -9999 -9999 -9999 -9999 -9999 -9999 -9999 -9999 -9999 -9999 -9999 -9999 -9999 -9999 -9999 -9999 -9999 -9999 -9999 -9999 -9999 -9999 -

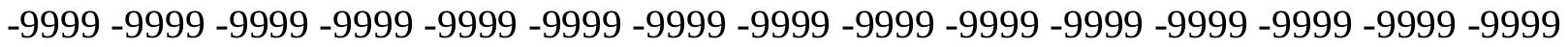
-9999 -9999 -9999 -9999 -9999 -9999 -9999 -9999 -9999 -9999 -9999 -9999 -9999 -9999 -9999 $-9999$

-9999 -9999 -9999 -9999 -9999 -9999 -9999 -9999 -9999 -9999 -9999 -9999 -9999 -9999 -9999 -9999 -9999 -9999 -9999 -9999 -9999 -9999 -9999 -9999 -9999 -9999 -9999 -9999 -9999 -9999 -9999 -9999 -9999 -9999 -9999 -9999 -9999 -9999 -9999 -9999 -9999 -9999 -9999 -9999 -9999 -

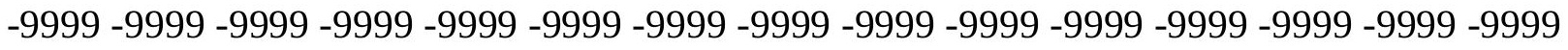
-9999 -9999 -9999 -9999 -9999 -9999 -9999 -9999 -9999 -9999 -9999 -9999 -9999 -9999 -9999 -999 -9999 -9999 -9999 -9999 -9999 -9999 -9999 -9999 -9999 -9999 -9999 -9999 -9999 -9999 -9999 -9999 -9999 -9999 -9999 -9999 -9999 -9999 -9999 -9999 -9999 -9999 -9999 -9999 -9999 -9999 -9999 -9999 -9999 -9999 -9999 -9999 -9999 -9999 -9999 -9999 -9999 -9999 -9999 -9999 -9999 -

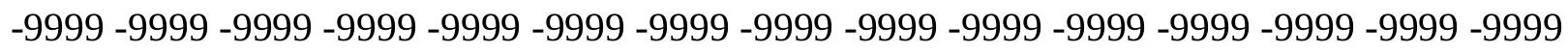
$-2.13349604607-2.43828105927-3.04785108566-3.35263609886-3.65742206573$ -3.96220707893 -4.26699209213-4.57177686691 -4.57177686691-4.87656211853 $-4.87656211853-5.18134689331-5.18134689331-5.48613214493-5.48613214493$ $-5.48613214493-5.48613214493-5.48613214493-5.79091691971-5.79091691971$ $-5.79091691971-5.79091691971-5.79091691971-5.48613214493-5.48613214493$ $-5.48613214493-5.18134689331-5.18134689331-4.87656211853-4.87656211853$ $-4.57177686691-4.26699209213-4.26699209213-3.96220707893-3.65742206573$ $-3.65742206573-3.35263609886-3.35263609886-3.35263609886-3.04785108566$ $-3.04785108566-2.74306607246-2.74306607246-2.43828105927-2.13349604607$ -1.82871103287 - $1.52392601967-.914355397224-.609570324421-.304785102606-9999$ .3047851026058.6095703244209 1.21914100647 1.828711032867 2.438281059265 3.3526360988623 .9622070789344 .5717768669135 .1813468933115 .790916919708 6.4004869461067 .0100579261787 .6196279525768 .2291984558118 .838768959045 9.4483394622810 .0579099655210 .6674804687510 .9722604751611 .58183002472 12.191410064712 .8009700775113 .41055011749 -9999 -9999 -9999 -9999 -9999 -9999 -9999 -9999 -9999 -9999 -9999 -9999 -9999 -9999 -9999 -9999 -9999 -9999 -9999 -9999 -9999 -9999 -

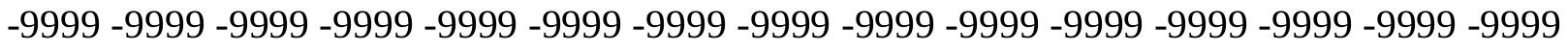
-9999 -9999 -9999 -9999 -9999 -9999 -9999 -9999 -9999 -9999 -9999 -9999 -9999 -9999 -9999 -9999 -9999 -9999 -9999 -9999 -9999 -9999 -9999 -9999-9999 -9999 -9999 -9999 -9999 -9999 -9999 -9999 -9999 -9999 -9999 -9999 -9999 -9999 -9999 -9999 -9999 -9999 -9999 -9999 -9999 -

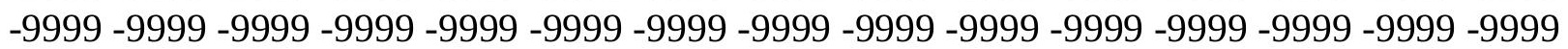


-9999 -9999 -9999 -9999 -9999 -9999 -9999 -9999 -9999 -9999 -9999 -9999 -9999 -9999 -9999 -9999 -9999 -9999 -9999 -9999 -9999 -9999 -9999 -9999 -9999 -9999 -9999 -9999 -9999 -9999 -9999 -9999 -9999 -9999 -9999 -9999 -9999 -9999 -9999 -9999 -9999 -9999 -9999 -9999 -9999 -9999 -9999 -9999 -9999 -9999 -9999 -9999 -9999 -9999 -9999 -9999 -9999 -9999 -9999 -9999

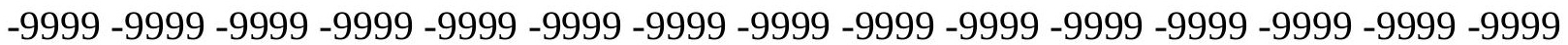
-9999 -9999 -9999 -9999 -9999 -9999 -9999 -9999

-9999 -9999 -9999 -9999 -9999 -9999 -9999 -9999 -9999 -9999 -9999 -9999 -9999 -9999 -9999

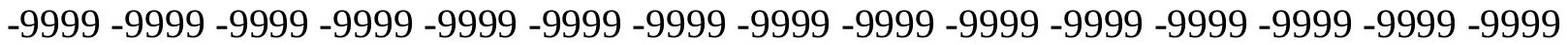

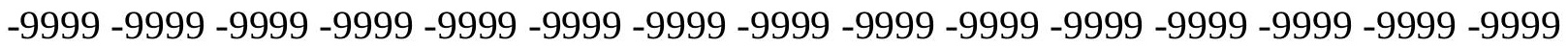
-9999 -9999 -9999 -9999 -9999 -9999 -9999 -9999 -9999 -9999 -9999 -9999 -9999 -9999 -9999 -

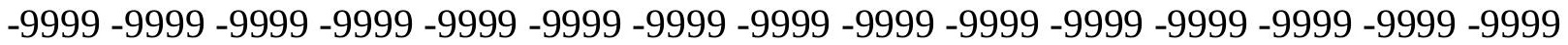
-9999 -9999 -9999 -9999 -9999 -9999 -9999 -9999 -9999 -9999 -9999 -9999 -9999 -9999 -9999

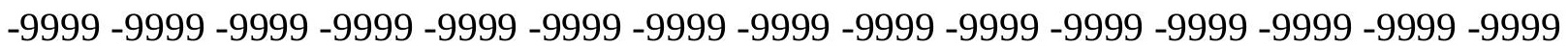
-9999 -9999 -9999 -9999 -9999 -9999 -9999 -9999 -9999 -9999 -9999 -9999 -9999 -9999 -9999 -9999 -9999 -9999 -9999 -9999 -9999 -9999 -9999 -9999 -9999 -9999 -9999 -9999 -9999 -3.35263609886 -3.96220707893 -4.26699209213 -4.87656211853 -5.18134689331 $-5.48613214493-5.48613214493-5.79091691971-6.095703125-6.095703125-6.40048694611$ $-6.7052731514-6.7052731514-6.7052731514-7.01005792618-7.01005792618$ $-7.01005792618-7.3148431778-7.3148431778-7.3148431778-7.3148431778-7.3148431778$ $-7.3148431778-7.3148431778-7.01005792618-7.01005792618-7.01005792618$ $-6.7052731514-6.7052731514-6.40048694611-6.095703125-5.79091691971-5.48613214493$ $-5.18134689331-4.87656211853-4.87656211853-4.57177686691-4.57177686691$ $-4.26699209213-4.26699209213-4.26699209213-4.26699209213-3.96220707893$ $-3.96220707893-3.65742206573-3.35263609886-3.04785108566-2.43828105927$ $-2.13349604607-1.82871103287-1.21914100647-.914355397224-.609570324421-9999$ -9999 9143553972244 1.523926019669 2.438281059265 3.047851085663 3.657422065735 4.2669920921334 .876562118535 .4861321449286 .0957031256 .705273151398 7.6196279525768 .2291984558118 .8387689590459 .4483394622810 .05790996552 10.3626899719210 .9722604751611 .5818300247211 .8866195678712 .49619007111 13.41055011749 -9999 -9999 -9999 -9999 -9999 -9999 -9999 -9999 -9999 -9999 -9999 -9999 -9999 -9999 -9999 -9999 -9999 -9999 -9999 -9999 -9999 -9999 -9999 -9999 -9999 -9999 -9999

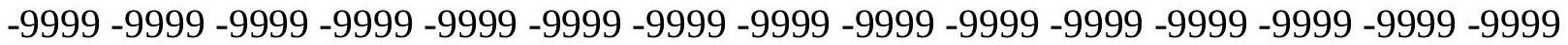
-9999 -9999 -9999 -9999 -9999 -9999 -9999 -9999 -9999 -9999 -9999 -9999 -9999 -9999 -9999 -9999 -9999 -9999 -9999 -9999 -9999 -9999 -9999 -9999 -9999 -9999 -9999 -9999 -9999 -9999 -

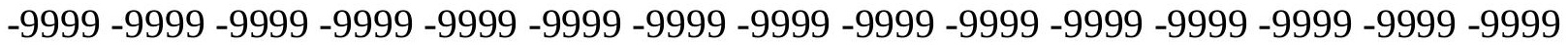
-9999 -9999 -9999 -9999 -9999 -9999 -9999 -9999 -9999 -9999 -9999 -9999 -9999 -9999 -9999 -9999 -9999 -9999 -9999 -9999 -9999 -9999 -9999 -9999 -9999 -9999 -9999 -9999 -9999 -9999

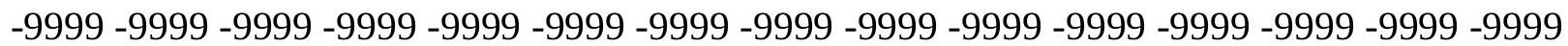
-9999 -9999 -9999 -9999 -9999 -9999 -9999 -9999 -9999 -9999 -9999 -9999 -9999 -9999 -9999 -9999 -9999 -9999 -9999 -9999 -9999 -9999 -9999 -9999 -9999 -9999 -9999 -9999 -9999 -9999 -

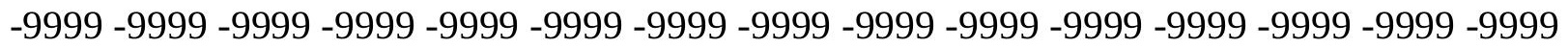
$-9999-9999$

-9999 -9999 -9999 -9999 -9999 -9999 -9999 -9999 -9999 -9999 -9999 -9999 -9999 -9999 -9999 -9999 -9999 -9999 -9999 -9999 -9999 -9999 -9999 -9999 -9999 -9999 -9999 -9999 -9999 -9999 -9999 -9999 -9999 -9999 -9999 -9999 -9999 -9999 -9999 -9999 -9999 -9999 -9999 -9999 -9999

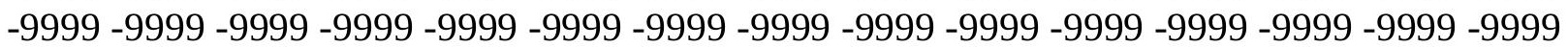


-9999 -9999 -9999 -9999 -9999 -9999 -9999 -9999 -9999 -9999 -9999 -9999 -9999 -9999 -9999 -9999 -9999 -9999 -9999 -9999 -9999 -9999 -9999 -9999 -9999 -9999 -9999 -9999 -9999 -9999 -9999 -9999 -9999 -9999 -9999 -9999 -9999 -9999 -9999 -9999 -9999 -9999 -9999 -9999 -9999 -9999 -9999 -9999 -9999 -9999 -9999 -9999 -9999 -9999 -9999 -9999 -9999 -9999 -9999 -9999 -9999 -9999 -9999 -9999 -9999 -9999 -9999 -9999 -9999 -9999 -9999 -9999 -4.26699209213 $-4.87656211853-5.18134689331-5.79091691971-6.095703125-6.40048694611$ $-6.7052731514-7.01005792618-7.3148431778-7.3148431778-7.61962795258$ $-7.92441320419-7.92441320419-8.22919845581-8.22919845581-8.53398323059$ -8.53398323059-8.53398323059-8.83876895905 -8.83876895905 -8.83876895905 -8.83876895905 -8.83876895905 -8.83876895905 -8.83876895905 -8.83876895905 $-8.83876895905-8.53398323059-8.53398323059-8.22919845581$-7.92441320419 $-7.92441320419-7.61962795258-7.01005792618-6.7052731514-6.40048694611$ $-6.095703125-5.79091691971-5.48613214493-5.48613214493-5.48613214493$ $-5.48613214493-5.48613214493-5.18134689331-5.18134689331-4.87656211853$ $-4.87656211853-4.26699209213-3.96220707893-3.65742206573-3.35263609886$ $-2.74306607246-2.43828105927-1.82871103287-1.52392601967-.914355397224$ -.609570324421 -9999.6095703244209 1.523926019669 2.133496046066 2.743066072464 3.3526360988623 .9622070789344 .5717768669135 .4861321449286 .095703125 6.7052731513987 .3148431777957 .9244132041938 .8387689590459 .44833946228 10.0579099655210 .3626899719210 .9722604751611 .5818300247211 .88661956787 12.4961900711113 .1057596206713 .7153301239 -9999 -9999 -9999 -9999 -9999 -9999 -9999 -9999 -9999 -9999 -9999 -9999 -9999 -9999 -9999 -9999 -9999 -9999 -9999 -9999 -9999 -9999 -9999 -9999 -9999 -9999 -9999 -9999 -9999 -9999 -9999 -9999 -9999 -9999 -9999 -9999 -9999 -9999 -9999 -9999 -9999 -9999 -9999 -9999 -9999 -9999 -9999 -9999 -9999 -9999 -9999 -9999

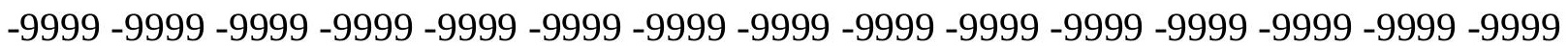
-9999 -9999 -9999 -9999 -9999 -9999 -9999 -9999 -9999 -9999 -9999 -9999 -9999 -9999 -9999 -9999 -9999 -9999 -9999 -9999 -9999 -9999 -9999 -9999 -9999 -9999 -9999 -9999 -9999 -9999 -9999 -9999 -9999 -9999 -9999 -9999 -9999 -9999 -9999 -9999 -9999 -9999 -9999 -9999 -9999 -9999 -9999 -9999 -9999 -9999 -9999 -9999 -9999 -9999 -9999 -9999 -9999 -9999 -9999 -9999

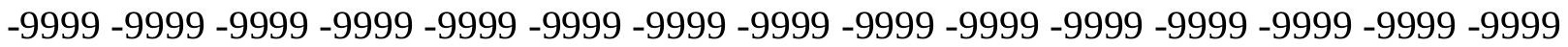
-9999 -9999 -9999 -9999 -9999 -9999 -9999 -9999 -9999 -9999 -9999 -9999 -9999 -9999 -9999 -

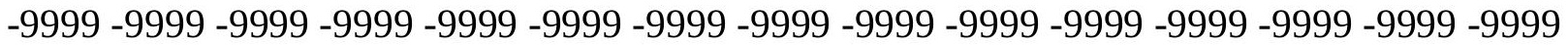
-9999 -9999-9999-9999-9999

-9999 -9999 -9999 -9999 -9999 -9999 -9999 -9999 -9999 -9999 -9999 -9999 -9999 -9999 -9999

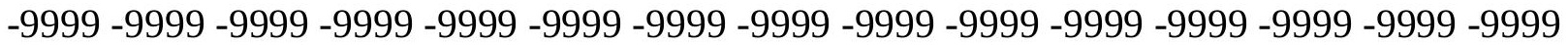
-9999 -9999 -9999 -9999 -9999 -9999 -9999 -9999 -9999 -9999 -9999 -9999 -9999 -9999 -9999 -9999 -9999 -9999 -9999 -9999 -9999 -9999 -9999 -9999 -9999 -9999 -9999 -9999 -9999 -9999

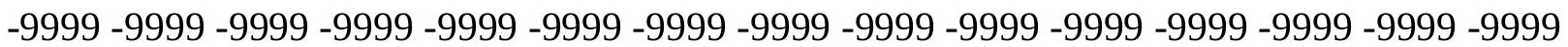
-9999 -9999 -9999 -9999 -9999 -9999 -9999 -9999 -9999 -9999 -9999 -9999 -9999 -9999 -9999 -9999 -9999 -9999 -9999 -9999 -9999 -9999 -9999 -9999 -9999 -9999 -9999 -9999 -9999 -9999 -9999 -9999 -9999 -9999 -9999 -9999 -9999 -9999 -9999 -9999 -9999 -9999 -9999 -9999 -9999 -9999 -9999 -9999 -9999 -9999 -9999 -9999 -9999 -9999 -9999 -9999 -5.79091691971 -6.095703125 -6.7052731514 -7.01005792618 -7.3148431778 -7.61962795258 -7.92441320419 $-8.22919845581-8.53398323059-8.83876895905-9.14355373383-9.14355373383$ $-9.44833946228-9.75312423706-9.753124237066 .4004869461066 .400486946106$ $6.4004869461066 .0957031256 .095703125-10.3626899719-10.3626899719-10.3626899719$ 
-10.3626899719 -10.3626899719-10.3626899719-10.3626899719-10.3626899719 $-10.0579099655-10.0579099655-9.75312423706-9.44833946228-9.14355373383$ $-8.83876895905-8.53398323059-7.92441320419-7.61962795258-7.01005792618$ $-6.7052731514-6.40048694611-6.40048694611-6.40048694611-6.40048694611$ $-6.40048694611-6.40048694611-6.40048694611-6.095703125-5.79091691971$ $-5.48613214493-5.18134689331-4.87656211853-4.26699209213-3.96220707893$ -3.35263609886 -3.04785108566 -2.43828105927-1.82871103287 -1.21914100647 -.609570324421 -9999.6095703244209 1.21914100647 1.828711032867 2.438281059265 3.3526360988623 .9622070789344 .5717768669135 .1813468933116 .095703125 6.7052731513987 .3148431777958 .2291984558118 .8387689590459 .44833946228 10.0579099655210 .6674804687510 .9722604751611 .5818300247211 .88661956787 12.191410064712 .8009700775113 .7153301239 -9999 -9999 -9999 -9999 -9999 -9999 -9999 -9999 -9999 -9999 -9999 -9999 -9999 -9999 -9999 -9999 -9999 -9999 -9999 -9999 -9999 -9999 -9999 -9999 -9999 -9999 -9999 -9999 -9999 -9999 -9999 -9999 -9999 -9999 -9999 -9999 -9999 -9999 -9999 -9999 -9999 -9999 -9999 -9999 -9999 -9999 -9999 -9999 -9999 -9999 -9999 -9999

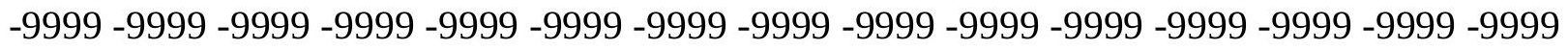
-9999 -9999 -9999 -9999 -9999 -9999 -9999 -9999 -9999 -9999 -9999 -9999 -9999 -9999 -9999 -9999 -9999 -9999 -9999 -9999 -9999 -9999 -9999 -9999 -9999 -9999 -9999 -9999 -9999 -9999 -

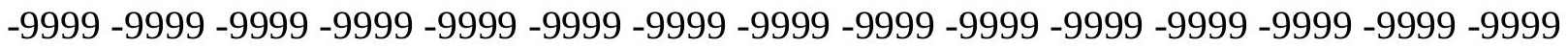

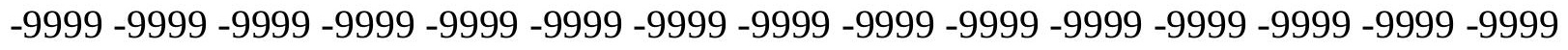

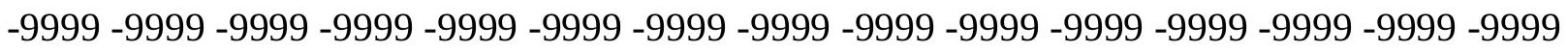
-9999 -9999 -9999 -9999 -9999 -9999 -9999 -9999 -9999 -9999 -9999 -9999 -9999 -9999 -9999 -

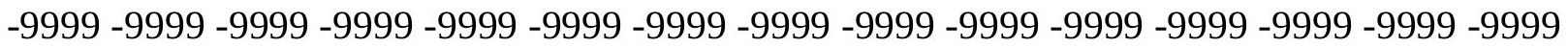
-9999 -9999 -9999-9999

-9999 -9999 -9999 -9999 -9999 -9999 -9999 -9999 -9999 -9999 -9999 -9999 -9999 -9999 -9999 -9999 -9999 -9999 -9999 -9999 -9999 -9999 -9999 -9999 -9999 -9999 -9999 -9999 -9999 -9999 -

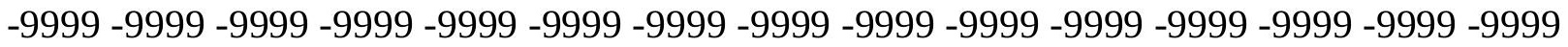

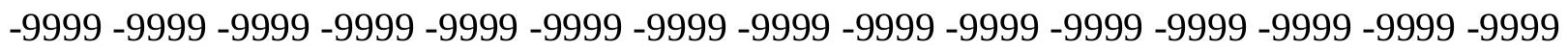
-9999 -9999 -9999 -9999 -9999 -9999 -9999 -9999 -9999 -9999 -9999 -9999 -9999 -9999 -9999 -9999 -9999 -9999 -9999 -9999 -9999 -9999 -9999 -9999 -9999 -9999 -9999 -9999 -9999 -9999 -9999 -9999 -9999 -9999 -9999 -9999 -9999 -9999 -9999-9999 -9999 -9999 -9999 -9999 -9999 -9999 -9999 -9999 -9999 -9999 -9999 -9999 -9999 -9999 -9999 -9999 -9999 -9999 -9999 -9999 -9999 -9999 -9999 -9999-9999 -9999-9999-9999 -9999-9999 -7.01005792618 $-7.61962795258-7.92441320419-8.22919845581-8.53398323059-8.83876895905$ 7.0100579261786 .7052731513986 .7052731513986 .4004869461066 .095703125 5.7909169197085 .7909169197085 .4861321449285 .4861321449285 .486132144928 5.1813468933115 .1813468933115 .1813468933115 .1813468933114 .87656211853 $4.876562118534 .876562118534 .5717768669134 .571776866913-12.1914100647$ -11.8866195679 -11.8866195679-11.8866195679 -11.8866195679-11.5818300247 $-11.2770500183-10.9722604752-10.6674804688-10.3626899719-10.0579099655$ $-9.44833946228-8.83876895905-8.22919845581-7.92441320419-7.61962795258$ $-7.3148431778-7.3148431778-7.61962795258-7.61962795258-7.92441320419$ $-7.61962795258-7.61962795258-7.01005792618-6.7052731514-6.40048694611$ $-5.79091691971-5.48613214493-4.87656211853-4.26699209213-3.96220707893$ -3.35263609886 -2.74306607246 -2.13349604607 -1.52392601967 -.609570324421 -9999 .30478510260581 .219141006471 .8287110328672 .4382810592653 .047851085663 
3.6574220657354 .5717768669135 .1813468933116 .0957031256 .705273151398 7.6196279525768 .2291984558119 .1435537338269 .75312423706110 .36268997192 10.6674804687511 .2770500183111 .5818300247211 .8866195678712 .1914100647 12.8009700775113 .41055011749 -9999 -9999 -9999 -9999 -9999 -9999 -9999 -9999 -9999 -9999 -9999 -9999 -9999 -9999 -9999 -9999 -9999 -9999 -9999 -9999 -9999 -9999 -9999 -9999 -9999 -9999 -9999 -9999 -9999 -9999 -9999 -9999 -9999 -9999 -9999 -9999 -9999 -9999 -9999

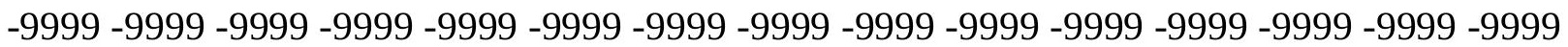

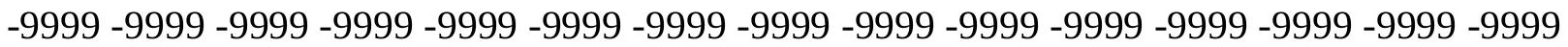
-9999 -9999 -9999 -9999 -9999 -9999 -9999 -9999 -9999 -9999 -9999 -9999 -9999 -9999 -9999 -9999 -9999 -9999 -9999 -9999 -9999 -9999 -9999 -9999 -9999 -9999 -9999 -9999 -9999 -9999 -

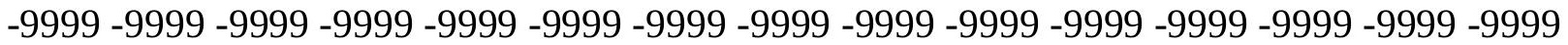
-9999 -9999 -9999 -9999 -9999 -9999 -9999 -9999 -9999 -9999 -9999 -9999 -9999 -9999 -9999 -9999 -9999 -9999 -9999 -9999 -9999 -9999 -9999 -9999 -9999 -9999 -9999 -9999 -9999 -9999 -9999 -9999 -9999 -9999 -9999 -9999 -9999 -9999 -9999 -9999 -9999 -9999 -9999 -9999 -9999 -

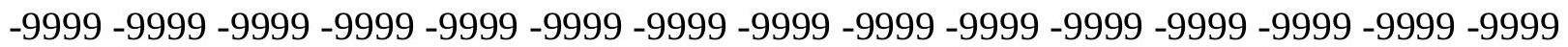
$-9999$

-9999 -9999 -9999 -9999 -9999 -9999 -9999 -9999 -9999 -9999 -9999 -9999 -9999 -9999 -9999 -9999 -9999 -9999 -9999 -9999 -9999 -9999 -9999 -9999 -9999 -9999 -9999 -9999 -9999 -9999 -999 -

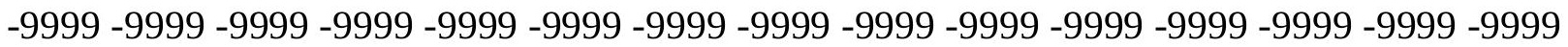

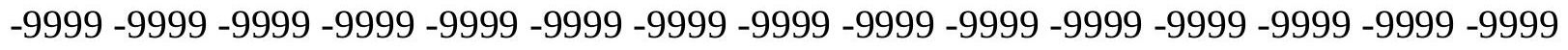

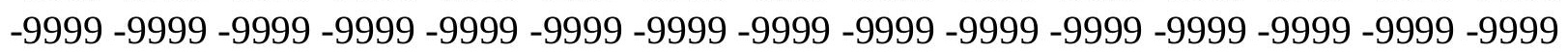

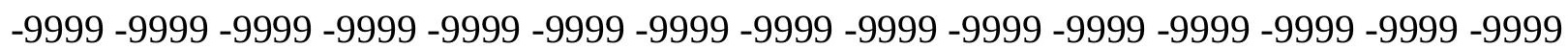
-9999 -9999 -9999 -9999 -9999 -9999 -9999 -9999 -9999 -9999 -9999 -9999 -9999 -9999 -9999 -9999 -9999 -9999 -9999 -9999 -9999 -9999 -9999 -9999 -9999 -9999 -9999 -9999 -9999 -9999 -9999-9999-9999 -9999-9999-9999-9999-9999-9999-8.53398323059-8.83876895905 $-9.143553733836 .7052731513986 .4004869461066 .0957031255 .790916919708$ 5.7909169197085 .4861321449285 .1813468933114 .876562118534 .87656211853 4.5717768669134 .5717768669134 .2669920921334 .2669920921334 .266992092133 4.2669920921333 .9622070789343 .9622070789343 .9622070789343 .962207078934 3.9622070789343 .6574220657353 .6574220657353 .3526360988623 .047851085663 $3.047851085663-13.4105501175-13.4105501175-13.4105501175-13.1057596207$ -12.8009700775 -12.8009700775 -12.1914100647 -11.8866195679 -11.5818300247 $-10.9722604752-10.3626899719-9.75312423706-9.14355373383-8.53398323059$ $-8.22919845581-8.53398323059-8.83876895905-9.14355373383-9.14355373383$ $-9.14355373383-8.83876895905-8.22919845581-7.92441320419-7.3148431778$ $-7.01005792618-6.40048694611-5.79091691971-5.18134689331-4.87656211853$ $-4.26699209213-3.65742206573-3.04785108566-2.13349604607-1.52392601967$ -914355397224-9999.3047851026058 9143553972244 1.523926019669 2.133496046066 3.0478510856633 .6574220657354 .5717768669135 .4861321449286 .400486946106 7.0100579261787 .9244132041938 .8387689590459 .4483394622810 .05790996552 10.6674804687510 .9722604751611 .5818300247211 .5818300247211 .88661956787 11.8866195678712 .8009700775113 .41055011749 -9999 -9999 -9999 -9999 -9999 -9999 -9999 -9999 -9999 -9999 -9999 -9999 -9999 -9999 -9999 -9999 -9999 -9999 -9999 -9999 -9999 -9999 -9999 -9999 -9999 -9999 -9999 -9999 -9999 -9999 -9999 -9999 -9999 -9999 -9999 -9999 -9999 -9999 -9999 -9999 -9999 -9999 -9999 -9999 -9999 -9999 -9999 -9999 -9999 -9999 -9999 -9999 -

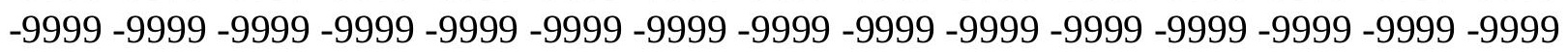


-9999 -9999 -9999 -9999 -9999 -9999 -9999 -9999 -9999 -9999 -9999 -9999 -9999 -9999 -9999 -9999 -9999 -9999 -9999 -9999 -9999 -9999 -9999 -9999 -9999 -9999 -9999 -9999 -9999 -9999 -9999 -9999 -9999 -9999 -9999 -9999 -9999 -9999 -9999 -9999 -9999 -9999 -9999 -9999 -9999 -9999 -9999 -9999 -9999 -9999 -9999 -9999 -9999 -9999 -9999 -9999 -9999 -9999 -9999 -9999 -9999 -9999 -9999 -9999 -9999 -9999 -9999 -9999 -9999 -9999 -9999 -9999 -9999 -9999 -9999 -9999 -9999 -9999 -9999 -9999 -9999 -9999 -9999 -9999 -9999 -9999 -9999 -9999 -9999 -9999 -

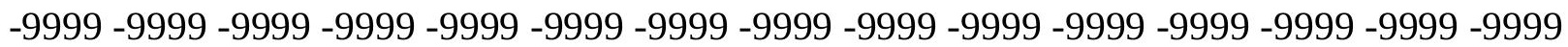
-9999-9999

-9999 -9999 -9999 -9999 -9999 -9999 -9999 -9999 -9999 -9999 -9999 -9999 -9999 -9999 -9999 -9999 -9999 -9999 -9999 -9999 -9999 -9999 -9999 -9999 -9999 -9999 -9999 -9999 -9999 -9999 -

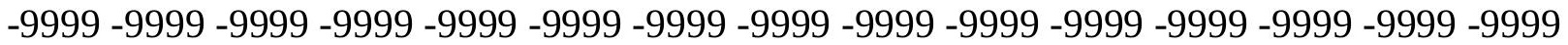
-9999 -9999 -9999 -9999 -9999 -9999 -9999 -9999 -9999 -9999 -9999 -9999 -9999 -9999 -9999

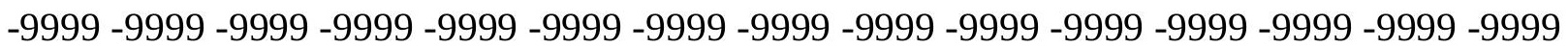
-9999 -9999 -9999 -9999 -9999 -9999 -9999 -9999 -9999 -9999 -9999 -9999 -9999 -9999 -9999 -9999 -9999 -9999 -9999 -9999 -9999 -9999 -9999 -9999 -9999 -9999 -9999 -9999 -9999 -9999 -9999 -9999 -9999 -9999 -9999 -9999 -9999 -9999 -9999 -9999 -9999 -9999 -9999 -9999 -9999 -999 -9999 -9999 -9999 -9999 -9999 -9999-9999 -9999 -9.75312423706 -10.0579099655 5.7909169197085 .4861321449285 .1813468933114 .876562118534 .571776866913 4.5717768669134 .2669920921333 .9622070789343 .6574220657353 .657422065735 3.3526360988623 .3526360988623 .0478510856633 .0478510856633 .047851085663 3.0478510856633 .0478510856633 .0478510856633 .0478510856632 .743066072464 2.7430660724642 .7430660724642 .7430660724642 .4382810592652 .133496046066 $2.1334960460661 .8287110328671 .523926019669-14.9344701767-14.9344701767$ -14.6296901703 -14.3248996735 -14.3248996735 -14.0201196671 -13.4105501175 $-13.1057596207-12.4961900711-11.8866195679-11.2770500183-10.6674804688$ $-10.0579099655-9.44833946228-10.0579099655-10.6674804688-10.6674804688$ $-10.6674804688-10.3626899719-10.0579099655-9.44833946228-8.83876895905$ -8.53398323059 -7.92441320419 -7.3148431778-6.7052731514-6.095703125 -5.48613214493 $-4.87656211853-4.26699209213-3.65742206573-3.04785108566-2.43828105927$ $-1.52392601967-.914355397224-.304785102606-9999.60957032442091 .523926019669$ 2.1334960460663 .0478510856633 .9622070789344 .876562118535 .790916919708 6.7052731513987 .6196279525768 .5339832305919 .14355373382610 .05790996552 10.6674804687510 .9722604751611 .2770500183111 .5818300247211 .88661956787 11.8866195678711 .8866195678712 .8009700775113 .41055011749 -9999-9999-9999-9999 -9999 -9999 -9999 -9999 -9999 -9999 -9999 -9999 -9999 -9999 -9999 -9999 -9999 -9999 -9999 -9999 -9999 -9999 -9999 -9999 -9999 -9999 -9999 -9999 -9999 -9999 -9999 -9999 -9999 -9999 -9999 -9999 -9999 -9999 -9999 -9999 -9999 -9999 -9999 -9999 -9999 -9999 -9999 -9999 -9999

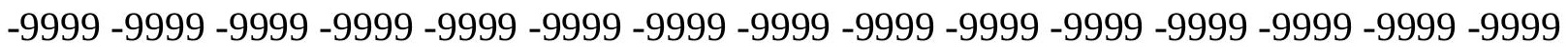
-9999 -9999 -9999 -9999 -9999 -9999 -9999 -9999 -9999 -9999 -9999 -9999 -9999 -9999 -9999 -9999 -9999 -9999 -9999 -9999 -9999 -9999 -9999 -9999 -9999 -9999 -9999 -9999 -9999 -9999 -9999 -9999 -9999 -9999 -9999 -9999 -9999 -9999 -9999 -9999 -9999 -9999 -9999 -9999 -9999

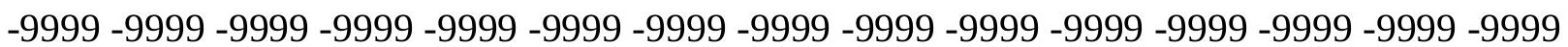
-9999 -9999 -9999 -9999 -9999 -9999 -9999 -9999 -9999 -9999 -9999 -9999 -9999 -9999 -9999 -9999 -9999 -9999 -9999 -9999 -9999 -9999 -9999 -9999 -9999 -9999 -9999 -9999 -9999 -9999 -9999 -9999 -9999 -9999 -9999 -9999 -9999 -9999 -9999 -9999 -9999 -9999 -9999 -9999 -9999 -9999 -9999-9999-9999 
-9999 -9999 -9999 -9999 -9999 -9999 -9999 -9999 -9999 -9999 -9999 -9999 -9999 -9999 -9999 -9999 -9999 -9999 -9999 -9999 -9999 -9999 -9999 -9999 -9999 -9999 -9999 -9999 -9999 -9999 -9999 -9999 -9999 -9999 -9999 -9999 -9999 -9999 -9999 -9999 -9999 -9999 -9999 -9999 -9999 -9999 -9999 -9999 -9999 -9999 -9999 -9999 -9999 -9999 -9999 -9999 -9999 -9999 -9999 -9999 -9999 -9999 -9999 -9999 -9999 -9999 -9999 -9999 -9999 -9999 -9999 -9999 -9999 -9999 -9999 -9999 -9999 -9999 -9999 -9999 -9999 -9999 -9999 -9999 -9999 -9999 -9999 -9999 -9999 -9999 -9999 -9999 -9999 -9999 -9999 -9999 -9999 -9999 -9999 -9999 -9999 -9999 -9999 -9999 -9999 -9999 -9999 -9999 -9999 -9999 -9999 -9999 -9999 -9999 -9999 -9999 -9999 -9999 -9999 -9999 -9999 -9999 -9999 -9999 -9999 -9999 -9999 -10.9722604752 -11.2770500183 4.571776866913 4.2669920921333 .9622070789343 .6574220657353 .3526360988623 .047851085663 3.0478510856632 .7430660724642 .7430660724642 .4382810592652 .133496046066 2.1334960460662 .1334960460661 .8287110328671 .8287110328671 .828711032867 1.8287110328671 .8287110328671 .8287110328671 .8287110328671 .828711032867 1.8287110328671 .5239260196691 .5239260196691 .219141006471 .21914100647 9143553972244.6095703244209.3047851026058 -9999-16.4584007263-16.1536102295 -15.8488302231 -15.8488302231 -15.5440397263 -15.2392597198 -14.6296901703 -14.3248996735 -13.7153301239 -13.1057596207 -12.4961900711 -12.1914100647 -12.1914100647 -12.1914100647 -12.4961900711 -12.4961900711 -12.1914100647 $-11.5818300247-11.2770500183-10.6674804688-10.0579099655-9.44833946228$ $-8.83876895905-8.22919845581-7.61962795258-7.01005792618-6.40048694611$ $-5.79091691971-5.18134689331-4.57177686691-3.65742206573-3.04785108566$ -2.43828105927 -1.82871103287 -1.21914100647-.304785102606 -9999.9143553972244 1.5239260196692 .4382810592653 .3526360988624 .2669920921335 .181346893311 6.4004869461067 .3148431777958 .5339832305919 .14355373382610 .05790996552 10.6674804687511 .2770500183111 .5818300247211 .5818300247211 .88661956787 $11.8866195678711 .8866195678711 .8866195678712 .4961900711113 .41055011749-9999$ -9999 -9999 -9999 -9999 -9999 -9999 -9999 -9999 -9999 -9999 -9999 -9999 -9999 -9999 -9999 -9999 -9999 -9999 -9999 -9999 -9999 -9999 -9999 -9999 -9999 -9999 -9999 -9999 -9999 -9999 -9999 -9999 -9999 -9999 -9999 -9999 -9999 -9999 -9999 -9999 -9999 -9999 -9999 -9999 -9999 -9999 -9999 -9999 -9999 -9999 -9999 -9999 -9999 -9999 -9999 -9999 -9999 -9999 -9999 -9999 -9999 -9999 -9999 -9999 -9999 -9999 -9999 -9999 -9999 -9999 -9999 -9999 -9999 -9999 -9999 -9999 -9999 -9999 -9999 -9999 -9999 -9999 -9999 -9999 -9999 -9999 -9999 -9999 -9999 -9999 -9999 -9999 -9999 -9999 -9999 -9999 -9999 -9999 -9999 -9999 -9999 -9999 -9999 -9999 -9999 -9999 -9999 -9999 -9999 -9999 -9999 -9999 -9999 -9999 -9999 -9999 -9999 -9999 -9999 -9999

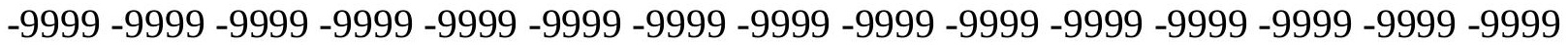
-9999 -9999 -9999 -9999 -9999 -9999 -9999 -9999 -9999 -9999 -9999 -9999 -9999 -9999 -9999

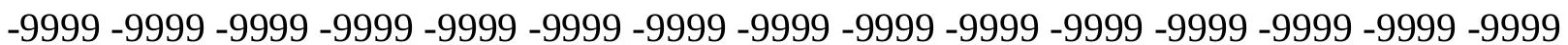
-9999 -9999 -9999-9999-9999-9999

-9999 -9999 -9999 -9999 -9999 -9999 -9999 -9999 -9999 -9999 -9999 -9999 -9999 -9999 -9999 -9999 -9999 -9999 -9999 -9999 -9999 -9999 -9999 -9999 -9999 -9999 -9999 -9999 - -9999 -9999 -9999 -9999 -9999 -9999 -9999 -9999 -9999 -9999 -9999 -9999 -9999 -9999 -9999 -9999 -9999

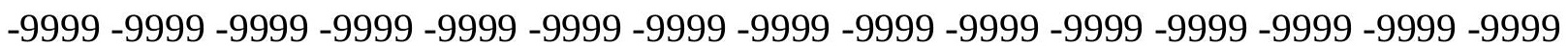
-9999 -9999 -9999 -9999 -9999 -9999 -9999 -9999 -9999 -9999 -9999 -9999 -9999 -9999 -9999 -9999 -9999 -9999 -9999 -9999 -9999 -9999 -9999 -9999 -9999 -9999 -9999 -9999 -9999 -9999 -9999 -9999 -9999 -9999 -9999 -9999 -9999 -9999 -9999 -9999 -9999 -9999 -9999 -9999 -9999

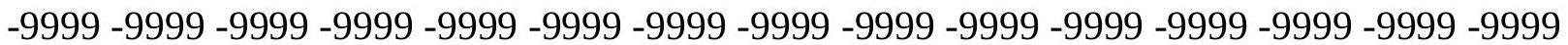


-9999 -9999 -9999 -9999 -9999 -9999 -12.1914100647 -12.4961900711 3.352636098862 3.0478510856632 .7430660724642 .4382810592652 .1334960460661 .828711032867 1.8287110328671 .5239260196691 .5239260196691 .219141006471 .21914100647 .6143553972244.9143553972244.9143553972244.6095703244209. .6095703244209 6095703244209 6095703244209.6095703244209.6095703244209. 3047851026058 -9999 -9999 -9999. -.304785102606 -.609570324421 -.914355397224 -.914355397224 -17.6775398254 -17.3727493286 -17.0679702759-17.0679702759-16.7631797791 -16.4584007263 -16.1536102295 -15.5440397263 -14.9344701767 -14.6296901703 -14.3248996735 -14.6296901703 -14.6296901703 -14.6296901703 -14.0201196671 -13.7153301239 -13.1057596207 -12.4961900711 -11.5818300247-10.9722604752 -10.3626899719 $-9.75312423706-9.14355373383-8.53398323059-7.92441320419-7.01005792618$ $-6.40048694611-5.79091691971-5.18134689331-4.57177686691-3.65742206573$ -3.04785108566 -2.43828105927 -1.82871103287 -1.21914100647 -.304785102606 -9999 .91435539722441 .8287110328672 .7430660724643 .6574220657354 .87656211853 6.0957031257 .3148431777958 .5339832305919 .4483394622810 .36268997192 10.9722604751611 .5818300247211 .8866195678711 .8866195678711 .88661956787 11.8866195678711 .8866195678711 .8866195678711 .8866195678712 .80097007751 13.41055011749 -9999 -9999 -9999 -9999 -9999 -9999 -9999 -9999 -9999 -9999 -9999 -9999

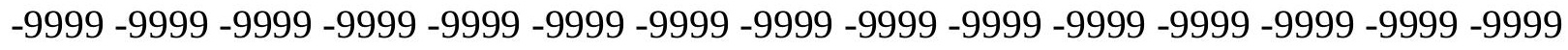
-9999 -9999 -9999 -9999 -9999 -9999 -9999 -9999 -9999 -9999 -9999 -9999 -9999 -9999 -9999 -999 -

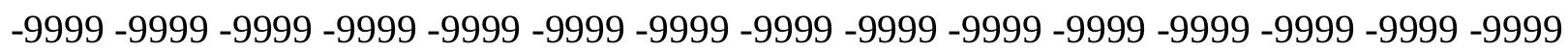
-9999 -9999 -9999 -9999 -9999 -9999 -9999 -9999 -9999 -9999 -9999 -9999 -9999 -9999 -9999 -

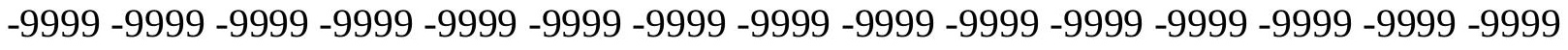

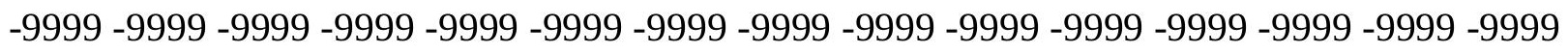
-9999 -9999 -9999 -9999 -9999 -9999 -9999 -9999 -9999 -9999 -9999 -9999 -9999 -9999 -9999

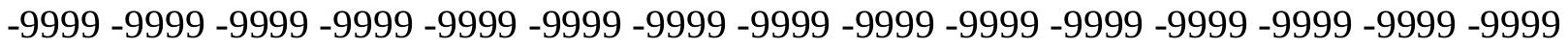

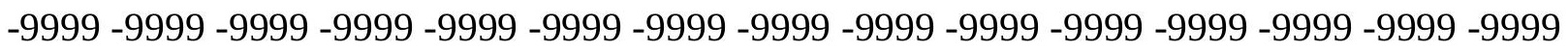
-9999 -9999 -9999 -9999 -9999 -9999 -9999 -9999 -9999 -9999 -9999 -9999 -9999 -9999 -9999 -9999 -9999 -9999 -9999 -9999 -9999 -9999 -9999 -9999 -9999 -9999 -9999 -9999 -9999 -9999 -9999 -9999 -9999 -9999 -9999 -9999 -9999 -9999 -9999 -9999 -9999 -9999 -9999 -9999 -9999 -9999 -9999 -9999 -9999 -9999 -9999 -9999 -9999 -9999 -

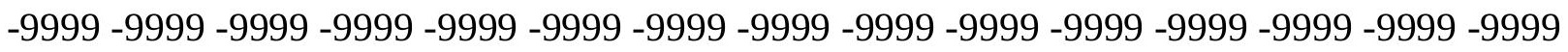
-9999 -9999 -9999 -9999 -9999 -9999 -9999 -9999 -9999 -9999 -9999 -9999 -9999 -9999 -9999 -9999 -9999 -9999 -9999 -9999 -9999 -9999 -9999 -9999 -9999 -9999 -9999 -9999 -9999 -9999 -

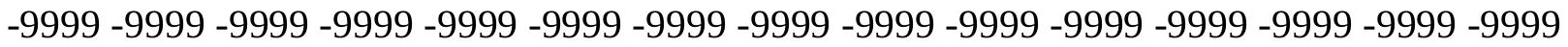

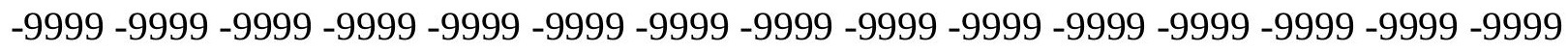

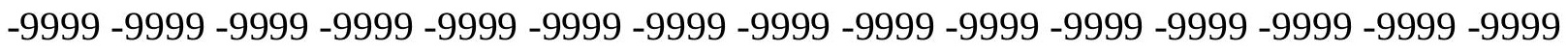
-9999 -9999 -9999 -9999-9999-13.1057596207 -13.7153301239 2.133496046066 1.8287110328671 .5239260196691 .21914100647 .9143553972244 .6095703244209 .6095703244209. 3047851026058 3047851026058 -9999-9999 -9999 -9999 -9999 -.304785102606 -.304785102606-.304785102606 - -304785102606-.304785102606 -.304785102606 -.304785102606 -.304785102606 -.304785102606 -.304785102606 -.609570324421 -.609570324421 -.914355397224 -1.21914100647 -1.21914100647 $-1.52392601967-1.82871103287-2.13349604607-2.13349604607-19.2014598846$ $-18.8966808319-18.5918903351-18.287109375-18.287109375-17.9823207855$ 
-17.6775398254 -17.3727493286 -16.7631797791 -16.4584007263 -16.4584007263 $-16.4584007263-16.7631797791-16.1536102295-15.5440397263-14.9344701767$ -14.0201196671 -13.4105501175 -12.8009700775 -12.1914100647 -11.2770500183 $-10.6674804688-10.0579099655-9.14355373383-8.53398323059-7.92441320419$ $-7.3148431778-6.40048694611-5.79091691971-5.18134689331-4.57177686691$ -3.96220707893 -3.35263609886 -2.43828105927 -1.82871103287 -1.21914100647 -.304785102606 -9999.9143553972244 2.133496046066 3.3526360988624.571776866913 5.7909169197087 .3148431777958 .5339832305919 .75312423706110 .66748046875 11.5818300247211 .8866195678712 .191410064712 .4961900711112 .49619007111 12.191410064712 .191410064711 .8866195678711 .8866195678711 .88661956787 12.8009700775113 .41055011749 -9999 -9999 -9999 -9999 -9999 -9999 -9999 -9999 -9999 -9999 -9999 -9999 -9999 -9999 -9999 -9999 -9999 -9999 -9999 -9999 -9999 -9999 -9999 -9999 -9999 -9999 -9999 -9999 -9999 -9999 -9999 -9999 -9999 -9999 -9999 -9999 -9999 -9999 -9999 -9999 -9999 -9999 -9999 -9999 -9999 -9999 -9999 -9999 -9999 -9999 -9999 -9999 -9999 -9999 -9999 -9999 -9999 -9999 -9999 -9999 -9999 -9999 -9999 -9999 -9999 -9999 -9999 -9999 -9999

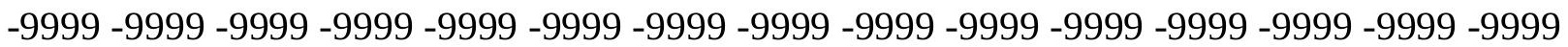

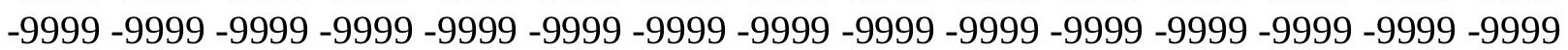
-9999 -9999 -9999 -9999 -9999 -9999 -9999 -9999 -9999 -9999 -9999 -9999 -9999 -9999 -9999 -999 -9999 -9999 -9999 -9999 -9999 -9999 -9999 -9999 -9999 -9999 -9999 -9999 -9999 -9999 -9999 -9999 -9999 -9999 -9999 -9999 -9999 -9999 -9999 -9999 -9999 -9999 -9999 -9999 -9999 -9999

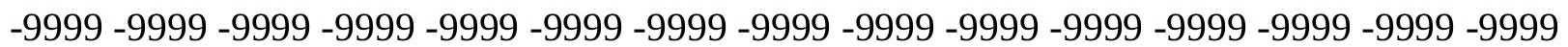
-9999 -9999 -9999 -9999 -9999 -9999 -9999 -9999 -9999 -9999 -9999 -9999 -9999 -9999 -9999 -9999 -9999 -9999 -9999 -9999 -9999 -9999 -9999 -9999 -9999 -9999 -9999 -9999 -9999 -9999 -9999 -9999 -9999 -9999 -9999 -9999 -9999 -9999 -9999 -9999 -9999

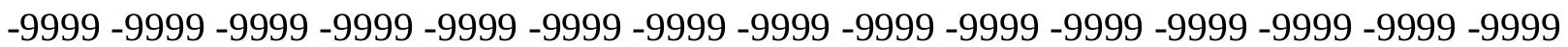
-9999 -9999 -9999 -9999 -9999 -9999 -9999 -9999 -9999 -9999 -9999 -9999 -9999 -9999 -9999 -9999 -9999 -9999 -9999 -9999 -9999 -9999 -9999 -9999 -9999 -9999 -9999 -9999 -9999 -9999 -9999 -9999 -9999 -9999 -9999 -9999 -9999 -9999 -9999 -9999 -9999 -9999 -9999 -9999 -9999

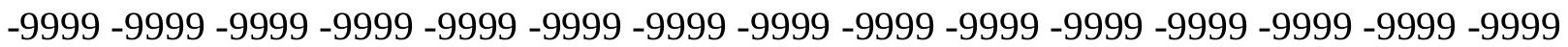
-9999 -9999 -9999 -9999 -9999 -9999 -9999 -9999 -9999 -9999 -9999 -9999 -9999 -9999 -9999 -9999 -9999 -9999 -9999-14.3248996735 -14.9344701767 1.21914100647.6095703244209 .3047851026058 -9999 -9999-.304785102606 -.304785102606 -.609570324421 $-.609570324421-.914355397224-.914355397224-.914355397224-1.21914100647$ $-1.21914100647-1.21914100647-1.52392601967-1.52392601967-1.52392601967$ -1.52392601967 -1.52392601967 - $1.52392601967-1.52392601967-1.52392601967$ $-1.52392601967-1.82871103287-1.82871103287-2.13349604607-2.13349604607$ $-2.43828105927-2.74306607246-2.74306607246-3.04785108566-3.35263609886$ -3.35263609886 -3.65742206573 -20.115819931 -19.8110294342 -19.5062503815 -19.5062503815 -19.5062503815 -19.2014598846 -18.5918903351 -18.287109375 -17.9823207855 -17.6775398254 -17.9823207855 -17.9823207855 -17.3727493286 -16.7631797791 -15.8488302231 -15.2392597198 -14.3248996735 -13.7153301239 -13.1057596207-12.1914100647-11.5818300247-10.6674804688 -10.0579099655 $-9.14355373383-8.53398323059-7.92441320419-7.01005792618-6.40048694611$ $-5.79091691971-5.18134689331-4.57177686691-3.96220707893-3.35263609886$ -2.74306607246 -1.82871103287-1.21914100647- -304785102606 .3047851026058 1.5239260196692 .7430660724644 .2669920921335 .7909169197087 .314843177795 
8.83876895904510 .3626899719211 .2770500183112 .191410064712 .49619007111 12.8009700775112 .8009700775112 .8009700775112 .8009700775112 .49619007111 12.191410064711 .8866195678711 .8866195678712 .191410064712 .80097007751 13.41055011749 -9999 -9999 -9999 -9999 -9999 -9999 -9999 -9999 -9999 -9999 -9999 -9999 -9999 -9999 -9999 -9999 -9999 -9999 -9999 -9999 -9999 -9999 -9999 -9999 -9999 -9999 -9999 -9999 -9999 -9999 -9999 -9999 -9999 -9999 -9999 -9999 -9999 -9999 -9999 -9999 -9999 -9999 -9999 -9999 -9999 -9999 -9999 -9999 -9999 -9999 -9999 -9999 -9999 -9999 -9999 -9999 -9999

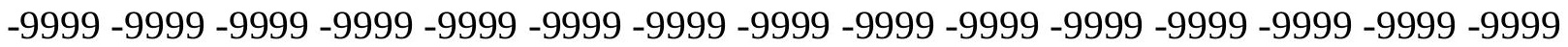
-9999 -9999 -9999 -9999 -9999 -9999 -9999 -9999 -9999 -9999 -9999 -9999 -9999 -9999 -9999 -9999 -9999 -9999 -9999 -9999 -9999 -9999 -9999 -9999 -9999 -9999 -9999 -9999 -9999 -9999 -

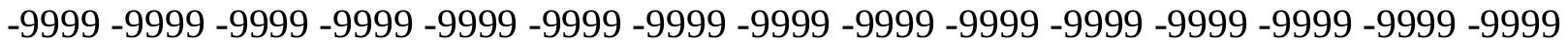
-9999 -9999 -9999 -9999 -9999 -9999 -9999 -9999 -9999 -9999 -9999 -9999 -9999 -9999 -9999 -9999 -9999 -9999 -9999 -9999 -9999 -9999 -9999 -9999 -9999 -9999 -9999 -9999 -9999 -9999 -9999 -9999 -9999 -9999 -9999 -9999 -9999 -9999 -9999 -9999 -9999 -9999 -9999 -9999 -9999 -9999 -9999 -9999 -9999-9999 -9999-9999

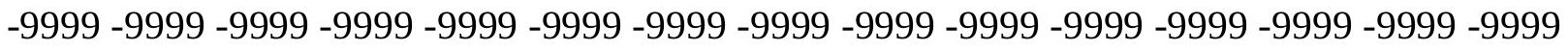

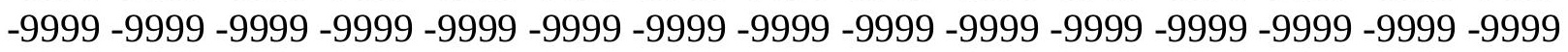

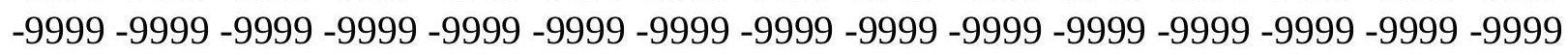

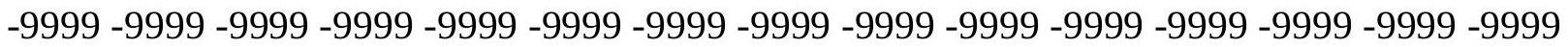

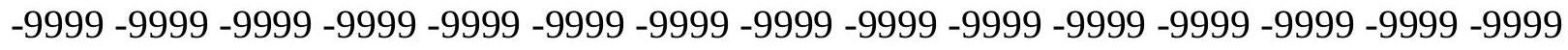

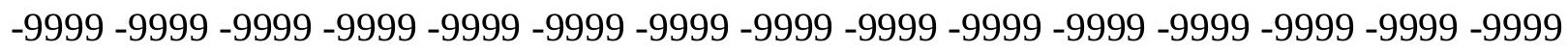

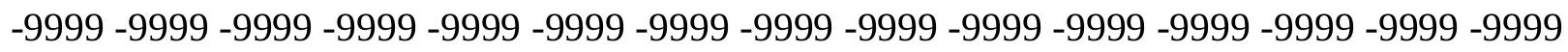
-9999 -9999 -9999 -9999 -9999 -9999 -9999 -9999 -9999 -9999 -9999 -9999 -9999 -9999 -9999 -9999 -9999-9999 -15.2392597198 -15.8488302231 -9999-9999-.304785102606 -.914355397224 -.914355397224 -1.21914100647 -1.52392601967 -1.82871103287 $-1.82871103287-2.13349604607-2.13349604607-2.13349604607-2.43828105927$ $-2.43828105927-2.43828105927-2.43828105927-2.74306607246-2.74306607246$ $-2.74306607246-2.74306607246-2.74306607246-2.74306607246-2.74306607246$ $-2.74306607246-3.04785108566-3.04785108566-3.04785108566-3.35263609886$ $-3.65742206573-3.65742206573-3.96220707893-4.26699209213-4.26699209213$ $-4.57177686691-4.57177686691-4.87656211853-21.3349609375-21.0301704407$ -20.7253894806 -20.4206008911 -20.4206008911 -20.115819931 -19.5062503815 -19.2014598846 -18.8966808319-18.8966808319-18.5918903351 -18.5918903351 -17.9823207855 -17.3727493286 -16.7631797791 -16.1536102295 -15.2392597198 -14.6296901703 -13.7153301239-13.1057596207-12.1914100647 -11.5818300247 $-10.6674804688-10.0579099655-9.14355373383-8.53398323059-7.92441320419$ $-7.01005792618-6.40048694611-5.79091691971-5.18134689331-4.57177686691$ -3.96220707893 -3.35263609886 -2.74306607246 -1.82871103287 -.914355397224-9999 .91435539722442 .4382810592653 .9622070789345 .7909169197087 .924413204193 9.4483394622810 .9722604751612 .191410064712 .8009700775113 .41055011749 13.715330123913 .4105501174913 .4105501174913 .1057596206712 .80097007751 12.4961900711112 .191410064712 .191410064711 .8866195678712 .1914100647 12.8009700775113 .41055011749 -9999 -9999 -9999 -9999 -9999 -9999 -9999 -9999 -9999 -9999 -9999 -9999 -9999 -9999 -9999 -9999 -9999 -9999 -9999 -9999 -9999 -9999 -9999 -9999 -9999 -9999 -9999 -9999 -9999 -9999 -9999 -9999 -9999 -9999 -9999 -9999 -9999 -9999 -9999 -

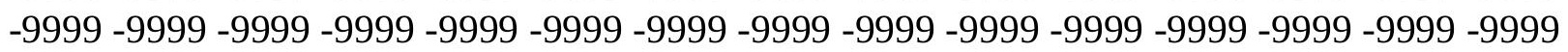


-9999 -9999 -9999 -9999 -9999 -9999 -9999 -9999 -9999 -9999 -9999 -9999 -9999 -9999 -9999 -9999 -9999 -9999 -9999 -9999 -9999 -9999 -9999 -9999 -9999 -9999 -9999 -9999 -9999 -9999 -9999 -9999 -9999 -9999 -9999 -9999 -9999 -9999 -9999 -9999 -9999 -9999 -9999 -9999 -9999 -9999 -9999 -9999 -9999 -9999 -9999 -9999 -9999 -9999 -9999 -9999 -9999 -9999 -9999 -9999 -9999 -9999 -9999 -9999 -9999 -9999 -9999 -9999 -9999 -9999 -9999 -9999 -9999 -9999 -9999 -9999 -9999 -9999 -9999 -9999 -9999 -9999 -9999 -9999 -9999 -9999 -9999 -9999 -9999 -9999 -

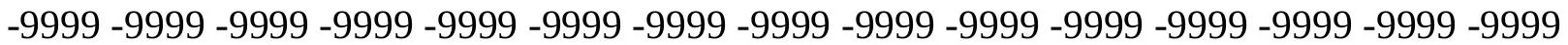
-9999 -9999 -9999 -9999 -9999 -9999 -9999 -9999 -9999

-9999 -9999 -9999 -9999 -9999 -9999 -9999 -9999 -9999 -9999 -9999 -9999 -9999 -9999 -9999 -9999 -9999 -9999 -9999 -9999 -9999 -9999 -9999 -9999 -9999 -9999 -9999 -9999 -9999 -9999 -9999 -9999 -9999 -9999 -9999 -9999 -9999 -9999 -9999 -9999 -9999 -9999 -9999 -9999 -9999 -9999 -9999 -9999 -9999 -9999 -9999 -9999 -9999 -9999 -9999 -9999 -9999 -9999 -9999 -9999

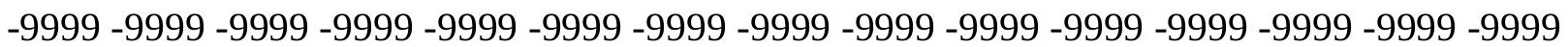
-9999 -9999 -9999 -9999 -9999 -9999 -9999 -9999 -9999 -9999 -9999 -9999 -9999 -9999 -9999 -9999 -9999 -9999 -9999 -9999 -9999 -9999 -9999 -9999 -9999 -9999 -9999 -9999 -9999 -9999 -9999 -9999 -9999 -9999 -9999 -9999 -9999 -9999 -9999 -9999 -9999 -9999 -9999 -9999 -9999 -9999 -9999 -9999 -17.0679702759 -17.3727493286 -1.21914100647 - 1.52392601967 $-1.82871103287-2.13349604607-2.43828105927-2.74306607246-2.74306607246$ $-3.04785108566-3.35263609886-3.35263609886-3.35263609886-3.65742206573$ $-3.65742206573-3.65742206573-3.65742206573-3.96220707893-3.96220707893$ $-3.96220707893-3.96220707893-3.96220707893-3.96220707893-3.96220707893$ $-4.26699209213-4.26699209213-4.26699209213-4.57177686691-4.57177686691$ $-4.87656211853-4.87656211853-5.18134689331-5.18134689331-5.48613214493$ $-5.79091691971-5.79091691971-5.79091691971-6.095703125-22.5541000366$ $-21.9445304871-21.6397399902-21.3349609375-20.7253894806-20.4206008911$ -20.115819931 -19.8110294342 -19.5062503815 -19.5062503815 -19.2014598846 -19.2014598846 -18.5918903351 -18.287109375 -17.6775398254 -16.7631797791 -16.1536102295 -15.5440397263 -14.6296901703 -13.7153301239-13.1057596207 $-12.1914100647-11.5818300247-10.6674804688-9.75312423706-9.14355373383$ $-8.22919845581-7.61962795258-7.01005792618-6.40048694611-5.79091691971$ $-5.18134689331-4.57177686691-3.96220707893-3.35263609886-2.74306607246$ $-1.82871103287-.609570324421$.3047851026058 1.8287110328673 .962207078934 6.0957031258 .22919845581110 .3626899719211 .8866195678713 .10575962067 14.0201196670514 .3248996734614 .3248996734614 .3248996734614 .02011966705 13.715330123913 .1057596206712 .8009700775112 .4961900711112 .1914100647 $12.191410064712 .191410064712 .4961900711113 .4105501174914 .62969017029-9999-9999$ -9999 -9999 -9999 -9999 -9999 -9999 -9999 -9999 -9999 -9999 -9999 -9999 -9999 -9999 -9999

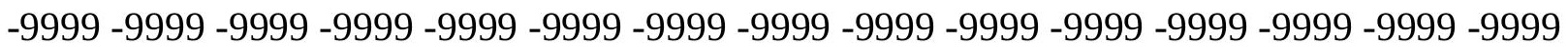
-9999 -9999 -9999 -9999 -9999 -9999 -9999 -9999 -9999 -9999 -9999 -9999 -9999 -9999 -9999 -9999 -9999 -9999 -9999 -9999 -9999 -9999 -9999 -9999 -9999 -9999 -9999 -9999 -9999 -9999 -9999 -9999 -9999 -9999 -9999 -9999 -9999 -9999 -9999 -9999 -9999 -9999 -9999 -9999 -9999

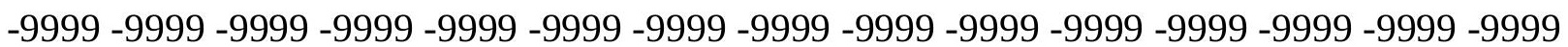
-9999 -9999 -9999 -9999 -9999 -9999 -9999 -9999 -9999 -9999 -9999 -9999 -9999 -9999 -9999 -9999 -9999 -9999 -9999 -9999 -9999 -9999 -9999 -9999 -9999 -9999 -9999 -9999 -9999 -9999 -9999 -9999 -9999 -9999 -9999 -9999 -9999 -9999 -9999 -9999 -9999 -9999 -9999 -9999 -9999 -9999 -9999 -9999 -9999 -9999 -9999 -9999 -9999 -9999 -9999 -9999 -9999 -9999 -9999 -9999 
-9999 -9999 -9999 -9999 -9999 -9999 -9999 -9999 -9999 -9999 -9999 -9999 -9999 -9999 -9999 -9999 -9999 -9999 -9999 -9999 -9999 -9999 -9999 -9999 -9999 -9999 -9999 -9999 -9999 -9999 -

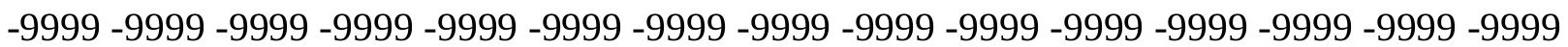
-9999 -9999 -9999 -9999 -9999 -9999 -9999 -9999 -9999 -9999 -9999 -9999 -9999 -9999 -9999 -9999 -9999 -9999 -9999 -9999 -9999 -9999 -9999 -9999 -9999 -9999 -9999 -9999 -9999 -9999 -9999 -9999 -9999 -9999 -9999 -9999 -9999 -9999 -9999 -9999 -9999 -9999 -9999 -9999 -9999 -9999 -9999 -9999 -9999 -9999 -9999 -9999 -9999 -9999 -9999 -9999 -9999 -9999 -9999 -9999

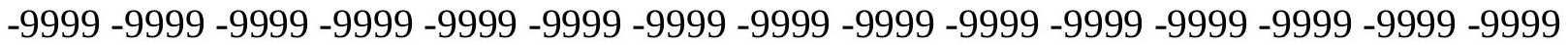
-9999 -9999 -9999 -9999 -9999 -9999 -9999 -9999 -9999 -9999 -9999 -9999 -9999 -9999 -9999 -9999 -9999 -17.9823207855 -18.5918903351 -2.13349604607 -2.74306607246 -3.04785108566 -3.35263609886 -3.65742206573 -3.96220707893 -3.96220707893 $-4.26699209213-4.57177686691-4.57177686691-4.57177686691-4.87656211853$ $-4.87656211853-4.87656211853-5.18134689331-5.18134689331-5.18134689331$ $-5.18134689331-5.18134689331-5.18134689331-5.18134689331-5.48613214493$ $-5.48613214493-5.48613214493-5.48613214493-5.79091691971-5.79091691971$ $-6.095703125-6.095703125-6.40048694611-6.40048694611-6.7052731514-6.7052731514$ $-7.01005792618-7.01005792618-7.3148431778-7.3148431778-23.4684505463$ $-22.8588790894-22.2493095398-21.9445304871-21.3349609375-20.7253894806$ $-20.4206008911-20.4206008911-20.115819931-20.115819931-19.8110294342$ $-19.5062503815-19.2014598846-18.8966808319-18.287109375-17.6775398254$ $-17.0679702759-16.1536102295-15.5440397263-14.6296901703-13.7153301239$ $-13.1057596207-12.1914100647-11.2770500183-10.3626899719-9.75312423706$ $-8.83876895905-8.22919845581-7.61962795258-7.01005792618-6.40048694611$ $-5.79091691971-5.18134689331-4.57177686691-3.96220707893-3.35263609886$ $-2.43828105927-1.52392601967-.3047851026061 .219141006473 .657422065735$ 6.4004869461068 .83876895904511 .2770500183113 .1057596206714 .32489967346 15.2392597198515 .5440397262615 .2392597198514 .934470176714 .62969017029 14.0201196670513 .715330123913 .1057596206712 .8009700775112 .49619007111 12.4961900711112 .191410064712 .4961900711113 .1057596206714 .32489967346 15.23925971985 -9999 -9999 -9999 -9999 -9999 -9999 -9999 -9999 -9999 -9999 -9999 -9999 -9999 -9999 -9999 -9999 -9999 -9999 -9999 -9999 -9999 -9999 -9999 -9999 -9999 -9999 -9999 -9999 -9999 -9999 -9999 -9999 -9999 -9999 -9999 -9999 -9999 -9999 -9999 -9999 -9999 -9999 -9999 -9999 -9999 -9999 -9999 -9999 -9999 -9999 -9999 -9999 -9999 -9999 -9999 -9999 -9999 -9999 -9999 -9999 -9999 -9999 -9999 -9999 -9999 -9999 -9999 -9999 -9999 -9999 -9999 -9999 -9999 -9999 -9999 -9999 -9999 -9999 -9999 -9999 -9999 -9999 -9999 -9999 -9999 -9999 -9999 -9999 -9999 -9999 -9999 -9999 -9999 -9999 -9999 -9999 -9999 -9999 -9999 -9999 -9999 -9999 -9999 -9999 -9999 -9999 -9999 -9999 -9999 -9999 -9999 -9999 -9999 -9999 -9999 -9999 -9999

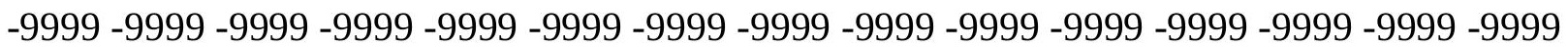
-9999 -9999 -9999 -9999 -9999 -9999 -9999 -9999 -9999 -9999 -9999 -9999 -9999 -9999 -9999 -9999 -9999 -9999 -9999 -9999 -9999 -9999 -9999 -9999 -9999 -9999 -9999 -9999 -9999 -9999 -9999 -9999 -9999-9999

-9999 -9999 -9999 -9999 -9999 -9999 -9999 -9999 -9999 -9999 -9999 -9999 -9999 -9999 -9999 -9999 -9999 -9999 -9999 -9999 -9999 -9999 -9999 -9999 -9999 -9999 -9999 -9999 -9999 -9999 -9999 -9999 -9999 -9999 -9999 -9999 -9999 -9999 -9999 -9999 -9999 -9999 -9999 -9999 -9999 -9999 -9999 -9999 -9999 -9999 -9999 -9999 -9999 -9999 -9999 -9999 -9999 -9999 -9999 -9999

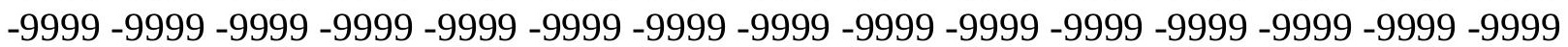


-9999 -9999 -9999 -9999 -9999 -9999 -9999 -9999 -9999 -9999 -9999 -9999 -9999 -9999 -9999 -9999 -9999 -9999 -9999 -9999 -9999 -9999 -9999 -9999 -9999 -9999 -9999 -9999 -9999 -9999 -9999 -9999 -9999 -9999 -9999 -9999 -9999 -9999 -9999 -9999 -9999 -9999 -9999 -9999 -9999 -9999 -18.8966808319-19.5062503815 -3.35263609886 -3.65742206573 -3.96220707893 $-4.57177686691-4.87656211853-5.18134689331-5.18134689331-5.48613214493$ $-5.79091691971-5.79091691971-5.79091691971-6.095703125-6.095703125-6.40048694611$ $-6.40048694611-6.40048694611-6.40048694611-6.40048694611-6.40048694611$ $-6.7052731514-6.7052731514-6.7052731514-6.7052731514-6.7052731514-7.01005792618$ $-7.01005792618-7.01005792618-7.3148431778-7.3148431778-7.61962795258$ $-7.61962795258-7.92441320419-8.22919845581-8.22919845581-8.22919845581$ $-8.53398323059-8.53398323059-8.53398323059-24.6875991821-24.0780296326$ -23.1636695862 -22.5541000366 -21.6397399902 -21.3349609375 -21.0301704407 -20.7253894806 -20.7253894806 -20.7253894806 -20.4206008911 -20.4206008911 -19.8110294342 -19.5062503815 -18.8966808319 -18.287109375 -17.6775398254 -17.0679702759 -16.1536102295 -15.2392597198 -14.6296901703 -13.7153301239 -12.8009700775 -11.8866195679 -10.9722604752 -10.3626899719-9.44833946228 $-8.83876895905-8.22919845581-7.61962795258-7.01005792618-6.40048694611$ -5.79091691971 -5.18134689331 -4.57177686691 -3.96220707893 -3.04785108566 -2.13349604607 -.914355397224 6095703244209 3.3526360988626 .400486946106 9.75312423706112 .4961900711114 .6296901702915 .8488302230816 .45840072632 16.4584007263216 .1536102294915 .5440397262614 .934470176714 .62969017029 14.0201196670513 .4105501174913 .1057596206712 .8009700775112 .49619007111 12.4961900711112 .4961900711112 .8009700775113 .4105501174914 .32489967346 14.62969017029 -9999 -9999 -9999 -9999 -9999 -9999 -9999 -9999 -9999 -9999 -9999 -9999 -9999 -9999 -9999 -9999 -9999 -9999 -9999 -9999 -9999 -9999 -9999 -9999 -9999 -9999 -9999 -9999 -9999 -9999 -9999 -9999 -9999 -9999 -9999 -9999 -9999 -9999 -9999 -9999 -9999 -9999 -9999 -9999 -9999 -9999 -9999 -9999 -9999 -9999 -9999 -9999 -9999 -9999 -9999 -9999 -9999 -9999 -9999 -9999 -9999 -9999 -9999 -9999 -9999 -9999 -9999 -9999 -9999 -9999 -9999 -9999 -9999 -9999 -9999 -9999 -9999 -9999 -9999 -9999 -9999 -9999 -9999 -9999 -9999 -9999 -9999 -9999 -9999 -9999 -9999 -9999 -9999 -9999 -9999 -9999 -9999 -9999 -9999 -9999 -9999 -9999 -9999 -9999 -9999 -9999 -9999 -9999 -9999 -9999 -9999 -9999 -9999 -9999 -9999 -9999 -9999 -

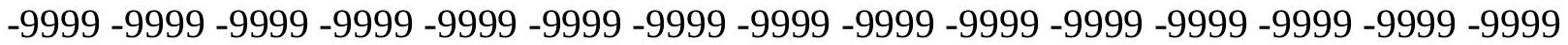
-9999 -9999 -9999 -9999 -9999 -9999 -9999 -9999 -9999 -9999 -9999 -9999 -9999 -9999 -9999 -

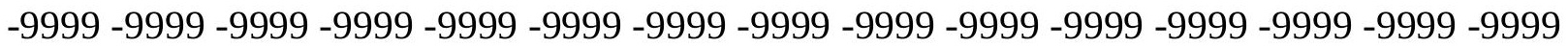
-9999 -9999-9999

-9999 -9999 -9999 -9999 -9999 -9999 -9999 -9999 -9999 -9999 -9999 -9999 -9999 -9999 -9999 -9999 -9999 -9999 -9999 -9999 -9999 -9999 -9999 -9999 -9999 -9999 -9999 -9999 -9999 -9999

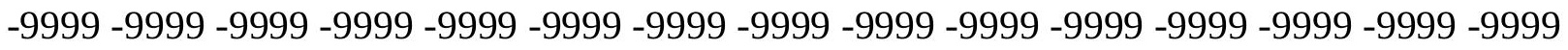
-9999 -9999 -9999 -9999 -9999 -9999 -9999 -9999 -9999 -9999 -9999 -9999 -9999 -9999 -9999 -9999 -9999 -9999 -9999 -9999 -9999 -9999 -9999 -9999 -9999 -9999 -9999 -9999 -9999 -9999 -

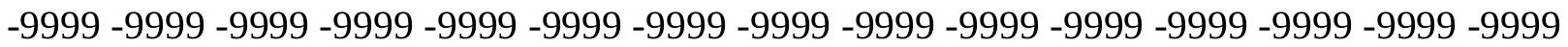
-9999 -9999 -9999 -9999 -9999 -9999 -9999 -9999 -9999 -9999 -9999 -9999 -9999 -9999 -9999 -9999 -9999 -9999 -9999 -9999 -9999 -9999 -9999 -9999 -9999 -9999 -9999 -9999 -9999 -9999 -9999 -20.4206008911 -21.0301704407-4.87656211853 -5.18134689331 -5.79091691971 $-6.095703125-6.40048694611-6.40048694611-6.7052731514-7.01005792618$ $-7.01005792618-7.3148431778-7.3148431778-7.3148431778-7.61962795258$ 
-7.61962795258 -7.61962795258 -7.92441320419 -7.92441320419 -7.92441320419 $-7.92441320419-7.92441320419-7.92441320419-7.92441320419-8.22919845581$ -8.22919845581 -8.22919845581 -8.53398323059-8.53398323059-8.83876895905 $-8.83876895905-9.14355373383-9.14355373383-9.44833946228-9.44833946228$ -9.75312423706 -9.75312423706 -9.75312423706 -10.0579099655 -26.5163097382 -25.9067401886 -24.9923801422 -24.0780296326 -23.1636695862 -22.2493095398 $-21.6397399902-21.3349609375-21.3349609375-21.3349609375-21.3349609375$ $-21.3349609375-21.0301704407-20.7253894806-20.4206008911-19.8110294342$ $-19.2014598846-18.5918903351-17.6775398254-17.0679702759-16.1536102295$ -15.2392597198 -14.3248996735 -13.4105501175 -12.4961900711 -11.5818300247 -10.6674804688 -10.0579099655 -9.14355373383 -8.53398323059 -7.92441320419 $-7.3148431778-7.01005792618-6.40048694611-5.79091691971-5.18134689331$ $-4.57177686691-3.65742206573-2.74306607246-1.21914100647 .3047851026058$ 3.0478510856636 .70527315139810 .3626899719213 .715330123916 .15361022949 17.6775398254417 .9823207855217 .6775398254417 .0679702758816 .15361022949 15.5440397262614 .6296901702914 .3248996734613 .715330123913 .41055011749 12.8009700775112 .8009700775112 .4961900711112 .8009700775112 .80097007751 12.8009700775113 .4105501174914 .02011966705 -9999 -9999 -9999 -9999 -9999 -9999 -9999 -9999 -9999 -9999 -9999 -9999 -9999 -9999 -9999 -9999 -9999 -9999 -9999 -9999 -9999 -9999

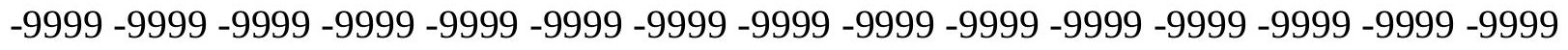

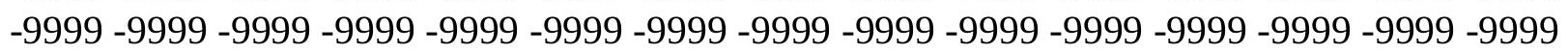

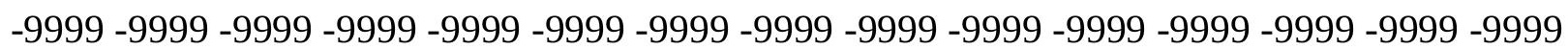
-9999 -9999 -9999 -9999 -9999 -9999 -9999 -9999 -9999 -9999 -9999 -9999 -9999 -9999 -9999 -9999 -9999 -9999 -9999 -9999 -9999 -9999 -9999 -9999 -9999 -9999 -9999 -9999 -9999 -9999 -

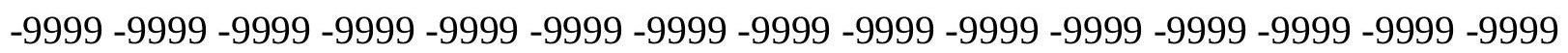
-9999 -9999 -9999 -9999 -9999 -9999 -9999 -9999 -9999 -9999 -9999 -9999 -9999 -9999 -9999 -9999 -9999 -9999 -9999 -9999 -9999 -9999 -9999 -9999 -9999 -9999 -9999 -9999 -9999 -9999

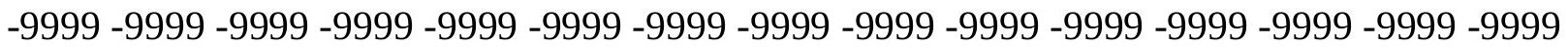
-9999 -9999 -9999 -9999 -9999 -9999-9999 -9999

-9999 -9999 -9999 -9999 -9999 -9999 -9999 -9999 -9999 -9999 -9999 -9999 -9999 -9999 -9999 -9999 -9999 -9999 -9999 -9999 -9999 -9999 -9999 -9999 -9999 -9999 -9999 -9999 -9999 -9999

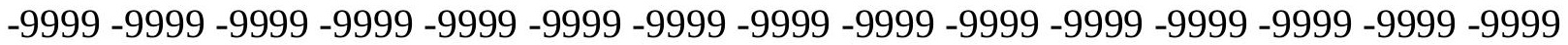

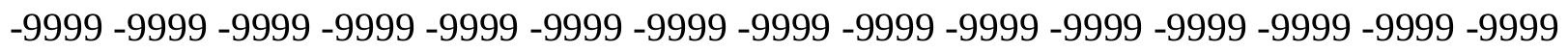

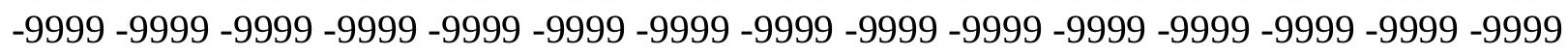
-9999 -9999 -9999 -9999 -9999 -9999 -9999 -9999 -9999 -9999 -9999 -9999 -9999 -9999 -9999

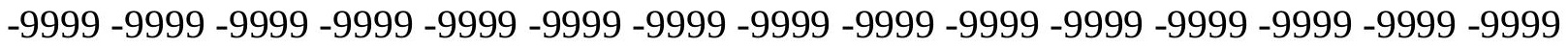

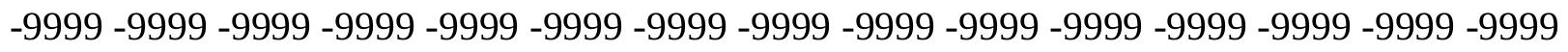
-21.3349609375 -21.9445304871 -5.79091691971 -6.40048694611-6.7052731514 $-7.3148431778-7.61962795258-7.92441320419-7.92441320419-8.22919845581$ -8.53398323059-8.53398323059-8.53398323059-8.83876895905 -8.83876895905 $-9.14355373383-9.14355373383-9.14355373383-9.14355373383-9.44833946228$ $-9.44833946228-9.44833946228-9.44833946228-9.44833946228-9.44833946228$ $-9.44833946228-9.75312423706-9.75312423706-10.0579099655-10.0579099655$ $-10.3626899719-10.3626899719-10.6674804688-10.6674804688-10.9722604752$ $-10.9722604752-11.2770500183-11.2770500183-11.2770500183-11.2770500183$ -28.0402297974 -27.1258792877 -26.2115192413 -25.2971591949 -24.3828105927 
-23.1636695862 -22.2493095398 -22.2493095398 -22.2493095398 -22.2493095398 $-22.2493095398-22.2493095398-21.9445304871-21.6397399902-21.3349609375$ $-20.7253894806-20.115819931-19.5062503815-18.5918903351-17.6775398254$ -16.7631797791 -15.8488302231 -14.9344701767-14.0201196671 -13.1057596207 $-12.1914100647-11.2770500183-10.3626899719-9.75312423706-9.14355373383$ $-8.53398323059-7.92441320419-7.3148431778-7.01005792618-6.40048694611$ -5.79091691971 -5.18134689331 -4.57177686691 -3.35263609886 -2.13349604607 -9999 2.4382810592656 .40048694610610 .6674804687514 .6296901702917 .67753982544 19.2014598846419 .2014598846418 .5918903350817 .3727493286116 .45840072632 15.5440397262614 .934470176714 .3248996734613 .715330123913 .41055011749 13.1057596206712 .8009700775112 .8009700775112 .4961900711112 .80097007751 12.8009700775112 .8009700775113 .1057596206714 .02011966705 -9999 -9999 -9999-9999 -9999 -9999 -9999 -9999 -9999 -9999 -9999 -9999 -9999 -9999 -9999 -9999 -9999 -9999 -9999 -9999 -9999 -9999 -9999 -9999 -9999 -9999 -9999 -9999 -9999 -9999 -9999 -9999 -9999 -9999 -9999 -9999 -9999 -9999 -9999 -9999 -9999 -9999 -9999 -9999 -9999 -9999 -9999 -9999 -9999 -9999 -9999 -9999 -9999 -9999 -9999 -9999 -9999 -9999 -9999 -9999 -9999 -9999 -9999 -9999 -9999 -9999 -9999 -9999 -9999 -9999 -9999 -9999 -9999 -9999 -9999 -9999 -9999 -9999 -9999 -9999 -9999 -9999 -9999 -9999 -9999 -9999 -9999 -9999 -9999 -9999 -9999 -9999 -9999 -9999 -9999 -9999 -9999 -9999 -9999 -9999 -9999 -9999 -9999 -9999 -9999 -9999 -9999 -9999 -9999 -9999 -9999 -9999 -9999 -9999 -9999 -9999 -9999 -9999 -9999 -9999 -9999 -9999 -9999 -9999

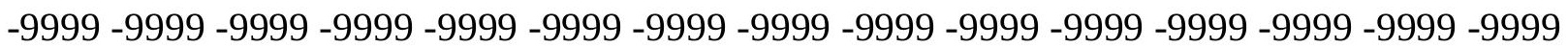

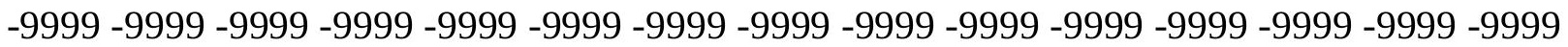
-9999 -9999 -9999 -9999 -9999 -9999 -9999 -9999 -9999 -9999

-9999 -9999 -9999 -9999 -9999 -9999 -9999 -9999 -9999 -9999 -9999 -9999 -9999 -9999 -9999

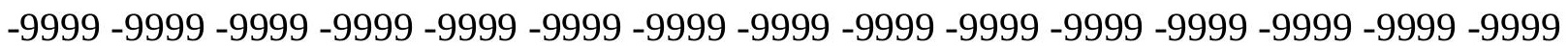
-9999 -9999 -9999 -9999 -9999 -9999 -9999 -9999 -9999 -9999 -9999 -9999 -9999 -9999 -9999 -9999 -9999 -9999 -9999 -9999 -9999 -9999 -9999 -9999 -9999 -9999 -9999 -9999 -9999 -9999 -9999 -9999 -9999 -9999 -9999 -9999 -9999 -9999 -9999 -9999 -9999 -9999 -9999 -9999 -9999 -9999 -9999 -9999 -9999 -9999 -9999 -9999 -9999 -9999 -9999 -9999 -9999 -9999 -9999 -9999 -9999 -9999 -9999 -9999 -9999 -9999 -9999 -9999 -9999 -9999 -9999 -9999 -9999 -9999 -9999 -9999 -9999 -9999 -9999 -9999 -9999 -9999 -9999 -9999 -9999 -9999 -9999 -9999 -9999 -9999 -23.1636695862 -7.01005792618 -7.61962795258 -8.22919845581 -8.53398323059 $-8.83876895905-9.14355373383-9.44833946228-9.75312423706-9.75312423706$ $-10.0579099655-10.0579099655-10.3626899719-10.3626899719-10.3626899719$ $-10.6674804688-10.6674804688-10.6674804688-10.9722604752-10.9722604752$ $-10.9722604752-10.9722604752-10.9722604752-10.9722604752-10.9722604752$ $-10.9722604752-11.2770500183-11.2770500183-11.5818300247-11.8866195679$ -11.8866195679 -11.8866195679-12.1914100647-12.1914100647-12.4961900711 -12.4961900711 -12.8009700775 -12.8009700775 -12.8009700775 -12.8009700775 -29.5641593933 -28.6497993469 -27.7354507446 -26.8210906982 -25.6019496918 $-24.6875991821-23.7732391357-23.4684505463-23.4684505463-23.4684505463$ $-23.4684505463-23.1636695862-22.8588790894-22.5541000366-22.2493095398$ -21.6397399902 -21.0301704407-20.115819931 -19.5062503815 -18.5918903351 $-17.6775398254-16.7631797791-15.5440397263-14.6296901703-13.7153301239$ $-12.8009700775-11.8866195679-10.9722604752-10.3626899719-9.44833946228$ $-8.83876895905-8.22919845581-7.92441320419-7.3148431778-7.01005792618$ 
-6.40048694611 -5.79091691971 -5.18134689331 -4.26699209213 -3.04785108566 -1.21914100647 1.219141006474.8765621185310.05790996552 15.23925971985 19.2014598846420 .4206008911119 .811029434218 .5918903350817 .37274932861 16.4584007263215 .5440397262614 .6296901702914 .0201196670513 .7153301239 13.1057596206712 .8009700775112 .8009700775112 .4961900711112 .49619007111 12.4961900711112 .4961900711112 .4961900711112 .4961900711113 .10575962067 13.7153301239 -9999 -9999 -9999 -9999 -9999 -9999 -9999 -9999 -9999 -9999 -9999 -9999

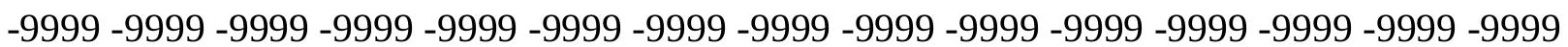
-9999 -9999 -9999 -9999 -9999 -9999 -9999 -9999 -9999 -9999 -9999 -9999 -9999 -9999 -9999 -9999 -9999 -9999 -9999 -9999 -9999 -9999 -9999 -9999 -9999 -9999 -9999 -9999 -9999 -9999 -9999 -9999 -9999 -9999 -9999 -9999 -9999 -9999 -9999 -9999 -9999 -9999 -9999 -9999 -9999 -9999 -9999 -9999 -9999 -9999 -9999 -9999 -9999 -9999 -9999 -9999 -9999 -9999 -9999 -9999

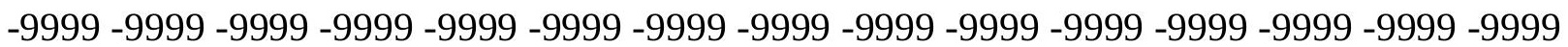
-9999 -9999 -9999 -9999 -9999 -9999 -9999 -9999 -9999 -9999 -9999 -9999 -9999 -9999 -9999 -9999 -9999 -9999 -9999 -9999 -9999 -9999 -9999 -9999 -9999 -9999 -9999 -9999 -9999 -9999

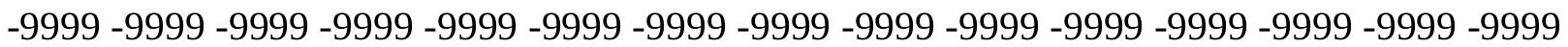
-9999 -9999 -9999 -9999 -9999 -9999 -9999 -9999 -9999 -9999 -9999 -9999 -9999 -9999 -9999 $-9999$

-9999 -9999 -9999 -9999 -9999 -9999 -9999 -9999 -9999 -9999 -9999 -9999 -9999 -9999 -9999 -9999 -9999 -9999 -9999 -9999 -9999 -9999 -9999 -9999 -9999 -9999 -9999 -9999 -9999 -9999

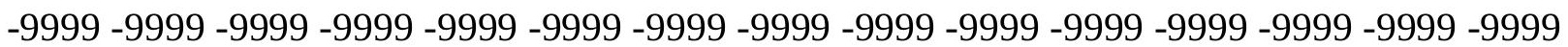
-9999 -9999 -9999 -9999 -9999 -9999 -9999 -9999 -9999 -9999 -9999 -9999 -9999 -9999 -9999 -9999 -9999 -9999 -9999 -9999 -9999 -9999 -9999 -9999 -9999 -9999 -9999 -9999 -9999 -9999 -9999 -9999 -9999 -9999 -9999 -9999 -9999 -9999 -9999 -9999 -9999 -9999 -9999 -9999 -9999

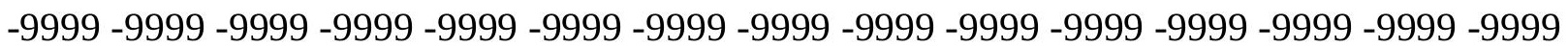
-9999 -9999 -9999 -9999 -9999 -9999 -9999 -9999 -9999 -9999 -9999 -9999 -9999 -9999 -24.3828105927 -24.9923801422 -8.83876895905 -9.44833946228 -9.75312423706 $-10.3626899719-10.6674804688-10.9722604752-11.2770500183-11.2770500183$ -11.5818300247 -11.5818300247-11.5818300247 -11.8866195679-11.8866195679 $-12.1914100647-12.1914100647-12.1914100647-12.4961900711-12.4961900711$ -12.4961900711 -12.4961900711 -12.8009700775 -12.8009700775 -12.8009700775 -12.8009700775 -12.8009700775 -12.8009700775 -13.1057596207 -13.1057596207 -13.4105501175 -13.4105501175 -13.7153301239-13.7153301239-13.7153301239 -14.0201196671 -14.0201196671 -14.3248996735 -14.3248996735 -14.3248996735 -14.3248996735 -31.0880794525 -30.1737308502 -29.2593708038 -28.3450202942 $-27.4306602478-26.5163097382-25.9067401886-25.2971591949-24.9923801422$ $-24.9923801422-24.6875991821-24.6875991821-24.0780296326-23.7732391357$ -23.1636695862 -22.5541000366 -21.9445304871 -21.3349609375 -20.4206008911 -19.5062503815 -18.287109375 -17.3727493286 -16.4584007263 -15.2392597198 -14.3248996735 -13.4105501175 -12.4961900711 -11.5818300247 -10.6674804688 -10.0579099655 -9.14355373383 -8.83876895905 -8.22919845581 -7.92441320419 $-7.3148431778-7.01005792618-6.40048694611-5.79091691971-5.18134689331$ $-4.26699209213-2.74306607246-.6095703244212 .7430660724647 .924413204193$ 14.3248996734619 .811029434220 .1158199310319 .2014598846417 .98232078552 16.7631797790515 .8488302230814 .934470176714 .3248996734613 .7153301239 13.4105501174913 .1057596206712 .8009700775112 .4961900711112 .49619007111 
12.4961900711112 .4961900711112 .4961900711112 .4961900711112 .49619007111 12.4961900711113 .1057596206713 .7153301239 -9999 -9999 -9999 -9999 -9999 -9999 -9999 -9999 -9999 -9999 -9999 -9999 -9999 -9999 -9999 -9999 -9999 -9999 -9999 -9999 -9999 -9999 -9999 -9999 -9999 -9999 -9999 -9999 -9999 -9999 -9999 -9999 -9999 -9999 -9999 -9999 -9999 -9999 -9999 -9999 -9999 -9999 -9999 -9999 -9999 -9999-9999 -9999 -9999 -9999 -9999 -9999 -9999 -9999 -9999 -9999 -9999 -9999 -9999 -9999 -9999 -9999 -9999 -9999 -9999 -9999 -9999

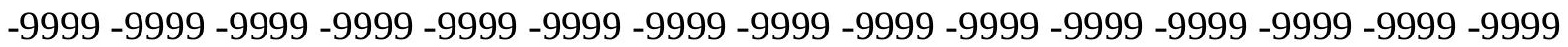

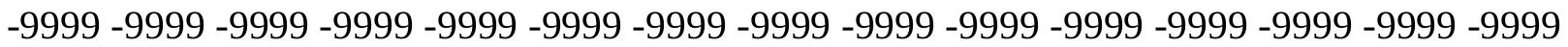

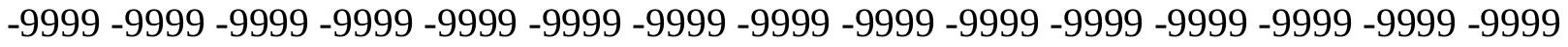
-9999 -9999 -9999 -9999 -9999 -9999 -9999 -9999 -9999 -9999 -9999 -9999 -9999 -9999 -9999

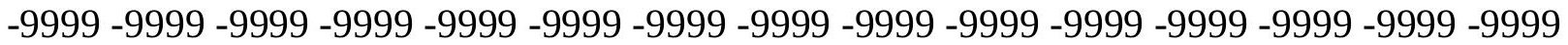

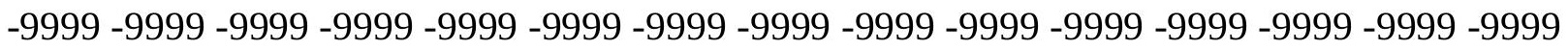
-9999 -9999-9999-9999-9999

-9999 -9999 -9999 -9999 -9999 -9999 -9999 -9999 -9999 -9999 -9999 -9999 -9999 -9999 -9999 -9999 -9999 -9999 -9999 -9999 -9999 -9999 -9999 -9999 -9999 -9999 -9999 -9999 -9999 -9999

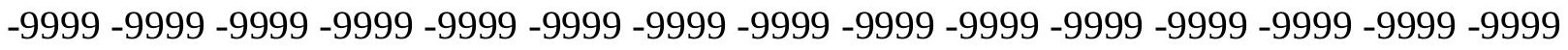
-9999 -9999 -9999 -9999 -9999 -9999 -9999 -9999 -9999 -9999 -9999 -9999 -9999 -9999 -9999 -9999 -9999 -9999 -9999 -9999 -9999 -9999 -9999 -9999 -9999 -9999 -9999 -9999 -9999 -9999 -9999 -9999 -9999 -9999 -9999 -9999 -9999 -9999 -9999 -9999 -9999 -9999 -9999 -9999 -9999 -

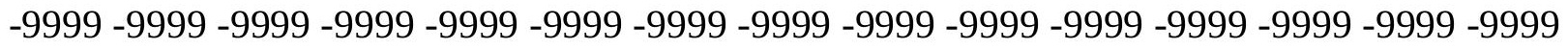
-9999 -9999 -9999 -9999 -9999 -9999 -9999 -9999 -9999 -9999 -9999 -9999 -9999 -9999 -26.2115192413 -26.8210906982 -10.6674804688 -11.2770500183 -11.5818300247 $-12.1914100647-12.4961900711-12.8009700775-12.8009700775-13.1057596207$ $-13.4105501175-13.4105501175-13.4105501175-13.4105501175-13.7153301239$ -13.7153301239-14.0201196671-14.0201196671 -14.3248996735 -14.3248996735 -14.3248996735 -14.3248996735 -14.3248996735 -14.3248996735 -14.3248996735 $-14.3248996735-14.3248996735-14.6296901703-14.6296901703-14.9344701767$ -14.9344701767 -15.2392597198 -15.2392597198 -15.2392597198 -15.5440397263 $-15.5440397263-15.8488302231-15.8488302231-15.8488302231-15.8488302231$ -16.1536102295 -32.6120109558 -32.0024414062 -31.0880794525 -30.1737308502 $-29.2593708038-28.3450202942-27.7354507446-27.4306602478-26.8210906982$ -26.5163097382 -26.2115192413 -25.9067401886 -25.6019496918 -24.9923801422 $-24.3828105927-23.7732391357-23.1636695862-22.2493095398-21.3349609375$ -20.4206008911 -19.2014598846 -18.287109375 -17.0679702759-15.8488302231 -14.9344701767 -13.7153301239-12.8009700775 -11.8866195679 -10.9722604752 $-10.3626899719-9.75312423706-9.14355373383-8.53398323059-8.22919845581$ -7.92441320419-7.3148431778 -7.01005792618 -6.7052731514-6.095703125 -5.18134689331 $-4.26699209213-2.74306607246-.3047851026065 .48613214492811 .27705001831$ 15.8488302230817 .3727493286117 .0679702758816 .4584007263215 .54403972626 14.6296901702914 .0201196670513 .4105501174913 .1057596206712 .80097007751 12.4961900711112 .4961900711112 .191410064712 .191410064712 .1914100647 12.191410064712 .191410064712 .191410064712 .191410064712 .1914100647 12.4961900711113 .1057596206714 .02011966705 -9999 -9999 -9999 -9999 -9999 -9999 -9999 -9999 -9999 -9999 -9999 -9999 -9999 -9999 -9999 -9999 -9999 -9999 -9999 -9999 -9999 -9999 -9999 -9999 -9999 -9999 -9999 -9999 -9999 -9999 -9999 -9999 -9999 -9999 -9999 -9999 -9999 -

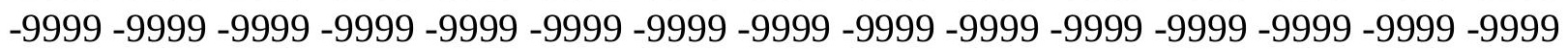


-9999 -9999 -9999 -9999 -9999 -9999 -9999 -9999 -9999 -9999 -9999 -9999 -9999 -9999 -9999 -9999 -9999 -9999 -9999 -9999 -9999 -9999 -9999 -9999 -9999 -9999 -9999 -9999 -9999 -9999 -9999 -9999 -9999 -9999 -9999 -9999 -9999 -9999 -9999 -9999 -9999 -9999 -9999 -9999 -9999 -9999 -9999 -9999 -9999 -9999 -9999 -9999 -9999 -9999 -9999 -9999 -9999 -9999 -9999 -9999 -9999 -9999 -9999 -9999 -9999 -9999 -9999 -9999 -9999 -9999 -9999 -9999 -9999 -9999 -9999 -9999 -9999 -9999 -9999 -9999 -9999 -9999 -9999 -9999 -9999 -9999 -9999 -9999 -9999 -9999 -

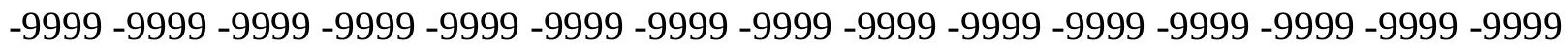
-9999 -9999-9999-9999

-9999 -9999 -9999 -9999 -9999 -9999 -9999 -9999 -9999 -9999 -9999 -9999 -9999 -9999 -9999 -9999 -9999 -9999 -9999 -9999 -9999 -9999 -9999 -9999 -9999 -9999 -9999 -9999 -9999 -9999 -9999 -9999 -9999 -9999 -9999 -9999 -9999 -9999 -9999 -9999 -9999 -9999 -9999 -9999 -9999 -9999 -9999 -9999 -9999 -9999 -9999 -9999 -9999 -9999 -9999 -9999 -9999 -9999 -9999 -9999

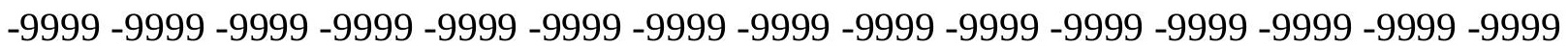
-9999 -9999 -9999 -9999 -9999 -9999 -9999 -9999 -9999 -9999 -9999 -9999 -9999 -9999 -9999 -9999 -9999 -9999 -9999 -9999 -9999 -9999 -9999 -9999 -9999 -9999 -9999 -9999 -9999 -9999 -9999 -9999 -9999 -9999 -9999 -9999 -9999 -9999 -9999 -9999 -9999 -9999 -9999 -9999 -28.0402297974 -28.6497993469-12.4961900711-13.1057596207-13.7153301239 -14.0201196671 -14.3248996735 -14.6296901703-14.9344701767 -14.9344701767 $-15.2392597198-15.2392597198-15.2392597198-15.2392597198-15.5440397263$ -15.5440397263 -15.8488302231 -15.8488302231 -16.1536102295 -16.1536102295 $-16.1536102295-16.1536102295-16.4584007263-16.4584007263-16.4584007263$ $-16.4584007263-16.4584007263-16.4584007263-16.4584007263-16.7631797791$ -16.7631797791 -16.7631797791 -17.0679702759-17.0679702759-17.0679702759 $-17.3727493286-17.3727493286-17.3727493286-17.6775398254-17.6775398254$ $-17.6775398254-17.6775398254-33.8311500549-32.9167900085-32.0024414062$ -31.3928699493 -30.478509903 -29.8689403534 -29.2593708038 -28.9545898438 $-28.3450202942-28.0402297974-27.4306602478-27.1258792877-26.5163097382$ $-25.9067401886-24.9923801422-24.0780296326-23.1636695862-22.2493095398$ $-21.3349609375-20.115819931-18.8966808319-17.6775398254-16.7631797791$ $-15.5440397263-14.3248996735-13.4105501175-12.4961900711-11.5818300247$ $-10.6674804688-10.0579099655-9.44833946228-8.83876895905-8.53398323059$ $-8.22919845581-7.92441320419-7.61962795258-7.3148431778-6.7052731514$ $-6.40048694611-5.48613214493-3.96220707893-1.219141006473 .047851085663$ 7.61962795257611 .2770500183113 .4105501174914 .0201196670514 .02011966705 13.715330123913 .1057596206712 .8009700775112 .4961900711112 .1914100647 12.191410064712 .191410064711 .8866195678711 .8866195678711 .88661956787 11.8866195678711 .8866195678711 .8866195678711 .8866195678711 .88661956787 $12.191410064712 .191410064712 .4961900711113 .1057596206714 .02011966705-9999-9999$ -9999 -9999 -9999 -9999 -9999 -9999 -9999 -9999 -9999 -9999 -9999 -9999 -9999 -9999 -9999 -9999 -9999 -9999 -9999 -9999 -9999 -9999 -9999 -9999 -9999 -9999 -9999 -9999 -9999 -9999 -9999 -9999 -9999 -9999 -9999 -9999 -9999 -9999 -9999 -9999 -9999 -9999 -9999 -9999 -9999

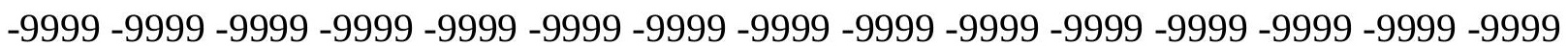
-9999 -9999 -9999 -9999 -9999 -9999 -9999 -9999 -9999 -9999 -9999 -9999 -9999 -9999 -9999 -9999 -9999 -9999 -9999 -9999 -9999 -9999 -9999 -9999 -9999 -9999 -9999 -9999 -9999 -9999 -9999 -9999 -9999 -9999 -9999 -9999 -9999 -9999 -9999 -9999 -9999 -9999 -9999 -9999 -9999

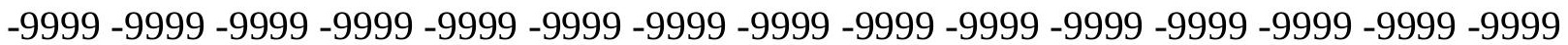


-9999 -9999 -9999 -9999 -9999 -9999 -9999 -9999 -9999 -9999 -9999 -9999 -9999 -9999 -9999 -9999 -9999 -9999 -9999 -9999 -9999 -9999 -9999 -9999 -9999 -9999 -9999 -9999 -9999 -9999 -9999 -9999 -9999 -9999 -9999 -9999 -9999 -9999

-9999 -9999 -9999 -9999 -9999 -9999 -9999 -9999 -9999 -9999 -9999 -9999 -9999 -9999 -9999

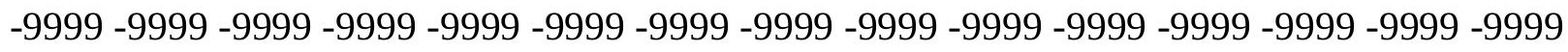
-9999 -9999 -9999 -9999 -9999 -9999 -9999 -9999 -9999 -9999 -9999 -9999 -9999 -9999 -9999 -9999 -9999 -9999 -9999 -9999 -9999 -9999 -9999 -9999 -9999 -9999 -9999 -9999 -9999 -9999

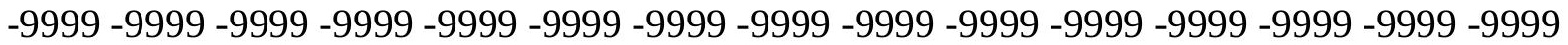

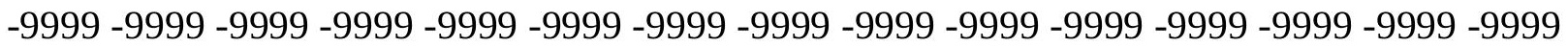
-9999 -9999 -9999 -9999 -9999 -9999 -9999 -9999 -9999 -9999 -9999 -9999 -9999 -9999 -9999 -9999 -9999 -9999 -9999 -9999 -9999 -9999 -9999 -9999 -9999 -9999 -9999 -9999 -9999 -999 -30.1737308502 -14.0201196671 -14.6296901703 -14.9344701767 -15.5440397263 -15.8488302231 -16.1536102295 -16.4584007263 -16.7631797791 -17.0679702759 -17.0679702759 -17.0679702759 -17.3727493286 -17.3727493286 -17.3727493286 -17.6775398254 -17.6775398254 -17.9823207855 -17.9823207855 -18.287109375 -18.287109375 -18.287109375 -18.287109375 -18.287109375 -18.287109375 -18.287109375 $-18.287109375-18.287109375-18.5918903351-18.5918903351-18.5918903351$ -18.5918903351 -18.8966808319-18.8966808319-18.8966808319-19.2014598846 $-19.2014598846-19.2014598846-19.2014598846-19.5062503815-19.5062503815$ -19.5062503815 -35.6598587036 -35.0502891541 -34.1359291077 -33.5263595581 $-32.6120109558-32.0024414062-31.3928699493-30.7833003998-30.1737308502$ -29.8689403534 -29.2593708038 -28.6497993469 -28.0402297974-27.1258792877 -26.2115192413 -25.2971591949 -24.3828105927 -23.4684505463 -22.2493095398 -21.0301704407 -19.8110294342 -18.5918903351 -17.3727493286-16.1536102295 $-14.9344701767-13.7153301239-12.8009700775-11.8866195679-10.9722604752$ -10.3626899719 -9.75312423706 -9.14355373383 -8.83876895905 -8.53398323059 $-8.22919845581-7.92441320419-7.61962795258$-7.3148431778 -7.01005792618 $-6.095703125-4.57177686691-2.13349604607 .91435539722444 .266992092133$ 7.3148431777959 .75312423706110 .6674804687511 .2770500183111 .27705001831 11.2770500183111 .2770500183111 .2770500183111 .2770500183111 .27705001831 11.2770500183111 .2770500183111 .2770500183111 .5818300247211 .58183002472 11.5818300247211 .5818300247211 .5818300247211 .8866195678711 .88661956787 $12.191410064712 .191410064712 .4961900711113 .4105501174914 .32489967346-9999-9999$ -9999 -9999 -9999 -9999 -9999 -9999 -9999 -9999 -9999 -9999 -9999 -9999 -9999 -9999 -9999

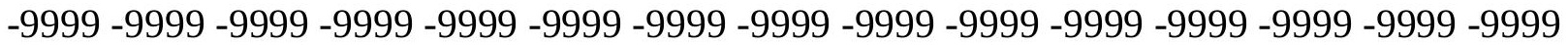
-9999 -9999 -9999 -9999 -9999 -9999 -9999 -9999 -9999 -9999 -9999 -9999 -9999 -9999 -9999 -9999 -9999 -9999 -9999 -9999 -9999 -9999 -9999 -9999 -9999 -9999 -9999 -9999 -9999 -9999

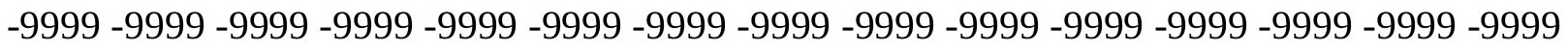
-9999 -9999 -9999 -9999 -9999 -9999 -9999 -9999 -9999 -9999 -9999 -9999 -9999 -9999 -9999 -9999 -9999 -9999 -9999 -9999 -9999 -9999 -9999 -9999 -9999 -9999 -9999 -9999 -9999 -9999 -

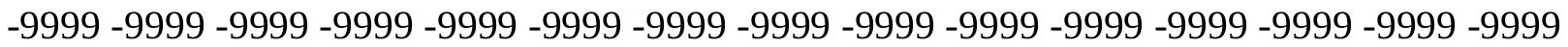
-9999 -9999 -9999 -9999 -9999 -9999 -9999 -9999 -9999 -9999 -9999 -9999 -9999 -9999 -9999 -

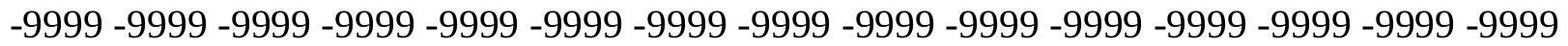
-9999 -9999 -9999 -9999 -9999 -9999 -9999 -9999 -9999 -9999 -9999 -9999 -9999 -9999 -9999 -9999 -9999 -9999 -9999 -9999 -9999 -9999

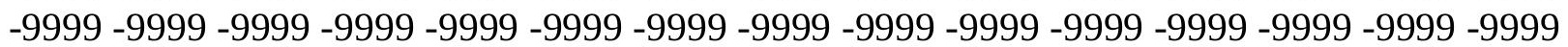


-9999 -9999 -9999 -9999 -9999 -9999 -9999 -9999 -9999 -9999 -9999 -9999 -9999 -9999 -9999 -9999 -9999 -9999 -9999 -9999 -9999 -9999 -9999 -9999 -9999 -9999 -9999 -9999 -9999 -9999 -

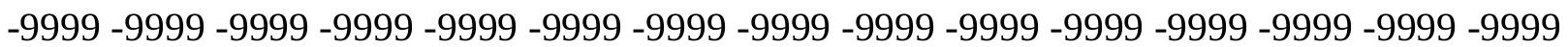
-9999 -9999 -9999 -9999 -9999 -9999 -9999 -9999 -9999 -9999 -9999 -9999 -9999 -9999 -9999 -9999 -9999 -9999 -9999 -9999 -9999 -9999 -9999 -9999 -9999 -9999 -9999 -9999 -9999 -9999 -9999 -9999 -9999 -9999 -9999 -9999 -9999 -9999 -9999 -9999 -9999 -9999 -9999 -9999 -32.307220459-16.1536102295 -16.7631797791 -17.0679702759-17.6775398254 -17.9823207855 -18.287109375 -18.5918903351 -18.8966808319 -19.2014598846 $-19.2014598846-19.5062503815-19.5062503815-19.5062503815-19.8110294342$ $-19.8110294342-19.8110294342-20.115819931-20.115819931-20.4206008911$ $-20.4206008911-20.4206008911-20.7253894806-20.7253894806-20.4206008911$ $-20.4206008911-20.4206008911-20.4206008911-20.4206008911-20.7253894806$ -20.7253894806 -20.7253894806 -20.7253894806 -20.7253894806 -20.7253894806 -21.0301704407 -21.0301704407 -21.0301704407 -21.0301704407 -21.3349609375 -21.3349609375 -21.3349609375 -37.488571167 -36.8790016174 -36.2694282532 -35.3550796509 -34.7455101013 -34.1359291077-33.5263595581 -32.9167900085 -32.307220459 -31.6976509094 -31.0880794525 -30.1737308502 -29.5641593933 -28.6497993469 -27.7354507446 -26.8210906982 -25.6019496918 -24.3828105927 -23.1636695862 -21.9445304871 -20.7253894806 -19.5062503815 -17.9823207855 $-16.7631797791-15.5440397263-14.3248996735-13.1057596207-12.1914100647$ $-11.2770500183-10.6674804688-9.75312423706-9.44833946228-8.83876895905$ $-8.53398323059-8.53398323059-8.22919845581-7.92441320419-7.92441320419$ $-7.3148431778-6.7052731514-5.18134689331-3.35263609886-.914355397224$ 1.5239260196694 .2669920921336 .0957031257 .6196279525768 .533983230591 8.8387689590459 .448339462289 .75312423706110 .0579099655210 .36268997192 10.3626899719210 .6674804687510 .6674804687510 .9722604751610 .97226047516 10.9722604751611 .2770500183111 .2770500183111 .2770500183111 .58183002472 11.5818300247211 .8866195678711 .8866195678712 .191410064712 .80097007751 13.7153301239 -9999 -9999 -9999 -9999 -9999 -9999 -9999 -9999 -9999 -9999 -9999 -9999 -9999 -9999 -9999 -9999 -9999 -9999 -9999 -9999 -9999 -9999 -9999 -9999 -9999 -9999 -9999 -9999 -9999 -9999 -9999 -9999 -9999 -9999 -9999 -9999 -9999 -9999 -9999 -9999 -9999 -9999 -9999 -9999 -9999 -9999 -9999 -9999 -9999 -9999 -9999 -9999 -9999 -9999 -9999 -9999 -9999 -9999 -9999 -9999 -9999 -9999 -9999 -9999 -9999 -9999 -9999 -9999 -9999 -9999 -9999 -9999 -9999 -9999 -9999 -9999 -9999 -9999 -9999 -9999 -9999 -9999 -9999 -9999 -9999 -9999 -9999

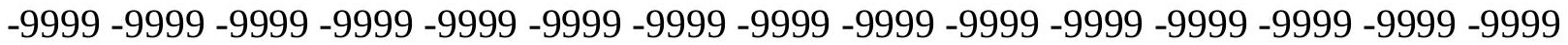
-9999 -9999 -9999 -9999 -9999 -9999 -9999 -9999 -9999 -9999 -9999 -9999 -9999 -9999 -9999 -9999 -9999 -9999 -9999 -9999 -9999 -9999 -9999 -9999 -9999 -9999 -9999 -9999 -9999 -9999

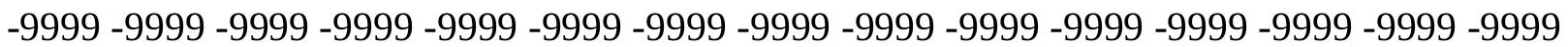
-9999 -9999 -9999 -9999 -9999 -9999 -9999 -9999 -9999 -9999 -9999 -9999 -9999 -9999 -9999 -9999 -9999 -9999 -9999 -9999 -9999 -9999 -9999 -9999 -9999 -9999 -9999 -9999 -9999 -9999 -9999 -9999 -9999 -9999 -9999 -9999 -9999 -9999 -9999 -9999 -9999 -9999

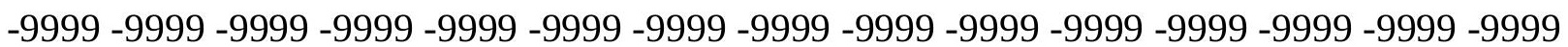
-9999 -9999 -9999 -9999 -9999 -9999 -9999 -9999 -9999 -9999 -9999 -9999 -9999 -9999 -9999 -9999 -9999 -9999 -9999 -9999 -9999 -9999 -9999 -9999 -9999 -9999 -9999 -9999 -9999 -9999 -9999 -9999 -9999 -9999 -9999 -9999 -9999 -9999 -9999 -9999 -9999 -9999 -9999 -9999 -9999

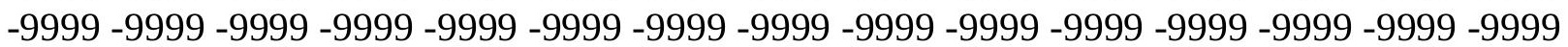


-9999 -9999 -9999 -9999 -9999 -9999 -9999 -9999 -9999 -9999 -9999 -9999 -9999 -9999 -34.4407196045 -18.287109375 -18.5918903351 -19.2014598846-19.5062503815 -20.115819931 -20.4206008911 -20.7253894806 -21.0301704407 -21.3349609375 $-21.6397399902-21.6397399902-21.9445304871-21.9445304871-21.9445304871$ $-21.9445304871-22.2493095398-22.2493095398-22.5541000366-22.8588790894$ $-22.8588790894-22.8588790894-22.8588790894-22.8588790894-22.8588790894$ $-22.8588790894-22.8588790894-22.8588790894-22.8588790894-22.8588790894$ $-22.8588790894-22.8588790894-22.8588790894-22.8588790894-22.8588790894$ $-22.8588790894-22.8588790894-22.8588790894-23.1636695862-23.1636695862$ $-23.1636695862-23.1636695862-39.6220703125-39.0125007629-38.4029312134$ -37.7933502197 -36.8790016174 -36.2694282532 -35.6598587036 -35.0502891541 $-34.1359291077-33.5263595581-32.9167900085-32.0024414062-31.0880794525$ $-30.1737308502-29.2593708038-28.0402297974-26.8210906982-25.6019496918$ -24.3828105927 -22.8588790894 -21.6397399902 -20.115819931 -18.8966808319 $-17.3727493286-16.1536102295-14.9344701767-13.7153301239-12.4961900711$ $-11.5818300247-10.6674804688-10.0579099655-9.44833946228-9.14355373383$ $-8.83876895905-8.53398323059-8.53398323059-8.22919845581-7.92441320419$ $-7.61962795258-7.01005792618-5.79091691971-4.26699209213-2.43828105927$ -.304785102606 1.219141006473.0478510856634.5717768669135.790916919708 6.7052731513987 .3148431777957 .9244132041938 .5339832305919 .143553733826 9.448339462289 .75312423706110 .0579099655210 .3626899719210 .36268997192 10.6674804687510 .9722604751610 .9722604751610 .9722604751611 .27705001831 11.2770500183111 .5818300247211 .5818300247211 .8866195678712 .1914100647 13.1057596206714 .02011966705 -9999 -9999 -9999 -9999 -9999 -9999 -9999 -9999 -9999 -9999 -9999 -9999 -9999 -9999 -9999 -9999 -9999 -9999 -9999 -9999 -9999 -9999 -9999 -9999 -9999 -9999 -9999 -9999 -9999 -9999 -9999 -9999 -9999 -9999 -9999 -9999 -9999 -9999 -9999 -9999 -9999 -9999 -9999 -9999 -9999 -9999 -9999 -9999 -9999 -9999 -9999 -9999 -9999 -9999 -9999 -9999 -9999 -9999 -9999 -9999 -9999 -9999 -9999 -9999 -9999 -9999 -9999 -9999 -9999 -9999 -9999 -9999 -9999 -9999 -9999 -9999 -9999 -9999 -9999 -9999 -9999 -9999 -9999 -9999 -9999 -9999 -9999 -9999 -9999 -9999 -9999 -9999 -9999 -9999 -9999 -9999 -9999 -9999 -999 -9999 -9999 -9999 -9999 -9999 -9999 -9999 -9999 -9999 -9999 -9999 -9999 -9999 -9999 -9999 -9999 -9999 -9999 -9999 -9999 -9999 -9999 -9999 -9999 -9999 -9999 -9999 -9999 -9999 -9999 -

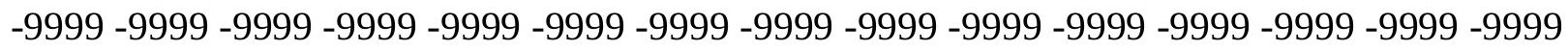
-9999 -9999 -9999 -9999 -9999 -9999 -9999 -9999 -9999 -9999 -9999 -9999 -9999 -9999 -9999 -9999 -9999 -9999 -9999 -9999 -9999 -9999 -9999 -9999 -9999 -9999 -9999 -9999 -9999

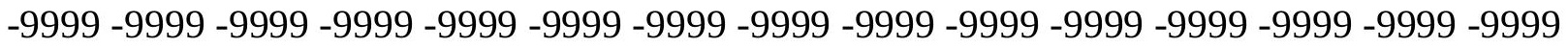

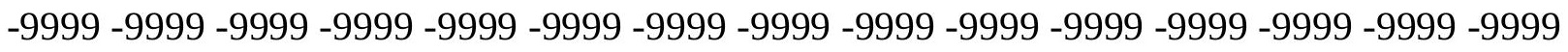

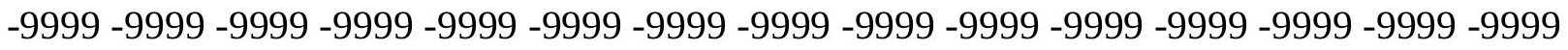
-9999 -9999 -9999 -9999 -9999 -9999 -9999 -9999 -9999 -9999 -9999 -9999 -9999 - 9999 - -999 -9999 -9999 -9999 -9999 -9999 -9999 -9999 -9999 -9999 -9999 -9999 -9999 -9999 -9999 -9999 -

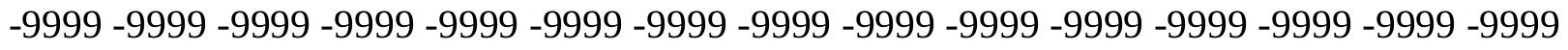
-9999 -9999 -9999 -9999 -9999 -9999 -9999 -9999 -9999 -9999 -9999 -9999 -9999 -9999 -36.5742111206 -20.115819931 -20.7253894806 -21.0301704407 -21.6397399902 $-22.2493095398-22.5541000366-22.8588790894-23.1636695862-23.7732391357$ $-24.0780296326-41.1459884644-40.8412094116-40.5364189148-40.5364189148$ $-40.2316398621-40.2316398621-40.2316398621-40.2316398621-40.5364189148$ 
$-40.8412094116-40.8412094116-41.1459884644-41.4507789612-41.7555618286$ $-42.0603485107-25.2971591949-24.9923801422-24.9923801422-24.9923801422$ -24.9923801422 -24.9923801422 -24.9923801422 -24.9923801422 -24.9923801422 $-24.9923801422-24.9923801422-24.9923801422-24.9923801422-24.9923801422$ -24.9923801422 -24.9923801422-41.4507789612 -41.1459884644-40.5364189148 -39.9268493652 -39.0125007629 -38.4029312134 -37.7933502197 -36.8790016174 $-36.2694282532-35.3550796509-34.7455101013-33.8311500549-32.9167900085$ -31.6976509094 -30.478509903 -29.5641593933 -28.0402297974 -26.8210906982 $-25.2971591949-24.0780296326-22.5541000366-21.0301704407-19.5062503815$ -17.9823207855 -16.7631797791 -15.2392597198 -14.0201196671 -12.8009700775 $-11.8866195679-10.9722604752-10.0579099655-9.44833946228-9.14355373383$ $-8.83876895905-8.53398323059-8.53398323059-8.22919845581-8.22919845581$ $-7.92441320419-7.3148431778-6.40048694611-5.18134689331-3.96220707893$ $-2.13349604607-.609570324421 .60957032442091 .8287110328673 .352636098862$ 4.5717768669135 .4861321449286 .4004869461067 .0100579261787 .924413204193 8.2291984558118 .8387689590459 .1435537338269 .448339462289 .753124237061 10.0579099655210 .3626899719210 .6674804687510 .6674804687510 .97226047516 11.2770500183111 .2770500183111 .5818300247211 .5818300247211 .88661956787 12.191410064713 .1057596206714 .02011966705 -9999 -9999 -9999 -9999 -9999 -9999 -9999 -9999 -9999 -9999 -9999 -9999 -9999 -9999 -9999 -9999 -9999 -9999 -9999 -9999 -9999 -9999

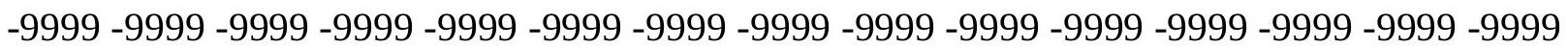
-9999 -9999 -9999 -9999 -9999 -9999 -9999 -9999 -9999 -9999 -9999 -9999 -9999 -9999 -9999 -9999 -9999 -9999 -9999 -9999 -9999 -9999 -9999 -9999 -9999 -9999 -9999 -9999 -9999 -9999 -9999 -9999 -9999 -9999 -9999 -9999 -9999 -9999 -9999 -9999 -9999 -9999 -9999 -9999 -9999

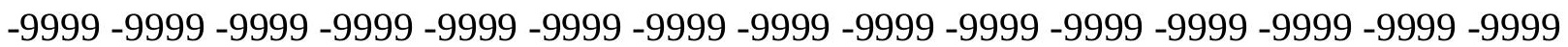
-9999 -9999 -9999 -9999 -9999 -9999 -9999 -9999 -9999 -9999 -9999 -9999 -9999 -9999 -9999 -9999 -9999 -9999 -9999 -9999 -9999 -9999 -9999 -9999 -9999 -9999 -9999 -9999 -9999 -9999 -9999 -9999 -9999 -9999 -9999 -9999 -9999 -9999 -9999 -9999 -9999 -9999 -9999 -9999 -9999

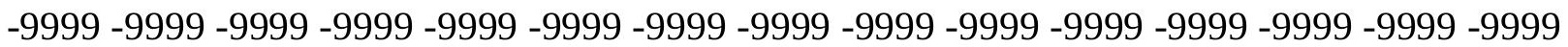
-9999 -9999 -9999 -9999 -9999 -9999 -9999 -9999 -9999 -9999 -9999 -9999 -9999 -9999 -9999 -9999 -9999 -9999 -9999 -9999 -9999 -9999 -9999 -9999 -9999 -9999 -9999 -9999 -9999 -9999 -

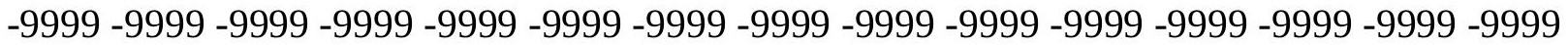
-9999 -9999 -9999 -9999 -9999 -9999 -9999 -9999 -9999 -9999 -9999 -9999 -9999 -9999 -9999 -9999 -9999 -9999 -9999 -9999 -9999 -9999 -9999 -9999 -9999 -9999 -9999 -9999 -9999 -9999 -

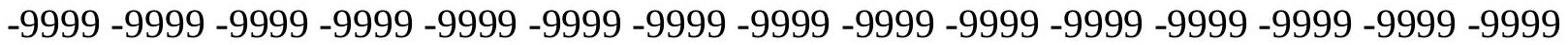
-9999 -9999 -9999 -9999 -9999 -9999 -9999 -9999 -9999 -9999 -9999 -9999 -9999 -9999 -9999 -9999 -9999 -9999 -9999 -9999 -9999 -9999 -9999 -9999 -9999 -9999 -9999 -9999 -9999 -38.4029312134-21.9445304871 -22.5541000366 -23.1636695862 -23.7732391357 -24.3828105927 -24.9923801422 -25.6019496918 -25.9067401886-42.669921875 $-42.3651313782-42.0603485107-41.7555618286-41.4507789612-41.1459884644$ $-41.1459884644-41.1459884644-41.1459884644-41.1459884644-41.4507789612$ $-41.4507789612-41.7555618286-42.0603485107-42.3651313782-42.669921875$ $-42.9747009277-43.2794914246-43.8890609741-44.1938400269-27.4306602478$ $-27.4306602478-27.1258792877-27.1258792877-27.1258792877-27.1258792877$ -27.1258792877 -27.1258792877 -27.1258792877 -27.1258792877 -27.1258792877 $-27.1258792877-27.1258792877-43.5842704773-42.9747009277-42.3651313782$ 
$-41.7555618286-41.1459884644-40.5364189148-39.9268493652-39.0125007629$ -38.4029312134 -37.488571167 -36.5742111206 -35.6598587036 -34.4407196045 -33.5263595581 -32.307220459 -30.7833003998 -29.5641593933 -28.0402297974 $-26.5163097382-24.9923801422-23.4684505463-21.9445304871-20.4206008911$ -18.5918903351 -17.0679702759-15.8488302231 -14.3248996735 -13.1057596207 -11.8866195679 -10.9722604752 -10.0579099655 -9.44833946228 -8.83876895905 -8.53398323059 -8.53398323059-8.22919845581 -8.22919845581 -8.22919845581 $-7.92441320419-7.61962795258-7.01005792618-6.095703125-5.18134689331$ $-3.65742206573-2.43828105927-1.21914100647-99991.219141006472 .438281059265$ 3.6574220657354 .5717768669135 .4861321449286 .4004869461067 .010057926178 7.9244132041938 .2291984558118 .8387689590459 .1435537338269 .753124237061 10.0579099655210 .0579099655210 .3626899719210 .6674804687510 .97226047516 10.9722604751611 .2770500183111 .5818300247211 .5818300247211 .88661956787 12.4961900711113 .4105501174914 .32489967346 -9999 -9999 -9999 -9999 -9999 -9999 -9999 -9999 -9999 -9999 -9999 -9999 -9999 -9999 -9999 -9999 -9999 -9999 -9999 -9999 -9999 -9999

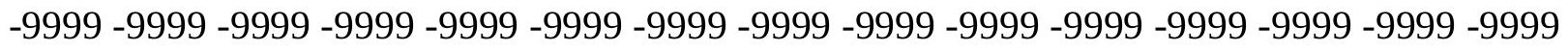
-9999 -9999 -9999 -9999 -9999 -9999 -9999 -9999 -9999 -9999 -9999 -9999 -9999 -9999 -9999 -9999 -9999 -9999 -9999 -9999 -9999 -9999 -9999 -9999 -9999 -9999 -9999 -9999 -9999 -9999 -

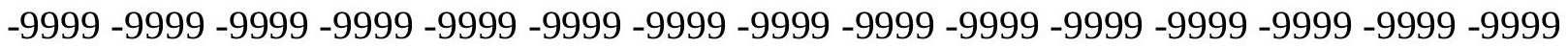

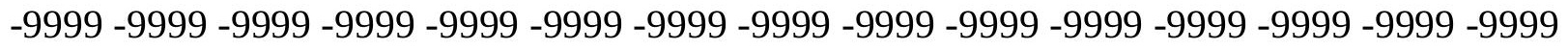

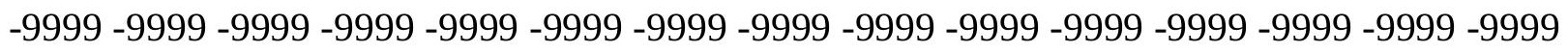

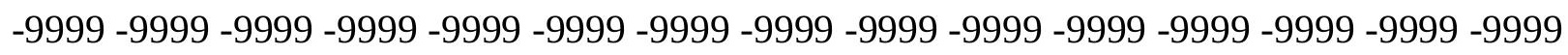
-9999 -9999 -9999 -9999 -9999 -9999 -9999 -9999 -9999 -9999 -9999 -9999 -9999 -9999 -9999 -

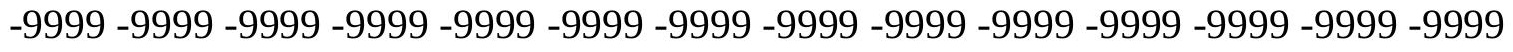

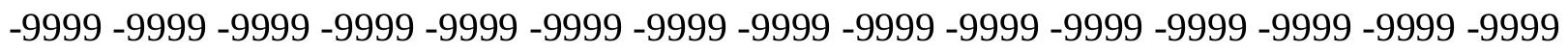
-9999 -9999 -9999 -9999 -9999 -9999 -9999 -9999 -9999 -9999 -9999 -9999 -9999 -9999 -9999

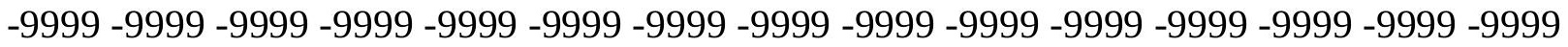

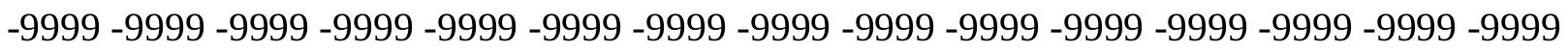
-9999 -9999 -9999 -9999 -9999 -9999 -9999 -9999 -9999 -9999 -9999 -9999 -9999 -9999 -9999 -9999 -9999 -9999 -9999 -9999 -9999 -9999 -9999 -9999 -9999 -9999 -9999 -9999 -9999 -9999 -9999 -9999 -9999 -9999 -9999 -9999 -9999 -9999 -9999 -9999 -9999 -9999 -9999 -9999 -9999 -9999 -9999 -9999 -9999 -9999 -9999 -9999 -9999 -9999 -9999 -9999 -9999 -9999 -9999 -39.9268493652 -23.7732391357-24.3828105927-24.9923801422 -25.9067401886 $-26.5163097382-27.4306602478-44.4986305237-44.1938400269-43.8890609741$ $-43.2794914246-42.9747009277-42.3651313782-42.0603485107-41.7555618286$ $-41.7555618286-41.7555618286-41.7555618286-41.7555618286-42.0603485107$ $-42.3651313782-42.669921875-42.9747009277-43.2794914246-43.8890609741$ $-44.1938400269-44.4986305237-44.8034095764-45.1082000732-45.412979126$ $-45.7177696228-46.0225486755-46.3273391724-29.5641593933-29.5641593933$ -29.5641593933 -29.5641593933 -29.5641593933 -29.5641593933 -29.5641593933 -29.2593708038 -46.0225486755 -45.412979126-45.1082000732 -44.4986305237 $-43.8890609741-43.2794914246-42.669921875-42.0603485107-41.1459884644$ $-40.2316398621-39.3172798157-38.4029312134-37.488571167-36.2694282532$ $-35.0502891541-33.8311500549-32.307220459-30.7833003998-29.2593708038$ $-27.7354507446-26.2115192413-24.3828105927-22.8588790894-21.0301704407$ $-19.5062503815-17.6775398254-16.1536102295-14.6296901703-13.1057596207$ 
-11.8866195679 -10.9722604752 -10.0579099655 -9.14355373383 -8.83876895905 -8.53398323059 -8.22919845581 -8.22919845581 -8.22919845581 -8.22919845581 -7.92441320419 -7.92441320419 -7.3148431778-6.7052731514-6.095703125 -5.18134689331 $-3.96220707893-3.04785108566-1.82871103287-.304785102606 .6095703244209$ 1.8287110328673 .0478510856633 .9622070789345 .1813468933116 .095703125 6.7052731513987 .3148431777957 .9244132041938 .5339832305919 .143553733826 9.448339462289 .75312423706110 .0579099655210 .3626899719210 .36268997192 10.6674804687510 .9722604751611 .2770500183111 .5818300247211 .88661956787 12.191410064712 .8009700775113 .7153301239 -9999 -9999 -9999 -9999 -9999 -9999 -9999 -9999 -9999 -9999 -9999 -9999 -9999 -9999 -9999 -9999 -9999 -9999 -9999 -9999 -9999 -9999 -9999 -9999 -9999 -9999 -9999 -9999 -9999 -9999 -9999 -9999 -9999 -9999 -9999 -9999 -9999 -999 -9999 -9999 -9999 -9999 -9999 -9999 -9999 -9999 -9999 -9999 -9999 -9999 -9999 -9999 -9999 -999 -9999 -9999 -9999 -9999 -9999 -9999 -9999 -9999 -9999 -9999 -9999 -9999 -9999 -9999 -9999 -9999 -9999 -9999 -9999 -9999 -9999 -9999 -9999 -9999 -9999 -9999 -9999 -9999 -9999 -9999 -9999 -9999 -9999 -9999 -9999 -9999 -9999 -9999 -9999 -9999 -9999 -9999 -9999 -9999 -9999

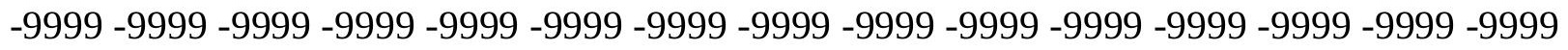
-9999 -9999 -9999 -9999 -9999 -9999 -9999 -9999 -9999 -9999 -9999 -9999 -9999 -9999 -9999 -9999 -9999 -9999 -9999 -9999 -9999 -9999 -9999 -9999 -9999 -9999 -9999 -9999 -9999 -9999 -9999 -9999 -9999 -9999 -9999 -9999 -9999 -9999 -9999 -9999 -9999 -9999 -9999 -9999 -

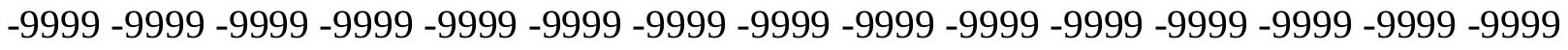

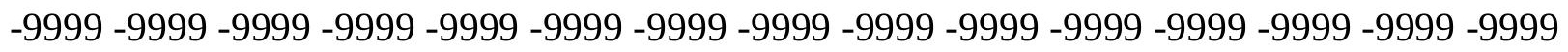

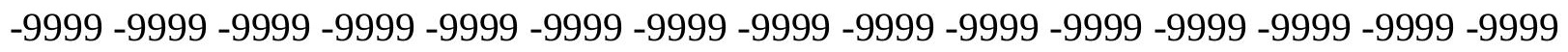
-9999 -9999 -9999 -9999 -9999 -9999 -9999 -9999 -9999 -9999 -9999 -9999 -9999 -9999 -9999 -

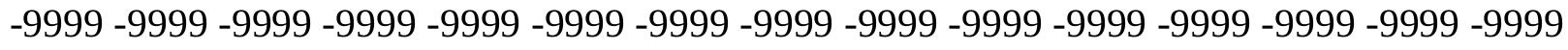

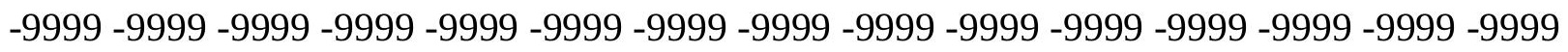

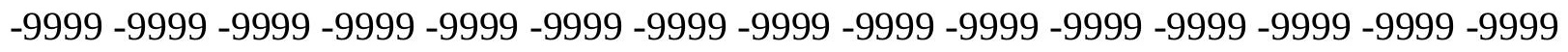
-9999 -9999 -9999 -9999 -9999 -9999 -9999 -9999 -9999 -9999 -9999 -9999 -9999 $-40.8412094116-41.4507789612$-25.2971591949 -25.9067401886 -26.8210906982 $-27.7354507446-28.9545898438-45.7177696228-45.412979126-45.1082000732$ $-44.4986305237-44.1938400269-43.5842704773-42.9747009277-42.669921875$ $-42.3651313782-42.0603485107-42.0603485107-42.3651313782-42.3651313782$ $-42.669921875-42.9747009277-43.5842704773-43.8890609741-44.1938400269$ $-44.8034095764-45.1082000732-45.412979126-46.0225486755-46.3273391724$ $-46.6321296692-46.9369087219-47.5464782715-47.5464782715-47.8512611389$ -48.1560516357-48.1560516357-48.4608306885 -48.4608306885 -48.4608306885 $-48.1560516357-48.1560516357-47.8512611389-47.5464782715-46.9369087219$ $-46.6321296692-46.0225486755-45.412979126-44.8034095764-43.8890609741$ $-43.2794914246-42.3651313782-41.4507789612-40.2316398621-39.3172798157$ -38.0981407166 -36.5742111206 -35.3550796509 -33.8311500549 -32.307220459 $-30.7833003998-28.9545898438-27.4306602478-25.6019496918-23.7732391357$ $-21.9445304871-20.115819931-18.287109375-16.4584007263-14.9344701767$ -13.4105501175 -11.8866195679 -10.6674804688 -9.75312423706 -9.14355373383 $-8.53398323059-7.92441320419-7.92441320419-7.92441320419-7.92441320419$ $-7.92441320419-7.92441320419-7.92441320419-7.92441320419-7.61962795258$ $-7.01005792618-6.40048694611-5.48613214493-4.57177686691-3.35263609886$ -2.13349604607 -.914355397224 -9999 1.523926019669 2.438281059265 3.657422065735 
4.5717768669135 .4861321449286 .4004869461067 .3148431777957 .924413204193 8.2291984558118 .8387689590459 .1435537338269 .448339462289 .753124237061 10.0579099655210 .3626899719210 .6674804687510 .9722604751611 .27705001831 $11.5818300247211 .8866195678712 .191410064713 .1057596206714 .02011966705-9999$ -9999 -9999 -9999 -9999 -9999 -9999 -9999 -9999 -9999 -9999 -9999 -9999 -9999 -9999 -9999 -9999 -9999 -9999 -9999 -9999 -9999 -9999 -9999 -9999 -9999 -9999 -9999 -9999 -9999 -9999 -9999 -9999 -9999 -9999 -9999 -9999 -9999 -9999 -9999 -9999 -9999 -9999 -9999 -9999 -9999 -9999 -9999 -9999 -9999 -9999 -9999 -9999 -9999 -9999 -9999 -9999 -9999 -9999 -9999 -9999

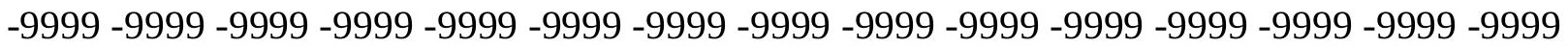
-9999 -9999 -9999 -9999 -9999 -9999 -9999 -9999 -9999 -9999 -9999 -9999 -9999 -9999 -9999 -

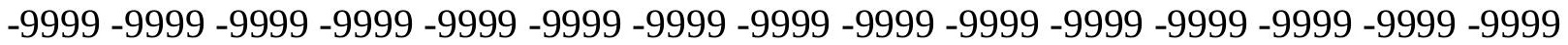
-9999 -9999 -9999 -9999 -9999 -9999 -9999 -9999 -9999 -9999 -9999 -9999 -9999 -9999 -9999

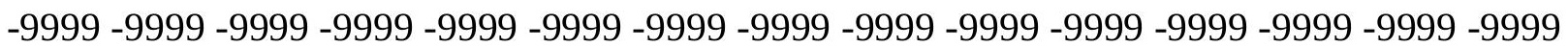
-9999 -9999 -9999 -9999 -9999 -9999 -9999 -9999 -9999 -9999 -9999 -9999 -9999 -9999 -9999 -9999 -9999-9999-9999

-9999 -9999 -9999 -9999 -9999 -9999 -9999 -9999 -9999 -9999 -9999 -9999 -9999 -9999 -9999

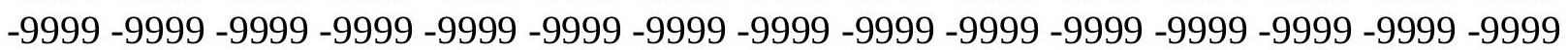
-9999 -9999 -9999 -9999 -9999 -9999 -9999 -9999 -9999 -9999 -9999 -9999 -9999 -9999 -9999 -9999 -9999 -9999 -9999 -9999 -9999 -9999 -9999 -9999 -9999 -9999 -9999 -9999 -9999 -9999 -9999 -9999 -9999 -9999 -9999 -9999 -9999 -9999 -9999 -9999 -9999 -9999 -9999 -9999 -9999

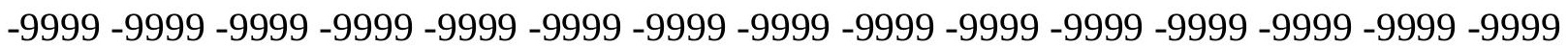

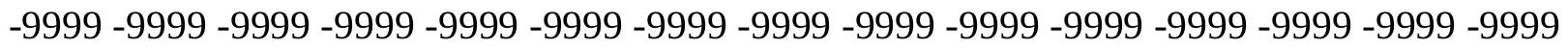
-9999 -9999 -9999 -9999 -9999 -9999 -9999 -9999 -9999 -9999 -9999 -9999 -9999 $-42.0603485107-42.3651313782-42.9747009277-27.1258792877-28.0402297974$ -29.5641593933 -46.6321296692-46.6321296692-46.3273391724-46.0225486755 $-45.412979126-44.4986305237-43.8890609741-43.2794914246-42.9747009277$ -42.669921875 -42.669921875-42.669921875 -42.669921875-42.9747009277 -43.2794914246 $-43.8890609741-44.1938400269-44.8034095764-45.1082000732-45.7177696228$ $-46.0225486755-46.6321296692-46.9369087219-47.5464782715-47.8512611389$ -48.1560516357-48.4608306885 -49.070400238-49.3751907349 -49.3751907349 $-49.6799812317-49.6799812317-49.9847602844-49.9847602844-49.9847602844$ $-49.6799812317-49.6799812317-49.3751907349-49.070400238-48.4608306885$ $-48.1560516357-47.5464782715-46.9369087219-46.0225486755-45.1082000732$ $-44.1938400269-43.2794914246-42.3651313782-41.1459884644-39.9268493652$ -38.4029312134 -36.8790016174 -35.3550796509-33.8311500549 -32.0024414062 -30.478509903 -28.6497993469 -26.5163097382 -24.6875991821 -22.8588790894 -20.7253894806 -18.8966808319-17.0679702759 -15.2392597198 -13.4105501175 $-11.8866195679-10.6674804688-9.44833946228-8.53398323059-7.92441320419$ $-7.61962795258-7.3148431778-7.3148431778-7.61962795258-7.61962795258$ $-7.92441320419-8.22919845581-8.22919845581-8.22919845581-7.92441320419$ $-7.3148431778-6.7052731514-5.79091691971-4.87656211853-3.65742206573$ -2.74306607246 -1.21914100647-9999.9143553972244 2.133496046066 3.352636098862 4.5717768669135 .4861321449286 .4004869461067 .0100579261787 .619627952576 8.2291984558118 .5339832305918 .8387689590459 .1435537338269 .753124237061 10.0579099655210 .3626899719210 .6674804687510 .9722604751611 .27705001831 $11.5818300247212 .191410064712 .4961900711113 .4105501174914 .62969017029-9999$ 
-9999 -9999 -9999 -9999 -9999 -9999 -9999 -9999 -9999 -9999 -9999 -9999 -9999 -9999 -9999 -9999 -9999 -9999 -9999 -9999 -9999 -9999 -9999 -9999 -9999 -9999 -9999 -9999 -9999 -9999 -9999 -9999 -9999 -9999 -9999 -9999 -9999 -9999 -9999 -9999 -9999 -9999 -9999 -9999 -9999 -9999 -9999 -9999 -9999 -9999 -9999 -9999 -9999 -9999 -9999 -9999 -9999 -9999 -9999 -9999 -9999 -9999 -9999 -9999 -9999 -9999 -9999 -9999 -9999 -9999 -9999 -9999 -9999 -9999 -9999 -9999 -9999 -9999 -9999 -9999 -9999 -9999 -9999 -9999 -9999 -9999 -9999 -9999 -9999 -9999 -9999 -9999 -9999 -9999 -9999 -9999 -9999 -9999 -9999 -9999 -9999 -9999 -9999 -9999 -9999

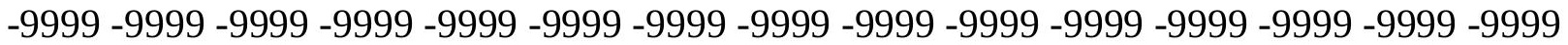
-9999 -9999 -9999 -9999 -9999 -9999 -9999 -9999 -9999 -9999 -9999 -9999 -9999 -9999 -9999 -9999 -9999 -9999 -9999 -9999 -9999 -9999 -9999 -9999 -9999 -9999 -9999 -9999 -9999 -9999 -9999-9999-9999

-9999 -9999 -9999 -9999 -9999 -9999 -9999 -9999 -9999 -9999 -9999 -9999 -9999 -9999 -9999 -9999 -9999 -9999 -9999 -9999 -9999 -9999 -9999 -9999 -9999 -9999 -9999 -9999 -9999 -9999 -9999 -9999 -9999 -9999 -9999 -9999 -9999 -9999 -9999 -9999 -9999 -9999 -9999 -9999 -9999 -9999 -9999 -9999 -9999 -9999 -9999 -9999 -9999 -9999 -9999 -9999 -9999 -9999 -9999 -9999

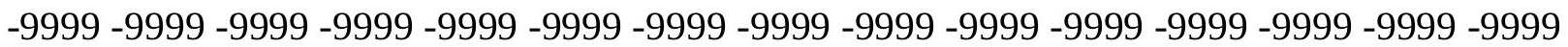

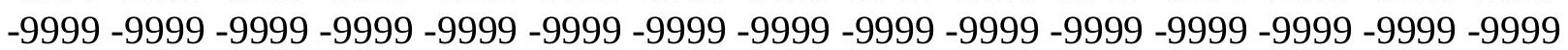
-9999 -9999 -9999 -9999 -9999 -9999 -9999 -9999 -9999 -9999 -9999 -9999 -9999 -9999 -9999 -9999 -9999 -9999 -9999 -9999 -9999 -9999 -9999 -9999 -9999 -9999 -9999 -42.0603485107 $-42.669921875-43.2794914246-43.8890609741-28.0402297974-29.2593708038$ $-47.2416992188-47.5464782715-47.5464782715-46.9369087219-46.3273391724$ $-45.7177696228-45.1082000732-44.1938400269-43.5842704773-42.9747009277$ $-42.9747009277-42.669921875-42.9747009277-42.9747009277-43.5842704773$ $-43.8890609741-44.4986305237-44.8034095764-45.412979126-46.0225486755$ $-46.6321296692-46.9369087219-47.5464782715-48.1560516357-48.4608306885$ $-49.070400238-49.3751907349-49.6799812317-50.2895507812-50.594329834$ $-50.8991203308-50.8991203308-51.2038993835-51.5086898804-51.5086898804$ $-51.5086898804-51.5086898804-51.2038993835-51.2038993835-50.8991203308$ $-50.2895507812-49.9847602844-49.3751907349-48.7656211853-48.1560516357$ $-47.2416992188-46.3273391724-45.1082000732-44.1938400269-42.9747009277$ $-41.4507789612-40.2316398621-38.7077102661-36.8790016174-35.3550796509$ -33.5263595581 -31.6976509094 -29.8689403534 -27.7354507446 -25.6019496918 -23.7732391357 -21.6397399902 -19.5062503815 -17.3727493286 -15.5440397263 -13.7153301239-11.8866195679-10.3626899719-9.14355373383 -8.22919845581 -7.3148431778 -7.01005792618 -7.01005792618 -7.01005792618 -7.3148431778 $-7.61962795258-7.92441320419-8.22919845581-8.53398323059-8.83876895905$ $-8.83876895905-8.53398323059-8.22919845581-7.3148431778-6.7052731514$ $-5.48613214493-4.26699209213-3.04785108566-1.82871103287-.304785102606$ .60957032442092 .1334960460663 .3526360988624 .2669920921335 .181346893311 6.0957031256 .705273151398 7.314843177795 7.924413204193 8.229198455811 8.8387689590459 .1435537338269 .448339462289 .75312423706110 .36268997192 10.6674804687510 .9722604751611 .2770500183111 .8866195678712 .1914100647 12.8009700775113 .715330123914 .9344701767 -9999 -9999 -9999 -9999 -9999 -9999 -9999 -9999 -9999 -9999 -9999 -9999 -9999 -9999 -9999 -9999 -9999 -9999 -9999 -9999 -9999 -9999 -9999 -9999 -9999 -9999 -9999 -9999 -9999 -9999 -9999 -9999 -9999 -9999 -9999 -9999 -9999

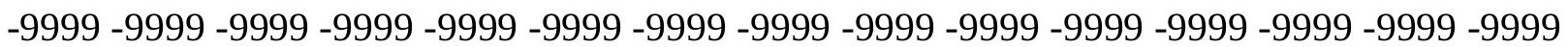


-9999 -9999 -9999 -9999 -9999 -9999 -9999 -9999 -9999 -9999 -9999 -9999 -9999 -9999 -9999 -9999 -9999 -9999 -9999 -9999 -9999 -9999 -9999 -9999 -9999 -9999 -9999 -9999 -9999 -9999 -9999 -9999 -9999 -9999 -9999 -9999 -9999 -9999 -9999 -9999 -9999 -9999 -9999 -9999 -9999 -9999 -9999 -9999 -9999 -9999 -9999 -9999 -9999 -9999 -9999 -9999 -9999 -9999 -9999 -9999 -9999 -9999 -9999 -9999 -9999 -9999 -9999 -9999 -9999 -9999 -9999 -9999 -9999 -9999 -9999 -9999 -9999 -9999 -9999 -9999 -9999 -9999 -9999 -9999 -9999 -9999 -9999 -9999 -9999 -9999 -999 -9999 -9999 -9999 -9999 -9999 -9999 -9999 -9999 -9999 -9999 -9999 -9999 -9999 -9999 -9999 -9999 -9999 -9999 -9999 -9999 -9999 -9999 -9999 -9999 -9999 -9999 -9999 -9999 -9999 -9999 -9999 -9999 -9999 -9999 -9999 -9999 -9999 -9999 -9999 -9999 -9999 -9999 -9999 -9999 -9999 -9999 -9999 -9999 -9999 -9999 -9999 -9999 -9999 -9999 -9999 -9999 -9999 -9999 -9999 -9999 -9999 -9999 -9999 -9999 -9999 -9999 -9999 -9999 -9999 -9999 -9999 -9999 -9999 -9999 -9999 -9999 -9999 -9999 -9999 -9999 -9999 -9999 -9999 -9999 -9999 -9999

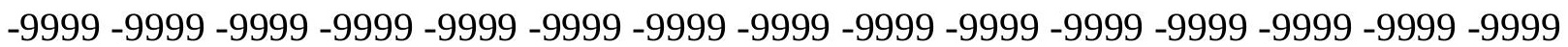
-9999 -9999 -9999 -9999 -9999 -9999 -9999 -9999 -9999 -9999 -9999 -9999 -9999 -9999 -9999 -9999 -9999 -9999 -9999 -9999 -9999 -9999 -9999 -9999 -9999 -9999 -9999 -42.3651313782 $-43.2794914246-43.8890609741-44.4986305237-28.6497993469-29.8689403534$ $-47.5464782715-47.8512611389-47.8512611389-47.5464782715-46.9369087219$ $-46.0225486755-45.1082000732-44.1938400269-43.5842704773-42.9747009277$ $-42.9747009277-42.9747009277-42.9747009277-43.5842704773-43.8890609741$ $-44.4986305237-45.1082000732-45.7177696228-46.3273391724-46.9369087219$ $-47.5464782715-47.8512611389-48.4608306885-49.070400238-49.3751907349$ $-49.9847602844-50.2895507812-50.8991203308-51.2038993835$-51.5086898804 $-52.1182594299-52.4230384827-52.4230384827-52.7278289795-53.0326118469$ $-53.0326118469-53.0326118469-53.0326118469-52.7278289795-52.4230384827$ $-52.1182594299-51.8134689331-51.2038993835-50.594329834-49.9847602844$ $-49.070400238-48.1560516357-47.2416992188-46.0225486755-44.8034095764$ $-43.2794914246-41.7555618286-40.2316398621-38.7077102661-36.8790016174$ -35.0502891541 -32.9167900085 -31.0880794525 -28.9545898438 -26.8210906982 $-24.6875991821-22.2493095398-20.115819931-17.9823207855-15.8488302231$ -13.7153301239-11.8866195679-10.0579099655 -8.83876895905 -7.61962795258 $-6.7052731514-6.40048694611-6.40048694611-6.40048694611-6.7052731514$ -7.3148431778 -7.92441320419-8.53398323059-9.14355373383 -9.44833946228 $-9.75312423706-9.75312423706-9.44833946228-9.14355373383-8.22919845581$ $-7.3148431778-6.40048694611-5.18134689331-3.65742206573-2.13349604607$ -.609570324421.6095703244209 2.1334960460663.0478510856634.266992092133 4.876562118535 .7909169197086 .4004869461067 .0100579261787 .619627952576 7.9244132041938 .5339832305918 .8387689590459 .448339462289 .753124237061 10.3626899719210 .6674804687510 .9722604751611 .5818300247211 .88661956787 12.4961900711113 .1057596206714 .02011966705 -9999 -9999 -9999 -9999 -9999 -9999 -9999 -9999 -9999 -9999 -9999 -9999 -9999 -9999 -9999 -9999 -9999 -9999 -9999 -9999 -9999 -9999 -9999 -9999 -9999 -9999 -9999 -9999 -9999 -9999 -9999 -9999 -9999 -9999 -9999 -9999 -9999

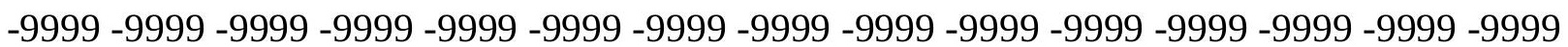
-9999 -9999 -9999 -9999 -9999 -9999 -9999 -9999 -9999 -9999 -9999 -9999 -9999 -9999 -9999 -9999 -9999 -9999 -9999 -9999 -9999 -9999 -9999 -9999 -9999 -9999 -9999 -9999 -9999 -9999 -9999 -9999 -9999 -9999 -9999 -9999 -9999 -9999 -9999 -9999 -9999 -9999 -9999 -9999 -9999

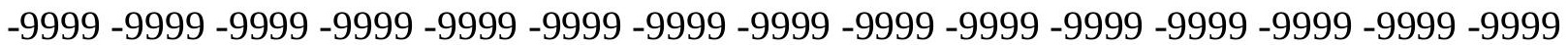


-9999 -9999 -9999 -9999 -9999 -9999 -9999 -9999 -9999 -9999 -9999 -9999 -9999 -9999 -9999 -9999 -9999 -9999 -9999 -9999 -9999 -9999 -9999 -9999 -9999 -9999 -9999 -9999 -9999 -9999 -9999 -9999 -9999 -9999 -9999 -9999 -9999 -9999 -9999 -9999 -9999

-9999 -9999 -9999 -9999 -9999 -9999 -9999 -9999 -9999 -9999 -9999 -9999 -9999 -9999 -9999 -9999 -9999 -9999 -9999 -9999 -9999 -9999 -9999 -9999 -9999 -9999 -9999 -9999 -9999 -9999 -9999 -9999 -9999 -9999 -9999 -9999 -9999 -9999 -9999 -9999 -9999 -9999 -9999 -9999 -9999 -9999 -9999 -9999 -9999 -9999 -9999 -9999 -9999 -9999 -9999 -9999 -9999 -9999 -9999 -9999

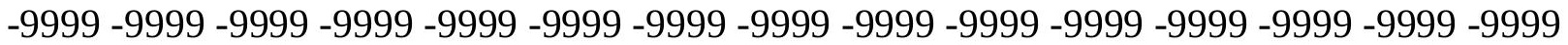
-9999 -9999 -9999 -9999 -9999 -9999 -9999 -9999 -9999 -9999 -9999 -9999 -9999 -9999 -9999 -9999 -9999 -9999 -9999 -9999 -9999 -9999 -9999 -9999 -9999 -9999 -9999 -9999 -9999 -9999 -9999 -9999 -9999 -9999 -9999 -9999 -9999 -9999 -9999 -9999 -9999-41.1459884644 $-42.3651313782-43.2794914246-44.1938400269-44.8034095764-45.412979126$ -30.1737308502 -47.8512611389-48.1560516357-48.1560516357-47.8512611389 $-46.9369087219-46.0225486755-45.1082000732-44.1938400269-43.5842704773$ $-42.9747009277-42.669921875-42.9747009277-43.2794914246-43.8890609741$ $-44.4986305237-45.1082000732-45.7177696228-46.3273391724-46.9369087219$ $-47.5464782715-48.1560516357-48.7656211853-49.3751907349-49.9847602844$ $-50.594329834-50.8991203308-51.5086898804-51.8134689331-52.4230384827$ $-52.7278289795-53.0326118469-53.6421813965-53.9469718933-53.9469718933$ $-54.251750946-54.5565414429-54.5565414429-54.5565414429-54.5565414429$ $-54.251750946-53.9469718933-53.6421813965-53.0326118469-52.4230384827$ -51.8134689331 -50.8991203308 -49.9847602844 -49.070400238 -47.8512611389 $-46.6321296692-45.1082000732-43.5842704773-42.0603485107-40.2316398621$ $-38.4029312134-36.5742111206-34.4407196045-32.307220459-30.1737308502$ $-28.0402297974-25.6019496918-23.1636695862-21.0301704407-18.5918903351$ -16.1536102295 -14.0201196671 -11.8866195679-10.0579099655 -8.22919845581 $-7.01005792618-6.095703125-5.79091691971-5.48613214493-5.79091691971$ $-6.40048694611-7.01005792618-7.92441320419-8.83876895905-9.75312423706$ $-10.3626899719-10.9722604752-11.2770500183-10.9722604752-10.6674804688$ $-10.0579099655-9.44833946228-8.22919845581-7.01005792618-5.79091691971$ $-3.96220707893-2.43828105927-.609570324421 .60957032442091 .828711032867$ 2.7430660724643 .6574220657354 .5717768669135 .1813468933115 .790916919708 6.7052731513987 .3148431777957 .6196279525768 .2291984558118 .838768959045 9.448339462289 .75312423706110 .3626899719210 .6674804687511 .27705001831 $11.5818300247212 .191410064712 .4961900711113 .4105501174914 .32489967346-9999$ -9999 -9999 -9999 -9999 -9999 -9999 -9999 -9999 -9999 -9999 -9999 -9999 -9999 -9999 -9999 -9999 -9999 -9999 -9999 -9999 -9999 -9999 -9999 -9999 -9999 -9999 -9999 -9999 -9999 -9999

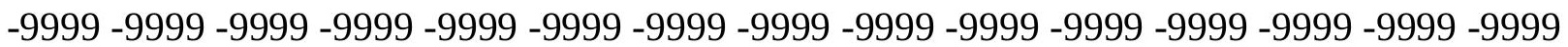
-9999 -9999 -9999 -9999 -9999 -9999 -9999 -9999 -9999 -9999 -9999 -9999 -9999 -9999 -9999 -9999 -9999 -9999 -9999 -9999 -9999 -9999 -9999 -9999 -9999 -9999 -9999 -9999 -9999 -9999 -9999 -9999 -9999 -9999 -9999 -9999 -9999 -9999 -9999 -9999 -9999 -9999 -9999 -9999 -9999

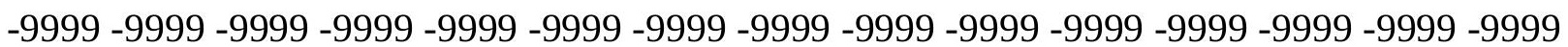
-9999 -9999 -9999 -9999 -9999 -9999 -9999 -9999 -9999 -9999 -9999 -9999 -9999 -9999 -9999 -9999 -9999 -9999 -9999 -9999 -9999 -9999 -9999 -9999 -9999 -9999 -9999 -9999 -9999 -9999 -9999 -9999 -9999 -9999 -9999 -9999 -9999 -9999 -9999 -9999 -9999 -9999 -9999 -9999 -9999 $-9999$ 
-9999 -9999 -9999 -9999 -9999 -9999 -9999 -9999 -9999 -9999 -9999 -9999 -9999 -9999 -9999 -9999 -9999 -9999 -9999 -9999 -9999 -9999 -9999 -9999 -9999 -9999 -9999 -9999 -9999 -9999 -

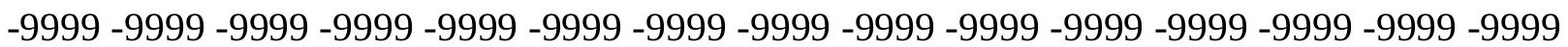
-9999 -9999 -9999 -9999 -9999 -9999 -9999 -9999 -9999 -9999 -9999 -9999 -9999 -9999 -9999 -9999 -9999 -9999 -9999 -9999 -9999 -9999 -9999 -9999 -9999 -9999 -9999 -9999 -9999 -9999 -9999 -9999 -9999 -9999 -9999 -9999 -9999 -9999 -9999 -9999 -9999 -9999 -9999 -9999 -9999 -9999 -9999 -9999 -9999 -9999 -9999 -9999 -9999 -9999 -9999 -9999 -9999 -9999 -9999 -9999 -9999 -9999 -9999 -9999 -9999 -9999 -9999 -9999 -9999 -9999 -9999-40.5364189148 $-42.0603485107-43.2794914246-43.8890609741-44.8034095764-45.412979126$ -29.8689403534 -47.8512611389-48.1560516357-48.1560516357-47.8512611389 $-46.9369087219-46.0225486755-45.1082000732-44.1938400269-43.2794914246$ $-42.669921875-42.669921875-42.9747009277-43.5842704773-44.1938400269$ $-45.1082000732-45.7177696228-46.6321296692-47.2416992188-47.8512611389$ $-48.4608306885-49.070400238-49.6799812317-50.2895507812-50.8991203308$ $-51.5086898804-51.8134689331-52.4230384827-52.7278289795-53.3373985291$ $-53.6421813965-54.251750946-54.5565414429-54.8613204956-55.1661109924$ $-55.4708900452-55.775680542-55.775680542-56.0804595947-56.0804595947$ $-55.775680542-55.4708900452-55.1661109924-54.8613204956-54.251750946$ $-53.6421813965-52.7278289795-51.8134689331-50.8991203308-49.6799812317$ $-48.1560516357-46.9369087219-45.412979126-43.5842704773-41.7555618286$ $-39.9268493652-38.0981407166-35.9646492004-33.8311500549-31.3928699493$ $-29.2593708038-26.8210906982-24.3828105927-21.6397399902-19.2014598846$ -16.7631797791 -14.0201196671 -11.8866195679 -9.75312423706 -7.92441320419 $-6.40048694611-5.48613214493-4.87656211853-4.87656211853-5.18134689331$ $-6.095703125-7.01005792618-8.22919845581-9.44833946228-10.3626899719$ $-11.5818300247-12.1914100647-12.4961900711-12.8009700775-12.8009700775$ $-12.1914100647-11.5818300247-10.3626899719-9.14355373383-7.92441320419$ $-6.095703125-4.26699209213-2.43828105927-.609570324421 .3047851026058$ 1.219141006472 .1334960460663 .0478510856633 .9622070789344 .87656211853 5.4861321449286 .4004869461067 .0100579261787 .6196279525768 .229198455811 8.8387689590459 .1435537338269 .75312423706110 .3626899719210 .66748046875 11.2770500183111 .5818300247212 .191410064712 .8009700775113 .7153301239 14.62969017029 -9999 -9999 -9999 -9999 -9999 -9999 -9999 -9999 -9999 -9999 -9999 -9999 -9999 -9999 -9999 -9999 -9999 -9999 -9999 -9999 -9999 -9999 -9999 -9999 -9999 -9999 -9999 -9999 -9999 -9999 -9999 -9999 -9999 -9999 -9999 -9999 -9999 -9999 -9999 -9999 -9999 -9999 -9999 -9999 -9999 -9999 -9999 -9999 -9999 -9999 -9999 -9999 -9999 -9999 -9999 -9999 -9999

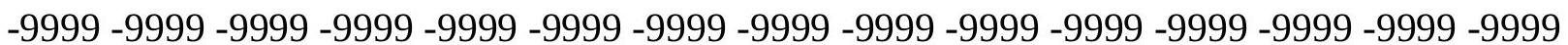

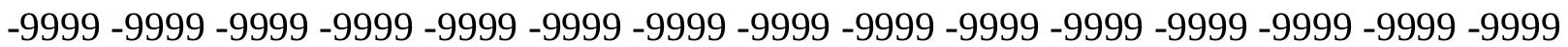
-9999 -9999 -9999 -9999 -9999 -9999 -9999 -9999 -9999 -9999 -9999 -9999 -9999 -9999 -9999 -9999 -9999 -9999 -9999 -9999 -9999 -9999 -9999 -9999 -9999 -9999 -9999 -9999 -9999 -9999 -9999 -9999 -9999 -9999 -9999 -9999 -9999 -9999 -9999 -9999 -9999 -9999 -9999 -9999 -9999

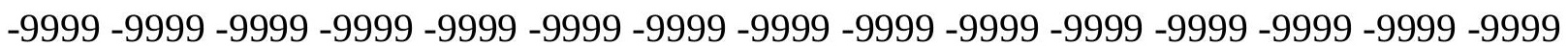
-9999 -9999-9999-9999 -9999 -9999 -9999 -9999 -9999 -9999 -9999 -9999 -9999 -9999 -9999 -9999 -9999 -9999 -9999 -9999 -9999 -9999 -9999 -9999 -9999 -9999 -9999 -9999 -9999 -9999 -9999 -9999 -9999 -9999

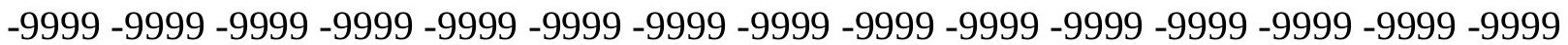


-9999 -9999 -9999 -9999 -9999 -9999 -9999 -9999 -9999 -9999 -9999 -9999 -9999 -9999 -9999 -9999 -9999 -9999 -9999 -9999 -9999 -9999 -9999 -9999 -9999 -9999 -9999 -9999 -9999 -9999 -

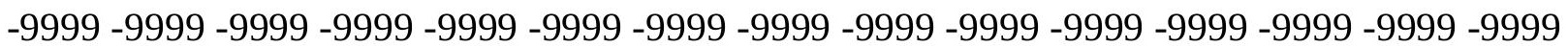
-9999 -9999 -9999 -9999 -9999 -9999 -9999 -9999 -9999 -9999 -9999 -9999 -9999 -9999 -9999 -9999 -9999 -9999 -9999 -9999 -9999 -9999 -9999 -9999 -9999 -9999 -39.9268493652 $-41.4507789612-42.9747009277-43.5842704773-44.4986305237-45.1082000732$ $-46.0225486755-47.5464782715-47.8512611389-47.8512611389-47.5464782715$ $-46.9369087219-46.0225486755-45.1082000732-43.8890609741-42.9747009277$ $-42.3651313782-42.3651313782-43.2794914246-43.8890609741-44.8034095764$ $-45.7177696228-46.6321296692-47.2416992188-48.1560516357-48.7656211853$ $-49.3751907349-49.9847602844-50.594329834-51.2038993835-51.8134689331$ -52.1182594299 -52.7278289795 -53.3373985291 -53.6421813965 -54.251750946 -54.8613204956 -55.1661109924 -55.4708900452 -56.0804595947 -56.3852500916 $-56.6900291443-56.9948196411-57.2995986938-57.2995986938-57.2995986938$ $-57.2995986938-56.9948196411-56.6900291443-56.3852500916-55.775680542$ $-55.1661109924-54.5565414429-53.6421813965-52.4230384827-51.2038993835$ $-49.9847602844-48.4608306885-46.9369087219-45.1082000732-43.5842704773$ $-41.4507789612-39.6220703125$-37.488571167 -35.0502891541 -32.9167900085 $-30.478509903-28.0402297974-25.2971591949-22.8588790894-20.115819931$ $-17.3727493286-14.6296901703-11.8866195679-9.44833946228-7.61962795258$ $-5.79091691971-4.57177686691-4.26699209213-4.26699209213-4.57177686691$ $-5.48613214493-7.01005792618-8.53398323059-10.0579099655-11.2770500183$ $-12.4961900711-13.7153301239-14.3248996735-14.6296901703-14.6296901703$ $-14.3248996735-13.7153301239-12.8009700775-11.5818300247-10.0579099655$ $-8.53398323059-6.7052731514-4.87656211853-3.04785108566-1.52392601967$ -.304785102606.6095703244209 1.5239260196692.438281059265 3.352636098862 4.2669920921335 .1813468933116 .0957031256 .7052731513987 .619627952576 8.2291984558118 .8387689590459 .1435537338269 .75312423706110 .36268997192 10.6674804687511 .2770500183111 .8866195678712 .191410064713 .10575962067 14.02011966705 -9999 -9999 -9999 -9999 -9999 -9999 -9999 -9999 -9999 -9999 -9999 -9999 -9999 -9999 -9999 -9999 -9999 -9999 -9999 -9999 -9999 -9999 -9999 -9999 -9999 -9999 -9999 -9999 -9999 -9999 -9999 -9999 -9999 -9999 -9999 -9999 -9999 -9999 -9999 -9999 -9999 -9999 -9999 -9999 -9999 -9999 -9999 -9999 -9999 -9999 -9999 -9999 -9999 -9999 -9999 -9999 -9999 -9999 -9999 -9999 -9999 -9999 -9999 -9999 -9999 -9999 -9999 -9999 -9999 -9999 -9999 -9999

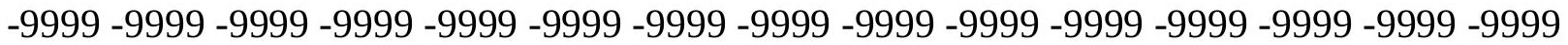
-9999 -9999 -9999 -9999 -9999 -9999 -9999 -9999 -9999 -9999 -9999 -9999 -9999 -9999 -9999 -9999 -9999 -9999 -9999 -9999 -9999 -9999 -9999 -9999 -9999 -9999 -9999 -9999 -9999 -9999

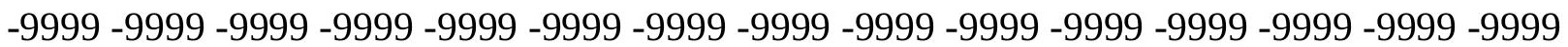
-9999 -9999 -9999 -9999 -9999 -9999 -9999 -9999 -9999 -9999 -9999 -9999 -9999 -9999 -9999 -9999-9999-9999-9999 -9999 -9999 -9999 -9999 -9999 -9999 -9999 -9999 -9999 -9999 -9999 -9999 -9999 -9999 -9999

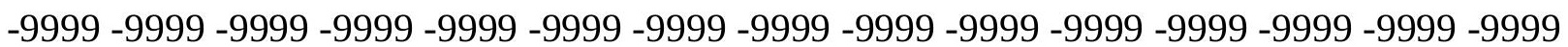
-9999 -9999 -9999 -9999 -9999 -9999 -9999 -9999 -9999 -9999 -9999 -9999 -9999 -9999 -9999 -9999 -9999 -9999 -9999 -9999 -9999 -9999 -9999 -9999 -9999 -9999 -9999 -9999 -9999 -9999 -9999 -9999 -9999 -9999 -9999 -9999 -9999 -9999 -9999 -9999 -9999 -9999 -9999 -9999 -9999

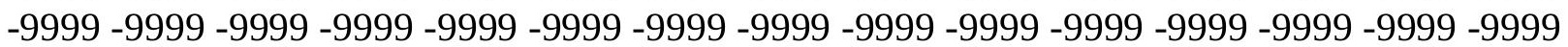


-9999 -9999 -9999 -9999 -9999 -9999 -9999 -9999 -9999 -9999 -9999 -9999 -9999 -9999 -9999 -9999 -9999 -9999 -9999 -9999 -9999 -9999 -9999 -9999 -9999 -35.9646492004 -38.4029312134 -40.5364189148-42.0603485107 -43.2794914246-43.8890609741 $-44.4986305237-45.1082000732-46.6321296692-47.2416992188-47.5464782715$ $-47.2416992188-46.9369087219-46.0225486755-45.1082000732-43.8890609741$ $-42.9747009277-42.0603485107-42.669921875-43.5842704773-44.8034095764$ $-45.7177696228-46.6321296692-47.5464782715-48.1560516357-49.070400238$ $-49.6799812317-50.2895507812-50.8991203308-51.5086898804-52.1182594299$ $-52.4230384827-53.0326118469-53.6421813965-53.9469718933-54.5565414429$ $-55.1661109924-55.4708900452-56.0804595947-56.3852500916-56.9948196411$ $-57.2995986938-57.9091796875-58.2139587402-58.2139587402-58.5187492371$ $-58.5187492371-58.5187492371-58.5187492371-58.2139587402-57.9091796875$ $-57.2995986938-56.6900291443-56.0804595947-55.1661109924-54.251750946$ $-53.0326118469-51.8134689331-50.2895507812-48.4608306885-46.9369087219$ $-45.1082000732-42.9747009277-41.1459884644-39.0125007629-36.5742111206$ $-34.4407196045-32.0024414062-29.5641593933-26.8210906982-24.0780296326$ $-21.0301704407-18.287109375-15.2392597198-12.4961900711-9.75312423706$ -7.3148431778 -5.48613214493 -3.96220707893 -3.35263609886 -3.35263609886 $-4.26699209213-5.48613214493-7.01005792618-8.83876895905-10.6674804688$ $-12.4961900711-14.0201196671-15.2392597198-16.1536102295-16.7631797791$ $-17.0679702759-16.7631797791-16.1536102295-15.2392597198-14.0201196671$ $-12.4961900711-10.9722604752-9.14355373383-7.3148431778-5.79091691971$ -3.96220707893 -2.43828105927-1.21914100647 -9999 .9143553972244 1.828711032867 3.0478510856633 .9622070789344 .876562118535 .7909169197086 .705273151398 7.3148431777957 .9244132041938 .5339832305919 .1435537338269 .753124237061 10.3626899719210 .6674804687511 .2770500183111 .8866195678712 .49619007111 13.1057596206714 .02011966705 -9999 -9999 -9999 -9999 -9999 -9999 -9999 -9999 -9999 -9999 -9999 -9999 -9999 -9999 -9999 -9999 -9999 -9999 -9999 -9999 -9999 -9999 -9999 -9999 -9999 -9999 -9999 -9999 -9999 -9999 -9999 -9999 -9999 -9999 -9999 -9999 -9999 -9999 -9999 -9999 -9999 -9999 -9999 -9999 -9999 -9999 -9999 -9999 -9999 -9999 -9999 -9999 -999 -9999 -9999 -9999 -9999 -9999 -9999 -9999 -9999 -9999 -9999 -9999 -9999 -9999 -9999 -9999

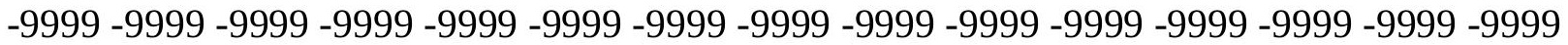

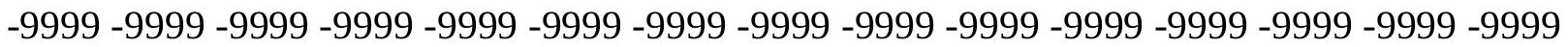

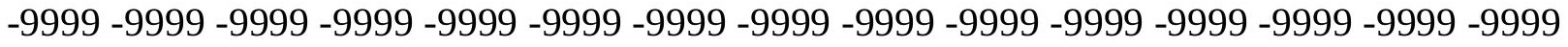
-9999 -9999 -9999 -9999 -9999 -9999 -9999 -9999 -9999 -9999 -9999 -9999 -9999 -9999 -9999 -9999 -9999 -9999 -9999 -9999 -9999 -9999 -9999 -9999 -9999 -9999 -9999 -9999 - 9999 - -9999 -9999 -9999 -9999-9999-9999-9999

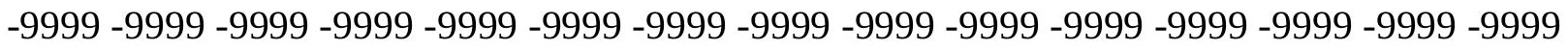

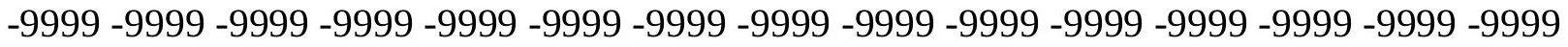
-9999 -9999 -9999 -9999 -9999 -9999 -9999 -9999 -9999 -9999 -9999 -9999 -9999 -9999 -9999 -

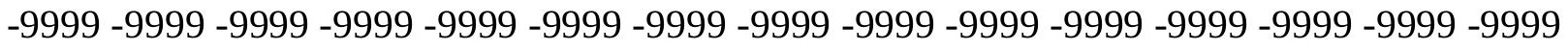

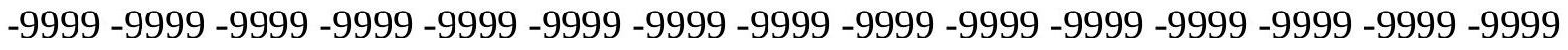
-9999 -9999 -9999 -9999 -9999 -9999 -9999 -9999 -9999 -9999 -9999 -9999 -9999 -9999 -9999 -9999 -9999 -9999 -9999 -9999 -9999 -9999 -9999 -9999 -9999 -9999 -9999 -9999 -9999 -9999 -9999 -9999 -9999 -9999 -9999 -9999 -9999 -9999 -9999 -9999 -34.1359291077

-36.5742111206 -39.0125007629-40.8412094116 -42.0603485107-42.9747009277 
$-43.5842704773-44.1938400269-44.8034095764-46.0225486755-46.6321296692$ -46.9369087219-46.6321296692 -46.0225486755 -45.412979126-44.4986305237 $-43.5842704773-43.2794914246-43.5842704773-44.4986305237-45.7177696228$ $-46.6321296692-47.5464782715-48.4608306885-49.070400238-49.9847602844$ $-50.594329834-51.2038993835-51.8134689331-52.4230384827-52.7278289795$ $-53.3373985291-53.6421813965-54.251750946-54.8613204956-55.1661109924$ $-55.775680542-56.0804595947-56.6900291443-57.2995986938-57.9091796875$ $-58.2139587402-58.8235282898-59.1283111572-59.4331016541-59.7378807068$ $-59.7378807068-59.7378807068-59.7378807068-59.4331016541-59.1283111572$ $-58.8235282898-58.2139587402-57.6043891907-56.6900291443-55.775680542$ $-54.5565414429-53.3373985291-51.8134689331-50.2895507812-48.4608306885$ $-46.6321296692-44.4986305237-42.669921875-40.5364189148-38.0981407166$ -35.9646492004 -33.5263595581 -31.0880794525 -28.3450202942 -25.6019496918 $-22.5541000366-19.5062503815-16.4584007263-13.1057596207-10.0579099655$ -7.3148431778 -5.18134689331 -3.65742206573 -3.04785108566 -3.04785108566 -3.96220707893 -5.48613214493 -7.61962795258 -9.75312423706 -11.8866195679 -14.0201196671 -15.8488302231 -17.3727493286 -18.287109375 -19.2014598846 -19.2014598846 -19.2014598846-18.5918903351 -17.9823207855 -16.7631797791 $-15.2392597198-13.7153301239-11.8866195679-10.0579099655-8.22919845581$ $-6.7052731514-4.87656211853-3.35263609886-2.13349604607-.609570324421$ .30478510260581 .5239260196692 .7430660724643 .9622070789344 .87656211853 5.7909169197086 .7052731513987 .3148431777957 .9244132041938 .533983230591 9.1435537338269 .75312423706110 .0579099655210 .6674804687511 .27705001831 11.8866195678712 .4961900711113 .1057596206714 .02011966705 -9999 -9999 -9999 -9999 -9999 -9999 -9999 -9999 -9999 -9999 -9999 -9999 -9999 -9999 -9999 -9999 -9999 -9999 -9999 -9999 -9999 -9999 -9999 -9999 -9999 -9999 -9999 -9999 -9999 -9999 -9999 -9999 -9999 -9999 -9999 -9999 -9999 -9999 -9999 -9999 -9999 -9999 -9999 -9999 -9999 -9999 -9999 -9999 -9999 -9999 -9999 -9999 -9999 -9999 -9999 -9999 -9999 -9999 -9999 -9999 -9999 -9999 -9999 -9999 -9999 -9999 -9999 -9999 -9999 -9999 -9999 -9999 -9999 -9999 -9999 -9999 -9999 -9999 -9999 -9999 -9999 -9999 -9999 -9999 -9999 -9999 -9999 -9999 -9999 -9999 -9999 -9999 -9999 -9999 -9999 -9999 -9999 -9999 -9999 -9999 -9999 -9999 -9999 -9999 -9999 -9999 -9999 -9999 -9999 -

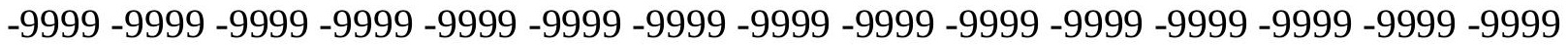
-9999 -9999 -9999 -9999 -9999 -9999 -9999 -9999 -9999 -9999 -9999 -9999 -9999 -9999 -9999 -9999 -9999 -9999 -9999 -9999 -9999 -9999 -9999 -9999 -9999 -9999 -9999 -9999 -9999 -9999 -9999 -9999 -9999 -9999 -9999 -9999 -9999 -9999 -9999 -9999 -9999 -9999 -9999 -9999 -9999 -9999 -9999 -9999 -9999 -9999 -9999 -9999 -9999 -9999 -9999 -9999 -9999 -9999 -9999 -9999 -9999 -9999 -9999 -9999 -9999 -9999 -9999 -9999 -9999 -9999

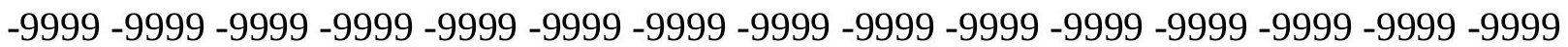
-9999 -9999 -9999 -9999 -9999 -9999 -9999 -9999 -9999 -9999 -9999 -9999 -9999 -9999 -9999 -9999 -9999 -9999 -9999 -9999 -9999 -9999 -9999 -9999 -9999 -9999 -9999 -9999 -9999 -9999 -9999 -9999 -9999 -9999 -9999 -9999 -9999 -9999 -9999 -9999 -9999 -9999 -9999 -9999 -9999 -9999 -9999 -9999 -9999 -9999 -9999 -9999 -9999 -9999 -27.1258792877-31.0880794525 -34.1359291077 -37.1837806702 -39.3172798157 -40.8412094116-41.7555618286 $-42.3651313782-43.2794914246-43.5842704773-44.4986305237-46.0225486755$ $-46.6321296692-46.6321296692-46.0225486755-45.412979126-44.8034095764$ $-44.4986305237-44.4986305237-45.1082000732-46.0225486755-46.9369087219$ 
$-47.8512611389-48.7656211853-49.3751907349-49.9847602844-50.8991203308$ -51.5086898804 -52.1182594299 -52.4230384827 -53.0326118469 -53.6421813965 $-53.9469718933-54.5565414429-54.8613204956-55.1661109924-55.775680542$ $-56.3852500916-56.6900291443-57.2995986938-57.9091796875-58.5187492371$ $-58.8235282898-59.4331016541-60.0426712036-60.3474502563-60.6522407532$ $-60.6522407532-60.9570198059-60.9570198059-60.6522407532-60.3474502563$ $-60.0426712036-59.4331016541-58.8235282898-58.2139587402-57.2995986938$ $-56.0804595947-54.8613204956-53.3373985291-51.8134689331-49.9847602844$ $-48.1560516357-46.0225486755-43.8890609741-41.7555618286-39.6220703125$ -37.488571167 -35.0502891541 -32.6120109558 -30.1737308502 -27.4306602478 -24.3828105927 -21.3349609375 -17.9823207855 -14.3248996735 -10.9722604752 $-7.92441320419-5.48613214493-3.65742206573-2.74306607246-3.04785108566$ $-4.26699209213-6.095703125-8.53398323059-10.9722604752-13.7153301239$ -16.1536102295 -17.9823207855 -19.8110294342 -20.7253894806 -21.6397399902 -21.9445304871 -21.9445304871 -21.3349609375 -20.7253894806 -19.5062503815 $-17.9823207855-16.4584007263-14.6296901703-12.8009700775-10.9722604752$ $-9.14355373383-7.3148431778-5.79091691971-4.26699209213-2.74306607246$ -1.21914100647 -9999 1.21914100647 2.438281059265 3.6574220657354 .87656211853 5.7909169197086 .4004869461067 .0100579261787 .6196279525768 .229198455811 8.8387689590459 .4483394622810 .0579099655210 .6674804687511 .27705001831 11.8866195678712 .4961900711113 .1057596206714 .02011966705 -9999 -9999 -9999 -9999 -9999 -9999 -9999 -9999 -9999 -9999 -9999 -9999 -9999 -9999 -9999 -9999 -9999 -9999 -9999 -9999 -9999 -9999 -9999 -9999 -9999 -9999 -9999 -9999 -9999 -9999 -9999 -9999 -9999 -9999 -9999 -9999 -9999 -9999 -9999 -9999 -9999 -9999 -9999 -9999 -9999 -9999 -9999 -9999 -9999

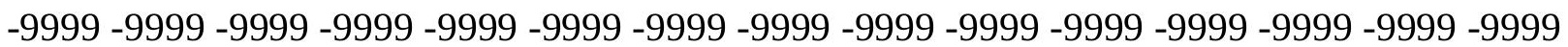
-9999 -9999 -9999 -9999 -9999 -9999 -9999 -9999 -9999 -9999 -9999 -9999 -9999 -9999 -9999 -9999 -9999 -9999 -9999 -9999 -9999 -9999 -9999 -9999 -9999 -9999 -9999 -9999 -9999 -9999 -9999 -9999 -9999 -9999 -9999 -9999 -9999 -9999 -9999 -9999 -9999 -9999 -9999 -9999 -9999

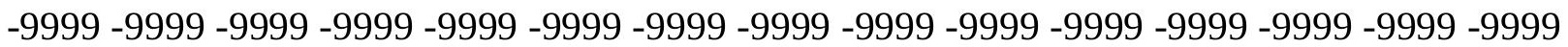

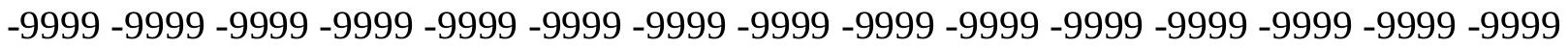
-9999 -9999 -9999 -9999 -9999 -9999 -9999 -9999 -9999

-9999 -9999 -9999 -9999 -9999 -9999 -9999 -9999 -9999 -9999 -9999 -9999 -9999 -9999 -9999 -9999 -9999 -9999 -9999 -9999 -9999 -9999 -9999 -9999 -9999 -9999 -9999 -9999 -9999 -9999 -9999 -9999 -9999 -9999 -9999 -9999 -9999 -9999 -9999 -9999 -9999 -9999 -9999 -9999 -9999 -

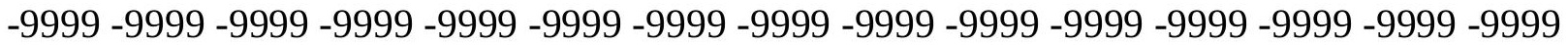
-9999 -9999 -9999 -9999 -9999 -9999 -9999 -9999 -9999 -9999 -9999 -9999 -9999 -9999 -9999 -9999 -9999 -9999 -9999 -9999 -9999 -9999 -9999 -9999 -9999 -9999 -9999 -9999 -9999 -9999

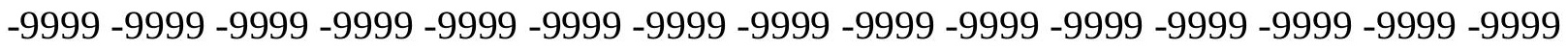
-9999 -9999 -9999-9999 -9999 -9999 -9999-9999 -9999-18.8966808319-24.9923801422 -31.0880794525 -35.0502891541 -37.488571167 -39.0125007629 -39.9268493652 $-40.8412094116-41.7555618286-42.669921875-43.8890609741-45.7177696228$ $-46.3273391724-46.3273391724-46.0225486755-45.7177696228-45.412979126$ $-45.412979126-45.7177696228-46.6321296692-47.2416992188-48.1560516357$ $-49.070400238-49.6799812317-50.2895507812-50.8991203308-51.5086898804$ $-52.1182594299-52.7278289795-53.3373985291-53.6421813965-54.251750946$ $-54.5565414429-54.8613204956-55.1661109924-55.775680542-56.0804595947$ 
-56.6900291443 -56.9948196411 -57.6043891907 -58.2139587402 -58.8235282898 $-59.4331016541-60.0426712036-60.6522407532-60.9570198059-61.2618103027$ $-61.5666007996-61.8713798523-61.8713798523-61.5666007996-61.2618103027$ $-60.9570198059-60.6522407532-60.0426712036-59.4331016541-58.5187492371$ $-57.6043891907-56.3852500916-54.8613204956-53.0326118469-51.5086898804$ $-49.3751907349-47.5464782715-45.412979126-43.2794914246-41.1459884644$ -39.0125007629 -36.8790016174 -34.4407196045 -32.307220459-29.5641593933 -26.5163097382 -23.4684505463-20.115819931-16.4584007263-12.8009700775 $-9.44833946228-6.40048694611-4.26699209213-3.04785108566-3.35263609886$ $-4.87656211853-7.3148431778-10.0579099655-13.1057596207-15.8488302231$ $-18.5918903351-20.7253894806-22.2493095398-23.4684505463-24.3828105927$ $-24.6875991821-24.6875991821-24.0780296326-23.4684505463-22.2493095398$ $-21.0301704407-19.2014598846-17.3727493286-15.5440397263-13.7153301239$ -11.8866195679-10.0579099655-8.22919845581-6.40048694611-4.57177686691 -3.04785108566 -1.52392601967-9999 1.21914100647 2.438281059265 3.657422065735 4.5717768669135 .4861321449286 .0957031256 .7052731513987 .314843177795 7.9244132041938 .5339832305919 .1435537338269 .75312423706110 .36268997192 10.9722604751611 .5818300247212 .191410064713 .10575962067 -9999 -9999 -9999 -9999 -9999 -9999 -9999 -9999 -9999 -9999 -9999 -9999 -9999 -9999 -9999 -9999 -9999 -9999 -9999 -9999 -9999 -9999 -9999 -9999 -9999 -9999 -9999 -9999 -9999 -9999 -9999 -9999 -9999 -9999 -9999 -9999 -9999 -9999 -9999 -9999 -9999 -9999 -9999 -9999 -9999 -9999 -9999 -9999 -9999

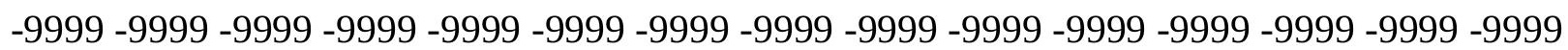
-9999 -9999 -9999 -9999 -9999 -9999 -9999 -9999 -9999 -9999 -9999 -9999 -9999 -9999 -9999 -9999 -9999 -9999 -9999 -9999 -9999 -9999 -9999 -9999 -9999 -9999 -9999 -9999 -9999 -9999 -9999 -9999 -9999 -9999 -9999 -9999 -9999 -9999 -9999 -9999 -9999 -9999 -9999 -9999 -9999 -9999 -9999 -9999 -9999 -9999 -9999 -9999 -9999 -9999 -9999 -9999 -9999 -9999 -9999 -9999 -9999 -9999 -9999 -9999 -9999 -9999 -9999 -9999 -9999 -9999 -9999 -9999 -9999 - 9999 - -9999 -9999 -9999 -9999 -9999 -9999 -9999 -9999 -9999 -9999

-9999 -9999 -9999 -9999 -9999 -9999 -9999 -9999 -9999 -9999 -9999 -9999 -9999 -9999 -9999

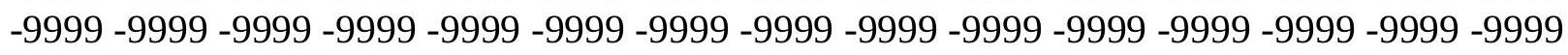
-9999 -9999 -9999 -9999 -9999 -9999 -9999 -9999 -9999 -9999 -9999 -9999 -9999 -9999 -9999

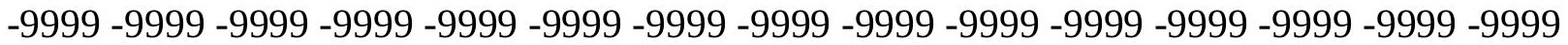

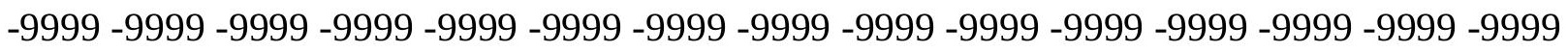

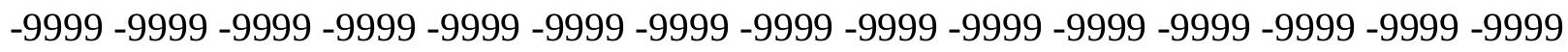
-9999 -9999 -9999 -9999 -9999 -9999 -9999 -9999 -9999 -9999 -9999 -9999 -9999 -9999 -9999 -999 -9999 -9999 -9999 -9999 -9999 -9999 -9999 -9999 -10.3626899719 - 11.2770500183 -18.287109375 -26.8210906982 -31.0880794525 -34.1359291077 -35.9646492004 -37.1837806702 -38.7077102661 -40.2316398621 -41.7555618286-43.2794914246 -28.0402297974-45.7177696228 -45.7177696228 -45.7177696228 -45.7177696228 $-45.7177696228-46.3273391724-46.9369087219-47.8512611389-48.7656211853$ $-49.6799812317-50.2895507812-50.8991203308-51.2038993835-51.8134689331$ $-52.4230384827-53.0326118469-53.6421813965-53.9469718933-54.251750946$ $-54.5565414429-54.8613204956-55.1661109924-55.4708900452-55.775680542$ $-56.3852500916-56.6900291443-57.2995986938-57.9091796875-58.5187492371$ $-59.1283111572-59.7378807068-60.3474502563-60.9570198059-61.5666007996$ $-61.8713798523-62.1761703491-62.4809494019-62.4809494019-62.4809494019$ 
$-62.1761703491-61.8713798523-61.5666007996-60.9570198059-60.3474502563$ $-59.7378807068-58.8235282898-57.6043891907-56.0804595947-54.5565414429$ $-52.7278289795-50.594329834-48.7656211853-46.6321296692-44.4986305237$ $-42.669921875-40.5364189148-38.7077102661-36.5742111206-34.4407196045$ -32.0024414062 -29.2593708038 -26.5163097382 -23.1636695862 -19.2014598846 -15.5440397263 -11.5818300247 -7.92441320419-5.48613214493 -4.26699209213 $-4.57177686691-6.40048694611-9.14355373383-12.4961900711-15.8488302231$ -18.8966808319 -21.3349609375 -23.7732391357-25.2971591949-26.5163097382 $-27.4306602478-27.7354507446-27.4306602478-27.1258792877-26.2115192413$ $-24.9923801422-23.7732391357-22.2493095398-20.4206008911-18.287109375$ -16.4584007263 -14.3248996735 -12.4961900711 -10.6674804688 -8.53398323059 -6.7052731514 -5.18134689331 -3.35263609886 -1.52392601967 -9999 1.21914100647 2.4382810592653 .3526360988624 .2669920921334 .876562118535 .790916919708 6.4004869461067 .0100579261787 .6196279525768 .2291984558119 .143553733826 9.75312423706110 .3626899719210 .9722604751611 .2770500183112 .1914100647 12.80097007751 -9999 -9999 -9999 -9999 -9999 -9999 -9999 -9999 -9999 -9999 -9999 -9999 -9999 -9999 -9999 -9999 -9999 -9999 -9999 -9999 -9999 -9999 -9999 -9999 -9999 -9999 -9999 -9999 -9999 -9999 -9999 -9999 -9999 -9999 -9999 -9999 -9999 -9999 -9999 -9999 -9999 -9999 -9999 -9999 -9999 -9999 -9999 -9999 -9999 -9999 -9999 -9999 -9999 -9999 -9999 -9999 -9999 -9999 -9999 -9999 -9999 -9999 -9999 -9999 -9999 -9999 -9999 -9999 -9999 -9999 -9999 -9999

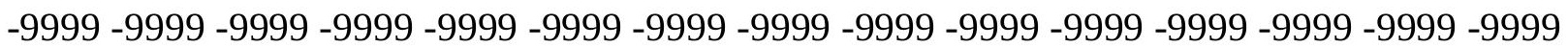
-9999 -9999 -9999 -9999 -9999 -9999 -9999 -9999 -9999 -9999 -9999 -9999 -9999 -9999 -9999 -9999 -9999 -9999 -9999 -9999 -9999 -9999 -9999 -9999 -9999 -9999 -9999 -9999 -9999 -9999 -9999 -9999 -9999 -9999 -9999 -9999 -9999 -9999 -9999 -9999 -9999 -9999 -9999 -9999 -9999

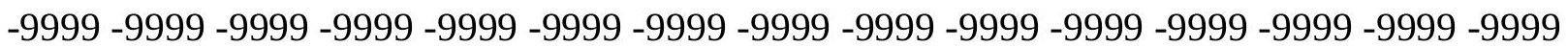
-9999 -9999 -9999 -9999 -9999 -9999 -9999 -9999 -9999 -9999 -9999 -9999 -9999 -9999 -9999 -9999 -9999 -9999 -9999 -9999 -9999 -9999 -9999 -9999 -9999 -9999 -9999 -9999 -9999 -9999 -9999 -9999 -9999 -9999 -9999 -9999 -9999 -9999 -9999 -9999 -9999 -9999 -9999 -9999 -9999 -9999 -9999 -9999 -9999 -9999 -9999 -9999 -9999 -9999 -9999 -9999 -9999 -9999 -9999 -9999 -999 -9999 -9999 -9999 -9999 -9999 -9999 -9999 -9999 -9999 -9999 -9999 -9999 -9999 -9999 -9999 -9999 -9999 -9999 -9999 -9999 -9999 -9999 -9999 -9999 -9999 -9999 -9999 -9999 -9999 -9999 -9999 -9999 -9999 -9999 -9999 -9999 -9999 -9999 -9999 -9999 -9999 -9999 -9999 -9999 -9999 -9999 -9999 -9999 -9999 -9999 -9999 -9999 -9999 -9.44833946228 -9.75312423706 $-13.7153301239-19.2014598846-23.1636695862-27.1258792877-30.7833003998$ -33.8311500549 -35.9646492004 -37.7933502197 -39.9268493652 -41.7555618286 $-43.5842704773-44.4986305237-44.8034095764-45.1082000732-45.1082000732$ $-45.7177696228-46.6321296692-47.8512611389-49.3751907349-50.2895507812$ $-51.2038993835-51.5086898804-51.8134689331-52.1182594299-52.4230384827$ -53.0326118469 -53.6421813965 -54.251750946 -54.5565414429 -54.8613204956 $-55.1661109924-55.1661109924-55.4708900452-55.4708900452-55.775680542$ $-56.3852500916-56.6900291443-57.2995986938-57.9091796875-58.5187492371$ $-59.1283111572-60.0426712036-60.6522407532-61.2618103027-61.8713798523$ $-62.4809494019-62.7857398987-62.7857398987-63.0905189514-62.7857398987$ $-62.7857398987-62.4809494019-62.1761703491-61.8713798523-61.2618103027$ $-60.6522407532-59.7378807068-58.8235282898-57.2995986938-55.775680542$ $-53.9469718933-51.8134689331-49.6799812317-47.5464782715-45.7177696228$ 
$-43.8890609741-42.0603485107-40.5364189148-38.7077102661$-36.8790016174 $-34.7455101013-32.6120109558-29.8689403534-26.8210906982-23.1636695862$ $-19.2014598846-14.9344701767-10.9722604752-7.61962795258-6.095703125$ $-6.7052731514-9.14355373383-12.4961900711-15.8488302231-19.2014598846$ $-22.2493095398-24.9923801422-27.1258792877-28.6497993469-29.8689403534$ $-30.478509903-30.7833003998-30.478509903-29.8689403534-29.2593708038$ $-28.0402297974-26.5163097382-24.9923801422-23.1636695862-21.0301704407$ $-19.2014598846-17.0679702759-14.9344701767-12.8009700775-10.9722604752$ -8.83876895905 -7.01005792618 -5.18134689331 -3.35263609886-1.52392601967-9999 .91435539722441 .8287110328673 .0478510856633 .6574220657354 .571776866913 5.1813468933116 .0957031256 .7052731513987 .3148431777957 .924413204193 8.5339832305919 .14355373382610 .0579099655210 .3626899719210 .97226047516 11.5818300247212 .49619007111 -9999 -9999 -9999 -9999 -9999 -9999 -9999 -9999 -9999 -9999 -9999 -9999 -9999 -9999 -9999 -9999 -9999 -9999 -9999 -9999 -9999 -9999 -9999 -9999 -9999 -9999 -9999 -9999 -9999 -9999 -9999 -9999 -9999 -9999 -9999 -9999 -9999 -9999 -9999 -

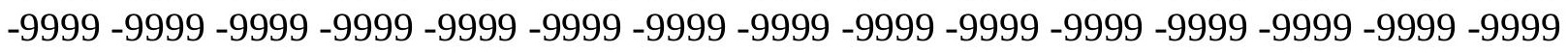
-9999 -9999 -9999 -9999 -9999 -9999 -9999 -9999 -9999 -9999 -9999 -9999 -9999 -9999 -9999 -9999 -9999 -9999 -9999 -9999 -9999 -9999 -9999 -9999 -9999 -9999 -9999 -9999 -9999 -9999 -9999 -9999 -9999 -9999 -9999 -9999 -9999 -9999 -9999 -9999 -9999 -9999 -9999 -9999 -9999 -9999 -9999 -9999 -9999 -9999 -9999 -9999 -9999 -9999 -9999 -9999 -9999 -9999 -9999 -9999 -9999 -9999 -9999 -9999 -9999 -9999 -9999 -9999 -9999 -9999 -9999 -9999 -9999 -9999 -9999

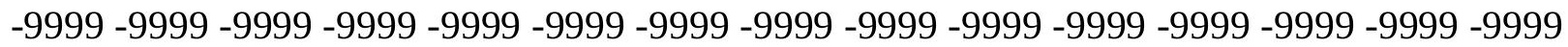
$-9999-9999$

-9999 -9999 -9999 -9999 -9999 -9999 -9999 -9999 -9999 -9999 -9999 -9999 -9999 -9999 -9999 -9999 -9999 -9999 -9999 -9999 -9999 -9999 -9999 -9999 -9999 -9999 -9999 -9999 -9999 -9999 -9999 -9999 -9999 -9999 -9999 -9999 -9999 -9999 -9999 -9999 -9999 -9999 -9999 -9999 -9999 -9999 -9999 -9999 -9999 -9999 -9999 -9999 -9999 -9999 -9999 -9999 -9999 -9999 -9999 -9999

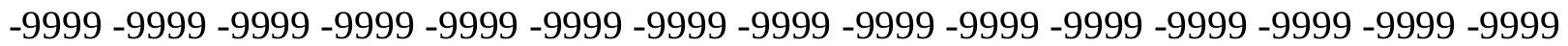
-9999 -9999 -9999 -9999 -9999 -9999 -9999 -9999 -9999 -9999 -9999 -9999 -9999 -9999 -9999 -9999 -9999 -9999 -9999 -9999 -9999 -9999 -9999 -9999 -9999 -9999 -9999 -9999 -9999 -9999 -9999 -9999 -9999 -9999 -9999 -9999 -9999 -9999 -5.79091691971 -8.53398323059 -10.9722604752 -12.8009700775 -16.1536102295 -19.8110294342 -24.6875991821 -29.5641593933 -32.307220459-34.4407196045 -36.8790016174 -39.0125007629 $-40.8412094116-42.3651313782-43.2794914246-43.8890609741-44.1938400269$ $-45.1082000732-46.9369087219-48.7656211853-50.594329834-51.8134689331$ $-52.4230384827-52.4230384827-52.4230384827-52.4230384827-52.7278289795$ $-53.3373985291-53.9469718933-54.5565414429-55.1661109924-55.1661109924$ $-55.1661109924-55.1661109924-55.1661109924-55.4708900452-55.775680542$ $-56.0804595947-56.3852500916-56.9948196411-57.6043891907-58.5187492371$ $-59.1283111572-59.7378807068-60.6522407532-61.2618103027-61.8713798523$ $-62.4809494019-62.7857398987-63.0905189514-63.0905189514-63.0905189514$ $-62.7857398987-62.7857398987-62.4809494019-62.1761703491-61.8713798523$ $-61.2618103027-60.6522407532-59.7378807068-58.5187492371-56.6900291443$ -54.8613204956 -52.7278289795 -50.2895507812 -48.4608306885-46.6321296692 $-45.1082000732-43.8890609741-42.3651313782-41.1459884644-39.6220703125$ $-38.0981407166-36.2694282532-33.8311500549-31.0880794525-28.0402297974$ 
-24.3828105927 -20.115819931 -15.5440397263 -11.5818300247 -9.14355373383 $-10.3626899719-13.4105501175-17.0679702759-20.7253894806-24.0780296326$ $-26.8210906982-29.2593708038-30.7833003998-32.307220459-32.9167900085$ $-33.5263595581-33.5263595581-33.5263595581-32.9167900085-32.0024414062$ $-30.7833003998-29.2593708038-27.7354507446-25.6019496918-23.7732391357$ $-21.6397399902-19.5062503815-17.3727493286-15.2392597198-13.1057596207$ $-10.9722604752-9.14355373383-7.01005792618-5.18134689331-3.35263609886$ -1.82871103287-.304785102606.3047851026058 1.5239260196692 .438281059265 3.3526360988623 .9622070789344 .876562118535 .4861321449286 .095703125 7.0100579261787 .6196279525768 .2291984558118 .8387689590459 .44833946228 10.0579099655210 .3626899719210 .97226047516 -9999 -9999 -9999 -9999 -9999 -9999 -9999 -9999-

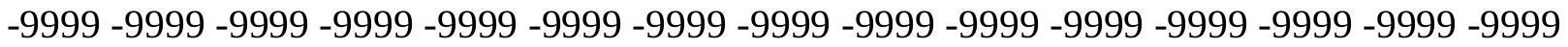

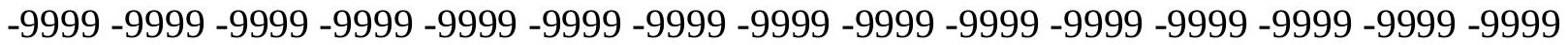

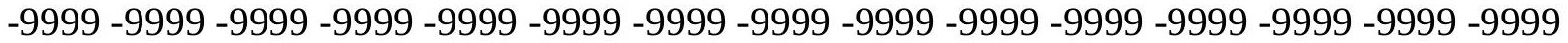

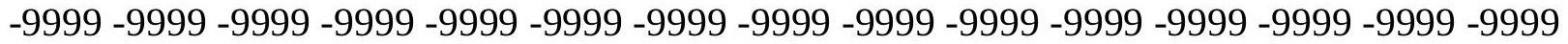

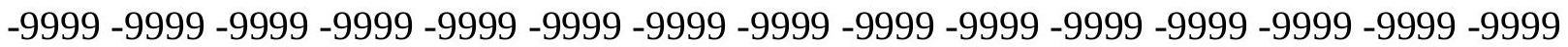

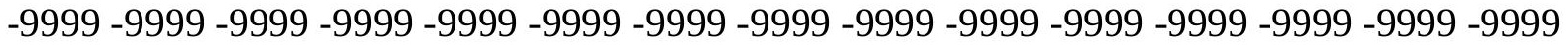

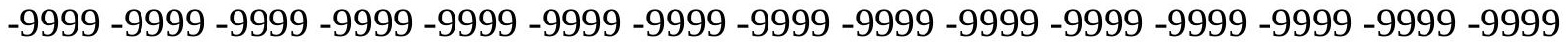

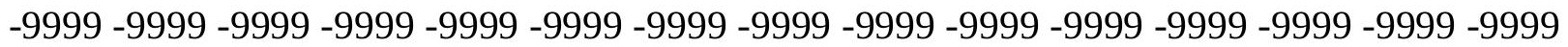
-9999 -9999 -9999 -9999

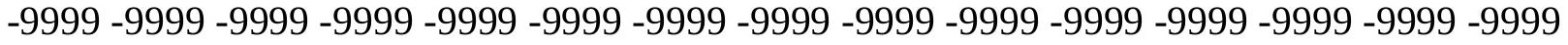
-9999 -

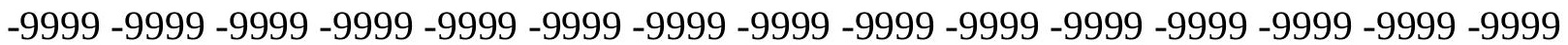

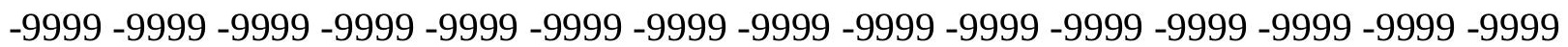
-9999 -

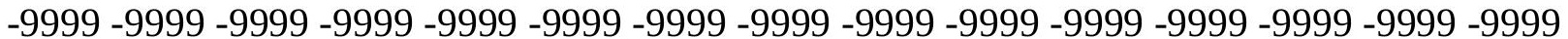

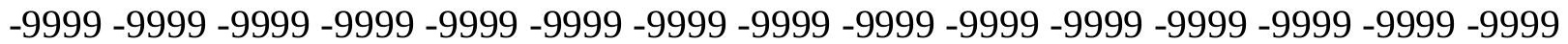
-9999 -9999 -9999 -9999 -9999 -9999 -9999 21.94453048706 6.095703125-4.26699209213 $-10.9722604752-14.3248996735-15.5440397263-17.0679702759-20.115819931$ $-23.7732391357-27.1258792877-29.8689403534-32.6120109558-35.0502891541$ $-36.8790016174-38.7077102661-39.9268493652-40.8412094116-42.0603485107$ $-44.1938400269-46.9369087219-49.6799812317-51.5086898804-52.7278289795$ $-53.0326118469-53.0326118469-52.7278289795-52.4230384827-52.4230384827$ $-53.0326118469-53.9469718933-54.8613204956-55.4708900452-55.4708900452$ $-55.1661109924-54.8613204956-54.8613204956-54.8613204956-55.1661109924$ $-55.4708900452-55.775680542-56.3852500916-57.2995986938-57.9091796875$ $-58.8235282898-59.4331016541-60.3474502563-60.9570198059-61.5666007996$ $-62.4809494019-62.7857398987-63.0905189514-63.0905189514-63.0905189514$ $-62.7857398987-62.4809494019-62.1761703491-62.1761703491-61.8713798523$ $-61.8713798523-61.5666007996-60.6522407532-59.4331016541-57.6043891907$ $-55.4708900452-53.0326118469-50.8991203308-49.070400238-47.5464782715$ $-46.3273391724-45.412979126-44.4986305237-43.5842704773-42.3651313782$ $-41.4507789612-39.9268493652-38.4029312134-36.2694282532-33.8311500549$ $-30.7833003998-26.8210906982-22.5541000366-17.9823207855-14.0201196671$ $-16.4584007263-19.8110294342-23.4684505463-26.8210906982-29.5641593933$ 
-32.0024414062 -33.8311500549 -35.0502891541 -35.9646492004 -36.2694282532 $-36.5742111206-36.5742111206-36.2694282532-35.6598587036-34.7455101013$ $-33.2215805054-32.0024414062-30.1737308502-28.0402297974-26.2115192413$ $-24.0780296326-21.6397399902-19.5062503815-17.3727493286-15.2392597198$ $-13.1057596207-10.9722604752-8.83876895905-7.01005792618-5.18134689331$ -3.65742206573 -2.13349604607 -.914355397224-9999 .9143553972244 1.828711032867 2.7430660724643 .6574220657354 .2669920921334 .876562118535 .790916919708 6.4004869461067 .0100579261787 .6196279525768 .2291984558118 .533983230591 9.1435537338269 .4483394622810 .36268997192 -9999 -9999 -9999 -9999 -9999 -9999 -9999 -9999 -9999 -9999 -9999 -9999 -9999 -9999 -9999 -9999 -9999 -9999 -9999 -9999 -9999 -9999 -

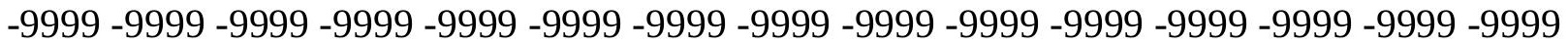
-9999 -9999 -9999 -9999 -9999 -9999 -9999 -9999 -9999 -9999 -9999 -9999 -9999 -9999 -9999 -9999 -9999 -9999 -9999 -9999 -9999 -9999 -9999 -9999 -9999 -9999 -9999 -9999 -9999 -9999 -9999 -9999 -9999 -9999 -9999 -9999 -9999 -9999 -9999 -9999 -9999 -9999 -9999 -9999 -9999 -9999 -9999 -9999 -9999 -9999 -9999 -9999 -9999 -9999 -9999 -9999 -9999 -9999 -9999 -9999 -9999 -9999 -9999 -9999 -9999 -9999 -9999 -9999 -9999 -9999 -9999 -9999 -9999 -9999 -9999

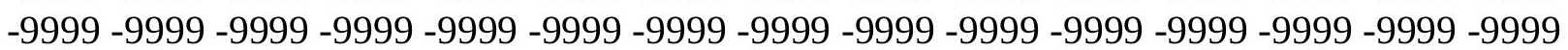

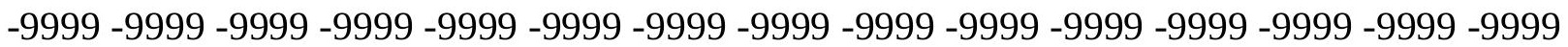
-9999-9999-9999

-9999 -9999 -9999 -9999 -9999 -9999 -9999 -9999 -9999 -9999 -9999 -9999 -9999 -9999 -9999 -9999 -9999 -9999 -9999 -9999 -9999 -9999 -9999 -9999 -9999 -9999 -9999 -9999 -9999 -9999 -9999 -9999 -9999 -9999 -9999 -9999 -9999 -9999 -9999 -9999 -9999 -9999 -9999 -9999 -9999 -9999 -9999 -9999 -9999 -9999 -9999 -9999 -9999 -9999 -9999 -9999 -9999 -9999 -9999 -9999 -9999 -9999 -9999 -9999 -9999 -9999 -9999 -9999 -9999 -9999 -9999 -9999 -9999 -9999 -9999

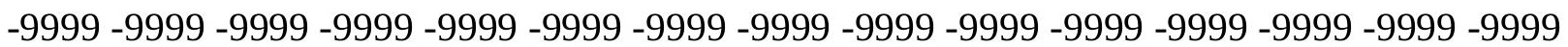
-9999 -9999 -9999 -9999 -9999 -9999 -9999 -9999 -9999 -9999 -9999 -9999 -9999 -9999 -9999 -9999 -9999 -9999 -9999 -9999 -9999-9999 46.63212966919 23.773239135745 .790916919708 $-6.095703125-12.8009700775-14.0201196671-13.7153301239-14.6296901703$ $-16.4584007263-19.5062503815-22.8588790894-25.6019496918-28.0402297974$ -30.478509903 -32.6120109558 -33.8311500549 -35.3550796509 -37.488571167 $-40.5364189148-45.1082000732-49.6799812317-52.1182594299-53.0326118469$ -35.0502891541 -32.6120109558 -35.6598587036 -51.5086898804 -50.8991203308 $-51.8134689331-53.6421813965-55.1661109924-55.775680542-55.1661109924$ $-54.5565414429-53.9469718933-53.9469718933-53.9469718933-54.251750946$ $-54.5565414429-55.1661109924-55.775680542-56.3852500916-57.2995986938$ $-58.2139587402-58.8235282898-59.4331016541-60.3474502563-61.2618103027$ $-61.8713798523-62.4809494019-62.7857398987-62.7857398987-62.4809494019$ $-62.1761703491-61.8713798523-61.8713798523-61.5666007996-61.8713798523$ $-61.8713798523-61.8713798523-61.2618103027-60.3474502563-58.5187492371$ -56.0804595947 -53.3373985291 -50.8991203308 -49.070400238-48.1560516357 $-47.5464782715-46.9369087219-46.6321296692-46.0225486755-45.412979126$ $-44.8034095764-43.8890609741-43.2794914246-42.0603485107-40.2316398621$ -38.0981407166 -35.3550796509 -31.6976509094 -28.0402297974 -25.9067401886 -26.5163097382 -28.6497993469 -31.3928699493 -34.1359291077 -36.2694282532 $-37.7933502197-38.7077102661-39.3172798157-39.6220703125-39.6220703125$ $-39.3172798157-39.3172798157-38.7077102661-38.0981407166-37.1837806702$ 
-35.6598587036 -34.1359291077 -32.307220459 -30.478509903 -28.3450202942 -25.9067401886 -23.7732391357 -21.6397399902 -19.2014598846 -17.0679702759 -14.9344701767 -12.8009700775 -10.6674804688 -8.83876895905 -7.01005792618 $-5.48613214493-3.96220707893-2.43828105927-1.21914100647-.304785102606$ .60957032442091 .5239260196692 .4382810592653 .0478510856633 .657422065735 4.26699209213321 .6397399902322 .2493095397922 .858879089366 .705273151398 7.0100579261787 .6196279525767 .9244132041938 .5339832305919 .44833946228 -9999 -9999 -9999 -9999 -9999 -9999 -9999 -9999 -9999 -9999 -9999 -9999 -9999 -9999 -9999 -9999 -9999 -9999 -9999 -9999 -9999 -9999 -9999 -9999 -9999 -9999 -9999 -9999 -9999 -9999 -9999 -9999 -9999 -9999 -9999 -9999 -9999 -9999 -9999 -9999 -9999 -9999 -9999 -9999 -9999 -9999 -

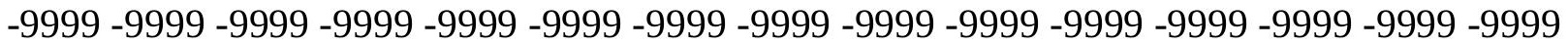
-9999 -9999 -9999 -9999 -9999 -9999 -9999 -9999 -9999 -9999 -9999 -9999 -9999 -9999 -9999 -9999 -9999 -9999 -9999 -9999 -9999 -9999 -9999 -9999 -9999 -9999 -9999 -9999 -9999 -9999 -9999 -9999 -9999 -9999 -9999 -9999 -9999 -9999 -9999 -9999 -9999 -9999 -9999 -9999 -9999 -9999 -9999 -9999 -9999 -9999 -9999 -9999 -9999 -9999 -9999 -9999 -9999 -9999 -9999 -9999

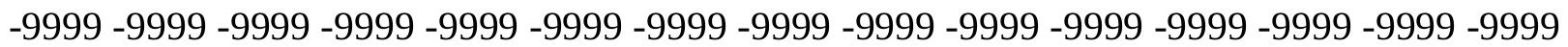
-9999 -9999 -9999-9999 -9999 -9999-9999 -9999

-9999 -9999 -9999 -9999 -9999 -9999 -9999 -9999 -9999 -9999 -9999 -9999 -9999 -9999 -9999 -9999 -9999 -9999 -9999 -9999 -9999 -9999 -9999 -9999 -9999 -9999 -9999 -9999 -9999 -9999 -9999 -9999 -9999 -9999 -9999 -9999 -9999 -9999 -9999 -9999 -9999 -9999 -9999 -9999 -9999 -9999 -9999 -9999 -9999 -9999 -9999 -9999 -9999 -9999 -9999 -9999 -9999 -9999 -9999 -9999 -9999 -9999 -9999 -9999 -9999 -9999 -9999 -9999 -9999 -9999 -9999 -9999 -9999 -9999 -9999 -9999 -9999 -9999 -9999 -9999 -9999 -9999 -9999 -9999 -9999 -9999 -9999 -9999 -9999 -9999 -9999 -9999 -9999 -9999 -9999 -9999 -9999 -9999 -9999 -9999 -9999 -9999 -9999 -9999 -9999 -9999 -9999 -9999 -9999 -9999 -9999 72.528739929260 .1982307434143 .88906097412 $25.906740188612 .496190071113 .657422065735-2.13349604607-5.48613214493$ $-7.01005792618-7.92441320419-9.75312423706-12.4961900711-15.5440397263$ -18.5918903351 -21.3349609375 -23.4684505463 -24.6875991821 -25.6019496918 $-27.7354507446-31.0880794525-37.1837806702-43.8890609741-47.8512611389$ $-50.594329834-51.5086898804-34.7455101013-51.8134689331-49.070400238$ $-48.4608306885-50.2895507812-53.0326118469-55.4708900452-55.775680542$ $-54.5565414429-53.3373985291-52.7278289795-52.4230384827-52.7278289795$ $-53.0326118469-53.3373985291-53.9469718933-54.5565414429-55.4708900452$ -56.3852500916 -57.2995986938 -57.9091796875 -58.5187492371 -59.1283111572 $-60.0426712036-60.9570198059-61.8713798523-62.1761703491-62.1761703491$ $-61.8713798523-61.5666007996-60.9570198059-60.6522407532-60.6522407532$ $-60.9570198059-61.2618103027-61.8713798523-61.8713798523-60.9570198059$ $-59.1283111572-56.0804595947-53.0326118469-50.2895507812-48.7656211853$ $-48.1560516357-48.1560516357-48.4608306885-48.4608306885-48.1560516357$ $-47.8512611389-47.8512611389-47.8512611389-47.8512611389-47.5464782715$ $-46.9369087219-46.0225486755-44.8034095764-42.669921875-40.2316398621$ -38.7077102661 -38.0981407166 -39.0125007629-40.5364189148-42.3651313782 $-43.5842704773-44.1938400269-44.1938400269-43.5842704773-42.9747009277$ $-42.3651313782-42.0603485107-41.4507789612-41.1459884644-40.5364189148$ -39.3172798157 -38.0981407166 -36.2694282532 -34.4407196045 -32.307220459 $-30.1737308502-27.7354507446-25.6019496918-23.1636695862-21.0301704407$ 
-18.5918903351 -16.4584007263 -14.3248996735 -12.1914100647 -10.3626899719 -8.53398323059 -7.01005792618 -5.48613214493 -3.96220707893 -2.74306607246 -1.82871103287 -.609570324421 -9999.9143553972244 1.828711032867 2.438281059265 20.1158199310320 .7253894805921 .334960937521 .6397399902321 .94453048706 5.4861321449285 .7909169197086 .4004869461066 .7052731513987 .314843177795 -9999 -9999 -9999 -9999 -9999 -9999 -9999 -9999 -9999 -9999 -9999 -9999 -9999 -9999 -9999 -9999 -9999 -9999 -9999 -9999 -9999 -9999 -9999 -9999 -9999 -9999 -9999 -9999 -9999 -9999 -9999

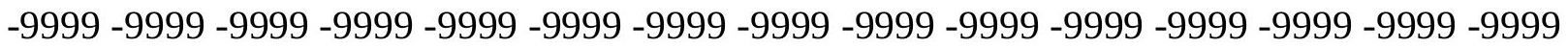
-9999 -9999 -9999 -9999 -9999 -9999 -9999 -9999 -9999 -9999 -9999 -9999 -9999 -9999 -9999 -9999 -9999 -9999 -9999 -9999 -9999 -9999 -9999 -9999 -9999 -9999 -9999 -9999 -9999 -9999 -

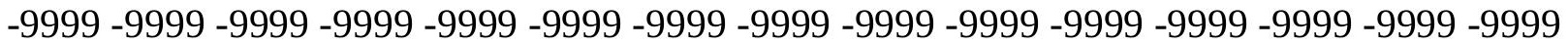
-9999 -9999 -9999 -9999 -9999 -9999 -9999 -9999 -9999 -9999 -9999 -9999 -9999 -9999 -9999 -9999 -9999 -9999 -9999 -9999 -9999 -9999 -9999 -9999 -9999 -9999 -9999 -9999 -9999 -9999 -9999 -9999-9999 -9999 -9999 -9999 -9999 -9999 -9999 -9999 -9999 -9999 -9999 -9999 -9999 -9999 -9999 -9999 -9999 -9999 -9999 -9999 -9999

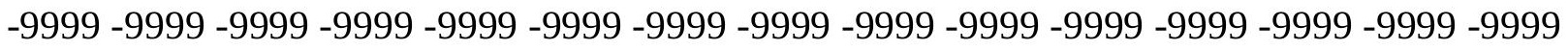

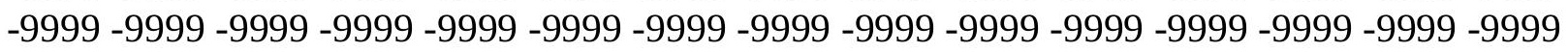

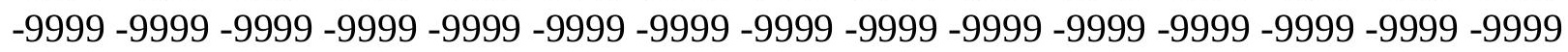

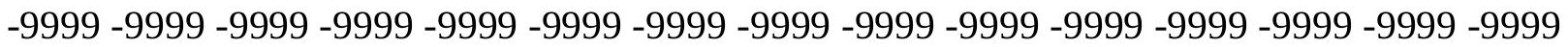

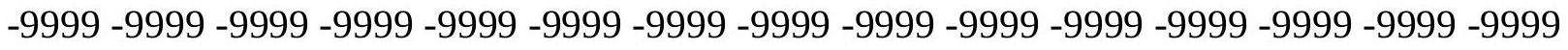

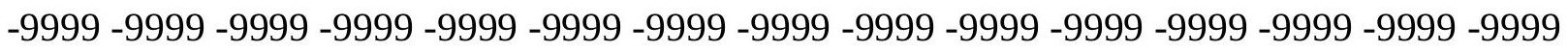

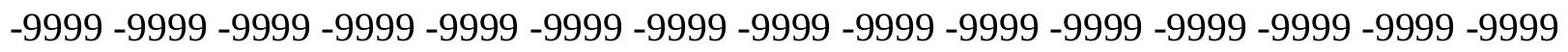
-9999 -9999 -9999 -9999 -9999-9999 75.7986297607468 .0785903930758 .47161102295 45.8520698547436 .5742111206126 .2115192413315 .848830223088 .533983230591 $6.0957031255 .1813468933113 .9622070789342 .438281059265-.304785102606$ $-3.65742206573-6.7052731514-9.44833946228-10.6674804688-11.2770500183$ -12.8009700775 -15.8488302231 -23.7732391357-32.0024414062 -36.5742111206 $-39.9268493652-44.8034095764-47.8512611389-45.7177696228-43.5842704773$ $-44.8034095764-30.478509903-51.8134689331-56.0804595947-54.8613204956$ $-52.7278289795-51.2038993835-50.594329834-50.8991203308-51.5086898804$ $-51.8134689331-51.8134689331-52.4230384827-53.3373985291-54.5565414429$ $-55.4708900452-56.0804595947-56.3852500916-56.6900291443-57.6043891907$ $-58.8235282898-60.0426712036-60.9570198059-61.2618103027-61.2618103027$ $-60.6522407532-60.3474502563-59.7378807068-59.4331016541-59.1283111572$ $-59.4331016541-60.3474502563-61.2618103027-62.1761703491-61.5666007996$ -59.4331016541 -56.0804595947 -52.1182594299-48.7656211853-47.2416992188 $-47.2416992188-48.7656211853-49.9847602844-50.594329834-49.6799812317$ $-49.3751907349-49.9847602844-51.2038993835-52.1182594299-52.7278289795$ -53.3373985291 -53.9469718933 -54.251750946 -53.6421813965 -52.4230384827 $-50.8991203308-49.6799812317-49.3751907349-49.9847602844-50.8991203308$ -51.2038993835 -50.594329834-49.3751907349-47.5464782715 -45.7177696228 $-44.4986305237-43.8890609741-43.5842704773-42.9747009277-42.3651313782$ $-41.4507789612-39.9268493652-38.0981407166-35.9646492004-33.5263595581$ -31.3928699493 -28.9545898438 -26.8210906982 -24.6875991821 -22.2493095398 -20.115819931 -17.9823207855 -15.8488302231 -13.7153301239-11.8866195679 $-10.0579099655-8.53398323059-7.01005792618-5.48613214493-4.26699209213$ 
-3.04785108566 -1.82871103287 -.914355397224 -9999.3047851026058 18.287109375 19.2014598846419 .811029434220 .1158199310320 .1158199310320 .11581993103 3.6574220657353 .9622070789344 .5717768669134 .5717768669135 .181346893311 6.400486946106 -9999 -9999 -9999 -9999 -9999 -9999 -9999 -9999 -9999 -9999 -9999 -9999 -9999 -9999 -9999 -9999 -9999 -9999 -9999 -9999 -9999 -9999 -9999 -9999-9999 -9999 -9999 -9999 -9999 -9999 -9999 -9999 -9999 -9999 -9999 -9999 -9999 -9999 -9999 -9999 -9999 -9999

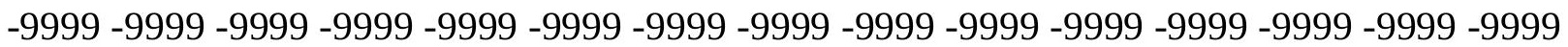

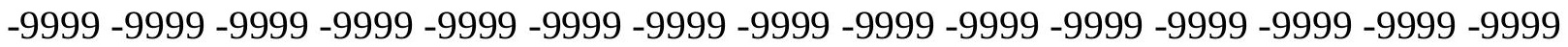
-9999 -9999 -9999 -9999 -9999 -9999 -9999 -9999 -9999 -9999 -9999 -9999 -9999 -9999 -9999 -9999 -9999 -9999 -9999 -9999 -9999 -9999 -9999 -9999 -9999 -9999 -9999 -9999 -9999 -9999 -9999 -9999 -9999 -9999 -9999 -9999 -9999 -9999 -9999 -9999 -9999 -9999 -9999 -9999 -9999 -

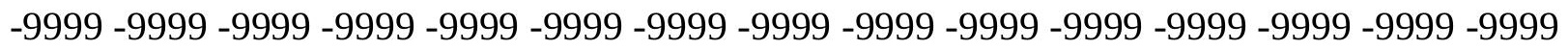

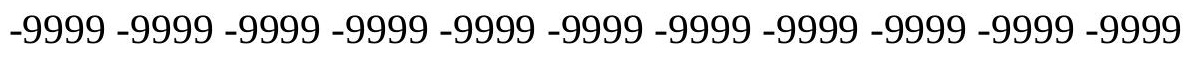

-9999 -9999 -9999 -9999 -9999 -9999 -9999 -9999 -9999 -9999 -9999 -9999 -9999 -9999 -9999 -9999 -9999 -9999 -9999 -9999 -9999 -9999 -9999 -9999 -9999 -9999 -9999 -9999 -9999 -9999

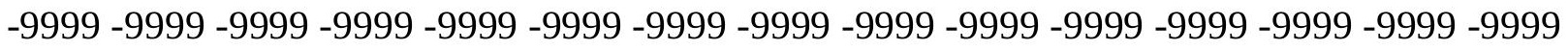
-9999 -9999 -9999 -9999 -9999 -9999 -9999 -9999 -9999 -9999 -9999 -9999 -9999 -9999 -9999 -9999 -9999 -9999 -9999 -9999 -9999 -9999 -9999 -9999 -9999 -9999 -9999 -9999 -9999 -9999 -

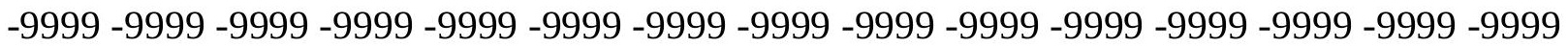

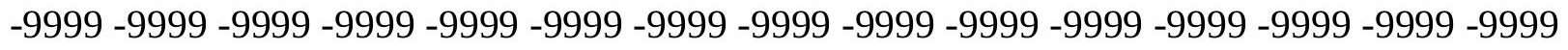
-9999 -9999 -9999-9999-9999 86.29413604736 78.88050079346 71.36750030518 64.1041793823257 .481861114551 .9503173828144 .7714576721238 .40293121338 32.9167900085430 .4785099029529 .2593708038327 .430660247825 .29715919495 22.8588790893620 .1158199310316 .4584007263212 .8009700775110 .66748046875 $9.1435537338268 .5339832305916 .095703125-.914355397224-8.83876895905$ -12.4961900711 -15.5440397263 -19.8110294342 -23.4684505463 -25.2971591949 -28.0402297974 -35.0502891541 -42.9747009277-49.070400238 -52.1182594299 $-50.594329834-47.8512611389-47.5464782715-47.8512611389-49.070400238$ $-49.9847602844-49.9847602844-49.9847602844-50.2895507812-51.2038993835$ $-53.0326118469-54.8613204956-55.1661109924-54.5565414429-54.5565414429$ -55.775680542 -57.2995986938 -58.8235282898 -59.7378807068 -60.0426712036 $-59.7378807068-59.4331016541-58.5187492371-57.9091796875-57.2995986938$ $-57.2995986938-57.2995986938-58.2139587402-60.0426712036-61.8713798523$ $-62.4809494019-60.0426712036-55.4708900452-49.9847602844-46.0225486755$ $-44.1938400269-45.1082000732-48.1560516357-51.5086898804-52.1182594299$ $-50.594329834-49.3751907349-51.5086898804-54.5565414429-37.488571167$ $-37.1837806702-40.2316398621-43.2794914246-44.1938400269-45.412979126$ $-63.700088501-61.8713798523-59.7378807068-58.5187492371-58.2139587402$ $-58.8235282898-58.5187492371-56.9948196411-53.9469718933-50.594329834$ $-47.8512611389-46.0225486755-45.1082000732-44.8034095764-44.8034095764$ $-44.1938400269-42.9747009277-41.1459884644-39.0125007629-36.8790016174$ -34.4407196045 -32.0024414062 -29.8689403534 -27.7354507446-25.6019496918 $-23.4684505463-21.3349609375-18.8966808319-16.7631797791-14.9344701767$ $-12.8009700775-11.2770500183-9.44833946228-8.22919845581-6.7052731514$ $-5.48613214493-4.26699209213-3.35263609886-2.13349604607-1.52392601967$ 16.1536102294917 .6775398254418 .28710937518 .8966808319118 .89668083191 
18.591890335081 .5239260196691 .8287110328672 .1334960460662 .438281059265 2.74306607246419 .506250381473 .9622070789345 .181346893311 -9999 -9999 -9999 -9999 -9999 -9999 -9999 -9999 -9999 -9999 -9999 -9999 -9999 -9999 -9999 -9999 -9999 -9999 -9999 -9999 -9999 -9999 -9999 -9999 -9999 -9999 -9999 -9999 -9999 -9999 -9999 -9999 -9999 -9999 -9999 -9999 -9999 -9999 -9999 -9999 -9999 -9999 -9999 -9999 -9999 -9999 -9999 -9999 -9999 -9999 -9999 -9999 -9999 -9999 -9999 -9999 -9999 -9999 -9999 -9999 -9999 -9999 -9999 -9999 -9999 -9999 -9999 -9999 -9999 -9999 -9999 -9999 -9999 -9999 -9999 -9999 -9999 -9999 -9999

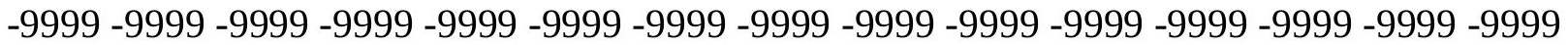

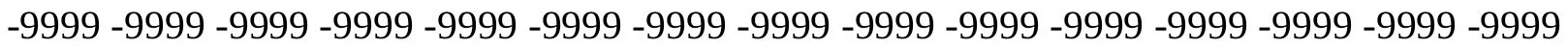
-9999 -9999 -9999 -9999 -9999 -9999 -9999 -9999 -9999 -9999 -9999 -9999 -9999 -9999 -9999 -

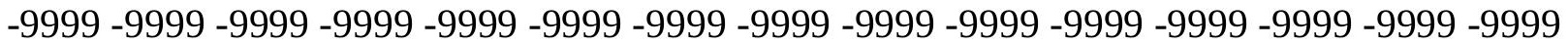
-9999-9999-9999

-9999 -9999 -9999 -9999 -9999 -9999 -9999 -9999 -9999 -9999 -9999 -9999 -9999 -9999 -9999 -9999 -9999 -9999 -9999 -9999 -9999 -9999 -9999 -9999 -9999 -9999 -9999 -9999 -9999 -9999 -9999 -9999 -9999 -9999 -9999 -9999 -9999 -9999 -9999 -9999 -9999 -9999 -9999 -9999 -9999

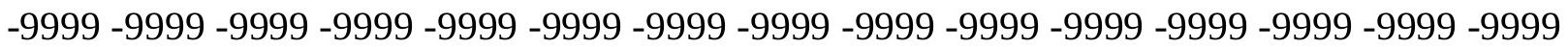

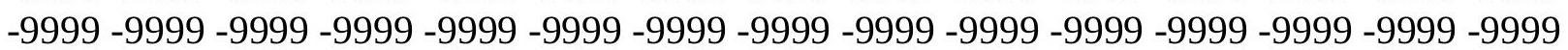
-9999 -9999 -9999 -9999 -9999 -9999 -9999 -9999 -9999 -9999 -9999 -9999 -9999 -9999 -9999 -9999 -9999 -9999 -9999 -9999 -9999 -9999 -9999 -9999 -9999 -9999 -9999 -9999 -9999 -9999 -9999 -9999 -9999 -9999 -9999 88.93398284912 81.83443450928 74.65767669678 67.7107009887761 .3269042968855 .821990966851 .3342971801847 .844581604 45.2456550598143 .3781433105542 .0038375854540 .8602256774939 .66528701782 38.2108116149936 .3742218017634 .1013679504431 .8700046539329 .3904876709 27.6423397064226 .1138668060323 .3504238128718 .8841819763214 .52816963196 12.8512248992914 .3248996734611 .886619567877 .9244132041931 .828711032867 $-6.40048694611-18.5918903351-30.478509903-36.8790016174-39.6220703125$ -37.1837806702 -33.8311500549 -35.0502891541 -37.488571167-40.5364189148 $-43.2794914246-44.8034095764-45.7177696228-47.2416992188-48.7656211853$ $-51.2038993835-53.9469718933-54.251750946-52.1182594299-52.4230384827$ $-53.3373985291-56.0804595947-57.9091796875-58.2139587402-57.9091796875$ $-58.2139587402-57.9091796875-56.3852500916-55.1661109924-55.4708900452$ -55.1661109924 -54.251750946 -37.1837806702 -57.6043891907-61.8713798523 $-63.0905189514-60.3474502563-53.9469718933-30.478509903-42.0603485107$ -39.9268493652 -40.8412094116-45.1082000732 -33.2215805054 -51.5086898804 -33.5263595581 -46.6321296692 -34.1359291077 -39.9268493652 -58.2139587402 $-58.8235282898-61.2618103027-48.4608306885-51.8134689331-54.251750946$ $-72.2340774536-69.795791626-66.7479400635-64.9192428589-64.9192428589$ $-65.5288009644-65.2240066528-62.7857398987-57.9091796875-52.7278289795$ $-48.7656211853-46.3273391724-45.412979126-45.412979126-45.7177696228$ $-45.412979126-44.1938400269-42.0603485107-39.6220703125-37.1837806702$ $-34.7455101013-32.307220459-29.8689403534-28.0402297974-25.9067401886$ -24.0780296326 -21.9445304871 -19.8110294342 -17.6775398254 -15.5440397263 $-13.7153301239-12.1914100647-10.6674804688-9.14355373383-7.92441320419$ $-6.7052731514-5.48613214493-4.57177686691-3.65742206573-2.74306607246$ 15.5440397262617 .0679702758817 .6775398254417 .6775398254417 .37274932861 16.76317977905 -9999-9999-9999.3047851026058.9143553972244.9143553972244 
1.219141006472 .743066072464 -9999 -9999 -9999 -9999 -9999 -9999 -9999 -9999 -9999 -9999 -9999 -9999 -9999 -9999 -9999 -9999 -9999 -9999 -9999 -9999 -9999 -9999 -9999 -9999 -9999 -9999 -9999 -9999 -9999 -9999 -9999 -9999 -9999 -9999 -9999 -9999 -9999 -9999 -9999 -9999 -9999 -9999 -9999 -9999 -9999 -9999 -9999 -9999 -9999 -9999 -9999 -9999 -9999 -9999 -9999 -9999 -9999 -9999 -9999 -9999 -9999 -9999 -9999 -9999 -9999 -9999 -9999 -9999 -9999 -9999 -9999 -9999 -9999 -9999 -9999 -9999 -9999 -9999 -9999 -9999 -9999 -9999 -9999 -9999 -9999 -9999 -9999 -9999 -9999 -9999 -9999 -9999 -9999 -9999 -9999 -9999 -9999 -9999 -9999

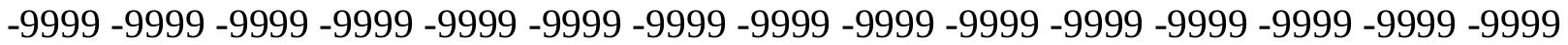

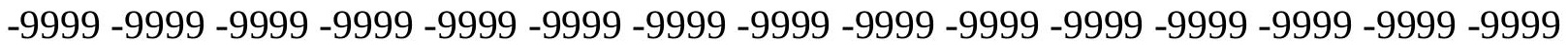
-9999 -9999 -9999 -9999 -9999 -9999 -9999 -9999 -9999 -9999 -9999 -9999 -9999 -9999 -9999 -9999 -9999 -9999 -9999 -9999 -9999 -9999 -9999 -9999 -9999 -9999 -9999 -9999 -9999 -9999 -9999 -9999 -9999 -9999 -9999 -9999 -9999 -9999 -9999 -9999 -9999 -9999 -9999

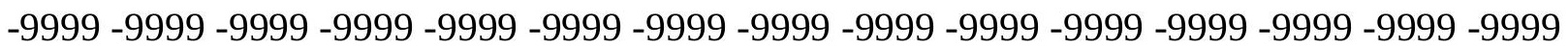
-9999 -9999 -9999 -9999 -9999 -9999 -9999 -9999 -9999 -9999 -9999 -9999 -9999 -9999 -9999 -9999 -9999 -9999 -9999 -9999 -9999 -9999 -9999 -9999 -9999 -9999 -9999 -9999 -9999 -9999 -9999 -9999 -9999 -9999 -9999 -9999 -9999 -9999 -9999 -9999 -9999 -9999 -9999 -9999 -9999 -9999 -9999 -9999 -9999 -9999 -9999 -9999 -9999 -9999 -9999 -9999 -9999 -9999 -9999 -9999 -9999 -9999 -9999 -9999-9999 91.3786239624 84.66796112061 77.88456726074 71.3000183105565 .186248779359 .7901573181255 .2521667480551 .58891296387 48.7244148254446 .5065841674844 .7436714172443 .229904174841 .78776931763 40.2604064941438 .6069946289137 .0031356811535 .9305152893136 .05079269409 37.6596832275439 .2906265258837 .8241539001533 .1608390808128 .06182479858 25.2066173553525 .3476715087929 .0675010681228 .0273895263721 .40201950073 $12.520489692692 .826386451721-3.68473601341$-3.04785108566 -8.22919845581 $-10.3626899719-12.1914100647-17.3727493286-22.8588790894-25.9067401886$ $-28.3450202942-32.0024414062-34.7455101013-33.8311500549-34.7455101013$ $-43.5842704773-50.8991203308-48.1560516357-43.5842704773-42.9747009277$ $-45.1082000732-50.8991203308-55.1661109924-53.3373985291-51.2038993835$ $-53.6421813965-55.775680542-51.2038993835-47.2416992188-51.5086898804$ $-54.8613204956-48.7656211853-44.4986305237-51.8134689331-60.3474502563$ $-61.5666007996-57.6043891907-49.070400238-40.2316398621-34.7455101013$ -31.6976509094 -31.0880794525 -35.0502891541 -46.0225486755 -53.9469718933 $-48.7656211853-43.2794914246-49.9847602844-57.9091796875-56.3852500916$ $-53.9469718933-59.1283111572-65.8335876465-70.1005783081-72.5388565063$ $-73.4532165527-72.2340774536-67.6623001099-64.6144485474-67.6623001099$ $-70.1005783081-70.4053573608-66.7479400635-59.7378807068-52.7278289795$ $-48.4608306885-45.7177696228-44.8034095764-45.412979126-46.3273391724$ $-46.6321296692-45.1082000732-42.0603485107-39.3172798157$-36.8790016174 -34.4407196045 -31.6976509094 -29.5641593933 -27.7354507446 -25.9067401886 -24.3828105927 -22.5541000366 -20.4206008911 -18.287109375 -16.1536102295 $-14.3248996735-12.8009700775-11.2770500183-10.0579099655-8.83876895905$ $-7.61962795258-6.40048694611-5.48613214493-4.57177686691-3.65742206573$ 14.934470176716 .4584007263217 .0679702758816 .4584007263215 .84883022308 $-1.52392601967-1.52392601967-1.52392601967-1.21914100647-.914355397224$ -.609570324421 -.304785102606 -9999 -9999 1.828711032867 -9999 -9999 -9999 -9999 -9999 -9999 -9999 -9999 -9999 -9999 -9999 -9999 -9999 -9999 -9999 -9999 -9999 -9999 -9999 -9999 
-9999 -9999 -9999 -9999 -9999 -9999 -9999 -9999 -9999 -9999 -9999 -9999 -9999 -9999 -9999 -9999 -9999 -9999 -9999 -9999 -9999 -9999 -9999 -9999 -9999 -9999 -9999 -9999 -9999 -9999

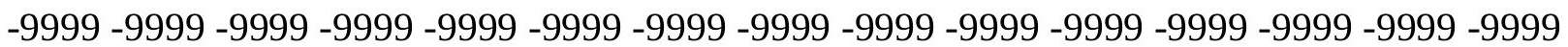
-9999 -9999 -9999 -9999 -9999 -9999 -9999 -9999 -9999 -9999 -9999 -9999 -9999 -9999 -9999 -9999 -9999 -9999 -9999 -9999 -9999 -9999 -9999 -9999 -9999 -9999 -9999 -9999 -9999 -9999 -9999 -9999 -9999 -9999 -9999 -9999 -9999 -9999 -9999 -9999 -9999 -9999 -9999 -9999 -9999 -9999 -9999 -9999 -9999 -9999 -9999 -9999 -9999 -9999 -9999 -9999 -9999 -9999 -9999 -9999

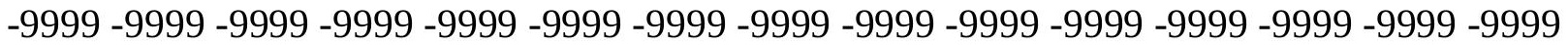
$-9999$

-9999 -9999 -9999 -9999 -9999 -9999 -9999 -9999 -9999 -9999 -9999 -9999 -9999 -9999 -9999 -9999 -9999 -9999 -9999 -9999 -9999 -9999 -9999 -9999 -9999 -9999 -9999 -9999 -9999 -9999 -9999 -9999 -9999 -9999 -9999 -9999 -9999 -9999 -9999 -9999 -9999 -9999 -9999 -9999 -9999

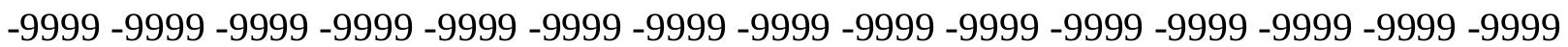
-9999 -9999 -9999 -9999 -9999 -9999 -9999 -9999 -9999 -9999 -9999 -9999 -9999 -9999 -9999 -9999 -9999 -9999 -9999 -9999 -9999 -9999 -9999 -9999 -9999 -9999 -9999 -9999 -9999 -9999 -9999 -9999 -9999 -9999 -9999 -9999 -9999 -9999 -9999 -9999 -9999 -9999 -9999 -9999 -9999 -9999 -9999 -9999 -9999 99.68402099609 93.67052459717 87.36393737793 80.98816680908 74.7646408081168 .9401168823263 .7099838256859 .1980819702155 .42175674438 52.3357849121149 .8251609802247 .7493629455645 .9514427185144 .32029342651 42.7724685668941 .3454170227140 .2426719665539 .7921562194840 .2544670105 41.4130477905342 .0609283447341 .1885452270538 .6629981994635 .95346832275 34.7998771667536 .3846435546940 .4589309692442 .267017364536 .73561859131 29.9685306549123 .759632110620 .0235519409218 .4259166717516 .36522865295 $14.8520135879514 .324899673464 .87656211853-3.04785108566-6.095703125$ $-8.22919845581-14.0201196671-18.5918903351-15.8488302231-15.5440397263$ -28.6497993469 -40.2316398621 -34.4407196045 -25.9067401886 -24.3828105927 -27.1258792877 -35.3550796509-42.3651313782 -38.7077102661 -34.4407196045 -38.7077102661 -41.7555618286 -34.1359291077 -28.0402297974 -35.9646492004 $-42.669921875-34.7455101013-27.4306602478-34.7455101013-43.8890609741$ $-44.4986305237-40.8412094116-34.1359291077-26.5163097382-19.5062503815$ -14.9344701767 -15.2392597198 -20.4206008911 -33.5263595581-44.4986305237 -39.0125007629 -33.2215805054-41.7555618286-49.3751907349-43.2794914246 -37.488571167-44.8034095764 -54.5565414429 -58.5187492371 -60.0426712036 $-61.2618103027-59.7378807068-52.4230384827-46.6321296692-51.5086898804$ $-57.9091796875-58.2139587402-55.4708900452-48.7656211853-42.0603485107$ -39.6220703125 -38.7077102661 -39.6220703125 -41.7555618286-45.412979126 $-47.2416992188-44.8034095764-40.2316398621-38.4029312134-36.2694282532$ -33.2215805054 -30.478509903 -28.3450202942 -26.8210906982 -25.6019496918 -24.3828105927 -22.5541000366 -20.4206008911 -18.287109375 -16.1536102295 -14.3248996735 -12.8009700775 -11.5818300247 -10.3626899719-9.14355373383 $-7.92441320419-7.01005792618-5.79091691971-4.8765621185312 .1914100647$ 14.934470176716 .4584007263216 .1536102294915 .2392597198514 .02011966705 -3.04785108566 -3.04785108566 -3.04785108566 -2.74306607246 -2.74306607246 $-2.43828105927-2.13349604607-2.13349604607-2.43828105927-.609570324421$ 1.523926019669 -9999 -9999 -9999 -9999 -9999 -9999 -9999 -9999 -9999 -9999 -9999 -9999 -9999 -9999 -9999 -9999 -9999 -9999 -9999 -9999 -9999 -9999 -9999 -9999 -9999 -9999 -9999 
-9999 -9999 -9999 -9999 -9999 -9999 -9999 -9999 -9999 -9999 -9999 -9999 -9999 -9999 -9999 -9999 -9999 -9999 -9999 -9999 -9999 -9999 -9999 -9999 -9999 -9999 -9999 -9999 -9999 -9999 -

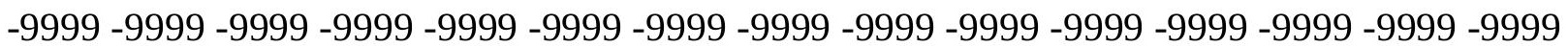
-9999 -9999 -9999 -9999 -9999 -9999 -9999 -9999 -9999 -9999 -9999 -9999 -9999 -9999 -9999 -9999 -9999 -9999 -9999 -9999 -9999 -9999 -9999 -9999 -9999 -9999 -9999 -9999 -9999 -9999 -9999 -9999 -9999 -9999 -9999 -9999 -9999 -9999 -9999 -9999 -9999 -9999 -9999 -9999 -9999

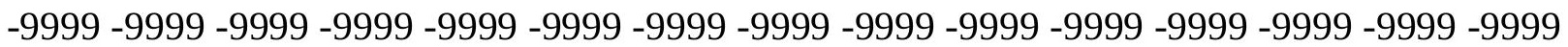
-9999 -9999 -9999 -9999 -9999 -9999-9999-9999

-9999 -9999 -9999 -9999 -9999 -9999 -9999 -9999 -9999 -9999 -9999 -9999 -9999 -9999 -9999 -9999 -9999 -9999 -9999 -9999 -9999 -9999 -9999 -9999 -9999 -9999 -9999 -9999 -9999 -9999 -9999 -9999 -9999 -9999 -9999 -9999 -9999 -9999 -9999 -9999 -9999 -9999 -9999 -9999 -9999 -9999 -9999 -9999 -9999 -9999 -9999 -9999 -9999 -9999 -9999 -9999 -9999 -9999 -9999 -9999

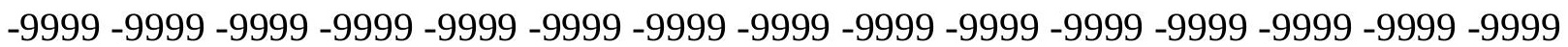
-9999 -9999 -9999 -9999 -9999 -9999 -9999 -9999 -9999 -9999 -9999 -9999 -9999 -9999 -9999 -9999 -9999 -9999 -9999 -9999 -9999 -9999 -9999 -9999 -9999 -9999 -9999 -9999 -9999 -9999 -9999 -9999 -9999 -9999 100.357307434195.80278015137 89.88719177246 83.89959716797 78.0473098754972 .5318832397567 .4972381591863 .0492095947359 .2188949585 55.974330902153 .2530250549350 .9495315551848 .95981597947 .20415496826 45.6557083129944 .3745231628443 .5093078613343 .2317428588943 .58131408691 44.2609214782744 .6612854003944 .352264404343 .4155654907242 .61430740356 42.9461631774944 .9982490539648 .2803649902350 .8370437622149 .10074615479 44.5770492553740 .6296272277838 .0434875488336 .3358840942435 .21105957031 33.6835708618230 .5735416412424 .4567260742218 .2391719818114 .33845043182 12.2892513275111 .277050018316 .0957031257 .9244132041937 .619627952576 $-2.74306607246-11.2770500183-6.0957031251 .219141006471 .21914100647$ $-2.13349604607-7.01005792618-10.9722604752-9.44833946228-6.7052731514$ $-6.7052731514-5.181346893311 .8287110328676 .400486946106-9999-6.40048694611$ -.914355397224 $4.876562118533 .352636098862-9999-.609570324421$-9999 -5.31029605865 $-4.49308729172-.9968508481981 .7975568771361 .989170432091-.224591687322$ $-1.82871103287-5.18134689331-5.48613214493-6.40048694611-12.8009700775$ $-15.8488302231-8.53398323059-3.04785108566-10.9722604752-20.4206008911$ -21.0301704407 -19.5062503815 -23.1636695862 -24.9923801422 -18.287109375 $-12.8009700775-18.5918903351-26.2115192413-28.3450202942-26.8210906982$ -21.3349609375 -16.1536102295 -16.7631797791 -18.5918903351 -19.2014598846 -20.7253894806 -23.7732391357 -26.5163097382 -26.2115192413 -25.2971591949 $-27.7354507446-29.8689403534-29.5641593933-28.6497993469-26.8210906982$ $-25.6019496918-24.9923801422-24.0780296326-22.2493095398-20.115819931$ -17.6775398254 -15.5440397263 -13.7153301239-12.4961900711 -11.5818300247 -10.6674804688 -9.44833946228 -8.22919845581 -6.7052731514 -5.79091691971 $-4.8765621185312 .4961900711115 .2392597198516 .7631797790515 .84883022308$ $13.7153301239-4.26699209213-4.26699209213-4.26699209213-4.26699209213$ $-4.26699209213-3.96220707893-3.96220707893-3.96220707893-3.96220707893$ -4.26699209213 -3.35263609886 -.914355397224 -9999 -9999 -9999 -9999 -9999 -9999 -9999 -9999 -9999 -9999 -9999 -9999 -9999 -9999 -9999 -9999 -9999 -9999 -9999 -9999 -9999 -9999 -9999 -9999 -9999 -9999 -9999 -9999 -9999 -9999 -9999 -9999 -9999 -9999 -9999 -9999 -9999

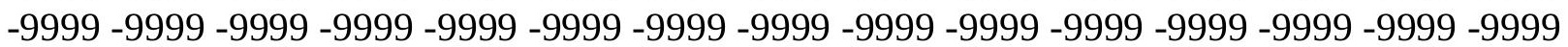


-9999 -9999 -9999 -9999 -9999 -9999 -9999 -9999 -9999 -9999 -9999 -9999 -9999 -9999 -9999 -9999 -9999 -9999 -9999 -9999 -9999 -9999 -9999 -9999 -9999 -9999 -9999 -9999 -9999 -9999

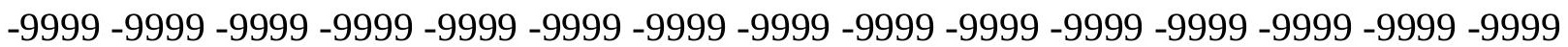
-9999 -9999 -9999 -9999 -9999 -9999 -9999 -9999 -9999 -9999 -9999 -9999 -9999 -9999 -9999 -9999 -9999 -9999 -9999 -9999 -9999 -9999 -9999 -9999 -9999 -9999 -9999 -9999 -9999 -9999 -9999 -9999 -9999 -9999 -9999 -9999 -9999 -9999 -9999 -9999 -9999 -9999 -9999 -9999 -9999 -9999 -9999 -9999 -9999 -9999 -9999 -9999 -9999 -9999 -9999 -9999 -9999 -9999

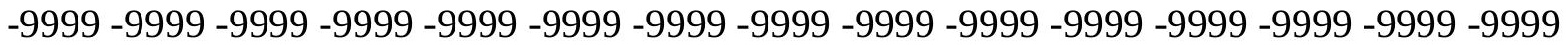

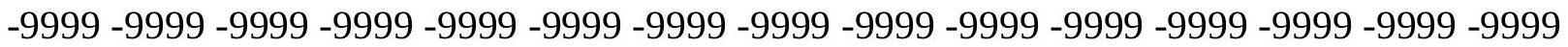
-9999 -9999 -9999 -9999 -9999 -9999 -9999 -9999 -9999 -9999 -9999 -9999 -9999 -9999 -9999 -9999 -9999 -9999 -9999 -9999 -9999 -9999 -9999 -9999 -9999 -9999 -9999 -9999 -9999 -9999 -9999 -9999 -9999 -9999 -9999 -9999 -9999 -9999 -9999 -9999 -9999 -9999 -9999 -9999 -9999

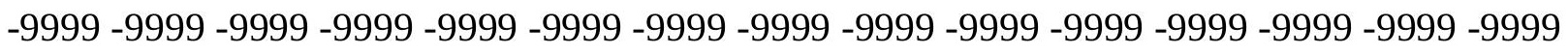
-9999 -9999 -9999 96.823104858497.6605300903395.8626785278392.19631958008 86.6046981811581 .1242141723675 .9127273559671 .0873718261766 .73525238037 62.8974266052259 .571571350156 .7171020507854 .2736740112352 .16596984863 50.3359603881848 .7859840393147 .5662307739346 .7659645080646 .45962142944 46.6167488098147 .0357894897547 .4353027343847 .6329421997147 .73865127563 48.1449012756349 .3332710266151 .4973907470754 .2551383972256 .8784942627 58.9096603393656 .0679893493753 .6017837524451 .80036544850 .51200866699 49.3961982727147 .7258567810144 .647464752240 .5213127136236 .21321868896 33.037803649931 .1632518768329 .7764968872128 .1815547943127 .42017745972 25.1705417633120 .199642181416 .6878852844218 .0599460601821 .35012817383 22.1956596374520 .2933330535917 .5588817596415 .9771804809616 .59160614014 18.5499114990220 .911411285424 .3649635314928 .6934413909930 .743019104 28.8551578521726 .9168376922628 .6168594360431 .4850997924832 .29411315918 31.171106338529 .3019275665326 .2932682037421 .8152790069619 .17701911926 19.0470638275119 .9041309356720 .5314731597920 .7053813934320 .87492370605 20.5335788726819 .4819526672417 .3820343017614 .7653656005914 .59418010712 17.7492675781219 .5225677490216 .3391036987311 .642038345349 .600308418274 8.9143257141117 .3716959953316 .9601945877089 .08757591247610 .10221481323 $6.8288483619691 .741901040077-1.26688301563-.9585794806481 .646410226822$ 4.1824631690985 .1929335594186 .0957031255 .1813468933114 .571776866913 2.438281059265 .6095703244209 .9143553972244.3047851026058 -3.65742206573 -8.53398323059 -9.44833946228 -10.0579099655 -11.8866195679-14.3248996735 $-17.6775398254-19.8110294342-19.8110294342-18.5918903351-16.4584007263$ $-13.7153301239-12.4961900711-11.5818300247-10.9722604752-10.0579099655$ -8.83876895905 -7.61962795258 -6.095703125 -4.87656211853 -4.26699209213 13.1057596206715 .8488302230816 .7631797790514 .934470176712 .1914100647 $-5.18134689331-5.18134689331-5.18134689331-5.18134689331-5.18134689331$ $-5.18134689331-5.18134689331-5.18134689331-5.48613214493-5.48613214493$ $-5.48613214493-3.65742206573-.914355397224-9999-9999-9999-9999-9999-9999-9999$ -9999 -9999 -9999 -9999 -9999 -9999 -9999 -9999 -9999 -9999 -9999 -9999 -9999 -9999 -9999 -9999 -9999 -9999 -9999 -9999 -9999 -9999 -9999 -9999 -9999 -9999 -9999 -9999 -9999 -9999 -9999 -9999 -9999 -9999 -9999 -9999 -9999 -9999 -9999 -9999 -9999 -9999 -9999 -9999 -9999

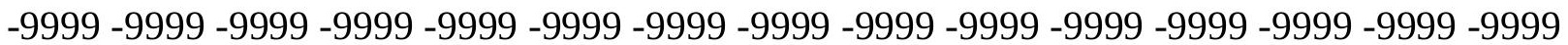


-9999 -9999 -9999 -9999 -9999 -9999 -9999 -9999 -9999 -9999 -9999 -9999 -9999 -9999 -9999 -9999 -9999 -9999 -9999 -9999 -9999 -9999 -9999 -9999 -9999 -9999 -9999 -9999 -9999 -9999

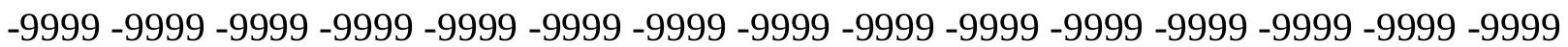
-9999 -9999 -9999 -9999 -9999 -9999 -9999 -9999 -9999 -9999 -9999 -9999 -9999 -9999 -9999 -9999 -9999 -9999 -9999 -9999 -9999 -9999 -9999 -9999 -9999 -9999 -9999 -9999 -9999 -9999 -9999 -9999 -9999 -9999 -9999 -9999 -9999 -9999 -9999 -9999 -9999 -9999 -9999 -9999 -9999 -9999 -9999 -9999 -9999 -9999 -9999 -9999 -9999 -9999 -9999 -9999 -9999

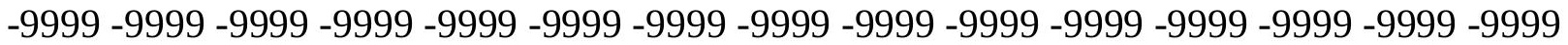

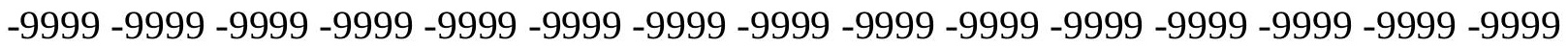
-9999 -9999 -9999 -9999 -9999 -9999 -9999 -9999 -9999 -9999 -9999 -9999 -9999 -9999 -9999 -9999 -9999 -9999 -9999 -9999 -9999 -9999 -9999 -9999 -9999 -9999 -9999 -9999 -9999 -9999 -9999 -9999 -9999 -9999 -9999 -9999 -9999 -9999 -9999 -9999 -9999 -9999 -9999 -9999 -9999 -9999 -9999 -9999 92.811935424893.2642517089892.6945037841890.84321594238 89.0985641479583 .9686737060579 .0460205078174 .4351119995170 .21299743652 66.4236145019563 .0797805786160 .1653327941957 .6453132629455 .47641372681 53.6118392944352 .0619277954150 .8601951599150 .0553703308149 .67743301392 49.6947822570850 .0021896362350 .4719238281251 .0356330871651 .75941467285 52.8237495422454 .4142608642656 .555381774959 .0291786193861 .55815505981 63.9535675048864 .8513946533263 .3948631286662 .2493667602561 .32758331299 60.3219108581558 .2241592407254 .9656372070351 .826583862349 .0849609375 47.1274757385347 .0010795593345 .8388328552245 .0008964538643 .77237701416 41.814449310338 .8788337707536 .1781120300337 .0111732482938 .51487731934 37.9757843017637 .0064048767137 .1192626953137 .8958892822338 .69250869751 40.6308288574243 .4405784606946 .7900695800849 .8478660583551 .49289321899 51.6859245300351 .6579856872652 .4124412536653 .7048797607454 .24726104736 53.3057136535650 .899417877247 .153186798143 .0686721801839 .62237548828 37.8389282226637 .4148445129437 .7396202087438 .4244766235439 .06080627441 39.3990173339838 .9222564697337 .7972717285236 .9855384826737 .37938690186 38.6359252929739 .1205787658737 .8603706359935 .5732002258333 .62755584717 32.2877922058131 .2924365997330 .8311519622830 .7013607025129 .73954772949 27.1772804260323 .684499740621 .0265636444120 .3109359741221 .09214782715 22.3614921569823 .5334262847924 .259691238424 .2216339111323 .67508125305 22.644594192521 .7229290008521 .0884952545219 .6923904418917 .11812973022 15.1012668609615 .8488302230813 .4105501174910 .057909965526 .095703125 $1.21914100647-2.13349604607-1.82871103287-1.21914100647-2.43828105927$ $-4.57177686691-8.22919845581-10.0579099655-10.0579099655-8.83876895905$ $-7.61962795258-6.095703125-4.26699209213-2.74306607246-2.43828105927$ $14.934470176715 .8488302230814 .934470176712 .80097007751-5.18134689331$ -5.48613214493 -5.79091691971 -5.79091691971 -5.79091691971 -6.095703125 -6.095703125 -6.095703125 -6.40048694611-6.40048694611-6.7052731514-6.40048694611 -6.095703125 -3.35263609886 - 304785102606 -9999 -9999 -9999 -9999 -9999 -9999 -9999 -9999 -9999 -9999 -9999 -9999 -9999 -9999 -9999 -9999 -9999 -9999 -9999 -9999 -9999 -9999-9999-9999 -9999 -9999 -9999 -9999 -9999 -9999 -9999 -9999 -9999 -9999 -9999 -9999 -9999 -9999 -9999 -9999 -9999 -9999 -9999 -9999 -9999 -9999 -9999 -9999 -9999 -9999 -9999 -9999 -9999 -9999 -999 -9999 -9999 -9999 -9999 -9999 -9999 -9999 -9999 -9999 -9999 -9999 -9999 -9999 -9999 -9999

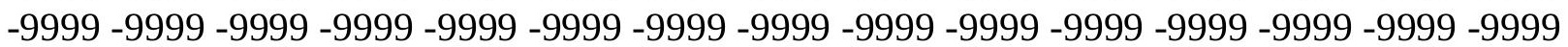


-9999 -9999 -9999 -9999 -9999 -9999 -9999 -9999 -9999 -9999 -9999 -9999 -9999 -9999 -9999 -9999 -9999 -9999 -9999 -9999 -9999 -9999 -9999 -9999 -9999 -9999 -9999 -9999 -9999 -9999 -9999 -9999 -9999 -9999 -9999 -9999 -9999 -9999 -9999 -9999 -9999 -9999 -9999 -9999 -9999 -9999 -9999 -9999 -9999 -9999 -9999 -9999 -9999 -9999

-9999 -9999 -9999 -9999 -9999 -9999 -9999 -9999 -9999 -9999 -9999 -9999 -9999 -9999 -9999 -9999 -9999 -9999 -9999 -9999 -9999 -9999 -9999 -9999 -9999 -9999 -9999 -9999 -9999 -9999 -9999 -9999 -9999 -9999 -9999 -9999 -9999 -9999 -9999 -9999 -9999 -9999 -9999 -9999 -9999

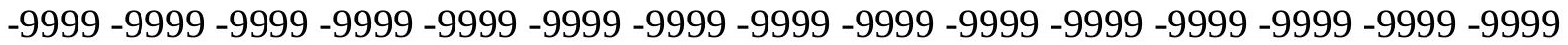

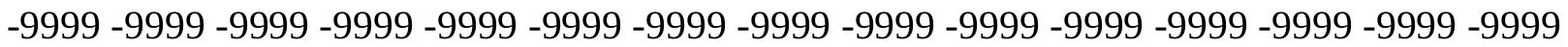
-9999 -9999 -9999 -9999 -9999 -9999 -9999 -9999 -9999 -9999 -9999 -9999 -9999 -9999 -9999 -9999 -9999 -9999 -9999 -9999 -9999 -9999 -9999 -9999 -9999 -9999 -9999 -9999 -9999 -9999 -9999 -9999 91.30567169189 88.7551651001 86.55898284912 86.55898284912 87.4897613525486 .7511978149486 .4770431518681 .9364547729577 .54627990723 73.4777145385769 .7762145996166 .4645462036163 .5435829162661 .00022125244 58.8115997314556 .9418067932155 .4014930725154 .2090339660653 .3910446167 52.9618148803752 .9053153991753 .1744232177753 .7132644653354 .49347686768 55.5363693237356 .8987846374558 .6181488037160 .6518707275462 .86855697632 65.108963012767 .2083663940468 .9639129638770 .0088729858469 .99110412598 68.7423400878966 .5086288452163 .8057785034261 .0828971862858 .50951766968 56.4293098449755 .1166687011754 .7744560241754 .3668289184653 .52012252808 51.5819206237849 .0694465637246 .5414695739744 .8183479309144 .38841629028 44.5984077453644 .6567077636744 .7073516845745 .3056373596246 .74038696289 49.0094947814952 .3605918884356 .8373489379961 .990512847966 .5380859375 68.3157196044969 .2752838134869 .8858566284270 .4531936645570 .9299621582 70.8020248413169 .5390701293966 .9816818237363 .4050331115759 .54192352295 56.1123809814553 .7602310180752 .6318054199252 .4826660156252 .94120025635 53.5864334106454 .0759162902854 .1518554687553 .9353981018153 .90782546997 54.3502883911154 .9701576232955 .155414581354 .5513648986853 .30722427368 51.8653831481950 .5700416564949 .5203437805248 .6105766296447 .52979278564 45.8769226074243 .5003662109440 .76994705238 .489681243937 .25987243652 37.0521583557137 .4682846069338 .109519958538 .5525283813538 .69699859619 38.4305763244637 .9706497192437 .4489212036136 .7821388244635 .77515792847 34.5706748962433 .7610969543533 .0605888366731 .0920944213927 .80452537537 23.7663688659719 .8813934326217 .6394195556618 .2119503021221 .03017044067 $18.8966808319114 .324899673465 .486132144928-2.13349604607$-3.96220707893 -3.96220707893 -5.18134689331 -3.96220707893 -.914355397224 -9999 -9999 $17.3727493286115 .84883022308-3.35263609886-4.26699209213-5.18134689331$ $-5.48613214493-5.79091691971-6.095703125-6.40048694611-6.40048694611$ $-6.7052731514-6.7052731514-7.01005792618-7.3148431778-7.3148431778-7.3148431778$ -7.3148431778 -5.48613214493 -2.43828105927 -9999 -9999 -9999 -9999 -9999 -9999 -9999 -9999 -9999 -9999 -9999 -9999 -9999 -9999 -9999 -9999 -9999 -9999 -9999 -9999 -9999 -9999

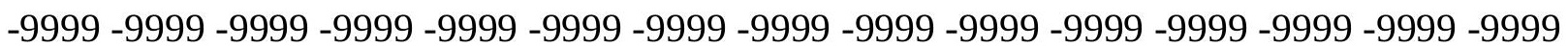
-9999 -9999 -9999 -9999 -9999 -9999 -9999 -9999 -9999 -9999 -9999 -9999 -9999 -9999 -9999 -9999 -9999 -9999 -9999 -9999 -9999 -9999 -9999 -9999 -9999 -9999 -9999 -9999 -9999 -9999 -999 -9999 -9999 -9999 -9999 -9999 -9999 -9999 -9999 -9999 -9999 -9999 -9999 -9999 -9999 -9999 -999 -

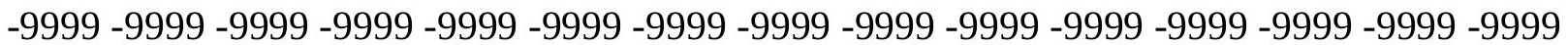


-9999 -9999 -9999 -9999 -9999 -9999 -9999 -9999 -9999 -9999 -9999 -9999 -9999 -9999 -9999 -9999 -9999 -9999 -9999 -9999 -9999 -9999 -9999 -9999 -9999 -9999 -9999 -9999 -9999 -9999 -9999 -9999 -9999 -9999 -9999 -9999 -9999 -9999 -9999 -9999 -9999

-9999 -9999 -9999 -9999 -9999 -9999 -9999 -9999 -9999 -9999 -9999 -9999 -9999 -9999 -9999 -9999 -9999 -9999 -9999 -9999 -9999 -9999 -9999 -9999 -9999 -9999 -9999 -9999 -9999 -9999 -9999 -9999 -9999 -9999 -9999 -9999 -9999 -9999 -9999 -9999 -9999 -9999 -9999 -9999 -9999 -9999 -9999 -9999 -9999 -9999 -9999 -9999 -9999 -9999 -9999 -9999 -9999 -9999 -9999 -9999

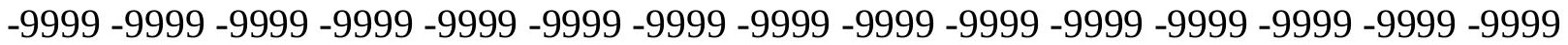
-9999 -9999 -9999 -9999 -9999 -9999 -9999 -9999 -9999 -9999 -9999 -9999 -9999 -9999 -9999 -9999 -9999 -9999 -9999 -9999 -9999 -9999 -9999 -9999 -9999 -9999 -9999 -9999 -9999 -9999 -9999 -9999 89.60682678223 86.2541885376 83.2063369751 82.59677124023 83.75540924072 83.7754287719784 .4543991088984 .5938110351680 .4261703491276 .52667236328 72.9408645629969 .6981582641666 .8111190795964 .280410766662 .10137557983 60.2508735656758 .7325210571357 .5558166503956 .7370376586956 .28583526611 56.1986503601156 .4563674926857 .0330848693857 .9084930419959 .07243728638 60.5152511596762 .2057495117264 .0741577148466 .0173492431667 .91424560547 69.6291198730570 .9867324829171 .7711715698271 .8029022216871 .01148986816 69.5232162475667 .5782928466865 .4275665283263 .3308219909761 .50988388062 60.1464042663659 .1393623352158 .1233062744156 .8500175476155 .0281791687 52.8949851989750 .9073295593349 .4912643432648 .761306762748 .59661483765 48.7792739868249 .2597770690950 .2428932189951 .9329986572354 .45895767212 57.8482589721761 .9777069091866 .4356765747170 .5593032836973 .87461090088 76.6297912597779 .5914993286183 .5669937133883 .5898513793982 .9691619873 81.4318771362378 .9008483886775 .6266174316472 .0947952270568 .87754821777 66.4245910644564 .9550628662164 .4018249511764 .5091018676864 .95612335205 65.4424743652365 .8050003051866 .0591049194366 .3749313354566 .82325744629 67.2519912719767 .3954696655367 .0775070190466 .3145751953165 .26924133301 64.1327133178762 .9940376281761 .7855072021560 .3216476440458 .46140289307 56.2371444702153 .895503997851 .8535041809150 .4230613708549 .68644714355 49.4978523254449 .6046867370649 .7616920471249 .8345527648949 .76149368286 49.6036987304749 .3879890441949 .0697822570848 .6297721862848 .14136123657 47.6322326660246 .6621398925844 .9424819946342 .2592849731439 .1187286377 36.4192962646535 .0885314941435 .3639984130935 .9495773315434 .42262649536 30.7426357269325 .906740188611 .581830024728 .2291984558118 .229198455811 6.0957031254 .5717768669134 .8765621185322 .5541000366221 .94453048706 19.50625038147 -9999 -2.13349604607 -3.35263609886 -4.57177686691 -5.18134689331 $-5.79091691971-6.095703125-6.40048694611-6.7052731514-6.7052731514-7.01005792618$ $-7.3148431778-7.61962795258-7.61962795258-7.61962795258-7.61962795258$ -7.3148431778 -4.57177686691 -1.21914100647 -9999 -9999 -9999 -9999 -9999 -9999 -9999 -9999 -9999 -9999 -9999 -9999 -9999 -9999 -9999 -9999 -9999 -9999 -9999 -9999 -9999 -9999 -9999 -9999 -9999 -9999 -9999 -9999 -9999 -9999 -9999 -9999 -9999 -9999 -9999 -9999 -9999

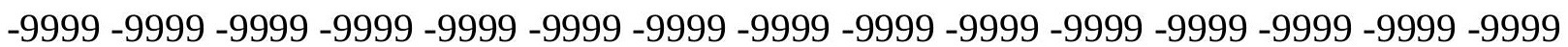
-9999 -9999 -9999 -9999 -9999 -9999 -9999 -9999 -9999 -9999 -9999 -9999 -9999 -9999 -9999 -9999 -9999 -9999 -9999 -9999 -9999 -9999 -9999 -9999 -9999 -9999 -9999 -9999 -9999 -9999 -9999 -9999 -9999 -9999 -9999 -9999 -9999 -9999 -9999 -9999 -9999 -9999 -9999 -9999 -9999

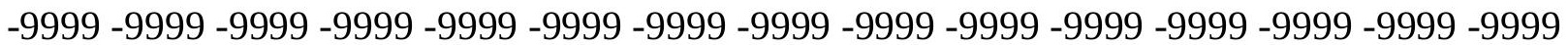


-9999 -9999 -9999 -9999 -9999 -9999 -9999 -9999 -9999 -9999 -9999 -9999 -9999 -9999 -9999 -9999 -9999 -9999 -9999 -9999 -9999 -9999 -9999 -9999 -9999

-9999 -9999 -9999 -9999 -9999 -9999 -9999 -9999 -9999 -9999 -9999 -9999 -9999 -9999 -9999 -9999 -9999 -9999 -9999 -9999 -9999 -9999 -9999 -9999 -9999 -9999 -9999 -9999 -9999 -9999 -9999 -9999 -9999 -9999 -9999 -9999 -9999 -9999 -9999 -9999 -9999 -9999-9999 -9999 -9999 -9999 -9999 -9999 -9999 -9999 -9999 -9999 -9999 -9999 -9999 -9999 -9999 -9999 -9999 -9999

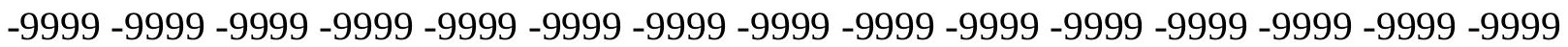
-9999 -9999 -9999 -9999 -9999 -9999 -9999 -9999 -9999 -9999 -9999 -9999 -9999 -9999 -9999 -999 -

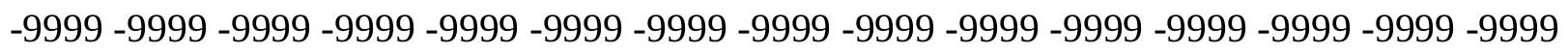
-9999 92.90771484375 88.38768768311 86.55898284912 81.68241119385 79.85370635986 79.812774658280 .7034149169982 .576736450283 .5312576293983 .08317565918 79.3617706298875 .9103317260772 .7622375488369 .9375991821367 .44770812988 65.2957687377963 .481864929261 .9904212951760 .838172912660 .02884674072 59.5730323791559 .4727020263759 .7187652587960 .2941780090361 .1759223938 62.3354110717863 .7323112487865 .3080139160266 .9826507568468 .66250610352 70.2468109130971 .6284332275472 .6862335205173 .2970046997173 .36176300049 72.8460083007871 .7983398437570 .3333740234468 .602951049866 .78514862061 65.0351715087963 .4513282775961 .9831619262760 .5203132629458 .91137695312 57.1167526245155 .2531661987353 .5868034362852 .3464622497651 .62142562866 51.4000701904351 .6272392272952 .2863922119153 .4552078247155 .24736785889 57.7424545288160 .9188766479564 .6334762573268 .5970306396572 .47888946533 76.1082305908279 .6557006835983 .5567092895588 .2816772460992 .45547485352 91.5483627319389 .8824462890687 .4644927978584 .4959259033281 .33085632324 78.3877639770576 .0143432617274 .4090728759873 .5805511474673 .3805770874 73.5848541259873 .9716339111374 .3987731933674 .8241424560575 .26553344727 75.7123413085976 .0747528076276 .2188262939576 .0422592163175 .52562713623 74.7265014648473 .7304382324272 .584678649971 .2636337280369 .70008850098 67.8636779785265 .8216552734463 .7500610351661 .8813209533760 .40731811523 59.4103088378958 .8464546203658 .5875511169458 .5004653930758 .48291778564 58.4956665039158 .5317192077658 .5838699340858 .6221771240258 .61637878418 58.5253639221258 .2110176086457 .435684204156 .0502853393654 .06760025024 51.8525657653850 .0005760192948 .9733963012748 .6901321411148 .24201965332 46.7478294372643 .3323211669937 .5223579406729 .5641593933125 .60194969177 25.906740188623 .1636695861820 .4206008911119 .2014598846417 .37274932861 $12.19141006477 .31484317779518 .287109375-.304785102606-1.82871103287$ -3.35263609886 -4.57177686691 -5.18134689331 -5.48613214493 -6.095703125 $-6.40048694611-6.7052731514-7.01005792618-7.3148431778-7.61962795258$ $-7.92441320419-7.92441320419-7.61962795258-7.3148431778-6.40048694611$ -3.04785108566 -9999 -9999 -9999 -9999 -9999 -9999 -9999 -9999 -9999 -9999 -9999 -9999 -9999 -9999 -9999 -9999 -9999 -9999 -9999 -9999 -9999 -9999 -9999 -9999 -9999 -9999 -9999

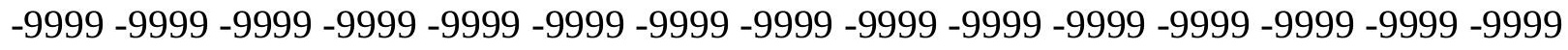

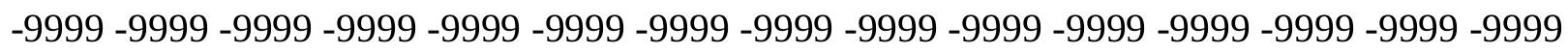

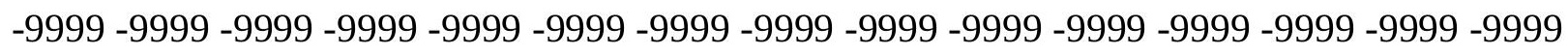
-9999 -9999 -9999 -9999 -9999 -9999 -9999 -9999 -9999 -9999 -9999 -9999 -9999 -9999 -9999 -

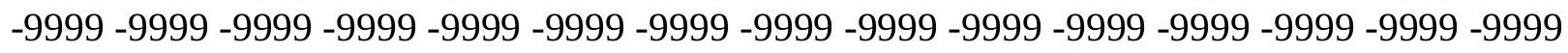

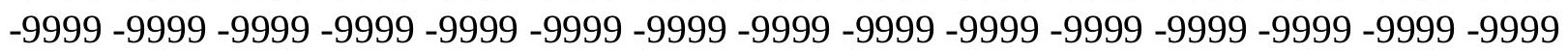


-9999 -9999 -9999 -9999 -9999 -9999 -9999 -9999 -9999 -9999 -9999 -9999 -9999 -9999 -9999 -9999 -9999-9999-9999-9999

-9999 -9999 -9999 -9999 -9999 -9999 -9999 -9999 -9999 -9999 -9999 -9999 -9999 -9999 -9999 -9999 -9999 -9999 -9999 -9999 -9999 -9999 -9999 -9999 -9999 -9999 -9999 -9999 -9999 -9999 -9999 -9999 -9999 -9999 -9999 -9999 -9999 -9999 -9999 -9999 -9999 -9999 -9999 - -9999 - -9999 -

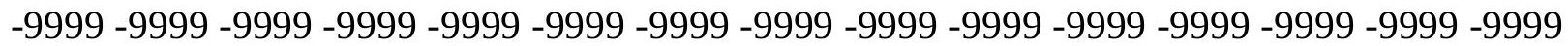

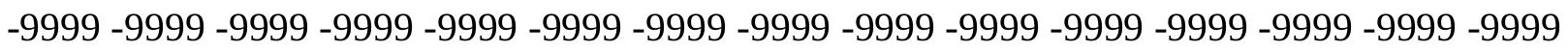

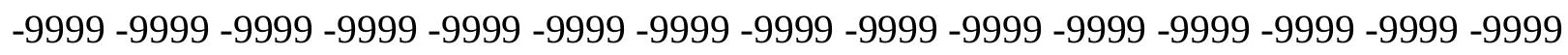

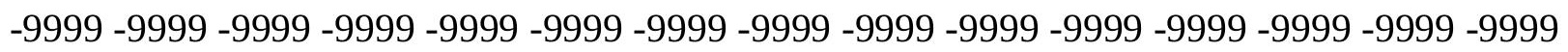
97.6801071167 93.26425170898 87.77810668945 86.2541885376 83.51112365723 79.8537063598676 .1962814331177 .7202072143680 .7680587768680 .70416259766 82.198379516681 .9880523681678 .6830673217875 .6461181640672 .90380096436 70.471122741768 .3607482910266 .576454162665 .1243515014664 .00118255615 63.1988449096762 .7416954040562 .62695312562 .8464698791563 .38391494751 64.2109832763765 .2882537841866 .5679626464867 .9867019653369 .46318054199 70.9104766845772 .2417831420973 .3730316162174 .2223663330174 .71501159668 74.7931747436574 .431083679273 .6402282714872 .4705276489371 .00630187988 69.3538589477567 .6195297241265 .8749313354564 .1395797729562 .39931488037 60.6261367797958 .8502044677757 .1640739440955 .7154769897554 .63537597656 53.9963226318453 .8145751953154 .0837821960454 .8098411560156 .02968215942 57.7992286682160 .1503105163663 .0518684387266 .3929290771570 .00109863281 73.7147674560577 .4832229614381 .4238357543985 .7913131713990 .84897613525 96.7205123901497 .2536621093895 .5703659057693 .3086547851690 .63562011719 87.8184127807685 .1630935668982 .9377517700281 .3094940185580 .31725311279 79.8841629028379 .8636322021580 .0974807739380 .4620056152380 .88516998291 81.3254165649481 .7387390136782 .056915283282 .1970138549882 .09069061279 81.7085266113381 .0622634887780 .1838455200279 .0968704223677 .8020324707 76.2925720214874 .5869827270572 .7558975219770 .9233245849669 .23484802246 67.8164672851666 .7365036010765 .9948272705165 .5402145385765 .30603790283 65.2356567382865 .2975387573265 .4703216552765 .7286911010766 .03091430664 66.3140487670966 .4819564819366 .3907318115265 .8996810913164 .92607116699 63.5448570251562 .0162162780860 .6872634887759 .7651634216359 .11074066162 58.2270088195856 .5416564941453 .5536422729549 .0917205810544 .78702926636 41.6744461059640 .2044677734438 .9686813354538 .8697357177741 .75556182861 33.2215805053721 .6397399902310 .667480468755 .4861321449283 .047851085663 -9999 $-2.43828105927-3.35263609886-3.96220707893-4.57177686691-5.18134689331$ $-5.48613214493-6.095703125-6.40048694611-6.7052731514-7.3148431778-7.61962795258$ -7.92441320419 -7.61962795258 -7.3148431778-6.7052731514 -4.57177686691 -.914355397224 -9999 -9999 -9999 -9999 -9999 -9999 -9999 -9999 -9999 -9999 -9999 -9999 -9999 -9999 -9999 -9999 -9999 -9999 -9999 -9999 -9999 -9999 -9999 -9999 -9999 -9999 -9999 -

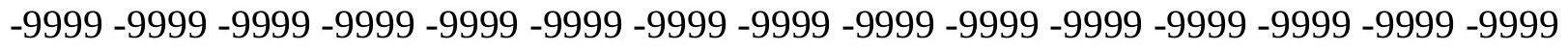

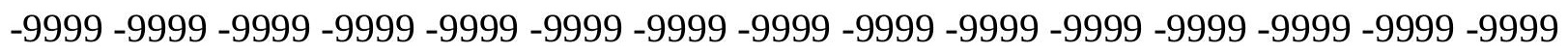

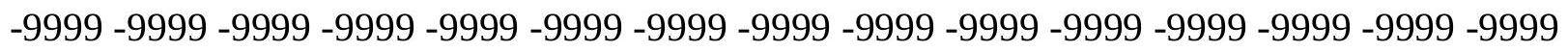
-9999 -9999 -9999 -9999 -9999 -9999 -9999 -9999 -9999 -9999 -9999 -9999 -9999 -9999 -9999 -

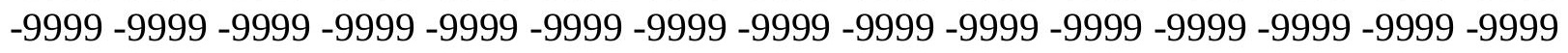
-9999 -9999 -9999 -9999 -9999 -9999 -9999 -9999 -9999 -9999 -9999 -9999 -9999 -9999 -9999 
-9999 -9999 -9999 -9999 -9999 -9999 -9999 -9999 -9999 -9999 -9999 -9999 -9999 -9999 -9999 -9999 -9999 -9999-9999

-9999 -9999 -9999 -9999 -9999 -9999 -9999 -9999 -9999 -9999 -9999 -9999 -9999 -9999 -9999 -9999 -9999 -9999 -9999 -9999 -9999 -9999 -9999 -9999 -9999 -9999 -9999 -9999 -9999 -9999 -9999 -9999 -9999 -9999 -9999 -9999 -9999 -9999 -9999 -9999 -9999 -9999 -9999 - -9999 - -9999 -

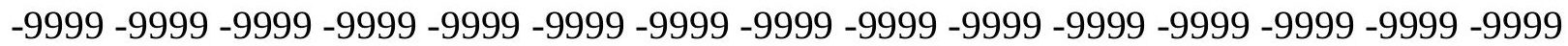

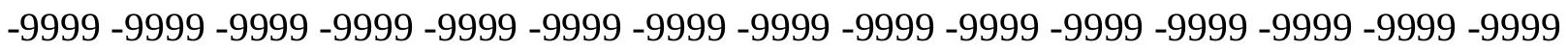

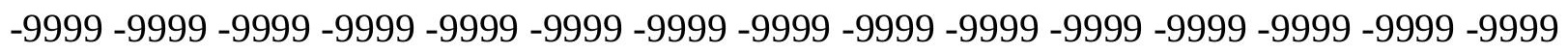
-9999 -9999 -9999 -9999 -9999 -9999 -9999 -9999 -9999 -9999 -9999 -9999 -9999 106.2865982056 103.318359375 98.445587158293.26425170898 87.16854858398 86.254188537685 .0350494384882 .5967712402379 .2441329956174 .97714233398 72.8436431884875 .8914871215879 .8537063598680 .341934204181 .25985717773 78.3449935913175 .6970291137773 .3347320556671 .2742156982469 .52445220947 68.0917816162166 .9824905395566 .1944198608465 .7304458618265 .58646392822 65.7570190429766 .2261810302766 .962196350167 .9137191772569 .03636932373 70.2818832397571 .5686798095772 .8149108886773 .9474563598674 .89613342285 75.5993499755976 .0058898925876 .0788955688575 .7968063354575 .15378570557 74.1662368774472 .8764038085971 .3480377197369 .6557464599667 .86731719971 66.0368118286164 .2028579711962 .4041366577160 .6964759826759 .15990066528 57.8858718872156 .9548225402856 .4182739257856 .298271179256 .60317611694 57.3444061279358 .5435981750560 .2264518737862 .401782989565 .04177856445 68.0754394531271 .4086380004974 .9665603637778 .7420654296982 .817237854 87.3415679931692.4631881713998.24768829346 100.737495422499.10092163086 97.0142440795994 .6179428100692 .1157226562589 .7356719970787 .68199157715 86.091934204185 .0148315429784 .416580200284 .2059478759884 .2712020874 84.510177612384 .8439788818485 .2116622924885 .5572357177785 .82051849365 85.9393692016685 .8612365722785 .5544738769585 .0111389160284 .23950195312 83.2528839111382 .0643768310580 .6926727294979 .1746063232477 .57479858398 75.9831771850674 .4988632202173 .2088928222772 .1694412231471 .39930725098 70.887413024970 .6079101562570 .5347213745170 .6458511352570 .91806793213 71.3167114257871 .7874069213972 .2500915527372 .5976867675872 .70944976807 72.4855880737371 .8867492675870 .9769134521569 .922714233468 .92972564697 68.0857696533267 .2849273681666 .255294799864 .6580886840862 .2812461853 59.2993240356456 .4590644836454 .2673988342352 .8840522766152 .3020362854 52.0655899047950 .1096725463942 .7541313171431 .7928256988521 .63973999023 15.8488302230811 .886619567874 .57177686691314 .9344701767 -.609570324421 $-2.13349604607-3.35263609886-3.65742206573-4.26699209213-4.87656211853$ $-5.18134689331-6.095703125-6.7052731514-7.01005792618-7.3148431778-7.3148431778$ $-7.01005792618-6.40048694611-5.48613214493-2.133496046071 .523926019669-9999$ -9999 -9999 -9999 -9999 -9999 -9999 -9999 -9999 -9999 -9999 -9999 -9999 -9999 -9999 -9999

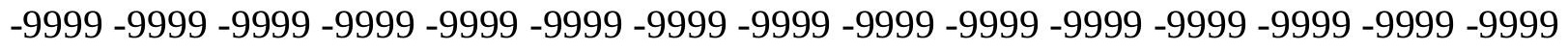

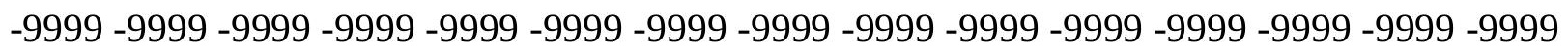

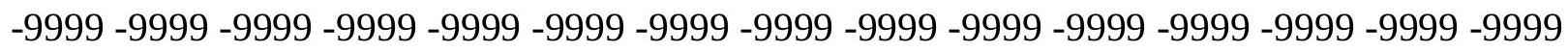
-9999 -9999 -9999 -9999 -9999 -9999 -9999 -9999 -9999 -9999 -9999 -9999 -9999 -9999 -9999 -

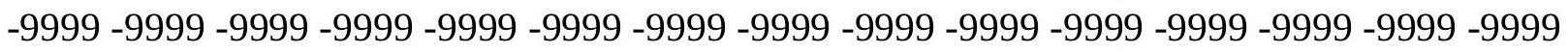
-9999 -9999 -9999 -9999 -9999 -9999 -9999 -9999 -9999 -9999 -9999 -9999 -9999 -9999 -9999 
-9999 -9999 -9999 -9999 -9999 -9999 -9999 -9999 -9999 -9999 -9999 -9999 -9999 -9999 -9999 -9999 -9999 -9999 -9999 -9999 -9999 -9999 -9999 -9999 -9999 -9999 -9999 -9999 -9999 -

-9999 -9999 -9999 -9999 -9999 -9999 -9999 -9999 -9999 -9999 -9999 -9999 -9999 -9999 -9999 -9999 -9999 -9999 -9999 -9999 -9999 -9999 -9999 -9999 -9999 -9999 -9999 -9999 -9999 -9999 -9999 -9999 -9999 -9999 -9999 -9999 -9999 -9999 -9999 -9999 -9999 -9999-9999 -9999 -9999 -9999 -9999 -9999 -9999 -9999 -9999 -9999 -9999 -9999 -9999 -9999 -9999 -9999 -9999 -9999

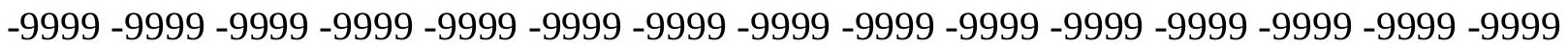
-9999 -9999 -9999 -9999 -9999 -9999 -9999 -9999 -9999 -9999 -9999 -9999 -9999 -9999 -9999 -9999 -9999 -9999 -9999 -9999 -9999 -9999 -9999 -9999 -9999 -9999 -9999 111.353843689 107.8938980103102 .102996826297 .2264633178792 .0450973510786 .86376190186 86.8637619018686 .254188537685 .3398437583 .5111236572380 .76805877686 76.8058471679771 .014930725171 .3197174072375 .2819290161179 .85370635986 80.8560485839878 .309982299876 .025810241774 .0217437744172 .30826568604 70.8953094482469 .7883224487368 .9858322143668 .4937133789168 .30111694336 68.3992004394568 .7711715698269 .3851623535270 .2008438110471 .17290496826 72.2377471923873 .3498306274474 .4113311767675 .3795776367276 .18975830078 76.7803192138777 .1107254028377 .1622695922976 .9168395996176 .36073303223 75.494277954174 .3380508422972 .9332122802771 .336639404369 .61318969727 67.8290328979566 .0477218627964 .3329238891662 .7504043579161 .36898422241 60.2537841796959 .4586029052759 .020092010558 .9589996337959 .28751754761 60.0172882080161 .1623764038162 .7350845336964 .7362823486367 .14640808105 69.9251327514673 .0247116088976 .4135208129980 .0988922119184 .13545227051 88.6093444824293 .6000671386799 .1335144043102 .5910339355101 .0329666138 99.1233749389696 .9790039062594 .7565307617292 .6277542114390 .74802398682 89.22804260254 88.11809539795 87.40866851807 87.04528045654 86.95037078857 87.0432281494187 .2511367797987 .5110015869187 .7654113769587 .95923614502 88.0403823852587 .9646606445387 .7012710571387 .2351989746186 .56533813477 85.7007293701284 .6585540771583 .46567535482 .1623687744180 .80430603027 79.4592742919978 .1985321044977 .0855026245176 .166580200275 .46742248535 74.9958038330174 .7479324340874 .714431762774 .8810806274475 .22506713867 75.7082595825276 .2717514038176 .8340072631877 .2962265014677 .55931854248 77.5500640869177 .2478332519576 .6766738891675 .9639129638775 .21585083008 74.477127075273 .6883163452172 .7046508789171 .3633575439569 .60478973389 67.6050720214865 .6712951660264 .08676910462 .9088630676361 .94960021973 60.500144958556 .8997344970750 .5997772216842 .2555885314934 .64057922363 $29.7116012573226 .5163097381613 .71533012393 .657422065735-.304785102606$ -.609570324421 -.609570324421 - $1.52392601967-2.13349604607-2.74306607246$ $-3.65742206573-4.57177686691-5.79091691971-6.40048694611-6.7052731514$ -7.01005792618 -6.7052731514-6.095703125 -5.18134689331 -3.35263609886 -9999 3.962207078934 -9999 -9999 -9999 -9999 -9999 -9999 -9999 -9999 -9999 -9999 -9999 -9999

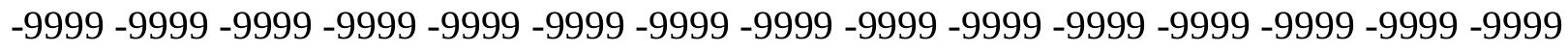

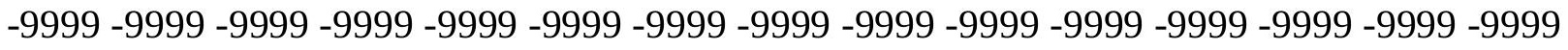
-9999 -9999 -9999 -9999 -9999 -9999 -9999 -9999 -9999 -9999 -9999 -9999 -9999 -9999 -9999 -9999 -9999 -9999 -9999 -9999 -9999 -9999 -9999 -9999 -9999 -9999 -9999 -9999 -9999 -9999 -9999 -9999 -9999 -9999 -9999 -9999 -9999 -9999 -9999 -9999 -9999 -9999 -9999 -9999 -9999 -

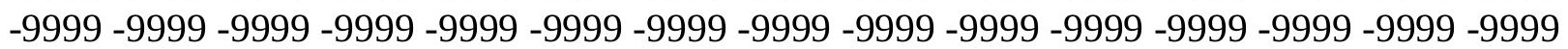


-9999 -9999 -9999 -9999 -9999 -9999 -9999 -9999 -9999 -9999 -9999 -9999 -9999 -9999 -9999 -9999 -9999 -9999 -9999 -9999 -9999 -9999 -9999 -9999 -9999 -9999 -9999 -9999 -9999 -9999 $-9999-9999$

-9999 -9999 -9999 -9999 -9999 -9999 -9999 -9999 -9999 -9999 -9999 -9999 -9999 -9999 -9999 -9999 -9999 -9999 -9999 -9999 -9999 -9999 -9999 -9999 -9999 -9999 -9999-9999 -9999 -9999 -9999 -9999 -9999 -9999 -9999 -9999 -9999 -9999 -9999 -9999 -9999 -9999 -9999 -9999 -9999 -9999 -9999 -9999 -9999 -9999 -9999 -9999 -9999 -9999 -9999 -9999 -9999 -9999 -9999 -9999 -9999 -9999 -9999 -9999 -9999 -9999 -9999 -9999 -9999 -9999 -9999 -9999 -9999 -9999 -9999 -999 -9999 -9999 -9999 -9999 -9999 -9999 -9999 -9999 -9999 -9999 -9999 -9999 -9999 -9999 -9999 -9999 -9999 -9999 -9999 -9999 -9999 -9999 -9999 -9999 -9999 -9999 115.8908157349 110.9418029785105 .455703735499 .9695205688594 .7881774902389 .60682678223 86.8637619018687 .1685485839887 .4733276367287 .7781066894587 .77810668945 87.1685485839885 .0350494384881 .9871978759877 .110626220768 .57665252686 71.6244964599676 .1962814331180 .741485595778 .5399398803776 .59632110596 74.9222793579173 .5284957885772 .4189224243271 .5972900390671 .06111907959 70.8037490844770 .8140945434671 .0723648071371 .551483154372 .21415710449 73.0174942016673 .9036254882874 .8313522338975 .7376327514676 .55199432373 77.2493438720777 .7415161132877 .9932556152378 .0094604492277 .77714538574 77.2754821777376 .4999084472775 .4623489379974 .1929931640672 .73824310303 71.156806945869 .5146102905367 .880302429266 .322128295964 .90519714355 63.68903732362 .7247657775962 .0525245666561 .7007675170961 .68821334839 62.0278511047462 .7307014465363 .8070220947365 .2639694213967 .10119628906 69.30747222971 .8621368408274 .7430648803777 .9388580322381 .4593963623 85.3380508422989 .6210250854594 .34487152199 .50846862793102 .712600708 101.8700180054100 .129539489798 .2100753784296 .2327957153394 .32786560059 92.6137924194391 .1788177490290 .0696487426889 .2902984619188 .80999755859 88.5761871337988 .5274429321388 .6023254394588 .7432403564588 .89669036865 89.01284027189 .0463409423888 .9588851928788 .7221984863388 .31993865967 87.7478713989387 .0128479003986 .1318588256885 .1318893432684 .05001068115 82.932479858481 .8316574096780 .8008193969779 .8881301879979 .13188934326 78.5583801269578 .1825942993278 .0104064941478 .0401153564578 .26163482666 78.6532592773479 .1774368286179 .7779693603580 .3810501098680 .90247344971 81.2619247436581 .4009017944381 .2916412353580 .984512329180 .52270507812 79.9722595214879 .3646469116278 .675498962477 .8375701904376 .78568267822 75.5187759399474 .1344223022572 .7688217163171 .5215682983470 .3293838501 68.9397659301866 .7665328979563 .108116149957 .8939247131351 .78193664551 46.0529518127441 .1886405944835 .8249588012728 .6497993469214 .9344701767 $10.362689971928 .5339832305914 .571776866913 .9143553972244 .9143553972244-9999$ -1.52392601967 -3.04785108566 -4.26699209213 -5.48613214493 -6.095703125 -6.095703125 $-6.095703125-5.48613214493-4.57177686691-3.35263609886-.914355397224$ 2.7430660724646 .705273151398 -9999 -9999 -9999 -9999 -9999 -9999 -9999 -9999 -9999 -9999 -9999 -9999 -9999 -9999 -9999 -9999 -9999 -9999 -9999 -9999 -9999 -9999 -9999 -9999 -9999 -9999 -9999 -9999 -9999 -9999 -9999 -9999 -9999 -9999 -9999 -9999 -9999 -9999 -9999 -9999 -9999 -9999 -9999 -9999 -9999 -9999 -9999 -9999 -9999 -9999 -9999 -9999 -9999 -9999 -9999 -9999 -9999 -9999 -9999 -9999 -9999 -9999 -9999 -9999 -9999 -9999 -9999 -9999 -9999

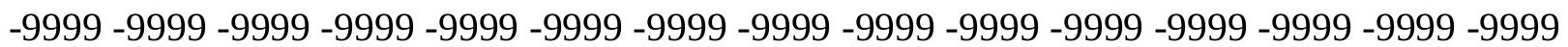


-9999 -9999 -9999 -9999 -9999 -9999 -9999 -9999 -9999 -9999 -9999 -9999 -9999 -9999 -9999 -9999 -9999 -9999 -9999 -9999 -9999 -9999 -9999 -9999 -9999 -9999 -9999 -9999 -9999 -9999 -9999 -9999 -9999 -9999 -9999 -9999 -9999 -9999 -9999 -9999 -9999 -9999 -9999 -9999 -9999 -9999 -9999 -9999-9999

-9999 -9999 -9999 -9999 -9999 -9999 -9999 -9999 -9999 -9999 -9999 -9999 -9999 -9999 -9999 -9999 -9999 -9999 -9999 -9999 -9999 -9999 -9999 -9999 -9999 -9999 -9999 -9999 -9999 -9999 -9999 -9999 -9999 -9999 -9999 -9999 -9999 -9999 -9999 -9999 -9999 -9999 -9999 -9999 -9999

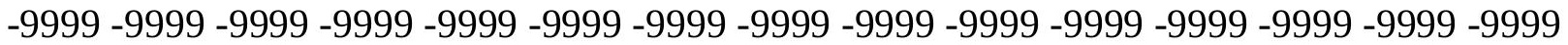

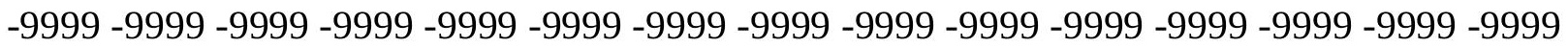
-9999 -9999 -9999 -9999 -9999 -9999 -9999 -9999 -9999 -9999 -9999 -9999 -9999 -9999 -9999 -999 -9999 -9999 -9999 -9999 -9999 -9999 -9999 -9999 -9999 -9999 117.0374984741 112.4656982422107 .2844009399102 .102996826296 .9216690063592 .04509735107 88.3876876831188 .0829010009888 .0829010009888 .6924667358489 .60682678223 91.1307525634893 .2642517089892 .6546783447391 .7403335571390 .82597351074 81.9871978759874 .062782287668 .5766525268673 .1484298706177 .41542053223 78.9939880371177 .3611297607475 .9871063232474 .8768615722774 .03116607666 73.4496231079173 .1229324340873 .0408477783273 .1813278198273 .52115631104 74.0234298706174 .6523284912175 .3605880737376 .0990371704176 .82421875 77.4907455444378 .0506515502978 .4496841430778 .6531295776478 .63704681396 78.4034042358477 .9381332397577 .2373428344776 .3108062744175 .1840057373 73.8956985473672 .4956970214871 .0429000854569 .6007995605568 .23320007324 66.998886108465 .9492034912165 .1266937255964 .5644760131864 .28702545166 64.311935424864 .6523132324265 .3186798095766 .3195419311567 .66038513184 69.3419265747171 .3591995239373 .7030563354576 .364540100179 .34075164795 82.6392517089886 .2777252197390 .2766571044994 .6456985473697 .53124237061 97.8360290527397 .8360290527397 .5312423706196 .9216690063596 .92166900635 95.2689590454193 .7078094482492 .3633270263791 .2768173217890 .45913696289 89.8946533203189 .5487747192489 .3762359619189 .3277740478589 .35425567627 89.40869140625 89.44732666016 89.43088531494 89.32632446289 89.10875701904 88.7629394531288 .2839202880987 .6769104003986 .9566879272586 .14684295654 85.2786941528384 .3895492553783 .520095825282 .7110900878981 .99987792969 81.4177703857480 .9885482788180 .7282714843880 .6454925537180 .74098968506 81.0063629150481 .4215240478581 .9522781372182 .549392700283 .15079498291 83.68774414062 84.0941848754984.31992340088 84.35905456543 84.22492980957 83.9422760009883 .5527648925883 .0816497802782 .5249023437581 .85645294189 81.0560684204180 .1340789794979 .1323623657278 .0952987670977 .01686096191 75.7812118530374 .1766281127971 .8627014160268 .5952606201264 .42658233643 59.8010711669955 .2282829284750 .7854270935145 .6642799377439 .55805206299 33.3664474487331 .3928699493423 .1636695861816 .153610229499 .753124237061 $5.4861321449283 .047851085663 .6095703244209-1.21914100647-2.74306607246$ $-4.26699209213-4.87656211853-5.48613214493-5.48613214493-5.18134689331$ $-4.26699209213-3.04785108566-1.523926019671 .5239260196695 .181346893311-9999$ -9999 -9999 -9999 -9999 -9999 -9999 -9999 -9999 -9999 -9999 -9999 -9999 -9999 -9999 -9999 -9999 -9999 -9999 -9999 -9999 -9999 -9999 -9999 -9999 -9999 -9999 -9999 -9999 -9999 -9999

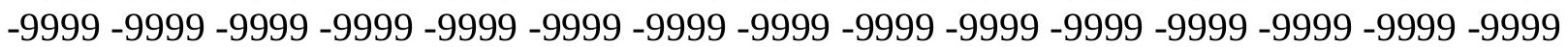

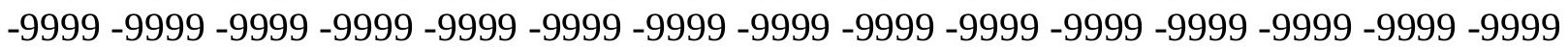


-9999 -9999 -9999 -9999 -9999 -9999 -9999 -9999 -9999 -9999 -9999 -9999 -9999 -9999 -9999 -9999 -9999 -9999 -9999 -9999 -9999 -9999 -9999 -9999 -9999 -9999 -9999 -9999 -9999 -9999

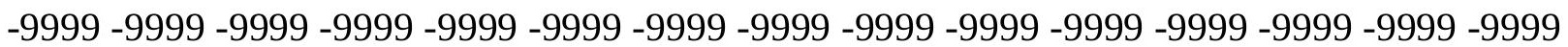
-9999 -9999 -9999 -9999 -9999 -9999 -9999 -9999 -9999 -9999 -9999 -9999 -9999 -9999 -9999 -9999 -9999 -9999 -9999 -9999 -9999 -9999 -9999 -9999 -9999 -9999 -9999 -9999 -9999 -9999 -9999 -9999 -9999 -9999 -9999 -9999 -9999 -9999 -9999 -9999 -9999 -9999 -9999 -9999 -9999 -9999 -9999 -9999 -9999 -9999 -9999 -9999 -9999 -9999 -9999 -9999 -9999

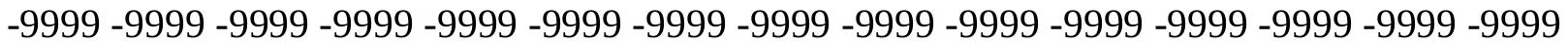

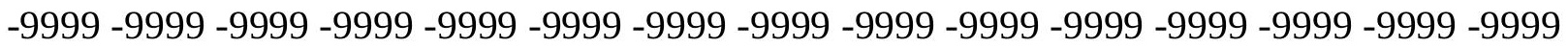
-9999 -9999 -9999 -9999 -9999 -9999 -9999 -9999 -9999 -9999 -9999 -9999 -9999 -9999 -9999 -9999 -9999 -9999 -9999 -9999 -9999 -9999 -9999 -9999 -9999 -9999 -9999 -9999 -9999 -9999 -999 -9999 -9999 -9999 -9999 -9999 -9999 -9999 -9999 -9999 113.9896011353111 .8561019897 107.8938980103103 .322196960498 .445587158293 .2642517089888 .38768768311 88.3876876831188 .3876876831188 .6924667358489 .302040100190 .52117919922 92.0450973510795 .397743225197 .2264633178797 .6792526245194 .91974639893 92.2483062744186 .254188537678 .9393463134871 .9292907714869 .79579162598 74.062782287679 .6259994506878 .2727279663177 .1606597900476 .29256439209 75.6642532348675 .2695312575 .0943374633875 .1213607788175 .32512664795 75.6764602661176 .1395492553776 .6759948730577 .2440338134877 .80139923096 78.3065719604578 .7256393432679 .0162200927779 .1521224975679 .10060882568 78.8570785522578 .4173965454177 .7791976928776 .953826904375 .9655456543 74.8467559814573 .6355133056672 .3801269531271 .13755035469 .96363830566 68.9085311889668 .0159835815467 .3226089477566 .8575210571366 .64311218262 66.6963272094767 .0300903320367 .6543655395568 .5767440795969 .80223083496 71.3328857421973 .1678085327175 .3042602539177 .7395706176880 .47360992432 83.5101089477586 .855613708590 .5144348144592 .6546783447393 .26425170898 93.5690307617293 .5690307617293 .2642517089892 .9594726562592 .3498916626 92.349891662692 .349891662693 .137130737392 .0879211425891 .25653839111 90.6368331909290 .2069320678789 .934432983489 .7812576293989 .70733642578 89.6731719970789 .6416244506889 .5794143676889 .4586257934689 .2580871582 88.9644699096788 .5728988647588 .0869979858487 .5184783935586 .88626861572 86.2152252197385 .5344696044984 .875282287684 .2688446044983 .74406433105 83.3259124755983 .0342483520582 .8832550048882 .8808746337983 .02802276611 83.3171691894583 .7306365966884 .2393417358484 .8028640747185 .37160491943 85.8912811279386 .309844970786 .5877151489386 .710235595786 .68418121338 86.5222549438586 .2539367675885 .9058456420985 .4768829345784 .95618438721 84.3428268432683 .6455383300882 .8732376098682 .0225448608481 .04042816162 79.8186645507878 .2122955322376 .06137847973 .2948303222770 .00103759766 66.4213714599662 .7614784240759 .0052909851154 .9963264465350 .72148513794 46.9795227050842 .8891906738336 .9227752685530 .1737308502221 .94453048706 13.71533012396 .4004869461063 .657422065735 .9143553972244 -.914355397224 $-2.43828105927-3.35263609886-4.26699209213-4.87656211853-4.57177686691$ -3.96220707893 -2.74306607246-1.21914100647.6095703244209 3.962207078934 7.619627952576 -9999 -9999 -9999 -9999 -9999 -9999 -9999 -9999 -9999 -9999 -9999 -9999 -9999 -9999 -9999 -9999 -9999 -9999 -9999 -9999 -9999 -9999 -9999 -9999 -9999 -9999 -9999

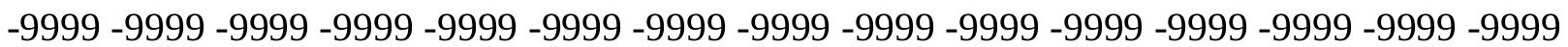


-9999 -9999 -9999 -9999 -9999 -9999 -9999 -9999 -9999 -9999 -9999 -9999 -9999 -9999 -9999 -9999 -9999 -9999 -9999 -9999 -9999 -9999 -9999 -9999 -9999 -9999 -9999 -9999 -9999 -9999 -9999 -9999 -9999 -9999 -9999 -9999 -9999 -9999 -9999 -9999 -9999 -9999 -9999 -9999 -9999 -9999 -9999 -9999 -9999 -9999 -9999 -9999 -9999 -9999 -9999 -9999 -9999 -9999 -9999 -9999 -9999 -9999 -9999 -9999 -9999 -9999 -9999 -9999 -9999 -9999 -9999 -9999 -9999 -9999 -9999 -9999 -9999 -9999 -9999 -9999 -9999 -9999 -9999 -9999 -9999 -9999 -9999 -9999 -9999 -9999 -9999 -9999 -9999 -9999 -9999 -9999 -9999 -9999 -9999 -9999 -9999 -9999 -9999 -9999 -9999

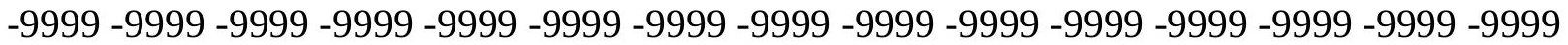

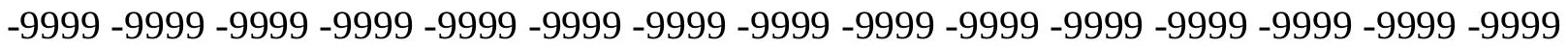
-9999 -9999 -9999 -9999 -9999 -9999 -9999 -9999 -9999 -9999 -9999 -9999 -9999 -9999 -9999 -9999 -9999 -9999 -9999 -9999 -9999 -9999 -9999 -9999 -9999 -9999 -9999 -9999 -9999 -9999 -9999 -9999 -9999 -9999 -9999 -9999 -9999 -9999 -9999 -9999 -9999 -9999 -9999 -9999 -9999 -9999 -9999 -9999 -9999 -9999 -9999 -9999 -9999 111.24659729109 .7226028442 107.5891036987103 .931701660299 .0551681518694 .1785964965888 .99725341797 88.0829010009888 .3876876831188 .6924667358489 .302040100189 .91161346436 91.1307525634893 .5690307617296 .6168823242299 .3599472045998 .90664672852 96.3079757690493 .7873687744191 .3732910156289 .0914611816482 .29197692871 76.5010681152371 .6244964599674 .6723632812580 .3873138427779 .27581787109 78.3864059448277 .7147293090877 .2544403076276 .992050170976 .91133880615 76.9890594482477 .1991577148477 .2506866455177 .7001647949278 .29716491699 78.7005538940479 .0629882812579 .3488769531279 .5326766967879 .58103942871 79.4824676513779 .2202148437578 .8001708984478 .2117080688577 .47219085693 76.6067733764675 .6440505981474 .6094818115273 .530693054272 .47306060791 71.4778976440470 .5858612060569 .834396362369 .255584716868 .87564086914 68.7152175903368 .7903518676869 .1131591796969 .692939758370 .53643798828 71.6484832763773 .0318984985474 .6882247924876 .6182403564578 .82259368896 81.3012542724684 .0541839599687 .0800476074290 .3734436035290 .21640014648 89.302040100189 .302040100189 .9116134643690 .2164001464890 .21640014648 89.9116134643690 .2164001464890 .2164001464890 .8259735107492 .04509735107 91.9529571533289 .9116134643690 .8159713745190 .4690704345790 .23384094238 90.0787200927789 .9716720581189 .8821945190489 .7829132080189 .65087127686 89.4685668945389 .2246932983488 .914627075288 .5404129028388 .11047363281 87.6388549804787 .1441268920986 .6480102539186 .1737518310585 .7445602417 85.382118225185 .1054077148484 .9297943115284 .8664245605584 .9215927124 85.095848083585 .3829421997185 .7686386108486 .2300720214886 .73606872559 87.24879455566 87.7267074585 88.12850189209 88.41850280762 88.57498168945 88.6169357299888 .5281372070388 .3590087890688 .090545654387 .77002716064 87.3459472656286 .8526687622186 .2927093505985 .6482696533284 .89823913574 83.9968566894582 .8460159301881 .3643417358479 .4912719726677 .22410583496 74.6421127319371 .8741302490269 .0196075439566 .0880889892663 .06260299683 59.9646301269556 .8233375549352 .883922576948 .1394691467342 .4303855896 35.9646492004424 .9923801422115 .544039726268 .2291984558114 .266992092133 $1.21914100647-9999-.914355397224-2.43828105927-3.65742206573-4.26699209213$ -3.96220707893 -2.74306607246-1.21914100647.6095703244209 2.743066072464 6.0957031259 .753124237061 -9999 -9999 -9999 -9999 -9999 -9999 -9999 -9999 -9999 -9999 -9999 -9999 -9999 -9999 -9999 -9999 -9999 -9999 -9999 -9999 -9999 -9999 -9999 -9999 -9999 
-9999 -9999 -9999 -9999 -9999 -9999 -9999 -9999 -9999 -9999 -9999 -9999-9999 -9999 -9999 -9999 -9999 -9999 -9999 -9999 -9999 -9999 -9999 -9999 -9999 -9999 -9999 -9999 -9999 -9999

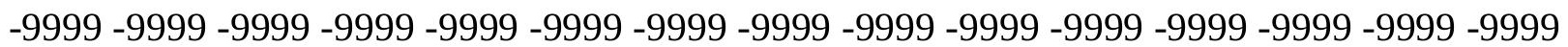
-9999 -9999 -9999 -9999 -9999 -9999 -9999 -9999 -9999 -9999 -9999 -9999 -9999 -9999 -9999 -9999 -9999 -9999 -9999 -9999 -9999 -9999 -9999 -9999 -9999 -9999 -9999 -9999 -9999 -9999 -9999 -9999 -9999 -9999 -9999 -9999 -9999 -9999 -9999 -9999 -9999 -9999 -9999 -9999 -9999

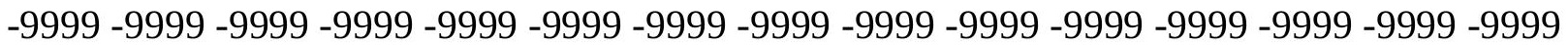
$-9999$

-9999 -9999 -9999 -9999 -9999 -9999 -9999 -9999 -9999 -9999 -9999 -9999 -9999 -9999 -9999 -9999 -9999 -9999 -9999 -9999 -9999 -9999 -9999 -9999 -9999 -9999 -9999 -9999 -9999 -9999 -9999 -9999 -9999 -9999 -9999 -9999 -9999 -9999 -9999 -9999 -9999 -9999 -9999 -9999 -9999 -9999 -9999 -9999 -9999 -9999 -9999 -9999 -9999 -9999 -9999 -9999 -9999 -9999 -9999 -9999

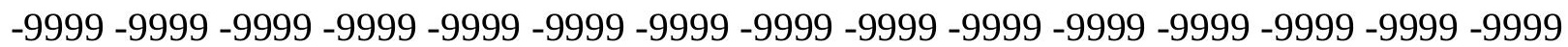
-9999 -9999 -9999 -9999 -9999 -9999 -9999 -9999 -9999 -9999 -9999 -9999 -9999 -9999 -9999 -9999 -9999 -9999 -9999 -9999 -9999 -9999 106.0652008057 107.5891036987106 .0652008057 103.626899719299 .3599472045994 .4833908081189 .6068267822386 .86376190186 87.7781066894588 .3876876831188 .9972534179789 .6068267822390 .21640014648 91.1307525634894 .1785964965897 .2264633178799 .96952056885100 .0090942383 97.5586471557695 .1785964965892 .8942718505990 .7285079956188 .7036819458 86.8379669189583 .5111236572380 .4632720947377 .7202072143681 .22764587402 80.3201065063579 .6093673706179 .0891952514678 .7469635009878 .49101257324 77.0502624511776 .3722381591876 .3916549682676 .9732818603577 .9757232666 79.281112670979 .7808151245179 .9517974853580 .0363616943480 .01248931885 79.8647079467879 .5854797363379 .1698913574278 .6206588745177 .95085144043 77.1803131103576 .3342056274475 .4455337524474 .5324783325273 .63787841797 72.7983932495172 .048133850171 .4197540283270 .9413681030370 .63664245605 70.5238342285270 .6172714233470 .9272689819371 .4627838134872 .2297744751 73.2328720092874 .4744491577175 .9575271606477 .6846313476679 .6595916748 81.8819122314584 .3484649658287 .0511169433689 .9791030883889 .3020401001 86.254188537686 .254188537687 .1685485839888 .0829010009888 .99725341797 89.6068267822390 .2164001464891 .1307525634891 .1307525634889 .60682678223 87.4733276367283 .5111236572383 .8159103393691 .1683120727590 .87463378906 90.6596069335990 .4980316162190 .3656616210990 .2406692504990 .10472106934 89.9437255859489 .7482757568489 .5139846801889 .2414398193488 .93597412109 88.6070709228588 .2675247192487 .9323272705187 .6175384521587 .33920288086 87.1122741699286 .9498138427786 .8624801635786 .8581848144586 .94167327881 87.1138305664187 .3707427978587 .7027816772588 .0939788818488 .52213287354 88.9597244262789 .3753128051889 .7356948852590 .0104980468890 .18144989014 90.2469024658290 .2176055908290 .0964202880989 .8931045532289 .61374664307 89.2613677978588 .8358917236388 .3391723632887 .7564620971787 .06178283691 86.2099227905385 .1503753662183 .8414840698282 .2676467895580 .45084381104 78.4513015747176 .3431472778374 .1786727905371 .968894958569 .69201660156 67.3010330200264 .6022872924861 .3154106140157 .3089942932152 .34455490112 46.2226829528838 .7077102661126 .8210906982417 .6775398254410 .66748046875 $6.0957031254 .2669920921332 .438281059265-9999-2.43828105927-3.35263609886$ $-3.35263609886-2.74306607246-1.21914100647 .30478510260582 .743066072464$ 
5.1813468933118 .22919845581111 .58183002472 -9999 -9999 -9999 -9999 -9999 -9999 -9999 -9999 -9999 -9999 -9999 -9999 -9999 -9999 -9999 -9999 -9999 -9999 -9999 -9999 -9999 -9999 -9999 -9999 -9999 -9999 -9999 -9999 -9999 -9999 -9999 -9999 -9999 -9999 -9999 -9999 -9999 -9999 -9999 -9999 -9999 -9999 -9999 -9999 -9999 -9999 -9999 -9999 -9999 -9999 -9999 -9999 -9999 -9999 -9999 -9999 -9999 -9999 -9999 -9999 -9999 -9999 -9999 -9999 -9999 -9999 -9999 -9999 -9999 -9999 -9999 -9999 -9999 -9999 -9999 -9999 -9999 -9999 -9999 -9999 -9999 -9999 -9999 -9999 -9999 -9999 -9999 -9999 -9999 -9999 -9999 -9999 -9999 -9999 -9999 -9999 -9999

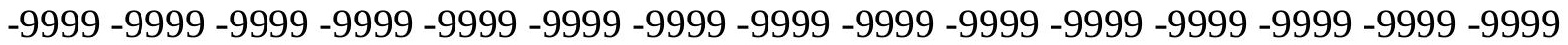

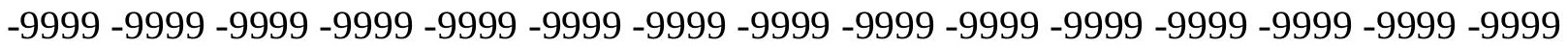
-9999-9999-9999

-9999 -9999 -9999 -9999 -9999 -9999 -9999 -9999 -9999 -9999 -9999 -9999 -9999 -9999 -9999 -9999 -9999 -9999 -9999 -9999 -9999 -9999 -9999 -9999 -9999 -9999 -9999 -9999 -9999 -9999

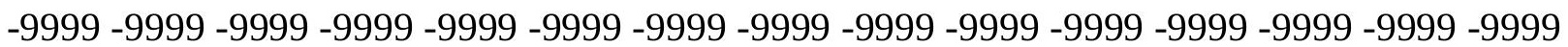
-9999 -9999 -9999 -9999 -9999 -9999 -9999 -9999 -9999 -9999 -9999 -9999 -9999 -9999 -9999 -9999 -9999 -9999 -9999 -9999 -9999 -9999 -9999 -9999 -9999 -9999 -9999 -9999 -9999 -9999 -9999 -9999 -9999 -9999 -9999 -9999 -9999 -9999 -9999 -9999 -9999 -9999 -9999 -9999 -9999 -999 -9999 -9999 -9999 -9999 -9999 -9999 103.9317016602100 .5791015625103 .9317016602 101.798202514699 .0551681518694 .7881774902390 .2164001464886 .2541885376 87.1685485839888 .0829010009888 .9972534179789 .6068267822390 .21640014648 90.8259735107492 .349891662694 .4833908081197 .2264633178799 .96952056885 100.996498107998 .6816329956196 .4313278198294 .2681045532292 .21188354492 90.2823257446388 .4957504272586 .8673629760785 .4072952270584 .12412261963 76.8058471679780 .7680587768681 .3547592163180 .7817230224679 .09128570557 77.0671463012775 .77846527175 .3018569946375 .5371551513776 .32918548584 77.5250015258879 .002372741780 .4808349609480 .549522399980 .54869842529 80.4599914550880 .2707443237379 .9726409912179 .5645294189579 .05010986328 78.4403762817477 .7512283325277 .0030517578176 .2240219116275 .44171905518 74.6864547729573 .9775543212973 .3478927612372 .8259429931672 .43573760986 72.1980819702172 .1296463012772 .2401657104572 .5378799438573 .03103637695 73.7278289794974 .6300811767675 .7393798828177 .0585174560578 .59229278564 80.3450317382882 .3228836059684 .517166137786 .911270141689 .49307250977 88.6924667358485 .6446228027385 .3398437586 .254188537688 .08290100098 89.9116134643691.7403335571392.9594726562593.8738174438593.56903076172 92.0450973510789 .6068267822386 .5589828491286 .5589828491292 .14791870117 91.8183746337991 .5646057128991 .3674087524491 .2081375122190 .52117919922 90.9384460449290 .8027114868290 .6551513671990 .491485595790 .31118011475 90.1170806884889 .9145812988389 .711357116789 .5161361694389 .33826446533 89.1869430542 89.0703125 88.99524688721 88.967491149988.99205780029 89.07307434082 89.2130889892689 .4120407104589 .6660232543989 .9663467407290 .29911804199 90.6454925537190 .9821777343891 .2824478149491 .5182647705191 .66837310791 91.750976562591 .7389907836991 .635322570891 .4522628784291 .18378448486 90.843605041590 .4376678466889 .9604568481489 .3979644775488 .72304534912 87.9108200073286 .9411849975685 .8024139404384 .5006484985483 .06324005127 81.5332260131879 .9536132812578 .3482360839876 .7100524902374 .99467468262 73.1083755493270 .8787536621168 .1345672607464 .6826477050860 .32174301147 54.638668060347 .2946853637738 .2177658081129 .5641593933119 .8110294342 
13.41055011749 9.44833946228 7.314843177795 3.657422065735 -.304785102606 -1.21914100647 -1.82871103287-2.13349604607 -1.52392601967 -9999 2.438281059265 4.876562118537 .31484317779510 .36268997192 -9999 -9999 -9999 -9999 -9999 -9999 -9999 -9999 -9999 -9999 -9999 -9999 -9999 -9999 -9999 -9999 -9999 -9999 -9999 -9999 -9999 -9999 -9999 -9999 -9999 -9999 -9999 -9999 -9999 -9999 -9999 -9999 -9999 -9999-9999 -9999 -9999 -9999 -9999 -9999 -9999 -9999 -9999 -9999 -9999 -9999 -9999 -9999 -9999 -9999 -9999 -9999

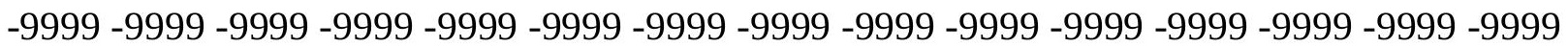

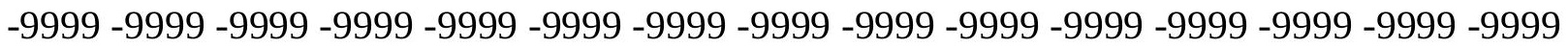

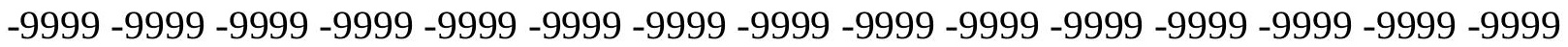
-9999 -9999 -9999 -9999 -9999 -9999 -9999 -9999 -9999 -9999 -9999 -9999 -9999 -9999 -9999 -

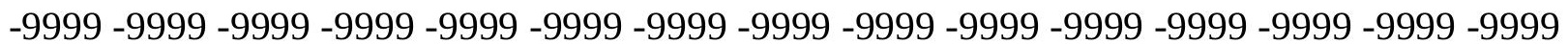
-9999 -9999-9999

-9999 -9999 -9999 -9999 -9999 -9999 -9999 -9999 -9999 -9999 -9999 -9999 -9999 -9999 -9999 -9999 -9999 -9999 -9999 -9999 -9999 -9999 -9999 -9999 -9999 -9999 -9999 -9999 -9999 - 9999 -9999 -9999 -9999 -9999 -9999 -9999 -9999 -9999 -9999 -9999 -9999 -9999 -9999 -9999 -9999

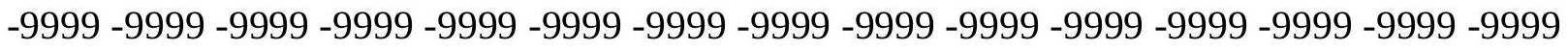
-9999 -9999 -9999 -9999 -9999 -9999 -9999 -9999 -9999 -9999 -9999 -9999 -9999 -9999 -9999 -9999 -9999 -9999 -9999 -9999 -9999 -9999 -9999 -9999 -9999 -9999 -9999 -9999 -9999 -9999 -9999 -9999 -9999-9999 106.979598999 103.0174026489 99.35994720459 102.1029968262 99.9695205688597 .5312423706194 .7881774902390 .5211791992288 .69246673584 88.3876876831188.69246673584 89.3020401001 89.9116134643690.21640014648 90.8259735107491 .4355392456192 .9594726562594 .7881774902396 .92166900635 99.35994720459101 .493400573799 .6875915527397 .5559158325295 .50437164307 93.5503921508891 .7108688354590 .0000381469788 .4315795898487 .01481628418 85.757530212484 .662384033275 .2819290161180 .4632720947379 .05513763428 76.9056472778375 .211349487374 .2757034301874 .1596908569374 .73542785645 75.8182601928777 .2485809326278 .9096145629980 .7216110229581 .15201568604 81.0773696899480 .9329605102580 .708427429280 .3972244262779 .9987411499 79.5165634155378 .960235595778 .3432388305777 .6837768554777 .00360870361 76.3239517211975 .673690795975 .0708312988374 .5451812744174 .11603546143 73.803848266673 .6245040893673 .5992050170973 .7268676757874 .01635742188 74.4706954956175 .109786987375 .9231872558676 .915313720778 .08543395996 79.4454345703180 .984657287682 .7389450073284 .6818695068486 .79680633545 89.06352996826 88.3876876831185.9494018554785.64462280273 86.86376190186 89.60682678223 92.95947265625 95.397743225197.22646331787 97.49111938477 96.5930633544995 .7746582031294 .7881774902394 .4213943481493 .89499664307 93.4640579223693 .1187744140692 .845420837492 .6301879882892 .4594039917 89.302040100188 .6924667358488 .3876876831183 .5111236572380 .76805877686 87.1685485839891 .7077941894591 .4355392456189 .9116134643691 .46389770508 91.404716491791 .3607940673891 .3329849243291 .3208160400491 .3249130249 91.3483200073291 .3962631225691 .475028991791 .590255737391 .74485015869 91.9374084472792 .1612854003992 .4045181274492 .6501693725692 .87677764893 93.0617141723693 .1876678466893 .2450180053793 .221267700293 .11075592041 92.9089813232492 .6144561767692 .2494659423891 .8192138671991 .31957244873 90.7441482543990 .0627517700289 .2714538574288 .3721542358487 .37275695801 86.2900085449285 .1497650146583 .9816513061582 .8085403442481 .63479614258 
80.436386108479 .1544952392677 .6850433349675 .8876800537173 .6022644043 70.6390457153366 .7743988037161 .7491493225155 .3548431396547 .95838928223 39.815841674831 .3928699493424 .0780296325718 .8966808319113 .10575962067 9.1435537338265 .1813468933112 .133496046066 .3047851026058 -.914355397224 -.914355397224.6095703244209 3.0478510856635 .1813468933117 .010057926178 9.753124237061 12.49619007111 -9999 -9999 -9999 -9999 -9999 -9999 -9999 -9999 -9999 -9999 -9999 -9999 -9999 -9999 -9999 -9999 -9999 -9999 -9999 -9999 -9999 -9999 -9999 -9999

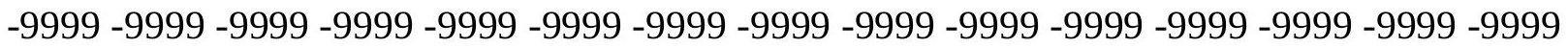

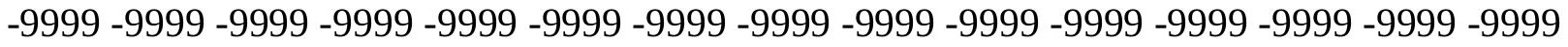
-9999 -9999 -9999 -9999 -9999 -9999 -9999 -9999 -9999 -9999 -9999 -9999 -9999 -9999 -9999 -9999 -9999 -9999 -9999 -9999 -9999 -9999 -9999 -9999 -9999 -9999 -9999 -9999 -9999 -9999 -9999 -9999 -9999 -9999 -9999 -9999 -9999 -9999 -9999 -9999 -9999 -9999 -9999 -9999 -9999 -9999 -9999 -9999 -9999 -9999 -9999 -9999 -9999 -9999 -9999 -9999 -9999 -9999 -9999 -9999 -

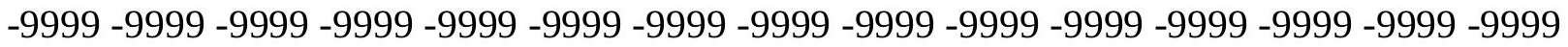
-9999 -9999 -9999 -9999 -9999 -9999 -9999 -9999 -9999 -9999 -9999 -9999 -9999 -9999 -9999

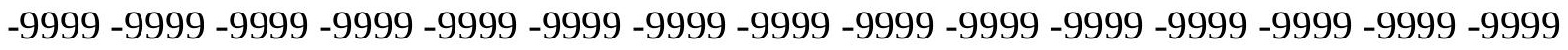
-9999 -9999 -9999 -9999 -9999 -9999 -9999 -9999 -9999 -9999 -9999 -9999 -9999 -9999 -9999 -9999 -9999 -9999 -9999 -9999 -9999 -9999 -9999 -9999 -9999 -9999 -9999 -9999 -9999 - 9999 -9999 -9999 -9999 -9999 -9999 -9999 -9999 -9999 -9999 -9999 -9999 -9999 -9999 -9999 -9999 -

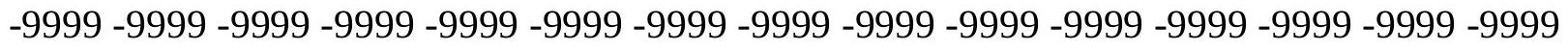
-9999 -9999 110.0273971558 106.0652008057 102.407798767198.75038146973 111.55139923197 .8360290527395 .0929565429793 .2642517089891 .43553924561 91.4355392456191 .1307525634890 .8259735107490 .8259735107490 .82597351074 91.1307525634891 .1307525634891 .1307525634891 .7403335571392 .95947265625 94.4833908081196 .3121032714898 .1408081054799 .96952056885100 .5854187012 98.5611419677796 .6112518310594 .7512435913192 .9957809448291 .35679626465 89.8461532592888 .4721527099687 .2417221069386 .1570358276478 .32978057861 75.5867080688577 .0080108642674 .7905349731473 .1235275268672 .66197967529 73.0778045654374 .0951766967875 .5193557739377 .2030868530379 .04508209229 80.9820175170981 .761436462481 .6245117187581 .4336090087981 .18029785156 80.8594055175880 .4707717895580 .0177612304779 .5087356567478 .95526885986 78.3728713989377 .7793197631877 .1944427490276 .6390304565476 .13359832764 75.6983642578175 .351280212475 .1091918945374 .9846420288174 .99136352539 75.1368103027375 .4239196777375 .8597183227576 .4486770629977 .19042205811 78.0849533081179 .1352615356480 .3407440185581 .7104110717883 .24890899658 84.9430999755986 .8059005737388 .7959899902388 .0829010009886 .86376190186 86.254188537687 .7781066894592 .349891662697 .53124237061100 .6294708252 99.7438354492298 .8863449096798 .0759277343897 .3279342651496 .65361785889 96.0602874755995 .5524749755995 .1306610107494 .7858810424894 .50828552246 94.2892990112394 .1202087402393 .9908828735493 .8921203613391 .13075256348 83.8159103393678.32978057861 79.85370635986 82.90155792236 81.07285308838 77.7202072143675 .8914871215877 .110626220781 .0728530883892 .3498916626 93.9522628784293 .9604187011793 .9517745971793 .9355621337993 .92501068115 93.9338455200293 .972801208594 .0470428466894 .1553344726694 .29042816162 94.4404525756894 .5885772705194 .7150115966894 .7994766235494 .82221221924 94.7681961059694 .6240997314594 .3801193237394 .0485687255993 .626121521 
93.1337356567492 .5712432861391 .9391250610491 .220291137790 .42125701904 89.5582504272588 .6509246826287 .720985412686 .7910232543985 .88137054443 85.00278472984 .1481933593883 .28432464682 .3480834960981 .24432373047

79.8429489135777 .9926910400475 .5268936157272 .2628631591868 .04267883301 62.8179321289156 .7884521484450 .2172889709543 .946292877238 .40293121338 30.4785099029522 .8588790893615 .8488302230810 .667480468756 .705273151398 3.3526360988621 .523926019669 .9143553972244 2.133496046066 3.962207078934 $6.0957031257 .9244132041939 .4483394622812 .191410064714 .62969017029-9999-9999$ -9999 -9999 -9999 -9999 -9999 -9999 -9999 -9999 -9999 -9999 -9999 -9999 -9999 -9999 -9999 -9999 -9999 -9999 -9999 -9999 -9999 -9999 -9999 -9999 -9999 -9999 -9999 -9999 -9999 -9999 -

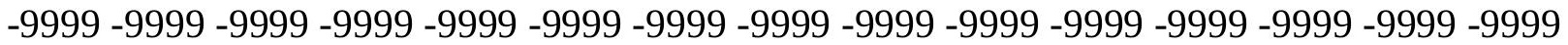
-9999 -9999 -9999 -9999 -9999 -9999 -9999 -9999 -9999 -9999 -9999 -9999 -9999 -9999 -9999 -9999 -9999 -9999 -9999 -9999 -9999 -9999 -9999 -9999 -9999 -9999 -9999 -9999 -9999 -9999 -9999 -9999 -9999 -9999 -9999 -9999 -9999 -9999 -9999 -9999 -9999 -9999 -9999 -9999 -9999 -9999 -9999 -9999 -9999 -9999 -9999 -9999 -9999 -9999 -9999 -9999 -9999 -9999 -9999 -9999

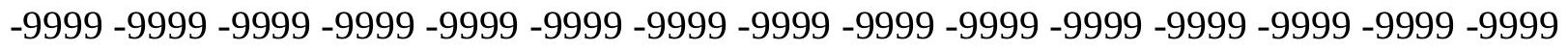
-9999 -9999 -9999-9999-9999-9999

-9999 -9999 -9999 -9999 -9999 -9999 -9999 -9999 -9999 -9999 -9999 -9999 -9999 -9999 -9999 -9999 -9999 -9999 -9999 -9999 -9999 -9999 -9999 -9999 -9999 -9999 -9999 -9999 -9999 -9999 -

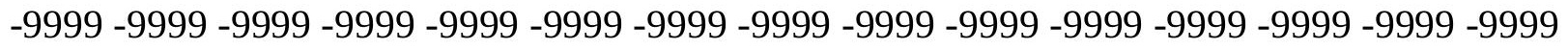

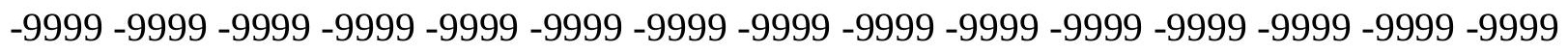

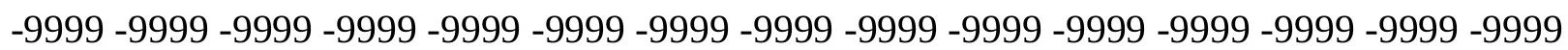
-9999 -9999 -9999 -9999 -9999 -9999 -9999 -9999 -9999 -9999 -9999 -9999 -9999 -9999 -9999 113.4622802734110 .3321990967105 .1509017944101 .188697814997 .83602905273 95.7025299072391 .1307525634892 .349891662689 .9116134643690 .82597351074 92.95947265625 93.8738174438593.5690307617292.9594726562592.65467834473 92.349891662692 .0450973510791 .7403335571391 .1307525634891 .74033355713 92.349891662693 .5690307617295 .0929565429796 .6168823242298 .4455871582 99.6647262573299 .4571151733497 .5989227294995 .8241271972794 .14575195312 92.5739212036191 .1184539794989 .7863235473688 .5833663940487 .51118469238 80.7680587768685 .7584075927775 .5867080688571 .6594085693471 .06923675537 71.3540267944372 .3169937133873 .7788314819375 .5398788452177 .45767211914 79.4513854980581 .4803848266682 .3738403320382 .1854858398481 .95685577393 81.6810531616281 .3540496826280 .9759521484480 .5499343872180 .08322143555 79.5858154296979 .0708618164178 .5534896850678 .0503921508877 .57914733887 77.1569900512776 .8009567260776 .5260238647576 .3462371826276 .27241516113 76.3142547607476 .4779357910276 .7689132690477 .1895065307677 .74211883545 78.4268188476679 .2446212768680 .1948242187581 .2795944213982 .50010681152 83.8597564697385 .3590393066486 .9931259155388 .7439041137788 .99725341797 89.3020401001 88.6924667358490.2164001464896.31210327148 101.1846160889 102.1179656982101 .3395004272100 .580955505499 .8580703735499 .1838760376 98.5683746337998 .0180969238397 .5364685058697 .1380462646596 .80419921875 96.532508850196 .3190231323296 .1604690551896 .0496978759895 .97360992432 95.9386062622192 .349891662686 .254188537684 .1206970214883 .2063369751 81.3776321411178 .9393463134875 .8914871215874 .6723632812576 .50106811523 80.7680587768681 .0728530883885 .0350494384896 .7757415771596 .6615524292 
96.5337066650496 .4175186157296 .3321609497196 .2872619628996 .28352355957 96.3153381347796 .3740844726696 .4483261108496 .5179748535296 .55774688721 96.5418777465896 .4474639892696 .256553649995 .9578857421995 .5511932373 95.0571670532294 .4620437622193 .8036727905393 .0857772827192 .29476928711 91.4510498046990 .5808944702189 .7103500366288 .8624114990288 .0569229126 87.30927276611 86.6263427734485.99684906006 85.38492584229 84.72665405273 83.9540176391682 .933181762781 .5247573852579 .5923461914177 .00190734863 73.6597137451269 .5757064819364 .8856124877959 .8738479614354 .87743377686 49.8056030273443 .8890609741233 .5263595581124 .3828105926516 .15361022949 10.057909965526 .4004869461063 .9622070789343 .3526360988623 .962207078934 5.7909169197087 .6196279525769 .4483394622810 .9722604751612 .1914100647 14.62969017029 -9999 -9999 -9999 -9999 -9999 -9999 -9999 -9999 -9999 -9999 -9999 -9999 -9999 -9999 -9999 -9999 -9999 -9999 -9999 -9999 -9999 -9999 -9999 -9999 -9999 -9999 -9999 -9999 -9999 -9999 -9999 -9999 -9999 -9999 -9999 -9999 -9999 -9999 -9999 -9999 -9999 - 9999 -9999 -9999 -9999 -9999 -9999 -9999 -9999 -9999 -9999 -9999 -9999 -9999 -9999 -9999 -9999

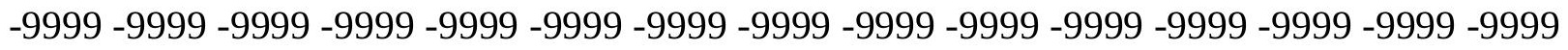
-9999 -9999 -9999 -9999 -9999 -9999 -9999 -9999 -9999 -9999 -9999 -9999 -9999 -9999 -9999 -9999 -9999 -9999 -9999 -9999 -9999 -9999 -9999 -9999 -9999 -9999 -9999 -9999 -9999 -9999 -9999 -9999 -9999 -9999 -9999 -9999 -9999 -9999 -9999 -9999 -9999 -9999 -9999 -9999 -9999 -

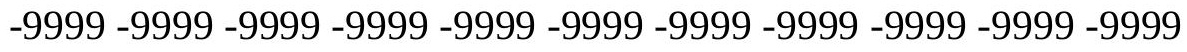

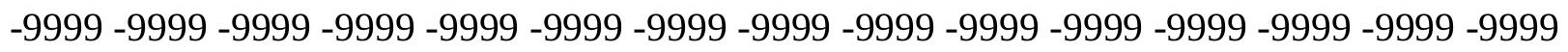
-9999 -9999 -9999 -9999 -9999 -9999 -9999 -9999 -9999 -9999 -9999 -9999 -9999 -9999 -9999 -9999 -9999 -9999 -9999 -9999 -9999 -9999 -9999 -9999 -9999 -9999 -9999 -9999 -9999 -9999 -

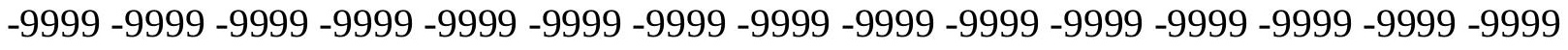

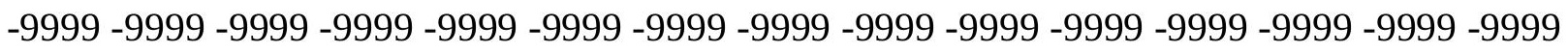
-9999 -9999 -9999 -9999 -9999 -9999 -9999 -9999 -9999 -9999 -9999 -9999 -9999 114.9282684326112 .4206085205108 .5035018921103 .017402648999 .05516815186 97.2264633178796 .3121032714894 .1785964965890 .5211791992290 .52117919922 92.0450973510793 .8738174438595 .397743225196 .0073165893695 .09295654297 94.1785964965893 .5690307617293 .2642517089892 .9594726562592 .04509735107 91.1307525634890 .8259735107491 .4355392456192 .0450973510793 .26425170898 94.7881774902396 .3121032714897 .5312423706198 .7503814697398 .47624969482 96.7779235839895 .1690597534293 .6585388183692 .2545623779390 .96255493164 89.78710937588 .7290344238384 .1206970214874 .9771423339871 .31971740723 70.5331802368270 .12570 .7391433715872 .1448287963973 .9859313964876 .00882720947 78.0862884521580 .1662216186582 .2317123413182 .9817657470782 .751953125 82.4936294555782 .2011947631881 .8714752197381 .5047988891681 .10406494141 80.6755447387780 .227813720779 .772048950279 .3211212158278 .88913726807 78.4909973144578 .1412429809677 .8542709350677 .6426086425877 .51802062988 77.4893722534277 .5646362304777 .7485961914178 .0455322265678 .4568862915 78.9843215942479 .627365112380 .3864974975681 .260604858482 .24989318848 83.35324859619 84.57388305664 85.90939331055 87.36192321777 88.91734313965 90.5691375732492 .3125839233493 .8738174438596 .0641403198298 .05670928955 100.1112976074102 .2230682373103 .2311172485102 .568397522101 .9323883057 101.3345870972100 .7837753296100 .286849975699 .8477020263799 .46876525879 99.149978637798 .8920593261798 .6917190551898 .545204162698 .45079040527 
98.4061431884898 .4086685180798 .4556655883898 .5440750122198 .66999053955 94.4833908081192 .349891662688 .6924667358483 .206336975178 .32978057861 77.110626220776 .5010681152374 .3675689697376 .1962814331186 .86376190186 99.0551681518699 .2280349731498 .9731597900498 .7652969360498 .6138381958 98.5151901245198 .4598922729598 .4371032714898 .452011108498 .48084259033 98.4835052490298 .4326553344798 .2965087890698 .0509033203197 .68431091309 97.1934814453196 .5910797119195 .8822021484495 .0948410034294 .2465133667 93.3439483642692 .4152069091891 .4912796020590 .6013107299889 .76623535156 89.005447387788 .3342285156287 .7600326538187 .2449111938586 .64319610596 86.0904235839885 .5516433715884 .9771423339884 .2913742065482 .95687866211 81.0518493652378 .5567321777375 .4770202636771 .895088195867 .9594039917 63.7228279113858 .8727340698252 .8202590942444 .8034095764233 .22158050537 22.8588790893614 .324899673468 .5339832305916 .0957031255 .4861321449286 .095703125 7.6196279525769 .4483394622811 .2770500183112 .191410064713 .10575962067 14.6296901702916 .45840072632 -9999 -9999 -9999 -9999 -9999 -9999 -9999 -9999 -9999 -9999 -9999 -9999 -9999 -9999 -9999 -9999 -9999 -9999-9999 -9999 -9999 -9999 -9999 -9999 -9999 -9999 -9999 -9999 -9999 -9999 -9999 -9999 -9999 -9999 -9999 -9999 -9999 -9999 -9999 -9999 -9999 -9999 -9999 -9999 -9999 -9999 -9999 -9999 -9999 -9999 -9999 -9999 -9999 -9999 -9999 -9999 -9999 -9999 -9999 -9999 -9999 -9999 -9999 -9999 -9999 -9999 -9999 -9999 -9999 -

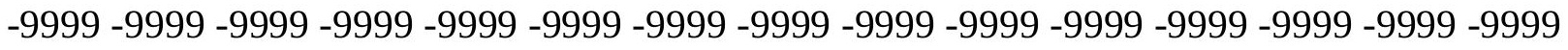

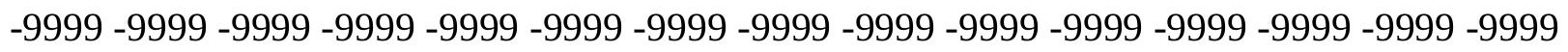
-9999 -9999 -9999 -9999 -9999 -9999 -9999 -9999 -9999 -9999 -9999 -9999 -9999 -9999 -9999 -9999 -9999 -9999 -9999 -9999 -9999 -9999 -9999 -9999 -9999 -9999 -9999 -9999 -

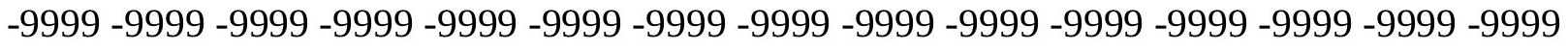

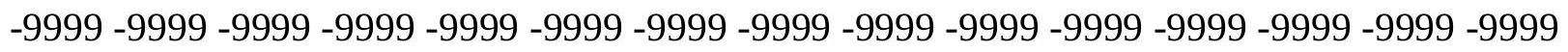
-9999 -9999 -9999 -9999 -9999 -9999 -9999 -9999 -9999 -9999 -9999 -9999 -9999 -9999 -9999 -9999 -9999 -9999 -9999 -9999 -9999 -9999 -9999 -9999 -9999 -9999 -9999 -9999 -9999 - -9999 -

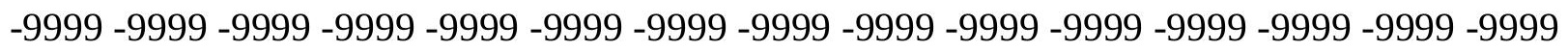
-9999 -9999 -9999 -9999 -9999 -9999 -9999 -9999-9999-9999-9999 112.8307495117 112.815574646111 .7455444336109 .113098144599 .3599472045996 .31210327148 96.0073165893695 .7025299072394 .7881774902393 .2642517089893 .56903076172 93.5690307617294 .7881774902396 .9216690063598 .1408081054797 .53124237061 95.7025299072394 .1785964965893 .2642517089892 .9594726562592 .65467834473 91.1307525634889 .9116134643689 .302040100189 .302040100189 .91161346436 91.1307525634892 .349891662693 .5690307617294 .7881774902396 .00731658936 97.2264633178797 .622772216896 .0759963989394 .620391845793 .26303863525 92.0081253051890 .8590469360489 .8159790039188 .8789062580 .76805877686 71.3197174072371 .6244964599670 .3164062571 .1332168579172 .88928222656 74.9296340942477 .0415954589879 .1444168090881 .2097625732483 .23485565186 83.5759124755983 .3133773803783 .0324020385782 .728378295982 .39891815186 82.0444259643681 .6675720214881 .2737045288180 .8702239990280 .46657562256 80.0737457275479 .7036743164179 .3690490722779 .0821914672978 .85533905029 78.6990585327178 .6232376098678 .6352233886778 .7415390014678 .94593811035 79.251678466879 .659591674880 .1706542968880 .784042358481 .49970245361 82.3162994384883 .2329483032284 .2503051757885 .3651351928786 .57877349854 87.8894577026489 .2938232421990 .7859649658292 .3714294433694 .03629302979 
95.7832870483497 .6115875244199 .50986480713101 .479057312103 .5242233276 104.6980667114104 .1481933594103 .6281356812103 .145942688102 .7083129883 102.3197402954101 .9837341309101 .7019348145101 .4754867554101 .3045578003 101.1886444092101 .1277770996101 .1207046509101 .1664581299101 .2633895874 101.4090652466101 .5995864868101 .8291397095102 .085723877101 .7982025146 94.1785964965886 .254188537681 .9871978759879 .8537063598680 .15849304199 83.206336975190 .2164001464895 .0929565429785 .0350494384876 .19628143311 84.4254837036197 .53124237061100 .8033676147100 .6897964478100 .6208496094 100.5922546387100 .5862350464100 .5710525513100 .4957962036100 .3259429932 100.024291992299 .5759811401498 .9799270629998 .2505416870197 .40431976318 96.4560928344795 .4488296508894 .3952865600693 .3367385864392 .31627655029 91.3544158935590 .4683609008889 .6800384521589 .0095901489388 .47064208984 87.94479370117 87.38648986816 86.8890838623 86.4146575927785.92105865479 85.3690872192484 .7551422119184 .1564483642682 .6590576171980 .39213562012 77.6235351562574 .366210937570 .5146408081165 .8082427978559 .77305984497 52.1980590820342 .9747009277329 .8689403533919 .2014598846411 .88661956787 7.6196279525767 .3148431777958 .22919845581110 .0579099655211 .88661956787 13.1057596206713 .715330123914 .3248996734614 .934470176716 .76317977905 -9999 -9999 -9999 -9999 -9999 -9999 -9999 -9999 -9999 -9999 -9999 -9999 -9999 -9999 -9999 -9999 -9999

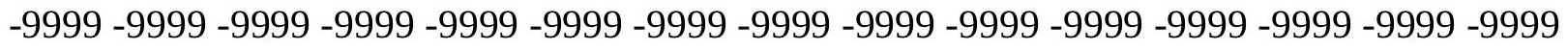

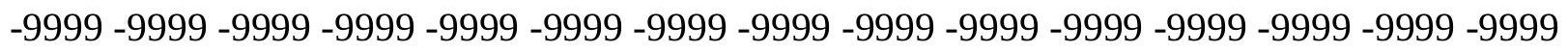
-9999 -9999 -9999 -9999 -9999 -9999 -9999 -9999 -9999 -9999 -9999 -9999 -9999 -9999 -9999 -9999 -9999 -9999 -9999 -9999 -9999 -9999 -9999 -9999 -9999 -9999 -9999 -9999 -9999 -9999 -

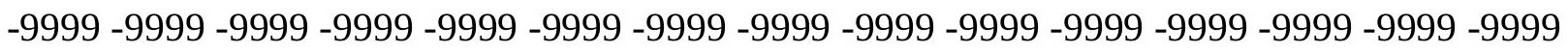

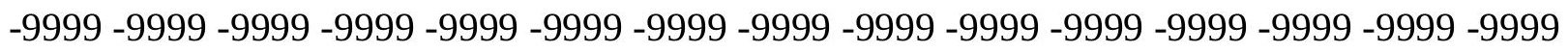

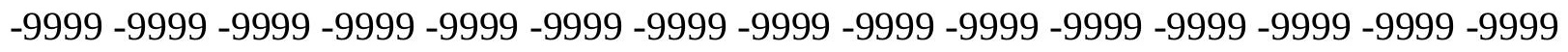
-9999 -9999-9999-9999-9999

-9999 -9999 -9999 -9999 -9999 -9999 -9999 -9999 -9999 -9999 -9999 -9999 -9999 -9999 -9999 -9999 -9999 -9999 -9999 -9999 -9999 -9999 -9999 -9999 -9999 -9999 -9999 -9999 -9999 -9999

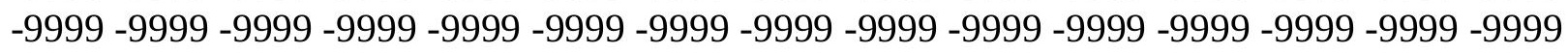
-9999 -9999 -9999 -9999 -9999 -9999 -9999 -9999 -9999 -9999 -9999 -9999 -9999 -9999 -9999

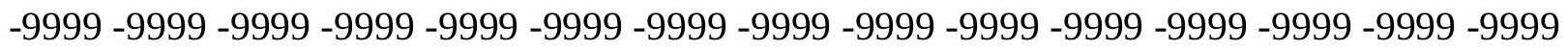
-9999 -9999 -9999 -9999-9999 -9999-9999-9999-9999 107.649520874 109.0182571411 109.6143417358109 .2180328369107 .5891036987102 .407798767198 .14080810547 95.7025299072394 .7881774902394 .1785964965893 .5690307617292 .65467834473 93.8738174438594 .7881774902396 .0073165893697 .8360290527399 .66472625732 97.2264633178794 .4833908081192 .6546783447391 .4355392456190 .82597351074 89.9116134643688 .6924667358487 .4733276367286 .8637619018686 .55898284912 87.1685485839888 .0829010009888 .9972534179790 .5211791992291 .74033355713 92.9594726562594 .1785964965895 .397743225196 .3121032714895 .46864318848 94.1525497436592 .9307022094791 .8057174682690 .7774276733489 .84558868408 88.08290100098 79.24413299561 71.31971740723 71.95515441895 73.22255706787 74.8429260253976 .7206878662178 .6836090087980 .6422271728582 .5707244873 84.4301910400484 .1466827392683 .8589477539183 .5612030029383 .24977874756 82.9229049682682 .5811080932682 .2267532348681 .8644104003981 .50038909912 81.1426925659280 .8006820678780 .4844970703180 .2050170898479 .97270965576 
79.7980804443479 .6900863647579 .6571807861379 .7054595947379 .84038543701 80.064865112380 .3814392089880 .7904357910281 .2923660278381 .88609313965 82.5712814331183 .3463821411184 .2109832763785 .1636657714886 .20235443115 87.32925415039 88.54133605957 89.83873748779 91.2162704467892.67678833008 94.2205810546995 .8432617187597 .5423812866299 .31434631348101 .1721878052 103.1154098511105 .1605300903106 .4245834351102 .102996826295 .09295654297 95.7025299072399 .96952056885104 .5412979126104 .3434677124104 .1578063965 104.0250701904103 .9469604492103 .9242630005103 .9580078125104 .0481185913 104.1943359375104 .3946380615104 .6458511353104 .9419326782105 .2741470337 105.6259689331105 .455703735496 .3121032714890 .8259735107488 .38768768311 88.9972534179790 .8259735107493 .5690307617293 .5690307617286 .86376190186 81.3776321411184.7302627563592.0450973510799.66472625732 102.9630661011 102.8668746948102 .8214569092102 .8152236938102 .8059997559102 .7266769409 102.529296875102 .1673431396101 .6314468384100 .9160690308100 .0428924561 99.0294570922997 .9026336669996 .6989059448295 .4561614990294 .21523284912 93.0685653686591.9843215942490.9880905151490.1078338623 89.37046813965 88.799804687588 .4116363525488 .2038345336987 .7568283081187 .35440063477 86.9749145507886 .6065292358486 .26757812586 .0165939331185 .9408493042 84.2987823486382 .0916061401479 .2521514892675 .6409149169971 .00843811035 65.074356079157 .514785766648 .124721527136 .8790016174323 .16366958618 15.5440397262611 .2770500183125 .906740188610 .6674804687513 .10575962067 14.934470176715 .2392597198514 .934470176714 .934470176715 .23925971985 16.7631797790518 .287109375 -9999 -9999 -9999 -9999 -9999 -9999 -9999 -9999 -9999 -9999 -9999 -9999 -9999 -9999 -9999 -9999 -9999 -9999 -9999 -9999 -9999 -9999 -9999 -9999 -9999 -9999 -9999 -9999 -9999 -9999 -9999 -9999 -9999 -9999 -9999 -9999 -9999 -9999 -9999 -9999 -9999 -9999 -9999 -9999 -9999 -9999 -9999 -9999 -9999 -9999 -9999 -9999 -9999 -9999 -9999 -9999 -9999 -9999 -9999 -9999 -9999 -9999 -9999 -9999 -9999 -9999 -9999 -9999 -9999 -9999 -

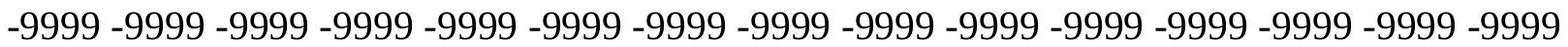
-9999 -9999 -9999 -9999 -9999 -9999 -9999 -9999 -9999 -9999 -9999 -9999 -9999 -9999 -9999 -9999 -9999 -9999 -9999 -9999 -9999 -9999 -9999 -9999 -9999 -9999 -9999 -9999 -9999 -9999 -9999 -9999 -9999 -9999 -9999 -9999 -9999 -9999 -9999 -9999 -9999

-9999 -9999 -9999 -9999 -9999 -9999 -9999 -9999 -9999 -9999 -9999 -9999 -9999 -9999 -9999

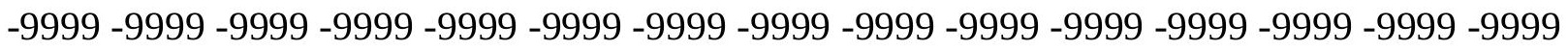
-9999 -9999 -9999 -9999 -9999 -9999 -9999 -9999 -9999 -9999 -9999 -9999 -9999 -9999 -9999 -9999 -9999 -9999 -9999 -9999 -9999 -9999 -9999 -9999 -9999 -9999 -9999 -9999 -9999 -9999 -9999 -9999 -9999 -9999 -9999 -9999 -9999 -9999 -9999 -9999 -9999 -9999 -9999 -9999 -9999 - -999 -9999 -9999 -9999 -9999-9999 -9999 -9999 -9999 102.4071121216 104.2163848877 105.888633728105 .9833984375104 .8460998535103 .0174026489100 .2742996216 97.5312423706195 .0929565429793 .8738174438593 .2642517089892 .65467834473 92.0450973510793 .2642517089893 .8738174438594 .7881774902396 .00731658936 96.0073165893694 .1785964965891 .1307525634889 .6068267822388 .38768768311 87.1685485839885 .9494018554784 .7302627563583 .8159103393683 .2063369751 83.2063369751 83.51112365723 84.42548370361 85.33984375 86.86376190186 88.0829010009889 .6068267822390 .8259735107492 .0450973510793 .26425170898 94.4833908081194 .9342193603593 .7414779663192 .6379623413191 .62343597412 90.6976013183689 .8583526611387 .4733276367279 .5489196777371 .62449645996 
75.5867080688577 .891464233479 .3059310913180 .878349304282 .52136993408 84.1946334838984 .9941940307684 .6857376098684 .3789978027384 .0691986084 83.7535171508883 .4308853149483 .1018753051882 .7686233520582 .43490600586 82.1061096191481 .7889556884881 .4914550781281 .222236633380 .9906463623 80.8056488037180 .6763229370180 .610351562580 .6150131225680 .69548797607 80.8563995361381 .1000671386781 .4284973144581 .8416976928782 .33985137939 82.9216918945383 .586639404384 .3331375122185 .1606216430786 .06777954102 87.0543746948288 .119422912689 .2629165649490 .4840545654391 .78302764893 93.1564025878994 .6136550903396 .1449356079197 .7596664428799 .45132446289 101.2387084961103 .1136550903105 .0868530273107 .165847778396 .61688232422 86.254188537687 .1685485839893 .26425170898101 .7982025146106 .9876556396 106.8484725952106 .7593383789106 .7231674194106 .741973877106 .818031311 106.9523773193107 .1458206177107 .3971786499107 .7040634155108 .0609741211 108.4596176147108 .8868484497109 .319152832109 .7438430786101 .7982025146 99.3599472045999 .6647262573299 .9695205688598 .445587158296 .31210327148 96.3121032714896 .9216690063595 .7025299072396 .0073165893699 .05516815186 103.3221969604105 .1284332275105 .1054382324105 .1407394409105 .1750488281 105.1199874878104 .9027481079104 .479850769103 .8378753662102 .9840927124 101.9417266846100 .739822387799 .4084167480597 .9896926879996 .53165435791 95.0906677246193 .7445373535292 .4830245971791 .3252029418990 .29781341553 89.43337249756 88.76955413818 88.34354400635 88.17670440674 88.25688934326 88.37088775635 88.11183929443 87.92975616455 87.84053039551 87.87049865723 88.0382843017687 .2750396728585 .4563064575282 .8971557617279 .45297241211 74.9289321899469 .1061019897561 .7258872985852 .5589485168541 .77684783936 30.1737308502221 .334960937517 .0679702758814 .0201196670513 .41055011749 16.1536102294917 .9823207855216 .7631797790515 .5440397262614 .9344701767 15.2392597198517 .0679702758818 .5918903350819 .20145988464 -9999 -9999 -9999 -9999 -9999 -9999 -9999 -9999 -9999 -9999 -9999 -9999 -9999 -9999 -9999 -9999 -9999 -9999 -9999 -9999 -9999 -9999 -9999 -9999 -9999 -9999 -9999 -9999 -9999 -9999 -9999 -9999 -9999 -9999

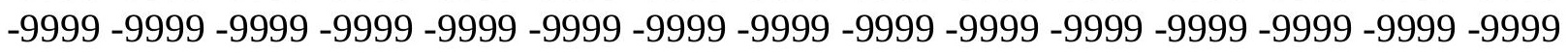
-9999 -9999 -9999 -9999 -9999 -9999 -9999 -9999 -9999 -9999 -9999 -9999 -9999 -9999 -9999

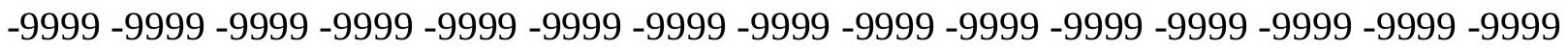

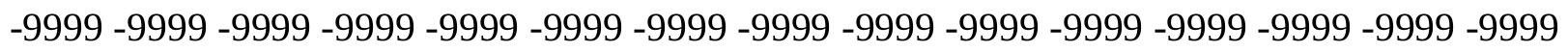

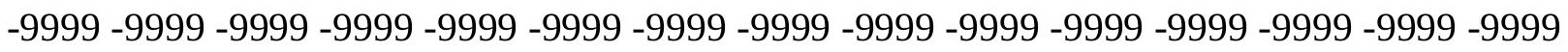

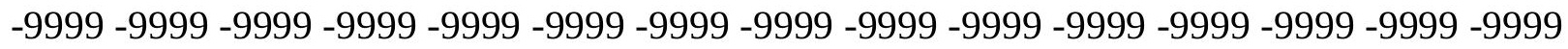
$-9999$

-9999 -9999 -9999 -9999 -9999 -9999 -9999 -9999 -9999 -9999 -9999 -9999 -9999 -9999 -9999

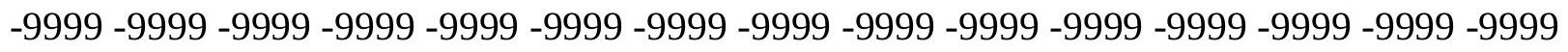

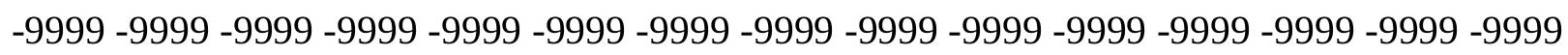
-9999 -9999 -9999 -9999 -9999 -9999 -9999 -9999 -9999 -9999 -9999 -9999 -9999 -9999 -9999 -

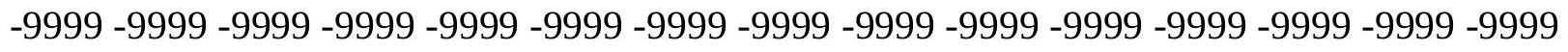
-9999 -9999 -9999 -9999 -9999-9999 140.9214477539 97.90510559082 98.08820343018 99.95791625977102 .712600708101 .7982025146100 .579101562599 .35994720459 97.8360290527396 .0073165893694 .1785964965893 .2642517089892 .3498916626 92.04509735107 91.4355392456191.4355392456191.4355392456191.43553924561 92.0450973510791 .4355392456189 .9116134643687 .7781066894585 .64462280273 
84.12069702148 82.59677124023 81.37763214111 80.15849304199 79.24413299561 78.9393463134878 .9393463134879 .2441329956180 .1584930419981 .37763214111 82.9015579223684 .1206970214885 .6446228027387 .1685485839888 .38768768311 89.9116134643691.1307525634892.6546783447394.4509277343893.36646270752 92.3644104003991 .444473266690 .6045684814589 .8424682617286 .86376190186 81.3776321411175 .5867080688578 .0249862670982 .421592712483 .43594360352 84.649276733485 .8528747558685 .5129394531285 .185684204184 .86511230469 84.547019958584 .2294464111383 .9120559692483 .5955810546983 .28186035156 82.9740142822382 .6765365600682 .3950805664182 .1365051269581 .90814971924 81.7180938720781 .5740432739381 .4838943481481 .4543075561581 .49163818359 81.6003494262781 .784461975182 .0458679199282 .3862533569382 .80541229248 83.3033905029383 .8788604736384 .5312118530385 .2588729858486 .06131744385 86.9373321533287 .8868408203188 .9091644287190 .0047607421991 .17349243164 92.416427612393 .7341232299895 .128494262796 .6011657714898 .15540313721 99.79441833496101 .5232696533103 .3469619751105 .2723007202101 .4934005737 90.2164001464881 .6824111938583 .5111236572391 .43553924561103 .0174026489 109.5553894043109 .4665222168109 .4243164062109 .4324874878109 .4940109253 109.6120986938109 .7887954712110 .0258712769110 .3231277466110 .6791381836 111.0893783569111 .5465621948112 .038482666112 .5461654663113 .0389022827 113.4483718872113 .6747207642109 .4179000854107 .5891036987104 .5412979126 103.0174026489103.3221969604 104.2365036011 103.9317016602 102.712600708 102.712600708103 .6268997192105 .1509017944106 .979598999107 .5492858887 107.695854187107 .7031402588107 .4778137207106 .5494995117105 .4074783325 104.2450332642103 .0652008057101 .8730010986100 .675430297999 .264503479 97.5605545043995 .8890380859494 .2994537353592 .8165130615291 .45471191406 90.2336273193489 .1860198974688 .3687896728587 .8502502441487 .69139862061 87.9012603759888 .4198074340889 .1175842285289 .2768707275489 .40813446045 89.67865753174 89.24212646484 88.37538909912 87.50927734375 85.56614685059 82.2971801757877 .9712295532272 .4375534057665 .5589828491257 .31939697266 48.088451385539 .1395339965831 .6976509094223 .4684505462620 .11581993103 19.5062503814719 .2014598846419 .5062503814717 .3727493286114 .9344701767 14.0201196670514 .934470176717 .6775398254419 .5062503814719 .20145988464 17.6775398254416 .45840072632 -9999 -9999 -9999 -9999 -9999 -9999 -9999 -9999 -9999 -9999 -9999 -9999 -9999 -9999 -9999 -9999 -9999 -9999 -9999 -9999 -9999 -9999 -9999 -9999 -9999 -9999 -9999 -9999 -9999 -9999 -9999 -9999 -9999 -9999 -9999 -9999 -9999 -9999 -9999 -9999 -9999 -9999 -9999 -9999 -9999 -9999 -9999 -9999 -9999 -9999 -9999 -9999 -9999 -9999

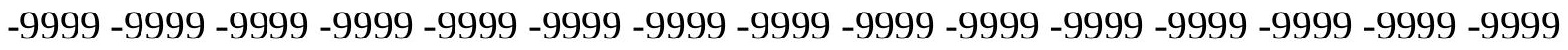

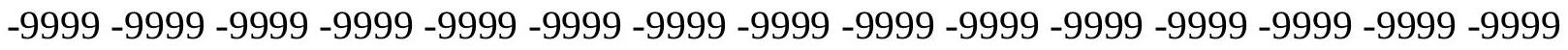
-9999 -9999 -9999 -9999 -9999 -9999 -9999 -9999 -9999 -9999 -9999 -9999 -9999 - 9999 - -999 -9999 -9999 -9999 -9999 -9999 -9999 -9999 -9999 -9999 -9999 -9999 -9999 -9999 -9999 -9999 -9999-9999-9999-9999-9999-9999-9999-9999-9999

-9999 -9999 -9999 -9999 -9999 -9999 -9999 -9999 -9999 -9999 -9999 -9999 -9999 -9999 -9999 -9999 -9999 -9999 -9999 -9999 -9999 -9999 -9999 -9999 -9999 -9999 -9999 -9999 -9999 -9999 -9999 -9999 -9999 -9999 -9999 -9999 -9999 -9999 -9999 -9999 -9999 -9999 -9999 -9999 -9999 -9999 -9999 -9999 -9999 -9999 -9999 -9999 -9999 -9999 -9999 -9999 -9999 -9999 -9999 -9999 -9999 -9999 -9999 -9999 -9999 -9999 -9999 -9999 -9999 -9999 -9999 -9999 -9999 -9999 -9999 
-9999 -9999 -9999 -9999 -9999 140.2012023926 97.1396636962995.66345214844 92.9594726562595 .0929565429796 .3121032714896 .9216690063596 .61688232422 96.0073165893695 .397743225194 .1785964965893 .2642517089892 .3498916626 92.0450973510791 .4355392456191 .4355392456188 .3876876831188 .08290100098 87.7781066894587 .4733276367286 .5589828491285 .0350494384883 .2063369751 81.0728530883879 .5489196777377 .7202072143676 .5010681152375 .28192901611 74.3675689697374 .062782287674 .3675689697374 .9771423339875 .89148712158 77.110626220778 .6345596313580 .1584930419981 .6824111938583 .2063369751 84.7302627563585 .9494018554787 .7781066894589 .302040100191 .13075256348 93.2642517089893 .0116348266692 .0970458984491 .2568511962990 .48894500732 88.9972534179787 .7072525024484 .7302627563579 .2441329956180 .15849304199 84.4254837036186 .7209625244186 .3409118652385 .9828720092885 .64141082764 85.3110580444384 .9879226684684 .6704330444384 .3589248657284 .05442047119 83.7585906982483 .4739227294983 .2041854858482 .9540710449282 .72946166992 82.5366058349682 .3825073242282 .2738189697382 .2174453735482 .21919250488 82.2846832275482 .417831420982 .6222000122182 .8994369506883 .2509765625 83.6766052246184 .1762847900484 .7487945556685 .3935241699286 .10905456543 86.8949203491287 .7500762939588 .6745910644589 .6680755615290 .73127746582 91.8645706176893 .0695266723694 .3473892211995 .700752258397 .13195800781 98.64488220215100 .2431640625101 .9321289062103 .7166519165103 .3221969604 94.4833908081185 .9494018554781 .3776321411184 .4254837036193 .56903076172 106.3700027466111 .9814224243111 .9450454712111 .9513320923112 .004524231 112.1082229614112 .2663879395112 .481880188112 .7573928833113 .0936889648 113.4904632568113 .9443054199114 .4492111206114 .9943237305115 .5637359619 116.1263580322116 .6167755127116 .9399414062116 .9799957275116 .5888290405 115.5652618408110 .3321990967109 .7226028442109 .4179000854110 .0273971558 110.0273971558108 .1986999512106 .6747970581106 .979598999108 .1986999512 110.0273971558110 .4080734253109 .4633331299108 .389175415107 .2955780029 106.1827774048 105.0520324707 103.9066009521 102.751449585101.5930557251 100.438796997198 .4634017944396 .5151062011794 .6549530029392 .91673278809 91.3159179687589 .859794616788 .568504333587 .5227966308686 .84378051758 86.6610336303787 .0170059204187 .8385772705188 .931228637790 .05551147461 89.75189971924 88.95766448975 88.2794342041 87.6402206420986.94160461426 86.0625686645584 .4075622558680 .394950866775 .3874969482469 .39115142822 62.5564918518155 .2863426208548 .1838073730541 .3339309692434 .44071960449 29.8689403533928 .6497993469225 .2971591949521 .6397399902317 .37274932861 13.715330123912 .8009700775114 .0201196670517 .0679702758819 .50625038147 17.9823207855215 .5440397262614 .0201196670513 .10575962067 -9999-9999-9999-9999 -9999 -9999 -9999 -9999 -9999 -9999 -9999 -9999 -9999 -9999 -9999 -9999 -9999 -9999 -9999 -9999 -9999 -9999 -9999 -9999 -9999 -9999 -9999 -9999 -9999 -9999 -9999 -9999 -9999 -9999 -

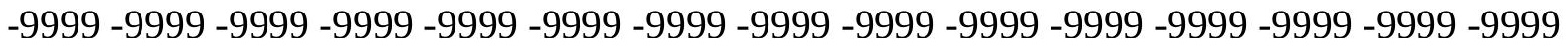

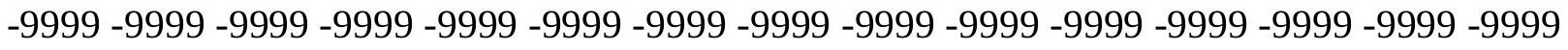
-9999 -9999 -9999 -9999 -9999 -9999 -9999 -9999 -9999 -9999 -9999 -9999 -9999 -9999 -9999 -9999 -9999 -9999 -9999 -9999 -9999 -9999 -9999 -9999-9999 -9999 -9999 -9999 -9999 -9999 -9999 -9999 -9999 -9999 -9999 -9999 -9999 -9999 -9999 -9999 -9999 -9999 -9999 -9999 -9999 -9999 -9999 -9999 -9999 -9999 -9999 -9999 -9999 -9999 -9999 -9999 -9999 -999 - 
-9999 -9999 -9999 -9999 -9999 -9999 -9999 -9999 -9999 -9999 -9999 -9999 -9999 -9999 -9999 -9999 -9999 -9999 -9999 -9999 -9999 -9999 -9999 -9999 -9999 -9999 -9999 -9999 -9999 -9999 -9999 -9999 -9999 -9999 -9999 -9999 -9999 -9999 -9999 -9999 -9999 -9999 -9999 -9999 -9999 -9999 -9999 -9999 -9999 -9999 -9999 -9999 -9999 -9999 -9999 -9999 -9999 -9999 -9999 -9999 -9999 -9999 -9999 -9999 -9999 -9999 -9999 -9999 -9999 -9999 -9999 -9999 -9999 -9999 -9999 -9999 -9999 -9999 -9999 -9999 96.19984436035 96.0908126831196.00731658936 90.5211791992290 .5211791992291 .7403335571392 .9594726562593 .26425170898 93.2642517089893 .2642517089892 .9594726562592 .349891662692 .04509735107 91.4355392456191 .1307525634885 .3398437584 .4254837036183 .81591033936 83.5111236572382 .5967712402381 .6824111938580 .1584930419978 .32978057861 76.1962814331174 .3675689697372 .8436431884871 .3197174072370 .10057830811 69.4910125732469 .1862335205169 .4910125732470 .1005783081171 .31971740723 72.5388565063574 .062782287675 .8914871215877 .4154205322378 .93934631348 80.4632720947381 .9871978759883 .8159103393685 .6446228027387 .77810668945 89.9116134643691 .7403335571392 .6648254394591 .8244171142691 .05165863037 90.3428649902389 .69419097989 .1005172729585 .3398437582 .29197692871 81.6824111938585 .3398437586 .7750778198286 .4026565551886 .05015563965 85.7128753662185 .3872528076285 .0716781616284 .7666320800884 .47342681885 84.1937561035283 .9296646118283 .6842803955183 .4615097045983 .26636505127 83.1042022705182 .9810714721782 .9027328491282 .8752593994182 .90372467041 82.993164062583 .147048950283 .3686065673883 .6593093872184 .02051544189 84.4520187377984 .9538497924885 .5249176025486 .164764404386 .87213897705 87.6467208862388 .4876480102589 .3951568603590 .3690414428791 .41031646729 92.5195999145593 .6987915039194 .9494628906296 .2745437622197 .67666625977 99.15990447998100 .7279586792102 .3859786987104 .1385116577103 .3221969604 96.6168823242288 .3876876831184 .1206970214889 .302040100198 .75038146973 109.7226028442114 .2132644653114 .2301483154114 .2850265503114 .3823242188 114.5260772705114 .7207336426114 .9698486328115 .2768783569115 .6435775757 116.0706558228116 .5559234619117 .0946426392117 .6775512695118 .2906570435 118.9150238037119 .4853668213119 .9212493896120 .1356201172120 .0487518311 119.5434570312118 .1190185547114 .5991973877113 .3800964355113 .9896011353 113.6848983765111 .8561019897110 .0273971558109 .7226028442110 .9418029785 112.2311019897111 .2198638916110 .1921005249109 .1471710205108 .0848083496 107.0056991577105 .9115905762104 .8060150146103 .6938781738102 .5811309814 101.474273681699 .1765670776496 .895927429294 .7171096801892 .67981719971 90.799522399989 .0629272460987 .4565505981486 .0514602661185 .10673522949 84.842361450285 .4024581909286 .6528396606488 .2528839111388 .28207397461 87.7892761230587 .3540267944386 .9265747070386 .4566421508885 .88258361816 85.1296386718884 .1167449951282 .2710876464877 .9425582885773 .02184295654 67.7142181396562 .3278999328657 .1733703613352 .4681243896548 .97114181519 46.9369087219241 .7555618286134 .4407196044926 .8210906982419 .20145988464 12.8009700775111 .2770500183112 .191410064714 .0201196670515 .54403972626 14.3248996734612 .4961900711110 .9722604751610 .057909965529 .44833946228 -9999 -9999 -9999 -9999 -9999 -9999 -9999 -9999 -9999 -9999 -9999 -9999 -9999 -9999 -9999 -9999 -9999 -9999 -9999 -9999 -9999 -9999 -9999 -9999 -9999 -9999 -9999 -9999 -9999 -9999 -9999 -

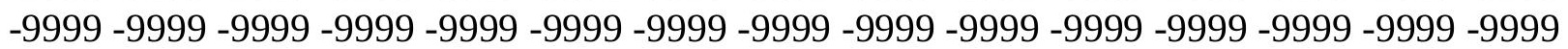


-9999 -9999 -9999 -9999 -9999 -9999 -9999 -9999 -9999 -9999 -9999 -9999 -9999 -9999 -9999 -9999 -9999 -9999 -9999 -9999 -9999 -9999 -9999 -9999 -9999 -9999 -9999 -9999 -9999 -9999 -9999 -9999 -9999 -9999 -9999 -9999 -9999 -9999 -9999 -9999 -9999 -9999 -9999 -9999 -9999 -9999 -9999 -9999 -9999 -9999 -9999 -9999 -9999 -9999 -9999 -9999 -9999 -9999 -9999 -9999 -9999 -9999 -9999 -9999 -9999 -9999 -9999 -9999 -9999 -9999 -9999 -9999-9999 -9999 -9999 -9999 -9999 -9999 -9999 -9999 -9999 -9999 -9999 -9999 -9999 -9999 -9999 -9999 -9999 -9999 -9999 -9999 -9999 -9999 -9999 -9999 -9999 -9999 -9999 -9999 -9999 -9999 -9999 -9999 -9999 -9999 -9999 -9999 -9999 -9999 -9999 -9999 -9999 -9999 -9999 -9999 -9999 -9999 -9999 -9999 -999 -9999 -9999 -9999 -9999 -9999 -9999 -9999 -9999 -9999 -9999 -9999 -9999 -9999 -9999 -9999 -9999 -9999 -9999 -9999 -9999 -9999 -9999 -9999 -9999 -9999 -9999 -9999 -9999 -9999 -9999 -9999 -9999 -9999 -9999 95.8558578491294.9978179931694.17802429199 93.26425170898 89.6068267822389 .302040100189 .9116134643690 .5211791992291 .13075256348 91.7403335571392 .0450973510792 .349891662692 .0450973510791 .74033355713 91.1307525634890 .5211791992280 .1584930419979 .5489196777379 .24413299561 78.6345596313577 .7202072143676 .5010681152374 .9771423339873 .14842987061 71.3197174072369 .4910125732467 .9670867919966 .4431610107465 .22400665283 64.6144485473664 .6144485473664 .9192428588965 .8335876464866 .74794006348 68.2718734741269 .7957916259871 .6244964599673 .1484298706174 .97714233398 76.5010681152378 .0249862670979 .8537063598681 .6824111938584 .12069702148 86.254188537688 .6924667358490 .5211791992292 .0450973510791 .54077911377 90.824363708590 .1649932861389 .558235168468986 .5589828491284 .12069702148 82.29197692871 85.33984375 86.77458190918 86.4133605957 86.0710067749 85.7444763183685 .432060241785 .1339797973684 .8514633178784 .58631896973 84.3403549194384 .1162261962983 .9171600341883 .7474517822383 .61164093018 83.51499938965 83.46249389648 83.45948028564 83.51042938232 83.61986541748 83.7909011840884 .02651214684 .3280639648484 .6968688964885 .13280487061 85.6360321044986 .2056503295986 .8414001464887 .542266845788 .30809783936 89.1382446289190 .0330734252990 .9925765991292 .0178756713993 .10975646973 94.270233154395 .5010147094796 .8050842285298 .1850814819399 .64498138428 101.1882705688102 .8197174072104 .5433044434106 .0652008057101 .7982025146 94.7881774902391 .1307525634896 .92166900635105 .7603988647113 .075302124 116.2169265747116 .2867355347116 .3890380859116 .5282363892116 .7085494995 116.9347305298117 .2108459473117 .5410232544117 .9278106689118 .3729248047 118.8752670288119 .4314727783120 .0328369141120 .6701812744121 .3310546875 121.9577255249122 .0661849976121 .9164810181121 .7814483643121 .6674041748 121.2530441284120 .3579406738117 .9517974854116 .4279022217115 .818397522 114.2944030762113 .3800964355113 .075302124113 .8976593018112 .9301757812 111.9482879639110 .9512329102109 .9387969971108 .9111328125107 .8694076538 106.8159332275105 .7546081543104 .6903533936103 .628692627102 .3706207275 99.6356887817496 .9535217285294 .3799514770591 .5050506591888 .04376983643 85.3523101806683 .5624084472782 .7034988403382 .2166748046981 .74687194824 82.6647415161184 .5881195068485 .7290573120185 .7360000610485 .70273590088 85.5799789428785 .3457183837984 .9849777221784 .4819107055783 .81910705566 82.9753646850681 .9325714111379 .8621749877976 .0240478515672 .19354248047 68.6112976074265 .5112762451263 .1409606933661 .7310371398960 .84964370728 58.5187492370645 .717769622832 .6120109558121 .0301704406713 .10575962067 
10.6674804687510 .9722604751610 .9722604751610 .9722604751610 .05790996552 9.1435537338267 .9244132041937 .0100579261786 .4004869461066 .705273151398 -9999 -9999 -9999 -9999 -9999 -9999 -9999 -9999 -9999 -9999 -9999 -9999 -9999 -9999 -9999 -9999 -9999 -9999 -9999 -9999 -9999 -9999 -9999 -9999 -9999 -9999 -9999 -9999 -9999 -9999 -9999 -9999 -9999 -9999 -9999 -9999 -9999 -9999 -9999 -9999-9999 -9999 -9999 -9999 -9999 -9999 -9999 -9999 -9999 -9999 -9999 -9999 -9999 -9999 -9999 -9999 -9999 -9999 -9999 -9999 -9999 -9999 -9999 -9999 -9999 -9999 -9999 -9999 -9999 -9999 -9999 -9999 -9999 -9999 -9999 -9999

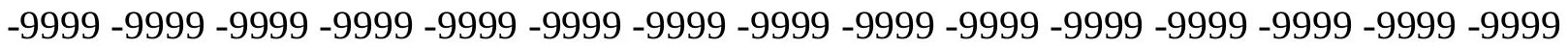

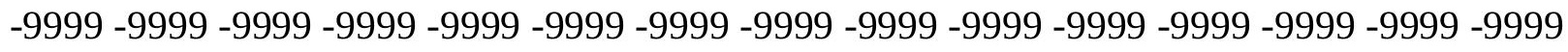
-9999 -9999 -9999 -9999 -9999 -9999 -9999 -9999 -9999 -9999 -9999 -9999 -9999 -9999 -9999 -9999 -9999 -9999 -9999 -9999 -9999 -9999 -9999 -9999 -9999 -9999 -9999 -9999 -9999 -9999 -9999 -9999 -9999 -9999 -9999 -9999 -9999 -9999 -9999 -9999 -9999 -9999 -9999 -9999 -9999 -9999 -9999 -9999 -9999 -9999 -9999 -9999 -9999 -9999 -9999 -9999 -9999 -9999 -9999 -9999 -9999 -9999 -9999 -9999 -9999 -9999 -9999 -9999 -9999 -9999 -9999 -9999 -9999 - 9999 -9999 -9999 -9999 -9999 -9999 -9999 -9999 -9999 -9999 -9999 -9999 -9999 -9999 -9999 -9999 -9999 -9999-9999 96.85929870605 95.71714782715 94.38101959229 92.48029327393 89.6068267822391 .1307525634891 .1307525634890 .5211791992290 .52117919922 90.8259735107491 .4355392456192 .0450973510792 .6546783447392 .65467834473 92.349891662691 .1307525634899 .9116134643674 .6723632812574 .36756896973 74.062782287673 .4532165527372 .8436431884871 .6244964599670 .10057830811 68.2718734741266 .7479400634864 .9192428588963 .3953094482462 .17617034912 60.9570198059160 .3474502563560 .6522407531760 .9570198059161 .87137985229 62.7857398986864 .3096618652366 .1383666992267 .6623001098669 .49101257324 71.014930725172 .5388565063574 .062782287675 .8914871215877 .72020721436 80.1584930419982 .5967712402385 .3398437587 .7781066894589 .91161346436 91.4355392456191 .2430801391690 .5747299194389 .9569854736389 .38648986816 88.8590774536187 .7781066894585 .6446228027382 .9015579223684 .42548370361 86.5589828491286 .3886337280386 .0620346069385 .7532348632885 .46216583252 85.1897201538184 .9376220703184 .7075653076284 .5018463134884 .32317352295 84.175216674884 .0618209838983 .9875488281283 .9567031860483 .97402191162 84.0434646606484 .1691360473684 .3538513183684 .6003494262784 .90991973877 85.2838516235485 .7221374511786 .2251052856486 .7920761108487 .42302703857 88.117187588 .8746337890689 .6948852539190 .5784683227591 .52550506592 92.5371780395593 .6143493652394 .7590255737395 .9728851318497 .25879669189 98.61922454834100 .0578384399101 .5777511597103 .1831970215104 .8775405884 106.6650619507106 .0652008057102 .712600708101 .7982025146107 .2844009399 113.6848983765117 .647102356117 .9704437256118 .0919647217118 .2395401001 118.4173049927118 .6295013428118 .8810043335119 .1762695312119 .519859314 119.9150695801120 .3643722534120 .8677368164121 .4229736328122 .0239562988 122.5645980835122 .424911499122 .2892456055122 .160987854122 .0441360474 121.9438247681121 .8671875121 .7197341919120 .8491897583119 .9759292603 119.09815979118 .2142105103117 .0374984741115 .818397522115 .5096817017 114.586151123113 .6497268677112 .6997909546111 .7360229492110 .7587127686 109.7685241699108 .7670974731107 .7572631836106 .743347168105 .7304458618 104.723815918102 .990615844799 .7934875488396 .6181335449293 .18556213379 88.46851348877 84.3348999023481.0993423461978.97691345215 78.01837158203 
77.334266662676 .590126037678 .2530288696381 .2273025512782 .63591003418 83.2297515869183.6021194458 83.74547576904 83.65357208252 83.34178924561 82.8438720703182 .2145996093881 .4973373413180 .7249832153379 .92892456055 77.9431838989375 .4317016601673 .4411087036172 .0860595703171 .40595245361 71.1459655761770 .2429351806666 .8700790405358 .8235282897935 .65985870361 23.4684505462617 .0679702758813 .4105501174911 .581830024729 .753124237061 8.5339832305917 .3148431777956 .0957031255 .1813468933114 .266992092133 3.6574220657353 .6574220657354 .266992092133 -9999 -9999 -9999 -9999 -9999 -9999 -9999

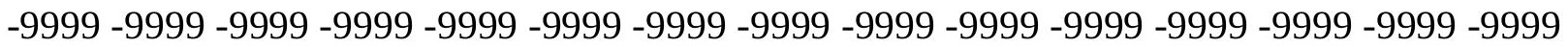
-9999 -9999 -9999 -9999 -9999 -9999 -9999 -9999 -9999 -9999 -9999 -9999 -9999 -9999 -9999 -9999 -9999 -9999 -9999 -9999 -9999 -9999 -9999 -9999 -9999 -9999 -9999 -9999 -9999 -9999 -9999 -9999 -9999 -9999 -9999 -9999 -9999 -9999 -9999 -9999 -9999 -9999 -9999 -9999 -9999 -9999 -9999 -9999 -9999 -9999 -9999 -9999 -9999 -9999 -9999 -9999 -9999 -9999 -9999 -9999 -9999 -9999 -9999 -9999 -9999 -9999 -9999 -9999 -9999 -9999 -9999 -9999 -9999 -9999 - 9999 -9999 -9999 -9999 -9999 -9999 -9999 -9999 -9999 -9999 -9999 -9999 -9999 -9999 -9999 -9999 -9999 -9999 -9999 -9999-9999-9999-9999

-9999 -9999 -9999 -9999 -9999 -9999 -9999 -9999 -9999 -9999 -9999 -9999 -9999 -9999 -9999 -9999 -9999 -9999 -9999 -9999 -9999 -9999 -9999 -9999 -9999 -9999 -9999 -9999 -9999 -9999 -9999 -9999 -9999 -9999 -9999 -9999 -9999 -9999 -9999 -9999 -9999 -9999 -9999 -9999 -9999 -

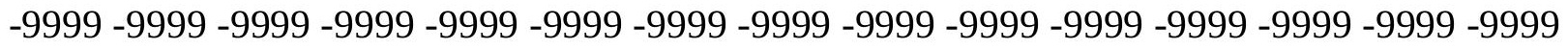

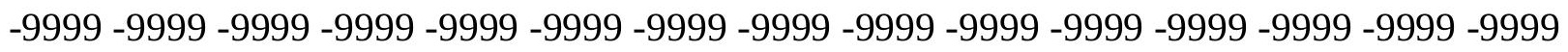
-9999 -9999 -9999 97.6550827026496.4302902221794.9606170654393.32321929932 92.1817703247192 .5844421386793 .0741195678793 .2642517089892 .3498916626 92.0450973510792 .6546783447393 .5690307617294 .4833908081194 .48339080811 93.87381744385 92.04509735107 68.88143920898 68.88143920898 68.88143920898 68.8814392089868 .5766525268667 .9670867919966 .7479400634865 .52880096436 64.004882812562 .4809494018660 .9570198059159 .4331016540558 .51874923706 57.6043891906757 .2995986938557 .2995986938557 .909179687558 .82352828979 59.7378807067960 .9570198059162 .7857398986864 .3096618652365 .83358764648 67.3575134277368 .8814392089870 .4053573608471 .9292907714874 .0627822876 76.5010681152379 .2441329956182 .2919769287185 .0350494384887 .77810668945 89.9116134643691 .4355392456190 .9330520629990 .306083679289 .72525024414 89.1870346069388 .6881484985488 .2248535156286 .8637619018683 .81591033936 82.9015579223684 .7302627563586 .254188537686 .0402679443485 .75573730469 85.4925079345785 .2520523071385 .0358886718884 .8460922241284 .68489074707 84.5554122924884 .4608840942484 .4052581787184 .3922271728584 .42602539062 84.5102233886784 .6485671997184 .8436355590885 .097938537685 .41264343262 85.78901672363 86.22718811035 86.72763061523 87.28993988037 87.91432952881 88.6002883911189 .3480834960990 .1574401855591 .0289993286191 .96298217773 92.9606323242294 .0227966308695 .1514129638796 .3480148315497 .61524963379 98.95528411865100 .3713989258101 .8662338257103 .4434204102105 .1056747437 106.8564682007108 .6979522705110 .3321990967112 .1608963013114 .7851409912 117.0020294189119 .3101272583119 .4688034058119 .6402206421119 .8301544189 120.0423355103120 .2808761597120 .5506362915120 .8563156128121 .2028274536 121.5939865112122 .0329284668122 .5204315186122 .7449951172122 .6279830933 122.5105514526122 .3957672119122 .286819458122 .1870498657122 .1005172729 
122.0324630737121 .9902877808121 .9825592041121 .3374099731120 .4919586182 119.6430664062118 .7889862061117 .927986145117 .0585403442116 .1791381836 115.288520813114 .385559082113 .4698181152112 .5413894653111 .6011657715 110.6504135132109 .6912384033108 .7268981934107 .7620697021106 .8021621704 105.8524475098103 .352676391699 .6242370605595 .8572158813591 .56158447266 86.010879516680 .9770736694376 .9947738647574 .4408111572373 .40950012207 68.8814392089868 .4296493530371 .7503280639675 .9906845092879 .49755859375 80.7552871704181 .4628067016681 .8458938598681 .8763732910281 .55885314941 80.9980697631880 .3349914550879 .6829071044979 .1246185302778 .7039642334 78.3621978759876 .9551010131876 .263946533276 .2342605590876 .63794708252 76.9172973632875 .9589691162171 .6282730102560 .9374313354542 .06034851074 30.1737308502224 .9923801422118 .5918903350814 .0201196670510 .66748046875 8.2291984558116 .4004869461064 .5717768669133 .3526360988622 .133496046066 1.5239260196691 .219141006471 .8287110328673 .047851085663 -9999 -9999 -9999 -9999 -9999 -9999 -9999 -9999 -9999 -9999 -9999 -9999 -9999 -9999 -9999 -9999 -9999 -9999 -9999 -9999 -9999 -9999 -9999 -9999 -9999 -9999 -9999 -9999 -9999 -9999 -9999 -9999 - -9999 - -9999 -

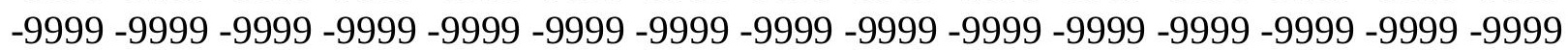
-9999 -9999 -9999 -9999 -9999 -9999 -9999 -9999 -9999 -9999 -9999 -9999 -9999 -9999 -9999 -999 -9999 -9999 -9999 -9999 -9999 -9999 -9999 -9999 -9999 -9999 -9999 -9999 -9999 -9999 -9999 -9999 -9999 -9999 -9999 -9999 -9999 -9999 -9999 -9999 -9999 -9999 -9999 -9999 -9999 -9999 -9999 -9999 -9999 -9999 -9999 -9999 -9999 -9999 -9999 -9999 -9999 -9999 -9999 -9999 -9999 -9999 -9999 -9999 -9999 -9999 -9999 -9999 -9999 -9999 -9999 -9999 -9999 -9999 -9999 -9999 -9999 -9999 -9999 -9999 -9999 -9999 -9999 -9999 -9999 -9999 -9999 -9999 -9999 -9999 -9999 -9999 -9999 -9999 -9999 -9999 -9999 -9999 -9999 -9999 -9999 -9999 -9999 -9999 -9999 -9999 -9999 -9999 -9999 -9999 -9999 -9999 -9999 -9999 -9999 -9999 -9999 -9999 -9999 -9999 -9999 -9999 -9999 -9999 -9999 -9999 -9999 -9999 -9999 -9999 -9999 -9999 -9999 -9999 -9999 -9999 -9999 -9999 -9999 -9999 -9999 -9999 -9999 -9999 -9999 -9999 -9999 100.072784423899.1828765869198.1511154174897.01504516602 95.9743423461995 .5220031738395 .6195831298896 .0547790527396 .19817352295 95.8563690185595 .4970779418995 .397743225196 .6168823242297 .22646331787 97.2264633178796 .6168823242295 .397743225163 .0905189514263 .09051895142 63.3953094482463 .7000885009864 .004882812563 .3953094482462 .48094940186 61.2618103027360 .0426712036158 .8235282897957 .6043891906756 .69002914429 55.7756805419955 .1661109924355 .1661109924355 .1661109924355 .47089004517 56.3852500915557 .2995986938558 .5187492370660 .0426712036161 .56660079956 63.0905189514264 .3096618652365 .5288009643666 .7479400634868 .27187347412 70.1005783081172 .8436431884875 .8914871215879 .2441329956182 .29197692871 85.33984375 88.0829010009890.2164001464891.2485351562590.61408996582 90.0247573852589 .4775695800888 .9697799682688 .498184204188 .06034851074 87.4733276367283 .8159103393680 .7680587768681 .6824111938582 .90155792236 85.0350494384885 .7655029296985 .5352478027385 .3311767578185 .15509796143 85.0088119506884 .8949203491284 .8160934448284 .7757110595784 .77696228027 84.8236694335984 .9190979003985 .0667495727585 .2689819335985 .52806091309 85.845008850186 .2210235595786 .6563415527387 .151641845787 .70677185059 88.32216644287 88.99754333496 89.7333450317490.5294647216891.38665771484 92.305252075293 .2865066528394 .3312301635795 .4412460327196 .6178817749 
97.8635025024499 .17992401123100 .5699768066102 .0358047485103 .5804367065 105.2059402466106 .9150543213108 .7091827393110 .5901184082112 .5578994751 114.6125717163116 .7520217896118 .9737091064120 .7150497437120 .9341125488 121.1629333496121 .4047012329121 .6633605957121 .9436340332122 .2504119873 122.5887908936122 .858291626122 .7790527344122 .6881408691122 .5905990601 122.4910507202122 .3932266235122 .3001251221122 .2147216797122 .1403045654 122.0810546875122 .0422744751122 .031211853122 .0562210083121 .8196487427 121.0041122437120 .1862945557119 .3643493652118 .5364532471117 .7009429932 116.8561782837116 .0007705688115 .1335067749114 .2539672852113 .3625793457 112.4608383179111 .5506668091110 .6346511841109 .7163696289108 .8007354736 107.8934173584106 .9999923706103 .475746154899 .1778030395594 .72266387939 90.1943664550884 .4584350585978 .1916503906273 .0935745239369 .97109222412 64.3096618652356 .3852500915557 .2995986938563 .0905189514267 .66230010986 72.2340774536176 .8033828735478 .3751068115279 .7174606323279 .91172027588 79.5434875488378 .8815689086978 .1265182495177 .4878311157277 .09394836426 76.9870071411176 .965957641676 .4756927490276 .8366470336977 .8229675293 79.0227050781279 .74887847978 .9325637817475 .2155838012767 .70332336426 58.5187492370645 .1082000732436 .2694282531726 .5163097381618 .287109375 13.4105501174910 .362689971927 .6196279525765 .1813468933113 .047851085663 1.523926019669 3047851026058 -9999 3047851026058 1.21914100647 2.743066072464 -9999 -9999 -9999 -9999 -9999 -9999 -9999 -9999 -9999 -9999 -9999 -9999 -9999 -9999 -9999 -9999 -9999 -9999 -9999 -9999 -9999 -9999 -9999 -9999 -9999 -9999 -9999 -9999 -9999 -9999 -9999 -9999 -9999 -9999 -9999 -9999 -9999 -9999 -9999 -9999 -9999 -9999 -9999 -9999 -9999 -

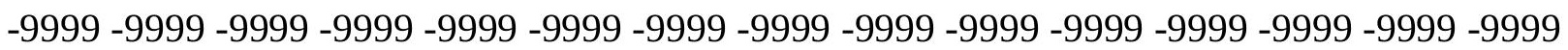
-9999 -9999 -9999 -9999 -9999 -9999 -9999 -9999 -9999 -9999 -9999 -9999 -9999 -9999 -9999 -9999 -9999 -9999 -9999 -9999 -9999 -9999 -9999 -9999 -9999 -9999 -9999 -9999 -9999 -9999

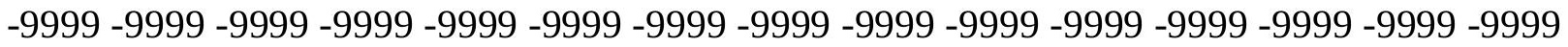
-9999 -9999 -9999 -9999 -9999 -9999 -9999 -9999 -9999 -9999 -9999 -9999

-9999 -9999 -9999 -9999 -9999 -9999 -9999 -9999 -9999 -9999 -9999 -9999 -9999 -9999 -9999 -9999 -9999 -9999 -9999 -9999 -9999 -9999 -9999 -9999 -9999 -9999 -9999 -9999 -9999 -9999 -9999 -9999 -9999 -9999 -9999 -9999 -9999 -9999 -9999 -9999 -9999 -9999-9999 -9999 -9999 -9999 -9999 -9999 -9999 -9999 -9999 -9999 -9999 -9999 -9999 -9999 -9999 -9999 -9999 -9999 -

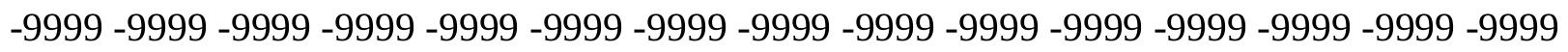
-9999 102.4273071289 101.9406661987 101.3588104248100.679847717399.97839355469 99.4370651245199 .262695312599 .4393005371199 .83790588379100 .1232147217 100.172492981100 .0509872437100 .0423812866100 .3245697021100 .4759368896 100.274299621699 .3599472045998 .7503814697356 .9948196411157 .60438919067 58.2139587402358 .8235282897959 .4331016540559 .1283111572358 .82352828979 57.909179687556 .9948196411156 .0804595947355 .1661109924354 .55654144287 53.9469718933153 .6421813964853 .3373985290553 .3373985290553 .64218139648 54.5565414428755 .1661109924356 .3852500915557 .6043891906759 .12831115723 60.6522407531761 .8713798522963 .0905189514264 .004882812564 .91924285889 66.7479400634869 .1862335205172 .8436431884876 .5010681152379 .85370635986 83.206336975186 .254188537688 .6924667358490 .5211791992290 .88914489746 90.2933654785289 .7392120361389 .2244415283288 .7463378906288 .3028717041 87.8919982910287 .5120773315484 .4254837036178 .9393463134878 .93934631348 
81.3776321411184 .1206970214885 .7943878173885 .6008224487385 .43659973145 85.3030624389685 .2022705078185 .1363677978585 .10825347985 .1206741333 85.1771011352585 .2805938720785 .4344406127985 .6408157348685 .90174865723 86.2180633544986 .5908660888787 .0205307006887 .5079345703188 .05317687988 88.6568679809689 .3188629150490 .0397415161190 .8195266723691 .65911865234 92.5589218139693 .520225524994 .54380035495 .6313095092896 .78385162354 98.0034637451299 .29160308838100 .6506500244102 .0822601318103 .5888900757 105.1720123291106 .8337097168108 .574760437110 .3962554932112 .2976608276 114.278427124116 .3360595703118 .467666626120 .6681594849121 .9140014648 121.9140014648121 .3044967651120 .9997024536119 .7806015015119 .7806015015 122.2188034058122 .6207046509122 .5478897095122 .465675354122 .3789291382 122.2922744751122 .209602356122 .1339035034122 .0679397583122 .0148696899 121.9788513184121 .9650650024121 .9803314209122 .0322570801122 .1290740967 121.5091934204120 .7244873047119 .9367828369119 .1441421509118 .3447341919 117.5367660522116 .7186584473115 .8890609741115 .0475158691114 .1946334839 113.3323745728112 .4632492065111 .5902709961110 .7172241211109 .8490905762 108.9917602539107 .9746932983103 .456016540598 .6042709350693 .39588928223 87.9082107543982 .3123779296976 .3973617553769 .4365310668965 .47760772705 58.5187492370651 .2038993835443 .8890609741247 .8512611389253 .64218139648 60.3474502563566 .1383666992271 .6244964599674 .9330062866276 .32080841064 77.0685424804776 .3435134887775 .4779129028374 .8497085571374 .61031341553 74.4100570678773 .5994262695373 .9356155395575 .2206192016677 .08106994629 78.2812576293978 .268974304277 .0373001098674 .0299148559669 .65355682373 66.012977600163 .3953094482450 .8991203308137 .1837806701725 .9067401886 19.5062503814715 .5440397262611 .277050018317 .9244132041934 .87656211853 2.133496046066 .6095703244209-.304785102606 -.304785102606 3047851026058 1.5239260196693 .657422065735 -9999 -9999 -9999 -9999 -9999 -9999 -9999 -9999 -9999 -9999 -9999 -9999 -9999 -9999 -9999 -9999 -9999 -9999 -9999 -9999 -9999 -9999 -9999 - 9999 -9999 -9999 -9999 -9999 -9999 -9999 -9999 -9999 -9999 -9999 -9999 -9999 -9999 -9999 -9999 -9999 -9999 -9999 -9999 -9999 -9999 -9999 -9999 -9999 -9999 -9999 -9999 -9999 -9999 -999 -9999 -9999 -9999 -9999 -9999 -9999 -9999 -9999 -9999-9999 -9999 -9999 -9999 -9999 -9999 -9999 -9999 -9999 -9999 -9999 -9999 -9999 -9999 -9999 -9999 -9999 -9999 -9999 -9999 -9999 -

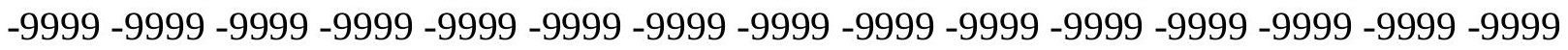

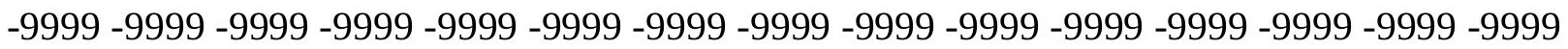
$-9999-9999$

-9999 -9999 -9999 -9999 -9999 -9999 -9999 -9999 -9999 -9999 -9999 -9999 -9999 -9999 -9999

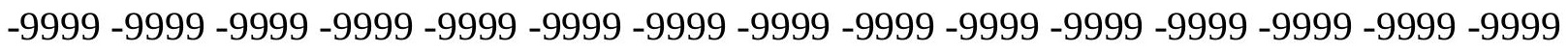

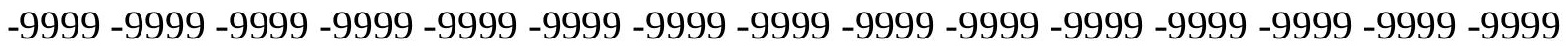

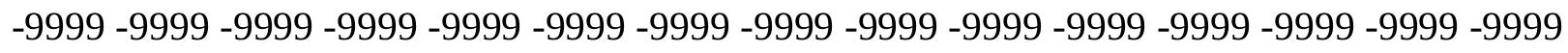
-9999 -9999 -9999 -9999 -9999 -9999 -9999 -9999 -9999 -9999 -9999 -9999 -9999 -9999 -9999 104.4262542725 104.3181533813104.1825637817103.9725265503103.6792068481 103.3615112305103 .1460800171103 .1556854248103 .4386672974103 .9136962891 104.4124526978104 .7474899292104 .7759170532104 .5068740845103 .9256973267 103.1270599365102 .2392044067101 .493400573799 .9695205688551 .81346893311 52.4230384826753 .3373985290553 .6421813964854 .8613204956155 .16611099243 55.1661109924354 .8613204956154 .5565414428753 .9469718933153 .33739852905 
53.0326118469252 .4230384826752 .1182594299352 .1182594299352 .11825942993 52.4230384826753 .0326118469253 .6421813964854 .5565414428755 .77568054199 57.2995986938558 .5187492370660 .0426712036161 .2618103027361 .87137985229 62.4809494018663 .3953094482466 .4431610107470 .1005783081174 .0627822876 77.7202072143681 .0728530883884 .4254837036187 .1685485839889 .3020401001 91.1307525634890 .537391662689 .9785461425889 .4589385986388 .9762802124 88.5288467407288 .1147918701287 .7327194213987 .3807296752985 .03504943848 82.29197692871 81.6824111938582.59677124023 83.81591033936 85.85263061523 85.6986465454185 .5759811401485 .4861297607485 .4307556152385 .41236877441 85.4333724975685 .4968948364385 .6057205200285 .7629241943485 .97051239014 86.2303314209 86.54305267334 86.9097442627 87.330909729 87.80764770508 88.3402786254988 .9294815063589 .5751571655390 .2779235839891 .03792572021 91.8561935424892 .7332687377993 .6704635620194 .6685028076295 .72888183594 96.8524475097798 .0409011840899 .29534912109100 .617729187102 .0092773438 103.4719161987105 .0066223145106 .6148910522108 .2969894409110 .0534515381 111.8833007812113 .7855377197115 .7574081421117 .7958450317119 .8957901001 122.051574707120 .9997024536117 .9517974854114 .5991973877111 .24659729 110.9418029785116 .7326965332122 .2188034058122 .2678604126122 .1882858276 122.1064987183122 .0270614624121 .9539871216121 .890335083121 .8387756348 121.802154541121 .784324646121 .7899856567121 .8252410889121 .8968963623 122.0127716064122 .0037841797121 .2540817261120 .5025863647119 .747215271 118.9859542847118 .2168045044117 .4379348755116 .6478042603115 .8458480835 115.0327682495114 .2107543945113 .3826599121112 .5517501831111 .7218551636 110.8978805542110 .0857086182108 .2370986938103 .491462707598 .18312835693 92.2237091064585 .668251037678 .7283325195371 .7475128173865 .07414245605 58.8235282897953 .0326118469245 .1082000732436 .8790016174339 .01250076294 43.8890609741249 .9847602844255 .7756805419960 .9570198059165 .52880096436 69.7957916259872 .2077941894572 .757537841872 .2908096313571 .0785369873 69.4122772216868 .5046920776468 .3330917358469 .5225448608471 .71801757812 74.424804687576 .2027893066475 .8316268920974 .4894485473672 .1838684082 69.5098114013767 .7926330566467 .5283355712965 .8335876464852 .42303848267 40.5364189147931 .0880794525123 .4684505462617 .9823207855213 .41055011749 8.8387689590454 .876562118532 .133496046066 .3047851026058 -9999. 3047851026058 1.5239260196693 .3526360988625 .181346893311 -9999 -9999 -9999 -9999 -9999 -9999 -9999 -9999 -9999 -9999 -9999 -9999 -9999 -9999 -9999 -9999 -9999 -9999 -9999 -9999 -9999 -9999

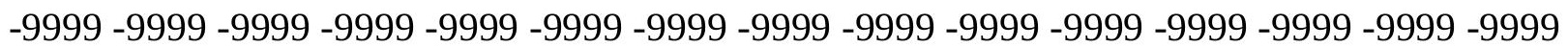

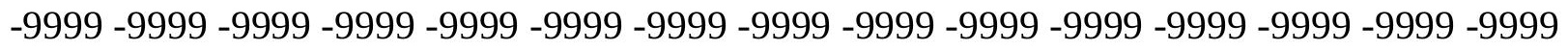

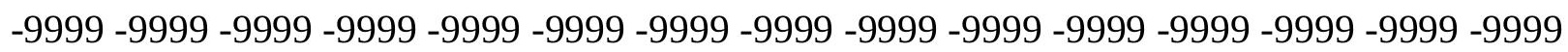

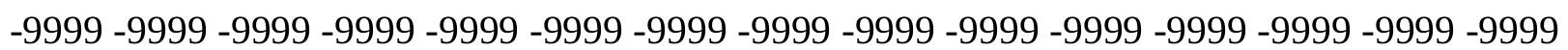
-9999 -9999 -9999 -9999 -9999 -9999 -9999 -9999 -9999 -9999 -9999 -9999 -9999 -9999 -9999 -

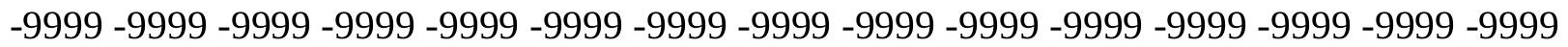
$-9999-9999-9999$ -9999 -9999 -9999 -9999 -9999 -9999 -9999 -9999 -9999 -9999 -9999 -9999 -9999 -9999 -9999 -9999 -9999 -9999 -9999 -9999 -9999 -9999 -9999 -9999 -9999 -9999 -9999 -9999 -9999 -9999 -9999 -9999 -9999 -9999 -9999 -9999 -9999 -9999 -9999 -9999 -9999 -9999 -9999 -9999 -9999 -

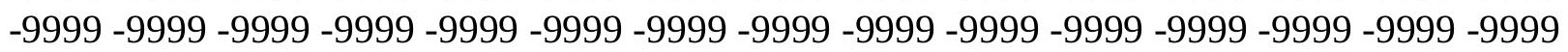


-9999 -9999 -9999 -9999 -9999 -9999 -9999 -9999 -9999 -9999 -9999 -9999 -9999 -9999 -9999 106.1580429077106 .3807830811106 .6026535034106 .7579498291106 .7999038696 106.7465820312106 .6830444336106 .7444763184107 .0386886597107 .5691452026 108.214630127108 .7477340698108 .773147583108 .001121521106 .3736190796 104.2412872314102 .102996826299 .6647262573297 .8360290527346 .93690872192 48.1560516357449 .0704002380449 .9847602844250 .8991203308151 .81346893311 52.4230384826752 .4230384826752 .4230384826752 .1182594299352 .11825942993 51.8134689331151 .5086898803751 .5086898803751 .2038993835451 .20389938354 51.5086898803751 .8134689331152 .4230384826753 .3373985290554 .25175094604 55.4708900451756 .9948196411158 .5187492370659 .7378807067960 .65224075317 61.2618103027362 .4809494018664 .9192428588968 .2718734741271 .92929077148 75.8914871215879 .2441329956182 .5967712402385 .3398437587 .77810668945 89.9116134643690 .7609939575290 .1996917724689 .6774368286189 .192237854 88.7426376342888 .3269348144587 .9439086914187 .5919952392687 .27008056641 86.254188537685 .0350494384885 .0350494384885 .3398437586 .09462738037 85.9494628906285 .8360214233485 .755302429285 .7084884643685 .6978225708 85.7254943847785 .794227600185 .9063262939586 .0644760131886 .27047729492 86.5261383056686 .8322372436587 .1899108886787 .5998306274488 .06327819824 88.5807113647589 .1527786254989 .7792892456190 .460792541591 .1975479126 91.9907455444392 .8410873413193 .7499313354594 .7179641723695 .74647521973 96.836074829197 .988143920999 .20343780518100 .4835281372101 .8292312622 103.2420349121 104.7224807739106.2716140747 107.8892822266 109.5755844116 111.3292312622113 .1489028931115 .0317153931116 .9745178223118 .9724349976 121.0200653076120 .3900985718115 .2088012695108 .8082962036102 .712600708 100.5791015625107 .8938980103116 .7326965332117 .9517974854117 .9517974854 120.0852966309121 .6886291504121 .6190643311121 .5616760254121 .5190353394 121.4935531616121 .4884033203121 .5074462891121 .555847168121 .6395263672 121.7659072876121 .9429168701121 .7715072632121 .0580291748120 .3417892456 119.6205825806118 .8921356201118 .1543502808117 .405380249116 .6444778442 115.8722915649115 .0910873413114 .3037261963113 .513343811112 .7236099243 111.9391403198111 .1656723022108 .5850143433103 .888229370198 .32209014893 91.7132873535284 .0849914550875 .6682739257866 .9121398925858 .62969970703 52.1182594299346 .6321296691940 .8412094116236 .8790016174336 .57421112061 38.7077102661141 .4507789611846 .0225486755450 .8991203308155 .16611099243 59.1283111572362 .1761703491264 .3096618652364 .9192428588964 .61444854736 62.0145263671960 .8724632263261 .5675811767663 .6890144348166 .81506347656 70.3640289306673 .7598037719773 .626678466872 .5766754150471 .10070800781 69.6935424804768 .949363708569 .0960388183669 .8542785644570 .10057830811 58.8235282897946 .6321296691935 .6598587036128 .3450202941922 .24930953979 15.239259719859 .448339462285 .4861321449282 .7430660724641 .828711032867 $1.8287110328672 .4382810592653 .9622070789345 .7909169197087 .314843177795-9999$ -9999 -9999 -9999 -9999 -9999 -9999 -9999 -9999 -9999 -9999 -9999 -9999 -9999 -9999 -9999 -9999 -9999 -9999 -9999 -9999 -9999 -9999 -9999 -9999 -9999 -9999 -9999 -9999 -9999 -9999 -9999 -9999 -9999 -9999 -9999 -9999 -9999 -9999 -9999 -9999 -9999 -9999 -9999 -9999 -9999 -

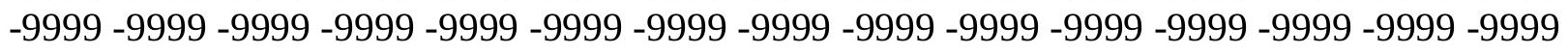

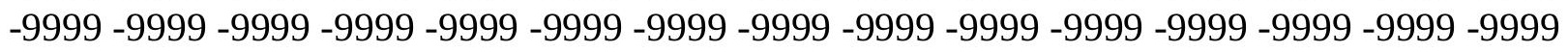


-9999 -9999 -9999 -9999 -9999 -9999 -9999 -9999 -9999 -9999 -9999 -9999 -9999 -9999 -9999 -9999 -9999 -9999 -9999 -9999 -9999 -9999 -9999 -9999 -9999 -9999 -9999 -9999 -9999 -9999 -9999 -9999 -9999 -9999-9999-9999-9999-9999

-9999 -9999 -9999 -9999 -9999 -9999 -9999 -9999 -9999 -9999 -9999 -9999 -9999 -9999 -9999 -9999 -9999 -9999 -9999 -9999 -9999 -9999 -9999 -9999 -9999 -9999 -9999-9999 -9999 -9999 -9999 -9999 -9999 -9999 -9999 -9999 -9999 -9999 -9999 -9999 -9999 -9999 -9999 -9999 -9999

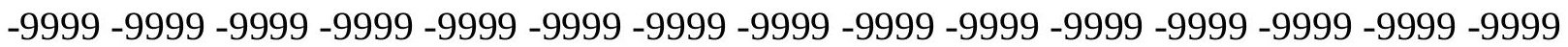
-9999 -9999 -9999 -9999 -9999 -9999 -9999 -9999 -9999 -9999 -9999 -9999 -9999 -9999 107.5145111084107 .924156189108 .4263763428108 .946723938109 .3998641968 109.6811523438109 .7231674194109 .603515625109 .4779281616109 .5809326172 110.0038146973110 .5977401733111 .1648101807111 .1411132812109 .741394043 106.8053665161103 .017402648999 .0551681518696 .0073165893692 .95947265625 43.2794914245644 .8034095764246 .0225486755446 .9369087219248 .15605163574 49.0704002380449 .9847602844250 .2895507812550 .5943298339850 .89912033081 50.8991203308150 .8991203308150 .8991203308150 .8991203308150 .59432983398 50.5943298339850 .8991203308151 .2038993835451 .5086898803752 .42303848267 53.3373985290554 .2517509460455 .7756805419956 .9948196411158 .51874923706 60.0426712036160 .3474502563561 .5666007995663 .7000885009866 .74794006348 70.4053573608474 .062782287677 .4154205322380 .7680587768683 .81591033936 86.254188537688 .3876876831190 .5211791992290 .4050750732489 .88220977783 89.39643859863 88.94652557373 88.53092956543 88.14859008789 87.79817962646 87.4788742065487 .1897735595786 .9306488037186 .7012176513786 .50187683105 86.3330459594786 .1956329345786 .0900878906286 .0171203613385 .97747802734 85.973075866786 .0059890747186 .0786209106486 .1925964355586 .34990692139 86.552032470786 .8008346557687 .0974731445387 .4434509277387 .83963775635 88.2873764038188 .7871246337989 .3394775390689 .9440765380990 .60133361816 91.3115615844792 .0761108398492 .8958663940493 .7722625732494 .70594024658 95.6980209350696 .7488937377997 .8596038818499 .03062438965100 .2631607056 101.5576934814102 .9153213501104 .3362503052105 .8211364746107 .3695373535 108.9812469482110 .6547470093112 .3885421753114 .1797027588116 .0251083374 117.9201202393119 .8597106934119 .4757995605114 .2944030762106 .0652008057 95.397743225188 .3876876831191 .4355392456199 .35994720459106 .979598999 113.9896011353118 .8662033081121 .2674407959121 .1949462891121 .1379547119 121.098739624121 .0790328979121 .0810852051121 .1075820923121 .1624984741 121.250793457121 .3793182373121 .5562210083121 .7919082642121 .5993041992 120.9239501953120 .2445755005119 .558631897118 .8636856079118 .1575469971 117.4391479492116 .7088928223115 .9689025879115 .2217483521114 .4701004028 113.7170333862112 .9667282104112 .2244567871109 .3018875122105 .0339813232 99.5124282836992 .4621124267683 .87612152174 .0364227294963 .50286102295 53.0022239685143 .5842704772940 .5364189147937 .4885711669935 .96464920044 35.9646492004437 .7933502197340 .2316398620642 .3651313781744 .19384002686 46.3273391723649 .9847602844252 .7278289794954 .5565414428754 .86132049561 54.2517509460452 .7278289794952 .7278289794954 .1024513244657 .08431243896 61.125564575265 .4493789672969 .3189926147571 .6549301147570 .96862792969 70.1827774047969 .6223831176869 .5413665771570 .0347595214870 .85293579102 71.5063476562571 .4692993164165 .5288009643653 .9469718933143 .88906097412 
34.4407196044923 .7732391357414 .93447017679 .7531242370617 .010057926178 5.4861321449284 .876562118535 .1813468933116 .0957031257 .010057926178 8.2291984558119 .44833946228 -9999 -9999 -9999 -9999 -9999 -9999 -9999 -9999 -9999 -9999 -9999 -9999 -9999 -9999 -9999 -9999 -9999 -9999 -9999 -9999 -9999 -9999 -9999 -9999 -9999 -9999 -9999 -9999 -9999 -9999 -9999 -9999 -9999 -9999 -9999 -9999-9999 -9999 -9999 -9999 -9999 -9999 -9999 -9999 -9999 -9999 -9999 -9999 -9999 -9999 -9999 -9999 -9999 -9999 -9999 -9999 -9999 -9999 -9999 -9999 -9999 -9999 -9999 -9999 -9999 -9999 -9999 - -9999 - -9999 -

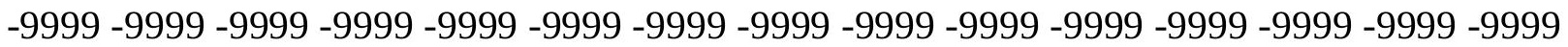
-9999 -9999 -9999 -9999 -9999 -9999 -9999 -9999 -9999 -9999 -9999 -9999 -9999 -9999 -9999 -9999 -9999 -9999 -9999 -9999 -9999 -9999 -9999 -9999 -9999 -9999 -9999 -9999 -9999 -9999 -9999 -9999 -9999 -9999 -9999 -9999 -9999 -9999 -9999 -9999 -9999 -9999 -9999 -9999 -9999 -9999 -9999 -9999 -9999 -9999 -9999 -9999 -9999 -9999 -9999 -9999 -9999 -9999 -9999 -9999 -9999 -9999 -9999 -9999 -9999 -9999 -9999 -9999 -9999 -9999 -9999 -9999 -9999 -9999 -9999 -9999 -9999 -9999 -9999 -9999 -9999 -9999 -9999 -9999 -9999 -9999 -9999 -9999 - 9999 -9999 -9999 -9999 -9999 -9999 -9999 -9999 -9999 -9999 -9999 -9999 -9999 -9999 108.5880584717108 .9983062744109 .561378479110 .2121429443110 .8887786865 111.5001983643111 .9073486328111 .8450546265111 .4097518921110 .7576293945 110.3792724609110 .4441833496110 .6968002319110 .7265396118110 .6370010376 108.5035018921104 .236503601199 .0551681518693 .8738174438590 .82597351074 38.4029312133840 .5364189147942 .0603485107443 .2794914245644 .80340957642 45.717769622846 .9369087219247 .8512611389248 .4608306884849 .07040023804 49.6799812316949 .9847602844250 .2895507812550 .5943298339850 .59432983398 50.2895507812550 .2895507812550 .2895507812550 .5943298339850 .89912033081 51.5086898803752 .1182594299353 .3373985290554 .5565414428755 .77568054199 57.2995986938558 .5187492370659 .4331016540560 .3474502563562 .78573989868 65.8335876464869 .1862335205172 .5388565063575 .8914871215878 .93934631348 81.9871978759884 .4254837036186 .8637619018688 .6924667358490 .52117919922 90.0753555297989 .5908126831189 .1423110961988 .7284927368288 .34846496582 88.0010528564587 .6855850219787 .4012451171987 .1477890014686 .92481231689 86.7324981689586 .5709762573286 .4408798217886 .3425292968886 .27654266357 86.2433776855586 .2444992065486 .2816925048886 .357139587486 .4719543457 86.6273574829186 .8243255615287 .0646972656287 .3500671386787 .682472229 88.063056945888 .4930648803788 .9727783203189 .5027770996190 .08279418945 90.7131042480591 .3939285278392 .1266632080192 .9123535156293 .75254058838 94.6478652954195 .599327087496 .607139587497 .6720886230598 .79438781738 99.97489929199101 .2137908936102 .5117950439103 .8688430786105 .2853240967 106.7605895996108 .2942123413109 .8845672607111 .5300674438113 .2278137207 114.9747848511116 .7666549683118 .5987854004118 .5614013672113 .6848983765 106.674797058194 .1785964965883 .8159103393682 .2919769287186 .86376190186 99.05516815186112 .1608963013118 .2565994263120 .7539749146120 .6719360352 120.6095809937120 .5685806274120 .5497894287120 .5542297363120 .5831375122 120.6390457153120 .7256546021120 .8489532471121 .0168533325121 .2402648926 121.5317687988121 .4901351929120 .8542251587120 .2124404907119 .5619812012 118.9002838135118 .2258682251117 .5386428833116 .8402481079116 .1327209473 115.4179992676114 .6982345581113 .9767990112111 .551399231107 .5891036987 107.3239212036102 .224174499595 .029159545985 .7123031616274 .60542297363 
62.3937873840350 .2747764587440 .3011703491235 .0502891540534 .74551010132 34.4407196044935 .3550796508837 .1837806701739 .3172798156741 .45077896118 43.2794914245644 .1938400268645 .1082000732446 .6321296691946 .63212966919 46.9369087219246 .6321296691946 .0225486755446 .3273391723646 .63212966919 50.2405471801855 .4774131774960 .1497840881364 .0552978515667 .48455810547 69.3783645629969 .1304168701269 .1600952148469 .589569091870 .3999786377 71.4113998413172 .2964782714872 .7188415527372 .4869613647571 .57739257812 62.1761703491249 .9847602844235 .9646492004424 .0780296325717 .06797027588 13.1057596206710 .667480468759 .7531242370619 .448339462289 .753124237061 9.75312423706110 .0579099655210 .3626899719210 .66748046875 -9999 -9999 -9999 -9999 -9999 -9999 -9999 -9999 -9999 -9999 -9999 -9999 -9999 -9999 -9999 -9999 -9999 -9999 -9999 -9999 -9999 -9999 -9999 -9999 -9999 -9999 -9999 -9999 -9999 -9999 -9999 -9999 -9999 -9999 -9999 -9999 -9999 -9999 -9999 -9999 -9999 -9999 -9999 -9999 -9999 -9999 -9999 -9999 -9999 -9999 -9999 -9999 -9999 -9999 -9999 -9999 -9999 -9999 -9999 -9999 -9999 -9999 -9999 -9999 -9999 -9999 -9999 -9999 -9999 -9999 -9999 -9999 -9999 -9999 -9999 -9999 -9999 -9999 -9999 -9999 -9999 -9999 -9999 -9999 -9999 -9999 -9999 -9999 -9999 -9999 -9999 -9999 -9999 -9999 -9999 -9999 -9999 -9999 -9999 -9999 -9999 -9999 -9999 -9999 -9999 -9999 -9999 -9999 -9999 -9999 -9999-9999

-9999 -9999 -9999 -9999 -9999 -9999 -9999 -9999 -9999 -9999 -9999 -9999 -9999 -9999 -9999 -9999 -9999 -9999 -9999 -9999 -9999 -9999 -9999 -9999 -9999 -9999 -9999 -9999 -9999 -9999 -9999 -9999 -9999 -9999 -9999 -9999 -9999 -9999 -9999 -9999 -9999 -9999 -9999 -9999 -9999 -9999 -9999 -9999 -9999 -9999 -9999 -9999 -9999 -9999 -9999 -9999 -9999 -9999 -9999 -9999 -9999 -9999 -9999 -9999 -9999 -9999 -9999 -9999 -9999 -9999 -9999 -9999 109.6079177856 109.8955612183110 .3665542603110 .8850479126111 .448348999112 .0302429199 112.540802002112 .883605957112 .6594696045111 .4692153931110 .036491394 108.8193664551108 .1986999512108 .1986999512106 .6747970581104 .5412979126 101.188697814996 .9216690063592 .6546783447388 .9972534179785 .33984375 36.8790016174338 .4029312133839 .9268493652341 .4507789611842 .669921875 44.1938400268645 .1082000732446 .3273391723647 .2416992187547 .85126113892 48.765621185349 .3751907348649 .9847602844250 .2895507812550 .28955078125 49.9847602844249 .9847602844249 .6799812316949 .9847602844250 .28955078125 50.8991203308151 .5086898803752 .4230384826753 .3373985290554 .55654144287 56.0804595947357 .2995986938558 .5187492370660 .0426712036162 .17617034912 64.9192428588967 .9670867919971 .3197174072374 .3675689697377 .41542053223 80.1584930419982 .5967712402385 .0350494384887 .1685485839888 .69246673584 90.2164001464889 .7771377563589 .331619262788 .9210739135788 .54474639893 88.2015838623 87.89099884033 87.61222076416 87.36497497559 87.14877319336 86.9636535644586 .8095169067486 .6867752075286 .5955429077186 .53633880615 86.5094528198286 .5159378051886 .5570373535286 .6345367431686 .74936676025 86.9022979736387 .0937881469787 .3254547119187 .5991058349687 .91715240479 88.2810287475688 .6918411254989 .1495819091889 .6547698974690 .20753479004 90.8084182739391 .4574661254992 .1558151245192 .9045257568493 .7052230835 94.5586242675895 .4656677246196 .4265060424897 .4418411254998 .51168060303 99.63655853271100 .8162994385102 .0512619019103 .3411407471104 .6861190796 106.08543396107 .5385437012109 .0437774658110 .5995101929112 .2029418945 113.8512039185115 .5402908325117 .2660064697119 .0230484009115 .5136032104 
110.9418029785106 .3700027466102 .102996826298 .7503814697399 .05516815186 105.7603988647114 .5991973877119 .7806015015120 .1371612549120 .0388793945 119.9654846191119 .9179382324119 .8959274292119 .8990249634119 .9267272949 119.9797592163120 .0601501465120 .1725387573120 .3240585327120 .5254516602 120.7900924683121 .1346969604121 .44581604120 .8496704102120 .245223999 119.6295013428119 .0005264282118 .3575363159117 .7013244629117 .0330505371 116.3537368774115 .6643600464114 .5991973877113 .075302124113 .1180419922 111.0138473511106 .738334655899 .7300262451289 .9680023193477 .90058135986 64.358123779350 .698657989531 .3928699493431 .3928699493432 .91679000854 33.5263595581134 .7455101013236 .2694282531738 .0981407165540 .23163986206 41.7555618286143 .2794914245644 .4986305236845 .1082000732445 .10820007324 43.5842704772941 .7555618286140 .8412094116240 .8412094116241 .14598846436 43.5842704772950 .5943298339854 .5992622375557 .8859901428261 .00923156738 64.591102600167 .8329238891668 .3277359008869 .1584320068470 .29428100586 71.5886917114372 .8217163085973 .7368774414174 .161270141673 .98066711426 73.1839218139667 .6623001098653 .3373985290539 .9268493652328 .34502029419 20.4206008911117 .3727493286116 .7631797790515 .8488302230814 .9344701767 14.0201196670512 .8009700775111 .8866195678710 .9722604751610 .66748046875 -9999 -9999 -9999 -9999 -9999 -9999 -9999 -9999 -9999 -9999 -9999 -9999 -9999 -9999 -9999 -9999

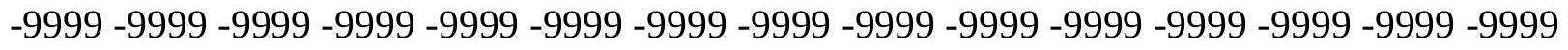

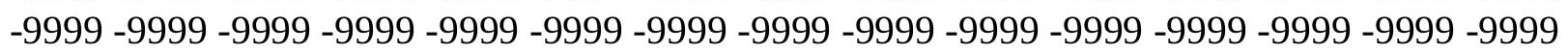

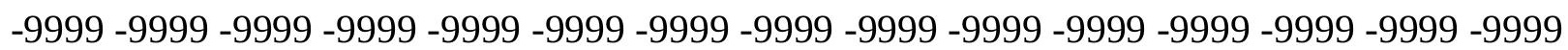
-9999 -9999 -9999 -9999 -9999 -9999 -9999 -9999 -9999 -9999 -9999 -9999 -9999 -9999 -9999 -

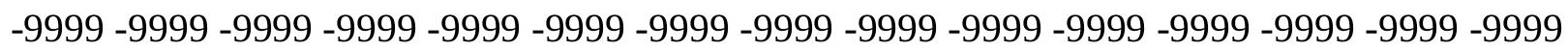

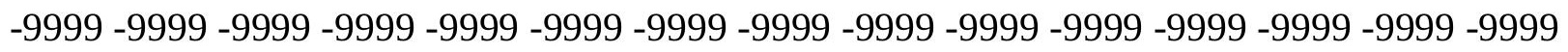
-9999 -9999-9999-9999-9999

-9999 -9999 -9999 -9999 -9999 -9999 -9999 -9999 -9999 -9999 -9999 -9999 -9999 -9999 -9999

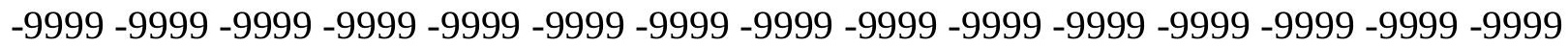

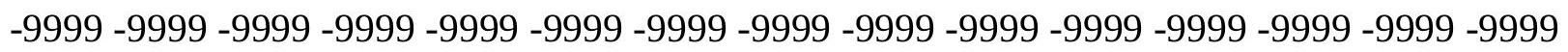

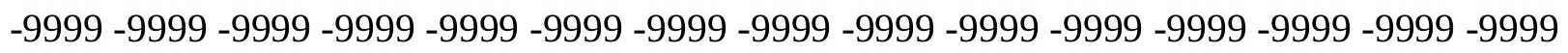
-9999 -9999 -9999 -9999 -9999 -9999 -9999 -9999 -9999 -9999 -9999 -9999 110.8102722168 111.1981658936111 .5701828003111 .7199401855111 .8309936523111 .9616699219 111.9188842773111 .6279220581111 .551399231108 .8082962036106 .979598999 104.8460998535103 .0174026489101 .798202514699 .6647262573296 .92166900635 92.9594726562588 .0829010009885 .3398437582 .2919769287178 .93934631348 35.6598587036137 .1837806701738 .7077102661140 .2316398620641 .45077896118 42.66992187543 .8890609741245 .1082000732446 .0225486755446 .93690872192 47.8512611389248 .765621185349 .3751907348649 .9847602844249 .98476028442 49.6799812316949 .3751907348649 .3751907348649 .3751907348649 .67998123169 49.9847602844250 .5943298339851 .5086898803752 .4230384826753 .64218139648 54.8613204956156 .3852500915557 .909179687559 .4331016540561 .56660079956 64.3096618652367 .0527267456170 .1005783081172 .8436431884875 .58670806885 78.3297805786180 .7680587768683 .206336975185 .0350494384886 .86376190186 88.3876876831189 .6068267822389 .516036987389 .1100616455188 .73863220215 88.4007644653388 .0959396362387 .7781066894587 .1685485839887 .16854858398 87.19606018066 87.04946136475 86.93419647217 86.85020446777 86.79783630371 
86.7772140502986 .789062586 .8340682983486 .9134826660287 .02799987793 87.17833709717 87.36469268799 87.58827972412 87.85076904297 88.15460968018 88.5013504028388 .8920745849689 .326591491789 .8053207397590 .32875823975 90.8980407714891 .5133819580192 .175506591892 .8851318359493 .6438293457 94.4524078369195 .3118515014696 .2223587036197 .1847457885798 .19908905029 99.26564788818100 .3837738037101 .5533981323102 .7739715576104 .0455245972 105.3672637939106 .7385787964108 .1578140259109 .623336792111 .1324691772 112.6824951172114 .2697525024115 .8904724121117 .5399932861117 .647102356 115.818397522119 .4757995605120 .5481033325119 .4757995605116 .1231002808 116.7326965332118 .8662033081119 .5575561523119 .4066543579119 .2855377197 119.195854187119 .1377487183119 .1096038818119 .1092910767119 .1342544556 119.1829681396119 .2552719116119 .3538131714119 .4842300415119 .6564559937 119.8839569092120 .1845397949120 .5778045654121 .0853805542120 .9090042114 120.3407669067119 .7587509155119 .1613464355118 .5482788086117 .9195022583 117.274848938116 .4279022217115 .2088012695115 .2470703125114 .5460739136 113.8385772705112 .9253005981106 .412185668996 .5114288330183 .79448699951 69.1830673217854 .1677551269540 .6839714050330 .7833003997832 .61201095581 33.2215805053734 .1359291076735 .3550796508837 .1837806701738 .70771026611 40.5364189147941 .7555618286142 .9747009277343 .5842704772943 .58427047729 42.66992187541 .1459884643639 .622070312537 .7933502197337 .79335021973 39.9268493652343 .5842704772948 .4608306884850 .5063323974653 .37186431885 56.9075393676861 .3253097534266 .9138259887768 .3567657470769 .79811859131 71.4604568481473 .1189804077174 .5136795043975 .457176208575 .83604431152 75.5097427368274 .2376632690471 .7176055908258 .5187492370643 .27949142456 31.3928699493427 .430660247826 .2115192413324 .0780296325721 .94453048706 19.5062503814716 .7631797790514 .3248996734612 .191410064710 .66748046875 9.75312423706110 .05790996552 -9999 -9999 -9999 -9999 -9999 -9999 -9999 -9999 -9999 -9999 -9999 -9999 -9999 -9999 -9999 -9999 -9999 -9999 -9999 -9999 -9999 -9999-9999 - 9999 -9999 -9999 -9999 -9999 -9999 -9999 -9999 -9999 -9999 -9999 -9999 -9999 -9999 -9999 -9999 -9999 -9999 -9999 -9999 -9999 -9999 -9999 -9999 -9999 -9999 -9999 -9999 -9999 -9999 -9999 -9999 -9999 -9999 -9999 -9999 -9999 -9999 -9999 -9999-9999 -9999 -9999 -9999 -9999 -9999 -9999 -9999 -9999 -9999 -9999 -9999 -9999 -9999 -9999 -9999 -9999 -9999 -9999 -9999 -9999 -

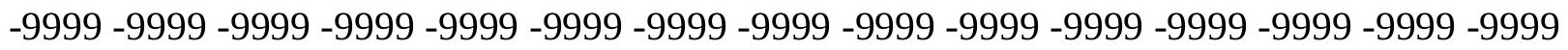
-9999 -9999 -9999 -9999 -9999 -9999 -9999 -9999 -9999 -9999

-9999 -9999 -9999 -9999 -9999 -9999 -9999 -9999 -9999 -9999 -9999 -9999 -9999 -9999 -9999

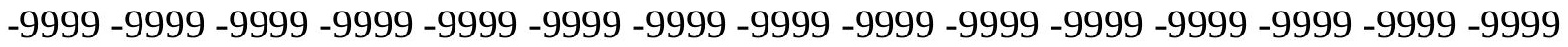

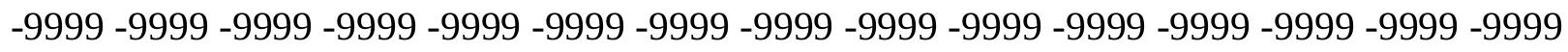

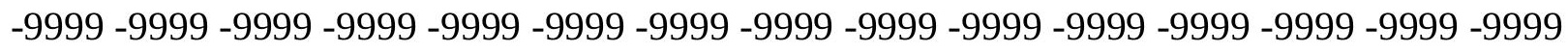
-9999 -9999 -9999 -9999 -9999 -9999 -9999 -9999 -9999 -9999 -9999 111.8502349854 112.0228042603112 .6122589111112 .6077957153111 .9793319702111 .0670013428 110.3321990967109 .4179000854107 .2844009399105 .1509017944103 .0174026489 101.188697814999.0551681518696.9216690063594.4833908081192.04509735107 88.99725341797 85.33984375 81.3776321411178.02498626709 74.67236328125 71.6244964599635 .0502891540536 .2694282531737 .7933502197339 .01250076294 40.5364189147941 .7555618286142 .9747009277343 .8890609741245 .10820007324 46.0225486755446 .9369087219247 .8512611389248 .765621185349 .07040023804 
49.3751907348649 .0704002380449 .0704002380449 .0704002380449 .07040023804 49.0704002380449 .6799812316949 .9847602844250 .8991203308151 .81346893311 52.7278289794954 .2517509460455 .4708900451757 .2995986938559 .12831115723 61.2618103027363 .7000885009866 .4431610107468 .8814392089871 .62449645996 74.062782287676 .5010681152378 .9393463134881 .0728530883882 .90155792236 84.7302627563586 .254188537687 .4733276367288 .3876876831188 .69246673584 88.38768768311 88.08290100098 87.16854858398 86.2541885376 85.94940185547 85.94940185547 86.55898284912 87.2917175293 87.18403625488 87.10735321045 87.0618515014687 .0474624633887 .0646286010787 .1136016845787 .19513702393 87.3096160888787 .4576797485487 .63950347987 .8559799194388 .10832214355 88.3986511230588 .7284469604589 .0987930297989 .5095672607489 .96118164062 90.4543304443490 .9905853271591 .5706558227592 .195175170992 .86435699463 93.579383850194 .3410797119195 .1505813598696 .0082626342896 .91512298584 97.8715515136798 .8777694702199 .93267059326101 .0356369019102 .1858520508 103.3832092285104 .6269073486105 .9163131714107 .2497787476108 .6256790161 110.0414276123111 .4944763184112 .9814529419114 .4989929199116 .0430297852 117.6094207764119 .1933135986120 .2720031738120 .0247268677119 .7559127808 119.4806289673119 .2122573853118 .9620819092118 .7394180298118 .5507583618 118.4004364014118 .2897415161118 .2180786133118 .1823959351118 .1786880493 118.2019805908118 .2480392456118 .3138580322118 .399307251118 .5077438354 118.647354126118 .8310546875119 .0770721436119 .4068450928119 .8444366455 120.4118499756121 .0278167725120 .4946975708119 .9447860718119 .3765182495 118.2565994263117 .0374984741116 .4279022217116 .4279022217116 .2056274414 115.4991989136114 .7706451416114 .0227584839113 .2584915161104 .5521087646 91.4524993896576 .1042022705159 .7311172485445 .3176116943436 .57421112061 33.8311500549333 .2215805053733 .5263595581134 .7455101013235 .96464920044 37.4885711669939 .0125007629440 .2316398620641 .4507789611842 .06034851074 42.0603485107441 .7555618286140 .8412094116239 .9268493652339 .01250076294 38.4029312133838 .0981407165537 .4885711669939 .622070312541 .75556182861 45.4129791259847 .8078689575252 .6994476318459 .0315780639666 .5385055542 69.0075225830171 .12573 .2835388183675 .1380081176876 .5007705688577 .29853820801 77.4365768432676 .7012710571374 .89340972972 .0906600952161 .87137985229 49.3751907348642 .66992187538 .4029312133834 .1359291076730 .17373085022 25.906740188621 .6397399902317 .3727493286113 .4105501174910 .66748046875 8.8387689590458 .2291984558118 .838768959045 -9999 -9999 -9999 -9999 -9999 -9999 -9999 -9999 -9999 -9999 -9999 -9999 -9999 -9999 -9999 -9999 -9999 -9999 -9999 -9999 -9999 -9999

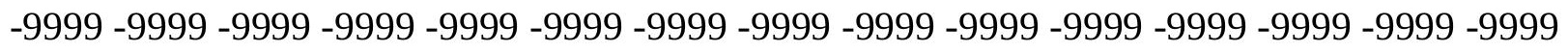

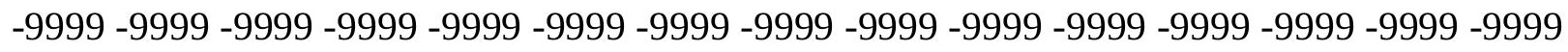
-9999 -9999 -9999 -9999 -9999 -9999 -9999 -9999 -9999 -9999 -9999 -9999 -9999 -9999 -9999 -9999 -9999 -9999 -9999 -9999 -9999 -9999 -9999 -9999 -9999 -9999 -9999 -9999 -9999 -9999 -

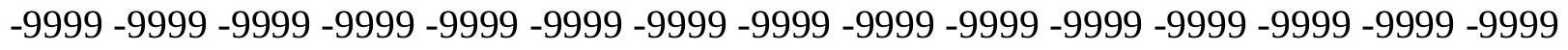
-9999 -9999 -9999 -9999-9999 -9999 -9999 -9999 -9999-9999-9999 - -999 -

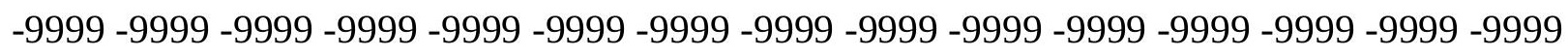
-9999 -9999 -9999 -9999 -9999 -9999 -9999 -9999 -9999-9999 -9999 -9999 -9999 -9999 -9999 -

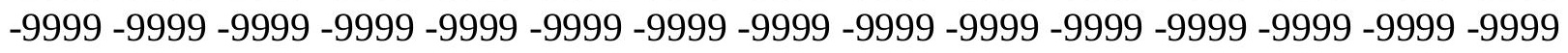

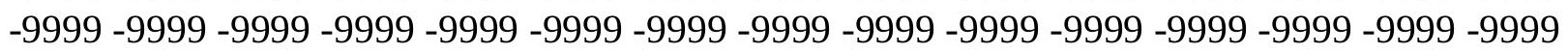


-9999 -9999 -9999 -9999 -9999 -9999 -9999 -9999 -9999 -9999 -9999 112.8605041504 113.1854705811114 .2944030762113 .3800964355111 .8561019897109 .4179000854 106.6747970581103 .6268997192100 .883903503498 .1408081054796 .31210327148 94.4833908081192 .6546783447390 .2164001464887 .4733276367285 .03504943848 81.6824111938578 .3297805786174 .6723632812571 .014930725167 .66230010986 64.004882812534 .7455101013235 .9646492004437 .1837806701738 .40293121338 39.622070312540 .8412094116242 .0603485107442 .9747009277344 .19384002686 45.1082000732446 .0225486755446 .9369087219247 .8512611389248 .15605163574 48.4608306884848 .4608306884848 .4608306884848 .4608306884848 .46083068848 48.765621185349 .0704002380449 .3751907348649 .9847602844250 .89912033081 52.1182594299353 .3373985290554 .8613204956156 .6900291442958 .51874923706 60.6522407531763 .0905189514265 .5288009643667 .6623001098670 .10057830811 72.2340774536174 .6723632812576 .8058471679778 .9393463134880 .76805877686 82.5967712402384 .1206970214885 .3398437586 .254188537686 .86376190186 86.8637619018686 .254188537685 .6446228027384 .7302627563584 .42548370361 84.7302627563585 .9494018554787 .1685485839887 .4371109008887 .36777496338 87.32910919189 87.3208694458 87.34325408936 87.39618682861 87.48004150391 87.59490203857 87.7412109375 87.919090271 88.12921142578 88.37230682373 88.6499786377 88.9634552002 89.31381225586 89.7011108398490.12587738037 90.5889053344791 .0918655395591 .6357727050892 .2215728759892 .84935760498 93.5197753906294 .2334365844794 .9916839599695 .7952423095796 .64524841309 97.5422210693498 .486610412699 .47724151611100 .5130233765101 .5927886963 102.7162475586103 .8825759888105 .0910720825106 .3400878906107 .6279602051 108.9521484375110 .3102035522111 .6989822388113 .1154937744114 .5561981201 116.0176467896117 .4958953857118 .2565994263114 .9039993286118 .8662033081 118.7264785767118 .3861846924118 .0718078613117 .7938766479117 .5597457886 117.3742752075117 .2387084961117 .151802063117 .1091308594117 .1046066284 117.1305389404117 .1794509888117 .2448043823117 .322807312117 .4135131836 117.5224075317117 .6608200073117 .8468170166118 .1033782959118 .4573974609 118.9337844849119 .5589141846120 .3670654297120 .0852966309119 .4757995605 117.647102356116 .7326965332116 .4279022217117 .0374984741117 .1457061768 116.4315643311115 .6775817871114 .883682251114 .0502166748112 .5171585083 99.5636367797983 .8548583984465 .7788619995148 .9085044860840 .53641891479 33.8311500549332 .6120109558132 .9167900085433 .8311500549335 .05028915405 36.2694282531737 .4885711669938 .4029312133839 .622070312540 .53641891479 40.8412094116241 .1459884643640 .8412094116240 .5364189147939 .92684936523 39.622070312539 .0125007629438 .0981407165535 .9646492004433 .83115005493 35.9646492004437 .7933502197343 .5842704772949 .3726692199758 .57814025879 67.9121322631870 .7398986816473 .4741134643675 .7274856567477 .36838531494 78.5275573730579 .2094726562579 .2390594482478 .4047470092876 .74494934082 74.7315292358468 .5766525268659 .4331016540551 .5086898803745 .10820007324 39.3172798156733 .5263595581127 .7354507446321 .334960937515 .84883022308 11.277050018318 .2291984558116 .7052731513986 .7052731513988 .838768959045 -9999 -9999 -9999 -9999 -9999 -9999 -9999 -9999 -9999 -9999 -9999 -9999 -9999 -9999 -9999 -9999 -9999 -9999 -9999 -9999 -9999 -9999 -9999 -9999 -9999 -9999 -9999 -9999 -9999 -9999 -9999 -

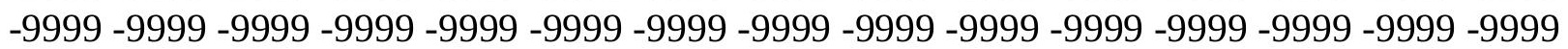


-9999 -9999 -9999 -9999 -9999 -9999 -9999 -9999 -9999 -9999 -9999 -9999 -9999 -9999 -9999 -9999 -9999 -9999 -9999 -9999 -9999 -9999 -9999 -9999 -9999 -9999 -9999 -9999 -9999 -9999

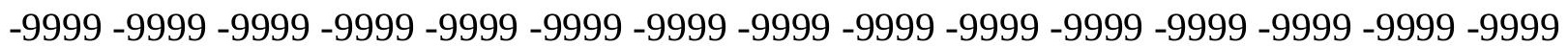
-9999 -9999 -9999 -9999 -9999 -9999 -9999 -9999 -9999 -9999 -9999 -9999 -9999 -9999 -9999 $-9999$

-9999 -9999 -9999 -9999 -9999 -9999 -9999 -9999 -9999 -9999 -9999 -9999 -9999 -9999 -9999 -9999 -9999 -9999 -9999 -9999 -9999 -9999 -9999 -9999 -9999 -9999 -9999 -9999 -9999 -9999 -9999 -9999 -9999 -9999 -9999 -9999 -9999 -9999 -9999 -9999 -9999 -9999 -9999 -9999 -9999 -9999 -9999 -9999 -9999 -9999 -9999 -9999 -9999 -9999 -9999 -9999 -9999 -9999 -9999 -9999 -9999 -9999 -9999 -9999 -9999 -9999 -9999 -9999 -9999-9999 -9999 114.2944030762 114.5991973877114 .9039993286113 .6848983765111 .551399231108 .1986999512 103.626899719298 .445587158294 .4833908081191 .1307525634889 .60682678223 88.6924667358486 .5589828491283 .8159103393681 .3776321411178 .63455963135 75.2819290161171 .9292907714868 .5766525268664 .6144485473660 .65224075317 56.6900291442934 .7455101013235 .9646492004436 .8790016174338 .09814071655 39.3172798156740 .2316398620641 .4507789611842 .3651313781743 .27949142456 44.4986305236845 .4129791259846 .0225486755446 .9369087219247 .24169921875 47.5464782714847 .8512611389247 .8512611389247 .8512611389248 .15605163574 48.1560516357448 .4608306884848 .765621185349 .3751907348650 .28955078125 51.2038993835452 .4230384826753 .9469718933156 .0804595947357 .9091796875 60.3474502563562 .4809494018664 .6144485473666 .4431610107468 .27187347412 70.4053573608472 .5388565063574 .6723632812576 .5010681152378 .63455963135 80.4632720947381 .9871978759883 .206336975184 .1206970214884 .73026275635 85.0350494384884 .7302627563584 .1206970214883 .5111236572382 .90155792236 83.8159103393685 .3398437586 .5589828491287 .6940841674887 .63214111328 87.6002960205187 .5981369018687 .6256408691487 .682479858487 .76873779297 87.8842468261788 .0292282104588 .2036285400488 .4078750610488 .64233398438 88.9080886840889 .206054687589 .5372390747189 .9019088745190 .30072784424 90.7345046997191 .204795837491 .7126235961992 .2591552734492 .84481048584 93.4701309204194 .1354064941494 .8419570922995 .5909729003996 .38385772705 97.2210388183698 .1029815673899 .0288314819399 .99752807617101 .0076065063 102.0584869385103 .1491928101104 .2788925171105 .4458465576106 .6482696533 107.8835983276109 .1493759155110 .4426193237111 .7605743408113 .1001815796 114.4585800171115 .8327102661117 .2195358276116 .4279022217118 .3089675903 117.8651885986117 .4418029785117 .0529403687116 .7106781006116 .4235916138 116.1975860596116 .0341949463115 .9319152832115 .8849487305115 .8851547241 115.9217376709115 .983543396116 .059715271116 .1418762207116 .2256317139 116.3124313354116 .4109115601116 .5378799438116 .7178344727116 .983039856 117.3583755493117 .8840484619118 .6111907959119 .5668792725118 .8662033081 117.647102356116 .7326965332116 .1231002808117 .0374984741118 .0715789795 117.3520355225116 .5738754272115 .73387146114 .8295593262110 .6417312622 102.100372314589 .6148834228571 .5132675170951 .5537490844729 .56415939331 31.3928699493432 .0024414062532 .3072204589832 .9167900085433 .83115005493 34.7455101013235 .6598587036136 .8790016174337 .7933502197338 .70771026611 39.622070312540 .5364189147940 .8412094116241 .1459884643641 .14598846436 40.8412094116240 .2316398620638 .7077102661136 .8790016174334 .74551010132 
33.2215805053732 .0024414062531 .3928699493438 .0981407165549 .37519073486 57.9630851745670 .0917510986373 .8937683105576 .3121185302777 .93941497803 79.3863449096780 .8040390014681 .8267974853581 .9300460815480 .98925018311 79.2687377929777 .2691040039171 .2509460449264 .3096618652356 .38525009155 49.0704002380441 .7555618286134 .4407196044926 .2115192413318 .89668083191 12.496190071117 .3148431777955 .1813468933114 .876562118536 .705273151398 10.05790996552 -9999 -9999 -9999 -9999 -9999 -9999 -9999 -9999 -9999 -9999 -9999 -9999 -9999 -9999 -9999 -9999 -9999 -9999 -9999 -9999 -9999 -9999 -9999 -9999 -9999 -9999 -9999

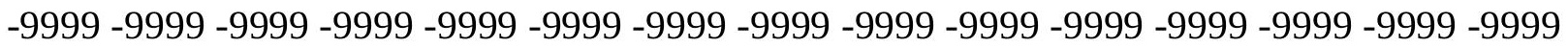
-9999 -9999 -9999 -9999 -9999 -9999 -9999 -9999 -9999 -9999 -9999 -9999 -9999 -9999 -9999

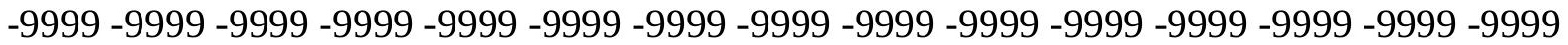
-9999 -9999 -9999 -9999 -9999 -9999 -9999 -9999 -9999 -9999 -9999 -9999 -9999 -9999 -9999 -

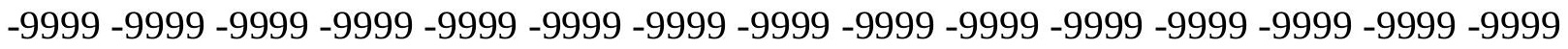
-9999 -9999-9999-9999

-9999 -9999 -9999 -9999 -9999 -9999 -9999 -9999 -9999 -9999 -9999 -9999 -9999 -9999 -9999

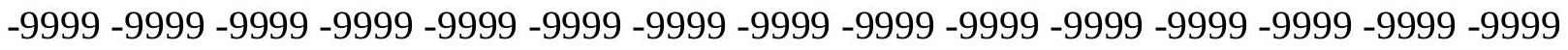

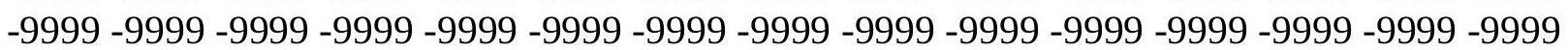

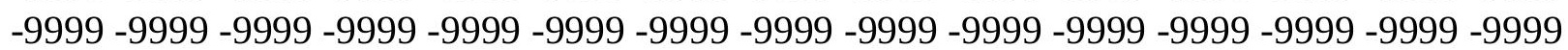
-9999 -9999 -9999 -9999 -9999 -9999 -9999 -9999 -9999 -9999 -9999 117.9517974854 117.0374984741117 .0374984741115 .818397522113 .075302124109 .1130981445 103.3221969604 95.70252990723 88.08290100098 85.9494018554784.73026275635 83.5111236572381 .3776321411178 .9393463134876 .1962814331173 .14842987061 70.1005783081166 .4431610107462 .7857398986858 .8235282897954 .55654144287 50.2895507812535 .0502891540535 .9646492004436 .8790016174337 .79335021973 38.7077102661139 .622070312540 .8412094116241 .7555618286142 .669921875 43.5842704772944 .4986305236845 .4129791259846 .0225486755446 .32733917236 46.9369087219246 .9369087219247 .2416992187547 .2416992187547 .54647827148 47.5464782714847 .8512611389248 .4608306884848 .765621185349 .37519073486 50.2895507812551 .2038993835452 .7278289794954 .2517509460456 .38525009155 58.8235282897961 .5666007995663 .0905189514264 .6144485473666 .44316101074 68.2718734741270 .1005783081172 .2340774536174 .3675689697376 .19628143311 78.0249862670979 .8537063598681 .0728530883882 .2919769287182 .90155792236 83.5111236572383 .5111236572383 .206336975182 .9015579223682 .90155792236 83.51112365723 84.73026275635 86.2541885376 87.77810668945 87.90083312988 87.8758468627987 .8797531127987 .9123306274487 .9730377197388 .06172943115 88.178009033288 .3218765258888 .4930801391688 .6917724609488 .91802215576 89.1724853515689 .4557342529389 .7686538696390 .1116485595790 .48550415039 90.8910293579191 .3295822143691 .8020629882892 .3096389770592 .85301971436 93.4330749511794 .0500640869194 .7051239013795 .3996658325296 .13552093506 96.9133071899497 .7333526611398 .595008850199 .49756622314100 .4395675659 101.4201126099102 .4379348755103 .49193573104 .5801773071105 .7006378174 106.8506011963108 .0274734497109 .228302002110 .4504623413111 .6912155151 112.9482498169114 .2192382812115 .502166748116 .7948913574117 .4328460693 116.8883209229116 .371673584115 .8986740112115 .4833984375115 .1363296509 114.8650512695114 .6720504761114 .5559005737114 .5097427368114 .5233154297 114.5826263428114 .6722946167114 .7764968872114 .8812866211114 .9765930176 
115.0583496094115 .1307907104115 .2081832886115 .3167648315115 .4819717407 115.7482757568116 .1677093506116 .814491272117 .7241363525118 .5614013672 118.2565994263117 .342300415116 .4279022217115 .818397522117 .647102356 118.2689971924117 .4747085571116 .5969161987113 .7638168335108 .8095626831 100.946479797487 .4733276367273 .4532165527363 .3953094482425 .29715919495 29.2593708038330 .7833003997831 .6976509094232 .3072204589832 .61201095581 33.5263595581134 .1359291076735 .0502891540535 .9646492004437 .18378067017 38.4029312133839 .622070312540 .8412094116241 .4507789611842 .06034851074 42.0603485107441 .1459884643639 .9268493652338 .0981407165535 .96464920044 34.1359291076732 .9167900085431 .6976509094230 .7833003997830 .17373085022 43.5842704772961 .5666007995669 .2680358886775 .2102890014677 .71965026855 79.3456726074281 .9427032470784 .283905029385 .4046936035284 .65689849854 82.5340957641679 .8822097778377 .2035064697372 .2308654785265 .54367828369 58.8235282897950 .8991203308142 .66992187533 .5263595581124 .07802963257 14.324899673467 .3148431777954 .2669920921334 .5717768669136 .400486946106 8.83876895904511 .58183002472 -9999 -9999 -9999 -9999 -9999 -9999 -9999 -9999 -9999 -9999 -9999 -9999 -9999 -9999 -9999 -9999 -9999 -9999 -9999 -9999 -9999 -9999 -9999 -9999 -9999 -9999 -9999 -9999 -9999 -9999 -9999 -9999 -9999 -9999 -9999 -9999 -9999 -9999 -9999 -9999 -9999 -9999 -9999 -9999 -9999 -9999 -9999 -9999 -9999 -9999 -9999 -9999 -9999 -9999 -

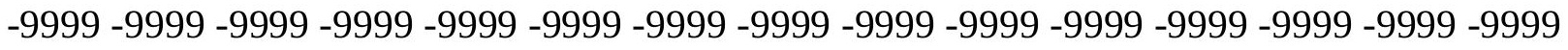

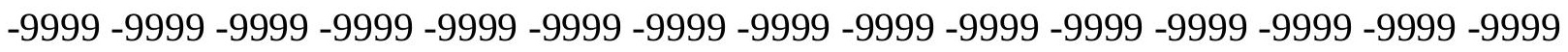
-9999 -9999 -9999 -9999 -9999 -9999 -9999 -9999 -9999 -9999 -9999 -9999 -9999 -9999 -9999 -9999 -9999 -9999-9999-9999-9999

-9999 -9999 -9999 -9999 -9999 -9999 -9999 -9999 -9999 -9999 -9999 -9999 -9999 -9999 -9999 -

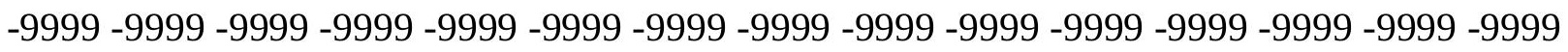
-9999 -9999 -9999 -9999 -9999 -9999 -9999 -9999 -9999 -9999 -9999 -9999 -9999 -9999 -9999

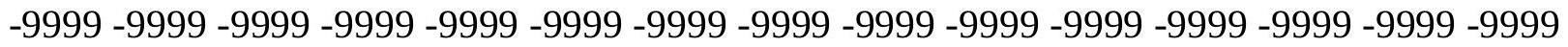
-9999 -9999 -9999 -9999-9999-9999 -9999 -9999 -9999 -9999 -9999 129.533706665 124.9618988037120 .6949005127119 .1709976196116 .7326965332112 .4656982422 106.370002746698 .7503814697389 .302040100185 .9494018554783 .51112365723 81.3776321411178 .6345596313575 .8914871215872 .5388565063569 .18623352051 65.8335876464862 .4809494018658 .5187492370654 .2517509460449 .67998123169 49.9847602844235 .3550796508835 .9646492004436 .8790016174337 .48857116699 38.4029312133839 .3172798156740 .2316398620641 .1459884643642 .06034851074 42.9747009277343 .8890609741244 .4986305236845 .1082000732445 .7177696228 46.0225486755446 .3273391723646 .6321296691946 .9369087219246 .93690872192 47.24169921875 47.54647827148 47.8512611389248.1560516357448.7656211853 49.0704002380449 .9847602844250 .8991203308152 .4230384826754 .25175094604 56.3852500915558 .8235282897960 .9570198059162 .7857398986864 .30966186523 66.1383666992267 .9670867919969 .7957916259871 .9292907714874 .0627822876 75.8914871215877 .4154205322378 .9393463134880 .1584930419981 .37763214111 81.9871978759882 .2919769287182 .5967712402382 .5967712402382 .90155792236 83.5111236572384 .7302627563585 .9494018554787 .4733276367288 .17403411865 88.1559982299888 .1660232543988 .2036972045988 .2682952880988 .35944366455 88.4765548706188 .6194000244188 .787528991788 .9808578491289 .19921112061 89.44289398193 89.7121353149490.0076217651490.3297882080190.67951202393 
91.0575790405391 .4652175903391 .9032135009892 .3726425170992 .8743057251 93.4093322753993 .9783096313594 .5823822021595 .2229461669995 .90216064453 96.6212005615297 .3806533813598 .1799011230599 .0184020996199 .89485931396 100.8081970215101 .7567749023102 .739112854103 .7529144287104 .7957611084 105.8646240234106 .9566116333108 .0686264038109 .1979904175110 .3422012329 111.4992904663112 .6676254272113 .8460769653115 .0337219238116 .2298965454 115.7889862061115 .1692352295114 .6030349731114 .1058807373113 .6929092407 113.3706817627113 .1496582031113 .0198974609112 .9850006104113 .0238800049 113.1220779419113 .2598190308113 .4155807495113 .5691375732113 .7035064697 113.807434082113 .8787002563113 .924697876113 .9741973877114 .0394363403 114.18334198114 .479888916115 .0411224365115 .9179229736117 .0689086914 117.342300415116 .7326965332116 .1231002808115 .5136032104114 .9039993286 116.1231002808116 .431427002114 .1884384155111 .1036529541105 .1509017944 95.0929565429788 .3876876831173 .1484298706162 .1761703491226 .51630973816 28.6497993469230 .1737308502230 .7833003997831 .3928699493431 .69765090942 32.0024414062532 .6120109558133 .2215805053734 .1359291076735 .35507965088 36.8790016174338 .7077102661140 .5364189147942 .0603485107442 .97470092773 42.9747009277342 .3651313781740 .8412094116239 .0125007629437 .18378067017 35.3550796508833 .8311500549332 .9167900085432 .3072204589832 .30722045898 32.3072204589836 .8790016174350 .5943298339865 .2240066528366 .04723358154 72.8696746826279 .7494964599685 .4462738037188 .4977874755987 .56285095215 84.4972991943480 .8697280883877 .5847625732474 .9259796142671 .88033294678 66.4332275390660 .3474502563552 .4230384826743 .2794914245632 .30722045898 17.067970275885 .1813468933113 .6574220657356 .4004869461068 .229198455811 9.75312423706110 .9722604751612 .1914100647 -9999 -9999 -9999 -9999 -9999 -9999 -9999 -9999 -9999 -9999 -9999 -9999 -9999 -9999 -9999 -9999 -9999 -9999 -9999 -9999 -9999 -9999 -9999 -9999 -9999 -9999 -9999 -9999 -9999 -9999 -9999 -9999 -9999 -9999 -9999 -9999 -9999 -

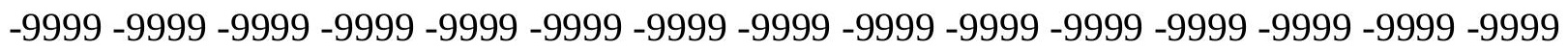
-9999 -9999 -9999 -9999 -9999 -9999 -9999 -9999 -9999 -9999 -9999 -9999 -9999 -9999 -9999 -9999 -9999 -9999 -9999 -9999 -9999 -9999 -9999 -9999 -9999 -9999 -9999 -9999 -9999 -9999

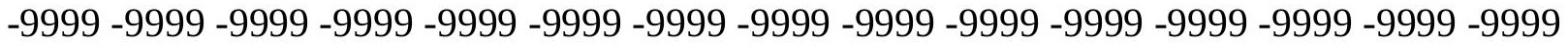
-9999 -9999-9999 -9999-9999-9999-9999

-9999 -9999 -9999 -9999 -9999 -9999 -9999 -9999 -9999-9999 -9999 -9999 -9999 -9999 -9999 -9999 -9999 -9999 -9999 -9999 -9999 -9999 -9999 -9999 -9999 -9999 -9999 -9999 -9999 -9999 -9999 -9999 -9999 -9999 -9999 -9999 -9999 -9999 -9999 -9999 -9999 -9999 -9999 -9999 -9999 -9999 -9999 -9999 -9999 -9999 -9999 -9999 -9999 -9999 -9999 -9999 -9999 -9999 -9999 - 9999 -9999 -9999-9999-9999 -9999-9999 -9999 -9999 -9999-9999 -9999-9999 138.9819946289 131.0576019287126 .4858016968121 .9140014648117 .647102356112 .7705001831 107.5891036987100 .883903503492 .0450973510787 .4733276367283 .51112365723 79.5489196777375 .2819290161171 .014930725167 .3575134277363 .39530944824 59.7378807067955 .4708900451750 .8991203308150 .5943298339849 .98476028442 35.6598587036136 .2694282531736 .8790016174337 .4885711669938 .09814071655 38.7077102661139 .622070312540 .5364189147941 .4507789611842 .06034851074 42.9747009277343 .8890609741244 .4986305236845 .1082000732445 .41297912598 46.0225486755446 .3273391723646 .3273391723646 .6321296691946 .93690872192 46.9369087219247 .2416992187547 .5464782714847 .8512611389248 .15605163574 
48.4608306884849 .0704002380449 .9847602844251 .2038993835453 .33739852905 55.7756805419958 .2139587402360 .3474502563561 .8713798522963 .39530944824 65.5288009643667 .6623001098669 .7957916259871 .6244964599673 .45321655273 75.2819290161176 .8058471679778 .3297805786179 .5489196777380 .46327209473 81.3776321411181 .9871978759882 .2919769287182 .9015579223683 .51112365723 84.4254837036185 .6446228027386 .8637619018688 .3876876831188 .44065093994 88.4569015502988 .4997711181688 .5683364868288 .6620254516688 .78002929688 88.9219207763789 .0870285034289 .2750854492289 .4856948852589 .7188873291 89.9746246337990 .2533340454190 .555381774990 .8816223144591 .23281097412 91.6100997924892 .014236450292 .4462203979592 .9068450927793 .39735412598 93.9186859130994 .4722747802795 .0596389770595 .6831359863396 .34455108643 97.0450744628997 .7843399047998 .5617752075299 .37609100342100 .2260894775 101.1098251343102 .0252990723102 .9696807861103 .9399795532104 .9326324463 105.9442596436106 .9714126587108 .0111999512109 .0611038208110 .1194076538 111.1849975586112 .2575683594113 .3373336792114 .4251174927114 .5591964722 113.8276672363113 .1585617065112 .5751342773112 .0876159668111 .7160720825 111.4651260376111 .334236145111 .3147583008111 .3932647705111 .5506820679 111.7617034912111 .9981460571112 .2375717163112 .4501037598112 .6237335205 112.7349624634112 .7911605835112 .7936477661112 .7679367065112 .7708587646 112.9071044922113 .3562011719114 .2053375244115 .397354126116 .1231002808 115.2088012695114 .2944030762113 .3800964355112 .1608963013111 .551399231 110.9418029785109 .1130981445105 .150901794499 .0551681518691 .13075256348 82.5967712402372 .2340774536161 .5666007995628 .6497993469229 .56415939331 30.1737308502230 .1737308502230 .1737308502230 .4785099029530 .47850990295 30.7833003997831 .0880794525132 .0024414062533 .5263595581135 .05028915405 37.4885711669939 .622070312542 .0603485107443 .5842704772944 .19384002686 43.2794914245641 .7555618286139 .622070312537 .4885711669935 .96464920044 34.7455101013234 .1359291076733 .5263595581132 .6120109558131 .08807945251 28.0402297973623 .4684505462633 .2215805053744 .4986305236860 .65224075317 75.4849472045983 .0617599487386 .8678054809687 .8137435913184 .6940612793 79.9799346923876 .3262100219773 .9548797607472 .0016021728570 .62959289551 68.1172485351663 .3953094482454 .8613204956143 .5842704772924 .99238014221 9.7531242370618 .83876895904512 .191410064712 .191410064711 .88661956787 11.2770500183111 .2770500183111 .88661956787 -9999 -9999 -9999 -9999 -9999 -9999 -9999

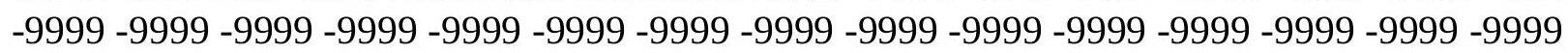

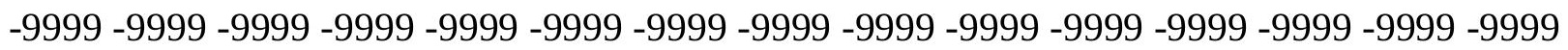

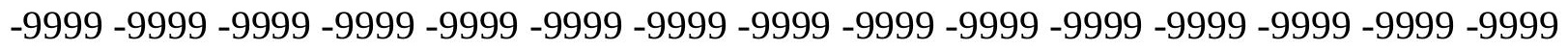

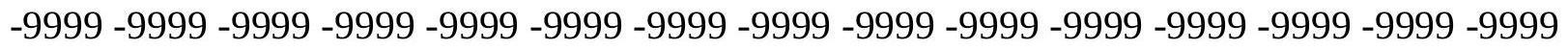

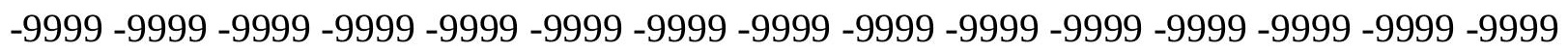
-9999 -9999 -9999 -9999 -9999 -9999 -9999 -9999 -9999 -9999 -9999 -9999 -9999 -9999 -9999 -9999 -9999 -9999 -9999-9999-9999

-9999 -9999 -9999 -9999 -9999 -9999 -9999 -9999 -9999 -9999 -9999 -9999 -9999 -9999 -9999

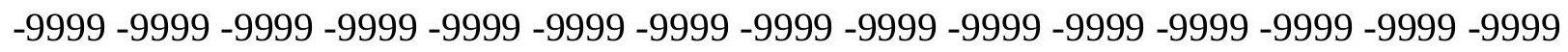
-9999 -9999 -9999 -9999 -9999 -9999 -9999 -9999 -9999 -9999 -9999 -9999 -9999 -9999 -9999 -

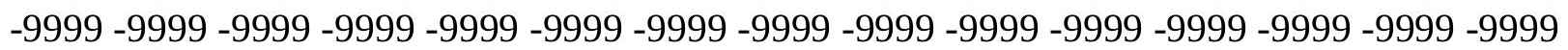
-9999 -9999 -9999 -9999 -9999 -9999 -9999 -9999 -9999 -9999 -9999 -9999 -9999 
144.1634063721136 .2389984131129 .533706665123 .43800354120 .3900985718 118.2565994263117 .647102356105 .455703735496 .0073165893690 .82597351074 84.7302627563577 .7202072143672 .2340774536167 .6623001098663 .39530944824 58.8235282897954 .2517509460449 .3751907348648 .765621185348 .15605163574 36.2694282531736 .2694282531736 .5742111206137 .1837806701737 .48857116699 38.4029312133839 .0125007629439 .622070312540 .5364189147941 .45077896118 42.3651313781742 .9747009277343 .8890609741244 .4986305236845 .10820007324 45.4129791259845 .717769622846 .0225486755446 .3273391723646 .32733917236 46.6321296691946 .9369087219246 .9369087219246 .9369087219247 .24169921875 47.2416992187547 .2416992187547 .5464782714848 .4608306884850 .28955078125 53.0326118469255 .4708900451757 .6043891906759 .4331016540560 .95701980591 63.0905189514265 .2240066528367 .3575134277369 .4910125732471 .31971740723 73.1484298706174 .6723632812576 .5010681152377 .7202072143679 .24413299561 80.1584930419981 .3776321411181 .9871978759882 .5967712402383 .2063369751 84.1206970214885 .0350494384886 .254188537687 .7781066894588 .72954559326 88.7521591186588 .8003540039188 .8730316162188 .9693832397589 .08840179443 89.2294235229589 .3915939331189 .5744171142689 .7773208618290 .00010681152 90.2425460815490 .5048446655390 .7872390747191 .0904388427791 .41512298584 91.7623519897592 .1329193115292 .5277862548892 .9477310180793 .39408111572 93.86811065674 94.3716964721794.9067230224695.475868225196.08139801025 96.7251510620197 .4071807861398 .1269989013798 .8832168579199 .67446136475 100.4984130859101 .3524780273102 .2331237793103 .1365661621104 .0585021973 104.9947814941105 .94140625106 .8949661255107 .8527908325108 .8131637573 109.7753982544110 .7398223877111 .7077789307112 .6814575195113 .1909942627 112.3416061401111 .5659179688110 .885269165110 .3283615112109 .9100799561 109.640586853109 .5196533203109 .5330657959109 .6725006104109 .9172668457 110.2320327759110 .5849990845110 .9517822266111 .2945175171111 .5812759399 111.7901000977111 .8963012695111 .9002914429111 .7953262329111 .6435928345 111.5874252319111 .8575134277112 .664855957113 .9056930542114 .5477523804 113.3800964355112 .1608963013111 .24659729107 .5891036987106 .979598999 105.4557037354103 .017402648999 .0551681518693 .5690307617286 .86376190186 80.1584930419971 .014930725161 .2618103027330 .1737308502230 .47850990295 29.8689403533929 .5641593933129 .2593708038329 .2593708038328 .95458984375 28.95458984375 29.25937080383 30.17373085022 31.39286994934 33.22158050537 35.6598587036138 .7077102661141 .4507789611843 .5842704772944 .49863052368 43.5842704772941 .7555618286139 .622070312537 .4885711669935 .96464920044 35.6598587036135 .3550796508834 .4407196044932 .9167900085430 .17373085022 26.5163097381622 .8588790893621 .9445304870631 .6976509094248 .15605163574 70.7101516723679 .4752044677783 .3080520629984 .1479492187582 .64601898193 77.1621780395573 .6416091918972 .21176910472 .0448837280372 .41558837891 73.047714233470 .6445617675865 .6069259643658 .2139587402345 .10820007324 33.2215805053726 .8210906982422 .5541000366218 .5918903350815 .23925971985 12.8009700775111 .5818300247210 .9722604751611 .58183002472 -9999-9999-9999-9999 -9999 -9999 -9999 -9999 -9999 -9999 -9999 -9999 -9999 -9999 -9999 -9999 -9999 -9999 -9999 -9999 -9999 -9999 -9999 -9999 -9999 -9999 -9999 -9999 -9999 -9999 -9999 -9999 -9999 -9999 -

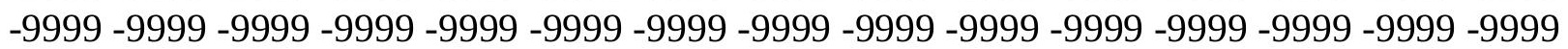


-9999 -9999 -9999 -9999 -9999 -9999 -9999 -9999 -9999 -9999 -9999 -9999 -9999 -9999 -9999 -9999 -9999 -9999 -9999 -9999 -9999 -9999 -9999 -9999 -9999 -9999 -9999 -9999 -9999 -9999 -9999 -9999 -9999 -9999 -9999 -9999 -9999 -9999 -9999 -9999 -9999 -9999 -9999 -9999 -9999 -9999 -9999 -9999 -9999-9999 -9999 -9999 -9999

-9999 -9999 -9999 -9999 -9999 -9999 -9999 -9999 -9999 -9999 -9999 -9999 -9999 -9999 -9999 -9999 -9999 -9999 -9999 -9999 -9999 -9999 -9999 -9999 -9999 -9999 -9999 -9999 -9999 -9999

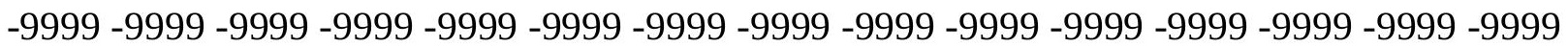
-9999 -9999 -9999 -9999 -9999 -9999 -9999 -9999 -9999 -9999 -9999 -9999 -9999 -9999 -9999 -9999 -9999 -9999 -9999 -9999 -9999 -9999 -9999 -9999 -9999 -9999 -9999 -9999 -9999 150.8686065674143 .8585968018137 .1533050537130 .7528076172125 .5715026855 123.7427978516117 .647102356110 .0273971558103 .322196960494 .48339080811 82.9015579223676 .8058471679771 .014930725165 .5288009643660 .34745025635 55.1661109924349 .6799812316948 .4608306884836 .2694282531736 .26942825317 36.2694282531736 .5742111206136 .5742111206137 .1837806701737 .48857116699 38.4029312133839 .0125007629439 .9268493652340 .8412094116241 .45077896118 42.3651313781743 .2794914245643 .8890609741244 .4986305236845 .10820007324 45.4129791259845 .717769622846 .0225486755446 .0225486755446 .32733917236 46.3273391723646 .6321296691946 .6321296691946 .3273391723646 .32733917236 46.0225486755445 .717769622845 .717769622848 .1560516357450 .59432983398 53.0326118469255 .1661109924357 .2995986938559 .1283111572360 .95701980591 63.0905189514265 .2240066528367 .3575134277369 .1862335205171 .0149307251 72.8436431884874 .3675689697375 .8914871215877 .4154205322378 .93934631348 80.1584930419981 .3776321411181 .9871978759882 .5967712402383 .2063369751 84.4254837036185 .6446228027387 .1685485839888 .3876876831189 .05126953125 89.1049652099689 .181922912689 .281112670989 .4013137817489 .54161834717 89.7009582519589 .8786087036190 .073799133390 .2861480712990 .51525115967 90.761154174891 .0239562988391 .3041992187591 .6024398803791 .91961669922 92.2565231323292 .6141433715892 .9932785034293 .3953933715893 .82221221924 94.2761688232494 .7597122192495 .2759704589895 .8276748657296 .41717529297 97.0449829101697 .7108154296998 .4132385253999 .1506423950299 .92024230957 100.71875101 .5417404175102 .3844528198103 .2415466309104 .1078567505104 .978477478 105.8492736816106 .7171173096107 .5801239014108 .4378128052109 .2910842896 110.1422119141110 .9947662354111 .7052230835110 .7344818115109 .8413696289 109.0625610352108 .4315490723107 .9716873169107 .695526123107 .6026763916 107.6814804077 107.9133300781 108.2714920044 108.7225494385109.232460022 109.7664794922110 .2855148315110 .747543335111 .1125259399111 .3413848877 111.4044647217111 .2892456055111 .0359802246110 .7806167603110 .7835388184 111.3972854614111 .7768936157111 .259147644111 .24659729108 .1986999512 105.1509017944103 .6268997192102 .4077987671100 .579101562597 .53124237061 93.5690307617288 .9972534179783 .5111236572377 .110626220769 .79579162598 62.1761703491230 .7833003997830 .1737308502229 .5641593933128 .64979934692 28.3450202941927 .7354507446327 .7354507446327 .430660247827 .73545074463 28.3450202941929 .2593708038330 .7833003997833 .8311500549337 .18378067017 39.9268493652342 .66992187544 .1938400268642 .3651313781740 .23163986206 38.0981407165536 .5742111206135 .0502891540536 .2694282531736 .26942825317 35.3550796508833 .2215805053730 .7833003997827 .7354507446326 .21151924133 
26.8210906982430 .1737308502242 .3651313781757 .6043891906771 .92929077148 77.3267440795978 .2238006591876 .6768341064573 .0588836669970 .58100891113 70.8845520019571 .4867172241273 .1562576293975 .595565795976 .0510559082 73.9763641357469 .5816802978563 .8864707946859 .7378807067947 .54647827148 35.0502891540526 .8210906982420 .4206008911116 .1536102294913 .41055011749 11.5818300247210 .9722604751611 .88661956787 -9999 -9999 -9999 -9999 -9999 -9999 -9999 -9999 -9999 -9999 -9999 -9999 -9999 -9999 -9999 -9999 -9999 -9999 -9999 -9999 -9999 -9999

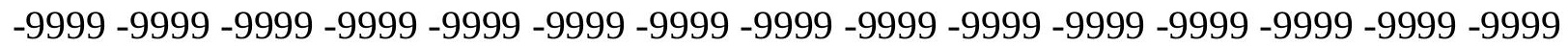
-9999 -9999 -9999 -9999 -9999 -9999 -9999 -9999 -9999 -9999 -9999 -9999 -9999 -9999 -9999 -9999 -9999 -9999 -9999 -9999 -9999 -9999 -9999 -9999 -9999 -9999 -9999 -9999 -9999 -9999 -9999 -9999 -9999 -9999 -9999 -9999 -9999 -9999 -9999 -9999 -9999 -9999 -9999 -9999 -9999 -999 -

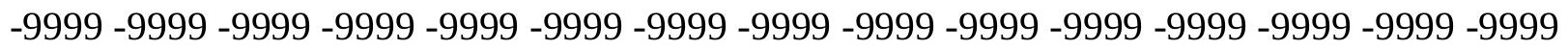
-9999 -9999-9999-9999

-9999 -9999 -9999 -9999 -9999 -9999 -9999 -9999 -9999 -9999 -9999 -9999 -9999 -9999 -9999 -9999 -9999 -9999 -9999 -9999 -9999 -9999 -9999 -9999 -9999 -9999 -9999 -9999 -9999 -9999 -9999 -9999 -9999 -9999 -9999 -9999 -9999 -9999 -9999 -9999 -9999 -9999 -9999 -9999 -9999 -999 -

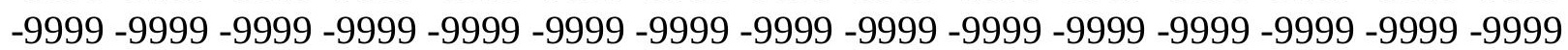

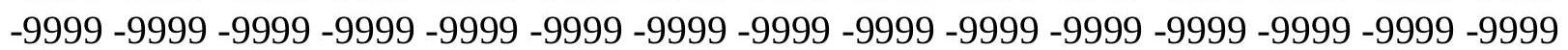
-9999 152.3925933838 145.9920959473139.5915985107132.5814971924128.6192932129 121.3044967651119 .4757995605107 .589103698795 .7025299072385 .64462280273 76.8058471679769 .7957916259863 .7000885009857 .909179687551 .81346893311 45.4129791259836 .2694282531735 .9646492004435 .9646492004435 .96464920044 36.2694282531736 .5742111206136 .8790016174337 .4885711669938 .09814071655 39.0125007629439 .9268493652340 .8412094116241 .7555618286142 .669921875 43.5842704772944 .1938400268644 .8034095764245 .1082000732445 .41297912598 45.717769622846 .0225486755446 .0225486755446 .0225486755446 .02254867554 46.0225486755446 .0225486755445 .717769622845 .4129791259845 .41297912598 45.717769622847 .2416992187549 .3751907348651 .5086898803753 .64218139648 55.4708900451757 .2995986938559 .1283111572361 .2618103027363 .09051895142 65.2240066528367 .0527267456168 .8814392089870 .7101516723672 .23407745361 74.062782287675 .5867080688577 .110626220778 .6345596313580 .15849304199 80.7680587768681 .3776321411182 .2919769287183 .5111236572384 .73026275635 86.254188537687 .7781066894588 .9972534179789 .4129562377989 .49440765381 89.5966567993289 .7182617187589 .8580474853590 .0147171020590 .18728637695 90.3747940063590 .5766296386790 .7922515869191 .0215301513791 .26445770264 91.5214385986391 .7929077148492 .079658508392 .3824386596792 .70223999023 93.0399780273493 .3973693847793 .7767105102594 .1811370849694 .6138458252 95.0785293579195 .5783691406296 .1161499023496 .6927795410297 .30825805664 97.9611816406298 .649696350199 .37049102783100 .119468689100 .8911743164 101.6795883179102 .4780654907103 .2800521851104 .0794296265104 .8709640503 105.6508407593106 .4167022705107 .1681900024107 .9065246582108 .6349029541 109.3580474854110 .0824279785109 .0712509155108 .0519638062107 .1617126465 106.4453353882105 .9358520508105 .6503219604105 .5892333984105 .7385406494 106.0731811523106 .5620193481107 .1720275879107 .8694000244108 .616645813 109.3694839478110 .0754241943110 .6774673462111 .1209487915111 .3605880737 111.3738327026111 .1726303101110 .8313598633110 .6073532104109 .1130981445 
106.0652008057103 .9317016602102 .712600708102 .1029968262101 .1886978149 100.274299621698 .7503814697396 .3121032714893 .2642517089899 .3020401001 85.6446228027381 .0728530883875 .8914871215870 .1005783081164 .0048828125 30.1737308502229 .2593708038328 .3450202941927 .430660247826 .82109069824 26.5163097381626 .2115192413326 .2115192413326 .2115192413326 .82109069824 27.7354507446329 .5641593933132 .0024414062534 .7455101013237 .48857116699 39.622070312540 .2316398620639 .0125007629436 .8790016174335 .35507965088 34.4407196044934 .7455101013235 .6598587036136 .2694282531735 .35507965088 33.2215805053731 .3928699493429 .8689403533929 .5641593933130 .78330039978 34.1359291076738 .7077102661146 .3273391723656 .3852500915563 .39530944824 67.6623001098667 .3575134277364 .7483139038165 .1398773193467 .54958343506 69.1280364990271 .9250640869175 .3643264770578 .6030654907279 .7840423584 78.4993286132875 .677589416570 .3945388793960 .6522407531747 .24169921875 35.3550796508826 .2115192413321 .0301704406717 .3727493286113 .41055011749 10.6674804687511 .2770500183113 .41055011749 -9999 -9999 -9999 -9999 -9999 -9999 -9999 -9999 -9999 -9999 -9999 -9999 -9999 -9999 -9999 -9999 -9999 -9999 -9999 -9999 -9999 -9999 -9999 -9999 -9999 -9999 -9999 -9999 -9999 -9999 -9999 -9999 -9999 -9999 -9999 -9999 -9999 -9999 -9999 -9999 -9999 -9999 -9999 -9999 -9999 -9999 -9999 -9999 -9999 -9999 -9999 -9999 -

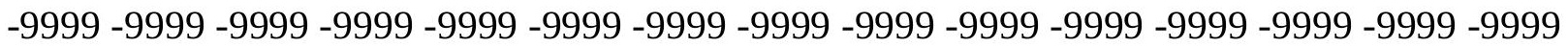

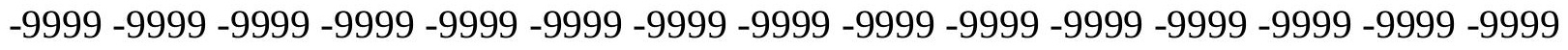
-9999 -9999-9999 -9999 -9999 -9999 -9999 -9999 -9999 -9999 -9999 -9999 -9999 -999 -999 -999 -9999-9999-9999

-9999 -9999 -9999 -9999 -9999 -9999 -9999 -9999 -9999 -9999 -9999 -9999 -9999 -9999 -9999

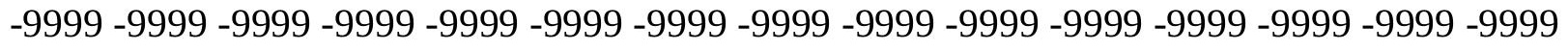

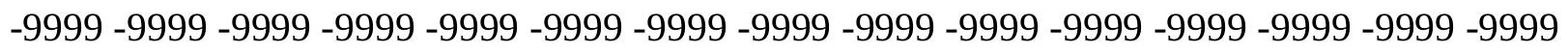
-9999 -9999 -9999 -9999 -9999 -9999 -9999 -9999 -9999 -9999 -9999 -9999 -9999 -9999 -9999 -9999 -9999 -9999 -9999 -9999-9999 -9999 -9999 -9999 -9999 -9999 -9999 -9999 -9999 - -9999 -9999 -9999 160.079498291 155.1356048584148.7351074219141.1154937744 133.1911010742128 .3144989014120 .3900985718109 .722602844297 .22646331787 85.0350494384876 .8058471679769 .4910125732462 .7857398986855 .77568054199 48.765621185335 .9646492004435 .6598587036135 .6598587036135 .35507965088 35.3550796508835 .6598587036135 .9646492004436 .5742111206137 .18378067017 38.0981407165539 .0125007629440 .2316398620641 .1459884643642 .06034851074 42.9747009277343 .8890609741244 .4986305236845 .1082000732445 .41297912598 45.717769622845 .717769622845 .717769622846 .0225486755446 .02254867554 46.0225486755445 .717769622845 .717769622845 .717769622845 .7177696228 46.6321296691947 .5464782714849 .0704002380450 .8991203308152 .42303848267 53.9469718933155 .7756805419957 .2995986938559 .1283111572361 .26181030273 63.0905189514264 .9192428588966 .7479400634868 .5766525268670 .40535736084 71.9292907714873 .4532165527374 .9771423339876 .5010681152377 .72020721436 78.6345596313579 .5489196777380 .7680587768682 .2919769287183 .81591033936 85.6446228027387 .1685485839888 .6924667358489 .72348785489 .80965423584 89.9152297973690 .038505554290 .1780319213990 .3322448730590 .49989318848 90.6797790527390 .8710632324291 .0730209350691 .2853546142691 .50797271729 91.7411422729591 .9852294921992 .2408447265692 .5086288452192 .78961181641 93.0849914550893 .3968658447393 .7281646728594 .0828247070394 .46488952637 
94.8787384033295 .3280715942495 .8160781860496 .3440551757896 .91233825684 97.5195999145598 .1637649536198 .8409729003999 .54623413086100 .2729187012 101.0135040283101 .7596817017102 .5031204224103 .2360687256103 .9518203735 104.6455383301105 .314201355105 .957321167106 .5764160156107 .1754150391 107.760093689108 .3383255005107 .4321670532106 .2730407715105 .2499847412 104.424156189103 .8408660889103 .5246429443103 .4774856567103 .6821136475 104.1084747314104 .7235107422105 .4976806641106 .4034881592107 .4066619873 108.4567565918109 .4860687256110 .4173583984111 .1813354492111 .7291259766 112.0461578369112 .1617889404112 .1580276489111 .8561019897107 .5891036987 103.9317016602101 .493400573799 .9695205688599 .0551681518698 .14080810547 97.2264633178795 .7025299072393 .2642517089890 .2164001464886 .55898284912 83.206336975179 .5489196777375 .2819290161170 .7101516723665 .83358764648 28.9545898437527 .7354507446326 .8210906982426 .2115192413325 .29715919495 24.9923801422124 .6875991821324 .3828105926524 .6875991821325 .29715919495 26.2115192413327 .7354507446329 .8689403533932 .0024414062534 .13592910767 35.3550796508835 .0502891540533 .5263595581131 .6976509094229 .86894035339 29.2593708038331 .0880794525130 .7833003997833 .8311500549332 .00244140625 31.3928699493431 .3928699493431 .3928699493431 .6976509094232 .91679000854 35.0502891540536 .5742111206136 .5742111206143 .5842704772948 .46083068848 51.5086898803750 .5943298339850 .2895507812554 .5565414428759 .53285598755 64.0066223144568 .2494659423873 .4897613525478 .8856735229582 .93055725098 83.63198089681 .9487762451277 .0811462402369 .049804687558 .51874923706 46.0225486755435 .0502891540528 .9545898437524 .3828105926517 .67753982544 12.8009700775112 .191410064713 .715330123914 .9344701767 -9999 -9999 -9999-9999 -9999 -9999 -9999 -9999 -9999 -9999 -9999 -9999 -9999 -9999 -9999 -9999 -9999 -9999 -9999 -9999 -9999 -9999 -9999 -9999 -9999 -9999 -9999 -9999 -9999 -9999 -9999 -9999 -9999 -9999 -9999 -9999 -9999 -9999 -9999 -9999 -9999 -9999 -9999 -9999 -9999 -9999 -9999 -9999 - 9999 - -999 -

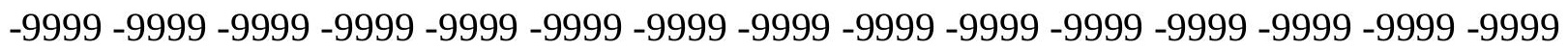
-9999 -9999 -9999 -9999 -9999 -9999 -9999 -9999 -9999 -9999 -9999 -9999 -9999 -9999 -9999 -9999 -9999 -9999 -9999 -9999 -9999 -9999 -9999 -9999 -9999 -9999 -9999 -9999 -9999 -9999 -9999 -9999-9999-9999-9999

-9999 -9999 -9999 -9999 -9999 -9999 -9999 -9999 -9999 -9999 -9999 -9999 -9999 -9999 -9999

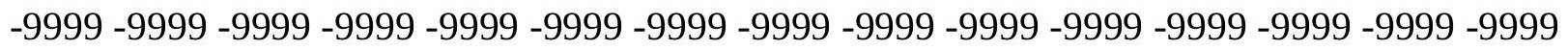
-9999 -9999 -9999 -9999 -9999 -9999 -9999 -9999 -9999 -9999 -9999 -9999 -9999 -9999 -9999 -9999 -9999 -9999 -9999 -9999 -9999 -9999 -9999 -9999 -9999 -9999 -9999 -9999 -9999 -9999 -9999 -9999 -9999 -9999 -9999 -9999 -9999 -9999 -9999 -9999 -9999 -9999 -9999 -9999 -9999 -9999 -9999 -9999 -9999 161.7635650635 154.8639984131147 .5160064697137 .7628936768 131.9720001221123 .7427978516110 .637001037697 .5312423706186 .2541885376 76.8058471679768 .5766525268660 .9570198059152 .7278289794935 .65985870361 35.0502891540534 .7455101013234 .7455101013234 .4407196044934 .44071960449 34.7455101013235 .3550796508835 .9646492004436 .8790016174338 .09814071655 39.3172798156740 .5364189147941 .7555618286142 .66992187543 .58427047729 44.1938400268644 .8034095764245 .1082000732445 .4129791259845 .7177696228 45.717769622845 .717769622845 .717769622845 .717769622845 .7177696228 46.0225486755446 .3273391723646 .6321296691947 .2416992187548 .46083068848 49.3751907348650.5943298339851.8134689331153.03261184692 54.25175094604 
55.7756805419957 .2995986938559 .1283111572360 .9570198059163 .09051895142 64.9192428588966 .7479400634868 .2718734741269 .7957916259871 .31971740723 72.5388565063573 .7580032348674 .6723632812575 .5867080688577 .1106262207 78.6345596313580 .7680587768682 .9015579223685 .0350494384886 .86376190186 88.3876876831189 .6068267822390 .1267395019590 .2359313964890 .36119842529 90.5007781982490 .6528244018690 .8157730102590 .9881591796991 .16887664795 91.3570251464891 .5521011352591 .7539138793991 .9626235961992 .17852020264 92.4020309448292 .6336746215892 .8745269775493 .1262359619193 .39147949219 93.6738662719793.9781112670994.3090972900494.672019958595.07122802734 95.5104217529395 .9913253784296 .5146408081197 .0791931152397 .682762146 98.3209228515698 .9877700805799 .67532348633100 .3743743896101 .0745697021 101.7652893066102 .436668396103 .080039978103 .6892318726104 .260269165 104.7924728394105 .2875137329105 .7500915527105 .6922073364105 .6065826416 105.6648025513104 .588760376103 .4048233032102 .4331207275101 .7351303101 101.3473129272101 .2748413086101 .4981307983101 .9809265137102 .6903915405 103.6069564819104 .7219085693106 .0151596069107 .4297485352108 .8709335327 110.2264328003111 .4065475464112 .3722686768113 .146522522113 .8075408936 114.2944030762 109.1130981445 104.8460998535 101.188697814998.75038146973 97.5312423706196 .3121032714895 .7025299072394 .4833908081192 .95947265625 90.8259735107487 .7781066894584 .7302627563581 .6824111938578 .63455963135 75.28192901611 71.92929077148 67.96708679199 27.12587928772 26.21151924133 25.2971591949524 .3828105926523 .7732391357423 .1636695861822 .85887908936 22.8588790893622 .8588790893623 .4684505462624 .3828105926525 .60194969177 27.1258792877228 .6497993469229 .8689403533930 .4785099029529 .56415939331 27.430660247824 .9923801422122 .5541000366220 .7253894805918 .59189033508 17.9823207855221 .334960937524 .9923801422127 .7354507446329 .86894035339 31.3928699493432 .3072204589832 .9167900085433 .2215805053732 .91679000854 31.3928699493432 .6120109558135 .9646492004438 .4029312133838 .70771026611 39.9268493652344 .1938400268650 .5943298339856 .9948196411163 .4642791748 70.6270141601677 .3095474243283 .1585540771585 .7387237548885 .13027191162 81.5881118774475 .4079666137767 .2030029296958 .1280136108450 .28955078125 42.3651313781734 .4407196044926 .2115192413319 .811029434216 .76317977905 15.54403972626 15.5440397262616 .45840072632 -9999 -9999 -9999 -9999 -9999 -9999 -9999

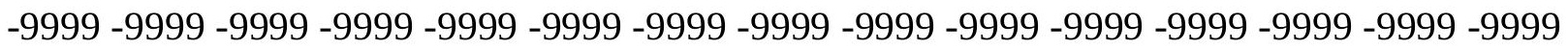

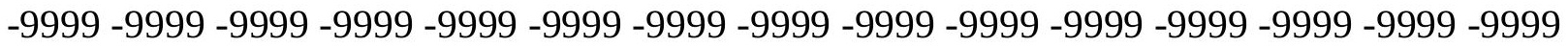

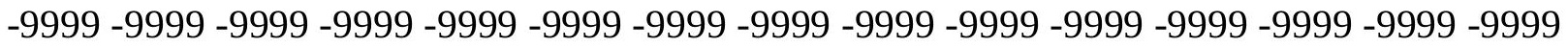

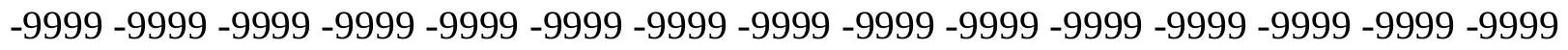

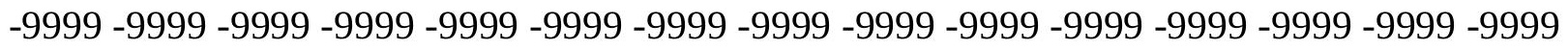

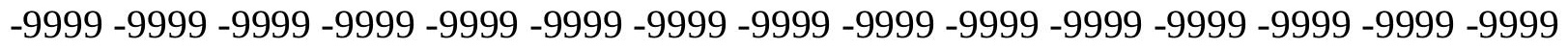
$-9999$

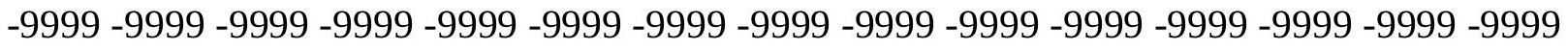

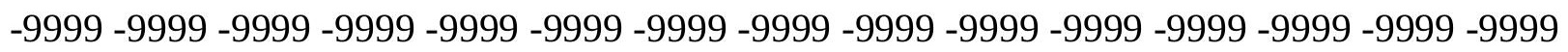

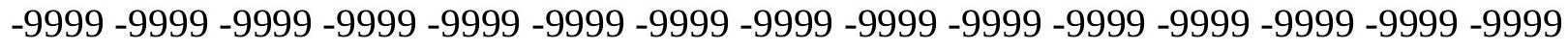

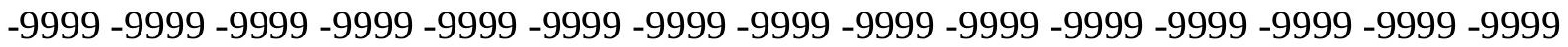
-9999 -9999 -9999 -9999 -9999 -9999 -9999 -9999 -9999 -9999 -9999 -999 -999 -999 -999 -999 -999 -9999 -9999 -9999 -9999 -9999 -9999 162.1312408447 156.6596069336 145.6873016357 
133.8007049561123 .7427978516110 .941802978596 .9216690063585 .33984375 75.2819290161166 .4431610107456 .6900291442935 .0502891540534 .44071960449 34.1359291076733 .5263595581133 .5263595581133 .2215805053733 .52635955811 33.8311500549334 .7455101013235 .9646492004437 .1837806701738 .40293121338 39.9268493652341 .1459884643642 .3651313781743 .2794914245644 .19384002686 44.8034095764245 .1082000732445 .4129791259845 .4129791259845 .7177696228 45.717769622845 .717769622845 .717769622846 .0225486755446 .32733917236 46.6321296691947 .2416992187548 .1560516357449 .0704002380449 .98476028442 50.2895507812551 .2038993835451 .8134689331153 .0326118469254 .25175094604 55.4708900451756 .9948196411158 .8235282897960 .9570198059162 .78573989868 64.6144485473666 .4431610107467 .9670867919969 .4910125732470 .40535736084 71.014930725171 .6244964599672 .5388565063574 .3675689697376 .50106811523 78.9393463134881 .6824111938584 .1206970214886 .254188537688 .08290100098 89.302040100190 .2164001464890 .5576705932690 .6853027343890 .82532501221 90.9755554199291 .1340942382891 .2991714477591 .4693832397591 .64361572266 91.8211593627992 .0016860961992 .1852340698292 .3720169067492 .56230926514 92.7565231323292 .9558181762793 .1623535156293 .3795242309693 .61166381836 93.8642120361394 .1428756713994 .4537658691494 .802040100195 .19206237793 95.6260833740296 .1052474975696 .628631591897 .1939697265697 .79637908936 98.4290161132899 .0825042724699 .74570465088100 .4058837891101 .0495910645 101.6641540527102 .2383956909102 .7643890381103 .2370223999103 .6553421021 103.6834793091103 .2773895264102 .9655914307102 .7843856812102 .7647171021 102.927482605101 .7019577026100 .544235229599 .6836547851699 .17223358154 99.0244750976699 .2150192260799 .69873809814100 .4406814575101 .4394454956 102.728515625104 .3284454346106 .1816940308108 .1348800659110 .0092773438 111.662322998113 .0851745605114 .1952438354113 .075302124109 .1130981445 104.8460998535100 .883903503498 .1408081054796 .0073165893694 .78817749023 93.8738174438592.9594726562592.0450973510790.52117919922 88.38768768311 85.6446228027383 .206336975180 .7680587768678 .6345596313576 .19628143311 73.4532165527370 .4053573608425 .2971591949524 .0780296325723 .16366958618 22.5541000366221 .9445304870621 .334960937521 .0301704406720 .72538948059 21.0301704406721 .334960937521 .9445304870622 .8588790893623 .77323913574 24.6875991821325 .2971591949524 .9923801422123 .7732391357421 .3349609375 18.5918903350815 .5440397262611 .886619567877 .31484317779520 .72538948059 10.3626899719217 .3727493286122 .5541000366226 .8210906982430 .17373085022 30.7833003997830 .7833003997830 .1737308502228 .9545898437526 .82109069824 24.0780296325725 .906740188628 .0402297973629 .5641593933132 .00244140625 35.6598587036140 .5364189147945 .4129791259853 .0326118469264 .91924285889 74.1719741821380 .878768920985 .0779266357485 .969169616782 .84264373779 73.1484298706174 .8739013671968 .8498992919962 .8019332885756 .38525009155 46.3273391723637 .1837806701729 .2593708038322 .8588790893619 .20145988464 17.6775398254418 .28710937519 .50625038147 -9999 -9999 -9999 -9999 -9999 -9999 -9999 -9999 -9999 -9999 -9999 -9999 -9999 -9999 -9999 -9999 -9999 -9999 -9999 -9999 -9999 -9999 -9999 -9999 -9999 -9999 -9999 -9999 -9999 -9999 -9999-9999 -9999 -9999 -9999 -9999 -9999 -9999 -9999 -9999 -9999 -9999 -9999 -9999 -9999 -9999 -9999 -9999 -9999 -9999 -9999 -9999 -

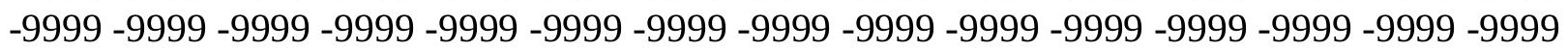


-9999 -9999 -9999 -9999 -9999 -9999 -9999 -9999 -9999 -9999 -9999 -9999 -9999 -9999 -9999 -9999 -9999 -9999 -9999 -9999 -9999 -9999 -9999 -9999 -9999 -9999 -9999 -9999 -9999 -9999

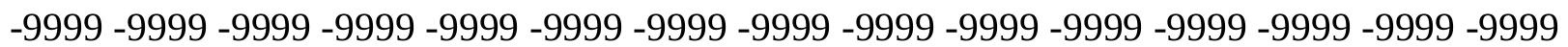
-9999 -9999 -9999 -9999 -9999 -9999 -9999 -9999 -9999 -9999 -9999 -9999 -9999 -9999 -9999 -9999 -9999 -9999 -9999 -9999 -9999 -9999 -9999 -9999 -9999 -9999 -9999 -9999 - -9999 - -9999 -9999 -9999 -9999 -9999 -9999 -9999 -9999 -9999 -9999 -9999 -9999 -9999 -9999 -9999 -9999 -9999 -9999 -9999 -9999 -9999 -9999 -9999 -9999 -9999 -9999 -9999 -9999 -9999 -9999 -9999 -9999 -9999 -9999 -9999 -9999 -9999 -9999 168.623260498159 .9080963135149 .9542999268 137.4580993652125 .2667007446109 .722602844293 .5690307617281 .37763214111 70.4053573608459 .4331016540534 .1359291076733 .5263595581132 .91679000854 32.3072204589832 .0024414062531 .6976509094231 .6976509094232 .30722045898 33.2215805053734 .7455101013236 .2694282531737 .7933502197339 .31727981567 40.8412094116242 .0603485107443 .2794914245643 .8890609741244 .49863052368 45.1082000732445 .4129791259845 .4129791259845 .4129791259845 .41297912598 45.4129791259845 .717769622845 .717769622846 .3273391723646 .93690872192 47.8512611389248 .765621185349 .6799812316950 .2895507812550 .28955078125 50.5943298339850 .8991203308151 .5086898803752 .4230384826753 .64218139648 55.1661109924356 .6900291442958 .8235282897960 .9570198059162 .48094940186 64.6144485473666 .4431610107467 .6623001098668 .2718734741268 .27187347412 68.2718734741269 .1862335205171 .3197174072374 .062782287677 .1106262207 80.4632720947383 .206336975185 .9494018554787 .7781066894588 .99725341797 89.9116134643690.8259735107491.0096435546991.1505584716891.29942321777 91.4539337158291 .6119842529391 .7718353271591 .9321289062592 .09191131592 92.250694274992 .4083862304792 .5650939941492 .7209472656292 .87633514404 93.0325317382893 .19223785493 .3595581054793 .5395736694393 .7384185791 93.9626388549894 .2192687988394 .5144500732494 .8534011840895 .23901367188 95.6729812622196 .1548004150496 .6824035644597 .2505722045997 .85163116455 98.474746704199 .1067581176899 .73223114014100 .3342819214100 .8966293335 101.4047927856101 .8486404419102 .2216110229101 .9638977051101 .4157028198 100.9085998535100 .4764633179100 .1619644165100 .0160980225100 .0839767456 100.194938659798 .8276672363397 .7757034301897 .1014633178796 .84624481201 96.9579849243297 .3855285644598 .0712585449299 .04137420654100 .409538269 102.2963027954104 .6787796021107 .2804412842108 .5035018921108 .1986999512 107.8938980103107 .2844009399105 .1509017944102 .102996826298 .75038146973 96.0073165893694 .4833908081193 .2642517089891 .7403335571390 .82597351074 90.2164001464889 .9116134643688 .3876876831186 .254188537683 .81591033936 81.6824111938580 .1584930419978 .9393463134877 .4154205322375 .28192901611 72.8436431884823 .1636695861822 .2493095397921 .334960937520 .42060089111 19.811029434219 .2014598846418 .8966808319118 .5918903350818 .59189033508 18.8966808319119 .2014598846419 .811029434220 .1158199310320 .42060089111 20.4206008911119 .5062503814717 .9823207855215 .8488302230812 .80097007751 9.448339462285 .4861321449281 .82871103286719 .201459884644 .87656211853 11.5818300247217 .6775398254422 .5541000366225 .906740188627 .12587928772 27.430660247826 .5163097381624 .9923801422122 .5541000366220 .11581993103 17.9823207855219 .5062503814721 .6397399902323 .7732391357426 .82109069824 30.7833003997835 .6598587036141 .7555618286151 .8134689331165 .52880096436 
75.4917373657281 .36244964684 .0359268188581 .2482299804778 .77809143066 80.8868103027377 .5425338745173 .1274261474667 .0527267456159 .12831115723 49.3751907348639 .0125007629429 .5641593933122 .8588790893621 .63973999023 22.8588790893623 .4684505462624 .9923801422128 .64979934692 -9999 -9999 -9999 -9999 -9999 -9999 -9999 -9999 -9999 -9999 -9999 -9999 -9999 -9999 -9999 -9999-9999 -9999 -9999 -9999 -9999 -9999 -9999 -9999 -9999 -9999 -9999 -9999 -9999 -9999 -9999 -9999 -9999 -9999 -9999 -9999 -9999 -9999 -9999 -9999 -9999 -9999 -9999 -9999 -9999 -9999 -9999 -9999 -9999

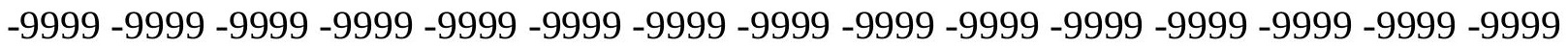
-9999 -9999 -9999 -9999 -9999 -9999 -9999 -9999 -9999 -9999 -9999 -9999 -9999 -9999 -9999

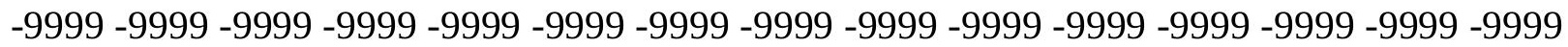
$-9999$

-9999 -9999 -9999 -9999 -9999 -9999 -9999 -9999 -9999 -9999 -9999 -9999 -9999 -9999 -9999 -9999 -9999 -9999 -9999 -9999 -9999 -9999 -9999 -9999 -9999 -9999 -9999 -9999 -9999 -9999 -9999 -9999 -9999 -9999 -9999 -9999 -9999 -9999 -9999 -9999 -9999 -9999 -9999 -9999 -9999 -9999 -9999 -9999 -9999 -9999 -9999 -9999 -9999 -9999 -9999 -9999 -9999 -9999 -9999 -9999 -

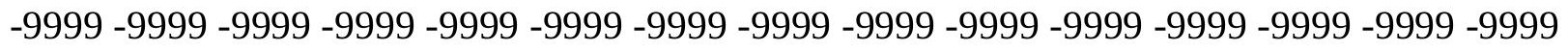
-9999 -9999 -9999 -9999 -9999 -9999 -9999 -9999 172.3004455566163 .7422790527 153.9165039062140 .8106994629122 .2188034058103 .322196960487 .77810668945 74.062782287660 .9570198059133 .2215805053732 .3072204589831 .69765090942 30.7833003997830 .1737308502230 .1737308502229 .8689403533930 .17373085022 31.6976509094233 .2215805053735 .0502891540536 .8790016174338 .70771026611 40.5364189147941 .7555618286142 .9747009277343 .8890609741244 .49863052368 45.1082000732445 .1082000732445 .4129791259845 .4129791259845 .10820007324 45.1082000732445 .4129791259845 .4129791259846 .0225486755446 .63212966919 47.5464782714848 .765621185349 .9847602844249 .9847602844249 .67998123169 49.6799812316949 .6799812316950 .2895507812550 .8991203308151 .81346893311 53.0326118469254 .5565414428756 .3852500915558 .5187492370660 .34745025635 62.7857398986865 .2240066528367 .0527267456167 .3575134277366 .13836669922 65.2240066528365 .8335876464868 .2718734741271 .6244964599675 .28192901611 78.9393463134882 .5967712402385 .3398437587 .4733276367288 .69246673584 89.6068267822390 .2164001464891 .1307525634891 .4751968383891 .62321472168 91.7741851806691 .9256057739392 .0753631591892 .2218017578192 .3636932373 92.5003738403392 .631561279392 .7572631835992 .8774795532292 .99258422852 93.10402679443 93.2149963378993.3302993774493.4557952880993.59828948975 93.7650833129993 .9641571044994 .2026901245194 .486892700294 .8204574585 95.2058410644595 .6432113647596 .131004333596 .6639785766697 .23373413086 97.8280334472798 .4316329956199 .0262756347799 .5912322998100 .105682373 100.5508575439100 .9134292603100 .692855835100 .087051391699 .47222137451 98.8619079589898 .2842788696397 .7910995483497 .4573974609497 .36996459961 97.5948410034297 .3401336669996 .123329162695 .3245239257894 .97875976562 95.01831817627 95.3597259521595.8856658935596.6569747924897.91427612305 99.98900604248102 .4077987671101 .7982025146101 .1886978149100 .5791015625 100.274299621699.3599472045997.8360290527395.397743225192.04509735107 91.1307525634890 .8259735107490 .2164001464888 .6924667358487 .77810668945 87.4733276367287 .1685485839886 .254188537684 .4254837036182 .59677124023 80.4632720947380 .4632720947380 .1584930419978 .9393463134877 .41542053223 
75.5867080688520 .7253894805919 .811029434218 .8966808319118 .287109375 17.6775398254417 .0679702758816 .4584007263216 .1536102294916 .15361022949 16.1536102294916 .4584007263216 .4584007263216 .4584007263216 .15361022949 15.5440397262614 .6296901702913 .1057596206710 .972260475168 .533983230591 5.4861321449282 .438281059265 -9999 .3047851026058 3.352636098862 8.533983230591 13.715330123918 .28710937521 .334960937522 .8588790893623 .16366958618 22.2493095397921 .0301704406718 .8966808319116 .7631797790514 .9344701767 13.4105501174914 .6296901702916 .7631797790519 .2014598846421 .94453048706 27.1258792877230 .1737308502236 .2694282531747 .5464782714865 .52880096436 72.7833175659278 .123184204180 .7167510986381 .2737731933682 .11376953125 81.3776321411179 .2441329956176 .1962814331170 .2471237182661 .56660079956 49.9847602844238 .4029312133829 .8689403533928 .9545898437530 .78330039978 30.4785099029531 .0880794525134 .7455101013239 .92684936523 -9999 -9999 -9999 -9999 -9999 -9999 -9999 -9999 -9999 -9999 -9999 -9999 -9999 -9999 -9999 -9999 -9999 -9999 -9999 -9999 -9999 -9999 -9999 -9999 -9999 -9999 -9999 -9999 -9999 -9999 -9999 -9999 -9999 -9999

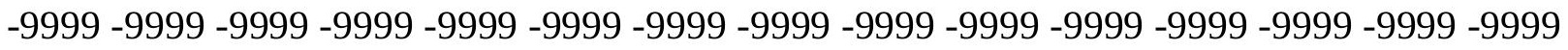

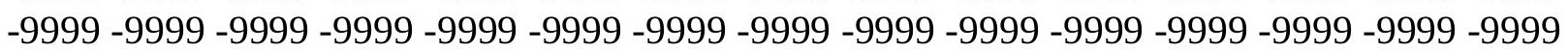
-9999 -9999 -9999 -9999 -9999 -9999 -9999 -9999 -9999 -9999 -9999 -9999 -9999 -9999 -9999 -999 -9999 -9999 -9999 -9999 -9999 -9999 -9999 -9999 -9999 -9999 -9999 -9999 -9999 -9999 -9999 -9999 -9999 -9999 -9999 -9999 -9999 -9999 -9999 -9999 -9999 -9999 -9999 -9999 -9999 -9999 -9999 -9999 -9999 -9999 -9999 -9999 -9999 -9999 -9999 -9999 -9999 -9999 -9999 -9999 -9999 -9999 -9999 -9999 -9999 -9999 -9999 -9999 -9999 -9999 -9999 -9999 -9999 -9999 -9999 -9999 -9999 -9999 -9999 -9999 -9999 -9999 -9999 -9999 -9999 -9999 -9999 -9999 -9999 -9999 -9999 -9999 -9999 -9999 -9999 -9999 -9999 -9999 -9999 -9999 -9999 -9999 -9999 -9999 -9999 -9999 -9999 -9999 -9999 -9999 -9999 -9999 -9999 -9999 182.5921173096174 .827331543 165.3990325928153 .0021057129134 .1054992676110 .637001037693 .56903076172 77.7202072143662 .7857398986832 .0024414062530 .7833003997829 .86894035339 28.6497993469228 .0402297973627 .430660247827 .430660247828 .34502029419 29.8689403533931 .6976509094233 .8311500549335 .9646492004438 .09814071655 39.9268493652341 .7555618286142 .9747009277343 .8890609741244 .49863052368 44.8034095764245 .1082000732445 .1082000732445 .1082000732444 .80340957642 44.8034095764244 .8034095764244 .8034095764245 .4129791259846 .02254867554 46.6321296691947 .8512611389248 .4608306884848 .765621185348 .46083068848 48.4608306884848 .4608306884848 .765621185349 .3751907348649 .98476028442 50.8991203308152 .4230384826754 .5565414428756 .3852500915558 .21395874023 60.9570198059164 .3096618652367 .0527267456167 .3575134277364 .91924285889 61.5666007995663 .0905189514265 .8335876464869 .4910125732473 .45321655273 77.4154205322381 .3776321411185 .0350494384886 .8637619018687 .77810668945 88.9972534179789 .6068267822390 .2164001464891 .1307525634891 .94557189941 92.093605041592 .2389373779392 .3790130615292 .5118331909292 .63584136963 92.7501678466892 .8542938232492 .9481353759893 .0315399169993 .10489654541 93.16979217529 93.2298965454193.2906570434693.3587188720793.44156646729 93.5472030639693 .6843566894593 .8612213134894 .0850372314594 .36051940918 94.691131591895 .0780715942495 .5207366943496 .0142517089896 .54981231689 97.1112213134897 .6958084106498 .2695770263798 .8146209716899 .29042053223 99.6818695068499 .7330780029399 .150245666598 .5409393310597 .88803863525 
97.1849670410296 .448242187595 .7346191406295 .1437683105594 .82247161865 94.9296798706195 .5317459106494 .8395004272594 .1918640136793 .80996704102 93.9450836181694 .1935195922994 .450752258394 .8030395507895 .64800262451 96.3121032714895 .7025299072394 .7881774902393 .8738174438592 .65467834473 92.9594726562592 .6546783447391 .4355392456189 .9116134643688 .08290100098 87.4733276367287 .1685485839886 .8637619018685 .6446228027384 .42548370361 84.7302627563585 .0350494384884 .4254837036183 .5111236572382 .29197692871 81.6824111938581 .6824111938581 .9871978759880 .7680587768679 .54891967773 78.3297805786118 .5918903350817 .6775398254416 .7631797790515 .84883022308 15.2392597198514 .6296901702914 .0201196670513 .715330123913 .41055011749 13.4105501174913 .1057596206713 .1057596206712 .8009700775111 .88661956787 11.2770500183110 .057909965528 .5339832305917 .0100579261785 .181346893311 3.047851085663.9143553972244-9999.6095703244209 3.047851085663 6.705273151398 10.9722604751614 .6296901702917 .0679702758818 .5918903350818 .89668083191 18.28710937517 .0679702758815 .5440397262613 .715330123912 .49619007111 11.2770500183111 .2770500183128 .6497993469213 .4105501174915 .23925971985 17.9823207855220 .4206008911122 .8588790893625 .906740188640 .23163986206 58.8235282897968 .069053649975 .4383544921980 .8700027465882 .76435089111 84.0459823608484 .6285552978583 .8159103393680 .0608978271571 .75701141357 61.5666007995651 .2038993835444 .1938400268642 .3651313781742 .669921875 42.0603485107442 .3651313781745 .4129791259849 .6799812316954 .55654144287 -9999 -9999 -9999 -9999 -9999 -9999 -9999 -9999 -9999 -9999 -9999 -9999 -9999 -9999 -9999 -9999 -9999 -9999 -9999 -9999 -9999 -9999 -9999 -9999 -9999 -9999 -9999 -9999 -9999 -9999 -9999 -

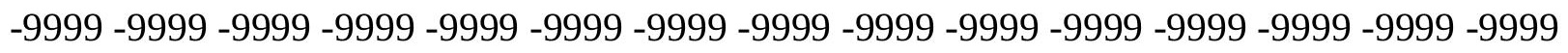

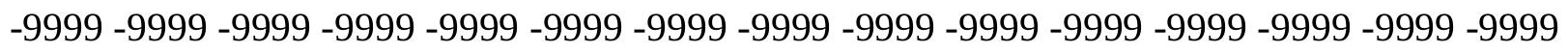
-9999 -9999 -9999 -9999 -9999 -9999 -9999 -9999 -9999 -9999 -9999 -9999 -9999 -9999 -9999

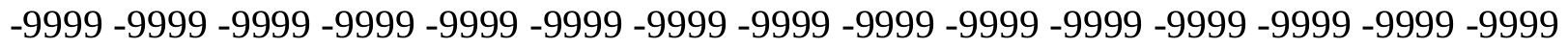
$-9999-9999$

-9999 -9999 -9999 -9999 -9999 -9999 -9999 -9999 -9999 -9999 -9999 -9999 -9999 -9999 -9999 -9999 -9999 -9999 -9999 -9999 -9999 -9999 -9999 -9999 -9999 -9999 -9999 -9999 -9999 -9999 -9999 -9999 -9999 -9999 -9999 -9999 -9999 -9999 -9999 -9999 -9999 -9999 -9999 -9999 -9999 -9999 -9999 -9999 -9999 -9999 -9999 -9999 -9999 -9999 -9999 -9999 -9999 -9999 -9999 -9999 -

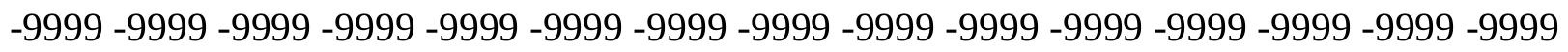
-9999 -9999-9999 -9999 -9999-9999-9999-9999-9999 182.9375762939 173.0838317871 159.9041595459142 .9441986084121 .914001464898 .1408081054780 .46327209473 64.004882812530 .4785099029528 .9545898437527 .430660247826 .21151924133 24.9923801422124 .6875991821324 .6875991821325 .906740188627 .4306602478 29.8689403533932 .3072204589835 .0502891540537 .4885711669939 .6220703125 41.4507789611842 .66992187543 .5842704772944 .4986305236844 .80340957642 44.8034095764244 .8034095764244 .8034095764244 .4986305236844 .19384002686 44.1938400268644 .1938400268644 .1938400268644 .8034095764245 .41297912598 46.0225486755446 .6321296691946 .9369087219246 .9369087219247 .24169921875 47.2416992187547 .5464782714848 .1560516357448 .4608306884849 .37519073486 50.8991203308153 .0326118469254 .8613204956157 .2995986938560 .04267120361 63.0905189514266 .4431610107468 .8814392089864 .004882812560 .65224075317 61.5666007995664 .004882812567 .6623001098671 .6244964599675 .89148712158 
79.8537063598683 .206336975185 .6446228027387 .1685485839888 .08290100098 88.9972534179789 .6068267822390 .5211791992291 .1307525634892 .04509735107 92.5507354736392 .6817092895592 .8013229370192 .9076538085992 .99953460693 93.0762023925893 .137420654393 .182891845793 .2130126953193 .22951507568 93.2365188598693 .2400665283293 .2474670410293 .266883850193 .3069229126 93.3768692016693 .4856414794993 .6415023803793 .8503189086994 .11688995361 94.4438400268694 .8320312595 .277626037695 .7687454223696 .31075286865 96.8816833496197 .4488754272597 .9764862060598 .426055908298 .75875854492 98.391189575297 .8625564575297 .3002395629996 .657501220795 .88648986816 95.0035018920994 .0544204711993 .1497802734492 .5000915527392 .40577697754 93.1527786254992 .9594726562591 .4355392456190 .8259735107490 .21640014648 90.2164001464890 .5211791992290 .8259735107490 .5211791992289 .91161346436 88.9972534179788 .0829010009887 .4733276367286 .8637619018686 .86376190186 86.8637619018686 .5589828491285 .6446228027385 .0350494384884 .42548370361 84.1206970214883 .8159103393683 .5111236572383 .206336975183 .2063369751 83.5111236572383 .5111236572383 .206336975182 .9015579223682 .59677124023 82.9015579223682 .9015579223682 .5967712402381 .6824111938580 .76805877686 15.8488302230814 .934470176714 .0201196670513 .4105501174912 .49619007111 11.8866195678711 .2770500183110 .9722604751610 .6674804687510 .36268997192 10.057909965529 .7531242370619 .1435537338268 .2291984558117 .010057926178 5.7909169197084 .876562118533 .9622070789342 .7430660724641 .523926019669 .3047851026058 -9999.9143553972244 2.743066072464 5.486132144928 8.533983230591 11.2770500183113 .1057596206714 .3248996734614 .6296901702914 .32489967346 13.4105501174912 .191410064711 .2770500183110 .362689971929 .753124237061 9.448339462289 .75312423706110 .0579099655210 .6674804687528 .34502029419 13.1057596206714 .6296901702917 .6775398254425 .2971591949536 .57421112061 53.0326118469265 .1538619995177 .0148315429782 .6643066406285 .84058380127 87.6068878173887 .5138931274483 .2152328491272 .5388565063572 .84364318848 64.9192428588959 .7378807067956 .6900291442955 .4708900451754 .86132049561 $55.1661109924356 .9948196411159 .7378807067963 .7000885009866 .13836669922-9999$ -9999 -9999 -9999 -9999 -9999 -9999 -9999 -9999 -9999 -9999 -9999 -9999 -9999 -9999 -9999 -9999 -9999 -9999 -9999 -9999 -9999 -9999 -9999 -9999 -9999 -9999 -9999 -9999 -9999 -9999 -

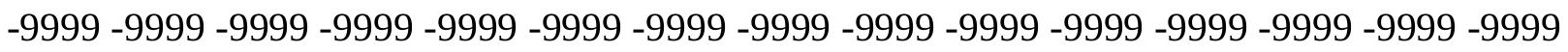
-9999 -9999 -9999 -9999 -9999 -9999 -9999 -9999 -9999 -9999 -9999 -9999 -9999 -9999 -9999 -9999 -9999 -9999 -9999 -9999 -9999 -9999 -9999 -9999 -9999 -9999 -9999 -9999 -9999 -9999 -

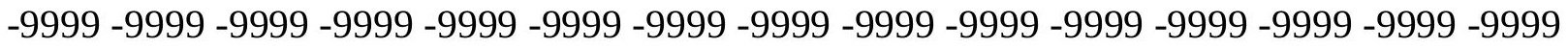
$-9999$

-9999 -9999 -9999 -9999 -9999 -9999 -9999 -9999 -9999 -9999 -9999 -9999 -9999 -9999 -9999 -9999 -9999 -9999 -9999 -9999 -9999 -9999 -9999 -9999 -9999 -9999 -9999 -9999 - 9999 - -999 -9999 -9999 -9999 -9999 -9999 -9999 -9999 -9999 -9999 -9999 -9999 -9999 -9999 -9999 -9999 -

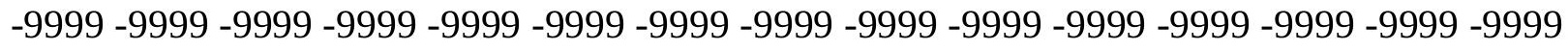

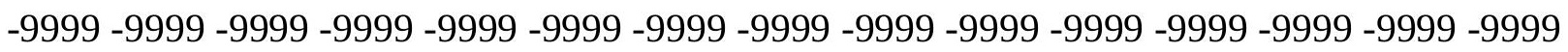
-9999 -9999-9999 -9999 -9999 -9999 -9999 -9999 -9999-9999 178.2704620361 164.73097229 146.6590576172122 .5235977173100 .883903503481 .6824111938564 .0048828125 29.5641593933127 .1258792877224 .9923801422123 .1636695861821 .63973999023 21.0301704406721 .334960937522 .5541000366224 .6875991821327 .4306602478 
30.4785099029533 .8311500549336 .5742111206139 .0125007629441 .14598846436 42.3651313781743 .5842704772944 .1938400268644 .4986305236844 .49863052368 44.4986305236844 .1938400268643 .8890609741243 .5842704772943 .27949142456 42.9747009277342 .9747009277343 .2794914245643 .5842704772943 .88906097412 44.4986305236844 .8034095764245 .4129791259845 .717769622846 .32733917236 46.6321296691947 .2416992187547 .8512611389248 .765621185350 .28955078125 52.1182594299354 .2517509460456 .3852500915559 .1283111572361 .56660079956 64.004882812564 .3096618652361 .2618103027360 .3474502563560 .95701980591 63.0905189514266 .1383666992270 .4053573608474 .6723632812578 .63455963135 81.6824111938584 .4254837036185 .9494018554787 .1685485839888 .38768768311 88.9972534179789 .9116134643690 .5211791992291 .4355392456192 .04509735107 92.6546783447393 .089286804293 .1783447265693 .2478942871193 .29685974121 93.3248214721793.33130645752 93.3167190551893.2829437255993.23457336426 93.1781311035293 .121513366793 .0733413696393 .0427246093893 .03928375244 93.0723495483493 .1508712768693 .2819747924893 .471961975193 .72531890869 94.04492187594 .4287567138794 .8776092529395 .3968505859495 .95962524414 96.5224685668997 .0373458862397 .4567413330197 .6559143066497 .14778900146 96.7324371337996 .2842483520595 .7043304443494 .8956222534293 .92286682129 92.7870712280391 .5757217407290 .5210876464890 .0693435668989 .3020401001 86.5589828491284 .4254837036182 .9015579223682 .9015579223683 .51112365723 84.1206970214884 .4254837036184 .1206970214883 .5111236572382 .90155792236 82.2919769287181 .9871978759881 .9871978759882 .2919769287182 .59677124023 82.5967712402382 .2919769287182 .2919769287181 .9871978759881 .98719787598 81.98719787598 81.98719787598 81.98719787598 82.29197692871 82.59677124023 82.9015579223683 .206336975183 .206336975183 .5111236572383 .81591033936 83.8159103393683 .8159103393683 .5111236572315 .2392597198513 .41055011749 12.4961900711111 .5818300247210 .667480468759 .7531242370619 .143553733826 8.5339832305917 .9244132041937 .6196279525767 .3148431777957 .010057926178 6.4004869461065 .7909169197084 .876562118533 .6574220657352 .133496046066 2.1334960460661 .8287110328671 .21914100647 .3047851026058 -9999 -9999 .6095703244209 2.133496046066 4.2669920921336.400486946106 8.229198455811 9.75312423706110 .6674804687510 .6674804687510 .6674804687510 .05790996552 9.448339462288 .5339832305918 .2291984558117 .9244132041937 .619627952576 7.6196279525767 .6196279525767 .6196279525768 .2291984558119 .44833946228 11.5818300247213 .1057596206715 .5440397262620 .7253894805929 .86894035339 51.5086898803768 .5056076049879 .1525344848684 .3838958740287 .90567779541 88.8135147094786 .1799011230582 .0145645141679 .4983596801876 .50106811523 71.014930725167 .6623001098665 .8335876464865 .5288009643666 .44316101074 67.3575134277368 .2718734741270 .1005783081170 .7101516723667 .96708679199 -9999 -9999 -9999 -9999 -9999 -9999 -9999 -9999 -9999 -9999 -9999 -9999 -9999 -9999 -9999 -9999

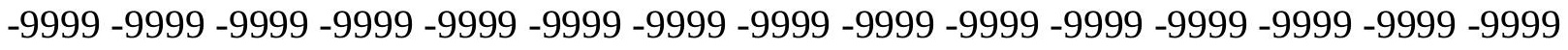

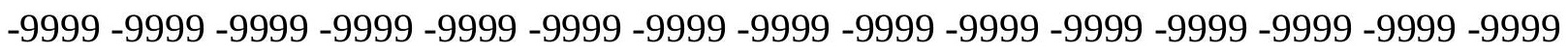
-9999 -9999 -9999 -9999 -9999 -9999 -9999 -9999 -9999 -9999 -9999 -9999 -9999 -9999 -9999 -9999 -9999 -9999 -9999 -9999 -9999 -9999 -9999 -9999 -9999 -9999 -9999 -9999 -9999 -9999 -9999 -9999 -9999 -9999 -9999 -9999 -9999 -9999 -9999 -9999 -9999 -9999 -9999 -9999 -9999 -

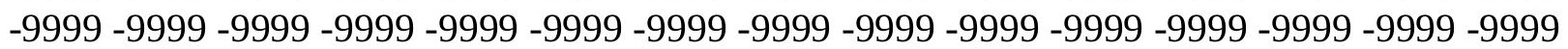


-9999 -9999 -9999 -9999 -9999 -9999 -9999 -9999 -9999 -9999 -9999 -9999 -9999 -9999 -9999 -9999 -9999 -9999 -9999 -9999 -9999 -9999 -9999 -9999 -9999 -9999 -9999 -9999 -9999 -9999 -9999 -9999 -9999 -9999 -9999 -9999 -9999 -9999 -9999 -9999 -9999 -9999 -9999 -9999 -9999 -9999 -9999 -9999 -9999 -9999 -9999 -9999 -9999 -9999 -9999 -9999 -9999 -9999 -9999 -9999 -9999 -9999 -9999 -9999-9999 -9999 -9999 -9999 -9999 -9999 -9999 167.6999206543 150.341003418130 .143203735499 .0551681518679 .5489196777362 .48094940186 28.6497993469225 .2971591949522 .5541000366220 .1158199310318 .287109375 17.37274932861 17.67753982544 18.8966808319121.3349609375 24.38281059265 28.0402297973632 .0024414062535 .3550796508838 .4029312133840 .53641891479 42.0603485107443 .2794914245643 .8890609741243 .8890609741243 .88906097412 43.8890609741243 .5842704772943 .2794914245642 .66992187542 .36513137817 42.0603485107441 .7555618286141 .4507789611841 .4507789611841 .75556182861 42.3651313781742 .9747009277343 .5842704772944 .4986305236845 .41297912598 46.0225486755446 .6321296691947 .5464782714848 .4608306884849 .98476028442 51.8134689331153 .6421813964855 .7756805419957 .909179687560 .04267120361 61.5666007995661 .5666007995660 .6522407531759 .7378807067960 .34745025635 62.1761703491265 .2240066528369 .1862335205173 .7580032348677 .41542053223 80.7680587768683 .206336975185 .0350494384886 .5589828491287 .47332763672 88.3876876831189 .302040100189 .9116134643690 .5211791992291 .13075256348 91.7403335571392 .349891662692 .9594726562593 .4947280883893 .5159072876 93.51008605957 93.4766311645593.41594696045 93.33009338379 93.22410583496 93.1049652099692 .9809494018692 .8609466552792 .7542724609492 .67069244385 92.6196136474692 .6103134155392 .6507644653392 .7487869262792 .91083526611 93.1424865722793.4446640014693.8378524780394.3354873657294.88744354248 95.441963195895 .9377212524495 .7025299072395 .397743225194 .78817749023 94.4833908081194 .1785964965893 .5690307617292 .9594726562592 .04509735107 91.1307525634890 .2164001464888 .6924667358486 .5589828491284 .12069702148 81.3776321411178 .3297805786175 .5867080688576 .5010681152377 .41542053223 78.3297805786178 .6345596313578 .3297805786178 .0249862670977 .41542053223 77.4154205322377 .4154205322378 .0249862670978 .3297805786178 .93934631348 79.5489196777379 .8537063598680 .1584930419980 .1584930419980 .46327209473 80.7680587768681 .0728530883881 .3776321411181 .9871978759882 .29197692871 82.9015579223683 .206336975183 .8159103393684 .1206970214884 .42548370361 84.7302627563585 .0350494384885 .3398437512 .191410064710 .36268997192 9.448339462288 .5339832305917 .9244132041937 .0100579261786 .095703125 5.4861321449284 .876562118534 .5717768669133 .9622070789343 .657422065735 3.3526360988622 .7430660724641 .828711032867 .9143553972244 .3047851026058 .3047851026058 3047851026058 -9999-.304785102606-.304785102606-.304785102606 .30478510260581 .5239260196692 .7430660724644 .2669920921335 .486132144928 6.4004869461067 .0100579261787 .3148431777957 .0100579261786 .705273151398 6.4004869461066 .0957031256 .0957031256 .0957031255 .7909169197085 .486132144928 5.1813468933114 .876562118535 .1813468933118 .22919845581116 .15361022949 15.5440397262614 .3248996734613 .4105501174917 .9823207855231 .69765090942 54.5565414428773 .2334747314580 .6374359130986 .5790252685589 .90433502197 90.3775711059689 .2666931152386 .6422882080183 .2466430664178 .64178466797 75.2819290161173 .4532165527372 .909317016673 .321853637774 .01001739502 
74.6723632812574 .3675689697373 .4532165527371 .014930725167 .35751342773 -9999 -9999 -9999 -9999 -9999 -9999 -9999 -9999 -9999 -9999 -9999 -9999 -9999 -9999 -9999 -9999

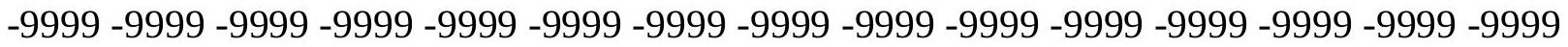
-9999 -9999 -9999 -9999 -9999 -9999 -9999 -9999 -9999 -9999 -9999 -9999 -9999 -9999 -9999 -9999 -9999 -9999 -9999 -9999 -9999 -9999 -9999 -9999-9999 -9999 -9999 -9999 -9999 -9999 -9999 -9999 -9999 -9999 -9999 -9999 -9999 -9999 -9999 -9999 -9999 -9999 -9999 -9999 -9999 -9999 -9999 -9999 -9999 -9999 -9999 -9999 -9999 -9999 -9999 -9999 -9999 -9999 -9999 -

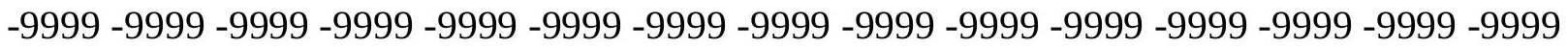
-9999 -9999 -9999 -9999 -9999 -9999 -9999 -9999 -9999 -9999 -9999 -9999 -9999 -9999 -9999 -9999 -9999 -9999 -9999 -9999 -9999 -9999 -9999 -9999 -9999 -9999 -9999 -9999 -9999 -9999 -

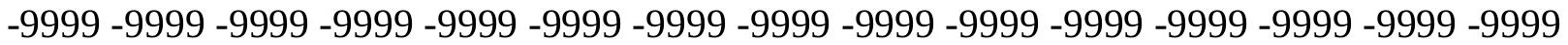
-9999 -9999 -9999 -9999 -9999 -9999 -9999 -9999 -9999 -9999 -9999 -9999 -9999 -9999 -9999 -9999 -9999 -9999 -9999 -9999 -9999 -9999 -9999 -9999 -9999 -9999 -9999 152.1164093018 129.4315032959102 .407798767171 .9292907714829 .5641593933127 .4306602478 24.0780296325720 .4206008911117 .3727493286114 .6296901702913 .41055011749 13.1057596206714 .6296901702917 .3727493286120 .7253894805924 .99238014221 29.5641593933133 .8311500549337 .1837806701739 .622070312541 .45077896118 42.66992187542 .9747009277343 .2794914245643 .2794914245642 .97470092773 42.66992187542 .3651313781741 .7555618286141 .1459884643640 .84120941162 40.2316398620639 .9268493652339 .622070312539 .622070312540 .23163986206 40.8412094116242 .0603485107443 .2794914245644 .4986305236845 .41297912598 46.3273391723647 .2416992187548 .4608306884849 .9847602844251 .50868988037 53.3373985290555 .1661109924356 .9948196411158 .5187492370659 .73788070679 60.0426712036159 .7378807067959 .4331016540559 .7378807067961 .26181030273 64.6144485473668 .8814392089873 .4532165527377 .4154205322380 .46327209473 82.5967712402384 .4254837036185 .9494018554786 .8637619018687 .77810668945 88.6924667358489 .302040100189 .9116134643690 .2164001464890 .82597351074 91.1307525634891 .7403335571392 .9594726562593 .7331695556693 .6930770874 93.6187744140693.5107345581193.37117004395 93.2055053710993.0210723877 92.8263854980592 .6303405761792 .4422225952192 .2715682983492 .12762451172 92.0194320678791 .9552459716891 .9435577392691 .9927139282292 .11135864258 92.308319091892 .6342391967892 .9594726562592 .9594726562592 .65467834473 92.6546783447392 .0450973510791 .4355392456190 .8259735107490 .52117919922 90.2164001464889 .6068267822388 .9972534179788 .3876876831187 .47332763672 86.254188537684 .4254837036182 .5967712402380 .1584930419977 .1106262207 74.6723632812572 .8436431884872 .5388565063573 .1484298706173 .75800323486 74.062782287673 .7580032348673 .1484298706172 .8436431884873 .14842987061 73.7580032348674 .6723632812575 .5867080688576 .5010681152377 .1106262207 78.0249862670978 .3297805786178 .9393463134879 .2441329956179 .85370635986 80.4632720947380 .7680587768681 .6824111938582 .2919769287182 .90155792236 83.5111236572384 .1206970214884 .4254837036185 .0350494384885 .33984375 85.9494018554786 .558982849128 .2291984558117 .3148431777956 .705273151398 5.7909169197084 .876562118533 .9622070789343 .0478510856632 .438281059265 1.8287110328671 .21914100647 .9143553972244 .3047851026058 -9999 -9999 -.609570324421 -1.21914100647 - $1.52392601967-1.21914100647-.609570324421$ -1.21914100647 -1.52392601967 - $1.52392601967-1.21914100647$-.304785102606 
.30478510260581 .219141006472 .1334960460663 .0478510856633 .657422065735 3.9622070789343 .9622070789343 .9622070789343 .6574220657353 .657422065735 3.9622070789344 .2669920921334 .2669920921334 .2669920921333 .962207078934 3.3526360988622 .7430660724642 .4382810592653 .35263609886211 .27705001831 15.8488302230815 .5440397262615 .5440397262618 .5918903350825 .29715919495 33.8311500549356 .0804595947374 .9311981201283 .5137634277389 .48037719727 92.8214187622193 .5315856933691 .6722335815487 .8883743286183 .19184112549 78.6345596313577 .110626220776 .6358413696376 .8360671997177 .32356262207 77.6373672485477 .4154205322375 .8914871215872 .5388565063568 .57665252686 64.61444854736 -9999 -9999 -9999 -9999 -9999 -9999 -9999 -9999 -9999 -9999 -9999 -9999

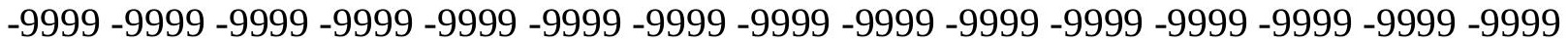

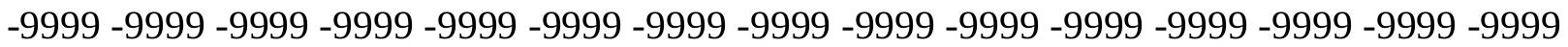

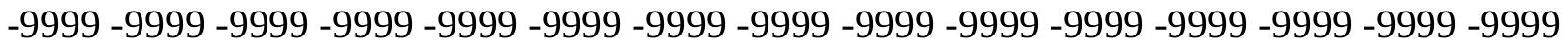

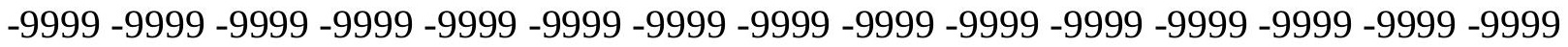

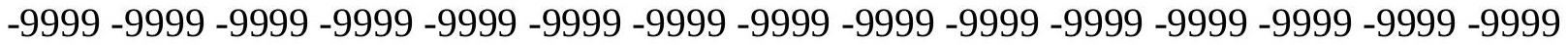
$-9999-9999$

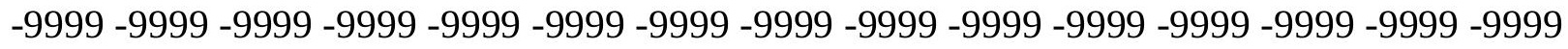

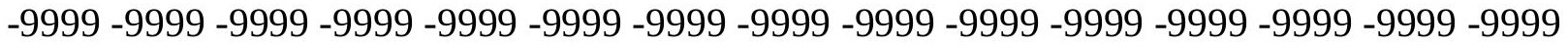

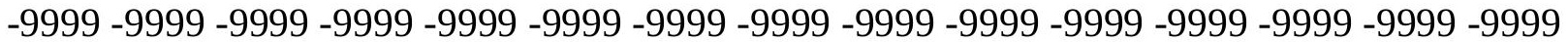

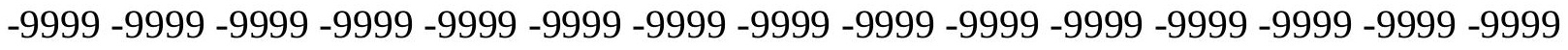

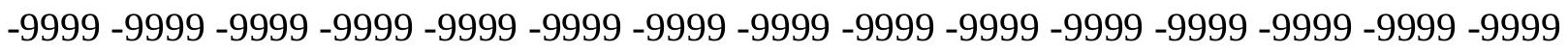
-9999 -9999 -9999 -9999 -9999 -9999 -9999 -9999 -9999 -9999 -9999 -9999 -9999 130.8493652344101 .51707458564 .004882812533 .8311500549328 .04022979736 23.7732391357419 .2014598846414 .934470176710 .972260475168 .838768959045 8.53398323059110 .0579099655212 .8009700775116 .7631797790521 .3349609375 26.5163097381631 .6976509094235 .3550796508838 .4029312133840 .23163986206 41.4507789611842 .0603485107442 .3651313781742 .3651313781742 .06034851074 41.7555618286141 .1459884643640 .8412094116240 .2316398620639 .6220703125 39.0125007629438 .4029312133838 .0981407165537 .7933502197338 .09814071655 39.3172798156740 .8412094116242 .66992187544 .1938400268645 .10820007324 46.0225486755447 .2416992187548 .4608306884849 .6799812316951 .20389938354 53.0326118469254 .5565414428756 .0804595947357 .2995986938558 .21395874023 58.8235282897959 .1283111572359 .4331016540559 .1283111572360 .65224075317 64.6144485473669 .4910125732474 .062782287677 .7202072143680 .46327209473 82.5967712402384 .1206970214885 .3398437586 .254188537687 .16854858398 88.08290100098 88.3876876831188.99725341797 89.3020401001 89.91161346436 90.2164001464890 .8259735107491 .4355392456191 .7403335571392 .04509735107 92.0450973510792 .0450973510792 .349891662692 .349891662692 .04509735107 91.4355392456191 .4355392456191 .7403335571391 .4355392456191 .13075256348 91.1307525634890 .8259735107490 .8259735107490 .8259735107490 .52117919922 90.2164001464889 .9116134643689 .6068267822388 .9972534179788 .69246673584 88.08290100098 87.47332763672 87.16854858398 86.86376190186 86.55898284912 86.2541885376 85.9494018554785.64462280273 84.7302627563583.81591033936 82.59677124023 81.07285308838 79.24413299561 76.80584716797 74.67236328125 72.5388565063571 .014930725170 .4053573608470 .7101516723670 .71015167236 70.7101516723670 .1005783081169 .4910125732469 .1862335205169 .79579162598 
70.7101516723671 .9292907714873 .1484298706174 .3675689697375 .58670806885 76.5010681152377 .110626220778 .0249862670978 .6345596313579 .24413299561 79.8537063598680 .4632720947381 .3776321411181 .9871978759882 .59677124023 83.5111236572383 .8159103393684 .4254837036185 .0350494384885 .64462280273 86.25418853765 .7909169197084 .876562118534 .2669920921333 .352636098862 2.7430660724641 .523926019669 6095703244209-9999-.609570324421 -1.21914100647 $-1.82871103287-2.43828105927-2.74306607246-3.04785108566-3.04785108566$ $-3.65742206573-3.65742206573-3.65742206573-3.35263609886-3.04785108566$ -3.04785108566 -3.04785108566 -3.04785108566 -2.43828105927-1.82871103287 -.914355397224 -.304785102606-9999.3047851026058.6095703244209.9143553972244 .91435539722441 .219141006471 .219141006471 .219141006471 .828711032867 2.4382810592652 .7430660724642 .7430660724642 .4382810592651 .828711032867 1.219141006471 .5239260196693 .6574220657358 .22919845581112 .80097007751 15.2392597198515 .8488302230818 .5918903350823 .7732391357429 .56415939331 34.7455101013254 .5565414428774 .9771423339885 .5460510253989 .91161346436 91.1307525634892 .349891662688 .3876876831184 .0054321289177 .72020721436 77.110626220776 .782646179277 .0151519775477 .406524658277 .49295806885 76.985488891675 .8914871215871 .9292907714867 .9670867919964 .61444854736 61.56660079956 -9999 -9999 -9999 -9999 -9999 -9999 -9999 -9999 -9999 -9999 -9999 -9999

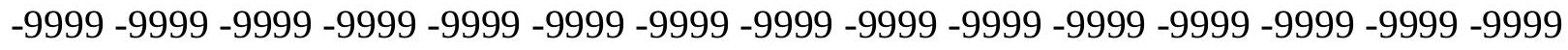
-9999 -9999 -9999 -9999 -9999 -9999 -9999 -9999 -9999 -9999 -9999 -9999 -9999 -9999 -9999

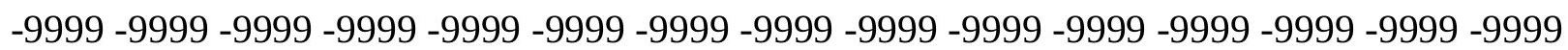
-9999 -9999 -9999 -9999 -9999 -9999 -9999 -9999 -9999 -9999 -9999 -9999 -9999 -9999 -9999 -9999 -9999 -9999 -9999 -9999 -9999 -9999 -9999 -9999 -9999 -9999 -9999 -9999 -9999 -9999 $-9999$

-9999 -9999 -9999 -9999 -9999 -9999 -9999 -9999 -9999 -9999 -9999 -9999 -9999 -9999 -9999 -9999 -9999 -9999 -9999 -9999 -9999 -9999 -9999 -9999 -9999 -9999 -9999 -9999 -9999 -9999

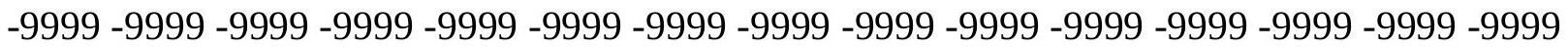

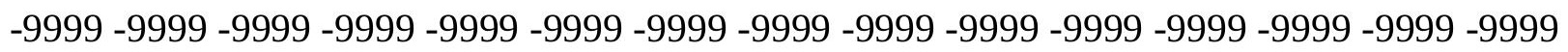

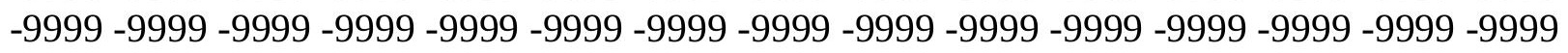
-9999 -9999 -9999 -9999 -9999 -9999 -9999 -9999 -9999 -9999 -9999 -9999 -9999 -9999 -999 108.459495544478 .6345596313540 .2316398620631 .6976509094224 .99238014221 18.8966808319112 .800970077517 .6196279525764 .5717768669133 .962207078934 5.4861321449288 .53398323059112 .191410064716 .7631797790521 .94453048706 27.7354507446332 .9167900085436 .5742111206138 .7077102661139 .92684936523 40.8412094116240 .8412094116240 .8412094116240 .8412094116240 .53641891479 39.9268493652339 .622070312539 .0125007629438 .4029312133837 .79335021973 37.4885711669936 .8790016174336 .5742111206136 .2694282531738 .09814071655 39.9268493652341 .7555618286143 .8890609741244 .8034095764245 .7177696228 46.9369087219248 .1560516357449 .3751907348650 .8991203308152 .72782897949 53.9469718933155 .1661109924356 .0804595947356 .6900291442957 .60438919067 58.5187492370659 .7378807067958 .8235282897959 .4331016540565 .22400665283 71.014930725175 .5867080688578 .9393463134881 .0728530883882 .59677124023 83.8159103393685 .0350494384885 .9494018554786 .5589828491287 .16854858398 87.7781066894588 .0829010009888 .3876876831188 .6924667358489 .3020401001 89.6068267822389 .9116134643690 .2164001464890 .2164001464890 .21640014648 
90.2164001464890 .2164001464889 .9116134643689 .302040100188 .69246673584 88.3876876831188 .6924667358488 .6924667358488 .6924667358488 .38768768311 88.3876876831188 .0829010009888 .0829010009887 .7781066894587 .16854858398 86.5589828491285 .9494018554785 .3398437584 .4254837036183 .51112365723 82.9015579223682 .5967712402382 .5967712402382 .5967712402382 .59677124023 82.5967712402382 .2919769287181 .6824111938580 .7680587768679 .85370635986 78.3297805786176 .5010681152374 .6723632812572 .8436431884871 .31971740723 70.1005783081169 .4910125732469 .1862335205168 .8814392089868 .57665252686 67.9670867919967 .0527267456166 .4431610107467 .3575134277368 .88143920898 70.4053573608471 .6244964599673 .1484298706174 .3675689697375 .28192901611 76.1962814331177 .110626220778 .0249862670978 .6345596313579 .24413299561 80.1584930419980 .7680587768681 .6824111938582 .2919769287182 .90155792236 83.5111236572384 .1206970214884 .7302627563585 .3398437586 .2541885376 $5.1813468933111 .828711032867 .9143553972244 .3047851026058-.304785102606$ $-1.52392601967-2.43828105927-3.35263609886-4.26699209213-4.87656211853$ $-5.48613214493-6.095703125-6.095703125-6.40048694611-6.40048694611-6.40048694611$ $-6.40048694611-6.40048694611-6.095703125-5.79091691971-5.48613214493$ $-5.18134689331-4.87656211853-4.26699209213-3.65742206573-3.04785108566$ $-2.43828105927-2.13349604607-1.82871103287-1.52392601967-1.21914100647$ -1.21914100647 -.914355397224-.914355397224 -.304785102606 .3047851026058 .9143553972244 1.21914100647 1.21914100647.9143553972244.6095703244209 .30478510260581 .219141006473 .3526360988626 .4004869461069 .753124237061 12.191410064714 .0201196670516 .1536102294920 .1158199310324 .68759918213 30.1737308502235 .3550796508856 .6900291442972 .5388565063581 .37763214111 85.0350494384884 .7302627563581 .6824111938578 .3297805786172 .53885650635 73.1484298706173 .4532165527374 .062782287674 .3675689697374 .36756896973 72.8436431884870 .7101516723667 .3575134277364 .3096618652362 .48094940186 60.9570198059158 .21395874023 -9999 -9999 -9999 -9999 -9999 -9999 -9999 -9999 -9999 -9999 -9999 -9999 -9999 -9999 -9999 -9999 -9999 -9999 -9999 -9999 -9999 -9999 -9999 -9999 -9999 -9999 -9999 -9999 -9999 -9999 -9999 -9999 -9999 -9999 -9999 -9999 -9999 -9999 -9999 -9999 -9999 -9999 -9999 -9999 -9999 -9999 -9999 -9999 -9999 -9999 -9999-9999 -9999 -9999 -9999 -9999 -9999 -9999 -9999 -9999 -9999 -9999 -9999 -9999 -9999 -9999 -9999 -9999 -9999 -

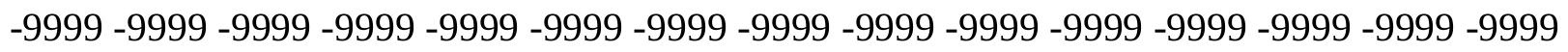
-9999 -9999-9999

-9999 -9999 -9999 -9999 -9999 -9999 -9999 -9999 -9999 -9999 -9999 -9999 -9999 -9999 -9999

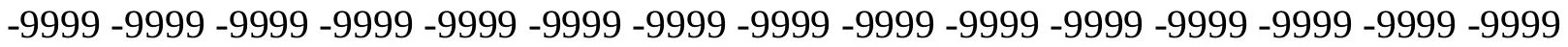

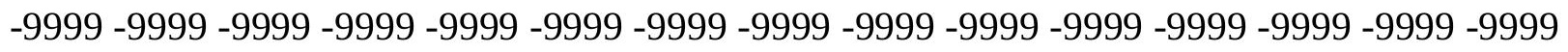

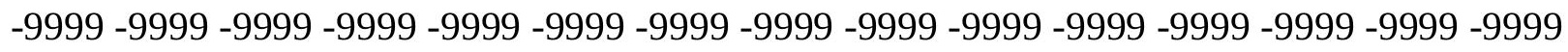
-9999 -9999 -9999 -9999 -9999 -9999 -9999 -9999 -9999 -9999 -9999 -9999 -9999 -9999 -9999 -9999 -9999 -9999 -9999 -9999 -9999 -9999 -9999 -9999 -9999 -9999 -9999 -9999 -9999 -9999 90.413085937556 .3852500915532 .9167900085427 .1258792877219 .20145988464 10.667480468753 .962207078934 .3047851026058 -9999 1.5239260196694.571776866913 8.22919845581112 .191410064716 .7631797790522 .5541000366229 .86894035339 33.8311500549336 .2694282531737 .7933502197338 .7077102661139 .31727981567 39.3172798156739 .3172798156739 .0125007629438 .7077102661138 .40293121338 38.0981407165537 .4885711669936 .8790016174336 .5742111206135 .96464920044 
35.9646492004436 .2694282531737 .4885711669939 .0125007629441 .14598846436 42.66992187544 .1938400268645 .1082000732446 .3273391723647 .54647827148 49.0704002380450 .5943298339852 .1182594299353 .3373985290554 .25175094604 54.8613204956155 .4708900451756 .0804595947356 .6900291442957 .60438919067 58.2139587402360 .9570198059166 .7479400634873 .4532165527377 .41542053223 79.8537063598681 .3776321411182 .5967712402383 .5111236572384 .42548370361 85.3398437585 .9494018554786 .254188537686 .8637619018687 .16854858398 87.47332763672 87.77810668945 88.08290100098 88.38768768311 88.38768768311 88.69246673584 88.69246673584 88.38768768311 88.3876876831188.08290100098 87.4733276367286 .8637619018685 .9494018554785 .0350494384885 .64462280273 85.6446228027385 .9494018554785 .9494018554785 .9494018554785 .64462280273 85.3398437585 .0350494384884 .4254837036183 .5111236572382 .59677124023 81.3776321411180 .1584930419978 .9393463134878 .3297805786178 .02498626709 78.3297805786178 .6345596313579 .2441329956179 .2441329956179 .24413299561 78.9393463134878 .3297805786177 .110626220775 .8914871215874 .67236328125 73.1484298706171 .6244964599670 .4053573608469 .4910125732468 .88143920898 68.5766525268668 .2718734741267 .6623001098667 .0527267456166 .44316101074 66.1383666992266 .7479400634867 .9670867919969 .4910125732470 .71015167236 72.2340774536173 .4532165527374 .3675689697375 .2819290161176 .19628143311 77.110626220778 .0249862670978 .6345596313579 .5489196777380 .15849304199 81.0728530883881 .6824111938581 .9871978759882 .5967712402382 .90155792236 83.5111236572384 .4254837036185 .644622802734 .5717768669131 .828711032867 $-1.82871103287-2.74306607246-3.65742206573-4.87656211853-5.79091691971$ $-7.01005792618-7.92441320419-8.83876895905-9.44833946228-9.44833946228$ $-9.44833946228-9.44833946228-9.44833946228-9.44833946228-9.14355373383$ $-8.83876895905-8.53398323059-8.22919845581-7.92441320419-7.61962795258$ $-7.01005792618-6.40048694611-5.79091691971-5.18134689331-4.87656211853$ $-4.57177686691-4.26699209213-3.96220707893-3.65742206573-3.35263609886$ -3.35263609886 -2.74306607246 -2.13349604607 -1.21914100647 -9999 -9999 -.304785102606 -.304785102606 -.609570324421-.304785102606.3047851026058 2.1334960460664 .2669920921336 .7052731513988 .83876895904510 .66748046875 12.4961900711115 .2392597198519 .2014598846424 .3828105926532 .00244140625 41.1459884643644 .8034095764266 .7479400634871 .3197174072371 .31971740723 69.4910125732464 .6144485473664 .3096618652366 .7479400634867 .66230010986 68.2718734741268 .5766525268667 .9670867919966 .1383666992263 .39530944824 60.6522407531758 .2139587402358 .5187492370658 .5187492370656 .38525009155 53.64218139648 -9999 -9999 -9999 -9999 -9999 -9999 -9999 -9999 -9999 -9999 -9999 -9999

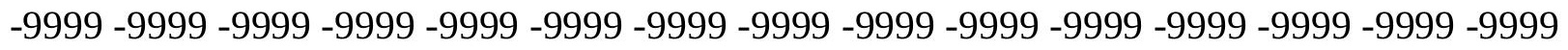
-9999 -9999 -9999 -9999 -9999 -9999 -9999 -9999 -9999 -9999 -9999 -9999 -9999 -9999 -9999 -9999 -9999 -9999 -9999 -9999 -9999 -9999 -9999 -9999 -9999 -9999 -9999 -9999 -9999 -9999 -

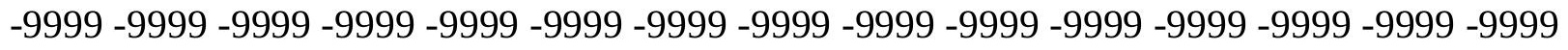

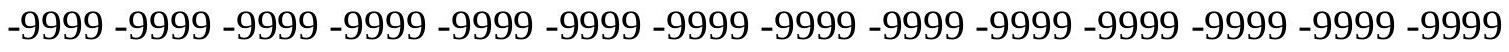
-9999 -9999 -9999 -9999 -9999 -9999 -9999 -9999 -9999 -9999 -9999 -9999 -9999 -9999 -9999 -9999 -9999 -9999 -9999 -9999 -9999 -9999 -9999 -9999 -9999 -9999 -9999 -9999 -9999 -9999 -9999 -9999 -9999 -9999 -9999 -9999 -9999 -9999 -9999 -9999 -9999 -9999 -9999 -9999 -9999 -

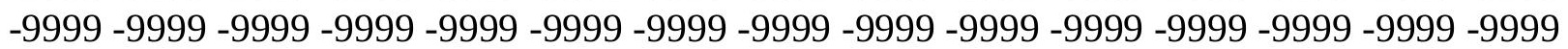


-9999 -9999 -9999 -9999 -9999 -9999 -9999 -9999 -9999 -9999 -9999 -9999 -9999 -9999 -9999 -9999 -9999 -9999 -9999 -9999 -9999 -9999 -9999 -9999 -9999 -9999 -9999 -9999 -9999 -9999 -9999 83.206336975135.65985870361 30.17373085022 17.67753982544 8.229198455811 $.6095703244209-2.13349604607-2.13349604607-.6095703244211 .523926019669$ 4.876562118538 .53398323059112 .191410064715 .8488302230823 .77323913574 30.1737308502233 .2215805053735 .0502891540536 .2694282531737 .18378067017 37.4885711669937 .4885711669937 .4885711669937 .4885711669937 .18378067017 36.8790016174336 .5742111206136 .2694282531735 .9646492004435 .65985870361 35.6598587036135 .9646492004437 .1837806701738 .7077102661140 .23163986206 41.7555618286142 .9747009277344 .1938400268645 .4129791259846 .93690872192 48.4608306884849 .9847602844251 .5086898803752 .7278289794953 .33739852905 53.6421813964853 .6421813964854 .2517509460454 .8613204956155 .47089004517 56.9948196411160 .3474502563566 .4431610107475 .8914871215878 .02498626709 79.8537063598681 .0728530883882 .2919769287183 .206336975183 .81591033936 84.4254837036185 .0350494384885 .3398437585 .9494018554786 .2541885376 86.5589828491286 .5589828491286 .8637619018686 .8637619018687 .16854858398 86.8637619018686 .8637619018686 .8637619018686 .5589828491285 .94940185547 85.3398437584 .7302627563583 .8159103393683 .206336975183 .206336975183 .2063369751 83.5111236572383 .5111236572383 .5111236572383 .206336975182 .90155792236 82.2919769287181 .6824111938580 .7680587768679 .5489196777378 .02498626709 76.5010681152374 .9771423339874 .062782287674 .062782287674 .67236328125 75.2819290161175 .8914871215876 .5010681152376 .5010681152376 .50106811523 75.8914871215874 .9771423339874 .062782287672 .8436431884871 .92929077148 70.7101516723669 .7957916259869 .1862335205168 .8814392089868 .27187347412 67.9670867919967 .6623001098667 .0527267456166 .7479400634866 .74794006348 67.0527267456167 .9670867919969 .1862335205170 .4053573608471 .31971740723 72.5388565063573 .4532165527374 .6723632812575 .5867080688576 .19628143311 77.110626220777 .7202072143678 .6345596313579 .2441329956179 .85370635986 80.4632720947380 .7680587768681 .0728530883881 .3776321411181 .68241119385 $82.291976928714 .5717768669132 .438281059265-3.65742206573-4.87656211853$ $-5.79091691971-7.01005792618-8.22919845581-9.44833946228-10.3626899719$ $-11.2770500183-12.1914100647-13.1057596207-12.8009700775-12.8009700775$ $-12.4961900711-12.1914100647-12.1914100647-11.8866195679-11.5818300247$ $-10.9722604752-10.6674804688-10.3626899719-9.75312423706-9.44833946228$ $-8.83876895905-8.22919845581-7.61962795258-7.3148431778-6.7052731514$ $-6.40048694611-6.095703125-6.095703125-5.79091691971-5.18134689331-4.87656211853$ -3.96220707893 -3.35263609886 -2.43828105927 -2.13349604607 -2.13349604607 $-2.13349604607-2.13349604607-1.52392601967-.914355397224 .3047851026058$ 1.8287110328673 .6574220657355 .4861321449287 .0100579261788 .533983230591 10.3626899719213 .1057596206717 .9823207855224 .3828105926531 .39286994934 35.6598587036138 .0981407165544 .8034095764253 .3373985290553 .03261184692 49.9847602844254 .2517509460457 .909179687560 .3474502563561 .26181030273 61.5666007995660 .9570198059158 .8235282897955 .7756805419951 .81346893311 50.2895507812551 .2038993835453 .6421813964853 .3373985290550 .89912033081 49.67998123169 -9999 -9999 -9999 -9999 -9999 -9999 -9999 -9999 -9999 -9999 -9999 -9999 -9999 -9999 -9999 -9999 -9999 -9999 -9999 -9999 -9999 -9999 -9999 -9999 -9999 -9999 -9999 
-9999 -9999 -9999 -9999 -9999 -9999 -9999 -9999 -9999 -9999 -9999 -9999 -9999 -9999 -9999 -9999 -9999 -9999 -9999 -9999 -9999 -9999 -9999 -9999 -9999 -9999 -9999 -9999 -9999 -9999

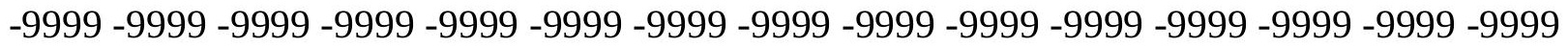
-9999 -9999 -9999 -9999 -9999 -9999 -9999 -9999 -9999 -9999 -9999 -9999 -9999

-9999 -9999 -9999 -9999 -9999 -9999 -9999 -9999 -9999 -9999 -9999 -9999 -9999 -9999 - -9999 -9999 -9999 -9999 -9999 -9999 -9999 -9999 -9999 -9999 -9999 -9999 -9999 -9999 -9999 -9999 -9999 -9999 -9999 -9999 -9999 -9999 -9999 -9999 -9999 -9999 -9999 -9999 -9999 -9999 -9999

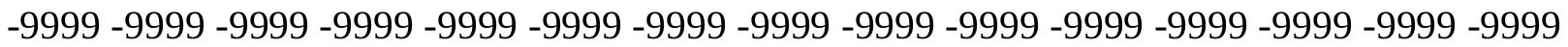

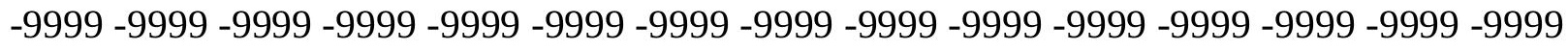
-9999 -9999 -9999 -9999 -9999 -9999 -9999 -9999 -9999 -9999 -9999 -9999 -9999 -9999 -9999 -9999 97.61939239502 58.82352828979 20.7253894805913.71533012396.705273151398 -9999 -3.04785108566 -3.65742206573 -2.13349604607-9999 2.743066072464 5.4861321449288 .83876895904513 .4105501174919 .5062503814725 .29715919495 29.2593708038332 .0024414062533 .5263595581134 .4407196044935 .05028915405 35.6598587036135 .9646492004435 .9646492004435 .9646492004435 .96464920044 35.6598587036135 .6598587036135 .3550796508835 .3550796508835 .35507965088 35.9646492004436 .8790016174338 .0981407165539 .3172798156740 .84120941162 42.0603485107443 .2794914245644 .4986305236845 .717769622847 .24169921875 48.765621185350 .5943298339852 .1182594299352 .1182594299351 .81346893311 51.8134689331152 .1182594299352 .7278289794953 .9469718933155 .77568054199 58.5187492370662 .1761703491270 .7101516723675 .8914871215878 .32978057861 80.1584930419981 .3776321411182 .2919769287182 .9015579223683 .51112365723 84.1206970214884 .4254837036184 .7302627563585 .0350494384885 .3398437585 .33984375 85.6446228027385 .6446228027385 .6446228027385 .3398437585 .3398437585 .03504943848 84.4254837036184 .1206970214883 .5111236572382 .5967712402381 .98719787598 81.6824111938581 .3776321411181 .3776321411181 .3776321411181 .37763214111 81.3776321411181 .0728530883880 .7680587768680 .1584930419979 .24413299561 78.3297805786176 .8058471679775 .2819290161173 .4532165527371 .62449645996 70.1005783081170 .7101516723671 .6244964599672 .5388565063573 .14842987061 73.7580032348674 .062782287674 .062782287673 .7580032348673 .14842987061 72.5388565063571 .6244964599670 .7101516723670 .1005783081169 .49101257324 69.1862335205168 .8814392089868 .5766525268668 .2718734741267 .96708679199 67.6623001098667 .3575134277367 .3575134277367 .9670867919968 .27187347412 69.1862335205169 .7957916259870 .7101516723671 .6244964599672 .84364318848 73.7580032348674 .3675689697375 .2819290161175 .8914871215876 .50106811523 77.110626220777 .7202072143678 .3297805786178 .6345596313578 .63455963135 78.6345596313578 .6345596313578 .9393463134879 .244132995613 .047851085663 $-4.57177686691-6.095703125-7.61962795258-8.83876895905-10.0579099655$ $-11.2770500183-12.4961900711-13.7153301239-14.6296901703-15.2392597198$ -15.5440397263 -15.8488302231 -15.5440397263 -15.2392597198 -14.9344701767 -14.6296901703 -14.3248996735 -14.0201196671 -13.4105501175 -13.1057596207 $-12.4961900711-12.1914100647-11.5818300247-10.9722604752-10.3626899719$ -10.0579099655 -9.44833946228 -9.14355373383 -8.83876895905 -8.53398323059 $-8.22919845581-7.92441320419-7.3148431778-7.01005792618-6.095703125$ $-5.48613214493-4.87656211853-4.57177686691-4.26699209213-4.26699209213$ -3.96220707893 -3.65742206573 -2.74306607246 -1.52392601967 -.304785102606 
.91435539722442 .1334960460663 .3526360988624 .5717768669136 .095703125 8.53398323059111 .5818300247215 .5440397262622 .2493095397928 .04022979736 33.2215805053738 .4029312133842 .66992187543 .8890609741244 .49863052368 46.9369087219250 .5943298339852 .7278289794954 .2517509460454 .55654144287 54.2517509460453 .3373985290550 .5943298339847 .8512611389245 .10820007324 45.717769622847 .5464782714848 .4608306884848 .765621185347 .54647827148 -9999 -9999 -9999 -9999 -9999 -9999 -9999 -9999 -9999 -9999 -9999 -9999 -9999 -9999 -9999 -9999 -9999

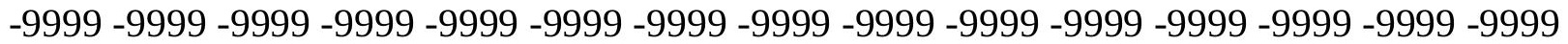
-9999 -9999 -9999 -9999 -9999 -9999 -9999 -9999 -9999 -9999 -9999 -9999 -9999 -9999 -9999 -9999 -9999 -9999 -9999 -9999 -9999 -9999 -9999 -9999 -9999 -9999 -9999 -9999 -9999 -9999 -

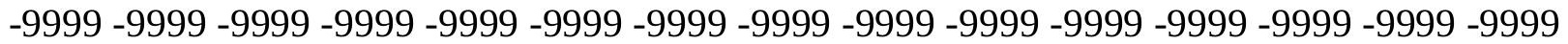
-9999 -9999 -9999 -9999-9999-9999-9999-9999

-9999 -9999 -9999 -9999 -9999 -9999 -9999 -9999 -9999 -9999 -9999 -9999 -9999 -9999 -9999 -9999 -9999 -9999 -9999 -9999 -9999 -9999 -9999 -9999 -9999 -9999 -9999 -9999 -9999 -9999 -9999 -9999 -9999 -9999 -9999 -9999 -9999 -9999 -9999 -9999 -9999 -9999 -9999 -9999 -9999

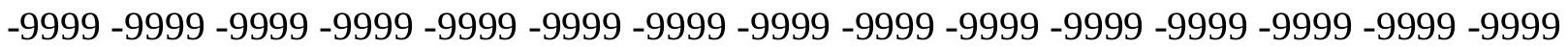

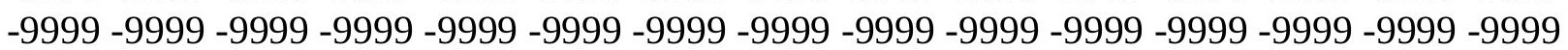
-9999 -9999 -9999 -9999 -9999 -9999 -9999 -9999 -9999 -9999 -9999 -9999 -9999 -9999 -9999 -9999 -9999 91.13075256348 47.24169921875 13.410550117496 .400486946106 .3047851026058 -3.04785108566 -3.96220707893 -2.74306607246 -.304785102606 1.219141006473 .6574220657356 .70527315139810 .9722604751615 .84883022308 21.0301704406725 .2971591949528 .3450202941930 .4785099029531 .69765090942 32.9167900085433 .8311500549334 .4407196044934 .7455101013235 .05028915405 35.0502891540535 .0502891540535 .0502891540535 .0502891540535 .05028915405 35.3550796508835 .9646492004436 .5742111206137 .4885711669938 .70771026611 39.9268493652340 .8412094116242 .0603485107443 .2794914245644 .49863052368 45.717769622847 .2416992187548 .4608306884849 .3751907348649 .98476028442 49.9847602844249 .9847602844250 .2895507812551 .2038993835452 .42303848267 54.2517509460457 .2995986938561 .5666007995667 .3575134277372 .53885650635 75.8914871215878 .3297805786179 .8537063598681 .0728530883881 .68241119385 82.2919769287182 .9015579223683 .206336975183 .5111236572383 .81591033936 84.1206970214884 .1206970214884 .1206970214884 .1206970214884 .12069702148 83.81591033936 83.51112365723 83.2063369751 82.59677124023 82.29197692871 81.6824111938581 .0728530883880 .4632720947379 .8537063598679 .54891967773 79.5489196777379 .5489196777379 .5489196777379 .2441329956178 .93934631348 78.6345596313578 .0249862670977 .110626220776 .1962814331174 .67236328125 73.1484298706171 .3197174072369 .7957916259868 .5766525268668 .57665252686 69.1862335205170 .1005783081171 .014930725171 .6244964599672 .23407745361 72.2340774536171 .9292907714871 .6244964599670 .7101516723670 .10057830811 69.4910125732469 .1862335205169 .1862335205168 .8814392089868 .88143920898 68.5766525268668 .2718734741267 .9670867919967 .9670867919967 .96708679199 68.2718734741268 .5766525268668 .8814392089868 .8814392089869 .49101257324 70.1005783081170 .7101516723671 .6244964599672 .5388565063573 .14842987061 73.7580032348674 .062782287674 .6723632812574 .9771423339875 .58670806885 75.8914871215875 .8914871215875 .5867080688575 .2819290161174 .67236328125 $74.6723632812575 .58670806885-4.57177686691-6.40048694611-8.22919845581$ 
-10.0579099655 -11.5818300247 -13.1057596207 -14.3248996735 -15.5440397263 -16.4584007263 -17.3727493286 -17.6775398254 -17.9823207855 -17.9823207855 -17.9823207855 -17.6775398254-17.0679702759 -16.7631797791 -16.4584007263 $-16.1536102295-15.8488302231-15.2392597198-14.9344701767-14.3248996735$ -13.7153301239 -13.1057596207 -12.8009700775 -12.1914100647 -11.5818300247 $-11.2770500183-10.9722604752-10.6674804688-10.3626899719-9.75312423706$ $-9.44833946228-9.14355373383-8.53398323059-7.92441320419-7.3148431778$ $-7.01005792618-6.7052731514-6.7052731514-6.40048694611-5.79091691971$ $-5.18134689331-3.96220707893-3.04785108566-1.82871103287-.914355397224-9999$ .91435539722442 .4382810592654 .2669920921337 .01005792617810 .66748046875 15.8488302230821 .334960937527 .430660247832 .6120109558137 .18378067017 40.5364189147942 .9747009277345 .4129791259848 .1560516357449 .98476028442 51.2038993835451 .8134689331151 .2038993835449 .9847602844247 .54647827148 44.8034095764241 .7555618286142 .0603485107442 .66992187544 .19384002686 45.4129791259845 .10820007324 -9999 -9999 -9999 -9999 -9999 -9999 -9999 -9999 -9999 -9999 -9999 -9999 -9999 -9999 -9999 -9999 -9999 -9999-9999 -9999 -9999 -9999 -9999 -9999 -9999 -9999 -9999 -9999 -9999 -9999 -9999 -9999 -9999 -9999 -9999 -9999 -9999 -9999 -9999 -9999 -9999 -9999 -9999 -9999 -9999 -9999 -9999 -9999 -9999 -9999 -9999 -9999 -9999 -9999 -

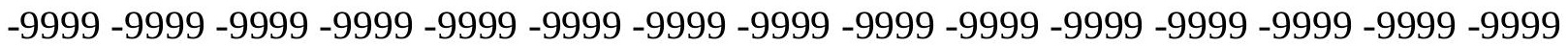

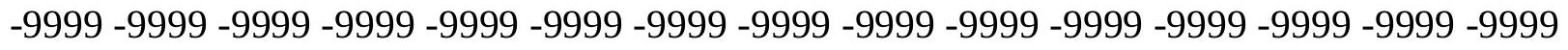
$-9999$

-9999 -9999 -9999 -9999 -9999 -9999 -9999 -9999 -9999 -9999 -9999 -9999 -9999 -9999 -9999 -9999 -9999 -9999 -9999 -9999 -9999 -9999 -9999 -9999 -9999 -9999 -9999 -9999 -9999 -9999 -

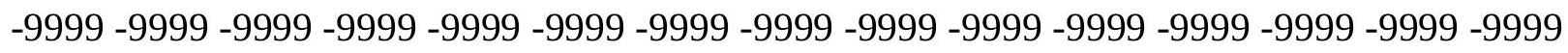

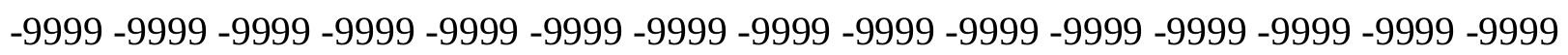
-9999 -9999 -9999 -9999 -9999 -9999 -9999 -9999 -9999 -9999 -9999 -9999 -9999 -9999 -9999 -9999 -9999 -9999 -9999 -9999 -9999 -9999 -9999 -9999 -9999 -9999 -9999 -9999 -9999 -9999 -9999 -9999-9999 79.24413299561 38.098140716556 .705273151398 .9143553972244 -2.43828105927 -3.65742206573 -3.35263609886-1.82871103287-9999 2.133496046066 5.1813468933118 .83876895904513 .1057596206717 .3727493286121 .3349609375 24.6875991821327 .1258792877228 .9545898437530 .4785099029531 .69765090942 32.6120109558133 .5263595581133 .8311500549334 .1359291076734 .44071960449 34.4407196044934 .7455101013235 .0502891540535 .3550796508835 .65985870361 36.2694282531737 .1837806701738 .0981407165539 .0125007629439 .92684936523 40.8412094116241 .7555618286142 .66992187543 .8890609741245 .10820007324 46.0225486755446 .9369087219247 .2416992187547 .5464782714847 .85126113892 48.4608306884849 .3751907348651 .2038993835453 .3373985290556 .69002914429 60.9570198059165 .5288009643670 .1005783081173 .4532165527376 .19628143311 78.0249862670979 .2441329956180 .4632720947381 .0728530883881 .68241119385 81.9871978759882 .2919769287182 .5967712402382 .5967712402382 .59677124023 82.5967712402382 .5967712402382 .5967712402382 .2919769287181 .98719787598 81.3776321411181 .0728530883880 .4632720947379 .8537063598679 .24413299561 78.9393463134878 .3297805786178 .0249862670978 .0249862670977 .72020721436 77.7202072143677 .4154205322377 .4154205322376 .8058471679776 .19628143311 75.2819290161174 .3675689697373 .1484298706171 .6244964599670 .10057830811 68.5766525268667 .6623001098667 .3575134277367 .6623001098668 .27187347412 
68.8814392089869 .4910125732470 .1005783081170 .4053573608470 .40535736084 69.7957916259868 .8814392089868 .2718734741267 .9670867919967 .96708679199 68.2718734741268 .5766525268668 .5766525268668 .2718734741267 .96708679199 67.6623001098667 .9670867919968 .2718734741268 .5766525268668 .88143920898 68.8814392089868 .5766525268668 .5766525268668 .5766525268669 .18623352051 70.1005783081171 .014930725171 .6244964599671 .9292907714871 .92929077148 71.9292907714872 .2340774536172 .5388565063572 .8436431884872 .53885650635 71.6244964599670 .4053573608469 .4910125732468 .881439208983 .047851085663 $-5.79091691971-8.22919845581-10.3626899719-12.4961900711-14.3248996735$ $-15.8488302231-17.0679702759-18.287109375-18.8966808319-19.5062503815$ -20.115819931 -20.115819931 -20.115819931 -19.8110294342 -19.5062503815 -19.2014598846 -18.8966808319-18.5918903351 -18.287109375 -17.6775398254 -17.3727493286 -16.7631797791 -16.4584007263 -15.8488302231 -15.2392597198 -14.6296901703 -14.3248996735 -13.7153301239 -13.4105501175 -13.1057596207 -12.8009700775 -12.1914100647 -11.8866195679 -11.5818300247 -11.2770500183 $-10.6674804688-10.3626899719-9.75312423706-9.44833946228-9.14355373383$ $-9.14355373383-8.83876895905-8.22919845581-7.3148431778-6.7052731514$ $-5.79091691971-4.87656211853-3.96220707893-3.35263609886-2.13349604607$ -.609570324421.9143553972244 3.657422065735 7.010057926178 10.97226047516 15.5440397262620 .4206008911126 .5163097381632 .3072204589837 .18378067017 40.5364189147942 .9747009277345 .1082000732446 .9369087219248 .15605163574 48.4608306884848 .1560516357446 .9369087219244 .8034095764242 .669921875 40.2316398620639 .3172798156740 .2316398620641 .4507789611842 .669921875 42.36513137817 -9999 -9999 -9999 -9999 -9999 -9999 -9999 -9999 -9999 -9999 -9999 -9999 -9999 -9999 -9999 -9999 -9999 -9999 -9999 -9999 -9999 -9999 -9999 -9999 -9999 -9999 -9999 -9999 -9999 -9999 -9999 -9999 -9999 -9999 -9999 -9999 -9999 -9999 -9999 -9999 -9999 -9999

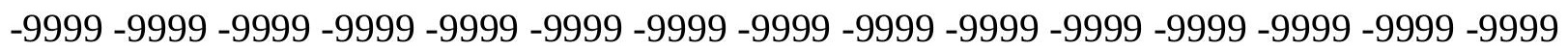

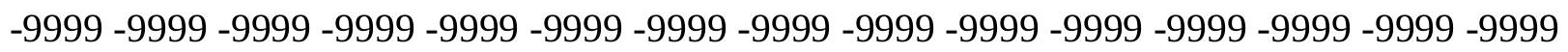
-9999 -9999 -9999 -9999 -9999 -9999 -9999 -9999 -9999 -9999 -9999 -9999 -9999 - -999 -9999 -9999 -9999 -9999 -9999 -9999 -9999 -9999 -9999 -9999 -9999 -9999 -9999 -9999 -9999 -9999 -9999 -9999 -9999 -9999 -9999 -9999 -9999 -9999 -9999 -9999 -9999 -9999 -9999 -9999

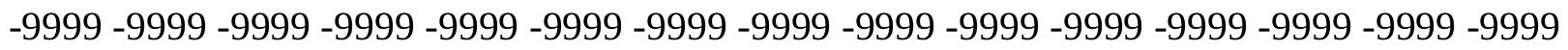

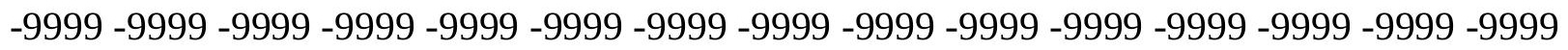
-9999 -9999 -9999 -9999 -9999 -9999 -9999 -9999 -9999 -9999 -9999 -9999 -9999 -9999 -9999

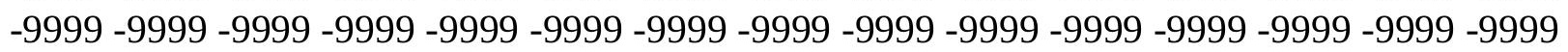
-9999 -9999-9999 109.7226028442 64.61444854736 23.468450546261.828711032867 $-1.21914100647-2.74306607246-3.35263609886-2.43828105927-.609570324421$ .91435539722443 .6574220657357 .01005792617810 .6674804687514 .62969017029 18.28710937521 .6397399902324 .0780296325726 .2115192413328 .34502029419 29.8689403533931 .0880794525132 .3072204589832 .9167900085433 .52635955811 33.8311500549334 .1359291076734 .4407196044934 .7455101013235 .05028915405 35.6598587036136 .2694282531736 .8790016174337 .4885711669938 .09814071655 38.7077102661139 .3172798156740 .2316398620641 .1459884643641 .75556182861 42.66992187543 .5842704772944 .1938400268644 .8034095764245 .10820007324 45.717769622846 .6321296691947 .8512611389249 .9847602844252 .42303848267 56.0804595947360 .0426712036164 .004882812567 .9670867919971 .31971740723 
74.062782287676 .1962814331177 .7202072143678 .9393463134879 .54891967773 80.1584930419980 .7680587768681 .0728530883881 .0728530883881 .37763214111 81.3776321411181 .3776321411181 .0728530883881 .0728530883880 .76805877686 80.1584930419979 .8537063598679 .2441329956178 .9393463134878 .32978057861 77.7202072143677 .4154205322377 .110626220776 .8058471679776 .50106811523 76.1962814331176 .1962814331175 .8914871215875 .5867080688575 .28192901611 74.6723632812573 .7580032348672 .8436431884871 .6244964599670 .40535736084 69.1862335205167 .9670867919967 .0527267456166 .4431610107466 .44316101074 66.4431610107466 .7479400634867 .3575134277367 .9670867919968 .57665252686 68.5766525268667 .6623001098666 .7479400634866 .1383666992265 .83358764648 66.1383666992267 .0527267456167 .3575134277367 .6623001098667 .05272674561 66.7479400634866 .4431610107466 .7479400634867 .3575134277368 .27187347412 68.5766525268667 .9670867919967 .3575134277366 .4431610107466 .44316101074 66.7479400634867 .6623001098668 .8814392089869 .1862335205169 .18623352051 68.5766525268668 .2718734741267 .9670867919967 .9670867919968 .27187347412 67.9670867919966 .1383666992264 .004882812562 .4809494018661 .87137985229 $-4.26699209213-7.01005792618-9.75312423706-12.1914100647-14.6296901703$ -16.7631797791 -18.5918903351 -19.8110294342 -20.7253894806 -21.3349609375 -21.6397399902 -21.9445304871 -21.9445304871 -21.9445304871 -21.6397399902 $-21.3349609375-21.0301704407-20.7253894806-20.4206008911-20.115819931$ $-19.5062503815-19.2014598846-18.8966808319-18.287109375-17.6775398254$ -17.3727493286 -16.7631797791 -16.1536102295 -15.8488302231 -15.5440397263 -14.9344701767 -14.6296901703 -14.3248996735 -14.0201196671 -13.7153301239 -13.1057596207 -12.8009700775 -12.4961900711 -12.1914100647-11.8866195679 $-11.5818300247-11.2770500183-10.9722604752-10.3626899719-9.75312423706$ $-9.14355373383-8.53398323059-7.92441320419-7.01005792618-6.40048694611$ -5.48613214493 -3.96220707893 -1.82871103287.6095703244209 3.657422065735 7.01005792617810 .0579099655213 .715330123920 .4206008911127 .4306602478 33.8311500549336 .8790016174339 .3172798156741 .7555618286143 .58427047729 44.8034095764245 .4129791259845 .1082000732444 .1938400268642 .669921875 40.8412094116239 .3172798156738 .4029312133838 .4029312133838 .70771026611 39.622070312540 .53641891479 -9999 -9999 -9999 -9999 -9999 -9999 -9999 -9999 -9999 -9999 -9999 -9999 -9999 -9999 -9999 -9999 -9999 -9999 -9999 -9999 -9999 -9999 -9999 -9999 -9999 -9999 -9999 -9999 -9999 -9999 -9999 -9999 -9999 -9999 -9999 -9999 -9999 -9999 -9999 -9999 -9999 -9999 -9999 -9999 -9999 -9999 -9999 -9999 -9999 -9999 -9999 -9999 -9999 -9999 -9999 -9999 -9999 -9999 -9999 -9999 -9999 -9999 -9999 -9999 -9999 -9999 -9999 -9999 -9999

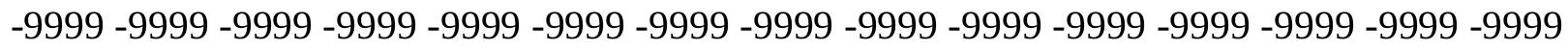
$-9999$

-9999 -9999 -9999 -9999 -9999 -9999 -9999 -9999 -9999 -9999 -9999 -9999 -9999 -9999 -9999 -9999 -9999 -9999 -9999 -9999 -9999 -9999 -9999 -9999 -9999 -9999 -9999 -9999 -9999 -9999 -

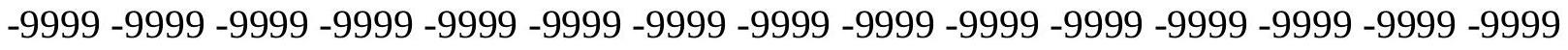

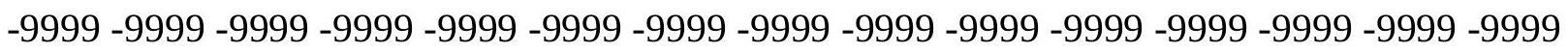
-9999 -9999 -9999 -9999 -9999 -9999 -9999 -9999 -9999 -9999 -9999 -9999 -9999 -9999 -9999 -9999 -9999 -9999 -9999 -9999 -9999 -9999 -9999 -9999 -9999 -9999 -9999 -9999 -9999 -9999 -9999 -9999 -9999 -9999 95.09295654297 48.15605163574 7.6196279525761 .828711032867 $-.914355397224-2.74306607246-3.04785108566-1.82871103287-99992.743066072464$ 
5.4861321449288 .83876895904512 .4961900711115 .8488302230818 .89668083191 21.6397399902324 .0780296325726 .5163097381628 .3450202941929 .86894035339 31.0880794525132 .3072204589832 .9167900085433 .5263595581134 .13592910767 34.4407196044934 .7455101013235 .0502891540535 .6598587036135 .96464920044 36.5742111206136 .8790016174337 .1837806701737 .7933502197338 .09814071655 38.7077102661139 .3172798156739 .9268493652340 .5364189147941 .14598846436 41.7555618286142 .3651313781742 .9747009277343 .8890609741244 .80340957642 46.6321296691948 .765621185351 .5086898803754 .8613204956158 .82352828979 62.1761703491265 .8335876464869 .1862335205171 .9292907714874 .0627822876 75.8914871215877 .110626220778 .0249862670978 .6345596313579 .24413299561 79.5489196777379 .8537063598679 .8537063598680 .1584930419979 .85370635986 79.8537063598679 .5489196777379 .2441329956178 .9393463134878 .32978057861 77.7202072143677 .110626220776 .8058471679776 .1962814331175 .89148712158 75.5867080688575 .2819290161174 .9771423339874 .97714233339874 .67236328125 74.6723632812574 .3675689697373 .7580032348673 .1484298706172 .53885650635 71.3197174072370 .4053573608469 .1862335205168 .2718734741267 .35751342773 66.1383666992265 .5288009643664 .9192428588964 .3096618652364 .30966186523 64.9192428588965 .5288009643666 .1383666992266 .1383666992265 .22400665283 63.7000885009862 .4809494018662 .4809494018663 .0905189514264 .30966186523 65.5288009643665 .2240066528364 .6144485473663 .7000885009863 .39530944824 63.7000885009864 .9192428588966 .1383666992267 .0527267456166 .13836669922 64.6144485473663 .3953094482463 .0905189514263 .3953094482464 .30966186523 65.5288009643666 .4431610107465 .5288009643664 .3096618652363 .09051895142 62.4809494018662 .1761703491262 .1761703491262 .1761703491258 .51874923706 $55.4708900451753 .03261184692-2.13349604607-5.48613214493-8.53398323059$ $-11.2770500183-14.0201196671-16.7631797791-19.2014598846-21.0301704407$ $-22.2493095398-23.1636695862-23.4684505463-23.7732391357-23.7732391357$ $-23.7732391357-23.4684505463-23.1636695862-22.8588790894-22.5541000366$ $-22.2493095398-21.9445304871-21.6397399902-21.3349609375-21.0301704407$ $-20.7253894806-20.115819931-19.5062503815-19.2014598846-18.5918903351$ $-18.287109375-17.6775398254-17.3727493286-17.0679702759-16.4584007263$ $-16.1536102295-15.8488302231-15.5440397263-15.2392597198-14.9344701767$ $-14.6296901703-14.3248996735-14.0201196671-13.7153301239-13.4105501175$ $-13.1057596207-12.8009700775-12.1914100647-11.5818300247-10.9722604752$ $-10.3626899719-10.0579099655-9.44833946228-8.53398323059-7.3148431778$ $-5.48613214493-2.13349604607 .91435539722443 .6574220657356 .095703125$ 9.75312423706115 .2392597198521 .6397399902327 .7354507446332 .00244140625 35.3550796508838 .0981407165539 .9268493652341 .4507789611842 .36513137817 42.3651313781741 .7555618286140 .8412094116239 .622070312538 .40293121338 $37.7933502197337 .4885711669937 .7933502197338 .0981407165539 .01250076294-9999$

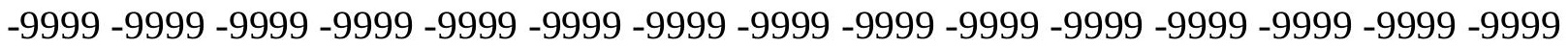

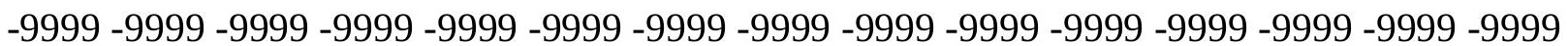

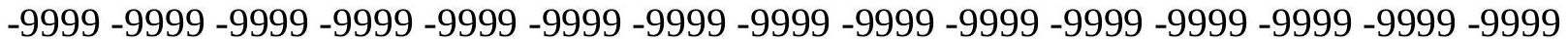

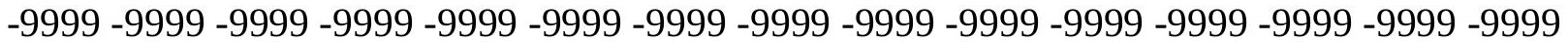

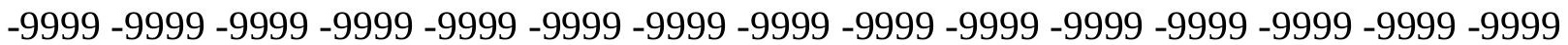
-9999 -9999 -9999 -9999 -9999 -9999 -9999 -9999 -9999 
-9999 -9999 -9999 -9999 -9999 -9999 -9999 -9999 -9999 -9999 -9999 -9999 -9999 -9999 -9999 -9999 -9999 -9999 -9999 -9999 -9999 -9999 -9999 -9999 -9999 -9999 -9999 -9999 -9999 -9999 -9999 -9999 -9999 -9999 -9999 -9999 -9999 -9999 -9999 -9999 -9999 -9999 -9999 -9999 -9999 -9999 -9999 -9999 -9999 -9999 -9999 -9999 -9999 -9999 -9999 -9999 -9999 -9999 -9999 -9999 -9999 -9999 -9999 -9999 -9999 -9999 -9999 -9999 -9999 -9999 -9999 -9999-9999 -9999 -9999 -

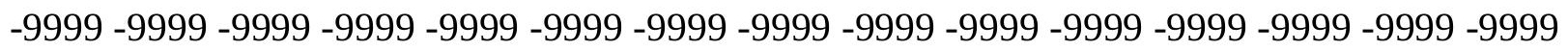
-9999 -9999 -9999 -9999 -9999 82.29197692871 36.57421112061 7.924413204193 $1.21914100647-1.82871103287-2.74306607246-1.82871103287-99992.133496046066$ 4.876562118537 .92441320419310 .9722604751614 .0201196670517 .06797027588 19.811029434222 .5541000366224 .9923801422127 .1258792877228 .95458984375 30.7833003997831 .6976509094232 .6120109558133 .5263595581134 .13592910767 34.4407196044935 .0502891540535 .3550796508835 .6598587036135 .96464920044 36.2694282531736 .5742111206136 .8790016174336 .8790016174337 .18378067017 37.4885711669937 .7933502197338 .0981407165538 .4029312133839 .01250076294 39.622070312540 .2316398620640 .8412094116242 .0603485107443 .27949142456 45.1082000732447 .2416992187550 .2895507812553 .3373985290556 .99481964111 60.3474502563563 .7000885009867 .0527267456170 .1005783081172 .23407745361 74.062782287675 .2819290161176 .5010681152377 .110626220777 .72020721436 78.0249862670978 .3297805786178 .6345596313578 .6345596313578 .63455963135 78.6345596313578 .3297805786178 .0249862670977 .4154205322376 .80584716797 76.5010681152375 .8914871215875 .2819290161174 .6723632812574 .36756896973 74.062782287674 .062782287673 .7580032348673 .4532165527373 .45321655273 73.1484298706172 .8436431884872 .2340774536171 .6244964599671 .0149307251 70.1005783081169 .1862335205168 .2718734741267 .0527267456166 .13836669922 65.2240066528364 .004882812562 .7857398986861 .8713798522961 .26181030273 61.2618103027361 .5666007995662 .4809494018663 .0905189514260 .95701980591 59.1283111572357 .909179687557 .2995986938557 .909179687559 .73788070679 62.1761703491260 .9570198059159 .7378807067959 .1283111572358 .51874923706 58.8235282897959 .7378807067961 .5666007995664 .004882812561 .87137985229 59.7378807067958 .5187492370657 .909179687558 .2139587402359 .12831115723 60.6522407531762 .1761703491260 .3474502563558 .5187492370656 .69002914429 55.4708900451754 .5565414428753 .6421813964851 .8134689331148 .46083068848 $45.1082000732442 .06034851074-4.26699209213-7.3148431778-10.0579099655$ $-13.1057596207-16.1536102295-19.2014598846-21.9445304871-23.7732391357$ $-24.9923801422-25.6019496918-25.6019496918-25.6019496918-25.2971591949$ $-24.9923801422-24.6875991821-24.3828105927-24.3828105927-24.0780296326$ -23.7732391357 -23.4684505463 -23.1636695862 -22.8588790894 -22.5541000366 $-22.2493095398-21.9445304871-21.3349609375-20.7253894806-20.4206008911$ $-19.8110294342-19.5062503815-19.2014598846-18.5918903351-18.287109375$ -17.9823207855 -17.6775398254-17.3727493286-17.0679702759-16.7631797791 -16.7631797791 -16.4584007263 -16.1536102295 -15.8488302231 -15.5440397263 -15.2392597198 -14.9344701767 -14.3248996735 -13.7153301239-13.4105501175 $-12.8009700775-12.4961900711-12.1914100647-11.5818300247-10.9722604752$ -9.44833946228 -6.40048694611 -1.21914100647 -9999 2.133496046066 5.790916919708 10.3626899719216 .1536102294921 .9445304870626 .8210906982430 .78330039978 34.1359291076736 .5742111206138 .4029312133839 .622070312539 .92684936523 
39.622070312539 .0125007629438 .4029312133837 .4885711669936 .87900161743 36.5742111206136 .5742111206136 .8790016174338 .09814071655 -9999 -9999 -9999 -9999 -9999 -9999 -9999 -9999 -9999 -9999 -9999 -9999 -9999 -9999 -9999 -9999 -9999 -9999 -9999 -9999 -9999 -9999 -9999 -9999 -9999 -9999 -9999 -9999 -9999 -9999 -9999 -9999 -9999 -9999 -9999 -9999 -9999 -9999 -9999 -9999 -9999 -9999 -9999-9999 -9999 -9999 -9999 -9999 -9999 -9999 -9999 -9999 -9999 -9999 -9999 -9999 -9999 -9999 -9999 -9999 -9999 -9999 -9999 -9999

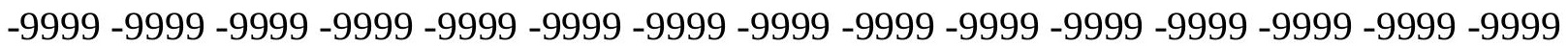
-9999 -9999 -9999-9999-9999-9999

-9999 -9999 -9999 -9999 -9999-9999 -9999 -9999 -9999 -9999 -9999 -9999 -9999 -9999 -9999 -9999 -9999 -9999 -9999 -9999 -9999 -9999 -9999 -9999 -9999 -9999 -9999 -9999 -9999 -9999

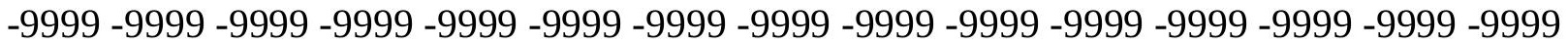
-9999 -9999 -9999 -9999 -9999 -9999 -9999 -9999 -9999 -9999 -9999 -9999 -9999 -9999 -9999 -9999 -9999 -9999 -9999 -9999 -9999 -9999 -9999 -9999 -9999 -9999 -9999 -9999 -9999 -9999 -9999 -9999 -9999 -9999 -9999 -9999 -9999 -9999 -9999 -9999 -9999 -9999 -9999 -9999 -9999 -9999 -9999 -9999 -9999 -9999 119.1709976196 70.1005783081125.60194969177 7.010057926178 -9999-.914355397224 -1.21914100647.3047851026058 2.438281059265 4.876562118537 .31484317779510 .3626899719213 .1057596206715 .84883022308 18.5918903350821 .334960937523 .7732391357426 .2115192413328 .34502029419 30.4785099029531 .6976509094232 .6120109558133 .5263595581134 .13592910767 34.7455101013235 .3550796508835 .9646492004436 .2694282531736 .57421112061 36.5742111206136 .5742111206136 .5742111206136 .5742111206136 .57421112061 36.2694282531736 .2694282531736 .5742111206136 .5742111206137 .18378067017 37.4885711669938 .0981407165539 .0125007629440 .2316398620641 .75556182861 43.5842704772946 .0225486755448 .765621185351 .8134689331155 .16611099243 58.5187492370661 .5666007995665 .5288009643668 .2718734741270 .71015167236 72.2340774536173 .7580032348674 .6723632812575 .5867080688576 .19628143311 76.8058471679777 .110626220777 .4154205322377 .4154205322377 .41542053223 77.4154205322377 .110626220776 .8058471679776 .1962814331175 .89148712158 75.2819290161174 .3675689697373 .7580032348673 .4532165527373 .14842987061 72.8436431884872 .8436431884872 .5388565063572 .2340774536171 .92929077148 71.6244964599671 .3197174072371 .014930725170 .4053573608469 .49101257324 68.5766525268667 .6623001098666 .4431610107465 .5288009643664 .61444854736 63.7000885009861 .8713798522959 .7378807067958 .2139587402356 .99481964111 56.6900291442956 .6900291442956 .6900291442956 .3852500915555 .16611099243 53.3373985290551 .8134689331150 .8991203308150 .8991203308152 .11825942993 53.3373985290553 .6421813964853 .3373985290552 .7278289794951 .81346893311 51.5086898803752 .1182594299353 .6421813964854 .8613204956154 .25175094604 53.0326118469252 .1182594299351 .5086898803751 .8134689331152 .42303848267 53.3373985290553 .6421813964852 .7278289794951 .2038993835449 .37519073486 47.8512611389246 .0225486755444 .1938400268641 .1459884643637 .48857116699 $33.8311500549330 .47850990295-6.7052731514-9.75312423706-12.1914100647$ -14.9344701767 -18.287109375 -21.9445304871 -24.6875991821 -26.8210906982 $-27.7354507446-27.7354507446-27.4306602478-27.1258792877-26.5163097382$ $-26.2115192413-25.9067401886-25.6019496918-25.2971591949-25.2971591949$ $-24.9923801422-24.6875991821-24.6875991821-24.3828105927-24.3828105927$ $-23.7732391357-23.4684505463-22.8588790894-22.5541000366-21.9445304871$ 
-21.6397399902 -21.0301704407 -20.7253894806 -20.4206008911 -20.115819931 $-19.8110294342-19.5062503815-19.2014598846-18.8966808319-18.8966808319$ $-18.5918903351-18.287109375-17.9823207855-17.6775398254-17.3727493286$ $-17.0679702759-16.7631797791-16.4584007263-15.8488302231-15.5440397263$ $-15.2392597198-14.9344701767-14.6296901703-14.3248996735-14.0201196671$ -13.4105501175 -12.1914100647 -7.3148431778 -3.96220707893 -1.52392601967 1.5239260196695 .79091691970810 .9722604751616 .7631797790521 .94453048706 26.8210906982430 .4785099029533 .5263595581135 .6598587036136 .87900161743 37.7933502197337 .7933502197337 .4885711669937 .1837806701736 .57421112061 35.9646492004435 .6598587036135 .6598587036136 .2694282531737 .18378067017 -9999 -9999 -9999 -9999 -9999 -9999 -9999 -9999 -9999 -9999 -9999 -9999 -9999 -9999 -9999 -9999 -9999 -9999 -9999 -9999 -9999 -9999 -9999 -9999 -9999 -9999 -9999 -9999 -9999 -9999 -9999 -9999 -9999 -9999 -9999 -9999 -9999 -9999 -9999 -9999 -9999 -9999 -9999 -9999 -9999 -9999 -9999 -9999 -9999 -9999 -9999 -9999 -9999 -9999 -9999 -9999 -9999 -9999 -9999 -9999 -9999 -9999 -9999 -9999 -9999 -9999 -9999 -9999 -9999 -9999 -9999 -9999 -9999 -9999 -9999 -9999 -9999 -9999 -9999 -9999 -9999 -9999 -9999 -9999 -9999

-9999 -9999 -9999 -9999 -9999 -9999 -9999 -9999 -9999 -9999 -9999 -9999 -9999 -9999 -9999

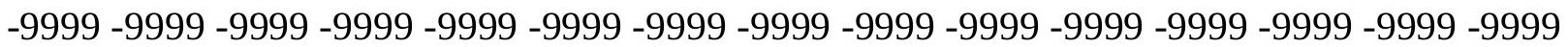
-9999 -9999 -9999 -9999 -9999 -9999 -9999 -9999 -9999 -9999 -9999 -9999 -9999 -9999 -9999 -9999 -9999 -9999 -9999 -9999 -9999 -9999 -9999 -9999 -9999 -9999 -9999 -9999 -9999 -9999 -9999 -9999 -9999 -9999 -9999 -9999 -9999 -9999 -9999 -9999 -9999 -9999 -9999 -9999 -9999 -9999 -9999 -9999 -9999 -9999 -9999 -9999 -9999 -9999 -9999 -9999 -9999 -9999 -9999 -9999 -9999 -9999 -9999 -9999 -9999-9999 102.71260070852 .1182594299310 .66748046875 5.7909169197083 .0478510856631 .5239260196691 .8287110328673 .352636098862 5.4861321449287 .92441320419310 .3626899719213 .1057596206715 .54403972626 17.9823207855220 .7253894805923 .1636695861825 .906740188628 .04022979736 30.1737308502231 .6976509094232 .9167900085433 .8311500549334 .74551010132 35.3550796508835 .9646492004436 .5742111206136 .8790016174337 .18378067017 37.1837806701737 .1837806701736 .8790016174336 .2694282531735 .96464920044 35.6598587036135 .3550796508835 .3550796508835 .3550796508835 .35507965088 35.9646492004436 .5742111206137 .4885711669938 .7077102661140 .23163986206 42.3651313781744 .4986305236847 .2416992187550 .2895507812553 .64218139648 56.9948196411160 .3474502563564 .004882812566 .7479400634868 .88143920898 70.7101516723671 .9292907714873 .1484298706174 .062782287674 .97714233398 75.5867080688575 .8914871215876 .1962814331176 .5010681152376 .50106811523 76.5010681152376 .1962814331175 .8914871215875 .2819290161174 .67236328125 74.062782287673 .4532165527372 .8436431884872 .2340774536171 .92929077148 71.6244964599671 .6244964599671 .3197174072371 .014930725170 .71015167236 70.4053573608470 .1005783081169 .4910125732468 .8814392089867 .96708679199 66.7479400634865 .5288009643664 .004882812563 .0905189514262 .17617034912 61.2618103027358 .5187492370655 .7756805419953 .6421813964851 .81346893311 50.8991203308150 .2895507812549 .6799812316949 .0704002380447 .85126113892 46.3273391723644 .4986305236843 .2794914245642 .3651313781742 .669921875 43.8890609741245 .1082000732445 .4129791259845 .1082000732444 .19384002686 42.9747009277342 .66992187543 .5842704772944 .8034095764245 .10820007324 44.8034095764244 .4986305236844 .1938400268644 .1938400268644 .19384002686 
44.8034095764244 .8034095764244 .1938400268642 .9747009277341 .45077896118 39.9268493652337 .7933502197335 .3550796508831 .6976509094227 .12587928772 $23.7732391357419 .20145988464-10.0579099655-12.8009700775-15.5440397263$ -17.3727493286 -21.6397399902 -24.9923801422 -27.7354507446 -29.8689403534 -29.8689403534 -29.5641593933 -28.9545898438 -28.3450202942 -27.7354507446 -27.1258792877 -26.8210906982 -26.5163097382 -26.2115192413 -26.2115192413 -25.9067401886 -25.9067401886 -25.9067401886 -25.9067401886 -25.6019496918 $-25.2971591949-24.6875991821-24.3828105927-24.0780296326-23.4684505463$ $-23.1636695862-22.8588790894-22.2493095398-21.9445304871-21.6397399902$ -21.3349609375 -21.3349609375 -21.0301704407 -20.7253894806 -20.4206008911 $-20.4206008911-20.115819931-19.8110294342-19.5062503815-19.2014598846$ -18.8966808319-18.5918903351 -17.9823207855 -17.6775398254 -17.3727493286 -17.0679702759-16.7631797791 -16.7631797791 -16.7631797791 .3047851026058 $1.5239260196692 .438281059265-11.2770500183-8.22919845581$-5.18134689331 -2.13349604607 1.21914100647 6.705273151398 12.49619007111 17.98232078552 22.8588790893627 .1258792877230 .7833003997833 .2215805053734 .74551010132 35.9646492004436 .2694282531736 .2694282531735 .9646492004435 .65985870361 35.0502891540534 .7455101013234 .7455101013235 .65985870361 -9999 -9999 -9999 -9999 -9999 -9999 -9999 -9999 -9999 -9999 -9999 -9999 -9999 -9999 -9999 -9999 -9999 -9999 -9999

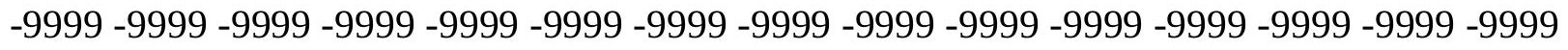

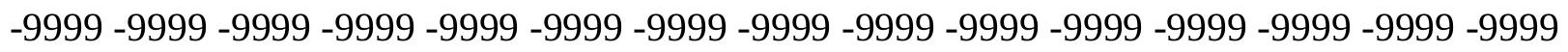
-9999 -9999 -9999 -9999 -9999 -9999 -9999 -9999 -9999 -9999 -9999 -9999 -9999 -9999 -9999 -

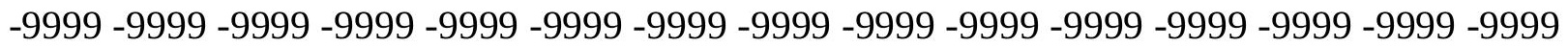
-9999 -9999 -9999 -9999-9999 -9999-9999

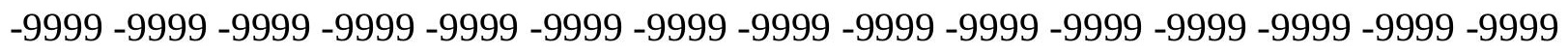
-9999 -9999 -9999 -9999 -9999 -9999 -9999 -9999 -9999 -9999 -9999 -9999 -9999 -9999 -9999 -

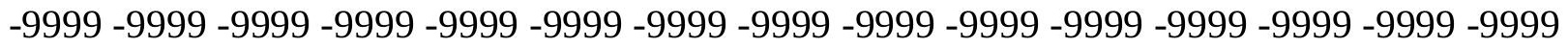

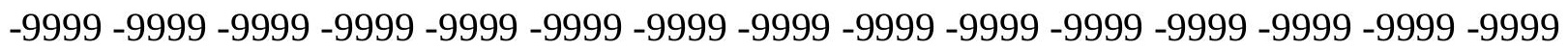
-9999 -9999 -9999 -9999 -9999 -9999 -9999 -9999 -9999 -9999 -9999 -9999 -9999 -9999 -9999 -9999 -9999 -9999 -9999 -9999 -9999 -9999 -9999 -9999 -9999 -9999 -9999 -9999 -9999 -9999 -9999 -9999 -9999 -9999 -9999 -9999 -9999 82.90155792236 34.7455101013212.49619007111 8.2291984558115 .1813468933114 .876562118535 .7909169197087 .314843177795 9.4483394622811 .2770500183113 .715330123915 .8488302230818 .287109375 20.4206008911123 .1636695861825 .6019496917728 .0402297973630 .17373085022 31.6976509094233 .2215805053734 .1359291076735 .3550796508836 .26942825317 37.1837806701737 .7933502197338 .4029312133838 .4029312133838 .40293121338 37.7933502197337 .4885711669936 .5742111206135 .9646492004435 .35507965088 34.7455101013234 .4407196044934 .4407196044934 .4407196044934 .74551010132 35.3550796508836 .2694282531737 .7933502197339 .3172798156741 .14598846436 43.2794914245646 .0225486755449 .0704002380452 .1182594299355 .77568054199 59.4331016540562 .7857398986865 .5288009643667 .3575134277369 .18623352051 70.4053573608471 .6244964599672 .5388565063573 .4532165527374 .36756896973 74.9771423339875 .2819290161175 .5867080688575 .5867080688575 .58670806885 75.2819290161174 .9771423339874 .6723632812574 .062782287673 .45321655273 72.8436431884871 .9292907714871 .6244964599671 .014930725170 .71015167236 70.4053573608470 .1005783081169 .7957916259869 .4910125732468 .88143920898 
68.2718734741267 .9670867919967 .0527267456165 .8335876464864 .30966186523 62.7857398986860 .9570198059159 .1283111572357 .6043891906756 .08045959473 53.3373985290550 .5943298339848 .1560516357446 .0225486755444 .19384002686 42.9747009277342 .0603485107441 .4507789611840 .2316398620639 .01250076294 37.1837806701735 .6598587036134 .1359291076732 .6120109558135 .05028915405 36.8790016174337 .4885711669937 .4885711669936 .2694282531734 .74551010132 32.9167900085434 .1359291076735 .3550796508835 .9646492004436 .26942825317 36.5742111206136 .5742111206136 .2694282531735 .9646492004435 .96464920044 35.9646492004435 .9646492004435 .0502891540533 .5263595581132 .30722045898 30.4785099029527 .7354507446324 .3828105926520 .4206008911116 .45840072632 $8.838768959045-13.1057596207-16.7631797791-20.115819931-23.1636695862$ -25.9067401886 -28.3450202942 -30.1737308502 -31.6976509094-32.0024414062 $-31.3928699493-30.478509903-29.5641593933-28.6497993469-28.0402297974$ $-27.7354507446-27.4306602478-27.1258792877-27.1258792877-26.8210906982$ -26.8210906982 -26.8210906982 -26.8210906982 -26.8210906982 -26.5163097382 -25.9067401886 -25.6019496918 -25.2971591949-24.9923801422 -24.3828105927 $-24.0780296326-23.7732391357-23.4684505463-23.1636695862-23.1636695862$ $-22.8588790894-22.5541000366-22.5541000366-22.2493095398-21.9445304871$ -21.9445304871 -21.6397399902 -21.3349609375 -21.0301704407 -20.7253894806 -20.115819931 -19.8110294342 -19.2014598846-18.8966808319-18.5918903351 -18.5918903351 -18.287109375 -1.21914100647 -.304785102606 -9999 .9143553972244 $-13.4105501175-10.9722604752-7.92441320419-4.87656211853-.914355397224$ 3.3526360988628 .83876895904514 .3248996734619 .5062503814724 .38281059265 28.0402297973630 .7833003997832 .9167900085434 .1359291076734 .74551010132 35.0502891540534 .7455101013234 .4407196044934 .1359291076733 .83115005493 34.13592910767 35.05028915405 -9999 -9999 -9999 -9999 -9999 -9999 -9999 -9999 -9999 -9999 -9999 -9999 -9999 -9999 -9999 -9999 -9999 -9999 -9999 -9999 -9999 -9999 -9999 -9999 -

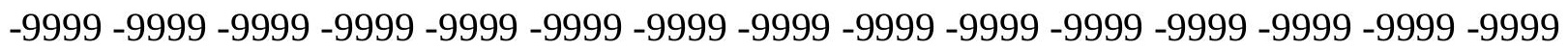
-9999 -9999 -9999 -9999 -9999 -9999 -9999 -9999 -9999 -9999 -9999 -9999 -9999 -9999 -9999 -9999 -9999 -9999 -9999 -9999 -9999 -9999 -9999 -9999 -9999 -9999 -9999 -9999 -9999 -9999

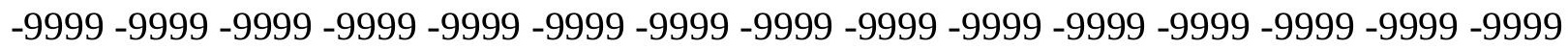
$-9999-9999$

-9999 -9999 -9999 -9999 -9999 -9999 -9999 -9999 -9999 -9999 -9999 -9999 -9999 -9999 -9999 -9999 -9999 -9999 -9999 -9999 -9999 -9999 -9999 -9999 -9999 -9999 -9999 -9999 -9999 -9999 -9999 -9999 -9999 -9999 -9999 -9999 -9999 -9999 -9999 -9999 -9999 -9999 -9999 -9999 -9999

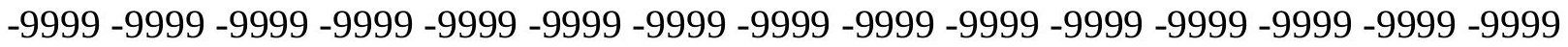

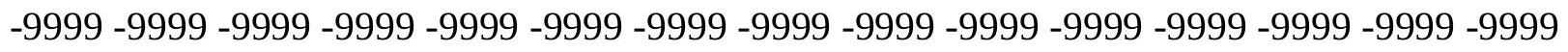

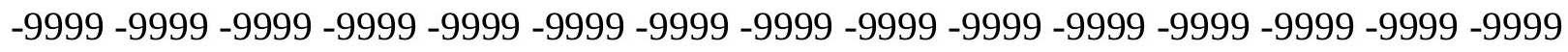
-9999 -9999 -9999 -9999-9999 -9999 -9999 119.170997619671 .014930725125 .60194969177 12.19141006478 .8387689590458 .5339832305919 .4483394622810 .36268997192 11.5818300247213 .4105501174914 .934470176716 .7631797790518 .89668083191 21.0301704406723 .4684505462625 .6019496917728 .0402297973630 .17373085022 32.0024414062533 .5263595581135 .0502891540536 .2694282531737 .48857116699 38.7077102661139 .622070312539 .9268493652340 .2316398620639 .92684936523 39.3172798156738 .4029312133837 .4885711669936 .5742111206135 .65985870361 34.7455101013234 .1359291076733 .8311500549333 .8311500549334 .13592910767 
34.7455101013235 .6598587036137 .1837806701738 .7077102661140 .53641891479 42.66992187545 .1082000732447 .8512611389250 .8991203308154 .55654144287 58.2139587402361 .8713798522964 .004882812565 .8335876464867 .66230010986 68.8814392089870 .1005783081171 .3197174072372 .2340774536173 .14842987061 73.7580032348674 .3675689697374 .6723632812574 .9771423339874 .97714233398 74.6723632812574 .6723632812574 .062782287673 .4532165527372 .84364318848 72.2340774536171 .6244964599671 .014930725170 .7101516723670 .10057830811 69.7957916259869 .1862335205168 .5766525268667 .9670867919967 .35751342773 66.4431610107465 .8335876464864 .9192428588963 .7000885009861 .56660079956 59.1283111572356 .6900291442954 .5565414428752 .4230384826749 .98476028442 47.5464782714844 .8034095764242 .0603485107439 .3172798156737 .18378067017 35.6598587036134 .7455101013233 .8311500549332 .9167900085432 .00244140625 30.4785099029528 .9545898437527 .430660247827 .1258792877228 .04022979736 29.5641593933130 .1737308502230 .1737308502229 .2593708038328 .04022979736 26.8210906982426 .8210906982427 .430660247827 .430660247828 .64979934692 29.2593708038329 .5641593933129 .2593708038328 .6497993469227 .4306602478 28.3450202941928 .6497993469228 .3450202941927 .430660247826 .21151924133 24.3828105926522 .2493095397919 .2014598846415 .5440397262611 .88661956787 -12.4961900711 -16.1536102295 -20.115819931 -24.3828105927 -28.9545898438 $-29.5641593933-31.0880794525-32.6120109558-33.5263595581-33.5263595581$ $-32.9167900085-32.0024414062-30.478509903-29.8689403534-29.2593708038$ -28.6497993469 -28.3450202942 -28.0402297974 -27.7354507446 -27.7354507446 $-27.7354507446-27.7354507446-27.7354507446-27.7354507446-27.4306602478$ $-27.1258792877-26.8210906982-26.5163097382-26.2115192413-25.9067401886$ $-25.6019496918-25.2971591949-24.9923801422-24.6875991821-24.6875991821$ $-24.3828105927-24.3828105927-24.0780296326-23.7732391357-23.7732391357$ $-23.4684505463-23.1636695862-22.8588790894-22.5541000366-22.2493095398$ $-21.6397399902-21.3349609375-20.7253894806-20.4206008911-20.115819931$ $-19.8110294342-2.74306607246-2.13349604607-1.52392601967-.914355397224$ $-16.4584007263-14.6296901703-12.1914100647-9.44833946228-6.40048694611$ $-2.743066072461 .219141006476 .40048694610611 .8866195678717 .06797027588$ 21.6397399902325 .906740188628 .9545898437531 .3928699493432 .91679000854 33.8311500549334 .1359291076733 .8311500549333 .5263595581133 .22158050537 32.9167900085433 .5263595581135 .05028915405 -9999 -9999 -9999 -9999 -9999 -9999 -9999 -9999 -9999 -9999 -9999 -9999 -9999 -9999 -9999 -9999 -9999 -9999 -9999 -9999 -9999 -9999 -9999 -9999 -9999 -9999 -9999 -9999 -9999 -9999 -9999 -9999 -9999 -9999 -9999 -9999 -9999 -

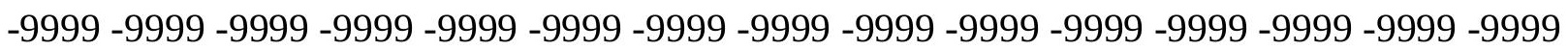

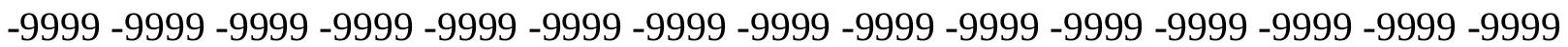
-9999 -9999 -9999 -9999 -9999 -9999 -9999 -9999 -9999 -9999 -9999 -9999 -9999 -9999 -9999 -9999 -9999-9999-9999 -9999 -9999 -9999 -9999 -9999 -9999 -9999 -9999 -9999 -9999 -9999 -9999 -9999 -9999 -9999 -9999 -9999 -9999 -9999 -9999 -9999 -9999 -9999 -9999 -9999 -9999 -9999 -9999 - -9999 - -9999 -9999 -9999 -9999 -9999 -9999 -9999 -9999 -9999 -9999 -9999 -9999 -9999 -9999 -9999 -9999 -9999 -9999 -9999 -9999 -9999 -9999 -9999 -9999 -9999 -9999 -9999 -9999 -9999 -9999 -9999 -9999 -9999 -9999 -9999 -9999 -9999 -9999 -9999 -9999 -9999 -9999 -9999 -9999 -9999 -9999

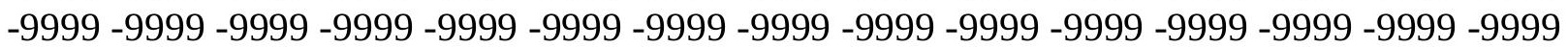


-9999 -9999 -9999 -9999 -9999 -9999 -9999 -9999 106.674797058153 .03261184692 13.715330123914 .0201196670514 .3248996734614 .3248996734614 .32489967346 14.934470176715 .8488302230817 .0679702758818 .5918903350820 .11581993103 22.2493095397924 .0780296325726 .2115192413328 .6497993469230 .78330039978 32.6120109558134 .4407196044936 .2694282531737 .7933502197339 .31727981567 40.5364189147941 .7555618286142 .3651313781742 .3651313781742 .06034851074 41.1459884643639 .9268493652338 .7077102661137 .4885711669936 .26942825317 35.3550796508834 .7455101013234 .4407196044934 .1359291076734 .44071960449 35.0502891540535 .9646492004437 .1837806701738 .7077102661140 .23163986206 42.3651313781744 .4986305236846 .9369087219249 .9847602844253 .03261184692 56.6900291442959 .7378807067962 .4809494018664 .3096618652366 .13836669922 67.3575134277368 .8814392089870 .1005783081171 .3197174072372 .23407745361 73.1484298706173 .7580032348674 .062782287674 .3675689697374 .67236328125 74.3675689697374 .062782287673 .7580032348673 .4532165527372 .84364318848 72.2340774536171 .3197174072370 .7101516723670 .1005783081169 .49101257324 68.8814392089868 .2718734741267 .3575134277366 .4431610107465 .52880096436 64.3096618652363 .0905189514261 .8713798522960 .6522407531757 .60438919067 54.5565414428751 .5086898803748 .765621185346 .3273391723643 .58427047729 40.8412094116238 .4029312133835 .6598587036132 .9167900085430 .47850990295 28.3450202941927 .7354507446327 .1258792877226 .2115192413325 .29715919495 24.0780296325723 .1636695861822 .2493095397921 .9445304870622 .55410003662 23.4684505462624 .0780296325724 .0780296325723 .4684505462622 .55410003662 21.6397399902321 .334960937521 .334960937521 .9445304870622 .55410003662 23.1636695861823 .4684505462623 .1636695861822 .8588790893622 .55410003662 22.5541000366222 .8588790893622 .8588790893622 .2493095397921 .3349609375 19.811029434217 .9823207855215 .5440397262612 .496190071119 .143553733826 -14.3248996735 -18.287109375 -22.8588790894 -26.8210906982 -30.1737308502 $-31.0880794525-33.2215805054-34.4407196045-35.3550796509-35.3550796509$ $-34.4407196045-33.5263595581-32.0024414062-31.0880794525-30.1737308502$ $-29.2593708038-28.9545898438-28.6497993469-28.6497993469-28.6497993469$ $-28.3450202942-28.3450202942-28.3450202942-28.3450202942-28.3450202942$ $-28.0402297974-27.7354507446-27.4306602478-27.4306602478-27.1258792877$ $-26.8210906982-26.5163097382-26.5163097382-26.2115192413-26.2115192413$ $-25.9067401886-25.9067401886-25.6019496918-25.6019496918-25.2971591949$ $-24.9923801422-24.6875991821-24.3828105927-24.0780296326-23.4684505463$ $-23.1636695862-22.5541000366-22.2493095398-21.6397399902-21.3349609375$ $-21.0301704407-20.4206008911-20.115819931-19.2014598846-18.287109375$ -16.7631797791 -14.9344701767-12.4961900711 -10.0579099655 -7.3148431778 -3.96220707893 -9999 4.571776866913 10.0579099655215 .2392597198519 .8110294342 24.0780296325727 .430660247830 .1737308502231 .6976509094232 .91679000854 33.2215805053732 .9167900085432 .6120109558132 .3072204589832 .30722045898 33.52635955811 34.74551010132 -9999 -9999 -9999 -9999 -9999 -9999 -9999 -9999 -9999 -9999 -9999 -9999 -9999 -9999 -9999 -9999 -9999 -9999 -9999 -9999 -9999 -9999 -9999 -9999 -9999 -9999 -9999 -9999 -9999 -9999 -9999 -9999 -9999-9999 -9999 -9999 -9999 -9999 -9999 -9999 -9999 -9999 -9999 -9999 -9999 -9999 -9999 -9999 -9999 -9999 -9999 -9999 -9999 -9999 -

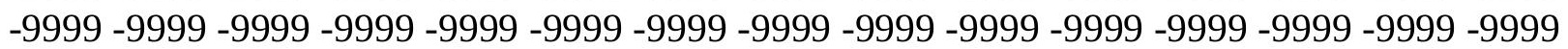


-9999 -9999 -9999 -9999 -9999 -9999 -9999 -9999 -9999 -9999 -9999 -9999 -9999 -9999 -9999 $-9999-9999$

-9999 -9999 -9999 -9999 -9999 -9999 -9999 -9999 -9999 -9999 -9999 -9999 -9999 -9999 -9999 -9999 -9999 -9999 -9999 -9999 -9999 -9999 -9999 -9999 -9999 -9999 -9999 -9999 -9999 -9999 -9999 -9999 -9999 -9999 -9999 -9999 -9999 -9999 -9999 -9999 -9999 -9999 -9999 - -9999 - -9999 -9999 -9999 -9999 -9999 -9999 -9999 -9999 -9999 -9999 -9999 -9999 -9999 -9999 -9999 -9999

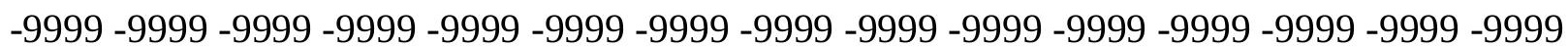

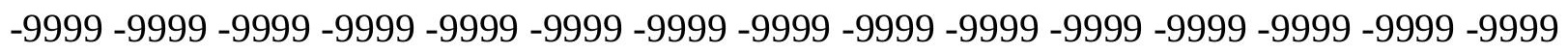
-9999 -9999-9999-9999-9999-9999-9999-9999 -9999 79.8537063598635 .35507965088 23.1636695861821 .6397399902320 .1158199310319 .2014598846419 .20145988464 19.5062503814720 .1158199310321 .0301704406722 .2493095397923 .77323913574 25.6019496917727 .7354507446329 .5641593933131 .6976509094233 .83115005493 35.9646492004437 .7933502197339 .622070312541 .4507789611842 .97470092773 44.4986305236845 .1082000732445 .4129791259844 .8034095764243 .58427047729 42.3651313781740 .8412094116239 .3172798156737 .7933502197336 .87900161743 35.9646492004435 .6598587036135 .3550796508835 .6598587036135 .96464920044 36.8790016174338 .0981407165539 .3172798156740 .8412094116242 .36513137817 44.4986305236846 .6321296691949 .0704002380451 .8134689331154 .86132049561 57.909179687560 .6522407531762 .7857398986864 .6144485473666 .13836669922 67.9670867919969 .1862335205170 .7101516723671 .6244964599672 .53885650635 73.4532165527373 .7580032348674 .062782287674 .3675689697374 .36756896973 74.062782287673 .7580032348673 .4532165527372 .8436431884872 .23407745361 71.3197174072370 .7101516723670 .1005783081169 .1862335205168 .57665252686 67.6623001098666 .4431610107465 .2240066528363 .3953094482461 .56660079956 59.7378807067957 .909179687555 .4708900451752 .4230384826749 .07040023804 46.0225486755442 .9747009277339 .9268493652337 .1837806701734 .44071960449 32.0024414062529 .5641593933127 .1258792877224 .6875991821322 .85887908936 21.6397399902321 .0301704406720 .4206008911119 .811029434218 .89668083191 17.9823207855217 .3727493286117 .3727493286117 .9823207855218 .59189033508 18.8966808319118 .8966808319118 .5918903350817 .9823207855217 .37274932861 17.0679702758817 .0679702758817 .3727493286117 .9823207855218 .287109375 18.5918903350818 .5918903350835 .3550796508835 .6598587036135 .96464920044 35.6598587036135 .3550796508835 .0502891540517 .3727493286116 .15361022949 $14.6296901702912 .8009700775110 .362689971927 .924413204193-15.2392597198$ $-19.5062503815-24.0780296326-28.0402297974-31.0880794525-33.2215805054$ $-35.0502891541-36.2694282532-36.8790016174-36.8790016174-35.9646492004$ $-34.7455101013-33.5263595581-32.307220459-31.0880794525-30.1737308502$ $-29.8689403534-29.5641593933-29.2593708038-29.2593708038-29.2593708038$ $-29.2593708038-29.2593708038-28.9545898438-28.9545898438-28.9545898438$ -28.6497993469 -28.6497993469 -28.3450202942 -28.3450202942 -28.0402297974 $-28.0402297974-27.7354507446-27.7354507446-27.7354507446-27.4306602478$ $-27.4306602478-27.4306602478-27.1258792877-26.8210906982-26.5163097382$ $-26.2115192413-25.9067401886-25.2971591949-24.9923801422-24.3828105927$ $-23.7732391357-23.4684505463-22.8588790894-22.2493095398-21.9445304871$ $-21.0301704407-20.4206008911-19.2014598846-17.9823207855-16.4584007263$ $-14.6296901703-12.1914100647-9.75312423706-7.3148431778-4.26699209213$ 
-.914355397224 3.657422065735 8.838768959045 13.715330123918 .59189033508 22.8588790893626 .2115192413328 .9545898437531 .0880794525132 .00244140625 32.6120109558132 .3072204589832 .0024414062531 .6976509094232 .00244140625 33.5263595581135 .05028915405 -9999 -9999 -9999 -9999 -9999 -9999 -9999 -9999 -9999 -9999 -9999 -9999 -9999 -9999 -9999 -9999 -9999 -9999 -9999 -9999 -9999 -9999 -9999 -9999 -9999 -9999 -9999 -9999 -9999 -9999 -9999 -9999 -9999 -9999 -9999 -9999 -9999 -9999 -9999 -9999 -9999 -9999 -9999 -9999 -9999 -9999 -9999 -9999 -9999 -9999 -9999 -9999 -9999 -9999

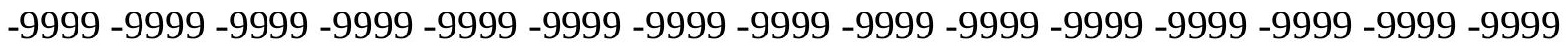
-9999 -9999 -9999 -9999 -9999 -9999 -9999 -9999 -9999 -9999 -9999 -9999 -9999 -9999 -999 - -999 -9999-9999

-9999 -9999 -9999 -9999 -9999 -9999 -9999 -9999 -9999 -9999 -9999 -9999 -9999 -9999 -9999 -9999 -9999 -9999 -9999 -9999 -9999 -9999 -9999 -9999 -9999 -9999 -9999 -9999 -9999 -9999 -9999 -9999 -9999 -9999 -9999 -9999 -9999 -9999 -9999 -9999 -9999 -9999 -9999 -9999 -9999 -9999 -9999 -9999 -9999 -9999 -9999 -9999 -9999 -9999 -9999 -9999 -9999 -9999 -9999 -9999 -9999 -9999 -9999 -9999 -9999 -9999 -9999 -9999 -9999 -9999 -9999 -9999 -9999 -9999 -9999

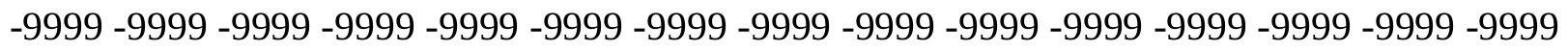
-9999 -9999 -9999 -9999-9999-9999 -9999 -9999 -9999 106.3700027466 67.35751342773 51.8134689331129 .8689403533925 .906740188624 .3828105926524 .07802963257 23.7732391357423 .7732391357424 .0780296325724 .9923801422126 .21151924133 27.7354507446329 .5641593933131 .6976509094233 .5263595581135 .96464920044 38.0981407165540 .2316398620642 .3651313781744 .1938400268646 .02254867554 47.5464782714848 .765621185349 .0704002380448 .1560516357446 .63212966919 45.1082000732443 .2794914245641 .7555618286140 .2316398620639 .01250076294 38.4029312133837 .7933502197337 .4885711669937 .7933502197338 .09814071655 39.0125007629440 .2316398620641 .1459884643642 .3651313781743 .58427047729 44.8034095764246 .6321296691948 .4608306884850 .8991203308153 .64218139648 56.3852500915558 .8235282897961 .2618103027363 .3953094482465 .22400665283 67.0527267456168 .5766525268670 .1005783081171 .3197174072372 .23407745361 73.1484298706173 .7580032348674 .062782287674 .3675689697374 .36756896973 74.062782287674 .062782287673 .4532165527372 .8436431884872 .23407745361 71.6244964599671 .014930725170 .1005783081169 .1862335205167 .96708679199 66.7479400634865 .5288009643663 .7000885009861 .5666007995658 .82352828979 56.0804595947353 .0326118469249 .9847602844246 .6321296691943 .27949142456 40.2316398620636 .8790016174333 .8311500549330 .7833003997828 .64979934692 26.5163097381624 .0780296325721 .9445304870619 .811029434217 .98232078552 16.7631797790516 .1536102294915 .2392597198514 .6296901702914 .02011966705 13.715330123913 .4105501174913 .4105501174913 .715330123914 .02011966705 14.6296901702914 .6296901702914 .6296901702914 .3248996734613 .7153301239 13.715330123913 .715330123913 .715330123914 .0201196670514 .62969017029 31.6976509094232 .3072204589833 .2215805053733 .5263595581133 .83115005493 33.8311500549333 .8311500549333 .5263595581133 .2215805053731 .69765090942 $28.9545898437510 .667480468758 .8387689590457 .010057926178-14.9344701767$ $-19.2014598846-24.0780296326-28.3450202942-32.0024414062-34.7455101013$ -36.5742111206 -37.7933502197 -38.4029312134 -38.0981407166 -37.1837806702 $-36.2694282532-34.7455101013-33.5263595581-32.307220459-31.3928699493$ $-30.7833003998-30.1737308502-30.1737308502-29.8689403534-29.8689403534$ 
-29.8689403534 -29.8689403534 -29.5641593933 -29.5641593933 -29.5641593933 $-29.5641593933-29.5641593933-29.5641593933-29.5641593933-29.2593708038$ $-29.2593708038-29.2593708038-28.9545898438-29.2593708038-29.2593708038$ $-29.2593708038-28.9545898438-28.6497993469-28.3450202942-28.0402297974$ $-27.7354507446-27.1258792877-26.8210906982-26.2115192413-25.6019496918$ $-24.9923801422-24.3828105927-23.7732391357-23.1636695862-22.5541000366$ $-21.6397399902-20.4206008911-19.2014598846-17.6775398254-15.8488302231$ -13.7153301239 -11.5818300247-9.14355373383 -6.40048694611 -3.65742206573 -9999 3.6574220657358 .22919845581113 .1057596206717 .6775398254421 .63973999023 25.2971591949528 .3450202941930 .7833003997831 .6976509094232 .00244140625 32.0024414062531 .6976509094231 .0880794525132 .3072204589833 .83115005493 35.35507965088 -9999 -9999 -9999 -9999 -9999 -9999 -9999 -9999 -9999 -9999 -9999 -9999 -9999 -9999 -9999 -9999 -9999 -9999 -9999 -9999 -9999 -9999 -9999 -9999 -9999 -9999 -9999 -9999 -9999 -9999 -9999 -9999 -9999 -9999 -9999 -9999 -9999 -9999 -9999 -9999 -9999 -9999 -9999 -9999 -9999 -9999 -9999 -9999 -9999 -9999 -9999 -9999 -9999 -9999 -9999 -9999 -9999 -9999 -9999 -9999 -9999 -9999 -9999 -9999 -9999 -9999 -9999 -9999 -9999 -9999 -9999 -9999 -9999 -9999 -9999 -9999 -9999 -9999 -9999 -9999 -9999 -9999 -9999 -9999 -9999 -9999 -9999 -9999 -9999 -9999 -9999 -9999 -9999 -9999 -9999 -9999 -9999 -9999 -9999 -9999 -9999 -9999 -9999 -9999 -9999 -9999 -9999 -9999 -9999 -9999 -9999 -9999 -9999 -9999 -9999 -9999 -9999 -9999 -9999 -9999 -9999 -9999 -9999 -9999 -9999 -9999 -9999 -9999 -9999 -9999 -9999 -9999 -9999 -9999 -9999 -9999 -9999 -9999 -9999 -9999 -9999 -9999 -9999 -9999 -9999 -9999 -9999 -9999 -9999 -9999 -9999 -9999 -9999 -9999 -9999 -9999 -9999 -9999 -9999 -9999 -9999 -9999 -9999 -9999 -9999 -9999 -9999 -9999 -9999 -9999 -9999 -9999 -9999 -9999 -9999 -9999 -9999 -9999 -9999 -9999 -9999 -9999 -9999 -9999 -9999 -9999 93.26425170898 57.2995986938537 .4885711669931 .3928699493430 .1737308502229 .86894035339 28.6497993469228 .0402297973628 .0402297973628 .6497993469229 .56415939331 30.7833003997832 .3072204589834 .1359291076736 .2694282531738 .40293121338 40.8412094116243 .2794914245645 .4129791259847 .5464782714849 .67998123169 51.5086898803752 .7278289794953 .6421813964852 .1182594299350 .28955078125 48.4608306884846 .3273391723644 .8034095764243 .5842704772942 .36513137817 41.7555618286141 .1459884643641 .1459884643641 .1459884643641 .45077896118 42.3651313781743 .5842704772944 .4986305236845 .1082000732445 .7177696228 46.3273391723647 .5464782714848 .765621185350 .5943298339853 .03261184692 55.4708900451757 .909179687560 .3474502563562 .7857398986864 .91924285889 66.7479400634868 .5766525268670 .1005783081171 .3197174072372 .53885650635 73.1484298706173 .7580032348674 .3675689697374 .3675689697374 .67236328125 74.3675689697374 .3675689697373 .7580032348673 .4532165527372 .84364318848 71.9292907714871 .3197174072370 .1005783081169 .1862335205167 .66230010986 66.4431610107464 .6144485473662 .4809494018659 .4331016540556 .08045959473 52.1182594299348 .4608306884844 .4986305236840 .8412094116237 .48857116699 34.4407196044931 .3928699493428 .6497993469225 .906740188623 .77323913574 21.6397399902319 .5062503814717 .3727493286115 .5440397262614 .02011966705 12.8009700775111 .8866195678710 .9722604751610 .3626899719210 .05790996552 9.7531242370619 .7531242370619 .75312423706110 .0579099655210 .36268997192 10.9722604751610 .9722604751610 .9722604751610 .9722604751610 .66748046875 10.6674804687510 .6674804687510 .9722604751611 .2770500183111 .58183002472 
29.2593708038329 .8689403533930 .7833003997831 .3928699493431 .69765090942 32.0024414062532 .0024414062532 .0024414062531 .6976509094230 .78330039978 $28.649799346929 .448339462287 .9244132041936 .400486946106-12.8009700775$ $-17.9823207855-23.1636695862-28.3450202942-32.307220459-35.3550796509$ $-37.488571167-38.7077102661-39.3172798157-39.0125007629-38.0981407166$ $-37.1837806702-35.6598587036-34.4407196045-33.2215805054-32.307220459$ $-31.6976509094-31.0880794525-30.7833003998-30.478509903-30.478509903$ $-30.478509903-30.478509903-30.1737308502-30.1737308502-30.478509903-30.478509903$ $-30.478509903-30.478509903-30.478509903-30.478509903-30.7833003998-30.478509903$ $-30.478509903-30.7833003998-30.7833003998-30.7833003998-30.7833003998$ $-30.478509903-29.8689403534-29.5641593933-29.2593708038-28.6497993469$ $-28.0402297974-27.4306602478-26.8210906982-25.9067401886-25.2971591949$ $-24.6875991821-24.0780296326-23.1636695862-21.9445304871-20.7253894806$ $-19.2014598846-17.3727493286-15.2392597198-12.8009700775-10.3626899719$ $-7.92441320419-5.18134689331-2.13349604607 .60957032442094 .266992092133$ 8.22919845581112 .4961900711116 .7631797790521 .0301704406724 .68759918213 28.0402297973630 .4785099029531 .3928699493431 .6976509094231 .69765090942 31.3928699493431 .3928699493432 .9167900085434 .4407196044935 .65985870361 -9999 -9999 -9999 -9999 -9999 -9999 -9999 -9999 -9999 -9999 -9999 -9999 -9999 -9999 -9999 - 9999 -

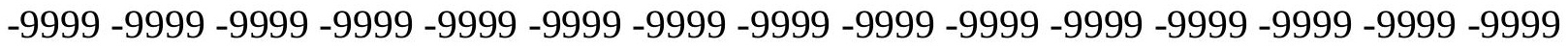
-9999 -

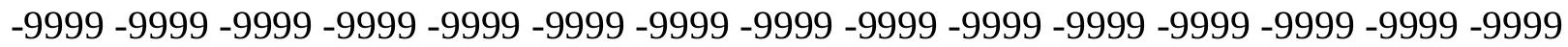

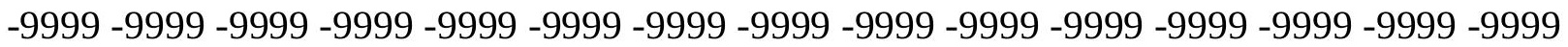
-9999 -9999 -9999 -9999 -9999 -9999 -9999 -9999 -9999-9999

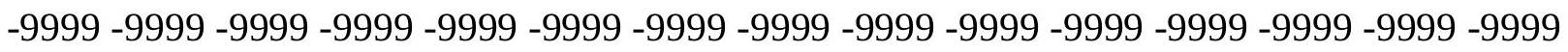

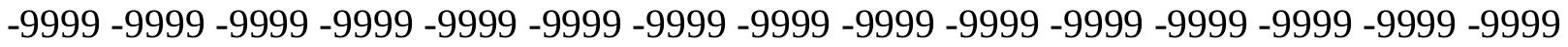

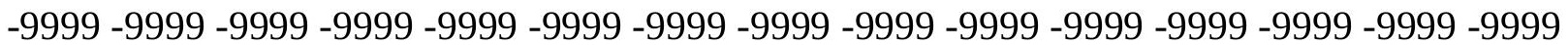

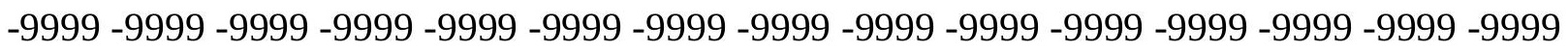

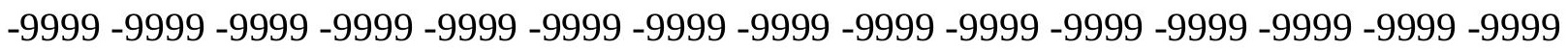

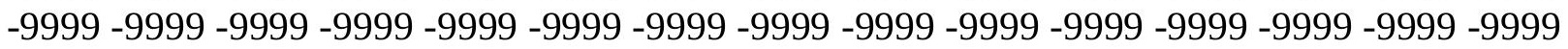
-9999 -9999 -9999 -9999 -9999 -9999 -9999 -9999 -9999 -9999 -9999 78.93934631348 47.5464782714840 .8412094116237 .4885711669935 .0502891540533 .52635955811 32.9167900085432 .6120109558132 .9167900085433 .8311500549334 .74551010132 35.9646492004437 .7933502197339 .622070312542 .0603485107444 .49863052368 46.9369087219249 .3751907348651 .5086898803753 .6421813964855 .77568054199 57.2995986938557 .6043891906756 .6900291442954 .5565414428752 .42303848267 50.5943298339849 .3751907348647 .8512611389246 .9369087219246 .32733917236 46.0225486755446 .0225486755446 .3273391723646 .9369087219247 .54647827148 48.4608306884848 .765621185349 .0704002380449 .0704002380449 .07040023804 49.0704002380449 .9847602844251 .2038993835453 .0326118469255 .16611099243 57.909179687560 .6522407531762 .7857398986864 .9192428588967 .05272674561 68.8814392089870 .4053573608471 .6244964599672 .8436431884873 .45321655273 74.062782287674 .6723632812574 .9771423339874 .9771423339874 .97714233398 74.6723632812574 .3675689697374 .062782287673 .4532165527372 .53885650635 71.6244964599670 .4053573608469 .1862335205167 .6623001098665 .83358764648 63.7000885009860 .9570198059157 .2995986938553 .3373985290548 .7656211853 
44.1938400268639 .622070312535 .6598587036132 .0024414062529 .25937080383 26.8210906982424 .3828105926521 .9445304870619 .5062503814717 .37274932861 15.5440397262613 .4105501174911 .8866195678710 .362689971929 .143553733826 8.2291984558117 .6196279525767 .0100579261786 .4004869461066 .400486946106 6.4004869461066 .4004869461067 .0100579261787 .3148431777957 .619627952576 7.9244132041938 .2291984558118 .2291984558118 .2291984558118 .229198455811 8.2291984558118 .5339832305918 .8387689590458 .83876895904526 .51630973816 27.430660247828 .3450202941928 .9545898437529 .5641593933129 .86894035339 30.1737308502230 .1737308502229 .8689403533929 .2593708038327 .73545074463 $25.906740188624 .078029632575 .790916919708-9.44833946228-15.2392597198$ -20.7253894806 -26.5163097382 -31.3928699493 -35.0502891541 -37.7933502197 -39.3172798157 -39.6220703125 -39.3172798157 -38.7077102661 -37.488571167 -36.2694282532 -35.0502891541 -33.8311500549 -32.9167900085 -32.307220459 -31.6976509094 -31.3928699493 -31.3928699493 -31.3928699493 -31.0880794525 $-31.0880794525-31.0880794525-31.0880794525-31.0880794525-31.0880794525$ $-31.3928699493-31.3928699493-31.6976509094-32.0024414062-32.0024414062$ -32.0024414062 -32.307220459 -32.6120109558 -32.6120109558 -32.6120109558 $-32.6120109558-32.307220459-32.0024414062-31.3928699493-30.7833003998$ -30.1737308502 -29.2593708038 -28.6497993469 -27.7354507446 -27.1258792877 $-26.2115192413-25.6019496918-24.6875991821-23.4684505463-22.2493095398$ $-20.7253894806-18.8966808319-16.7631797791-14.3248996735-11.8866195679$ $-9.14355373383-6.40048694611-3.65742206573-.9143553972241 .523926019669$ 4.876562118538 .22919845581112 .191410064716 .1536102294920 .42060089111 24.0780296325727 .430660247829 .8689403533931 .3928699493431 .69765090942 31.6976509094231 .3928699493432 .0024414062533 .5263595581135 .05028915405 36.26942825317 -9999 -9999 -9999 -9999 -9999 -9999 -9999 -9999 -9999 -9999 -9999 -9999 -9999 -9999 -9999 -9999 -9999 -9999 -9999 -9999 -9999 -9999 -9999 -9999 -9999 -9999 -9999 -

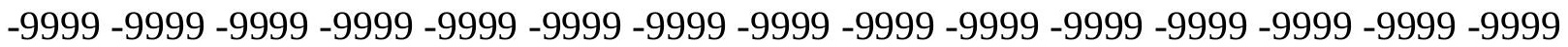
-9999 -9999 -9999 -9999 -9999 -9999 -9999 -9999 -9999 -9999 -9999 -9999 -9999 -9999 -9999 -9999 -9999 -9999 -9999 -9999 -9999 -9999 -9999 -9999 -9999 -9999 -9999 -9999 -9999 -9999 -9999 -9999 -9999 -9999 -9999 -9999 -9999 -9999 -9999 -9999 -9999 -9999 -9999 -9999 -9999 -9999 -9999 -9999 -9999 -9999 -9999 -9999 -9999 -9999 -9999 -9999 -9999 -9999 -9999

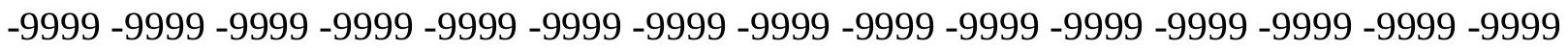
-9999 -9999 -9999 -9999 -9999 -9999 -9999 -9999 -9999 -9999 -9999 -9999 -9999 -9999 -9999 -9999 -9999 -9999 -9999 -9999 -9999 -9999 -9999 -9999 -9999 -9999 -9999 -9999 -9999 -9999 -9999 -9999 -9999 -9999 -9999 -9999 -9999 -9999 -9999 -9999 -9999 -9999 -9999 -9999 -9999

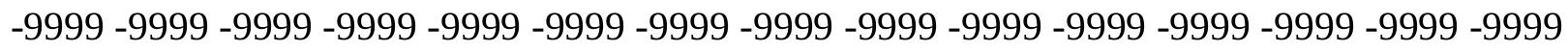
-9999 -9999 -9999 -9999-9999 -9999-9999-9999 -9999-9999 -9999 104.8460998535 76.5010681152351 .2038993835444 .8034095764240 .8412094116239 .31727981567 38.7077102661138 .4029312133838 .4029312133838 .7077102661139 .6220703125 40.8412094116242 .3651313781744 .1938400268646 .3273391723649 .07040023804 51.8134689331154 .2517509460456 .3852500915558 .5187492370660 .34745025635 62.1761703491263 .0905189514261 .8713798522959 .7378807067957 .60438919067 56.0804595947355 .1661109924353 .9469718933152 .7278289794952 .11825942993 52.1182594299352 .7278289794953 .3373985290553 .9469718933154 .25175094604 54.8613204956154 .8613204956154 .2517509460453 .6421813964852 .72782897949 
52.1182594299352 .1182594299352 .7278289794954 .2517509460456 .38525009155 58.8235282897961 .5666007995664 .004882812566 .1383666992268 .27187347412 69.7957916259871 .3197174072372 .5388565063573 .4532165527374 .0627822876 74.6723632812575 .2819290161175 .2819290161175 .5867080688575 .58670806885 75.5867080688575 .2819290161174 .6723632812574 .062782287673 .45321655273 72.2340774536171 .014930725169 .7957916259867 .9670867919965 .83358764648 63.0905189514259 .7378807067956 .0804595947351 .5086898803746 .63212966919 41.1459884643635 .6598587036131 .0880794525127 .7354507446325 .60194969177 23.1636695861821 .0301704406718 .8966808319116 .4584007263214 .32489967346 12.4961900711110 .362689971928 .8387689590457 .3148431777956 .095703125 5.1813468933114 .5717768669133 .9622070789343 .6574220657353 .352636098862 3.6574220657353 .6574220657354 .2669920921334 .5717768669135 .181346893311 5.4861321449285 .7909169197085 .7909169197085 .7909169197086 .0957031256 .095703125 6.4004869461066 .7052731513987 .0100579261787 .31484317779524 .38281059265 25.2971591949526 .2115192413327 .1258792877227 .7354507446328 .04022979736 28.0402297973628 .0402297973627 .430660247826 .5163097381625 .60194969177 $24.6875991821322 .24930953979-5.48613214493-11.2770500183-17.3727493286$ -23.7732391357 -29.8689403534 -33.8311500549 -36.8790016174 -39.0125007629 -39.3172798157 -39.0125007629 -38.4029312134 -37.488571167 -36.2694282532 -35.3550796509-34.1359291077 -33.5263595581 -32.9167900085 -32.307220459 $-32.0024414062-32.0024414062-32.0024414062-31.6976509094-31.6976509094$ -31.6976509094 -31.6976509094 -31.6976509094 -32.0024414062 -32.0024414062 -32.307220459 -32.6120109558 -32.9167900085 -33.2215805054 -33.5263595581 -33.8311500549 -34.1359291077 -34.4407196045 -34.4407196045 -34.4407196045 $-34.1359291077-33.8311500549-33.2215805054-32.6120109558-31.6976509094$ $-30.7833003998-29.8689403534-28.9545898438-28.0402297974-27.1258792877$ $-26.2115192413-25.2971591949-24.0780296326-22.5541000366-20.7253894806$ -18.5918903351 -16.1536102295 -13.4105501175 -10.6674804688 -7.92441320419 -4.87656211853 -2.13349604607-9999 2.438281059265 4.87656211853 8.229198455811 11.5818300247215 .5440397262619 .811029434223 .7732391357427 .12587928772 29.5641593933131 .0880794525132 .0024414062532 .0024414062531 .69765090942 32.9167900085434 .4407196044935 .9646492004437 .18378067017 -9999 -9999 -9999 -9999 -9999 -9999 -9999 -9999 -9999 -9999 -9999 -9999 -9999 -9999 -9999 -9999 -9999 -9999 -9999 -9999 -9999 -9999 -9999 -9999 -9999 -9999 -9999 -9999 -9999 -9999 -9999 -9999 -9999 -9999 -9999 -9999 -9999 -9999 -9999 -9999 -9999 -9999 -9999 -9999 -9999 -9999 -9999 -9999 -9999

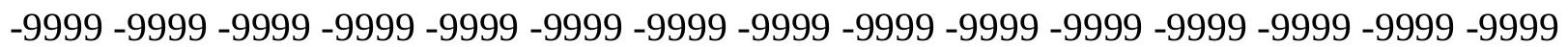

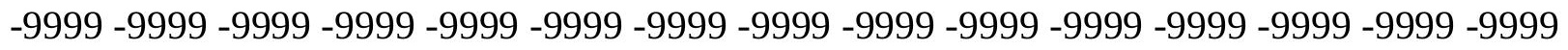
-9999 -9999-9999-9999-9999-9999-9999

-9999 -9999 -9999 -9999 -9999 -9999 -9999 -9999 -9999 -9999 -9999 -9999 -9999 -9999 - -9999 -9999 -9999 -9999 -9999 -9999 -9999 -9999 -9999 -9999 -9999 -9999 -9999 -9999 -9999 -9999 -

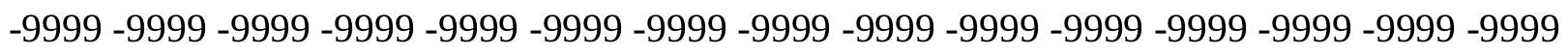

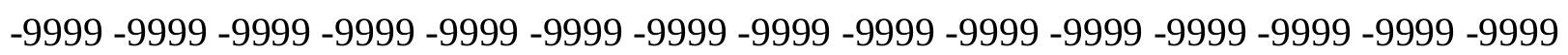

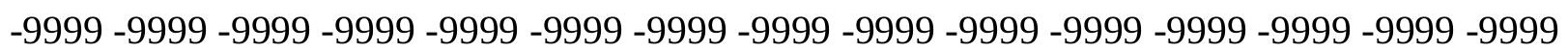
-9999 -9999 -9999 -9999 -9999 -9999 -9999 -9999 -9999 -9999 -9999 -9999 -9999 -9999 -9999 -9999 -9999 -9999 -9999 -9999 -9999 -9999 -9999 -9999 -9999 -9999 -9999 106.0652008057 72.8436431884850 .8991203308147 .8512611389246 .9369087219246 .02254867554 
45.1082000732444 .4986305236844 .8034095764245 .717769622846 .93690872192 48.1560516357449 .6799812316952 .1182594299354 .8613204956157 .60438919067 60.0426712036162 .4809494018664 .3096618652366 .4431610107467 .96708679199 68.8814392089868 .5766525268666 .7479400634864 .3096618652363 .70008850098 63.0905189514262 .1761703491260 .6522407531759 .4331016540560 .04267120361 60.6522407531761 .2618103027361 .8713798522962 .1761703491262 .48094940186 62.1761703491261 .2618103027359 .7378807067957 .909179687556 .38525009155 55.7756805419955 .7756805419956 .6900291442958 .8235282897961 .26181030273 63.7000885009866 .1383666992268 .2718734741270 .1005783081171 .31971740723 72.5388565063573 .7580032348674 .3675689697374 .9771423339875 .58670806885 75.8914871215876 .1962814331176 .1962814331176 .5010681152376 .19628143311 76.1962814331175 .5867080688575 .2819290161174 .3675689697373 .14842987061 71.9292907714870 .4053573608468 .2718734741266 .1383666992263 .09051895142 59.4331016540555 .4708900451750 .8991203308145 .4129791259839 .92684936523 33.8311500549328 .0402297973625 .6019496917723 .4684505462621 .03017044067 18.8966808319116 .7631797790514 .3248996734612 .191410064710 .05790996552 8.2291984558116 .4004869461065 .1813468933113 .9622070789343 .047851085663 2.1334960460661 .5239260196691 .219141006471 .219141006471 .21914100647 1.5239260196691 .8287110328672 .4382810592653 .0478510856633 .352636098862 3.6574220657353 .9622070789343 .9622070789344 .2669920921334 .571776866913 4.876562118534 .876562118535 .1813468933115 .4861321449285 .790916919708 5.79091691970823 .1636695861824 .0780296325724 .9923801422125 .29715919495 25.6019496917725 .6019496917725 .6019496917724 .9923801422124 .38281059265 $24.3828105926522 .55410003662-1.52392601967-7.01005792618-13.4105501175$ $-20.115819931-26.5163097382-31.3928699493-35.0502891541-37.1837806702$ -38.0981407166 -38.0981407166 -37.488571167 -36.8790016174 -35.9646492004 -35.0502891541 -34.1359291077 -33.5263595581 -32.9167900085 -32.6120109558 -32.307220459 -32.307220459-32.307220459-32.307220459-32.0024414062 -32.0024414062 $-32.0024414062-32.307220459-32.6120109558-32.9167900085-33.2215805054$ -33.5263595581 -34.1359291077 -34.4407196045 -35.0502891541 -35.3550796509 -35.9646492004 -36.2694282532 -36.2694282532 -36.2694282532 -36.2694282532 -35.6598587036 -35.0502891541 -34.4407196045 -33.2215805054 -32.307220459 $-31.0880794525-29.8689403534-28.9545898438-28.0402297974-27.1258792877$ -25.9067401886 -24.6875991821 -22.8588790894 -20.7253894806 -18.287109375 $-15.5440397263-12.8009700775-9.75312423706-6.7052731514-3.65742206573$ -.609570324421.9143553972244 2.743066072464 4.87656211853 7.619627952576 10.9722604751614 .6296901702918 .8966808319123 .1636695861826 .82109069824 29.5641593933131 .3928699493432 .3072204589832 .9167900085449 .67998123169 34.4407196044935 .6598587036136 .8790016174338 .09814071655 -9999 -9999 -9999 -9999 -9999 -9999 -9999 -9999 -9999 -9999 -9999 -9999 -9999 -9999 -9999 -9999 -9999 -9999 -9999

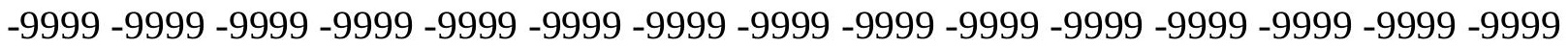
-9999 -9999 -9999 -9999 -9999 -9999 -9999 -9999 -9999 -9999 -9999 -9999 -9999 -9999 -9999 -9999 -9999 -9999 -9999 -9999 -9999 -9999 -9999 -9999 -9999 -9999 -9999 -9999 -9999 -9999 -9999 -9999 -9999 -9999 -9999 -9999 -9999 -9999 -9999 -9999 -9999 -9999 -9999 -9999 -9999 -9999 -9999 -9999 -9999 -9999 -9999 -9999

-9999 -9999 -9999 -9999 -9999 -9999 -9999 -9999 -9999 -9999 -9999 -9999 -9999 -9999 -9999 
-9999 -9999 -9999 -9999 -9999 -9999 -9999 -9999 -9999 -9999 -9999 -9999 -9999 -9999 -9999 -9999 -9999 -9999 -9999 -9999 -9999 -9999 -9999 -9999 -9999 -9999 -9999 -9999 -9999 -9999

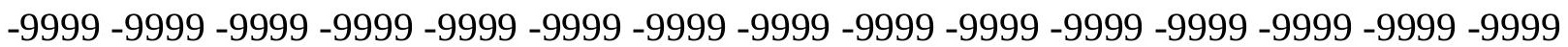
-9999 -9999 -9999 -9999 -9999 -9999 -9999 -9999 -9999 -9999 -9999 -9999 -9999 -9999 -9999

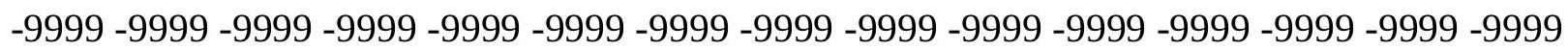
-9999 -9999 -9999 -9999 -9999 -9999 -9999 -9999 -9999 -9999 -9999 -9999 -9999 96.6168823242269 .1862335205157 .6043891906756 .6900291442954 .86132049561 52.7278289794951 .8134689331151 .8134689331153 .3373985290555 .47089004517 56.3852500915556 .0804595947360 .0426712036162 .1761703491264 .61444854736 67.0527267456169 .4910125732471 .6244964599673 .4532165527374 .97714233398 76.5010681152377 .110626220776 .5010681152375 .2819290161174 .0627822876 73.1484298706171 .9292907714871 .014930725170 .1005783081170 .10057830811 70.1005783081170 .4053573608470 .4053573608471 .014930725171 .0149307251 70.7101516723669 .4910125732467 .6623001098664 .9192428588962 .17617034912 61.5666007995660 .9570198059160 .9570198059163 .0905189514265 .22400665283 67.35751342773 69.49101257324 71.014930725172.5388565063573.75800323486 74.6723632812575 .2819290161175 .5867080688576 .1962814331176 .50106811523 76.8058471679777 .110626220777 .110626220777 .4154205322377 .41542053223 77.110626220776 .8058471679776 .1962814331175 .5867080688574 .36756896973 73.1484298706171 .3197174072369 .4910125732466 .7479400634863 .70008850098 60.0426712036156 .0804595947351 .5086898803746 .0225486755440 .53641891479 34.7455101013229 .5641593933125 .906740188623 .1636695861820 .72538948059 17.9823207855215 .5440397262613 .1057596206710 .667480468758 .533983230591 6.7052731513984 .876562118533 .6574220657352 .4382810592651 .21914100647 $.6095703244209-9999-.304785102606-.304785102606-.304785102606$-9999 -9999 .91435539722441 .5239260196691 .8287110328672 .1334960460662 .133496046066 2.4382810592652 .7430660724643 .0478510856633 .3526360988623 .657422065735 3.6574220657353 .9622070789344 .2669920921334 .5717768669134 .571776866913 4.876562118535 .1813468933115 .48613214492822 .5541000366222 .85887908936 22.8588790893622 .8588790893622 .8588790893623 .1636695861821 .63973999023 $1.21914100647-3.04785108566-9.44833946228-16.4584007263-23.1636695862$ -28.6497993469 -32.6120109558 -35.0502891541 -36.2694282532 -36.5742111206 $-36.2694282532-35.6598587036-35.0502891541-34.1359291077-33.5263595581$ -33.2215805054 -32.6120109558 -32.307220459-32.307220459-32.307220459 -32.307220459 -32.307220459 -32.307220459-32.307220459-32.307220459-32.6120109558 -32.9167900085 $-33.2215805054-33.8311500549-34.4407196045-35.0502891541-35.6598587036$ -36.2694282532 -36.8790016174 -37.488571167 -37.7933502197 -38.0981407166 $-38.4029312134-38.0981407166-37.7933502197-37.1837806702-36.2694282532$ $-35.0502891541-33.5263595581-32.307220459-30.7833003998-30.1737308502$ $-29.2593708038-28.3450202942-26.8210906982-25.2971591949-23.1636695862$ $-20.7253894806-17.9823207855-15.2392597198-12.1914100647-9.14355373383$ $-6.095703125-3.04785108566-.609570324421 .91435539722442 .438281059265$ 4.2669920921336 .4004869461069 .4483394622813 .4105501174917 .98232078552 22.5541000366226 .5163097381629 .5641593933132 .0024414062533 .22158050537 33.5263595581134 .1359291076735 .3550796508836 .5742111206137 .79335021973 38.70771026611 -9999 -9999 -9999 -9999 -9999 -9999 -9999 -9999 -9999 -9999 -9999 -9999 
-9999 -9999 -9999 -9999 -9999 -9999 -9999 -9999 -9999 -9999 -9999 -9999 -9999 -9999 -9999 -9999 -9999 -9999 -9999 -9999 -9999 -9999 -9999 -9999 -9999 -9999 -9999 -9999 -9999 -9999

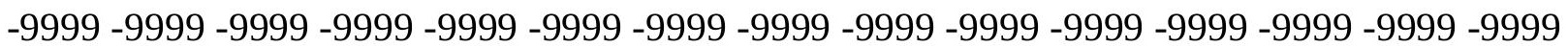
-9999 -9999 -9999 -9999 -9999 -9999 -9999 -9999 -9999 -9999 -9999 -9999 -9999 -9999 -9999 -9999 -9999 -9999 -9999 -9999 -9999 -9999 -9999 -9999 -9999 -9999 -9999 -9999 -9999 -9999 -9999 -9999 -9999 -9999 -9999 -9999 -9999 -9999 -9999 -9999 -9999 -9999 -9999 -9999 -9999 -9999 -9999 -9999 -9999 -9999 -9999 -9999 -9999 -9999 -9999 -9999 -9999 -9999 -9999

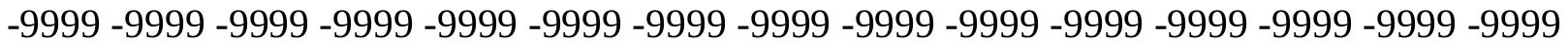

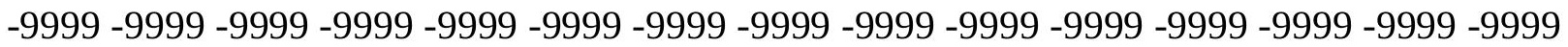
-9999 -9999 -9999 -9999 -9999 -9999 -9999 -9999 -9999 -9999 -9999 -9999 -9999 -9999 -9999

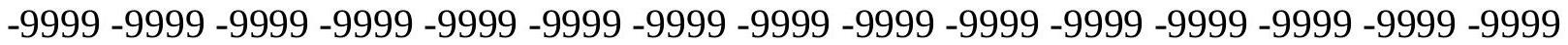
-9999 -9999 -9999 -9999 -9999 -9999 -9999 -9999 -9999 -9999 -9999 -9999 -9999 -9999 94.7881774902378 .0249862670968 .8814392089864 .6144485473660 .65224075317 59.7378807067960 .3474502563561 .5666007995666 .7479400634867 .66230010986 67.3575134277368 .2718734741270 .7101516723672 .8436431884875 .58670806885 78.3297805786180 .4632720947381 .9871978759884 .1206970214885 .94940185547 87.7781066894588 .6924667358488 .0829010009886 .254188537684 .73026275635 83.206336975182 .2919769287181 .6824111938580 .7680587768680 .15849304199 79.5489196777379 .5489196777379 .8537063598680 .1584930419979 .85370635986 78.6345596313576 .5010681152373 .7580032348671 .014930725169 .18623352051 68.2718734741267 .9670867919969 .1862335205170 .7101516723672 .23407745361 73.4532165527374 .6723632812575 .5867080688576 .1962814331176 .80584716797 77.110626220777 .4154205322377 .4154205322377 .4154205322377 .72020721436 78.0249862670978 .3297805786178 .3297805786178 .3297805786178 .32978057861 78.0249862670977 .7202072143676 .8058471679775 .8914871215874 .67236328125 72.8436431884870 .7101516723668 .2718734741265 .2240066528361 .87137985229 57.909179687553 .3373985290548 .4608306884842 .9747009277337 .79335021973 32.6120109558128 .3450202941924 .9923801422121 .6397399902318 .59189033508 15.5440397262612 .8009700775110 .362689971927 .9244132041936 .095703125 4.2669920921332 .7430660724641 .523926019669 .3047851026058 -.304785102606 -.914355397224 -1.52392601967 - $1.82871103287-1.82871103287-1.52392601967$ -1.21914100647 -.304785102606 -9999 3047851026058 .3047851026058 .6095703244209 .91435539722441 .5239260196691 .8287110328672 .1334960460662 .438281059265 2.7430660724642 .7430660724643 .0478510856633 .0478510856633 .352636098862 3.6574220657353 .9622070789344 .2669920921334 .5717768669134 .87656211853 4.876562118535 .1813468933114 .876562118534 .5717768669133 .657422065735 2.438281059265 -9999 -6.40048694611 -13.4105501175 -2.43828105927 -6.7052731514 $-11.5818300247-32.6120109558-33.8311500549-34.4407196045-34.4407196045$ -34.1359291077 -33.5263595581 -33.2215805054 -32.9167900085 -32.6120109558 -32.307220459 -32.0024414062 -32.0024414062 -32.0024414062 -32.0024414062 $-32.307220459-32.307220459-32.307220459-32.6120109558-32.9167900085$ $-33.2215805054-33.5263595581-34.1359291077-34.7455101013-35.6598587036$ -36.2694282532 -37.1837806702 -37.7933502197 -38.7077102661 -39.3172798157 -39.6220703125 -39.9268493652 -39.9268493652 -39.6220703125 -38.7077102661 $-37.7933502197-36.5742111206-35.0502891541-33.8311500549-32.6120109558$ $-31.3928699493-30.478509903-29.2593708038-27.7354507446-25.9067401886$ 
-23.4684505463 -21.0301704407 -17.9823207855 -14.9344701767 -11.8866195679 -8.83876895905 -5.79091691971 -3.04785108566 -.914355397224 .6095703244209 1.8287110328673 .0478510856635 .1813468933117 .92441320419311 .58183002472 16.4584007263221 .6397399902326 .2115192413329 .8689403533932 .30722045898 33.5263595581134 .1359291076735 .0502891540536 .2694282531737 .48857116699 38.4029312133839 .31727981567 -9999 -9999 -9999 -9999 -9999 -9999 -9999 -9999 -9999 -9999 -9999 -9999 -9999 -9999 -9999 -9999 -9999 -9999 -9999 -9999 -9999 -9999 -9999 -9999

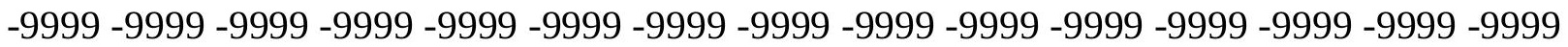

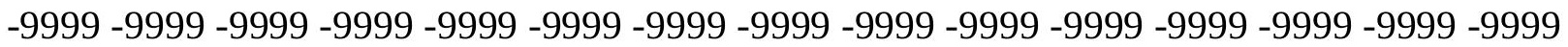
-9999 -9999 -9999 -9999 -9999 -9999 -9999 -9999 -9999 -9999 -9999 -9999 -9999 -9999 -9999

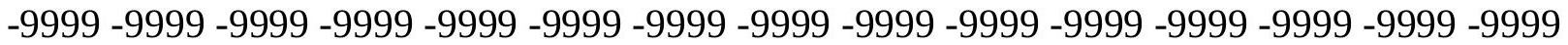
$-9999-9999$

-9999 -9999 -9999 -9999 -9999 -9999 -9999 -9999 -9999 -9999 -9999 -9999 -9999 -9999 -9999 -9999 -9999 -9999 -9999 -9999 -9999 -9999 -9999 -9999 -9999 -9999 -9999 -9999 -9999 -9999 -9999 -9999 -9999 -9999 -9999 -9999 -9999 -9999 -9999 -9999 -9999 -9999 -9999 -9999 -9999

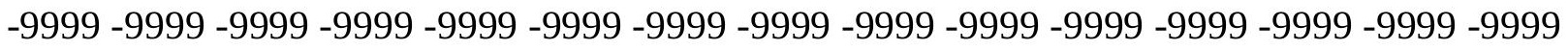

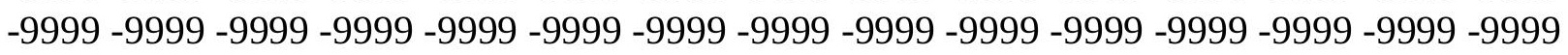
-9999 -9999 -9999 -9999 -9999 -9999 -9999 -9999 -9999 -9999 -9999 -9999 -9999 -9999 -9999 -999 -9999 -9999 -9999 -9999 -9999 -9999 -9999 -9999 -9999 -9999 -9999 -9999 -9999 -9999 -9999 98.1408081054782 .9015579223673 .7580032348669 .4910125732468 .27187347412 69.4910125732473 .4532165527381 .0728530883878 .0249862670976 .50106811523 77.4154205322379 .8537063598682 .9015579223685 .6446228027390 .21640014648 92.6546783447392 .6546783447395 .7025299072397 .22646331787100 .2742996216 101.4934005737101 .7982025146100 .274299621697 .5312423706194 .17859649658 92.6546783447392 .9594726562590 .8259735107489 .6068267822388 .69246673584 88.6924667358488 .6924667358489 .6068267822389 .6068267822388 .08290100098 85.9494018554783 .206336975180 .1584930419977 .7202072143676 .50106811523 75.8914871215876 .1962814331176 .8058471679777 .7202072143678 .32978057861 78.9393463134879 .2441329956179 .5489196777379 .5489196777379 .24413299561 79.2441329956178 .9393463134878 .9393463134878 .9393463134878 .93934631348 79.2441329956179 .5489196777379 .8537063598679 .8537063598679 .54891967773 79.2441329956178 .6345596313577 .4154205322376 .1962814331174 .67236328125 72.5388565063570 .1005783081167 .3575134277364 .004882812560 .65224075317 56.3852500915552 .1182594299347 .2416992187542 .0603485107436 .87900161743 32.3072204589828 .0402297973623 .7732391357420 .1158199310316 .76317977905 13.715330123910 .667480468758 .2291984558116 .0957031254 .266992092133 2.4382810592651 .21914100647 -9999 -.609570324421 -1.52392601967 -2.13349604607 $-2.43828105927-2.74306607246-2.74306607246-2.43828105927-1.82871103287$ -1.52392601967 -.914355397224 -.609570324421 - 304785102606-9999.3047851026058 .91435539722441 .219141006471 .5239260196691 .5239260196691 .523926019669 1.8287110328672 .1334960460662 .1334960460662 .4382810592652 .743066072464 3.0478510856633 .3526360988623 .6574220657353 .6574220657353 .962207078934 $3.9622070789343 .6574220657352 .7430660724641 .523926019669-.914355397224$ -5.79091691971 -11.8866195679 1.21914100647 -1.52392601967-4.26699209213 $-9.14355373383-31.0880794525-32.0024414062-32.0024414062-32.307220459$ $-32.0024414062-32.0024414062-32.0024414062-31.6976509094-31.6976509094$ 
-31.6976509094 -31.6976509094 -31.6976509094 -31.6976509094 -32.0024414062 -32.0024414062 -32.307220459 -32.307220459-32.6120109558 -33.2215805054 -33.5263595581 -34.4407196045 -35.0502891541 -35.9646492004 -36.8790016174 $-37.7933502197-38.7077102661-39.6220703125-40.2316398621-41.1459884644$ $-41.4507789612-41.4507789612-41.1459884644-40.2316398621-39.3172798157$ -37.7933502197 -36.5742111206 -35.3550796509 -34.1359291077 -32.9167900085 -31.6976509094 -30.478509903 -28.6497993469 -26.5163097382 -24.0780296326 $-21.0301704407-17.9823207855-14.9344701767-11.5818300247-8.53398323059$ $-5.48613214493-3.04785108566-.914355397224 .30478510260581 .21914100647$ 2.1334960460663 .3526360988625 .48613214492827 .430660247832 .30722045898 20.1158199310324 .9923801422129 .5641593933131 .6976509094233 .52635955811 34.4407196044935 .0502891540536 .5742111206137 .7933502197338 .70771026611 39.92684936523 -9999 -9999 -9999 -9999 -9999 -9999 -9999 -9999 -9999 -9999 -9999 -9999 -9999 -9999 -9999 -9999 -9999 -9999 -9999 -9999 -9999 -9999 -9999 -9999 -9999 -9999 -9999 -9999 -9999 -9999 -9999 -9999 -9999 -9999 -9999 -9999 -9999 -9999 -9999 -9999 -9999 -9999 -9999 -9999 -9999 -9999 -9999 -9999 -9999 -9999 -9999 -9999 -9999 -9999 -9999 -9999 -9999 -

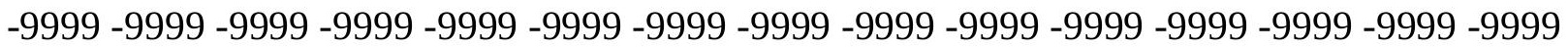
-9999 -9999 -9999 -9999 -9999 -9999 -9999 -9999 -9999 -9999 -9999 -9999 -9999 -9999 -9999 -9999 -9999 -9999 -9999 -9999 -9999 -9999 -9999 -9999 -9999 -9999 -9999 -9999 -9999 -9999 -9999 -9999 -9999 -9999 -9999 -9999 -9999 -9999 -9999 -9999 -9999 -9999 -9999 -9999

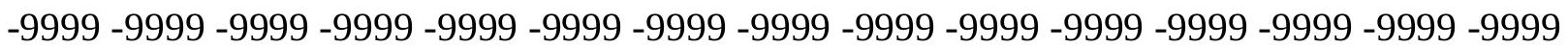
-9999 -9999 -9999 -9999 -9999 -9999 -9999 -9999 -9999 -9999 -9999 -9999 -9999 -9999 -9999 -9999 -9999 -9999 -9999 -9999 -9999 -9999 -9999 -9999 -9999 -9999 -9999 -9999 -9999 -9999 -9999 -9999 -9999 -9999 -9999 -9999 -9999 -9999 -9999 -9999 -9999 -9999 -9999 -9999 -9999 -9999 -9999 -9999 -9999 -9999 -9999 -9999 -9999 -9999 -9999 -9999 -9999 -9999 -9999 -9999 -9999 99.66472625732 85.94940185547 76.50106811523 77.1106262207 78.02498626709 80.1584930419982 .2919769287183 .206336975183 .8159103393685 .64462280273 88.9972534179794 .4833908081198 .9932708740299 .3105163574299 .80330657959 100.4810180664101 .3434143066102 .3830337524103 .5804672241104 .9079589844 106.3278503418107 .7989654541109 .2702255249109 .4179000854104 .8502655029 102.1988143921100 .336631774999 .2471084594799 .47290802002101 .9768829346 107.2844009399103 .931701660299 .6647262573296 .9216690063594 .48339080811 91.7403335571388 .9972534179786 .254188537684 .4254837036183 .81591033936 83.5111236572383 .5111236572383 .5111236572383 .206336975183 .2063369751 83.206336975182 .9015579223682 .5967712402381 .9871978759881 .07285308838 80.4632720947380 .1584930419980 .1584930419980 .4632720947380 .76805877686 81.0728530883881 .3776321411181 .3776321411181 .3776321411181 .07285308838 80.4632720947379 .2441329956178 .0249862670976 .5010681152374 .67236328125 72.5388565063569 .7957916259867 .0527267456164 .004882812560 .65224075317 56.6900291442952 .1182594299347 .2416992187542 .0603485107436 .87900161743 32.0024414062527 .1258792877222 .8588790893618 .8966808319115 .23925971985 12.19141006479 .448339462287 .0100579261784 .876562118533 .047851085663 $1.523926019669 .3047851026058-.304785102606-1.52392601967-2.43828105927$ -3.04785108566 -3.35263609886 -3.65742206573 -3.35263609886 -3.35263609886 $-2.74306607246-2.43828105927-2.13349604607-1.82871103287-1.21914100647$ -609570324421 -9999. 3047851026058. 3047851026058. 3047851026058. 
6095703244209.9143553972244 1.219141006471.21914100647 1.523926019669 1.8287110328671 .8287110328672 .1334960460662 .4382810592652 .438281059265 $2.4382810592651 .828711032867 .9143553972244-9999-2.74306607246-6.40048694611$ $-11.27705001833 .0478510856631 .523926019669 .9143553972244-.609570324421$ $-7.3148431778-29.5641593933-29.8689403534-30.1737308502-30.478509903$ $-30.7833003998-30.7833003998-30.7833003998-30.7833003998-30.7833003998$ $-31.0880794525-31.0880794525-31.3928699493-31.3928699493-31.6976509094$ -32.0024414062 -32.0024414062 -32.307220459-32.9167900085 -33.5263595581 $-34.1359291077-34.7455101013-35.9646492004-36.8790016174-38.0981407166$ -39.0125007629 -39.9268493652-40.8412094116 -41.7555618286-42.3651313782 $-42.669921875-42.0603485107-41.1459884644-40.2316398621-39.0125007629$ -37.7933502197 -36.2694282532 -35.0502891541 -33.8311500549-32.6120109558 -31.3928699493 -29.5641593933 -27.4306602478 -24.3828105927 -21.3349609375 $-18.287109375-14.9344701767-11.5818300247-8.22919845581-5.18134689331$ $-2.74306607246-.914355397224-9999.60957032442091 .219141006471 .828711032867$ 20.4206008911128 .0402297973632 .3072204589835 .3550796508822 .24930953979 26.8210906982430 .4785099029532 .9167900085434 .4407196044935 .35507965088 36.26942825317 37.4885711669938 .7077102661139 .92684936523 -9999 -9999 -9999 -9999 -9999 -9999 -9999 -9999 -9999 -9999 -9999 -9999 -9999 -9999 -9999 -9999 -9999 -9999 -9999

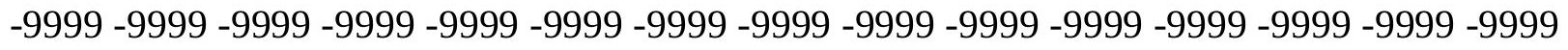
-9999 -9999 -9999 -9999 -9999 -9999 -9999 -9999 -9999 -9999 -9999 -9999 -9999 -9999 -9999

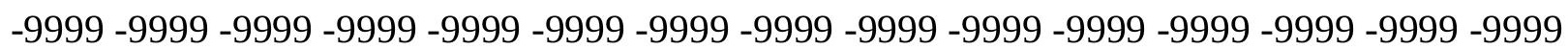

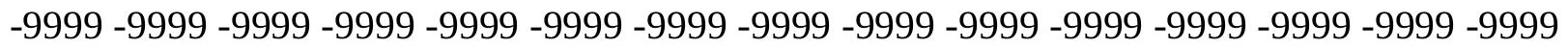
-9999 -9999 -9999 -9999 -9999 -9999 -9999

-9999 -9999 -9999 -9999 -9999 -9999 -9999 -9999 -9999 -9999 -9999 -9999 -9999 -9999 -9999 -9999 -9999 -9999 -9999 -9999 -9999 -9999 -9999 -9999 -9999 -9999 -9999 -9999 -9999 -9999 -9999 -9999 -9999 -9999 -9999 -9999 -9999 -9999 -9999 -9999 -9999 -9999 -9999 -9999 - -9999 -

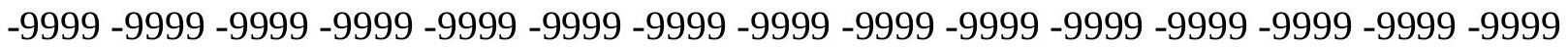
-9999 -9999 -9999 -9999 -9999 -9999 -9999 -9999 -9999 -9999 -9999 -9999 -9999 -9999 -9999

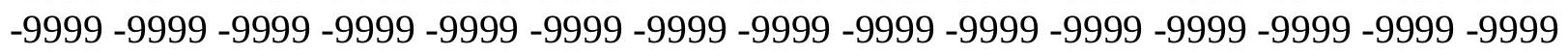
-9999 -9999 -9999 -9999 -9999 -9999 -9999 -9999 -9999 -9999 -9999 -9999 -9999 -9999 -9999 -9999 -9999 99.8338928222793.87381744385 88.08290100098 101.1886978149 84.12069702148 83.2063369751 85.9494018554798.872344970794.48339080811 98.47747039795 98.4722518920998.6254501342898.959960937599.49324798584 100.2393417358101 .201385498102 .3738937378103 .7358779907105 .2552490234 106.8815078735108 .5700912476110 .2635955811111 .9062576294113 .1512374878 110.1762390137108 .3074569702107 .6914672852108 .7280883789110 .8010940552 109.8395690918108 .8110809326107 .7102737427106 .1553115845104 .5401763916 103.931701660296 .9216690063592 .9594726562591 .1307525634890 .52117919922 90.5211791992289 .9116134643688 .6924667358487 .7781066894587 .47332763672 87.1685485839886 .5589828491285 .6446228027384 .4254837036183 .2063369751 82.2919769287181 .6824111938581 .3776321411181 .6824111938582 .29197692871 82.90155792236 83.2063369751 83.51112365723 83.2063369751 82.90155792236 82.2919769287181 .3776321411180 .1584930419978 .9393463134877 .1106262207 74.9771423339872 .8436431884870 .4053573608467 .9670867919964 .91924285889 61.5666007995657 .909179687553 .0326118469247 .8512611389242 .36513137817 
36.8790016174331 .3928699493426 .5163097381621 .9445304870617 .98232078552 14.6296901702911 .581830024728 .8387689590456 .4004869461064 .571776866913 $2.7430660724641 .21914100647-9999-.914355397224-1.82871103287-2.74306607246$ $-3.35263609886-3.96220707893-4.26699209213-4.26699209213-3.96220707893$ -3.65742206573 -3.35263609886 -3.04785108566 -2.43828105927 -1.82871103287 $-1.21914100647-.914355397224-.609570324421-.609570324421-.609570324421$ -304785102606 -9999-9999 -9999 .3047851026058.3047851026058. . 6095703244209 6095703244209.9143553972244.9143553972244. 6095703244209-9999 - 914355397224 $-2.13349604607-4.57177686691-7.61962795258-11.27705001833 .352636098862$ $2.7430660724642 .7430660724641 .523926019669-2.13349604607-6.7052731514$ -8.83876895905 -10.3626899719 -10.9722604752 -11.5818300247 -12.4961900711 $-29.8689403534-29.8689403534-30.1737308502-30.478509903-30.478509903$ $-30.7833003998-31.0880794525-31.3928699493-31.3928699493-31.6976509094$ -32.0024414062 -32.307220459 -32.9167900085 -33.5263595581 -34.4407196045 -35.3550796509 -36.5742111206 -37.7933502197 -39.0125007629-40.2316398621 $-41.1459884644-42.0603485107-42.669921875-42.669921875-42.3651313782$ $-41.7555618286-40.5364189148-39.6220703125-38.4029312134-37.1837806702$ -35.9646492004 -34.7455101013 -33.5263595581 -32.0024414062 -30.478509903 -27.7354507446 -24.9923801422 -21.6397399902 -18.287109375 -14.9344701767 $-11.5818300247-8.22919845581-4.87656211853-2.43828105927-.609570324421$ .3047851026058.6095703244209.9143553972244 1.21914100647 19.8110294342 26.2115192413329 .8689403533932 .9167900085436 .2694282531723 .77323913574 28.3450202941932 .0024414062534 .1359291076735 .3550796508835 .65985870361 36.5742111206138 .0981407165539 .6220703125 -9999 -9999 -9999 -9999 -9999 -9999 -9999 -9999 -9999 -9999 -9999 -9999 -9999 -9999 -9999 -9999 -9999 -9999 -9999 -9999 -9999 -9999 -9999 -9999 -9999 -9999 -9999 -9999 -9999 -9999 -9999 -9999 -9999 -9999 -9999 -9999 -9999 -9999 -9999 -9999 -9999 -9999 -9999 -9999 -9999 -9999 -9999 -9999 -9999 -9999 -9999 -9999

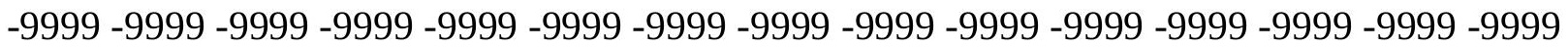

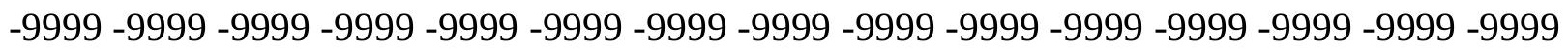
-9999 -9999-9999-9999

-9999 -9999 -9999 -9999 -9999 -9999 -9999 -9999 -9999 -9999 -9999 -9999 -9999 -9999 -9999

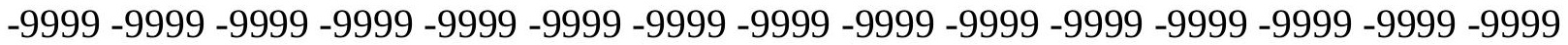

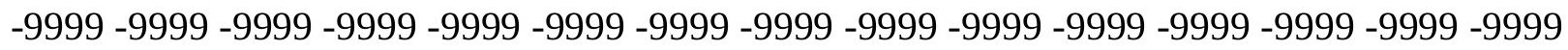
-9999 -9999 -9999 -9999 -9999 -9999 -9999 -9999 -9999 -9999 -9999 -9999 -9999 -9999 -9999 -9999 -9999 -9999 -9999 -9999 -9999 -9999 -9999 -9999 -9999 -9999 -9999 -9999 -9999 -9999

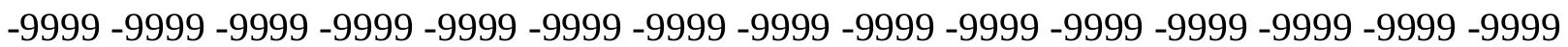

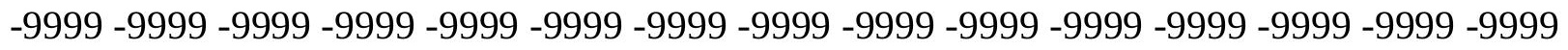
-9999 -9999-9999 104.8821411133102.2517166138101.884506225697.02870178223 96.4757614135798 .9621582031298 .5678100585998 .2699584960998 .08924102783 98.0524749755998 .1865539550898 .5196456909299 .0748672485499 .87255859375 100.9214172363102 .2197265625103 .7464599609105 .4604263306107 .3144302368 109.2456512451 111.1819152832 113.0500259399 114.7881469727 115.0114212036 113.9855880737113 .5634460449112 .7837371826111 .9593811035111 .0827331543 110.1455154419109 .1412353516108 .0639572144106 .9102401733105 .6783981323 104.3715591431102 .7350921631101 .570915222299 .0551681518697 .22646331787 94.7881774902392 .6546783447391 .4355392456191 .1307525634890 .82597351074 
90.2164001464888 .9972534179787 .1685485839885 .3398437583 .81591033936 82.9015579223682 .9015579223683 .5111236572384 .1206970214884 .73026275635 85.3398437585 .6446228027385 .3398437585 .0350494384884 .4254837036183 .51112365723 82.5967712402381 .0728530883879 .5489196777378 .0249862670976 .19628143311 74.062782287671 .6244964599669 .4910125732466 .7479400634863 .70008850098 58.8235282897953 .3373985290547 .8512611389242 .3651313781736 .87900161743 31.3928699493426 .2115192413321 .6397399902317 .9823207855214 .32489967346 11.277050018318 .5339832305916 .4004869461064 .5717768669132 .743066072464 $1.21914100647-9999-.914355397224-2.13349604607-3.04785108566-3.96220707893$ $-4.57177686691-4.87656211853-4.57177686691-4.57177686691-4.26699209213$ -3.96220707893 -3.65742206573 -3.04785108566 -2.74306607246 -2.13349604607 $-2.13349604607-1.82871103287-1.82871103287-1.52392601967-1.21914100647$ $-1.21914100647-.914355397224-.914355397224-.914355397224-.609570324421$ -.609570324421 -.609570324421 -.914355397224 -1.21914100647-1.82871103287 -3.04785108566 -4.57177686691 -6.40048694611 -9.14355373383-11.8866195679 2.4382810592652 .1334960460661 .523926019669 .6095703244209-1.21914100647 $-4.26699209213-6.095703125-7.61962795258-8.53398323059-9.14355373383$ -8.83876895905 -8.53398323059-9.14355373383 -10.6674804688 -29.8689403534 -30.1737308502 -30.1737308502 -30.478509903 -30.7833003998 -30.7833003998 $-31.0880794525-31.0880794525-31.3928699493-31.6976509094-32.307220459$ $-33.2215805054-34.4407196045-35.6598587036-36.8790016174-38.4029312134$ $-39.6220703125-40.5364189148-41.4507789612-42.0603485107-42.3651313782$ $-42.0603485107-41.4507789612-40.5364189148-39.6220703125$-38.7077102661 $-37.488571167-36.2694282532-35.0502891541-33.8311500549-32.307220459$ $-30.478509903-28.0402297974-25.2971591949-21.9445304871-18.5918903351$ -15.2392597198 -11.5818300247-8.22919845581 -4.87656211853 -1.82871103287-9999 6095703244209.6095703244209.6095703244209.9143553972244 19.20145988464 23.7732391357427 .1258792877230 .1737308502233 .5263595581120 .11581993103 25.906740188630 .7833003997833 .5263595581134 .7455101013235 .05028915405 35.0502891540536 .8790016174338 .70771026611 -9999 -9999 -9999 -9999 -9999 -9999 -9999 -9999 -9999 -9999 -9999 -9999 -9999 -9999 -9999 -9999 -9999 -9999 -9999 -9999 -9999 -9999 -9999 -9999 -9999 -9999 -9999 -9999 -9999 -9999 -9999 -9999 -9999 -9999 -9999 -9999 -9999 -

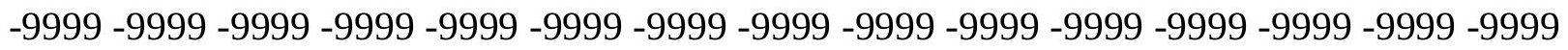
-9999 -9999 -9999 -9999 -9999 -9999 -9999 -9999 -9999 -9999 -9999 -9999 -9999 -9999 -9999

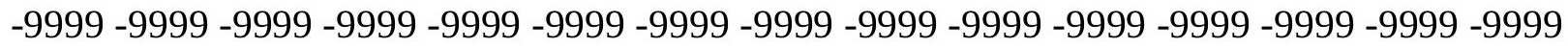
-9999 -9999 -9999-9999 -9999 -9999-9999 -9999 -9999 -9999 -9999 -9999 -9999 -9999 -9999 -9999 -9999 -9999 - 9999 -

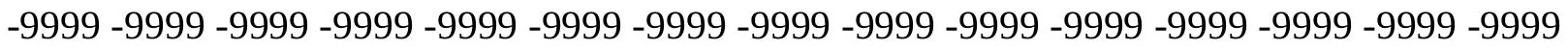

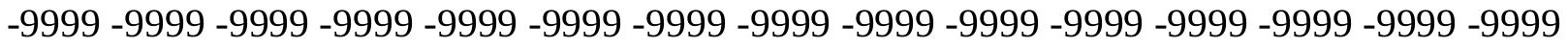
-9999 -9999 -9999 -9999 -9999 -9999 -9999 -9999 -9999 -9999 -9999 -9999 -9999 -9999 -9999 -

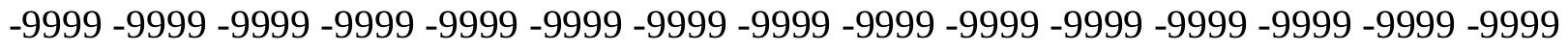

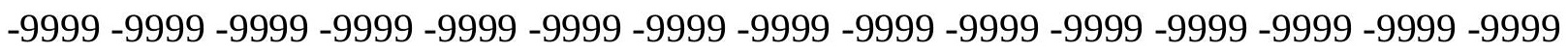
-9999 -9999 -9999 -9999 -9999 -9999 -9999 -9999 -9999 -9999 -9999 -9999 -9999 -9999 -9999 -9999 -9999 -9999 -9999 -9999 -9999 -9999 -9999 110.393882751598 .25936889648 97.9048233032297 .6693496704197 .5826797485497 .6759490966897 .98295593262 98.5343551635799 .35712432861100 .4705429077101 .8774108887103 .5616226196 
105.48387146107 .5897903442109 .7989120483112 .0124588013114 .1294708252 116.0670013428115 .9724349976115 .3281326294114 .6553115845113 .9518432617 113.212387085112 .4293899536111 .5939483643110 .6983947754109 .7355041504 108.7001190186107 .5885238647106 .4014892578105 .1441497803103 .8287200928 102.4738235474101 .10575866799 .7572708129998 .4653930664195 .3977432251 93.5690307617294 .4833908081193 .2642517089891 .7403335571389 .60682678223 86.8637619018685 .0350494384884 .1206970214884 .4254837036185 .33984375 86.254188537687 .1685485839887 .7781066894587 .7781066894587 .47332763672 87.1685485839886 .5589828491285 .6446228027384 .7302627563583 .81591033936 82.2919769287181 .0728530883879 .2441329956177 .4154205322375 .58670806885 73.4532165527371 .014930725167 .9670867919963 .7000885009859 .12831115723 53.9469718933148 .4608306884842 .9747009277337 .1837806701731 .39286994934 26.8210906982422 .5541000366218 .28710937514 .6296901702911 .58183002472 9.1435537338267 .0100579261785 .1813468933113 .3526360988621 .828711032867 $.3047851026058-.609570324421-2.13349604607$-3.35263609886 -4.26699209213 $-4.87656211853-4.87656211853-4.87656211853-4.87656211853-4.57177686691$ $-4.26699209213-3.96220707893-3.65742206573-3.65742206573-3.35263609886$ $-3.35263609886-3.04785108566-3.04785108566-2.74306607246-2.74306607246$ $-2.43828105927-2.43828105927-2.43828105927-2.43828105927-2.43828105927$ $-2.74306607246-3.04785108566-3.35263609886-4.26699209213-5.18134689331$ $-6.7052731514-8.53398323059-10.6674804688-13.1057596207-15.5440397263$ $-.914355397224-1.52392601967-2.43828105927-3.65742206573-5.18134689331$ $-6.40048694611-7.61962795258-8.53398323059-8.83876895905-8.83876895905$ -8.53398323059 -8.53398323059 -9.75312423706 -12.1914100647 -29.5641593933 $-29.8689403534-30.1737308502-30.478509903-30.478509903-30.1737308502$ -30.1737308502 -30.1737308502 -30.478509903 -30.7833003998 -31.6976509094 -32.9167900085 -34.1359291077 -35.3550796509 -36.8790016174 -38.4029312134 $-39.6220703125-40.5364189148-41.1459884644-41.1459884644-41.1459884644$ $-40.5364189148-39.9268493652-39.3172798157-38.4029312134-37.488571167$ $-36.2694282532-35.3550796509-33.8311500549-32.307220459-30.478509903$ $-28.0402297974-25.6019496918-22.5541000366-19.2014598846-15.8488302231$ -12.1914100647-8.53398323059 -5.18134689331 -2.13349604607.3047851026058 6095703244209.6095703244209.6095703244209.6095703244209 18.287109375 22.5541000366225 .2971591949527 .430660247830 .1737308502216 .15361022949 22.8588790893629 .5641593933132 .0024414062533 .5263595581134 .44071960449 34.7455101013235 .0502891540537 .18378067017 -9999 -9999 -9999 -9999 -9999 -9999 -9999

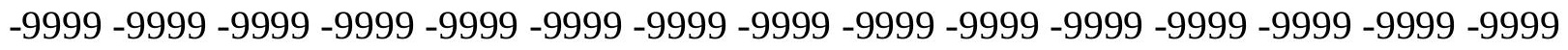

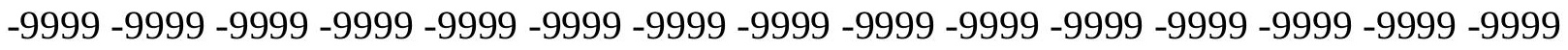
-9999 -9999 -9999 -9999 -9999 -9999 -9999 -9999 -9999 -9999 -9999 -9999 -9999 -9999 -9999 -9999 -9999 -9999 -9999 -9999 -9999 -9999 -9999 -9999 -9999 -9999 -9999 -9999 -9999 -9999 -

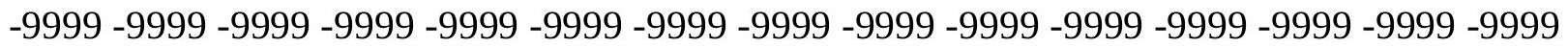
$-9999-9999-9999-9999$ -9999 -9999 -9999 -9999 -9999 -9999 -9999 -9999 -9999 -9999 -9999 -9999 -9999 -9999 -9999 -9999 -9999 -9999 -9999 -9999 -9999 -9999 -9999 -9999 -9999 -9999 -9999 -9999 -9999 -9999 -9999 -9999 -9999 -9999 -9999 -9999 -9999 -9999 -9999 -9999 -9999 -9999 -9999 -9999 -9999 -

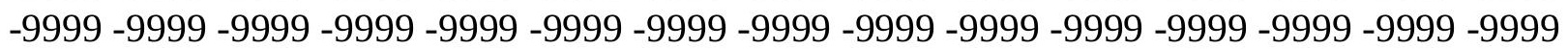


-9999 -9999 -9999 -9999 -9999 -9999 -9999 -9999 -9999 -9999 -9999 -9999 -9999 -9999 -9999 -9999 -9999 -9999 -9999 -9999 -9999 -9999 -9999 -9999 -9999 -9999 -9999 -9999 -9999 -9999

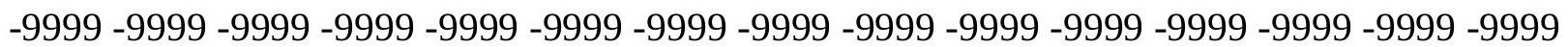
-9999 -9999 -9999 -9999 -9999 -9999 -9999 -9999 -9999 -9999 97.53749084473 97.231025695897 .0739593505997 .1009445190497 .3512344360497 .86339569092 98.67494964699 .81647491455101 .3028793335103 .130065918105 .266418457 107.6549530029110 .1913375854112 .7345733643115 .1361236572117 .2764816284 116.9936141968116 .414390564115 .8136672974115 .1905822754114 .5411605835 113.8585662842113 .1335906982112 .3573455811111 .5209884644110 .6172332764 109.639831543108 .5867080688107 .4599990845106 .2687835693105 .0280303955 103.7598419189102 .491973877101 .256149292100 .085075378499 .00595092773 98.0385131835997 .1950531005994 .7881774902391 .4355392456188 .08290100098 85.9494018554785 .0350494384885 .9494018554787 .4733276367288 .69246673584 89.6068267822390 .2164001464890 .2164001464889 .9116134643689 .3020401001 88.3876876831187 .7781066894586 .8637619018685 .9494018554785 .03504943848 83.8159103393682 .5967712402381 .0728530883879 .2441329956177 .41542053223 74.9771423339872 .2340774536168 .5766525268664 .3096618652359 .73788070679 55.1661109924349 .9847602844244 .8034095764239 .3172798156733 .83115005493 28.0402297973623 .1636695861818 .8966808319115 .5440397262612 .80097007751 10.667480468758 .5339832305916 .4004869461064 .5717768669132 .743066072464 $.9143553972244-.304785102606-1.82871103287-3.04785108566-3.96220707893$ $-4.57177686691-4.87656211853-4.87656211853-4.87656211853-4.87656211853$ $-4.57177686691-4.57177686691-4.57177686691-4.26699209213-4.26699209213$ $-4.26699209213-4.26699209213-3.96220707893-3.96220707893-3.96220707893$ $-3.96220707893-4.26699209213-4.26699209213-4.57177686691-4.87656211853$ $-5.18134689331-5.79091691971-6.7052731514-7.61962795258-9.14355373383$ -10.6674804688 -12.4961900711 -14.3248996735 -16.1536102295 -17.9823207855 $-19.5062503815-21.0301704407-22.2493095398-23.1636695862-23.7732391357$ $-24.6875991821-25.2971591949-25.9067401886-26.5163097382-26.8210906982$ $-27.4306602478-28.0402297974-28.6497993469-29.2593708038-29.8689403534$ $-30.1737308502-30.1737308502-29.8689403534-29.5641593933-29.2593708038$ -28.9545898438 -28.6497993469 -28.9545898438 -29.5641593933 -30.478509903 $-31.6976509094-33.2215805054-34.7455101013-36.2694282532-37.7933502197$ -39.0125007629 -39.6220703125 -39.6220703125 -39.6220703125 -39.3172798157 -39.0125007629 -38.4029312134 -37.7933502197 -37.1837806702 -36.2694282532 -35.0502891541 -33.8311500549 -32.307220459 -30.478509903 -28.3450202942 -25.9067401886 -22.8588790894 -19.8110294342-16.4584007263 -13.1057596207 $-9.44833946228-6.095703125-2.74306607246-609570324421.3047851026058$ .6095703244209.6095703244209.3047851026058.6095703244209 21.3349609375 23.4684505462624 .9923801422126 .2115192413311 .8866195678718 .59189033508 24.6875991821328 .9545898437531 .6976509094233 .2215805053733 .83115005493 34.1359291076735 .0502891540537 .79335021973 -9999 -9999 -9999 -9999 -9999 -9999 -9999 -9999 -9999 -9999 -9999 -9999 -9999 -9999 -9999 -9999 -9999 -9999 -9999 -9999 -9999 -9999 -9999 -9999 -9999 -9999 -9999 -9999 -9999 -9999 -9999 -9999 -9999 -9999 -9999 -9999 -9999 -9999 -9999 -9999 -9999 -9999 -9999 -9999 -9999 -9999 -9999 -9999 -9999 -9999 -9999 -9999 -999 -

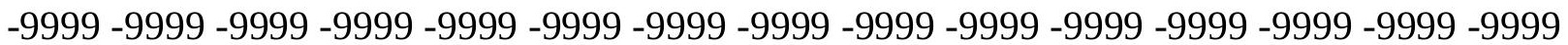


-9999 -9999 -9999 -9999 -9999 -9999 -9999 -9999 -9999 -9999 -9999 -9999 -9999 -9999 -9999 -9999-9999-9999

-9999 -9999 -9999 -9999 -9999 -9999 -9999 -9999 -9999 -9999 -9999 -9999 -9999 -9999 -9999 -9999 -9999 -9999 -9999 -9999 -9999 -9999 -9999 -9999 -9999 -9999 -9999 -9999 -9999 -9999 -9999 -9999 -9999 -9999 -9999 -9999 -9999 -9999 -9999 -9999 -9999 -9999 -9999 - -9999 - -9999 -9999 -9999 -9999 -9999 -9999 -9999 -9999 -9999 -9999 -9999 -9999 -9999 -9999 -9999 -9999

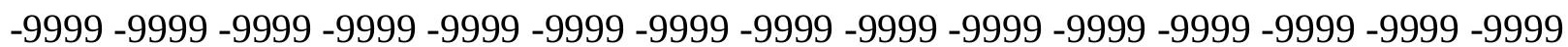
-9999 -9999 -9999 -9999 -9999 -9999 -9999 -9999 -9999 -9999 -9999 -9999 -9999 -9999 -9999

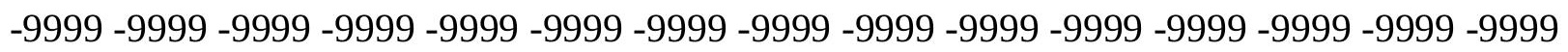
-9999 -9999 -9999 -9999 -9999 -9999-9999 -9999 -9999-9999 -9999 96.79431152344 96.5453720092896 .4781875610496 .6368408203197 .0688323974697 .81873321533 98.9458694458100 .4642715454102 .3788833618104 .7187652588107 .4220352173 110.3489456177113 .2955474854116 .0332946777118 .3798217773118 .0533065796 117.5501785278117 .0233230591116 .4828033447115 .9262924194115 .3482971191 114.7400665283114 .091506958113 .3917388916112 .6307830811111 .7993545532 110.892036438109 .9075546265108 .8516921997107 .7359390259106 .5788879395 105.4047851562104 .2425231934103 .1225357056102 .0767288208101 .1270675659 100.314231872699 .6942672729599 .3619537353596 .0073165893689 .60682678223 86.8637619018687 .7781066894589 .9116134643691 .1307525634892 .3498916626 92.9594726562592 .6546783447391 .7403335571390 .8259735107490 .21640014648 89.6068267822388 .9972534179788 .3876876831187 .7781066894586 .55898284912 85.6446228027384 .1206970214882 .5967712402380 .7680587768678 .63455963135 76.1962814331173 .1484298706169 .4910125732465 .5288009643661 .56660079956 57.2995986938553 .0326118469247 .8512611389241 .7555618286135 .05028915405 28.6497993469224 .0780296325720 .4206008911117 .3727493286114 .9344701767 12.4961900711110 .057909965527 .9244132041935 .4861321449283 .352636098862 $1.523926019669-9999-1.52392601967-2.74306607246-3.35263609886-3.96220707893$ $-4.26699209213-4.57177686691-4.87656211853-4.87656211853-5.18134689331$ $-5.18134689331-5.18134689331-5.18134689331-5.18134689331-5.18134689331$ $-5.18134689331-5.48613214493-5.48613214493-5.48613214493-5.79091691971$ $-6.095703125-6.40048694611-6.7052731514-7.3148431778-8.22919845581-9.14355373383$ -10.3626899719-11.5818300247 -12.8009700775 -14.3248996735 -15.8488302231 -17.0679702759 -18.5918903351 -19.8110294342 -20.7253894806-21.6397399902 $-22.5541000366-23.1636695862-23.7732391357-24.3828105927-24.9923801422$ $-25.6019496918-26.2115192413-26.8210906982-27.7354507446-28.3450202942$ $-28.9545898438-29.5641593933-29.8689403534-29.8689403534-29.5641593933$ -28.6497993469 -28.0402297974 -27.4306602478 -26.8210906982 -26.5163097382 $-26.8210906982-27.1258792877-28.3450202942-29.5641593933-31.3928699493$ -33.5263595581 -35.3550796509 -36.5742111206 -37.1837806702 -37.488571167 -37.7933502197 -37.7933502197 -37.488571167 -37.1837806702 -36.8790016174 -36.2694282532 -35.6598587036 -34.7455101013 -33.5263595581 -32.307220459 $-30.478509903-28.6497993469-26.2115192413-23.4684505463-20.7253894806$ -17.3727493286 -14.0201196671 -10.6674804688 -7.3148431778 -4.26699209213 -1.82871103287 - 304785102606 3047851026058 3047851026058 .3047851026058 -9999 19.2014598846421 .0301704406721 .334960937521 .944530487069 .143553733826 14.6296901702920 .4206008911125 .2971591949528 .9545898437531 .69765090942 
32.9167900085432 .9167900085432 .6120109558135 .96464920044 -9999 -9999 -9999 -9999 -9999 -9999 -9999 -9999 -9999 -9999 -9999 -9999 -9999 -9999 -9999 -9999 -9999 -9999 -9999

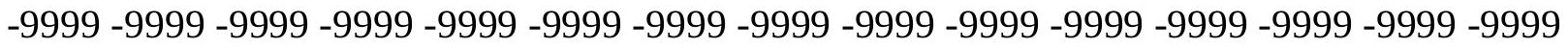
-9999 -9999 -9999 -9999 -9999 -9999 -9999 -9999 -9999 -9999 -9999 -9999 -9999 -9999 -9999 -9999 -9999 -9999 -9999 -9999 -9999 -9999 -9999 -9999-9999 -9999 -9999 -9999 -9999 -9999 -

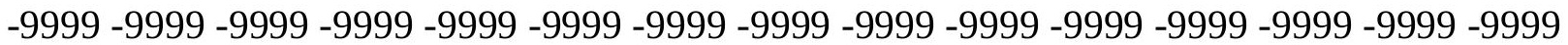
-9999 -9999 -9999-9999-9999-9999

-9999 -9999 -9999 -9999 -9999 -9999 -9999 -9999 -9999 -9999 -9999 -9999 -9999 -9999 -9999

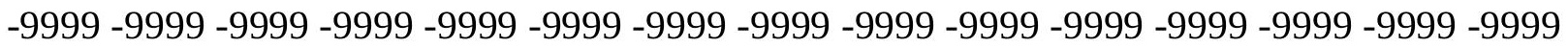
-9999 -9999 -9999 -9999 -9999 -9999 -9999 -9999 -9999 -9999 -9999 -9999 -9999 -9999 -9999 -

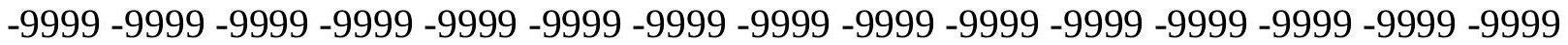
-9999 -9999 -9999 -9999 -9999 -9999 -9999 -9999 -9999 -9999 -9999 -9999 -9999 -9999 -9999 -9999 -9999 -9999 -9999 -9999 -9999 -9999 -9999 -9999 -9999 -9999 -9999 -9999 -9999 -9999 -9999 -9999 -9999 -9999 -9999 -9999 -9999 -9999 -9999 -9999 -9999 -9999 -9999 -9999 -9999 -9999 -9999 -9999 -9999 -9999 -9999 -9999 -9999 -9999 -9999 -9999 -9999 -9999 95.8377609252995 .8708953857496 .1800308227596 .8073043823297 .81381988525 99.25913238525101 .208190918103 .7140731812106 .7465438843110 .1320343018 113.5749969482116 .7185592651116 .4224853516115 .9323501587115 .6279678345 115.5888748169115 .8241119385116 .269241333116 .8160095215116 .3860855103 115.8703079224115 .3141555786114 .7043151855114 .0278701782113 .275604248 112.4424133301111 .5305709839110 .5484237671109 .5120315552108 .4436645508 107.3716964722 106.3283233643105.3482208252104.4683074951 103.7386169434 103.2302398682103 .036781311103 .284286499100 .3486022949101 .1886978149 101.188697814999 .6647262573297 .5312423706194 .4833908081195 .3977432251 94.4833908081193 .5690307617292 .349891662691 .7403335571391 .13075256348 90.8259735107490 .5211791992290 .2164001464889 .302040100188 .38768768311 87.1685485839885 .9494018554784 .1206970214882 .2919769287180 .15849304199 77.4154205322374 .3675689697371 .014930725167 .6623001098664 .0048828125 60.3474502563556 .6900291442949 .3751907348642 .3651313781735 .96464920044 30.4785099029526 .2115192413323 .1636695861820 .1158199310317 .37274932861 14.6296901702911 .886619567879 .1435537338266 .7052731513984 .266992092133 $2.133496046066 .3047851026058-.609570324421-1.82871103287-2.43828105927$ $-3.35263609886-3.96220707893-4.26699209213-4.57177686691-5.18134689331$ $-5.48613214493-5.48613214493-5.79091691971-6.095703125-6.095703125-6.40048694611$ $-6.40048694611-6.7052731514-7.01005792618-7.3148431778-7.61962795258$ $-8.22919845581-8.83876895905-9.75312423706-10.6674804688-11.5818300247$ $-12.8009700775-14.0201196671-15.2392597198-16.4584007263-17.6775398254$ -18.8966808319 -19.8110294342 -20.4206008911 -21.3349609375 -21.9445304871 $-22.2493095398-22.8588790894-23.4684505463-23.7732391357-24.3828105927$ -24.9923801422 -25.9067401886 -26.5163097382 -27.1258792877 -28.0402297974 -28.6497993469 -28.9545898438 -29.5641593933 -29.5641593933 -28.6497993469 $-27.7354507446-26.8210906982-25.6019496918-24.6875991821-24.0780296326$ -23.4684505463 -23.4684505463 -23.7732391357 -24.9923801422 -26.8210906982 -29.5641593933 -32.0024414062 -33.5263595581 -34.1359291077 -34.7455101013 $-35.0502891541-35.6598587036-35.6598587036-35.9646492004-35.6598587036$ -35.3550796509 -35.0502891541 -34.4407196045 -33.5263595581 -32.307220459 
-30.7833003998 -28.9545898438 -26.8210906982 -24.3828105927 -21.6397399902 -18.5918903351 -15.5440397263 -11.8866195679-8.83876895905 -5.48613214493 -3.04785108566-.914355397224 -9999.3047851026058.6095703244209.9143553972244 1.5239260196691 .2191410064717 .677539825443 .0478510856636 .400486946106 11.2770500183116 .4584007263221 .6397399902326 .2115192413329 .86894035339 31.6976509094231 .6976509094231 .0880794525134 .4407196044938 .70771026611 -9999 -9999 -9999 -9999 -9999 -9999 -9999 -9999 -9999 -9999 -9999 -9999 -9999 -9999 -9999 -9999

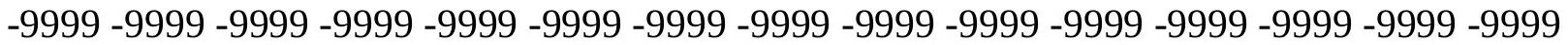

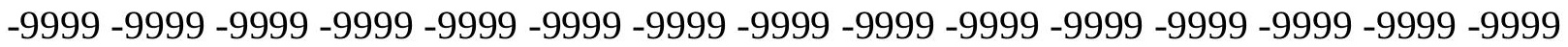
-9999 -9999 -9999 -9999 -9999 -9999 -9999 -9999 -9999 -9999 -9999 -9999 -9999 -9999 -9999 -

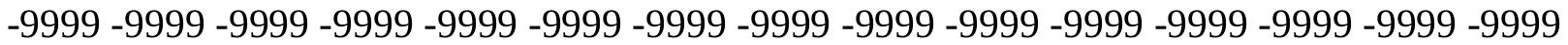
-9999 -9999 -9999 -9999-9999-9999-9999-9999

-9999 -9999 -9999 -9999 -9999 -9999 -9999 -9999 -9999 -9999 -9999 -9999 -9999 -9999 -9999 -9999 -9999 -9999 -9999 -9999 -9999 -9999 -9999 -9999 -9999 -9999 -9999 -9999 -9999 -9999 -9999 -9999 -9999 -9999 -9999 -9999 -9999 -9999 -9999 -9999 -9999 -9999 -9999 -9999 -9999

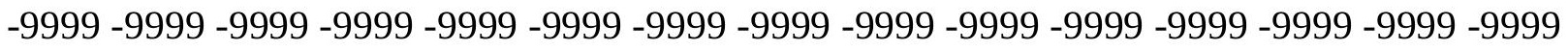

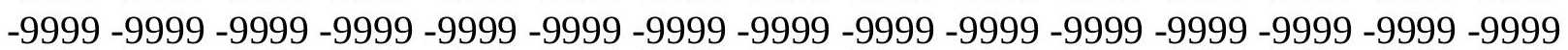
-9999 -9999 -9999 -9999 -9999 -9999 -9999 -9999 -9999 -9999 -9999 -9999 -9999 -9999 -9999 -999 -9999 -9999 -9999 -9999 -9999 -9999 -9999 -9999 -9999 -9999 -9999 -9999 -9999 -9999 -9999 -9999 -9999 -9999 -9999 -9999 -9999 -9999 -9999 -9999 -9999 -9999 -9999 -9999 -9999 95.1019134521595 .227813720795 .6502075195396 .4382629394597 .68983459473 99.53098297119102 .0880966187105 .4076156616109 .3084182739113 .3296890259 113.3602600098113 .2129516602112 .9761886597112 .7886657715112 .7653427124 112.963218689113 .3775863647113 .953086853114 .612701416115 .2793579102 115.8975601196116 .4392166138116 .2838363647115 .6930007935115 .0172729492 114.2551498413113 .4121627808112 .5028839111111 .5493087769110 .5808868408 109.6324462891 108.7429656982 107.9577178955 107.3330612183106.9421005249 106.8709793091107 .20262146108 .0352859497109 .3905487061110 .7320175171 112.1594924927114 .9388122559111 .24659729106 .065200805799 .96952056885 94.4833908081193 .2642517089892 .6546783447392 .349891662692 .65467834473 92.6546783447392 .349891662691 .7403335571390 .8259735107489 .91161346436 88.6924667358487 .1685485839885 .6446228027383 .5111236572381 .37763214111 78.6345596313575 .8914871215872 .8436431884869 .7957916259866 .13836669922 61.8713798522956 .0804595947349 .6799812316943 .5842704772937 .79335021973 32.9167900085429 .8689403533926 .8210906982423 .4684505462620 .11581993103 16.7631797790513 .4105501174910 .362689971927 .6196279525764 .87656211853 3.0478510856631 .523926019669 .3047851026058 -.609570324421 -1.52392601967 $-2.43828105927-3.04785108566-3.96220707893-4.57177686691-5.18134689331$ $-5.48613214493-5.79091691971-6.40048694611-6.7052731514-7.01005792618$ -7.3148431778 -7.61962795258 -7.92441320419-8.53398323059-9.14355373383 $-9.75312423706-10.6674804688-11.5818300247-12.8009700775-14.0201196671$ -15.2392597198 -16.7631797791 -17.9823207855 -19.2014598846-20.115819931 -20.7253894806 -21.3349609375 -21.9445304871 -22.2493095398 -22.5541000366 $-22.8588790894-23.1636695862-23.4684505463-23.7732391357-24.3828105927$ $-24.9923801422-25.6019496918-26.2115192413-26.8210906982-27.4306602478$ $-28.0402297974-28.6497993469-28.6497993469-28.6497993469-28.0402297974$ 
-26.8210906982 -25.6019496918 -24.0780296326 -22.5541000366 -21.3349609375 -20.115819931 -19.2014598846 -18.8966808319-19.5062503815 -21.0301704407 $-24.0780296326-28.0402297974-28.9545898438-29.8689403534-31.0880794525$ -32.307220459 -33.2215805054 -33.8311500549 -34.1359291077 -34.4407196045 $-34.4407196045-34.1359291077-33.8311500549-33.2215805054-32.0024414062$ $-30.7833003998-29.5641593933-27.4306602478-25.2971591949-22.8588790894$ -20.115819931 -17.0679702759 -13.7153301239-10.3626899719 -7.3148431778 -4.26699209213 -1.82871103287- -304785102606.3047851026058.9143553972244 1.219141006471 .21914100647 .6095703244209 .60957032442091 .828711032867 4.2669920921337 .92441320419312 .4961900711117 .6775398254422 .85887908936 28.0402297973630 .7833003997830 .4785099029529 .5641593933133 .52635955811 39.0125007629442 .06034851074 -9999 -9999 -9999 -9999 -9999 -9999 -9999 -9999 -9999 -9999 -9999 -9999 -9999 -9999 -9999 -9999 -9999 -9999 -9999 -9999 -9999 -9999 -9999 -9999 -9999 -9999 -9999 -9999 -9999 -9999 -9999 -9999 -9999 -9999 -9999 -9999 -9999 -9999 -9999 -9999 -9999 -9999 -9999 -9999 -9999 -9999 -9999 -9999 -9999 -9999 -9999 -9999 -9999 -9999 -9999 -9999 -9999 -9999 -9999 -9999 -9999 -9999 -9999 -9999 -9999 -9999 -9999 -9999 -9999 -9999 -9999 -9999 -9999 -9999 -9999 -9999 -9999 -9999 -9999 -9999 -9999 -9999 -9999 -9999 -9999 -9999 -9999 -9999 -9999 -9999 -9999 -9999 -9999 -9999 -9999 -9999 -9999 -9999 -9999 -9999 -9999 -9999 -9999 -9999 -9999 -9999 -9999 -9999 -9999 -9999 -9999 -9999 -9999 -9999 -9999 -9999 -9999 -9999 -9999 -9999 -9999 -9999 -9999 -9999 -9999 -9999 -9999 -9999

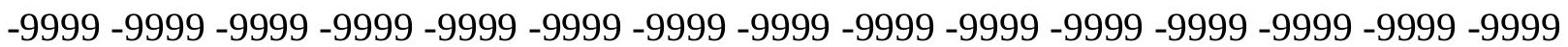
-9999 -9999 -9999 -9999 -9999 -9999 -9999 -9999 -9999 -9999 -9999 -9999 -9999 -9999 -9999 -9999 -9999 -9999 -9999 -9999 -9999 -9999 -9999 -9999 -9999 -9999 -9999 -9999 -9999 -9999 -9999 -9999 -9999 -9999 -9999 -9999 -9999 -9999 -9999 -9999 -9999 -9999 -9999 -9999 -9999 -9999 -9999 -9999 -9999 -9999 -9999 -9999 -9999 -9999 -9999 -9999 -9999 -9999 -9999 -9999 -9999 94.4205780029394.8845901489395.7913055419997.3185119628999.69178771973 103.1127471924107 .5300750732108 .7631988525109 .3809432983109 .5631027222 109.4711761475109 .3105926514109 .2493515015109 .393737793109 .7861862183 110.4022369385111 .1751327515112 .0231246948112 .871307373113 .665397644 114.3778533936114 .9832458496115 .456741333115 .7745513916115 .9125061035 115.4874801636114 .6526031494113 .7948379517112 .9498443604112 .1632385254 111.4831848145110 .965927124110 .677116394110 .681098938111 .0319595337 111.773765564112 .8832244873114 .243270874115 .5915222168116 .551109314 116.7651290894116 .1517791748114 .2944030762106 .979598999101 .1886978149 96.9216690063593 .5690307617294 .1785964965894 .1785964965894 .17859649658 93.8738174438592 .9594726562592 .0450973510791 .1307525634889 .91161346436 88.6924667358486 .8637619018685 .0350494384882 .5967712402380 .15849304199 77.4154205322374 .3675689697370 .7101516723666 .4431610107461 .56660079956 56.3852500915550 .8991203308146 .0225486755441 .7555618286137 .79335021973 34.1359291076730 .1737308502226 .2115192413322 .2493095397918 .287109375 14.6296901702911 .277050018318 .2291984558116 .0957031254 .266992092133 $3.0478510856631 .828711032867 .6095703244209-9999-1.21914100647-2.43828105927$ $-3.35263609886-4.26699209213-4.87656211853-5.48613214493-6.095703125$ $-6.7052731514-7.3148431778-7.61962795258-8.22919845581-8.53398323059$ $-9.44833946228-10.0579099655-10.9722604752-12.1914100647-13.4105501175$ $-14.9344701767-16.4584007263-17.9823207855-19.5062503815-20.7253894806$ 
-21.9445304871 -22.8588790894 -23.1636695862 -23.4684505463 -23.7732391357 $-24.0780296326-24.0780296326-24.0780296326-24.0780296326-24.0780296326$ $-24.3828105927-24.6875991821-24.9923801422-25.6019496918-26.2115192413$ $-26.8210906982-27.1258792877-27.7354507446-28.0402297974-28.0402297974$ -27.7354507446 -27.1258792877 -25.9067401886 -24.3828105927 -22.5541000366 -20.7253894806 -18.8966808319-17.0679702759 -15.2392597198 -14.0201196671 -13.4105501175 -14.0201196671 -16.1536102295 -19.5062503815 -22.5541000366 $-24.9923801422-27.1258792877-28.9545898438-30.478509903-31.6976509094$ -32.6120109558 -33.2215805054 -33.5263595581 -33.5263595581 -33.2215805054 -32.9167900085 -32.0024414062 -31.0880794525 -29.8689403534-28.3450202942 -26.5163097382 -24.3828105927 -21.6397399902 -18.5918903351 -15.5440397263 $-12.1914100647-8.83876895905-5.79091691971-3.04785108566-.609570324421-9999$ 6095703244209.9143553972244.9143553972244.3047851026058. 3047851026058 .91435539722442 .4382810592655 .1813468933118 .53398323059113 .10575962067 18.8966808319125 .2971591949530 .7833003997829 .5641593933127 .12587928772 34.1359291076741 .4507789611844 .1938400268645 .41297912598 -9999 -9999 -9999-9999 -9999 -9999 -9999 -9999 -9999 -9999 -9999 -9999 -9999 -9999 -9999 -9999 -9999 -9999 -9999 -9999 -9999 -9999 -9999 -9999 -9999 -9999 -9999 -9999 -9999 -9999 -9999 -9999 -9999 -9999 -999 -9999 -9999 -9999 -9999 -9999 -9999 -9999 -9999 -9999 -9999 -9999 -9999 -9999 -9999 -9999 -9999 -9999 -9999 -9999 -9999 -9999 -9999 -9999 -9999 -9999 -9999 -9999 -9999 -9999 -9999 -

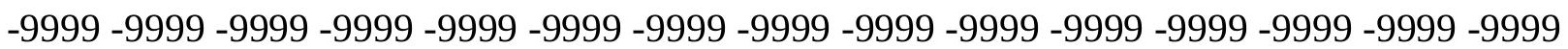
-9999-9999-9999

-9999 -9999 -9999 -9999 -9999 -9999 -9999 -9999 -9999 -9999 -9999 -9999 -9999 -9999 -9999 -9999 -9999 -9999 -9999 -9999 -9999 -9999 -9999 -9999 -9999 -9999 -9999 -9999 -9999 -9999 -9999 -9999 -9999 -9999 -9999 -9999 -9999 -9999 -9999 -9999 -9999 -9999 -9999 -9999 -9999 -9999 -9999 -9999 -9999 -9999 -9999 -9999 -9999 -9999 -9999 -9999 -9999 -9999 -9999 -9999 -9999 -9999 -9999 -9999 -9999 -9999 -9999 -9999 -9999 -9999 -9999 -9999 -9999 -9999 -9999

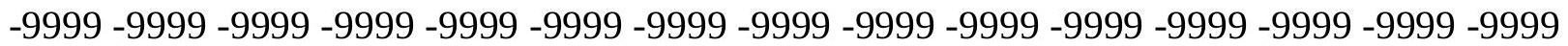
-9999 -9999 -9999 -9999 -9999 -9999 -9999 -9999 -9999 -9999 -9999 -9999 -9999 -9999 -9999 -9999 -9999 -9999 -9999 -9999 -9999 -9999 -9999 -9999 -9999 -9999 -9999 -9999 -9999 -9999 -9999 -9999 93.3011703491293.7217178344794.7010803222796.52731323242 99.59694671631102 .3105010986104 .1820220947105 .3261260986105 .6888885498 105.6257629395105 .4072189331105 .2473449707105 .3161697388105 .6903381348 106.371711731 107.2678909302 108.2921447754109.333190918110.3207931519 111.1863479614111 .9188613892112 .4796142578112 .8656845093113 .0801315308 113.1623535156113 .1913909912113 .2737121582113 .5014572144113 .9041824341 114.4238586426114 .5238647461114 .2978744507114 .323135376114 .6338882446 115.2292251587116 .0453720093116 .9672393799117 .7699737549118 .2066345215 118.0699539185117 .2791137695115 .9402313232114 .5526657104111 .2894058228 109.4179000854 106.0652008057 102.71260070898.7503814697395.3977432251 95.0929565429794.4833908081193.8738174438593.2642517089892.3498916626 91.4355392456189 .9116134643688 .3876876831186 .254188537683 .81591033936 81.0728530883878 .0249862670974 .6723632812571 .014930725166 .74794006348 62.4809494018658 .2139587402354 .2517509460450 .5943298339846 .32733917236 41.7555618286137 .4885711669932 .9167900085428 .3450202941923 .77323913574 19.5062503814715 .5440397262612 .19141006479 .7531242370617 .924413204193 
6.7052731513985 .4861321449284 .2669920921332 .7430660724641 .21914100647 -9999 -1.52392601967 -2.43828105927 -3.35263609886 -4.26699209213 -5.18134689331 $-6.095703125-6.7052731514-7.61962795258-8.22919845581-8.83876895905$ $-9.75312423706-10.6674804688-11.8866195679-13.4105501175-14.9344701767$ $-16.7631797791-18.5918903351-20.4206008911-22.2493095398-23.7732391357$ -25.2971591949 -25.9067401886 -26.2115192413 -26.2115192413 -26.2115192413 $-26.5163097382-26.2115192413-25.9067401886-25.6019496918-25.6019496918$ $-25.6019496918-25.6019496918-25.6019496918-25.9067401886-26.2115192413$ -26.8210906982 -27.1258792877 -27.4306602478 -27.7354507446 -27.7354507446 $-27.1258792877-26.5163097382-25.2971591949-23.7732391357-21.6397399902$ -19.5062503815 -17.0679702759 -14.6296901703 -12.1914100647 -9.75312423706 $-7.92441320419-7.01005792618-7.92441320419-11.2770500183-15.8488302231$ $-20.115819931-23.4684505463-25.9067401886-28.0402297974-29.8689403534$ $-31.0880794525-32.0024414062-32.307220459-32.6120109558-32.6120109558$ -32.307220459 -32.0024414062 -31.3928699493 -30.478509903 -29.2593708038 $-27.7354507446-25.6019496918-23.1636695862-20.4206008911-17.3727493286$ $-14.0201196671-10.9722604752-7.61962795258-4.87656211853-2.43828105927$ -609570324421 -9999.6095703244209.3047851026058 -9999-9999-9999.9143553972244 2.4382810592654 .876562118538 .53398323059114 .3248996734621 .03017044067 26.8210906982428 .9545898437529 .5641593933138 .7077102661146 .63212966919 49.6799812316949 .9847602844248 .7656211853 -9999 -9999 -9999 -9999 -9999 -9999 -9999 -9999 -9999 -9999 -9999 -9999 -9999 -9999 -9999 -9999 -9999 -9999 -9999 -9999 -9999 -9999 -9999 -9999 -9999 -9999 -9999 -9999 -9999 -9999 -9999 -9999 -9999 -9999 -9999 -9999 -9999 -9999 -9999 -9999 -9999 -9999 -9999 -9999 -9999 -9999 -9999 -9999 -9999 -9999 -9999 -9999 -

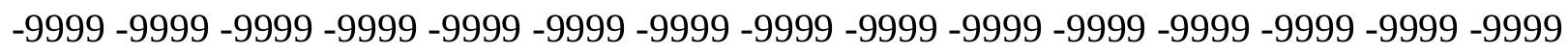
-9999 -9999 -9999 -9999 -9999 -9999 -9999 -9999 -9999 -9999 -9999 -9999 -9999 -9999 -9999 -9999 -9999 -9999 -9999 -9999 -9999 -9999 -9999 -9999 -9999 -9999 -9999 -9999 -9999

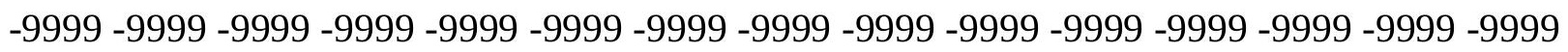
-9999 -9999 -9999 -9999 -9999 -9999 -9999 -9999 -9999 -9999 -9999 -9999 -9999 -9999 -9999 -9999 -9999 -9999 -9999 -9999 -9999 -9999 -9999 -9999 -9999 -9999 -9999 -9999 -9999 -9999 -9999 -9999 -9999 -9999 -9999 -9999 -9999 -9999 -9999 -9999 -9999 -9999 -9999 -9999 -9999

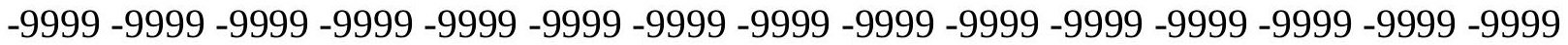

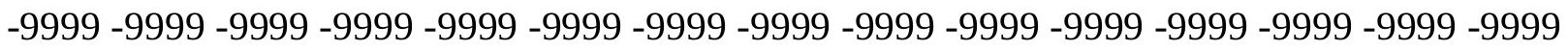
-9999 -9999 -9999 -9999 -9999 -9999 -9999 -9999 -9999 -9999 -9999 -9999 -9999 -9999 -9999 -9999 -9999 -9999 -9999 88.0829010009890.6975708007893.6726150512797.03482818604 99.89929962158101 .2755279541101 .6688766479101 .5804367065101 .2595672607 100.9429702759100 .9262542725101 .3037414551102 .0874481201103 .1472167969 104.3674316406 105.6029281616106.733581543107.6859588623108.4510574341 109.0221099854 109.3879165649 109.5746307373109.6456756592109.7011795044 109.8659362793110 .2492370605110 .9025802612111 .7876205444112 .8129577637 113.9075698853115 .0896148682116 .4693908691118 .1607284546118 .9856491089 119.5371246338119 .9194335938119 .9746017456119 .5900192261118 .7488937378 117.6117782593116 .5243606567115 .9251861572116 .051902771116 .2750854492 116.1231002808111 .24659729106 .0652008057101 .493400573797 .22646331787 95.0929565429794 .4833908081194 .1785964965893 .5690307617292 .65467834473 91.1307525634889 .302040100187 .1685485839884 .4254837036181 .37763214111 
78.3297805786174 .9771423339871 .3197174072367 .6623001098664 .61444854736 61.5666007995658 .8235282897954 .2517509460449 .3751907348644 .80340957642 39.9268493652335 .0502891540529 .8689403533924 .9923801422120 .42060089111 16.7631797790514 .0201196670512 .4961900711111 .2770500183110 .05790996552 $8.5339832305917 .0100579261785 .1813468933113 .3526360988621 .523926019669-9999$ $-.914355397224-2.43828105927-3.65742206573-4.87656211853-5.79091691971$ $-6.7052731514-7.61962795258-8.53398323059-9.44833946228-10.9722604752$ $-12.4961900711-14.3248996735-16.1536102295-18.5918903351-20.7253894806$ $-22.8588790894-24.6875991821-26.8210906982-28.6497993469-29.5641593933$ $-29.8689403534-29.8689403534-29.2593708038-29.5641593933-29.2593708038$ -28.6497993469 -28.3450202942 -28.0402297974 -27.4306602478 -27.1258792877 $-26.8210906982-26.8210906982-26.8210906982-27.1258792877-27.4306602478$ $-27.7354507446-27.7354507446-27.4306602478-26.8210906982-26.2115192413$ -24.9923801422 -23.4684505463 -21.3349609375 -18.8966808319-16.1536102295 $-13.1057596207-10.0579099655-7.3148431778-4.57177686691-2.13349604607$ $-.609570324421-5.79091691971-11.2770500183-16.1536102295-20.115819931$ $-23.4684505463-26.2115192413-28.0402297974-29.5641593933-30.7833003998$ $-31.3928699493-31.6976509094-32.0024414062-32.0024414062-31.6976509094$ -31.3928699493 -30.7833003998 -30.1737308502 -28.9545898438 -27.1258792877 $-24.9923801422-22.2493095398-19.2014598846-16.1536102295-13.1057596207$ -10.0579099655 -7.01005792618-4.57177686691 -2.43828105927-.914355397224-9999 -.304785102606 -.914355397224 -1.21914100647-.914355397224 -9999.6095703244209 1.8287110328673 .9622070789349 .14355373382617 .6775398254425 .29715919495 29.8689403533934 .4407196044943 .8890609741251 .2038993835454 .55654144287 54.2517509460451 .2038993835447 .24169921875 -9999 -9999 -9999 -9999 -9999 -9999 -9999 -9999 -9999 -9999 -9999 -9999 -9999 -9999 -9999 -9999 -9999 -9999 -9999 -9999 -9999 -9999 -9999 -9999 -9999 -9999 -9999 -9999 -9999 -9999 -9999 -9999 -9999 -9999 -9999 -9999 -9999

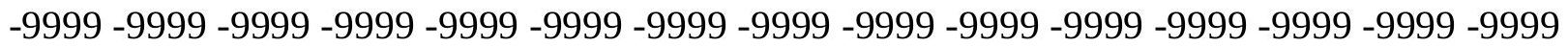
-9999 -9999 -9999 -9999 -9999 -9999 -9999 -9999 -9999 -9999 -9999 -9999 -9999 -9999 -9999 -9999 -9999 -9999 -9999 -9999 -9999 -9999 -9999 -9999 -9999 -9999 -9999 -9999 -9999 -9999 -9999 -9999 -9999 -9999 -9999 -9999 -9999 -9999 -9999 -9999 -9999 -9999 -9999

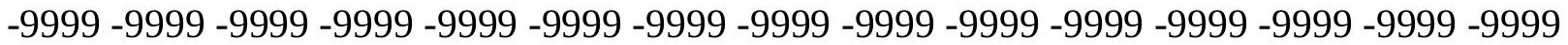

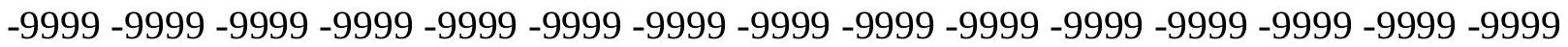
-9999 -9999 -9999 -9999 -9999 -9999 -9999 -9999 -9999 -9999 -9999 -9999 -9999 -9999 -9999 -9999 -9999 -9999 -9999 -9999 -9999 -9999 -9999 -9999 -9999 -9999 -9999 -9999 -9999 -9999 -9999 -9999 -9999 -9999 -9999 -9999 -9999 -9999 -9999 -9999 -9999 -9999 -9999 -9999 -9999

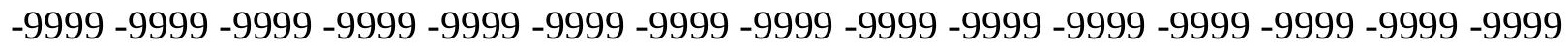

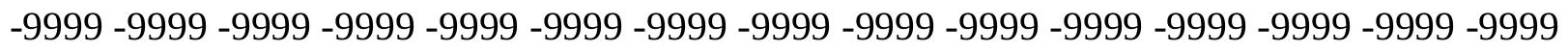
-9999 -9999 -9999 -9999 -9999 -9999 87.7781066894591 .7403335571396 .00731658936 96.8985671997197 .4273986816497 .4931106567497 .0579376220796 .54090881348 96.3121032714896 .919509887797 .8097534179799 .05330657959100 .5239486694 101.9571228027 103.2125473022 104.1954650879 104.9517211914 105.4614486694 105.7214202881105 .772567749105 .6943206787105 .604019165105 .6831665039 106.1081619263106 .9793243408108 .2656478882109 .8466567993111 .5820236206 113.4012451172115 .3067932129117 .3260421753119 .4432525635121 .5361480713 122.0774841309121 .8507614136121 .2977294922120 .4614334106119 .4868087769 
118.596786499118 .0330963135117 .8771057129118 .0177993774118 .1460800171 117.8761291504115 .818397522110 .9418029785106 .979598999103 .3221969604 99.6647262573296 .6168823242295 .0929565429794 .7881774902393 .56903076172 92.0450973510789 .6068267822387 .1685485839884 .4254837036181 .37763214111 78.3297805786175 .2819290161172 .5388565063569 .7957916259867 .35751342773 64.3096618652360 .6522407531756 .3852500915551 .8134689331146 .93690872192 42.0603485107436 .8790016174331 .3928699493425 .906740188621 .94453048706 19.5062503814718 .28710937517 .0679702758815 .5440397262614 .02011966705 11.886619567879 .7531242370617 .9244132041935 .7909169197083 .657422065735 $1.828711032867-9999-1.52392601967-3.04785108566-4.26699209213-5.48613214493$ $-6.40048694611-7.3148431778-8.83876895905-10.3626899719-12.1914100647$ -14.6296901703 -17.0679702759-19.8110294342 -22.2493095398 -24.6875991821 $-27.1258792877-29.2593708038-31.3928699493-33.2215805054-34.1359291077$ -34.4407196045 -34.4407196045 -34.1359291077 -33.8311500549-33.2215805054 -32.6120109558 -31.6976509094 -30.478509903 -29.8689403534 -28.9545898438 $-28.0402297974-27.7354507446-27.7354507446-28.0402297974-28.0402297974$ -28.0402297974 -27.7354507446 -27.1258792877 -26.5163097382 -25.2971591949 -23.7732391357 -21.9445304871 -19.2014598846 -16.1536102295 -13.1057596207 $-9.75312423706-6.40048694611-3.35263609886-1.21914100647-1.21914100647$ $-4.26699209213-9.14355373383-14.0201196671-18.287109375-21.6397399902$ $-24.3828105927-26.8210906982-28.3450202942-29.8689403534-30.478509903$ $-31.0880794525-31.3928699493-31.6976509094-31.6976509094-31.3928699493$ -31.3928699493 -30.7833003998 -29.8689403534 -28.6497993469 -26.5163097382 $-24.0780296326-21.3349609375-18.287109375-15.2392597198-12.1914100647$ $-9.44833946228-7.01005792618-4.87656211853-3.35263609886-2.13349604607$ -2.13349604607 -2.13349604607 -2.13349604607 -1.82871103287 -1.21914100647 -9999 .6095703244209 1.8287110328674 .57177686691317 .6775398254427 .73545074463 32.6120109558139 .3172798156745 .717769622849 .9847602844254 .25175094604 55.7756805419951 .8134689331146 .93690872192 -9999 -9999 -9999 -9999 -9999 -9999 -9999 -9999 -9999 -9999 -9999 -9999 -9999 -9999 -9999 -9999 -9999 -9999 -9999 -9999 -9999 -9999 -9999 -9999 -9999 -9999 -9999 -9999 -9999 -9999 -9999 -9999 -9999 -9999 -9999 -9999 -9999

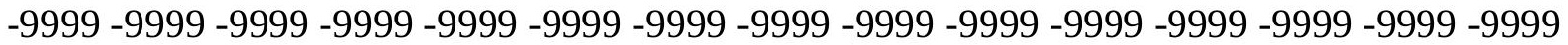

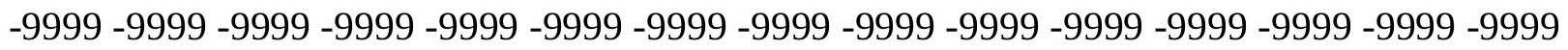
-9999 -9999 -9999 -9999 -9999 -9999 -9999 -9999 -9999 -9999 -9999 -9999 -9999 -9999 -9999 -9999 -9999 -9999 -9999 -9999 -9999 -9999 -9999 -9999 -9999 -9999 -9999 -9999

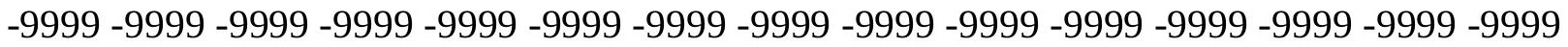

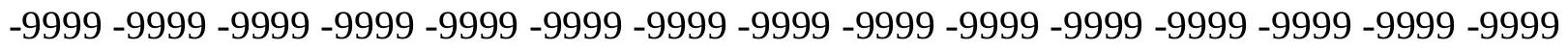

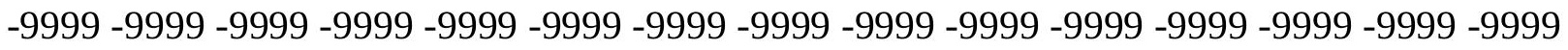

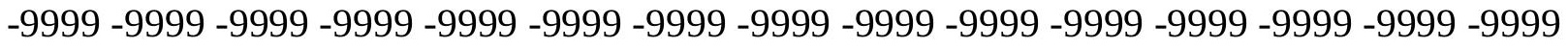
-9999 -9999 -9999 -9999 -9999 -9999 -9999 -9999 -9999 -9999 -9999 -9999 -9999 -9999 -9999 -

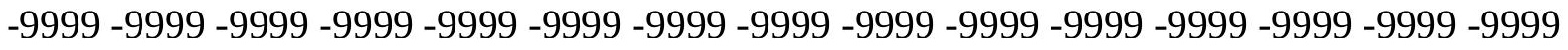
-9999 -9999 -9999 -9999 -9999 -9999 -9999 -9999 -9999 -9999 -9999 -9999 -9999 -9999 -9999 -9999 -9999 -9999 -9999 -9999 -9999 -9999 86.2541885376 89.6068267822392 .04509735107 93.2642517089893.5690307617292.9594726562592.3498916626 92.04509735107 92.9594726562593 .8078308105595 .2377853393696 .9785995483498 .6974029541 99.97262573242100 .9937820435101 .759475708102 .188949585102 .2789535522 
102.1226806641101 .7857437134101 .3718566895101 .1596603394101 .4890975952 102.523147583104 .2448501587106 .4047470093108 .734046936111 .0645828247 113.3258132935115 .501625061117 .572013855119 .4785919189121 .1234664917 122.4077224731123 .0749053955122 .2205734253121 .3188018799120 .4908981323 119.8317871094119 .3582229614118 .9864578247118 .5581512451117 .9232406616 117.0596389771116 .0129318237114 .8914413452111 .24659729107 .5891036987 104.5412979126101 .798202514699 .0551681518696 .0073165893693 .87381744385 91.7403335571389 .302040100186 .8637619018684 .1206970214881 .37763214111 78.9393463134876 .1962814331174 .062782287671 .6244964599669 .18623352051 66.1383666992262 .4809494018658 .5187492370654 .2517509460449 .37519073486 44.4986305236839 .0125007629433 .5263595581128 .0402297973626 .82109069824 25.6019496917724 .0780296325722 .2493095397920 .1158199310317 .98232078552 15.5440397262613 .1057596206710 .667480468758 .2291984558116 .095703125 $3.6574220657351 .523926019669-.304785102606-2.13349604607$-3.35263609886 $-4.26699209213-5.79091691971-7.3148431778-9.14355373383-11.5818300247$ $-14.0201196671-17.0679702759-20.4206008911-23.7732391357-26.5163097382$ $-29.2593708038-31.3928699493-34.4407196045-37.1837806702-39.0125007629$ -39.9268493652 -40.2316398621 -39.9268493652 -39.3172798157-38.4029312134 -37.7933502197 -36.8790016174 -35.9646492004 -34.4407196045 -31.3928699493 $-30.1737308502-29.2593708038-28.9545898438-28.9545898438-28.9545898438$ $-28.6497993469-28.0402297974-27.7354507446-27.1258792877-26.2115192413$ $-24.9923801422-22.8588790894-20.4206008911-17.3727493286-14.0201196671$ $-10.6674804688-7.3148431778-4.87656211853-3.35263609886-3.65742206573$ $-5.79091691971-9.44833946228-13.4105501175-17.3727493286-20.7253894806$ $-23.4684505463-25.6019496918-27.4306602478-28.9545898438-29.8689403534$ -30.478509903 -30.7833003998 -31.0880794525 -31.3928699493 -31.3928699493 -31.3928699493 -31.0880794525 -30.7833003998 -29.8689403534 -28.0402297974 -25.6019496918 -22.8588790894 -20.115819931 -17.0679702759-14.3248996735 $-11.8866195679-9.44833946228-7.3148431778-5.79091691971-4.87656211853$ $-4.26699209213-3.96220707893-3.65742206573-3.04785108566-2.13349604607$ -.914355397224.60957032442093.96220707893410.66748046875 22.24930953979 33.8311500549335 .6598587036144 .1938400268646 .6321296691947 .24169921875 $52.4230384826755 .7756805419951 .5086898803745 .717769622844 .19384002686-9999$ -9999 -9999 -9999 -9999 -9999 -9999 -9999 -9999 -9999 -9999 -9999 -9999 -9999 -9999 -9999

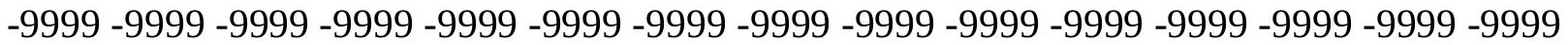
-9999 -9999 -9999 -9999 -9999 -9999 -9999 -9999 -9999 -9999 -9999 -9999 -9999 -9999 -9999 -9999 -9999 -9999 -9999 -9999 -9999 -9999 -9999 -9999 -9999 -9999 -9999 -9999 -9999 -9999

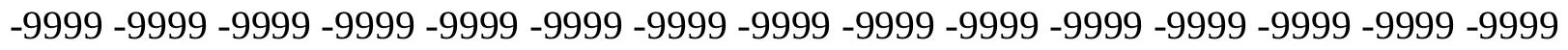
-9999 -9999-9999

-9999 -9999 -9999 -9999 -9999 -9999 -9999 -9999 -9999 -9999 -9999 -9999 -9999 -9999 -9999

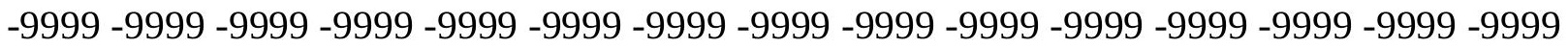
-9999 -9999 -9999 -9999 -9999 -9999 -9999 -9999 -9999 -9999 -9999 -9999 -9999 -9999 -9999 -9999 -9999 -9999 -9999 -9999 -9999 -9999 -9999 -9999 -9999 -9999 -9999 -9999 -9999 -9999 -9999 -9999 -9999 -9999 -9999 -9999 -9999 -9999 -9999 -9999 -9999 -9999 -9999 -9999 -9999 -999 -9999 -9999 -9999 -9999 -9999 -9999 -9999 -9999 -9999 -9999 -9999 -9999 -9999 -9999 -9999

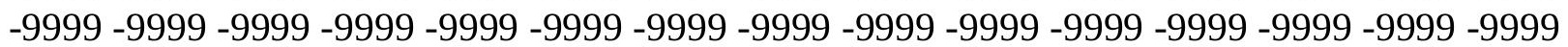


-9999 -9999 -9999 -9999 -9999 -9999 -9999 -9999 -9999 -9999 -9999 -9999 -9999 -9999 -9999 -9999 -9999 -9999 -9999 -9999 -9999 -9999 -9999 -9999 88.08290100098 89.3020401001 89.302040100188.9972534179788.9972534179788.9972534179789.3020401001 90.5211791992292 .0450973510793 .8738174438596 .0073165893697 .01975250244 98.3219528198299 .3131256103599 .6189422607499 .491630554299 .16366577148 98.5157928466897 .6233520507896 .8522415161196 .8930358886798 .0347366333 100.2613983154103 .0048446655105 .8530502319108 .5558700562111 .0140838623 113.1952667236115 .1001434326116 .742401123118 .1411361694119 .3175506592 120.2948455811121 .1041717529121 .8006591797122 .1361999512121 .3273010254 120.5189819336119 .6566009521118 .6911239624117 .6138839722116 .4637756348 115.3124923706114 .2280654907113 .2295684814112 .2077407837110 .9418029785 107.8938980103105 .1509017944102 .102996826298 .445587158294 .48339080811 91.1307525634888 .6924667358486 .5589828491284 .1206970214881 .68241119385 79.5489196777377 .4154205322375 .5867080688573 .4532165527371 .0149307251 68.2718734741264 .9192428588961 .2618103027357 .2995986938552 .72782897949 65.2240066528342 .9747009277339 .0125007629436 .5742111206134 .44071960449 32.3072204589830 .1737308502227 .430660247824 .6875991821321 .94453048706 18.8966808319116 .1536102294913 .4105501174910 .972260475168 .229198455811 $5.7909169197083 .352636098862 .9143553972244-9999-1.52392601967$-3.04785108566 $-4.87656211853-7.3148431778-9.75312423706-13.1057596207-16.4584007263$ $-20.4206008911-24.3828105927-28.0402297974-30.7833003998-34.1359291077$ $-37.7933502197-41.4507789612-44.1938400269-45.7177696228-46.3273391724$ $-46.0225486755-45.1082000732-44.1938400269-42.9747009277-41.7555618286$ $-41.1459884644-40.2316398621-35.3550796509-32.307220459-30.478509903$ -29.8689403534 -29.5641593933 -29.8689403534 -29.2593708038 -28.6497993469 -28.6497993469 -28.3450202942 -27.7354507446 -26.5163097382 -24.9923801422 $-22.5541000366-19.5062503815-16.1536102295-12.8009700775-10.0579099655$ $-7.61962795258-6.40048694611-6.7052731514-8.53398323059-11.2770500183$ -14.6296901703 -17.6775398254 -20.7253894806 -23.1636695862 -25.2971591949 $-26.8210906982-28.0402297974-29.2593708038-29.8689403534-30.1737308502$ $-30.7833003998-31.0880794525-31.3928699493-31.3928699493-31.0880794525$ $-31.0880794525-31.0880794525-28.9545898438-26.8210906982-24.3828105927$ $-21.6397399902-18.8966808319-16.4584007263-14.0201196671-11.8866195679$ -10.0579099655 -8.53398323059 -7.3148431778-6.40048694611 -5.79091691971 $-4.87656211853-3.96220707893-2.43828105927-.6095703244211 .828711032867$ 7.92441320419316 .4584007263226 .5163097381635 .3550796508840 .84120941162 46.9369087219248 .4608306884848 .4608306884852 .1182594299354 .25175094604 49.9847602844244 .4986305236842 .66992187541 .75556182861 -9999 -9999 -9999 -9999 -9999 -9999 -9999 -9999 -9999 -9999 -9999 -9999 -9999 -9999 -9999 -9999 -9999 -9999 -9999 -9999 -9999 -9999 -9999 -9999 -9999 -9999 -9999 -9999 -9999 -9999 -9999 -9999 -9999 -9999 -

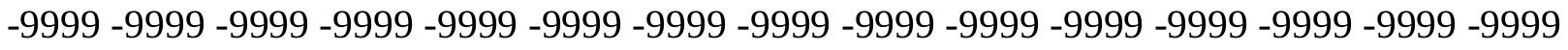
-9999 -9999 -9999 -9999 -9999 -9999 -9999 -9999 -9999 -9999 -9999 -9999 -9999 - -9999 - -9999 -

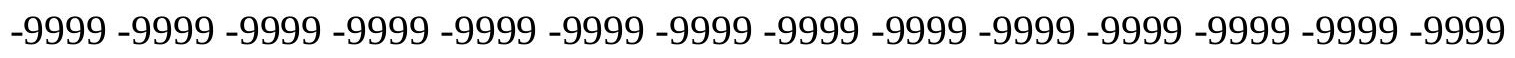
-9999 -9999 -9999 -9999 -9999 -9999 -9999 -9999 -9999 -9999 -9999 -9999 -9999 -9999 -9999 -

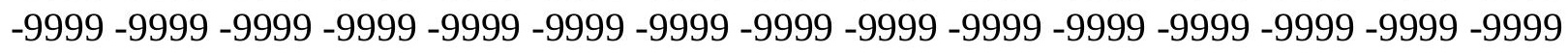

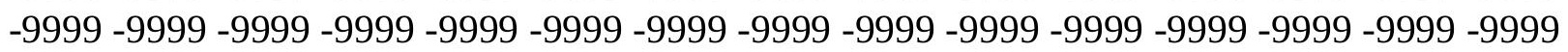


-9999 -9999 -9999 -9999 -9999 -9999 -9999 -9999 -9999 -9999 -9999 -9999 -9999 -9999 -9999 -9999 -9999 -9999 -9999 -9999 -9999 -9999 -9999 -9999 -9999 -9999 -9999 -9999 -9999 -9999

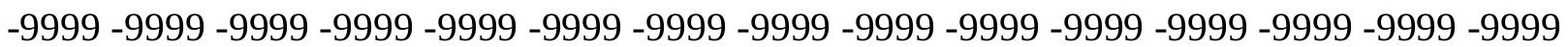
-9999 -9999 -9999 -9999 -9999 -9999 -9999 -9999 -9999 -9999 -9999 -9999 -9999 -9999 -9999 -9999 -9999 -9999 -9999 -9999 -9999 -9999 -9999 -9999 -9999 -9999 -9999 -9999 -9999 -9999 -9999 -9999 -9999 -9999 -9999 -9999 -9999 -9999 -9999 -9999 88.08290100098 88.0829010009888 .0829010009888 .0829010009888 .0829010009888 .38768768311 88.99725341797 89.9116134643691.4355392456192.6546783447394.48339080811 96.6168823242298 .1408081054798 .1408081054797 .8360290527397 .51623535156 96.5495376586995 .1405105590893 .5836639404392 .8668441772593 .87381744385 97.07264709473100 .3181686401103 .5098648071106 .3787231445108 .85206604 110.8777923584112 .4823455811113 .7450485229114 .7953262329115 .771194458 116.7729873657117 .8309631348118 .9105300903119 .9364929199120 .824432373 121.468132019120 .1024398804118 .5575942993116 .9430389404115 .3922729492 114.0237503052112 .8952102661111 .9764862061111 .1751251221110 .4084320068 109.5696792603108 .5022583008106 .0652008057102 .407798767199 .05516815186 95.7025299072392 .349891662688 .9972534179786 .254188537684 .12069702148 82.2919769287180 .4632720947378 .9393463134877 .4154205322375 .58670806885 73.4532165527371 .014930725168 .2718734741264 .9192428588961 .56660079956 76.1962814331153 .6421813964850 .2895507812547 .5464782714844 .49863052368 41.4507789611838 .0981407165535 .0502891540531 .6976509094228 .34502029419 25.2971591949522 .2493095397919 .2014598846416 .4584007263213 .7153301239 10.667480468758 .2291984558115 .7909169197083 .9622070789342 .133496046066 .3047851026058 -1.82871103287 -4.57177686691 -7.61962795258 -10.9722604752 $-14.9344701767-19.2014598846-23.7732391357-28.6497993469-31.0880794525$ -35.3550796509-40.5364189148-45.7177696228 -49.6799812317-51.8134689331 $-52.4230384827-51.8134689331-50.8991203308-49.3751907349-47.5464782715$ $-46.0225486755-44.1938400269-41.4507789612-37.488571167-33.8311500549$ $-31.3928699493-30.478509903-30.1737308502-30.1737308502-30.1737308502$ $-29.8689403534-29.8689403534-29.5641593933-29.2593708038-28.3450202942$ $-27.1258792877-24.9923801422-22.2493095398-18.8966808319-15.8488302231$ -13.1057596207 -11.2770500183 -10.3626899719 -10.3626899719-11.5818300247 $-13.7153301239-16.4584007263-18.8966808319-21.3349609375-23.4684505463$ $-25.2971591949-26.5163097382-27.7354507446-28.9545898438-29.5641593933$ -30.1737308502 -30.7833003998 -31.0880794525 -31.0880794525 -31.0880794525 $-30.7833003998-30.478509903-30.478509903-29.2593708038-27.4306602478$ -25.2971591949 -22.8588790894 -20.7253894806 -18.287109375 -16.1536102295 $-14.0201196671-12.1914100647-10.6674804688-9.44833946228-8.22919845581$ -7.01005792618 -5.79091691971-4.26699209213 -2.13349604607.9143553972244 5.48613214492811 .8866195678720 .1158199310329 .2593708038337 .48857116699 43.8890609741248 .765621185350 .2895507812550 .5943298339852 .42303848267 52.4230384826747 .8512611389242 .3651313781740 .8412094116240 .23163986206 38.70771026611 -9999 -9999 -9999 -9999 -9999 -9999 -9999 -9999 -9999 -9999 -9999 -9999 -9999 -9999 -9999 -9999 -9999 -9999 -9999 -9999 -9999 -9999 -9999 -9999 -9999 -9999 -9999 -9999 -9999 -9999 -9999 -9999 -9999 -9999 -9999 -9999 -9999 -9999 -9999 -9999 -9999 -9999

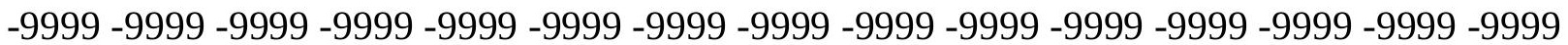


-9999 -9999 -9999 -9999 -9999 -9999 -9999 -9999 -9999 -9999 -9999 -9999 -9999 -9999 -9999 -9999 -9999 -9999 -9999 -9999

-9999 -9999 -9999 -9999 -9999 -9999 -9999 -9999 -9999 -9999 -9999 -9999 -9999 -9999 -9999 -9999 -9999 -9999 -9999 -9999 -9999 -9999 -9999 -9999 -9999 -9999 -9999 -9999 -9999 -9999 -9999 -9999 -9999 -9999 -9999 -9999 -9999 -9999 -9999 -9999 -9999 -9999 -9999 - -9999 - -9999 -

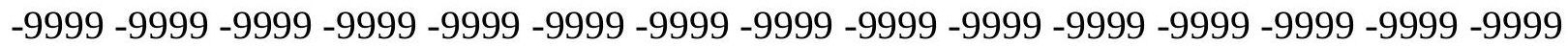

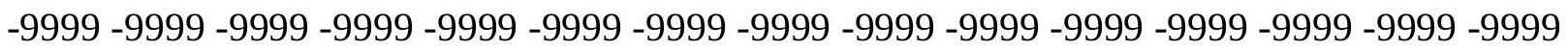
-9999 -9999 -9999 -9999 -9999 -9999 -9999 -9999 -9999 -9999 -9999 -9999 -9999 -9999 -9999

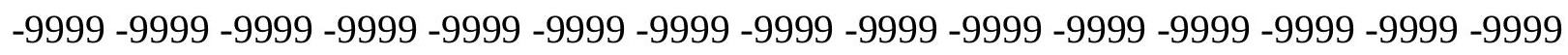

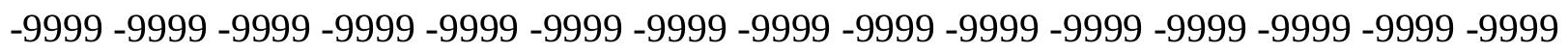
-9999 -9999 -9999 -9999 -9999 -9999 -9999 -9999 -9999 -9999 -9999 -9999 88.99725341797 88.99725341797 88.9972534179789.3020401001 89.3020401001 89.91161346436 90.8259735107491 .7403335571393 .8738174438596 .0073165893697 .83602905273 98.445587158298 .445587158297 .5312423706196 .3121032714894 .78817749023 92.6546783447390 .2164001464888 .9972534179794 .1785964965899 .09394836426 101.7982025146105 .0089569092107 .2805557251108 .9854888916110 .1434707642 110.8814697266111 .4459991455112 .1107940674113 .0538024902114 .288520813 115.6508407593116 .9068603516117 .8375167847118 .3343505859118 .4287796021 118.2196884155115 .9446258545113 .8765563965112 .2143478394111 .0214385986 110.2252197266109 .6765518188109 .2057952881108 .6586151123107 .9344863892 107.0293045044105 .1509017944102 .102996826299 .0551681518696 .00731658936 92.6546783447389 .6068267822386 .8637619018684 .4254837036183 .2063369751 81.9871978759881 .0728530883879 .8537063598678 .6345596313576 .80584716797 74.6723632812571 .9292907714869 .4910125732466 .4431610107463 .39530944824 60.9570198059158 .5187492370654 .2517509460450 .2895507812546 .32733917236 42.66992187539 .0125007629435 .3550796508831 .6976509094228 .64979934692 25.2971591949522 .2493095397919 .2014598846416 .4584007263213 .7153301239 11.277050018319 .1435537338266 .7052731513984 .2669920921331 .828711032867 -.914355397224 -4.57177686691 -8.22919845581 -12.1914100647-16.7631797791 -21.3349609375 -25.6019496918 -28.9545898438 -35.6598587036 -42.669921875 $-49.3751907349-54.5565414429-57.2995986938-57.9091796875-57.2995986938$ $-55.775680542-53.9469718933-51.8134689331-49.3751907349-46.3273391724$ $-42.3651313782-38.0981407166-34.1359291077-32.0024414062-31.0880794525$ $-30.7833003998-30.7833003998-30.7833003998-30.7833003998-30.7833003998$ -30.478509903 -30.478509903 -30.1737308502 -29.8689403534 -27.7354507446 -24.9923801422 -21.9445304871 -19.2014598846 -16.7631797791 -14.9344701767 $-14.0201196671-14.3248996735-15.2392597198-16.7631797791-18.5918903351$ $-20.7253894806-22.5541000366-24.0780296326-25.6019496918-26.8210906982$ $-27.7354507446-28.6497993469-29.5641593933-30.1737308502-30.478509903$ $-31.0880794525-31.0880794525-31.0880794525-30.7833003998-30.478509903$ -30.1737308502 -29.2593708038 -28.0402297974 -26.2115192413 -24.0780296326 -21.9445304871 -20.115819931 -17.9823207855 -16.1536102295 -14.3248996735 -12.4961900711 -10.9722604752 -9.75312423706 -8.22919845581 -6.7052731514 $-4.26699209213-1.219141006473 .0478510856638 .83876895904515 .23925971985$ 22.2493095397929 .2593708038337 .4885711669944 .8034095764248 .15605163574 50.5943298339851 .5086898803751 .8134689331149 .9847602844244 .80340957642 
$39.9268493652338 .4029312133838 .0981407165536 .8790016174335 .96464920044-9999$ -9999 -9999 -9999 -9999 -9999 -9999 -9999 -9999 -9999 -9999 -9999 -9999 -9999 -9999 -9999 -9999 -9999 -9999 -9999 -9999 -9999 -9999 -9999 -9999 -9999 -9999 -9999 -9999 -9999 -9999 -9999 -9999 -9999 -9999 -9999 -9999 -9999 -9999 -9999 -9999 -9999 -9999 -9999 -9999 -9999 -9999 -9999 -9999 -9999 -9999 -9999 -9999 -9999 -9999 -9999 -9999 -9999-9999 -9999 -9999 -

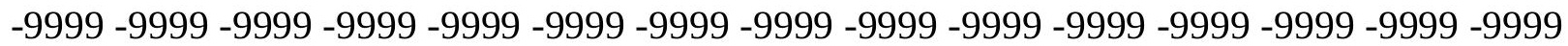

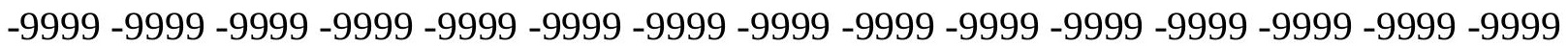
-9999 -9999 -9999 -9999 -9999 -9999 -9999 -9999 -9999 -9999 -9999 -9999 -9999 -9999 -9999 -999 -9999 -9999 -9999 -9999 -9999 -9999 -9999 -9999 -9999 -9999 -9999 -9999 -9999 -9999 -9999 -9999 -9999 -9999 -9999 -9999 -9999 -9999 -9999 -9999 -9999 -9999 -9999 -9999 -9999 -9999 -9999 -9999 -9999 -9999 -9999 -9999 -9999 -9999 -9999 -9999 -9999 -9999 -9999 -9999 -9999 -

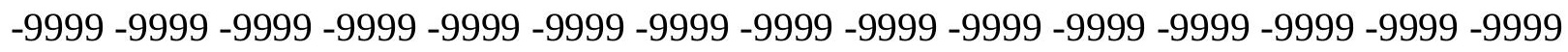
-9999 -9999 -9999 -9999 -9999 -9999 -9999 -9999 -9999 -9999 -9999 -9999 -9999 -9999 -9999 -9999 -9999 -9999 -9999 -9999 -9999 -9999 -9999 -9999 -9999 -9999 -9999 -9999 -9999 -9999 -9999 -9999 -9999 -9999 -9999 -9999 -9999 -9999 -9999 -9999 -9999 -9999 -9999 92.0450973510791.7403335571391.7403335571391.7403335571392.04509735107 92.0450973510792 .6546783447394 .7881774902396 .9216690063598 .4455871582 99.3599472045999 .6647262573299 .0551681518698 .1408081054796 .61688232422 94.7881774902393 .5690307617293 .8738174438596 .6168823242299 .96952056885 102.4077987671103 .9317016602105 .1509017944107 .9012145996108 .4901428223 108.5635910034108 .4949188232108 .7370071411109 .5637435913110 .9650497437 112.5885467529113 .9894256592114 .7761230469114 .8305358887114 .2764511108 113.4644775391112 .8763198853111 .951385498109 .9534912109108 .7329559326 108.139793396107 .9170150757107 .8054504395107 .6144104004107 .244758606 106.6727676392105 .9595336914103 .9317016602101 .188697814998 .4455871582 95.397743225192 .9594726562590 .5211791992288 .0829010009886 .2541885376 84.7302627563584 .4254837036184 .1206970214883 .5111236572382 .90155792236 82.2919769287180 .4632720947376 .5010681152374 .3675689697372 .23407745361 69.4910125732466 .1383666992262 .4809494018658 .2139587402353 .94697189331 49.9847602844246 .0225486755442 .0603485107438 .4029312133834 .74551010132 31.3928699493428 .3450202941925 .2971591949522 .5541000366219 .8110294342 17.0679702758814 .6296901702911 .886619567879 .1435537338266 .095703125 $2.743066072464-.609570324421-4.57177686691-8.83876895905-13.1057596207$ $-17.6775398254-22.2493095398-27.7354507446-34.4407196045-42.669921875$ $-51.5086898804-59.1283111572-61.5666007996-62.7857398987-61.8713798523$ $-60.0426712036-57.9091796875-55.1661109924-52.1182594299-48.1560516357$ $-43.8890609741-39.0125007629-34.1359291077-32.9167900085-32.0024414062$ $-31.6976509094-31.3928699493-31.3928699493-31.3928699493-31.3928699493$ $-31.3928699493-31.3928699493-31.3928699493-31.0880794525-29.8689403534$ $-27.4306602478-24.6875991821-22.2493095398-20.115819931-18.5918903351$ -17.6775398254 -17.6775398254 -18.287109375 -19.5062503815 -21.0301704407 $-22.5541000366-23.7732391357-24.9923801422-25.9067401886-27.1258792877$ $-28.0402297974-28.9545898438-29.5641593933-30.1737308502-30.478509903$ $-31.0880794525-31.0880794525-31.0880794525-31.0880794525-30.7833003998$ $-30.1737308502-29.2593708038-28.3450202942-26.8210906982-24.9923801422$ -23.1636695862 -21.3349609375 -19.5062503815 -17.6775398254-15.8488302231 
-14.0201196671 -12.4961900711 -10.9722604752 -9.14355373383 -7.01005792618 $-4.26699209213-.3047851026065 .18134689331111 .8866195678718 .287109375$ 23.4684505462628 .3450202941937 .7933502197344 .4986305236847 .54647827148 50.8991203308152 .4230384826750 .8991203308147 .2416992187542 .06034851074 37.1837806701735 .9646492004435 .6598587036135 .0502891540534 .44071960449 33.83115005493 -9999 -9999 -9999 -9999 -9999 -9999 -9999 -9999 -9999 -9999 -9999 -9999 -9999 -9999 -9999 -9999 -9999 -9999 -9999 -9999 -9999 -9999 -9999 -9999 -9999 -9999 -9999

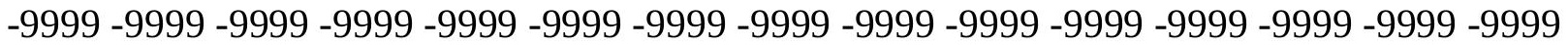

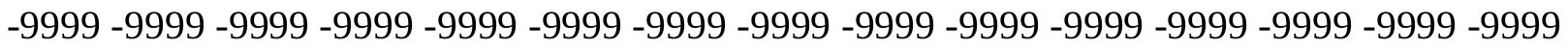

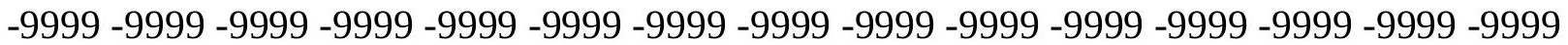
-9999-9999-9999

-9999 -9999 -9999 -9999 -9999 -9999 -9999 -9999 -9999 -9999 -9999 -9999 -9999 -9999 -9999 -9999 -9999 -9999 -9999 -9999 -9999 -9999 -9999 -9999 -9999 -9999 -9999 -9999 -9999 -9999 -9999 -9999 -9999 -9999 -9999 -9999 -9999 -9999 -9999 -9999 -9999 -9999 -9999 -9999 -9999 -9999 -9999 -9999 -9999 -9999 -9999 -9999 -9999 -9999 -9999 -9999 -9999 -9999 -9999 -9999

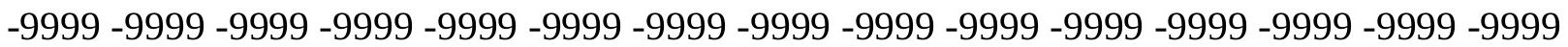

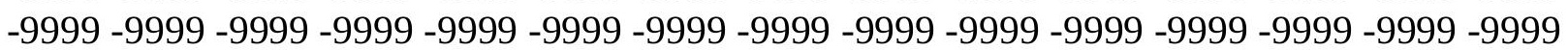
-9999 -9999 -9999 -9999 -9999 -9999 -9999 -9999 -9999 -9999 -9999 -9999 -9999 -9999 -9999 -999 -9999 -9999 -9999 -9999 -9999 -9999 -9999 -9999 -9999 -9999 -9999 -9999 -9999 -9999 -9999 -9999 -9999 -9999 -9999 -9999-9999 -9999 -9999 -9999 -9999 -9999 -9999 -9999 -9999 -9999 95.7025299072395 .7025299072395 .397743225195 .7025299072395 .3977432251 96.9216690063598 .75038146973100 .2742996216101 .1886978149101 .4934005737 101.1886978149100 .579101562599 .3599472045998 .1408081054797 .83602905273 98.75038146973100 .5791015625102 .712600708104 .5412979126105 .7603988647 106.979598999107 .8938980103107 .8938980103106 .3700027466103 .9317016602 104.5412979126106 .9061431885108 .4603042603110 .3924484253111 .831703186 112.2727890015111 .617805481110 .0391082764108 .0712356567106 .5458679199 106.2301177979 107.3435516357 106.2015380859 105.9454727173 106.1480331421 106.4511184692106 .6352310181106 .6006622314106 .3329467773105 .8856658936 104.5412979126102 .102996826299 .6647262573297 .2264633178795 .09295654297 92.9594726562591 .1307525634889 .6068267822388 .6924667358488 .08290100098 87.4733276367286 .8637619018686 .5589828491285 .3398437584 .42548370361 82.9015579223680 .7680587768679 .2441329956176 .1962814331172 .84364318848 69.1862335205165 .2240066528360 .9570198059156 .6900291442969 .49101257324 48.4608306884844 .4986305236840 .8412094116237 .4885711669934 .13592910767 31.0880794525128 .3450202941925 .6019496917723 .1636695861820 .42060089111 17.3727493286114 .0201196670510 .667480468757 .0100579261783 .047851085663 -.609570324421 -4.57177686691 -8.83876895905 -13.7153301239 -18.5918903351 $-24.3828105927-31.6976509094-40.5364189148-50.594329834-59.7378807068$ $-64.6144485474-66.1383666992-65.8335876465-64.0048828125-61.5666007996$ $-58.2139587402-54.5565414429-50.2895507812-45.7177696228-41.1459884644$ -37.1837806702 -35.0502891541 -33.5263595581 -32.9167900085-32.307220459 $-32.0024414062-32.0024414062-32.0024414062-32.307220459-32.307220459$ -32.307220459 -32.0024414062 -31.0880794525 -29.2593708038 -27.1258792877 -24.9923801422 -23.1636695862 -21.6397399902 -21.0301704407 -20.7253894806 $-21.3349609375-22.2493095398-23.4684505463-24.3828105927-25.2971591949$ 
-25.9067401886 -26.8210906982 -27.4306602478 -28.3450202942 -28.9545898438 $-29.5641593933-30.1737308502-30.7833003998-31.0880794525-31.0880794525$ $-31.0880794525-31.0880794525-30.7833003998-30.1737308502-29.5641593933$ $-28.6497993469-27.1258792877-25.6019496918-24.0780296326-22.2493095398$ -20.4206008911 -18.8966808319-17.0679702759-15.2392597198 -13.4105501175 -11.5818300247 -9.44833946228 -7.01005792618 -3.65742206573.3047851026058 7.31484317779514 .934470176721 .6397399902325 .6019496917726 .51630973816 35.3550796508844 .1938400268649 .6799812316952 .4230384826752 .42303848267 50.5943298339846 .6321296691940 .2316398620634 .4407196044933 .22158050537 $33.2215805053732 .9167900085432 .6120109558132 .3072204589832 .30722045898-9999$ -9999 -9999 -9999 -9999 -9999 -9999 -9999 -9999 -9999 -9999 -9999 -9999 -9999 -9999 -9999 -9999 -9999 -9999 -9999 -9999 -9999 -9999 -9999 -9999 -9999 -9999 -9999 -9999 -9999 -9999

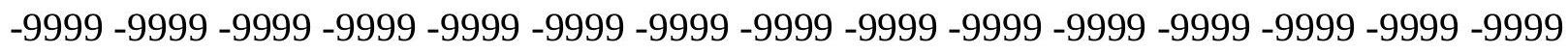
-9999 -9999 -9999 -9999 -9999 -9999 -9999 -9999 -9999 -9999 -9999 -9999 -9999 -9999 -9999 -9999 -9999 -9999 -9999 -9999 -9999 -9999 -9999 -9999 -9999 -9999 -9999 -9999 -

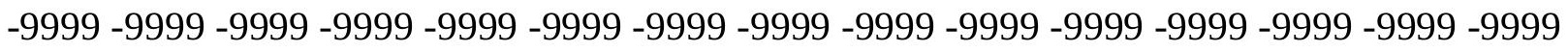
-9999 -9999 -9999 -9999 -9999 -9999 -9999 -9999 -9999 -9999 -9999 -9999 -9999 -9999 -9999 -9999 -9999 -9999 -9999 -9999 -9999 -9999 -9999 -9999 -9999 -9999 -9999 -9999 -9999 -9999 -9999 -9999 -9999 -9999 -9999 -9999 -9999 -9999 -9999 -9999 -9999 -9999 -9999 -9999 -9999 -

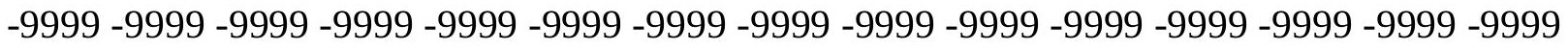

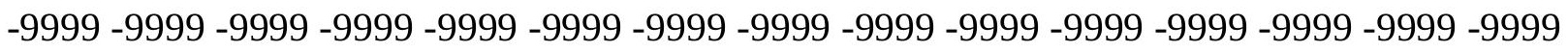
-9999 -9999 -9999 -9999 -9999 -9999 -9999 -9999 -9999 -9999 -9999 -9999 -9999 -9999 -9999 -9999 -9999 -9999 -9999 -9999 -9999 -9999 -9999 -9999 -9999 -9999 -9999 -9999 -9999 -9999 -

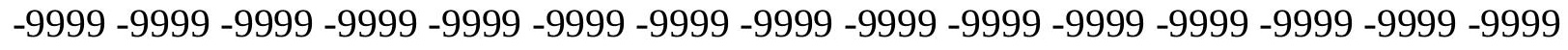
-9999 -9999 100.274299621699.66472625732 99.35994720459 100.2742996216 101.7982025146103 .0174026489103 .9317016602104 .2365036011104 .2365036011 103.6268997192102 .712600708102 .1029968262102 .1029968262103 .0174026489 104.8460998535105 .7603988647106 .6747970581107 .5891036987108 .5035018921 108.8082962036108 .5035018921107 .2844009399106 .0652008057105 .4557037354 106.0652008057107 .5891036987109 .8035507202110 .9523162842110 .8299484253 109.2926254272106 .4331359863102 .828895568899 .751533508398 .67533111572 100.0966491699102 .661781311103 .9774017334104 .6747436523105 .3912506104 105.907409668106 .1465835571106 .1073455811105 .8623657227104 .5412979126 102.4077987671100 .579101562598 .445587158296 .6168823242294 .78817749023 93.5690307617292 .349891662691 .7403335571391 .4355392456191 .43553924561 91.1307525634889 .6068267822388 .3876876831187 .1685485839886 .55898284912 85.33984375 83.51112365723 81.07285308838 78.02498626709 74.67236328125 70.7101516723666 .7479400634881 .9871978759879 .8537063598673 .75800323486 50.5943298339846 .6321296691943 .2794914245639 .9268493652336 .87900161743 33.8311500549331 .3928699493428 .6497993469225 .906740188622 .55410003662 18.8966808319115 .2392597198511 .581830024727 .6196279525763 .657422065735 -9999 $-4.26699209213-8.83876895905-14.0201196671-19.8110294342-27.1258792877$ $-35.3550796509-46.3273391724-58.8235282898-64.6144485474-67.3575134277$ $-68.2718734741-67.0527267456-64.3096618652-60.6522407532-56.6900291443$ $-52.4230384827-48.1560516357-43.8890609741-40.2316398621-37.7933502197$ -35.9646492004 -34.4407196045 -33.5263595581 -32.9167900085 -32.6120109558 
-32.6120109558 -32.9167900085 -33.2215805054 -33.2215805054 -32.9167900085 -32.0024414062 -30.7833003998 -29.2593708038 -27.4306602478 -25.9067401886 $-24.3828105927-23.7732391357-23.4684505463-23.7732391357-24.6875991821$ $-25.6019496918-25.9067401886-26.5163097382-26.8210906982-27.4306602478$ $-28.0402297974-28.6497993469-29.2593708038-29.8689403534-30.1737308502$ $-30.7833003998-31.0880794525-31.0880794525-31.3928699493-31.0880794525$ -30.7833003998 -30.478509903 -29.5641593933 -28.6497993469-27.7354507446 $-26.2115192413-24.6875991821-23.1636695862-21.3349609375-19.5062503815$ $-17.6775398254-15.8488302231-14.0201196671-11.8866195679-9.44833946228$ $-6.40048694611-2.438281059272 .4382810592659 .4483394622817 .37274932861$ 25.2971591949531 .0880794525123 .1636695861834 .1359291076744 .80340957642 51.8134689331152 .8385620117250 .8991203308149 .3751907348645 .7177696228 38.4029312133832 .0024414062530 .7833003997831 .0880794525131 .08807945251 31.0880794525131 .0880794525131 .08807945251 -9999 -9999 -9999 -9999 -9999 -9999 -9999 -9999 -9999 -9999 -9999 -9999 -9999 -9999 -9999 -9999 -9999 -9999 -9999 -9999 -9999 -9999

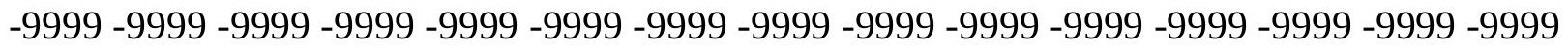
-9999 -9999 -9999 -9999 -9999 -9999 -9999 -9999 -9999 -9999 -9999 -9999 -9999 -9999 -9999 -9999 -9999 -9999 -9999 -9999 -9999 -9999 -9999 -9999 -9999 -9999 -9999 -9999 -9999 -9999 -9999 -9999 -9999 -9999-9999-9999 -9999

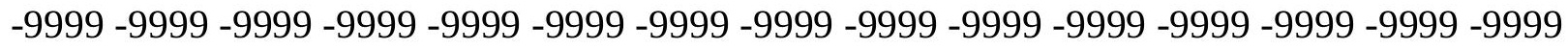

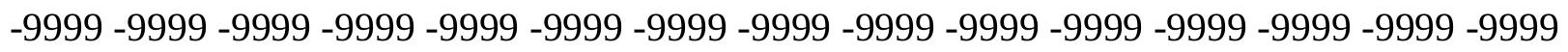

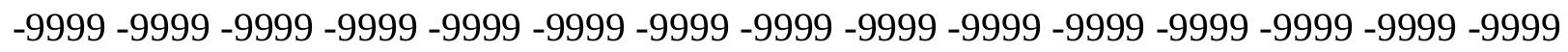
-9999 -9999 -9999 -9999 -9999 -9999 -9999 -9999 -9999 -9999 -9999 -9999 -9999 -9999 -9999 -

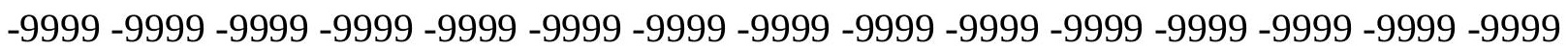

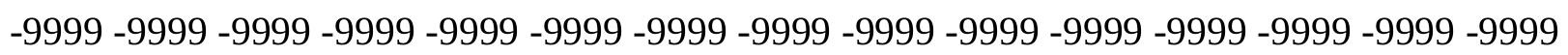
-9999 -9999 -9999 -9999 -9999 -9999 -9999 -9999 -9999 -9999 -9999 -9999 -9999 -9999 -9999 -9999 -9999 -9999 -9999 -9999 -9999 -9999 -9999 -9999 -9999 -9999 -9999 -9999 -9999 - -9999 -

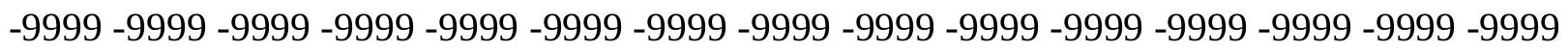
-9999 -9999-9999 105.4557037354 104.2365036011 104.2365036011 105.4557037354 106.6747970581107 .5891036987107 .8938980103107 .5891036987106 .979598999 106.3700027466106.0652008057 106.0652008057 106.6747970581 107.5891036987 108.5035018921109 .1130981445109 .4179000854110 .0273971558110 .0273971558 109.7226028442109 .1130981445108 .5035018921108 .5035018921108 .8082962036 110.0273971558110 .9418029785111 .24659729110 .6370010376108 .2819747925 104.23274993998 .8132705688593 .4692001342891 .0039825439593 .04654693604 97.39703369141101 .5342254639103 .8365249634104 .8570022583105 .581817627 105.9829864502106 .082611084105 .4557037354103 .9317016602102 .1029968262 100.579101562598 .7503814697397 .2264633178796 .0073165893694 .78817749023 93.8738174438593 .5690307617292 .6546783447391 .1307525634890 .21640014648 89.3020401001 88.99725341797 88.99725341797 88.99725341797 88.38768768311 88.3876876831187 .7781066894587 .7781066894588 .3876876831188 .99725341797 89.6068267822388 .3876876831185 .9494018554780 .7680587768674 .0627822876 52.1182594299348 .4608306884845 .1082000732442 .0603485107439 .01250076294 36.2694282531733 .8311500549331 .3928699493427 .430660247823 .77323913574 19.811029434216 .1536102294912 .496190071118 .5339832305914 .571776866913 $.6095703244209-3.65742206573-8.53398323059-14.3248996735$-20.7253894806 
-28.6497993469 -37.1837806702 -51.5086898804 -61.8713798523 -66.4431610107 $-69.4910125732-69.4910125732-66.4431610107-62.1761703491-58.5187492371$ $-54.5565414429-50.594329834-46.6321296692-43.2794914246-40.5364189148$ $-38.4029312134-36.5742111206-35.0502891541-33.8311500549-33.2215805054$ $-33.2215805054-33.5263595581-33.8311500549-33.8311500549-33.8311500549$ -33.2215805054 -32.307220459 -31.0880794525 -29.5641593933 -28.0402297974 $-26.8210906982-25.9067401886-25.6019496918-25.6019496918-26.2115192413$ $-26.8210906982-27.1258792877-27.4306602478-27.7354507446-28.0402297974$ $-28.3450202942-28.9545898438-29.5641593933-29.8689403534-30.478509903$ $-30.7833003998-31.0880794525-31.0880794525-31.3928699493-31.0880794525$ -30.7833003998 -30.478509903 -29.8689403534 -28.9545898438 -27.7354507446 $-26.5163097382-25.2971591949-23.4684505463-21.9445304871-20.115819931$ -18.287109375 -16.4584007263 -14.3248996735 -11.8866195679 -9.44833946228 -5.79091691971 -1.52392601967 3.96220707893411 .2770500183119 .20145988464 26.2115192413330 .7833003997832 .9167900085441 .1459884643649 .37519073486 51.6031913757351 .7293701171948 .765621185345 .717769622841 .45077896118 35.0502891540529 .8689403533928 .9545898437529 .5641593933129 .56415939331 29.8689403533929 .8689403533930 .1737308502230 .47850990295 -9999 -9999 -9999 -9999 -9999 -9999 -9999 -9999 -9999 -9999 -9999 -9999 -9999 -9999 -9999 -9999 -9999 -9999 -9999 -9999 -9999 -9999 -9999 -9999 -9999 -9999 -9999 -9999 -9999 -9999 -9999 -9999 -9999 -9999 -9999 -9999 -9999 -9999 -9999 -9999 -9999 -9999 -9999 -9999 -9999 -9999 -9999 -9999 -9999 -9999 -9999 -9999 -9999 -9999 -9999 -9999 -9999 -9999 -9999 -9999 -9999 -9999 -9999 -9999 -9999 -9999 -9999 -9999 -9999 -9999 -9999 -9999 -9999

-9999 -9999 -9999 -9999 -9999 -9999 -9999 -9999 -9999 -9999 -9999 -9999 -9999 -9999 -9999 -9999 -9999 -9999 -9999 -9999 -9999 -9999 -9999 -9999 -9999 -9999 -9999 -9999 -9999 -9999 -9999 -9999 -9999 -9999 -9999 -9999 -9999 -9999 -9999 -9999 -9999 -9999 -9999 -9999 -9999 -9999 -9999 -9999 -9999 -9999 -9999 -9999 -9999 -9999 -9999 -9999 -9999 -9999 -9999 -9999 -

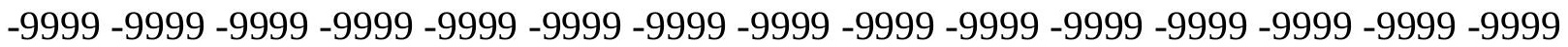
-9999 -9999 -9999 -9999 -9999 -9999 -9999 -9999 -9999 -9999 -9999 -9999 -9999 -9999 -9999

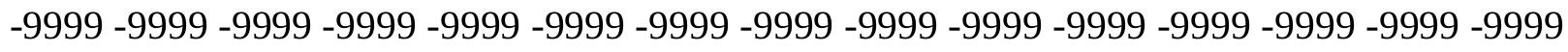
-9999 -9999 -9999 -9999 -9999 -9999 -9999 -9999 -9999 -9999 -9999 -9999 -9999 -9999 -9999 -9999 -9999 -9999 -9999 -9999 -9999 -9999 -9999 -9999 -9999 -9999 -9999 -9999 -9999 -9999 -9999 -9999-9999 -9999 110.9418029785 109.4179000854109.7226028442110.9418029785 111.551399231111 .8561019897111 .551399231110 .9418029785110 .3321990967 109.7226028442109 .7226028442110 .3321990967110 .6370010376110 .9418029785 111.24659729111 .551399231111 .551399231111 .551399231111 .551399231111 .24659729 110.9418029785111 .24659729111 .551399231112 .1608963013112 .7705001831 112.4656982422111 .24659729108 .5035018921103 .931701660297 .53124237061 89.60682678223 84.73026275635 88.0829010009893.5690307617297.22646331787 100.2742996216102 .4077987671103 .9317016602104 .5412979126104 .2365036011 103.6268997192102 .712600708101 .493400573799 .9695205688598 .75038146973 97.2264633178796.3121032714895.397743225194.7881774902394.48339080811 94.4833908081193 .5690307617292 .6546783447390 .8259735107490 .21640014648 89.6068267822389 .302040100189 .302040100188 .9972534179787 .47332763672 85.3398437582 .9015579223696 .9216690063594 .7881774902392 .65467834473 89.9116134643686 .254188537681 .3776321411176 .1962814331153 .64218139648 
49.9847602844246 .6321296691943 .8890609741240 .8412094116238 .09814071655 35.0502891540531 .6976509094227 .7354507446324 .0780296325720 .42060089111 17.0679702758813 .410550117499 .7531242370615 .7909169197081 .828711032867 $-2.43828105927-7.92441320419-14.0201196671-21.3349609375-31.3928699493$ $-43.8890609741-57.6043891907-64.6144485474-69.4910125732-70.4053573608$ $-67.967086792-64.0048828125-60.0426712036-56.3852500916-52.7278289795$ $-49.070400238-46.0225486755-43.2794914246-40.8412094116-38.7077102661$ -36.8790016174 -35.3550796509 -34.1359291077 -34.1359291077 -34.4407196045 $-34.7455101013-34.7455101013-34.4407196045-34.1359291077-33.2215805054$ -32.307220459-31.0880794525 -29.5641593933 -28.3450202942 -27.4306602478 $-27.1258792877-27.1258792877-27.1258792877-27.4306602478-27.7354507446$ $-28.0402297974-28.0402297974-28.3450202942-28.9545898438-29.2593708038$ $-29.5641593933-30.1737308502-30.478509903-30.7833003998-31.0880794525$ $-31.0880794525-31.3928699493-31.0880794525-30.7833003998-30.478509903$ $-29.8689403534-28.9545898438-28.0402297974-26.8210906982-25.2971591949$ $-23.7732391357-22.2493095398-20.4206008911-18.5918903351-16.4584007263$ -14.3248996735 -11.8866195679 -9.14355373383 -5.48613214493 -.914355397224 4.8765621185311 .8866195678719 .5062503814726 .8210906982432 .61201095581 38.0981407165546 .9369087219249 .2370414733950 .2895507812547 .54647827148 43.5842704772939 .9268493652336 .2694282531731 .6976509094228 .04022979736 27.430660247828 .3450202941928 .3450202941928 .6497993469228 .95458984375 29.25937080383 29.8689403533930 .47850990295 -9999 -9999 -9999 -9999 -9999 -9999 -9999 -9999 -9999 -9999 -9999 -9999 -9999 -9999 -9999 -9999 -9999 -9999 -9999 -9999 -9999 -9999 -9999 -9999 -9999 -9999 -9999 -9999 -9999 -9999 -9999 -9999 -9999 -9999 -9999 -9999 -9999 -9999 -9999 -9999 -9999 -9999 -9999 -9999 -9999 -9999 -9999 -9999 -9999 -9999 -9999 -9999 -9999 -9999 -9999 -9999 -9999 -9999 -9999 -9999 -9999 -9999 -9999 -9999 -9999 -9999 -9999 -9999 -9999-9999-9999-9999

-9999 -9999 -9999 -9999 -9999 -9999 -9999 -9999 -9999 -9999 -9999 -9999 -9999 -9999 -9999 -9999 -9999 -9999 -9999 -9999 -9999 -9999 -9999 -9999 -9999 -9999 -9999 -9999 -9999 -9999 -9999 -9999 -9999 -9999 -9999 -9999 -9999 -9999 -9999 -9999 -9999 -9999 -9999 -9999 -9999 -9999 -9999 -9999 -9999 -9999 -9999 -9999 -9999 -9999 -9999 -9999 -9999 -9999 -9999 -9999

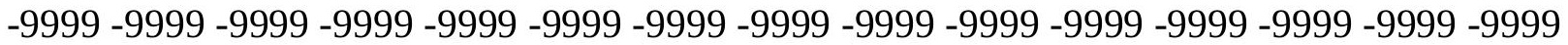

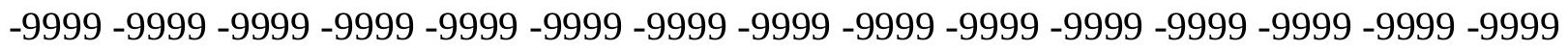
-9999 -9999 -9999 -9999 -9999 -9999 -9999 -9999 -9999 -9999 -9999 -9999 -9999 -9999 -9999 -9999 -9999 -9999 -9999 -9999 -9999 -9999 -9999 -9999 -9999 -9999 -9999 -9999 -9999 -9999 -9999 -9999 -9999 -9999 -9999 -9999 -9999 -9999 -9999 -9999 -9999 -9999 -9999 -9999 -9999 -9999 -9999 -9999 -9999 118.5614013672 116.4279022217 114.5991973877 115.5136032104 116.1231002808115 .818397522115 .5136032104114 .5991973877113 .9896011353 113.3800964355113 .3800964355113 .3800964355113 .6848983765113 .6848983765 113.6848983765113 .6848983765113 .3800964355113 .3800964355113 .3800964355 113.3800964355113 .3800964355113 .3800964355113 .6848983765113 .9896011353 113.9896011353113 .6848983765112 .1608963013109 .1130981445104 .5412979126 98.7503814697392 .349891662687 .7781066894587 .1685485839891 .43553924561 93.2642517089896 .6168823242299 .05516815186100 .8839035034102 .1029968262 102.1029968262102 .1029968262101 .1886978149100 .274299621699 .05516815186 98.1408081054796.9216690063596.0073165893695.397743225194.78817749023 
94.4833908081194 .7881774902395 .0929565429793 .8738174438592 .65467834473 91.1307525634891 .1307525634890 .8259735107490 .5211791992290 .52117919922 90.8259735107489 .9116134643690 .2164001464890 .8259735107498 .14080810547 96.0073165893693 .5690307617290 .8259735107487 .7781066894584 .73026275635 80.4632720947373 .7580032348651 .2038993835448 .1560516357445 .10820007324 41.7555618286138 .7077102661135 .0502891540531 .6976509094228 .04022979736 24.9923801422121 .6397399902318 .28710937514 .934470176711 .27705001831 $7.6196279525763 .352636098862-1.21914100647-6.7052731514-14.0201196671$ $-23.1636695862-33.8311500549-46.0225486755-57.6043891907-67.3575134277$ $-68.5766525269-67.3575134277-64.6144485474-60.6522407532-57.2995986938$ -54.251750946 -51.2038993835 -48.1560516357 -45.412979126 -42.9747009277 $-40.8412094116-38.7077102661-37.1837806702-35.9646492004-35.3550796509$ -35.3550796509 -35.6598587036 -35.6598587036 -35.3550796509 -35.0502891541 $-34.1359291077-33.2215805054-32.0024414062-30.7833003998-29.5641593933$ -28.6497993469 -28.3450202942 -28.0402297974 -28.0402297974 -28.0402297974 $-28.3450202942-28.3450202942-28.6497993469-28.9545898438-29.2593708038$ $-29.5641593933-29.8689403534-30.1737308502-30.478509903-30.7833003998$ $-31.0880794525-31.0880794525-31.0880794525-31.0880794525$-30.7833003998 -30.478509903 -29.8689403534 -28.9545898438 -28.0402297974 -26.8210906982 $-25.6019496918-24.0780296326-22.2493095398-20.4206008911-18.5918903351$ $-16.4584007263-14.3248996735-11.8866195679-8.83876895905-5.48613214493$ -.914355397224 4.8765621185311.88661956787 19.20145988464 26.21151924133 32.6120109558138 .7077102661143 .2794914245643 .5842704772939 .92684936523 35.6598587036131 .6976509094230 .7833003997830 .1737308502228 .04022979736 26.2115192413326 .5163097381627 .1258792877228 .0402297973630 .78330039978 28.9545898437529 .2593708038329 .2593708038329 .8689403533930 .47850990295 -9999 -9999 -9999 -9999 -9999 -9999 -9999 -9999 -9999 -9999 -9999 -9999 -9999 -9999 -9999 -9999 -9999 -9999 -9999 -9999 -9999 -9999 -9999 -9999 -9999 -9999 -9999 -9999 -9999 -9999 -9999 -9999 -9999 -9999 -9999 -9999 -9999 -9999 -9999 -9999 -9999 -9999 -9999 -9999 -9999 -9999

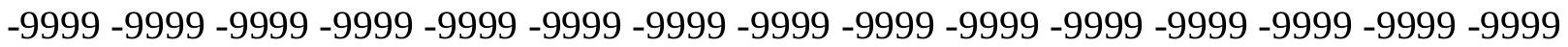
-9999 -9999 -9999 -9999 -9999 -9999 -9999 -9999 -9999 -9999

-9999 -9999 -9999 -9999 -9999 -9999 -9999 -9999 -9999 -9999 -9999 -9999 -9999 -9999 -9999 -9999 -9999 -9999 -9999 -9999 -9999 -9999 -9999 -9999 -9999 -9999 -9999 -9999 -9999 -9999 -9999 -9999 -9999 -9999 -9999 -9999 -9999 -9999 -9999 -9999 -9999 -9999 -9999 -9999 -9999 -

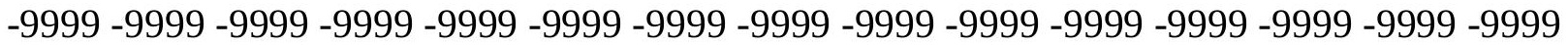
-9999 -9999 -9999 -9999 -9999 -9999 -9999 -9999 -9999 -9999 -9999 -9999 -9999 -9999 -9999 -9999 -9999 -9999 -9999 -9999 -9999 -9999 -9999 -9999 -9999 -9999 -9999 -9999 -9999 -9999

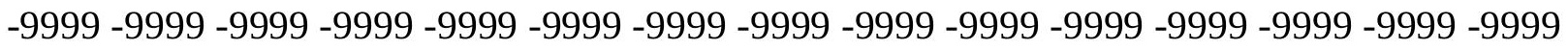
-9999 -9999 -9999 -9999 -9999 -9999 -9999 -9999 -9999 -9999 -9999 -9999 -9999 -9999 -9999 -9999 -9999 -9999 -9999 -9999 -9999 -9999 -9999 -9999 -9999 -9999 -9999 -9999 -9999 -9999 -9999 -9999 -9999 -9999-9999 122.3868637085120 .8488235474120 .3900985718 120.6949005127120 .0852966309119 .4757995605118 .5614013672117 .647102356 117.0374984741116 .7326965332117 .0374984741117 .0374984741116 .7326965332 116.4279022217115 .818397522115 .5136032104115 .5136032104115 .2088012695 115.2088012695115 .2088012695115 .5136032104115 .5136032104115 .2088012695 115.2088012695114 .2944030762112 .7705001831110 .3321990967106 .3700027466 
101.188697814996.3121032714892.9594726562592.0450973510792.95947265625 94.7881774902396 .6168823242298 .1408081054799 .0551681518699 .96952056885 100.2742996216100 .274299621699 .9695205688599 .0551681518698 .14080810547 97.2264633178796 .3121032714895 .397743225194 .7881774902394 .17859649658 94.1785964965894 .1785964965894 .1785964965894 .4833908081193 .87381744385 92.9594726562592 .6546783447392 .6546783447392 .349891662692 .04509735107 91.4355392456190 .2164001464888 .9972534179787 .1685485839885 .94940185547 87.7781066894596 .0073165893694 .1785964965892 .0450973510790 .82597351074 88.0829010009881 .6824111938573 .4532165527352 .1182594299348 .7656211853 45.4129791259842 .0603485107438 .4029312133835 .0502891540532 .00244140625 28.9545898437526 .2115192413323 .1636695861820 .1158199310316 .76317977905 $13.410550117499 .7531242370615 .486132144928 .3047851026058-5.48613214493$ -13.4105501175 -22.8588790894 -32.307220459-46.6321296692 -57.2995986938 $-63.3953094482-64.9192428589-63.0905189514-59.7378807068-57.6043891907$ $-55.1661109924-52.4230384827-49.9847602844-47.5464782715-45.1082000732$ $-42.9747009277-40.8412094116-39.0125007629-37.7933502197-37.1837806702$ -36.8790016174 -36.5742111206 -36.5742111206 -36.2694282532 -35.6598587036 -35.0502891541 -34.1359291077 -32.9167900085 -31.6976509094 -30.478509903 $-29.8689403534-29.2593708038$-28.6497993469 -28.6497993469 -28.6497993469 -28.6497993469 -28.6497993469 -28.9545898438 -28.9545898438 -29.2593708038 -29.5641593933 -29.8689403534-30.1737308502 -30.478509903 -30.7833003998 $-31.0880794525-31.0880794525-31.0880794525-31.0880794525-30.7833003998$ $-30.478509903-29.8689403534-28.9545898438-28.0402297974-26.8210906982$ -25.2971591949 -23.7732391357 -22.2493095398 -20.4206008911 -18.287109375 -16.1536102295 -14.0201196671 -11.2770500183-8.53398323059-5.18134689331 -1.21914100647 4.57177686691311.27705001831 17.9823207855224 .68759918213 30.7833003997835 .6598587036138 .4029312133836 .2694282531730 .17373085022 26.5163097381622 .8588790893624 .6875991821326 .5163097381627 .4306602478 27.430660247827 .7354507446328 .6497993469229 .5641593933130 .17373085022 29.8689403533929 .5641593933129 .5641593933128 .9545898437529 .56415939331 -9999 -9999 -9999 -9999 -9999 -9999 -9999 -9999 -9999 -9999 -9999 -9999 -9999 -9999 -9999 -9999

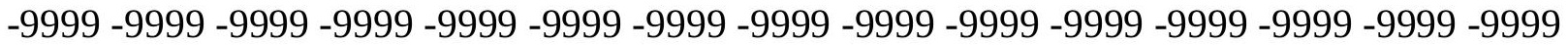
-9999 -9999 -9999 -9999 -9999 -9999 -9999 -9999 -9999-9999 -9999 -9999 -9999-9999-999 - -999 -9999 -9999 -9999 -9999 -9999 -9999 -9999 -9999 -9999 -9999 -9999 -9999 -9999 -9999 -9999 -9999 -9999 -9999 -9999 -9999 -9999 -9999 -9999 -9999-9999

-9999 -9999 -9999 -9999 -9999 -9999 -9999 -9999 -9999 -9999 -9999 -9999 -9999 -9999 -9999

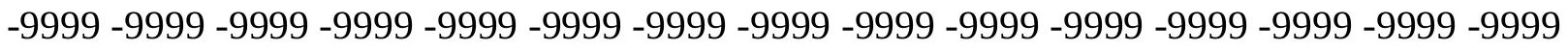

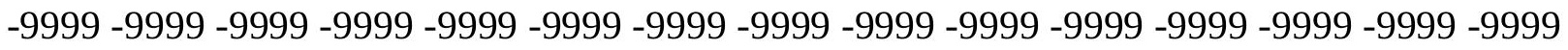
-9999 -9999 -9999 -9999 -9999 -9999 -9999 -9999 -9999 -9999 -9999 -9999 -9999 -9999 -9999 -9999 -9999 -9999 -9999 -9999 -9999 -9999 -9999 -9999 -9999 -9999 -9999 -9999 -9999 -9999 -

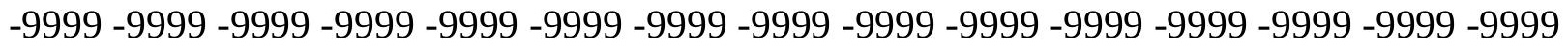

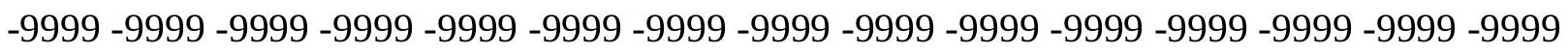
-9999 -9999 -9999 -9999 -9999 -9999 -9999 -9999 -9999 -9999 -9999 -9999 -9999 -9999 -9999 -9999 -9999 -9999 -9999 -9999 -9999 -9999 -9999 -9999 -9999 -9999 -9999 -9999 -9999 -9999 -9999 -9999 -9999 -9999 -9999 -9999 126.1888198853 125.2206726074 124.6692276001 124.0475006104123 .1332015991122 .8283996582121 .9140014648120 .3900985718 
120.6949005127120 .6949005127120 .6949005127120 .0852966309119 .1709976196 118.5614013672117 .9517974854117 .647102356117 .342300415117 .342300415 117.342300415117 .342300415117 .0374984741116 .4279022217116 .1231002808 115.2088012695114 .2944030762111 .8561019897108 .8082962036104 .8460998535 100.883903503498 .1408081054796 .9216690063596 .9216690063597 .83602905273 98.7503814697399 .66472625732100 .2742996216100 .5791015625100 .2742996216 99.6647262573299 .0551681518698 .1408081054796 .9216690063596 .00731658936 95.0929565429794 .4833908081193 .8738174438593 .5690307617293 .26425170898 92.9594726562592 .9594726562592 .6546783447392 .6546783447392 .95947265625 93.5690307617293 .5690307617293 .5690307617293 .2642517089892 .95947265625 92.349891662691 .4355392456190 .2164001464888 .3876876831185 .94940185547 82.9015579223679 .2441329956194 .1785964965892 .9594726562590 .52117919922 85.3398437579 .2441329956173 .7580032348652 .4230384826748 .7656211853 45.4129791259841 .7555618286138 .4029312133835 .6598587036133 .22158050537 30.4785099029527 .7354507446324 .9923801422122 .2493095397918 .89668083191 15.8488302230811 .886619567877 .6196279525762 .133496046066 -3.96220707893 $-13.1057596207-23.4684505463-35.6598587036-46.6321296692-54.8613204956$ $-60.3474502563-60.0426712036-58.5187492371-56.9948196411-55.1661109924$ $-53.3373985291-51.2038993835-49.070400238-46.6321296692-44.4986305237$ $-42.669921875-40.8412094116-39.6220703125-38.7077102661-38.0981407166$ -37.7933502197 -37.488571167-36.8790016174 -36.5742111206 -35.6598587036 $-34.7455101013-33.8311500549-32.6120109558-31.3928699493-30.478509903$ $-29.8689403534-29.2593708038-28.9545898438-28.9545898438-28.9545898438$ $-28.9545898438-28.9545898438-29.2593708038-29.5641593933-29.8689403534$ $-29.8689403534-30.1737308502-30.478509903-30.7833003998-31.0880794525$ $-31.0880794525-31.0880794525-30.7833003998-30.478509903-30.1737308502$ -29.5641593933 -28.6497993469 -27.7354507446 -26.5163097382 -25.2971591949 $-23.7732391357-21.9445304871-20.115819931-17.9823207855-15.8488302231$ $-13.4105501175-10.9722604752-7.92441320419-4.87656211853-.609570324421$ 4.26699209213310 .3626899719216 .7631797790522 .5541000366227 .73545074463 31.0880794525133 .8311500549333 .2215805053730 .1737308502226 .82109069824 24.9923801422125 .2971591949526 .5163097381627 .7354507446328 .34502029419 29.2593708038330 .1737308502230 .4785099029530 .4785099029530 .47850990295 $29.8689403533929 .5641593933128 .9545898437528 .9545898437529 .25937080383-9999$ -9999 -9999 -9999 -9999 -9999 -9999 -9999 -9999 -9999 -9999 -9999 -9999 -9999 -9999 -9999 -9999 -9999 -9999 -9999 -9999 -9999 -9999 -9999 -9999 -9999 -9999 -9999 -9999 -9999 -9999

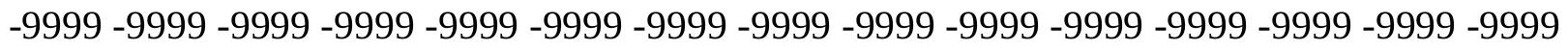

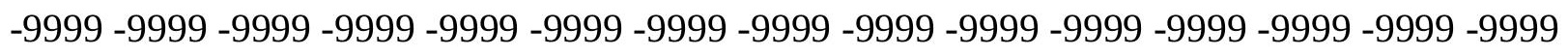
-9999 -9999 -9999 -9999 -9999 -9999 -9999 -9999 -9999 -9999 -9999 -9999 -9999 -9999 -9999 -9999 -9999 -9999 -9999 -9999 -9999 -9999 -9999 -9999

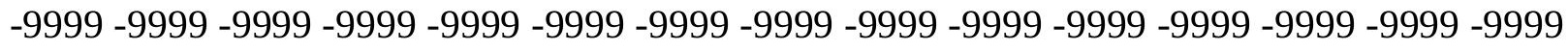

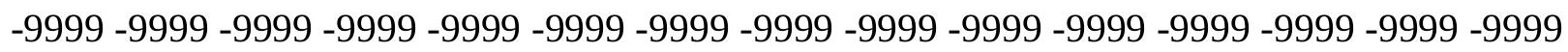
-9999 -9999 -9999 -9999 -9999 -9999 -9999 -9999 -9999 -9999 -9999 -9999 -9999 -9999 -9999 -

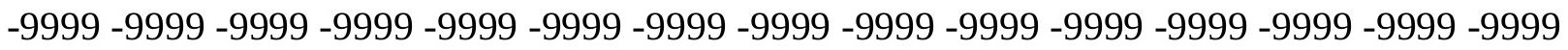
-9999 -9999 -9999 -9999 -9999 -9999 -9999 -9999 -9999 -9999 -9999 -9999 -9999 -9999 -9999 -

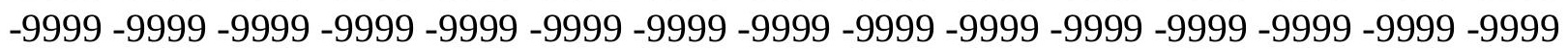


-9999 -9999 -9999 -9999 -9999 -9999 -9999 -9999 -9999 -9999 -9999 -9999 -9999 -9999 -9999 -9999 -9999 -9999 -9999 -9999 -9999 -9999 -9999 -9999 -9999 -9999 -9999 -9999 -9999 -9999 -9999 -9999 -9999 -9999 -9999 -9999 -9999 -9999 127.9923934937127 .4699401855 127.1120681763126 .6310272217125 .6832809448124 .8645019531124 .7254714966 124.7172851562124 .3742141724124 .0475006104122 .5235977173120 .9997024536 120.6949005127120 .3900985718119 .7806015015119 .4757995605119 .1709976196 119.1709976196119 .1709976196118 .2565994263117 .0374984741117 .0374984741 116.4279022217114 .5991973877111 .551399231108 .5035018921105 .1509017944 102.712600708101 .1886978149100 .5791015625100 .5791015625100 .8839035034 101.1886978149101 .1886978149101 .1886978149100 .579101562599 .66472625732 98.7503814697397 .8360290527396 .6168823242295 .7025299072394 .48339080811 93.5690307617292 .9594726562592 .6546783447392 .0450973510792 .3498916626 92.9594726562592 .9594726562593 .2642517089893 .2642517089893 .26425170898 92.9594726562593 .5690307617294 .1785964965894 .1785964965894 .17859649658 93.5690307617292 .9594726562591 .4355392456189 .302040100186 .55898284912 83.206336975179 .2441329956192 .6546783447390 .2164001464886 .86376190186 82.5967712402378 .9393463134874 .062782287652 .1182594299348 .7656211853 45.4129791259842 .3651313781739 .622070312537 .1837806701734 .74551010132 32.3072204589829 .8689403533927 .1258792877224 .3828105926521 .63973999023 $18.28710937514 .324899673469 .448339462283 .352636098862-4.57177686691$ $-14.6296901703-25.2971591949-35.6598587036-44.8034095764-51.5086898804$ $-54.5565414429-55.4708900452-55.4708900452-54.8613204956-53.3373985291$ $-51.8134689331-49.9847602844-47.8512611389-46.0225486755-44.1938400269$ $-42.3651313782-41.1459884644-39.9268493652-39.3172798157-38.7077102661$ $-38.4029312134-37.7933502197-37.1837806702-36.5742111206-35.6598587036$ -34.7455101013 -33.5263595581 -32.307220459 -31.3928699493 -30.478509903 $-29.8689403534-29.5641593933-29.2593708038-28.9545898438-28.9545898438$ $-29.2593708038-29.2593708038-29.5641593933-29.8689403534-29.8689403534$ $-30.1737308502-30.478509903-30.7833003998-30.7833003998-31.0880794525$ -30.7833003998 -30.7833003998 -30.478509903 -29.8689403534-29.2593708038 $-28.3450202942-27.4306602478-26.2115192413-24.9923801422-23.1636695862$ $-21.6397399902-19.5062503815-17.3727493286-15.2392597198-12.8009700775$ $-10.0579099655-7.3148431778-4.26699209213-.3047851026064 .266992092133$ 9.4483394622814 .934470176720 .4206008911124 .9923801422128 .64979934692 31.3928699493432 .0024414062530 .7833003997828 .9545898437527 .73545074463 27.430660247828 .0402297973628 .6497993469229 .2593708038329 .86894035339 30.4785099029530 .7833003997830 .7833003997830 .4785099029530 .17373085022 29.5641593933128 .9545898437528 .3450202941928 .6497993469229 .25937080383 -9999 -9999 -9999 -9999 -9999 -9999 -9999 -9999 -9999 -9999 -9999 -9999 -9999 -9999 -9999 -9999 -9999 -9999 -9999 -9999 -9999 -9999 -9999 -9999 -9999 -9999 -9999 -9999 -9999 - -9999 -9999 -9999 -9999 -9999 -9999 -9999 -9999 -9999 -9999 -9999 -9999 -9999 -9999 -9999 -9999 -9999

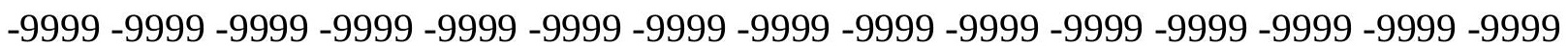
-9999 -9999 -9999 -9999 -9999 -9999 -9999 -9999 -9999 -9999 -9999 -9999 -9999 -9999 -9999 -9999 -9999 -9999 -9999 -9999 -9999 -9999 -9999 -9999 -9999 -9999 -9999 -9999 -9999 -9999 -9999 -9999 -9999 -9999 -9999 -9999 -9999 -9999

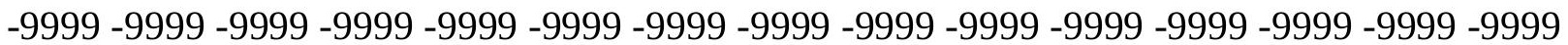


-9999 -9999 -9999 -9999 -9999 -9999 -9999 -9999 -9999 -9999 -9999 -9999 -9999 -9999 -9999 -9999 -9999 -9999 -9999 -9999 -9999 -9999 -9999 -9999 -9999 -9999 -9999 -9999 -9999 -9999

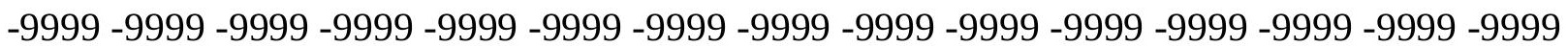
-9999 -9999 -9999 -9999 -9999 -9999 -9999 -9999 -9999 -9999 -9999 -9999 -9999 -9999 -9999 -9999 -9999 -9999 -9999 -9999 -9999 -9999 -9999 -9999 -9999 -9999 -9999 -9999 -9999 -9999 -9999 -9999 -9999 -9999 -9999 -9999 -9999 -9999 -9999 -9999 -9999 -9999 -9999 -9999 -9999 -9999 -9999 -9999 -9999 -9999 -9999 -9999 -9999 -9999 -9999 131.2121582031 130.2970275879128 .3616638184127 .0803604126126 .2381057739125 .7838287354 125.5442657471125 .3220062256124 .7499008179124 .7974853516123 .7427978516 123.1332015991122 .5235977173121 .6092987061120 .9997024536121 .6092987061 122.2188034058121 .6092987061119 .1709976196120 .6949005127119 .7806015015 117.647102356114 .9039993286112 .1608963013109 .1130981445106 .979598999 105.1509017944104 .2365036011103 .6268997192103 .3221969604102 .712600708 102.4077987671101 .4934005737100 .883903503499 .6647262573298 .75038146973 97.2264633178796 .0073165893694 .7881774902393 .8738174438592 .95947265625 92.349891662692 .9594726562592 .9594726562592 .9594726562593 .26425170898 93.5690307617293 .5690307617293 .5690307617292 .9594726562592 .95947265625 93.8738174438594 .4833908081195 .0929565429795 .0929565429795 .09295654297 94.7881774902393 .8738174438592 .0450973510789 .9116134643686 .86376190186 82.5967712402378 .3297805786173 .7580032348669 .7957916259883 .81591033936 81.0728530883876 .8058471679755 .4708900451752 .1182594299349 .07040023804 46.0225486755443 .2794914245640 .8412094116238 .7077102661136 .57421112061 34.1359291076732 .0024414062529 .2593708038327 .1258792877224 .38281059265 $20.7253894805916 .1536102294910 .362689971922 .743066072464-5.48613214493$ $-15.2392597198-24.6875991821-34.4407196045-42.0603485107-47.8512611389$ $-51.2038993835-53.0326118469-53.3373985291-53.0326118469-51.8134689331$ $-50.2895507812-48.7656211853-46.9369087219-45.1082000732-43.5842704773$ $-42.0603485107-41.1459884644-40.2316398621-39.6220703125-39.0125007629$ -38.7077102661 -38.0981407166 -37.1837806702 -36.2694282532 -35.3550796509 -34.1359291077 -33.2215805054 -32.0024414062 -31.0880794525 -30.478509903 $-29.8689403534-29.5641593933-29.2593708038-29.2593708038-29.2593708038$ $-29.2593708038-29.5641593933-29.8689403534-29.8689403534-30.1737308502$ $-30.478509903-30.478509903-30.7833003998-30.7833003998-30.7833003998$ -30.478509903 -30.1737308502 -29.5641593933 -28.9545898438 -28.0402297974 -27.1258792877 -25.9067401886 -24.3828105927 -22.8588790894 -21.0301704407 -18.8966808319 -16.7631797791 -14.3248996735 -11.8866195679 -9.44833946228 $-6.7052731514-3.65742206573-.3047851026063 .6574220657358 .229198455811$ 13.1057596206717 .9823207855222 .5541000366226 .5163097381629 .86894035339 31.6976509094231 .6976509094230 .7833003997829 .8689403533929 .56415939331 29.5641593933129 .5641593933129 .8689403533930 .1737308502230 .78330039978 30.7833003997830 .7833003997830 .4785099029530 .1737308502229 .56415939331 28.9545898437528 .0402297973628 .0402297973628 .34502029419 -9999 -9999 -9999 -9999 -9999 -9999 -9999 -9999 -9999 -9999 -9999 -9999 -9999 -9999 -9999 -9999 -9999 -9999 -9999 -9999 -9999 -9999 -9999 -9999 -9999 -9999 -9999 -9999 -9999 -9999 -9999 -9999 -9999 -9999 -9999 -9999 -9999 -9999 -9999 -9999 -9999 -9999 -9999 -9999 -9999 -9999 -9999 -9999 -9999

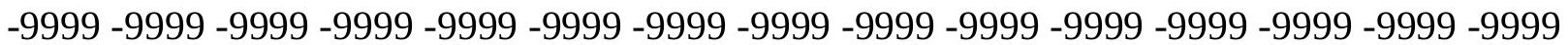


-9999 -9999 -9999-9999 -9999

-9999 -9999 -9999 -9999 -9999 -9999 -9999 -9999 -9999 -9999 -9999 -9999 -9999 -9999 -9999

-9999 -9999 -9999 -9999 -9999 -9999 -9999 -9999 -9999 -9999 -9999 -9999 -9999 -9999 - 9999 -

-9999 -9999 -9999 -9999 -9999 -9999 -9999 -9999 -9999 -9999 -9999 -9999 -9999 -9999 -9999

-9999 -9999 -9999 -9999 -9999 -9999 -9999 -9999 -9999 -9999 -9999 -9999-9999 -9999 -9999 -

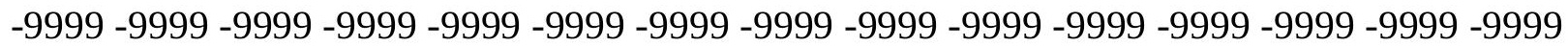

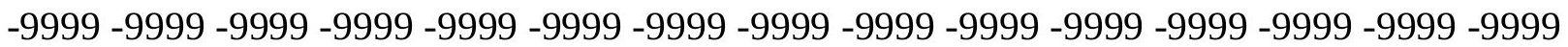

-9999 -9999 -9999 -9999 -9999 -9999 -9999 -9999 -9999 -9999 -9999 -9999 -9999 -9999 -9999 -999 -

-9999 -9999 -9999 -9999 -9999 -9999 -9999 -9999 -9999 -9999 -9999 -9999 -9999 -9999 -9999

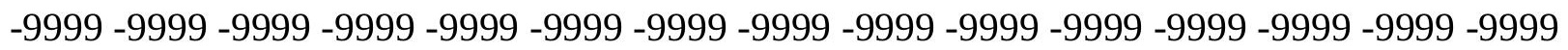

-9999 -9999 -9999 -9999 -9999 -9999 -9999 -9999 -9999 -9999 -9999 -9999 -9999

140.8106994629138 .9819946289131 .6075897217126 .6886825562126 .2448501587

126.0145950317125 .9193496704126 .1294021606126 .0580062866125 .2667007446

124.3523025513124 .0475006104124 .6570968628125 .5715026855127 .4001998901

128.6192932129126 .7906036377123 .7427978516120 .6949005127117 .9517974854

115.2088012695112 .7705001831110 .6370010376108 .8082962036107 .2844009399

106.3700027466105 .1509017944104 .2365036011103 .3221969604102 .4077987671

101.188697814999 .6647262573298 .445587158296 .9216690063595 .3977432251

94.1785964965893 .2642517089892 .349891662692 .6546783447392 .95947265625

92.9594726562592 .9594726562593 .2642517089893 .2642517089893 .26425170898 93.2642517089893 .2642517089892 .9594726562593 .8738174438594 .78817749023 95.397743225196.0073165893696.3121032714896.0073165893695.3977432251 94.1785964965892 .0450973510789 .302040100185 .0350494384880 .76805877686 76.1962814331172 .2340774536168 .2718734741264 .6144485473661 .26181030273 58.2139587402355 .1661109924352 .1182594299349 .3751907348646 .93690872192 44.4986305236842 .3651313781740 .2316398620638 .4029312133836 .26942825317 34.4407196044932 .3072204589829 .8689403533926 .8210906982422 .55410003662 $17.3727493286110 .667480468753 .047851085663-5.18134689331-14.3248996735$ -23.7732391357-32.6120109558-40.5364189148 -46.3273391724-49.6799812317 $-51.2038993835-51.5086898804-51.2038993835-49.9847602844-48.7656211853$ $-47.2416992188-45.7177696228-44.1938400269-42.9747009277-41.7555618286$ $-40.8412094116-40.2316398621-39.9268493652-39.3172798157-38.7077102661$ -38.0981407166 -37.1837806702 -35.9646492004 -35.0502891541 -33.8311500549 -32.6120109558 -31.6976509094 -30.7833003998 -30.1737308502 -29.5641593933 $-29.2593708038-29.2593708038-29.2593708038-29.2593708038-29.5641593933$ $-29.8689403534-29.8689403534-30.1737308502-30.478509903-30.478509903$ $-30.478509903-30.478509903-30.478509903-30.1737308502-29.8689403534$ -29.2593708038 -28.6497993469 -27.7354507446 -26.8210906982 -25.6019496918 -24.0780296326 -22.2493095398 -20.4206008911 -18.5918903351 -16.1536102295 -13.7153301239 -11.2770500183 -8.83876895905 -6.095703125 -3.35263609886 -.609570324421 2.743066072464 6.705273151398 11.27705001831 15.84883022308 20.1158199310324 .0780296325728 .0402297973631 .3928699493431 .39286994934 31.3928699493431 .0880794525131 .0880794525130 .7833003997830 .47850990295 30.4785099029530 .4785099029530 .4785099029530 .7833003997830 .78330039978 30.4785099029530 .1737308502229 .5641593933128 .6497993469228 .04022979736 27.430660247827 .7354507446328 .34502029419 -9999 -9999 -9999 -9999 -9999 -9999 -9999 
-9999 -9999 -9999 -9999 -9999 -9999 -9999 -9999 -9999 -9999 -9999 -9999 -9999 -9999 -9999 -9999 -9999 -9999 -9999 -9999 -9999 -9999 -9999 -9999 -9999 -9999 -9999 -9999 -9999 -9999 -

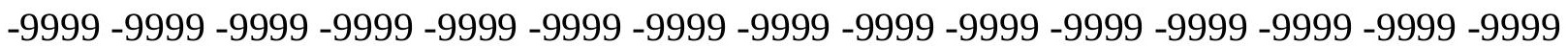
-9999 -9999 -9999 -9999 -9999 -9999 -9999 -9999 -9999 -9999 -9999 -9999 -9999 -9999 -9999 $-9999$

-9999 -9999 -9999 -9999 -9999 -9999 -9999 -9999 -9999 -9999 -9999 -9999 -9999 -9999 -9999 -9999 -9999 -9999 -9999 -9999 -9999 -9999 -9999 -9999 -9999 -9999 -9999 -9999 -9999 -9999 -9999 -9999 -9999 -9999 -9999 -9999 -9999 -9999 -9999 -9999 -9999 -9999 -9999 -9999 -9999 -9999 -9999 -9999 -9999 -9999 -9999 -9999 -9999 -9999 -9999 -9999 -9999 -9999 -9999 -9999 -9999 -9999 -9999 -9999 -9999 -9999 -9999 -9999 -9999 -9999 -9999 -9999 -9999 -9999 -9999

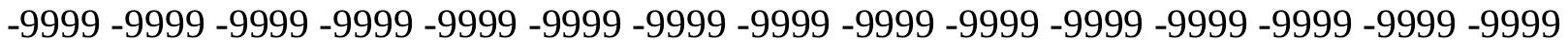
-9999 -9999 -9999 -9999 -9999 -9999 -9999 -9999 -9999 -9999 -9999 -9999 -9999 -9999 -9999 -9999 -9999 -9999 -9999 -9999 -9999 -9999 -9999 -9999 -9999 -9999 -9999 -9999 -9999 -9999 -9999 -9999 -9999 -9999 -9999 -9999 -9999 -9999 -9999 -9999 -9999 -9999 -9999 -9999 -9999 -9999 -9999 -9999 -9999 -9999 -9999 -9999 -9999 -9999 -9999 -9999 -9999 -9999 -9999 -9999 -9999-9999 142.0299072266139.8963928223 131.1245574951 130.0255889893 129.0173339844128 .1576385498127 .5023193359127 .2738723755126 .7906036377 127.7050018311130 .7528076172137 .4580993652130 .7528076172126 .4858016968 123.43800354120 .9997024536118 .2565994263115 .818397522113 .6848983765 111.8561019897110 .3321990967108 .8082962036107 .2844009399105 .7603988647 104.5412979126103 .0174026489101 .493400573799 .9695205688598 .4455871582 96.6168823242295 .0929565429793 .5690307617292 .349891662691 .43553924561 92.6546783447392 .6546783447392 .9594726562592 .9594726562592 .65467834473 92.6546783447392 .6546783447392 .6546783447392 .6546783447392 .95947265625 93.8738174438594 .4833908081195 .397743225196 .0073165893696 .61688232422 96.6168823242296 .3121032714895 .0929565429792 .9594726562589 .91161346436 86.254188537681 .9871978759877 .7202072143673 .7580032348670 .10057830811 66.7479400634863 .3953094482460 .6522407531757 .909179687555 .16611099243 52.4230384826749 .9847602844247 .5464782714845 .4129791259843 .58427047729 41.7555618286140 .2316398620638 .7077102661136 .8790016174335 .05028915405 32.3072204589828 .6497993469224 .0780296325718 .28710937511 .88661956787 4.266992092133 -3.96220707893 -13.1057596207 -23.1636695862 -32.9167900085 $-41.1459884644-46.0225486755-48.4608306885-49.3751907349-49.6799812317$ $-49.3751907349-48.4608306885-47.2416992188-45.7177696228-44.4986305237$ $-43.2794914246-42.0603485107-41.4507789612-40.8412094116-40.5364189148$ $-39.9268493652-39.3172798157-38.7077102661-37.7933502197-36.8790016174$ $-35.6598587036-34.4407196045-33.2215805054-32.307220459-31.0880794525$ $-30.1737308502-29.8689403534-29.5641593933-29.2593708038-29.2593708038$ $-29.2593708038-29.5641593933-29.5641593933-29.8689403534-30.1737308502$ $-30.1737308502-30.1737308502-30.478509903-30.478509903-30.1737308502$ -29.8689403534 -29.5641593933 -28.9545898438 -28.3450202942 -27.4306602478 $-26.2115192413-24.9923801422-23.4684505463-21.9445304871-20.115819931$ -17.9823207855 -15.5440397263 -13.1057596207 -10.6674804688 -7.92441320419 $-5.79091691971-3.65742206573-1.219141006471 .5239260196695 .181346893311$ 9.14355373382613 .1057596206717 .0679702758820 .7253894805924 .38281059265 27.430660247829 .2593708038330 .4785099029531 .0880794525131 .39286994934 
31.0880794525130 .7833003997830 .4785099029530 .4785099029530 .47850990295 30.4785099029530 .4785099029530 .1737308502229 .8689403533929 .25937080383 28.6497993469228 .0402297973627 .430660247827 .1258792877227 .73545074463 -9999 -9999 -9999 -9999 -9999 -9999 -9999 -9999 -9999 -9999 -9999 -9999 -9999 -9999 -9999 -9999 -9999 -9999 -9999 -9999 -9999 -9999 -9999 -9999 -9999-9999 -9999 -9999 -9999 -9999 -9999 -9999 -9999 -9999 -9999 -9999 -9999 -9999 -9999 -9999 -9999 -9999 -9999 -9999 -9999 -9999

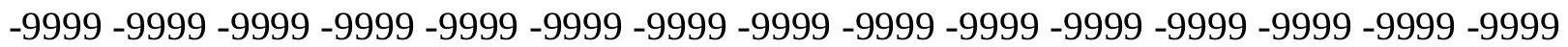
-9999 -9999 -9999 -9999 -9999 -9999-9999

-9999 -9999 -9999 -9999 -9999 -9999 -9999 -9999 -9999 -9999 -9999 -9999 -9999 -9999 -9999 -9999 -9999 -9999 -9999 -9999 -9999 -9999 -9999 -9999 -9999 -9999 -9999 -9999 -9999 -9999

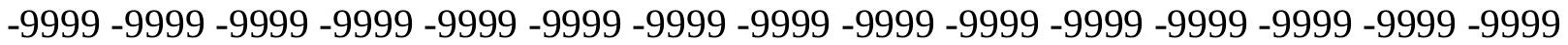
-9999 -9999 -9999 -9999 -9999 -9999 -9999 -9999 -9999 -9999 -9999 -9999 -9999 -9999 -9999 -9999 -9999 -9999 -9999 -9999 -9999 -9999 -9999 -9999 -9999 -9999 -9999 -9999 -9999 -9999 -9999 -9999 -9999 -9999 -9999 -9999 -9999 -9999 -9999 -9999 -9999 -9999 -9999 -9999 - 9999 -9999 -9999 -9999 -9999 -9999 -9999 -9999 -9999 -9999 -9999 -9999 -9999 -9999 -9999 -9999

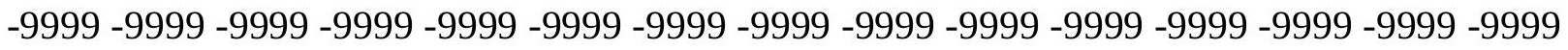
-9999 -9999 -9999 -9999 -9999 -9999 -9999 -9999 -9999 -9999 -9999 -9999 -9999 -9999 -9999 -9999 -9999 -9999 -9999 -9999 -9999 -9999 -9999 -9999 -9999 -9999 -9999 -9999 -9999 -9999 -9999 -9999 -9999 -9999 -9999 -9999 141.1154937744 131.21484375 130.6932983398 130.4714508057130 .6511383057131 .6492919922129 .8385009766128 .6192932129 129.533706665127 .0953979492125 .5715026855123 .43800354120 .6949005127 118.5614013672116 .4279022217114 .5991973877112 .7705001831110 .9418029785 109.1130981445107 .2844009399105 .4557037354103 .9317016602102 .1029968262 100.274299621698 .445587158296 .6168823242294 .4833908081192 .95947265625 91.4355392456191 .7403335571391 .7403335571391 .7403335571392 .04509735107 92.04509735107 92.0450973510792.349891662692.349891662692.3498916626 92.349891662692 .9594726562593 .5690307617294 .1785964965895 .09295654297 95.7025299072396 .6168823242296 .9216690063596 .6168823242295 .3977432251 93.2642517089890 .2164001464886 .5589828491282 .5967712402378 .32978057861 74.6723632812571 .014930725167 .9670867919964 .9192428588962 .48094940186 60.0426712036157 .2995986938554 .8613204956152 .4230384826749 .98476028442 48.1560516357446 .3273391723644 .8034095764243 .5842704772942 .36513137817 41.1459884643639 .622070312537 .4885711669934 .7455101013230 .78330039978 $25.906740188620 .4206008911114 .020119667056 .095703125-2.43828105927$ -12.4961900711 -24.0780296326 -35.6598587036 -40.5364189148-43.8890609741 $-46.3273391724-47.5464782715-47.8512611389-47.5464782715-46.6321296692$ $-45.412979126-44.1938400269-42.9747009277-42.3651313782-41.7555618286$ $-41.4507789612-41.1459884644-40.5364189148-39.9268493652-39.3172798157$ -38.4029312134 -37.488571167 -36.2694282532 -35.3550796509 -33.8311500549 -32.6120109558 -31.6976509094 -30.7833003998 -30.1737308502 -29.5641593933 -29.5641593933 -29.2593708038 -29.5641593933 -29.5641593933 -29.5641593933 $-29.8689403534-29.8689403534-30.1737308502-30.1737308502-30.1737308502$ $-30.1737308502-29.8689403534-29.5641593933-29.2593708038-28.6497993469$ -28.0402297974 -27.1258792877 -25.9067401886 -24.6875991821 -23.1636695862 $-21.3349609375-19.5062503815-17.3727493286-15.2392597198-12.8009700775$ $-10.0579099655-7.3148431778-5.79091691971-3.65742206573-1.82871103287$ 
.30478510260583 .6574220657357 .01005792617810 .3626899719213 .41055011749 16.4584007263219 .811029434222 .5541000366225 .2971591949527 .73545074463 29.8689403533930 .1737308502230 .1737308502230 .4785099029530 .17373085022 30.1737308502230 .1737308502230 .1737308502230 .1737308502229 .86894035339 29.5641593933128 .9545898437528 .3450202941928 .0402297973627 .4306602478 26.8210906982427 .1258792877227 .73545074463 -9999 -9999 -9999 -9999 -9999 -9999 -9999 -9999 -9999 -9999 -9999 -9999 -9999 -9999 -9999 -9999 -9999 -9999 -9999 -9999 -9999 -9999

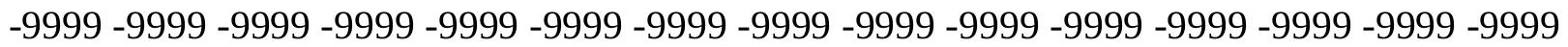

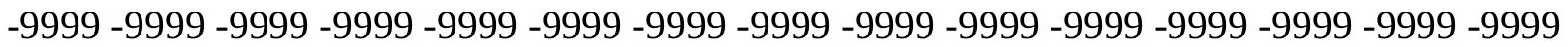
-9999 -9999 -9999 -9999 -9999 -9999 -9999 -9999 -9999 -9999 -9999 -9999 -9999 -9999 -9999 -9999 -9999 -9999 -9999 -9999 -9999 -9999 -9999 -9999 -9999 -9999 -9999 -9999 -9999 -9999 -999 -9999 -9999 -9999 -9999 -9999 -9999 -9999 -9999 -9999 -9999 -9999 -9999 -9999 -9999 -9999 -9999 -9999 -9999 -9999 -9999 -9999 -9999 -9999 -9999 -9999 -9999 -9999 -9999 -9999 -9999 -9999 -9999 -9999 -9999 -9999 -9999 -9999 -9999 -9999 -9999 -9999 -9999 -9999 -9999 -9999 -9999 -9999 -9999 -9999 -9999 -9999 -9999 -9999 -9999 -9999 -9999 -9999 -9999 -9999 -9999

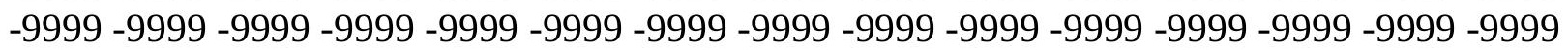

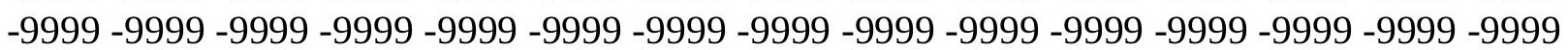
-9999 -9999 -9999 -9999 -9999 -9999 -9999 -9999 -9999 -9999 -9999 -9999 -9999 -9999 -9999 -999 -9999 -9999 -9999 -9999 -9999 -9999 -9999 -9999 -9999 -9999 -9999 -9999 -9999 -9999 -9999 -9999 -9999 -9999 -9999 -9999 -9999 -9999 -9999 -9999 -9999 -9999 -9999 -9999 -9999 -9999 -9999 -9999 -9999 -9999 -9999 -9999 -9999 -9999 -9999 -9999 141.4203033447 134.5106964111134 .9783630371133 .8882904053131 .6600799561129 .4342651367 127.8540420532126 .1809997559123 .7427978516121 .9140014648120 .0852966309 117.9517974854116 .1231002808113 .9896011353111 .551399231109 .7226028442 107.5891036987105 .4557037354103 .3221969604101 .493400573799 .05516815186 96.6168823242294 .4833908081192 .6546783447391 .1307525634891 .43553924561 91.4355392456191 .4355392456191 .4355392456191 .7403335571392 .04509735107 92.349891662692 .349891662692 .349891662692 .349891662692 .65467834473 92.9594726562593 .5690307617294 .1785964965894 .7881774902395 .70252990723 96.3121032714896 .3121032714895 .0929565429792 .6546783447389 .60682678223 85.9494018554781 .9871978759878 .0249862670974 .3675689697371 .31971740723 68.2718734741265 .8335876464863 .7000885009861 .5666007995658 .82352828979 56.3852500915554 .2517509460452 .1182594299349 .9847602844248 .46083068848 47.2416992187546 .0225486755445 .1082000732444 .1938400268643 .27949142456 42.0603485107439 .9268493652337 .4885711669933 .8311500549328 .95458984375 $22.8588790893615 .544039726267 .010057926178-1.52392601967-14.3248996735$ -25.6019496918 -33.2215805054-38.4029312134-42.0603485107-44.4986305237 $-45.7177696228-46.0225486755-45.7177696228-44.8034095764-43.5842704773$ $-42.669921875-42.0603485107-41.7555618286-41.7555618286-41.4507789612$ $-41.1459884644-40.5364189148$-39.9268493652 -39.0125007629 -38.0981407166 $-37.1837806702-35.9646492004-34.7455101013-33.2215805054-32.0024414062$ $-31.0880794525-30.1737308502-29.8689403534-29.5641593933-29.5641593933$ $-29.5641593933-29.5641593933-29.5641593933-29.5641593933-29.8689403534$ -29.8689403534 -29.8689403534-29.8689403534 -29.8689403534-29.5641593933 $-29.2593708038-28.9545898438-28.3450202942-27.4306602478-26.5163097382$ $-25.6019496918-24.0780296326-22.8588790894-21.0301704407-19.2014598846$ 
-17.0679702759 -14.9344701767 -12.4961900711 -10.0579099655 -7.92441320419 -5.79091691971 -4.26699209213 -2.13349604607 -9999 2.133496046066 4.87656211853 7.61962795257610 .0579099655212 .191410064714 .3248996734617 .06797027588 20.1158199310323 .1636695861825 .2971591949526 .8210906982427 .73545074463 28.6497993469228 .9545898437529 .5641593933129 .5641593933129 .56415939331 29.2593708038329 .2593708038328 .9545898437528 .6497993469228 .34502029419 27.7354507446327 .430660247826 .8210906982426 .5163097381627 .12587928772 -9999 -9999 -9999 -9999 -9999 -9999 -9999 -9999 -9999 -9999 -9999 -9999 -9999 -9999 -9999 -9999 -9999 -9999 -9999 -9999 -9999 -9999 -9999 -9999 -9999 -9999 -9999 -9999 -9999 -9999 -9999 -9999 -9999 -9999 -9999 -9999 -9999 -9999 -9999 -9999 -9999 -9999 -9999 -9999 -9999 -9999 -

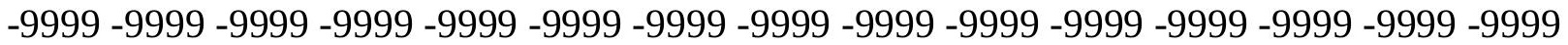
-9999 -9999 -9999-9999-9999-9999

-9999 -9999 -9999 -9999 -9999 -9999 -9999 -9999 -9999 -9999 -9999 -9999 -9999 -9999 -9999 -9999 -9999 -9999 -9999 -9999 -9999 -9999 -9999 -9999 -9999 -9999 -9999 -9999 -9999 -9999 -9999 -9999 -9999 -9999 -9999 -9999 -9999 -9999 -9999 -9999 -9999 -9999 -9999 -9999 -9999

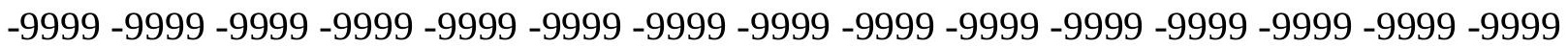

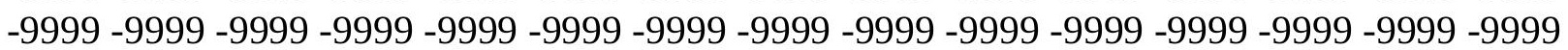
-9999 -9999 -9999 -9999 -9999 -9999 -9999 -9999 -9999 -9999 -9999 -9999 -9999 -9999 -9999 -999 -9999 -9999 -9999 -9999 -9999 -9999 -9999 -9999 -9999 -9999 -9999 -9999 -9999 -9999 -9999 -9999 -9999 -9999 -9999 -9999 -9999 -9999 -9999 -9999 -9999 -9999 -9999 -9999 -9999 -9999 -9999 -9999 -9999 -9999 -9999 -9999 -9999 -9999 -9999 -9999 -9999 -9999 -9999 -9999 -9999 -9999 -9999 -9999 -9999 -9999 -9999 -9999 -9999 -9999 -9999 -9999 -9999 -9999 -9999 -9999 -9999 -9999 -9999 -9999 -9999 -9999 -9999 -9999 -9999 -9999 -9999 -9999 -9999 -9999 -9999 -9999 -9999 -9999 -9999 -9999 -9999 -9999 121.6092987061118 .8662033081116 .1231002808 113.6848983765111 .24659729108 .5035018921106 .0652008057103 .3221969604 100.579101562597 .8360290527395 .0929565429793 .2642517089891 .74033355713 91.4355392456191 .4355392456191 .4355392456192 .349891662692 .95947265625 93.2642517089893 .2642517089892 .9594726562592 .6546783447392 .3498916626 92.349891662692 .349891662692 .6546783447392 .9594726562593 .56903076172 94.17859649658 94.7881774902395.397743225193.8738174438591.74033355713 88.3876876831184 .7302627563580 .7680587768677 .110626220773 .75800323486 70.7101516723668 .2718734741266 .1383666992264 .004882812562 .17617034912 60.0426712036157 .6043891906755 .1661109924353 .0326118469251 .20389938354 49.6799812316948 .4608306884847 .5464782714846 .9369087219246 .63212966919 46.0225486755445 .4129791259844 .4986305236842 .9747009277340 .53641891479 36.8790016174331 .0880794525123 .7732391357414 .629690170294 .87656211853 -5.79091691971 -16.1536102295 -24.9923801422 -31.6976509094-36.8790016174 $-40.5364189148-42.9747009277-43.8890609741-44.1938400269-43.5842704773$ -42.669921875 -41.7555618286 -41.7555618286-41.7555618286-41.7555618286 $-41.7555618286-41.4507789612-41.1459884644-40.5364189148-39.6220703125$ -38.7077102661 -37.488571167 -36.5742111206 -35.0502891541 -33.8311500549 -32.6120109558 -31.3928699493 -30.478509903 -29.8689403534-29.8689403534 -29.5641593933 -29.5641593933 -29.5641593933 -29.5641593933 -29.5641593933 -29.5641593933 -29.5641593933 -29.5641593933 -29.5641593933 -29.2593708038 -29.2593708038 -28.9545898438 -28.3450202942 -27.7354507446 -27.1258792877 $-26.2115192413-24.9923801422-23.7732391357-22.2493095398-20.7253894806$ 
-18.8966808319 -16.7631797791 -14.9344701767 -12.4961900711 -10.3626899719 $-8.22919845581-6.40048694611-4.57177686691-2.74306607246-.609570324421$ 1.219141006473 .3526360988625 .1813468933117 .0100579261788 .229198455811 9.14355373382611 .8866195678714 .934470176717 .6775398254420 .11581993103 22.2493095397924 .0780296325725 .6019496917726 .8210906982428 .04022979736 28.3450202941928 .3450202941928 .3450202941928 .3450202941928 .34502029419 28.3450202941928 .0402297973627 .7354507446327 .430660247826 .82109069824 26.2115192413326 .82109069824 -9999 -9999 -9999 -9999 -9999 -9999 -9999 -9999 -9999

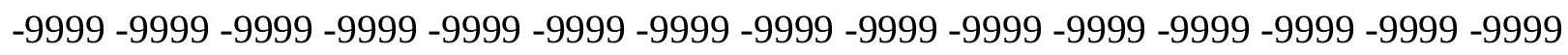
-9999 -9999 -9999 -9999 -9999 -9999 -9999 -9999 -9999 -9999 -9999 -9999 -9999 -9999 -9999

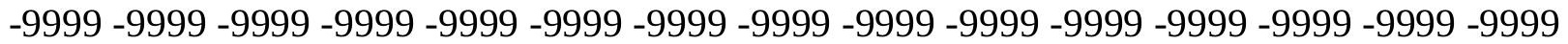
-9999 -9999 -9999 -9999 -9999 -9999 -9999 -9999 -9999 -9999 -9999 -9999 -9999 -

-9999 -9999 -9999 -9999 -9999 -9999 -9999 -9999 -9999 -9999 -9999 -9999 -9999 -9999 -9999 -9999 -9999 -9999 -9999 -9999 -9999 -9999 -9999 -9999 -9999 -9999 -9999 -9999 -9999 -9999 -9999 -9999 -9999 -9999 -9999 -9999 -9999 -9999 -9999 -9999 -9999 -9999 -9999 -9999 -9999

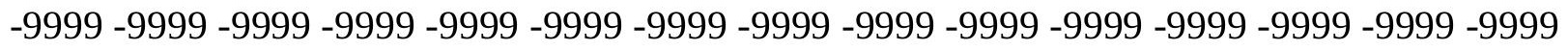

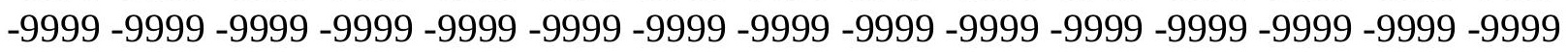

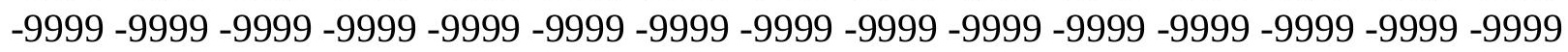

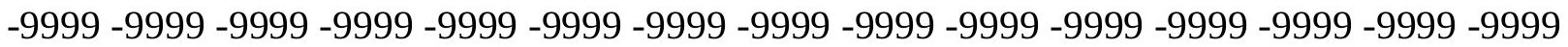

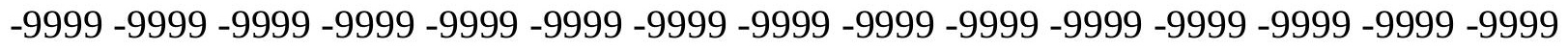

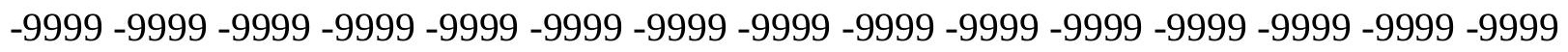

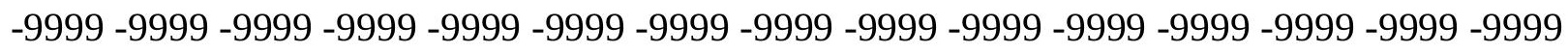
-9999 -9999 -9999 -9999 -9999 -9999 -9999 -9999 -9999 -9999 -9999 -9999 -9999 -9999 -9999 -

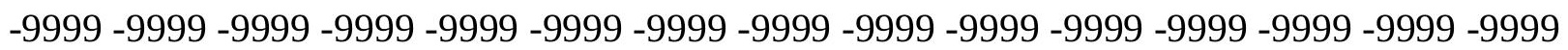
103.3221969604 100.274299621697.2264633178794.1785964965891.74033355713 91.4355392456191 .7403335571392 .6546783447393 .5690307617294 .17859649658 94.4833908081194 .1785964965893 .5690307617292 .9594726562592 .3498916626 92.0450973510791 .7403335571391 .7403335571391 .7403335571392 .04509735107 92.0450973510792 .6546783447392 .349891662691 .4355392456189 .3020401001 86.254188537682 .5967712402378 .9393463134875 .2819290161172 .23407745361 69.4910125732467 .3575134277365 .5288009643664 .004882812562 .17617034912 60.3474502563557 .909179687555 .7756805419953 .6421813964851 .81346893311 50.2895507812549 .0704002380448 .4608306884847 .8512611389247 .85126113892 47.8512611389247 .5464782714847 .5464782714846 .9369087219245 .7177696228 43.5842704772938 .4029312133829 .5641593933120 .4206008911110 .66748046875 $1.21914100647-8.22919845581-16.7631797791-24.0780296326-30.7833003998$ -35.9646492004 -39.3172798157-41.1459884644 -42.3651313782-42.3651313782 $-41.7555618286-40.8412094116-41.4507789612-41.7555618286-42.0603485107$ $-42.0603485107-42.0603485107-41.4507789612-40.8412094116-39.9268493652$ -39.0125007629 -38.0981407166 -36.8790016174 -35.6598587036 -34.4407196045 $-33.2215805054-32.0024414062-30.7833003998-30.1737308502-29.8689403534$ $-29.8689403534-29.5641593933-29.5641593933-29.5641593933-29.5641593933$ $-29.2593708038-29.2593708038-29.2593708038-29.2593708038-28.9545898438$ $-28.6497993469-28.3450202942-28.0402297974-27.4306602478-26.5163097382$ $-25.6019496918-24.6875991821-23.4684505463-21.9445304871-20.4206008911$ $-18.5918903351-16.7631797791-14.6296901703-12.8009700775-10.6674804688$ 
-8.53398323059 -6.7052731514 -4.87656211853 -3.04785108566 -1.21914100647 .3047851026058 2.1334960460663.657422065735 4.571776866913 5.486132144928 6.0957031257 .6196279525769 .75312423706112 .191410064714 .62969017029 17.3727493286119 .811029434221 .9445304870624 .0780296325725 .29715919495 26.2115192413326 .8210906982427 .1258792877227 .430660247827 .73545074463 27.7354507446327 .7354507446327 .7354507446327 .1258792877226 .82109069824 26.2115192413326 .2115192413327 .12587928772 -9999 -9999 -9999 -9999 -9999 -9999 -9999 -9999 -9999 -9999 -9999 -9999 -9999 -9999 -9999 -9999 -9999 -9999 -9999 -9999 -9999 -9999

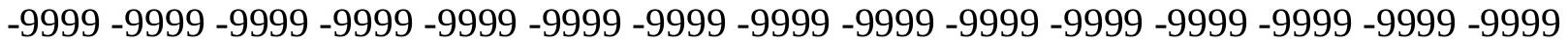
-9999 -9999 -9999 -9999 -9999 -9999 -9999 -9999 -9999 -9999 -9999 -9999 -9999 -9999 -9999 -9999 -9999 -9999 -9999 -9999 -9999 -9999 -9999 -9999 -9999 -9999 -9999 -9999 -9999 -9999 -9999 -9999 -9999 -9999 -9999 -9999 -9999 -9999 -9999 -9999 -9999 -9999 -9999 -9999 -9999 -9999 -9999 -9999 -9999 -9999 -9999 -9999 -9999 -9999 -9999 -9999 -9999 -9999 -9999 -9999 -9999 -9999 -9999 -9999 -9999 -9999 -9999 -9999 -9999 -9999 -9999 -9999 -9999 - 9999 -9999 -9999 -9999 -9999 -9999 -9999 -9999 -9999 -9999 -9999 -9999 -9999 -9999 -9999 -9999

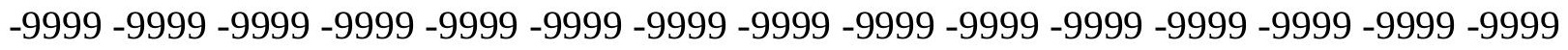
-9999 -9999 -9999 -9999 -9999 -9999 -9999 -9999 -9999 -9999 -9999 -9999 -9999 -9999 -9999 -9999 -9999 -9999 -9999 -9999 -9999 -9999 -9999 -9999 -9999 -9999 -9999 -9999 -9999 -9999 -9999 -9999 -9999 -9999 -9999 -9999 -9999 -9999 -9999 -9999 -9999 -9999 -9999 -9999 -9999 -

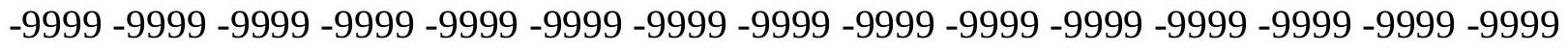

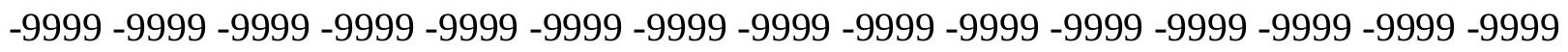
-9999 -9999 -9999 -9999 -9999 -9999 -9999 -9999 -9999 -9999 -9999 -9999 -9999 -9999 -9999 -9999 -9999 -9999 -9999 -9999 -9999 -9999 -9999 -9999 -9999 -9999 -9999 -9999 -9999 -9999 -9999-9999 100.2742996216 96.61688232422 93.8738174438593.87381744385 94.7881774902394 .7881774902395 .397743225195 .7025299072395 .70252990723 95.397743225194 .4833908081193 .5690307617292 .349891662691 .74033355713 91.1307525634890 .8259735107490 .5211791992290 .5211791992290 .21640014648 90.2164001464889 .6068267822388 .6924667358486 .5589828491283 .81591033936 80.4632720947376 .8058471679773 .1484298706170 .1005783081167 .66230010986 65.8335876464864 .3096618652363 .3953094482461 .8713798522960 .04267120361 57.6043891906755 .4708900451753 .3373985290551 .5086898803749 .98476028442 48.765621185348 .1560516357447 .8512611389247 .8512611389248 .15605163574 48.4608306884848 .765621185348 .765621185348 .4608306884847 .24169921875 44.4986305236832 .6120109558124 .3828105926515 .848830223087 .314843177795 -.609570324421 -8.53398323059-15.8488302231 -22.8588790894 -30.1737308502 -33.8311500549 -37.1837806702 -39.6220703125 -41.1459884644-41.4507789612 $-41.1459884644-41.4507789612-42.0603485107-42.3651313782-42.3651313782$ $-42.0603485107-41.4507789612-40.8412094116-40.2316398621-39.3172798157$ -38.4029312134 -37.1837806702 -36.2694282532 -35.0502891541 -33.5263595581 $-32.307220459-31.3928699493-30.7833003998-30.1737308502-29.8689403534$ $-29.5641593933-29.5641593933-29.2593708038-29.2593708038-29.2593708038$ -28.9545898438 -28.9545898438 -28.6497993469-28.6497993469 -28.3450202942 $-28.0402297974-27.4306602478-26.8210906982-26.2115192413-25.2971591949$ -24.0780296326 -22.8588790894 -21.6397399902 -20.115819931 -18.287109375 $-16.4584007263-14.6296901703-12.8009700775-10.9722604752-8.83876895905$ -7.01005792618 -5.18134689331 -3.35263609886-1.82871103287 -9999 1.21914100647 
2.7430660724643 .3526360988623 .6574220657353 .9622070789344 .571776866913 5.4861321449287 .0100579261789 .75312423706112 .8009700775115 .84883022308 18.5918903350820 .7253894805922 .5541000366224 .0780296325724 .99238014221 25.906740188626 .5163097381626 .8210906982427 .430660247827 .4306602478 27.430660247827 .1258792877226 .5163097381626 .2115192413325 .9067401886 26.82109069824 -9999 -9999 -9999 -9999 -9999 -9999 -9999 -9999 -9999 -9999 -9999 -9999

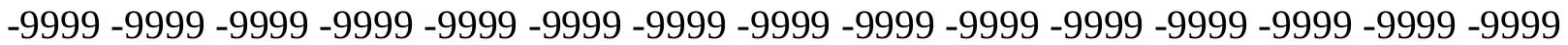

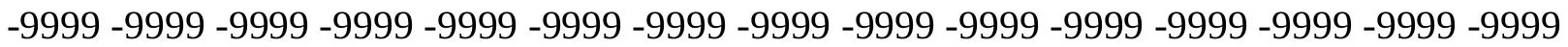

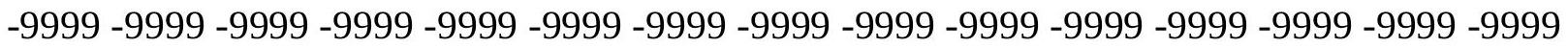
-9999 -9999 -9999 -9999 -9999 -9999 -9999 -9999 -9999

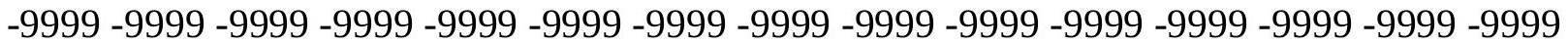

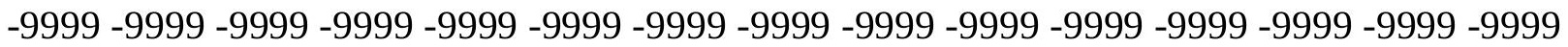

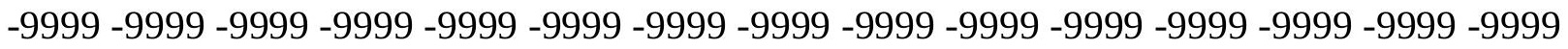

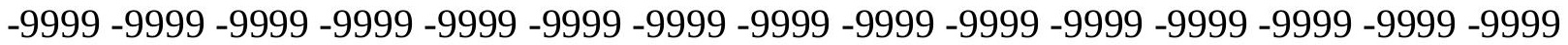

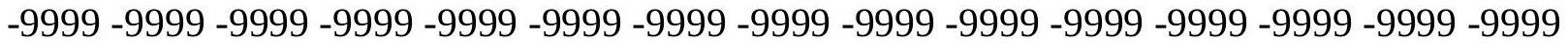

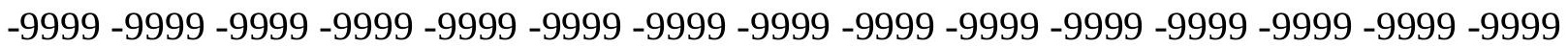

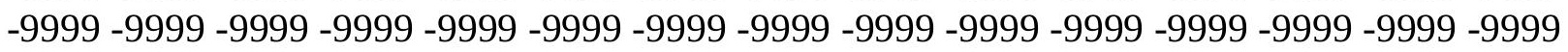

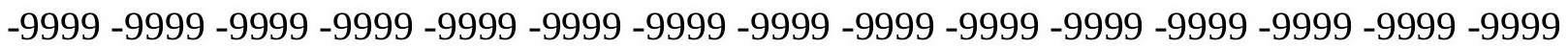

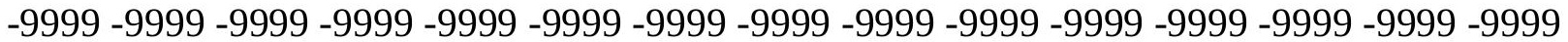

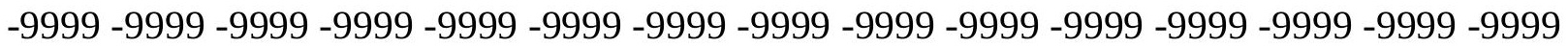

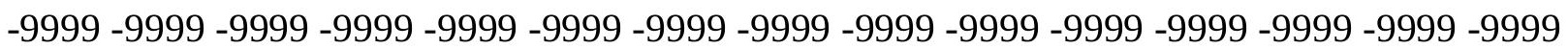

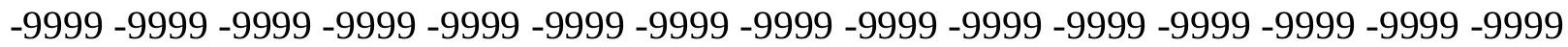
-9999 -9999 -9999 -9999 -9999 99.05516815186 99.35994720459 99.05516815186 98.1408081054797 .5312423706197 .2264633178796 .3121032714895 .3977432251 93.8738174438592 .349891662691 .1307525634890 .2164001464889 .91161346436 89.60682678223 89.3020401001 88.6924667358488.3876876831187.47332763672 85.9494018554784 .1206970214881 .3776321411178 .0249862670974 .67236328125 71.014930725167 .6623001098665 .2240066528363 .7000885009862 .78573989868 62.1761703491261 .2618103027359 .1283111572356 .6900291442954 .55654144287 52.4230384826750 .5943298339849 .0704002380447 .8512611389246 .93690872192 46.6321296691946 .6321296691946 .9369087219247 .2416992187547 .85126113892 48.1560516357448 .1560516357446 .9369087219242 .9747009277335 .65985870361 $27.7354507446320 .1158199310312 .800970077515 .790916919708-.609570324421$ $-7.01005792618-13.1057596207-19.8110294342-26.2115192413-32.0024414062$ $-36.5742111206-39.3172798157-40.5364189148-40.8412094116-41.1459884644$ $-41.7555618286-42.0603485107-42.0603485107-41.7555618286-41.4507789612$ $-40.8412094116-39.9268493652-39.3172798157-38.4029312134-37.488571167$ -36.2694282532 -35.3550796509 -34.1359291077 -32.9167900085 -32.0024414062 $-31.0880794525-30.478509903-30.1737308502-29.5641593933-29.2593708038$ $-29.2593708038-28.9545898438-28.6497993469-28.6497993469-28.6497993469$ $-28.3450202942-28.0402297974-27.7354507446-27.4306602478-26.8210906982$ $-26.2115192413-25.6019496918-24.6875991821-23.7732391357-22.5541000366$ $-21.3349609375-19.8110294342-18.287109375-16.4584007263-14.6296901703$ $-12.8009700775-10.9722604752-9.14355373383-7.3148431778-5.48613214493$ $-3.65742206573-2.13349604607-.609570324421 .91435539722442 .133496046066$ 2.7430660724642 .7430660724642 .4382810592652 .1334960460662 .133496046066 
2.7430660724645 .7909169197089 .14355373382612 .191410064715 .23925971985 17.6775398254420 .1158199310321 .9445304870623 .4684505462624 .38281059265 25.6019496917726 .2115192413326 .8210906982427 .1258792877227 .12587928772 $26.8210906982426 .5163097381626 .2115192413325 .906740188626 .51630973816-9999$ -9999 -9999 -9999 -9999 -9999 -9999 -9999 -9999 -9999 -9999 -9999 -9999 -9999 -9999 -9999 -9999 -9999 -9999 -9999 -9999 -9999 -9999 -9999 -9999 -9999 -9999 -9999 -9999 -9999 -9999 -9999 -9999 -9999 -9999 -9999 -9999 -9999 -9999 -9999 -9999 -9999 -9999 -9999 -9999 -9999

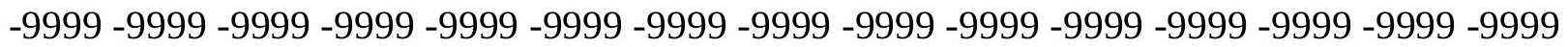
-9999 -9999-9999-9999-9999

-9999 -9999 -9999 -9999 -9999 -9999 -9999 -9999 -9999 -9999 -9999 -9999 -9999 -9999 -9999

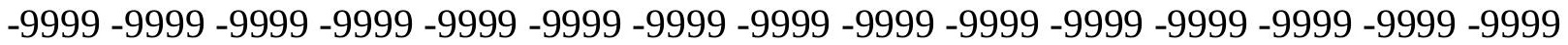
-9999 -9999 -9999 -9999 -9999 -9999 -9999 -9999 -9999 -9999 -9999 -9999 -9999 -9999 -9999 -9999 -9999 -9999 -9999 -9999 -9999 -9999 -9999 -9999 -9999 -9999 -9999 -9999 -9999 -9999 -9999 -9999 -9999 -9999 -9999 -9999 -9999 -9999 -9999 -9999 -9999 -9999 -9999 -9999 -9999 -9999 -9999 -9999 -9999 -9999 -9999 -9999 -9999 -9999 -9999 -9999 -9999 -9999 -9999 -9999

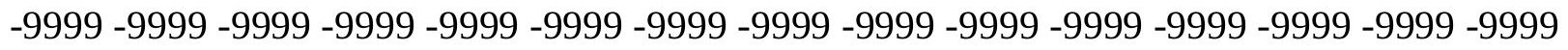
-9999 -9999 -9999 -9999 -9999 -9999 -9999 -9999 -9999 -9999 -9999 -9999 -9999 -9999 -9999 -

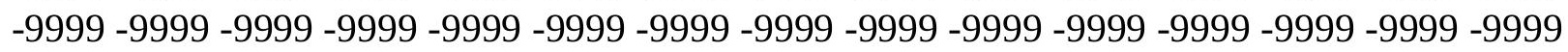

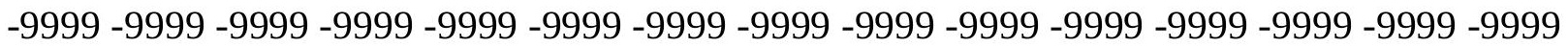

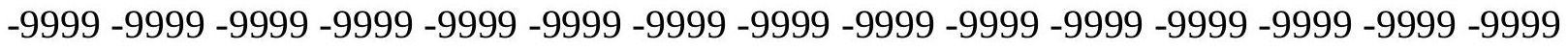

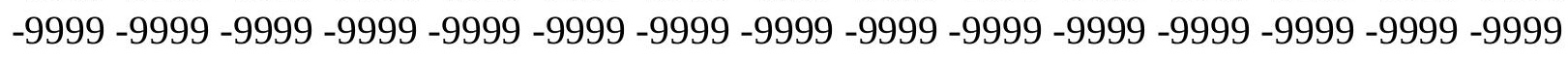
-9999 -9999 -9999 -9999-9999-9999-9999 103.9317016602102 .712600708100 .8839035034 98.7503814697397 .5312423706196 .0073165893694 .4833908081192 .3498916626 90.5211791992289 .6068267822388 .9972534179788 .6924667358488 .08290100098 87.4733276367286 .5589828491285 .6446228027383 .8159103393681 .68241119385 79.2441329956175 .8914871215872 .5388565063568 .8814392089865 .22400665283 62.7857398986861 .5666007995660 .9570198059160 .3474502563559 .12831115723 57.6043891906755 .4708900451753 .3373985290551 .2038993835449 .07040023804 47.5464782714846 .0225486755445 .1082000732444 .4986305236844 .49863052368 44.4986305236844 .8034095764245 .1082000732445 .4129791259845 .10820007324 43.8890609741240 .5364189147935 .6598587036129 .5641593933123 .46845054626 $17.3727493286111 .581830024726 .4004869461061 .523926019669-2.74306607246$ -8.53398323059 -17.0679702759-26.2115192413 -33.2215805054 -36.8790016174 $-38.4029312134-39.0125007629-39.9268493652-40.8412094116-41.4507789612$ $-41.4507789612-41.1459884644-40.8412094116-40.2316398621-39.6220703125$ -38.7077102661 -38.0981407166 -37.1837806702 -36.2694282532 -35.3550796509 $-34.1359291077-33.2215805054-32.307220459-31.3928699493-30.478509903$ -29.8689403534 -29.5641593933 -28.9545898438 -28.6497993469 -28.6497993469 $-28.3450202942-28.0402297974-28.0402297974-27.7354507446-27.4306602478$ $-27.4306602478-26.8210906982-26.5163097382-25.9067401886-24.9923801422$ -24.3828105927 -23.1636695862 -22.2493095398 -21.0301704407 -19.5062503815 -17.9823207855 -16.4584007263 -14.6296901703 -12.8009700775 -10.9722604752 $-9.44833946228-7.61962795258-5.79091691971-3.96220707893-2.43828105927$ -.609570324421.6095703244209 1.828711032867 2.743066072464 2.133496046066 1.523926019669 .9143553972244 .60957032442091 .5239260196693 .657422065735 6.4004869461069 .4483394622812 .4961900711115 .2392597198517 .67753982544 
19.811029434221 .6397399902323 .1636695861824 .3828105926525 .29715919495 26.2115192413326 .5163097381626 .8210906982426 .8210906982426 .51630973816 26.2115192413325 .906740188626 .21151924133 -9999 -9999 -9999 -9999 -9999 -9999 -9999 -9999 -9999 -9999 -9999 -9999 -9999 -9999 -9999 -9999 -9999 -9999 -9999 -9999 -9999 -9999 -9999 -9999 -9999 -9999 -9999 -9999 -9999 -9999 -9999-9999 -9999 -9999 -9999 -9999 -9999 -9999 -9999 -9999 -9999 -9999 -9999 -9999 -9999 -9999 -9999 -9999 -9999 -9999 -9999 -9999 -9999 -9999 -9999 -9999 -9999 -9999 -9999 -9999 -9999 -9999 -9999 -9999 -9999 -9999 -

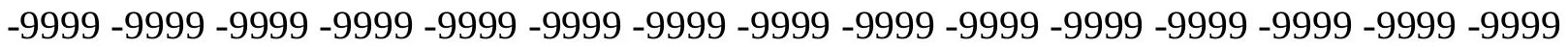

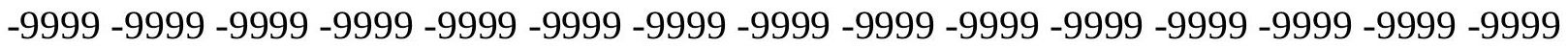
-9999 -9999 -9999 -9999 -9999 -9999 -9999 -9999 -9999 -9999 -9999 -9999 -9999 -9999 -9999

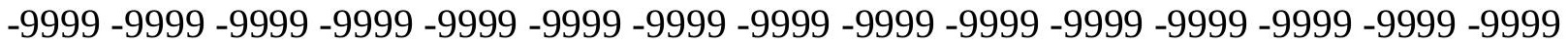
-9999 -9999 -9999 -9999 -9999 -9999 -9999 -9999 -9999 -9999 -9999 -9999 -9999 -9999 -9999 -9999 -9999 -9999 -9999 -9999 -9999 -9999 -9999 -9999 -9999 -9999 -9999 -9999 -9999 -9999 -9999 -9999 -9999 -9999 -9999 -9999 -9999 -9999 -9999 -9999 -9999 -9999 -9999 -9999 -9999 -9999 -9999 -9999 -9999 -9999 -9999 -9999 -9999 -9999 -9999 -9999 -9999 -9999 -9999 -9999

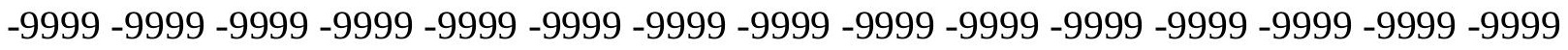

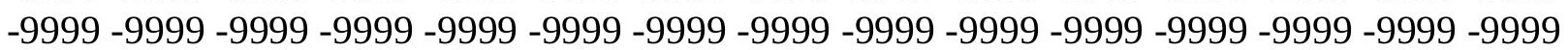
-9999 -9999 -9999 -9999 -9999 -9999 -9999 -9999 -9999 -9999 -9999 -9999 -9999 -9999 -9999 -999 -9999 -9999 -9999 -9999 -9999 -9999 -9999 -9999 -9999 -9999 -9999 -9999 -9999 -9999 -9999 -9999 -9999 -9999-9999 -9999 -9999 -9999-9999 -9999 105.1509017944 102.712600708 99.9695205688596 .9216690063595 .0929565429792 .6546783447390 .21640014648 89.6068267822388 .9972534179788 .0829010009887 .4733276367286 .55898284912 85.3398437584 .1206970214882 .2919769287180 .1584930419977 .41542053223 74.3675689697371 .014930725167 .3575134277363 .7000885009860 .34745025635 59.4331016540558 .8235282897958 .2139587402356 .9948196411155 .47089004517 53.6421813964851 .5086898803749 .3751907348647 .5464782714845 .7177696228 43.8890609741242 .66992187541 .7555618286141 .4507789611841 .14598846436 41.1459884643641 .1459884643641 .1459884643640 .8412094116239 .6220703125 37.7933502197334 .4407196044930 .1737308502225 .2971591949520 .42060089111 16.1536102294911 .886619567878 .5339832305915 .4861321449282 .133496046066 -8.53398323059 -19.8110294342 -29.8689403534 -32.6120109558 -34.1359291077 -35.6598587036 -37.1837806702 -38.7077102661 -39.6220703125 -40.2316398621 -39.9268493652 -39.6220703125 -39.0125007629-38.4029312134-38.0981407166 -37.488571167 -36.8790016174 -35.9646492004 -35.0502891541 -34.1359291077 -33.2215805054 -32.0024414062 -31.0880794525 -30.478509903 -29.5641593933 -29.2593708038 -28.6497993469 -28.3450202942 -28.0402297974 -27.7354507446 $-27.7354507446-27.4306602478-27.1258792877-26.8210906982-26.8210906982$ $-26.2115192413-25.9067401886-25.2971591949-24.6875991821-23.7732391357$ -22.8588790894 -21.6397399902 -20.4206008911 -19.2014598846-17.6775398254 -16.1536102295 -14.6296901703 -12.8009700775 -11.2770500183 -9.44833946228 -7.61962795258 -5.79091691971-4.26699209213 - 2.43828105927- -.914355397224 .30478510260581 .219141006471 .8287110328671 .523926019669 .9143553972244 .3047851026058.3047851026058 91435539722442.743066072464 4.87656211853 7.92441320419310 .6674804687513 .4105501174916 .1536102294918 .287109375 20.4206008911122 .2493095397923 .7732391357424 .6875991821325 .60194969177 26.2115192413326 .5163097381626 .8210906982426 .5163097381626 .21151924133 
25.906740188626 .2115192413326 .82109069824 -9999 -9999 -9999 -9999 -9999 -9999 -9999 -9999 -9999 -9999 -9999 -9999 -9999 -9999 -9999 -9999 -9999 -9999 -9999 -9999 -9999 -9999

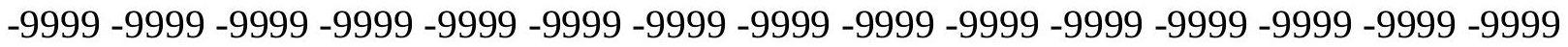
-9999 -9999 -9999 -9999 -9999 -9999 -9999 -9999 -9999 -9999 -9999 -9999 -9999 -9999 -9999 -9999 -9999 -9999 -9999 -9999 -9999 -9999 -9999 -9999 -9999 -9999 -9999 -9999 -9999 -9999 -9999 -9999 -9999 -9999 -9999 -9999 -9999 -9999 -9999 -9999 -9999 -9999 -9999

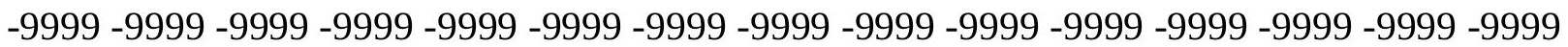

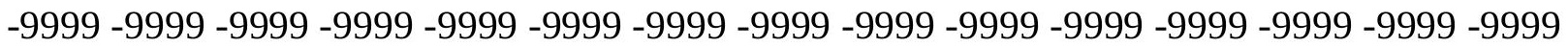
-9999 -9999 -9999 -9999 -9999 -9999 -9999 -9999 -9999 -9999 -9999 -9999 -9999 -9999 -9999 -9999 -9999 -9999 -9999 -9999 -9999 -9999 -9999 -9999 -9999 -9999 -9999 -9999 -9999 -9999 -

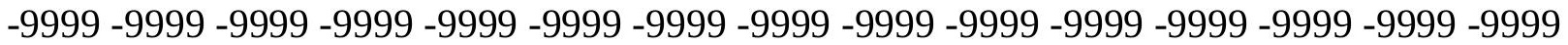

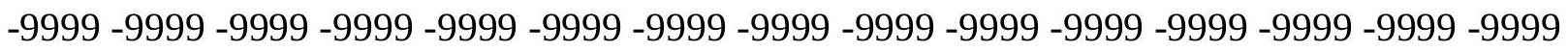
-9999 -9999 -9999 -9999 -9999 -9999 -9999 -9999 -9999 -9999 -9999 -9999 -9999 -9999 -9999 -9999 -9999 -9999 -9999 -9999 -9999 -9999 -9999 -9999 -9999 -9999 -9999 -9999 -9999 -9999 -9999 -9999 -9999 -9999 -9999 -9999 -9999 -9999 -9999 -9999 -9999 -9999 -9999 -9999 -9999

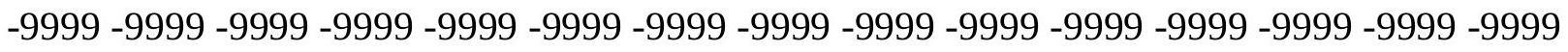
-9999 -9999 -9999 -9999 -9999 -9999 -9999 -9999 -9999 -9999 -9999 -9999 -9999 -9999 -9999 -9999 -9999 -9999 -9999 -9999 -9999 -9999 -9999 -9999 -9999 106.979598999 103.9317016602100 .579101562596 .9216690063593 .5690307617291 .74033355713 90.2164001464888 .9972534179788 .0829010009887 .1685485839885 .94940185547 84.7302627563583 .206336975181 .3776321411179 .2441329956176 .50106811523 73.7580032348670 .4053573608466 .7479400634863 .0905189514260 .34745025635 58.5187492370657 .6043891906756 .6900291442955 .4708900451753 .94697189331 52.1182594299349 .9847602844247 .8512611389245 .717769622843 .58427047729 41.7555618286139 .9268493652338 .7077102661137 .7933502197337 .48857116699 37.1837806701736 .8790016174336 .2694282531735 .6598587036135 .35507965088 34.4407196044932 .6120109558129 .8689403533926 .5163097381622 .55410003662 19.2014598846416 .1536102294913 .4105501174910 .362689971925 .181346893311 $-2.74306607246-12.4961900711-20.4206008911-25.2971591949-27.7354507446$ -29.8689403534 -32.307220459-35.0502891541 -37.1837806702 -37.7933502197 -37.7933502197 -37.488571167-37.1837806702 -36.8790016174 -36.5742111206 $-36.2694282532-35.6598587036-35.0502891541-34.4407196045-33.5263595581$ $-32.6120109558-31.6976509094-30.7833003998-29.8689403534-28.9545898438$ $-28.3450202942-28.0402297974-27.7354507446-27.4306602478-27.1258792877$ -26.8210906982 -26.8210906982 -26.5163097382 -26.2115192413 -25.9067401886 $-25.6019496918-25.2971591949-24.6875991821-24.0780296326-23.1636695862$ -22.2493095398 -21.3349609375 -20.115819931 -18.8966808319-17.3727493286 -16.1536102295 -14.3248996735 -12.8009700775 -11.2770500183 -9.44833946228 -7.61962795258 -6.095703125 -4.26699209213 -2.74306607246 -1.21914100647-9999 .6095703244209.9143553972244.9143553972244.6095703244209. 3047851026058 .3047851026058.91435539722442.4382810592654.2669920921337.010057926178 9.4483394622812 .191410064714 .934470176717 .3727493286119 .50625038147 21.334960937522 .8588790893624 .3828105926525 .2971591949526 .21151924133 26.5163097381626 .8210906982426 .8210906982426 .8210906982426 .82109069824 25.906740188626 .51630973816 -9999 -9999 -9999 -9999 -9999 -9999 -9999 -9999 -9999 -9999 -9999 -9999 -9999 -9999 -9999 -9999 -9999 -9999 -9999 -9999 -9999 -9999 -9999 -9999 
-9999 -9999 -9999 -9999 -9999 -9999 -9999 -9999 -9999 -9999 -9999 -9999 -9999 -9999 -9999 -9999 -9999 -9999 -9999 -9999 -9999 -9999 -9999 -9999 -9999 -9999 -9999 -9999 -9999 -9999 -9999 -9999 -9999 -9999 -9999 -9999 -9999 -9999 -9999 -9999 -9999

-9999 -9999 -9999 -9999 -9999 -9999 -9999 -9999 -9999 -9999 -9999 -9999 -9999 -9999 -9999 -9999 -9999 -9999 -9999 -9999 -9999 -9999 -9999 -9999 -9999 -9999 -9999 -9999 -9999 -9999 -9999 -9999 -9999 -9999 -9999 -9999 -9999 -9999 -9999 -9999 -9999 -9999 -9999 -9999 -9999 -9999 -9999 -9999 -9999 -9999 -9999 -9999 -9999 -9999 -9999 -9999 -9999 -9999 -9999 -9999

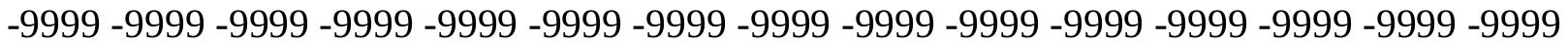
-9999 -9999 -9999 -9999 -9999 -9999 -9999 -9999 -9999 -9999 -9999 -9999 -9999 -9999 -9999 -9999 -9999 -9999 -9999 -9999 -9999 -9999 -9999 -9999 -9999 -9999 -9999 -9999 -9999 -9999 -9999 -9999 -9999 -9999 -9999 -9999 -9999 -9999 -9999 -9999 -9999 -9999 -9999 -9999 -9999 -9999 -9999 -9999 -9999 -9999 -9999 -9999 -9999 -9999 -9999 -9999 -9999 -9999 -9999 -9999

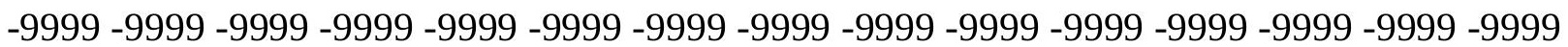
-9999 -9999 -9999 -9999 -9999 -9999 -9999 -9999 -9999 -9999 -9999 -9999 -9999 -9999 -9999 -9999 -9999 -9999 -9999 -9999 -9999 -9999 -9999 -9999 -9999 -9999 -9999 -9999 -9999 -9999 -9999 -9999 -9999 -9999 -9999 -9999 -9999 -9999 -9999 -9999 -9999 -9999 104.8460998535 101.188697814997.2264633178792.9594726562591.13075256348 89.60682678223 88.38768768311 87.16854858398 85.64462280273 84.12069702148 82.59677124023 80.7680587768678 .6345596313576 .1962814331173 .4532165527370 .40535736084 67.3575134277364 .004882812560 .9570198059158 .8235282897957 .29959869385 56.0804595947354 .8613204956153 .0326118469251 .2038993835449 .07040023804 46.6321296691944 .1938400268641 .7555618286139 .3172798156737 .18378067017 35.3550796508834 .1359291076733 .5263595581133 .2215805053732 .61201095581 31.6976509094230 .7833003997831 .0880794525131 .0880794525130 .47850990295 28.9545898437526 .5163097381623 .7732391357421 .0301704406718 .287109375 $15.8488302230812 .800970077517 .9244132041931 .523926019669-5.48613214493$ -11.8866195679 -16.4584007263 -19.5062503815 -22.2493095398 -25.2971591949 -29.2593708038 -33.2215805054 -33.8311500549 -34.1359291077 -34.1359291077 $-34.4407196045-34.4407196045-34.7455101013-34.4407196045-34.1359291077$ $-33.8311500549-33.2215805054-32.6120109558-31.6976509094-30.7833003998$ $-29.8689403534-28.9545898438-28.0402297974-27.4306602478-27.1258792877$ -26.8210906982 -26.5163097382 -26.2115192413 -25.9067401886 -25.9067401886 $-25.6019496918-25.6019496918-25.2971591949-24.9923801422-24.3828105927$ $-24.0780296326-23.4684505463-22.5541000366-21.6397399902-20.7253894806$ $-19.8110294342-18.5918903351-17.0679702759-15.8488302231-14.3248996735$ $-12.8009700775-10.9722604752-9.44833946228-7.61962795258-6.095703125$ -4.26699209213 -2.74306607246-1.21914100647-9999.3047851026058 .6095703244209 6095703244209. 3047851026058. 3047851026058.6095703244209 1.21914100647 2.4382810592654 .2669920921336 .7052731513989 .14355373382611 .58183002472 14.0201196670516 .4584007263218 .8966808319120 .7253894805922 .55410003662 24.0780296325724 .9923801422125 .906740188626 .8210906982427 .12587928772 27.430660247827 .430660247826 .8210906982425 .6019496917726 .21151924133 -9999 -9999 -9999 -9999 -9999 -9999 -9999 -9999 -9999 -9999 -9999 -9999 -9999 -9999 -9999 -9999 -9999 -9999 -9999 -9999 -9999 -9999 -9999 -9999 -9999 -9999 -9999 -9999 -9999 -9999 -9999 -9999 -9999 -9999 -9999 -9999 -9999 -9999 -9999 -9999 -9999 -9999 -9999 -9999 -9999 -9999 -9999

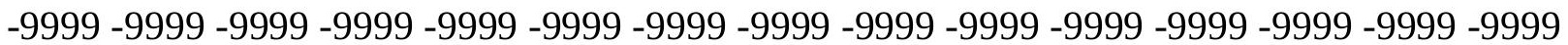


-9999 -9999 -9999

-9999 -9999 -9999 -9999 -9999 -9999 -9999 -9999 -9999 -9999 -9999 -9999 -9999 -9999 -9999

-9999 -9999 -9999 -9999 -9999 -9999 -9999 -9999 -9999 -9999 -9999 -9999 -9999 -9999 - 9999 -

-9999 -9999 -9999 -9999 -9999 -9999 -9999 -9999 -9999 -9999 -9999 -9999 -9999 -9999 -9999

-9999 -9999 -9999 -9999 -9999 -9999 -9999 -9999 -9999 -9999 -9999 -9999-9999 -9999 -9999 -

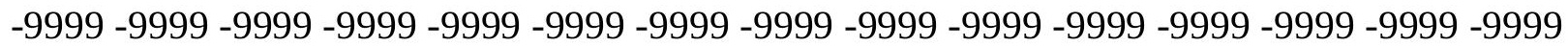

-9999 -9999 -9999 -9999 -9999 -9999 -9999 -9999 -9999 -9999 -9999 -9999 -9999 -9999 -9999

-9999 -9999 -9999 -9999 -9999 -9999 -9999 -9999 -9999 -9999 -9999 -9999 -9999 -9999 -9999

-9999 -9999 -9999 -9999 -9999 -9999 -9999 -9999 -9999 -9999 -9999 -9999 -9999 -9999 -9999

-9999 -9999 -9999 -9999 -9999 -9999 -9999 -9999 -9999 -9999 -9999 -9999 -9999 -9999 -9999 -

-9999 -9999 -9999 -9999 -9999 -9999 -9999 -9999 -9999 -9999 -9999 -9999 -9999 -9999 -9999

-9999 -9999 -9999 -9999 -9999 -9999 -9999 -9999 -9999 -9999 -9999 -9999 -9999 -9999 -9999

-9999 -9999 -9999 -9999 -9999 -9999 -9999 -9999 -9999 -9999 -9999 -9999 -9999 -9999 -9999 -

-9999 -9999 -9999 -9999 -9999 -9999 -9999 -9999 -9999 -9999 -9999 -9999 -9999 -9999 -

102.102996826298 .1408081054793 .8738174438590 .5211791992288 .99725341797

87.4733276367285 .9494018554784 .1206970214882 .5967712402380 .76805877686

78.9393463134876 .8058471679774 .3675689697371 .6244964599668 .57665252686

65.5288009643662 .4809494018659 .7378807067957 .909179687556 .38525009155

54.8613204956153 .0326118469250 .8991203308148 .4608306884845 .7177696228

42.9747009277340 .2316398620637 .4885711669934 .7455101013232 .61201095581

31.0880794525130 .1737308502229 .8689403533929 .2593708038328 .64979934692

28.0402297973628.34502029419 28.3450202941928.3450202941927.4306602478

25.906740188623 .7732391357421 .6397399902319 .5062503814717 .37274932861

$14.3248996734610 .362689971925 .790916919708 .3047851026058-3.96220707893$

$-7.92441320419-10.6674804688-13.4105501175-16.7631797791-21.0301704407$

$-24.9923801422-27.7354507446-29.2593708038-30.1737308502-30.7833003998$

$-31.3928699493-32.0024414062-32.307220459-32.0024414062-31.6976509094$

$-31.3928699493-30.7833003998-30.478509903-29.2593708038-28.3450202942$

$-27.4306602478-26.8210906982-26.2115192413-25.9067401886-25.6019496918$

-25.2971591949 -25.2971591949-24.9923801422 -24.9923801422 -24.6875991821

$-24.6875991821-24.3828105927-24.0780296326-23.7732391357-23.1636695862$

-22.5541000366 -21.9445304871 -21.0301704407 -20.115819931 -19.2014598846

-17.9823207855 -16.7631797791 -15.5440397263-14.0201196671 -12.4961900711

$-10.9722604752-9.44833946228-7.61962795258-6.095703125-4.57177686691$

-3.04785108566 -1.52392601967-.609570324421 -9999.3047851026058 .3047851026058

.6095703244209.6095703244209 1.21914100647 1.828711032867 3.047851085663

4.5717768669136 .7052731513989 .14355373382611 .5818300247214 .02011966705

16.1536102294918 .5918903350820 .4206008911122 .2493095397923 .77323913574

24.9923801422126 .2115192413327 .1258792877227 .7354507446328 .34502029419

28.0402297973627 .1258792877225 .2971591949525 .60194969177 -9999 -9999 -9999 -9999

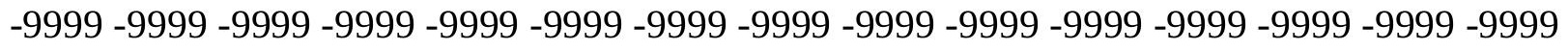

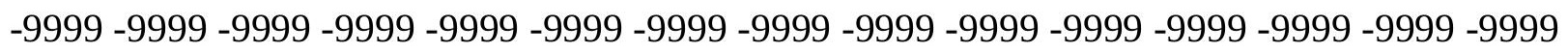
-9999 -9999 -9999 -9999 -9999 -9999 -9999 -9999 -9999 -9999 -9999 -9999 -9999 -9999 -9999

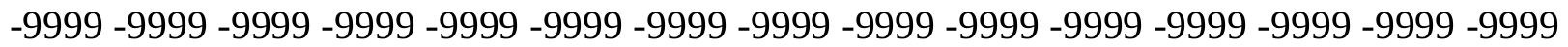
$-9999$

-9999 -9999 -9999 -9999 -9999 -9999 -9999 -9999 -9999 -9999 -9999 -9999 -9999 -9999 -9999 
-9999 -9999 -9999 -9999 -9999 -9999 -9999 -9999 -9999 -9999 -9999 -9999 -9999 -9999 -9999 -9999 -9999 -9999 -9999 -9999 -9999 -9999 -9999 -9999 -9999 -9999 -9999 -9999 -9999 -9999 -9999 -9999 -9999 -9999 -9999 -9999 -9999 -9999 -9999 -9999 -9999 -9999 -9999 -9999 -9999 -9999 -9999 -9999 -9999 -9999 -9999 -9999 -9999 -9999 -9999 -9999 -9999 -9999 -9999 -9999 -9999 -9999 -9999 -9999 -9999 -9999 -9999 -9999 -9999 -9999 -9999 -9999 -9999 -9999 -9999 -9999 -9999 -9999 -9999 -9999 -9999 -9999 -9999 -9999 -9999 -9999 -9999 -9999 -9999 -9999 -9999 -9999 -9999 -9999 -9999 -9999 -9999 -9999 -9999 -9999 -9999 -9999 -9999 -9999 -9999

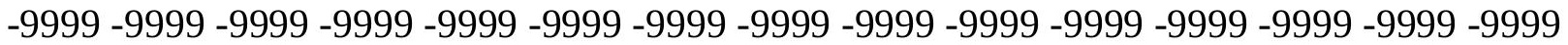

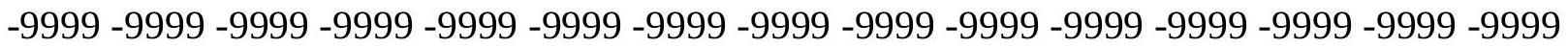
-9999 -9999 -9999 -9999 -9999 -9999 -9999 -9999 -9999 -9999 -9999 -9999 -9999 -9999 -9999 -9999 -9999 -9999 -9999 -9999 -9999 -9999 -9999 -9999 -9999 -9999 -9999 -9999 -9999 -9999 -9999 -9999 -9999 -9999 -9999 -9999 -9999 -9999 -9999 -9999 -9999 -9999 -9999 -9999 -9999 103.322196960499 .3599472045995 .0929565429790 .8259735107488 .08290100098 86.2541885376 84.7302627563582.9015579223681.07285308838 79.54891967773 77.7202072143675 .8914871215873 .4532165527370 .7101516723667 .96708679199 64.6144485473661 .5666007995659 .7378807067957 .909179687555 .77568054199 53.6421813964851 .2038993835448 .4608306884845 .4129791259842 .36513137817 39.3172798156735 .9646492004433 .2215805053730 .7833003997828 .95458984375 28.0402297973627 .430660247826 .8210906982426 .5163097381626 .21151924133 26.2115192413326 .2115192413326 .2115192413325 .906740188624 .68759918213 23.4684505462621 .9445304870620 .1158199310318 .28710937515 .84883022308 12.800970077519 .448339462285 .7909169197082 .438281059265 -9999-2.13349604607 $-4.26699209213-7.01005792618-11.8866195679-16.7631797791-20.7253894806$ $-23.4684505463-25.2971591949-26.8210906982-27.7354507446-28.6497993469$ $-29.2593708038-29.2593708038-28.9545898438-28.6497993469-28.3450202942$ $-28.0402297974-27.1258792877-26.5163097382-25.9067401886-25.2971591949$ $-24.6875991821-24.3828105927-24.3828105927-24.0780296326-24.0780296326$ $-23.7732391357-23.7732391357-23.7732391357-23.4684505463-23.4684505463$ $-23.1636695862-22.8588790894-22.2493095398-21.9445304871-21.3349609375$ $-20.4206008911-19.5062503815-18.5918903351-17.6775398254-16.4584007263$ $-15.2392597198-13.7153301239-12.1914100647-10.6674804688-9.14355373383$ -7.61962795258 -6.095703125-4.57177686691 -3.04785108566 -1.82871103287 -.609570324421 -9999.3047851026058.6095703244209.9143553972244 1.21914100647 1.8287110328672 .7430660724643 .6574220657355 .4861321449287 .314843177795 9.4483394622811 .5818300247214 .0201196670516 .4584007263218 .59189033508 20.4206008911122 .2493095397923 .7732391357425 .2971591949526 .51630973816 27.430660247828 .3450202941929 .2593708038329 .2593708038328 .34502029419 25.6019496917725 .2971591949525 .9067401886 -9999 -9999 -9999 -9999 -9999 -9999 -9999 -9999 -9999 -9999 -9999 -9999 -9999 -9999 -9999 -9999 -9999 -9999 -9999 -9999 -9999 -9999 -9999 -9999 -9999 -9999 -9999 -9999 -9999 -9999 -9999 -9999 -9999 -9999 -9999 -9999 -9999 -9999 -9999 -9999 -9999 -9999 -9999 -9999 -9999 -9999 -9999 -9999 -9999 -9999 -9999 -9999 -999 -9999 -9999 -9999 -9999 -9999 -9999 -9999 -9999 -9999 -9999 -9999 -9999 -9999 -9999 -9999 -9999 -9999 -9999 -9999 -9999 -9999 -9999 -9999 -9999 -9999 -9999 -9999 -9999 -9999 -9999 -9999 -9999 -9999 -9999 -9999 -9999 -9999 -9999 -9999 -9999 -9999 -9999 -9999 -9999 -9999 -9999 -9999 -9999 -9999 -9999 -9999 -9999 -9999 -9999 -9999 -9999 -9999

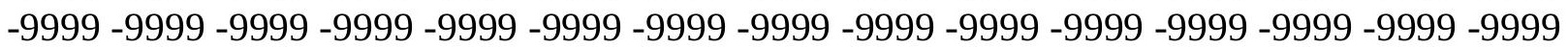


-9999 -9999 -9999 -9999 -9999 -9999 -9999 -9999 -9999 -9999 -9999 -9999 -9999 -9999 -9999 -9999 -9999 -9999 -9999 -9999 -9999 -9999 -9999 -9999 -9999 -9999 -9999 -9999 -9999 -9999

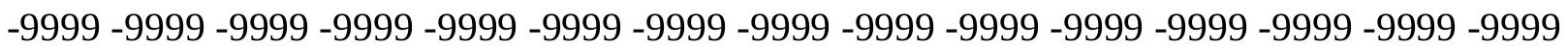
-9999 -9999 -9999 -9999 -9999 -9999 -9999 -9999 -9999 -9999 -9999 -9999 -9999 -9999 -9999 -9999 -9999 -9999 -9999 -9999 -9999 -9999 -9999 -9999 -9999 -9999 -9999 -9999 -9999 -9999 -9999 -9999 -9999 -9999 -9999 -9999 -9999 -9999 -9999 -9999 -9999 -9999 -9999 -9999 -9999 -9999 -9999 -9999 -9999 -9999 -9999 -9999 -9999 -9999 -9999 -9999 -9999 -9999 -9999 -9999

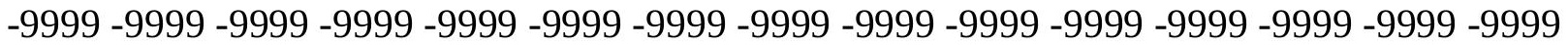
-9999 -9999 -9999 -9999 -9999 -9999 -9999 -9999 -9999 -9999 -9999 -9999 -9999 -9999 -9999 -9999 -9999 100.161628723196.61688232422 92.3498916626 88.69246673584 85.33984375 83.5111236572382 .2919769287180 .7680587768679 .2441329956177 .72020721436 76.1962814331173 .7580032348671 .3197174072368 .2718734741265 .22400665283 62.7857398986860 .3474502563557 .909179687555 .4708900451752 .42303848267 49.3751907348646 .0225486755442 .66992187539 .0125007629435 .65985870361 32.3072204589829 .5641593933128 .0402297973626 .8210906982426 .21151924133 25.6019496917724 .9923801422124 .9923801422124 .6875991821324 .99238014221 24.6875991821324 .3828105926523 .7732391357423 .1636695861821 .94453048706 20.7253894805919 .2014598846417 .3727493286115 .2392597198512 .80097007751 10.362689971927 .9244132041936 .0957031254 .5717768669133 .352636098862 $1.828711032867-3.65742206573-9.44833946228-14.0201196671-17.6775398254$ $-20.115819931-22.2493095398-23.7732391357-24.6875991821-25.2971591949$ $-25.6019496918-25.6019496918-25.6019496918-25.2971591949-24.9923801422$ $-24.6875991821-24.0780296326-23.4684505463-23.1636695862-22.8588790894$ $-22.8588790894-22.8588790894-22.5541000366-22.5541000366-22.5541000366$ $-22.5541000366-22.5541000366-22.5541000366-22.2493095398-22.2493095398$ $-21.9445304871-21.3349609375-21.0301704407-20.4206008911-19.8110294342$ $-18.8966808319-17.9823207855-17.0679702759-15.8488302231-14.6296901703$ $-13.4105501175-11.8866195679-10.3626899719-8.83876895905-7.3148431778$ $-5.79091691971-4.26699209213-3.04785108566-1.52392601967-.609570324421-9999$ .3047851026058.9143553972244 1.21914100647 1.828711032867 2.438281059265 3.6574220657354 .5717768669136 .0957031257 .92441320419310 .05790996552 12.191410064714 .3248996734616 .4584007263218 .5918903350820 .72538948059 22.5541000366224 .0780296325725 .6019496917726 .8210906982428 .04022979736 28.9545898437529 .8689403533930 .4785099029530 .4785099029526 .82109069824 24.6875991821325 .29715919495 -9999 -9999 -9999 -9999 -9999 -9999 -9999 -9999 -9999 -9999 -9999 -9999 -9999 -9999 -9999 -9999 -9999 -9999 -9999 -9999 -9999 -9999 -9999 -9999

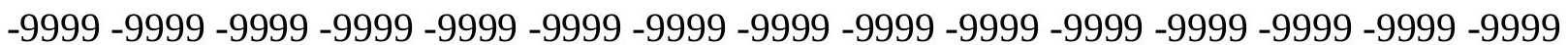

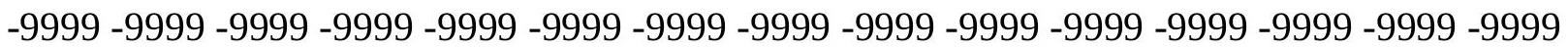
-9999 -9999 -9999 -9999 -9999 -9999 -9999 -9999 -9999 -9999 -9999 -9999 -9999 -9999 -9999 -9999 -9999 -9999 -9999 -9999 -9999 -9999 -9999 -9999 -9999 -9999 -9999 -9999 -9999 -9999 -9999 -9999 -9999 -9999 -9999 -9999 -9999 -9999 -9999 -9999

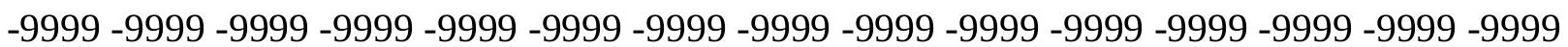
-9999 -9999 -9999 -9999 -9999 -9999 -9999 -9999 -9999 -9999 -9999 -9999 -9999 -9999 -9999 -9999 -9999 -9999 -9999 -9999 -9999 -9999 -9999 -9999 -9999 -9999 -9999 -9999 -9999 -9999 -9999 -9999 -9999 -9999 -9999 -9999 -9999 -9999 -9999 -9999 -9999 -9999 -9999 -9999 -9999

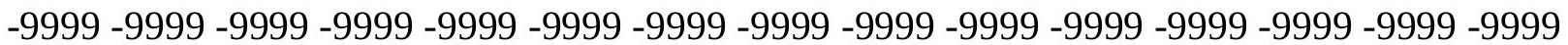


-9999 -9999 -9999 -9999 -9999 -9999 -9999 -9999 -9999 -9999 -9999 -9999 -9999 -9999 -9999 -9999 -9999 -9999 -9999 -9999 -9999 -9999 -9999 -9999 -9999 -9999 -9999 -9999 -9999 -9999

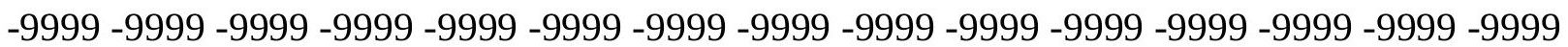
-9999 -9999 -9999 -9999 -9999 -9999 -9999 -9999 -9999 -9999 -9999 -9999 -9999 -9999 -9999 -9999 -9999 -9999 -9999 -9999 -9999 -9999 -9999 -9999 -9999 -9999 -9999 -9999 -9999 -9999 -9999 -9999 -9999 -9999 -9999 -9999 -9999 -9999 -9999 -9999 -9999 -9999 -9999 -9999 -9999 -9999 -9999 -9999 -9999 98.4455871582 94.1785964965890.52117919922 87.16854858398 84.4254837036182 .2919769287181 .3776321411180 .4632720947379 .24413299561 77.7202072143675 .2819290161172 .5388565063569 .4910125732466 .74794006348 63.7000885009860 .9570198059157 .909179687554 .5565414428750 .89912033081 47.2416992187543 .5842704772939 .9268493652335 .9646492004432 .61201095581 29.5641593933127 .7354507446326 .8210906982425 .906740188625 .29715919495 24.6875991821324 .3828105926524 .0780296325724 .0780296325723 .77323913574 23.7732391357423 .1636695861822 .8588790893621 .9445304870621 .03017044067 19.811029434218 .5918903350817 .0679702758815 .5440397262613 .7153301239 12.191410064710 .667480468759 .448339462288 .2291984558115 .486132144928 $1.21914100647-3.65742206573-8.53398323059-12.1914100647-15.2392597198$ -17.3727493286 -19.2014598846-20.4206008911 -21.0301704407 -21.6397399902 $-21.6397399902-21.6397399902-21.6397399902-21.6397399902-21.6397399902$ $-21.3349609375-21.0301704407-21.0301704407-21.0301704407-21.0301704407$ $-21.0301704407-21.0301704407-21.0301704407-21.0301704407-21.3349609375$ -21.3349609375 -21.3349609375 -21.0301704407 -21.0301704407 -20.7253894806 -20.4206008911 -20.115819931 -19.5062503815 -18.8966808319-17.9823207855 -17.3727493286 -16.1536102295 -15.2392597198 -14.0201196671 -12.8009700775 $-11.2770500183-10.0579099655-8.53398323059-7.01005792618-5.48613214493$ -3.96220707893 -2.74306607246 -1.52392601967-.304785102606 .3047851026058 .91435539722441 .5239260196692 .1334960460662 .7430660724643 .657422065735 4.5717768669135 .7909169197087 .3148431777958 .83876895904510 .97226047516 12.8009700775114 .934470176717 .0679702758819 .2014598846421 .03017044067 22.8588790893624 .3828105926525 .906740188627 .1258792877228 .34502029419 29.2593708038330 .1737308502230 .1737308502229 .2593708038326 .82109069824 24.3828105926524 .99238014221 -9999 -9999 -9999 -9999 -9999 -9999 -9999 -9999 -9999 -9999 -9999 -9999 -9999 -9999 -9999 -9999 -9999 -9999 -9999 -9999 -9999 -9999 -9999 -9999 -9999 -9999 -9999 -9999 -9999 -9999 -9999 -9999 -9999 -9999 -9999 -9999 -9999 -9999 -9999

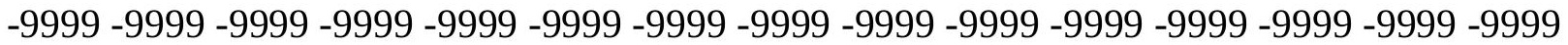
-9999 -9999 -9999 -9999 -9999 -9999 -9999 -9999 -9999 -9999 -9999 -9999 -9999 -9999 -9999 -9999 -9999 -9999 -9999 -9999 -9999 -9999-9999-9999-9999 -9999 -9999 -9999 -9999 -9999 -9999 -9999 -9999 -9999 -9999 -9999 -9999 -9999 -9999 -9999 -9999 -9999 -9999 -9999 -9999 -9999 -9999 -9999 -9999 -9999 -9999 -9999 -9999 -9999 -9999 -9999 -9999 -9999 -9999 -9999 -9999 -9999 -9999 -9999 -9999 -9999 -9999 -9999 - -9999 -9999 -9999 -9999 -9999 -9999 -9999 -9999 -9999 -9999 -9999 -9999 -9999 -9999 -9999 -9999 -9999

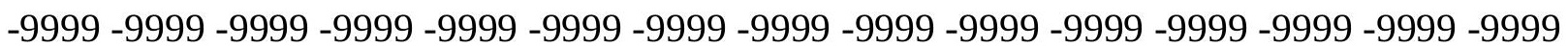
-9999 -9999 -9999 -9999 -9999 -9999 -9999 -9999 -9999 -9999 -9999 -9999 -9999 -9999 -9999 -9999 -9999 -9999 -9999 -9999 -9999 -9999 -9999 -9999 -9999 -9999 -9999 -9999 -9999 -9999 -9999 -9999 -9999 -9999 -9999 -9999 -9999 -9999 -9999 -9999 -9999 -9999 -9999 -9999 -9999

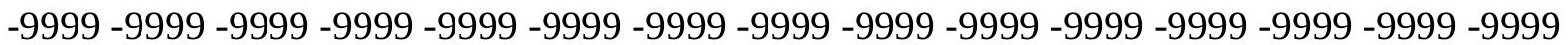


-9999 -9999 -9999 -9999 -9999 -9999 -9999 -9999 -9999 -9999 -9999 -9999 -9999 -9999 -9999 -9999 -9999 -9999 -9999 -9999 -9999 -9999 -9999 -9999 -9999 -9999 -9999 -9999 -9999 -9999 -9999 -9999 -9999 -9999 -9999 -9999 -9999 -9999 -9999 -9999 -9999 -9999 -9999 -9999 -9999 -9999 -9999 -9999 -9999 -9999 -9999 -9999 92.65467834473 89.91161346436 87.47332763672 85.6446228027383 .8159103393682 .9015579223681 .6824111938579 .85370635986 77.110626220774 .062782287670 .7101516723667 .6623001098664 .30966186523 60.9570198059156 .9948196411153 .3373985290549 .3751907348645 .41297912598 41.4507789611837 .7933502197334 .1359291076731 .0880794525128 .95458984375 27.430660247826 .5163097381625 .6019496917724 .9923801422124 .38281059265 23.7732391357423 .7732391357423 .4684505462623 .1636695861823 .16366958618 22.5541000366222 .2493095397921 .6397399902320 .7253894805919 .8110294342 18.5918903350817 .6775398254416 .4584007263215 .2392597198514 .02011966705 12.8009700775110 .972260475168 .2291984558114 .571776866913 -9999 -3.96220707893 $-7.61962795258-10.6674804688-12.8009700775-14.6296901703-15.8488302231$ $-16.4584007263-17.0679702759-17.3727493286-17.6775398254-17.9823207855$ -17.9823207855 -18.287109375 -18.287109375 -18.287109375 -18.5918903351 $-18.5918903351-18.5918903351-18.8966808319-19.2014598846-19.2014598846$ -19.5062503815 -19.5062503815 -19.8110294342 -19.8110294342 -19.8110294342 $-19.8110294342-19.5062503815-19.2014598846-18.8966808319-18.5918903351$ -17.9823207855 -17.0679702759 -16.4584007263 -15.5440397263 -14.3248996735 $-13.4105501175-12.1914100647-10.6674804688-9.44833946228-7.92441320419$ $-6.40048694611-5.18134689331-3.65742206573-2.43828105927-1.21914100647-9999$ .6095703244209 1.219141006472.133496046066 2.743066072464 3.657422065735 4.5717768669135 .4861321449286 .7052731513988 .22919845581110 .05790996552 11.8866195678713 .715330123915 .5440397262617 .6775398254419 .8110294342 21.6397399902323 .4684505462624 .9923801422126 .2115192413327 .73545074463 28.6497993469229 .5641593933129 .8689403533929 .5641593933128 .34502029419 26.2115192413324 .0780296325724 .38281059265 -9999 -9999 -9999 -9999 -9999 -9999 -9999 -9999 -9999 -9999 -9999 -9999 -9999 -9999 -9999 -9999 -9999 -9999 -9999 -9999 -9999 -9999

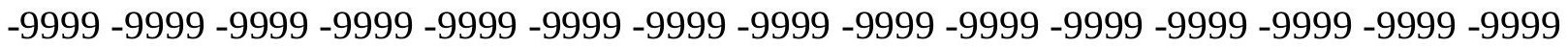
-9999 -9999 -9999 -9999 -9999 -9999 -9999 -9999 -9999 -9999 -9999 -9999 -9999 -9999 -9999 -9999 -9999 -9999 -9999 -9999 -9999 -9999 -9999 -9999 -9999 -9999 -9999 -9999 -9999 -9999 -9999 -9999 -9999 -9999 -9999 -9999 -9999 -9999 -9999 -9999 -9999 -9999 -9999 -9999 -9999 -9999 -9999 -9999 -9999 -9999 -9999 -9999 -9999 -9999 -9999 -9999 -9999 -

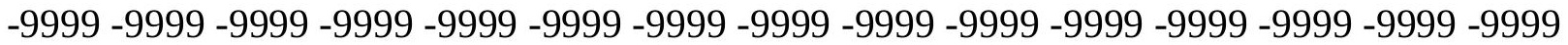
-9999 -9999 -9999 -9999 -9999 -9999 -9999 -9999 -9999 -9999 -9999 -9999 -9999 -9999 -9999 -9999 -9999 -9999 -9999 -9999 -9999 -9999 -9999 -9999 -9999 -9999 -9999 -9999 -9999 -9999

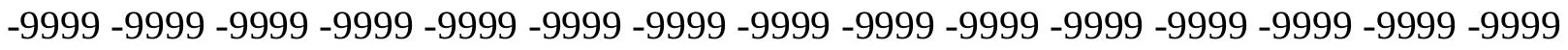
-9999 -9999 -9999 -9999 -9999 -9999 -9999 -9999 -9999 -9999 -9999 -9999 -9999 -9999 -9999 -9999 -9999 -9999 -9999 -9999 -9999 -9999 -9999 -9999 -9999 -9999 -9999 -9999 -9999 -9999 -

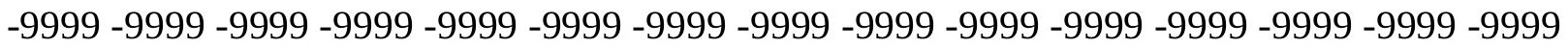
-9999 -9999 -9999 -9999 -9999 -9999 -9999 -9999 -9999 -9999 -9999 -9999 -9999 -9999 -9999 -9999 -9999 -9999 -9999 -9999 -9999 -9999 -9999 -9999 -9999 -9999 -9999 -9999 -9999 -9999 -9999 -9999 -9999 -9999 -9999 -9999 -9999 -9999 -9999 -9999 -9999 -9999 -9999 -9999 -9999 -9999 -9999 -9999 -9999 -9999 -9999 -9999 -9999 -9999 -9999 -9999 -9999 -9999 -9999 -9999 -9999 -9999 -9999 -9999 -9999 -9999 -9999 -9999 -9999 92.3498916626 90.82597351074 
89.6068267822388 .3876876831186 .5589828491284 .1206970214881 .37763214111 78.3297805786174 .9771423339871 .6244964599667 .9670867919964 .30966186523 60.3474502563556 .0804595947352 .1182594299347 .8512611389243 .88906097412 40.2316398620636 .5742111206133 .5263595581131 .0880794525129 .25937080383 27.7354507446326 .8210906982425 .6019496917724 .9923801422124 .38281059265 23.7732391357423 .7732391357423 .4684505462623 .1636695861822 .85887908936 22.5541000366221 .9445304870621 .334960937520 .7253894805920 .11581993103 19.2014598846418 .28710937517 .3727493286116 .1536102294914 .62969017029 $12.8009700775110 .057909965526 .7052731513983 .047851085663-.304785102606$ -3.65742206573 -6.40048694611 -8.53398323059-10.0579099655 -11.2770500183 $-12.1914100647-12.8009700775-13.1057596207-13.7153301239-14.0201196671$ -14.3248996735 -14.9344701767 -15.2392597198 -15.5440397263 -15.8488302231 -16.1536102295 -16.4584007263 -16.7631797791 -17.0679702759 -17.3727493286 -17.6775398254 -17.9823207855 -17.9823207855 -18.287109375 -18.287109375 -18.287109375 -17.9823207855 -17.9823207855 -17.6775398254 -17.3727493286 -16.7631797791 -16.1536102295 -15.2392597198 -14.6296901703 -13.4105501175 $-12.4961900711-11.2770500183-10.0579099655-8.83876895905-7.3148431778$ -6.095703125 -4.57177686691 -3.35263609886-1.82871103287 -.609570324421 -9999 1.219141006471 .8287110328672 .7430660724643 .6574220657354 .571776866913 5.4861321449286 .7052731513987 .9244132041939 .4483394622810 .97226047516 12.8009700775114 .6296901702916 .4584007263218 .28710937520 .42060089111 22.2493095397923 .7732391357425 .2971591949526 .8210906982428 .04022979736 29.2593708038329 .8689403533929 .8689403533929 .2593708038328 .04022979736 25.906740188624 .0780296325724 .07802963257 -9999 -9999 -9999 -9999 -9999 -9999 -9999 -9999 -9999 -9999 -9999 -9999 -9999 -9999 -9999 -9999 -9999 -9999 -9999 -9999 -9999 -9999 -9999 -9999 -9999 -9999 -9999 -9999 -9999 -9999 -9999 -9999 -9999 -9999 -9999 -9999 -9999 -9999 -9999 -9999 -9999 -9999 -9999 -9999 -9999 -9999 -9999 -9999 -9999 -9999 -9999 -9999 -999 -9999 -9999 -9999 -9999 -9999 -9999 -9999 -9999 -9999 -9999 -9999 -9999 -9999 -9999 -9999 -9999 -9999 -9999 -9999 -9999 -9999 -9999 -9999 -9999 -9999 - -9999 -9999 -

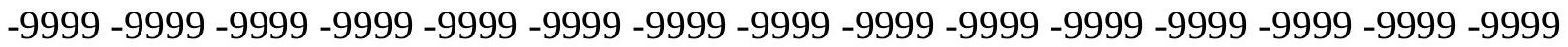
-9999 -9999 -9999 -9999 -9999 -9999 -9999 -9999 -9999 -9999 -9999 -9999 -9999 -9999 -9999 -9999 -9999 -9999 -9999 -9999 -9999 -9999 -9999 -9999 -9999 -9999 -9999 -9999 -9999 -9999 -9999 -9999 -9999 -9999 -9999 -9999 -9999 -9999 -9999 -9999 -9999 -9999 -9999 -9999 -9999 -9999 -9999 -9999 -9999 -9999 -9999 -9999 -9999 -9999 -9999 -9999 -9999 -9999 -9999 -9999 -

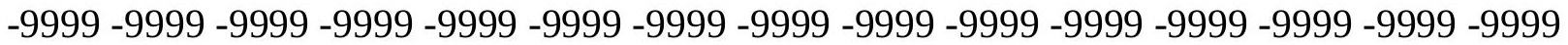
-9999 -9999 -9999 -9999 -9999 -9999 -9999 -9999 -9999 -9999 -9999 -9999 -9999 -9999 -9999 -9999 -9999 -9999 -9999 -9999 -9999 -9999 -9999 -9999 -9999 -9999 -9999 -9999 -9999 -9999

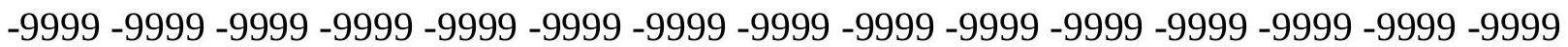
-9999 -9999 -9999 -9999 -9999 -9999 -9999 -9999 -9999 -9999 -9999 -9999 -9999 -9999 -9999 -9999 -9999 -9999 -9999 -9999 -9999 -9999 -9999 -9999 -9999 -9999 -9999 -9999 -9999 -9999 -9999 -9999 -9999 -9999 -9999 -9999 -9999 -9999 -9999 -9999 -9999 -9999 -9999 -9999 -9999 -9999 -9999 -9999 -9999 -9999 -9999 -9999 -9999 -9999 -9999 -9999 94.78817749023 94.1785964965892 .6546783447389 .302040100185 .0350494384881 .98719787598 78.9393463134875 .5867080688571 .9292907714867 .6623001098663 .70008850098 59.4331016540555 .1661109924351 .2038993835447 .2416992187543 .27949142456 39.9268493652336 .5742111206133 .8311500549331 .6976509094229 .86894035339 
28.3450202941927 .1258792877226 .2115192413325 .2971591949524 .68759918213 24.3828105926524 .0780296325723 .7732391357423 .4684505462623 .16366958618 22.5541000366222 .2493095397921 .6397399902321 .0301704406720 .42060089111 19.5062503814718 .5918903350817 .3727493286115 .8488302230814 .02011966705 11.581830024728 .8387689590455 .4861321449282 .438281059265 -9999 -2.43828105927 $-4.57177686691-6.095703125-7.01005792618-7.61962795258-8.22919845581$ $-8.83876895905-9.44833946228-10.0579099655-10.6674804688-11.2770500183$ -11.8866195679 -12.4961900711 -12.8009700775 -13.4105501175 -14.0201196671 -14.3248996735 -14.9344701767 -15.5440397263 -15.8488302231 -16.1536102295 $-16.1536102295-16.4584007263-16.4584007263-16.4584007263-16.4584007263$ -16.4584007263 -16.1536102295 -15.8488302231 -15.5440397263 -14.9344701767 -14.3248996735 -13.4105501175 -12.4961900711 -11.2770500183 -10.3626899719 $-9.14355373383-7.92441320419-6.40048694611-5.18134689331-3.96220707893$ -2.43828105927 -1.21914100647-9999.6095703244209 1.828711032867 2.743066072464 3.6574220657354 .5717768669135 .4861321449286 .7052731513987 .619627952576 9.14355373382610 .3626899719212 .191410064713 .715330123915 .54403972626 17.3727493286119 .2014598846421 .0301704406722 .8588790893624 .38281059265 25.906740188627 .430660247828 .6497993469229 .5641593933130 .17373085022 30.1737308502229 .5641593933128 .0402297973626 .2115192413324 .38281059265 24.07802963257 -9999 -9999 -9999 -9999 -9999 -9999 -9999 -9999 -9999 -9999 -9999 -9999 -9999 -9999 -9999 -9999 -9999 -9999 -9999 -9999 -9999 -9999 -9999 -9999 -9999 -9999 -9999 -9999 -9999 -9999 -9999 -9999 -9999 -9999 -9999 -9999 -9999 -9999 -9999 -9999 -9999 -9999 -

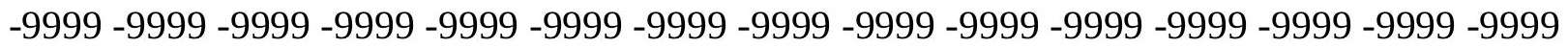
-9999 -9999 -9999 -9999-9999-9999-9999

-9999 -9999 -9999 -9999 -9999 -9999 -9999 -9999 -9999 -9999 -9999 -9999 -9999 -9999 -9999 -9999 -9999 -9999 -9999 -9999 -9999 -9999 -9999 -9999 -9999 -9999 -9999 -9999 -9999 -9999 -9999 -9999 -9999 -9999 -9999 -9999 -9999 -9999 -9999 -9999 -9999 -9999 -9999 -9999 - -9999 -

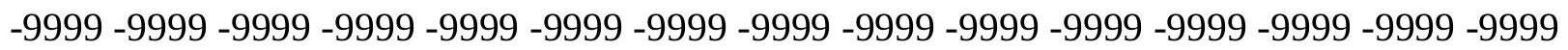
-9999 -9999 -9999 -9999 -9999 -9999 -9999 -9999 -9999 -9999 -9999 -9999 -9999 -9999 -9999 -9999 -9999 -9999 -9999 -9999 -9999 -9999 -9999 -9999 -9999 -9999 -9999 -9999 -9999 -9999 -9999 -9999 -9999 -9999 -9999 -9999 -9999 -9999 -9999 -9999 -9999 -9999-9999 -9999 -9999 -9999 -9999 -9999 -9999 -9999 -9999 -9999 -9999 -9999 -9999 -9999 -9999 -9999 -9999 -9999 -

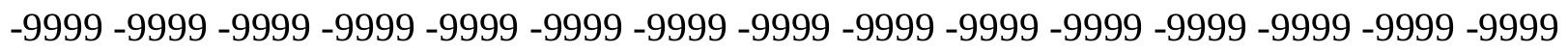
-9999 -9999 -9999 -9999 -9999 -9999 -9999 -9999 -9999 -9999 -9999 -9999 -9999 -9999 -9999 -9999 -9999 -9999 -9999 -9999 -9999 -9999 -9999 -9999 -9999 -9999 -9999 -9999 -9999 -9999

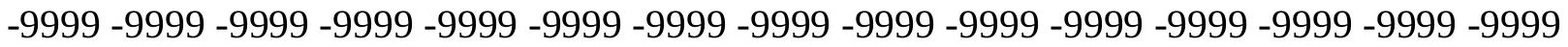

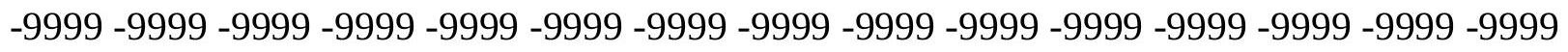
-9999 -9999-9999-9999 -9999-9999 -9999 -9999-9999-9999 -9999-9999 98.14080810547 96.6168823242293 .5690307617289 .6068267822385 .9494018554782 .90155792236 79.2441329956175 .2819290161171 .3197174072367 .0527267456162 .78573989868 58.5187492370654 .5565414428750 .8991203308147 .2416992187543 .58427047729 39.9268493652336 .8790016174334 .4407196044932 .3072204589830 .78330039978 28.9545898437527 .7354507446326 .5163097381625 .906740188625 .29715919495 24.9923801422124 .6875991821324 .3828105926523 .7732391357423 .46845054626 22.8588790893622 .5541000366221 .9445304870621 .334960937520 .42060089111 19.5062503814718 .28710937517 .0679702758815 .2392597198512 .80097007751 
10.362689971927 .6196279525765 .1813468933112 .743066072464 .6095703244209 -.914355397224 -2.13349604607 -3.04785108566 -3.65742206573 -4.26699209213 $-4.57177686691-5.48613214493-6.40048694611-7.3148431778-7.92441320419$ $-8.83876895905-9.44833946228-10.0579099655-10.6674804688-11.2770500183$ $-12.1914100647-12.8009700775-13.1057596207-13.7153301239-14.0201196671$ -14.3248996735 -14.3248996735 -14.6296901703 -14.6296901703 -14.6296901703 -14.6296901703 -14.3248996735 -14.3248996735 -14.0201196671 -13.4105501175 $-12.8009700775-11.8866195679-11.2770500183-10.0579099655-9.14355373383$ $-7.92441320419-6.7052731514-5.48613214493-4.26699209213-3.04785108566$ -1.82871103287-.609570324421.3047851026058 1.523926019669 2.438281059265 3.3526360988624 .5717768669135 .4861321449286 .7052731513987 .619627952576 8.83876895904510 .0579099655211 .5818300247213 .1057596206714 .62969017029 16.4584007263218 .28710937519 .811029434221 .6397399902323 .46845054626 24.9923801422126 .5163097381627 .7354507446329 .2593708038330 .17373085022 31.0880794525131 .0880794525130 .1737308502228 .6497993469226 .82109069824 24.6875991821324 .07802963257 -9999 -9999 -9999 -9999 -9999 -9999 -9999 -9999 -9999 -9999 -9999 -9999 -9999 -9999 -9999 -9999 -9999 -9999 -9999 -9999 -9999 -9999 -9999 -9999 -9999 -9999 -9999 -9999 -9999 -9999 -9999 -9999 -9999 -9999 -9999 -9999 -9999 -9999 -9999 -9999 -9999 -9999 -9999 -9999 -9999 -9999 -9999 -9999 -9999 -9999 -9999 -9999 -9999 -9999 -9999 -9999 -9999 -9999-9999 -9999-9999 -9999 -9999 -9999

-9999 -9999 -9999 -9999 -9999 -9999 -9999 -9999 -9999 -9999 -9999 -9999 -9999 -9999 -9999 -9999 -9999 -9999 -9999 -9999 -9999 -9999 -9999 -9999 -9999 -9999 -9999 -9999 -9999 -9999 -9999 -9999 -9999 -9999 -9999 -9999 -9999 -9999 -9999 -9999 -9999 -9999 -9999 -9999 -9999 -9999 -9999 -9999 -9999 -9999 -9999 -9999 -9999 -9999 -9999 -9999 -9999 -9999 -9999 -9999 -9999 -9999 -9999 -9999 -9999 -9999 -9999 -9999 -9999 -9999 -9999 -9999 -9999 -9999 -9999 -9999 -9999 -9999 -9999 -9999 -9999 -9999 -9999 -9999 -9999 -9999 -9999 -9999 -9999 -9999 -9999 -9999 -9999 -9999 -9999 -9999 -9999 -9999 -9999 -9999 -9999 -9999 -9999 -9999 -9999 -

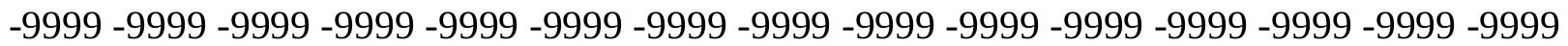

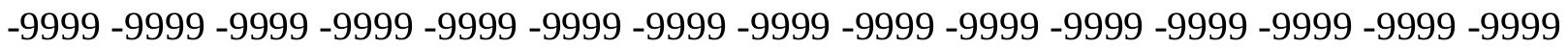
-9999 -9999 -9999 -9999 -9999 -9999 -9999 -9999 -9999 -9999 -9999 -9999 -9999 -9999 -999 -9999 -9999 -9999 -9999 -9999 -9999 -9999 -9999 -9999 -9999 -9999 -9999 -9999 -9999 -9999

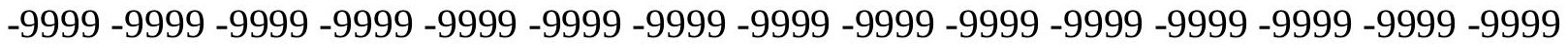
-9999 -9999 -9999 -9999 -9999 -9999 -9999 -9999 -9999 -9999 -9999 -9999 -9999 -9999 -9999 -9999 -9999 -9999 -9999 -9999 -9999 -9999 -9999 -9999 -9999 -9999 -9999 -9999 -9999 96.9216690063593 .8738174438590 .2164001464886 .254188537682 .90155792236 78.6345596313574 .3675689697370 .1005783081166 .1383666992262 .17617034912 58.5187492370654 .8613204956151 .2038993835447 .5464782714843 .88906097412 40.2316398620637 .1837806701734 .7455101013232 .9167900085431 .08807945251 29.8689403533928 .6497993469227 .7354507446327 .1258792877226 .51630973816 25.906740188625 .2971591949524 .9923801422124 .3828105926523 .77323913574 23.1636695861822 .5541000366221 .9445304870621 .334960937520 .42060089111 19.2014598846417 .6775398254416 .1536102294914 .0201196670511 .88661956787 9.7531242370617 .3148431777955 .4861321449283 .6574220657352 .133496046066 $.9143553972244-9999-.304785102606-.609570324421-.609570324421-1.82871103287$ -3.04785108566 -3.96220707893 -4.87656211853 -5.79091691971 -6.40048694611 $-7.3148431778-7.92441320419-8.83876895905-9.44833946228-10.3626899719$ 
-10.9722604752 -11.5818300247 -11.8866195679 -12.1914100647 -12.1914100647 $-12.1914100647-12.1914100647-12.1914100647-12.4961900711-12.4961900711$ -12.1914100647 -12.1914100647 -11.5818300247 -11.2770500183 -10.3626899719 $-9.75312423706-8.83876895905-7.92441320419-6.7052731514-5.79091691971$ $-4.57177686691-3.35263609886-2.13349604607-.914355397224-99991.21914100647$ 2.1334960460663 .3526360988624 .2669920921335 .4861321449286 .400486946106 7.6196279525768 .83876895904510 .0579099655211 .2770500183112 .80097007751 14.3248996734615 .8488302230817 .3727493286118 .8966808319120 .72538948059 22.24930953979 24.0780296325725.6019496917726.8210906982428.04022979736 29.5641593933130 .7833003997831 .6976509094232 .3072204589831 .69765090942 29.8689403533927 .430660247824 .9923801422124 .38281059265 -9999 -9999 -9999 -9999 -9999 -9999 -9999 -9999 -9999 -9999 -9999 -9999 -9999 -9999 -9999 -9999 -9999 -9999 -9999 -9999 -9999 -9999 -9999 -9999 -9999 -9999 -9999 -9999 -9999 -9999 -9999 -9999 -9999 -9999 -9999 -9999 -9999 -9999 -9999 -9999 -9999 -9999 -9999 -9999 -9999 -9999 -9999 -9999 - 9999 -9999 -9999 -9999 -9999 -9999 -9999 -9999 -9999 -9999 -9999 -9999 -9999 -9999 -9999 -9999

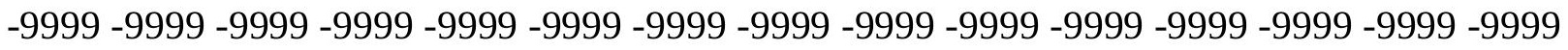
-9999 -9999 -9999 -9999 -9999 -9999 -9999 -9999 -9999 -9999 -9999 -9999 -9999 -9999 -9999 -9999 -9999 -9999 -9999 -9999 -9999 -9999 -9999 -9999 -9999 -9999 -9999 -9999 -9999 -9999 -999 -9999 -9999 -9999 -9999 -9999 -9999 -9999 -9999 -9999 -9999 -9999 -9999 -9999 -9999 -9999 -9999 -9999 -9999 -9999 -9999 -9999 -9999 -9999 -9999 -9999 -9999 -9999 -9999 -9999 -9999 -9999 -9999 -9999 -9999 -9999 -9999 -9999 -9999 -9999 -9999 -9999 -9999 -9999 -9999 -9999 -9999 -9999 -9999 -9999 -9999 -9999 -9999 -9999 -9999 -9999 -9999 -9999 -9999 -9999 -9999 -9999 -9999 -9999 -9999 -9999 -9999 -9999 -9999 -9999 -9999 -9999 -9999 -9999 -9999 -9999 -9999 -9999 -9999 -9999 -9999 -9999 -9999 -9999 -9999 -9999 -9999 -9999 -9999 -9999 -9999 -9999 -9999 -9999 -9999 -9999 -9999 -9999 -9999 -9999 -9999 -9999 -9999 -9999 -9999 -9999 -9999 -9999 -9999 -9999 -9999 -9999 -9999 -9999 -9999 -9999 -9999 -9999 -9999 -9999 -9999 -9999 -9999 -9999 -9999 -9999 -9999 -9999 -9999 -9999 -9999 -9999 -9999 -9999 -9999 -9999

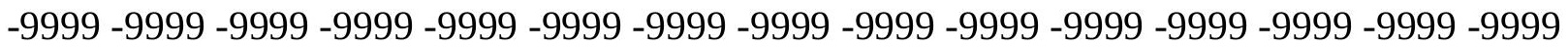
-9999 -9999 -9999 -9999 -9999 -9999 -9999 -9999 -9999 -9999 -9999 -9999 -9999 -9999 -9999 -9999 93.87381744385 89.91161346436 85.64462280273 81.68241119385 77.41542053223 73.1484298706169 .1862335205165 .5288009643661 .8713798522958 .82352828979 55.4708900451751 .8134689331147 .8512611389244 .1938400268640 .53641891479 37.4885711669935 .3550796508833 .8311500549332 .3072204589831 .08807945251 29.8689403533929 .2593708038328 .3450202941927 .7354507446326 .82109069824 26.2115192413325 .2971591949524 .6875991821324 .0780296325723 .46845054626 22.8588790893621 .9445304870621 .0301704406719 .811029434218 .59189033508 17.0679702758815 .2392597198513 .4105501174911 .277050018319 .44833946228 7.6196279525766 .0957031254 .876562118533 .6574220657353 .047851085663 2.4382810592652 .1334960460661 .523926019669 6095703244209-9999-.914355397224 $-1.82871103287-2.74306607246-3.65742206573-4.26699209213-5.18134689331$ $-6.095703125-7.01005792618-7.92441320419-8.53398323059-9.14355373383$ $-9.75312423706-9.75312423706-9.75312423706-9.75312423706-9.44833946228$ $-9.75312423706-9.75312423706-9.75312423706-10.0579099655-10.0579099655$ -9.75312423706 -9.44833946228 -8.83876895905 -7.92441320419 -7.3148431778 $-6.40048694611-5.48613214493-4.26699209213-3.35263609886-2.13349604607$ -.914355397224-9999.9143553972244 2.133496046066 3.3526360988624 .266992092133 
5.4861321449286 .4004869461067 .6196279525768 .8387689590459 .753124237061 10.9722604751612 .4961900711113 .715330123915 .2392597198516 .76317977905 18.28710937519 .811029434221 .334960937523 .1636695861824 .38281059265 25.906740188627 .1258792877228 .3450202941929 .5641593933130 .78330039978 32.6120109558133 .8311500549333 .5263595581131 .3928699493428 .04022979736 24.9923801422125 .29715919495 -9999 -9999 -9999 -9999 -9999 -9999 -9999 -9999 -9999 -9999 -9999 -9999 -9999 -9999 -9999 -9999 -9999 -9999 -9999 -9999 -9999 -9999 -9999 -9999

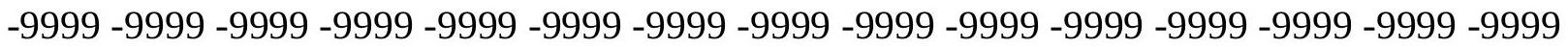

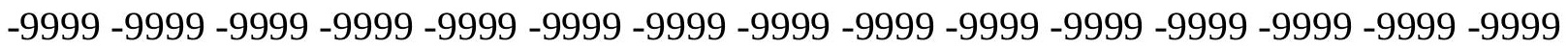
-9999 -9999 -9999 -9999 -9999 -9999 -9999 -9999 -9999 -9999

-9999 -9999 -9999 -9999 -9999 -9999 -9999 -9999 -9999 -9999 -9999 -9999 -9999 -9999 -9999 -9999 -9999 -9999 -9999 -9999 -9999 -9999 -9999 -9999 -9999 -9999 -9999 -9999 -9999 -9999 -9999 -9999 -9999 -9999 -9999 -9999 -9999 -9999 -9999 -9999 -9999 -9999 -9999 -9999 -9999 -9999 -9999 -9999 -9999 -9999 -9999 -9999 -9999 -9999 -9999 -9999 -9999 -9999 -9999 -9999 -9999 -9999 -9999 -9999 -9999 -9999 -9999 -9999 -9999 -9999 -9999 -9999 -9999 -9999 -9999

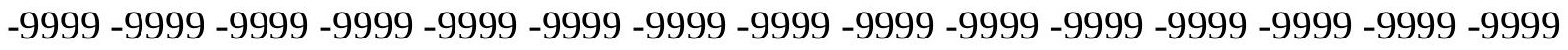
-9999 -9999 -9999 -9999 -9999 -9999 -9999 -9999 -9999 -9999 -9999 -9999 -9999 -9999 -9999 -9999 -9999 -9999 -9999 -9999 -9999 -9999 -9999 -9999 -9999 -9999 -9999 -9999 -9999 -9999 -9999 -9999 -9999 -9999 -9999 -9999 -9999 -9999 -9999 -9999 -9999 -9999 -9999 -9999 -9999

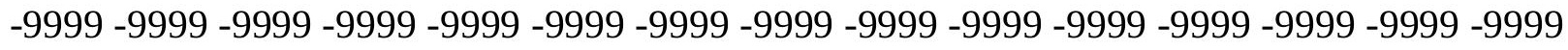

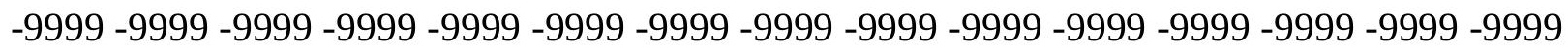
-9999 -9999 -9999 -9999 -9999 -9999 -9999 -9999 -9999 -9999 -9999 -9999 -9999 -9999 -9999 -9999 -9999 -9999 -9999 -9999 -9999 -9999 -9999 -9999 -9999 -9999 -9999 -9999 -9999 -9999 -9999 -9999 -9999 -9999 -9999 -9999 -9999 -9999 -9999 -9999 -9999 -9999 -9999 -9999 -9999 -9999 -9999 92.95947265625 88.69246673584 84.12069702148 79.85370635986 75.5867080688571 .9292907714868 .2718734741265 .2240066528362 .48094940186 59.7378807067955 .7756805419951 .8134689331148 .1560516357444 .49863052368 40.8412094116239 .0125007629437 .4885711669935 .6598587036134 .13592910767 32.9167900085431 .6976509094230 .7833003997829 .5641593933128 .64979934692 27.7354507446326 .8210906982425 .906740188624 .9923801422124 .38281059265 23.7732391357422 .8588790893621 .9445304870620 .7253894805919 .50625038147 17.9823207855216 .4584007263214 .6296901702913 .1057596206711 .27705001831 9.7531242370618 .5339832305917 .3148431777956 .4004869461065 .486132144928 5.1813468933114 .5717768669133 .9622070789343 .0478510856632 .133496046066 $1.21914100647 .6095703244209-9999-.609570324421-1.52392601967-2.43828105927$ -3.35263609886-4.57177686691 -5.48613214493-6.095703125 -6.7052731514 -7.3148431778 $-7.3148431778-7.01005792618-6.7052731514-6.40048694611-6.40048694611$ $-6.40048694611-7.01005792618-7.3148431778-7.61962795258-7.61962795258$ -7.3148431778 -6.7052731514-6.095703125 -5.48613214493 -4.57177686691 -3.65742206573 -3.04785108566 -1.82871103287-.914355397224-9999.9143553972244 2.133496046066 3.0478510856634 .2669920921335 .4861321449286 .4004869461067 .619627952576 8.5339832305919 .75312423706110 .9722604751612 .191410064713 .41055011749 14.934470176716 .1536102294917 .6775398254419 .2014598846420 .72538948059 22.2493095397923 .7732391357424 .9923801422126 .2115192413327 .4306602478 28.3450202941929 .2593708038330 .4785099029532 .3072204589834 .44071960449 35.6598587036132 .0024414062528 .3450202941941 .7555618286126 .51630973816 -9999 
-9999 -9999 -9999 -9999 -9999 -9999 -9999 -9999 -9999 -9999 -9999 -9999 -9999 -9999 -9999 -9999 -9999 -9999 -9999 -9999 -9999 -9999 -9999 -9999 -9999 -9999 -9999 -9999 -9999 -9999 -

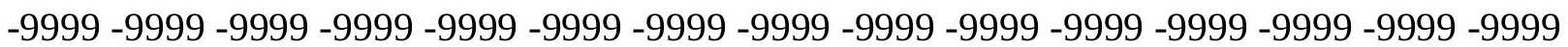

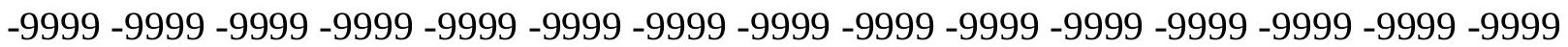
-9999 -9999-9999

-9999 -9999 -9999 -9999 -9999 -9999 -9999 -9999 -9999 -9999 -9999 -9999 -9999 -9999 -9999 -9999 -9999 -9999 -9999 -9999 -9999 -9999 -9999 -9999 -9999 -9999 -9999 -9999 -9999 -9999 -9999 -9999 -9999 -9999 -9999 -9999 -9999 -9999 -9999 -9999 -9999 -9999 -9999 -9999 -9999 -9999 -9999 -9999 -9999 -9999 -9999 -9999 -9999 -9999 -9999 -9999 -9999 -9999 -9999 -9999 -9999 -9999 -9999 -9999 -9999 -9999 -9999 -9999 -9999 -9999 -9999 -9999 -9999 -9999 -9999

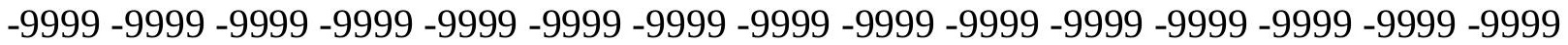
-9999 -9999 -9999 -9999 -9999 -9999 -9999 -9999 -9999 -9999 -9999 -9999 -9999 -9999 -9999 -9999 -9999 -9999 -9999 -9999 -9999 -9999 -9999 -9999 -9999 -9999 -9999 -9999 -9999 -9999 -9999 -9999 -9999 -9999 -9999 -9999 -9999 -9999 -9999 -9999 -9999 -9999 -9999 -9999 -9999 -9999 -9999 -9999 -9999 -9999 -9999 -9999 -9999 -9999 -9999 -9999 -9999 -9999 -9999 -9999 -9999 -9999 -9999 -9999 -9999 -9999 -9999 -9999 -9999 -9999 -9999 -9999 -9999 -9999 -9999

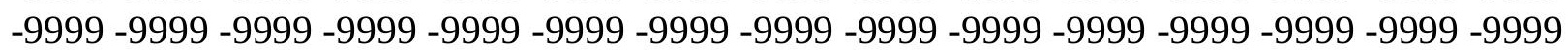
-9999 -9999 -9999 -9999 -9999 -9999 -9999 -9999 -9999 -9999 -9999 -9999 -9999 -9999 -9999 -999 -9999 -9999 -9999 -9999 -9999 -9999 -9999 -9999 -9999 -9999 -9999 -9999 -9999 -9999 -9999 -9999 -9999 -9999-9999 87.16854858398 81.98719787598 77.72020721436 74.0627822876 71.014930725168 .2718734741265 .5288009643662 .7857398986859 .43310165405 56.0804595947352 .4230384826749 .0704002380446 .0225486755443 .88906097412 41.7555618286139 .9268493652338 .0981407165536 .2694282531734 .74551010132 33.2215805053732 .0024414062530 .4785099029529 .2593708038328 .34502029419 27.1258792877226 .2115192413325 .6019496917724 .6875991821323 .77323913574 22.8588790893621 .6397399902320 .4206008911118 .8966808319117 .67753982544 16.1536102294914 .6296901702913 .1057596206711 .8866195678710 .66748046875 9.448339462288 .5339832305917 .9244132041937 .3148431777956 .705273151398 6.0957031255 .1813468933114 .5717768669133 .6574220657353 .047851085663 2.1334960460661 .523926019669 .9143553972244 -9999-.914355397224-1.82871103287 -2.74306607246 -3.35263609886 -3.96220707893 -4.57177686691 -4.57177686691 -3.96220707893 -3.04785108566 -2.43828105927 -2.43828105927 -2.74306607246 $-3.35263609886-4.26699209213-4.87656211853-4.87656211853-4.87656211853$ $-4.26699209213-3.96220707893-3.35263609886-2.74306607246-2.13349604607$ -1.21914100647-.304785102606 .3047851026058 1.21914100647 2.133496046066 3.3526360988624 .2669920921335 .4861321449286 .4004869461067 .619627952576 8.8387689590459 .75312423706110 .9722604751612 .191410064713 .41055011749 14.6296901702915 .8488302230817 .3727493286118 .5918903350820 .11581993103 21.6397399902322 .8588790893624 .3828105926525 .6019496917726 .82109069824 27.7354507446328 .3450202941928 .9545898437529 .8689403533932 .00244140625 33.5263595581133 .8311500549331 .6976509094228 .6497993469227 .12587928772 28.04022979736 -9999 -9999 -9999 -9999 -9999 -9999 -9999 -9999 -9999 -9999 -9999 -9999 -9999 -9999 -9999 -9999 -9999 -9999 -9999 -9999 -9999 -9999 -9999 -9999 -9999 -9999 -9999 -9999 -9999 -9999 -9999 -9999 -9999 -9999 -9999 -9999 -9999 -9999 -9999 -9999 -9999 -9999 -

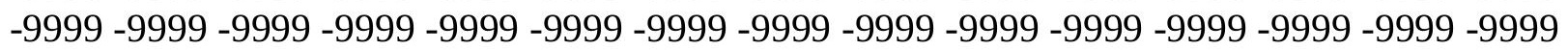
-9999 -9999 -9999 -9999 -9999 -9999 -9999 
-9999 -9999 -9999 -9999 -9999 -9999 -9999 -9999 -9999 -9999 -9999 -9999 -9999 -9999 -9999 -9999 -9999 -9999 -9999 -9999 -9999 -9999 -9999 -9999 -9999 -9999 -9999 -9999 -9999 -9999 -9999 -9999 -9999 -9999 -9999 -9999 -9999 -9999 -9999 -9999 -9999 -9999 -9999 -9999 -9999 -9999 -9999 -9999 -9999 -9999 -9999 -9999 -9999 -9999 -9999 -9999 -9999 -9999 -9999 -9999 -9999 -9999 -9999 -9999 -9999 -9999 -9999 -9999 -9999 -9999 -9999 -9999 -9999 -9999 -9999 -9999 -9999 -9999 -9999 -9999 -9999 -9999 -9999 -9999 -9999 -9999 -9999 -9999 -9999 -9999 -9999 -9999 -9999 -9999 -9999 -9999 -9999 -9999 -9999 -9999 -9999 -9999 -9999 -9999 -9999

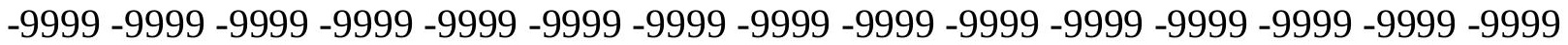

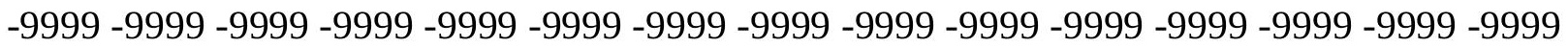
-9999 -9999 -9999 -9999 -9999 -9999 -9999 -9999 -9999 -9999 -9999 -9999 -9999 -9999 -9999 -

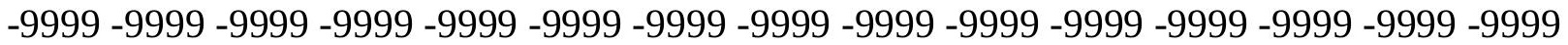
-9999 -9999 -9999 -9999 -9999 -9999 -9999 -9999 -9999 -9999 -9999 -9999 -9999 -9999 -9999

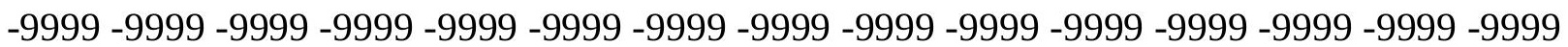
-9999 -9999 -9999 -9999 -9999 -9999 -9999 -9999 -9999 -9999 -9999 -9999 -9999 -9999 -9999 -9999 -9999 -9999 -9999 -9999 85.33984375 79.8537063598676 .19628143311 73.1484298706170 .7101516723668 .2718734741265 .5288009643662 .78573989868 60.0426712036156 .9948196411154 .2517509460451 .8134689331149 .37519073486 46.9369087219244 .4986305236842 .0603485107439 .9268493652337 .79335021973 36.2694282531734 .4407196044932 .9167900085431 .3928699493430 .17373085022 28.6497993469227 .7354507446326 .8210906982425 .906740188624 .99238014221 23.7732391357422 .8588790893621 .6397399902320 .1158199310318 .89668083191 17.37274932861 16.15361022949 14.9344701767 13.715330123912.49619007111 11.5818300247210 .667480468759 .7531242370619 .1435537338268 .533983230591 7.9244132041937 .3148431777956 .4004869461065 .7909169197085 .181346893311 4.5717768669133 .6574220657353 .0478510856632 .1334960460661 .21914100647 .6095703244209-9999 -.609570324421 -.914355397224 -1.21914100647 - 1.21914100647 -9999.9143553972244 1.828711032867 2.133496046066 1.828711032867.6095703244209 -.304785102606 -1.52392601967 -2.13349604607 -1.82871103287 -1.52392601967 -1.21914100647 -.914355397224-.609570324421 -9999.3047851026058.9143553972244 1.8287110328672 .7430660724643 .6574220657354 .5717768669135 .790916919708 6.7052731513987 .6196279525768 .8387689590459 .75312423706110 .97226047516 12.191410064713 .4105501174914 .3248996734615 .8488302230817 .06797027588 18.28710937519 .5062503814721 .0301704406722 .2493095397923 .77323913574 24.9923801422126 .2115192413327 .1258792877228 .0402297973628 .64979934692 29.2593708038330 .1737308502231 .6976509094232 .6120109558132 .61201095581 31.0880794525128 .3450202941929 .2593708038329 .86894035339 -9999 -9999 -9999 -9999 -9999 -9999 -9999 -9999 -9999 -9999 -9999 -9999 -9999 -9999 -9999 -9999 -9999 -9999 -9999

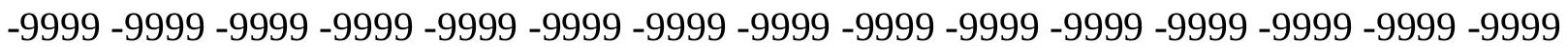
-9999 -9999 -9999 -9999 -9999 -9999 -9999 -9999 -9999 -9999 -9999 -9999 -9999 -9999 -9999 -9999 -9999 -9999 -9999 -9999 -9999 -9999 -9999 -9999 -9999 -9999 -9999 -9999 -9999 -9999 -9999 -9999 -9999 -9999 -9999 -9999 -9999 -9999 -9999 -9999 -9999 -9999 -9999 -9999 -9999

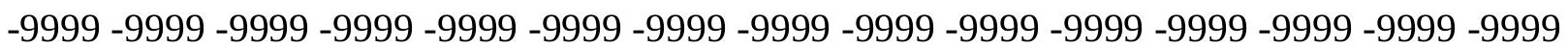
-9999 -9999 -9999 -9999 -9999 -9999 -9999 -9999 -9999 -9999 -9999 -9999 -9999 -9999 -9999 -9999 -9999 -9999 -9999 -9999 -9999 -9999 -9999 -9999 -9999 -9999 -9999 -9999 -9999 -9999 -9999 -9999 -9999 -9999 -9999 -9999 -9999 -9999 -9999 -9999 -9999 -9999 -9999 -9999 -9999

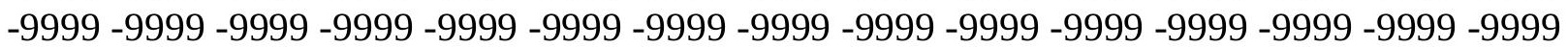


-9999 -9999 -9999 -9999 -9999 -9999 -9999 -9999 -9999 -9999 -9999 -9999 -9999 -9999 -9999 -9999 -9999 -9999 -9999 -9999 -9999 -9999 -9999 -9999 -9999 -9999 -9999 -9999 -9999 -9999 -9999 -9999 -9999 -9999 -9999 -9999 -9999 -9999 -9999 -9999 -9999 -9999 -9999 -9999 -9999 -9999 -9999 -9999 -9999 -9999 -9999 -9999 -9999 -9999 -9999 -9999 -9999 -9999 -9999 -9999 -9999 -9999 -9999 -9999 -9999 -9999 -9999 -9999 -9999 -9999 -9999 -9999 -9999 -9999 -9999 -9999 -9999 -9999 -9999 -9999 -9999 -9999 -9999 -9999 -9999 -9999 -9999 -9999 -9999 -9999 -9999 -9999 -9999 -9999 -9999 -9999 -9999 -9999 -9999 -9999 -9999 -9999 -9999 -9999 -9999 -9999 -9999 -9999 -9999 -9999 -9999 -9999 -9999 -9999 -9999 -9999 -9999 -9999 -9999 -9999 -9999 -9999 -9999 -9999 -9999 -9999 83.8159103393678 .6345596313575 .58670806885 72.8436431884870 .7101516723668 .2718734741266 .1383666992263 .70008850098 61.5666007995659 .1283111572357 .2995986938554 .8613204956152 .11825942993 49.0704002380446 .3273391723643 .5842704772941 .4507789611839 .31727981567 37.1837806701735 .3550796508833 .8311500549332 .0024414062530 .47850990295 29.5641593933128 .3450202941927 .430660247826 .2115192413324 .99238014221 24.0780296325722 .8588790893621 .6397399902320 .1158199310318 .89668083191 17.6775398254416 .4584007263215 .2392597198514 .3248996734613 .41055011749 12.4961900711111 .8866195678710 .9722604751610 .362689971929 .753124237061 9.1435537338268 .5339832305917 .9244132041937 .0100579261786 .400486946106 5.7909169197085 .1813468933114 .5717768669133 .6574220657353 .047851085663 2.4382810592652 .1334960460662 .1334960460662 .1334960460662 .743066072464 3.9622070789345 .4861321449287 .0100579261787 .6196279525767 .314843177795 6.0957031253 .9622070789341 .8287110328671 .5239260196691 .21914100647 1.219141006471 .5239260196691 .5239260196691 .5239260196691 .828711032867 2.4382810592653 .0478510856633 .6574220657354 .2669920921335 .181346893311 6.0957031257 .0100579261787 .9244132041939 .14355373382610 .05790996552 11.2770500183112 .191410064713 .4105501174914 .3248996734615 .54403972626 16.7631797790517 .9823207855219 .2014598846420 .4206008911121 .94453048706 23.1636695861824 .3828105926525 .6019496917726 .8210906982427 .73545074463 28.6497993469229 .2593708038329 .8689403533930 .7833003997831 .39286994934 $32.0024414062531 .6976509094231 .0880794525130 .7833003997831 .39286994934-9999$ -9999 -9999 -9999 -9999 -9999 -9999 -9999 -9999 -9999 -9999 -9999 -9999 -9999 -9999 -9999 -9999 -9999 -9999 -9999 -9999 -9999 -9999 -9999 -9999 -9999 -9999 -9999 -9999 -9999 -9999 -9999 -9999 -9999 -9999 -9999 -9999 -9999 -9999 -9999 -9999 -9999 -9999 -9999 -9999 -9999 -9999 -9999 -9999 -9999 -9999 -9999 -9999 -9999 -9999 -9999 -9999 -9999 -9999 -9999 -9999 -9999 -9999-9999-9999

-9999 -9999 -9999 -9999 -9999 -9999 -9999 -9999 -9999 -9999 -9999 -9999 -9999 -9999 -9999

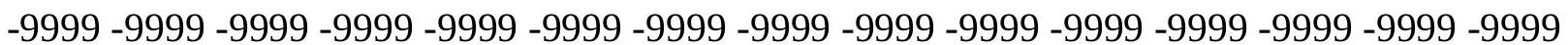

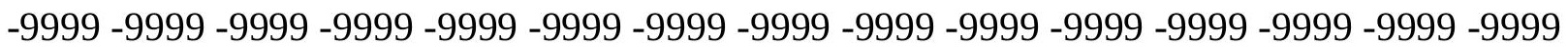
-9999 -9999 -9999 -9999 -9999 -9999 -9999 -9999 -9999 -9999 -9999 -9999 -9999 -9999 -9999 -9999 -9999 -9999 -9999 -9999 -9999 -9999 -9999 -9999 -9999 -9999 -9999 -9999 - -9999 -9999 -9999 -9999 -9999 -9999 -9999 -9999 -9999 -9999 -9999 -9999 -9999 -9999 -9999 -9999 -9999

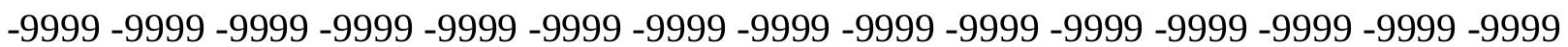
-9999 -9999 -9999 -9999 -9999 -9999 -9999 -9999 -9999 -9999 -9999 -9999 -9999 -9999 -9999 -9999 -9999 -9999 -9999 -9999 -9999 -9999 -9999 -9999 -9999 -9999 -9999 -9999 -9999 -9999 -9999 -9999 -9999 -9999 -9999 -9999 -9999 -9999 -9999 -9999 -9999 -9999 -9999 -9999 -9999

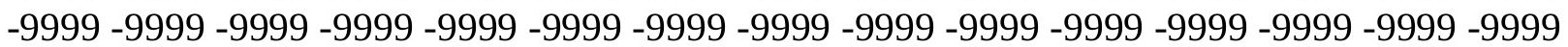


-9999 -9999 -9999 -9999 -9999 -9999 -9999 -9999 -9999 -9999 -9999 -9999 -9999 -9999 -9999 -9999 -9999 -9999 -9999 -9999 -9999 -9999 -9999 -9999 -9999 -9999 -9999 -9999 -9999 -9999 -9999 -9999 -9999 -9999 -9999 -9999 -9999 -9999 -9999 -9999 -9999 -9999 -9999 -9999 -9999 -9999 -9999 -9999 -9999 -9999 -9999 -9999 83.206336975178 .0249862670975 .28192901611 73.1484298706171 .014930725169 .1862335205167 .3575134277365 .52880096436 63.7000885009862 .1761703491260 .3474502563556 .9948196411153 .64218139648 50.2895507812547 .5464782714844 .8034095764242 .3651313781740 .23163986206 38.0981407165536 .2694282531734 .4407196044932 .9167900085431 .39286994934 30.1737308502228 .9545898437527 .7354507446326 .5163097381625 .29715919495 24.0780296325722 .8588790893621 .6397399902320 .4206008911119 .20145988464 17.9823207855217 .0679702758816 .1536102294915 .2392597198514 .32489967346 13.4105501174912 .8009700775112 .191410064711 .5818300247210 .97226047516 10.362689971929 .7531242370619 .1435537338268 .5339832305917 .924413204193 7.3148431777956 .7052731513986 .0957031255 .7909169197085 .486132144928 5.4861321449285 .4861321449286 .0957031257 .3148431777958 .838768959045 10.6674804687512 .4961900711113 .4105501174913 .4105501174912 .1914100647 9.7531242370617 .3148431777956 .0957031255 .1813468933114 .87656211853 4.5717768669134 .2669920921334 .2669920921334 .2669920921334 .571776866913 4.876562118535 .4861321449286 .0957031256 .7052731513987 .619627952576 8.5339832305919 .4483394622810 .3626899719211 .2770500183112 .49619007111 13.4105501174914 .6296901702915 .5440397262616 .7631797790517 .98232078552 19.2014598846420 .1158199310321 .334960937522 .5541000366223 .77323913574 24.9923801422126 .2115192413327 .430660247828 .3450202941929 .25937080383 29.8689403533930 .4785099029531 .0880794525131 .3928699493431 .69765090942 31.3928699493432 .3072204589832 .9167900085433 .83115005493 -9999 -9999 -9999 -9999 -9999 -9999 -9999 -9999 -9999 -9999 -9999 -9999 -9999 -9999 -9999 -9999 -9999 -9999 -9999 -9999 -9999 -9999 -9999 -9999 -9999 -9999 -9999 -9999 -9999 -9999 -9999 -9999 -9999 -9999 -9999 -9999 -9999 -9999 -9999 -9999 -9999 -9999 -9999 -9999 -9999 -9999 -9999 -9999 -9999

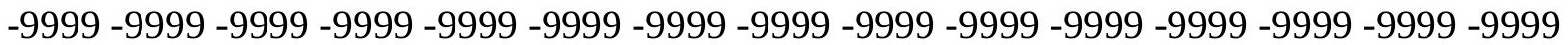
$-9999$

-9999 -9999 -9999 -9999 -9999 -9999 -9999 -9999 -9999 -9999 -9999 -9999 -9999 -9999 -9999 -9999 -9999 -9999 -9999 -9999 -9999 -9999 -9999 -9999 -9999 -9999 -9999 -9999 -9999 -9999 -9999 -9999 -9999 -9999 -9999 -9999 -9999 -9999 -9999 -9999 -9999 -9999 -9999 -9999 -9999 -9999 -9999 -9999 -9999 -9999 -9999 -9999 -9999 -9999 -9999 -9999 -9999 -9999 -9999 -9999 -

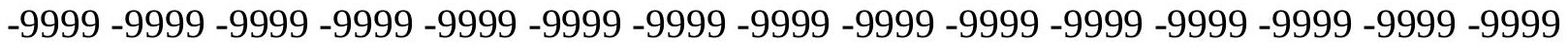
-9999 -9999 -9999 -9999 -9999 -9999 -9999 -9999 -9999 -9999 -9999 -9999 -9999 -9999 -9999 -9999 -9999 -9999 -9999 -9999 -9999 -9999 -9999 -9999 -9999 -9999 -9999 -9999 -9999 -9999

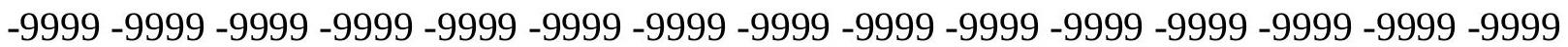
-9999 -9999 -9999 -9999 -9999 -9999 -9999 -9999 -9999 -9999 -9999 -9999 -9999 -9999 -9999 -9999 -9999 -9999 -9999 -9999 -9999 -9999 -9999 -9999 -9999 -9999 -9999 -9999 -9999 -9999 -

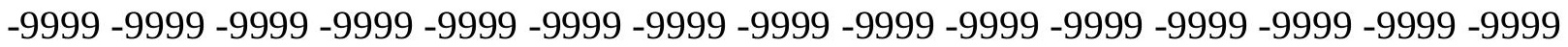
-9999 -9999 -9999 -9999 -9999 -9999 -9999 -9999 -9999 -9999 -9999 -9999 -9999 -9999 -9999 -9999 -9999 -9999 -9999 -9999 -9999 -9999 -9999 -9999 -9999 -9999 -9999 -9999 -9999 -9999 -9999 -9999 -9999 -9999 -9999 -9999 -9999 -9999 -9999 -9999 -9999 -9999 -9999 -9999 -9999 -9999 -9999 -9999 -9999 -9999 -9999 -9999 -9999 83.2063369751 78.32978057861 75.5867080688573 .7580032348672 .2340774536170 .7101516723669 .49101257324 
67.9670867919966 .1383666992264 .004882812560 .9570198059157 .60438919067 54.2517509460450 .8991203308148 .1560516357445 .717769622843 .27949142456 41.1459884643639 .0125007629437 .1837806701735 .3550796508833 .83115005493 32.3072204589831 .0880794525129 .5641593933128 .3450202941927 .12587928772 25.906740188624 .6875991821323 .4684505462622 .2493095397921 .03017044067 19.811029434218 .5918903350817 .6775398254416 .7631797790515 .84883022308 15.2392597198514 .6296901702913 .715330123913 .1057596206712 .49619007111 11.8866195678711 .2770500183110 .6674804687510 .362689971929 .753124237061 9.1435537338268 .8387689590458 .5339832305918 .2291984558118 .229198455811 8.5339832305919 .14355373382610 .0579099655211 .5818300247213 .41055011749 15.5440397262617 .6775398254419 .5062503814719 .811029434218 .287109375 15.5440397262612 .8009700775110 .972260475169 .448339462288 .533983230591 7.6196279525767 .3148431777957 .0100579261786 .7052731513986 .705273151398 7.0100579261787 .3148431777957 .9244132041938 .5339832305919 .143553733826 10.0579099655210 .9722604751611 .8866195678712 .8009700775113 .7153301239 14.934470176715 .8488302230816 .7631797790517 .9823207855218 .89668083191 20.1158199310321 .334960937522 .2493095397923 .4684505462624 .68759918213 25.906740188627 .1258792877228 .0402297973629 .2593708038329 .86894035339 30.4785099029531 .0880794525131 .3928699493448 .4608306884833 .22158050537 34.1359291076735 .0502891540535 .6598587036135 .96464920044 -9999 -9999 -9999-9999 -9999 -9999 -9999 -9999 -9999 -9999 -9999 -9999 -9999 -9999 -9999 -9999 -9999 -9999 -9999 -9999 -9999 -9999 -9999 -9999 -9999 -9999 -9999 -9999 -9999 -9999 -9999 -9999 -9999 -9999 -9999 -9999 -9999 -9999 -9999 -9999 -9999 -9999 -9999 -9999 -9999 -9999 -9999 -9999 -9999 -

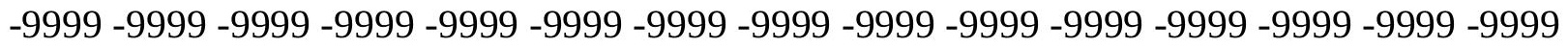
$-9999$

-9999 -9999 -9999 -9999 -9999 -9999 -9999 -9999 -9999 -9999 -9999 -9999 -9999 -9999 -9999 -9999 -9999 -9999 -9999 -9999 -9999 -9999 -9999 -9999 -9999 -9999 -9999 -9999 -9999 -9999 -

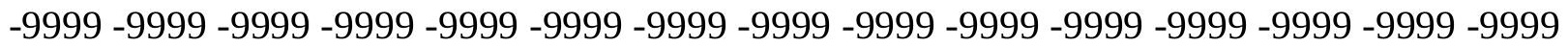
-9999 -9999 -9999 -9999 -9999 -9999 -9999 -9999 -9999 -9999 -9999 -9999 -9999 -9999 -9999

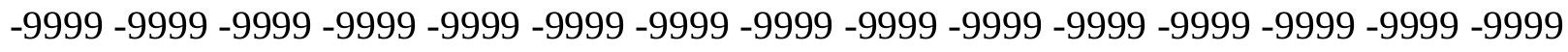
-9999 -9999 -9999 -9999 -9999 -9999 -9999 -9999 -9999 -9999 -9999 -9999 -9999 -9999 -9999

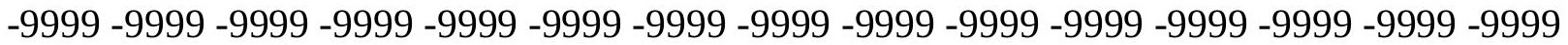

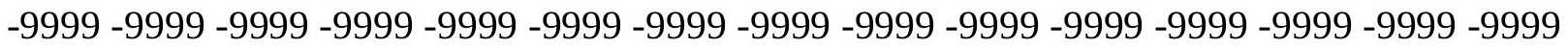
-9999 -9999 -9999 -9999 -9999 -9999 -9999 -9999 -9999 -9999 -9999 -9999 -9999 -9999 -9999 -9999 -9999 -9999 -9999 -9999 -9999 -9999 -9999 -9999 -9999 -9999 -9999 -9999 -9999 -9999 -9999 -9999 -9999 -9999 -9999 -9999 -9999 -9999 -9999 -9999 -9999 -9999 -9999 -9999 -9999

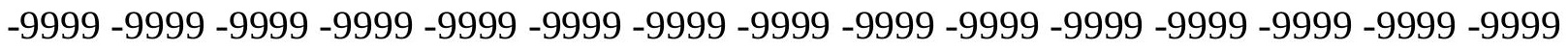

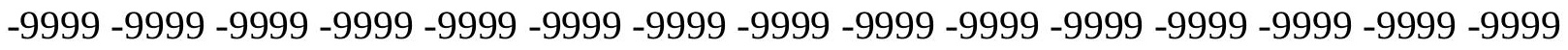
-9999 -9999 -9999 -9999 -9999 -9999 -9999 -9999 -9999 -9999 -9999 -9999 -9999 -9999 -9999 -9999 -9999 -9999 -9999 -9999 -9999 -9999 -9999 -9999 83.8159103393679 .54891967773 76.8058471679775 .2819290161174 .062782287672 .8436431884871 .62449645996 69.7957916259867 .3575134277364 .3096618652360 .9570198059157 .60438919067 54.5565414428751 .5086898803749 .0704002380446 .3273391723644 .19384002686 42.0603485107439 .9268493652338 .0981407165536 .2694282531734 .74551010132 33.2215805053731 .6976509094230 .1737308502228 .9545898437527 .73545074463 26.2115192413324 .9923801422123 .7732391357422 .5541000366221 .63973999023 
20.4206008911119 .5062503814718 .5918903350817 .6775398254416 .76317977905 16.1536102294915 .5440397262614 .934470176714 .3248996734613 .7153301239 13.1057596206712 .4961900711111 .8866195678711 .5818300247211 .27705001831 10.9722604751610 .6674804687510 .6674804687510 .9722604751611 .58183002472 12.191410064713 .4105501174915 .2392597198517 .0679702758819 .50625038147 21.9445304870624 .0780296325725 .6019496917723 .1636695861820 .42060089111 17.3727493286115 .2392597198513 .4105501174911 .8866195678710 .97226047516 10.057909965529 .448339462289 .1435537338269 .1435537338269 .143553733826 9.448339462289 .75312423706110 .3626899719210 .9722604751611 .58183002472 12.4961900711113 .4105501174914 .3248996734615 .2392597198516 .15361022949 17.0679702758818 .28710937519 .2014598846420 .1158199310321 .3349609375 22.24930953979 23.46845054626 24.38281059265 25.6019496917726.51630973816 27.7354507446328 .9545898437529 .8689403533930 .4785099029531 .08807945251 31.3928699493432 .9167900085434 .4407196044935 .9646492004436 .87900161743 37.4885711669938 .0981407165538 .4029312133838 .70771026611 -9999 -9999 -9999 -9999 -9999 -9999 -9999 -9999 -9999 -9999 -9999 -9999 -9999 -9999 -9999 -9999 -9999 -9999 -9999 -9999 -9999 -9999 -9999 -9999 -9999 -9999 -9999 -9999 -9999 -9999 -9999 -9999 -9999 -9999 -9999 -9999 -9999 -9999 -9999 -9999 -9999 -9999 -9999 -9999 -9999 -9999 -9999 -9999 -9999 -

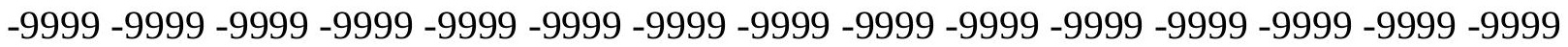

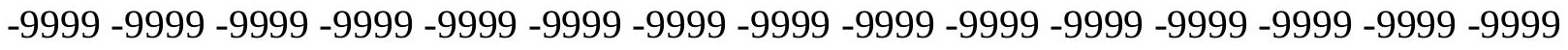

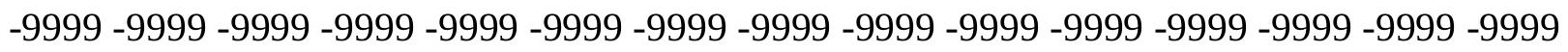
-9999 -9999 -9999 -9999 -9999 -9999 -9999 -9999 -9999 -9999 -9999 -9999 -9999 -9999 -9999 -9999 -9999 -9999 -9999 -9999 -9999 -9999 -9999 -9999 -9999 -9999 -9999 -9999 -9999 -9999 -

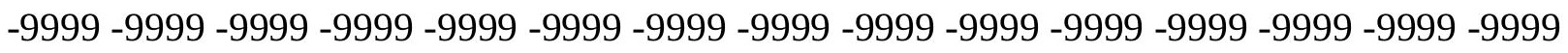

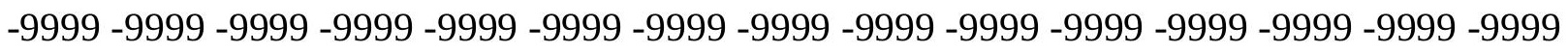
-9999 -9999 -9999 -9999 -9999 -9999 -9999 -9999 -9999 -9999 -9999 -9999 -9999 -9999 -9999

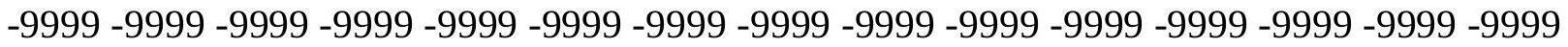

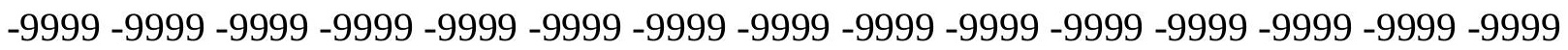
-9999 -9999 -9999 -9999 -9999 -9999 -9999 -9999 -9999 -9999 -9999 -9999 -9999 -9999 -9999 -9999 -9999 -9999 -9999 -9999 -9999 -9999 -9999 -9999 -9999 -9999 -9999 -9999 -9999 -9999 -9999 -9999 -9999 -9999 -9999 -9999 -9999 -9999 -9999-9999 -9999 -9999 -9999 -9999 -9999 -9999 -9999 -9999 -9999 -9999 -9999 -9999 -9999 -9999 -9999 -9999 -9999 -9999 -9999 -9999 -

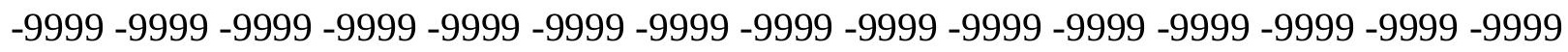
-9999 -9999 -9999 -9999-9999 -9999-9999 -9999 -9999-9999 85.33984375 81.68241119385 78.6345596313577 .4154205322376 .5010681152374 .9771423339873 .14842987061 70.4053573608467 .3575134277364 .3096618652360 .9570198059157 .9091796875 54.8613204956152 .1182594299349 .6799812316947 .2416992187544 .80340957642 42.66992187540 .8412094116238 .7077102661137 .1837806701735 .35507965088 33.8311500549332 .3072204589831 .0880794525129 .5641593933128 .34502029419 27.1258792877225 .6019496917724 .6875991821323 .4684505462622 .24930953979 21.334960937520 .4206008911119 .5062503814718 .5918903350817 .98232078552 17.0679702758816 .4584007263215 .8488302230815 .2392597198514 .62969017029 14.3248996734613 .715330123913 .4105501174913 .1057596206712 .80097007751 12.8009700775113 .1057596206713 .4105501174914 .0201196670514 .9344701767 16.4584007263217 .9823207855220 .1158199310322 .5541000366224 .68759918213 26.5163097381627 .430660247825 .906740188623 .4684505462621 .03017044067 
18.5918903350816 .4584007263214 .934470176713 .715330123912 .49619007111 11.8866195678711 .2770500183111 .2770500183111 .2770500183111 .27705001831 11.5818300247212 .191410064712 .8009700775113 .4105501174914 .02011966705 14.934470176715 .8488302230816 .4584007263217 .3727493286118 .59189033508 19.5062503814720 .4206008911121 .334960937522 .2493095397923 .46845054626 24.3828105926525 .2971591949526 .2115192413327 .430660247828 .64979934692 29.5641593933130 .4785099029531 .0880794525132 .6120109558134 .44071960449 35.9646492004437 .4885711669938 .7077102661139 .622070312540 .23163986206 40.8412094116240 .8412094116241 .14598846436 -9999 -9999 -9999 -9999 -9999 -9999 -9999 -9999 -9999 -9999 -9999 -9999 -9999 -9999 -9999 -9999 -9999 -9999 -9999 -9999 -9999 -9999 -9999 -9999 -9999 -9999 -9999 -9999 -9999 -9999 -9999 -9999 -9999 -9999 -9999 -9999 -9999 -999 -9999 -9999 -9999 -9999 -9999 -9999 -9999 -9999 -9999 -9999 -9999 -9999 -9999 -9999 -9999 -999 -9999 -9999 -9999 -9999 -9999 -9999 -9999 -9999 -9999 -9999 -9999 -9999 -

-9999 -9999 -9999 -9999 -9999 -9999 -9999 -9999 -9999 -9999 -9999 -9999 -9999 -9999 - 9999 -9999 -9999 -9999 -9999 -9999 -9999 -9999 -9999 -9999 -9999 -9999 -9999 -9999 -9999 -9999

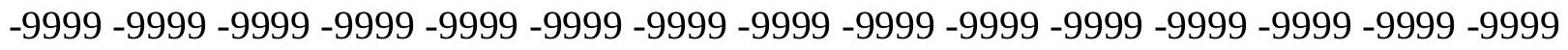

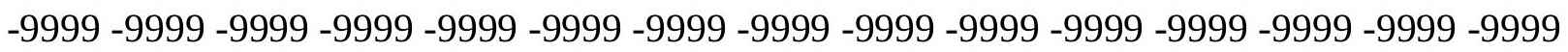
-9999 -9999 -9999 -9999 -9999 -9999 -9999 -9999 -9999 -9999 -9999 -9999 -9999 -9999 -9999 -999 -9999 -9999 -9999 -9999 -9999 -9999 -9999 -9999 -9999 -9999 -9999 -9999 -9999 -9999 -9999

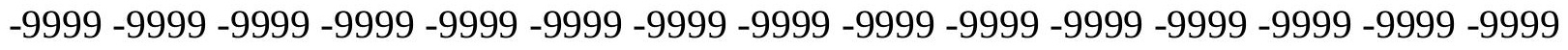
-9999 -9999 -9999 -9999 -9999 -9999 -9999 -9999 -9999 -9999 -9999 -9999 -9999 -9999 -9999 -9999 -9999 -9999 -9999 -9999 -9999 -9999 -9999 -9999 -9999 -9999 -9999 -9999 -9999 -9999 -9999 -9999 -9999 -9999 -9999 -9999 -9999 -9999 -9999 -9999 -9999 -9999-9999-9999-9999 -999 -9999 -9999 -9999 -9999 -9999 -9999 -9999 -9999 -9999 -9999 -9999 -9999 -9999 -9999 -9999 -9999 -9999 -9999 -9999 -9999 -9999 -9999 -9999 -9999 -9999 -9999 -9999 -9999 -9999 -9999 -9999 -9999 -9999 -9999 -9999 -9999 -9999 -9999 -9999 -9999 -9999 -9999 -9999 -9999 -9999 -9999 -9999 -9999 -9999 -9999-9999 -9999 -9999 -9999 -9999 -9999 -9999 -9999 -9999 - 9999 -9999 -9999 -9999 -9999 -9999 -9999-9999 -9999 -9999 -9999 -9999 87.47332763672 84.1206970214880 .7680587768679 .8537063598678 .3297805786176 .19628143311 73.7580032348670 .7101516723667 .3575134277364 .004882812560 .95701980591 58.2139587402355 .4708900451752 .7278289794950 .2895507812547 .85126113892 45.717769622843 .5842704772941 .4507789611839 .622070312537 .79335021973 36.2694282531734 .7455101013233 .2215805053731 .6976509094230 .47850990295 28.9545898437527 .7354507446326 .5163097381625 .2971591949524 .38281059265 23.1636695861822 .2493095397921 .334960937520 .4206008911119 .50625038147 18.8966808319118 .28710937517 .3727493286116 .7631797790516 .15361022949 15.8488302230815 .5440397262614 .934470176714 .934470176714 .62969017029 14.934470176715 .2392597198515 .5440397262616 .4584007263217 .37274932861 18.5918903350820 .4206008911122 .2493095397924 .3828105926526 .21151924133 27.430660247828 .0402297973627 .1258792877225 .2971591949523 .16366958618 21.0301704406718 .8966808319117 .3727493286115 .8488302230814 .9344701767 14.0201196670513 .4105501174913 .1057596206713 .1057596206713 .10575962067 13.4105501174913 .715330123914 .3248996734614 .934470176715 .54403972626 16.4584007263217 .0679702758817 .9823207855218 .8966808319119 .8110294342 20.7253894805921 .6397399902322 .5541000366223 .4684505462624 .38281059265 25.2971591949526 .2115192413327 .1258792877228 .0402297973629 .25937080383 
30.1737308502231 .3928699493433 .5263595581135 .3550796508837 .18378067017 39.0125007629440 .5364189147941 .7555618286142 .3651313781742 .97470092773 43.2794914245643 .2794914245643 .27949142456 -9999 -9999 -9999 -9999 -9999 -9999 -9999 -9999 -9999 -9999 -9999 -9999 -9999 -9999 -9999 -9999 -9999 -9999 -9999 -9999 -9999 -9999 -9999 -9999 -9999 -9999 -9999 -9999 -9999 -9999 -9999 -9999 -9999 -9999-9999 -9999 -9999 -9999 -9999 -9999 -9999 -9999 -9999 -9999 -9999 -9999 -9999 -9999 -9999 -9999 -9999 -9999 -9999 -9999 -9999 -9999 -9999 -9999 -9999 -9999 -9999 -9999 -9999 -9999

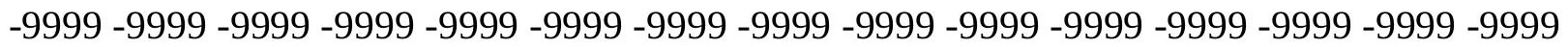

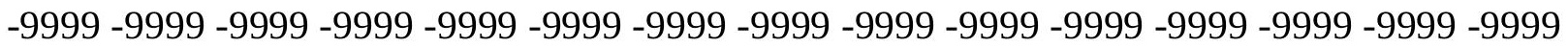
-9999 -9999 -9999 -9999 -9999 -9999 -9999 -9999 -9999 -9999 -9999 -9999 -9999 -9999 -9999 -

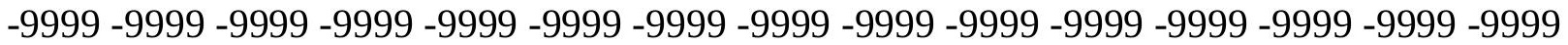
-9999 -9999 -9999 -9999 -9999 -9999 -9999 -9999 -9999 -9999 -9999 -9999 -9999 -9999 -9999 -9999 -9999 -9999 -9999 -9999 -9999 -9999 -9999 -9999 -9999 -9999 -9999 -9999 -9999 -9999 -9999 -9999 -9999 -9999 -9999 -9999 -9999 -9999 -9999 -9999 -9999 -9999 -9999 -9999 -9999 -9999 -9999 -9999 -9999 -9999 -9999 -9999 -9999 -9999 -9999 -9999 -9999 -9999 -9999 -9999

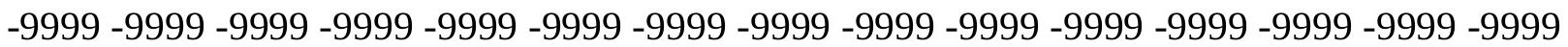

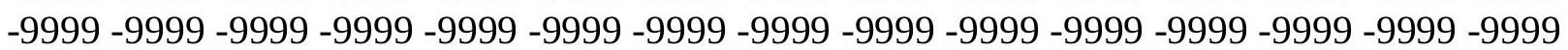
-9999 -9999 -9999 -9999 -9999 -9999 -9999 -9999 -9999 -9999 -9999 -9999 -9999 -9999 -9999 -9999 -9999 -9999 -9999 -9999 -9999 -9999 -9999 -9999 -9999 -9999 -9999 -9999 -9999 -9999 -9999 -9999 -9999 -9999 -9999 -9999 -9999 -9999 -9999 -9999 -9999 -9999 -9999 -9999 -9999 -9999 -9999 -9999 -9999 -9999 -9999 -9999 -9999 -9999 -9999 -9999 -9999 -9999 -9999 -9999 -9999 -9999 -9999 -9999 -9999 -9999 -9999 -9999 -9999 -9999 -9999 -9999 90.21640014648 87.4733276367284 .1206970214881 .9871978759879 .5489196777376 .80584716797 73.7580032348670 .7101516723667 .6623001098664 .6144485473661 .56660079956 58.5187492370655 .7756805419953 .3373985290550 .8991203308148 .46083068848 46.3273391723644 .1938400268642 .3651313781740 .5364189147938 .70771026611 37.1837806701735 .6598587036134 .1359291076732 .6120109558131 .39286994934 30.1737308502228 .6497993469227 .430660247826 .2115192413325 .29715919495 24.0780296325723 .1636695861822 .2493095397921 .6397399902320 .72538948059 19.811029434219 .2014598846418 .5918903350817 .9823207855217 .37274932861 17.0679702758816 .7631797790516 .4584007263216 .4584007263216 .76317977905 17.0679702758817 .3727493286118 .28710937519 .2014598846420 .42060089111 21.9445304870623 .4684505462625 .2971591949526 .8210906982427 .73545074463 28.0402297973627 .430660247825 .906740188624 .3828105926522 .55410003662 20.7253894805919 .2014598846417 .9823207855216 .7631797790516 .15361022949 15.5440397262615 .2392597198514 .934470176714 .934470176715 .23925971985 15.5440397262616 .1536102294916 .4584007263217 .3727493286117 .98232078552 18.5918903350819 .5062503814720 .4206008911121 .0301704406721 .94453048706 22.8588790893623 .7732391357424 .6875991821325 .6019496917726 .51630973816 27.1258792877228 .0402297973628 .9545898437530 .4785099029532 .00244140625 33.8311500549335 .6598587036137 .7933502197339 .9268493652342 .06034851074 43.5842704772944 .4986305236845 .1082000732445 .4129791259845 .7177696228 45.717769622845 .7177696228 -9999 -9999 -9999 -9999 -9999 -9999 -9999 -9999 -9999 -9999 -9999 -9999 -9999 -9999 -9999 -9999 -9999 -9999 -9999 -9999 -9999 -9999 -9999 -9999 -9999 -9999 -9999 -9999 -9999 -9999 -9999 -9999 -9999 -9999 -9999 -9999 -9999 -9999 -9999 -9999

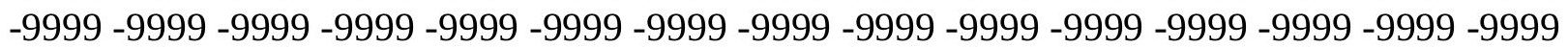


-9999 -9999 -9999 -9999 -9999 -9999 -9999 -9999 -9999

-9999 -9999 -9999 -9999 -9999 -9999 -9999 -9999 -9999 -9999 -9999 -9999 -9999 -9999 -9999

-9999 -9999 -9999 -9999 -9999 -9999 -9999 -9999 -9999 -9999 -9999 -9999 -9999 -9999 -9999

-9999 -9999 -9999 -9999 -9999 -9999 -9999 -9999 -9999 -9999 -9999 -9999 -9999 -9999 -9999

-9999 -9999 -9999 -9999 -9999 -9999 -9999 -9999 -9999 -9999 -9999 -9999 -9999 -9999 -9999 -

-9999 -9999 -9999 -9999 -9999 -9999 -9999 -9999 -9999 -9999 -9999 -9999 -9999 -9999 -9999 -

-9999 -9999 -9999 -9999 -9999 -9999 -9999 -9999 -9999 -9999 -9999 -9999 -9999 -9999 -9999

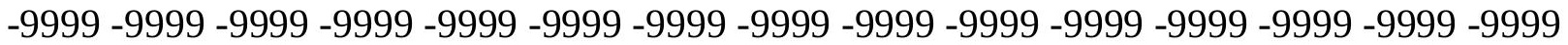

-9999 -9999 -9999 -9999 -9999 -9999 -9999 -9999 -9999 -9999 -9999 -9999 -9999 -9999 -9999

-9999 -9999 -9999 -9999 -9999 -9999 -9999 -9999 -9999 -9999 -9999 -9999 -9999 -9999 -9999 -

-9999 -9999 -9999 -9999 -9999 -9999 -9999 -9999 -9999 -9999 -9999 -9999 -9999 -9999 -9999 -

-9999 -9999 -9999 -9999 -9999 -9999 -9999 -9999 -9999 -9999 -9999 -9999 -9999 -9999 -9999

-9999 -9999 -9999 -9999 -9999 -9999 -9999 -9999 -9999 -9999 -9999 -9999 -9999 -9999 -9999 -

-9999 -9999 -9999 -9999 -9999 -9999 -9999 -9999 -9999 -9999 -9999 -9999 -9999 -9999 -9999 -

-9999 -9999 -9999 -9999 -9999 -9999 -9999 -9999 -9999 -9999 -9999 -9999 -9999 -9999 -9999 -

-9999 -9999 -9999 -9999 -9999 -9999 -9999 -9999 -9999 -9999 -9999 -9999 -9999

93.2642517089890 .5211791992286 .254188537682 .2919769287179 .85370635986

77.110626220774 .062782287671 .014930725167 .9670867919964 .91924285889

61.8713798522959 .1283111572356 .3852500915553 .9469718933151 .50868988037

49.0704002380446 .9369087219244 .8034095764242 .9747009277341 .45077896118

39.622070312538 .0981407165536 .5742111206135 .3550796508833 .83115005493

32.6120109558131 .0880794525129 .8689403533928 .3450202941927 .4306602478

26.2115192413325 .2971591949524 .3828105926523 .4684505462622 .55410003662 21.6397399902321 .0301704406720 .1158199310319 .5062503814719 .20145988464 18.5918903350818 .28710937518 .28710937518 .28710937518 .28710937518 .59189033508 19.2014598846419 .811029434220 .7253894805921 .6397399902323 .16366958618 24.3828105926525 .6019496917726 .8210906982427 .430660247827 .73545074463 27.1258792877226 .2115192413324 .9923801422123 .4684505462621 .94453048706 20.7253894805919 .5062503814718 .5918903350817 .6775398254417 .37274932861 16.7631797790516 .7631797790516 .7631797790517 .0679702758817 .37274932861 17.6775398254418 .28710937518 .8966808319119 .5062503814720 .11581993103 21.0301704406721 .6397399902322 .5541000366223 .4684505462624 .07802963257 24.9923801422125 .906740188626 .5163097381627 .430660247828 .34502029419 29.5641593933130 .7833003997832 .3072204589834 .1359291076735 .96464920044 37.7933502197339 .9268493652342 .0603485107444 .4986305236846 .32733917236 47.2416992187547 .5464782714847 .5464782714847 .8512611389247 .85126113892 47.54647827148 -9999 -9999 -9999 -9999 -9999 -9999 -9999 -9999 -9999 -9999 -9999 -9999 -9999 -9999 -9999 -9999 -9999 -9999 -9999 -9999 -9999 -9999 -9999 -9999 -9999 -9999 -9999 -9999 -9999 -9999 -9999 -9999 -9999 -9999 -9999 -9999 -9999 -9999 -9999 -9999 -9999 -9999 -9999 -9999 -9999 -9999 -9999 -9999 -9999 -9999 -9999 -9999 -9999 -9999 -9999 -9999 -9999 -9999 -9999 -9999 -9999 -9999 -9999-9999

-9999 -9999 -9999 -9999 -9999 -9999 -9999 -9999 -9999 -9999 -9999 -9999 -9999 -9999 -9999 -9999 -9999 -9999 -9999 -9999 -9999 -9999 -9999 -9999 -9999 -9999 -9999 -9999 -9999 -9999 -9999 -9999 -9999 -9999 -9999 -9999 -9999 -9999 -9999 -9999 -9999 -9999 -9999 -9999 -9999 -9999 -9999 -9999 -9999 -9999 -9999 -9999 -9999 -9999 -9999 -9999 -9999 -9999 -9999 -9999

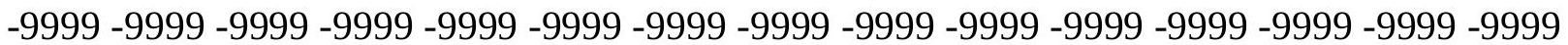


-9999 -9999 -9999 -9999 -9999 -9999 -9999 -9999 -9999 -9999 -9999 -9999 -9999 -9999 -9999 -9999 -9999 -9999 -9999 -9999 -9999 -9999 -9999 -9999 -9999 -9999 -9999 -9999 -9999 -9999 -9999 -9999 -9999 -9999 -9999 -9999 -9999 -9999 -9999 -9999 -9999 -9999 -9999 -9999 -9999 -9999 -9999 -9999 -9999 -9999 -9999 -9999 -9999 -9999 -9999 -9999 -9999 -9999 -9999 -9999 -9999 -9999 -9999 -9999 -9999 -9999 -9999 -9999 -9999 -9999 -9999 -9999 -9999 -9999 -9999 -9999 -9999 -9999 -9999 -9999 -9999 -9999 -9999 -9999 -9999 -9999 -9999 -9999 -9999 -9999 -9999 -9999 -9999 -9999 -9999 -9999 -9999 -9999 -9999 -9999 -9999 -9999 -9999 -9999 -9999

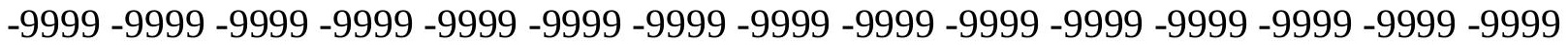

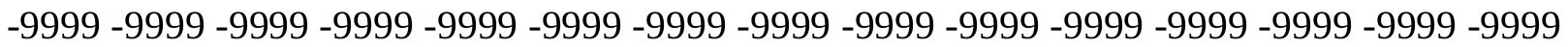
-9999 -9999 -9999 -9999 -9999 -9999 -9999 -9999 -9999 -9999 -9999 -9999 -9999 -9999 94.4833908081190 .5211791992285 .9494018554782 .5967712402380 .15849304199 77.4154205322374 .3675689697371 .3197174072368 .2718734741265 .22400665283 62.4809494018659 .7378807067956 .9948196411154 .5565414428752 .11825942993 49.6799812316947 .8512611389245 .717769622843 .8890609741242 .36513137817 40.8412094116239 .3172798156737 .7933502197336 .5742111206135 .05028915405 33.5263595581132 .3072204589830 .7833003997829 .5641593933128 .64979934692 27.430660247826 .5163097381625 .6019496917724 .6875991821323 .77323913574 22.8588790893621 .9445304870621 .334960937520 .7253894805920 .42060089111 19.811029434219 .811029434219 .811029434219 .811029434219 .8110294342 20.4206008911121 .0301704406721 .6397399902322 .5541000366223 .77323913574 24.6875991821325 .6019496917726 .5163097381627 .1258792877227 .12587928772 26.8210906982425 .906740188624 .9923801422123 .7732391357422 .85887908936 21.6397399902320 .7253894805919 .811029434219 .2014598846418 .89668083191 18.5918903350818 .5918903350818 .5918903350818 .5918903350818 .89668083191 19.5062503814719 .811029434220 .4206008911121 .0301704406721 .63973999023 22.5541000366223 .1636695861824 .0780296325724 .6875991821325 .60194969177 26.2115192413327 .1258792877227 .7354507446328 .9545898437530 .17373085022 31.3928699493432 .9167900085434 .4407196044935 .9646492004437 .79335021973 39.9268493652341 .7555618286143 .8890609741246 .3273391723647 .85126113892 48.765621185349 .3751907348649 .6799812316949 .6799812316949 .67998123169 49.67998123169 -9999 -9999 -9999 -9999 -9999 -9999 -9999 -9999 -9999 -9999 -9999 -9999 -9999 -9999 -9999 -9999 -9999 -9999 -9999 -9999 -9999 -9999 -9999 -9999 -9999 -9999 -9999 -9999 -9999 -9999 -9999 -9999 -9999 -9999 -9999 -9999 -9999 -9999 -9999 -9999 -9999 -9999

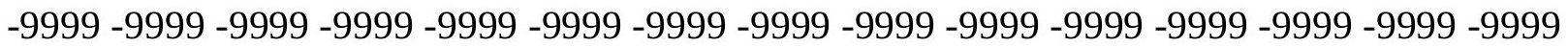
-9999 -9999 -9999 -9999 -9999 -9999 -9999

-9999 -9999 -9999 -9999 -9999 -9999 -9999 -9999 -9999 -9999 -9999 -9999 -9999 -9999 -9999 -9999 -9999 -9999 -9999 -9999 -9999 -9999 -9999 -9999 -9999 -9999 -9999 -9999 -9999 -9999

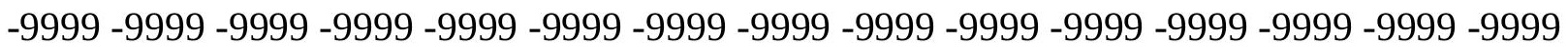
-9999 -9999 -9999 -9999 -9999 -9999 -9999 -9999 -9999 -9999 -9999 -9999 -9999 -9999 -9999 -9999 -9999 -9999 -9999 -9999 -9999 -9999 -9999 -9999 -9999 -9999 -9999 -9999 -9999 -9999 -9999 -9999 -9999 -9999 -9999 -9999 -9999 -9999 -9999 -9999 -9999 -9999 -9999 -9999 -9999

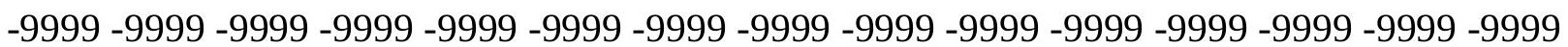
-9999 -9999 -9999 -9999 -9999 -9999 -9999 -9999 -9999 -9999 -9999 -9999 -9999 -9999 -9999 -9999 -9999 -9999 -9999 -9999 -9999 -9999 -9999 -9999 -9999 -9999 -9999 -9999 -9999 -9999 -9999 -9999 -9999 -9999 -9999 -9999 -9999 -9999 -9999 -9999 -9999 -9999 -9999 -9999 -9999

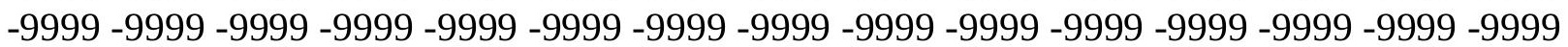


-9999 -9999 -9999 -9999 -9999 -9999 -9999 -9999 -9999 -9999 -9999 -9999 -9999 -9999 -9999 -9999 -9999 -9999 -9999 -9999 -9999 -9999 -9999 -9999 -9999 -9999 -9999 -9999 -9999 -9999 -9999 -9999 -9999 -9999 -9999 -9999 -9999 -9999 -9999 -9999 -9999 -9999 -9999 -9999 -9999 -9999 -9999 -9999 -9999 -9999 -9999 -9999 -9999 -9999 -9999 -9999 -9999 -9999 -9999 -9999 93.8738174438589 .9116134643686 .5589828491283 .206336975180 .46327209473 77.7202072143674 .6723632812571 .6244964599668 .5766525268665 .52880096436 62.7857398986860 .0426712036157 .6043891906754 .8613204956152 .72782897949 50.5943298339848 .4608306884846 .9369087219245 .1082000732443 .58427047729 42.0603485107440 .8412094116239 .3172798156737 .7933502197336 .26942825317 35.0502891540533 .5263595581132 .0024414062531 .0880794525130 .17373085022 29.2593708038328.0402297973627.12587928772 25.906740188624.99238014221 23.7732391357423 .1636695861822 .5541000366221 .9445304870621 .63973999023 21.334960937521 .0301704406721 .0301704406721 .334960937521 .3349609375 21.9445304870622 .5541000366223 .1636695861824 .0780296325724 .68759918213 25.6019496917726 .2115192413326 .5163097381626 .5163097381626 .21151924133 25.6019496917724 .9923801422124 .0780296325723 .1636695861822 .24930953979 21.6397399902321 .0301704406720 .4206008911120 .1158199310320 .11581993103 20.1158199310320 .1158199310320 .4206008911120 .7253894805921 .03017044067 21.334960937521 .9445304870622 .5541000366223 .1636695861823 .77323913574 24.6875991821325 .2971591949525 .906740188626 .8210906982427 .4306602478 28.6497993469229 .5641593933130 .7833003997832 .0024414062533 .22158050537 34.4407196044935 .9646492004437 .7933502197339 .622070312541 .45077896118 43.2794914245645 .4129791259847 .2416992187548 .765621185349 .98476028442 $50.8991203308151 .2038993835451 .5086898803751 .5086898803751 .20389938354-9999$ -9999 -9999 -9999 -9999 -9999 -9999 -9999 -9999 -9999 -9999 -9999 -9999 -9999 -9999 -9999 -9999 -9999 -9999 -9999 -9999 -9999 -9999 -9999 -9999 -9999 -9999 -9999 -9999 -9999 -9999 -9999 -9999 -9999 -9999 -9999 -9999 -9999 -9999 -9999 -9999 -9999 -9999 -9999 -9999 -9999 -

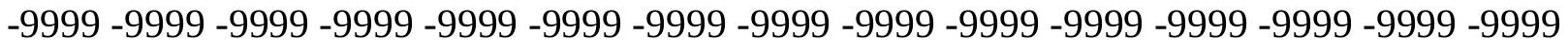
$-9999-9999-9999$

-9999 -9999 -9999 -9999 -9999 -9999 -9999 -9999 -9999 -9999 -9999 -9999 -9999 -9999 -9999 -9999 -9999 -9999 -9999 -9999 -9999 -9999 -9999 -9999 -9999 -9999 -9999 -9999 -9999 -9999 -9999 -9999 -9999 -9999 -9999 -9999 -9999 -9999 -9999 -9999 -9999 -9999 -9999 -9999 -9999 -9999 -9999 -9999 -9999 -9999 -9999 -9999 -9999 -9999 -9999 -9999 -9999 -9999 -9999 -9999 -9999 -9999 -9999 -9999 -9999 -9999 -9999 -9999 -9999 -9999 -9999 -9999 -9999 -9999 -9999

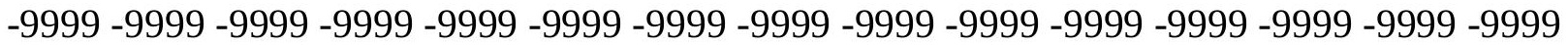
-9999 -9999 -9999 -9999 -9999 -9999 -9999 -9999 -9999 -9999 -9999 -9999 -9999 -9999 -9999

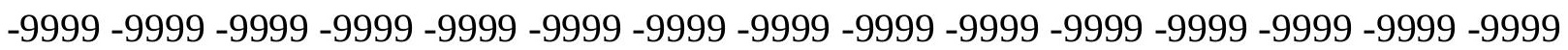

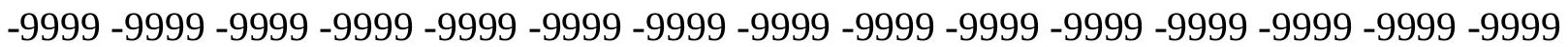
-9999 -9999 -9999 -9999 -9999 -9999 -9999 -9999 -9999 -9999 -9999 -9999 -9999 -9999 -9999 -9999 -9999 -9999 -9999 -9999 -9999 -9999 -9999 -9999 -9999 -9999 -9999 -9999 - -9999 -9999 -9999 -9999 -9999 -9999 -9999 -9999 -9999 -9999 -9999 -9999 -9999 -9999 -9999 -9999 -9999

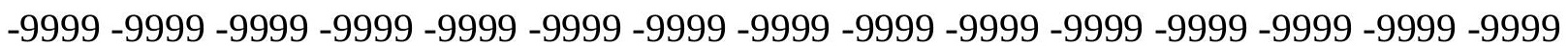
-9999 -9999 -9999 -9999 -9999 -9999 -9999 -9999 -9999 -9999 -9999 -9999 -9999 -9999 -9999 -9999 -9999 -9999 -9999 -9999 -9999 -9999 -9999 -9999 -9999 -9999 -9999 -9999 -9999 -9999 -9999 93.26425170898 89.91161346436 86.55898284912 83.51112365723 80.76805877686 77.7202072143674 .6723632812571 .6244964599668 .8814392089865 .83358764648 
63.0905189514260 .3474502563557 .909179687572 .2340774536170 .40535736084 68.2718734741249 .6799812316948 .1560516357446 .6321296691945 .10820007324 43.5842704772942 .3651313781740 .8412094116239 .3172798156737 .79335021973 36.2694282531735 .0502891540533 .8311500549332 .9167900085431 .69765090942 30.7833003997829 .5641593933128 .0402297973627 .1258792877225 .9067401886 24.9923801422124 .3828105926523 .7732391357423 .1636695861822 .85887908936 22.5541000366222 .2493095397922 .2493095397922 .5541000366222 .55410003662 23.1636695861823 .4684505462624 .0780296325724 .6875991821325 .29715919495 25.6019496917725 .906740188625 .906740188625 .6019496917725 .29715919495 24.6875991821324 .0780296325723 .4684505462622 .8588790893622 .55410003662 21.9445304870621 .6397399902321 .6397399902321 .334960937521 .63973999023 21.6397399902321 .9445304870622 .2493095397922 .5541000366222 .85887908936 23.4684505462624 .0780296325724 .6875991821325 .2971591949525 .9067401886 26.5163097381627 .430660247828 .3450202941929 .2593708038330 .17373085022 31.3928699493432 .3072204589833 .5263595581134 .7455101013235 .96464920044 37.4885711669939 .0125007629440 .8412094116242 .66992187544 .49863052368 46.3273391723648 .1560516357449 .6799812316951 .2038993835452 .11825942993 52.7278289794953 .0326118469253 .0326118469253 .03261184692 -9999 -9999 -9999 -9999 -9999 -9999 -9999 -9999 -9999 -9999 -9999 -9999 -9999 -9999 -9999 -9999 -9999 -9999 -9999

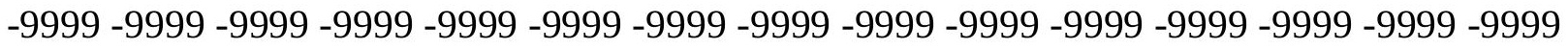
-9999 -9999 -9999 -9999 -9999 -9999 -9999 -9999 -9999 -9999 -9999 -9999 -9999 -9999 -9999 -9999 -9999 -9999 -9999 -9999 -9999 -9999 -9999 -9999 -9999 -9999 -9999 -9999 -9999 -9999 -9999 -9999 -9999 -9999 -9999 -9999 -9999 -9999 -9999 -9999 -9999 -9999 -9999 -9999 -9999 -9999 -9999 -9999 -9999 -9999 -9999 -9999 -9999 -9999 -9999 -9999 -9999 -9999 -9999 -9999 -9999 -9999 -9999 -9999 -9999 -9999 -9999 -9999 -9999 -9999 -9999 -9999 -9999 -9999 -9999 -9999 -9999 -9999 -9999 -9999 -9999 -9999 -9999 -9999 -9999 -9999 -9999 -9999 -9999 -9999 -9999 -9999 -9999 -9999 -9999 -9999 -9999 -9999 -9999 -9999 -9999 -9999 -9999 -9999 -9999

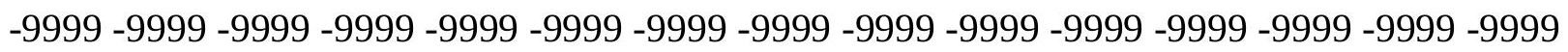
-9999 -9999 -9999 -9999 -9999 -9999 -9999 -9999 -9999 -9999 -9999 -9999 -9999 -9999 -9999 -9999 -9999 -9999 -9999 -9999 -9999 -9999 -9999 -9999 -9999 -9999 -9999 -9999 -9999 -9999 -9999 -9999 -9999 -9999 -9999 -9999 -9999 -9999 -9999 -9999 -9999 -9999 -9999 -9999 -9999 -9999 -9999 -9999 -9999 -9999 -9999 -9999 -9999 -9999 -9999 -9999 -9999 -9999 -9999 -9999 -

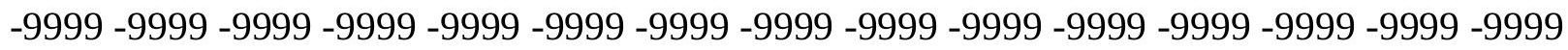
-9999 -9999 -9999 -9999 -9999 -9999 -9999 -9999 -9999 -9999 -9999 -9999 -9999 -9999 -9999 -9999 -9999 -9999 -9999 -9999 -9999 -9999 -9999 -9999 -9999 -9999 -9999 -9999 -9999 -9999 -

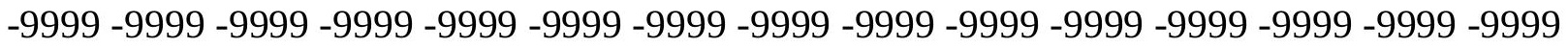

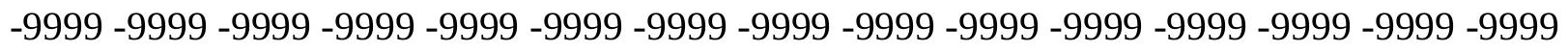
-9999 -9999 92.95947265625 89.91161346436 86.55898284912 83.51112365723 80.7680587768677 .7202072143675 .2819290161173 .4532165527372 .23407745361 69.4910125732466 .4431610107464 .004882812560 .6522407531758 .51874923706 57.6043891906755 .4708900451753 .3373985290549 .6799812316948 .15605163574 46.6321296691945 .4129791259843 .8890609741242 .3651313781740 .84120941162 39.622070312538 .0981407165537 .1837806701735 .9646492004434 .74551010132 33.5263595581132 .0024414062530 .7833003997829 .2593708038328 .34502029419 27.430660247826 .5163097381625 .6019496917724 .9923801422124 .38281059265 23.7732391357423 .4684505462623 .4684505462623 .1636695861823 .46845054626 
23.4684505462623 .7732391357424 .0780296325724 .6875991821324 .99238014221 24.9923801422125 .2971591949525 .2971591949524 .9923801422124 .68759918213 24.3828105926524 .0780296325723 .7732391357423 .4684505462623 .16366958618 22.8588790893622 .8588790893622 .5541000366222 .8588790893622 .85887908936 23.1636695861823 .4684505462623 .7732391357424 .0780296325724 .38281059265 24.9923801422125 .6019496917726 .2115192413326 .8210906982427 .4306602478 28.3450202941929 .2593708038330 .1737308502230 .7833003997831 .69765090942 32.6120109558133 .8311500549334 .7455101013235 .9646492004437 .18378067017 38.7077102661139 .9268493652341 .7555618286143 .5842704772945 .41297912598 46.9369087219248 .765621185350 .2895507812551 .8134689331153 .03261184692 53.9469718933154 .2517509460454 .2517509460454 .25175094604 -9999 -9999 -9999 -9999 -9999 -9999 -9999 -9999 -9999 -9999 -9999 -9999 -9999 -9999 -9999 -9999 -9999 -9999 -9999 -9999 -9999 -9999 -9999 -9999 -9999 -9999 -9999 -9999 -9999 -9999 -9999 -9999 -9999 -9999 -9999 -9999 -9999 -9999 -9999 -9999 -9999 -9999 -9999 -9999 -9999 -9999 -9999 -9999 - 9999 -9999 -9999 -9999 -9999 -9999 -9999 -9999 -9999 -9999 -9999 -9999 -9999 -9999 -9999 -9999

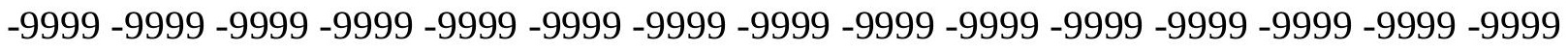

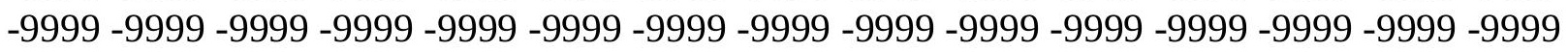
-9999 -9999 -9999 -9999 -9999 -9999 -9999 -9999 -9999 -9999 -9999 -9999 -9999 -9999 -9999 -999 -9999 -9999 -9999 -9999 -9999 -9999 -9999 -9999 -9999 -9999 -9999 -9999 -9999 -9999 -9999 -9999 -9999 -9999 -9999 -9999 -9999 -9999 -9999 -9999 -9999 -9999 -9999 -9999 -9999 -9999 -9999 -9999 -9999 -9999 -9999 -9999 -9999 -9999 -9999 -9999 -9999 -9999 -9999 -9999 -9999 -9999 -9999 -9999 -9999 -9999 -9999 -9999 -9999 -9999 -9999 -9999 -9999 -9999 -9999 -9999 -9999 -9999 -9999 -9999 -9999 -9999 -9999 -9999 -9999 -9999 -9999 -9999 -9999 -9999 -9999 -9999 -9999 -9999 -9999 -9999 -9999 -9999 -9999 -9999 -9999 -9999 -9999 -9999 -9999 -9999 -9999 -9999 -9999 -9999 -9999 -9999 -9999 -9999 -9999 -9999 -9999 -9999 -9999 -9999 -9999 -9999 -9999 -9999 -9999 -9999 -9999 -9999 -9999 -9999 -9999 -9999 -9999 -9999 -9999 -9999 -9999 -9999 -9999 -9999 -9999 -9999 -9999 -9999 -9999 -9999 -9999 -9999 -9999 -9999 -9999 -

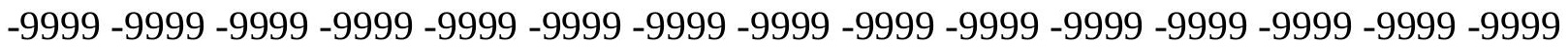
-9999 -9999 -9999 -9999 -9999 -9999 -9999 -9999 -9999 -9999 -9999 -9999 -9999 -9999 -9999 -9999 -9999 -9999 -9999 -9999 -9999 -9999 -9999 -9999 -9999 -9999 -9999 -9999 -9999 -9999 -9999 -9999 -9999 -9999 89.60682678223 86.55898284912 83.51112365723 80.46327209473 78.0249862670976 .8058471679774 .9771423339872 .2340774536169 .79579162598 67.3575134277365 .2240066528362 .1761703491260 .6522407531759 .12831115723 56.6900291442954 .2517509460451 .8134689331149 .9847602844248 .46083068848 46.9369087219245 .4129791259844 .1938400268642 .66992187541 .45077896118 40.2316398620639 .0125007629437 .7933502197336 .5742111206135 .05028915405 33.5263595581132 .0024414062530 .7833003997829 .8689403533928 .95458984375 27.7354507446326 .8210906982425 .906740188625 .2971591949524 .68759918213 24.3828105926524 .0780296325724 .0780296325724 .0780296325724 .07802963257 24.3828105926524 .3828105926524 .6875991821324 .6875991821324 .68759918213 24.6875991821324 .3828105926524 .3828105926524 .0780296325724 .07802963257 23.7732391357423 .7732391357423 .7732391357423 .7732391357423 .77323913574 23.7732391357424 .0780296325724 .0780296325724 .3828105926524 .68759918213 24.9923801422125 .6019496917725 .906740188626 .5163097381627 .12587928772 28.0402297973628 .6497993469229 .2593708038330 .1737308502230 .78330039978 31.6976509094232 .3072204589833 .2215805053733 .8311500549334 .74551010132 
35.9646492004436 .8790016174338 .0981407165539 .3172798156740 .84120941162 42.3651313781743 .8890609741245 .717769622847 .2416992187549 .07040023804 50.5943298339852 .1182594299353 .6421813964854 .5565414428755 .47089004517 55.4708900451755 .16611099243 -9999 -9999 -9999 -9999 -9999 -9999 -9999 -9999 -9999 -9999 -9999 -9999 -9999 -9999 -9999 -9999 -9999 -9999 -9999 -9999 -9999 -9999 -9999 -9999 -9999 -9999 -9999 -9999 -9999 -9999 -9999 -9999 -9999 -9999 -9999 -9999 -9999 -9999 -9999

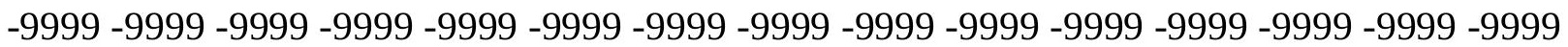
-9999 -9999 -9999 -9999 -9999 -9999 -9999 -9999 -9999 -9999

-9999 -9999 -9999 -9999 -9999 -9999 -9999 -9999 -9999 -9999 -9999 -9999 -9999 -9999 -9999 -9999 -9999 -9999 -9999 -9999 -9999 -9999 -9999 -9999 -9999 -9999 -9999 -9999 -9999 -9999

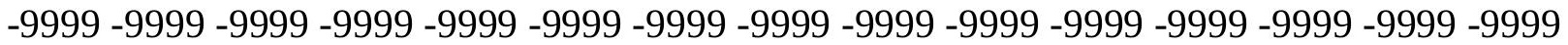
-9999 -9999 -9999 -9999 -9999 -9999 -9999 -9999 -9999 -9999 -9999 -9999 -9999-9999-9999 -

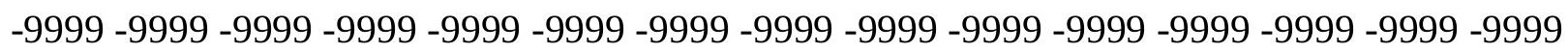
-9999 -9999 -9999 -9999 -9999 -9999 -9999 -9999 -9999 -9999 -9999 -9999 -9999 -9999 -9999 -9999 -9999 -9999 -9999 -9999 -9999 -9999 -9999 -9999 -9999 -9999 -9999 -9999 -9999 -9999

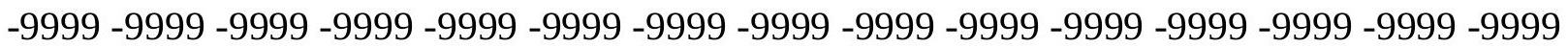

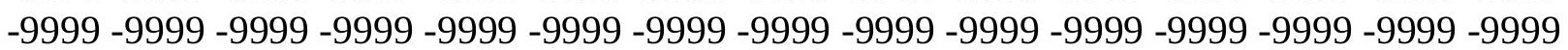

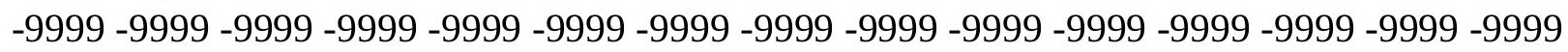
-9999 -9999 -9999 -9999 -9999 -9999 -9999 -9999 -9999 -9999 -9999 -9999 -9999 -9999 -9999 -9999 -9999 -9999 -9999 -9999 -9999 -9999 -9999 -9999 -9999 -9999 -9999 -9999 -9999 -9999 -9999 -9999 -9999 -9999 -9999 -9999 -9999 -9999 -9999 -9999 -9999 -9999 -9999 -9999 -9999 -999 -

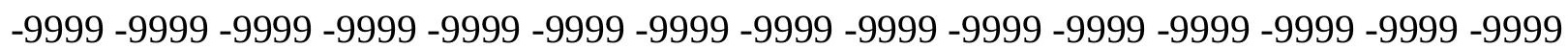
-9999 -9999 -9999 -9999 -9999 -9999 -9999 -9999 -9999 -9999 -9999 -9999 -9999 -9999 -9999 -9999 -9999 -9999 -9999 -9999 88.9972534179785.9494018554782.90155792236 80.7680587768679 .2441329956177 .7202072143675 .2819290161172 .84364318848 70.4053573608468 .2718734741265 .8335876464863 .7000885009860 .95701980591 59.1283111572357 .909179687554 .8613204956153 .0326118469251 .81346893311 50.2895507812548 .4608306884847 .2416992187545 .717769622844 .49863052368 43.5842704772942 .3651313781741 .1459884643639 .622070312538 .09814071655 36.5742111206135 .0502891540533 .8311500549332 .6120109558131 .39286994934 30.1737308502228 .9545898437527 .7354507446326 .8210906982425 .9067401886 25.2971591949524 .6875991821324 .3828105926524 .3828105926524 .38281059265 24.3828105926524 .3828105926524 .3828105926524 .3828105926524 .38281059265 24.0780296325724 .0780296325724 .0780296325724 .0780296325724 .07802963257 24.0780296325724 .0780296325724 .0780296325724 .3828105926524 .68759918213 24.6875991821324 .9923801422125 .6019496917725 .906740188626 .21151924133 26.8210906982427 .430660247828 .0402297973628 .6497993469229 .25937080383 29.5641593933130 .1737308502231 .0880794525131 .6976509094232 .30722045898 32.9167900085433 .5263595581134 .4407196044935 .0502891540535 .96464920044 36.8790016174337 .7933502197338 .7077102661139 .9268493652341 .14598846436 42.66992187544 .1938400268645 .717769622847 .2416992187549 .07040023804 50.5943298339852 .1182594299353 .6421813964855 .1661109924356 .08045959473 56.0804595947355 .77568054199 -9999 -9999 -9999 -9999 -9999 -9999 -9999 -9999 -9999 -9999 -9999 -9999 -9999 -9999 -9999 -9999 -9999 -9999 -9999 -9999 -9999 -9999 -9999 -9999

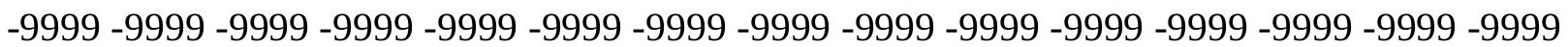

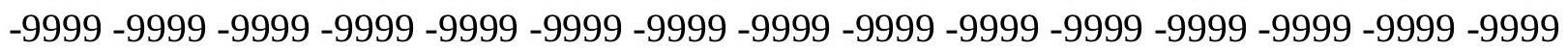


-9999 -9999 -9999 -9999 -9999 -9999 -9999 -9999 -9999 -9999

-9999 -9999 -9999 -9999 -9999 -9999 -9999 -9999 -9999 -9999 -9999 -9999 -9999 -9999 -9999 -9999 -9999 -9999 -9999 -9999 -9999 -9999 -9999 -9999 -9999 -9999 -9999 -9999 -9999 -9999 -9999 -9999 -9999 -9999 -9999 -9999 -9999 -9999 -9999 -9999 -9999 -9999 -9999 -9999 -9999 -9999 -9999 -9999 -9999 -9999 -9999 -9999 -9999 -9999 -9999 -9999 -9999 -9999 -9999 -9999 -9999 -9999 -9999 -9999 -9999 -9999 -9999 -9999 -9999 -9999 -9999 -9999 -9999 -9999 -9999 -9999 -9999 -9999 -9999 -9999 -9999 -9999 -9999 -9999 -9999 -9999 -9999 -9999 -9999 -9999

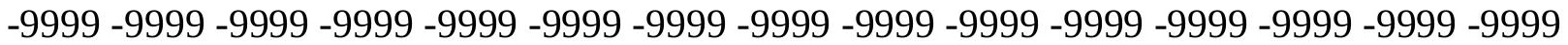
-9999 -9999 -9999 -9999 -9999 -9999 -9999 -9999 -9999 -9999 -9999 -9999 -9999 -9999 -9999 -9999 -9999 -9999 -9999 -9999 -9999 -9999 -9999 -9999 -9999 -9999 -9999 -9999 -9999 -9999 -9999 -9999 -9999 -9999 -9999 -9999 -9999 -9999 -9999 -9999 -9999 -9999 -9999 -9999 -9999 -9999 -9999 -9999 -9999 -9999 -9999 -9999 -9999 -9999 -9999 -9999 -9999 -9999 -9999 -9999

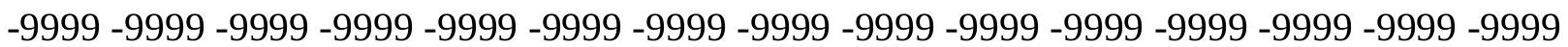
-9999 -9999 -9999 -9999 -9999 -9999 -9999 -9999 -9999 -9999 -9999 -9999 -9999 -9999 -9999 -9999 -9999 -9999 -9999 -9999 -9999 -9999 -9999 -9999 -9999 -9999 -9999 -9999 -9999 -9999 -9999 -9999 -9999 -9999 -9999 -9999 -9999 -9999 -9999 -9999 -9999 -9999 -9999 -9999 -9999 -999 -9999 -9999 -9999 -9999 -9999 -9999 88.3876876831185.64462280273 82.59677124023 80.7680587768679 .2441329956178 .0249862670976 .1962814331173 .45321655273 71.3197174072369 .4910125732467 .6623001098664 .6144485473662 .17617034912 60.6522407531757 .909179687556 .0804595947355 .4708900451753 .33739852905 51.5086898803749 .9847602844248 .765621185347 .8512611389246 .63212966919 45.4129791259844 .1938400268642 .9747009277341 .4507789611839 .92684936523 38.4029312133836 .8790016174335 .6598587036134 .1359291076732 .61201095581 31.0880794525129 .5641593933128 .0402297973627 .1258792877226 .21151924133 25.6019496917724 .9923801422124 .6875991821324 .6875991821324 .68759918213 24.3828105926524 .3828105926524 .0780296325724 .0780296325723 .77323913574 23.7732391357423 .7732391357424 .0780296325724 .0780296325724 .38281059265 24.3828105926524 .9923801422125 .2971591949525 .6019496917725 .9067401886 26.2115192413326 .8210906982427 .7354507446328 .3450202941928 .95458984375 29.5641593933129 .8689403533930 .4785099029531 .0880794525131 .39286994934 32.0024414062532 .6120109558132 .9167900085433 .5263595581134 .13592910767 34.7455101013235 .3550796508835 .9646492004436 .5742111206137 .48857116699 38.4029312133839 .3172798156740 .2316398620641 .4507789611842 .669921875 44.1938400268645 .4129791259846 .9369087219248 .4608306884850 .28955078125 51.8134689331153 .3373985290554 .5565414428755 .4708900451756 .08045959473 55.7756805419955 .77568054199 -9999 -9999 -9999 -9999 -9999 -9999 -9999 -9999 -9999 -9999 -9999 -9999 -9999 -9999 -9999 -9999 -9999 -9999 -9999 -9999 -9999 -9999 -9999-9999 -9999 -9999 -9999 -9999 -9999 -9999 -9999 -9999 -9999 -9999 -9999 -9999 -9999 -9999 -9999 -9999 -9999 -9999 -9999 -9999 -9999 -9999 -9999 -9999 -9999 -9999 -9999 -9999 -9999 -9999 -9999 -9999 -9999 -9999 -9999 -9999 -9999 -9999 -9999 -9999 -9999 -9999 -9999 -9999 -9999 -9999 -9999 -9999 -9999 -9999 -9999 -9999 -9999 -9999 -9999 -9999 -9999 -9999 -9999 -9999 -9999 -9999 -9999 -9999 -9999 -9999-9999-9999-9999 -9999 -9999 -9999 -9999 -9999 -9999 -9999 -9999 -9999 -9999 -9999 -9999 -9999 -9999 -9999 -9999 -9999 -9999 -9999 -9999 -9999 -9999 -9999 -9999 -9999 -9999 -9999 -9999 -9999 -9999 -9999 -9999 -9999 -9999 -9999 -9999 -9999 -9999 -9999 -9999 -9999 -9999 -9999 -9999 -9999

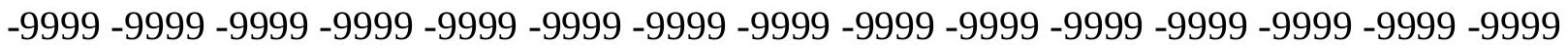


-9999 -9999 -9999 -9999 -9999 -9999 -9999 -9999 -9999 -9999 -9999 -9999 -9999 -9999 -9999 -9999 -9999 -9999 -9999 -9999 -9999 -9999 -9999 -9999 -9999 -9999 -9999 -9999 -9999 -9999 -9999 -9999 -9999 -9999 -9999 -9999 -9999 -9999 -9999 -9999 -9999 -9999 -9999 -9999 -9999 -9999 -9999 -9999 -9999 -9999 -9999 -9999 -9999 -9999 -9999 -9999 -9999 -9999 -9999 -9999 -9999 -9999 -9999 -9999 -9999 -9999 -9999 -9999 -9999 -9999 -9999 -9999 -9999 -9999 -9999 -9999 -9999 -9999 -9999 -9999 -9999 -9999 -9999 -9999 -9999 -9999 -9999 -9999 -9999 -9999 -9999 -9999 -9999 -9999 -9999 -9999 -9999 -9999 -9999 -9999 -9999 -9999 -9999 -9999 -9999

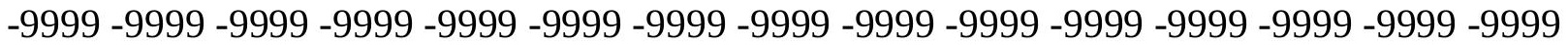
-9999 -9999 -9999 -9999 -9999 -9999 -9999 -9999 -9999 -9999 -9999 -9999 -9999 -9999 -9999 -9999 -9999 -9999 -9999 -9999 -9999 -9999 -9999 85.03504943848 82.59677124023 80.1584930419978 .0249862670976 .8058471679774 .6723632812573 .14842987061 70.7101516723668 .8814392089866 .7479400634864 .9192428588962 .78573989868 61.2618103027359 .7378807067957 .909179687555 .7756805419954 .25175094604 53.0326118469251 .8134689331150 .5943298339849 .6799812316948 .46083068848 47.2416992187546 .0225486755444 .8034095764243 .2794914245641 .75556182861 40.2316398620638 .4029312133836 .8790016174335 .0502891540533 .22158050537 31.6976509094229 .8689403533928 .6497993469227 .430660247826 .51630973816 25.906740188625 .2971591949525 .2971591949524 .9923801422124 .68759918213 24.6875991821324 .3828105926524 .0780296325724 .0780296325724 .07802963257 24.0780296325724 .0780296325724 .3828105926524 .6875991821324 .99238014221 25.6019496917725 .906740188626 .8210906982427 .430660247828 .34502029419 28.9545898437529 .8689403533930 .4785099029531 .0880794525131 .39286994934 31.6976509094232 .3072204589832 .6120109558132 .9167900085433 .52635955811 33.8311500549334 .4407196044934 .7455101013235 .3550796508835 .65985870361 36.2694282531736 .8790016174337 .4885711669938 .0981407165538 .70771026611 39.622070312540 .5364189147941 .4507789611842 .66992187543 .88906097412 45.1082000732446 .3273391723647 .8512611389249 .3751907348650 .89912033081 52.4230384826753 .6421813964854 .5565414428755 .1661109924355 .77568054199 55.77568054199 -9999 -9999 -9999 -9999 -9999 -9999 -9999 -9999 -9999 -9999 -9999 -9999

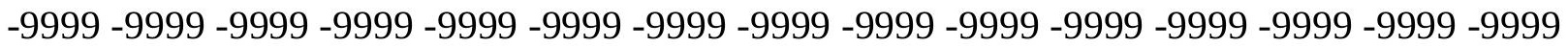
-9999 -9999 -9999 -9999 -9999 -9999 -9999 -9999 -9999 -9999 -9999 -9999 -9999 -9999 -9999 -

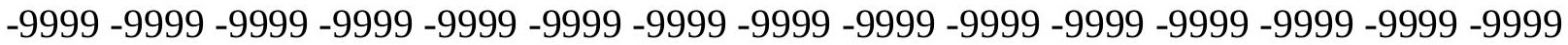
-9999 -9999 -9999-9999-9999-9999

-9999 -9999 -9999 -9999 -9999 -9999 -9999 -9999 -9999 -9999 -9999 -9999 -9999 -9999 -9999

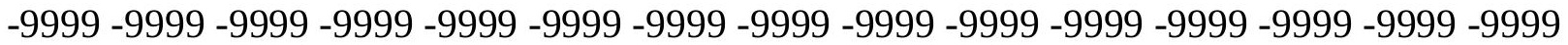
-9999 -9999 -9999 -9999 -9999 -9999 -9999 -9999 -9999 -9999 -9999 -9999 -9999 -9999 -9999 -9999 -9999 -9999 -9999 -9999 -9999 -9999 -9999 -9999 -9999 -9999 -9999 -9999 -9999 -9999

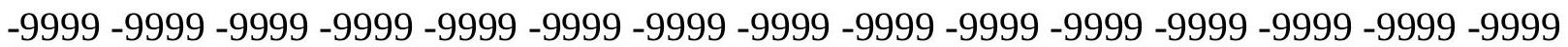
-9999 -9999 -9999 -9999 -9999 -9999 -9999 -9999 -9999 -9999 -9999 -9999 -9999 -9999 -9999 -9999 -9999 -9999 -9999 -9999 -9999 -9999 -9999 -9999 -9999 -9999 -9999 -9999 -9999 -9999 -9999 -9999 -9999 -9999 -9999 -9999 -9999 -9999 -9999 -9999 -9999 -9999 -9999 -9999 -9999

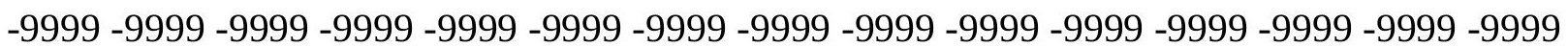
-9999 -9999 -9999 -9999 -9999 -9999 -9999 -9999 -9999 -9999 -9999 -9999 -9999 -9999 -9999 -9999 -9999 -9999 -9999 -9999 -9999 -9999 -9999 -9999 -9999 -9999 -9999 -9999 -9999 -9999 -9999 -9999 -9999 -9999 -9999 -9999 -9999 -9999 -9999 -9999 -9999 -9999 -9999 -9999 -9999

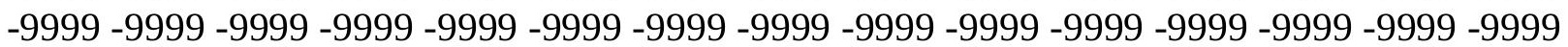


-9999 -9999 -9999 -9999 -9999 -9999 -9999 -9999 -9999 -9999 -9999 -9999 -9999 -9999 -9999 -9999 -9999 -9999 -9999 -9999 -9999 -9999 -9999 -9999 -9999 -9999 -9999 -9999 -9999 -9999 -9999 -9999 -9999 -9999 -9999 -9999 -9999 -9999 -9999 -9999 82.59677124023 80.4632720947378 .6345596313576 .5010681152374 .6723632812572 .84364318848 70.7101516723668 .8814392089867 .0527267456165 .2240066528363 .39530944824 61.8713798522960 .3474502563558 .8235282897957 .6043891906756 .38525009155 55.1661109924353 .9469718933152 .7278289794951 .5086898803750 .59432983398 49.0704002380447 .8512611389246 .3273391723644 .8034095764242 .97470092773 41.1459884643639 .3172798156737 .4885711669935 .6598587036133 .83115005493 32.0024414062530 .4785099029528 .9545898437527 .7354507446326 .82109069824 26.2115192413325 .906740188625 .6019496917725 .2971591949524 .99238014221 24.6875991821324 .3828105926541 .1459884643624 .3828105926524 .68759918213 24.9923801422125 .2971591949525 .906740188626 .5163097381627 .4306602478 28.0402297973628 .9545898437529 .5641593933130 .1737308502231 .08807945251 31.6976509094232 .3072204589832 .6120109558133 .2215805053733 .52635955811 33.8311500549334 .1359291076734 .4407196044935 .0502891540535 .35507965088 35.6598587036135 .9646492004436 .2694282531736 .5742111206137 .18378067017 37.4885711669938 .0981407165538 .4029312133839 .0125007629439 .6220703125 40.5364189147941 .1459884643642 .0603485107443 .2794914245644 .19384002686 45.4129791259846 .9369087219248 .4608306884849 .6799812316951 .20389938354 52.4230384826753 .6421813964854 .5565414428755 .1661109924355 .47089004517 -9999 -9999 -9999 -9999 -9999 -9999 -9999 -9999 -9999 -9999 -9999 -9999 -9999 -9999 -9999 -9999 -9999 -9999 -9999 -9999 -9999 -9999 -9999 -9999 -9999 -9999 -9999 -9999 -9999 -9999 -9999 -9999 -9999 -9999 -9999 -9999 -9999 -9999 -9999 -9999 -9999 -9999 -9999 -9999 -9999 -9999

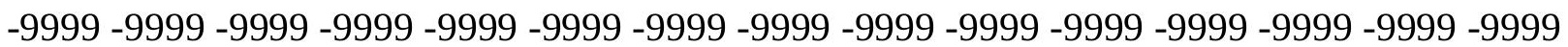
$-9999-9999$

-9999 -9999 -9999 -9999 -9999 -9999 -9999 -9999 -9999 -9999 -9999 -9999 -9999 -9999 -9999 -9999 -9999 -9999 -9999 -9999 -9999 -9999 -9999 -9999 -9999 -9999 -9999 -9999 -9999 -9999 -9999 -9999 -9999 -9999 -9999 -9999 -9999 -9999 -9999 -9999 -9999 -9999 -9999 -9999 -9999 -9999 -9999 -9999 -9999 -9999 -9999 -9999 -9999 -9999 -9999 -9999 -9999 -9999 -9999 -9999 -9999 -9999 -9999 -9999 -9999 -9999 -9999 -9999 -9999 -9999 -9999 -9999 -9999 -9999 -9999 -

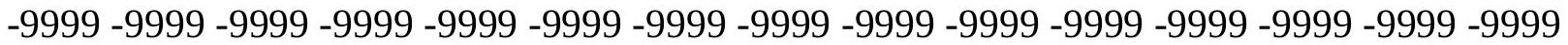
-9999 -9999 -9999 -9999 -9999 -9999 -9999 -9999 -9999 -9999 -9999 -9999 -9999 -9999 -9999 -9999 -9999 -9999 -9999 -9999 -9999 -9999 -9999 -9999 -9999 -9999 -9999 -9999 -9999 -9999 -

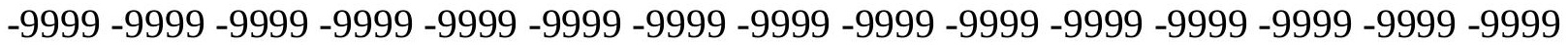
-9999 -9999 -9999 -9999 -9999 -9999 -9999 -9999 -9999 -9999 -9999 -9999 -9999 -9999 -9999 -9999 -9999 -9999 -9999 -9999 -9999 -9999 -9999 -9999 -9999 -9999 -9999 -9999 -9999 -9999

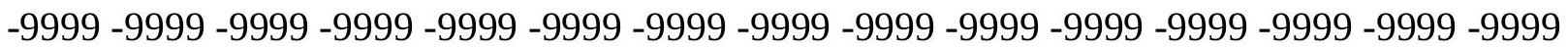
-9999 -9999 -9999 -9999 -9999 -9999 -9999 -9999 -9999 -9999 -9999 -9999 -9999 -9999 -9999 -9999 -9999 -9999 -9999 -9999 -9999 -9999 -9999 -9999 -9999 -9999 -9999 -9999 -9999 -9999 -9999 -9999 -9999 -9999 -9999 -9999 -9999 -9999 -9999 -9999 -9999 -9999 -9999 -9999 -9999 -999 -9999 -9999 -9999 -9999 -9999 -9999 -9999 -9999 -9999 -9999 -9999 -9999 -9999 -9999 -9999 -9999 -9999 -9999 -9999 -9999 -9999 -9999 -9999 -9999 -9999 -9999 -9999 57.29959869385 56.0804595947355 .1661109924353 .9469718933152 .7278289794951 .50868988037 49.9847602844248 .4608306884846 .9369087219245 .1082000732443 .27949142456 41.1459884643639 .3172798156737 .1837806701735 .3550796508833 .22158050537 
31.3928699493430 .1737308502228 .9545898437528 .6497993469228 .34502029419 28.0402297973627 .430660247827 .1258792877226 .8210906982426 .51630973816 26.5163097381626 .5163097381626 .8210906982427 .1258792877227 .4306602478 28.0402297973628 .6497993469229 .2593708038330 .1737308502230 .78330039978 31.3928699493432 .3072204589832 .9167900085433 .5263595581133 .83115005493 34.4407196044934 .7455101013235 .0502891540535 .3550796508835 .65985870361 35.9646492004436 .2694282531736 .5742111206136 .8790016174337 .18378067017 37.1837806701737 .4885711669937 .7933502197338 .0981407165538 .40293121338 38.7077102661139 .3172798156739 .622070312540 .2316398620640 .84120941162 41.7555618286142 .3651313781743 .2794914245644 .4986305236845 .7177696228 46.9369087219248 .4608306884849 .9847602844251 .2038993835452 .42303848267 53.6421813964854 .5565414428755 .16611099243 -9999 -9999 -9999 -9999 -9999 -9999 -9999 -9999 -9999 -9999 -9999 -9999 -9999 -9999 -9999 -9999 -9999 -9999 -9999 -9999 -9999 -9999 -9999 -9999 -9999 -9999 -9999 -9999 -9999 -9999 -9999 -9999 -9999 -9999 -9999 -9999 - 9999 -9999 -9999 -9999 -9999 -9999 -9999 -9999 -9999 -9999 -9999 -9999 -9999 -9999 -9999 -9999 -9999 -9999 -9999 -9999-9999 -9999 -9999 -9999 -9999-9999-9999 -

-9999 -9999 -9999 -9999 -9999 -9999 -9999 -9999 -9999 -9999 -9999 -9999 -9999 -9999 -9999 -9999 -9999 -9999 -9999 -9999 -9999 -9999 -9999 -9999 -9999 -9999 -9999 -9999 -9999 -9999 -9999 -9999 -9999 -9999 -9999 -9999 -9999 -9999 -9999 -9999 -9999 -9999 -9999 -9999 -9999 -

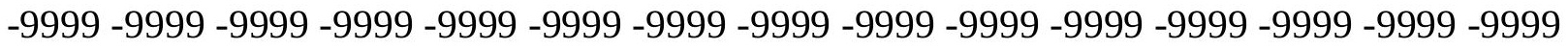

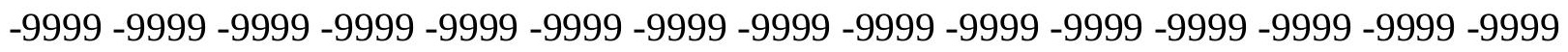
-9999 -9999 -9999 -9999 -9999 -9999 -9999 -9999 -9999 -9999 -9999 -9999 -9999 -9999 -9999 -9999 -9999 -9999 -9999 -9999 -9999 -9999 -9999 -9999 -9999 -9999 -9999 -9999 -9999 -9999 -

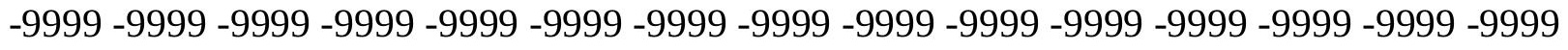

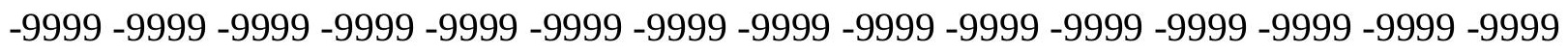
-9999 -9999 -9999 -9999 -9999 -9999 -9999 -9999 -9999 -9999 -9999 -9999 -9999 -9999 -9999 -9999 -9999 -9999 -9999 -9999 -9999 -9999 -9999 -9999 -9999 -9999 -9999 -9999 -9999 -9999 -

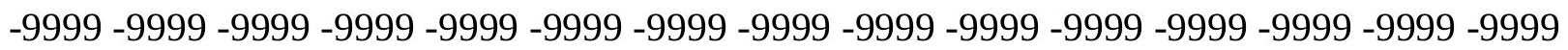
-9999 -9999 -9999 -9999 -9999 -9999 -9999 -9999 -9999 -9999 -9999 -9999 -9999 -9999 -9999 -9999 -9999 -9999 -9999 -9999 -9999 -9999 -9999 -9999 -9999 -9999 -9999 -9999 -9999 -999 -9999 -9999 -9999 -9999 -9999 -9999 -9999 -9999 -9999-9999 -9999 -9999 -9999 -9999 -9999 -9999 -9999 -9999 -9999 -9999 -9999 -9999 -9999 -9999 -9999 -9999 -9999 -9999 -9999 -9999 -

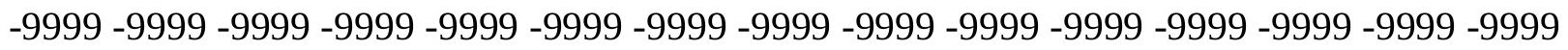
-9999 -9999 -9999 -9999 -9999 -9999 -9999 -9999 -9999 -9999 -9999 -9999 -9999 -9999 -9999 -9999 -9999 -9999 -9999 -9999 -9999 29.2593708038328.95458984375 28.64979934692 28.6497993469228 .9545898437529 .2593708038329 .5641593933130 .17373085022 30.7833003997831 .3928699493432 .0024414062532 .6120109558133 .52635955811 34.1359291076734 .4407196044935 .0502891540535 .6598587036135 .96464920044 36.2694282531736 .5742111206136 .8790016174337 .1837806701737 .18378067017 37.4885711669937 .7933502197337 .7933502197338 .0981407165538 .09814071655 38.4029312133838 .7077102661138 .7077102661139 .0125007629439 .01250076294 39.3172798156739 .622070312540 .2316398620640 .5364189147941 .14598846436 41.7555618286142 .3651313781743 .2794914245644 .4986305236845 .7177696228 46.9369087219248 .4608306884849 .9847602844251 .5086898803752 .72782897949 53.9469718933154 .55654144287 -9999 -9999 -9999 -9999 -9999 -9999 -9999 -9999 -9999 -9999 -9999 -9999 -9999 -9999 -9999 -9999 -9999 -9999 -9999 -9999 -9999 -9999 -9999 -9999 
-9999 -9999 -9999 -9999 -9999 -9999 -9999 -9999 -9999 -9999 -9999 -9999 -9999 -9999 -9999 -9999 -9999 -9999 -9999 -9999 -9999 -9999 -9999 -9999 -9999 -9999 -9999 -9999 -9999 -9999 -9999 -9999 -9999 -9999 -9999 -9999 -9999 -9999 -9999

-9999 -9999 -9999 -9999 -9999 -9999 -9999 -9999 -9999 -9999 -9999 -9999 -9999 -9999 -9999 -9999 -9999 -9999 -9999 -9999 -9999 -9999 -9999 -9999 -9999 -9999 -9999 -9999 -9999 -9999 -9999 -9999 -9999 -9999 -9999 -9999 -9999 -9999 -9999 -9999 -9999 -9999 -9999 -9999 -9999 -9999 -9999 -9999 -9999 -9999 -9999 -9999 -9999 -9999 -9999 -9999 -9999 -9999 -9999 -9999

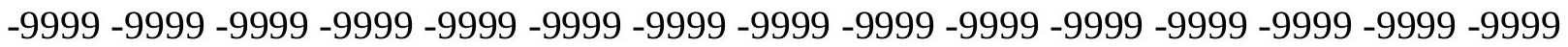
-9999 -9999 -9999 -9999 -9999 -9999 -9999 -9999 -9999 -9999 -9999 -9999 -9999 -9999 -9999 -9999 -9999 -9999 -9999 -9999 -9999 -9999 -9999 -9999 -9999 -9999 -9999 -9999 -9999 -9999 -

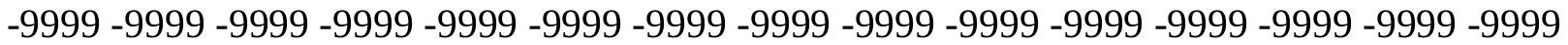
-9999 -9999 -9999 -9999 -9999 -9999 -9999 -9999 -9999 -9999 -9999 -9999 -9999 -9999 -9999 -9999 -9999 -9999 -9999 -9999 -9999 -9999 -9999 -9999 -9999 -9999 -9999 -9999 -9999 -9999 -9999 -9999 -9999 -9999 -9999 -9999 -9999 -9999 -9999 -9999 -9999 -9999 -9999 -9999 -9999 -9999 -9999 -9999 -9999 -9999 -9999 -9999 -9999 -9999 -9999 -9999 -9999 -9999 -9999 -9999

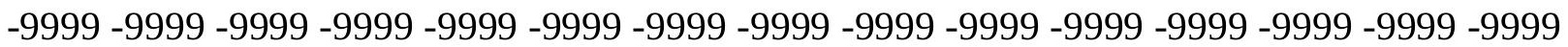
-9999 -9999 -9999 -9999 -9999 -9999 -9999 -9999 -9999 -9999 -9999 -9999 -9999 -9999 -9999 -9999 -9999 -9999 -9999 -9999 -9999 -9999 -9999 -9999 -9999 -9999 -9999 -9999 -9999 -9999 -9999 -9999 -9999 -9999 -9999 -9999 -9999 -9999 -9999 -9999 -9999 -9999 -9999 -9999 -9999 -9999 -9999 -9999 -9999 -9999 -9999 -9999 -9999 -9999 -9999 -9999 -9999 -9999 -9999 -9999 -9999 -9999 -9999 -9999 -9999 -9999 -9999 -9999 -9999 -9999 -9999 -9999 -9999 -9999 -9999 -9999 -9999 -9999 -9999 -9999 -9999 -9999 -9999 30.7833003997831 .08807945251 31.0880794525131 .3928699493431 .6976509094232 .3072204589832 .91679000854 33.5263595581134 .1359291076734 .7455101013235 .0502891540535 .65985870361 36.2694282531736 .5742111206137 .1837806701737 .4885711669937 .79335021973 38.0981407165538 .0981407165538 .4029312133838 .4029312133838 .70771026611 38.7077102661139 .0125007629439 .0125007629439 .0125007629439 .31727981567 39.3172798156739 .3172798156739 .3172798156739 .3172798156739 .6220703125 39.622070312539 .9268493652340 .2316398620640 .5364189147940 .84120941162 41.4507789611842 .0603485107442 .9747009277344 .1938400268645 .41297912598 47.2416992187548 .765621185350 .2895507812551 .8134689331153 .33739852905 54.25175094604 -9999 -9999 -9999 -9999 -9999 -9999 -9999 -9999 -9999 -9999 -9999 -9999 -9999 -9999 -9999 -9999 -9999 -9999 -9999 -9999 -9999 -9999 -9999 -9999 -9999 -9999 -9999 -9999 -9999 -9999 -9999 -9999 -9999 -9999 -9999 -9999 -9999 -9999 -9999 -9999 -9999 -9999 -

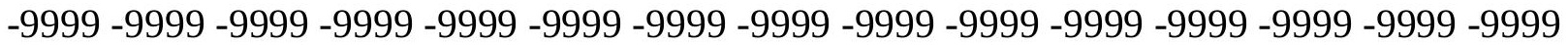
-9999 -9999 -9999 -9999-9999-9999

-9999 -9999 -9999 -9999 -9999 -9999 -9999 -9999 -9999 -9999 -9999 -9999 -9999 -9999 -9999

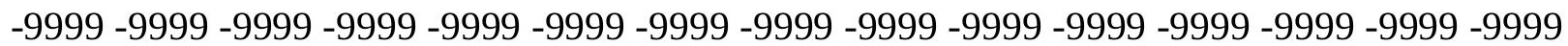
-9999 -9999 -9999 -9999 -9999 -9999 -9999 -9999 -9999 -9999 -9999 -9999 -9999 -9999 -9999 -9999 -9999 -9999 -9999 -9999 -9999 -9999 -9999 -9999 -9999 -9999 -9999 -9999 -9999 -9999 -9999 -9999 -9999 -9999 -9999 -9999 -9999 -9999 -9999 -9999 -9999 -9999 -9999 -9999 -9999 -999 -9999 -9999 -9999 -9999 -9999 -9999 -9999 -9999 -9999 -9999 -9999 -9999 -9999 -9999 -9999 -9999 -9999 -9999 -9999 -9999 -9999 -9999 -9999 -9999 -9999 -9999 -9999 -9999 -9999 -9999 -9999 -9999 -9999 -9999 -9999 -9999 -9999 -9999 -9999 -9999 -9999 -9999 -9999 -9999 -9999 -9999 -9999 -9999 -9999 -9999 -9999 -9999 -9999 -9999 -9999 -9999 -9999 -9999 -9999 -9999

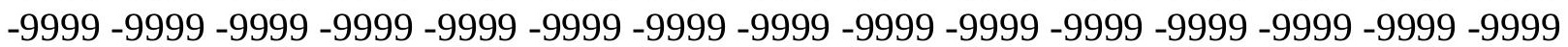


-9999 -9999 -9999 -9999 -9999 -9999 -9999 -9999 -9999 -9999 -9999 -9999 -9999 -9999 -9999 -9999 -9999 -9999 -9999 -9999 -9999 -9999 -9999 -9999 -9999 -9999 -9999 -9999 -9999 -9999 -9999 -9999 -9999 -9999 -9999 -9999 -9999 -9999 -9999 -9999 -9999 -9999 -9999 -9999 -9999 -9999 -9999 -9999 -9999 -9999 -9999 -9999 -9999 -9999 -9999 -9999 -9999 -9999 -9999 -9999 -9999 -9999 -9999 -9999 -9999 -9999 -9999 -9999 -9999 -9999 -9999 -9999 -9999 -9999 -9999 -9999 -9999 -9999 -9999 -9999 -9999 -9999 -9999 -9999 -9999 -9999 -9999 -9999 -9999 -9999 -9999 -9999 -9999 -9999 -9999 -9999 -9999 -9999 -9999 -9999 -9999 -9999 -9999 -9999 -9999 -9999 -9999 -9999 -9999 -9999 -9999 -9999 -9999 -9999 -9999 -9999 -9999 -9999 -9999 -9999 -9999 -9999 -9999 -9999 -9999 -9999 -9999 -9999 -9999 33.5263595581133 .83115005493 33.8311500549334 .1359291076734 .4407196044935 .0502891540535 .35507965088 35.9646492004436 .5742111206136 .8790016174337 .4885711669937 .79335021973 38.0981407165538 .4029312133838 .7077102661139 .0125007629439 .31727981567 39.3172798156739 .622070312539 .622070312539 .9268493652339 .92684936523 39.9268493652339 .9268493652339 .9268493652339 .9268493652339 .92684936523 39.9268493652339 .9268493652339 .9268493652339 .9268493652339 .92684936523 39.9268493652339 .9268493652339 .9268493652340 .2316398620640 .53641891479 40.8412094116241 .4507789611842 .66992187544 .1938400268645 .7177696228 47.5464782714849 .6799812316951 .2038993835452 .7278289794953 .94697189331 -9999 -9999 -9999 -9999 -9999 -9999 -9999 -9999 -9999 -9999 -9999 -9999 -9999 -9999 -9999 -9999 -9999 -9999 -9999 -9999 -9999 -9999 -9999 -9999 -9999 -9999 -9999 -9999 -9999 -9999 -9999 -9999 -9999 -9999 -9999 -9999 -9999 -9999 -9999 -9999 -9999 -9999 -9999 -9999 -9999 -9999 -999 -

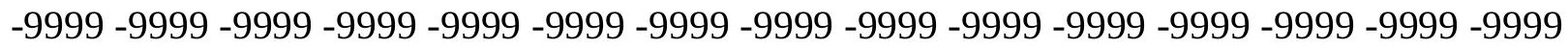
$-9999-9999$

-9999 -9999 -9999 -9999 -9999 -9999 -9999 -9999 -9999 -9999 -9999 -9999 -9999 -9999 -9999

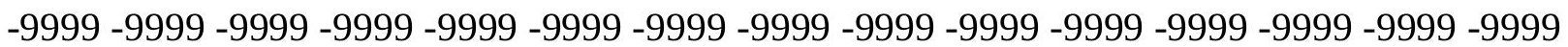
-9999 -9999 -9999 -9999 -9999 -9999 -9999 -9999 -9999 -9999 -9999 -9999 -9999 -9999 -9999 -9999 -9999 -9999 -9999 -9999 -9999 -9999 -9999 -9999 -9999 -9999 -9999 -9999 -9999 -9999 -9999 -9999 -9999 -9999 -9999 -9999 -9999 -9999 -9999 -9999 -9999 -9999 -9999 -9999 -9999 -9999 -9999 -9999 -9999 -9999 -9999 -9999 -9999 -9999 -9999 -9999 -9999 -9999 -9999 -9999 -9999 -9999 -9999 -9999 -9999 -9999 -9999 -9999 -9999 -9999 -9999 -9999 -9999 -9999 -9999 -9999 -9999 -9999 -9999 -9999 -9999 -9999 -9999 -9999 -9999 -9999 -9999 -9999 -9999 -9999 -

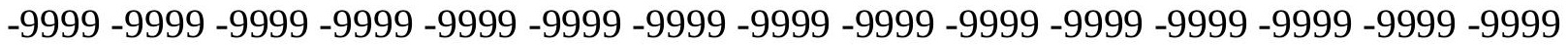
-9999 -9999 -9999 -9999 -9999 -9999 -9999 -9999 -9999 -9999 -9999 -9999 -9999 -9999 -9999 -9999 -9999 -9999 -9999 -9999 -9999 -9999 -9999 -9999 -9999 -9999 -9999 -9999 -9999 -9999 -9999 -9999 -9999 -9999 -9999 -9999 -9999 -9999 -9999 -9999 -9999 -9999 -9999 -9999 -9999 -9999 -9999 -9999 -9999 -9999 -9999 -9999 -9999 -9999 -9999 -9999 -9999 -9999 -9999 -9999 -9999 -9999 -9999 -9999 -9999 -9999 -9999 -9999 -9999 -9999 -9999 -9999 -9999 -9999 -9999

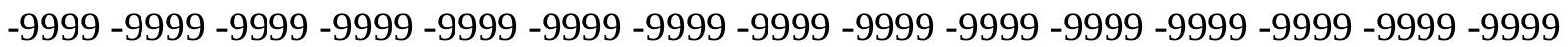
-9999 -9999 -9999 -9999 -9999 -9999 -9999 -9999 -9999 -9999 -9999 -9999 -9999 -9999 -9999 -9999 -9999 -9999 -9999 -9999 -9999 -9999 -9999 -9999 -9999 -9999 -9999 -9999 - -9999 -9999 -9999 -9999 -9999 -9999 -9999 -9999 -9999 -9999 -9999 -9999 -9999 -9999 -9999 -9999 -9999 -9999 -9999 -9999 -9999 -9999 -9999 -9999 -9999 -9999 -9999 -9999 36.26942825317 36.5742111206136 .8790016174337 .1837806701737 .4885711669937 .79335021973 38.4029312133838 .7077102661139 .0125007629439 .3172798156739 .6220703125 39.9268493652340 .2316398620640 .2316398620640 .5364189147940 .53641891479 40.8412094116240 .8412094116240 .8412094116240 .8412094116240 .84120941162 
40.8412094116240 .8412094116240 .8412094116240 .5364189147940 .53641891479 40.5364189147940 .2316398620640 .2316398620639 .9268493652339 .92684936523 39.9268493652339 .9268493652339 .622070312539 .622070312539 .92684936523 40.5364189147941 .4507789611842 .9747009277344 .8034095764246 .93690872192 49.0704002380450 .8991203308152 .7278289794953 .94697189331 -9999 -9999 -9999 -9999 -9999 -9999 -9999 -9999 -9999 -9999 -9999 -9999 -9999 -9999 -9999 -9999 -9999 -9999 -9999 -9999 -9999 -9999 -9999 -9999 -9999 -9999 -9999 -9999 -9999 -9999 -9999 -9999 -9999 -9999 -9999 -9999 -9999 -9999 -9999 -9999 -9999 -9999 -9999 -9999 -9999 -9999 -9999 -999 -999 -9999 -9999 -9999 -9999 -9999 -9999 -9999 -9999 -9999 -9999 -9999 -9999 -9999 -9999 -9999 -9999 -9999 -9999 -9999 -9999 -9999 -9999 -9999 -9999 -9999 -9999 -9999 -9999 -9999

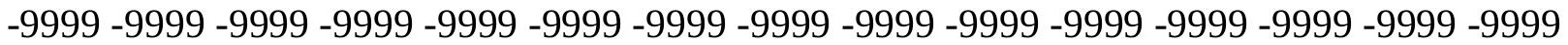
-9999 -9999 -9999 -9999 -9999 -9999 -9999 -9999 -9999 -9999 -9999 -9999 -9999 -9999 -9999 -9999 -9999 -9999 -9999 -9999 -9999 -9999 -9999 -9999 -9999 -9999 -9999 -9999 -9999 -9999 -9999 -9999 -9999 -9999 -9999 -9999 -9999 -9999 -9999 -9999 -9999 -9999 -9999 -9999 -9999 -9999 -9999 -9999 -9999 -9999 -9999 -9999 -9999 -9999 -9999 -9999 -9999 -9999 -9999 -9999

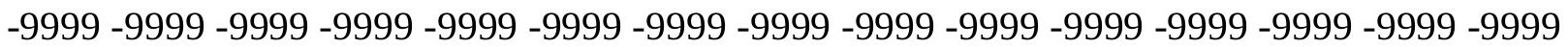

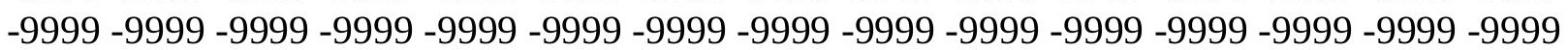
-9999 -9999 -9999 -9999 -9999 -9999 -9999 -9999 -9999 -9999 -9999 -9999 -9999 -9999 -9999 -999 -9999 -9999 -9999 -9999 -9999 -9999 -9999 -9999 -9999 -9999 -9999 -9999 -9999 -9999 -9999 -9999 -9999 -9999 -9999 -9999 -9999 -9999 -9999 -9999 -9999 -9999 -9999 -9999 -9999 -9999 -9999 -9999 -9999 -9999 -9999 -9999 -9999 -9999 -9999 -9999 -9999 -9999 -9999 -9999 -9999 -9999 -9999 -9999 -9999 -9999 -9999 -9999 -9999 -9999 -9999 -9999 -9999 -9999 -9999 -9999 -9999 -9999 -9999 -9999 -9999 -9999 -9999 -9999 -9999 -9999 -9999 -9999 -9999 -9999 -9999 -9999 -9999 -9999 -9999 -9999 -9999 -9999 -9999 -9999 -9999 -9999 -9999 -9999 -9999 -9999 -9999 -9999 -9999 -9999 -9999 -9999 -9999 -9999 -9999 -9999 -9999 -9999 -9999 -9999 -9999 -9999 -9999 -9999 -9999 -9999 -9999 -9999 -9999 -9999 -9999 -9999 -9999 -9999 -9999 -9999 -9999 -9999 -9999 -9999 -9999 -9999 -9999 -9999 -9999 -9999 -9999 -9999 -9999 -9999 -9999 -9999 -9999 -9999 -9999 -9999 -9999 -9999 -9999 -9999 -9999 -9999 -9999 39.01250076294 39.0125007629439 .3172798156739 .622070312539 .622070312539 .92684936523 40.2316398620640 .5364189147940 .8412094116241 .1459884643641 .45077896118 41.4507789611841 .7555618286141 .7555618286141 .7555618286141 .75556182861 41.7555618286141 .7555618286141 .7555618286141 .7555618286141 .75556182861 41.7555618286141 .4507789611841 .4507789611841 .1459884643641 .14598846436 40.8412094116240 .5364189147940 .5364189147940 .2316398620640 .23163986206 39.9268493652339 .9268493652339 .622070312539 .622070312539 .31727981567 39.9268493652341 .7555618286144 .1938400268646 .6321296691949 .07040023804 50.8991203308152 .7278289794954 .25175094604 -9999 -9999 -9999 -9999 -9999 -9999 -9999

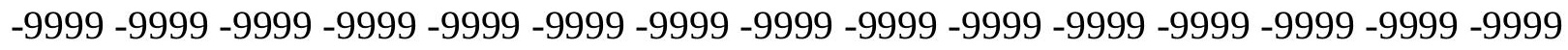
-9999 -9999 -9999 -9999 -9999 -9999 -9999 -9999 -9999 -9999 -9999 -9999 -9999 -9999 -9999 -9999 -9999 -9999 -9999 -9999 -9999 -9999 -9999 -9999 -9999 -9999 -9999 -9999 -9999 -9999 -9999 -9999 -9999 -9999 -9999 -9999 -9999 -9999 -9999 -9999 -9999

-9999 -9999 -9999 -9999 -9999 -9999 -9999 -9999 -9999 -9999 -9999 -9999 -9999 -9999 -9999 -9999 -9999 -9999 -9999 -9999 -9999 -9999 -9999 -9999 -9999 -9999 -9999 -9999 -9999 -9999 -9999 -9999 -9999 -9999 -9999 -9999 -9999 -9999 -9999 -9999 -9999 -9999 -9999 -9999 -9999 -9999 -9999 -9999 -9999 -9999 -9999 -9999 -9999 -9999 -9999 -9999 -9999 -9999 -9999 -9999

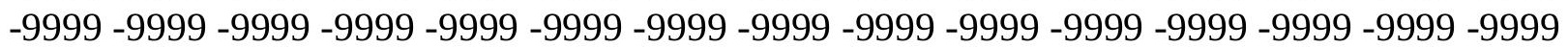


-9999 -9999 -9999 -9999 -9999 -9999 -9999 -9999 -9999 -9999 -9999 -9999 -9999 -9999 -9999 -9999 -9999 -9999 -9999 -9999 -9999 -9999 -9999 -9999 -9999 -9999 -9999 -9999 -9999 -9999 -9999 -9999 -9999 -9999 -9999 -9999 -9999 -9999 -9999 -9999 -9999 -9999 -9999 -9999 - 9999 -9999 -9999 -9999 -9999 -9999 -9999 -9999 -9999 -9999 -9999 -9999 -9999 -9999 -9999 -9999 -9999 -9999 -9999 -9999 -9999 -9999 -9999 -9999 -9999-9999 -9999 -9999 -9999 -9999 -9999 -9999 -9999 -9999 -9999 -9999 -9999 -9999 -9999 -9999 -9999 -9999 -9999 -9999 -9999 -9999 -

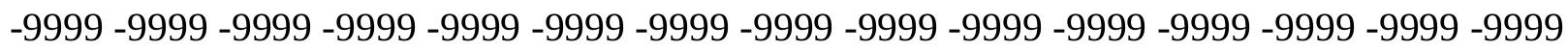

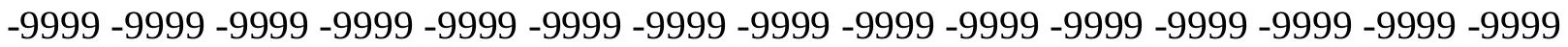
-9999 -9999 -9999 -9999 -9999 -9999 -9999 -9999 -9999 -9999 -9999 -9999 -9999 -9999 -9999 -9999 -9999 -9999 -9999 -9999 -9999 -9999 -9999 -9999 -9999 -9999 -9999 -9999 -9999 -9999

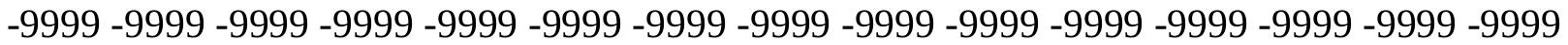
-9999 -9999 -9999 -9999 -9999 -9999 -9999 -9999 -9999 -9999 -9999 -9999 -9999 -9999 -9999 -9999 -9999 -9999 -9999 -9999 -9999 -9999 -9999 -9999 -9999 -9999 -9999 -9999 -9999 -9999 -9999 -9999 -9999 -9999 -9999 -9999 -9999 -9999 -9999 -9999 -9999 -9999 -9999 -9999 41.4507789611841 .4507789611841 .7555618286141 .7555618286142 .06034851074 42.0603485107442 .3651313781742 .3651313781742 .66992187542 .669921875 42.9747009277342 .9747009277342 .9747009277342 .9747009277342 .97470092773 42.9747009277342 .9747009277342 .66992187542 .66992187542 .36513137817 42.3651313781742 .0603485107442 .0603485107441 .7555618286141 .45077896118 41.1459884643641 .1459884643640 .8412094116240 .5364189147940 .53641891479 40.2316398620639 .9268493652339 .622070312539 .3172798156739 .6220703125 41.7555618286144 .4986305236846 .9369087219249 .3751907348651 .20389938354 53.0326118469254 .55654144287 -9999 -9999 -9999 -9999 -9999 -9999 -9999 -9999 -9999 -9999 -9999 -9999 -9999 -9999 -9999 -9999 -9999 -9999 -9999 -9999 -9999 -9999 -9999 -9999 -9999 -9999 -9999 -9999 -9999 -9999 -9999 -9999 -9999 -9999 -9999 -9999 -9999 -9999 -9999 -9999 -9999 -9999 -9999 -9999 -9999 -9999 -9999 -9999 -9999 -9999 -9999 -9999 -9999 -9999 -9999 -9999 -9999-9999 -9999 -9999 -9999 -9999 -9999

-9999 -9999 -9999 -9999 -9999 -9999 -9999 -9999 -9999 -9999 -9999 -9999 -9999 -9999 -9999 -9999 -9999 -9999 -9999 -9999 -9999 -9999 -9999 -9999 -9999 -9999 -9999 -9999 -9999 -9999

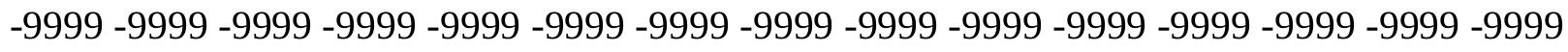
-9999 -9999 -9999 -9999 -9999 -9999 -9999 -9999 -9999-9999 -9999 -9999 -9999 -9999 -9999 -9999 -9999 -9999 -9999 -9999 -9999 -9999 -9999 -9999 -9999 -9999 -9999 -9999 -9999 -9999 -

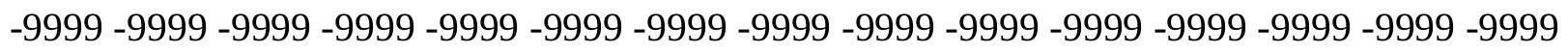
-9999 -9999 -9999 -9999 -9999 -9999 -9999 -9999 -9999 -9999 -9999 -9999 -9999 -9999 -9999 -9999 -9999 -9999 -9999 -9999 -9999 -9999 -9999 -9999 -9999 -9999 -9999 -9999 -9999 -9999 -

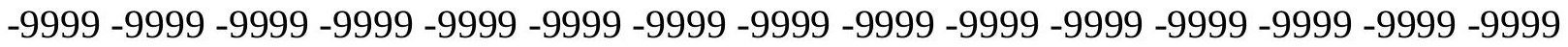

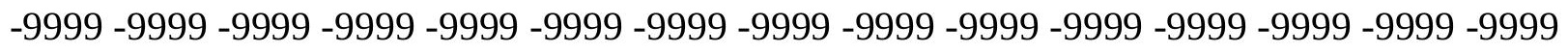

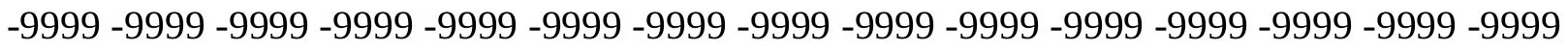
-9999 -9999 -9999 -9999 -9999 -9999 -9999 -9999 -9999 -9999 -9999 -9999 -9999 - 9999 - -999 -9999 -9999 -9999 -9999 -9999 -9999 -9999 -9999 -9999 -9999 -9999 -9999 -9999 -9999 -9999 -

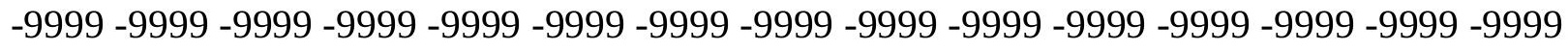

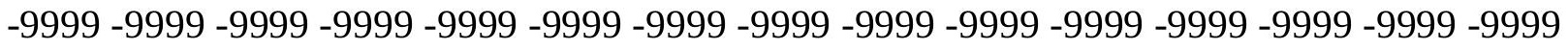
-9999 -9999 -9999 -9999 -9999 -9999 -9999 -9999 -9999 -9999 -9999 -9999 -9999 -9999 -9999 -9999 -9999 -9999 -9999 -9999 -9999 -9999 -9999 -9999-9999 -9999 -9999 -9999 -9999 -9999 -9999 -9999 -9999 -9999 -9999 -9999 -9999 -9999 -9999 -9999 -9999 -9999 -9999 -9999 -9999 -

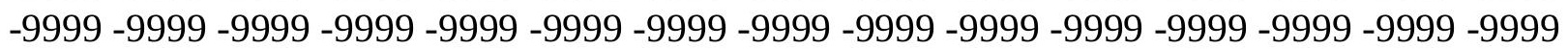


43.2794914245643 .2794914245643 .5842704772943 .5842704772943 .58427047729 43.8890609741243 .8890609741243 .8890609741243 .8890609741243 .88906097412 43.8890609741243 .8890609741243 .8890609741243 .8890609741243 .88906097412 43.8890609741243 .5842704772943 .5842704772943 .2794914245643 .27949142456 42.9747009277342 .66992187542 .66992187542 .3651313781742 .06034851074 42.0603485107441 .7555618286141 .4507789611841 .4507789611841 .14598846436 41.1459884643640 .8412094116240 .8412094116241 .4507789611843 .27949142456 45.717769622847 .8512611389249 .9847602844252 .1182594299353 .64218139648 55.1661109924356 .38525009155 -9999 -9999 -9999 -9999 -9999 -9999 -9999 -9999 -9999 -9999 -9999 -9999 -9999 -9999 -9999 -9999 -9999 -9999 -9999 -9999 -9999 -9999 -9999 -9999 -9999 -9999 -9999 -9999 -9999 -9999 -9999 -9999 -9999 -9999 -9999 -9999 -9999 -9999 -9999 -9999 -9999 -9999 -9999 -9999-9999 -9999 -9999 -9999 -9999 -9999 -9999 -9999 -999 -999 -999 -9999 -9999 -9999 -9999 -9999 -9999-9999 -9999

-9999 -9999 -9999 -9999 -9999 -9999 -9999 -9999 -9999 -9999 -9999 -9999 -9999 -9999 -9999 -9999 -9999 -9999 -9999 -9999 -9999 -9999 -9999 -9999 -9999 -9999 -9999 -9999 -9999 -9999

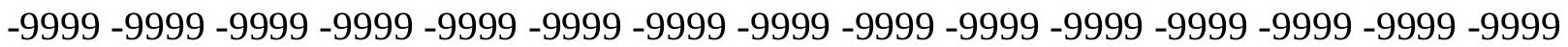

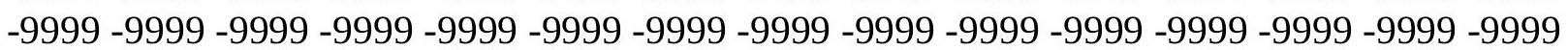
-9999 -9999 -9999 -9999 -9999 -9999 -9999 -9999 -9999 -9999 -9999 -9999 -9999 -9999 -9999 -999 -9999 -9999 -9999 -9999 -9999 -9999 -9999 -9999 -9999 -9999 -9999 -9999 -9999 -9999 -9999 -9999 -9999 -9999 -9999 -9999 -9999 -9999 -9999 -9999 -9999 -9999 -9999 -9999 -9999 -9999 -

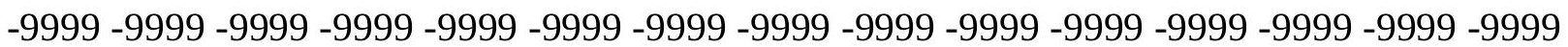
-9999 -9999 -9999 -9999 -9999 -9999 -9999 -9999 -9999 -9999 -9999 -9999 -9999 -9999 -9999 -9999 -9999 -9999 -9999 -9999 -9999 -9999 -9999 -9999 -9999 -9999 -9999 -9999 -9999 -9999 -9999 -9999 -9999 -9999 -9999 -9999 -9999 -9999 -9999 -9999 -9999 -9999 -9999 -9999 -9999

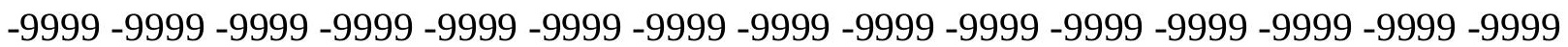
-9999 -9999 -9999 -9999 -9999 -9999 -9999 -9999 -9999 -9999 -9999 -9999 -9999 -9999 -9999 -9999 -9999 -9999 -9999 -9999 -9999 -9999 -9999 -9999 -9999 -9999 -9999 -9999 -9999 -9999 -9999 -9999 -9999 -9999 -9999 -9999 -9999 -9999 -9999 -9999 -9999 -9999 -9999 -9999 -9999

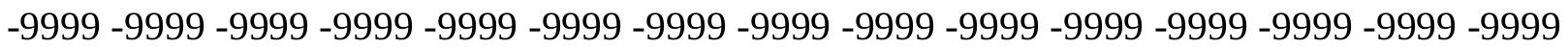

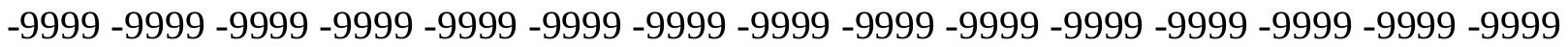
-9999 -9999 -9999 -9999 -9999 -9999 -9999 -9999 -9999 -9999 -9999 -9999 -9999 -9999 -9999 -9999 -9999 -9999 -9999 -9999 -9999 -9999 -9999 -9999 -9999 -9999 -9999 -9999 -9999 -9999 -9999 -9999 45.10820007324 45.10820007324 45.10820007324 45.10820007324 45.1082000732445 .1082000732445 .1082000732445 .1082000732445 .10820007324 45.1082000732445 .1082000732445 .1082000732444 .8034095764244 .80340957642 44.4986305236844 .4986305236844 .1938400268644 .1938400268643 .88906097412 43.5842704772943 .5842704772943 .2794914245643 .2794914245642 .97470092773 42.9747009277342 .66992187542 .66992187542 .66992187542 .66992187542 .97470092773 43.2794914245644 .1938400268645 .717769622847 .5464782714849 .37519073486 51.5086898803753 .0326118469254 .8613204956156 .0804595947356 .99481964111 -9999 -9999 -9999 -9999 -9999 -9999 -9999 -9999 -9999 -9999 -9999 -9999 -9999 -9999 -9999 -9999 -9999 -9999 -9999 -9999 -9999 -9999 -9999 -9999 -9999 -9999 -9999 -9999 -9999 -9999 -9999 -9999 -9999 -9999 -9999 -9999 -9999 -9999 -9999 -9999 -9999 -9999 -9999 -9999 -9999 -9999 -

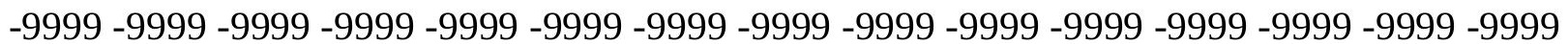
$-9999$

-9999 -9999 -9999 -9999 -9999 -9999 -9999 -9999 -9999 -9999 -9999 -9999 -9999 -9999 -9999 
-9999 -9999 -9999 -9999 -9999 -9999 -9999 -9999 -9999 -9999 -9999 -9999 -9999 -9999 -9999 -9999 -9999 -9999 -9999 -9999 -9999 -9999 -9999 -9999 -9999 -9999 -9999 -9999 -9999 -9999 -9999 -9999 -9999 -9999 -9999 -9999 -9999 -9999 -9999 -9999 -9999 -9999 -9999 -9999 - 9999 -9999 -9999 -9999 -9999 -9999 -9999 -9999 -9999 -9999 -9999 -9999 -9999 -9999 -9999 -9999 -9999 -9999 -9999 -9999 -9999 -9999 -9999 -9999 -9999-9999 -9999 -9999 -9999 -9999 -9999 -9999 -9999 -9999 -9999 -9999 -9999 -9999 -9999 -9999 -9999 -9999 -9999 -9999 -9999 -9999 -9999 -9999 -9999 -9999 -9999 -9999 -9999 -9999 -9999 -9999 -9999 -9999 -9999 -9999 -9999 -999 -

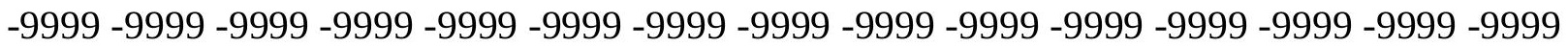
-9999 -9999 -9999 -9999 -9999 -9999 -9999 -9999 -9999 -9999 -9999 -9999 -9999 -9999 -9999 -9999 -9999 -9999 -9999 -9999 -9999 -9999 -9999 -9999 -9999 -9999 -9999 -9999 -9999 -9999 -

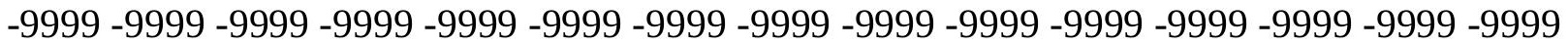
-9999 -9999 -9999 -9999 -9999 -9999 -9999 -9999 -9999 -9999 -9999 -9999 -9999 -9999 -9999 -9999 -9999 -9999 -9999 -9999 -9999 -9999 -9999 -9999 -9999 -9999 -9999 -9999 -9999 -9999 -9999 -9999 -9999 -9999 -9999 -9999 -9999 -9999 -9999 -9999 -9999 -9999 -9999 -9999 -9999 -9999 -9999 -9999 -9999 -9999 -9999 -9999 -9999 -9999 -9999 -9999 -9999 -9999 -9999 -9999

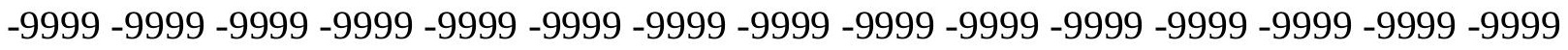
-9999 -9999 -9999 -9999 -9999 -9999 -9999 -9999 -9999 -9999 -9999 -9999 -9999 -9999 -9999 -9999 -9999 -9999 -9999 -9999 -9999 -9999 -9999 -9999 -9999 -9999 -9999 -9999 -9999 -9999 -9999 -9999 -9999 46.6321296691946.6321296691946.3273391723646.32733917236 46.3273391723646 .3273391723646 .3273391723646 .3273391723646 .02254867554 46.0225486755446 .0225486755445 .717769622845 .717769622845 .7177696228 45.4129791259845 .1082000732445 .1082000732444 .8034095764244 .80340957642 44.4986305236844 .4986305236844 .1938400268644 .1938400268644 .19384002686 44.1938400268644 .4986305236844 .4986305236844 .8034095764245 .41297912598 46.0225486755446 .9369087219248 .4608306884849 .9847602844251 .50868988037 53.3373985290554 .5565414428756 .0804595947356 .9948196411157 .9091796875 -9999 -9999 -9999 -9999 -9999 -9999 -9999 -9999 -9999 -9999 -9999 -9999 -9999 -9999 -9999 -9999 -9999 -9999 -9999 -9999 -9999 -9999 -9999 -9999 -9999 -9999 -9999 -9999 -9999 -9999 -9999

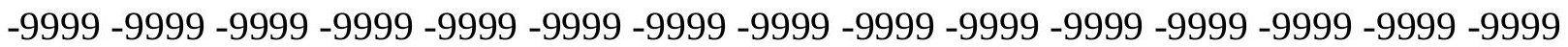

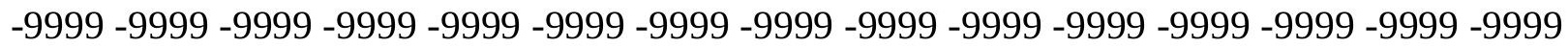
$-9999$

-9999 -9999 -9999 -9999 -9999 -9999 -9999 -9999 -9999 -9999 -9999 -9999 -9999 -9999 -9999 -9999 -9999 -9999 -9999 -9999 -9999 -9999 -9999 -9999 -9999 -9999 -9999 -9999 -9999 -9999 -9999 -9999 -9999 -9999 -9999 -9999 -9999 -9999 -9999 -9999 -9999 -9999 -9999 -9999 -9999 -

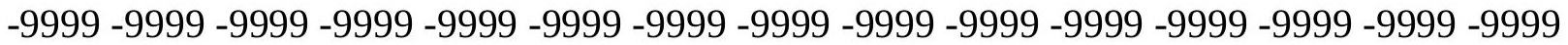
-9999 -9999 -9999 -9999 -9999 -9999 -9999 -9999 -9999 -9999 -9999 -9999 -9999 -9999 -9999 -9999 -9999 -9999 -9999 -9999 -9999 -9999 -9999 -9999 -9999 -9999 -9999 -9999 -9999 -9999

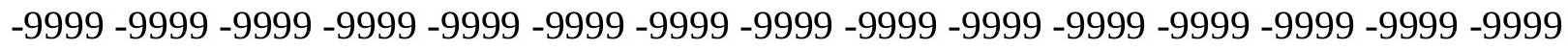
-9999 -9999 -9999 -9999 -9999 -9999 -9999 -9999 -9999 -9999 -9999 -9999 -9999 -9999 -9999 -9999 -9999 -9999 -9999 -9999 -9999 -9999 -9999 -9999 -9999 -9999 -9999 -9999 -9999 -9999 -9999 -9999 -9999 -9999 -9999 -9999 -9999 -9999 -9999 -9999 -9999 -9999 -9999 -9999 -9999 -999 -9999 -9999 -9999 -9999 -9999 -9999 -9999 -9999 -9999 -9999 -9999 -9999 -9999 -9999 -9999 -9999 -9999 -9999 -9999 -9999 -9999 -9999 -9999 -9999 -9999 -9999 -9999 -9999 -9999 -9999 -9999 -9999 -9999 -9999 -9999 -9999 -9999 -9999 -9999 -9999 -9999 -9999 -9999 -9999 -9999 -9999 -9999 -9999 -9999 -9999 -9999 -9999 -9999 -9999 -9999 -9999 -9999 -9999 -9999 -9999

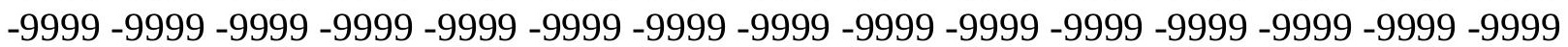


-9999 -9999 -9999 -9999 -9999 -9999 -9999 -9999 -9999 -9999 -9999 -9999 -9999 -9999 -9999 -9999 -9999 -9999 -9999 -9999 -9999 -9999 -9999 -9999 -9999 -9999 -9999 -9999 -9999 -9999 -9999 -9999 -9999 -9999 -9999 -9999 -9999 -9999 -9999 -9999 -9999 -9999 -9999 -9999 -9999 -9999 -9999 -9999 -9999 -9999 -9999 -9999 -9999 -9999 -9999 -9999 -9999 -9999 -9999 -9999 -9999 -9999 -9999 -9999 -9999 47.85126113892 47.54647827148 47.54647827148 47.5464782714847 .2416992187547 .2416992187547 .2416992187546 .93690872192 46.9369087219246 .9369087219246 .6321296691946 .6321296691946 .32733917236 46.3273391723646 .0225486755446 .0225486755445 .717769622845 .7177696228 45.717769622845 .717769622845 .717769622845 .717769622846 .02254867554 46.3273391723646 .6321296691947 .2416992187547 .8512611389249 .07040023804 49.9847602844251 .2038993835452 .7278289794953 .9469718933155 .16611099243 56.3852500915557 .2995986938558 .2139587402359 .12831115723 -9999 -9999 -9999-9999 -9999 -9999 -9999 -9999 -9999 -9999 -9999 -9999 -9999 -9999 -9999 -9999 -9999 -9999 -9999 -9999 -9999 -9999 -9999 -9999 -9999 -9999 -9999 -9999 -9999 -9999 -9999 -9999 -9999 -9999 -9999 -9999 -9999 -9999 -9999 -9999 -9999 -9999 -9999 -9999 -9999 -9999 -9999 -9999 -9999 -9999 -9999 -9999 -9999 -9999 -9999 -9999 -9999 -9999 -9999 -9999 -9999 -9999 -

-9999 -9999 -9999 -9999 -9999 -9999 -9999 -9999 -9999 -9999 -9999 -9999 -9999 -9999 -9999 -9999 -9999 -9999 -9999 -9999 -9999 -9999 -9999 -9999 -9999 -9999 -9999 -9999 -9999 -9999 -9999 -9999 -9999 -9999 -9999 -9999 -9999 -9999 -9999 -9999 -9999 -9999 -9999 -9999 -9999 -9999 -9999 -9999 -9999 -9999 -9999 -9999 -9999 -9999 -9999 -9999 -9999 -9999 -9999 -9999

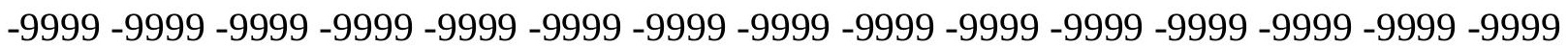
-9999 -9999 -9999 -9999 -9999 -9999 -9999 -9999 -9999 -9999 -9999 -9999 -9999 -9999 -9999 -9999 -9999 -9999 -9999 -9999 -9999 -9999 -9999 -9999 -9999 -9999 -9999 -9999 -9999 -9999 -9999 -9999 -9999 -9999 -9999 -9999 -9999 -9999 -9999 -9999 -9999 -9999 -9999 -9999 -9999

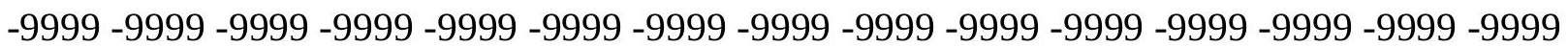
-9999 -9999 -9999 -9999 -9999 -9999 -9999 -9999 -9999 -9999 -9999 -9999 -9999 -9999 -9999 -9999 -9999 -9999 -9999 -9999 -9999 -9999 -9999 -9999 -9999 -9999 -9999 -9999 -9999 -9999 -9999 -9999 -9999 -9999 -9999 -9999 -9999 -9999 -9999 -9999 -9999 -9999 -9999 -9999 -9999 -9999 -9999 -9999 -9999 -9999 -9999 -9999 -9999 -9999 -9999 -9999 -9999 -9999 -9999 -9999 -9999 -9999 -9999 -9999 -9999 -9999 -9999 -9999 -9999 -9999 -9999 -9999 -9999 -9999 -9999 -9999 -9999 -9999 -9999 -9999 -9999 -9999 -9999 -9999 -9999 -9999 -9999 -9999 -9999 -9999 -

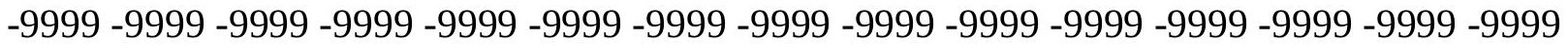
-9999 -9999 -9999 -9999 -9999 -9999 -9999 -9999 -9999 -9999 -9999 -9999 -9999 -9999 -9999 -9999 -9999 -9999 -9999 -9999 -9999 -9999 -9999 -9999 -9999 -9999 -9999 -9999 -9999 -9999 -9999 -9999 -9999 -9999 -9999 -9999 -9999 -9999 -9999 -9999 -9999 -9999 -9999 -9999 -9999 -9999 -9999 -9999 -9999 -9999 -9999 48.765621185348 .765621185348 .46083068848 48.4608306884848 .1560516357448 .1560516357447 .8512611389247 .85126113892 47.8512611389247 .5464782714847 .5464782714847 .2416992187547 .24169921875 46.9369087219246 .9369087219246 .9369087219246 .9369087219246 .93690872192 46.9369087219247 .2416992187547 .5464782714847 .8512611389248 .46083068848 49.0704002380449 .9847602844250 .8991203308151 .8134689331153 .03261184692 54.2517509460455 .4708900451756 .6900291442957 .6043891906758 .21395874023 58.8235282897959 .4331016540560 .34745025635 -9999 -9999 -9999 -9999 -9999 -9999 -9999 -9999 -9999 -9999 -9999 -9999 -9999 -9999 -9999 -9999 -9999 -9999 -9999 -9999 -9999 -9999 -9999 -9999 -9999 -9999 -9999 -9999 -9999 -9999 -9999 -9999 -9999 -9999 -9999 -9999 -9999

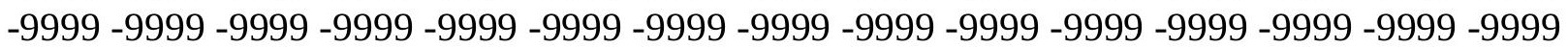


-9999 -9999 -9999 -9999 -9999 -9999 -9999 -9999 -9999 -9999

-9999 -9999 -9999 -9999 -9999 -9999 -9999 -9999 -9999 -9999 -9999 -9999 -9999 -9999 -9999 -9999 -9999 -9999 -9999 -9999 -9999 -9999 -9999 -9999 -9999 -9999 -9999 -9999 -9999 -9999 -9999 -9999 -9999 -9999 -9999 -9999 -9999 -9999 -9999 -9999 -9999 -9999 -9999 -9999 -9999 -9999 -9999 -9999 -9999 -9999 -9999 -9999 -9999 -9999 -9999 -9999 -9999 -9999 -9999 -9999 -9999 -9999 -9999 -9999 -9999 -9999 -9999 -9999 -9999 -9999 -9999 -9999 -9999 -9999 -9999 -9999 -9999 -9999 -9999 -9999 -9999 -9999 -9999 -9999 -9999 -9999 -9999 -9999 -9999 -9999 -

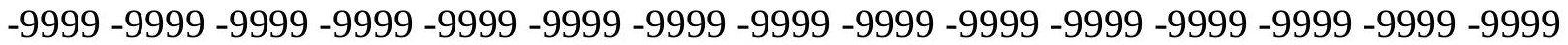
-9999 -9999 -9999 -9999 -9999 -9999 -9999 -9999 -9999 -9999 -9999 -9999 -9999 -9999 -9999 -9999 -9999 -9999 -9999 -9999 -9999 -9999 -9999 -9999 -9999 -9999 -9999 -9999 -9999 -9999 -

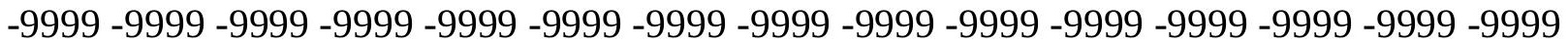
-9999 -9999 -9999 -9999 -9999 -9999 -9999 -9999 -9999 -9999 -9999 -9999 -9999 -9999 -9999 -9999 -9999 -9999 -9999 -9999 -9999 -9999 -9999 -9999 -9999 -9999 -9999 -9999 -9999 -9999 -9999 -9999 -9999 -9999 -9999 -9999 -9999 -9999 -9999 -9999 -9999 -9999 -9999 -9999 -9999 -9999 -9999 -9999 -9999 -9999 -9999 -9999 -9999 -9999 -9999 -9999 -9999 -9999 -9999 -9999 -9999 -9999 -9999 -9999 -9999 -9999 -9999 -9999 -9999 -9999 -9999 -9999 -9999 -9999 -9999 -9999 -9999 -9999 -9999 -9999 -9999 -9999 -9999 -9999 -9999 -9999 -9999 -9999 -9999 -9999 -9999 -9999 -9999 -9999 -9999 -9999 -9999 -9999 -9999 -9999 -9999 -9999 -9999 -9999 -9999 -9999 -9999 -9999 -9999 -9999 -9999 -9999 -9999 -9999 -9999 -9999 -9999 -9999 -9999 -9999 -9999 -9999 -9999 -9999 -9999 -9999 -9999 -9999 -9999 -9999 -9999 -9999 -9999 -9999 -9999 -9999 -9999 -9999 -9999 -9999 -9999 -9999 -9999 49.6799812316949 .37519073486 49.3751907348649 .0704002380449 .0704002380448 .765621185348 .7656211853 48.4608306884848 .4608306884848 .1560516357448 .1560516357448 .15605163574 48.1560516357448 .1560516357448 .1560516357448 .1560516357448 .46083068848 48.765621185349 .0704002380449 .6799812316950 .2895507812551 .20389938354 52.4230384826753 .6421813964854 .8613204956156 .0804595947356 .99481964111 57.909179687559 .1283111572359 .7378807067960 .0426712036160 .34745025635 60.9570198059161 .56660079956 -9999 -9999 -9999 -9999 -9999 -9999 -9999 -9999 -9999 -9999 -9999 -9999 -9999 -9999 -9999 -9999 -9999 -9999 -9999 -9999 -9999 -9999 -9999 -9999 -9999 -9999 -9999 -9999 -9999 -9999 -9999 -9999 -9999 -9999 -9999 -9999 -9999 -9999 -9999 -9999 -9999 -9999 -9999 -9999 -9999 -9999 -9999 -9999 -9999 -9999 -9999 -9999 -9999 -9999 -9999 -9999 -9999 -9999 -9999 -9999 -9999 -9999 -9999 -9999 -9999 -9999 -9999 -9999 -9999 -9999 -9999 -9999 -9999 -9999 -9999 -9999 -9999 -9999 -9999 -9999 -9999 -9999 -9999 -9999 -9999 -9999 -9999 -9999 -9999 -9999 -9999 -9999 -9999 -9999 -9999 -9999 -9999 -9999 -9999 -9999 -9999 -9999 -9999 -9999 -9999 -9999 -9999 -9999 -9999 -9999 -9999 -9999 -9999 -9999 -9999 -9999 -9999 -9999 -9999 -9999 -9999 -9999 -9999 -9999 -9999 -9999 -9999 -9999 -9999 -9999 -9999 -9999 -9999 -9999 -9999 -9999 -9999

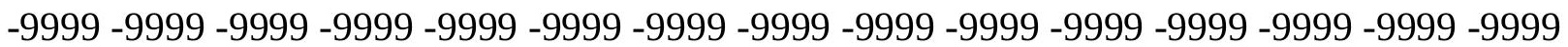
-9999 -9999 -9999 -9999 -9999 -9999 -9999 -9999 -9999 -9999 -9999 -9999 -9999 -9999 -9999 -9999 -9999 -9999 -9999 -9999 -9999 -9999 -9999 -9999 -9999 -9999 -9999 -9999 -9999 -9999 -9999 -9999 -9999 -9999 -9999 -9999 -9999 -9999 -9999 -9999 -9999 -9999 -9999 -9999 -9999 -9999 -9999 -9999 -9999 -9999 -9999 -9999 -9999 -9999 -9999 -9999 -9999-9999-9999-9999 -9999 -9999 -9999 -9999 -9999 -9999 -9999 -9999 -9999 -9999 -9999 -9999 -9999 -9999 -9999 -9999 -9999 -9999 -9999 -9999 -9999 -9999 -9999 -9999 -9999 -9999 -9999 -9999 -9999 -9999 -9999 -9999 -9999 -9999 -9999 -9999 -9999 -9999 -9999 -9999 -9999 -9999 -9999 -9999 -9999

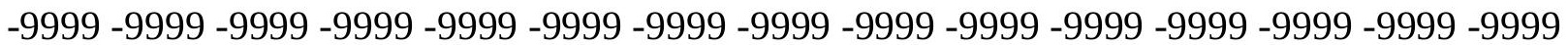


-9999 -9999 -9999 -9999 -9999 -9999 -9999 -9999 -9999 -9999 -9999 -9999 -9999 -9999 -9999 -9999 -9999 -9999 -9999 -9999 -9999 -9999 -9999 -9999 -9999 -9999 -9999 -9999 -9999 -9999 -9999 -9999 -9999 -9999 -9999 -9999 -9999 -9999 -9999 -9999 -9999 -9999 -9999 -9999 -9999 -9999 -9999 -9999 -9999 -9999 -9999 -9999 -9999 -9999 -9999 -9999 -9999 -9999 -9999 -9999 -9999 -9999 -9999 -9999 -9999 -9999 -9999 -9999 -9999 -9999 -9999 -9999 -9999 -9999 -9999 -9999 -9999 -9999 -9999 -9999 -9999 -9999 -9999 -9999 50.28955078125 50.28955078125 49.9847602844249 .9847602844249 .6799812316949 .6799812316949 .37519073486 49.3751907348649 .3751907348649 .0704002380449 .0704002380449 .07040023804 49.0704002380449 .3751907348649 .3751907348649 .6799812316950 .28955078125 50.8991203308151 .5086898803752 .4230384826753 .3373985290554 .55654144287 56.0804595947357 .6043891906759 .1283111572359 .7378807067960 .34745025635 60.9570198059161 .5666007995661 .8713798522961 .8713798522962 .17617034912 62.78573989868 -9999 -9999 -9999 -9999 -9999 -9999 -9999 -9999 -9999 -9999 -9999 -9999 -9999 -9999 -9999 -9999 -9999 -9999 -9999 -9999 -9999 -9999 -9999 -9999 -9999 -9999 -9999 -9999 -9999 -9999 -9999 -9999 -9999 -9999 -9999 -9999 -9999 -9999 -9999 -9999 -9999 -9999

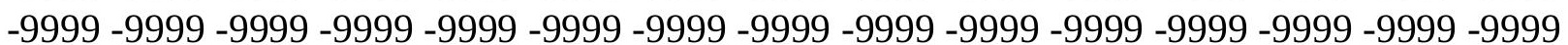
$-9999-9999-9999-9999-9999$

-9999 -9999 -9999 -9999 -9999 -9999 -9999 -9999 -9999 -9999 -9999 -9999 -9999 -9999 -9999 -9999 -9999 -9999 -9999 -9999 -9999 -9999 -9999 -9999 -9999 -9999 -9999 -9999 -9999 -9999 -9999 -9999 -9999 -9999 -9999 -9999 -9999 -9999 -9999 -9999 -9999 -9999 -9999 -9999 -9999

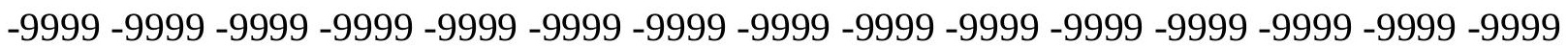
-9999 -9999 -9999 -9999 -9999 -9999 -9999 -9999 -9999 -9999 -9999 -9999 -9999 -9999 -9999 -9999 -9999 -9999 -9999 -9999 -9999 -9999 -9999 -9999 -9999 -9999 -9999 -9999 -9999 -9999 -9999 -9999 -9999 -9999 -9999 -9999 -9999 -9999 -9999 -9999 -9999 -9999 -9999 -9999 -9999

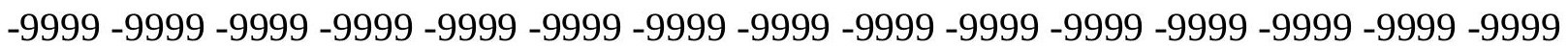
-9999 -9999 -9999 -9999 -9999 -9999 -9999 -9999 -9999 -9999 -9999 -9999 -9999 -9999 -9999 -9999 -9999 -9999 -9999 -9999 -9999 -9999 -9999 -9999 -9999 -9999 -9999 -9999 -9999 -9999 -9999 -9999 -9999 -9999 -9999 -9999 -9999 -9999 -9999 -9999 -9999 -9999 -9999 -9999 -9999 -9999 -9999 -9999 -9999 -9999 -9999 -9999 -9999 -9999 -9999 -9999 -9999 -9999-999 -999 -9999 -9999 -9999 -9999 -9999 -9999 -9999 -9999 -9999 -9999 -9999 -9999 -9999 -9999 -9999 -9999 -9999 -9999 -9999 -9999 -9999 -9999 -9999 -9999 -9999 -9999 -9999 -9999 -9999 -9999 -

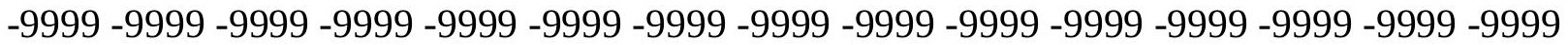
-9999 -9999 -9999 -9999 -9999 -9999 -9999 -9999 -9999 -9999 -9999 -9999 -9999 -9999 -9999 -9999 -9999 -9999 -9999 -9999 -9999 -9999 -9999 -9999 -9999 -9999 -9999 -9999 -9999 -9999 -9999 -9999 -9999 -9999 -9999 -9999 -9999 -9999 -9999 -9999 -9999 -9999 -9999 -9999 -9999 -9999 -9999 -9999 -9999 -9999 -9999 -9999 -9999 -9999 -9999 -9999 -9999 -9999 -9999 -9999 -9999 -9999 -9999 -9999 -9999 -9999 -9999 -9999 -9999 -9999 -9999 50.89912033081 50.8991203308150 .5943298339850 .5943298339850 .2895507812550 .28955078125 50.2895507812549 .9847602844249 .9847602844250 .2895507812550 .28955078125 50.5943298339850 .8991203308151 .2038993835451 .8134689331152 .42303848267 53.0326118469254 .2517509460455 .4708900451756 .6900291442958 .21395874023 60.0426712036161 .5666007995662 .1761703491262 .4809494018662 .78573989868 63.0905189514263 .3953094482463 .7000885009863 .7000885009864 .0048828125 -9999 -9999 -9999 -9999 -9999 -9999 -9999 -9999 -9999 -9999 -9999 -9999 -9999 -9999 -9999 -9999 -9999 -9999 -9999 -9999 -9999 -9999 -9999 -9999 -9999 -9999 -9999 -9999 -9999 -9999 -9999

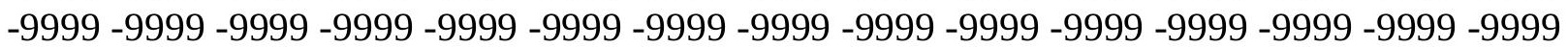


-9999 -9999 -9999 -9999 -9999 -9999 -9999 -9999 -9999 -9999 -9999 -9999 -9999 -9999 -9999 $-9999$

-9999 -9999 -9999 -9999 -9999 -9999 -9999 -9999 -9999 -9999 -9999 -9999 -9999 -9999 -9999 -9999 -9999 -9999 -9999 -9999 -9999 -9999 -9999 -9999 -9999 -9999 -9999 -9999 -9999 -9999 -9999 -9999 -9999 -9999 -9999 -9999 -9999 -9999 -9999 -9999 -9999 -9999-9999 -9999 -9999 -9999 -9999 -9999 -9999 -9999 -9999 -9999 -9999 -9999 -9999 -9999 -9999 -9999 -9999 -9999 -9999 -9999 -9999 -9999 -9999 -9999 -9999 -9999 -9999 -9999 -9999 -9999 -9999 -9999 -9999 -9999 -9999 -9999 -9999 -9999 -9999 -9999 -9999 -9999 -9999 -9999 -9999 -9999 -9999 -9999 -9999 -9999 -9999 -9999 -9999 -9999 -9999 -9999 -9999 -9999 -9999 -9999 -9999 -9999 -9999 -9999 -9999 -9999 -9999 -9999 -9999 -9999 -9999 -9999 -9999 -9999 -9999 -9999 -9999 -9999 -9999 -9999 -9999 -9999 -9999 -9999 -9999 -9999 -9999 -9999 -9999 -9999 -9999 -9999 -9999 -9999 -9999 -9999 -9999 -9999 -9999 -9999 -9999 -9999 -9999 -9999 -9999 -9999 -9999 -9999 -9999 -9999 -9999 -9999 -9999 -9999 -9999 -9999 -9999 -9999 -9999 -9999 -9999 -9999 -9999 -9999 -9999 -9999 -9999 -9999 -9999 -9999 -9999 -9999 -9999 -9999 -9999 -9999 -9999 -9999 -9999 -9999 -9999 -9999 -9999 -9999 -9999 -9999 -9999 -9999 -9999 -9999 -9999 -9999 -9999

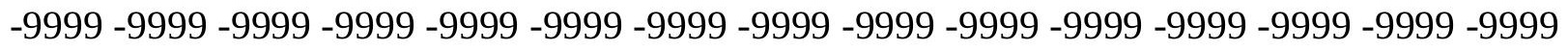
-9999 -9999 -9999 -9999 -9999 -9999 -9999 -9999 -9999 -9999 -9999 -9999 -9999 -9999 -9999 -

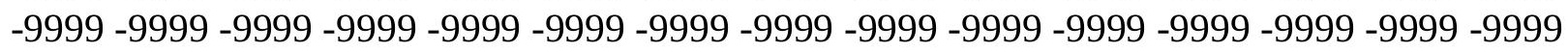

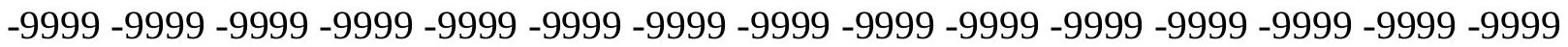

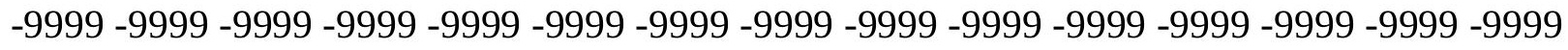

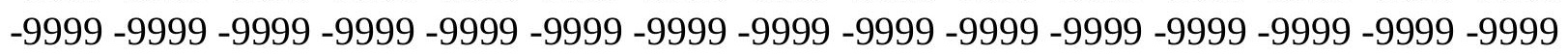
-9999 -9999-9999-9999 -9999 -9999 -9999 -9999 -9999-9999-9999 -9999 51.50868988037 51.5086898803751 .2038993835451 .2038993835451 .2038993835451 .20389938354 51.2038993835451 .2038993835451 .2038993835451 .5086898803751 .50868988037 51.8134689331152 .4230384826753 .0326118469253 .6421813964854 .55654144287 55.7756805419956 .9948196411158 .2139587402359 .7378807067961 .56660079956 62.7857398986863 .7000885009864 .004882812564 .3096618652364 .61444854736 64.9192428588964 .9192428588964 .9192428588965 .22400665283 -9999 -9999 -9999-9999 -9999 -9999 -9999 -9999 -9999 -9999 -9999 -9999 -9999 -9999 -9999 -9999 -9999 -9999 -9999

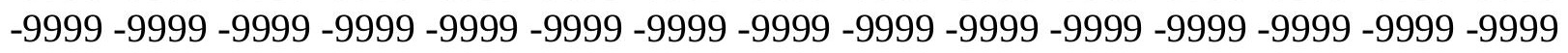
-9999 -9999 -9999 -9999 -9999 -9999 -9999 -9999 -9999 -9999 -9999 -9999 -9999 -9999 -9999 -9999 -9999 -9999 -9999 -9999 -9999 -9999 -9999 -9999 -9999 -9999 -9999 -9999 -

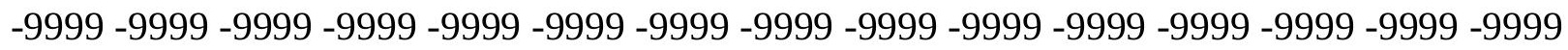

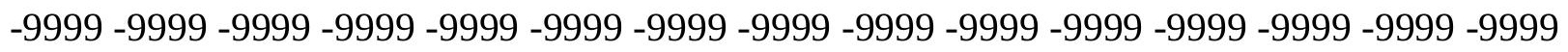
-9999 -9999 -9999 -9999 -9999 -9999 -9999 -9999 -9999 -9999 -9999 -9999 -9999 -9999 -9999 -

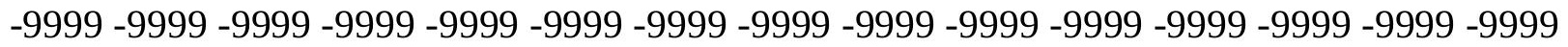

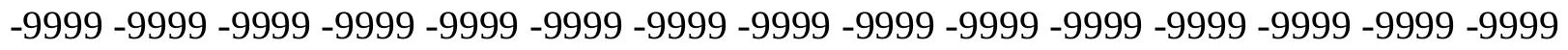

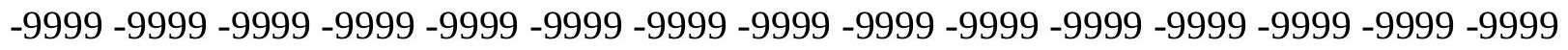

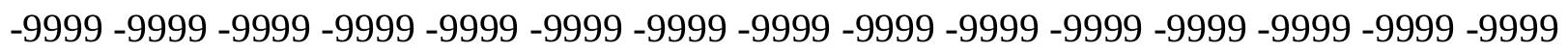
-9999 -9999 -9999 -9999 -9999 -9999 -9999 -9999 -9999 -9999 -9999 -9999 -9999 -9999 -9999 -

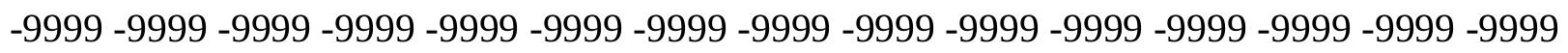

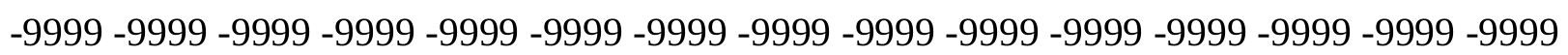
-9999 -9999 -9999 -9999 -9999 -9999 -9999 -9999 -9999 -9999 -9999 -9999 -9999 -9999 -9999 -9999 -9999 -9999 -9999 -9999 -9999 -9999 -9999 -9999 -9999 -9999 -9999 -9999 -9999 -9999 -

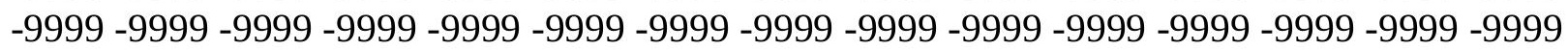

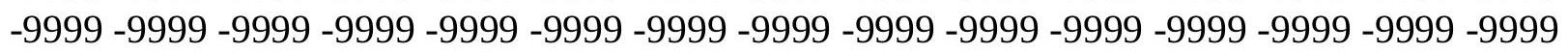


-9999 -9999 -9999 -9999 -9999 -9999 -9999 -9999 -9999 -9999 -9999 -9999 -9999 -9999 -9999 -9999 -9999 -9999 -9999 -9999 -9999 -9999 -9999 -9999 -9999 -9999 -9999 -9999 -9999 -9999 -9999 -9999 -9999 -9999 -9999 -9999 -9999 -9999 -9999 -9999 -9999 -9999 -9999 -9999 -9999 -9999 -9999 -9999 -9999 -9999 -9999 -9999 -9999 -9999 -9999 -9999 -9999 -9999 -9999 -9999 -9999 -9999 -9999 -9999 -9999 -9999 -9999 -9999 -9999 -9999 -9999 -9999 -9999 -9999 -9999 -9999 -9999 -9999 -9999 -9999 -9999 -9999 -9999 -9999 -9999 -9999 -9999 -9999 -9999 52.1182594299352 .1182594299352 .1182594299352 .1182594299352 .11825942993 52.1182594299352 .1182594299352 .4230384826752 .7278289794953 .03261184692 53.6421813964854 .2517509460455 .1661109924356 .0804595947357 .29959869385 58.5187492370659 .7378807067960 .9570198059162 .4809494018664 .0048828125 64.9192428588965 .5288009643665 .8335876464866 .1383666992266 .13836669922 66.1383666992266 .1383666992266 .13836669922 -9999 -9999 -9999 -9999 -9999 -9999 -9999 -9999 -9999 -9999 -9999 -9999 -9999 -9999 -9999 -9999 -9999 -9999 -9999 -9999 -9999 -9999 -9999 -9999 -9999 -9999 -9999 -9999 -9999 -9999 -9999 -9999 -9999 -9999 -9999 -9999 - 9999 - -999 -9999 -9999 -9999 -9999 -9999 -9999 -9999 -9999 -9999 -9999 -9999 -9999 -9999 -9999 -9999 -9999 -9999-9999 -9999 -9999 -9999 -9999 -9999 -9999 - -9999 -

-9999 -9999 -9999 -9999 -9999 -9999 -9999 -9999 -9999 -9999 -9999 -9999 -9999 -9999 -9999 -9999 -9999 -9999 -9999 -9999 -9999 -9999 -9999 -9999 -9999 -9999 -9999 -9999 -9999 -9999 -9999 -9999 -9999 -9999 -9999 -9999 -9999 -9999 -9999 -9999 -9999 -9999 -9999 -9999 -9999 -9999 -9999 -9999 -9999 -9999 -9999 -9999 -9999 -9999 -9999 -9999 -9999 -9999 -9999 -9999

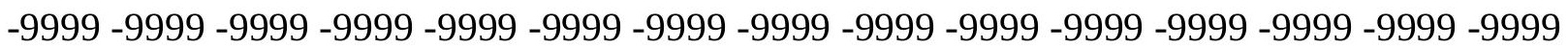
-9999 -9999 -9999 -9999 -9999 -9999 -9999 -9999 -9999 -9999 -9999 -9999 -9999 -9999 -9999 -9999 -9999 -9999 -9999 -9999 -9999 -9999 -9999 -9999 -9999 -9999 -9999 -9999 -9999 -9999 -9999 -9999 -9999 -9999 -9999 -9999 -9999 -9999 -9999 -9999 -9999 -9999 -9999 -9999 -9999

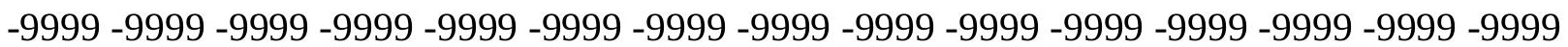
-9999 -9999 -9999 -9999 -9999 -9999 -9999 -9999 -9999 -9999 -9999 -9999 -9999 -9999 -9999 -9999 -9999 -9999 -9999 -9999 -9999 -9999 -9999 -9999 -9999 -9999 -9999 -9999 -9999 -9999 -9999 -9999 -9999 -9999 -9999 -9999 -9999 -9999 -9999 -9999 -9999 -9999 -9999 -9999 -9999 -9999 -9999 -9999 -9999 -9999 -9999 -9999 -9999 -9999 -9999 -9999 -9999 -9999 -9999 -9999 -9999 -9999 -9999 -9999 -9999 -9999 -9999 -9999 -9999 -9999 -9999 -9999 -9999 -9999 -9999 -9999 -9999 -9999 -9999 -9999 -9999 -9999 -9999 -9999 -9999 -9999 -9999 -9999 -9999 -9999 -9999 -9999 -9999 -9999 -9999 -9999 -9999 -9999 -9999 -9999 -9999 -9999 -9999 -9999 -9999 -9999 -9999 -9999 -9999 -9999 -9999 -9999 -9999 -9999 -9999 -9999 -9999 -9999 -9999 -9999 -9999 -9999 -9999 -9999 -9999 -9999 -9999 -9999 -9999 -9999 -9999 -9999 -9999 -9999 -9999 -

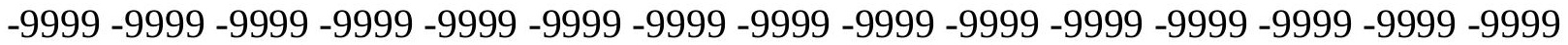
-9999 -9999 -9999 -9999 -9999 -9999 -9999 -9999 -9999 -9999 -9999 -9999 -9999 -9999 -9999 53.0326118469252 .7278289794952 .7278289794952 .7278289794953 .03261184692 53.0326118469253 .3373985290553 .6421813964854 .2517509460454 .86132049561 55.4708900451756 .3852500915557 .2995986938558 .5187492370659 .73788070679 60.9570198059162 .1761703491263 .7000885009864 .9192428588965 .83358764648 66.7479400634867 .0527267456167 .3575134277367 .3575134277367 .35751342773 67.3575134277367 .3575134277367 .05272674561 -9999 -9999 -9999 -9999 -9999 -9999 -9999 -9999 -9999 -9999 -9999 -9999 -9999 -9999 -9999 -9999 -9999 -9999 -9999 -9999 -9999 -9999 -9999 -9999 -9999 -9999 -9999 -9999 -9999 -9999 -9999 -9999 -9999 -9999 -9999 -9999 -9999 -9999 -9999 -9999 -9999 -9999 -9999 -9999 -9999 -9999 -9999 -9999 -9999 -9999 -9999 -9999 -9999 -9999 -9999 -9999 -9999 -9999 -9999 -9999 -9999 
-9999 -9999 -9999 -9999 -9999 -9999 -9999 -9999 -9999 -9999 -9999 -9999 -9999 -9999 -9999 -9999 -9999 -9999 -9999 -9999 -9999 -9999 -9999 -9999 -9999 -9999 -9999 -9999 -9999 -9999 -9999 -9999 -9999 -9999 -9999 -9999 -9999 -9999 -9999 -9999 -9999 -9999 -9999 -9999 -9999 -9999 -9999 -9999 -9999 -9999 -9999 -9999 -9999 -9999 -9999 -9999 -9999 -9999 -9999 -9999 -9999 -9999 -9999 -9999 -9999 -9999 -9999 -9999 -9999 -9999 -9999 -9999 -9999 -9999 -9999 -9999 -9999 -9999 -9999 -9999 -9999 -9999 -9999 -9999 -9999 -9999 -9999 -9999 -9999 -9999 -9999 -9999 -9999 -9999 -9999 -9999 -9999 -9999 -9999 -9999 -9999 -9999 -9999 -9999 -9999 -

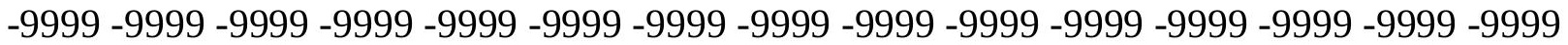
-9999 -9999 -9999 -9999 -9999 -9999 -9999 -9999 -9999 -9999 -9999 -9999 -9999 -9999 -9999 -9999 -9999 -9999 -9999 -9999 -9999 -9999 -9999 -9999 -9999 -9999 -9999 -9999 -9999 -9999 -

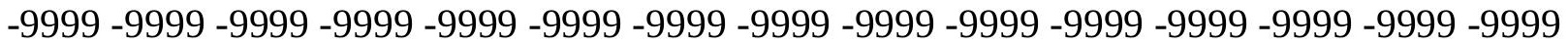
-9999 -9999 -9999 -9999 -9999 -9999 -9999 -9999 -9999 -9999 -9999 -9999 -9999 -9999 -9999

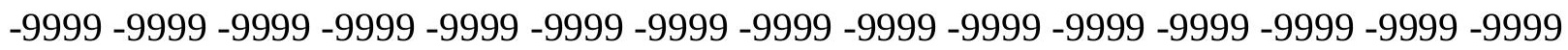
-9999 -9999 -9999 -9999 -9999 -9999 -9999 -9999 -9999 -9999 -9999 -9999 -9999 -9999 -9999 -9999 -9999 -9999 -9999 -9999 -9999 -9999 -9999 -9999 -9999 -9999 -9999 -9999 -9999 -9999

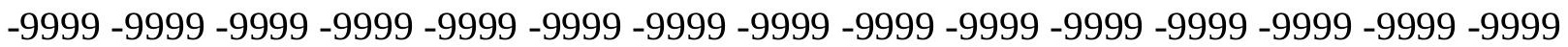
-9999 -9999 -9999 -9999 -9999 -9999 -9999 -9999 -9999 -9999 -9999 -9999 -9999 -9999 -9999 -9999 -9999 -9999 -9999 -9999 -9999 -9999 -9999 -9999 -9999 -9999 -9999 -9999 -9999 -9999 -9999 -9999 -9999 -9999 -9999 -9999 -9999 -9999 -9999 -9999 -9999 -9999 -9999 -9999 -9999 -9999 -9999 -9999 -9999 -9999 -9999 -9999 -9999 -9999 -9999 -9999 -9999 -9999 -9999 -9999 -9999 -999953.6421813964853.64218139648 53.9469718933153 .94697189331 54.2517509460454 .5565414428755 .1661109924355 .7756805419956 .38525009155 57.2995986938558 .2139587402359 .4331016540560 .6522407531762 .48094940186 64.004882812564 .9192428588966 .1383666992267 .0527267456167 .66230010986 68.2718734741268 .5766525268668 .5766525268668 .5766525268668 .27187347412 68.2718734741267 .96708679199 -9999 -9999 -9999 -9999 -9999 -9999 -9999 -9999 -9999 -9999 -9999 -9999 -9999 -9999 -9999 -9999 -9999 -9999 -9999 -9999 -9999 -9999 -9999 -9999 -9999 -9999 -9999 -9999 -9999 -9999 -9999 -9999 -9999 -9999 -9999 -9999 -9999 -9999 -9999

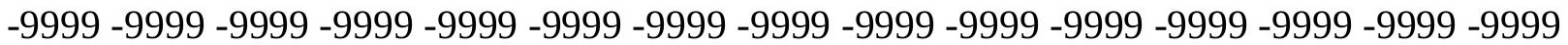
-9999 -9999 -9999 -9999 -9999 -9999 -9999 -9999 -9999 -9999 -9999 -9999 -9999 -9999 -9999 -9999 -9999 -9999 -9999 -9999 -9999 -9999 -9999 -9999 -9999 -9999 -9999 -9999 -9999 -9999 -9999 -9999 -9999 -9999 -9999 -9999 -9999 -9999 -9999 -9999 -9999 -9999 -9999 -9999 -9999 -9999 -9999 -9999 -9999 -9999 -9999 -9999 -9999 -9999 -9999 -9999 -9999 -9999 -9999 -9999 -9999 -9999 -9999 -9999 -9999 -9999 -9999 -

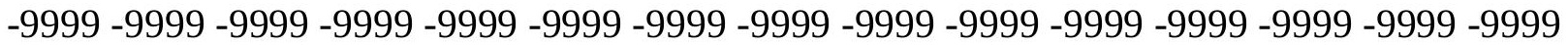
-9999 -9999 -9999 -9999 -9999 -9999 -9999 -9999 -9999 -9999 -9999 -9999 -9999 -9999 -9999 -9999 -9999 -9999 -9999 -9999 -9999 -9999 -9999 -9999 -9999 -9999 -9999 -9999 -9999 -9999

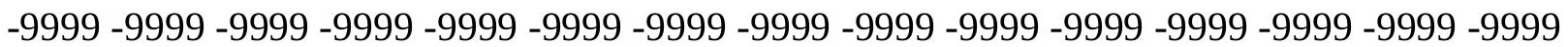
-9999 -9999 -9999 -9999 -9999 -9999 -9999 -9999 -9999 -9999 -9999 -9999 -9999 -9999 -9999 -9999 -9999 -9999 -9999 -9999 -9999 -9999 -9999 -9999 -9999 -9999 -9999 -9999 -9999 -9999 -9999 -9999 -9999 -9999 -9999 -9999 -9999 -9999 -9999 -9999 -9999 -9999 -9999 -9999 -9999 -9999 -9999 -9999 -9999 -9999 -9999 -9999 -9999 -9999 -9999 -9999 -9999 -9999 -9999 -9999 -9999 -9999 -9999 -9999 -9999 -9999 -9999 -9999 -9999 -9999 -9999 -9999 -9999 -9999 -9999 -9999 -9999 -9999 -9999 -9999 -9999 -9999 -9999 -9999 -9999 -9999 -9999 -9999 -9999 -9999 -9999 -9999 -9999 -9999 -9999 -9999 -9999 -9999 -9999 -9999 -9999 -9999 -9999 -9999 -9999

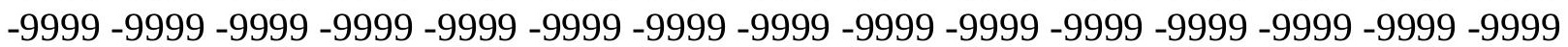


-9999 -9999 -9999 -9999 -9999 -9999 -9999 -9999 -9999 -9999 -9999 -9999 -9999 -9999 -9999 -9999 -9999 -9999 -9999 -9999 -9999 -9999 -9999 -9999 -9999 -9999 -9999 -9999 -9999 -9999 -9999 -9999 -9999 -9999 -9999 -9999 -9999 -9999 -9999 -9999 -9999 -9999 -9999 -9999 - 9999 -9999 -9999 -9999 -9999 -9999 -9999 -9999 -9999 -9999 -9999 -9999 -9999 -9999 -9999 -9999 -9999 -9999 -9999 54.5565414428754.5565414428754.8613204956155.16611099243 55.4708900451755 .7756805419956 .3852500915557 .2995986938558 .21395874023 59.1283111572360 .3474502563561 .5666007995663 .3953094482464 .61444854736 66.1383666992267 .3575134277368 .5766525268669 .1862335205169 .49101257324 69.4910125732469 .4910125732469 .4910125732469 .4910125732469 .18623352051 68.57665252686 -9999 -9999 -9999 -9999 -9999 -9999 -9999 -9999 -9999 -9999 -9999 -9999 -9999 -9999 -9999 -9999 -9999 -9999 -9999 -9999 -9999 -9999 -9999 -9999 -9999 -9999 -9999 -9999 -9999 -9999 -9999 -9999 -9999 -9999 -9999 -9999 -9999 -9999 -9999 -9999 -9999 -9999 -

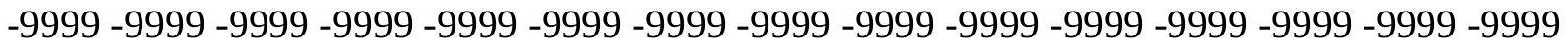
-9999 -9999-9999-9999

-9999 -9999 -9999 -9999 -9999 -9999 -9999 -9999 -9999 -9999 -9999 -9999 -9999 -9999 -9999

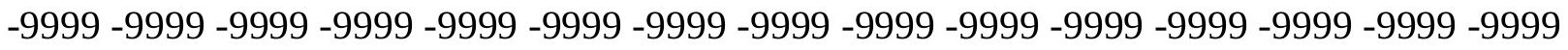
-9999 -9999 -9999 -9999 -9999 -9999 -9999 -9999 -9999 -9999 -9999 -9999 -9999 -9999 -9999 -9999 -9999 -9999 -9999 -9999 -9999 -9999 -9999 -9999 -9999 -9999 -9999 -9999 -9999 -9999 -9999 -9999 -9999 -9999 -9999 -9999 -9999 -9999 -9999 -9999 -9999 -9999 -9999 -9999 -9999 -

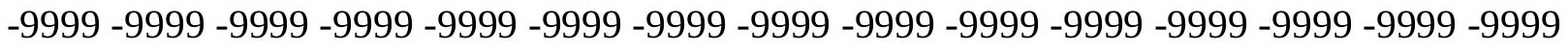

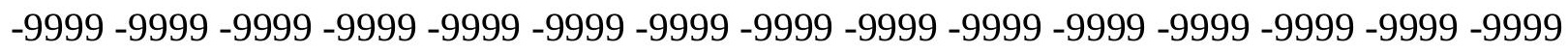
-9999 -9999 -9999 -9999 -9999 -9999 -9999 -9999 -9999 -9999 -9999 -9999 -9999 -9999 -9999 -9999 -9999 -9999 -9999 -9999 -9999 -9999 -9999 -9999 -9999 -9999 -9999 -9999 -9999 -9999 -

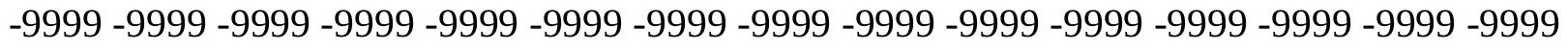

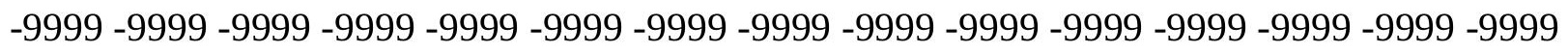
-9999 -9999 -9999 -9999 -9999 -9999 -9999 -9999 -9999 -9999 -9999 -9999 -9999 -9999 -9999 -9999 -9999 -9999 -9999 -9999 -9999 -9999 -9999 -9999 -9999 -9999 -9999 -9999 -9999 -9999 -

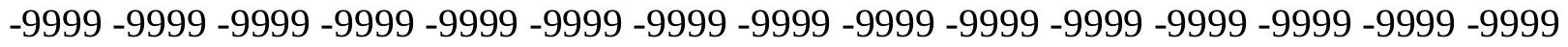
-9999 -9999 -9999 -9999 -9999 -9999 -9999 -9999 -9999 -9999 -9999 -9999 -9999 -9999 -9999 -9999 -9999 -9999 -9999 -9999 -9999 -9999 -9999 -9999 -9999 -9999 -9999 -9999 -9999 -999 -9999 -9999 -9999 -9999 -9999 -9999 -9999 -9999 -9999-9999 -9999 -9999 -9999 -9999 -9999 -9999 -9999 -9999 -9999 -9999 -9999 -9999 -9999 -9999 -9999 -9999 -9999 -9999 -9999 -9999 -

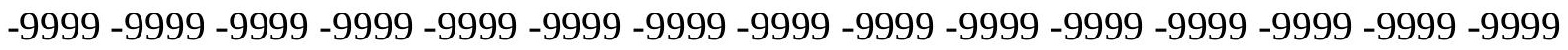
-9999 -9999 -9999 -9999 -9999 -9999 -9999 -9999 -9999 -9999 -9999 -9999 -9999 -9999 -9999 -9999 -9999 -9999 -9999-9999 55.4708900451755.77568054199 56.08045959473 56.6900291442957 .2995986938557 .909179687558 .8235282897959 .73788070679 60.9570198059163 .0905189514264 .004882812565 .5288009643667 .35751342773 69.1862335205170 .4053573608471 .014930725171 .3197174072371 .0149307251 70.7101516723670 .4053573608470 .1005783081169 .7957916259869 .49101257324 -9999 -9999 -9999 -9999 -9999 -9999 -9999 -9999 -9999 -9999 -9999 -9999 -9999 -9999 -9999 -9999

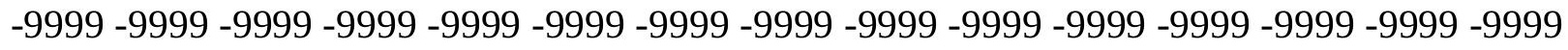

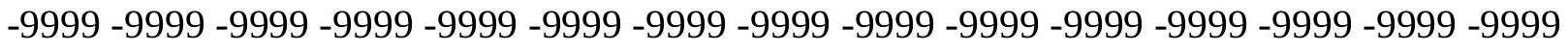
-9999 -9999 -9999 -9999 -9999 -9999 -9999 -9999 -9999 -9999 -9999 -9999 -9999 -9999 -9999 -9999 -9999 -9999 -9999 -9999 -9999 -9999 -9999 -9999-9999 -9999 -9999 -9999 -9999 -9999 -9999 -9999 -9999 -9999 -9999 -9999 -9999 -9999 -9999 -9999 -9999 -9999 -9999 -9999 -9999 -

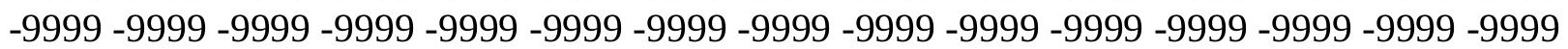


-9999 -9999 -9999 -9999 -9999 -9999 -9999 -9999 -9999 -9999 -9999 -9999 -9999 -9999 -9999 -9999 -9999 -9999 -9999 -9999 -9999 -9999 -9999 -9999 -9999 -9999 -9999 -9999 -9999 -9999 -9999 -9999 -9999 -9999 -9999 -9999 -9999 -9999 -9999 -9999 -9999 -9999 -9999 -9999 - 9999 -9999 -9999 -9999 -9999 -9999 -9999 -9999 -9999 -9999 -9999 -9999 -9999 -9999 -9999 -9999 -9999 -9999 -9999 -9999 -9999 -9999 -9999 -9999 -9999-9999 -9999 -9999 -9999 -9999 -9999 -9999 -9999 -9999 -9999 -9999 -9999 -9999 -9999 -9999 -9999 -9999 -9999 -9999 -9999 -9999 -9999 -9999 -9999 -9999 -9999 -9999 -9999 -9999 -9999 -9999 -9999 -9999 -9999 -9999 -9999

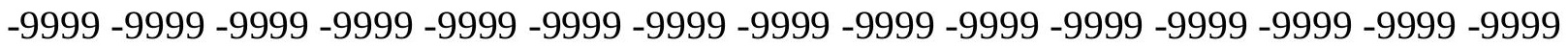

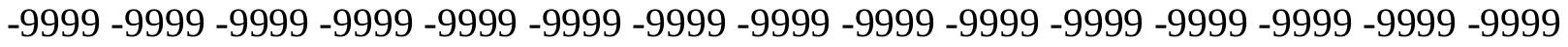
-9999 -9999 -9999 -9999 -9999 -9999 -9999 -9999 -9999 -9999 -9999 -9999 -9999 -9999 -9999 -9999 -9999 -9999 -9999 -9999 -9999 -9999 -9999 -9999 -9999 -9999 -9999 -9999 -9999 -9999 -9999 -9999 -9999 -9999 -9999 -9999 -9999 -9999 -9999 -9999 -9999 -9999 -9999 -9999 -9999 -9999 -9999 -9999 -9999 -9999 -9999 -9999 -9999 -9999 -9999 -9999 -9999 -9999 -9999 -9999 -

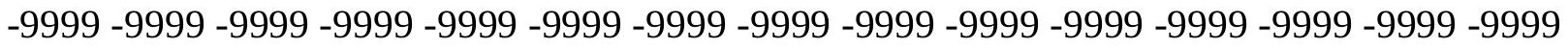
-9999 -9999 -9999 -9999 -9999 -9999 -9999 -9999 -9999 -9999 -9999 -9999 -9999 -9999 -9999

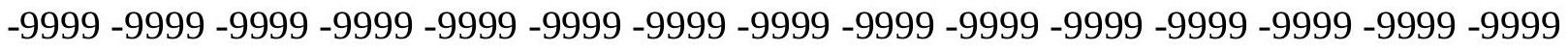
-9999 -9999 -9999 -9999 -9999 -9999 -9999 -9999 -9999 -9999 -9999 -9999 -9999 -9999 -9999 -9999 -9999 -9999 -9999 -9999 -9999 56.38525009155 56.69002914429 57.29959869385 57.909179687558 .5187492370659 .4331016540560 .3474502563561 .56660079956 63.0905189514264 .9192428588966 .7479400634868 .8814392089871 .0149307251 72.2340774536173 .1484298706173 .1484298706172 .8436431884872 .23407745361 71.3197174072371 .014930725170 .4053573608469 .79579162598 -9999 -9999 -9999 -9999 -9999 -9999 -9999 -9999 -9999 -9999 -9999 -9999 -9999 -9999 -9999 -9999 -9999 -9999 -9999 -9999 -9999 -9999 -9999 -9999 -9999 -9999 -9999 -9999 -9999 -9999 -9999 -9999 -9999 -9999 -9999 -9999 -9999 -9999 -9999 -9999 -9999 -9999 -9999 -9999 -9999 -9999 -9999 -9999 -9999 -9999 -9999 -9999 -9999 -9999 -9999 -9999 -9999 -9999 -9999 -9999 -9999 -9999 -9999 -9999 -9999 -9999 -9999 -9999 -9999 -9999 -9999 -9999 -9999 -9999 -9999 -9999 -9999 -9999 -9999 -9999 -9999 -9999 -9999 -9999 -9999 -9999 -9999 -9999 -9999 -9999 -9999 -9999 -9999 -9999 -9999 -9999 -9999 -9999 -9999 -9999 -9999 -9999 -9999 -9999 -9999 -9999 -9999 -9999 -9999 -9999 -9999 -9999 -9999 -9999 -9999 -9999 -9999 -9999 -9999 -9999 -999 -9999 -9999 -9999 -9999 -9999 -9999 -9999 -9999 -9999 -9999 -9999 -9999 -9999 -9999 -9999 -9999 -9999 -9999 -9999 -9999 -9999 -9999 -9999 -9999 -9999 -9999 -9999 -9999 -9999 -9999 -

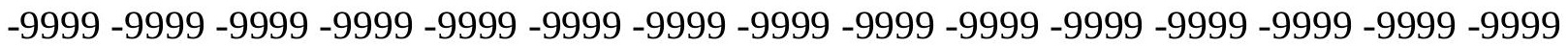

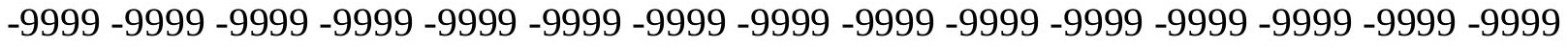

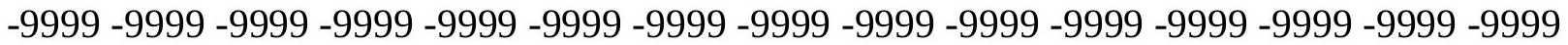
-9999 -9999 -9999 -9999 -9999 -9999 -9999 -9999 -9999 -9999 -9999 -9999 -9999 -9999 -9999 -

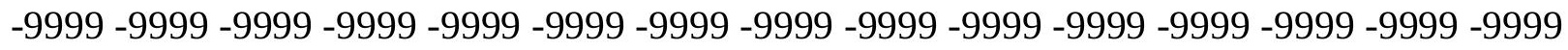

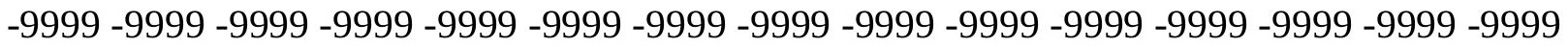
-9999 -9999 -9999 -9999 -9999 -9999 -9999 -9999 -9999 -9999 -9999 -9999 -9999 - 9999 - -999 -9999 -9999 -9999 -9999 -9999 -9999 -9999 -9999 -9999 -9999 -9999 -9999 -9999 -9999 -9999 -

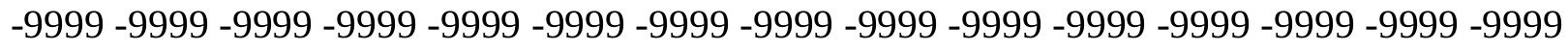

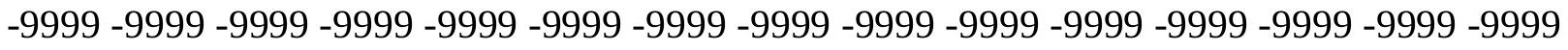
-9999 -9999 -9999 -9999 -9999 -9999 -9999 -9999 -9999 -9999 -9999 -9999 -9999 -9999 -9999 -9999 -9999 -9999 -9999 -9999 -9999 -9999 -9999 -9999-9999 -9999 -9999 -9999 -9999 -9999 -9999 -9999 -9999 -9999 -9999 -9999 -9999 -9999 -9999 -9999 -9999 -9999 -9999 -9999 -9999 -

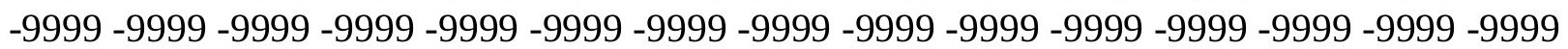


-9999 -9999 -9999 -9999 -9999 -9999 -9999 -9999 57.60438919067 58.21395874023 58.8235282897959 .7378807067960 .6522407531761 .8713798522963 .39530944824 65.5288009643667 .9670867919970 .7101516723672 .8436431884874 .67236328125 75.2819290161175 .2819290161174 .6723632812573 .4532165527372 .53885650635 71.6244964599670 .7101516723670 .10057830811 -9999 -9999 -9999 -9999 -9999 -9999 -9999 -9999 -9999 -9999 -9999 -9999 -9999 -9999 -9999 -9999 -9999 -9999 -9999 -9999 -9999 -9999

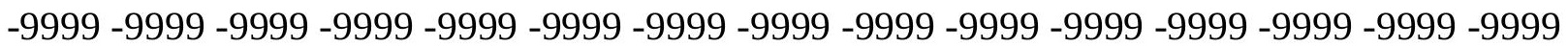

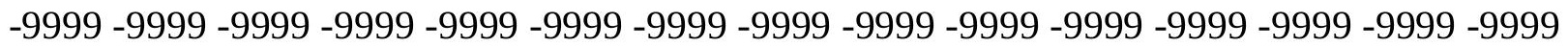
-9999 -9999 -9999 -9999 -9999 -9999 -9999 -9999 -9999 -9999 -9999 -9999 -9999 -9999 -9999 -9999 -9999 -9999 -9999 -9999 -9999 -9999 -9999 -9999

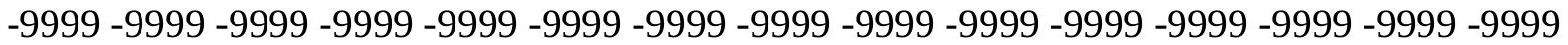

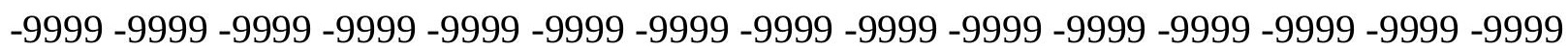
-9999 -9999 -9999 -9999 -9999 -9999 -9999 -9999 -9999 -9999 -9999 -9999 -9999 -9999 -9999 -9999 -9999 -9999 -9999 -9999 -9999 -9999 -9999 -9999 -9999 -9999 -9999 -9999 -9999 - 9999 -9999 -9999 -9999 -9999 -9999 -9999 -9999 -9999 -9999 -9999 -9999 -9999 -9999 -9999 -9999

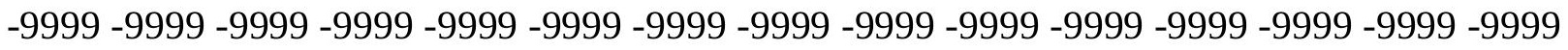
-9999 -9999 -9999 -9999 -9999 -9999 -9999 -9999 -9999 -9999 -9999 -9999 -9999 -9999 -9999 -9999 -9999 -9999 -9999 -9999 -9999 -9999 -9999 -9999 -9999 -9999 -9999 -9999 -9999 -9999 -9999 -9999 -9999 -9999 -9999 -9999 -9999 -9999 -9999 -9999 -9999 -9999 -9999 -9999 -9999 -9999 -9999 -9999 -9999 -9999 -9999 -9999 -9999 -9999 -9999 -9999 -9999 -9999 -9999 -9999 -9999 -9999 -9999 -9999 -9999 -9999 -9999 -9999 -9999 -9999 -9999 -9999 -9999 -9999 -9999 -9999 -9999 -9999 -9999 -9999 -9999 -9999 -9999 -9999 -9999 -9999 -9999 -9999 -9999 -9999 -9999 -9999 -9999 -9999 -9999 -9999 -9999 -9999 -9999 -9999 -9999 -9999 -9999 -9999 -9999 -9999 -9999 -9999 -9999 -9999 -9999 -9999 -9999 -9999 -9999 -9999 -9999 -9999 -9999 -9999 -9999 -9999 -9999 -9999 -9999 -9999 -9999 -9999 -9999 -9999 -9999 -9999 -9999 -9999 -9999 -9999 -9999 -9999 -9999 -9999 -9999 -9999 -9999 -9999 -9999 -9999 -9999 -9999 -9999 -9999 -9999 -9999 -9999 -9999 -9999 -9999 -9999 -9999 -9999 -9999 -9999 -9999 -9999 -9999 -9999 -9999 -9999 -9999 -9999 -9999 -9999 -9999 -9999 -9999 -9999 -9999 -9999 -9999 -9999 -9999 -9999 -9999 -9999 -9999 -9999 -9999 -9999 -9999 -9999 -9999 -9999 -9999 -9999 -9999 -9999 -9999 -9999 -9999 -9999 -9999 -9999 -9999 -9999 -9999 58.51874923706 59.12831115723 60.0426712036160 .9570198059162 .1761703491264 .3096618652366 .13836669922 68.8814392089871 .9292907714874 .9771423339877 .110626220777 .03234863281 76.2478027343875 .4271545410274 .6021423339873 .4532165527372 .23407745361 71.014930725170 .40535736084 -9999 -9999 -9999 -9999 -9999 -9999 -9999 -9999 -9999 -9999 -9999 -9999 -9999 -9999 -9999 -9999 -9999 -9999 -9999 -9999 -9999 -9999 -9999 -9999 -9999 -9999 -9999 -9999 -9999 -9999 -9999 -9999 -9999 -9999 -9999 -9999 -9999 -9999 -9999

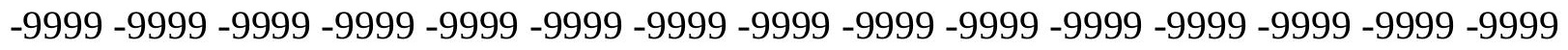
-9999 -9999 -9999 -9999-9999-9999-9999

-9999 -9999 -9999 -9999 -9999 -9999 -9999 -9999 -9999 -9999 -9999 -9999 -9999 -9999 - 9999 -9999 -9999 -9999 -9999 -9999 -9999 -9999 -9999 -9999 -9999 -9999 -9999 -9999 -9999 -9999 -

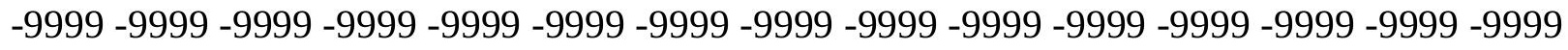

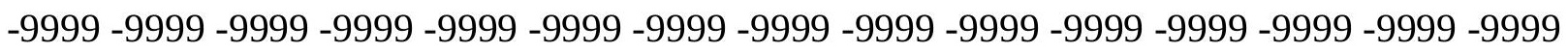
-9999 -9999 -9999 -9999 -9999 -9999 -9999 -9999 -9999 -9999 -9999 -9999 -9999 -9999 -9999 -9999 -9999 -9999 -9999 -9999 -9999 -9999 -9999 -9999-9999 -9999 -9999 -9999 -9999 -9999 -9999 -9999 -9999 -9999 -9999 -9999 -9999 -9999 -9999 -9999 -9999 -9999 -9999 -9999 -9999 -

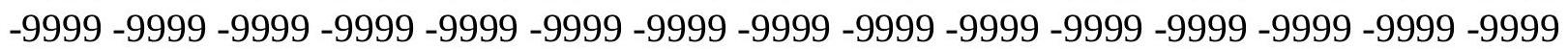


-9999 -9999 -9999 -9999 -9999 -9999 -9999 -9999 -9999 -9999 -9999 -9999 -9999 -9999 -9999 -9999 -9999 -9999 -9999 -9999 -9999 -9999 -9999 -9999 -9999 -9999 -9999 -9999 -9999 -9999 -

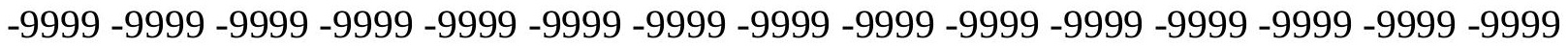
-9999 -9999 -9999 -9999 -9999 -9999 -9999 -9999 -9999 -9999 -9999 -9999 -9999 -9999 -9999 -9999 -9999 -9999 -9999 -9999 -9999 -9999 -9999 -9999-9999 -9999 -9999 -9999 -9999 -9999 -9999 -9999 -9999 -9999 -9999 -9999 -9999 -9999 -9999 -9999 -9999 -9999 -9999 -9999 -9999 -9999 -9999 -9999 -9999 -9999 -9999 -9999 -9999 -9999 -9999 -9999 -9999 -9999 -9999 -9999

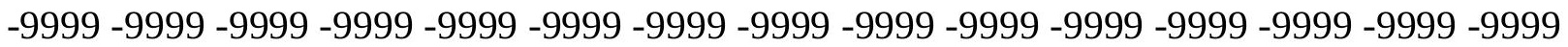

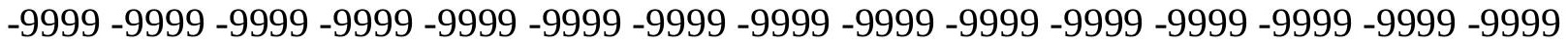
-9999 -9999 -9999 -9999 -9999 -9999 -9999 -9999 -9999 -9999 -9999 -9999 -9999 -9999 -9999 -9999 -9999 -9999 -9999 -9999 -9999 -9999 -9999 -9999 -9999 -9999 -9999 -9999 -9999 -9999 -9999 -9999 -9999 -9999 -9999 -9999 -9999 -9999 -9999 -9999 -9999 -9999 -9999 -9999 -9999 -9999 -9999 -9999 -9999 -9999 -9999 -9999 -9999 -9999 -9999 -9999 60.04267120361 60.9570198059162 .1761703491263 .7000885009866 .1383666992269 .18623352051 72.8436431884876 .5010681152377 .7525024414176 .9565048217876 .13064575195 75.3245697021574 .5454559326273 .7580032348672 .2340774536171 .31971740723 70.4053573608469 .79579162598 -9999 -9999 -9999 -9999 -9999 -9999 -9999 -9999 -9999 -9999 -9999 -9999 -9999 -9999 -9999 -9999 -9999 -9999 -9999 -9999 -9999 -9999 -9999 -9999 -9999 -9999 -9999 -9999 -9999 -9999 -9999 -9999 -9999 -9999 -9999 -9999 -9999 -9999 -9999

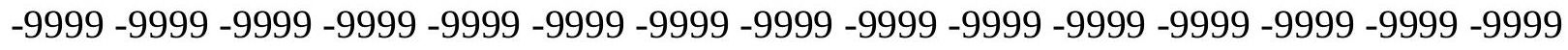
-9999 -9999 -9999-9999-9999-9999

-9999 -9999 -9999 -9999 -9999 -9999 -9999 -9999 -9999 -9999 -9999 -9999 -9999 -9999 -9999 -9999 -9999 -9999 -9999 -9999 -9999 -9999 -9999 -9999 -9999 -9999 -9999 -9999 -9999 -9999 -9999 -9999 -9999 -9999 -9999 -9999 -9999 -9999 -9999 -9999 -9999 -9999 -9999 -9999 -9999 -

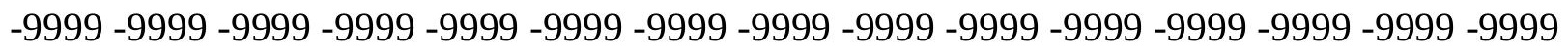
-9999 -9999 -9999 -9999 -9999 -9999 -9999 -9999 -9999 -9999 -9999 -9999 -9999 -9999 -9999 -9999 -9999 -9999 -9999 -9999 -9999 -9999 -9999 -9999 -9999 -9999 -9999 -9999 -9999 -9999 -9999 -9999 -9999 -9999 -9999 -9999 -9999 -9999 -9999 -9999 -9999 -9999 -9999 -9999 -9999 -9999 -9999 -9999 -9999 -9999 -9999 -9999 -9999 -9999 -9999 -9999 -9999 -9999 -9999 -9999 -9999 -9999 -9999 -9999 -9999 -9999 -9999 -9999 -9999 -9999 -9999 -9999 -9999 -9999 -999 -

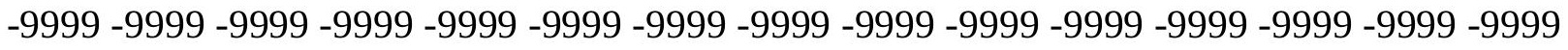
-9999 -9999 -9999 -9999 -9999 -9999 -9999 -9999 -9999 -9999 -9999 -9999 -9999 -9999 -9999 -

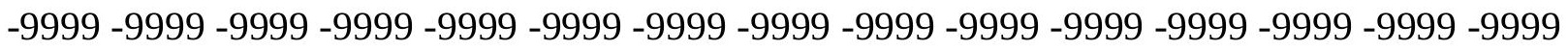

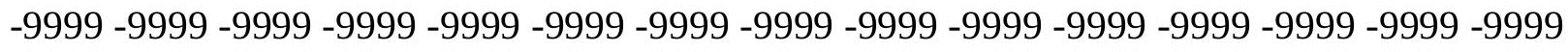
-9999 -9999 -9999 -9999 -9999 -9999 -9999 -9999 -9999 -9999 -9999 -9999 -9999 -9999 -9999 -

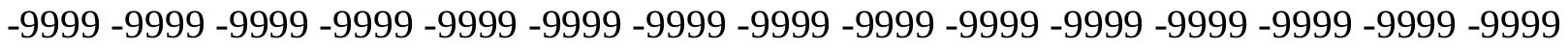

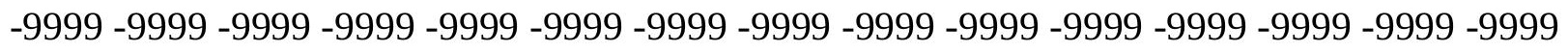

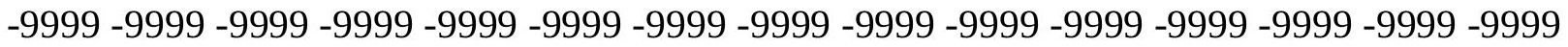
-9999 -9999 -9999 -9999 -9999 -9999 -9999 -9999 -9999 -9999 -9999 -9999 -9999 - 9999 - -999 -9999 -9999 -9999 -9999 -9999 -9999 -9999 -9999 -9999 -9999 -9999 -9999 -9999 -9999 -9999 -

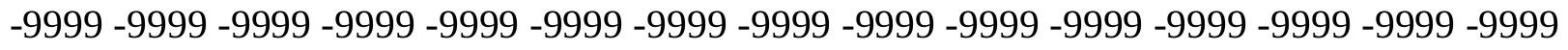
-9999 -9999 -9999-9999 -9999 -9999 -9999 -9999 -9999-9999 -9999-9999 61.26181030273 62.1761703491263 .7000885009865 .5288009643668 .2718734741272 .23407745361 76.5010681152377 .639083862376 .7080230712975 .8731002807675 .11891937256 74.4173202514673 .4532165527372 .2340774536171 .014930725170 .10057830811 69.49101257324 -9999 -9999 -9999 -9999 -9999 -9999 -9999 -9999 -9999 -9999 -9999 -9999 
-9999 -9999 -9999 -9999 -9999 -9999 -9999 -9999 -9999 -9999 -9999 -9999 -9999 -9999 -9999 -9999 -9999 -9999 -9999 -9999 -9999 -9999 -9999 -9999 -9999 -9999 -9999 -9999 -9999 -9999 -9999 -9999 -9999 -9999 -9999 -9999 -9999 -9999 -9999 -9999 -9999 -9999 -9999 -9999 -9999 -9999 -9999-9999

-9999 -9999 -9999 -9999 -9999 -9999 -9999 -9999 -9999 -9999 -9999 -9999 -9999 -9999 -9999 -9999 -9999 -9999 -9999 -9999 -9999 -9999 -9999 -9999 -9999 -9999 -9999 -9999 -9999 -9999 -9999 -9999 -9999 -9999 -9999 -9999 -9999 -9999 -9999 -9999 -9999 -9999 -9999 -9999 -9999

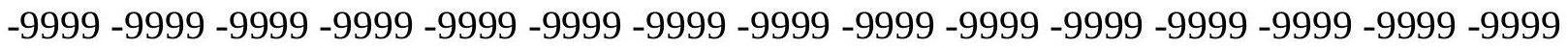

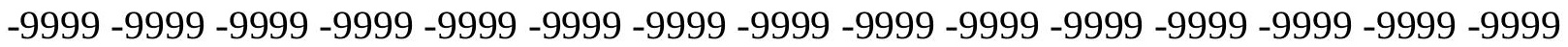
-9999 -9999 -9999 -9999 -9999 -9999 -9999 -9999 -9999 -9999 -9999 -9999 -9999 -9999 -9999 -

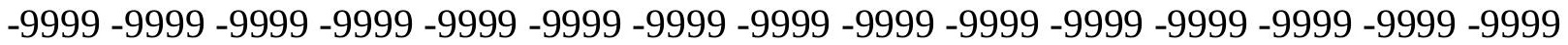
-9999 -9999 -9999 -9999 -9999 -9999 -9999 -9999 -9999 -9999 -9999 -9999 -9999 -9999 -9999 -9999 -9999 -9999 -9999 -9999 -9999 -9999 -9999 -9999 -9999 -9999 -9999 -9999 -9999 -9999 -9999 -9999 -9999 -9999 -9999 -9999 -9999 -9999 -9999 -9999 -9999 -9999 -9999 -9999 -9999 -9999 -9999 -9999 -9999 -9999 -9999 -9999 -9999 -9999 -9999 -9999 -9999 -9999 -9999 -9999 -9999 -9999 -9999 -9999 -9999 -9999 -9999 -9999 -9999 -9999 -9999 -9999 -9999 -9999 -9999 -9999 -9999 -9999 -9999 -9999 -9999 -9999 -9999 -9999 -9999 -9999 -9999 -9999 -9999 -9999 -9999 -9999 -9999 -9999 -9999 -9999 -9999 -9999 -9999 -9999 -9999 -9999 -9999 -9999 -9999 -999 -9999 -9999 -9999 -9999 -9999 -9999 -9999 -9999 -9999 -9999 -9999 -9999 -9999 -9999 -9999 -9999 -9999 -9999 -9999 -9999 -9999 -9999 -9999 -9999 -9999 -9999 -9999 -9999 -9999 -9999 -9999 -9999 -9999 -9999 -9999 -9999 -9999 -9999 -9999 -9999 -9999 -9999 -9999 -9999 -9999 -9999 -9999 -9999 -9999 -9999 -9999 -9999 -9999 -9999 -9999 -9999 -9999 -9999 -9999 -9999 -9999 -9999 -9999 -9999 -9999 -9999 -9999 -9999 -9999 -9999 -9999 -9999 -9999 -9999 -9999 -9999 -9999 -9999 -9999 -9999 -9999 -9999 -9999 -9999 -9999 -9999 -9999 -9999 -9999 -9999 -9999 -9999 -9999 -9999 -9999 -9999 -9999 -9999 -9999 -9999 -9999 -9999 -9999 -9999 63.3953094482464 .9192428588967 .0527267456170 .4053573608474 .0627822876 76.8058471679776 .3624954223675 .5510330200274 .8856735229574 .0627822876 72.8436431884871 .6244964599670 .4053573608469 .7957916259869 .18623352051 -9999 -9999 -9999 -9999 -9999 -9999 -9999 -9999 -9999 -9999 -9999 -9999 -9999 -9999 -9999 -9999

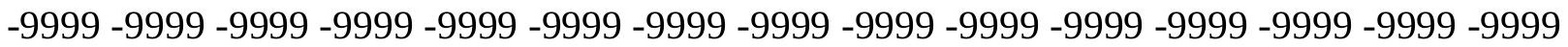
-9999 -9999 -9999 -9999 -9999 -9999 -9999 -9999 -9999 -9999 -9999 -9999 -9999 -9999 -9999 -9999 -9999 -9999 -9999 -9999 -9999 -9999 -9999 -9999 -9999 -9999 -9999 -9999 -9999 -9999 -9999 -9999 -9999 -9999 -9999 -9999 -9999 -9999 -9999 -9999 -9999 -9999 -9999 -9999 -9999 -9999 -9999 -9999 -9999 -9999 -9999 -9999 -9999 -9999 -9999 -9999 -9999 -9999 -9999 -9999 -9999 -9999 -9999 -9999 -9999 -9999 -9999 -9999 -9999 -9999 -9999 -9999 -9999 -9999 -9999 -9999 -9999 -9999 -9999 -9999 -9999 -9999 -9999 -9999 -9999 -9999 -9999 -9999 -9999 -9999 -9999 -9999 -9999 -9999 -9999 -9999 -9999 -9999 -9999 -9999 -9999 -9999 -9999 -9999

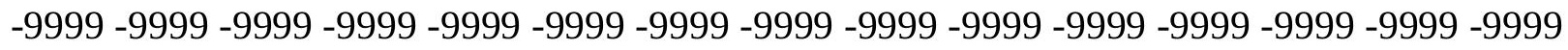
-9999 -9999 -9999 -9999 -9999 -9999 -9999 -9999 -9999 -9999 -9999 -9999 -9999 -9999 -9999 -9999 -9999 -9999 -9999 -9999 -9999 -9999 -9999 -9999 -9999 -9999 -9999 -9999 -9999 -9999 -9999 -9999 -9999 -9999 -9999 -9999 -9999 -9999 -9999 -9999 -9999 -9999 -9999 -9999 -9999 -999 -9999 -9999 -9999 -9999 -9999 -9999 -9999 -9999 -9999 -9999 -9999 -9999 -9999 -9999 -9999 -9999 -9999 -9999 -9999 -9999 -9999 -9999 -9999 -9999 -9999 -9999 -9999 -9999 -9999 -9999 -9999 -9999 -9999 -9999 -9999 -9999 -9999 -9999 -9999 -9999 -9999 -9999 -9999 -9999 -9999 -9999 -9999 -9999 -9999 -9999 -9999 -9999 -9999 -9999 -9999 -9999 -9999 -9999 -9999 -9999

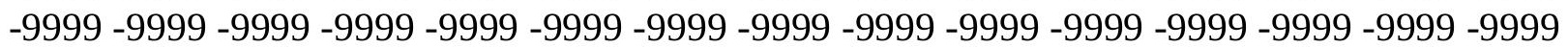


-9999 -9999 -9999 -9999 -9999 -9999 -9999 -9999 -9999 -9999 -9999 -9999 -9999 -9999 -9999 -9999 -9999 -9999 -9999 -9999 -9999 -9999 -9999 -9999 -9999 -9999 -9999 -9999 -9999 -9999 -

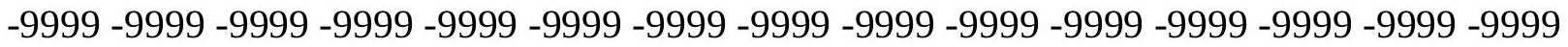
-9999 -9999 -9999 -9999 -9999 -9999 -9999 -9999 -9999 -9999 -9999 -9999 -9999 -9999 -9999 -9999 -9999 -9999 -9999 -9999 -9999 -9999 -9999 -9999-9999 -9999 -9999 -9999 -9999 -9999 -9999 -9999 -9999 -9999 -9999 -9999 -9999 -9999 -9999 -9999 -9999 -9999 -9999 -9999 -9999 -9999 -9999 -9999 -9999 -9999 -9999 -9999 -9999 -9999 -9999 -9999 -9999 -9999 -9999 -9999 64.3096618652365 .8335876464867 .9670867919970 .7101516723672 .84364318848 74.062782287674 .062782287673 .4532165527372 .5388565063571 .31971740723 70.4053573608469 .7957916259869 .1862335205168 .88143920898 -9999 -9999 -9999 -9999 -9999 -9999 -9999 -9999 -9999 -9999 -9999 -9999 -9999 -9999 -9999 -9999 -9999 -9999 -9999 -9999 -9999 -9999 -9999 -9999 -9999 -9999 -9999 -9999 -9999 -9999 -9999 -9999 -9999 -9999 -

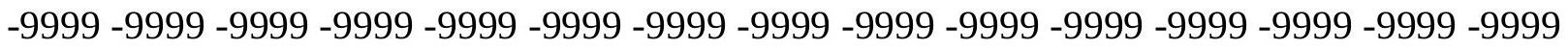
-9999 -9999 -9999 -9999 -9999 -9999 -9999 -9999 -9999 -9999 -9999

-9999 -9999 -9999 -9999 -9999 -9999 -9999 -9999 -9999 -9999 -9999 -9999 -9999 -9999 -9999

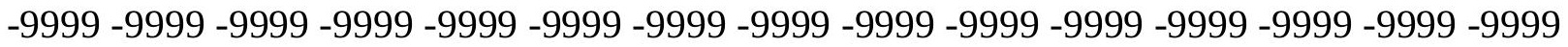
-9999 -9999 -9999 -9999 -9999 -9999 -9999 -9999 -9999 -9999 -9999 -9999 -9999 -9999 -9999 -9999 -9999 -9999 -9999 -9999 -9999 -9999 -9999 -9999 -9999 -9999 -9999 -9999 -9999 -9999 -9999 -9999 -9999 -9999 -9999 -9999 -9999 -9999 -9999 -9999 -9999 -9999 -9999 -9999 -9999 -

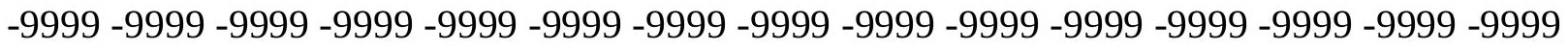

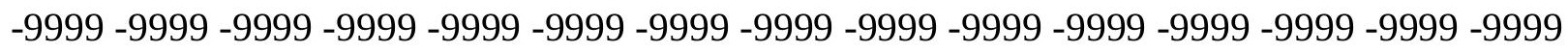
-9999 -9999 -9999 -9999 -9999 -9999 -9999 -9999 -9999 -9999 -9999 -9999 -9999 -9999 -9999 -9999 -9999 -9999 -9999 -9999 -9999 -9999 -9999 -9999 -9999 -9999 -9999 -9999 -9999 -9999 -9999 -9999 -9999 -9999 -9999 -9999 -9999 -9999 -9999 -9999 -9999 -9999 -9999 -9999 -9999 -9999 -9999 -9999 -9999 -9999 -9999 -9999 -9999 -9999 -9999 -9999 -9999 -9999 -9999 -9999 -9999 -9999 -9999 -9999 -9999 -9999 -9999 -9999 -9999 -9999 -9999 -9999 -9999 -9999 -9999 -9999 -9999 -9999 -9999 -9999 -9999 -9999 -9999 -9999 -9999 -9999 -9999 -9999 -9999 -9999 -9999 -9999 -9999 -9999 -9999 -9999 -9999 -9999 -9999 -9999 -9999 -9999 -9999 -9999 -9999 -9999 -9999 -9999 -9999 -9999 -9999 -9999 -9999 -9999 -9999 -9999 -9999 -9999 -9999 -9999 -9999 -9999 -9999 -9999 -9999 -9999 -9999 -9999 -9999 -9999 -9999 -9999 -9999 -9999 -999 -9999 -9999 -9999 -9999 -9999 -9999 -9999 -9999 -9999 -9999 -9999 -9999 -9999 -9999 -9999 -9999 -9999 -9999 -9999 -9999 -9999 -9999 -9999 -9999 -9999 -9999 -9999 -9999 -9999 -9999 -

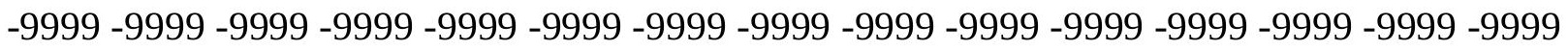

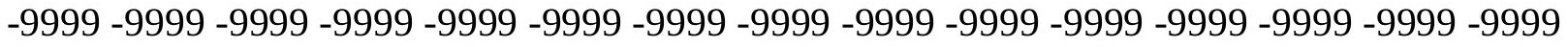
-9999 -9999 -9999 -9999 -9999 -9999 -9999 -9999 -9999 -9999 -9999 -9999 -9999 -9999 -9999 -999964.61444854736 66.13836669922 67.9670867919969.49101257324 70.40535736084 71.014930725171 .014930725170 .4053573608469 .7957916259869 .79579162598 69.18623352051 68.57665252686 68.27187347412 -9999 -9999 -9999 -9999 -9999 -9999 -9999 -9999 -9999 -9999 -9999 -9999 -9999 -9999 -9999 -9999 -9999 -9999 -9999 -9999 -9999 -9999 -9999 -9999 -9999 -9999 -9999 -9999 -9999 -9999 -9999 -9999 -9999 -9999 -9999 -9999 -9999 -

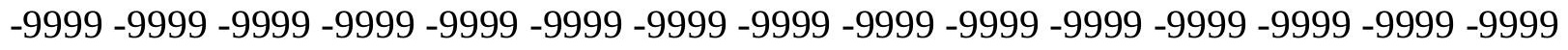
-9999 -9999-9999 -9999-9999-9999-9999-9999 -9999 -9999 -9999 -9999 -9999 -9999 -9999 -9999 -9999 -9999 -9999 -9999 -9999 -9999-9999 -9999 -9999 -9999 -9999 -9999 -9999 -9999 -9999 -9999-9999 -9999 -9999 -9999 -9999 -9999 -9999 -9999 -9999 -9999 -9999 -9999 -9999 -9999 -9999 -9999 -9999 -9999 -9999 -9999 -9999 -

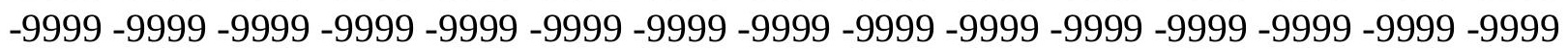


-9999 -9999 -9999 -9999 -9999 -9999 -9999 -9999 -9999 -9999 -9999 -9999 -9999 -9999 -9999 -9999 -9999 -9999 -9999 -9999 -9999 -9999 -9999 -9999 -9999 -9999 -9999 -9999 -9999 -9999 -

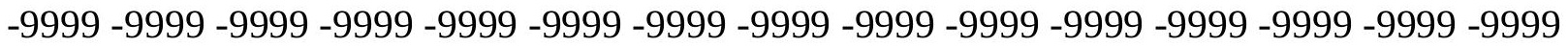
-9999 -9999 -9999 -9999 -9999 -9999 -9999 -9999 -9999 -9999 -9999 -9999 -9999 -9999 -9999 -9999 -9999 -9999 -9999 -9999 -9999 -9999 -9999 -9999-9999 -9999 -9999 -9999 -9999 -9999 -9999 -9999 -9999 -9999 -9999 -9999 -9999 -9999 -9999 -9999 -9999 -9999 -9999 -9999 -9999 -9999 -9999 -9999 -9999 -9999 -9999 -9999 -9999 -9999 -9999 -9999 -9999 -9999 -9999 -9999

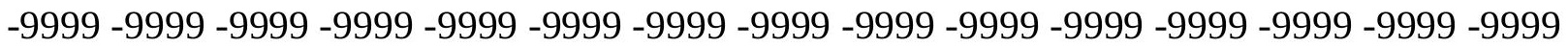

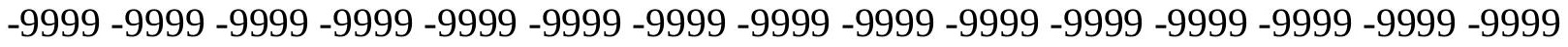
-9999 -9999 -9999 -9999 -9999 -9999 -9999 -9999 -9999 -9999 -9999 -9999 -9999 -9999 -9999 -9999 -9999 -9999 -9999 -9999 -9999 -9999 -9999 -9999 -9999 -9999 -9999 -9999 -9999 -9999 -9999 -9999 -9999 -9999 -9999 -9999 -9999 -9999 -9999 -9999 -9999 -9999 -9999 -9999 -9999 -9999 -9999 -9999 -9999 -9999 -9999 -9999 -9999 -9999 -9999 -9999 -9999 -9999 -9999 -9999 -9999 -9999 -9999 -9999 -9999 -9999 -9999 -9999 -9999 -9999 -9999 -9999 -9999 -9999 -9999 -9999 -9999 -9999 -9999 -9999 -9999 -9999 -9999 -9999 -9999 -9999 -9999 -9999 -9999 -9999

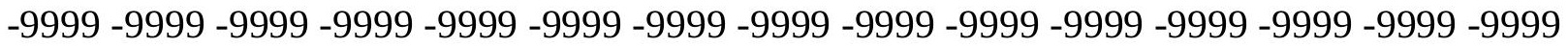
-9999 -9999 -9999 -9999 -9999 -9999 -9999 -9999 -9999 -9999 -9999 -9999 -9999 -9999 -9999 -9999 -9999 64.61444854736 66.13836669922 67.35751342773 68.27187347412 68.5766525268668 .8814392089869 .1862335205169 .1862335205168 .57665252686 67.9670867919967 .66230010986 -9999 -9999 -9999 -9999 -9999 -9999 -9999 -9999 -9999 -9999 -9999 -9999 -9999 -9999 -9999 -9999 -9999 -9999 -9999 -9999 -9999 -9999 -9999 -9999 -9999 -9999 -9999 -9999 -9999 -9999 -9999 -9999 -9999 -9999 -9999 -9999 -9999 -9999 -9999 -9999 -9999 -9999 -9999 -9999 -9999 -9999 -9999 -9999 -9999 -9999 -9999 -9999 -9999 -9999 -9999 -9999 -9999 -9999-9999-9999-9999

-9999 -9999 -9999 -9999 -9999 -9999 -9999 -9999 -9999 -9999 -9999 -9999 -9999 -9999 -9999 -9999 -9999 -9999 -9999 -9999 -9999 -9999 -9999 -9999 -9999 -9999 -9999 -9999 -9999 -9999 -9999 -9999 -9999 -9999 -9999 -9999 -9999 -9999 -9999 -9999 -9999 -9999 -9999 -9999 -9999 -

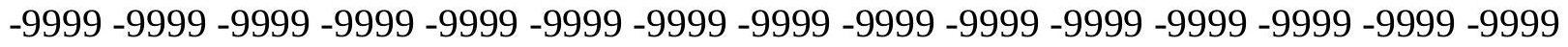
-9999 -9999 -9999 -9999 -9999 -9999 -9999 -9999 -9999 -9999 -9999 -9999 -9999 -9999 -9999 -9999 -9999 -9999 -9999 -9999 -9999 -9999 -9999 -9999 -9999 -9999 -9999 -9999 -9999 -999 -

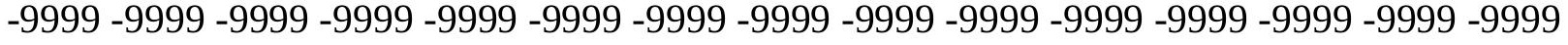
-9999 -9999 -9999 -9999 -9999 -9999 -9999 -9999 -9999 -9999 -9999 -9999 -9999 -9999 -9999 -

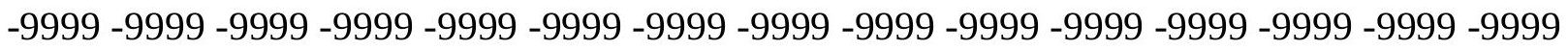

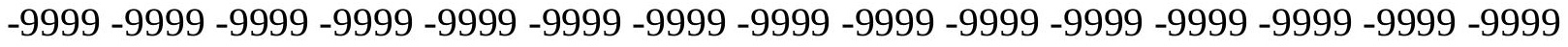

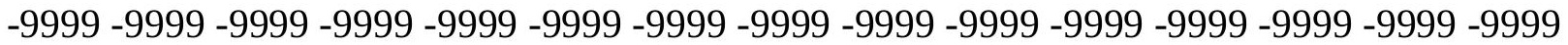

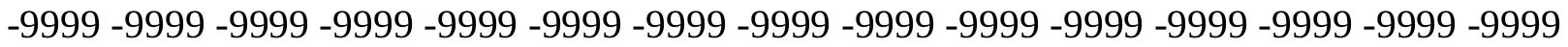

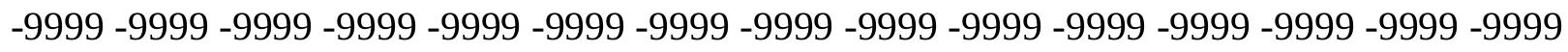

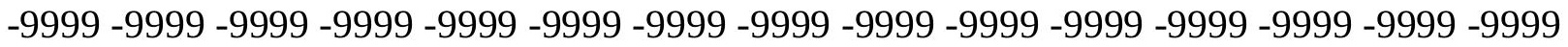

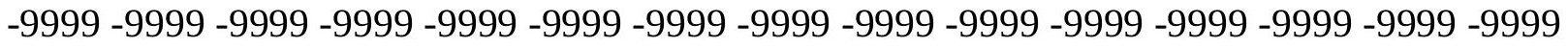
-9999 -9999 -9999 -9999 -9999 -9999 -9999 -9999 -9999 -9999 -9999 -9999 -9999 -9999 -9999 -

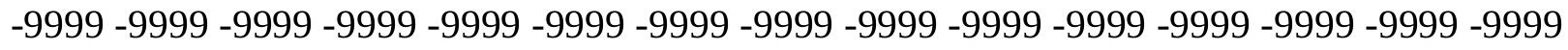

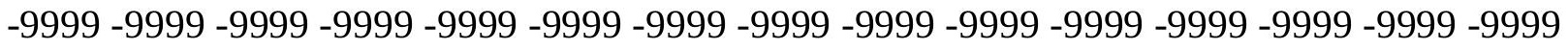
-9999 -9999 -9999 -9999 -9999 -9999 -9999 -9999 -9999 -9999 -9999 -9999 -9999 -9999 -9999 -9999 -9999 -9999 -9999 -9999 -9999 -9999 -9999 -9999-9999 -9999 -9999 -9999 -9999 -9999 -9999 -9999 -9999 -9999 -9999 -9999 -9999 -9999 -9999 -9999 -9999 -9999 -9999 -9999 -9999 -9999 -9999 -9999 -9999-9999 66.13836669922 66.44316101074 66.74794006348 
66.7479400634867 .0527267456167 .0527267456167 .05272674561 -9999 -9999 -9999 -9999 -9999 -9999 -9999 -9999 -9999 -9999 -9999 -9999 -9999 -9999 -9999 -9999 -9999 -9999 -9999 -9999 -9999 -9999 -9999 -9999 -9999 -9999 -9999 -9999 -9999 -9999 -9999 -9999 -9999 -9999 -9999 -9999 -9999 -9999 -9999 -9999 -9999 -9999 -9999 -9999 -9999 -9999 -9999 -9999 -9999 -9999 -9999 -9999 -9999 -9999 -9999 -9999 -9999 -9999 -9999 -9999 -9999 -9999 -9999 -9999 -9999 -9999 -9999 -9999 -9999 -9999 -9999 -9999 -9999 -9999 -9999 -9999 -9999 -9999 -9999 -9999 -9999 -9999 -9999 -9999 -9999 -9999 -9999 -9999 -9999 -9999 -9999 -9999 -

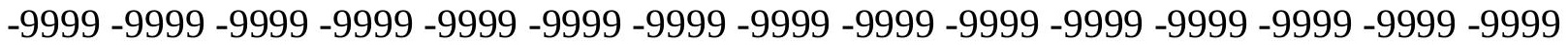
-9999 -9999 -9999 -9999 -9999 -9999 -9999 -9999 -9999 -9999 -9999 -9999 -9999 -9999 -9999 -9999 -9999 -9999 -9999 -9999 -9999 -9999 -9999 -9999 -9999 -9999 -9999 -9999 -9999 -9999 -9999 -9999 -9999 -9999 -9999 -9999 -9999 -9999 -9999 -9999 -9999 -9999 -9999 -9999 -9999 -9999 -9999 -9999 -9999 -9999 -9999 -9999 -9999 -9999 -9999 -9999 -9999 -9999 -9999 -9999

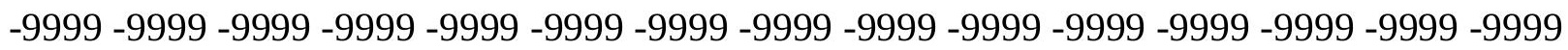
-9999 -9999 -9999 -9999 -9999 -9999 -9999 -9999 -9999 -9999 -9999 -9999 -9999 -9999 -9999 -9999 -9999 -9999 -9999 -9999 -9999 -9999 -9999 -9999 -9999 -9999 -9999 -9999 -9999 -9999 -9999 -9999 -9999 -9999 -9999 -9999 -9999 -9999 -9999 -9999 -9999 -9999 -9999 -9999 -9999 -9999 -9999 -9999 -9999 -9999 -9999 -9999 -9999 -9999 -9999 -9999 -9999 -9999 -9999 -9999 -9999 -9999 -9999 -9999 -9999 -9999 -9999 -9999 -9999 -9999 -9999 -9999 -9999 -9999 -9999 -9999 -9999 -9999 -9999 -9999 -9999 -9999 -9999 -9999 -9999 -9999 -9999 -9999 -9999 -9999 -9999 -9999 -9999 -9999 -9999 -9999 -9999 -9999 -9999 -9999 -9999 -9999 -9999 -9999 -9999

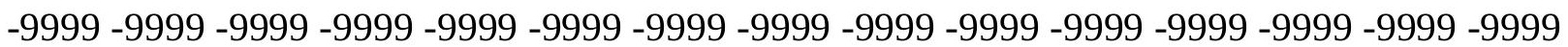
-9999 -9999 -9999 -9999 -9999 -9999 -9999 -9999 -9999 -9999 -9999 -9999 -9999 -9999 -9999 -9999 -9999 -9999 -9999 -9999 -9999 -9999 -9999 -9999 -9999 -9999 -9999 -9999 -9999 -9999 -9999 -9999 -9999 -9999 -9999 -9999 -9999 -9999 -9999 -9999 -9999 -9999 -9999 -9999 -9999

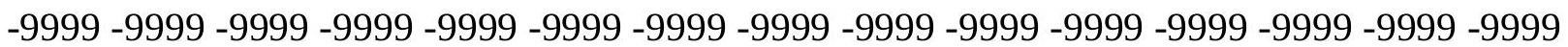
-9999 -9999 -9999 -9999 -9999 -9999 -9999 -9999 -9999 -9999 -9999 -9999 -9999 -9999 -9999 -9999 -9999 -9999 -9999 -9999 -9999 -9999 -9999 -9999 -9999 -9999 -9999 -9999 -9999 -9999 -9999 -9999 -9999 -9999 -9999 -9999 -9999 -9999 -9999 -9999 -9999 -9999 -9999 -9999 -9999 -9999 -9999 -9999 -9999 -9999 -9999 -9999 -9999 -9999 -9999 -9999 -9999 -9999 -9999 -9999 -9999 -9999 -9999 -9999 -9999 -9999 -9999 -9999 -9999 -9999 -9999 -9999 -9999 -9999 -9999 -9999 -9999 -9999 -9999 -9999 -9999 -9999 -9999 -9999 -9999 -9999 -9999 -9999 -9999 -9999 -9999 -9999 -9999 -9999 -9999 -9999 -9999 -9999 -9999 -9999 -9999 -9999 -9999 -9999 -9999 -9999 -9999 -9999 -9999 -9999 -9999 -9999 -9999 -9999 -9999 -9999 -9999 -9999 -9999 -9999 -9999 -9999 -9999 -9999 -9999 -9999 -9999 -9999 -9999 -9999 -9999 -9999 -9999 -9999 -9999 -9999 -9999 -9999 -9999 -9999 -9999 -9999 -9999 -9999 -9999 -9999 -9999 -9999 -9999 -9999 -9999 -9999 -9999 -9999 -9999 -9999 -9999 -9999 -9999 -9999 -9999 -9999 -9999 -9999 -9999 -9999 -9999 -9999 -9999 -9999 -9999 -9999 -9999 -9999 -9999 -9999 -9999 -9999 -9999

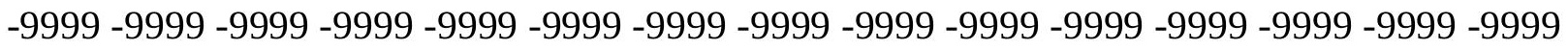
-9999 -9999 -9999 -9999 -9999 -9999 -9999 -9999 -9999 -9999 -9999 -9999 -9999 -9999 -9999 -9999 -9999 -9999 -9999 -9999 -9999 -9999 -9999 -9999 -9999 -9999 -9999 -9999 -9999 -9999 -9999 -9999 -9999 -9999 -9999 -9999 -9999 -9999 -9999 -9999 -9999 -9999 -9999 -9999 -9999 -999 -9999 -9999 -9999 -9999 -9999 -9999 -9999 -9999 -9999 -9999 -9999 -9999 -9999 -9999 -9999 -9999 -9999 -9999 -9999 -9999 -9999 -9999 -9999 -9999 -9999 -9999 -9999 -9999 -9999 -9999 -9999 -9999 -9999 -9999 -9999 -9999 -9999 -9999 -9999 -9999 -9999 -9999 -9999 -9999 -9999 -9999 -9999 -9999 -9999 -9999 -9999 -9999 -9999 -9999 -9999 -9999 -9999 -9999 -9999 -9999

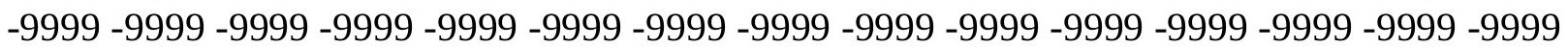


-9999 -9999 -9999 -9999 -9999 -9999 -9999 -9999 -9999 -9999 -9999 -9999 -9999 -9999 -9999 -9999 -9999 -9999 -9999 -9999 -9999 -9999 -9999 -9999 -9999 -9999 -9999 -9999 -9999 -9999 -

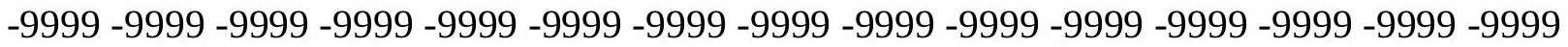
-9999 -9999 -9999 -9999 -9999 -9999 -9999 -9999 -9999 -9999 -9999 -9999 -9999 -9999 -9999 -9999 -9999 -9999 -9999 -9999 -9999 -9999 -9999 -9999-9999 -9999 -9999 -9999 -9999 -9999 -9999 -9999 -9999 -9999 -9999 -9999 -9999 -9999 -9999 -9999 -9999 -9999 -9999 -9999 -9999 -9999 -9999 -9999 -9999 -9999 -9999 -9999 -9999 -9999 -9999 -9999 -9999 -9999 -9999 -9999

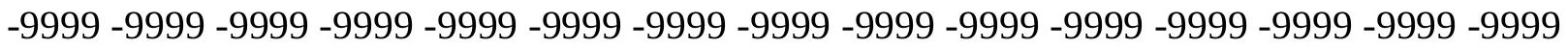

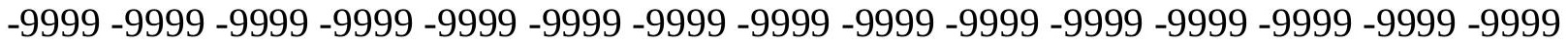

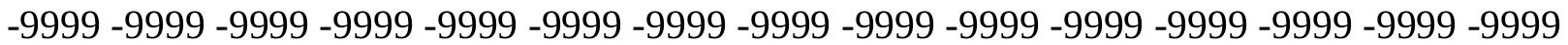
-9999 -9999 -9999 -9999 -9999 -9999 -9999 -9999 -9999 -9999 -9999 -9999 -9999 -9999 -9999 -9999 -9999 -9999 -9999 -9999 -9999 -9999 -9999 -9999 -9999 -9999 -9999 -9999 -9999 -9999 -9999 -9999 -9999 -9999 -9999 -9999 -9999 -9999 -9999 -9999 -9999 -9999 -9999 -9999 -

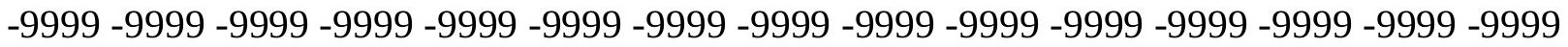
-9999 -9999 -9999 -9999 -9999 -9999 -9999 -9999 -9999 -9999 -9999 -9999 -9999 -9999 -9999 -

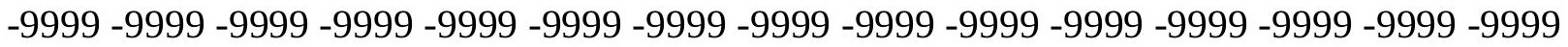
-9999 -9999 -9999 -9999 -9999 -9999 -9999 -9999 -9999 -9999 -9999 -9999 -9999 -9999 -9999 -9999 -9999 -9999 -9999 -9999 -9999 -9999 -9999 -9999 -9999 -9999 -9999 -9999 -9999 -9999 -9999 -9999 -9999 -9999 -9999 -9999 -9999 -9999 -9999 -9999 -9999 -9999 -9999 -9999 -9999 -

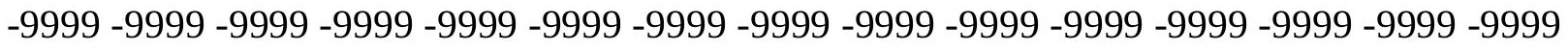

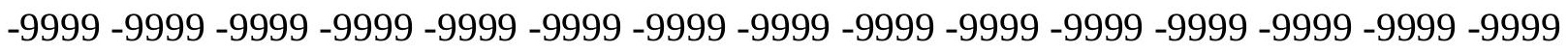
-9999 -9999 -9999 -9999 -9999 -9999 -9999 -9999 -9999 -9999 -9999 -9999 -9999 -9999 -9999 -9999 -9999 -9999 -9999 -9999 -9999 -9999 -9999 -9999 -9999 -9999 -9999 -9999 -9999 -9999 -9999 -9999 -9999 -9999 -9999 -9999 -9999 -9999 -9999 -9999 -9999 -9999 -9999 -9999 -9999 -

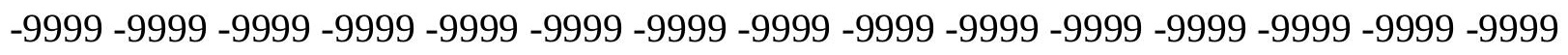
-9999 -9999 -9999 -9999 -9999 -9999 -9999 -9999 -9999 -9999 -9999 -9999 -9999 -9999 -9999 -9999 -9999 -9999 -9999 -9999 -9999 -9999 -9999 -9999 -9999 -9999 -9999 -9999 -9999 -9999 -

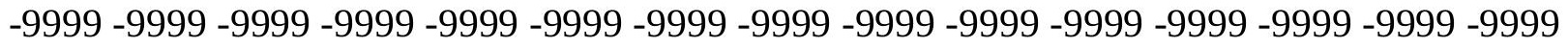
-9999 -9999 -9999 -9999 -9999 -9999 -9999 -9999 -9999 -9999 -9999 -9999 -9999 -9999 -9999 -9999 -9999 -9999 -9999 -9999 -9999 -9999 -9999 -9999 -9999 -9999 -9999 -9999 -9999 -999 -9999 -9999 -9999 -9999 -9999 -9999 -9999 -9999 -9999 -9999 -9999 -9999 -9999 -9999 -9999 -9999 -9999 -9999 -9999 -9999 -9999 -9999 -9999 -9999 -9999 -9999 -9999 -9999 -9999 -9999 -

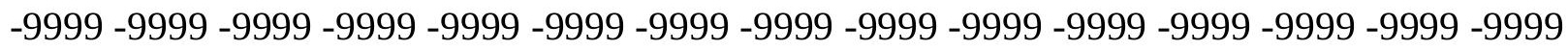

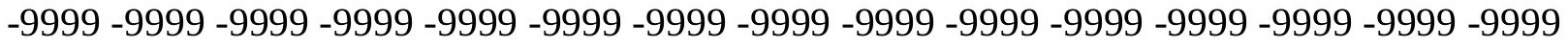

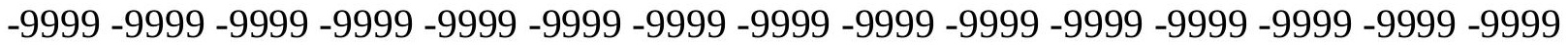
-9999 -9999 -9999 -9999 -9999 -9999 -9999 -9999 -9999 -9999 -9999 -9999 -9999 -9999 -9999 -

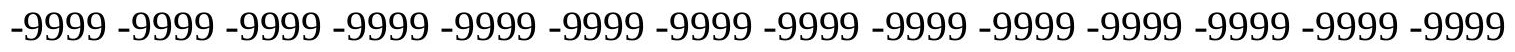

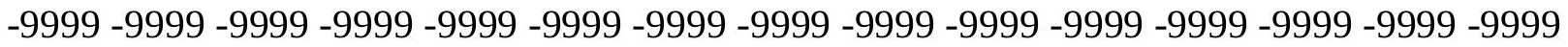
-9999 -9999 -9999 -9999 -9999 -9999 -9999 -9999 -9999 -9999 -9999 -9999 -9999 - 9999 - -999 -9999 -9999 -9999 -9999 -9999 -9999 -9999 -9999 -9999 -9999 -9999 -9999 -9999 -9999 -9999 -

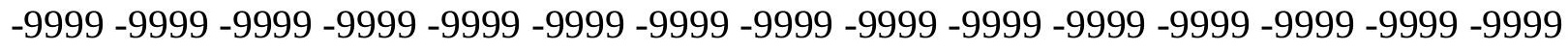

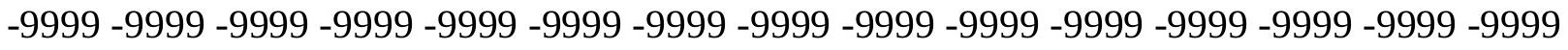
-9999 -9999 -9999 -9999 -9999 -9999 -9999 -9999 -9999 -9999 -9999 -9999 -9999 -9999 -9999 -9999 -9999 -9999 -9999 -9999 -9999 -9999 -9999 -9999-9999 -9999 -9999 -9999 -9999 -9999 -9999 -9999 -9999 -9999 -9999 -9999 -9999 -9999 -9999 -9999 -9999 -9999 -9999 -9999 -9999 -

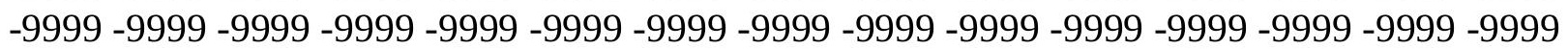


-9999 -9999 -9999 -9999 -9999 -9999 -9999 -9999 -9999 -9999 -9999 -9999 -9999 -9999 -9999 -9999 -9999 -9999 -9999 -9999 -9999 -9999 -9999 -9999 -9999 -9999 -9999 -9999 -9999 -9999 -

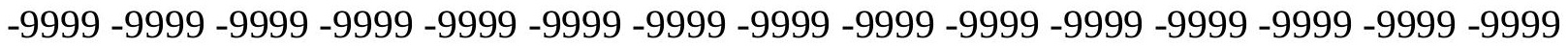
-9999 -9999 -9999 -9999 -9999 -9999 -9999 -9999 -9999 -9999 -9999 -9999 -9999 -9999 -9999 -9999 -9999 -9999 -9999 -9999 -9999 -9999 -9999 -9999-9999 -9999 -9999 -9999 -9999 -9999 -9999 -9999 -9999 -9999 -9999 -9999 -9999 -9999 -9999 -9999 -9999 -9999 -9999 -9999 -9999 -9999 -9999 -9999 -9999 -9999 -9999 -9999 -9999 -9999 -9999 -9999 -9999 -9999 -9999 -9999

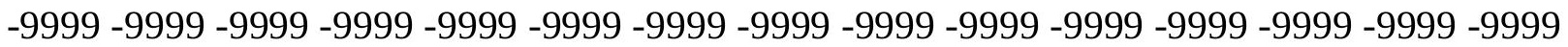

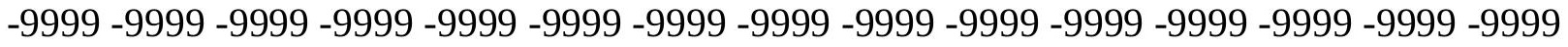
-9999 -9999 -9999 -9999 -9999 -9999 -9999 -9999 -9999 -9999 -9999 -9999 -9999 -9999 -9999 -9999 -9999 -9999 -9999 -9999 -9999 -9999 -9999 -9999 -9999 -9999 -9999 -9999 -9999 -9999 -9999 -9999 -9999 -9999 -9999 -9999 -9999 -9999 -9999 -9999 -9999 -9999 -9999 -9999 -9999 -9999 -9999 -9999 -9999 -9999 -9999 -9999 -9999 -9999 -9999 -9999 -9999 -9999 -9999 -9999 -9999 -9999 -9999 -9999 -9999 -9999 -9999 -9999 -9999 -9999 -9999 -9999 -9999 -9999 -9999 -9999 -9999 -9999 -9999 -9999 -9999 -9999 -9999 -9999 -9999 -9999 -9999 -9999 -9999 -9999 -

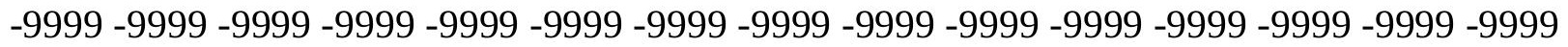
-9999 -9999 -9999 -9999 -9999 -9999 -9999 -9999 -9999 -9999 -9999 -9999 -9999 -9999 -9999 -9999 -9999 -9999 -9999 -9999 -9999 -9999 -9999 -9999 -9999 -9999 -9999 -9999 -9999 -9999 -9999 -9999 -9999 -9999 -9999 -9999 -9999 -9999 -9999 -9999 -9999 -9999 -9999 -9999 -

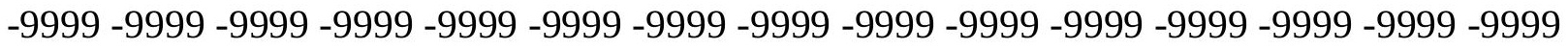
-9999 -9999 -9999 -9999 -9999 -9999 -9999 -9999 -9999 -9999 -9999 -9999 -9999 -9999 -9999 -999 -

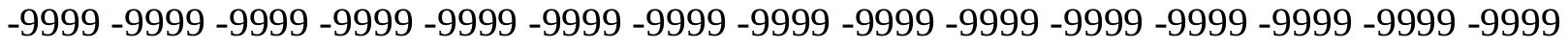
-9999 -9999 -9999 -9999 -9999 -9999 -9999 -9999 -9999 -9999 -9999 -9999 -9999 -9999 -9999 -9999 -9999 -9999 -9999 -9999 -9999 -9999 -9999 -9999 -9999 -9999 -9999 -9999 -9999 -9999 -9999 -9999 -9999 -9999 -9999 -9999 -9999 -9999 -9999 -9999 -9999 -9999 -9999 -9999 -9999 -9999 -9999 -9999 -9999 -9999 -9999 -9999 -9999 -9999 -9999 -9999 -9999 -9999 -9999 -9999 -9999 -9999 -9999 -9999 -9999 -9999 -9999 -9999 -9999 -9999 -9999 -9999 -9999 -9999 -9999 -

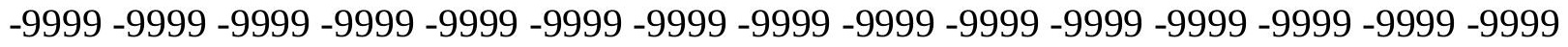
-9999 -9999 -9999 -9999 -9999 -9999 -9999 -9999 -9999 -9999 -9999 -9999 -9999 -9999 -9999 -9999 -9999 -9999 -9999 -9999 -9999 -9999 -9999 -9999 -9999 -9999 -9999 -9999 -9999 -999 -9999 -9999 -9999 -9999 -9999 -9999 -9999 -9999 -9999 -9999 -9999 -9999 -9999 -9999 -9999 -9999 -9999 -9999 -9999 -9999 -9999 -9999 -9999 -9999 -9999 -9999 -9999 -9999 -9999 -9999 -

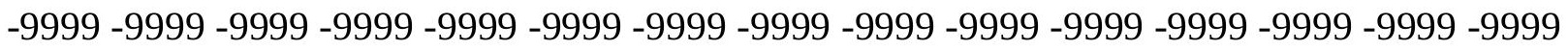

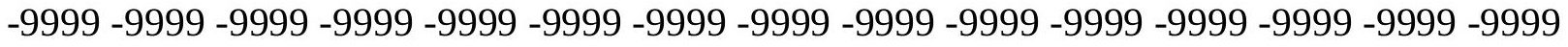

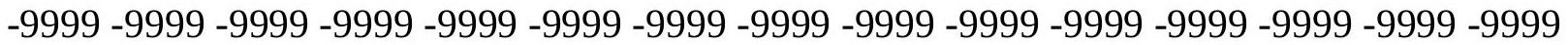
-9999 -9999 -9999 -9999 -9999 -9999 -9999 -9999 -9999 -9999 -9999 -9999 -9999 -9999 -9999

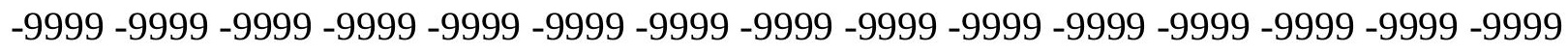

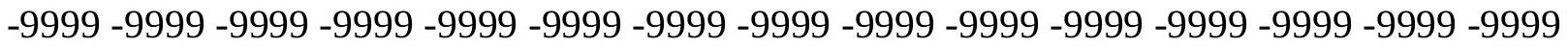
-9999 -9999 -9999 -9999 -9999 -9999 -9999 -9999 -9999 -9999 -9999 -9999 -9999 - 9999 - -999 -9999 -9999 -9999 -9999 -9999 -9999 -9999 -9999 -9999 -9999 -9999 -9999 -9999 -9999 -9999 -

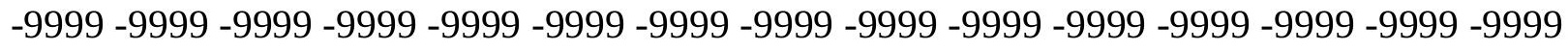

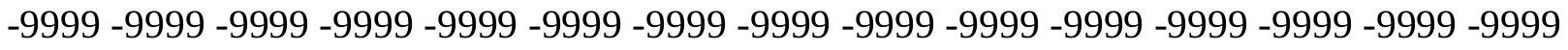
-9999 -9999 -9999 -9999 -9999 -9999 -9999 -9999 -9999 -9999 -9999 -9999 -9999 -9999 -9999 -9999 -9999 -9999 -9999 -9999 -9999 -9999 -9999 -9999 -9999 -9999 -9999 -9999 -9999 -9999 -9999 -9999 -9999 -9999 -9999 -9999 -9999 -9999 -9999 -9999 -9999 -9999 -9999 -9999 -

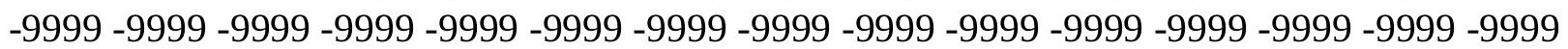


-9999 -9999 -9999 -9999 -9999 -9999 -9999 -9999 -9999 -9999 -9999 -9999 -9999 -9999 -9999 -9999 -9999 -9999 -9999 -9999 -9999 -9999 -9999 -9999 -9999 -9999 -9999 -9999 -9999 -9999 -9999 -9999 -9999 -9999 -9999 -9999 -9999 -9999 -9999 -9999 -9999 -9999 -9999 -9999 - 9999 -9999 -9999 -9999 -9999 -9999 -9999 -9999 -9999 -9999 -9999 -9999 -9999 -9999 -9999 -9999 -9999 -9999 -9999 -9999 -9999 -9999 -9999 -9999 -9999-9999 -9999 -9999 -9999 -9999 -9999 -9999 -9999 -9999 -9999 -9999 -9999 -9999 -9999 -9999 -9999 -9999 -9999 -9999 -9999 -9999 -9999 -9999 -9999 -9999 -9999 -9999 -9999 -9999 -9999 -9999 -9999 -9999 -9999 -9999 -9999

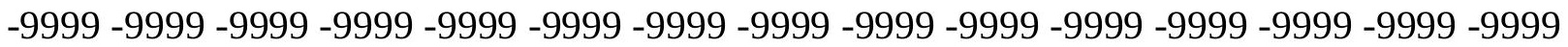

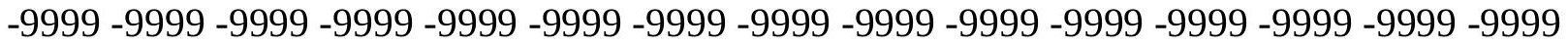
-9999 -9999 -9999 -9999 -9999 -9999 -9999 -9999 -9999 -9999 -9999 -9999 -9999 -9999 -9999 -9999 -9999 -9999 -9999 -9999 -9999 -9999 -9999 -9999 -9999 -9999 -9999 -9999 -9999 -9999 -9999 -9999 -9999 -9999 -9999 -9999 -9999 -9999 -9999 -9999 -9999 -9999 -9999 -9999 -9999 -9999 -9999 -9999 -9999 -9999 -9999 -9999 -9999 -9999 -9999 -9999 -9999 -9999 -9999 -9999 -

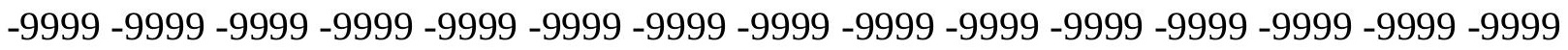
-9999 -9999 -9999 -9999 -9999 -9999 -9999 -9999 -9999 -9999 -9999 -9999 -9999 -9999 -9999 -

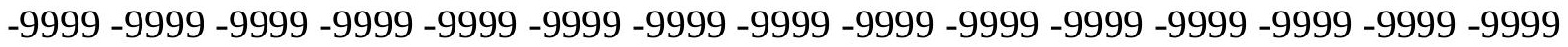
-9999 -9999 -9999 -9999 -9999 -9999 -9999 -9999 -9999 -9999 -9999 -9999 -9999 -9999 -9999 -9999 -9999 -9999 -9999 -9999 -9999 -9999 -9999 -9999 -9999 -9999 -9999 -9999 -9999 -9999 -9999 -9999 -9999 -9999 -9999 -9999 -9999 -9999 -9999 -9999 -9999 -9999 -9999 -9999 -9999 -

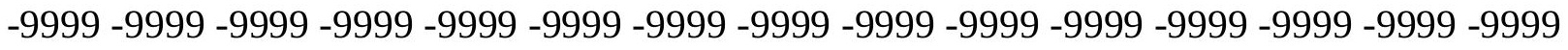
-9999 -9999 -9999 -9999 -9999 -9999 -9999 -9999 -9999 -9999 -9999 -9999 -9999 -9999 -9999 -999 -9999 -9999 -9999 -9999 -9999 -9999 -9999 -9999 -9999 -9999 -9999 -9999 -9999 -9999 - 9999 -9999 -9999 -9999 -9999 -9999 -9999 -9999 -9999 -9999 -9999 -9999 -9999 -9999 -9999 -

-9999 -9999 -9999 -9999 -9999 -9999 -9999 -9999 -9999 -9999 -9999 -9999 -9999 -9999 -9999 -

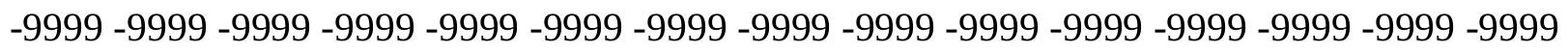
-9999 -9999 -9999 -9999 -9999 -9999 -9999 -9999 -9999 -9999 -9999 -9999 -9999 -9999 -9999 -9999 -9999 -9999 -9999 -9999 -9999 -9999 -9999 -9999 -9999 -9999 -9999 -9999 -9999 -9999 -

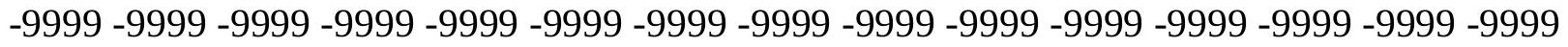
-9999 -9999 -9999 -9999 -9999 -9999 -9999 -9999 -9999 -9999 -9999 -9999 -9999 -9999 -9999 -9999 -9999 -9999 -9999 -9999 -9999 -9999 -9999 -9999 -9999 -9999 -9999 -9999 -9999 -999 -

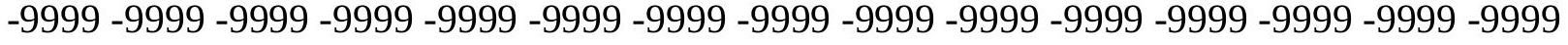
-9999 -9999 -9999 -9999 -9999 -9999 -9999 -9999 -9999 -9999 -9999 -9999 -9999 -9999 -9999 -

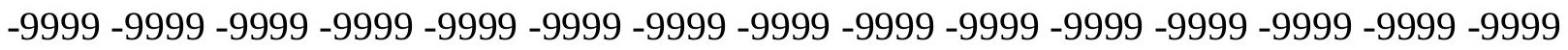

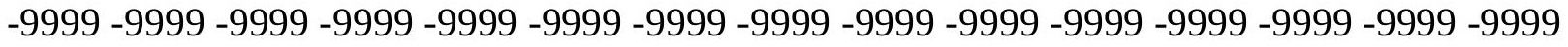

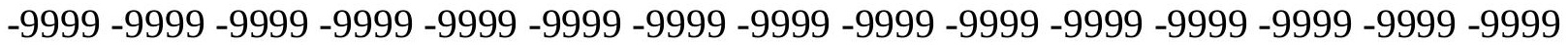

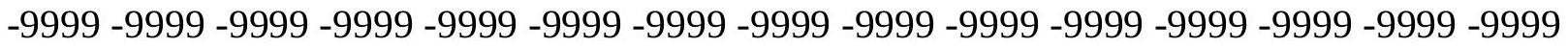

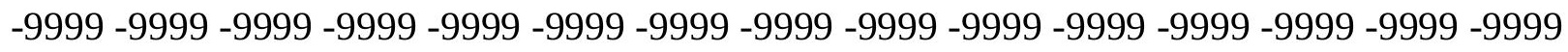

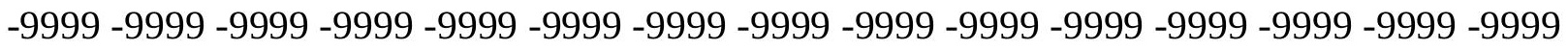

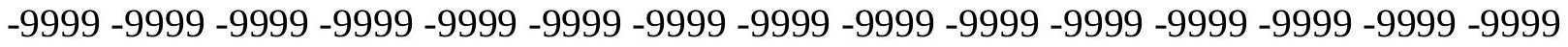
-9999 -9999 -9999 -9999 -9999 -9999 -9999 -9999 -9999 -9999 -9999 -9999 -9999 -9999 -9999 -

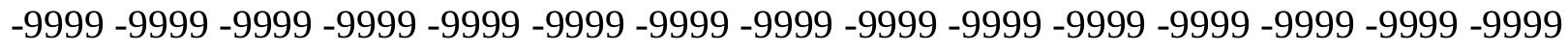

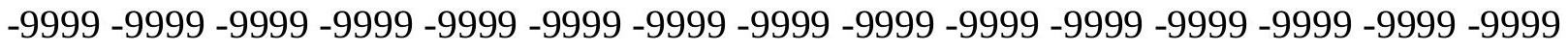
-9999 -9999 -9999 -9999 -9999 -9999 -9999 -9999 -9999 -9999 -9999 -9999 -9999 -9999 -9999 -9999 -9999 -9999 -9999 -9999 -9999 -9999 -9999 -9999-9999 -9999 -9999 -9999 -9999 -9999 -9999 -9999 -9999 -9999 -9999 -9999 -9999 -9999 -9999 -9999 -9999 -9999 -9999 -9999 -9999 -

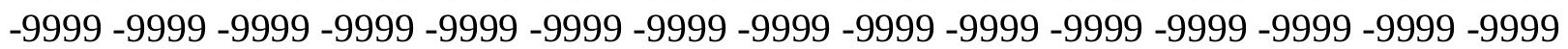


-9999 -9999 -9999 -9999 -9999 -9999 -9999 -9999 -9999 -9999 -9999 -9999 -9999 -9999 -9999 -9999 -9999 -9999 -9999 -9999 -9999 -9999 -9999 -9999 -9999 -9999 -9999 -9999 -9999 -9999 -9999 -9999 -9999 -9999 -9999 -9999 -9999 -9999 -9999 -9999 -9999 -9999 -9999 -9999 -9999 -9999 -9999 -9999 -9999 -9999 -9999 -9999 -9999 -9999 -9999 -9999 -9999 -9999 -9999 -9999 -9999 -9999 -9999 -9999 -9999 -9999 -9999 -9999-9999 -9999 -9999 -9999 -9999 -9999 -9999 -9999 -9999 -9999 -9999 -9999 -9999 -9999 -9999 -9999 -9999 -9999 -9999 -9999 -9999 -9999 -9999 -9999 -9999 -9999 -9999 -9999 -9999 -9999 -9999 -9999 -9999 -9999 -9999 -9999

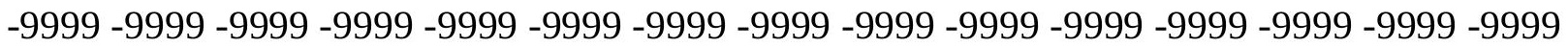

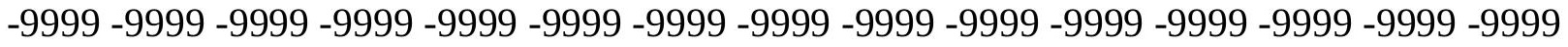
-9999 -9999 -9999 -9999 -9999 -9999 -9999 -9999 -9999 -9999 -9999 -9999 -9999 -9999 -9999 -9999 -9999 -9999 -9999 -9999 -9999 -9999 -9999 -9999 -9999 -9999 -9999 -9999 -9999 -9999 -9999 -9999 -9999 -9999 -9999 -9999 -9999 -9999 -9999 -9999 -9999 -9999 -9999 -9999 -9999 -9999 -9999 -9999 -9999 -9999 -9999 -9999 -9999 -9999 -9999 -9999 -9999 -9999 -9999 -9999 -

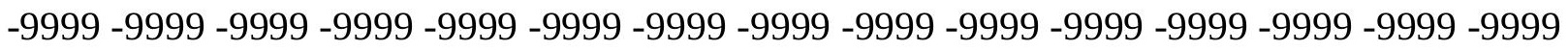
-9999 -9999 -9999 -9999 -9999 -9999 -9999 -9999 -9999 -9999 -9999 -9999 -9999 -9999 -9999 -

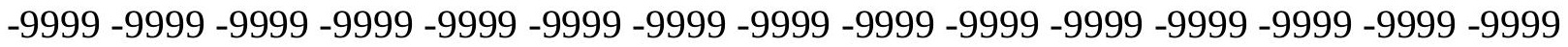
-9999 -9999 -9999 -9999 -9999 -9999 -9999 -9999 -9999 -9999 -9999 -9999 -9999 -9999 -9999 -9999 -9999 -9999 -9999 -9999 -9999 -9999 -9999 -9999 -9999 -9999 -9999 -9999 -9999 -9999 -9999 -9999 -9999 -9999 -9999 -9999 -9999 -9999 -9999 -9999 -9999 -9999 -9999 -9999 -9999 -

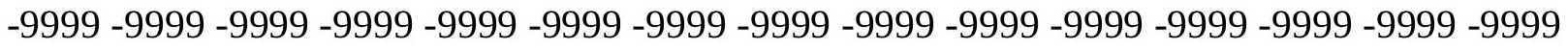

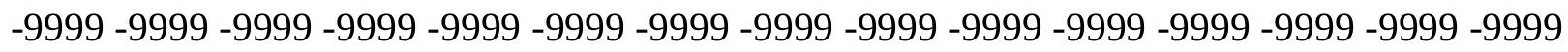
-9999 -9999 -9999 -9999 -9999 -9999 -9999 -9999 -9999 -9999 -9999 -9999 -9999 -9999 -9999 -9999 -9999 -9999 -9999 -9999 -9999 -9999 -9999 -9999 -9999 -9999 -9999 -9999 -9999 -9999 -9999 -9999 -9999 -9999 -9999 -9999 -9999 -9999 -9999 -9999 -9999 -9999 -9999 -9999 -9999 -

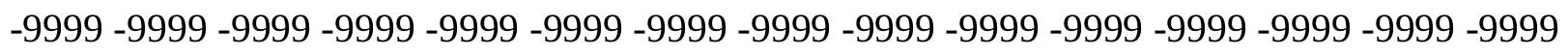
-9999 -9999 -9999 -9999 -9999 -9999 -9999 -9999 -9999 -9999 -9999 -9999 -9999 -9999 -9999 -9999 -9999 -9999 -9999 -9999 -9999 -9999 -9999 -9999 -9999 -9999 -9999 -9999 -9999 -9999 -

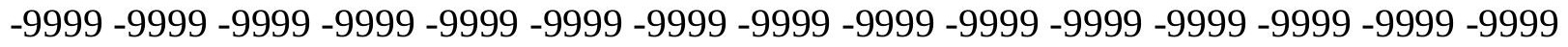
-9999 -9999 -9999 -9999 -9999 -9999 -9999 -9999 -9999 -9999 -9999 -9999 -9999 -9999 -9999 -9999 -9999 -9999 -9999 -9999 -9999 -9999 -9999 -9999 -9999 -9999 -9999 -9999 - -999 -

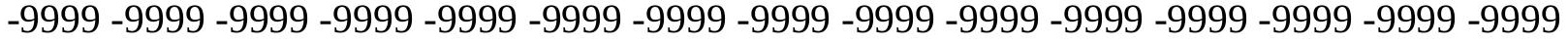
-9999 -9999 -9999 -9999 -9999 -9999 -9999 -9999 -9999 -9999 -9999 -9999 -9999 -9999 -9999 -

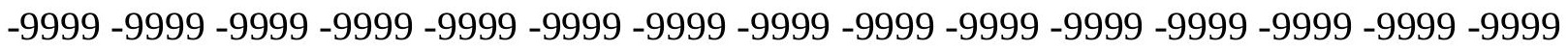

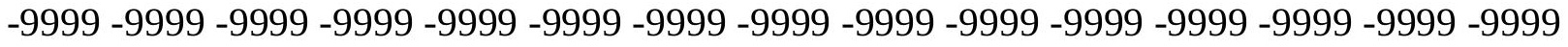

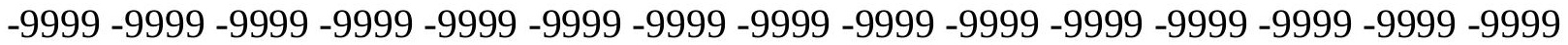

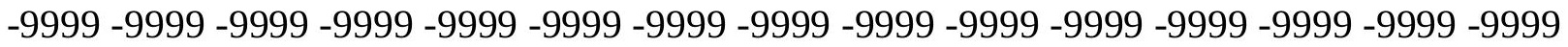

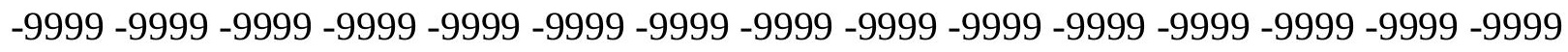

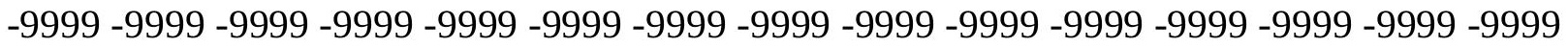

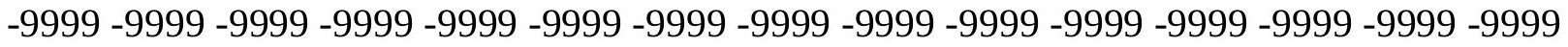
-9999 -9999 -9999 -9999 -9999 -9999 -9999 -9999 -9999 -9999 -9999 -9999 -9999 -9999 -9999 -

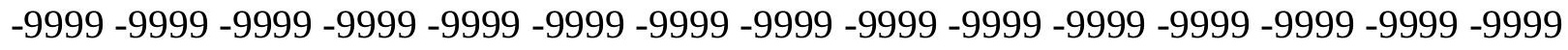

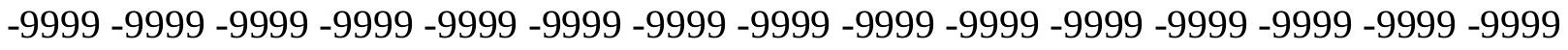
-9999 -9999 -9999 -9999 -9999 -9999 -9999 -9999 -9999 -9999 -9999 -9999 -9999 -9999 -9999 -9999 -9999 -9999 -9999 -9999 -9999 -9999 -9999 -9999-9999 -9999 -9999 -9999 -9999 -9999 -9999 -9999 -9999 -9999 -9999 -9999 -9999 -9999 -9999 -9999 -9999 -9999 -9999 -9999 -9999 -

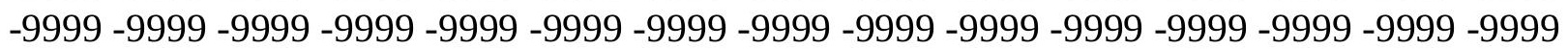


-9999 -9999 -9999 -9999 -9999 -9999 -9999 -9999 -9999 -9999 -9999 -9999 -9999 -9999 -9999 -9999 -9999 -9999 -9999 -9999 -9999 -9999 -9999 -9999 -9999 -9999 -9999 -9999 -9999 -9999 -

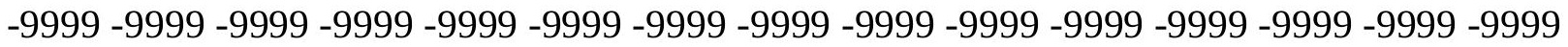
-9999 -9999 -9999 -9999 -9999 -9999 -9999 -9999 -9999 -9999 -9999 -9999 -9999 -9999 -9999 -9999 -9999 -9999 -9999 -9999 -9999 -9999 -9999 -9999-9999 -9999 -9999 -9999 -9999 -9999 -9999 -9999 -9999 -9999 -9999 -9999 -9999 -9999 -9999 -9999 -9999 -9999 -9999 -9999 -9999 -9999 -9999 -9999 -9999 -9999 -9999 -9999 -9999 -9999 -9999 -9999 -9999 -9999 -9999 -9999

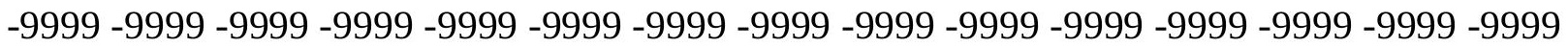
-9999 -9999 -9999 -9999 -9999 -9999 -9999 -9999 -9999 -9999 -9999 -9999 -9999 -9999 -9999 -9999 -9999 -9999 -9999 -9999 -9999 -9999 -9999 -9999 -9999 -9999 -9999 -9999 -9999

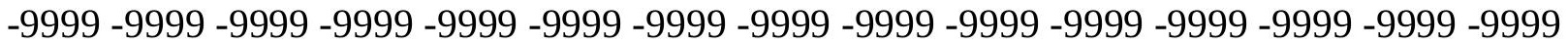
-9999 -9999 -9999 -9999 -9999 -9999 -9999 -9999 -9999 -9999 -9999 -9999 -9999 -9999 -9999 -9999 -9999 -9999 -9999 -9999 -9999 -9999 -9999 -9999 -9999 -9999 -9999 -9999 -9999 -9999 -9999 -9999 -9999 -9999 -9999 -9999 -9999 -9999 -9999 -9999 -9999 -9999 -9999 -9999 - 9999 -9999 -9999 -9999 -9999 -9999 -9999 -9999 -9999 -9999 -9999 -9999 -9999 -9999 -9999 -9999

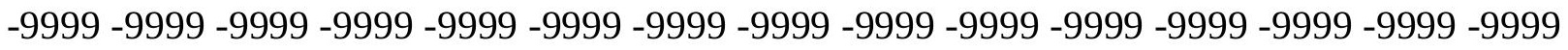
-9999 -9999 -9999 -9999 -9999 -9999 -9999 -9999 -9999 -9999 -9999 -9999 -9999 -9999 -9999 -9999 -9999 -9999 -9999 -9999 -9999 -9999 -9999 -9999 -9999 -9999 -9999 -9999 -9999 -9999 -9999 -9999 -9999 -9999 -9999 -9999 -9999 -9999 -9999 -9999 -9999 -9999 -9999 -9999 -9999 -

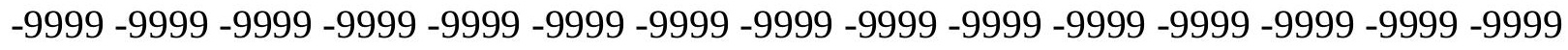

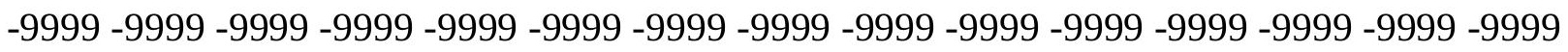
-9999 -9999 -9999 -9999 -9999 -9999 -9999 -9999 -9999 -9999 -9999 -9999 -9999 -9999 -9999 -9999 -9999 -9999 -9999 -9999 -9999 -9999 -9999 -9999 -9999 -9999 -9999 -9999 -9999 -9999 -9999 -9999 -9999 -9999 -9999 -9999 -9999 -9999 -9999 -9999 -9999 -9999 -9999 -9999 -9999 -

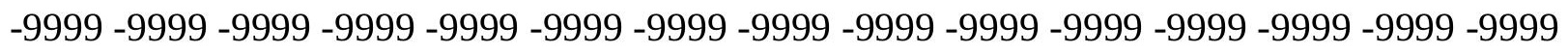
-9999 -9999 -9999 -9999 -9999 -9999 -9999 -9999 -9999 -9999 -9999 -9999 -9999 -9999 -9999 -9999 -9999 -9999 -9999 -9999 -9999 -9999 -9999 -9999 -9999 -9999 -9999 -9999 -9999 -9999 -

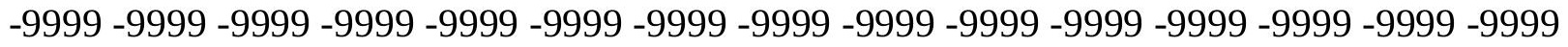
-9999 -9999 -9999 -9999 -9999 -9999 -9999 -9999 -9999 -9999 -9999 -9999 -9999 -9999 -9999 -9999 -9999 -9999 -9999 -9999 -9999 -9999 -9999 -9999 -9999 -9999 -9999 -9999 -9999 -999 -9999 -9999 -9999 -9999 -9999 -9999 -9999 -9999 -9999 -9999 -9999 -9999 -9999 -9999 -9999 -9999 -9999 -9999 -9999 -9999 -9999 -9999 -9999 -9999 -9999 -9999 -9999 -9999 -9999 -9999 -

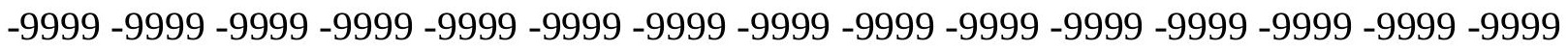

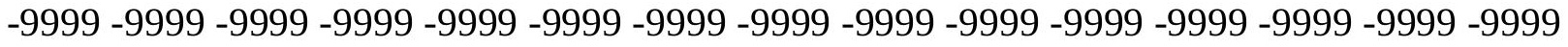
-9999 -9999 -9999 -9999 -9999 -9999 -9999 -9999 -9999 -9999 -9999 -9999 -9999 -9999 -

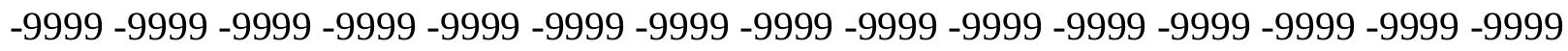

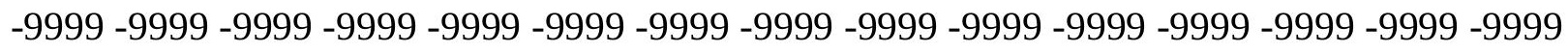

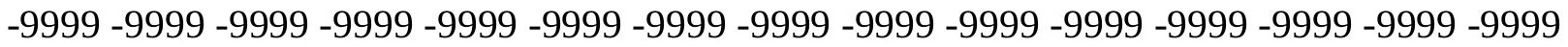
-9999 -9999 -9999 -9999 -9999 -9999 -9999 -9999 -9999 -9999 -9999 -9999 -9999 - 9999 - -999 -9999 -9999 -9999 -9999 -9999 -9999 -9999 -9999 -9999 -9999 -9999 -9999 -9999 -9999 -9999 -

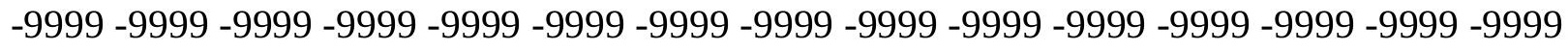

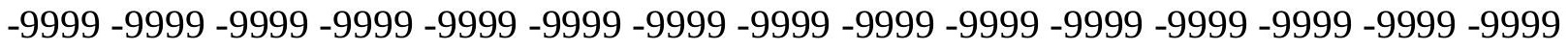
-9999 -9999 -9999 -9999 -9999 -9999 -9999 -9999 -9999 -9999 -9999 -9999 -9999 -9999 -9999 -9999 -9999 -9999 -9999 -9999 -9999 -9999 -9999 -9999-9999 -9999 -9999 -9999 -9999 -9999 -9999 -9999 -9999 -9999 -9999 -9999 -9999 -9999 -9999 -9999 -9999 -9999 -9999 -9999 -9999 -

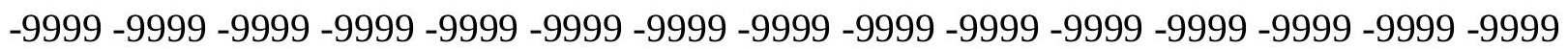


-9999 -9999 -9999 -9999 -9999 -9999 -9999 -9999 -9999 -9999 -9999 -9999 -9999 -9999 -9999 -9999 -9999 -9999 -9999 -9999 -9999 -9999 -9999 -9999 -9999 -9999 -9999 -9999 -9999 -9999 -

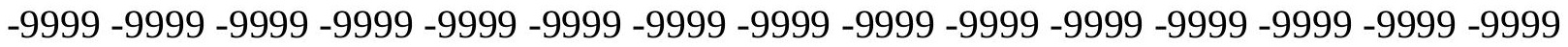
-9999 -9999 -9999 -9999 -9999 -9999 -9999 -9999 -9999 -9999 -9999 -9999 -9999 -9999 -9999 -9999 -9999 -9999 -9999 -9999 -9999 -9999 -9999 -9999-9999 -9999 -9999 -9999 -9999 -9999 -9999 -9999 -9999 -9999 -9999 -9999 -9999 -9999 -9999 -9999 -9999 -9999 -9999 -9999 -9999 -9999 -9999 -9999 -9999 -9999 -9999 -9999 -9999 -9999 -9999 -9999 -9999 -9999 -9999 -9999

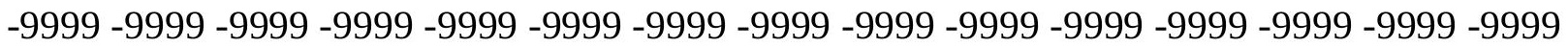

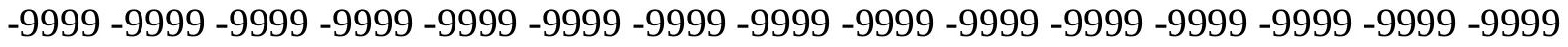
-9999 -9999 -9999 -9999 -9999 -9999 -9999 -9999 -9999 -9999 -9999 -9999 -9999 -9999 -9999 -9999 -9999 -9999 -9999 -9999 -9999 -9999 -9999 -9999 -9999 -9999 -9999 -9999 -9999 -9999 -9999 -9999 -9999 -9999 -9999 -9999 -9999 -9999 -9999 -9999 -9999 -9999 -9999 -9999 -9999 -9999 -9999 -9999 -9999 -9999 -9999 -9999 -9999 -9999 -9999 -9999 -9999 -9999 -9999 -9999 -9999 -9999 -9999 -9999 -9999 -9999 -9999 -9999 -9999 -9999 -9999 -9999 -9999 -9999 -9999 -9999 -9999 -9999 -9999 -9999 -9999 -9999 -9999 -9999 -9999 -9999 -9999 -9999 -9999 -9999 -9999 -9999 -9999 -9999 -9999 -9999 -9999 -9999 -9999 -9999 -9999 -9999 - 9999 - -999 -

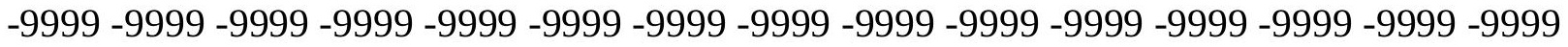
-9999 -9999 -9999 -9999 -9999 -9999 -9999 -9999 -9999 -9999 -9999 -9999 -9999 -9999 -9999 -9999 -9999 -9999 -9999 -9999 -9999 -9999 -9999 -9999 -9999 -9999 -9999 -9999 -9999 -9999 -

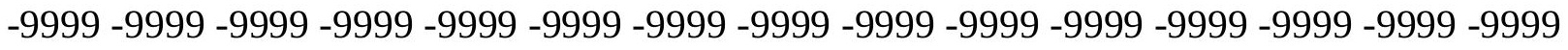
-9999 -9999 -9999 -9999 -9999 -9999 -9999 -9999 -9999 -9999 -9999 -9999 -9999 -9999 -9999

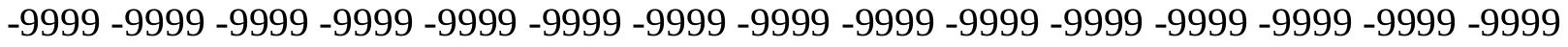
-9999 -9999 -9999 -9999 -9999 -9999 -9999 -9999 -9999 -9999 -9999 -9999 -9999 -9999 -9999 -9999 -9999 -9999 -9999 -9999 -9999 -9999 -9999 -9999 -9999 -9999 -9999 -9999 -9999 -9999 -

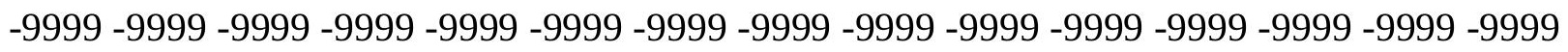
-9999 -9999 -9999 -9999 -9999 -9999 -9999 -9999 -9999 -9999 -9999 -9999 -9999 -9999 -9999 -9999 -9999 -9999 -9999 -9999 -9999 -9999 -9999 -9999 -9999 -9999 -9999 -9999 -9999 -9999 -

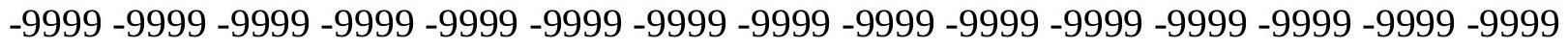
-9999 -9999 -9999 -9999 -9999 -9999 -9999 -9999 -9999 -9999 -9999 -9999 -9999 -9999 -9999 -9999 -9999 -9999 -9999 -9999 -9999 -9999 -9999 -9999 -9999 -9999 -9999 -9999 -9999 -999 -

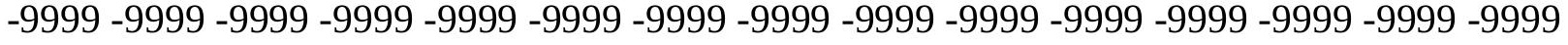
-9999 -9999 -9999 -9999 -9999 -9999 -9999 -9999 -9999 -9999 -9999 -9999 -9999 -9999 -9999 -

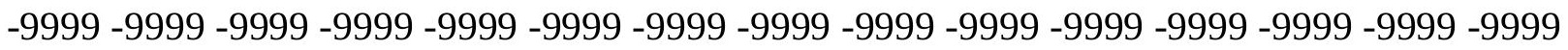

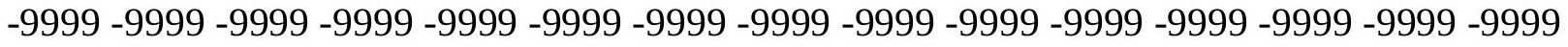

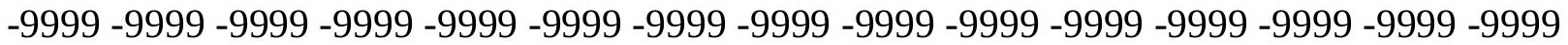
-9999 -9999 -9999 -9999 -9999 -9999 -9999 -9999 -9999 -9999 -9999 -9999 -9999 -9999 -9999 -

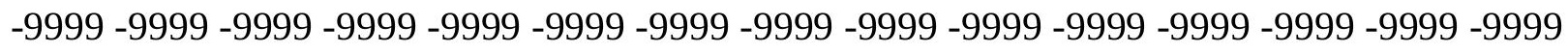

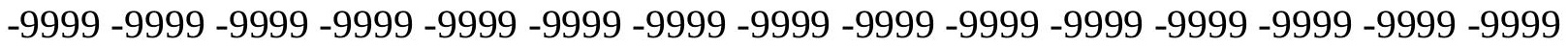
-9999 -9999 -9999 -9999 -9999 -9999 -9999 -9999 -9999 -9999 -9999 -9999 -9999 - 9999 - -999 -9999 -9999 -9999 -9999 -9999 -9999 -9999 -9999 -9999 -9999 -9999 -9999 -9999 -9999 -9999 -

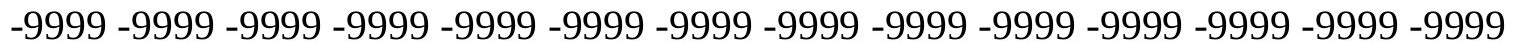

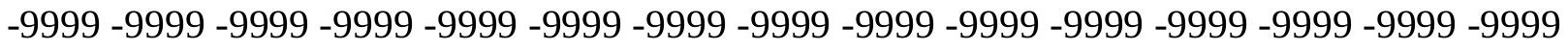
-9999 -9999 -9999 -9999 -9999 -9999 -9999 -9999 -9999 -9999 -9999 -9999 -9999 -9999 -9999 -9999 -9999 -9999 -9999 -9999 -9999 -9999 -9999 -9999-9999 -9999 -9999 -9999 -9999 -9999 -9999 -9999 -9999 -9999 -9999 -9999 -9999 -9999 -9999 -9999 -9999 -9999 -9999 -9999 -9999 -

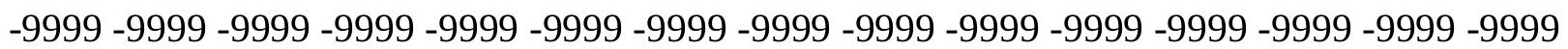


-9999 -9999 -9999 -9999 -9999 -9999 -9999 -9999 -9999 -9999 -9999 -9999 -9999 -9999 -9999 -9999 -9999 -9999 -9999 -9999 -9999 -9999 -9999 -9999 -9999 -9999 -9999 -9999 -9999 -9999 -9999 -9999 -9999 -9999 -9999 -9999 -9999 -9999 -9999 -9999 -9999 -9999 -9999 -9999 - 9999 -9999 -9999 -9999 -9999 -9999 -9999 -9999 -9999 -9999 -9999 -9999 -9999 -9999 -9999 -9999 -9999 -9999 -9999 -9999 -9999 -9999 -9999 -9999 -9999-9999 -9999 -9999 -9999 -9999 -9999 -9999 -9999 -9999 -9999 -9999 -9999 -9999 -9999 -9999 -9999 -9999 -9999 -9999 -9999 -9999 -9999 -9999 -9999 -9999 -9999 -9999 -9999 -9999 -9999 -9999 -9999 -9999 -9999 -9999 -9999

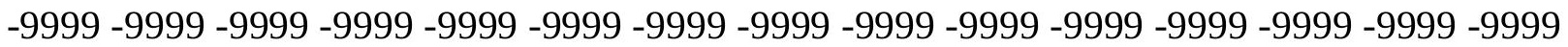
-9999 -9999 -9999 -9999 -9999 -9999 -9999 -9999 -9999 -9999 -9999 -9999 -9999 -9999 -9999 -9999 -9999 -9999 -9999 -9999 -9999 -9999 -9999 -9999 -9999 -9999 -9999 -9999 -9999 -9999

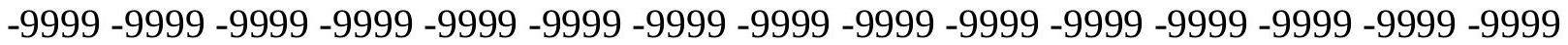
-9999 -9999 -9999 -9999 -9999 -9999 -9999 -9999 -9999 -9999 -9999 -9999 -9999 -9999 -9999 -9999 -9999 -9999 -9999 -9999 -9999 -9999 -9999 -9999 -9999 -9999 -9999 -9999 -9999 -9999 -

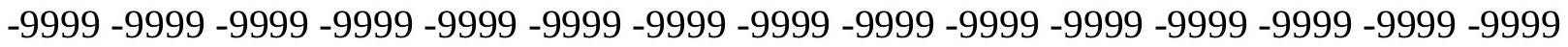
-9999 -9999 -9999 -9999 -9999 -9999 -9999 -9999 -9999 -9999 -9999 -9999 -9999 -9999 -9999

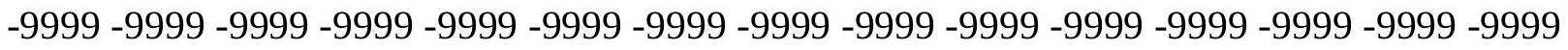
-9999 -9999 -9999 -9999 -9999 -9999 -9999 -9999 -9999 -9999 -9999 -9999 -9999 -9999 -9999 -9999 -9999 -9999 -9999 -9999 -9999 -9999 -9999 -9999 -9999 -9999 -9999 -9999 -9999 - 9999 -9999 -9999 -9999 -9999 -9999 -9999 -9999 -9999 -9999 -9999 -9999 -9999 -9999 -9999 -9999 -9999 -9999 -9999 -9999 -9999 -9999 -9999 -9999 -9999 -9999 -9999 -9999 -9999 -9999 -9999 -9999 -9999 -9999 -9999 -9999 -9999 -9999 -9999 -9999 -9999 -9999 -9999 -9999 -9999 -9999 -9999 -9999 -9999 -9999 -9999 -9999 -9999 -9999 -9999 -9999 -9999 -9999 -9999 -9999 -9999 -9999 -9999 -9999 -9999 -9999 -9999 -9999 -9999 -9999 -9999 -9999 -9999 -9999 -9999 -9999 -9999 -9999 -9999 -9999 -9999 -9999 -9999 -9999 -9999 -9999 -9999 -9999 -9999 -9999 -9999 -9999 -9999 -9999 -9999 -9999 -9999 -9999 -9999 -9999 -9999 -9999 -9999 -9999 -9999 -9999 -9999 -9999 -9999 -9999 -9999 -9999 -9999 -9999 -9999 -9999 -9999 -9999 -9999 -9999 -9999 -9999 -9999 -9999 -9999 -9999 -9999 -9999 -9999 -9999 -9999 -9999 -9999 -9999 -9999 -9999 -9999 -9999 -9999 -9999 -9999 -9999 -9999 -9999 -9999 -9999 -9999 -9999 -9999 -9999 -9999 -9999 -9999 -9999 -9999 -9999 -9999 -9999 -9999 -9999 -9999 -9999 -9999 -9999 -9999 -9999 -9999 -9999 -9999 -9999 -9999 -9999 -9999 -9999 -9999 -9999 -9999 -9999 -9999 -999 -9999 -9999 -9999 -9999 -9999 -9999 -9999 -9999 -9999 -9999 -9999 -9999 -9999 -9999 -9999 -9999 -9999 -9999 -9999 -9999 -9999 -9999 -9999 -9999 -9999 -9999 -9999 -9999 -9999 -9999 -

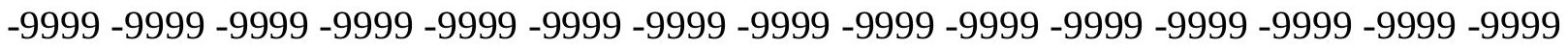

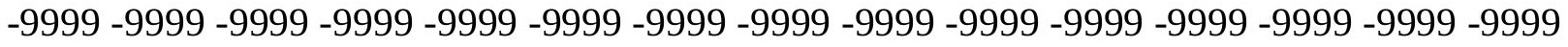

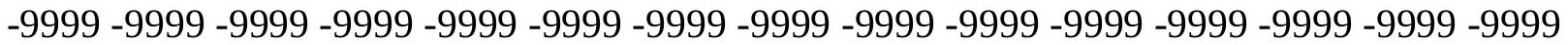
-9999 -9999 -9999 -9999 -9999 -9999 -9999 -9999 -9999 -9999 -9999 -9999 -9999 -9999 -9999

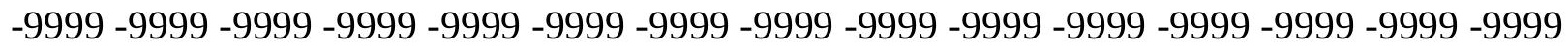

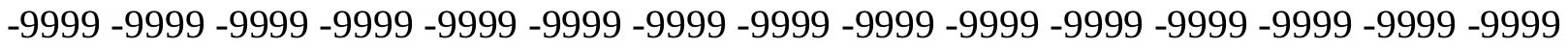

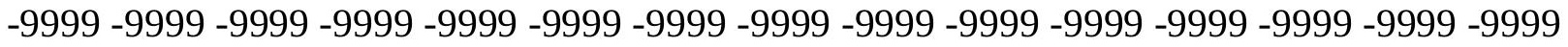
-9999 -9999 -9999 -9999 -9999 -9999 -9999 -9999 -9999 -9999 -9999 -9999 -9999 -9999 -9999 -

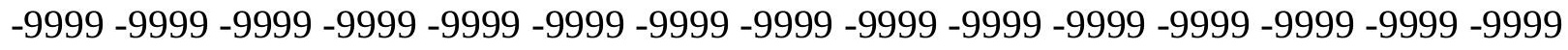

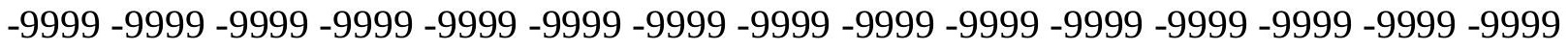
-9999 -9999 -9999 -9999 -9999 -9999 -9999 -9999 -9999 -9999 -9999 -9999 -9999 -9999 -9999 -9999 -9999 -9999 -9999 -9999 -9999 -9999 -9999 -9999-9999 -9999 -9999 -9999 -9999 -9999 -9999 -9999 -9999 -9999 -9999 -9999 -9999 -9999 -9999 -9999 -9999 -9999 -9999 -9999 -9999 -

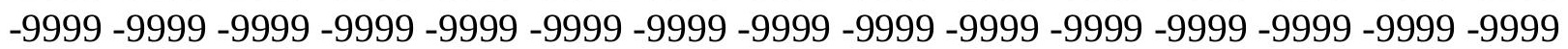


-9999 -9999 -9999 -9999 -9999 -9999 -9999 -9999 -9999 -9999 -9999 -9999 -9999 -9999 -9999 -9999 -9999 -9999 -9999 -9999 -9999 -9999 -9999 -9999 -9999 -9999 -9999 -9999 -9999 -9999 -9999 -9999 -9999 -9999 -9999 -9999 -9999 -9999 -9999 -9999 -9999 -9999 -9999 -9999 -9999 -9999 -9999 -9999 -9999 -9999 -9999 -9999 -9999 -9999 -9999 -9999 -9999 -9999 -9999 -9999 -9999 -9999 -9999 -9999 -9999 -9999 -9999 -9999 -9999 -9999 -9999 -9999 -9999 -9999 -9999 -9999 -9999 -9999 -9999 -9999 -9999 -9999 -9999 -9999 -9999 -9999 -9999 -9999 -9999 -9999 -9999 -9999 -9999 -9999 -9999 -9999 -9999 -9999 -9999 -9999 -9999 -9999 -9999 -9999 -

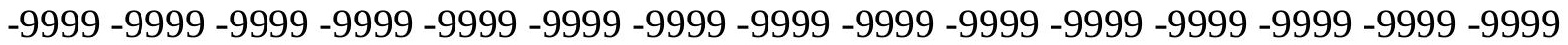
-9999 -9999 -9999 -9999 -9999 -9999 -9999 -9999 -9999 -9999 -9999 -9999 -9999 -9999 -9999 -9999 -9999 -9999 -9999 -9999 -9999 -9999 -9999 -9999 -9999 -9999 -9999 -9999 -9999 -9999 -

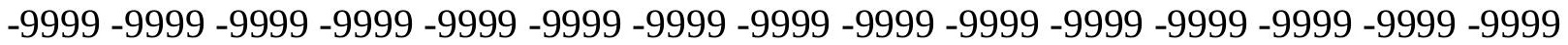
-9999 -9999 -9999 -9999 -9999 -9999 -9999 -9999 -9999 -9999 -9999 -9999 -9999 -9999 -9999 -9999 -9999 -9999 -9999 -9999 -9999 -9999 -9999 -9999 -9999 -9999 -9999 -9999 -9999 -9999 -9999 -9999 -9999 -9999 -9999 -9999 -9999 -9999 -9999 -9999 -9999 -9999 -9999 -9999 -9999 -9999 -9999 -9999 -9999 -9999 -9999 -9999 -9999 -9999 -9999 -9999 -9999 -9999 -9999 -9999 -9999 -9999 -9999 -9999 -9999 -9999 -9999 -9999 -9999 -9999 -9999 -9999 -9999 -9999 -9999 -9999 -9999 -9999 -9999 -9999 -9999 -9999 -9999 -9999 -9999 -9999 -9999 -9999 -9999 -9999 -9999 -9999 -9999 -9999 -9999 -9999 -9999 -9999 -9999 -9999 -9999 -9999 -9999 -9999 -9999 -9999 -9999 -9999 -9999 -9999 -9999 -9999 -9999 -9999 -9999 -9999 -9999 -9999 -9999 -9999 -9999 -9999 -9999 -9999 -9999 -9999 -9999 -9999 -9999 -9999 -9999 -9999 -9999 -9999 -9999

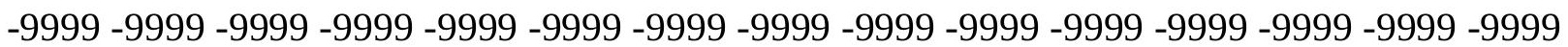
-9999 -9999 -9999 -9999 -9999 -9999 -9999 -9999 -9999 -9999 -9999 -9999 -9999 -9999 -9999 -9999 -9999 -9999 -9999 -9999 -9999 -9999 -9999 -9999 -9999 -9999 -9999 -9999 -9999 -9999 -9999 -9999 -9999 -9999 -9999 -9999 -9999 -9999 -9999 -9999 -9999 -9999 -9999 -9999 -9999

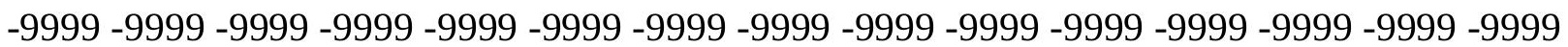
-9999 -9999 -9999 -9999 -9999 -9999 -9999 -9999 -9999 -9999 -9999 -9999 -9999 -9999 -9999 -9999 -9999 -9999 -9999 -9999 -9999 -9999 -9999 -9999 -9999 -9999 -9999 -9999 -9999 -9999 -9999 -9999 -9999 -9999 -9999 -9999 -9999 -9999 -9999 -9999 -9999 -9999 -9999 -9999

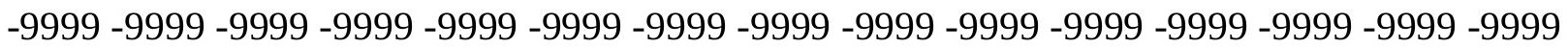
-9999 -9999 -9999 -9999 -9999 -9999 -9999 -9999 -9999 -9999 -9999 -9999 -9999 -9999 -9999 -9999 -9999 -9999 -9999 -9999 -9999 -9999 -9999 -9999 -9999 -9999 -9999 -9999 -9999 -9999 -

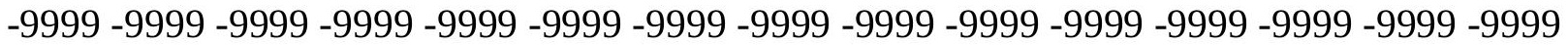
-9999 -9999 -9999 -9999 -9999 -9999 -9999 -9999 -9999 -9999 -9999 -9999 -9999 -9999 -9999 -9999 -9999 -9999 -9999 -9999 -9999 -9999 -9999 -9999 -9999 -9999 -9999 -9999 -9999 -9999 -9999 -9999 -9999 -9999 -9999 -9999 -9999 -9999 -9999 -9999 -9999 -9999 -9999 -9999 -9999 -9999 -9999 -9999 -9999 -9999 -9999 -9999 -9999 -9999 -9999 -9999 -9999 -9999 -9999 -9999 -9999 -9999 -9999 -9999 -9999 -9999 -9999 -9999 -9999 -9999 -9999 -9999 -9999 -9999 -9999

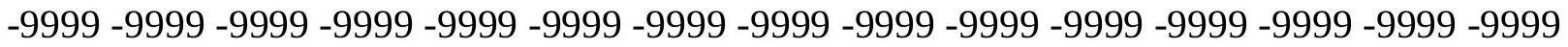
-9999 -9999 -9999 -9999 -9999 -9999 -9999 -9999 -9999 -9999 -9999 -9999 -9999 -9999 -9999 -9999 -9999 -9999 -9999 -9999 -9999 -9999 -9999 -9999 -9999 -9999 -9999 -9999 -9999 -9999 -

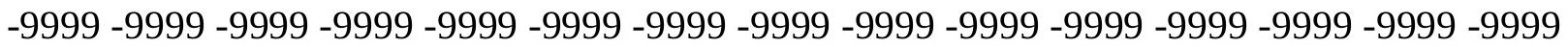
-9999 -9999 -9999 -9999 -9999 -9999 -9999 -9999 -9999 -9999 -9999 -9999 -9999 -9999 -9999 -9999 -9999 -9999 -9999 -9999 -9999 -9999 -9999 -9999 -9999 -9999 -9999 -9999 -9999 -9999 -9999 -9999 -9999 -9999 -9999 -9999 -9999 -9999 -9999 -9999 -9999 -9999 -9999 -9999 -9999 -9999 -9999 -9999 -9999 -9999 -9999 -9999 -9999 -9999 -9999 -9999 -9999 -9999 -9999 -9999

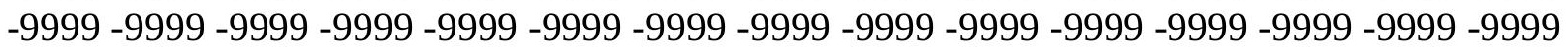


-9999 -9999 -9999 -9999 -9999 -9999 -9999 -9999 -9999 -9999 -9999 -9999 -9999 -9999 -9999 -9999 -9999 -9999 -9999 -9999 -9999 -9999 -9999 -9999 -9999 -9999 -9999 -9999 -9999 -9999 -

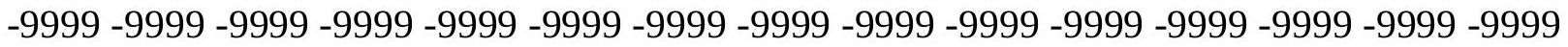
-9999 -9999 -9999 -9999 -9999 -9999 -9999 -9999 -9999 -9999 -9999 -9999 -9999 -9999 -9999 -9999 -9999 -9999 -9999 -9999 -9999 -9999 -9999 -9999-9999 -9999 -9999 -9999 -9999 -9999 -9999 -9999 -9999 -9999 -9999 -9999 -9999 -9999 -9999 -9999 -9999 -9999 -9999 -9999 -9999 -9999 -9999 -9999 -9999 -9999 -9999 -9999 -9999 -9999 -9999 -9999 -9999 -9999 -9999 -

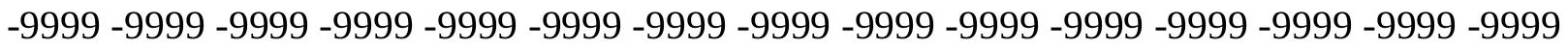

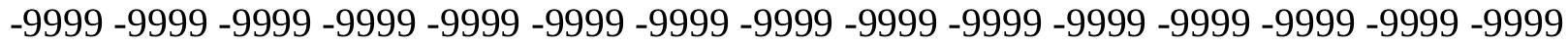
-9999 -9999 -9999 -9999 -9999 -9999 -9999 -9999 -9999 -9999 -9999 -9999 -9999 -9999 -9999 -9999 -9999 -9999 -9999 -9999 -9999 -9999 -9999 -9999 -9999 -9999 -9999 -9999 -9999 -9999 -9999 -9999 -9999 -9999 -9999 -9999 -9999 -9999 -9999 -9999 -9999 -9999 -9999 -9999 -9999 -9999 -9999 -9999 -9999 -9999 -9999 -9999 -9999 -9999 -9999 -9999 -9999 -9999 -9999 -9999 -9999 -9999 -9999 -9999 -9999 -9999 -9999 -9999 -9999 -9999 -9999 -9999 -9999 -9999 -9999 -9999 -9999 -9999 -9999 -9999 -9999 -9999 -9999 -9999 -9999 -9999 -9999 -9999 -9999 -9999 -

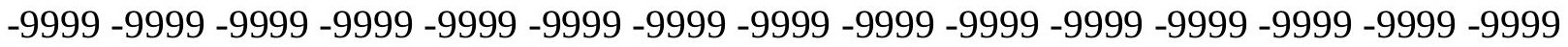
-9999 -9999 -9999 -9999 -9999 -9999 -9999 -9999 -9999 -9999 -9999 -9999 -9999 -9999 -9999 -9999 -9999 -9999 -9999 -9999 -9999 -9999 -9999 -9999 -9999 -9999 -9999 -9999 -9999 -9999 -9999 -9999 -9999 -9999 -9999 -9999 -9999 -9999 -9999 -9999 -9999 -9999 -9999 -9999 -9999 -

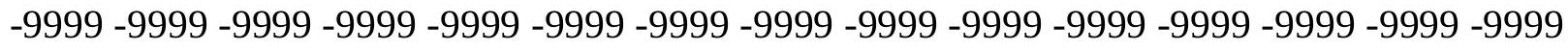

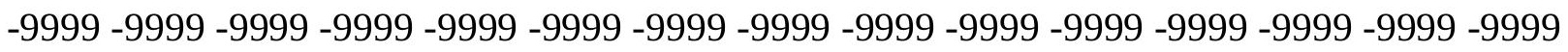

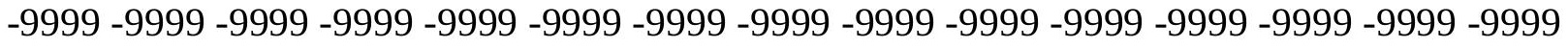
-9999 -9999 -9999 -9999 -9999 -9999 -9999 -9999 -9999 -9999 -9999 -9999 -9999 -9999 -9999 -9999 -9999 -9999 -9999 -9999 -9999 -9999 -9999 -9999 -9999 -9999 -9999 -9999 -9999 -9999 -

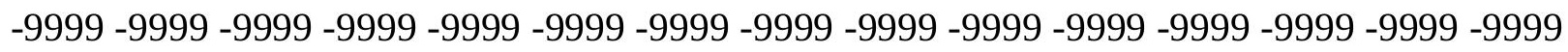
-9999 -9999 -9999 -9999 -9999 -9999 -9999 -9999 -9999 -9999 -9999 -9999 -9999 -9999 -9999 -9999 -9999 -9999 -9999 -9999 -9999 -9999 -9999 -9999 -9999 -9999 -9999 -9999 -9999 -9999 -

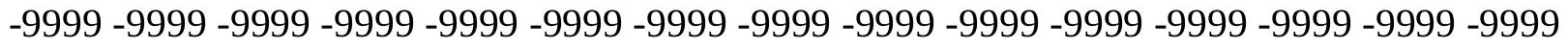
-9999 -9999 -9999 -9999 -9999 -9999 -9999 -9999 -9999 -9999 -9999 -9999 -9999 -9999 -9999 -9999 -9999 -9999 -9999 -9999 -9999 -9999 -9999 -9999 -9999 -9999 -9999 -9999 -9999 -999 -9999 -9999 -9999 -9999 -9999 -9999 -9999 -9999 -9999 -9999 -9999 -9999 -9999 -9999 -9999 -

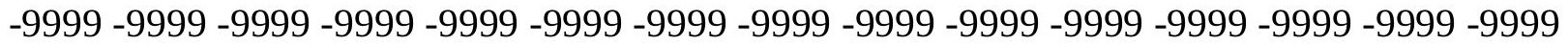

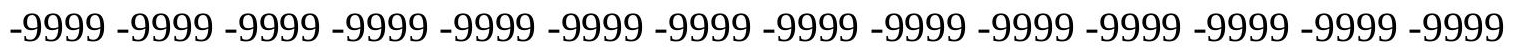

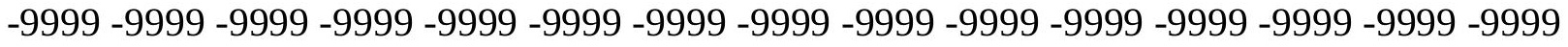

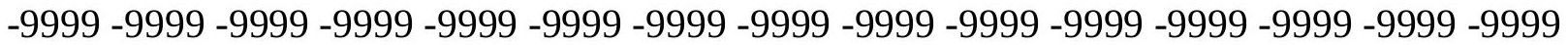

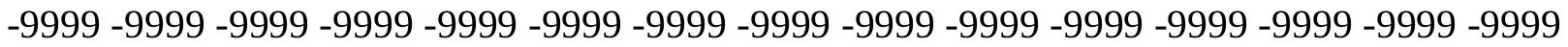

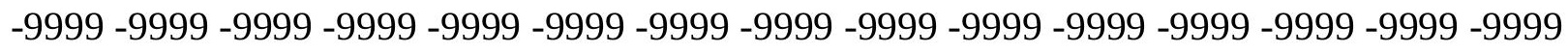

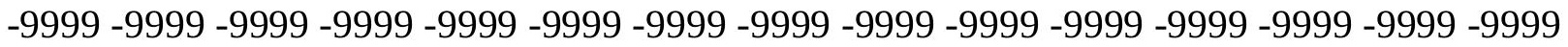

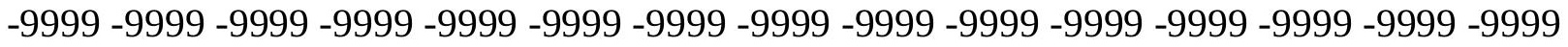
-9999 -9999 -9999 -9999 -9999 -9999 -9999 -9999 -9999 -9999 -9999 -9999 -9999 -9999 -9999 -

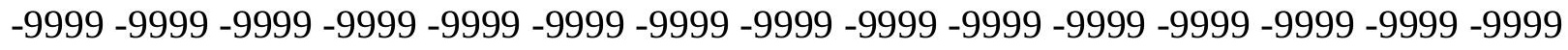

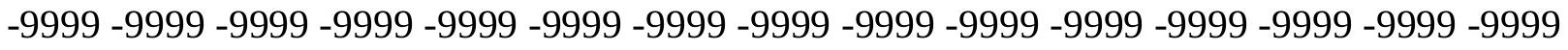
-9999 -9999 -9999 -9999 -9999 -9999 -9999 -9999 -9999 -9999 -9999 -9999 -9999 -9999 -9999 -9999 -9999 -9999 -9999 -9999 -9999 -9999 -9999 -9999-9999 -9999 -9999 -9999 -9999 -9999 -9999 -9999 -9999 -9999 -9999 -9999 -9999 -9999 -9999 -9999 -9999 -9999 -9999 -9999 -9999 -

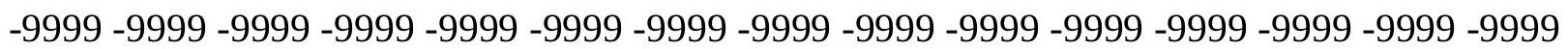


-9999 -9999 -9999 -9999 -9999 -9999 -9999 -9999 -9999 -9999 -9999 -9999 -9999 -9999 -9999 -9999 -9999 -9999 -9999 -9999 -9999 -9999 -9999 -9999 -9999 -9999 -9999 -9999 -9999 -9999 -

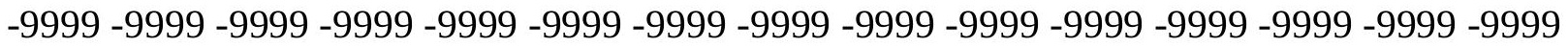
-9999 -9999 -9999 -9999 -9999 -9999 -9999 -9999 -9999 -9999 -9999 -9999 -9999 -9999 -9999 -9999 -9999 -9999 -9999 -9999 -9999 -9999 -9999 -9999-9999 -9999 -9999 -9999 -9999 -9999 -9999 -9999 -9999 -9999 -9999 -9999 -9999 -9999 -9999 -9999 -9999 -9999 -9999 -9999 -9999 -9999 -9999 -9999 -9999 -9999 -9999 -9999 -9999 -9999 -9999 -9999 -9999 -9999 -9999 -9999

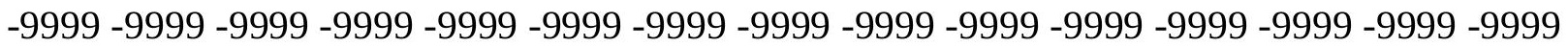

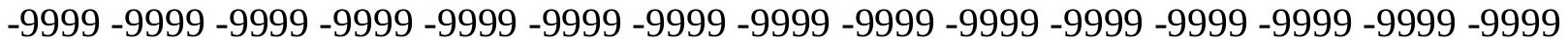
-9999 -9999 -9999 -9999 -9999 -9999 -9999 -9999 -9999 -9999 -9999 -9999 -9999 -9999 -9999 -9999 -9999 -9999 -9999 -9999 -9999 -9999 -9999 -9999 -9999 -9999 -9999 -9999 -9999 -9999 -9999 -9999 -9999 -9999 -9999 -9999 -9999 -9999 -9999 -9999 -9999 -9999 -9999 -9999 -9999 -9999 -9999 -9999 -9999 -9999 -9999 -9999 -9999 -9999 -9999 -9999 -9999 -9999 -9999 -9999 -9999 -9999 -9999 -9999 -9999 -9999 -9999 -9999 -9999 -9999 -9999 -9999 -9999 -9999 -9999 -9999 -9999 -9999 -9999 -9999 -9999 -9999 -9999 -9999 -9999 -9999 -9999 -9999 -9999 -

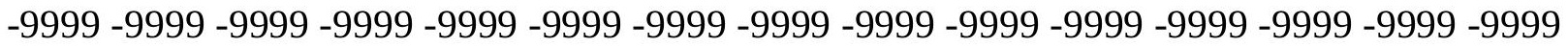
-9999 -9999 -9999 -9999 -9999 -9999 -9999 -9999 -9999 -9999 -9999 -9999 -9999 -9999 -9999 -9999 -9999 -9999 -9999 -9999 -9999 -9999 -9999 -9999 -9999 -9999 -9999 -9999 -9999 -9999 -9999 -9999 -9999 -9999 -9999 -9999 -9999 -9999 -9999 -9999 -9999 -9999 -9999 -9999 -9999 -

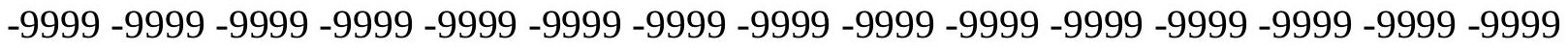
-9999 -9999 -9999 -9999 -9999 -9999 -9999 -9999 -9999 -9999 -9999 -9999 -9999 -9999 -9999

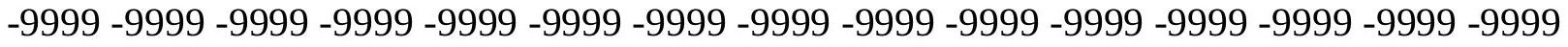
-9999 -9999 -9999 -9999 -9999 -9999 -9999 -9999 -9999 -9999 -9999 -9999 -9999 -9999 -9999 -9999 -9999 -9999 -9999 -9999 -9999 -9999 -9999 -9999 -9999 -9999 -9999 -9999 -9999 -9999 -

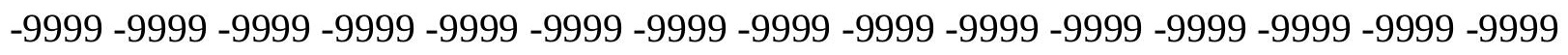
-9999 -9999 -9999 -9999 -9999 -9999 -9999 -9999 -9999 -9999 -9999 -9999 -9999 -9999 -9999 -9999 -9999 -9999 -9999 -9999 -9999 -9999 -9999 -9999 -9999 -9999 -9999 -9999 -9999 -9999 -

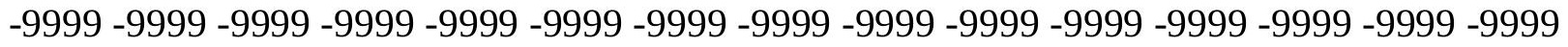
-9999 -9999 -9999 -9999 -9999 -9999 -9999 -9999 -9999 -9999 -9999 -9999 -9999 -9999 -9999 -9999 -9999 -9999 -9999 -9999 -9999 -9999 -9999 -9999 -9999 -9999 -9999 -9999 -9999 -999 -9999 -9999 -9999 -9999 -9999 -9999 -9999 -9999 -9999 -9999 -9999 -9999 -9999 -9999 -9999 -9999 -9999 -9999 -9999 -9999 -9999 -9999 -9999 -9999 -9999 -9999 -9999 -9999 -9999 -9999 -

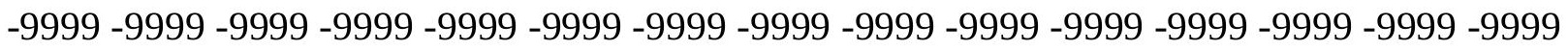

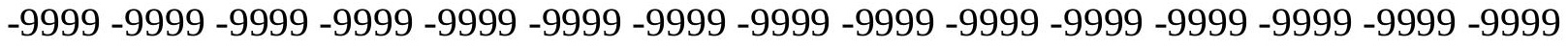

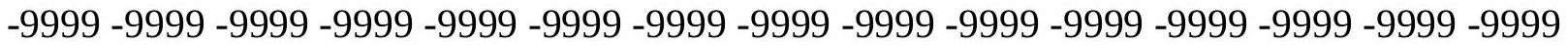
-9999 -9999 -9999 -9999 -9999 -9999 -9999 -9999 -9999 -9999 -9999 -9999 -9999 -9999 -9999 -

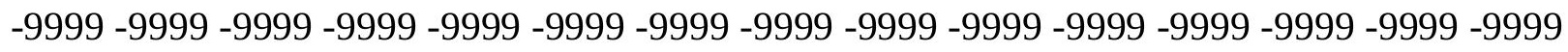

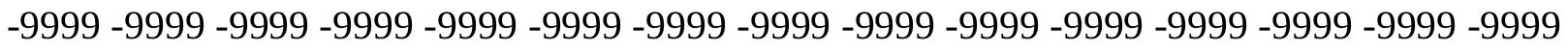
-9999 -9999 -9999 -9999 -9999 -9999 -9999 -9999 -9999 -9999 -9999 -9999 -9999 -9999 - -999 -9999 -9999 -9999 -9999 -9999 -9999 -9999 -9999 -9999 -9999 -9999 -9999 -9999 -9999 -9999 -

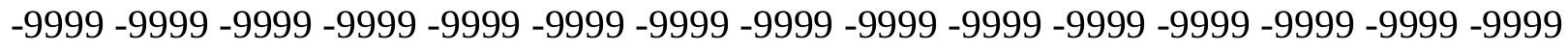

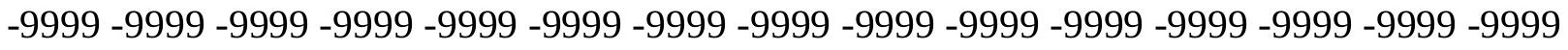
-9999 -9999 -9999 -9999 -9999 -9999 -9999 -9999 -9999 -9999 -9999 -9999 -9999 -9999 -9999 -9999 -9999 -9999 -9999 -9999 -9999 -9999 -9999 -9999-9999 -9999 -9999 -9999 -9999 -9999 -9999 -9999 -9999 -9999 -9999 -9999 -9999 -9999 -9999 -9999 -9999 -9999 -9999 -9999 -9999 -

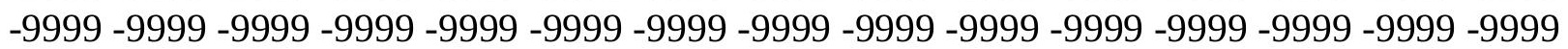


-9999 -9999 -9999 -9999 -9999 -9999 -9999 -9999 -9999 -9999 -9999 -9999 -9999 -9999 -9999 -9999 -9999 -9999 -9999 -9999 -9999 -9999 -9999 -9999 -9999 -9999 -9999 -9999 -9999 -9999 -

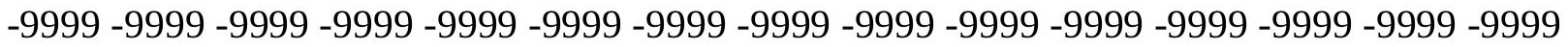
-9999 -9999 -9999 -9999 -9999 -9999 -9999 -9999 -9999 -9999 -9999 -9999 -9999 -9999 -9999 -9999 -9999 -9999 -9999 -9999 -9999 -9999 -9999 -9999-9999 -9999 -9999 -9999 -9999 -9999 -9999 -9999 -9999 -9999 -9999 -9999 -9999 -9999 -9999 -9999 -9999 -9999 -9999 -9999 -9999 -9999 -9999 -9999 -9999 -9999 -9999 -9999 -9999 -9999 -9999 -9999 -9999 -9999 -9999 -9999

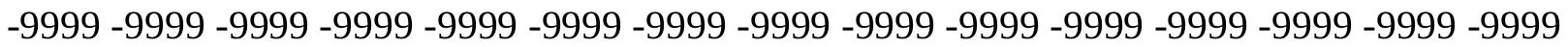

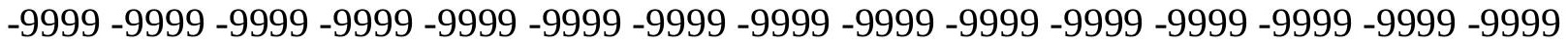
-9999 -9999 -9999 -9999 -9999 -9999 -9999 -9999 -9999 -9999 -9999 -9999 -9999 -9999 -9999 -9999 -9999 -9999 -9999 -9999 -9999 -9999 -9999 -9999 -9999 -9999 -9999 -9999 -9999 -9999 -9999 -9999 -9999 -9999 -9999 -9999 -9999 -9999 -9999 -9999 -9999 -9999 -9999 -9999 -9999 -9999 -9999 -9999 -9999 -9999 -9999 -9999 -9999 -9999 -9999 -9999 -9999 -9999 -9999 -9999 -

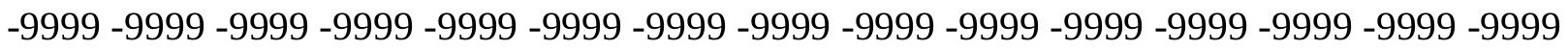
-9999 -9999 -9999 -9999 -9999 -9999 -9999 -9999 -9999 -9999 -9999 -9999 -9999 -9999 -9999 -

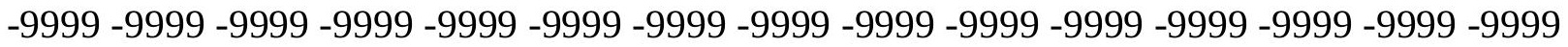
-9999 -9999 -9999 -9999 -9999 -9999 -9999 -9999 -9999 -9999 -9999 -9999 -9999 -9999 -9999 -9999 -9999 -9999 -9999 -9999 -9999 -9999 -9999 -9999 -9999 -9999 -9999 -9999 -9999 -9999 -9999 -9999 -9999 -9999 -9999 -9999 -9999 -9999 -9999 -9999 -9999 -9999 -9999 -9999 - -999 -

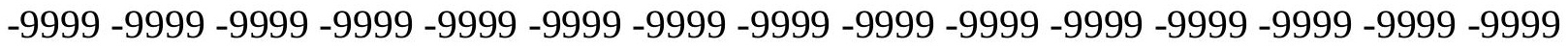

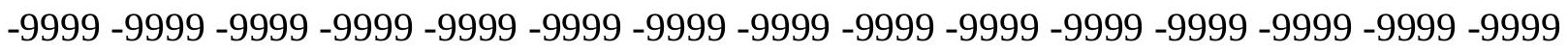
-9999 -9999 -9999 -9999 -9999 -9999 -9999 -9999 -9999 -9999 -9999 -9999 -9999 -9999 -9999 -9999 -9999 -9999 -9999 -9999 -9999 -9999 -9999 -9999 -9999 -9999 -9999 -9999 -9999 -9999 -9999 -9999 -9999 -9999 -9999 -9999 -9999 -9999 -9999 -9999 -9999 -9999 -9999 -9999 -9999 -

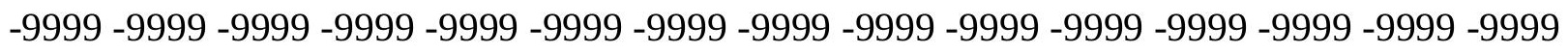
-9999 -9999 -9999 -9999 -9999 -9999 -9999 -9999 -9999 -9999 -9999 -9999 -9999 -9999 -9999 -9999 -9999 -9999 -9999 -9999 -9999 -9999 -9999 -9999 -9999 -9999 -9999 -9999 -9999 -9999 -

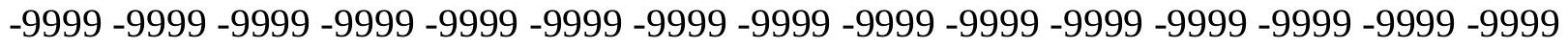
-9999 -9999 -9999 -9999 -9999 -9999 -9999 -9999 -9999 -9999 -9999 -9999 -9999 -9999 -9999 -9999 -9999 -9999 -9999 -9999 -9999 -9999 -9999 -9999 -9999 -9999 -9999 -9999 -9999 -999 -

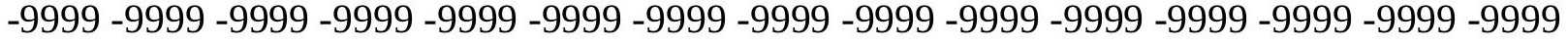
-9999 -9999 -9999 -9999 -9999 -9999 -9999 -9999 -9999 -9999 -9999 -9999 -9999 -9999 -9999 -

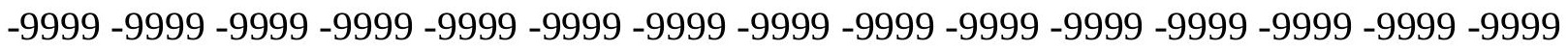

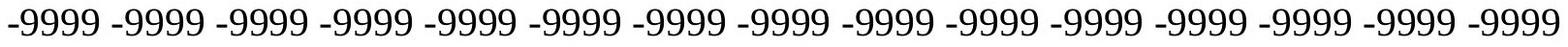

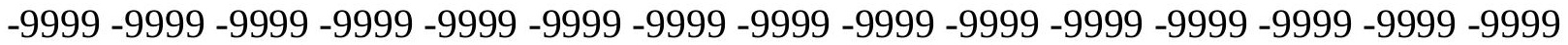

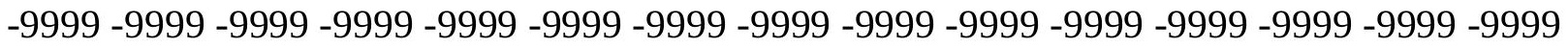

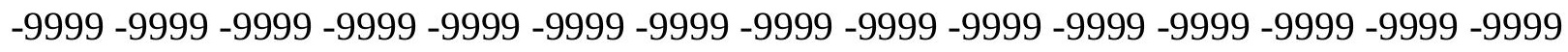

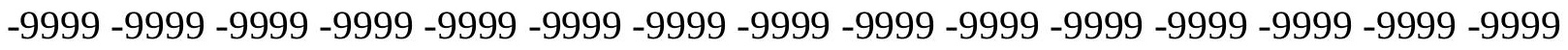

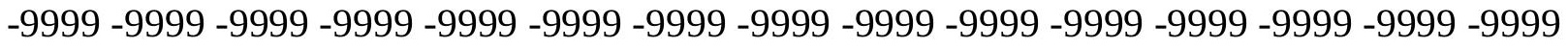
-9999 -9999 -9999 -9999 -9999 -9999 -9999 -9999 -9999 -9999 -9999 -9999 -9999 -9999 -9999 -

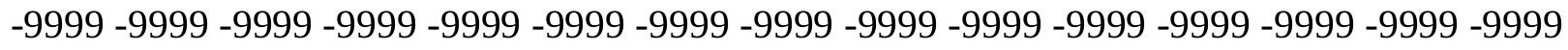

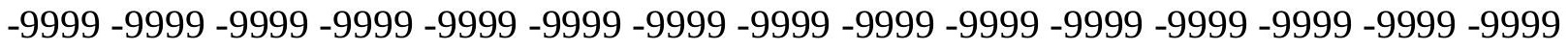
-9999 -9999 -9999 -9999 -9999 -9999 -9999 -9999 -9999 -9999 -9999 -9999 -9999 -9999 -9999 -9999 -9999 -9999 -9999 -9999 -9999 -9999 -9999 -9999 -9999 -9999 -9999 -9999 -9999 -9999 -9999 -9999 -9999 -9999 -9999 -9999 -9999 -9999 -9999 -9999 -9999 -9999 -9999 -9999 -

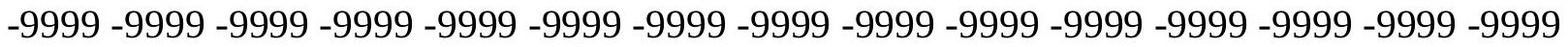


-9999 -9999 -9999 -9999 -9999 -9999 -9999 -9999 -9999 -9999 -9999 -9999 -9999 -9999 -9999 -9999 -9999 -9999 -9999 -9999 -9999 -9999 -9999 -9999 -9999 -9999 -9999 -9999 -9999 -9999 -

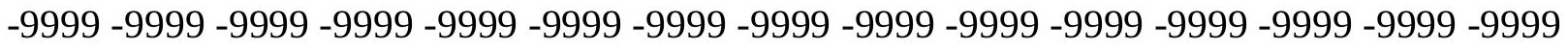
-9999 -9999 -9999 -9999 -9999 -9999 -9999 -9999 -9999 -9999 -9999 -9999 -9999 -9999 -9999 -9999 -9999 -9999 -9999 -9999 -9999 -9999 -9999 -9999-9999 -9999 -9999 -9999 -9999 -9999 -9999 -9999 -9999 -9999 -9999 -9999 -9999 -9999 -9999 -9999 -9999 -9999 -9999 -9999 -9999 -9999 -9999 -9999 -9999 -9999 -9999 -9999 -9999 -9999 -9999 -9999 -9999 -9999 -9999 -9999

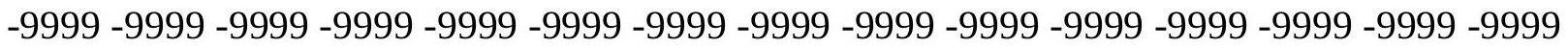

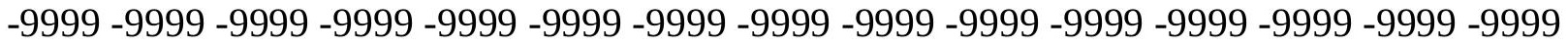
-9999 -9999 -9999 -9999 -9999 -9999 -9999 -9999 -9999 -9999 -9999 -9999 -9999 -9999 -9999 -9999 -9999 -9999 -9999 -9999 -9999 -9999 -9999 -9999 -9999 -9999 -9999 -9999 -9999 -9999 -9999 -9999 -9999 -9999 -9999 -9999 -9999 -9999 -9999 -9999 -9999 -9999 -9999 -9999 -9999 -9999 -9999 -9999 -9999 -9999 -9999 -9999 -9999 -9999 -9999 -9999 -9999 -9999 -9999 -9999 -

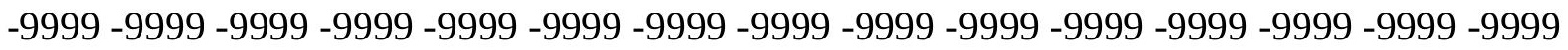
-9999 -9999 -9999 -9999 -9999 -9999 -9999 -9999 -9999 -9999 -9999 -9999 -9999 -9999 -9999 -

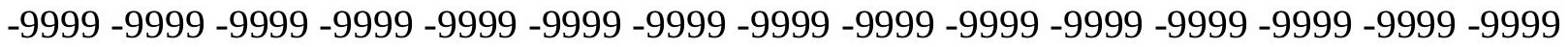
-9999 -9999 -9999 -9999 -9999 -9999 -9999 -9999 -9999 -9999 -9999 -9999 -9999 -9999 -9999 -9999 -9999 -9999 -9999 -9999 -9999 -9999 -9999 -9999 -9999 -9999 -9999 -9999 -9999 - 9999 -9999 -9999 -9999 -9999 -9999 -9999 -9999 -9999 -9999 -9999 -9999 -9999 -9999 -9999 -9999 -

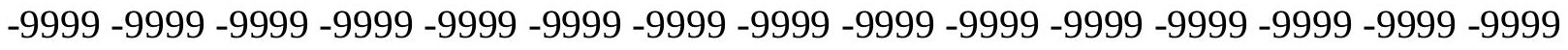

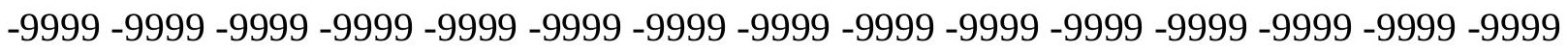
-9999 -9999 -9999 -9999 -9999 -9999 -9999 -9999 -9999 -9999 -9999 -9999 -9999 -9999 - 9999 -9999 -9999 -9999 -9999 -9999 -9999 -9999 -9999 -9999 -9999 -9999 -9999 -9999 -9999 -9999 -9999 -9999 -9999 -9999 -9999 -9999 -9999 -9999 -9999 -9999 -9999 -9999 -9999 -9999 -9999 -9999 -9999 -9999 -9999 -9999 -9999 -9999 -9999 -9999 -9999 -9999 -9999 -9999 -9999 -9999 -9999 -9999 -9999 -9999 -9999 -9999 -9999 -9999 -9999 -9999 -9999 -9999 -9999 -9999 -9999 -9999 -9999 -9999 -9999 -9999 -9999 -9999 -9999 -9999 -9999 -9999 -9999 -9999 -9999 -

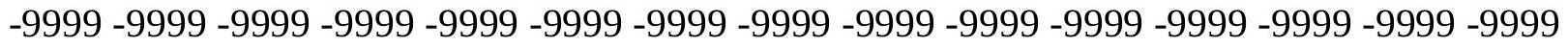
-9999 -9999 -9999 -9999 -9999 -9999 -9999 -9999 -9999 -9999 -9999 -9999 -9999 -9999 -9999 -9999 -9999 -9999 -9999 -9999 -9999 -9999 -9999 -9999 -9999 -9999 -9999 -9999 -9999 -999 -9999 -9999 -9999 -9999 -9999 -9999 -9999 -9999 -9999 -9999 -9999 -9999 -9999 -9999 -9999 -9999 -9999 -9999 -9999 -9999 -9999 -9999 -9999 -9999 -9999 -9999 -9999 -9999 -9999 -9999 -

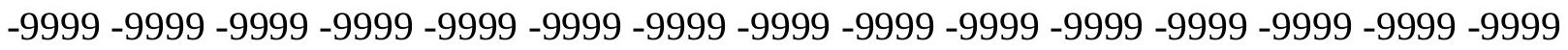

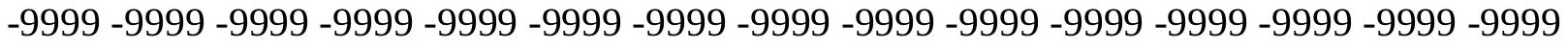

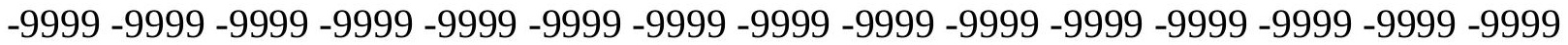

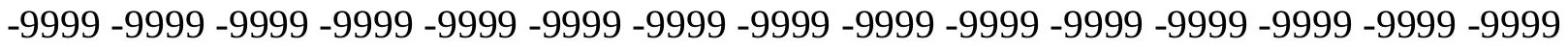

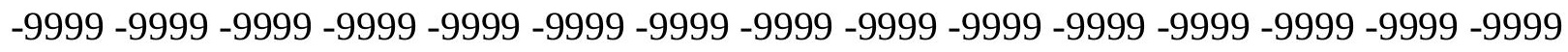

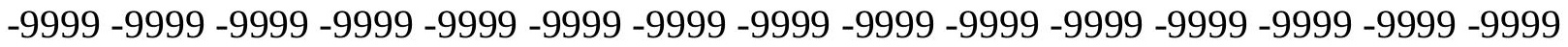

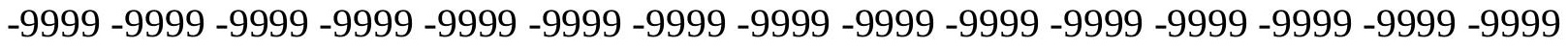
-9999 -9999 -9999 -9999 -9999 -9999 -9999 -9999 -9999 -9999 -9999 -9999 -9999 -9999 -9999 -

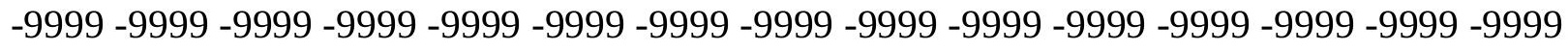

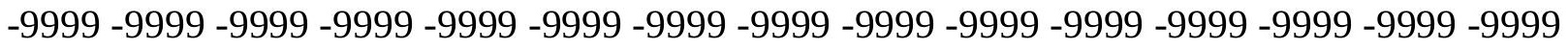
-9999 -9999 -9999 -9999 -9999 -9999 -9999 -9999 -9999 -9999 -9999 -9999 -9999 -9999 -9999 -9999 -9999 -9999 -9999 -9999 -9999 -9999 -9999 -9999-9999 -9999 -9999 -9999 -9999 -9999 -9999 -9999 -9999 -9999 -9999 -9999 -9999 -9999 -9999 -9999 -9999 -9999 -9999 -9999 -9999 -

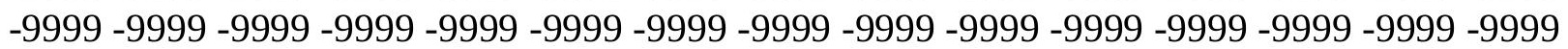


-9999 -9999 -9999 -9999 -9999 -9999 -9999 -9999 -9999 -9999 -9999 -9999 -9999 -9999 -9999 -9999 -9999 -9999 -9999 -9999 -9999 -9999 -9999 -9999 -9999 -9999 -9999 -9999 -9999 -9999 -9999 -9999 -9999 -9999 -9999 -9999 -9999 -9999 -9999 -9999 -9999 -9999 -9999 -9999 - 9999 -9999 -9999 -9999 -9999 -9999 -9999 -9999 -9999 -9999 -9999 -9999 -9999 -9999 -9999 -9999 -9999 -9999 -9999 -9999 -9999 -9999 -9999 -9999 -9999 -9999 -9999 -9999 -9999 -9999 -9999 -9999 -9999 -9999 -9999 -9999 -9999 -9999 -9999 -9999 -9999 -9999 -9999 -9999 -9999 -9999 -9999 -9999 -9999 -9999 -9999 -9999 -9999 -9999 -9999 -9999 -9999 -9999 -9999 -9999

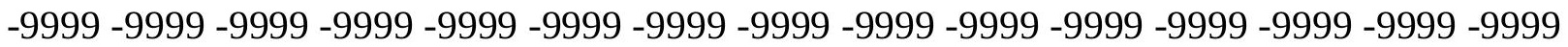

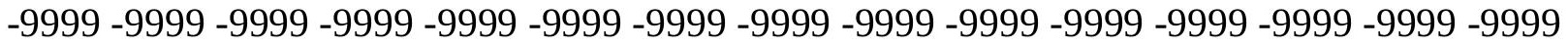
-9999 -9999 -9999 -9999 -9999 -9999 -9999 -9999 -9999 -9999 -9999 -9999 -9999 -9999 -9999 -9999 -9999 -9999 -9999 -9999 -9999 -9999 -9999 -9999 -9999 -9999 -9999 -9999 -9999 -9999 -9999 -9999 -9999 -9999 -9999 -9999 -9999 -9999 -9999 -9999 -9999 -9999 -9999 -9999 -9999 -9999 -9999 -9999 -9999 -9999 -9999 -9999 -9999 -9999 -9999 -9999 -9999 -9999 -9999 -9999 -9999 -9999 -9999 -9999 -9999 -9999 -9999 -9999 -9999 -9999 -9999 -9999 -9999 -9999 -9999 -9999 -9999 -9999 -9999 -9999 -9999 -9999 -9999 -9999 -9999 -9999 -9999 -9999 -9999 -9999 -

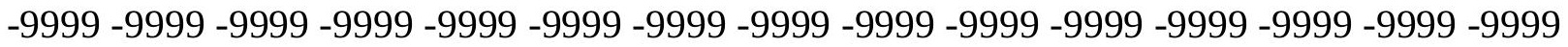
-9999 -9999 -9999 -9999 -9999 -9999 -9999 -9999 -9999 -9999 -9999 -9999 -9999 -9999 -9999 -9999 -9999 -9999 -9999 -9999 -9999 -9999 -9999 -9999 -9999 -9999 -9999 -9999 -9999 - 9999 -9999 -9999 -9999 -9999 -9999 -9999 -9999 -9999 -9999 -9999 -9999 -9999 -9999 -9999 -9999 -

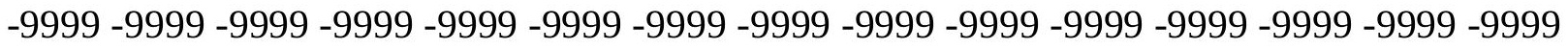

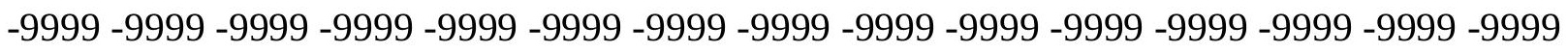

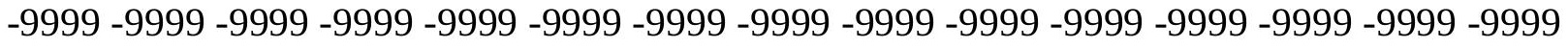
-9999 -9999 -9999 -9999 -9999 -9999 -9999 -9999 -9999 -9999 -9999 -9999 -9999 -9999 -9999 -9999 -9999 -9999 -9999 -9999 -9999 -9999 -9999 -9999 -9999 -9999 -9999 -9999 -9999 -9999 -

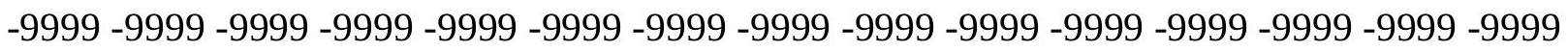
-9999 -9999 -9999 -9999 -9999 -9999 -9999 -9999 -9999 -9999 -9999 -9999 -9999 -9999 -9999 -9999 -9999 -9999 -9999 -9999 -9999 -9999 -9999 -9999 -9999 -9999 -9999 -9999 -9999 -9999 -

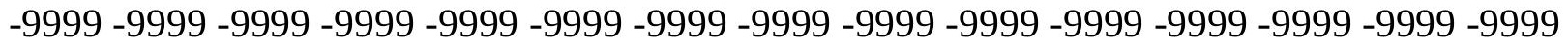
-9999 -9999 -9999 -9999 -9999 -9999 -9999 -9999 -9999 -9999 -9999 -9999 -9999 -9999 -9999 -9999 -9999 -9999 -9999 -9999 -9999 -9999 -9999 -9999 -9999 -9999 -9999 -9999 -9999 -999 -9999 -9999 -9999 -9999 -9999 -9999 -9999 -9999 -9999 -9999 -9999 -9999 -9999 -9999 -9999 -9999 -9999 -9999 -9999 -9999 -9999 -9999 -9999 -9999 -9999 -9999 -9999 -9999 -9999 -

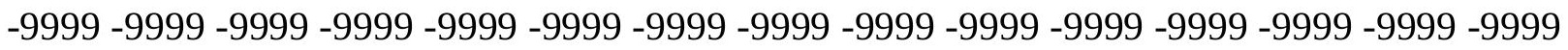

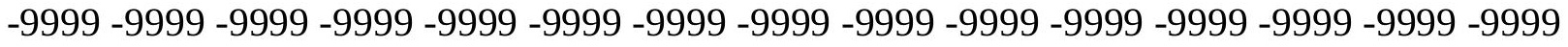

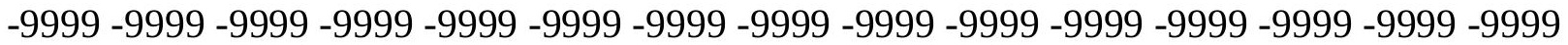

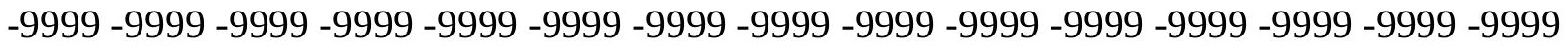

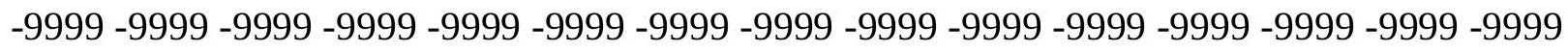

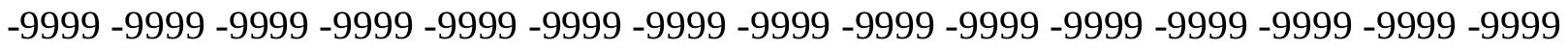

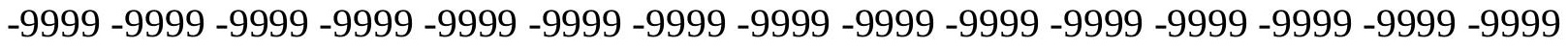
-9999 -9999 -9999 -9999 -9999 -9999 -9999 -9999 -9999 -9999 -9999 -9999 -9999 -9999 -9999 -

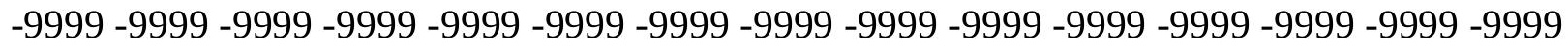

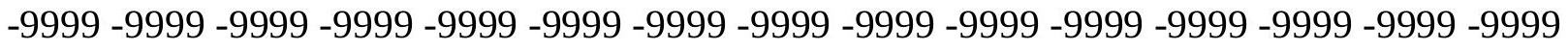
-9999 -9999 -9999 -9999 -9999 -9999 -9999 -9999 -9999 -9999 -9999 -9999 -9999 -9999 -9999 -9999 -9999 -9999 -9999 -9999 -9999 -9999 -9999 -9999-9999 -9999 -9999 -9999 -9999 -9999 -9999 -9999 -9999 -9999 -9999 -9999 -9999 -9999 -9999 -9999 -9999 -9999 -9999 -9999 -9999 -

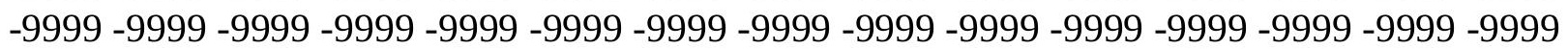


-9999 -9999 -9999 -9999 -9999 -9999 -9999 -9999 -9999 -9999 -9999 -9999 -9999 -9999 -9999 -9999 -9999 -9999 -9999 -9999 -9999 -9999 -9999 -9999 -9999 -9999 -9999 -9999 -9999 -9999 -

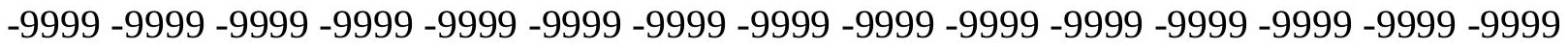
-9999 -9999 -9999 -9999 -9999 -9999 -9999 -9999 -9999 -9999 -9999 -9999 -9999 -9999 -9999 -9999 -9999 -9999 -9999 -9999 -9999 -9999 -9999 -9999-9999 -9999 -9999 -9999 -9999 -9999 -9999 -9999 -9999 -9999 -9999 -9999 -9999 -9999 -9999 -9999 -9999 -9999 -9999 -9999 -9999 -9999 -9999 -9999 -9999 -9999 -9999 -9999 -9999 -9999 -9999 -9999 -9999 -9999 -9999 -9999

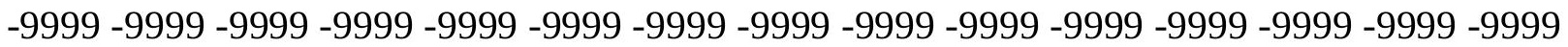

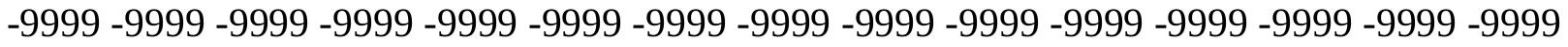

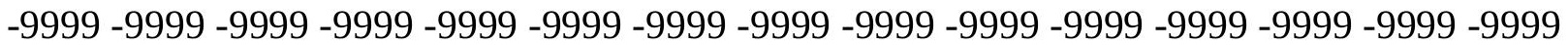
-9999 -9999 -9999 -9999 -9999 -9999 -9999 -9999 -9999 -9999 -9999 -9999 -9999 -9999 -9999 -9999 -9999 -9999 -9999 -9999 -9999 -9999 -9999 -9999 -9999 -9999 -9999 -9999 -9999 -9999 -9999 -9999 -9999 -9999 -9999 -9999 -9999 -9999 -9999 -9999 -9999 -9999 -9999 -9999 -

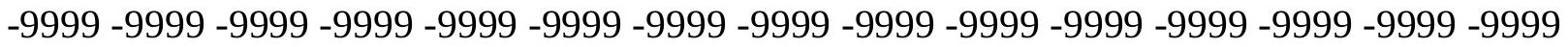
-9999 -9999 -9999 -9999 -9999 -9999 -9999 -9999 -9999 -9999 -9999 -9999 -9999 -9999 -9999 -

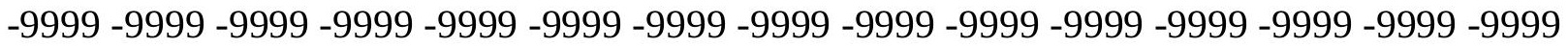
-9999 -9999 -9999 -9999 -9999 -9999 -9999 -9999 -9999 -9999 -9999 -9999 -9999 -9999 -9999 -9999 -9999 -9999 -9999 -9999 -9999 -9999 -9999 -9999 -9999 -9999 -9999 -9999 -9999 -9999 -9999 -9999 -9999 -9999 -9999 -9999 -9999 -9999 -9999 -9999 -9999 -9999 -9999 -9999 -9999 -

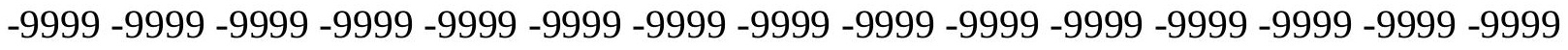

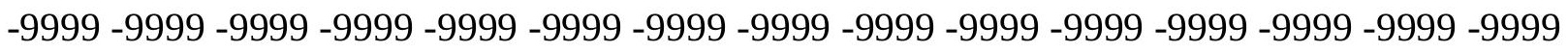
-9999 -9999 -9999 -9999 -9999 -9999 -9999 -9999 -9999 -9999 -9999 -9999 -9999 -9999 -9999 -9999 -9999 -9999 -9999 -9999 -9999 -9999 -9999 -9999 -9999 -9999 -9999 -9999 -9999 -9999 -9999 -9999 -9999 -9999 -9999 -9999 -9999 -9999 -9999 -9999 -9999 -9999 -9999 -9999 -9999 -

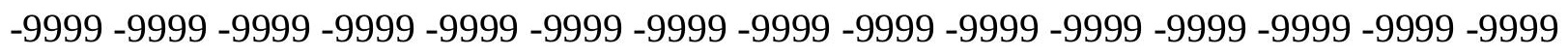
-9999 -9999 -9999 -9999 -9999 -9999 -9999 -9999 -9999 -9999 -9999 -9999 -9999 -9999 -9999 -9999 -9999 -9999 -9999 -9999 -9999 -9999 -9999 -9999 -9999 -9999 -9999 -9999 -9999 -9999 -

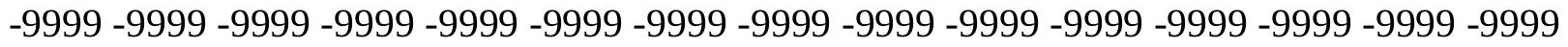
-9999 -9999 -9999 -9999 -9999 -9999 -9999 -9999 -9999 -9999 -9999 -9999 -9999 -9999 -9999 -9999 -9999 -9999 -9999 -9999 -9999 -9999 -9999 -9999 -9999 -9999 -9999 -9999 -9999 -999 -9999 -9999 -9999 -9999 -9999 -9999 -9999 -9999 -9999 -9999 -9999 -9999 -9999 -9999 -9999 -9999 -9999 -9999 -9999 -9999 -9999 -9999 -9999 -9999 -9999 -9999 -9999 -9999 -9999 -9999 -

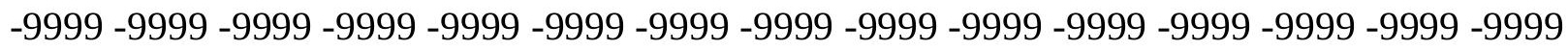

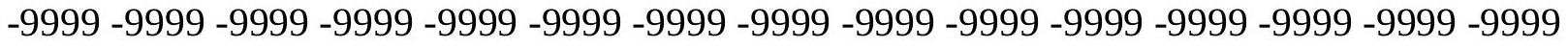

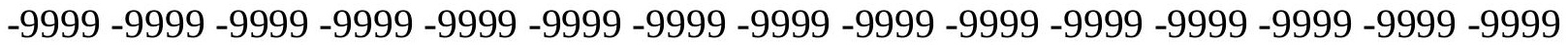
-9999 -9999 -9999 -9999 -9999 -9999 -9999 -9999 -9999 -9999 -9999 -9999 -9999 -9999 -9999 -

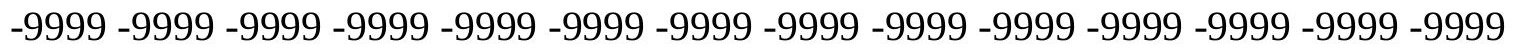

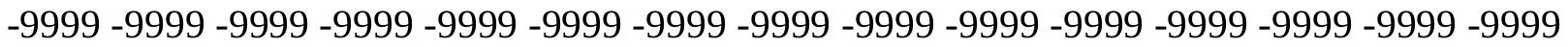
-9999 -9999 -9999 -9999 -9999 -9999 -9999 -9999 -9999 -9999 -9999 -9999 -9999 - 9999 - -999 -9999 -9999 -9999 -9999 -9999 -9999 -9999 -9999 -9999 -9999 -9999 -9999 -9999 -9999 -9999 -

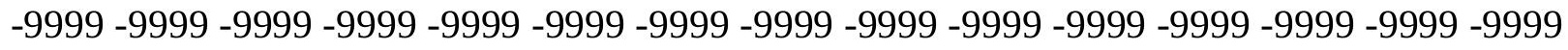

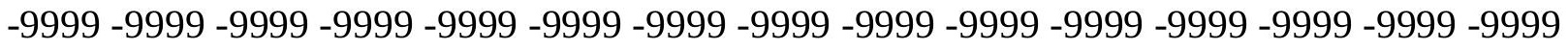
-9999 -9999 -9999 -9999 -9999 -9999 -9999 -9999 -9999 -9999 -9999 -9999 -9999 -9999 -9999 -9999 -9999 -9999 -9999 -9999 -9999 -9999 -9999 -9999-9999 -9999 -9999 -9999 -9999 -9999 -9999 -9999 -9999 -9999 -9999 -9999 -9999 -9999 -9999 -9999 -9999 -9999 -9999 -9999 -9999 -

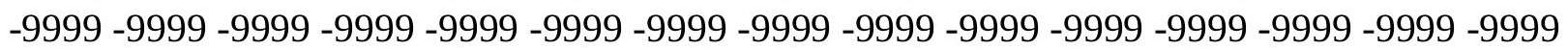


-9999 -9999 -9999 -9999 -9999 -9999 -9999 -9999 -9999 -9999 -9999 -9999 -9999 -9999 -9999 -9999 -9999 -9999 -9999 -9999 -9999 -9999 -9999 -9999 -9999 -9999 -9999 -9999 -9999 -9999 -

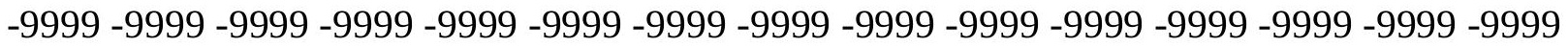
-9999 -9999 -9999 -9999 -9999 -9999 -9999 -9999 -9999 -9999 -9999 -9999 -9999 -9999 -9999 -9999 -9999 -9999 -9999 -9999 -9999 -9999 -9999 -9999-9999 -9999 -9999 -9999 -9999 -9999 -9999 -9999 -9999 -9999 -9999 -9999 -9999 -9999 -9999 -9999 -9999 -9999 -9999 -9999 -9999 -9999 -9999 -9999 -9999 -9999 -9999 -9999 -9999 -9999 -9999 -9999 -9999 -9999 -9999 -9999

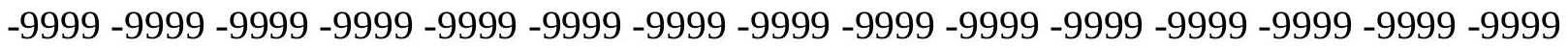

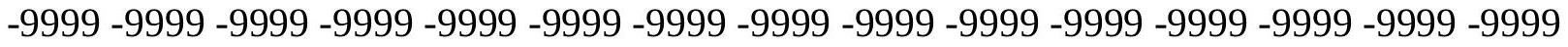
-9999 -9999 -9999 -9999 -9999 -9999 -9999 -9999 -9999 -9999 -9999 -9999 -9999 -9999 -9999 -9999 -9999 -9999 -9999 -9999 -9999 -9999 -9999 -9999 -9999 -9999 -9999 -9999 -9999 -9999 -9999 -9999 -9999 -9999 -9999 -9999 -9999 -9999 -9999 -9999 -9999 -9999 -9999 -9999 -9999 -9999 -9999 -9999 -9999 -9999 -9999 -9999 -9999 -9999 -9999 -9999 -9999 -9999 -9999 -9999 -9999 -9999 -9999 -9999 -9999 -9999 -9999 -9999 -9999 -9999 -9999 -9999 -9999 -9999 -9999 -9999 -9999 -9999 -9999 -9999 -9999 -9999 -9999 -9999 -9999 -9999 -9999 -9999 -9999 -9999 -

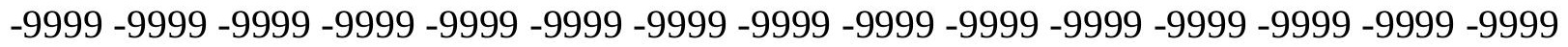
-9999 -9999 -9999 -9999 -9999 -9999 -9999 -9999 -9999 -9999 -9999 -9999 -9999 -9999 -9999 -9999 -9999 -9999 -9999 -9999 -9999 -9999 -9999 -9999 -9999 -9999 -9999 -9999 -9999 -9999 -9999 -9999 -9999 -9999 -9999 -9999 -9999 -9999 -9999 -9999 -9999 -9999 -9999 -9999 -

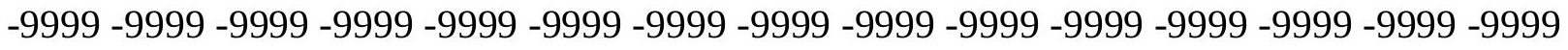
-9999 -9999 -9999 -9999 -9999 -9999 -9999 -9999 -9999 -9999 -9999 -9999 -9999 -9999 -9999 -999 -

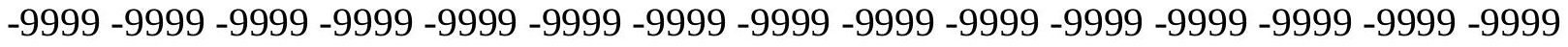
-9999 -9999 -9999 -9999 -9999 -9999 -9999 -9999 -9999 -9999 -9999 -9999 -9999 -9999 -9999 -9999 -9999 -9999 -9999 -9999 -9999 -9999 -9999 -9999 -9999 -9999 -9999 -9999 -9999 -9999 -9999 -9999 -9999 -9999 -9999 -9999 -9999 -9999 -9999 -9999 -9999 -9999 -9999 -9999 -9999 -9999 -9999 -9999 -9999 -9999 -9999 -9999 -9999 -9999 -9999 -9999 -9999 -9999 -9999 -9999 -9999 -9999 -9999 -9999 -9999 -9999 -9999 -9999 -9999 -9999 -9999 -9999 -9999 -9999 -9999 -

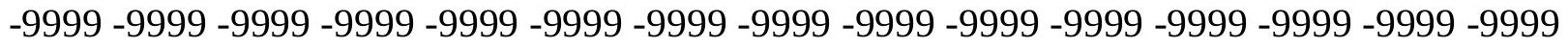
-9999 -9999 -9999 -9999 -9999 -9999 -9999 -9999 -9999 -9999 -9999 -9999 -9999 -9999 -9999 -9999 -9999 -9999 -9999 -9999 -9999 -9999 -9999 -9999 -9999 -9999 -9999 -9999 -9999 -999 -9999 -9999 -9999 -9999 -9999 -9999 -9999 -9999 -9999 -9999 -9999 -9999 -9999 -9999 -9999 -9999 -9999 -9999 -9999 -9999 -9999 -9999 -9999 -9999 -9999 -9999 -9999 -9999 -9999 -9999 -

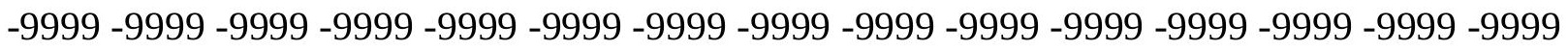

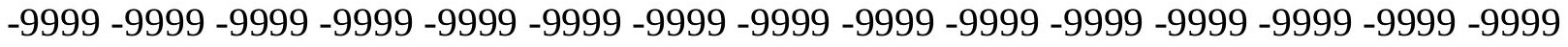

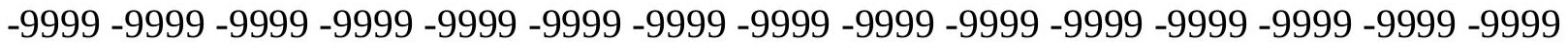
-9999 -9999 -9999 -9999 -9999 -9999 -9999 -9999 -9999 -9999 -9999 -9999 -9999 -9999 -9999

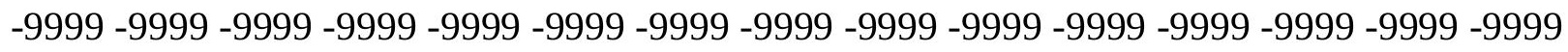

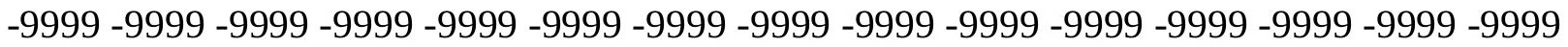
-9999 -9999 -9999 -9999 -9999 -9999 -9999 -9999 -9999 -9999 -9999 -9999 -9999 - 9999 - -999 -9999 -9999 -9999 -9999 -9999 -9999 -9999 -9999 -9999 -9999 -9999 -9999 -9999 -9999 -9999 -

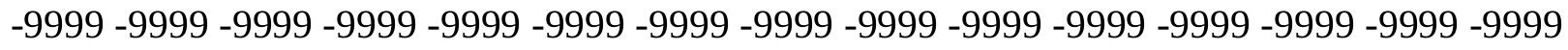

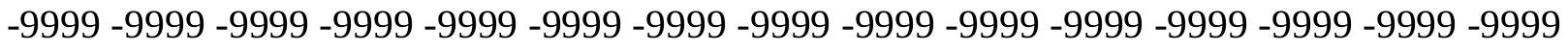
-9999 -9999 -9999 -9999 -9999 -9999 -9999 -9999 -9999 -9999 -9999 -9999 -9999 -9999 -9999 -9999 -9999 -9999 -9999 -9999 -9999 -9999 -9999 -9999 -9999 -9999 -9999 -9999 -9999 -9999 -9999 -9999 -9999 -9999 -9999 -9999 -9999 -9999 -9999 -9999 -9999 -9999 -9999 -9999 -

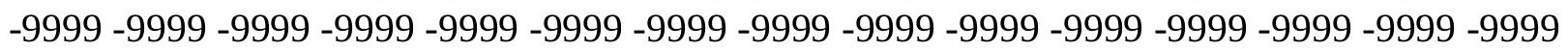


-9999 -9999 -9999 -9999 -9999 -9999 -9999 -9999 -9999 -9999 -9999 -9999 -9999 -9999 -9999 -9999 -9999 -9999 -9999 -9999 -9999 -9999 -9999 -9999 -9999 -9999 -9999 -9999 -9999 -9999 -9999 -9999 -9999 -9999 -9999 -9999 -9999 -9999 -9999 -9999 -9999 -9999 -9999 -9999 - 9999 -9999 -9999 -9999 -9999 -9999 -9999 -9999 -9999 -9999 -9999 -9999 -9999 -9999 -9999 -9999 -9999 -9999 -9999 -9999 -9999 -9999 -9999 -9999 -9999-9999 -9999 -9999 -9999 -9999 -9999 -9999 -9999 -9999 -9999 -9999 -9999 -9999 -9999 -9999 -9999 -9999 -9999 -9999 -9999 -9999 -9999 -9999 -9999 -9999 -9999 -9999 -9999 -9999 -9999 -9999 -9999 -9999 -9999 -9999 -9999

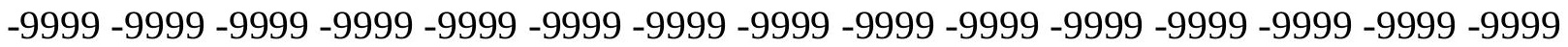

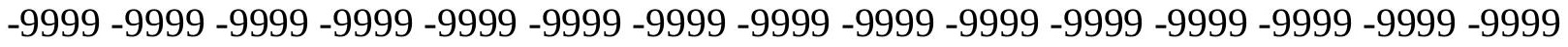
-9999 -9999 -9999 -9999 -9999 -9999 -9999 -9999 -9999 -9999 -9999 -9999 -9999 -9999 -9999 -9999 -9999 -9999 -9999 -9999 -9999 -9999 -9999 -9999 -9999 -9999 -9999 -9999 -9999 -9999 -9999 -9999 -9999 -9999 -9999 -9999 -9999 -9999 -9999 -9999 -9999 -9999 -9999 -9999 -9999 -9999 -9999 -9999 -9999 -9999 -9999 -9999 -9999 -9999 -9999 -9999 -9999 -9999 -9999 -9999 -

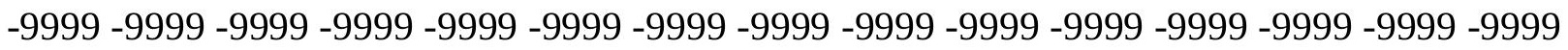
-9999 -9999 -9999 -9999 -9999 -9999 -9999 -9999 -9999 -9999 -9999 -9999 -9999 -9999 -9999 -

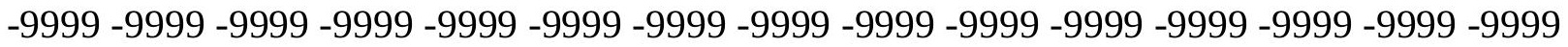
-9999 -9999 -9999 -9999 -9999 -9999 -9999 -9999 -9999 -9999 -9999 -9999 -9999 -9999 -9999 -9999 -9999 -9999 -9999 -9999 -9999 -9999 -9999 -9999 -9999 -9999 -9999 -9999 -9999 -9999 -9999 -9999 -9999 -9999 -9999 -9999 -9999 -9999 -9999 -9999 -9999 -9999 -9999 -9999 -9999 -

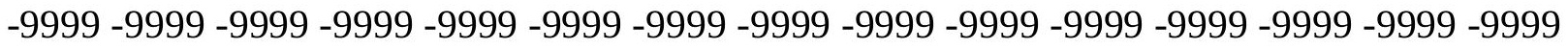
-9999 -9999 -9999 -9999 -9999 -9999 -9999 -9999 -9999 -9999 -9999 -9999 -9999 -9999 -9999 -999 -9999 -9999 -9999 -9999 -9999 -9999 -9999 -9999 -9999 -9999 -9999 -9999 -9999 -9999 - 9999 -9999 -9999 -9999 -9999 -9999 -9999 -9999 -9999 -9999 -9999 -9999 -9999 -9999 -9999 -

-9999 -9999 -9999 -9999 -9999 -9999 -9999 -9999 -9999 -9999 -9999 -9999 -9999 -9999 -9999 -

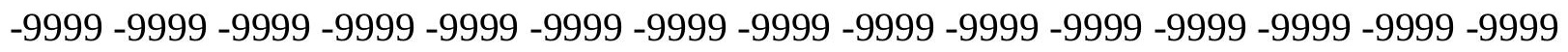
-9999 -9999 -9999 -9999 -9999 -9999 -9999 -9999 -9999 -9999 -9999 -9999 -9999 -9999 -9999 -9999 -9999 -9999 -9999 -9999 -9999 -9999 -9999 -9999 -9999 -9999 -9999 -9999 -9999 -9999 -

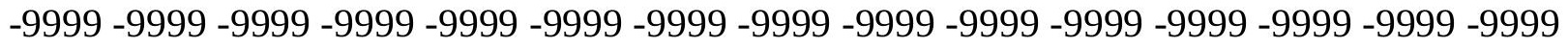
-9999 -9999 -9999 -9999 -9999 -9999 -9999 -9999 -9999 -9999 -9999 -9999 -9999 -9999 -9999 -9999 -9999 -9999 -9999 -9999 -9999 -9999 -9999 -9999 -9999 -9999 -9999 -9999 -9999 -999 -

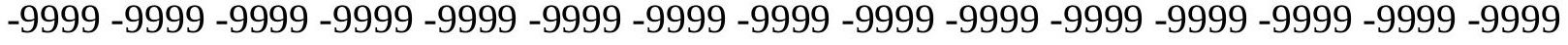
-9999 -9999 -9999 -9999 -9999 -9999 -9999 -9999 -9999 -9999 -9999 -9999 -9999 -9999 -9999 -

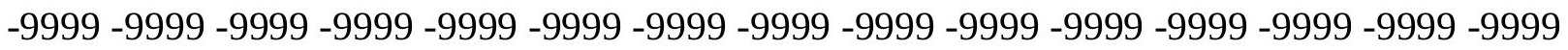

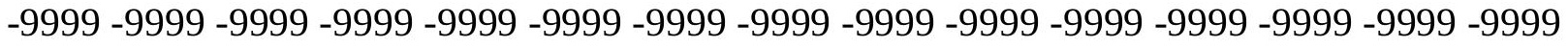

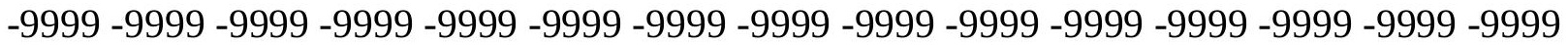

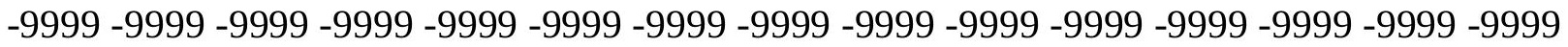

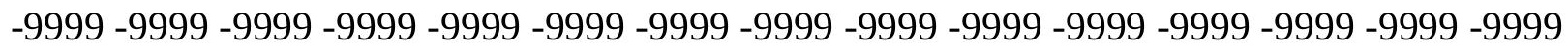

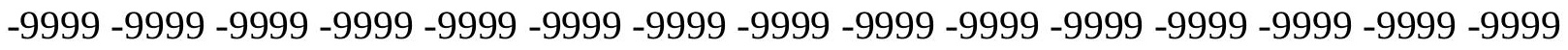

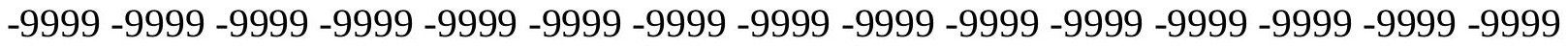
-9999 -9999 -9999 -9999 -9999 -9999 -9999 -9999 -9999 -9999 -9999 -9999 -9999 -9999 -9999 -

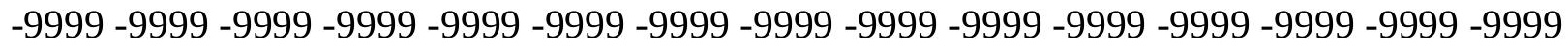

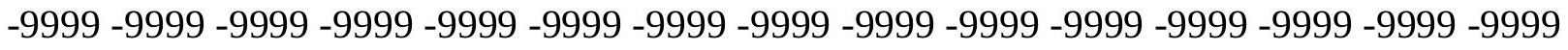
-9999 -9999 -9999 -9999 -9999 -9999 -9999 -9999 -9999 -9999 -9999 -9999 -9999 -9999 -9999 -9999 -9999 -9999 -9999 -9999 -9999 -9999 -9999 -9999-9999 -9999 -9999 -9999 -9999 -9999 -9999 -9999 -9999 -9999 -9999 -9999 -9999 -9999 -9999 -9999 -9999 -9999 -9999 -9999 -9999 -

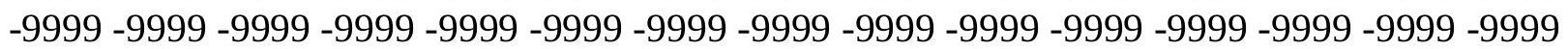


-9999 -9999 -9999 -9999 -9999 -9999 -9999 -9999 -9999 -9999 -9999 -9999 -9999 -9999 -9999 -9999 -9999 -9999 -9999 -9999 -9999 -9999 -9999 -9999 -9999 -9999 -9999 -9999 -9999 -9999 -9999 -9999 -9999 -9999 -9999 -9999 -9999 -9999 -9999 -9999 -9999 -9999 -9999 -9999 -9999 -9999 -9999 -9999 -9999 -9999 -9999 -9999 -9999 -9999 -9999 -9999 -9999 -9999 -9999 -9999 -9999 -9999 -9999 -9999 -9999 -9999 -9999 -9999-9999 -9999 -9999 -9999 -9999 -9999 -9999 -9999 -9999 -9999 -9999 -9999 -9999 -9999 -9999 -9999 -9999 -9999 -9999 -9999 -9999 -9999 -9999 -9999 -9999 -9999 -9999 -9999 -9999 -9999 -9999 -9999 -9999 -9999 -9999 -9999

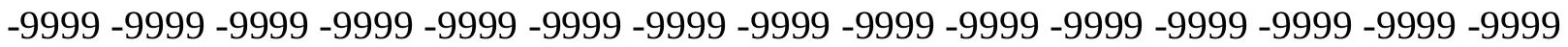

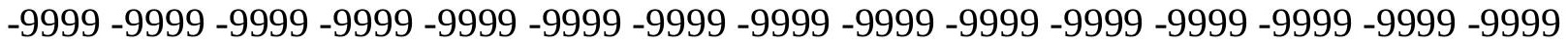
-9999 -9999 -9999 -9999 -9999 -9999 -9999 -9999 -9999 -9999 -9999 -9999 -9999 -9999 -9999 -9999 -9999 -9999 -9999 -9999 -9999 -9999 -9999 -9999 -9999 -9999 -9999 -9999 -9999 -9999 -9999 -9999 -9999 -9999 -9999 -9999 -9999 -9999 -9999 -9999 -9999 -9999 -9999 -9999 -9999 -9999 -9999 -9999 -9999 -9999 -9999 -9999 -9999 -9999 -9999 -9999 -9999 -9999 -9999 -9999 -

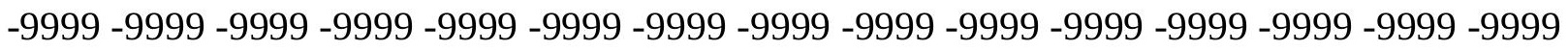
-9999 -9999 -9999 -9999 -9999 -9999 -9999 -9999 -9999 -9999 -9999 -9999 -9999 -9999 -9999 -

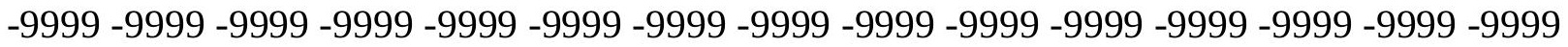
-9999 -9999 -9999 -9999 -9999 -9999 -9999 -9999 -9999 -9999 -9999 -9999 -9999 -9999 -9999 -9999 -9999 -9999 -9999 -9999 -9999 -9999 -9999 -9999 -9999 -9999 -9999 -9999 -9999 -9999 -9999 -9999 -9999 -9999 -9999 -9999 -9999 -9999 -9999 -9999 -9999 -9999 -9999 -9999 -9999 -

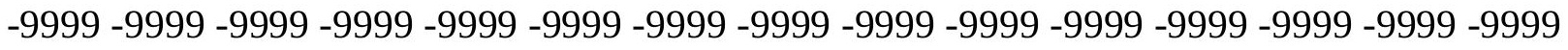

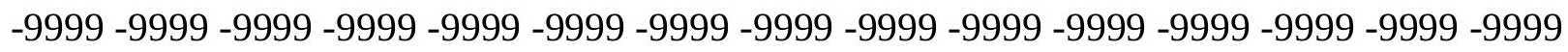
-9999 -9999 -9999 -9999 -9999 -9999 -9999 -9999 -9999 -9999 -9999 -9999 -9999 -9999 -9999 -9999 -9999 -9999 -9999 -9999 -9999 -9999 -9999 -9999 -9999 -9999 -9999 -9999 -9999 -9999 -9999 -9999 -9999 -9999 -9999 -9999 -9999 -9999 -9999 -9999 -9999 -9999 -9999 -9999 -9999 -

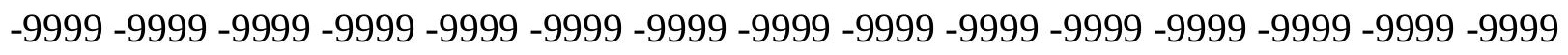
-9999 -9999 -9999 -9999 -9999 -9999 -9999 -9999 -9999 -9999 -9999 -9999 -9999 -9999 -9999 -9999 -9999 -9999 -9999 -9999 -9999 -9999 -9999 -9999 -9999 -9999 -9999 -9999 -9999 -9999 -

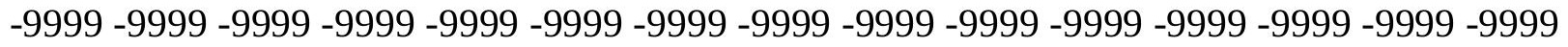
-9999 -9999 -9999 -9999 -9999 -9999 -9999 -9999 -9999 -9999 -9999 -9999 -9999 -9999 -9999 -9999 -9999 -9999 -9999 -9999 -9999 -9999 -9999 -9999 -9999 -9999 -9999 -9999 - -999 -

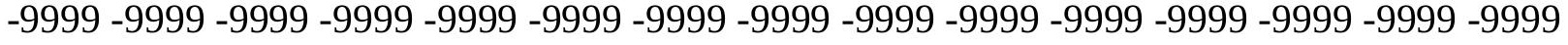
-9999 -9999 -9999 -9999 -9999 -9999 -9999 -9999 -9999 -9999 -9999 -9999 -9999 -9999 -9999 -

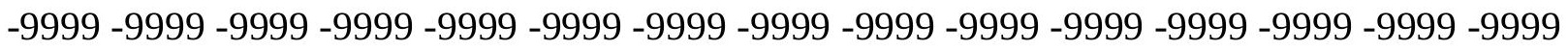

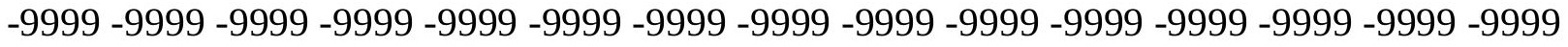

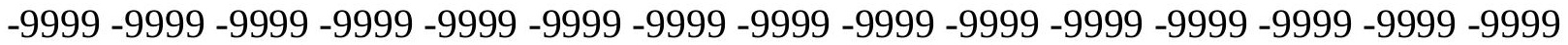

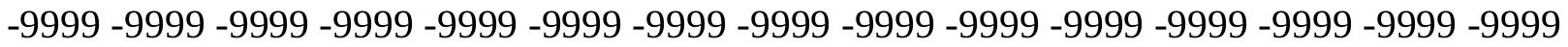

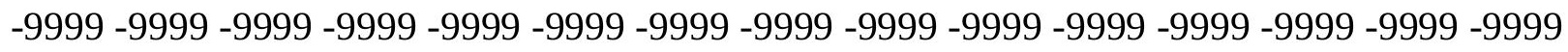

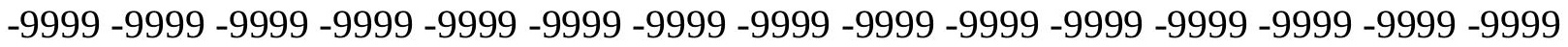

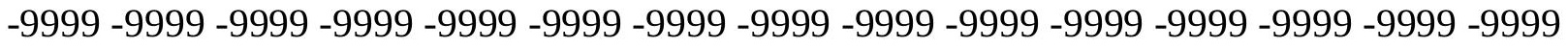
-9999 -9999 -9999 -9999 -9999 -9999 -9999 -9999 -9999 -9999 -9999 -9999 -9999 -9999 -9999 -

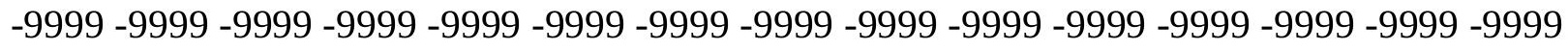

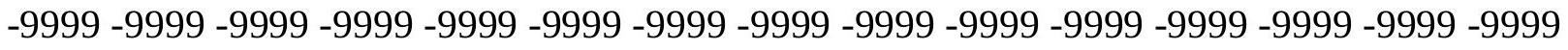
-9999 -9999 -9999 -9999 -9999 -9999 -9999 -9999 -9999 -9999 -9999 -9999 -9999 -9999 -9999 -9999 -9999 -9999 -9999 -9999 -9999 -9999 -9999 -9999-9999 -9999 -9999 -9999 -9999 -9999 -9999 -9999 -9999 -9999 -9999 -9999 -9999 -9999 -9999 -9999 -9999 -9999 -9999 -9999 -9999 -

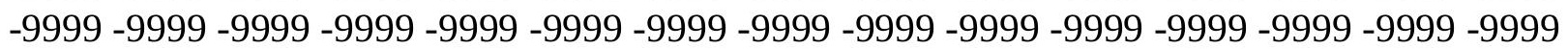


-9999 -9999 -9999 -9999 -9999 -9999 -9999 -9999 -9999 -9999 -9999 -9999 -9999 -9999 -9999 -9999 -9999 -9999 -9999 -9999 -9999 -9999 -9999 -9999 -9999 -9999 -9999 -9999 -9999 -9999 -

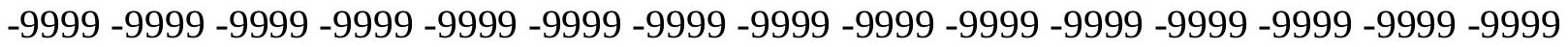
-9999 -9999 -9999 -9999 -9999 -9999 -9999 -9999 -9999 -9999 -9999 -9999 -9999 -9999 -9999 -9999 -9999 -9999 -9999 -9999 -9999 -9999 -9999 -9999-9999 -9999 -9999 -9999 -9999 -9999 -9999 -9999 -9999 -9999 -9999 -9999 -9999 -9999 -9999 -9999 -9999 -9999 -9999 -9999 -9999 -9999 -9999 -9999 -9999 -9999 -9999 -9999 -9999 -9999 -9999 -9999 -9999 -9999 -9999 -9999

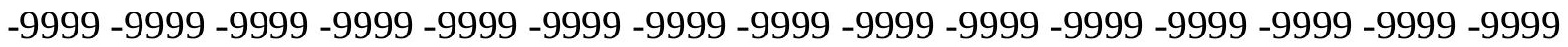
-9999 -9999 -9999 -9999 -9999 -9999 -9999 -9999 -9999 -9999 -9999 -9999 -9999 -9999 -9999 -9999 -9999 -9999 -9999 -9999 -9999 -9999 -9999 -9999 -9999 -9999 -9999 -9999 -9999

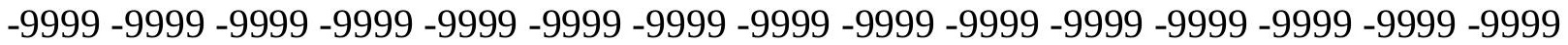
-9999 -9999 -9999 -9999 -9999 -9999 -9999 -9999 -9999 -9999 -9999 -9999 -9999 -9999 -9999 -9999 -9999 -9999 -9999 -9999 -9999 -9999 -9999 -9999 -9999 -9999 -9999 -9999 -9999 -9999 -9999 -9999 -9999 -9999 -9999 -9999 -9999 -9999 -9999 -9999 -9999 -9999 -9999 -9999 - 9999 -9999 -9999 -9999 -9999 -9999 -9999 -9999 -9999 -9999 -9999 -9999 -9999 -9999 -9999 -9999

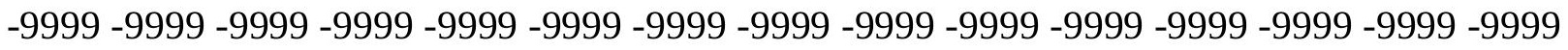
-9999 -9999 -9999 -9999 -9999 -9999 -9999 -9999 -9999 -9999 -9999 -9999 -9999 -9999 -9999 -9999 -9999 -9999 -9999 -9999 -9999 -9999 -9999 -9999 -9999 -9999 -9999 -9999 -9999 -9999 -9999 -9999 -9999 -9999 -9999 -9999 -9999 -9999 -9999 -9999 -9999 -9999 -9999 -9999 -9999 -

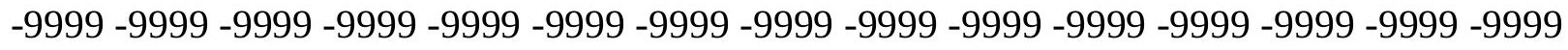

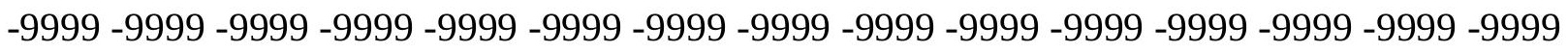
-9999 -9999 -9999 -9999 -9999 -9999 -9999 -9999 -9999 -9999 -9999 -9999 -9999 -9999 -9999 -9999 -9999 -9999 -9999 -9999 -9999 -9999 -9999 -9999 -9999 -9999 -9999 -9999 -9999 -9999 -9999 -9999 -9999 -9999 -9999 -9999 -9999 -9999 -9999 -9999 -9999 -9999 -9999 -9999 -9999 -

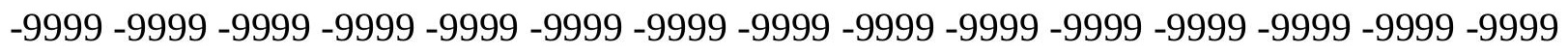
-9999 -9999 -9999 -9999 -9999 -9999 -9999 -9999 -9999 -9999 -9999 -9999 -9999 -9999 -9999 -9999 -9999 -9999 -9999 -9999 -9999 -9999 -9999 -9999 -9999 -9999 -9999 -9999 -9999 -9999 -

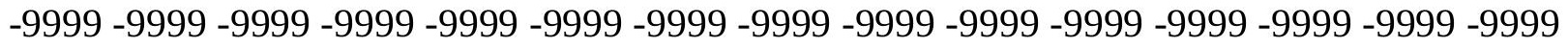
-9999 -9999 -9999 -9999 -9999 -9999 -9999 -9999 -9999 -9999 -9999 -9999 -9999 -9999 -9999 -9999 -9999 -9999 -9999 -9999 -9999 -9999 -9999 -9999 -9999 -9999 -9999 -9999 -9999 -999 -9999 -9999 -9999 -9999 -9999 -9999 -9999 -9999 -9999 -9999 -9999 -9999 -9999 -9999 -9999 -9999 -9999 -9999 -9999 -9999 -9999 -9999 -9999 -9999 -9999 -9999 -9999 -9999 -9999 -9999 -

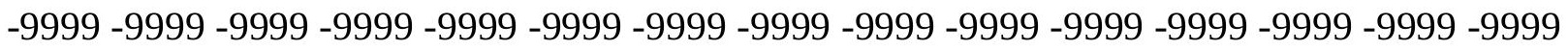

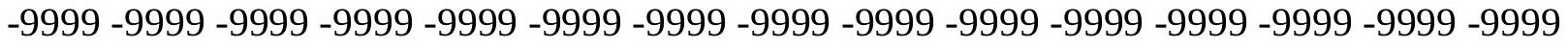
-9999 -9999 -9999 -9999 -9999 -9999 -9999 -9999 -9999 -9999 -9999 -9999 -9999 -9999 -

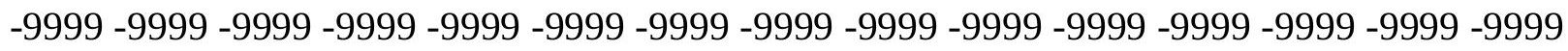

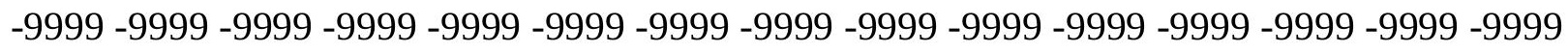

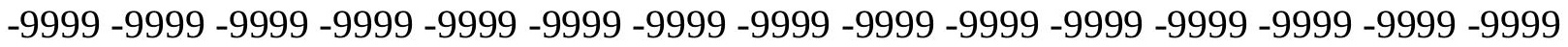
-9999 -9999 -9999 -9999 -9999 -9999 -9999 -9999 -9999 -9999 -9999 -9999 -9999 - 9999 - -999 -9999 -9999 -9999 -9999 -9999 -9999 -9999 -9999 -9999 -9999 -9999 -9999 -9999 -9999 -9999 -

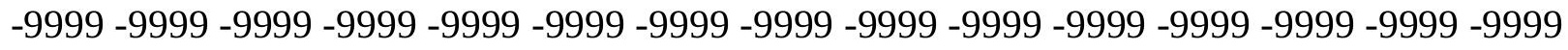

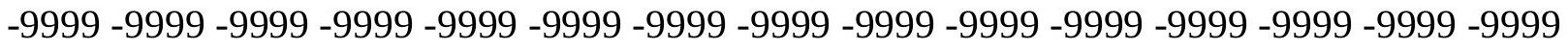
-9999 -9999 -9999 -9999 -9999 -9999 -9999 -9999 -9999 -9999 -9999 -9999 -9999 -9999 -9999 -9999 -9999 -9999 -9999 -9999 -9999 -9999 -9999 -9999-9999 -9999 -9999 -9999 -9999 -9999 -9999 -9999 -9999 -9999 -9999 -9999 -9999 -9999 -9999 -9999 -9999 -9999 -9999 -9999 -9999 -

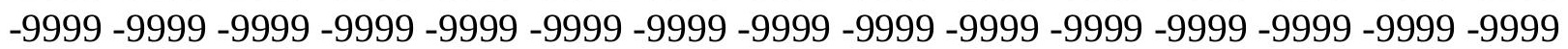


-9999 -9999 -9999 -9999 -9999 -9999 -9999 -9999 -9999 -9999 -9999 -9999 -9999 -9999 -9999 -9999 -9999 -9999 -9999 -9999 -9999 -9999 -9999 -9999 -9999 -9999 -9999 -9999 -9999 -9999 -

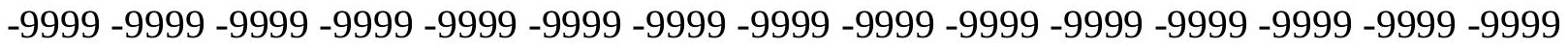
-9999 -9999 -9999 -9999 -9999 -9999 -9999 -9999 -9999 -9999 -9999 -9999 -9999 -9999 -9999 -9999 -9999 -9999 -9999 -9999 -9999 -9999 -9999 -9999-9999 -9999 -9999 -9999 -9999 -9999 -9999 -9999 -9999 -9999 -9999 -9999 -9999 -9999 -9999 -9999 -9999 -9999 -9999 -9999 -9999 -9999 -9999 -9999 -9999 -9999 -9999 -9999 -9999 -9999 -9999 -9999 -9999 -9999 -9999 -9999

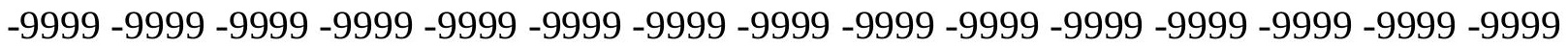

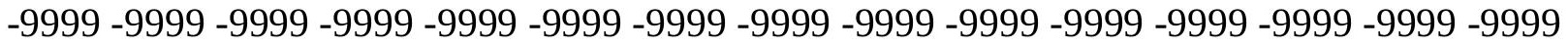
-9999 -9999 -9999 -9999 -9999 -9999 -9999 -9999 -9999 -9999 -9999 -9999 -9999 -9999 -9999 -9999 -9999 -9999 -9999 -9999 -9999 -9999 -9999 -9999 -9999 -9999 -9999 -9999 -9999 -9999 -9999 -9999 -9999 -9999 -9999 -9999 -9999 -9999 -9999 -9999 -9999 -9999 -9999 -9999 -9999 -9999 -9999 -9999 -9999 -9999 -9999 -9999 -9999 -9999 -9999 -9999 -9999 -9999 -9999 -9999 -9999 -9999 -9999 -9999 -9999 -9999 -9999 -9999 -9999 -9999 -9999 -9999 -9999 -9999 -9999 -9999 -9999 -9999 -9999 -9999 -9999 -9999 -9999 -9999 -9999 -9999 -9999 -9999 -9999 -9999 -9999 -9999 -9999 -9999 -9999 -9999 -9999 -9999 -9999 -9999 -9999 -9999 - 9999 - -999 -

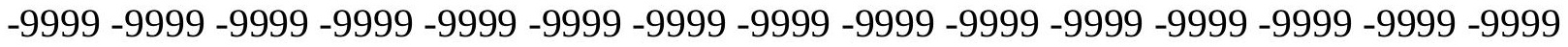
-9999 -9999 -9999 -9999 -9999 -9999 -9999 -9999 -9999 -9999 -9999 -9999 -9999 -9999 -9999 -9999 -9999 -9999 -9999 -9999 -9999 -9999 -9999 -9999 -9999 -9999 -9999 -9999 -9999 -9999 -

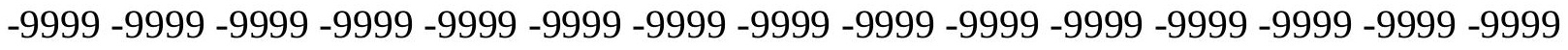
-9999 -9999 -9999 -9999 -9999 -9999 -9999 -9999 -9999 -9999 -9999 -9999 -9999 -9999 -9999

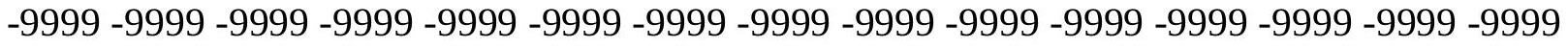
-9999 -9999 -9999 -9999 -9999 -9999 -9999 -9999 -9999 -9999 -9999 -9999 -9999 -9999 -9999 -9999 -9999 -9999 -9999 -9999 -9999 -9999 -9999 -9999 -9999 -9999 -9999 -9999 -9999 -9999 -

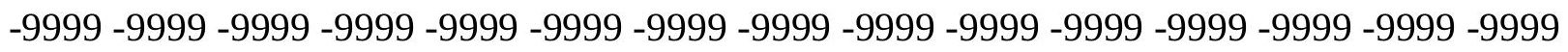
-9999 -9999 -9999 -9999 -9999 -9999 -9999 -9999 -9999 -9999 -9999 -9999 -9999 -9999 -9999 -9999 -9999 -9999 -9999 -9999 -9999 -9999 -9999 -9999 -9999 -9999 -9999 -9999 -9999 -9999 -

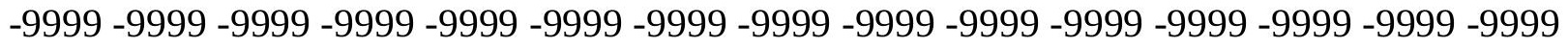
-9999 -9999 -9999 -9999 -9999 -9999 -9999 -9999 -9999 -9999 -9999 -9999 -9999 -9999 -9999 -9999 -9999 -9999 -9999 -9999 -9999 -9999 -9999 -9999 -9999 -9999 -9999 -9999 -9999 -999 -

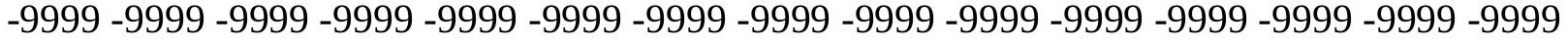
-9999 -9999 -9999 -9999 -9999 -9999 -9999 -9999 -9999 -9999 -9999 -9999 -9999 -9999 -9999 -

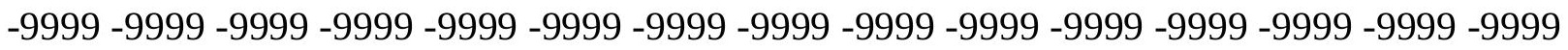

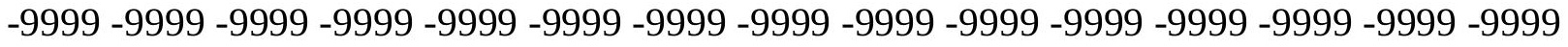

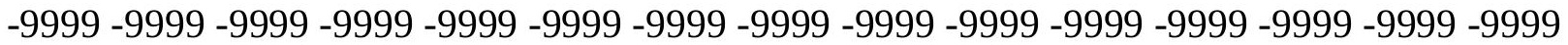
-9999 -9999 -9999 -9999 -9999 -9999 -9999 -9999 -9999 -9999 -9999 -9999 -9999 -9999 -9999 -

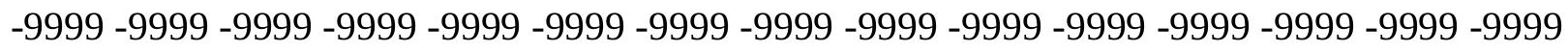

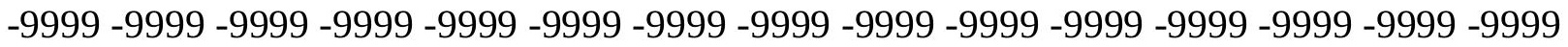
-9999 -9999 -9999 -9999 -9999 -9999 -9999 -9999 -9999 -9999 -9999 -9999 -9999 - 9999 - -999 -9999 -9999 -9999 -9999 -9999 -9999 -9999 -9999 -9999 -9999 -9999 -9999 -9999 -9999 -9999 -

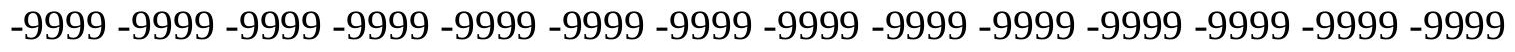

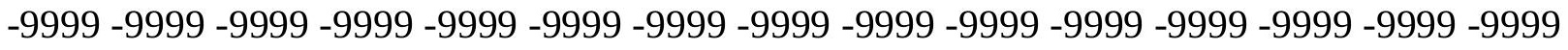
-9999 -9999 -9999 -9999 -9999 -9999 -9999 -9999 -9999 -9999 -9999 -9999 -9999 -9999 -9999 -9999 -9999 -9999 -9999 -9999 -9999 -9999 -9999 -9999-9999 -9999 -9999 -9999 -9999 -9999 -9999 -9999 -9999 -9999 -9999 -9999 -9999 -9999 -9999 -9999 -9999 -9999 -9999 -9999 -9999 -

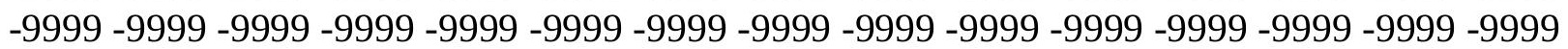


-9999 -9999 -9999 -9999 -9999 -9999 -9999 -9999 -9999 -9999 -9999 -9999 -9999 -9999 -9999 -9999 -9999 -9999 -9999 -9999 -9999 -9999 -9999 -9999 -9999 -9999 -9999 -9999 -9999 -9999 -9999 -9999 -9999 -9999 -9999 -9999 -9999 -9999 -9999 -9999 -9999 -9999 -9999 -9999 - 9999 -9999 -9999 -9999 -9999 -9999 -9999 -9999 -9999 -9999 -9999 -9999 -9999 -9999 -9999 -9999 -9999 -9999 -9999 -9999 -9999 -9999 -9999 -9999 -9999-9999 -9999 -9999 -9999 -9999 -9999 -9999 -9999 -9999 -9999 -9999 -9999 -9999 -9999 -9999 -9999 -9999 -9999 -9999 -9999 -9999 -9999 -9999 -9999 -9999 -9999 -9999 -9999 -9999 -9999 -9999 -9999 -9999 -9999 -9999 -9999

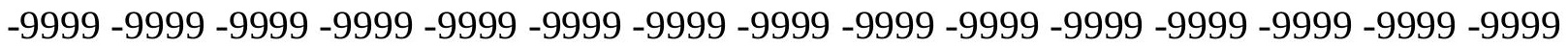
-9999 -9999 -9999 -9999 -9999 -9999 -9999 -9999 -9999 -9999 -9999 -9999 -9999 -9999 -9999 -9999 -9999 -9999 -9999 -9999 -9999 -9999 -9999 -9999 -9999 -9999 -9999 -9999 -9999 -9999

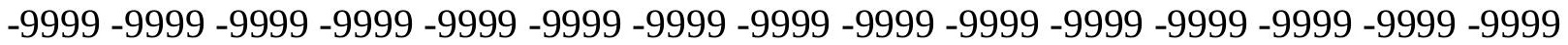
-9999 -9999 -9999 -9999 -9999 -9999 -9999 -9999 -9999 -9999 -9999 -9999 -9999 -9999 -9999 -9999 -9999 -9999 -9999 -9999 -9999 -9999 -9999 -9999 -9999 -9999 -9999 -9999 -9999 -9999 -

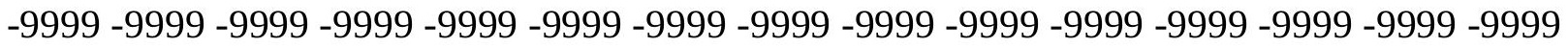
-9999 -9999 -9999 -9999 -9999 -9999 -9999 -9999 -9999 -9999 -9999 -9999 -9999 -9999 -9999

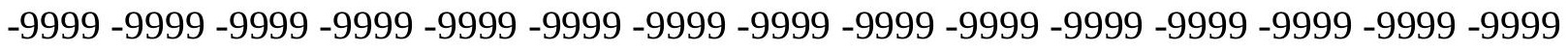
-9999 -9999 -9999 -9999 -9999 -9999 -9999 -9999 -9999 -9999 -9999 -9999 -9999 -9999 -9999 -9999 -9999 -9999 -9999 -9999 -9999 -9999 -9999 -9999 -9999 -9999 -9999 -9999 -9999 - 9999 -9999 -9999 -9999 -9999 -9999 -9999 -9999 -9999 -9999 -9999 -9999 -9999 -9999 -9999 -9999 -9999 -9999 -9999 -9999 -9999 -9999 -9999 -9999 -9999 -9999 -9999 -9999 -9999 -9999 -9999 -9999 -9999 -9999 -9999 -9999 -9999 -9999 -9999 -9999 -9999 -9999 -9999 -9999 -9999 -9999 -9999 -9999 -9999 -9999 -9999 -9999 -9999 -9999 -9999 -9999 -9999 -9999 -9999 -9999 -9999 -9999 -9999 -9999 -9999 -9999 -9999 -9999 -9999 -9999 -9999 -9999 -9999 -9999 -9999 -9999 -9999 -9999 -9999 -9999 -9999 -9999 -9999 -9999 -9999 -9999 -9999 -9999 -9999 -9999 -9999 -9999 -9999 -9999 -9999 -9999 -9999 -9999 -9999 -9999 -9999 -9999 -9999 -9999 -9999 -9999 -9999 -9999 -9999 -9999 -9999 -9999 -9999 -9999 -9999 -9999 -9999 -9999 -9999 -9999 -9999 -9999 -9999 -9999 -9999 -9999 -9999 -9999 -9999 -9999 -9999 -9999 -9999 -9999 -9999 -9999 -9999 -9999 -9999 -9999 -9999 -9999 -9999 -9999 -9999 -9999 -9999 -9999 -9999 -9999 -9999 -9999 -9999 -9999 -9999 -9999 -9999 -9999 -9999 -9999 -9999 -9999 -9999 -9999 -9999 -9999 -9999 -9999 -9999 -9999 -9999 -9999 -9999 -9999 -9999 -9999 -9999 -9999 -9999 -999 -9999 -9999 -9999 -9999 -9999 -9999 -9999 -9999 -9999 -9999 -9999 -9999 -9999 -9999 -9999 -9999 -9999 -9999 -9999 -9999 -9999 -9999 -9999 -9999 -9999 -9999 -9999 -9999 -9999 -9999 -

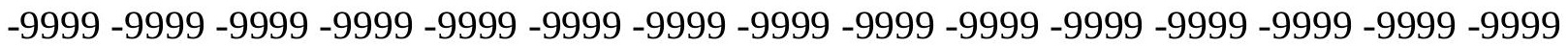

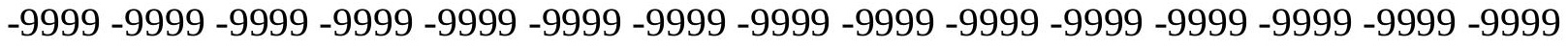

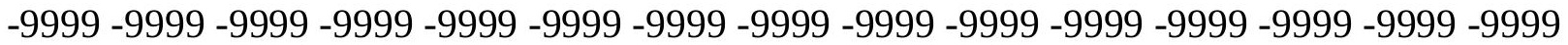
-9999 -9999 -9999 -9999 -9999 -9999 -9999 -9999 -9999 -9999 -9999 -9999 -9999 -9999 -9999

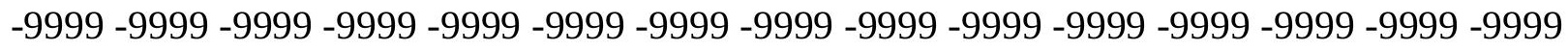

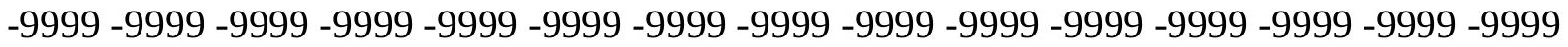

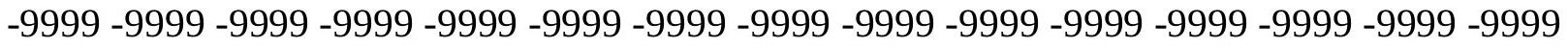
-9999 -9999 -9999 -9999 -9999 -9999 -9999 -9999 -9999 -9999 -9999 -9999 -9999 -9999 -9999 -

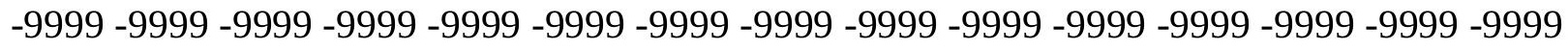

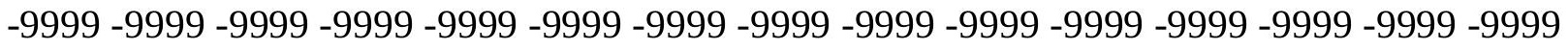
-9999 -9999 -9999 -9999 -9999 -9999 -9999 -9999 -9999 -9999 -9999 -9999 -9999 -9999 -9999 -9999 -9999 -9999 -9999 -9999 -9999 -9999 -9999 -9999-9999 -9999 -9999 -9999 -9999 -9999 -9999 -9999 -9999 -9999 -9999 -9999 -9999 -9999 -9999 -9999 -9999 -9999 -9999 -9999 -9999 -

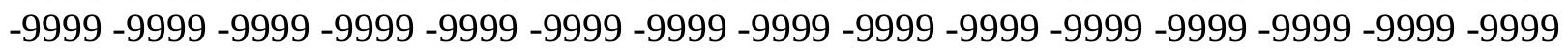


-9999 -9999 -9999 -9999 -9999 -9999 -9999 -9999 -9999 -9999 -9999 -9999 -9999 -9999 -9999 -9999 -9999 -9999 -9999 -9999 -9999 -9999 -9999 -9999 -9999 -9999 -9999 -9999 -9999 -9999 -9999 -9999 -9999 -9999 -9999 -9999 -9999 -9999 -9999 -9999 -9999 -9999 -9999 -9999 -9999 -9999 -9999 -9999 -9999 -9999 -9999 -9999 -9999 -9999 -9999 -9999 -9999 -9999 -9999 -9999 -9999 -9999 -9999 -9999 -9999 -9999 -9999 -9999 -9999 -9999 -9999 -9999 -9999 -9999 -9999 -9999 -9999 -9999 -9999 -9999 -9999 -9999 -9999 -9999 -9999 -9999 -9999 -9999 -9999 -9999 -9999 -9999 -9999 -9999 -9999 -9999 -9999 -9999 -9999 -9999 -9999 -9999 -9999 -9999 -

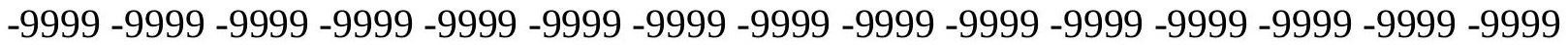
-9999 -9999 -9999 -9999 -9999 -9999 -9999 -9999 -9999 -9999 -9999 -9999 -9999 -9999 -9999 -9999 -9999 -9999 -9999 -9999 -9999 -9999 -9999 -9999 -9999 -9999 -9999 -9999 -9999 -9999 -

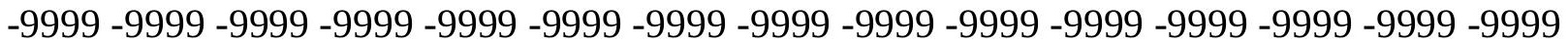
-9999 -9999 -9999 -9999 -9999 -9999 -9999 -9999 -9999 -9999 -9999 -9999 -9999 -9999 -9999 -9999 -9999 -9999 -9999 -9999 -9999 -9999 -9999 -9999 -9999 -9999 -9999 -9999 -9999 -9999 -9999 -9999 -9999 -9999 -9999 -9999 -9999 -9999 -9999 -9999 -9999 -9999 -9999 -9999 -9999 -9999 -9999 -9999 -9999 -9999 -9999 -9999 -9999 -9999 -9999 -9999 -9999 -9999 -9999 -9999 -9999 -9999 -9999 -9999 -9999 -9999 -9999 -9999 -9999 -9999 -9999 -9999 -9999 -9999 -9999 -9999 -9999 -9999 -9999 -9999 -9999 -9999 -9999 -9999 -9999 -9999 -9999 -9999 -9999 -9999 -9999 -9999 -9999 -9999 -9999 -9999 -9999 -9999 -9999 -9999 -9999 -9999 -9999 -9999 -9999 -9999 -9999 -9999 -9999 -9999 -9999 -9999 -9999 -9999 -9999 -9999 -9999 -9999 -9999 -9999 -9999 -9999 -9999 -9999 -9999 -9999 -9999 -9999 -9999 -9999 -9999 -9999 -9999 -9999 -9999

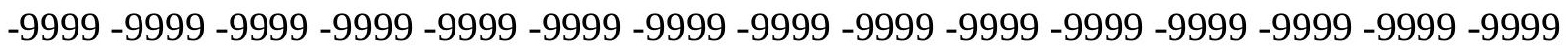
-9999 -9999 -9999 -9999 -9999 -9999 -9999 -9999 -9999 -9999 -9999 -9999 -9999 -9999 -9999 -9999 -9999 -9999 -9999 -9999 -9999 -9999 -9999 -9999 -9999 -9999 -9999 -9999 -9999 -9999 -9999 -9999 -9999 -9999 -9999 -9999 -9999 -9999 -9999 -9999 -9999 -9999 -9999 -9999 -9999

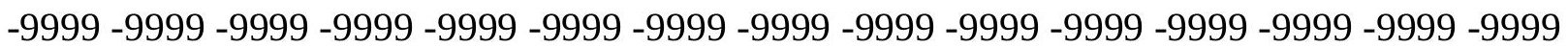
-9999 -9999 -9999 -9999 -9999 -9999 -9999 -9999 -9999 -9999 -9999 -9999 -9999 -9999 -9999 -9999 -9999 -9999 -9999 -9999 -9999 -9999 -9999 -9999 -9999 -9999 -9999 -9999 -9999 -9999 -9999 -9999 -9999 -9999 -9999 -9999 -9999 -9999 -9999 -9999 -9999 -9999 -9999 -9999

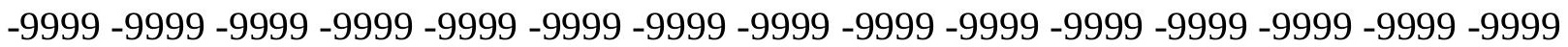
-9999 -9999 -9999 -9999 -9999 -9999 -9999 -9999 -9999 -9999 -9999 -9999 -9999 -9999 -9999 -9999 -9999 -9999 -9999 -9999 -9999 -9999 -9999 -9999 -9999 -9999 -9999 -9999 -9999 -9999 -

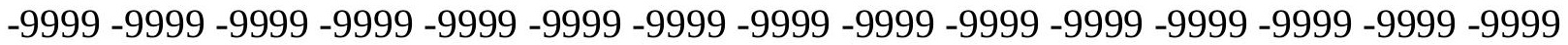
-9999 -9999 -9999 -9999 -9999 -9999 -9999 -9999 -9999 -9999 -9999 -9999 -9999 -9999 -9999 -9999 -9999 -9999 -9999 -9999 -9999 -9999 -9999 -9999 -9999 -9999 -9999 -9999 -9999 -9999 -9999 -9999 -9999 -9999 -9999 -9999 -9999 -9999 -9999 -9999 -9999 -9999 -9999 -9999 -9999 -9999 -9999 -9999 -9999 -9999 -9999 -9999 -9999 -9999 -9999 -9999 -9999 -9999 -9999 -9999 -9999 -9999 -9999 -9999 -9999 -9999 -9999 -9999 -9999 -9999 -9999 -9999 -9999 -9999 -9999

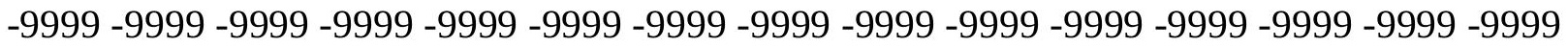
-9999 -9999 -9999 -9999 -9999 -9999 -9999 -9999 -9999 -9999 -9999 -9999 -9999 -9999 -9999 -9999 -9999 -9999 -9999 -9999 -9999 -9999 -9999 -9999 -9999 -9999 -9999 -9999 -9999 -9999 -

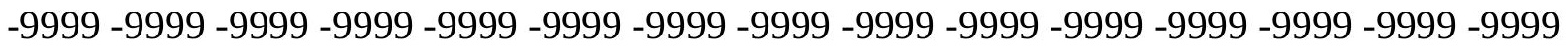
-9999 -9999 -9999 -9999 -9999 -9999 -9999 -9999 -9999 -9999 -9999 -9999 -9999 -9999 -9999 -9999 -9999 -9999 -9999 -9999 -9999 -9999 -9999 -9999 -9999 -9999 -9999 -9999 -9999 -9999 -9999 -9999 -9999 -9999 -9999 -9999 -9999 -9999 -9999 -9999 -9999 -9999 -9999 -9999 -9999 -9999 -9999 -9999 -9999 -9999 -9999 -9999 -9999 -9999 -9999 -9999 -9999 -9999 -9999 -9999

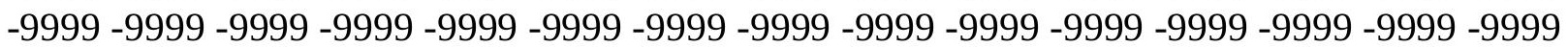


-9999 -9999 -9999 -9999 -9999 -9999 -9999 -9999 -9999 -9999 -9999 -9999 -9999 -9999 -9999 -9999 -9999 -9999 -9999 -9999 -9999 -9999 -9999 -9999 -9999 -9999 -9999 -9999 -9999 -9999 -

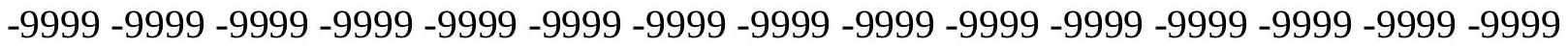
-9999 -9999 -9999 -9999 -9999 -9999 -9999 -9999 -9999 -9999 -9999 -9999 -9999 -9999 -9999 -9999 -9999 -9999 -9999 -9999 -9999 -9999 -9999 -9999-9999 -9999 -9999 -9999 -9999 -9999 -9999 -9999 -9999 -9999 -9999 -9999 -9999 -9999 -9999 -9999 -9999 -9999 -9999 -9999 -9999 -9999 -9999 -9999 -9999 -9999 -9999 -9999 -9999 -9999 -9999 -9999 -9999 -9999 -9999 -

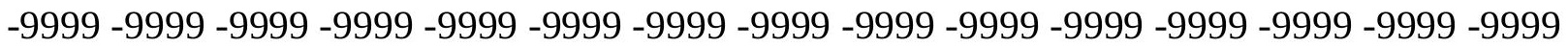

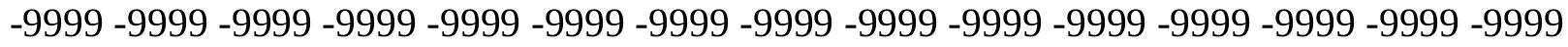
-9999 -9999 -9999 -9999 -9999 -9999 -9999 -9999 -9999 -9999 -9999 -9999 -9999 -9999 -9999 -9999 -9999 -9999 -9999 -9999 -9999 -9999 -9999 -9999 -9999 -9999 -9999 -9999 -9999 -9999 -9999 -9999 -9999 -9999 -9999 -9999 -9999 -9999 -9999 -9999 -9999 -9999 -9999 -9999 -9999 -9999 -9999 -9999 -9999 -9999 -9999 -9999 -9999 -9999 -9999 -9999 -9999 -9999 -9999 -9999 -9999 -9999 -9999 -9999 -9999 -9999 -9999 -9999 -9999 -9999 -9999 -9999 -9999 -9999 -9999 -9999 -9999 -9999 -9999 -9999 -9999 -9999 -9999 -9999 -9999 -9999 -9999 -9999 -9999 -9999 -

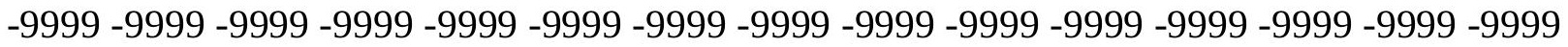
-9999 -9999 -9999 -9999 -9999 -9999 -9999 -9999 -9999 -9999 -9999 -9999 -9999 -9999 -9999 -9999 -9999 -9999 -9999 -9999 -9999 -9999 -9999 -9999 -9999 -9999 -9999 -9999 -9999 -9999 -9999 -9999 -9999 -9999 -9999 -9999 -9999 -9999 -9999 -9999 -9999 -9999 -9999 -9999 -9999 -

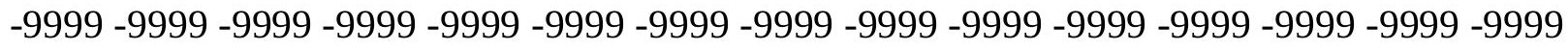

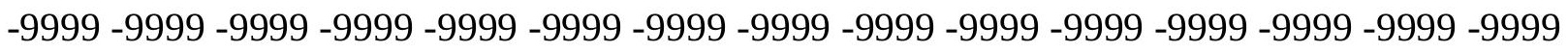

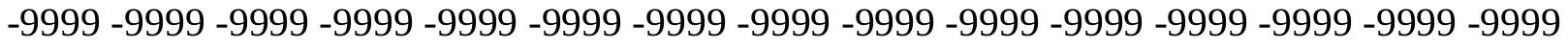
-9999 -9999 -9999 -9999 -9999 -9999 -9999 -9999 -9999 -9999 -9999 -9999 -9999 -9999 -9999 -9999 -9999 -9999 -9999 -9999 -9999 -9999 -9999 -9999 -9999 -9999 -9999 -9999 -9999 -9999 -

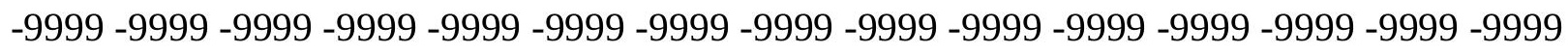
-9999 -9999 -9999 -9999 -9999 -9999 -9999 -9999 -9999 -9999 -9999 -9999 -9999 -9999 -9999 -9999 -9999 -9999 -9999 -9999 -9999 -9999 -9999 -9999 -9999 -9999 -9999 -9999 -9999 -9999 -

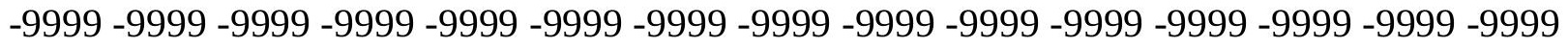
-9999 -9999 -9999 -9999 -9999 -9999 -9999 -9999 -9999 -9999 -9999 -9999 -9999 -9999 -9999 -9999 -9999 -9999 -9999 -9999 -9999 -9999 -9999 -9999 -9999 -9999 -9999 -9999 -9999 -999 -9999 -9999 -9999 -9999 -9999 -9999 -9999 -9999 -9999 -9999 -9999 -9999 -9999 -9999 -9999 -

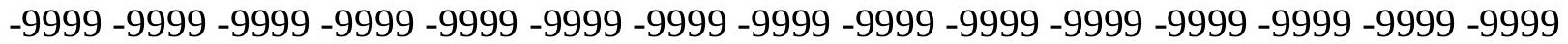

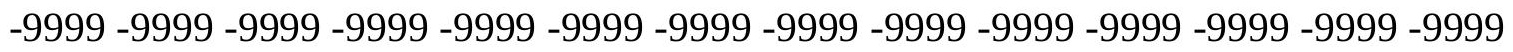

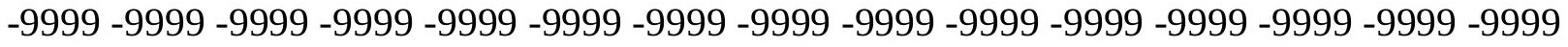

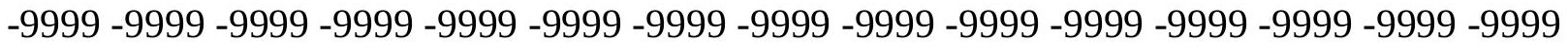

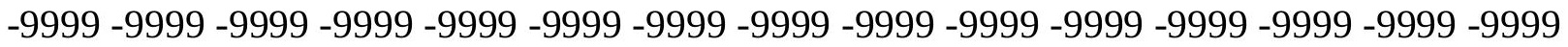

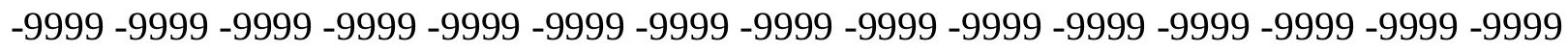

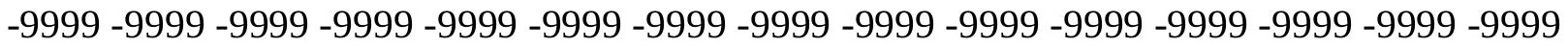

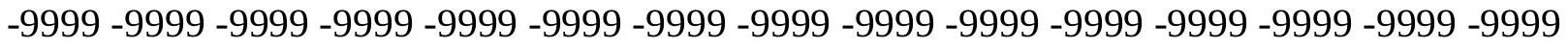
-9999 -9999 -9999 -9999 -9999 -9999 -9999 -9999 -9999 -9999 -9999 -9999 -9999 -9999 -9999 -

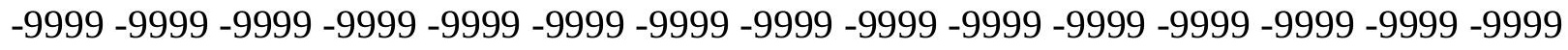

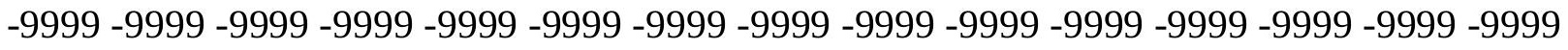
-9999 -9999 -9999 -9999 -9999 -9999 -9999 -9999 -9999 -9999 -9999 -9999 -9999 -9999 -9999 -9999 -9999 -9999 -9999 -9999 -9999 -9999 -9999 -9999-9999 -9999 -9999 -9999 -9999 -9999 -9999 -9999 -9999 -9999 -9999 -9999 -9999 -9999 -9999 -9999 -9999 -9999 -9999 -9999 -9999 -

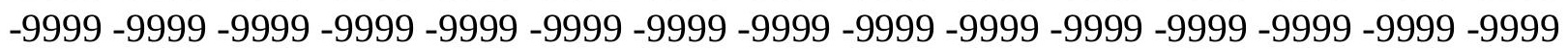


-9999 -9999 -9999 -9999 -9999 -9999 -9999 -9999 -9999 -9999 -9999 -9999 -9999 -9999 -9999 -9999 -9999 -9999 -9999 -9999 -9999 -9999 -9999 -9999 -9999 -9999 -9999 -9999 -9999 -9999 -

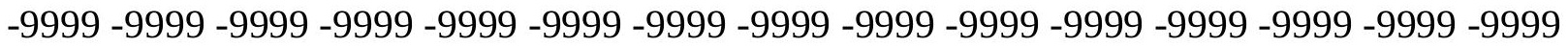
-9999 -9999 -9999 -9999 -9999 -9999 -9999 -9999 -9999 -9999 -9999 -9999 -9999 -9999 -9999 -9999 -9999 -9999 -9999 -9999 -9999 -9999 -9999 -9999-9999 -9999 -9999 -9999 -9999 -9999 -9999 -9999 -9999 -9999 -9999 -9999 -9999 -9999 -9999 -9999 -9999 -9999 -9999 -9999 -9999 -9999 -9999 -9999 -9999 -9999 -9999 -9999 -9999 -9999 -9999 -9999 -9999 -9999 -9999 -9999

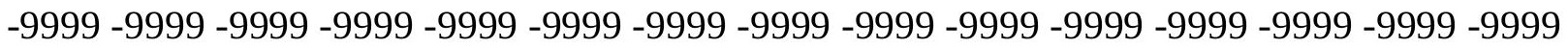

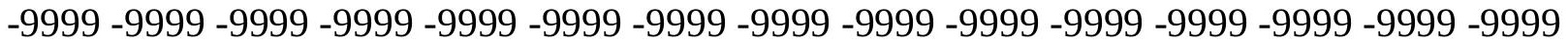
-9999 -9999 -9999 -9999 -9999 -9999 -9999 -9999 -9999 -9999 -9999 -9999 -9999 -9999 -9999 -9999 -9999 -9999 -9999 -9999 -9999 -9999 -9999 -9999 -9999 -9999 -9999 -9999 -9999 -9999 -9999 -9999 -9999 -9999 -9999 -9999 -9999 -9999 -9999 -9999 -9999 -9999 -9999 -9999 -9999 -9999 -9999 -9999 -9999 -9999 -9999 -9999 -9999 -9999 -9999 -9999 -9999 -9999 -9999 -9999 -9999 -9999 -9999 -9999 -9999 -9999 -9999 -9999 -9999 -9999 -9999 -9999 -9999 -9999 -9999 -9999 -9999 -9999 -9999 -9999 -9999 -9999 -9999 -9999 -9999 -9999 -9999 -9999 -9999 -

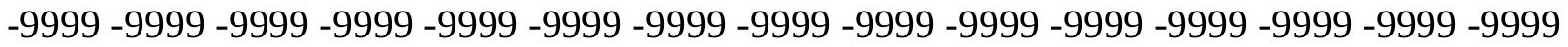
-9999 -9999 -9999 -9999 -9999 -9999 -9999 -9999 -9999 -9999 -9999 -9999 -9999 -9999 -9999 -9999 -9999 -9999 -9999 -9999 -9999 -9999 -9999 -9999 -9999 -9999 -9999 -9999 -9999 -9999 -9999 -9999 -9999 -9999 -9999 -9999 -9999 -9999 -9999 -9999 -9999 -9999 -9999 -9999 -9999 -

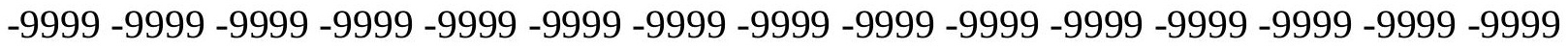
-9999 -9999 -9999 -9999 -9999 -9999 -9999 -9999 -9999 -9999 -9999 -9999 -9999 -9999 -9999

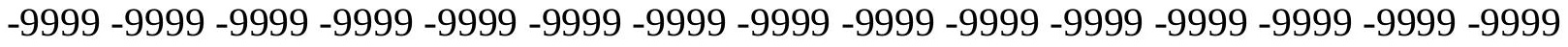
-9999 -9999 -9999 -9999 -9999 -9999 -9999 -9999 -9999 -9999 -9999 -9999 -9999 -9999 -9999 -9999 -9999 -9999 -9999 -9999 -9999 -9999 -9999 -9999 -9999 -9999 -9999 -9999 -9999 -9999 -

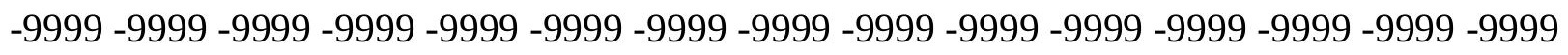
-9999 -9999 -9999 -9999 -9999 -9999 -9999 -9999 -9999 -9999 -9999 -9999 -9999 -9999 -9999 -9999 -9999 -9999 -9999 -9999 -9999 -9999 -9999 -9999 -9999 -9999 -9999 -9999 -9999 -9999 -

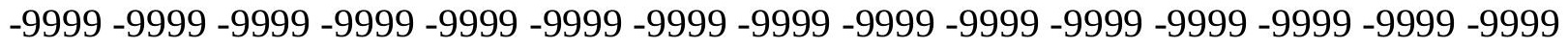
-9999 -9999 -9999 -9999 -9999 -9999 -9999 -9999 -9999 -9999 -9999 -9999 -9999 -9999 -9999 -9999 -9999 -9999 -9999 -9999 -9999 -9999 -9999 -9999 -9999 -9999 -9999 -9999 -9999 -999 -9999 -9999 -9999 -9999 -9999 -9999 -9999 -9999 -9999 -9999 -9999 -9999 -9999 -9999 -9999 -9999 -9999 -9999 -9999 -9999 -9999 -9999 -9999 -9999 -9999 -9999 -9999 -9999 -9999 -9999 -

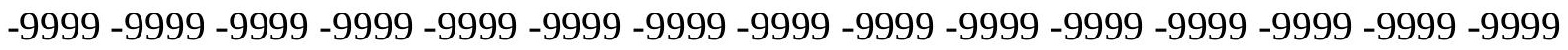

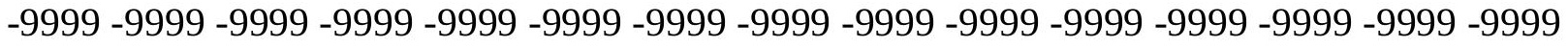

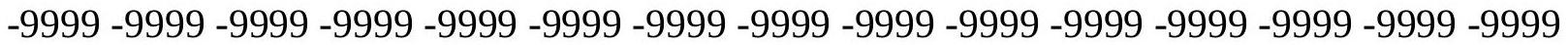
-9999 -9999 -9999 -9999 -9999 -9999 -9999 -9999 -9999 -9999 -9999 -9999 -9999 -9999 -9999 -

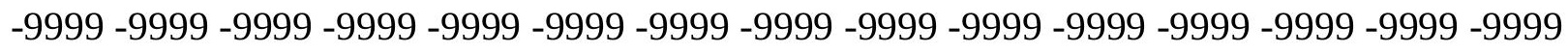

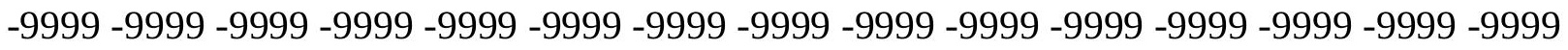
-9999 -9999 -9999 -9999 -9999 -9999 -9999 -9999 -9999 -9999 -9999 -9999 -9999 -9999 - -999 -9999 -9999 -9999 -9999 -9999 -9999 -9999 -9999 -9999 -9999 -9999 -9999 -9999 -9999 -9999 -

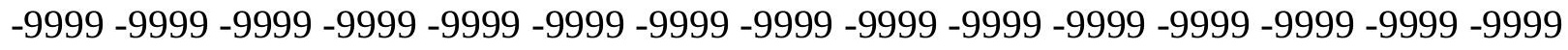

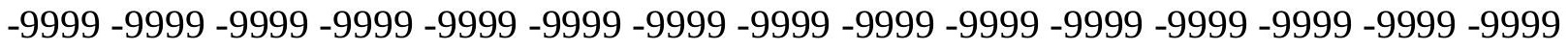
-9999 -9999 -9999 -9999 -9999 -9999 -9999 -9999 -9999 -9999 -9999 -9999 -9999 -9999 -9999 -9999 -9999 -9999 -9999 -9999 -9999 -9999 -9999 -9999-9999 -9999 -9999 -9999 -9999 -9999 -9999 -9999 -9999 -9999 -9999 -9999 -9999 -9999 -9999 -9999 -9999 -9999 -9999 -9999 -9999 -

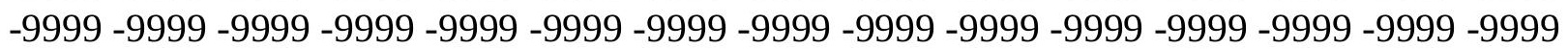


-9999 -9999 -9999 -9999 -9999 -9999 -9999 -9999 -9999 -9999 -9999 -9999 -9999 -9999 -9999 -9999 -9999 -9999 -9999 -9999 -9999 -9999 -9999 -9999 -9999 -9999 -9999 -9999 -9999 -9999 -

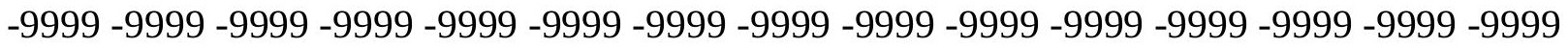
-9999 -9999 -9999 -9999 -9999 -9999 -9999 -9999 -9999 -9999 -9999 -9999 -9999 -9999 -9999 -9999 -9999 -9999 -9999 -9999 -9999 -9999 -9999 -9999-9999 -9999 -9999 -9999 -9999 -9999 -9999 -9999 -9999 -9999 -9999 -9999 -9999 -9999 -9999 -9999 -9999 -9999 -9999 -9999 -9999 -9999 -9999 -9999 -9999 -9999 -9999 -9999 -9999 -9999 -9999 -9999 -9999 -9999 -9999 -9999

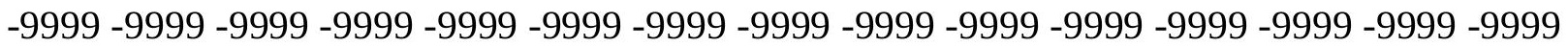

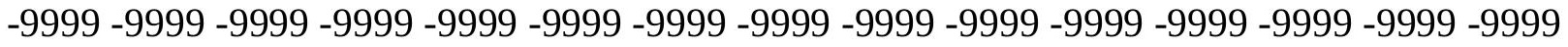
-9999 -9999 -9999 -9999 -9999 -9999 -9999 -9999 -9999 -9999 -9999 -9999 -9999 -9999 -9999 -9999 -9999 -9999 -9999 -9999 -9999 -9999 -9999 -9999 -9999 -9999 -9999 -9999 -9999 -9999 -9999 -9999 -9999 -9999 -9999 -9999 -9999 -9999 -9999 -9999 -9999 -9999 -9999 -9999 -9999 -9999 -9999 -9999 -9999 -9999 -9999 -9999 -9999 -9999 -9999 -9999 -9999 -9999 -9999 -9999 -

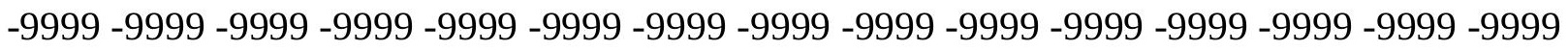
-9999 -9999 -9999 -9999 -9999 -9999 -9999 -9999 -9999 -9999 -9999 -9999 -9999 -9999 -9999 -

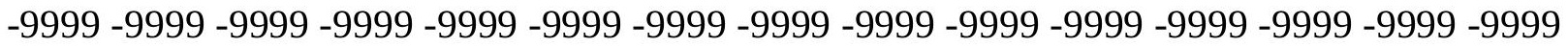
-9999 -9999 -9999 -9999 -9999 -9999 -9999 -9999 -9999 -9999 -9999 -9999 -9999 -9999 -9999 -9999 -9999 -9999 -9999 -9999 -9999 -9999 -9999 -9999 -9999 -9999 -9999 -9999 -9999 -9999 -9999 -9999 -9999 -9999 -9999 -9999 -9999 -9999 -9999 -9999 -9999 -9999 -9999 -9999 - -999 -

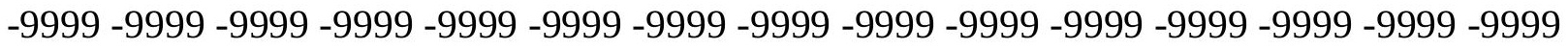

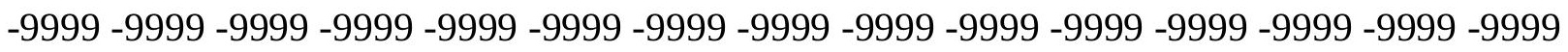
-9999 -9999 -9999 -9999 -9999 -9999 -9999 -9999 -9999 -9999 -9999 -9999 -9999 -9999 -9999 -9999 -9999 -9999 -9999 -9999 -9999 -9999 -9999 -9999 -9999 -9999 -9999 -9999 -9999 -9999 -9999 -9999 -9999 -9999 -9999 -9999 -9999 -9999 -9999 -9999 -9999 -9999 -9999 -9999 -9999 -

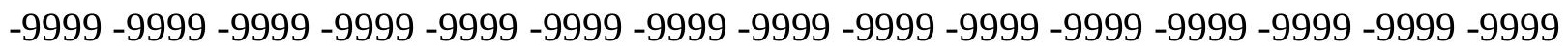
-9999 -9999 -9999 -9999 -9999 -9999 -9999 -9999 -9999 -9999 -9999 -9999 -9999 -9999 -9999 -9999 -9999 -9999 -9999 -9999 -9999 -9999 -9999 -9999 -9999 -9999 -9999 -9999 -9999 -9999 -

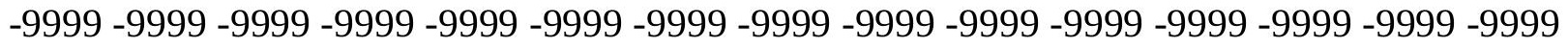
-9999 -9999 -9999 -9999 -9999 -9999 -9999 -9999 -9999 -9999 -9999 -9999 -9999 -9999 -9999 -9999 -9999 -9999 -9999 -9999 -9999 -9999 -9999 -9999 -9999 -9999 -9999 -9999 -9999 -999 -

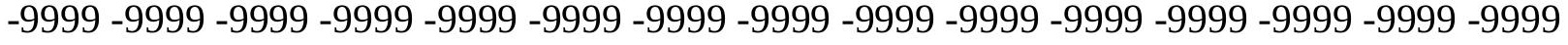
-9999 -9999 -9999 -9999 -9999 -9999 -9999 -9999 -9999 -9999 -9999 -9999 -9999 -9999 -9999 -

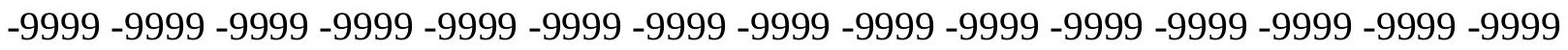

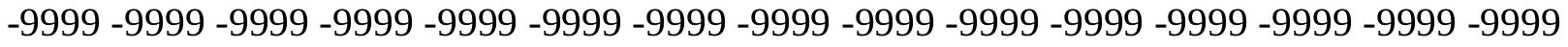

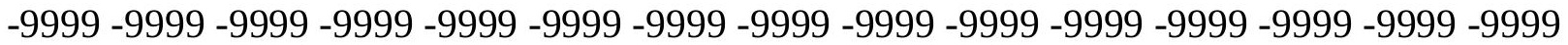

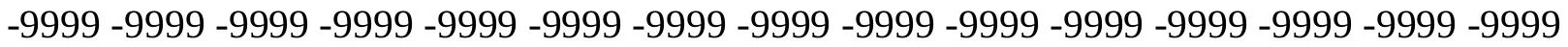

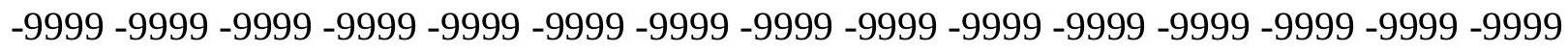

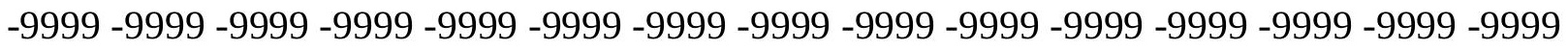

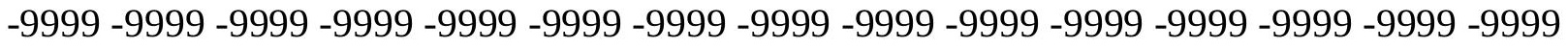
-9999 -9999 -9999 -9999 -9999 -9999 -9999 -9999 -9999 -9999 -9999 -9999 -9999 -9999 -9999 -

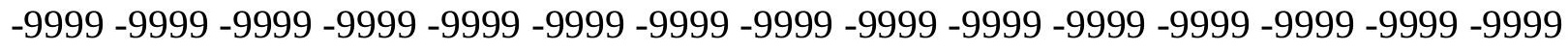

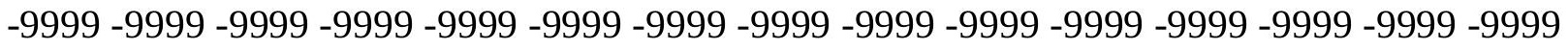
-9999 -9999 -9999 -9999 -9999 -9999 -9999 -9999 -9999 -9999 -9999 -9999 -9999 -9999 -9999 -9999 -9999 -9999 -9999 -9999 -9999 -9999 -9999 -9999 -9999 -9999 -9999 -9999 -9999 -9999 -9999 -9999 -9999 -9999 -9999 -9999 -9999 -9999 -9999 -9999 -9999 -9999 -9999 -9999 -

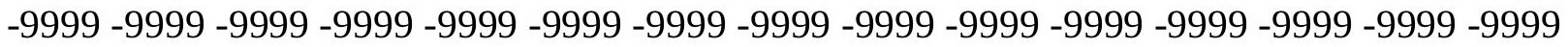


-9999 -9999 -9999 -9999 -9999 -9999 -9999 -9999 -9999 -9999 -9999 -9999 -9999 -9999 -9999 -9999 -9999 -9999 -9999 -9999 -9999 -9999 -9999 -9999 -9999 -9999 -9999 -9999 -9999 -9999 -

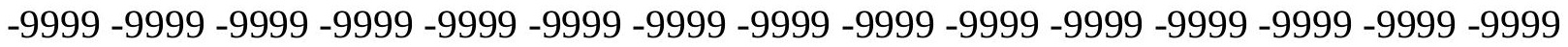
-9999 -9999 -9999 -9999 -9999 -9999 -9999 -9999 -9999 -9999 -9999 -9999 -9999 -9999 -9999 -9999 -9999 -9999 -9999 -9999 -9999 -9999 -9999 -9999-9999 -9999 -9999 -9999 -9999 -9999 -9999 -9999 -9999 -9999 -9999 -9999 -9999 -9999 -9999 -9999 -9999 -9999 -9999 -9999 -9999 -9999 -9999 -9999 -9999 -9999 -9999 -9999 -9999 -9999 -9999 -9999 -9999 -9999 -9999 -9999

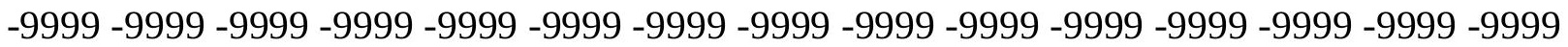

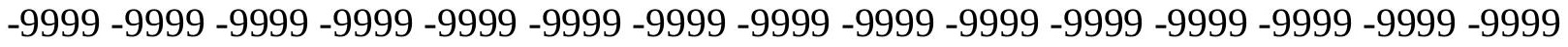
-9999 -9999 -9999 -9999 -9999 -9999 -9999 -9999 -9999 -9999 -9999 -9999 -9999 -9999 -9999 -9999 -9999 -9999 -9999 -9999 -9999 -9999 -9999 -9999 -9999 -9999 -9999 -9999 -9999 -9999 -9999 -9999 -9999 -9999 -9999 -9999 -9999 -9999 -9999 -9999 -9999 -9999 -9999 -9999 -9999 -9999 -9999 -9999 -9999 -9999 -9999 -9999 -9999 -9999 -9999 -9999 -9999 -9999 -9999 -9999 -

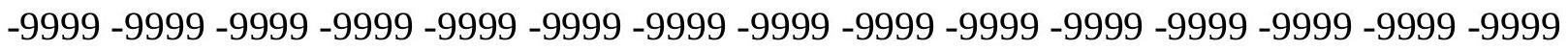
-9999 -9999 -9999 -9999 -9999 -9999 -9999 -9999 -9999 -9999 -9999 -9999 -9999 -9999 -9999 -

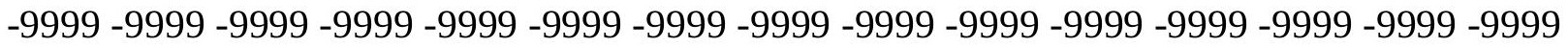
-9999 -9999 -9999 -9999 -9999 -9999 -9999 -9999 -9999 -9999 -9999 -9999 -9999 -9999 -9999 -9999 -9999 -9999 -9999 -9999 -9999 -9999 -9999 -9999 -9999 -9999 -9999 -9999 -9999 - 9999 -9999 -9999 -9999 -9999 -9999 -9999 -9999 -9999 -9999 -9999 -9999 -9999 -9999 -9999 -9999 -

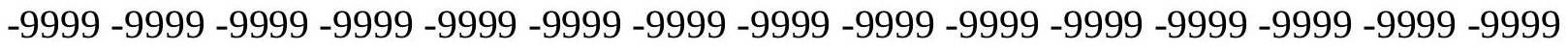

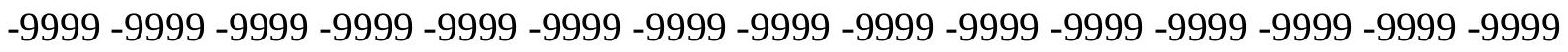
-9999 -9999 -9999 -9999 -9999 -9999 -9999 -9999 -9999 -9999 -9999 -9999 -9999 -9999 - 9999 -9999 -9999 -9999 -9999 -9999 -9999 -9999 -9999 -9999 -9999 -9999 -9999 -9999 -9999 -9999 -9999 -9999 -9999 -9999 -9999 -9999 -9999 -9999 -9999 -9999 -9999 -9999 -9999 -9999 -9999 -9999 -9999 -9999 -9999 -9999 -9999 -9999 -9999 -9999 -9999 -9999 -9999 -9999 -9999 -9999 -9999 -9999 -9999 -9999 -9999 -9999 -9999 -9999 -9999 -9999 -9999 -9999 -9999 -9999 -9999 -9999 -9999 -9999 -9999 -9999 -9999 -9999 -9999 -9999 -9999 -9999 -9999 -9999 -9999 -

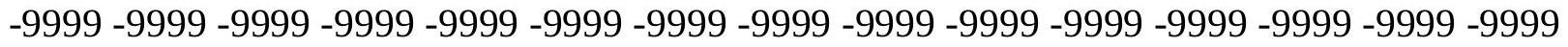
-9999 -9999 -9999 -9999 -9999 -9999 -9999 -9999 -9999 -9999 -9999 -9999 -9999 -9999 -9999 -9999 -9999 -9999 -9999 -9999 -9999 -9999 -9999 -9999 -9999 -9999 -9999 -9999 -9999 -999 -9999 -9999 -9999 -9999 -9999 -9999 -9999 -9999 -9999 -9999 -9999 -9999 -9999 -9999 -9999 -9999 -9999 -9999 -9999 -9999 -9999 -9999 -9999 -9999 -9999 -9999 -9999 -9999 -9999 -9999 -

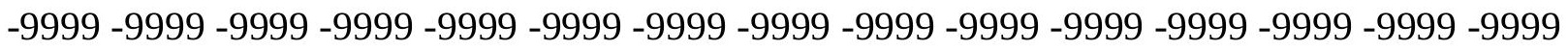

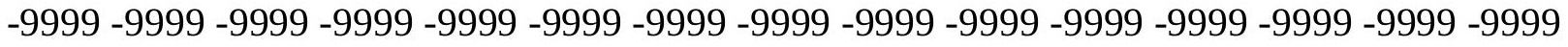

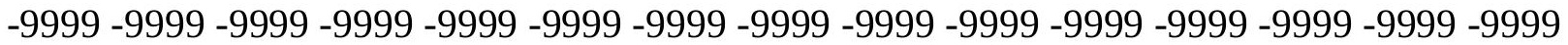

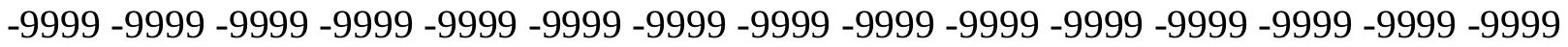

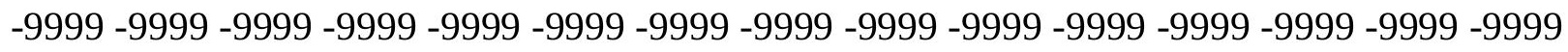

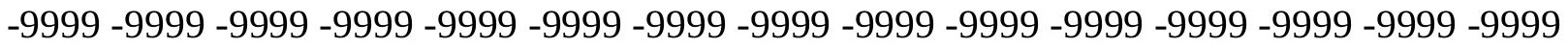

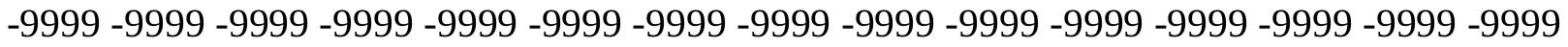
-9999 -9999 -9999 -9999 -9999 -9999 -9999 -9999 -9999 -9999 -9999 -9999 -9999 -9999 -9999 -

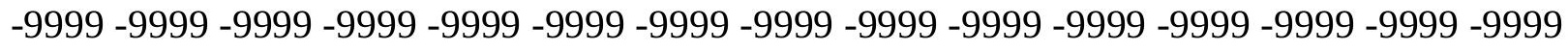

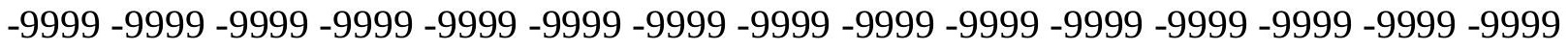
-9999 -9999 -9999 -9999 -9999 -9999 -9999 -9999 -9999 -9999 -9999 -9999 -9999 -9999 -9999 -9999 -9999 -9999 -9999 -9999 -9999 -9999 -9999 -9999-9999 -9999 -9999 -9999 -9999 -9999 -9999 -9999 -9999 -9999 -9999 -9999 -9999 -9999 -9999 -9999 -9999 -9999 -9999 -9999 -9999 -

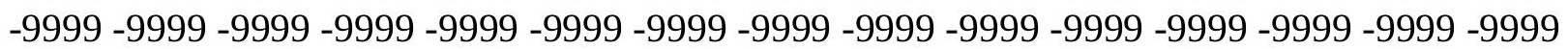


-9999 -9999 -9999 -9999 -9999 -9999 -9999 -9999 -9999 -9999 -9999 -9999 -9999 -9999 -9999 -9999 -9999 -9999 -9999 -9999 -9999 -9999 -9999 -9999 -9999 -9999 -9999 -9999 -9999 -9999 -9999 -9999 -9999 -9999 -9999 -9999 -9999 -9999 -9999 -9999 -9999 -9999 -9999 -9999 - 9999 -9999 -9999 -9999 -9999 -9999 -9999 -9999 -9999 -9999 -9999 -9999 -9999 -9999 -9999 -9999 -9999 -9999 -9999 -9999 -9999 -9999 -9999 -9999 -9999 -9999 -9999 -9999 -9999 -9999 -9999 -9999 -9999 -9999 -9999 -9999 -9999 -9999 -9999 -9999 -9999 -9999 -9999 -9999 -9999 -9999 -9999 -9999 -9999 -9999 -9999 -9999 -9999 -9999 -9999 -9999 -9999 -9999 -9999 -9999

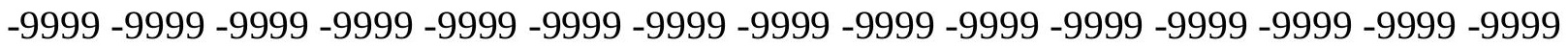

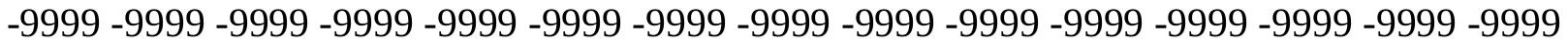
-9999 -9999 -9999 -9999 -9999 -9999 -9999 -9999 -9999 -9999 -9999 -9999 -9999 -9999 -9999 -9999 -9999 -9999 -9999 -9999 -9999 -9999 -9999 -9999 -9999 -9999 -9999 -9999 -9999 -9999 -9999 -9999 -9999 -9999 -9999 -9999 -9999 -9999 -9999 -9999 -9999 -9999 -9999 -9999 -9999 -9999 -9999 -9999 -9999 -9999 -9999 -9999 -9999 -9999 -9999 -9999 -9999 -9999 -9999 -9999 -9999 -9999 -9999 -9999 -9999 -9999 -9999 -9999 -9999 -9999 -9999 -9999 -9999 -9999 -9999 -9999 -9999 -9999 -9999 -9999 -9999 -9999 -9999 -9999 -9999 -9999 -9999 -9999 -9999 -9999 -

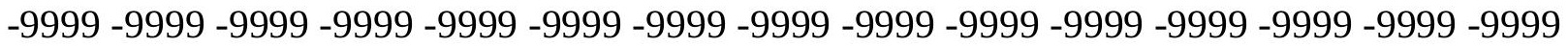
-9999 -9999 -9999 -9999 -9999 -9999 -9999 -9999 -9999 -9999 -9999 -9999 -9999 -9999 -9999 -9999 -9999 -9999 -9999 -9999 -9999 -9999 -9999 -9999 -9999 -9999 -9999 -9999 -9999 - 9999 -9999 -9999 -9999 -9999 -9999 -9999 -9999 -9999 -9999 -9999 -9999 -9999 -9999 -9999 -9999 -

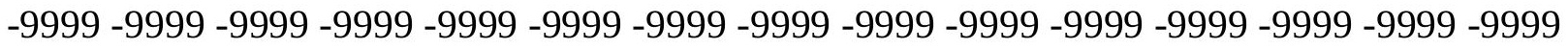

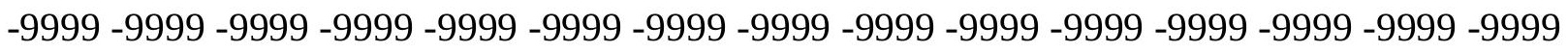

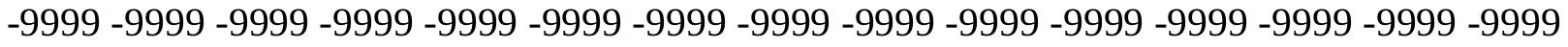
-9999 -9999 -9999 -9999 -9999 -9999 -9999 -9999 -9999 -9999 -9999 -9999 -9999 -9999 -9999 -9999 -9999 -9999 -9999 -9999 -9999 -9999 -9999 -9999 -9999 -9999 -9999 -9999 -9999 -9999 -

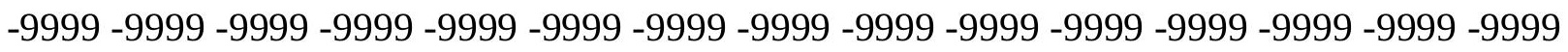
-9999 -9999 -9999 -9999 -9999 -9999 -9999 -9999 -9999 -9999 -9999 -9999 -9999 -9999 -9999 -9999 -9999 -9999 -9999 -9999 -9999 -9999 -9999 -9999 -9999 -9999 -9999 -9999 -9999 -9999 -

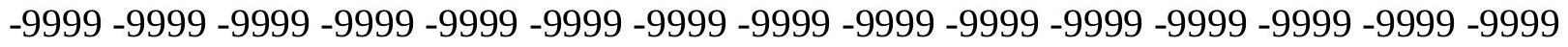
-9999 -9999 -9999 -9999 -9999 -9999 -9999 -9999 -9999 -9999 -9999 -9999 -9999 -9999 -9999 -9999 -9999 -9999 -9999 -9999 -9999 -9999 -9999 -9999 -9999 -9999 -9999 -9999 -9999 -999 -9999 -9999 -9999 -9999 -9999 -9999 -9999 -9999 -9999 -9999 -9999 -9999 -9999 -9999 -9999 -9999 -9999 -9999 -9999 -9999 -9999 -9999 -9999 -9999 -9999 -9999 -9999 -9999 -9999 -

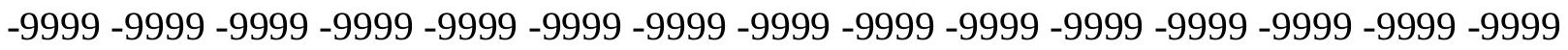

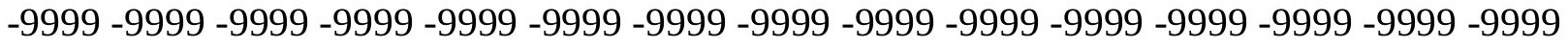

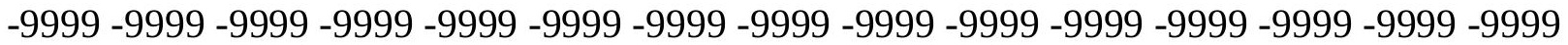

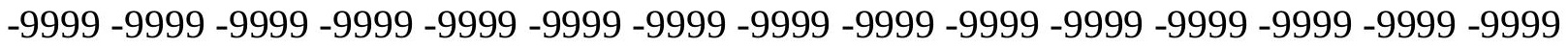

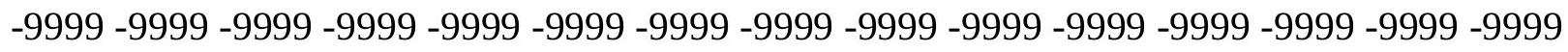

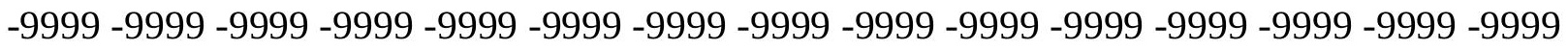

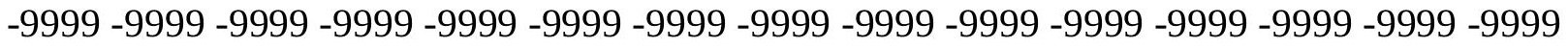
-9999 -9999 -9999 -9999 -9999 -9999 -9999 -9999 -9999 -9999 -9999 -9999 -9999 -9999 -9999 -

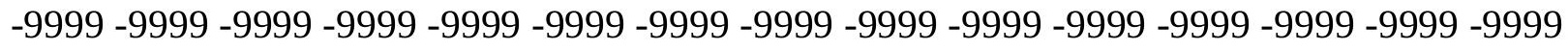

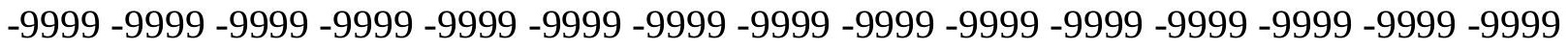
-9999 -9999 -9999 -9999 -9999 -9999 -9999 -9999 -9999 -9999 -9999 -9999 -9999 -9999 -9999 -9999 -9999 -9999 -9999 -9999 -9999 -9999 -9999 -9999-9999 -9999 -9999 -9999 -9999 -9999 -9999 -9999 -9999 -9999 -9999 -9999 -9999 -9999 -9999 -9999 -9999 -9999 -9999 -9999 -9999 -

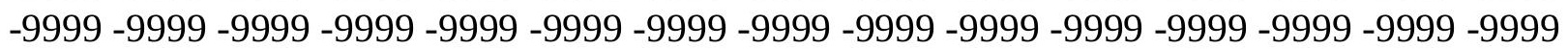


-9999 -9999 -9999 -9999 -9999 -9999 -9999 -9999 -9999 -9999 -9999 -9999 -9999 -9999 -9999 -9999 -9999 -9999 -9999 -9999 -9999 -9999 -9999 -9999 -9999 -9999 -9999 -9999 -9999 -9999 -

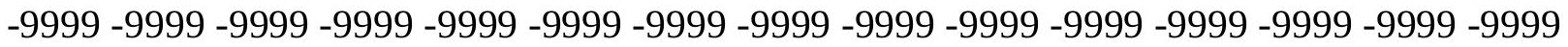
-9999 -9999 -9999 -9999 -9999 -9999 -9999 -9999 -9999 -9999 -9999 -9999 -9999 -9999 -9999 -9999 -9999 -9999 -9999 -9999 -9999 -9999 -9999 -9999-9999 -9999 -9999 -9999 -9999 -9999 -9999 -9999 -9999 -9999 -9999 -9999 -9999 -9999 -9999 -9999 -9999 -9999 -9999 -9999 -9999 -9999 -9999 -9999 -9999 -9999 -9999 -9999 -9999 -9999 -9999 -9999 -9999 -9999 -9999 -9999

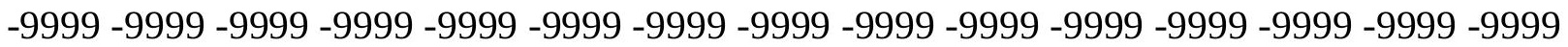

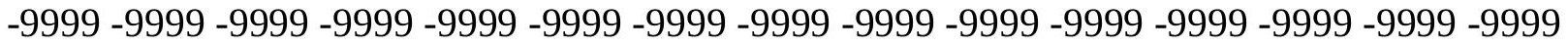

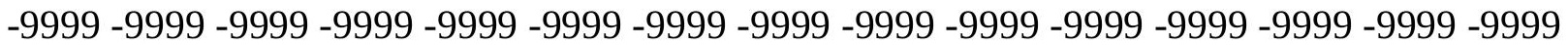
-9999 -9999 -9999 -9999 -9999 -9999 -9999 -9999 -9999 -9999 -9999 -9999 -9999 -9999 -9999 -9999 -9999 -9999 -9999 -9999 -9999 -9999 -9999 -9999 -9999 -9999 -9999 -9999 -9999 -9999 -9999 -9999 -9999 -9999 -9999 -9999 -9999 -9999 -9999 -9999 -9999 -9999 -9999 -9999 -

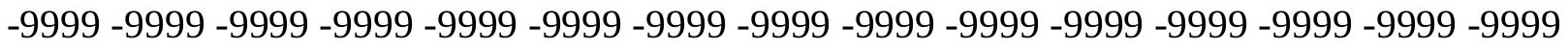
-9999 -9999 -9999 -9999 -9999 -9999 -9999 -9999 -9999 -9999 -9999 -9999 -9999 -9999 -9999 -

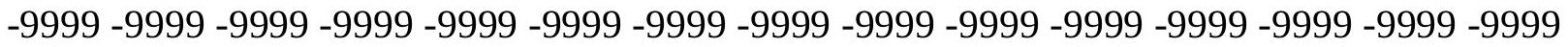
-9999 -9999 -9999 -9999 -9999 -9999 -9999 -9999 -9999 -9999 -9999 -9999 -9999 -9999 -9999 -9999 -9999 -9999 -9999 -9999 -9999 -9999 -9999 -9999 -9999 -9999 -9999 -9999 -9999 -9999 -9999 -9999 -9999 -9999 -9999 -9999 -9999 -9999 -9999 -9999 -9999 -9999 -9999 -9999 -9999 -

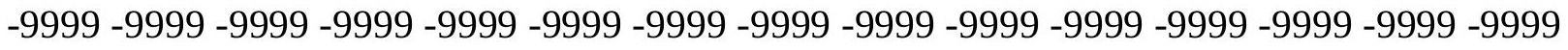

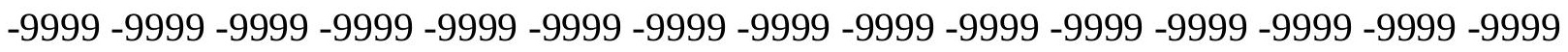
-9999 -9999 -9999 -9999 -9999 -9999 -9999 -9999 -9999 -9999 -9999 -9999 -9999 -9999 -9999 -9999 -9999 -9999 -9999 -9999 -9999 -9999 -9999 -9999 -9999 -9999 -9999 -9999 -9999 -9999 -9999 -9999 -9999 -9999 -9999 -9999 -9999 -9999 -9999 -9999 -9999 -9999 -9999 -9999 -9999 -

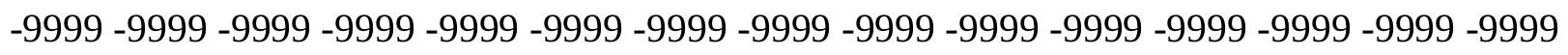
-9999 -9999 -9999 -9999 -9999 -9999 -9999 -9999 -9999 -9999 -9999 -9999 -9999 -9999 -9999 -9999 -9999 -9999 -9999 -9999 -9999 -9999 -9999 -9999 -9999 -9999 -9999 -9999 -9999 -9999 -

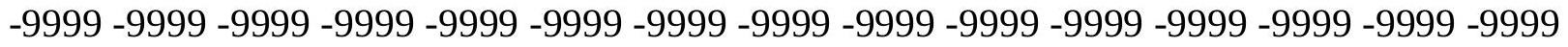
-9999 -9999 -9999 -9999 -9999 -9999 -9999 -9999 -9999 -9999 -9999 -9999 -9999 -9999 -9999 -9999 -9999 -9999 -9999 -9999 -9999 -9999 -9999 -9999 -9999 -9999 -9999 -9999 -9999 -999 -9999 -9999 -9999 -9999 -9999 -9999 -9999 -9999 -9999 -9999 -9999 -9999 -9999 -9999 -9999 -9999 -9999 -9999 -9999 -9999 -9999 -9999 -9999 -9999 -9999 -9999 -9999 -9999 -9999 -9999 -

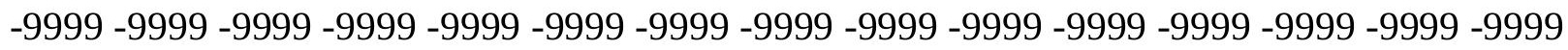

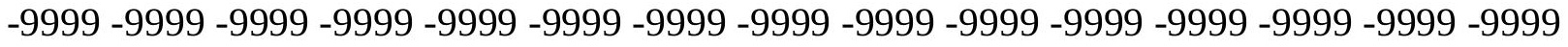

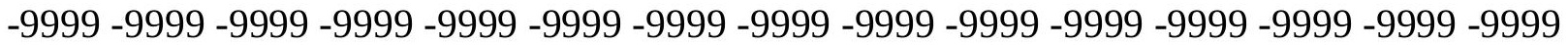
-9999 -9999 -9999 -9999 -9999 -9999 -9999 -9999 -9999 -9999 -9999 -9999 -9999 -9999 -9999 -

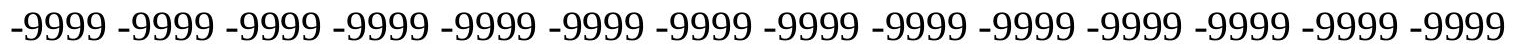

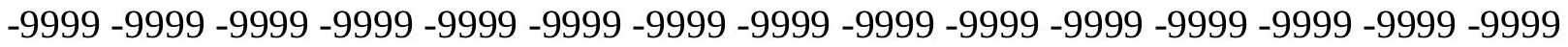
-9999 -9999 -9999 -9999 -9999 -9999 -9999 -9999 -9999 -9999 -9999 -9999 -9999 - 9999 - -999 -9999 -9999 -9999 -9999 -9999 -9999 -9999 -9999 -9999 -9999 -9999 -9999 -9999 -9999 -9999 -

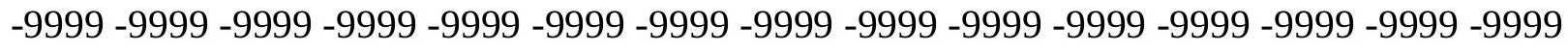

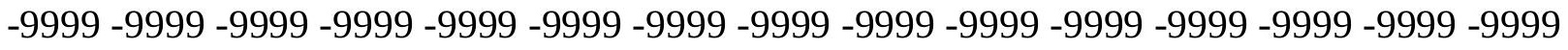
-9999 -9999 -9999 -9999 -9999 -9999 -9999 -9999 -9999 -9999 -9999 -9999 -9999 -9999 -9999 -9999 -9999 -9999 -9999 -9999 -9999 -9999 -9999 -9999-9999 -9999 -9999 -9999 -9999 -9999 -9999 -9999 -9999 -9999 -9999 -9999 -9999 -9999 -9999 -9999 -9999 -9999 -9999 -9999 -9999 -

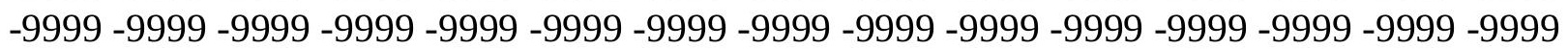


-9999 -9999 -9999 -9999 -9999 -9999 -9999 -9999 -9999 -9999 -9999 -9999 -9999 -9999 -9999 -9999 -9999 -9999 -9999 -9999 -9999 -9999 -9999 -9999 -9999 -9999 -9999 -9999 -9999 -9999 -

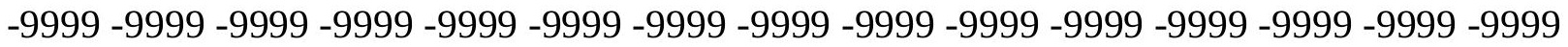
-9999 -9999 -9999 -9999 -9999 -9999 -9999 -9999 -9999 -9999 -9999 -9999 -9999 -9999 -9999 -9999 -9999 -9999 -9999 -9999 -9999 -9999 -9999 -9999-9999 -9999 -9999 -9999 -9999 -9999 -9999 -9999 -9999 -9999 -9999 -9999 -9999 -9999 -9999 -9999 -9999 -9999 -9999 -9999 -9999 -9999 -9999 -9999 -9999 -9999 -9999 -9999 -9999 -9999 -9999 -9999 -9999 -9999 -9999 -9999

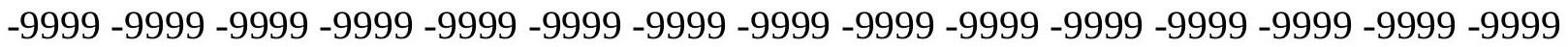

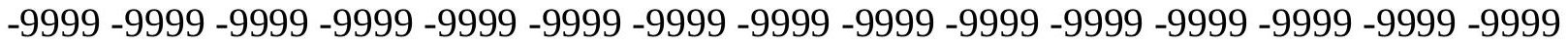
-9999 -9999 -9999 -9999 -9999 -9999 -9999 -9999 -9999 -9999 -9999 -9999 -9999 -9999 -9999 -9999 -9999 -9999 -9999 -9999 -9999 -9999 -9999 -9999 -9999 -9999 -9999 -9999 -9999 -9999 -9999 -9999 -9999 -9999 -9999 -9999 -9999 -9999 -9999 -9999 -9999 -9999 -9999 -9999 -9999 -9999 -9999 -9999 -9999 -9999 -9999 -9999 -9999 -9999 -9999 -9999 -9999 -9999 -9999 -9999 -9999 -9999 -9999 -9999 -9999 -9999 -9999 -9999 -9999 -9999 -9999 -9999 -9999 -9999 -9999 -9999 -9999 -9999 -9999 -9999 -9999 -9999 -9999 -9999 -9999 -9999 -9999 -9999 -9999 -9999 -

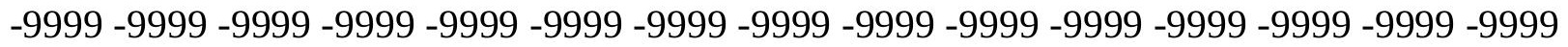
-9999 -9999 -9999 -9999 -9999 -9999 -9999 -9999 -9999 -9999 -9999 -9999 -9999 -9999 -9999 -9999 -9999 -9999 -9999 -9999 -9999 -9999 -9999 -9999 -9999 -9999 -9999 -9999 -9999 -9999 -9999 -9999 -9999 -9999 -9999 -9999 -9999 -9999 -9999 -9999 -9999 -9999 -9999 -9999 -

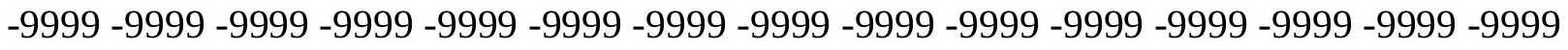
-9999 -9999 -9999 -9999 -9999 -9999 -9999 -9999 -9999 -9999 -9999 -9999 -9999 -9999 -9999 -999 -

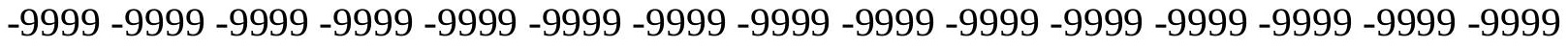
-9999 -9999 -9999 -9999 -9999 -9999 -9999 -9999 -9999 -9999 -9999 -9999 -9999 -9999 -9999 -9999 -9999 -9999 -9999 -9999 -9999 -9999 -9999 -9999 -9999 -9999 -9999 -9999 -9999 -9999 -9999 -9999 -9999 -9999 -9999 -9999 -9999 -9999 -9999 -9999 -9999 -9999 -9999 -9999 -9999 -9999 -9999 -9999 -9999 -9999 -9999 -9999 -9999 -9999 -9999 -9999 -9999 -9999 -9999 -9999 -9999 -9999 -9999 -9999 -9999 -9999 -9999 -9999 -9999 -9999 -9999 -9999 -9999 -9999 -9999 -

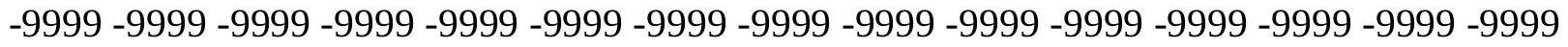
-9999 -9999 -9999 -9999 -9999 -9999 -9999 -9999 -9999 -9999 -9999 -9999 -9999 -9999 -9999 -9999 -9999 -9999 -9999 -9999 -9999 -9999 -9999 -9999 -9999 -9999 -9999 -9999 -9999 -999 -9999 -9999 -9999 -9999 -9999 -9999 -9999 -9999 -9999 -9999 -9999 -9999 -9999 -9999 -9999 -9999 -9999 -9999 -9999 -9999 -9999 -9999 -9999 -9999 -9999 -9999 -9999 -9999 -9999 -9999 -

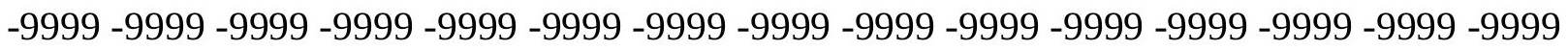

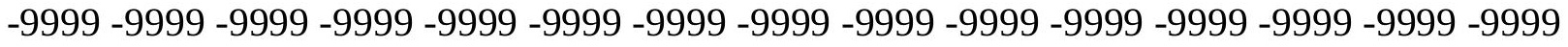

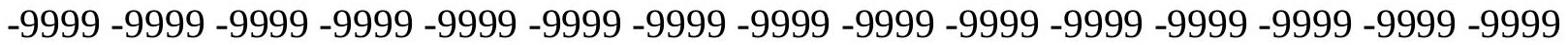
-9999 -9999 -9999 -9999 -9999 -9999 -9999 -9999 -9999 -9999 -9999 -9999 -9999 -9999 -9999

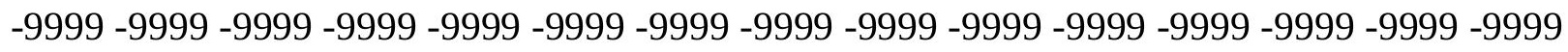

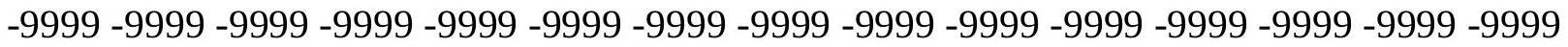
-9999 -9999 -9999 -9999 -9999 -9999 -9999 -9999 -9999 -9999 -9999 -9999 -9999 - 9999 - -999 -9999 -9999 -9999 -9999 -9999 -9999 -9999 -9999 -9999 -9999 -9999 -9999 -9999 -9999 -9999 -

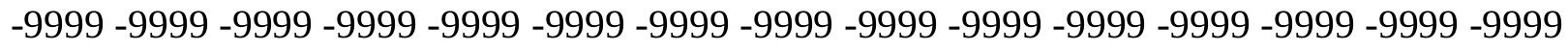

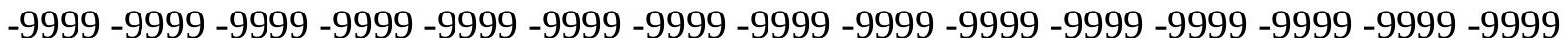
-9999 -9999 -9999 -9999 -9999 -9999 -9999 -9999 -9999 -9999 -9999 -9999 -9999 -9999 -9999 -9999 -9999 -9999 -9999 -9999 -9999 -9999 -9999 -9999 -9999 -9999 -9999 -9999 -9999 -9999 -9999 -9999 -9999 -9999 -9999 -9999 -9999 -9999 -9999 -9999 -9999 -9999 -9999 -9999 -

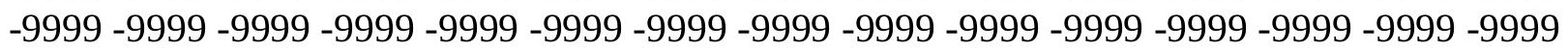


-9999 -9999 -9999 -9999 -9999 -9999 -9999 -9999 -9999 -9999 -9999 -9999 -9999 -9999 -9999 -9999 -9999 -9999 -9999 -9999 -9999 -9999 -9999 -9999 -9999 -9999 -9999 -9999 -9999 -9999 -9999 -9999 -9999 -9999 -9999 -9999 -9999 -9999 -9999 -9999 -9999 -9999 -9999 -9999 - 9999 -9999 -9999 -9999 -9999 -9999 -9999 -9999 -9999 -9999 -9999 -9999 -9999 -9999 -9999 -9999 -9999 -9999 -9999 -9999 -9999 -9999 -9999 -9999 -9999-9999 -9999 -9999 -9999 -9999 -9999 -9999 -9999 -9999 -9999 -9999 -9999 -9999 -9999 -9999 -9999 -9999 -9999 -9999 -9999 -9999 -9999 -9999 -9999 -9999 -9999 -9999 -9999 -9999 -9999 -9999 -9999 -9999 -9999 -9999 -9999

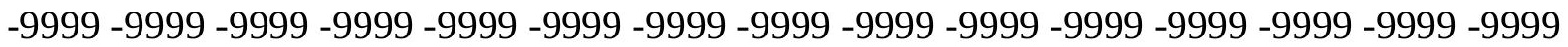

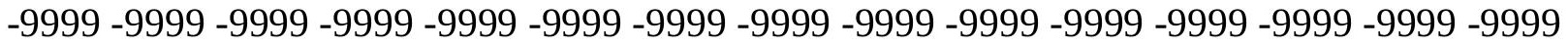
-9999 -9999 -9999 -9999 -9999 -9999 -9999 -9999 -9999 -9999 -9999 -9999 -9999 -9999 -9999 -9999 -9999 -9999 -9999 -9999 -9999 -9999 -9999 -9999 -9999 -9999 -9999 -9999 -9999 -9999 -9999 -9999 -9999 -9999 -9999 -9999 -9999 -9999 -9999 -9999 -9999 -9999 -9999 -9999 -9999 -9999 -9999 -9999 -9999 -9999 -9999 -9999 -9999 -9999 -9999 -9999 -9999 -9999 -9999 -9999 -

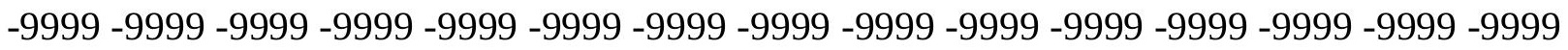
-9999 -9999 -9999 -9999 -9999 -9999 -9999 -9999 -9999 -9999 -9999 -9999 -9999 -9999 -9999 -

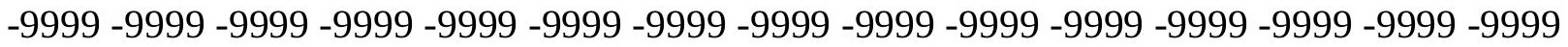
-9999 -9999 -9999 -9999 -9999 -9999 -9999 -9999 -9999 -9999 -9999 -9999 -9999 -9999 -9999 -9999 -9999 -9999 -9999 -9999 -9999 -9999 -9999 -9999 -9999 -9999 -9999 -9999 -9999 -9999 -9999 -9999 -9999 -9999 -9999 -9999 -9999 -9999 -9999 -9999 -9999 -9999 -9999 -9999 -9999 -

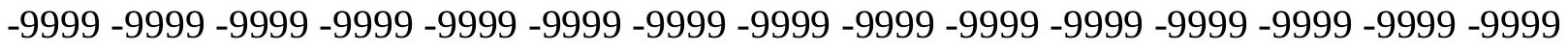
-9999 -9999 -9999 -9999 -9999 -9999 -9999 -9999 -9999 -9999 -9999 -9999 -9999 -9999 -9999 -999 -9999 -9999 -9999 -9999 -9999 -9999 -9999 -9999 -9999 -9999 -9999 -9999 -9999 -9999 - 9999 -9999 -9999 -9999 -9999 -9999 -9999 -9999 -9999 -9999 -9999 -9999 -9999 -9999 -9999 -

-9999 -9999 -9999 -9999 -9999 -9999 -9999 -9999 -9999 -9999 -9999 -9999 -9999 -9999 -9999 -

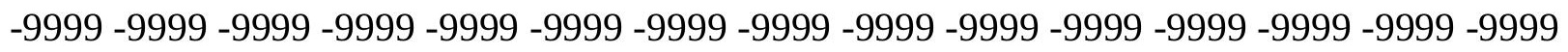
-9999 -9999 -9999 -9999 -9999 -9999 -9999 -9999 -9999 -9999 -9999 -9999 -9999 -9999 -9999 -9999 -9999 -9999 -9999 -9999 -9999 -9999 -9999 -9999 -9999 -9999 -9999 -9999 -9999 -9999 -

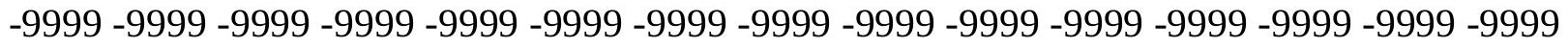
-9999 -9999 -9999 -9999 -9999 -9999 -9999 -9999 -9999 -9999 -9999 -9999 -9999 -9999 -9999 -9999 -9999 -9999 -9999 -9999 -9999 -9999 -9999 -9999 -9999 -9999 -9999 -9999 -9999 -999 -

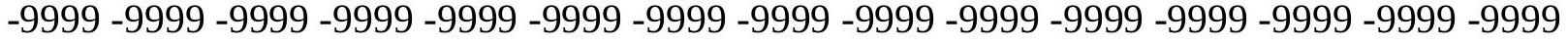
-9999 -9999 -9999 -9999 -9999 -9999 -9999 -9999 -9999 -9999 -9999 -9999 -9999 -9999 -9999 -

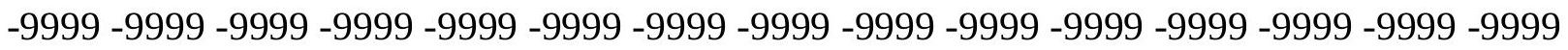

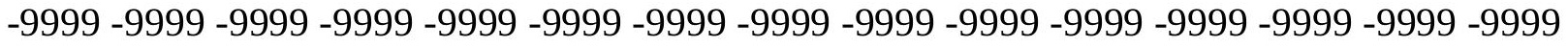

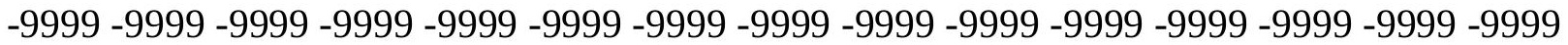

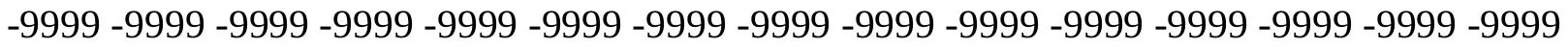

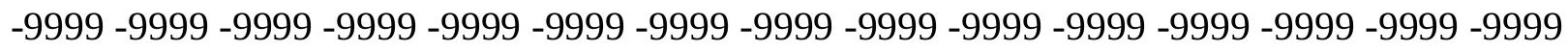

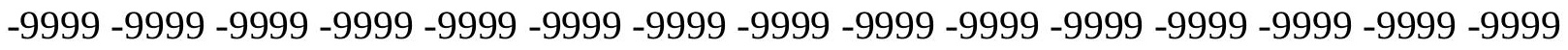

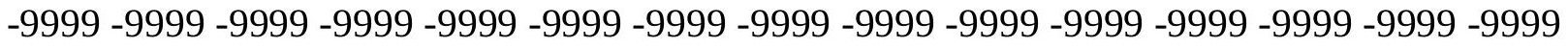
-9999 -9999 -9999 -9999 -9999 -9999 -9999 -9999 -9999 -9999 -9999 -9999 -9999 -9999 -9999 -

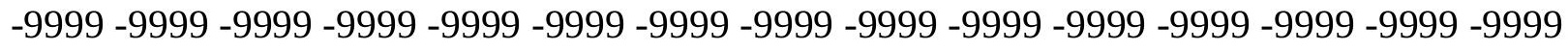

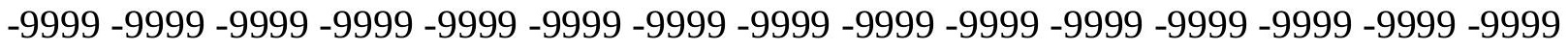
-9999 -9999 -9999 -9999 -9999 -9999 -9999 -9999 -9999 -9999 -9999 -9999 -9999 -9999 -9999 -9999 -9999 -9999 -9999 -9999 -9999 -9999 -9999 -9999-9999 -9999 -9999 -9999 -9999 -9999 -9999 -9999 -9999 -9999 -9999 -9999 -9999 -9999 -9999 -9999 -9999 -9999 -9999 -9999 -9999 -

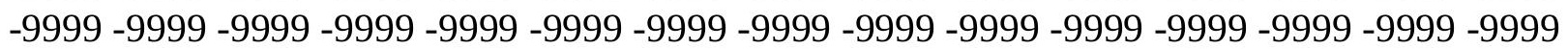


-9999 -9999 -9999 -9999 -9999 -9999 -9999 -9999 -9999 -9999 -9999 -9999 -9999 -9999 -9999 -9999 -9999 -9999 -9999 -9999 -9999 -9999 -9999 -9999 -9999 -9999 -9999 -9999 -9999 -9999 -9999 -9999 -9999 -9999 -9999 -9999 -9999 -9999 -9999 -9999 -9999 -9999 -9999 -9999 -9999 -9999 -9999 -9999 -9999 -9999 -9999 -9999 -9999 -9999 -9999 -9999 -9999 -9999 -9999 -9999 -9999 -9999 -9999 -9999 -9999 -9999 -9999 -9999-9999 -9999 -9999 -9999 -9999 -9999 -9999 -9999 -9999 -9999 -9999 -9999 -9999 -9999 -9999 -9999 -9999 -9999 -9999 -9999 -9999 -9999 -9999 -9999 -9999 -9999 -9999 -9999 -9999 -9999 -9999 -9999 -9999 -9999 -9999 -9999

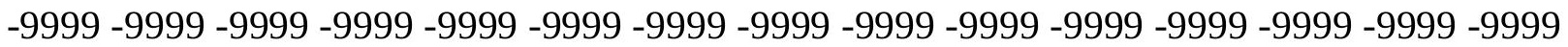

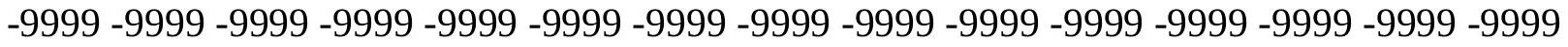
-9999 -9999 -9999 -9999 -9999 -9999 -9999 -9999 -9999 -9999 -9999 -9999 -9999 -9999 -9999 -9999 -9999 -9999 -9999 -9999 -9999 -9999 -9999 -9999 -9999 -9999 -9999 -9999 -9999 -9999 -9999 -9999 -9999 -9999 -9999 -9999 -9999 -9999 -9999 -9999 -9999 -9999 -9999 -9999 -9999 -9999 -9999 -9999 -9999 -9999 -9999 -9999 -9999 -9999 -9999 -9999 -9999 -9999 -9999 -9999 -

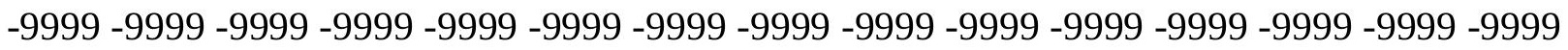
-9999 -9999 -9999 -9999 -9999 -9999 -9999 -9999 -9999 -9999 -9999 -9999 -9999 -9999 -9999 -

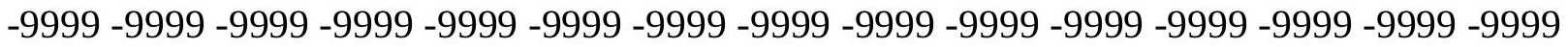
-9999 -9999 -9999 -9999 -9999 -9999 -9999 -9999 -9999 -9999 -9999 -9999 -9999 -9999 -9999 -9999 -9999 -9999 -9999 -9999 -9999 -9999 -9999 -9999 -9999 -9999 -9999 -9999 -9999 -9999 -9999 -9999 -9999 -9999 -9999 -9999 -9999 -9999 -9999 -9999 -9999 -9999 -9999 -9999 -9999 -

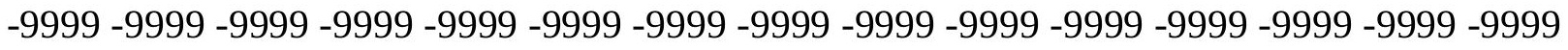

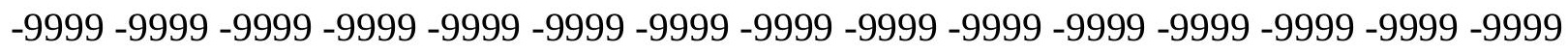
-9999 -9999 -9999 -9999 -9999 -9999 -9999 -9999 -9999 -9999 -9999 -9999 -9999 -9999 -9999 -9999 -9999 -9999 -9999 -9999 -9999 -9999 -9999 -9999 -9999 -9999 -9999 -9999 -9999 -9999 -9999 -9999 -9999 -9999 -9999 -9999 -9999 -9999 -9999 -9999 -9999 -9999 -9999 -9999 -9999 -

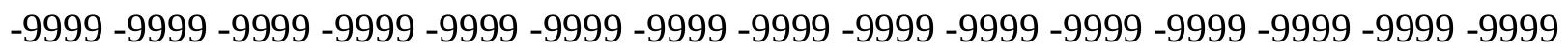
-9999 -9999 -9999 -9999 -9999 -9999 -9999 -9999 -9999 -9999 -9999 -9999 -9999 -9999 -9999 -9999 -9999 -9999 -9999 -9999 -9999 -9999 -9999 -9999 -9999 -9999 -9999 -9999 -9999 -9999 -

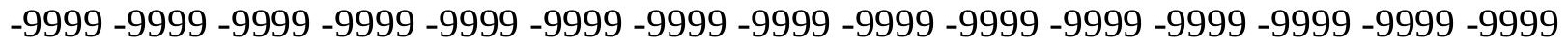
-9999 -9999 -9999 -9999 -9999 -9999 -9999 -9999 -9999 -9999 -9999 -9999 -9999 -9999 -9999 -9999 -9999 -9999 -9999 -9999 -9999 -9999 -9999 -9999 -9999 -9999 -9999 -9999 - -999 -

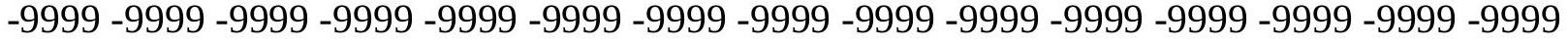
-9999 -9999 -9999 -9999 -9999 -9999 -9999 -9999 -9999 -9999 -9999 -9999 -9999 -9999 -9999 -

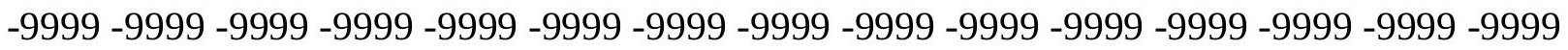

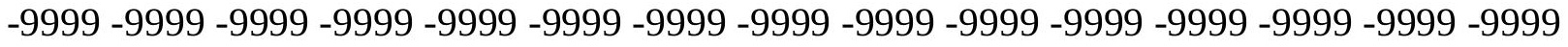

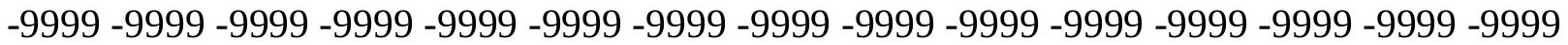

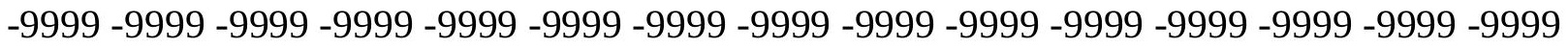

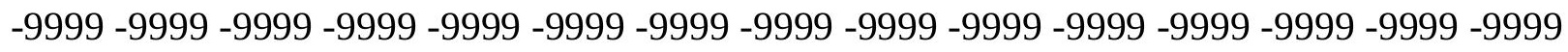

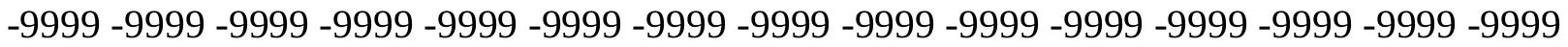

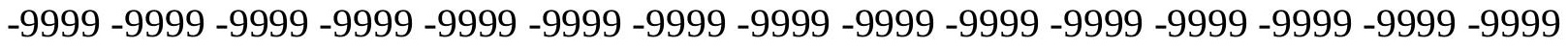
-9999 -9999 -9999 -9999 -9999 -9999 -9999 -9999 -9999 -9999 -9999 -9999 -9999 -9999 -9999 -

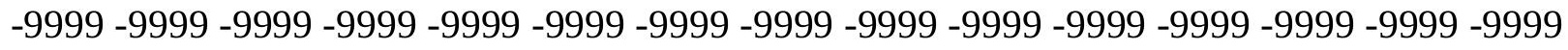

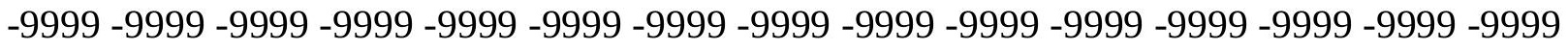
-9999 -9999 -9999 -9999 -9999 -9999 -9999 -9999 -9999 -9999 -9999 -9999 -9999 -9999 -9999 -9999 -9999 -9999 -9999 -9999 -9999 -9999 -9999 -9999-9999 -9999 -9999 -9999 -9999 -9999 -9999 -9999 -9999 -9999 -9999 -9999 -9999 -9999 -9999 -9999 -9999 -9999 -9999 -9999 -9999 -

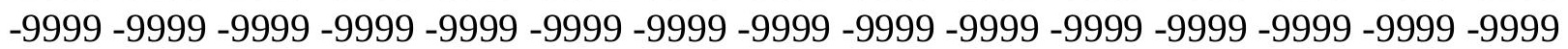


-9999 -9999 -9999 -9999 -9999 -9999 -9999 -9999 -9999 -9999 -9999 -9999 -9999 -9999 -9999 -9999 -9999 -9999 -9999 -9999 -9999 -9999 -9999 -9999 -9999 -9999 -9999 -9999 -9999 -9999 -

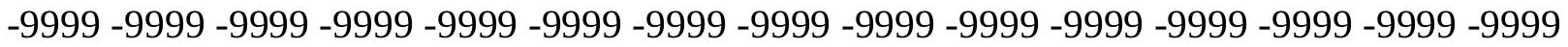
-9999 -9999 -9999 -9999 -9999 -9999 -9999 -9999 -9999 -9999 -9999 -9999 -9999 -9999 -9999 -9999 -9999 -9999 -9999 -9999 -9999 -9999 -9999 -9999-9999 -9999 -9999 -9999 -9999 -9999 -9999 -9999 -9999 -9999 -9999 -9999 -9999 -9999 -9999 -9999 -9999 -9999 -9999 -9999 -9999 -9999 -9999 -9999 -9999 -9999 -9999 -9999 -9999 -9999 -9999 -9999 -9999 -9999 -9999 -9999

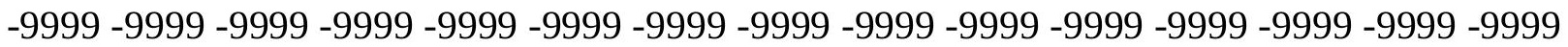
-9999 -9999 -9999 -9999 -9999 -9999 -9999 -9999 -9999 -9999 -9999 -9999 -9999 -9999 -9999 -9999 -9999 -9999 -9999 -9999 -9999 -9999 -9999 -9999 -9999 -9999 -9999 -9999 -9999

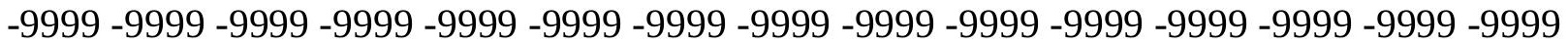
-9999 -9999 -9999 -9999 -9999 -9999 -9999 -9999 -9999 -9999 -9999 -9999 -9999 -9999 -9999 -9999 -9999 -9999 -9999 -9999 -9999 -9999 -9999 -9999 -9999 -9999 -9999 -9999 -9999 -9999 -9999 -9999 -9999 -9999 -9999 -9999 -9999 -9999 -9999 -9999 -9999 -9999 -9999 -9999 - 9999 -9999 -9999 -9999 -9999 -9999 -9999 -9999 -9999 -9999 -9999 -9999 -9999 -9999 -9999 -9999

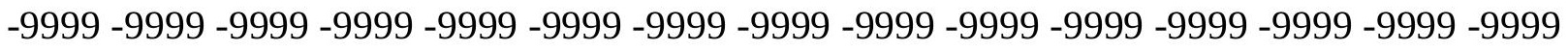
-9999 -9999 -9999 -9999 -9999 -9999 -9999 -9999 -9999 -9999 -9999 -9999 -9999 -9999 -9999 -9999 -9999 -9999 -9999 -9999 -9999 -9999 -9999 -9999 -9999 -9999 -9999 -9999 -9999 -9999 -9999 -9999 -9999 -9999 -9999 -9999 -9999 -9999 -9999 -9999 -9999 -9999 -9999 -9999 -9999 -

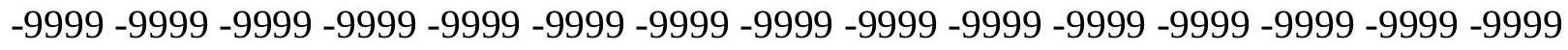

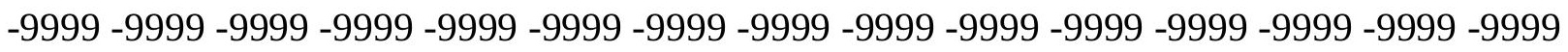
-9999 -9999 -9999 -9999 -9999 -9999 -9999 -9999 -9999 -9999 -9999 -9999 -9999 -9999 -9999 -9999 -9999 -9999 -9999 -9999 -9999 -9999 -9999 -9999 -9999 -9999 -9999 -9999 -9999 -9999 -9999 -9999 -9999 -9999 -9999 -9999 -9999 -9999 -9999 -9999 -9999 -9999 -9999 -9999 -9999 -

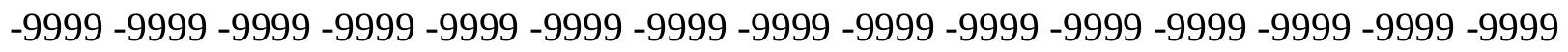
-9999 -9999 -9999 -9999 -9999 -9999 -9999 -9999 -9999 -9999 -9999 -9999 -9999 -9999 -9999 -9999 -9999 -9999 -9999 -9999 -9999 -9999 -9999 -9999 -9999 -9999 -9999 -9999 -9999 -9999 -

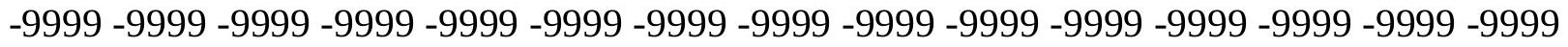
-9999 -9999 -9999 -9999 -9999 -9999 -9999 -9999 -9999 -9999 -9999 -9999 -9999 -9999 -9999 -9999 -9999 -9999 -9999 -9999 -9999 -9999 -9999 -9999 -9999 -9999 -9999 -9999 -9999 -999 -9999 -9999 -9999 -9999 -9999 -9999 -9999 -9999 -9999 -9999 -9999 -9999 -9999 -9999 -9999 -9999 -9999 -9999 -9999 -9999 -9999 -9999 -9999 -9999 -9999 -9999 -9999 -9999 -9999 -9999 -

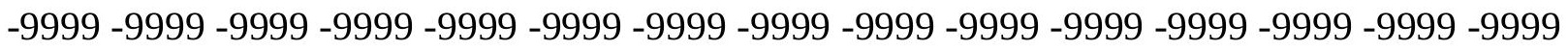

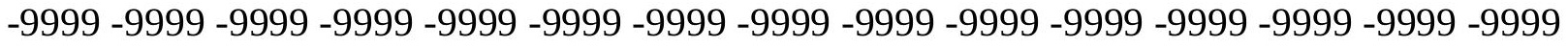
-9999 -9999 -9999 -9999 -9999 -9999 -9999 -9999 -9999 -9999 -9999 -9999 -9999 -9999 -

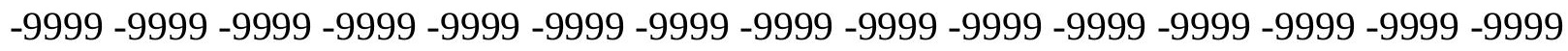

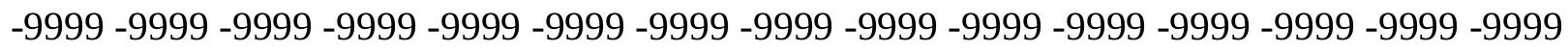

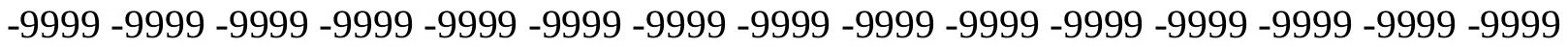
-9999 -9999 -9999 -9999 -9999 -9999 -9999 -9999 -9999 -9999 -9999 -9999 -9999 - 9999 - -999 -9999 -9999 -9999 -9999 -9999 -9999 -9999 -9999 -9999 -9999 -9999 -9999 -9999 -9999 -9999 -

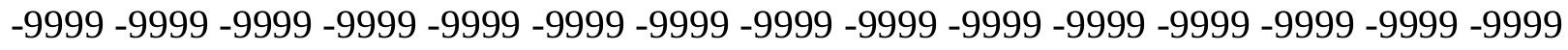

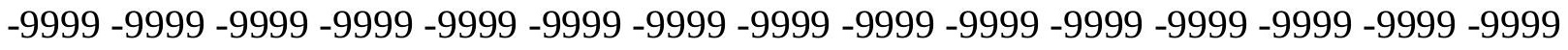
-9999 -9999 -9999 -9999 -9999 -9999 -9999 -9999 -9999 -9999 -9999 -9999 -9999 -9999 -9999 -9999 -9999 -9999 -9999 -9999 -9999 -9999 -9999 -9999-9999 -9999 -9999 -9999 -9999 -9999 -9999 -9999 -9999 -9999 -9999 -9999 -9999 -9999 -9999 -9999 -9999 -9999 -9999 -9999 -9999 -

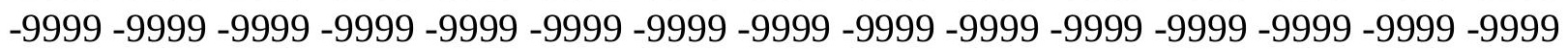


-9999 -9999 -9999 -9999 -9999 -9999 -9999 -9999 -9999 -9999 -9999 -9999 -9999 -9999 -9999 -9999 -9999 -9999 -9999 -9999 -9999 -9999 -9999 -9999 -9999 -9999 -9999 -9999 -9999 -9999 -

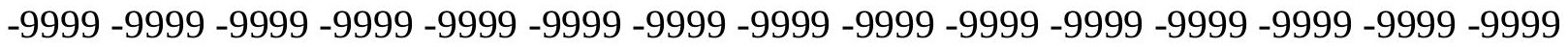
-9999 -9999 -9999 -9999 -9999 -9999 -9999 -9999 -9999 -9999 -9999 -9999 -9999 -9999 -9999 -9999 -9999 -9999 -9999 -9999 -9999 -9999 -9999 -9999-9999 -9999 -9999 -9999 -9999 -9999 -9999 -9999 -9999 -9999 -9999 -9999 -9999 -9999 -9999 -9999 -9999 -9999 -9999 -9999 -9999 -9999 -9999 -9999 -9999 -9999 -9999 -9999 -9999 -9999 -9999 -9999 -9999 -9999 -9999 -9999

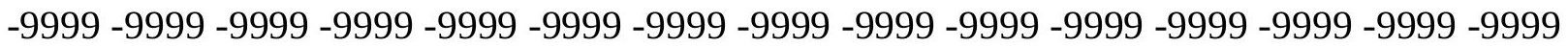

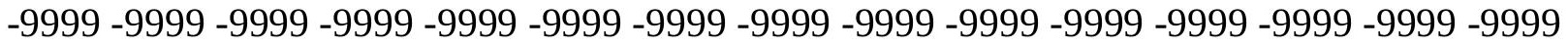
-9999 -9999 -9999 -9999 -9999 -9999 -9999 -9999 -9999 -9999 -9999 -9999 -9999 -9999 -9999 -9999 -9999 -9999 -9999 -9999 -9999 -9999 -9999 -9999 -9999 -9999 -9999 -9999 -9999 -9999 -9999 -9999 -9999 -9999 -9999 -9999 -9999 -9999 -9999 -9999 -9999 -9999 -9999 -9999 -9999 -9999 -9999 -9999 -9999 -9999 -9999 -9999 -9999 -9999 -9999 -9999 -9999 -9999 -9999 -9999 -9999 -9999 -9999 -9999 -9999 -9999 -9999 -9999 -9999 -9999 -9999 -9999 -9999 -9999 -9999 -9999 -9999 -9999 -9999 -9999 -9999 -9999 -9999 -9999 -9999 -9999 -9999 -9999 -9999 -9999 -9999 -9999 -9999 -9999 -9999 -9999 -9999 -9999 -9999 -9999 -9999 -9999 - 9999 - -999 -

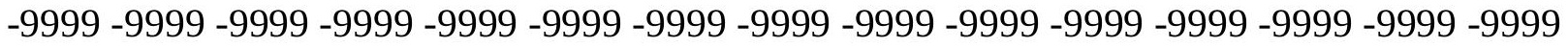
-9999 -9999 -9999 -9999 -9999 -9999 -9999 -9999 -9999 -9999 -9999 -9999 -9999 -9999 -9999 -9999 -9999 -9999 -9999 -9999 -9999 -9999 -9999 -9999 -9999 -9999 -9999 -9999 -9999 -9999 -

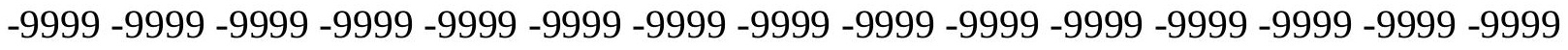
-9999 -9999 -9999 -9999 -9999 -9999 -9999 -9999 -9999 -9999 -9999 -9999 -9999 -9999 -9999

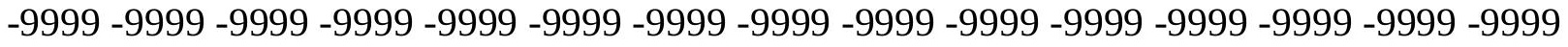
-9999 -9999 -9999 -9999 -9999 -9999 -9999 -9999 -9999 -9999 -9999 -9999 -9999 -9999 -9999 -9999 -9999 -9999 -9999 -9999 -9999 -9999 -9999 -9999 -9999 -9999 -9999 -9999 -9999 -9999 -

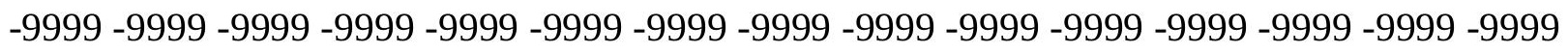
-9999 -9999 -9999 -9999 -9999 -9999 -9999 -9999 -9999 -9999 -9999 -9999 -9999 -9999 -9999 -9999 -9999 -9999 -9999 -9999 -9999 -9999 -9999 -9999 -9999 -9999 -9999 -9999 -9999 -9999 -

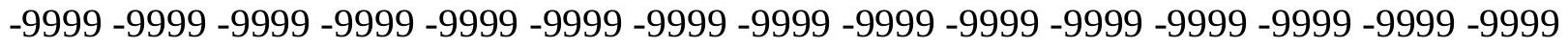
-9999 -9999 -9999 -9999 -9999 -9999 -9999 -9999 -9999 -9999 -9999 -9999 -9999 -9999 -9999 -9999 -9999 -9999 -9999 -9999 -9999 -9999 -9999 -9999 -9999 -9999 -9999 -9999 -9999 -999 -

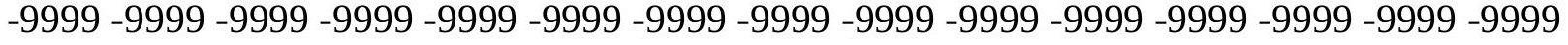
-9999 -9999 -9999 -9999 -9999 -9999 -9999 -9999 -9999 -9999 -9999 -9999 -9999 -9999 -9999 -

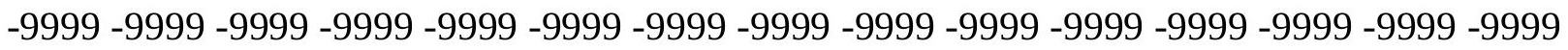

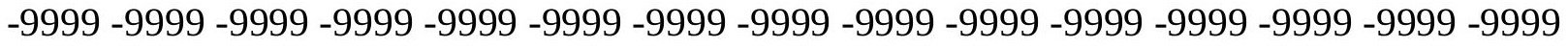

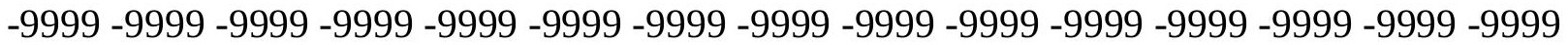
-9999 -9999 -9999 -9999 -9999 -9999 -9999 -9999 -9999 -9999 -9999 -9999 -9999 -9999 -9999 -

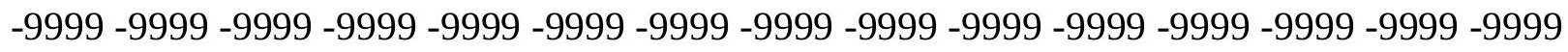

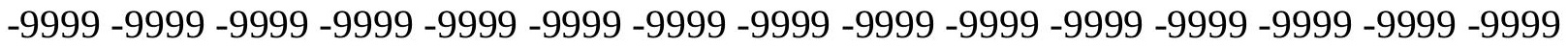
-9999 -9999 -9999 -9999 -9999 -9999 -9999 -9999 -9999 -9999 -9999 -9999 -9999 - 9999 - -999 -9999 -9999 -9999 -9999 -9999 -9999 -9999 -9999 -9999 -9999 -9999 -9999 -9999 -9999 -9999 -

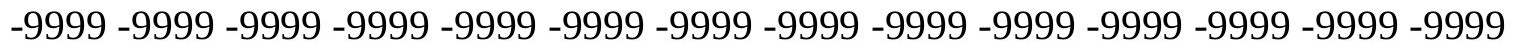

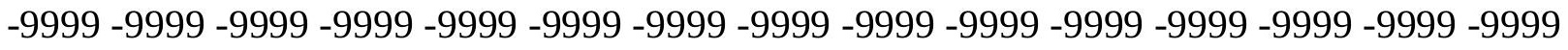
-9999 -9999 -9999 -9999 -9999 -9999 -9999 -9999 -9999 -9999 -9999 -9999 -9999 -9999 -9999 -9999 -9999 -9999 -9999 -9999 -9999 -9999 -9999 -9999-9999 -9999 -9999 -9999 -9999 -9999 -9999 -9999 -9999 -9999 -9999 -9999 -9999 -9999 -9999 -9999 -9999 -9999 -9999 -9999 -9999 -

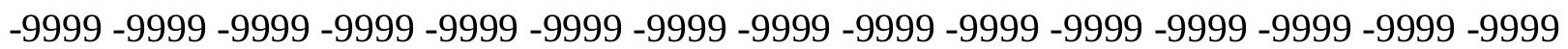


-9999 -9999 -9999 -9999 -9999 -9999 -9999 -9999 -9999 -9999 -9999 -9999 -9999 -9999 -9999 -9999 -9999 -9999 -9999 -9999 -9999 -9999 -9999 -9999 -9999 -9999 -9999 -9999 -9999 -9999 -9999 -9999 -9999 -9999 -9999 -9999 -9999 -9999 -9999 -9999 -9999 -9999 -9999 -9999 - 9999 -9999 -9999 -9999 -9999 -9999 -9999 -9999 -9999 -9999 -9999 -9999 -9999 -9999 -9999 -9999 -9999 -9999 -9999 -9999 -9999 -9999 -9999 -9999 -9999-9999 -9999 -9999 -9999 -9999 -9999 -9999 -9999 -9999 -9999 -9999 -9999 -9999 -9999 -9999 -9999 -9999 -9999 -9999 -9999 -9999 -9999 -9999 -9999 -9999 -9999 -9999 -9999 -9999 -9999 -9999 -9999 -9999 -9999 -9999 -9999

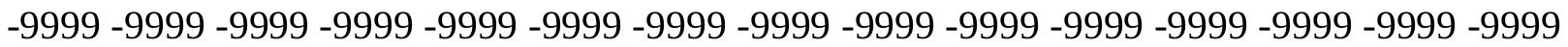
-9999 -9999 -9999 -9999 -9999 -9999 -9999 -9999 -9999 -9999 -9999 -9999 -9999 -9999 -9999 -9999 -9999 -9999 -9999 -9999 -9999 -9999 -9999 -9999 -9999 -9999 -9999 -9999 -9999 -9999

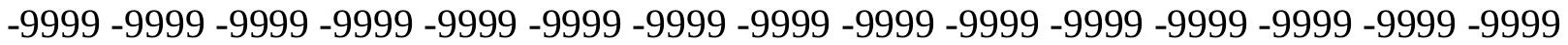
-9999 -9999 -9999 -9999 -9999 -9999 -9999 -9999 -9999 -9999 -9999 -9999 -9999 -9999 -9999 -9999 -9999 -9999 -9999 -9999 -9999 -9999 -9999 -9999 -9999 -9999 -9999 -9999 -9999 -9999 -

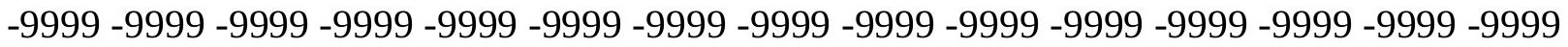
-9999 -9999 -9999 -9999 -9999 -9999 -9999 -9999 -9999 -9999 -9999 -9999 -9999 -9999 -9999

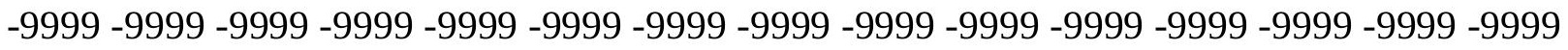
-9999 -9999 -9999 -9999 -9999 -9999 -9999 -9999 -9999 -9999 -9999 -9999 -9999 -9999 -9999 -9999 -9999 -9999 -9999 -9999 -9999 -9999 -9999 -9999 -9999 -9999 -9999 -9999 -9999 - 9999 -9999 -9999 -9999 -9999 -9999 -9999 -9999 -9999 -9999 -9999 -9999 -9999 -9999 -9999 -9999 -9999 -9999 -9999 -9999 -9999 -9999 -9999 -9999 -9999 -9999 -9999 -9999 -9999 -9999 -9999 -9999 -9999 -9999 -9999 -9999 -9999 -9999 -9999 -9999 -9999 -9999 -9999 -9999 -9999 -9999 -9999 -9999 -9999 -9999 -9999 -9999 -9999 -9999 -9999 -9999 -9999 -9999 -9999 -9999 -9999 -9999 -9999 -9999 -9999 -9999 -9999 -9999 -9999 -9999 -9999 -9999 -9999 -9999 -9999 -9999 -9999 -9999 -9999 -9999 -9999 -9999 -9999 -9999 -9999 -9999 -9999 -9999 -9999 -9999 -9999 -9999 -9999 -9999 -9999 -9999 -9999 -9999 -9999 -9999 -9999 -9999 -9999 -9999 -9999 -9999 -9999 -9999 -9999 -9999 -9999 -9999 -9999 -9999 -9999 -9999 -9999 -9999 -9999 -9999 -9999 -9999 -9999 -9999 -9999 -9999 -9999 -9999 -9999 -9999 -9999 -9999 -9999 -9999 -9999 -9999 -9999 -9999 -9999 -9999 -9999 -9999 -9999 -9999 -9999 -9999 -9999 -9999 -9999 -9999 -9999 -9999 -9999 -9999 -9999 -9999 -9999 -9999 -9999 -9999 -9999 -9999 -9999 -9999 -9999 -9999 -9999 -9999 -9999 -9999 -9999 -9999 -9999 -9999 -9999 -9999 -9999 -9999 -9999 -999 -9999 -9999 -9999 -9999 -9999 -9999 -9999 -9999 -9999 -9999 -9999 -9999 -9999 -9999 -9999 -9999 -9999 -9999 -9999 -9999 -9999 -9999 -9999 -9999 -9999 -9999 -9999 -9999 -9999 -9999 -

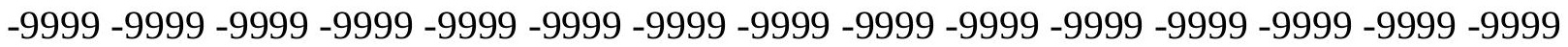

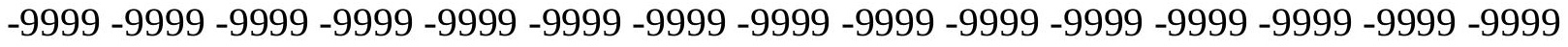

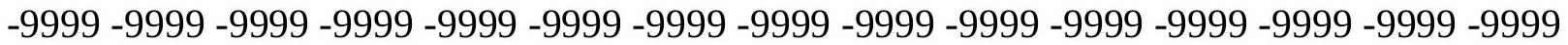
-9999 -9999 -9999 -9999 -9999 -9999 -9999 -9999 -9999 -9999 -9999 -9999 -9999 -9999 -9999

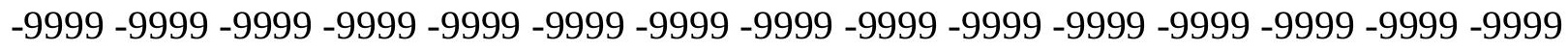

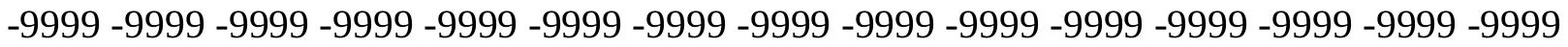

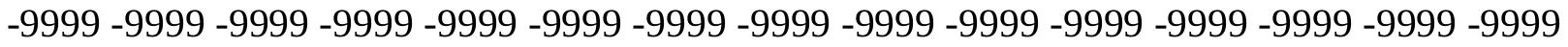
-9999 -9999 -9999 -9999 -9999 -9999 -9999 -9999 -9999 -9999 -9999 -9999 -9999 -9999 -9999 -

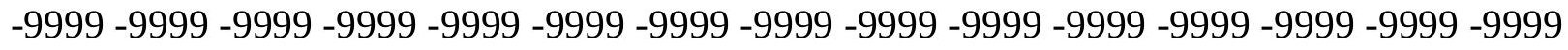

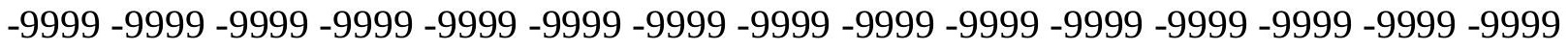
-9999 -9999 -9999 -9999 -9999 -9999 -9999 -9999 -9999 -9999 -9999 -9999 -9999 -9999 -9999 -9999 -9999 -9999 -9999 -9999 -9999 -9999 -9999 -9999-9999 -9999 -9999 -9999 -9999 -9999 -9999 -9999 -9999 -9999 -9999 -9999 -9999 -9999 -9999 -9999 -9999 -9999 -9999 -9999 -9999 -

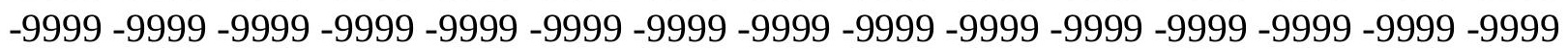


-9999 -9999 -9999 -9999 -9999 -9999 -9999 -9999 -9999 -9999 -9999 -9999 -9999 -9999 -9999 -9999 -9999 -9999 -9999 -9999 -9999 -9999 -9999 -9999 -9999 -9999 -9999 -9999 -9999 -9999 -9999 -9999 -9999 -9999 -9999 -9999 -9999 -9999 -9999 -9999 -9999 -9999 -9999 -9999 -9999 -9999 -9999 -9999 -9999 -9999 -9999 -9999 -9999 -9999 -9999 -9999 -9999 -9999 -9999 -9999 -9999 -9999 -9999 -9999 -9999 -9999 -9999 -9999 -9999 -9999 -9999 -9999 -9999 -9999 -9999 -9999 -9999 -9999 -9999 -9999 -9999 -9999 -9999 -9999 -9999 -9999 -9999 -9999 -9999 -9999 -9999 -9999 -9999 -9999 -9999 -9999 -9999 -9999 -9999 -9999 -9999 -9999 -9999 -9999 -

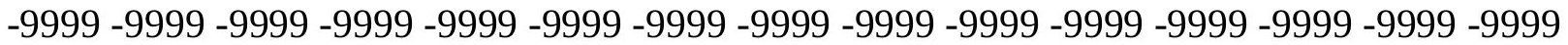
-9999 -9999 -9999 -9999 -9999 -9999 -9999 -9999 -9999 -9999 -9999 -9999 -9999 -9999 -9999 -9999 -9999 -9999 -9999 -9999 -9999 -9999 -9999 -9999 -9999 -9999 -9999 -9999 -9999 -9999 -

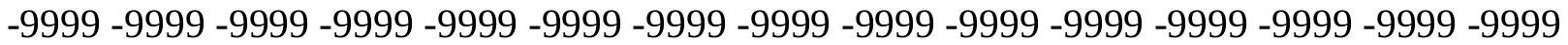
-9999 -9999 -9999 -9999 -9999 -9999 -9999 -9999 -9999 -9999 -9999 -9999 -9999 -9999 -9999 -9999 -9999 -9999 -9999 -9999 -9999 -9999 -9999 -9999 -9999 -9999 -9999 -9999 -9999 -9999 -9999 -9999 -9999 -9999 -9999 -9999 -9999 -9999 -9999 -9999 -9999 -9999 -9999 -9999 -9999 -9999 -9999 -9999 -9999 -9999 -9999 -9999 -9999 -9999 -9999 -9999 -9999 -9999 -9999 -9999 -9999 -9999 -9999 -9999 -9999 -9999 -9999 -9999 -9999 -9999 -9999 -9999 -9999 -9999 -9999 -9999 -9999 -9999 -9999 -9999 -9999 -9999 -9999 -9999 -9999 -9999 -9999 -9999 -9999 -9999 -9999 -9999 -9999 -9999 -9999 -9999 -9999 -9999 -9999 -9999 -9999 -9999 -9999 -9999 -9999 -9999 -9999 -9999 -9999 -9999 -9999 -9999 -9999 -9999 -9999 -9999 -9999 -9999 -9999 -9999 -9999 -9999 -9999 -9999 -9999 -9999 -9999 -9999 -9999 -9999 -9999 -9999 -9999 -9999 -9999

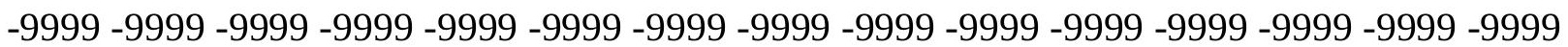
-9999 -9999 -9999 -9999 -9999 -9999 -9999 -9999 -9999 -9999 -9999 -9999 -9999 -9999 -9999 -9999 -9999 -9999 -9999 -9999 -9999 -9999 -9999 -9999 -9999 -9999 -9999 -9999 -9999 -9999 -9999 -9999 -9999 -9999 -9999 -9999 -9999 -9999 -9999 -9999 -9999 -9999 -9999 -9999 -9999

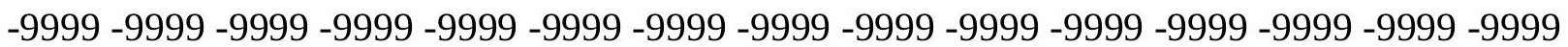
-9999 -9999 -9999 -9999 -9999 -9999 -9999 -9999 -9999 -9999 -9999 -9999 -9999 -9999 -9999 -9999 -9999 -9999 -9999 -9999 -9999 -9999 -9999 -9999 -9999 -9999 -9999 -9999 -9999 -9999 -9999 -9999 -9999 -9999 -9999 -9999 -9999 -9999 -9999 -9999 -9999 -9999 -9999 -9999

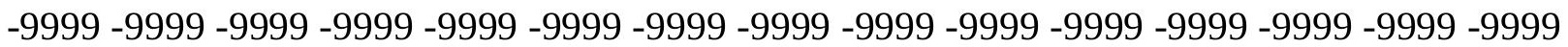
-9999 -9999 -9999 -9999 -9999 -9999 -9999 -9999 -9999 -9999 -9999 -9999 -9999 -9999 -9999 -9999 -9999 -9999 -9999 -9999 -9999 -9999 -9999 -9999 -9999 -9999 -9999 -9999 -9999 -9999 -

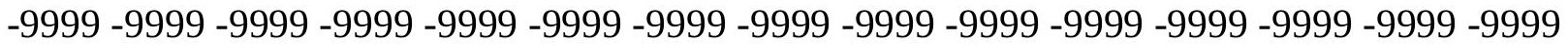
-9999 -9999 -9999 -9999 -9999 -9999 -9999 -9999 -9999 -9999 -9999 -9999 -9999 -9999 -9999 -9999 -9999 -9999 -9999 -9999 -9999 -9999 -9999 -9999 -9999 -9999 -9999 -9999 -9999 -9999 -9999 -9999 -9999 -9999 -9999 -9999 -9999 -9999 -9999 -9999 -9999 -9999 -9999 -9999 -9999 -9999 -9999 -9999 -9999 -9999 -9999 -9999 -9999 -9999 -9999 -9999 -9999 -9999 -9999 -9999 -9999 -9999 -9999 -9999 -9999 -9999 -9999 -9999 -9999 -9999 -9999 -9999 -9999 -9999 -9999

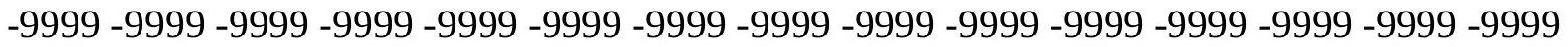
-9999 -9999 -9999 -9999 -9999 -9999 -9999 -9999 -9999 -9999 -9999 -9999 -9999 -9999 -9999 -9999 -9999 -9999 -9999 -9999 -9999 -9999 -9999 -9999 -9999 -9999 -9999 -9999 -9999 -9999 -

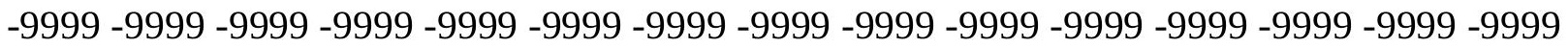
-9999 -9999 -9999 -9999 -9999 -9999 -9999 -9999 -9999 -9999 -9999 -9999 -9999 -9999 -9999 -9999 -9999 -9999 -9999 -9999 -9999 -9999 -9999 -9999 -9999 -9999 -9999 -9999 -9999 -9999 -9999 -9999 -9999 -9999 -9999 -9999 -9999 -9999 -9999 -9999 -9999 -9999 -9999 -9999 -9999 -9999 -9999 -9999 -9999 -9999 -9999 -9999 -9999 -9999 -9999 -9999 -9999 -9999 -9999 -9999

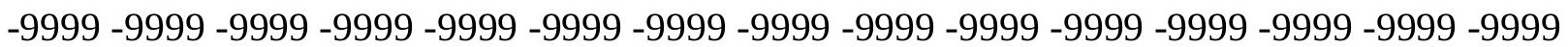


-9999 -9999 -9999 -9999 -9999 -9999 -9999 -9999 -9999 -9999 -9999 -9999 -9999 -9999 -9999 -9999 -9999 -9999 -9999 -9999 -9999 -9999 -9999 -9999 -9999 -9999 -9999 -9999 -9999 -9999 -

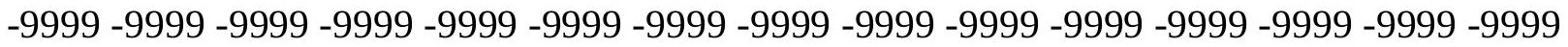
-9999 -9999 -9999 -9999 -9999 -9999 -9999 -9999 -9999 -9999 -9999 -9999 -9999 -9999 -9999 -9999 -9999 -9999 -9999 -9999 -9999 -9999 -9999 -9999-9999 -9999 -9999 -9999 -9999 -9999 -9999 -9999 -9999 -9999 -9999 -9999 -9999 -9999 -9999 -9999 -9999 -9999 -9999 -9999 -9999 -9999 -9999 -9999 -9999 -9999 -9999 -9999 -9999 -9999 -9999 -9999 -9999 -9999 -9999 -

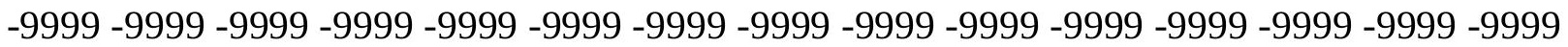

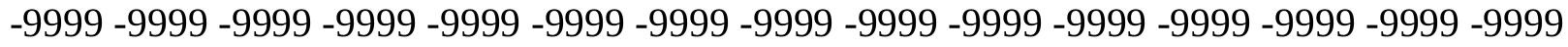
-9999 -9999 -9999 -9999 -9999 -9999 -9999 -9999 -9999 -9999 -9999 -9999 -9999 -9999 -9999 -9999 -9999 -9999 -9999 -9999 -9999 -9999 -9999 -9999 -9999 -9999 -9999 -9999 -9999 -9999 -9999 -9999 -9999 -9999 -9999 -9999 -9999 -9999 -9999 -9999 -9999 -9999 -9999 -9999 -9999 -9999 -9999 -9999 -9999 -9999 -9999 -9999 -9999 -9999 -9999 -9999 -9999 -9999 -9999 -9999 -9999 -9999 -9999 -9999 -9999 -9999 -9999 -9999 -9999 -9999 -9999 -9999 -9999 -9999 -9999 -9999 -9999 -9999 -9999 -9999 -9999 -9999 -9999 -9999 -9999 -9999 -9999 -9999 -9999 -9999 -

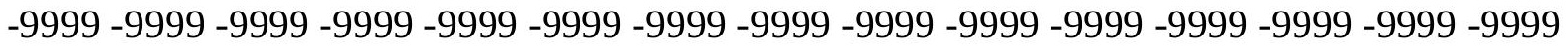
-9999 -9999 -9999 -9999 -9999 -9999 -9999 -9999 -9999 -9999 -9999 -9999 -9999 -9999 -9999 -9999 -9999 -9999 -9999 -9999 -9999 -9999 -9999 -9999 -9999 -9999 -9999 -9999 -9999 -9999 -9999 -9999 -9999 -9999 -9999 -9999 -9999 -9999 -9999 -9999 -9999 -9999 -9999 -9999 -9999 -

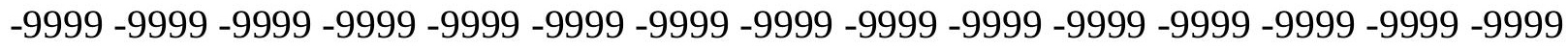

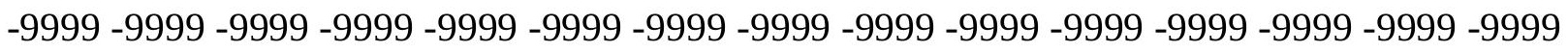

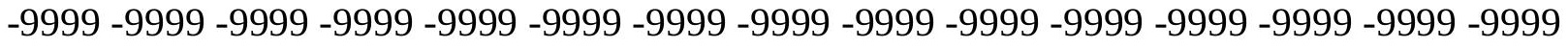
-9999 -9999 -9999 -9999 -9999 -9999 -9999 -9999 -9999 -9999 -9999 -9999 -9999 -9999 -9999 -9999 -9999 -9999 -9999 -9999 -9999 -9999 -9999 -9999 -9999 -9999 -9999 -9999 -9999 -9999 -

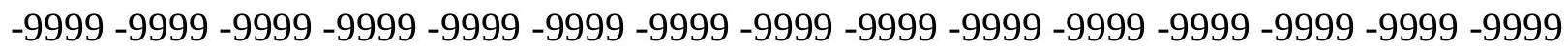
-9999 -9999 -9999 -9999 -9999 -9999 -9999 -9999 -9999 -9999 -9999 -9999 -9999 -9999 -9999 -9999 -9999 -9999 -9999 -9999 -9999 -9999 -9999 -9999 -9999 -9999 -9999 -9999 -9999 -9999 -

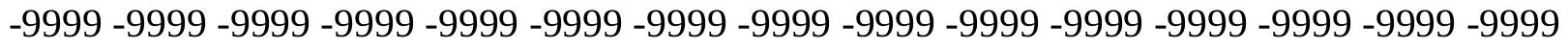
-9999 -9999 -9999 -9999 -9999 -9999 -9999 -9999 -9999 -9999 -9999 -9999 -9999 -9999 -9999 -9999 -9999 -9999 -9999 -9999 -9999 -9999 -9999 -9999 -9999 -9999 -9999 -9999 -9999 -999 -9999 -9999 -9999 -9999 -9999 -9999 -9999 -9999 -9999 -9999 -9999 -9999 -9999 -9999 -9999 -

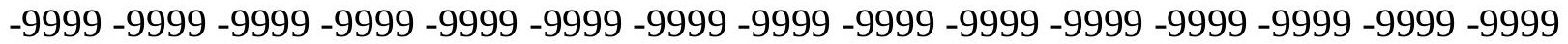

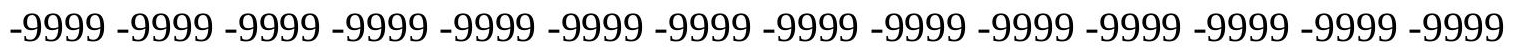

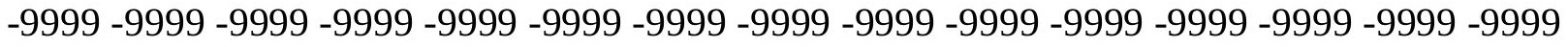

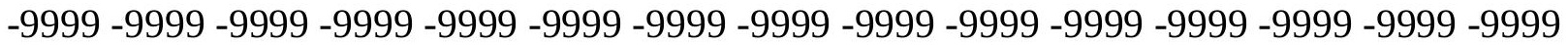

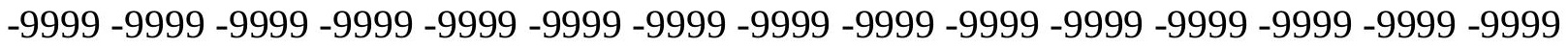

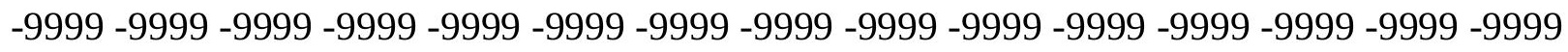

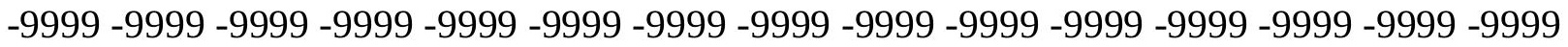

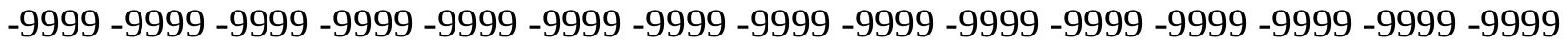
-9999 -9999 -9999 -9999 -9999 -9999 -9999 -9999 -9999 -9999 -9999 -9999 -9999 -9999 -9999 -

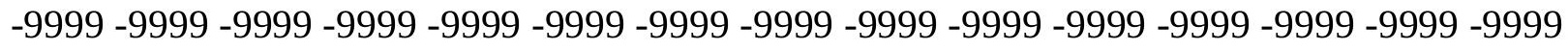

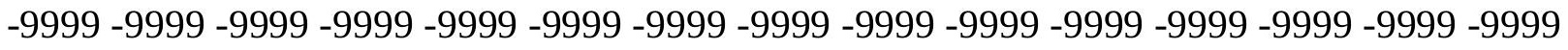
-9999 -9999 -9999 -9999 -9999 -9999 -9999 -9999 -9999 -9999 -9999 -9999 -9999 -9999 -9999 -9999 -9999 -9999 -9999 -9999 -9999 -9999 -9999 -9999-9999 -9999 -9999 -9999 -9999 -9999 -9999 -9999 -9999 -9999 -9999 -9999 -9999 -9999 -9999 -9999 -9999 -9999 -9999 -9999 -9999 -

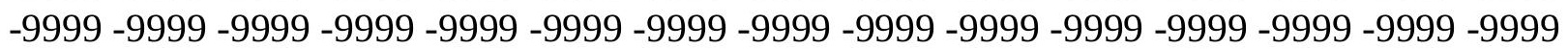


-9999 -9999 -9999 -9999 -9999 -9999 -9999 -9999 -9999 -9999 -9999 -9999 -9999 -9999 -9999 -9999 -9999 -9999 -9999 -9999 -9999 -9999 -9999 -9999 -9999 -9999 -9999 -9999 -9999 -9999 -

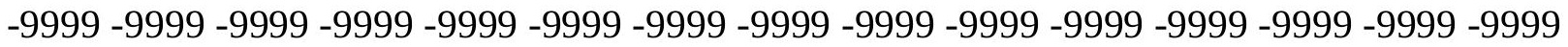
-9999 -9999 -9999 -9999 -9999 -9999 -9999 -9999 -9999 -9999 -9999 -9999 -9999 -9999 -9999 -9999 -9999 -9999 -9999 -9999 -9999 -9999 -9999 -9999-9999 -9999 -9999 -9999 -9999 -9999 -9999 -9999 -9999 -9999 -9999 -9999 -9999 -9999 -9999 -9999 -9999 -9999 -9999 -9999 -9999 -9999 -9999 -9999 -9999 -9999 -9999 -9999 -9999 -9999 -9999 -9999 -9999 -9999 -9999 -9999

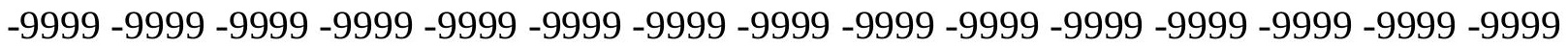

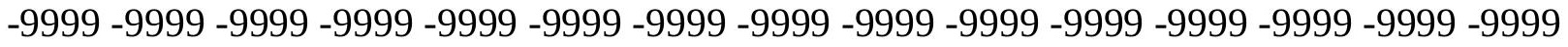
-9999 -9999 -9999 -9999 -9999 -9999 -9999 -9999 -9999 -9999 -9999 -9999 -9999 -9999 -9999 -9999 -9999 -9999 -9999 -9999 -9999 -9999 -9999 -9999 -9999 -9999 -9999 -9999 -9999 -9999 -9999 -9999 -9999 -9999 -9999 -9999 -9999 -9999 -9999 -9999 -9999 -9999 -9999 -9999 -9999 -9999 -9999 -9999 -9999 -9999 -9999 -9999 -9999 -9999 -9999 -9999 -9999 -9999 -9999 -9999 -9999 -9999 -9999 -9999 -9999 -9999 -9999 -9999 -9999 -9999 -9999 -9999 -9999 -9999 -9999 -9999 -9999 -9999 -9999 -9999 -9999 -9999 -9999 -9999 -9999 -9999 -9999 -9999 -9999 -

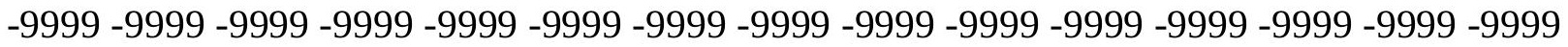
-9999 -9999 -9999 -9999 -9999 -9999 -9999 -9999 -9999 -9999 -9999 -9999 -9999 -9999 -9999 -9999 -9999 -9999 -9999 -9999 -9999 -9999 -9999 -9999 -9999 -9999 -9999 -9999 -9999 -9999 -9999 -9999 -9999 -9999 -9999 -9999 -9999 -9999 -9999 -9999 -9999 -9999 -9999 -9999 -9999 -

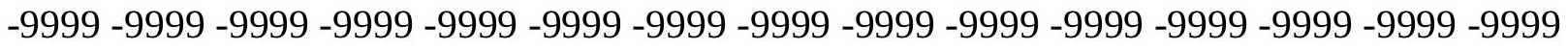
-9999 -9999 -9999 -9999 -9999 -9999 -9999 -9999 -9999 -9999 -9999 -9999 -9999 -9999 -9999

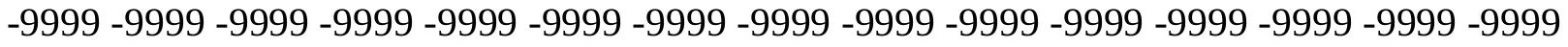
-9999 -9999 -9999 -9999 -9999 -9999 -9999 -9999 -9999 -9999 -9999 -9999 -9999 -9999 -9999 -9999 -9999 -9999 -9999 -9999 -9999 -9999 -9999 -9999 -9999 -9999 -9999 -9999 -9999 -9999 -

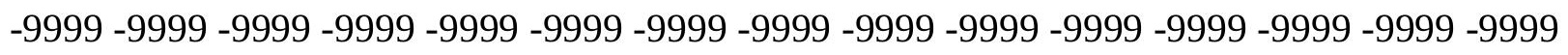
-9999 -9999 -9999 -9999 -9999 -9999 -9999 -9999 -9999 -9999 -9999 -9999 -9999 -9999 -9999 -9999 -9999 -9999 -9999 -9999 -9999 -9999 -9999 -9999 -9999 -9999 -9999 -9999 -9999 -9999 -

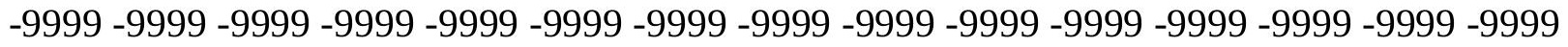
-9999 -9999 -9999 -9999 -9999 -9999 -9999 -9999 -9999 -9999 -9999 -9999 -9999 -9999 -9999 -9999 -9999 -9999 -9999 -9999 -9999 -9999 -9999 -9999 -9999 -9999 -9999 -9999 -9999 -999 -9999 -9999 -9999 -9999 -9999 -9999 -9999 -9999 -9999 -9999 -9999 -9999 -9999 -9999 -9999 -9999 -9999 -9999 -9999 -9999 -9999 -9999 -9999 -9999 -9999 -9999 -9999 -9999 -9999 -9999 -

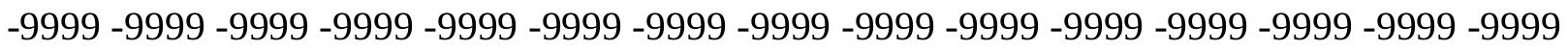

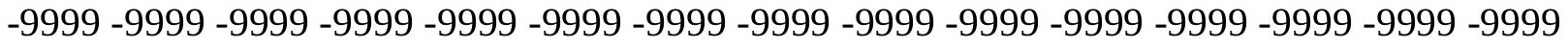

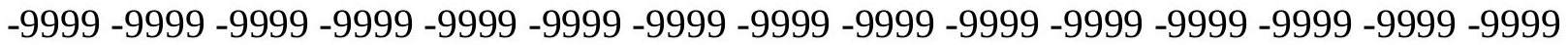
-9999 -9999 -9999 -9999 -9999 -9999 -9999 -9999 -9999 -9999 -9999 -9999 -9999 -9999 -9999 -

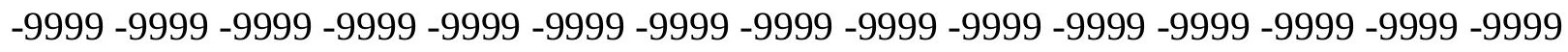

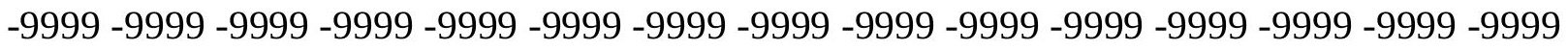
-9999 -9999 -9999 -9999 -9999 -9999 -9999 -9999 -9999 -9999 -9999 -9999 -9999 -9999 - -999 -9999 -9999 -9999 -9999 -9999 -9999 -9999 -9999 -9999 -9999 -9999 -9999 -9999 -9999 -9999 -

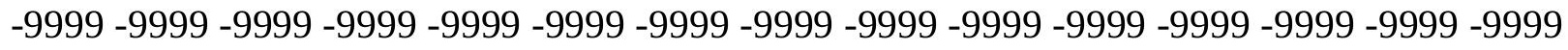

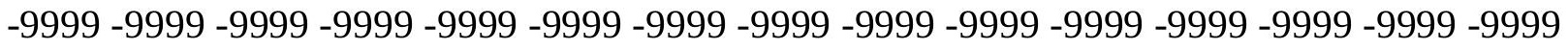
-9999 -9999 -9999 -9999 -9999 -9999 -9999 -9999 -9999 -9999 -9999 -9999 -9999 -9999 -9999 -9999 -9999 -9999 -9999 -9999 -9999 -9999 -9999 -9999-9999 -9999 -9999 -9999 -9999 -9999 -9999 -9999 -9999 -9999 -9999 -9999 -9999 -9999 -9999 -9999 -9999 -9999 -9999 -9999 -9999 -

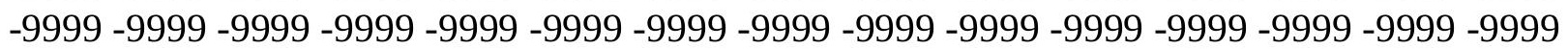


-9999 -9999 -9999 -9999 -9999 -9999 -9999 -9999 -9999 -9999 -9999 -9999 -9999 -9999 -9999 -9999 -9999 -9999 -9999 -9999 -9999 -9999 -9999 -9999 -9999 -9999 -9999 -9999 -9999 -9999 -

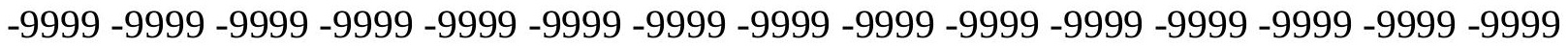
-9999 -9999 -9999 -9999 -9999 -9999 -9999 -9999 -9999 -9999 -9999 -9999 -9999 -9999 -9999 -9999 -9999 -9999 -9999 -9999 -9999 -9999 -9999 -9999-9999 -9999 -9999 -9999 -9999 -9999 -9999 -9999 -9999 -9999 -9999 -9999 -9999 -9999 -9999 -9999 -9999 -9999 -9999 -9999 -9999 -9999 -9999 -9999 -9999 -9999 -9999 -9999 -9999 -9999 -9999 -9999 -9999 -9999 -9999 -9999

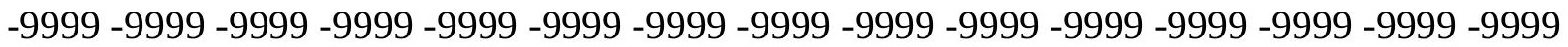

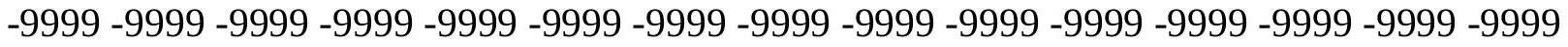
-9999 -9999 -9999 -9999 -9999 -9999 -9999 -9999 -9999 -9999 -9999 -9999 -9999 -9999 -9999 -9999 -9999 -9999 -9999 -9999 -9999 -9999 -9999 -9999 -9999 -9999 -9999 -9999 -9999 -9999 -9999 -9999 -9999 -9999 -9999 -9999 -9999 -9999 -9999 -9999 -9999 -9999 -9999 -9999 -9999 -9999 -9999 -9999 -9999 -9999 -9999 -9999 -9999 -9999 -9999 -9999 -9999 -9999 -9999 -9999 -

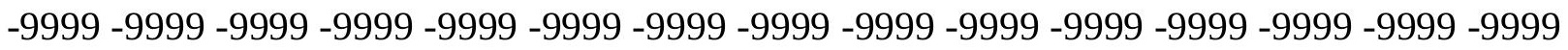
-9999 -9999 -9999 -9999 -9999 -9999 -9999 -9999 -9999 -9999 -9999 -9999 -9999 -9999 -9999 -

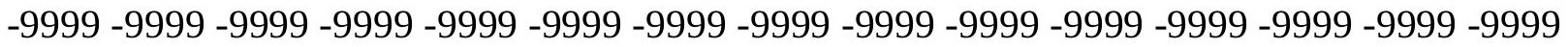
-9999 -9999 -9999 -9999 -9999 -9999 -9999 -9999 -9999 -9999 -9999 -9999 -9999 -9999 -9999 -9999 -9999 -9999 -9999 -9999 -9999 -9999 -9999 -9999 -9999 -9999 -9999 -9999 -9999 -9999 -9999 -9999 -9999 -9999 -9999 -9999 -9999 -9999 -9999 -9999 -9999 -9999 -9999 -9999 - -999 -

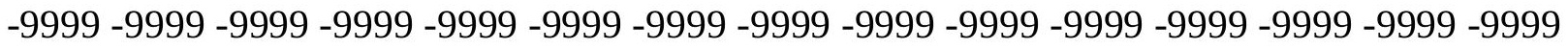

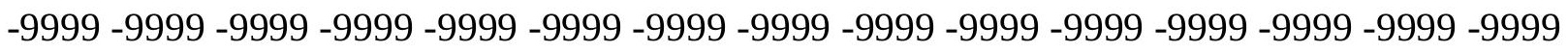
-9999 -9999 -9999 -9999 -9999 -9999 -9999 -9999 -9999 -9999 -9999 -9999 -9999 -9999 -9999 -9999 -9999 -9999 -9999 -9999 -9999 -9999 -9999 -9999 -9999 -9999 -9999 -9999 -9999 -9999 -9999 -9999 -9999 -9999 -9999 -9999 -9999 -9999 -9999 -9999 -9999 -9999 -9999 -9999 -9999 -

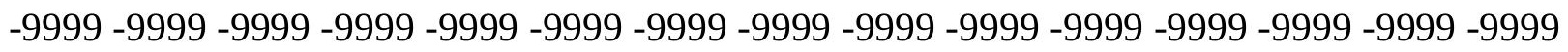
-9999 -9999 -9999 -9999 -9999 -9999 -9999 -9999 -9999 -9999 -9999 -9999 -9999 -9999 -9999 -9999 -9999 -9999 -9999 -9999 -9999 -9999 -9999 -9999 -9999 -9999 -9999 -9999 -9999 -9999 -

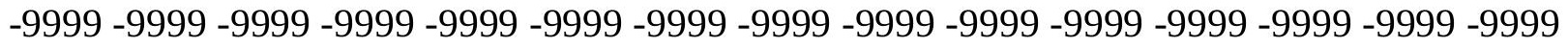
-9999 -9999 -9999 -9999 -9999 -9999 -9999 -9999 -9999 -9999 -9999 -9999 -9999 -9999 -9999 -9999 -9999 -9999 -9999 -9999 -9999 -9999 -9999 -9999 -9999 -9999 -9999 -9999 -9999 -999 -

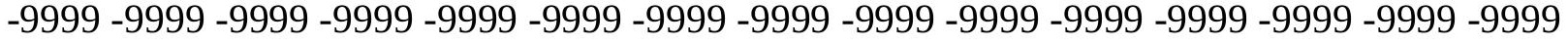
-9999 -9999 -9999 -9999 -9999 -9999 -9999 -9999 -9999 -9999 -9999 -9999 -9999 -9999 -9999 -

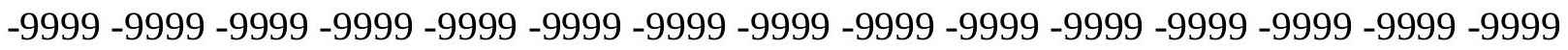

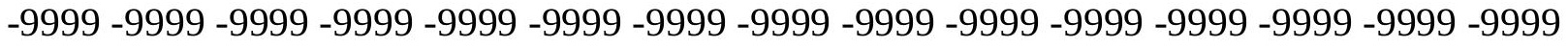

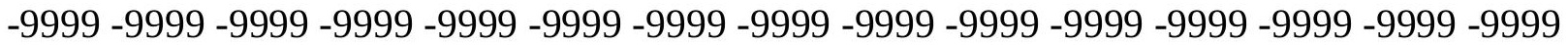

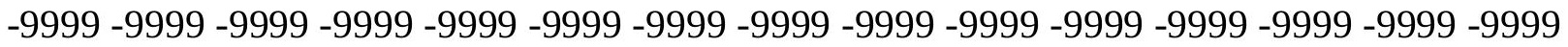

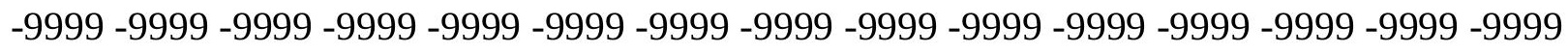

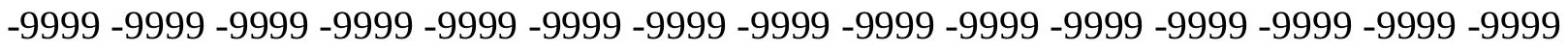

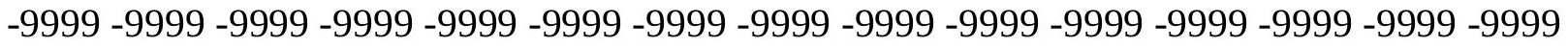
-9999 -9999 -9999 -9999 -9999 -9999 -9999 -9999 -9999 -9999 -9999 -9999 -9999 -9999 -9999 -

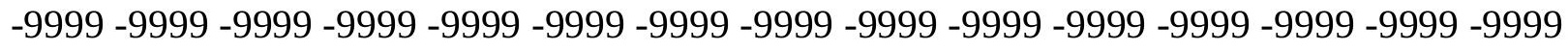

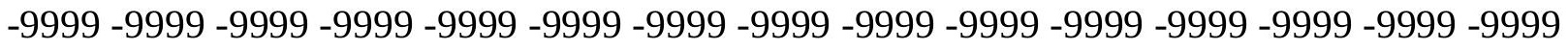
-9999 -9999 -9999 -9999 -9999 -9999 -9999 -9999 -9999 -9999 -9999 -9999 -9999 -9999 -9999 -9999 -9999 -9999 -9999 -9999 -9999 -9999 -9999 -9999 -9999 -9999 -9999 -9999 -9999 -9999 -9999 -9999 -9999 -9999 -9999 -9999 -9999 -9999 -9999 -9999 -9999 -9999 -9999 -9999 -

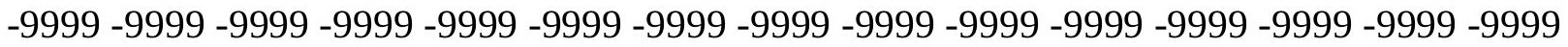


-9999 -9999 -9999 -9999 -9999 -9999 -9999 -9999 -9999 -9999 -9999 -9999 -9999 -9999 -9999 -9999 -9999 -9999 -9999 -9999 -9999 -9999 -9999 -9999 -9999 -9999 -9999 -9999 -9999 -9999 -

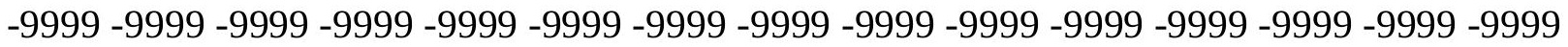
-9999 -9999 -9999 -9999 -9999 -9999 -9999 -9999 -9999 -9999 -9999 -9999 -9999 -9999 -9999 -9999 -9999 -9999 -9999 -9999 -9999 -9999 -9999 -9999-9999 -9999 -9999 -9999 -9999 -9999 -9999 -9999 -9999 -9999 -9999 -9999 -9999 -9999 -9999 -9999 -9999 -9999 -9999 -9999 -9999 -9999 -9999 -9999 -9999 -9999 -9999 -9999 -9999 -9999 -9999 -9999 -9999 -9999 -9999 -9999

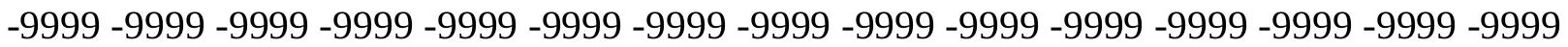

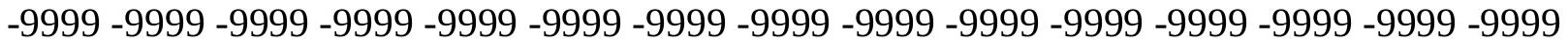
-9999 -9999 -9999 -9999 -9999 -9999 -9999 -9999 -9999 -9999 -9999 -9999 -9999 -9999 -9999 -9999 -9999 -9999 -9999 -9999 -9999 -9999 -9999 -9999 -9999 -9999 -9999 -9999 -9999 -9999 -9999 -9999 -9999 -9999 -9999 -9999 -9999 -9999 -9999 -9999 -9999 -9999 -9999 -9999 -9999 -9999 -9999 -9999 -9999 -9999 -9999 -9999 -9999 -9999 -9999 -9999 -9999 -9999 -9999 -9999 -

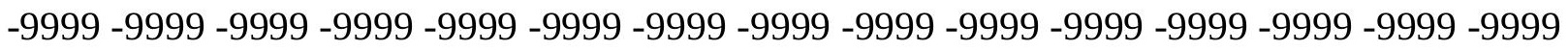
-9999 -9999 -9999 -9999 -9999 -9999 -9999 -9999 -9999 -9999 -9999 -9999 -9999 -9999 -9999 -

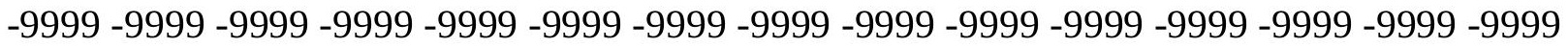
-9999 -9999 -9999 -9999 -9999 -9999 -9999 -9999 -9999 -9999 -9999 -9999 -9999 -9999 -9999 -9999 -9999 -9999 -9999 -9999 -9999 -9999 -9999 -9999 -9999 -9999 -9999 -9999 -9999 - 9999 -9999 -9999 -9999 -9999 -9999 -9999 -9999 -9999 -9999 -9999 -9999 -9999 -9999 -9999 -9999 -

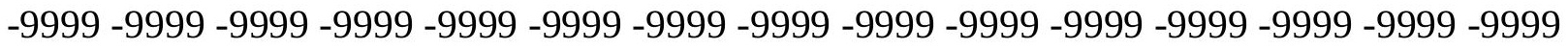

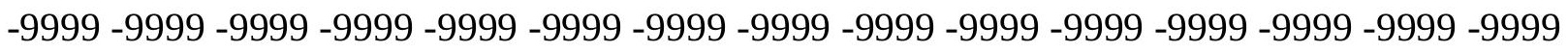
-9999 -9999 -9999 -9999 -9999 -9999 -9999 -9999 -9999 -9999 -9999 -9999 -9999 -9999 - 9999 -9999 -9999 -9999 -9999 -9999 -9999 -9999 -9999 -9999 -9999 -9999 -9999 -9999 -9999 -9999 -9999 -9999 -9999 -9999 -9999 -9999 -9999 -9999 -9999 -9999 -9999 -9999 -9999 -9999 -9999 -9999 -9999 -9999 -9999 -9999 -9999 -9999 -9999 -9999 -9999 -9999 -9999 -9999 -9999 -9999 -9999 -9999 -9999 -9999 -9999 -9999 -9999 -9999 -9999 -9999 -9999 -9999 -9999 -9999 -9999 -9999 -9999 -9999 -9999 -9999 -9999 -9999 -9999 -9999 -9999 -9999 -9999 -9999 -9999 -

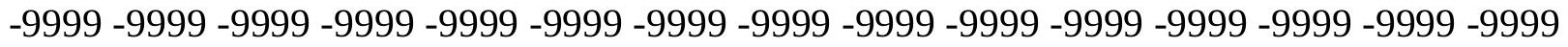
-9999 -9999 -9999 -9999 -9999 -9999 -9999 -9999 -9999 -9999 -9999 -9999 -9999 -9999 -9999 -9999 -9999 -9999 -9999 -9999 -9999 -9999 -9999 -9999 -9999 -9999 -9999 -9999 -9999 -999 -9999 -9999 -9999 -9999 -9999 -9999 -9999 -9999 -9999 -9999 -9999 -9999 -9999 -9999 -9999 -9999 -9999 -9999 -9999 -9999 -9999 -9999 -9999 -9999 -9999 -9999 -9999 -9999 -9999 -9999 -

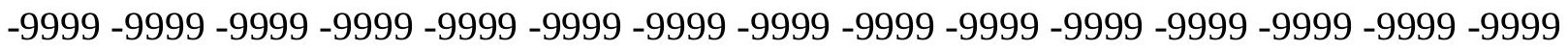

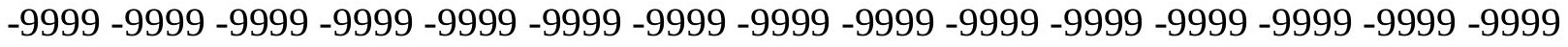

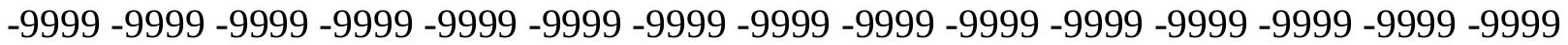

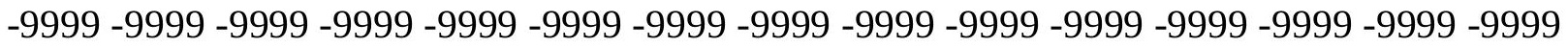

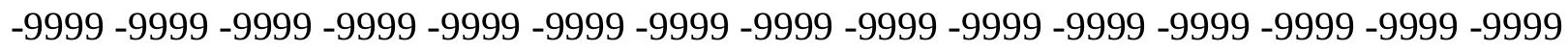

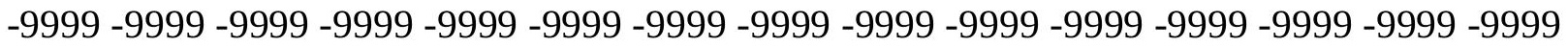

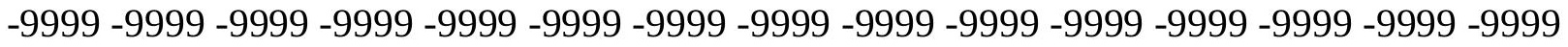
-9999 -9999 -9999 -9999 -9999 -9999 -9999 -9999 -9999 -9999 -9999 -9999 -9999 -9999 -9999 -

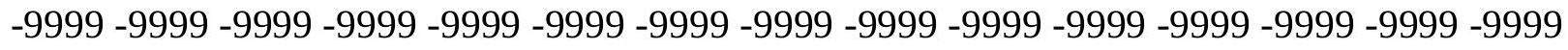

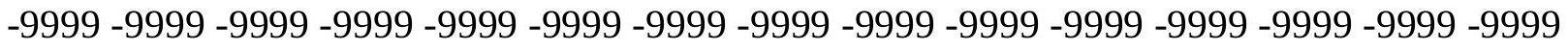
-9999 -9999 -9999 -9999 -9999 -9999 -9999 -9999 -9999 -9999 -9999 -9999 -9999 -9999 -9999 -9999 -9999 -9999 -9999 -9999 -9999 -9999 -9999 -9999-9999 -9999 -9999 -9999 -9999 -9999 -9999 -9999 -9999 -9999 -9999 -9999 -9999 -9999 -9999 -9999 -9999 -9999 -9999 -9999 -9999 -

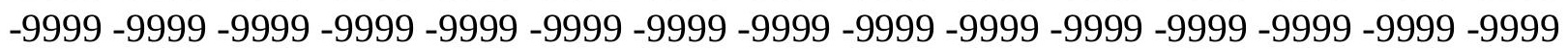


-9999 -9999 -9999 -9999 -9999 -9999 -9999 -9999 -9999 -9999 -9999 -9999 -9999 -9999 -9999 -9999 -9999 -9999 -9999 -9999 -9999 -9999 -9999 -9999 -9999 -9999 -9999 -9999 -9999 -9999 -9999 -9999 -9999 -9999 -9999 -9999 -9999 -9999 -9999 -9999 -9999 -9999 -9999 -9999 - 9999 -9999 -9999 -9999 -9999 -9999 -9999 -9999 -9999 -9999 -9999 -9999 -9999 -9999 -9999 -9999 -9999 -9999 -9999 -9999 -9999 -9999 -9999 -9999 -9999 -9999 -9999 -9999 -9999 -9999 -9999 -9999 -9999 -9999 -9999 -9999 -9999 -9999 -9999 -9999 -9999 -9999 -9999 -9999 -9999 -9999 -9999 -9999 -9999 -9999 -9999 -9999 -9999 -9999 -9999 -9999 -9999 -9999 -9999 -9999

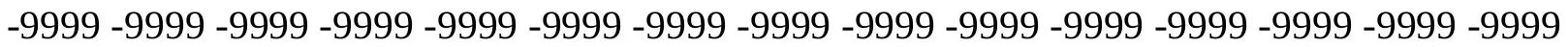

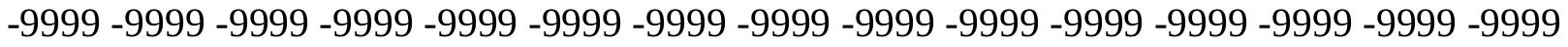
-9999 -9999 -9999 -9999 -9999 -9999 -9999 -9999 -9999 -9999 -9999 -9999 -9999 -9999 -9999 -9999 -9999 -9999 -9999 -9999 -9999 -9999 -9999 -9999 -9999 -9999 -9999 -9999 -9999 -9999 -9999 -9999 -9999 -9999 -9999 -9999 -9999 -9999 -9999 -9999 -9999 -9999 -9999 -9999 -9999 -9999 -9999 -9999 -9999 -9999 -9999 -9999 -9999 -9999 -9999 -9999 -9999 -9999 -9999 -9999 -9999 -9999 -9999 -9999 -9999 -9999 -9999 -9999 -9999 -9999 -9999 -9999 -9999 -9999 -9999 -9999 -9999 -9999 -9999 -9999 -9999 -9999 -9999 -9999 -9999 -9999 -9999 -9999 -9999 -9999 -

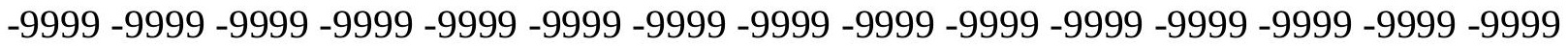
-9999 -9999 -9999 -9999 -9999 -9999 -9999 -9999 -9999 -9999 -9999 -9999 -9999 -9999 -9999 -9999 -9999 -9999 -9999 -9999 -9999 -9999 -9999 -9999 -9999 -9999 -9999 -9999 -9999 - 9999 -9999 -9999 -9999 -9999 -9999 -9999 -9999 -9999 -9999 -9999 -9999 -9999 -9999 -9999 -9999 -

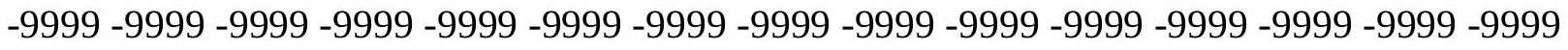

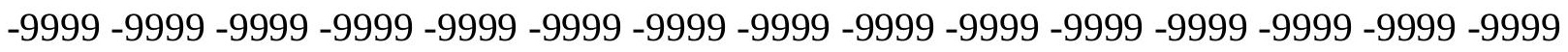

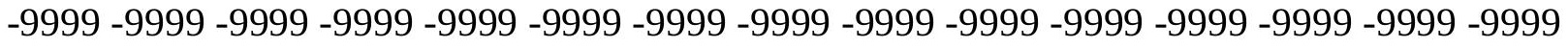
-9999 -9999 -9999 -9999 -9999 -9999 -9999 -9999 -9999 -9999 -9999 -9999 -9999 -9999 -9999 -9999 -9999 -9999 -9999 -9999 -9999 -9999 -9999 -9999 -9999 -9999 -9999 -9999 -9999 -9999 -

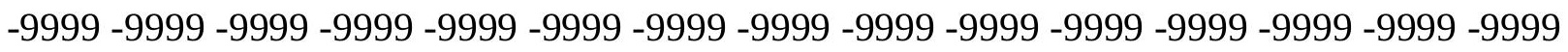
-9999 -9999 -9999 -9999 -9999 -9999 -9999 -9999 -9999 -9999 -9999 -9999 -9999 -9999 -9999 -9999 -9999 -9999 -9999 -9999 -9999 -9999 -9999 -9999 -9999 -9999 -9999 -9999 -9999 -9999 -

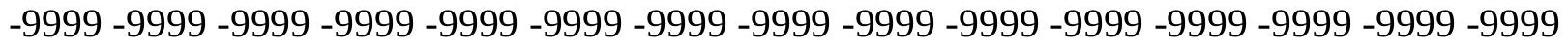
-9999 -9999 -9999 -9999 -9999 -9999 -9999 -9999 -9999 -9999 -9999 -9999 -9999 -9999 -9999 -9999 -9999 -9999 -9999 -9999 -9999 -9999 -9999 -9999 -9999 -9999 -9999 -9999 -9999 -999 -9999 -9999 -9999 -9999 -9999 -9999 -9999 -9999 -9999 -9999 -9999 -9999 -9999 -9999 -9999 -9999 -9999 -9999 -9999 -9999 -9999 -9999 -9999 -9999 -9999 -9999 -9999 -9999 -9999 -

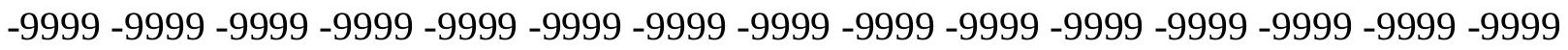

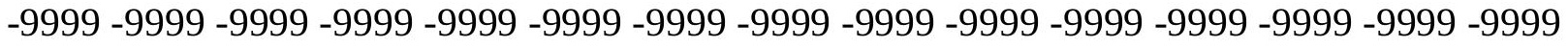

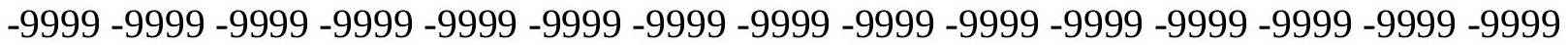

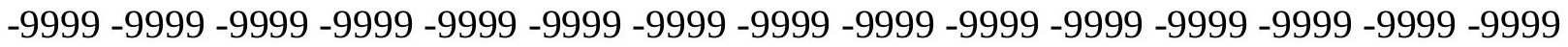

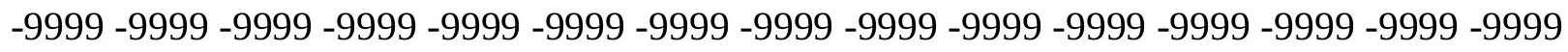

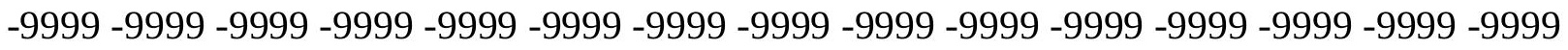

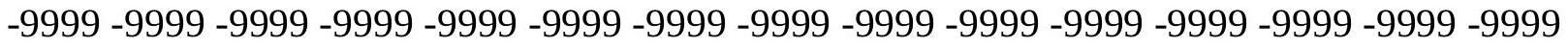
-9999 -9999 -9999 -9999 -9999 -9999 -9999 -9999 -9999 -9999 -9999 -9999 -9999 -9999 -9999 -

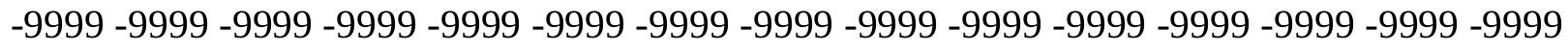

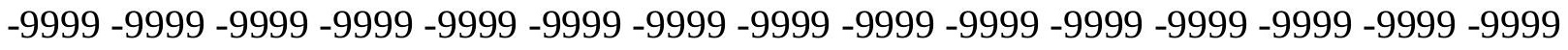
-9999 -9999 -9999 -9999 -9999 -9999 -9999 -9999 -9999 -9999 -9999 -9999 -9999 -9999 -9999 -9999 -9999 -9999 -9999 -9999 -9999 -9999 -9999 -9999-9999 -9999 -9999 -9999 -9999 -9999 -9999 -9999 -9999 -9999 -9999 -9999 -9999 -9999 -9999 -9999 -9999 -9999 -9999 -9999 -9999 -

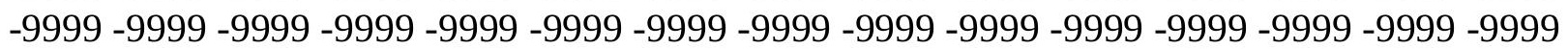


-9999 -9999 -9999 -9999 -9999 -9999 -9999 -9999 -9999 -9999 -9999 -9999 -9999 -9999 -9999 -9999 -9999 -9999 -9999 -9999 -9999 -9999 -9999 -9999 -9999 -9999 -9999 -9999 -9999 -9999 -

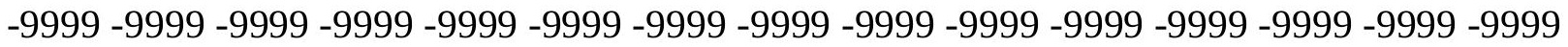
-9999 -9999 -9999 -9999 -9999 -9999 -9999 -9999 -9999 -9999 -9999 -9999 -9999 -9999 -9999 -9999 -9999 -9999 -9999 -9999 -9999 -9999 -9999 -9999-9999 -9999 -9999 -9999 -9999 -9999 -9999 -9999 -9999 -9999 -9999 -9999 -9999 -9999 -9999 -9999 -9999 -9999 -9999 -9999 -9999 -9999 -9999 -9999 -9999 -9999 -9999 -9999 -9999 -9999 -9999 -9999 -9999 -9999 -9999 -9999

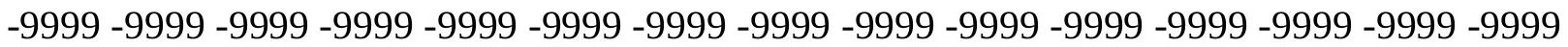

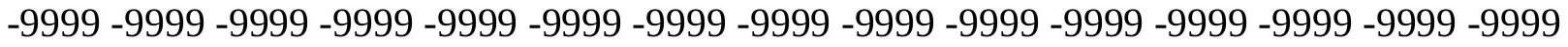

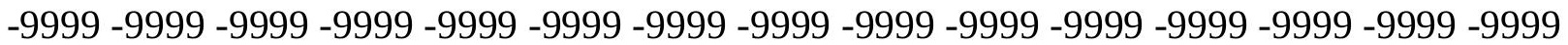
-9999 -9999 -9999 -9999 -9999 -9999 -9999 -9999 -9999 -9999 -9999 -9999 -9999 -9999 -9999 -9999 -9999 -9999 -9999 -9999 -9999 -9999 -9999 -9999 -9999 -9999 -9999 -9999 -9999 -9999 -9999 -9999 -9999 -9999 -9999 -9999 -9999 -9999 -9999 -9999 -9999 -9999 -9999 -9999 -

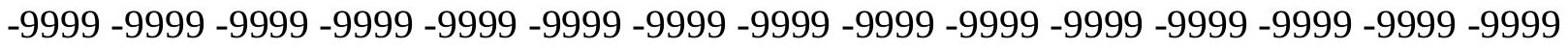
-9999 -9999 -9999 -9999 -9999 -9999 -9999 -9999 -9999 -9999 -9999 -9999 -9999 -9999 -9999 -

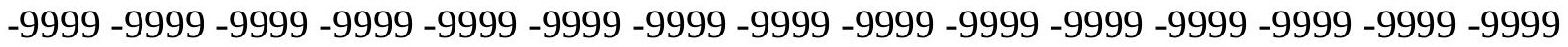
-9999 -9999 -9999 -9999 -9999 -9999 -9999 -9999 -9999 -9999 -9999 -9999 -9999 -9999 -9999 -9999 -9999 -9999 -9999 -9999 -9999 -9999 -9999 -9999 -9999 -9999 -9999 -9999 -9999 -9999 -9999 -9999 -9999 -9999 -9999 -9999 -9999 -9999 -9999 -9999 -9999 -9999 -9999 -9999 -9999 -

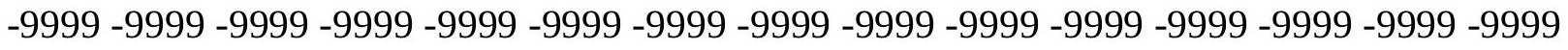

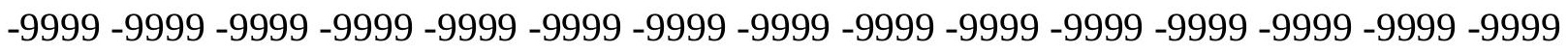
-9999 -9999 -9999 -9999 -9999 -9999 -9999 -9999 -9999 -9999 -9999 -9999 -9999 -9999 -9999 -9999 -9999 -9999 -9999 -9999 -9999 -9999 -9999 -9999 -9999 -9999 -9999 -9999 -9999 -9999 -9999 -9999 -9999 -9999 -9999 -9999 -9999 -9999 -9999 -9999 -9999 -9999 -9999 -9999 -9999 -

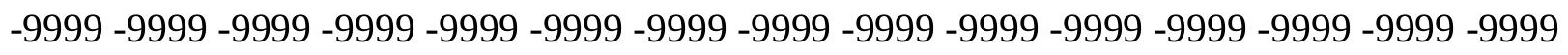
-9999 -9999 -9999 -9999 -9999 -9999 -9999 -9999 -9999 -9999 -9999 -9999 -9999 -9999 -9999 -9999 -9999 -9999 -9999 -9999 -9999 -9999 -9999 -9999 -9999 -9999 -9999 -9999 -9999 -9999 -

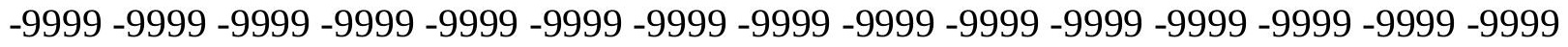
-9999 -9999 -9999 -9999 -9999 -9999 -9999 -9999 -9999 -9999 -9999 -9999 -9999 -9999 -9999 -9999 -9999 -9999 -9999 -9999 -9999 -9999 -9999 -9999 -9999 -9999 -9999 -9999 -9999 -999 -9999 -9999 -9999 -9999 -9999 -9999 -9999 -9999 -9999 -9999 -9999 -9999 -9999 -9999 -9999 -9999 -9999 -9999 -9999 -9999 -9999 -9999 -9999 -9999 -9999 -9999 -9999 -9999 -9999 -9999 -

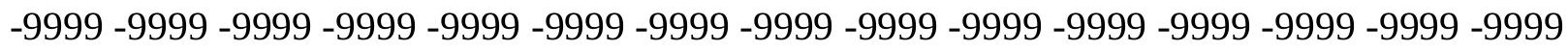

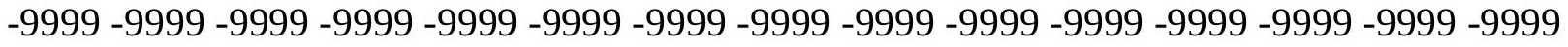

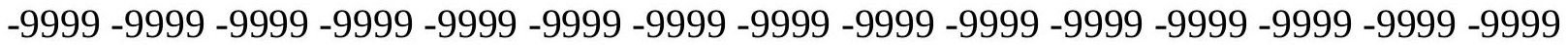
-9999 -9999 -9999 -9999 -9999 -9999 -9999 -9999 -9999 -9999 -9999 -9999 -9999 -9999 -9999 -

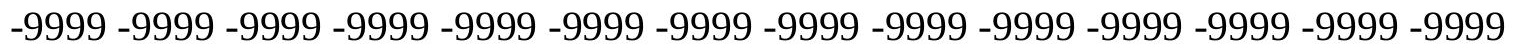

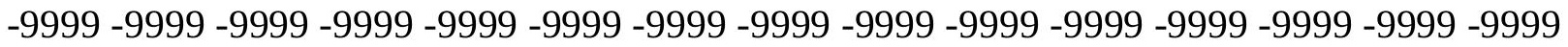
-9999 -9999 -9999 -9999 -9999 -9999 -9999 -9999 -9999 -9999 -9999 -9999 -9999 - 9999 - -999 -9999 -9999 -9999 -9999 -9999 -9999 -9999 -9999 -9999 -9999 -9999 -9999 -9999 -9999 -9999 -

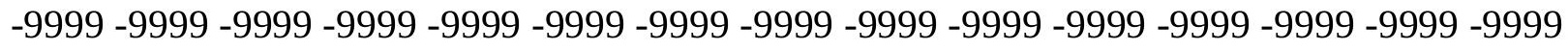

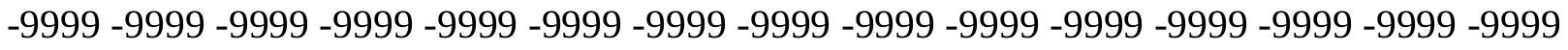
-9999 -9999 -9999 -9999 -9999 -9999 -9999 -9999 -9999 -9999 -9999 -9999 -9999 -9999 -9999 -9999 -9999 -9999 -9999 -9999 -9999 -9999 -9999 -9999-9999 -9999 -9999 -9999 -9999 -9999 -9999 -9999 -9999 -9999 -9999 -9999 -9999 -9999 -9999 -9999 -9999 -9999 -9999 -9999 -9999 -

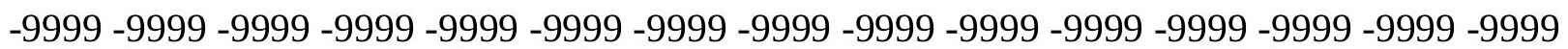


-9999 -9999 -9999 -9999 -9999 -9999 -9999 -9999 -9999 -9999 -9999 -9999 -9999 -9999 -9999 -9999 -9999 -9999 -9999 -9999 -9999 -9999 -9999 -9999 -9999 -9999 -9999 -9999 -9999 -9999 -

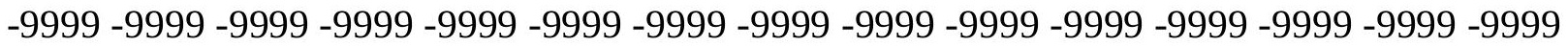
-9999 -9999 -9999 -9999 -9999 -9999 -9999 -9999 -9999 -9999 -9999 -9999 -9999 -9999 -9999 -9999 -9999 -9999 -9999 -9999 -9999 -9999 -9999 -9999-9999 -9999 -9999 -9999 -9999 -9999 -9999 -9999 -9999 -9999 -9999 -9999 -9999 -9999 -9999 -9999 -9999 -9999 -9999 -9999 -9999 -9999 -9999 -9999 -9999 -9999 -9999 -9999 -9999 -9999 -9999 -9999 -9999 -9999 -9999 -9999

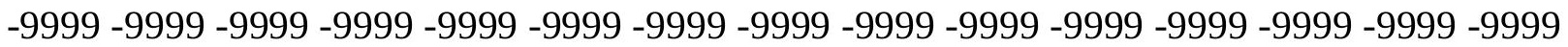

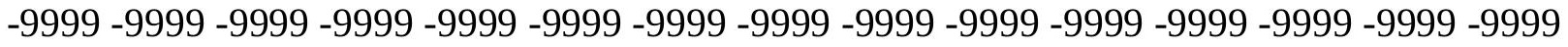
-9999 -9999 -9999 -9999 -9999 -9999 -9999 -9999 -9999 -9999 -9999 -9999 -9999 -9999 -9999 -9999 -9999 -9999 -9999 -9999 -9999 -9999 -9999 -9999 -9999 -9999 -9999 -9999 -9999 -9999 -9999 -9999 -9999 -9999 -9999 -9999 -9999 -9999 -9999 -9999 -9999 -9999 -9999 -9999 -9999 -9999 -9999 -9999 -9999 -9999 -9999 -9999 -9999 -9999 -9999 -9999 -9999 -9999 -9999 -9999 -9999 -9999 -9999 -9999 -9999 -9999 -9999 -9999 -9999 -9999 -9999 -9999 -9999 -9999 -9999 -9999 -9999 -9999 -9999 -9999 -9999 -9999 -9999 -9999 -9999 -9999 -9999 -9999 -9999 -9999 -

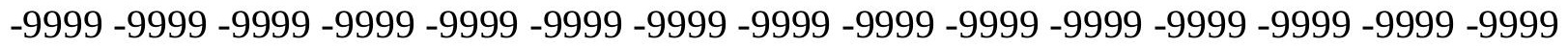
-9999 -9999 -9999 -9999 -9999 -9999 -9999 -9999 -9999 -9999 -9999 -9999 -9999 -9999 -9999 -9999 -9999 -9999 -9999 -9999 -9999 -9999 -9999 -9999 -9999 -9999 -9999 -9999 -9999 -9999 -9999 -9999 -9999 -9999 -9999 -9999 -9999 -9999 -9999 -9999 -9999 -9999 -9999 -9999 -

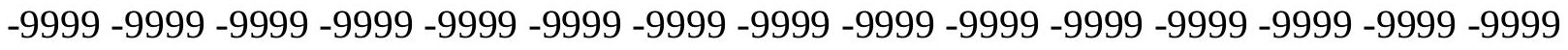
-9999 -9999 -9999 -9999 -9999 -9999 -9999 -9999 -9999 -9999 -9999 -9999 -9999 -9999 -9999 -999 -

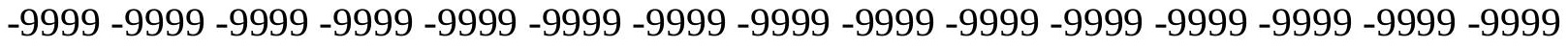
-9999 -9999 -9999 -9999 -9999 -9999 -9999 -9999 -9999 -9999 -9999 -9999 -9999 -9999 -9999 -9999 -9999 -9999 -9999 -9999 -9999 -9999 -9999 -9999 -9999 -9999 -9999 -9999 -9999 -9999 -9999 -9999 -9999 -9999 -9999 -9999 -9999 -9999 -9999 -9999 -9999 -9999 -9999 -9999 -9999 -9999 -9999 -9999 -9999 -9999 -9999 -9999 -9999 -9999 -9999 -9999 -9999 -9999 -9999 -9999 -9999 -9999 -9999 -9999 -9999 -9999 -9999 -9999 -9999 -9999 -9999 -9999 -9999 -9999 -9999 -

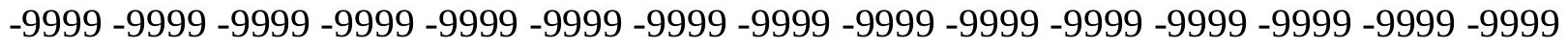
-9999 -9999 -9999 -9999 -9999 -9999 -9999 -9999 -9999 -9999 -9999 -9999 -9999 -9999 -9999 -9999 -9999 -9999 -9999 -9999 -9999 -9999 -9999 -9999 -9999 -9999 -9999 -9999 -9999 -999 -9999 -9999 -9999 -9999 -9999 -9999 -9999 -9999 -9999 -9999 -9999 -9999 -9999 -9999 -9999 -9999 -9999 -9999 -9999 -9999 -9999 -9999 -9999 -9999 -9999 -9999 -9999 -9999 -9999 -9999 -

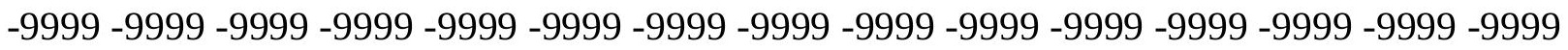

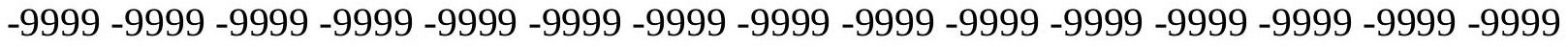

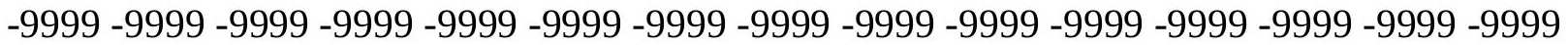
-9999 -9999 -9999 -9999 -9999 -9999 -9999 -9999 -9999 -9999 -9999 -9999 -9999 -9999 -9999

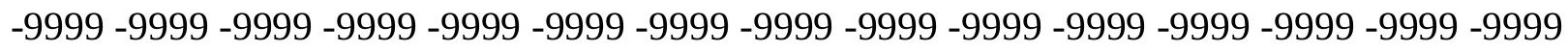

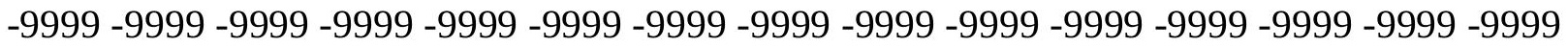
-9999 -9999 -9999 -9999 -9999 -9999 -9999 -9999 -9999 -9999 -9999 -9999 -9999 - 9999 - -999 -9999 -9999 -9999 -9999 -9999 -9999 -9999 -9999 -9999 -9999 -9999 -9999 -9999 -9999 -9999 -

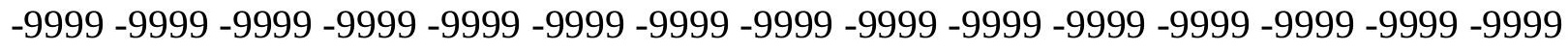

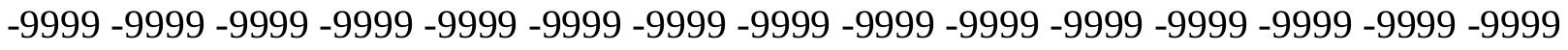
-9999 -9999 -9999 -9999 -9999 -9999 -9999 -9999 -9999 -9999 -9999 -9999 -9999 -9999 -9999 -9999 -9999 -9999 -9999 -9999 -9999 -9999 -9999 -9999 -9999 -9999 -9999 -9999 -9999 -9999 -9999 -9999 -9999 -9999 -9999 -9999 -9999 -9999 -9999 -9999 -9999 -9999 -9999 -9999 -

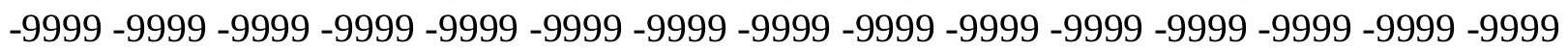


-9999 -9999 -9999 -9999 -9999 -9999 -9999 -9999 -9999 -9999 -9999 -9999 -9999 -9999 -9999 -9999 -9999 -9999 -9999 -9999 -9999 -9999 -9999 -9999 -9999 -9999 -9999 -9999 -9999 -9999 -9999 -9999 -9999 -9999 -9999 -9999 -9999 -9999 -9999 -9999 -9999 -9999 -9999 -9999 - 9999 -9999 -9999 -9999 -9999 -9999 -9999 -9999 -9999 -9999 -9999 -9999 -9999 -9999 -9999 -9999 -9999 -9999 -9999 -9999 -9999 -9999 -9999 -9999 -9999-9999 -9999 -9999 -9999 -9999 -9999 -9999 -9999 -9999 -9999 -9999 -9999 -9999 -9999 -9999 -9999 -9999 -9999 -9999 -9999 -9999 -9999 -9999 -9999 -9999 -9999 -9999 -9999 -9999 -9999 -9999 -9999 -9999 -9999 -9999 -9999

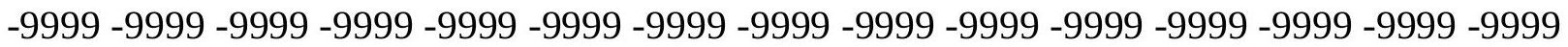

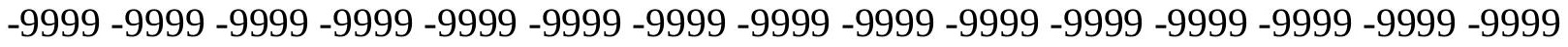
-9999 -9999 -9999 -9999 -9999 -9999 -9999 -9999 -9999 -9999 -9999 -9999 -9999 -9999 -9999 -9999 -9999 -9999 -9999 -9999 -9999 -9999 -9999 -9999 -9999 -9999 -9999 -9999 -9999 -9999 -9999 -9999 -9999 -9999 -9999 -9999 -9999 -9999 -9999 -9999 -9999 -9999 -9999 -9999 -9999 -9999 -9999 -9999 -9999 -9999 -9999 -9999 -9999 -9999 -9999 -9999 -9999 -9999 -9999 -9999 -

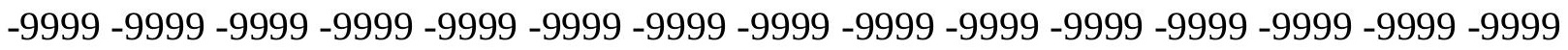
-9999 -9999 -9999 -9999 -9999 -9999 -9999 -9999 -9999 -9999 -9999 -9999 -9999 -9999 -9999 -

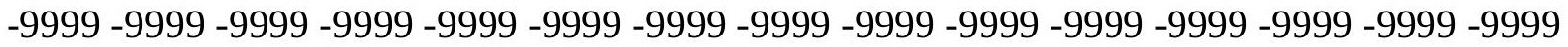
-9999 -9999 -9999 -9999 -9999 -9999 -9999 -9999 -9999 -9999 -9999 -9999 -9999 -9999 -9999 -9999 -9999 -9999 -9999 -9999 -9999 -9999 -9999 -9999 -9999 -9999 -9999 -9999 -9999 -9999 -9999 -9999 -9999 -9999 -9999 -9999 -9999 -9999 -9999 -9999 -9999 -9999 -9999 -9999 -9999 -

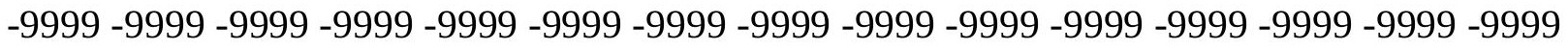
-9999 -9999 -9999 -9999 -9999 -9999 -9999 -9999 -9999 -9999 -9999 -9999 -9999 -9999 -9999 -999 -9999 -9999 -9999 -9999 -9999 -9999 -9999 -9999 -9999 -9999 -9999 -9999 -9999 -9999 - 9999 -9999 -9999 -9999 -9999 -9999 -9999 -9999 -9999 -9999 -9999 -9999 -9999 -9999 -9999 -

-9999 -9999 -9999 -9999 -9999 -9999 -9999 -9999 -9999 -9999 -9999 -9999 -9999 -9999 -9999 -

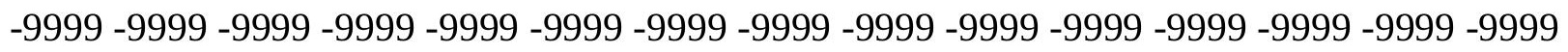
-9999 -9999 -9999 -9999 -9999 -9999 -9999 -9999 -9999 -9999 -9999 -9999 -9999 -9999 -9999 -9999 -9999 -9999 -9999 -9999 -9999 -9999 -9999 -9999 -9999 -9999 -9999 -9999 -9999 -9999 -

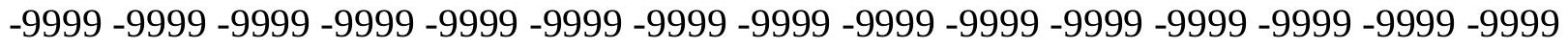
-9999 -9999 -9999 -9999 -9999 -9999 -9999 -9999 -9999 -9999 -9999 -9999 -9999 -9999 -9999 -9999 -9999 -9999 -9999 -9999 -9999 -9999 -9999 -9999 -9999 -9999 -9999 -9999 -9999 -999 -

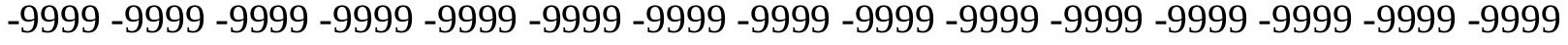
-9999 -9999 -9999 -9999 -9999 -9999 -9999 -9999 -9999 -9999 -9999 -9999 -9999 -9999 -9999 -

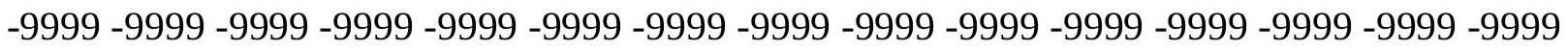

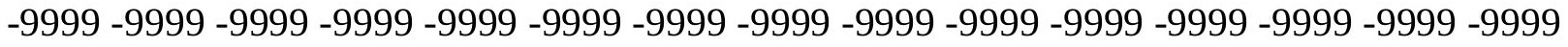

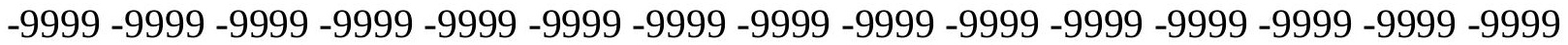

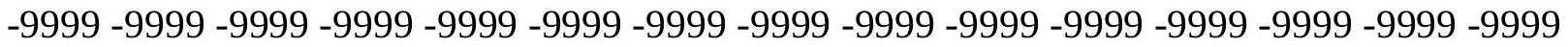

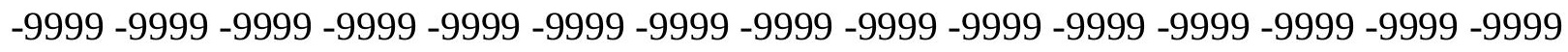

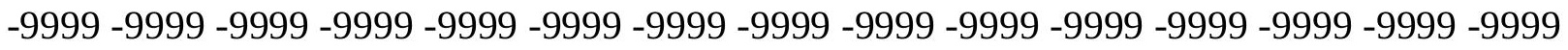

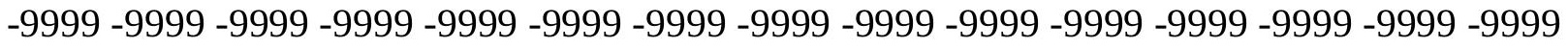
-9999 -9999 -9999 -9999 -9999 -9999 -9999 -9999 -9999 -9999 -9999 -9999 -9999 -9999 -9999 -

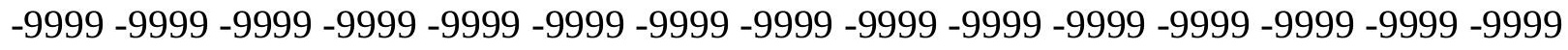

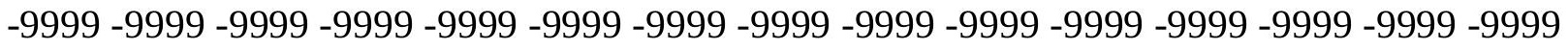
-9999 -9999 -9999 -9999 -9999 -9999 -9999 -9999 -9999 -9999 -9999 -9999 -9999 -9999 -9999 -9999 -9999 -9999 -9999 -9999 -9999 -9999 -9999 -9999-9999 -9999 -9999 -9999 -9999 -9999 -9999 -9999 -9999 -9999 -9999 -9999 -9999 -9999 -9999 -9999 -9999 -9999 -9999 -9999 -9999 -

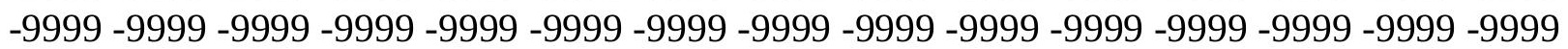


-9999 -9999 -9999 -9999 -9999 -9999 -9999 -9999 -9999 -9999 -9999 -9999 -9999 -9999 -9999 -9999 -9999 -9999 -9999 -9999 -9999 -9999 -9999 -9999 -9999 -9999 -9999 -9999 -9999 -9999 -9999 -9999 -9999 -9999 -9999 -9999 -9999 -9999 -9999 -9999 -9999 -9999 -9999 -9999 -9999 -9999 -9999 -9999 -9999 -9999 -9999 -9999 -9999 -9999 -9999 -9999 -9999 -9999 -9999 -9999 -9999 -9999 -9999 -9999 -9999 -9999 -9999 -9999-9999 -9999 -9999 -9999 -9999 -9999 -9999 -9999 -9999 -9999 -9999 -9999 -9999 -9999 -9999 -9999 -9999 -9999 -9999 -9999 -9999 -9999 -9999 -9999 -9999 -9999 -9999 -9999 -9999 -9999 -9999 -9999 -9999 -9999 -9999 -9999

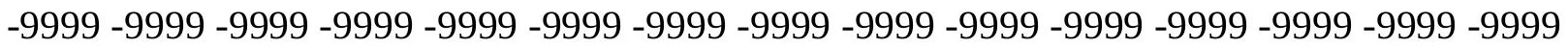

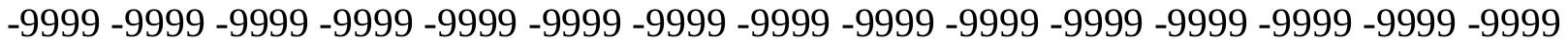
-9999 -9999 -9999 -9999 -9999 -9999 -9999 -9999 -9999 -9999 -9999 -9999 -9999 -9999 -9999 -9999 -9999 -9999 -9999 -9999 -9999 -9999 -9999 -9999 -9999 -9999 -9999 -9999 -9999 -9999 -9999 -9999 -9999 -9999 -9999 -9999 -9999 -9999 -9999 -9999 -9999 -9999 -9999 -9999 -9999 -9999 -9999 -9999 -9999 -9999 -9999 -9999 -9999 -9999 -9999 -9999 -9999 -9999 -9999 -9999 -

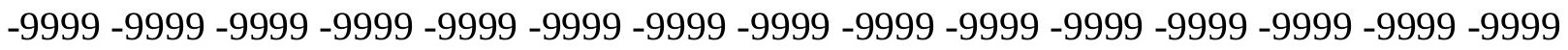
-9999 -9999 -9999 -9999 -9999 -9999 -9999 -9999 -9999 -9999 -9999 -9999 -9999 -9999 -9999 -

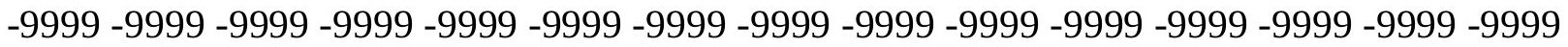
-9999 -9999 -9999 -9999 -9999 -9999 -9999 -9999 -9999 -9999 -9999 -9999 -9999 -9999 -9999 -9999 -9999 -9999 -9999 -9999 -9999 -9999 -9999 -9999 -9999 -9999 -9999 -9999 -9999 -9999 -9999 -9999 -9999 -9999 -9999 -9999 -9999 -9999 -9999 -9999 -9999 -9999 -9999 -9999 -9999 -

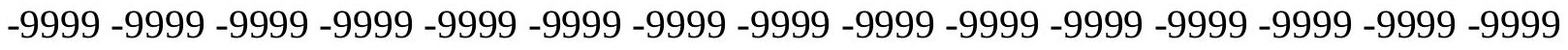

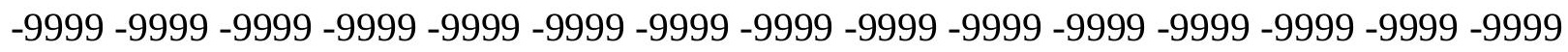
-9999 -9999 -9999 -9999 -9999 -9999 -9999 -9999 -9999 -9999 -9999 -9999 -9999 -9999 -9999 -9999 -9999 -9999 -9999 -9999 -9999 -9999 -9999 -9999 -9999 -9999 -9999 -9999 -9999 -9999 -9999 -9999 -9999 -9999 -9999 -9999 -9999 -9999 -9999 -9999 -9999 -9999 -9999 -9999 -9999 -

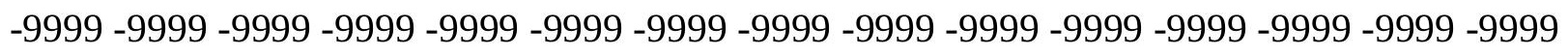
-9999 -9999 -9999 -9999 -9999 -9999 -9999 -9999 -9999 -9999 -9999 -9999 -9999 -9999 -9999 -9999 -9999 -9999 -9999 -9999 -9999 -9999 -9999 -9999 -9999 -9999 -9999 -9999 -9999 -9999 -

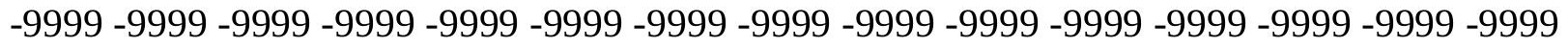
-9999 -9999 -9999 -9999 -9999 -9999 -9999 -9999 -9999 -9999 -9999 -9999 -9999 -9999 -9999 -9999 -9999 -9999 -9999 -9999 -9999 -9999 -9999 -9999 -9999 -9999 -9999 -9999 - -999 -

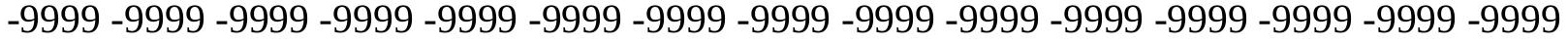
-9999 -9999 -9999 -9999 -9999 -9999 -9999 -9999 -9999 -9999 -9999 -9999 -9999 -9999 -9999 -

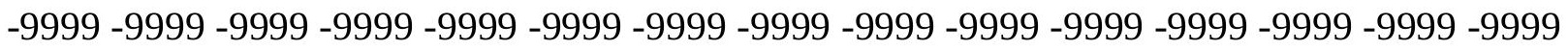

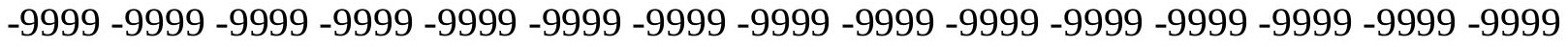

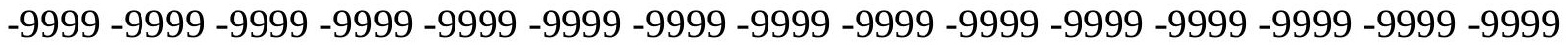

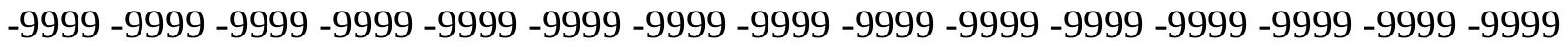

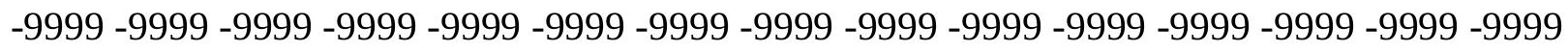

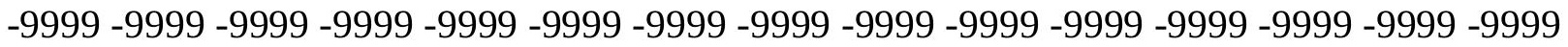

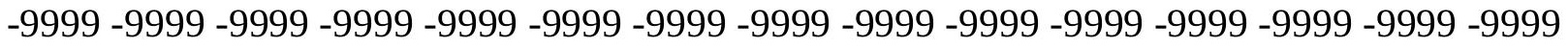
-9999 -9999 -9999 -9999 -9999 -9999 -9999 -9999 -9999 -9999 -9999 -9999 -9999 -9999 -9999 -

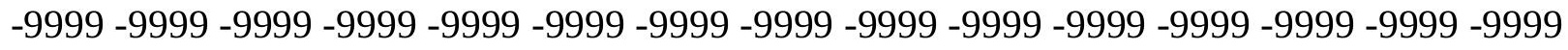

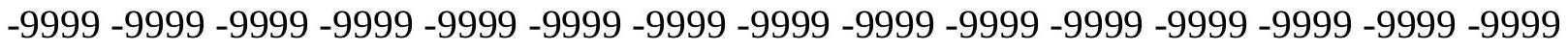
-9999 -9999 -9999 -9999 -9999 -9999 -9999 -9999 -9999 -9999 -9999 -9999 -9999 -9999 -9999 -9999 -9999 -9999 -9999 -9999 -9999 -9999 -9999 -9999-9999 -9999 -9999 -9999 -9999 -9999 -9999 -9999 -9999 -9999 -9999 -9999 -9999 -9999 -9999 -9999 -9999 -9999 -9999 -9999 -9999 -

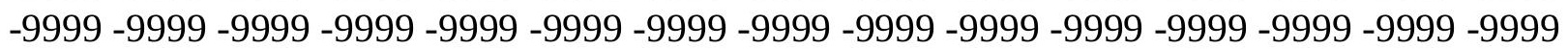


-9999 -9999 -9999 -9999 -9999 -9999 -9999 -9999 -9999 -9999 -9999 -9999 -9999 -9999 -9999 -9999 -9999 -9999 -9999 -9999 -9999 -9999 -9999 -9999 -9999 -9999 -9999 -9999 -9999 -9999 -

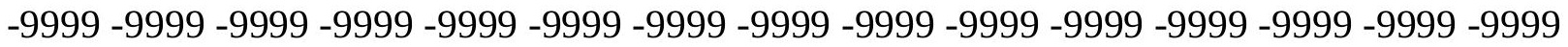
-9999 -9999 -9999 -9999 -9999 -9999 -9999 -9999 -9999 -9999 -9999 -9999 -9999 -9999 -9999 -9999 -9999 -9999 -9999 -9999 -9999 -9999 -9999 -9999-9999 -9999 -9999 -9999 -9999 -9999 -9999 -9999 -9999 -9999 -9999 -9999 -9999 -9999 -9999 -9999 -9999 -9999 -9999 -9999 -9999 -9999 -9999 -9999 -9999 -9999 -9999 -9999 -9999 -9999 -9999 -9999 -9999 -9999 -9999 -9999

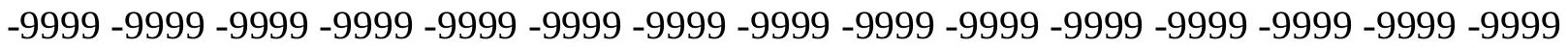
-9999 -9999 -9999 -9999 -9999 -9999 -9999 -9999 -9999 -9999 -9999 -9999 -9999 -9999 -9999 -9999 -9999 -9999 -9999 -9999 -9999 -9999 -9999 -9999 -9999 -9999 -9999 -9999 -9999

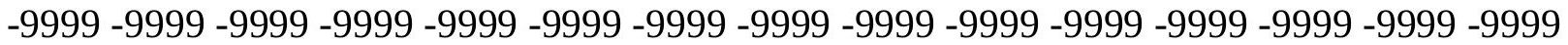
-9999 -9999 -9999 -9999 -9999 -9999 -9999 -9999 -9999 -9999 -9999 -9999 -9999 -9999 -9999 -9999 -9999 -9999 -9999 -9999 -9999 -9999 -9999 -9999 -9999 -9999 -9999 -9999 -9999 -9999 -9999 -9999 -9999 -9999 -9999 -9999 -9999 -9999 -9999 -9999 -9999 -9999 -9999 -9999 - 9999 -9999 -9999 -9999 -9999 -9999 -9999 -9999 -9999 -9999 -9999 -9999 -9999 -9999 -9999 -9999

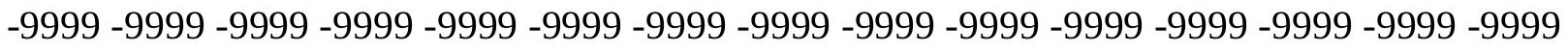
-9999 -9999 -9999 -9999 -9999 -9999 -9999 -9999 -9999 -9999 -9999 -9999 -9999 -9999 -9999 -9999 -9999 -9999 -9999 -9999 -9999 -9999 -9999 -9999 -9999 -9999 -9999 -9999 -9999 -9999 -9999 -9999 -9999 -9999 -9999 -9999 -9999 -9999 -9999 -9999 -9999 -9999 -9999 -9999 -9999 -

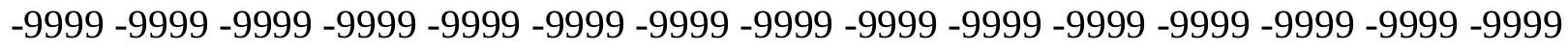

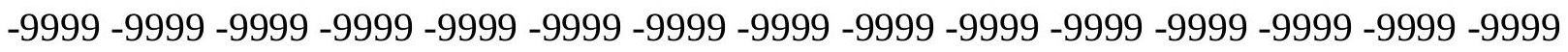
-9999 -9999 -9999 -9999 -9999 -9999 -9999 -9999 -9999 -9999 -9999 -9999 -9999 -9999 -9999 -9999 -9999 -9999 -9999 -9999 -9999 -9999 -9999 -9999 -9999 -9999 -9999 -9999 -9999 -9999 -9999 -9999 -9999 -9999 -9999 -9999 -9999 -9999 -9999 -9999 -9999 -9999 -9999 -9999 -9999 -

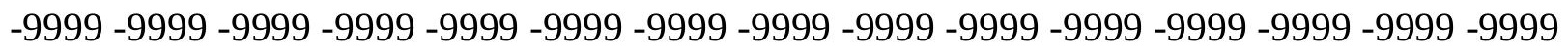
-9999 -9999 -9999 -9999 -9999 -9999 -9999 -9999 -9999 -9999 -9999 -9999 -9999 -9999 -9999 -9999 -9999 -9999 -9999 -9999 -9999 -9999 -9999 -9999 -9999 -9999 -9999 -9999 -9999 -9999 -

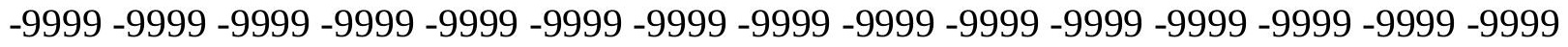
-9999 -9999 -9999 -9999 -9999 -9999 -9999 -9999 -9999 -9999 -9999 -9999 -9999 -9999 -9999 -9999 -9999 -9999 -9999 -9999 -9999 -9999 -9999 -9999 -9999 -9999 -9999 -9999 -9999 -999 -9999 -9999 -9999 -9999 -9999 -9999 -9999 -9999 -9999 -9999 -9999 -9999 -9999 -9999 -9999 -9999 -9999 -9999 -9999 -9999 -9999 -9999 -9999 -9999 -9999 -9999 -9999 -9999 -9999 -9999 -

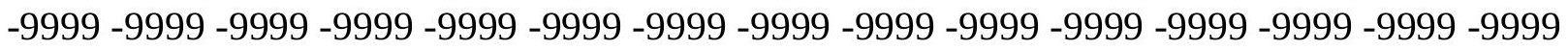

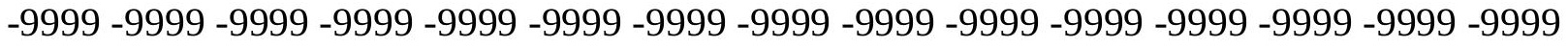
-9999 -9999 -9999 -9999 -9999 -9999 -9999 -9999 -9999 -9999 -9999 -9999 -9999 -9999 -

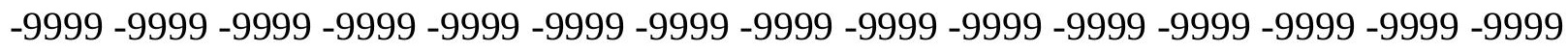

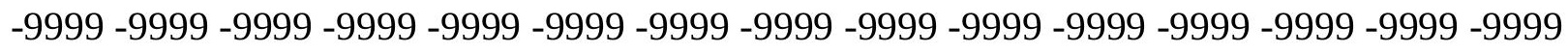

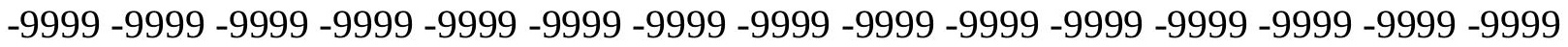
-9999 -9999 -9999 -9999 -9999 -9999 -9999 -9999 -9999 -9999 -9999 -9999 -9999 - 9999 - -999 -9999 -9999 -9999 -9999 -9999 -9999 -9999 -9999 -9999 -9999 -9999 -9999 -9999 -9999 -9999 -

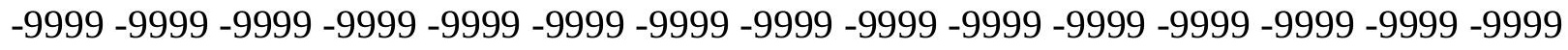

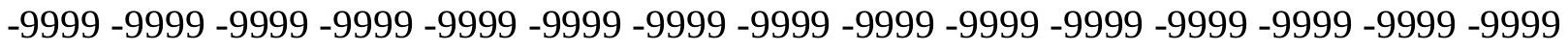
-9999 -9999 -9999 -9999 -9999 -9999 -9999 -9999 -9999 -9999 -9999 -9999 -9999 -9999 -9999 -9999 -9999 -9999 -9999 -9999 -9999 -9999 -9999 -9999-9999 -9999 -9999 -9999 -9999 -9999 -9999 -9999 -9999 -9999 -9999 -9999 -9999 -9999 -9999 -9999 -9999 -9999 -9999 -9999 -9999 -

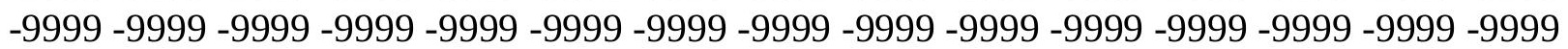


-9999 -9999 -9999 -9999 -9999 -9999 -9999 -9999 -9999 -9999 -9999 -9999 -9999 -9999 -9999 -9999 -9999 -9999 -9999 -9999 -9999 -9999 -9999 -9999 -9999 -9999 -9999 -9999 -9999 -9999 -

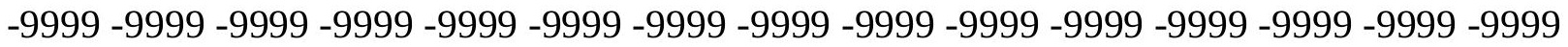
-9999 -9999 -9999 -9999 -9999 -9999 -9999 -9999 -9999 -9999 -9999 -9999 -9999 -9999 -9999 -9999 -9999 -9999 -9999 -9999 -9999 -9999 -9999 -9999-9999 -9999 -9999 -9999 -9999 -9999 -9999 -9999 -9999 -9999 -9999 -9999 -9999 -9999 -9999 -9999 -9999 -9999 -9999 -9999 -9999 -9999 -9999 -9999 -9999 -9999 -9999 -9999 -9999 -9999 -9999 -9999 -9999 -9999 -9999 -9999

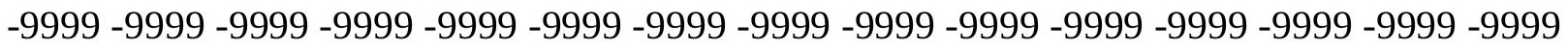

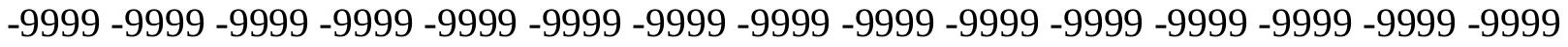
-9999 -9999 -9999 -9999 -9999 -9999 -9999 -9999 -9999 -9999 -9999 -9999 -9999 -9999 -9999 -9999 -9999 -9999 -9999 -9999 -9999 -9999 -9999 -9999 -9999 -9999 -9999 -9999 -9999 -9999 -9999 -9999 -9999 -9999 -9999 -9999 -9999 -9999 -9999 -9999 -9999 -9999 -9999 -9999 -9999 -9999 -9999 -9999 -9999 -9999 -9999 -9999 -9999 -9999 -9999 -9999 -9999 -9999 -9999 -9999 -9999 -9999 -9999 -9999 -9999 -9999 -9999 -9999 -9999 -9999 -9999 -9999 -9999 -9999 -9999 -9999 -9999 -9999 -9999 -9999 -9999 -9999 -9999 -9999 -9999 -9999 -9999 -9999 -9999 -9999 -9999 -9999 -9999 -9999 -9999 -9999 -9999 -9999 -9999 -9999 -9999 -9999 - 9999 - -999 -

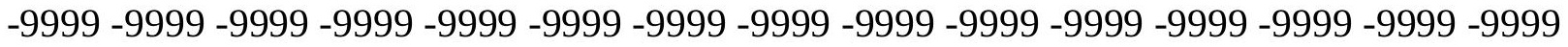
-9999 -9999 -9999 -9999 -9999 -9999 -9999 -9999 -9999 -9999 -9999 -9999 -9999 -9999 -9999 -9999 -9999 -9999 -9999 -9999 -9999 -9999 -9999 -9999 -9999 -9999 -9999 -9999 -9999 -9999 -

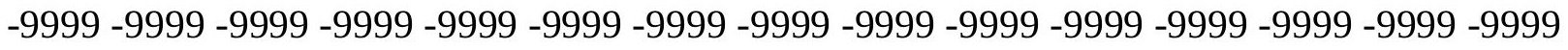
-9999 -9999 -9999 -9999 -9999 -9999 -9999 -9999 -9999 -9999 -9999 -9999 -9999 -9999 -9999

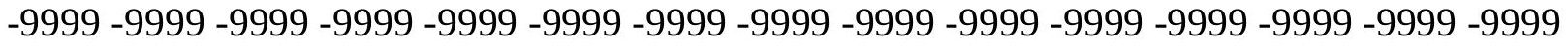
-9999 -9999 -9999 -9999 -9999 -9999 -9999 -9999 -9999 -9999 -9999 -9999 -9999 -9999 -9999 -9999 -9999 -9999 -9999 -9999 -9999 -9999 -9999 -9999 -9999 -9999 -9999 -9999 -9999 -9999 -

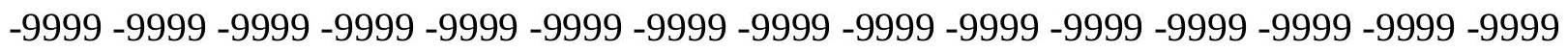
-9999 -9999 -9999 -9999 -9999 -9999 -9999 -9999 -9999 -9999 -9999 -9999 -9999 -9999 -9999 -9999 -9999 -9999 -9999 -9999 -9999 -9999 -9999 -9999 -9999 -9999 -9999 -9999 -9999 -9999 -

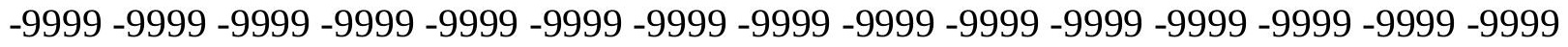
-9999 -9999 -9999 -9999 -9999 -9999 -9999 -9999 -9999 -9999 -9999 -9999 -9999 -9999 -9999 -9999 -9999 -9999 -9999 -9999 -9999 -9999 -9999 -9999 -9999 -9999 -9999 -9999 -9999 -999 -

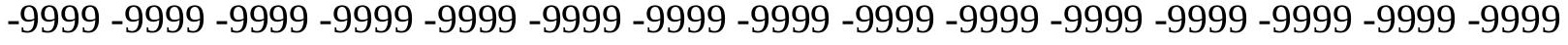
-9999 -9999 -9999 -9999 -9999 -9999 -9999 -9999 -9999 -9999 -9999 -9999 -9999 -9999 -9999 -

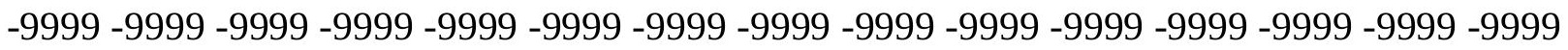

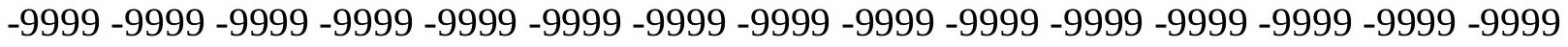

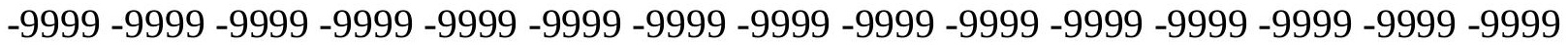
-9999 -9999 -9999 -9999 -9999 -9999 -9999 -9999 -9999 -9999 -9999 -9999 -9999 -9999 -9999 -

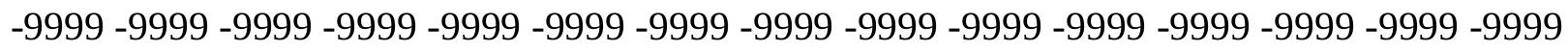

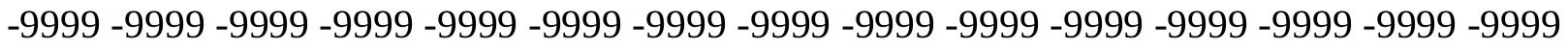
-9999 -9999 -9999 -9999 -9999 -9999 -9999 -9999 -9999 -9999 -9999 -9999 -9999 - 9999 - -999 -9999 -9999 -9999 -9999 -9999 -9999 -9999 -9999 -9999 -9999 -9999 -9999 -9999 -9999 -9999 -

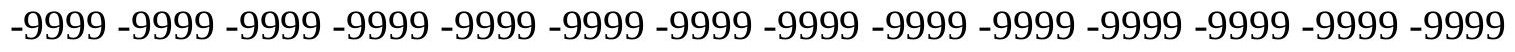

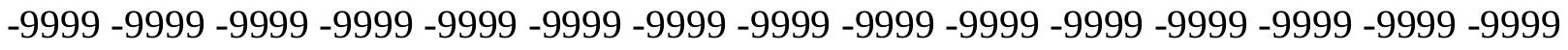
-9999 -9999 -9999 -9999 -9999 -9999 -9999 -9999 -9999 -9999 -9999 -9999 -9999 -9999 -9999 -9999 -9999 -9999 -9999 -9999 -9999 -9999 -9999 -9999-9999 -9999 -9999 -9999 -9999 -9999 -9999 -9999 -9999 -9999 -9999 -9999 -9999 -9999 -9999 -9999 -9999 -9999 -9999 -9999 -9999 -

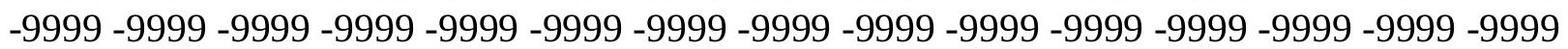


-9999 -9999 -9999 -9999 -9999 -9999 -9999 -9999 -9999 -9999 -9999 -9999 -9999 -9999 -9999 -9999 -9999 -9999 -9999 -9999 -9999 -9999 -9999 -9999 -9999 -9999 -9999 -9999 -9999 -9999 -9999 -9999 -9999 -9999 -9999 -9999 -9999 -9999 -9999 -9999 -9999 -9999 -9999 -9999 - 9999 -9999 -9999 -9999 -9999 -9999 -9999 -9999 -9999 -9999 -9999 -9999 -9999 -9999 -9999 -9999 -9999 -9999 -9999 -9999 -9999 -9999 -9999 -9999 -9999-9999 -9999 -9999 -9999 -9999 -9999 -9999 -9999 -9999 -9999 -9999 -9999 -9999 -9999 -9999 -9999 -9999 -9999 -9999 -9999 -9999 -9999 -9999 -9999 -9999 -9999 -9999 -9999 -9999 -9999 -9999 -9999 -9999 -9999 -9999 -9999

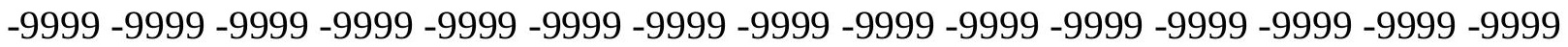
-9999 -9999 -9999 -9999 -9999 -9999 -9999 -9999 -9999 -9999 -9999 -9999 -9999 -9999 -9999 -9999 -9999 -9999 -9999 -9999 -9999 -9999 -9999 -9999 -9999 -9999 -9999 -9999 -9999 -9999

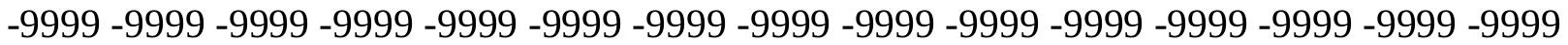
-9999 -9999 -9999 -9999 -9999 -9999 -9999 -9999 -9999 -9999 -9999 -9999 -9999 -9999 -9999 -9999 -9999 -9999 -9999 -9999 -9999 -9999 -9999 -9999 -9999 -9999 -9999 -9999 -9999 -9999 -

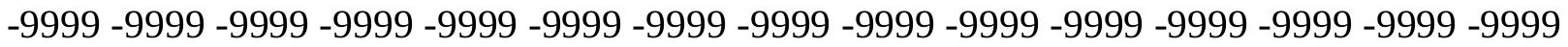
-9999 -9999 -9999 -9999 -9999 -9999 -9999 -9999 -9999 -9999 -9999 -9999 -9999 -9999 -9999

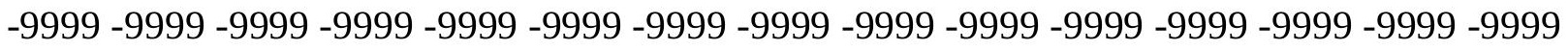
-9999 -9999 -9999 -9999 -9999 -9999 -9999 -9999 -9999 -9999 -9999 -9999 -9999 -9999 -9999 -9999 -9999 -9999 -9999 -9999 -9999 -9999 -9999 -9999 -9999 -9999 -9999 -9999 -9999 - 9999 -9999 -9999 -9999 -9999 -9999 -9999 -9999 -9999 -9999 -9999 -9999 -9999 -9999 -9999 -9999 -9999 -9999 -9999 -9999 -9999 -9999 -9999 -9999 -9999 -9999 -9999 -9999 -9999 -9999 -9999 -9999 -9999 -9999 -9999 -9999 -9999 -9999 -9999 -9999 -9999 -9999 -9999 -9999 -9999 -9999 -9999 -9999 -9999 -9999 -9999 -9999 -9999 -9999 -9999 -9999 -9999 -9999 -9999 -9999 -9999 -9999 -9999 -9999 -9999 -9999 -9999 -9999 -9999 -9999 -9999 -9999 -9999 -9999 -9999 -9999 -9999 -9999 -9999 -9999 -9999 -9999 -9999 -9999 -9999 -9999 -9999 -9999 -9999 -9999 -9999 -9999 -9999 -9999 -9999 -9999 -9999 -9999 -9999 -9999 -9999 -9999 -9999 -9999 -9999 -9999 -9999 -9999 -9999 -9999 -9999 -9999 -9999 -9999 -9999 -9999 -9999 -9999 -9999 -9999 -9999 -9999 -9999 -9999 -9999 -9999 -9999 -9999 -9999 -9999 -9999 -9999 -9999 -9999 -9999 -9999 -9999 -9999 -9999 -9999 -9999 -9999 -9999 -9999 -9999 -9999 -9999 -9999 -9999 -9999 -9999 -9999 -9999 -9999 -9999 -9999 -9999 -9999 -9999 -9999 -9999 -9999 -9999 -9999 -9999 -9999 -9999 -9999 -9999 -9999 -9999 -9999 -9999 -9999 -9999 -9999 -9999 -9999 -9999 -999 -9999 -9999 -9999 -9999 -9999 -9999 -9999 -9999 -9999 -9999 -9999 -9999 -9999 -9999 -9999 -9999 -9999 -9999 -9999 -9999 -9999 -9999 -9999 -9999 -9999 -9999 -9999 -9999 -9999 -9999 -

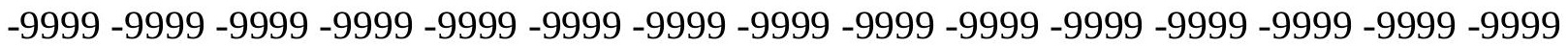

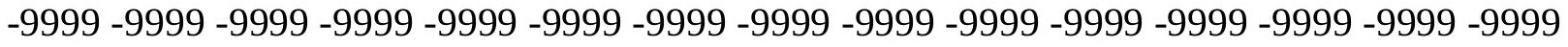

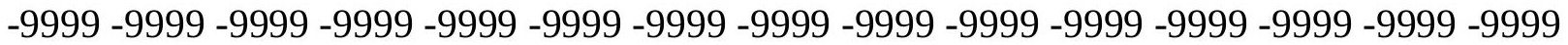
-9999 -9999 -9999 -9999 -9999 -9999 -9999 -9999 -9999 -9999 -9999 -9999 -9999 -9999 -9999

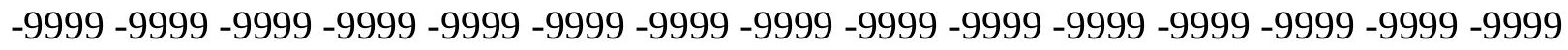

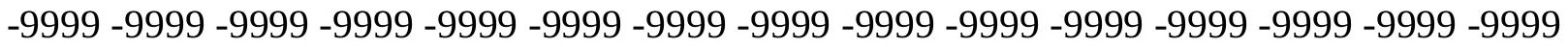

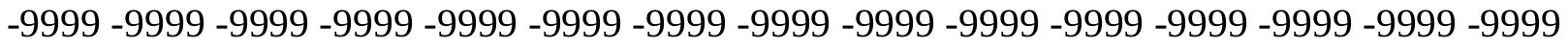
-9999 -9999 -9999 -9999 -9999 -9999 -9999 -9999 -9999 -9999 -9999 -9999 -9999 -9999 -9999 -

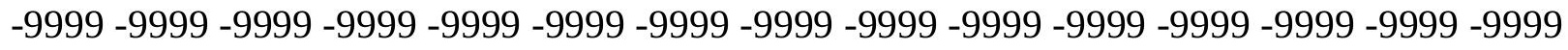

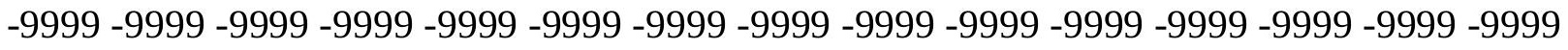
-9999 -9999 -9999 -9999 -9999 -9999 -9999 -9999 -9999 -9999 -9999 -9999 -9999 -9999 -9999 -9999 -9999 -9999 -9999 -9999 -9999 -9999 -9999 -9999-9999 -9999 -9999 -9999 -9999 -9999 -9999 -9999 -9999 -9999 -9999 -9999 -9999 -9999 -9999 -9999 -9999 -9999 -9999 -9999 -9999 -

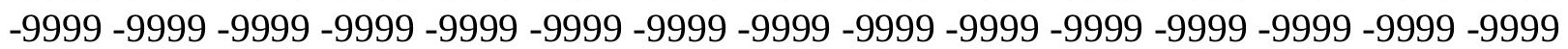


-9999 -9999 -9999 -9999 -9999 -9999 -9999 -9999 -9999 -9999 -9999 -9999 -9999 -9999 -9999 -9999 -9999 -9999 -9999 -9999 -9999 -9999 -9999 -9999 -9999 -9999 -9999 -9999 -9999 -9999 -9999 -9999 -9999 -9999 -9999 -9999 -9999 -9999 -9999 -9999 -9999 -9999 -9999 -9999 -9999 -9999 -9999 -9999 -9999 -9999 -9999 -9999 -9999 -9999 -9999 -9999 -9999 -9999 -9999 -9999 -9999 -9999 -9999 -9999 -9999 -9999 -9999 -9999 -9999 -9999 -9999 -9999 -9999 -9999 -9999 -9999 -9999 -9999 -9999 -9999 -9999 -9999 -9999 -9999 -9999 -9999 -9999 -9999 -9999 -9999 -9999 -9999 -9999 -9999 -9999 -9999 -9999 -9999 -9999 -9999 -9999 -9999 -9999 -9999 -

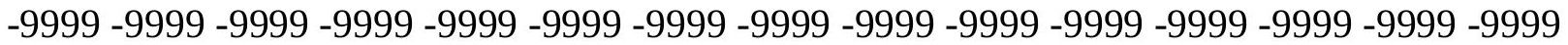
-9999 -9999 -9999 -9999 -9999 -9999 -9999 -9999 -9999 -9999 -9999 -9999 -9999 -9999 -9999 -9999 -9999 -9999 -9999 -9999 -9999 -9999 -9999 -9999 -9999 -9999 -9999 -9999 -9999 -9999 -

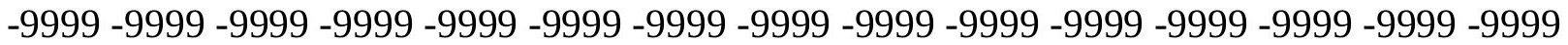
-9999 -9999 -9999 -9999 -9999 -9999 -9999 -9999 -9999 -9999 -9999 -9999 -9999 -9999 -9999 -9999 -9999 -9999 -9999 -9999 -9999 -9999 -9999 -9999 -9999 -9999 -9999 -9999 -9999 -9999 -9999 -9999 -9999 -9999 -9999 -9999 -9999 -9999 -9999 -9999 -9999 -9999 -9999 -9999 -9999 -9999 -9999 -9999 -9999 -9999 -9999 -9999 -9999 -9999 -9999 -9999 -9999 -9999 -9999 -9999 -9999 -9999 -9999 -9999 -9999 -9999 -9999 -9999 -9999 -9999 -9999 -9999 -9999 -9999 -9999 -9999 -9999 -9999 -9999 -9999 -9999 -9999 -9999 -9999 -9999 -9999 -9999 -9999 -9999 -9999 -9999 -9999 -9999 -9999 -9999 -9999 -9999 -9999 -9999 -9999 -9999 -9999 -9999 -9999 -9999 -9999 -9999 -9999 -9999 -9999 -9999 -9999 -9999 -9999 -9999 -9999 -9999 -9999 -9999 -9999 -9999 -9999 -9999 -9999 -9999 -9999 -9999 -9999 -9999 -9999 -9999 -9999 -9999 -9999 -9999

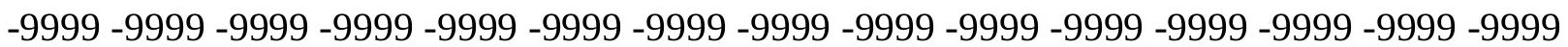
-9999 -9999 -9999 -9999 -9999 -9999 -9999 -9999 -9999 -9999 -9999 -9999 -9999 -9999 -9999 -9999 -9999 -9999 -9999 -9999 -9999 -9999 -9999 -9999 -9999 -9999 -9999 -9999 -9999 -9999 -9999 -9999 -9999 -9999 -9999 -9999 -9999 -9999 -9999 -9999 -9999 -9999 -9999 -9999 -9999

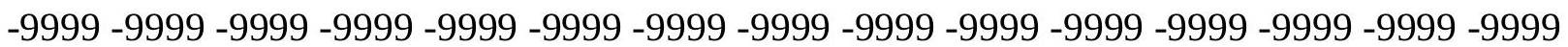
-9999 -9999 -9999 -9999 -9999 -9999 -9999 -9999 -9999 -9999 -9999 -9999 -9999 -9999 -9999 -9999 -9999 -9999 -9999 -9999 -9999 -9999 -9999 -9999 -9999 -9999 -9999 -9999 -9999 -9999 -9999 -9999 -9999 -9999 -9999 -9999 -9999 -9999 -9999 -9999 -9999 -9999 -9999 -9999

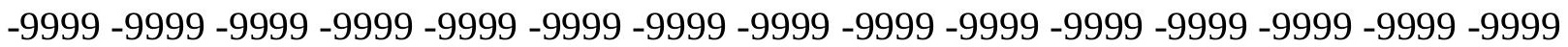
-9999 -9999 -9999 -9999 -9999 -9999 -9999 -9999 -9999 -9999 -9999 -9999 -9999 -9999 -9999 -9999 -9999 -9999 -9999 -9999 -9999 -9999 -9999 -9999 -9999 -9999 -9999 -9999 -9999 -9999 -

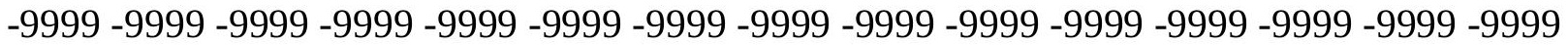
-9999 -9999 -9999 -9999 -9999 -9999 -9999 -9999 -9999 -9999 -9999 -9999 -9999 -9999 -9999 -9999 -9999 -9999 -9999 -9999 -9999 -9999 -9999 -9999 -9999 -9999 -9999 -9999 -9999 -9999 -9999 -9999 -9999 -9999 -9999 -9999 -9999 -9999 -9999 -9999 -9999 -9999 -9999 -9999 -9999 -9999 -9999 -9999 -9999 -9999 -9999 -9999 -9999 -9999 -9999 -9999 -9999 -9999 -9999 -9999 -9999 -9999 -9999 -9999 -9999 -9999 -9999 -9999 -9999 -9999 -9999 -9999 -9999 -9999 -9999

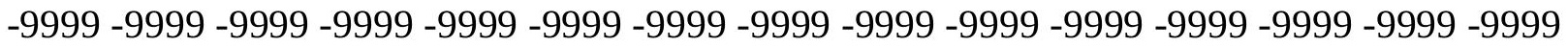
-9999 -9999 -9999 -9999 -9999 -9999 -9999 -9999 -9999 -9999 -9999 -9999 -9999 -9999 -9999 -9999 -9999 -9999 -9999 -9999 -9999 -9999 -9999 -9999 -9999 -9999 -9999 -9999 -9999 -9999 -

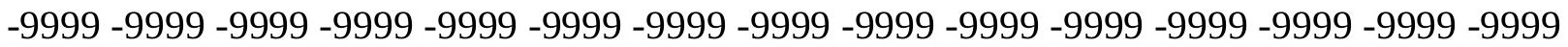
-9999 -9999 -9999 -9999 -9999 -9999 -9999 -9999 -9999 -9999 -9999 -9999 -9999 -9999 -9999 -9999 -9999 -9999 -9999 -9999 -9999 -9999 -9999 -9999 -9999 -9999 -9999 -9999 -9999 -9999 -9999 -9999 -9999 -9999 -9999 -9999 -9999 -9999 -9999 -9999 -9999 -9999 -9999 -9999 -9999 -9999 -9999 -9999 -9999 -9999 -9999 -9999 -9999 -9999 -9999 -9999 -9999 -9999 -9999 -9999

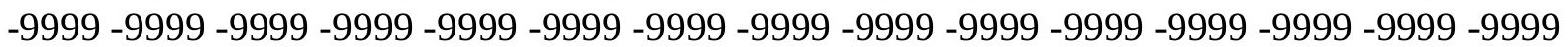


-9999 -9999 -9999 -9999 -9999 -9999 -9999 -9999 -9999 -9999 -9999 -9999 -9999 -9999 -9999 -9999 -9999 -9999 -9999 -9999 -9999 -9999 -9999 -9999 -9999 -9999 -9999 -9999 -9999 -9999 -

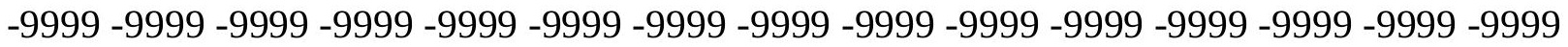
-9999 -9999 -9999 -9999 -9999 -9999 -9999 -9999 -9999 -9999 -9999 -9999 -9999 -9999 -9999 -9999 -9999 -9999 -9999 -9999 -9999 -9999 -9999 -9999-9999 -9999 -9999 -9999 -9999 -9999 -9999 -9999 -9999 -9999 -9999 -9999 -9999 -9999 -9999 -9999 -9999 -9999 -9999 -9999 -9999 -9999 -9999 -9999 -9999 -9999 -9999 -9999 -9999 -9999 -9999 -9999 -9999 -9999 -9999 -

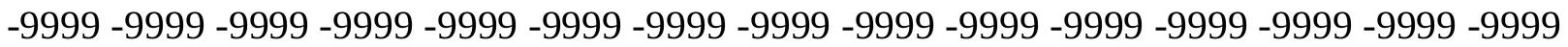

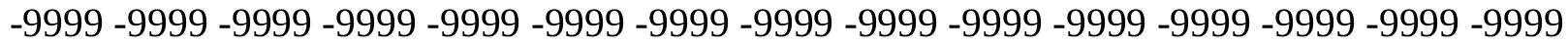
-9999 -9999 -9999 -9999 -9999 -9999 -9999 -9999 -9999 -9999 -9999 -9999 -9999 -9999 -9999 -9999 -9999 -9999 -9999 -9999 -9999 -9999 -9999 -9999 -9999 -9999 -9999 -9999 -9999 -9999 -9999 -9999 -9999 -9999 -9999 -9999 -9999 -9999 -9999 -9999 -9999 -9999 -9999 -9999 -9999 -9999 -9999 -9999 -9999 -9999 -9999 -9999 -9999 -9999 -9999 -9999 -9999 -9999 -9999 -9999 -9999 -9999 -9999 -9999 -9999 -9999 -9999 -9999 -9999 -9999 -9999 -9999 -9999 -9999 -9999 -9999 -9999 -9999 -9999 -9999 -9999 -9999 -9999 -9999 -9999 -9999 -9999 -9999 -9999 -9999 -

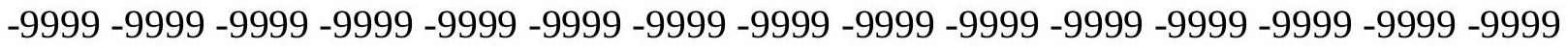
-9999 -9999 -9999 -9999 -9999 -9999 -9999 -9999 -9999 -9999 -9999 -9999 -9999 -9999 -9999 -9999 -9999 -9999 -9999 -9999 -9999 -9999 -9999 -9999 -9999 -9999 -9999 -9999 -9999 -9999 -9999 -9999 -9999 -9999 -9999 -9999 -9999 -9999 -9999 -9999 -9999 -9999 -9999 -9999 -9999 -

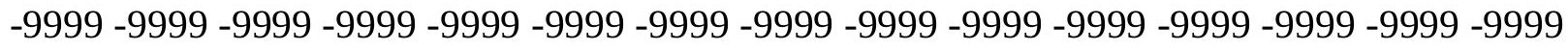

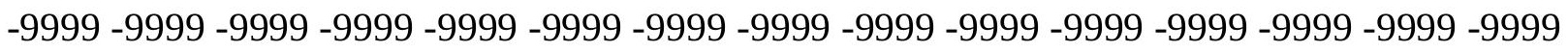

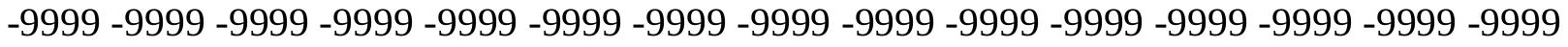
-9999 -9999 -9999 -9999 -9999 -9999 -9999 -9999 -9999 -9999 -9999 -9999 -9999 -9999 -9999 -9999 -9999 -9999 -9999 -9999 -9999 -9999 -9999 -9999 -9999 -9999 -9999 -9999 -9999 -9999 -

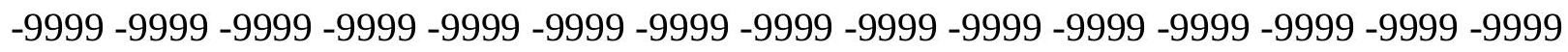
-9999 -9999 -9999 -9999 -9999 -9999 -9999 -9999 -9999 -9999 -9999 -9999 -9999 -9999 -9999 -9999 -9999 -9999 -9999 -9999 -9999 -9999 -9999 -9999 -9999 -9999 -9999 -9999 -9999 -9999 -

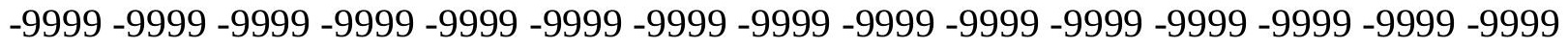
-9999 -9999 -9999 -9999 -9999 -9999 -9999 -9999 -9999 -9999 -9999 -9999 -9999 -9999 -9999 -9999 -9999 -9999 -9999 -9999 -9999 -9999 -9999 -9999 -9999 -9999 -9999 -9999 -9999 -999 -9999 -9999 -9999 -9999 -9999 -9999 -9999 -9999 -9999 -9999 -9999 -9999 -9999 -9999 -9999 -

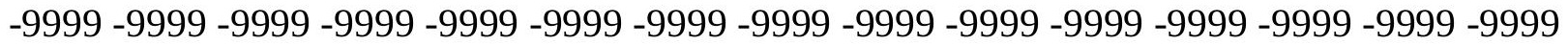

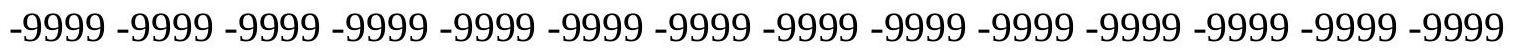

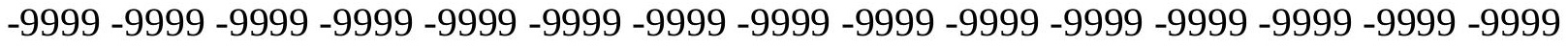

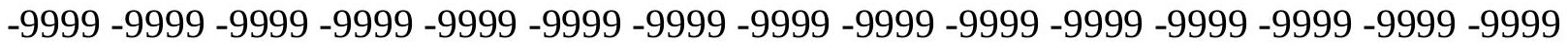

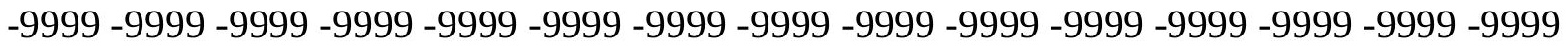

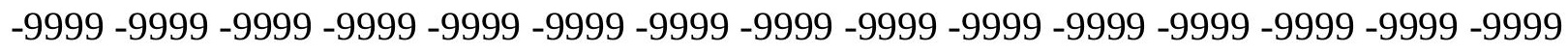

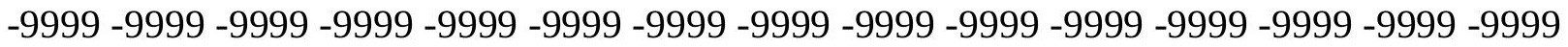

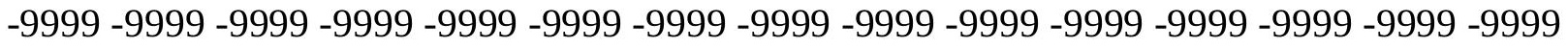
-9999 -9999 -9999 -9999 -9999 -9999 -9999 -9999 -9999 -9999 -9999 -9999 -9999 -9999 -9999 -

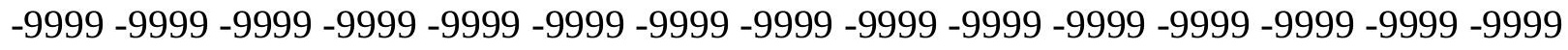

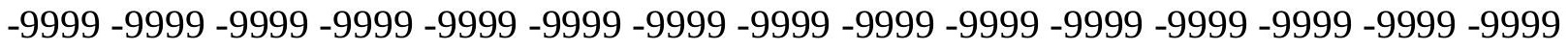
-9999 -9999 -9999 -9999 -9999 -9999 -9999 -9999 -9999 -9999 -9999 -9999 -9999 -9999 -9999 -9999 -9999 -9999 -9999 -9999 -9999 -9999 -9999 -9999-9999 -9999 -9999 -9999 -9999 -9999 -9999 -9999 -9999 -9999 -9999 -9999 -9999 -9999 -9999 -9999 -9999 -9999 -9999 -9999 -9999 -

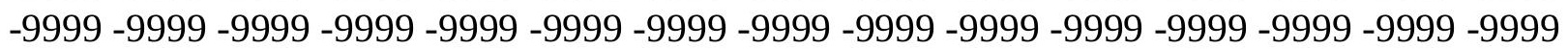


-9999 -9999 -9999 -9999 -9999 -9999 -9999 -9999 -9999 -9999 -9999 -9999 -9999 -9999 -9999 -9999 -9999 -9999 -9999 -9999 -9999 -9999 -9999 -9999 -9999 -9999 -9999 -9999 -9999 -9999 -

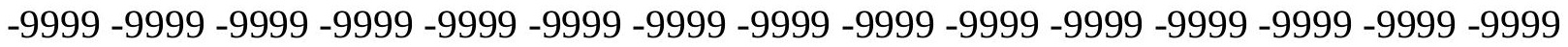
-9999 -9999 -9999 -9999 -9999 -9999 -9999 -9999 -9999 -9999 -9999 -9999 -9999 -9999 -9999 -9999 -9999 -9999 -9999 -9999 -9999 -9999 -9999 -9999-9999 -9999 -9999 -9999 -9999 -9999 -9999 -9999 -9999 -9999 -9999 -9999 -9999 -9999 -9999 -9999 -9999 -9999 -9999 -9999 -9999 -9999 -9999 -9999 -9999 -9999 -9999 -9999 -9999 -9999 -9999 -9999 -9999 -9999 -9999 -9999

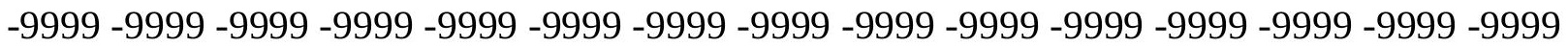

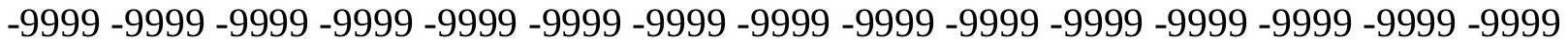
-9999 -9999 -9999 -9999 -9999 -9999 -9999 -9999 -9999 -9999 -9999 -9999 -9999 -9999 -9999 -9999 -9999 -9999 -9999 -9999 -9999 -9999 -9999 -9999 -9999 -9999 -9999 -9999 -9999 -9999 -9999 -9999 -9999 -9999 -9999 -9999 -9999 -9999 -9999 -9999 -9999 -9999 -9999 -9999 -9999 -9999 -9999 -9999 -9999 -9999 -9999 -9999 -9999 -9999 -9999 -9999 -9999 -9999 -9999 -9999 -9999 -9999 -9999 -9999 -9999 -9999 -9999 -9999 -9999 -9999 -9999 -9999 -9999 -9999 -9999 -9999 -9999 -9999 -9999 -9999 -9999 -9999 -9999 -9999 -9999 -9999 -9999 -9999 -9999 -

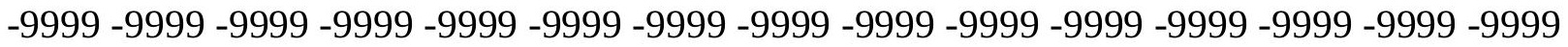
-9999 -9999 -9999 -9999 -9999 -9999 -9999 -9999 -9999 -9999 -9999 -9999 -9999 -9999 -9999 -9999 -9999 -9999 -9999 -9999 -9999 -9999 -9999 -9999 -9999 -9999 -9999 -9999 -9999 -9999 -9999 -9999 -9999 -9999 -9999 -9999 -9999 -9999 -9999 -9999 -9999 -9999 -9999 -9999 -9999 -

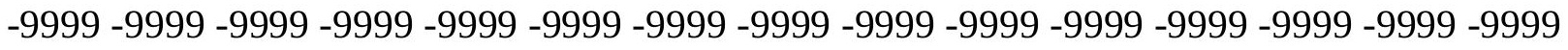
-9999 -9999 -9999 -9999 -9999 -9999 -9999 -9999 -9999 -9999 -9999 -9999 -9999 -9999 -9999

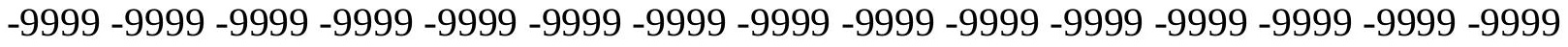
-9999 -9999 -9999 -9999 -9999 -9999 -9999 -9999 -9999 -9999 -9999 -9999 -9999 -9999 -9999 -9999 -9999 -9999 -9999 -9999 -9999 -9999 -9999 -9999 -9999 -9999 -9999 -9999 -9999 -9999 -

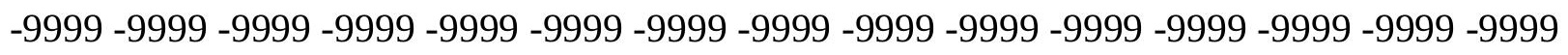
-9999 -9999 -9999 -9999 -9999 -9999 -9999 -9999 -9999 -9999 -9999 -9999 -9999 -9999 -9999 -9999 -9999 -9999 -9999 -9999 -9999 -9999 -9999 -9999 -9999 -9999 -9999 -9999 -9999 -9999 -

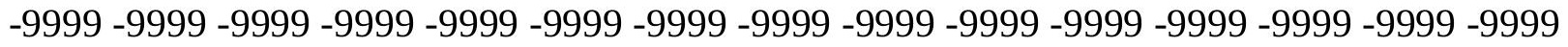
-9999 -9999 -9999 -9999 -9999 -9999 -9999 -9999 -9999 -9999 -9999 -9999 -9999 -9999 -9999 -9999 -9999 -9999 -9999 -9999 -9999 -9999 -9999 -9999 -9999 -9999 -9999 -9999 -9999 -999 -9999 -9999 -9999 -9999 -9999 -9999 -9999 -9999 -9999 -9999 -9999 -9999 -9999 -9999 -9999 -9999 -9999 -9999 -9999 -9999 -9999 -9999 -9999 -9999 -9999 -9999 -9999 -9999 -9999 -9999 -

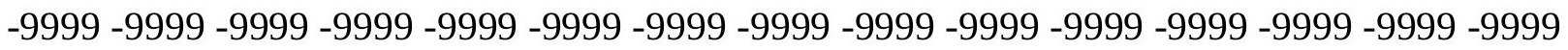

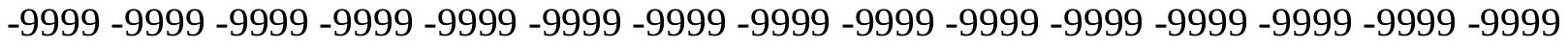

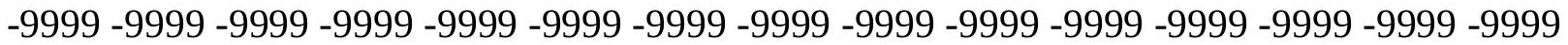
-9999 -9999 -9999 -9999 -9999 -9999 -9999 -9999 -9999 -9999 -9999 -9999 -9999 -9999 -9999 -

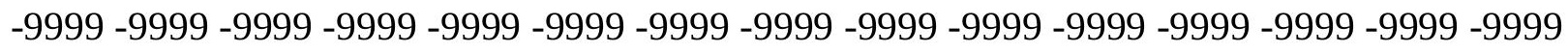

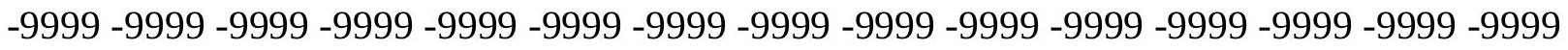
-9999 -9999 -9999 -9999 -9999 -9999 -9999 -9999 -9999 -9999 -9999 -9999 -9999 -9999 - -999 -9999 -9999 -9999 -9999 -9999 -9999 -9999 -9999 -9999 -9999 -9999 -9999 -9999 -9999 -9999 -

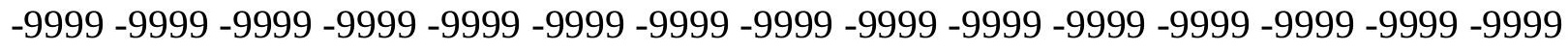

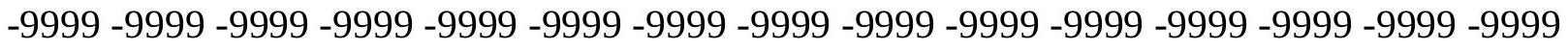
-9999 -9999 -9999 -9999 -9999 -9999 -9999 -9999 -9999 -9999 -9999 -9999 -9999 -9999 -9999 -9999 -9999 -9999 -9999 -9999 -9999 -9999 -9999 -9999-9999 -9999 -9999 -9999 -9999 -9999 -9999 -9999 -9999 -9999 -9999 -9999 -9999 -9999 -9999 -9999 -9999 -9999 -9999 -9999 -9999 -

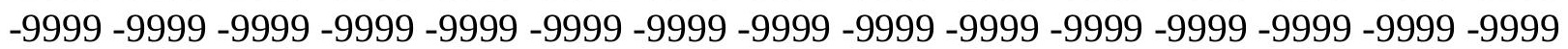


-9999 -9999 -9999 -9999 -9999 -9999 -9999 -9999 -9999 -9999 -9999 -9999 -9999 -9999 -9999 -9999 -9999 -9999 -9999 -9999 -9999 -9999 -9999 -9999 -9999 -9999 -9999 -9999 -9999 -9999 -

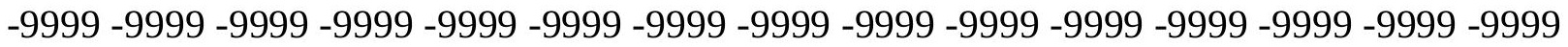
-9999 -9999 -9999 -9999 -9999 -9999 -9999 -9999 -9999 -9999 -9999 -9999 -9999 -9999 -9999 -9999 -9999 -9999 -9999 -9999 -9999 -9999 -9999 -9999-9999 -9999 -9999 -9999 -9999 -9999 -9999 -9999 -9999 -9999 -9999 -9999 -9999 -9999 -9999 -9999 -9999 -9999 -9999 -9999 -9999 -9999 -9999 -9999 -9999 -9999 -9999 -9999 -9999 -9999 -9999 -9999 -9999 -9999 -9999 -9999

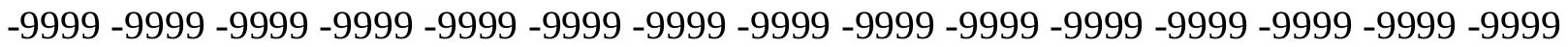

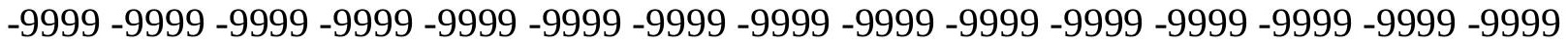
-9999 -9999 -9999 -9999 -9999 -9999 -9999 -9999 -9999 -9999 -9999 -9999 -9999 -9999 -9999 -9999 -9999 -9999 -9999 -9999 -9999 -9999 -9999 -9999 -9999 -9999 -9999 -9999 -9999 -9999 -9999 -9999 -9999 -9999 -9999 -9999 -9999 -9999 -9999 -9999 -9999 -9999 -9999 -9999 -9999 -9999 -9999 -9999 -9999 -9999 -9999 -9999 -9999 -9999 -9999 -9999 -9999 -9999 -9999 -9999 -

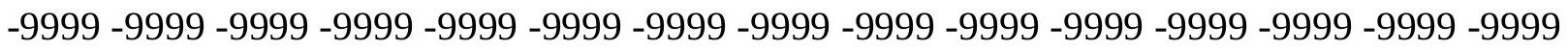
-9999 -9999 -9999 -9999 -9999 -9999 -9999 -9999 -9999 -9999 -9999 -9999 -9999 -9999 -9999 -

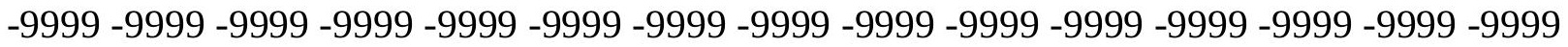
-9999 -9999 -9999 -9999 -9999 -9999 -9999 -9999 -9999 -9999 -9999 -9999 -9999 -9999 -9999 -9999 -9999 -9999 -9999 -9999 -9999 -9999 -9999 -9999 -9999 -9999 -9999 -9999 -9999 -9999 -9999 -9999 -9999 -9999 -9999 -9999 -9999 -9999 -9999 -9999 -9999 -9999 -9999 -9999 - -999 -

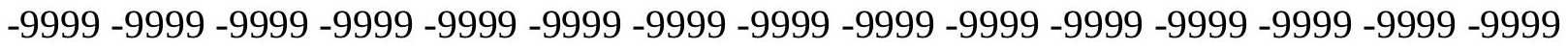

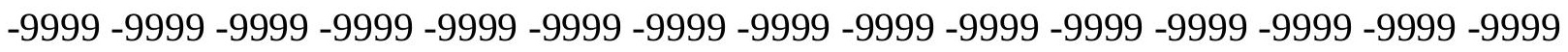
-9999 -9999 -9999 -9999 -9999 -9999 -9999 -9999 -9999 -9999 -9999 -9999 -9999 -9999 -9999 -9999 -9999 -9999 -9999 -9999 -9999 -9999 -9999 -9999 -9999 -9999 -9999 -9999 -9999 -9999 -9999 -9999 -9999 -9999 -9999 -9999 -9999 -9999 -9999 -9999 -9999 -9999 -9999 -9999 -9999 -

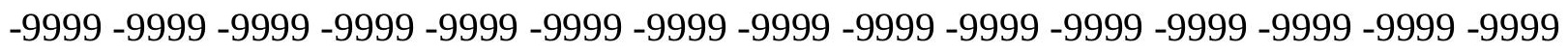
-9999 -9999 -9999 -9999 -9999 -9999 -9999 -9999 -9999 -9999 -9999 -9999 -9999 -9999 -9999 -9999 -9999 -9999 -9999 -9999 -9999 -9999 -9999 -9999 -9999 -9999 -9999 -9999 -9999 -9999 -

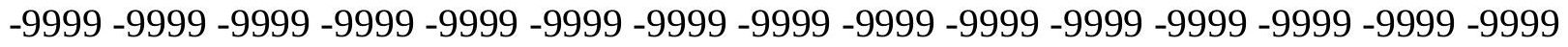
-9999 -9999 -9999 -9999 -9999 -9999 -9999 -9999 -9999 -9999 -9999 -9999 -9999 -9999 -9999 -9999 -9999 -9999 -9999 -9999 -9999 -9999 -9999 -9999 -9999 -9999 -9999 -9999 -9999 -999 -

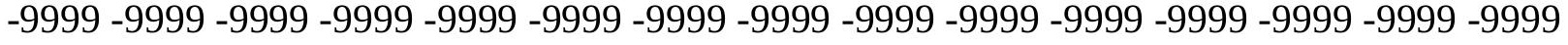
-9999 -9999 -9999 -9999 -9999 -9999 -9999 -9999 -9999 -9999 -9999 -9999 -9999 -9999 -9999 -

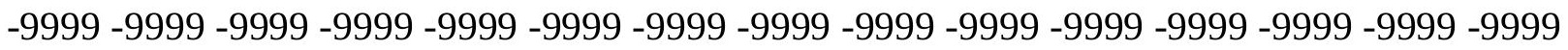

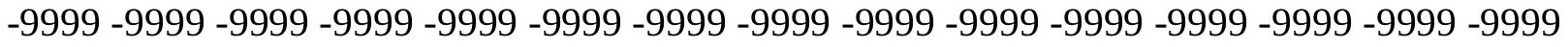

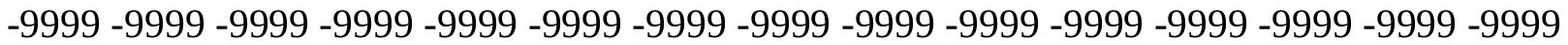

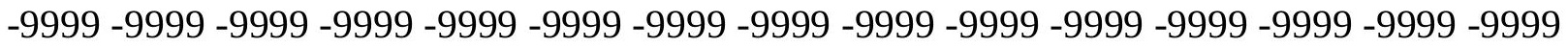

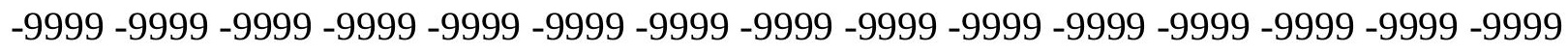

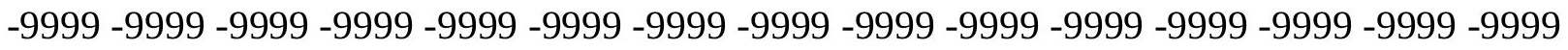

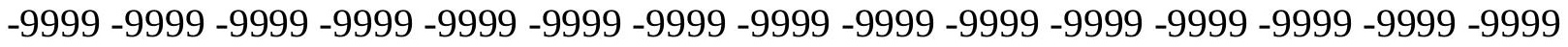
-9999 -9999 -9999 -9999 -9999 -9999 -9999 -9999 -9999 -9999 -9999 -9999 -9999 -9999 -9999 -

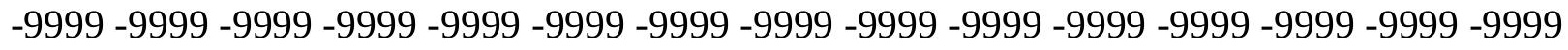

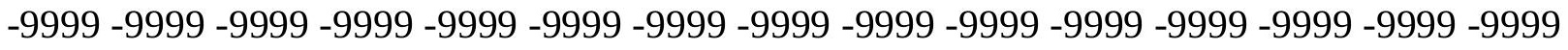
-9999 -9999 -9999 -9999 -9999 -9999 -9999 -9999 -9999 -9999 -9999 -9999 -9999 -9999 -9999 -9999 -9999 -9999 -9999 -9999 -9999 -9999 -9999 -9999 -9999 -9999 -9999 -9999 -9999 -9999 -9999 -9999 -9999 -9999 -9999 -9999 -9999 -9999 -9999 -9999 -9999 -9999 -9999 -9999 -

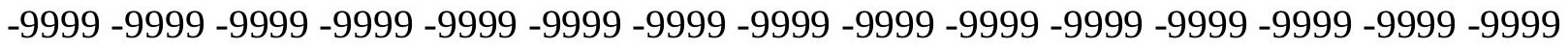


-9999 -9999 -9999 -9999 -9999 -9999 -9999 -9999 -9999 -9999 -9999 -9999 -9999 -9999 -9999 -9999 -9999 -9999 -9999 -9999 -9999 -9999 -9999 -9999 -9999 -9999 -9999 -9999 -9999 -9999 -

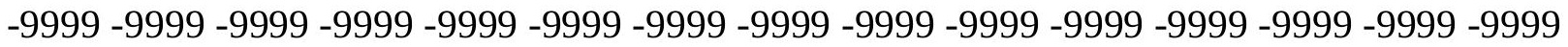
-9999 -9999 -9999 -9999 -9999 -9999 -9999 -9999 -9999 -9999 -9999 -9999 -9999 -9999 -9999 -9999 -9999 -9999 -9999 -9999 -9999 -9999 -9999 -9999-9999 -9999 -9999 -9999 -9999 -9999 -9999 -9999 -9999 -9999 -9999 -9999 -9999 -9999 -9999 -9999 -9999 -9999 -9999 -9999 -9999 -9999 -9999 -9999 -9999 -9999 -9999 -9999 -9999 -9999 -9999 -9999 -9999 -9999 -9999 -9999

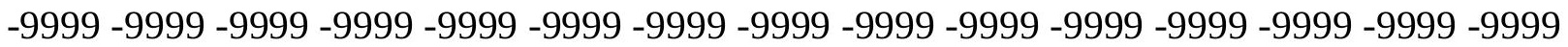

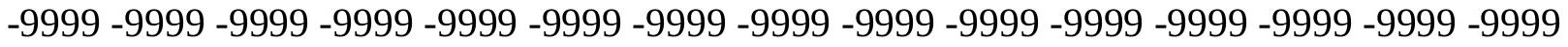
-9999 -9999 -9999 -9999 -9999 -9999 -9999 -9999 -9999 -9999 -9999 -9999 -9999 -9999 -9999 -9999 -9999 -9999 -9999 -9999 -9999 -9999 -9999 -9999 -9999 -9999 -9999 -9999 -9999 -9999 -9999 -9999 -9999 -9999 -9999 -9999 -9999 -9999 -9999 -9999 -9999 -9999 -9999 -9999 -9999 -9999 -9999 -9999 -9999 -9999 -9999 -9999 -9999 -9999 -9999 -9999 -9999 -9999 -9999 -9999 -

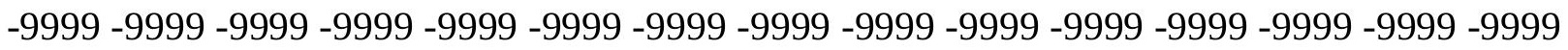
-9999 -9999 -9999 -9999 -9999 -9999 -9999 -9999 -9999 -9999 -9999 -9999 -9999 -9999 -9999 -

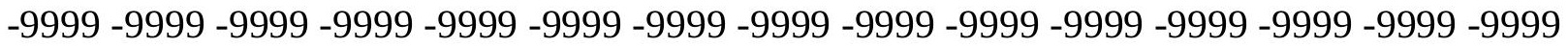
-9999 -9999 -9999 -9999 -9999 -9999 -9999 -9999 -9999 -9999 -9999 -9999 -9999 -9999 -9999 -9999 -9999 -9999 -9999 -9999 -9999 -9999 -9999 -9999 -9999 -9999 -9999 -9999 -9999 - 9999 -9999 -9999 -9999 -9999 -9999 -9999 -9999 -9999 -9999 -9999 -9999 -9999 -9999 -9999 -9999 -

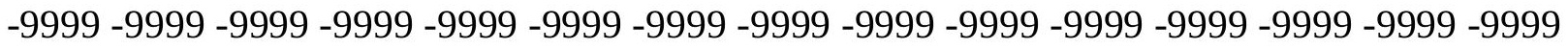

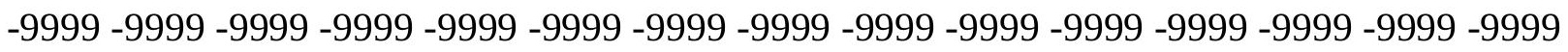
-9999 -9999 -9999 -9999 -9999 -9999 -9999 -9999 -9999 -9999 -9999 -9999 -9999 -9999 - 9999 -9999 -9999 -9999 -9999 -9999 -9999 -9999 -9999 -9999 -9999 -9999 -9999 -9999 -9999 -9999 -9999 -9999 -9999 -9999 -9999 -9999 -9999 -9999 -9999 -9999 -9999 -9999 -9999 -9999 -9999 -9999 -9999 -9999 -9999 -9999 -9999 -9999 -9999 -9999 -9999 -9999 -9999 -9999 -9999 -9999 -9999 -9999 -9999 -9999 -9999 -9999 -9999 -9999 -9999 -9999 -9999 -9999 -9999 -9999 -9999 -9999 -9999 -9999 -9999 -9999 -9999 -9999 -9999 -9999 -9999 -9999 -9999 -9999 -9999 -

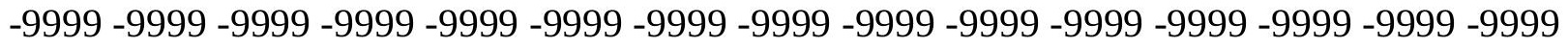
-9999 -9999 -9999 -9999 -9999 -9999 -9999 -9999 -9999 -9999 -9999 -9999 -9999 -9999 -9999 -9999 -9999 -9999 -9999 -9999 -9999 -9999 -9999 -9999 -9999 -9999 -9999 -9999 -9999 -999 -9999 -9999 -9999 -9999 -9999 -9999 -9999 -9999 -9999 -9999 -9999 -9999 -9999 -9999 -9999 -9999 -9999 -9999 -9999 -9999 -9999 -9999 -9999 -9999 -9999 -9999 -9999 -9999 -9999 -9999 -

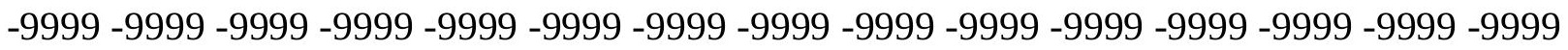

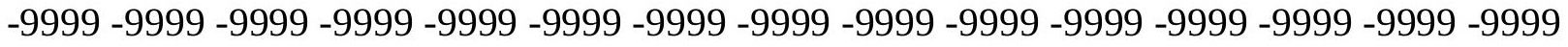

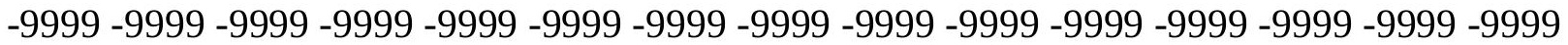

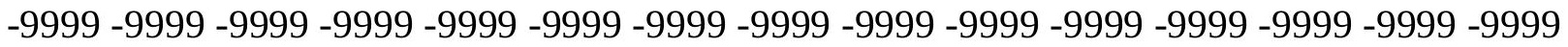

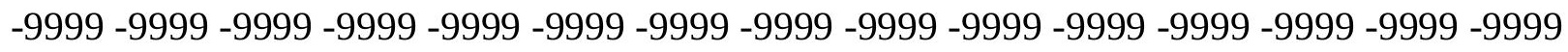

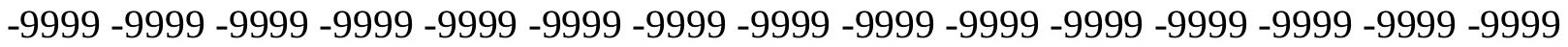

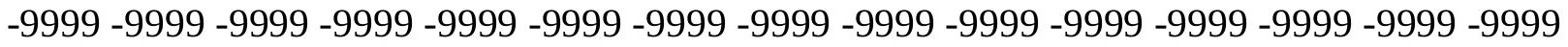
-9999 -9999 -9999 -9999 -9999 -9999 -9999 -9999 -9999 -9999 -9999 -9999 -9999 -9999 -9999 -

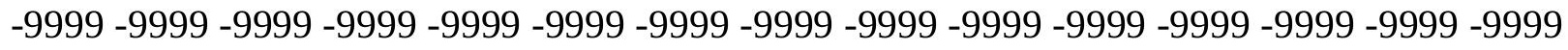

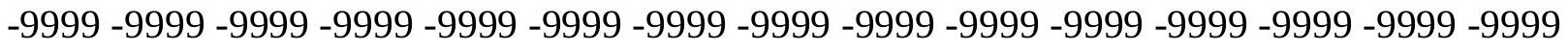
-9999 -9999 -9999 -9999 -9999 -9999 -9999 -9999 -9999 -9999 -9999 -9999 -9999 -9999 -9999 -9999 -9999 -9999 -9999 -9999 -9999 -9999 -9999 -9999-9999 -9999 -9999 -9999 -9999 -9999 -9999 -9999 -9999 -9999 -9999 -9999 -9999 -9999 -9999 -9999 -9999 -9999 -9999 -9999 -9999 -

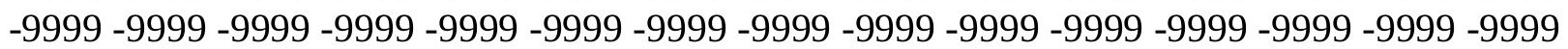


-9999 -9999 -9999 -9999 -9999 -9999 -9999 -9999 -9999 -9999 -9999 -9999 -9999 -9999 -9999 -9999 -9999 -9999 -9999 -9999 -9999 -9999 -9999 -9999 -9999 -9999 -9999 -9999 -9999 -9999 -9999 -9999 -9999 -9999 -9999 -9999 -9999 -9999 -9999 -9999 -9999 -9999 -9999 -9999 - 9999 -9999 -9999 -9999 -9999 -9999 -9999 -9999 -9999 -9999 -9999 -9999 -9999 -9999 -9999 -9999 -9999 -9999 -9999 -9999 -9999 -9999 -9999 -9999 -9999 -9999 -9999 -9999 -9999 -9999 -9999 -9999 -9999 -9999 -9999 -9999 -9999 -9999 -9999 -9999 -9999 -9999 -9999 -9999 -9999 -9999 -9999 -9999 -9999 -9999 -9999 -9999 -9999 -9999 -9999 -9999 -9999 -9999 -9999 -9999

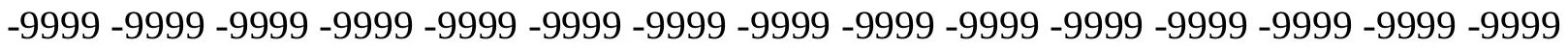

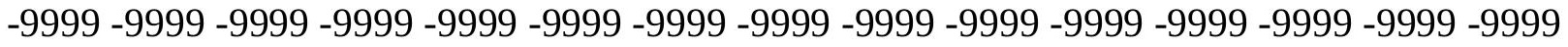
-9999 -9999 -9999 -9999 -9999 -9999 -9999 -9999 -9999 -9999 -9999 -9999 -9999 -9999 -9999 -9999 -9999 -9999 -9999 -9999 -9999 -9999 -9999 -9999 -9999 -9999 -9999 -9999 -9999 -9999 -9999 -9999 -9999 -9999 -9999 -9999 -9999 -9999 -9999 -9999 -9999 -9999 -9999 -9999 -9999 -9999 -9999 -9999 -9999 -9999 -9999 -9999 -9999 -9999 -9999 -9999 -9999 -9999 -9999 -9999 -9999 -9999 -9999 -9999 -9999 -9999 -9999 -9999 -9999 -9999 -9999 -9999 -9999 -9999 -9999 -9999 -9999 -9999 -9999 -9999 -9999 -9999 -9999 -9999 -9999 -9999 -9999 -9999 -9999 -9999 -

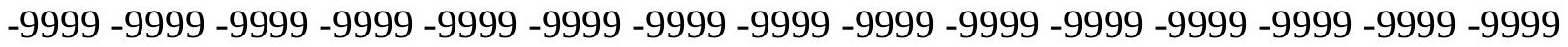
-9999 -9999 -9999 -9999 -9999 -9999 -9999 -9999 -9999 -9999 -9999 -9999 -9999 -9999 -9999 -9999 -9999 -9999 -9999 -9999 -9999 -9999 -9999 -9999 -9999 -9999 -9999 -9999 -9999 - 9999 -9999 -9999 -9999 -9999 -9999 -9999 -9999 -9999 -9999 -9999 -9999 -9999 -9999 -9999 -9999 -

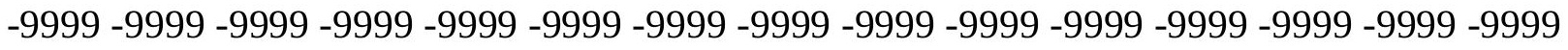

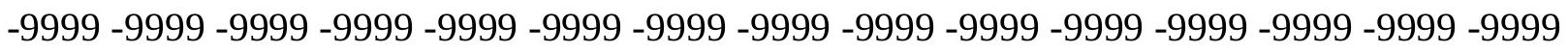

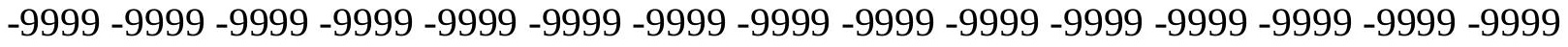
-9999 -9999 -9999 -9999 -9999 -9999 -9999 -9999 -9999 -9999 -9999 -9999 -9999 -9999 -9999 -9999 -9999 -9999 -9999 -9999 -9999 -9999 -9999 -9999 -9999 -9999 -9999 -9999 -9999 -9999 -

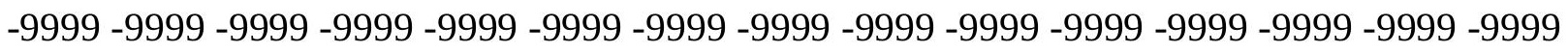
-9999 -9999 -9999 -9999 -9999 -9999 -9999 -9999 -9999 -9999 -9999 -9999 -9999 -9999 -9999 -9999 -9999 -9999 -9999 -9999 -9999 -9999 -9999 -9999 -9999 -9999 -9999 -9999 -9999 -9999 -

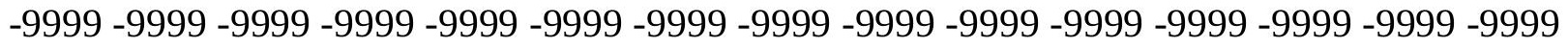
-9999 -9999 -9999 -9999 -9999 -9999 -9999 -9999 -9999 -9999 -9999 -9999 -9999 -9999 -9999 -9999 -9999 -9999 -9999 -9999 -9999 -9999 -9999 -9999 -9999 -9999 -9999 -9999 -9999 -999 -9999 -9999 -9999 -9999 -9999 -9999 -9999 -9999 -9999 -9999 -9999 -9999 -9999 -9999 -9999 -9999 -9999 -9999 -9999 -9999 -9999 -9999 -9999 -9999 -9999 -9999 -9999 -9999 -9999 -

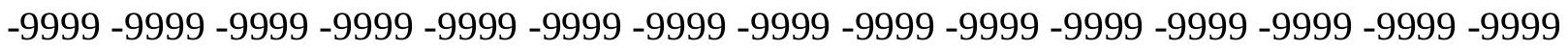

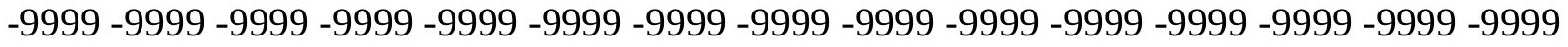

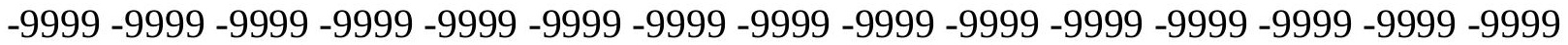

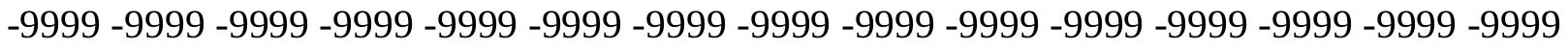

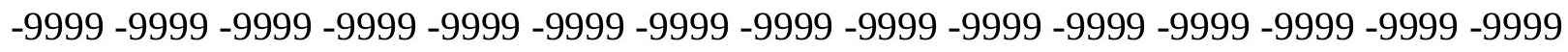

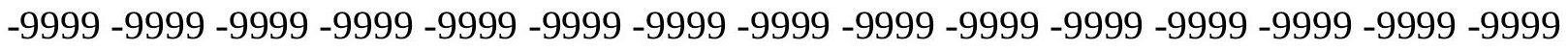

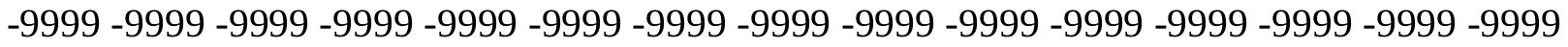
-9999 -9999 -9999 -9999 -9999 -9999 -9999 -9999 -9999 -9999 -9999 -9999 -9999 -9999 -9999 -

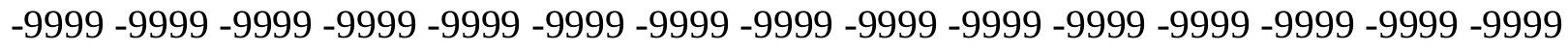

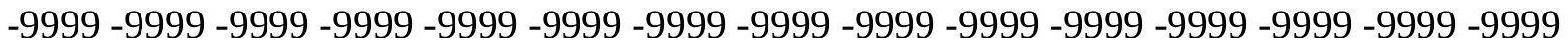
-9999 -9999 -9999 -9999 -9999 -9999 -9999 -9999 -9999 -9999 -9999 -9999 -9999 -9999 -9999 -9999 -9999 -9999 -9999 -9999 -9999 -9999 -9999 -9999-9999 -9999 -9999 -9999 -9999 -9999 -9999 -9999 -9999 -9999 -9999 -9999 -9999 -9999 -9999 -9999 -9999 -9999 -9999 -9999 -9999 -

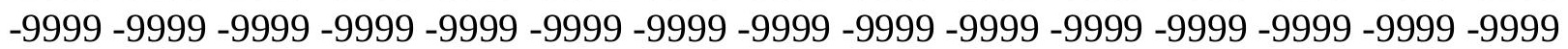


-9999 -9999 -9999 -9999 -9999 -9999 -9999 -9999 -9999 -9999 -9999 -9999 -9999 -9999 -9999 -9999 -9999 -9999 -9999 -9999 -9999 -9999 -9999 -9999 -9999 -9999 -9999 -9999 -9999 -9999 -

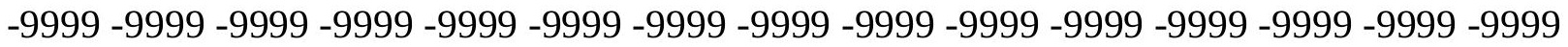
-9999 -9999 -9999 -9999 -9999 -9999 -9999 -9999 -9999 -9999 -9999 -9999 -9999 -9999 -9999 -9999 -9999 -9999 -9999 -9999 -9999 -9999 -9999 -9999-9999 -9999 -9999 -9999 -9999 -9999 -9999 -9999 -9999 -9999 -9999 -9999 -9999 -9999 -9999 -9999 -9999 -9999 -9999 -9999 -9999 -9999 -9999 -9999 -9999 -9999 -9999 -9999 -9999 -9999 -9999 -9999 -9999 -9999 -9999 -9999

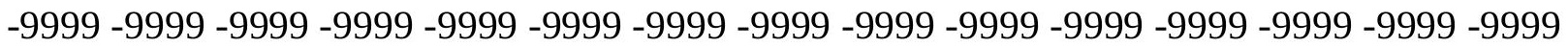

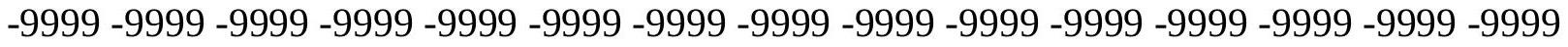

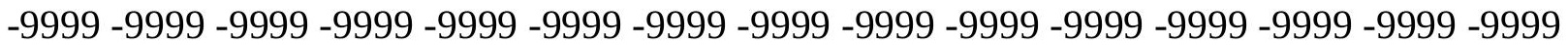
-9999 -9999 -9999 -9999 -9999 -9999 -9999 -9999 -9999 -9999 -9999 -9999 -9999 -9999 -9999 -9999 -9999 -9999 -9999 -9999 -9999 -9999 -9999 -9999 -9999 -9999 -9999 -9999 -9999 -9999 -9999 -9999 -9999 -9999 -9999 -9999 -9999 -9999 -9999 -9999 -9999 -9999 -9999 -9999 -

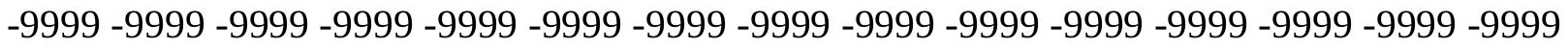
-9999 -9999 -9999 -9999 -9999 -9999 -9999 -9999 -9999 -9999 -9999 -9999 -9999 -9999 -9999 -

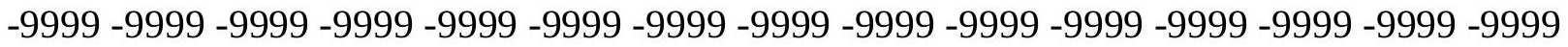
-9999 -9999 -9999 -9999 -9999 -9999 -9999 -9999 -9999 -9999 -9999 -9999 -9999 -9999 -9999 -9999 -9999 -9999 -9999 -9999 -9999 -9999 -9999 -9999 -9999 -9999 -9999 -9999 -9999 -9999 -9999 -9999 -9999 -9999 -9999 -9999 -9999 -9999 -9999 -9999 -9999 -9999 -9999 -9999 -9999 -

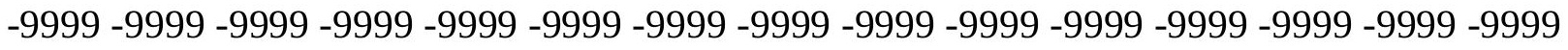

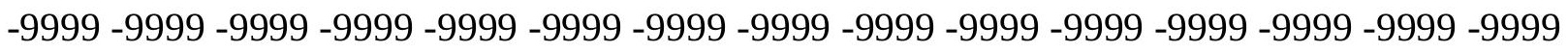
-9999 -9999 -9999 -9999 -9999 -9999 -9999 -9999 -9999 -9999 -9999 -9999 -9999 -9999 -9999 -9999 -9999 -9999 -9999 -9999 -9999 -9999 -9999 -9999 -9999 -9999 -9999 -9999 -9999 -9999 -9999 -9999 -9999 -9999 -9999 -9999 -9999 -9999 -9999 -9999 -9999 -9999 -9999 -9999 -9999 -

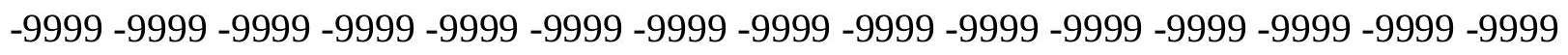
-9999 -9999 -9999 -9999 -9999 -9999 -9999 -9999 -9999 -9999 -9999 -9999 -9999 -9999 -9999 -9999 -9999 -9999 -9999 -9999 -9999 -9999 -9999 -9999 -9999 -9999 -9999 -9999 -9999 -9999 -

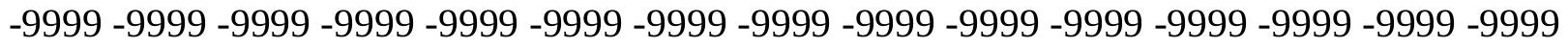
-9999 -9999 -9999 -9999 -9999 -9999 -9999 -9999 -9999 -9999 -9999 -9999 -9999 -9999 -9999 -9999 -9999 -9999 -9999 -9999 -9999 -9999 -9999 -9999 -9999 -9999 -9999 -9999 -9999 -999 -9999 -9999 -9999 -9999 -9999 -9999 -9999 -9999 -9999 -9999 -9999 -9999 -9999 -9999 -9999 -9999 -9999 -9999 -9999 -9999 -9999 -9999 -9999 -9999 -9999 -9999 -9999 -9999 -9999 -9999 -

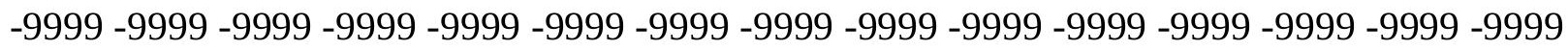

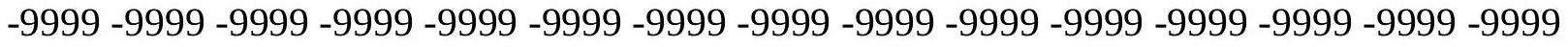

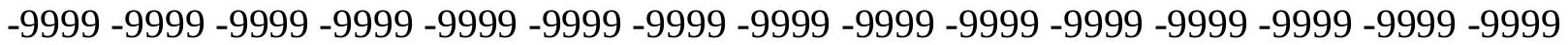
-9999 -9999 -9999 -9999 -9999 -9999 -9999 -9999 -9999 -9999 -9999 -9999 -9999 -9999 -9999 -

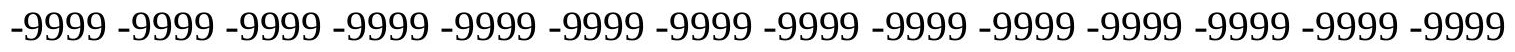

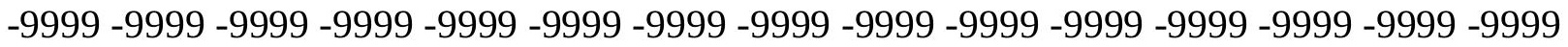
-9999 -9999 -9999 -9999 -9999 -9999 -9999 -9999 -9999 -9999 -9999 -9999 -9999 - 9999 - -999 -9999 -9999 -9999 -9999 -9999 -9999 -9999 -9999 -9999 -9999 -9999 -9999 -9999 -9999 -9999 -

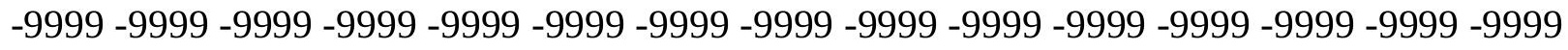

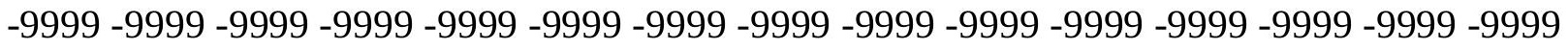
-9999 -9999 -9999 -9999 -9999 -9999 -9999 -9999 -9999 -9999 -9999 -9999 -9999 -9999 -9999 -9999 -9999 -9999 -9999 -9999 -9999 -9999 -9999 -9999-9999 -9999 -9999 -9999 -9999 -9999 -9999 -9999 -9999 -9999 -9999 -9999 -9999 -9999 -9999 -9999 -9999 -9999 -9999 -9999 -9999 -

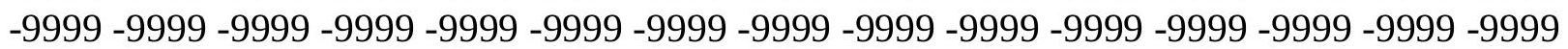


-9999 -9999 -9999 -9999 -9999 -9999 -9999 -9999 -9999 -9999 -9999 -9999 -9999 -9999 -9999 -9999 -9999 -9999 -9999 -9999 -9999 -9999 -9999 -9999 -9999 -9999 -9999 -9999 -9999 -9999 -

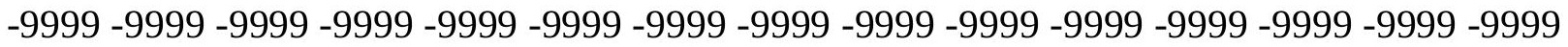
-9999 -9999 -9999 -9999 -9999 -9999 -9999 -9999 -9999 -9999 -9999 -9999 -9999 -9999 -9999 -9999 -9999 -9999 -9999 -9999 -9999 -9999 -9999 -9999-9999 -9999 -9999 -9999 -9999 -9999 -9999 -9999 -9999 -9999 -9999 -9999 -9999 -9999 -9999 -9999 -9999 -9999 -9999 -9999 -9999 -9999 -9999 -9999 -9999 -9999 -9999 -9999 -9999 -9999 -9999 -9999 -9999 -9999 -9999 -9999

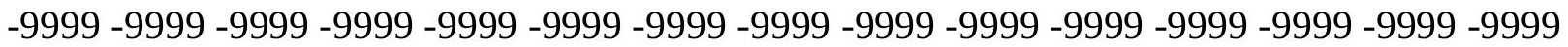

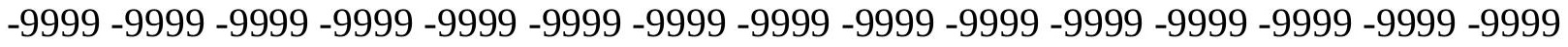
-9999 -9999 -9999 -9999 -9999 -9999 -9999 -9999 -9999 -9999 -9999 -9999 -9999 -9999 -9999 -9999 -9999 -9999 -9999 -9999 -9999 -9999 -9999 -9999 -9999 -9999 -9999 -9999 -9999 -9999 -9999 -9999 -9999 -9999 -9999 -9999 -9999 -9999 -9999 -9999 -9999 -9999 -9999 -9999 -9999 -9999 -9999 -9999 -9999 -9999 -9999 -9999 -9999 -9999 -9999 -9999 -9999 -9999 -9999 -9999 -9999 -9999 -9999 -9999 -9999 -9999 -9999 -9999 -9999 -9999 -9999 -9999 -9999 -9999 -9999 -9999 -9999 -9999 -9999 -9999 -9999 -9999 -9999 -9999 -9999 -9999 -9999 -9999 -9999 -9999 -

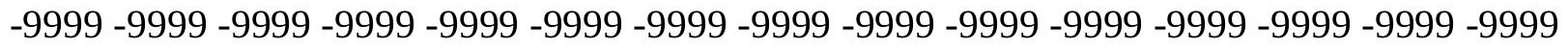
-9999 -9999 -9999 -9999 -9999 -9999 -9999 -9999 -9999 -9999 -9999 -9999 -9999 -9999 -9999 -9999 -9999 -9999 -9999 -9999 -9999 -9999 -9999 -9999 -9999 -9999 -9999 -9999 -9999 -9999 -9999 -9999 -9999 -9999 -9999 -9999 -9999 -9999 -9999 -9999 -9999 -9999 -9999 -9999 -

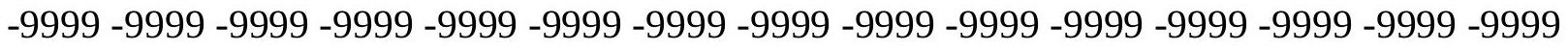
-9999 -9999 -9999 -9999 -9999 -9999 -9999 -9999 -9999 -9999 -9999 -9999 -9999 -9999 -9999 -999 -

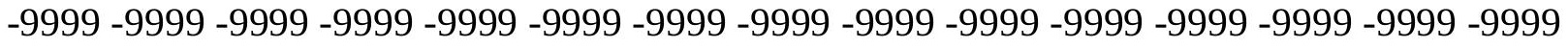
-9999 -9999 -9999 -9999 -9999 -9999 -9999 -9999 -9999 -9999 -9999 -9999 -9999 -9999 -9999 -9999 -9999 -9999 -9999 -9999 -9999 -9999 -9999 -9999 -9999 -9999 -9999 -9999 -9999 -9999 -9999 -9999 -9999 -9999 -9999 -9999 -9999 -9999 -9999 -9999 -9999 -9999 -9999 -9999 -9999 -9999 -9999 -9999 -9999 -9999 -9999 -9999 -9999 -9999 -9999 -9999 -9999 -9999 -9999 -9999 -9999 -9999 -9999 -9999 -9999 -9999 -9999 -9999 -9999 -9999 -9999 -9999 -9999 -9999 -9999 -

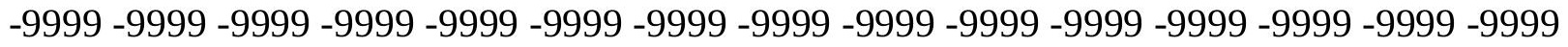
-9999 -9999 -9999 -9999 -9999 -9999 -9999 -9999 -9999 -9999 -9999 -9999 -9999 -9999 -9999 -9999 -9999 -9999 -9999 -9999 -9999 -9999 -9999 -9999 -9999 -9999 -9999 -9999 -9999 -999 -9999 -9999 -9999 -9999 -9999 -9999 -9999 -9999 -9999 -9999 -9999 -9999 -9999 -9999 -9999 -9999 -9999 -9999 -9999 -9999 -9999 -9999 -9999 -9999 -9999 -9999 -9999 -9999 -9999 -9999 -

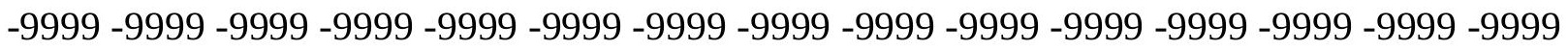

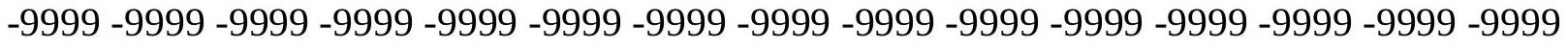

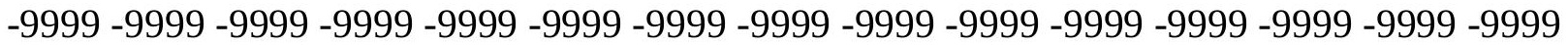
-9999 -9999 -9999 -9999 -9999 -9999 -9999 -9999 -9999 -9999 -9999 -9999 -9999 -9999 -9999

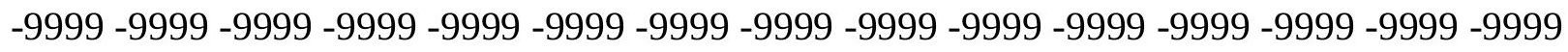

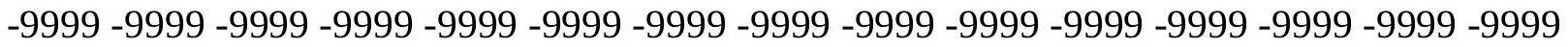
-9999 -9999 -9999 -9999 -9999 -9999 -9999 -9999 -9999 -9999 -9999 -9999 -9999 - 9999 - -999 -9999 -9999 -9999 -9999 -9999 -9999 -9999 -9999 -9999 -9999 -9999 -9999 -9999 -9999 -9999 -

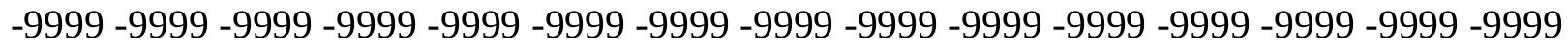

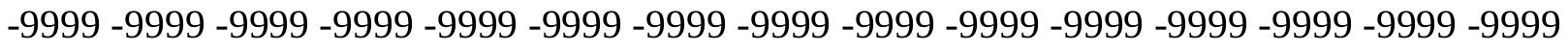
-9999 -9999 -9999 -9999 -9999 -9999 -9999 -9999 -9999 -9999 -9999 -9999 -9999 -9999 -9999 -9999 -9999 -9999 -9999 -9999 -9999 -9999 -9999 -9999 -9999 -9999 -9999 -9999 -9999 -9999 -9999 -9999 -9999 -9999 -9999 -9999 -9999 -9999 -9999 -9999 -9999 -9999 -9999 -9999 -

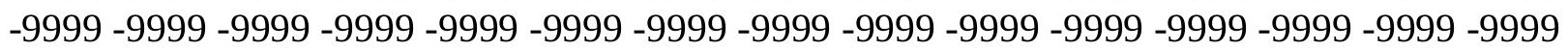


-9999 -9999 -9999 -9999 -9999 -9999 -9999 -9999 -9999 -9999 -9999 -9999 -9999 -9999 -9999 -9999 -9999 -9999 -9999 -9999 -9999 -9999 -9999 -9999 -9999 -9999 -9999 -9999 -9999 -9999 -9999 -9999 -9999 -9999 -9999 -9999 -9999 -9999 -9999 -9999 -9999 -9999 -9999 -9999 - 9999 -9999 -9999 -9999 -9999 -9999 -9999 -9999 -9999 -9999 -9999 -9999 -9999 -9999 -9999 -9999 -9999 -9999 -9999 -9999 -9999 -9999 -9999 -9999 -9999-9999 -9999 -9999 -9999 -9999 -9999 -9999 -9999 -9999 -9999 -9999 -9999 -9999 -9999 -9999 -9999 -9999 -9999 -9999 -9999 -9999 -9999 -9999 -9999 -9999 -9999 -9999 -9999 -9999 -9999 -9999 -9999 -9999 -9999 -9999 -9999

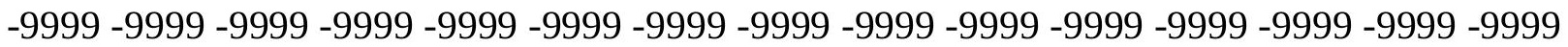

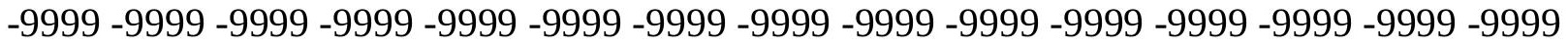
-9999 -9999 -9999 -9999 -9999 -9999 -9999 -9999 -9999 -9999 -9999 -9999 -9999 -9999 -9999 -9999 -9999 -9999 -9999 -9999 -9999 -9999 -9999 -9999 -9999 -9999 -9999 -9999 -9999 -9999 -9999 -9999 -9999 -9999 -9999 -9999 -9999 -9999 -9999 -9999 -9999 -9999 -9999 -9999 -9999 -9999 -9999 -9999 -9999 -9999 -9999 -9999 -9999 -9999 -9999 -9999 -9999 -9999 -9999 -9999 -

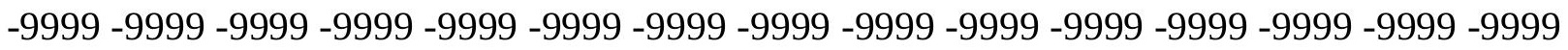
-9999 -9999 -9999 -9999 -9999 -9999 -9999 -9999 -9999 -9999 -9999 -9999 -9999 -9999 -9999 -

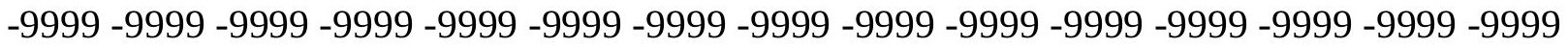
-9999 -9999 -9999 -9999 -9999 -9999 -9999 -9999 -9999 -9999 -9999 -9999 -9999 -9999 -9999 -9999 -9999 -9999 -9999 -9999 -9999 -9999 -9999 -9999 -9999 -9999 -9999 -9999 -9999 -9999 -9999 -9999 -9999 -9999 -9999 -9999 -9999 -9999 -9999 -9999 -9999 -9999 -9999 -9999 -9999 -

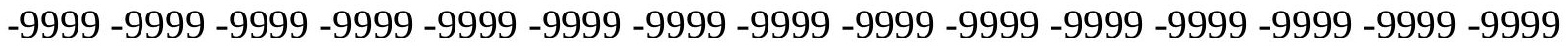
-9999 -9999 -9999 -9999 -9999 -9999 -9999 -9999 -9999 -9999 -9999 -9999 -9999 -9999 -9999 -999 -9999 -9999 -9999 -9999 -9999 -9999 -9999 -9999 -9999 -9999 -9999 -9999 -9999 -9999 - 9999 -9999 -9999 -9999 -9999 -9999 -9999 -9999 -9999 -9999 -9999 -9999 -9999 -9999 -9999 -

-9999 -9999 -9999 -9999 -9999 -9999 -9999 -9999 -9999 -9999 -9999 -9999 -9999 -9999 -9999 -

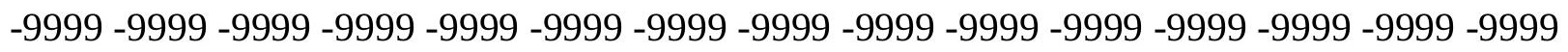
-9999 -9999 -9999 -9999 -9999 -9999 -9999 -9999 -9999 -9999 -9999 -9999 -9999 -9999 -9999 -9999 -9999 -9999 -9999 -9999 -9999 -9999 -9999 -9999 -9999 -9999 -9999 -9999 -9999 -9999 -

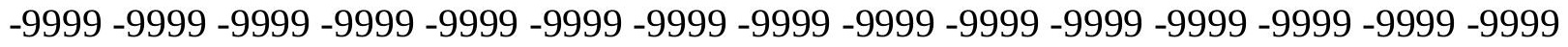
-9999 -9999 -9999 -9999 -9999 -9999 -9999 -9999 -9999 -9999 -9999 -9999 -9999 -9999 -9999 -9999 -9999 -9999 -9999 -9999 -9999 -9999 -9999 -9999 -9999 -9999 -9999 -9999 -9999 -999 -

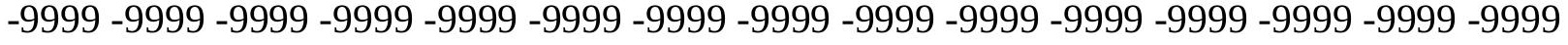
-9999 -9999 -9999 -9999 -9999 -9999 -9999 -9999 -9999 -9999 -9999 -9999 -9999 -9999 -9999 -

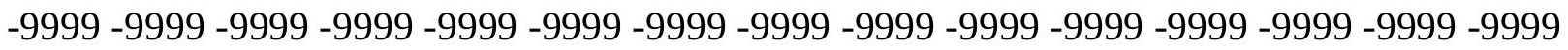

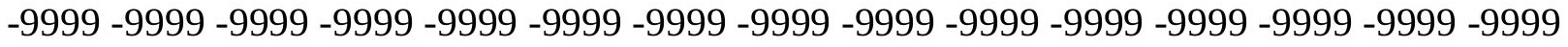

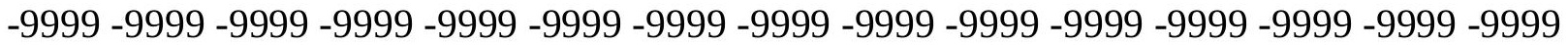

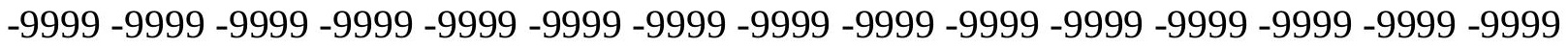

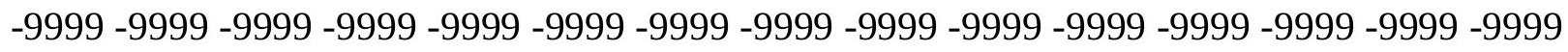

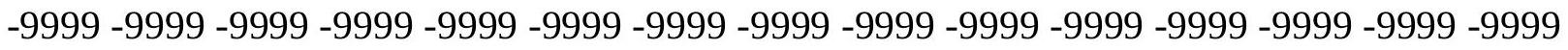

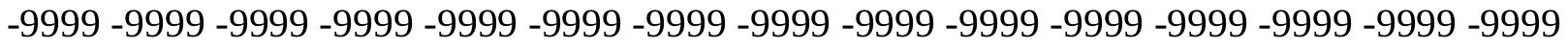
-9999 -9999 -9999 -9999 -9999 -9999 -9999 -9999 -9999 -9999 -9999 -9999 -9999 -9999 -9999 -

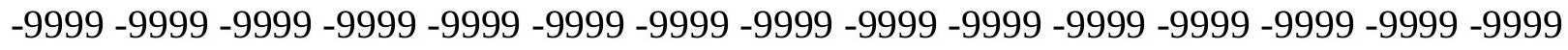

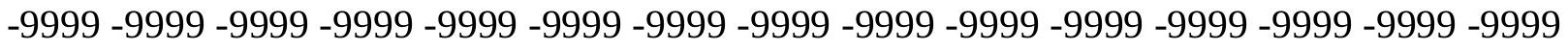
-9999 -9999 -9999 -9999 -9999 -9999 -9999 -9999 -9999 -9999 -9999 -9999 -9999 -9999 -9999 -9999 -9999 -9999 -9999 -9999 -9999 -9999 -9999 -9999-9999 -9999 -9999 -9999 -9999 -9999 -9999 -9999 -9999 -9999 -9999 -9999 -9999 -9999 -9999 -9999 -9999 -9999 -9999 -9999 -9999 -

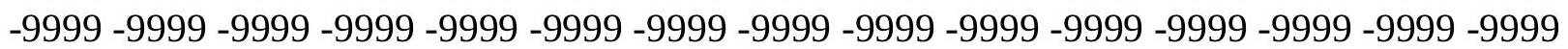


-9999 -9999 -9999 -9999 -9999 -9999 -9999 -9999 -9999 -9999 -9999 -9999 -9999 -9999 -9999 -9999 -9999 -9999 -9999 -9999 -9999 -9999 -9999 -9999 -9999 -9999 -9999 -9999 -9999 -9999 -9999 -9999 -9999 -9999 -9999 -9999 -9999 -9999 -9999 -9999 -9999 -9999 -9999 -9999 -9999 -9999 -9999 -9999 -9999 -9999 -9999 -9999 -9999 -9999 -9999 -9999 -9999 -9999 -9999 -9999 -9999 -9999 -9999 -9999 -9999 -9999 -9999 -9999-9999 -9999 -9999 -9999 -9999 -9999 -9999 -9999 -9999 -9999 -9999 -9999 -9999 -9999 -9999 -9999 -9999 -9999 -9999 -9999 -9999 -9999 -9999 -9999 -9999 -9999 -9999 -9999 -9999 -9999 -9999 -9999 -9999 -9999 -9999 -9999

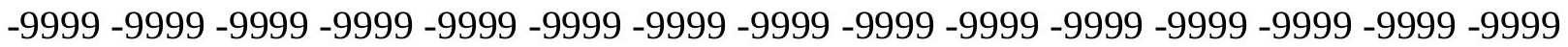

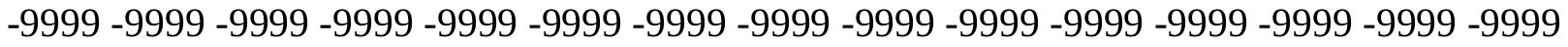
-9999 -9999 -9999 -9999 -9999 -9999 -9999 -9999 -9999 -9999 -9999 -9999 -9999 -9999 -9999 -9999 -9999 -9999 -9999 -9999 -9999 -9999 -9999 -9999 -9999 -9999 -9999 -9999 -9999 -9999 -9999 -9999 -9999 -9999 -9999 -9999 -9999 -9999 -9999 -9999 -9999 -9999 -9999 -9999 -9999 -9999 -9999 -9999 -9999 -9999 -9999 -9999 -9999 -9999 -9999 -9999 -9999 -9999 -9999 -9999 -

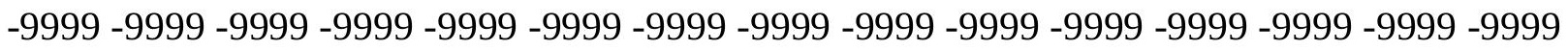
-9999 -9999 -9999 -9999 -9999 -9999 -9999 -9999 -9999 -9999 -9999 -9999 -9999 -9999 -9999 -

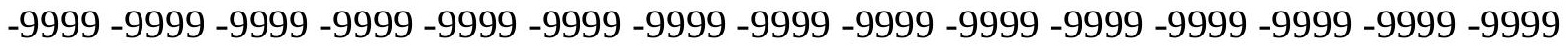
-9999 -9999 -9999 -9999 -9999 -9999 -9999 -9999 -9999 -9999 -9999 -9999 -9999 -9999 -9999 -9999 -9999 -9999 -9999 -9999 -9999 -9999 -9999 -9999 -9999 -9999 -9999 -9999 -9999 -9999 -9999 -9999 -9999 -9999 -9999 -9999 -9999 -9999 -9999 -9999 -9999 -9999 -9999 -9999 -9999 -

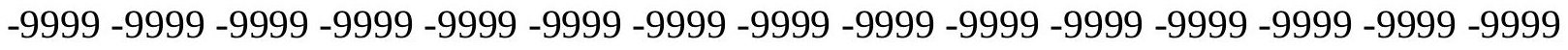

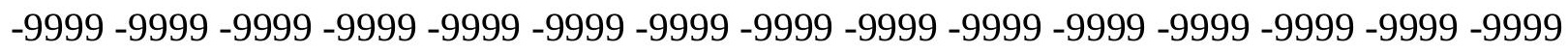
-9999 -9999 -9999 -9999 -9999 -9999 -9999 -9999 -9999 -9999 -9999 -9999 -9999 -9999 -9999 -9999 -9999 -9999 -9999 -9999 -9999 -9999 -9999 -9999 -9999 -9999 -9999 -9999 -9999 -9999 -9999 -9999 -9999 -9999 -9999 -9999 -9999 -9999 -9999 -9999 -9999 -9999 -9999 -9999 -9999 -

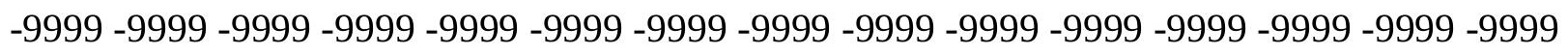
-9999 -9999 -9999 -9999 -9999 -9999 -9999 -9999 -9999 -9999 -9999 -9999 -9999 -9999 -9999 -9999 -9999 -9999 -9999 -9999 -9999 -9999 -9999 -9999 -9999 -9999 -9999 -9999 -9999 -9999 -

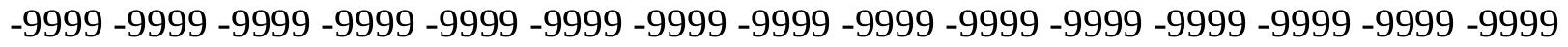
-9999 -9999 -9999 -9999 -9999 -9999 -9999 -9999 -9999 -9999 -9999 -9999 -9999 -9999 -9999 -9999 -9999 -9999 -9999 -9999 -9999 -9999 -9999 -9999 -9999 -9999 -9999 -9999 - -999 -

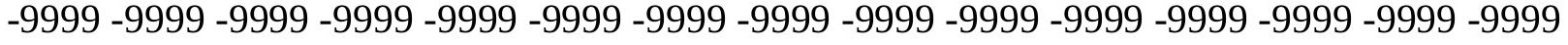
-9999 -9999 -9999 -9999 -9999 -9999 -9999 -9999 -9999 -9999 -9999 -9999 -9999 -9999 -9999 -

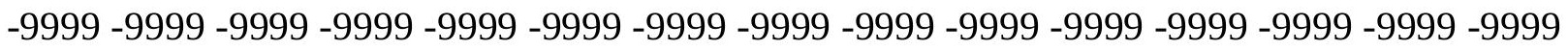

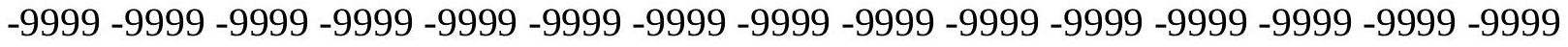

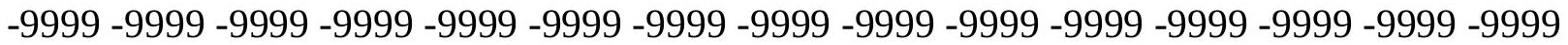

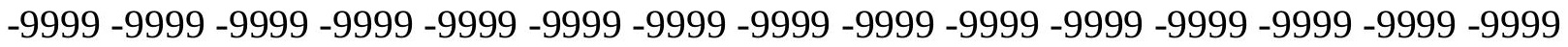

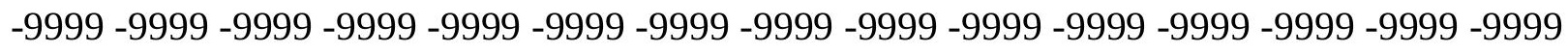

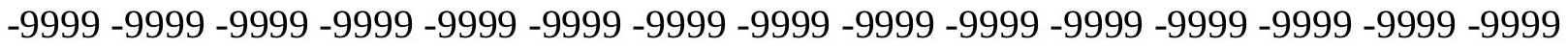

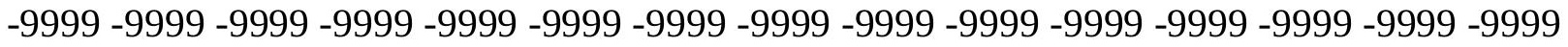
-9999 -9999 -9999 -9999 -9999 -9999 -9999 -9999 -9999 -9999 -9999 -9999 -9999 -9999 -9999 -

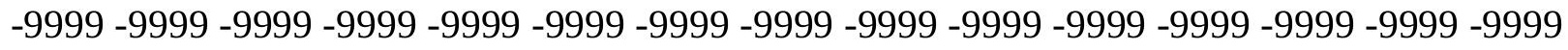

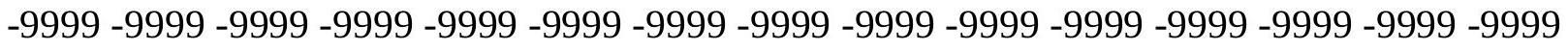
-9999 -9999 -9999 -9999 -9999 -9999 -9999 -9999 -9999 -9999 -9999 -9999 -9999 -9999 -9999 -9999 -9999 -9999 -9999 -9999 -9999 -9999 -9999 -9999-9999 -9999 -9999 -9999 -9999 -9999 -9999 -9999 -9999 -9999 -9999 -9999 -9999 -9999 -9999 -9999 -9999 -9999 -9999 -9999 -9999 -

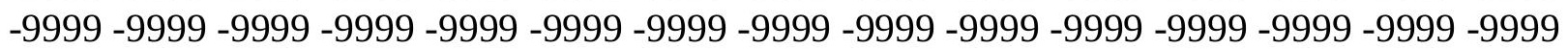


-9999 -9999 -9999 -9999 -9999 -9999 -9999 -9999 -9999 -9999 -9999 -9999 -9999 -9999 -9999 -9999 -9999 -9999 -9999 -9999 -9999 -9999 -9999 -9999 -9999 -9999 -9999 -9999 -9999 -9999 -

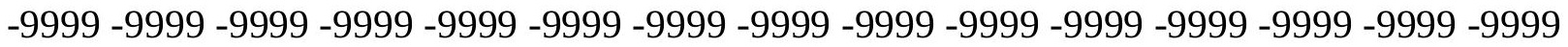
-9999 -9999 -9999 -9999 -9999 -9999 -9999 -9999 -9999 -9999 -9999 -9999 -9999 -9999 -9999 -9999 -9999 -9999 -9999 -9999 -9999 -9999 -9999 -9999-9999 -9999 -9999 -9999 -9999 -9999 -9999 -9999 -9999 -9999 -9999 -9999 -9999 -9999 -9999 -9999 -9999 -9999 -9999 -9999 -9999 -9999 -9999 -9999 -9999 -9999 -9999 -9999 -9999 -9999 -9999 -9999 -9999 -9999 -9999 -9999

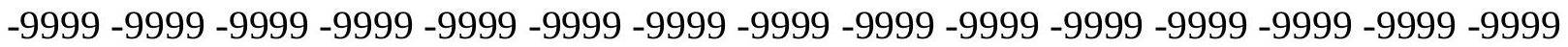
-9999 -9999 -9999 -9999 -9999 -9999 -9999 -9999 -9999 -9999 -9999 -9999 -9999 -9999 -9999 -9999 -9999 -9999 -9999 -9999 -9999 -9999 -9999 -9999 -9999 -9999 -9999 -9999 -9999

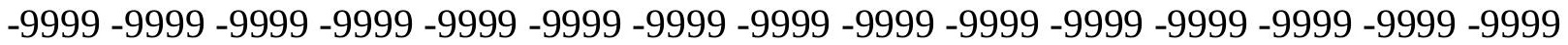
-9999 -9999 -9999 -9999 -9999 -9999 -9999 -9999 -9999 -9999 -9999 -9999 -9999 -9999 -9999 -9999 -9999 -9999 -9999 -9999 -9999 -9999 -9999 -9999 -9999 -9999 -9999 -9999 -9999 -9999 -9999 -9999 -9999 -9999 -9999 -9999 -9999 -9999 -9999 -9999 -9999 -9999 -9999 -9999 - 9999 -9999 -9999 -9999 -9999 -9999 -9999 -9999 -9999 -9999 -9999 -9999 -9999 -9999 -9999 -9999

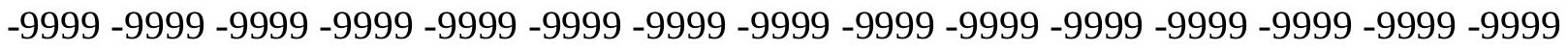
-9999 -9999 -9999 -9999 -9999 -9999 -9999 -9999 -9999 -9999 -9999 -9999 -9999 -9999 -9999 -9999 -9999 -9999 -9999 -9999 -9999 -9999 -9999 -9999 -9999 -9999 -9999 -9999 -9999 -9999 -9999 -9999 -9999 -9999 -9999 -9999 -9999 -9999 -9999 -9999 -9999 -9999 -9999 -9999 -9999 -

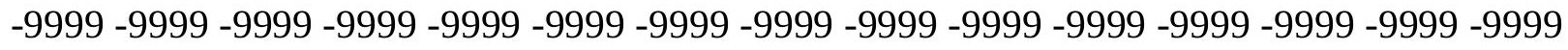

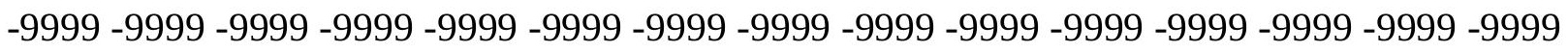
-9999 -9999 -9999 -9999 -9999 -9999 -9999 -9999 -9999 -9999 -9999 -9999 -9999 -9999 -9999 -9999 -9999 -9999 -9999 -9999 -9999 -9999 -9999 -9999 -9999 -9999 -9999 -9999 -9999 -9999 -9999 -9999 -9999 -9999 -9999 -9999 -9999 -9999 -9999 -9999 -9999 -9999 -9999 -9999 -9999 -

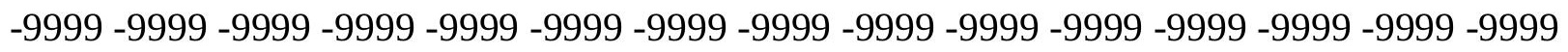
-9999 -9999 -9999 -9999 -9999 -9999 -9999 -9999 -9999 -9999 -9999 -9999 -9999 -9999 -9999 -9999 -9999 -9999 -9999 -9999 -9999 -9999 -9999 -9999 -9999 -9999 -9999 -9999 -9999 -9999 -

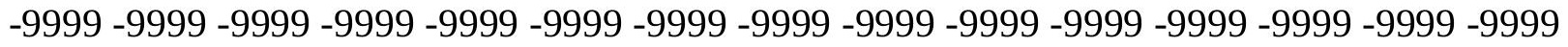
-9999 -9999 -9999 -9999 -9999 -9999 -9999 -9999 -9999 -9999 -9999 -9999 -9999 -9999 -9999 -9999 -9999 -9999 -9999 -9999 -9999 -9999 -9999 -9999 -9999 -9999 -9999 -9999 -9999 -999 -9999 -9999 -9999 -9999 -9999 -9999 -9999 -9999 -9999 -9999 -9999 -9999 -9999 -9999 -9999 -9999 -9999 -9999 -9999 -9999 -9999 -9999 -9999 -9999 -9999 -9999 -9999 -9999 -9999 -9999 -

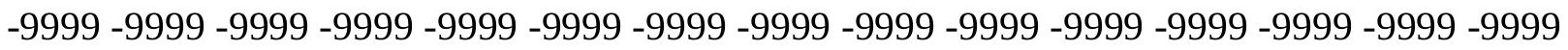

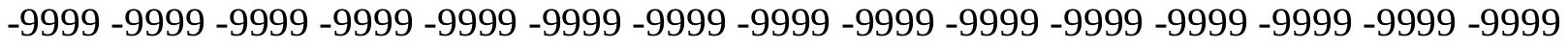
-9999 -9999 -9999 -9999 -9999 -9999 -9999 -9999 -9999 -9999 -9999 -9999 -9999 -9999 -

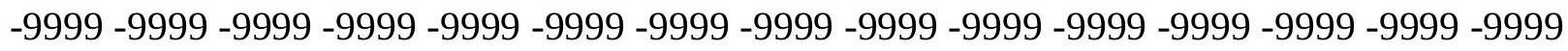

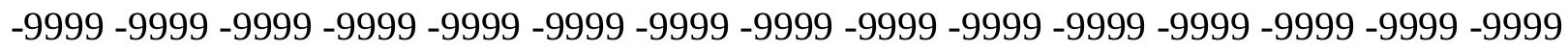

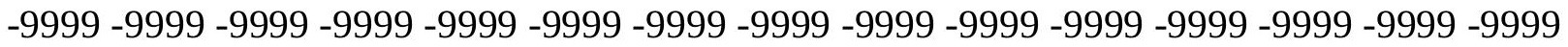
-9999 -9999 -9999 -9999 -9999 -9999 -9999 -9999 -9999 -9999 -9999 -9999 -9999 - 9999 - -999 -9999 -9999 -9999 -9999 -9999 -9999 -9999 -9999 -9999 -9999 -9999 -9999 -9999 -9999 -9999 -

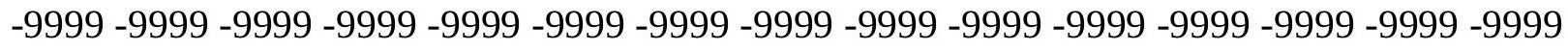

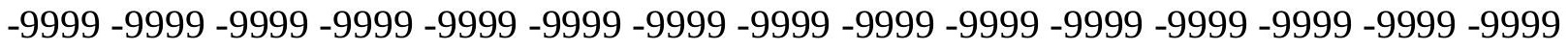
-9999 -9999 -9999 -9999 -9999 -9999 -9999 -9999 -9999 -9999 -9999 -9999 -9999 -9999 -9999 -9999 -9999 -9999 -9999 -9999 -9999 -9999 -9999 -9999-9999 -9999 -9999 -9999 -9999 -9999 -9999 -9999 -9999 -9999 -9999 -9999 -9999 -9999 -9999 -9999 -9999 -9999 -9999 -9999 -9999 -

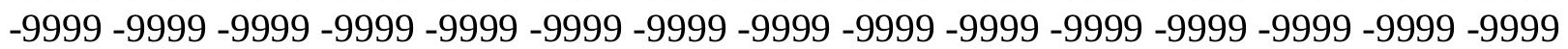


-9999 -9999 -9999 -9999 -9999 -9999 -9999 -9999 -9999 -9999 -9999 -9999 -9999 -9999 -9999 -9999 -9999 -9999 -9999 -9999 -9999 -9999 -9999 -9999 -9999 -9999 -9999 -9999 -9999 -9999 -9999 -9999 -9999 -9999 -9999 -9999 -9999 -9999 -9999 -9999 -9999 -9999 -9999 -9999 -9999 -9999 -9999 -9999 -9999 -9999 -9999 -9999 -9999 -9999 -9999 -9999 -9999 -9999 -9999 -9999 -9999 -9999 -9999 -9999 -9999 -9999 -9999 -9999 -9999 -9999 -9999 -9999 -9999 -9999 -9999 -9999 -9999 -9999 -9999 -9999 -9999 -9999 -9999 -9999 -9999 -9999 -9999 -9999 -9999 -9999 -9999 -9999 -9999 -9999 -9999 -9999 -9999 -9999 -9999 -9999 -9999 -9999 -9999 -9999 -9999 -

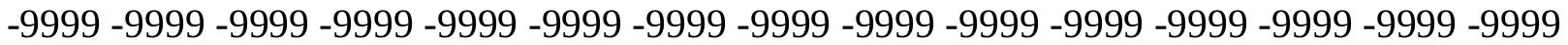
-9999 -9999 -9999 -9999 -9999 -9999 -9999 -9999 -9999 -9999 -9999 -9999 -9999 -9999 -9999 -9999 -9999 -9999 -9999 -9999 -9999 -9999 -9999 -9999 -9999 -9999 -9999 -9999 -9999 -9999 -

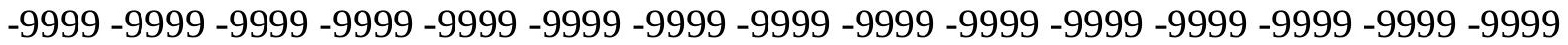
-9999 -9999 -9999 -9999 -9999 -9999 -9999 -9999 -9999 -9999 -9999 -9999 -9999 -9999 -9999 -9999 -9999 -9999 -9999 -9999 -9999 -9999 -9999 -9999 -9999 -9999 -9999 -9999 -9999 -9999 -9999 -9999 -9999 -9999 -9999 -9999 -9999 -9999 -9999 -9999 -9999 -9999 -9999 -9999 -9999 -9999 -9999 -9999 -9999 -9999 -9999 -9999 -9999 -9999 -9999 -9999 -9999 -9999 -9999 -9999 -9999 -9999 -9999 -9999 -9999 -9999 -9999 -9999 -9999 -9999 -9999 -9999 -9999 -9999 -9999 -9999 -9999 -9999 -9999 -9999 -9999 -9999 -9999 -9999 -9999 -9999 -9999 -9999 -9999 -9999 -9999 -9999 -9999 -9999 -9999 -9999 -9999 -9999 -9999 -9999 -9999 -9999 -9999 -9999 -9999 -9999 -9999 -9999 -9999 -9999 -9999 -9999 -9999 -9999 -9999 -9999 -9999 -9999 -9999 -9999 -9999 -9999 -9999 -9999 -9999 -9999 -9999 -9999 -9999 -9999 -9999 -9999 -9999 -9999

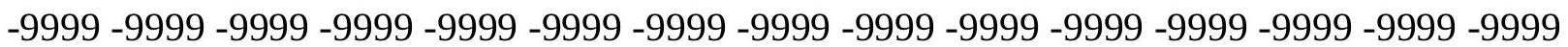
-9999 -9999 -9999 -9999 -9999 -9999 -9999 -9999 -9999 -9999 -9999 -9999 -9999 -9999 -9999 -9999 -9999 -9999 -9999 -9999 -9999 -9999 -9999 -9999 -9999 -9999 -9999 -9999 -9999 -9999 -9999 -9999 -9999 -9999 -9999 -9999 -9999 -9999 -9999 -9999 -9999 -9999 -9999 -9999 -9999

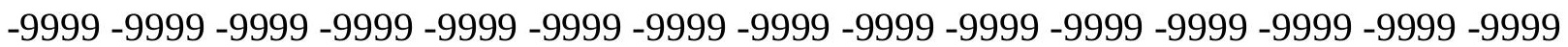
-9999 -9999 -9999 -9999 -9999 -9999 -9999 -9999 -9999 -9999 -9999 -9999 -9999 -9999 -9999 -9999 -9999 -9999 -9999 -9999 -9999 -9999 -9999 -9999 -9999 -9999 -9999 -9999 -9999 -9999 -9999 -9999 -9999 -9999 -9999 -9999 -9999 -9999 -9999 -9999 -9999 -9999 -9999 -9999 -9999 -9999 -9999 -9999 -9999 -9999 -9999 -9999 -9999 -9999 -9999 -9999 -9999 -9999 -9999 -9999 -9999 -9999 -9999 -9999 -9999 -9999 -9999 -9999 -9999 -9999 -9999 -9999 -9999 -9999 -9999 -9999 -9999 -9999 -9999 -9999 -9999 -9999 -9999 -9999 -9999 -9999 -9999 -9999 -9999 -9999 -

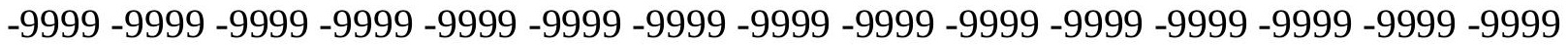
-9999 -9999 -9999 -9999 -9999 -9999 -9999 -9999 -9999 -9999 -9999 -9999 -9999 -9999 -9999 -9999 -9999 -9999 -9999 -9999 -9999 -9999 -9999 -9999 -9999 -9999 -9999 -9999 -9999 -9999 -9999 -9999 -9999 -9999 -9999 -9999 -9999 -9999 -9999 -9999 -9999 -9999 -9999 -9999 -9999 -9999 -9999 -9999 -9999 -9999 -9999 -9999 -9999 -9999 -9999 -9999 -9999 -9999 -9999 -9999 -9999 -9999 -9999 -9999 -9999 -9999 -9999 -9999 -9999 -9999 -9999 -9999 -9999 -9999 -9999

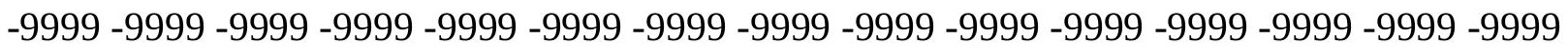
-9999 -9999 -9999 -9999 -9999 -9999 -9999 -9999 -9999 -9999 -9999 -9999 -9999 -9999 -9999 -9999 -9999 -9999 -9999 -9999 -9999 -9999 -9999 -9999 -9999 -9999 -9999 -9999 -9999 -9999 -9999 -9999 -9999 -9999 -9999 -9999 -9999 -9999 -9999 -9999 -9999 -9999 -9999 -9999 - 
yak_river_CA 
node,X_coord,Y_coord,elev,comment 12484,597073.69,103182.51,104.748,Yakima_Columbia_Confluence_Lake 12485,597371.19,103823.50,104.748,Yakima_Columbia_Confluence_Lake 12673,597792.88,103352.00,104.748,Yakima_Columbia_Confluence_Lake 12674,598324.50,102709.30,104.748,Yakima_Columbia_Confluence_Lake 12486,596917.50,102624.30,104.748,Yakima_Columbia_Confluence_Lake 12483,597243.60,103714.01,104.748,Yakima_Columbia_Confluence_Lake 12481,596180.31,103190.50,104.76,Yakima River - Biased to new confluence elev 12480,595557.88,102900.80,104.773,Yakima River - Biased to new confluence elev 12479,594768.19,102659.20,104.785,Yakima River - Biased to new confluence elev 12478,594031.12,102705.70,104.835,Yakima River - Biased to new confluence elev 12477,593658.69,102989.00,105.006,Yakima River - Biased to new confluence elev 12280,593410.38,103439.00,105.185,Yakima River - Biased to new confluence elev 12086,593061.19,103881.30,105.506,Yakima River - Biased to new confluence elev 12085,592521.62,104116.60,105.944,Yakima River - Biased to new confluence elev 12084,591951.69,104191.60,106.44,Yakima River - Biased to new confluence elev 11888,591579.31,104711.50,107.185,Yakima River - Biased to new confluence elev 11887,591245.62,105177.00,107.818,Yakima River - Biased to new confluence elev 11677,591113.69,105700.80,108.295,Yakima River - Biased to new confluence elev 11461,590686.88,106393.10,109.09,Yakima River - Biased to new confluence elev 11460,590343.62,106779.30,109.546,Yakima River - Biased to new confluence elev 11233,590633.31,107401.60,110.297,Yakima River - Biased to new confluence elev 10997,589764.31,108045.40,111.157,Yakima River - Biased to new confluence elev 10758,590120.50,108327.20,111.484,Yakima River - Biased to new confluence elev 10521,590204.12,109171.90,111.927,Yakima River - Biased to new confluence elev 10520,589302.88,109633.30,112.594,Yakima River - Biased to new confluence elev 10289,589442.38,110062.40,112.885,Yakima River - Biased to new confluence elev 10066,589410.19,110738.40,113.273,Yakima River - Biased to new confluence elev 10065,588941.12,110585.10,113.548,Yakima River - Biased to new confluence elev 